\title{
Interactome analysis of the NS1 protein encoded by influenza A H1N1 virus reveals a positive regulatory role of host protein PRP19 in viral replication
}

\section{Supporting Information}

Rei-Lin Kuo ${ }^{\mathrm{a}, \mathrm{b}, \mathrm{c}, \mathrm{d}}$, Zong-Hua $\mathrm{Li}^{\mathrm{a}}$, Li-Hsin $\mathrm{Li}^{\mathrm{a}}$, Kuo-Ming Lee ${ }^{\mathrm{b}}$, Ee-Hong Tam ${ }^{\mathrm{a}}$, Helene M. Liu ${ }^{\mathrm{e}}$, Hao-Ping Liu ${ }^{\mathrm{f}}$, Shin-Ru Shih",b,c,g, and Chih-Ching $\mathrm{Wu}^{\mathrm{a}, \mathrm{c}, \mathrm{h}}$

a Department of Medical Biotechnology and Laboratory Science, ${ }^{\mathrm{b}}$ Research Center for Emerging Viral Infections, c Graduate Institute of Biomedical Sciences, College of Medicine, Chang Gung University, Taoyuan, Taiwan

${ }^{\mathrm{d}}$ Department of Pediatrics, ${ }^{\mathrm{g}}$ Clinical Virology Laboratory, ${ }^{\mathrm{h}}$ Department of OtolaryngologyHead \& Neck Surgery, Chang Gung Memorial Hospital, Linkou, Taiwan

e Department of Clinical Laboratory Sciences and Medical Technology, College of Medicine, National Taiwan University, Taipei, Taiwan

${ }^{\mathrm{f}}$ Department of Veterinary Medicine, National Chung Hsing University, Taichung, Taiwan

\section{Table of contents}

- Table S-1. List of proteins identified in immunoprecipitation product of vector control and NS1 protein.

○ Table S-1-1. List of proteins identified in immunoprecipitation product of vector control (Replicate 1).

○ Table S-1-2. List of proteins identified in immunoprecipitation product of vector control (Replicate 2).

○ Table S-1-3. List of proteins identified in immunoprecipitation product of vector control (Replicate 3).

○ Table S-1-4. List of proteins identified in immunoprecipitation product of NS1 protein (Replicate 1).

- Table S-1-5. List of proteins identified in immunoprecipitation product of NS1 protein (Replicate 2).

○ Table S-1-6. List of proteins identified in immunoprecipitation product of NS1 protein (Replicate 3).

- Table S-2. Spectral counting-based identification of proteins co-immunoprecipitating with NS1. 
Peptide index $\begin{array}{lllll}\text { [3-methyl-2-oxobutanoate dehydrogenase [lipoamide]] kinase, mitochondrial GN=BCKDK } & \text { BCKD_HUMAN } & 46.36 & 100.0 \% & 4 \\ \text { [3-methyl-2-oxobutanoate dehydrogenase [lipoamide] ] kinase, mitochondrial GN=BCKDK } & \text { BCKD_HUMAN } & 46.36 & 100.0 \% & 4\end{array}$ [3-methyl-2-oxobutanoate dehydrogenase [lipoamide] kinase, mitochondrial GN=BCKDK BCKD_HUMAN $46.36 \quad 100.0 \%$

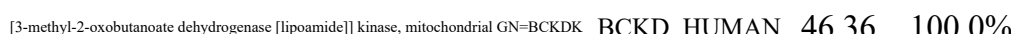
[Pyruvate dehydrogenase (acecyl-transferring)] kinase isozyme 3, mitcochondral GN=PDK3 $\quad$ PDK3_HUMAN $46.94 \quad 100.0 \%$

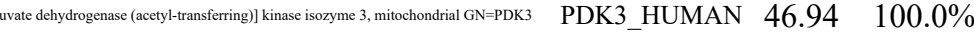
$116 \mathrm{kDa}$ U5 small nuclear ribonucleoprotein component GN=EFTUD2 U5S1_HUMAN $109.44100 .0 \%$ 116 kDa U5 small nuclear ribonucleoprotein component GN=EFTUD2 U5S1_HUMAN $109.44 \quad 100.0 \%$ $116 \mathrm{kDa}$ U5 small nuclear ribonucleoprotein component GN=EFTUD2 U5S1_HUMAN $109.44100 .0 \%$ $116 \mathrm{kDa}$ U5 small nuclear ribonucleoprotein component GN=EFTUD2 U5S1_HUMAN $109.44 \quad 100.0 \%$ $116 \mathrm{kDa}$ U5 small nuclear ribonucleoprotein component GN=EFTUD2 U5S1_HUMAN $109.44 \quad 100.0 \%$ $116 \mathrm{kDa}$ U5 small nuclear ribonucleoprotein component GN=EFTUD2 U5S1 HUMAN $109.44100 .0 \%$ $116 \mathrm{kDa}$ U5 small nuclear ribonucleoprotein component GN=EFTUD2 U5S1_HUMAN $109.44 \quad 100.0 \%$ $116 \mathrm{kDa}$ U5 small nuclear ribonucleoprotein component GN=EFTUD2 U5S1 HUMAN $109.44100 .0 \%$ 14-3-3 protein zeta/delta GN=YWHAZ 14-3-3 protein zeta/delta $\mathrm{GN}=\mathrm{YWHAZ}$ 1433Z HUMAN $27.75 \quad 100.0 \%$ 1433Z_HUMAN $27.75 \quad 100.0 \%$ 1433Z HUMAN $27.75 \quad 100.0 \%$ 2',3'-cyclic-nucleotide 3 '-phosphodiesterase GN=CNP CN37_HUMAN $47.58 \quad 100.0 \%$ 2',3'-cyclic-nucleotide 3 '-phosphodiesterase GN=CNP CN37_HUMAN $47.58 \quad 100.0 \%$ 2',3'-cyclic-nucleotide 3'-phosphodiesterase GN=CNP CN37_HUMAN $47.58 \quad 100.0 \%$ 2',3'-cyclic-nucleotide 3 '-phosphodiesterase GN=CNP CN37_HUMAN $47.58 \quad 100.0 \%$ 2',3'-cyclic-nucleotide 3 '-phosphodiesterase GN=CNP CN37_HUMAN $47.58 \quad 100.0 \%$ 2',3'-cyclic-nucleotide 3'-phosphodiesterase GN=CNP CN37_HUMAN $47.58 \quad 100.0 \%$ 2',3'-cyclic-nucleotide 3'-phosphodiesterase GN=CNP CN37_HUMAN $47.58 \quad 100.0 \%$ 2',3'-cyclic-nucleotide 3'-phosphodiesterase GN=CNP CN37_HUMAN $47.58 \quad 100.0 \%$ $26 \mathrm{~S}$ protease regulatory subunit 10B GN=PSMC6 PRS10_HUMAN $44.17 \quad 100.0 \%$ $26 \mathrm{~S}$ protease regulatory subunit $10 \mathrm{~B}$ GN=PSMC6 PRS10_HUMAN $44.17 \quad 100.0 \%$ $26 \mathrm{~S}$ protease regulatory subunit 10B GN=PSMC6 PRS10_HUMAN $44.17 \quad 100.0 \%$ 26S protease regulatory subunit 10B GN=PSMC6 PRS10_HUMAN $44.17 \quad 100.0 \%$ $26 \mathrm{~S}$ protease regulatory subunit 10B GN=PSMC6 PRS10_HUMAN $44.17 \quad 100.0 \%$ $26 \mathrm{~S}$ protease regulatory subunit 10B GN=PSMC6 PRS10_HUMAN $44.17 \quad 100.0 \%$ $26 \mathrm{~S}$ protease regulatory subunit 10B GN=PSMC6 PRS10_HUMAN $44.17 \quad 100.0 \%$ $26 \mathrm{~S}$ protease regulatory subunit 10B GN=PSMC6 PRS10_HUMAN $44.17 \quad 100.0 \%$ $26 \mathrm{~S}$ protease regulatory subunit 10B GN=PSMC6 PRS10_HUMAN $44.17 \quad 100.0 \%$ $26 \mathrm{~S}$ protease regulatory subunit 10B GN=PSMC6 PRS10_HUMAN $44.17 \quad 100.0 \%$ 26S protease regulatory subunit 10B GN=PSMC6 PRS10_HUMAN $44.17 \quad 100.0 \%$ 26S protease regulatory subunit 4 GN=PSMC1 PRS4_HUMAN $49.19 \quad 100.0 \%$ $26 \mathrm{~S}$ protease regulatory subunit $4 \mathrm{GN}=\mathrm{PSMC} 1 \mathrm{PRS} 4 \mathrm{HUMAN} 49.19 \quad 100.0 \%$ 26S protease regulatory subunit 4 GN=PSMC1 PRS4_HUMAN $49.19 \quad 100.0 \%$ 26S protease regulatory subunit 4 GN=PSMC1 PRS4_HUMAN $49.19 \quad 100.0 \%$ $26 \mathrm{~S}$ protease regulatory subunit $4 \mathrm{GN}=\mathrm{PSMC} 1 \mathrm{PRS} 4 \mathrm{HUMAN} 49.19 \quad 100.0 \%$

$\begin{array}{llll}10 & 0.01 \% & 12.1 \% & \text { TVTSFYNQSAIDAAAE } \\ 10 & 0.01 \% & 12.1 \% & \text { LTPTMMLYAGR }\end{array}$

$10 \quad 0.01 \% \quad 12.1 \%$ SQDGSHLLK

$10 \quad 0.01 \% \quad 12.1 \%$ YLQQELPVR

$5 \quad 0.01 \% \quad 7.4 \%$ AAPLAGFGYGLPISR

$5 \quad 0.01 \% \quad 7.4 \% \quad$ ALSSESFERLPVFNK

$12 \quad 0.02 \% \quad 8.0 \% \quad$ STPVTVVLPDTK

$12 \quad 0.02 \% \quad 8.0 \%$ STPVTVVLPDTKGK

$12 \quad 0.02 \% \quad 8.0 \%$ VLSGTIHAGQPVK

$0.02 \% \quad 8.0 \% \quad$ IAVEPVNPSELPK

$0.02 \% \quad 8.0 \%$ FKILDAVVAQEPLHR

$0.02 \% \quad 8.0 \%$ ILDAVVAQEPLHR

$0.02 \% \quad 8.0 \%$ GGGQIIPTAR

$\quad 0.02 \% \quad 8.0 \% \quad$ RVVYSAFLMATPR

$0.01 \% \quad 16.3 \%$ NLLSVAYKNVVGAR

$0.01 \% \quad 16.3 \%$ VVSSIEQKTEGAEK

$0.01 \% \quad 16.3 \%$ YLAEVAAGDDKK

$3 \quad 0.02 \% \quad 19.2 \%$ MVSADAYKITPGAR

$13 \quad 0.02 \% \quad 19.2 \%$ AGQVFLEELGNHK

$0.02 \% \quad 19.2 \%$ QFVPGDEPREK

$0.02 \% \quad 19.2 \%$ APGAEEYAQQDVLK

$\begin{array}{lll}0.02 \% & 19.2 \% & \text { APGAEEYAQQDVLKK }\end{array}$

$0.02 \% \quad 19.2 \%$ GEEVGELSR

$0.02 \% \quad 19.2 \%$ AIFTGYYGK

$0.02 \% \quad 19.2 \%$ GKPVPTQGSR

$0.04 \% \quad 35.0 \%$ DKALQDYR

$0.04 \% \quad 35.0 \%$ VALDMTTLTIMR

$0.04 \% \quad 35.0 \%$ EVIELPLTNPELFQR

$0.04 \% \quad 35.0 \%$ VGIIPPKGCLLYGPPGTGK

$0.04 \% \quad 35.0 \%$ AVASQLDCNFLK

$0.04 \% \quad 35.0 \%$ VVSSSIVDKYIGESAR

$0.04 \% \quad 35.0 \%$ LIREMFNYAR

$0.04 \% \quad 35.0 \%$ FSEGTSADREIQR

$0.04 \% \quad 35.0 \%$ KIHIDLPNEQAR

$0.04 \% 35.0 \%$ IHAGPITK

$0.04 \% \quad 35.0 \%$ HGEIDYEAIVK

$0.01 \% \quad 15.5 \%$ KYEPPVPTR

$0.01 \% \quad 15.5 \%$ GVILYGPPGTGK

$0.01 \% \quad 15.5 \%$ AVANQTSATFLR

$0.01 \% \quad 15.5 \%$ VVGSELIQKYLGDGPK

$0.01 \% \quad 15.5 \%$ IFQIHTSR
$99.7 \% \quad 49.3$

$99.7 \% \quad 37.3$

$99.7 \% \quad 44.5$

$99.7 \% \quad 53.7$

$99.0 \% \quad 22.4$

$99.7 \% \quad 30.4$

$99.7 \% \quad 70.9$

$95.7 \% \quad 16.4$

$99.7 \% \quad 49.4$

$99.7 \% \quad 26.4$

$99.7 \% \quad 41.1$

$99.7 \% \quad 38.4$

$98.4 \% \quad 18.0$

$99.7 \% 60.6$

$99.7 \% \quad 51.7$

$99.7 \% \quad 66.4$

$99.7 \% \quad 42.2$

$99.7 \% \quad 50.6$

$95.2 \% \quad 15.8$

$\begin{array}{lll}99.5 \% & 22.1\end{array}$

$98.6 \% 17.5$

$96.6 \% 37.2$

$99.7 \% \quad 39.8$

$97.1 \% \quad 15.8$

$99.0 \% \quad 27.3$

$99.7 \% \quad 48.6$

$99.7 \% \quad 37.3$

$\begin{array}{ll}98.6 \% & 19.1\end{array}$

$99.7 \% \quad 52.1$

$99.7 \% \quad 53.0$

$97.2 \% \quad 17.5$

$99.6 \% \quad 22.3$

$99.7 \% \quad 32.8$

$99.0 \% 27.0$

$99.7 \% \quad 55.4$

$99.7 \% \quad 38.5$

$99.2 \% \quad 57.2$

$99.7 \% \quad 54.8$

$95.8 \% \quad 15.7$

$99.0 \% \quad 39.7$

$\begin{array}{ccc}25.0 & 27.2 & 0 \\ 25.0 & 42.2 & 4 \\ 25.0 & 27.2 & 2 \\ 25.0 & 30.9 & 2 \\ 25.0 & 53.6 & 4 \\ 25.0 & 18.7 & 1 \\ 25.0 & 30.2 & 1 \\ 25.0 & 70.9 & 2 \\ 25.0 & 13.8 & 1 \\ 25.0 & 43.8 & 3 \\ 25.0 & 26.4 & 0 \\ 25.0 & 41.1 & 1 \\ 25.0 & 32.1 & 6 \\ 25.0 & 18.0 & 0 \\ 25.0 & 60.6 & 2 \\ 25.0 & 45.8 & 2 \\ 25.0 & 55.0 & 2 \\ 25.0 & 39.2 & 2 \\ 25.0 & 44.7 & 2 \\ 25.0 & 14.1 & 1 \\ 25.0 & 18.1 & 1 \\ 25.0 & 17.5 & 0 \\ 25.0 & 13.4 & 2 \\ 25.0 & 28.2 & 2 \\ 25.0 & 15.8 & 2 \\ 25.0 & 26.6 & 2 \\ 25.0 & 47.7 & 8 \\ 25.0 & 37.3 & 2 \\ 25.0 & 17.4 & 0 \\ 25.0 & 48.1 & 2 \\ 25.0 & 53.0 & 2 \\ 25.0 & 14.8 & 1 \\ 25.0 & 22.3 & 1 \\ 25.0 & 32.8 & 0 \\ 25.0 & 27.0 & 2 \\ 25.0 & 49.4 & 2 \\ 25.0 & 28.5 & 3 \\ 25.0 & 0.0 & 3 \\ 25.0 & 44.8 & 2 \\ 25.0 & 15.7 & 0 \\ 25.0 & 26.7 & 2\end{array}$

2255.13

start stop

.

984.51

1145.63

1489.82

1723.90

1256.7

1441.83

1306.75

1392.77

1735.99

1460.82

969.55

1510.82

1503.86

1504.79

1279.65

1479.76

1441.74

1301.65

1518.74

1646.84

975.47

1019.52

1026.57

1008.51

1380.72

1797.97

1924.07

1365.68

1709.91

1312.68

1495.71

1433.79

836.50

1273.64

1086.59

1158.65

1278.68

1702.94

1001.55

\begin{tabular}{cc}
\hline 49 & 69 \\
70 & 80 \\
81 & 89 \\
93 & 101 \\
318 & 332 \\
360 & 374 \\
183 & 194 \\
183 & 196 \\
496 & 508 \\
590 & 602 \\
789 & 803 \\
791 & 803 \\
804 & 813 \\
814 & 826 \\
42 & 55 \\
61 & 74 \\
128 & 139 \\
80 & 93 \\
205 & 217 \\
225 & 235 \\
262 & 275 \\
262 & 276 \\
361 & 369 \\
392 & 400 \\
401 & 410 \\
6 & 13 \\
98 & 109 \\
147 & 161 \\
162 & 180 \\
186 & 197 \\
198 & 213 \\
214 & 223 \\
243 & 255 \\
298 & 309 \\
315 & 322 \\
323 & 333 \\
24 & 32 \\
221 & 232 \\
238 & 249 \\
250 & 265 \\
364 & 371 \\
& \\
\hline 13
\end{tabular}

Page 1 of Table S-1- 1 
$26 \mathrm{~S}$ protease regulatory subunit $4 \mathrm{GN}=\mathrm{PSMC} 1$ PRS4_HUMAN $49.19 \quad 100.0 \%$ $26 \mathrm{~S}$ protease regulatory subunit $6 \mathrm{~A}$ GN=PSMC3 PRS6A_HUMAN $49.21 \quad 100.0 \%$ $26 \mathrm{~S}$ protease regulatory subunit $6 \mathrm{~A}$ GN=PSMC3 PRS6A_HUMAN $49.21 \quad 100.0 \%$ $26 \mathrm{~S}$ protease regulatory subunit $6 \mathrm{~A}$ GN=PSMC3 PRS6A HUMAN $49.21 \quad 100.0 \%$ 26S protease regulatory subunit 6A GN=PSMC3 PRS6A_HUMAN $49.21 \quad 100.0 \%$ $26 \mathrm{~S}$ protease regulatory subunit 6A GN=PSMC3 PRS6A_HUMAN $49.21 \quad 100.0 \%$ $26 \mathrm{~S}$ protease regulatory subunit $6 \mathrm{~A} \mathrm{GN}=\mathrm{PSMC} 3$ PRS6A_HUMAN $49.21 \quad 100.0 \%$ 26S protease regulatory subunit 6A GN=PSMC3 PRS6A_HUMAN $49.21 \quad 100.0 \%$ $26 \mathrm{~S}$ protease regulatory subunit $6 \mathrm{~A} \mathrm{GN}=\mathrm{PSMC} 3 \mathrm{PRS} 6 \mathrm{~A}$ HUMAN $49.21 \quad 100.0 \%$ $26 \mathrm{~S}$ protease regulatory subunit 6A GN=PSMC3 PRS6A_HUMAN $49.21 \quad 100.0 \%$ $26 \mathrm{~S}$ protease regulatory subunit $6 \mathrm{~A}$ GN=PSMC3 $\mathrm{PRS6A}$ _HUMAN $49.21 \quad 100.0 \%$ 26 protease regulatory subunit $6 \mathrm{~B}$ GN=PSMC4 PRS6B HUMAN $47.37 \quad 100.0 \%$ $26 \mathrm{~S}$ protease regulatory subunit $6 \mathrm{~B} \mathrm{GN}=\mathrm{PSMC} 4$ PRS6B_HUMAN 47.37 $26 \mathrm{~S}$ protease regulatory subunit $6 \mathrm{~B} \mathrm{GN}=\mathrm{PSMC} 4$ PRS6B_HUMAN 47.3 $26 \mathrm{~S}$ protease regulatory subunit $6 \mathrm{~B} \mathrm{GN}=\mathrm{PSMC} 4 \mathrm{PRS} 6 \mathrm{~B}$ HUMAN 47.37 $26 \mathrm{~S}$ protease regulatory subunit $6 \mathrm{~B}$ GN=PSMC4 PRS6B_HUMAN 47.3 $26 \mathrm{~S}$ protease regulatory subunit $6 \mathrm{~B} \mathrm{GN}=\mathrm{PSMC} 4 \mathrm{PRS} 6 \mathrm{~B}$ HUMAN 47.37 26S protease regulatory subunit $6 \mathrm{~B}$ GN=PSMC4 PRS6B_HUMAN 47.37 $26 \mathrm{~S}$ protease regulatory subunit $6 \mathrm{~B}$ GN=PSMC4 PRS6B_HUMAN 47.37 $26 \mathrm{~S}$ protease regulatory subunit $7 \mathrm{GN}=\mathrm{PSMC} 2 \mathrm{PRS} 7$ HUMAN 48.64 $26 \mathrm{~S}$ protease regulatory subunit $7 \mathrm{GN}=\mathrm{PSMC} 2$ PRS7_HUMAN 48.64 $26 \mathrm{~S}$ protease regulatory subunit $7 \mathrm{GN}=\mathrm{PSMC} 2 \mathrm{PRS} 7$ HUMAN 48.64 $26 \mathrm{~S}$ protease regulatory subunit $7 \mathrm{GN}=\mathrm{PSMC} 2 \mathrm{PRS} 7 \mathrm{HUMAN} 48.64$ $26 \mathrm{~S}$ protease regulatory subunit $7 \mathrm{GN}=\mathrm{PSMC} 2 \mathrm{PRS} 7$ HUMAN 48.64 $26 \mathrm{~S}$ protease regulatory subunit $7 \mathrm{GN}=\mathrm{PSMC} 2 \mathrm{PRS} 7 \mathrm{HUMAN} 48.64$ $26 \mathrm{~S}$ protease regulatory subunit $7 \mathrm{GN}=\mathrm{PSMC} 2 \mathrm{PRS7}$ _HUMAN 48.64 $26 \mathrm{~S}$ protease regulatory subunit $7 \mathrm{GN}=\mathrm{PSMC} 2$ PRS7 HUMAN 48.64 $26 \mathrm{~S}$ protease regulatory subunit $7 \mathrm{GN}=\mathrm{PSMC} 2 \mathrm{PRS} 7$ HUMAN 48.64 $26 \mathrm{~S}$ protease regulatory subunit $7 \mathrm{GN}=\mathrm{PSMC} 2 \mathrm{PRS7}$ _HUMAN 48.64 $26 \mathrm{~S}$ protease regulatory subunit $7 \mathrm{GN}=\mathrm{PSMC} 2 \mathrm{PRS} 7 \mathrm{HUMAN} 48.64$ $26 \mathrm{~S}$ protease regulatory subunit $8 \mathrm{GN}=\mathrm{PSMC} 5$ PRS 8 HUMAN 45.63 $26 \mathrm{~S}$ protease regulatory subunit $8 \mathrm{GN}=\mathrm{PSMC5}$ PRS8_HUMAN 45.63 $26 \mathrm{~S}$ protease regulatory subunit $8 \mathrm{GN}=\mathrm{PSMC} 5 \mathrm{PRS} 8$ _HUMAN 45.63 $26 \mathrm{~S}$ protease regulatory subunit $8 \mathrm{GN}=\mathrm{PSMC} 5 \mathrm{PRS} 8$ _HUMAN 45.63 $26 \mathrm{~S}$ protease regulatory subunit $8 \mathrm{GN}=\mathrm{PSMC} 5 \mathrm{PRS} 8 \mathrm{HUMAN} 45.63$ $26 \mathrm{~S}$ protease regulatory subunit $8 \mathrm{GN}=\mathrm{PSMC} 5$ PRS8_HUMAN 45.63 $26 \mathrm{~S}$ protease regulatory subunit $8 \mathrm{GN}=\mathrm{PSMC} 5$ PRS8_HUMAN 45.63 $26 \mathrm{~S}$ protease regulatory subunit $8 \mathrm{GN}=\mathrm{PSMC} 5 \mathrm{PRS} 8 \mathrm{HUMAN} 45.63$ 26S protease regulatory subunit $8 \mathrm{GN}=$ PSMC5 PRS8_HUMAN 45.63 $26 \mathrm{~S}$ protease regulatory subunit $8 \mathrm{GN}=\mathrm{PSMC} 5$ PRS8_HUMAN 45.63 $26 \mathrm{~S}$ protease regulatory subunit $8 \mathrm{GN}=\mathrm{PSMC} 5$ PRS8_HUMAN 45.63100 .0 $26 \mathrm{~S}$ protease regulatory subunit $8 \mathrm{GN}=\mathrm{PSMC} 5 \mathrm{PRS} 8$ _HUMAN $45.63 \quad 100.0 \%$ $26 \mathrm{~S}$ protease regulatory subunit $8 \mathrm{GN}=\mathrm{PSMC} 5 \mathrm{PRS} 8 \mathrm{HUMAN} 45.63 \quad 100.0 \%$ $26 \mathrm{~S}$ protease regulatory subunit $8 \mathrm{GN}=\mathrm{PSMC} 5 \mathrm{PRS} 8$ _HUMAN $45.63 \quad 100.0 \%$ 26S proteasome non-ATPase regulatory subunit $1 \mathrm{GN}=\mathrm{PSMD} 1$ PSMD1_HUMAN $105.84 \quad 100.0 \%$ $26 \mathrm{~S}$ proteasome non-ATPase regulatory subunit $1 \mathrm{GN}=\mathrm{PSMD} 1$ PSMD1_HUMAN $105.84100 .0 \%$ $26 \mathrm{~S}$ proteasome non-ATPase regulatory subunit 1 GN=PSMD1 PSMD1_HUMAN $105.84 \quad 100.0 \%$

$100.0 \%$

$00.0 \%$

$00.0 \%$
$0.01 \% \quad 15.5 \%$ KQEGTPEGLYL

$0.02 \% \quad 28.5 \%$ QTYFLPVIGLVDAEK

$0.02 \% \quad 28.5 \%$ LAGPQLVQMFIGDGAK

$94.6 \% 20.7$

$99.6 \% 22.9$

$99.7 \% \quad 35.2$

$99.7 \% 38$.

$0.02 \% \quad 28.5 \%$ LVRDAFALAK

$0.02 \% \quad 28.5 \%$ VIAATNRVDILDPALLR

$0.02 \% \quad 28.5 \%$ KMNVSPDVNYEELAR

$99.7 \% 58.8$

$99.7 \% \quad 54.0$

$99.7 \% 33.3$

$99.7 \% \quad 39.6$

$0.02 \% \quad 28.5 \%$ AVCVEAGMIALR

$0.02 \% \quad 28.5 \%$ AVCVEAGMIALRR

$97.0 \% \quad 19.3$

$0.02 \% \quad 28.5 \%$ GATELTHEDYMEGILEVQAK $99.7 \% 26.6$

$0.02 \% \quad 28.5 \%$ KANLQYYA

$0.02 \% \quad 17.5 \%$ EFLHAQEEVKR

$0.02 \% \quad 17.5 \%$ EAVELPLTHFELYK

$0.02 \% \quad 17.5 \%$ AVAHHTTAAFIR

$0.02 \% \quad 17.5 \%$ VVGSEFVQK

$0.02 \% \quad 17.5 \%$ VVGSEFVQKYLGEGPR

$0.02 \% \quad 17.5 \%$ RLIFSTITSK

$0.02 \% \quad 17.5 \%$ LIFSTITSK

$0.02 \% \quad 17.5 \%$ YIVLAKDFEK

$0.04 \% 32.1 \%$ PDYLGADQRK

$0.04 \% \quad 32.1 \%$ ALDEGDIALLK

$0.04 \% \quad 32.1 \%$ TYGQSTYSR

$0.04 \% \quad 32.1 \%$ IINADSEDPKYIINVK

$\begin{array}{lll}0.04 \% & 32.1 \% & \text { FVVDLSDQVAPTDIEEGMR }\end{array}$

$0.04 \% \quad 32.1 \%$ FVNLGIEPPK

$0.04 \% \quad 32.1 \%$ AVANRTDACFIR

$0.04 \% \quad 32.1 \%$ VIGSELVQKYVGEGAR

$0.04 \% \quad 32.1 \%$ FDDGAGGDNEVQR

$0.04 \% \quad 32.1 \%$ LCPNSTGAEIR

$0.04 \% \quad 32.1 \%$ SVCTEAGMFAIR

$0.05 \% \quad 34.2 \%$ LQAQRNELNAK

$0.05 \% \quad 34.2 \%$ NELNAKVR

$0.05 \% 34.2 \%$ VLVKVHPEGK

$0.05 \% \quad 34.2 \%$ FVVDVDKNIDINDVTPNCR

$99.0 \% \quad 22.6$

$99.7 \% \quad 34.4$

$99.5 \% \quad 23.5$

$99.7 \% \quad 48.8$

$99.7 \% \quad 26.0$

$99.7 \% \quad 46.5$

$99.7 \% \quad 28.8$

$99.7 \% \quad 40.5$

$99.7 \% \quad 47.1$

$99.7 \% \quad 41.4$

$99.7 \% \quad 55.7$

$99.7 \% \quad 35.7$

$99.7 \% \quad 31.0$

$99.7 \% \quad 53.7$

$99.7 \% \quad 36.8$

$\begin{array}{lll}99.7 \% & 36.2\end{array}$

$99.7 \% \quad 36.3$

$99.7 \% \quad 44.2$

$99.7 \% \quad 39.5$

$99.7 \% \quad 57.2$

$99.7 \% \quad 52.5$

$94.5 \% \quad 18.1$

$99.7 \% \quad 34.8$

$00.0 \%$

$100.0 \%$

$0 \% \quad 14$

14
$0 \%$

14

0
6

19

$\begin{array}{llll}99.7 \% & 54.9 & 25.0 & 26.1\end{array}$

$\begin{array}{llll}99.7 \% & 67.0 & 25.0 & 67.0\end{array}$

$\begin{array}{lllll}98.2 \% & 21.1 & 25.0 & 16.1 & 1\end{array}$

$\begin{array}{lllll}99.7 \% & 55.9 & 25.0 & 46.2 & 4\end{array}$

$\begin{array}{lllll}99.7 \% & 46.3 & 25.0 & 46.3 & 2\end{array}$ 
列 26S proteasome non-ATPase regulatory subunit $1 \mathrm{GN}=$ PSMD1 PSMD1_HUMAN $105.84 \quad 100.0 \%$ $26 \mathrm{~S}$ proteasome non-ATPase regulatory subunit $1 \mathrm{GN}=$ PSMD1 PSMD1_HUMAN $105.84 \quad 100.0 \%$ $26 \mathrm{~S}$ proteasome non-ATPase regulatory subunit $11 \mathrm{GN}=$ PSMD11 PSD11 HUMAN $47.47 \quad 100.0 \%$ 26S proteasome non-ATPase regulatory subunit 11 GN=PSMD11 PSD11_HUMAN $47.47 \quad 100.0 \%$ 26S proteasome non-ATPase regulatory subunit 11 GN=PSMD11 PSD11_HUMAN $47.47 \quad 100.0 \%$ $26 \mathrm{~S}$ proteasome non-ATPase regulatory subunit $14 \mathrm{GN}=\mathrm{PSMD} 14$ PSDE HUMAN $34.58 \quad 100.0 \%$ $26 \mathrm{~S}$ proteasome non-ATPase regulatory subunit $14 \mathrm{GN}=\mathrm{PSMD} 14$ PSDE_HUMAN $34.58 \quad 100.0 \%$ 26S proteasome non-ATPase regulatory subunit $14 \mathrm{GN}=$ PSMD14 PSDE HUMAN $34.58 \quad 100.0 \%$ 26S proteasome non-ATPase regulatory subunit 2 GN=PSMD2 PSMD2_HUMAN $100.20 \quad 100.0 \%$ 26S proteasome non-ATPase regulatory subunit 2 GN=PSMD2 PSMD2_HUMAN $100.20 \quad 100.0 \%$ $26 \mathrm{~S}$ proteasome non-ATPase regulatory subunit $2 \mathrm{GN}=\mathrm{PSMD} 2 \mathrm{PSMD} 2$ HUMAN $100.20 \quad 100.0 \%$ $26 \mathrm{~S}$ proteasome non-ATPase regulatory subunit 2 GN=PSMD2 PSMD2_HUMAN $100.20 \quad 100.0 \%$ $26 \mathrm{~S}$ proteasome non-ATPase regulatory subunit $2 \mathrm{GN}=$ PSMD2 PSMD2_HUMAN $100.20 \quad 100.0 \%$ 26S proteasome non-ATPase regulatory subunit 2 GN=PSMD2 PSMD2_HUMAN $100.20 \quad 100.0 \%$ 26S proteasome non-ATPase regulatory subunit 2 GN=PSMD2 PSMD2_HUMAN $100.20 \quad 100.0 \%$ $26 \mathrm{~S}$ proteasome non-ATPase regulatory subunit $2 \mathrm{GN}=\mathrm{PSMD} 2 \mathrm{PSMD} 2 \mathrm{HUMAN} 100.20 \quad 100.0 \%$ 26S proteasome non-ATPase regulatory subunit 2 GN=PSMD2 PSMD2_HUMAN $100.20 \quad 100.0 \%$ 26S proteasome non-ATPase regulatory subunit 2 GN=PSMD2 PSMD2_HUMAN $100.20 \quad 100.0 \%$ $26 \mathrm{~S}$ proteasome non-ATPase regulatory subunit $2 \mathrm{GN}=\mathrm{PSMD} 2 \mathrm{PSMD} 2$ HUMAN $100.20 \quad 100.0 \%$ 26S proteasome non-ATPase regulatory subunit 2 GN=PSMD2 PSMD2_HUMAN $100.20 \quad 100.0 \%$ $26 \mathrm{~S}$ proteasome non-ATPase regulatory subunit $3 \mathrm{GN}=\mathrm{PSMD} 3 \mathrm{PSMD} 3$ HUMAN $60.98 \quad 100.0 \%$ 26S proteasome non-ATPase regulatory subunit $3 \mathrm{GN}=$ PSMD3 PSMD3_HUMAN $60.98 \quad 100.0 \%$ $26 \mathrm{~S}$ proteasome non-ATPase regulatory subunit $3 \mathrm{GN}=$ PSMD3 $3 S M D 3$ _HUMAN $60.98 \quad 100.0 \%$ $26 \mathrm{~S}$ proteasome non-ATPase regulatory subunit $3 \mathrm{GN}=\mathrm{PSMD} 3$ PSMD3 HUMAN $60.98 \quad 100.0^{\circ}$ 26S proteasome non-ATPase regulatory subunit 3 GN=PSMD3 PSMD3_HUMAN $60.98 \quad 100.0 \%$ 26S proteasome non-ATPase regulatory subunit $3 \mathrm{GN}=$ PSMD3 PSMD3_HUMAN $60.98 \quad 100.0 \%$ $26 \mathrm{~S}$ proteasome non-ATPase regulatory subunit $3 \mathrm{GN}=\mathrm{PSMD} 3$ PSMD3 HUMAN $60.98100 .0 \%$ $26 \mathrm{~S}$ proteasome non-ATPase regulatory subunit $3 \mathrm{GN}=\mathrm{PSMD} 3 \mathrm{PSMD} 3$ _HUMAN $60.98 \quad 100.0 \%$ $26 \mathrm{~S}$ proteasome non-ATPase regulatory subunit $3 \mathrm{GN}=\mathrm{PSMD} 3$ PSMD3 HUMAN $60.98 \quad 100.0 \%$ 26S proteasome non-ATPase regulatory subunit 3 GN=PSMD3 PSMD3_HUMAN $60.98 \quad 100.0 \%$ 26S proteasome non-ATPase regulatory subunit $3 \mathrm{GN}=$ PSMD3 PSMD3_HUMAN $60.98 \quad 100.0 \%$ SOS proteasome non-ATPase regulatory subunit 3 GN=PSMD3 PSMD3_HUMAN $60.98 \quad 100.0^{\circ}$ 26S proteasome non-ATPase regulatory subunit $3 \mathrm{GN}=$ PSMD3 PSMD3_HUMAN $60.98 \quad 100.0 \%$ 26S proteasome non-ATPase regulatory subunit $3 \mathrm{GN}=$ PSMD3 PSMD3_HUMAN $60.98100 .0 \%$ $26 \mathrm{~S}$ proteasome non-ATPase regulatory subunit $3 \mathrm{GN}=\mathrm{PSMD} 3$ PSMD3_HUMAN $60.98 \quad 100.0 \%$ $26 \mathrm{~S}$ proteasome non-ATPase regulatory subunit $3 \mathrm{GN}=$ PSMD3 $\quad$ PSMD3_HUMAN $60.98 \quad 100.0 \%$ $26 \mathrm{~S}$ proteasome non-ATPase regulatory subunit $3 \mathrm{GN}=\mathrm{PSMD} 3$ PSMD3 HUMAN $60.98 \quad 100.0^{\circ} \%$ 26S proteasome non-ATPase regulatory subunit 4 GN=PSMD4 PSMD4_HUMAN $40.74 \quad 100.0 \%$ 26S proteasome non-ATPase regulatory subunit 4 GN=PSMD4 PSMD4_HUMAN $40.74 \quad 100.0 \%$ $26 \mathrm{~S}$ proteasome non-ATPase regulatory subunit $4 \mathrm{GN}=\mathrm{PSMD} 4 \mathrm{PSMD} 4$ HUMAN $40.74 \quad 100.0 \%$ 26S proteasome non-ATPase regulatory subunit 4 GN=PSMD4 PSMD4_HUMAN $40.74 \quad 100.0 \%$ 26S proteasome non-ATPase regulatory subunit 4 GN=PSMD4 PSMD4_HUMAN $40.74100 .0 \%$ 26S proteasome non-ATPase regulatory subunit 6 GN=PSMD6 PSMD6_HUMAN $45.53 \quad 100.0 \%$ 26S proteasome non-ATPase regulatory subunit $6 \mathrm{GN}=$ PSMD6 PSMD6_HUMAN $45.53 \quad 100.0 \%$ 26S proteasome non-ATPase regulatory subunit 7 GN=PSMD7 PSMD7_HUMAN $37.03 \quad 100.0 \%$ 26S proteasome non-ATPase regulatory subunit 7 GN=PSMD7 PSMD7_HUMAN $37.03 \quad 100.0 \%$
$10 \quad 0.01 \% \quad 7.7 \% \quad$ VNQFRQLYSK

$0.01 \% \quad 7.7 \% \quad$ VLTMPETCR

$0.00 \% \quad 8.1 \%$ TGQAAELGGLLK

$0.00 \% \quad 8.1 \%$ LYDNLLEQNLIR

$0.00 \% \quad 8.1 \%$ VVDSLYNKAK

$0.01 \% \quad 7.1 \%$ AVAVVVDPIQSVK

$0.01 \% \quad 7.1 \%$ AVAVVVDPIQSVKGK

$0.01 \% \quad 7.1 \%$ GKVVIDAFR

$0.05 \% \quad 15.5 \%$ SSTTSMTSVPKPLK

$0.05 \% \quad 15.5 \%$ CALGVFRK

$0.05 \% \quad 15.5 \%$ QMAFMLGR

$0.05 \% \quad 15.5 \%$ FGGSGSQVDSAR

$0.05 \% \quad 15.5 \%$ SGALLACGIVNSGVR

$0.05 \% \quad 15.5 \%$ SETELKDTYAR

$0.05 \% \quad 15.5 \%$ YGEPTLRR

$0.05 \% \quad 15.5 \%$ AVPLALALISVSNPR

$0.05 \% \quad 15.5 \%$ LNILDTLSK

$0.05 \% \quad 15.5 \%$ DPNNLFMVR

$0.05 \% \quad 15.5 \%$ MLVTFDEELRPLPVSVR

$0.05 \% \quad 15.5 \%$ VGQAVDVVGQAGKPK

$0.06 \% \quad 32.6 \%$ TAAAAAEHSQR

$0.06 \% 32.6 \%$ AVSGKEPR

$0.06 \% 32.6 \%$ RLNHYVLYK

$0.06 \% 32.6 \%$ AVQGFFTSNNATR

$0.06 \% 32.6 \%$ ISDDLMQK

$0.06 \% 32.6 \%$ VYEFLDKLDVVR

$0.06 \% 32.6 \%$ HDADGQATLLNLLLR

$0.06 \% \quad 32.6 \%$ NYLHYSLYDQAEK

$0.06 \% 32.6 \%$ NYLHYSLYDQAEKL

$0.06 \% \quad 32.6 \%$ IKAIQLEYSEAR

$0.06 \% 32.6 \%$ AIQLEYSEAR

$0.06 \% \quad 32.6 \%$ TMTNALRK

$0.06 \% 32.6 \%$ SLMPYFLLTQAVR

$0.06 \% 32.6 \%$ FNQVLDQFGEK

$0.06 \% \quad 32.6 \%$ ISLADIAQK

$0.06 \% \quad 32.6 \%$ LQLDSPEDAEFIVAK

$0.06 \% \quad 32.6 \%$ ISFCLDIHNMSVK

$0.03 \% \quad 17.8 \%$ VLESTMVCVDNSEYMR

$0.03 \% \quad 17.8 \%$ ILSKLHTVQPK

$0.03 \% \quad 17.8 \%$ GKITFCTGIR

$0.03 \% \quad 17.8 \%$ IIAFVGSPVEDNEKDLVK

$0.03 \% \quad 17.8 \%$ NAMGSLASQATK

$0.01 \% \quad 7.7 \%$ PLENLEEEGLPKNPDLR

$0.01 \% \quad 7.7 \%$ IGLFYMDNDLITR

$0.00 \% \quad 6.8 \%$ DIKDTTVGTLSQR

$0.00 \% \quad 6.8 \% \quad$ ITNQVHGLK $\begin{array}{llllllll}97.6 \% & 16.2 & 25.0 & 15.9 & 1 & 0 & 0 & 1282.69\end{array}$

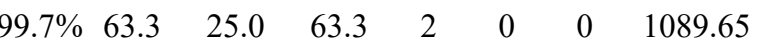

$\begin{array}{llllllll}99.3 \% & 19.6 & 25.0 & 19.1 & 1 & 0 & 0 & 1106.53\end{array}$

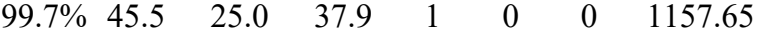

$\begin{array}{llll}99.7 \% & 37.8 & 25.0 & 37.8\end{array}$

$99.7 \% \quad 34.4 \quad 25.0 \quad 33.5$

$99.7 \% \quad 42.5 \quad 25.0 \quad 42.5$

$\begin{array}{lllll}99.7 \% & 35.5 & 25.0 & 35.5 & 2\end{array}$

$99.5 \% \quad 22.8 \quad 25.0 \quad 22.8$

$\begin{array}{llll}99.7 \% & 52.3 & 25.0 & 45.3\end{array}$

$\begin{array}{llll}94.6 \% & 17.2 & 25.0 & 13.6\end{array}$

$99.0 \% \quad 30.4 \quad 25.0 \quad 21.9$

$\begin{array}{llll}99.7 \% & 57.2 & 25.0 & 52.6\end{array}$

$\begin{array}{llll}99.7 \% & 48.2 & 25.0 & 48.2\end{array}$

$\begin{array}{llll}99.7 \% & 33.2 & 25.0 & 33.2\end{array}$

$\begin{array}{llll}95.8 \% & 15.0 & 25.0 & 14.5\end{array}$

$\begin{array}{llll}99.7 \% & 26.7 & 25.0 & 26.7\end{array}$

$\begin{array}{llll}99.4 \% & 32.9 & 25.0 & 10.9\end{array}$

$\begin{array}{llll}99.5 \% & 25.8 & 25.0 & 21.0\end{array}$

$\begin{array}{llll}99.7 \% & 29.0 & 25.0 & 29.0\end{array}$

$\begin{array}{llll}99.7 \% & 44.0 & 25.0 & 39.0\end{array}$

$99.7 \% \quad 29.5 \quad 25.0 \quad 25.4$

$\begin{array}{llll}99.0 \% & 32.9 & 25.0 & 15.3\end{array}$

$\begin{array}{lllll}99.7 \% & 31.1 & 25.0 & 16.1 & 2\end{array}$

$99.7 \% \quad 75.4 \quad 25.0 \quad 75.4$

$\begin{array}{llll}99.0 \% & 34.5 & 25.0 & 21.3\end{array}$

$\begin{array}{llll}99.7 \% & 52.3 & 25.0 & 52.1\end{array}$

$99.7 \% \quad 70.8 \quad 25.0 \quad 70.8$

$\begin{array}{llll}99.7 \% & 61.9 & 25.0 & 52.6\end{array}$

$\begin{array}{llll}99.7 \% & 27.9 & 25.0 & 24.3\end{array}$

$\begin{array}{llll}99.7 \% & 51.8 & 25.0 & 51.5\end{array}$

$\begin{array}{lllll}99.7 \% & 59.3 & 25.0 & 55.9 & 2\end{array}$

$98.4 \% \quad 19.6 \quad 25.0 \quad 15.9$

$\begin{array}{llll}99.7 \% & 46.8 & 25.0 & 46.8\end{array}$

$99.7 \% \quad 53.5 \quad 25.0 \quad 40.8$

$\begin{array}{llll}99.1 \% & 37.1 & 25.0 & 0.0\end{array}$

$\begin{array}{lllll}99.7 \% & 65.4 & 25.0 & 54.2 & 2\end{array}$

$99.7 \% \quad 52.9 \quad 25.0 \quad 50.2$

$\begin{array}{llll}99.7 \% & 44.9 & 25.0 & 44.9\end{array}$

$\begin{array}{llll}99.7 \% & 39.0 & 25.0 & 39.0\end{array}$

$\begin{array}{llll}99.7 \% & 43.9 & 25.0 & 41.8\end{array}$

$\begin{array}{llll}99.7 \% & 44.2 & 25.0 & 39.7\end{array}$

$\begin{array}{llll}99.7 \% & 48.2 & 25.0 & 48.2\end{array}$

$99.7 \% \quad 29.1 \quad 25.0 \quad 27.9$

$\begin{array}{lllll}99.7 \% & 50.2 & 25.0 & 50.2 & 2\end{array}$

$\begin{array}{llll}99.7 \% & 47.1 & 25.0 & 47.1\end{array}$

$\begin{array}{llll}97.5 \% & 16.9 & 25.0 & 16.9\end{array}$

1503.82

1136.63

1324.78

1509.90

1004.59

1463.78

950.52

953.47

1167.54

1473.78

1312.64

991.53

1520.92

1016.60

1105.55

2001.08

1452.82

1112.54

843.47

1205.68

1412.69

949.47

1495.82

1649.90

1643.77

2071.05

1420.78

1179.60

934.51

1554.84

1324.65

958.56

1674.86

1563.77

1948.84

1263.78

1152.62

1973.06

1178.58

1963.01

1586.79

1433.76

1009.58 
28 S ribosomal protein S18b, mitochondrial GN=MRPS18B RT18B_HUMAN $29.40 \quad 100.0 \%$ $28 \mathrm{~S}$ ribosomal protein S18b, mitochondrial GN=MRPS18B RT18B_HUMAN $29.40 \quad 100.0 \%$ $28 \mathrm{~S}$ ribosomal protein S18b, mitochondrial GN=MRPS18B RT18B_HUMAN $29.40 \quad 100.0 \%$ $28 \mathrm{~S}$ ribosomal protein S18b, mitochondrial GN=MRPS18B RT18B_HUMAN $29.40 \quad 100.0 \%$ $28 \mathrm{~S}$ ribosomal protein S18b, mitochondrial GN=MRPS18B RT18B_HUMAN $29.40 \quad 100.0 \%$ $28 \mathrm{~S}$ ribosomal protein S2, mitochondrial GN=MRPS2 RT02_HUMAN $33.25 \quad 100.0 \%$ $28 \mathrm{~S}$ ribosomal protein S2, mitochondrial GN=MRPS2 RT02_HUMAN $33.25 \quad 100.0 \%$ $28 \mathrm{~S}$ ribosomal protein S22, mitochondrial GN=MRPS22 RT22_HUMAN $41.28 \quad 100.0 \%$ $28 \mathrm{~S}$ ribosomal protein S22, mitochondrial GN=MRPS22 RT22 HUMAN $41.28 \quad 100.0 \%$ $28 \mathrm{~S}$ ribosomal protein S22, mitochondrial GN=MRPS22 RT22_HUMAN $41.28 \quad 100.0 \%$ $28 \mathrm{~S}$ ribosomal protein S22, mitochondrial GN=MRPS22 RT22_HUMAN $41.28 \quad 100.0 \%$ $28 \mathrm{~S}$ ribosomal protein S22, mitochondrial GN=MRPS22 RT22_HUMAN $41.28 \quad 100.0 \%$ $28 \mathrm{~S}$ ribosomal protein S22, mitochondrial GN=MRPS22 RT22_HUMAN $41.28 \quad 100.0 \%$ $28 \mathrm{~S}$ ribosomal protein S22, mitochondrial GN=MRPS22 RT22_HUMAN $41.28 \quad 100.0 \%$ $28 \mathrm{~S}$ ribosomal protein S22, mitochondrial GN=MRPS22 RT22_HUMAN $41.28 \quad 100.0 \%$ $28 \mathrm{~S}$ ribosomal protein S23, mitochondrial GN=MRPS23 RT23_HUMAN $21.77 \quad 100.0 \%$ $28 \mathrm{~S}$ ribosomal protein S23, mitochondrial GN=MRPS23 RT23 HUMAN $21.77 \quad 100.0 \%$ $28 \mathrm{~S}$ ribosomal protein S23, mitochondrial GN=MRPS23 RT23_HUMAN $21.77 \quad 100.0 \%$ $28 \mathrm{~S}$ ribosomal protein S23, mitochondrial GN=MRPS23 RT23_HUMAN $21.77 \quad 100.0 \%$ $28 \mathrm{~S}$ ribosomal protein S23, mitochondrial GN=MRPS23 RT23_HUMAN $21.77 \quad 100.0 \%$ $28 \mathrm{~S}$ ribosomal protein S23, mitochondrial GN=MRPS23 RT23_HUMAN $21.77 \quad 100.0 \%$ $28 \mathrm{~S}$ ribosomal protein S23, mitochondrial GN=MRPS23 RT23_HUMAN $21.77 \quad 100.0 \%$ $28 \mathrm{~S}$ ribosomal protein S25, mitochondrial GN=MRPS25 RT25_HUMAN $20.12 \quad 100.0 \%$ $28 \mathrm{~S}$ ribosomal protein S25, mitochondrial GN=MRPS25 RT25_HUMAN $20.12 \quad 100.0 \%$ $28 \mathrm{~S}$ ribosomal protein S27, mitochondrial GN=MRPS27 RT27_HUMAN $47.61 \quad 100.0 \%$ $28 \mathrm{~S}$ ribosomal protein S27, mitochondrial GN=MRPS27 RT27_HUMAN $47.61 \quad 100.0 \%$ $28 \mathrm{~S}$ ribosomal protein S27, mitochondrial GN=MRPS27 RT27_HUMAN $47.61 \quad 100.0 \%$ $28 \mathrm{~S}$ ribosomal protein S27, mitochondrial GN=MRPS27 RT27_HUMAN $47.61 \quad 100.0 \%$ $28 \mathrm{~S}$ ribosomal protein S27, mitochondrial GN=MRPS27 RT27_HUMAN $47.61 \quad 100.0 \%$ $28 \mathrm{~S}$ ribosomal protein S27, mitochondrial GN=MRPS27 RT27_HUMAN $47.61 \quad 100.0 \%$ $28 \mathrm{~S}$ ribosomal protein S29, mitochondrial GN=DAP3 RT29_HUMAN $45.57 \quad 100.0 \%$ $28 \mathrm{~S}$ ribosomal protein S29, mitochondrial GN=DAP3 RT29_HUMAN $45.57 \quad 100.0 \%$ $28 \mathrm{~S}$ ribosomal protein $\mathrm{S} 29$, mitochondrial GN=DAP3 RT29_HUMAN $45.57 \quad 100.0 \%$ $28 \mathrm{~S}$ ribosomal protein S29, mitochondrial GN=DAP3 RT29_HUMAN $45.57 \quad 100.0 \%$ $28 \mathrm{~S}$ ribosomal protein S29, mitochondrial GN=DAP3 RT29_HUMAN $45.57 \quad 100.0 \%$ $28 \mathrm{~S}$ ribosomal protein $\mathrm{S} 29$, mitochondrial GN=DAP3 RT29_HUMAN $45.57 \quad 100.0 \%$ $28 \mathrm{~S}$ ribosomal protein $\mathrm{S} 29$, mitochondrial GN=DAP3 RT29_HUMAN $45.57 \quad 100.0 \%$ $28 \mathrm{~S}$ ribosomal protein $\mathrm{S} 29$, mitochondrial GN=DAP3 RT29 HUMAN $45.57 \quad 100.0 \%$ $28 \mathrm{~S}$ ribosomal protein S31, mitochondrial GN=MRPS31 RT31_HUMAN $45.32 \quad 100.0 \%$ $28 \mathrm{~S}$ ribosomal protein S31, mitochondrial GN=MRPS31 RT31_HUMAN $45.32 \quad 100.0 \%$ $28 \mathrm{~S}$ ribosomal protein S31, mitochondrial GN=MRPS31 RT31_HUMAN $45.32 \quad 100.0 \%$ $28 \mathrm{~S}$ ribosomal protein S31, mitochondrial GN=MRPS31 RT31_HUMAN $45.32 \quad 100.0 \%$ $28 \mathrm{~S}$ ribosomal protein S31, mitochondrial GN=MRPS31 RT31_HUMAN $45.32 \quad 100.0 \%$ $28 \mathrm{~S}$ ribosomal protein S35, mitochondrial GN=MRPS35 RT35_HUMAN $36.85 \quad 100.0 \%$ $28 \mathrm{~S}$ ribosomal protein $\mathrm{S} 35$, mitochondrial GN=MRPS35 RT35_HUMAN $36.85 \quad 100.0 \%$ $28 \mathrm{~S}$ ribosomal protein $\mathrm{S} 35$, mitochondrial GN=MRPS35 RT35_HUMAN 36.85 28S ribosomal protein $\mathrm{S} 35$, mitochondrial GN=MRPS35 RT35_HUMAN 36.85
$0.01 \% \quad 29.1 \%$ NKVVGNPCPICR

$0.01 \% \quad 29.1 \%$ RLTQAIQK

$99.7 \% \quad 35.3 \quad 25.0 \quad 35.3$

$\begin{array}{llll}97.5 \% & 17.3 & 25.0 & 15.6\end{array}$

$99.2 \% \quad 22.0 \quad 25.0 \quad 22.0$

$\begin{array}{lllll}0.01 \% & 29.1 \% & \text { LYQGHLQEESGPPPESMPK } & 99.7 \% & 52.4 \\ 0.01 \% & 29.1 \% & \text { MPPRTPAEASSTGQTGPQSAL } & 99.7 \% & 50.5\end{array}$

$0.00 \% \quad 6.4 \%$ FMEPYIFGSR

$0.00 \% \quad 6.4 \%$ RQQVEALYR

$0.02 \% \quad 25.0 \%$ MTGLNLQK

$0.02 \% \quad 25.0 \%$ TFKPAIQELKPPTYK

$0.02 \% \quad 25.0 \%$ LMTQAQLEEATR

$0.02 \% \quad 25.0 \%$ FIVVREPSGTLR

$0.02 \% \quad 25.0 \%$ MIQVYFPK

$0.02 \% \quad 25.0 \%$ ILTPIIFKEENLR

$0.02 \% \quad 25.0 \%$ IDGLLIDQIQR

$0.02 \% \quad 25.0 \%$ DQAAEGINLIK

$0.02 \% \quad 35.8 \%$ LETVGSIFSR

$0.02 \% 35.8 \%$ AKFYSVYGSGQR

$0.02 \% \quad 35.8 \%$ AFDLFNPNFK

$0.02 \% \quad 35.8 \%$ FVEKYTELQK

$0.02 \% \quad 35.8 \%$ LGETDEEKLFVETGK

$0.02 \% \quad 35.8 \%$ ALLAEGVILR

$0.02 \% 35.8 \%$ ALLAEGVILRR

$0.00 \% \quad 15.0 \%$ TLQYLSQGNVVFKDSVK

$0.00 \% \quad 15.0 \%$ AALKADAQD

$0.02 \% \quad 15.7 \%$ KLPVSSLTISR

$0.02 \% \quad 15.7 \%$ LIDNISSR

$0.02 \% \quad 15.7 \%$ NFGASLLLPGLK

$0.02 \% \quad 15.7 \%$ VAASPEDIKLCR

$0.02 \% \quad 15.7 \%$ EALDVLGAVLK

$0.02 \% \quad 15.7 \%$ EQAKQEYQAQK

$0.02 \% \quad 22.4 \%$ TFSEACLMVR

$0.02 \% \quad 22.4 \%$ NTSFAYPAIR

$0.02 \% \quad 22.4 \%$ FDQPLEASTWLK

$0.02 \% \quad 22.4 \%$ FLNQIKVQEK

$\begin{array}{llll}94.9 \% & 14.4 & 25.0 & 14.4\end{array}$

$\begin{array}{llll}99.5 \% & 26.7 & 25.0 & 16.2\end{array}$

$\begin{array}{lllll}98.7 \% & 25.1 & 25.0 & 13.2 & 2\end{array}$

$99.2 \% \quad 18.9 \quad 25.0 \quad 18.9$

$\begin{array}{llll}99.7 \% & 51.3 & 25.0 & 44.7\end{array}$

$\begin{array}{lllll}99.6 \% & 23.7 & 25.0 & 18.5 & 2\end{array}$

$99.0 \% \quad 41.2 \quad 25.0 \quad 39.8$

$\begin{array}{llll}99.7 \% & 33.1 & 25.0 & 33.1\end{array}$

$99.7 \% \quad 31.0 \quad 25.0 \quad 21.9$

$\begin{array}{llll}99.7 \% & 47.4 & 25.0 & 36.8\end{array}$

$\begin{array}{lllll}99.7 \% & 53.9 & 25.0 & 41.8 & 2\end{array}$

$\begin{array}{llll}99.7 \% & 37.3 & 25.0 & 37.3\end{array}$

$99.7 \% \quad 40.9 \quad 25.0 \quad 38.9$

$\begin{array}{llll}99.7 \% & 32.7 & 25.0 & 32.7\end{array}$

$99.7 \% \quad 24.4 \quad 25.0 \quad 24.4$

$\begin{array}{llll}99.7 \% & 61.6 & 25.0 & 38.4\end{array}$

$\begin{array}{llll}99.6 \% & 23.6 & 25.0 & 19.6\end{array}$

$99.7 \% \quad 54.7$

$\begin{array}{lll}97.6 \% & 22.8\end{array}$

$99.7 \% \quad 47.9$

$95.8 \% \quad 25.0$

$99.7 \% \quad 42.0$

$99.7 \% \quad 49.0$

$99.7 \% \quad 62.7$

$99.7 \% \quad 35.2$

$99.7 \% \quad 32.9$

$99.7 \% \quad 48.8$

$99.7 \% \quad 43.8$

$99.7 \% \quad 33.2$

$0.02 \% \quad 22.4 \%$ ESTEKGSPLGEVVEQ

$0.02 \% \quad 22.4 \%$ GSPLGEVVEQGITR

$0.02 \% \quad 22.4 \%$ VRNATDAVGIVLK

$0.02 \% \quad 22.4 \%$ ELLFLSNANPSLLER

$0.02 \% \quad 8.6 \%$ GMKVELSTVNVR

$0.02 \% \quad 8.6 \%$ VELSTVNVR

$0.02 \% \quad 8.6 \%$ RATEYAPK

$0.02 \% \quad 8.6 \%$ ISFSNIISDMK

$0.02 \% \quad 8.6 \%$ ISFSNIISDMKVAR

$0.01 \% \quad 9.9 \%$ VKLSSLNLDDHAK

$0.01 \% \quad 9.9 \%$ LSSLNLDDHAK

$0.01 \% \quad 9.9 \%$ LVGERYCK

$0.01 \% \quad 9.9 \%$ TTDVLTIKTDR
$99.7 \% 71.1$

$95.1 \% \quad 20.7$

$99.7 \% \quad 51.4$

$99.7 \% \quad 30.1$

$99.7 \% \quad 43.3$

$99.0 \% \quad 21.6$

$99.7 \% \quad 53.0$

$99.7 \% \quad 30.5$

$99.7 \% \quad 37.6$

$99.7 \% \quad 43.8$

$98.5 \% \quad 17.5$

$99.7 \% \quad 34.3$
141

1413.71

1786.96

2140.00

2100.00

1246.59

1162.63

904.49

1760.99

1390.70

1373.79

1025.55

1585.93

1283.73

1171.63

1108.60

1362.68

1212.60

1284.68

1694.85

1054.66

1210.76

1926.03

902.46

1200.73

917.51

1229.73

1358.71

1127.67

1350.66

1229.57

1139.58

1434.73

1246.72

2016.02

1441.76

1355.80

1715.93

1332.73

1016.57

935.49

1270.63

1596.84

1439.79

1212.62

1024.52

1262.70
$49 \quad 156$

$19 \quad 237$

$238 \quad 258$

$101 \quad 110$

$264 \quad 272$

$82 \quad 89$

$90 \quad 104$

$105 \quad 116$

$192 \quad 199$

$204 \quad 216$

$281 \quad 291$

319329

$\begin{array}{ll}6 & 15 \\ 72 & 83\end{array}$

$84 \quad 93$

$99 \quad 108$

$109 \quad 123$

$124 \quad 133$

$124 \quad 134$

$165 \quad 173$

$75 \quad 82$

$203 \quad 214$

$266 \quad 277$

$\begin{array}{ll}278 & 288 \\ 398 & 408\end{array}$

$93 \quad 102$

$114 \quad 123$

$178 \quad 189$

$198 \quad 207$

$214 \quad 232$

$219 \quad 232$

379

$105 \quad 116$

$108 \quad 116$

$138 \quad 145$

$199 \quad 209$

$199 \quad 212$

$175 \quad 187$

$177 \quad 187$

$193 \quad 200$

201211 
$28 \mathrm{~S}$ ribosomal protein $\mathrm{S} 5$, mitochondrial GN=MRPS5 RT05_HUMAN $48.01 \quad 100.0 \%$ $28 \mathrm{~S}$ ribosomal protein S5, mitochondrial GN=MRPS5 RT05_HUMAN $48.01 \quad 100.0 \%$ $28 \mathrm{~S}$ ribosomal protein S5, mitochondrial GN=MRPS5 RT05_HUMAN $48.01 \quad 100.0 \%$ $28 \mathrm{~S}$ ribosomal protein $\mathrm{S} 5$, mitochondrial GN=MRPS5 RT05 HUMAN $48.01 \quad 100.0 \%$ $28 \mathrm{~S}$ ribosomal protein S5, mitochondrial GN=MRPS5 RT05_HUMAN $48.01 \quad 100.0 \%$ $28 \mathrm{~S}$ ribosomal protein S5, mitochondrial GN=MRPS5 RT05_HUMAN $48.01 \quad 100.0 \%$ $28 \mathrm{~S}$ ribosomal protein S5, mitochondrial GN=MRPS5 RT05_HUMAN $48.01 \quad 100.0 \%$ $28 \mathrm{~S}$ ribosomal protein S9, mitochondrial GN=MRPS9 RT09_HUMAN $45.84 \quad 100.0 \%$ $28 \mathrm{~S}$ ribosomal protein $\mathrm{S} 9$, mitochondrial GN=MRPS9 RT09 HUMAN $45.84 \quad 100.0 \%$ $28 \mathrm{~S}$ ribosomal protein $\mathrm{S} 9$, mitochondrial GN=MRPS9 RT09_HUMAN $45.84 \quad 100.0 \%$ $28 \mathrm{~S}$ ribosomal protein $\mathrm{S} 9$, mitochondrial GN=MRPS9 RT09_HUMAN $45.84 \quad 100.0 \%$ 8 ribosomal protein $\mathrm{S} 9$, mitochondrial GN=MRPS9 RT09 HUMAN $45.84 \quad 100.0 \%$ $28 \mathrm{~S}$ ribosomal protein S9, mitochondrial GN=MRPS9 RT09_HUMAN $45.84 \quad 100.0 \%$ 2-amino-3-ketobutyrate coenzyme A ligase, mitochondrial GN=GCAT KBL HUMAN 45.29 100.0\% 2-amino-3-ketobutyrate coenzyme A ligase, mitochondrial GN=GCAT KBL HUMAN $45.29 \quad 100.0 \%$ 2-amino-3-ketobutyrate coenzyme A ligase, mitochondrial GN=GCAT KBL_HUMAN $45.29 \quad 100.0 \%$ 2-amino-3-ketobutyrate conzyme A ligase, mitochondrial $\mathrm{GN}=\mathrm{GCAT} \quad \mathrm{KBL} H \mathrm{HUMAN} 45.29 \quad 100.0 \%$ 2-oxoisovalerate dehydrogenase subunit beta, mitochondrial GN=BCKDHB ODBB_HUMAN $43.12 \quad 100.0 \%$ 2-oxoisovalerate dehydrogenase subunit beta, mitochondrial GN=BCKDHB ODBB_HUMAN $43.12 \quad 100.0 \%$ 39S ribosomal protein L1, mitochondrial GN=MRPL1 RM01_HUMAN $36.91 \quad 100.0 \%$ 39S ribosomal protein L1, mitochondrial GN=MRPL1 RM01_HUMAN $36.91 \quad 100.0 \%$ 39S ribosomal protein $\mathrm{L} 1$, mitochondrial GN=MRPL1 RM01_HUMAN $36.91 \quad 100.0 \%$ 39S ribosomal protein L11, mitochondrial GN=MRPL11 RM11_HUMAN $20.68 \quad 100.0 \%$ 39S ribosomal protein L11, mitochondrial GN=MRPL11 RM11_HUMAN $20.68 \quad 100.0 \%$ 39S ribosomal protein L15, mitochondrial GN=MRPL15 RM15 HUMAN $33.42 \quad 100.0^{\circ}$ 39S ribosomal protein L15, mitochondrial GN=MRPL15 RM15_HUMAN $33.42 \quad 100.0 \%$ 39S ribosomal protein L15, mitochondrial GN=MRPL15 RM15_HUMAN $33.42 \quad 100.0 \%$ 39S ribosomal protein L15, mitochondrial GN=MRPL15 RM15_HUMAN $33.42 \quad 100.0 \%$ 39S ribosomal protein L15, mitochondrial GN=MRPL15 RM15_HUMAN $33.42 \quad 100.0 \%$ 39S ribosomal protein $\mathrm{L} 15$, mitochondrial GN=MRPL15 RM15 HUMAN $33.42100 .0 \%$ 39S ribosomal protein L15, mitochondrial GN=MRPL15 RM15_HUMAN $33.42 \quad 100.0 \%$ 39S ribosomal protein L15, mitochondrial GN=MRPL15 RM15_HUMAN $33.42 \quad 100.0 \%$ 39S ribosomal protein $\mathrm{L} 15$, mitochondrial GN=MRPL15 RM15 HUMAN $33.42 \quad 100.0 \%$ 39S ribosomal protein L15, mitochondrial GN=MRPL15 RM15_HUMAN $33.42 \quad 100.0 \%$ 39S ribosomal protein L19, mitochondrial GN=MRPL19 RM19 HUMAN $33.54 \quad 100.0 \%$ 39S ribosomal protein L19, mitochondrial GN=MRPL19 RM19_HUMAN $33.54 \quad 100.0 \%$ 39S ribosomal protein L19, mitochondrial GN=MRPL19 RM19_HUMAN $33.54 \quad 100.0 \%$ $39 \mathrm{~S}$ ribosomal protein $\mathrm{L} 2$, mitochondrial GN=MRPL2 RM02 HUMAN $33.30 \quad 100.0 \%$ 39S ribosomal protein L2, mitochondrial GN=MRPL2 RM02_HUMAN $33.30 \quad 100.0 \%$ 39S ribosomal protein L2, mitochondrial GN=MRPL2 RM02_HUMAN $33.30 \quad 100.0 \%$ 39S ribosomal protein $\mathrm{L} 3$, mitochondrial GN=MRPL3 RM03 HUMAN $38.63 \quad 100.0 \%$ 39S ribosomal protein $\mathrm{L} 3$, mitochondrial GN=MRPL3 RM03_HUMAN $38.63 \quad 100.0 \%$ 39S ribosomal protein $\mathrm{L} 37$, mitochondrial GN=MRPL37 RM37_HUMAN $48.12 \quad 100.0 \%$ 39S ribosomal protein $\mathrm{L} 37$, mitochondrial GN=MRPL37 RM37_HUMAN $48.12 \quad 100.0 \%$ 39S ribosomal protein L37, mitochondrial GN=MRPL37 RM37_HUMAN $48.12 \quad 100.0 \%$ 39S ribosomal protein $\mathrm{L} 37$, mitochondrial GN=MRPL37 RM37_HUMAN $48.12 \quad 100.0 \%$ 39 S ribosomal protein $\mathrm{L} 37$, mitochondrial GN=MRPL37 RM37_HUMAN $48.12 \quad 100.0 \%$
17.7\% GALAETGAGAK

$0.02 \% \quad 17.7 \%$ LIGIKDMYAK

$0.02 \% \quad 17.7 \%$ VSGSINMLSLTQGLFR

$0.02 \% \quad 17.7 \%$ SVWSNLKR

$0.02 \% \quad 12.6 \%$ QIEEFNIGKR

$0.02 \% \quad 12.6 \%$ SLLPEKTVTR

$0.02 \% \quad 12.6 \%$ TAKAEAIVYK

$0.02 \% \quad 12.6 \%$ AEAIVYKHGSGR

$0.02 \% \quad 12.6 \%$ LGKHDVTCTVSGGGR

$0.02 \% \quad 12.6 \%$ HDVTCTVSGGGR

$0.02 \% \quad 14.6 \%$ ALGGASGGYTTGPGPLVSLLR

$0.02 \% \quad 14.6 \%$ ALDLLMGSNTIVQSMAAK

$0.02 \% \quad 14.6 \%$ MADDMLKR

$0.02 \% \quad 14.6 \%$ GIFVIGFSYPVVPK

$0.01 \% \quad 6.1 \%$ SGDLFNCGSLTIR

$0.01 \% \quad 6.1 \%$ LGVSCEVIDLR

$0.01 \% \quad 6.2 \% \quad$ KFQILDFTSPK

$0.01 \% \quad 6.2 \% \quad$ FQILDFTSPK

$0.01 \% \quad 6.2 \%$ NSIGRDIPK

$0.00 \% \quad 14.6 \%$ AGLAMPGPPLGPVLGQR

$0.00 \% \quad 14.6 \%$ IGQPTVSYFLK

$0.03 \% \quad 35.1 \%$ VSLANLKPNPGSK

$0.03 \% \quad 35.1 \%$ LGFEGGQTPFYIR

$0.03 \% 35.1 \%$ LGFEGGQTPFYIRIPK

$0.03 \% \quad 35.1 \%$ YGFNEGHSFRR

$0.03 \% \quad 35.1 \%$ GVTIQPLKR

$0.03 \% \quad 35.1 \%$ NGGVVTTAFYDPR

$0.03 \% \quad 35.1 \%$ SLDIVCKPVPFFLR

$0.03 \% \quad 35.1 \%$ GYLADPAKFPEAR

$0.03 \% \quad 35.1 \%$ ILKPTDENLLK

$0.03 \% \quad 35.1 \%$ ILKPTDENLLKYYTS

$0.01 \% \quad 10.3 \%$ FLSPEFIPR

$0.01 \% \quad 10.3 \%$ VQEIQVVKLEK

$0.01 \% \quad 10.3 \%$ RLDDSLLYLR

$0.01 \% \quad 10.2 \%$ TKYTITPVK

$0.01 \% \quad 10.2 \%$ SADIALVAGGSR

$0.01 \% \quad 10.2 \%$ AAGTCGVLLR

$0.01 \% \quad 4.9 \%$ MATLSVGGK

$0.01 \% \quad 4.9 \%$ GFQGVMKR

$0.01 \% \quad 14.9 \%$ VYEIPGLEPITFAGK

$0.01 \% \quad 14.9 \%$ TKLIEGLPEK

$0.01 \% \quad 14.9 \%$ ESLLLQVR

$0.01 \% \quad 14.9 \%$ MILFAFGSALAQAR

$0.01 \% \quad 14.9 \%$ VLEQPVVVQSVGTDGR

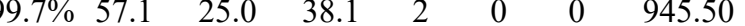

$\begin{array}{llllllll}99.7 \% & 33.6 & 25.0 & 31.6 & 1 & 0 & 0 & 1327.71\end{array}$

$\begin{array}{llllllll}99.7 \% & 64.3 & 25.0 & 41.8 & 4 & 0 & 0 & 1057.57\end{array}$

$\begin{array}{llllllll}99.7 \% & 28.3 & 25.0 & 28.0 & 1 & 0 & 0 & 856.53\end{array}$

$\begin{array}{llll}99.7 \% & 32.2 & 25.0 & 24.5\end{array}$

$\begin{array}{llll}99.7 \% & 67.8 & 25.0 & 63.5\end{array}$

$\begin{array}{llll}98.8 \% & 26.7 & 25.0 & 11.9\end{array}$

$\begin{array}{llll}99.5 \% & 22.1 & 25.0 & 18.3\end{array}$

$\begin{array}{llll}99.7 \% & 32.4 & 25.0 & 13.3\end{array}$

$\begin{array}{llll}99.7 \% & 34.1 & 25.0 & 24.9\end{array}$

$\begin{array}{llll}99.7 \% & 29.8 & 25.0 & 28.9\end{array}$

$\begin{array}{llll}99.7 \% & 32.8 & 25.0 & 32.8\end{array}$

$99.7 \% \quad 31.6 \quad 25.0 \quad 31.6$

$99.7 \% \quad 41.8$

$99.0 \% \quad 25.1$

$99.7 \% \quad 56.8$

$99.7 \% \quad 61.0$

$99.7 \% \quad 45.2$

$99.7 \% \quad 32.6$

$99.7 \% \quad 47.1$

$99.1 \% \quad 19.7$

$99.7 \% 33.5$

$99.7 \% \quad 39.4$

$99.7 \% \quad 44.0$

$99.7 \% \quad 56.3$

$99.7 \% \quad 51.1$

$99.6 \% 22.1$

$99.6 \% \quad 22.9$

$99.7 \% \quad 46.8$

$99.7 \% \quad 27.6$

$99.7 \% \quad 50.5$

$99.7 \% \quad 46.4$

$99.7 \% \quad 25.9$

$99.7 \% \quad 33.4$

$99.7 \% \quad 30.7$

$\begin{array}{lll}95.6 \% & 21.8\end{array}$

$99.7 \% \quad 26.7$

$99.7 \% \quad 56.4$

$99.7 \% 34.1$

$99.7 \% 33.6$

$98.3 \% \quad 22.7$

$99.7 \% \quad 33.9$

$99.7 \% \quad 27.9$

$99.0 \% \quad 47.6$

$99.7 \% \quad 44.8$

$99.7 \% \quad 31.6$

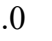

0
49.3

56.2

$\begin{array}{ll}.0 & 61.0\end{array}$

\begin{tabular}{ll}
5.0 & 34.3 \\
\hline
\end{tabular}

$\begin{array}{ll}5.0 & 31.0\end{array}$

$\begin{array}{ll}5.0 & 36.9\end{array}$

$\begin{array}{ll}25.0 & 18.2\end{array}$

$\begin{array}{ll}27.0 & 27.0\end{array}$

39.4

$\begin{array}{ll}0 & 38.9\end{array}$

\begin{tabular}{ll}
5.0 & 44.8 \\
\hline
\end{tabular}

51.1

\begin{tabular}{ll}
02.1 \\
\hline
\end{tabular}

$\begin{array}{lll}22.0 & 22.9 & 2\end{array}$

\begin{tabular}{ll}
.0 & 46.8 \\
\hline
\end{tabular}

$25.0 \quad 27.6$

$\begin{array}{lll}5.0 & 50.5 & 2\end{array}$

$\begin{array}{ll}25.0 & 42.5\end{array}$

$\begin{array}{ll}25.0 & 25.9\end{array}$

$\begin{array}{ll}3.0 & 31.5\end{array}$

$\begin{array}{ll}25.0 & 22.9\end{array}$

$\begin{array}{ll}21.0 & 21.8\end{array}$

$\begin{array}{ll}25.0 & 26.7 \\ 25.0 & 2\end{array}$

$25.0 \quad 45.2$

$\begin{array}{ll}52.0 & 32.9\end{array}$

\begin{tabular}{ll}
22.5 \\
\hline
\end{tabular}

$\begin{array}{ll}25.0 & 13.8\end{array}$

$\begin{array}{lll}33.0 & 33.9\end{array}$

$\begin{array}{ll}27.9 & 1\end{array}$

$\begin{array}{lll}25.0 & 25.4 & 2\end{array}$

20.6

11 $151 \quad 160$ $43 \quad 251$ $326 \quad 335$ 351
427 78 $83 \quad 192$ $278 \quad 287$ 1292 337 $26 \quad 337$ 286 326 383 $11 \quad 183$ $95 \quad 305$ $108 \quad 118$ $09 \quad 118$ $4 \quad 232$ 42 34 34
80 80 91 $\begin{array}{ll}6 & 134 \\ 0 & 182\end{array}$ $183 \quad 196$ $221 \quad 233$ 2292 $2 \quad 296$ 583 $1 \quad 181$ $2 \quad 191$ $36 \quad 147$ $209 \quad 218$ $142 \quad 150$ $214 \quad 221$ $\begin{array}{lc}49 & 63 \\ 126 & 135\end{array}$ $\begin{array}{ll}126 & 135 \\ 216 & 223\end{array}$

216
313 326 
39S ribosomal protein L38, mitochondrial GN=MRPL38 RM38 HUMAN $44.60 \quad 100.0 \%$ 39S ribosomal protein $\mathrm{L} 38$, mitochondrial GN=MRPL38 RM38 HUMAN $44.60 \quad 100.0 \%$ 39 S ribosomal protein L38, mitochondrial GN=MRPL38 RM38_HUMAN $44.60 \quad 100.0 \%$ 39 ribosomal protein $\mathrm{L} 39$, mitochondrial GN=MRPL39 RM39 HUMAN $38.71 \quad 100.0^{\circ}$ 39S ribosomal protein L39, mitochondrial GN=MRPL39 RM39_HUMAN $38.71 \quad 100.0 \%$ 39S ribosomal protein L39, mitochondrial GN=MRPL39 RM39_HUMAN $38.71 \quad 100.0 \%$ 39S ribosomal protein L39, mitochondrial GN=MRPL39 RM39 HUMAN $38.71 \quad 100.0 \%$ 39S ribosomal protein L39, mitochondrial GN=MRPL39 RM39_HUMAN $38.71 \quad 100.0 \%$ 39S ribosomal protein L39, mitochondrial GN=MRPL39 RM39 HUMAN $38.71 \quad 100.0 \%$ 39 S ribosomal protein L4, mitochondrial GN=MRPL4 RM04_HUMAN $34.92 \quad 100.0 \%$ 39S ribosomal protein L4, mitochondrial GN=MRPL4 RM04_HUMAN $34.92 \quad 100.0 \%$ 39 ribosomal protein $\mathrm{L} 44$, mitochondrial GN=MRPL44 RM44 HUMAN $37.54 \quad 100.0 \%$ 39S ribosomal protein L44, mitochondrial GN=MRPL44 RM44_HUMAN $37.54 \quad 100.0 \%$ 39S ribosomal protein L44, mitochondrial GN=MRPL44 RM44 HUMAN $37.54 \quad 100.0 \%$ 39S ribosomal protein $\mathrm{L} 44$, mitochondrial GN=MRPL44 RM44_HUMAN $37.54 \quad 100.0 \%$ 39S ribosomal protein L44, mitochondrial GN=MRPL44 RM44_HUMAN $37.54 \quad 100.0 \%$ 39S ribosomal protein $\mathrm{L} 44$, mitochondrial GN=MRPL44 RM44 HUMAN $37.54 \quad 100.0 \%$ 39S ribosomal protein L44, mitochondrial GN=MRPL44 RM44_HUMAN $37.54 \quad 100.0 \%$ 39S ribosomal protein L48, mitochondrial GN=MRPL48 RM48_HUMAN $23.94 \quad 100.0 \%$ 39S ribosomal protein L48, mitochondrial GN=MRPL48 RM48 HUMAN $23.94 \quad 100.0 \%$ $40 \mathrm{~S}$ ribosomal protein $\mathrm{S} 11 \mathrm{GN}=\mathrm{RPS} 11$ $40 \mathrm{~S}$ ribosomal protein $\mathrm{S} 11 \mathrm{GN}=\mathrm{RPS} 1$; $40 \mathrm{~S}$ ribosomal protein $\mathrm{S} 11 \mathrm{GN}=\mathrm{RPS} 11$ $40 \mathrm{~S}$ ribosomal protein $\mathrm{S} 2 \mathrm{GN}=\mathrm{RPS} 2$ $40 \mathrm{~S}$ ribosomal protein $\mathrm{S} 2 \mathrm{GN}=\mathrm{RPS} 2$ $40 \mathrm{~S}$ ribosomal protein $\mathrm{S} 2 \mathrm{GN}=\mathrm{RPS} 2$ $40 \mathrm{~S}$ ribosomal protein $\mathrm{S} 2 \mathrm{GN}=\mathrm{RPS} 2$ $40 \mathrm{~S}$ ribosomal protein $\mathrm{S} 2 \mathrm{GN}=\mathrm{RPS} 2$ $40 \mathrm{~S}$ ribosomal protein $\mathrm{S} 2 \mathrm{GN}=\mathrm{RPS} 2$ $40 \mathrm{~S}$ ribosomal protein $\mathrm{S} 2 \mathrm{GN}=\mathrm{RPS} 2$ $40 \mathrm{~S}$ ribosomal protein $\mathrm{S} 2 \mathrm{GN}=\mathrm{RPS} 2$ $40 \mathrm{~S}$ ribosomal protein $\mathrm{S} 2 \mathrm{GN}=\mathrm{RPS} 2$ $40 \mathrm{~S}$ ribosomal protein $\mathrm{S} 2 \mathrm{GN}=\mathrm{RPS} 2$ $40 \mathrm{~S}$ ribosomal protein $\mathrm{S} 2 \mathrm{GN}=\mathrm{RPS} 2$ $40 \mathrm{~S}$ ribosomal protein $\mathrm{S} 2 \mathrm{GN}=\mathrm{RPS} 2$ $40 \mathrm{~S}$ ribosomal protein $\mathrm{S} 2 \mathrm{GN}=\mathrm{RPS} 2$ $40 \mathrm{~S}$ ribosomal protein $\mathrm{S} 2 \mathrm{GN}=\mathrm{RPS} 2$ $40 \mathrm{~S}$ ribosomal protein $\mathrm{S} 2 \mathrm{GN}=\mathrm{RPS} 2$ $40 \mathrm{~S}$ ribosomal protein $\mathrm{S} 2 \mathrm{GN}=\mathrm{RPS} 2$ $40 \mathrm{~S}$ ribosomal protein $\mathrm{S} 2 \mathrm{GN}=\mathrm{RPS} 2$ $40 \mathrm{~S}$ ribosomal protein $\mathrm{S} 2 \mathrm{GN}=\mathrm{RPS} 2$ $40 \mathrm{~S}$ ribosomal protein $\mathrm{S} 2 \mathrm{GN}=\mathrm{RPS} 2$ $40 \mathrm{~S}$ ribosomal protein $\mathrm{S} 2 \mathrm{GN}=\mathrm{RPS} 2$ $40 \mathrm{~S}$ ribosomal protein $\mathrm{S} 3 \mathrm{GN}=\mathrm{RPS} 3$ $40 \mathrm{~S}$ ribosomal protein $\mathrm{S} 3 \mathrm{GN}=\mathrm{RPS} 3$ $40 \mathrm{~S}$ ribosomal protein $\mathrm{S} 3 \mathrm{GN}=\mathrm{RPS} 3$ $40 \mathrm{~S}$ ribosomal protein $\mathrm{S} 3 \mathrm{GN}=\mathrm{RPS} 3$

RS11_HUMAN $18.43 \quad 100.0 \%$

RS11_HUMAN $18.43 \quad 100.0 \%$ RS2_HUMAN $31.33 \quad 100.0 \%$ RS2 HUMAN $31.33 \quad 100.0 \% \quad 20$
$0.01 \% \quad 9.2 \%$ TQQLLERK

$0.01 \% \quad 9.2 \%$ ANVEEERAAR

$99.7 \% \quad 32$.

$\begin{array}{lllll}99.7 \% & 30.5 & 25.0 & 30.0 & 1\end{array}$

$0.02 \% \quad 18.9 \%$ HVGKTDPGTVFVMNK

$\begin{array}{llll}98.3 \% & 17.0 & 25.0 & 17.0\end{array}$

$\begin{array}{llll}99.7 \% & 25.7 & 25.0 & 25.7\end{array}$

$0.02 \% \quad 18.9 \%$ SCAMMMGCVIER

$0.02 \%-18.9 \%$

$1 \quad 0.02 \% \quad 18.9 \%$ VALEIFQHSK

$\begin{array}{cccccccc}11 & 0.02 \% & 18.9 \% & \text { IGDFIDVSEGPLIPR } & 99.7 \% & 57.2 & 25.0 & 54.8 \\ 4 & 0.01 \% & 9.3 \% & \text { ATENPEQVASEGLPEPVLR } & 99.7 \% & 48.8 & 25.0 & 48.8\end{array}$

$\begin{array}{llll}99.7 \% & 43.6 & 25.0 & 37.1\end{array}$

$99.7 \% \quad 28.8 \quad 25.0 \quad 28.8$

$\begin{array}{lllll}98.8 \% & 25.2 & 25.0 & 21.4 & 2\end{array}$

$\begin{array}{lllllll}0.01 \% & 9.3 \% & \text { KVELPVPTHR } & 99.7 \% & 35.6 & 25.0 & 34.5\end{array}$

$0.02 \% \quad 21.7 \%$ LQENFSLDLLK

$0.02 \% \quad 21.7 \%$ TAFVNSCYIK

$0.02 \% \quad 21.7 \%$ QQLGIEKEAVLLNLK

$99.7 \% \quad 56.1 \quad 25.0 \quad 39.0$

$\begin{array}{lllll}99.7 \% & 29.9 & 25.0 & 29.9 & 2\end{array}$

$\begin{array}{llll}98.0 \% & 16.8 & 25.0 & 16.8\end{array}$

$\begin{array}{llll}95.7 \% & 14.2 & 25.0 & 14.2\end{array}$

$11 \quad 0.02 \% \quad 21.7 \%$ NVSAPESR

$1 \quad 0.02 \% \quad 21.7 \%$ LIAEGPGETVLVAEEEAAR

$0.02 \% \quad 21.7 \%$ KLYGFTENR

$0.02 \% \quad 21.7 \%$ LYGFTENR

$0.00 \% \quad 11.3 \%$ TIEVLQLQDQGSK

$0.00 \% \quad 11.3 \%$ ARPELEELLAK

$0.00 \% \quad 20.3 \%$ AYQKQPTIFQNK

$0.00 \% \quad 20.3 \%$ YYKNIGLGFK RS2_HUMAN $31.33 \quad 100.0 \% \quad 20$ RS2_HUMAN $31.33 \quad 100.0 \% \quad 20$ RS2 HUMAN $31.33 \quad 100.0 \% \quad 20$ RS2_HUMAN $31.33 \quad 100.0 \% \quad 20$ RS2 HUMAN $31.33 \quad 100.0 \% \quad 20$ RS2_HUMAN $31.33 \quad 100.0 \% \quad 20$ RS2_HUMAN $31.33 \quad 100.0 \% \quad 20$ RS2 HUMAN $31.33 \quad 100.0 \% \quad 20$ RS2_HUMAN $31.33 \quad 100.0 \% \quad 20$ RS2_HUMAN $31.33 \quad 100.0 \% \quad 20$ RS2_HUMAN $31.33 \quad 100.0 \% \quad 20$ RS2_HUMAN $31.33 \quad 100.0 \% \quad 20$ RS2 HUMAN $31.33 \quad 100.0 \% \quad 20$ RS2_HUMAN $31.33 \quad 100.0 \% \quad 20$ RS2_HUMAN $31.33 \quad 100.0 \% \quad 20$ RS2 HUMAN $31.33 \quad 100.0 \% \quad 20$ RS2_HUMAN $31.33 \quad 100.0 \% \quad 20$ RS2 HUMAN $31.33 \quad 100.0 \% \quad 20$ RS3_HUMAN $26.69 \quad 100.0 \% \quad 23$ RS3_HUMAN $26.69 \quad 100.0 \% \quad 23$ RS3_HUMAN $26.69 \quad 100.0 \% \quad 23$ RS3_HUMAN $26.69 \quad 100.0 \% \quad 23$
$0.00 \% \quad 20.3 \%$ CPFTGNVSIR

$109 \quad 0.15 \% \quad 57.0 \%$ AEDKEWMPVTK

$109 \quad 0.15 \% \quad 57.0 \%$ SLEEIYLFSLPIK

$109 \quad 0.15 \% \quad 57.0 \%$ IMPVQKQTR

$109 \quad 0.15 \% \quad 57.0 \%$ FKAFVAIGDYNGHVGLGVK

$109 \quad 0.15 \% \quad 57.0 \%$ AFVAIGDYNGHVGLGVK

$109 \quad 0.15 \% \quad 57.0 \%$ CSKEVATAIR

$109 \quad 0.15 \% \quad 57.0 \%$ EVATAIRGAIILAK

$109 \quad 0.15 \% \quad 57.0 \%$ LSIVPVRR

$109 \quad 0.15 \% \quad 57.0 \%$ IGKPHTVPCK

$109 \quad 0.15 \% \quad 57.0 \%$ IGKPHTVPCKVTGR

$109 \quad 0.15 \% \quad 57.0 \%$ GTGIVSAPVPK

$109 \quad 0.15 \% \quad 57.0 \%$ GTGIVSAPVPKK

$109 \quad 0.15 \% \quad 57.0 \%$ KLLMMAGIDDCYTSAR

$109 \quad 0.15 \% \quad 57.0 \%$ LLMMAGIDDCYTSAR

$109 \quad 0.15 \% \quad 57.0 \%$ GCTATLGNFAK

$109 \quad 0.15 \% \quad 57.0 \%$ ATFDAISK

$109 \quad 0.15 \% \quad 57.0 \%$ SPYQEFTDHLVK

$109 \quad 0.15 \% \quad 57.0 \%$ SPYQEFTDHLVKTHTR

$109 \quad 0.15 \% \quad 57.0 \%$ VSVQRTQAPAVATT

$109 \quad 0.15 \% \quad 57.0 \%$ TQAPAVATT

$98 \quad 0.14 \% \quad 81.1 \%$ KFVADGIFK

$98 \quad 0.14 \% \quad 81.1 \%$ FVADGIFK

$98 \quad 0.14 \% \quad 81.1 \%$ AELNEFLTR

$98 \quad 0.14 \% \quad 81.1 \%$ ELAEDGYSGVEVR
$99.7 \%+72.6$

$99.7 \%$

$99.0 \% \quad 21.6$

$99.7 \% \quad 63.8$

$95.2 \% \quad 18.4$

$99.7 \% \quad 48.1$

$97.5 \% 15.9$

$99.7 \% 26.3$

$98.4 \% \quad 20.4$

$98.9 \% \quad 19.2$

$98.9 \% \quad 18.2$

$\begin{array}{ll}99.7 \% & 29.4 \\ 99.7 \% & 48.5\end{array}$

$99.7 \% \quad 58.9$

$99.7 \% \quad 46.4$

$99.0 \% \quad 43.4$

$99.7 \% \quad 35.1$

$99.7 \% \quad 35.0$

$99.7 \% \quad 42.0$

$99.7 \% \quad 46.4$

$99.7 \% \quad 53.0$

$\begin{array}{lll}99.7 \% & 54.5\end{array}$

$99.7 \% \quad 57.8$

$99.0 \% \quad 50.9$

$\begin{array}{lll}99.7 \% & 56.3\end{array}$

$99.7 \% \quad 44.9$

$99.7 \% \quad 33.5$

$96.4 \% \quad 16.1$

$99.7 \% \quad 32.3$

$99.0 \% \quad 26.7$

$99.7 \% \quad 51.6$

$99.7 \% \quad 53.4$
1015.59

1144.57

1901.96

1645.84

1224.59

1492.57

1500.75

1171.65

1627.87

2036.03

1175.69

1319.72

1202.59

1696.00

859.43

1954.01

1127.58

999.49

1458.78

1268.72

1465.78

1202.66

1150.57

1349.64

1551.87

1116.62

1992.07

1716.91

1134.59

1425.88

939.61

1136.62

1549.86

1025.60

1153.69

1876.86

1716.78

1139.55

852.45

1463.72

1958.97

1428.78

859.45

1024.58

896.49

1092.5

1423.67

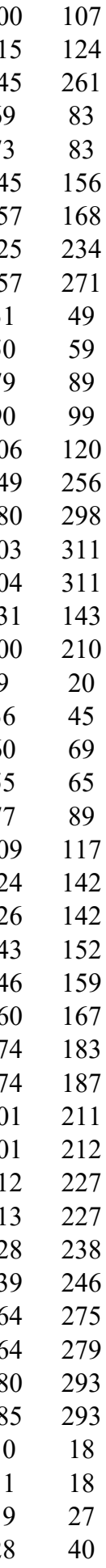

Page 6 of Table S-1-1 
$40 \mathrm{~S}$ ribosomal protein $\mathrm{S} 3 \mathrm{GN}=\mathrm{RPS} 3$ $40 \mathrm{~S}$ ribosomal protein $\mathrm{S} 3 \mathrm{GN}=\mathrm{RPS} 3$ $40 \mathrm{~S}$ ribosomal protein $\mathrm{S} 3 \mathrm{GN}=\mathrm{RPS} 3$ $40 \mathrm{~S}$ ribosomal protein $\mathrm{S} 3 \mathrm{GN}=\mathrm{RPS} 3$ $40 \mathrm{~S}$ ribosomal protein $\mathrm{S} 3 \mathrm{GN}=\mathrm{RPS} 3$ $40 \mathrm{~S}$ ribosomal protein $\mathrm{S} 3 \mathrm{GN}=\mathrm{RPS} 3$ $40 \mathrm{~S}$ ribosomal protein $\mathrm{S} 3 \mathrm{GN}=\mathrm{RPS} 3$ $40 \mathrm{~S}$ ribosomal protein $\mathrm{S} 3 \mathrm{GN}=\mathrm{RPS} 3$ $40 \mathrm{~S}$ ribosomal protein $\mathrm{S} 3 \mathrm{GN}=\mathrm{RPS} 3$ $40 \mathrm{~S}$ ribosomal protein $\mathrm{S} 3 \mathrm{GN}=\mathrm{RPS} 3$ $40 \mathrm{~S}$ ribosomal protein $\mathrm{S} 3 \mathrm{GN}=\mathrm{RPS} 3$ $40 \mathrm{~S}$ ribosomal protein $\mathrm{S} 3 \mathrm{GN}=\mathrm{RPS} 3$ $40 \mathrm{~S}$ ribosomal protein $\mathrm{S} 3 \mathrm{GN}=\mathrm{RPS} 3$ $40 \mathrm{~S}$ ribosomal protein $\mathrm{S} 3 \mathrm{GN}=\mathrm{RPS} 3$ $40 \mathrm{~S}$ ribosomal protein $\mathrm{S} 3 \mathrm{GN}=\mathrm{RPS} 3$ $40 \mathrm{~S}$ ribosomal protein $\mathrm{S} 3 \mathrm{GN}=\mathrm{RPS} 3$ $40 \mathrm{~S}$ ribosomal protein $\mathrm{S} 3 \mathrm{GN}=\mathrm{RPS} 3$ $40 \mathrm{~S}$ ribosomal protein $\mathrm{S} 3 \mathrm{GN}=\mathrm{RPS} 3$ $40 \mathrm{~S}$ ribosomal protein $\mathrm{S} 3 \mathrm{GN}=\mathrm{RPS} 3$ $40 \mathrm{~S}$ ribosomal protein $\mathrm{S} 30 \mathrm{GN}=\mathrm{FAU}$ $40 \mathrm{~S}$ ribosomal protein $\mathrm{S} 30 \mathrm{GN}=\mathrm{FAU}$ $40 \mathrm{~S}$ ribosomal protein $\mathrm{S} 3 \mathrm{a} \mathrm{GN}=\mathrm{RPS} 3 \mathrm{~A}$ $40 \mathrm{~S}$ ribosomal protein $\mathrm{S} 3 \mathrm{a} \mathrm{GN}=\mathrm{RPS} 3 \mathrm{~A}$ $40 \mathrm{~S}$ ribosomal protein $\mathrm{S} 3 \mathrm{a} \mathrm{GN}=\mathrm{RPS} 3 \mathrm{~A}$ $40 \mathrm{~S}$ ribosomal protein $\mathrm{S} 3 \mathrm{a} \mathrm{GN}=\mathrm{RPS} 3 \mathrm{~A}$ $40 \mathrm{~S}$ ribosomal protein $\mathrm{S} 3 \mathrm{a} \mathrm{GN}=\mathrm{RPS} 3 \mathrm{~A}$ $40 \mathrm{~S}$ ribosomal protein $\mathrm{S} 3 \mathrm{a} \mathrm{GN}=\mathrm{RPS} 3 \mathrm{~A}$ $40 \mathrm{~S}$ ribosomal protein $\mathrm{S} 3 \mathrm{a} \mathrm{GN}=\mathrm{RPS} 3 \mathrm{~A}$ $40 \mathrm{~S}$ ribosomal protein $\mathrm{S} 3 \mathrm{a} \mathrm{GN}=\mathrm{RPS} 3 \mathrm{~A}$ $40 \mathrm{~S}$ ribosomal protein $\mathrm{S} 3 \mathrm{a} \mathrm{GN}=\mathrm{RPS} 3 \mathrm{~A}$ $40 \mathrm{~S}$ ribosomal protein $\mathrm{S} 3 \mathrm{a} \mathrm{GN}=\mathrm{RPS} 3 \mathrm{~A}$ $40 \mathrm{~S}$ ribosomal protein $\mathrm{S} 3 \mathrm{a} \mathrm{GN}=\mathrm{RPS} 3 \mathrm{~A}$ $40 \mathrm{~S}$ ribosomal protein $\mathrm{S} 3 \mathrm{a} \mathrm{GN}=\mathrm{RPS} 3 \mathrm{~A}$ $40 \mathrm{~S}$ ribosomal protein $\mathrm{S} 3 \mathrm{a} \mathrm{GN}=\mathrm{RPS} 3 \mathrm{~A}$ 40 S ribosomal protein $\mathrm{S} 3 \mathrm{a} \mathrm{GN}=\mathrm{RPS} 3 \mathrm{~A}$ $40 \mathrm{~S}$ ribosomal protein $\mathrm{S} 3 \mathrm{a} \mathrm{GN}=\mathrm{RPS} 3 \mathrm{~A}$ $40 \mathrm{~S}$ ribosomal protein $\mathrm{S} 3 \mathrm{a} \mathrm{GN}=\mathrm{RPS} 3 \mathrm{~A}$ $40 \mathrm{~S}$ ribosomal protein $\mathrm{S} 3 \mathrm{a} \mathrm{GN}=\mathrm{RPS} 3 \mathrm{~A}$ $40 \mathrm{~S}$ ribosomal protein $\mathrm{S} 3 \mathrm{a} \mathrm{GN}=\mathrm{RPS} 3 \mathrm{~A}$ $40 \mathrm{~S}$ ribosomal protein $\mathrm{S} 3 \mathrm{a} \mathrm{GN}=\mathrm{RPS} 3 \mathrm{~A}$ $40 \mathrm{~S}$ ribosomal protein $\mathrm{S} 3 \mathrm{a} \mathrm{GN}=\mathrm{RPS} 3 \mathrm{~A}$ $40 \mathrm{~S}$ ribosomal protein $\mathrm{S} 3 \mathrm{a} \mathrm{GN}=\mathrm{RPS} 3 \mathrm{~A}$ $40 \mathrm{~S}$ ribosomal protein $\mathrm{S} 3 \mathrm{a} \mathrm{GN}=\mathrm{RPS} 3 \mathrm{~A}$ $40 \mathrm{~S}$ ribosomal protein $\mathrm{S} 3 \mathrm{a} \mathrm{GN}=\mathrm{RPS} 3 \mathrm{~A}$ $40 \mathrm{~S}$ ribosomal protein $\mathrm{S} 3 \mathrm{a} \mathrm{GN}=\mathrm{RPS} 3 \mathrm{~A}$ $40 \mathrm{~S}$ ribosomal protein $\mathrm{S} 3 \mathrm{a} \mathrm{GN}=\mathrm{RPS} 3 \mathrm{~A}$ $40 \mathrm{~S}$ ribosomal protein $\mathrm{S} 3 \mathrm{a} \mathrm{GN}=\mathrm{RPS} 3 \mathrm{~A}$
RS3_HUMAN $26.69 \quad 100.0 \% \quad 23$ RS3_HUMAN $26.69 \quad 100.0 \% \quad 23$ RS3_HUMAN $26.69 \quad 100.0 \% \quad 23$ RS3 HUMAN $26.69 \quad 100.0 \% \quad 23$ RS3_HUMAN $26.69 \quad 100.0 \% \quad 23$ RS3_HUMAN $26.69 \quad 100.0 \% \quad 23$ RS3 HUMAN $26.69 \quad 100.0 \% \quad 23$ RS3_HUMAN $26.69 \quad 100.0 \% \quad 23$ RS3 HUMAN $26.69 \quad 100.0 \% \quad 23$ RS3_HUMAN $26.69 \quad 100.0 \% \quad 23$ RS3_HUMAN $26.69 \quad 100.0 \% \quad 23$ RS3 HUMAN $26.69 \quad 100.0 \% \quad 23$ RS3_HUMAN $26.69 \quad 100.0 \% \quad 23$ RS3_HUMAN $26.69 \quad 100.0 \% \quad 23$ RS3 HUMAN $26.69 \quad 100.0 \% \quad 23$ RS3_HUMAN $26.69 \quad 100.0 \% \quad 23$ RS3 HUMAN $26.69 \quad 100.0 \% \quad 23$ RS3_HUMAN $26.69 \quad 100.0 \% \quad 23$ RS3_HUMAN $26.69 \quad 100.0 \% \quad 23$ RS30 HUMAN $6.65 \quad 100.0 \% \quad 2$ RS30_HUMAN $6.65 \quad 100.0 \% \quad 2$ RS3A_HUMAN $29.95 \quad 100.0 \% \quad 29$ RS3A_HUMAN $29.95 \quad 100.0 \% \quad 29$ RS3A_HUMAN $29.95 \quad 100.0 \% \quad 29$ RS3A HUMAN $29.95 \quad 100.0 \% \quad 29$ RS3A_HUMAN $29.95 \quad 100.0 \% \quad 29$ RS3A_HUMAN $29.95 \quad 100.0 \% \quad 29$ RS3A HUMAN $29.95 \quad 100.0 \% \quad 29$ RS3A_HUMAN $29.95 \quad 100.0 \% \quad 29$ RS3A HUMAN $29.95 \quad 100.0 \% \quad 29$ RS3A_HUMAN $29.95 \quad 100.0 \% \quad 29$ RS3A_HUMAN $29.95 \quad 100.0 \% \quad 29$ RS3A HUMAN $29.95 \quad 100.0 \% \quad 29$ RS3A_HUMAN $29.95 \quad 100.0 \% \quad 29$ RS3A_HUMAN $29.95 \quad 100.0 \% \quad 29$ RS3A_HUMAN $29.95 \quad 100.0 \% \quad 29$ RS3A_HUMAN $29.95 \quad 100.0 \% \quad 29$ RS3A HUMAN $29.95 \quad 100.0 \% \quad 29$ RS3A_HUMAN $29.95 \quad 100.0 \% \quad 29$ RS3A_HUMAN $29.95 \quad 100.0 \% \quad 29$ RS3A HUMAN $29.95 \quad 100.0 \% \quad 29$ RS3A_HUMAN $29.95 \quad 100.0 \% \quad 29$ RS3A HUMAN $29.95 \quad 100.0 \% \quad 29$ RS3A_HUMAN $29.95 \quad 100.0 \% \quad 29$ RS3A_HUMAN $29.95 \quad 100.0 \% \quad 29$ RS3A HUMAN $29.95 \quad 100.0 \% \quad 29$ RS3A_HUMAN $29.95 \quad 100.0 \% \quad 29$
$80.14 \% \quad 81.1 \%$ VTPTRTEIIILATR $0.14 \% \quad 81.1 \%$ TEIIILATR

$0.14 \% \quad 81.1 \%$ IRELTAVVQK

$0.14 \% \quad 81.1 \%$ ELTAVVQKR

$0.14 \% \quad 81.1 \%$ RFGFPEGSVELYAEK

$0.14 \% \quad 81.1 \%$ FGFPEGSVELYAEK

$0.14 \% \quad 81.1 \%$ FGFPEGSVELYAEKVATR

$0.14 \% \quad 81.1 \%$ GLCAIAQAESLR

$0.14 \% \quad 81.1 \%$ GLCAIAQAESLRYK

$0.14 \% \quad 81.1 \%$ YKLLGGLAVR

$0.14 \% \quad 81.1 \%$ RACYGVLR

$0.14 \% \quad 81.1 \%$ FIMESGAK

$0.14 \% \quad 81.1 \%$ FIMESGAKGCEVVVSGK

$0.14 \% \quad 81.1 \%$ GCEVVVSGK

$0.14 \% \quad 81.1 \%$ GCEVVVSGKLR

$0.14 \% \quad 81.1 \%$ FVDGLMIHSGDPVNYYVDTAVR

$0.14 \% \quad 81.1 \%$ IMLPWDPTGK

$0.14 \% \quad 81.1 \%$ KPLPDHVSIVEPKDEILPTTPISEQK

$0.14 \% \quad 81.1 \%$ GGKPEPPAMPQPVPTA

$0.00 \% \quad 18.6 \%$ FVNVVPTFGK

$0.00 \% \quad 18.6 \%$ FVNVVPTFGKK

$104 \quad 0.14 \% \quad 76.5 \%$ APAMFNIR

$104 \quad 0.14 \% \quad 76.5 \%$ NIGKTLVTR

$104 \quad 0.14 \% \quad 76.5 \%$ TLVTRTQGTK

$104 \quad 0.14 \% \quad 76.5 \%$ TQGTKIASDGLK

$104 \quad 0.14 \% \quad 76.5 \%$ IASDGLKGR

$1040.14 \% \quad 76.5 \%$ VFEVSLADLQNDEVAFR

$104 \quad 0.14 \% \quad 76.5 \%$ VFEVSLADLQNDEVAFRK

$104 \quad 0.14 \% \quad 76.5 \%$ FKLITEDVQGK

$104 \quad 0.14 \% \quad 76.5 \%$ LITEDVQGK

$104 \quad 0.14 \% \quad 76.5 \%$ LITEDVQGKNCLTNFHGMDLTR

$104 \quad 0.14 \% \quad 76.5 \%$ NCLTNFHGMDLTR

$104 \quad 0.14 \% \quad 76.5 \%$ DKMCSMVK

$104 \quad 0.14 \% \quad 76.5 \%$ TTDGYLLR

$104 \quad 0.14 \% \quad 76.5 \%$ LFCVGFTK

$104 \quad 0.14 \% \quad 76.5 \%$ LFCVGFTKK

$104 \quad 0.14 \% \quad 76.5 \%$ KTSYAQHQQVR

$104 \quad 0.14 \% \quad 76.5 \%$ TSYAQHQQVR

$104 \quad 0.14 \% \quad 76.5 \%$ KMMEIMTR

$104 \quad 0.14 \% \quad 76.5 \%$ EVQTNDLKEVVNK

$104 \quad 0.14 \% \quad 76.5 \%$ LIPDSIGKDIEK

$104 \quad 0.14 \% \quad 76.5 \%$ ACQSIYPLHDVFVR

$104 \quad 0.14 \% \quad 76.5 \%$ ACQSIYPLHDVFVRK

$104 \quad 0.14 \% \quad 76.5 \%$ KPKFELGK

$104 \quad 0.14 \% \quad 76.5 \%$ FELGKLMELHGEGSSSGK

$104 \quad 0.14 \% \quad 76.5 \%$ LMELHGEGSSSGK

$104 \quad 0.14 \% \quad 76.5 \%$ LMELHGEGSSSGKATGDETGAK $\quad 99.7 \% \quad 47.8$

$99.7 \% \quad 39.5$ $99.7 \% \quad 42.0$

$99.7 \% \quad 34.1$

$99.7 \% \quad 47.6$

$99.7 \% \quad 50.3$

$99.7 \% \quad 51.9$

$99.7 \% 71.5$

$99.7 \% 55.1$

$99.7 \% \quad 50.5$

$99.7 \% \quad 41.5$

$96.4 \% \quad 23.7$

$95.6 \% \quad 21.7$

$99.7 \% \quad 54.3$

$99.7 \% \quad 26.0$

$99.7 \% \quad 55.3$

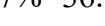

$9.7 \% \quad 38.4$

$99.2 \% \quad 28.1$

$99.7 \% \quad 42.9$

$99.1 \% 21.4$

$99.0 \% \quad 55.5$

$99.7 \% \quad 40.2$

$99.7 \% \quad 34.3$

$99.6 \% \quad 22.6$

$99.7 \% \quad 58.8$

$99.7 \% \quad 47.3$

\% 50.8

$\begin{array}{ll}7 \% & 65.1 \\ 7 \% & 48.0\end{array}$

$99.0 \% \quad 21.0$

$99.0 \% \quad 65.1$

$99.0 \% \quad 47.9$

$99.7 \% \quad 26.0$

$99.7 \% \quad 64.7$

$99.7 \% \quad 61.7$

$99.0 \% \quad 33.0$

$99.7 \% \quad 64.9$

$99.7 \% \quad 30.8$

$\begin{array}{lll}99.7 \% & 42.0\end{array}$

$99.7 \% \quad 35.3$

$99.0 \% \quad 24.6$

$99.7 \% \quad 35.1$

49
1583.95

1029.63

1156.70

1043.62

1728.86

1572.76

2000.01

1288.67

1579.83

1089.68

994.53

898.43

1797.89

934.47

1203.65

2484.19

1173.60

2910.58

1589.80

1107.62

1235.71

919.48

1001.61

1104.64

1218.67

916.52

1951.98

2080.07

1277.71

1002.55

2562.24

1578.72

998.45

938.49

971.50

1099.60

1345.70

1217.60

1055.50

1515.80

1327.75

1704.85

1832.95

946.57

1905.94

1331.63 2162.00

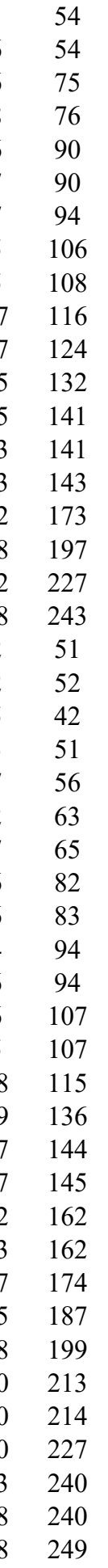


$40 \mathrm{~S}$ ribosomal protein $\mathrm{S} 3 \mathrm{a} \mathrm{GN}=\mathrm{RPS} 3 \mathrm{~A}$ $40 \mathrm{~S}$ ribosomal protein $\mathrm{S} 3 \mathrm{a} \mathrm{GN}=\mathrm{RPS} 3 \mathrm{~A}$ 40 S ribosomal protein $\mathrm{S} 3 \mathrm{a} \mathrm{GN}=\mathrm{RPS} 3 \mathrm{~A}$ RS3A HUMAN $29.95 \quad 100.0 \% \quad 29$ RS3A_HUMAN $29.95 \quad 100.0 \% \quad 29$ RS3A_HUMAN $29.95 \quad 100.0 \% \quad 29$ (o) ribosomal protein $\mathrm{S} 4 \mathrm{X}$ isoform GN=RPS4X RS4X HUMAN $29.60 \quad 100.0 \%$ 40S ribosomal protein S4, X isoform GN=RPS4X RS4X_HUMAN $29.60 \quad 100.0 \% \quad 19$ 40S ribosomal protein S4, X isoform GN=RPS4X RS4X_HUMAN $29.60 \quad 100.0 \% \quad 19$ 40S ribosomal protein S4, X isoform GN=RPS4X RS4X_HUMAN $29.60 \quad 100.0 \% \quad 19$ 40S ribosomal protein S4, X isoform GN=RPS4X RS4X_HUMAN $29.60 \quad 100.0 \% \quad 19$ $40 \mathrm{~S}$ ribosomal protein $\mathrm{S} 4, \mathrm{X}$ isoform $\mathrm{GN}=\mathrm{RPS} 4 \mathrm{X}$ RS4X_HUMAN $29.60 \quad 100.0 \%$ 40S ribosomal protein S4, X isoform GN=RPS4X RS4X_HUMAN $29.60 \quad 100.0 \% \quad 19$ 40S ribosomal protein S4, X isoform GN=RPS4X RS4X_HUMAN $29.60 \quad 100.0 \% \quad 19$ $40 \mathrm{~S}$ ribosomal protein $\mathrm{S} 4, \mathrm{X}$ isoform GN=RPS4X RS4X_HUMAN $29.60 \quad 100.0 \%$ 40S ribosomal protein S4, X isoform GN=RPS4X RS4X_HUMAN $29.60 \quad 100.0 \% \quad 19$ $40 \mathrm{~S}$ ribosomal protein $\mathrm{S} 4, \mathrm{X}$ isoform GN=RPS4X RS4X_HUMAN $29.60 \quad 100.0 \% \quad 19$ $40 \mathrm{~S}$ ribosomal protein $\mathrm{S} 4, \mathrm{X}$ isoform GN=RPS4X RS4X_HUMAN $29.60 \quad 100.0 \%$ 40S ribosomal protein S4, X isoform GN=RPS4X RS4X HUMAN $29.60 \quad 100.0 \% \quad 19$ $40 \mathrm{~S}$ ribosomal protein $\mathrm{S} 4, \mathrm{X}$ isoform GN=RPS4X RS4X_HUMAN $29.60 \quad 100.0 \%$ 40S ribosomal protein S4, X isoform GN=RPS4X RS4X_HUMAN $29.60 \quad 100.0 \% \quad 19$ 40S ribosomal protein S4, X isoform GN=RPS4X RS4X_HUMAN $29.60 \quad 100.0 \% \quad 19$ 40S ribosomal protein S4, X isoform GN=RPS4X RS4X_HUMAN $29.60 \quad 100.0 \% 19$ 40S ribosomal protein S4, X isoform GN=RPS4X RS4X_HUMAN $29.60 \quad 100.0 \% \quad 19$ 40S ribosomal protein S4, X isoform GN=RPS4X RS4X HUMAN $29.60 \quad 100.0 \% \quad 19$ 40S ribosomal protein $\mathrm{S} 5 \mathrm{GN}=\mathrm{RPS} 5$ $40 \mathrm{~S}$ ribosomal protein $\mathrm{S} 5 \mathrm{GN}=\mathrm{RPS} 5$ 40S ribosomal protein $\mathrm{S} 5 \mathrm{GN}=\mathrm{RPS} 5$ $40 \mathrm{~S}$ ribosomal protein $\mathrm{S} 5 \mathrm{GN}=\mathrm{RPS} 5$ $40 \mathrm{~S}$ ribosomal protein $\mathrm{S} 5 \mathrm{GN}=\mathrm{RPS} 5$ $40 \mathrm{~S}$ ribosomal protein $\mathrm{S} 5 \mathrm{GN}=\mathrm{RPS} 5$ $40 \mathrm{~S}$ ribosomal protein $\mathrm{S} 5 \mathrm{GN}=\mathrm{RPS} 5$ $40 \mathrm{~S}$ ribosomal protein $\mathrm{S} 5 \mathrm{GN}=\mathrm{RPS} 5$ $40 \mathrm{~S}$ ribosomal protein $\mathrm{S} 5 \mathrm{GN}=\mathrm{RPS} 5$ $40 \mathrm{~S}$ ribosomal protein $\mathrm{S} 6 \mathrm{GN}=\mathrm{RPS} 6$ 40S ribosomal protein $\mathrm{S} 6 \mathrm{GN}=\mathrm{RPS} 6$ $40 \mathrm{~S}$ ribosomal protein $\mathrm{S} 6 \mathrm{GN}=\mathrm{RPS} 6$ $40 \mathrm{~S}$ ribosomal protein $\mathrm{S} 6 \mathrm{GN}=\mathrm{RPS} 6$ $40 \mathrm{~S}$ ribosomal protein $\mathrm{S} 6 \mathrm{GN}=\mathrm{RPS} 6$ 40 S ribosomal protein $\mathrm{S} 6 \mathrm{GN}=\mathrm{RPS} 6$ $40 \mathrm{~S}$ ribosomal protein $\mathrm{S} 6 \mathrm{GN}=\mathrm{RPS} 6$ $40 \mathrm{~S}$ ribosomal protein $\mathrm{S} 6 \mathrm{GN}=\mathrm{RPS} 6$ $40 \mathrm{~S}$ ribosomal protein $\mathrm{S} 6 \mathrm{GN}=\mathrm{RPS} 6$ $40 \mathrm{~S}$ ribosomal protein $\mathrm{S} 6 \mathrm{GN}=\mathrm{RPS} 6$ $40 \mathrm{~S}$ ribosomal protein $\mathrm{S} 6 \mathrm{GN}=\mathrm{RPS} 6$ $40 \mathrm{~S}$ ribosomal protein $\mathrm{S} 6 \mathrm{GN}=\mathrm{RPS} 6$ $40 \mathrm{~S}$ ribosomal protein $\mathrm{S} 6 \mathrm{GN}=\mathrm{RPS} 6$ $40 \mathrm{~S}$ ribosomal protein $\mathrm{S} 6 \mathrm{GN}=\mathrm{RPS} 6$ $40 \mathrm{~S}$ ribosomal protein $\mathrm{S} 6 \mathrm{GN}=\mathrm{RPS} 6$ $40 \mathrm{~S}$ ribosomal protein $\mathrm{S} 6 \mathrm{GN}=\mathrm{RPS} 6$ RS5 HUMAN $22.88 \quad 100.0 \%$ RS5_HUMAN $22.88 \quad 100.0 \%$ RS5 HUMAN $22.88 \quad 100.0 \% \quad 9$ RS5_HUMAN $22.88 \quad 100.0 \% \quad 9$ RS5_HUMAN $22.88 \quad 100.0 \% \quad 9$ RS5 HUMAN $22.88 \quad 100.0 \%$ RS5_HUMAN $22.88 \quad 100.0 \% \quad 9$ RS5 HUMAN $22.88 \quad 100.0 \% \quad 9$ RS5_HUMAN $22.88 \quad 100.0 \% \quad 9$ RS6_HUMAN $28.68 \quad 100.0 \% \quad 17$ RS6 HUMAN $28.68 \quad 100.0 \% \quad 17$ RS6_HUMAN $28.68 \quad 100.0 \% \quad 17$ RS6_HUMAN $28.68 \quad 100.0 \% \quad 17$ RS6 HUMAN $28.68 \quad 100.0 \% \quad 17$ RS6_HUMAN $28.68 \quad 100.0 \% \quad 17$ RS6 HUMAN $28.68 \quad 100.0 \% \quad 17$ RS6_HUMAN $28.68 \quad 100.0 \% \quad 17$ RS6_HUMAN $28.68 \quad 100.0 \% \quad 17$ RS6 HUMAN $28.68 \quad 100.0 \% \quad 17$ RS6_HUMAN $28.68 \quad 100.0 \% \quad 17$ RS6 HUMAN $28.68 \quad 100.0 \% \quad 17$ RS6_HUMAN $28.68 \quad 100.0 \% \quad 17$ RS6_HUMAN $28.68 \quad 100.0 \% \quad 17$ RS6 HUMAN $28.68 \quad 100.0 \% \quad 17$ RS6_HUMAN $28.68 \quad 100.0 \% \quad 17$
$49 \quad 104 \quad 0.14 \% \quad 76.5 \%$ ATGDETGAKVER $49 \quad 104 \quad 0.14 \% \quad 76.5 \%$ VERADGYEPPVQESV 49 23
23 23 23 23
$104 \quad 0.14 \% \quad 76.5 \%$ ADGYEPPVQESV

$49 \quad 0.07 \% \quad 66.5 \%$ LTGVFAPRPSTGPHK

$49 \quad 0.07 \% \quad 66.5 \%$ LRECLPLIIFLR

$49 \quad 0.07 \% \quad 66.5 \%$ LKYALTGDEVK

$49 \quad 0.07 \% \quad 66.5 \%$ YALTGDEVK

$49 \quad 0.07 \% \quad 66.5 \%$ TDITYPAGFMDVISIDK

$49 \quad 0.07 \% \quad 66.5 \%$ TGENFRLIYDTK

$49 \quad 0.07 \% \quad 66.5 \%$ LIYDTKGR

$49 \quad 0.07 \% \quad 66.5 \%$ IFVGTKGIPHLVTHDAR

$49 \quad 0.07 \% \quad 66.5 \%$ GIPHLVTHDAR

$49 \quad 0.07 \% \quad 66.5 \%$ TIRYPDPLIK

$49 \quad 0.07 \% \quad 66.5 \%$ FDTGNLCMVTGGANLGR

$49 \quad 0.07 \% \quad 66.5 \%$ IGVITNRER

$49 \quad 0.07 \% \quad 66.5 \%$ ERHPGSFDVVHVK

$0.07 \% \quad 66.5 \%$ HPGSFDVVHVK

$49 \quad 0.07 \% \quad 66.5 \%$ HPGSFDVVHVKDANGNSFATR

$49 \quad 0.07 \% \quad 66.5 \%$ DANGNSFATR

$49 \quad 0.07 \% \quad 66.5 \%$ LSNIFVIGK

$49 \quad 0.07 \% \quad 66.5 \%$ GNKPWISLPR

$17 \quad 0.02 \% \quad 36.8 \%$ YLPHSAGR

$17 \quad 0.02 \% \quad 36.8 \%$ KAQCPIVER

$17 \quad 0.02 \% \quad 36.8 \%$ AQCPIVER

$17 \quad 0.02 \% \quad 36.8 \%$ LTNSMMMHGR

$17 \quad 0.02 \% \quad 36.8 \%$ QAVDVSPLR

$17 \quad 0.02 \% \quad 36.8 \%$ QAVDVSPLRR

$17 \quad 0.02 \% \quad 36.8 \%$ VNQAIWLLCTGAR

$17 \quad 0.02 \% \quad 36.8 \%$ TIAECLADELINAAK

$17 \quad 0.02 \% \quad 36.8 \%$ GSSNSYAIKK

$60 \quad 0.08 \% \quad 63.9 \%$ LNISFPATGCQK

$60 \quad 0.08 \% \quad 63.9 \%$ LIEVDDER

$60 \quad 0.08 \% \quad 63.9 \%$ LIEVDDERK

$60 \quad 0.08 \% \quad 63.9 \%$ MATEVAADALGEEWKGYVVR

$60 \quad 0.08 \% \quad 63.9 \%$ ISGGNDKQGFPMK

$60 \quad 0.08 \% \quad 63.9 \%$ QGVLTHGR

$60 \quad 0.08 \% \quad 63.9 \%$ GHSCYRPR

$60 \quad 0.08 \% \quad 63.9 \%$ GCIVDANLSVLNLVIVK

$60 \quad 0.08 \% \quad 63.9 \%$ DIPGLTDTTVPR

$60 \quad 0.08 \% \quad 63.9 \%$ LFNLSKEDDVR

$60 \quad 0.08 \% \quad 63.9 \%$ EDDVRQYVVR

$60 \quad 0.08 \% \quad 63.9 \%$ IQRLVTPR

$60 \quad 0.08 \% \quad 63.9 \%$ NKEEAAEYAK

$60 \quad 0.08 \% \quad 63.9 \%$ LSSLRASTSK
$49 \quad 0.07 \% \quad 66.5 \%$ VNDTIQIDLETGK

$60 \quad 0.08 \% \quad 63.9 \%$ MKLNISFPATGCQK

$60 \quad 0.08 \% \quad 63.9 \%$ KPLNKEGK $\begin{array}{llll}99.7 \% & 57.8 & 25.0 & 40.9\end{array}$

$\begin{array}{lllll}99.7 \% & 56.5 & 25.0 & 56.5 & 2\end{array}$

$\begin{array}{lllll}99.7 \% & 43.0 & 25.0 & 43.0 & 2\end{array}$

$99.7 \% \quad 30.4 \quad 25.0 \quad 25.6$

$99.7 \% \quad 44.5 \quad 25.0 \quad 44.5$

$99.7 \% \quad 40.9 \quad 25.0 \quad 36.8$

$\begin{array}{llll}99.7 \% & 27.3 & 25.0 & 19.2\end{array}$

$\begin{array}{llll}99.7 \% & 40.5 & 25.0 & 40.5\end{array}$

$\begin{array}{llll}99.7 \% & 33.8 & 25.0 & 27.9\end{array}$

$\begin{array}{llll}99.0 \% & 44.4 & 25.0 & 34.9\end{array}$

$\begin{array}{llll}98.6 \% & 17.7 & 25.0 & 17.7\end{array}$

$99.7 \% \quad 57.7 \quad 25.0 \quad 50.3$

$\begin{array}{llll}99.7 \% & 32.6 & 25.0 & 21.7\end{array}$

$\begin{array}{llll}99.7 \% & 58.6 & 25.0 & 58.5\end{array}$

$\begin{array}{llll}99.7 \% & 58.4 & 25.0 & 53.9\end{array}$

$\begin{array}{llll}99.0 \% & 30.4 & 25.0 & 7.9\end{array}$

$99.7 \% \quad 27.0 \quad 25.0 \quad 25.5$

$\begin{array}{llll}99.7 \% & 32.8 & 25.0 & 31.0\end{array}$

$99.7 \% \quad 28.0$

$99.7 \% \quad 54.2$

$99.7 \% \quad 57.1$

$99.7 \% \quad 34.7$

$99.0 \% 33.9$

$99.7 \% \quad 44.6$

$99.0 \% \quad 29.7$

$95.9 \% \quad 14.4$

$99.7 \% \quad 49.2$

$99.4 \% \quad 21.8$

$99.7 \% \quad 69.4$

$99.7 \% \quad 64.2$

$99.7 \% \quad 29.0$

$99.7 \% \quad 52.5$

$99.7 \% \quad 41.4$

$99.0 \% \quad 38.4$

$\begin{array}{lll}99.7 \% & 42.8\end{array}$

$99.7 \% \quad 49.5$

$\begin{array}{lll}99.7 \% & 37.8\end{array}$

$99.0 \% \quad 37.2$

$99.0 \% \quad 28.8$

$99.7 \% \quad 60.9$

$99.7 \% \quad 45.2$

$99.7 \% \quad 55.5$

$99.7 \% \quad 31.6$

$99.0 \% \quad 26.2$

$99.0 \% \quad 24.9$

$99.7 \% \quad 33.8$

$99.7 \% \quad 33.0$

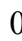


$40 \mathrm{~S}$ ribosomal protein $\mathrm{S} 6 \mathrm{GN}=\mathrm{RPS} 6$ 40S ribosomal protein $\mathrm{S} 7 \mathrm{GN}=\mathrm{RPS} 7$ $40 \mathrm{~S}$ ribosomal protein $\mathrm{S} 7 \mathrm{GN}=\mathrm{RPS} 7$ $40 \mathrm{~S}$ ribosomal protein $\mathrm{S} 7 \mathrm{GN}=\mathrm{RPS} 7$ $40 \mathrm{~S}$ ribosomal protein $\mathrm{S} 7 \mathrm{GN}=\mathrm{RPS} 7$ 40S ribosomal protein $\mathrm{S} 7 \mathrm{GN}=\mathrm{RPS} 7$ $40 \mathrm{~S}$ ribosomal protein $\mathrm{S} 7 \mathrm{GN}=\mathrm{RPS} 7$ $40 \mathrm{~S}$ ribosomal protein $\mathrm{S} 7 \mathrm{GN}=\mathrm{RPS} 7$ $40 \mathrm{~S}$ ribosomal protein $\mathrm{S} 7 \mathrm{GN}=\mathrm{RPS} 7$ $40 \mathrm{~S}$ ribosomal protein $\mathrm{S} 7 \mathrm{GN}=\mathrm{RPS} 7$ $40 \mathrm{~S}$ ribosomal protein $\mathrm{S} 7 \mathrm{GN}=\mathrm{RPS} 7$ 40S ribosomal protein $\mathrm{S} 7 \mathrm{GN}=\mathrm{RPS} 7$ $40 \mathrm{~S}$ ribosomal protein $\mathrm{S} 7 \mathrm{GN}=\mathrm{RPS} 7$ $40 \mathrm{~S}$ ribosomal protein $\mathrm{S} 8 \mathrm{GN}=\mathrm{RPS} 8$ $40 \mathrm{~S}$ ribosomal protein $\mathrm{S} 8 \mathrm{GN}=\mathrm{RPS} 8$ $40 \mathrm{~S}$ ribosomal protein $\mathrm{S} 8 \mathrm{GN}=\mathrm{RPS} 8$ $40 \mathrm{~S}$ ribosomal protein $\mathrm{S} 8 \mathrm{GN}=\mathrm{RPS} 8$ $40 \mathrm{~S}$ ribosomal protein $\mathrm{S} 8 \mathrm{GN}=\mathrm{RPS} 8$ $40 \mathrm{~S}$ ribosomal protein $\mathrm{S} 8 \mathrm{GN}=\mathrm{RPS} 8$ $40 \mathrm{~S}$ ribosomal protein $\mathrm{S} 8 \mathrm{GN}=\mathrm{RPS} 8$ $40 \mathrm{~S}$ ribosomal protein $\mathrm{S} 8 \mathrm{GN}=\mathrm{RPS} 8$ $40 \mathrm{~S}$ ribosomal protein $\mathrm{S} 8 \mathrm{GN}=\mathrm{RPS} 8$ $40 \mathrm{~S}$ ribosomal protein $\mathrm{S} 8 \mathrm{GN}=\mathrm{RPS} 8$ $40 \mathrm{~S}$ ribosomal protein $\mathrm{S} 9 \mathrm{GN}=\mathrm{RPS} 9$ $40 \mathrm{~S}$ ribosomal protein $\mathrm{S} 9 \mathrm{GN}=\mathrm{RPS} 9$ $40 \mathrm{~S}$ ribosomal protein $\mathrm{S} 9 \mathrm{GN}=\mathrm{RPS} 9$ $40 \mathrm{~S}$ ribosomal protein $\mathrm{S} 9 \mathrm{GN}=\mathrm{RPS} 9$ $40 \mathrm{~S}$ ribosomal protein $\mathrm{S} 9 \mathrm{GN}=\mathrm{RPS} 9$ $40 \mathrm{~S}$ ribosomal protein $\mathrm{S} 9 \mathrm{GN}=\mathrm{RPS} 9$ $40 \mathrm{~S}$ ribosomal protein $\mathrm{S} 9 \mathrm{GN}=\mathrm{RPS} 9$ $40 \mathrm{~S}$ ribosomal protein $\mathrm{S} 9 \mathrm{GN}=\mathrm{RPS} 9$ $40 \mathrm{~S}$ ribosomal protein $\mathrm{S} 9 \mathrm{GN}=\mathrm{RPS} 9$ $40 \mathrm{~S}$ ribosomal protein $\mathrm{S} 9 \mathrm{GN}=\mathrm{RPS} 9$ $40 \mathrm{~S}$ ribosomal protein $\mathrm{S} 9 \mathrm{GN}=\mathrm{RPS} 9$ $40 \mathrm{~S}$ ribosomal protein $\mathrm{S} 9 \mathrm{GN}=\mathrm{RPS} 9$ $40 \mathrm{~S}$ ribosomal protein $\mathrm{S} 9 \mathrm{GN}=\mathrm{RPS} 9$ $40 \mathrm{~S}$ ribosomal protein $\mathrm{S} 9 \mathrm{GN}=\mathrm{RPS} 9$ $40 \mathrm{~S}$ ribosomal protein $\mathrm{S} 9 \mathrm{GN}=\mathrm{RPS} 9$ $40 \mathrm{~S}$ ribosomal protein $\mathrm{S} 9 \mathrm{GN}=\mathrm{RPS} 9$ $40 \mathrm{~S}$ ribosomal protein $\mathrm{SA} \mathrm{GN}=\mathrm{RPSA}$ $40 \mathrm{~S}$ ribosomal protein $\mathrm{SA} \mathrm{GN}=\mathrm{RPSA}$ $40 \mathrm{~S}$ ribosomal protein $\mathrm{SA} \mathrm{GN}=\mathrm{RPSA}$ $40 \mathrm{~S}$ ribosomal protein $\mathrm{SA} \mathrm{GN}=\mathrm{RPSA}$ $40 \mathrm{~S}$ ribosomal protein $\mathrm{SA}$ GN=RPSA $40 \mathrm{~S}$ ribosomal protein $\mathrm{SA} G \mathrm{GN}=\mathrm{RPSA}$ $\begin{array}{llll}\text { 4F2 cell-surface antigen heavy chain GN=SLC3A2 } & \text { 4F2_HUMAN } & 68.00 & 100.0 \% \\ \text { 4F2 cell-surface antigen heavy chain GN=SLC3A2 } & \text { 4F2_HUMAN } & 68.00 & 100.0 \%\end{array}$ $\begin{array}{lllllll}\text { RS6 HUMAN } 28.68 & 100.0 \% & 17 & 20 & 60 & 0.08 \% & 63.9 \% \\ \text { ASTSKSESSQK }\end{array}$ RS7_HUMAN $22.13 \quad 100.0 \% \quad 12 \quad 12 \quad 26 \quad 0.04 \% \quad 44.8 \%$ ELNITAAK RS7_HUMAN $22.13 \quad 100.0 \% \quad 12 \quad 12 \quad 26 \quad 0.04 \% \quad 44.8 \%$ ELNITAAKEIEVGGGR RS7_HUMAN $22.13 \quad 100.0 \% \quad 12 \quad 12 \quad 26 \quad 0.04 \% \quad 44.8 \%$ EIEVGGGR RS7_HUMAN $22.13 \quad 100.0 \% \quad 12 \quad 12 \quad 26 \quad 0.04 \% \quad 44.8 \%$ KAIIIFVPVPQLK RS7_HUMAN $22.13 \quad 100.0 \% \quad 12 \quad 12 \quad 26 \quad 0.04 \% \quad 44.8 \%$ AIIIFVPVPQLK RS7_HUMAN $22.13 \quad 100.0 \% \quad 12 \quad 12 \quad 26 \quad 0.04 \% \quad 44.8 \%$ SFQKIQVR RS7_HUMAN $22.13 \quad 100.0 \% \quad 12 \quad 12 \quad 26 \quad 0.04 \% \quad 44.8 \%$ HVVFIAQR RS7_HUMAN $22.13 \quad 100.0 \% \quad 12 \quad 12 \quad 26 \quad 0.04 \% \quad 44.8 \%$ HVVFIAQRR RS7_HUMAN $22.13 \quad 100.0 \% \quad 12 \quad 12 \quad 26 \quad 0.04 \% \quad 44.8 \%$ RILPKPTR RS7_HUMAN $22.13 \quad 100.0 \% \quad 12$ RS7 HUMAN $22.13 \quad 100.0 \% \quad 12$ RS7_HUMAN $22.13 \quad 100.0 \% \quad 12$ RS8_HUMAN $24.21 \quad 100.0 \% \quad 10$ RS8 HUMAN $24.21 \quad 100.0 \% \quad 10$ RS8_HUMAN $24.21 \quad 100.0 \% \quad 10$ RS8 HUMAN $24.21 \quad 100.0 \% \quad 10$ RS8_HUMAN $24.21 \quad 100.0 \% \quad 10$ RS8_HUMAN $24.21 \quad 100.0 \% \quad 10$ RS8 HUMAN $24.21 \quad 100.0 \% \quad 10$ RS8_HUMAN $24.21 \quad 100.0 \% \quad 10$ RS8 HUMAN $24.21 \quad 100.0 \% \quad 10$ RS8_HUMAN $24.21 \quad 100.0 \% \quad 10$ RS9_HUMAN $22.59 \quad 100.0 \% \quad 16$ RS9 HUMAN $22.59 \quad 100.0 \% \quad 16$ RS9_HUMAN $22.59 \quad 100.0 \% \quad 16$ RS9_HUMAN $22.59 \quad 100.0 \% \quad 16$ RS9 HUMAN $22.59 \quad 100.0 \% \quad 16$ RS9_HUMAN $22.59 \quad 100.0 \% \quad 16$ RS9 HUMAN $22.59 \quad 100.0 \% \quad 16$ RS9_HUMAN $22.59 \quad 100.0 \% \quad 16$ RS9_HUMAN $22.59 \quad 100.0 \% \quad 16$ RS9 HUMAN $22.59 \quad 100.0 \% \quad 16$ RS9_HUMAN $22.59 \quad 100.0 \% \quad 16$ RS9 HUMAN $22.59 \quad 100.0 \% \quad 16$ RS9 HUMAN $22.59 \quad 100.0 \% \quad 16$ RS9_HUMAN $22.59 \quad 100.0 \% \quad 16$ RS9 HUMAN $22.59 \quad 100.0 \% \quad 16$ RS9_HUMAN $22.59 \quad 100.0 \% \quad 16$ RSSA_HUMAN $32.85 \quad 100.0 \% \quad 6$ RSSA HUMAN $32.85 \quad 100.0 \% \quad 6$ RSSA_HUMAN $32.85 \quad 100.0 \% \quad 6$ RSSA HUMAN $32.85 \quad 100.0 \%-6$ RSSA HUMAN $32.85 \quad 100.0 \%$ $\begin{array}{llll}\text { RSSA_HUMAN } & 32.85 & 100.0 \% & 6 \\ \text { RSSA HUMAN } & 32.85 & 100.0 \% & 6\end{array}$ 4F2_HUMAN $68.00 \quad 100.0 \%$ $\begin{array}{lllll}99.7 \% & 48.4 & 25.0 & 37.3 & 2\end{array}$ $99.0 \% \quad 61.7 \quad 25.0 \quad 42.3 \quad 2$ $\begin{array}{llll}99.7 \% & 48.2 & 25.0 & 42.6\end{array}$ $99.0 \% \quad 39.4 \quad 25.0 \quad 36.2$ $\begin{array}{lllll}99.7 \% & 53.7 & 25.0 & 53.7\end{array}$ $\begin{array}{llll}99.7 \% & 38.5 & 25.0 & 38.5\end{array}$ $99.0 \% \quad 24.7 \quad 25.0 \quad 24.7$ $\begin{array}{lllll}99.0 \% & 34.2 & 25.0 & 34.2 & 2\end{array}$ $99.6 \% \quad 24.1 \quad 25.0 \quad 18.2$ $\begin{array}{llll}99.0 \% & 38.3 & 25.0 & 27.2\end{array}$

\begin{tabular}{|c|c|c|c|c|c|c|c|c|c|c|}
\hline 7 & 20 & 60 & $.08 \%$ & $63.9 \%$ ASTSKSESSOK & $99.7 \%$ & 48.4 & 25.0 & 37.3 & 2 & 0 \\
\hline 12 & 12 & 26 & $0.04 \%$ & $44.8 \%$ ELNITAAK & $99.0 \%$ & 61.7 & 25.0 & 42.3 & 2 & 0 \\
\hline 12 & 12 & 26 & $0.04 \%$ & 44.8\% ELNITAAKEIEVGGGR & $99.7 \%$ & 48.2 & 25.0 & 42.6 & 0 & 2 \\
\hline 12 & 12 & 26 & $0.04 \%$ & $44.8 \%$ EIEVGGGR & $99.0 \%$ & 39.4 & 25.0 & 36.2 & 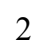 & 0 \\
\hline 12 & 12 & 26 & $0.04 \%$ & $44.8 \%$ KAIIIFVPVPQLK & $99.7 \%$ & 53.7 & 25.0 & 53.7 & & \\
\hline 12 & 12 & 26 & $0.04 \%$ & 44.8\% AIIIFVPVPQLK & $99.7 \%$ & 38.5 & 25.0 & 38.5 & 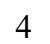 & 0 \\
\hline 12 & 12 & 26 & $0.04 \%$ & $44.8 \%$ SFQKIQVR & $99.0 \%$ & 24.7 & 25.0 & 24.7 & 1 & 0 \\
\hline 12 & 12 & 26 & $0.04 \%$ & $44.8 \%$ HVVFIAQR & $99.0 \%$ & 34.2 & 25.0 & 34.2 & & \\
\hline 12 & 12 & 26 & $0.04 \%$ & $44.8 \%$ HVVFIAQRR & $99.6 \%$ & 24.1 & 25.0 & 18.2 & 2 & ) \\
\hline 12 & 12 & 26 & $0.04 \%$ & 44.8\% RILPKPTR & $99.0 \%$ & 38.3 & 25.0 & 27.2 & 2 & 0 \\
\hline 12 & 12 & 26 & $0.04 \%$ & 44.8\% AQQNNVEHKVETFSGVYK & $99.7 \%$ & 34.8 & 25.0 & 34.8 & & \\
\hline 12 & 12 & 26 & $0.04 \%$ & 44.8\% VETFSGVYKK & $99.5 \%$ & 36.2 & 25.0 & 23.0 & . & \\
\hline 12 & 12 & 26 & $0.04 \%$ & $44.8 \%$ LTGKDVNFEFPEFQL & $99.7 \%$ & 43.4 & 25.0 & 43.4 & 2 & ) \\
\hline 10 & 14 & 34 & $0.05 \%$ & $54.3 \%$ KYELGRPAANTK & $99.7 \%$ & 47.0 & 25.0 & 41.3 & 2 & \\
\hline 10 & 14 & 34 & $0.05 \%$ & $54.3 \%$ YELGRPAANTK & $99.7 \%$ & 47.5 & 25.0 & 40.4 & 2 & \\
\hline 10 & 14 & 34 & $0.05 \%$ & $54.3 \%$ ALRLDVGNFSWGSECCTR & $99.7 \%$ & 31.2 & 25.0 & 31.2 & ( & \\
\hline 10 & 14 & 34 & $0.05 \%$ & $54.3 \%$ TRIIDVVYNASNNELVR & $99.7 \%$ & 26.7 & 25.0 & 26.7 & 0 & \\
\hline 10 & 14 & 34 & $0.05 \%$ & $54.3 \%$ IIDVVYNASNNELVR & $99.7 \%$ & 39.6 & 25.0 & 39.6 & 0 & \\
\hline 10 & 14 & 34 & $0.05 \%$ & $54.3 \%$ NCIVLIDSTPYR & $99.7 \%$ & 50.6 & 25.0 & 48.3 & 2 & ) \\
\hline 10 & 14 & 34 & $0.05 \%$ & 54.3\% LTPEEEEILNK & $99.7 \%$ & 41.1 & 25.0 & 37.5 & 2 & \\
\hline 10 & 14 & 34 & $0.05 \%$ & $54.3 \%$ ISSLLEEQFQQGK & $99.7 \%$ & 58.5 & 25.0 & 51.4 & 4 & ) \\
\hline 10 & 14 & 34 & $0.05 \%$ & $54.3 \%$ LLACIASRPGQCGR & $99.7 \%$ & 32.2 & 25.0 & 32.2 & 2 & 2 \\
\hline 10 & 14 & 34 & $0.05 \%$ & 54.3\% ADGYVLEGKELEFYLR & $99.7 \%$ & 42.0 & 25.0 & 39.6 & 0 & \\
\hline 16 & 19 & 36 & $0.05 \%$ & $54.1 \%$ SRLDQELK & $99.0 \%$ & 42.3 & 25.0 & 19.6 & 2 & ) \\
\hline 16 & 19 & 36 & $0.05 \%$ & $54.1 \%$ LDQELKLIGEYGLR & $99.7 \%$ & 43.1 & 25.0 & 39.0 & 2 & 2 \\
\hline 16 & 19 & 36 & $0.05 \%$ & $54.1 \%$ LIGEYGLR & $99.0 \%$ & 48.0 & 25.0 & 34.8 & 2 & 0 \\
\hline 16 & 19 & 36 & $0.05 \%$ & $54.1 \%$ ELLTLDEKDPR & $99.6 \%$ & 22.1 & 25.0 & 22.1 & 1 & 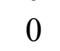 \\
\hline 16 & 19 & 36 & $0.05 \%$ & $54.1 \%$ RLFEGNALLR & $99.7 \%$ & 41.9 & 25.0 & 18.7 & 2 & 0 \\
\hline 16 & 19 & 36 & $0.05 \%$ & $54.1 \%$ LFEGNALLR & $99.7 \%$ & 59.7 & 25.0 & 38.5 & 3 & 0 \\
\hline 16 & 19 & 36 & $0.05 \%$ & $54.1 \%$ LFEGNALLRR & $98.6 \%$ & 24.4 & 25.0 & 19.7 & 2 & 0 \\
\hline 16 & 19 & 36 & $0.05 \%$ & $54.1 \%$ IGVLDEGK & $99.0 \%$ & 59.7 & 25.0 & 32.7 & 2 & 0 \\
\hline 16 & 19 & 36 & $0.05 \%$ & $54.1 \%$ IGVLDEGKMK & $99.7 \%$ & 34.6 & 25.0 & 26.9 & 1 & 0 \\
\hline 16 & 19 & 36 & $0.05 \%$ & $54.1 \%$ RLQTQVFK & $99.0 \%$ & 30.9 & 25.0 & 21.9 & 1 & 0 \\
\hline 16 & 19 & 36 & $0.05 \%$ & $54.1 \%$ KQVVNIPSFIVR & $99.7 \%$ & 49.2 & 25.0 & 49.2 & 2 & 2 \\
\hline 16 & 19 & 36 & $0.05 \%$ & $54.1 \%$ QVVNIPSFIVR & $99.7 \%$ & 49.4 & 25.0 & 40.8 & 3 & 0 \\
\hline 16 & 19 & 36 & $0.05 \%$ & $54.1 \%$ QVVNIPSFIVRLDSQK & $95.0 \%$ & 13.6 & 25.0 & 13.6 & 0 & 1 \\
\hline 16 & 19 & 36 & $0.05 \%$ & $54.1 \%$ LDSQKHIDFSLR & $99.7 \%$ & 47.9 & 25.0 & 45.6 & 2 & 2 \\
\hline 16 & 19 & 36 & $0.05 \%$ & $54.1 \%$ SPYGGGRPGR & $99.7 \%$ & 54.4 & 25.0 & 45.5 & 2 & 0 \\
\hline 16 & 19 & 36 & $0.05 \%$ & $54.1 \%$ KGQGGAGAGDDEEED & $99.7 \%$ & 65.5 & 25.0 & 65.5 & 2 & 0 \\
\hline 6 & 6 & 11 & $0.02 \%$ & $21.7 \%$ SDGIYIINLKR & $99.7 \%$ & 31.0 & 25.0 & 26.2 & 2 & 0 \\
\hline 6 & 6 & 11 & $0.02 \%$ & 21.7\% AIVAIENPADVSVISSR & $99.7 \%$ & 75.9 & 25.0 & 75.9 & 2 & 0 \\
\hline 6 & 6 & 11 & $0.02 \%$ & 21.7\% AVLKFAAATGATPIAGR & $99.7 \%$ & 27.6 & 25.0 & 27.4 & 1 & 0 \\
\hline 6 & 6 & 11 & $0.02 \%$ & $21.7 \%$ FAAATGATPIAGR & $99.7 \%$ & 67.1 & 25.0 & 61.2 & 2 & 0 \\
\hline 6 & 6 & 11 & $0.02 \%$ & $21.7 \%$ LLVVTDPR & $99.0 \%$ & 48.0 & 25.0 & 36.8 & 2 & 0 \\
\hline 6 & 6 & 11 & $0.02 \%$ & $21.7 \%$ YVDIAIPCNNK & $99.7 \%$ & 33.9 & 25.0 & 33.9 & 2 & 0 \\
\hline 3 & 4 & 7 & $0.01 \%$ & 7.1\% IKVAEDEAEAAAAAK & $99.7 \%$ & 60.1 & 25.0 & 53.6 & 2 & 1 \\
\hline 3 & 4 & 7 & $0.01 \%$ & $7.1 \%$ FTGLSKEELLK & $99.7 \%$ & 46.0 & 25.0 & 44.7 & 2 & 0 \\
\hline
\end{tabular}

$\begin{array}{ccc}1139.55 & 239 & 249 \\ 859.49 & 42 & 49 \\ 1656.89 & 42 & 57 \\ 816.42 & 50 & 57 \\ 1465.95 & 58 & 70 \\ 1337.86 & 59 & 70 \\ 1005.58 & 71 & 78 \\ 969.56 & 91 & 98 \\ 1125.66 & 91 & 99 \\ 980.64 & 99 & 106 \\ 2078.03 & 161 & 178 \\ 1157.62 & 170 & 179 \\ 1783.89 & 180 & 194 \\ 1347.74 & 26 & 37 \\ 1219.64 & 27 & 37 \\ 2127.97 & 57 & 74 \\ 1976.06 & 76 & 92 \\ 1718.91 & 78 & 92 \\ 1450.74 & 99 & 110 \\ 1314.68 & 129 & 139 \\ 1506.78 & 158 & 170 \\ 1558.79 & 171 & 184 \\ 1901.96 & 185 & 200 \\ 988.54 & 23 & 30 \\ 1646.91 & 25 & 38 \\ 920.52 & 31 & 38 \\ 1328.71 & 59 & 69 \\ 1188.68 & 70 & 79 \\ 1032.58 & 71 & 79 \\ 1188.68 & 71 & 80 \\ 830.46 & 84 & 91 \\ 1089.60 & 84 & 93 \\ 1019.60 & 109 & 116 \\ 1399.84 & 139 & 150 \\ 1271.75 & 140 & 150 \\ 1843.04 & 140 & 155 \\ 1458.77 & 151 & 162 \\ 1003.51 & 163 & 172 \\ 1434.56 & 180 & 194 \\ 1291.74 & 43 & 53 \\ 1740.95 & 64 & 80 \\ 1614.93 & 86 & 102 \\ 1203.65 & 90 & 102 \\ 912.55 & 121 & 128 \\ 1306.65 & 156 & 166 \\ 1486.77 & 146 & 160 \\ 1264.71 & 161 & 171 \\ & & \end{array}$ 
$4 \mathrm{~F} 2$ cell-surface antigen heavy chain GN=SLC3A2 $4 \mathrm{~F} 2$ HUMAN $68.00 \quad 100.0 \%$ $5^{\prime}-3^{\prime}$ exoribonuclease $2 \mathrm{GN}=\mathrm{XRN} 2$ $5^{\prime}-3^{\prime}$ exoribonuclease $2 \mathrm{GN}=\mathrm{XRN} 2$ $5^{\prime}-3^{\prime}$ exoribonuclease $2 \mathrm{GN}=\mathrm{XRN} 2$ $5^{\prime}-3^{\prime}$ exoribonuclease $2 \mathrm{GN}=\mathrm{XRN} 2$ $\begin{array}{lll}5 '-3 ' \text { exoribonuclease } 2 \mathrm{GN}=\mathrm{XRN2} \quad \text { XRN2_HUMAN } 108.59 & 100.0 \%\end{array}$ 5'-AMP-activated protein kinase subunit gamma-1 GN=PRKAG1 AAKG1_HUMAN $37.58 \quad 100.0 \%$ $60 \mathrm{kDa}$ heat shock protein, mitochondrial GN=HSPD1 CH60_HUMAN $61.06 \quad 100.0 \%$ $60 \mathrm{kDa}$ heat shock protein, mitochondrial GN=HSPD1 CH60_HUMAN $61.06 \quad 100.0 \%$ $60 \mathrm{kDa}$ heat shock protein, mitochondrial GN=HSPD1 CH60_HUMAN $61.06 \quad 100.0 \%$ $60 \mathrm{kDa}$ heat shock protein, mitochondrial GN=HSPD1 CH60_HUMAN $61.06 \quad 100.0 \%$ $60 \mathrm{kDa}$ heat shock protein, mitochondrial GN=HSPD1 CH60_HUMAN $61.06 \quad 100.0 \%$ $60 \mathrm{kDa}$ heat shock protein, mitochondrial GN=HSPD1 CH60_HUMAN $61.06 \quad 100.0 \%$ $60 \mathrm{kDa}$ heat shock protein, mitochondrial GN=HSPD1 CH60_HUMAN $61.06 \quad 100.0 \%$ $60 \mathrm{kDa}$ heat shock protein, mitochondrial GN=HSPD1 CH60_HUMAN $61.06 \quad 100.0 \%$ $60 \mathrm{kDa}$ heat shock protein, mitochondrial GN=HSPD1 CH60 HUMAN $61.06 \quad 100.0 \%$ $60 \mathrm{kDa}$ heat shock protein, mitochondrial GN=HSPD1 CH60_HUMAN $61.06 \quad 100.0 \%$ $60 \mathrm{kDa}$ heat shock protein, mitochondrial GN=HSPD1 CH60_HUMAN $61.06 \quad 100.0 \%$ $60 \mathrm{kDa}$ heat shock protein, mitochondrial GN=HSPD1 CH60 HUMAN $61.06 \quad 100.0 \%$ $60 \mathrm{kDa}$ SS-A/Ro ribonucleoprotein GN=TROVE2 RO60_HUMAN $60.67 \quad 100.0 \%$ $60 \mathrm{kDa}$ SS-A/Ro ribonucleoprotein GN=TROVE2 RO60_HUMAN $60.67 \quad 100.0 \%$ $60 \mathrm{kDa}$ SS-A/Ro ribonucleoprotein GN=TROVE2 RO60_HUMAN $60.67 \quad 100.0 \%$ $60 \mathrm{~S}$ acidic ribosomal protein P0 GN=RPLP0 RLA0_HUMAN 34.27 $60 \mathrm{~S}$ acidic ribosomal protein $\mathrm{P} 0 \mathrm{GN}=\mathrm{RPLP0}$ RLA0_HUMAN 34.27 $60 \mathrm{~S}$ acidic ribosomal protein P0 GN=RPLP0 RLA0_HUMAN 34.27 $60 \mathrm{~S}$ acidic ribosomal protein P0 GN=RPLP0 RLA0_HUMAN 34.27 $60 \mathrm{~S}$ acidic ribosomal protein P0 GN=RPLP0 RLA0 HUMAN 34.27 $60 \mathrm{~S}$ acidic ribosomal protein P0 GN=RPLP0 RLA0_HUMAN 34.27 $60 \mathrm{~S}$ acidic ribosomal protein $\mathrm{P} 0 \mathrm{GN}=\mathrm{RPLP0}$ RLA0_HUMAN 34.27 $60 \mathrm{~S}$ acidic ribosomal protein P0 GN=RPLP0 RLA0_HUMAN 34.27 $60 \mathrm{~S}$ acidic ribosomal protein P0 GN=RPLP0 RLA0_HUMAN 34.27 $60 \mathrm{~S}$ acidic ribosomal protein P0 GN=RPLP0 RLA0_HUMAN 34.27 $60 \mathrm{~S}$ acidic ribosomal protein P0 GN=RPLP0 RLA0_HUMAN 34.27 $60 \mathrm{~S}$ acidic ribosomal protein P0 GN=RPLP0 RLA0_HUMAN 34.27 $60 \mathrm{~S}$ acidic ribosomal protein P0 GN=RPLP0 RLA0_HUMAN 34.27 $60 \mathrm{~S}$ acidic ribosomal protein P0 GN=RPLP0 RLA0_HUMAN 34.27 $60 \mathrm{~S}$ acidic ribosomal protein P0 GN=RPLP0 RLA0 HUMAN 34.27 60S acidic ribosomal protein P0 GN=RPLP0 RLA0_HUMAN 34.27 $60 \mathrm{~S}$ ribosomal protein $\mathrm{L} 10 \mathrm{GN}=\mathrm{RPL} 10$ $60 \mathrm{~S}$ ribosomal protein $\mathrm{L} 10 \mathrm{GN}=\mathrm{RPL} 10$ $60 \mathrm{~S}$ ribosomal protein $\mathrm{L} 10 \mathrm{GN}=\mathrm{RPL} 10$ $60 \mathrm{~S}$ ribosomal protein $\mathrm{L} 10 \mathrm{GN}=\mathrm{RPL} 10$ $60 \mathrm{~S}$ ribosomal protein $\mathrm{L} 10 \mathrm{GN}=\mathrm{RPL} 10$ $60 \mathrm{~S}$ ribosomal protein $\mathrm{L} 10 \mathrm{GN}=\mathrm{RPL} 10$ $60 \mathrm{~S}$ ribosomal protein $\mathrm{L} 10 \mathrm{GN}=\mathrm{RPL} 10$ $60 \mathrm{~S}$ ribosomal protein $\mathrm{L} 10 \mathrm{GN}=\mathrm{RPL} 10$ RL10_HUMAN $24.60 \quad 100.0 \%$ RL10 HUMAN $24.60 \quad 100.0 \%$ RL10_HUMAN $24.60 \quad 100.0 \%$ RL10 HUMAN $24.60 \quad 100.0 \%$ RL10_HUMAN $24.60 \quad 100.0 \%$ RL10_HUMAN $24.60 \quad 100.0 \%$ RL10 HUMAN $24.60 \quad 100.0 \%$ RL10_HUMAN $24.60 \quad 100.0 \%$
$0.01 \% \quad 7.1 \%$ IGDLQAFQGHGAGNLAGL $0.02 \% \quad 7.7 \%$ RLLYMAIDGVAPR $99.4 \% 22.1$ $0.02 \% \quad 7.7 \%$ DQPAFTPSGILTPHA

$0.02 \% \quad 7.7 \% \quad$ NSPGSQVASNPR

$0.02 \% \quad 7.7 \%$ AALEEVYPDLTPEETRR

$0.02 \% \quad 7.7 \%$ GVGAEPLLPWNR

$0.00 \% \quad 6.7 \%$ AFFALVTNGVR

$0.00 \% \quad 6.7 \% \quad$ TYNNLDVSVTK

$0.04 \% 26.9 \%$ VTKDGVTVAK

$0.04 \% \quad 26.9 \%$ LVQDVANNTNEEAGDGTTTATVLAR

$0.04 \% \quad 26.9 \%$ GANPVEIRR

$0.04 \% \quad 26.9 \%$ ISSIQSIVPALEIANAHR

$0.04 \% \quad 26.9 \%$ VGLQVVAVK

$0.04 \% \quad 26.9 \%$ APGFGDNRK

$0.04 \% \quad 26.9 \%$ VGEVIVTKDDAMLLK

$0.04 \% \quad 26.9 \%$ LSDGVAVLK

$99.7 \% \quad 31.3$

$99.7 \% \quad 44.9$

$99.7 \% \quad 35.5$

$\begin{array}{lll}99.7 \% & 28.7\end{array}$

$99.7 \% \quad 39.5$

$99.7 \% \quad 44.1$

$99.7 \% \quad 40.8$

$99.7 \% \quad 36.6$

$99.7 \% \quad 32.0$

$99.7 \% \quad 29.9$

$99.7 \% \quad 43.6$

$99.6 \% \quad 33.6$

$99.7 \% 36.6$

$99.7 \% \quad 47.2$

$0.04 \% \quad 26.9 \%$ AAVEEGIVLGGGCALLR $\quad 99.7 \% 51.7$

$0.04 \% \quad 26.9 \%$ TLKIPAMTIAK

$0.04 \% \quad 26.9 \%$ NAGVEGSLIVEK

$0.04 \% 26.9 \%$ GIIDPTKVVR

$0.01 \% \quad 6.5 \% \quad$ LGLENAEALIR

$0.01 \% \quad 6.5 \%$ ALSVETEKLLK

$0.01 \% \quad 6.5 \%$ ALLQEMPLTALLR

$0.07 \% \quad 52.1 \%$ IIQLLDDYPK

$98.4 \% \quad 20.2$

$99.7 \% \quad 46.2$

$99.7 \% \quad 30.6$

$99.7 \% \quad 45.3$

$99.7 \% \quad 26.3$

$99.7 \% \quad 70.5$

$99.7 \% \quad 59.4$

$0.07 \% \quad 52.1 \%$ IIQLLDDYPKCFIVGADNVGSK $99.7 \% \quad 33.5$

$0.07 \% \quad 52.1 \%$ CFIVGADNVGSK

$99.7 \% \quad 50.6$

$0.07 \% \quad 52.1 \%$ CFIVGADNVGSKQMQQIR $99.7 \% \quad 29.0$

$0.07 \% \quad 52.1 \%$ GKAVVLMGK

$0.07 \% \quad 52.1 \%$ AVVLMGKNTMMR

$0.07 \% \quad 52.1 \%$ AIRGHLENNPALEK

$0.07 \% \quad 52.1 \%$ GHLENNPALEK

$0.07 \% \quad 52.1 \%$ GNVGFVFTK

$99.7 \% 33.8$

$99.7 \% \quad 29.3$

$99.7 \% \quad 37.0$

$99.7 \% \quad 64.4$

$99.7 \% \quad 35.4$

$0.07 \% \quad 52.1 \%$ AGAIAPCEVTVPAQNTGLGPEK $\quad 99.7 \% \quad 45.2$

$0.07 \% \quad 52.1 \%$ TSFFQALGITTK

$0.07 \% \quad 52.1 \%$ ISRGTIEILSDVQLIK

$99.7 \% \quad 50.7$

$98.9 \% \quad 20.0$

$99.7 \% \quad 53.9$

$0.07 \% \quad 52.1 \%$ GTIEILSDVQLIK

$99.7 \% \quad 58.6$

$\begin{array}{lllll}0.07 \% & 52.1 \% & \text { VLALSVETDYTFPLAEKVK } & 99.7 \% & 33.1\end{array}$

$0.07 \% \quad 52.1 \%$ AFLADPSAFVAAAPVAAATTAAPAAAAAPAK

$0.06 \% \quad 39.3 \%$ GVPDAKIR

$0.06 \% \quad 39.3 \%$ IRIFDLGR

$0.06 \% \quad 39.3 \%$ ICANKYMVK

$0.06 \% \quad 39.3 \%$ MLSCAGADRLQTGMR

$0.06 \% \quad 39.3 \%$ GAFGKPQGTVAR

$0.06 \% \quad 39.3 \%$ VHIGQVIMSIR

$0.06 \% 39.3 \%$ FNADEFEDMVAEKR

$0.06 \% \quad 39.3 \%$ RLIPDGCGVK
$99.0 \% \quad 30.0$

$99.7 \% \quad 35.9$

$99.7 \% \quad 33.3$

$99.7 \% \quad 58.3$

$99.7 \% \quad 49.8$

$99.7 \% \quad 47.0$

$99.7 \% \quad 46.8$ $\begin{array}{ll}99.7 \% & 38.2 \\ 99.0 \% & 25.7\end{array}$
1866.98

1474.82

1965.02

1213.59

1988.99

1308.71

1194.66

1253.64

1017.59

2560.25

1011.57

1919.07

912.59

961.49

1630.91

901.54

1684.91

1186.72

1215.66

1097.67

1198.68

1230.73

1468.86

1217.68

2465.27

1266.61

2067.01

918.54

1350.71

1561.84

1221.62

968.52

2180.10

1313.71

1785.05

1428.83

1896.00

2123.16

2752.47

855.50

989.59

1126.57

1698.77

1188.65

1268.71

1716.75

1114.60 $\begin{array}{cc}27 & 245 \\ 6 & 108 \\ 28 & 446 \\ 47 & 458 \\ 60 & 676 \\ 84 & 895 \\ 0 & 70 \\ 54 & 264 \\ 3 & 82 \\ 7 & 121 \\ 34 & 142 \\ 51 & 268 \\ 93 & 301 \\ 02 & 310 \\ 45 & 359 \\ 97 & 405 \\ 30 & 446 \\ 71 & 481 \\ 82 & 493 \\ 17 & 526 \\ 3 & 63 \\ 17 & 227 \\ 71 & 283 \\ 7 & 26 \\ 7 & 38 \\ 7 & 38 \\ 7 & 44 \\ 9 & 57 \\ 1 & 62 \\ 4 & 77 \\ 7 & 77 \\ 4 & 92 \\ 13 & 134 \\ 35 & 146 \\ 47 & 162 \\ 50 & 162 \\ 48 & 264 \\ 48 & 266 \\ 67 & 297 \\ 5 & 32 \\ 1 & 38 \\ 0 & 78 \\ 02 & 116 \\ 17 & 128 \\ 29 & 139 \\ 89 & 189 \\ & \end{array}$

Page 10 of Table S-1- 1 
60S ribosomal protein L10a GN=RPL10A RL10A_HUMAN $24.83 \quad 100.0 \%$ 60 S ribosomal protein L10a GN=RPL10A RL10A_HUMAN $24.83 \quad 100.0 \%$ $60 \mathrm{~S}$ ribosomal protein $\mathrm{L} 10 \mathrm{a}$ GN=RPL10A RL10A_HUMAN $24.83 \quad 100.0 \%$ $60 \mathrm{~S}$ ribosomal protein L10a GN=RPL10A RL10A_HUMAN $24.83 \quad 100.0 \%$ 60S ribosomal protein L10a GN=RPL10A RL10A_HUMAN $24.83 \quad 100.0 \%$ $60 \mathrm{~S}$ ribosomal protein $\mathrm{L} 10 \mathrm{a} \mathrm{GN}=\mathrm{RPL10A}$ RL10A_HUMAN $24.83 \quad 100.0 \%$ $60 \mathrm{~S}$ ribosomal protein L10a GN=RPL10A RL10A_HUMAN $24.83 \quad 100.0 \%$ $60 \mathrm{~S}$ ribosomal protein $\mathrm{L} 11 \mathrm{GN}=\mathrm{RPL} 11$ $60 \mathrm{~S}$ ribosomal protein $\mathrm{L} 11 \mathrm{GN}=\mathrm{RPL} 11$ $60 \mathrm{~S}$ ribosomal protein $\mathrm{L} 11 \mathrm{GN}=\mathrm{RPL} 11$ $60 \mathrm{~S}$ ribosomal protein $\mathrm{L} 11 \mathrm{GN}=\mathrm{RPL} 11$ $60 \mathrm{~S}$ ribosomal protein $\mathrm{L} 11 \mathrm{GN}=\mathrm{RPL} 11$ $60 \mathrm{~S}$ ribosomal protein $\mathrm{L} 11 \mathrm{GN}=\mathrm{RPL} 11$ $60 \mathrm{~S}$ ribosomal protein $\mathrm{L} 13 \mathrm{GN}=\mathrm{RPL} 13$ $60 \mathrm{~S}$ ribosomal protein $\mathrm{L} 13 \mathrm{GN}=\mathrm{RPL} 13$ $60 \mathrm{~S}$ ribosomal protein $\mathrm{L} 13 \mathrm{GN}=\mathrm{RPL} 13$ $60 \mathrm{~S}$ ribosomal protein $\mathrm{L} 13 \mathrm{GN}=\mathrm{RPL} 13$ $60 \mathrm{~S}$ ribosomal protein $\mathrm{L} 13 \mathrm{GN}=\mathrm{RPL} 13$ 60 S ribosomal protein $\mathrm{L} 13 \mathrm{GN}=\mathrm{RPL} 13$ $60 \mathrm{~S}$ ribosomal protein $\mathrm{L} 13 \mathrm{GN}=\mathrm{RPL} 13$ $60 \mathrm{~S}$ ribosomal protein $\mathrm{L} 13 \mathrm{GN}=\mathrm{RPL} 13$ $60 \mathrm{~S}$ ribosomal protein $\mathrm{L} 13 \mathrm{GN}=\mathrm{RPL} 13$ $60 \mathrm{~S}$ ribosomal protein $\mathrm{L} 13 \mathrm{GN}=\mathrm{RPL} 13$ $60 \mathrm{~S}$ ribosomal protein $\mathrm{L} 13 \mathrm{GN}=\mathrm{RPL} 13$ $60 \mathrm{~S}$ ribosomal protein $\mathrm{L} 13 \mathrm{GN}=\mathrm{RPL} 13$ $60 \mathrm{~S}$ ribosomal protein $\mathrm{L} 13 \mathrm{GN}=\mathrm{RPL} 13$ $60 \mathrm{~S}$ ribosomal protein $\mathrm{L} 13 \mathrm{GN}=\mathrm{RPL} 13$ $60 \mathrm{~S}$ ribosomal protein $\mathrm{L} 13 \mathrm{GN}=\mathrm{RPL} 13$ $60 \mathrm{~S}$ ribosomal protein $\mathrm{L} 13 \mathrm{GN}=\mathrm{RPL} 13$ $60 \mathrm{~S}$ ribosomal protein $\mathrm{L} 13 \mathrm{GN}=\mathrm{RPL} 13$ 60S ribosomal protein 13 GN=RPL13A RL13A_HUMAN 23.58 $60 \mathrm{~S}$ ribosomal protein L13a GN=RPL13A RL13A_HUMAN 23.58 60S ribosomal protein L13a GN=RPL13A RL13A_HUMAN 23.58 60S ribosomal protein L13a GN=RPL13A RL13A_HUMAN 23.58 $60 \mathrm{~S}$ ribosomal protein L13a GN=RPL13A RL13A_HUMAN 23.58 60S ribosomal protein L13a GN=RPL13A RL13A_HUMAN 23.58 60S ribosomal protein L13a GN=RPL13A RL13A_HUMAN 23.58 60S ribosomal protein L13a GN=RPL13A RL13A_HUMAN 23.58 60S ribosomal protein L13a GN=RPL13A RL13A_HUMAN 23.58 60S ribosomal protein L13a GN=RPL13A RL13A_HUMAN 23.58 60S ribosomal protein L13a GN=RPL13A RL13A_HUMAN 23.58 60S ribosomal protein L13a GN=RPL13A RL13A_HUMAN 23.58 60S ribosomal protein L13a GN=RPL13A RL13A_HUMAN 23.58 60S ribosomal protein L13a GN=RPL13A RL13A_HUMAN 23.58 60S ribosomal protein L14 GN=RPL14 RL14_HUMAN 23.43
$0.03 \% \quad 38.2 \%$ VSRDTLYEAVR

$0.03 \% \quad 38.2 \%$ DTLYEAVREVLHGNQR

$0.03 \% \quad 38.2 \%$ FSVCVLGDQQHCDEAK

$0.03 \% \quad 38.2 \%$ KYDAFLASESLIK

$0.03 \% \quad 38.2 \%$ ILGPGLNK

$99.7 \% \quad 35.7$

$99.7 \% \quad 39.5$

$99.7 \% \quad 53.8$

$96.5 \% \quad 23.3$

$\begin{array}{lll}0.03 \% & 38.2 \% & \text { AGKFPSLLT } \\ 0.03 \% & 38.2 \% & \text { STMGKPQR }\end{array}$

$\begin{array}{lll}0.03 \% & 38.2 \% & \text { STMGKPQRLY }\end{array}$

$0.01 \% 30.3 \%$ VLEQLTGQTPVFSK

$0.01 \% \quad 30.3 \%$ IAVHCTVR

$10 \quad 0.01 \% \quad 30.3 \%$ GAKAEEILEK

$10 \quad 0.01 \% \quad 30.3 \%$ ISKEEAMR

$10 \quad 0.01 \% \quad 30.3 \%$ WFQQKYDGIILPGK

$10 \quad 0.01 \% \quad 30.3 \%$ YDGIILPGK

$0.10 \% \quad 54.0 \%$ RVATWFNQPAR

$0.10 \% \quad 54.0 \%$ VATWFNQPAR

$0.10 \% \quad 54.0 \%$ VATWFNQPARK

$0.10 \% \quad 54.0 \%$ IAPRPASGPIRPIVR

$0.10 \% \quad 54.0 \%$ AGRGFSLEELR

$0.10 \% \quad 54.0 \%$ GFSLEELR

$0.10 \% \quad 54.0 \%$ TIGISVDPR

$0.10 \% \quad 54.0 \%$ TIGISVDPRR

$0.10 \% \quad 54.0 \%$ NKSTESLQANVQR

$0.10 \% \quad 54.0 \%$ STESLQANVQR

$0.10 \% \quad 54.0 \%$ SKLILFPR

$0.10 \% \quad 54.0 \%$ KGDSSAEELK

$0.10 \% \quad 54.0 \%$ LATQLTGPVMPVR

$0.10 \% \quad 54.0 \%$ VITEEEKNFK

$0.10 \% \quad 54.0 \%$ AKEAAEQDVEK

$0.10 \% \quad 54.0 \%$ EAAEQDVEK

$0.10 \% \quad 54.0 \%$ EAAEQDVEKK

$0.05 \% \quad 51.2 \%$ CEGINISGNFYR

$0.05 \% \quad 51.2 \%$ LKYLAFLR

$0.05 \% \quad 51.2 \%$ MNTNPSRGPYHFR

$0.05 \% \quad 51.2 \%$ TVRGMLPHK

$0.05 \% \quad 51.2 \%$ RGQAALDR

$0.05 \% \quad 51.2 \%$ GQAALDRLK

$0.05 \% \quad 51.2 \%$ LKVFDGIPPPYDK

$0.05 \% \quad 51.2 \%$ VFDGIPPPYDK

$0.05 \% \quad 51.2 \%$ VFDGIPPPYDKK

$0.05 \% \quad 51.2 \%$ MVVPAALK

$0.05 \% \quad 51.2 \%$ MVVPAALKVVR

$0.05 \% \quad 51.2 \%$ LAHEVGWK

$0.05 \% \quad 51.2 \%$ YQAVTATLEEK

$0.05 \% \quad 51.2 \%$ YQAVTATLEEKR

$0.05 \% \quad 51.2 \%$ IDKYTEVLK

$0.02 \% \quad 26.5 \%$ LVAIVDVIDQNR
$99.0 \% \quad 30.0$

$99.7 \% \quad 36.4$

$99.7 \% 57.1$

$99.0 \% 35.4$

$99.7 \% \quad 41.5$

$99.0 \% \quad 29.5$

$99.2 \% \quad 20.5$

$\begin{array}{lll}99.7 \% & 33.8\end{array}$

$99.7 \% \quad 39.5$

$99.7 \% \quad 49.9$

$99.7 \% \quad 52.0$

$99.1 \% \quad 18.7$

$97.8 \% \quad 24.5$

$99.0 \% \quad 46.0$

$99.7 \% \quad 43.0$

$99.7 \% \quad 39.2$

$99.7 \% \quad 60.9$

$99.7 \% \quad 55.2$

$99.0 \% \quad 45.4$

$99.7 \% \quad 36.1$

$99.7 \% \quad 33.2$

$99.7 \% \quad 47.0$

$99.7 \% \quad 70.2$

$97.8 \% 21.6$

$99.7 \% \quad 38.6$

$99.7 \% \quad 67.8$

$99.0 \% \quad 27.9$

$98.7 \% \quad 20.6$

$94.7 \% \quad 17.0$

$99.0 \% \quad 36.7$

$99.7 \% \quad 41.3$

$99.7 \% \quad 28.9$

$99.7 \% \quad 27.1$

$99.6 \% 23.1$

$99.0 \% \quad 24.3$

$99.7 \% \quad 28.2$

$99.0 \% \quad 49.6$

$99.7 \% \quad 51.6$

$99.7 \% \quad 44.8$

$99.6 \% \quad 22.5$

$99.7 \% \quad 51.8$
1308.69

1899.97

1892.83

1484.80

811.50

1872.96

904.47

1180.61

1546.85

955.51

1087.60

979.49

1692.91

975.55

1345.71

1189.61

1317.71

1599.98

1234.65

950.49

957.54

1113.64

1474.76

1232.62

973.62

1063.53

1398.78

1236.65

1217.60

1018.47

1146.56

1429.65

1023.64

1576.74

1054.58

886.49

971.56

1488.81

1247.63

1375.73

828.50

1198.73

939.50

1252.64

1408.74

1108.63

1108.63
1354.77

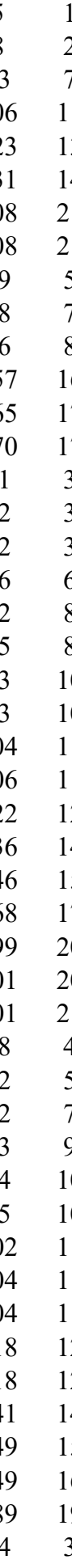


60S ribosomal protein L18a GN=RPL18A RL18A_HUMAN $20.76 \quad 100.0 \% \quad 18 \quad 25 \quad 58 \quad 0.08 \% \quad 72.7 \%$ DLTTAGAVTQCYR

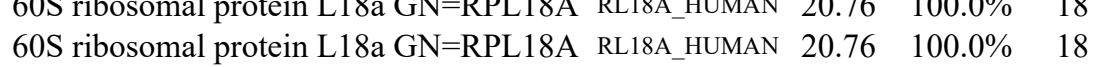
60S ribosomal protein L18a GN=RPL18A RL18A_HUMAN $20.76 \quad 100.0 \% \quad 18$ $60 \mathrm{~S}$ ribosomal protein L18a GN=RPL18A RL18A HUMAN $20.76 \quad 100.0 \%-18$ 60S ribosomal protein L18a GN=RPL18A RL18A_HUMAN $20.76 \quad 100.0 \% \quad 18$ 60S ribosomal protein L18a GN=RPL18A RL18A_HUMAN $20.76 \quad 100.0 \% \quad 18$ $60 \mathrm{~S}$ ribosomal protein L18a GN=RPL18A RL18A HUMAN $20.76 \quad 100.0 \%$ $60 \mathrm{~S}$ ribosomal protein $\mathrm{L} 19 \mathrm{GN}=\mathrm{RPL} 19$ $60 \mathrm{~S}$ ribosomal protein $\mathrm{L} 19 \mathrm{GN}=\mathrm{RPL} 19$ $60 \mathrm{~S}$ ribosomal protein $\mathrm{L} 19 \mathrm{GN}=\mathrm{RPL} 19$ $60 \mathrm{~S}$ ribosomal protein $\mathrm{L} 19 \mathrm{GN}=\mathrm{RPL} 19$ $60 \mathrm{~S}$ ribosomal protein $\mathrm{L} 19 \mathrm{GN}=\mathrm{RPL} 19$ $60 \mathrm{~S}$ ribosomal protein $\mathrm{L} 19 \mathrm{GN}=\mathrm{RPL} 19$ $60 \mathrm{~S}$ ribosomal protein $\mathrm{L} 19 \mathrm{GN}=\mathrm{RPL} 19$ $60 \mathrm{~S}$ ribosomal protein $\mathrm{L} 19 \mathrm{GN}=\mathrm{RPL} 19$ $60 \mathrm{~S}$ ribosomal protein $\mathrm{L} 19 \mathrm{GN}=\mathrm{RPL} 19$ $60 \mathrm{~S}$ ribosomal protein $\mathrm{L} 21 \mathrm{GN}=\mathrm{RPL} 21$ $60 \mathrm{~S}$ ribosomal protein $\mathrm{L} 21 \mathrm{GN}=\mathrm{RPL} 21$ $60 \mathrm{~S}$ ribosomal protein $\mathrm{L} 21 \mathrm{GN}=\mathrm{RPL} 21$ $60 \mathrm{~S}$ ribosomal protein $\mathrm{L} 21 \mathrm{GN}=\mathrm{RPL} 21$ $60 \mathrm{~S}$ ribosomal protein $\mathrm{L} 21 \mathrm{GN}=\mathrm{RPL} 21$ $60 \mathrm{~S}$ ribosomal protein $\mathrm{L} 21 \mathrm{GN}=\mathrm{RPL} 21$ $60 \mathrm{~S}$ ribosomal protein $\mathrm{L} 21 \mathrm{GN}=\mathrm{RPL} 21$ $60 \mathrm{~S}$ ribosomal protein $\mathrm{L} 21 \mathrm{GN}=\mathrm{RPL} 21$ $60 \mathrm{~S}$ ribosomal protein $\mathrm{L} 21 \mathrm{GN}=\mathrm{RPL} 21$ 60S ribosomal protein L23a GN=RPL23A RL23A_HUMAN 18.57 60S ribosomal protein L23a GN=RPL23A RL23A_HUMAN 17.70 60S ribosomal protein L23a GN=RPL23A RL23A_HUMAN 17.70 $60 \mathrm{~S}$ ribosomal protein $\mathrm{L} 23 \mathrm{a} \mathrm{GN}=\mathrm{RPL} 23 \mathrm{~A}$ $60 \mathrm{~S}$ ribosomal protein $\mathrm{L} 24 \mathrm{GN}=\mathrm{RPL} 24$ $60 \mathrm{~S}$ ribosomal protein $\mathrm{L} 24 \mathrm{GN}=\mathrm{RPL} 24$ $60 \mathrm{~S}$ ribosomal protein $\mathrm{L} 24 \mathrm{GN}=\mathrm{RPL} 24$ $60 \mathrm{~S}$ ribosomal protein $\mathrm{L} 24 \mathrm{GN}=\mathrm{RPL} 24$ $60 \mathrm{~S}$ ribosomal protein $\mathrm{L} 24 \mathrm{GN}=\mathrm{RPL} 24$ $60 \mathrm{~S}$ ribosomal protein $\mathrm{L} 24 \mathrm{GN}=\mathrm{RPL} 24$ $60 \mathrm{~S}$ ribosomal protein $\mathrm{L} 24 \mathrm{GN}=\mathrm{RPL} 24$ $60 \mathrm{~S}$ ribosomal protein $\mathrm{L} 24 \mathrm{GN}=\mathrm{RPL} 24$ $60 \mathrm{~S}$ ribosomal protein $\mathrm{L} 24 \mathrm{GN}=\mathrm{RPL} 24$ $60 \mathrm{~S}$ ribosomal protein $\mathrm{L} 24 \mathrm{GN}=\mathrm{RPL} 24$ $60 \mathrm{~S}$ ribosomal protein $\mathrm{L} 24 \mathrm{GN}=\mathrm{RPL} 24$ $60 \mathrm{~S}$ ribosomal protein $\mathrm{L} 24 \mathrm{GN}=\mathrm{RPL} 24$ $60 \mathrm{~S}$ ribosomal protein $\mathrm{L} 24 \mathrm{GN}=\mathrm{RPL} 24$ $60 \mathrm{~S}$ ribosomal protein $\mathrm{L} 24 \mathrm{GN}=\mathrm{RPL} 24$ $60 \mathrm{~S}$ ribosomal protein $\mathrm{L} 24 \mathrm{GN}=\mathrm{RPL} 24$ $60 \mathrm{~S}$ ribosomal protein $\mathrm{L} 29 \mathrm{GN}=\mathrm{RPL} 29$ $60 \mathrm{~S}$ ribosomal protein $\mathrm{L} 29 \mathrm{GN}=\mathrm{RPL} 29$ $60 \mathrm{~S}$ ribosomal protein $\mathrm{L} 29 \mathrm{GN}=\mathrm{RPL} 29$
RL19_HUMAN $23.47 \quad 100.0 \%$ RL19 HUMAN $23.47 \quad 100.0 \%$ RL19_HUMAN $23.47 \quad 100.0 \%$ RL19_HUMAN $23.47 \quad 100.0 \%$ RL19 HUMAN $23.47 \quad 100.0 \%$ RL19_HUMAN $23.47 \quad 100.0 \%$ RL19_HUMAN $23.47 \quad 100.0 \%$ RL19 HUMAN $23.47 \quad 100.0 \%$ RL19_HUMAN $23.47 \quad 100.0 \%$ RL21_HUMAN $18.57 \quad 100.0 \%$ RL21 HUMAN $18.57 \quad 100.0 \%$ RL21_HUMAN $18.57 \quad 100.0 \%$ RL21_HUMAN $18.57 \quad 100.0 \%$ RL21_HUMAN $18.57 \quad 100.0 \%$ RL21_HUMAN $18.57 \quad 100.0 \%$ $\begin{array}{ll}\text { RL21_HUMAN } 18.57 & 100.0 \%\end{array}$ $100.0 \%$ $100.0 \%$ $100.0 \%$ $100.0 \%$ RL23A_HUMAN $17.70 \quad 100.0 \%$ RL24 HUMAN $17.78 \quad 100.0 \%$ RL24_HUMAN $17.78 \quad 100.0 \%$ RL24_HUMAN $17.78 \quad 100.0 \% \quad 15$ RL24_HUMAN $17.78 \quad 100.0 \% \quad 15$ RL24_HUMAN $17.78 \quad 100.0 \% \quad 15$ RL24_HUMAN $17.78 \quad 100.0 \% \quad 15$ RL24_HUMAN $17.78 \quad 100.0 \% \quad 15$ RL24_HUMAN $17.78 \quad 100.0 \% \quad 15$ RL24 HUMAN $17.78 \quad 100.0 \% \quad 15$ RL24_HUMAN $17.78 \quad 100.0 \% \quad 15$ RL24_HUMAN $17.78 \quad 100.0 \% \quad 15$ RL24 HUMAN $17.78 \quad 100.0 \% \quad 15$ RL24_HUMAN $17.78 \quad 100.0 \% \quad 15$ RL24_HUMAN $17.78 \quad 100.0 \% \quad 15$ RL24_HUMAN $17.78 \quad 100.0 \% \quad 15$ RL29_HUMAN $17.75 \quad 100.0 \% \quad 5$ RL29 HUMAN $17.75 \quad 100.0 \% \quad 5$ RL29_HUMAN $17.75 \quad 100.0 \%$ RL21_HUMAN $18.57 \quad 100.0 \%$
$58 \quad 0.0$

58

0.08\% $72.7 \%$ ARAHSIQIMK

$0.08 \% \quad 72.7 \%$ AHSIQIMK

.08\% $72.7 \%$ AHSIQIMKVEEIAASK

72.7\% IKFPLPHR

$0.08 \% \quad 72.7 \%$ FTTKRPNTFF

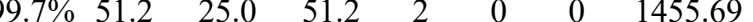
$99.7 \% \quad 28.4 \quad 25.0 \quad 28.4 \quad 2=0-001154.65$ $99.0 \% \quad 33.7$ $99.7 \% \quad 57.8$ $99.0 \% \quad 44.0$ $99.0 \% 24.4$ $99.7 \% \quad 47.1$ $99.0 \% \quad 26.8$ $0.03 \% \quad 34.7 \%$ KVWLDPNETNEIANANSR $99.7 \% 32.6$

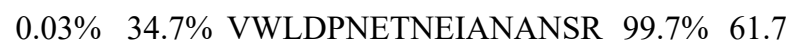
$0.03 \% \quad 34.7 \%$ DGLIIRKPVTVHSR $99.6 \% \quad 22.3$ $99.0 \% 35.3$ $99.7 \% \quad 58.6$ $99.7 \% \quad 58.3$ $99.3 \% 27.0$ $99.7 \% \quad 37.2$ $99.7 \% \quad 43.8$ $99.7 \% \quad 45.1$ $99.7 \% \quad 48.9$ $0.03 \% \quad 34.7 \%$ KLLADQAEAR $0.03 \% \quad 34.7 \%$ LLADQAEAR $0.03 \% \quad 34.7 \%$ LLADQAEARR $0.03 \% \quad 34.7 \%$ TLSKEEETK $0.04 \% \quad 58.1 \%$ HGVVPLATYMR $0.04 \% \quad 58.1 \%$ GDIVDIKGMGTVQK $\begin{array}{ll}99.7 \% & 52.5\end{array}$ $0.04 \% \quad 58.1 \%$ VYNVTQHAVGIVVNK $99.7 \% \quad 33.3$ $0.04 \% \quad 58.1 \%$ INVRIEHIK

$0.04 \% \quad 58.1 \%$ IEHIKHSK

$0.04 \% \quad 58.1 \%$ GTWVQLKR

$99.0 \% \quad 27.2$

$99.0 \% \quad 43.7$

$99.0 \% \quad 24.6$ $99.7 \% \quad 49.7$ $99.7 \% \quad 36.9$ $95.1 \% \quad 13.9$ $99.7 \% \quad 47.4$ $0.02 \% \quad 30.1 \%$ LYDIDVAK $0.02 \% \quad 30.1 \%$ VNTLIRPDGEK $0.02 \% \quad 30.1 \%$ LAPDYDALDVANKIGII $0.11 \% \quad 64.3 \%$ MKVELCSFSGYK $0.11 \% \quad 64.3 \%$ IYPGHGRR $0.11 \% \quad 64.3 \%$ TDGKVFQFLNAK $0.11 \% \quad 64.3 \%$ VFQFLNAK $0.11 \% \quad 64.3 \%$ CESAFLSK $0.11 \% \quad 64.3 \%$ CESAFLSKR $0.11 \% \quad 64.3 \%$ QINWTVLYR $0.11 \% \quad 64.3 \%$ KGQSEEIQK $0.11 \% \quad 64.3 \%$ GQSEEIQK $0.11 \% \quad 64.3 \%$ AITGASLADIMAK $0.11 \% \quad 64.3 \%$ AITGASLADIMAKR $0.11 \% \quad 64.3 \%$ RNQKPEVR $0.11 \% \quad 64.3 \%$ AQREQAIR $0.11 \% \quad 64.3 \%$ QKIVKPVK $0.11 \% \quad 64.3 \%$ IVKPVKVSAPR $0.04 \% \quad 25.8 \%$ SQRYESLK $0.04 \% \quad 25.8 \%$ LAYIAHPK $0.04 \% \quad 25.8 \%$ AQAAAPASVPAQAPK 
60 S ribosomal protein $\mathrm{L} 29 \mathrm{GN}=\mathrm{RPL} 29$ $60 \mathrm{~S}$ ribosomal protein $\mathrm{L} 29 \mathrm{GN}=\mathrm{RPL} 29$ $60 \mathrm{~S}$ ribosomal protein $\mathrm{L} 3 \mathrm{GN}=\mathrm{RPL} 3$ $60 \mathrm{~S}$ ribosomal protein $\mathrm{L} 3 \mathrm{GN}=\mathrm{RPL} 3$ $60 \mathrm{~S}$ ribosomal protein $\mathrm{L} 3 \mathrm{GN}=\mathrm{RPL} 3$ $60 \mathrm{~S}$ ribosomal protein $\mathrm{L} 3 \mathrm{GN}=\mathrm{RPL} 3$ $60 \mathrm{~S}$ ribosomal protein $\mathrm{L} 3 \mathrm{GN}=\mathrm{RPL} 3$ $60 \mathrm{~S}$ ribosomal protein $\mathrm{L} 3 \mathrm{GN}=\mathrm{RPL} 3$ $60 \mathrm{~S}$ ribosomal protein $\mathrm{L} 3 \mathrm{GN}=\mathrm{RPL} 3$ $60 \mathrm{~S}$ ribosomal protein $\mathrm{L} 3 \mathrm{GN}=\mathrm{RPL} 3$ $60 \mathrm{~S}$ ribosomal protein $\mathrm{L} 3 \mathrm{GN}=\mathrm{RPL} 3$ $60 \mathrm{~S}$ ribosomal protein $\mathrm{L} 3 \mathrm{GN}=\mathrm{RPL} 3$ $60 \mathrm{~S}$ ribosomal protein $\mathrm{L} 3 \mathrm{GN}=\mathrm{RPL} 3$ $60 \mathrm{~S}$ ribosomal protein $\mathrm{L} 3 \mathrm{GN}=\mathrm{RPL} 3$ $60 \mathrm{~S}$ ribosomal protein $\mathrm{L} 3 \mathrm{GN}=\mathrm{RPL} 3$ $60 \mathrm{~S}$ ribosomal protein $\mathrm{L} 3 \mathrm{GN}=\mathrm{RPL} 3$ $60 \mathrm{~S}$ ribosomal protein $\mathrm{L} 3 \mathrm{GN}=\mathrm{RPL} 3$ $60 \mathrm{~S}$ ribosomal protein $\mathrm{L} 3 \mathrm{GN}=\mathrm{RPL} 3$ $60 \mathrm{~S}$ ribosomal protein $\mathrm{L} 3 \mathrm{GN}=\mathrm{RPL} 3$ $60 \mathrm{~S}$ ribosomal protein $\mathrm{L} 3 \mathrm{GN}=\mathrm{RPL} 3$ $60 \mathrm{~S}$ ribosomal protein $\mathrm{L} 3 \mathrm{GN}=\mathrm{RPL} 3$ $60 \mathrm{~S}$ ribosomal protein $\mathrm{L} 3 \mathrm{GN}=\mathrm{RPL} 3$ $60 \mathrm{~S}$ ribosomal protein $\mathrm{L} 3 \mathrm{GN}=\mathrm{RPL} 3$ $60 \mathrm{~S}$ ribosomal protein $\mathrm{L} 34 \mathrm{GN}=\mathrm{RPL} 34$ $60 \mathrm{~S}$ ribosomal protein $\mathrm{L} 34 \mathrm{GN}=\mathrm{RPL} 34$ $60 \mathrm{~S}$ ribosomal protein $\mathrm{L} 34 \mathrm{GN}=\mathrm{RPL} 34$ $60 \mathrm{~S}$ ribosomal protein $\mathrm{L} 4 \mathrm{GN}=\mathrm{RPL} 4$ $60 \mathrm{~S}$ ribosomal protein $\mathrm{L} 4 \mathrm{GN}=\mathrm{RPL} 4$ $60 \mathrm{~S}$ ribosomal protein $\mathrm{L} 4 \mathrm{GN}=\mathrm{RPL} 4$ $60 \mathrm{~S}$ ribosomal protein $\mathrm{L} 4 \mathrm{GN}=\mathrm{RPL} 4$ $60 \mathrm{~S}$ ribosomal protein $\mathrm{L} 4 \mathrm{GN}=\mathrm{RPL} 4$ $60 \mathrm{~S}$ ribosomal protein $\mathrm{L} 4 \mathrm{GN}=\mathrm{RPL} 4$ $60 \mathrm{~S}$ ribosomal protein $\mathrm{L} 4 \mathrm{GN}=\mathrm{RPL} 4$ $60 \mathrm{~S}$ ribosomal protein $\mathrm{L} 4 \mathrm{GN}=\mathrm{RPL} 4$ $60 \mathrm{~S}$ ribosomal protein $\mathrm{L} 4 \mathrm{GN}=\mathrm{RPL} 4$ $60 \mathrm{~S}$ ribosomal protein $\mathrm{L} 4 \mathrm{GN}=\mathrm{RPL} 4$ $60 \mathrm{~S}$ ribosomal protein $\mathrm{L} 4 \mathrm{GN}=\mathrm{RPL} 4$ $60 \mathrm{~S}$ ribosomal protein $\mathrm{L} 4 \mathrm{GN}=\mathrm{RPL} 4$ $60 \mathrm{~S}$ ribosomal protein $\mathrm{L} 4 \mathrm{GN}=\mathrm{RPL} 4$ $60 \mathrm{~S}$ ribosomal protein $\mathrm{L} 4 \mathrm{GN}=\mathrm{RPL} 4$ $60 \mathrm{~S}$ ribosomal protein $\mathrm{L} 4 \mathrm{GN}=\mathrm{RPL} 4$ $60 \mathrm{~S}$ ribosomal protein $\mathrm{L} 4 \mathrm{GN}=\mathrm{RPL} 4$ $60 \mathrm{~S}$ ribosomal protein $\mathrm{L} 4 \mathrm{GN}=\mathrm{RPL} 4$ $60 \mathrm{~S}$ ribosomal protein $\mathrm{L} 4 \mathrm{GN}=\mathrm{RPL} 4$ $60 \mathrm{~S}$ ribosomal protein $\mathrm{L} 4 \mathrm{GN}=\mathrm{RPL} 4$ $60 \mathrm{~S}$ ribosomal protein $\mathrm{L} 4 \mathrm{GN}=\mathrm{RPL} 4$ $60 \mathrm{~S}$ ribosomal protein $\mathrm{L} 4 \mathrm{GN}=\mathrm{RPL} 4$
RL29_HUMAN $17.75 \quad 100.0 \%$ RL29 HUMAN $17.75 \quad 100.0 \%$ RL3_HUMAN $46.11 \quad 100.0 \% \quad 2$ RL3 HUMAN $46.11 \quad 100.0 \% \quad 2$ RL3_HUMAN $46.11 \quad 100.0 \% \quad 2$ RL3_HUMAN $46.11 \quad 100.0 \% \quad 21$ RL3 HUMAN $46.11 \quad 100.0 \% \quad 21$ RL3_HUMAN $46.11 \quad 100.0 \% \quad 21$ RL3 HUMAN $46.11 \quad 100.0 \% \quad 21$ RL3_HUMAN $46.11 \quad 100.0 \% \quad 21$ RL3_HUMAN $46.11 \quad 100.0 \% \quad 21$ RL3 HUMAN $46.11 \quad 100.0 \% \quad 21$ RL3_HUMAN $46.11 \quad 100.0 \% \quad 21$ RL3_HUMAN $46.11 \quad 100.0 \% \quad 21$ RL3 HUMAN $46.11 \quad 100.0 \% \quad 21$ RL3_HUMAN $46.11 \quad 100.0 \% \quad 21$ RL3 HUMAN $46.11 \quad 100.0 \% \quad 21$ RL3_HUMAN $46.11 \quad 100.0 \% \quad 21$ RL3_HUMAN $46.11 \quad 100.0 \% \quad 21$ RL3 HUMAN $46.11 \quad 100.0 \% \quad 21$ RL3_HUMAN $46.11 \quad 100.0 \% \quad 21$ RL3_HUMAN $46.11 \quad 100.0 \% \quad 21$ RL3 HUMAN $46.11 \quad 100.0 \% \quad 21$ RL34_HUMAN $13.29 \quad 100.0 \% \quad 3$ RL34_HUMAN $13.29 \quad 100.0 \% \quad 3$ RL34_HUMAN $13.29 \quad 100.0 \% \quad 3$ RL4_HUMAN $47.70 \quad 100.0 \% \quad 31$ RL4 HUMAN $47.70 \quad 100.0 \% \quad 31$ RL4_HUMAN $47.70 \quad 100.0 \% \quad 31$ RL4 HUMAN $47.70 \quad 100.0 \% \quad 31$ RL4_HUMAN $47.70 \quad 100.0 \% \quad 31$ RL4_HUMAN $47.70 \quad 100.0 \% \quad 31$ RL4 HUMAN $47.70 \quad 100.0 \% \quad 31$ RL4_HUMAN $47.70 \quad 100.0 \% \quad 31$ RL4_HUMAN $47.70 \quad 100.0 \% \quad 31$ RL4 HUMAN $47.70 \quad 100.0 \% \quad 31$ RL4_HUMAN $47.70 \quad 100.0 \% \quad 31$ RL4 HUMAN $47.70 \quad 100.0 \% \quad 31$ RL4_HUMAN $47.70 \quad 100.0 \% \quad 31$ RL4_HUMAN $47.70 \quad 100.0 \% \quad 31$ RL4 HUMAN $47.70 \quad 100.0 \% \quad 31$ RL4_HUMAN $47.70 \quad 100.0 \% \quad 31$ RL4 HUMAN $47.70 \quad 100.0 \% \quad 31$ RL4 HUMAN $47.70 \quad 100.0 \% \quad 31$ RL4_HUMAN $47.70 \quad 100.0 \% \quad 31$ RL4 HUMAN $47.70 \quad 100.0 \% \quad 31$ RL4_HUMAN $47.70 \quad 100.0 \% \quad 31$
$31 \quad 0.04 \% \quad 25.8 \%$ AQAAAPASVPAQAPKR $31 \quad 0.04 \% \quad 25.8 \%$ TQAPTKASE

$106 \quad 0.15 \% \quad 38.0 \%$ HGSLGFLPR

$106 \quad 0.15 \% \quad 38.0 \% \quad$ AGMTHIVR

$106 \quad 0.15 \% \quad 38.0 \%$ EVDRPGSK

$106 \quad 0.15 \% \quad 38.0 \%$ TVFAEHISDECK

$106 \quad 0.15 \% \quad 38.0 \%$ TVFAEHISDECKR

$106 \quad 0.15 \% \quad 38.0 \%$ VIAHTQMR

$106 \quad 0.15 \% \quad 38.0 \%$ AHLMEIQVNGGTVAEK

$106 \quad 0.15 \% \quad 38.0 \%$ GYKGVTSR

$106 \quad 0.15 \% \quad 38.0 \%$ KVACIGAWHPAR

$106 \quad 0.15 \% \quad 38.0 \%$ VACIGAWHPAR

$106 \quad 0.15 \% \quad 38.0 \%$ IGQGYLIK

$106 \quad 0.15 \% \quad 38.0 \%$ IGQGYLIKDGK

$106 \quad 0.15 \% \quad 38.0 \%$ LIKNNASTDYDLSDK

$106 \quad 0.15 \% \quad 38.0 \%$ NNASTDYDLSDK

$106 \quad 0.15 \% \quad 38.0 \%$ KSLLVQTK

$106 \quad 0.15 \% \quad 38.0 \%$ SLLVQTKR

$106 \quad 0.15 \% \quad 38.0 \%$ ALEKIDLK

$106 \quad 0.15 \% \quad 38.0 \%$ IDLKFIDTTSK

$106 \quad 0.15 \% \quad 38.0 \%$ FIDTTSKFGHGR

$106 \quad 0.15 \% \quad 38.0 \%$ FQTMEEKK

$106 \quad 0.15 \% \quad 38.0 \%$ AFMGPLKK

$5 \quad 0.01 \% \quad 16.2 \%$ RLSYNTASNK

$5 \quad 0.01 \% \quad 16.2 \%$ LSYNTASNK

$0.01 \% \quad 16.2 \%$ SACGVCPGR

$187 \quad 0.26 \% \quad 57.8 \%$ GESSGKNVTLPAVFK

$187 \quad 0.26 \% \quad 57.8 \%$ NVTLPAVFK

$187 \quad 0.26 \% \quad 57.8 \%$ APIRPDIVNFVHTNLR

$187 \quad 0.26 \% \quad 57.8 \%$ SGQGAFGNMCR

$187 \quad 0.26 \% \quad 57.8 \%$ SGQGAFGNMCRGGR

$187 \quad 0.26 \% \quad 57.8 \%$ YAICSALAASALPALVMSK

$187 \quad 0.26 \% \quad 57.8 \%$ TKEAVLLLK

$187 \quad 0.26 \% \quad 57.8 \%$ EAVLLLKK

$187 \quad 0.26 \% \quad 57.8 \%$ RGPCIIYNEDNGIIK

$187 \quad 0.26 \% \quad 57.8 \%$ GPCIIYNEDNGIIK

$187 \quad 0.26 \% \quad 57.8 \%$ GPCIIYNEDNGIIKAFR

$187 \quad 0.26 \% \quad 57.8 \%$ AFRNIPGITLLNVSK

$187 \quad 0.26 \% \quad 57.8 \%$ NIPGITLLNVSK

$187 \quad 0.26 \% \quad 57.8 \%$ LAPGGHVGR

$187 \quad 0.26 \% \quad 57.8 \%$ FCIWTESAFR

$44 \quad 187 \quad 0.26 \% \quad 57.8 \%$ KLDELYGTWR

$44 \quad 187 \quad 0.26 \% \quad 57.8 \%$ AASLKSNYNLPMHK

$44 \quad 187 \quad 0.26 \% \quad 57.8 \%$ SNYNLPMHK

$44 \quad 187 \quad 0.26 \% \quad 57.8 \%$ MINTDLSR

$44 \quad 187 \quad 0.26 \% \quad 57.8 \%$ ILKSPEIQR

$44 \quad 187 \quad 0.26 \% \quad 57.8 \%$ IMLKLNPYAK $99.7 \% 56.0$ $99.0 \% \quad 54.8$ $\begin{array}{lll}97.6 \% & 23.9\end{array}$ $99.7 \% \quad 61.9$ $99.7 \% \quad 53.3$ $99.0 \% 39.6$ $98.7 \% \quad 17.6$ $99.0 \% \quad 34.9$ $99.7 \% \quad 37.8$ $99.7 \% \quad 57.6$ $99.0 \% \quad 44.2$ $99.7 \% \quad 57.6$ $98.4 \% \quad 19.1$ $99.7 \% \quad 51.7$ $99.0 \% \quad 25.4$ $99.0 \% \quad 37.6$ $98.9 \% 28$. $99.7 \% \quad 39.9$ $99.7 \% \quad 61.0$ $99.0 \% \quad 32.8$ $99.0 \% \quad 39.5$ $99.7 \% \quad 27.7$ $99.7 \% \quad 44.8$ $99.6 \% \quad 24.3$ $\begin{array}{lll}99.7 \% & 33.9\end{array}$ $99.7 \% \quad 30.9$

$99.1 \% \quad 21.1$ $99.7 \% \quad 52.3$ $99.7 \% \quad 34.5$

$99.7 \% 51.4$ $99.7 \% \quad 37.5$ $99.0 \% \quad 52.4$ $99.7 \% \quad 51.0$ $99.7 \% \quad 47.3$ $97.2 \% \quad 17.8$ $99.7 \% \quad 56.0$

$99.7 \% \quad 53.1$ $99.7 \% \quad 38.7$ $99.7 \% \quad 38.1$ $99.6 \% \quad 28.5$ $99.7 \% 33.8$ $99.7 \% \quad 34.7$

$99.0 \% 50.1$

$99.7 \% \quad 29.7$

$99.7 \% \quad 32.7$ 932.47

983.54

884.48

887.46

1435.65

1591.75

971.51

1712.86

867.47

1365.72

1237.63

891.53

1191.67

1696.84

1342.58

916.58

944.59

929.57

1280.7

1365.69

1040.51

891.51

1153.60

997.49

963.41

1533.83

988.58

1862.04

1184.49

1454.64

1937.02

1014.66

913.61

1761.90

1605.79

1980.00

1642.96

1268.76

863.48

1316.61

1280.66

1573.82

1103.53

949.48

1083.65

1190.70

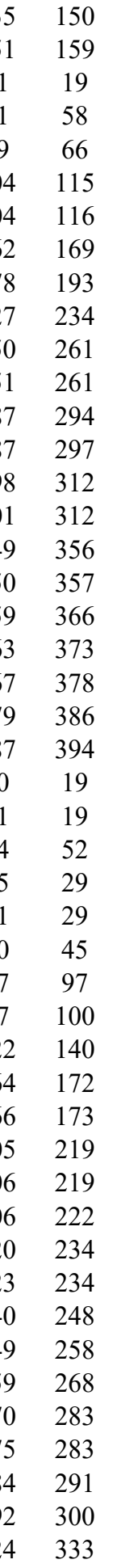

Page 14 of Table S-1-1 
$60 \mathrm{~S}$ ribosomal protein $\mathrm{L} 4 \mathrm{GN}=\mathrm{RPL} 4$ $60 \mathrm{~S}$ ribosomal protein $\mathrm{L} 4 \mathrm{GN}=\mathrm{RPL} 4$ $60 \mathrm{~S}$ ribosomal protein $\mathrm{L} 4 \mathrm{GN}=\mathrm{RPL} 4$ $60 \mathrm{~S}$ ribosomal protein $\mathrm{L} 4 \mathrm{GN}=\mathrm{RPL} 4$ $60 \mathrm{~S}$ ribosomal protein $\mathrm{L} 4 \mathrm{GN}=\mathrm{RPL} 4$ $60 \mathrm{~S}$ ribosomal protein $\mathrm{L} 4 \mathrm{GN}=\mathrm{RPL} 4$ $60 \mathrm{~S}$ ribosomal protein $\mathrm{L} 4 \mathrm{GN}=\mathrm{RPL} 4$ $60 \mathrm{~S}$ ribosomal protein $\mathrm{L} 4 \mathrm{GN}=\mathrm{RPL} 4$ $60 \mathrm{~S}$ ribosomal protein $\mathrm{L} 4 \mathrm{GN}=\mathrm{RPL} 4$ $60 \mathrm{~S}$ ribosomal protein $\mathrm{L} 4 \mathrm{GN}=\mathrm{RPL} 4$ $60 \mathrm{~S}$ ribosomal protein $\mathrm{L} 5 \mathrm{GN}=\mathrm{RPL} 5$ $60 \mathrm{~S}$ ribosomal protein $\mathrm{L} 5 \mathrm{GN}=\mathrm{RPL} 5$ $60 \mathrm{~S}$ ribosomal protein $\mathrm{L} 5 \mathrm{GN}=\mathrm{RPL} 5$ $60 \mathrm{~S}$ ribosomal protein $\mathrm{L} 5 \mathrm{GN}=\mathrm{RPL} 5$ $60 \mathrm{~S}$ ribosomal protein $\mathrm{L} 5 \mathrm{GN}=\mathrm{RPL} 5$ $60 \mathrm{~S}$ ribosomal protein $\mathrm{L} 5 \mathrm{GN}=\mathrm{RPL} 5$ $60 \mathrm{~S}$ ribosomal protein $\mathrm{L} 5 \mathrm{GN}=\mathrm{RPL} 5$ $60 \mathrm{~S}$ ribosomal protein $\mathrm{L} 5 \mathrm{GN}=\mathrm{RPL} 5$ $60 \mathrm{~S}$ ribosomal protein $\mathrm{L} 5 \mathrm{GN}=\mathrm{RPL} 5$ $60 \mathrm{~S}$ ribosomal protein $\mathrm{L} 5 \mathrm{GN}=\mathrm{RPL} 5$ $60 \mathrm{~S}$ ribosomal protein $\mathrm{L} 5 \mathrm{GN}=\mathrm{RPL} 5$ $60 \mathrm{~S}$ ribosomal protein $\mathrm{L} 5 \mathrm{GN}=\mathrm{RPL} 5$ $60 \mathrm{~S}$ ribosomal protein $\mathrm{L} 5 \mathrm{GN}=\mathrm{RPL} 5$ $60 \mathrm{~S}$ ribosomal protein $\mathrm{L} 5 \mathrm{GN}=\mathrm{RPL} 5$ $60 \mathrm{~S}$ ribosomal protein $\mathrm{L} 5 \mathrm{GN}=\mathrm{RPL} 5$ $60 \mathrm{~S}$ ribosomal protein L5 GN=RPL5 $60 \mathrm{~S}$ ribosomal protein $\mathrm{L} 5 \mathrm{GN}=\mathrm{RPL} 5$ $60 \mathrm{~S}$ ribosomal protein $\mathrm{L} 5 \mathrm{GN}=\mathrm{RPL} 5$ $60 \mathrm{~S}$ ribosomal protein L5 GN=RPL5 $60 \mathrm{~S}$ ribosomal protein $\mathrm{L} 6 \mathrm{GN}=\mathrm{RPL} 6$ $60 \mathrm{~S}$ ribosomal protein $\mathrm{L} 6 \mathrm{GN}=\mathrm{RPL} 6$ $60 \mathrm{~S}$ ribosomal protein $\mathrm{L} 6 \mathrm{GN}=\mathrm{RPL} 6$ $60 \mathrm{~S}$ ribosomal protein $\mathrm{L} 6 \mathrm{GN}=\mathrm{RPL} 6$ $60 \mathrm{~S}$ ribosomal protein $\mathrm{L} 6 \mathrm{GN}=\mathrm{RPL} 6$ $60 \mathrm{~S}$ ribosomal protein $\mathrm{L} 6 \mathrm{GN}=\mathrm{RPL} 6$ $60 \mathrm{~S}$ ribosomal protein $\mathrm{L} 6 \mathrm{GN}=\mathrm{RPL} 6$ $60 \mathrm{~S}$ ribosomal protein $\mathrm{L} 6 \mathrm{GN}=\mathrm{RPL} 6$ $60 \mathrm{~S}$ ribosomal protein $\mathrm{L} 6 \mathrm{GN}=\mathrm{RPL} 6$ 60S ribosomal protein $\mathrm{L} 6 \mathrm{GN}=\mathrm{RPL} 6$ $60 \mathrm{~S}$ ribosomal protein $\mathrm{L} 6 \mathrm{GN}=\mathrm{RPL} 6$ $60 \mathrm{~S}$ ribosomal protein $\mathrm{L} 6 \mathrm{GN}=\mathrm{RPL} 6$ 60S ribosomal protein $\mathrm{L} 6 \mathrm{GN}=\mathrm{RPL} 6$ $60 \mathrm{~S}$ ribosomal protein $\mathrm{L} 6 \mathrm{GN}=\mathrm{RPL} 6$ $60 \mathrm{~S}$ ribosomal protein $\mathrm{L} 6 \mathrm{GN}=\mathrm{RPL} 6$ $60 \mathrm{~S}$ ribosomal protein $\mathrm{L} 6 \mathrm{GN}=\mathrm{RPL} 6$ $60 \mathrm{~S}$ ribosomal protein $\mathrm{L} 6 \mathrm{GN}=\mathrm{RPL} 6$ $60 \mathrm{~S}$ ribosomal protein $\mathrm{L} 6 \mathrm{GN}=\mathrm{RPL} 6$
RL4_HUMAN $47.70 \quad 100.0 \% \quad 31 \quad 44 \quad 187 \quad 0.26 \% \quad 57.8 \%$ NTILRQAR

RL4_HUMAN $47.70 \quad 100.0 \% \quad 31$ RL4_HUMAN $47.70 \quad 100.0 \% \quad 31$ RL4 HUMAN $47.70 \quad 100.0 \% \quad 31$ RL4_HUMAN $47.70 \quad 100.0 \% \quad 31$ RL4_HUMAN $47.70 \quad 100.0 \% \quad 31$ RL4 HUMAN $47.70 \quad 100.0 \% \quad 31$ RL4_HUMAN $47.70 \quad 100.0 \% \quad 31$ RL4_HUMAN $47.70 \quad 100.0 \% \quad 31$ RL4_HUMAN $47.70 \quad 100.0 \% \quad 31$ RL5_HUMAN $34.36 \quad 100.0 \% \quad 19$ RL5 HUMAN $34.36 \quad 100.0 \% \quad 19$ RL5_HUMAN $34.36 \quad 100.0 \% \quad 19$ RL5_HUMAN $34.36 \quad 100.0 \% \quad 19$ RL5 HUMAN $34.36 \quad 100.0 \% \quad 19$ RL5_HUMAN $34.36 \quad 100.0 \% \quad 19$ RL5 HUMAN $34.36 \quad 100.0 \% \quad 19$ RL5_HUMAN $34.36 \quad 100.0 \% \quad 19$ RL5_HUMAN $34.36 \quad 100.0 \% \quad 19$ RL5 HUMAN $34.36 \quad 100.0 \% \quad 19$ RL5_HUMAN $34.36 \quad 100.0 \% \quad 19$ RL5 HUMAN $34.36 \quad 100.0 \% \quad 19$ RL5_HUMAN $34.36 \quad 100.0 \% \quad 19$ RL5_HUMAN $34.36 \quad 100.0 \% \quad 19$ RL5 HUMAN $34.36 \quad 100.0 \% \quad 19$ RL5_HUMAN $34.36 \quad 100.0 \% \quad 19$ RL5_HUMAN $34.36 \quad 100.0 \% \quad 19$ RL5 HUMAN $34.36 \quad 100.0 \% \quad 19$ RL5_HUMAN $34.36 \quad 100.0 \% \quad 19$ RL6 HUMAN $32.73 \quad 100.0 \% \quad 21$ RL6_HUMAN $32.73 \quad 100.0 \% \quad 21$ RL6_HUMAN $32.73 \quad 100.0 \% \quad 21$ RL6 HUMAN $32.73 \quad 100.0 \% \quad 21$ RL6_HUMAN $32.73 \quad 100.0 \% \quad 21$ RL6_HUMAN $32.73 \quad 100.0 \% \quad 21$ RL6_HUMAN $32.73 \quad 100.0 \% \quad 21$ RL6_HUMAN $32.73 \quad 100.0 \% \quad 21$ RL6 HUMAN $32.73 \quad 100.0 \% \quad 21$ RL6_HUMAN $32.73 \quad 100.0 \% \quad 21$ RL6_HUMAN $32.73 \quad 100.0 \% \quad 21$ RL6 HUMAN $32.73 \quad 100.0 \% \quad 21$ RL6_HUMAN $32.73 \quad 100.0 \% \quad 21$ RL6 HUMAN $32.73 \quad 100.0 \% \quad 21$ RL6_HUMAN $32.73 \quad 100.0 \% \quad 21$ RL6_HUMAN $32.73 \quad 100.0 \% \quad 21$ RL6 HUMAN $32.73 \quad 100.0 \% \quad 21$ RL6_HUMAN $32.73 \quad 100.0 \% \quad 21$
$44 \quad 187 \quad 0.26 \% \quad 57.8 \%$ VDKAAAAAAALQAK

$44 \quad 187 \quad 0.26 \% \quad 57.8 \%$ AAAAAAALQAK

$44 \quad 187 \quad 0.26 \% \quad 57.8 \%$ AAAAAAALQAKSDEK

$44 \quad 187 \quad 0.26 \% \quad 57.8 \%$ SDEKAAVAGK

$44 \quad 187 \quad 0.26 \% \quad 57.8 \%$ AAVAGKKPVVGK

$44 \quad 187 \quad 0.26 \% \quad 57.8 \%$ QKKPLVGK

$44 \quad 187 \quad 0.26 \% \quad 57.8 \%$ AAATKKPAPEK

$44 \quad 187 \quad 0.26 \% \quad 57.8 \%$ KPAPEKKPAEK

$44 \quad 187 \quad 0.26 \% \quad 57.8 \%$ KPTTEEKKPAA

$35 \quad 72 \quad 0.10 \% \quad 58.6 \%$ EGKTDYYAR

$35 \quad 72 \quad 0.10 \% \quad 58.6 \%$ LVIQDKNK

$35 \quad 72 \quad 0.10 \% \quad 58.6 \%$ VTNRDIICQIAYAR $0.10 \% 58.6 \%$ TTTGNKVFGALK $0.10 \% \quad 58.6 \%$ GAVDGGLSIPHSTK $0.10 \% \quad 58.6 \%$ EFNAEVHRK $0.10 \% 58.6 \%$ HIMGQNVADYMR $0.10 \% \quad 58.6 \%$ YLMEEDEDAYKK $0.10 \% \quad 58.6 \%$ NSVTPDMMEEMYK $0.10 \% \quad 58.6 \%$ NSVTPDMMEEMYKK $0.10 \% \quad 58.6 \%$ AHAAIRENPVYEK $0.10 \% \quad 58.6 \%$ ENPVYEKKPK $0.14 \% 55.6 \%$ AGEKVEKPDTK $0.14 \% \quad 55.6 \%$ VLATVTKPVGGDK $0.14 \% \quad 55.6 \%$ YYPTEDVPR $0.14 \% \quad 55.6 \%$ YYPTEDVPRK $0.14 \% 55.6 \%$ KPFSQHVR $0.14 \% \quad 55.6 \%$ ASITPGTILIILTGR $0.14 \% \quad 55.6 \%$ THQKFVIATSTK $0.14 \% \quad 55.6 \%$ FVIATSTK $0.14 \% \quad 55.6 \%$ IDISNVKIPK $0.14 \% \quad 55.6 \%$ HLTDAYFK $0.14 \% \quad 55.6 \%$ HLTDAYFKK $0.14 \% \quad 55.6 \%$ EKYEITEQR $0.14 \% \quad 55.6 \%$ IDQKAVDSQILPK $0.14 \% \quad 55.6 \%$ AVDSQILPK $0.14 \% \quad 55.6 \%$ AVDSQILPKIK $0.14 \% \quad 55.6 \%$ IKAIPQLQGYLR $\begin{array}{llllll}99.0 \% & 30.7 & 25.0 & 17.0 & 3 & 0\end{array}$ $\begin{array}{llllll}99.7 \% & 53.2 & 25.0 & 48.3 & 6 & 3\end{array}$ $\begin{array}{lllllll}0.10 \% & 58.6 \% & \text { IEGDMIVCAAYAHELPK } & 99.7 \% & 62.1 & 25.0 & 62.1\end{array}$ $\begin{array}{lllllll}0.10 \% & 58.6 \% & \text { VGLTNYAAAYCTGLLLAR } & 99.7 \% & 51.7 & 25.0 & 51.7\end{array}$ $\begin{array}{lllllll}0.10 \% & 58.6 \% & \text { VFGALKGAVDGGLSIPHSTK } & 99.5 \% & 29.0 & 25.0 & 25.7\end{array}$ $\begin{array}{lllllll}0.10 \% & 58.6 \% & \text { GAVDGGLSIPHSTKR } & 99.7 \% & 43.8 & 25.0 & 42.4\end{array}$ $0.10 \% \quad 58.6 \%$ FPGYDSESKEFNAEVHR

$0.10 \% \quad 58.6 \%$ KHIMGQNVADYMR $\begin{array}{llll}99.7 \% & 28.2 & 25.0 & 27.7\end{array}$ $\begin{array}{llll}99.7 \% & 60.9 & 25.0 & 47.8\end{array}$ $0.14 \% \quad 55.6 \%$ QLASGLLLVTGPLVLNR

$\begin{array}{llll}99.7 \% & 37.9 & 25.0 & 33.6\end{array}$ $\begin{array}{llllll}99.7 \% & 57.4 & 25.0 & 48.7 & 23 & 0\end{array}$ $99.7 \% \quad 70.6 \quad 25.0 \quad 65.1 \quad 2 \quad 00$ $\begin{array}{lllll}99.7 \% & 59.8 & 25.0 & 53.2 & 4\end{array}$ $\begin{array}{llll}99.7 \% & 33.8 & 25.0 & 24.5\end{array}$ $96.7 \% \quad 20.4 \quad 25.0 \quad 12.4$ $99.7 \% \quad 43.9 \quad 25.0 \quad 37.5 \quad 2$ $99.7 \% \quad 28.9 \quad 25.0 \quad 28.9 \quad 0$ $\begin{array}{llll}99.7 \% & 47.2 & 25.0 & 38.2\end{array}$ $99.0 \% \quad 26.5 \quad 25.0 \quad 13.0 \quad 2$ $99.0 \% \quad 37.9 \quad 25.0 \quad 23.2$ $\begin{array}{llll}99.7 \% & 59.8 & 25.0 & 59.8\end{array}$ $\begin{array}{llll}98.0 \% & 16.8 & 25.0 & 16.8\end{array}$ $99.7 \% \quad 26.6 \quad 25.0 \quad 22.9 \quad 2$ $\begin{array}{llll}99.7 \% & 57.7 & 25.0 & 47.5\end{array}$ $\begin{array}{llll}99.7 \% & 30.0 & 25.0 & 18.9\end{array}$ $\begin{array}{llll}99.2 \% & 20.0 & 25.0 & 20.0\end{array}$ $99.7 \% \quad 44.8 \quad 25.0 \quad 37.8$ $99.7 \% \quad 44.3 \quad 25.0 \quad 44.3$ $99.7 \% \quad 52.9 \quad 25.0 \quad 52.9$ $99.7 \% \quad 64.0 \quad 25.0 \quad 59.5$ $\begin{array}{lllll}99.7 \% & 33.4 & 25.0 & 29.7 & 2\end{array}$ $99.7 \% \quad 47.2 \quad 25.0 \quad 34.7$ $99.7 \% \quad 53.4 \quad 25.0 \quad 51.0$ $99.7 \% \quad 52.2$ $\begin{array}{lllll}99.7 \% & 33.7 & 25.0 & 27.6\end{array}$ $\begin{array}{llll}99.7 \% & 25.9 & 25.0 & 20.0\end{array}$ $99.0 \% \quad 37.6 \quad 25.0 \quad 16.1$ $99.7 \% \quad 39.9 \quad 25.0 \quad 39.9$ $99.7 \% \quad 50.9$

1298.74

956.55

1415.75

975.51

1124.72

897.59

1111.65

1222.72

1199.66

1102.52

957.57

1692.89

1932.92

1927.01

1109.58

1236.69

1954.08

1338.70

1494.80

2011.91

1129.57

1578.75

1434.66

1533.68

1574.65

1702.75

1497.78

1231.67

1201.64

1284.75

1769.99

1139.54

1267.63

998.55

1525.93

1764.07

1360.76

866.50

1126.68

$\begin{array}{llll}99.0 \% & 37.2 & 25.0 & 37.2\end{array}$

$\begin{array}{llll}99.7 \% & 42.3 & 25.0 & 42.3\end{array}$

$99.0 \% \quad 31.1 \quad 25.0 \quad 25.4$

$\begin{array}{llll}99.7 \% & 61.8 & 25.0 & 51.5\end{array}$

$94.8 \% \quad 17.9 \quad 25.0 \quad 11.0$

$\begin{array}{llll}99.7 \% & 50.7 & 25.0 & 27.8\end{array}$

$99.7 \% \quad 29.3 \quad 25.0 \quad 26.0$

$\begin{array}{llll}99.7 \% & 35.2 & 25.0 & 35.2\end{array}$ $\begin{array}{cc}38 & 345 \\ 51 & 364 \\ 54 & 364 \\ 54 & 368 \\ 65 & 374 \\ 69 & 380 \\ 92 & 399 \\ 01 & 411 \\ 06 & 416 \\ 17 & 427 \\ 5 & 33 \\ 6 & 43 \\ 5 & 68 \\ 9 & 85 \\ 0 & 107 \\ 09 & 117 \\ 53 & 164 \\ 59 & 178 \\ 65 & 178 \\ 65 & 179 \\ 80 & 196 \\ 89 & 197 \\ 97 & 209 \\ 98 & 209 \\ 10 & 221 \\ 29 & 241 \\ 29 & 242 \\ 43 & 255 \\ 49 & 258 \\ 2 & 12 \\ 8 & 100 \\ 8 & 105 \\ 15 & 123 \\ 15 & 124 \\ 31 & 138 \\ 42 & 156 \\ 67 & 183 \\ 89 & 200 \\ 93 & 200 \\ 01 & 210 \\ 11 & 218 \\ 11 & 219 \\ 38 & 246 \\ 48 & 260 \\ 52 & 260 \\ 52 & 262 \\ 61 & 272 \\ & \end{array}$

Page 15 of Table S-1- 1 
$60 \mathrm{~S}$ ribosomal protein $\mathrm{L} 6 \mathrm{GN}=\mathrm{RPL} 6$ $60 \mathrm{~S}$ ribosomal protein $\mathrm{L} 6 \mathrm{GN}=\mathrm{RPL} 6$ 60 S ribosomal protein $\mathrm{L} 6 \mathrm{GN}=\mathrm{RPL} 6$ $60 \mathrm{~S}$ ribosomal protein $\mathrm{L} 7 \mathrm{GN}=\mathrm{RPL} 7$ $60 \mathrm{~S}$ ribosomal protein $\mathrm{L} 7 \mathrm{GN}=\mathrm{RPL} 7$ $60 \mathrm{~S}$ ribosomal protein $\mathrm{L} 7 \mathrm{GN}=\mathrm{RPL} 7$ $60 \mathrm{~S}$ ribosomal protein $\mathrm{L} 7 \mathrm{GN}=\mathrm{RPL} 7$ $60 \mathrm{~S}$ ribosomal protein $\mathrm{L} 7 \mathrm{GN}=\mathrm{RPL} 7$ $60 \mathrm{~S}$ ribosomal protein $\mathrm{L} 7 \mathrm{GN}=\mathrm{RPL} 7$ $60 \mathrm{~S}$ ribosomal protein $\mathrm{L} 7 \mathrm{GN}=\mathrm{RPL} 7$ $60 \mathrm{~S}$ ribosomal protein $\mathrm{L} 7 \mathrm{GN}=\mathrm{RPL} 7$ $60 \mathrm{~S}$ ribosomal protein $\mathrm{L} 7 \mathrm{GN}=\mathrm{RPL} 7$ $60 \mathrm{~S}$ ribosomal protein $\mathrm{L} 7 \mathrm{GN}=\mathrm{RPL} 7$ $60 \mathrm{~S}$ ribosomal protein $\mathrm{L} 7 \mathrm{GN}=\mathrm{RPL} 7$ $60 \mathrm{~S}$ ribosomal protein $\mathrm{L} 7 \mathrm{GN}=\mathrm{RPL} 7$ $60 \mathrm{~S}$ ribosomal protein $\mathrm{L} 7 \mathrm{GN}=\mathrm{RPL} 7$ $60 \mathrm{~S}$ ribosomal protein $\mathrm{L} 7 \mathrm{GN}=\mathrm{RPL} 7$ $60 \mathrm{~S}$ ribosomal protein $\mathrm{L} 7 \mathrm{GN}=\mathrm{RPL} 7$ $60 \mathrm{~S}$ ribosomal protein $\mathrm{L} 7 \mathrm{GN}=\mathrm{RPL} 7$ $60 \mathrm{~S}$ ribosomal protein $\mathrm{L} 7 \mathrm{GN}=\mathrm{RPL} 7$ $60 \mathrm{~S}$ ribosomal protein $\mathrm{L} 7 \mathrm{GN}=\mathrm{RPL} 7$ $60 \mathrm{~S}$ ribosomal protein $\mathrm{L} 7 \mathrm{GN}=\mathrm{RPL} 7$ $60 \mathrm{~S}$ ribosomal protein $\mathrm{L} 7 \mathrm{a} \mathrm{GN}=\mathrm{RPL} 7 \mathrm{~A}$ $60 \mathrm{~S}$ ribosomal protein $\mathrm{L} 7 \mathrm{a} \mathrm{GN}=\mathrm{RPL} 7 \mathrm{~A}$ $60 \mathrm{~S}$ ribosomal protein $\mathrm{L} 7 \mathrm{a} \mathrm{GN}=\mathrm{RPL} 7 \mathrm{~A}$ $60 \mathrm{~S}$ ribosomal protein $\mathrm{L} 7 \mathrm{a} \mathrm{GN}=\mathrm{RPL} 7 \mathrm{~A}$ $60 \mathrm{~S}$ ribosomal protein $\mathrm{L} 7 \mathrm{a} \mathrm{GN}=\mathrm{RPL} 7 \mathrm{~A}$ $60 \mathrm{~S}$ ribosomal protein $\mathrm{L} 7 \mathrm{a} \mathrm{GN}=\mathrm{RPL} 7 \mathrm{~A}$ $60 \mathrm{~S}$ ribosomal protein $\mathrm{L} 7 \mathrm{a} \mathrm{GN}=\mathrm{RPL} 7 \mathrm{~A}$ $60 \mathrm{~S}$ ribosomal protein $\mathrm{L} 7 \mathrm{a} \mathrm{GN}=\mathrm{RPL} 7 \mathrm{~A}$ $60 \mathrm{~S}$ ribosomal protein $\mathrm{L} 7 \mathrm{a} \mathrm{GN}=\mathrm{RPL} 7 \mathrm{~A}$ $60 \mathrm{~S}$ ribosomal protein $\mathrm{L} 7 \mathrm{a} \mathrm{GN}=\mathrm{RPL} 7 \mathrm{~A}$ $60 \mathrm{~S}$ ribosomal protein $\mathrm{L} 7 \mathrm{a} \mathrm{GN}=\mathrm{RPL} 7 \mathrm{~A}$ $60 \mathrm{~S}$ ribosomal protein $\mathrm{L} 7 \mathrm{a} \mathrm{GN}=\mathrm{RPL7A}$ $60 \mathrm{~S}$ ribosomal protein $\mathrm{L} 7 \mathrm{a} \mathrm{GN}=\mathrm{RPL} 7 \mathrm{~A}$ $60 \mathrm{~S}$ ribosomal protein $\mathrm{L} 7 \mathrm{a} \mathrm{GN}=\mathrm{RPL} 7 \mathrm{~A}$ $60 \mathrm{~S}$ ribosomal protein $\mathrm{L} 7 \mathrm{a} \mathrm{GN}=\mathrm{RPL} 7 \mathrm{~A}$ $60 \mathrm{~S}$ ribosomal protein $\mathrm{L} 7 \mathrm{a} \mathrm{GN}=\mathrm{RPL} 7 \mathrm{~A}$ $60 \mathrm{~S}$ ribosomal protein $\mathrm{L} 7 \mathrm{a} \mathrm{GN}=\mathrm{RPL} 7 \mathrm{~A}$ $60 \mathrm{~S}$ ribosomal protein $\mathrm{L} 7 \mathrm{a} \mathrm{GN}=\mathrm{RPL} 7 \mathrm{~A}$ $60 \mathrm{~S}$ ribosomal protein $\mathrm{L} 7 \mathrm{a} \mathrm{GN}=\mathrm{RPL} 7 \mathrm{~A}$ $60 \mathrm{~S}$ ribosomal protein $\mathrm{L} 7 \mathrm{a} \mathrm{GN}=\mathrm{RPL} 7 \mathrm{~A}$ $60 \mathrm{~S}$ ribosomal protein $\mathrm{L} 7 \mathrm{a} \mathrm{GN}=\mathrm{RPL7A}$ $60 \mathrm{~S}$ ribosomal protein $\mathrm{L} 7 \mathrm{a} \mathrm{GN}=\mathrm{RPL} 7 \mathrm{~A}$ $60 \mathrm{~S}$ ribosomal protein $\mathrm{L} 8 \mathrm{GN}=\mathrm{RPL} 8$ $60 \mathrm{~S}$ ribosomal protein $\mathrm{L} 8 \mathrm{GN}=\mathrm{RPL} 8$ $60 \mathrm{~S}$ ribosomal protein $\mathrm{L} 8 \mathrm{GN}=\mathrm{RPL} 8$

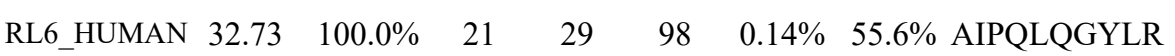
RL6_HUMAN $32.73 \quad 100.0 \% \quad 21 \quad 29 \quad 98 \quad 0.14 \% \quad 55.6 \%$ SVFALTNGIYPHK RL6_HUMAN $32.73 \quad 100.0 \% \quad 21$ RL7 HUMAN $29.23 \quad 100.0 \% \quad 19$ RL7_HUMAN $29.23 \quad 100.0 \% \quad 19$ RL7_HUMAN $29.23 \quad 100.0 \% \quad 19$ RL7_HUMAN $29.23 \quad 100.0 \% \quad 19$ RL7_HUMAN $29.23 \quad 100.0 \% \quad 19$ RL7 HUMAN $29.23 \quad 100.0 \% \quad 19$ RL7_HUMAN $29.23 \quad 100.0 \% \quad 19$ RL7_HUMAN $29.23 \quad 100.0 \% \quad 19$ RL7 HUMAN $29.23 \quad 100.0 \% \quad 19$ RL7_HUMAN $29.23 \quad 100.0 \% \quad 19$ RL7_HUMAN $29.23 \quad 100.0 \% \quad 19$ RL7_HUMAN $29.23 \quad 100.0 \% \quad 19$ RL7_HUMAN $29.23 \quad 100.0 \% \quad 19$ RL7 HUMAN $29.23 \quad 100.0 \% \quad 19$ RL7_HUMAN $29.23 \quad 100.0 \% \quad 19$ RL7_HUMAN $29.23 \quad 100.0 \% \quad 19$ RL7 HUMAN $29.23 \quad 100.0 \% \quad 19$ RL7_HUMAN $29.23 \quad 100.0 \% \quad 19$ RL7 HUMAN $29.23 \quad 100.0 \% \quad 19$ RL7A_HUMAN $30.00 \quad 100.0 \% \quad 22$ RL7A_HUMAN $30.00 \quad 100.0 \% \quad 22$ RL7A HUMAN $30.00 \quad 100.0 \% \quad 22$ RL7A_HUMAN $30.00 \quad 100.0 \% \quad 22$ RL7A_HUMAN $30.00 \quad 100.0 \% \quad 22$ RL7A_HUMAN $30.00 \quad 100.0 \% \quad 22$ RL7A_HUMAN $30.00 \quad 100.0 \% \quad 22$ RL7A_HUMAN $30.00 \quad 100.0 \% \quad 22$ RL7A_HUMAN $30.00 \quad 100.0 \% \quad 22$ RL7A_HUMAN $30.00 \quad 100.0 \% \quad 22$ RL7A_HUMAN $30.00 \quad 100.0 \% \quad 22$ RL7A_HUMAN $30.00 \quad 100.0 \% \quad 22$ RL7A_HUMAN $30.00 \quad 100.0 \% \quad 22$ RL7A_HUMAN $30.00 \quad 100.0 \% \quad 22$ RL7A_HUMAN $30.00 \quad 100.0 \% \quad 22$ RL7A HUMAN $30.00 \quad 100.0 \% \quad 22$ RL7A_HUMAN $30.00 \quad 100.0 \% \quad 22$ RL7A_HUMAN $30.00 \quad 100.0 \% \quad 22$ RL7A HUMAN $30.00 \quad 100.0 \% \quad 22$ RL7A_HUMAN $30.00 \quad 100.0 \% \quad 22$ RL7A_HUMAN $30.00 \quad 100.0 \% \quad 22$ RL7A_HUMAN $30.00 \quad 100.0 \% \quad 22$ RL8_HUMAN $28.02 \quad 100.0 \% \quad 16$ RL8 HUMAN $28.02 \quad 100.0 \% \quad 16$

RL8_HUMAN $28.02 \quad 100.0 \% \quad 16$

$0.06 \% \quad 56.9 \%$ EVPAVPETLKK

$0.06 \% \quad 56.9 \%$ NFAELKIK

$0.06 \% \quad 56.9 \%$ KAGNFYVPAEPK

$0.06 \% \quad 56.9 \%$ AGNFYVPAEPK $0.06 \% \quad 56.9 \%$ IRGINGVSPK

$0.06 \% \quad 56.9 \%$ GINGVSPKVR

$0.06 \% \quad 56.9 \%$ LRQIFNGTFVK

$0.06 \% \quad 56.9 \%$ QIFNGTFVK

$0.06 \% \quad 56.9 \%$ QIFNGTFVKLNK

$0.06 \% \quad 56.9 \%$ LNKASINMLR

$0.06 \% \quad 56.9 \%$ SVNELIYK

$0.06 \% \quad 56.9 \%$ SVNELIYKR

$0.06 \% \quad 56.9 \%$ RIALTDNALIAR

$0.06 \% \quad 56.9 \%$ IALTDNALIAR

$0.06 \% \quad 56.9 \%$ FKEANNFLWPFK

$0.08 \% \quad 54.1 \%$ MGVPYCIIK

$0.09 \% \quad 47.1 \%$ KGAGSVFR $\begin{array}{llllllll}99.7 \% & 36.0 & 25.0 & 29.0 & 7 & 0 & 0 & 1158.66\end{array}$ $\begin{array}{llllll}99.7 \% & 43.4 & 25.0 & 43.4 & 5 & 2\end{array}$ $\begin{array}{llllll}99.7 \% & 35.0 & 25.0 & 35.0 & 0 & 2\end{array}$ $99.7 \% \quad 26.7 \quad 25.0 \quad 18.2$ $\begin{array}{llll}97.5 \% & 15.9 & 25.0 & 15.9\end{array}$ $\begin{array}{llll}99.7 \% & 55.3 & 25.0 & 52.1\end{array}$

$\begin{array}{llll}99.7 \% & 42.2 & 25.0 & 42.0\end{array}$

$0.06 \% \quad 56.9 \%$ AGNFYVPAEPKLAFVIR

$0.06 \% \quad 56.9 \%$ IVEPYIAWGYPNLK

$0.06 \% \quad 56.9 \%$ EANNFLWPFKLSSPR

$99.7 \% \quad 37.3$

$25.0 \quad 15.8$

$25.0 \quad 24.6$

$\begin{array}{llll}99.7 \% & 29.6 & 25.0 & 29.6\end{array}$

$99.0 \% \quad 19.9 \quad 25.0 \quad 17.4$

$\begin{array}{lllll}99.7 \% & 38.2 & 25.0 & 35.3 & 2\end{array}$

$99.5 \% \quad 23.4 \quad 25.0 \quad 18.1$

$99.7 \% \quad 42.9 \quad 25.0 \quad 34.3$

$\begin{array}{llll}98.8 \% & 25.9 & 25.0 & 13.2\end{array}$

$99.7 \% \quad 41.6 \quad 25.0 \quad 33.6$

$\begin{array}{llll}99.7 \% & 57.7 & 25.0 & 46.3\end{array}$

$\begin{array}{llll}99.7 \% & 55.8 & 25.0 & 43.5\end{array}$

$\begin{array}{llll}99.7 \% & 51.7 & 25.0 & 43.8\end{array}$

$\begin{array}{llll}99.6 \% & 22.7 & 25.0 & 19.5\end{array}$

$0.06 \% \quad 56.9 \%$ TTHFVEGGDAGNREDQINR

$99.7 \% \quad 46.1$

$\begin{array}{llll}99.7 \% & 29.0 & 25.0 & 29.0\end{array}$

$\begin{array}{llll}97.2 \% & 17.8 & 25.0 & 17.8\end{array}$

$99.7 \% \quad 25.2 \quad 25.0 \quad 25.2$

$99.7 \% \quad 38.4 \quad 25.0 \quad 23.4 \quad 2$

$99.0 \% \quad 23.0 \quad 25.0 \quad 19.1$

$\begin{array}{llll}99.7 \% & 39.8 & 25.0 & 39.8\end{array}$

$\begin{array}{lllll}99.7 \% & 62.4 & 25.0 & 54.2 & 2\end{array}$

$99.7 \% \quad 61.2 \quad 25.0 \quad 51.6$

$\begin{array}{llll}99.7 \% & 32.6 & 25.0 & 32.5\end{array}$

$\begin{array}{llll}99.7 \% & 47.1 & 25.0 & 43.2\end{array}$

$\begin{array}{llll}99.0 \% & 31.2 & 25.0 & 14.5\end{array}$

$99.7 \% \quad 32.0 \quad 25.0 \quad 27.3$

$\begin{array}{llll}99.6 \% & 28.4 & 25.0 & 15.1\end{array}$

$\begin{array}{llll}99.7 \% & 53.5 & 25.0 & 33.9\end{array}$

$\begin{array}{llll}98.4 \% & 17.1 & 25.0 & 17.1\end{array}$

$99.7 \% \quad 74.1 \quad 25.0 \quad 73.7$

$\begin{array}{llll}99.7 \% & 56.1 & 25.0 & 52.2\end{array}$

$99.7 \% \quad 34.8 \quad 25.0 \quad 34.7$

$\begin{array}{llll}95.7 \% & 14.1 & 25.0 & 14.1\end{array}$

$\begin{array}{lllll}96.4 \% & 15.1 & 25.0 & 15.1 & 2\end{array}$

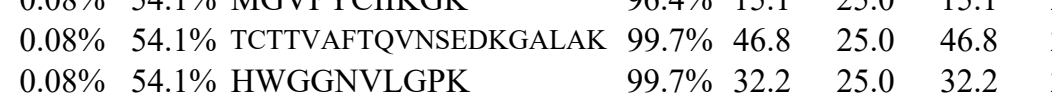

$99.0 \% \quad 48.2 \quad 25.0 \quad 31.3$

$99.7 \% \quad 41.9 \quad 25.0 \quad 29.4$

$\begin{array}{llll}99.7 \% & 37.7 & 25.0 & 30.8\end{array}$
$0.09 \% \quad 47.1 \%$ LRAVDFAER
$0.09 \% \quad 47.1 \%$ AVDFAERHGYIK

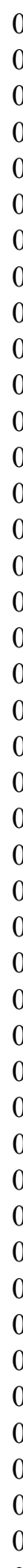

14.77

1805.99

1210.70

962.57

1320.69

1192.60

1892.04

1040.62

1026.61

1322.76

1053.57

1408.79

1175.66

1662.89

965.53

1121.63

1326.79

1170.68

1540.79

1805.93

2115.98

979.63

851.53

979.63

1073.64

945.54

1326.79

1216.63

1372.73

1811.02

1569.84

902.53

1242.70

1178.62

943.52

1334.79

1345.73

1473.83

1208.65

1096.55

1281.67

2141.05

1064.56

821.46

1076.58

1405.72 

$60 \mathrm{~S}$ ribosomal protein $\mathrm{L} 8 \mathrm{GN}=\mathrm{RPL} 8$ $60 \mathrm{~S}$ ribosomal protein $\mathrm{L} 8 \mathrm{GN}=\mathrm{RPL} 8$ $60 \mathrm{~S}$ ribosomal protein $\mathrm{L} 8 \mathrm{GN}=\mathrm{RPL} 8$ $60 \mathrm{~S}$ ribosomal protein $\mathrm{L} 8 \mathrm{GN}=\mathrm{RPL} 8$ $60 \mathrm{~S}$ ribosomal protein $\mathrm{L} 8 \mathrm{GN}=\mathrm{RPL} 8$ $60 \mathrm{~S}$ ribosomal protein $\mathrm{L} 8 \mathrm{GN}=\mathrm{RPL} 8$ $60 \mathrm{~S}$ ribosomal protein $\mathrm{L} 8 \mathrm{GN}=\mathrm{RPL} 8$ $60 \mathrm{~S}$ ribosomal protein $\mathrm{L} 8 \mathrm{GN}=\mathrm{RPL} 8$ $60 \mathrm{~S}$ ribosomal protein $\mathrm{L} 8 \mathrm{GN}=\mathrm{RPL} 8$ $60 \mathrm{~S}$ ribosomal protein $\mathrm{L} 8 \mathrm{GN}=\mathrm{RPL} 8$ $60 \mathrm{~S}$ ribosomal protein $\mathrm{L} 8 \mathrm{GN}=\mathrm{RPL} 8$ $60 \mathrm{~S}$ ribosomal protein $\mathrm{L} 9 \mathrm{GN}=\mathrm{RPL} 9$ 60 S ribosomal protein $\mathrm{L} 9 \mathrm{GN}=\mathrm{RPL} 9$ $60 \mathrm{~S}$ ribosomal protein $\mathrm{L} 9 \mathrm{GN}=\mathrm{RPL} 9$ $60 \mathrm{~S}$ ribosomal protein $\mathrm{L} 9 \mathrm{GN}=\mathrm{RPL} 9$ $60 \mathrm{~S}$ ribosomal protein $\mathrm{L} 9 \mathrm{GN}=\mathrm{RPL} 9$ $60 \mathrm{~S}$ ribosomal protein $\mathrm{L} 9 \mathrm{GN}=\mathrm{RPL} 9$ $60 \mathrm{~S}$ ribosomal protein $\mathrm{L} 9 \mathrm{GN}=\mathrm{RPL} 9$ $60 \mathrm{~S}$ ribosomal protein $\mathrm{L} 9 \mathrm{GN}=\mathrm{RPL} 9$ $60 \mathrm{~S}$ ribosomal protein $\mathrm{L} 9 \mathrm{GN}=\mathrm{RPL} 9$ $60 \mathrm{~S}$ ribosomal protein $\mathrm{L} 9 \mathrm{GN}=\mathrm{RPL} 9$
$60 \mathrm{~S}$ ribosomal protein $\mathrm{L} 8 \mathrm{GN}=\mathrm{RPL} 8$ $60 \mathrm{~S}$ ribosomal protein $\mathrm{L} 8 \mathrm{GN}=\mathrm{RPL} 8$ $60 \mathrm{~S}$ ribosomal protein $\mathrm{L} 9 \mathrm{GN}=\mathrm{RPL} 9$

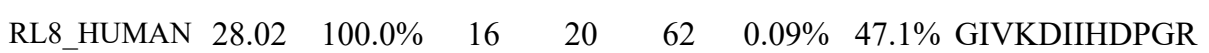
$\begin{array}{lllllll}\text { RL8_HUMAN } 28.02 & 100.0 \% & 16 & 20 & 62 & 0.09 \% & 47.1 \% \\ \text { DIIHDPGRGAPLAK }\end{array}$

$0.09 \% \quad 47.1 \%$ TELFIAAEGIHTGQFVYCGK $99.7 \% \quad 45.4$ RL__HUMAN $28.02 \quad 100.0 \%$ $100.0 \% \quad 16$ RL8_HUMAN $28.02 \quad 100.0 \% \quad 16$ RL8_HUMAN $28.02 \quad 100.0 \% \quad 16$ RL8 HUMAN $28.02 \quad 100.0 \% \quad 16$ RL8_HUMAN $28.02 \quad 100.0 \% \quad 16$ RL8 HUMAN $28.02 \quad 100.0 \% \quad 16$ RL8_HUMAN $28.02 \quad 100.0 \% \quad 16$ RL8_HUMAN $28.02 \quad 100.0 \% \quad 16$ RL8 HUMAN $28.02 \quad 100.0 \% \quad 16$ RL8_HUMAN $28.02 \quad 100.0 \% \quad 16$ RL9 HUMAN $21.86 \quad 100.0 \% \quad 11$ RL9 HUMAN $21.86 \quad 100.0 \% \quad 11$ RL9_HUMAN $21.86 \quad 100.0 \% \quad 11$ RL9 HUMAN $21.86 \quad 100.0 \% \quad 11$ RL9_HUMAN $21.86 \quad 100.0 \% \quad 11$ RL9_HUMAN $21.86 \quad 100.0 \% \quad 11$ RL9 HUMAN $21.86 \quad 100.0 \% \quad 11$ RL9_HUMAN $21.86 \quad 100.0 \% \quad 11$ RL9 HUMAN $21.86 \quad 100.0 \% \quad 11$ RL9_HUMAN $21.86 \quad 100.0 \% \quad 11$ RL9_HUMAN $21.86 \quad 100.0 \% \quad 11$

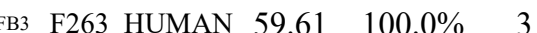

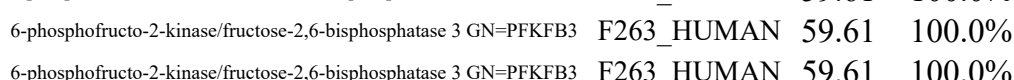
78 kDa glucose-regulated protein GN=HSPA5 GRP78_HUMAN $72.33 \quad 100.0 \%$ $78 \mathrm{kDa}$ glucose-regulated protein GN=HSPA5 GRP78_HUMAN $72.33 \quad 100.0 \%$ $78 \mathrm{kDa}$ glucose-regulated protein GN=HSPA5 GRP78 HUMAN $72.33 \quad 100.0 \%$ $78 \mathrm{kDa}$ glucose-regulated protein GN=HSPA5 GRP78_HUMAN $72.33 \quad 100.0 \%$

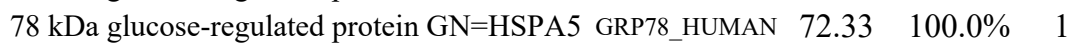
$\begin{array}{lll}78 \mathrm{kDa} \text { glucose-regulated protein GN=HSPA5 GRP78_HUMAN } & 72.33 & 100.0 \%\end{array}$ $\begin{array}{llll}78 \mathrm{kDa} \text { glucose-regulated protein GN=HSPA5 GRP78_HUMAN } & 72.33 & 100.0 \% & 17\end{array}$ $\begin{array}{llll}78 \mathrm{kDa} \text { glucose-regulated protein GN=HSPA5 GRP78_HUMAN } & 72.33 & 100.0 \% & 17\end{array}$

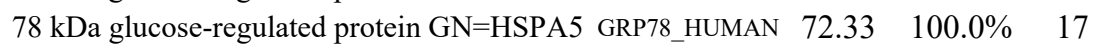
$\begin{array}{llll}78 \mathrm{kDa} \text { glucose-regulated protein GN=HSPA5 GRP78_HUMAN } & 72.33 & 100.0 \% & 17\end{array}$ $\begin{array}{llll}78 \mathrm{kDa} \text { glucose-regulated protein GN=HSPA5 GRP78_HUMAN } & 72.33 & 100.0 \% & 17\end{array}$

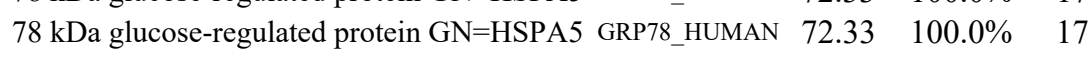
$\begin{array}{llll}78 \mathrm{kDa} \text { glucose-regulated protein GN=HSPA5 GRP78_HUMAN } & 72.33 & 100.0 \% & 17\end{array}$

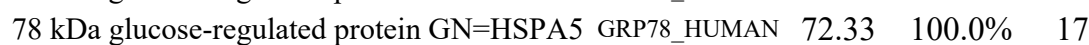

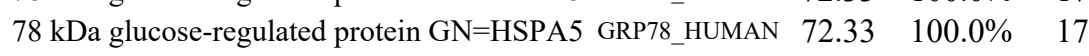
$\begin{array}{llll}78 \mathrm{kDa} \text { glucose-regulated protein GN=HSPA5 GRP78_HUMAN } & 72.33 & 100.0 \% & 17\end{array}$ $\begin{array}{llll}78 \mathrm{kDa} \text { glucose-regulated protein GN=HSPA5 GRP78_HUMAN } & 72.33 & 100.0 \% & 17\end{array}$

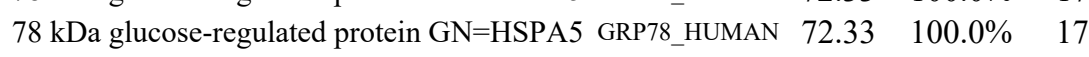
7-dehydrocholesterol reductase GN=DHCR7 DHCR7 HUMAN $54.49 \quad 100.0 \% \quad 6$ 7-dehydrocholesterol reductase GN=DHCR7 DHCR7_HUMAN $54.49 \quad 100.0 \%$ $\begin{array}{llll}0.09 \% & 47.1 \% & \text { TELFIAAEGIHTGQFVYCGKK } \quad 99.7 \% \quad 32.5\end{array}$

$\begin{array}{llll}0.09 \% & 47.1 \% & \text { ASGNYATVISHNPETK } \quad 99.7 \% & 53.6\end{array}$

$0.09 \% \quad 47.1 \%$ ASGNYATVISHNPETKK

$99.7 \% \quad 41.4$

$99.0 \% \quad 28.5$

$96.5 \% \quad 25.8$

$0.09 \% \quad 47.1 \%$ KVISSANR

$\begin{array}{lll}98.3 \% & 16.8\end{array}$

$0.09 \% \quad 47.1 \%$ AVVGVVAGGGR

$99.7 \% \quad 63.4$

$0.09 \% \quad 47.1 \%$ AVVGVVAGGGRIDKPILK $\quad 99.7 \% \quad 59.4$

$0.09 \% \quad 47.1 \%$ KVGLIAAR

$99.0 \% \quad 45.2$

$99.0 \% \quad 32.3$

$0.09 \% \quad 47.1 \%$ VGLIAARR

$99.7 \% \quad 33.9$

$\begin{array}{llllll}0.05 \% & 44.3 \% & \text { TILSNQTVDIPENVDITLK } & 99.7 \% & 45.7\end{array}$

$\begin{array}{lllll}0.05 \% & 44.3 \% & \text { TILSNQTVDIPENVDITLKGR } & 99.7 \% & 49.5\end{array}$

$0.05 \% \quad 44.3 \%$ TVIVKGPR

$0.05 \% \quad 44.3 \%$ DFNHINVELSLLGK

$0.05 \% \quad 44.3 \%$ DFNHINVELSLLGKK

$99.0 \% \quad 42.5$

$99.7 \% \quad 55.4$

$99.7 \% \quad 47.1$

$99.7 \% \quad 52.7$

$\begin{array}{lll}0.05 \% & 44.3 \% & \text { TICSHVQNMIK } \\ 0.05 \% & 44.3 \% \text { NFLGEKYIR }\end{array}$

$0.05 \% \quad 44.3 \%$ KFLDGIYVSEK

$0.05 \% \quad 44.3 \%$ FLDGIYVSEK

$99.7 \% \quad 31.7$

$99.7 \% \quad 53.5$

$99.7 \% \quad 62.9$

$\begin{array}{llll}0.05 \% & 44.3 \% & \text { FLDGIYVSEKGTVQQADE } \quad 99.7 \% \quad 39.5\end{array}$

$0.01 \% \quad 7.1 \%$ HGENEHNLQGR

$0.01 \% \quad 7.1 \%$ IGGDSGLSSR

$0.01 \% \quad 7.1 \%$ NSVTPLASPEPTKKPR

$0.06 \% \quad 30.9 \%$ ITPSYVAFTPEGER

$99.7 \% \quad 32.6$

$99.7 \% \quad 55.2$

$99.7 \% \quad 48.1$

$99.7 \% \quad 51.9$

$0.06 \% \quad 30.9 \%$ ITPSYVAFTPEGERLIGDAAK $\quad 95.1 \% \quad 14.4$

$0.06 \% \quad 30.9 \%$ NQLTSNPENTVFDAK

$0.06 \% \quad 30.9 \%$ NQLTSNPENTVFDAKR

$0.06 \% \quad 30.9 \%$ KTKPYIQVDIGGGQTK

$99.7 \% \quad 45.5$

$99.7 \% \quad 55.5$

$0.06 \% \quad 30.9 \%$ TKPYIQVDIGGGQTK

$0.06 \% \quad 30.9 \%$ TFAPEEISAMVLTK

$99.7 \% \quad 67.7$

$99.7 \% \quad 60.5$

$0.06 \% \quad 30.9 \%$ VTHAVVTVPAYFNDAQR $\quad 99.7 \% \quad 51.9$

$0.06 \% \quad 30.9 \%$ QATKDAGTIAGLNVMR $\quad 99.7 \% 39.8$

$0.06 \% \quad 30.9 \%$ DAGTIAGLNVMR

$99.7 \% \quad 39.5$

$99.7 \% 70.0$

$0.06 \% \quad 30.9 \%$ IINEPTAAAIAYGLDK

$0.06 \% \quad 30.9 \%$ IINEPTAAAIAYGLDKR

$0.06 \% \quad 30.9 \%$ ALSSQHQAR

$99.7 \% \quad 41.5$

$0.06 \% \quad 30.9 \%$ IEIESFYEGEDFSETLTR

$0.06 \% \quad 30.9 \%$ AKFEELNMDLFR

$0.06 \% \quad 30.9 \%$ SQIFSTASDNQPTVTIK

$99.7 \% \quad 64.6$

$99.7 \% \quad 58.9$

$99.7 \% \quad 51.7$

$99.2 \% \quad 20.0$

$99.7 \% \quad 36.6$

$99.7 \% 44.7$

$0.06 \% \quad 30.9 \%$ ELEEIVQPIISK

$0.02 \% \quad 10.5 \%$ SLDGVTNDR

GR $99.6 \% \quad 23.2$
$0.09 \% \quad 47.1 \%$ VKLPSGSK

$99.7 \% \quad 39.2$

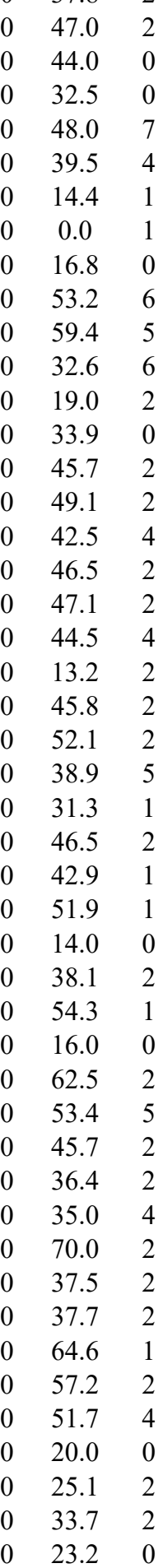

2113.14

2326.26

869.56

1598.85

1726.95

1330.66

1139.62

1298.70

1170.60

1998.97

1290.59

948.47

1721.95

1566.78

2235.17

1677.81

1833.91

1732.96

1604.86

1536.80

1887.97

1645.87

1233.63

1659.90

1816.00

997.52

2164.99

1512.75

1836.93

2042.05

1397.79

976.47 1947.93 
7-dehydrocholesterol reductase GN=DHCR7 DHCR7_HUMAN $54.49 \quad 100.0 \%$ 7-dehydrocholesterol reductase GN=DHCR7 DHCR7_HUMAN $54.49 \quad 100.0 \%$ 7-dehydrocholesterol reductase GN=DHCR7 DHCR7_HUMAN $54.49 \quad 100.0 \%$ 7-dehydrocholesterol reductase GN=DHCR7 DHCR7_HUMAN $54.49 \quad 100.0 \%$ Acetolactate synthase-like protein GN=ILVBL ILVBL_HUMAN $67.87 \quad 100.0 \%$ Acetolactate synthase-like protein GN=ILVBL ILVBL_HUMAN $67.87 \quad 100.0 \%$ Acetolactate synthase-like protein GN=ILVBL ILVBL_HUMAN $67.87 \quad 100.0 \%$ Acetolactate synthase-like protein GN=ILVBL ILVBL_HUMAN $67.87 \quad 100.0 \%$ Acetolactate synthase-like protein GN=ILVBL ILVBL HUMAN $67.87 \quad 100.0 \%$ Acetyl-CoA acetyltransferase, mitochondrial GN=ACAT1 THIL_HUMAN $45.20 \quad 100.0 \%$ Acetyl-CoA acetyltransferase, mitochondrial GN=ACAT1 THIL_HUMAN $45.20 \quad 100.0 \%$ Acetyl-CoA carboxylase $1 \mathrm{GN}=$ ACACA ACACA_HUMAN $265.56 \quad 100.0 \%$ Acetyl-CoA carboxylase 1 GN=ACACA ACACA_HUMAN $265.56 \quad 100.0 \%$ Acetyl-CoA carboxylase $1 \mathrm{GN}=\mathrm{ACACA} \quad$ ACACA_HUMAN $265.56 \quad 100.0 \%$ Acetyl-CoA carboxylase $1 \mathrm{GN}=$ ACACA ACACA_HUMAN $265.56 \quad 100.0 \%$ Acetyl-CoA carboxylase $1 \mathrm{GN}=\mathrm{ACACA} \quad$ ACACA_HUMAN $265.56 \quad 100.0 \%$ Acetyl-CoA carboxylase $1 \mathrm{GN}=\mathrm{ACACA}$ ACACA HUMAN $265.56 \quad 100.0 \%$ Acetyl-CoA carboxylase 1 GN=ACACA ACACA_HUMAN $265.56 \quad 100.0 \%$ Actin, cytoplasmic $1 \mathrm{GN}=\mathrm{ACTB}$

Actin, cytoplasmic $1 \mathrm{GN}=\mathrm{ACTB}$ Actin, cytoplasmic $1 \mathrm{GN}=\mathrm{ACTB}$ Actin, cytoplasmic $1 \mathrm{GN}=\mathrm{ACTB}$ Actin, cytoplasmic $1 \mathrm{GN}=\mathrm{ACTB}$ Actin, cytoplasmic $1 \mathrm{GN}=\mathrm{ACTB}$ Actin, cytoplasmic $1 \mathrm{GN}=\mathrm{ACTB}$ Actin, cytoplasmic $1 \mathrm{GN}=\mathrm{ACTB}$ Actin, cytoplasmic $1 \mathrm{GN}=\mathrm{ACTB}$ Actin, cytoplasmic $1 \mathrm{GN}=\mathrm{ACTB}$ Actin, cytoplasmic $1 \mathrm{GN}=\mathrm{ACTB}$ Actin, cytoplasmic $1 \mathrm{GN}=\mathrm{ACTB}$ Actin, cytoplasmic $1 \mathrm{GN}=\mathrm{ACTB}$ Actin, cytoplasmic $1 \mathrm{GN}=\mathrm{ACTB}$ Actin, cytoplasmic $1 \mathrm{GN}=\mathrm{ACTB}$ Actin, cytoplasmic $1 \mathrm{GN}=\mathrm{ACTB}$ Actin, cytoplasmic $1 \mathrm{GN}=\mathrm{ACTB}$ Actin, cytoplasmic $1 \mathrm{GN}=\mathrm{ACTB}$ Actin, cytoplasmic $1 \mathrm{GN}=\mathrm{ACTB}$ Actin, cytoplasmic $1 \mathrm{GN}=\mathrm{ACTB}$ Actin, cytoplasmic $1 \mathrm{GN}=\mathrm{ACTB}$ Actin, cytoplasmic $1 \mathrm{GN}=\mathrm{ACTB}$ Actin-related protein $2 \mathrm{GN}=\mathrm{ACTR} 2$ Actin-related protein $2 \mathrm{GN}=\mathrm{ACTR} 2$ Actin-related protein $2 \mathrm{GN}=\mathrm{ACTR} 2$ Actin-related protein $2 \mathrm{GN}=\mathrm{ACTR} 2$ ACTB_HUMAN $41.74 \quad 100.0 \%$ ACTB HUMAN $41.74 \quad 100.0 \%$ ACTB_HUMAN $41.74 \quad 100.0 \% \quad 22$ ACTB HUMAN $41.74 \quad 100.0 \% \quad 22$ ACTB_HUMAN $41.74 \quad 100.0 \% \quad 22$ ACTB_HUMAN $41.74 \quad 100.0 \% \quad 22$ ACTB HUMAN $41.74 \quad 100.0 \% \quad 22$ ACTB_HUMAN $41.74 \quad 100.0 \% \quad 22$ ACTB_HUMAN $41.74 \quad 100.0 \% \quad 22$ ACTB_HUMAN $41.74 \quad 100.0 \% \quad 22$ ACTB_HUMAN $41.74 \quad 100.0 \% \quad 22$ ACTB HUMAN $41.74 \quad 100.0 \% \quad 22$ ACTB HUMAN $41.74 \quad 100.0 \% \quad 22$ ACTB_HUMAN $\quad 41.74 \quad 100.0 \% \quad 22$ ACTB HUMAN $41.74 \quad 100.0 \% \quad 22$ ACTB_HUMAN $41.74 \quad 100.0 \% \quad 22$ ACTB_HUMAN $41.74 \quad 100.0 \% \quad 22$ ACTB_HUMAN $41.74 \quad 100.0 \% \quad 22$ ACTB_HUMAN $41.74 \quad 100.0 \% \quad 22$ ACTB HUMAN $41.74 \quad 100.0 \% \quad 22$ ACTB_HUMAN $41.74 \quad 100.0 \% \quad 22$ ACTB_HUMAN $41.74 \quad 100.0 \% \quad 22$ ARP2 HUMAN $44.76 \quad 100.0 \%$ ARP2_HUMAN $44.76 \quad 100.0 \%$ ARP2 HUMAN $44.76 \quad 100.0 \%$ ARP2_HUMAN $44.76 \quad 100.0 \%$ Activating signal cointegrator 1 complex subunit $3 \mathrm{GN}=\mathrm{ASCC} 3$ ASCC3_HUMAN $251.47 \quad 100.0 \%$ Activating signal cointegrator 1 complex subunit $3 \mathrm{GN}=\mathrm{ASCC} 3 \mathrm{ASCC} 3 \mathrm{HUMAN} 251.47 \quad 100.0 \%$ Activating signal cointegrator 1 complex subunit $3 \mathrm{GN}=\mathrm{ASCC} 3 \mathrm{ASCC} 3$ HUMAN $251.47 \quad 100.0 \%$ $0.02 \% \quad 10.5 \%$ VIEC $0.02 \% \quad 10.5 \%$ LLVSGFWGVAR $0.02 \% \quad 10.5 \%$ YTAAVPYR

$99.7 \% \quad 49$

$99.7 \% \quad 47.8$ $99.0 \% \quad 25.8$

$\begin{array}{lllll}0.02 \% & 14.1 \% & \text { LSGTVGVAAVTAGPGLTNTVTAVK } & 99.7 \% & 32.3\end{array}$

$\begin{array}{llll}0.02 \% & 14.1 \% \text { GALQAVDQLSLFRPLCK } 99.0 \% & 19.9\end{array}$

$0.02 \% \quad 14.1 \%$ AAVETLGVPCFLGGMAR $99.7 \% \quad 31.5$

$0.02 \% \quad 14.1 \%$ EQVPSLGSNVACGLAYTDYHK $\quad 97.2 \% \quad 15.7$

$0.02 \% \quad 14.1 \%$ TDFRDGSIAV

$0.01 \% \quad 4.9 \% \quad$ NEQDAYAINSYTR

$0.01 \% \quad 4.9 \% \quad$ LNVTPLAR

$0.01 \% \quad 3.8 \%$ DFTVASPAEFVTR

$0.01 \% \quad 3.8 \%$ FGGNKVIEK

$0.01 \% \quad 3.8 \%$ QVQAEVPGSPIFVMR

$97.3 \% \quad 18.2$

$99.7 \% \quad 54.7$

$99.0 \% 35.4$

$99.7 \% \quad 45.3$

$96.2 \% \quad 23.1$

$99.7 \% \quad 32.5$

$0.01 \% \quad 3.8 \%$ ITSENPDEGFKPSSGTVOELNFR $99.7 \% \quad 27.4$

$0.01 \% \quad 3.8 \%$ GNIPTLNR

$0.01 \% \quad 3.8 \% \quad$ YLYLTPQDYKR

$0.01 \% \quad 3.8 \%$ AIGIGAYLVR

$188 \quad 0.26 \% \quad 52.0 \%$ AGFAGDDAPR

$188 \quad 0.26 \% \quad 52.0 \%$ AVFPSIVGRPR

$188 \quad 0.26 \% \quad 52.0 \%$ HQGVMVGMGQK

$96.6 \% 16.6$

$99.1 \% \quad 18.6$

$99.7 \% \quad 34.8$

$99.7 \% \quad 57.4$

$99.7 \% \quad 56.2$

$99.7 \% \quad 56.7$

40

40

40
40

40

40

40

40

40

40

40
40

40

40

40

40

40
40
4

4

4

$188 \quad 0.26 \% \quad 52.0 \%$ DSYVGDEAQSK

$99.7 \% \quad 46.6$

$0.26 \% \quad 52.0 \%$ DSYVGDEAQSKR

$188 \quad 0.26 \% \quad 52.0 \%$ VAPEEHPVLLTEAPLNPK $99.7 \% \quad 48.4$

$188 \quad 0.26 \% \quad 52.0 \%$ VAPEEHPVLLTEAPLNPKANR

$188 \quad 0.26 \% \quad 52.0 \%$ LDLAGRDLTDYLMK

$99.7 \% \quad 37.1$

$99.7 \% \quad 43.4$

$99.0 \% 22.0$

$88 \quad 0.26 \% \quad 52.0 \% \quad$ ILTERGYSFTTTAER

$188 \quad 0.26 \% \quad 52.0 \%$ GYSFTTTAER

$99.7 \% \quad 29.8$

$99.7 \% \quad 53.1$

$99.7 \% \quad 35.1$

$\begin{array}{lll}99.7 \% & 26.8\end{array}$

$188 \quad 0.26 \% \quad 52.0 \%$ SYELPDGQVITIGNER $\quad 99.7 \% \quad 54.0$

$188 \quad 0.26 \% \quad 52.0 \%$ DLYANTVLSGGTTMYPGIADR $\quad 99.7 \% \quad 44.9$

$188 \quad 0.26 \% \quad 52.0 \%$ MQKEITALAPSTMK

$99.7 \% \quad 57.7$

$99.7 \% \quad 62.4$

$99.7 \% \quad 36.0$

$99.7 \% \quad 36.5$

$99.7 \% \quad 46.9$

$99.7 \% \quad 49.4$

$99.5 \% \quad 22.9$

$98.8 \% \quad 21.2$

$99.7 \% \quad 35.2$

$99.7 \% \quad 54.4$

$98.9 \% \quad 21.7$

$99.7 \% \quad 49.2$

$99.1 \% \quad 18.5$
990.48

485.66

1204.68

940.49

2184.22

1916.04

1748.88

2309.09

1080.53

1544.70

883.54

1439.72

991.56

1657.87

2552.23

884.49

1459.76

1032.62

976.45

1198.71

1171.57

2351.08

1198.52

1354.62

1954.06

2295.25

1639.84

1014.48

1744.89

1132.53

1629.82

2566.17

1790.89

2231.07

1580.80

1161.62

1402.80

1036.65

1516.70

1644.80

1422.74

1353.74

1613.73

1113.70

1137.74

1090.63

1083.58

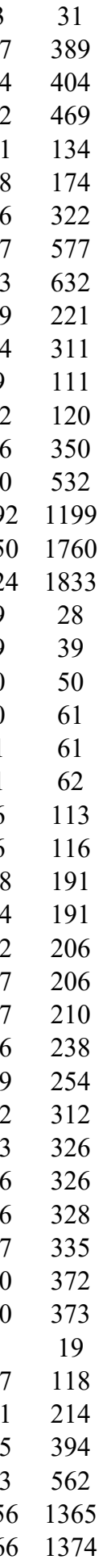

Page 18 of Table S-1-1 
Activating signal cointegrator 1 complex subunit $3 \mathrm{GN}=\mathrm{ASCC} 3 \mathrm{ASCC} 3$ HUMAN $251.47 \quad 100.0 \%$ Activator of $90 \mathrm{kDa}$ heat shock protein ATPase homolog $1 \mathrm{GN}=\mathrm{AHSA}$ AHSA1_HUMAN $38.27 \quad 100.0 \%$ Activator of $90 \mathrm{kDa}$ heat shock protein ATPase homolog $1 \mathrm{GN}=\mathrm{AHSA}$ AHSA1_HUMAN $38.27 \quad 100.0 \%$ Activator of $90 \mathrm{kDa}$ heat shock protein ATPase homolog $1 \mathrm{GN}=\mathrm{AHSA} 1$ AHSA1_HUMAN $38.27 \quad 100.0 \%$ Activator of basal transcription $1 \mathrm{GN}=\mathrm{ABT} 1$ ABT1_HUMAN $31.08 \quad 100.0 \%$ Activator of basal transcription $1 \mathrm{GN}=\mathrm{ABT} 1 \mathrm{ABT1}$ HUMAN $31.08 \quad 100.0 \%$ Activator of basal transcription $1 \mathrm{GN}=\mathrm{ABT} 1 \mathrm{ABT} 1$ HUMAN $31.08 \quad 100.0 \%$ Activator of basal transcription $1 \mathrm{GN}=\mathrm{ABT} 1 \mathrm{ABT1}$ _HUMAN $31.08 \quad 100.0 \%$ Acyl-coenzyme A thioesterase $1 \mathrm{GN}=$ ACOT1 ACOT1_HUMAN $46.28 \quad 100.0 \%$ Acyl-coenzyme A thioesterase $1 \mathrm{GN}=\mathrm{ACOT} 1$ ACOT1_HUMAN $46.28 \quad 100.0 \%$ Acyl-coenzyme A thioesterase $8 \mathrm{GN}=$ ACOT8 ACOT8_HUMAN $35.91 \quad 100.0 \%$ Acyl-coenzyme A thioesterase $8 \mathrm{GN}=\mathrm{ACOT} 8$ ACOT8 HUMAN $35.91 \quad 100.0 \%$ Acyl-coenzyme A thioesterase 9, mitochondrial GN=ACOT9 ACOT9_HUMAN $49.90 \quad 100.0 \%$ Acyl-coenzyme A thioesterase 9, mitochondrial GN=ACOT9 ACOT9_HUMAN $49.90 \quad 100.0 \%$ Acyl-coenzyme A thioesterase 9, mitochondrial GN=ACOT9 ACOT9 HUMAN $49.90 \quad 100.0 \%$ Acylglycerol kinase, mitochondrial GN=AGK AGK_HUMAN $47.14 \quad 100.0 \%$ Acylglycerol kinase, mitochondrial GN=AGK AGK HUMAN 47.14 100.0\% Adenine phosphoribosyltransferase GN=APRT APT_HUMAN $19.61 \quad 100.0 \%$ Adenine phosphoribosyltransferase GN=APRT APT_HUMAN $19.61 \quad 100.0 \%$ Adenine phosphoribosyltransferase GN=APRT APT HUMAN $19.61 \quad 100.0 \%$ Adenine phosphoribosyltransferase GN=APRT APT_HUMAN $19.61 \quad 100.0 \%$ Adenosylhomocysteinase GN=AHCY SAHH HUMAN $47.72 \quad 100.0 \%$ Adenosylhomocysteinase GN=AHCY SAHH_HUMAN $47.72 \quad 100.0 \%$ Adenosylhomocysteinase GN=AHCY SAHH_HUMAN $47.72 \quad 100.0 \%$ Adenylate kinase 4, mitochondrial GN=AK4 KAD4_HUMAN $25.27 \quad 100.0^{\circ}$ Adenylate kinase 4, mitochondrial GN=AK4 KAD4_HUMAN $25.27 \quad 100.0 \%$ Adenylate kinase 4, mitochondrial GN=AK4 KAD4_HUMAN $25.27 \quad 100.0 \%$ Adenylosuccinate synthetase isozyme $2 \mathrm{GN}=$ ADSS PURA2_HUMAN $50.10 \quad 100.0 \%$ Adenylosuccinate synthetase isozyme $2 \mathrm{GN}=$ ADSS PURA2_HUMAN $50.10 \quad 100.0 \%$ Adenylosuccinate synthetase isozyme $2 \mathrm{GN}=\mathrm{ADSS}$ PURA2 HUMAN 50.10 ADP/ATP translocase $1 \mathrm{GN}=\mathrm{SLC} 25 \mathrm{~A} 4$ $\mathrm{ADP} / \mathrm{ATP}$ translocase $1 \mathrm{GN}=\mathrm{SLC} 25 \mathrm{~A} 4$ ADP/ATP translocase $1 \mathrm{GN}=\mathrm{SLC} 25 \mathrm{~A} 4$ ADP/ATP translocase $1 \mathrm{GN}=\mathrm{SLC} 25 \mathrm{~A}^{2}$ $\mathrm{ADP} / \mathrm{ATP}$ translocase $1 \mathrm{GN}=\mathrm{SLC} 25 \mathrm{~A} 4$ ADP/ATP translocase $1 \mathrm{GN}=\mathrm{SLC} 25 \mathrm{~A} 4$ $\mathrm{ADP} / \mathrm{ATP}$ translocase $1 \mathrm{GN}=\mathrm{SLC} 25 \mathrm{~A} 4$ ADP/ATP translocase $1 \mathrm{GN}=\mathrm{SLC} 25 \mathrm{~A} 4$ ADP/ATP translocase $1 \mathrm{GN}=\mathrm{SLC} 25 \mathrm{~A} 4$ ADP/ATP translocase $1 \mathrm{GN}=\mathrm{SLC} 25 \mathrm{~A} 4$ ADP/ATP translocase $1 \mathrm{GN}=\mathrm{SLC} 25 \mathrm{~A} 4$ ADP/ATP translocase $1 \mathrm{GN}=\mathrm{SLC} 25 \mathrm{~A} 4$ ADP/ATP translocase $1 \mathrm{GN}=\mathrm{SLC} 25 \mathrm{~A}$ $\mathrm{ADP} / \mathrm{ATP}$ translocase $1 \mathrm{GN}=\mathrm{SLC} 25 \mathrm{~A} 4$ $\mathrm{ADP} / \mathrm{ATP}$ translocase $1 \mathrm{GN}=\mathrm{SLC} 25 \mathrm{~A} 4$ ADP/ATP translocase $2 \mathrm{GN}=\mathrm{SLC} 25 \mathrm{~A} 5$ ADP/ATP translocase $2 \mathrm{GN}=\mathrm{SLC} 25 \mathrm{~A} 5$
$11 \quad 0.02 \% \quad 1.8 \% \quad$ VSDSLTDLALK $0.01 \% \quad 10.4$ $0.01 \% \quad 10.4 \%$ GIPAPEEERTR

$0.01 \% \quad 10.4 \%$ YYFEGIKQTFGYGAR $0.01 \% \quad 12.5 \%$ NLLSAYGEVGR $0.01 \% \quad 12.5 \%$ RVAASLHNTPMGAR $0.01 \% \quad 12.5 \%$ VAASLHNTPMGAR $0.01 \% \quad 12.5 \%$ LRAEVAQAK $0.01 \% \quad 5.2 \%$ AATLILEPAGR $0.01 \% \quad 5.2 \%$ GLAPEQPVTLR $0.01 \% \quad 8.2 \%$ LFGGQIVGQALVAAAK $0.01 \% \quad 8.2 \%$ VKPQVSESKL $0.01 \% \quad 6.6 \%$ YLTVQNTVR $0.01 \% \quad 6.6 \%$ IAFSSTSLLK $0.01 \% \quad 6.6 \%$ SLEICHPQER $0.01 \% \quad 3.3 \% \quad$ KATVFLNPAACK $0.01 \% \quad 3.3 \%$ ATVFLNPAACKGK $0.01 \% \quad 23.3 \%$ SFPDFPTPGVVFR $0.01 \% \quad 23.3 \%$ DISPVLKDPASFR $0.01 \% \quad 23.3 \%$ ATHGGRIDYIAGLDSR $0.01 \% \quad 23.3 \%$ IDYIAGLDSR $0.01 \% \quad 7.6 \%$ GISEETTTGVHNLYK $0.01 \% \quad 7.6 \%$ SKFDNLYGCR $0.01 \% \quad 7.6 \%$ IILLAEGR

$0.01 \% \quad 12.6 \%$ AVILGPPGSC $0.01 \% \quad 12.6 \%$ AVILGPPGSGKGTVCQR $0.01 \% \quad 12.6 \%$ SLLVPDHVITR $0.01 \% \quad 7.2 \%$ GREFGVTTGR $0.01 \% \quad 7.2 \%$ AFKELPVNAQNYVR $0.01 \% \quad 7.2 \%$ SRESMIQLF $0.01 \% \quad 40.3 \%$ TAVAPIER $0.01 \% \quad 40.3 \%$ TAVAPIERVK $0.01 \% \quad 40.3 \%$ VKLLLQVQHASK $0.01 \% \quad 40.3 \%$ LLLQVQHASK $0.01 \% \quad 40.3 \%$ GIIDCVVR $0.01 \% \quad 40.3 \%$ GIIDCVVRIPK $0.01 \% \quad 40.3 \%$ YFPTQALNFAFK $0.01 \% \quad 40.3 \%$ YFPTQALNFAFKDK $0.01 \% \quad 40.3 \%$ YFAGNLASGGAAGATSLCFVYPLDFAR $0.01 \% \quad 40.3 \%$ TRLAADVGK $0.01 \% \quad 40.3 \%$ LAADVGKGAAQR $0.01 \% \quad 40.3 \%$ EFHGLGDCIIK $0.01 \% \quad 40.3 \%$ AAYFGVYDTAK $0.01 \% \quad 40.3 \%$ AFFKGAWSNVLR $0.01 \% \quad 40.3 \%$ GAWSNVLR

$0.11 \% \quad 50.0 \%$ DFLAGGVAAAISK $0.11 \% \quad 50.0 \%$ TAVAPIER $\begin{array}{llll}99.7 \% & 68.8 & 25.0 & 68.8\end{array}$

$\begin{array}{llll}99.2 \% & 31.9 & 25.0 & 7.7\end{array}$

$\begin{array}{llll}99.7 \% & 51.4 & 25.0 & 44.5\end{array}$

$99.4 \% \quad 21.0 \quad 25.0 \quad 18.6 \quad 2$

$\begin{array}{llll}99.7 \% & 49.2 & 25.0 & 49.2\end{array}$

$\begin{array}{llll}99.7 \% & 36.5 & 25.0 & 36.5\end{array}$

$\begin{array}{lllll}99.0 \% & 40.9 & 25.0 & 26.9 & 2\end{array}$

$\begin{array}{llll}99.7 \% & 68.5 & 25.0 & 60.0\end{array}$

$99.0 \% \quad 34.8 \quad 25.0 \quad 33.3$
955.57

1254.64

1799.88

1178.62

1496.78

1324.68

985.58

1111.65

1180.67

1542.90

1114.65

1093.60

1066.61

1268.61

1319.71

1376.74

1465.75

1444.78

1701.87

1122.58

1648.82

1259.58

884.56

995.59

1696.92

1249.73

1079.56

1648.88

1110.56

856.49

1083.65

1363.84

1136.68

931.50

1269.74

1446.74

1689.86

2796.35

930.54

1156.64

1288.64

1205.58

1395.75

902.48

1219.67

856.49

$\begin{array}{cc}92 & 2202 \\ 95 & 203 \\ 66 & 316 \\ 22 & 336 \\ 4 & 74 \\ 20 & 133 \\ 21 & 133 \\ 71 & 179 \\ 2 & 12 \\ 5 & 35 \\ 4 & 69 \\ 10 & 319 \\ 04 & 112 \\ 41 & 250 \\ 95 & 304 \\ 2 & 73 \\ 3 & 75 \\ 5 & 27 \\ 8 & 40 \\ 2 & 67 \\ 8 & 67 \\ 52 & 166 \\ 87 & 196 \\ 36 & 343 \\ 8 & 18 \\ 8 & 24 \\ 1 & 71 \\ 25 & 334 \\ 17 & 430 \\ 48 & 456 \\ 4 & 31 \\ 4 & 33 \\ 2 & 43 \\ 4 & 43 \\ 3 & 60 \\ 3 & 63 \\ 1 & 92 \\ 1 & 94 \\ 12 & 138 \\ 39 & 147 \\ 41 & 152 \\ 53 & 163 \\ 99 & 199 \\ 69 & 280 \\ 73 & 280 \\ 1 & 23 \\ & 31 \\ & \\ 49\end{array}$


ADP/ATP translocase $2 \mathrm{GN}=\mathrm{SLC} 25 \mathrm{~A} 5$ $\mathrm{ADP} / \mathrm{ATP}$ translocase $2 \mathrm{GN}=\mathrm{SLC} 25 \mathrm{~A}$ ADP/ATP translocase $2 \mathrm{GN}=\mathrm{SLC} 25 \mathrm{~A}$ : ADP/ATP translocase $2 \mathrm{GN}=\mathrm{SLC} 25 \mathrm{~A} 5$ ADP/ATP translocase $2 \mathrm{GN}=\mathrm{SLC} 25 \mathrm{~A} 5$ $\mathrm{ADP} / \mathrm{ATP}$ translocase $2 \mathrm{GN}=\mathrm{SLC} 25 \mathrm{~A} 5$ $\mathrm{ADP} / \mathrm{ATP}$ translocase $2 \mathrm{GN}=\mathrm{SLC} 25 \mathrm{~A} 5$ ADP/ATP translocase $2 \mathrm{GN}=\mathrm{SLC} 25 \mathrm{~A} 5$ $\mathrm{ADP} / \mathrm{ATP}$ translocase $2 \mathrm{GN}=\mathrm{SLC} 25 \mathrm{~A} 5$ ADP/ATP translocase $2 \mathrm{GN}=\mathrm{SLC} 25 \mathrm{~A} 5$ ADP/ATP translocase $2 \mathrm{GN}=\mathrm{SLC} 25 \mathrm{~A} 5$ ADP/ATP translocase $2 \mathrm{GN}=\mathrm{SLC} 25 \mathrm{~A}$ ADP/ATP translocase $2 \mathrm{GN}=\mathrm{SLC} 25 \mathrm{~A} 5$ ADP/ATP translocase $2 \mathrm{GN}=\mathrm{SLC} 25 \mathrm{~A} 5$ $\mathrm{ADP} / \mathrm{ATP}$ translocase $2 \mathrm{GN}=\mathrm{SLC} 25 \mathrm{~A} 5$ ADP/ATP translocase $2 \mathrm{GN}=\mathrm{SLC} 25 \mathrm{~A} 5$ ADP/ATP translocase $2 \mathrm{GN}=\mathrm{SLC} 25 \mathrm{~A} 5$ ADP/ATP translocase $2 \mathrm{GN}=\mathrm{SLC} 25 \mathrm{~A} 5$ ADP/ATP translocase $2 \mathrm{GN}=\mathrm{SLC} 25 \mathrm{~A}$ : $\mathrm{ADP} / \mathrm{ATP}$ translocase $2 \mathrm{GN}=\mathrm{SLC} 25 \mathrm{~A} 5$ $\mathrm{ADP} / \mathrm{ATP}$ translocase $2 \mathrm{GN}=\mathrm{SLC} 25 \mathrm{~A} 5$ ADP/ATP translocase $2 \mathrm{GN}=\mathrm{SLC} 25 \mathrm{~A} 5$ ADP/ATP translocase $2 \mathrm{GN}=\mathrm{SLC} 25 \mathrm{~A} 5$ ADP/ATP translocase $2 \mathrm{GN}=\mathrm{SLC} 25 \mathrm{~A} 5$ ADP/ATP translocase $3 \mathrm{GN}=\mathrm{SLC} 25 \mathrm{~A}$ ADP/ATP translocase $3 \mathrm{GN}=\mathrm{SLC} 25 \mathrm{~A} 6$ ADP/ATP translocase $3 \mathrm{GN}=\mathrm{SLC} 25 \mathrm{~A} 6$ ADP/ATP translocase $3 \mathrm{GN}=\mathrm{SLC} 25 \mathrm{~A} 6$ $\mathrm{ADP} / \mathrm{ATP}$ translocase $3 \mathrm{GN}=\mathrm{SLC} 25 \mathrm{~A} 6$ ADP/ATP translocase $3 \mathrm{GN}=\mathrm{SLC} 25 \mathrm{~A} 6$ ADP/ATP translocase $3 \mathrm{GN}=\mathrm{SLC} 25 \mathrm{~A} 6$ ADP/ATP translocase $3 \mathrm{GN}=\mathrm{SLC} 25 \mathrm{AC}$ ADP/ATP translocase $3 \mathrm{GN}=\mathrm{SLC} 25 \mathrm{AC}$ $\mathrm{ADP} / \mathrm{ATP}$ translocase $3 \mathrm{GN}=\mathrm{SLC} 25 \mathrm{~A} 6$ ADP/ATP translocase $3 \mathrm{GN}=\mathrm{SLC} 25 \mathrm{~A} 6$ ADP/ATP translocase $3 \mathrm{GN}=\mathrm{SLC} 25 \mathrm{~A} 6$ ADP/ATP translocase $3 \mathrm{GN}=\mathrm{SLC} 25 \mathrm{AC}$ $\mathrm{ADP} / \mathrm{ATP}$ translocase $3 \mathrm{GN}=\mathrm{SLC} 25 \mathrm{~A} 6$ ADP/ATP translocase $3 \mathrm{GN}=\mathrm{SLC} 25 \mathrm{~A} 6$ ADP/ATP translocase $3 \mathrm{GN}=\mathrm{SLC} 25 \mathrm{~A} 6$ ADP/ATP translocase $3 \mathrm{GN}=\mathrm{SLC} 25 \mathrm{~A} 6$ $\mathrm{ADP} / \mathrm{ATP}$ translocase $3 \mathrm{GN}=\mathrm{SLC} 25 \mathrm{~A} 6$ ADP/ATP translocase $3 \mathrm{GN}=\mathrm{SLC} 25 \mathrm{~A} 6$ $\mathrm{ADP} / \mathrm{ATP}$ translocase $3 \mathrm{GN}=\mathrm{SLC} 25 \mathrm{~A} 6$ AFG3-like protein $2 \mathrm{GN}=\mathrm{AFG} 3 \mathrm{~L} 2$ AFG3-like protein $2 \mathrm{GN}=\mathrm{AFG} 3 \mathrm{~L}$ AFG3-like protein $2 \mathrm{GN}=\mathrm{AFG} 3 \mathrm{~L} 2$

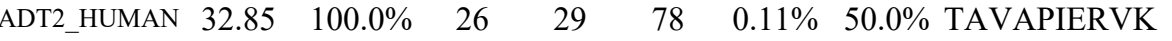
ADT2 HUMAN $32.85 \quad 100.0 \% \quad 26$ ADT2_HUMAN $32.85 \quad 100.0 \% \quad 26$ ADT2 HUMAN $32.85 \quad 100.0 \% \quad 26$ ADT2_HUMAN $32.85 \quad 100.0 \% \quad 26$ ADT2_HUMAN $32.85 \quad 100.0 \% \quad 26$ ADT2 HUMAN $32.85 \quad 100.0 \% \quad 26$ ADT2_HUMAN $32.85 \quad 100.0 \% \quad 26$ ADT2 HUMAN $32.85 \quad 100.0 \% \quad 26$ ADT2_HUMAN $32.85 \quad 100.0 \% \quad 26$ ADT2_HUMAN $32.85 \quad 100.0 \% \quad 26$ ADT2 HUMAN $32.85 \quad 100.0 \% \quad 26$ ADT2_HUMAN $32.85 \quad 100.0 \% \quad 26$ ADT2_HUMAN $32.85 \quad 100.0 \% \quad 26$ ADT2 HUMAN $32.85 \quad 100.0 \% \quad 26$ ADT2_HUMAN $32.85 \quad 100.0 \% \quad 26$ ADT2 HUMAN $32.85 \quad 100.0 \% \quad 26$ ADT2_HUMAN $32.85 \quad 100.0 \% \quad 26$ ADT2_HUMAN $32.85 \quad 100.0 \% \quad 26$ ADT2 HUMAN $32.85 \quad 100.0 \% \quad 26$ ADT2_HUMAN $32.85 \quad 100.0 \% \quad 26$ ADT2_HUMAN $32.85 \quad 100.0 \% \quad 26$ ADT2 HUMAN $32.85 \quad 100.0 \% \quad 26$ ADT2_HUMAN $32.85 \quad 100.0 \% \quad 26$ ADT3 HUMAN $32.87 \quad 100.0 \% \quad 5$ ADT3_HUMAN $32.87 \quad 100.0 \% \quad 5$ ADT3_HUMAN $32.87 \quad 100.0 \% \quad 5$ ADT3 HUMAN $32.87 \quad 100.0 \% \quad 5$ ADT3_HUMAN $32.87 \quad 100.0 \%$ ADT3 HUMAN $32.87 \quad 100.0 \%$ ADT3 HUMAN $32.87 \quad 100.0 \%$ ADT3_HUMAN $32.87 \quad 100.0 \% \quad 5$ ADT3 HUMAN $32.87 \quad 100.0 \% \quad 5$ ADT3_HUMAN $32.87 \quad 100.0 \%$ ADT3_HUMAN $32.87 \quad 100.0 \%$ ADT3 HUMAN $32.87 \quad 100.0 \%$ ADT3_HUMAN $32.87 \quad 100.0 \%$ ADT3 HUMAN $32.87 \quad 100.0 \%$ ADT3_HUMAN $32.87 \quad 100.0 \%$ ADT3_HUMAN $32.87 \quad 100.0 \%$ ADT3 HUMAN $32.87 \quad 100.0 \%$ ADT3_HUMAN $32.87 \quad 100.0 \%$ ADT3 HUMAN $32.87 \quad 100.0 \%$ ADT3_HUMAN $32.87 \quad 100.0 \%$ AFG32_HUMAN $88.59 \quad 100.0 \%$ AFG32 HUMAN $88.59 \quad 100.0 \%$ AFG32_HUMAN $88.59 \quad 100.0 \%$

$0.11 \% 50.0 \%$ LLLQVQHASK

$0.11 \% \quad 50.0 \%$ GIIDCVVR

$0.11 \% \quad 50.0 \%$ GIIDCVVRIPK

$0.11 \% \quad 50.0 \%$ EQGVLSFWR

$0.11 \% \quad 50.0 \%$ QIFLGGVDK

$0.11 \% \quad 50.0 \%$ QIFLGGVDKR

$0.11 \% \quad 50.0 \%$ TRLAADVGK

$0.11 \% \quad 50.0 \%$ AGAEREFR

$0.11 \% 50.0 \%$ GLGDCLVK

$0.11 \% \quad 50.0 \%$ DEGGKAFFK

$0.11 \% \quad 50.0 \%$ GAWSNVLR

$0.02 \% \quad 50.7 \%$ TAVAPIER

$0.02 \% \quad 50.7 \%$ TAVAPIERVK

$0.02 \% \quad 50.7 \%$ LLLQVQHASK

$0.02 \% \quad 50.7 \%$ EQGVLSFWR

$0.02 \% \quad 50.7 \%$ QIFLGGVDK

$0.02 \% \quad 50.7 \%$ TRLAADVGK

$0.02 \% \quad 50.7 \%$ GLGDCLVK

$0.02 \% \quad 50.7 \%$ DEGGKAFFK

$0.02 \% \quad 50.7 \%$ GAWSNVLR
$99.7 \% \quad 42.5$

\begin{tabular}{lllllll}
\hline & 25.0 & 38.3 & 2 & 0 & 0 & 1083.65
\end{tabular}

1363.84

1136.68

931.50

$0.11 \% \quad 50.0 \%$ IPKEQGVLSFWR

$0.11 \% \quad 50.0 \%$ YFPTQALNFAFK

$0.11 \% \quad 50.0 \%$ YFPTQALNFAFKDK

$0.11 \% \quad 50.0 \%$ LAADVGKAGAER

$0.11 \% \quad 50.0 \%$ EFRGLGDCLVK

$0.11 \% \quad 50.0 \%$ GLGDCLVKIYK

$0.11 \% \quad 50.0 \%$ AAYFGIYDTAK

$0.11 \% \quad 50.0 \%$ KGTDIMYTGTLDCWR

$0.11 \% 50.0 \%$ GTDIMYTGTLDCWR

$0.11 \% \quad 50.0 \%$ GTDIMYTGTLDCWRK

$0.11 \% \quad 50.0 \%$ AFFKGAWSNVLR

$0.02 \% \quad 50.7 \%$ DFLAGGIAAAISK

$0.02 \% \quad 50.7 \%$ VKLLLQVQHASK

$0.02 \% \quad 50.7 \%$ IPKEQGVLSFWR

$0.02 \% \quad 50.7 \%$ YFPTQALNFAFK

$0.02 \% \quad 50.7 \%$ YFPTQALNFAFKDK

$0.02 \% \quad 50.7 \%$ YFAGNLASGGAAGATSLCFVYPLDFAR

$0.02 \% \quad 50.7 \%$ LAADVGKSGTER

$0.02 \% \quad 50.7 \%$ EFRGLGDCLVK

$0.02 \% \quad 50.7 \%$ GLGDCLVKITK

$0.02 \% \quad 50.7 \%$ AAYFGVYDTAK

$0.02 \% \quad 50.7 \%$ AFFKGAWSNVLR

$99.7 \% \quad 53.0$

$\begin{array}{lll}45.6 & 13 & 0\end{array}$

$\begin{array}{llll}99.7 \% & 35.3 & 25.0 & 35.3\end{array}$

$\begin{array}{llll}99.7 \% & 30.3 & 25.0 & 27.5\end{array}$

$\begin{array}{lllll}99.7 \% & 53.1 & 25.0 & 43.3 & 4\end{array}$

$99.7 \% \quad 53.0 \quad 25.0 \quad 49.1$

$\begin{array}{llll}95.4 \% & 16.7 & 25.0 & 12.1\end{array}$

$\begin{array}{lllll}99.7 \% & 47.4 & 25.0 & 36.8 & 3\end{array}$

$99.2 \% \quad 31.9 \quad 25.0 \quad 7.7$

$\begin{array}{llll}99.7 \% & 74.5 & 25.0 & 58.3\end{array}$

$95.2 \% \quad 21.4 \quad 25.0 \quad 7.6$

$\begin{array}{llll}99.7 \% & 39.8 & 25.0 & 31.8\end{array}$

$\begin{array}{llll}99.0 \% & 26.5 & 25.0 & 15.8\end{array}$

$99.7 \% \quad 60.0 \quad 25.0-52.0$

$\begin{array}{llll}99.7 \% & 53.0 & 25.0 & 41.9\end{array}$

$99.7 \% \quad 47.0 \quad 25.0 \quad 47.0$

$99.7 \% \quad 26.9 \quad 25.0 \quad 26.9$

$\begin{array}{llll}98.3 \% & 17.2 & 25.0 & 17.2\end{array}$

$\begin{array}{llll}99.7 \% & 31.0 & 25.0 & 24.3\end{array}$

$\begin{array}{llll}99.7 \% & 36.5 & 25.0 & 36.5\end{array}$

$99.0 \% \quad 40.9 \quad 25.0 \quad 26.9 \quad 2$

$\begin{array}{llll}99.7 \% & 51.9 & 25.0 & 45.3\end{array}$

$\begin{array}{llll}99.0 \% & 34.8 & 25.0 & 33.3\end{array}$

$\begin{array}{llll}99.7 \% & 42.5 & 25.0 & 38.3\end{array}$

$\begin{array}{llll}99.7 \% & 54.7 & 25.0 & 44.1\end{array}$

$\begin{array}{lllll}99.7 \% & 53.0 & 25.0 & 45.6 & 13\end{array}$

$\begin{array}{llll}99.7 \% & 35.3 & 25.0 & 35.3\end{array}$

$\begin{array}{llll}99.7 \% & 30.3 & 25.0 & 27.5\end{array}$

$\begin{array}{lllll}99.7 \% & 53.1 & 25.0 & 43.3 & 4\end{array}$

$\begin{array}{llll}99.7 \% & 53.0 & 25.0 & 49.1\end{array}$

$\begin{array}{llll}95.4 \% & 16.7 & 25.0 & 12.1\end{array}$

$\begin{array}{llll}99.7 \% & 68.8 & 25.0 & 68.8\end{array}$

$\begin{array}{llll}99.2 \% & 31.9 & 25.0 & 7.7\end{array}$

$\begin{array}{lllll}99.7 \% & 45.2 & 25.0 & 38.0 & 2\end{array}$

$99.7 \% \quad 39.8 \quad 25.0 \quad 31.8$

$\begin{array}{llll}99.0 \% & 26.5 & 25.0 & 15.8\end{array}$

$\begin{array}{llll}99.7 \% & 38.8 & 25.0 & 33.1\end{array}$

$\begin{array}{llll}99.7 \% & 49.2 & 25.0 & 49.2\end{array}$

$\begin{array}{llll}99.7 \% & 31.0 & 25.0 & 24.3\end{array}$

$\begin{array}{llll}99.7 \% & 36.5 & 25.0 & 36.5\end{array}$

$\begin{array}{llll}99.0 \% & 40.9 & 25.0 & 26.9\end{array}$

$\begin{array}{lllllll}0.01 \% & 7.8 \% & \text { TGRGMGGLFSVGETTAK } & 99.4 \% & 27.7 & 25.0 & 27.7\end{array}$

$0.01 \% \quad 7.8 \%$ GMGGLFSVGETTAK

25.0

$\begin{array}{lllllll}0.01 \% & 7.8 \% & \text { GAILTGPPGTGKTLLAK } & 99.7 \% & 40.5 & 25.0 & 40.5\end{array}$

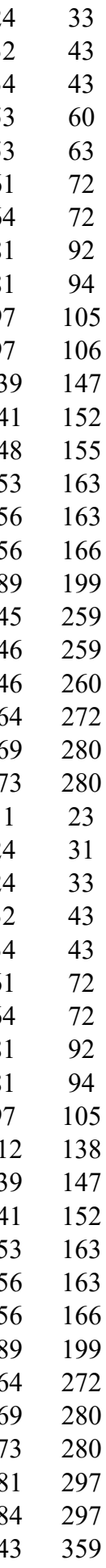


AFG3-like protein $2 \mathrm{GN}=\mathrm{AFG} 3 \mathrm{~L} 2$ AFG3-like protein $2 \mathrm{GN}=\mathrm{AFG} 3 \mathrm{~L} 2$ AFG3-like protein $2 \mathrm{GN}=\mathrm{AFG} 3 \mathrm{~L} 2$

A

A-kinase anchor protein 8-like GN=AKAP8L AKP8L_HUMAN $71.65 \quad 100.0 \%$

Aladin GN=AAAS

Aladin GN=AAAS

AAAS_HUMAN $59.57 \quad 100.0 \%$

AAAS HUMAN $59.57 \quad 100.0 \%$

Alanine--tRNA ligase, mitochondrial GN=AARS2 SYAM_HUMAN $107.34 \quad 100.0 \%$

Alanine--tRNA ligase, mitochondrial GN=AARS2 SYAM HUMAN $107.34 \quad 100.0 \%$

Alanine--tRNA ligase, mitochondrial GN=AARS2 SYAM_HUMAN $107.34 \quad 100.0 \%$

Aldehyde dehydrogenase family 16 member A1 GN=ALDH16A1 A16A1_HUMAN $85.13 \quad 100.0 \%$

Aldehyde dehydrogenase family 16 member A1 GN=ALDH16A1 A16A1 HUMAN 85.13 100.0\%

Aldehyde dehydrogenase family 16 member Al GN=ALDH16A1 A16A1_HUMAN $85.13 \quad 100.0 \%$

Aldehyde dehydrogenase family 16 member Al GN=ALDH16A1 A16A1_HUMAN $85.13 \quad 100.0 \%$

Aldehyde dehydrogenase family 16 member A1 GN=ALDH16A1 A16A1_HUMAN $85.13 \quad 100.0 \%$

Aldehyde dehydrogenase $\mathrm{X}$, mitochondrial GN=ALDH1B1 AL1B1_HUMAN $57.21 \quad 100.0 \%$

Aldehyde dehydrogenase $X$, mitochondrial GN=ALDH1B1 AL1B1 HUMAN $57.21 \quad 100.0 \%$

Alpha-aminoadipic semialdehyde synthase, mitochondrial GN=AASS AASS_HUMAN $102.14 \quad 100.0 \%$

Alpha-centractin GN=ACTR $1 \mathrm{~A}$

Alpha-centractin $\mathrm{GN}=\mathrm{ACTR} 1 \mathrm{~A}$

Alpha-centractin GN=ACTR1A

Alpha-centractin GN=ACTR1A

Alpha-centractin GN=ACTR1A

Alpha-centractin GN=ACTR1A

Alpha-centractin GN=ACTR1A

Alpha-enolase $\mathrm{GN}=\mathrm{ENO}$

Alpha-enolase $\mathrm{GN}=\mathrm{ENO}$

Alpha-enolase GN=ENO

Alpha-internexin $\mathrm{GN}=\mathrm{INA}$

Alpha-internexin GN=INA

Alpha-internexin GN=INA

Alpha-internexin GN=INA

Alpha-internexin GN=INA

Alpha-internexin $\mathrm{GN}=\mathrm{INA}$

Alpha-internexin GN=INA

Alpha-internexin GN=INA

Alpha-internexin GN=INA

UMAN $102.14 \quad 100.0 \%$

ACTZ HUMAN $42.62 \quad 100.0 \%$

ACTZ_HUMAN $42.62 \quad 100.0 \%$

ACTZ_HUMAN $42.62 \quad 100.0 \%$

ACTZ_HUMAN $42.62 \quad 100.0 \%$

ACTZ_HUMAN $42.62 \quad 100.0 \%$

ACTZ HUMAN $42.62 \quad 100.0 \%$

ACTZ_HUMAN $42.62 \quad 100.0 \%$

ENOA_HUMAN $47.17 \quad 100.0 \%$

ENOA HUMAN $47.17 \quad 100.0 \%$

ENOA_HUMAN $47.17 \quad 100.0 \%$

AINX HUMAN $55.39 \quad 100.0 \%$

AINX_HUMAN $55.39 \quad 100.0 \%$

AINX_HUMAN $55.39 \quad 100.0 \%$

AINX HUMAN $55.39 \quad 100.0 \%$

AINX_HUMAN $55.39 \quad 100.0 \%$

AINX_HUMAN $55.39 \quad 100.0 \%$

AINX_HUMAN $55.39 \quad 100.0 \%$

AINX_HUMAN $55.39 \quad 100.0 \%$

AINX HUMAN $55.39 \quad 100.0 \%$

AIMP1_HUMAN $34.35 \quad 100.0 \%$

AIMP1_HUMAN $34.35 \quad 100.0 \%$

$100.0 \%$

$100.0 \%$

$100.0 \%$

$100.0 \%$

$100.0 \%$

$100.0 \%$
$0.01 \% \quad 7.8 \%$ VRDLFALAR

$0.01 \% \quad 7.8 \%$ VSEEIFFGR

$0.01 \% \quad 7.8 \%$ VGQISFDLPR

$0.00 \% \quad 3.3 \%$ SGRPMASGYGR

$0.00 \% \quad 3.3 \% \quad$ SILNNKLISK

$0.01 \% \quad 4.2 \% \quad$ ILATTPSAVFR

$0.01 \% \quad 4.2 \%$ VQDGKPVILLFR

$0.01 \% \quad 3.6 \%$ LVPSASVRPR

$0.01 \% \quad 3.6 \%$ AGQEDVLFPVAR

$0.01 \% \quad 3.6 \%$ LLAVTGEQAQQAR

$0.01 \% \quad 7.6 \%$ LAEVIQKHQR

$0.01 \% \quad 7.6 \%$ VAFCGAPEEGR

$0.01 \% \quad 7.6 \%$ GLDGAVDMGAR

$0.01 \% \quad 7.6 \%$ GAAACDLVQR

$0.01 \% \quad 7.6 \%$ VQAQGHTLQVAGLRGPVLR

$0.00 \% \quad 4.5 \% \quad$ LAPALATGNTVVMK

$0.00 \% \quad 4.5 \%$ TVTIKVPQK

$0.00 \% \quad 3.0 \%$ SIGPLTFVFTGTGNVSK

$0.00 \% \quad 3.0 \%$ TVGLPTAMAAK

$0.03 \% \quad 25.0 \%$ AGFAGDQIPK

$0.03 \% \quad 25.0 \%$ YCFPNYVGRPK

$9 \quad 0.03 \% \quad 25.0 \%$ VMAGALEGDIFIGPK

$0.03 \% \quad 25.0 \%$ IDIAGRDVSR

$19 \quad 0.03 \% \quad 25.0 \%$ EGYDFHSSSEFEIVK

$19 \quad 0.03 \% \quad 25.0 \%$ AQYYLPDGSTIEIGPSR

$19 \quad 0.03 \% \quad 25.0 \%$ TLFSNIVLSGGSTLFK

$11 \quad 0.02 \% \quad 9.9 \%$ AVEHINKTIAPALVSK

$11 \quad 0.02 \% \quad 9.9 \%$ AGAVEKGVPLYR

$11 \quad 0.02 \% \quad 9.9 \%$ VNQIGSVTESLQACK

$10 \quad 0.01 \% \quad 21.4 \%$ LSGAGGAGGFR

$10 \quad 0.01 \% \quad 21.4 \%$ ALEAELAALR

$10 \quad 0.01 \% \quad 21.4 \%$ AQLEEASSAR

$10 \quad 0.01 \% \quad 21.4 \%$ SQALLERDGLAEEVQR

$10 \quad 0.01 \% \quad 21.4 \%$ DVDGATLAR

$10 \quad 0.01 \% \quad 21.4 \%$ FANLNEQAAR

$10 \quad 0.01 \% \quad 21.4 \%$ TIEIEGLRGANESLER

$10 \quad 0.01 \% \quad 21.4 \%$ HLREYQDLLNVK

$10 \quad 0.01 \% \quad 21.4 \%$ SNIEETTISSQKI

$12 \quad 0.02 \% \quad 17.6 \%$ AILQATLREEK

$12 \quad 0.02 \% \quad 17.6 \%$ KQQSIAGSADSKPIDVSR

$0.02 \% \quad 17.6 \%$ IGCIITAR

$99.7 \% \quad 64.0$

$99.7 \% \quad 50.5$

$98.7 \% \quad 17.6$

$99.0 \% \quad 28.2$

$99.7 \% \quad 39.3$

$99.7 \% \quad 40.1$

$99.3 \% \quad 20.3$

$99.7 \% \quad 47.6$

$99.7 \% \quad 59.5$

$97.7 \% \quad 18.3$

$99.7 \% \quad 38.5$

$99.7 \% \quad 48.1$

$99.7 \% \quad 44.3$

$99.6 \% \quad 21.6$

$99.7 \% \quad 55.6$

$99.7 \% \quad 31.1$

$99.7 \% 36.6$

$99.7 \% \quad 30.3$

$99.7 \% \quad 52.2$

$99.7 \% \quad 40.9$

$99.1 \% \quad 57.9$

$99.7 \% \quad 34.0$

$99.7 \% \quad 36.2$

$99.7 \% \quad 44.2$

$99.7 \% \quad 84.2$

$99.7 \% \quad 35.9$

$99.7 \% \quad 37.9$

$99.1 \% \quad 50.7$

$99.7 \% \quad 43.1$

$99.7 \% \quad 47.0$

$99.7 \% \quad 44.0$

$99.7 \% \quad 33.7$

$99.7 \% \quad 29.4$

$99.7 \% \quad 56.8$

$97.3 \% 18.2$

$99.7 \% \quad 25.6$

$99.7 \% \quad 50.7$

$99.7 \% \quad 35.4$

$99.7 \% \quad 32.6$

$99.0 \% \quad 37.5$

$0.02 \% \quad 17.6 \%$ TVVSGLVNHVPLEQMQNR

$10 \quad 0.01 \% \quad 18.8 \%$ LYELKAAVDGLSK

$10 \quad 0.01 \% \quad 18.8 \%$ FSIQTMCPIEGEGNIAR

$10 \quad 0.01 \% \quad 18.8 \%$ FLFSLFGQK

$10 \quad 0.01 \% \quad 18.8 \%$ SMNSALGK

$0.01 \% \quad 18.8 \%$ SCENLAPFNTALK
$99.7 \% \quad 50.7$

$99.7 \% \quad 44.4$

$98.7 \% \quad 21.4$

$99.0 \% \quad 23.9$

$99.7 \% \quad 47.0$
1060.63

1083.55

1131.62

1138.54

1129.69

1175.68

1384.83

1081.65

1301.68

1384.75

1221.71

1192.54

1061.50

1060.52

2000.15

1385.78

1013.64

1724.92

1059.59

1003.52

1400.68

1517.80

1101.60

1773.80

1866.92

1683.93

1690.99

1259.71

1633.82

949.49

1056.60

1061.52

1813.94

917.47

1133.57

1786.93

1527.83

1449.74

1271.73

1886.99

903.51

2037.05

1406.79

1922.91

1086.60

807.40

1464.72

$\begin{array}{cc}89 & 397 \\ 33 & 641 \\ 70 & 679 \\ 89 & 199 \\ 28 & 537 \\ 02 & 312 \\ 21 & 432 \\ 8 & 67 \\ 81 & 592 \\ 78 & 790 \\ 08 & 117 \\ 46 & 256 \\ 35 & 345 \\ 46 & 355 \\ 38 & 656 \\ 96 & 209 \\ 07 & 515 \\ 13 & 229 \\ 73 & 883 \\ 3 & 32 \\ 3 & 43 \\ 7 & 61 \\ 83 & 192 \\ 01 & 215 \\ 39 & 255 \\ 93 & 308 \\ 5 & 80 \\ 21 & 132 \\ 44 & 358 \\ 9 & 39 \\ 21 & 130 \\ 52 & 161 \\ 62 & 177 \\ 02 & 210 \\ 91 & 300 \\ 23 & 338 \\ 75 & 386 \\ 87 & 499 \\ 6 & 46 \\ 37 & 154 \\ 59 & 166 \\ 88 & 205 \\ 6 & 78 \\ 99 & 215 \\ 16 & 224 \\ 58 & 265 \\ 05 & 317 \\ & \end{array}$

Page 21 of Table S-1-1 
Anaphase-promoting complex subunit $1 \mathrm{GN}=\mathrm{ANAPC} 1$ APC1 HUMAN $216.50 \quad 100.0 \%$ Anaphase-promoting complex subunit $1 \mathrm{GN}=$ ANAPC1 APC1_HUMAN $216.50 \quad 100.0 \%$ Anaphase-promoting complex subunit $1 \mathrm{GN}=$ ANAPC1 APC1_HUMAN $216.50 \quad 100.0 \%$ Anaphase-promoting complex subunit $1 \mathrm{GN}=\mathrm{ANAPC} 1 \mathrm{APC1}$ HUMAN $216.50 \quad 100.0 \%$ Anaphase-promoting complex subunit $1 \mathrm{GN}=\mathrm{ANAPC} 1$ APC1_HUMAN $216.50 \quad 100.0 \%$ Anaphase-promoting complex subunit $1 \mathrm{GN}=$ ANAPC1 APC1_HUMAN $216.50 \quad 100.0 \%$ Anaphase-promoting complex subunit $1 \mathrm{GN}=$ ANAPC1 APC1_HUMAN $216.50 \quad 100.0 \%$ Anaphase-promoting complex subunit $7 \mathrm{GN}=\mathrm{ANAPC} 7 \mathrm{APC7}$ _HUMAN $66.86 \quad 100.0 \%$ Anaphase-promoting complex subunit $7 \mathrm{GN}=\mathrm{ANAPC} 7 \mathrm{APC} 7 \mathrm{HUMAN} 66.86 \quad 100.0 \%$ Anaphase-promoting complex subunit $7 \mathrm{GN}=$ ANAPC7 APC7_HUMAN $66.86 \quad 100.0 \%$ Annexin A6 GN=ANXA6

Annexin A6 GN=ANXA ANXA6_HUMAN $75.88 \quad 100.0 \%$ ANXA6_HUMAN $75.88 \quad 100.0 \%$ AP-1 complex subunit gamma-1 GN=AP1G1 AP1G1_HUMAN $91.35 \quad 100.0 \%$ AP-1 complex subunit gamma-1 GN=AP1G1 AP1G1_HUMAN $91.35 \quad 100.0 \%$ AP-1 complex subunit gamma-1 GN=AP1G1 AP1G1_HUMAN $91.35100 .0 \%$ AP-1 complex subunit mu-1 GN=AP1M1 AP1M1_HUMAN $48.59 \quad 100.0 \%$ AP-1 complex subunit mu-1 GN=AP1M1 AP1M1 HUMAN $48.59 \quad 100.0 \%$ AP-1 complex subunit mu-1 GN=AP1M1 AP1M1_HUMAN $48.59 \quad 100.0 \%$ AP-1 complex subunit mu-1 GN=AP1M1 AP1M1_HUMAN $48.59 \quad 100.0 \%$ AP-1 complex subunit mu-1 GN=AP1M1 AP1M1 HUMAN $48.59 \quad 100.0 \%$ AP-1 complex subunit mu-1 GN=AP1M1 AP1M1_HUMAN $48.59 \quad 100.0 \%$ AP-1 complex subunit mu-1 GN=AP1M1 AP1M1 HUMAN $48.59 \quad 100.0 \%$ AP-1 complex subunit mu-1 GN=AP1M1 AP1M1_HUMAN $48.59 \quad 100.0 \%$ AP-2 complex subunit alpha-1 GN=AP2A1 AP2A1_HUMAN $107.55100 .0 \%$ AP-2 complex subunit alpha-1 GN=AP2A1 AP2A1_HUMAN $107.55100 .0 \%$ AP-2 complex subunit alpha-1 GN=AP2A1 AP2A1_HUMAN $107.55 \quad 100.0 \%$ AP-2 complex subunit alpha-1 GN=AP2A1 AP2A1_HUMAN $107.55100 .0 \%$ AP-2 complex subunit alpha-1 GN=AP2A1 AP2A1_HUMAN $107.55100 .0 \%$ AP-2 complex subunit alpha-2 GN=AP2A2 AP2A2_HUMAN $103.96100 .0 \%$ AP-2 complex subunit alpha-2 GN=AP2A2 AP2A2 HUMAN $103.96 \quad 100.0 \%$ AP-2 complex subunit alpha-2 GN=AP2A2 AP2A2_HUMAN $103.96 \quad 100.0 \%$ AP-2 complex subunit mu GN=AP2M1 AP2M1_HUMAN $49.66 \quad 100.0 \%$ AP-2 complex subunit mu GN=AP2M1 AP2M1_HUMAN $49.66 \quad 100.0 \%$ AP-3 complex subunit beta-1 GN=AP3B1 AP3B1_HUMAN $121.32 \quad 100.0 \%$ AP-3 complex subunit beta-1 GN=AP3B1 AP3B1_HUMAN $121.32 \quad 100.0 \%$ AP-3 complex subunit mu-1 GN=AP3M1 AP3M1_HUMAN $46.94 \quad 100.0 \%$ AP-3 complex subunit mu-1 GN=AP3M1 AP3M1_HUMAN $46.94 \quad 100.0 \%$ AP-3 complex subunit mu-1 GN=AP3M1 AP3M1_HUMAN $46.94 \quad 100.0 \%$ AP-3 complex subunit mu-1 GN=AP3M1 AP3M1_HUMAN $46.94 \quad 100.0 \%$ Apoptosis-inducing factor 1, mitochondrial GN=AIFM1 AIFM1_HUMAN $66.90 \quad 100.0 \%$ Apoptosis-inducing factor 1, mitochondrial GN=AIFM1 AIFM1_HUMAN $66.90 \quad 100.0 \%$ Apoptosis-inducing factor 1, mitochondrial GN=AIFM1 AIFM1_HUMAN $66.90 \quad 100.0 \%$ Apoptosis-inducing factor 1, mitochondrial GN=AIFM1 AIFM1 HUMAN $66.90 \quad 100.0 \%$ Apoptosis-inducing factor 1, mitochondrial GN=AIFM1 AIFM1_HUMAN $66.90 \quad 100.0 \%$ Apoptosis-inducing factor 1, mitochondrial GN=AIFM1 AIFM1_HUMAN $66.90 \quad 100.0 \%$ Apoptosis-inducing factor 1, mitochondrial GN=AIFM1 AIFM1 HUMAN $66.90 \quad 100.0 \%$ Apoptosis-inducing factor 1, mitochondrial GN=AIFM1 AIFM1_HUMAN $66.90 \quad 100.0 \%$
11

0.5\% STSSPSLHSR

$0.02 \% \quad 4.5 \% \quad$ SPSISNMAALSR

$0.02 \% \quad 4.5 \%$ NFDFEGSLSPVIAPK

$0.02 \% \quad 4.5 \%$ LLQSAHPVR

$0.02 \% \quad 4.5 \%$ HLYVLAAEPR

$0.02 \% \quad 4.5 \% \quad$ LVLEFFSSR

$0.01 \% \quad 6.5 \%$ GMDVYGYLLAR

$0.01 \% \quad 6.5 \%$ AIQLNSNSVQALLLK

$0.01 \% \quad 6.5 \% \quad$ NALANQSDCVLHR

$0.00 \% \quad 3.4 \%$ NKPLFFADKLYK

$0.00 \% \quad 3.4 \%$ GAGTDEKTLTR

$0.01 \% \quad 2.7 \%$ SSFREEDNTYR

$0.01 \% \quad 2.7 \%$ KAALCAVHVIR

$0.01 \% \quad 2.7 \%$ AALCAVHVIR

$0.02 \% \quad 21.5 \%$ VFLSGMPELR

$0.02 \% \quad 21.5 \%$ LGLNDKVLFDNTGR

$0.02 \% \quad 21.5 \%$ SVELEDVKFHQCVR

$0.02 \% \quad 21.5 \%$ STANNVEIHIPVPNDADSPK

$0.02 \% \quad 21.5 \%$ FKTTVGSVK

$0.02 \% \quad 21.5 \%$ SFPGGKEYLMR

$0.02 \% \quad 21.5 \%$ YITQNGDYQLR

$0.02 \% \quad 21.5 \%$ YITQNGDYQLRTQ

$0.00 \% \quad 6.6 \%$ GLAVFISDIRNCK

$0.00 \% \quad 6.6 \%$ EMGEAFAADIPR

$0.00 \% \quad 6.6 \%$ LVECLETVLNK

$0.00 \% \quad 6.6 \%$ VGGYILGEFGNLIAGDPR

$0.00 \% \quad 6.6 \%$ HLCELLAQQF

$0.01 \% \quad 4.8 \%$ GLAVFISDIRNCK

$0.01 \% \quad 4.8 \%$ VGGYILGEFGNLIAGDPR

$0.01 \% \quad 4.8 \%$ QLSNPQQEVQNIFK

$0.01 \% \quad 3.7 \% \quad$ LSKFDSER

$0.01 \% \quad 3.7 \%$ SGIYETRC

$0.00 \% \quad 1.9 \%$ NASELFPAVVK

$0.00 \% \quad 1.9 \%$ ALKDPNQLIR

$0.01 \% \quad 12.4 \%$ SVVSQSVCDYFFEAQEK

$0.01 \% \quad 12.4 \%$ ELIKPPTILR

$0.01 \% \quad 12.4 \%$ LLDDVSFHPCIR

$0.01 \% \quad 12.4 \%$ TIEGITVTVHMPK

$0.03 \% \quad 20.2 \%$ ISGLGLTPEQK

$0.03 \% \quad 20.2 \%$ ISGLGLTPEQKQK

$0.03 \% \quad 20.2 \%$ VLIVSEDPELPYMRPPLSK

$0.03 \% \quad 20.2 \%$ CLIATGGTPR

$0.03 \% \quad 20.2 \%$ SLSAIDRAGAEVK

$0.03 \% \quad 20.2 \%$ ALGTEVIQLFPEK

$0.03 \% \quad 20.2 \%$ ALGTEVIQLFPEKGNMGK $99.7 \% \quad 51.1$

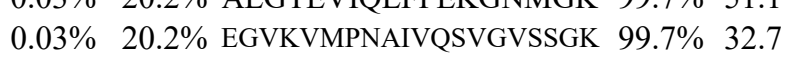

$99.7 \% \quad 34.8$ $99.7 \% \quad 37.3$

$99.7 \% \quad 65.3$

$99.7 \% \quad 47.1$

$99.3 \% \quad 20.7$

$99.7 \% \quad 33.8$

$99.7 \% \quad 34.6$

$99.7 \% \quad 51.2$

$99.7 \% \quad 55.8$

$99.7 \% \quad 44.3$

$96.2 \% \quad 16.5$

$99.7 \% 57$.

$99.4 \% \quad 20.3$

$99.1 \% \quad 18.6$

$99.7 \% \quad 68.3$

$99.7 \% \quad 28.2$

$99.7 \% 28.7$

$\begin{array}{lll}99.7 \% & 42.6\end{array}$

$95.9 \% \quad 14.4$

$97.6 \% 21.1$

$99.7 \% 28.3$

$99.7 \% \quad 52.8$

$99.7 \% \quad 30.2$

$99.7 \% \quad 38.4$

$99.7 \% \quad 40.0$

$99.7 \% \quad 64.5$

$99.7 \% \quad 30.2$

$99.7 \% \quad 64.5$

$99.7 \% \quad 44.6$

$99.0 \% \quad 29.8$

$99.3 \% \quad 23.8$

$\begin{array}{lll}95.8 \% & 17.8\end{array}$

$99.7 \% 39.4$

$\begin{array}{lll}99.5 \% & 20.7\end{array}$

$97.1 \%-19.6$

$99.7 \% \quad 38.2$

$99.7 \% \quad 56.6$

$99.7 \% \quad 41.6$

$99.7 \% \quad 29.7$

$99.7 \% \quad 60$.

$99.7 \% \quad 56.9$

$\begin{array}{ll}99.7 \% & 38.6\end{array}$

$13 \quad 23$

$13 \quad 23$

$\begin{array}{ccc}2288.13 & 285 & 306 \\ 1058.52 & 331 & 340 \\ 1233.63 & 341 & 352 \\ 1620.83 & 680 & 694 \\ 1020.59 & 1040 & 1048 \\ 1168.65 & 1608 & 1617 \\ 1097.60 & 1816 & 1824 \\ 1257.63 & 307 & 317 \\ 1611.94 & 365 & 379 \\ 1497.72 & 501 & 513 \\ 1483.83 & 599 & 610 \\ 1148.59 & 614 & 624 \\ 1403.62 & 36 & 46 \\ 1237.72 & 156 & 166 \\ 1109.62 & 157 & 166 \\ 1164.61 & 202 & 211 \\ 1561.83 & 212 & 225 \\ 1745.86 & 230 & 243 \\ 2118.05 & 305 & 324 \\ 966.56 & 325 & 333 \\ 1284.64 & 347 & 357 \\ 1370.67 & 411 & 421 \\ 1599.78 & 411 & 423 \\ 1492.79 & 12 & 24 \\ 1306.61 & 142 & 153 \\ 1317.71 & 280 & 290 \\ 1847.97 & 499 & 516 \\ 1258.63 & 968 & 977 \\ 1492.79 & 12 & 24 \\ 1847.97 & 498 & 515 \\ 1672.87 & 843 & 856 \\ 981.50 & 254 & 261 \\ 985.44 & 428 & 435 \\ 1174.65 & 75 & 85 \\ 1167.68 & 123 & 132 \\ 2022.91 & 22 & 38 \\ 1179.75 & 132 & 141 \\ 1471.74 & 227 & 238 \\ 1425.78 & 304 & 316 \\ 1142.64 & 99 & 109 \\ 1398.80 & 99 & 111 \\ 2183.18 & 159 & 177 \\ 1045.55 & 256 & 265 \\ 1316.72 & 266 & 278 \\ 1444.80 & 325 & 337 \\ 1948.02 & 325 & 342 \\ 2002.06 & 359 & 378 \\ & & \end{array}$

Page 22 of Table S-1-1 

Apoptosis-inducing factor 1, mitochondrial GN=AIFM1 AIFM1_HUMAN $66.90 \quad 100.0 \%$ G Apoptotic chromatin condensation inducer in the nucleus $\mathrm{GN}=\mathrm{ACIN} 1$ ACINU_HUMAN $151.86 \quad 100.0 \%$ Apoptotic chromatin condensation inducer in the nucleus $\mathrm{GN}=\mathrm{ACIN} 1 \quad \mathrm{ACINU} \_$HUMAN $151.86 \quad 100.0 \%$ Apoptotic chromatin condensation inducer in the nucleus $\mathrm{GN}=\mathrm{ACIN} 1 \quad \mathrm{ACINU} \_$HUMAN $151.86 \quad 100.0 \%$ Apoptotic chromatin condensation inducer in the nucleus GN=ACIN1 ACINU_HUMAN $151.86 \quad 100.0 \%$ Apoptotic chromatin condensation inducer in the nucleus GN=ACIN1 ACINU HUMAN $151.86 \quad 100.0 \%$ Apoptotic chromatin condensation inducer in the nucleus GN=ACIN1 ACINU_HUMAN $151.86 \quad 100.0 \%$ Apoptotic chromatin condensation inducer in the nucleus GN=ACIN1 ACINU_HUMAN $151.86 \quad 100.0 \%$ Apoptotic chromatin condenstion inducer in the nucleus $\mathrm{GN}=\mathrm{ACIN} 1 \quad \mathrm{ACINU}$ HUMAN $151.86 \quad 100.0^{\circ}$ Apoptotic chromatin condensation inducer in the nucleus GN=ACIN1 ACINU_HUMAN $151.86 \quad 100.0 \%$ Apoptotic chromatin condensation inducer in the nucleus $\mathrm{GN}=\mathrm{ACIN} 1 \quad \mathrm{ACINU} \_$HUMAN $151.86 \quad 100.0 \%$ Apoptotic chromatin condensation inducer in the nucleus $\mathrm{GN}=\mathrm{ACIN} 1$ ACINU_HUMAN $151.86 \quad 100.0 \%$ Apoptotic chromatin condensation inducer in the nucleus GN=ACIN1 ACINU_HUMAN $151.86 \quad 100.0 \%$ Apoptotic chromatin condensation inducer in the nucleus GN=ACIN1 ACINU HUMAN $151.86 \quad 100.0 \%$ Apoptotic chromatin condensation inducer in the nucleus $\mathrm{GN}=\mathrm{ACIN} 1$ ACINU_HUMAN $151.86 \quad 100.0 \%$ Apoptotic chromatin condensation inducer in the nucleus GN=ACIN1 ACINU_HUMAN $151.86 \quad 100.0 \%$ Apoptotic chromatin condenstion inder in the nucleus GN=ACIN1 ACINU_HUMAN $151.86 \quad 100.0 \%$ Apoptotic chromatin condensation inducer in the nucleus GN=ACIN1 ACINU_HUMAN $151.86 \quad 100.0 \%$ Apoptotic chromatin condensation inducer in the nucleus GN=ACIN 1 ACINU_HUMAN $151.86 \quad 100.0 \%$ Arginine--tRNA ligase, cytoplasmic GN=RARS SYRC_HUMAN $75.38 \quad 100.0 \%$ Arginine--tRNA ligase, cytoplasmic GN=RARS SYRC_HUMAN $75.38 \quad 100.0 \%$ Arginine--tRNA ligase, cytoplasmic GN=RARS SYRC HUMAN $75.38 \quad 100.0^{\circ}$ Arginine--tRNA ligase, cytoplasmic GN=RARS SYRC_HUMAN $75.38 \quad 100.0 \%$ Arginine--tRNA ligase, cytoplasmic GN=RARS SYRC_HUMAN $75.38 \quad 100.0 \%$ Arginine--tRNA ligase, cytoplasmic GN=RARS SYRC_HUMAN $75.38 \quad 100.0 \%$ Arginine--tRNA ligase, cytoplasmic GN=RARS SYRC_HUMAN $75.38 \quad 100.0 \%$ Arginine--tRNA ligase, cytoplasmic GN=RARS SYRC HUMAN $75.38100 .0 \%$ Arginine--tRNA ligase, cytoplasmic GN=RARS SYRC_HUMAN $75.38 \quad 100.0 \%$ Arginine--tRNA ligase, cytoplasmic GN=RARS SYRC_HUMAN $75.38 \quad 100.0 \%$ Arginine--tRNA ligase, cytoplasmic GN=RARS SYRC HUMAN $75.38 \quad 100.0^{\circ}$ Arginine--tRNA ligase, cytoplasmic GN=RARS SYRC_HUMAN $75.38 \quad 100.0 \%$ Arginine--tRNA ligase, cytoplasmic GN=RARS SYRC_HUMAN $75.38 \quad 100.0 \%$ Arginine--tRNA ligase, cytoplasmic GN=RARS SYRC_HUMAN $75.38 \quad 100.0 \%$ Arginine--tRNA ligase, cytoplasmic GN=RARS SYRC_HUMAN $75.38 \quad 100.0 \%$ Asparagine synthetase [glutamine-hydrolyzing] GN=ASNS ASNS HUMAN $64.37 \quad 100.0 \%$ Asparagine synthetase [glutamine-hydrolyzing] GN=ASNS ASNS_HUMAN $64.37 \quad 100.0 \%$ Asparagine synthetase [glutamine-hydrolyzing] GN=ASNS ASNS_HUMAN $64.37 \quad 100.0 \%$ Asparagine synthetase [glutamine-hydrolyzing] GN=ASNS ASNS HUMAN $64.37 \quad 100.0 \%$ Asparagine synthetase [glutamine-hydrolyzing] GN=ASNS ASNS_HUMAN $64.37 \quad 100.0 \%$ Aspartate aminotransferase, mitochondrial GN=GOT2 AATM HUMAN $47.52 \quad 100.0 \%$ Aspartate aminotransferase, mitochondrial GN=GOT2 AATM_HUMAN $47.52 \quad 100.0 \%$ Aspartate aminotransferase, mitochondrial GN=GOT2 AATM_HUMAN 47.52 $100.0 \%$ Aspartate aminotransferase, mitochondrial GN=GOT2 AATM_HUMAN $47.52 \quad 100.0 \%$ Aspartate--tRNA ligase, cytoplasmic GN=DARS SYDC_HUMAN $57.14 \quad 100.0 \%$

20

20
20

19

19

19
19

19

19

19

19

19
19

19

19

19

19

19

19

19

15

15

5

5

521

21

5

5

5

15
15
15

15

2

$15 \quad 21$

152

$15 \quad 21$

$\begin{array}{ll}5 & 21 \\ 5 & 21\end{array}$

(5)

5

5
5

5
5
5

5
4
4

4
4
4
4

$\begin{array}{ll}4 & 5 \\ 4 & 5 \\ 2 & 5\end{array}$

$0.03 \% \quad 20.2 \%$ SATEQSGTGIR

$\begin{array}{ll}99.7 \% & 69.2\end{array}$

$99.7 \% \quad 55.2$

$99.7 \% \quad 46.2$

$99.7 \% \quad 31.7$

$99.7 \% \quad 39.9$

$99.7 \% \quad 46.7$

14.8\% SQEQEVLER

$99.7 \% \quad 51.7$

$95.1 \% \quad 13.8$

$99.7 \% \quad 55.2$

$99.7 \% \quad 28.4$

$99.7 \% \quad 45.6$

$0.07 \% \quad 14.8 \%$ KISVVSATK

$0.07 \% \quad 14.8 \%$ GVPAGNSDTEGGQPGR

$0.07 \% \quad 14.8 \%$ WGASTATTQK

$0.07 \% \quad 14.8 \%$ WGASTATTQKKPSISITTESLI

$0.07 \% \quad 14.8 \%$ KPSISITTESLK

$0.07 \% \quad 14.8 \%$ VTLGDTLTR

$0.07 \% \quad 14.8 \%$ VTLGDTLTRR

$0.07 \% \quad 14.8 \%$ SGVSITIDDPVR

$99.7 \% \quad 32.9$

$99.7 \% \quad 43.4$

$99.7 \% \quad 32.5$

$99.7 \% \quad 26.4$

$99.7 \% \quad 57.9$

$0.07 \% \quad 14.8 \%$ SHCFVTYSTVEEAVATR

$0.07 \% \quad 14.8 \%$ LLDDLFRK

$0.05 \% \quad 27.3 \%$ LLQQEEEIK

$0.05 \% \quad 27.3 \%$ NMINIISR

$99.0 \% \quad 25.8$

$97.3 \% 19.9$

$99.0 \% \quad 27.6$

$0.05 \% \quad 27.3 \%$ AAYPDLENPPLLVTPSQQAK $\quad 99.7 \% \quad 54.1$

$0.05 \% \quad 27.3 \%$ FGDYQCNSAMGISQMLK

$0.05 \% \quad 27.3 \%$ EIAENITK

$0.05 \% \quad 27.3 \%$ STIIGESISR

$0.05 \% \quad 27.3 \%$ LFEFAGYDVLR

$0.05 \% \quad 27.3 \%$ AYQCVVLLQGK

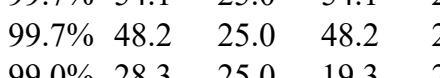

$\begin{array}{lllll}99.0 \% & 28.3 & 25.0 & 19.3 & 2\end{array}$

$\begin{array}{llll}99.7 \% & 45.6 & 25.0 & 36.6\end{array}$

$99.7 \% \quad 47.3 \quad 25.0 \quad 44.2$

$99.0 \% \quad 28.0 \quad 25.0 \quad 14.1$

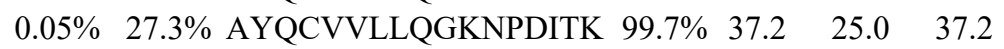

$0.05 \% \quad 27.3 \%$ IVFVPGCSIPLTIVK

$99.7 \% \quad 41.4$

$0.05 \% \quad 27.3 \%$ SDGGYTYDTSDLAAIKQR $\quad 99.7 \% \quad 37.1$

$0.05 \% \quad 27.3 \%$ LMDLLGEGLKR

$0.05 \% \quad 27.3 \%$ LANIDEEMLQK

$0.05 \% \quad 27.3 \%$ MLLCEAVAAVMAK

$0.05 \% \quad 27.3 \%$ GFDILGIKPVQR

$0.01 \% \quad 10.7 \%$ LAVVDPLFGMQPIR

$0.01 \% \quad 10.7 \%$ DTYGVRPLFK

$0.01 \% \quad 10.7 \%$ AMTEDGFLAVCSEAK

$0.01 \% \quad 10.7 \%$ EAFSDGITSVK

$0.01 \% \quad 10.7 \%$ WINATDPSAR

$0.01 \% \quad 11.2 \%$ ASAELALGENSEVLK

$0.01 \% \quad 11.2 \%$ FVTVQTISGTGALR

$0.01 \% \quad 11.2 \%$ DAGMQLQGYR

$0.01 \% \quad 11.2 \%$ TQLVSNLKK

$\begin{array}{lllll}0.00 \% & 6.0 \% & \text { FAANINKESIVDVEGVVR } & 99.7 \% & 38.1\end{array}$

\section{$\begin{array}{ll}99.7 \% & 35.2 \\ 99.7 \% & 52.3\end{array}$}

$99.7 \% 59.7$

$99.7 \% \quad 39.0$

$99.7 \% \quad 47.0$

$99.7 \% \quad 25.3$

$99.7 \% \quad 46.8$

$99.7 \% \quad 28.0$

$98.5 \% \quad 19.6$

$99.7 \% \quad 51.3$

$\begin{array}{lll}99.7 \% & 91.4\end{array}$

$\begin{array}{ll}99.7 \% & 32.5 \\ 99.6 \% & 23.2\end{array}$
1572.84

2104.13

1106.54

1243.70

1357.79

1116.61

2117.91

1117.55

2421.28

1118.61

1110.54

1144.60

932.58

1498.69

1050.52

2335.25

1303.75

975.55

1131.65

1258.66

1956.91

1019.59

1129.61

960.53

2152.13

1949.86

917.49

1062.58

1329.68

1278.69

1947.04

1642.96

1960.92

1244.70

1303.66

1422.72

1342.78

1571.86

1195.65

1628.73

1153.57

1130.56

1530.80

1449.81

1138.53

1030.63

1960.05

Page 23 of Table S-1-1 

ATP synthase subunit gamma, mitochondrial GN=ATP5C1 ATPG_HUMAN $33.00 \quad 100.0 \%$ ATP synthase subunit gamma, mitochondrial GN=ATP5C1 ATPG_HUMAN $33.00 \quad 100.0 \%$ ATP synthase subunit gamma, mitochondrial GN=ATP5C1 ATPG_HUMAN $33.00 \quad 100.0 \%$ ATP synthase subunit gamma, mitochondrial GN=ATP5C1 ATPG_HUMAN $_{3} 33.00 \quad 100.0 \% \quad 10$ $\begin{array}{lllll}\text { ATP synthase subunit gamma, mitochondrial GN=ATP5C1 } & \text { ATPG_HUMAN } & 33.00 & 100.0 \% & 10\end{array}$ ATP synthase subunit $\mathrm{O}$, mitochondrial $\mathrm{GN}=\mathrm{ATP} 5 \mathrm{O}$ ATPO HUMAN $23.28 \quad 100.0 \%$ ATP synthase subunit $\mathrm{O}$, mitochondrial GN=ATP5O ATPO_HUMAN $23.28 \quad 100.0 \%$

2
4
4
4
4
23
23
23
23
23
23
23
23
23
23
23
23
23
23
23
23
23
20
20
20
20
20
20
20
20
20
20
20
20
20
16
16
16
16
16
16
16
16
16
16
10
10

$2 \quad 0.00 \% \quad 6.0 \%$ VTMLFLGLHNVR $0.01 \% \quad 10.3 \%$ ALTALFKEQR

$0.01 \% \quad 10.3 \%$ NACIECSVNQNSIR

$\begin{array}{llll}9.7 \% & 32.5 & 25.0 & 32.5\end{array}$ $99.7 \% \quad 53.8 \quad 25.0 \quad 53.8 \quad 2$ $0.01 \% \quad 10.3 \%$ ITSDEPLTKDDIPVFLR $0.01 \% \quad 10.3 \%$ LIGNLCYK

$114 \quad 0.16 \% \quad 30.6 \%$ VLSIGDGIAR

$\begin{array}{llll}99.7 \% & 62.9 & 25.0 & 62.9\end{array}$

$\begin{array}{llll}95.7 \% & 19.7 & 25.0 & 19.7\end{array}$

$\begin{array}{llll}99.0 \% & 26.3 & 25.0 & 26.3\end{array}$

$99.7 \% \quad 40.8 \quad 25.0 \quad 23.2$

$\begin{array}{lllllllll}114 & 0.16 \% & 30.6 \% & \text { TGAIVDVPVGEELLGR } & 99.7 \% & 50.3 & 25.0 & 50.3\end{array}$

$114 \quad 0.16 \% \quad 30.6 \%$ VVDALGNAIDGKGPIGSK

$114 \quad 0.16 \% \quad 30.6 \%$ VGLKAPGIIPR

$114 \quad 0.16 \% \quad 30.6 \%$ ISVREPMQTGIK

$114 \quad 0.16 \% \quad 30.6 \%$ AVDSLVPIGR

$114 \quad 0.16 \% \quad 30.6 \%$ AVDSLVPIGRGQR

$114 \quad 0.16 \% \quad 30.6 \%$ ELIIGDRQTGK

$114 \quad 0.16 \% \quad 30.6 \%$ TSIAIDTIINQK

$114 \quad 0.16 \% \quad 30.6 \%$ TSIAIDTIINQKR

$114 \quad 0.16 \% \quad 30.6 \%$ STVAQLVK

$114 \quad 0.16 \% \quad 30.6 \%$ STVAQLVKR

$\begin{array}{lll}114 & 0.16 \% & 30.6 \% \\ 11 & \text { HALIIYDDLSK }\end{array}$

$114 \quad 0.16 \% \quad 30.6 \%$ EAYPGDVFYLHSR

$114 \quad 0.16 \% \quad 30.6 \%$ EAYPGDVFYLHSRLLER

$114 \quad 0.16 \% \quad 30.6 \%$ GIRPAINVGLSVSR

$114 \quad 0.16 \% \quad 30.6 \%$ LKEIVTNFLAGFEA

$0.11 \% 35.2 \%$ LVLEVAQHLGESTVR

$0.11 \% \quad 35.2 \%$ TIAMDGTEGLVR

$0.11 \% 35.2 \%$ VLDSGAPIKIPVGPETLGR

$0.11 \% \quad 35.2 \%$ VVDLLAPYAK

$0.11 \% 35.2 \%$ IGLFGGAGVGK

$0.11 \% \quad 35.2 \%$ TVLIMELINNVAK

$0.11 \% 35.2 \%$ AHGGYSVFAGVGER

$0.11 \% 35.2 \%$ VALVYGQMNEPPGAR

$0.11 \% 35.2 \%$ FTQAGSEVSALLGR

$0.11 \% \quad 35.2 \%$ AIAELGIYPAVDPLDSTS

$\begin{array}{ll}0.11 \% & 35.2 \% \text { IMDPNIVGSEHYDVAR } \\ 0.11 \% & 35.2 \% \\ 0.11 \% & 35.2 \%\end{array}$

$0.11 \% 35.2 \%$ ADKLAEEHSS

$0.05 \% 36.6 \%$ SMKMVAAAK

$0.05 \% 36.6 \%$ IYGLGSLALYEK

$0.05 \% 36.6 \%$ HLLIGVSSDR

$0.05 \% \quad 36.6 \%$ GLCGAIHSSIAK

$0.05 \% \quad 36.6 \%$ SEVATLTAAGK

$0.05 \% \quad 36.6 \%$ EVMLVGIGDKIR

$0.05 \% 36.6 \%$ THSDQFLVAFK

$0.05 \% \quad 36.6 \%$ THSDQFLVAFKEVGR

$0.05 \% \quad 36.6 \%$ NASEMIDKLTLTFNR

$34 \quad 0.05 \% \quad 36.6 \%$ ELIEIISGAAALD

$19 \quad 0.03 \% \quad 36.6 \%$ LVRPPVQVYGIEGR $0.03 \% \quad 36.6 \%$ YATALYSAASK
$99.7 \% 43.1$

$99.7 \% \quad 46.1$

$99.7 \% \quad 48.2$

$99.7 \% \quad 50.5$

$99.7 \% \quad 34.9$

$99.7 \% \quad 47.5$

$99.7 \% \quad 50.5$

$99.7 \% 53.8$

$99.0 \% \quad 56.5$

$99.7 \% \quad 58.5$

$99.7 \% \quad 54.6$

$99.7 \% \quad 43.6$

$99.7 \% \quad 61.2$

$99.7 \% \quad 57.6$

$\begin{array}{lll}99.7 \% & 52.9\end{array}$

$99.7 \% \quad 51.1$

$\begin{array}{lll}99.7 \% & 38.1 \\ 99.7 \% & 30.4\end{array}$

$\begin{array}{llll}99.7 \% & 30.4\end{array}$

$99.7 \% \quad 56.4$

$\begin{array}{llll}99.7 \% & 48.2 \\ 99.7 \% & 59.0 & 2\end{array}$

$99.7 \% \quad 59.0$

$99.7 \% \quad 74.2$

$99.7 \% 47.5$

$\begin{array}{lll}97.4 \% & 18.8\end{array}$

$\begin{array}{lll}99.7 \% & 46.4\end{array}$

$\begin{array}{lll}95.5 \% & 24.1\end{array}$

$99.7 \% \quad 43.0$

$99.7 \% \quad 33.7$

$99.7 \% \quad 67.7$

$\begin{array}{lll}99.7 \% & 52.5\end{array}$

$99.7 \% \quad 49.8$

$99.7 \% \quad 49.2$

$\begin{array}{llll}99.7 \% & 54.7\end{array}$

$99.7 \% \quad 51.0$

$\begin{array}{llll}99.7 \% & 27.5\end{array}$

$\begin{array}{lll}99.7 \% & 33.2\end{array}$

$99.7 \% \quad 72.9$
1399.79

1176.67

1664.75

1959.04

980.52

1000.58

1624.89

1710.94

1120.72

1358.75

1026.59

1367.78

1229.69

1316.74

1472.84

845.51

1001.6

1287.69

1553.74

2065.05

1438.85

1551.84

1650.92

1262.64

1919.10

1088.64

975.56

1473.83

1406.68

1601.81

1435.75

1988.03

1815.87

2023.01

1086.51

952.50

1326.73

1096.61

1213.64

1047.57

1329.76

1292.66

1733.90

1768.89

1314.72

1582.91

1145.58

\begin{tabular}{cc}
76 & 487 \\
28 & 37 \\
90 & 103 \\
54 & 270 \\
77 & 384 \\
74 & 83 \\
34 & 149 \\
50 & 167 \\
72 & 182 \\
83 & 194 \\
95 & 204 \\
95 & 207 \\
08 & 218 \\
19 & 230 \\
19 & 231 \\
54 & 261 \\
54 & 262 \\
06 & 316 \\
35 & 347 \\
35 & 351 \\
03 & 416 \\
40 & 553 \\
5 & 109 \\
10 & 121 \\
25 & 143 \\
89 & 198 \\
02 & 212 \\
13 & 225 \\
26 & 239 \\
65 & 279 \\
11 & 324 \\
88 & 406 \\
07 & 422 \\
63 & 480 \\
20 & 529 \\
47 & 55 \\
58 & 79 \\
1 & 100 \\
01 & 112 \\
16 & 126 \\
27 & 138 \\
44 & 154 \\
44 & 158 \\
63 & 277 \\
86 & 298 \\
27 & 40 \\
41 & 51 \\
\hline & \\
\hline 1
\end{tabular}



ATP synthase subunit $\mathrm{O}$, mitochondrial GN=ATP5O ATPO HUMAN $23.28 \quad 100.0 \%$ ATP synthase subunit $\mathrm{O}$, mitochondrial GN=ATP5O ATPO_HUMAN $23.28 \quad 100.0 \%$ ATP synthase subunit $\mathrm{O}$, mitochondrial GN=ATP5O ATPO HUMAN $23.28 \quad 100.0^{\circ}$ ATP synthase subunit $\mathrm{O}$, mitochondrial GN=ATP5O ATPO_HUMAN $23.28 \quad 100.0 \%$ ATP synthase subunit $\mathrm{O}$, mitochondrial GN=ATP5O ATPO_HUMAN $23.28 \quad 100.0 \%$ ATPase family AAA do ATPase family AAA domain-containing protein $3 \mathrm{~A}$ GN=ATAD3A ATD3A_HUMAN 71.37 ATPase family AAA domain-containing protein $3 \mathrm{~A}$ GN=ATAD3A ATD3A_HUMAN 71.37 ATPase family AAA domain-containing protein $3 \mathrm{~A}$ GN=ATAD3A ATD3A_HUMAN 71.37 ATPase family AAA domain-containing protein $3 \mathrm{~A}$ GN=ATAD3A ATD3A_HUMAN 71.37 ATPase family AAA domain-containing protein 3A GN=ATAD3A ATD3A_HUMAN 71.37 ATPase family AAA domain-containing protein $3 \mathrm{~A}$ GN=ATAD3A ATD3A_HUMAN 71.37 ATPase family AAA domain-containing protein 3A GN=ATAD3A ATD3A_HUMAN 71.37 ATPase family AAA domain-containing protein $3 \mathrm{~A}$ GN=ATAD3A ATD3A HUMAN $71.3^{\circ}$ ATPase family AAA domain-containing protein 3A GN=ATAD3A ATD3A_HUMAN 71.3 ATPase family AAA domain-containing protein 3A GN=ATAD3A ATD3A_HUMAN 71.37 ATPase family AAA domain-containing protein 3A GN=ATAD3A ATD3A_HUMAN 71.37 ATPase family AAA domain-containing protein 3A GN=ATAD3A ATD3A_HUMAN 71.3 ATPase family AAA domain-containing protein 3A GN=ATAD3A ATD3A_HUMAN 71.37 ATPase family AAA domain-containing protein 3A GN=ATAD3A ATD3A_HUMAN 71.37 ATPase family AAA domain-containing protein 3A GN=ATAD3A ATD3A_HUMAN 71.37 ATPase family AAA domain-containing protein 3A GN=ATAD3A ATD3A_HUMAN 71.37 ATPase family AAA domain-containing protein 3A GN=ATAD3A ATD3A_HUMAN 71.3 ATPase family AAA domain-containing protein $3 \mathrm{~A}$ GN=ATAD3A ATD3A_HUMAN 71.3 ATPase family AAA domain-containing protein 3A GN=ATAD3A ATD3A_HUMAN 71.37 ATPase family AAA domain-containing protein 3A GN=ATAD3A ATD3A_HUMAN 71.3 ATPase family AAA domain-containing protein $3 \mathrm{~A}$ GN=ATAD3A ATD3A HUMAN 71.37 ATPase family AAA domain-containing protein 3A GN=ATAD3A ATD3A_HUMAN 71.3 ATPase family AAA domain-containing protein $3 \mathrm{~B} G \mathrm{GN}=\mathrm{ATAD} 3 \mathrm{~B} \quad \mathrm{ATD} 3 \mathrm{~B}$ HUMAN $72.5^{\circ}$ ATPase family AAA domain-containing protein 3B GN=ATAD3B ATD3B_HUMAN 72.57 ATPase family AAA domain-containing protein 3B GN=ATAD3B ATD3B_HUMAN 72.57 ATPase family AAA domain-containing protein $3 \mathrm{~B}$ GN=ATAD3B ATD3B HUMAN $72.5^{\circ}$ ATPase family AAA domain-containing protein $3 \mathrm{~B} G \mathrm{GN}=\mathrm{ATAD} 3 \mathrm{~B} \quad$ ATD3B_HUMAN 72.57 ATPase family AAA domain-containing protein 3B GN=ATAD3B ATD3B_HUMAN 72.57 ATPase family AAA domain-containing protein $3 \mathrm{~B}$ GN=ATAD3B ATD3B HUMAN 72.57 ATPase family AAA domain-containing protein 3B GN=ATAD3B ATD3B_HUMAN 72.5 ATPase family AAA domain-containing protein $3 \mathrm{~B}$ GN=ATAD3B $\mathrm{ATD} 3 \mathrm{~B}$ HUMAN $72.5^{\circ}$ ATPase family AAA domain-containing protein $3 \mathrm{~B}$ GN=ATAD3B ATD3B_HUMAN 72.57 ATPase family AAA domain-containing protein 3B GN=ATAD3B ATD3B_HUMAN 72.5 ATPase family AAA domain-containing protein $3 \mathrm{~B} G \mathrm{GN}=\mathrm{ATAD} 3 \mathrm{~B} \quad \mathrm{ATD} 3 \mathrm{~B}$ HUMAN $725^{\circ}$ ATPase family AAA domain-containing protein $3 \mathrm{~B}$ GN=ATAD3B ATD3B_HUMAN $72.5^{\circ}$ ATPase family AAA domain-containing protein 3B GN=ATAD3B ATD3B HUMAN 72.57 ATPase family AAA domain-containing protein $3 \mathrm{~B}$ GN=ATAD3B ATD3B HUMAN 72.57 ATPase family AAA domain-containing protein 3B GN=ATAD3B ATD3B_HUMAN 72.57 ATPase family AAA domain-containing protein 3B GN=ATAD3B ATD3B_HUMAN 72.57 ATPase WRNIP1 GN=WRNIP1 $\begin{array}{llll}10 & 19 & 0.03 \% & 36.6 \% \\ 10 & 19 & 0.03 \% & 36.6 \% \text { VAQILKEPK }\end{array}$

10

10

10

26

26

$100.0 \% \quad 23$

$100.0 \% \quad 23$

$100.0 \% \quad 23$

$100.0 \% \quad 23$

$100.0 \% \quad 23$

$100.0 \% \quad 23$

$100.0 \% \quad 23$

$100.0 \% \quad 23$

$100.0 \% \quad 23$

$100.0 \% \quad 23$

$100.0 \% \quad 23$

$100.0 \% \quad 23$

$100.0 \% \quad 23$

$100.0 \% \quad 23$

$100.0 \% \quad 23$

$100.0 \% \quad 23$

$100.0 \% \quad 23$

$100.0 \% \quad 23$

$100.0 \% \quad 23$

$100.0 \% \quad 23$

$100.0 \% \quad 23$

$100.0 \%$

$100.0 \%$

$100.0 \%$

$100.0 \%$

$100.0 \%$

$100.0 \%$

$100.0 \%$

$100.0 \%$

$100.0 \%$

$100.0 \%$

$100.0 \%$

$100.0 \%$

$100.0 \%$

$100.0 \%$

$100.0 \%$

$100.0 \%$

$100.0 \%$
$0.03 \% 36.6 \%$ VAASVLNPYVK

$0.03 \% \quad 36.6 \%$ VAASVLNPYVKR

$0.03 \% \quad 36.6 \%$ SLNDITAKER

$0.03 \% \quad 36.6 \%$ SFLSQGQVLK

$0.03 \% \quad 36.6 \%$ TDPSILGGMIVR

$0.09 \% \quad 34.1 \%$ TLSEETRQHQAR

$0.09 \% \quad 34.1 \%$ AQYQDKLAR

$0.09 \% \quad 34.1 \%$ ENADIIREQIR

$0.09 \% \quad 34.1 \%$ AAEHRQTVLESIR

$0.09 \% \quad 34.1 \%$ QTVLESIR

$0.09 \% \quad 34.1 \%$ TAGTLFGEGFR

$0.09 \% \quad 34.1 \%$ NATLVAGR

$0.09 \% \quad 34.1 \%$ NATLVAGRFIEAR

$0.09 \% \quad 34.1 \%$ LGKPSLVR

$0.09 \% \quad 34.1 \%$ ITVLEALR

$0.09 \% \quad 34.1 \%$ ITVLEALRHPIQVSR

$0.09 \% \quad 34.1 \%$ LLSRPQDALEGVVLSPSLEA

$0.09 \% \quad 34.1 \%$ VRDIAIATR

$0.09 \% \quad 34.1 \%$ NILMYGPPGTGK

$0.09 \% \quad 34.1 \%$ EGVTAMHK

$0.09 \% \quad 34.1 \%$ LFDWANTSR

$0.09 \% \quad 34.1 \%$ ISEDLRATLNAFLYR

$63 \quad 0.09 \% \quad 34.1 \%$ MYFDKYVLKPATEGK

$0.09 \% \quad 34.1 \%$ LKLAQFDYGR

$0.09 \% \quad 34.1 \%$ LAQFDYGR

$63 \quad 0.09 \% \quad 34.1 \%$ LAQFDYGRK

$0.09 \% \quad 34.1 \%$ VQDAVQQHQQK

$0.09 \% \quad 34.1 \%$ AEGPGRGDEPSPS

$0.01 \% \quad 24.1 \%$ TLSEETRQHQAR

$0.01 \% \quad 24.1 \%$ AQYQDKLAR

$0.01 \% \quad 24.1 \%$ ENADIIREQIR

$0.01 \% \quad 24.1 \%$ QTVLESIR

$0.01 \% \quad 24.1 \%$ TAGTLFGEGFR

$0.01 \% 24.1 \%$ LGKPSLVR

$0.01 \% \quad 24.1 \%$ ITVLEALR

$0.01 \% \quad 24.1 \%$ ITVLEALRHPIQVSR

$0.01 \% \quad 24.1 \%$ LLSRPQDVLEGVVLSPSLEAR

$0.01 \% \quad 24.1 \%$ VRDIAIATR

$0.01 \% \quad 24.1 \%$ EGVTAMHK

$0.01 \% \quad 24.1 \%$ LFDWANTSR

$0.01 \% \quad 24.1 \%$ GLLLFMDEADAFLR

$0.01 \% \quad 24.1 \%$ ATEEISKDLR

$0.01 \% \quad 24.1 \%$ LKLAQFDYGR

$0.01 \% \quad 24.1 \%$ LAQFDYGR

$0.01 \% \quad 24.1 \%$ LAQFDYGRK

$0.01 \% \quad 7.4 \%$ FVTLSATNAK $\begin{array}{llllllll}99.7 \% & 37.8 & 25.0 & 27.2 & 2 & 0 & 0 & 1025.64\end{array}$

$\begin{array}{llllllll}99.7 \% & 60.5 & 25.0 & 55.5 & 2 & 0 & 0 & 1160.67\end{array}$

$\begin{array}{llllllll}99.7 \% & 35.0 & 25.0 & 30.6 & 2 & 0 & 0 & 1316.77\end{array}$

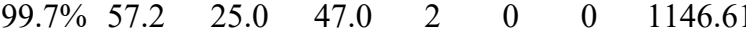

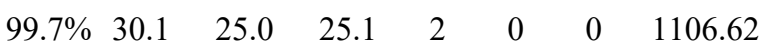

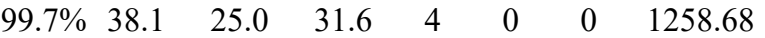

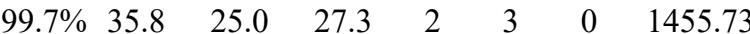

$\begin{array}{llllllll}99.7 \% & 50.3 & 25.0 & 41.9 & 5 & 0 & 0 & 1092.58\end{array}$

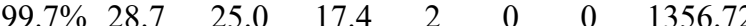

$\begin{array}{llllllll}99.7 \% & 31.9 & 25.0 & 30.8 & 2 & 2 & 0 & 1509.81\end{array}$

$\begin{array}{llllllll}99.0 \% & 34.8 & 25.0 & 16.4 & 2 & 0 & 0 & 945.54\end{array}$

$\begin{array}{llllllll}99.7 \% & 57.3 & 25.0 & 52.6 & 4 & 0 & 0 & 1155.58\end{array}$

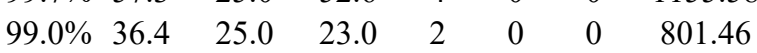

$\begin{array}{llllllll}99.7 \% & 24.2 & 25.0 & 23.0 & 2 & 0 & 0 & 1417.79\end{array}$

$\begin{array}{llllllll}99.0 \% & 36.6 & 25.0 & 24.9 & 4 & 0 & 0 & 869.56\end{array}$

$\begin{array}{llllllll}99.0 \% & 43.5 & 25.0 & 21.3 & 3 & 0 & 0 & 914.57\end{array}$

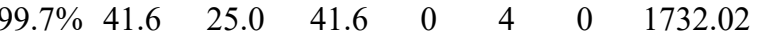

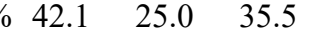

$\begin{array}{llll}99.7 \% & 49.8 & 25.0 & 42.2\end{array}$

$\begin{array}{lllll}99.0 \% & 32.3 & 25.0 & 20.2 & 2\end{array}$

$\begin{array}{llll}99.7 \% & 26.1 & 25.0 & 19.2\end{array}$

$\begin{array}{llll}99.7 \% & 37.7 & 25.0 & 37.7\end{array}$

$\begin{array}{llll}99.6 \% & 22.4 & 25.0 & 22.4\end{array}$

$99.7 \% \quad 48.1 \quad 25.0 \quad 48.1$

$\begin{array}{lllll}99.0 \% & 37.5 & 25.0 & 16.6 & 2\end{array}$

$\begin{array}{llll}99.6 \% & 22.4 & 25.0 & 19.6\end{array}$

$99.7 \% \quad 46.6 \quad 25.0 \quad 30.6$

$\begin{array}{llll}99.7 \% & 51.5 & 25.0 & 50.7\end{array}$

$\begin{array}{llll}99.7 \% & 35.8 & 25.0 & 27.3\end{array}$

$\begin{array}{llll}99.7 \% & 50.3 & 25.0 & 41.9\end{array}$

$\begin{array}{lllll}99.7 \% & 28.7 & 25.0 & 17.4 & 2\end{array}$

$\begin{array}{llll}99.0 \% & 34.8 & 25.0 & 16.4\end{array}$

$\begin{array}{llll}99.7 \% & 57.3 & 25.0 & 52.6\end{array}$

$99.0 \% \quad 36.6 \quad 25.0 \quad 24.9$

$99.0 \% \quad 43.5 \quad 25.0 \quad 21.3$

$\begin{array}{llll}99.7 \% & 41.6 & 25.0 & 41.6\end{array}$

$\begin{array}{llll}99.1 \% & 19.5 & 25.0 & 19.5\end{array}$

$\begin{array}{llll}99.7 \% & 42.1 & 25.0 & 35.5\end{array}$

$\begin{array}{llll}99.0 \% & 32.3 & 25.0 & 20.2\end{array}$

$\begin{array}{llll}99.7 \% & 26.1 & 25.0 & 19.2\end{array}$

$\begin{array}{llll}99.7 \% & 46.2 & 25.0 & 46.2\end{array}$

$\begin{array}{llll}99.7 \% & 49.5 & 25.0 & 18.1\end{array}$

$\begin{array}{llll}99.7 \% & 48.1 & 25.0 & 48.1\end{array}$

$\begin{array}{lllll}99.0 \% & 37.5 & 25.0 & 16.6\end{array}$

$\begin{array}{lllll}99.6 \% & 22.4 & 25.0 & 19.6 & 2\end{array}$

$\begin{array}{llll}99.7 \% & 34.4 & 25.0 & 30.1\end{array}$
2250.25

1014.61

1263.64

74

74

91
163
177

177

$178 \quad 186$

$250 \quad 260$

$263 \quad 275$

$268 \quad 275$

$314 \quad 321$

$314 \quad 326$

339346

$355 \quad 375$

872.43

1109.54

1781.95

1789.92

1210.66

969.48

1097.57

1308.67

1255.56

1455.73

1092.58

1356.72

945.54

1155.58

869.56

914.57

1732.02

2278.28

1014.61

872.43

1109.54

1626.82

1161.6

1210.66

969.48

1097.57

1051.58 
ATPase WRNIP1 GN=WRNIP1 ATPase WRNIP1 GN=WRNIP1 ATPase WRNIP1 GN=WRNIP1
WRIP1_HUMAN $72.13 \quad 100.0 \%$ WRIP1_HUMAN $72.13 \quad 100.0 \%$ WRIP1_HUMAN $72.13 \quad 100.0 \%$ ABCB7 HUMAN $82.64 \quad 100.0 \%$ ATP-binding cassette sub-family B member 7, mitochondrial $\mathrm{GN}=\mathrm{ABCB} 7 \mathrm{ABCB} 7$ HUMAN $82.64 \quad 100.0 \%$ ATP-binding cassette sub-family D member $3 \mathrm{GN}=\mathrm{ABCD} 3 \mathrm{ABCD} 3$ _HUMAN $75.48 \quad 100.0 \%$ ATP-binding cassette sub-family D member $3 \mathrm{GN}=\mathrm{ABCD} 3 \quad \mathrm{ABCD} 3$ _HUMAN $75.48 \quad 100.0 \%$ ATP-binding cassette sub-family D member $3 \mathrm{GN}=\mathrm{ABCD} 3 \quad \mathrm{ABCD} 3$ _HUMAN $75.48 \quad 100.0 \%$ ATP-binding cassette sub-family D member $3 \mathrm{GN}=\mathrm{ABCD} 3 \mathrm{ABCD} 3$ HUMAN $75.48 \quad 100.0^{\circ} \%$ ATP-binding cassette sub-family D member $3 \mathrm{GN}=\mathrm{ABCD} 3 \mathrm{ABCD} 3$ _HUMAN $75.48 \quad 100.0 \%$ ATP-binding cassette sub-family D member $3 \mathrm{GN}=\mathrm{ABCD} 3 \mathrm{ABCD} 3$ _HUMAN $75.48 \quad 100.0 \%$ ATP-binding cassette sub-family D member $3 \mathrm{GN}=\mathrm{ABCD} 3 \quad \mathrm{ABCD} 3$ HUMAN $75.48 \quad 100.0^{\circ}$ ATP-binding cassette sub-family D member $3 \mathrm{GN}=\mathrm{ABCD} 3 \mathrm{ABCD} 3$ _HUMAN $75.48 \quad 100.0 \%$ ATP-binding cassette sub-family F member $2 \mathrm{GN}=\mathrm{ABCF} 2 \mathrm{ABCF} 2$ _HUMAN $71.29 \quad 100.0 \%$ ATP-binding cassette sub-family F member $2 \mathrm{GN}=\mathrm{ABCF} 2 \mathrm{ABCF} 2$ HUMAN $71.29 \quad 100.0 \%$ ATP-binding cassette sub-family F member $2 \mathrm{GN}=\mathrm{ABCF} 2 \mathrm{ABCF} 2$ _HUMAN $71.29 \quad 100.0 \%$ ATP-binding cassette sub-family F member $2 \mathrm{GN}=\mathrm{ABCF} 2$ ABCF2 HUMAN $71.29 \quad 100.0 \%$ ATP-binding cassette sub-family F member $2 \mathrm{GN}=\mathrm{ABCF} 2 \mathrm{ABCF} 2$ _HUMAN $71.29 \quad 100.0 \%$ ATP-binding cassette sub-family F member $2 \mathrm{GN}=\mathrm{ABCF} 2 \mathrm{ABCF} 2$ _HUMAN $71.29 \quad 100.0 \%$ ATP-binding cassette sub-family F member $2 \mathrm{GN}=\mathrm{ABCF} 2 \mathrm{ABCF} 2$ HUMAN $71.29 \quad 100.0 \%$ ATP-binding cassette sub-family F member $2 \mathrm{GN}=\mathrm{ABCF} 2 \mathrm{ABCF} 2$ HUMAN $71.29 \quad 100.0 \%$ ATP-binding cassette sub-family F member $2 \mathrm{GN}=\mathrm{ABCF} 2 \mathrm{ABCF} 2$ _HUMAN $71.29 \quad 100.0 \%$ ATP-binding cassette sub-family F member $2 \mathrm{GN}=\mathrm{ABCF} 2 \mathrm{ABCF} 2$ _HUMAN $71.29 \quad 100.0 \%$ ATP-binding cassette sub-family F member $2 \mathrm{GN}=\mathrm{ABCF} 2$ ABCF2_HUMAN $71.29 \quad 100.0 \%$ ATP-binding cassette sub-family F member 2 GN=ABCF2 ABCF2 HUMAN $71.29 \quad 100.0^{\circ}$ ATP-binding cassette sub-family F member $2 \mathrm{GN}=\mathrm{ABCF} 2 \mathrm{ABCF} 2$ _HUMAN $71.29 \quad 100.0 \%$ ATP-citrate synthase $\mathrm{GN}=\mathrm{ACLY}$ ATP-citrate synthase $\mathrm{GN}=\mathrm{ACLY}$ ATP-citrate synthase $\mathrm{GN}=\mathrm{ACLY}$ ATP-citrate synthase $\mathrm{GN}=\mathrm{ACLY}$ ATP-citrate synthase $\mathrm{GN}=\mathrm{ACLY}$ ATP-citrate synthase $\mathrm{GN}=\mathrm{ACLY}$ ATP-citrate synthase $\mathrm{GN}=\mathrm{ACLY}$ ATP-citrate synthase $\mathrm{GN}=\mathrm{ACLY}$ ATP-citrate synthase $\mathrm{GN}=\mathrm{ACLY}$ ATP-citrate synthase $\mathrm{GN}=\mathrm{ACLY}$ ATP-citrate synthase $\mathrm{GN}=\mathrm{ACLY}$ ATP-citrate synthase $\mathrm{GN}=\mathrm{ACLY}$ ATP-citrate synthase $\mathrm{GN}=\mathrm{ACLY}$ ATP-citrate synthase $\mathrm{GN}=\mathrm{ACLY}$ ATP-citrate synthase $\mathrm{GN}=\mathrm{ACLY}$ ATP-citrate synthase $\mathrm{GN}=\mathrm{ACLY}$ ATP-citrate synthase $\mathrm{GN}=\mathrm{ACLY}$ ATP-citrate synthase $\mathrm{GN}=\mathrm{ACLY}$ ATP-citrate synthase $\mathrm{GN}=\mathrm{ACLY}$ ATP-citrate synthase $\mathrm{GN}=\mathrm{ACLY}$ ATP-citrate synthase GN=ACLY ACLY_HUMAN $120.84 \quad 100.0 \% \quad 33$ ACLY HUMAN $120.84 \quad 100.0 \% \quad 33$ ACLY_HUMAN $120.84 \quad 100.0 \% \quad 33$ ACLY HUMAN $120.84 \quad 100.0 \% \quad 33$ ACLY_HUMAN $120.84 \quad 100.0 \% \quad 33$ ACLY_HUMAN $120.84 \quad 100.0 \% \quad 33$ ACLY HUMAN $120.84 \quad 100.0 \% \quad 33$ ACLY_HUMAN $120.84 \quad 100.0 \% \quad 33$ ACLY_HUMAN $120.84 \quad 100.0 \% \quad 33$ ACLY_HUMAN $120.84 \quad 100.0 \% \quad 33$ ACLY_HUMAN $120.84 \quad 100.0 \% \quad 33$ ACLY HUMAN $120.84 \quad 100.0 \% \quad 33$ ACLY_HUMAN $120.84 \quad 100.0 \% \quad 33$ ACLY_HUMAN $120.84 \quad 100.0 \% \quad 33$ ACLY HUMAN $120.84 \quad 100.0 \% \quad 33$ ACLY_HUMAN $120.84 \quad 100.0 \% \quad 33$ ACLY HUMAN $120.84 \quad 100.0 \% \quad 33$ ACLY_HUMAN $120.84 \quad 100.0 \% \quad 33$ ACLY_HUMAN $120.84 \quad 100.0 \% \quad 33$ ACLY_HUMAN $120.84 \quad 100.0 \% \quad 33$ ACLY_HUMAN $120.84 \quad 100.0 \% \quad 33$
$0.01 \% \quad 7.4 \%$ AGLNGLQLAVLAR $0.01 \% \quad 7.4 \%$ VLITENDVKEGLQR $0.01 \% \quad 7.4 \%$ SIEVYSAYNNVK $0.00 \% \quad 2.9 \%$ VAISLGFLGGAK $0.00 \% \quad 2.9 \%$ AGAAFFNEVR $0.02 \% \quad 15.6 \%$ SGKPPLQNNEK $0.02 \% \quad 15.6 \%$ AVVDKVFFSR $0.02 \% \quad 15.6 \%$ IANPDQLLTQDVEK $4 \quad 0.02 \% \quad 15.6 \%$ LITNSEEIAFYNGNKR $4 \quad 0.02 \% \quad 15.6 \%$ STHSELLEDYYQSGR $14 \quad 0.02 \% \quad 15.6 \%$ IVLAGREMTR

$14 \quad 0.02 \% \quad 15.6 \%$ SGANVLICGPNGCGK $14 \quad 0.02 \% \quad 15.6 \%$ VLGELWPLFGGR $30 \quad 0.04 \% \quad 20.2 \%$ YGLIGLNGIGK $\quad 0.04 \% \quad 20.2 \%$ SMLLSAIGKR $30 \quad 0.04 \% \quad 20.2 \%$ EVPIPEHIDIYHLTR $0.04 \% \quad 20.2 \%$ ILHGLGFTPAMQR $\begin{array}{lll}0.04 \% & 20.2 \% & \text { YYTGNYDQYVK }\end{array}$ $30 \quad 0.04 \% \quad 20.2 \%$ IPPPVIMVQNVSFK $30 \quad 0.04 \% \quad 20.2 \%$ VALVGPNGAGK $30 \quad 0.04 \% \quad 20.2 \%$ LLTGELLPTDGMIR $30 \quad 0.04 \% \quad 20.2 \%$ LLTGELLPTDGMIRK $30 \quad 0.04 \% \quad 20.2 \%$ YGLTGKQQVSPIR $30 \quad 0.04 \% \quad 20.2 \%$ SKLVDEEPQLTK $30 \quad 0.04 \% \quad 20.2 \%$ LVDEEPQLTK

$30 \quad 0.04 \% \quad 20.2 \%$ LVDEEPQLTKR

$108 \quad 0.15 \% \quad 30.3 \%$ AISEQTGKELLYK

$108 \quad 0.15 \% \quad 30.3 \%$ FICTTSAIQNR

$108 \quad 0.15 \% \quad 30.3 \%$ GKLGLVGVNLTLDGVK $108 \quad 0.15 \% \quad 30.3 \%$ LGLVGVNLTLDGVK

$108 \quad 0.15 \% \quad 30.3 \%$ LGQEATVGK

$108 \quad 0.15 \% \quad 30.3 \%$ LGQEATVGKATGFLK

$108 \quad 0.15 \% \quad 30.3 \%$ VDATADYICK

$108 \quad 0.15 \% \quad 30.3 \%$ EAYPEEAYIADLDAK

$108 \quad 0.15 \% \quad 30.3 \%$ TIL SLMTR

$108 \quad 0.15 \% \quad 30.3 \%$ RGGPNYQEGLR

$108 \quad 0.15 \% \quad 30.3 \%$ GGPNYQEGLR

$108 \quad 0.15 \% \quad 30.3 \%$ TASFSESRADEVAPAK

$108 \quad 0.15 \% \quad 30.3 \%$ KAKPAMPQDSVPSPR

$108 \quad 0.15 \% \quad 30.3 \%$ AKPAMPQDSVPSPR

$108 \quad 0.15 \% \quad 30.3 \%$ SLQGKSTTLFSR

$108 \quad 0.15 \% \quad 30.3 \%$ SAYDSTMETMNYAQIR

$108 \quad 0.15 \% \quad 30.3 \%$ TIAIIAEGIPEALTR

$108 \quad 0.15 \% \quad 30.3 \%$ TIAIIAEGIPEALTRK

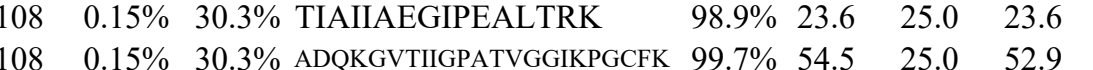
$\begin{array}{llllllll}108 & 0.15 \% & 30.3 \% & \text { ADQKGVTIIGPATVGGIKPGCFK } & 99.7 \% & 54.5 & 25.0 & 52.9 \\ 108 & 0.15 \% & 30.3 \% & \text { GVTIIGPATVGGIKPGCFK } & 99.7 \% & 45.5 & 25.0 & 45.5\end{array}$

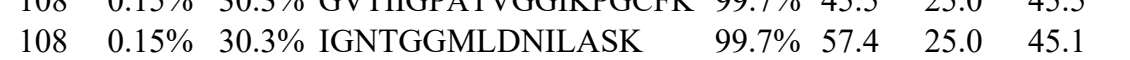

$\begin{array}{lllll}99.7 \% & 40.4 & 25.0 & 40.4 & 1\end{array}$ $\begin{array}{llll}99.7 \% & 45.1 & 25.0 & 42.4\end{array}$ $99.7 \% \quad 25.8 \quad 25.0 \quad 23.4$ $\begin{array}{llll}99.7 \% & 55.8 & 25.0 & 53.4\end{array}$ $99.7 \% \quad 44.5 \quad 25.0 \quad 38.5$ $\begin{array}{llll}99.5 \% & 21.3 & 25.0 & 21.3\end{array}$ $\begin{array}{lllll}99.7 \% & 40.1 & 25.0 & 32.6\end{array}$ $99.7 \% \quad 66.9 \quad 25.0 \quad 61.6 \quad 2$ $\begin{array}{llll}99.7 \% & 29.4 & 25.0 & 27.7\end{array}$ $\begin{array}{llll}99.7 \% & 48.3 & 25.0 & 48.3\end{array}$ $99.7 \% \quad 29.1 \quad 25.0 \quad 24.2$ $\begin{array}{llll}99.7 \% & 53.2 & 25.0 & 53.2\end{array}$ $99.7 \% \quad 26.7 \quad 25.0 \quad 26.2$ $\begin{array}{llll}99.7 \% & 31.7 & 25.0 & 28.3\end{array}$ $\begin{array}{llll}99.7 \% & 30.4 & 25.0 & 19.4\end{array}$ $99.7 \% \quad 53.1 \quad 25.0 \quad 51.1$ $\begin{array}{lllll}99.7 \% & 44.9 & 25.0 & 38.8 & 4\end{array}$ $\begin{array}{llll}96.7 \% & 17.5 & 25.0 & 14.2 \\ 99.6 \% & 22.5 & 25.0 & 22.5\end{array}$ $99.7 \% \quad 48.3 \quad 25.0 \quad 48.1$ $\begin{array}{llll}99.1 \% & 18.5 & 25.0 & 18.5\end{array}$ $\begin{array}{llll}99.7 \% & 40.9 & 25.0 & 36.8 \\ 99.7 \% & 31.1 & 25.0 & 14.7\end{array}$ $\begin{array}{llll}99.7 \% & 37.5 & 25.0 & 30.5\end{array}$ $\begin{array}{llll}99.7 \% & 50.2 & 25.0 & 50.2\end{array}$ $\begin{array}{llll}99.7 \% & 53.3 & 25.0 & 48.5\end{array}$ $\begin{array}{llll}99.7 \% & 44.1 & 25.0 & 44.1 \\ 99.7 \% & 56.2 & 25.0 & 55.9\end{array}$ $99.7 \% \quad 51.0 \quad 25.0 \quad 38.4$ $\begin{array}{lllll}99.7 \% & 57.3 & 25.0 & 51.6 & 2\end{array}$ $\begin{array}{llll}99.7 \% & 35.5 & 25.0 & 35.5\end{array}$ $\begin{array}{llll}99.7 \% & 42.8 & 25.0 & 42.8\end{array}$ $\begin{array}{llll}99.0 \% & 33.7 & 25.0 & 30.0\end{array}$ $\begin{array}{llll}99.7 \% & 39.8 & 25.0 & 35.2\end{array}$ $\begin{array}{rrrr}99.7 \% & 36.0 & 25.0 & 22.6 \\ 99.7 \% & 56.0 & 25.0 & 56.0\end{array}$ $\begin{array}{llll}98.4 \% & 19.6 & 25.0 & 16.3\end{array}$ $\begin{array}{llll}99.7 \% & 45.6 & 25.0 & 41.5\end{array}$ $\begin{array}{llll}99.7 \% & 40.1 & 25.0 & 40.1\end{array}$ $\begin{array}{lllll}99.7 \% & 52.4 & 25.0 & 52.4 & 4\end{array}$ $\begin{array}{lllll}99.7 \% & 52.7 & 25.0 & 52.4 & 7\end{array}$ $\begin{array}{llll}99.7 \% & 52.1 & 25.0 & 49.5\end{array}$ $\begin{array}{llll}99.7 \% & 58.8 & 25.0 & 58.8\end{array}$
1784.81

1145.65

1503.70

1343.75

1104.64

1091.62

1831.97

1440.78

1413.63

1568.89

982.57

1544.84

1656.94

1446.81

1386.75

1171.62

1327.72

1479.81

1310.65

1582.95

1397.84

902.49

1519.85

1155.54

1697.79

934.54

1246.63

1090.53

1665.81

1624.85

1480.76

1324.72

1880.82

1567.91

1696.00

2314.26

1872.04 1503.78

$\begin{array}{cc}42 & 454 \\ 74 & 487 \\ 90 & 601 \\ 40 & 151 \\ 01 & 210 \\ 0 & 50 \\ 7 & 66 \\ 82 & 195 \\ 72 & 287 \\ 48 & 362 \\ 74 & 383 \\ 65 & 479 \\ 85 & 496 \\ 14 & 124 \\ 25 & 134 \\ 35 & 149 \\ 11 & 223 \\ 05 & 315 \\ 91 & 404 \\ 26 & 436 \\ 42 & 455 \\ 42 & 456 \\ 03 & 515 \\ 07 & 618 \\ 09 & 618 \\ 09 & 619 \\ 5 & 17 \\ 8 & 28 \\ 7 & 82 \\ 9 & 82 \\ 9 & 97 \\ 9 & 103 \\ 21 & 230 \\ 45 & 259 \\ 22 & 329 \\ 79 & 389 \\ 80 & 389 \\ 53 & 468 \\ 69 & 483 \\ 70 & 483 \\ 94 & 495 \\ 77 & 592 \\ 93 & 607 \\ 93 & 608 \\ 13 & 635 \\ 17 & 635 \\ 36 & 650 \\ & \end{array}$


ATP-citrate synthase GN=ACLY ATP-citrate synthase $\mathrm{GN}=\mathrm{ACLY}$ ATP-citrate synthase $\mathrm{GN}=\mathrm{ACLY}$ ATP-citrate synthase $\mathrm{GN}=\mathrm{ACLY}$ ATP-citrate synthase GN=ACLY ATP-citrate synthase $\mathrm{GN}=\mathrm{ACLY}$ ATP-citrate synthase GN=ACLY ATP-citrate synthase GN=ACLY ATP-citrate synthase GN=ACLY ATP-citrate synthase GN=ACLY ATP-citrate synthase GN=ACLY ATP-citrate synthase GN=ACLY $\begin{array}{llll} & \end{array}$ ATP-dependent 6-phosphofructokinase, liver type GN=PFKL PFKAL_HUMAN $85.02 \quad 100.0 \% \quad 18$ ATP-dependent 6-phosphofructokinase, liver type GN=PFKL PFKAL_HUMAN $85.02 \quad 100.0 \% \quad 18$ ATP-dependent 6-phosphofructokinase, liver type GN=PFKL PFKAL_HUMAN $85.02 \quad 100.0 \% \quad 18$ ATP-dependent 6-phosphofructokinase, liver type GN=PFKL PFKAL_HUMAN $85.02 \quad 100.0 \% \quad 18$ ATP-dependent 6-phosphofructokinase, liver type GN=PFKL PFKAL_HUMAN $85.02 \quad 100.0 \% \quad 18$ $\begin{array}{llll}\text { ATP-dependent 6-phosphofructokinase, liver type GN=PFKL PFKAL_HUMAN } & 85.02 & 100.0 \% & 18\end{array}$ ATP-dependent 6-phosphofructokinase, liver type GN=PFKL PFKAL_HUMAN $85.02 \quad 100.0 \% \quad 18$ ATP-dependent 6-phosphofructokinase, liver type GN=PFKL PFKAL_HUMAN $85.02 \quad 100.0 \% \quad 18$ ATP-dependent 6-phosphofructokinase, liver type GN=PFKL PFKAL_HUMAN $85.02 \quad 100.0 \% \quad 18$ $\begin{array}{llll}\text { ATP-dependent 6-phosphofructokinase, liver type GN=PFKL PFKAL_HUMAN } & 85.02 & 100.0 \% & 18\end{array}$ ATP-dependent 6-phosphofructokinase, liver type GN=PFKL PFKAL_HUMAN $85.02 \quad 100.0 \% \quad 18$ ATP-dependent 6-phosphofructokinase, liver type GN=PFKL PFKAL_HUMAN $85.02 \quad 100.0 \% \quad 18$ ATP-dependent 6-phosphofructokinase, liver type GN=PFKL PFKAL_HUMAN $85.02 \quad 100.0 \% \quad 18$ $\begin{array}{llll}\text { ATP-dependent 6-phosphofructokinase, liver type GN=PFKL PFKAL_HUMAN } & 85.02 & 100.0 \% & 18\end{array}$ ATP-dependent 6-phosphofructokinase, liver type GN=PFKL PFKAL_HUMAN $85.02 \quad 100.0 \% \quad 18$ ATP-dependent 6-phosphofructokinase, liver type GN=PFKL PFKAL_HUMAN $85.02 \quad 100.0 \% \quad 18$ ATP-dependent 6-phosphofructokinase, liver type GN=PFKL PFKAL HUMAN $85.02 \quad 100.0 \% \quad 18$ ATP-dependent 6-phosphofructokinase, muscle type GN=PFKM PFKAM_HUMAN $85.18 \quad 100.0 \%$ ATP-dependent 6-phosphofructokinase, muscle type GN=PFKM PFKAM_HUMAN $85.18 \quad 100.0 \%$ ATP-dependent 6-phosphofructokinase, muscle type GN=PFKM PFKAM_HUMAN $85.18 \quad 100.0 \%$ ATP-dependent 6-phosphofructokinase, muscle type GN=PFKM PFKAM_HUMAN $85.18 \quad 100.0 \%$ ATP-dependent 6-phosphofructokinase, muscle type GN=PFKM PFKAM_HUMAN $85.18 \quad 100.0 \%$ ATP-dependent 6-phosphofructokinase, muscle type GN=PFKM PFKAM_HUMAN $85.18 \quad 100.0 \%$ ATP-dependent 6-phosphofructokinase, muscle type GN=PFKM PFKAM_HUMAN $85.18 \quad 100.0 \%$ ATP-dependent 6-phosphofructokinase, muscle type GN=PFKM PFKAM_HUMAN $85.18 \quad 100.0 \%$ ATP-dependent 6-phosphofructokinase, muscle type GN=PFKM PFKAM_HUMAN $85.18 \quad 100.0 \%$ ATP-dependent 6-phosphofructokinase, muscle type GN=PFKM PFKAM_HUMAN $85.18 \quad 100.0 \%$ ATP-dependent 6-phosphofructokinase, muscle type GN=PFKM PFKAM_HUMAN $85.18 \quad 100.0 \%$ ATP-dependent 6-phosphofructokinase, muscle type GN=PFKM PFKAM_HUMAN $85.18 \quad 100.0 \%$ ATP-dependent 6-phosphofructokinase, muscle type GN=PFKM PFKAM HUMAN $85.18 \quad 100.0 \%$ ATP-dependent 6-phosphofructokinase, platelet type GN=PFKP PFKAP_HUMAN $85.60 \quad 100.0 \%$ ATP-dependent 6-phosphofructokinase, platelet type GN=PFKP PFKAP_HUMAN $85.60 \quad 100.0 \%$ ATP-dependent 6-phosphofructokinase, platelet type GN=PFKP PFKAP_HUMAN $85.60 \quad 100.0 \%$ ATP-dependent 6-phosphofructokinase, platelet type GN=PFKP PFKAP_HUMAN $85.60 \quad 100.0 \%$

$9 \quad 11$

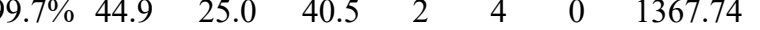
$\begin{array}{llllllll}99.7 \% & 52.0 & 25.0 & 47.2 & 9 & 0 & 0 & 1507.72\end{array}$ $\begin{array}{llllllll}99.0 \% & 31.7 & 25.0 & 19.9 & 2 & 0 & 0 & 907.45\end{array}$

$108 \quad 0.15 \% \quad 30.3 \%$ AFDSGIIPMEFVNK

$108 \quad 0.15 \% \quad 30.3 \%$ EGKLIMGIGHR

$108 \quad 0.15 \% \quad 30.3 \%$ VKSINNPDMR

$108 \quad 0.15 \% \quad 30.3 \%$ SINNPDMR

$108 \quad 0.15 \% \quad 30.3 \%$ VQILKDYVR

$108 \quad 0.15 \% \quad 30.3 \%$ SMGFIGHYLDQKR

$\begin{array}{llll}99.7 \% & 40.9 & 25.0 & 40.6\end{array}$

$99.0 \% \quad 22.9 \quad 25.0 \quad 17.2$

$99.7 \% \quad 41.5 \quad 25.0 \quad 41.5$

$\begin{array}{llll}99.7 \% & 33.9 & 25.0 & 29.1 \\ 97.9 \% & 17.5 & 25.0 & 16.2\end{array}$

$97.9 \% \quad 17.5 \quad 25.0 \quad 16.2$

$\begin{array}{llll}99.0 \% & 32.2 & 25.0 & 23.1\end{array}$

$99.7 \% \quad 44.5 \quad 25.0 \quad 37.6 \quad 2$

$99.5 \% \quad 24.1 \quad 25.0 \quad 22.2$

$46 \quad 0.06 \% \quad 25.9 \%$ AIGVLTSGGDAQGMNAAVR

$46 \quad 0.06 \% \quad 25.9 \%$ IMEVIDAITTTAQSHQR

$\quad 0.06 \% \quad 25.9 \%$ TFVLEVMGR

$46 \quad 0.06 \% \quad 25.9 \%$ LNIIIIAEGAIDR

$6.06 \% \quad 25.9 \%$ VTVLGHVQR

$\begin{array}{lll}0.06 \% & 25.9 \% \text { GGTPSAFDR }\end{array}$

$46 \quad 0.06 \% \quad 25.9 \%$ GGTPSAFDRILSSK

$0.06 \% \quad 25.9 \%$ LPLMECVQMTK

$\begin{array}{cccc}99.7 \% & 39.2 & 25.0 & 39.2 \\ 99.1 \% & 37.0 & 25.0 & 9.7\end{array}$

$\begin{array}{llll}99.7 \% & 53.5 & 25.0 & 48.7\end{array}$

$\begin{array}{lllll}99.7 \% & 66.6 & 25.0 & 66.6 & 2\end{array}$

$\begin{array}{llll}99.7 \% & 38.4 & 25.0 & 30.5\end{array}$

$\begin{array}{llll}98.5 \% & 23.1 & 25.0 & 13.9\end{array}$

$\begin{array}{llll}99.7 \% & 43.9 & 25.0 & 37.2\end{array}$

$\begin{array}{llll}99.7 \% & 47.6 & 25.0 & 47.6\end{array}$

$0.06 \% \quad 25.9 \%$ SNFSLAILNVGAPAAGMNAAVR

$0.06 \% \quad 25.9 \%$ GGSMLGTKR

$99.7 \% \quad 51.5$

$99.7 \% \quad 43.3$

$99.7 \% \quad 44.8$

$98.8 \% \quad 28.0$

$0.06 \% \quad 25.9 \%$ GLVLRNEK

$99.7 \% 24.2$

$\begin{array}{lllll}0.06 \% & 25.9 \% & \text { TNVLGHLQQGGAPTPFDR } & 99.7 \% & 24.2 \\ 0.06 \% & 25.9 \% & \text { TNVLGHLQQGGAPTPFDRNYGTK } & 99.7 \% & 57.6\end{array}$

$0.06 \% \quad 25.9 \%$ GRVFANAPDSACVIGLK

$99.7 \% \quad 30.5$

$0.06 \% \quad 25.9 \%$ VFANAPDSACVIGLK

$0.06 \% \quad 25.9 \%$ AVAFSPVTELKK

$0.06 \% \quad 25.9 \%$ TLSMDKGF

$\begin{array}{llll}99.7 \% & 53.6 & 25.0 & 50.2\end{array}$

$\begin{array}{lllllll}0.02 \% & 18.5 \% & \text { AIAVLTSGGDAQGMNAAVR } & 99.7 \% & 76.3 & 25.0 & 76.3\end{array}$

$0.02 \% \quad 18.5 \%$ VGIFTGAR

$0.02 \% \quad 18.5 \%$ AAYNLVKR

$99.0 \% \quad 31.6 \quad 25.0 \quad 23.9 \quad 2$

$\begin{array}{llll}99.0 \% & 39.0 & 25.0 & 38.0\end{array}$

$0.02 \% \quad 18.5 \%$ IMEIVDAITTTAQSHQR

$0.02 \% \quad 18.5 \%$ TFVLEVMGR

$0.02 \% \quad 18.5 \%$ LGYDTRVTVLGHVQR

$0.02 \% \quad 18.5 \%$ VTVLGHVQR

$0.02 \% \quad 18.5 \%$ GGTPSAFDR

$98.9 \% \quad 65.0$

$99.7 \% \quad 53.5$

$99.7 \% \quad 36.2$

$\begin{array}{rr}25.0 & 48.7 \\ 25.0 & 36.2\end{array}$

$\begin{array}{llll}99.7 \% & 38.4 & 25.0 & 30.5\end{array}$

$\begin{array}{llll}98.5 \% & 23.1 & 25.0 & 13.9\end{array}$

$\begin{array}{llll}98.7 \% & 20.4 & 25.0 & 20.4\end{array}$

$0.02 \% \quad 18.5 \%$ GGTPSAFDRILGSR

$97.7 \% \quad 17.0$

$0.02 \% \quad 18.5 \%$ IGLIQGNR

$0.02 \% \quad 18.5 \%$ GLVLRNEK

$0.02 \% \quad 18.5 \%$ IFANTPDSGCVLGMR

$98.8 \% \quad 28.0$

$99.7 \% \quad 52.6$

$99.7 \% \quad 27.0$

$0.03 \% \quad 21.9 \%$ FLEHLSGAGK

$\begin{array}{lll} & 99.7 \% & 39.2 \\ & 99.0 \% & 46.3 \\ \text { RK } & 99.7 \% & 38.0\end{array}$

$0.03 \% \quad 21.9 \%$ AACNLLQR 2067.06

1428.80

1567.78

$704 \quad 711$

$712 \quad 729$

$776 \quad 788$

$81 \quad 788$

949
966 976

$\begin{array}{lll}1173.60 & 977 \quad 986\end{array}$

946.44

1133.67

1551.77

1787.9

1913.98

1051.56

1410.83

1008.59

907.43

1435.75

1349.66

2160.12

906.48

1257.68

928.56

1907.97

2471.24

1774.93

1561.80

1289.75

898.43

1817.92

820.47

934.55

1913.98

1051.56

1713.94

1008.59

907.43

1433.75

2168.07

870.52

928.56

1637.78

1058.56

1787.91

945.49 2263.19
$979 \quad 986$

$987 \quad 995$

$1066 \quad 1078$

$202 \quad 210$

$257 \quad 269$

$302 \quad 310$

$302 \quad 315$

$346 \quad 356$

$398 \quad 419$

$475 \quad 485$

$622 \quad 629$

$655 \quad 672$

$655 \quad 677$

$699 \quad 713$

$716 \quad 727$

$17 \quad 35$

$40 \quad 47$

$101 \quad 108$

$185 \quad 201$

$287 \quad 301$

$293 \quad 301$

$302 \quad 310$

$302 \quad 315$

$398 \quad 420$

$425 \quad 432$

$623 \quad 630$

$700 \quad 714$

$\begin{array}{cc}26 & 44 \\ 10 & 117\end{array}$

$118 \quad 139$ 
ATP-dependent 6-phosphofructokinase, platelet type GN=PFKP PFKAP_HUMAN $85.60 \quad 100.0 \% \quad 1$ ATP-dependent 6-phosphofructokinase, platelet type GN=PFKP PFKAP_HUMAN $85.60 \quad 100.0 \% \quad 12$ $\begin{array}{lllll}\text { ATP-dependent 6-phosphofructokinase, platelet type GN=PFKP } & \text { PFKAP_HUMAN } & 85.60 & 100.0 \% & 12\end{array}$ ATP-dependent 6-phosphofructokinase, platelet type GN=PFKP PFKAP HUMAN $85.60 \quad 100.0 \%$ $\begin{array}{lllll}\text { ATP-dependent 6-phosphofructokinase, platelet type GN=PFKP } & \text { PFKAP_HUMAN } & 85.60 & 100.0 \% & 12\end{array}$ $\begin{array}{lllll}\text { ATP-dependent 6-phosphofructokinase, platelet type GN=PFKP } & \text { PFKAP_HUMAN } & 85.60 & 100.0 \% & 12\end{array}$ $\begin{array}{lllll}\text { ATP-dependent 6-phosphofructokinase, platelet type GN=PFKP } & \text { PFKAP_HUMAN } & 85.60 & 100.0 \% & 12\end{array}$ $\begin{array}{lllll}\text { ATP-dependent 6-phosphofructokinase, platelet type GN=PFKP } & \text { PFKAP_HUMAN } & 85.60 & 100.0 \% & 12\end{array}$ ATP-dependent 6-phosphofructokinase, platelet type GN=PFKP PFKAP HUMAN $85.60 \quad 100.0 \%$ $\begin{array}{lllll}\text { ATP-dependent 6-phosphofructokinase, platelet type GN=PFKP } & \text { PFKAP_HUMAN } & 85.60 & 100.0 \% & 12\end{array}$ $\begin{array}{lllll}\text { ATP-dependent 6-phosphofructokinase, platelet type GN=PFKP } & \text { PFKAP_HUMAN } & 85.60 & 100.0 \% & 12\end{array}$ ATP-dependent RNA helicase A GN=DHX9 DHX9_HUMAN $140.96 \quad 100.0 \% 22$ ATP-dependent RNA helicase A GN=DHX9 DHX9_HUMAN $140.96 \quad 100.0 \%$ ATP-dependent RNA helicase A GN=DHX9 DHX9_HUMAN $140.96 \quad 100.0 \% 22$ ATP-dependent RNA helicase A GN=DHX9 DHX9_HUMAN $140.96 \quad 100.0 \% 22$ ATP-dependent RNA helicase A GN=DHX9 DHX9_HUMAN $140.96 \quad 100.0 \% \quad 22$ ATP-dependent RNA helicase A GN=DHX9 DHX9 HUMAN $140.96 \quad 100.0 \% 22$ ATP-dependent RNA helicase A GN=DHX9 DHX9_HUMAN $140.96 \quad 100.0 \% \quad 22$ ATP-dependent RNA helicase A GN=DHX9 DHX9_HUMAN $140.96 \quad 100.0 \% \quad 22$ ATP-dependent RNA helicase A GN=DHX9 DHX9_HUMAN $140.96 \quad 100.0 \% 22$ ATP-dependent RNA helicase A GN=DHX9 DHX9_HUMAN $140.96 \quad 100.0 \% \quad 22$ ATP-dependent RNA helicase A GN=DHX9 DHX9_HUMAN $140.96 \quad 100.0 \% 22$ ATP-dependent RNA helicase A GN=DHX9 DHX9_HUMAN $140.96 \quad 100.0 \% 22$ ATP-dependent RNA helicase A GN=DHX9 DHX9_HUMAN $140.96 \quad 100.0 \% \quad 22$ ATP-dependent RNA helicase A GN=DHX9 DHX9_HUMAN $140.96 \quad 100.0 \% 22$ ATP-dependent RNA helicase A GN=DHX9 DHX9_HUMAN $140.96 \quad 100.0 \% \quad 22$ ATP-dependent RNA helicase A GN=DHX9 DHX9_HUMAN $140.96 \quad 100.0 \% 22$ ATP-dependent RNA helicase A GN=DHX9 DHX9_HUMAN $140.96 \quad 100.0 \% \quad 22$ ATP-dependent RNA helicase A GN=DHX9 DHX9_HUMAN $140.96 \quad 100.0 \% 22$ ATP-dependent RNA helicase A GN=DHX9 DHX9_HUMAN $140.96 \quad 100.0 \% 22$ ATP-dependent RNA helicase A GN=DHX9 DHX9_HUMAN $140.96 \quad 100.0 \% 22$ ATP-dependent RNA helicase A GN=DHX9 DHX9_HUMAN $140.96 \quad 100.0 \% 22$ ATP-dependent RNA helicase A GN=DHX9 DHX9_HUMAN $140.96 \quad 100.0 \% 22$ ATP-dependent RNA helicase DDX1 GN=DDX1 DDX1_HUMAN $82.43 \quad 100.0 \% \quad 2$ ATP-dependent RNA helicase DDX1 GN=DDX1 DDX1_HUMAN $82.43 \quad 100.0 \%$ ATP-dependent RNA helicase DDX18 GN=DDX18 DDX18_HUMAN $75.41 \quad 100.0 \%$ ATP-dependent RNA helicase DDX18 GN=DDX18 DDX18_HUMAN $75.41 \quad 100.0 \%$ ATP-dependent RNA helicase DDX18 GN=DDX18 DDX18_HUMAN $75.41 \quad 100.0 \%$ ATP-dependent RNA helicase DDX18 GN=DDX18 DDX18_HUMAN $75.41 \quad 100.0 \%$ ATP-dependent RNA helicase DDX18 GN=DDX18 DDX18_HUMAN 75.41 $100.0 \%$ ATP-dependent RNA helicase DDX18 GN=DDX18 DDX18_HUMAN $75.41 \quad 100.0 \%$ ATP-dependent RNA helicase DDX19A GN=DDX19A DD19A_HUMAN $53.98 \quad 100.0 \%$ ATP-dependent RNA helicase DDX19A GN=DDX19A DD19A_HUMAN $53.98 \quad 100.0 \%$ ATP-dependent RNA helicase DDX3X GN=DDX3X DDX3X_HUMAN $73.25 \quad 100.0 \%$ ATP-dependent RNA helicase DDX3X GN=DDX3X DDX3X_HUMAN $73.25 \quad 100.0 \%$ ATP-dependent RNA helicase DDX3X GN=DDX3X DDX3X_HUMAN $73.25 \quad 100.0 \%$ ATP-dependent RNA helicase DDX3X GN=DDX3X DDX3X_HUMAN $73.25 \quad 100.0 \%$

6

8
8
8
8

8

$0.03 \% \quad 21.9 \%$ IIEVVDAIMTTAQSHQR $0.03 \% \quad 21.9 \%$ TFVLEVMGR $0.03 \% 21.9 \%$ VTILGHVQR $0.03 \% \quad 21.9 \%$ GGTPSAFDR

$0.03 \% \quad 21.9 \%$ SFAGNLNTYKR

$0.03 \% \quad 21.9 \%$ LAIKLPDDQIPK

$0.03 \% \quad 21.9 \%$ TNCNVAVINVGAPAAGMNAAVR

$0.03 \% \quad 21.9 \%$ SAVRVGIADGHR

$0.03 \% 21.9 \%$ VGIADGHR

$0.03 \% \quad 21.9 \%$ NVIFQPVAELK

$0.03 \% \quad 21.9 \%$ NVIFQPVAELKK

$0.12 \% \quad 14.4 \%$ KMTPSYEIR

$0.12 \% \quad 14.4 \%$ MTPSYEIR

$0.12 \% \quad 14.4 \%$ DAQSNAARDFVNYLVR

$0.12 \% \quad 14.4 \%$ DFVNYLVR

$0.12 \% \quad 14.4 \%$ GANLKDYYSR

$0.12 \% \quad 14.4 \%$ LNQYFQKEK

$0.12 \% \quad 14.4 \%$ LAAQSCALSLVR

$0.12 \% \quad 14.4 \%$ LAQFEPSQR

$0.12 \% \quad 14.4 \%$ AAECNIVVTQPR

$0.12 \% \quad 14.4 \%$ RISAVSVAER

$0.12 \% \quad 14.4 \%$ ISAVSVAER

$0.12 \% \quad 14.4 \%$ KVFDPVPVGVTK

$0.12 \% \quad 14.4 \%$ VFDPVPVGVTK

$0.12 \% \quad 14.4 \%$ VRPGFCFHLCSR

$0.12 \% \quad 14.4 \%$ LGGIGQFLAK

$0.12 \% \quad 14.4 \%$ ILAKLPIEPR

$0.12 \% \quad 14.4 \%$ KILTTEGR

$0.12 \% \quad 14.4 \%$ ILTTEGRNALIHK

$0.12 \% \quad 14.4 \%$ QISRPSAAGINLMIGSTR

$0.12 \% \quad 14.4 \%$ YGDGPRPPK

$0.12 \% \quad 14.4 \%$ YGDGPRPPKMAR

$0.12 \% \quad 14.4 \%$ YDNGSGYR

$0.01 \% \quad 3.1 \%$ SQHSGNAQVTQTK

$0.01 \% \quad 3.1 \%$ FLICTDVAAR

$0.02 \% \quad 10.4 \%$ SIRPLLEGRDLLAAAK

$0.02 \% \quad 10.4 \%$ NGTGVLILSPTR

$0.02 \% \quad 10.4 \%$ SAEAQKLGNGINIIVATPGR

$0.02 \% \quad 10.4 \%$ LGNGINIIVATPGR

$0.02 \% \quad 10.4 \%$ QTMLFSATQTR

$0.02 \% \quad 10.4 \%$ SAQEAYKSYIR

$0.01 \% \quad 7.3 \%$ SNLVDNTNQVEVLQRDPNSPLYSVK

$0.01 \% \quad 7.3 \% \quad$ VLVTTNVCAR

$0.08 \% \quad 26.9 \%$ SSFFSDRGSGSR

$0.08 \% \quad 26.9 \%$ YTRPTPVQK

$0.08 \% \quad 26.9 \%$ DLMACAQTGSGK

$0.08 \% \quad 26.9 \%$ KQYPISLVLAPTR
$99.7 \% \quad 66.2$ $99.7 \% \quad 53.5$ $99.6 \% \quad 48.2$ $98.5 \% \quad 23.1$

$99.7 \% \quad 49.7$ $99.7 \% \quad 37.4$ $99.7 \% 29$. $99.2 \% \quad 19.4$ $99.0 \% \quad 47.0$ $99.7 \% \quad 31.8$ $99.7 \% \quad 37.9$ $99.7 \% \quad 38.1$ $99.0 \% \quad 19.5$ $99.7 \% \quad 33.8$ $99.0 \% \quad 45.6$ $99.7 \% \quad 25.8$ $99.7 \% \quad 32.7$ $99.7 \% \quad 55.8$ $\begin{array}{lll}99.7 \% & 49.7\end{array}$ $99.7 \% \quad 53.1$ $99.7 \% \quad 43.2$ $99.7 \% \quad 61.0$ $99.7 \% \quad 44.9$ $99.7 \% \quad 28.7$ $99.7 \% \quad 34.4$ $99.7 \% \quad 56.6$ $99.7 \% \quad 35.3$ $\begin{array}{lll}97.8 \% & 26.5\end{array}$ $99.7 \% \quad 29.1$ $99.7 \% \quad 53.8$ $99.7 \% \quad 49.1$ $\begin{array}{lll}95.8 \% & 14.5\end{array}$ $99.0 \% 37.1$ $99.7 \% \quad 43.3$ $\begin{array}{lll}99.7 \% & 49.7\end{array}$ $99.7 \% 26.0$ $99.7 \% \quad 39.0$ $99.7 \% \quad 34.3$ $\begin{array}{ll}99.7 \% & 51.9\end{array}$ $99.7 \% \quad 59.5$ $99.7 \% \quad 46.8$ $99.7 \% \quad 49.1$ $\begin{array}{lll}99.7 \% & 28.0\end{array}$ $99.7 \% \quad 25.6$ $97.7 \% \quad 21.1$ $99.7 \% \quad 54.0$ $99.7 \% \quad 49.8$
912.00 1051.56

1022.61

907.43

1270.65

1350.80

2170.09

1237.68

824.44

1257.72

1385.82

1124.58

996.48

1838.91

1025.54

1186.59

1197.63

1288.70

1075.55

1357.69

1087.62

931.52

1285.75

1157.66

1535.74

1003.59

1149.74

917.54

1465.85

1888.0

986.51

1360.68

931.39

1385.68

1165.60

1723.02

1227.71

2009.11

1394.81

1299.64

1315.66

2829.44

1132.61

1289.59

1089.61

1238.55 1485.88 $\begin{array}{cc}94 & 210 \\ 11 & 219 \\ 02 & 310 \\ 11 & 319 \\ 86 & 396 \\ 97 & 408 \\ 09 & 430 \\ 31 & 442 \\ 35 & 442 \\ 26 & 736 \\ 26 & 737 \\ 16 & 24 \\ 17 & 24 \\ 56 & 71 \\ 54 & 71 \\ 42 & 151 \\ 85 & 193 \\ 37 & 248 \\ 15 & 323 \\ 35 & 446 \\ 47 & 456 \\ 48 & 456 \\ 97 & 708 \\ 98 & 708 \\ 68 & 779 \\ 10 & 819 \\ 54 & 863 \\ 011 & 1018 \\ 012 & 1024 \\ 137 & 1154 \\ 155 & 1163 \\ 155 & 1166 \\ 167 & 1174 \\ 69 & 281 \\ 68 & 577 \\ 09 & 224 \\ 50 & 261 \\ 92 & 311 \\ 98 & 311 \\ 59 & 369 \\ 78 & 588 \\ 57 & 91 \\ 85 & 394 \\ 92 & 93 \\ 00 & 208 \\ 19 & 230 \\ 64 & 276\end{array}$ 
Bcl-2-associated transcription factor 1 GN=BCLAF1 BCLF1_HUMAN $106.13 \quad 100.0 \% \quad 24$ Bcl-2-associated transcription factor 1 GN=BCLAF1 BCLF1_HUMAN $106.13 \quad 100.0 \% 24$ Bcl-2-associated transcription factor 1 GN=BCLAF1 BCLF1_HUMAN $106.13 \quad 100.0 \% 24$ Bcl-2-associated transcription factor $1 \mathrm{GN}=\mathrm{BCLAF} 1 \mathrm{BCLF} 1$ HUMAN $106.13 \quad 100.0 \% 24$ $\begin{array}{lllll}\text { Bcl-2-associated transcription factor } 1 \mathrm{GN}=\mathrm{BCLAF} 1 & \mathrm{BCLF} 1 \text { HUMAN } & 106.13 & 100.0 \% & 24\end{array}$ Bcl-2-associated transcription factor 1 GN=BCLAF1 BCLF1_HUMAN $106.13 \quad 100.0 \% 24$ Bcl-2-associated transcription factor $1 \mathrm{GN}=\mathrm{BCLAF} 1$ BCLF1_HUMAN $106.13 \quad 100.0 \%$ Bcl-2-associated transcription factor $1 \mathrm{GN}=\mathrm{BCLAF} 1 \mathrm{BCLF} 1$ HUMAN $106.13 \quad 100.0 \% \quad 24$ Bcl-2-associated transcription factor $1 \mathrm{GN}=\mathrm{BCLAF} 1$ BCLF1_HUMAN $106.13 \quad 100.0 \%$ Bcl-2-associated transcription factor $1 \mathrm{GN}=\mathrm{BCLAF} 1 \mathrm{BCLF} 1$ HUMAN $106.13 \quad 100.0 \% 24$ Bcl-2-associated transcription factor $1 \mathrm{GN}=\mathrm{BCLAF} 1$ BCLF1_HUMAN $106.13 \quad 100.0 \% \quad 24$ Bcl-2-associated transcription factor 1 GN=BCLAF1 BCLF1_HUMAN $106.13 \quad 100.0 \% 24$ Bcl-2-associated transcription factor $1 \mathrm{GN}=\mathrm{BCLAF} 1 \mathrm{BCLF} 1$ HUMAN $106.13 \quad 100.0 \% \quad 24$ Bcl-2-associated transcription factor $1 \mathrm{GN}=\mathrm{BCLAF} 1$ BCLF1_HUMAN $106.13 \quad 100.0 \%$ Bcl-2-associated transcription factor $1 \mathrm{GN}=\mathrm{BCLAF} 1$ BCLF1_HUMAN $106.13 \quad 100.0 \% \quad 24$ Beta-galactosidase $\mathrm{GN}=\mathrm{GLB}$ Beta-galactosidase $\mathrm{GN}=\mathrm{GLB} 1$ Beta-galactosidase $\mathrm{GN}=\mathrm{GLB} 1$ Beta-galactosidase $\mathrm{GN}=\mathrm{GLB}$ Beta-galactosidase $\mathrm{GN}=\mathrm{GLB}$ Beta-galactosidase $\mathrm{GN}=\mathrm{GLB}$ Beta-galactosidase $\mathrm{GN}=\mathrm{GLB}$ Beta-galactosidase $\mathrm{GN}=\mathrm{GLB} 1$ BGAL_HUMAN $76.08 \quad 100.0 \%$ BGAL_HUMAN $76.08 \quad 100.0 \% \quad 8$ BGAL_HUMAN $76.08 \quad 100.0 \%$ BGAL_HUMAN $76.08 \quad 100.0 \%$ BGAL HUMAN $76.08 \quad 100.0 \% \quad 8$ BGAL_HUMAN $76.08 \quad 100.0 \% \quad 8$ BGAL_HUMAN $76.08 \quad 100.0 \%$ BGAL_HUMAN $76.08 \quad 100.0 \%$ Bifunctional glutamate/proline--tRNA ligase GN=EPRS SYEP_HUMAN $170.59 \quad 100.0 \%$ Bifunctional glutamate/proline--tRNA ligase GN=EPRS SYEP_HUMAN $170.59 \quad 100.0 \%$ Bifunctional glutamate/proline--tRNA ligase GN=EPRS SYEP_HUMAN $170.59100 .0 \%$ Bifunctional glutamate/proline--tRNA ligase GN=EPRS SYEP_HUMAN $170.59 \quad 100.0 \%$ Bifunctional glutamate/proline--tRNA ligase GN=EPRS SYEP_HUMAN $170.59 \quad 100.0 \%$ Bifunctional glutamate/proline--tRNA ligase GN=EPRS SYEP HUMAN $170.59100 .0 \%$ Bifunctional glutamate/proline--tRNA ligase GN=EPRS SYEP_HUMAN $170.59 \quad 100.0 \%$ Bifunctional glutamate/proline--tRNA ligase GN=EPRS SYEP_HUMAN $170.59 \quad 100.0 \%$ Bifunctional glutamate/proline--tRNA ligase GN=EPRS SYEP HUMAN $170.59100 .0 \%$ Bifunctional glutamate/proline--tRNA ligase GN=EPRS SYEP_HUMAN $170.59 \quad 100.0 \%$ Bifunctional glutamate/proline--tRNA ligase GN=EPRS SYEP_HUMAN $170.59 \quad 100.0 \%$ Bifunctional glutamate/proline--tRNA ligase GN=EPRS SYEP_HUMAN $170.59 \quad 100.0 \%$ Bifunctional glutamate/proline--tRNA ligase GN=EPRS SYEP_HUMAN $170.59 \quad 100.0 \%$ Bifunctional glutamate/proline--tRNA ligase GN=EPRS SYEP HUMAN $170.59 \quad 100.0 \%$

2 MTDC_HUMAN $37.90 \quad 100.0 \%$ MTDC HUMAN $37.90 \quad 100.0 \%$ MTDC HUMAN 37.90 MTDC_HUMAN $37.90 \quad 100.0 \%$ BLM HUMAN $159.01 \quad 100.0 \%$ $\begin{array}{lll}\text { BLM_HUMAN } & 159.01 & 100.0 \% \\ \text { BRAT1_HUMAN } 88.12 & 100.0 \%\end{array}$ Bloom syndrome protein $\mathrm{GN}=\mathrm{BLN}$ Bloom syndrome protein $\mathrm{GN}=\mathrm{BLM}$ BRCA1-associated ATM activator $1 \mathrm{GN}=$ BRAT1 BRAT1 HUMAN $88.12 \quad 100.0 \%$

(5)

5

5

15

2

2

$0.11 \% \quad 22.8 \%$ SFATASHR

$0.11 \% \quad 22.8 \%$ ETQSPEQVKSEK

$0.11 \% \quad 22.8 \%$ LKDLFDYSPPLHK

$0.11 \% 22.8 \%$ STFREESPLR

$0.11 \% 22.8 \%$ MIASDSHRPEVK

$0.11 \% 22.8 \%$ LLASTLVHSVK

$0.11 \% \quad 22.8 \%$ SIFDHIKLPQASK

$0.11 \% \quad 22.8 \%$ SAAMTLNER

$0.11 \% \quad 22.8 \%$ SAAMTLNERFTSYQK

$0.11 \% 22.8 \%$ RIDISPSTLR

$0.11 \% \quad 22.8 \%$ IDISPSTLRK

$0.11 \% \quad 22.8 \%$ SSSSSASPSSPSSR

$0.11 \% \quad 22.8 \%$ RPKEEEWDPEYTPK

$0.02 \% \quad 16.8 \%$ DSFLKDGQPFR

$0.02 \% \quad 16.8 \%$ YISGSIHYSR

$0.02 \% \quad 16.8 \%$ TEAVASSLYDILAR

$0.02 \% \quad 16.8 \%$ TVGAALDILCPSGPIK

$0.02 \% \quad 16.8 \%$ SLYPLTFIQVK

$0.02 \% \quad 16.8 \%$ TTLPQDCSNPAPLSSPLNGVHDR

$0.02 \% \quad 16.8 \%$ AYVAVDGIPQGVLER

$0.02 \% \quad 16.8 \%$ AGATLDLLVENMGR

$0.04 \% \quad 10.6 \%$ FVELPGAEMGK

$0.04 \% \quad 10.6 \%$ GSQFGQSCCLR

$0.04 \% \quad 10.6 \%$ LNLNNTVLSK

$0.04 \% \quad 10.6 \%$ LNLNNTVLSKR

$0.04 \% \quad 10.6 \%$ NPEVGLKPVWYSPK

$0.04 \% \quad 10.6 \%$ VAVQGDVVR

$0.04 \% \quad 10.6 \%$ VAVQGDVVRELK

$0.04 \% \quad 10.6 \%$ SLYDEVAAQGEVVR

$0.04 \% \quad 10.6 \%$ SLYDEVAAQGEVVRK

$0.04 \% \quad 10.6 \%$ NSEPAGLETPEAK

$\begin{array}{ll}0.04 \% & 10.6 \% \\ 0.04 \% & 10.6 \% \text { VLFDKVASQGEVVR }\end{array}$

$0.04 \% \quad 10.6 \%$ NQGGGLSSSGAGEGQGPK

$0.04 \% \quad 10.6 \%$ AIQGGTSHHLGQNFSK

$0.04 \% \quad 10.6 \%$ RLLSVNIR

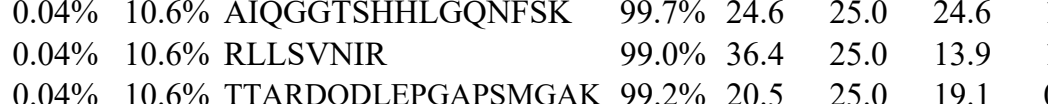

$0.01 \% \quad 9.1 \%$ VHDPVTAKPK

$0.01 \% \quad 9.1 \%$ LVGDVDFEGVR

$0.01 \% \quad 9.1 \%$ LVGDVDFEGVRQK

$0.01 \% \quad 9.1 \%$ SKELGVATN

$0.00 \% \quad 1.6 \%$ LISTLENLYER

$0.00 \% \quad 1.6 \%$ SVEGYYQESGR

$0.00 \% \quad 2.8 \%$ VTQALNVLTTTFGR

$0.00 \% \quad 2.8 \% \quad$ SSCAGLLCR

$0.01 \% \quad 1.6 \%$ TCYNIYLASK
$99.0 \% 029.5$

$\begin{array}{lllll}99.7 \% & 56.2 & 25.0 & 36.8 & 12\end{array}$

$\begin{array}{llll}99.7 \% & 43.9 & 25.0 & 40.5\end{array}$

$\begin{array}{llll}97.0 \% & 15.9 & 25.0 & 15.9\end{array}$

$\begin{array}{llll}99.4 \% & 20.3 & 25.0 & 19.1\end{array}$

$\begin{array}{llll}99.7 \% & 32.9 & 25.0 & 31.7\end{array}$

$\begin{array}{lllll}99.7 \% & 29.3 & 25.0 & 29.3 & 2\end{array}$

$\begin{array}{llll}99.7 \% & 32.1 & 25.0 & 25.5\end{array}$

$\begin{array}{llll}99.7 \% & 34.0 & 25.0 & 21.7\end{array}$

$99.7 \% \quad 27.4 \quad 25.0 \quad 27.4$

$\begin{array}{llll}99.7 \% & 39.2 & 25.0 & 29.8\end{array}$

$\begin{array}{lllll}97.6 \% & 20.4 & 25.0 & 14.6 & 2\end{array}$

$\begin{array}{llll}99.7 \% & 42.6 & 25.0 & 42.6\end{array}$

$99.7 \% \quad 32.6 \quad 25.0 \quad 32.6$

$\begin{array}{llll}99.4 \% & 27.5 & 25.0 & 27.5\end{array}$

$\begin{array}{llll}99.7 \% & 52.5 & 25.0 & 52.3\end{array}$

$\begin{array}{lllll}99.7 \% & 63.9 & 25.0 & 55.1\end{array}$

$\begin{array}{llll}99.7 \% & 62.5 & 25.0 & 62.5\end{array}$

$\begin{array}{llll}99.7 \% & 27.3 & 25.0 & 27.3\end{array}$

$\begin{array}{llll}99.7 \% & 32.6 & 25.0 & 32.6\end{array}$

$\begin{array}{lllll}99.7 \% & 41.1 & 25.0 & 41.1 & 2\end{array}$

$\begin{array}{llll}99.7 \% & 73.7 & 25.0 & 64.6\end{array}$

$\begin{array}{llll}98.6 \% & 23.1 & 25.0 & 17.4\end{array}$

$\begin{array}{llll}99.7 \% & 40.5 & 25.0 & 40.5\end{array}$

$99.7 \% \quad 49.0 \quad 25.0 \quad 47.6$

$\begin{array}{llll}99.7 \% & 26.9 & 25.0 & 17.7\end{array}$

$\begin{array}{llll}99.7 \% & 39.0 & 25.0 & 36.1\end{array}$

$\begin{array}{lllll}99.6 \% & 26.9 & 25.0 & 17.3 & 2\end{array}$

$\begin{array}{llll}99.7 \% & 42.5 & 25.0 & 31.5\end{array}$

$\begin{array}{lllll}99.7 \% & 54.4 & 25.0 & 54.4 & 2\end{array}$

$\begin{array}{llll}99.7 \% & 35.1 & 25.0 & 34.2\end{array}$

$\begin{array}{llll}99.7 \% & 54.6 & 25.0 & 48.9\end{array}$

$\begin{array}{llll}99.7 \% & 50.0 & 25.0 & 50.0\end{array}$

$\begin{array}{llll}99.2 \% & 20.5 & 25.0 & 19.1 \\ 98.6 \% & 17.9 & 25.0 & 17.9\end{array}$

$99.7 \% \quad 55.7 \quad 25.0 \quad 54.8 \quad 2$

$\begin{array}{llll}99.7 \% & 52.2 & 25.0 & 48.6\end{array}$

$\begin{array}{lllll}99.7 \% & 35.6 & 25.0 & 32.7 & 2\end{array}$

$\begin{array}{llll}99.7 \% & 30.8 & 25.0 & 28.2\end{array}$

$\begin{array}{lllll}99.7 \% & 60.4 & 25.0 & 60.4\end{array}$

$\begin{array}{lllll}99.7 \% & 35.0 & 25.0 & 35.0 & 1\end{array}$

$\begin{array}{lllll}99.7 \% & 34.6 & 25.0 & 18.0\end{array}$

$99.7 \% \quad 34.9 \quad 25.0 \quad 19.9$ $\begin{array}{llll}99.7 \% & 55.0 & 25.0 & 55.0\end{array}$ 
C-1-tetrahydrofolate synthase, cytoplasmic GN=MTHFD1 C1TC_HUMAN $101.56 \quad 100.0 \%$

C-1-tetrahydrofolate synthase, cytoplasmic GN=MTHFD1 C1TC_HUMAN $101.56 \quad 100.0 \%$

C-1-tetrahydrofolate synthase, cytoplasmic GN=MTHFD1 C1TC_HUMAN $101.56 \quad 100.0 \%$

C-1-tetrahydrofolate synthase, cytoplasmic GN=MTHFD1 C1TC_HUMAN $101.56 \quad 100.0 \%$

C-1-tetrahydrofolate synthase, cytoplasmic GN=MTHFD1 C1TC_HUMAN $101.56 \quad 100.0 \%$

C-1-tetrahydrofolate synthase, cytoplasmic GN=MTHFD1 C1TC_HUMAN $101.56 \quad 100.0 \%$

C-1-tetrahydrofolate synthase, cytoplasmic GN=MTHFD1 C1TC_HUMAN $101.56 \quad 100.0 \%$

C-1-tetrahydrofolate synthase, cytoplasmic GN=MTHFD1 C1TC_HUMAN $101.56 \quad 100.0 \%$

C-1-tetrahydrofolate synthase, cytoplasmic GN=MTHFD1 C1TC HUMAN $101.56100 .0 \%$

C-1-tetrahydrofolate synthase, cytoplasmic GN=MTHFD1 C1TC_HUMAN $101.56 \quad 100.0 \%$

C-1-tetrahydrofolate synthase, cytoplasmic GN=MTHFD1 C1TC_HUMAN $101.56 \quad 100.0 \%$

C-1-tetrahydrofolate synthase, cytoplasmic GN=MTHFD1 C1TC HUMAN $101.56100 .0 \%$

C-1-tetrahydrofolate synthase, cytoplasmic GN=MTHFD1 C1TC_HUMAN $101.56 \quad 100.0 \%$

$\mathrm{CAD}$ protein $\mathrm{GN}=\mathrm{CAD}$

$\mathrm{CAD}$ protein $\mathrm{GN}=\mathrm{CAD}$

$\mathrm{CAD}$ protein $\mathrm{GN}=\mathrm{CAD}$

$\mathrm{CAD}$ protein $\mathrm{GN}=\mathrm{CAD}$

$\mathrm{CAD}$ protein $\mathrm{GN}=\mathrm{CAD}$

$\mathrm{CAD}$ protein $\mathrm{GN}=\mathrm{CAD}$

$\mathrm{CAD}$ protein $\mathrm{GN}=\mathrm{CAD}$

$\mathrm{CAD}$ protein $\mathrm{GN}=\mathrm{CAD}$

$\mathrm{CAD}$ protein $\mathrm{GN}=\mathrm{CAD}$

$\mathrm{CAD}$ protein $\mathrm{GN}=\mathrm{CAD}$

$\mathrm{CAD}$ protein $\mathrm{GN}=\mathrm{CAD}$

$\mathrm{CAD}$ protein $\mathrm{GN}=\mathrm{CAD}$

$\mathrm{CAD}$ protein $\mathrm{GN}=\mathrm{CAD}$

$\mathrm{CAD}$ protein $\mathrm{GN}=\mathrm{CAD}$

$\mathrm{CAD}$ protein $\mathrm{GN}=\mathrm{CAD}$

$\mathrm{CAD}$ protein $\mathrm{GN}=\mathrm{CAD}$

$\mathrm{CAD}$ protein $\mathrm{GN}=\mathrm{CAD}$

$\mathrm{CAD}$ protein $\mathrm{GN}=\mathrm{CAD}$

$\mathrm{CAD}$ protein $\mathrm{GN}=\mathrm{CAD}$

$\mathrm{CAD}$ protein $\mathrm{GN}=\mathrm{CAD}$

$\mathrm{CAD}$ protein $\mathrm{GN}=\mathrm{CAD}$

$\mathrm{CAD}$ protein $\mathrm{GN}=\mathrm{CAD}$

$\mathrm{CAD}$ protein $\mathrm{GN}=\mathrm{CAD}$

$\mathrm{CAD}$ protein $\mathrm{GN}=\mathrm{CAD}$

$\mathrm{CAD}$ protein $\mathrm{GN}=\mathrm{CAD}$

$\mathrm{CAD}$ protein $\mathrm{GN}=\mathrm{CAD}$

PYR1_HUMAN $242.98 \quad 100.0 \% \quad 32$ PYR1_HUMAN $242.98 \quad 100.0 \% \quad 32$ PYR1_HUMAN $242.98 \quad 100.0 \% \quad 32$ PYR1_HUMAN $242.98 \quad 100.0 \% \quad 32$ PYR1_HUMAN $242.98 \quad 100.0 \% \quad 32$ PYR1_HUMAN $242.98 \quad 100.0 \% \quad 32$ PYR1 HUMAN $242.98 \quad 100.0 \% \quad 32$ PYR1_HUMAN $242.98 \quad 100.0 \% \quad 32$ PYR1 HUMAN $242.98 \quad 100.0 \% \quad 32$ PYR1_HUMAN $242.98 \quad 100.0 \% \quad 32$ PYR1_HUMAN $242.98 \quad 100.0 \% \quad 32$ PYR1 HUMAN $242.98 \quad 100.0 \% \quad 32$ PYR1_HUMAN $242.98 \quad 100.0 \% \quad 32$ PYR1_HUMAN $242.98 \quad 100.0 \% \quad 32$ PYR1 HUMAN $242.98 \quad 100.0 \% \quad 32$ PYR1_HUMAN $242.98 \quad 100.0 \% \quad 32$ PYR1 HUMAN $242.98 \quad 100.0 \% \quad 32$ PYR1_HUMAN $242.98 \quad 100.0 \% \quad 32$ PYR1_HUMAN $242.98 \quad 100.0 \% \quad 32$ PYR1 HUMAN $242.98 \quad 100.0 \% \quad 32$ PYR1_HUMAN $242.98 \quad 100.0 \% \quad 32$ PYR1_HUMAN $242.98 \quad 100.0 \% \quad 32$ PYR1 HUMAN $242.98 \quad 100.0 \% \quad 32$ PYR1_HUMAN $242.98 \quad 100.0 \% \quad 32$ PYR1 HUMAN $242.98 \quad 100.0 \% \quad 32$ PYR1_HUMAN $242.98 \quad 100.0 \% \quad 32$

$0.01 \% \quad 1.6 \%$ ALMEAVSHAK $0.01 \% \quad 1.6 \%$ AFNSNYEQR $0.01 \% \quad 3.5 \%$ GKLSSSFSSR $0.01 \% \quad 3.5 \%$ SANNTPENSPNFPNFR $0.01 \% \quad 3.5 \% \quad$ LSLQESESK $\begin{array}{llll} & \end{array}$ $0.00 \% \quad 9.2 \%$ GVGGQEKHAPLADQILAGNAVR $\quad 99.7 \% \quad 34.6$ $\begin{array}{llllll}0.00 \% & 9.2 \% & \text { ELQSAVPRDVEDVPITVE } & 99.7 \% & 31.2\end{array}$ $0.03 \% \quad 18.0 \%$ APAEILNGKEISAQIR $0.03 \% \quad 18.0 \%$ GDLNDCFIPCTPK $0.03 \% \quad 18.0 \%$ VVGDVAYDEAKER $0.03 \% \quad 18.0 \%$ TPVPSDIDISR $0.03 \% \quad 18.0 \%$ VLLSALER $0.03 \% \quad 18.0 \%$ YVVVTGITPTPLGEGK $0.03 \% \quad 18.0 \%$ FSDIQIRR $0.03 \% \quad 18.0 \%$ VLDTNDRFLR $99.7 \% \quad 53.8$ $99.7 \% \quad 29.2$ $99.7 \% \quad 65.1$ $99.7 \% \quad 28.9$ $99.0 \% \quad 42.6$ $99.7 \% \quad 50.0$ $99.0 \% \quad 22.1$ $97.3 \% \quad 18.6$ 0.03\% $18.0 \%$ YSGLCPHVVVLVATVR $\quad 99.7 \% \quad 52.3$ $0.03 \% \quad 18.0 \%$ ALKMHGGGPTVTAGLPLPK $0.03 \% \quad 18.0 \%$ QGFGNLPICMAK $0.03 \% \quad 18.0 \%$ THLSLSHNPEQK $0.03 \% \quad 18.0 \%$ GVPTGFILPIRDIR $0.12 \% \quad 15.4 \%$ VFNTGGAPR

$0.12 \% \quad 15.4 \%$ ILALDCGLKYNQIR $0.12 \% \quad 15.4 \%$ GHNQPCLLVGSGR $0.12 \% \quad 15.4 \%$ LCPPGIPTPGSGLPPPR $0.12 \% \quad 15.4 \%$ LGYPVLVR $0.12 \% \quad 15.4 \%$ ATGYPLAYVAAK $0.12 \% \quad 15.4 \%$ LALGIPLPELR $\begin{array}{llll}99.1 \% & 21.1 & 25.0 & 21.1\end{array}$ $\begin{array}{llll}99.7 \% & 36.5 & 25.0 & 34.7\end{array}$ $99.7 \% \quad 54.2 \quad 25.0 \quad 47.3$ $95.7 \% \quad 18.0 \quad 25.0 \quad 12.6$ $99.7 \% \quad 35.5 \quad 25.0 \quad 23.2$ $99.7 \% \quad 54.8 \quad 25.0 \quad 54.8$ $\begin{array}{lllll}99.7 \% & 33.8 & 25.0 & 33.8 & 2\end{array}$ $99.7 \% \quad 24.2 \quad 25.0 \quad 22.5$ $99.0 \% \quad 49.0 \quad 25.0 \quad 43.2$ $99.7 \% \quad 52.0 \quad 25.0 \quad 52.0$ $99.7 \% \quad 39.7 \quad 25.0 \quad 39.7$ $\begin{array}{lllllll}0.12 \% & 15.4 \% & \text { NSVTGGTAAFEPSVDYCVVK } & 99.7 \% & 53.6 & 25.0 & 53.6\end{array}$

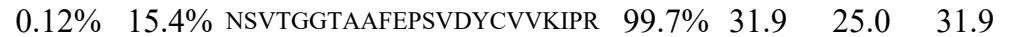
$0.12 \% \quad 15.4 \%$ SVGEVMGIGR $0.12 \% \quad 15.4 \%$ SFEEAFQK $0.12 \% \quad 15.4 \%$ IIAHAQLLEQHR $0.12 \% \quad 15.4 \%$ GQPLPPDLLQQAK $0.12 \% \quad 15.4 \%$ TPHVLVLGSGVYR $0.12 \% \quad 15.4 \%$ VLGTSPEAIDSAENR $0.12 \% \quad 15.4 \%$ VLGTSPEAIDSAENRFK $0.12 \% \quad 15.4 \%$ LLDTIGISQPQWR

$0.12 \% \quad 15.4 \%$ ELSDLESAR $99.7 \% \quad 34.1 \quad 25.0 \quad 22.3$ $99.0 \% \quad 28.8 \quad 25.0 \quad 23.2$ $99.7 \% \quad 40.2 \quad 25.0 \quad 40.2$ $99.2 \% \quad 21.9 \quad 25.0 \quad 21.9$ $99.7 \% \quad 44.1 \quad 25.0 \quad 44.1$ $99.7 \% \quad 32.0 \quad 25.0 \quad 32.0$ $\begin{array}{llll}99.7 \% & 34.2 & 25.0 & 34.2\end{array}$ $99.7 \% \quad 44.8 \quad 25.0 \quad 44.8$ $\begin{array}{llll}99.7 \% & 46.3 & 25.0 & 38.3\end{array}$

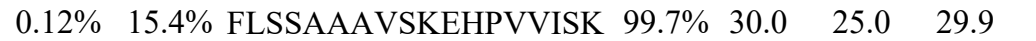
$0.12 \% \quad 15.4 \%$ EHPVVISK $0.12 \% \quad 15.4 \%$ TLGVDLVALATR $0.12 \% \quad 15.4 \%$ VPQFSFSR $0.12 \% \quad 15.4 \%$ KNILLTIGSYK $0.12 \% \quad 15.4 \%$ NKSELLPTVR $0.12 \% \quad 15.4 \%$ SELLPTVR $0.12 \% \quad 15.4 \%$ KEEILLIK

105

0

1676.92

1394.70

1712.92

916.56

1224.66

1191.75

2100.99

2467.23

1004.52

985.46

1428.81

1404.78

1397.79

1558.77

1833.93

1526.83

1019.50

1870.04

908.52

1228.73

967.50

1249.75

1156.67

914.53

985.63 
$\mathrm{CAD}$ protein $\mathrm{GN}=\mathrm{CAD}$ $\mathrm{CAD}$ protein $\mathrm{GN}=\mathrm{CAD}$ $\mathrm{CAD}$ protein $\mathrm{GN}=\mathrm{CAD}$ $\mathrm{CAD}$ protein $\mathrm{GN}=\mathrm{CAD}$ $\mathrm{CAD}$ protein $\mathrm{GN}=\mathrm{CAD}$ $\mathrm{CAD}$ protein $\mathrm{GN}=\mathrm{CAD}$

PYR1_HUMAN $242.98 \quad 100.0 \% \quad 32 \quad 36 \quad 84 \quad 0.12 \% \quad 15.4 \%$ AHWTPFEGQK PYR1_HUMAN $242.98 \quad 100.0 \% \quad 32 \quad 36 \quad 84 \quad 0.12 \% \quad 15.4 \%$ ASDPGLPAEEPKEK PYR1_HUMAN $242.98 \quad 100.0 \% \quad 32$ PYR1_HUMAN $242.98 \quad 100.0 \% \quad 32$ PYR1_HUMAN $242.98 \quad 100.0 \% \quad 32$ PYR1_HUMAN $242.98 \quad 100.0 \% \quad 32$ Calcium-binding mitochondrial carrier protein Aralar1 GN=SLC25A12 CMC1_HUMAN $74.76 \quad 100.0 \% \quad 2$ $\begin{array}{llll}\text { Calcium-binding mitochondrial carrier protein Aralar1 } \mathrm{GN}=\mathrm{SLC} 25 \mathrm{~A} 12 & \mathrm{CMC} 1 \text { _HUMAN } & 74.76 & 100.0 \%\end{array}$

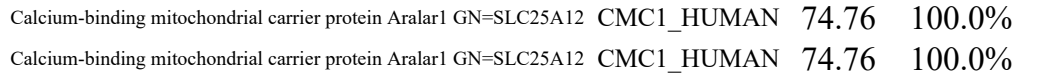
$\begin{array}{llll}\text { Calcium-binding mitochondrial carrier protein Aralarl GN=SLC25A12 } & \mathrm{CMC1} 1 \mathrm{HUMAN} & 74.76 & 100.0 \% \\ \text { Calcium-binding mitochondrial carrier protein Aralar1 GN=SLC25A12 } & \mathrm{CMC1} 1 \text { HUMAN } & 74.76 & 100.0 \%\end{array}$ Calcium-binding mitochondrial carrier protein Aralarl GN=SLC25A12 CMC1_HUMAN 74.76 100.0\% Calcium-binding mitochondrial carrier protein Aralar $1 \mathrm{GN}=\mathrm{SLC} 25 \mathrm{~A} 12 \mathrm{CMC} 1$ _HUMAN $74.76 \quad 100.0 \%$ Calcium-binding mitochondrial carrier protein Aralarl GN=SLC25A12 CMC1_HUMAN $74.76 \quad 100.0 \%$ Calcium-binding mitochondrial carrier protein Aralarl GN=SLC25A12 CMC1_HUMAN $74.76 \quad 100.0 \%$ Calcium-binding mitochondrial carrier protein Aralar2 GN=SLC25A13 CMC2_HUMAN $74.18 \quad 100.0 \%$ Calcium-binding mitochondrial carrier protein Aralar2 GN=SLC25A13 CMC2 HUMAN $74.18100 .0 \%$ Calcium-binding mitochondrial carrier protein Aralar2 GN=SLC25A13 CMC2_HUMAN 74.18 $100.0 \%$ Calcium-binding mitochondrial carrier protein Aralar2 $\mathrm{GN}=\mathrm{SLC} 25 \mathrm{~A} 13 \mathrm{CMC} 2$ HUMAN $74.18 \quad 100.0 \%$ Calcium-binding mitochondrial carrier protein Aralar2 $\mathrm{GN}=\mathrm{SLC} 25 \mathrm{~A} 13 \mathrm{CMC} 2$ HUMAN $74.18 \quad 100.0 \%$ Calcium-binding mitochondrial carrier protein Aralar2 GN=SLC25A13 CMC2_HUMAN $74.18 \quad 100.0 \%$ Calcium-binding mitochondrial carrier protein Aralar2 GN=SLC25A13 CMC2_HUMAN $74.18 \quad 100.0 \%$ Calcium-binding mitochondrial carrier protein Aralar2 $\mathrm{GN}=\mathrm{SLC} 25 \mathrm{~A} 13 \mathrm{CMC} 2$ HUMAN $74.18 \quad 100.0 \%$ Calcium-binding mitochondrial carrier protein Aralar2 GN=SLC25A13 CMC2_HUMAN 74.18 $100.0 \%$ Calcium-binding mitochondrial carrier protein Aralar2 $\mathrm{GN}=\mathrm{SLC} 25 \mathrm{~A} 13 \mathrm{CMC} 2 \mathrm{HUMAN} 74.18 \quad 100.0^{\circ}$ Calcium-binding mitochondrial carrier protein Aralar2 GN=SLC25A13 $\mathrm{CMC}_{2}$ HUMAN $74.18 \quad 100.0 \%$ Calcium-binding mitochondrial carrier protein Aralar2 GN=SLC25A13 CMC2_HUMAN $74.18 \quad 100.0 \%$ Calcium-binding mitochondrial carrier protein Aralar2 $\mathrm{GN}=\mathrm{SLC} 25 \mathrm{~A} 13 \mathrm{CMC} 2$ HUMAN $74.18 \quad 100.0 \%$ Calcium-binding mitochondrial carrier protein Aralar2 GN=SLC25A13 CMC2_HUMAN $74.18 \quad 100.0 \%$ Calcium-binding mitochondrial carrier protein Aralar2 GN=SLC25A13 $\mathrm{CMC} 2$ HUMAN $74.18 \quad 100.0^{\circ}$ Calcium-binding mitochondrial carrier protein Aralar2 $\mathrm{GN}=\mathrm{SLC} 25 \mathrm{~A} 13 \quad \mathrm{CMC} 2$ _HUMAN $74.18 \quad 100.0 \%$ Calcium-binding mitochondrial carrier protein Aralar2 GN=SLC25A13 CMC2_HUMAN $74.18 \quad 100.0 \%$ Calcium-binding mitochondrial carrier protein Aralar2 GN=SLC25A13 CMC2 HUMAN $74.18 \quad 100.0 \%$ Calcium-binding mitochondrial carrier protein SCaMC-1 GN=SLC25A24 SCMC1_HUMAN $53.36 \quad 100.0 \%$ Calcium-binding mitochondrial carrier protein SCaMC-1 GN=SLC25A24 SCMC1_HUMAN 53.36 Calcium-binding mitochondrial carrier protein SCaMC-1 GN=SLC25A24 SCMC1_HUMAN 53.36100 .0 Calcium-binding mitochondrial carrier protein SCaMC-1 GN=SLC25A24 SCMC1_HUMAN $53.36 \quad 100.0$ Calcium-binding mitochondrial carrier protein SCaMC-1 GN=SLC25A24 SCMC1 HUMAN $53.36 \quad 100.0^{\circ}$ Calcium-binding mitochondrial carrier protein SCaMC-1 GN=SLC25A24 SCMC1_HUMAN $53.36 \quad 100.0 \%$ Calcium-binding mitochondrial carrier protein SCaMC-1 GN=SLC25A24 SCMC1_HUMAN 53.36 Calcium-binding mitochondrial carrier protein SCaMC-1 GN=SLC25A24 SCMC1_HUMAN 53.36100 .0 Calcium-binding mitochondrial carrier protein SCaMC-1 GN=SLC25A24 SCMC1_HUMAN $53.36 \quad 100.0$ Calcium-binding mitochondrial carrier protein SCaMC-1 GN=SLC25A24 SCMC1_HUMAN $53.36100 .0^{\circ}$ Calcium-binding mitochondrial carrier protein SCaMC-1 GN=SLC25A24 SCMC1 HUMAN $53.36 \quad 100.0 \%$ Calcium-binding mitochondrial carrier protein SCaMC-1 GN=SLC25A24 SCMC1_HUMAN $53.36 \quad 100.0$ Calmodulin-regulated spectrin-associated protein $3 \mathrm{GN}=\mathrm{CAMSAP3}$ CAMP3 HUMAN $134.75100 .0 \%$ Calmodulin-regulated spectrin-associated protein 3 GN=CAMSAP3 CAMP3_HUMAN $134.75 \quad 100.0 \%$

$40 \quad 0.05 \% \quad 27.0 \%$ DLGFFGIYKGAK
$0.12 \% \quad 15.4 \%$ TSSSFAAAMAR

$\begin{array}{llllllll}99.7 \% & 25.6 & 25.0 & 25.6 & 2 & 0 & 0 & 1200.58\end{array}$ $99.7 \% \quad 35.4$ $99.7 \% \quad 67.9$

0.12\% LGGAVLSFSEATSSVQK

$0.12 \% \quad 15.4 \%$ YVAPPSLR

$0.12 \% \quad 15.4 \%$ VNEISVEVDSDPR

$99.0 \% 34.6$

$0.00 \% \quad 12.1 \%$ IAPLAEGALPYNLAELQR

$0.00 \% \quad 12.1 \%$ YEGFFGLYR

$0.00 \% \quad 12.1 \%$ GLIPQLIGVAPEK

$0.00 \% \quad 12.1 \%$ AIKLTVNDFVR

$0.00 \% \quad 12.1 \%$ LTVNDFVR

$0.00 \% \quad 12.1 \%$ VSALNVLR

$0.00 \% \quad 12.1 \%$ TRLQVAAR

$0.00 \% \quad 12.1 \%$ AGQTTYSGVIDCFR

$0.00 \% \quad 12.1 \%$ AGQTTYSGVIDCFRK

$0.05 \% \quad 27.0 \%$ YLNIFGESQPNPK

$0.05 \% \quad 27.0 \%$ TVELLSGVVDQTK

$40 \quad 0.05 \% \quad 27.0 \%$ DVEVTKEEFVLAAQK

$40 \quad 0.05 \% \quad 27.0 \%$ MTLADIER

$99.7 \% 55.7$

$99.7 \% 52.3$

$99.2 \% \quad 48.6$

$99.7 \% \quad 40.7$

$99.0 \% \quad 50.8$

$99.0 \% \quad 34.2$

$95.6 \% \quad 21.7$

$99.7 \% \quad 58.4$

$99.7 \% 72.2$

$99.7 \% \quad 72.3$

$99.7 \% \quad 58.6$

$99.7 \% \quad 62.1$

$99.0 \% \quad 33.8$

$0.05 \% \quad 27.0 \%$ IAPLEEGTLPFNLAEAQR $99.7 \% \quad 40.9$

$0.05 \% \quad 27.0 \%$ ASGDSARPVLLQVAESAYR

$0.05 \% \quad 27.0 \%$ STGSFVGELMYK

$0.05 \% \quad 27.0 \%$ YEGFFGLYR

$40 \quad 0.05 \% \quad 27.0 \%$ GLLPQLLGVAPEK

$40 \quad 0.05 \% \quad 27.0 \%$ AIKLTVNDFVR

$40 \quad 0.05 \% \quad 27.0 \%$ LTVNDFVR

$40 \quad 0.05 \% \quad 27.0 \%$ VSALSVVR

$40 \quad 0.05 \% \quad 27.0 \%$ DLGFFGIYK

$40 \quad 0.05 \% \quad 27.0 \%$ TRLQVAAR

$40 \quad 0.05 \% \quad 27.0 \%$ AGQTTYSGVIDCFR

$40 \quad 0.05 \% \quad 27.0 \%$ AGQTTYSGVIDCFRK

$0.05 \% \quad 27.0 \%$ ILREEGPK

$0.07 \% \quad 22.4 \%$ QLLAGGIAGAVSR

$0.07 \% \quad 22.4 \%$ TSTAPLDRLK

$0.07 \% \quad 22.4 \%$ IMMQVHGSK

$\quad 0.07 \% \quad 22.4 \%$ SDKMNIFGGFR

$0.07 \% \quad 22.4 \%$ LLTEEGQKIGTFER

$0.07 \% \quad 22.4 \%$ TGQYSGIYDCAK

$0.07 \% \quad 22.4 \%$ TGQYSGIYDCAKK

$0.07 \% \quad 22.4 \%$ HEGLGAFYK

$0.07 \% \quad 22.4 \%$ IISKEGIPGLYR

$53 \quad 0.07 \% \quad 22.4 \%$ EGIPGLYR

$53 \quad 0.07 \% \quad 22.4 \%$ GITPNFMK

$53 \quad 0.07 \% \quad 22.4 \%$ QTLGVTQK

$0.02 \% \quad 7.8 \%$ AAASLAWVLR

$18 \quad 0.02 \% \quad 7.8 \%$ GTVPALPERPVR
$99.7 \% \quad 48.6$

$99.7 \% \quad 52.3$

$99.2 \% \quad 48.6$

$99.7 \% \quad 40.7$

$99.0 \% \quad 50.8$

$\begin{array}{lll}99.0 \% & 47.3\end{array}$

$99.7 \% 34.8$

$99.7 \% \quad 44.3$

$95.6 \% \quad 21.7$

$99.7 \% \quad 58.4$

$99.7 \% \quad 72.2$

$99.0 \% \quad 40.3$

$99.7 \% \quad 66.3$

$99.7 \% \quad 39.4$

$99.7 \% \quad 39.4$

$99.7 \% \quad 35.0$

$99.7 \% \quad 57.2$

$99.7 \% \quad 65.2$

$99.7 \% \quad 46.1$

$99.1 \% \quad 18.4$

$99.7 \% \quad 36.2$

$97.3 \% 19.0$

$99.0 \% \quad 27.6$

$99.0 \% \quad 22.3$

$99.7 \% \quad 42.1$

$95.6 \% \quad 14.0$
1467.73

1099.52

1680.88

902.51

1458.71

1939.06

1151.55

1334.80

1275.74

963.53

871.54

914.55

1574.73

1702.82

1506.76

1388.76

1705.90

948.48

1969.04

1990.04

1318.63

1151.55

1334.80

1275.74

963.53

830.51

1059.55

1315.70

914.55

1574.73

1702.82

941.54

1212.71

1101.63

1030.52

1271.62

1620.86

1362.60

1490.69

1021.51

1345.78

904.49

907.47

874.50

1057.62

1291.75 

Casein kinase II subunit alpha' GN=CSNK2A2 CSK22_HUMAN $41.21 \quad 100.0 \%$ Cat eye syndrome critical region protein $5 \mathrm{GN}=$ CECR5 CECR5 HUMAN $46.32 \quad 100.0 \%$ Cat eye syndrome critical region protein $5 \mathrm{GN}=\mathrm{CECR} 5$ CECR5_HUMAN $46.32 \quad 100.0 \%$ Cat eye syndrome critical region protein $5 \mathrm{GN}=\mathrm{CECR} 5$ CECR5_HUMAN $46.32 \quad 100.0 \%$ Cat eye syndrome critical region protein $5 \mathrm{GN}=$ CECR5 CECR5_HUMAN $46.32 \quad 100.0 \%$ Cat eye syndrome critical region protein $5 \mathrm{GN}=\mathrm{CECR} 5$ CECR5_HUMAN $46.32 \quad 100.0 \%$ Catenin delta-1 GN=CTNND

Catenin delta- $1 \mathrm{GN}=\mathrm{CTNND} 1$

Catenin delta- $1 \mathrm{GN}=\mathrm{CTNND}$

Catenin delta- $1 \mathrm{GN}=\mathrm{CTNND}$

CTND1_HUMAN $108.17 \quad 100.0 \%$ CTND1_HUMAN $108.17 \quad 100.0 \%$ CTND1_HUMAN $108.17 \quad 100.0 \%$ CTND1_HUMAN $108.17 \quad 100.0 \%$ $\begin{array}{llll}\text { Catenin delta-1 GN=CTNND1 } & \text { CTND1_HUMAN } & 108.17 & 100.0 \% \\ \text { CCAAT/enhancer-binding protein zeta GN=CEBPZ } & \text { CEBPZ_HUMAN } & 120.98 & 100.0 \%\end{array}$ CCAAT/enhancer-binding protein zeta GN=CEBPZ CEBPZ_HUMAN $120.98 \quad 100.0 \%$ CCAAT/enhancer-binding protein zeta GN=CEBPZ CEBPZ_HUMAN $120.98 \quad 100.0 \%$ CCR4-NOT transcription complex subunit $1 \mathrm{GN}=\mathrm{CNOT1}$ CNOT1 HUMAN $266.94 \quad 100.0 \%$ CCR4-NOT transcription complex subunit $1 \mathrm{GN}=\mathrm{CNOT1}$ CNOT1_HUMAN $266.94 \quad 100.0 \%$ CCR4-NOT transcription complex subunit $1 \mathrm{GN}=$ CNOT1 CNOT1_HUMAN $266.94100 .0 \%$ CCR4-NOT transcription complex subunit $1 \mathrm{GN}=\mathrm{CNOT1}$ CNOT1_HUMAN $266.94 \quad 100.0 \%$ Cell cycle and apoptosis regulator protein $2 \mathrm{GN}=\mathrm{CCAR} 2$ CCAR2_HUMAN $102.90 \quad 100.0 \%$ Cell cycle and apoptosis regulator protein $2 \mathrm{GN}=\mathrm{CCAR} 2$ CCAR2_HUMAN $102.90 \quad 100.0 \%$ Cell cycle and apoptosis regulator protein $2 \mathrm{GN}=\mathrm{CCAR} 2$ CCAR2_HUMAN $102.90 \quad 100.0 \%$ Cell cycle and apoptosis regulator protein $2 \mathrm{GN}=\mathrm{CCAR} 2$ CCAR2_HUMAN $102.90 \quad 100.0 \%$ ell cycle and apoptosis regulator protein $2 \mathrm{GN}=\mathrm{CCAR} 2 \mathrm{CCAR} 2$ HUMAN $102.90 \quad 100.0 \%$ Cell division cycle 5-like protein $\mathrm{GN}=\mathrm{CDC} 5 \mathrm{~L}$ CDC5L_HUMAN $92.25 \quad 100.0 \%$

$0.02 \% \quad 7.8 \%$ SPGPGPSQSPR

14.6

$0.02 \% \quad 7.8 \%$ APAEEEVGPR

$0.02 \% \quad 7.8 \%$ SGCCDDSALAR

$99.7 \% \quad 67.1$

$99.7 \% \quad 30.8$

$97.5 \% \quad 29.6$

$99.5 \% 28.0$

$0.01 \% \quad 5.1 \%$ TLGTGSFGR

$0.01 \% \quad 5.1 \%$ KVEAPFIPK

$99.7 \% \quad 33.6$

$99.7 \% \quad 52.9$

$0.02 \% \quad 45.3 \%$ HVFLTGPPGVGK

$99.7 \% \quad 64.4$

$0.02 \% \quad 45.3 \%$ SSGVPVDGFYTEEVR

$95.2 \% \quad 15.5$

$\begin{array}{lll}0.02 \% & 45.3 \% & \text { SSGVPVDGFYTEE } \\ 0.02 \% & 45.3 \% & \text { IGFDVVTLSGTR }\end{array}$

$99.7 \% \quad 42.7$

$99.7 \% \quad 43.7$

$0.02 \% \quad 45.3 \%$ IGFDVVTLSGTRGPLSR

$99.7 \% \quad 44.5$

$99.7 \% \quad 46.5$

$99.7 \% \quad 37.3$

$99.7 \% \quad 58.3$

$0.02 \% \quad 45.3 \%$ VFNVTKENR

$0.02 \% \quad 18.1 \%$ LFSGDVVLTAR

$\begin{array}{ll}99.7 \% & 28.5\end{array}$

$\begin{array}{lll}0.02 \% & 18.1 \% & \text { GQAAVQQLQAEGLSPR } \quad 99.7 \% \quad 63.3\end{array}$

$0.02 \% \quad 18.1 \%$ VVNVSSIMSVR

$0.02 \% \quad 18.1 \%$ IGVTVLSR

$0.01 \% \quad 3.1 \%$ ARVYAEVNSLR

$0.01 \% \quad 3.1 \%$ VYAEVNSLR

$0.02 \% \quad 10.2 \%$ RLVNSQGQLR

$0.02 \% \quad 10.2 \%$ LVNSQGQLR

$0.02 \% \quad 10.2 \%$ LFSEYHEKR

$0.02 \% \quad 10.2 \%$ NVVTVDELR

$0.02 \% \quad 10.2 \%$ ATHDGAPELGAGGTR

$0.02 \% \quad 6.2 \%$ GSLASLDSLRK

$0.02 \% \quad 6.2 \%$ NCDGVPALVR

$0.02 \% \quad 6.2 \%$ GYELLFQPEVVR

$0.02 \% \quad 6.2 \% \quad$ ALSAIADLLTNEHER

$0.02 \% \quad 6.2 \%$ SDFQVNLNNASR

$0.01 \% \quad 3.3 \% \quad$ INNKNTAESQR

$0.01 \% \quad 3.3 \%$ MLSALLTGVNR

$0.01 \% \quad 3.3 \%$ GKENTDSVVMQPK

$0.01 \% \quad 1.7 \%$ SLDLIESLLR

$0.01 \% \quad 1.7 \% \quad$ LAEVGQYEQVK

$0.01 \% \quad 1.7 \%$ NLDEQLSAPK

$0.01 \% \quad 1.7 \%$ SLLEVVVLSR

$0.01 \% \quad 8.2 \%$ VQTLSNQPLLK

$99.7 \% \quad 56.1$

$\begin{array}{llll}99.0 \% & 36.2\end{array}$

$\begin{array}{lll}99.7 \% & 34.7\end{array}$

$99.7 \% \quad 43.4$

$96.0 \% \quad 20.1$

$97.9 \% \quad 19.1$

$99.7 \% \quad 28.2$

$99.7 \% \quad 34.0$

$99.7 \% \quad 47.2$

$99.6 \% \quad 25.0$

$96.0 \% 15.3$

$\begin{array}{ll}99.7 \% & 50.2\end{array}$

$99.7 \% \quad 69.3$

$99.7 \% \quad 60.8$

$99.7 \% \quad 35.0$

$99.7 \% \quad 48.9$

$99.7 \% \quad 28.5$

$\begin{array}{lll}99.7 \% & 32.8\end{array}$

$99.6 \% \quad 22.3$

$99.7 \% \quad 28.9$

$99.4 \% \quad 27.1$

$99.2 \% \quad 20.6$

$\begin{array}{llll}99.7 \% & 31.8\end{array}$

$\begin{array}{lll}0.01 \% & 8.2 \% & \text { QGILGAQPQLIFT }\end{array}$

$0.01 \% \quad 8.2 \%$ VVTQNICQYR

$0.01 \% \quad 8.2 \% \quad$ LTPLQLEIQR

$\begin{array}{llll}99.7 \% & 27.2 & 25.0 & 27.2\end{array}$

$\begin{array}{llll}99.7 \% & 33.9 & 25.0 & 33.9\end{array}$

$\begin{array}{llll}99.7 \% & 28.8 & 25.0 & 28.0\end{array}$

$0.01 \% \quad 5.2 \%$ IASLLHRK

$\begin{array}{llll}99.0 \% & 20.7 & 25.0 & 20.7\end{array}$

1066.53

1054.52

1211.48

935.52

895.46

1028.61

1208.68

1641.78

2039.98

1264.69

1774.98

1836.08

1224.73

1106.60

1177.66

2124.12

1652.87

1190.66

844.53

1277.70

1050.56

1170.67

1014.57

1208.61

1044.57

1409.68

1146.65

1100.55

1449.77

1652.86

1364.66

1274.64

1174.66

1432.71

1158.67

1263.66

1114.57

1114.68

1240.73

1803.00

2934.39

1280.64

1210.72

937.59 
Cell division cycle 5-like protein GN=CDC5L CDC5L_HUMAN $92.25 \quad 100.0 \%$ Cell division cycle 5-like protein GN=CDC5L CDC5L_HUMAN $92.25 \quad 100.0 \%$ Cell division cycle 5-like protein $\mathrm{GN}=\mathrm{CDC} 5 \mathrm{~L} \quad \mathrm{CDC} 5 \mathrm{~L} \_$HUMAN $92.25 \quad 100.0 \%$ Cell division cycle and apoptosis regulator protein $1 \mathrm{GN}=\mathrm{CCAR} 1$ CCAR1_HUMAN $132.82 \quad 100.0 \%$ Cell division cycle and apoptosis regulator protein $1 \mathrm{GN}=$ CCAR1 CCAR1_HUMAN $132.82 \quad 100.0 \%$ Cell growth-regulating nucleolar protein GN=LYAR LYAR_HUMAN $43.62 \quad 100.0 \%$ Cell growth-regulating nucleolar protein GN=LYAR LYAR_HUMAN $43.62 \quad 100.0 \%$ Cell growth-regulating nucleolar protein GN=LYAR LYAR_HUMAN $43.62 \quad 100.0 \%$ Cell growth-regulating nucleolar protein GN=LYAR LYAR HUMAN $43.62 \quad 100.0 \%$ Cell growth-regulating nucleolar protein GN=LYAR LYAR_HUMAN $43.62 \quad 100.0 \%$ Cell growth-regulating nucleolar protein GN=LYAR LYAR_HUMAN $43.62 \quad 100.0 \%$ Cell growth-regulating nucleolar protein GN=LYAR LYAR HUMAN $43.62 \quad 100.0 \%$ Cell growth-regulating nucleolar protein GN=LYAR LYAR_HUMAN $43.62 \quad 100.0 \%$ Cellular tumor antigen p53 GN=TP53 Cellular tumor antigen $\mathrm{p} 53 \mathrm{GN}=\mathrm{TP} 53$ Cellular tumor antigen $\mathrm{p} 53 \mathrm{GN}=\mathrm{TP} 53$ Cellular tumor antigen $\mathrm{p} 53 \mathrm{GN}=\mathrm{TP} 53$ Cellular tumor antigen $\mathrm{p} 53 \mathrm{GN}=\mathrm{TP} 53$ Centromere protein $\mathrm{V} \mathrm{GN}=\mathrm{CENPV}$ Centromere protein $\mathrm{V}$ GN $=\mathrm{CENPV}$ Centromere protein $\mathrm{V}$ GN $=\mathrm{CENPV}$ Centromere protein $\mathrm{V}$ GN $=\mathrm{CENPV}$ Centromere protein $\mathrm{V}$ GN $=\mathrm{CENPV}$ Centromere protein $\mathrm{V}$ GN $=\mathrm{CENPV}$ Centromere protein $\mathrm{V}$ GN $=\mathrm{CENPV}$ Centromere protein $\mathrm{V}$ GN $=\mathrm{CENPV}$ P53 HUMAN $43.65 \quad 100.0 \%$ P53 HUMAN $43.65 \quad 100.0 \%$ P53_HUMAN $43.65 \quad 100.0 \%$ P53 HUMAN $43.65 \quad 100.0 \%$ P53_HUMAN $43.65 \quad 100.0 \%$ CENPV_HUMAN $29.95 \quad 100.0 \%$ CENPV HUMAN $29.95 \quad 100.0 \%$ CENPV_HUMAN $29.95 \quad 100.0 \%$ CENPV_HUMAN $29.95 \quad 100.0 \%$ CENPV_HUMAN $29.95 \quad 100.0 \%$ CENPV_HUMAN $29.95 \quad 100.0 \%$ CENPV HUMAN $29.95 \quad 100.0 \%$ CENPV_HUMAN $29.95 \quad 100.0 \%$ Centromere/kinetochore protein zw10 homolog GN=ZW10 ZW10_HUMAN $88.83 \quad 100.0 \%$ Centromere/kinetochore protein Zw10 homolog GN=ZW10 ZW10_HUMAN $88.83 \quad 100.0 \%$ Centromere/kinetochore protein Zw10 homolog GN=ZW10 ZW10_HUMAN $88.83 \quad 100.0 \%$ Centromere/kinetochore protein Zw10 homolog GN=ZW10 ZW10 HUMAN $88.83 \quad 100.0 \%$ Centromere/kinetochore protein Zw10 homolog GN=ZW10 ZW10_HUMAN $88.83 \quad 100.0 \%$ Centromere/kinetochore protein zw10 homolog GN=ZW10 ZW10_HUMAN $88.83 \quad 100.0 \%$ Centromere/kinetochore protein $z w 10$ homolog GN=ZW10 ZW10_HUMAN $88.83 \quad 100.0^{\circ}$ Centromere/kinetochore protein Zw10 homolog GN=ZW10 ZW10_HUMAN $88.83 \quad 100.0 \%$ Centromere/kinetochore protein zw10 homolog GN=ZW10 ZW10_HUMAN $88.83 \quad 100.0 \%$ Charged multivesicular body protein 4b GN=CHMP4B CHM4B_HUMAN $24.95 \quad 100.0 \%$ Charged multivesicular body protein $4 \mathrm{~b}$ GN=CHMP4B CHM4B_HUMAN $24.95 \quad 100.0 \%$ Charged multivesicular body protein $4 \mathrm{~b} \mathrm{GN}=$ CHMP4B CHM4B_HUMAN $24.95 \quad 100.0 \%$ Charged multivesicular body protein 4b GN=CHMP4B CHM4B_HUMAN $24.95 \quad 100.0 \%$ Chromatin target of PRMT1 protein GN=CHTOP CHTOP_HUMAN $26.40 \quad 100.0 \%$ Chromatin target of PRMT1 protein GN=CHTOP CHTOP_HUMAN $26.40 \quad 100.0 \%$ Chromatin target of PRMT1 protein GN=CHTOP CHTOP_HUMAN $26.40 \quad 100.0 \%$ Chromatin target of PRMT1 protein GN=CHTOP CHTOP_HUMAN $26.40 \quad 100.0 \%$ Chromatin target of PRMT1 protein GN=CHTOP CHTOP_HUMAN $26.40 \quad 100.0 \%$ Chromodomain-helicase-DNA-binding protein 1-like GN=CHD1L CHD1L_HUMAN $100.99 \quad 100.0 \%$ Chromodomain-helicase-DNA-binding protein 1-like GN=CHD1L CHD1L_HUMAN $100.99100 .0 \%$ Chromodomain-helicase-DNA-binding protein 1-like GN=CHDIL CHD1L_HUMAN $100.99 \quad 100.0 \%$
$0.01 \% \quad 5.2 \%$ SGTTPKPVINSTPGR $0.01 \% \quad 5.2 \%$ LGLLGLPAPK $0.01 \% \quad 5.2 \%$ ILLGGYQSR $0.00 \% \quad 1.6 \%$ IVSQPQPAR $0.00 \% \quad 1.6 \%$ GLKSQLIAR $0.02 \% \quad 21.6 \%$ VFFTCNACGESVK $0.02 \% \quad 21.6 \%$ VFFTCNACGESVKK $0.02 \% \quad 21.6 \%$ CISEDQKYGGK $0.02 \% 21.6 \%$ ISELIKRPNVSPK $0.02 \% \quad 21.6 \%$ ELLEQISAFDNVPR $0.02 \% \quad 21.6 \%$ VKDAVEQQGEVK $0.02 \% \quad 21.6 \%$ QAPDNEITIK $0.02 \% \quad 21.6 \%$ ISKNPTFK $0.01 \% \quad 11.5 \%$ TYQGSYGFRLGFLHSGTAK $0.01 \% \quad 11.5 \%$ LGFLHSGTAK $0.01 \% \quad 11.5 \%$ SVTCTYSPALNK $0.01 \% \quad 11.5 \%$ RALPNNTSSSPQPK $0.01 \% \quad 11.5 \%$ ALPNNTSSSPQPK $\begin{array}{lllllll}0.03 \% & 40.4 \% & \text { SGASGASAAPAASAAAALAPSATR } & 99.7 \% & 56.0 & 25.0 & 50.1\end{array}$

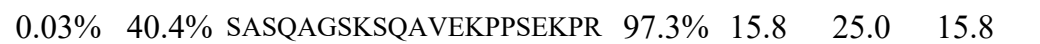
$0.03 \% \quad 40.4 \%$ SQAVEKPPSEKPR $0.03 \% \quad 40.4 \%$ QKLTSEGAAK $0.03 \% \quad 40.4 \%$ LLLDTFEYQGLVK $0.03 \% \quad 40.4 \%$ GAEHITTYTFNTHK $0.03 \% \quad 40.4 \%$ CGVQSFYTPR $0.03 \% \quad 40.4 \%$ SNPGGFGIAPHCLDEGTVR $0.02 \% \quad 13.0 \%$ NCLVYSIPTNSSK $0.02 \% \quad 13.0 \%$ FLKGDTTDLLK $0.02 \% \quad 13.0 \%$ NINSHFANKK $0.02 \% \quad 13.0 \%$ CQDVIVAAR $0.02 \% \quad 13.0 \%$ NLMTSEIHNTVK $0.02 \% \quad 13.0 \%$ LGTECFLAQMR $0.02 \% \quad 13.0 \%$ NFSNMDDEENYSAASK $0.02 \% \quad 13.0 \%$ YQEEVPVYVPK $0.02 \% \quad 13.0 \%$ ALFQNTER $0.01 \% \quad 14.3 \%$ AGKGGPTPQEAIQR $0.01 \% \quad 14.3 \%$ GGPTPQEAIQR $0.01 \% \quad 14.3 \%$ KIEQELTAAK $0.01 \% \quad 14.3 \%$ AALQALKR $0.03 \% \quad 24.6 \%$ NKQPTPVNIR $0.03 \% \quad 24.6 \%$ ASMQQQQQLASAR $0.03 \% \quad 24.6 \%$ LAQQMENRPSVQAALK $0.03 \% \quad 24.6 \%$ LGKSNIQAR $0.03 \% \quad 24.6 \%$ EQLDNQLDAYMSK $0.01 \% \quad 4.6 \%$ GGQAPGFLLR $0.01 \% \quad 4.6 \%$ SFEQLVNLQK $0.01 \% \quad 4.6 \%$ GGLFTALEKR
$95.0 \% \quad 16.6 \quad 25.0 \quad 12.6$ $96.4 \% \quad 16.0$ $97.1 \% \quad 19.1 \quad 25.0$ $99.1 \% \quad 25.1 \quad 25.0 \quad 23.8$ $\begin{array}{llll}98.3 \% & 25.1 & 25.0 & 12.0\end{array}$ $\begin{array}{llll}99.7 \% & 44.9 & 25.0 & 44.9\end{array}$ $\begin{array}{llll}99.7 \% & 36.4 & 25.0 & 36.4\end{array}$ $\begin{array}{lllll}99.7 \% & 28.8 & 25.0 & 21.3 & 2\end{array}$ $\begin{array}{llll}99.7 \% & 45.6 & 25.0 & 45.6\end{array}$ $\begin{array}{llll}99.7 \% & 60.6 & 25.0 & 58.5\end{array}$ $99.7 \% \quad 40.4 \quad 25.0 \quad 34.1$ $\begin{array}{llll}97.7 \% & 16.8 & 25.0 & 15.8\end{array}$ $\begin{array}{llll}99.0 \% & 28.8 & 25.0 & 17.9\end{array}$ $\begin{array}{llll}97.5 \% & 16.0 & 25.0 & 16.0\end{array}$ $\begin{array}{llll}99.5 \% & 24.3 & 25.0 & 17.4\end{array}$ $99.7 \% \quad 34.5 \quad 25.0 \quad 32.4 \quad 4$ $\begin{array}{llll}99.7 \% & 24.1 & 25.0 & 24.1\end{array}$ $\begin{array}{llll}99.7 \% & 54.8 & 25.0 & 51.7\end{array}$ $\begin{array}{llll}99.7 \% & 36.0 & 25.0 & 32.2\end{array}$ $99.2 \% \quad 21.3 \quad 25.0 \quad 18.1$ $\begin{array}{llll}99.7 \% & 51.4 & 25.0 & 47.2\end{array}$ $99.7 \% \quad 55.1 \quad 25.0 \quad 44.9$ $\begin{array}{llll}99.7 \% & 50.2 & 25.0 & 49.8\end{array}$ $\begin{array}{llll}99.7 \% & 37.1 & 25.0 & 37.1\end{array}$ $99.7 \% \quad 36.9 \quad 25.0 \quad 27.0$ $\begin{array}{llll}95.0 \% & 20.5 & 25.0 & 9.5\end{array}$ $\begin{array}{llll}95.9 \% & 21.5 & 25.0 & 9.6\end{array}$ $\begin{array}{llll}99.7 \% & 54.3 & 25.0 & 52.6\end{array}$ $\begin{array}{llll}99.7 \% & 47.0 & 25.0 & 46.0\end{array}$ $\begin{array}{llll}99.7 \% & 35.5 & 25.0 & 35.5\end{array}$ $\begin{array}{llll}95.8 \% & 18.2 & 25.0 & 13.6\end{array}$ $\begin{array}{llll}97.4 \% & 21.6 & 25.0 & 13.0\end{array}$ $\begin{array}{llll}99.7 \% & 29.9 & 25.0 & 26.8\end{array}$ $\begin{array}{llll}99.7 \% & 36.4 & 25.0 & 29.5\end{array}$ $\begin{array}{llll}99.4 \% & 22.1 & 25.0 & 18.0\end{array}$ $\begin{array}{llll}99.0 \% & 33.9 & 25.0 & 11.6\end{array}$ $\begin{array}{llll}99.2 \% & 19.3 & 25.0 & 19.3\end{array}$ $\begin{array}{llll}99.7 \% & 55.1 & 25.0 & 48.5\end{array}$ $\begin{array}{llll}99.7 \% & 50.9 & 25.0 & 37.1\end{array}$ $\begin{array}{llll}99.7 \% & 38.8 & 25.0 & 36.6\end{array}$ $99.7 \% \quad 45.6 \quad 25.0 \quad 45.6$ $\begin{array}{llll}97.0 \% & 25.1 & 25.0 & 8.4\end{array}$ $\begin{array}{llll}99.6 \% & 30.6 & 25.0 & 24.2\end{array}$ $99.7 \% \quad 41.6 \quad 25.0 \quad 31.9$ $\begin{array}{lllll}99.7 \% & 63.3 & 25.0 & 60.9 & 2\end{array}$ $\begin{array}{ccc}1511.82 & 427 & 441 \\ 978.63 & 478 & 487 \\ 1006.57 & 719 & 727 \\ 995.56 & 285 & 293 \\ 985.62 & 657 & 665 \\ 1518.67 & 2 & 14 \\ 1646.77 & 2 & 15 \\ 1284.59 & 51 & 61 \\ 1480.88 & 81 & 93 \\ 1630.84 & 96 & 109 \\ 1329.70 & 174 & 185 \\ 1128.59 & 321 & 330 \\ 934.54 & 362 & 369 \\ 2090.05 & 102 & 120 \\ 1030.57 & 111 & 120 \\ 1340.65 & 121 & 132 \\ 1496.78 & 306 & 319 \\ 1340.68 & 307 & 319 \\ 1985.00 & 18 & 41 \\ 2169.13 & 45 & 65 \\ 1452.78 & 53 & 65 \\ 1032.57 & 125 & 134 \\ 1538.85 & 135 & 147 \\ 1619.78 & 197 & 210 \\ 1214.56 & 219 & 228 \\ 1983.93 & 229 & 247 \\ 1482.73 & 345 & 357 \\ 1250.70 & 380 & 390 \\ 1172.62 & 394 & 403 \\ 1031.53 & 404 & 412 \\ 1386.70 & 413 & 424 \\ 1325.63 & 584 & 594 \\ 1821.72 & 609 & 624 \\ 1350.69 & 709 & 719 \\ 978.50 & 763 & 770 \\ 1409.75 & 15 & 28 \\ 1153.60 & 18 & 28 \\ 1130.64 & 46 & 55 \\ 870.55 & 64 & 71 \\ 1166.66 & 29 & 38 \\ 1446.71 & 39 & 51 \\ 1783.95 & 55 & 70 \\ 986.57 & 79 & 87 \\ 1570.71 & 214 & 226 \\ 1015.57 & 10 & 19 \\ 1205.65 & 591 & 600 \\ 1091.62 & 749 & 758 \\ & & \end{array}$ 
$0.01 \% \quad 4.6 \%$ GIPTYIYYFPR

$0.01 \% \quad 2.0 \%$ VLIFSQMTK

$99.7 \% \quad 33.1$

$99.4 \% 22.0$

$99.7 \% \quad 44.9$

$0.01 \% \quad 2.0 \%$ VGGNIEVLGFNAR

$99.7 \% \quad 41.1$

$\begin{array}{lll}0.00 \% & 4.5 \% & \text { IVPNVLLEQGK }\end{array}$

$0.00 \% \quad 4.5 \%$ ALGFPLERPK

$0.03 \% \quad 6.9 \% \quad$ NNLAGAEELFAR

$99.7 \% 28$.

$99.0 \% \quad 18.7$

$99.7 \% \quad 68.7$

$0.03 \% \quad 6.9 \% \quad$ KFNALFAQGNYSEAAK

$0.03 \% \quad 6.9 \% \quad$ SVDPTLALSVYLR

$0.03 \% \quad 6.9 \%$ ALEHFTDLYDIKR

$0.03 \% \quad 6.9 \%$ TGQIKEVER

$0.03 \% \quad 6.9 \% \quad$ IYIDSNNNPER

$0.03 \% \quad 6.9 \%$ LLYNNVSNFGR

$99.0 \% \quad 19.3$

$99.7 \% \quad 58.5$

$99.7 \% \quad 42.3$

$99.7 \% \quad 36.2$

$99.7 \% \quad 56.5$

$99.7 \% \quad 51.8$

$\begin{array}{lll}0.03 \% & 6.9 \% & \text { LASTLVHLGEYQAAVI } \\ 0.03 \% & 6.9 \% & \text { VKQLPLVKPYLR }\end{array}$

$0.03 \% \quad 6.9 \%$ CAAMLVYGTR

$0.03 \% \quad 6.9 \%$ ESLAEEHEGLVGEGQR

$0.03 \% \quad 6.9 \% \quad$ SSFLPSYIIDVR

$0.03 \% \quad 6.9 \%$ LGGARDELGGR

$0.03 \% \quad 6.9 \%$ VLVDSSFGQPTTQGEAR

$0.03 \% \quad 6.9 \%$ EVLLVALGSR

$0.03 \% \quad 6.9 \%$ VYAVATSTNTPCAR

$0.03 \% \quad 6.9 \% \quad$ NVLDGELLNR

$0.00 \% \quad 4.5 \% \quad$ LGLNCAIYATIPVYK

$99.7 \% 29.7$

$99.2 \% \quad 20.1$

$99.7 \% \quad 27.4$

$99.2 \% \quad 19.8$

$99.7 \% \quad 42.3$ $98.6 \% \quad 25.8$

$0.00 \% \quad 4.5 \%$ QLIIVHGPPEASQDLAECCR

$0.00 \% \quad 10.8 \%$ SGAAVCEFFLK

$99.7 \% \quad 54.8$

$99.7 \% \quad 52.7$

$99.7 \% \quad 29.0$

$99.6 \% 27.8$

$98.8 \% \quad 23.0$

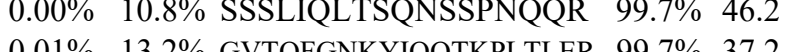

$0.01 \% \quad 13.2 \%$ KLFLVQLQEK

$98.7 \%$

$0.01 \% \quad 13.2 \%$ LFLVQLQEK

$99.7 \% \quad 45.4$

$0.02 \% \quad 21.2 \%$ ANGQSKGFALVGVGSEASSK $95.5 \% \quad 13.9$

$0.02 \% \quad 21.2 \%$ GFALVGVGSEASSK

$0.02 \% \quad 21.2 \%$ GFALVGVGSEASSKK

$0.02 \% \quad 21.2 \%$ RELHGQNPVVTPCNK

$0.02 \% \quad 21.2 \%$ QFLSQFEMQSR

$99.7 \% \quad 65.8$

$99.0 \% \quad 20.5$

$99.7 \% \quad 51.9$

$0.02 \% \quad 21.2 \%$ TTQSGQMSGEGKAGPPGGSSR $\quad 99.7 \% \quad 31.2$

$0.02 \% \quad 21.2 \%$ GDYGPPGR

$0.02 \% \quad 21.2 \%$ TPLSEAEFEEIMNR

$0.02 \% \quad 21.2 \%$ TPLSEAEFEEIMNRNR

$0.02 \% \quad 21.2 \%$ AISSSAISR

$0.02 \% \quad 21.2 \%$ VLISSLQDCLHGIESK

$0.00 \% \quad 4.9 \%$ QNLSQFEAQAR

$0.00 \% \quad 4.9 \%$ SYSVGASGSSSR

$0.03 \% \quad 12.7 \%$ NLSPGAVESDVR

$0.03 \% \quad 12.7 \%$ GITGVDLFGTTDAVVK

$0.03 \% \quad 12.7 \%$ ASNLENSTYDLYTIPK

$0.03 \% \quad 12.7 \%$ SSGLTAVWVAR
$96.7 \% \quad 15.2$

$99.7 \% \quad 50.1$

$98.6 \% \quad 17.4$ $99.7 \% \quad 40.3$

$99.7 \% \quad 54.0$

$98.6 \% \quad 31.2$

$99.7 \% \quad 32.9$

$99.7 \% \quad 47.5$

$99.7 \% \quad 44.9$

$99.7 \% \quad 35.5$

$99.7 \% \quad 60.5$
1209.72

1127.66

1304.66

1758.88

1433.80

1620.84

1059.58

1334.63

1296.67

1971.03

1453.93

1141.55

1739.82

1396.75

1100.58

1791.89

1056.64

1510.73

1142.62

1695.9

2293.11

1228.60

1974.98

2321.26

1245.76

1117.66

1893.97

1308.68

1436.77

1748.89

1400.66

1976.9

818.38

1665.78

1951.92

891.49

1798.94

1291.64

1144.52

1243.63

1592.85

1828.90

1146.63 
Coatomer subunit alpha $\mathrm{GN}=\mathrm{COPA}$ Coatomer subunit alpha $\mathrm{GN}=\mathrm{COPA}$ Coatomer subunit alpha $\mathrm{GN}=\mathrm{COPA}$ Coatomer subunit alpha $\mathrm{GN}=\mathrm{COPA}$ Coatomer subunit alpha $\mathrm{GN}=\mathrm{COPA}$ Coatomer subunit alpha $\mathrm{GN}=\mathrm{COPA}$ Coatomer subunit alpha $\mathrm{GN}=\mathrm{COPA}$ Coatomer subunit alpha $\mathrm{GN}=\mathrm{COPA}$ Coatomer subunit alpha $\mathrm{GN}=\mathrm{COPA}$ Coatomer subunit beta $\mathrm{GN}=\mathrm{COPB} 1$ Coatomer subunit beta $\mathrm{GN}=\mathrm{COPB} 1$ Coatomer subunit beta $\mathrm{GN}=\mathrm{COPB} 1$ Coatomer subunit beta $\mathrm{GN}=\mathrm{COPB} 1$ Coatomer subunit beta $\mathrm{GN}=\mathrm{COPB} 1$ Coatomer subunit beta $\mathrm{GN}=\mathrm{COPB} 1$ Coatomer subunit beta' $\mathrm{GN}=\mathrm{COPB} 2$ Coatomer subunit beta' $\mathrm{GN}=\mathrm{COPB} 2$ Coatomer subunit delta $\mathrm{GN}=\mathrm{ARCN} 1$ Coatomer subunit delta $\mathrm{GN}=\mathrm{ARCN}$ Coatomer subunit delta $\mathrm{GN}=\mathrm{ARCN} 1$ Coatomer subunit epsilon $\mathrm{GN}=\mathrm{COPE}$ Coatomer subunit epsilon $\mathrm{GN}=\mathrm{COPE}$ Coatomer subunit epsilon $\mathrm{GN}=\mathrm{COPE}$ Coatomer subunit epsilon $\mathrm{GN}=\mathrm{COPE}$

Coatomer subunit gamma-1 GN=COPG1

Coatomer subunit gamma-1 GN=COPG1

Coatomer subunit gamma-1 GN=COPG1

Coatomer subunit gamma-1 GN=COPG1

Coatomer subunit gamma- $1 \mathrm{GN}=\mathrm{COPG} 1$

Coatomer subunit gamma-1 $\mathrm{GN}=\mathrm{COPG} 1$

Coatomer subunit gamma- $1 \mathrm{GN}=\mathrm{COPG} 1$

Coatomer subunit gamma-1 GN=COPG1

Coatomer subunit gamma-2 $\mathrm{GN}=\mathrm{COPG} 2$

Coatomer subunit gamma- $2 \mathrm{GN}=\mathrm{COPG} 2$

Coatomer subunit gamma-2 $\mathrm{GN}=\mathrm{COPG} 2$

Coatomer subunit gamma- $2 \mathrm{GN}=\mathrm{COPG} 2$

Coatomer subunit gamma-2 $\mathrm{GN}=\mathrm{COPG} 2$

Coatomer subunit gamma- $2 \mathrm{GN}=\mathrm{COPG} 2$

Coatomer subunit gamma-2 GN=COPG2 COPG2_HUMAN 97.62

COBW domain-containing protein $1 \mathrm{GN}=\mathrm{CBWD} 1$ CBWD1_HUMAN 44.07

COBW domain-containing protein $1 \mathrm{GN}=\mathrm{CBWD} 1 \mathrm{CBWD} 1$ HUMAN 44.07 COBW domain-containing protein $1 \mathrm{GN}=$ CBWD1 CBWD1_HUMAN $44.07 \quad 100.0 \%$ Coiled-coil domain-containing protein $137 \mathrm{GN}=\mathrm{CCDC} 137 \quad \mathrm{CC} 137$ HUMAN $33.23 \quad 100.0^{\circ}$ Coiled-coil domain-containing protein $137 \mathrm{GN}=\mathrm{CCDC} 137$ CC137_HUMAN $33.23 \quad 100.0 \%$ Coiled-coil domain-containing protein $137 \mathrm{GN}=\mathrm{CCDC} 137 \quad \mathrm{CC} 137$ HUMAN $33.23 \quad 100.0 \%$ Coiled-coil domain-containing protein $137 \mathrm{GN}=\mathrm{CCDC} 137 \quad \mathrm{CC} 137$ HUMAN $33.23 \quad 100.0^{\circ}$ Coilin GN=COIL

14

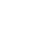

13

COP $138.35 \quad 100.0 \% \quad 13$

COPB_HUMAN $107.15 \quad 100.0 \%$ COPB_HUMAN $107.15 \quad 100.0 \%$ COPB HUMAN $107.15 \quad 100.0 \%$ COPB HUMAN $107.15 \quad 100.0 \%$ COPB HUMAN $107.15 \quad 100.0 \%$ $102.49 \quad 100.0 \%$ HUMAN $102.49 \quad 100.0 \%$ COPD HUMAN $57.21 \quad 100.0 \%$ COPD HUMAN $57.21 \quad 100.0 \%$ $34.48 \quad 100.0 \%$ N $34.48 \quad 100.0 \%$ COPE HUMAN $34.48 \quad 100.0 \%$ 100.0\% $\begin{array}{ll}7.72 & 100.0 \% \\ 7.72 & 100.0 \%\end{array}$ $100.0 \%$ $100.0 \%$ $100.0 \%$ $100.0 \%$ $100.0 \%$ $100.0 \%$ $100.0 \%$ $100.0 \%$ $100.0 \%$ $0 \%$ 3 4
4

4

$0.03 \% \quad 12.7 \%$ DADSITLFDVQQKR $0.03 \% \quad 12.7 \%$ TLDLPIYVTR $0.03 \% \quad 12.7 \%$ VLTIDPTEFKFK $0.03 \% \quad 12.7 \%$ KYDEVLHMVR $0.03 \% \quad 12.7 \%$ GFFEGTIASK $0.03 \% \quad 12.7 \%$ GFFEGTIASKGK $0.03 \% \quad 12.7 \%$ LLELGPKPEVAQQTR $0.03 \% \quad 12.7 \%$ VTTVTEIGKDVIGLR $0.02 \% \quad 9.7 \% \quad$ VLQDLVMDILR $0.02 \% \quad 9.7 \%$ SLGEIPIVESEIKK $\begin{array}{llll}99.7 \% & 30.9 & 25.0 & 30.9\end{array}$ $\begin{array}{llll}95.6 \% & 15.0 & 25.0 & 15.0\end{array}$ $\begin{array}{llll}99.7 \% & 52.5 & 25.0 & 52.5\end{array}$ $98.0 \% \quad 16.7 \quad 25.0 \quad 16.7$ $99.5 \% \quad 27.6 \quad 25.0 \quad 27.6$ $\begin{array}{llll}99.7 \% & 47.1 & 25.0 & 38.8\end{array}$ $\begin{array}{llll}99.7 \% & 38.5 & 25.0 & 23.5\end{array}$ $\begin{array}{llll}99.7 \% & 36.8 & 25.0 & 36.8\end{array}$ $99.7 \% \quad 50.5 \quad 25.0 \quad 50.5$ $99.7 \% \quad 50.9 \quad 25.0 \quad 50.9$ $99.7 \% \quad 46.9 \quad 25.0 \quad 45.7 \quad 2$ $\begin{array}{lllllll}0.02 \% & 9.7 \% & \text { EAGELKPEEEITVGPVQK } & 99.7 \% & 30.9 & 25.0 & 30.9\end{array}$ $\begin{array}{lllllll}0.02 \% & 9.7 \% & \text { LVTEMGTYATQSALSSSRPTK } & 99.7 \% & 27.0 & 25.0 & 26.1\end{array}$ $0.02 \% \quad 9.7 \%$ EAADPLASKLNK $99.7 \% \quad 29.1 \quad 25.0 \quad 19.8$

$\begin{array}{llllllll}0.02 \% & 9.7 \% & \text { ALSGYCGFMAANLYAR } & 99.7 \% & 60.5 & 25.0 & 60.5\end{array}$ $0.01 \% \quad 2.1 \%$ HSEVQQANLK $0.01 \% \quad 2.1 \%$ TYLPSQVSR

$0.01 \% \quad 7.6 \%$ TRIEGLLAAFPK

$0.01 \% \quad 7.6 \%$ NSNILEDLETLR $99.7 \% \quad 40.3$ $99.7 \% \quad 26.3$ $99.7 \% \quad 25.4$ $99.7 \% \quad 52.5$ $99.7 \% \quad 58.1$

$0.01 \% \quad 7.6 \%$ LFTAESLIGLKNPEK $99.7 \% \quad 47.5$ $\begin{array}{lll}99.5 \% & 22.8\end{array}$ $99.7 \% \quad 38.4$ $0.01 \% \quad 18.8 \%$ DSIVAELDREMSR

$0.01 \% \quad 18.8 \%$ YLSQLKDAHR $0.01 \% \quad 18.8 \%$ ENDFDRLVLQYAPSA $96.8 \% \quad 15.8$ $99.0 \% \quad 34.8$

$0.04 \% \quad 12.6 \%$ SAVLQEAR

$0.04 \% \quad 12.6 \%$ ELAPAVSVLQLFCSSPK

$0.04 \% \quad 12.6 \%$ SIATLAITTLLK

$0.04 \% \quad 12.6 \%$ ILHLLGQEGPK

$0.04 \% \quad 12.6 \%$ TTNPSKYIR

$99.7 \% \quad 65.3$

$99.7 \% \quad 61.8$

$99.7 \% \quad 53.4$

$95.0 \% \quad 13.6$

$\begin{array}{llll}0.04 \% & 12.6 \% & \text { ALQQYTLEPSEKPFDLK } \quad 98.6 \% & 18.2\end{array}$

$0.04 \% \quad 12.6 \%$ SSPEPVALTESETEYVIR

$0.04 \% \quad 12.6 \%$ SLPYNQPGTCYTLVALPK

$0.02 \% \quad 9.3 \%$ SAVLQEAR

$0.02 \% \quad 9.3 \% \quad$ IFNETPINPR

$0.02 \% \quad 9.3 \%$ ISYDVVKR

$0.02 \% \quad 9.3 \%$ SIATLAITTLLK

$0.02 \% \quad 9.3 \%$ TGSESSVDRLMK

$0.02 \% \quad 9.3 \%$ FIFNRVVLENEAVR

$0.02 \% \quad 9.3 \%$ SSEPVQLTEAETEYFVR

$0.00 \% \quad 10.9 \%$ IPVTIITGYLGAGK

$0.00 \% \quad 10.9 \%$ VAVILNEFGEGSALEK

$0.00 \% \quad 10.9 \%$ SINGLGQILETQR

$0.01 \% \quad 20.8 \%$ KGESDGAYIHR

$0.01 \% \quad 20.8 \%$ NQAIRQPEVQAAPK

$99.7 \% \quad 66.5$

$99.7 \% \quad 40.4$

$99.0 \% \quad 34.8$

$99.7 \% 35.1$

$99.0 \% \quad 57.1$

$99.7 \% \quad 61.8$

$\begin{array}{lll}96.8 \% & 19.2\end{array}$

$99.7 \% \quad 35.7$

$99.7 \% \quad 65.3$

$99.7 \% \quad 36.6$

$99.7 \% \quad 55.8$

$98.9 \% \quad 21.2$

$99.7 \% 27.6$

$99.7 \% 37.0$

20.8\% FGEVVLQPPELTARPQR $\quad 99.6 \% \quad 23.0$

$0.01 \% \quad 20.8 \%$ MLLSPGGVSQPLTASLAR $\quad 99.7 \% \quad 44.0$

$99.7 \% \quad 51.5$ 


\section{Coilin GN=COIL}

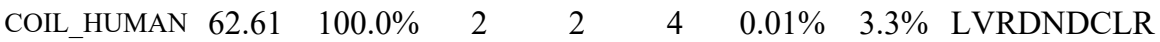

Compin complex subunit $1 \mathrm{GN}=$ NCAPD2 CND1_HUMAN $157.19 \quad 100.0 \%$ Condensin complex subunit $1 \mathrm{GN}=\mathrm{NCAPD} 2 \mathrm{CND} 1$ _HUMAN $157.19 \quad 100.0 \%$ Condensin complex subunit 1 GN=NCAPD2 CND1 HUMAN $157.19 \quad 100.0 \%$ Condensin complex subunit $3 \mathrm{GN}=\mathrm{NCAPG}$ CND3_HUMAN $114.34 \quad 100.0 \%$ Condensin complex subunit 3 GN=NCAPG CND3_HUMAN $114.34 \quad 100.0 \%$ Condensin complex subunit $3 \mathrm{GN}=\mathrm{NCAPG}$ CND3_HUMAN $114.34 \quad 100.0 \%$ Condensin-2 complex subunit D3 GN=NCAPD3 CNDD3_HUMAN $168.89 \quad 100.0 \%$ Condensin-2 complex subunit D3 GN=NCAPD3 CNDD3 HUMAN $168.89 \quad 100.0 \%$ Conserved oligomeric Golgi complex subunit $1 \mathrm{GN}=\mathrm{COG} 1$ COG1_HUMAN $108.98 \quad 100.0 \%$ Conserved oligomeric Golgi complex subunit $1 \mathrm{GN}=\mathrm{COG} 1$ COG1_HUMAN $108.98 \quad 100.0 \%$ Conserved oligomeric Golgi complex subunit 5 GN=COG5 COG5 HUMAN $92.75 \quad 100.0 \%$ Conserved oligomeric Golgi complex subunit 5 GN=COG5 COG5_HUMAN $92.75 \quad 100.0 \%$ Constitutive coactivator of PPAR-gamma-like protein 1 GN=FAM120A F120A_HUMAN $121.89 \quad 100.0 \%$ Constitutive coactivator of PPAR-gamma-like protein $1 \mathrm{GN}=$ FAM120A F120A_HUMAN $121.89 \quad 100.0 \%$ Constitutive coactivator of PPAR-gamma-like protein 1 GN=FAM120A F120A_HUMAN $121.89 \quad 100.0 \%$

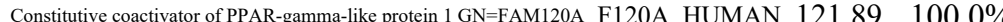
Coordinator of PRMT5 and differentiation stimulator GN=COPRS COPRS_HUMAN $20.07 \quad 100.0 \%$ Coordinator of PRMT5 and differentiation stimulator GN=COPRS COPRS_HUMAN $20.07 \quad 100.0 \%$ COUP transcription factor $2 \mathrm{GN}=\mathrm{NR} 2 \mathrm{~F} 2 \quad \mathrm{COT} 2 \mathrm{HUMAN} 45.57 \quad 100.0 \%$ COUP transcription factor $2 \mathrm{GN}=\mathrm{NR} 2 \mathrm{~F} 2 \quad \mathrm{COT} 2$ _HUMAN $45.57 \quad 100.0 \%$ Creatine kinase B-type $\mathrm{GN}=\mathrm{CKB}$

Creatine kinase B-type $\mathrm{GN}=\mathrm{CKB}$

Creatine kinase B-type $\mathrm{GN}=\mathrm{CKB}$

Creatine kinase $\mathrm{B}$-type $\mathrm{GN}=\mathrm{CKB}$

Creatine kinase B-type $\mathrm{GN}=\mathrm{CKB}$

Creatine kinase $\mathrm{B}$-type $\mathrm{GN}=\mathrm{CKB}$

Crk-like protein $\mathrm{GN}=\mathrm{CRKL}$

Crk-like protein $\mathrm{GN}=\mathrm{CRKL}$

$\mathrm{C}$-terminal-binding protein $1 \mathrm{GN}=\mathrm{CTBP} 1$

CTP synthase $1 \mathrm{GN}=\mathrm{CTPS} 1$

CTP synthase $1 \mathrm{GN}=\mathrm{CTPS}$

CTP synthase $1 \mathrm{GN}=\mathrm{CTPS} 1$

CTP synthase $1 \mathrm{GN}=\mathrm{CTPS} 1$

CTP synthase $1 \mathrm{GN}=\mathrm{CTPS} 1$

CTP synthase $1 \mathrm{GN}=\mathrm{CTPS}$

CTP synthase $1 \mathrm{GN}=\mathrm{CTPS}$

CTP synthase $1 \mathrm{GN}=\mathrm{CTPS} 1$

CTP synthase $1 \mathrm{GN}=\mathrm{CTPS}$

CTP synthase $1 \mathrm{GN}=\mathrm{CTPS} 1$

CTP synthase $1 \mathrm{GN}=\mathrm{CTPS}$

CTP synthase $1 \mathrm{GN}=\mathrm{CTPS}$

CTP synthase $2 \mathrm{GN}=\mathrm{CTPS} 2$

CTP synthase $2 \mathrm{GN}=\mathrm{CTPS} 2$

CTP synthase $2 \mathrm{GN}=\mathrm{CTPS} 2$

CTP synthase $2 \mathrm{GN}=\mathrm{CTPS} 2$
KCRB HUMAN $42.65 \quad 100.0 \%$

KCRB_HUMAN $42.65 \quad 100.0 \%$ KCRB_HUMAN $42.65 \quad 100.0 \%$ KCRB HUMAN $42.65 \quad 100.0 \%$ KCRB_HUMAN $42.65 \quad 100.0 \%$ KCRB_HUMAN $42.65 \quad 100.0 \%$ CRKL HUMAN $33.78 \quad 100.0 \%$ CRKL_HUMAN $33.78 \quad 100.0 \%$ MAN $47.54 \quad 100.0 \%$ PYRG1_HUMAN $66.69 \quad 100.0 \%$ PYRG1 HUMAN $66.69 \quad 100.0 \%$ PYRG1_HUMAN $66.69 \quad 100.0 \%$ PYRG1 HUMAN $66.69 \quad 100.0 \%$ PYRG1 HUMAN $66.69 \quad 100.0 \%$ PYRG1_HUMAN $66.69 \quad 100.0 \%$ PYRG1_HUMAN $66.69 \quad 100.0 \%$ PYRG1_HUMAN $66.69 \quad 100.0 \%$ PYRG1_HUMAN $66.69 \quad 100.0 \%$ PYRG1_HUMAN $66.69 \quad 100.0 \%$ PYRG1_HUMAN $66.69 \quad 100.0 \%$ PYRG1 HUMAN $66.69 \quad 100.0 \%$ PYRG2_HUMAN $65.68 \quad 100.0 \%$ PYRG2_HUMAN $65.68 \quad 100.0 \%$ PYRG2 HUMAN $65.68 \quad 100.0 \%$ PYRG2_HUMAN $65.68 \quad 100.0 \%$
$0.01 \% \quad 3.4 \%$ ESTGNMVTGQTVCK

$99.7 \% \quad 32.3$

$99.7 \% \quad 38.5$

$0.01 \% \quad 3.4 \%$ YQPLASTASDNDFVTPEPR $\quad 99.7 \% \quad 52.0$

$0.01 \% \quad 3.4 \%$ IQAVLALSR

$0.01 \% \quad 3.4 \%$ AVLSCIAPSAK

$0.01 \% \quad 3.4 \% \quad$ LLSDFLDSEVSELR

$99.7 \% \quad 44.2$

$99.7 \% \quad 43.5$

$99.7 \% \quad 25.1$

$99.7 \% \quad 41.0$

$0.01 \% \quad 1.9 \%$ NSSAFSYQR

$0.01 \% \quad 1.9 \% \quad$ ASAGHVAVSSPTPETGPLQR

$0.00 \% \quad 2.9 \%$ QALTDFLLAR

$99.7 \%$

$99.7 \% \quad 30.7$

$\begin{array}{lll}0.00 \% & 2.9 \% & \text { TSVLFGLVTGTEI } \\ 0.00 \% & 3.0 \% & \text { IVEPYNKIVAR }\end{array}$

$0.00 \% \quad 3.0 \% \quad$ LFDPINLVFPPGGR

$99.0 \% \quad 19.0$

$99.7 \% \quad 39.4$

$99.1 \% \quad 18.5$

$0.01 \% \quad 4.4 \%$ QRPPQTPLR

$99.7 \% \quad 54.2$

$99.7 \% \quad 38.4$

$99.7 \% \quad 46.6$

$\begin{array}{lll}99.7 \% & 29.3\end{array}$

$99.2 \% \quad 28.2$

$99.7 \% \quad 30.7$

$99.5 \% \quad 21.2$

$99.7 \% \quad 49.2$

$99.7 \% \quad 59.0$

$99.7 \% \quad 26.0$

$99.7 \% \quad 66.0$

$99.7 \% \quad 32.7$

$99.7 \% \quad 51.5$

$0.02 \% \quad 16.3 \%$ GGNMKEVFTR

$0.02 \% \quad 16.3 \%$ FCTGLTQIETLFK

$99.7 \% \quad 42.0$

$0.01 \% \quad 9.6 \%$ DSSTCPGDYVLSVSENSR

$0.01 \% \quad 9.6 \%$ VGMIPVPYVEK

$0.01 \% \quad 4.3 \%$ IGSGFDNIDIK

$0.01 \% \quad 4.3 \%$ VGQAVALR

$0.05 \% \quad 22.5 \%$ MKYILVTGGVISGIGK

$0.05 \% \quad 22.5 \%$ GIIASSVGTILK

$0.05 \% \quad 22.5 \%$ FLDIRLTK

$0.05 \% \quad 22.5 \%$ IYQYVINKER

$0.05 \% \quad 22.5 \%$ ENFCNIHVSLVPQPSSTGEQK

$0.05 \% \quad 22.5 \%$ TKPTQNSVR

$0.05 \% 22.5 \%$ GLGLSPDLVVCR

$0.05 \% \quad 22.5 \%$ CSNPLDTSVKEK

$0.05 \% \quad 22.5 \%$ RLDLPIER

$0.05 \% \quad 22.5 \%$ LLETCSIALVGK

$0.05 \% \quad 22.5 \%$ LLETCSIALVGKYTK

$0.05 \% \quad 22.5 \%$ FSDSYASVIK

$0.01 \% \quad 11.1 \%$ MKYILVTGGVISGIGK

$0.01 \% \quad 11.1 \%$ GIIASSIGTILK

$0.01 \% \quad 11.1 \%$ TKPTQNSVR

$0.01 \% \quad 11.1 \%$ ALRGLGLSPDLIVCR
$99.7 \% \quad 25.3$

$99.7 \% \quad 29.0$

$99.0 \% \quad 56.9$

$99.7 \% \quad 44.5$

$99.7 \% \quad 60.2$

$99.0 \% \quad 26.0$

$99.6 \% \quad 22.5$

$.7 \% \quad 28$

$\begin{array}{lll}98.2 \% & 24.3\end{array}$

$99.7 \% \quad 57.3$

$99.7 \% \quad 30.2$

$99.0 \% 43.6$

$99.7 \% \quad 36.2$

$99.7 \% \quad 34.8$

$99.7 \% \quad 46.6$

$99.7 \% \quad 44.5$

$99.7 \% \quad 45.0$

$98.2 \% \quad 24.3$

$99.6 \% \quad 23.4$
1160.58

1527.68

1664.83

2107.99

970.60

1116.61

1622.83

1059.49

1962.00

1147.65

1903.03

1301.76

1541.85

1092.63

1723.75

941.58

1386.71

1242.61

1519.59

1254.58

1422.71

1114.56

1303.73

1502.86

1586.84

1138.57

1557.80

1972.86

1247.67

1178.61

813.49

1635.95

1158.71

1005.61

1325.72

2371.13

1030.56

1285.69

1377.67

1011.59

1303.73

1695.94

1116.56

1635.95

1172.73

1030.56

1639.93

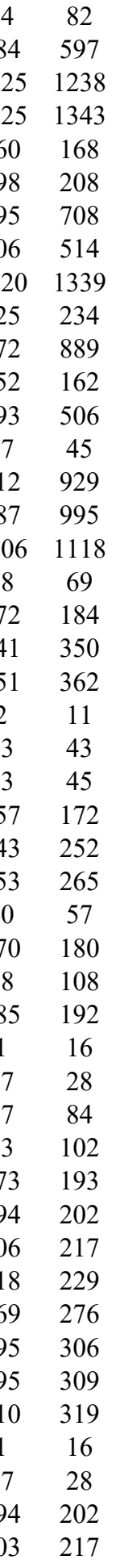

Page 37 of Table S-1-1 
CTP synthase $2 \mathrm{GN}=\mathrm{CTPS} 2$ $\mathrm{CTP}$ synthase $2 \mathrm{GN}=\mathrm{CTPS} 2$ Cullin-1 GN=CUL1

Cullin-1 GN=CUL1

Cullin-4B GN=CUL4B

Cullin-4B GN=CUL4B

Cullin-associoted NEDD8-dissocisted potein $1 \mathrm{GN}=\mathrm{CAND} 1 \mathrm{C}$ Cullin-associated NEDD8-dissociated protein 1 GN=CAND1 CAND1_HUMAN $136.38 \quad 100.0 \%$ Cullin-associated NEDD8-dissociated protein $1 \mathrm{GN}=\mathrm{CAND} 1$ CAND1 HUMAN $136.38 \quad 100.0 \%$ Cullin-associated NEDD8-dissociated protein 1 GN=CAND1 CAND1_HUMAN $136.38 \quad 100.0 \%$ Cullin-associated NEDD8-dissociated protein $1 \mathrm{GN}=$ CAND1 CAND1_HUMAN $136.38 \quad 100.0 \%$ Cullin-associated NEDD8-dissociated protein $1 \mathrm{GN}=$ CAND1 CAND1_HUMAN $136.38 \quad 100.0 \%$ Cullin-associated NEDD8-dissociated protein $1 \mathrm{GN}=$ CAND1 CAND1_HUMAN $136.38 \quad 100.0 \%$ Cullin-associated NEDD8-dissociated protein $1 \mathrm{GN}=\mathrm{CAND} 1$ CAND1_HUMAN $136.38 \quad 100.0 \%$ Cullin-associated NEDD8-dissociated protein $1 \mathrm{GN}=$ CAND1 CAND1_HUMAN $136.38 \quad 100.0 \%$ Cullin-associated NEDD8-dissociated protein 1 GN=CAND1 CAND1_HUMAN $136.38 \quad 100.0 \%$ Cullin-associated NEDD8-dissociated protein $1 \mathrm{GN}=\mathrm{CAND} 1$ CAND1 HUMAN $136.38100 .0 \%$ Cullin-associated NEDD8-dissociated protein 1 GN=CAND1 CAND1_HUMAN $136.38 \quad 100.0 \%$ Cullin-associated NEDD8-dissociated protein $1 \mathrm{GN}=$ CAND1 CAND1_HUMAN $136.38 \quad 100.0 \%$ Cullin-associated NEDD8-dissocited protein $2 \mathrm{GN}=\mathrm{CAND2}$ CAND2 HUMAN $135.26 \quad 100.0 \%$ Cullin-associated NEDD8-dissociated protein 2 GN=CAND2 CAND2_HUMAN $135.26 \quad 100.0 \%$ Cyclin-dependent kinase $1 \mathrm{GN}=\mathrm{CDK} 1$ Cyclin-dependent kinase $1 \mathrm{GN}=\mathrm{CDK} 1$ Cyclin-dependent kinase $1 \mathrm{GN}=\mathrm{CDK} 1$ Cyclin-dependent kinase $1 \mathrm{GN}=\mathrm{CDK} 1$ Cyclin-dependent kinase $1 \mathrm{GN}=\mathrm{CDK} 1$ Cyclin-dependent kinase $1 \mathrm{GN}=\mathrm{CDK} 1$ Cyclin-dependent kinase $1 \mathrm{GN}=\mathrm{CDK} 1$ Cyclin-dependent kinase $1 \mathrm{GN}=\mathrm{CDK} 1$ Cyclin-dependent kinase $1 \mathrm{GN}=\mathrm{CDK} 1$ Cyclin-dependent kinase $1 \mathrm{GN}=\mathrm{CDK} 1$ Cyclin-dependent kinase $1 \mathrm{GN}=\mathrm{CDK} 1$ Cyclin-dependent kinase $1 \mathrm{GN}=\mathrm{CDK} 1$ Cyclin-dependent kinase $1 \mathrm{GN}=\mathrm{CDK} 1$ Cyclin-dependent kinase $2 \mathrm{GN}=\mathrm{CDK} 2$ Cyclin-dependent kinase $2 \mathrm{GN}=\mathrm{CDK} 2$ Cyclin-dependent kinase $2 \mathrm{GN}=\mathrm{CDK} 2$ Cyclin-dependent kinase $2 \mathrm{GN}=\mathrm{CDK} 2$ Cyclin-dependent kinase $2 \mathrm{GN}=\mathrm{CDK} 2$ Cyclin-dependent kinase $2 \mathrm{GN}=\mathrm{CDK} 2$

Cyclin-dependent kinase $2 \mathrm{GN}=\mathrm{CDK} 2$ CDK1 HUMAN $34.10 \quad 100.0 \%$ CDK1_HUMAN $34.10 \quad 100.0 \%$ CDK1_HUMAN $34.10 \quad 100.0 \%$ CDK1 HUMAN $34.10 \quad 100.0 \% \quad 13$ CDK1_HUMAN $34.10 \quad 100.0 \%$ CDK1_HUMAN $34.10 \quad 100.0 \%$ CDK1_HUMAN $34.10 \quad 100.0 \%$ CDK1_HUMAN $34.10 \quad 100.0 \%$ CDK1_HUMAN $34.10 \quad 100.0 \% \quad 13$ CDK1_HUMAN $34.10 \quad 100.0 \%$ CDK1_HUMAN $34.10 \quad 100.0 \% \quad 13$ CDK1_HUMAN $34.10 \quad 100.0 \% \quad 13$ CDK1_HUMAN $34.10 \quad 100.0 \%$ CDK2_HUMAN $33.93 \quad 100.0 \%$ CDK2_HUMAN $33.93 \quad 100.0 \%$ CDK2_HUMAN $33.93 \quad 100.0 \%$ CDK2 HUMAN $33.93 \quad 100.0 \%$ CDK2_HUMAN $33.93 \quad 100.0 \%$ CDK2_HUMAN $33.93 \quad 100.0 \%$ CDK2 HUMAN $33.93 \quad 100.0 \%$ Cyclin-dependent-like kinase 5 GN=CDK5 CDK5_HUMAN $33.31 \quad 100.0 \%$ Cyclin-dependent-like kinase $5 \mathrm{GN}=\mathrm{CDK} 5 \mathrm{CDK} 5$ HUMAN $33.31 \quad 100.0 \%$ Cyclin-dependent-like kinase $5 \mathrm{GN}=\mathrm{CDK} 5$ CDK5_HUMAN $33.31 \quad 100.0 \%$ Cystathionine beta-synthase $\mathrm{GN}=\mathrm{CBS}$ CBS_HUMAN $60.59 \quad 100.0 \%$ $\begin{array}{llll}\text { Cystathionine beta-synthase GN=CBS } & \text { CBS_HUMAN } & 60.59 & 100.0 \% \\ \text { Cysteine desulfurase, mitochondrial GN=NFS1 } & \text { NFS1_HUMAN } & 50.20 & 100.0 \%\end{array}$
$0.01 \% \quad 11.1 \%$ GLGLSPDLIVCR

$0.01 \% \quad 11.1 \%$ ADGILVPGGFGIR

$0.00 \% \quad 2.2 \%$ FINNNAVTK

$0.00 \% \quad 2.2 \% \quad$ FTAFYASR

$0.00 \% \quad 2.9 \% \quad$ SSTTVSSFANSKPGSAK

$0.00 \% \quad 2.9 \%$ TLQSLACGK

$0.06 \% \quad 11.1 \%$ CLGPLVSK

$0.06 \% \quad 11.1 \%$ TYIQCIAAISR

$0.06 \% \quad 11.1 \%$ TVSPALISR

$0.06 \% \quad 11.1 \%$ ITSEALLVTQQLVK

$0.06 \% \quad 11.1 \%$ AADIDQEVKER

$0.06 \% \quad 11.1 \%$ ALTLIAGSPLK

$0.06 \% \quad 11.1 \%$ QSYYSIAK

$0.06 \% \quad 11.1 \%$ EGPAVVGQFIQDVK

$0.06 \% \quad 11.1 \%$ EGPAVVGQFIQDVKNSR

$0.06 \% \quad 11.1 \%$ LTLIDPETLLPR

$0.06 \% \quad 11.1 \%$ LKGYLISGSSYAR

$0.06 \% \quad 11.1 \%$ TLEDPDLNVR

$0.06 \% \quad 11.1 \%$ LVEPLRATCTTK

$0.01 \% \quad 1.6 \%$ VPTSPTAIR

$0.01 \% \quad 1.6 \%$ TLIQCLGSVGR

$0.06 \% \quad 39.1 \%$ IGEGTYGVVYK

$3 \quad 0.06 \% \quad 39.1 \%$ IGEGTYGVVYKGR

$0.06 \% \quad 39.1 \%$ HKTTGQVVAMK

$0.06 \% \quad 39.1 \%$ TTGQVVAMKK

$0.06 \% \quad 39.1 \%$ IRLESEEEGVPSTAIR

$0.06 \% \quad 39.1 \%$ LESEEEGVPSTAIR

$0.06 \% 39.1 \%$ EISLLKELR

$43 \quad 0.06 \% \quad 39.1 \%$ DLKPQNLLIDDKGTIK

$0.06 \% 39.1 \%$ LADFGLAR

$0.06 \% \quad 39.1 \%$ SPEVLLGSAR

$43 \quad 0.06 \% \quad 39.1 \%$ WKPGSLASHVK

$43 \quad 0.06 \% \quad 39.1 \%$ NLDENGLDLLSK

$43 \quad 0.06 \% \quad 39.1 \%$ MLIYDPAKR

$10 \quad 0.01 \% \quad 30.2 \%$ IGEGTYGVVYK

$10 \quad 0.01 \% \quad 30.2 \%$ IRLDTETEGVPSTAIR

$10 \quad 0.01 \% \quad 30.2 \%$ ELNHPNIVK

$10 \quad 0.01 \% \quad 30.2 \%$ FMDASALTGIPLPLIK

$10 \quad 0.01 \% \quad 30.2 \%$ DLKPQNLLINTEGAIK

$10 \quad 0.01 \% \quad 30.2 \%$ LADFGLAR

$10 \quad 0.01 \% \quad 30.2 \%$ ALFPGDSEIDQLFR

$0.00 \% \quad 10.3 \%$ IGEGTYGTVFK

$0.00 \% \quad 10.3 \%$ DLKPQNLLINR

$0.00 \% \quad 10.3 \%$ LADFGLAR

$0.00 \% \quad 3.8 \% \quad$ SNDEEAFTFAR

$0.00 \% \quad 3.8 \%$ AAQELQEGQR

$0.01 \% \quad 8.3 \%$ SLEAEGFQVTYLPVQK $\begin{array}{llllll}99.7 \% & 57.6 & 25.0 & 47.0 & 3 & 0\end{array}$

$\begin{array}{lllllll}97.0 \% & 21.4 & 25.0 & 12.0 & 2 & 0 & 0\end{array}$

$99.6 \% \quad 28.6 \quad 25.0 \quad 15.6$

$99.0 \% \quad 21.9 \quad 25.0 \quad 21.9$

$\begin{array}{llll}99.1 \% & 21.5 & 25.0 & 21.5\end{array}$

$\begin{array}{lllll}99.6 \% & 23.2 & 25.0 & 21.4 & 2\end{array}$

$\begin{array}{llll}95.8 \% & 24.9 & 25.2 & 7.0\end{array}$

$\begin{array}{lllll}99.7 \% & 55.4 & 25.0 & 51.7 & 4\end{array}$

$\begin{array}{llll}99.7 \% & 39.8 & 25.0 & 24.5\end{array}$

$\begin{array}{llll}99.7 \% & 35.1 & 25.0 & 35.1\end{array}$

$\begin{array}{lllll}99.7 \% & 49.7 & 25.0 & 43.1\end{array}$

$99.7 \% \quad 56.3 \quad 25.0 \quad 50.8$

$\begin{array}{llll}95.8 \% & 20.6 & 25.0 & 12.8\end{array}$

$\begin{array}{llll}99.7 \% & 35.7 & 25.0 & 35.7\end{array}$

$\begin{array}{llll}99.7 \% & 42.6 & 25.0 & 42.6\end{array}$

$\begin{array}{llll}99.7 \% & 51.5 & 25.0 & 51.5\end{array}$

$\begin{array}{llll}99.7 \% & 38.6 & 25.0 & 30.2\end{array}$

$\begin{array}{llll}97.1 \% & 20.6 & 25.0 & 17.3\end{array}$

$96.0 \% \quad 15.5 \quad 25.0 \quad 14.1$

$\begin{array}{llll}98.3 \% & 19.0 & 25.0 & 16.0\end{array}$

$99.7 \% \quad 41.3 \quad 25.0 \quad 34.5$

$\begin{array}{llll}99.7 \% & 76.7 & 25.0 & 29.5\end{array}$

$\begin{array}{llll}99.7 \% & 54.4 & 25.0 & 33.8\end{array}$

$\begin{array}{llll}99.7 \% & 49.1 & 25.0 & 42.8\end{array}$

$99.7 \% \quad 36.8 \quad 25.0 \quad 28.0$

$\begin{array}{llll}99.7 \% & 40.2 & 25.0 & 40.2\end{array}$

$\begin{array}{llll}99.7 \% & 31.0 & 25.0 & 27.8\end{array}$

$\begin{array}{llll}99.6 \% & 30.2 & 25.0 & 12.7\end{array}$

$\begin{array}{lllll}99.7 \% & 60.3 & 25.0 & 60.3 & 2\end{array}$

$\begin{array}{llll}99.0 \% & 38.4 & 25.0 & 0.0\end{array}$

$\begin{array}{llll}99.7 \% & 60.5 & 25.0 & 49.8\end{array}$

$\begin{array}{llll}98.2 \% & 16.7 & 25.0 & 16.7\end{array}$

$\begin{array}{llll}99.7 \% & 53.6 & 25.0 & 43.5\end{array}$

$\begin{array}{llll}99.7 \% & 37.8 & 25.0 & 27.3\end{array}$

$99.7 \% \quad 76.7 \quad 25.0 \quad 29.5$

$\begin{array}{llll}99.7 \% & 38.5 & 25.0 & 38.5\end{array}$

$\begin{array}{llll}98.5 \% & 23.8 & 25.0 & 13.4\end{array}$

$\begin{array}{llll}99.7 \% & 55.3 & 25.0 & 55.3\end{array}$

$\begin{array}{llll}99.7 \% & 35.8 & 25.0 & 35.8\end{array}$

$\begin{array}{llll}99.0 \% & 38.4 & 25.0 & 0.0\end{array}$

$\begin{array}{llll}99.7 \% & 35.6 & 25.0 & 30.7\end{array}$

$\begin{array}{llll}99.7 \% & 25.7 & 25.0 & 25.7\end{array}$

$\begin{array}{llll}95.6 \% & 18.4 & 25.0 & 14.2\end{array}$

$\begin{array}{llll}99.0 \% & 38.4 & 25.0 & 0.0\end{array}$

$\begin{array}{lllll}99.7 \% & 56.4 & 25.0 & 56.4 & 2\end{array}$

$\begin{array}{llll}99.7 \% & 54.8 & 25.0 & 44.3\end{array}$

$\begin{array}{llll}99.7 \% & 38.0 & 25.0 & 38.0\end{array}$
1271.71

1020.55

462.47

1655.82

977.51

873.49

1295.68

943.56

1542.91

1273.64

083.68

959.48

1486.79

1843.97

1380.81

414.77

1171.60

1388.76

941.54

1203.65

1185.62

1398.74

1199.66

1062.60

1785.93

1516.75

1100.67

1811.03

862.48

1028.57

1209.67

330.69

1122.60

1185.62

1757.94

1063.59

(702.95

1767.00

862.48

607.81

1171.60

1323.77

862.48

1286.56

1129.56 1808.94

$\begin{array}{cc}06 & 217 \\ 64 & 376 \\ 02 & 410 \\ 66 & 573 \\ 79 & 195 \\ 81 & 789 \\ 1 & 78 \\ 33 & 243 \\ 74 & 382 \\ 35 & 548 \\ 78 & 588 \\ 31 & 641 \\ 94 & 801 \\ 13 & 826 \\ 13 & 829 \\ 58 & 969 \\ 70 & 982 \\ 14 & 1023 \\ 45 & 1156 \\ 27 & 235 \\ 36 & 246 \\ 0 & 20 \\ 0 & 22 \\ 3 & 33 \\ 5 & 34 \\ 5 & 50 \\ 7 & 50 \\ 1 & 59 \\ 28 & 143 \\ 44 & 151 \\ 71 & 180 \\ 44 & 254 \\ 55 & 266 \\ 67 & 275 \\ 0 & 20 \\ 5 & 50 \\ 7 & 65 \\ 0 & 105 \\ 27 & 142 \\ 43 & 150 \\ 01 & 214 \\ 0 & 20 \\ 26 & 136 \\ 42 & 149 \\ 26 & 336 \\ 60 & 369 \\ 65 & 180 \\ & \end{array}$

Page 38 of Table S-1-1 
$0.01 \% \quad 8.3 \%$ GVGAIYIR

$0.01 \% \quad 8.3 \%$ AIGTDEDLAHSSIR

$0.01 \% \quad 7.7 \%$ ADLTEYLSTHYKAPR

$0.01 \% \quad 7.7 \%$ LCTSATESEVAR

$0.01 \% \quad 7.7 \%$ IAEVDASVVR

$0.06 \% 32.0 \%$ AGSRYEDF

$0.06 \% 32.0 \%$ LTSSLTTKGASSFK

$0.06 \% 32.0 \%$ GASSFKITR

$0.06 \% 32.0 \%$ GIEAVGGKLSVTATR

$0.06 \% 32.0 \%$ WEVADLQPQLK

$0.06 \% 32.0 \%$ NALANPLYCPDYR

$0.06 \% 32.0 \%$ MALIGLGVSHPVLK

$0.06 \% 32.0 \%$ QVAEQFLNMR

$0.06 \% 32.0 \%$ GSNTTSHLHQAVAK

$0.06 \% 32.0 \%$ TIAQGNLSNTDVQAAK

$42 \quad 0.06 \% \quad 32.0 \%$ SMAASGNLGHTPFVD

$223 \quad 0.31 \% \quad 14.2 \%$ FLSDPQVHTVLVER

$223 \quad 0.31 \% \quad 14.2 \%$ TPVIDADKPVSSQLR

$223 \quad 0.31 \% \quad 14.2 \%$ ESPEVLLTLDILK

$223 \quad 0.31 \% \quad 14.2 \%$ LRDQLGTAK

$223 \quad 0.31 \% \quad 14.2 \%$ GAIREYQTQLIQR

$223 \quad 0.31 \% \quad 14.2 \%$ EYQTQLIQR

$223 \quad 0.31 \% \quad 14.2 \%$ VQYPQSQACK

$223 \quad 0.31 \% \quad 14.2 \%$ LKQDGDSFR

$223 \quad 0.31 \% \quad 14.2 \%$ IFTIESTR

$223 \quad 0.31 \% \quad 14.2 \%$ MVVLSLPR

$223 \quad 0.31 \% \quad 14.2 \%$ GTFDNAETKK

$223 \quad 0.31 \% \quad 14.2 \%$ FGQMLGSNMTEFHSQIS

$223 \quad 0.31 \% \quad 14.2 \%$ DSAIQQQVANLQMK

$223 \quad 0.31 \% \quad 14.2 \%$ IVQEDRAVESR

$223 \quad 0.31 \% \quad 14.2 \%$ QNLDALLNQLK

$223 \quad 0.31 \% \quad 14.2 \%$ LRQYASYEFVQR

$223 \quad 0.31 \% \quad 14.2 \%$ QYASYEFVQR

$223 \quad 0.31 \% \quad 14.2 \%$ HLLPVETQR

$223 \quad 0.31 \% \quad 14.2 \%$ FQSISTEFLALMK

$223 \quad 0.31 \% \quad 14.2 \%$ SPLVMDVLNIQGVQR

$223 \quad 0.31 \% \quad 14.2 \%$ TPVSITEHPK

$223 \quad 0.31 \% \quad 14.2 \%$ LLAESVTEVEIFGK

$223 \quad 0.31 \% \quad 14.2 \%$ SFEWLSQMR

$223 \quad 0.31 \% \quad 14.2 \%$ LGGSPFGPAGTGK

$223 \quad 0.31 \% \quad 14.2 \%$ LGGSPFGPAGTGKTESVK

$223 \quad 0.31 \% \quad 14.2 \%$ ALGHQLGR

$223 \quad 0.31 \% \quad 14.2 \%$ TSAPITCELLNK

$223 \quad 0.31 \% \quad 14.2 \%$ SNLPDNLKK

$223 \quad 0.31 \% \quad 14.2 \%$ SLAMTKPDR

$223 \quad 0.31 \% \quad 14.2 \%$ TAEVLANK
$99.0 \% \quad 40.2$

$99.7 \% \quad 29.1$

$99.7 \% \quad 30.5$

$99.7 \% \quad 67.2$

$99.7 \% \quad 25.0$

$\begin{array}{lll}98.7 \% & 21.7\end{array}$

$99.0 \% 21.5$

$98.2 \% \quad 16.6$

$99.7 \% \quad 56.4$

$99.7 \% \quad 54.4$

$99.7 \% \quad 51.8$

$99.7 \% \quad 52.4$

$99.7 \% \quad 54.0$

$99.7 \% \quad 55.1$

$99.7 \% \quad 62.3$

$99.7 \% \quad 69.0$

$99.7 \% \quad 43.8$

$\begin{array}{lll}99.7 \% & 49.0\end{array}$

$99.7 \% \quad 53.6$

$99.7 \% \quad 34.2$

$99.7 \% \quad 55.7$

$99.7 \% \quad 36.6$

$99.7 \% \quad 45.5$

$94.5 \% \quad 14.7$

$99.7 \% \quad 39.6$

$95.4 \% 22.1$

$99.0 \% \quad 34.0$

$99.6 \% \quad 22.7$

$98.1 \% \quad 16.9$

$99.7 \% \quad 45.1$

$\begin{array}{lll}99.7 \% & 39.3\end{array}$

$\begin{array}{lll}99.7 \% & 41.8\end{array}$

$\begin{array}{lll}99.7 \% & 30.8\end{array}$

$99.7 \% \quad 43.9$

$95.0 \% \quad 15.1$

$99.7 \% \quad 60.8$

$99.7 \% \quad 48.3$

$99.7 \% \quad 45.2$

$99.7 \% \quad 60.2$

$99.7 \% \quad 41.9$

$99.7 \% \quad 50.3$

$99.6 \% 22.4$

$99.0 \% \quad 36.5$

$99.7 \% \quad 52.3$

$99.5 \% \quad 21.9$

$94.9 \% \quad 20.7$

$99.0 \% \quad 32.5$
35.9

$\begin{array}{ll}0.0 & 24.1\end{array}$

0
59.6

$\begin{array}{ll}25.0 & 19.9\end{array}$

$\begin{array}{ll}0 & 20.8\end{array}$

$\begin{array}{ll}0 & 21.5\end{array}$

$.0 \quad 16.6$

$\begin{array}{ll}0 & 44.6\end{array}$

\begin{tabular}{ll}
54.0 & 54.4 \\
\hline
\end{tabular}

$\begin{array}{ll}51.8 \\ 25.0 & 41.3\end{array}$

\begin{tabular}{l}
047.2 \\
\hline
\end{tabular}

$\begin{array}{ll}0 & 47.2 \\ & 51.6\end{array}$

$\begin{array}{ll}25.0 & 63.8\end{array}$

\begin{tabular}{ll}
0 & 63.8 \\
\hline & 43.8
\end{tabular}

48.7

$\begin{array}{ll}.0 & 48.7 \\ 0 & 27.4\end{array}$

\begin{tabular}{ll} 
& 0 \\
\hline & 41.3
\end{tabular}

$\begin{array}{ll}36.3 \\ 25.0 & 27.0\end{array}$

\begin{tabular}{ll}
.0 & 36.3 \\
\hline & 27.0
\end{tabular}

\begin{tabular}{ll}
14.7 \\
\hline
\end{tabular}

$\begin{array}{ll}.0 & 14.7 \\ 25.0 & 37.9\end{array}$

33.0

\begin{tabular}{ll}
.0 & 33.0 \\
\hline & 19.0
\end{tabular}

$\begin{array}{ll}25.0 & 16.9\end{array}$

$\begin{array}{ll}0 & 16.9 \\ 0 & 42.3\end{array}$

$\begin{array}{ll}0 & 42.3\end{array}$

$\begin{array}{ll}5.0 & 29.0 \\ 27.0 & 27.9\end{array}$

$\begin{array}{ll}27.9 \\ 25.0 & 30.8\end{array}$

$\begin{array}{ll}25.0 & 38.0\end{array}$

$\begin{array}{ll}25.0 & 15.1\end{array}$

\begin{tabular}{ll}
.0 & 15.1 \\
\hline & 58.3
\end{tabular}

$\begin{array}{ll}58.3 \\ .0 & 41.9\end{array}$

848.50

0

10

0

848.50

1484.73

1764.89

1058.58

850.49

1427.77

966.54

1458.83

1326.71

1566.74

1450.85

1235.62

1450.74

1630.84

1761.81

1639.88

1625.89

1469.85

1001.57

1575.86

1178.62

1208.57

1065.53

966.53

914.55

1110.54

2073.94

1573.80

1301.68

1269.72

1559.80

1290.61

1092.62

1530.79

1668.91

1108.60

1534.84

1199.55

1145.60

1689.88

851.48

1346.70

1028.57

1018.54 845.47
$394 \quad 407$

$\begin{array}{ll}214 & 228 \\ 379 & 390\end{array}$

$379 \quad 390$

$433 \quad 442$

$85 \quad 92$

$85 \quad 98$

93101

$102 \quad 116$

196

$218 \quad 231$

$232 \quad 241$

$302 \quad 315$

$360 \quad 375$

$68 \quad 81$

$122 \quad 136$

$568 \quad 576$

$603 \quad 611$

$682 \quad 690$

$717 \quad 724$

$991 \quad 998$

$1091 \quad 1100$

1229

$1243 \quad 1253$

$1361 \quad 1371$

$1377 \quad 1388$

13791388

15591567

15681580

$\begin{array}{ll}1585 & 1599 \\ 1688 & 1697\end{array}$

$1716 \quad 1729$

18351843

19001912

$\begin{array}{ll}1900 & 1917 \\ 1918 & 1925\end{array}$

$\begin{array}{ll}1918 & 1925 \\ 1993 & 2004\end{array}$

$2026 \quad 2034$

$2038 \quad 2046$ 
$223 \quad 0.31 \% \quad 14.2 \%$ SVLVSAGNVK

$0.31 \% \quad 14.2 \%$ SVLVSAGNVKR

$223 \quad 0.31 \% \quad 14.2 \%$ SIPLDEGEDEAQR

$223 \quad 0.31 \% \quad 14.2 \%$ SIPLDEGEDEAQRR

$223 \quad 0.31 \% \quad 14.2 \%$ DAATIMQPYFTSNGLVTK

$223 \quad 0.31 \% \quad 14.2 \%$ AELGEYIRR

$223 \quad 0.31 \% \quad 14.2 \%$ VPQIEVETHK

$223 \quad 0.31 \% \quad 14.2 \%$ TMTLFSALR

$223 \quad 0.31 \% \quad 14.2 \%$ TPNGVVLAPVQLGK

$223 \quad 0.31 \% \quad 14.2 \%$ TSDQTWVKLER

$223 \quad 0.31 \% \quad 14.2 \%$ IQFVGACNPPTDPGR

$223 \quad 0.31 \% \quad 14.2 \%$ FTQDTQPHYIYSPR

$223 \quad 0.31 \% \quad 14.2 \%$ AATSPALFNR

$223 \quad 0.31 \% \quad 14.2 \%$ SMANPPAAVK

$223 \quad 0.31 \% \quad 14.2 \%$ NYMSNPSYNYEIVNR

$223 \quad 0.31 \% \quad 14.2 \%$ ASLACGPMVK

$223 \quad 0.31 \% \quad 14.2 \%$ TEYLSNADERLR

$223 \quad 0.31 \% \quad 14.2 \%$ TSFLDDAFRK

$223 \quad 0.31 \% \quad 14.2 \%$ VTFVNFTVTR

$223 \quad 0.31 \% \quad 14.2 \%$ SSLQSQCLNEVLK

$223 \quad 0.31 \% \quad 14.2 \%$ LQGEFQLR

$223 \quad 0.31 \% \quad 14.2 \%$ SLLQALNEVK

$223 \quad 0.31 \% \quad 14.2 \%$ SLLQALNEVKGR

$223 \quad 0.31 \% \quad 14.2 \%$ GVTDHTQR

$223 \quad 0.31 \% \quad 14.2 \%$ DLFQVAFNR

$223 \quad 0.31 \% \quad 14.2 \%$ GNEIVLSAGSTPR

$223 \quad 0.31 \% \quad 14.2 \%$ IQGLTVEQAEAVVR

$223 \quad 0.31 \% \quad 14.2 \%$ LFLTMEINPK

$223 \quad 0.31 \% \quad 14.2 \%$ IFVFEPPPGVK

$223 \quad 0.31 \% \quad 14.2 \%$ TFSSIPVSR

$223 \quad 0.31 \% \quad 14.2 \%$ KYEFGESDLR

$223 \quad 0.31 \% \quad 14.2 \%$ TLMAQSIYGGR

$223 \quad 0.31 \% \quad 14.2 \%$ LLNTFLER

$223 \quad 0.31 \% \quad 14.2 \%$ VLLTTQGVDMISK

$0.01 \% \quad 9.2 \%$ SVSSNVASVSPIPAGSK

$0.01 \% \quad 9.2 \%$ TGSPGGPGVSGGSPAGGAGGGSSGLPPSTKK

$13 \quad 0.02 \% \quad 6.5 \% \quad$ YSNSEVVTGSGR

$13 \quad 0.02 \% \quad 6.5 \% \quad$ SGFDIKVPR

$13 \quad 0.02 \% \quad 6.5 \% \quad$ SIDLNRLITQR

$13 \quad 0.02 \% \quad 6.5 \% \quad$ TVLPFSQEFQR

$13 \quad 0.02 \% \quad 6.5 \% \quad$ ALNLAYSSIYGSYR

$13 \quad 0.02 \% \quad 6.5 \%$ LGTPQQIAIAR

$13 \quad 0.02 \% \quad 6.5 \% \quad$ CFQPPIHQSLASS

$0.01 \% \quad 5.4 \%$ GGFDIKVPR

$0.01 \% \quad 5.4 \%$ SIDLNRLITQR

$6 \quad 0.01 \% \quad 5.4 \%$ TAIPFTQEPQR

$6 \quad 0.01 \% \quad 5.4 \% \quad$ LGTPQQIAIAR
$99.7 \% \quad 52.7$

$95.9 \% 16.2$

$99.7 \% \quad 34.7$

$99.7 \% \quad 45.8$

$99.7 \% \quad 46.8$

$99.7 \% \quad 41.1$

$99.7 \% \quad 57.6$

$99.7 \% \quad 48.2$

$\begin{array}{lll}99.7 \% & 45.2\end{array}$

$99.7 \% \quad 46.1$

$99.7 \% \quad 52.5$

$99.3 \% 28.8$

$98.0 \% \quad 17.0$

$99.7 \% \quad 50.1$

$99.7 \% \quad 68.2$

$99.7 \% \quad 56.1$

$99.0 \% \quad 38.4$

$99.7 \% \quad 39.8$

$99.7 \% \quad 61.3$

$97.9 \% 19.1$

$99.7 \% \quad 58.2$

$99.7 \% \quad 57.1$

$99.7 \% \quad 54.0$

$99.7 \% \quad 36.7$

$99.7 \% \quad 31.4$

$99.7 \% \quad 35.8$

$99.4 \% \quad 31.0$

$99.7 \% \quad 37.3$

$99.0 \% \quad 24.5$

$99.7 \% \quad 53.7$

$99.7 \% \quad 58.5$

$99.7 \% \quad 35.2$

$99.7 \% \quad 30.8$

$99.7 \% \quad 47.0$

$95.5 \% \quad 17.0$

$\begin{array}{lll}98.5 \% & 22.8\end{array}$

$99.7 \% \quad 33.2$

$99.7 \% \quad 51.8$

$98.6 \% 20.4$

$99.7 \% \quad 42.3$

$\begin{array}{lll}95.5 \% & 17.0\end{array}$

$99.3 \% \quad 20.0$

$99.7 \% \quad 51.8$ $\begin{array}{lll}1362.70 & 2695 & 2705\end{array}$ $\begin{array}{lll}1628.79 & 2706 & 2720\end{array}$ $\begin{array}{lll}1752.83 & 2784 & 2797\end{array}$ $\begin{array}{lll}1047.56 & 3079 & 3088\end{array}$ $\begin{array}{lll}1001.51 & 3309 & 3318\end{array}$ $1863.83 \quad 3370 \quad 3384$ $\begin{array}{lll}1049.51 & 3385 & 3394\end{array}$ $1466.72 \quad 3550 \quad 3561$ $\begin{array}{lll}1199.61 & 3612 & 3621\end{array}$ $\begin{array}{lll}1183.65 & 3696 & 3705\end{array}$ $1505.76 \quad 3706 \quad 3718$ $\begin{array}{llll}990.54 & 3734 & 3741\end{array}$ $\begin{array}{lll}1114.65 & 3748 & 3757\end{array}$ $\begin{array}{lll}1327.77 & 3748 \quad 3759\end{array}$ $\begin{array}{lll}913.45 & 3848 & 3855\end{array}$ $1109.57 \quad 3862 \quad 3870$ $\begin{array}{lll}1300.69 & 3911 & 3923\end{array}$ $\begin{array}{lll}1512.84 & 3924 & 3937\end{array}$ $1205.66 \quad 4124 \quad 4133$ $1229.69 \quad 4144 \quad 4154$ $993.54 \quad 4160 \quad 4168$ $\begin{array}{lll}1243.60 & 4204 \quad 4213\end{array}$ $\begin{array}{lll}1196.61 & 4245 & 4255\end{array}$ $1005.57 \quad 4264 \quad 4271$ $\begin{array}{lll}1420.77 & 4330 & 4342\end{array}$ $1586.84 \quad 412 \quad 428$ $2523.24 \quad 456 \quad 486$ $\begin{array}{lll}1255.59 & 366 & 377\end{array}$ $\begin{array}{lll}1018.57 & 541 \quad 549\end{array}$ 1328.76 1351.70 1577.80 1167.68 
Cytoskeleton-associated protein $5 \mathrm{GN}=\mathrm{CKAP} 5$ CKAP5_HUMAN $225.50 \quad 100.0 \%$ Cytoskeleton-associated protein 5 GN=CKAP5 CKAP5_HUMAN $225.50 \quad 100.0 \%$ Cytoskeleton-associated protein $5 \mathrm{GN}=\mathrm{CKAP} 5$ CKAP5 HUMAN $225.50 \quad 100.0 \%$ D-3-phosphoglycerate dehydrogenase GN=PHGDH SERA_HUMAN $56.65 \quad 100.0 \%$ D-3-phosphoglycerate dehydrogenase GN=PHGDH SERA_HUMAN $56.65 \quad 100.0 \%$ D-3-phosphoglycerate dehydrogenase GN=PHGDH SERA_HUMAN $56.65100 .0 \%$ D-3-phosphoglycerate dehydrogenase GN=PHGDH SERA_HUMAN $56.65 \quad 100.0 \%$ D-3-phosphoglycerate dehydrogenase GN=PHGDH SERA_HUMAN $56.65 \quad 100.0 \%$ D-3-phosphoglycerate dehydrogenase GN=PHGDH SERA_HUMAN $56.65 \quad 100.0 \%$ D-3-phosphoglycerate dehydrogenase GN=PHGDH SERA_HUMAN $56.65 \quad 100.0 \%$ DBIRD complex subunit ZNF326 GN=ZNF326 ZN326 HUMAN $65.65 \quad 100.0 \%$ DBIRD complex subunit ZNF326 GN=ZNF326 ZN326_HUMAN $65.65 \quad 100.0 \%$ DBIRD complex subunit ZNF326 GN=ZNF326 ZN326_HUMAN $65.65 \quad 100.0 \%$ DBIRD complex subunit ZNF326 GN=ZNF326 ZN326_HUMAN $65.65 \quad 100.0 \%$ DDRGK domain-containing protein $1 \mathrm{GN}=$ DDRGK1 DDRGK_HUMAN $35.61 \quad 100.0 \%$ DDRGK domain-containing protein $1 \mathrm{GN}=$ DDRGK1 DDRGK_HUMAN $35.61 \quad 100.0 \%$ Dedicator of cytokinesis protein $11 \mathrm{GN}=$ DOCK11 DOC11_HUMAN $237.68 \quad 100.0 \%$ Dedicator of cytokinesis protein $11 \mathrm{GN}=$ DOCK11 DOC11_HUMAN $237.68 \quad 100.0 \%$ Dedicator of cytokinesis protein $4 \mathrm{GN}=$ DOCK4 DOCK4_HUMAN $225.21 \quad 100.0 \%$ Dedicator of cytokinesis protein 4 GN=DOCK4 DOCK4_HUMAN $225.21 \quad 100.0 \%$ Dedicator of cytokinesis protein $4 \mathrm{GN}=$ DOCK4 DOCK4_HUMAN $225.21 \quad 100.0 \%$ Dedicator of cytokinesis protein 4 GN=DOCK4 DOCK4_HUMAN $225.21 \quad 100.0 \%$ Dedicator of cytokinesis protein 4 GN=DOCK4 DOCK4_HUMAN $225.21 \quad 100.0 \%$ Dedicator of cytokinesis protein $4 \mathrm{GN}=$ DOCK4 DOCK4_HUMAN $225.21 \quad 100.0 \%$ Dedicator of cytokinesis protein 4 GN=DOCK4 DOCK4_HUMAN $225.21 \quad 100.0 \%$ Dedicator of cytokinesis protein 4 GN=DOCK4 DOCK4_HUMAN $225.21 \quad 100.0 \%$ Dedicator of cytokinesis protein 4 GN=DOCK4 DOCK4_HUMAN $225.21 \quad 100.0 \%$ Dedicator of cytokinesis protein 4 GN=DOCK4 DOCK4_HUMAN $225.21 \quad 100.0 \%$ Dedicator of cytokinesis protein 4 GN=DOCK4 DOCK4_HUMAN $225.21 \quad 100.0 \%$ Dedicator of cytokinesis protein 4 GN=DOCK4 DOCK4_HUMAN $225.21 \quad 100.0 \%$ Dedicator of cytokinesis protein $4 \mathrm{GN}=$ DOCK4 DOCK4_HUMAN $225.21 \quad 100.0 \%$ Dedicator of cytokinesis protein 4 GN=DOCK4 DOCK4_HUMAN $225.21 \quad 100.0 \%$ Dedicator of cytokinesis protein 4 GN=DOCK4 DOCK4_HUMAN $225.21 \quad 100.0 \%$ Dedicator of cytokinesis protein $7 \mathrm{GN}=$ DOCK7 DOCK7_HUMAN $242.57 \quad 100.0 \%$ Dedicator of cytokinesis protein $7 \mathrm{GN}=$ DOCK7 DOCK7_HUMAN $242.57 \quad 100.0 \%$ Dehydrogenase/reductase SDR family member 7B GN=DHRS7B DRS7B_HUMAN $35.12 \quad 100.0 \%$ Dehydrogenase/reductase SDR family member 7B GN=DHRS7B DRS7B HUMAN $35.12 \quad 100.0 \%$ Dehydrogenase/reductase SDR family member 7B GN=DHRS7B DRS7B_HUMAN $35.12 \quad 100.0 \%$ Delta-1-pyrroline-5-carboxylate synthase GN=ALDH18A1 P5CS_HUMAN 87.30 $100.0 \%$ Delta-1-pyrroline-5-carboxylate synthase GN=ALDH18A1 P5CS HUMAN 87.30 $100.0 \%$ Delta-1-pyrroline-5-carboxylate synthase GN=ALDH18A1 P5CS_HUMAN $87.30 \quad 100.0 \%$

$0.01 \% \quad 5.4 \% \quad$ SVETDSSTVEHVR $0.01 \% \quad 5.4 \%$ CFQPPIHQSLATTC $0.00 \% \quad 8.3 \%$ GGGLGSPGEGGALPR $0.00 \% \quad 8.3 \%$ ALCQACALLDGLNR $0.01 \% \quad 2.9 \%$ TTGEVVSGVVSK $0.01 \% \quad 2.9 \%$ QQTSLFIAR

$0.01 \% \quad 2.9 \%$ TEISDKITSELVSK $0.01 \% \quad 2.9 \% \quad$ AQNISSNANMLR $0.01 \% \quad 2.9 \% \quad$ NSSQFFQSYVER $0.04 \% \quad 15.6 \%$ VLISDSLDPCCR $0.04 \% \quad 15.6 \%$ AGTGVDNVDLEAATR $0.04 \% \quad 15.6 \%$ IGREVATR

$0.04 \% \quad 15.6 \%$ GGIVDEGALLR $0.04 \% \quad 15.6 \%$ CGEEIAVQFVDMVKGK $0.04 \% \quad 15.6 \%$ GTIQVITQGTSLK $0.04 \% \quad 15.6 \%$ DLPLLLFR

$0.01 \% \quad 7.7 \%$ SSLGGRDLYR $0.01 \% \quad 7.7 \% \quad$ STNVTVAAAR $0.01 \% \quad 7.7 \%$ MAFTCSFCK

$0.01 \% \quad 7.7 \%$ ESVLTATSILNNPIVK $0.00 \% \quad 10.2 \%$ AASAGQEPLHNEELAGAGR $0.00 \% \quad 10.2 \%$ VAQPGPLEPEEPR

$0.00 \% \quad 1.0 \%$ SYASTPELRK $0.00 \% \quad 1.0 \% \quad$ LTGLSEISLR $0.03 \% \quad 8.9 \%$ GFALKNPNIK $0.03 \% \quad 8.9 \%$ NACSVQYR $0.03 \% \quad 8.9 \%$ EYSSVFSHGVSITR $0.03 \% \quad 8.9 \% \quad$ YLKLPFSK $0.03 \% \quad 8.9 \%$ GIFLGNNNQAMK $0.03 \% \quad 8.9 \% \quad$ ESFCITSFLCSTK $0.03 \% \quad 8.9 \%$ TVESQLYTNPDSR $0.03 \% \quad 8.9 \% \quad$ IGCTVSLLNFYK $0.03 \% \quad 8.9 \%$ TSLYLVQSLPGISR $0.03 \% \quad 8.9 \%$ TLISQCQTR $0.03 \% \quad 8.9 \% \quad$ LVDQFFVMK $0.03 \% \quad 8.9 \% \quad$ NSAPASVSPDGTR $0.03 \% \quad 8.9 \%$ RSPLSYPAVNR $0.03 \% \quad 8.9 \% \quad$ ERPCSAIYPTPVEPSQR $0.03 \% \quad 8.9 \%$ HTTSVSPSPAGR $0.01 \% \quad 1.2 \%$ SAVRPASLNLNR $0.01 \% \quad 1.2 \%$ SPSGSAFGSQENLR $0.01 \% \quad 12.3 \%$ VMETNYFGPVALTK $0.01 \% \quad 12.3 \%$ YGVMDTTTAQGR $0.01 \% \quad 12.3 \%$ TLAPGLFFSLMASR $0.07 \% \quad 33.3 \%$ LGSAVVTR
1445.69 1659.76

1281.65

1574.78

1162.63

1063.59

1549.83

1318.65

1491.69

1434.67

1488.73

901.52

1099.6

1809.89

1345.77

986.60

1123.5

989.54

1151.47

1698.96

1877.91

1418.73

1151.61

1088.63

1101.64

997.45

1568.77

995.59

1306.66

1579.71

1509.72

1414.74

1533.86

1106.56

1126.60

1258.60

1259.69

1986.97

1196.60

1297.73

1436.68

1569.80

1299.60

1526.80

802.48

1830.95 1047.49 $\begin{array}{cc}252 & 1264 \\ 95 & 1278 \\ 95 & 209 \\ 97 & 310 \\ 85 & 96 \\ 14 & 422 \\ 55 & 868 \\ 442 & 1453 \\ 771 & 1882 \\ 9 & 20 \\ 76 & 90 \\ 56 & 163 \\ 37 & 247 \\ 95 & 310 \\ 52 & 364 \\ 62 & 469 \\ 11 & 90 \\ 26 & 235 \\ 10 & 318 \\ 44 & 459 \\ 28 & 46 \\ 47 & 59 \\ 610 & 1619 \\ 789 & 1798 \\ 45 & 54 \\ 91 & 298 \\ 74 & 387 \\ 42 & 549 \\ 50 & 561 \\ 65 & 577 \\ 15 & 827 \\ 179 & 1190 \\ 441 & 1454 \\ 485 & 1493 \\ 576 & 1584 \\ 613 & 1625 \\ 630 & 1640 \\ 720 & 1736 \\ 303 & 1814 \\ 82 & 893 \\ 430 & 1443 \\ 62 & 175 \\ 56 & 267 \\ 02 & 315 \\ 77 & 84 \\ 77 & 94 \\ 75 & 94\end{array}$ 
Delta-1-pyrroline-5-carboxylate synthase GN=ALDH18A1 P5CS_HUMAN $87.30 \quad 100.0 \% \quad 24$ $\begin{array}{lllll} & \end{array}$ Delta-1-pyrroline-5-carboxylate synthase GN=ALDH18A1 P5CS HUMAN $87.30 \quad 100.0 \%$ Delta-1-pyrroline-5-carboxylate synthase GN=ALDH18A1 P5CS_HUMAN $87.30 \quad 100.0 \%$ Delta-1-pyrroline-5-carboxylate synthase GN=ALDH18A1 $\quad$ P5CS_HUMAN $87.30 \quad 100.0 \% \quad 2$ $\begin{array}{llll}\text { Delta-1-pyrroline-5-carboxylate synthase GN=ALDH18A1 P5CS_HUMAN } 87.30 & 100.0 \% & 24\end{array}$ Delta-1-pyrroline-5-carboxylate synthase GN=ALDH18A1 P5CS_HUMAN $87.30 \quad 100.0 \%$ $\begin{array}{llll}\text { Delta-1-pyrroline-5-carboxylate synthase GN=ALDH18A1 P5CS_HUMAN } 87.30 & 100.0 \% & 24\end{array}$ Delta-1-pyrroline-5-carboxylate synthase GN=ALDH18A1 P5CS HUMAN 87.30 $100.0 \%$ $\begin{array}{llll}\text { Delta-1-pyrroline-5-carboxylate synthase GN=ALDH18A1 P5CS_HUMAN } 87.30 & 100.0 \% & 24\end{array}$ Delta-1-pyrroline-5-carboxylate synthase GN=ALDH18A1 P5CS_HUMAN $87.30 \quad 100.0 \% \quad 24$ Delta-1-pyrroline-5-carboxylate synthase GN=ALDH18A1 P5CS HUMAN $87.30 \quad 100.0 \% \quad 24$ $\begin{array}{lllll}\text { Delta-1-pyrroline-5-carboxylate synthase GN=ALDH18A1 P5CS_HUMAN } 87.30 & 100.0 \% & 24\end{array}$ Delta-1-pyrroline-5-carboxylate synthase GN=ALDH18A1 P5CS HUMAN $87.30 \quad 100.0 \%$ Delta-1-pyrroline-5-carboxylate synthase GN=ALDH18A1 P5CS HUMAN 87.30 $100.0 \%$ $\begin{array}{lllll}\text { Delta-1-pyrroline-5-carboxylate synthase GN=ALDH18A1 } & \text { P5CS_HUMAN } & 87.30 & 100.0 \% & 24\end{array}$ Delta-1-pyrroline-5-carboxylate synthase GN=ALDH18A1 P5CS_HUMAN $87.30 \quad 100.0 \%$ $\begin{array}{llll}\text { Delta-1-pyrroline-5-carboxylate synthase GN=ALDH18A1 P5CS_HUMAN } 87.30 & 100.0 \% & 24\end{array}$ Delta-1-pyrroline-5-carboxylate synthase GN=ALDH18A1 P5CS_HUMAN $87.30 \quad 100.0 \% \quad 24$ Delta-1-pyrroline-5-carboxylate synthase GN=ALDH18A1 P5CS HUMAN 87.30 $100.0 \%$ $\begin{array}{llll}\text { Delta-1-pyrroline-5-carboxylate synthase GN=ALDH18A1 P5CS_HUMAN } 87.30 & 100.0 \% & 24\end{array}$ Deoxynucleoside triphosphate triphosphohydrolase SAMHDI GN=SAMHD1 SAMH1_HUMAN $72.20 \quad 100.0 \%$ Deoxynucleoside triphosphate triphosphohydrolase SAMHD1 GN=SAMHD1 SAMH1_HUMAN $72.20 \quad 100.0 \%$ Deoxynucleoside triphosphate triphosphohydrolase SAMHDI GN=SAMHD1 SAMH1_HUMAN $72.20 \quad 100.0 \%$ SAMHDI GN=SAMHDI SAMH1 HUMAN $72.20 \quad 100.0 \%$ Deoxynucleoside triphosphate triphosphohydrolase SAMHDI GN=SAMHDI SAMH1_HUMAN $72.20 \quad 100.0 \%$ Deoxyribose-phosphate aldolase GN=DERA DEOC_HUMAN $35.23 \quad 100.0 \%$ Deoxyribose-phosphate aldolase GN=DERA DEOC HUMAN $35.23 \quad 100.0 \%$ Deoxyribose-phosphate aldolase GN=DERA DEOC_HUMAN $35.23 \quad 100.0 \%$ Deoxyribose-phosphate aldolase GN=DERA DEOC HUMAN $35.23 \quad 100.0^{\circ}$ Deoxyribose-phosphate aldolase GN=DERA DEOC_HUMAN $35.23 \quad 100.0 \%$ Deoxyribose-phosphate aldolase GN=DERA DEOC_HUMAN $35.23 \quad 100.0 \%$ Derlin-1 GN=DERL1 Derlin-1 GN=DERL Dermcidin GN=DCD Dermcidin $\mathrm{GN}=\mathrm{DCD}$ Dermcidin $\mathrm{GN}=\mathrm{DCD}$ Dermcidin GN=DCD Dermcidin $\mathrm{GN}=\mathrm{DCD}$ Desmoplakin GN=DSP Desmoplakin GN=DSP Desmoplakin $\mathrm{GN}=\mathrm{DSP}$ Desmoplakin GN=DSP Desmoplakin GN=DSP Desmoplakin GN=DSF Desmoplakin GN=DSF Desmoplakin GN=DSP DERL1_HUMAN $28.80 \quad 100.0 \%$ DERL1_HUMAN $28.80 \quad 100.0 \%$ DCD HUMAN $11.28 \quad 100.0 \%$ DCD HUMAN $11.28 \quad 100.0 \%$ DCD_HUMAN $11.28 \quad 100.0 \%$ DCD HUMAN $11.28 \quad 100.0 \%$ DCD_HUMAN $11.28 \quad 100.0 \%$ DESP_HUMAN $331.78 \quad 100.0 \%$ DESP_HUMAN $331.78 \quad 100.0 \%$ DESP_HUMAN $331.78 \quad 100.0 \%$ DESP_HUMAN $331.78 \quad 100.0 \%$ DESP_HUMAN $331.78 \quad 100.0 \%$ DESP_HUMAN $331.78 \quad 100.0 \%$ DESP_HUMAN $331.78 \quad 100.0 \%$ DESP_HUMAN $331.78 \quad 100.0 \%$
$0.07 \% \quad 33.3 \%$ LASIVEQVSVLQNQGR $0.07 \% \quad 33.3 \%$ EMMLVTSGAVAFGK

$0.07 \% \quad 33.3 \%$ LRHEILLSQSVR

$0.07 \% \quad 33.3 \%$ EMAIPVLEAR

$0.07 \% \quad 33.3 \%$ NLNGTLHELLR

$0.07 \% \quad 33.3 \%$ LIDIFYPGDQQSVTFGTK

$0.07 \% \quad 33.3 \%$ VGMGGMEAK

$0.07 \% \quad 33.3 \%$ VSGHVITDIVEGK

$0.07 \% \quad 33.3 \%$ VSGHVITDIVEGKK

$0.07 \% \quad 33.3 \%$ VGTFFSEVKPAGPTVEQQGEMAR

$0.07 \% \quad 33.3 \%$ LAAPLLKR

$0.07 \% \quad 33.3 \%$ LSLSTSKLNSLAIGLR

$0.07 \% \quad 33.3 \%$ LNSLAIGLRQIAASSQDSVGR

$0.07 \% \quad 33.3 \%$ QIAASSQDSVGR

$0.07 \% \quad 33.3 \%$ MIDLIIPR

$0.07 \% \quad 33.3 \%$ GSSQLVRDIQK

$0.07 \% \quad 33.3 \%$ FASYLTFSPSEVK

$0.07 \% \quad 33.3 \%$ FGLGAEVGISTSR

$0.07 \% \quad 33.3 \%$ GPVGLEGLLTTK

$0.07 \% \quad 33.3 \%$ GKDHVVSDFSEHGSLK

$0.07 \% \quad 33.3 \%$ YLHENLPIPQR

$0.01 \% \quad 9.1 \%$ ADSEQPSKRPR

$0.01 \% \quad 9.1 \%$ GGFEEPVLLK

$0.01 \% \quad 9.1 \%$ SFLYEIVSNKR

$0.01 \% \quad 9.1 \%$ VCEVDNELRICAR

$0.01 \% \quad 9.1 \% \quad$ YVGETQPTGQIK

$10 \quad 0.01 \% \quad 27.0 \%$ IQVNHPAVLR

$10 \quad 0.01 \% \quad 27.0 \%$ TILATGELGTLTNVYK

$0.01 \% \quad 27.0 \%$ ETVNATFPVAIVMLR

$0.01 \% \quad 27.0 \%$ IGFKPAGGIR

$10 \quad 0.01 \% \quad 27.0 \%$ IGASTLLSDIER

$0.00 \% \quad 10.0 \%$ YWFAATVAVPLVGK

$0.00 \% \quad 10.0 \%$ NFLSTPQFLYR

$0.04 \% \quad 46.4 \%$ ENAGEDPGLAR

$0.04 \% \quad 46.4 \%$ SSLLEKGLDGAK

$0.04 \% \quad 46.4 \%$ LGKDAVEDLESVGK

$0.04 \% \quad 46.4 \%$ DAVEDLESVGK

$0.04 \% \quad 46.4 \%$ GAVHDVKDVLDSVL

$0.03 \% \quad 3.1 \%$ AELIVQPELK

$0.03 \% \quad 3.1 \% \quad$ LLQLQEQMR

$0.03 \% \quad 3.1 \%$ QLQNIIQATSR

$0.03 \% \quad 3.1 \%$ QVQNLVNK

$0.03 \% \quad 3.1 \% \quad$ RVEEDIQQQK

$0.03 \% \quad 3.1 \% \quad$ YKQSLDDAAK

$0.03 \% \quad 3.1 \% \quad$ SVEEVASEIQPFLR

$0.03 \% \quad 3.1 \%$ GLVGIEFKEK $\begin{array}{lll}99.7 \% & 34.8\end{array}$

$\begin{array}{llllllll}99.7 \% & 59.3 & 25.0 & 50.3 & 2 & 0 & 0 & 1740.96\end{array}$

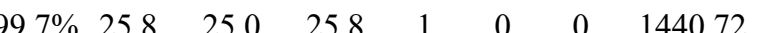

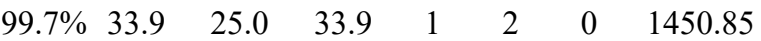

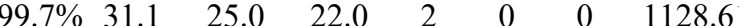
$99.7 \% \quad 57.8$ $99.7 \% \quad 48.2$ $97.4 \% 21.0$ $99.7 \% \quad 49.6$ $99.7 \% \quad 48.8$ $\begin{array}{ll}99.7 \% & 52.9 \\ 99.0 \% & 40.2\end{array}$ $99.7 \% \quad 42.4$ $98.9 \% 23$. $99.7 \% \quad 49.1$ $99.0 \% \quad 41.5$ $99.7 \% \quad 40.5$ $99.7 \% \quad 81.2$ $99.7 \% \quad 53.3$ $99.7 \% \quad 75.0$

$98.1 \% 17.2$ $99.7 \% \quad 27.0$ $99.6 \% \quad 23.0$ $99.7 \% \quad 43.8$ $99.7 \% \quad 52.4$ $98.9 \% 23.4$

$99.7 \% 35$.

$\begin{array}{ll}99.7 \% & 38.5 \\ 99.7 \% & 57.4\end{array}$ $99.7 \% 29.6$ $\begin{array}{lll}99.4 \% & 22.6\end{array}$ $\begin{array}{lll}99.7 \% & 57.3\end{array}$ $96.3 \% 15.1$ $99.7 \% \quad 42.5$ $99.7 \% \quad 58.6$ $99.7 \% \quad 56.3$ $99.7 \% \quad 58.8$ $99.7 \% \quad 49$. $99.7 \% \quad 38.8$ $99.7 \% \quad 44.9$ $99.7 \% \quad 39.4$ $99.7 \% \quad 42.3$ $99.0 \% \quad 27.2$ $99.7 \% \quad 43.2$ $\begin{array}{lll}99.7 \% & 28.7\end{array}$ $99.7 \% \quad 42.7$ $99.0 \% \quad 25.9$
$111 \quad 124$

1279.7

2029.03

879.41

1353.74

1481.83

2481.21

881.59

1673.00

2156.18

1218.61

970.58

1230.68

1475.74

1293.68

1184.69

1741.85

1379.74

1270.65

1088.60

1355.73

1633.78

1320.68

1146.67

2237.15

1693.94

1660.91

1015.60

1274.70

1521.85

1385.72

1128.53

1217.67

1459.76

1161.56

1466.79

1139.67

1158.63

1271.71

942.54

1272.65

1138.57

1603.83

1119.64 

DNA mismatch repair protein Msh2 GN=MSH2 MSH2_HUMAN $104.75 \quad 100.0 \%$ DNA mismatch repair protein Msh2 GN=MSH2 MSH2_HUMAN $104.75100 .0 \%$ DNA mismatch repair protein Msh6 GN=MSH6 MSH6_HUMAN $152.79 \quad 100.0 \%$ DNA mismatch repair protein Msh6 GN=MSH6 MSH6_HUMAN $152.79 \quad 100.0 \%$ DNA mismatch repair protein Msh6 GN=MSH6 MSH6_HUMAN $152.79 \quad 100.0 \%$ DNA mismatch repair protein Msh6 GN=MSH6 MSH6_HUMAN $152.79 \quad 100.0 \%$ DNA mismatch repair protein Msh6 GN=MSH6 MSH6_HUMAN $152.79 \quad 100.0 \%$ DNA mismatch repair protein Msh6 GN=MSH6 MSH6_HUMAN $152.79 \quad 100.0 \%$ DNA mismatch repair protein Msh6 GN=MSH6 MSH6_HUMAN $152.79 \quad 100.0 \%$ DNA polymerase delta catalytic subunit GN=POLD1 DPOD1_HUMAN $123.63 \quad 100.0 \%$ DNA polymerase delta catalytic subunit GN=POLD1 DPOD1_HUMAN $123.63 \quad 100.0 \%$ DNA polymerase delta catalytic subunit GN=POLD1 DPOD1_HUMAN $123.63 \quad 100.0 \%$ DNA polymerase delta catalytic subunit GN=POLD1 DPOD1_HUMAN $123.63100 .0 \%$ DNA polymerase epsilon catalytic subunit A GN=POLE DPOE1_HUMAN $261.52 \quad 100.0 \%$ DNA polymerase epsilon catalytic subunit A GN=POLE DPOE1_HUMAN $261.52 \quad 100.0 \%$ DNA polymerase epsilon catalytic subunit A GN=POLE DPOE1_HUMAN $261.52 \quad 100.0 \%$ DNA polymerase epsilon catalytic subunit A GN=POLE DPOE1_HUMAN $261.52 \quad 100.0 \%$ DNA polymerase epsilon catalytic subunit A GN=POLE DPOE1_HUMAN $261.52 \quad 100.0 \%$ DNA polymerase epsilon catalytic subunit A GN=POLE DPOE1_HUMAN $261.52 \quad 100.0 \%$ DNA polymerase epsilon catalytic subunit A GN=POLE DPOE1_HUMAN $261.52 \quad 100.0 \%$ DNA polymerase epsilon catalytic subunit A GN=POLE DPOE1_HUMAN $261.52 \quad 100.0 \%$ DNA polymerase epsilon catalytic subunit A GN=POLE DPOE1_HUMAN $261.52 \quad 100.0 \%$ DNA repair protein RAD50 GN=RAD50 RAD50_HUMAN $153.90 \quad 100.0 \%$ DNA repair protein RAD50 GN=RAD50 RAD50_HUMAN $153.90 \quad 100.0 \%$ DNA repair protein RAD50 GN=RAD50 RAD50_HUMAN $153.90 \quad 100.0 \%$ DNA repair protein RAD50 GN=RAD50 RAD50_HUMAN $153.90 \quad 100.0 \%$ DNA repair protein XRCC1 GN=XRCC1 XRCC1_HUMAN $69.48 \quad 100.0 \%$ DNA repair protein XRCC1 GN=XRCC1 XRCC1_HUMAN $69.48 \quad 100.0 \%$ DNA repair protein XRCC1 GN=XRCC1 XRCC1_HUMAN $69.48 \quad 100.0 \%$ DNA replication licensing factor MCM3 GN=MCM3 MCM3_HUMAN $90.98 \quad 100.0 \%$

$0.00 \% \quad 6.5 \%$ GGGGGGPGEGFDVAK

$0.00 \% \quad 6.5 \%$ GRQVIAVAR

$0.01 \% \quad 5.3 \%$ VFVSPLAK

$0.01 \% \quad 5.3 \%$ SKISVNDFIIK

$0.01 \% \quad 5.3 \%$ GVETIANDVVSLATK

$10 \quad 0.01 \% \quad 18.5 \%$ QLSQNFLLDLR

$10 \quad 0.01 \% \quad 18.5 \%$ KAGNLTNAYVYEVGPGPGGITR $0.01 \% \quad 18.5 \%$ AGNLTNAYVYEVGPGPGGITR

$0.01 \% \quad 18.5 \%$ MLFPEAQR

$0.01 \% \quad 9.9 \%$ KGPLENPK

$0.01 \% \quad 9.9 \%$ ELLDQLQQK

$0.01 \% \quad 9.9 \%$ SATVIDHLR

$0.01 \% \quad 3.5 \%$ QVGVGYVDSIQR

$0.01 \% \quad 3.5 \% \quad$ LTSLNEEYTK

$0.01 \% \quad 3.5 \%$ NNSFVNEIISR

$0.02 \% \quad 6.0 \%$ SPALSDANKASAR

$0.02 \% \quad 6.0 \% \quad$ QATSISSETKNTLR

$0.02 \% \quad 6.0 \% \quad$ YSDSLVQKGYK

$0.02 \% \quad 6.0 \%$ SGAIFTKAYQR

$0.02 \% \quad 6.0 \%$ TIVYWGIGR

$0.02 \% \quad 6.0 \% \quad$ NLPEEYELKSTK

$0.02 \% \quad 6.0 \% \quad$ LANLPEEVIQK

$0.01 \% \quad 3.9 \%$ VQTFPFLGR

$0.01 \% \quad 3.9 \% \quad$ VTGVPLSYLLSR

$0.01 \% \quad 3.9 \%$ GQQVKVVSQLLR

$0.01 \% \quad 3.9 \% \quad$ IFEPILGEGR

$0.02 \% \quad 4.5 \%$ GGVITDEEETSKK

$0.02 \% \quad 4.5 \%$ DSYLPVGSHNLK

$0.02 \% \quad 4.5 \% \quad$ KLEDYGEQK

$0.02 \% \quad 4.5 \%$ AIPLAIFQAEPTVR

$0.02 \% \quad 4.5 \%$ SLAQFSYLEPGSIR

$0.02 \% \quad 4.5 \%$ ASVFVLDTVR

$0.02 \% \quad 4.5 \% \quad$ FLLAYKEER

$0.02 \% \quad 4.5 \%$ LGSSVIYANFNR

$0.02 \% \quad 4.5 \%$ SYVLPEVICR

$0.01 \% \quad 3.0 \% \quad$ IIELKSEILSK

$0.01 \% \quad 3.0 \%$ WLQDNLTLR

$0.01 \% \quad 3.0 \%$ NHNLALGR

$0.01 \% \quad 3.0 \%$ CSVSSLGFNVH

$0.01 \% \quad 4.7 \%$ TPATAPVPAR

$0.01 \% \quad 4.7 \%$ AQGAVTGKPR

$0.01 \% \quad 4.7 \% \quad$ YSQVLGLGGR

$0.02 \% \quad 11.1 \%$ LLNNAFEELVAFQR $\begin{array}{llll}99.0 \% & 18.3 & 25.0 & 18.3\end{array}$

$\begin{array}{llll}97.2 \% & 20.5 & 25.0 & 17.6\end{array}$

$\begin{array}{lllll}99.7 \% & 23.6 & 25.0 & 23.6 & 2\end{array}$

$\begin{array}{llll}95.8 \% & 17.5 & 25.0 & 12.7\end{array}$

$\begin{array}{lllll}99.7 \% & 25.5 & 25.0 & 19.5 & 2\end{array}$

$\begin{array}{llll}99.7 \% & 46.1 & 25.0 & 46.1\end{array}$

$99.7 \% \quad 41.0 \quad 25.0 \quad 31.8$

$\begin{array}{llll}99.6 \% & 24.3 & 25.0 & 24.3 \\ 99.7 \% & 56.5 & 25.0 & 56.5\end{array}$

$\begin{array}{llll}99.7 \% & 33.0 & 25.0 & 33.0\end{array}$

$\begin{array}{llll}99.0 \% & 24.4 & 25.0 & 20.3\end{array}$

$\begin{array}{llll}99.7 \% & 35.1 & 25.0 & 30.5\end{array}$

$\begin{array}{llll}99.6 \% & 22.4 & 25.0 & 21.8\end{array}$

$99.0 \% \quad 36.4 \quad 25.0 \quad 26.4$

$\begin{array}{llll}96.4 \% & 21.9 & 25.0 & 10.4\end{array}$

$99.7 \% \quad 45.7 \quad 25.0 \quad 31.5$

$99.7 \% \quad 56.0 \quad 25.0 \quad 44.7$

$\begin{array}{llll}96.7 \% & 16.7 & 25.0 & 15.9\end{array}$

$\begin{array}{llll}99.7 \% & 44.5 & 25.0 & 37.5\end{array}$

$99.7 \% \quad 25.6 \quad 25.0 \quad 18.5$

$\begin{array}{lllll}99.7 \% & 59.4 & 25.0 & 47.9 & 2\end{array}$

$\begin{array}{llll}99.6 \% & 24.6 & 25.0 & 20.9\end{array}$

$\begin{array}{llll}99.1 \% & 19.0 & 25.0 & 19.0\end{array}$

$\begin{array}{lllll}99.6 \% & 21.9 & 25.0 & 21.9 & 2\end{array}$

$\begin{array}{llll}94.5 \% & 14.3 & 25.0 & 12.9\end{array}$

$\begin{array}{llll}96.9 \% & 19.7 & 25.0 & 13.8\end{array}$

$\begin{array}{llll}98.8 \% & 25.2 & 25.0 & 14.4\end{array}$

$\begin{array}{llll}99.7 \% & 24.2 & 25.0 & 24.2\end{array}$

$97.4 \% \quad 16.0 \quad 25.0 \quad 16.0$

$\begin{array}{llll}99.7 \% & 31.5 & 25.0 & 31.5\end{array}$

$\begin{array}{llll}99.7 \% & 36.7 & 25.0 & 32.2\end{array}$

$\begin{array}{llll}99.6 \% & 22.5 & 25.0 & 22.3\end{array}$

$97.3 \% \quad 17.6 \quad 25.0 \quad 14.8$

$\begin{array}{llll}99.7 \% & 58.0 & 25.0 & 52.6\end{array}$

$\begin{array}{llll}99.7 \% & 45.7 & 25.0 & 41.8\end{array}$

$\begin{array}{llll}99.7 \% & 37.9 & 25.0 & 36.2\end{array}$

$\begin{array}{llll}99.7 \% & 34.3 & 25.0 & 17.5\end{array}$

$99.7 \% \quad 24.7 \quad 25.0 \quad 24.7$

$99.7 \% \quad 32.2 \quad 25.0 \quad 23.2$

$99.1 \% \quad 18.6 \quad 25.0 \quad 18.6$

$\begin{array}{llll}99.7 \% & 29.4 & 25.0 & 24.5\end{array}$

$\begin{array}{llll}97.8 \% & 16.3 & 25.0 & 16.3\end{array}$

$\begin{array}{lllll}99.7 \% & 57.5 & 25.0 & 54.4 & 2\end{array}$

$\begin{array}{llll}99.7 \% & 42.3 & 25.0 & 36.2\end{array}$

$\begin{array}{llll}99.5 \% & 22.4 & 25.0 & 18.9\end{array}$

$\begin{array}{llll}99.7 \% & 31.0 & 25.0 & 27.3\end{array}$

$\begin{array}{llll}99.7 \% & 44.7 & 25.0 & 44.7\end{array}$
862.50

$0 \quad 0$

(1)

1261.58

969.60

860.52

1263.73

1516.82

1346.74

2234.16

2106.06

1136.62

991.50

1621.93

1286.69

882.50

1114.61

1011.56

1320.69

1197.60

1292.66

1287.67

1535.80

1287.66

1241.66

1064.59

1450.74

1253.71

1064.59

1304.76

1354.82

130.62

1392.69

1329.68

109.55

1525.87

1567.81

1106.62

1168.64

340.70

1235.65

1272.78

1158.63

894.49

206.56

980.55

984.56

1049.57 1663.88

$\begin{array}{cc}93 & 2600 \\ 7 & 61 \\ 32 & 140 \\ 55 & 362 \\ 72 & 482 \\ 33 & 547 \\ 2 & 42 \\ 0 & 71 \\ 1 & 71 \\ 48 & 256 \\ 66 & 273 \\ 80 & 293 \\ 58 & 170 \\ 77 & 284 \\ 87 & 295 \\ 32 & 340 \\ 60 & 171 \\ 56 & 565 \\ 19 & 929 \\ 4 & 26 \\ 25 & 338 \\ 69 & 479 \\ 22 & 732 \\ 66 & 974 \\ 89 & 1000 \\ 05 & 1315 \\ 15 & 423 \\ 38 & 549 \\ 50 & 561 \\ 69 & 978 \\ 98 & 210 \\ 14 & 425 \\ 42 & 1050 \\ 93 & 1106 \\ 72 & 1485 \\ 10 & 1519 \\ 71 & 1579 \\ 59 & 1870 \\ 50 & 2159 \\ 42 & 452 \\ 17 & 1025 \\ 70 & 1077 \\ 02 & 1312 \\ 81 & 290 \\ 91 & 300 \\ 70 & 379 \\ 5 & 78 \\ & \end{array}$

Page 43 of Table $S-1-1$ 
DNA replication licensing factor MCM3 GN=MCM3 MCM3_HUMAN $90.98 \quad 100.0 \%$ DNA replication licensing factor MCM3 GN=MCM3 MCM3_HUMAN $90.98 \quad 100.0 \%$ DNA replication licensing factor MCM3 GN=MCM3 MCM3_HUMAN $90.98 \quad 100.0 \%$ DNA replication licensing factor MCM3 GN=MCM3 MCM3 HUMAN $90.98 \quad 100.0 \%$ DNA replication licensing factor MCM3 GN=MCM3 MCM3_HUMAN $90.98 \quad 100.0 \%$ DNA replication licensing factor MCM3 GN=MCM3 MCM3_HUMAN $90.98 \quad 100.0 \%$ DNA replication licensing factor MCM3 GN=MCM3 MCM3_HUMAN $90.98 \quad 100.0 \%$ DNA replication licensing factor MCM4 GN=MCM4 MCM4_HUMAN $96.56 \quad 100.0 \%$ DNA replication licensing factor MCM4 GN=MCM4 MCM4 HUMAN $96.56 \quad 100.0 \%$ DNA replication licensing factor MCM4 GN=MCM4 MCM4_HUMAN $96.56 \quad 100.0 \%$ DNA replication licensing factor MCM4 GN=MCM4 MCM4_HUMAN $96.56 \quad 100.0 \%$ DNA replication licensing factor MCM5 GN=MCM5 MCM5_HUMAN 82.29 DNA replication licensing factor MCM5 GN=MCM5 MCM5_HUMAN 82.29 DNA replication licensing factor MCM5 GN=MCM5 MCM5_HUMAN 82.29 DNA replication licensing factor MCM5 GN=MCM5 MCM5_HUMAN 82.29 DNA replication licensing factor MCM5 GN=MCM5 MCM5_HUMAN 82.29 DNA replication licensing factor MCM5 GN=MCM5 MCM5 HUMAN 82.29 DNA replication licensing factor MCM5 GN=MCM5 MCM5_HUMAN 82.29 DNA replication licensing factor MCM5 GN=MCM5 MCM5_HUMAN 82.29 DNA replication licensing factor MCM5 GN=MCM5 MCM5 HUMAN 82.29 DNA replication licensing factor MCM5 GN=MCM5 MCM5_HUMAN 82.29 DNA replication licensing factor MCM5 GN=MCM5 MCM5_HUMAN 82.29 DNA replication licensing factor MCM5 GN=MCM5 MCM5_HUMAN 82.29 DNA replication licensing factor MCM5 GN=MCM5 MCM5_HUMAN 82.29 DNA replication licensing factor MCM5 GN=MCM5 MCM5 HUMAN 82.29 DNA replication licensing factor MCM5 GN=MCM5 MCM5_HUMAN 82.29 DNA replication licensing factor MCM5 GN=MCM5 MCM5_HUMAN 82.29 DNA replication licensing factor MCM5 GN=MCM5 MCM5 HUMAN 82.2 DNA replication licensing factor MCM5 GN=MCM5 MCM5_HUMAN 82.29 DNA replication licensing factor MCM5 GN=MCM5 MCM5 HUMAN 82.29 DNA replication licensing factor MCM5 GN=MCM5 MCM5_HUMAN 82.29 DNA replication licensing factor MCM6 GN=MCM6 MCM6_HUMAN 92.89 DNA replication licensing factor MCM6 GN=MCM6 MCM6_HUMAN 92.89 DNA replication licensing factor MCM6 GN=MCM6 MCM6_HUMAN 92.89 DNA replication licensing factor MCM6 GN=MCM6 MCM6_HUMAN 92.89 DNA replication licensing factor MCM7 GN=MCM7 MCM7_HUMAN 81.31 DNA replication licensing factor MCM7 GN=MCM7 MCM7_HUMAN 81.31 DNA replication licensing factor MCM7 GN=MCM7 MCM7 HUMAN 81.31 DNA replication licensing factor MCM7 GN=MCM7 MCM7_HUMAN 81.31 DNA replication licensing factor MCM7 GN=MCM7 MCM7_HUMAN 81.31 DNA replication licensing factor MCM7 GN=MCM7 MCM7_HUMAN 81.31 DNA replication licensing factor MCM7 GN=MCM7 MCM7_HUMAN 81.3 DNA replication licensing factor MCM7 GN=MCM7 MCM7_HUMAN 81.31 DNA replication licensing factor MCM7 GN=MCM7 MCM7_HUMAN 81.3 DNA replication licensing factor MCM7 GN=MCM7 MCM7_HUMAN 81.31 DNA replication licensing factor MCM7 GN=MCM7 MCM7_HUMAN 81.31 DNA replication licensing factor MCM7 GN=MCM7 MCM7_HUMAN 81.31
$100.0 \%$ $100.0 \% \quad 20$ $100.0 \% \quad 20$ $100.0 \% \quad 20$ $100.0 \% \quad 20$ $100.0 \% \quad 20$ $100.0 \% \quad 20$ $100.0 \% \quad 20$ $100.0 \% \quad 20$ $100.0 \% \quad 20$ $100.0 \% \quad 20$ $100.0 \% \quad 20$ $100.0 \% \quad 20$ $100.0 \% \quad 20$ $100.0 \% \quad 20$ $100.0 \% \quad 20$ $100.0 \% \quad 20$ $100.0 \% \quad 20$ $100.0 \% \quad 20$ $100.0 \% \quad 20$ $100.0 \%$ $100.0 \%$ $100.0 \%$ $100.0 \%$ $100.0 \% \quad 20$ $100.0 \% \quad 20$ $100.0 \% \quad 20$ $100.0 \% \quad 20$ $100.0 \% \quad 20$ $100.0 \% \quad 20$ $100.0 \% \quad 20$ $100.0 \% \quad 20$ $100.0 \% \quad 20$ $100.0 \% \quad 20$ $100.0 \% \quad 20$ $100.0 \% \quad 20$ $\begin{array}{lll}15 & 0.02 \% & 11.1 \% \text { SVHYCPATK }\end{array}$ $0.02 \% \quad 11.1 \%$ TVLIACNVK $0.02 \% \quad 11.1 \%$ SKDIFDQLAK

$0.02 \% \quad 11.1 \%$ YVLCTAPR

(15)

$\begin{array}{llll}99.0 \% & 54.1 & 25.0 & 34.1\end{array}$
$0.02 \% \quad 11.1 \%$ GSSGVGLTAAVTTDQETGER

$0.02 \% \quad 11.1 \%$ LRSQDSMSSDTAR

$99.7 \%$

$98.9 \% \quad 19.9$

$0.02 \% \quad 6.6 \%$ LGEINVIGEPFLNVNCEHIK $98.2 \% 18.1$

$0.02 \% \quad 6.6 \%$ IAEPSVCGR

$0.02 \% \quad 6.6 \% \quad$ AGIICQLNAR

$99.7 \% \quad 35.0$

$99.7 \% \quad 60.3$

$0.06 \% \quad 32.6 \%$ VGTDRTGFTFK

$0.06 \% 32.6 \%$ IPGIIIAASAVR

$99.7 \% \quad 51.2$

$99.7 \% \quad 27.3$

$99.7 \% \quad 53.8$

$0.06 \% \quad 32.6 \%$ NTLTNIAMRPGLEGYALPR $\quad 99.7 \% 32.1$

$0.06 \% 32.6 \%$ KCNTDQAGRPK

$0.06 \% \quad 32.6 \%$ CPLDPYFIMPDKCK

$0.06 \% 32.6 \%$ HMQLYCDR

$99.7 \% \quad 28.7$

$97.5 \% \quad 16.0$

$99.0 \% \quad 30.6$

$0.06 \% \quad 32.6 \%$ SSYIRVLGIQVDTDGSGR $99.3 \% 21.7$

$0.06 \% 32.6 \%$ VLGIQVDTDGSGR

$99.7 \% \quad 67.8$

$99.7 \% \quad 29.3$

$0.06 \% 32.6 \%$ LAALPNVYEVISK

$0.06 \% 32.6 \%$ SIAPSIFGGTDMKK

$99.7 \% \quad 43.9$

$99.7 \% \quad 41.5$

$99.7 \% \quad 69.2$

$99.7 \% \quad 33.5$

$0.06 \% \quad 32.6 \%$ AIACLLFGGSRK

$0.06 \% 32.6 \%$ RGDINLLMLGDPGTAK

$0.06 \% 32.6 \%$ CSPIGVYTSGK

$0.06 \% 32.6 \%$ GSSAAGLTASVMR

$0.06 \% 32.6 \%$ AGITTTLNSR

$0.06 \% 32.6 \%$ CSVLAAANSVFGR

$0.06 \% \quad 32.6 \%$ LSAEAAEKLK

$0.06 \% \quad 32.6 \%$ FAIGSQVSEHSIIKDFTK

$0.01 \% \quad 6.6 \%$ VSGVDGYETEGIRGLR

$0.01 \% \quad 6.6 \%$ GVLLMLFGGVPK

$0.01 \% \quad 6.6 \%$ TSILAAANPISGHYDR

$0.01 \% \quad 6.6 \%$ ISNLIVLHLR

$0.08 \% \quad 31.8 \%$ LFADAVQELLPQYK

$0.08 \% \quad 31.8 \%$ LFADAVQELLPQYKER

$0.08 \% 31.8 \%$ SPQNQYPAELMR

$0.08 \% \quad 31.8 \%$ RFELYFQGPSSNKPR

$0.08 \% \quad 31.8 \%$ ADSVGKLVTVR

$0.08 \% \quad 31.8 \%$ SITVLVEGENTR

$99.7 \% \quad 24.8$

$99.7 \% \quad 42.8$

$99.7 \% \quad 37.8$

$99.7 \% \quad 53.7$

$99.7 \% \quad 51.5$

$99.7 \% \quad 44.5$

$99.7 \% \quad 30.7$

$99.7 \% \quad 49.6$

$99.7 \% \quad 46.5$

$99.7 \% \quad 52.1$

$99.7 \% \quad 31.0$

$96.2 \% \quad 23.2$

$99.7 \% \quad 32.1$

$99.7 \% \quad 41.0$

$99.7 \% \quad 53.0$

$99.7 \% \quad 48.3$

$99.7 \% \quad 75.7$

$0.08 \% \quad 31.8 \%$ IAQPGDHVSVTGIFLPILR

$0.08 \% \quad 31.8 \%$ ALLLLLVGGVDQSPR

$99.7 \% 34.0$

$0.08 \% \quad 31.8 \%$ IRGNINICLMGDPGVAK

$0.08 \% \quad 31.8 \%$ GNINICLMGDPGVAK

$0.08 \% \quad 31.8 \%$ SQLLSYIDR

$99.7 \% \quad 34.8$

$99.7 \% \quad 46.5$

$99.7 \% \quad 34.6$

$0.08 \% \quad 31.8 \%$ SQLLSYIDRLAPR
$99.7 \% \quad 34.3$
$0.06 \% \quad 32.6 \%$ SFAGAVSPQEEEEFRR $258 \quad 266$ $292 \quad 301$ $357 \quad 364$ 2632.32

1453.67 2295.18

988.49

1115.60

1822.96

1228.63

1180.74

2087.11

1274.63

1783.82

1122.48

1922.99

1316.68

1838.87

1416.81

1451.76

1164.62

1292.71

1686.88

1168.57

1207.61

1033.56

1351.68

1059.60

2007.05

1707.87

1230.73

1685.86

1177.74

1634.88

1920.02

1433.68

1825.93

1144.67

1317.70

2033.15

1550.93

1843.95

1574.77

1094.58 1531.86

372

$597 \quad 609$

$197 \quad 216$

$601 \quad 610$

$778 \quad 795$

$44 \quad 54$

$151 \quad 162$

$177 \quad 195$

$196 \quad 206$

$44 \quad 251$

$\begin{array}{ll}244 & 251 \\ 291 & 308\end{array}$

$296 \quad 308$

$309 \quad 324$

$325 \quad 337$

$338 \quad 351$

$352 \quad 362$

363
382

$397 \quad 407$ 
DNA replication licensing factor MCM7 GN=MCM7 MCM7_HUMAN $81.31 \quad 100.0 \% \quad 20 \quad 26 \quad 56 \quad 0.08 \% \quad 31.8 \%$ GSSGVGLTAAVLR

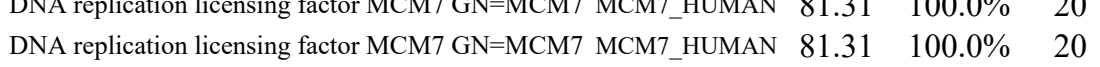
DNA replication licensing factor MCM7 GN=MCM7 MCM7_HUMAN $81.31 \quad 100.0 \% \quad 20$ DNA replication licensing factor MCM7 GN=MCM7 MCM7_HUMAN $81.31 \quad 100.0 \% 20$ DNA replication licensing factor MCM7 GN=MCM7 MCM7_HUMAN $81.31 \quad 100.0 \% \quad 20$ DNA replication licensing factor MCM7 GN=MCM7 MCM7_HUMAN $81.31 \quad 100.0 \% \quad 20$ DNA replication licensing factor MCM7 GN=MCM7 MCM7 HUMAN $81.31 \quad 100.0 \%$ DNA replication licensing factor MCM7 GN=MCM7 MCM7_HUMAN $81.31 \quad 100.0 \% \quad 20$ DNA topoisomerase $1 \mathrm{GN}=\mathrm{TOP} 1$ DNA topoisomerase $1 \mathrm{GN}=\mathrm{TOP} 1$ DNA topoisomerase $1 \mathrm{GN}=\mathrm{TOP} 1$ DNA topoisomerase $1 \mathrm{GN}=\mathrm{TOP} 1$ DNA topoisomerase $1 \mathrm{GN}=\mathrm{TOP} 1$ DNA topoisomerase $1 \mathrm{GN}=\mathrm{TOP} 1$ DNA topoisomerase $1 \mathrm{GN}=\mathrm{TOP} 1$ TOP1 HUMAN $90.73 \quad 100.0 \%$ TOP1_HUMAN $90.73 \quad 100.0 \%$ TOP1_HUMAN $90.73 \quad 100.0 \%$ TOP1_HUMAN $90.73 \quad 100.0 \%$ TOP1_HUMAN $90.73 \quad 100.0 \%$ TOP1_HUMAN $90.73 \quad 100.0 \%$ TOP1_HUMAN $90.73 \quad 100.0 \%$ DNA topoisomerase 2-alpha GN=TOP2A TOP2A_HUMAN $174.39 \quad 100.0 \%$ DNA topoisomerase 2-alpha GN=TOP2A $\quad$ TOP2A_HUMAN $174.39 \quad 100.0 \%$ DNA topoisomerase 2-alpha GN=TOP2A TOP2A_HUMAN $174.39 \quad 100.0 \%$ DNA topoisomerase 2-alpha GN=TOP2A $\quad$ TOP2A_HUMAN $174.39 \quad 100.0 \% \quad 1$ DNA topoisomerase 2-alpha GN=TOP2A TOP2A_HUMAN $174.39 \quad 100.0 \% \quad 17$ $\begin{array}{lllll}\text { DNA topoisomerase 2-alpha GN=TOP2A } & \text { TOP2A_HUMAN } & 174.39 & 100.0 \% & 17\end{array}$ $\begin{array}{lllll}\text { DNA topoisomerase 2-alpha GN=TOP2A } & \text { TOP2A_HUMAN } & 174.39 & 100.0 \% & 17\end{array}$ $\begin{array}{lllll}\text { DNA topoisomerase 2-alpha GN=TOP2A } & \text { TOP2A_HUMAN } & 174.39 & 100.0 \% & 17\end{array}$ DNA topoisomerase 2-alpha GN=TOP2A TOP2A_HUMAN $174.39 \quad 100.0 \% \quad 17$ DNA topoisomerase 2-alpha GN=TOP2A TOP2A_HUMAN $174.39 \quad 100.0 \% \quad 17$ DNA topoisomerase 2-alpha GN=TOP2A TOP2A_HUMAN $174.39 \quad 100.0 \% \quad 17$ DNA topoisomerase 2-alpha GN=TOP2A TOP2A_HUMAN $174.39 \quad 100.0 \% \quad 17$ DNA topoisomerase 2-alpha GN=TOP2A $\quad$ TOP2A_HUMAN $174.39 \quad 100.0 \% \quad 17$ DNA topoisomerase 2-alpha GN=TOP2A TOP2A_HUMAN $174.39 \quad 100.0 \% \quad 17$ DNA topoisomerase 2-alpha GN=TOP2A TOP2A HUMAN $174.39 \quad 100.0 \%$ DNA topoisomerase 2-alpha GN=TOP2A TOP2A_HUMAN $174.39 \quad 100.0 \% \quad 17$ DNA topoisomerase 2-alpha GN=TOP2A TOP2A_HUMAN $174.39 \quad 100.0 \% \quad 17$ DNA topoisomerase 2-beta GN=TOP2B TOP2B HUMAN $183.27 \quad 100.0 \%$ DNA topoisomerase 2-beta GN=TOP2B TOP2B_HUMAN $183.27 \quad 100.0 \%$ DNA topoisomerase 2-beta GN=TOP2B TOP2B_HUMAN $183.27 \quad 100.0 \%$ DNA topoisomerase 2-beta GN=TOP2B $\quad$ TOP2B_HUMAN $183.27 \quad 100.0 \%$ DNA topoisomerase 2-beta GN=TOP2B $\quad$ TOP2B_HUMAN $183.27 \quad 100.0 \%$ DNA topoisomerase 2-beta GN=TOP2B TOP2B HUMAN $183.27 \quad 100.0 \%$ DNA topoisomerase 2-beta GN=TOP2B TOP2B_HUMAN $183.27 \quad 100.0 \%$ DNA topoisomerase 2-beta GN=TOP2B TOP2B_HUMAN $183.27 \quad 100.0 \%$ DNA topoisomerase 2-beta $\mathrm{GN}=\mathrm{TOP} 2 \mathrm{~B}$ DNA topoisomerase 2-beta $\mathrm{GN}=\mathrm{TOP} 2 \mathrm{~B}$ DNA topoisomerase 2-beta $\mathrm{GN}=\mathrm{TOP} 2 \mathrm{~B}$ DNA topoisomerase 2-beta $\mathrm{GN}=\mathrm{TOP} 2 \mathrm{~B}$ DNA topoisomerase 2-beta $\mathrm{GN}=\mathrm{TOP} 2 \mathrm{~B}$ DNA topoisomerase 2-beta $\mathrm{GN}=\mathrm{TOP} 2 \mathrm{~B}$ TOP2B HUMAN $183.27 \quad 100.0 \%$ TOP2B_HUMAN $183.27 \quad 100.0 \%$ TOP2B HUMAN $183.27 \quad 100.0 \%$ TOP2B HUMAN $183.27 \quad 100.0 \%$ TOP2B_HUMAN $183.27 \quad 100.0 \%$ TOP2B_HUMAN $183.27 \quad 100.0 \%$ DNA-dependent protein kinase catalytic subunit GN=PRKDC PRKDC_HUMAN $469.10 \quad 100.0 \%$
$56-0.08 \% \quad 31.8 \%$ AGILTTLNAR

$56 \quad 0.08 \% \quad 31.8 \%$ CSILAAANPAYGR

$\quad 0.08 \% \quad 31.8 \%$ SLEQNIQLPAALLSR

$0.08 \% \quad 31.8 \%$ LAQHITYVHQHSR

$0.08 \% \quad 31.8 \%$ QPPSQFEPLDMK

$0.08 \% \quad 31.8 \%$ TQRPADVIFATVR

$0.08 \% \quad 31.8 \%$ SVRFSEAEQR

$0.02 \% \quad 9.4 \%$ LSPKAEEVATFFAK

$0.02 \% \quad 9.4 \%$ AEEVATFFAK

$6 \quad 0.02 \% \quad 9.4 \% \quad$ CDFTQMSQYFK

$6 \quad 0.02 \% \quad 9.4 \%$ IANFKIEPPGLFR

$0.02 \% \quad 9.4 \%$ IMPEDIIINCSK

$0.02 \% \quad 9.4 \%$ AVALYFIDKLALR

$0.02 \% \quad 9.4 \%$ ILSYNRANR

$0.05 \% \quad 11.4 \%$ EVTFVPGLYK

$0.05 \% \quad 11.4 \%$ IFDEILVNAADNKQR

$0.05 \% \quad 11.4 \%$ GIPVVEHKVEK

$0.05 \% \quad 11.4 \%$ LCNIFSTK

$0.05 \% \quad 11.4 \%$ RAYDIAGSTK

$0.05 \% \quad 11.4 \%$ AYDIAGSTKDVK

$0.05 \% \quad 11.4 \%$ HVDYVADQIVTK

$0.05 \% \quad 11.4 \%$ SFGSTCQLSEK

$0.05 \% \quad 11.4 \%$ SFGSTCQLSEKFIK

$0.05 \% \quad 11.4 \%$ NSTECTLILTEGDSAK

$0.05 \% \quad 11.4 \%$ TLAVSGLGVVGR

$0.05 \% \quad 11.4 \%$ DKYGVFPLR

$0.05 \% \quad 11.4 \%$ QIMENAEINNIIK

$0.05 \% \quad 11.4 \%$ IVGLQYKK

$0.05 \% \quad 11.4 \%$ NYEDEDSLKTLR

$0.05 \% \quad 11.4 \%$ YIFTMLSSLAR

$0.05 \% \quad 11.4 \%$ TQMAEVLPSPR

$0.03 \% \quad 9.8 \%$ EVTFVPGLYK

$0.03 \% \quad 9.8 \%$ IFDEILVNAADNKQR

$0.03 \% \quad 9.8 \%$ GIPVVEHKVEK

$0.03 \% \quad 9.8 \% \quad$ LCNIFSTK

$19 \quad 0.03 \% \quad 9.8 \%$ HVDYVVDQVVGK

$19 \quad 0.03 \% \quad 9.8 \%$ AGVSVKPFQVK

$19 \quad 0.03 \% \quad 9.8 \%$ SLAVSGLGVIGR

$19 \quad 0.03 \% \quad 9.8 \% \quad$ QIMENAEINNIIK

$19 \quad 0.03 \% \quad 9.8 \% \quad$ IVGLQYKK

$19 \quad 0.03 \% \quad 9.8 \% \quad$ SYDDAESLKTLR

$19 \quad 0.03 \% \quad 9.8 \% \quad$ YAGPEDDAAITLAFSK

$19 \quad 0.03 \% \quad 9.8 \% \quad$ LLFPAVDDNLLK

$19 \quad 0.03 \% \quad 9.8 \% \quad$ DLIQMLVQR

$19 \quad 0.03 \% \quad 9.8 \% \quad$ TPTSSGKPSAK

$125 \quad 526 \quad 0.72 \% \quad 25.1 \%$ LQETLSAADR $\begin{array}{llllllll}99.7 \% & 59.1 & 25.0 & 53.2 & 2 & 0 & 0 & 1187.67\end{array}$

$\begin{array}{lllllll}99.7 \% & 59.5 & 25.0 & 36.0 & 6 & 0 & 0\end{array}$

$\begin{array}{lllll}99.7 \% & 58.2 & 25.0 & 55.4 & 2\end{array}$

$99.7 \% \quad 52.0 \quad 25.0 \quad 52.0$

$99.7 \% \quad 26.2 \quad 25.0 \quad 26.2$

$\begin{array}{llll}98.4 \% & 17.9 & 25.0 & 17.2\end{array}$

$\begin{array}{llll}99.7 \% & 49.3 & 25.0 & 43.6\end{array}$

$\begin{array}{lllll}99.7 \% & 39.8 & 25.0 & 26.3 & 2\end{array}$

$\begin{array}{lllll}99.7 \% & 38.3 & 25.0 & 35.6 & 2\end{array}$

$99.7 \% \quad 39.0 \quad 25.0 \quad 34.8$

$99.7 \% \quad 41.2 \quad 25.0 \quad 35.3$

$99.7 \% \quad 38.4 \quad 25.0 \quad 38.4$

$99.7 \% \quad 45.8 \quad 25.0 \quad 37.6 \quad 2$

$99.7 \% \quad 44.9 \quad 25.0 \quad 44.9$

$\begin{array}{llll}97.7 \% & 20.4 & 25.0 & 14.3\end{array}$

$\begin{array}{lllll}98.9 \% & 20.3 & 25.0 & 20.3 & 3\end{array}$

$99.7 \% \quad 41.7 \quad 25.0 \quad 41.2$

$\begin{array}{llll}99.0 \% & 19.2 & 25.0 & 19.2\end{array}$

$\begin{array}{lllll}99.0 \% & 30.5 & 25.0 & 30.5 & 2\end{array}$

$\begin{array}{llll}99.7 \% & 42.5 & 25.0 & 34.7\end{array}$

$99.6 \% \quad 24.4 \quad 25.0 \quad 18.5 \quad 2$

$\begin{array}{llll}99.7 \% & 52.1 & 25.0 & 51.8\end{array}$

$\begin{array}{llll}99.1 \% & 20.1 & 25.0 & 20.1\end{array}$

$\begin{array}{lllll}99.7 \% & 46.2 & 25.0 & 45.2 & 2\end{array}$

$\begin{array}{llll}99.7 \% & 54.2 & 25.0 & 45.1\end{array}$

$\begin{array}{lllll}99.7 \% & 61.3 & 25.0 & 61.3 & 4\end{array}$

$\begin{array}{llll}98.4 \% & 17.3 & 25.0 & 17.3\end{array}$

$\begin{array}{llll}99.7 \% & 68.9 & 25.0 & 62.1\end{array}$

$\begin{array}{lllll}99.0 \% & 25.2 & 25.0 & 25.2 & 3\end{array}$

$99.7 \% \quad 31.4 \quad 25.0 \quad 27.5$

$\begin{array}{llll}99.7 \% & 52.7 & 25.0 & 50.2\end{array}$

$\begin{array}{lllll}99.7 \% & 34.7 & 25.0 & 30.7 & 4\end{array}$

$\begin{array}{llll}98.9 \% & 20.3 & 25.0 & 20.3\end{array}$

$\begin{array}{llll}99.7 \% & 41.7 & 25.0 & 41.2\end{array}$

$\begin{array}{llll}99.0 \% & 19.2 & 25.0 & 19.2\end{array}$

$\begin{array}{llll}99.0 \% & 30.5 & 25.0 & 30.5\end{array}$

$\begin{array}{llll}99.7 \% & 48.8 & 25.0 & 47.7\end{array}$

$99.7 \% \quad 27.6 \quad 25.0 \quad 22.0$

$\begin{array}{llll}99.7 \% & 35.0 & 25.0 & 35.0\end{array}$

$99.7 \% \quad 68.9 \quad 25.0 \quad 62.1$

$99.0 \% \quad 25.2 \quad 25.0 \quad 25.2$

$99.7 \% \quad 48.0 \quad 25.0 \quad 48.0 \quad 2$

$\begin{array}{lllll}99.7 \% & 48.9 & 25.0 & 48.9 & 3\end{array}$

$\begin{array}{llll}99.7 \% & 36.6 & 25.0 & 32.8\end{array}$

$\begin{array}{lllll}99.7 \% & 41.0 & 25.0 & 26.7 & 2\end{array}$

$99.7 \% \quad 26.6 \quad 25.0 \quad 26.6$

$\begin{array}{llll}99.7 \% & 49.3 & 25.0 & 40.2\end{array}$
1029.61

1363.68

1652.93

1589.83

1416.68

1473.82

1208.60

1537.83

1112.56

1454.61

1501.85

1432.72

1492.89

1106.61

1152.63

1745.92

1234.72

982.50

1081.56

1267.65

1387.72

1243.56

1631.81

1738.82

1128.67

1094.60

1529.80

948.59

1482.71

1317.69

1228.64

1152.63

1745.92

1234.72

982.50

1357.71

1159.68

1128.67

1529.80

948.59

1397.69

1668.81

1357.77

1115.62

1060.56 1103.57 $\begin{array}{cc}08 & 420 \\ 72 & 481 \\ 82 & 494 \\ 00 & 514 \\ 33 & 545 \\ 46 & 557 \\ 54 & 666 \\ 74 & 683 \\ 49 & 262 \\ 53 & 262 \\ 00 & 310 \\ 50 & 362 \\ 77 & 388 \\ 76 & 488 \\ 16 & 624 \\ 4 & 83 \\ 4 & 98 \\ 24 & 134 \\ 69 & 176 \\ 42 & 251 \\ 43 & 254 \\ 25 & 336 \\ 87 & 397 \\ 87 & 400 \\ 51 & 466 \\ 67 & 478 \\ 79 & 487 \\ 00 & 512 \\ 13 & 520 \\ 21 & 532 \\ 05 & 815 \\ 05 & 1215 \\ 5 & 104 \\ 05 & 119 \\ 45 & 155 \\ 90 & 197 \\ 46 & 357 \\ 68 & 378 \\ 88 & 499 \\ 21 & 533 \\ 34 & 541 \\ 42 & 553 \\ 61 & 676 \\ 37 & 848 \\ 93 & 1101 \\ 5 & 1327 \\ & 24\end{array}$

Page 45 of Table S-1-1 
DNA-dependent protein kinase catalytic subunit GN=PRKDC PRKDC_HUMAN $469.10 \quad 100.0 \% \quad 97$ DNA-dependent protein kinase catalytic subunit GN=PRKDC PRKDC_HUMAN $469.10 \quad 100.0 \% \quad 97$ DNA-dependent protein kinase catalytic subunit GN=PRKDC PRKDC_HUMAN $469.10 \quad 100.0 \% \quad 97$ DNA-dependent protein kinase catalytic subunit GN=PRKDC PRKDC_HUMAN $469.10 \quad 100.0 \% 97$ DNA-dependent protein kinase catalytic subunit GN=PRKDC PRKDC_HUMAN $469.10 \quad 100.0 \% 97$ DNA-dependent protein kinase catalytic subunit GN=PRKDC PRKDC_HUMAN $469.10 \quad 100.0 \% \quad 97$ DNA-dependent protein kinase catalytic subunit GN=PRKDC PRKDC_HUMAN $469.10 \quad 100.0 \% 97$ DNA-dependent protein kinase catalytic subunit GN=PRKDC PRKDC_HUMAN $469.10 \quad 100.0 \% \quad 97$ DNA-dependent protein kinase catalytic subunit GN=PRKDC PRKDC_HUMAN $469.10 \quad 100.0 \% 97$ DNA-dependent protein kinase catalytic subunit GN=PRKDC PRKDC_HUMAN $469.10 \quad 100.0 \% 97$ $\begin{array}{llll}\text { DNA-dependent protein kinase catalytic subunit GN=PRKDC PRKDC_HUMAN } & 469.10 & 100.0 \% & 97\end{array}$ DNA-dependent protein kinase catalytic subunit GN=PRKDC PRKDC HUMAN $469.10 \quad 100.0 \%$ DNA-dependent protein kinase catalytic subunit GN=PRKDC PRKDC_HUMAN $469.10 \quad 100.0 \% \quad 97$ DNA-dependent protein kinase catalytic subunit GN=PRKDC PRKDC_HUMAN $469.10 \quad 100.0 \% \quad 97$ DNA-dependent protein kinase catalytic subunit GN=PRKDC PRKDC_HUMAN $469.10 \quad 100.0 \% 97$ DNA-dependent protein kinase catalytic subunit GN=PRKDC PRKDC_HUMAN $469.10 \quad 100.0 \% \quad 97$ DNA-dependent protein kinase catalytic subunit GN=PRKDC PRKDC_HUMAN $469.10 \quad 100.0 \%$ DNA-dependent protein kinase catalytic subunit GN=PRKDC PRKDC_HUMAN $469.10 \quad 100.0 \% \quad 97$ DNA-dependent protein kinase catalytic subunit GN=PRKDC PRKDC_HUMAN $469.10 \quad 100.0 \% \quad 97$ DNA-dependent protein kinase catalytic subunit GN=PRKDC PRKDC_HUMAN $469.10 \quad 100.0 \% 97$ DNA-dependent protein kinase catalytic subunit GN=PRKDC PRKDC_HUMAN $469.10 \quad 100.0 \% 97$ DNA-dependent protein kinase catalytic subunit GN=PRKDC PRKDC_HUMAN $469.10 \quad 100.0 \% \quad 97$ DNA-dependent protein kinase catalytic subunit GN=PRKDC PRKDC_HUMAN $469.10 \quad 100.0 \% 97$ $\begin{array}{llll}\text { DNA-dependent protein kinase catalytic subunit GN=PRKDC PRKDC_HUMAN } & 469.10 & 100.0 \% & 97\end{array}$ DNA-dependent protein kinase catalytic subunit GN=PRKDC PRKDC HUMAN $469.10 \quad 100.0 \% 97$ DNA-dependent protein kinase catalytic subunit GN=PRKDC PRKDC_HUMAN $469.10 \quad 100.0 \% 97$ DNA-dependent protein kinase catalytic subunit GN=PRKDC PRKDC_HUMAN $469.10 \quad 100.0 \% 97$ DNA-dependent protein kinase catalytic subunit GN=PRKDC PRKDC_HUMAN $469.10 \quad 100.0 \% 97$ DNA-dependent protein kinase catalytic subunit GN=PRKDC PRKDC_HUMAN $469.10 \quad 100.0 \% 97$ DNA-dependent protein kinase catalytic subunit GN=PRKDC PRKDC HUMAN $469.10 \quad 100.0 \% 97$ DNA-dependent protein kinase catalytic subunit GN=PRKDC PRKDC_HUMAN $469.10 \quad 100.0 \% 97$ DNA-dependent protein kinase catalytic subunit GN=PRKDC PRKDC_HUMAN $469.10 \quad 100.0 \% 97$ DNA-dependent protein kinase catalytic subunit GN=PRKDC PRKDC_HUMAN $469.10 \quad 100.0 \% 97$ DNA-dependent protein kinase catalytic subunit GN=PRKDC PRKDC_HUMAN $469.10 \quad 100.0 \% 97$ DNA-dependent protein kinase catalytic subunit GN=PRKDC PRKDC_HUMAN $469.10 \quad 100.0 \% 97$ DNA-dependent protein kinase catalytic subunit GN=PRKDC PRKDC_HUMAN $469.10 \quad 100.0 \% 97$ DNA-dependent protein kinase catalytic subunit GN=PRKDC PRKDC_HUMAN $469.10 \quad 100.0 \% 97$ DNA-dependent protein kinase catalytic subunit GN=PRKDC PRKDC HUMAN $469.10 \quad 100.0 \% 97$ DNA-dependent protein kinase catalytic subunit GN=PRKDC PRKDC_HUMAN $469.10 \quad 100.0 \% 97$ DNA-dependent protein kinase catalytic subunit GN=PRKDC PRKDC_HUMAN $469.10 \quad 100.0 \% 97$ DNA-dependent protein kinase catalytic subunit GN=PRKDC PRKDC_HUMAN $469.10 \quad 100.0 \% 97$ DNA-dependent protein kinase catalytic subunit GN=PRKDC PRKDC_HUMAN $469.10 \quad 100.0 \% \quad 97$ DNA-dependent protein kinase catalytic subunit GN=PRKDC PRKDC_HUMAN $469.10 \quad 100.0 \% 97$ DNA-dependent protein kinase catalytic subunit GN=PRKDC PRKDC_HUMAN $469.10 \quad 100.0 \% 97$ DNA-dependent protein kinase catalytic subunit GN=PRKDC PRKDC_HUMAN $469.10 \quad 100.0 \% \quad 97$ DNA-dependent protein kinase catalytic subunit GN=PRKDC PRKDC_HUMAN $469.10 \quad 100.0 \% 97$ DNA-dependent protein kinase catalytic subunit GN=PRKDC PRKDC_HUMAN $469.10 \quad 100.0 \% \quad 97$
$0.72 \% \quad 25.1 \%$ CGAALAGHQLIR

25.1\% IAPYSVEIK

$\quad 0.72 \% \quad 25.1 \%$ NTCTSVYTKDR

$526 \quad 0.72 \% \quad 25.1 \%$ TQMTSAVREPK

$526 \quad 0.72 \% \quad 25.1 \%$ LPVLAGCLK

$526 \quad 0.72 \% \quad 25.1 \%$ GLSSLLCNFTK

$526 \quad 0.72 \% \quad 25.1 \%$ SMEEDPQTSR

$526 \quad 0.72 \% \quad 25.1 \%$ EIFNFVLK

$526 \quad 0.72 \% \quad 25.1 \%$ AIRPQIDLKR

$526 \quad 0.72 \% \quad 25.1 \%$ YAVPSAGLR

$526 \quad 0.72 \% \quad 25.1 \%$ AALSALESFLK

$526 \quad 0.72 \% \quad 25.1 \%$ NVDSNNKELSIAIR

$526 \quad 0.72 \% \quad 25.1 \%$ DVDFMYVELIQR

$526 \quad 0.72 \% \quad 25.1 \%$ VFLALAAK

$526 \quad 0.72 \% \quad 25.1 \%$ NCISTVVHQGLIR

$526 \quad 0.72 \% \quad 25.1 \%$ ICSKPVVLPK

$526 \quad 0.72 \% \quad 25.1 \%$ GPESESEDHR

$526 \quad 0.72 \% \quad 25.1 \%$ GPESESEDHRASGEVR

$526 \quad 0.72 \% \quad 25.1 \%$ IKYFEGVSPK

$526 \quad 0.72 \% \quad 25.1 \%$ FGKEVAVK

$526 \quad 0.72 \% \quad 25.1 \%$ TSALSDETKNNWEVSALSR

$526 \quad 0.72 \% \quad 25.1 \%$ GFNKVVLK

$526 \quad 0.72 \% \quad 25.1 \%$ NLSSNEAISLEEIR

$526 \quad 0.72 \% \quad 25.1 \%$ VVQMLGSLGGQINK

$526 \quad 0.72 \% \quad 25.1 \%$ NLLTVTSSDEMMK

$526 \quad 0.72 \% \quad 25.1 \%$ SYVAWDREK

$526 \quad 0.72 \% \quad 25.1 \%$ RLSFAVPFR

$526 \quad 0.72 \% \quad 25.1 \%$ VTELALTASDR

$526 \quad 0.72 \% \quad 25.1 \%$ VTELALTASDRQTK

$526 \quad 0.72 \% \quad 25.1 \%$ ATQMPEGGQGAPPMYQLYKR

$526 \quad 0.72 \% \quad 25.1 \%$ LACDVDQVTR

$526 \quad 0.72 \% \quad 25.1 \%$ QITPQQQEK

$526 \quad 0.72 \% \quad 25.1 \%$ LYSLALHPNAFKR

$526 \quad 0.72 \% \quad 25.1 \%$ LGASLAFNNIYR

$526 \quad 0.72 \% \quad 25.1 \%$ SLGTIQQCCDAIDHLCR

$526 \quad 0.72 \% \quad 25.1 \%$ FVPLLPGNR

$526 \quad 0.72 \% \quad 25.1 \%$ TVGALQVLGTEAQSSLLK

$526 \quad 0.72 \% \quad 25.1 \%$ CFGTGAAGNR

$526 \quad 0.72 \% \quad 25.1 \%$ TSPQEGERYNYSK

$526 \quad 0.72 \% \quad 25.1 \%$ DLCNTHLMR

$526 \quad 0.72 \% \quad 25.1 \%$ SRLAAVVSACK

$526 \quad 0.72 \% \quad 25.1 \%$ LAAVVSACK

$526 \quad 0.72 \% \quad 25.1 \%$ GIAPGDER

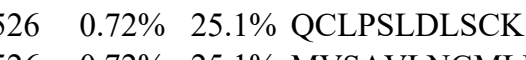

$26 \quad 0.72 \% \quad 25.1 \%$ MVSAVLNGMLDQ $\begin{array}{llll}99.7 \% & 56.0 & 25.0 & 51.8\end{array}$

$\begin{array}{llll}98.7 \% & 29.2 & 25.0 & 22.9\end{array}$

$95.5 \% \quad 21.4$

$99.6 \% \quad 23.4$

$98.4 \% \quad 21.6$

$99.7 \% \quad 38.5$

$99.7 \% \quad 58.1$

$99.7 \% \quad 32.4$

$94.7 \% \quad 18.8$

$98.7 \% \quad 26.0$

$99.6 \% 23.9$

$99.7 \% \quad 49.8$

$99.7 \% \quad 55.5$

$99.7 \% \quad 46.1$

$99.0 \% \quad 31.4$

$99.7 \% \quad 55.9$

$99.7 \% \quad 35.1$

$99.7 \% \quad 51.0$

$99.7 \% \quad 40.3$

$99.7 \% \quad 36.4$

$99.0 \% \quad 44.7$

$\begin{array}{ll}99.7 \% & 42.0\end{array}$

$99.0 \% \quad 30.3$

$99.7 \% \quad 63.2$

$99.7 \% \quad 51.4$

$99.7 \% \quad 55.2$

$99.4 \% 20.4$

$95.7 \% \quad 19.1$

$99.7 \% \quad 53.6$

$99.7 \% \quad 54.5$

$99.7 \% \quad 38.0$

$99.7 \% \quad 59.7$

$99.7 \% \quad 46.4$

$99.7 \% \quad 53.5$

$99.7 \% \quad 36.2$

$99.7 \% \quad 33.5$

$99.7 \% \quad 29.6$

$7 \% \quad 48.9$

$99.7 \% \quad 54.2$

$99.7 \% \quad 44.8$

$99.7 \% \quad 44.6$

$99.7 \% \quad 31.7$

$99.7 \% \quad 52.1$

$99.0 \% \quad 28.5$

$99.7 \% \quad 44.8$

$\begin{array}{ll}96.2 \% & 18.6 \\ 99.2 \% & 19.7\end{array}$
1065.61
1019.58

1344.62

1247.64

970.58

1239.64

1179.49

1009.57

1209.74

933.52

1149.65

1572.83

1543.75

832.53

1496.80

1140.68

1142.47

1741.77

1167.64

877.51

2108.03

904.56

1574.80

1459.79

1500.69

1153.56

1092.63

1175.63

1532.83

2239.06

1176.57

1099.57

1529.86

1338.72

2046.92

1012.59

1815.02

1010.45

1558.71

1175.53

1161.64

918.51

814.41

1320.63

1984.96 1210.69

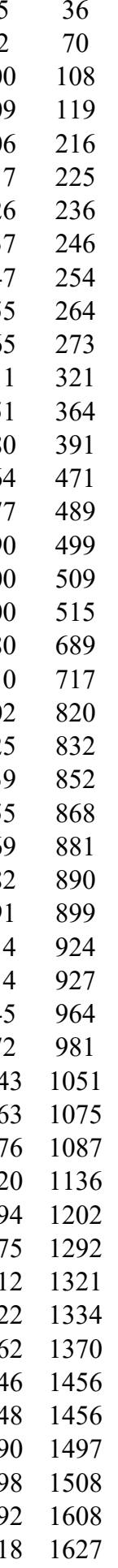

Page 46 of Table S-1-1 
DNA-dependent protein kinase catalytic subunit GN=PRKDC PRKDC_HUMAN $469.10 \quad 100.0 \% \quad 97$ DNA-dependent protein kinase catalytic subunit GN=PRKDC PRKDC_HUMAN $469.10 \quad 100.0 \% 97$ DNA-dependent protein kinase catalytic subunit GN=PRKDC PRKDC_HUMAN $469.10 \quad 100.0 \% \quad 97$ DNA-dependent protein kinase catalytic subunit GN=PRKDC PRKDC_HUMAN $469.10 \quad 100.0 \% 97$ $\begin{array}{llll}\text { DNA-dependent protein kinase catalytic subunit GN=PRKDC PRKDC_HUMAN } & 469.10 & 100.0 \% & 97\end{array}$ DNA-dependent protein kinase catalytic subunit GN=PRKDC PRKDC_HUMAN $469.10 \quad 100.0 \% \quad 97$ DNA-dependent protein kinase catalytic subunit GN=PRKDC PRKDC_HUMAN $469.10 \quad 100.0 \% 97$ DNA-dependent protein kinase catalytic subunit GN=PRKDC PRKDC_HUMAN $469.10 \quad 100.0 \% \quad 97$ DNA-dependent protein kinase catalytic subunit GN=PRKDC PRKDC_HUMAN $469.10 \quad 100.0 \% 97$ DNA-dependent protein kinase catalytic subunit GN=PRKDC PRKDC_HUMAN $469.10 \quad 100.0 \% 97$ $\begin{array}{llll}\text { DNA-dependent protein kinase catalytic subunit GN=PRKDC PRKDC_HUMAN } & 469.10 & 100.0 \% & 97\end{array}$ DNA-dependent protein kinase catalytic subunit GN=PRKDC PRKDC HUMAN $469.10 \quad 100.0 \%$ DNA-dependent protein kinase catalytic subunit GN=PRKDC PRKDC_HUMAN $469.10 \quad 100.0 \% \quad 97$ DNA-dependent protein kinase catalytic subunit GN=PRKDC PRKDC_HUMAN $469.10 \quad 100.0 \% 97$ DNA-dependent protein kinase catalytic subunit GN=PRKDC PRKDC_HUMAN $469.10 \quad 100.0 \% 97$ DNA-dependent protein kinase catalytic subunit GN=PRKDC PRKDC_HUMAN $469.10 \quad 100.0 \% \quad 97$ DNA-dependent protein kinase catalytic subunit GN=PRKDC PRKDC_HUMAN $469.10 \quad 100.0 \%$ DNA-dependent protein kinase catalytic subunit GN=PRKDC PRKDC_HUMAN $469.10 \quad 100.0 \% \quad 97$ DNA-dependent protein kinase catalytic subunit GN=PRKDC PRKDC_HUMAN $469.10 \quad 100.0 \% 97$ DNA-dependent protein kinase catalytic subunit GN=PRKDC PRKDC_HUMAN $469.10 \quad 100.0 \% 97$ DNA-dependent protein kinase catalytic subunit GN=PRKDC PRKDC_HUMAN $469.10 \quad 100.0 \% \quad 97$ DNA-dependent protein kinase catalytic subunit GN=PRKDC PRKDC_HUMAN $469.10 \quad 100.0 \% \quad 97$ DNA-dependent protein kinase catalytic subunit GN=PRKDC PRKDC_HUMAN $469.10 \quad 100.0 \% 97$ $\begin{array}{llll}\text { DNA-dependent protein kinase catalytic subunit GN=PRKDC PRKDC_HUMAN } & 469.10 & 100.0 \% & 97\end{array}$ DNA-dependent protein kinase catalytic subunit GN=PRKDC PRKDC HUMAN 469.10 100.0\% DNA-dependent protein kinase catalytic subunit GN=PRKDC PRKDC_HUMAN $469.10 \quad 100.0 \% \quad 97$ DNA-dependent protein kinase catalytic subunit GN=PRKDC PRKDC_HUMAN $469.10 \quad 100.0 \% \quad 97$ DNA-dependent protein kinase catalytic subunit GN=PRKDC PRKDC_HUMAN $469.10 \quad 100.0 \% 97$ DNA-dependent protein kinase catalytic subunit GN=PRKDC PRKDC_HUMAN $469.10 \quad 100.0 \% 97$ DNA-dependent protein kinase catalytic subunit GN=PRKDC PRKDC HUMAN $469.10 \quad 100.0 \% 97$ DNA-dependent protein kinase catalytic subunit GN=PRKDC PRKDC_HUMAN $469.10 \quad 100.0 \% 97$ DNA-dependent protein kinase catalytic subunit GN=PRKDC PRKDC_HUMAN $469.10 \quad 100.0 \% 97$ DNA-dependent protein kinase catalytic subunit GN=PRKDC PRKDC_HUMAN $469.10 \quad 100.0 \%$ DNA-dependent protein kinase catalytic subunit GN=PRKDC PRKDC_HUMAN $469.10 \quad 100.0 \% 97$ DNA-dependent protein kinase catalytic subunit GN=PRKDC PRKDC_HUMAN $469.10 \quad 100.0 \% 97$ DNA-dependent protein kinase catalytic subunit GN=PRKDC PRKDC_HUMAN $469.10 \quad 100.0 \% 97$ DNA-dependent protein kinase catalytic subunit GN=PRKDC PRKDC_HUMAN $469.10 \quad 100.0 \% 97$ DNA-dependent protein kinase catalytic subunit GN=PRKDC PRKDC HUMAN $469.10 \quad 100.0 \% 97$ DNA-dependent protein kinase catalytic subunit GN=PRKDC PRKDC_HUMAN $469.10 \quad 100.0 \% 97$ DNA-dependent protein kinase catalytic subunit GN=PRKDC PRKDC_HUMAN $469.10 \quad 100.0 \% 97$ DNA-dependent protein kinase catalytic subunit GN=PRKDC PRKDC_HUMAN $469.10 \quad 100.0 \% 97$ DNA-dependent protein kinase catalytic subunit GN=PRKDC PRKDC_HUMAN $469.10 \quad 100.0 \% \quad 97$ DNA-dependent protein kinase catalytic subunit GN=PRKDC PRKDC_HUMAN $469.10 \quad 100.0 \% 97$ DNA-dependent protein kinase catalytic subunit GN=PRKDC PRKDC_HUMAN $469.10 \quad 100.0 \% 97$ DNA-dependent protein kinase catalytic subunit GN=PRKDC PRKDC_HUMAN $469.10 \quad 100.0 \% \quad 97$ DNA-dependent protein kinase catalytic subunit GN=PRKDC PRKDC_HUMAN $469.10 \quad 100.0 \% 97$ DNA-dependent protein kinase catalytic subunit GN=PRKDC PRKDC_HUMAN $469.10 \quad 100.0 \% \quad 97$
$526 \quad 0.72 \% \quad 25.1 \%$ LPKDDVHAK

$99.7 \% \quad 48.7$

$\begin{array}{llllll}526 & 0.72 \% & 25.1 \% & \text { LCYDAFTENMAGENQLLER } & 99.7 \% & 49.2\end{array}$

$526 \quad 0.72 \% \quad 25.1 \%$ YNFPVEVEVPMER

$526 \quad 0.72 \% \quad 25.1 \%$ SLGPPQGEEDSVPR

$526 \quad 0.72 \% \quad 25.1 \%$ LGNPIVPLNIR

$526 \quad 0.72 \% \quad 25.1 \%$ LVINTEEVFRPYAK

$526 \quad 0.72 \% \quad 25.1 \%$ SKDFVQVMR

$526 \quad 0.72 \% \quad 25.1 \%$ VCLDIIYK

$526 \quad 0.72 \% \quad 25.1 \%$ LPSNTLDR

$526 \quad 0.72 \% \quad 25.1 \%$ STVLTPMFVETQASQGTLQTR

$526 \quad 0.72 \% \quad 25.1 \%$ TQEGSLSAR

$99.7 \% 51.8$

$99.7 \% \quad 50.2$

$99.7 \% \quad 44.2$

$99.7 \% \quad 53.1$

$99.7 \% \quad 51.0$

$99.0 \% \quad 30.1$

$98.1 \% \quad 23.5$

$526 \quad 0.72 \% \quad 25.1 \%$ ATQQQHDFTLTQTADGR

$526 \quad 0.72 \% \quad 25.1 \%$ SVGPDFGK

$526 \quad 0.72 \% \quad 25.1 \%$ LGLPGDEVDNKVK

$526 \quad 0.72 \% \quad 25.1 \%$ MKQDAQVVLYR

$526 \quad 0.72 \% \quad 25.1 \%$ QDAQVVLYR

$526 \quad 0.72 \% \quad 25.1 \%$ HGDLPDIQIK

$526 \quad 0.72 \% \quad 25.1 \%$ HSSLITPLQAVAQR

$526 \quad 0.72 \% \quad 25.1 \%$ TLSEKNNITQK

$526 \quad 0.72 \% \quad 25.1 \%$ LLEEALLR

$526 \quad 0.72 \% \quad 25.1 \%$ LLPAELPAKR

$526 \quad 0.72 \% \quad 25.1 \%$ SIGEYDVLR

$526 \quad 0.72 \% \quad 25.1 \%$ GIFTSEIGTK

$526 \quad 0.72 \% \quad 25.1 \%$ QITQSALLAEAR

$526 \quad 0.72 \% \quad 25.1 \%$ SDYSEAAK

$526 \quad 0.72 \% \quad 25.1 \%$ QGNLSSQVPLKR

$526 \quad 0.72 \% \quad 25.1 \%$ LLNTWTNRYPDAK

$526 \quad 0.72 \% \quad 25.1 \%$ KQNNFSLAMK

$526 \quad 0.72 \% \quad 25.1 \%$ SRSQGCSEQVLTVLK

$526 \quad 0.72 \% \quad 25.1 \%$ SQGCSEQVLTVLK

$526 \quad 0.72 \% \quad 25.1 \%$ TVSLLDENNVSSYLSK

$526 \quad 0.72 \% \quad 25.1 \%$ ALKLNSNEAR

$526 \quad 0.72 \% \quad 25.1 \%$ NIEKMYER

$526 \quad 0.72 \% \quad 25.1 \%$ MYAALGDPK

$526 \quad 0.72 \% \quad 25.1 \%$ NELEIPGQYDGR

$526 \quad 0.72 \% \quad 25.1 \%$ VTVMASLR

$526 \quad 0.72 \% \quad 25.1 \%$ TYSVVPMTSR

$526 \quad 0.72 \% \quad 25.1 \%$ GANRTETVTSFR

$526 \quad 0.72 \% \quad 25.1 \%$ TETVTSFR

$526 \quad 0.72 \% \quad 25.1 \%$ VPADLLKR

$526 \quad 0.72 \% \quad 25.1 \%$ MSTSPEAFLALR
$99.7 \% \quad 45.3$

$99.7 \% \quad 52.1$

$95.5 \% \quad 19.7$

$\begin{array}{lll}99.7 \% & 40.3\end{array}$

$99.7 \% \quad 58.4$

$99.7 \% \quad 35.4$

$99.7 \% \quad 55.4$

$99.7 \% \quad 59.5$

$99.7 \% \quad 32.0$

$99.0 \% \quad 51.9$

$99.7 \% \quad 40.2$

$99.7 \% \quad 41.1$

$99.7 \% \quad 43.2$

$99.7 \% \quad 53.2$

$99.0 \% \quad 38.8$

$99.7 \% \quad 34.2$

$99.6 \% \quad 22.0$

$99.7 \% \quad 32.1$

$99.7 \% \quad 44.6$

$99.7 \% \quad 51.9$

$99.7 \% \quad 51.2$

$99.7 \% \quad 43.4$

$99.0 \% \quad 27.5$

$99.7 \% \quad 55.9$

$99.7 \% \quad 42.5$

$99.0 \% \quad 28.2$

$99.7 \% 34.6$

$99.7 \% \quad 38.1$

$99.0 \% \quad 21.7$

$99.0 \% \quad 54.2$

$99.7 \% \quad 53.9$
$99.7 \% \quad 58.3$
945.58

1334.59

1396.70

1524.79

996.52

1022.56

2046.99

2290.01

1608.77

1467.71

1205.74

1678.92

1109.58

1023.55

915.49

2295.17

948.47

1917.91

806.40

1383.75

1350.72

1091.58

1135.61

1520.85

1275.69

956.58

1107.69

1051.54

1052.56

1300.72

870.38

1326.75

1591.82

1180.6

1691.87

1448.74

1768.90

1115.62

1082.53

965.48

1390.66

876.50

1140.57

1338.68

940.47

911.57 1338.67 
DNA-dependent protein kinase catalytic subunit GN=PRKDC PRKDC_HUMAN $469.10 \quad 100.0 \% \quad 97 \quad 125 \quad 526 \quad 0.72 \% \quad 25.1 \%$ AQEPESGLSEETQVK

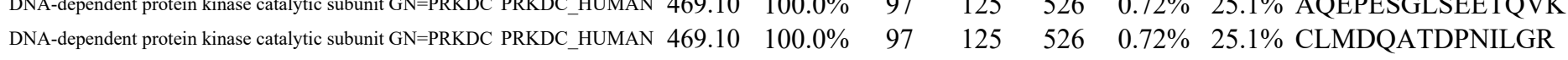
DNA-directed RNA polymerase I subunit RPA34 GN=CD3EAP RPA34_HUMAN $54.99 \quad 100.0 \%$ DNA-directed RNA polymerase I subunit RPA34 GN=CD3EAP RPA34 HUMAN $54.99 \quad 100.0 \%$ DNA-directed RNA polymerase I subunit RPA34 GN=CD3EAP RPA34_HUMAN $54.99 \quad 100.0 \%$ DNA-directed RNA polymerase I subunit RPA34 GN=CD3EAP RPA34_HUMAN $54.99 \quad 100.0 \%$ DNA-directed RNA polymerase II subunit RPB1 GN=POLR2A RPB1_HUMAN $217.18 \quad 100.0 \%$ DNA-directed RNA polymerase II subunit RPB1 GN=POLR2A RPB1_HUMAN $217.18 \quad 100.0 \%$ DNA-directed RNA polymerase II subunit RPB1 GN=POLR2A RPB1_HUMAN $217.18 \quad 100.0 \%$ DNA-directed RNA polymerase II subunit RPB3 GN=POLR2C RPB3_HUMAN $31.44 \quad 100.0 \%$ DNA-directed RNA polymerase II subunit RPB3 GN=POLR2C RPB3_HUMAN $31.44 \quad 100.0 \%$ DNA-directed RNA polymerases I and III subunit RPAC1 GN=POLRIC RPAC1_HUMAN $39.25 \quad 100.0 \%$ DNA-directed RNA polymerases I and III subunit RPAC1 GN=POLRIC RPAC1_HUMAN $39.25 \quad 100.0 \%$ DNA-directed RNA polymerases I and III subunit RPAC1 GN=POLRIC RPAC1_HUMAN $39.25 \quad 100.0 \%$ DnaJ homolog subfamily A member $1 \mathrm{GN}=$ DNAJA1 DNJA1_HUMAN $44.87 \quad 100.0 \%$ DnaJ homolog subfamily A member 1 GN=DNAJA1 DNJA1_HUMAN $44.87 \quad 100.0 \%$ DnaJ homolog subfamily A member $1 \mathrm{GN}=$ DNAJA1 DNJA1 HUMAN $44.87 \quad 100.0 \%$ DnaJ homolog subfamily A member 1 GN=DNAJA1 DNJA1_HUMAN $44.87 \quad 100.0 \%$ DnaJ homolog subfamily A member 1 GN=DNAJA1 DNJA1_HUMAN $44.87 \quad 100.0 \%$ DnaJ homolog subfamily A member 2 GN=DNAJA2 DNJA2_HUMAN $45.75 \quad 100.0 \%$ DnaJ homolog subfamily A member 2 GN=DNAJA2 DNJA2_HUMAN $45.75 \quad 100.0 \%$ DnaJ homolog subfamily A member 2 GN=DNAJA2 DNJA2_HUMAN $45.75 \quad 100.0 \%$ DnaJ homolog subfamily A member 3, mitochondrial GN=DNAJA3 DNJA3_HUMAN $52.49 \quad 100.0 \%$ DnaJ homolog subfamily A member 3, mitochondrial GN=DNAJA3 DNJA3_HUMAN $52.49 \quad 100.0 \%$ DnaJ homolog subfamily A member 3, mitochondrial GN=DNAJA3 DNJA3_HUMAN $52.49 \quad 100.0 \%$ DnaJ homolog subfamily A member 3, mitochondrial GN=DNAJA3 DNJA3_HUMAN $52.49 \quad 100.0 \%$ DnaJ homolog subfamily A member 3, mitochondrial GN=DNAJA3 DNJA3_HUMAN $52.49 \quad 100.0 \%$ DnaJ homolog subfamily A member 3, mitochondrial GN=DNAJA3 DNJA3_HUMAN $52.49 \quad 100.0 \%$ DnaJ homolog subfamily A member 3, mitochondrial GN=DNAJA3 DNJA3_HUMAN $52.49 \quad 100.0 \%$ DnaJ homolog subfamily A member 3, mitochondrial GN=DNAJA3 DNJA3_HUMAN $52.49 \quad 100.0 \%$ DnaJ homolog subfamily A member 3, mitochondrial GN=DNAJA3 DNJA3_HUMAN $52.49 \quad 100.0 \%$ DnaJ homolog subfamily A member 3, mitochondrial GN=DNAJA3 DNJA3_HUMAN $52.49 \quad 100.0 \%$ DnaJ homolog subfamily C member $10 \mathrm{GN}=$ DNAJC10 DJC10_HUMAN $91.08 \quad 100.0 \%$ DnaJ homolog subfamily C member $10 \mathrm{GN}=$ DNAJC10 DJC10_HUMAN $91.08 \quad 100.0 \%$ DnaJ homolog subfamily C member $10 \mathrm{GN}=$ DNAJC10 DJC10_HUMAN $91.08 \quad 100.0 \%$ DnaJ homolog subfamily C member $10 \mathrm{GN}=$ DNAJC10 DJC10_HUMAN $91.08 \quad 100.0 \%$ DnaJ homolog subfamily C member $10 \mathrm{GN}=$ DNAJC10 DJC10_HUMAN $91.08 \quad 100.0 \%$ DnaJ homolog subfamily C member $10 \mathrm{GN}=$ DNAJC10 DJC10_HUMAN $91.08 \quad 100.0 \%$ DnaJ homolog subfamily C member $10 \mathrm{GN}=$ DNAJC10 DJC10_HUMAN $91.08 \quad 100.0 \%$ DnaJ homolog subfamily C member $10 \mathrm{GN}=$ DNAJC10 DJC10_HUMAN $91.08 \quad 100.0 \%$ DnaJ homolog subfamily C member $10 \mathrm{GN}=$ DNAJC10 DJC10_HUMAN $91.08 \quad 100.0 \%$ DnaJ homolog subfamily C member $10 \mathrm{GN}=$ DNAJC10 DJC10_HUMAN $91.08 \quad 100.0 \%$ DnaJ homolog subfamily C member $10 \mathrm{GN}=$ DNAJC10 DJC10_HUMAN $91.08 \quad 100.0 \%$ DnaJ homolog subfamily C member $10 \mathrm{GN}=$ DNAJC10 DJC10_HUMAN $91.08 \quad 100.0 \%$ DnaJ homolog subfamily C member $10 \mathrm{GN}=$ DNAJC10 DJC10_HUMAN $91.08 \quad 100.0 \%$

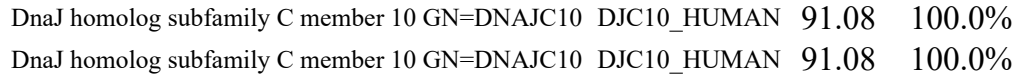

$6 \quad 0.01 \% \quad 10.0 \%$ FCAFGGNPPVTGPR

$6.01 \% \quad 10.0 \%$ SALAPNLLTSGK

$0.01 \% \quad 10.0 \%$ SALAPNLLTSGKK

$0.01 \% \quad 10.0 \%$ GHTVTEPIQPLEPELPGEGQPEAR

$0.01 \% \quad 2.3 \% \quad$ TVITPDPNLSIDQVGVPR

$\begin{array}{lll}0.01 \% & 2.3 \% & \text { YSPTSPTYSPTTPK }\end{array}$

$0.01 \% \quad 2.3 \% \quad$ YSPTSPTYSPTSPK

$0.00 \% \quad 6.2 \% \quad$ PYANQPTVR

$0.00 \% \quad 6.2 \% \quad$ DLISNSPR

$0.01 \% \quad 9.3 \% \quad$ VVLGEFGVR

$0.01 \% \quad 9.3 \% \quad$ ILLAEVPTMAVEK

$0.01 \% \quad 9.3 \% \quad$ FSPVATASYR

$10 \quad 0.01 \% \quad 14.9 \%$ QISQAYEVLSDAK

$10 \quad 0.01 \% \quad 14.9 \%$ ELYDKGGEQAIK

$10 \quad 0.01 \% \quad 14.9 \%$ NVICDKCEGR

$10 \quad 0.01 \% \quad 14.9 \%$ TIVITSHPGQIVK

$10 \quad 0.01 \% \quad 14.9 \%$ CVLNEGMPIYR

$5 \quad 0.01 \% \quad 7.8 \%$ NVLCSACSGQGGK

$0.01 \% \quad 7.8 \%$ ILEVHVDKGMK

$0.01 \% \quad 7.8 \%$ VIEPGCVR

$0.03 \% \quad 23.5 \%$ KAYYQLAK

$0.03 \% \quad 23.5 \%$ GGPTVDPEELFR

$0.03 \% \quad 23.5 \%$ GVNKEFTVNIMDTCER

$0.03 \% \quad 23.5 \%$ CGGRGSIIISPCVVCR

$0.03 \% 23.5 \%$ GSIIISPCVVCR

$0.03 \% \quad 23.5 \%$ VMIPVPAGVEDGQTVR

$0.03 \% \quad 23.5 \%$ EIFITFRVQK

$0.03 \% \quad 23.5 \%$ MGGKGIPR

$0.03 \% \quad 23.5 \%$ INSYGYGDHYIHIK

$0.03 \% \quad 23.5 \%$ REAGEDEEGFLSK

$0.06 \% \quad 18.7 \%$ DFAKEVDGLLR

$0.06 \% \quad 18.7 \%$ IGAVNCGDDRMLCR

$0.06 \% \quad 18.7 \%$ MKGVNSYPSLFIFR

$0.06 \% \quad 18.7 \%$ GVNSYPSLFIFR

$\quad 0.06 \% \quad 18.7 \%$ SGMAPVKYHGDR

$\quad 0.06 \% \quad 18.7 \%$ GGDCLTSQTR

$46 \quad 0.06 \% \quad 18.7 \%$ TLLKNDHIQVGR

$46 \quad 0.06 \% \quad 18.7 \%$ ILYDILAFAK

$0.06 \% \quad 18.7 \%$ ASNLLYGQLK

$0.06 \% \quad 18.7 \%$ AGKVDCQAYAQTCQK

$0.06 \% \quad 18.7 \%$ VDCQAYAQTCQK

$0.06 \% \quad 18.7 \%$ AYPTVKFYFYER

$46 \quad 0.06 \% \quad 18.7 \%$ RNFQEEQINTR

$\quad 0.06 \% \quad 18.7 \%$ NFQEEQINTR

$0.06 \% \quad 18.7 \%$ NFQEEQINTRDAK $\begin{array}{lllllll}99.7 \% & 58.8 & 25.0 & 53.7 & 3 & 0 & 0\end{array}$ $\begin{array}{lllllll}99.7 \% & 56.3 & 25.0 & 50.6 & 6 & 0 & 0\end{array}$ $\begin{array}{lllll}99.7 \% & 52.7 & 25.0 & 52.7 & 2\end{array}$ $\begin{array}{llll}94.9 \% & 21.0 & 25.0 & 16.2\end{array}$ $\begin{array}{lllll}99.7 \% & 31.1 & 25.0 & 31.1 & 0\end{array}$ $\begin{array}{llll}99.7 \% & 37.2 & 25.0 & 36.0\end{array}$ $\begin{array}{llll}99.5 \% & 21.3 & 25.0 & 20.2 \\ 99.5 \% & 22.8 & 25.0 & 22.8\end{array}$ $\begin{array}{llll}99.7 \% & 33.2 & 25.0 & 28.7\end{array}$ $\begin{array}{llll}97.0 \% & 24.1 & 25.0 & 10.2\end{array}$ $\begin{array}{llll}96.5 \% & 27.0 & 25.0 & 14.8\end{array}$ $\begin{array}{llll}99.7 \% & 42.0 & 25.0 & 42.0\end{array}$ $\begin{array}{lllll}99.7 \% & 34.0 & 25.0 & 33.0 & 2\end{array}$ $99.7 \% \quad 34.1 \quad 25.0 \quad 33.8 \quad 2$ $\begin{array}{lllll}99.7 \% & 31.1 & 25.0 & 24.6 & 2\end{array}$ $\begin{array}{lllll}99.7 \% & 27.5 & 25.0 & 27.4 & 2\end{array}$ $\begin{array}{llll}99.7 \% & 54.4 & 25.0 & 53.5\end{array}$ $\begin{array}{llll}99.7 \% & 41.3 & 25.0 & 41.3\end{array}$ $99.7 \% \quad 70.7 \quad 25.0 \quad 68.9$ $\begin{array}{llll}95.4 \% & 14.2 & 25.0 & 14.2\end{array}$ $\begin{array}{llll}99.0 \% & 35.4 & 25.0 & 29.5\end{array}$ $\begin{array}{llll}98.5 \% & 25.7 & 25.0 & 12.0\end{array}$ $\begin{array}{lllll}99.7 \% & 38.0 & 25.0 & 38.0 & 4\end{array}$ $\begin{array}{llll}99.5 \% & 20.9 & 25.0 & 20.9\end{array}$ $\begin{array}{llll}99.6 \% & 22.0 & 25.0 & 21.8\end{array}$ $\begin{array}{llll}99.7 \% & 54.3 & 25.0 & 41.9\end{array}$ $\begin{array}{llll}99.7 \% & 58.2 & 25.0 & 50.5\end{array}$ $\begin{array}{lllll}99.7 \% & 35.6 & 25.0 & 27.0 & 2\end{array}$ $99.0 \% \quad 39.5 \quad 25.0 \quad 26.4$ $\begin{array}{llll}95.7 \% & 15.1 & 25.0 & 15.1\end{array}$ $\begin{array}{llll}99.7 \% & 37.0 & 25.0 & 37.0\end{array}$ $\begin{array}{lllll}99.7 \% & 26.0 & 25.0 & 26.0 & 2\end{array}$ $\begin{array}{lllll}99.7 \% & 43.8 & 25.0 & 43.8 & 2\end{array}$ $\begin{array}{llll}99.7 \% & 49.2 & 25.0 & 49.2\end{array}$ $\begin{array}{llll}99.7 \% & 41.5 & 25.0 & 40.7\end{array}$ $\begin{array}{llll}99.5 \% & 23.0 & 25.0 & 23.0\end{array}$ $99.7 \% \quad 54.5 \quad 25.0 \quad 33.2$ $99.7 \% \quad 41.6 \quad 25.0 \quad 41.6$ $\begin{array}{lllll}99.7 \% & 40.3 & 25.0 & 39.1 & 2\end{array}$ $\begin{array}{llll}99.7 \% & 57.5 & 25.0 & 50.1\end{array}$ $\begin{array}{lllll}99.7 \% & 57.4 & 25.0 & 57.4 & 2\end{array}$ $\begin{array}{lllll}99.7 \% & 40.2 & 25.0 & 34.8 & 2\end{array}$ $\begin{array}{llll}97.4 \% & 16.4 & 25.0 & 16.4\end{array}$ $\begin{array}{llll}96.0 \% & 20.7 & 25.0 & 17.2\end{array}$ $\begin{array}{llll}99.7 \% & 72.7 & 25.0 & 54.7\end{array}$ $\begin{array}{llll}99.7 \% & 38.4 & 25.0 & 31.1\end{array}$

0
0

$\begin{array}{ll}0 & 147 \\ 0 & 117\end{array}$

$\begin{array}{lll}1476.71 & 149 & 162\end{array}$

$\begin{array}{lll}1171.67 & 163 & 174\end{array}$

$1299.76 \quad 163 \quad 175$

$\begin{array}{lll}2581.29 & 431 & 454\end{array}$

$1921.04 \quad 365 \quad 382$

$\begin{array}{lll}1526.74 & 1874 & 1887\end{array}$

$1512.72 \quad 1909 \quad 1922$

$\begin{array}{lll}1045.54 & 2 & 10\end{array}$

$901.47 \quad 119 \quad 126$

$\begin{array}{lll}975.56 & 14 & 22\end{array}$

$\begin{array}{lll}1413.80 & 79 & 91\end{array}$

$\begin{array}{lll}1098.56 & 225 & 234\end{array}$

$\begin{array}{lll}1451.74 & 47 & 59\end{array}$

1350.69

1250.56

1392.82

1351.65

1337.59

1284.70

929.49

984.55

1316.65

1912.89

1790.88

1360.71

1683.87

1280.74

815.46

1679.82

1466.68

1262.67

1636.74

1674.87

1399.74

1317.64

1094.49

1393.79

1166.68

1106.62

1727.78

1471.63

1583.79

1434.71

1278.61

1592.77 

DnaJ homolog subfamily $\mathrm{C}$ member $11 \mathrm{GN}=$ DNAJC11 DJC11_HUMAN $63.28 \quad 100.0 \%$ DnaJ homolog subfamily C member 11 GN=DNAJC11 DJC11_HUMAN $63.28 \quad 100.0 \%$ DnaJ homolog subfamily C member 11 GN=DNAJC11 DJC11 HUMAN $63.28 \quad 100.0^{\circ}$ DnaJ homolog subfamily C member 11 GN=DNAJC11 DJC11_HUMAN $63.28 \quad 100.0 \%$ DnaJ homolog subfamily $\mathrm{C}$ member $11 \mathrm{GN}=$ DNAJC11 DJC11_HUMAN $63.28100 .0 \%$ DnaJ homolog subfamily C member 11 GN=DNAJC11 DJC11 HUMAN $63.28 \quad 100.0 \%$ DnaJ homolog subfamily C member 11 GN=DNAJC11 DJC11_HUMAN $63.28 \quad 100.0 \%$ DnaJ homolog subfamily $\mathrm{C}$ member $11 \mathrm{GN}=$ DNAJC11 DJC11 HUMAN $63.28100 .0 \%$ DnaJ homolog subfamily C member $13 \mathrm{GN}=$ DNAJC13 DJC13_HUMAN $254.42 \quad 100.0 \%$ DnaJ homolog subfamily C member 13 GN=DNAJC13 DJC13_HUMAN $254.42 \quad 100.0 \%$ DnaJ homolog subfamily C member $13 \mathrm{GN}=$ DNAJC13 DJC13 HUMAN $254.42 \quad 100.0 \%$ DnaJ homolog subfamily C member 13 GN=DNAJC13 DJC13_HUMAN $254.42 \quad 100.0 \%$ DnaJ homolog subfamily C member $13 \mathrm{GN}=$ DNAJC13 DJC13 HUMAN $254.42100 .0 \%$ DnaJ homolog subfamily C member 13 GN=DNAJC13 DJC13_HUMAN $254.42 \quad 100.0 \%$ DnaJ homolog subfamily C member 13 GN=DNAJC13 DJC13_HUMAN $254.42 \quad 100.0 \%$ DnaJ homolog subfamily C member $13 \mathrm{GN}=$ DNAJC13 DJC13 HUMAN $254.42100 .0 \%$ DnaJ homolog subfamily C member 13 GN=DNAJC13 DJC13_HUMAN $254.42 \quad 100.0 \%$ DnaJ homolog subfamily C member $13 \mathrm{GN}=$ DNAJC13 DJC13_HUMAN $254.42 \quad 100.0 \%$ DnaJ homolog subfamily C member $13 \mathrm{GN}=$ DNAJC13 DJC13 HUMAN $254.42 \quad 100.0 \%$ DnaJ homolog subfamily C member 13 GN=DNAJC13 DJC13_HUMAN $254.42 \quad 100.0 \%$ DnaJ homolog subfamily C member 13 GN=DNAJC13 DJC13_HUMAN $254.42 \quad 100.0 \%$ DnaJ homolog subfamily C member 13 GN=DNAJC13 DJC13_HUMAN $254.42 \quad 100.0 \%$ DnaJ homolog subfamily C member 9 GN=DNAJC9 DNJC9_HUMAN $29.91 \quad 100.0 \%$ DnaJ homolog subfamily C member 9 GN=DNAJC9 DNJC9 HUMAN $29.91 \quad 100.0 \%$ Dolichol-phosphate mannosyltransferase subunit 1 GN=DPM1 DPM1_HUMAN $29.64 \quad 100.0 \%$ Dolichol-phosphate mannosyltransferase subunit 1 GN=DPM1 DPM1_HUMAN $29.64100 .0 \%$

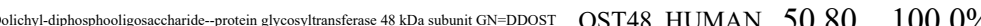
Dolichyl-diphosphooligosaccharide-protetin glycosyltransferase 48 kDa subunit GN=DDOST OST48_HUMAN 50.80 $100.0 \%$ $100.0 \%$ $100.0 \%$ $100.0 \%$ $100.0 \%$ $100.0 \%$ $\begin{array}{llll}\text { Dolichyl-phosphate beta-glucosyltransferase GN=ALG5 } & \text { ALG5_HUMAN } 36.95 & 100.0 \% \\ \text { Dolichyl-phosphate beta-glucosyltransferase GN=ALG5 } & \text { ALG5_HUMAN } 36.95 & 100.0 \%\end{array}$ Dolichyl-phosphate beta-glucosyltransferase GN=ALG5 ALG5 HUMAN 36.95 $100.0 \%$ Double-stranded RNA-binding protein Staufen homolog 1 GN=STAU1 STAU1_HUMAN $63.18 \quad 100.0 \%$ Double-stranded RNA-binding protein Staufen homolog 1 GN=STAU1 STAU1_HUMAN $63.18 \quad 100.0 \%$ Double-stranded RNA-specific adenosine deaminase GN=ADAR DSRAD HUMAN $136.07 \quad 100.0 \%$ Double-stranded RNA-specific adenosine deaminase GN=ADAR DSRAD_HUMAN $136.07 \quad 100.0 \%$
$46 \quad 0.06 \% \quad 18.7 \%$ AIAALISEKLETLR $0.02 \% \quad 18.2 \%$ EASSEELK $0.02 \% \quad 18.2 \%$ AIYDIYGKR

$0.02 \% \quad 18.2 \%$ CFVTTNCALQFSSR

$0.02 \% \quad 18.2 \%$ GIRPGLTTVLAR

$0.02 \% \quad 18.2 \%$ AGFFGTVVEYGAER

$0.02 \% \quad 18.2 \%$ HSVLGAAVSVGVPQGVSLK

$0.02 \% \quad 18.2 \%$ KQEAESAVR

$0.02 \% \quad 18.2 \%$ VIDVTVPLQCLVK

$0.03 \% \quad 7.7 \%$ GQGTEFNLTFR

$0.03 \% \quad 7.7 \%$ ASGNRDVCVK

$0.03 \% \quad 7.7 \%$ AGFLAFTQLPK

$0.03 \% \quad 7.7 \%$ AIIEEGDKEIATK

$0.03 \% \quad 7.7 \%$ LLLEEDENEESGSIKR

$0.03 \% \quad 7.7 \%$ AYEFLCTK

$0.03 \% \quad 7.7 \% \quad$ IVDGPDPENIILILK

$0.03 \% \quad 7.7 \%$ TQSILFNR

$0.03 \% \quad 7.7 \%$ SEETNQQEVANSLAK

$\begin{array}{lll}0.03 \% & 7.7 \% & \text { LGGYLAEEQATP } \\ 0.03 \% & 7.7 \% & \text { LAVASVTEILK }\end{array}$

$\begin{array}{lll}0.03 \% & 7.7 \% & \text { VYNEVPTFQLEVPK }\end{array}$

$0.03 \% \quad 7.7 \%$ VEMALEALR

$0.03 \% \quad 7.7 \%$ VIHALSENELCVR

$0.01 \% \quad 8.5 \% \quad$ VYSVLSDREQR

$0.01 \% \quad 8.5 \% \quad$ ISLEDIQAFEK

$0.01 \% \quad 9.2 \%$ QKEGNFDIVSGTR

$0.01 \% \quad 9.2 \%$ LGGNEIVSFLK

$0.01 \% \quad 9.9 \%$ SSLNPILFR

$0.01 \% \quad 9.9 \%$ NTLLIAGLQAR

$0.01 \% \quad 9.9 \%$ YSQTGNYELAVALSR

$0.01 \% \quad 9.9 \%$ WVFKEEGVLR

$0.02 \% \quad 19.1 \%$ VTAEVVLAHLGGGSTS

$0.02 \% \quad 19.1 \%$ YDYQRQPDSGISSIR

$0.02 \% \quad 19.1 \%$ NIEIDSPYEISR

$0.02 \% \quad 19.1 \%$ VACITEQVLTLVNKR

$0.02 \% \quad 19.1 \%$ DISTLNSGKK

$0.02 \% \quad 19.1 \%$ ALTSEIALLQSR

$0.02 \% \quad 19.1 \%$ SAVEAERLVAGK

$0.02 \% \quad 19.1 \%$ IDHILDAL

$0.01 \% \quad 10.5 \%$ QLSVVVPSYNEEK

$0.01 \% \quad 10.5 \%$ MGIFSSRGEK

$0.01 \% \quad 10.5 \%$ AHLEKESIAQR

$0.00 \% \quad 4.7 \%$ VSVGEFVGEGEGK

$0.00 \% \quad 4.7 \% \quad$ VGNHTAEGTGTNKK

$0.00 \% \quad 2.1 \%$ YLNTNPVGGLLEYAR

$0.00 \% \quad 2.1 \%$ VLIGENEKAER $\begin{array}{llllllll}99.7 \% & 54.1 & 25.0 & 48.8 & 2 & 1 & 0 & 1527.91\end{array}$

1353.66

1353.66
1098.59

1690.77

1253.77

1502.73

1805.03

1017.53

1483.86

1269.62

1105.54

1192.67

1416.76

1860.92

1031.49

1648.95

978.54

1647.78

2087.08

1143.70

1662.87

1031.56

1539.79

1351.70

1292.67

1450.73

1176.66

1046.60

1169.70

1671.83

1262.69

1653.89

1659.90

1784.86

1435.71

1743.98

1062.58

1301.74

1229.68

909.50

1491.77

1111.56

1281.69

1293.63

$\begin{array}{llllllll}99.7 \% & 27.5 & 25.0 & 27.5 & 0 & 1 & 0 & 1413.71 \\ 99.7 \% & 48.4 & 25.0 & 45.0 & 2 & 0 & 0 & 1679.88\end{array}$

$\begin{array}{llllllll}99.7 \% & 27.5 & 25.0 & 27.5 & 0 & 1 & 0 & 1413.71 \\ 99.7 \% & 48.4 & 25.0 & 45.0 & 2 & 0 & 0 & 1679.88\end{array}$

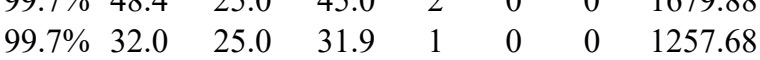


Dual specificity mitogen-activated protein kinase kinase 2 GN=MAP2K2 MP2K2_HUMAN $44.43 \quad 100.0 \%$ Dual specificity mitogen-activated protein kinase kinase 2 GN=MAP2K2 2 MP2K2_HUMAN $44.43 \quad 100.0 \%$ Dual specificity mitogen-activated protein kinase kinase 3 GN=MAP2K3 $\quad$ MP2K3_HUMAN $39.32 \quad 100.0 \%$ Dual specificity mitogen-activated protein kinase kinase $3 \mathrm{GN}=\mathrm{MAP} 2 \mathrm{~K} 3 \mathrm{MP} 2 \mathrm{~K} 3 \mathrm{HUMAN} 39.32 \quad 100.0^{\circ}$ Dual specificity mitogen-activated protein kinase kinase 4 GN=MAP2K4 MP2K4_HUMAN $44.29 \quad 99.9 \%$ Dual specificity mitogen-activated protein kinase kinase $4 \mathrm{GN}=$ MAP2K4 MP2K4_HUMAN $44.29 \quad 99.9 \%$ Dual specificity mitogen-activated protein kinase kinase $7 \mathrm{GN}=\mathrm{MAP} 2 \mathrm{~K} 7 \quad \mathrm{MP} 2 \mathrm{~K} 7$ _HUMAN $47.49 \quad 100.0 \%$ Dual specificity mitogen-activated protein kinase kinase 7 GN=MAP2K7 $\quad$ MP2K7_HUMAN $47.49 \quad 100.0 \%$ Dynactin subunit $1 \mathrm{GN}=\mathrm{DCTN} 1$ Dynactin subunit $1 \mathrm{GN}=\mathrm{DCTN} 1$ Dynactin subunit $1 \mathrm{GN}=\mathrm{DCTN} 1$ Dynamin-2 GN=DNM2 Dynamin-2 GN=DNM2 Dynamin-2 GN=DNM2

Dynamin-2 GN=DNM2 DCTN1_HUMAN $141.70 \quad 100.0 \%$ DCTN1_HUMAN $141.70 \quad 100.0 \%$ DCTN1_HUMAN $141.70 \quad 100.0 \%$ DYN2 HUMAN $98.07 \quad 100.0 \%$ DYN2_HUMAN $98.07 \quad 100.0 \%$ DYN2_HUMAN $98.07 \quad 100.0 \%$ DYN2_HUMAN $98.07 \quad 100.0 \%$ Dynamin-like $120 \mathrm{kDa}$ protein, mitochondrial GN=OPA1 OPA1_HUMAN $111.63 \quad 100.0 \%$ Dynamin-like $120 \mathrm{kDa}$ protein, mitochondrial GN=OPA1 OPA1 HUMAN $111.63100 .0 \%$ Dynamin-like $120 \mathrm{kDa}$ protein, mitochondrial GN=OPA1 OPA1_HUMAN $111.63 \quad 100.0 \%$ Dynein assembly factor 5, axonemal GN=DNAAF5 DAAF5_HUMAN $93.52 \quad 100.0 \%$ Dynein assembly factor 5, axonemal GN=DNAAF5 DAAF5_HUMAN $93.52 \quad 100.0 \%$ Dynein assembly factor 5, axonemal GN=DNAAF5 DAAF5_HUMAN $93.52 \quad 100.0 \%$ Dynein assembly factor 5, axonemal GN=DNAAF5 DAAF5_HUMAN $93.52 \quad 100.0 \%$ Dynein assembly factor 5, axonemal GN=DNAAF5 DAAF5_HUMAN $93.52 \quad 100.0 \%$ Dynein assembly factor 5 , axonemal GN=DNAAF5 DAAF5_HUMAN $93.52 \quad 100.0 \%$ Dynein assembly factor 5, axonemal GN=DNAAF5 DAAF5_HUMAN $93.52 \quad 100.0 \%$ Dynein assembly factor 5, axonemal GN=DNAAF5 DAAF5_HUMAN $93.52 \quad 100.0 \%$ E3 SUMO-protein ligase RanBP2 GN=RANBP2 RBP2_HUMAN $358.20 \quad 100.0 \%$ E3 SUMO-protein ligase RanBP2 GN=RANBP2 RBP2_HUMAN $358.20 \quad 100.0 \%$ E3 SUMO-protein ligase RanBP2 GN=RANBP2 RBP2_HUMAN $358.20 \quad 100.0 \%$ E3 SUMO-protein ligase RanBP2 GN=RANBP2 RBP2 HUMAN $358.20 \quad 100.0 \%$ E3 SUMO-protein ligase RanBP2 GN=RANBP2 RBP2_HUMAN $358.20 \quad 100.0 \%$ E3 ubiquitin-protein ligase HUWE1 GN=HUWE1 HUWE1_HUMAN $481.89 \quad 100.0 \%$ E3 ubiquitin-protein ligase HUWE1 GN=HUWE1 HUWE1_HUMAN $481.89 \quad 100.0 \%$ E3 ubiquitin-protein ligase HUWE1 GN=HUWE1 HUWE1_HUMAN $481.89 \quad 100.0 \%$ E3 ubiquitin-protein ligase HUWE1 GN=HUWE1 HUWE1_HUMAN $481.89 \quad 100.0 \%$ E3 ubiquitin-protein ligase HUWE1 GN=HUWE1 HUWE1_HUMAN $481.89100 .0 \%$ E3 ubiquitin-protein ligase HUWE1 GN=HUWE1 HUWE1_HUMAN $481.89 \quad 100.0 \%$ E3 ubiquitin-protein ligase HUWE1 GN=HUWE1 HUWE1_HUMAN $481.89100 .0 \%$ E3 ubiquitin-protein ligase HUWE1 GN=HUWE1 HUWE1_HUMAN $481.89 \quad 100.0 \%$ E3 ubiquitin-protein ligase HUWE1 GN=HUWE1 HUWE1_HUMAN $481.89 \quad 100.0 \%$ E3 ubiquitin-protein ligase HUWE1 GN=HUWE1 HUWE1_HUMAN $481.89 \quad 100.0 \%$ E3 ubiquitin-protein ligase HUWE1 GN=HUWE1 HUWE1_HUMAN $481.89 \quad 100.0 \%$ E3 ubiquitin-protein ligase HUWE1 GN=HUWE1 HUWE1_HUMAN $481.89100 .0 \%$ E3 ubiquitin-protein ligase MYCBP2 GN=MYCBP2 MYCB2_HUMAN $510.08 \quad 100.0 \%$ E3 ubiquitin-protein ligase MYCBP2 GN=MYCBP2 MYCB2_HUMAN $510.08 \quad 100.0 \%$ E3 ubiquitin-protein ligase TRIM21 GN=TRIM21 RO52 HUMAN $54.17 \quad 100.0 \%$ E3 ubiquitin-protein ligase TRIM21 GN=TRIM21 RO52_HUMAN $54.17 \quad 100.0 \%$ $0.00 \%$ $0.01 \% \quad 7.5 \%$ ISCMSKPPAPNPTPPR $0.01 \% \quad 7.5 \%$ ATVNSQEQKR $0.00 \% \quad 7.0 \% \quad$ FTLNPNPTGVQNPHIER $0.00 \% \quad 7.0 \%$ DIKPSNILLDR

$0.00 \% \quad 5.5 \%$ LCDFGISGR

$0.00 \% \quad 5.5 \%$ TSGVLSQPHLPFFR

$0.01 \% \quad 3.4 \%$ ASLASLPPLHVAK

$0.01 \% \quad 3.4 \%$ LSHEGPGSELPAGALYR $0.01 \% \quad 3.4 \%$ SPSAQLMEQVAQLK

$0.01 \% \quad 4.7 \%$ SSVLENFVGRDFLPR $0.01 \% \quad 4.7 \%$ GISPVPINLR

$10 \quad 0.01 \% \quad 4.7 \% \quad$ EVDPQGLR

$0.01 \% \quad 4.7 \%$ GYIGVVNR

$0.00 \% \quad 3.4 \%$ VDLAEKNVASPSR

$0.00 \% \quad 3.4 \%$ TALNHCNLCR

$0.00 \% \quad 3.4 \%$ MLAITANTLR

$0.02 \% \quad 10.8 \%$ LLPGLEADSKPGR

$0.02 \% \quad 10.8 \%$ CLSDPAEGCR

$0.02 \% \quad 10.8 \%$ ALAVHLLDLGLRR

$0.02 \% \quad 10.8 \%$ LLPALAAR

$0.02 \% \quad 10.8 \%$ SVDDVLSHFAQR

$0.02 \% \quad 10.8 \%$ LFDDVPQVR

$0.02 \% \quad 10.8 \%$ TPSASGLLVLASAMR

$0.02 \% \quad 10.8 \%$ ACLQPSQDPQMR

$0.01 \% \quad 1.8 \%$ YIASVQGSTPSPR

$0.01 \% \quad 1.8 \%$ FGTSETSKAPK

$0.01 \% \quad 1.8 \%$ FGISEPGNQEK

$0.01 \% \quad 1.8 \%$ IAVAVLEETTR

$0.01 \% \quad 1.8 \%$ NSDIEQSSDSKVK

$0.05 \% \quad 3.7 \%$ TPTEAPADCR

$0.05 \% \quad 3.7 \% \quad$ AIQDPAFSDGIR

$0.05 \% \quad 3.7 \%$ GLQSFVQCQPFER

$0.05 \% \quad 3.7 \% \quad$ ADGTATAPPPR

$0.05 \% \quad 3.7 \%$ HIIEDPCTLR

$0.05 \% \quad 3.7 \%$ SAATSGAGSTTSGVVSGSLGSR

$0.05 \% \quad 3.7 \% \quad$ IVNQPSSLFGSK

$0.05 \% \quad 3.7 \%$ HADHSSLTLGSGSSTTR

$0.05 \% \quad 3.7 \%$ AGSSTPGDAPPAVAEVQGR

$0.05 \% \quad 3.7 \%$ DSAVAISGADSR

$0.05 \% \quad 3.7 \%$ TNIFQIQR

$0.05 \% \quad 3.7 \%$ LGSSGLGSASSIQAAVR

$0.01 \% \quad 0.4 \%$ IGSGYSGTVR

$0.01 \% \quad 0.4 \%$ ALSVVSTVVR

$0.01 \% \quad 6.1 \%$ GGGSVCPVCR

$0.01 \% \quad 6.1 \%$ IHAEFVQQK $\begin{array}{llll}99.7 \% & 28.1 & 25.0 & 27.5\end{array}$

$\begin{array}{llll}97.5 \% & 18.9 & 25.0 & 15.8\end{array}$

$99.3 \% \quad 22.6 \quad 25.0 \quad 22.6$

$\begin{array}{llll}99.7 \% & 39.3 & 25.0 & 30.3\end{array}$

$\begin{array}{llll}99.5 \% & 26.4 & 25.0 & 26.4\end{array}$

$\begin{array}{llll}95.3 \% & 19.3 & 25.0 & 19.3\end{array}$

$\begin{array}{llll}99.7 \% & 30.8 & 25.0 & 19.8\end{array}$

$\begin{array}{llll}99.7 \% & 26.6 & 25.0 & 21.3\end{array}$

$\begin{array}{llll}99.7 \% & 27.2 & 25.0 & 27.2\end{array}$

$\begin{array}{llll}99.6 \% & 25.1 & 25.0 & 25.1\end{array}$

$\begin{array}{llll}99.7 \% & 51.6 & 25.0 & 49.4\end{array}$

$\begin{array}{llll}99.7 \% & 31.3 & 25.0 & 30.3\end{array}$

$99.7 \% \quad 32.1 \quad 25.0 \quad 32.1$

$99.0 \% \quad 48.1 \quad 25.0 \quad 40.6$

$\begin{array}{llll}99.0 \% & 36.1 & 25.0 & 29.9\end{array}$

$\begin{array}{llll}99.7 \% & 27.7 & 25.0 & 27.7\end{array}$

$\begin{array}{llll}99.6 \% & 23.4 & 25.0 & 22.9\end{array}$

$\begin{array}{llll}99.7 \% & 33.5 & 25.0 & 27.2\end{array}$

$\begin{array}{llll}99.7 \% & 59.6 & 25.0 & 57.3\end{array}$

$99.7 \% \quad 30.4 \quad 25.0 \quad 30.4$

$\begin{array}{llll}99.7 \% & 40.7 & 25.0 & 40.7\end{array}$

$\begin{array}{llll}99.0 \% & 22.0 & 25.0 & 19.4\end{array}$

$\begin{array}{llll}99.7 \% & 30.6 & 25.0 & 28.4\end{array}$

$\begin{array}{llll}99.7 \% & 40.6 & 25.0 & 32.8\end{array}$

$\begin{array}{llll}99.7 \% & 52.3 & 25.0 & 51.3\end{array}$

$\begin{array}{llll}99.7 \% & 41.1 & 25.0 & 33.2\end{array}$

$\begin{array}{llll}99.7 \% & 38.6 & 25.0 & 38.6\end{array}$

$\begin{array}{llll}97.9 \% & 23.5 & 25.0 & 23.4\end{array}$

$99.7 \% \quad 28.9 \quad 25.0 \quad 21.4$

$99.7 \% \quad 41.3 \quad 25.0-41.3$

$99.7 \% \quad 44.0 \quad 25.0 \quad 34.9$

$\begin{array}{llll}99.7 \% & 32.4 & 25.0 & 32.4\end{array}$

$99.4 \% \quad 24.6 \quad 25.0 \quad 24.6$

$99.7 \% \quad 53.1 \quad 25.0 \quad 52.9$

$\begin{array}{llll}99.7 \% & 35.9 & 25.0 & 34.8\end{array}$

$\begin{array}{llll}98.8 \% & 19.5 & 25.0 & 19.5\end{array}$

$\begin{array}{llll}99.7 \% & 53.7 & 25.0 & 50.1 \\ 99.7 \% & 45.8 & 25.0 & 36.3\end{array}$

$25.0 \quad 36.3$

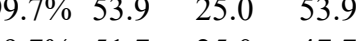

$\begin{array}{llll}99.0 \% & 30.8 & 25.0 & 18.0\end{array}$

$\begin{array}{llll}99.7 \% & 55.3 & 25.0 & 51.8\end{array}$

$\begin{array}{llll}99.6 \% & 22.3 & 25.0 & 22.1\end{array}$

$\begin{array}{llll}99.7 \% & 33.8 & 25.0 & 33.8\end{array}$

$\begin{array}{llll}97.2 \% & 20.3 & 25.0 & 13.2\end{array}$

$99.7 \% \quad 37.5 \quad 25.0 \quad 31.1$
1353.76

1749.88

1160.60

1933.99

1283.73

1024.49

1585.85

1303.77

1753.89

1529.80

1735.91

1065.64

913.47

877.49

1385.74

1258.58

1103.62

1352.75

1164.48

1446.89

824.54

1373.68

1088.57

1473.81

1430.65

1362.70

1152.59

1205.58

1201.68

1436.69

1117.49

1289.65

1595.76

1053.53

1253.63

1896.93

1276.69

1713.82

1766.87

1148.55

1019.56

1560.83

996.51

1030.63

1048.47

1099.59

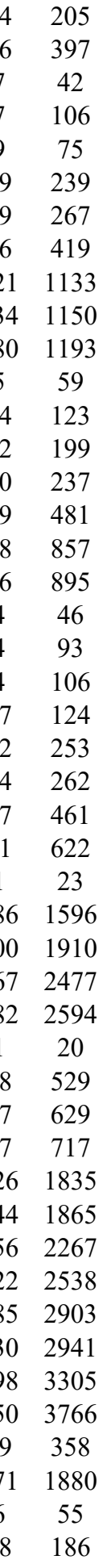

Page 50 of Table S-1-1 
E3 ubiquitin-protein ligase TRIM21 GN=TRIM21 RO52_HUMAN $54.17 \quad 100.0 \%$ E3 ubiquitin-protein ligase TRIP12 GN=TRIP12 TRIPC_HUMAN $220.44 \quad 100.0 \%$ E3 ubiquitin-protein ligase TRIP12 GN=TRIP12 TRIPC_HUMAN $220.44 \quad 100.0 \%$ E3 ubiquitin-protein ligase UBR4 GN=UBR4 UBR4 HUMAN $573.84100 .0 \%$ E3 ubiquitin-protein ligase UBR4 GN=UBR4 UBR4_HUMAN $573.84 \quad 100.0 \%$ E3 ubiquitin-protein ligase UBR4 GN=UBR4 UBR4_HUMAN $573.84 \quad 100.0 \%$ E3 ubiquitin-protein ligase UBR4 GN=UBR4 UBR4_HUMAN $573.84 \quad 100.0 \%$ E3 UFM1-protein ligase $1 \mathrm{GN}=\mathrm{UFL} 1$ E3 UFM1-protein ligase $1 \mathrm{GN}=\mathrm{UFL} 1$ E3 UFM1-protein ligase $1 \mathrm{GN}=\mathrm{UFL} 1$ E3 UFM1-protein ligase $1 \mathrm{GN}=\mathrm{UFL} 1$ E3 UFM1-protein ligase $1 \mathrm{GN}=\mathrm{UFL} 1$ E3 UFM1-protein ligase $1 \mathrm{GN}=\mathrm{UFL} 1$ E3 UFM1-protein ligase $1 \mathrm{GN}=\mathrm{UFL} 1$

EH domain-containing protein $1 \mathrm{GN}=1$ EH domain-containing protein $4 \mathrm{GN}=\mathrm{EHD} 4$ EHD4 HUMAN $61.18 \quad 100.0 \%$ EH domain-containing protein $4 \mathrm{GN}=$ EHD4 EHD4_HUMAN $61.18 \quad 100.0 \%$ EH domain-containing protein 4 GN=EHD4 EHD4_HUMAN $61.18 \quad 100.0 \%$ ELAV-like protein $1 \mathrm{GN}=\mathrm{ELAVL} 1$ ELAV-like protein $1 \mathrm{GN}=\mathrm{ELAVL}$ : ELAV-like protein $1 \mathrm{GN}=\mathrm{ELAVL} 1$ ELAV-like protein $1 \mathrm{GN}=\mathrm{ELAVL} 1$ ELAV-like protein $1 \mathrm{GN}=\mathrm{ELAVL}$. ELAV-like protein $1 \mathrm{GN}=\mathrm{ELAVL} 1$ ELAV-like protein $1 \mathrm{GN}=\mathrm{ELAVL} 1$ ELAV-like protein $1 \mathrm{GN}=\mathrm{ELAVL} 1$ ELAV-like protein $1 \mathrm{GN}=\mathrm{ELAVL} 1$ ELAV-like protein $1 \mathrm{GN}=\mathrm{ELAVL}$. ELAV-like protein $1 \mathrm{GN}=$ ELAVL1 ELAV-like protein $1 \mathrm{GN}=\mathrm{ELAVL} 1$ ELAV-like protein $1 \mathrm{GN}=\mathrm{ELAVL} 1$ ELAV-like protein $1 \mathrm{GN}=\mathrm{ELAVL}$. ELAV-like protein $2 \mathrm{GN}=\mathrm{ELAVL} 2$ ELAV-like protein $2 \mathrm{GN}=$ ELAVL2 ELAV-like protein $2 \mathrm{GN}=$ ELAVL2 ELAV-like protein $2 \mathrm{GN}=\mathrm{ELAVL} 2$ ELAV-like protein $2 \mathrm{GN}=\mathrm{ELAVL} 2$ UFL1_HUMAN $89.60 \quad 100.0 \%$ UFL1_HUMAN $89.60 \quad 100.0 \%$ UFL1_HUMAN $89.60 \quad 100.0 \%$ UFL1_HUMAN $89.60 \quad 100.0 \%$ UFL1_HUMAN $89.60 \quad 100.0 \%$ UFL1_HUMAN $89.60 \quad 100.0 \%$

$100.0 \%$ $100.0 \%$ ELAV1_HUMAN $36.09 \quad 100.0 \%$ ELAV1_HUMAN $36.09 \quad 100.0 \%$ ELAV1_HUMAN $36.09 \quad 100.0 \%$ ELAV1_HUMAN $36.09 \quad 100.0 \%$ ELAV1_HUMAN $36.09 \quad 100.0 \%$ ELAV1 HUMAN $36.09 \quad 100.0 \%$ ELAV1_HUMAN $36.09 \quad 100.0 \%$ ELAV1_HUMAN $36.09 \quad 100.0 \%$ ELAV1 HUMAN $36.09 \quad 100.0 \%$ ELAV1_HUMAN $36.09 \quad 100.0 \%$ ELAV1 HUMAN $36.09 \quad 100.0 \%$ ELAV1_HUMAN $36.09 \quad 100.0 \%$ ELAV1_HUMAN $36.09 \quad 100.0 \%$ ELAV1 HUMAN $36.09 \quad 100.0 \%$ ELAV2_HUMAN $39.51 \quad 100.0 \%$ ELAV2_HUMAN $39.51 \quad 100.0 \%$ ELAV2_HUMAN $39.51 \quad 100.0 \%$ ELAV2_HUMAN $39.51 \quad 100.0 \%$ ELAV2 HUMAN $39.51 \quad 100.0 \%$ EH domain-containing protein $1 \mathrm{GN}=$ EHD1 EHD1_HUMAN $60.63 \quad 100.0 \%$ GN=ETFA ETFA_HUMAN $35.08 \quad 100.0 \%$ Electron transfer flavoprotein subunit alpha, mitochondrial GN=ETFA ETFA_HUMAN $35.08 \quad 100.0 \%$ Electron transfer flavoprotein subunit alpha, mitochondrial GN=ETFA ETFA HUMAN $35.08 \quad 100.0 \%$ Electron transfer flavoprotein subunit alpha, mitochondrial GN=ETFA ETFA_HUMAN $35.08 \quad 100.0 \%$ Electron transfer flavoprotein subunit alpha, mitochondrial GN=ETFA ETFA_HUMAN $35.08 \quad 100.0 \%$ Electron transfer flavoprotein subunit alpha, mitochondrial GN=ETFA ETFA_HUMAN $35.08 \quad 100.0 \%$ Electron transfer flavoprotein subunit alpha, mitochondrial GN=ETFA ETFA_HUMAN $35.08 \quad 100.0 \%$ Electron transfer flavoprotein subunit alpha, mitochondrial GN=ETFA ETFA HUMAN $35.08 \quad 100.0 \%$ Electron transfer flavoprotein subunit alpha, mitochondrial GN=ETFA ETFA_HUMAN $35.08 \quad 100.0 \%$
$0.01 \% \quad 6.1 \%$ SVCHVPGLKK

$0.01 \% \quad 1.2 \% \quad$ LSTQSNSNNIEPAR

$0.01 \% \quad 1.2 \%$ SVYHLEDIVR

$0.01 \% \quad 0.8 \% \quad$ IQIGTQAIER

$0.01 \% \quad 0.8 \%$ SLLASLHTSR

$0.01 \% \quad 0.8 \%$ TVQAIVELK

$0.01 \% \quad 0.8 \%$ TSVQPTFTASQYR

$0.02 \% \quad 11.5 \%$ TYDLPGNFLTQALTQR

$0.02 \% \quad 11.5 \%$ GLFSAITRPTAVNSLISK

$0.02 \% \quad 11.5 \%$ AVFVPDIYSR

$0.02 \% \quad 11.5 \%$ LGIPDAVSYIK

$0.02 \% \quad 11.5 \%$ SVFMSSTTSASGTGR

$0.02 \% \quad 11.5 \%$ FFADDTQAALTK

$0.02 \% \quad 11.5 \%$ ERQILFQHR

$0.00 \% \quad 4.9 \% \quad$ LNAFGNAFLNR

$0.00 \% \quad 4.9 \%$ LLDTVDDMLANDIAR

$0.01 \% \quad 8.1 \%$ AGGADAVQTVTGGLR

$0.01 \% \quad 8.1 \%$ FMCSQLPNQVLK

$0.01 \% \quad 8.1 \%$ SISVIDSPGILSGEKQR

$0.06 \% \quad 48.2 \%$ TNLIVNYLPQNMTQDELR

$0.06 \% \quad 48.2 \%$ SLFSSIGEVESAK

$0.06 \% \quad 48.2 \%$ AINTLNGLR

$0.06 \% \quad 48.2 \%$ AINTLNGLRLQSK

$0.06 \% \quad 48.2 \%$ TMTQKDVEDMFSR

$0.06 \% \quad 48.2 \%$ VLVDQTTGLSR

$0.06 \% \quad 48.2 \%$ GVAFIRFDK

$0.06 \% \quad 48.2 \%$ SEAEEAITSFNGHKPPGSSEPITVK

$0.06 \% \quad 48.2 \%$ FAANPNQNK

$0.06 \% \quad 48.2 \%$ NVALLSQLYHSPAR

$0.06 \% \quad 48.2 \%$ NVALLSQLYHSPARR

$0.06 \% \quad 48.2 \%$ FGGPVHHQAQR

$0.06 \% \quad 48.2 \%$ VIRDFNTNK

$0.06 \% \quad 48.2 \%$ LGDKILQVSFK

$0.01 \% \quad 15.3 \%$ AINTLNGLR

$0.01 \% \quad 15.3 \%$ DANLYVSGLPK

$0.01 \% \quad 15.3 \%$ ILVDQVTGISR

$0.01 \% \quad 15.3 \%$ TNQAILSQLYQSPNR

$0.01 \% \quad 15.3 \%$ VIRDFNTNK

$19 \quad 0.03 \% \quad 45.3 \%$ LGGEVSCLVAGTK

$19 \quad 0.03 \% \quad 45.3 \%$ VLVAQHDVYK

$0.03 \% \quad 45.3 \%$ GLLPEELTPLILATQK

$9 \quad 0.03 \% \quad 45.3 \%$ QFNYTHICAGASAFGK

$0.03 \% \quad 45.3 \%$ LEVAPISDIIAIK

$0.03 \% \quad 45.3 \%$ LEVAPISDIIAIKSPDTFVR

$0.03 \% \quad 45.3 \%$ TIYAGNALCTVK

$0.03 \% \quad 45.3 \%$ GTSFDAAATSGGSASSEK 99.70

$0.03 \% \quad 45.3 \%$ SDRPELTGAK $\begin{array}{ll}95.7 \% & 20.5 \\ 99.7 \% & 32.7\end{array}$

$7 \% \quad 32.7$

$96.5 \% \quad 20.8$

$97.7 \% \quad 22.7$

$99.7 \% \quad 39.5$

$99.3 \% \quad 20.8$

$99.7 \% \quad 35.8$

$99.7 \% \quad 55.2$

$99.7 \% \quad 28.9$

$98.0 \% \quad 21.4$

$\begin{array}{lll}98.1 \% & 27.9\end{array}$

$99.7 \% \quad 59.3$

$\begin{array}{lll}99.7 \% & 52.7\end{array}$

$95.6 \% \quad 14.1$

$99.7 \% \quad 33.1$

$99.7 \% \quad 95.3$

$99.7 \% \quad 57.8$

$99.5 \% \quad 21.2$

$99.7 \% \quad 64.4$

$7 \% \quad 36.3$

$99.7 \% \quad 39.4$

$99.7 \% \quad 38.5$

$99.7 \% \quad 51.6$

$99.7 \% \quad 67.0$

$99.6 \% \quad 23.8$

$\begin{array}{ll}98.2 \% & 18.4 \\ 99.7 \% & 36.7\end{array}$

$99.7 \% \quad 49.5$

$99.0 \% \quad 18.1$

$99.7 \% \quad 48.2$

$99.7 \% \quad 41.8$

$99.7 \% \quad 43.5$

$99.7 \% \quad 39.4$

$99.7 \% \quad 43.0$

$99.7 \% \quad 87.2$

$99.7 \% \quad 50.6$

$99.7 \% \quad 41.8$

$99.7 \% \quad 63.2$

$\begin{array}{lll}99.7 \% & 29.7\end{array}$

$99.7 \% \quad 46.7$

$99.7 \% \quad 33.6$

$99.7 \% \quad 45.4$

$98.1 \% 17.8$

\begin{tabular}{lll}
$99.7 \%$ & 54.5 \\
\hline
\end{tabular}

$99.7 \% \quad 43.9$

112

1084.61

1485.73

1837.94

1875.07

1166.62

1175.67

1475.68

1327.65

1226.68

1236.65

1674.84

1372.72

1464.73

1785.97

2162.09

1353.69

971.56

1427.83

1587.71

1188.66

1052.59

2612.28

1003.50

1568.85

1724.96

1233.62

1106.60

1247.74

971.56

1176.63

1200.69

1732.90

106.60

1290.67

1171.65

1736.02

1771.82

1381.83

2184.23

1310.68

1630.72

1073.56 

ETFA HUMAN $35.08 \quad 100.0 \%$ Elongation factor 1-alpha $1 \mathrm{GN}=\mathrm{EEF} 1 \mathrm{~A} 1$ EF1A1_HUMAN $50.14 \quad 100.0 \%$ Elongation factor 1-alpha 1 GN=EEF1A1 EF1A1 HUMAN $50.14 \quad 100.0 \%$ Elongation factor 1-alpha $1 \mathrm{GN}=\mathrm{EEF} 1 \mathrm{~A} 1$ EF1A1_HUMAN $50.14 \quad 100.0 \%$ Elongation factor 1-alpha $1 \mathrm{GN}=\mathrm{EEF} 1 \mathrm{~A} 1$ EF1A1_HUMAN $50.14 \quad 100.0 \%$ Elongation factor 1-alpha $1 \mathrm{GN}=\mathrm{EEF} 1 \mathrm{~A} 1 \quad$ EF1A1_HUMAN $50.14 \quad 100.0 \%$ Elongation factor 1-alpha $1 \mathrm{GN}=\mathrm{EEF} 1 \mathrm{~A} 1 \quad$ EF1A1_HUMAN $50.14 \quad 100.0 \%$ Elongation factor 1-alpha $1 \mathrm{GN}=\mathrm{EEF} 1 \mathrm{~A} 1 \quad$ EF1A1 HUMAN $50.14 \quad 100.0 \%$ Elongation factor 1-alpha $1 \mathrm{GN}=\mathrm{EEF} 1 \mathrm{~A} 1 \quad$ EF1A1_HUMAN $50.14 \quad 100.0 \%$ Elongation factor 1-alpha $1 \mathrm{GN}=\mathrm{EEF} 1 \mathrm{~A} 1$ EF1A1_HUMAN $50.14 \quad 100.0 \%$ Elongation factor 1-alpha $1 \mathrm{GN}=\mathrm{EEF} 1 \mathrm{~A} 1 \mathrm{EF} 1 \mathrm{~A} 1$ HUMAN $50.14 \quad 100.0^{\circ}$ Elongation factor 1-alpha $1 \mathrm{GN}=\mathrm{EEF} 1 \mathrm{~A} 1 \mathrm{EF1A1}$-HUMAN $50.14 \quad 100.0 \%$ Elongation factor 1-alpha $1 \mathrm{GN}=\mathrm{EEF} 1 \mathrm{~A} 1 \quad$ EF1A1 HUMAN $50.14 \quad 100.0 \%$ Elongation factor 1-alpha $1 \mathrm{GN}=\mathrm{EEF1A1}$ EF1A1_HUMAN $50.14100 .0 \%$ Elongation factor 1-delta GN=EEF1D Elongation factor 1-delta GN=EEF1D Elongation factor 1-delta GN=EEF1D Elongation factor 1-gamma GN=EEF1G Elongation factor 1-gamma GN=EEF1G Elongation factor 1-gamma GN=EEF1G Elongation factor 1-gamma GN=EEF1G Elongation factor 1-gamma $\mathrm{GN}=\mathrm{EEF} 1 \mathrm{G}$ Elongation factor 1-gamma GN=EEF1G Elongation factor 1-gamma GN=EEF1G Elongation factor 1-gamma GN=EEF1G Elongation factor 1-gamma GN=EEF1G Elongation factor $2 \mathrm{GN}=\mathrm{EEF} 2$ Elongation factor $2 \mathrm{GN}=\mathrm{EEF} 2$ Elongation factor $2 \mathrm{GN}=\mathrm{EEF} 2$ Elongation factor $2 \mathrm{GN}=\mathrm{EEF} 2$ Elongation factor $2 \mathrm{GN}=\mathrm{EEF} 2$ Elongation factor $2 \mathrm{GN}=\mathrm{EEF} 2$ Elongation factor $2 \mathrm{GN}=\mathrm{EEF} 2$ Elongation factor $2 \mathrm{GN}=\mathrm{EEF} 2$ Elongation factor $2 \mathrm{GN}=\mathrm{EEF} 2$ Elongation factor $2 \mathrm{GN}=\mathrm{EEF} 2$ Elongation factor $2 \mathrm{GN}=\mathrm{EEF} 2$ Elongation factor $2 \mathrm{GN}=\mathrm{EEF} 2$ Elongation factor $2 \mathrm{GN}=\mathrm{EEF} 2$ EF1A1 HUMAN $50.14 \quad 100.0 \%$ EF1D_HUMAN $31.12 \quad 100.0 \%$ EF1D HUMAN $31.12 \quad 100.0 \%$ EF1D_HUMAN $31.12 \quad 100.0 \%$ EF1G_HUMAN $50.12 \quad 100.0 \%$ EF1G HUMAN $50.12 \quad 100.0 \%$ EF1G_HUMAN $50.12 \quad 100.0 \%$ EF1G HUMAN $50.12 \quad 100.0 \%$ EF1G_HUMAN $50.12 \quad 100.0 \%$ EF1G_HUMAN $50.12 \quad 100.0 \%$ EF1G_HUMAN $50.12 \quad 100.0 \%$ EF1G_HUMAN $50.12 \quad 100.0 \%$ EF1G_HUMAN $50.12 \quad 100.0 \%$ EF2 HUMAN $95.34 \quad 100.0 \%$ EF2_HUMAN $95.34 \quad 100.0 \%$ EF2 HUMAN $95.34 \quad 100.0 \%$ EF2 HUMAN $95.34 \quad 100.0 \%$ EF2 HUMAN $95.34 \quad 100.0 \%$ EF2 HUMAN $95.34 \quad 100.0 \%$ EF2_HUMAN $95.34 \quad 100.0 \% \quad 13$ EF2 HUMAN $95.34 \quad 100.0 \% \quad 13$ EF2 HUMAN $95.34 \quad 100.0 \% \quad 13$ EF2_HUMAN $95.34 \quad 100.0 \% \quad 13$ EF2 HUMAN $95.34 \quad 100.0 \% \quad 13$ EF2_HUMAN $95.34 \quad 100.0 \% \quad 13$ EF2_HUMAN $95.34 \quad 100.0 \% \quad 13$ Elongation factor Tu, mitochondrial GN=TUFM EFTU_HUMAN $49.54 \quad 100.0 \% \quad 17$ Elongation factor Tu, mitochondrial GN=TUFM EFTU_HUMAN $49.54 \quad 100.0 \% \quad 17$ Elongation factor Tu, mitochondrial GN=TUFM EFTU_HUMAN $49.54 \quad 100.0 \% \quad 17$ Elongation factor Tu, mitochondrial GN=TUFM EFTU_HUMAN $49.54 \quad 100.0 \% \quad 17$ Elongation factor Tu, mitochondrial GN=TUFM EFTU_HUMAN $49.54 \quad 100.0 \% \quad 17$ Elongation factor Tu, mitochondrial GN=TUFM EFTU_HUMAN $49.54 \quad 100.0 \% \quad 1$ Elongation factor Tu, mitochondrial GN=TUFM EFTU_HUMAN $49.54 \quad 100.0 \% \quad 17$

3

18

18
18

$\begin{array}{ll}3 & 18 \\ 3 & 18 \\ 3 & 18\end{array}$

18
4
4

9

9
9
9

$9 \begin{array}{lll}9 & 1 \\ 9 & 10\end{array}$

9
9
9

9

$\begin{array}{ll}9 & 10 \\ 9 & 10 \\ 9 & 10\end{array}$

9
13
13
13

$\begin{array}{ll}13 & 16 \\ 13 & 16 \\ 13 & 16 \\ 13 & 16\end{array}$

13.16

$\begin{array}{ll}16 \\ 3 & 16 \\ 3 & 16\end{array}$

16
16

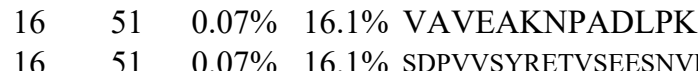

\section{$\begin{array}{llll}16 & 51 & 0.07 \% & 16.1 \% \\ 16 & 51 & 0.07 \% & 16.1 \%\end{array}$}

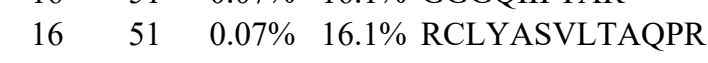

$16 \quad 51 \quad 0.07 \% \quad 16.1 \%$ CLYASVLTAQPR

$16 \quad 51 \quad 0.07 \% \quad 16.1 \%$ GHVFEESQVAGTPMFVVK

$\begin{array}{cccc}16 & 51 & 0.07 \% & 16.1 \% \\ 26 & 110 & 0.15 \% & 34.1 \%\end{array}$

$26 \quad 110 \quad 0.15 \% \quad 34.1 \%$ ILAEGGGAK

$26 \quad 110 \quad 0.15 \% \quad 34.1 \%$ ILAEGGGAKFK

$26 \quad 110 \quad 0.15 \% \quad 34.1 \%$ KYEEIDNAPEER

$26 \quad 110 \quad 0.15 \% \quad 34.1 \%$ YEEIDNAPEERAR

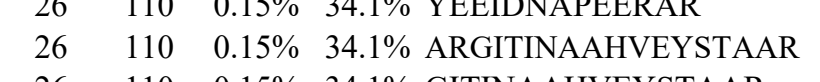

$\begin{array}{lllllllll}26 & 110 & 0.15 \% & 34.1 \% & \text { GITINAAHVEYSTAAR } & 99.7 \% & 59.1 & 25.0 & 51.8 \\ 26 & 110 & 0.15 \% & 34.1 \% \text { QIGVEHVVVYVNK } & 99.7 \% & 34.7 & 25.0 & 26.8\end{array}$

$\begin{array}{ccccc}99.7 \% & 32.5 & 25.0 & 24.8 & 0 \\ 99.7 \% & 38.6 & 25.0 & 38.6 & 4 \\ 99.7 \% & 53.6 & 25.0 & 53.6 & 5 \\ 99.7 \% & 44.4 & 25.0 & 39.7 & 23 \\ 99.7 \% & 27.5 & 25.0 & 18.5 & 2 \\ 99.7 \% & 54.6 & 25.0 & 44.6 & 12 \\ 99.0 \% & 32.8 & 25.0 & 22.6 & 8 \\ 98.9 \% & 22.8 & 25.0 & 15.5 & 6 \\ 99.0 \% & 49.1 & 25.0 & 37.8 & 4 \\ 99.7 \% & 55.0 & 25.0 & 47.3 & 32 \\ 99.7 \% & 31.7 & 25.0 & 31.7 & 0 \\ 99.7 \% & 28.1 & 25.0 & 28.1 & 0 \\ 99.7 \% & 52.6 & 25.0 & 43.5 & 4 \\ 99.7 \% & 46.4 & 25.0 & 35.0 & 8 \\ 99.7 \% & 35.1 & 25.0 & 30.9 & 2 \\ 99.7 \% & 45.9 & 25.0 & 45.9 & 0 \\ 99.7 \% & 42.4 & 25.0 & 30.4 & 3 \\ 96.1 \% & 14.7 & 25.0 & 14.7 & 1 \\ 99.7 \% & 47.4 & 25.0 & 47.4 & 0 \\ 99.7 \% & 87.1 & 25.0 & 84.6 & 2 \\ 99.7 \% & 38.6 & 25.0 & 38.3 & 3 \\ 99.7 \% & 32.9 & 25.0 & 32.9 & 2 \\ 99.7 \% & 56.0 & 25.0 & 55.8 & 2 \\ 98.5 \% & 26.6 & 25.0 & 11.9 & 2 \\ 99.7 \% & 48.7 & 25.0 & 44.9 & 3 \\ 99.7 \% & 65.8 & 25.0 & 59.4 & 2 \\ 99.7 \% & 28.9 & 25.0 & 24.3 & 2 \\ 99.7 \% & 55.2 & 25.0 & 42.0 & 4 \\ 99.7 \% & 55.0 & 25.0 & 54.4 & 2 \\ 99.7 \% & 52.9 & 25.0 & 52.9 & 2 \\ 99.7 \% & 31.3 & 25.0 & 23.2 & 2 \\ 99.7 \% & 45.2 & 25.0 & 37.9 & 2 \\ 99.7 \% & 52.8 & 25.0 & 52.8 & 4 \\ 99.7 \% & 43.6 & 25.0 & 41.0 & 3 \\ 99.4 \% & 21.8 & 25.0 & 21.8 & 0 \\ 99.7 \% & 38.4 & 25.0 & 32.1 & 6 \\ 99.7 \% & 38.5 & 25.0 & 38.5 & 2 \\ 99.7 \% & 57.4 & 25.0 & 51.2 & 10 \\ 98.3 \% & 17.3 & 25.0 & 17.3 & 0 \\ 99.7 \% & 52.6 & 25.0 & 50.6 & 4 \\ 99.7 \% & 38.3 & 25.0 & 26.8 & 3 \\ 99.5 \% & 30.1 & 25.0 & 15.4 & 2 \\ 99.7 \% & 54.2 & 25.0 & 54.2 & 2 \\ 99.7 \% & 35.7 & 25.0 & 35.7 & 3 \\ 99.4 \% & 22.7 & 25.0 & 19.8 & 0 \\ 99.7 \% & 59.1 & 25.0 & 51.8 & 5 \\ 99.7 \% & 34.7 & 25.0 & 26.8 & 3\end{array}$

920.9

1588.88

1120.60

1139.54

1314.74

870.54

967.55

975.55

1025.61

2531.38

3027.39

1316.74

914.57

802.48

2185.05

1423.71

973.58

1693.94

1347.74

1118.68

1375.83

1245.69

948.52

1241.65

1572.82

1052.59

1091.58

1123.57

1430.74

1013.50

1107.64

1362.81

1351.76

2498.21

969.55

1534.82

1378.71

1961.98

1799.90

815.46

1090.63

1492.69

1591.73

1901.00

1673.86 1483.83 $\begin{array}{cc}33 & 249 \\ 50 & 268 \\ 6 & 20 \\ 1 & 30 \\ 2 & 51 \\ 35 & 146 \\ 47 & 154 \\ 73 & 180 \\ 48 & 255 \\ 56 & 266 \\ 67 & 290 \\ 96 & 423 \\ 28 & 439 \\ 31 & 439 \\ 45 & 453 \\ 0 & 83 \\ 24 & 136 \\ 33 & 241 \\ 5 & 30 \\ 8 & 30 \\ 38 & 147 \\ 38 & 149 \\ 02 & 212 \\ 20 & 227 \\ 86 & 295 \\ 01 & 414 \\ 29 & 437 \\ 2 & 10 \\ 3 & 42 \\ 36 & 249 \\ 40 & 249 \\ 16 & 426 \\ 16 & 428 \\ 07 & 519 \\ 73 & 594 \\ 17 & 726 \\ 27 & 739 \\ 28 & 739 \\ 68 & 785 \\ 86 & 801 \\ 0 & 88 \\ 0 & 90 \\ 1 & 102 \\ 2 & 104 \\ 03 & 120 \\ 05 & 120 \\ 70 & 182 \\ & \end{array}$

Page 52 of Table S-1-1 
Elongation factor Tu, mitochondrial GN=TUFM EFTU_HUMAN $49.54 \quad 100.0 \% \quad 1$

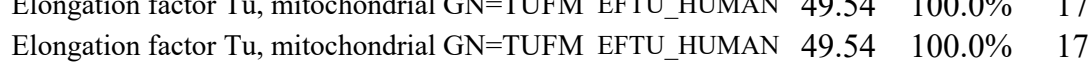
Elongation factor Tu, mitochondrial GN=TUFM EFTU_HUMAN $49.54 \quad 100.0 \% \quad 17$ Elongation factor $\mathrm{Tu}$, mitochondrial GN=TUFM EFTU_HUMAN $49.54 \quad 100.0 \% \quad 17$ Elongation factor Tu, mitochondrial GN=TUFM EFTU_HUMAN $49.54 \quad 100.0 \% \quad 17$ Elongation factor Tu, mitochondrial GN=TUFM EFTU_HUMAN $49.54 \quad 100.0 \% \quad 17$ Elongation factor Tu, mitochondrial GN=TUFM EFTU_HUMAN $49.54 \quad 100.0 \% \quad 17$ Elongation factor Tu, mitochondrial GN=TUFM EFTU_HUMAN $49.54 \quad 100.0 \% \quad 17$ Elongation factor Tu, mitochondrial GN=TUFM EFTU HUMAN $49.54 \quad 100.0 \%$ Elongtion factor Tu, mitochond GN=TUFM EFTU_HUMAN $49.54 \quad 100.0 \%$ Emerin $\mathrm{GN}=\mathrm{EMD}$

Emerin GN=EMD

Emerin $\mathrm{GN}=\mathrm{EMD}$

Emerin GN=EMD

Emerin GN=EMD

Emerin $\mathrm{GN}=\mathrm{EMD}$

Emerin $\mathrm{GN}=\mathrm{EMD}$

Emerin $\mathrm{GN}=\mathrm{EMD}$

ER membrane protein complex subunit 3 GN=EMC3 EMC3 HUMAN $29.95 \quad 100.0 \%$

ER membrane protein complex subunit $3 \mathrm{GN}=\mathrm{EMC} 3$ EMC3_HUMAN $29.95 \quad 100.0 \%$

Erlin-1 GN=ERLIN 1

Erlin-1 GN=ERLIN

Erlin-1 GN=ERLIN1

Erlin-1 GN=ERLIN 1

Erlin-1 GN=ERLIN1

Erlin-1 GN=ERLIN1

Erlin-1 GN=ERLIN

Erlin-1 GN=ERLIN1

Erlin-1 GN=ERLIN 1

Erlin-1 GN=ERLIN

Erlin-1 GN=ERLIN1

Erlin-1 GN=ERLIN 1

Erlin-1 GN=ERLIN

Erlin-1 GN=ERLIN

Erlin-2 GN=ERLIN 2

Erlin-2 GN=ERLIN2

Erlin-2 GN=ERLIN2

Erlin-2 GN=ERLIN 2

Erlin-2 GN=ERLIN2

Erlin-2 GN=ERLIN 2

Erlin-2 GN=ERLIN2

Erlin-2 GN=ERLIN 2

Erlin-2 GN=ERLIN 2

Erlin-2 GN=ERLIN2

Erlin-2 GN=ERLIN2

Erlin-2 GN=ERLIN 2

Erlin-2 GN=ERLIN2
EMD_HUMAN $28.99 \quad 100.0 \% \quad 8$

EMD HUMAN $28.99 \quad 100.0 \% \quad 8$

EMD_HUMAN $28.99 \quad 100.0 \% \quad 8$

EMD_HUMAN $28.99 \quad 100.0 \% \quad 8$

EMD HUMAN $28.99 \quad 100.0 \% \quad 8$

EMD_HUMAN $28.99 \quad 100.0 \% \quad 8$

EMD_HUMAN $28.99 \quad 100.0 \%$

EMD_HUMAN $28.99 \quad 100.0 \% \quad 8$ ERLN1_HUMAN $38.93 \quad 100.0 \%$ ERLN1_HUMAN $38.93 \quad 100.0 \%$ ERLN1_HUMAN $38.93 \quad 100.0 \%$ ERLN1_HUMAN $38.93 \quad 100.0 \%$ ERLN1_HUMAN $38.93 \quad 100.0 \%$ ERLN1_HUMAN $38.93 \quad 100.0 \%$ ERLN1_HUMAN $38.93 \quad 100.0 \%$ ERLN1 HUMAN $38.93 \quad 100.0 \%$ ERLN1_HUMAN $38.93 \quad 100.0 \%$ ERLN1 HUMAN $38.93 \quad 100.0 \% \quad 9$ ERLN1 HUMAN $38.93 \quad 100.0 \%$ ERLN1_HUMAN $38.93 \quad 100.0 \%$ ERLN1_HUMAN $38.93 \quad 100.0 \% \quad 9$ ERLN1_HUMAN $38.93 \quad 100.0 \% \quad 9$ ERLN2_HUMAN $37.84 \quad 100.0 \% \quad 17$ ERLN2_HUMAN $37.84 \quad 100.0 \% \quad 17$ ERLN2 HUMAN $37.84 \quad 100.0 \% \quad 17$ ERLN2_HUMAN $37.84 \quad 100.0 \% \quad 17$ ERLN2 HUMAN $37.84 \quad 100.0 \% \quad 17$ ERLN2_HUMAN $37.84 \quad 100.0 \% \quad 17$ ERLN2 HUMAN $37.84 \quad 100.0 \% \quad 17$ ERLN2 HUMAN $37.84 \quad 100.0 \% \quad 17$ ERLN2_HUMAN $37.84 \quad 100.0 \% \quad 17$ ERLN2_HUMAN $37.84 \quad 100.0 \% \quad 17$ ERLN2_HUMAN $37.84 \quad 100.0 \% \quad 17$ ERLN2_HUMAN $37.84 \quad 100.0 \% \quad 17$ ERLN2_HUMAN $37.84 \quad 100.0 \% \quad 17$
$26 \quad 110 \quad 0.15 \% \quad 34.1 \%$ LLDAVDTYIPVPAR

$110 \quad 0.15 \% \quad 34.1 \%$ GTVVTGTLER

$26 \quad 110 \quad 0.15 \% \quad 34.1 \%$ GTVVTGTLERGILK

$110 \quad 0.15 \% \quad 34.1 \%$ KGDECELLGHSK

$110 \quad 0.15 \% \quad 34.1 \%$ TVVTGIEMFHK

$110 \quad 0.15 \% \quad 34.1 \%$ SLERAEAGDNLGALVR

$110 \quad 0.15 \% \quad 34.1 \%$ AEAGDNLGALVR

$110 \quad 0.15 \% \quad 34.1 \%$ VEAQVYILSK

$110 \quad 0.15 \% \quad 34.1 \%$ VEAQVYILSKEEGGR

$110 \quad 0.15 \% \quad 34.1 \%$ TIGTGLVTNTLAMTEEEK

$26 \quad 0.04 \% \quad 34.3 \%$ RYNIPHGPVVGSTR

$26 \quad 0.04 \% \quad 34.3 \%$ YNIPHGPVVGSTR

$26 \quad 0.04 \% \quad 34.3 \%$ KIFEYETQR

$26 \quad 0.04 \% \quad 34.3 \%$ KEDALLYQSK

$26 \quad 0.04 \% \quad 34.3 \%$ GYNDDYYEESYFTTR

$26 \quad 0.04 \% \quad 34.3 \%$ TYGEPESAGPSR

$26 \quad 0.04 \% \quad 34.3 \%$ DSAYQSITHYRPVSASR

$26 \quad 0.04 \% \quad 34.3 \%$ APGAGLGQDR

$0.00 \% \quad 11.9 \%$ LTQEQVSDSQVLIR

$0.00 \% \quad 11.9 \%$ SIYSLILGQDNAADQSR

$0.02 \% \quad 43.4 \%$ SVQTTLQTDEVK

$0.02 \% \quad 43.4 \%$ DLNLMAPGLTIQAVR

$0.02 \% \quad 43.4 \%$ NFELMEAEKTK

$0.02 \% \quad 43.4 \%$ TKLLIAAQK

$0.02 \% \quad 43.4 \%$ VVEKEAETER

$0.02 \% \quad 43.4 \%$ AVIEAEKIAQVAK

$0.02 \% \quad 43.4 \%$ ISEIEDAAFLAR

$0.02 \% \quad 43.4 \%$ ISEIEDAAFLAREK

$0.02 \% \quad 43.4 \%$ ADAEYYAAHK

$0.02 \% \quad 43.4 \%$ KYQAIASNSK

$0.02 \% \quad 43.4 \%$ YQAIASNSK

$\begin{array}{lllll}0.02 \% & 43.4 \% & \text { IYFGSNIPNMFVDSSCALK } & 99.7 \% & 23.8\end{array}$

$0.02 \% \quad 43.4 \%$ YSDIRTGR

$0.02 \% \quad 43.4 \%$ ESSLPSKEALEPSGENVIQNK

$0.06 \% \quad 40.4 \%$ SVQTTLQTDEVK

$0.06 \% \quad 40.4 \%$ VTKPNIPEAIR

$0.06 \% \quad 40.4 \%$ VTKPNIPEAIRR

$0.06 \% \quad 40.4 \%$ NYELMESEKTK

$0.06 \% \quad 40.4 \%$ TKLLIAAQK

$0.06 \% \quad 40.4 \%$ VVEKEAETER

$0.06 \% \quad 40.4 \%$ ALIEAEKVAQVAEITYGQK

$0.06 \% \quad 40.4 \%$ VAQVAEITYGQK

$0.06 \% \quad 40.4 \%$ KISEIEDAAFLAR

$0.06 \% \quad 40.4 \%$ ISEIEDAAFLAR

$0.06 \% \quad 40.4 \%$ ISEIEDAAFLAREK

$0.06 \% \quad 40.4 \%$ AKADAECYTAMK

$0.06 \% \quad 40.4 \%$ ADAECYTAMK $\begin{array}{lllll}99.7 \% & 51.5 & 25.0 & 51.5 & 6\end{array}$ $\begin{array}{lllll}99.7 \% & 57.4 & 25.0 & 40.7 & 11\end{array}$

$\begin{array}{lllll}99.4 \% & 25.8 & 25.0 & 23.0 & 2\end{array}$

$\begin{array}{llll}99.7 \% & 47.5 & 25.0 & 37.9\end{array}$

$\begin{array}{lllll}99.7 \% & 50.8 & 25.0 & 34.8 & 13\end{array}$

$\begin{array}{llll}9.7 \% & 56.1 & 25.0 & 49.3\end{array}$

$\begin{array}{llll}99.7 \% & 77.2 & 25.0 & 61.7\end{array}$

$\begin{array}{lllll}99.7 \% & 57.5 & 25.0 & 47.4 & 7\end{array}$

$\begin{array}{llll}99.7 \% & 48.6 & 25.0 & 48.6\end{array}$

$\begin{array}{llll}99.7 \% & 31.0 & 25.0 & 31.0\end{array}$

$\begin{array}{lllll}9.5 \% & 21.6 & 25.0 & 21.6 & 0\end{array}$

$\begin{array}{lll}34.4 & 25.0 & 33.7\end{array}$

$\begin{array}{llll}99.7 \% & 47.5 & 25.0 & 40.5\end{array}$

$\begin{array}{llll}99.7 \% & 45.9 & 25.0 & 36.4\end{array}$

$\begin{array}{llll}99.7 \% & 59.0 & 25.0 & 59.0\end{array}$

$\begin{array}{llll}99.7 \% & 51.2 & 25.0 & 49.6\end{array}$

$\begin{array}{llll}97.2 & 25.0 & 46.9\end{array}$

$\begin{array}{llll}99.7 \% & 49.4 & 25.0 & 43.0\end{array}$

$99.7 \% \quad 35.0 \quad 25.0 \quad 25.9$

$\begin{array}{llll}99.7 \% & 48.3 & 25.0 & 48.3\end{array}$

$\begin{array}{llll}99.7 \% & 57.7 & 25.0 & 51.7\end{array}$

$\begin{array}{llll}99.7 \% & 55.5 & 25.0 & 46.2\end{array}$

$\begin{array}{llll}99.7 \% & 45.1 & 25.0 & 33.5\end{array}$

$\begin{array}{llll}99.7 \% & 36.4 & 25.0 & 36.4\end{array}$

$\begin{array}{llll}99.7 \% & 52.5 & 25.0 & 51.0\end{array}$

$\begin{array}{llll}99.7 \% & 57.3 & 25.0 & 55.0\end{array}$

$99.7 \% \quad 77.8 \quad 25.0 \quad 69.3$

$99.7 \% \quad 75.5 \quad 25.0 \quad 70.4$

$\begin{array}{lllll}99.7 \% & 48.5 & 25.0 & 48.5 & 2\end{array}$

$\begin{array}{llll}99.7 \% & 29.7 & 25.0 & 29.7\end{array}$

$\begin{array}{llll}99.7 \% & 26.3 & 25.0 & 26.3\end{array}$

$\begin{array}{lll}23.8 & 25.0 & 23.8\end{array}$

$\begin{array}{llll}9.4 \% & 20.9 & 25.0 & 13.2\end{array}$

$99.7 \% \quad 40.3$

$99.0 \% \quad 19.9$

$99.7 \% \quad 46.4$

$99.7 \% \quad 36.4$

$99.7 \% \quad 52.5$

$99.7 \% \quad 42.2$

$99.7 \% \quad 58.3$

$99.7 \% \quad 64.6$

$99.7 \% \quad 77.8$

$99.7 \% \quad 75.5$

$99.7 \% \quad 57.9$

$99.7 \% \quad 48.2$
1542.85

1032.57

1443.85

1372.65

1277.66

1670.88

1185.62

1149.65

1677.88

1907.96

1552.83

1396.73

1213.62

1194.64

1922.77

1250.56

1937.95

941.48

1615.87

1850.92

1348.70

1627.88

1339.66

985.64

1189.61

1369.81

1334.70

1591.83

1138.52

1109.59

981.50

2179.02

967.50

2256.14

1348.70

1237.73

1393.83

1371.65

985.64

1189.61

2061.12

1306.70

1462.79

1334.70

1591.83

1358.61

1159.48 $\begin{array}{cc}39 & 252 \\ 72 & 281 \\ 72 & 285 \\ 86 & 297 \\ 01 & 311 \\ 12 & 327 \\ 16 & 327 \\ 52 & 361 \\ 52 & 366 \\ 30 & 447 \\ 8 & 31 \\ 9 & 31 \\ 7 & 45 \\ 9 & 88 \\ 9 & 103 \\ 04 & 115 \\ 58 & 174 \\ 12 & 221 \\ 4 & 57 \\ 81 & 197 \\ 1 & 72 \\ 55 & 169 \\ 82 & 192 \\ 91 & 199 \\ 02 & 211 \\ 14 & 226 \\ 42 & 253 \\ 42 & 255 \\ 58 & 267 \\ 85 & 294 \\ 86 & 294 \\ 95 & 313 \\ 14 & 321 \\ 22 & 342 \\ 1 & 72 \\ 70 & 180 \\ 70 & 181 \\ 82 & 192 \\ 91 & 199 \\ 02 & 211 \\ 14 & 232 \\ 21 & 232 \\ 41 & 253 \\ 42 & 253 \\ 42 & 255 \\ 56 & 267 \\ 58 & 267 \\ & \end{array}$

Page 53 of Table S-1-1 
Erlin-2 GN=ERLIN2 Erlin-2 GN=ERLIN2 Erlin-2 GN=ERLIN2 Erlin-2 GN=ERLIN2 $\begin{array}{lll}\text { Eukaryotic initiation factor 4A-I GN=EIF4A1 IF4A1_HUMAN } & 46.16 & 100.0 \% \\ \text { Eukaryotic initiation factor 4A-I GN=EIF4A1 IF4A1_HUMAN } & 46.16 & 100.0 \%\end{array}$ Eukaryotic initiation factor 4A-I GN=EIF4A1 IF4A1_HUMAN $46.16 \quad 100.0 \%$ Eukaryotic initiation factor 4A-I GN=EIF4A1 IF4A1_HUMAN $46.16 \quad 100.0 \%$ Eukaryotic initiation factor 4A-I GN=EIF4A1 IF4A1 HUMAN $46.16 \quad 100.0 \%$ Eukaryotic initiation factor 4A-I GN=EIF4A1 IF4A1_HUMAN $46.16 \quad 100.0 \%$ Eukaryotic initiation factor 4A-I GN=EIF4A1 IF4A1_HUMAN $46.16 \quad 100.0 \%$ Eukaryotic initiation factor 4A-I GN=EIF4A1 IF4A1_HUMAN $46.16 \quad 100.0 \%$ Eukaryotic initiation factor 4A-I GN=EIF4A1 IF4A1_HUMAN $46.16 \quad 100.0 \%$ Eukaryotic initiation factor 4A-III GN=EIF4A3 IF4A3_HUMAN $46.87 \quad 100.0 \%$ Eukaryotic initiation factor 4A-III GN=EIF4A3 IF4A3_HUMAN $46.87 \quad 100.0 \%$ Eukaryotic initiation factor 4A-III GN=EIF4A3 IF4A3_HUMAN $46.87 \quad 100.0 \%$ Eukaryotic initiation factor 4A-III GN=EIF4A3 IF4A3 HUMAN $46.87 \quad 100.0 \%$ Eukaryotic initiation factor 4A-III GN=EIF4A3 IF4A3_HUMAN $46.87 \quad 100.0 \%$ Eukaryotic initiation factor 4A-III GN=EIF4A3 IF4A3_HUMAN $46.87 \quad 100.0 \%$ Eukaryotic initiation factor 4A-III GN=EIF4A3 IF4A3_HUMAN $46.87 \quad 100.0 \%$ Eukaryotic initiation factor 4A-III GN=EIF4A3 IF4A3_HUMAN $46.87 \quad 100.0 \%$ Eukaryotic translation initiation factor 2 subunit $1 \mathrm{GN}=\mathrm{EIF} 2 \mathrm{~S} 1 \mathrm{IF} 2 \mathrm{~A}$ HUMAN $36.11 \quad 100.0 \%$ Eukaryotic translation initiation factor 2 subunit 1 GN=EIF2S1 IF2A_HUMAN $36.11 \quad 100.0 \%$ Eukaryotic translation initiation factor 2 subunit 1 GN=EIF2S1 IF2A_HUMAN $36.11 \quad 100.0 \%$ Eukaryotic translation initiation factor 3 subunit A GN=EIF3A EIF3A_HUMAN $166.57 \quad 100.0 \%$ Eukaryotic translation initiation factor 3 subunit A GN=EIF3A EIF3A_HUMAN $166.57 \quad 100.0 \%$ Eukaryotic translation initiation factor 3 subunit A GN=EIF3A EIF3A_HUMAN $166.57 \quad 100.0 \%$ Eukaryotic translation initiation factor 3 subunit A GN=EIF3A EIF3A_HUMAN $166.57 \quad 100.0 \%$ Eukaryotic translation initiation factor 3 subunit A GN=EIF3A EIF3A_HUMAN $166.57 \quad 100.0 \%$ Eukaryotic translation initiation factor 3 subunit A GN=EIF3A EIF3A HUMAN $166.57 \quad 100.0 \%$ Eukaryotic translation initiation factor 3 subunit A GN=EIF3A EIF3A_HUMAN $166.57 \quad 100.0 \%$ Eukaryotic translation initiation factor 3 subunit A GN=EIF3A EIF3A_HUMAN $166.57 \quad 100.0 \%$ Eukaryotic translation initiation factor 3 subunit A GN=EIF3A EIF3A_HUMAN $166.57 \quad 100.0 \%$ Eukaryotic translation initiation factor 3 subunit A GN=EIF3A EIF3A_HUMAN $166.57 \quad 100.0 \%$ Eukaryotic translation initiation factor 3 subunit A GN=EIF3A EIF3A HUMAN $166.57 \quad 100.0 \%$ Eukaryotic translation initiation factor 3 subunit A GN=EIF3A EIF3A_HUMAN $166.57 \quad 100.0 \%$ Eukaryotic translation initiation factor 3 subunit A GN=EIF3A EIF3A_HUMAN $166.57 \quad 100.0 \%$ Eukaryotic translation initiation factor 3 subunit A GN=EIF3A EIF3A HUMAN $166.57 \quad 100.0 \%$ Eukaryotic translation initiation factor 3 subunit A GN=EIF3A EIF3A_HUMAN $166.57 \quad 100.0 \%$ Eukaryotic translation initiation factor 3 subunit A GN=EIF3A EIF3A_HUMAN $166.57 \quad 100.0 \%$ Eukaryotic translation initiation factor 3 subunit A GN=EIF3A EIF3A HUMAN $166.57 \quad 100.0 \%$ Eukaryotic translation initiation factor 3 subunit A GN=EIF3A EIF3A_HUMAN $166.57 \quad 100.0 \%$ Eukaryotic translation initiation factor 3 subunit A GN=EIF3A EIF3A HUMAN $166.57 \quad 100.0 \%$ Eukaryotic translation initiation factor 3 subunit A GN=EIF3A EIF3A_HUMAN $166.57 \quad 100.0 \%$ Eukaryotic translation initiation factor 3 subunit A GN=EIF3A EIF3A_HUMAN $166.57 \quad 100.0 \%$ Eukaryotic translation initiation factor 3 subunit B GN=EIF3B EIF3B HUMAN $92.48 \quad 100.0 \%$ Eukaryotic translation initiation factor 3 subunit B GN=EIF3B EIF3B_HUMAN $92.48 \quad 100.0 \%$
$0.06 \% \quad 40.4 \%$ YKAIASNSK

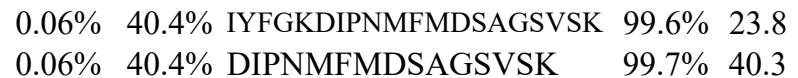

$0.06 \% \quad 40.4 \%$ DIPNMFMDSAGSVSK

$99.7 \% \quad 71.7$

$40 \quad 0.05 \% \quad 24.9 \%$ AILPCIKGYDVIAQAQSGTGK

$98.4 \% 50.1$

$\begin{array}{llll}40 & 0.05 \% & 24.9 \% & \text { ELAQQIQK } \\ 40 & 0.05 \% & 24.9 \% & \text { AEVQKLQMEAPHIIVGTPGR }\end{array}$

$99.7 \% 79.1$

$97.0 \% \quad 25.5$

7

7

7

$40 \quad 0.05 \% \quad 24.9 \%$ LQMEAPHIIVGTPGR

$40 \quad 0.05 \% \quad 24.9 \%$ MFVLDEADEMLSR

$40 \quad 0.05 \% \quad 24.9 \%$ VLITTDLLAR

$40 \quad 0.05 \% \quad 24.9 \%$ GVAINMVTEEDKR

$10 \quad 0.01 \% \quad 20.2 \%$ GIYAYGFEKPSAIQQR

$10 \quad 0.01 \% \quad 20.2 \%$ GRDVIAQSQSGTGK

$10 \quad 0.01 \% \quad 20.2 \%$ ELAVQIQK

$10 \quad 0.01 \% \quad 20.2 \%$ KLDYGQHVVAGTPGR

$10 \quad 0.01 \% \quad 20.2 \%$ LDYGQHVVAGTPGR

$10 \quad 0.01 \% \quad 20.2 \%$ GFKEQIYDVYR

$10 \quad 0.01 \% \quad 20.2 \%$ VLISTDVWAR

$10 \quad 0.01 \% \quad 20.2 \%$ KGVAINFVK

$5 \quad 0.01 \% \quad 9.2 \% \quad$ SKTVYSILR

$0.01 \% \quad 9.2 \%$ RLTPQAVK

$0.01 \% \quad 9.2 \% \quad$ VVTDTDETELAR

$0.07 \% \quad 13.9 \%$ PAYFQRPENALKR

$0.07 \% \quad 13.9 \%$ ANEFLEVGK

$0.07 \% \quad 13.9 \%$ ANEFLEVGKK

$0.07 \% \quad 13.9 \%$ YLELCVDLRK

$0.07 \% \quad 13.9 \%$ NLTQDEMQR

$0.07 \% \quad 13.9 \%$ VLLATLSIPITPER

$0.07 \% \quad 13.9 \%$ VLLATLSIPITPERTDIAR

$52 \quad 0.07 \% \quad 13.9 \%$ LLDMDGIIVEK

$\quad 0.07 \% \quad 13.9 \%$ LLDMDGIIVEKQR

$0.07 \% \quad 13.9 \%$ RLATLLGLQAPPTR

$2 \quad 0.07 \% \quad 13.9 \%$ LATLLGLQAPPTR

$2 \quad 0.07 \% \quad 13.9 \%$ IGLINDMVR

$52 \quad 0.07 \% \quad 13.9 \%$ LTSLVPFVDAFQLER

$0.07 \% \quad 13.9 \%$ TLSFGSDLNYATR

$20.07 \% \quad 13.9 \%$ NQLTAMSSVLAK

$52 \quad 0.07 \% \quad 13.9 \%$ LESLNIQR

$52 \quad 0.07 \% \quad 13.9 \%$ ILQEHEQIKK

$52 \quad 0.07 \% \quad 13.9 \%$ RLEEIPLIK

$52 \quad 0.07 \% \quad 13.9 \%$ RLGDSSLSR

$52 \quad 0.07 \% \quad 13.9 \%$ NTDDDRPPRR

$52 \quad 0.07 \% \quad 13.9 \%$ RVPPPALSR

$99.7 \% \quad 41.7$

$99.7 \% \quad 53.7$

$99.7 \% \quad 53.3$

$99.7 \% \quad 50.6$

$99.7 \% \quad 71.7$

$99.7 \% \quad 69.8$

$96.7 \% \quad 21.3$

$99.7 \% \quad 27.1$

$99.7 \% \quad 50.9$

$99.5 \% \quad 22.5$

$99.7 \% \quad 50.8$

$99.7 \% \quad 24.1$

$99.7 \% \quad 26.9$

$97.3 \% \quad 24.9$

$99.7 \% \quad 60.5$

$99.7 \% \quad 25.8$

$99.7 \% \quad 34.1$

$97.8 \% \quad 20.0$

$99.7 \% \quad 33.6$

$99.7 \% \quad 34.2$

$99.7 \% \quad 32.3$

$99.7 \% \quad 40.8$

$99.7 \% \quad 48.9$

$99.4 \% \quad 22.3$

$98.9 \% \quad 20.5$

$99.7 \% \quad 40.5$

$99.7 \% \quad 35.8$

$99.7 \% \quad 24.7$

$99.7 \% \quad 53.4$

$99.7 \% \quad 48.6$

$99.0 \% \quad 33.0$

$99.7 \% \quad 28.7$

$99.7 \% \quad 29.3$

$99.7 \% \quad 27.7$

$99.6 \% \quad 22.4$

$97.6 \% 23.1$

$0.04 \% \quad 13.6 \%$ AQAVSEDAGGNEGRAAEAEPR $99.7 \% \quad 43.9$

$99.7 \% \quad 54.6$
1251.67

981.54

2239.04

1598.72

1827.94

2190.16

1394.69

957.54

2190.17

1634.87

1555.71

1114.68

1461.74

1827.94

1403.72

928.55

1597.84

1469.75

1417.71

1159.65

975.60

1066.63

912.56

1348.66

1589.85

1006.52

1134.62

1308.70

1134.52

1522.92

2079.22

1245.68

1529.84

1506.91

1350.81

1046.57

1734.94

1444.71

1262.68

972.55

1265.72

1110.69

990.53

1241.60

992.60

2084.96

1193.61 
Eukaryotic translation initiation factor 3 subunit B GN=EIF3B EIF3B_HUMAN $92.48 \quad 100.0 \%$ Eukaryotic translation initiation factor 3 subunit B GN=EIF3B EIF3B_HUMAN $92.48 \quad 100.0 \%$ Eukaryotic translation initiation factor 3 subunit B GN=EIF3B EIF3B_HUMAN $92.48 \quad 100.0 \%$ Eukaryotic translation initiation factor 3 subunit B GN=EIF3B EIF3B_HUMAN $92.48 \quad 100.0 \%$ Eukaryotic translation initiation factor 3 subunit B GN=EIF3B EIF3B_HUMAN $92.48 \quad 100.0 \%$ Eukaryotic translation initiation factor 3 subunit B GN=EIF3B EIF3B_HUMAN $92.48 \quad 100.0 \%$ Eukaryotic translation initiation factor 3 subunit B GN=EIF3B EIF3B_HUMAN $92.48 \quad 100.0 \%$ Eukaryotic translation initiation factor 3 subunit B GN=EIF3B EIF3B_HUMAN $92.48 \quad 100.0 \%$ Eukaryotic translation initiation factor 3 subunit B GN=EIF3B EIF3B HUMAN $92.48 \quad 100.0 \%$ Eukaryotic translation initiation factor 3 subunit $\mathrm{C}$ GN=EIF3C EIF3C_HUMAN $105.35 \quad 100.0 \%$ Eukaryotic translation initiation factor 3 subunit C GN=EIF3C EIF3C_HUMAN $105.35100 .0 \%$ Eukaryotic translation initiation factor 3 subunit D GN=EIF3D EIF3D_HUMAN $63.97 \quad 100.0 \%$ Eukaryotic translation initiation factor 3 subunit D GN=EIF3D EIF3D_HUMAN $63.97 \quad 100.0 \%$ Eukaryotic translation initiation factor 3 subunit D GN=EIF3D EIF3D_HUMAN $63.97 \quad 100.0 \%$ Eukaryotic translation initiation factor 3 subunit D GN=EIF3D EIF3D_HUMAN $63.97 \quad 100.0 \%$ Eukaryotic translation initiation factor 3 subunit D GN=EIF3D EIF3D_HUMAN $63.97 \quad 100.0 \%$ Eukaryotic translation initiation factor 3 subunit D GN=EIF3D EIF3D HUMAN $63.97 \quad 100.0 \%$ Eukaryotic translation initiation factor 3 subunit E GN=EIF3E EIF3E_HUMAN $52.22 \quad 100.0 \%$ Eukaryotic translation initiation factor 3 subunit E GN=EIF3E EIF3E_HUMAN $52.22 \quad 100.0 \%$ Eukaryotic translation initiation factor 3 subunit E GN=EIF3E EIF3E_HUMAN $52.22 \quad 100.0 \%$ Eukaryotic translation initiation factor 3 subunit E GN=EIF3E EIF3E_HUMAN $52.22 \quad 100.0 \%$ Eukaryotic translation initiation factor 3 subunit E GN=EIF3E EIF3E_HUMAN $52.22 \quad 100.0 \%$ Eukaryotic translation initiation factor 3 subunit $\mathrm{E}$ GN=EIF3E EIF3E_HUMAN $52.22 \quad 100.0 \%$ Eukaryotic translation initiation factor 3 subunit E GN=EIF3E EIF3E_HUMAN $52.22 \quad 100.0 \%$ Eukaryotic translation initiation factor 3 subunit $\mathrm{E}$ GN=EIF3E EIF3E HUMAN $52.22 \quad 100.0 \%$ Eukaryotic translation initiation factor 3 subunit $\mathrm{E}$ GN=EIF3E EIF3E_HUMAN $52.22 \quad 100.0 \%$ Eukaryotic translation initiation factor 3 subunit $\mathrm{E}$ GN=EIF3E EIF3E_HUMAN $52.22 \quad 100.0 \%$ Eukaryotic translation initiation factor 3 subunit E GN=EIF3E EIF3E_HUMAN $52.22 \quad 100.0 \%$ Eukaryotic translation initiation factor 3 subunit E GN=EIF3E EIF3E_HUMAN $52.22 \quad 100.0 \%$ Eukaryotic translation initiation factor 3 subunit $\mathrm{E}$ GN=EIF3E EIF3E_HUMAN $52.22 \quad 100.0 \%$ Eukaryotic translation initiation factor 3 subunit F GN=EIF3F EIF3F_HUMAN $37.56 \quad 100.0 \%$ Eukaryotic translation initiation factor 3 subunit $F$ GN=EIF3F EIF3F_HUMAN $37.56 \quad 100.0 \%$ Eukaryotic translation initiation factor 3 subunit F GN=EIF3F EIF3F HUMAN $37.56 \quad 100.0 \%$ Eukaryotic translation initiation factor 3 subunit G GN=EIF3G EIF3G_HUMAN $35.61 \quad 100.0 \%$ Eukaryotic translation initiation factor 3 subunit G GN=EIF3G EIF3G_HUMAN $35.61 \quad 100.0 \%$ Eukaryotic translation initiation factor 3 subunit $\mathrm{G}$ GN=EIF3G EIF3G_HUMAN $35.61 \quad 100.0 \%$ Eukaryotic translation initiation factor 3 subunit $\mathrm{H}$ GN=EIF3H EIF3H_HUMAN $39.93 \quad 100.0 \%$ Eukaryotic translation initiation factor 3 subunit $\mathrm{H}$ GN=EIF3H EIF3H_HUMAN $39.93 \quad 100.0 \%$ Eukaryotic translation initiation factor 3 subunit $\mathrm{H}$ GN=EIF3H EIF3H_HUMAN $39.93 \quad 100.0 \%$ Eukaryotic translation initiation factor 3 subunit $\mathrm{H}$ GN=EIF3H EIF3H_HUMAN $39.93 \quad 100.0 \%$ Eukaryotic translation initiation factor 3 subunit I GN=EIF3I EIF3I_HUMAN $36.50 \quad 100.0 \%$ Eukaryotic translation initiation factor 3 subunit I GN=EIF3I EIF3I_HUMAN $36.50 \quad 100.0 \%$ Eukaryotic translation initiation factor 3 subunit I GN=EIF3I EIF3I HUMAN $36.50 \quad 100.0 \%$ Eukaryotic translation initiation factor 3 subunit I GN=EIF3I EIF3I_HUMAN $36.50 \quad 100.0 \%$ Eukaryotic translation initiation factor 3 subunit I GN=EIF3I EIF3I_HUMAN $36.50 \quad 100.0 \%$ Eukaryotic translation initiation factor 3 subunit I GN=EIF3I EIF3I HUMAN $36.50 \quad 100.0 \%$ Eukaryotic translation initiation factor 3 subunit I GN=EIF3I EIF3I_HUMAN $36.50 \quad 100.0 \%$

11

11

6

6

6

6

6

13
13
13

4

4

4

4
8
8

8
8
8
8

$0.04 \% \quad 13.6 \%$ VTLMQLPTR

$0.04 \% 13.6 \%$ VTLMQLPTRQEIR

$0.04 \% \quad 13.6 \%$ TPKGTQGVVTNFEIFR

$0.04 \% \quad 13.6 \%$ GTQGVVTNFEIFR

$0.04 \% \quad 13.6 \%$ FAVLHGEAPR

$0.04 \% \quad 13.6 \%$ ISVSFYHVK

$0.04 \% \quad 13.6 \%$ ASKELVER

$0.04 \% \quad 13.6 \%$ TMMEDFRK

$0.01 \% \quad 1.3 \%$ AKELLGQGLLLR

$0.01 \% \quad 1.3 \%$ ELLGQGLLLR

$0.02 \% \quad 11.9 \%$ NMLQFNLQILPK

$0.02 \% \quad 11.9 \%$ IFHTVTTTDDPVIR

$0.02 \% \quad 11.9 \%$ IFHTVTTTDDPVIRK

$0.02 \% \quad 11.9 \%$ SVYSWDIVVQR

$0.02 \% \quad 11.9 \%$ NLAMEATYINHNFSQQCLR

$0.02 \% \quad 11.9 \%$ YHVKDSSR

$0.05 \% \quad 28.1 \%$ RTTVVAQLK

$0.05 \% \quad 28.1 \%$ TTVVAQLK

$0.05 \% \quad 28.1 \%$ TTVVAQLKQLQAETEPIVK $99.7 \% \quad 41.2$

$0.05 \% \quad 28.1 \%$ QLQAETEPIVK

$0.05 \% \quad 28.1 \%$ MFEDPETTR

$0.05 \% \quad 28.1 \%$ VLVPATDR

$0.05 \% \quad 28.1 \%$ LKETIDNNSVSSPLQSLQQR $99.7 \% \quad 23.9$

$\begin{array}{lllll}0.05 \% & 28.1 \% & \text { YLTTAVITNKDVR } & 99.7 \% & 59.8\end{array}$

$0.05 \% \quad 28.1 \%$ LFIFETFCR

$94.7 \% \quad 14.9$

$0.05 \% \quad 28.1 \%$ LGHVVMGNNAVSPYQQVIEK $99.7 \% 33.8$

$0.05 \% \quad 28.1 \%$ LGHVVMGNNAVSPYQQVIEKTK $\quad 99.4 \% \quad 26.1$

$0.05 \% \quad 28.1 \%$ SQMLAMNIEK

$0.05 \% \quad 28.1 \%$ SEAPNWATQDSGFY

$0.01 \% \quad 11.5 \%$ AYVSTLMGVPGR

$99.7 \% \quad 44.9$

$99.7 \% \quad 30.6$

$99.7 \% \quad 33.5$

$0.01 \% \quad 11.5 \%$ TMGVMFTPLTVK

$99.0 \% \quad 18.4$

$0.01 \% \quad 11.5 \%$ VIGLSSDLQQVGGASAR $\quad 99.7 \% \quad 84.7$

$0.01 \% \quad 7.5 \%$ TGKYVPPSLR

$\begin{array}{llll}0.01 \% & 7.5 \% & \text { YVPPSLRDGASR }\end{array}$

$98.3 \% \quad 18.1$

$99.6 \% \quad 24.7$

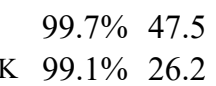

$0.01 \% \quad 7.5 \%$ RADDNATIR

$\begin{array}{lllll}0.01 \% & 9.7 \% & \text { EGTGSTATSSSSTAGAAGK } & 99.7 \% & 33.7\end{array}$

$\begin{array}{llllll}0.01 \% & 9.7 \% & \text { EGTGSTATSSSSTAGAAGKGK } & 98.0 \% & 18.7\end{array}$

$0.01 \% \quad 9.7 \%$ LFMAQALQEYNN

$99.7 \% \quad 30.4$

$99.7 \% \quad 47.3$

$\begin{array}{lll}0.04 \% & 29.8 \% & \text { SITQIKYNR } \\ 0.04 \% & 29.8 \% & \text { HVLTGSADNSCR }\end{array}$

$0.04 \% \quad 29.8 \%$ SGEVLVNVKEHSR

$0.04 \% 29.8 \%$ QINDIQLSR

$0.04 \% \quad 29.8 \%$ DMTMFVTASKDNTAK

$0.04 \% \quad 29.8 \%$ LFDSTTLEHQK

$99.7 \% \quad 53.4$

$99.7 \% \quad 47.6$

$99.7 \% \quad 45.7$

$99.7 \% \quad 50.9$

$0.04 \% \quad 29.8 \%$ GHFGPINSVAFHPDGK
1058.60

1584.89

1793.95

1467.76

1096.59

1079.59

931.52

1057.48

1310.82

1111.68

1458.81

1614.85

1742.94

1351.70

2310.08

991.50

1015.63

859.52

2096.20

1255.69

1125.49

870.50

2257.18

1493.83

1232.61

2199.12

2428.27

1164.58

1572.66

1250.66

1324.70

1657.89

1117.64

1317.69

1031.52

1755.84

1627.74

1812.86

1441.68

1122.63

1316.60

1453.78

1086.59

1659.77

1318.66

1679.83

Page 55 

Eukaryotic translation initiation factor 4B GN=EIF4B IF4B_HUMAN $69.15 \quad 100.0 \%$ Eukaryotic translation initiation factor 4B GN=EIF4B IF4B_HUMAN $69.15 \quad 100.0 \% 26$ Eukaryotic translation initiation factor 4B GN=EIF4B IF4B HUMAN $69.15 \quad 100.0 \%$ Eukaryotic translation initiation factor 4B GN=EIF4B IF4B_HUMAN $69.15 \quad 100.0 \% \quad 26$ Eukaryotic translation initiation factor 4B GN=EIF4B IF4B_HUMAN $69.15 \quad 100.0 \% 26$ Eukaryotic translation initiation factor 4B GN=EIF4B IF4B HUMAN $69.15 \quad 100.0 \%$ Eukaryotic translation initiation factor 4B GN=EIF4B IF4B_HUMAN $69.15 \quad 100.0 \%$ Eukaryotic translation initiation factor 4B GN=EIF4B IF4B_HUMAN $69.15 \quad 100.0 \%$ Eukaryotic translation initiation factor 4B GN=EIF4B IF4B HUMAN $69.15 \quad 100.0 \%$ Eukaryotic translation initiation factor 4B GN=EIF4B IF4B_HUMAN $69.15 \quad 100.0 \%$ Eukaryotic translation initiation factor 4B GN=EIF4B IF4B HUMAN $69.15 \quad 100.0 \%$ Eukaryotic translation initiation factor 4B GN=EIF4B IF4B_HUMAN $69.15 \quad 100.0 \% \quad 26$ Eukaryotic translation initiation factor 4B GN=EIF4B IF4B_HUMAN $69.15 \quad 100.0 \% 26$ Eukaryotic translation initiation factor 4B GN=EIF4B IF4B HUMAN $69.15 \quad 100.0 \% 26$ Eukaryotic translation initiation factor 4B GN=EIF4B IF4B_HUMAN $69.15 \quad 100.0 \% 26$ Eukaryotic translation initiation factor 4B GN=EIF4B IF4B_HUMAN $69.15 \quad 100.0 \%$ Eukaryotic translation initiation factor 4B GN=EIF4B IF4B_HUMAN $69.15 \quad 100.0 \% 26$ Eukaryotic translation initiation factor 4B GN=EIF4B IF4B_HUMAN $69.15 \quad 100.0 \% 26$ Eukaryotic translation initiation factor 4B GN=EIF4B IF4B HUMAN $69.15 \quad 100.0 \% \quad 26$ Eukaryotic translation initiation factor 4B GN=EIF4B IF4B_HUMAN $69.15 \quad 100.0 \% \quad 26$

$29 \quad 0.04 \% \quad 29.8 \%$ SYSSGGEDGYVR $0.01 \% \quad 13.3 \%$ GIDRYNPENLATLER

$0.01 \% \quad 13.3 \%$ ALTNLPHTDFTLCK

$99.7 \% \quad 55.7$

$99.7 \% \quad 52.0$

$99.7 \% \quad 57.9$

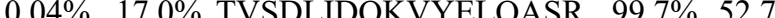

$0.04 \% \quad 17.0 \%$ VSGGPSLEQR

$0.04 \% \quad 17.0 \%$ KSEEEIDFLR

$99.1 \% 33.9$

$99.7 \% \quad 49.6$

$99.7 \% \quad 54.2$

$0.04 \% \quad 17.0 \%$ SEEEIDFLR

$\begin{array}{lllll}0.04 \% & 17.0 \% & \text { QLEVYTSGGDPESVAGEYGR } & 99.7 \% & 74.3 \\ 0.04 \% & 17.0 \% & \text { VFSDEVQQQAQL STIR } & 99.7 \% & 38.2\end{array}$

$0.04 \% \quad 17.0 \%$ SFLKLYTTMPVAK

$0.04 \% \quad 17.0 \%$ LYTTMPVAK

$99.7 \% 30.6$

$99.7 \% \quad 25.7$

$99.7 \% \quad 28.5$

$\begin{array}{lllllll}0.01 \% & 2.9 \% & \text { ITKPGSIDSNNQLFAPGGR } & 99.0 \% & 20.9\end{array}$

$0.01 \% \quad 2.9 \% \quad$ FSALQQAVPTESTDNRR $\quad 99.7 \% \quad 45.6$

$0.01 \% \quad 2.9 \%$ EAALPPVSPLK

$0.01 \% \quad 8.1 \%$ GAPQHYPK

$96.3 \% \quad 15.9$

$95.0 \% \quad 20.7$

$10 \quad 0.01 \% \quad 8.1 \% \quad$ LAEDAPNFDGPAAEGQPGQK $\quad 99.7 \% \quad 37.0$

$10 \quad 0.01 \% \quad 8.1 \% \quad$ SLMDQYFAR

$10 \quad 0.01 \% \quad 8.1 \%$ TQTPPLGQTPQLGLK

$10 \quad 0.01 \% \quad 8.1 \%$ TNPPLIQEKPAK

$10 \quad 0.01 \% \quad 8.1 \% \quad$ SYLAQFAAR

$200 \quad 0.28 \% \quad 38.1 \%$ APPIDRSILPTAPR

$200 \quad 0.28 \% \quad 38.1 \%$ SILPTAPR

$200 \quad 0.28 \% \quad 38.1 \%$ AAREPNIDR

$200 \quad 0.28 \% \quad 38.1 \%$ GLNISAVR

$200 \quad 0.28 \% \quad 38.1 \%$ GLNISAVRLPR

$200 \quad 0.28 \% \quad 38.1 \%$ LPREPSNPER

$200 \quad 0.28 \% \quad 38.1 \%$ ARPATDSFDDYPPR

$200 \quad 0.28 \% \quad 38.1 \%$ DYDRGYDSR

$200 \quad 0.28 \% \quad 38.1 \%$ AFGSGYRR

$200 \quad 0.28 \% \quad 38.1 \%$ DDRGPPQRPK

$200 \quad 0.28 \% \quad 38.1 \%$ STPKEDDSSASTSQSTR

$200 \quad 0.28 \% \quad 38.1 \%$ AASIFGGAKPVDTAAR

$200 \quad 0.28 \% \quad 38.1 \%$ AASIFGGAKPVDTAARER

$200 \quad 0.28 \% \quad 38.1 \%$ QLDEPKLER

$200 \quad 0.28 \% \quad 38.1 \%$ SEETQERER

$99.2 \% \quad 19.5$

$99.7 \% \quad 39.7$

$99.7 \% \quad 35.0$

$99.7 \% \quad 49.5$

$97.4 \% \quad 17.5$

$99.0 \% 31.0$

$99.7 \% \quad 33.5$

$99.0 \% \quad 55.7$

$99.6 \% \quad 27.0$

$98.2 \% \quad 20.9$

$99.7 \% 31.5$

$99.7 \% 33.6$

$95.7 \% \quad 25.3$

$96.6 \% 19.7$

$99.7 \% \quad 52.2$

$99.7 \% \quad 56.7$

$200 \quad 0.28 \% \quad 38.1 \%$ SRTGSESSQTGTSTTSSR

$99.7 \% \quad 43.5$

$99.6 \% \quad 27.0$

$200 \quad 0.28 \% \quad 38.1 \%$ TGSESSQTGTSTTSSRNAR $99.7 \% \quad 37.4$

$200 \quad 0.28 \% \quad 38.1 \%$ SSNPPARSQSSDTEQQSPTSGGGK $\quad 99.7 \% \quad 53.2$

$200 \quad 0.28 \% \quad 38.1 \%$ SQSSDTEQQSPTSGGGK $\quad 99.7 \% \quad 56.2$

$200 \quad 0.28 \% \quad 38.1 \%$ VAPAQPSEEGPGR

$200 \quad 0.28 \% \quad 38.1 \%$ SAPEPKKPEENPASK

$99.7 \% \quad 54.9$

$99.7 \% \quad 40.3$

$99.7 \% \quad 37.4$

$200 \quad 0.28 \% \quad 38.1 \%$ KPEENPASKFSSASK

$99.7 \% \quad 47.5$

$200 \quad 0.28 \% \quad 38.1 \%$ FSSASKYAALSVDGEDENEGEDYAE $99.7 \% \quad 48.7$

$200 \quad 0.28 \% \quad 38.1 \%$ YAALSVDGEDENEGEDYAE $\quad 99.6 \% \quad 23.1$
1137.54

2113.97

1848.95

1498.83

1039.55

1313.70

1972.02

1919.96

1121.66 897.46

2011.94

1130.53

1578.89

1335.76

1026.54

1503.86

854.51

1041.54

829.49

1195.73

1194.62

1607.75

1146.48

913.46

1165.61

1783.79

1531.82

1816.97

1127.61

1163.53

1816.83

1573.69

1914.87

2390.08

1680.73

1294.64

1608.82

999.51

1606.81

2683.12 2075.82 
Exocyst complex component 4 GN=EXOC4 EXOC4_HUMAN $110.50 \quad 100.0 \%$ Exocyst complex component $4 \mathrm{GN}=$ EXOC4 EXOC4_HUMAN $110.50 \quad 100.0 \%$ Exocyst complex component $4 \mathrm{GN}=\mathrm{EXOC} 4$ EXOC4_HUMAN $110.50 \quad 100.0 \%$ Exocyst complex component $4 \mathrm{GN}=\mathrm{EXOC} 4$ EXOC4_HUMAN $110.50100 .0 \%$ Exocyst complex component 6 GN=EXOC6 EXOC6_HUMAN $93.73 \quad 100.0 \%$ Exocyst complex component 6 GN=EXOC6 EXOC6_HUMAN $93.73 \quad 100.0 \%$ Exocyst complex component 6 GN=EXOC6 EXOC6_HUMAN $93.73 \quad 100.0 \%$ Exocyst complex component $8 \mathrm{GN}=\mathrm{EXOC} 8$ EXOC8_HUMAN $81.80 \quad 100.0 \%$ Exocyst complex component $8 \mathrm{GN}=$ EXOC8 EXOC8_HUMAN $81.80 \quad 100.0 \%$ Exosome complex component CSL4 GN=EXOSC1 EXOS1_HUMAN $21.45 \quad 100.0 \%$ Exosome complex component CSL4 GN=EXOSC1 EXOS1_HUMAN $21.45 \quad 100.0 \%$ Exosome complex component MTR3 GN=EXOSC6 EXOS6_HUMAN $28.24 \quad 100.0 \%$ Exosome complex component MTR3 GN=EXOSC6 EXOS6_HUMAN $28.24 \quad 100.0 \%$ Exosome complex component MTR3 GN=EXOSC6 EXOS6_HUMAN $28.24 \quad 100.0 \%$ Exosome complex component RRP4 GN=EXOSC2 EXOS2_HUMAN $32.79 \quad 100.0 \%$ Exosome complex component RRP4 GN=EXOSC2 EXOS2_HUMAN $32.79 \quad 100.0 \%$ Exosome complex component RRP43 GN=EXOSC8 EXOS8 HUMAN $30.04 \quad 100.0 \%$ Exosome complex component RRP43 GN=EXOSC8 EXOS8_HUMAN $30.04 \quad 100.0 \%$ Exosome complex component RRP43 GN=EXOSC8 EXOS8_HUMAN $30.04 \quad 100.0 \%$ Exosome complex exonuclease RRP44 GN=DIS3 RRP44_HUMAN $109.01 \quad 100.0 \%$ Exosome complex exonuclease RRP44 GN=DIS3 RRP44_HUMAN $109.01 \quad 100.0 \%$ Exportin-1 GN=XPO1

Exportin-1 GN=XPO1 Exportin-1 GN=XPO1 Exportin-1 GN=XPO1 Exportin-1 GN=XPO1 Exportin-1 GN=XPO1 Exportin-1 GN=XPO1 Exportin-1 GN=XPO1 Exportin-1 GN=XPO1 Exportin-1 GN=XPO1 Exportin-1 GN=XPO1 Exportin $-2 \mathrm{GN}=\mathrm{CSE} 1 \mathrm{~L}$ Exportin-2 GN=CSE1L Exportin-2 GN=CSE1L Exportin-2 GN=CSE1L Exportin-2 GN=CSE1L Exportin-2 GN=CSE1L Exportin-2 GN=CSE1L Exportin-2 GN=CSE1L Exportin-2 GN=CSE1L Exportin-2 GN=CSE1L Exportin-2 GN $=\mathrm{CSE} 1 \mathrm{~L}$ Exportin-2 GN=CSE1L Exportin-2 GN=CSE1L Exportin-2 GN=CSE1L Exportin-2 GN=CSE1L
XPO1_HUMAN $123.39 \quad 100.0 \%$ XPO1_HUMAN $123.39 \quad 100.0 \%$ XPO1_HUMAN $123.39 \quad 100.0 \%$ XPO1_HUMAN $123.39 \quad 100.0 \%$ XPO1_HUMAN $123.39 \quad 100.0 \%$ XPO1_HUMAN $123.39 \quad 100.0 \%$ XPO1_HUMAN $123.39 \quad 100.0 \%$ XPO1_HUMAN $123.39 \quad 100.0 \%$ XPO1 HUMAN $123.39 \quad 100.0 \%$ XPO1_HUMAN $123.39 \quad 100.0 \%$ XPO1_HUMAN $123.39 \quad 100.0 \%$ XPO2 HUMAN $110.42 \quad 100.0 \%$ XPO2_HUMAN $110.42 \quad 100.0 \%$ XPO2 HUMAN $110.42 \quad 100.0 \%$ XPO2_HUMAN $110.42 \quad 100.0 \%$ XPO2_HUMAN $110.42 \quad 100.0 \%$ XPO2 HUMAN $110.42 \quad 100.0 \%$ XPO2_HUMAN $110.42 \quad 100.0 \%$ XPO2_HUMAN $110.42 \quad 100.0 \% \quad 15$ XPO2_HUMAN $110.42 \quad 100.0 \% \quad 15$ XPO2_HUMAN $110.42 \quad 100.0 \% \quad 15$ XPO2_HUMAN $110.42 \quad 100.0 \% \quad 15$ XPO2_HUMAN $110.42 \quad 100.0 \% \quad 15$ XPO2_HUMAN $110.42 \quad 100.0 \% \quad 15$ XPO2_HUMAN $110.42 \quad 100.0 \% \quad 15$ XPO2_HUMAN $110.42 \quad 100.0 \% \quad 15$
$0.01 \% \quad 6.0 \% \quad$ SKDPSGLLISVIR $0.01 \% \quad 6.0 \%$ DASVPLIDVTNLPTPR

$0.01 \% \quad 6.0 \% \quad$ KFLDTSHYSTAGSSSVR $0.01 \% \quad 6.0 \%$ STTQVADSGYQR

$0.01 \% \quad 4.2 \%$ FCQLMIENLPK

$0.01 \% \quad 4.2 \%$ TLSSCLLNLIR

$0.01 \% \quad 4.2 \% \quad$ VNPNTALTLLEK

$0.00 \% \quad 3.3 \%$ RFEEGVGKPAK

$0.00 \% \quad 3.3 \%$ LIRVNPESTTSVV

$0.00 \% \quad 14.4 \%$ ETESQLLPDVGAIVTCK

$0.00 \% \quad 14.4 \%$ SFRPGDIVLAK

$99.7 \% \quad 39.9$

$99.7 \% \quad 26.1$

$99.7 \% 38.5$

$99.7 \% \quad 29.5$

$99.7 \% 41.4$

$99.7 \% 27.0$

$\begin{array}{llll}99.0 \% & 20.8\end{array}$

$99.7 \% \quad 27.3$

$99.7 \% \quad 38.0$

$99.7 \% \quad 36.0$

$0.01 \% \quad 17.3 \%$ GSAYLEAGGTKVLCAVSGPR $99.7 \% \quad 39.2$

$0.01 \% \quad 17.3 \%$ GGGPAGAGGEAPAALR

$0.01 \% \quad 17.3 \%$ LYPVLQQSLVR

$\begin{array}{ll}99.7 \% & 53.2 \\ 99.7 \% & 38.3\end{array}$

$\begin{array}{ll}99.7 \% & 35.0\end{array}$

$0.01 \% \quad 8.9 \%$ LGQGVLVQVSPSLVKR

$0.01 \% \quad 8.9 \%$ NCIISLVTQR

$99.7 \% \quad 44.8$

$0.01 \% \quad 13.8 \%$ TTTVNIGSISTADGSALVK $\quad 99.7 \% \quad 97.0$

$0.01 \% \quad 13.8 \%$ LGNTTVICGVK

$0.01 \% \quad 13.8 \%$ KLMDEVIK

$0.01 \% \quad 2.5 \%$ AVHEDIVAVELLPK

$0.01 \% \quad 2.5 \%$ NLEIKTDTAK

$0.04 \% \quad 13.3 \%$ PAIMTMLADHAAR

$0.04 \% \quad 13.3 \%$ TSSDPTCVEKEK

$99.7 \% 50.4$

$99.0 \% \quad 29.5$

$99.7 \% \quad 37.9$

$99.7 \% \quad 29.1$

$99.7 \% \quad 43.4$

$99.7 \% \quad 47.1$

$0.04 \% \quad 13.3 \%$ TSESLCQNNMVILK

$99.7 \% \quad 44.9$

$0.04 \% \quad 13.3 \%$ LLSEEVFDFSSGQITQVK $99.7 \% \quad 49.8$

$0.04 \% \quad 13.3 \%$ MAKPEEVLVVENDQGEVVR

$0.04 \% \quad 13.3 \%$ NVDILKDPETVK

$0.04 \% \quad 13.3 \%$ AVGHPFVIQLGR

$99.6 \% \quad 23.9$

$99.7 \% \quad 37.6$

$0.04 \% \quad 13.3 \%$ IYLDMLNVYK

$99.7 \% \quad 36.8$

$0.04 \% \quad 13.3 \%$ NVPAAREPEVL STMAIIVNK $99.7 \% 27.4$

$0.04 \% \quad 13.3 \%$ EPEVLSTMAIIVNK

$0.04 \% \quad 13.3 \%$ SAFPHLQDAQVK

$0.05 \% \quad 17.5 \%$ TLDPDPAIR

$0.05 \% \quad 17.5 \%$ TAHSLFKR

$0.05 \% \quad 17.5 \%$ NLFEDQNTLTSICEK

$0.05 \% \quad 17.5 \%$ VIVPNMEFR

$0.05 \% \quad 17.5 \%$ AADEEAFEDNSEEYIRR

$0.05 \% \quad 17.5 \%$ DLEGSDIDTRR

$0.05 \% \quad 17.5 \%$ RAACDLVR

$0.05 \% \quad 17.5 \%$ ALTLPGSSENEYIMK

$0.05 \% \quad 17.5 \%$ TGNIPALVR

$99.7 \% \quad 45.0$

$99.7 \% \quad 29.5$

$99.6 \% \quad 23.1$

$99.0 \% \quad 47.4$

$99.7 \% \quad 63.3$

$95.7 \% \quad 14.9$

$99.6 \% \quad 22.9$

$\begin{array}{lll}99.5 \% & 23.8\end{array}$

$99.0 \% \quad 29.1$

$96.1 \% \quad 19.3$

$99.7 \% \quad 51.6$

$99.0 \% \quad 53.1$

$0.05 \% \quad 17.5 \%$ LLQAFLER

$0.05 \% \quad 17.5 \%$ IIIPEIQK

$0.05 \% \quad 17.5 \%$ KICAVGITK

$0.05 \% \quad 17.5 \%$ EHDPVGQMVNNPK

$0.05 \% \quad 17.5 \%$ IHLAQSLHK
$98.2 \% 30.0$

$99.7 \% \quad 51.3$

$99.7 \% \quad 52.5$

$99.7 \% \quad 40.3$
138

0

0

1842.90

1312.61

1392.70

1289.72

1312.75

1217.66

1414.79

1859.94

1202.69

1993.02

1308.67

1315.77

1680.02

1203.65

1834.98

1161.63

975.55

1532.87

1132.62

1397.70

1380.63

1636.80

2027.03

2141.09

1370.75

1293.74

1271.67

2152.18

1543.84

1340.70

997.53

959.54

1811.85

1104.59

2043.89

1276.61

960.50

1668.82

940.56

989.58

2158.19

953.60

989.58

1464.69

1046.61

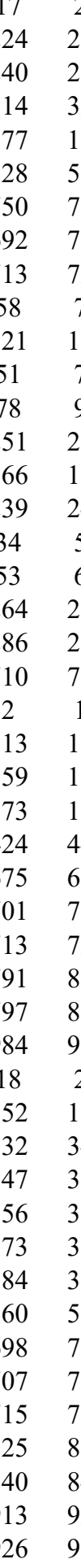

Page 57 of Table S-1-1 
Exportin-5 GN=XPO5 Exportin-5 GN=XPO5 Exportin-5 GN=XPO5 Exportin-7 GN=XPO7 Exportin-7 GN=XPO7 Exportin-7 GN=XPO7

Exportin- $\mathrm{T}$ GN $=\mathrm{XPOT}$ Exportin- $\mathrm{T}$ GN $=$ XPOT Fanconi anemia group I protein GN=FANCI FANCI_HUMAN $149.33 \quad 100.0 \%$ Fanconi anemia group I protein GN=FANCI FANCI_HUMAN $149.33 \quad 100.0 \%$ Far upstream element-binding protein 2 GN=KHSRP FUBP2_HUMAN $73.12 \quad 100.0 \%$ Far upstream element-binding protein 2 GN=KHSRP FUBP2_HUMAN $73.12 \quad 100.0 \%$ Far upstream element-binding protein 2 GN=KHSRP FUBP2_HUMAN $73.12 \quad 100.0 \%$ Far upstream element-binding protein 2 GN=KHSRP FUBP2_HUMAN $73.12 \quad 100.0 \%$ Far upstream element-binding protein 2 GN=KHSRP FUBP2_HUMAN $73.12 \quad 100.0 \%$ Farnesyl pyrophosphate synthase GN=FDPS FPPS_HUMAN $48.28 \quad 100.0 \%$ Farnesyl pyrophosphate synthase GN=FDPS FPPS HUMAN $48.28 \quad 100.0 \%$ Fatty acid synthase GN=FASN Fatty acid synthase GN=FASN Fatty acid synthase GN=FASN Fatty acid synthase GN=FASN Fatty acid synthase GN=FASN Fatty acid synthase GN=FASN Fatty acid synthase GN=FASN Fatty acid synthase GN=FASN Fatty acid synthase GN=FASN Fatty acid synthase GN=FASN Fatty acid synthase GN=FASN Fatty acid synthase GN=FASN Fatty acid synthase GN=FASN Fatty acid synthase GN=FASN Fatty acid synthase GN=FASN Fatty acid synthase GN=FASN Fatty acid synthase GN=FASN Fatty acid synthase GN=FASN Fatty acid synthase GN=FASN Fatty acid synthase GN=FASN Fatty acid synthase GN=FASN Fatty acid synthase GN=FASN Fatty acid synthase GN=FASN Fatty acid synthase GN=FASN Fatty acid synthase GN=FASN Fibronectin $\mathrm{GN}=\mathrm{FN} 1$

Fibronectin $\mathrm{GN}=\mathrm{FN} 1$

Fibronectin $\mathrm{GN}=\mathrm{FN} 1$

Fibronectin $\mathrm{GN}=\mathrm{FN} 1$

Filamin-A GN=FLNA
XPO5 HUMAN $136.31 \quad 100.0 \%$ XPO5_HUMAN $136.31 \quad 100.0 \%$ XPO5_HUMAN $136.31 \quad 100.0 \%$ $123.91 \quad 100.0 \%$ XPO7_HUMAN $123.91 \quad 100.0 \%$ XPO7_HUMAN $123.91 \quad 100.0 \%$ XPOT_HUMAN $109.97 \quad 100.0 \%$ XPOT_HUMAN $109.97 \quad 100.0 \%$ $\begin{array}{ll}\text { FPPS_HUMAN } 48.28 & 100.0 \% \\ \text { FAS_HUMAN } 273.43 & 100.0 \%\end{array}$ FAS_HUMAN $273.43 \quad 100.0 \% \quad 25$ FAS HUMAN $273.43 \quad 100.0 \% \quad 25$ FAS_HUMAN $273.43 \quad 100.0 \% \quad 25$ FAS_HUMAN $273.43 \quad 100.0 \% \quad 25$ FAS_HUMAN $273.43 \quad 100.0 \% \quad 25$ FAS_HUMAN $273.43 \quad 100.0 \% \quad 25$ FAS HUMAN $273.43 \quad 100.0 \% \quad 25$ FAS_HUMAN $273.43 \quad 100.0 \% \quad 25$ FAS_HUMAN $273.43 \quad 100.0 \% \quad 25$ FAS_HUMAN $273.43 \quad 100.0 \% \quad 25$ FAS_HUMAN $273.43 \quad 100.0 \% \quad 25$ FAS HUMAN $273.43 \quad 100.0 \% \quad 25$ FAS_HUMAN $273.43 \quad 100.0 \% \quad 25$ FAS_HUMAN $273.43 \quad 100.0 \% \quad 25$ FAS HUMAN $273.43 \quad 100.0 \% \quad 25$ FAS_HUMAN $273.43 \quad 100.0 \% \quad 25$ FAS_HUMAN $273.43 \quad 100.0 \% \quad 25$ FAS_HUMAN $273.43 \quad 100.0 \% \quad 25$ FAS_HUMAN $273.43 \quad 100.0 \% \quad 25$ FAS_HUMAN $273.43 \quad 100.0 \% \quad 25$ FAS_HUMAN $273.43 \quad 100.0 \% \quad 25$ FAS_HUMAN $273.43 \quad 100.0 \% \quad 25$ FAS HUMAN $273.43 \quad 100.0 \% \quad 25$ FAS_HUMAN $273.43 \quad 100.0 \% \quad 25$ FINC_HUMAN $262.62 \quad 100.0 \%$ FINC_HUMAN $262.62 \quad 100.0 \%$ FINC_HUMAN $262.62 \quad 100.0 \%$ FINC HUMAN $262.62 \quad 100.0 \%$ FLNA_HUMAN $280.73 \quad 100.0 \% \quad 25$
$0.01 \% \quad 2.5 \%$ TDTSQESKAQANCR $0.01 \% \quad 2.5 \%$ ASMTNLVK $0.01 \% \quad 2.5 \%$ AQQGEVMR

$0.01 \% \quad 3.1 \%$ ALVEFTNSPDCLSK

$0.01 \% \quad 3.1 \%$ VLQLMNLTDSR

$0.01 \% \quad 3.1 \%$ TTFYTALGR

$0.00 \% \quad 1.9 \%$ ALAYFEQLK

$0.00 \% \quad 1.9 \%$ SRTAYLFSR

$0.00 \% \quad 1.5 \%$ TIETSPSLSR

$0.00 \% \quad 1.5 \%$ TAFQIRQFQR

$0.01 \% \quad 9.9 \%$ DAFADAVQR

$0.01 \% \quad 9.9 \%$ IGGDAATTVNNSTPDFGFGGQKR

$0.01 \% \quad 9.9 \%$ SVSLTGAPESVQK

$0.01 \% \quad 9.9 \%$ IGGGIDVPVPR

$0.01 \% \quad 9.9 \%$ AINQQTGAFVEISR

$0.01 \% \quad 6.4 \%$ VLTEDEMGHPEIGDAIAR

$0.01 \% \quad 6.4 \%$ KQDADSLQR

$0.06 \% \quad 11.1 \%$ AGLYGLPR

$0.06 \% \quad 11.1 \%$ FDASFFGVHPK

$0.06 \% \quad 11.1 \%$ AFDTAGNGYCR

$0.06 \% 11.1 \%$ SEGVVAVLLTK

$0.06 \% \quad 11.1 \%$ SEGVVAVLLTKK

$0.06 \% \quad 11.1 \%$ ALCATRQEPLLIGSTK

$0.06 \% \quad 11.1 \%$ QEPLLIGSTK

$0.06 \% \quad 11.1 \%$ LQVVDQPLPVR

$0.06 \% \quad 11.1 \%$ TGTVSLEVR

$0.06 \% \quad 11.1 \%$ AFEVSENGNLVVSGK

$0.06 \% \quad 11.1 \%$ VYQWDDPDPR

$0.06 \% \quad 11.1 \%$ HGLYLPTR

$0.06 \% \quad 11.1 \%$ RQQEQQVPILEK

$0.06 \% \quad 11.1 \%$ AALQEELQLCK

$0.06 \% \quad 11.1 \%$ GLVQALQTK

$0.06 \% \quad 11.1 \%$ SFYGSTLFLCR

$0.06 \% \quad 11.1 \%$ AINCATSGVVGLVNCLR

$0.06 \% \quad 11.1 \%$ VVVQVLAEEPEAVLK

$0.06 \% \quad 11.1 \%$ QGVQVQVSTSNISSLEGAR

$0.06 \% \quad 11.1 \%$ GNAGQSNYGFANSAMER

$0.06 \% \quad 11.1 \%$ EDGLAQQQTQLNLR

$0.06 \% \quad 11.1 \%$ SLLVNPEGPTLMR

$0.06 \% \quad 11.1 \%$ LSIPTYGLQCTR

$0.06 \% \quad 11.1 \%$ VAAAVDLIIK

$0.06 \% \quad 11.1 \%$ AAEQYTPK

$0.01 \% \quad 2.1 \% \quad$ ISCTIANR

$0.01 \% \quad 2.1 \%$ LGVRPSQGGEAPR

$0.01 \% \quad 2.1 \%$ STTPDITGYR

$0.01 \% \quad 2.1 \% \quad$ SSPVVIDASTAIDAPSNLR $99.7 \% \quad 53.5$

$0.11 \% \quad 12.8 \%$ IQQNTFTR
$99.7 \% \quad 53.0 \quad 25.0 \quad 52.6$

$99.0 \% 34.5$

$95.0 \% \quad 20.7$

$99.7 \% \quad 30.0$

$99.7 \% 33.3$

$99.7 \% \quad 33.0$

$99.7 \% \quad 36.6$

$99.7 \% \quad 26.8$

$99.7 \% 27.8$

$99.7 \% \quad 25.6$

$99.7 \% \quad 36.8$

$99.7 \% \quad 51.6$

$\begin{array}{lll}99.6 \% & 24.4\end{array}$

$99.7 \% \quad 57.7$

$99.7 \% \quad 63.5$

$99.7 \% 29.2$

$99.0 \% \quad 42.6$

$99.7 \% \quad 41.0$

$99.7 \% \quad 34.5$

$99.7 \% \quad 62.9$

$99.7 \% \quad 38.5$

$98.6 \% \quad 17.5$

$98.6 \% \quad 18.9$

$99.7 \% \quad 45.5$

$99.7 \% \quad 49.1$

$\begin{array}{lll}99.7 \% & 38.9\end{array}$

$99.6 \% \quad 24.3$

$99.0 \% \quad 22.3$

$99.7 \% \quad 26.3$

$99.7 \% \quad 45.4$

$99.7 \% \quad 44.4$

$99.7 \% \quad 57.5$

$\begin{array}{ll}98.2 \% & 16.8 \\ 99.7 \% & 58.7\end{array}$

$99.7 \% \quad 58.7$

$\begin{array}{ll}99.7 \% & 64.8\end{array}$

$99.7 \% \quad 45.7$

$99.7 \% \quad 40.0$

$99.7 \% 33.1$

$\begin{array}{lll}99.7 \% & 26.8\end{array}$

$99.0 \% \quad 28.0$

$99.0 \% \quad 24.7$

$99.6 \% \quad 22.2$

$\begin{array}{lll}99.7 \% & 28.7\end{array}$

$98.6 \% 26.4$
863.47

918.45

1580.76

1289.69

1029.54

1082.59

1100.58

1090.57

1294.70

992.48

2310.11

1302.69

1079.62

1533.80

1952.94

1060.54

846.48

1251.62

1231.52

1115.67

1243.76

1757.96

1085.62

1263.74

961.53

1549.79

1290.58

956.53

1495.82

1302.67

957.57

1350.65

1803.92

1622.94

1960.01

1773.76

1613.82

1426.77

1408.73

1012.64

907.45

934.48

1323.71

1110.54

1913.00

1007.53

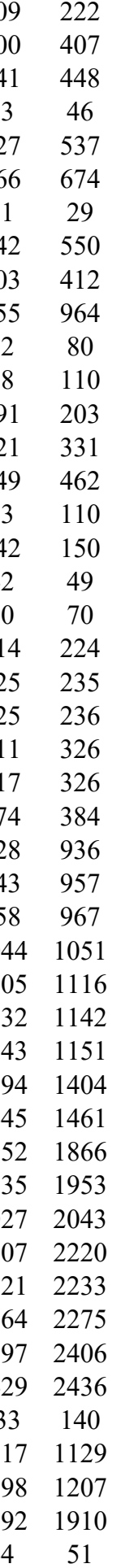

Page 58 of Table S-1-1 
Filamin-A GN=FLNA Filamin-A GN=FLNA Filamin-A GN=FLNA Filamin-A GN=FLNA Filamin-A GN=FLNA Filamin-A GN=FLNA

Filamin-A GN=FLNA Filamin-A GN=FLNA Filamin-A GN=FLNA Filamin-A GN=FLNA Filamin-A GN=FLNA Filamin-A GN=FLNA Filamin-A GN=FLNA Filamin-A GN=FLNA

Filamin-A GN=FLNA Filamin-A GN=FLNA Filamin-A GN=FLNA
Filamin-A GN=FLNA Filamin-A GN=FLNA Filamin-A GN=FLNA Filamin-A GN=FLNA Filamin-A GN=FLNA Filamin-A GN=FLNA Filamin-A GN=FLNA

Flap endonuclease $1 \mathrm{GN}=\mathrm{FEN} 1$ Flap endonuclease $1 \mathrm{GN}=\mathrm{FEN} 1$ Flap endonuclease $1 \mathrm{GN}=\mathrm{FEN} 1$

Flap endonuclease $1 \mathrm{GN}=\mathrm{FEN} 1$ Fragile X mental retardation protein 1 GN=FMR1 FMR1_HUMAN $71.17 \quad 100.0 \%$ Fragile X mental retardation protein 1 GN=FMR1 FMR1_HUMAN $71.17 \quad 100.0 \%$ Fragile X mental retardation protein 1 GN=FMR1 FMR1_HUMAN $71.17 \quad 100.0 \%$ Fragile X mental retardation protein $1 \mathrm{GN}=\mathrm{FMR} 1$ FMR1_HUMAN $71.17 \quad 100.0 \%$ Fragile X mental retardation protein 1 GN=FMR1 FMR1_HUMAN $71.17 \quad 100.0 \%$ Fragile X mental retardation protein 1 GN=FMR1 FMR1_HUMAN $71.17 \quad 100.0 \%$ Fragile X mental retardation protein 1 GN=FMR1 FMR1_HUMAN $71.17 \quad 100.0 \%$ Fragile X mental retardation syndrome-related protein 2 GN=FXR2 FXR2_HUMAN $74.22 \quad 100.0 \%$ Fragile X mental retardation syndrome-related protein $2 \mathrm{GN}=\mathrm{FXR} 2 \mathrm{FXR} 2$ HUMAN $74.22 \quad 100.0^{\circ}$ Fragile X mental retardation syndrome-related protein 2 GN=FXR2 $\quad$ FXR2_HUMAN $74.22 \quad 100.0 \%$ Fragile X mental retardation syndrome-related protein 2 GN=FXR2 FXR2_HUMAN $74.22 \quad 100.0 \%$ Fragile $X$ mental retardation syndrome-related protein 2 GN=FXR2 FXR2_HUMAN $74.22 \quad 100.0 \%$ Fragile X mental retardation syndrome-related protein 2 GN=FXR2 FXR2_HUMAN $74.22 \quad 100.0 \%$ Fructose-bisphosphate aldolase A GN=ALDOA ALDOA HUMAN $39.42 \quad 100.0 \%$ Fructose-bisphosphate aldolase A GN=ALDOA ALDOA_HUMAN $39.42 \quad 100.0 \%$ Fructose-bisphosphate aldolase A GN=ALDOA ALDOA_HUMAN $39.42 \quad 100.0 \%$ Galactokinase GN=GALK1 Galactokinase $\mathrm{GN}=\mathrm{GALK} 1$

GALK1_HUMAN $42.27 \quad 100.0 \%$
$80 \quad 0.11 \% \quad 12.8 \%$ VTVLFAGQHIAK $99.7 \% \quad 29.8$

$0.11 \% \quad 12.8 \%$ VTAQGPGLEPSGNIANK $9.7 \% \quad 24.5$

25.0$$
80
$$$$
80
$$

80

80

$$
\begin{aligned}
& 80 \\
& 80
\end{aligned}
$$

80

80

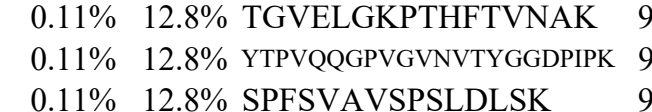

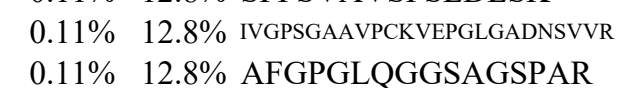

$0.11 \% \quad 12.8 \%$ AHVVPCFDASK

$0.11 \% \quad 12.8 \%$ CSGPGLER

$0.11 \% \quad 12.8 \%$ YGGQPVPNFPSK

$0.11 \% \quad 12.8 \%$ EATTEFSVDAR

$0.11 \% \quad 12.8 \%$ ALTQTGGPHVK

$0.11 \% 12.8 \%$ GAGTGGLGLAVEGPSEAK

$0.11 \% \quad 12.8 \%$ ANLPQSFQVDTSK

$0.11 \% \quad 12.8 \%$ AGVAPLQVK

$0.11 \% \quad 12.8 \%$ YGGDEIPFSPYR

$0.11 \% \quad 12.8 \%$ KGEITGEVR

$0.11 \% \quad 12.8 \%$ ATCAPQHGAPGPGPADASK

$0.11 \% \quad 12.8 \%$ TPCEEILVK

$0.01 \% \quad 11.3 \%$ LIADVAPSAIRENDIK

$0.01 \% \quad 11.3 \%$ HLTASEAK

$0.01 \% \quad 11.3 \%$ KLPIQEFHLSR

$0.01 \% \quad 11.3 \%$ RAVDLIQK

$0.04 \% \quad 13.9 \%$ SVNPNKPATK

$0.04 \% \quad 13.9 \%$ SVNPNKPATKDTFHK

$0.04 \% \quad 13.9 \%$ SFLEFAEDVIQVPR

$0.04 \% 13.9 \%$ LIQEIVDKSGVVR

$0.04 \% 13.9 \%$ VGPNAPEEK

$0.04 \% \quad 13.9 \%$ VLVASSVVAGESQKPELK

$0.04 \% \quad 13.9 \%$ LQIDEQLR

$0.04 \% \quad 13.9 \%$ TLQNTSSEGSR

$0.02 \% \quad 11.9 \%$ LRPVNPNPLATK

$0.02 \% \quad 11.9 \%$ ASLLGDMHFR

$0.02 \% \quad 11.9 \%$ VIQEIVDKSGVVR

$0.02 \% \quad 11.9 \%$ LQIDEQLR

$0.02 \% \quad 11.9 \%$ AGYSTDESSSSSLHATR $99.7 \% \quad 51.3$

$0.02 \% \quad 11.9 \%$ TDGSISGDRQPVTVADYISR $\quad 99.7 \% \quad 48.5$

$0.01 \% \quad 11.0 \%$ IVAPGKGILAADESTGSIAK $\quad 99.7 \% \quad 40.9$

$0.01 \% \quad 11.0 \%$ AAQEEYVKR

$0.01 \% \quad 11.0 \%$ ALANSLACQGK

$0.02 \% \quad 20.4 \%$ SLEPGTPR $\begin{array}{lllll}99.7 \% & 46.3 & 25.0 & 38.8 & 2\end{array}$ $\begin{array}{lllll}99.7 \% & 40.2 & 25.0 & 36.0 & 2\end{array}$ $96.6 \% \quad 19.0 \quad 25.0 \quad 14.1-1$ $99.7 \% \quad 34.1 \quad 25.0 \quad 32.1$
652.86

1867.84

145.65

1646.87

1079.56

1698.92

2286.18

1533.82

2449.29

429.72

1230.59
875.40

1290.65

1225.57

1108.61

1570.81

1434.72

882.54

1400.65

988.54

1789.83

1088.57

1724.95
856.45

1367.78

942.57

1055.58

1683.88
1649.85

1455.85

940.47

1841.04

1014.56

1179.56

1319.78

146.57

1441.84

1014.56

755.78

2137.05

898.06

1093.56

1132.58

856.45 1054.55 
Galactokinase GN=GALK1 Galactokinase GN $=$ GALK 1 Galactokinase GN=GALK1 Galactokinase $\mathrm{GN}=\mathrm{GALK} 1$ Galactokinase GN $=$ GALK1 Galactokinase $\mathrm{GN}=\mathrm{GALK} 1$

GDP-mannose 4,6 dehydratase GN=GMDS GDP-mannose 4,6 dehydratase GN=GMDS GMD__HUMAN $41.95 \quad 100.0 \%$ GDP-mannose 4,6 dehydratase GN=GMDS GMDS_HUMAN $41.95 \quad 100.0 \%$ Gem-associated protein $2 \mathrm{GN}=$ GEMIN2 $\quad$ GEMI2_HUMAN $31.59 \quad 100.0 \%$ Gem-associated protein 2 GN=GEMIN2 GEMI2_HUMAN $31.59 \quad 100.0 \%$ General transcription factor 3C polypeptide $1 \mathrm{GN}=\mathrm{GTF} 3 \mathrm{C} 1 \quad$ TF3C1_HUMAN $238.88 \quad 100.0 \%$ General transcription factor 3C polypeptide $1 \mathrm{GN}=\mathrm{GTF3Cl} \quad$ TF3C1_HUMAN $238.88 \quad 100.0 \%$ General transcription factor 3C polypeptide $1 \mathrm{GN}=\mathrm{GTF} 3 \mathrm{C} 1 \quad$ TF3C1_HUMAN $238.88 \quad 100.0 \%$ General transcription factor 3C polypeptide $1 \mathrm{GN}=\mathrm{GTF} 3 \mathrm{C} 1 \quad \mathrm{TF} 3 \mathrm{C} 1 \_$HUMAN $238.88 \quad 100.0 \%$ General transcription factor $3 \mathrm{C}$ polypeptide $1 \mathrm{GN}=\mathrm{GTF} 3 \mathrm{C} 1 \quad \mathrm{TF} 3 \mathrm{C} 1$ _HUMAN $238.88 \quad 100.0 \%$ General transcription factor $3 \mathrm{C}$ polypeptide $1 \mathrm{GN}=\mathrm{GTF} 3 \mathrm{C} 1$ TF3C1_HUMAN $238.88 \quad 100.0 \%$ General transcription factor $3 \mathrm{C}$ polypeptide $1 \mathrm{GN}=\mathrm{GTF} 3 \mathrm{C} 1 \quad \mathrm{TF} 3 \mathrm{C} 1$ _HUMAN $238.88 \quad 100.0 \%$ General transcription factor 3C polypeptide $1 \mathrm{GN}=\mathrm{GTF} 3 \mathrm{C} 1 \quad$ TF3C1_HUMAN $238.88 \quad 100.0 \%$ General transcription factor $3 \mathrm{C}$ polypeptide $1 \mathrm{GN}=\mathrm{GTF} 3 \mathrm{C} 1$ TF3C1_HUMAN $238.88 \quad 100.0 \%$ General transcription factor $3 \mathrm{C}$ polypeptide $1 \mathrm{GN}=\mathrm{GTF} 3 \mathrm{Cl} 1 \mathrm{TF} 3 \mathrm{C} 1 \_\mathrm{HUMAN} 238.88 \quad 100.0 \%$ General transcription factor 3C polypeptide $1 \mathrm{GN}=\mathrm{GTF} 3 \mathrm{C} 1 \quad$ TF3C1_HUMAN $238.88 \quad 100.0 \%$ General transcription factor 3C polypeptide $1 \mathrm{GN}=\mathrm{GTF} 3 \mathrm{C} 1 \quad$ TF3C1_HUMAN $238.88 \quad 100.0 \%$ General transcription factor 3C polypeptide $3 \mathrm{GN}=\mathrm{GTF} 3 \mathrm{C} 3$ TF3C3_HUMAN $101.28 \quad 100.0 \%$ General transcription factor $3 \mathrm{C}$ polypeptide $3 \mathrm{GN}=\mathrm{GTF} 3 \mathrm{C} 3$ TF3C3_HUMAN $101.28100 .0 \%$ General transcription factor $3 \mathrm{C}$ polypeptide $3 \mathrm{GN}=\mathrm{GTF} 3 \mathrm{C} 3 \quad \mathrm{TF} 3 \mathrm{C} 3$ _HUMAN $101.28 \quad 100.0 \%$ General transcription factor 3C polypeptide $4 \mathrm{GN}=\mathrm{GTF} 3 \mathrm{C} 4 \quad \mathrm{TF} 3 \mathrm{C} 4$ _HUMAN $91.98 \quad 100.0 \%$ General transcription factor $3 \mathrm{C}$ polypeptide $4 \mathrm{GN}=\mathrm{GTF} 3 \mathrm{C} 4 \quad \mathrm{TF} 3 \mathrm{C} 4$ HUMAN $91.98 \quad 100.0 \%$ General vesicular transport factor p115 GN=USO1 USO1_HUMAN $107.90 \quad 100.0 \%$ General vesicular transport factor $\mathrm{p} 115 \mathrm{GN}=$ USO1 USO1 HUMAN $107.90 \quad 100.0 \%$ General vesicular transport factor p115 GN=USO1 USO1_HUMAN $107.90 \quad 100.0 \%$ General vesicular transport factor p115 GN=USO1 USO1_HUMAN $107.90 \quad 100.0 \%$ Girdin $\mathrm{GN}=\mathrm{CCDC} 88 \mathrm{~A}$ Girdin $\mathrm{GN}=\mathrm{CCDC} 88 \mathrm{~A}$ Girdin $\mathrm{GN}=\mathrm{CCDC} 88 \mathrm{~A}$ Girdin $\mathrm{GN}=\mathrm{CCDC} 88 \mathrm{~A}$ Girdin $\mathrm{GN}=\mathrm{CCDC} 88 \mathrm{~A}$ Girdin $\mathrm{GN}=\mathrm{CCDC} 88 \mathrm{~A}$ Glioma tumor suppressor candidate region gene 2 protein GN=GLTSCR2 GSCR2_HUMAN $54.39 \quad 100.0 \%$ Glioma tumor suppressor candidate region gene 2 protein GN=GLTSCR2 GSCR2_HUMAN $54.39100 .0 \%$ Glutamine--fructose-6-phosphate aminotransferase [isomerizing] 1 GN=GFPT1 GFPT1 HUMAN 78.81 100.0\% Glutamine--fructose-6-phosphate aminotransferase [isomerizing] 1 GN=GFPT1 GFPT1_HUMAN 78.81 $100.0 \%$ Gumamine--fructose-6-phosphate aminotransferase [isomerizing] 1 GN=GFPT1 GFPT1_HUMAN 78.81 100.0\% Glutamine--tRNA ligase $\mathrm{GN}=\mathrm{QARS}$ Glutamine--tRNA ligase GN=QARS Glutamine--tRNA ligase $\mathrm{GN}=\mathrm{QARS}$
GRDN_HUMAN $216.05 \quad 100.0 \%$ GRDN_HUMAN $216.05 \quad 100.0 \%$ GRDN_HUMAN $216.05 \quad 100.0 \%$ GRDN_HUMAN $216.05 \quad 100.0 \%$ GRDN HUMAN $216.05 \quad 100.0 \%$ GDN_HUMAN 216.05 \begin{tabular}{ll} 
GFPT1_HUMAN 78.81 & $100.0 \%$ \\
\hline
\end{tabular} GFPT1_HUMAN $78.81 \quad 100.0 \%$ SYQ_HUMAN $87.80 \quad 100.0 \%$ SYQ HUMAN $87.80 \quad 100.0 \%$ SYQ_HUMAN $87.80 \quad 100.0 \%$
$0.02 \% \quad 20.4 \%$ SLETSLVPLSDPK $0.02 \% \quad 20.4 \%$ LAVLITNSNVR $0.02 \% \quad 20.4 \%$ HSLASSEYPVR $0.02 \% \quad 20.4 \%$ RQCEEVAR $0.02 \% \quad 20.4 \%$ EVQLEELEAAR $0.02 \% \quad 20.4 \%$ TAQAAAALR $0.01 \% \quad 8.6 \%$ GSGDGEMGKPR $0.01 \% \quad 8.6 \%$ TCGLINSVK $0.01 \% \quad 8.6 \%$ FYQASTSELYGK $0.00 \% \quad 8.6 \% \quad$ SQQLDSNVTMPK $0.00 \% \quad 8.6 \% \quad$ YFDQRDLADEPS $0.03 \% \quad 6.6 \%$ LYQYMLNAGLAK $9 \quad 0.03 \% \quad 6.6 \%$ LQEIHPECGPCK $19 \quad 0.03 \% \quad 6.6 \%$ GISQAEIR

$19 \quad 0.03 \% \quad 6.6 \% \quad$ YISCVFAEESDLSR $19 \quad 0.03 \% \quad 6.6 \% \quad$ NLIIEAVTNLR $19 \quad 0.03 \% \quad 6.6 \% \quad$ NLSEEGLLR $19 \quad 0.03 \% \quad 6.6 \% \quad$ TTVIQDGIKK $19 \quad 0.03 \% \quad 6.6 \% \quad$ NYHPIVVPGLGR $0.03 \% \quad 6.6 \%$ NAVIVDTTICDPHYNLAR $19 \quad 0.03 \% \quad 6.6 \% \quad$ ALVGDFMNR $0.03 \% \quad 6.6 \%$ SYQSFQTFR $0.03 \% \quad 6.6 \% \quad$ NLNPNDSIVVNSCQMK $0.01 \% \quad 4.1 \% \quad$ ILNLLSPSDGER $0.01 \% \quad 4.1 \%$ ISLSTLQQQLGQPEK $0.01 \% \quad 4.1 \%$ STLLFSQGK $0.00 \% \quad 2.6 \%$ TSVPAPLNSCLLK $0.00 \% \quad 2.6 \%$ VLIGHISK $0.01 \% \quad 5.9 \% \quad$ IVAFENAFER $0.01 \% \quad 5.9 \%$ VLVSPTNPPGATSSCQK $0.01 \% \quad 5.9 \% \quad$ LGFISKHELYSR $0.01 \% \quad 5.9 \% \quad$ SSQTSGTNEQSSAIVSAR $0.02 \% \quad 4.3 \%$ LQQENMNLLSDAR $0.02 \% \quad 4.3 \%$ TSELSEAPQK $0.02 \% \quad 4.3 \%$ SLGHEVNELTSSR $0.02 \% \quad 4.3 \% \quad$ ILEQENEHLNQTVSSLR $0.02 \% \quad 4.3 \% \quad$ NLEELKISSK $0.02 \% \quad 4.3 \%$ QTVSLQEQNTTLQTQNAK $0.00 \% \quad 4.2 \%$ DVLAHQVPNAK $0.00 \% \quad 4.2 \% \quad$ LRVQQAALR

$0.01 \% \quad 7.3 \%$ GSPLLIGVR

$0.01 \% \quad 7.3 \%$ AVQTLQMELQQIMK $0.01 \% \quad 7.3 \%$ GALTVGITNTVGSSISR $0.01 \% \quad 7.3 \%$ CQNALQQVVAR $0.02 \% \quad 12.6 \%$ NSALSAQLR $0.02 \% \quad 12.6 \%$ ATGILLYGLASR $0.02 \% \quad 12.6 \%$ LSFLVSYIASK $\begin{array}{llllllll}99.7 \% & 34.5 & 25.0 & 25.2 & 2 & 0 & 0 & 1385.75\end{array}$ $\begin{array}{llllllll}99.7 \% & 31.8 & 25.0 & 22.7 & 1 & 0 & 0 & 1199.71\end{array}$ $\begin{array}{llllllll}99.7 \% & 42.2 & 25.0 & 30.5 & 2 & 0 & 0 & 1245.62\end{array}$

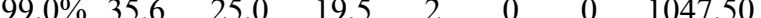
$99.4 \% \quad 22.4 \quad 25.0 \quad 18.0$ $\begin{array}{llll}99.7 \% & 39.8 & 25.0 & 31.2\end{array}$ $\begin{array}{llll}99.7 \% & 35.8 & 25.0 & 32.9\end{array}$ $99.4 \% \quad 25.4 \quad 25.0 \quad 16.2 \quad 2$ $\begin{array}{llll}99.7 \% & 60.3 & 25.0 & 60.0\end{array}$ $99.7 \% \quad 41.3 \quad 25.0 \quad 29.8$ $\begin{array}{llll}99.7 \% & 28.3 & 25.0 & 28.3\end{array}$ $99.7 \% \quad 41.5 \quad 25.0 \quad 34.0$ $\begin{array}{llll}99.7 \% & 43.2 & 25.0 & 40.2\end{array}$ $99.0 \% \quad 35.7 \quad 25.0 \quad 21.1$ $99.7 \% \quad 61.4 \quad 25.0 \quad 56.7$ $\begin{array}{llll}99.7 \% & 53.4 & 25.0 & 48.8\end{array}$ $\begin{array}{llll}99.7 \% & 37.7 & 25.0 & 22.8\end{array}$ $\begin{array}{llll}99.3 \% & 24.8 & 25.0 & 24.8\end{array}$ $\begin{array}{llll}94.5 \% & 13.4 & 25.0 & 13.4\end{array}$ $\begin{array}{lllll}99.7 \% & 46.3 & 25.0 & 43.6 & 0\end{array}$ $\begin{array}{lllll}99.7 \% & 31.1 & 25.0 & 31.1 & 2\end{array}$ $\begin{array}{llll}99.7 \% & 26.2 & 25.0 & 26.2\end{array}$ $\begin{array}{llll}99.7 \% & 37.7 & 25.0 & 37.7\end{array}$ $\begin{array}{llll}99.2 \% & 21.7 & 25.0 & 21.7\end{array}$ $\begin{array}{llll}99.7 \% & 43.9 & 25.0 & 39.6\end{array}$ $96.6 \% \quad 16.0 \quad 25.0 \quad 16.0$ $\begin{array}{llll}99.7 \% & 26.0 & 25.0 & 19.0\end{array}$ $\begin{array}{llll}99.0 \% & 22.0 & 25.0 & 18.7\end{array}$ $\begin{array}{llll}99.1 \% & 23.1 & 25.0 & 23.1\end{array}$ $\begin{array}{llll}99.7 \% & 56.8 & 25.0 & 56.8\end{array}$ $\begin{array}{lllll}98.6 \% & 21.4 & 25.0 & 21.4 & 0\end{array}$ $\begin{array}{llll}99.7 \% & 65.7 & 25.0 & 65.7\end{array}$ $\begin{array}{llll}99.7 \% & 54.2 & 25.0 & 44.0\end{array}$ $\begin{array}{llll}99.7 \% & 55.9 & 25.0 & 48.0\end{array}$ $\begin{array}{llll}99.7 \% & 49.6 & 25.0 & 49.6\end{array}$ $\begin{array}{llll}99.7 \% & 38.2 & 25.0 & 35.6\end{array}$ $\begin{array}{lllll}99.7 \% & 42.2 & 25.0 & 38.7 & 2\end{array}$ $\begin{array}{llll}99.7 \% & 35.3 & 25.0 & 35.3\end{array}$ $\begin{array}{llll}99.7 \% & 39.9 & 25.0 & 32.7\end{array}$ $\begin{array}{llll}98.7 \% & 26.7 & 25.0 & 14.0\end{array}$ $99.7 \% \quad 42.0 \quad 25.0 \quad 42.0 \quad 2$ $99.7 \% \quad 84.1 \quad 25.0 \quad 83.6 \quad 2$ $\begin{array}{llll}99.7 \% & 64.1 & 25.0 & 55.0\end{array}$ $\begin{array}{lllll}99.7 \% & 36.5 & 25.0 & 34.0\end{array}$ $\begin{array}{llll}95.6 \% & 18.3 & 25.0 & 11.6\end{array}$ $\begin{array}{llll}99.7 \% & 59.7 \quad 25.0 & 55.8\end{array}$
1286.6

1090.49

991.52

1393.66

1347.66

1455.64

1384.73

1467.67

873.48

1675.76

1255.74

1030.55

1102.65

1321.74

2072.02

1022.51

1163.55

1832.86

1313.71

1669.91

980.54

1399.76

866.55

1195.61

1742.87

1449.78

1809.86

1531.75

1089.54

1428.71

2010.03

1160.65

2032.03

1191.65

1054.65

911.57

1660.88

1632.89

1286.66

959.53

1234.72 1227.70 
Glutamine--tRNA ligase GN=QARS Glutamine--tRNA ligase GN=QARS Glutamine--tRNA ligase $\mathrm{GN}=\mathrm{QARS}$ Glutamine--tRNA ligase GN=QARS Glutamine--tRNA ligase GN=QARS Glutamine--tRNA ligase GN=QARS
SYQ_HUMAN $87.80 \quad 100.0 \%$ SYQ HUMAN $87.80 \quad 100.0 \%$ SYQ_HUMAN $87.80 \quad 100.0 \%$ SYQ HUMAN $87.80 \quad 100.0 \%$ SYQ_HUMAN $87.80 \quad 100.0 \%$ SYQ_HUMAN $87.80 \quad 100.0 \%$ TL QPCTL_HUMAN $42.93 \quad 100.0 \%$ Glutaminyl-peptide cyclotransferase-like protein GN=QPCTL QPCTL_HUMAN $42.93 \quad 100.0 \%$ Glutaminyl-peptide cyclotransferase-like protein GN=QPCTL QPCTL HUMAN $42.93 \quad 100.0 \%$ Glutaminyl-peptide cyclotransferase-like protein GN=QPCTL QPCTL_HUMAN $42.93 \quad 100.0 \%$ Glutaminyl-peptide cyclotransferase-like protein GN=QPCTL QPCTL_HUMAN $42.93 \quad 100.0 \%$ Glutaminyl-peptide cyclotransferase-like protein GN=QPCTL QPCTL_HUMAN $42.93 \quad 100.0^{\circ}$ Glutaminyl-peptide cyclotransferase-like protein GN=QPCTL QPCTL_HUMAN $42.93 \quad 100.0 \%$ Glutaminyl-peptide cyclotransferase-like protein GN=QPCTL QPCTL_HUMAN $42.93 \quad 100.0 \%$ Glutaminyl-peptide cyclotransferase-like protein GN=QPCTL QPCTL_HUMAN $42.93 \quad 100.0 \%$ Glyceraldehyde-3-phosphate dehydrogenase GN=GAPDH G3P_HUMAN $36.05 \quad 100.0 \%$ Glyceraldehyde-3-phosphate dehydrogenase GN=GAPDH G3P HUMAN $36.05 \quad 100.0 \%$ Glyceraldehyde-3-phosphate dehydrogenase GN=GAPDH G3P_HUMAN $36.05 \quad 100.0 \%$ Glyceraldehyde-3-phosphate dehydrogenase GN=GAPDH G3P_HUMAN $36.05 \quad 100.0 \%$ Glyceraldehyde-3-phosphate dehydrogenase GN=GAPDH G3P HUMAN $36.05 \quad 100.0 \%$ Glyceraldehyde-3-phosphate dehydrogenase GN=GAPDH G3P_HUMAN $36.05 \quad 100.0 \%$ Glycogen [starch] synthase, muscle GN=GYS1 GYS1_HUMAN $83.79 \quad 100.0 \%$ Glycogen [starch] synthase, muscle GN=GYS1 GYS1_HUMAN $83.79 \quad 100.0 \%$ Glycogen phosphorylase, liver form GN=PYGL PYGL_HUMAN $97.15 \quad 100.0 \%$ Glycogen phosphorylase, liver form GN=PYGL PYGL HUMAN 97.15 100.0\% Glycogen phosphorylase, liver form GN=PYGL PYGL_HUMAN $97.15 \quad 100.0 \%$ Glycogen phosphorylase, liver form GN=PYGL PYGL_HUMAN $97.15 \quad 100.0 \%$ Glycogen phosphorylase, liver form GN=PYGL PYGL_HUMAN $97.15 \quad 100.0 \%$ Glycogen phosphorylase, liver form GN=PYGL PYGL_HUMAN $97.15 \quad 100.0 \%$ Glycogen phosphorylase, liver form GN=PYGL PYGL HUMAN $97.15 \quad 100.0 \%$ Glycogen phosphorylase, liver form GN=PYGL PYGL_HUMAN $97.15 \quad 100.0 \%$ Golgi-specific brefeldin A-resistance guanine nucleotide exchange factor $1 \mathrm{GN}=\mathrm{GBF} 1$ GBF1_HUMAN $206.45 \quad 100.0 \%$ BF1 GBF1_HUMAN $206.45 \quad 100.0 \%$ GBF1_HUMAN $206.45 \quad 100.0 \%$ GBF1 HUMAN $206.45 \quad 100.0 \%$ GBF1_HUMAN $206.45 \quad 100.0 \%$ GPI8_HUMAN $45.25 \quad 100.0 \%$ GPI8 HUMAN $45.25 \quad 100.0 \%$ GPI8_HUMAN $45.25 \quad 100.0 \%$ 2 GASP2_HUMAN 93.77 $100.0 \%$ $100.0 \%$ $100.0 \%$ $100.0 \%$ $100.0 \%$ $100.0 \%$ $100.0 \%$ $100.0 \%$
$15 \quad 0.02 \% \quad 12.6 \%$ AINFNFGYAK $0.02 \%$ $0.02 \% \quad 12.6 \%$ GKFSEGEATLR $0.02 \% \quad 12.6 \%$ LFTLTALR

$0.02 \% \quad 12.6 \%$ AMAVLESLR $0.02 \% \quad 12.6 \%$ LGYFSVDPDSHQG $0.04 \% \quad 20.2 \%$ GLMEPLLPPK $0.04 \% \quad 20.2 \%$ TEELPLGR $0.04 \% \quad 20.2 \%$ ELRVPLIGSLPEAR $0.04 \% \quad 20.2 \%$ VPLIGSLPEAR $0.04 \% \quad 20.2 \%$ VVGQLDPQR $0.04 \% \quad 20.2 \%$ TPGSPGNLQVR $0.04 \% \quad 20.2 \%$ TPGSPGNLQVRK $0.04 \% \quad 20.2 \%$ KFLEATLR $0.04 \% \quad 20.2 \%$ HLAQLMESIPHSPGPTR $0.03 \% \quad 19.4 \%$ VGVNGFGR $0.03 \% \quad 19.4 \%$ AGAHLQGGAK

$0.03 \% \quad 19.4 \%$ IISNASCTTNCLAPLAK $0.03 \% \quad 19.4 \%$ DGRGALQNIIPASTGAAK $0.03 \% \quad 19.4 \%$ GALQNIIPASTGAAK $0.03 \% \quad 19.4 \%$ VVDLMAHMASKE $0.01 \% \quad 3.4 \%$ TQVELLEAPTPALKR $0.01 \% \quad 3.4 \%$ TNNFNVETLK $0.02 \% \quad 10.5 \%$ GIVGVENVAELKK $0.02 \% \quad 10.5 \%$ VLYPNDNFFEGKELR $0.02 \% \quad 10.5 \%$ FSQFLETEYKVK $0.02 \% \quad 10.5 \%$ INPSSMFDVQVKR $0.02 \% \quad 10.5 \%$ LKVIFLENYR $0.02 \% \quad 10.5 \%$ VIFLENYR $0.02 \% \quad 10.5 \%$ LVIDQIDNGFFSPK $0.02 \% \quad 10.5 \%$ NIAASGKFSSDR $0.01 \% \quad 3.2 \%$ VLNSLTQQEK $0.01 \% \quad 3.2 \% \quad$ FSCLLPDPR $0.01 \% \quad 3.2 \%$ LLITGTEQFNQKPK $0.01 \% \quad 3.2 \%$ KGIQFLQEK $0.01 \% \quad 3.2 \%$ AASSSSPGSPVASSPSR $0.01 \% \quad 7.9 \%$ HVANTLSVYR $0.01 \% \quad 7.9 \%$ SYEVTVENFLR $0.01 \% \quad 7.9 \%$ SLCVSTPGHR $0.01 \% \quad 2.9 \%$ TEAQAMSGARPK $0.01 \% \quad 2.9 \%$ TEAQGITGARPK $0.00 \% \quad 6.3 \%$ SFLAGGIAGCCAK $0.00 \% \quad 6.3 \%$ GLSLNYIR $0.01 \% \quad 14.9 \%$ STLSNQLLGR $0.01 \% \quad 14.9 \%$ DPNTQSVGNPQR

$\begin{array}{llll}99.7 \% & 52.5 & 25.0 & 38.8\end{array}$ $99.7 \% \quad 48.5$ $99.7 \% \quad 51.2$ $99.0 \% \quad 26.4$ $99.7 \% \quad 52.6$ $\begin{array}{lll}99.6 \% & 22.5\end{array}$ $99.7 \% \quad 36.0$ $\begin{array}{lll}99.0 \% & 27.2\end{array}$ $99.7 \% \quad 32.8$ $99.7 \% \quad 41.4$ $\begin{array}{lll}99.7 \% & 26.7\end{array}$ $99.7 \% \quad 55.7$ $99.7 \% \quad 38.3$ $94.7 \% \quad 20.0$

$99.7 \% \quad 28.8$ $99.0 \% \quad 38.6$ $99.4 \% \quad 21.3$

$99.7 \% \quad 54.5$

$99.7 \% \quad 53.2$ $99.7 \% \quad 43.9$ $99.7 \% \quad 48.9$ $99.7 \% \quad 36.5$ $99.2 \% \quad 21.5$ $99.7 \% \quad 58.6$ $99.7 \% \quad 44.5$ $\begin{array}{lll}99.7 \% & 42.8\end{array}$ $99.7 \% \quad 52.5$ $99.7 \% \quad 35.6$ $99.0 \% \quad 27.0$ $99.7 \% \quad 37.2$ $99.7 \% \quad 56.5$ $\begin{array}{lll}97.4 \% & 17.4\end{array}$ $99.4 \% \quad 22.1$ $\begin{array}{lll}99.7 \% & 56.3\end{array}$ $99.7 \% \quad 25.2$ $99.7 \% \quad 49.1$ $99.7 \% \quad 30.5$ $\begin{array}{lll}99.7 \% & 39.9\end{array}$

$99.7 \% \quad 25.3$ $\begin{array}{lll}99.7 \% & 33.8\end{array}$ $99.7 \% \quad 33.8$ $99.7 \% 53.1$ $\begin{array}{lll}98.2 \% & 23.2\end{array}$ $99.7 \% \quad 49.5$ $99.7 \% \quad 27.4$ 列 $\quad 97.6 \% \quad 17.4$

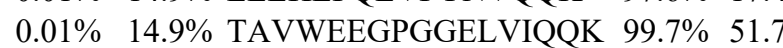

1144.58 1064.53 1194.61 934.57 989.54 2179.09 1094.63 914.49 1549.91

1151.68 1011.56

1125.60

1253.70

977.58

1870.96

805.43

909.49

1833.92

1739.94

1411.79

1362.64

1665.95

1179.60

1355.79

1840.92

1518.78

1520.79

1294.75

1053.57

1592.83

1252.63

1159.63

1104.5

1616.90

1090.63

1531.73

1159.62

1356.68

1113.55

1262.62

1228.66

1311.62

935.53

1088.61

1312.62

1935.03 1840.94

$\begin{array}{cc}83 & 292 \\ 93 & 301 \\ 93 & 403 \\ 16 & 523 \\ 68 & 576 \\ 46 & 764 \\ 7 & 26 \\ 9 & 66 \\ 7 & 80 \\ 0 & 80 \\ 4 & 92 \\ 06 & 116 \\ 06 & 117 \\ 17 & 124 \\ 42 & 258 \\ 6 & 13 \\ 08 & 117 \\ 46 & 162 \\ 98 & 215 \\ 01 & 215 \\ 24 & 335 \\ 5 & 89 \\ 72 & 381 \\ 8 & 30 \\ 79 & 293 \\ 46 & 557 \\ 58 & 570 \\ 41 & 650 \\ 43 & 650 \\ 41 & 754 \\ 05 & 816 \\ 96 & 605 \\ 83 & 691 \\ 02 & 715 \\ 16 & 724 \\ 76 & 1792 \\ 1 & 70 \\ 23 & 133 \\ 78 & 287 \\ 4 & 75 \\ 8 & 99 \\ 9 & 51 \\ 03 & 310 \\ 27 & 136 \\ 85 & 296 \\ 56 & 371 \\ 72 & 388\end{array}$


GTPase Era, mitochondrial GN=ERAL1 ERAL1_HUMAN $48.35 \quad 100.0 \%$ GTPa GTP-binding nuclear protein Ran GN=RAN RAN_HUMAN $24.42 \quad 100.0 \%$ GTP-binding protein $10 \mathrm{GN}=$ GTPBP10 $\quad$ GTPBA_HUMAN $42.93 \quad 100.0 \%$ GTP-binding protein $10 \mathrm{GN}=$ GTPBP10 GTPBA_HUMAN $42.93 \quad 100.0 \%$ GTP-binding protein $10 \mathrm{GN}=$ GTPBP10 GTPBA_HUMAN $42.93 \quad 100.0 \%$ Guanine nucleotide-binding protein $\mathrm{G}(\mathrm{I}) / \mathrm{G}(\mathrm{S}) / \mathrm{G}(\mathrm{T})$ subunit beta-1 $\mathrm{GN}=\mathrm{GNB} 1 \quad \mathrm{GBB} 1 \_\mathrm{HUMAN} 37.38 \quad 100.0 \%$ Guanine nucleotide-binding protein $\mathrm{G}(\mathrm{I}) / \mathrm{G}(\mathrm{S}) / \mathrm{G}(\mathrm{T})$ subunit beta-1 $\mathrm{GN}=\mathrm{GNB1}$ GBB1_HUMAN $37.38 \quad 100.0 \%$ Guanine nucleotide-binding protein $\mathrm{G}(\mathrm{I} / \mathrm{G} / \mathrm{G}(\mathrm{S}) / \mathrm{G}(\mathrm{T})$ subunit beta-1 $\mathrm{GN}=\mathrm{GNB} 1 \mathrm{GBB} 1$ HUMAN $37.38 \quad 100.0 \%$ Guanine nucleotide-binding protein $\mathrm{G}(\mathrm{I}) / \mathrm{G}(\mathrm{S}) / \mathrm{G}(\mathrm{T})$ subunit beta-1 GN=GNB1 $\quad \mathrm{GBB} 1$ _HUMAN $37.38 \quad 100.0 \%$ Guanine nucleotide-binding protein $\mathrm{G}(\mathrm{I}) / \mathrm{G}(\mathrm{S}) / \mathrm{G}(\mathrm{T})$ subunit beta-2 $\mathrm{GN}=\mathrm{GNB} 2 \quad \mathrm{GBB} 2$ _HUMAN $37.33 \quad 100.0 \%$ Guanine nucleotide-binding protein $\mathrm{G}(\mathrm{I}) / \mathrm{G}(\mathrm{S}) / \mathrm{G}(\mathrm{T})$ subunit beta-2 $\mathrm{GN}=\mathrm{GNB} 2 \quad \mathrm{GBB} 2$ HUMAN $37.33 \quad 100.0 \%$ Guanine nucleotide-binding protein $\mathrm{G}(\mathrm{I}) / \mathrm{G}(\mathrm{S}) / \mathrm{G}(\mathrm{T})$ subunit beta-2 $\mathrm{GN}=\mathrm{GNB} 2 \quad \mathrm{GBB} 2$ _HUMAN $37.33 \quad 100.0 \%$ Guanine nucleotide-binding protein $\mathrm{G}(\mathrm{I}) / \mathrm{G}(\mathrm{S}) / \mathrm{G}(\mathrm{T})$ subunit beta-2 $\mathrm{GN}=\mathrm{GNB} 2 \quad \mathrm{GBB} 2$ _HUMAN $37.33 \quad 100.0 \%$ Guanine nucleotide-binding protein $\mathrm{G}(\mathrm{I}) / \mathrm{G}(\mathrm{S}) / \mathrm{G}(\mathrm{T})$ subunit beta-2 $\mathrm{GN}=\mathrm{GNB} 2 \quad \mathrm{GBB} 2$ HUMAN $37.33 \quad 100.0 \%$ Guanine nucleotide-binding protein $\mathrm{G}(\mathrm{k})$ subunit alpha $\mathrm{GN}=\mathrm{GNAI3}$ GNAI3_HUMAN $40.53 \quad 100.0 \%$ Guanine nucleotide-binding protein $\mathrm{G}(\mathrm{k})$ subunit alpha $\mathrm{GN}=\mathrm{GNAI3}$ GNAI3 HUMAN $40.53100 .0 \%$ Guanine nucleotide-binding protein $\mathrm{G}(\mathrm{k})$ subunit alpha $\mathrm{GN}=\mathrm{GNAI3}$ GNAI3_HUMAN $40.53 \quad 100.0 \%$ Guanine nucleotide-binding protein $\mathrm{G}(\mathrm{k})$ subunit alpha $\mathrm{GN}=\mathrm{GNAI} 3$ GNAI3_HUMAN 40.53 Guanine nucleotide-binding protein $\mathrm{G}(\mathrm{s})$ subunit alpha isoforms short $\mathrm{GN}=\mathrm{GNAS}$ GNAS2_HUMAN 45.67 Guanine nucleotide-binding protein $\mathrm{G}(\mathrm{s})$ subunit alpha isoforms shor $\mathrm{GN}=\mathrm{GNAS}$ GNAS2_HUMAN 45.67 nnine nucleotide-binding protein $\mathrm{G}(\mathrm{s})$ subunit alpha isoforms shor $\mathrm{GN}=\mathrm{GNAS}$ GNAS2_HUMAN 45.67 mine nucleotide-binding protein G(s) subunit alpha isoforms short GN=GNAS GNAS2_HUMAN 45.67 ine nucleotide-binding protein subunit alpha-11 GN=GNA11 GNA11_HUMAN 42.13 Guanine nucleotide-binding protein subunit alpha-11 GN=GNA11 GNA11 HUMAN 42.13 Guanine nucleotide-binding protein subunit beta-2-like 1 GN=GNB2L1 GBLP_HUMAN 35.08 Guanine nucleotide-binding protein subunit beta-2-like 1 GN=GNB2L1 GBLP_HUMAN 35.08 Guanine nucleotide-binding protein subunit beta-2-like $1 \mathrm{GN}=$ GNB2L1 GBLP_HUMAN 35.08 Guanine nucleotide-binding protein subunit beta-2-like 1 GN=GNB2L1 GBLP_HUMAN 35.08 Guanine nucleotide-binding protein subunit beta-2-like 1 GN=GNB2L1 GBLP_HUMAN 35.08 Guanine nucleotide-binding protein subunit beta-2-like 1 GN=GNB2L1 GBLP_HUMAN 35.08 Guanine nucleotide-binding protein subunit beta-2-like $1 \mathrm{GN}=\mathrm{GNB} 2 \mathrm{~L} 1$ GBLP_HUMAN 35.08 Guanine nucleotide-binding protein subunit beta-2-like $1 \mathrm{GN}=\mathrm{GNB} 2 \mathrm{~L} 1$ GBLP HUMAN 35.08 Guanine nucleotide-binding protein subunit beta-2-like $1 \mathrm{GN}=$ GNB2L1 GBLP_HUMAN 35.08 Guanine nucleotide-binding protein-like 3 GN=GNL3 GNL3_HUMAN 61.99 Guanine nucleotide-binding protein-like $3 \mathrm{GN}=\mathrm{GNL} 3$ GNL3_HUMAN 61.99 Guanine nucleotide-binding protein-like 3 GN=GNL3 GNL3_HUMAN 61.99 Guanine nucleotide-binding protein-like $3 \mathrm{GN}=\mathrm{GNL} 3$ GNL3 HUMAN 61.99 Guanine nucleotide-binding protein-like 3 GN=GNL3 GNL3_HUMAN 61.99 Guanine nucleotide-binding protein-like 3-like protein GN=GNL3L GNL3L_HUMAN 65.57 Guanine nucleotide-binding protein-like 3-like protein GN=GNL3L GNL3L HUMAN 65.57 Guanine nucleotide-binding protein-like 3-like protein GN=GNL3L GNL3L_HUMAN 65.5 $\mathrm{H} / \mathrm{ACA}$ ribonucleoprotein complex subunit $1 \mathrm{GN}=\mathrm{GAR} 1$ GAR1 HUMAN 22.3 H/ACA ribonucleoprotein complex subunit $1 \mathrm{GN}=\mathrm{GAR} 1$ GAR1_HUMAN 22.35 H/ACA ribonucleoprotein complex subunit $1 \mathrm{GN}=$ GAR1 GAR1_HUMAN 22.3 $\mathrm{H} / \mathrm{ACA}$ ribonucleoprotein complex subunit $4 \mathrm{GN}=\mathrm{DKC} 1 \mathrm{DKC1}$ HUMAN 57.68 $\mathrm{H} / \mathrm{ACA}$ ribonucleoprotein complex subunit $4 \mathrm{GN}=\mathrm{DKC1} \mathrm{DKC1}{ }_{-} \mathrm{HUMAN} 57.68$ $100.0 \%$
$100.0 \%$ $100.0 \%$ $100.0 \%$ $100.0 \%$ $100.0 \%$ $100.0 \%$ $100.0 \%$ $100.0 \%$ $100.0 \%$ $100.0 \%$ $100.0 \%$ $100.0 \%$ $100.0 \%$ $100.0 \%$ $100.0 \%$ $100.0 \%$ $100.0 \%$ $100.0 \%$ $100.0 \%$ $100.0 \%$ $100.0 \%$ $100.0 \%$

$100.0 \%$ $100.0 \%$ $100.0 \%$ $100.0 \%$ $100.0 \%$
$0.01 \% \quad 14.9 \%$ LLVPKESYVK $0.00 \% \quad 11.1 \%$ NLQYYDISAK $0.00 \% \quad 11.1 \%$ SNYNFEKPFLWLAR $0.01 \% \quad 9.8 \%$ GGSGGMGYPR $0.01 \% \quad 9.8 \%$ LGGEGGKGGDVWVVAQNR $0.01 \% \quad 9.8 \%$ FVAGVGANSK

$0.01 \% \quad 16.2 \%$ KACADATL $0.01 \% \quad 16.2 \%$ ELAGHTGYLSCCR $0.01 \% \quad 16.2 \%$ LFVSGACDASAK

$0.01 \% \quad 16.2 \%$ AGVLAGHDNR $\begin{array}{lllll}0.01 \% & 16.2 \% & \text { KACGDSTLTQITAGLDPVGR } & 99.7 \% & 33.0\end{array}$ $0.01 \% \quad 16.2 \%$ ACGDSTLTQITAGLDPVGR $99.7 \% \quad 50.1$ $0.01 \% \quad 16.2 \%$ ELPGHTGYLSCCR $0.01 \% \quad 16.2 \%$ TFVSGACDASIK

$0.01 \% \quad 16.2 \%$ AGVLAGHDNR $0.00 \% \quad 11.6 \%$ LLLLGAGESGK $0.00 \% \quad 11.6 \%$ LLLLGAGESGKSTIVK $0.00 \% \quad 11.6 \%$ DGGVQACFSR $0.00 \% \quad 11.6 \%$ ISQSNYIPTQQDVLR

$\begin{array}{lllll}0.02 \% & 11.7 \% & \text { LLLLGAGESGKSTIVK } & 99.7 \% & 31.0 \\ 0.02 \% & 11.7 \% & \text { YTTPEDATPEPGEDPRVTR } & 98.1 \% & 17.0\end{array}$

$0.02 \% \quad 11.7 \%$ VFNDCRDIIQR

$0.00 \% \quad 5.3 \%$ LLLLGTGESGK

$0.00 \% \quad 5.3 \% \quad$ MVDVGGQR

$\begin{array}{llll}99.7 \% & 25.7 & 25.0 & 16.4\end{array}$

$99.5 \% \quad 45.3 \quad 25.0 \quad 23.8$

$98.0 \% \quad 21.0 \quad 25.0 \quad 15.9$

$0.03 \% \quad 33.4 \%$ LTRDETNYGIPQR

$0.03 \% \quad 33.4 \%$ DETNYGIPQR

$\begin{array}{lll}0.03 \% & 33.4 \% & \text { FVGHTKDVLSVAFSSDNR } 99.7 \% \quad 29.3\end{array}$

$0.03 \% \quad 33.4 \%$ DVLSVAFSSDNR

$99.7 \% \quad 66.7$

$0.03 \% \quad 33.4 \%$ DVLSVAFSSDNRQIVSGSR $\quad 99.7 \% \quad 45.0$

$\begin{array}{lllll}0.03 \% & 33.4 \% & \text { YTVQDESHSEWVSCVR } \quad 99.7 \% & 36.6\end{array}$

$\begin{array}{lllll}0.03 \% & 33.4 \% & \text { TNHIGHTGYLNTVTVSPDGSLCASGGK } & 99.7 \% & 54.1\end{array}$

$\begin{array}{llll}0.03 \% & 33.4 \% & \text { IIVDELKOEVISTSSK } \quad 99.7 \% & 31.7\end{array}$

$0.03 \% \quad 33.4 \%$ VWQVTIGTR

$0.02 \% \quad 10.6 \%$ ELPTVVFR

$0.02 \% \quad 10.6 \%$ LLGGFQETCSK

$0.02 \% \quad 10.6 \%$ VGVIGFPNVGK

$0.02 \% \quad 10.6 \%$ GGIPNVEGAAK

$99.7 \% 53.3$

$99.0 \% \quad 41.9$

$99.5 \% \quad 20.7$

$99.7 \% \quad 41.0$

$98.7 \% \quad 20.0$

$0.02 \% \quad 10.6 \%$ SGFNLEELEKNNAQSIR

$99.7 \% \quad 53.7$

$0.01 \% \quad 7.7 \%$ TIESYCQDVLR

$99.7 \% \quad 50.8$

$0.01 \% \quad 7.7 \% \quad$ LLDAPGIVPGPNSEVGTILR $\quad 99.7 \% \quad 28.5$

$0.01 \% \quad 7.7 \%$ LADPVTPVETILQR

$99.7 \% \quad 33.7$

$99.7 \% \quad 39.9$

$0.01 \% \quad 18.4 \%$ GQDQGPPER

$\begin{array}{ll}99.7 \% & 26.4\end{array}$

$0.01 \% \quad 18.4 \%$ VVLLGEFLHPCEDDIVCK

$0.01 \% \quad 18.4 \%$ FYIDPYKLLPLQR

$\begin{array}{lll}99.7 \% & 33.4\end{array}$

$99.7 \% \quad 59.0$

$\begin{array}{lll}0.01 \% & 5.3 \% & \text { LHNAIEGGTQLSR }\end{array}$ $\begin{array}{ccc}1175.70 & 389 & 398 \\ 1214.61 & 143 & 152 \\ 1784.91 & 153 & 166 \\ 938.42 & 25 & 34 \\ 1798.92 & 35 & 52 \\ 949.51 & 67 & 76 \\ 2144.08 & 23 & 42 \\ 1523.67 & 138 & 150 \\ 1225.59 & 198 & 209 \\ 1009.52 & 305 & 314 \\ 2060.04 & 23 & 42 \\ 1931.95 & 24 & 42 \\ 1549.69 & 138 & 150 \\ 1255.60 & 198 & 209 \\ 1009.52 & 305 & 314 \\ 1057.63 & 36 & 46 \\ 1585.95 & 36 & 51 \\ 1096.48 & 133 & 142 \\ 1761.91 & 162 & 176 \\ 1057.63 & 43 & 53 \\ 1585.95 & 43 & 58 \\ 2130.99 & 318 & 336 \\ 1435.71 & 375 & 385 \\ 1087.64 & 42 & 52 \\ 861.42 & 203 & 210 \\ 1562.79 & 45 & 57 \\ 1192.56 & 48 & 57 \\ 1979.00 & 101 & 118 \\ 1309.64 & 107 & 118 \\ 2037.04 & 107 & 125 \\ 1981.87 & 140 & 155 \\ 2743.31 & 186 & 212 \\ 1789.00 & 265 & 280 \\ 1059.59 & 309 & 317 \\ 960.55 & 198 & 205 \\ 1239.60 & 243 & 253 \\ 1086.63 & 257 & 267 \\ 1012.54 & 378 & 388 \\ 1948.97 & 425 & 441 \\ 1383.66 & 84 & 94 \\ 2018.13 & 301 & 320 \\ 1551.87 & 328 & 341 \\ 983.45 & 61 & 69 \\ 2143.06 & 70 & 87 \\ 1665.94 & 144 & 156 \\ 1521.80 & 145 & 158 \\ 1395.73 & 159 & 171 \\ & & \end{array}$

Page 62 of Table S-1-1 
HAUS augmin-like complex subunit 5 GN=HAUS5 HAUS5_HUMAN $71.68 \quad 99.9 \%$ HAUS augmin-like complex subunit 5 GN=HAUS5 HAUS5_HUMAN $71.68 \quad 99.9 \%$ HCLS1-associated protein X-1 GN=HAX1 HAX1_HUMAN $31.62 \quad 100.0 \%$ HCLS1-associated protein X-1 GN=HAX1 HAX1_HUMAN $31.62 \quad 100.0 \%$ HCLS1-associated protein X-1 GN=HAX1 HAX1_HUMAN $31.62 \quad 100.0 \%$ HCLS1-associated protein X-1 GN=HAX1 HAX1_HUMAN $31.62 \quad 100.0 \%$ HCLS1-associated protein X-1 GN=HAX1 HAX1_HUMAN $31.62 \quad 100.0 \%$ HEAT repeat-containing protein 1 GN=HEATR1 HEAT1_HUMAN $242.38 \quad 100.0 \%$ HEAT repeat-containing protein $1 \mathrm{GN}=$ HEATR1 HEAT1_HUMAN $242.38 \quad 100.0 \%$ HEAT repeat-containing protein $1 \mathrm{GN}=$ HEATR1 HEAT1_HUMAN $242.38 \quad 100.0 \%$ HEAT repeat-containing protein 1 GN=HEATR1 HEAT1_HUMAN $242.38 \quad 100.0 \%$ HEAT repeat-containing protein $1 \mathrm{GN}=$ HEATR1 HEAT1_HUMAN $242.38 \quad 100.0 \%$ Heat shock $70 \mathrm{kDa}$ protein 1A/1B GN=HSPA1A HSP71_HUMAN $70.05 \quad 100.0 \%$ Heat shock $70 \mathrm{kDa}$ protein 1A/1B GN=HSPA1A HSP71_HUMAN 70.05 Heat shock $70 \mathrm{kDa}$ protein $1 \mathrm{~A} / 1 \mathrm{~B}$ GN=HSPA1A HSP71_HUMAN 70.05 Heat shock $70 \mathrm{kDa}$ protein $1 \mathrm{~A} / 1 \mathrm{~B}$ GN=HSPA1A HSP71_HUMAN 70.05 Heat shock $70 \mathrm{kDa}$ protein 1A/1B GN=HSPA1A HSP71_HUMAN 70.05 Heat shock $70 \mathrm{kDa}$ protein $1 \mathrm{~A} / 1 \mathrm{~B}$ GN=HSPA1A HSP71_HUMAN 70.05 Heat shock $70 \mathrm{kDa}$ protein 1A/1B GN=HSPA1A HSP71_HUMAN 70.05 Heat shock $70 \mathrm{kDa}$ protein 1A/1B GN=HSPA1A HSP71_HUMAN 70.05 Heat shock $70 \mathrm{kDa}$ protein 1A/1B GN=HSPA1A HSP71_HUMAN 70.05 Heat shock $70 \mathrm{kDa}$ protein 1A/1B GN=HSPA1A HSP71_HUMAN 70.05 Heat shock $70 \mathrm{kDa}$ protein $1 \mathrm{~A} / 1 \mathrm{~B}$ GN=HSPA1A HSP71_HUMAN 70.05 Heat shock $70 \mathrm{kDa}$ protein 1A/1B GN=HSPA1A HSP71_HUMAN 70.05 Heat shock $70 \mathrm{kDa}$ protein 1A/1B GN=HSPA1A HSP71_HUMAN 70.05 Heat shock $70 \mathrm{kDa}$ protein 1A/1B GN=HSPA1A HSP71_HUMAN 70.05 Heat shock $70 \mathrm{kDa}$ protein $1 \mathrm{~A} / 1 \mathrm{~B}$ GN=HSPA1A HSP71_HUMAN 70.05 Heat shock $70 \mathrm{kDa}$ protein $1 \mathrm{~A} / 1 \mathrm{~B}$ GN=HSPA1A HSP71_HUMAN 70.05 Heat shock $70 \mathrm{kDa}$ protein $1 \mathrm{~A} / 1 \mathrm{~B}$ GN=HSPA1A HSP71_HUMAN 70.05 Heat shock $70 \mathrm{kDa}$ protein 1A/1B GN=HSPA1A HSP71_HUMAN 70.05 Heat shock $70 \mathrm{kDa}$ protein 1A/1B GN=HSPA1A HSP71_HUMAN 70.05 Heat shock $70 \mathrm{kDa}$ protein 1A/1B GN=HSPA1A HSP71_HUMAN 70.05 Heat shock $70 \mathrm{kDa}$ protein 1A/1B GN=HSPA1A HSP71_HUMAN 70.05 Heat shock $70 \mathrm{kDa}$ protein 1A/1B GN=HSPA1A HSP71_HUMAN 70.05 Heat shock cognate $71 \mathrm{kDa}$ protein GN=HSPA8 HSP7C_HUMAN 70.90 Heat shock cognate $71 \mathrm{kDa}$ protein GN=HSPA8 HSP7C_HUMAN 70.90 Heat shock cognate $71 \mathrm{kDa}$ protein GN=HSPA8 HSP7C_HUMAN 70.90 Heat shock cognate $71 \mathrm{kDa}$ protein GN=HSPA8 HSP7C_HUMAN 70.90 Heat shock cognate $71 \mathrm{kDa}$ protein GN=HSPA8 HSP7C_HUMAN 70.90 Heat shock cognate $71 \mathrm{kDa}$ protein GN=HSPA8 HSP7C_HUMAN 70.90 Heat shock cognate $71 \mathrm{kDa}$ protein GN=HSPA8 HSP7C_HUMAN 70.90 Heat shock cognate $71 \mathrm{kDa}$ protein GN=HSPA8 HSP7C_HUMAN 70.90 Heat shock cognate $71 \mathrm{kDa}$ protein GN=HSPA8 HSP7C_HUMAN 70.90 Heat shock cognate $71 \mathrm{kDa}$ protein GN=HSPA8 HSP7C_HUMAN 70.90 Heat shock cognate $71 \mathrm{kDa}$ protein GN=HSPA8 HSP7C_HUMAN 70.90 Heat shock cognate $71 \mathrm{kDa}$ protein GN=HSPA8 HSP7C_HUMAN 70.90 Heat shock cognate $71 \mathrm{kDa}$ protein GN=HSPA8 HSP7C_HUMAN 70.90
$0.00 \% \quad 2.8 \%$ MELAQEAR

$0.00 \% \quad 2.8 \%$ KLELEAAVTR

$0.02 \% \quad 20.4 \%$ GFFGFPGPR

$0.02 \% \quad 20.4 \%$ IFGGVLESDAR

$0.02 \% \quad 20.4 \%$ TREDNDLDSQVSQEGLGPVLQPQPK

$0.02 \% \quad 20.4 \%$ ITKPDGIVEER

$0.02 \% \quad 20.4 \%$ ITKPDGIVEERR

$0.01 \% \quad 2.9 \% \quad$ LLESKYPR

$0.01 \% \quad 2.9 \% \quad$ LDDTYSFQVINK

$0.01 \% \quad 2.9 \%$ GLVGNPLPSVR

$0.01 \% \quad 2.9 \%$ LVPDLLAIVQR

$0.01 \% \quad 2.9 \% \quad$ NFGAENPDPFVPVLNTA

$\begin{array}{ll}99.4 \% & 24.0 \\ 97.7 \% & 18.2\end{array}$

$\begin{array}{lll}99.7 \% & 28.1\end{array}$

$0.12 \% \quad 29.2 \%$ TTPSYVAFTDTER

$99.7 \% \quad 53.0$

$100.0 \% \quad 22$

$100.0 \% \quad 22$

$100.0 \% \quad 22$

$100.0 \% \quad 22$

$100.0 \% \quad 22$

$100.0 \% \quad 22$

$100.0 \% \quad 22$

$100.0 \% \quad 22$

$100.0 \% \quad 22$

$100.0 \% \quad 22$

$100.0 \% \quad 22$

$100.0 \% \quad 22$

$100.0 \% \quad 22$

$100.0 \% \quad 22$

$100.0 \% \quad 22$

$100.0 \% \quad 22$

$100.0 \% \quad 22$

$100.0 \% \quad 22$

$100.0 \% \quad 22$

$100.0 \% \quad 22$

$100.0 \% \quad 22$

$100.0 \% \quad 20$

$100.0 \% \quad 20$

$100.0 \% \quad 20$

$100.0 \% \quad 20$

$100.0 \% \quad 20$

$100.0 \% \quad 20$

$100.0 \% \quad 20$

$100.0 \% \quad 20$

$100.0 \% \quad 20$

$100.0 \% \quad 20$

$100.0 \% \quad 20$

$100.0 \% \quad 20$ $100.0 \% \quad 20$
$0.12 \% \quad 29.2 \%$ TTPSYVAFTDTERLIGDAAK

$0.12 \% \quad 29.2 \%$ LIGDAAKNQVALNPQNTVFDAK $99.7 \%$

$0.12 \% \quad 29.2 \%$ NQVALNPQNTVFDAKR

$0.12 \% \quad 29.2 \%$ VQVSYKGETK

$99.7 \% \quad 62.3$

$99.7 \% \quad 41.0$

$99.7 \% \quad 47.5$

$0.12 \% \quad 29.2 \%$ QATKDAGVIAGLNVLR $\quad 99.7 \% \quad 49.5$

$0.12 \% \quad 29.2 \%$ DAGVIAGLNVLR

$99.7 \% \quad 73.8$

$99.7 \% 53.6$

$0.12 \% \quad 29.2 \%$ IINEPTAAAIAYGLDR

$99.7 \% \quad 53.6$

$99.7 \% \quad 49.2$

$99.0 \% \quad 29.4$

$99.7 \% \quad 69.4$

29.2\% FEELCSDLFR

$0.12 \% \quad 29.2 \%$ STLEPVEK

$0.12 \% \quad 29.2 \%$ AQIHDLVLVGGSTR

0.12\% 29.2\% AQIHDLVLVGGSTRIPK

$99.2 \% \quad 20.6$

$99.7 \% \quad 50.9$

$99.7 \% \quad 61.5$

$99.7 \% \quad 57.2$

$99.0 \% \quad 55.2$

$0.12 \% \quad 29.2 \%$ ITITNDKGR

$0.12 \% \quad 29.2 \%$ LSKEEIER

$89 \quad 0.12 \% \quad 29.2 \%$ GGSGSGPTIEEVD

$69 \quad 0.09 \% \quad 33.7 \%$ TTPSYVAFTDTER

$99.7 \% \quad 53.7$

$99.7 \% \quad 35.3$

$99.7 \% \quad 53.0$

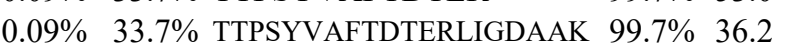

$0.09 \% \quad 33.7 \%$ NQVAMNPTNTVFDAK $\quad 99.7 \% \quad 54.6$

$0.09 \% \quad 33.7 \%$ NQVAMNPTNTVFDAKR $\quad 99.7 \% \quad 57.6$

$99.7 \% \quad 54.2$

$99.7 \% \quad 59.8$

$99.7 \% \quad 69.3$

$0.09 \% \quad 33.7 \%$ MKEIAEAYLGK

QR $99.7 \% \quad 55.6$

$0.09 \% \quad 33.7 \%$ TVTNAVVTVPAYFNDSQRQATK $\quad 95.8 \% \quad 22.0$

$0.09 \% \quad 33.7 \%$ QATKDAGTIAGLNVLR

$99.7 \% \quad 50.9$

$\begin{array}{lll}99.7 \% & 67.3\end{array}$

$99.7 \% \quad 70.0$

69
$0.09 \% \quad 33.7 \%$ IINEPTAAAIAYGLDK

$0.09 \% \quad 33.7 \%$ IINEPTAAAIAYGLDKK
$99.7 \% \quad 58.5$ $\begin{array}{lllll}0.12 \% & 29.2 \% & \text { NQVALNPQNTVFDAK } & 99.7 \% & 50.5\end{array}$

$0.12 \% \quad 29.2 \%$ AFYPEEISSMVLTK

$0.12 \% \quad 29.2 \%$ NALESYAFNMK

$69 \quad 0.09 \% \quad 33.7 \%$ SFYPEEVSSMVLTK

129.66

981.49

1163.61

2750.36

1256.68

1412.79

1005.57

1442.72

1108.65

1236.77

2029.04

1487.70

2156.09

2327.24

1658.85

1814.95

1138.61

1630.80

1625.93

1197.70

1687.90

1542.74

1315.60

902.48

1465.81

1804.04

1109.57

1579.82

1017.57

1003.54

1672.84

1287.60

1204.53

1487.70

2156.09

1665.79

1805.90

1180.62

1632.78

1252.66

1982.00

2410.24

1627.91

1199.67

1659.90

1787.99 
Heat shock cognate $71 \mathrm{kDa}$ protein GN=HSPA8 HSP7C_HUMAN $70.90 \quad 100.0 \% \quad 20$ Heat shock cognate $71 \mathrm{kDa}$ protein GN=HSPA8 HSP7C_HUMAN $70.90 \quad 100.0 \% \quad 20$ Heat shock cognate $71 \mathrm{kDa}$ protein GN=HSPA8 HSP7C_HUMAN $70.90 \quad 100.0 \% \quad 2$ Heat shock cognate $71 \mathrm{kDa}$ protein GN=HSPA8 HSP7C_HUMAN $70.90 \quad 100.0 \% \quad 2$ Heat shock cognate $71 \mathrm{kDa}$ protein GN=HSPA8 HSP7C_HUMAN $70.90 \quad 100.0 \% \quad 2$ Heat shock cognate $71 \mathrm{kDa}$ protein GN=HSPA8 HSP7C_HUMAN $70.90 \quad 100.0 \% \quad 2$ Heat shock cognate $71 \mathrm{kDa}$ protein GN=HSPA8 HSP7C_HUMAN $70.90 \quad 100.0 \% \quad 20$ Heat shock cognate $71 \mathrm{kDa}$ protein GN=HSPA8 HSP7C_HUMAN $70.90 \quad 100.0 \% \quad 20$ Heat shock cognate $71 \mathrm{kDa}$ protein GN=HSPA8 HSP7C HUMAN $70.90 \quad 100.0 \%$ Heat shock cognate $71 \mathrm{kDa}$ protein GN=HSPA8 HSP7C_HUMAN $70.90 \quad 100.0 \% \quad 20$ Heat shock protein $105 \mathrm{kDa}$ GN=HSPH1 HS105_HUMAN $96.87 \quad 100.0 \%$ Heat shock protein $105 \mathrm{kDa}$ GN=HSPH1 HS105 HUMAN $96.87 \quad 100.0 \%$ Heat shock protein $105 \mathrm{kDa}$ GN=HSPH1 HS105_HUMAN $96.87 \quad 100.0 \%$ Heat shock protein $75 \mathrm{kDa}$, mitochondrial GN=TRAP1 TRAP1_HUMAN $80.11 \quad 100.0 \%$ Heat shock protein $75 \mathrm{kDa}$, mitochondrial GN=TRAP1 TRAP1_HUMAN $80.11 \quad 100.0 \%$ Heat shock protein $75 \mathrm{kDa}$, mitochondrial GN=TRAP1 TRAP1_HUMAN $80.11 \quad 100.0 \%$ Heat shock protein $75 \mathrm{kDa}$, mitochondrial GN=TRAP1 TRAP1_HUMAN $80.11 \quad 100.0 \%$ Heat shock protein $75 \mathrm{kDa}$, mitochondrial GN=TRAP1 TRAP1_HUMAN $80.11 \quad 100.0 \%$ Heat shock protein $75 \mathrm{kDa}$, mitochondrial GN=TRAP1 TRAP1_HUMAN $80.11 \quad 100.0 \%$ Heat shock protein $75 \mathrm{kDa}$, mitochondrial GN=TRAP1 TRAP1_HUMAN $80.11 \quad 100.0 \%$ Heat shock protein $75 \mathrm{kDa}$, mitochondrial GN=TRAP1 TRAP1_HUMAN $80.11 \quad 100.0 \%$ Heat shock protein $75 \mathrm{kDa}$, mitochondrial GN=TRAP1 TRAP1_HUMAN $80.11 \quad 100.0 \%$ Heat shock protein $75 \mathrm{kDa}$, mitochondrial GN=TRAP1 TRAP1_HUMAN $80.11 \quad 100.0 \%$ Heat shock protein $75 \mathrm{kDa}$, mitochondrial GN=TRAP1 TRAP1_HUMAN $80.11 \quad 100.0 \%$ Heat shock protein beta-1 GN=HSPB1 HSPB1 HUMAN $22.78 \quad 100.0 \%$ Heat shock protein beta-1 GN=HSPB1 HSPB1_HUMAN $22.78 \quad 100.0 \%$ Heat shock protein HSP 90-alpha GN=HSP90AA1 HS90A_HUMAN $84.66 \quad 100.0 \%$ Heat shock protein HSP 90-alpha GN=HSP90AA1 HS90A_HUMAN $84.66 \quad 100.0 \%$ Heat shock protein HSP 90-alpha GN=HSP90AA1 HS90A_HUMAN $84.66 \quad 100.0 \%$ Heat shock protein HSP 90-alpha GN=HSP90AA1 HS90A HUMAN $84.66 \quad 100.0 \%$ Heat shock protein HSP 90-alpha GN=HSP90AA1 HS90A_HUMAN $84.66 \quad 100.0 \%$ Heat shock protein HSP 90-alpha GN=HSP90AA1 HS90A_HUMAN $84.66 \quad 100.0 \%$ Heat shock protein HSP 90-alpha GN=HSP90AA1 HS90A_HUMAN $84.66 \quad 100.0 \%$ Heat shock protein HSP 90-alpha GN=HSP90AA1 HS90A_HUMAN $84.66 \quad 100.0 \%$ Heat shock protein HSP 90-alpha GN=HSP90AA1 HS90A_HUMAN $84.66 \quad 100.0 \%$ Heat shock protein HSP 90-alpha GN=HSP90AA1 HS90A_HUMAN $84.66 \quad 100.0 \%$ Heat shock protein HSP 90-alpha GN=HSP90AA1 HS90A_HUMAN $84.66 \quad 100.0 \%$ Heat shock protein HSP 90-alpha GN=HSP90AA1 HS90A HUMAN $84.66 \quad 100.0 \%$ Heat shock protein HSP 90-alpha GN=HSP90AA1 HS90A_HUMAN $84.66 \quad 100.0 \%$ Heat shock protein HSP 90-alpha GN=HSP90AA1 HS90A_HUMAN $84.66 \quad 100.0 \%$ Heat shock protein HSP 90-alpha GN=HSP90AA1 HS90A_HUMAN $84.66 \quad 100.0 \%$ Heat shock protein HSP 90-alpha GN=HSP90AA1 HS90A_HUMAN $84.66 \quad 100.0 \%$ Heat shock protein HSP 90-alpha GN=HSP90AA1 HS90A HUMAN $84.66 \quad 100.0 \%$ Heat shock protein HSP 90-alpha GN=HSP90AA1 HS90A_HUMAN $84.66 \quad 100.0 \%$ Heat shock protein HSP 90-alpha GN=HSP90AA1 HS90A_HUMAN $84.66 \quad 100.0 \%$ Heat shock protein HSP 90-alpha GN=HSP90AA1 HS90A_HUMAN $84.66 \quad 100.0 \%$ Heat shock protein HSP 90-alpha GN=HSP90AA1 HS90A_HUMAN $84.66 \quad 100.0 \%$

10

10
10

10

10

10
10

10
10

10
10

10
10

10

2

2
9

$17 \quad 0.02 \% \quad 18.3 \%$ AFLDALQNQAEASSK

$17 \quad 0.02 \% \quad 18.3 \%$ YTLHYKTDAPLNIR

$17 \quad 0.02 \% \quad 18.3 \%$ TDAPLNIR

$17 \quad 0.02 \% \quad 18.3 \%$ GVVDSEDIPLNLSR

$17 \quad 0.02 \% \quad 18.3 \%$ ELLQESALIRK

$17 \quad 0.02 \% \quad 18.3 \%$ FFEDYGLFMR

$0.02 \% \quad 18.3 \%$ EGIVTATEQEVKEDIAK

$17 \quad 0.02 \% \quad 18.3 \%$ YESSALPSGQLTSLSEYASR

$0.02 \% \quad 18.3 \%$ NIYYLCAPNR

$0.02 \% \quad 18.3 \%$ TQEERAQLLQPTLEINPR

$17 \quad 0.02 \% \quad 18.3 \%$ AQLLQPTLEINPR

$0.01 \% \quad 16.6 \%$ LATQSNEITIPVTFESR

$0.01 \% \quad 16.6 \%$ AQLGGPEAAKSDETAAK

$19 \quad 0.03 \% \quad 30.2 \%$ YESLTDPSKLDSGK

$19 \quad 0.03 \% \quad 30.2 \%$ TLTIVDTGIGMTK

$19 \quad 0.03 \% \quad 30.2 \%$ TLTIVDTGIGMTKADLINNLGTIAK

$19 \quad 0.03 \% \quad 30.2 \%$ ADLINNLGTIAK

$19 \quad 0.03 \% \quad 30.2 \%$ TDTGEPMGR

$19 \quad 0.03 \% \quad 30.2 \%$ VILHLKEDQTEYLEER

$19 \quad 0.03 \% \quad 30.2 \%$ EKYIDQEELNK

$19 \quad 0.03 \% \quad 30.2 \%$ YIDQEELNK

$19 \quad 0.03 \% \quad 30.2 \%$ YIDQEELNKTKPIWTR

$19 \quad 0.03 \% \quad 30.2 \%$ NPDDITNEEYGEFYK

$19 \quad 0.03 \% \quad 30.2 \%$ HFSVEGQLEFR

$19 \quad 0.03 \% \quad 30.2 \%$ RAPFDLFENR

$19 \quad 0.03 \% \quad 30.2 \%$ APFDLFENR

$19 \quad 0.03 \% \quad 30.2 \%$ NNIKLYVR

$19 \quad 0.03 \% \quad 30.2 \%$ GVVDSEDLPLNISR

$19 \quad 0.03 \% \quad 30.2 \%$ GVVDSEDLPLNISREMLQQSK

$19 \quad 0.03 \% \quad 30.2 \%$ LGIHEDSQNR

$19 \quad 0.03 \% \quad 30.2 \%$ YYTSASGDEMVSLKDYCTR

$13 \quad 19 \quad 0.03 \% \quad 30.2 \%$ DQVANSAFVER

$19 \quad 0.03 \% \quad 30.2 \%$ IMKAQALR

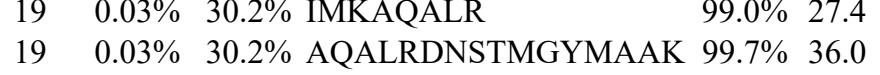

1480.75

1253.62

1481.81

1820.04

1565.83

1017.57

989.53

1319.59

1871.95

1628.88

1535.77

1592.79

1704.91

899.49

1513.79

1299.76

1324.60

1859.96

2146.03

1283.62

2136.14

1492.85

1905.99

1643.82

1539.75

1349.73

2589.42

1242.71

979.42

2015.04

1408.70

1151.56

2034.07

1833.78

1348.66

1264.64

1108.54

1019.60

1513.79

2374.19

1168.57

2245.97

1235.60

946.55

1727.82
$37 \quad 246$

311

31

$329 \quad 345$

$349 \quad 361$

$501 \quad 509$

$540 \quad 550$

$\begin{array}{cc}54 & 69 \\ 155 & 169\end{array}$

$375 \quad 388$

$182 \quad 196$

$327 \quad 340$

$333 \quad 340$

389402

$403 \quad 413$

$40 \quad 449$

$470 \quad 489$

$496 \quad 505$

$630 \quad 647$

$635 \quad 647$

$172 \quad 188$

$189 \quad 205$

$\begin{array}{cc}61 & 74 \\ 88 & 100\end{array}$

$88 \quad 112$

$101 \quad 112$

$174 \quad 182$

$186 \quad 201$

$284 \quad 292$

$300 \quad 314$

$328 \quad 338$

$346 \quad 355$

$347 \quad 355$

359366

$387 \quad 400$

$387 \quad 407$

$447 \quad 456$

465483

$500 \quad 510$

$613 \quad 620$

$616 \quad 631$ 

Heat shock protein HSP 90-beta GN=HSP90AB1 HS90B_HUMAN $83.27 \quad 100.0 \%$ Heat shock protein HSP 90-beta GN=HSP90AB1 HS90B_HUMAN $83.27 \quad 100.0 \% 37$ Heat shock protein HSP 90-beta GN=HSP90AB1 HS90B_HUMAN $83.27 \quad 100.0 \% 37$ Heat shock protein HSP 90-beta GN=HSP90AB1 HS90B_HUMAN $83.27 \quad 100.0 \% 37$ Heat shock protein HSP 90-beta GN=HSP90AB1 HS90B_HUMAN $83.27 \quad 100.0 \% 37$ Heat shock protein HSP 90-beta GN=HSP90AB1 HS90B_HUMAN $83.27 \quad 100.0 \% \quad 37$ Heat shock protein HSP 90-beta GN=HSP90AB1 HS90B HUMAN $83.27 \quad 100.0 \% 37$ Heat shock protein HSP 90-beta GN=HSP90AB1 HS90B_HUMAN $83.27 \quad 100.0 \% 37$ Heat shock protein HSP 90-beta GN=HSP90AB1 HS90B_HUMAN $83.27 \quad 100.0 \% 37$ Heat shock protein HSP 90-beta GN=HSP90AB1 HS90B_HUMAN $83.27 \quad 100.0 \% 37$ Heat shock protein HSP 90-beta GN=HSP90AB1 HS90B_HUMAN $83.27 \quad 100.0 \% \quad 37$ Heat shock protein HSP 90-beta GN=HSP90AB1 HS90B_HUMAN $83.27 \quad 100.0 \% 37$ Heat shock protein HSP 90-beta GN=HSP90AB1 HS90B_HUMAN $83.27 \quad 100.0 \% 37$ Heat shock protein HSP 90-beta GN=HSP90AB1 HS90B_HUMAN $83.27 \quad 100.0 \% 37$ Heat shock protein HSP 90-beta GN=HSP90AB1 HS90B HUMAN $83.27 \quad 100.0 \% 37$ Heat shock protein HSP 90-beta GN=HSP90AB1 HS90B_HUMAN $83.27 \quad 100.0 \% \quad 37$ Heat shock protein HSP 90-beta GN=HSP90AB1 HS90B_HUMAN $83.27 \quad 100.0 \% 37$ Heat shock protein HSP 90-beta GN=HSP90AB1 HS90B HUMAN $83.27 \quad 100.0 \% 37$ Heat shock protein HSP 90-beta GN=HSP90AB1 HS90B_HUMAN $83.27 \quad 100.0 \% 37$ Heat shock protein HSP 90-beta GN=HSP90AB1 HS90B_HUMAN $83.27 \quad 100.0 \% 37$ Heat shock protein HSP 90-beta GN=HSP90AB1 HS90B_HUMAN $83.27 \quad 100.0 \% 37$ Heat shock protein HSP 90-beta GN=HSP90AB1 HS90B_HUMAN $83.27 \quad 100.0 \% 37$ Heat shock protein HSP 90-beta GN=HSP90AB1 HS90B HUMAN $83.27 \quad 100.0 \%$ Heat shock protein HSP 90-beta GN=HSP90AB1 HS90B_HUMAN $83.27 \quad 100.0 \% 37$ Heat shock protein HSP 90-beta GN=HSP90AB1 HS90B_HUMAN $83.27 \quad 100.0 \% 37$ Heat shock protein HSP 90-beta GN=HSP90AB1 HS90B HUMAN $83.27 \quad 100.0 \% 37$ Heat shock protein HSP 90-beta GN=HSP90AB1 HS90B_HUMAN $83.27 \quad 100.0 \% \quad 37$ Heat shock protein HSP 90-beta GN=HSP90AB1 HS90B HUMAN $83.27 \quad 100.0 \% 37$ Heat shock protein HSP 90-beta GN=HSP90AB1 HS90B_HUMAN $83.27 \quad 100.0 \% \quad 37$ Heat shock protein HSP 90-beta GN=HSP90AB1 HS90B_HUMAN $83.27 \quad 100.0 \% 37$ Heat shock protein HSP 90-beta GN=HSP90AB1 HS90B HUMAN $83.27 \quad 100.0 \%$ $\begin{array}{lllll}\text { Heat shock protein HSP 90-beta GN=HSP90AB1 HS90B_HUMAN } 83.27 & 100.0 \% & 37\end{array}$ Heat shock protein HSP 90-beta GN=HSP90AB1 HS90B_HUMAN $83.27 \quad 100.0 \% 37$ Heat shock protein HSP 90-beta GN=HSP90AB1 HS90B_HUMAN $83.27 \quad 100.0 \% 37$ Heat shock protein HSP 90-beta GN=HSP90AB1 HS90B_HUMAN $83.27 \quad 100.0 \% \quad 37$ Heat shock protein HSP 90-beta GN=HSP90AB1 HS90B HUMAN $83.27 \quad 100.0 \% 37$ Helicase-like transcription factor GN=HLTF HLTF_HUMAN $113.93 \quad 100.0 \%$ Helicase-like transcription factor GN=HLTF HLTF_HUMAN $113.93 \quad 100.0 \%$ Helicase-like transcription factor GN=HLTF HLTF HUMAN $113.93 \quad 100.0 \%$ Hermansky-Pudlak syndrome 6 protein GN=HPS6 HPS6_HUMAN $82.98 \quad 100.0 \%$ Hermansky-Pudlak syndrome 6 protein GN=HPS6 HPS6 HUMAN $82.98 \quad 100.0 \%$ Hermansky-Pudlak syndrome 6 protein GN=HPS6 HPS6_HUMAN $82.98 \quad 100.0 \%$ Hermansky-Pudlak syndrome 6 protein GN=HPS6 HPS6_HUMAN $82.98 \quad 100.0 \%$ Heterochromatin protein 1-binding protein $3 \mathrm{GN}=\mathrm{HP} 1 \mathrm{BP} 3 \mathrm{HP} 1 \mathrm{~B} 3$ HUMAN 61.21 Heterochromatin protein 1-binding protein $3 \mathrm{GN}=\mathrm{HP} 1 \mathrm{BP} 3 \mathrm{HP} 1 \mathrm{~B} 3$ _HUMAN 61.21

$19 \quad 0.03 \% \quad 30.2 \%$ HLEINPDHSIIETLR $60 \quad 0.22 \% \quad 43.8 \%$ YESLTDPSKLDSGK

$160 \quad 0.22 \% \quad 43.8 \%$ ELKIDIIPNPQER

$60 \quad 0.22 \% \quad 43.8 \%$ IDIIPNPQER

$160 \quad 0.22 \% \quad 43.8 \%$ TLTLVDTGIGMTK

$160 \quad 0.22 \% \quad 43.8 \%$ TLTLVDTGIGMTKADLINNLGTIAK

$160 \quad 0.22 \% \quad 43.8 \%$ ADLINNLGTIAK

$160 \quad 0.22 \% \quad 43.8 \%$ ADHGEPIGR

$160 \quad 0.22 \% \quad 43.8 \%$ ADHGEPIGRGTK

$160 \quad 0.22 \% \quad 43.8 \%$ VILHLKEDQTEYLEER

$160 \quad 0.22 \% \quad 43.8 \%$ HSQFIGYPITLYLEK

$160 \quad 0.22 \% \quad 43.8 \%$ EKYIDQEELNK

$160 \quad 0.22 \% \quad 43.8 \%$ YIDQEELNK

$160 \quad 0.22 \% \quad 43.8 \%$ YIDQEELNKTKPIWTR

$160 \quad 0.22 \% \quad 43.8 \%$ NPDDITQEEYGEFYK

$160 \quad 0.22 \% \quad 43.8 \%$ HFSVEGQLEFR

$160 \quad 0.22 \% \quad 43.8 \%$ ALLFIPRR

$160 \quad 0.22 \% \quad 43.8 \%$ RAPFDLFENK

$160 \quad 0.22 \% \quad 43.8 \%$ APFDLFENKK

$160 \quad 0.22 \% \quad 43.8 \%$ NNIKLYVR

$160 \quad 0.22 \% \quad 43.8 \%$ GVVDSEDLPLNISR

$160 \quad 0.22 \% \quad 43.8 \%$ GVVDSEDLPLNISREMLQQSK

$160 \quad 0.22 \% \quad 43.8 \%$ FYEAFSKNLK

$160 \quad 0.22 \% \quad 43.8 \%$ NLKLGIHEDSTNR

$160 \quad 0.22 \% \quad 43.8 \%$ LGIHEDSTNR

$160 \quad 0.22 \% \quad 43.8 \%$ LGIHEDSTNRR

$160 \quad 0.22 \% \quad 43.8 \%$ LSELLRYHTSQSGDEMTSLSEYVSR

$160 \quad 0.22 \% \quad 43.8 \%$ YHTSOSGDEMTSLSEYVSR

$160 \quad 0.22 \% \quad 43.8 \%$ SIYYITGESK

$160 \quad 0.22 \% \quad 43.8 \%$ SIYYITGESKEQVANSAFVER

$160 \quad 0.22 \% \quad 43.8 \%$ EQVANSAFVER

$160 \quad 0.22 \% \quad 43.8 \%$ AKFENLCK

$160 \quad 0.22 \% \quad 43.8 \%$ LVSSPCCIVTSTYC

$160 \quad 0.22 \% \quad 43.8 \%$ IMKAQALR

0.22\% 43.8\% AQALRDNSTMGYMMAK 99.7\% 51.1

$160 \quad 0.22 \% \quad 43.8 \%$ DNSTMGYMMAK

$160 \quad 0.22 \% \quad 43.8 \%$ KHLEINPDHPIVETLR

$160 \quad 0.22 \% \quad 43.8 \%$ HLEINPDHPIVETLR

$4 \quad 0.01 \% \quad 3.9 \%$ VILDEGHAIRNPNAQQTK

$4 \quad 0.01 \% \quad 3.9 \%$ LGQKQEVIITK

$0.01 \% \quad 3.9 \% \quad$ INEIRTLIDL

$0.01 \% \quad 6.8 \%$ LLSDLSAFGGAAR

$0.01 \% \quad 6.8 \%$ TLEPSGEASTSLGR

$0.01 \% \quad 6.8 \%$ KVLGGITAGK

$0.01 \% \quad 6.8 \%$ ALDAGLALGPSSPLLR

$29 \quad 0.04 \% \quad 18.8 \%$ TIPSWATLSASQLAR

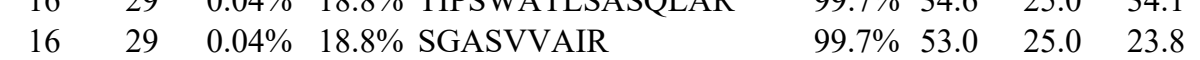

$99.7 \% \quad 31.8$

$99.7 \% \quad 61.5$

$99.7 \%$

$99.7 \% \quad 47.4$

$99.7 \% \quad 33.8$

$99.0 \% \quad 67.6$

$99.7 \% \quad 55.9$

$99.7 \% \quad 45.2$

$99.7 \% \quad 42.1$

$99.7 \% \quad 42.9$

$99.7 \% \quad 54.0$

$99.5 \% \quad 21.4$

$99.7 \% \quad 52.3$

$99.0 \% 29.6$

$99.7 \% \quad 41.5$

$99.0 \% 42.8$

$99.2 \% \quad 56.8$

$99.7 \% \quad 37.5$

$99.7 \% \quad 55.9$

$99.7 \% \quad 50.6$

$99.7 \% 25.8$

$99.7 \% \quad 45.7$

$\begin{array}{ll}99.7 \% & 47.8 \\ 99.7 \% & 56.9\end{array}$

$99.7 \% \quad 46.8$

$99.7 \% \quad 26.0$

$\begin{array}{lll}98.4 \% & 23.3\end{array}$

$99.7 \% \quad 38.0$

$99.7 \% \quad 53.0$

$99.7 \% \quad 44.3$

$99.0 \% \quad 24.4$

$99.5 \% \quad 22.1$

$99.7 \% \quad 34.6$

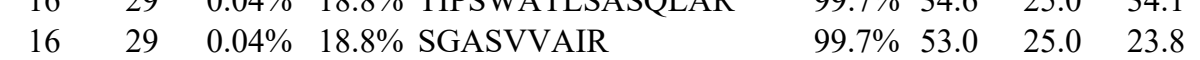

$0 \quad 28.5$

$5.0 \quad 45.5$

.0 30.6

$5.0 \quad 0.0$

$\begin{array}{ll}25.0 & 0.0\end{array}$

$0 \quad 50.0$

34.5

37.6

$\begin{array}{lll}25.0 & 42.1 & 2\end{array}$

$\begin{array}{lll}.0 & 0.0 & 2\end{array}$

$\begin{array}{ll}53.0 & 33.4\end{array}$

$\begin{array}{ll}5.0 & 21.3\end{array}$

$\begin{array}{ll}5.0 & 54.4\end{array}$

\begin{tabular}{ll}
52.3 \\
\hline
\end{tabular}

\begin{tabular}{ll}
5.0 & 29.6 \\
\hline & 19.4
\end{tabular}

41.4

33.8

$\begin{array}{ll}25.0 & 0.0\end{array}$

$\begin{array}{ll}5.0 & 54.2\end{array}$

$\begin{array}{ll}.0 & 33.5\end{array}$

50.5

$\begin{array}{ll}0 & 49.4\end{array}$

\begin{tabular}{ll}
03.9 \\
\hline
\end{tabular}

$\begin{array}{ll}5.0 & 51.8\end{array}$

$\begin{array}{ll}25.0 & 45.7\end{array}$

$\begin{array}{lll}25.0 & 47.8 \quad 2\end{array}$

$\begin{array}{ll}56.0 & 56.9\end{array}$

$\begin{array}{ll}5.0 & 42.2\end{array}$

$\begin{array}{lll}26.0 & 26.0 & 2\end{array}$

$\begin{array}{ll}21.0 & 18.3\end{array}$

\begin{tabular}{ll}
0 & 51.1 \\
\hline
\end{tabular}

$\begin{array}{ll}54.0 \\ 5.0 & 30.9\end{array}$

\begin{tabular}{ll}
57.7 \\
\hline
\end{tabular}

$\begin{array}{ll}5.0 & 26.0\end{array}$

$25.0 \quad 21.5$

$\begin{array}{ll}.0 & 24.5\end{array}$

$\begin{array}{ll}24.0 & 42.3\end{array}$

$\begin{array}{ll}37.0 & 37.6\end{array}$

25.6
-15.6

$\begin{array}{ll}5.0 & 20.0\end{array}$

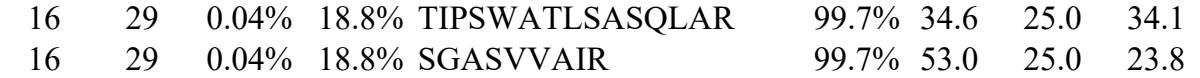

1539.75

1564.87

1194.65

1349.73

2589.42

1242.71

951.46

1237.63

2015.04

1808.96

1408.70

1151.56

2034.07

1847.80

1348.66

985.63

1236.64

1208.63

1019.60

1513.79

2374.19

1246.65

1496.78

1141.56

1297.66

2904.37

2192.94

1160.58

2391.18

1249.62

1009.51

2448.10

946.55

1787.82

1248.51

1911.04

1782.95

2004.06

1256.76

1199.70

1277.68

1404.70

943.59

1550.89

1601.86

859.50

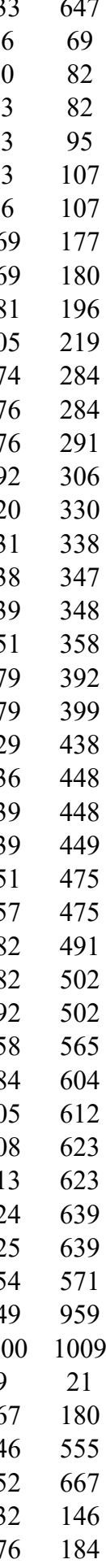

Page 65 of Table S-1-1 

$\begin{array}{lllllllll}\text { Heterochromatin protein 1-binding protein } 3 \text { GN=HP1BP3 HP1B3_HUMAN } & 61.21 & 100.0 \% & 14 & 16 & 29 & 0.04 \% & 18.8 \% \text { SGASVVAIRK } \\ \text { Heterochromatin protein 1-binding protein 3 GN=HP1BP3 HP1B3_HUMAN } & 61.21 & 100.0 \% & 14 & 16 & 29 & 0.04 \% & 18.8 \% \text { YIIHKYPSLELEI }\end{array}$ Heterochromatin protein 1-binding protein $3 \mathrm{GN}=\mathrm{HP} 1 \mathrm{BP} 3$ HP1B3_HUMAN $61.21 \quad 100.0 \% \quad]$ Heterochromatin protein 1-binding protein $3 \mathrm{GN}=\mathrm{HP} 1 \mathrm{BP} 3 \mathrm{HP} 1 \mathrm{~B} 3 \mathrm{HUMAN} 61.21 \quad 100.0 \%$ Heterochromatin protein 1-binding protein $3 \mathrm{GN}=\mathrm{HP} 1 \mathrm{BP} 3 \mathrm{HP} 1 \mathrm{~B} 3$ _HUMAN $61.21 \quad 100.0 \%$ Heterochromatin protein 1-binding protein $3 \mathrm{GN}=\mathrm{HP1BP} 3$ HP1B3_HUMAN 61.21 Heterochromatin protein 1-binding protein $3 \mathrm{GN}=\mathrm{HP} 1 \mathrm{BP} 3$ HP1B3 HUMAN 612 Heterochromatin protein 1-binding protein $3 \mathrm{GN}=\mathrm{HP} 1 \mathrm{BP} 3 \mathrm{HP1B} 3$ _HUMAN 61.2 Heterochromatin protein 1-binding protein $3 \mathrm{GN}=\mathrm{HP} 1 \mathrm{BP} 3 \mathrm{HP} 1 \mathrm{~B} 3$ _HUMAN 61.21 Heterochromatin protein 1-binding protein $3 \mathrm{GN}=\mathrm{HP} 1 \mathrm{BP} 3 \mathrm{HP} 1 \mathrm{~B} 3$ _HUMAN 61.2 Heterochromatin protein 1-binding protein $3 \mathrm{GN}=\mathrm{HP} 1 \mathrm{BP} 3 \mathrm{HP} 1 \mathrm{~B} 3$ _HUMAN 61.21 Heterochromatin protein 1-binding protein $3 \mathrm{GN}=\mathrm{HP} 1 \mathrm{BP} 3 \mathrm{HP} 1 \mathrm{~B} 3$ _HUMAN 61.21 Heterogeneous nuclear ribonucleoprotein A/B GN=HNRNPAB ROAA_HUMAN 36.23 Heterogeneous nuclear ribonucleoprotein A/B GN=HNRNPAB ROAA_HUMAN 36.23 Heterogeneous nuclear ribonucleoprotein A/B GN=HNRNPAB ROAA_HUMAN 36.23 Heterogeneous nuclear ribonucleoprotein A/B GN=HNRNPAB ROAA_HUMAN 36.2 ? Heterogeneous nuclear ribonucleoprotein A/B GN=HNRNPAB ROAA_HUMAN 36.23 Heterogeneous nuclear ribonucleoprotein A0 GN=HNRNPA0 ROA0_HUMAN 30.84 Heterogeneous nuclear ribonucleoprotein A0 GN=HNRNPA0 ROA0_HUMAN 30.84 Heterogeneous nuclear ribonucleoprotein A0 GN=HNRNPA0 ROA0 HUMAN 30.84 Heterogeneous nuclear ribonucleoprotein A0 GN=HNRNPA0 ROA0_HUMAN 30.84 Heterogeneous nuclear ribonucleoprotein A0 GN=HNRNPA0 ROA0_HUMAN 30.84 Heterogeneous nuclear ribonucleoprotein A0 GN=HNRNPA0 ROA0_HUMAN 30.84 Heterogeneous nuclear ribonucleoprotein A0 GN=HNRNPA0 ROA0_HUMAN 30.84 Heterogeneous nuclear ribonucleoprotein A1 GN=HNRNPA1 ROA1_HUMAN 38.75 Heterogeneous nuclear ribonucleoprotein A1 GN=HNRNPA1 ROA1_HUMAN 38.75 Heterogeneous nuclear ribonucleoprotein A1 GN=HNRNPA1 ROA1_HUMAN 38.75 Heterogeneous nuclear ribonucleoprotein A1 GN=HNRNPA1 ROA1_HUMAN 38.75 Heterogeneous nuclear ribonucleoprotein A1 GN=HNRNPA1 ROA1_HUMAN 38.7 . Heterogeneous nuclear ribonucleoprotein $\mathrm{A} 1 \mathrm{GN}=\mathrm{HNRNPA} 1 \mathrm{ROA} 1$ HUMAN 38.75 Heterogeneous nuclear ribonucleoprotein A1 GN=HNRNPA1 ROA1_HUMAN 38.75 Heterogeneous nuclear ribonucleoprotein A1 GN=HNRNPA1 ROA1_HUMAN 38.75 Heterogeneous nuclear ribonucleoprotein A1 GN=HNRNPA1 ROA1_HUMAN 38.75 Heterogeneous nuclear ribonucleoprotein A3 GN=HNRNPA3 ROA3_HUMAN 39.60 Heterogeneous nuclear ribonucleoprotein A3 GN=HNRNPA3 ROA3_HUMAN 39.60 Heterogeneous nuclear ribonucleoprotein A3 GN=HNRNPA3 ROA3_HUMAN 39.60 Heterogeneous nuclear ribonucleoprotein A3 GN=HNRNPA3 ROA3_HUMAN 39.60 Heterogeneous nuclear ribonucleoprotein $\mathrm{A} 3 \mathrm{GN}=\mathrm{HNRNPA} 3 \mathrm{ROA} 3$ HUMAN 39.60 Heterogeneous nuclear ribonucleoprotein D0 GN=HNRNPD HNRPD HUMAN 38.43 Heterogeneous nuclear ribonucleoprotin D0 GN=HNRNPD HNRPD_HUMAN 38.43 Heterogeneous nuclear ribonucleoprotein D0 GN=HNRNPD HNRPD_HUMAN 38.43 Heterogeneous nuclear ribonucleoprotein D0 GN=HNRNPD HNRPD_HUMAN 38.43 Heterogeneous nuclear ribonucleoprotein D0 GN=HNRNPD HNRPD_HUMAN $38.43 \quad 100.0$ Heterogeneous nuclear ribonucleoprotein D-like GN=HNRNPDL HNRDL_HUMAN $46.44 \quad 100.0 \%$ Heterogeneous nuclear ribonucleoprotein D-like GN=HNRNPDL HNRDL_HUMAN $46.44 \quad 100.0 \%$ Heterogeneous nuclear ribonucleoprotein D-like GN=HNRNPDL HNRDL_HUMAN $46.44 \quad 100.0 \%$

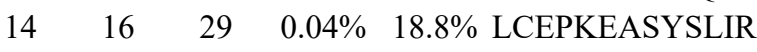

$\begin{array}{lllllll}14 & 16 & 29 & 0.04 \% & 18.8 \% & \text { EASYSLIR }\end{array}$

$\begin{array}{lllllll}00.0 \% & 14 & 16 & 29 & 0.04 \% & 18.8 \% & \text { KYVSQYYPK }\end{array}$

$\begin{array}{lllllll}10.0 \% & 14 & 16 & 29 & 0.04 \% & 18.8 \% & \text { YVSQYYPK }\end{array}$

$\begin{array}{lllllll}100.0 \% & 14 & 16 & 29 & 0.04 \% & 18.8 \% & \text { AVERGQLEQITGK }\end{array}$

$\begin{array}{lllllll}100.0 \% & 14 & 16 & 29 & 0.04 \% & 18.8 \% & \text { GQLEQITGK }\end{array}$

$\begin{array}{llllll}100.0 \% & 14 & 16 & 29 & 0.04 \% & 18.8 \% \\ \text { TRPSSTVIK }\end{array}$

$0.03 \% \quad 13.0 \%$ FGEVVDCTIK

$0.03 \% \quad 13.0 \%$ FGEVVDCTIK

$\begin{array}{ll}0.03 \% & 13.0 \% \text { VLDQKEHR } \\ 0.03 \% & 13.0 \% \text { VAQPKEVYQQQ }\end{array}$

$0.03 \% \quad 13.0 \%$ EVYQQQQYGSGGR

$0.03 \% \quad 25.9 \%$ LFIGGLNVQTSESGLR

$0.03 \% \quad 25.9 \%$ AVSREDSARPGAHAK

$0.03 \% \quad 25.9 \%$ AEIIADKQSGK

$0.03 \% \quad 25.9 \%$ GFGFVYFQNHDAADK

$\begin{array}{lll}0.03 \% & 25.9 \% & \text { GFGFVYFQNHDAADKAAVVK } \\ 0.03 \% & 25.9 \% & \text { AVPKEDIYSGGGGGGSR }\end{array}$

$0.09 \% \quad 28.5 \%$ SESPKEPEQLR

$0.09 \% \quad 28.5 \%$ LFIGGLSFETTDESLR

$0.09 \% \quad 28.5 \%$ VDGRVVEPK

$0.09 \% \quad 28.5 \%$ EDSQRPGAHLTVK

$0.09 \% \quad 28.5 \%$ EDSQRPGAHLTVKK

$0.09 \% \quad 28.5 \%$ IEVIEIMTDR

$0.09 \% \quad 28.5 \%$ YHTVNGHNCEVR

$100.0 \%$

$100.0 \%$

$100.0 \%$

$100.0 \%$

$100.0 \%$

$100.0 \%$

$100.0 \%$

$00.0 \%$

$100.0 \%$

$100.0 \%$

$00.0 \%$

$100.0 \%$

$00.0 \%$

$100.0 \%$

$0.02 \% \quad 13.0 \%$ VDGRVVEPK

$0.02 \% \quad 13.0 \%$ EDSVKPGAHLTVK

$0.02 \% \quad 13.0 \%$ EDSVKPGAHLTVKK

$0.02 \% \quad 14.1 \%$ DLKDYFSK

$0.02 \% \quad 14.1 \%$ FGEVVDCTLK

$0.02 \% \quad 14.1 \%$ IFVGGLSPDTPEEK

$0.02 \% \quad 14.1 \%$ IFVGGLSPDTPEEKIR
$0.03 \% \quad 17.1 \%$ QLAPLLPSLAPSSAR

$0.03 \% \quad 17.1 \%$ HVTAQQPSR

$0.03 \% \quad 17.1 \%$ FGEVVDCTIK $\begin{array}{lll}0.03 \% & 25.9 \% & \text { AVPKEDIYSGGGGGG } \\ 0.03 \% & 25.9 \% & \text { EDIYSGGGGGGSR }\end{array}$

$\begin{array}{lllllll}45.6 & 25.0 & 41.7 & 2 & 0 & 0 & 987.59\end{array}$

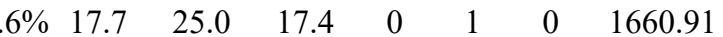

$\begin{array}{llllllll}99.7 \% & 59.7 & 25.0 & 53.5 & 2 & 0 & 0 & 1263.71\end{array}$

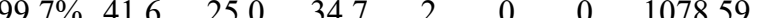

$\begin{array}{llllllll}99.7 \% & 32.4 & 25.0 & 32.4 & 2 & 2 & 0 & 1565.80\end{array}$

$\begin{array}{llllllll}99.0 \% & 36.7 & 25.0 & 22.2 & 2 & 0 & 0 & 938.49\end{array}$

$\begin{array}{llllllll}99.7 \% & 37.1 & 25.0 & 28.5 & 4 & 0 & 0 & 1175.61\end{array}$

$\begin{array}{llllllll}99.0 \% & 37.9 & 25.0 & 37.9 & 2 & 0 & 0 & 1047.51\end{array}$

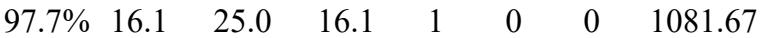

$\begin{array}{llllllll}99.7 \% & 39.4 & 25.0 & 39.4 & 2 & 2 & 0 & 1428.78\end{array}$

$\begin{array}{llll}99.7 \% & 25.8 & 25.0 & 21.3\end{array}$

$95.2 \% \quad 24.0-25.0-0.3$

$\begin{array}{llll}98.6 \% & 30.4 & 25.0 & 0.0\end{array}$

1428.78
973.53

988.58

1167.57

1954.90

1024.55

2023.00

1499.69

1690.91

1551.80

1159.63

1715.78

2184.09

1606.78

1211.53

1299.65

1784.91

998.56

1437.74

1565.84

1234.64

1485.67

1628.78

1694.70

$\begin{array}{llll}0.09 \% & 28.5 \% \text { NQGGYGGSSSSSSYGSGR } & 99.7 \% & 64.7\end{array}$

$95.3 \% \quad 19.0$

$0.02 \% \quad 13.0 \%$ AVSREDSVKPGAHLTVK $95.2 \% 13.7$

$99.7 \% \quad 32.1$

$99.7 \% \quad 25.8$

$\begin{array}{lllll}0.02 \% & 13.0 \% & \text { SSGSPYGGGYGGGGGGYGSR } \quad 99.7 \% \quad 48.7\end{array}$

$95.9 \% \quad 19.3$

$98.6 \% \quad 30.4$

$0.02 \% \quad 14.1 \%$ FGEVVDCTLKLDPITGR $\quad 99.7 \% \quad 41.6$

$99.7 \% \quad 40.4$

$99.7 \% \quad 28.8$

$98.9 \% 22.2$

$99.5 \% \quad 21.7$

$99.7 \% \quad 24.2$

$98.6 \% \quad 30.4$

998.56

1793.99

1380.75

1508.84

1910.79

1015.51

1167.57

1919.99

1488.76

1757.94

1045.58

1520.88

1023.53

1167.57 
Heterogeneous nuclear ribonucleoprotein D-like GN=HNRNPDL HNRDL_HUMAN $46.44 \quad 100.0 \%$ Heterogeneous nuclear ribonucleoprotein D-like GN=HNRNPDL HNRDL_HUMAN $46.44 \quad 100.0 \%$ Heterogeneous nuclear ribonucleoprotein D-like GN=HNRNPDL HNRDL_HUMAN $46.44 \quad 100.0 \%$ Heterogeneous nuclear ribonucleoprotein D-like GN=HNRNPDL HNRDL_HUMAN $46.44 \quad 100.0 \%$ Heterogeneous nuclear ribonucleoprotein F GN=HNRNPF HNRPF_HUMAN $45.67 \quad 100.0 \%$ Heterogeneous nuclear ribonucleoprotein F GN=HNRNPF HNRPF_HUMAN $45.67 \quad 100.0 \%$ Heterogeneous nuclear ribonucleoprotein F GN=HNRNPF HNRPF_HUMAN $45.67 \quad 100.0 \%$ Heterogeneous nuclear ribonucleoprotein F GN=HNRNPF HNRPF_HUMAN $45.67 \quad 100.0 \%$ Heterogeneous nuclear ribonucleoprotein $\mathrm{F}$ GN=HNRNPF HNRPF HUMAN $45.67 \quad 100.0 \%$ Heterogeneous nuclear ribonucleoprotein F GN=HNRNPF HNRPF_HUMAN $45.67 \quad 100.0 \%$ Heterogeneous nuclear ribonucleoprotein F GN=HNRNPF HNRPF_HUMAN $45.67 \quad 100.0 \%$ Heterogeneous nuclear ribonucleoprotein $\mathrm{H}$ GN=HNRNPH1 HNRH1_HUMAN $49.23 \quad 100.0 \%$ Heterogeneous nuclear ribonucleoprotein H GN=HNRNPH1 HNRH1_HUMAN $49.23 \quad 100.0 \%$ Heterogeneous nuclear ribonucleoprotein $\mathrm{H}$ GN=HNRNPH1 HNRH1_HUMAN $49.23 \quad 100.0 \%$ Heterogeneous nuclear ribonucleoprotein $\mathrm{H}$ GN=HNRNPH1 HNRH1_HUMAN $49.23 \quad 100.0 \%$ Heterogeneous nuclear ribonucleoprotein H GN=HNRNPH1 HNRH1_HUMAN $49.23 \quad 100.0 \%$ Heterogeneous nuclear ribonucleoprotein $\mathrm{H}$ GN=HNRNPH1 HNRH1 HUMAN $49.23 \quad 100.0 \%$ Heterogeneous nuclear ribonucleoprotein H GN=HNRNPH1 HNRH1_HUMAN $49.23 \quad 100.0 \%$ Heterogeneous nuclear ribonucleoprotein $\mathrm{H}$ GN=HNRNPH1 HNRH1_HUMAN $49.23 \quad 100.0 \%$ Heterogeneous nuclear ribonucleoprotein H GN=HNRNPH1 HNRH1_HUMAN $49.23 \quad 100.0 \%$ Heterogeneous nuclear ribonucleoprotein $\mathrm{H} 3 \mathrm{GN}=\mathrm{HNRNPH} 3 \mathrm{HNRH} 3$ _HUMAN $36.93 \quad 100.0 \%$ Heterogeneous nuclear ribonucleoprotein $\mathrm{H} 3 \mathrm{GN}=\mathrm{HNRNPH} 3$ HNRH3 HUMAN $36.93 \quad 100.0 \%$ Heterogeneous nuclear ribonucleoprotein $\mathrm{H} 3 \mathrm{GN}=\mathrm{HNRNPH} 3$ HNRH3_HUMAN $36.93 \quad 100.0 \%$ Heterogeneous nuclear ribonucleoprotein $\mathrm{H} 3 \mathrm{GN}=\mathrm{HNRNPH} 3$ HNRH3_HUMAN $36.93 \quad 100.0 \%$ Heterogeneous nuclear ribonucleoprotein $\mathrm{H} 3 \mathrm{GN}=\mathrm{HNRNPH} 3$ HNRH3 HUMAN $36.93 \quad 100.0 \%$ Heterogeneous nuclear ribonucleoprotein K GN=HNRNPK HNRPK_HUMAN $50.98 \quad 100.0 \%$ Heterogeneous nuclear ribonucleoprotein $\mathrm{K}$ GN=HNRNPK HNRPK_HUMAN $50.98 \quad 100.0 \%$ Heterogeneous nuclear ribonucleoprotein K GN=HNRNPK HNRPK_HUMAN $50.98 \quad 100.0 \%$ Heterogeneous nuclear ribonucleoprotein K GN=HNRNPK HNRPK_HUMAN $50.98 \quad 100.0 \%$ Heterogeneous nuclear ribonucleoprotein K GN=HNRNPK HNRPK HUMAN $50.98100 .0 \%$ Heterogeneous nuclear ribonucleoprotein K GN=HNRNPK HNRPK_HUMAN $50.98 \quad 100.0 \%$ Heterogeneous nuclear ribonucleoprotein K GN=HNRNPK HNRPK_HUMAN $50.98 \quad 100.0 \%$ Heterogeneous nuclear ribonucleoprotein K GN=HNRNPK HNRPK_HUMAN 50.98 Heterogeneous nuclear ribonucleoprotein K GN=HNRNPK HNRPK_HUMAN 50.98 Heterogeneous nuclear ribonucleoprotein K GN=HNRNPK HNRPK_HUMAN 50.98 Heterogeneous nuclear ribonucleoprotein $\mathrm{K}$ GN=HNRNPK HNRPK HUMAN 50.98 Heterogeneous nuclear ribonucleoprotein K GN=HNRNPK HNRPK_HUMAN 50.98 Heterogeneous nuclear ribonucleoprotein $\mathrm{K}$ GN=HNRNPK HNRPK HUMAN 50.9 Heterogeneous nuclear ribonucleoprotein L GN=HNRNPL HNRPL_HUMAN 64.1: Heterogeneous nuclear ribonucleoprotein L GN=HNRNPL HNRPL_HUMAN 64.1 Heterogeneous nuclear ribonucleoprotein L GN=HNRNPL HNRPL_HUMAN 64.13 Heterogeneous nuclear ribonucleoprotein L GN=HNRNPL HNRPL_HUMAN 64.1. Heterogeneous nuclear ribonucleoprotein L GN=HNRNPL HNRPL HUMAN 64.1 Heterogeneous nuclear ribonucleoprotein L GN=HNRNPL HNRPL_HUMAN $64.13 \quad 100.0 \%$ Heterogeneous nuclear ribonucleoprotein L GN=HNRNPL HNRPL_HUMAN $64.13 \quad 100.0 \%$ Heterogeneous nuclear ribonucleoprotein L GN=HNRNPL HNRPL HUMAN $64.13 \quad 100.0 \%$ Heterogeneous nuclear ribonucleoprotein L GN=HNRNPL HNRPL_HUMAN $64.13 \quad 100.0 \%$
$0.03 \% \quad 17.1 \%$ FGEVVDCTIKTDPVTGR

$0.03 \% \quad 17.1 \%$ VAQPKEVYR

$0.03 \% \quad 17.1 \%$ EVYRQQQQQQK

$0.02 \% \quad 21.9 \%$ QSGEAFVELGSEDDVK

$0.02 \% \quad 21.9 \%$ HSGPNSADSANDGFVR

$\begin{array}{lll}0.02 \% & 21.9 \% & \text { HSGPNSADSANDGFVRLR } \\ 0.02 \% & 21.9 \% & \text { ITGEAFVQFASQELAEK }\end{array}$

$0.02 \% \quad 21.9 \%$ YIEVFKSSQEEVR

$0.02 \% \quad 21.9 \%$ ATENDIYNFFSPLNPVR

$0.02 \% \quad 21.9 \%$ VHIEIGPDGR

$0.09 \% \quad 22.9 \%$ GLPWSCSADEVQR

$0.09 \% \quad 22.9 \%$ FFSDCKIQNGAQGIR

$0.09 \% \quad 22.9 \%$ HTGPNSPDTANDGFVR

$0.09 \% \quad 22.9 \%$ HTGPNSPDTANDGFVRLR

$0.09 \% \quad 22.9 \%$ STGEAFVQFASQEIAEK

$0.09 \% \quad 22.9 \%$ IGHRYIEIFK

$0.09 \% \quad 22.9 \%$ YIEIFKSSR

$0.09 \% \quad 22.9 \%$ ATENDIYNFFSPLNPVR

$0.09 \% \quad 22.9 \%$ VHIEIGPDGR

$0.02 \% \quad 18.8 \%$ HNGPNDASDGTVR

$0.02 \% \quad 18.8 \%$ STGEAFVQFASK

$0.02 \% \quad 18.8 \%$ EIAENALGK

$0.02 \% \quad 18.8 \%$ ATENDIANFFSPLNPIR

$0.02 \% \quad 18.8 \%$ DGMDNQGGYGSVGR

$0.03 \% \quad 28.1 \%$ RPAEDMEEEQAFKR

$0.03 \% \quad 28.1 \%$ SRNTDEMVELR

$0.03 \% \quad 28.1 \%$ NAGAVIGKGGK

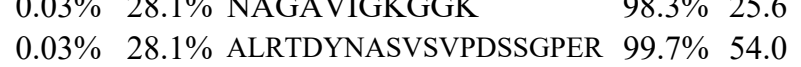

$0.03 \% \quad 28.1 \%$ TDYNASVSVPDSSGPER $\quad 99.7 \% \quad 69.4$

$0.03 \% \quad 28.1 \%$ IILDLISESPIK

$0.03 \% \quad 28.1 \%$ IILDLISESPIKGR

$0.03 \% \quad 28.1 \%$ DYDDMSPR

$0.03 \% \quad 28.1 \%$ NLPLPPPPPPR

$0.03 \% \quad 28.1 \%$ GGDLMAYDR

$99.7 \% \quad 54.1$

$99.7 \% \quad 49.3$

$99.0 \% \quad 39.1$

$97.6 \% \quad 23.0$

$99.7 \% \quad 41.7$

$0.03 \% \quad 28.1 \%$ GSYGDLGGPIITTQVTIPK $99.7 \% \quad 60.8$

$0.03 \% \quad 28.1 \%$ GSYGDLGGPIITQVTIPKDLAGSIIGK

$0.03 \% \quad 28.1 \%$ DLAGSIIGKGGQR

$0.03 \% \quad 19.7 \%$ YYGGGSEGGRAPK

$0.03 \% \quad 19.7 \%$ ISRPGDSDDSR

$99.1 \% \quad 29.1$

$99.7 \% \quad 50.8$

$99.7 \% \quad 58.2$

$99.7 \% \quad 40.6$

$0.03 \% \quad 19.7 \%$ NGVQAMVEFDSVQSAQR $99.7 \% 97.1$

$0.03 \% \quad 19.7 \%$ VFNVFCLYGNVEK

$99.7 \% \quad 60.8$

$0.03 \% \quad 19.7 \%$ SKPGAAMVEMADGYAVDR $99.7 \% \quad 28.5$

$0.03 \% \quad 19.7 \%$ AITHLNNNFMFGQK

$0.03 \% \quad 19.7 \%$ NNRFSTPEQAAK

$0.03 \% \quad 19.7 \%$ VFSGKSER

$0.03 \% \quad 19.7 \%$ LCFSTAQHAS

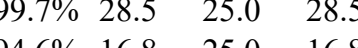

$\begin{array}{llll}99.7 \% & 48.8 & 25.0 & 41.7\end{array}$

$99.0 \% \quad 34.2 \quad 25.0 \quad 24.3$

$\begin{array}{llll}99.7 \% & 43.3 & 25.0 & 43.3\end{array}$
1893.94

1833.87

1089.61

1462.74

1709.79

1630.72

1899.9

1867.94

1613.82

1996.98

1092.58

1504.69

1740.85

1684.77

1953.95

1841.89

1275.72

1142.62

1996.98

1092.58

1339.60

1271.63

944.50

1918.97

1428.58

1735.81

1349.65

971.56

2121.02

1780.80

1340.80

1553.93

998.39

1194.70

997.44

1917.03

2771.52

1271.71

1298.61

1204.56

1865.88

1588.78

1867.87

1634.81

1362.68

909.48

1121.50

$\begin{array}{cc}71 & 187 \\ 75 & 289 \\ 07 & 315 \\ 12 & 322 \\ 3 & 68 \\ 9 & 114 \\ 9 & 116 \\ 51 & 167 \\ 80 & 192 \\ 00 & 316 \\ 17 & 326 \\ 7 & 29 \\ 0 & 44 \\ 9 & 114 \\ 9 & 116 \\ 51 & 167 \\ 76 & 185 \\ 80 & 188 \\ 00 & 316 \\ 17 & 326 \\ 7 & 19 \\ 6 & 67 \\ 8 & 76 \\ 06 & 222 \\ 88 & 301 \\ 2 & 35 \\ 6 & 46 \\ 3 & 63 \\ 7 & 86 \\ 0 & 86 \\ 08 & 219 \\ 08 & 221 \\ 79 & 286 \\ 06 & 316 \\ 17 & 325 \\ 78 & 396 \\ 78 & 405 \\ 97 & 409 \\ 7 & 59 \\ 79 & 189 \\ 30 & 246 \\ 99 & 411 \\ 17 & 434 \\ 35 & 448 \\ 82 & 493 \\ 34 & 541 \\ 80 & 589\end{array}$


Heterogeneous nuclear ribonucleoprotein M GN=HNRNPM HNRPM_HUMAN $77.52 \quad 100.0 \% \quad 56$ Heterogeneous nuclear ribonucleoprotein M GN=HNRNPM HNRPM_HUMAN $77.52 \quad 100.0 \% \quad 56$ Heterogeneous nuclear ribonucleoprotein M GN=HNRNPM HNRPM_HUMAN $77.52 \quad 100.0 \% \quad 56$ Heterogeneous nuclear ribonucleoprotein M GN=HNRNPM HNRPM_HUMAN $77.52 \quad 100.0 \% \quad 56$ Heterogeneous nuclear ribonucleoprotein M GN=HNRNPM HNRPM_HUMAN $77.52 \quad 100.0 \% \quad 56$ Heterogeneous nuclear ribonucleoprotein M GN=HNRNPM HNRPM_HUMAN $77.52 \quad 100.0 \% \quad 56$ Heterogeneous nuclear ribonucleoprotein M GN=HNRNPM HNRPM_HUMAN $77.52 \quad 100.0 \% \quad 56$ Heterogeneous nuclear ribonucleoprotein M GN=HNRNPM HNRPM_HUMAN $77.52 \quad 100.0 \% \quad 56$ Heterogeneous nuclear ribonucleoprotein M GN=HNRNPM HNRPM HUMAN $77.52 \quad 100.0 \% 56$ Heterogeneous nuclear ribonucleoprotein M GN=HNRNPM HNRPM_HUMAN $77.52 \quad 100.0 \% \quad 56$ Heterogeneous nuclear ribonucleoprotein M GN=HNRNPM HNRPM_HUMAN $77.52 \quad 100.0 \% \quad 56$ Heterogeneous nuclear ribonucleoprotein M GN=HNRNPM HNRPM_HUMAN $77.52 \quad 100.0 \%$ Heterogeneous nuclear ribonucleoprotein M GN=HNRNPM HNRPM_HUMAN $77.52 \quad 100.0 \% \quad 56$ Heterogeneous nuclear ribonucleoprotein M GN=HNRNPM HNRPM_HUMAN $77.52 \quad 100.0 \% \quad 56$ Heterogeneous nuclear ribonucleoprotein M GN=HNRNPM HNRPM_HUMAN $77.52 \quad 100.0 \% 56$ Heterogeneous nuclear ribonucleoprotein M GN=HNRNPM HNRPM_HUMAN $77.52 \quad 100.0 \% \quad 56$ Heterogeneous nuclear ribonucleoprotein M GN=HNRNPM HNRPM HUMAN $77.52 \quad 100.0 \% 56$ Heterogeneous nuclear ribonucleoprotein M GN=HNRNPM HNRPM_HUMAN $77.52 \quad 100.0 \% \quad 56$ Heterogeneous nuclear ribonucleoprotein M GN=HNRNPM HNRPM_HUMAN $77.52 \quad 100.0 \% \quad 56$ Heterogeneous nuclear ribonucleoprotein M GN=HNRNPM HNRPM_HUMAN $77.52 \quad 100.0 \% \quad 56$ Heterogeneous nuclear ribonucleoprotein M GN=HNRNPM HNRPM_HUMAN $77.52 \quad 100.0 \% \quad 56$ Heterogeneous nuclear ribonucleoprotein M GN=HNRNPM HNRPM HUMAN $77.52 \quad 100.0 \% 56$ Heterogeneous nuclear ribonucleoprotein M GN=HNRNPM HNRPM_HUMAN $77.52 \quad 100.0 \% 56$ Heterogeneous nuclear ribonucleoprotein M GN=HNRNPM HNRPM_HUMAN $77.52 \quad 100.0 \% \quad 56$ Heterogeneous nuclear ribonucleoprotein M GN=HNRNPM HNRPM HUMAN $77.52 \quad 100.0 \%$ Heterogeneous nuclear ribonucleoprotein M GN=HNRNPM HNRPM_HUMAN $77.52 \quad 100.0 \% \quad 56$ Heterogeneous nuclear ribonucleoprotein M GN=HNRNPM HNRPM_HUMAN $77.52 \quad 100.0 \% \quad 56$ Heterogeneous nuclear ribonucleoprotein M GN=HNRNPM HNRPM_HUMAN $77.52 \quad 100.0 \% 56$ Heterogeneous nuclear ribonucleoprotein M GN=HNRNPM HNRPM_HUMAN $77.52 \quad 100.0 \% \quad 56$ Heterogeneous nuclear ribonucleoprotein M GN=HNRNPM HNRPM HUMAN $77.52 \quad 100.0 \% 56$ Heterogeneous nuclear ribonucleoprotein M GN=HNRNPM HNRPM_HUMAN $77.52 \quad 100.0 \% \quad 56$ Heterogeneous nuclear ribonucleoprotein M GN=HNRNPM HNRPM_HUMAN $77.52 \quad 100.0 \% \quad 56$ Heterogeneous nuclear ribonucleoprotein M GN=HNRNPM HNRPM_HUMAN $77.52 \quad 100.0 \% 56$ Heterogeneous nuclear ribonucleoprotein M GN=HNRNPM HNRPM_HUMAN $77.52 \quad 100.0 \% \quad 56$ Heterogeneous nuclear ribonucleoprotein M GN=HNRNPM HNRPM_HUMAN $77.52 \quad 100.0 \% 56$ Heterogeneous nuclear ribonucleoprotein M GN=HNRNPM HNRPM_HUMAN $77.52 \quad 100.0 \% 56$ Heterogeneous nuclear ribonucleoprotein M GN=HNRNPM HNRPM_HUMAN $77.52 \quad 100.0 \% \quad 56$ Heterogeneous nuclear ribonucleoprotein M GN=HNRNPM HNRPM HUMAN $77.52 \quad 100.0 \% 56$ Heterogeneous nuclear ribonucleoprotein M GN=HNRNPM HNRPM_HUMAN $77.52 \quad 100.0 \% \quad 56$ Heterogeneous nuclear ribonucleoprotein M GN=HNRNPM HNRPM_HUMAN $77.52 \quad 100.0 \% \quad 56$ Heterogeneous nuclear ribonucleoprotein M GN=HNRNPM HNRPM HUMAN $77.52 \quad 100.0 \% 56$ Heterogeneous nuclear ribonucleoprotein M GN=HNRNPM HNRPM_HUMAN $77.52 \quad 100.0 \% \quad 56$ Heterogeneous nuclear ribonucleoprotein M GN=HNRNPM HNRPM_HUMAN $77.52 \quad 100.0 \% \quad 56$ Heterogeneous nuclear ribonucleoprotein M GN=HNRNPM HNRPM_HUMAN $77.52 \quad 100.0 \% \quad 56$ Heterogeneous nuclear ribonucleoprotein M GN=HNRNPM HNRPM_HUMAN $77.52 \quad 100.0 \% \quad 5$ Heterogeneous nuclear ribonucleoprotein M GN=HNRNPM HNRPM_HUMAN $77.52 \quad 100.0 \%$ Heterogeneous nuclear ribonucleoprotein M GN=HNRNPM HNRPM_HUMAN $77.52 \quad 100.0 \% \quad 56$
$97 \quad 327 \quad 0.45 \% \quad 65.6 \%$ GEGERPAQNEK

$97 \quad 327 \quad 0.45 \% \quad 65.6 \%$ GEGERPAQNEKR

$97 \quad 327 \quad 0.45 \% \quad 65.6 \%$ GGNRFEPYANPTK

$97 \quad 327 \quad 0.45 \% \quad 65.6 \%$ FEPYANPTKR

$97 \quad 327 \quad 0.45 \% \quad 65.6 \%$ AFITNIPFDVK

$97 \quad 327 \quad 0.45 \% \quad 65.6 \%$ VGEVTYVELLMDAEGK

$97 \quad 327 \quad 0.45 \% \quad 65.6 \%$ GCAVVEFK

$97 \quad 327 \quad 0.45 \% \quad 65.6 \%$ KAAEVLNK

$97 \quad 327 \quad 0.45 \% \quad 65.6 \%$ AAEVLNKHSLSGRPLK

$97 \quad 327 \quad 0.45 \% \quad 65.6 \%$ HSLSGRPLK

$97 \quad 327 \quad 0.45 \% \quad 65.6 \%$ VKEDPDGEHAR

$97 \quad 327 \quad 0.45 \% \quad 65.6 \%$ LGSTVFVANLDYK

$97 \quad 327 \quad 0.45 \% \quad 65.6 \%$ LKEVFSMAGVVVR

$97 \quad 327 \quad 0.45 \% \quad 65.6 \%$ EVFSMAGVVVR

$97 \quad 327 \quad 0.45 \% \quad 65.6 \%$ ADILEDKDGK

$97 \quad 327 \quad 0.45 \% \quad 65.6 \%$ MDERALPK

$97 \quad 327 \quad 0.45 \% \quad 65.6 \%$ GIGMGNIGPAGMGMEGIGFGINK

$97 \quad 327 \quad 0.45 \% \quad 65.6 \%$ MGGMEGPFGGGMENMGR

$97 \quad 327 \quad 0.45 \% \quad 65.6 \%$ FGSGMNMGR

$97 \quad 327 \quad 0.45 \% \quad 65.6 \%$ FGSGMNMGRINEILSNALK

$97 \quad 327 \quad 0.45 \% \quad 65.6 \%$ INEILSNALK

$97 \quad 327 \quad 0.45 \% \quad 65.6 \%$ INEILSNALKR

$97 \quad 327 \quad 0.45 \% \quad 65.6 \%$ QGGGGGGGSVPGIER

$97 \quad 327 \quad 0.45 \% \quad 65.6 \%$ QGGGGGGGSVPGIERMGPGID

$97 \quad 327 \quad 0.45 \% \quad 65.6 \%$ MGPGIDRLGGAGMER

$97 \quad 327 \quad 0.45 \% \quad 65.6 \%$ LGGAGMER

$97 \quad 327 \quad 0.45 \% \quad 65.6 \%$ MGAGLGHGMDR

$97 \quad 327 \quad 0.45 \% \quad 65.6 \%$ MGAGLGHGMDRVGSEIER

$97 \quad 327 \quad 0.45 \% \quad 65.6 \%$ MGLVMDRMGSVER

$97 \quad 327 \quad 0.45 \% \quad 65.6 \%$ MGPLGLDHMASSIER

$97 \quad 327 \quad 0.45 \% \quad 65.6 \%$ MGQTMERIGSGVER

$97 \quad 327 \quad 0.45 \% \quad 65.6 \%$ IGSGVERMGAGMGFGI

$97 \quad 327 \quad 0.45 \% \quad 65.6 \%$ MGAGMGFGLER

$97 \quad 327 \quad 0.45 \% \quad 65.6 \%$ MAAPIDRVGQTIER

$97 \quad 327 \quad 0.45 \% \quad 65.6 \%$ VGQTIERMGSGVER

$97 \quad 327 \quad 0.45 \% \quad 65.6 \%$ MGSGVERMGPAIER

$97 \quad 327 \quad 0.45 \% \quad 65.6 \%$ MGPAIERMGLSMER

$97 \quad 327 \quad 0.45 \% \quad 65.6 \%$ MVPAGMGAGLER

$97 \quad 327 \quad 0.45 \% \quad 65.6 \%$ MGPVMDRMATGLER

$97 \quad 327 \quad 0.45 \% \quad 65.6 \%$ MATGLERMGANNLER

$97 \quad 327 \quad 0.45 \% \quad 65.6 \%$ MGANNLER

$97 \quad 327 \quad 0.45 \% \quad 65.6 \%$ MGANNLERMGLER

$97 \quad 327 \quad 0.45 \% \quad 65.6 \%$ MGLERMGANSLER

$97 \quad 327 \quad 0.45 \% \quad 65.6 \%$ MGANSLER

$97 \quad 327 \quad 0.45 \% \quad 65.6 \%$ MGANSLERMGLER

$97 \quad 327 \quad 0.45 \% \quad 65.6 \%$ MGANSLERMGPAMGPALGAGIER

$97 \quad 327 \quad 0.45 \% \quad 65.6 \%$ MGPAMGPALGAGIER
$99.7 \% \quad 55.4$

$99.7 \% \quad 43.5$

$99.7 \% \quad 39.1$

$98.2 \% \quad 20.6$

$99.7 \% \quad 53.6$

$99.7 \% \quad 41.7$

$99.0 \% \quad 44.3$

$99.0 \% \quad 30.6$

$99.7 \% \quad 25.0$

$99.6 \% \quad 30.0$

$99.7 \% \quad 49.9$

$99.7 \% \quad 59.2$

$99.7 \% 57.1$

$99.7 \% \quad 45.1$

$99.7 \% \quad 39.0$

$99.0 \% \quad 37.2$ $99.7 \% \quad 54.5$

$99.5 \% \quad 21.1$

$99.7 \% \quad 57.8$

$99.7 \% \quad 50.0$

$99.7 \% \quad 50.4$

$\begin{array}{lll}99.7 \% & 44.6\end{array}$

$99.7 \% \quad 53.5$

$99.0 \% \quad 43.3$

$99.7 \% \quad 48.2$

$7 \% \quad 28.6$

$99.7 \% \quad 30.7$

$99.7 \% \quad 57.1$

$99.7 \% \quad 34.6$

$99.7 \% \quad 51.6$

$99.7 \% \quad 63.3$

$99.7 \% \quad 50.4$

$99.7 \% \quad 25.9$

$99.7 \% 27.1$

$99.7 \% \quad 29.0$

$99.7 \% \quad 60.3$

$99.7 \% \quad 49.2$

$99.7 \% \quad 35.9$

$99.0 \% \quad 70.9$

$99.7 \% \quad 32.4$

$99.7 \% 33.7$

$99.0 \% 70.6$

$99.7 \% \quad 33.1$

$99.7 \% \quad 63.2$

$99.7 \% \quad 52.1$
1370.68

1450.71

1222.62

1264.69

1768.87

909.45

872.52

1719.99

994.58

1252.59

1426.76

1450.81

1193.63

1103.56

959.50

2178.05

1746.67

956.41

2084.03

1114.65

1270.75

1284.63

2026.97

1516.74

806.38

1117.49

1887.88

1480.71

1629.77

1550.74

1855.88

1141.51

1556.82

1518.77

1521.72

1625.74

1188.59

1563.74

1678.80

904.43

1490.72

1495.70

877.42

1463.71

2318.11

1459.70

48
49
69
70
83
110
120
134
143
143
154
214
232
232
242
285
345
362
371
381
381
382
403
410
418
418
429
436
449
471
485
496
496
510
517
524
531
543
557
565
565
570
578

578
53
56

Page 68 of Table S-1-1 
Heterogeneous nuclear ribonucleoprotein M GN=HNRNPM HNRPM_HUMAN $77.52 \quad 100.0 \% \quad 56$ Heterogeneous nuclear ribonucleoprotein M GN=HNRNPM HNRPM_HUMAN $77.52 \quad 100.0 \% \quad 56$ Heterogeneous nuclear ribonucleoprotein M GN=HNRNPM HNRPM_HUMAN $77.52 \quad 100.0 \% \quad 56$ Heterogeneous nuclear ribonucleoprotein M GN=HNRNPM HNRPM_HUMAN $77.52 \quad 100.0 \%$ Heterogeneous nuclear ribonucleoprotein M GN=HNRNPM HNRPM_HUMAN $77.52 \quad 100.0 \% \quad 56$ Heterogeneous nuclear ribonucleoprotein M GN=HNRNPM HNRPM_HUMAN $77.52 \quad 100.0 \% \quad 56$ Heterogeneous nuclear ribonucleoprotein M GN=HNRNPM HNRPM_HUMAN $77.52 \quad 100.0 \% \quad 56$ Heterogeneous nuclear ribonucleoprotein M GN=HNRNPM HNRPM_HUMAN $77.52 \quad 100.0 \% \quad 56$ Heterogeneous nuclear ribonucleoprotein M GN=HNRNPM HNRPM HUMAN $77.52 \quad 100.0 \% 56$ Heterogeneous nuclear ribonucleoprotein Q GN=SYNCRIP HNRPQ_HUMAN $69.60 \quad 100.0 \%$ 7 Heterogeneous nuclear ribonucleoprotein Q GN=SYNCRIP HNRPQ_HUMAN $69.60 \quad 100.0 \%$ Heterogeneous nuclear ribonucleoprotein Q GN=SYNCRIP HNRPQ_HUMAN $69.60 \quad 100.0 \%$ $\begin{array}{llll}\text { Heterogeneous nuclear ribonucleoprotein Q GN=SYNCRIP } & \text { HNRPQ_HUMAN } 69.60 \quad 100.0 \%\end{array}$ Heterogeneous nuclear ribonucleoprotein Q GN=SYNCRIP HNRPQ_HUMAN $69.60 \quad 100.0 \%$ Heterogeneous nuclear ribonucleoprotein Q GN=SYNCRIP HNRPQ_HUMAN $69.60 \quad 100.0 \%$ $\begin{array}{llll}\text { Heterogeneous nuclear ribonucleoprotein Q GN=SYNCRIP } \quad \text { HNRPQ_HUMAN } 69.60 \quad 100.0 \% & 0.00 \%\end{array}$ Heterogeneous nuclear ribonucleoprotein Q GN=SYNCRIP HNRPQ HUMAN $69.60 \quad 100.0 \%$ Heterogeneous nuclear ribonucleoprotein Q GN=SYNCRIP $\quad$ HNRPQ_HUMAN $69.60 \quad 100.0 \%$ Heterogeneous nuclear ribonucleoprotein Q GN=SYNCRIP HNRPQ_HUMAN $69.60 \quad 100.0 \%$ Heterogeneous nuclear ribonucleoprotein Q GN=SYNCRIP HNRPQ_HUMAN $69.60 \quad 100.0 \%$ Heterogeneous nuclear ribonucleoprotein Q GN=SYNCRIP HNRPQ_HUMAN $69.60 \quad 100.0 \%$ Heterogeneous nuclear ribonucleoprotein Q GN=SYNCRIP HNRPQ HUMAN $69.60 \quad 100.0 \%$ Heterogeneous nuclear ribonucleoprotein R GN=HNRNPR HNRPR_HUMAN $70.94 \quad 100.0 \%$ Heterogeneous nuclear ribonucleoprotein R GN=HNRNPR HNRPR_HUMAN $70.94 \quad 100.0 \%$ Heterogeneous nuclear ribonucleoprotein R GN=HNRNPR HNRPR_HUMAN $70.94 \quad 100.0^{\circ}$ Heterogeneous nuclear ribonucleoprotein R GN=HNRNPR HNRPR_HUMAN $70.94 \quad 100.0 \%$ Heterogeneous nuclear ribonucleoprotein R GN=HNRNPR HNRPR_HUMAN $70.94 \quad 100.0 \%$ Heterogeneous nuclear ribonucleoprotein R GN=HNRNPR HNRPR HUMAN $70.94 \quad 100.0 \%$ Heterogeneous nuclear ribonucleoprotein R GN=HNRNPR HNRPR_HUMAN $70.94 \quad 100.0 \%$ Heterogeneous nuclear ribonucleoprotein R GN=HNRNPR HNRPR HUMAN $70.94100 .0 \%$ Heterogeneous nuclear ribonucleoprotein R GN=HNRNPR HNRPR_HUMAN $70.94 \quad 100.0 \%$ Heterogeneous nuclear ribonucleoprotein R GN=HNRNPR HNRPR_HUMAN $70.94 \quad 100.0 \%$ Heterogeneous nuclear ribonucleoprotein R GN=HNRNPR HNRPR HUMAN 70.94 Heterogeneous nuclear ribonucleoprotein R GN=HNRNPR HNRPR_HUMAN 70.94 Heterogeneous nuclear ribonucleoprotein R GN=HNRNPR HNRPR_HUMAN 70.94 Heterogeneous nuclear ribonucleoprotein U GN=HNRNPU HNRPU HUMAN 90.59 Heterogeneous nuclear ribonucleoprotein U GN=HNRNPU HNRPU_HUMAN 90.59 Heterogeneous nuclear ribonucleoprotein U GN=HNRNPU HNRPU HUMAN 90.59 Heterogeneous nuclear ribonucleoprotein U GN=HNRNPU HNRPU_HUMAN 90.59 Heterogeneous nuclear ribonucleoprotein U GN=HNRNPU HNRPU_HUMAN 90.59 Heterogeneous nuclear ribonucleoprotein U GN=HNRNPU HNRPU HUMAN 90.59 Heterogeneous nuclear ribonucleoprotein U GN=HNRNPU HNRPU_HUMAN 90.5 Heterogeneous nuclear ribonucleoprotein U GN=HNRNPU HNRPU_HUMAN 90.59 Heterogeneous nuclear ribonucleoprotein U GN=HNRNPU HNRPU_HUMAN 90.59 Heterogeneous nuclear ribonucleoprotein U GN=HNRNPU HNRPU_HUMAN 90.5 Heterogeneous nuclear ribonucleoprotein U GN=HNRNPU HNRPU HUMAN 90.5 Heterogeneous nuclear ribonucleoprotein U GN=HNRNPU HNRPU_HUMAN 90.59

(1)

7

7

7
7
7

7
7
7
7

7

7
7
7

13

13
13
13

13
13
13
13

13

13
13
13

13

13
13
13

$100.0 \% \quad 13$ $100.0 \% \quad 13$

$100.0 \% \quad 13$

$100.0 \% \quad 24$

$100.0 \% \quad 24$

$100.0 \% \quad 24$ $100.0 \% \quad 24$ $100.0 \% \quad 24$ $100.0 \% \quad 24$ $100.0 \% \quad 24$ $100.0 \% \quad 24$ $100.0 \% \quad 24$ $100.0 \% \quad 24$ $100.0 \% \quad 24$ $100.0 \% \quad 24$

40

40

40

40
40

40
40

40
40

40

40
40

40
40

40
40 $\begin{array}{lllllll}327 & 0.45 \% & 65.6 \% & \text { MGLAMGGGGGASASF } & 99.7 \% & 52.9 & 25.0\end{array}$

$\begin{array}{lllll}0.45 \% & 65.6 \% & \text { AIEMERGNGGGSFAGSFGGGOHAPGVAR } & 99.7 \% & 32.2\end{array}$

65.6\% GNFGGSFAGSFGGAGGHAPGVAR $99.7 \% \quad 51.7$

$\begin{array}{llll}327 & 0.45 \% & 65.6 \% & \text { KACQIFVR }\end{array}$

$\begin{array}{llll}99.7 \% & 42.4 & 25.0 & 42.4\end{array}$

$99.0 \% \quad 61.8 \quad 25.0 \quad 51.6$

0.45\% $65.6 \%$ GCGVVKFESPEVAER

$99.7 \% \quad 46.3$

$99.7 \% \quad 35.0$

$98.3 \% \quad 35.0 \quad 25.0$

$327 \quad 0.45 \% \quad 65.6 \%$ EIDVRIDR

$16 \quad 0.02 \% \quad 20.2 \%$ SAFLCGVMK

$16 \quad 0.02 \% \quad 20.2 \%$ ALLERTGYTLDVTTGQR

$16 \quad 0.02 \% \quad 20.2 \%$ TGYTLDVTTGQR

$16 \quad 0.02 \% \quad 20.2 \%$ TGYTLDVTTGQRK

$16 \quad 0.02 \% \quad 20.2 \%$ DLFEDELVPLFEK

$16 \quad 0.02 \% \quad 20.2 \%$ LMMDPLTGLNR

$16 \quad 0.02 \% \quad 20.2 \%$ EAAQEAVKLYNNHEIR

$6 \quad 0.02 \% \quad 20.2 \%$ LYNNHEIR

$16 \quad 0.02 \% \quad 20.2 \%$ LFVGSIPK

$16 \quad 0.02 \% \quad 20.2 \%$ GFCFLEYEDHKTAAQAR 99.7

$16 \quad 0.02 \% \quad 20.2 \%$ NLANTVTEEILEK

$16 \quad 0.02 \% \quad 20.2 \%$ AFSQFGKLER

$16 \quad 0.02 \% \quad 20.2 \%$ KADGYNQPDSK

$60 \quad 0.08 \% \quad 21.3 \%$ SAFLCGVMK

$60 \quad 0.08 \% \quad 21.3 \%$ VQESTKGPDEAK

$\begin{array}{llll}99.7 \% & 49.2 & 25.0 & 44.0\end{array}$

$99.7 \% \quad 48.6 \quad 25.0 \quad 43.2$

$99.7 \% \quad 33.6 \quad 25.0 \quad 33.6$

$98.9 \% \quad 18.0 \quad 25.0 \quad 18.0$

$99.0 \% \quad 30.3 \quad 25.0 \quad 11.5$

$\begin{array}{llll}99.0 \% & 32.0 & 25.0 & 16.8\end{array}$

$\begin{array}{llll}99.7 \% & 25.1 & 25.0 & 25.1\end{array}$

$99.7 \% \quad 57.4 \quad 25.0 \quad 53.2$

$\begin{array}{llll}99.7 \% & 34.3 & 25.0 & 33.8\end{array}$

$98.1 \% \quad 17.1 \quad 25.0 \quad 17.1$

$\begin{array}{llll}99.7 \% & 35.2 & 25.0 & 29.5\end{array}$

$\begin{array}{llll}99.7 \% & 25.5 & 25.0 & 22.5\end{array}$

$\begin{array}{lllllll}6.08 \% & 21.3 \% & \text { ALLERTGYTLDVTTGQR } & 99.7 \% & 28.1 & 25.0 & 28.1\end{array}$

$60 \quad 0.08 \% \quad 21.3 \%$ TGYTLDVTTGQR

$60 \quad 0.08 \% \quad 21.3 \%$ TGYTLDVTTGQRK

$99.7 \% \quad 53.0 \quad 25.0 \quad 53.0$

$99.7 \% \quad 49.2 \quad 25.0 \quad 44.0$

$99.7 \% \quad 44.9 \quad 25.0 \quad 43.9$

$99.7 \% \quad 49.9 \quad 25.0 \quad 49.9$

$\begin{array}{llll}99.0 \% & 32.0 & 25.0 & 16.8\end{array}$

60.08\% $21.3 \%$ GYAFITFCGK

$60 \quad 0.08 \% \quad 21.3 \%$ LFVGSIPK

$\begin{array}{llll}99.0 \% & 32.0 & 25.0 & 16.8 \\ 99.7 \% & 39.9 & 25.0 & 39.9\end{array}$

$60 \quad 0.08 \% \quad 21.3 \%$ NFCFLEYEDHKS

$60 \quad 0.08 \% \quad 21.3 \%$ SFSEFGKLER

$60 \quad 0.08 \% \quad 21.3 \%$ STAYEDYYYHPPPR

$60 \quad 0.08 \% \quad 21.3 \%$ KADGYNQPDSK

$\begin{array}{llll}99.7 \% & 54.0 & 25.0 & 50.7 \\ 99.7 \% & 53.7 & 25.0 & 41.3\end{array}$

$\begin{array}{llll}99.7 \% & 53.7 & 25.0 & 41.3 \\ 99.7 \% & 49.3 & 25.0 & 49.3\end{array}$

$98.1 \% \quad 17.1 \quad 25.0 \quad 17.1$
1415.60

2112.96

2764.30

2034.95

2163.05

1021.56

1663.81

1063.51

1015.55

1012.50

1894.00

1311.65

1439.75

1593.80

1260.64

1884.96

1058.54

860.52

2042.94

1473.78

1182.63

1222.57

1012.50

1288.64

1894.00

1311.65

1439.75

1609.80

1163.56

860.52

2028.92

1460.78

1199.61

1758.78

1222.57

3142.43

2171.15

1714.91

1666.83

2024.97

1697.78

998.48

941.58

996.51

1048.54

1376.75

2203.08 \begin{tabular}{cc} 
& 621 \\
27 & 627 \\
22 & 650 \\
28 & 650 \\
28 & 651 \\
51 & 658 \\
93 & 707 \\
99 & 707 \\
21 & 728 \\
2 & 100 \\
26 & 142 \\
31 & 142 \\
31 & 143 \\
72 & 184 \\
93 & 203 \\
14 & 229 \\
22 & 229 \\
45 & 252 \\
87 & 303 \\
44 & 356 \\
57 & 366 \\
66 & 576 \\
5 & 103 \\
15 & 126 \\
29 & 145 \\
34 & 145 \\
34 & 146 \\
75 & 187 \\
07 & 216 \\
48 & 255 \\
90 & 306 \\
47 & 359 \\
60 & 369 \\
28 & 441 \\
74 & 584 \\
8 & 69 \\
82 & 204 \\
87 & 204 \\
15 & 234 \\
16 & 238 \\
56 & 268 \\
32 & 339 \\
40 & 347 \\
53 & 360 \\
24 & 433 \\
& 536 \\
\hline
\end{tabular} 
Heterogeneous nuclear ribonucleoprotein U GN=HNRNPU HNRPU_HUMAN $90.59 \quad 100.0 \% \quad 24$ Heterogeneous nuclear ribonucleoprotein U GN=HNRNPU HNRPU_HUMAN $90.59 \quad 100.0 \% \quad 24$ Heterogeneous nuclear ribonucleoprotein U GN=HNRNPU HNRPU_HUMAN $90.59 \quad 100.0 \% \quad 24$ Heterogeneous nuclear ribonucleoprotein U GN=HNRNPU HNRPU_HUMAN $90.59 \quad 100.0 \% 24$ Heterogeneous nuclear ribonucleoprotein U GN=HNRNPU HNRPU_HUMAN $90.59 \quad 100.0 \% \quad 24$ Heterogeneous nuclear ribonucleoprotein U GN=HNRNPU HNRPU_HUMAN $90.59 \quad 100.0 \% \quad 24$ Heterogeneous nuclear ribonucleoprotein U GN=HNRNPU HNRPU_HUMAN $90.59 \quad 100.0 \% \quad 24$ Heterogeneous nuclear ribonucleoprotein U GN=HNRNPU HNRPU_HUMAN $90.59 \quad 100.0 \% \quad 24$ Heterogeneous nuclear ribonucleoprotein U GN=HNRNPU HNRPU_HUMAN $90.59 \quad 100.0 \%$ Heterogeneous nuclear ribonucleoprotein U GN=HNRNPU HNRPU_HUMAN $90.59 \quad 100.0 \% 24$ Heterogeneous nuclear ribonucleoprotein U GN=HNRNPU HNRPU_HUMAN $90.59 \quad 100.0 \% 24$ Heterogeneous nuclear ribonucleoprotein U GN=HNRNPU HNRPU_HUMAN $90.59 \quad 100.0 \% 24$

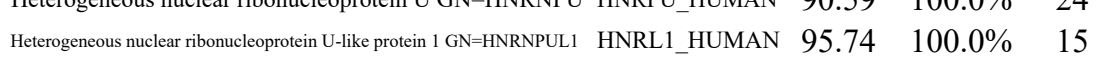
Heterogeneous nuclear ribonucleoprotein U-like protein $1 \mathrm{GN}=$ HNRNPUL1 $\quad$ HNRL1_HUMAN $95.74 \quad 100.0 \% \quad 15$

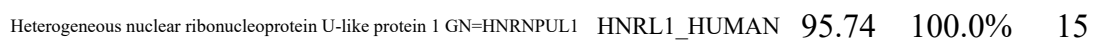
Heterogeneous nuclear ribonucleoprotein U-like protein 1 GN=HNRNPUL1 HNRL1_HUMAN $95.74 \quad 100.0 \% \quad 15$ Heterogeneous nuclear ribonucleoprotein U-like protein 1 GN=HNRNPUL1 HNRL1_HUMAN $95.74 \quad 100.0 \% \quad 15$ Heterogeneous nuclear ribonucleoprotein U-like protein 1 GN=HNRNPUL1 HNRL1_HUMAN $95.74 \quad 100.0 \% \quad 15$ Heterogeneous nuclear ribonucleoprotein U-like protein 1 GN=HNRNPUL1 HNRL1_HUMAN $95.74 \quad 100.0 \%$ Heterogeneous nuclear ribonucleoprotein U-like protein 1 GN=HNRNPUL1 $\quad$ HNRL1_HUMAN $95.74 \quad 100.0 \% \quad 15$ Heterogeneous nuclear ribonucleoprotein U-like protein 1 GN=HNRNPUL1 $\quad$ HNRL1_HUMAN $95.74 \quad 100.0 \% \quad 15$ Heterogeneous nuclear ribonucleoprotein U-like protein 1 GN=HNRNPUL1 HNRL1_HUMAN $95.74 \quad 100.0 \%$ Heterogeneous nuclear ribonucleoprotein U-like protein 1 GN=HNRNPUL1 HNRL1_HUMAN $95.74 \quad 100.0 \% \quad 15$ Heterogeneous nuclear ribonucleoprotein U-like protein 1 GN=HNRNPUL1 HNRL1_HUMAN $95.74 \quad 100.0 \% \quad 15$ Heterogeneous nuclear ribonucleoprotein U-like protein $1 \mathrm{GN}=$ HNRNPUL1 $\quad$ HNRL1_HUMAN $95.74 \quad 100.0 \% \quad 15$ Heterogeneous nuclear ribonucleoprotein U-like protein 1 GN=HNRNPUL1 $\quad$ HNRL1_HUMAN $95.74 \quad 100.0 \% \quad 15$ Heterogeneous nuclear ribonucleoprotein U-like protein 1 GN=HNRNPUL1 HNRL1_HUMAN $95.74 \quad 100.0 \% 15$ Heterogeneous nuclear ribonucleoprotein U-like protein 2 GN=HNRNPUL2 HNRL2_HUMAN $85.11 \quad 100.0 \%$ Heterogeneous nuclear ribonucleoprotein U-like protein 2 GN=HNRNPUL2 $\quad$ HNRL2_HUMAN $85.11 \quad 100.0 \% \quad 2$ Heterogeneous nuclear ribonucleoproteins A2/B1 GN=HNRNPA2B1 ROA2_HUMAN $37.43 \quad 100.0 \% \quad 16$ $\begin{array}{lllll}\text { Heterogeneous nuclear ribonucleoproteins A2/B1 GN=HNRNPA2B1 } & \text { ROA2_HUMAN } 37.43 & 100.0 \% & 16\end{array}$ Heterogeneous nuclear ribonucleoproteins A2/B1 GN=HNRNPA2B1 ROA2_HUMAN $37.43 \quad 100.0 \% \quad 16$ Heterogeneous nuclear ribonucleoproteins A2/B1 GN=HNRNPA2B1 ROA2 HUMAN $37.43 \quad 100.0 \% \quad 16$ $\begin{array}{lllll}\text { Heterogeneous nuclear ribonucleoproteins A2/B1 GN=HNRNPA2B1 } & \text { ROA2_HUMAN } & 37.43 & 100.0 \% & 16\end{array}$ $\begin{array}{lllll}\text { Heterogeneous nuclear ribonucleoproteins A2/B1 GN=HNRNPA2B1 } & \text { ROA2_HUMAN } 37.43 \quad 100.0 \% & 16\end{array}$ Heterogeneous nuclear ribonucleoproteins A2/B1 GN=HNRNPA2B1 $\quad$ ROA2_HUMAN $37.43 \quad 100.0 \% \quad 16$ $\begin{array}{lllll}\text { Heterogeneous nuclear ribonucleoproteins A2/B1 GN=HNRNPA2B1 } & \text { ROA2_HUMAN } 37.43 \quad 100.0 \% & 16\end{array}$ Heterogeneous nuclear ribonucleoproteins $\mathrm{A2} / \mathrm{B} 1 \mathrm{GN}=\mathrm{HNRNPA} 2 \mathrm{~B} 1 \quad \mathrm{ROA} 2$ HUMAN $37.43 \quad 100.0 \%-16$ $\begin{array}{lllll}\text { Heterogeneous nuclear ribonucleoproteins A2/B1 GN=HNRNPA2B1 } & \text { ROA2_HUMAN } & 37.43 & 100.0 \% & 16\end{array}$ $\begin{array}{lllll}\text { Heterogeneous nuclear ribonucleoproteins A2/B1 GN=HNRNPA2B1 } & \text { ROA2_HUMAN } & 37.43 & 100.0 \% & 16\end{array}$ Heterogeneous nuclear ribonucleoproteins A2/B1 GN=HNRNPA2B1 $\quad$ ROA2 HUMAN $37.43 \quad 100.0 \% \quad 16$ Heterogeneous nuclear ribonucleoproteins A2/B1 GN=HNRNPA2B1 $\quad$ ROA2_HUMAN $37.43 \quad 100.0 \% \quad 16$ Heterogeneous nuclear ribonucleoproteins A2/B1 GN=HNRNPA2B1 ROA2_HUMAN $37.43 \quad 100.0 \% \quad 16$ $\begin{array}{lllll}\text { Heterogeneous nuclear ribonucleoproteins A2/B1 GN=HNRNPA2B1 } & \text { ROA2_HUMAN } 37.43 \quad 100.0 \% & 16\end{array}$ $\begin{array}{lllll}\text { Heterogeneous nuclear ribonucleoproteins A2/B1 GN=HNRNPA2B1 } & \text { ROA2_HUMAN } 37.43 \quad 100.0 \% \quad 16\end{array}$ Heterogeneous nuclear ribonucleoproteins $\mathrm{C} 1 / \mathrm{C} 2 \mathrm{GN}=$ HNRNPC HNRPC_HUMAN $33.67 \quad 100.0 \% \quad 15$ Heterogeneous nuclear ribonucleoproteins $\mathrm{C} 1 / \mathrm{C} 2 \mathrm{GN}=$ HNRNPC HNRPC_HUMAN $33.67 \quad 100.0 \% \quad 15$
$40 \quad 177 \quad 0.24 \% \quad 29.5 \%$ MMVAGFKK

$40 \quad 177 \quad 0.24 \% \quad 29.5 \%$ QMADTGKLNTLLQR

$40 \quad 177 \quad 0.24 \% \quad 29.5 \%$ APQCLGKFIEIAAR

$40 \quad 177 \quad 0.24 \% \quad 29.5 \%$ RNFILDQTNVSAAAQR

$\begin{array}{llll}40 & 177 & 0.24 \% & 29.5 \% \\ 40 & \text { NFILDQTNVSAAAQR }\end{array}$

$40 \quad 177 \quad 0.24 \% \quad 29.5 \%$ NFILDQTNVSAAAQRR

$40 \quad 177 \quad 0.24 \% \quad 29.5 \%$ KMCLFAGFQR

$40 \quad 177 \quad 0.24 \% \quad 29.5 \%$ MCLFAGFQR

$40 \quad 177 \quad 0.24 \% \quad 29.5 \%$ MCLFAGFQRK

$40 \quad 177 \quad 0.24 \% \quad 29.5 \%$ KAVVVCPK

$40 \quad 177 \quad 0.24 \% \quad 29.5 \%$ AEVEGKDLPEHAVLK

$40 \quad 177 \quad 0.24 \% \quad 29.5 \%$ SGKNQFNR

$\begin{array}{lllll}17 & 37 & 0.05 \% & 16.0 \% & \text { KRPYEENR }\end{array}$

$17 \quad 37 \quad 0.05 \% \quad 16.0 \%$ GYFEHREDR

$17 \quad 37 \quad 0.05 \% \quad 16.0 \%$ HLPSTEPDPHVVR

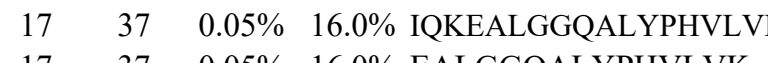

$17 \quad 37 \quad 0.05 \% \quad 16.0 \%$ EALGGQALYPHVLVK

$\begin{array}{llll}17 & 37 & 0.05 \% & 16.0 \% \\ 17 & 37 & 0.05 \% & 16.0 \%\end{array}$

$17 \quad 37 \quad 0.05 \% \quad 16.0 \%$ IRGTVGPK

$17 \quad 37 \quad 0.05 \% \quad 16.0 \%$ YNILGTNAIMDK

$17 \quad 37 \quad 0.05 \% \quad 16.0 \%$ YNILGTNAIMDKMR

$\begin{array}{llll}17 & 37 & 0.05 \% & 16.0 \% \\ 17 & 37 & 0.05 \% & 16.0 \%\end{array}$

$17 \quad 37 \quad 0.05 \% \quad 16.0 \%$ NYILDQTNVYGSAQR

$\begin{array}{llll}17 & 37 & 0.05 \% & 16.0 \%\end{array}$

$17 \quad 37 \quad 0.05 \% \quad 16.0 \%$ AIVICPTDEDLKDR

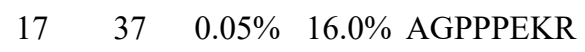

$17 \quad 37 \quad 0.05 \% \quad 16.0 \%$ NPPGASTYNK

$5 \quad 0.01 \% \quad 3.1 \% \quad$ YNVLGAETVLNQMR

$5 \quad 0.01 \% \quad 3.1 \% \quad$ NYYGYQGYR

$107 \quad 0.15 \% \quad 45.3 \%$ TLETVPLER

$107 \quad 0.15 \% \quad 45.3 \%$ LFIGGLSFETTEESLR

$107 \quad 0.15 \% \quad 45.3 \%$ AVAREESGKPGAHVTVK

$107 \quad 0.15 \% \quad 45.3 \%$ EESGKPGAHVTVK

$107 \quad 0.15 \% \quad 45.3 \%$ EESGKPGAHVTVKK

$107 \quad 0.15 \% \quad 45.3 \%$ GFGFVTFDDHDPVDK

$107 \quad 0.15 \% \quad 45.3 \% \quad$ YHTINGHNAEVR

$107 \quad 0.15 \% \quad 45.3 \%$ ALSRQEMQEVQSSR

$107 \quad 0.15 \% \quad 45.3 \%$ QEMQEVQSSR

$107 \quad 0.15 \% \quad 45.3 \%$ SGRGGNFGFGDSR

$107 \quad 0.15 \% \quad 45.3 \%$ GGNFGFGDSR

$99.7 \% \quad 48.0$

$107 \quad 0.15 \% \quad 45.3 \%$ GGGGNFGPGPGSNFRGGSDGYGSGR

$107 \quad 0.15 \% \quad 45.3 \%$ NMGGPYGGGNYGPGGSGGSGGYGGR

24

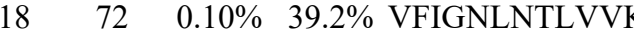

$18 \quad 72 \quad 0.10 \% \quad 39.2 \%$ VFIGNLNTLVVKK
$99.7 \% \quad 46.2$

$99.0 \% \quad 28.8$

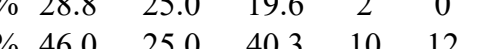

$\begin{array}{lll}38.8 & 25.0 & 35.0\end{array}$

$99.4 \% \quad 20.3 \quad 25.0$

$97.4 \% \quad 25.1 \quad 25.0$

$99.7 \% \quad 57.8 \quad 25.0$

$99.0 \% \quad 41.1 \quad 25.0$

$97.0 \% \quad 16.5$

$9.5 \% 20.7$

$99.7 \% \quad 40.4$

$99.7 \% \quad 34.0$

$99.7 \% \quad 52.6$

$99.0 \% \quad 32.5$

$99.7 \% \quad 45.4$

$98.7 \% \quad 17.6$

$99.7 \% \quad 63.8$

$99.2 \% \quad 19.5$

$99.0 \% \quad 40.6$

$98.0 \% \quad 16.5$

$99.7 \% \quad 54.5$

$99.7 \% \quad 36.2$

$99.7 \% \quad 59.6$

$98.6 \% 22.4$

$99.6 \% \quad 22.5$

$99.7 \% \quad 54.0$

$99.7 \% \quad 52.3$

$99.7 \% \quad 37$

$\begin{array}{ll}99.7 \% & 46.2 \\ 99.7 \% & 54.3\end{array}$

$99.7 \% \quad 52.5$

$99.7 \% \quad 47.7$
911.48

1604.84

1573.85

1803.95

1647.84

1803.95

1257.62

1129.53

1257.62

900.53

1634.88

950.48

1091.56

1208.54

1483.77

1964.13

1594.90

1341.60

827.51

1352.69

1639.83

912.60

1741.85

1897.95

1644.83

851.47

1048.51

1607.82

1183.52

1057.59

1798.92

1735.95

1338.70

1466.80

2277.16

1410.69

1648.81

1237.55

1313.60

1013.44

2372.06

1377.63

2270.99

2968.24

2189.91

1316.79

1444.89

\begin{tabular}{cc}
37 & 544 \\
45 & 558 \\
59 & 572 \\
75 & 590 \\
76 & 590 \\
76 & 591 \\
92 & 601 \\
93 & 601 \\
93 & 602 \\
02 & 609 \\
21 & 635 \\
95 & 702 \\
72 & 179 \\
82 & 190 \\
71 & 283 \\
58 & 375 \\
61 & 375 \\
76 & 386 \\
09 & 416 \\
50 & 461 \\
50 & 463 \\
91 & 498 \\
01 & 515 \\
01 & 516 \\
28 & 541 \\
01 & 608 \\
22 & 731 \\
81 & 494 \\
39 & 747 \\
4 & 12 \\
3 & 38 \\
6 & 112 \\
00 & 112 \\
00 & 113 \\
54 & 173 \\
74 & 185 \\
87 & 200 \\
91 & 200 \\
01 & 213 \\
04 & 213 \\
04 & 228 \\
14 & 228 \\
14 & 238 \\
18 & 350 \\
& 350 \\
\hline
\end{tabular}

Page 70 of Table S-1-1 

Hero $33.67 \quad 100.0 \%$ Heterogeneous nuclear ribonucleoproteins $\mathrm{Cl} / \mathrm{C} 2 \mathrm{GN}=\mathrm{HNRNPC}$ HNRPC HUMAN $33.67 \quad 100.0 \%$ Heterogeneous nuclear ribonucleoproteins $\mathrm{Cl} / \mathrm{C} 2 \mathrm{GN}=\mathrm{HNRNPC}$ HNRPC_HUMAN $33.67 \quad 100.0 \% \quad 15$ Heterogeneous nuclear ribonucleoproteins $\mathrm{Cl} / \mathrm{C} 2 \mathrm{GN}=\mathrm{HNRNPC}$ HNRPC_HUMAN $33.67 \quad 100.0 \% \quad 1$ Heterogeneous nuclear ribonucleoproteins $\mathrm{Cl} / \mathrm{C} 2$ GN=HNRNPC HNRPC_HUMAN $33.67 \quad 100.0 \% \quad 15$ Heterogeneous nuclear ribonucleoproteins $\mathrm{C} 1 / \mathrm{C} 2 \mathrm{GN}=\mathrm{HNRNPC}$ HNRPC_HUMAN $33.67 \quad 100.0 \% \quad 15$ Heterogeneous nuclear ribonucleoproteins $\mathrm{Cl} / \mathrm{C} 2 \mathrm{GN}=\mathrm{HNRNPC}$ HNRPC HUMAN $33.67 \quad 100.0 \% \quad 15$ Heterogeneous nuclear ribonucleoproteins $\mathrm{C} 1 / \mathrm{C} 2 \mathrm{GN}=$ HNRNPC HNRPC_HUMAN $33.67 \quad 100.0 \% \quad 15$ Heterogeneous nuclear ribonucleoproteins $\mathrm{Cl} / \mathrm{C} 2 \mathrm{GN}=\mathrm{HNRNPC}$ HNRPC_HUMAN $33.67 \quad 100.0 \% \quad 1$ Heterogeneous nuclear ribonucleoproteins $\mathrm{C} 1 / \mathrm{C} 2 \mathrm{GN}=\mathrm{HNRNPC}$ HNRPC_HUMAN $33.67 \quad 100.0 \%$ Histone H1.2 GN=HIST1H1C Histone H1.2 GN=HIST1H1C Histone $\mathrm{H} 1.2 \mathrm{GN}=\mathrm{HIST} 1 \mathrm{H} 1 \mathrm{C}$ Histone H1.2 GN=HIST1H1C Histone $\mathrm{H} 1.2 \mathrm{GN}=\mathrm{HIST} 1 \mathrm{H} 1 \mathrm{C}$ Histone H1.2 GN=HIST1H1C Histone H1.2 GN=HIST1H1C Histone H1.2 GN=HIST1H1C Histone H1.2 GN=HIST1H1C Histone H1.2 GN=HIST1H1C Histone H1.2 GN=HIST1H1C Histone H1.2 GN=HIST1H1C Histone H1.2 GN=HIST1H1C Histone H1.2 GN=HIST1H1C Histone $\mathrm{H} 1.2 \mathrm{GN}=\mathrm{HIST} 1 \mathrm{H} 1 \mathrm{C}$ Histone H1.2 GN=HIST1H1C Histone $\mathrm{H} 1 \mathrm{x} \mathrm{GN}=\mathrm{H} 1 \mathrm{FX}$ Histone $\mathrm{H} 1 \mathrm{x}$ GN=H1FX Histone $\mathrm{H} 1 \mathrm{x}$ GN=H1FX Histone $\mathrm{H} 1 \mathrm{x} \mathrm{GN}=\mathrm{H} 1 \mathrm{FX}$ Hornerin GN=HRNR Hornerin GN=HRNR Hornerin GN $=$ HRNR Hornerin GN=HRNR Hornerin GN $=\mathrm{HRNR}$ Hornerin GN $=\mathrm{HRNR}$ Hornerin GN $=\mathrm{HRNR}$

Hornerin GN=HRNR H12 HUMAN 21.37 \begin{tabular}{ll}
$100.0 \%$ \\
\hline
\end{tabular} H12 HUMAN $21.37 \quad 100.0 \% \quad 16$ H12_HUMAN $21.37 \quad 100.0 \% \quad 16$ H12_HUMAN $21.37 \quad 100.0 \% \quad 16$ H12 HUMAN $21.37 \quad 100.0 \% \quad 16$ H12_HUMAN $21.37 \quad 100.0 \% \quad 16$ H12 HUMAN $21.37 \quad 100.0 \% \quad 16$ H12_HUMAN $21.37 \quad 100.0 \% \quad 16$ H12_HUMAN $21.37 \quad 100.0 \% \quad 16$ H12 HUMAN $21.37 \quad 100.0 \% \quad 16$ H12_HUMAN $21.37 \quad 100.0 \% \quad 16$ H12_HUMAN $21.37 \quad 100.0 \% \quad 16$ H12 HUMAN $21.37 \quad 100.0 \% \quad 16$ H12_HUMAN $21.37 \quad 100.0 \% \quad 16$ H1X_HUMAN $22.49 \quad 100.0 \%$ H1X_HUMAN $22.49 \quad 100.0 \%$ H1X_HUMAN $22.49 \quad 100.0 \%$ H1X HUMAN $22.49 \quad 100.0 \%$ HORN_HUMAN $282.37 \quad 100.0 \%$ HORN HUMAN $282.37 \quad 100.0 \%$ HORN HUMAN $282.37 \quad 100.0 \%$ HORN_HUMAN $282.37 \quad 100.0 \%$ HORN HUMAN $282.37 \quad 100.0 \%$ HORN_HUMAN $282.37 \quad 100.0 \%$ HORN_HUMAN $282.37 \quad 100.0 \%$ HORN HUMAN $282.37 \quad 100.0 \%$ Hydroxyacyl-coenzyme A dehydrogenase, mitochondrial GN=HADH $\quad$ HCDH_HUMAN $34.29 \quad 100.0 \%$ Hydroxyacyl-coenzyme A dehydrogenase, mitochondrial GN=HADH HCDH HUMAN $34.29 \quad 100.0 \%$ Hydroxysteroid dehydrogenase-like protein 2 GN=HSDL2 HSDL2_HUMAN $45.40 \quad 100.0 \%$ Hydroxysteroid dehydrogenase-like protein 2 GN=HSDL2 HSDL2_HUMAN $45.40 \quad 100.0 \%$ Hydroxysteroid dehydrogenase-like protein $2 \mathrm{GN}=\mathrm{HSDL} 2$ HSDL2_HUMAN $45.40 \quad 100.0 \%$ Hydroxysteroid dehydrogenase-like protein 2 GN=HSDL2 HSDL2_HUMAN $45.40 \quad 100.0 \%$
$0.10 \% \quad 39.2 \%$

$0.10 \% \quad 39.2 \%$ YGKIVGCSVHK

$99.7 \% \quad 57.7$

$99.7 \% 50.8$

$99.0 \% 23.3$

$99.0 \% 26.7$

$99.7 \% \quad 53.9$

$99.7 \% 47$.

$0.10 \% \quad 39.2 \%$ GFAFVQYVNER

$0.10 \% \quad 39.2 \%$ AAVAGEDGR

$99.7 \% 57.4$

$99.7 \% \quad 51.5$

$0.10 \% \quad 39.2 \%$ MIAGQVLDINLAAEPK

$0.10 \% \quad 39.2 \%$ MYSYPARVPPPPPIAR

$0.10 \% \quad 39.2 \%$ VPPPPPIAR

$0.10 \% \quad 39.2 \%$ GDDLQAIKK

$0.10 \% \quad 39.2 \%$ QKVDSLLENLEK

$72 \quad 0.10 \% \quad 39.2 \%$ NDKSEEEQSSSSVK

$299 \quad 0.41 \% \quad 47.4 \%$ KASGPPVSELITK

$299 \quad 0.41 \% \quad 47.4 \%$ ASGPPVSELITK

$299 \quad 0.41 \% \quad 47.4 \%$ AVAASKER

$299 \quad 0.41 \% \quad 47.4 \%$ SGVSLAALK

$299 \quad 0.41 \% \quad 47.4 \%$ SGVSLAALKK

$299 \quad 0.41 \% \quad 47.4 \%$ ALAAAGYDVEK

$299 \quad 0.41 \% \quad 47.4 \%$ ALAAAGYDVEKNNSR

$299 \quad 0.41 \% \quad 47.4 \%$ SLVSKGTLVQTK

$299 \quad 0.41 \% \quad 47.4 \%$ GTLVQTKGTGASGSFK

$299 \quad 0.41 \% \quad 47.4 \%$ GTGASGSFK

$299 \quad 0.41 \% \quad 47.4 \%$ GTGASGSFKLNK

$299 \quad 0.41 \% \quad 47.4 \%$ KAASGEAKPK

$299 \quad 0.41 \% \quad 47.4 \%$ KAAGGATPK

$299 \quad 0.41 \% \quad 47.4 \%$ AKKPAAATVTK

$299 \quad 0.41 \% \quad 47.4 \%$ KPAAATVTK

$299 \quad 0.41 \% \quad 47.4 \%$ KPAAATVTKK

$18 \quad 0.02 \% \quad 17.8 \%$ YSQLVVETIR

$18 \quad 0.02 \% \quad 17.8 \%$ ALVQNDTLLQVK

$0.02 \% \quad 17.8 \%$ RGAPAAATAPAPTAHK

$0.02 \% \quad 17.8 \%$ GAPAAATAPAPTAHK

$0.08 \% \quad 4.4 \%$ GSGSGQSPSSGQHGTGFGR

$0.08 \% \quad 4.4 \%$ QSSSYGPHGYGSGR

$0.08 \% \quad 4.4 \%$ YGQQGSGSGQSPSR

$0.08 \% \quad 4.4 \%$ GSGSGQSPSYGR

$\begin{array}{lll}36.0 & 25.0 & 36.0\end{array}$

$\begin{array}{llll}99.7 \% & 31.8 & 25.0 & 24.6\end{array}$

$\begin{array}{llll}97.5 \% & 27.0 & 25.0 & 20.9\end{array}$

$99.7 \% \quad 27.5$

$99.7 \% \quad 44.5$

$99.7 \% \quad 57.0$

$99.7 \% \quad 53.0$

$99.0 \% \quad 59.8$

$99.7 \% \quad 55.7$

$99.7 \% \quad 57.0$

$99.7 \% \quad 58.1$

$99.7 \% 58.0$

$99.7 \% \quad 58.3$

$99.7 \% \quad 41.1$

$99.7 \% \quad 32.4$

$99.7 \% \quad 55.8$

$99.7 \% \quad 62.6$

$99.7 \% \quad 42.8$

$99.7 \% \quad 37.2$

$99.7 \% \quad 43.5$

$99.7 \% 39.1$

$99.7 \% \quad 72.4$

$99.7 \% \quad 57.2$

$\begin{array}{lll}99.7 \% & 25.7\end{array}$

$99.7 \% \quad 53.6$

$99.7 \% \quad 41.5$

$99.7 \% \quad 27.8$

$\begin{array}{lll}99.7 \% & 54.7\end{array}$

$\begin{array}{lll}99.7 \% & 39.7\end{array}$

$0.08 \% \quad 4.4 \% \quad$ QSLGHGQHGSGSGQSPSPSR $\quad 99.7 \% \quad 42.8$

$0.08 \% \quad 4.4 \%$ GPYESGSGHSSGLGHR

$99.6 \% \quad 24.9$

$99.7 \% \quad 50.4$

$0.08 \% \quad 4.4 \%$ HGSSSGSSSSYGQHGSGSR $99.7 \% \quad 51.7$

$99.7 \% \quad 36$.

$99.7 \% \quad 23.8$

$99.7 \% \quad 59.9$

$99.7 \% \quad 55.6$

$0.00 \% \quad 6.7 \% \quad$ LLVPYLMEAIR

$0.01 \% \quad 12.7 \%$ LAGCTVFITGASR

$99.7 \% 53.0$

$\begin{array}{lllll}0.01 \% & 12.7 \% & \text { LLGTIYTAAEEIEAVGGK } & 99.7 \% & 53.0 \\ 0.01 \% & 12.7 \% & \text { SGAVEETFR } & 99.7 \% & 52.7\end{array}$

$\begin{array}{lll}99.7 \% & 52.7 & 25.0\end{array}$

0
0
0
0
0
0
0
0
0
0
0
0
0
0
0
0
0
0
0
0
0
0
0
0
0
0
0
0
0
0
0
0
0
0
0
0
0
0
0
0
0
0
0
0
0
0
0
0
0
0
0
0
0
0
0
0
0
0
0
0
0
0
0

$\begin{array}{ccc}1123.60 & 30 & 39 \\ 995.50 & 31 & 39 \\ 1247.66 & 40 & 50 \\ 899.48 & 43 & 50 \\ 1329.66 & 51 & 61 \\ 845.41 & 65 & 73 \\ 2509.31 & 65 & 89 \\ 1682.91 & 74 & 89 \\ 1811.96 & 136 & 151 \\ 943.57 & 143 & 151 \\ 987.55 & 190 & 198 \\ 1415.77 & 205 & 216 \\ 1553.69 & 230 & 243 \\ 1326.76 & 34 & 46 \\ 1198.67 & 35 & 46 \\ 831.47 & 47 & 54 \\ 845.51 & 55 & 63 \\ 973.60 & 55 & 64 \\ 1107.57 & 65 & 75 \\ 1578.79 & 65 & 79 \\ 1260.75 & 86 & 97 \\ 1538.82 & 91 & 106 \\ 811.39 & 98 & 106 \\ 1166.62 & 98 & 109 \\ 986.56 & 110 & 119 \\ 800.46 & 140 & 148 \\ 1085.67 & 158 & 168 \\ 886.54 & 160 & 168 \\ 1014.63 & 160 & 169 \\ 1207.67 & 48 & 57 \\ 1341.77 & 95 & 106 \\ 1487.81 & 128 & 143 \\ 1331.71 & 129 & 143 \\ 1747.77 & 430 & 448 \\ 1439.63 & 554 & 567 \\ 1395.62 & 649 & 662 \\ 1139.51 & 897 & 908 \\ 1947.90 & 992 & 1011 \\ 1584.72 & 1038 & 1053 \\ 1125.53 & 1268 & 1277 \\ 1808.75 & 1443 & 1461 \\ 1172.58 & 193 & 202 \\ 1317.76 & 222 & 232 \\ 1352.70 & 8 & 20 \\ 1241.72 & 30 & 42 \\ 1834.98 & 50 & 67 \\ 995.48 & 307 & 315 \\ & & \end{array}$ 
Ig kappa chain V-I region Lay OS=Homo sapiens KV113_HUMAN $11.83 \quad 100.0 \%$ Ig kappa chain V-I region Lay OS=Homo sapiens KV113_HUMAN $11.83 \quad 100.0 \%$ Ig kappa chain V-II region RPMI 6410 OS=Homo sapiens KV206_HUMAN $14.71 \quad 100.0 \%$ Ig kappa chain V-II region RPMI 6410 OS=Homo sapiens KV206 HUMAN $14.71 \quad 100.0 \%$ Ig kappa chain V-II region RPMI 6410 OS=Homo sapiens KV206_HUMAN $14.71 \quad 100.0 \%$ Importin subunit alpha-1 GN=KPNA2 Importin subunit alpha-1 GN=KPNA2 Importin subunit beta-1 GN=KPNB1 Importin subunit beta-1 GN=KPNB1 Importin subunit beta-1 GN=KPNB1 Importin subunit beta- $1 \mathrm{GN}=\mathrm{KPNB} 1$ Importin subunit beta-1 $\mathrm{GN}=\mathrm{KPNB} 1$ Importin subunit beta-1 GN=KPNB1 Importin subunit beta-1 GN=KPNB1 Importin-11 GN=IPO11 Importin-11 GN=IPO11 Importin-4 GN=IPO4 Importin-4 GN=IPO4 Importin- $4 \mathrm{GN}=\mathrm{IPO} 4$ Importin- $4 \mathrm{GN}=\mathrm{IPO} 4$ Importin- $4 \mathrm{GN}=\mathrm{IPO} 4$ Importin- $4 \mathrm{GN}=\mathrm{IPO} 4$ Importin-4 GN=IPO4 Importin- $4 \mathrm{GN}=\mathrm{IPO} 4$ Importin-5 GN=IPO5 Importin-5 GN=IPO5 Importin-5 GN=IPO5 Importin-7 GN=IPO7 Importin-7 GN=IPO7 Importin-7 GN=IPO7 IMA1_HUMAN $57.86 \quad 100.0 \%$ IMA1 HUMAN $57.86 \quad 100.0 \%$ IMA1_HUMAN $57.86 \quad 100.0 \%$ IMB1_HUMAN $97.17 \quad 100.0 \%$ IMB1_HUMAN $97.17 \quad 100.0 \%$ IMB1_HUMAN $97.17 \quad 100.0 \%$ IMB1_HUMAN $97.17 \quad 100.0 \%$ IMB1_HUMAN $97.17 \quad 100.0 \%$ IMB1_HUMAN $97.17 \quad 100.0 \%$ IMB1_HUMAN $97.17 \quad 100.0 \%$ IPO11_HUMAN $112.54 \quad 100.0 \%$ IPO11_HUMAN $112.54 \quad 100.0 \%$ IPO4_HUMAN $118.72 \quad 100.0 \%$ IPO4_HUMAN $118.72 \quad 100.0 \%$ IPO4 HUMAN $118.72 \quad 100.0 \%$ IPO4_HUMAN $118.72 \quad 100.0 \%$ IPO4_HUMAN $118.72 \quad 100.0 \%$ IPO4 HUMAN $118.72 \quad 100.0 \%$ IPO5_HUMAN $123.63 \quad 100.0 \%$ IPO5 HUMAN $123.63 \quad 100.0 \%$ IPO5 HUMAN $123.63 \quad 100.0 \%$ IPO7_HUMAN $119.52 \quad 100.0 \%$ IPO7 HUMAN $119.52 \quad 100.0 \%$ IPO7_HUMAN $119.52 \quad 100.0 \%$ Importin subunit alpha- $1 \mathrm{GN}=\mathrm{KPNA} 2$ IPO4_HUMAN $118.72 \quad 100.0 \%$ IPO4_HUMAN $118.72 \quad 100.0 \%$

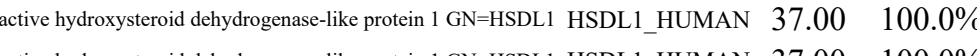
Insulin receptor substrate $4 \mathrm{GN}=\mathrm{IRS} 4$ Insulin receptor substrate $4 \mathrm{GN}=\mathrm{IRS} 4$ Insulin receptor substrate $4 \mathrm{GN}=\mathrm{IRS} 4$ Insulin receptor substrate $4 \mathrm{GN}=\mathrm{IRS} 4$ IRS4_HUMAN $133.77 \quad 100.0 \%$ IRS4_HUMAN $133.77 \quad 100.0 \%$ IRS4_HUMAN $133.77 \quad 100.0 \%$ IRS4_HUMAN $133.77 \quad 100.0 \%$ IF2B1_HUMAN $63.48 \quad 100.0 \%$ Insulin-like growth factor 2 mRNA-binding protein 1 GN=IGF2BP1 $\quad$ IF2B1_HUMAN $63.48 \quad 100.0 \%$ Insulin-like growth factor 2 mRNA-binding protein 1 GN=IGF2BP1 IF2B1_HUMAN $63.48 \quad 100.0 \%$ Insulin-like growth factor 2 mRNA-binding protein $1 \mathrm{GN}=I \mathrm{GF} 2 \mathrm{BP} 1 \quad$ IF2B1_HUMAN $63.48 \quad 100.0 \%$ Insulin-like growth factor 2 mRNA-binding protein 1 GN=IGF2BP1 IF2B1_HUMAN $63.48 \quad 100.0 \%$ Insulin-like growth factor 2 mRNA-binding protein 1 GN=IGF2BP1 IF2B1_HUMAN $63.48 \quad 100.0 \%$ Insulin-like growth factor 2 mRNA-binding protein 1 GN=IGF2BP1 $\quad$ IF2B1_HUMAN $63.48 \quad 100.0 \%$ Insulin-like growth factor 2 mRNA-binding protein 1 GN=IGF2BP1 IF2B1_HUMAN $63.48 \quad 100.0 \%$ Insulin-like growth factor 2 mRNA-binding protein $1 \mathrm{GN}=I \mathrm{GF} 2 \mathrm{BP} 1$ IF2B1_HUMAN $63.48 \quad 100.0 \%$ Insulin-like growth factor 2 mRNA-binding protein 1 GN=IGF2BP1 $\quad$ IF2B1_HUMAN $63.48 \quad 100.0 \%$
$0.09 \% \quad 45.6 \%$ LLVPTQYVGAIIGK $0.09 \% \quad 45.6 \%$ AISVHSTPEGCSSACK 18
54 $\begin{array}{lllll}99.7 \% & 36.8 & 25.0 & 30.7 & 1\end{array}$ $\begin{array}{lllll}99.7 \% & 55.3 & 25.0 & 49.3 & 2\end{array}$ $\begin{array}{lllll}99.7 \% & 32.8 & 25.0 & 32.8 & 2\end{array}$ $\begin{array}{lllll}99.7 \% & 54.3 & 25.0 & 48.9 & 2\end{array}$ $\begin{array}{llll}99.7 \% & 48.6 & 25.0 & 48.6\end{array}$ $\begin{array}{llll}99.7 \% & 41.7 & 25.0 & 31.1\end{array}$ $\begin{array}{lllll}99.7 \% & 47.7 & 25.0 & 47.7 & 4\end{array}$ $\begin{array}{lllll}99.7 \% & 52.8 & 25.0 & 52.8 & 2\end{array}$ $\begin{array}{llll}99.0 \% & 21.9 & 25.0 & 17.9\end{array}$ $\begin{array}{llllllll}97.9 \% & 18.5 & 25.0 & 18.5 & 2 & 0 & 0 & 992.59\end{array}$

1303.62

1659.83

1322.74

940.58

1549.93

1556.83

1658.91

1225.66

799.50

1605.88

1878.94

1356.67

1680.89

1192.67

1170.68

1995.01

1293.80

1305.75

1286.69

1002.57

1851.02

1244.65

1117.57

1171.66

1630.83

908.45

2012.92

1228.73

1063.59

1008.49

1326.68

1158.62

984.49

2032.00

1875.97

1141.63

1506.82

1207.68

1053.57

2131.16

1096.61

1471.89

1690.75 1014.55 
$\begin{array}{lllll}\text { Insulin-like growth factor } 2 \text { mRNA-binding protein } 1 \text { GN=IGF2BP1 } & \text { IF2B1_HUMAN } & 63.48 & 100.0 \% & 26\end{array}$ $\begin{array}{lllll}\text { Insulin-like growth factor } 2 \text { mRNA-binding protein } 1 \text { GN=IGF2BP1 } & \text { IF2B1_HUMAN } & 63.48 & 100.0 \% & 26\end{array}$ Insulin-like growth factor 2 mRNA-binding protein 1 GN=IGF2BP1 $\quad$ IF2B1_HUMAN $63.48 \quad 100.0 \% \quad 26$ $\begin{array}{lllll}\text { Insulin-like growth factor } 2 \text { mRNA-binding protein } 1 \text { GN=IGF2BP1 } & \text { IF2B1_HUMAN } 63.48 \quad 100.0 \% & 26\end{array}$ Insulin-like growth factor 2 mRNA-binding protein 1 GN=IGF2BP1 $\quad$ IF2B1_HUMAN $63.48 \quad 100.0 \% \quad 26$ Insulin-like growth factor 2 mRNA-binding protein 1 GN=IGF2BP1 $\quad$ IF2B1_HUMAN $63.48 \quad 100.0 \% \quad 26$ Insulin-like growth factor 2 mRNA-binding protein 1 GN=IGF2BP1 $\quad$ IF2B1_HUMAN $63.48 \quad 100.0 \% \quad 26$ Insulin-like growth factor 2 mRNA-binding protein 1 GN=IGF2BP1 $\quad$ IF2B1_HUMAN $63.48 \quad 100.0 \% \quad 26$ Insulin-like growth factor 2 mRNA-binding protein $1 \mathrm{GN}=I \mathrm{GF} 2 \mathrm{BP} 1 \quad$ IF2B1_HUMAN $63.48 \quad 100.0 \%$ Insulin-like growth factor 2 mRNA-binding protein 1 GN=IGF2BP1 $\quad$ IF2B1_HUMAN $63.48 \quad 100.0 \% \quad 26$ Insulin-like growth factor 2 mRNA-binding protein $1 \mathrm{GN}=$ IGF2BP1 $\quad$ IF2B1_HUMAN $63.48 \quad 100.0 \% \quad 26$ Insulin-like growth factor 2 mRNA-binding protein 1 GN=IGF2BP1 $\quad$ IF2B1_HUMAN $63.48 \quad 100.0 \%$ Insulin-like growth factor 2 mRNA-binding protein $1 \mathrm{GN}=$ IGF2BP1 1 IF2B1_HUMAN $63.48 \quad 100.0 \% \quad 26$ Insulin-like growth factor 2 mRNA-binding protein $1 \mathrm{GN}=[\mathrm{IGF} 2 \mathrm{BP} 1 \quad$ IF2B1_HUMAN $63.48 \quad 100.0 \% \quad 2$ Insulin-like growth factor 2 mRNA-binding protein $1 \mathrm{GN}=[\mathrm{GF} 2 \mathrm{BP} 1 \quad$ IF2B1_HUMAN $63.48 \quad 100.0 \% \quad 26$ Insulin-like growth factor 2 mRNA-binding protein 1 GN=IGF2BP1 $\quad$ IF2B1_HUMAN $63.48 \quad 100.0 \% \quad 26$ Insulin-like growth factor 2 mRNA-binding protein $3 \mathrm{GN}=I$ GF2BP3 $\quad$ IF2B3 HUMAN $63.71 \quad 100.0 \%$ Insulin-like growth factor 2 mRNA-binding protein 3 GN=IGF2BP3 IF2B3_HUMAN $63.71 \quad 100.0 \%$ Insulin-like growth factor 2 mRNA-binding protein 3 GN=IGF2BP3 IF2B3_HUMAN $63.71 \quad 100.0 \%$ Insulin-like growth factor 2 mRNA-binding protein 3 GN=IGF2BP3 IF2B3 HUMAN $63.71 \quad 100.0 \%$ Insulin-like growth factor 2 mRNA-binding protein $3 \mathrm{GN}=\mathrm{IGF} 2 \mathrm{BP} 3 \quad \mathrm{IF} 2 \mathrm{~B} 3$ _HUMAN $63.71 \quad 100.0 \%$ Insulin-like growth factor 2 mRNA-binding protein $3 \mathrm{GN}=\mathrm{IGF} 2 \mathrm{BP} 3 \quad \mathrm{IF} 2 \mathrm{~B} 3$ _HUMAN $63.71 \quad 100.0 \%$ Insulin-like growth factor 2 mRNA-binding protein 3 GN=IGF2BP3 IF2B3_HUMAN $63.71 \quad 100.0 \%$ Insulin-like growth factor 2 mRNA-binding protein 3 GN=IGF2BP3 $\quad$ IF2B3_HUMAN $63.71 \quad 100.0 \%$ Insulin-like growth factor 2 mRNA-binding protein 3 GN=IGF2BP3 IF2B3 HUMAN $63.71 \quad 100.0^{\circ}$ Insulin-like growth factor 2 mRNA-binding protein 3 GN=IGF2BP3 $\quad$ IF2B3_HUMAN $63.71 \quad 100.0 \%$ Insulin-like growth factor 2 mRNA-binding protein 3 GN=IGF2BP3 IF2B3_HUMAN $63.71 \quad 100.0 \%$ Integrator complex subunit $1 \mathrm{GN}=\mathrm{INTS} 1 \quad \mathrm{INT} 1$ HUMAN $244.30 \quad 100.0 \%$ Integrator complex subunit $1 \mathrm{GN}=\mathrm{INTS} 1 \quad$ INT1_HUMAN $244.30 \quad 100.0 \%$ Integrator complex subunit $1 \mathrm{GN}=\mathrm{INTS} 1 \quad \mathrm{INT} 1$ HUMAN $244.30 \quad 100.0 \%$ Integrator complex subunit $1 \mathrm{GN}=\mathrm{INTS} 1 \quad$ INT1_HUMAN $244.30 \quad 100.0 \%$ Integrator complex subunit $1 \mathrm{GN}=\mathrm{INTS} 1 \quad$ INT1_HUMAN $244.30 \quad 100.0 \%$ Integrator complex subunit $1 \mathrm{GN}=\mathrm{INTS} 1 \quad$ INT1_HUMAN $244.30 \quad 100.0 \%$ Integrator complex subunit $1 \mathrm{GN}=\mathrm{INTS} 1 \quad$ INT1_HUMAN $244.30 \quad 100.0 \%$ Integrator complex subunit $1 \mathrm{GN}=\mathrm{INTS} 1$ INT1 HUMAN $244.30 \quad 100.0 \%$ Interleukin enhancer-binding factor 2 GN=ILF2 ILF2 HUMAN $43.06 \quad 100.0 \%$ Interleukin enhancer-binding factor $2 \mathrm{GN}=\mathrm{ILF} 2 \mathrm{ILF} 2$ _HUMAN $43.06 \quad 100.0 \%$ Interleukin enhancer-binding factor $2 \mathrm{GN}=\mathrm{ILF} 2 \mathrm{ILF} 2$ HUMAN $43.06 \quad 100.0 \%$ Interleukin enhancer-binding factor 2 GN=ILF2 ILF2_HUMAN $43.06 \quad 100.0 \%$ Interleukin enhancer-binding factor 2 GN=ILF2 ILF2_HUMAN $43.06 \quad 100.0 \%$ Interleukin enhancer-binding factor $2 \mathrm{GN}=\mathrm{ILF} 2 \mathrm{ILF} 2$ HUMAN $43.06 \quad 100.0 \%$ Interleukin enhancer-binding factor 2 GN=ILF2 ILF2_HUMAN $43.06 \quad 100.0 \%$ Interleukin enhancer-binding factor 2 GN=ILF2 ILF2 HUMAN $43.06 \quad 100.0 \%$ Interleukin enhancer-binding factor $2 \mathrm{GN}=\mathrm{ILF} 2 \mathrm{ILF} 2$ HUMAN $43.06 \quad 100.0 \%$ Interleukin enhancer-binding factor $2 \mathrm{GN}=\mathrm{ILF} 2 \mathrm{ILF} 2$ HUMAN $43.06 \quad 100.0 \%$ Interleukin enhancer-binding factor $2 \mathrm{GN}=\mathrm{ILF} 2 \mathrm{ILF} 2$ HUMAN $43.06 \quad 100.0 \%$ Interleukin enhancer-binding factor $3 \mathrm{GN}=\mathrm{ILF} 3 \mathrm{ILF} 3$ _HUMAN $95.34 \quad 100.0 \%$

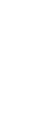

8

8
8
8

8
8
8
8

8
8
8
8

8
11
11

$\begin{array}{ll}11 & 15 \\ 1 & 15 \\ 1 & 15\end{array}$

$\begin{array}{ll}11 & 15 \\ 11 & 15 \\ 11 & 15\end{array}$

11

11

11

115

$0.09 \% \quad 45.6 \%$ TADEVPLKILAHNNFVGR

$0.09 \% \quad 45.6 \%$ ILAHNNFVGR

$99.7 \% \quad 39.9$

$0.09 \% \quad 45.6 \%$ GAIENCCR

$0.09 \% \quad 45.6 \%$ GQHIKQLSR

$0.09 \% \quad 45.6 \%$ FASASIKIAPPETPDSK

$0.09 \% \quad 45.6 \%$ IAPPETPDSK

$0.09 \% \quad 45.6 \%$ IAPPETPDSKVR

$0.09 \% \quad 45.6 \%$ MVIITGPPEAQFK

$0.09 \% \quad 45.6 \%$ MVIITGPPEAQFKAQGR

$0.09 \% \quad 45.6 \%$ LETHIRVPASAAGR

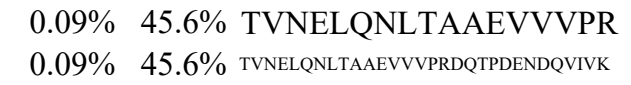

$0.09 \% \quad 45.6 \%$ DQTPDENDQVIVK

$0.09 \% \quad 45.6 \%$ IIGHFYASQMAQR

$0.09 \% \quad 45.6 \%$ IRDILAQVK

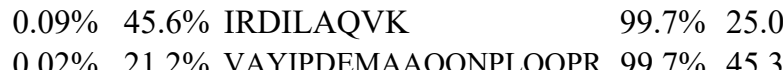

$\begin{array}{llll}99.0 \% & 31.3 & 25.0 & 31.3\end{array}$

$\begin{array}{llll}99.6 \% & 21.8 & 25.0 & 21.8\end{array}$

$\begin{array}{llll}99.7 \% & 36.0 & 25.0 & 35.2\end{array}$

$99.4 \% \quad 24.6 \quad 25.0 \quad 24.4$

$\begin{array}{llll}99.7 \% & 44.9 & 25.0 & 40.9\end{array}$

$\begin{array}{llll}99.7 \% & 53.5 & 25.0 & 43.8\end{array}$

$\begin{array}{llll}99.7 \% & 44.8 & 25.0 & 44.8\end{array}$

$\begin{array}{llll}99.5 \% & 24.9 & 25.0 & 17.1\end{array}$

$\begin{array}{llll}7 \% & 35.8 & 25.0 & 35.8\end{array}$

$\begin{array}{llll}99.7 \% & 46.0 & 25.0 & 43.8\end{array}$

$\begin{array}{llll}99.7 \% & 47.7 & 25.0 & 44.3\end{array}$

$\begin{array}{llll}99.7 \% & 66.2 & 25.0 & 61.1\end{array}$

$0.02 \% \quad 21.2 \%$ LLVPTQFVGAIIGK

$0.02 \% \quad 21.2 \%$ SITILSTPEGTSAACK

$0.02 \% \quad 21.2 \%$ ILAHNNFVGR

$0.02 \% \quad 21.2 \%$ IAPAEAPDAK

$0.02 \% \quad 21.2 \%$ IAPAEAPDAKVR

$0.02 \% \quad 21.2 \%$ MVIITGPPEAQFK

$\begin{array}{llll}9.7 \% & 45.3 & 25.0 & 45.3\end{array}$

$\begin{array}{llll}99.0 \% & 50.8 & 25.0 & 0.0\end{array}$

$\begin{array}{llll}99.6 \% & 22.8 & 25.0 & 22.3\end{array}$

$\begin{array}{llll}99.7 \% & 48.2 & 25.0 & 47.0\end{array}$

$\begin{array}{llll}98.9 \% & 19.3 & 25.0 & 19.3\end{array}$

$\begin{array}{llll}99.7 \% & 55.9 & 25.0 & 54.2\end{array}$

$\begin{array}{llll}99.7 \% & 53.5 & 25.0 & 43.8\end{array}$

$0.02 \% \quad 21.2 \%$ MVIITGPPEAQFKAQGR

$99.7 \% \quad 44.8$

$0.02 \% \quad 21.2 \%$ VPSFAAGR

$99.0 \% \quad 30.4$

$0.02 \% \quad 21.2 \%$ TVNELQNLSSAEVVVPR

$0.02 \% \quad 21.2 \%$ ALQSGPPQSR

$\begin{array}{llll}99.7 \% & 53.8 & 25.0 & 52.4\end{array}$

$0.02 \% \quad 4.4 \%$ DAAAALSSASALTGLTK

$0.02 \% \quad 4.4 \%$ LAEAAVAEKR

$0.02 \% \quad 4.4 \%$ TFVDNIQTAFNTR

$0.02 \% \quad 4.4 \%$ SVLLQGEAGR

$0.02 \% \quad 4.4 \%$ RQPIDNVSR

$0.02 \% \quad 4.4 \%$ SFQNQIAAIQR

$0.02 \% \quad 4.4 \%$ LGSSQVASR

$\begin{array}{lllll}99.7 \% & 46.0 & 25.0 & 43.3 & 2\end{array}$

$\begin{array}{llll}99.7 \% & 49.9 & 25.0 & 38.2\end{array}$

$\begin{array}{llll}99.7 \% & 50.9 & 25.0 & 50.9\end{array}$

$\begin{array}{llll}99.7 \% & 43.2 & 25.0 & 28.8\end{array}$

$\begin{array}{llll}99.7 \% & 27.3 & 25.0 & 18.4\end{array}$

$\begin{array}{llll}99.7 \% & 40.7 & 25.0 & 36.7\end{array}$

$\begin{array}{llll}99.7 \% & 43.0 & 25.0 & 36.8\end{array}$

$\begin{array}{lllllll}0.06 \% & 33.1 \% & \text { VKPAPDETSFSEALLK } & 99.7 \% & 43.6 & 25.0 & 42.6 \\ 0.06 \% & 33.1 \% \text { NQDLAPNSAEQASILSLVTK } & 99.7 \% & 47.5 & 25.0 & 47.5\end{array}$

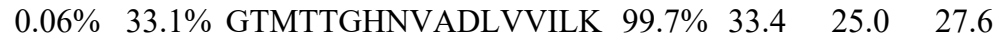

$0.06 \% 33.1 \%$ ILPTLEAVAALGNK

$99.7 \% \quad 55.1 \quad 25.0 \quad 49.0$

$\begin{array}{llll}99.7 \% & 38.8 & 25.0 & 38.8\end{array}$

$99.7 \% \quad 63.9 \quad 25.0 \quad 48.2$

$99.7 \% \quad 60.6 \quad 25.0 \quad 59.4$

$99.7 \% \quad 50.1 \quad 25.0 \quad 41.5$

$\begin{array}{llll}99.0 \% & 19.4 & 25.0 & 17.9\end{array}$

$\begin{array}{llll}95.2 \% & 16.5 & 25.0 & 12.0\end{array}$

$\begin{array}{llll}99.7 \% & 32.0 & 25.0 & 19.8\end{array}$

$0.06 \% 33.1 \%$ AYEKPPEKK

$\begin{array}{llll}99.7 \% & 44.3 & 25.0 & 33.5\end{array}$
1994.08

1862.99

979.41

1066.61

1758.93

1054.54

1309.71

1446.77

1842.99

1477.82

1853.0

3334.71

1500.72

1521.76

1055.66

2185.07

1455.89

1635.83

1140.63

982.52

1237.69

1446.77

1842.99

804.44

1854.99

1040.55

1724.95

1547.83

1057.60

1526.76

1029.57

1084.59

1275.68

904.48

1731.92

2099.10

1784.96

1409.84

1236.77

1041.64

1425.66

1144.65

1300.75

1014.58

1089.59

1444.74 $\begin{array}{cc}3 & 290 \\ 81 & 290 \\ 10 & 325 \\ 31 & 338 \\ 25 & 433 \\ 34 & 450 \\ 41 & 450 \\ 41 & 452 \\ 53 & 465 \\ 53 & 469 \\ 88 & 501 \\ 09 & 525 \\ 09 & 538 \\ 26 & 538 \\ 39 & 551 \\ 53 & 561 \\ 51 & 169 \\ 00 & 213 \\ 43 & 258 \\ 81 & 290 \\ 41 & 450 \\ 41 & 452 \\ 53 & 465 \\ 53 & 469 \\ 94 & 501 \\ 09 & 525 \\ 68 & 577 \\ 1 & 57 \\ 0 & 76 \\ 2 & 101 \\ 48 & 260 \\ 65 & 274 \\ 40 & 348 \\ 77 & 587 \\ 79 & 987 \\ 4 & 59 \\ 1 & 80 \\ 11 & 127 \\ 28 & 141 \\ 75 & 185 \\ 97 & 206 \\ 10 & 221 \\ 60 & 269 \\ 60 & 270 \\ 20 & 328 \\ 57 & 365 \\ 6 & 17 \\ & \end{array}$

Page 73 of Table S-1-1 
Interleukin enhancer-binding factor $3 \mathrm{GN}=$ ILF3 ILF3_HUMAN $95.34 \quad 100.0 \%$ Interleukin enhancer-binding factor $3 \mathrm{GN}=\mathrm{ILF} 3$ ILF3_HUMAN $95.34 \quad 100.0 \% \quad 18$ Interleukin enhancer-binding factor $3 \mathrm{GN}=\mathrm{ILF} 3 \mathrm{ILF} 3$ HUMAN $95.34 \quad 100.0 \% \quad 18$ Interleukin enhancer-binding factor $3 \mathrm{GN}=\mathrm{ILF} 3 \mathrm{ILF} 3$ HUMAN $95.34 \quad 100.0 \% \quad 18$ Interleukin enhancer-binding factor $3 \mathrm{GN}=\mathrm{ILF} 3 \mathrm{ILF} 3$ _HUMAN $95.34 \quad 100.0 \% \quad 18$ Interleukin enhancer-binding factor $3 \mathrm{GN}=$ ILF3 ILF3_HUMAN $95.34 \quad 100.0 \% \quad 18$ Interleukin enhancer-binding factor 3 GN=ILF3 ILF3_HUMAN $95.34 \quad 100.0 \% \quad 18$ Interleukin enhancer-binding factor $3 \mathrm{GN}=\mathrm{ILF} 3 \mathrm{ILF} 3$ _HUMAN $95.34 \quad 100.0 \% \quad 18$ Interleukin enhancer-binding factor $3 \mathrm{GN}=\mathrm{ILF} 3 \mathrm{ILF} 3 \mathrm{HUMAN} 95.34 \quad 100.0 \%$ Interleukin enhancer-binding factor $3 \mathrm{GN}=\mathrm{ILF} 3 \mathrm{ILF} 3$ HUMAN $95.34 \quad 100.0 \% \quad 18$ Interleukin enhancer-binding factor $3 \mathrm{GN}=\mathrm{ILF} 3 \mathrm{ILF} 3$ _HUMAN $95.34 \quad 100.0 \% \quad 18$ Interleukin enhancer-binding factor $3 \mathrm{GN}=\mathrm{ILF} 3 \mathrm{ILF} 3$ HUMAN $95.34 \quad 100.0 \% \quad 18$ Interleukin enhancer-binding factor 3 GN=ILF3 ILF3_HUMAN $95.34 \quad 100.0 \% \quad 18$ Interleukin enhancer-binding factor $3 \mathrm{GN}=$ ILF3 ILF3_HUMAN $95.34 \quad 100.0 \% \quad 18$ Interleukin enhancer-binding factor 3 GN=ILF3 ILF3_HUMAN $95.34 \quad 100.0 \% \quad 18$ Interleukin enhancer-binding factor $3 \mathrm{GN}=\mathrm{ILF} 3 \mathrm{ILF} 3$ HUMAN $95.34 \quad 100.0 \%$ Interleukin enhancer-binding factor $3 \mathrm{GN}=\mathrm{ILF} 3 \mathrm{ILF} 3$ HUMAN $95.34 \quad 100.0 \%$ Isocitrate dehydrogenase $[\mathrm{NAD}]$ subunit alpha, mitochondrial GN=IDH3A IDH3A_HUMAN $39.59 \quad 100.0 \%$ Isocitrate dehydrogenase [NAD] subunit alpha, mitochondrial GN=IDH3A IDH3A_HUMAN 39.59 Isocitrate dehydrogenase [NAD] subunit alpha, mitochondrial GN=IDH3A IDH3A_HUMAN 39.59 Isocitrate dehydrogenase $[\mathrm{NAD}]$ subunit alpha, mitochondrial GN=IDH3A IDH3A_HUMAN 39.59 Isocitrate dehydrogenase [NAD] subunit alpha, mitochondrial GN=IDH3A IDH3A_HUMAN 39.59 Isocitrate dehydrogenase [NAD] subunit alpha, mitochondrial GN=IDH3A IDH3A_HUMAN 39.59 Isocitrate dehydrogenase [NAD] subunit alpha, mitochondrial GN=IDH3A IDH3A_HUMAN 39.59 Iscitrate dehydrogenase $[\mathrm{NAD}]$ subunit al Isocitrate dehydrogenase [NAD] subunit alpha, mitochondrial GN=IDH3A IDH3A_HUMAN 39.59 Isocitrate dehydrogenase [NAD] subunit beta, mitochondrial GN=IDH3B IDH3B_HUMAN 42.18 Isocitrate dehydrogenase [NAD] subunit beta, mitochondrial GN=IDH3B IDH3B HUMAN 42.18 Isocitrate dehydrogenase [NAD] subunit beta, mitochondrial GN=IDH3B IDH3B_HUMAN 42.18 Isocitrate dehydrogenase $[\mathrm{NAD}]$ subunit beta, mitochondrial $\mathrm{GN}=\mathrm{IDH} 3 \mathrm{~B}$ IDH3B HUMAN 42.18 I. GN-IDHOB IDH3B_HUMAN Isocitrate dehydrogenase [NAD] subunit beta, mitochondrial GN=IDH3B IDH3B_HUMAN 42.18 Isocitrate dehydrogenase [NAD] subunit beta, mitochondrial GN=IDH3B IDH3B HUMAN 42.18 Isocitrate dehydrogenase [NAD] subunit beta, mitochondrial GN=IDH3B IDH3B_HUMAN 42.18 Isocitrate dehydrogenase [NAD] subunit beta, mitochondrial GN=IDH3B IDH3B_HUMAN 42.18 Isocitrate dehydrogenase [NAD] subunit gamma, mitochondrial GN=IDH3G IDH3G HUMAN 42.79 Isocitrate dehydrogenase [NAD] subunit gamma, mitochondrial GN=IDH3G IDH3G_HUMAN 42.79 Isocitrate dehydrogenase [NAD] subunit gamma mitochondrial GN=IDH3G IDH3G_HUMAN 42.79 Isocitrate dehydrogenase [NADP], mitochondrial GN=IDH2 IDHP_HUMAN 50.91 Jocitrate dehydrog $[\mathrm{NADP}]$ mitochondrial GN=IDH2 IDHP_HUMAN 50.91 Isocitrate dehydrogenase [NADP], mitochondrial GN=IDH2 IDHP_HUMAN 50.91 Isocitrate dehydrogenase [NADP], mitochondrial GN=IDH2 IDHP_HUMAN 50.91 Isocitrate dehydrogenase [NADP], mitochondrial GN=IDH2 IDHP_HUMAN $50.91 \quad 100.0$ Isocitrate dehydrogenase [NADP], mitochondrial GN=IDH2 IDHP_HUMAN $50.91 \quad 100.0^{\circ}$ Isocitrate dehydrogenase [NADP], mitochondrial GN=IDH2 IDHP HUMAN $50.91 \quad 100.0^{\circ}$ Isocitrate dehydrogenase [NADP], mitochondrial GN=IDH2 IDHP_HUMAN $50.91 \quad 100.0 \%$
60

60

60

60$$
\begin{aligned}
& 60 \\
& 60
\end{aligned}
$$$$
\begin{aligned}
& 60 \\
& 60
\end{aligned}
$$$$
60
$$

60

$$
\begin{aligned}
& 60 \\
& 60
\end{aligned}
$$$$
\begin{aligned}
& 60 \\
& 60
\end{aligned}
$$$$
60
$$

60
22 2166.14 974.55

1329.77

1600.82

1756.92

1780.91

984.56

$0.08 \%$ 20.8\% LAAFGQLHK

$0.08 \% 20.8 \%$ VLGMDPLPSK

$0.08 \% 20.8 \%$ VLGMDPLPSKMPK

$0.08 \% 20.8 \%$ AEPPQAMNALMR

$0.08 \% \quad 20.8 \%$ LNQLKPGLQYK

$0.08 \% \quad 20.8 \%$ TAKLHVAVK

$0.08 \% 20.8 \%$ VLQDMGLPTGAEGR

$0.08 \% 20.8 \%$ HGKNPVMELNEK

$0.08 \% 20.8 \%$ AYAALAALEK

$0.08 \% 20.8 \%$ NADHSMNYQYR

$0.03 \% 24.6 \%$ TPIAAGHPSMNLLLR

$0.03 \% 24.6 \%$ LITEGASKR

$0.03 \% \quad 24.6 \%$ IAEFAFEYAR

$0.03 \% \quad 24.6 \%$ SNVTAVHK

$0.03 \% \quad 24.6 \%$ SNVTAVHKANIMR

$0.03 \% \quad 24.6 \%$ MSDGLFLQK

$0.03 \% \quad 24.6 \%$ IEAACFATIKDGK

$0.03 \% \quad 24.6 \%$ SLTKDLGGNAK

$0.03 \% \quad 24.6 \%$ CSDFTEEICR

$0.03 \% \quad 19.7 \%$ HNNLDLVIIR

$0.03 \% \quad 19.7 \%$ GVIECLKIVTR

$0.03 \% \quad 19.7 \%$ IAKFAFDYATK

$0.03 \% \quad 19.7 \%$ FAFDYATKK

$0.03 \% \quad 19.7 \%$ NIANPTAMLLSASNMLR

$0.03 \% \quad 19.7 \%$ TRDMGGYSTTTDFIK

$0.03 \% \quad 19.7 \%$ DMGGYSTTTDFIK

$0.03 \% \quad 19.7 \%$ SVIGHLQTK

$0.03 \% \quad 19.7 \%$ SVIGHLQTKGS

$0.01 \% \quad 11.7 \%$ TSLDLYANVIHCK

$0.01 \% \quad 11.7 \%$ SLPGVVTR

$0.01 \% \quad 11.7 \%$ IAEYAFKLAQESGR

$0.01 \% \quad 11.7 \%$ LGDGLFLQCCR

$0.03 \% \quad 24.1 \%$ CATITPDEAR

$0.03 \% \quad 24.1 \%$ NILGGTVFREPIICK

$0.03 \% \quad 24.1 \%$ ATDFVADR

$0.03 \% \quad 24.1 \%$ ATDFVADRAGTFK

$0.03 \% \quad 24.1 \%$ LIDDMVAQVLK

$0.03 \% \quad 24.1 \%$ SSGGFVWACK

$0.03 \% \quad 24.1 \%$ TIEAEAAHGTVTR

$0.03 \% \quad 24.1 \%$ GKLDGNQDLIR
$99.7 \% \quad 51.8$

$97.5 \% \quad 30.0$

$99.7 \% \quad 32.5$

$\begin{array}{lll}99.7 \% & 53.4\end{array}$

$99.7 \% \quad 45.8$

$99.7 \% \quad 30.8$

$99.7 \% \quad 28.3$

$99.7 \% \quad 27.5$

$99.7 \% \quad 42.5$

$99.7 \% \quad 34.6$

$99.7 \% \quad 58.4$

$99.7 \% \quad 24.3$

$99.7 \% \quad 54.6$

$99.7 \% \quad 35.3$

$99.7 \% \quad 29.3$

$95.6 \% \quad 22.6$

$99.7 \% \quad 68.6$

$99.0 \% \quad 33.8$

$99.7 \% 31.0$

$99.7 \% \quad 36.4$

$99.7 \% \quad 53.9$

$\begin{array}{lll}99.7 \% & 34.7\end{array}$

$99.7 \% \quad 60.0$

$99.5 \% \quad 22.7$

$99.7 \% \quad 57.0$

$99.7 \% \quad 28.0$

$99.7 \% 26.5$

$\begin{array}{lll}99.7 \% & 53.3\end{array}$

$99.7 \% \quad 29.8$

$99.7 \% \quad 47.2$

$99.7 \% \quad 26.9$

$99.7 \% \quad 31.7$

$99.7 \% \quad 37.4$

$\begin{array}{lll}98.3 \% & 21.7\end{array}$

$\begin{array}{lll}99.7 \% & 49.8\end{array}$

$99.7 \% \quad 49.9$

$99.7 \% \quad 48.4$

$99.0 \% 21.9$

$99.7 \% \quad 44.3$

$99.7 \% \quad 41.6$

$99.7 \% \quad 56.3$

$99.7 \% \quad 82.0$

$99.7 \% \quad 44.6$
056.58

1412.76

1328.65

1301.76

966.61

1443.73

1395.71

1020.57

1398.59

1590.88

974.56

1216.60

855.47

1440.77

1038.53

1423.73

1103.6

1316.52

1206.70

1287.75

1274.68

1090.56

1832.94

1692.79

1435.64

982.57

1126.62

1533.77

828.49

1582.82

1338.63

1133.53

1716.95

894.43

1398.70

1260.69

1098.50

1355.69

1228.66 
Isocitrate dehydrogenase [NADP], mitochondrial GN=IDH2 IDHP_HUMAN $50.91 \quad 100.0 \%$ Isocitrate dehydrogenase [NADP], mitochondrial GN=IDH2 IDHP_HUMAN $50.91 \quad 100.0 \%$ Isoleucine--tRNA ligase, cytoplasmic GN=IARS SYIC_HUMAN $144.50 \quad 100.0 \%$ Isoleucine--tRNA ligase, cytoplasmic GN=IARS SYIC HUMAN $144.50100 .0 \%$ Isoleucine--tRNA ligase, cytoplasmic GN=IARS SYIC_HUMAN $144.50 \quad 100.0 \%$ Isoleucine--tRNA ligase, cytoplasmic GN=IARS SYIC_HUMAN $144.50 \quad 100.0 \%$ Isoleucine--tRNA ligase, cytoplasmic GN=IARS SYIC_HUMAN $144.50 \quad 100.0 \%$ Isoleucine--tRNA ligase, mitochondrial GN=IARS2 SYIM_HUMAN $113.79 \quad 100.0 \%$ Isoleucine--tRNA ligase, mitochondrial GN=IARS2 SYIM HUMAN $113.79 \quad 100.0 \%$ Isoleucine--tRNA ligase, mitochondrial GN=IARS2 SYIM_HUMAN $113.79 \quad 100.0 \%$ Isoleucine--tRNA ligase, mitochondrial GN=IARS2 SYIM_HUMAN $113.79 \quad 100.0 \%$ Isoleucine--tRNA ligase, mitochondrial GN=IARS2 SYIM HUMAN $113.79 \quad 100.0^{\circ}$ Junction plakoglobin GN=JUP Junction plakoglobin GN=JUP Junction plakoglobin GN=JUP Ketosamine-3-kinase GN=FN3KRP Ketosamine-3-kinase GN=FN3KRP PLAK_HUMAN $81.75 \quad 100.0 \%$ PLAK HUMAN $81.75 \quad 100.0 \%$ PLAK_HUMAN $81.75 \quad 100.0 \%$ KT3K_HUMAN $34.41 \quad 99.8 \%$ KT3K HUMAN $34.41 \quad 99.8 \%$ KHDR1_HUMAN $48.23 \quad 100.0 \%$ KHDR1_HUMAN $48.23 \quad 100.0 \%$ $\begin{array}{lll}\text { Kinesin-like protein KIF14 GN=KIF14 } & \text { KIF14_HUMAN } 186.50 & 100.0 \% \\ \text { Kinesin-like protein KIF14 GN=KIF14 } & \text { KIF14_HUMAN } 186.50 & 100.0 \%\end{array}$ Kinetochore-associated protein $1 \mathrm{GN}=\mathrm{KNTC1}$ KNTC1_HUMAN $250.76 \quad 100.0 \%$ Kinetochore-associated protein $1 \mathrm{GN}=\mathrm{KNTC1} \mathrm{KNTC1}$ HUMAN $250.76 \quad 100.0 \%$ Kinetochore-associated protein $1 \mathrm{GN}=\mathrm{KNTC1} \mathrm{KNTC1}$ HUMAN $250.76 \quad 100.0 \%$ Kinetochore-associated protein $1 \mathrm{GN}=\mathrm{KNTC1}$ KNTC1_HUMAN $250.76 \quad 100.0 \%$ Kinetochore-associated protein $1 \mathrm{GN}=\mathrm{KNTC1}$ KNTC1_HUMAN $250.76 \quad 100.0 \%$ Kinetochore-associated protein $1 \mathrm{GN}=\mathrm{KNTC1}$ KNTC1_HUMAN $250.76 \quad 100.0 \%$ KRR1 small subunit processome component homolog GN=KRR1 KRR1_HUMAN $43.67 \quad 100.0 \%$ KRR1 small subunit processome component homolog GN=KRR1 KRR1_HUMAN $43.67 \quad 100.0 \%$ KRR1 small subunit processome component homolog GN=KRR1 KRR1 HUMAN $43.67 \quad 100.0 \%$ KRR1 small subunit processome component homolog GN=KRR1 KRR1_HUMAN $43.67 \quad 100.0 \%$ KRR1 small subunit processome component homolog GN=KRR1 KRR1_HUMAN $43.67 \quad 100.0 \%$ KRR1 small subunit processome component homolog GN=KRR1 KRR1 HUMAN $43.67 \quad 100.0 \%$ L-2-hydroxyglutarate dehydrogenase, mitochondrial GN=L2HGDH L2HDH_HUMAN $50.32 \quad 100.0 \%$ L-2-hydroxyglutarate dehydrogenase, mitochondrial GN=L2HGDH L2HDH HUMAN $50.32100 .0 \%$ L-2-hydroxyglutarate dehydrogenase, mitochondrial GN=L2HGDH L2HDH_HUMAN $50.32 \quad 100.0 \%$ Lactadherin GN=MFGE8 Lactadherin GN=MFGE8 Lamina-associated polypeptide 2, isoform alpha GN=TMPO LAP2A_HUMAN $75.49 \quad 100.0 \%$ Lamina-associated polypeptide 2, isoform alpha GN=TMPO LAP2A_HUMAN $75.49 \quad 100.0 \%$ Lamina-associated polypeptide 2, isoform alpha GN=TMPO LAP2A_HUMAN $75.49 \quad 100.0 \%$ Lamin-B receptor $\mathrm{GN}=\mathrm{LBR}$ Lamin-B receptor $\mathrm{GN}=\mathrm{LBR}$ Lamin-B receptor $\mathrm{GN}=\mathrm{LBR}$ Lamin-B receptor $\mathrm{GN}=\mathrm{LBR}$ Lamin-B receptor $\mathrm{GN}=\mathrm{LBR}$ Lamin-B receptor $\mathrm{GN}=\mathrm{LBR}$

LBR HUMAN $70.71 \quad 100.0 \%$

LBR_HUMAN $70.71 \quad 100.0 \%$

LBR_HUMAN $70.71 \quad 100.0 \%$

LBR HUMAN $70.71 \quad 100.0 \%$

LBR_HUMAN $70.71 \quad 100.0 \%$
$0.03 \% \quad 24.1 \%$ VCVETVESGAMTK

$0.03 \% 24.1 \%$ DLAGCIHGLSNVK

$0.01 \% \quad 4.3 \% \quad$ MGITEYNNQCR

$0.01 \% \quad 4.3 \%$ SDTPLIYK

$0.01 \% \quad 4.3 \%$ NYPDPVSIIQK

$0.01 \% \quad 4.3 \% \quad$ LYLINSPVVR

$0.01 \% \quad 4.3 \%$ TQLKGSELEITLTR

$0.01 \% \quad 5.8 \%$ EAQNLSAMEIR

$0.01 \% \quad 5.8 \%$ TALAEAELEYNPEHVSR

$0.01 \% \quad 5.8 \%$ SIYVKFPLLKPSPK

$0.01 \% \quad 5.8 \%$ FPLLKPSPK

$0.01 \% \quad 5.8 \%$ TKDEYLINSQTTEHIVK

$0.00 \% \quad 5.0 \%$ LAEPSQLLK

$0.00 \% \quad 5.0 \%$ HLTSNSPR

$0.00 \% \quad 5.0 \% \quad$ NLALCPANHAPLQEAAVIPR

$0.00 \% \quad 7.8 \%$ SYDTDQGRVFVK

$0.00 \% \quad 7.8 \%$ GGGQEERPFVAR

$0.01 \% \quad 5.6 \%$ SGSMDPSGAHPSVR

$0.01 \% \quad 5.6 \% \quad$ ILGPQGNTIKR

$0.00 \% \quad 1.3 \%$ SSFLANKQER

$0.00 \% \quad 1.3 \%$ INLIDLAGSER

$0.01 \% \quad 3.4 \%$ TYQNLVIEK

$0.01 \% \quad 3.4 \%$ IQQAIENVDFSTAK

$0.01 \% \quad 3.4 \%$ LSEDSVSVLVLR

$0.01 \% \quad 3.4 \%$ LTTFYGAFGPEK

$0.01 \% \quad 3.4 \%$ LGISFQPVFR

$0.01 \% \quad 3.4 \%$ IQNSSGTDYPDIHAAAK

$0.02 \% \quad 17.1 \%$ GLLEESSFATLFPK

$0.02 \% \quad 17.1 \%$ TFDPYIIIR

$0.02 \% \quad 17.1 \%$ SVSFEQAVR

$0.02 \% \quad 17.1 \%$ ILQDDVACDIIK

$0.02 \% \quad 17.1 \%$ NIHPIYNIK

$0.02 \% \quad 17.1 \%$ LGALTAEEIALK

$0.01 \% \quad 7.8 \%$ LIVAVEQEEIPR

$0.01 \% \quad 7.8 \%$ SIDGMQYPIVIK

$0.01 \% \quad 7.8 \%$ FIPEITISDILR

$0.00 \% \quad 4.7 \%$ LASHEYLK

$0.00 \% \quad 4.7 \% \quad$ NLFETPILAR

$0.01 \% \quad 6.5 \% \quad$ YGVNPGPIVGTTR

$0.01 \% \quad 6.5 \%$ SSTPLPTISSSAENTR

$0.01 \% \quad 6.5 \%$ TVVSHSLTTLGLEVAK

$0.04 \% \quad 10.9 \%$ KFADGEVVR

$0.04 \% \quad 10.9 \%$ SRSPGRPPK

$0.04 \% \quad 10.9 \%$ LTPLILKPFGNSISR

$0.04 \% \quad 10.9 \%$ TFEVTPIR

$0.04 \% 10.9 \%$ VVEGTPLIDGR $\begin{array}{llllllll}99.7 \% & 69.0 & 25.0 & 55.1 & 4 & 0 & 0 & 1410.66\end{array}$

$\begin{array}{llllllll}99.7 \% & 42.3 & 25.0 & 42.3 & 2 & 0 & 0 & 1383.71\end{array}$

$\begin{array}{llll}99.7 \% & 27.5 & 25.0 & 27.5\end{array}$

$99.0 \% \quad 24.6 \quad 25.0 \quad 14.8$

$\begin{array}{llll}99.4 \% & 20.4 & 25.0 & 20.4\end{array}$

$\begin{array}{llll}99.7 \% & 59.7 & 25.0 & 58.3\end{array}$

$99.7 \% \quad 44.9 \quad 25.0 \quad 42.9$

$\begin{array}{llll}99.6 \% & 29.7 & 25.0 & 29.7\end{array}$

$\begin{array}{llll}99.7 \% & 63.8 & 25.0 & 63.8\end{array}$

$\begin{array}{llll}98.8 \% & 17.9 & 25.0 & 17.9\end{array}$

$\begin{array}{llll}99.4 \% & 21.4 & 25.0 & 21.4\end{array}$

$\begin{array}{llll}99.4 \% & 20.7 & 25.0 & 20.7\end{array}$

$\begin{array}{llll}98.7 \% & 27.2 & 25.0 & 11.7\end{array}$

$\begin{array}{llll}99.0 \% & 25.7 & 25.0 & 25.4\end{array}$

$98.9 \% \quad 23.1$

$98.6 \% 23.9$

$94.9 \% \quad 21.7$

$99.7 \% 32.0$

$99.3 \% \quad 20.0$

$99.7 \% \quad 41.3$

$97.4 \% \quad 15.9$

$99.5 \% 25.8$

$99.7 \% \quad 32.7$

$99.7 \% \quad 50.2$

$99.7 \% \quad 58.5$

$99.7 \% \quad 46.2$

$99.4 \% \quad 20.4$

$99.7 \% \quad 49.4$

$99.7 \% \quad 32.6$

$99.7 \% \quad 40.8$

$99.7 \% \quad 46.7$

$99.7 \% \quad 28.4$

$99.7 \% \quad 43.1$

$99.7 \% \quad 48.8$

$99.2 \% \quad 23.8$

$99.7 \% \quad 41.1$

$99.0 \% \quad 24.3$

$99.7 \% \quad 36.5$

$99.7 \% \quad 42.2$

$99.7 \% \quad 48.3$

$99.0 \% \quad 19.5$

$99.7 \% \quad 36.6$

$99.1 \% \quad 21.0$

$99.7 \% \quad 49.4$

$99.7 \% \quad 29.3$

$99.0 \% \quad 32.4$

$99.7 \% \quad 43.0$

1173.70

1026.63

2155.14

1196.71

1107.60

1316.74

1111.63
1383.71
1385.59

936.50

1273.68

1588.89

1261.62

1928.93

1616.98

2019.04

998.59

911.47

1414.70

1302.66

1400.62

1179.61

1200.66

1563.80

1330.67

1163.66

1787.86

1538.81

1137.63

1022.53

1402.73

1228.71

1395.78

1379.72

1416.81

960.51

1173.66

1330.71

1647.82

1654.94

1020.55

981.56

1470.73

1413

$14 \quad 426$

410

$607 \quad 617$

$625 \quad 634$

$1058 \quad 1071$

$251 \quad 267$

$268 \quad 281$

281
555

$116 \quad 124$

$360 \quad 367$

$507 \quad 526$

$\begin{array}{cc}30 & 4 \\ 131 & 142\end{array}$

$18 \quad 31$

$176 \quad 186$

319328

$599 \quad 609$

$135 \quad 143$

$172 \quad 185$

$522 \quad 533$

$1414 \quad 1423$

$786 \quad 1802$

$53 \quad 66$

$107 \quad 115$

$126 \quad 134$

$135 \quad 146$

369

$137 \quad 148$

$232 \quad 243$

$388 \quad 399$

$149 \quad 156$

$356 \quad 365$

$127 \quad 139$

$158 \quad 173$

$84 \quad 92$

$655.98 \quad 117 \quad 131$

$962.53 \quad 196 \quad 203$

$\begin{array}{lll}1155.64 & 280 & 290\end{array}$ 
Lamin-B receptor $\mathrm{GN}=\mathrm{LBR}$ Lamin-B1 GN=LMNB Lamin-B1 GN=LMNB Lamin-B1 GN=LMNB1 Lamin-B1 GN=LMNB Lamin-B1 GN=LMNB Lamin-B1 GN=LMNB Lamin-B1 GN=LMNB Lamin-B1 GN=LMNB1 Lamin-B1 GN=LMNB Lamin-B1 GN=LMNB1 Lamin-B1 GN=LMNB Lamin-B1 GN=LMNB Lamin-B1 GN=LMNB Lamin-B1 GN=LMNB Lamin-B1 GN=LMNB Lamin-B1 GN=LMNB1 Lamin-B1 GN=LMNB1 Lamin-B1 GN=LMNB Lamin-B1 GN=LMNB Lamin-B1 GN=LMNB Lamin-B1 GN=LMNB1 Lamin-B1 GN=LMNB Lamin-B1 GN=LMNB1 Lamin-B1 GN=LMNB1 Lamin-B1 GN=LMNB Lamin-B1 GN=LMNB Lamin-B1 GN=LMNB Lamin-B1 GN=LMNB Lamin-B1 GN=LMNB1 Lamin-B1 GN=LMNB1 Lamin-B1 GN=LMNB Lamin-B1 GN=LMNB Lamin-B1 GN=LMNB Lamin-B1 GN=LMNB Lamin-B1 GN=LMNB1 Lamin-B2 GN=LMNB Lamin-B2 GN=LMNB2 Lamin-B2 GN=LMNB2 Lamin-B2 GN=LMNB2 Lamin-B2 GN=LMNB2 Lamin-B2 GN=LMNB2 Lamin-B2 GN=LMNB2 Lamin-B2 GN=LMNB2 Lamin-B2 GN=LMNB2 Lamin-B2 GN=LMNB2 Lamin-B2 GN=LMNB2 \begin{tabular}{lllllll} 
LBR_HUMAN 70.71 & $100.0 \%$ & 7 & 8 & 29 & $0.04 \%$ & $10.9 \%$ \\
\hline
\end{tabular} LMNB1_HUMAN $66.41 \quad 100.0 \% \quad 35 \quad 45 \quad 113 \quad 0.16 \% \quad 50.7 \%$ AGGPTTPLSPTR

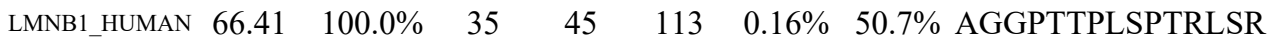
LMNB1_HUMAN $66.41 \quad 100.0 \% \quad 35$ LMNB1_HUMAN $66.41 \quad 100.0 \% \quad 35$ LMNB1_HUMAN $66.41 \quad 100.0 \% \quad 35$ LMNB1_HUMAN $66.41 \quad 100.0 \% \quad 35$ LMNB1_HUMAN $66.41 \quad 100.0 \% \quad 35$ LMNB1_HUMAN $66.41 \quad 100.0 \% \quad 35$ LMNB1_HUMAN $66.41 \quad 100.0 \% \quad 35$ LMNB1_HUMAN $66.41 \quad 100.0 \% \quad 35$ LMNB1_HUMAN $66.41 \quad 100.0 \% \quad 35$ LMNB1_HUMAN $66.41 \quad 100.0 \% \quad 35$ LMNB1_HUMAN $66.41 \quad 100.0 \% \quad 35$ LMNB1 HUMAN $66.41 \quad 100.0 \% \quad 35$ LMNB1_HUMAN $66.41 \quad 100.0 \% \quad 35$ LMNB1 HUMAN $66.41 \quad 100.0 \% \quad 35$ LMNB1_HUMAN $66.41 \quad 100.0 \% \quad 35$ LMNB1_HUMAN $66.41 \quad 100.0 \% \quad 35$ LMNB1_HUMAN $66.41 \quad 100.0 \% \quad 35$ LMNB1_HUMAN $66.41 \quad 100.0 \% \quad 35$ LMNB1_HUMAN $66.41 \quad 100.0 \% \quad 35$ LMNB1_HUMAN $66.41 \quad 100.0 \% \quad 35$ LMNB1_HUMAN $66.41 \quad 100.0 \% \quad 35$ LMNB1 HUMAN $66.41 \quad 100.0 \% \quad 35$ LMNB1_HUMAN $66.41 \quad 100.0 \% \quad 35$ LMNB1_HUMAN $66.41 \quad 100.0 \% \quad 35$ LMNB1_HUMAN $66.41 \quad 100.0 \% \quad 35$ LMNB1_HUMAN $66.41 \quad 100.0 \% \quad 35$ LMNB1 HUMAN $66.41 \quad 100.0 \% \quad 35$ LMNB1_HUMAN $66.41 \quad 100.0 \% \quad 35$ LMNB1_HUMAN $66.41 \quad 100.0 \% \quad 35$ LMNB1 HUMAN $66.41 \quad 100.0 \% \quad 35$ LMNB1_HUMAN $66.41 \quad 100.0 \% \quad 35$ LMNB1_HUMAN $66.41 \quad 100.0 \% \quad 35$ LMNB1 HUMAN $66.41 \quad 100.0 \% \quad 35$ LMNB2_HUMAN $67.69 \quad 100.0 \% \quad 12$ LMNB2 HUMAN $67.69 \quad 100.0 \% \quad 12$ LMNB2_HUMAN $67.69 \quad 100.0 \% \quad 12$ LMNB2_HUMAN $67.69 \quad 100.0 \% \quad 12$ LMNB2 HUMAN $67.69 \quad 100.0 \% \quad 12$ LMNB2_HUMAN $67.69 \quad 100.0 \% \quad 12$ LMNB2_HUMAN $67.69 \quad 100.0 \% \quad 12$ LMNB2_HUMAN $67.69 \quad 100.0 \% \quad 12$ LMNB2_HUMAN $67.69 \quad 100.0 \% \quad 12$ LMNB2 HUMAN $67.69 \quad 100.0 \% \quad 12$ LMNB2_HUMAN $67.69 \quad 100.0 \% \quad 12$

$17 \quad 37 \quad 0.05 \% \quad 23.2 \%$ AELDEVNKSAK $\begin{array}{llll}96.2 \% & 14.8 & 25.0 & 14.8\end{array}$ $99.7 \% \quad 39.3-25.0-29.5 \quad 11$ $99.3 \% \quad 20.2 \quad 25.0 \quad 20.2$ $99.0 \% \quad 36.7 \quad 25.0 \quad 18.1$ $13 \quad 0.16 \% \quad 50.7 \%$ LQEKEELR $99.7 \% \quad 75.1$ $\begin{array}{lll}96.8 \% & 25.9\end{array}$ $99.7 \% \quad 53.3$ $99.5 \% \quad 23.3$ $99.3 \% \quad 31.2$ $99.7 \% \quad 59.0$ $99.7 \% \quad 33.5$ $99.7 \% \quad 53.5$ $99.7 \% \quad 65.5$ $99.7 \% \quad 32.2$ $99.7 \% \quad 39.3$ $\begin{array}{lll}99.7 \% & 28.3\end{array}$ $97.3 \% \quad 16.2$ $99.7 \% \quad 56.0$ $95.3 \% \quad 15.1$ $99.0 \% \quad 34.7$ $96.8 \% \quad 27.7$ $99.7 \% \quad 34.3$ $99.7 \% \quad 35.6$

$\begin{array}{llll}45 & 113 & 0.16 \% & 50.7 \%\end{array}$

$99.7 \% \quad 38.0$ $\begin{array}{lll}99.7 \% & 42.9\end{array}$ $98.1 \% \quad 25.2$ $99.0 \% \quad 50.3$ $99.7 \% 52.1$ $99.6 \% \quad 28.7$ $99.7 \% \quad 32.4$ $99.7 \% \quad 51.0$ $\begin{array}{llll}99.7 \% & 34.4 & 25.0 & 31.2\end{array}$ $45 \quad 113 \quad 0.16 \% \quad 50.7 \%$ IGDTSVSYKYTSR

$\begin{array}{lllll}45 & 113 & 0.16 \% & 50.7 \% & \text { NQNSWGTGEDVKVILK } \\ 45 & 113 & 0.16 \% & 50.7 \% & \text { VILKNSQGEEVAQR }\end{array}$ $45 \quad 113 \quad 0.16 \% \quad 50.7 \%$ VILKNSQGEEVAQR

$45 \quad 113 \quad 0.16 \% \quad 50.7 \%$ NSQGEEVAQR

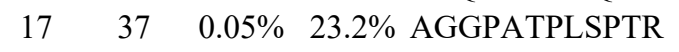

$17 \quad 37 \quad 0.05 \% \quad 23.2 \%$ AGGPATPLSPTRLSR

$17 \quad 37 \quad 0.05 \% \quad 23.2 \%$ LQEKEELR

$\begin{array}{llll}17 & 37 & 0.05 \% & 23.2 \% \\ 17 & 37 & \text { ALYESELADAR }\end{array}$

$17 \quad 37 \quad 0.05 \% \quad 23.2 \%$ ALYESELADARR

$\begin{array}{llll}17 & 37 & 0.05 \% & 23.2 \% \\ 17 & \text { EGELTVAQGR }\end{array}$

$17 \quad 37 \quad 0.05 \% \quad 23.2 \%$ GLESDVAELR

$\begin{array}{llll}17 & 37 & 0.05 \% & 23.2 \% \\ 17 & 37 & 0.05 \% & 23.2 \%\end{array}$

$\begin{array}{llll}17 & 37 & 0.05 \% & 23.2 \% \\ 17 & \text { MRLESLSYQLSGLQK }\end{array}$

$99.7 \% \quad 58.5$

$99.7 \% \quad 50.7$

$99.3 \% \quad 20.0$

$99.0 \% \quad 36.7$

$99.7 \% \quad 52.6$

$99.0 \% 22.1$

$99.5 \% \quad 21.2$

$\begin{array}{lll}99.7 \% & 60.7\end{array}$

$99.7 \% \quad 40.3$

$99.0 \% \quad 18.4$

$99.7 \% \quad 33.5$

$99.0 \% \quad 50.3$
1510.83

1044.57

2331.18

873.52

1251.62

1407.72

1046.52

999.62

1702.86

1293.68

1173.65

1158.67

1030.58

1756.94

1525.73

1400.60

1556.70

874.46

982.47

1651.83

1512.70

2387.08

1733.92

1818.96

1171.66

1281.65

974.48

1215.66

1097.58

969.49

1476.73

1787.93

1570.85

1117.52

1124.61

1480.82

1044.57

1237.61

1393.7

1203.62

1059.54

1088.56

1599.87

1768.93

974.48 
Lamin-B2 GN=LMNB2 Lamin-B2 GN=LMNB2 Lamin-B2 GN=LMNB2 Lamin-B2 GN=LMNB2 La-related protein $1 \mathrm{GN}=\mathrm{LARP} 1$ La-related protein $1 \mathrm{GN}=\mathrm{LARP} 1$ La-related protein $1 \mathrm{GN}=\mathrm{LARP} 1$ La-related protein $1 \mathrm{GN}=\mathrm{LARP}$ La-related protein $1 \mathrm{GN}=\mathrm{LARP} 1$ La-related protein $1 \mathrm{GN}=\mathrm{LARP} 1$ La-related protein $1 \mathrm{GN}=\mathrm{LARP}$ La-related protein $1 \mathrm{GN}=\mathrm{LARP} 1$ La-related protein $1 \mathrm{GN}=\mathrm{LARP} 1$ La-related protein $7 \mathrm{GN}=$ LARP7 La-related protein $7 \mathrm{GN}=\mathrm{LARP} 7$

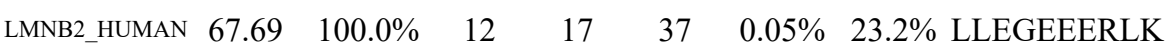
LMNB2_HUMAN $67.69 \quad 100.0 \% \quad 12 \quad 17 \quad 37 \quad 0.05 \% \quad 23.2 \%$ ATSSSSGSLSATGR

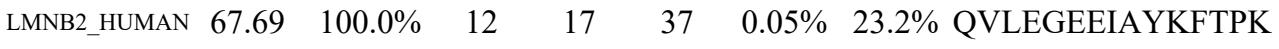

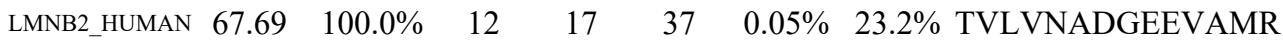
$\begin{array}{llllllll}\text { LARP1_HUMAN } 123.51 & 100.0 \% & 9 & 11 & 21 & 0.03 \% & 9.5 \% & \text { SVQPQSHKPQPTR }\end{array}$ LARP1_HUMAN $123.51 \quad 100.0 \%$ LARP1 HUMAN $123.51 \quad 100.0 \%$ LARP1_HUMAN $123.51 \quad 100.0 \%$ LARP1 HUMAN $123.51 \quad 100.0 \%$ LARP1_HUMAN $123.51 \quad 100.0 \%$ LARP1_HUMAN $123.51 \quad 100.0 \%$ LARP1_HUMAN $123.51 \quad 100.0 \%$ LARP1_HUMAN $123.51 \quad 100.0 \%$ LARP7_HUMAN $66.90 \quad 100.0 \%$ LARP7_HUMAN $66.90 \quad 100.0 \%$

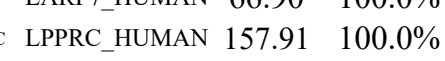
RC LPRC HUMAN $157.91 \quad 100.0 \%$ RC LPPRC_HUMAN $157.91 \quad 100.0 \%$ RC LPRC_HUMAN $157.91 \quad 100.0 \%$ C LPPRC_HUMAN $157.91 \quad 100.0 \%$ RC LPPRC_HUMAN $157.91 \quad 100.0 \%$ RC LPPRC_HUMAN $157.91 \quad 100.0 \%$ RC LPPRC_HUMAN $157.91 \quad 100.0 \%$ RC LPPRC_HUMAN $157.91 \quad 100.0 \%$ 40 LRC40_HUMAN $68.25 \quad 100.0 \%$ LRC40_HUMAN $68.25 \quad 100.0 \%$ $100.0 \%$
$100.0 \%$ $100.0 \%$ $100.0 \%$ $100.0 \%$ $100.0 \%$ $100.0 \%$ $100.0 \%$ $100.0 \%$ $100.0 \%$ $100.0 \%$ $100.0 \%$ $100.0 \%$ $100.0 \%$ $100.0 \%$ $100.0 \% \quad 26$ $100.0 \% \quad 26$ $100.0 \% \quad 26$ $100.0 \% \quad 26$ $100.0 \% \quad 26$ $100.0 \% \quad 26$ $100.0 \% \quad 26$

$\begin{array}{llll}0.03 \% & 9.5 \% & \text { SVQPQSHKPQP } \\ 0.03 \% & 9.5 \% & \text { KFDGVEGPR }\end{array}$

$0.03 \% \quad 9.5 \%$ SLPTTVPESPNYR

$0.03 \% \quad 9.5 \%$ TPQLKDSSQTSR

$0.03 \% \quad 9.5 \%$ FYPVVKEGR

$0.03 \% \quad 9.5 \%$ TLDAKMPR

$0.03 \% \quad 9.5 \%$ HSVVAGGGGGEGR

$0.00 \% \quad 4.5 \%$ AIEFLNNPPEEAPR

$0.00 \% \quad 4.5 \%$ SSSEDAESLAPR

$0.02 \% \quad 8.3 \%$ EKDIQEESTFSSR

$0.02 \% \quad 8.3 \%$ SGGLGGSHALLLLR

$0.02 \% \quad 8.3 \%$ LIASYCNVGDIEGASK

$0.02 \% \quad 8.3 \% \quad$ NVQGIIEILK

$0.02 \% \quad 8.3 \%$ SNTLPISLQSIR

$0.02 \% \quad 8.3 \%$ KIIETPGIR

$0.02 \% \quad 8.3 \% \quad$ TVLDQQQTPSR

$0.02 \% \quad 8.3 \% \quad$ SYVSEKDVTSAK

$0.02 \% \quad 13.0 \%$ KSGQLNLSGR

$0.02 \% \quad 13.0 \%$ ILPEEITNLRNLK

$0.02 \% \quad 13.0 \%$ FLPEFPSCSLLK

$0.02 \% \quad 13.0 \%$ SVPDEIILLR

$0.02 \% \quad 13.0 \%$ FLALEGNPLR

$0.02 \% \quad 13.0 \%$ LQTINLSFNR

$0.02 \% \quad 13.0 \%$ TLLLDGNPFRVPR

$\begin{array}{lll}0.00 \% & 5.5 \% & \text { NALGPGLSPELGPLPAI } \\ 0.00 \% & 5.5 \% & \text { VLHVSENPVPLTVR }\end{array}$

$0.00 \% \quad 7.1 \%$ QANVQIQEIQR

$0.00 \% \quad 7.1 \% \quad$ LTADLSAETLQAR

$0.02 \% \quad 1.7 \%$ SAAAIALPPIAK

$0.02 \% \quad 1.7 \%$ ATDAQLCLESSPK

$0.02 \% \quad 1.7 \%$ VANEAEFILSR

$13 \quad 0.02 \% \quad 1.7 \% \quad$ VGVGTSFGLPQTR

$107 \quad 0.15 \% \quad 52.4 \%$ DQLIYNLLK

$107 \quad 0.15 \% \quad 52.4 \%$ GEMMDLQHGSLFLR

$107 \quad 0.15 \% \quad 52.4 \%$ IVSGKDYNVTANSK
$0.03 \% \quad 9.5 \%$ FQQVPTDALANKLFGAPEPSTIAR

$0.03 \% \quad 9.5 \%$ SLPTTVPESPNYRNTR

$0.02 \% \quad 8.3 \%$ VIQALAMKGDVENIEVVQK

$\begin{array}{llll}99.7 \% & 52.1 & 25.0 & 43.8\end{array}$

$\begin{array}{llll}99.7 \% & 45.8 & 25.0 & 45.0\end{array}$

$\begin{array}{lllll}99.7 \% & 42.4 & 25.0 & 35.9 & 2\end{array}$

$\begin{array}{llll}99.7 \% & 85.3 & 25.0 & 85.2\end{array}$

$\begin{array}{llll}99.5 \% & 22.6 & 25.0 & 19.7\end{array}$

$99.7 \% \quad 40.9 \quad 25.0 \quad 31.8$

\begin{tabular}{llll}
$99.4 \%$ & 20.4 & 25.0 & 20.3 \\
\hline
\end{tabular}

$\begin{array}{rrrr}9.4 \% & 15.6 & 25.0 & 14.6 \\ 99.2 \% & 23.4 & 25.0 & 23.4\end{array}$

$99.7 \% \quad 35.6 \quad 25.0 \quad 34.2$

$\begin{array}{llll}99.7 \% & 38.4 & 25.0 & 38.4\end{array}$

$98.8 \% \quad 18.6 \quad 25.0 \quad 17.6$

$\begin{array}{llll}99.7 \% & 53.6 & 25.0 & 46.5\end{array}$

$99.7 \% \quad 45.1 \quad 25.0 \quad 45.1 \quad 2$

$\begin{array}{llll}98.6 \% & 24.4 & 25.0 & 15.4\end{array}$

$99.7 \% \quad 70.1 \quad 25.0 \quad 68.3$

$99.7 \% \quad 46.5 \quad 25.0 \quad 44.3$

$\begin{array}{llll}99.7 \% & 39.9 & 25.0 & 37.7\end{array}$

$\begin{array}{lllll}99.7 \% & 30.8 & 25.0 & 28.2 & 2\end{array}$

$\begin{array}{lllll}99.7 \% & 51.8 & 25.0 & 36.7 & 2\end{array}$

$\begin{array}{lllll}99.7 \% & 29.3 & 25.0 & 24.1 & 2\end{array}$

$\begin{array}{llll}99.7 \% & 34.9 & 25.0 & 28.4\end{array}$

$99.0 \% \quad 25.8$

$\begin{array}{lll}99.7 \% & 50.0\end{array}$

$99.7 \% \quad 32.8$

$99.6 \% \quad 21.7$

$95.8 \% \quad 17.7$

$99.7 \% \quad 48.8$

$99.7 \% \quad 56.3$

$99.7 \% \quad 41.4$

$98.7 \% \quad 18.1$

$\begin{array}{lll}99.7 \% & 35.7\end{array}$

$99.7 \% \quad 55.7$

$99.7 \% \quad 41.3$

$99.7 \% \quad 67.3$

$99.7 \% \quad 44.5$

$99.7 \% \quad 51.4$

$99.7 \% \quad 31.3$

$99.7 \% \quad 28.3$

$99.7 \% \quad 35.8$

$107 \quad 0.15 \% \quad 52.4 \%$ DQLIYNLLKEEQTPQNK $\quad 99.7 \% \quad 35.7$

$107 \quad 0.15 \% \quad 52.4 \%$ LKGEMMDLQHGSLFLR

$98.3 \% 19.3$

$99.7 \% \quad 46.1$

$99.7 \% \quad 50.2$

$99.7 \% \quad 49.2$

$107 \quad 0.15 \% \quad 52.4 \%$ DYNVTANSKLVIITAGAR $99.3 \% \quad 19.9$

$99.7 \% \quad 55.7$

121

0

1215.66

751.92

1503.75

1489.79

1004.52

2571.36

1460.74

831.93

1347.69

1094.60

947.50

1139.56

1596.80

1248.57

1555.72

350.79

1696.82

1126.68

1328.75

1026.63

272.65

2100.14

1313.66

059.59

1552.91

1437.74

1154.68

1129.64

1205.66

1497.85

1772.01

1559.89

1326.71

1388.74

1122.69

1419.68

1248.66

1318.71

1119.64

2074.08

1906.95

633.78

1495.78

1011.47

1906.04

913.58

$\begin{array}{cc}74 & 383 \\ 97 & 410 \\ 86 & 500 \\ 42 & 555 \\ 86 & 198 \\ 67 & 375 \\ 42 & 765 \\ 66 & 778 \\ 66 & 781 \\ 88 & 799 \\ 00 & 808 \\ 09 & 816 \\ 39 & 1051 \\ 82 & 195 \\ 98 & 309 \\ 55 & 77 \\ 15 & 128 \\ 03 & 218 \\ 54 & 463 \\ 30 & 541 \\ 09 & 917 \\ 29 & 1139 \\ 45 & 1163 \\ 327 & 1338 \\ 37 & 46 \\ 42 & 154 \\ 57 & 268 \\ 03 & 312 \\ 38 & 347 \\ 97 & 506 \\ 69 & 581 \\ 35 & 102 \\ 11 & 324 \\ 92 & 202 \\ 49 & 261 \\ 13 & 224 \\ 25 & 437 \\ 395 & 1905 \\ 83 & 2195 \\ 6 & 14 \\ 6 & 22 \\ 58 & 73 \\ 60 & 73 \\ 77 & 90 \\ 32 & 90 \\ & 99 \\ & \end{array}$

Page 77 of Table S-1-1 
L-lactate dehydrogenase A chain GN=LDHA LDHA_HUMAN $36.69 \quad 100.0 \%$ L-lactate dehydrogenase A chain GN=LDHA LDHA_HUMAN $36.69 \quad 100.0 \% \quad 26$ L-lactate dehydrogenase A chain GN=LDHA LDHA_HUMAN 36.69 L-lactate dehydrogenase A chain GN=LDHA LDHA_HUMAN 36.69 L-lactate dehydrogenase A chain GN=LDHA LDHA_HUMAN 36.69 L-lactate dehydrogenase A chain GN=LDHA LDHA_HUMAN 36.69 L-lactate dehydrogenase A chain GN=LDHA LDHA_HUMAN 36.69 L-lactate dehydrogenase A chain GN=LDHA LDHA_HUMAN 36.69 L-lactate dehydrogenase A chain GN=LDHA LDHA_HUMAN 36.69 L-lactate dehydrogenase A chain GN=LDHA LDHA_HUMAN 36.69 L-lactate dehydrogenase A chain GN=LDHA LDHA_HUMAN 36.69 L-lactate dehydrogenase A chain GN=LDHA LDHA_HUMAN 36.69 L-lactate dehydrogenase A chain GN=LDHA LDHA_HUMAN 36.69 L-lactate dehydrogenase A chain GN=LDHA LDHA_HUMAN 36.69 L-lactate dehydrogenase A chain GN=LDHA LDHA_HUMAN 36.69 L-lactate dehydrogenase A chain GN=LDHA LDHA_HUMAN 36.69 L-lactate dehydrogenase A chain GN=LDHA LDHA_HUMAN 36.69 L-lactate dehydrogenase A chain GN=LDHA LDHA_HUMAN 36.69 L-lactate dehydrogenase B chain GN=LDHB LDHB_HUMAN 36.64 L-lactate dehydrogenase B chain GN=LDHB LDHB_HUMAN 36.64 L-lactate dehydrogenase B chain GN=LDHB LDHB_HUMAN 36.64 L-lactate dehydrogenase B chain GN=LDHB LDHB_HUMAN 36.64 L-lactate dehydrogenase B chain GN=LDHB LDHB_HUMAN 36.64 L-lactate dehydrogenase B chain GN=LDHB LDHB_HUMAN 36.64 L-lactate dehydrogenase B chain GN=LDHB LDHB_HUMAN 36.64 L-lactate dehydrogenase B chain GN=LDHB LDHB_HUMAN 36.64 L-lactate dehydrogenase B chain GN=LDHB LDHB_HUMAN 36.64 L-lactate dehydrogenase B chain GN=LDHB LDHB_HUMAN 36.64 L-lactate dehydrogenase B chain GN=LDHB LDHB_HUMAN 36.64 L-lactate dehydrogenase B chain GN=LDHB LDHB_HUMAN 36.64 L-lactate dehydrogenase B chain GN=LDHB LDHB_HUMAN 36.64 L-lactate dehydrogenase B chain GN=LDHB LDHB_HUMAN 36.64 L-lactate dehydrogenase B chain GN=LDHB LDHB_HUMAN 36.64 L-lactate dehydrogenase B chain GN=LDHB LDHB_HUMAN 36.64 L-lactate dehydrogenase B chain GN=LDHB LDHB_HUMAN 36.64 L-lactate dehydrogenase B chain GN=LDHB LDHB_HUMAN 36.6 L-lactate dehydrogenase B chain GN=LDHB LDHB_HUMAN $36.64 \quad 100.0 \%$ Long-chain fatty acid transport protein $4 \mathrm{GN}=$ SLC27A4 S27A4_HUMAN 72.07 Long-chain fatty acid transport protein 4 GN=SLC27A4 S27A4_HUMAN 72.07 Long-chain fatty acid transport protein 4 GN=SLC27A4 S27A4_HUMAN 72.07 Long-chain-fatty-acid--CoA ligase 3 GN=ACSL3 ACSL3_HUMAN 80.42 Long-chain-fatty-acid--CoA ligase 3 GN=ACSL3 ACSL3_HUMAN 80.42 Long-chain-fatty-acid--CoA ligase $3 \mathrm{GN}=$ ACSL 3 ACSL3 HUMAN 80.42 Long-chain-fatty-acid--CoA ligase 3 GN=ACSL3 ACSL3_HUMAN $80.42 \quad 100.0 \%$ Lupus La protein $\mathrm{GN}=\mathrm{SSB}$ Lupus La protein $\mathrm{GN}=\mathrm{SSB}$ Lupus La protein $\mathrm{GN}=\mathrm{SSB}$ LA_HUMAN $46.84 \quad 100.0 \%$ LA HUMAN $46.84 \quad 100.0 \%$ LA_HUMAN $46.84 \quad 100.0 \%$
$0.15 \% \quad 52.4 \%$ LVIITAGARQQEGESR

52.4\% NVNIFKFIIPNVVK

$52.4 \%$ FIIPNVVKYSPNCK

$0.15 \% \quad 52.4 \%$ NRVIGSGCNLDSAR

$107 \quad 0.15 \% \quad 52.4 \%$ VIGSGCNLDSAR

$0.15 \% \quad 52.4 \%$ VIGSGCNLDSARFR

$0.15 \% \quad 52.4 \%$ FRYLMGER

$107 \quad 0.15 \% \quad 52.4 \%$ TLHPDLGTDK

$107 \quad 0.15 \% \quad 52.4 \%$ EVHKQVVESAYEVIK

$107 \quad 0.15 \% \quad 52.4 \%$ QVVESAYEVIK

$107 \quad 0.15 \% \quad 52.4 \%$ QVVESAYEVIKLK

$107 \quad 0.15 \% \quad 52.4 \%$ RVHPVSTMIK

$107 \quad 0.15 \% \quad 52.4 \%$ VTLTSEEEAR

$107 \quad 0.15 \% \quad 52.4 \%$ VTLTSEEEARLK

$107 \quad 0.15 \% \quad 52.4 \%$ SADTLWGIQK

$107 \quad 0.15 \% \quad 52.4 \%$ SADTLWGIQKELQF

$81 \quad 0.11 \% \quad 50.3 \%$ EKLIAPVAEEEATVPNNK

$81 \quad 0.11 \% \quad 50.3 \%$ LIAPVAEEEATVPNNK $0.11 \% \quad 50.3 \%$ ITVVGVGQVGMACAISILGK $\begin{array}{llll}81 & 0.11 \% & 50.3 \% & \text { GEMMDLQHGSLFLQT } \\ 81 & 0.11 \% & 50.3 \% & \text { IVADKDYSVTANSK }\end{array}$

$81 \quad 0.11 \% \quad 50.3 \%$ IVVVTAGVR

$81 \quad 0.11 \% \quad 50.3 \%$ IVVVTAGVRQQEGESR

$0.11 \% 50.3 \%$ QQEGESRLNLVQR

$0.11 \% \quad 50.3 \%$ NVNVFKFIIPQIVK

$0.11 \% \quad 50.3 \%$ FIIPQIVK

$\begin{array}{lll}81 & 0.11 \% & 50.3 \% \text { HRVIGSGCNLDSAR }\end{array}$

$81 \quad 0.11 \% \quad 50.3 \%$ VIGSGCNLDSAR

$10.11 \% \quad 50.3 \%$ VIGSGCNLDSARFR

$81 \quad 0.11 \% \quad 50.3 \%$ FRYLMAEK

$81 \quad 0.11 \% \quad 50.3 \%$ MVVESAYEVIK

$1 \quad 0.11 \% \quad 50.3 \%$ MVVESAYEVIKLK

$81 \quad 0.11 \% \quad 50.3 \%$ IHPVSTMVK

$0.11 \% \quad 50.3 \%$ GLTSVINQK

$81 \quad 0.11 \% \quad 50.3 \%$ LKDDEVAQLK

$0.01 \% \quad 4.8 \%$ TVPILFASTVR

$0.01 \% \quad 4.8 \%$ DALLHCLTTSR

$0.01 \% \quad 4.8 \%$ ILSFVYPIR

$0.01 \% \quad 7.1 \%$ LKDIVSLVPR

$0.01 \% \quad 7.1 \%$ IGYSSPQTLADQSSK

$0.01 \% \quad 7.1 \%$ NTPLCDSFVFR

$0.01 \% \quad 7.1 \%$ LLLCGGAPLSATTQR

$0.01 \% \quad 6.4 \%$ LTTDFNVIVEALSK

$9 \quad 0.01 \% \quad 6.4 \% \quad$ AKDANNGNLQLR

$9 \quad 0.01 \% \quad 6.4 \%$ DANNGNLQLR $\begin{array}{llllllll}99.7 \% & 40.5 & 25.0 & 22.4 & 2 & 2 & 0 & 1727.94\end{array}$

$99.7 \% \quad 32.0-25.0-15.2-2$

$\begin{array}{llllllll}99.7 \% & 53.6 & 25.0 & 53.6 & 2 & 2 & 0 & 1644.98\end{array}$

$\begin{array}{llllllll}99.0 \% & 38.8 & 25.0 & 27.1 & 7 & 0 & 0 & 929.58\end{array}$

$\begin{array}{llllllll}99.7 \% & 44.1 & 25.0 & 34.5 & 2 & 0 & 0 & 1678.90\end{array}$

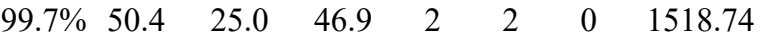

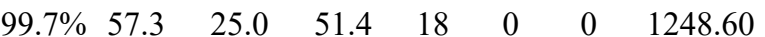

$\begin{array}{llllllll}99.7 \% & 29.2 & 25.0 & 24.6 & 0 & 1 & 0 & 1551.77\end{array}$

$\begin{array}{llllllll}99.0 \% & 29.9 & 25.0 & 21.9 & 2 & 0 & 0 & 1071.54\end{array}$

$\begin{array}{llllllll}95.2 \% & 16.2 & 25.0 & 14.0 & 1 & 0 & 0 & 1096.56\end{array}$

$\begin{array}{llllllll}99.7 \% & 52.9 & 25.0 & 48.2 & 2 & 1 & 0 & 1757.94\end{array}$

$\begin{array}{llllllll}99.7 \% & 60.7 & 25.0 & 53.0 & 2 & 0 & 0 & 1264.68\end{array}$

$\begin{array}{llllllll}99.7 \% & 62.3 & 25.0 & 60.7 & 2 & 2 & 0 & 1505.86\end{array}$

$\begin{array}{llllllll}99.7 \% & 31.2 & 25.0 & 27.5 & 4 & 0 & 0 & 1183.66\end{array}$

$\begin{array}{llllllll}99.7 \% & 50.7 & 25.0 & 41.5 & 9 & 0 & 0 & 1134.56\end{array}$

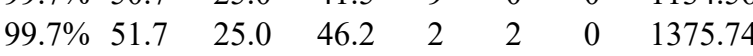

$99.7 \% 037.5 \quad 25.0 \quad 30.4 \quad 1 \quad 00001118.58$

$99.7 \% \quad 45.1 \quad 25.0 \quad 44.6$

$\begin{array}{lllll}99.7 \% & 53.9 & 25.0 & 47.7 & 2\end{array}$

$\begin{array}{llll}99.7 \% & 50.2 & 25.0 & 44.3\end{array}$

$\begin{array}{llll}99.7 \% & 60.5 & 25.0 & 60.5\end{array}$

$\begin{array}{llll}99.7 \% & 39.1 & 25.0 & 39.1 \\ 9 & 0\end{array}$

$\begin{array}{lllll}99.7 \% & 53.3 & 25.0 & 47.3 & 11\end{array}$

$\begin{array}{lllll}99.7 \% & 55.8 & 25.0 & 37.1 & 2\end{array}$

$99.7 \% \quad 47.0 \quad 25.0 \quad 31.5$

$\begin{array}{llll}99.7 \% & 32.0 & 25.0 & 15.2\end{array}$

$\begin{array}{llll}99.7 \% & 50.1 & 25.0 & 50.1\end{array}$

$\begin{array}{llll}99.0 \% & 29.9 & 25.0 & 24.2\end{array}$

$\begin{array}{lllll}99.7 \% & 47.8 & 25.0 & 41.7 & 2\end{array}$

$\begin{array}{llll}99.7 \% & 57.3 & 25.0 & 51.4\end{array}$

$\begin{array}{llll}99.7 \% & 29.2 & 25.0 & 24.6\end{array}$

$\begin{array}{llll}99.0 \% & 38.7 & 25.0 & 27.9\end{array}$

$99.7 \% \quad 51.7 \quad 25.0 \quad 47.8$

$\begin{array}{llll}99.7 \% & 58.2 & 25.0 & 58.2\end{array}$

$\begin{array}{llll}97.9 \% & 20.2 & 25.0 & 14.4\end{array}$

$99.7 \% \quad 56.6 \quad 25.0 \quad 41.7$

$99.7 \% \quad 49.0 \quad 25.0 \quad 33.1$

$99.7 \% \quad 38.8 \quad 25.0 \quad 36.6$

$\begin{array}{llll}94.6 \% & 18.9 & 25.0 & 17.0\end{array}$

$\begin{array}{llll}98.0 \% & 25.8 & 25.0 & 16.3\end{array}$

$\begin{array}{llll}99.7 \% & 48.5 & 25.0 & 45.6\end{array}$

$\begin{array}{lllll}99.7 \% & 40.5 & 25.0 & 40.5 & 2\end{array}$

$\begin{array}{llll}99.5 \% & 28.5 & 25.0 & 25.8\end{array}$

$\begin{array}{llll}99.7 \% & 56.0 & 25.0 & 52.2\end{array}$

$\begin{array}{lllll}99.7 \% & 56.4 & 25.0 & 40.8 & 3\end{array}$

$\begin{array}{llll}99.7 \% & 50.4 & 25.0 & 50.4\end{array}$

$\begin{array}{llll}99.7 \% & 38.6 & 25.0 & 29.8\end{array}$ $\begin{array}{cc}1 & 106 \\ 00 & 112 \\ 13 & 126 \\ 19 & 126 \\ 19 & 132 \\ 56 & 169 \\ 58 & 169 \\ 58 & 171 \\ 70 & 177 \\ 13 & 222 \\ 29 & 243 \\ 33 & 243 \\ 33 & 245 \\ 69 & 278 \\ 06 & 315 \\ 06 & 317 \\ 19 & 328 \\ 19 & 332 \\ 6 & 23 \\ 8 & 23 \\ 4 & 43 \\ 1 & 77 \\ 8 & 91 \\ 2 & 100 \\ 2 & 107 \\ 01 & 113 \\ 14 & 127 \\ 20 & 127 \\ 57 & 170 \\ 59 & 170 \\ 59 & 172 \\ 71 & 178 \\ 34 & 244 \\ 34 & 246 \\ 71 & 279 \\ 00 & 308 \\ 09 & 318 \\ 5 & 85 \\ 63 & 173 \\ 09 & 417 \\ 21 & 230 \\ 49 & 363 \\ 25 & 435 \\ 47 & 461 \\ 88 & 297 \\ & \end{array}$ 


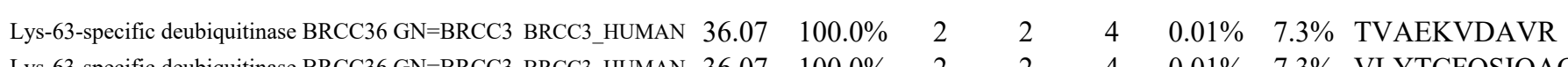
Lysine--tRNA ligase GN=KARS Lysine--tRNA ligase GN=KARS Lysine--tRNA ligase GN=KARS Lysine--tRNA ligase GN=KARS

Lysozyme C GN=LYZ

Lysozyme C GN=LYZ SYK_HUMAN $68.05 \quad 100.0 \%$ SYK HUMAN $68.05 \quad 100.0 \%$ SYK_HUMAN $68.05 \quad 100.0 \%$ SYK_HUMAN $68.05 \quad 100.0 \%$ LYSC HUMAN $16.54 \quad 100.0 \%$ LYSC_HUMAN $16.54 \quad 100.0 \%$

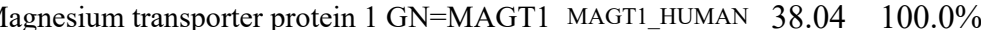
Magnesium transporter protein $1 \mathrm{GN}=$ MAGT1 MAGT1_HUMAN $38.04 \quad 100.0 \%$ Major centromere autoantigen B GN=CENPB CENPB_HUMAN $65.17 \quad 100.0 \%$ Major centromere autoantigen B GN=CENPB CENPB HUMAN $65.17 \quad 100.0^{\circ}$ Malectin GN=MLEC

Malectin GN=MLEC MLEC_HUMAN $32.23 \quad 100.0 \%$ MLEC_HUMAN $32.23 \quad 100.0 \%$

Manganese-transporting ATPase 13A1 GN=ATP13A1 AT131_HUMAN $132.96 \quad 100.0 \%$ Manganese-transporting ATPase 13A1 GN=ATP13A1 AT131_HUMAN $132.96 \quad 100.0 \%$ Manganese-transporting ATPase 13A1 GN=ATP13A1 AT131 HUMAN $132.96100 .0 \%$ Mannose-1-phosphate guanyltransferase alpha GN=GMPPA GMPPA_HUMAN $46.29 \quad 100.0 \%$ Mannose-1-phosphate guanyltransferase alpha GN=GMPPA GMPPA_HUMAN $46.29 \quad 100.0 \%$ Mannose-1-phosphate guanyltransferase alpha GN=GMPPA GMPPA HUMAN $46.29 \quad 100.0 \%$ Mannose-1-phosphate guanyltransferase beta GN=GMPPB GMPPB_HUMAN $39.83 \quad 100.0 \%$ Mannose-1-phosphate guanyltransferase beta GN=GMPPB GMPPB_HUMAN $39.83 \quad 100.0 \%$ Matrin-3 GN=MATR3 Matrin-3 GN=MATR3

Matrin-3 GN=MATR3

Matrin-3 GN=MATR3

Matrin-3 GN=MATR3

Matrin-3 GN=MATR3

Matrin-3 GN=MATR3

Matrin-3 GN=MATR3

Matrin-3 GN=MATR3

Matrin-3 GN=MATR3

Matrin-3 GN=MATR3

MATR3_HUMAN $94.63 \quad 100.0 \%$

MATR3_HUMAN $94.63 \quad 100.0 \%$

MATR3 HUMAN $94.63 \quad 100.0 \%$

MATR3_HUMAN $94.63 \quad 100.0 \%$

MATR3_HUMAN $94.63 \quad 100.0 \%$

MATR3_HUMAN $94.63 \quad 100.0 \%$

MATR__HUMAN $94.63 \quad 100.0 \%$

MATR3 HUMAN $94.63 \quad 100.0 \%$

MATR__HUMAN $94.63 \quad 100.0 \%$

MATR3_HUMAN $94.63 \quad 100.0 \%$

MATR3 HUMAN $94.63 \quad 100.0 \%$

MAX gene-associated protein GN=MGA MGAP_HUMAN $331.84 \quad 100.0 \%$

MAX gene-associated protein GN=MGA MGAP_HUMAN $331.84 \quad 100.0 \%$

MAX gene-associated protein GN=MGA MGAP_HUMAN $331.84 \quad 100.0 \%$

MAX gene-associated protein GN=MGA MGAP_HUMAN $331.84 \quad 100.0 \%$

Mediator of DNA damage checkpoint protein $1 \mathrm{GN}=\mathrm{MDC} 1$ MDC1 HUMAN $226.66 \quad 100.0 \%$

Mediator of DNA damage checkpoint protein $1 \mathrm{GN}=\mathrm{MDC1}$ MDC1_HUMAN $226.66 \quad 100.0 \%$

Mediator of DNA damage checkpoint protein $1 \mathrm{GN}=\mathrm{MDC1}$ MDC1_HUMAN $226.66 \quad 100.0 \%$

Mediator of RNA polymerase II transcription subunit 16 GN=MED16 MED16 HUMAN $96.80 \quad 100.0^{\circ} \%$

Mediator of RNA polymerase II transcription subunit 16 GN=MED16 MED16_HUMAN $96.80 \quad 100.0 \%$

Mediator of RNA polymerase II transcription subunit 24 GN=MED24 MED24_HUMAN $110.31 \quad 100.0 \%$ Mediator of RNA polymerase II transcription subunit $24 \mathrm{GN}=\mathrm{MED} 24$ MED24 HUMAN $110.31 \quad 100.0 \%$ Medium-chain specific acyl-CoA dehydrogenase, mitochondrial GN=ACADM ACADM_HUMAN $46.59 \quad 100.0 \%$ dium-chain specific acyl-CoA dehydrogenase, mitochondrial GN=ACADM ACADM_HUMAN 46.59 100.0\% Medium-chain specific acyl-CoA dehydrogenase, mitochondrial GN=ACADM ACADM_HUMAN $46.59 \quad 100.0 \%$

$0.00 \% \quad 14.2 \%$ STDYGIFQINSR
$0.01 \% \quad 7.3 \%$ VLYTCFQSIQAQK

$0.01 \% \quad 7.9 \%$ RGDIIGVQGNPGK

$0.01 \% \quad 7.9 \% \quad$ YLDLILNDFVR

$0.01 \% \quad 7.9 \%$ SKIITYIR

$0.01 \% \quad 7.9 \%$ MLVVGGIDRVYEIGR

$0.00 \% \quad 14.2 \%$ ATNYNAGDR

$0.01 \% \quad 5.7 \%$ RGDTYELQVR

$0.01 \% \quad 5.7 \%$ GFSAEQIAR

$0.00 \% \quad 3.5 \%$ HGVVSCSGVAR

$0.00 \% \quad 3.5 \%$ GGVTTQALAK

$0.00 \% \quad 8.6 \%$ SNPEDQILYQTER

$0.00 \% \quad 8.6 \%$ FAEVYFAQSQQK

$0.01 \% \quad 3.0 \%$ SIDGSIVLPLAR

$0.01 \% \quad 3.0 \%$ DSPTLSNSGIR

$0.01 \% \quad 3.0 \%$ LGDASIAAPFTSK

$0.01 \% \quad 9.3 \%$ AVILIGGPQK

$0.01 \% \quad 9.3 \%$ VAPSAVLGPNVSIGK

$0.01 \% \quad 9.3 \%$ VEGTPSDPNPNDPR

$0.00 \% \quad 8.1 \%$ ALILVGGYGTR

$0.00 \% \quad 8.1 \%$ LCSGPGIVGNVLVDPSAR

$0.04 \% \quad 16.6 \%$ SFQQSSLSR

$0.04 \% \quad 16.6 \%$ TEEGPTLSYGR

$0.04 \% \quad 16.6 \%$ MGRGPGPLQER

$0.04 \% \quad 16.6 \%$ GAPPSSNIEDFHGLLPK

$0.04 \% \quad 16.6 \%$ GNLGAGNGNLQGPR

$0.04 \% \quad 16.6 \%$ VVHIMDFQR

$0.04 \% \quad 16.6 \%$ IKKPEGKPDQK

$0.04 \% \quad 16.6 \%$ FDQKQELGR

$0.04 \% \quad 16.6 \%$ VIHLSNLPHSGYSDSAVLK

$0.04 \% \quad 16.6 \%$ IGPYQPNVPVGIDYVIPK

$0.04 \% \quad 16.6 \%$ LCSLFYTNEEVAK

$0.03 \% \quad 1.9 \%$ GLPFYAGLSPAGK

$0.03 \% \quad 1.9 \%$ TTGITTPVASVAFPK

$0.03 \% \quad 1.9 \%$ VLQSEGEAVDPEANVIK

$0.03 \% \quad 1.9 \% \quad$ ISNPSAFSIVPR

$0.01 \% \quad 2.2 \% \quad$ NQLVTPEPTSR

$0.01 \% \quad 2.2 \% \quad$ TPEPVVPTAPEPHPTTSTDQPVTPK

$0.01 \% \quad 2.2 \% \quad$ SRFTPELQPK

$0.00 \% \quad 3.3 \% \quad$ ILSATNDLDRVSAVALPK

$0.00 \% \quad 3.3 \%$ LPISLTNTDLK

$0.00 \% \quad 2.7 \% \quad$ SQAEQCGTLIR

$0.00 \% \quad 2.7 \%$ SGENANIQPNIQLILR

$0.01 \% \quad 14.3 \%$ ANWYFLLAR

$0.01 \% \quad 14.3 \%$ GIVFEDVKVPK

$0.01 \% \quad 14.3 \%$ TRPVVAAGAVGLAQR

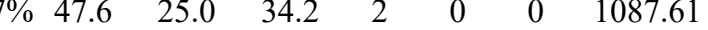

$\begin{array}{llllllll}99.7 \% & 56.8 & 25.0 & 52.6 & 2 & 0 & 0 & 1585.80\end{array}$

$\begin{array}{llllllll}99.7 \% & 56.9 & 25.0 & 56.9 & 2 & 0 & 0 & 1310.72\end{array}$

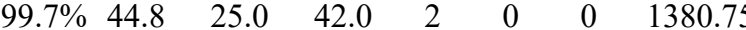

$99.0 \% \quad 25.0 \quad 25.0 \quad 25.0$

$\begin{array}{llll}99.7 \% & 28.3 & 25.0 & 22.0\end{array}$

$\begin{array}{llll}99.7 \% & 39.3 & 25.0 & 32.0\end{array}$

$\begin{array}{llll}99.7 \% & 59.7 & 25.0 & 58.3\end{array}$

$99.5 \% \quad 27.5 \quad 25.0 \quad 15.0$

$\begin{array}{llll}99.7 \% & 33.5 & 25.0 & 17.0\end{array}$

$99.7 \% \quad 42.5 \quad 25.0 \quad 38.4$

$99.7 \% \quad 32.0 \quad 25.0 \quad 21.7$

$\begin{array}{llll}99.7 \% & 53.2 & 25.0 & 44.8\end{array}$

$99.7 \% \quad 47.3 \quad 25.0 \quad 47.3$

$99.7 \% \quad 28.3 \quad 25.0 \quad 28.2$

$96.4 \% \quad 16.5 \quad 25.0 \quad 14.6$

$99.7 \% \quad 29.2 \quad 25.0 \quad 29.2$

$\begin{array}{llll}99.7 \% & 40.1 & 25.0 & 40.1\end{array}$

$\begin{array}{lllll}99.7 \% & 43.8 & 25.0 & 43.8 & 2\end{array}$

$\begin{array}{llll}99.7 \% & 34.8 & 25.0 & 20.9\end{array}$

$\begin{array}{lllll}99.7 \% & 36.1 & 25.0 & 36.1 & 2\end{array}$

$\begin{array}{llll}99.7 \% & 38.2 & 25.0 & 38.2 \\ 99.7 \% & 56.6 & 25.0 & 40.8\end{array}$

$\begin{array}{llll}99.7 \% & 30.4 & 25.0 & 18.9\end{array}$

$98.6 \% \quad 19.9 \quad 25.0 \quad 18.0$

$\begin{array}{llll}99.6 \% & 21.8 & 25.0 & 20.3\end{array}$

$\begin{array}{llll}99.7 \% & 57.1 & 25.0 & 49.7\end{array}$

$\begin{array}{llll}99.7 \% & 38.2 & 25.0 & 26.1\end{array}$

$\begin{array}{llll}99.7 \% & 26.1 & 25.0 & 23.7\end{array}$

$99.6 \% \quad 24.1 \quad 25.0 \quad 20.8$

$\begin{array}{ll}99.7 \% & 39.0\end{array}$

$99.7 \% \quad 30.7$

$99.7 \% \quad 44.8$

$99.7 \% \quad 38.1$

$99.7 \% \quad 40.5$

$99.7 \% \quad 55.8$

$99.7 \% \quad 39.9$

$\begin{array}{lll}99.7 \% & 32.1\end{array}$

$96.2 \% \quad 17.0$

$99.2 \% \quad 25.2$

$99.7 \% \quad 50.9$

$99.3 \% \quad 20.1$

$\begin{array}{lll}98.4 \% & 22.7\end{array}$

$99.7 \% \quad 37.1$

$97.3 \% \quad 19.2$

$96.0 \% \quad 16.4$
993.61

1676.92

981.44

1400.68

1236.63

978.50

1128.56

945.54

1592.76

1445.71

1240.73

1146.58

1277.67

995.63

1408.82

1494.68

1119.65

1810.95

1039.52

1209.57

1213.61

1778.91

1324.67

1144.59

1267.74

1120.57

2037.08

1969.08

1573.76

1277.69

1489.83

1797.92

1287.71

1241.65

2623.33

1202.65

1883.06

1214.70

1262.62

1779.97

1153.62

1230.71

1465.86

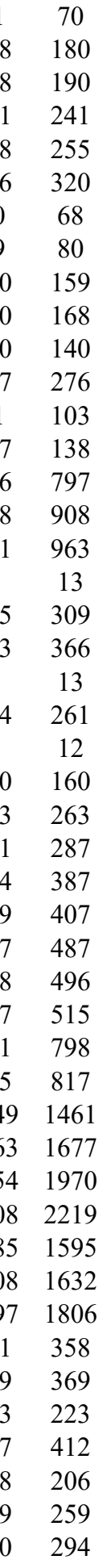

Page 79 of Table S-1-1 

hain specific acyl-CoA dehydrogenase, mitochondrial GN=ACADM ACADM_HUMAN $46.59 \quad 100.0 \%$ Melanoma-associated antigen D2 GN=MAGED2 MAGD2_HUMAN $64.96 \quad 100.0 \%$ Melanoma-associated antigen D2 GN=MAGED2 MAGD2_HUMAN $64.96 \quad 100.0 \%$ Methionine--tRNA ligase, cytoplasmic GN=MARS SYMC_HUMAN $101.12 \quad 100.0 \%$ Methionine--tRNA ligase, cytoplasmic GN=MARS SYMC_HUMAN $101.12 \quad 100.0 \%$ Methionine--tRNA ligase, cytoplasmic GN=MARS SYMC_HUMAN $101.12 \quad 100.0 \%$ Methionine--tRNA ligase, cytoplasmic GN=MARS SYMC_HUMAN $101.12 \quad 100.0 \%$ Methionine--tRNA ligase, cytoplasmic GN=MARS SYMC_HUMAN $101.12 \quad 100.0 \%$ Methionine--tRNA ligase, cytoplasmic GN=MARS SYMC_HUMAN $101.12 \quad 100.0 \%$ Methionine--tRNA ligase, cytoplasmic GN=MARS SYMC_HUMAN $101.12 \quad 100.0 \%$ Methionine--tRNA ligase, cytoplasmic GN=MARS SYMC_HUMAN $101.12 \quad 100.0 \%$ Methionine--tRNA ligase, cytoplasmic GN=MARS SYMC_HUMAN $101.12 \quad 100.0 \%$ Methionine--tRNA ligase, cytoplasmic GN=MARS SYMC_HUMAN $101.12 \quad 100.0 \%$ Methionine--tRNA ligase, cytoplasmic GN=MARS SYMC_HUMAN $101.12 \quad 100.0 \%$ Methionine--tRNA ligase, cytoplasmic GN=MARS SYMC_HUMAN $101.12 \quad 100.0 \%$ Methionine--tRNA ligase, cytoplasmic GN=MARS SYMC_HUMAN $101.12 \quad 100.0 \%$ Methionine--tRNA ligase, cytoplasmic GN=MARS SYMC_HUMAN $101.12 \quad 100.0 \%$ Methionine--tRNA ligase, cytoplasmic GN=MARS SYMC_HUMAN $101.12 \quad 100.0 \%$ Methionine--tRNA ligase, cytoplasmic GN=MARS SYMC_HUMAN $101.12 \quad 100.0 \%$ Methionine--tRNA ligase, cytoplasmic GN=MARS SYMC_HUMAN $101.12 \quad 100.0 \%$ Methionine--tRNA ligase, cytoplasmic GN=MARS SYMC_HUMAN $101.12 \quad 100.0 \%$ Methyl-CpG-binding domain protein 3 GN=MBD3 MBD3_HUMAN $32.84 \quad 99.4 \%$ Methyl-CpG-binding domain protein 3 GN=MBD3 MBD3_HUMAN $32.84 \quad 99.4 \%$ Methylcytosine dioxygenase TET2 GN=TET2 TET2_HUMAN $223.81 \quad 100.0 \%$ Methylcytosine dioxygenase TET2 GN=TET2 TET2_HUMAN $223.81 \quad 100.0 \%$ Methylosome protein $50 \mathrm{GN}=$ WDR77

Methylosome protein $50 \mathrm{GN}=$ WDR77 Methylosome protein $50 \mathrm{GN}=$ WDR77 Methylosome protein $50 \mathrm{GN}=\mathrm{WDR} 77$ Methylosome protein $50 \mathrm{GN}=$ WDR77 Methylosome protein $50 \mathrm{GN}=\mathrm{WDR} 77$ Methylosome protein $50 \mathrm{GN}=$ WDR77 Methylosome protein $50 \mathrm{GN}=\mathrm{WDR} 77$ Methylosome protein $50 \mathrm{GN}=$ WDR77 Methylosome protein $50 \mathrm{GN}=$ WDR77 Methylosome protein $50 \mathrm{GN}=\mathrm{WDR} 77$ Methylosome protein $50 \mathrm{GN}=$ WDR77 Methylosome protein $50 \mathrm{GN}=\mathrm{WDR} 77$ MEP50_HUMAN $36.72 \quad 100.0 \%$ MEP50 HUMAN $36.72 \quad 100.0 \%$ MEP50_HUMAN $36.72 \quad 100.0 \%$ MEP50 HUMAN $36.72 \quad 100.0 \%$ MEP50_HUMAN $36.72 \quad 100.0 \%$ MEP50_HUMAN $36.72 \quad 100.0 \%$ MEP50_HUMAN $36.72 \quad 100.0 \% \quad 13$ MEP50_HUMAN $36.72 \quad 100.0 \% \quad 13$ MEP50_HUMAN $36.72 \quad 100.0 \% \quad 13$ MEP50_HUMAN $36.72 \quad 100.0 \% \quad 13$ MEP50_HUMAN $36.72 \quad 100.0 \% \quad 13$ MEP50 HUMAN $36.72 \quad 100.0 \% \quad 13$ MEP50_HUMAN $36.72 \quad 100.0 \% \quad 13$ Methylosome subunit pICln GN=CLNS1A ICLN_HUMAN $26.22 \quad 100.0 \%$ Methylosome subunit pICln GN=CLNS1A ICLN_HUMAN $26.22 \quad 100.0 \%$ Methylosome subunit pICln GN=CLNS1A ICLN_HUMAN $26.22 \quad 100.0 \%$ Methylosome subunit pICln GN=CLNS1A ICLN HUMAN $26.22 \quad 100.0 \%$ Methylosome subunit pICln GN=CLNS1A ICLN_HUMAN $26.22 \quad 100.0 \%$ Methylosome subunit pICln GN=CLNS1A ICLN_HUMAN $26.22 \quad 100.0 \%$ Methylthioribose-1-phosphate isomerase GN=MRI1 MTNA_HUMAN $39.15 \quad 100.0 \%$ Methylthioribose-1-phosphate isomerase GN=MRI1 MTNA_HUMAN $39.15 \quad 100.0 \%$
$0.01 \% \quad 14.3 \%$ ALDEATKYALER $0.01 \% \quad 14.3 \%$ IYQIYEGTSQIQR $99.7 \% \quad 52.1$ $99.7 \% \quad 58.4$ $99.7 \% \quad 29.8$ $0.00 \% \quad 5.0 \%$ LQSSQEPEAPPPRDVALLQGR $\quad 99.7 \% \quad 41.5$

$\begin{array}{llllllll}0.05 \% & 24.9 \% & \text { MRLFVSDGVPGCLPVLAAAGR } & 99.7 \% & 33.2\end{array}$

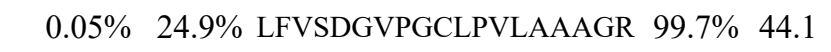

$0.05 \% \quad 24.9 \%$ KGEDVLGSVR

$0.05 \% \quad 24.9 \%$ ALTHIDHSLSR $99.7 \% 27.3$ $99.7 \% \quad 34.8$

$0.05 \% \quad 24.9 \%$ AAETVLKQQGVLALRPYLQK $98.7 \% \quad 20.0$

$0.05 \% \quad 24.9 \%$ QPQPSPAEGR $99.7 \% \quad 47.7$

2

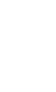

$0.05 \% \quad 24.9 \%$ ITQDIFQQLLK

$0.05 \% \quad 24.9 \%$ ITQDIFQQLLKR

$0.05 \% \quad 24.9 \%$ GFVLQDTVEQLR $\begin{array}{lll}95.3 \% & 15.0\end{array}$ $99.7 \% 52.3$ $99.7 \% \quad 51.6$ $\begin{array}{lll}99.7 \% & 62.0\end{array}$

$0.05 \% \quad 24.9 \%$ GFVLQDTVEQLRCEHCAR $99.0 \% \quad 18.4$

$0.05 \% \quad 24.9 \%$ LINAVELKKPQCK $94.7 \% \quad 14.1$

$0.05 \% \quad 24.9 \%$ SCPVVQSSOHLFLDLPKLEK $94.6 \% \quad 18.4$

$0.05 \% \quad 24.9 \%$ RLEEWLGR

$34 \quad 0.05 \% \quad 24.9 \%$ TLPGSDWTPNAQFITR

$0.05 \% \quad 24.9 \%$ NNSELLNNLGNFINR

$0.05 \% \quad 24.9 \%$ HGNQYIQVNEPWKR

$0.05 \% \quad 24.9 \%$ QLAVAEGKPPEAPK

$0.00 \% \quad 7.9 \%$ GKPDLNTALPVR

$0.00 \% \quad 7.9 \% \quad$ SDPQKAVDQPR

$0.01 \% \quad 1.0 \%$ SGAIQVLSSFR

$0.01 \% \quad 1.0 \%$ VTGPYNRYI

$131 \quad 0.18 \% \quad 40.1 \%$ KETPPPLVPPAAR

$131 \quad 0.18 \% \quad 40.1 \%$ ETPPPLVPPAAR

$131 \quad 0.18 \% \quad 40.1 \%$ EWNLPPNAPACMER

$131 \quad 0.18 \% \quad 40.1 \%$ QLEAARYR

$25.0 \quad 18.4$

$\begin{array}{llll}99.0 \% & 25.9 & 25.0 & 16.5\end{array}$

$99.7 \% \quad 53.1 \quad 25.0 \quad 53.1$

$99.7 \% \quad 58.5 \quad 25.0 \quad 51.6$

$\begin{array}{llll}99.7 \% & 35.1 & 25.0 & 34.1\end{array}$

$99.7 \% \quad 37.6 \quad 25.0 \quad 30.5$

$94.7 \% \quad 16.0 \quad 25.0 \quad 16.0$

$95.9 \% \quad 18.9 \quad 25.0 \quad 16.9$

$99.7 \% \quad 34.7 \quad 25.0 \quad 34.7$

$99.2 \% \quad 19.5 \quad 25.0 \quad 19.5$

$\begin{array}{llll}99.7 \% & 40.2 & 25.0 & 34.5\end{array}$

$\begin{array}{llll}99.7 \% & 33.5 & 25.0 & 26.9\end{array}$

$99.7 \% \quad 47.1 \quad 25.0 \quad 47.1 \quad 12$

$99.0 \% \quad 29.8 \quad 25.0 \quad 10.0$

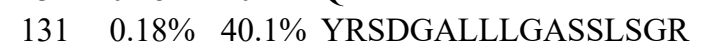

$131 \quad 0.18 \% \quad 40.1 \%$ SDGALLLGASSLSGR

$99.7 \% \quad 51.9$

$131 \quad 0.18 \% \quad 40.1 \%$ CWAGSLWLFK

$99.7 \% \quad 29.3$

$131 \quad 0.18 \% \quad 40.1 \%$ FCKYEHDDIVSTVSVLSSGTQAVSGSK $99.7 \% \quad 76.7$

$131 \quad 0.18 \% \quad 40.1 \%$ YEHDDIVSTVSVLSSGTQAVSGSK $99.7 \% \quad 47.6$

$131 \quad 0.18 \% \quad 40.1 \%$ VWDLAQQVVLSSYR

$131 \quad 0.18 \% \quad 40.1 \%$ AHAAQVTCVAASPHK

$99.7 \% \quad 55.1$

$131 \quad 0.18 \% \quad 40.1 \%$ DSVFLSCSEDNR

$131 \quad 0.18 \% \quad 40.1 \%$ SQAHRDFVR

$26 \quad 0.04 \% \quad 31.2 \%$ SFPPPGPAEGLLR

$99.7 \% \quad 49.9$

$99.7 \% \quad 49.2$

$99.7 \% \quad 41.2$

$99.7 \% \quad 45.0$

$99.7 \% \quad 51.2$

$0.04 \% \quad 31.2 \%$ QQPDTEAVLNGK

$0.04 \% \quad 31.2 \%$ QQPDTEAVLNGKGLGTGTLYIAESR

$0.04 \% \quad 31.2 \%$ GLGTGTLYIAESR

$\begin{array}{ll}99.7 \% & 59.4 \\ 99.7 \% & 68.6\end{array}$

$\begin{array}{lllll}0.04 \% & 31.2 \% & \text { DRSDCLGEHLYVMVNAK } & 99.4 \% & 24.0\end{array}$

$\begin{array}{llll}0.04 \% & 31.2 \% & \text { LEGMLSQSVSSQYNMAGVR } \quad 99.7 \% \quad 53.8\end{array}$

$0.01 \% \quad 19.2 \%$ GSLQILDQLLLPK

$99.7 \% \quad 48.2$

$0.01 \% \quad 19.2 \%$ YEAVGSVHQAWEAIR $\begin{array}{ccc}1379.72 & 295 & 306 \\ 1598.82 & 396 & 408 \\ 984.62 & 241 & 249 \\ 2288.20 & 262 & 282 \\ 2186.16 & 1 & 21 \\ 1899.02 & 3 & 21 \\ 1059.58 & 109 & 118 \\ 1249.66 & 120 & 130 \\ 2226.30 & 185 & 204 \\ 1066.53 & 205 & 214 \\ 2367.31 & 243 & 264 \\ 1346.77 & 365 & 375 \\ 1502.87 & 365 & 376 \\ 1404.75 & 377 & 388 \\ 2218.05 & 377 & 394 \\ 1540.89 & 424 & 436 \\ 2325.23 & 440 & 459 \\ 1058.57 & 460 & 467 \\ 1803.90 & 468 & 483 \\ 1731.88 & 642 & 656 \\ 1768.89 & 714 & 727 \\ 1434.80 & 882 & 895 \\ 1280.73 & 91 & 102 \\ 1240.63 & 125 & 135 \\ 1164.64 & 1441 & 1451 \\ 1082.56 & 1994 & 2002 \\ 1372.79 & 3 & 15 \\ 1244.70 & 4 & 15 \\ 1684.76 & 16 & 29 \\ 1006.54 & 30 & 37 \\ 1722.91 & 36 & 52 \\ 1403.75 & 38 & 52 \\ 1267.63 & 53 & 62 \\ 2901.39 & 119 & 145 \\ 2466.20 & 122 & 145 \\ 1663.88 & 151 & 164 \\ 1547.77 & 165 & 179 \\ 1428.61 & 180 & 191 \\ 1115.57 & 293 & 301 \\ 1337.72 & 6 & 18 \\ 1299.65 & 19 & 30 \\ 2618.34 & 19 & 43 \\ 1337.71 & 31 & 43 \\ 2022.94 & 69 & 85 \\ 2088.97 & 188 & 206 \\ 1437.87 & 11 & 23 \\ 1715.85 & 27 & 41 \\ & & \end{array}$

Page 80 of Table S-1-1 
MICOS complex subunit MIC60 GN=IMMT MIC60_HUMAN $83.68 \quad 100.0 \%$ MICOS complex subunit MIC60 GN=IMMT MIC60_HUMAN $83.68 \quad 100.0 \%$ MICOS complex subunit MIC60 GN=IMMT MIC60 HUMAN $83.68 \quad 100.0 \%$ MICOS complex subunit MIC60 GN=IMMT MIC60_HUMAN $83.68 \quad 100.0 \%$ MICOS complex subunit MIC60 GN=IMMT MIC60_HUMAN $83.68 \quad 100.0 \%$ MICOS complex subunit MIC60 GN=IMMT MIC60 HUMAN $83.68 \quad 100.0 \%$ MICOS complex subunit MIC60 GN=IMMT MIC60_HUMAN $83.68 \quad 100.0 \%$ MICOS complex subunit MIC60 GN=IMMT MIC60_HUMAN $83.68 \quad 100.0 \%$ MICOS complex subunit MIC60 GN=IMMT MIC60_HUMAN $83.68 \quad 100.0 \%$ MICOS complex subunit MIC60 GN=IMMT MIC60_HUMAN $83.68 \quad 100.0 \%$ Microtubule-associated protein 1B GN=MAP1B MAP1B_HUMAN $270.63 \quad 100.0 \%$ Microtubule-associated protein 1B GN=MAP1B MAP1B_HUMAN $270.63 \quad 100.0 \%$ Microtubule-associated protein 1B GN=MAP1B MAP1B_HUMAN $270.63 \quad 100.0 \%$ Midasin GN=MDN1 Midasin GN=MDN1 Midasin GN=MDN1

Midasin GN=MDN1

Midasin $\mathrm{GN}=\mathrm{MDN} 1$

Midasin GN=MDN1

Midasin GN=MDN1

Midasin GN=MDN1

Midasin $\mathrm{GN}=\mathrm{MDN} 1$

Midasin GN=MDN1

Midasin GN=MDN1

MDN1_HUMAN $632.83 \quad 100.0 \%$ MDN1_HUMAN $632.83 \quad 100.0 \%$ MDN1 HUMAN $632.83 \quad 100.0 \%$ MDN1_HUMAN $632.83 \quad 100.0 \%$ MDN1_HUMAN $632.83 \quad 100.0 \%$ MDN1 HUMAN $632.83 \quad 100.0 \%$ MDN1_HUMAN $632.83 \quad 100.0 \%$ MDN1_HUMAN $632.83 \quad 100.0 \%$ MDN1 HUMAN $632.83 \quad 100.0 \%$ MDN1_HUMAN $632.83 \quad 100.0 \%$ MDN1 HUMAN $632.83 \quad 100.0 \%$

Mitochondrial 10-formyltetrahydrofolate dehydrogenase GN=ALDHIL2 AL1L2_HUMAN $101.75 \quad 100.0 \%$ Mitochondrial 10-formyltetrahydrofolate dehydrogenase GN=ALDH1L2 AL1L2_HUMAN $101.75 \quad 100.0 \%$ Mitochondrial 10-formyltetrahydrofolate dehydrogenase GN=ALDH1L2 AL1L2 HUMAN $101.75100 .0 \%$ Mitochondrial 10-formyltetrahydrofolate dehydrogenase GN=ALDH1L2 AL1L2_HUMAN $101.75 \quad 100.0 \%$ Mitochondrial 10-formyltetrahydrofolate dehydrogenase GN=ALDH1L2 AL1L2 HUMAN $101.75 \quad 100.0 \%$ Mitochondrial 10-formyltetrahydrofolate dehydrogenase GN=ALDH1L2 AL1L2 HUMAN $101.75 \quad 100.0 \%$ Mitochondrial 2-oxoglutarate/malate carrier protein GN=SLC25A11 M2OM_HUMAN $34.06 \quad 100.0 \%$ Mitochondrial 2-oxoglutarate/malate carrier protein GN=SLC25A11 M2OM_HUMAN $34.06 \quad 100.0 \%$ Mitochondrial 2-oxoglutarate/malate carrier protein GN=SLC25A11 M2OM_HUMAN $34.06 \quad 100.0 \%$

$10 \quad 0.01 \% \quad 19.2 \%$ DLADVAAR

$10 \quad 0.01 \% \quad 19.2 \%$ GVSAVVVGADR

$10 \quad 0.01 \% \quad 19.2 \%$ VGTYQLAIVAK

$10 \quad 0.01 \% \quad 19.2 \%$ TALTTTISSR

$3 \quad 0.00 \% \quad 4.3 \% \quad$ YTLHVVDSPTVKPSR

$0.00 \% \quad 4.3 \% \quad$ LATPELLETAQALER

$0.01 \% \quad 6.4 \%$ HLPVEPEELQR

$0.01 \% \quad 6.4 \%$ LDGGFAAVSR

$0.01 \% \quad 6.4 \%$ FSMVILAR

$30 \quad 0.04 \% \quad 20.4 \%$ YSTSGSSGLTTGK

$0.04 \% \quad 20.4 \%$ ESKQPASQLQK

$0.04 \% \quad 20.4 \%$ ERPPEEVAAR

$30 \quad 0.04 \% \quad 20.4 \%$ AAMDNSEIAGEKK

$0.04 \% \quad 20.4 \%$ TVEGALKER

$0.04 \% \quad 20.4 \%$ KVQAAQSEAK

$0.04 \% \quad 20.4 \%$ VVSQYHELVVQAR

$0.04 \% \quad 20.4 \%$ AFDSAVAK

$\begin{array}{llllllll}99.0 \% & 28.0 & 25.0 & 12.5 & 2 & 0 & 0 & 1128.61\end{array}$

$99.0 \% 29.8$

$99.7 \% 58.6$

$99.7 \% \quad 31.2$

$99.7 \% \quad 32.2$

$94.9 \% 13.7$

$99.7 \% \quad 58.9$

$98.7 \% \quad 20.6$

$99.7 \% \quad 37.9$

$97.8 \% \quad 16.7$

$99.7 \% \quad 41.5$

$96.7 \% \quad 17.4$

$98.5 \% \quad 26.0$

$99.7 \% \quad 51.8$

$99.7 \% 37.8$

$99.7 \% \quad 43.3$

$99.7 \% \quad 65.5$

$99.0 \% 33.0$

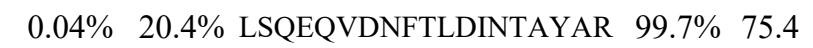

$0.04 \% \quad 20.4 \%$ TSSAETPTIPLGSAVEAIK $99.7 \% \quad 51.5$

$0.04 \% \quad 20.4 \%$ GVYSEETLR

$0.04 \% \quad 20.4 \%$ GVYSEETLRAR

$0.04 \% \quad 20.4 \%$ FYAVQKLAR

$\begin{array}{ll}0.04 \% & 20.4 \% \text { FVNQLKGESR }\end{array}$

$0.01 \% \quad 1.5 \%$ SVGNTIDPVILFQK

$0.01 \% \quad 1.5 \%$ DLTGQVPTPVVK

$0.01 \% \quad 1.5 \%$ AAKPTTTPEVK

$0.03 \% \quad 2.2 \% \quad$ LFLESSDANPVR

$0.03 \% \quad 2.2 \% \quad$ FAASNPCGNIQR

$0.03 \% \quad 2.2 \% \quad$ ASGNTLVR

$0.03 \% \quad 2.2 \% \quad$ LLEKVEGTVR

$0.03 \% \quad 2.2 \%$ GMIDGSTPTITPNPNFR

$0.03 \% \quad 2.2 \%$ DGQILVYCLNR

$0.03 \% \quad 2.2 \%$ VFTEANLVSVGSK

$0.03 \% \quad 2.2 \%$ GLSLGFLEK

$0.03 \% \quad 2.2 \%$ TDSQLQGQVLFR

$0.03 \% \quad 2.2 \% \quad$ APAVQDLLTR

$0.03 \% \quad 2.2 \% \quad$ LQSGHLTK

$10 \quad 0.01 \% \quad 8.9 \% \quad$ AMVEAVQLIADGKAPR

$10 \quad 0.01 \% \quad 8.9 \%$ NGLVLFGNDGK

$0.01 \% \quad 8.9 \%$ NGLVLFGNDGKALTVR

$10 \quad 0.01 \% \quad 8.9 \% \quad$ SAACLAAGNTLVLKPAQVTPLTALK

$10 \quad 0.01 \% \quad 8.9 \% \quad$ GVINIIPGSGGIAGQR

$0.01 \% \quad 8.9 \%$ LSEHPDIRK

$6 \quad 0.02 \% \quad 23.9 \%$ LGIYTVLFER

$0.02 \% \quad 23.9 \%$ LTGADGTPPGFLLK

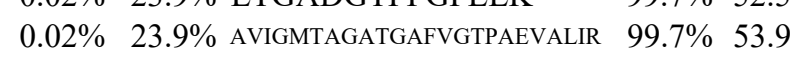

$\begin{array}{ll}99.7 \% & 49.1 \\ 99.7 \% & 38.4\end{array}$

$99.4 \% \quad 20.4$

$99.7 \% \quad 36.4$

$99.7 \% \quad 50.0$

$99.7 \% \quad 41.3$

$99.7 \% \quad 31.6$

$99.7 \% \quad 49.2$

$99.7 \% \quad 44.2$

$96.8 \% \quad 20.3$

$99.7 \% \quad 27.2$

$99.7 \% \quad 38.1$

$99.7 \% \quad 44.4$

$99.7 \% \quad 56.1$

$97.9 \% \quad 17.9$

$99.7 \% \quad 39.2$

$\begin{array}{lll}99.7 \% & 30.7\end{array}$

$99.0 \% \quad 29.8$

$95.9 \% \quad 16.4$

$99.7 \% \quad 28.4$

$96.2 \% \quad 15.4$

$99.7 \% \quad 51.3$

$96.7 \% \quad 17.1$

$99.7 \% \quad 46.0$
830.44

1029.57

1162.68

1050.58

1698.92

1654.90

1346.71

992.52

936.53

1245.60

1243.66

1153.60

1363.65

1002.56

1059.58

1527.83

808.42

2198.07

1872.00

1053.52

1280.66

1095.63

1177.63

1530.85

1253.71

1142.64

1347.69

1334.63

817.45

1143.67

1833.88

1350.68

1350.73

963.55

1391.73

1083.62

883.50

1668.91

1133.60

1673.93

2508.42

1508.85

1094.60

1210.68

1386.76 2289.23

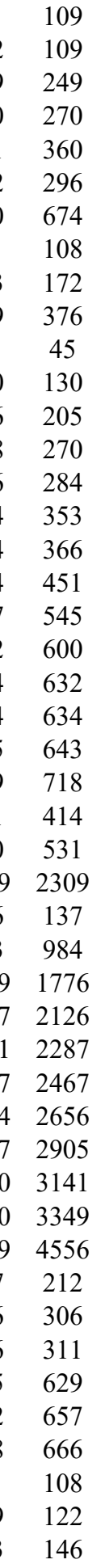

Page 81 of Table S-1-1 
Mitochondrial glutamate carrier $1 \mathrm{GN}=\mathrm{SLC} 25 \mathrm{~A} 22 \mathrm{GHC1}$ _HUMAN $34.47 \quad 100.0 \%$ Mitochondrial glutamate carrier $1 \mathrm{GN}=\mathrm{SLC} 25 \mathrm{~A} 22 \mathrm{GHC1}$ _HUMAN $34.47 \quad 100.0 \%$ Mitochondrial glutamate carrier $1 \mathrm{GN}=\mathrm{SLC} 25 \mathrm{~A} 22 \mathrm{GHC} 1$ HUMAN $34.47 \quad 100.0 \%$ Mitochondrial glutamate carrier $1 \mathrm{GN}=\mathrm{SLC} 25 \mathrm{~A} 22 \mathrm{GHC1}$ _HUMAN $34.47 \quad 100.0 \%$ Mitochondrial glutamate carrier $1 \mathrm{GN}=\mathrm{SLC} 25 \mathrm{~A} 22$ GHC1_HUMAN $34.47 \quad 100.0 \%$ Mitochondrial glutamate carrier $1 \mathrm{GN}=\mathrm{SLC} 25 \mathrm{~A} 22 \mathrm{GHC} 1$ HUMAN $34.47 \quad 100.0 \%$ Mitochondrial import inner membrane translocase subunit TIM44 GN=TIMM44 TIM44_HUMAN $51.36 \quad 100.0 \%$ Mitochondrial inner membrane protein OXA1L GN=OXA1L OXA1L_HUMAN 48.55 Mitochondrial inner membrane protein OXA1L GN=OXAIL OXA1L HUMAN 48.55 Mitochondrial inner membrane protein OXA1L GN=OXA1L OXA1L_HUMAN 48.55 Mitochondrial inner membrane protein OXA1L GN=OXA1L OXA1L_HUMAN 48.55 Mitochondrial inner membrane protein OXA1L GN=OXA1L OXA1L HUMAN 48.55 Mitochondrial Rho GTPase 1 GN=RHOT1 MIRO1_HUMAN 70.79 Mitochondrial Rho GTPase 1 GN=RHOT1 MIRO1_HUMAN 70.79 Mitochondrial Rho GTPase 1 GN=RHOT1 MIRO1_HUMAN $70.79 \quad 100.0 \%$ Mitochondrial Rho GTPase 2 GN=RHOT2 MIRO2_HUMAN $68.12 \quad 100.0 \%$ Mitochondrial Rho GTPase 2 GN=RHOT2 MIRO2_HUMAN $68.12 \quad 100.0 \%$ Mitochondrial Rho GTPase 2 GN=RHOT2 MIRO2_HUMAN $68.12 \quad 100.0 \%$

$0.02 \% \quad 35.3 \%$ VYTSMSDCLIK

$0.02 \% \quad 35.3 \%$ SEGYFGMYR

$17 \quad 0.02 \% \quad 35.3 \%$ GAAVNLTLVTPEK

$\begin{array}{llll}99.7 \% & 45.7 & 25.0 & 38.0\end{array}$

$0.02 \% \quad 35.3 \%$ LAANDFFR

$\begin{array}{llll}99.7 \% & 30.7 & 25.0 & 30.7\end{array}$

$\begin{array}{lll}0.02 \% & 35.3 \% & \text { LAANDFFR } \\ 0.02 \% & 35.3 \% & \text { IQLQDAGR }\end{array}$

$\begin{array}{lllll}9.7 \% & 41.7 & 25.0 & 32.9\end{array}$

$0.02 \% \quad 35.3 \%$ GLGATLLR

$0.02 \% \quad 35.3 \%$ GVNEDTYSGILDCAR

$99.0 \% \quad 46.1$

$99.0 \% \quad 28.6$

$0.02 \% \quad 35.3 \%$ HEGPSAFLK

$0.00 \% \quad 5.3 \%$ ALSQGVESVKK

$0.00 \% \quad 5.3 \% \quad$ ILDIDNVDLAMGK

$\begin{array}{llll}9.7 \% & 56.7 & 25.0 & 56.7\end{array}$

$97.8 \% \quad 17.2 \quad 25.0 \quad 17.2$

$\begin{array}{llll}97.7 \% & 16.2 & 25.0 & 16.2\end{array}$

$0.02 \% \quad 17.8 \%$ RAPDQAAEIGSR

$\begin{array}{llll}99.7 \% & 35.9 & 25.0 & 33.4\end{array}$

$0.02 \% \quad 17.8 \%$ AQGPQQQPGSEGPSYAK $99.7 \% 33.8$

$0.02 \% \quad 17.8 \%$ AQGPQQQPGSEGPSYAKK $99.5 \% \quad 21.3$

$0.02 \% \quad 17.8 \%$ VVVVDCKK

$0.02 \% \quad 17.8 \%$ QSRLEQEEQQR

$0.02 \% \quad 17.8 \%$ SNKQNLFLGSLTSR

$0.02 \% \quad 17.8 \%$ QNLFLGSLTSR

$0.02 \% \quad 18.0 \%$ SKMAIQTQQSK

$0.02 \% \quad 18.0 \%$ MAIQTQQSK

$0.02 \% \quad 18.0 \%$ FVNWQVDGEYR

$\begin{array}{lll}25.0 & 21.3\end{array}$

$\begin{array}{llll}99.0 \% & 38.7 & 25.0 & 36.2\end{array}$

$99.7 \% \quad 29.6 \quad 25.0 \quad 17.5$

$99.7 \% \quad 61.8 \quad 25.0 \quad 57.1$

$\begin{array}{llll}99.4 \% & 25.2 & 25.0 & 22.8\end{array}$

$99.7 \% \quad 37.4 \quad 25.0 \quad 30.8$

$99.7 \% \quad 48.8 \quad 25.0 \quad 41.7$

$\begin{array}{llll}96.2 \% & 24.2 & 25.0 & 24.2\end{array}$

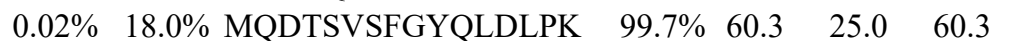

$0.02 \% \quad 18.0 \%$ GSVDSNWIVGATLEK

$0.02 \% \quad 18.0 \%$ NKFQCGFGLTIG

$0.01 \% \quad 11.5 \%$ CLIFPLIVTGQR

$0.01 \% \quad 11.5 \%$ LAGDHIEYYK

$0.01 \% \quad 11.5 \%$ TVLKIPQR

$0.01 \% \quad 11.5 \%$ MRNQLELAAR

$0.01 \% \quad 11.5 \%$ NQLELAAR

$0.01 \% \quad 11.5 \%$ SKYPWHDTLG

$0.01 \% \quad 4.7 \% \quad$ ILLVGEPR

$0.01 \% \quad 4.7 \%$ NISELFYYAQK

$0.01 \% \quad 4.7 \%$ SGVLQALLGR

$0.01 \% \quad 7.3 \%$ ILLLGEAQVGK

$0.01 \% \quad 7.3 \%$ VPIILVGNK

$0.01 \% \quad 7.3 \% \quad$ VPIILVGNKSDLR

$99.7 \% \quad 54.2$

$25.0 \quad 64.3$

\begin{tabular}{llll}
\hline $.7 \%$ & 55.0 & 25.0 & 46.5
\end{tabular}

$99.5 \% \quad 28.0 \quad 25.0 \quad 14.6$

$\begin{array}{llll}99.0 \% & 33.5 & 25.0 & 16.1\end{array}$

$98.9 \% \quad 19.6 \quad 25.0 \quad 19.6$

$\begin{array}{lllll}99.0 \% & 28.8 & 25.0 & 22.5 & 2\end{array}$

$\begin{array}{llll}99.7 \% & 30.7 & 25.0 & 26.1\end{array}$

$99.7 \% \quad 31.9 \quad 25.0 \quad 22.9$

$99.7 \% \quad 45.9 \quad 25.0 \quad 34.1$

$\begin{array}{llll}96.5 \% & 26.1 & 25.0 & 0.0\end{array}$

$\begin{array}{llll}99.7 \% & 25.8 & 25.0 & 25.8\end{array}$

$\begin{array}{cc}160 & 170 \\ 191 & 206 \\ 32 & 41 \\ 54 & 70 \\ 92 & 102 \\ 103 & 126 \\ 127 & 138 \\ 140 & 150 \\ 160 & 170 \\ 171 & 186 \\ 232 & 246 \\ 45 & 55 \\ 59 & 67 \\ 68 & 80 \\ 84 & 91 \\ 129 & 136 \\ 143 & 175 \\ 189 & 196 \\ 259 & 273 \\ 278 & 286 \\ 178 & 188 \\ 369 & 381 \\ 32 & 43 \\ 48 & 64 \\ 48 & 65 \\ 244 & 251 \\ 315 & 325 \\ 332 & 345 \\ 335 & 345 \\ 174 & 184 \\ 176 & 184 \\ 185 & 195 \\ 294 & 309 \\ 316 & 330 \\ 350 & 361 \\ 153 & 164 \\ 188 & 197 \\ 340 & 347 \\ 385 & 394 \\ 387 & 394 \\ 426 & 435 \\ 7 & 14 \\ 154 & 164 \\ 432 & 441 \\ 111 & 17 \\ 111 & 123 \\ & \end{array}$

Page 82 of Table S-1-1 
Mitochondrial Rho GTPase 2 GN=RHOT2 MIRO2_HUMAN $68.12 \quad 100.0 \%$ Mitochondrial Rho GTPase 2 GN=RHOT2 MIRO2_HUMAN $68.12 \quad 100.0 \%$ Mitochondrial ribonuclease P protein 1 GN=TRMT10C MRRP1_HUMAN $47.35 \quad 100.0 \%$ Mitochondrial ribonuclease P protein 1 GN=TRMT10C MRRP1_HUMAN $47.35100 .0 \%$ Mitochondrial ribonuclease P protein 1 GN=TRMT10C MRRP1_HUMAN $47.35 \quad 100.0 \%$ Mitochondrial ribonuclease P protein 1 GN=TRMT10C MRRP1_HUMAN $47.35100 .0 \%$ Mitochondrial thiamine pyrophosphate carrier GN=SLC25A19 TPC HUMAN $35.51 \quad 100.0 \%$ Mitochondrial thiamine pyrophosphate carrier GN=SLC25A19 TPC_HUMAN 35.51 $100.0 \%$ Mitochondrial thiamine pyrophosphate carrier GN=SLC25A19 TPC HUMAN $35.51 \quad 100.0 \%$ Mitochondrial-processing peptidase subunit beta GN=PMPCB MPPB_HUMAN $54.37 \quad 100.0 \%$ Mitochondrial-processing peptidase subunit beta GN=PMPCB MPPB_HUMAN $54.37 \quad 100.0 \%$ Mitogen-activated protein kinase kinase kinase $7 \mathrm{GN}=\mathrm{MAP} 3 \mathrm{~K} 7 \mathrm{M} 3 \mathrm{~K} 7$ HUMAN $67.20 \quad 100.0 \%$ Mitogen-activated protein kinase kinase kinase 7 GN=MAP3K7 M3K7_HUMAN $67.20 \quad 100.0 \%$ Mitogen-activated protein kinase kinase kinase $7 \mathrm{GN}=\mathrm{MAP} 3 \mathrm{~K} 7 \mathrm{M} 3 \mathrm{~K} 7$ HUMAN $67.20 \quad 100.0 \%$ Mitogen-activated protein kinase kinase kinase 7 GN=MAP3K7 M3K7 HUMAN $67.20 \quad 100.0 \%$ Mitotic checkpoint protein BUB3 GN=BUB3 BUB3_HUMAN $37.15 \quad 100.0 \%$ Mitotic checkpoint protein BUB3 GN=BUB3 BUB3 HUMAN $37.15 \quad 100.0 \%$ Mitotic checkpoint protein BUB3 GN=BUB3 BUB3_HUMAN $37.15 \quad 100.0 \%$ MKI67 FHA domain-interacting nucleolar phosphoprotein GN=NIFK MK67I_HUMAN $34.22 \quad 100.0 \%$ MKI67 FHA domain-interacting nucleolar phosphoprotein GN=NIFK MK67I HUMAN $34.22 \quad 100.0 \%$ MMS19 nucleotide excision repair protein homolog GN=MMS19 MMS19_HUMAN $113.29 \quad 100.0 \%$ 等 MOB kinase activator $2 \mathrm{GN}=\mathrm{MOB} 2$ MOB kinase activator $2 \mathrm{GN}=\mathrm{MOB} 2$ MOB kinase activator $2 \mathrm{GN}=\mathrm{MOB} 2$ MOB kinase activator $2 \mathrm{GN}=\mathrm{MOB} 2$ MOB kinase activator $2 \mathrm{GN}=\mathrm{MOB} 2$ MOB kinase activator $2 \mathrm{GN}=\mathrm{MOB} 2$ MOB2_HUMAN $26.93 \quad 100.0 \%$ MOB2_HUMAN $26.93 \quad 100.0 \%$ MOB2 HUMAN $26.93 \quad 100.0 \%$ MOB2_HUMAN $26.93 \quad 100.0 \%$ MOB2_HUMAN $26.93 \quad 100.0 \%$ MOB2 HUMAN $26.93 \quad 100.0 \%$ Monocarboxylate transporter $1 \mathrm{GN}=\mathrm{SLC} 16 \mathrm{~A} 1 \mathrm{MOT} 1$ HUMAN $53.95 \quad 100.0 \%$ Monocarboxylate transporter $1 \mathrm{GN}=\mathrm{SLC16A1}$ MOT1 HUMAN $53.95100 .0 \%$ Monocarboxylate transporter $1 \mathrm{GN}=\mathrm{SLC} 16 \mathrm{~A} 1$ MOT1_HUMAN $53.95 \quad 100.0 \%$ Monofunctional C1-tetrahydrofolate synthase, mitochondrial GN=MTHFDIL C1TM_HUMAN $105.79 \quad 100.0 \%$ 作 $105.79 \quad 100.0 \%$ Monofunctional C1-tetrahydrofolate synthase, mitochondrial GN=MTHFDIL C1TM_HUMAN $105.79 \quad 100.0 \%$ Monofunctional C1-tetrahydrofolate synthase, mitochondrial GN=MTHFDIL C1TM HUMAN $105.79 \quad 100.0 \%$ Monofunctional C1-tetrahydrofolate synthase, mitochondrial GN=MTHFDIL C1TM HUMAN $105.79 \quad 100.0 \%$ Monofunctional C1-tetrahydrofolate synthase, mitochondrial GN=MTHFDIL C1TM_HUMAN $105.79 \quad 100.0 \%$ 作 $105.79 \quad 100.0 \%$ Monofunctional C1-tetrahydrofolate synthase, mitochondrial GN=MTHFDIL C1TM_HUMAN $105.79 \quad 100.0 \%$ Nofunctional Cl-tetrahydrofolate synthase, mitochondrial GN=MTHFDIL CITM_HUMAN $105.79 \quad 100.0 \%$ mRNA export factor $\mathrm{GN}=\mathrm{RAE}$. mRNA export factor $\mathrm{GN}=\mathrm{RAE} 1$ mRNA export factor $\mathrm{GN}=\mathrm{RAE} 1$ mRNA export factor $\mathrm{GN}=\mathrm{RAE}$ mRNA turnover protein 4 homolog GN=MRTO4 MRT4_HUMAN $27.56 \quad 100.0 \%$
$0.01 \% \quad 7.3 \%$ NISELFYYAQK $0.01 \% \quad 7.3 \%$ SAFLQAFLGR $0.01 \% \quad 9.7 \%$ TLMECVSNTAK $0.01 \% \quad 9.7 \% \quad$ SHVDLFPK $0.01 \% \quad 9.7 \%$ VYVIGSFVDK $0.01 \% \quad 9.7 \%$ SMQPGTSLAK

$0.00 \% \quad 11.9 \%$ ALISPFDVIK

$0.00 \% \quad 11.9 \%$ NENLQNLLCGSGAGVISK $0.00 \% \quad 11.9 \%$ TLTYPLDLFK

$0.00 \% \quad 5.7 \% \quad$ STQAATQVVLNVPETR $0.00 \% \quad 5.7 \% \quad$ LCTSVTESEVAR

$99.7 \% \quad 30.7$ $99.7 \% \quad 56.5$ $99.7 \% \quad 44.3$ $99.0 \% \quad 27.0$ $99.7 \% \quad 24.7$ $99.7 \% \quad 40.8$ $99.2 \% \quad 19.2$ $99.7 \% \quad 41.7$ $98.8 \% 19.2$

$99.7 \% \quad 33.7$ $99.7 \% \quad 34.3$

$0.01 \% \quad 10.6 \%$ DLKPPNLLLVAGGTVLK $99.7 \% \quad 39.5$

$0.01 \% \quad 10.6 \%$ GSSVESLPPTSEGKR $99.0 \% \quad 21.4$

$0.01 \% \quad 10.6 \%$ SIQDLTVTGTEPGQVSS

$0.01 \% \quad 10.6 \%$ MITTSGPTSEKPTR

$0.01 \% \quad 10.1 \%$ ESSLKYQTR

$0.01 \% \quad 10.1 \%$ VAVEYLDPSPEVQK

$0.01 \% \quad 10.1 \%$ QVTDAETKPK

$0.00 \% \quad 9.6 \%$ VSGTLDTPEK

$0.00 \% \quad 9.6 \%$ TVDSQGPTPVCTPTFLER

$0.01 \% \quad 1.8 \%$ LLQAAAGASAR

$0.01 \% \quad 1.8 \%$ GLSHVLNR

$0.03 \% \quad 27.8 \%$ AYLEPEHTKAR

$0.03 \% \quad 27.8 \%$ ITDFQFKELVVLPR

$99.7 \% \quad 79.3$

$99.7 \% \quad 46.5$

$99.5 \% \quad 23.8$

$99.7 \% \quad 30.6$

$99.7 \% \quad 36.8$

$99.7 \% \quad 36.3$

$99.7 \% \quad 64.4$

$98.2 \% \quad 17.3$

$99.7 \% \quad 29.0$

$99.7 \% \quad 55.9$

$0.03 \% 27.8 \%$ CTAPQYVDFVMSSVQK

$0.03 \% \quad 27.8 \%$ LVTDEDVFPTK

$0.03 \% \quad 27.8 \%$ LVTDEDVFPTKYGR

$0.03 \% \quad 27.8 \%$ EFPSSFESLVR

$0.01 \% \quad 7.0 \%$ DLHDANTDLIGR

$0.01 \% \quad 7.0 \%$ DLHDANTDLIGRHPK

$0.01 \% \quad 7.0 \%$ ESKEEETSIDVAGKPNEVTK

$0.04 \% \quad 12.7 \%$ LVRGDAHECFVSPVAK

$0.04 \% \quad 12.7 \%$ GDAHECFVSPVAK

$0.04 \% \quad 12.7 \%$ LQPLSPVPSDIEISR

$0.04 \% \quad 12.7 \%$ VRLSVLER

$0.04 \% \quad 12.7 \%$ ILHENTQTDK

$0.04 \% \quad 12.7 \%$ VLDTNDRFLR

$0.04 \% \quad 12.7 \%$ ASGLVPNVVVLVATVR

$0.04 \% \quad 12.7 \%$ TIAQAVYGAK

$0.04 \% \quad 12.7 \%$ DIELSPEAQAK

$0.04 \% \quad 12.7 \%$ IDRYTQQGFGNLPICMAK

$0.04 \% \quad 12.7 \%$ DFILPISDVR

$0.02 \% \quad 10.3 \%$ SSNPMMVLQLPER

$0.02 \% \quad 10.3 \%$ GLIVYQLENQPSEFR

$0.02 \% \quad 10.3 \%$ GLIVYQLENQPSEFRR

$0.02 \% \quad 10.3 \%$ NAAEELKPR

$0.00 \% \quad 8.4 \%$ GEVGLLFTNR $\begin{array}{llll}99.7 \% & 38.8 & 25.0 & 38.2\end{array}$

$99.7 \% \quad 53.6 \quad 25.0 \quad 53.6$

$99.7 \% \quad 28.5 \quad 25.0 \quad 28.5$

$99.7 \% \quad 29.1 \quad 25.0 \quad 25.7$

$99.5 \% \quad 21.7 \quad 25.0-21.7$

$\begin{array}{llll}99.7 \% & 44.2 & 25.0 & 44.2\end{array}$

$\begin{array}{llll}99.6 \% & 23.3 & 25.0 & 23.3\end{array}$

$99.4 \% \quad 25.5 \quad 25.0 \quad 25.5$

$99.7 \% \quad 47.2 \quad 25.0 \quad 45.3$

$98.9 \% \quad 22.8 \quad 25.0 \quad 15.3$

$\begin{array}{llll}98.4 \% & 20.8 & 25.0 & 16.1\end{array}$

$\begin{array}{llll}97.3 \% & 18.6 & 25.0 & 14.6\end{array}$

$\begin{array}{llll}99.7 \% & 56.6 & 25.0 & 56.6\end{array}$

$\begin{array}{llll}99.7 \% & 33.2 & 25.0 & 27.3\end{array}$

$\begin{array}{llll}99.7 \% & 43.9 & 25.0 & 30.3\end{array}$

$\begin{array}{llll}99.7 \% & 41.1 & 25.0 & 37.9\end{array}$

$\begin{array}{lllll}99.7 \% & 33.1 & 25.0 & 30.1 & 2\end{array}$

$\begin{array}{llll}99.7 \% & 44.5 & 25.0 & 41.8\end{array}$

$\begin{array}{llll}99.7 \% & 62.7 & 25.0 & 62.7\end{array}$

$\begin{array}{llll}99.7 \% & 38.0 & 25.0 & 38.0\end{array}$

$\begin{array}{llll}99.7 \% & 52.0 & 25.0 & 41.5\end{array}$

$99.7 \% \quad 38.8 \quad 25.0 \quad 28.9$

0
0
0
0
0
0
0
0
0
0
0
0
0
0
0
0
0
0
0
0
0
0
0
0
0
0
0
0
0
0
0
0
0
0
0
0
0
0
0
0
0
0
0
0
0
0
0
0
0
0
0

1109.61

1253.59

942.50

1126.61

1019.52

1102.65

1873.94

1210.67

1713.91

1351.65

1748.07

1530.78

1874.95

1505.76

1111.57

1573.81

1116.59

1046.54

2004.97

1028.58

895.51

1314.68

1704.97

1875.86

1263.65

1639.83

1297.64

1339.66

1701.87

2190.08

1784.91

1416.66

1650.9

971.60

1198.61

1248.67

1593.97

1021.57

1200.61

2112.04

1174.65

1501.75

1792.92

1949.02

1027.55

1105.60
164
439
129
284
315
325
40
231
241
59
399
172
387
456
477
183
216
324
226
244
384
901
34
48
120
131
134
145
236
239
479
205
205
365
107
467
405
516
585
745
880
891
909
935
172
205
206

Page 83 of Table S-1-1 
mRNA turnover protein 4 homolog GN=MRTO4 MRT4_HUMAN $27.56 \quad 100.0 \%$ Multifunctional protein ADE2 GN=PAICS PUR6_HUMAN $47.08 \quad 100.0 \%$ Multifunctional protein ADE2 GN=PAICS PUR6_HUMAN $47.08 \quad 100.0 \%$ Multifunctional protein ADE2 GN=PAICS PUR6 HUMAN $47.08 \quad 100.0 \%$ Multifunctional protein ADE2 GN=PAICS PUR6_HUMAN $47.08 \quad 100.0 \%$ Multifunctional protein ADE2 GN=PAICS PUR6_HUMAN $47.08 \quad 100.0 \%$ Myb-binding protein 1A GN=MYBBP1A MBB1A_HUMAN $148.86 \quad 100.0 \%$ Myb-binding protein 1A GN=MYBBP1A MBB1A_HUMAN $148.86 \quad 100.0 \%$ Myb-binding protein 1A GN=MYBBP1A MBB1A_HUMAN $148.86 \quad 100.0 \%$ Myb-binding protein 1A GN=MYBBP1A MBB1A_HUMAN $148.86 \quad 100.0 \%$ Myb-binding protein 1A GN=MYBBP1A MBB1A_HUMAN $148.86 \quad 100.0 \%$ Myb-binding protein 1A GN=MYBBP1A MBB1A_HUMAN $148.86 \quad 100.0 \%$ Myb-binding protein 1A GN=MYBBP1A MBB1A_HUMAN $148.86 \quad 100.0 \%$ Myb-binding protein 1A GN=MYBBP1A MBB1A_HUMAN $148.86 \quad 100.0 \%$ Myb-binding protein 1A GN=MYBBP1A MBB1A_HUMAN $148.86 \quad 100.0 \%$ Myb-binding protein 1A GN=MYBBP1A MBB1A_HUMAN $148.86 \quad 100.0 \%$ Myb-binding protein 1A GN=MYBBP1A MBB1A_HUMAN $148.86 \quad 100.0 \%$ Myb-binding protein 1A GN=MYBBP1A MBB1A_HUMAN $148.86 \quad 100.0 \%$ Myb-binding protein 1A GN=MYBBP1A MBB1A_HUMAN $148.86 \quad 100.0 \%$ Myb-binding protein 1A GN=MYBBP1A MBB1A_HUMAN $148.86 \quad 100.0 \%$ Myb-binding protein 1A GN=MYBBP1A MBB1A_HUMAN $148.86 \quad 100.0 \%$ Myb-binding protein 1A GN=MYBBP1A MBB1A_HUMAN $148.86 \quad 100.0 \%$ Myosin-10 GN=MYH10 Myosin-10 GN=MYH10 Myosin-10 GN=MYH10 Myosin-10 GN=MYH10 Myosin-10 GN=MYH10 Myosin-10 GN=MYH10 Myosin-10 GN=MYH10 Myosin-10 GN=MYH10 Myosin-10 GN=MYH10 Myosin-10 GN=MYH10 Myosin-10 GN=MYH10 Myosin-10 GN=MYH10 Myosin-10 GN=MYH10 Myosin-10 GN=MYH10 Myosin-10 GN=MYH10 Myosin-10 GN=MYH10 Myosin-10 GN=MYH10 Myosin-14 GN=MYH14 Myosin-14 GN=MYH14 Myosin-14 GN=MYH14 Myosin-14 GN=MYH14 Myosin-14 GN=MYH14 Myosin-14 GN=MYH14 Myosin-14 GN=MYH14 Myosin-14 GN=MYH14 MYH10_HUMAN $229.01 \quad 100.0 \%$ MYH10_HUMAN $229.01 \quad 100.0 \%$ MYH10_HUMAN $229.01 \quad 100.0 \%$ MYH10_HUMAN $229.01 \quad 100.0 \%$ MYH10_HUMAN $229.01 \quad 100.0 \%$ MYH10_HUMAN $229.01 \quad 100.0 \% \quad 17$ MYH10_HUMAN $229.01 \quad 100.0 \%$ MYH10_HUMAN $229.01 \quad 100.0 \% \quad 17$ MYH10_HUMAN $229.01 \quad 100.0 \%$ MYH10_HUMAN $229.01 \quad 100.0 \% \quad 17$ MYH10_HUMAN $229.01 \quad 100.0 \% \quad 17$ MYH10_HUMAN $229.01 \quad 100.0 \% \quad 17$ MYH10_HUMAN $229.01 \quad 100.0 \% \quad 17$ MYH10_HUMAN $229.01 \quad 100.0 \% \quad 17$ MYH10_HUMAN $229.01 \quad 100.0 \% \quad 17$ MYH10_HUMAN $229.01 \quad 100.0 \% \quad 17$ MYH10_HUMAN $229.01 \quad 100.0 \% \quad 17$ MYH14_HUMAN $227.87 \quad 100.0 \%$ MYH14_HUMAN $227.87 \quad 100.0 \%$ MYH14_HUMAN $227.87 \quad 100.0 \%$ MYH14_HUMAN $227.87 \quad 100.0 \%$ MYH14_HUMAN $227.87 \quad 100.0 \%$ MYH14_HUMAN $227.87 \quad 100.0 \%$ MYH14_HUMAN $227.87 \quad 100.0 \%$ MYH14_HUMAN $227.87 \quad 100.0 \%$
$11.8 \%$ ACGNFGIPCELR

$10 \quad 0.01 \% \quad 11.8 \%$ VTSAHKGPDETLR

$17 \quad 37 \quad 0.05 \% \quad 9.6 \%$ LVGSVNLFSDENVPR

$\begin{array}{lllll}17 & 37 & 0.05 \% & 9.6 \% & \text { IFTHHLCR }\end{array}$

$\begin{array}{lllll}17 & 37 & 0.05 \% & 9.6 \% & \text { AGALHAQVER }\end{array}$

$\begin{array}{lllll}17 & 37 & 0.05 \% & 9.6 \% & \text { VYSTALSSFLTK }\end{array}$

$17 \quad 37 \quad 0.05 \% \quad 9.6 \% \quad$ VYSTALSSFLTKR

$\begin{array}{lllll}17 & 37 & 0.05 \% & 9.6 \% & \text { HQACLLLQK }\end{array}$

$17 \quad 37 \quad 0.05 \% \quad 9.6 \%$ DAKEIPSATQSPISK

$\begin{array}{lllll}17 & 37 & 0.05 \% & 9.6 \% & \text { EIPSATQSPISK }\end{array}$

$\begin{array}{lllll}17 & 37 & 0.05 \% & 9.6 \% & \text { AKVPAQANGTPTTK }\end{array}$

$\begin{array}{lllll}17 & 37 & 0.05 \% & 9.6 \% & \text { SPAPGAPTR }\end{array}$

$17 \quad 37 \quad 0.05 \% \quad 9.6 \% \quad$ SPAPGAPTRSPSTPAK

$17 \quad 37 \quad 0.05 \% \quad 9.6 \%$ SPSTPAKSPK

$\begin{array}{lllll}17 & 37 & 0.05 \% & 9.6 \% & \text { SPLSALAR }\end{array}$

$\begin{array}{lllll}17 & 37 & 0.05 \% & 9.6 \% & \text { LSLVIRSPSLLQSGAK }\end{array}$

$17 \quad 37 \quad 0.05 \% \quad 9.6 \%$ SPSLLQSGAK

$\begin{array}{lllll}17 & 37 & 0.05 \% & 9.6 \% & \text { SPSLLQSGAKK }\end{array}$

$\begin{array}{lllll}17 & 29 & 0.04 \% & 9.1 \% & \text { AMVNKDDIQK }\end{array}$

$\begin{array}{lllll}17 & 29 & 0.04 \% & 9.1 \% & \text { QLLQANPILESFGNAK }\end{array}$

$\begin{array}{lllll}17 & 29 & 0.04 \% & 9.1 \% & \text { NTDQASMPENTVAQK }\end{array}$

$17 \quad 29 \quad 0.04 \% \quad 9.1 \%$ EQADFAVEALAK

$\begin{array}{lllll}17 & 29 & 0.04 \% & 9.1 \% & \text { LVQEQGSHSK }\end{array}$

$\begin{array}{lllll}17 & 29 & 0.04 \% & 9.1 \% & \text { CNGVLEGIR }\end{array}$

$\begin{array}{lllll}17 & 29 & 0.04 \% & 9.1 \% & \text { QRYEILTPNAIPK }\end{array}$

$17 \quad 29 \quad 0.04 \% \quad 9.1 \% \quad$ YEILTPNAIPK

$17 \quad 29 \quad 0.04 \% \quad 9.1 \%$ ALELDPNLYR

$17 \quad 29 \quad 0.04 \% \quad 9.1 \% \quad$ ALAYDKLEK

$17 \quad 29 \quad 0.04 \% \quad 9.1 \% \quad$ ASRDEIFAQSK

$\begin{array}{lllll}17 & 29 & 0.04 \% & 9.1 \% & \text { SALLDEKR }\end{array}$

$17 \quad 29 \quad 0.04 \% \quad 9.1 \% \quad$ TTLQVDTLNAELAAER

$17 \quad 29 \quad 0.04 \% \quad 9.1 \%$ IGQLEEQLEQEAKER

$17 \quad 29 \quad 0.04 \% \quad 9.1 \%$ ELDDATEANEGLSR

$17 \quad 29 \quad 0.04 \% \quad 9.1 \%$ RGGPISFSSSR

$17 \quad 29 \quad 0.04 \% \quad 9.1 \% \quad$ GGPISFSSSR

$2 \quad 0.00 \% \quad 4.3 \%$ QLLQANPILEAFGNAK

$0.00 \% \quad 4.3 \%$ EQADFALEALAK

$0.00 \% \quad 4.3 \%$ ATDKSFVEK

$0.00 \% \quad 4.3 \% \quad$ CNGVLEGIR

$0.00 \% \quad 4.3 \% \quad$ QRYEILTPNAIPK

$0.00 \% \quad 4.3 \%$ YEILTPNAIPK

$0.00 \% \quad 4.3 \%$ AQAELENVSGALNEAESK

$0.00 \% \quad 4.3 \%$ EAEALTQR $\begin{array}{lllll}99.6 \% & 21.8 & 25.0 & 19.8 & 1\end{array}$

$\begin{array}{llll}1 & 0 & 0 & 1096.68 \\ 1 & 2 & 0 & 1684.93\end{array}$

$\begin{array}{lllll}99.7 \% & 43.3 & 25.0 & 38.2 & 2\end{array}$

$99.7 \% \quad 53.5 \quad 25.0 \quad 53.5$

$\begin{array}{llll}99.7 \% & 38.0 & 25.0 & 37.7\end{array}$

$99.7 \% \quad 51.2 \quad 25.0 \quad 48.2$

$\begin{array}{lllll}99.0 \% & 32.4 & 25.0 & 22.9 & 2\end{array}$

$99.7 \% \quad 33.7 \quad 25.0 \quad 17.4$

$\begin{array}{llll}99.7 \% & 30.6 & 25.0 & 28.4\end{array}$

$\begin{array}{llll}99.7 \% & 29.8 & 25.0 & 29.8\end{array}$

$\begin{array}{llll}99.7 \% & 24.4 & 25.0 & 20.4\end{array}$

$\begin{array}{llll}99.7 \% & 31.8 & 25.0 & 22.7\end{array}$

$\begin{array}{llll}99.7 \% & 33.7 & 25.0 & 27.4\end{array}$

$\begin{array}{llll}99.6 \% & 24.2 & 25.0 & 19.1\end{array}$

$\begin{array}{lllll}99.7 \% & 42.5 & 25.0 & 28.9\end{array}$

$99.7 \% \quad 31.0 \quad 25.0 \quad 31.0$

$\begin{array}{llll}99.6 \% & 29.0 & 25.0 & 15.3\end{array}$

$\begin{array}{llll}99.0 \% & 46.2 & 25.0 & 23.5\end{array}$

$\begin{array}{llll}99.7 \% & 30.5 & 25.0 & 30.5\end{array}$

$\begin{array}{llll}99.7 \% & 40.2 & 25.0 & 30.8\end{array}$

$99.7 \% \quad 34.8 \quad 25.0 \quad 30.1$

$\begin{array}{llll}99.7 \% & 36.9 & 25.0 & 27.4\end{array}$

$\begin{array}{lllll}99.7 \% & 53.5 & 25.0 & 53.5 & 2\end{array}$

$99.7 \% \quad 39.3 \quad 25.0 \quad 34.6$

$99.7 \% \quad 49.4 \quad 25.0 \quad 45.0$

$\begin{array}{llll}99.7 \% & 41.1 & 25.0 & 24.2\end{array}$

$\begin{array}{llll}99.7 \% & 36.7 & 25.0 & 30.9\end{array}$

$\begin{array}{llll}96.0 \% & 17.6 & 25.0 & 17.6\end{array}$

$\begin{array}{llll}99.7 \% & 34.7 & 25.0 & 34.7\end{array}$

$\begin{array}{llll}99.7 \% & 45.8 & 25.0 & 42.3\end{array}$

$\begin{array}{llll}98.3 \% & 22.0 & 25.0 & 14.0\end{array}$

$99.7 \% \quad 35.0 \quad 25.0 \quad 34.0$

$\begin{array}{llll}99.0 \% & 42.5 & 25.0 & 29.1\end{array}$

$\begin{array}{llll}99.7 \% & 64.6 & 25.0 & 55.6\end{array}$

$\begin{array}{llll}99.7 \% & 26.6 & 25.0 & 24.7\end{array}$

$\begin{array}{llll}99.7 \% & 41.2 & 25.0 & 37.2\end{array}$

$99.7 \% \quad 37.4 \quad 25.0 \quad 31.1$

$\begin{array}{llll}99.7 \% & 38.5 & 25.0 & 38.3\end{array}$

$\begin{array}{llll}99.7 \% & 40.5 & 25.0 & 39.7\end{array}$

$\begin{array}{llll}97.9 \% & 33.2 & 25.0 & 0.0\end{array}$

$\begin{array}{lllll}98.1 \% & 21.2 & 25.0 & 14.0 & 2\end{array}$

$\begin{array}{llll}99.7 \% & 36.7 & 25.0 & 30.9\end{array}$

$96.0 \% \quad 17.6 \quad 25.0 \quad 17.6$

$\begin{array}{llll}99.7 \% & 34.7 & 25.0 & 34.7\end{array}$

$\begin{array}{llll}99.7 \% & 33.2 & 25.0 & 33.2\end{array}$
1016.51

992.59

1393.64

1410.73

1645.85

1083.55

1051.56

1316.71

1472.81

1110.61

1571.83

1257.67

1383.76

853.45

1521.80

999.55

814.48

1669.00

987.55

1115.64

1161.59

1742.94

1633.75

1291.65

1112.57

1017.51

1542.86

1258.70

1203.64

1050.58

1251.63

931.52

1744.91

1799.91

1519.69

1150.60

994.50

1726.95

1305.67

1024.53

1017.51

1542.86

1258.70

1859.90

917.47 
Myosin- 9 GN=MYH9

Myosin-9 GN=MYH9

Myosin- 9 GN=MYH9

Myosin-9 GN=MYH9

Myosin-9 GN=MYH9

Myosin-9 GN=MYH9

Myosin-9 GN=MYH9

Myosin-9 GN=MYH9

Myosin-9 GN=MYH9

Myosin-9 GN=MYH9

Myosin- 9 GN=MYH9

Myosin-9 GN=MYH9

Myosin-9 GN=MYH9

Myosin-9 GN=MYH9

Myosin-9 GN=MYH9

Myosin-9 GN=MYH9

Myosin-9 GN=MYH9

$\mathrm{N}$-acetyltransferase $10 \mathrm{GN}=\mathrm{NAT} 10$

$\mathrm{N}$-acetyltransferase $10 \mathrm{GN}=\mathrm{NAT} 10$

$\mathrm{N}$-acetyltransferase $10 \mathrm{GN}=\mathrm{NAT} 10$

$\mathrm{N}$-acetyltransferase $10 \mathrm{GN}=\mathrm{NAT} 10$

$\mathrm{N}$-acylneuraminate cytidylyltransferase GN=CMAS NEUA_HUMAN 48.38

$\mathrm{N}$-acylneuraminate cytidylyltransferase GN=CMAS NEUA_HUMAN $48.38 \quad 100.0 \%$

NADH dehydrogenase [ubiqunone] I alph subcomplex subunit 10, mitochondrial GN=NDUFA10 NDUAA_HUMAN $40.75 \quad 100.0 \%$

$\begin{array}{lll} & 100.0 \%\end{array}$

ADDH dehydrogenase [ubiquinone] I alpha subcomplex subunit 10, mitochondral GN=NDUFA10 NDUAA_HUMAN $40.75 \quad 100.0 \%$

NADH dehydrogenase [ubiquinone] 1 alph subbomplex subunit 10, mitochondral GN=NDUFA 10 NDUAA_HUMAN $40.75 \quad 100.0 \%$

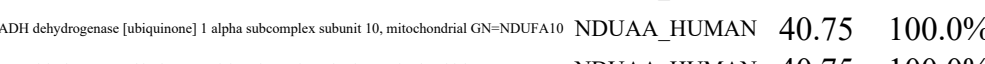

作

NDUAA_HUMAN $40.75 \quad 100.0 \%$ NDUA9_HUMAN $42.51 \quad 100.0 \%$ NDUA9 HUMAN $42.51 \quad 100.0 \%$ NDUA9_HUMAN $42.51 \quad 100.0 \%$ A9 NDUA9_HUMAN $42.51 \quad 100.0 \%$ O $42.51 \quad 100.0 \%$ NADH dehydrogenase [ubiquinone] iron-sulfur protein 2, mitochondrial GN=NDUFS2 NDUS2_HUMAN $52.55 \quad 100.0 \%$ NADH-cytochrome b5 reductase 3 GN=CYB5R3 NB5R3_HUMAN $34.24 \quad 100.0 \%$ NADH-cytochrome b5 reductase $3 \mathrm{GN}=\mathrm{CYB} 5 \mathrm{R} 3$ NB5R3_HUMAN $34.24 \quad 100.0 \%$ NADH-ubiquinone oxidoreductase 75 kDa subunit, mitochondrial GN=NDUFS1 NDUS1_HUMAN $79.47 \quad 100.0 \%$ NADH-ubiquinone oxidoreductase 75 kDa subunit, mitochondrial GN=NDUFS1 NDUS1_HUMAN $79.47 \quad 100.0 \%$ NADH-ubiquinone oxidoreductase 75 kDa subunit, mitochondrial GN=NDUFS1 NDUS1_HUMAN $79.47 \quad 100.0 \%$ NADH-ubiquinone oxidoreductase 75 kDa subunit, mitochondrial GN=NDUFS1 NDUS1_HUMAN $79.47 \quad 100.0 \%$

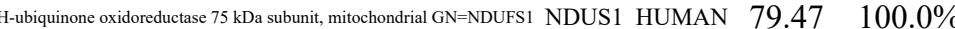
N-alpha-acetyltransferase 10 GN=NAA10 NAA10_HUMAN $26.46 \quad 100.0 \%$ $\begin{array}{lllll}16 & 25 & 0.03 \% & 9.6 \% & \text { VIQYLAYVASSHK }\end{array}$

$\begin{array}{lllll}16 & 25 & 0.03 \% & 9.6 \% & \text { QLLQANPILEAFGNAK }\end{array}$

$16 \quad 25$

$16 \quad 25$

$16 \quad 25$

$16 \quad 25$

$16 \quad 25$

$16 \quad 25$

$16 \quad 25$

$16 \quad 25$

$16 \quad 25$

$16 \quad 25$

$16 \quad 25$

$16 \quad 25$

$16 \quad 25$

$16 \quad 25$

$16 \quad 25$

9

$$
9
$$

$0.03 \% \quad 9.6 \%$ NTDQASMPDNTAAQK

$0.03 \% \quad 9.6 \%$ EQADFAIEALAK

$0.03 \% \quad 9.6 \%$ ATDKSFVEK

$0.03 \% \quad 9.6 \%$ VMQEQGTHPK

$0.03 \% \quad 9.6 \%$ TVGQLYKEQLAK

$0.03 \% \quad 9.6 \%$ CNGVLEGIR

$0.03 \% \quad 9.6 \%$ YEILTPNSIPK

$0.03 \% \quad 9.6 \%$ ALELDSNLYR

$0.03 \% \quad 9.6 \%$ GALALEEKR

$0.03 \% \quad 9.6 \%$ ANLQIDQINTDLNLER

$0.03 \% \quad 9.6 \%$ VKLQEMEGTVK

$0.03 \% \quad 9.6 \%$ YKASITALEAK

$0.03 \% \quad 9.6 \%$ ASITALEAK

$0.03 \% \quad 9.6 \%$ IAQLEEQLDNETKER

$0.03 \% \quad 9.6 \%$ RGDLPFVVPR

$0.01 \% \quad 4.5 \% \quad$ QSILNSLSR

$0.01 \% \quad 4.5 \%$ IAVHPDYQGMGYGSR

$0.01 \% \quad 4.5 \%$ LDYLGVSYGLTPR

$0.01 \% \quad 4.5 \%$ AGFVPVYLR

$0.00 \% \quad 6.0 \%$ GAATSVSNPR

$0.00 \% \quad 6.0 \%$ VGLSGAPADACSTAQK

$0.02 \% \quad 17.7 \%$ SRVITVDGNICTGK

$0.02 \% \quad 17.7 \%$ VITVDGNICTGK

$0.02 \% \quad 17.7 \%$ VITVDGNICTGKGK

$0.02 \% \quad 17.7 \%$ LQSWLYSSR

$0.02 \% \quad 17.7 \%$ TFLPEMSEKCEVLQYSAR

$0.02 \% \quad 17.7 \%$ KVVEDIEYLK

$0.02 \% \quad 17.7 \%$ VVEDIEYLK

$0.02 \% \quad 17.7 \%$ QDNRTLYHLR

$0.02 \% \quad 17.8 \%$ YVVNHLGR

$0.02 \% \quad 17.8 \%$ MGSQVIIPYR

$0.02 \% \quad 17.8 \%$ TVKQPVYVVDVSK

$0.02 \% \quad 17.8 \%$ GIVNAVKDPDANGK

$0.02 \% \quad 17.8 \%$ SFAFVGPSR

$0.02 \% \quad 17.8 \%$ WLSAEIEDVKPAK

$0.01 \% \quad 4.1 \%$ LVMELSGEMVR

$0.01 \% \quad 4.1 \%$ IIAQCLNK

$0.00 \% \quad 12.0 \%$ STPAITLESPDIKYPLR

$0.00 \% \quad 12.0 \%$ SVGMIAGGTGITPMLQVIR

$0.01 \% \quad 10.2 \%$ AVEDKNIGPLVK

$$
10
$$

$0.01 \% \quad 10.2 \%$ FEAPLFNAR

$0.01 \% \quad 10.2 \%$ ILQDIASGSHPFSQVLK

$0.01 \% \quad 10.2 \%$ NDGAAILAAVSSIAQK

$0.01 \% \quad 10.2 \%$ IASQVAALDLGYKPGVEAIR

$0.01 \% \quad 17.0 \%$ LGLAQKLMDQASR

$\begin{array}{llllllll}99.7 \% & 40.5 & 25.0 & 39.7 & 2 & 0 & 0 & 1726.95\end{array}$

$\begin{array}{llllllll}99.7 \% & 36.5 & 25.0 & 36.5 & 1 & 0 & 0 & 1591.70\end{array}$

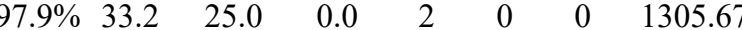

$\begin{array}{llllllll}98.1 \% & 21.2 & 25.0 & 14.0 & 2 & 0 & 0 & 1024.53\end{array}$

$\begin{array}{llllllll}99.7 \% & 35.6 & 25.0 & 34.4 & 2 & 0 & 0 & 1154.56\end{array}$

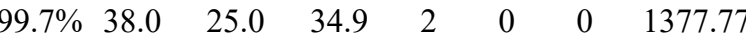

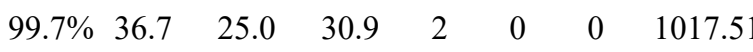

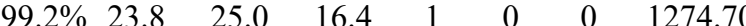

$99.7 \% \quad 46.6 \quad 25.0 \quad 40.1$

$\begin{array}{llll}99.7 \% & 36.0 & 25.0 & 20.2\end{array}$

$99.7 \% \quad 51.7 \quad 25.0 \quad 44.1$

$99.1 \% \quad 23.4 \quad 25.0 \quad 19.2$

$99.7 \% \quad 24.5 \quad 25.0 \quad 24.5$

$99.7 \% \quad 36.6 \quad 25.0 \quad 26.2$

$99.7 \% \quad 45.1 \quad 25.0 \quad 45.1$

$99.7 \% \quad 42.4 \quad 25.0 \quad 33.3$

$98.0 \% \quad 21.0 \quad 25.0 \quad 18.4$

$99.7 \% \quad 41.0 \quad 25.0 \quad 41.0$

$99.7 \% \quad 54.1 \quad 25.0 \quad 40.3$

$99.7 \% \quad 29.9 \quad 25.0 \quad 24.4 \quad 2$

$99.7 \% \quad 51.0 \quad 25.0 \quad 30.9$

$99.7 \% \quad 46.3 \quad 25.0 \quad 44.2$

$\begin{array}{llll}99.6 \% & 22.8 & 25.0 & 22.8\end{array}$

$99.7 \% \quad 51.0 \quad 25.0 \quad 51.0$

$\begin{array}{llll}99.7 \% & 33.0 & 25.0 & 31.5\end{array}$

$\begin{array}{llll}99.7 \% & 32.5 & 25.0 & 32.5\end{array}$

$\begin{array}{llll}9.7 \% & 16.5 & 25.0 & 12.1\end{array}$

$\begin{array}{llll}99.7 \% & 44.7 & 25.0 & 42.3\end{array}$

$97.9 \% \quad 18.0 \quad 25.0 \quad 18.0$

$\begin{array}{llll}99.0 \% & 30.5 & 25.0 & 19.0\end{array}$

$99.7 \% \quad 36.3 \quad 25.0 \quad 35.3$

$99.7 \% \quad 43.4 \quad 25.0 \quad 43.4$

$99.7 \% \quad 41.3 \quad 25.0 \quad 41.3$

$\begin{array}{llll}99.7 \% & 33.1 & 25.0 & 33.1\end{array}$

$\begin{array}{llll}99.7 \% & 44.9 & 25.0 & 37.1\end{array}$

$\begin{array}{lllll}99.7 \% & 53.2 & 25.0 & 48.5\end{array}$

$99.0 \% \quad 35.4 \quad 25.0 \quad 24.7$

$\begin{array}{llll}99.7 \% & 35.2 & 25.0 & 34.8\end{array}$

$\begin{array}{llll}99.7 \% & 39.2 \quad 25.0 & 36.9\end{array}$

$\begin{array}{llll}99.7 \% & 24.6 & 25.0 & 24.6\end{array}$

$\begin{array}{llll}98.5 \% & 17.6 & 25.0 & 17.6\end{array}$

$\begin{array}{llll}99.7 \% & 24.6 & 25.0 & 24.5\end{array}$

$\begin{array}{llll}99.7 \% & 53.5 & 25.0 & 53.5\end{array}$

$\begin{array}{llll}99.7 \% & 47.2 & 25.0 & 47.2\end{array}$

$\begin{array}{llll}99.7 \% & 43.4 & 25.0 & 22.2\end{array}$
1193.62

1869.97

1261.68

1194.67

903.51

1815.91

1155.66

1017.57

1666.76

1453.77

1021.58

959.49

1532.74

1519.79

1276.66

1461.77

1139.58

2188.04

1235.69

1107.59

1315.69

957.53

1163.62

1461.83

1397.74

967.50

1485.79

1263.64

959.53

1901.04

1901.04

1282.74

1064.55

1840.00

1528.83

2071.15 1446.77 $\begin{array}{cc} & \\ 10 & 199 \\ 10 & 225 \\ 59 & 373 \\ 98 & 419 \\ 37 & 545 \\ 46 & 555 \\ 45 & 656 \\ 94 & 702 \\ 21 & 731 \\ 46 & 755 \\ 17 & 1725 \\ 55 & 1770 \\ 92 & 1802 \\ 05 & 1815 \\ 07 & 1815 \\ 16 & 1830 \\ 23 & 1932 \\ 38 & 596 \\ 29 & 643 \\ 96 & 718 \\ 26 & 734 \\ 7 & 16 \\ 94 & 399 \\ 7 & 70 \\ 9 & 70 \\ 9 & 72 \\ 31 & 139 \\ 44 & 261 \\ 68 & 277 \\ 69 & 277 \\ 86 & 295 \\ 8 & 75 \\ 6 & 85 \\ 35 & 247 \\ 48 & 261 \\ 62 & 270 \\ 61 & 373 \\ 7 & 107 \\ 43 & 350 \\ 0 & 46 \\ 74 & 192 \\ 59 & 170 \\ 99 & 417 \\ 51 & 467 \\ 94 & 499 \\ & 538 \\ & \\ 49\end{array}$

Page 85 of Table S-1-1 
N-alpha-acetyltransferase $10 \mathrm{GN}=\mathrm{NAA} 10 \quad$ NAA10_HUMAN $26.46 \quad 100.0 \%$ N-alpha-acetyltransferase 10 GN=NAA10 NAA10_HUMAN $26.46 \quad 100.0 \%$ N-alpha-acetyltransferase 15 , NatA auxiliary subunit GN=NAA15 NAA15_HUMAN $101.28 \quad 100.0 \%$ N-alpha-acetyltransferase 15, NatA auxiliary subunit GN=NAA15 NAA15_HUMAN $101.28100 .0 \%$ N-alpha-acetyltransferase 15 , NatA auxiliary subunit GN=NAA15 NAA15_HUMAN $101.28 \quad 100.0 \%$ N-alpha-acetyltransferase 15 , NatA auxiliary subunit GN=NAA15 NAA15_HUMAN $101.28 \quad 100.0 \%$ N-alpha-acetyltransferase 15 , NatA auxiliary subunit GN=NAA15 NAA15_HUMAN $101.28 \quad 100.0 \%$ N-alpha-acetyltransferase 15 , NatA auxiliary subunit GN=NAA15 NAA15_HUMAN $101.28 \quad 100.0 \%$ N-alpha-acetyltransferase 15 , NatA auxiliary subunit GN=NAA15 NAA15_HUMAN $101.28 \quad 100.0 \%$ N-alpha-acetyltransferase 15 , NatA auxiliary subunit GN=NAA15 NAA15_HUMAN $101.28 \quad 100.0 \%$ N-alpha-acetyltransferase 15 , NatA auxiliary subunit GN=NAA15 NAA15_HUMAN $101.28 \quad 100.0 \%$ $\mathrm{N}$-alpha-acetyltransferase 15 , NatA auxiliary subunit GN=NAA15 NAA15_HUMAN $101.28 \quad 100.0 \%$ N-alpha-acetyltransferase 25 , NatB auxiliary subunit GN=NAA25 NAA25_HUMAN $112.30 \quad 100.0 \%$ N-alpha-acetyltransferase 25, NatB auxiliary subunit GN=NAA25 NAA25_HUMAN $112.30 \quad 100.0 \%$ Nck-associated protein $1 \mathrm{GN}=\mathrm{NCKAP} 1 \quad$ NCKP1_HUMAN $128.79 \quad 100.0 \%$ Nck-associated protein 1 GN=NCKAP1 NCKP1_HUMAN $128.79 \quad 100.0 \%$ Neuroblastoma-amplified sequence GN=NBAS NBAS HUMAN $268.58 \quad 100.0 \%$ Neuroblastoma-amplified sequence GN=NBAS NBAS_HUMAN $268.58 \quad 100.0 \%$ Neurofibromin GN=NF1

Neurofibromin $\mathrm{GN}=\mathrm{NF} 1$ NF1_HUMAN $319.38 \quad 100.0 \%$ NF1 HUMAN $319.38 \quad 100.0 \%$ NF1_HUMAN $319.38 \quad 100.0 \%$ Neurofibromin GN=NF1

Neurofilament medium polypeptide GN=NEFM NFM HUMAN $102.47 \quad 100.0 \%$ Neurofilament medium polypeptide GN=NEFM NFM_HUMAN $102.47 \quad 100.0 \%$ Neurofilament medium polypeptide GN=NEFM NFM_HUMAN $102.47 \quad 100.0 \%$ Neurofilament medium polypeptide GN=NEFM NFM_HUMAN $102.47 \quad 100.0 \%$ Neutral alpha-glucosidase AB GN=GANAB GANAB_HUMAN $106.88 \quad 100.0 \%$ Neutral alpha-glucosidase AB GN=GANAB GANAB_HUMAN $106.88 \quad 100.0 \%$ Neutral alpha-glucosidase $A B$ GN=GANAB GANAB_HUMAN $106.88 \quad 100.0 \%$ Neutral alpha-glucosidase AB GN=GANAB GANAB_HUMAN $106.88 \quad 100.0 \%$ Neutral alpha-glucosidase AB GN=GANAB GANAB HUMAN $106.88 \quad 100.0 \%$ Neutral amino acid transporter B(0) GN=SLC1A5 AAAT_HUMAN $56.60 \quad 100.0 \%$ Neutral amino acid transporter B(0) GN=SLC1A5 AAAT_HUMAN $56.60 \quad 100.0 \%$ Neutral amino acid transporter B(0) GN=SLC1A5 AAAT HUMAN $56.60 \quad 100.0 \%$ NF-kappa-B-repressing factor GN=NKRF NKRF_HUMAN $77.67 \quad 100.0 \%$ NF-kappa-B-repressing factor GN=NKRF NKRF_HUMAN $77.67 \quad 100.0 \%$ NF-kappa-B-repressing factor GN=NKRF NKRF_HUMAN $77.67 \quad 100.0 \%$ NF-kappa-B-repressing factor GN=NKRF NKRF_HUMAN $77.67 \quad 100.0 \%$ Nicalin GN=NCLN

Nicalin GN=NCLN NCLN HUMAN $62.97 \quad 100.0 \%$ NCLN_HUMAN $62.97 \quad 100.0 \%$ Nicotinamide phosphoribosyltransferase GN=NAMPT NAMPT_HUMAN $55.52 \quad 100.0 \%$ Nicotinamide phosphoribosyltransferase GN=NAMPT NAMPT_HUMAN $55.52 \quad 100.0 \%$ Nischarin GN=NISCH Nischarin GN=NISCH NISCH_HUMAN $166.63 \quad 100.0 \%$ NISCH HUMAN $166.63 \quad 100.0 \%$ Non-POU domain-containing octamer-binding protein GN=NONO NONO_HUMAN $54.23 \quad 100.0 \%$ Non-POU domain-containing octamer-binding protein GN=NONO NONO_HUMAN $54.23 \quad 100.0 \%$ Non-POU domain-containing octamer-binding protein GN=NONO NONO HUMAN $54.23 \quad 100.0 \%$ Non-POU domain-containing octamer-binding protein GN=NONO NONO_HUMAN $54.23 \quad 100.0 \%$
$0.01 \% \quad 17.0 \%$ YYADGEDAYAMKR $0.01 \% \quad 17.0 \%$ HVVLGAIENKVESK $0.03 \% \quad 13.6 \%$ FAEHGETLAMK $0.03 \% \quad 13.6 \%$ YQLLQLRPAQR $0.03 \% \quad 13.6 \%$ LEDAADVYR $0.03 \% \quad 13.6 \%$ ALKPANMLER $0.03 \% \quad 13.6 \%$ RLPLNFLSGEK $0.03 \% \quad 13.6 \%$ LFNTAVCESKDLSDTVR $0.03 \% \quad 13.6 \%$ NFNETFLKR

$0.03 \% \quad 13.6 \%$ NSDSLPHRLSAAK $0.03 \% \quad 13.6 \%$ MVYYLDPSSQKR $0.03 \% \quad 13.6 \%$ AIELATTLDESLTNR $0.00 \% \quad 2.5 \%$ TMFLPLAER $0.00 \% \quad 2.5 \%$ LISGLPSLNHPVEPK $0.00 \% \quad 2.3 \%$ TSFDKPDQMAALFKR $0.00 \% \quad 2.3 \% \quad$ IGQETDKTTTR $0.01 \% \quad 0.9 \%$ SAKDDFTSIIGK $0.01 \% \quad 0.9 \% \quad$ FTADDQYKR $0.00 \% \quad 1.3 \% \quad$ VAQLAVINSLEK $0.00 \% \quad 1.3 \%$ TLSIFYQAGTSK $0.00 \% \quad 1.3 \%$ VGSTAVQVTSAER $0.01 \% \quad 5.1 \%$ VSGSPSSGFR $0.01 \% \quad 5.1 \%$ GSPSTVSSSYKR $0.01 \% \quad 5.1 \% \quad$ LTEAAEQNKEAIR $0.01 \% \quad 5.1 \%$ HLREYQDLLNVK $0.01 \% \quad 7.0 \%$ SIRPGLSPYR $0.01 \% \quad 7.0 \% \quad$ YRVPDVLVADPPIAR $0.01 \% \quad 7.0 \%$ GLLEFEHQRAPR $0.01 \% \quad 7.0 \%$ SGGMERPFVLAR $0.01 \% \quad 7.0 \%$ VVIIGAGKPAAVVLQTK $0.01 \% \quad 8.0 \%$ NIFPSNLVSAAFR $0.01 \% \quad 8.0 \%$ LGPEGELLIR

$0.01 \% \quad 8.0 \%$ SELPLDPLPVPTEEGNPLLK $0.01 \% \quad 7.5 \%$ DASGQPIFNASAK $0.01 \% \quad 7.5 \%$ HAAADEALKILQK $0.01 \% \quad 7.5 \%$ GAVEDVISRNEIQGR $0.01 \% \quad 7.5 \%$ SESHTDLTFSR $0.01 \% \quad 3.6 \%$ NAVLNTEAR $0.01 \% \quad 3.6 \%$ LLDFSYEQYQK $0.01 \% \quad 4.1 \% \quad$ AVPEGFVIPR $0.01 \% \quad 4.1 \%$ GYKLLPPYLR $0.00 \% \quad 1.5 \%$ LLAAFPGVTPR $0.00 \% \quad 1.5 \%$ VPLSTVLLDPTR $19 \quad 0.03 \% \quad 8.3 \% \quad$ AVVIVDDRGRPSGK

$19 \quad 0.03 \% \quad 8.3 \%$ GIVEFSGKPAAR

$19 \quad 0.03 \% \quad 8.3 \% \quad$ GIVEFSGKPAARK $19 \quad 0.03 \% \quad 8.3 \% \quad$ AAPGAEFAPNKR
1395.73

1502.73

1646.86

1077.58

1600.91

1754.89

1249.64

1281.67

1143.54

1284.75

1315.69

1304.68

980.48

1255.63

1472.77

1527.83

1145.64

1680.94

1452.77

1319.69

1664.05

1435.77

1096.64

2158.16

1305.64

1407.80

1642.85

1279.59

987.52

1433.69

1084.62

1219.72

1141.67

1310.77

1468.82

1231.68

1359.77

1228.64

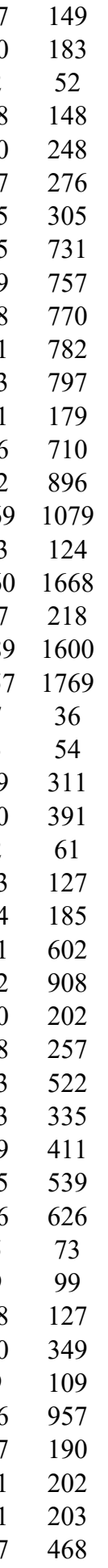


Nuclear cap-binding protein subunit $1 \mathrm{GN}=\mathrm{NCBP} 1 \mathrm{NCBP} 1 \_$HUMAN $91.84 \quad 100.0 \%$ Nuclear cap-binding protein subunit $1 \mathrm{GN}=\mathrm{NCBP} 1 \mathrm{NCBP} 1$ _HUMAN $91.84 \quad 100.0 \%$ Nuclear cap-binding protein subunit $1 \mathrm{GN}=\mathrm{NCBP} 1 \mathrm{NCBP} 1 \_$HUMAN $91.84 \quad 100.0 \%$ Nuclear cap-binding protein subunit $1 \mathrm{GN}=\mathrm{NCBP} 1 \mathrm{NCBP} 1$ HUMAN $91.84 \quad 100.0 \%$ Nuclear cap-binding protein subunit $1 \mathrm{GN}=\mathrm{NCBP} 1 \mathrm{NCBP} 1$ HUMAN $91.84 \quad 100.0 \%$ Nuclear cap-binding protein subunit $1 \mathrm{GN}=\mathrm{NCBP} 1 \mathrm{NCBP} 1$ _HUMAN $91.84 \quad 100.0 \%$ Nuclear mitotic apparatus protein 1 GN=NUMA1 NUMA1_HUMAN $238.26 \quad 100.0 \%$ Nuclear mitotic apparatus protein 1 GN=NUMA1 NUMA1_HUMAN $238.26 \quad 100.0 \%$ Nuclear mitotic apparatus protein 1 GN=NUMA1 NUMA1_HUMAN $238.26 \quad 100.0 \%$ Nuclear mitotic apparatus protein 1 GN=NUMA1 NUMA1_HUMAN $238.26 \quad 100.0 \%$ Nuclear mitotic apparatus protein 1 GN=NUMA1 NUMA1_HUMAN $238.26 \quad 100.0 \%$ ? Nuclear mitotic apparatus protein 1 GN=NUMA1 NUMA1_HUMAN $238.26 \quad 100.0 \% \quad 27$ $\begin{array}{llll}\text { Nuclear mitotic apparatus protein } 1 \mathrm{GN}=\text { NUMA1 NUMA1_HUMAN } & 238.26 & 100.0 \% & 27\end{array}$ Nuclear mitotic apparatus protein 1 GN=NUMA1 NUMA1_HUMAN $238.26 \quad 100.0 \%$ Nuclear mitotic apparatus protein 1 GN=NUMA1 NUMA1_HUMAN $238.26 \quad 100.0 \% \quad 27$ $\begin{array}{lllll}\text { Nuclear mitotic apparatus protein } 1 \text { GN=NUMA1 NUMA1_HUMAN } 238.26 & 100.0 \% & 27\end{array}$ Nuclear mitotic apparatus protein 1 GN=NUMA1 NUMA1_HUMAN $238.26 \quad 100.0 \% \quad 27$ $\begin{array}{llll}\text { Nuclear mitotic apparatus protein } 1 \mathrm{GN}=\mathrm{NUMA} 1 \text { NUMA1_HUMAN } & 238.26 & 100.0 \% & 27\end{array}$ Nuclear mitotic apparatus protein 1 GN=NUMA1 NUMA1_HUMAN $238.26 \quad 100.0 \% \quad 27$ Nuclear mitotic apparatus protein 1 GN=NUMA1 NUMA1_HUMAN $238.26 \quad 100.0 \% \quad 27$ $\begin{array}{llll}\text { Nuclear mitotic apparatus protein } 1 \text { GN=NUMA1 NUMA1_HUMAN } 238.26 & 100.0 \% & 27\end{array}$ Nuclear mitotic apparatus protein 1 GN=NUMA1 NUMA1_HUMAN $238.26 \quad 100.0 \% \quad 27$ Nuclear mitotic apparatus protein 1 GN=NUMA1 NUMA1_HUMAN $238.26 \quad 100.0 \% \quad 27$ Nuclear mitotic apparatus protein 1 GN=NUMA1 NUMA1_HUMAN $238.26 \quad 100.0 \% \quad 27$ Nuclear mitotic apparatus protein 1 GN=NUMA1 NUMA1_HUMAN $238.26 \quad 100.0 \%$ Nuclear mitotic apparatus protein 1 GN=NUMA1 NUMA1_HUMAN $238.26 \quad 100.0 \% \quad 27$ Nuclear mitotic apparatus protein 1 GN=NUMA1 NUMA1_HUMAN $238.26 \quad 100.0 \%$ 2 Nuclear mitotic apparatus protein 1 GN=NUMA1 NUMA1_HUMAN $238.26 \quad 100.0 \%$ $\begin{array}{llll}\text { Nuclear mitotic apparatus protein } 1 \text { GN=NUMA1 NUMA1_HUMAN } 238.26 & 100.0 \% & 27\end{array}$ Nuclear mitotic apparatus protein $1 \mathrm{GN}=\mathrm{NUMA1}$ NUMA1 HUMAN $238.26 \quad 100.0 \%$ $\begin{array}{llll}\text { Nuclear mitotic apparatus protein } 1 \mathrm{GN}=\text { NUMA1 NUMA1_HUMAN } 238.26 & 100.0 \% & 27\end{array}$ Nuclear mitotic apparatus protein 1 GN=NUMA1 NUMA1_HUMAN $238.26 \quad 100.0 \% \quad 27$ Nuclear mitotic apparatus protein $1 \mathrm{GN}=$ NUMA1 NUMA1_HUMAN $238.26 \quad 100.0 \% \quad 27$ Nuclear pore complex protein Nup107 GN=NUP107 NU107_HUMAN $106.38 \quad 100.0 \%$ Nuclear pore complex protein Nup107 GN=NUP107 NU107_HUMAN $106.38 \quad 100.0 \%$ Nuclear pore complex protein Nup107 GN=NUP107 NU107_HUMAN $106.38 \quad 100.0 \%$ Nuclear pore complex protein Nup107 GN=NUP107 NU107_HUMAN $106.38 \quad 100.0 \%$ Nuclear pore complex protein Nup133 GN=NUP133 NU133 HUMAN $128.98 \quad 100.0 \%$ Nuclear pore complex protein Nup133 GN=NUP133 NU133_HUMAN $128.98 \quad 100.0 \%$ Nuclear pore complex protein Nup160 GN=NUP160 NU160_HUMAN $162.13 \quad 100.0 \%$ Nuclear pore complex protein Nup160 GN=NUP160 NU160_HUMAN $162.13 \quad 100.0 \%$ Nuclear pore complex protein Nup160 GN=NUP160 NU160_HUMAN $162.13 \quad 100.0 \%$ Nuclear pore complex protein Nup205 GN=NUP205 NU205 HUMAN $227.93 \quad 100.0 \%$ Nuclear pore complex protein Nup205 GN=NUP205 NU205_HUMAN $227.93 \quad 100.0 \%$ Nuclear pore complex protein Nup205 GN=NUP205 NU205_HUMAN $227.93 \quad 100.0 \% \quad 22$ Nuclear pore complex protein Nup205 GN=NUP205 NU205_HUMAN $227.93 \quad 100.0 \%$ Nuclear pore complex protein Nup205 GN=NUP205 NU205_HUMAN $227.93 \quad 100.0 \% \quad 22$
$13 \quad 0.02 \% \quad 7.6 \% \quad$ FVIEENLHCIIK $0.02 \% \quad 7.6 \% \quad$ KTCAAQLVSYPGK

$0.02 \% \quad 7.6 \%$ TCAAQLVSYPGK

$\begin{array}{llllllll}9.7 \% & 28.4 & 25.0 & 21.3 & 2 & 0 & 0 & 1514.80\end{array}$ $99.7 \% 73.2$ $99.7 \% \quad 60.6$

$0.02 \% \quad 7.6 \%$ ILDIVPPTFSALCPANPTCIYK $99.7 \% \quad 37.8$ $0.02 \% \quad 7.6 \%$ SKATNDEIFSILK $0.02 \% \quad 7.6 \%$ ATNDEIFSILK

$0.09 \% \quad 14.9 \%$ VEMLETERGQQEAK $0.09 \% \quad 14.9 \%$ HQVEQLSSSLK $0.09 \% \quad 14.9 \%$ DSAQTSVTQAQR

$0.09 \% \quad 14.9 \%$ DSAQTSVTQAQREK $0.09 \% \quad 14.9 \%$ AADALEEQQR

$0.09 \% \quad 14.9 \%$ CISELKAETR

$0.09 \% \quad 14.9 \%$ SLVEQHKR

$99.7 \% \quad 45.4$

$99.7 \% \quad 46.3$

$99.7 \% 26.6$

$99.7 \% \quad 37.7$

$99.7 \% \quad 56.0$

$99.7 \% \quad 26.0$

$99.7 \% \quad 58.4$

$99.7 \% 38.6$

$99.0 \% 43.1$

$0.09 \% \quad 14.9 \%$ LQQLGEAHQAETEVLRR $\quad 99.7 \% \quad 27.4$

$0.09 \% \quad 14.9 \%$ VAGIESHSELQISR

$0.09 \% \quad 14.9 \%$ ALQQVQEKEVR

$0.09 \% \quad 14.9 \%$ LADDLSTLQEK

$0.09 \% \quad 14.9 \%$ ELVKEPAR

$0.09 \% \quad 14.9 \%$ GRAQADLALEK

$0.09 \% \quad 14.9 \%$ AQADLALEK

$0.09 \% \quad 14.9 \%$ EHASGSGAQSEAAGR

$0.09 \% \quad 14.9 \%$ QQEQADSLER

$0.09 \% \quad 14.9 \%$ LLQAETASNSAR

$0.09 \% \quad 14.9 \%$ AHGLLAEENRGLGER

$0.09 \% \quad 14.9 \%$ LADSDQASKVQQQK

$0.09 \% \quad 14.9 \%$ AVQAQGGESQQEAQR

$0.09 \% \quad 14.9 \%$ TTQIINITMTK

$0.09 \% \quad 14.9 \%$ SAPASQASLR

$0.09 \% \quad 14.9 \%$ ATSSTQSLAR

$0.09 \% \quad 14.9 \%$ SQAGVSSGAPPGR

$0.09 \% \quad 14.9 \%$ ASMQPIQIAEGTGITTR

$0.09 \% \quad 14.9 \%$ VSLEPHQGPGTPESK

$0.09 \% \quad 14.9 \%$ IATTTASAATAAAIGATPR

$0.01 \% \quad 5.0 \%$ SGFGEISSPVIR

$0.01 \% \quad 5.0 \%$ SGFGEISSPVIREAEVTR

$0.01 \% \quad 5.0 \%$ VLLQASQDENFGNTTPR

$0.01 \% \quad 5.0 \%$ EADLDVATITK

$0.01 \% \quad 1.9 \%$ RGPLAGLGPGSTPR

$0.01 \% \quad 1.9 \%$ AAFLQYCR

$0.01 \% \quad 2.2 \%$ SFVELSGAER

$0.01 \% \quad 2.2 \%$ LQYYDKVLR

$0.01 \% \quad 2.2 \%$ QGNCYLAALNCLR

$\quad 0.06 \% \quad 11.9 \%$ ASTEGVAIQGQQGTR

$0.06 \% \quad 11.9 \%$ FTDELMEQGLTYK

$44 \quad 0.06 \% \quad 11.9 \%$ VLTLVSQIDVNNEFEK

$0.06 \% \quad 11.9 \%$ EVSDLIKECR

$0.06 \% \quad 11.9 \%$ QYIATIHSR
$99.7 \% \quad 73.1$

$99.7 \% \quad 53.3$

$9.7 \% 51.9$

$99.0 \% \quad 22.5$

$99.7 \% \quad 28.4$

$95.7 \% \quad 14.1$

$99.7 \% 38$.

$99.7 \% 35$.

$99.7 \% \quad 56.2$

$99.7 \% \quad 37.2$

$99.7 \% \quad 54.0$

$99.7 \% \quad 57.5$

$99.7 \% \quad 46.8$

$99.7 \% \quad 45.0$

$99.7 \% \quad 36.8$

$99.7 \% \quad 29.3$

$99.7 \% \quad 53.6$

$99.6 \% \quad 26.2$

$99.7 \% \quad 37.2$

$99.7 \% \quad 27.4$

$99.7 \% \quad 45.4$

99.7\% \#\#\#\#

$99.7 \% \quad 53.0$

$99.7 \% \quad 28.6$

$99.0 \% \quad 43.9$

$99.7 \% \quad 44.0$

$99.7 \% \quad 36.5$

$98.5 \% \quad 28.7$

$99.7 \% \quad 56.8$

$99.7 \% \quad 47.7$

$99.7 \% \quad 57.2$

$99.7 \% 35.1$

$99.6 \% \quad 23.1$
1422.74

1294.65

2490.28

1465.79

1250.66

1647.80

1255.66

1291.62

1548.76

1130.54

1206.6

996.56

1978.05

1525.80

1327.73

1232.64

941.54

1171.64

958.52

1414.63

1203.56

1260.65

1621.84

1545.79

1586.75

1263.70

987.52

1021.53

1170.59

1789.91

1562.78

1715.93

1248.66

1934.00

1889.94

1175.62

1335.75

1028.50

1094.55

1197.66

1552.74

1502.76

1590.74

1847.98

1248.63

1088.58

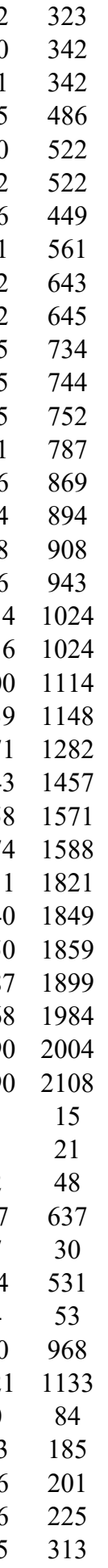

Page 87 of Table S-1-1 
Nuclear pore complex protein Nup205 GN=NUP205 NU205_HUMAN $227.93 \quad 100.0 \% \quad 22$ Nuclear pore complex protein Nup205 GN=NUP205 NU205_HUMAN $227.93 \quad 100.0 \% \quad 22$ Nuclear pore complex protein Nup205 GN=NUP205 NU205_HUMAN $227.93 \quad 100.0 \% \quad 22$ Nuclear pore complex protein Nup205 GN=NUP205 NU205_HUMAN $227.93 \quad 100.0 \% 22$ Nuclear pore complex protein Nup205 GN=NUP205 NU205_HUMAN $227.93 \quad 100.0 \% \quad 22$ Nuclear pore complex protein Nup205 GN=NUP205 NU205_HUMAN $227.93 \quad 100.0 \% \quad 22$ Nuclear pore complex protein Nup205 GN=NUP205 NU205_HUMAN $227.93 \quad 100.0 \% 22$ Nuclear pore complex protein Nup205 GN=NUP205 NU205_HUMAN $227.93 \quad 100.0 \% \quad 22$ Nuclear pore complex protein Nup205 GN=NUP205 NU205 HUMAN $227.93 \quad 100.0 \% \quad 22$ Nuclear pore complex protein Nup205 GN=NUP205 NU205_HUMAN $227.93 \quad 100.0 \% \quad 22$ Nuclear pore complex protein Nup205 GN=NUP205 NU205_HUMAN $227.93 \quad 100.0 \% \quad 22$ Nuclear pore complex protein Nup205 GN=NUP205 NU205_HUMAN $227.93 \quad 100.0 \% 22$ Nuclear pore complex protein Nup205 GN=NUP205 NU205_HUMAN $227.93 \quad 100.0 \% \quad 22$ Nuclear pore complex protein Nup205 GN=NUP205 NU205_HUMAN $227.93 \quad 100.0 \% \quad 22$ Nuclear pore complex protein Nup205 GN=NUP205 NU205_HUMAN $227.93 \quad 100.0 \% \quad 22$ Nuclear pore complex protein Nup205 GN=NUP205 NU205_HUMAN $227.93 \quad 100.0 \% \quad 22$ Nuclear pore complex protein Nup205 GN=NUP205 NU205 HUMAN $227.93 \quad 100.0 \%$ Nuclear pore complex protein Nup214 GN=NUP214 NU214_HUMAN $213.62 \quad 100.0 \%$ Nuclear pore complex protein Nup214 GN=NUP214 NU214_HUMAN $213.62 \quad 100.0 \%$ Nuclear pore complex protein Nup214 GN=NUP214 NU214_HUMAN $213.62100 .0 \%$ Nuclear pore complex protein Nup214 GN=NUP214 NU214_HUMAN $213.62100 .0 \%$ Nuclear pore complex protein Nup85 GN=NUP85 NUP85_HUMAN $75.02 \quad 100.0 \%$ Nuclear pore complex protein Nup85 GN=NUP85 NUP85_HUMAN $75.02 \quad 100.0 \%$ Nuclear pore complex protein Nup85 GN=NUP85 NUP85_HUMAN $75.02 \quad 100.0 \%$ Nuclear pore complex protein Nup85 GN=NUP85 NUP85 HUMAN 75.02 $100.0^{\circ}$ Nuclear pore complex protein Nup88 GN=NUP88 NUP88_HUMAN $83.54 \quad 100.0 \%$ Nuclear pore complex protein Nup88 GN=NUP88 NUP88_HUMAN $83.54 \quad 100.0 \%$ Nuclear pore complex protein Nup88 GN=NUP88 NUP88 HUMAN $83.54 \quad 100.0 \%$ Nuclear pore complex protein Nup93 GN=NUP93 NUP93_HUMAN $93.49 \quad 100.0 \%$ Nuclear pore complex protein Nup93 GN=NUP93 NUP93 HUMAN $93.49100 .0 \%$ Nuclear pore complex protein Nup93 GN=NUP93 NUP93_HUMAN $93.49 \quad 100.0 \%$ Nuclear pore complex protein Nup93 GN=NUP93 NUP93_HUMAN $93.49 \quad 100.0 \%$ Nuclear pore complex protein Nup93 GN=NUP93 NUP93 HUMAN 93.48 Nuclear pore complex protein Nup93 GN=NUP93 NUP93_HUMAN 93.49 Nuclear porecomplex protein $\mathrm{Nup} 93 \mathrm{GN}=\mathrm{NUP} 93$ NUP93_HUMAN Nuclear pore complex protein Nup93 GN=NUP93 NUP93_HUMAN 93.49 Nuclear pore complex protein Nup93 GN=NUP93 NUP93_HUMAN 93.49 Nuclear pore complex protein Nup93 GN=NUP93 NUP93_HUMAN 93.49 Nuclear pore complex protein Nup93 GN=NUP93 NUP93_HUMAN 93.49 Nuclear pore complex protein Nup93 GN=NUP93 NUP93_HUMAN 93.49 Nuclear pore complex protein Nup93 GN=NUP93 NUP93_HUMAN 93.49 Nuclear pore complex protein Nup93 GN=NUP93 NUP93_HUMAN 93.49 Nuclear pore complex protein Nup93 GN=NUP93 NUP93_HUMAN 93.49 Nuclear pore complex protein Nup93 GN=NUP93 NUP93_HUMAN 93.49 Nuclear pore complex protein Nup93 GN=NUP93 NUP93_HUMAN 93.49 Nuclear pore complex protein Nup93 GN=NUP93 NUP93_HUMAN 93.49

4

4

4

4

3

3

3

21

$21 \quad 28$

21
21
21

21

21
21
21

21
21
21

21

$\begin{array}{ll}21 & 28 \\ 21 & 28 \\ 21 & 28\end{array}$

21

21

$\begin{array}{ll}21 & 28 \\ 21 & 28 \\ 21 & 28 \\ 21 & 28\end{array}$

$\begin{array}{ll}21 & 28 \\ 21 & 28 \\ 21 & 28\end{array}$

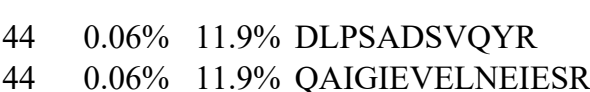

$44 \quad 0.06 \% \quad 11.9 \%$ KADNVVNIAR

$44 \quad 0.06 \% \quad 11.9 \%$ ADNVVNIAR

$44 \quad 0.06 \% \quad 11.9 \%$ YLYHGNTNPELAFESAK

$44 \quad 0.06 \% \quad 11.9 \%$ ILCCISCNSNIQIK

$0.06 \% \quad 11.9 \%$ LVGDFTHDQSISQK

$0.06 \% \quad 11.9 \%$ SVSGFLHFDTATK

$\quad 0.06 \% \quad 11.9 \%$ GQTVCNVK

$4 \quad 0.06 \% \quad 11.9 \%$ LTAPEDVFSK

$44 \quad 0.06 \% \quad 11.9 \%$ LTAPEDVFSKLQR

$44 \quad 0.06 \% \quad 11.9 \%$ IQQGALELLR

$4 \quad 0.06 \% \quad 11.9 \%$ QCLGLLSR

$\quad 0.06 \% \quad 11.9 \%$ FGGSDRLR

$0.06 \% \quad 11.9 \%$ RLQDSFASETNLDFR

$44 \quad 0.06 \% \quad 11.9 \%$ KLLDIEGLYSK

$4 \quad 0.06 \% \quad 11.9 \%$ YSFIQALVR

$0.01 \% \quad 2.8 \%$ AAPGPGPSTFSFVPPSK

$0.01 \% \quad 2.8 \%$ TPHPVLTPVAANQAK

$0.01 \% \quad 2.8 \%$ VGQADDSTKPTNK

$0.01 \% \quad 2.8 \%$ ASSTSLTSTQPTK

$0.01 \% \quad 6.4 \%$ DVDVYSQILR

$0.01 \% \quad 6.4 \%$ EADASPASAGICR

$0.01 \% \quad 6.4 \% \quad$ IPLNTEQK

$0.01 \% \quad 6.4 \%$ AIIREGSLEGS

$0.01 \% \quad 5.5 \% \quad$ LRGPSGGGEEPALSQYQR

$0.01 \% \quad 5.5 \%$ VLAETPDSFEKHIR

$0.01 \% \quad 5.5 \%$ SVANPAFLK

$46 \quad 0.06 \% \quad 27.2 \%$ NLQEIQQAGER

$0.06 \% \quad 27.2 \%$ NLQEIQQAGERLR

$0.06 \% \quad 27.2 \%$ TSQETADVKASVLLGSR

$46 \quad 0.06 \% \quad 27.2 \%$ GLDISHISQR

$0.06 \% \quad 27.2 \%$ SSLDNIEMAYAR

$0.06 \% 27.2 \%$ QMTDVLLTPATDALK

$0.06 \% \quad 27.2 \%$ QMTDVLLTPATDALKNR

$0.06 \% \quad 27.2 \%$ CGDLLAASQVVNR

$0.06 \% \quad 27.2 \%$ LSPATENKLR

$0.06 \% \quad 27.2 \%$ AVYCIIGR

$99.7 \% \quad 40.6$

$99.7 \% \quad 47.8$

$99.7 \% \quad 61.2$

$96.1 \% \quad 21.1$

$99.7 \% \quad 26.6$

$99.7 \% \quad 52.9$

$99.7 \% \quad 51.3$

$99.7 \% \quad 35.8$

$97.4 \% \quad 21.8$

$96.5 \% \quad 18.3$

$\begin{array}{lll}99.7 \% & 37.2\end{array}$

$99.7 \% \quad 46.9$

$99.0 \% \quad 28.2$

$99.0 \% \quad 31.3$

$99.7 \% \quad 28.3$

$99.7 \% \quad 48.9$

$99.7 \% \quad 51.4$

$98.4 \% \quad 17.6$

$\begin{array}{lll}99.7 \% & 27.1\end{array}$

$\begin{array}{lll}99.7 \% & 29.7\end{array}$

$99.6 \% \quad 24.1$

$99.7 \% \quad 54.2$

$99.7 \% \quad 47.7$

$96.6 \% \quad 21.9$

$99.7 \% \quad 57.6$

$\begin{array}{lll}99.7 \% & 38.5\end{array}$

$95.8 \% 15.6$

$99.5 \% \quad 22.2$

$99.7 \% \quad 62.1$

$99.7 \% \quad 34.5$

$99.7 \% \quad 35.6$

$99.7 \% \quad 33.1$

$99.7 \% \quad 60.7$

$99.7 \% \quad 31.2$

$99.7 \% \quad 32.3$

$99.7 \% \quad 59.4$

$99.7 \% \quad 53.3$

$99.0 \% \quad 35.1$

46

$\begin{array}{lll}0.06 \% & 27.2 \% \text { SSGQSAQLLSHEPGDPPCLR } \\ 46 & 0.06 \% & 27.2 \% \text { KPGVIDKFTSDTKPINK }\end{array}$

$46 \quad 0.06 \% \quad 27.2 \%$ LKNMALSIAER

$46 \quad 0.06 \% \quad 27.2 \%$ AFDIIERLK

$46 \quad 0.06 \% \quad 27.2 \%$ LKLVPLNQESVEER

$46 \quad 0.06 \% \quad 27.2 \%$ LVPLNQESVEER

$46 \quad 0.06 \% \quad 27.2 \%$ LKGTSPSSSSRPQR

$0.06 \% \quad 27.2 \%$ VIEDRDSQLR

$46 \quad 0.06 \% \quad 27.2 \%$ TLITFAGMIPYR

\section{$97.8 \%$}

$\begin{array}{llll}97.8 \% & 16.5 & 25.0 & 16.5\end{array}$

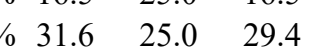

$\begin{array}{llll}99.7 \% & 33.8 & 25.0 & 23.8\end{array}$

$\begin{array}{llll}9.7 \% & 43.7 & 25.0 & 43.7\end{array}$

$\begin{array}{llll}95.4 \% & 15.1 & 25.0 & 14.8\end{array}$

$\begin{array}{llll}98.7 \% & 19.6 & 25.0 & 17.4\end{array}$

$\begin{array}{llll}98.4 \% & 25.0 & 25.0 & 13.3\end{array}$

$\begin{array}{llll}99.7 \% & 55.8 & 25.0 & 51.8\end{array}$

1699.89

1099.62

971.53

1953.93

1722.83

1574.78

1409.71

905.45

1106.57

1503.82

1140.67

946.51

907.47

1798.87

1278.73

1096.6

1643.84

1543.86

1360.67

1308.66

1207.63

1304.59

942.53

1131.60

1901.95

1641.86

946.54

1285.65

1554.83

1761.93

1125.60

1369.64

1616.86

1887.00

1402.71

1128.64

951.51

2136.01

2001.14

1261.69

1104.64

1653.92

1412.74

1487.79

1230.64

1382.75

Page 88 of Table S-1-1 
Nuclear pore complex protein Nup93 GN=NUP93 NUP93_HUMAN $93.49 \quad 100.0 \% \quad 2$ Nuclear pore complex protein Nup93 GN=NUP93 NUP93_HUMAN $93.49 \quad 100.0 \%$ Nuclear RNA export factor 1 GN=NXF1 NXF1_HUMAN $70.19 \quad 100.0 \%$ Nuclear RNA export factor $1 \mathrm{GN}=\mathrm{NXF} 1 \quad$ NXF1 HUMAN $70.19 \quad 100.0 \%$ Nuclease-sensitive element-binding protein $1 \mathrm{GN}=\mathrm{YBX} 1$ YBOX1_HUMAN $35.92 \quad 100.0 \%$ Nuclease-sensitive element-binding protein $1 \mathrm{GN}=\mathrm{YBX} 1$ YBOX1_HUMAN $35.92 \quad 100.0 \%$ Nuclease-sensitive element-binding protein $1 \mathrm{GN}=$ YBX1 YBOX1_HUMAN $35.92 \quad 100.0 \%$ Nuclease-sensitive element-binding protein $1 \mathrm{GN}=\mathrm{YBX} 1$ YBOX1_HUMAN $35.92 \quad 100.0 \%$ Nuclease-sensitive element-binding protein $1 \mathrm{GN}=\mathrm{YBX} 1$ YBOX1 HUMAN $35.92 \quad 100.0 \%$ Nuclease-sensitive element-binding protein $1 \mathrm{GN}=$ YBX1 YBOX1_HUMAN $35.92 \quad 100.0 \%$ Nuclease-sensitive element-binding protein $1 \mathrm{GN}=\mathrm{YBX} 1$ YBOX1_HUMAN $35.92 \quad 100.0 \%$ 等 Nucleolar complex protein 2 homolog GN=NOC2L NOC2L_HUMAN $84.92 \quad 100.0 \%$ Nucleolar complex protein 2 homolog GN=NOC2L NOC2L_HUMAN $84.92 \quad 100.0 \%$ Nucleolar complex protein 2 homolog GN=NOC2L NOC2L_HUMAN $84.92 \quad 100.0 \%$ Nucleolar complex protein 2 homolog GN=NOC2L NOC2L_HUMAN $84.92 \quad 100.0 \%$ Nucleolar complex protein 2 homolog GN=NOC2L NOC2L HUMAN $84.92 \quad 100.0^{\circ}$ Nucleolar complex protein 2 homolog GN=NOC2L NOC2L_HUMAN $84.92 \quad 100.0 \%$ Nucleolar complex protein 2 homolog GN=NOC2L NOC2L_HUMAN $84.92 \quad 100.0 \%$ Nucleolar complex protein 2 homolog GN=NOC2L NOC2L_HUMAN $84.92 \quad 100.0 \%$ Nucleolar complex protein 3 homolog GN=NOC3L NOC3L_HUMAN $92.55 \quad 100.0 \%$ Nucleolar complex protein 3 homolog GN=NOC3L NOC3L_HUMAN $92.55 \quad 100.0 \%$ Nucleolar complex protein 3 homolog GN=NOC3L NOC3L_HUMAN $92.55 \quad 100.0 \%$ Nucleolar complex protein 3 homolog GN=NOC3L NOC3L_HUMAN $92.55 \quad 100.0 \%$ Nucleolar complex protein 3 homolog GN=NOC3L NOC3L HUMAN $92.55 \quad 100.0^{\circ}$ Nucleolar complex protein 3 homolog GN=NOC3L NOC3L_HUMAN $92.55 \quad 100.0 \%$ Nucleolar complex protein 3 homolog GN=NOC3L NOC3L_HUMAN $92.55100 .0 \%$ Nucleolar GTP-binding protein $1 \mathrm{GN}=$ GTPBP4 NOG1_HUMAN $73.97 \quad 100.0 \%$ Nucleolar GTP-binding protein $1 \mathrm{GN}=$ GTPBP4 NOG1_HUMAN $73.97 \quad 100.0 \%$ Nucleolar GTP-binding protein $1 \mathrm{GN}=\mathrm{GTPBP} 4$ NOG1 HUMAN $73.97 \quad 100.0 \%$ Nucleolar GTP-binding protein $1 \mathrm{GN}=$ GTPBP4 NOG1_HUMAN $73.97 \quad 100.0 \%$ Nucleolar GTP-binding protein $1 \mathrm{GN}=\mathrm{GTPBP} 4$ NOG1_HUMAN $73.97 \quad 100.0 \%$ Nucleolar GTP-binding protein $1 \mathrm{GN}=$ GTPBP4 NOG1 HUMAN $73.97 \quad 100.0 \%$ Nucleolar MIF4G domain-containing protein $1 \mathrm{GN}=\mathrm{NOM} 1$ NOM1_HUMAN $96.26 \quad 100.0 \%$ Nucleolar MIF4G domain-containing protein $1 \mathrm{GN}=\mathrm{NOM} 1$ NOM1 HUMAN $96.26100 .0 \%$ Nucleolar MIF4G domain-containing protein $1 \mathrm{GN}=\mathrm{NOM} 1$ NOM1_HUMAN $96.26 \quad 100.0 \%$ Nucleolar MIF4G domain-containing protein 1 GN=NOM1 NOM1_HUMAN $96.26 \quad 100.0 \%$ Nucleolar pre-ribosomal-associated protein $1 \mathrm{GN}=\mathrm{URB} 1 \mathrm{NPA1P}$ HUMAN $254.39100 .0^{\circ}$ Nucleolar pre-ribosomal-associated protein 1 GN=URB1 NPA1P_HUMAN $254.39 \quad 100.0 \%$ Nucleolar protein $56 \mathrm{GN}=\mathrm{NOP} 56$ Nucleolar protein $56 \mathrm{GN}=\mathrm{NOP} 56$ Nucleolar protein $56 \mathrm{GN}=\mathrm{NOP} 56$ Nucleolar protein $56 \mathrm{GN}=\mathrm{NOP} 56$ Nucleolar protein $56 \mathrm{GN}=\mathrm{NOP} 56$ Nucleolar protein $56 \mathrm{GN}=\mathrm{NOP} 56$ Nucleolar protein $56 \mathrm{GN}=\mathrm{NOP} 56$ Nucleolar protein $56 \mathrm{GN}=\mathrm{NOP} 56$

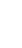

(9)

列

8

8
8

4

2

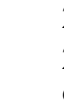

$\begin{array}{lll}\text { NPA1P_HUMAN } & 254.39 & 100.0 \% \\ \text { NOP56_HUMAN } & 66.05 & 100.0 \%\end{array}$ \begin{tabular}{ll} 
NOP56_HUMAN $66.05 \quad 100.0 \%$ \\
\hline
\end{tabular} NOP56_HUMAN $66.05 \quad 100.0 \%$ NOP56_HUMAN $66.05 \quad 100.0 \%$ NOP56_HUMAN $66.05 \quad 100.0 \%$ NOP56_HUMAN $66.05 \quad 100.0 \%$ NOP56_HUMAN $66.05 \quad 100.0 \%$ NOP56_HUMAN $66.05 \quad 100.0 \%$
$0.06 \% \quad 27.2 \%$ TSGDTNARLVQMEVLMN $0.06 \% \quad 27.2 \%$ LVQMEVLMN

$0.00 \% \quad 3.6 \% \quad$ YNPYTTRPNR

$0.00 \% \quad 3.6 \%$ LNVVAFLNELPK

$0.02 \% \quad 38.6 \%$ VIATKVLGTVK

$0.02 \% \quad 38.6 \%$ VLGTVKWFNVR

$0.02 \% 38.6 \%$ NDTKEDVFVHQTAIK

$0.02 \% \quad 38.6 \%$

$0.02 \% 38.6 \%$ GAEAANVTGPGGVPVQGSK

$0.02 \% \quad 38.6 \%$ YAADRNHYR

$0.03 \% \quad 9.2 \% \quad$ ASEHKDQLSR

$0.03 \% \quad 9.2 \% \quad$ NSVPVTVAMVER

$0.03 \% \quad 9.2 \%$ LFHEVVQAFR

$0.03 \% \quad 9.2 \% \quad$ LSNVNLQEK

$0.03 \% \quad 9.2 \%$ QVQQLLGK

$0.03 \% \quad 9.2 \%$ QVQQLLGKVQENSAYICSR

$0.03 \% \quad 9.2 \%$ VQENSAYICSR

$0.03 \% \quad 9.2 \%$ GILRPLSTR

$0.02 \% \quad 10.9 \%$ DLSSSEPVHAK

$0.02 \% \quad 10.9 \%$ SMLMEQDPDVAVTVR

$0.02 \% \quad 10.9 \%$ IRPLTEAEKSTK

$0.02 \% \quad 10.9 \%$ SNVVSLKAYK

$0.02 \% \quad 10.9 \%$ SPLLPAVLEGLAK

$0.02 \% \quad 10.9 \%$ HYHPIVQR

$0.02 \% \quad 10.9 \%$ YSSEVATESPLDFTKYLK

$0.02 \% \quad 11.4 \%$ ITVVPSAKDFIDLTLSK

$0.02 \% \quad 11.4 \%$ NLVDNVAKDYVR

$0.02 \% \quad 11.4 \%$ TLLLCGYPNVGK

$0.02 \% \quad 11.4 \%$ SSFINKVTR

$0.02 \% \quad 11.4 \%$ ADVDVQPYAFTTK

$0.02 \% \quad 11.4 \%$ DVSGLRDVK

$0.01 \% \quad 5.8 \%$ SAGEAGPGGSQGR

$0.01 \% \quad 5.8 \%$ SGAEEASGHRQDTEER

$0.01 \% \quad 5.8 \%$ TRPSAAATAAAR

$0.01 \% \quad 5.8 \%$ SADEANVLR

$0.01 \% \quad 0.8 \% \quad$ IYEAQPEISR

$0.01 \% \quad 0.8 \% \quad$ SVAEHPLSR

$0.02 \% \quad 18.4 \%$ VLLGVGDPK

$0.02 \% \quad 18.4 \%$ AQLGLGHSYSR

$0.02 \% \quad 18.4 \%$ IINDNATYCR

$0.02 \% \quad 18.4 \%$ AKAILDASR

$0.02 \% \quad 18.4 \%$ LIAHAGSLTNLAK

$0.02 \% \quad 18.4 \%$ YPASTVQILGAEK

$0.02 \% \quad 18.4 \%$ YGLIFHSTFIGR

$0.02 \% \quad 18.4 \%$ EAMVQAEEAAAEITR $\begin{array}{lll}99.7 \% & 35.2 \\ 99.7 \% & 33.6\end{array}$

$94.5 \% \quad 17.8$

$99.7 \% \quad 49.9$

$99.1 \% 32.6$

$99.7 \% 37.0$

$99.7 \% \quad 37.9$

$99.7 \% \quad 27.7$

$99.7 \% 27$.

$\begin{array}{lll}99.7 \% & 49.0\end{array}$

$\begin{array}{ll}99.7 \% & 39.0 \\ 99.7 \% & 47.0\end{array}$

$99.7 \% \quad 45.8$

$99.7 \% \quad 39.4$

$98.9 \% \quad 20.0$

$97.8 \% \quad 18.3$

$99.7 \% 28$

$\begin{array}{ll}99.4 \% & 21.0 \\ 99.7 \% & 50.5\end{array}$

$\begin{array}{lll}97.0 \% & 15.9\end{array}$

$\begin{array}{lll}99.7 \% & 25.7\end{array}$

$95.9 \% \quad 14.9$

$99.7 \% \quad 35.3$

$95.2 \% \quad 17.0$

$\begin{array}{lll}-1 & -1 \\ 9 & 22.5 \\ 99.7 \% & 37.5\end{array}$

$99.7 \% \quad 52.4$

$99.7 \% \quad 47.8$

$\begin{array}{lll}99.7 \% & 38.8\end{array}$

$99.7 \% \quad 44.8$

$95.4 \% \quad 19.6$

$99.5 \% 23.6$

$99.2 \% \quad 22.6$

$99.6 \% \quad 24.0$

$95.2 \% \quad 24.4$

$99.7 \% \quad 37.6$

$99.7 \% \quad 36.5$

$99.7 \% \quad 49.5$

$99.7 \% \quad 31.9$

$99.7 \% \quad 52.6$

$99.0 \% \quad 18.4$

$99.7 \% \quad 53.4$

$99.7 \% \quad 44.6$

$99.7 \% \quad 39.6$

$99.7 \% \quad 57.2$

$\begin{array}{lccccccc}\text { VLMN } & 99.7 \% & 35.2 & 25.0 & 35.2 & 2 & 0 & 0 \\ & 99.7 \% & 33.6 & 25.0 & 30.1 & 4 & 0 & 0 \\ & 94.5 \% & 17.8 & 25.0 & 10.5 & 1 & 0 & 0 \\ & 99.7 \% & 49.9 & 25.0 & 49.9 & 1 & 0 & 0 \\ & 99.1 \% & 32.6 & 25.0 & 0.0 & 1 & 0 & 0 \\ & 99.7 \% & 37.0 & 25.0 & 37.0 & 2 & 1 & 0 \\ & 99.7 \% & 37.9 & 25.0 & 34.1 & 1 & 2 & 0 \\ \text { AIK } & 99.7 \% & 27.7 & 25.0 & 27.7 & 0 & 1 & 0 \\ \text { QGGVGK } & 99.7 \% & 69.1 & 25.0 & 69.1 & 2 & 0 & 0 \\ & 99.7 \% & 27.1 & 25.0 & 17.9 & 1 & 0 & 0 \\ & 99.7 \% & 61.6 & 25.0 & 61.6 & 0 & 2 & 0 \\ & 99.7 \% & 49.0 & 25.0 & 49.0 & 2 & 0 & 0 \\ & 99.7 \% & 39.0 & 25.0 & 31.6 & 4 & 0 & 0 \\ & 99.7 \% & 47.0 & 25.0 & 38.3 & 4 & 0 & 0 \\ & 99.7 \% & 45.8 & 25.0 & 44.3 & 2 & 4 & 0 \\ & 99.7 \% & 39.4 & 25.0 & 25.9 & 3 & 0 & 0 \\ & 98.9 \% & 20.0 & 25.0 & 18.1 & 1 & 0 & 0 \\ & 97.8 \% & 18.3 & 25.0 & 18.3 & 0 & 1 & 0 \\ & 99.7 \% & 28.1 & 25.0 & 28.1 & 1 & 0 & 0 \\ & 99.4 \% & 21.0 & 25.0 & 18.9 & 1 & 0 & 0 \\ & 99.7 \% & 50.5 & 25.0 & 45.8 & 2 & 0 & 0 \\ & 99.7 \% & 44.6 & 25.0 & 34.8 & 2 & 0 & 0 \\ & 99.7 \% & 39.6 & 25.0 & 39.6 & 0 & 2 & 0 \\ & 99.7 \% & 57.2 & 25.0 & 48.6 & 1 & 0 & 0\end{array}$

$\begin{array}{ccc}1878.90 & 803 & 819 \\ 1092.54 & 811 & 819 \\ 1281.63 & 72 & 81 \\ 1356.79 & 460 & 471 \\ 1128.74 & 54 & 64 \\ 1318.76 & 59 & 69 \\ 1744.89 & 78 & 92 \\ 3472.67 & 102 & 137 \\ 1695.87 & 119 & 137 \\ 1165.55 & 138 & 146 \\ 3257.40 & 157 & 185 \\ 1897.80 & 305 & 324 \\ 1170.59 & 66 & 75 \\ 1301.69 & 145 & 156 \\ 1245.67 & 169 & 178 \\ 1044.57 & 508 & 516 \\ 913.55 & 569 & 576 \\ 2221.14 & 569 & 587 \\ 1326.61 & 577 & 587 \\ 1012.63 & 685 & 693 \\ 1169.58 & 113 & 123 \\ 1690.81 & 241 & 255 \\ 1372.78 & 275 & 286 \\ 1108.64 & 327 & 336 \\ 1307.79 & 512 & 524 \\ 1049.56 & 699 & 706 \\ 2078.03 & 779 & 796 \\ 1847.05 & 9 & 25 \\ 1405.74 & 104 & 115 \\ 1334.71 & 170 & 181 \\ 1051.59 & 182 & 190 \\ 1454.72 & 191 & 203 \\ 988.54 & 576 & 584 \\ 1130.52 & 6 & 18 \\ 1758.76 & 114 & 129 \\ 1143.62 & 160 & 171 \\ 974.49 & 834 & 842 \\ 1205.62 & 400 & 409 \\ 995.53 & 2107 & 2115 \\ 897.54 & 91 & 99 \\ 1188.61 & 144 & 154 \\ 1239.58 & 203 & 212 \\ 944.55 & 241 & 249 \\ 1308.76 & 308 & 320 \\ 1376.74 & 321 & 333 \\ 1410.75 & 348 & 359 \\ 1618.77 & 423 & 437\end{array}$

Page 89 of Table S-1-1 
Nucleolar protein $56 \mathrm{GN}=\mathrm{NOP} 56$ Nucleolar protein $58 \mathrm{GN}=\mathrm{NOP} 58$ Nucleolar protein $58 \mathrm{GN}=\mathrm{NOP} 58$ Nucleolar protein $58 \mathrm{GN}=\mathrm{NOP} 58$ Nucleolar protein $58 \mathrm{GN}=\mathrm{NOP} 58$ Nucleolar protein $58 \mathrm{GN}=\mathrm{NOP} 58$ Nucleolar protein $58 \mathrm{GN}=\mathrm{NOP} 58$ Nucleolar RNA helicase 2 GN=DDX21 Nucleolar RNA helicase 2 GN=DDX2 Nucleolar RNA helicase 2 GN=DDX21 Nucleolar RNA helicase 2 GN=DDX2 Nucleolar RNA helicase $2 \mathrm{GN}=\mathrm{DDX} 2$ Nucleolar RNA helicase 2 GN=DDX21 Nucleolar RNA helicase $2 \mathrm{GN}=\mathrm{DDX} 2$ Nucleolar RNA helicase 2 GN=DDX2 Nucleolar RNA helicase 2 GN=DDX21 Nucleolar RNA helicase 2 GN=DDX2 Nucleolar RNA helicase 2 GN=DDX2 1 Nucleolar RNA helicase $2 \mathrm{GN}=\mathrm{DDX} 2$ Nucleolar RNA helicase 2 GN=DDX2 Nucleolar RNA helicase 2 GN=DDX21 Nucleolar RNA helicase 2 GN=DDX2 Nucleolar RNA helicase 2 GN=DDX2 1 Nucleolar RNA helicase 2 GN=DDX2 Nucleolar RNA helicase 2 GN=DDX2 Nucleolar RNA helicase 2 GN=DDX21 Nucleolar RNA helicase 2 GN=DDX21 Nucleolar RNA helicase 2 GN=DDX21 Nucleolar RNA helicase 2 GN=DDX2 1 Nucleolar RNA helicase 2 GN=DDX21 Nucleolar transcription factor $1 \mathrm{GN}$ Nucleolar transcription factor $1 \mathrm{GN}=\mathrm{UBTF}$ Nucleolin GN=NCL Nucleolin $\mathrm{GN}=\mathrm{NCL}$ Nucleolin $\mathrm{GN}=\mathrm{NCL}$ Nucleolin $\mathrm{GN}=\mathrm{NCL}$ Nucleolin $\mathrm{GN}=\mathrm{NCL}$ Nucleolin GN=NCL Nucleolin GN=NCL Nucleolin $\mathrm{GN}=\mathrm{NCL}$ Nucleolin $\mathrm{GN}=\mathrm{NCL}$ Nucleolin GN=NCL Nucleolin $\mathrm{GN}=\mathrm{NCL}$ Nucleolin GN=NCL Nucleolin $\mathrm{GN}=\mathrm{NCL}$ Nucleolin $\mathrm{GN}=\mathrm{NCL}$ Nucleolin GN=NCL
NOP56_HUMAN $66.05 \quad 100.0 \%$ NOP58 HUMAN $59.58 \quad 100.0 \%$ NOP58_HUMAN $59.58 \quad 100.0 \%$ NOP58 HUMAN $59.58 \quad 100.0 \%$ NOP58_HUMAN $59.58 \quad 100.0 \%$ NOP58_HUMAN $59.58 \quad 100.0 \%$ NOP58 HUMAN $59.58 \quad 100.0 \%$ DDX21_HUMAN $87.35 \quad 100.0 \% \quad 23$ DDX21 HUMAN $87.35 \quad 100.0 \% \quad 23$ DDX21_HUMAN $87.35 \quad 100.0 \% \quad 23$ DDX21_HUMAN $87.35 \quad 100.0 \% \quad 23$ DDX21_HUMAN $87.35 \quad 100.0 \% \quad 23$ DDX21_HUMAN $87.35 \quad 100.0 \% \quad 23$ DDX21_HUMAN $87.35 \quad 100.0 \% \quad 23$ DDX21 HUMAN $87.35 \quad 100.0 \% \quad 23$ DDX21_HUMAN $87.35 \quad 100.0 \% \quad 23$ DDX21 HUMAN $87.35 \quad 100.0 \% \quad 23$ DDX21_HUMAN $87.35 \quad 100.0 \% \quad 23$ DDX21_HUMAN $87.35 \quad 100.0 \% \quad 23$ DDX21_HUMAN $87.35 \quad 100.0 \% \quad 23$ DDX21_HUMAN $87.35 \quad 100.0 \% \quad 23$ DDX21_HUMAN $87.35 \quad 100.0 \% \quad 23$ DDX21_HUMAN $87.35 \quad 100.0 \% \quad 23$ DDX21_HUMAN $87.35 \quad 100.0 \% \quad 23$ DDX21 HUMAN $87.35 \quad 100.0 \% \quad 23$ DDX21_HUMAN $87.35 \quad 100.0 \% \quad 23$ DDX21_HUMAN $87.35 \quad 100.0 \% \quad 23$ DDX21_HUMAN $87.35 \quad 100.0 \% \quad 23$ DDX21_HUMAN $87.35 \quad 100.0 \% \quad 23$ $\begin{array}{llll}\text { DDX21_HUMAN } & 87.35 & 100.0 \% & 23 \\ \end{array}$ $\begin{array}{lll} & \end{array}$ NUCL HUMAN $76.62 \quad 100.0 \% \quad 20$ NUCL_HUMAN $76.62 \quad 100.0 \% \quad 20$ NUCL_HUMAN $76.62 \quad 100.0 \% \quad 20$ NUCL HUMAN $76.62 \quad 100.0 \% \quad 20$ NUCL_HUMAN $76.62 \quad 100.0 \% \quad 20$ NUCL HUMAN $76.62 \quad 100.0 \% \quad 20$ NUCL_HUMAN $76.62 \quad 100.0 \% \quad 20$ NUCL_HUMAN $76.62 \quad 100.0 \% \quad 20$ NUCL HUMAN $76.62 \quad 100.0 \% \quad 20$ NUCL_HUMAN $76.62 \quad 100.0 \% \quad 20$ NUCL_HUMAN $76.62 \quad 100.0 \% \quad 20$ NUCL_HUMAN $76.62 \quad 100.0 \% \quad 20$ NUCL_HUMAN $76.62 \quad 100.0 \% \quad 20$ NUCL HUMAN $76.62 \quad 100.0 \% \quad 20$ NUCL_HUMAN $76.62 \quad 100.0 \% \quad 20$
$0.02 \% \quad 18.4 \%$ STPKEETVNDPEEAGHR $0.03 \% \quad 15.9 \%$ IVKEAHEPLAVADAK

$95.9 \% \quad 16.3$ $99.7 \% \quad 31.5$ $99.7 \% \quad 47.7$ $99.7 \% \quad 41.8$ $0.03 \% \quad 15.9 \%$ LSELLPEEVEAEVK

$99.7 \% 29.9$

$\begin{array}{ll}99.7 \% & 29.9 \\ 99.7 \% & 56.5\end{array}$ $99.7 \% \quad 56.5$

$99.7 \% \quad 50.9$

$0.03 \% \quad 15.9 \%$ HAASTVQILGAEK $\begin{array}{llll}99.7 \% & 39.0\end{array}$

$0.03 \% \quad 15.9 \%$ YGLIYHASLVGQTSPK

$99.5 \% \quad 23.0$

$0.09 \% \quad 31.9 \%$ VTKNEEPSEEEIDAPKP $99.7 \% \quad 36.0$ $99.7 \% \quad 42.1$ $99.7 \% \quad 51.3$

$0.09 \% \quad 31.9 \%$ GRGVTFLFPIQAK

$0.09 \% \quad 31.9 \%$ GVTFLFPIQAK

$0.09 \% \quad 31.9 \%$ TFHHVYSGKDLIAQAR

$0.09 \% \quad 31.9 \%$ TGTGKTFSFAIPLIEK

$99.7 \% \quad 28.5$

$\begin{array}{lll}99.6 \% & 22.8\end{array}$

$99.7 \% \quad 54.1$

$99.7 \% \quad 53.0$

$0.09 \% \quad 31.9 \%$ APQVLVLAPTR

$99.7 \% \quad 32.3$

$\begin{array}{llllll}0.09 \% & 31.9 \% & \text { KLSVACFYGGTPYGGQFER } & 99.7 \% & 32.3 \\ 0.09 \% & 31.9 \% & \text { LSVACFYGGTPYGGQFER } & 99.7 \% & 45.2\end{array}$

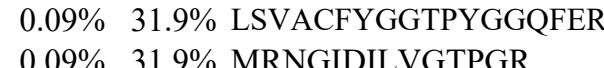

$97.0 \% 18.2$

$99.7 \% \quad 57.9$

$0.09 \% \quad 31.9 \%$ NGIDILVGTPGR

$0.09 \% \quad 31.9 \%$ STYEQVDLIGK

$0.09 \% \quad 31.9 \%$ TAITVEHLAIK

$99.7 \% \quad 31.5$

$99.7 \% \quad 24.9$

$99.7 \% \quad 38.0$

$0.09 \% \quad 31.9 \%$ AAVIGDVIR

$99.7 \% \quad 36.9$

$\begin{array}{llll}0.09 \% & 31.9 \% & \text { NGSFGVLVATNVAAR } \quad 99.7 \% \quad 62.7\end{array}$

$99.7 \% \quad 25.7$

$94.9 \% \quad 13.9$

$0.09 \% \quad 31.9 \%$ IGVPSATEIIK

$0.09 \% \quad 31.9 \%$ LLDSVPPTAISHFK

$99.7 \% \quad 65.0$

$99.7 \% \quad 29.5$

$99.0 \% \quad 32.2$

$99.7 \% \quad 29.8$

$99.0 \% \quad 39.0$

$99.0 \% \quad 21.0$

$99.7 \% \quad 39.0$

$99.0 \% \quad 23.9$

$99.7 \% 41.6$

$99.5 \% \quad 21.5$

$99.0 \% \quad 30.5$

$103 \quad 0.14 \% \quad 30.3 \%$ ALVATPGKK

$103 \quad 0.14 \% \quad 30.3 \%$ AAKVVPVK

$\begin{array}{llll}99.7 \% & 36.3 & 25.0 & 36.3\end{array}$

$103 \quad 0.14 \% \quad 30.3 \%$ SAPELKTGISDVFAK

$99.7 \% \quad 37.4$

$103 \quad 0.14 \% \quad 30.3 \%$ TGISDVFAK

$\begin{array}{llll}99.7 \% & 50.3 & 25.0 & 47.7\end{array}$

$103 \quad 0.14 \% \quad 30.3 \%$ NDLAVVDVR

$103 \quad 0.14 \% \quad 30.3 \%$ KFGYVDFESAEDLEK

$99.7 \% \quad 49.6$

$99.5 \% \quad 23.2$

$99.6 \% \quad 24.1$

$99.7 \% \quad 44.0$

$99.7 \% \quad 26.4$ $\begin{array}{ccc}1895.87 & 537 & 553 \\ 1590.89 & 79 & 93 \\ 1414.70 & 121 & 133 \\ 1584.84 & 222 & 235 \\ 1320.80 & 298 & 310 \\ 1324.72 & 311 & 323 \\ 1733.92 & 338 & 353 \\ 1447.67 & 61 & 73 \\ 2040.01 & 114 & 131 \\ 1668.81 & 185 & 199 \\ 1433.83 & 203 & 215 \\ 1220.70 & 205 & 215 \\ 1842.96 & 216 & 231 \\ 1709.95 & 232 & 247 \\ 1377.83 & 258 & 270 \\ 1164.71 & 260 & 270 \\ 2137.02 & 286 & 304 \\ 2008.92 & 287 & 304 \\ 1514.81 & 305 & 318 \\ 1211.67 & 307 & 318 \\ 1252.64 & 392 & 402 \\ 1195.70 & 407 & 417 \\ 913.55 & 424 & 432 \\ 1797.97 & 424 & 440 \\ 1475.80 & 485 & 499 \\ 1127.67 & 563 & 573 \\ 1524.84 & 582 & 595 \\ 1839.92 & 703 & 718 \\ 1126.54 & 719 & 728 \\ 871.43 & 776 & 783 \\ 1582.80 & 179 & 191 \\ 905.51 & 280 & 287 \\ 857.55 & 64 & 71 \\ 884.56 & 72 & 80 \\ 1270.74 & 97 & 109 \\ 1267.74 & 111 & 124 \\ 884.56 & 117 & 125 \\ 811.54 & 221 & 228 \\ 2568.31 & 296 & 318 \\ 1562.84 & 319 & 333 \\ 937.50 & 325 & 333 \\ 1919.02 & 325 & 342 \\ 1000.54 & 334 & 342 \\ 1776.83 & 348 & 362 \\ 1401.81 & 371 & 382 \\ 1160.58 & 458 & 467 \\ 1444.79 & 509 & 521 \\ & & \end{array}$

Page 90 of Table S-1- 1 
Nucleolin GN=NCL

Nucleolin GN=NCL

Nucleolin GN=NCL

Nucleolin $\mathrm{GN}=\mathrm{NCL}$

Nucleolin GN=NCL

Nucleophosmin GN=NPM1

Nucleophosmin GN=NPM1

Nucleophosmin GN=NPM1

Nucleophosmin GN=NPM1

Nucleophosmin GN=NPM1

Nucleophosmin GN=NPM

Nucleophosmin GN=NPM1

Nucleophosmin GN=NPM1

Nucleophosmin GN=NPM1

Nucleophosmin GN=NPM1

Nucleophosmin GN=NPM1

Nucleophosmin GN=NPM1

Nucleophosmin GN=NPM1

Nucleophosmin GN=NPM

Nucleophosmin GN=NPM

Nucleoporin NDC1 GN=NDC1

Nucleoporin $\mathrm{NDC} 1 \mathrm{GN}=\mathrm{NDC} 1$

Nucleoporin NDC1 GN=NDC1

Nucleoporin NDC1 GN=NDC1 Nucleoporin NUP188 homolog GN=NUP188 NU188_HUMAN $196.05 \quad 100.0 \%$ Nucleoporin NUP188 homolog GN=NUP188 NU188_HUMAN $196.05 \quad 100.0 \%$ Origin recognition complex subunit 5 GN=ORC5 ORC5_HUMAN $50.29 \quad 100.0 \%$ Origin recognition complex subunit $5 \mathrm{GN}=$ ORC5 ORC5_HUMAN $50.29 \quad 100.0 \%$ Ornithine aminotransferase, mitochondrial GN=OAT OAT HUMAN $48.54 \quad 100.0 \%$ $\begin{array}{llll}\text { Ornithine aminotransferase, mitochondrial GN=OAT OAT_HUMAN } & 48.54 & 100.0 \% & 13\end{array}$ $\begin{array}{llll}\text { Ornithine aminotransferase, mitochondrial GN=OAT OAT_HUMAN } & 48.54 & 100.0 \% & 1\end{array}$ $\begin{array}{llll}\text { Ornithine aminotransferase, mitochondrial GN=OAT OAT_HUMAN } & 48.54 & 100.0 \% & 13\end{array}$ $\begin{array}{llll}\text { Ornithine aminotransferase, mitochondrial GN=OAT OAT_HUMAN } & 48.54 & 100.0 \% & 13\end{array}$ $\begin{array}{llll}\text { Ornithine aminotransferase, mitochondrial GN=OAT OAT_HUMAN } & 48.54 & 100.0 \% & 13\end{array}$ $\begin{array}{llll}\text { Ornithine aminotransferase, mitochondrial GN=OAT OAT_HUMAN } & 48.54 & 100.0 \% & 13\end{array}$ Ornithine aminotransferase, mitochondrial GN=OAT OAT_HUMAN $48.54 \quad 100.0 \% \quad 13$ $\begin{array}{llll}\text { Ornithine aminotransferase, mitochondrial GN=OAT OAT HUMAN } 48.54 & 100.0 \% & 13\end{array}$ Ornithine aminotransferase, mitochondrial GN=OAT OAT_HUMAN $48.54 \quad 100.0 \%$ $\begin{array}{llll}\text { Ornithine aminotransferase, mitochondrial GN=OAT OAT_HUMAN } & 48.54 & 100.0 \% & 13\end{array}$ $\begin{array}{llll}\text { Ornithine aminotransferase, mitochondrial GN=OAT OAT_HUMAN } & 48.54 & 100.0 \% & 13\end{array}$ $\begin{array}{llll}\text { Ornithine aminotransferase, mitochondrial GN=OAT OAT_HUMAN } & 48.54 & 100.0 \% & 13\end{array}$ Oxysterol-binding protein-related protein $8 \mathrm{GN}=$ OSBPL8 OSBL8 HUMAN $101.20 \quad 99.9 \%$ Oxysterol-binding protein-related protein 8 GN=OSBPL8 OSBL8_HUMAN $101.20 \quad 99.9 \%$ Pachytene checkpoint protein 2 homolog GN=TRIP13 PCH2_HUMAN $48.55 \quad 100.0 \%$ Pachytene checkpoint protein 2 homolog GN=TRIP13 PCH2 HUMAN $48.55 \quad 100.0 \%$ Pachytene checkpoint protein 2 homolog GN=TRIP13 PCH2_HUMAN $48.55 \quad 100.0 \%$ $\begin{array}{lll}103 & 0.14 \% & 30.3 \% \\ & \text { AIRLELQGPR }\end{array}$

$103 \quad 0.14 \% \quad 30.3 \%$ SQPSKTL

$99.7 \% \quad 48.5$

$99.5 \% \quad 23.9$

25.0

$0.14 \% \quad 30.3 \%$ GLSEDTTEETLKESFDGSVR

$103 \quad 0.14 \% \quad 30.3 \%$ IVTDRETGSSK

$103 \quad 0.14 \% \quad 30.3 \%$ GFGFVDFNSEEDAK

$0.12 \% \quad 42.9 \%$ VDNDENEHQLSLR

$99.7 \% \quad 62.1$

$99.7 \% \quad 42.8$

$99.7 \% \quad 46.8$

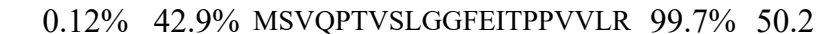

$0.12 \% \quad 42.9 \%$ LLSISGKR

$0.12 \% \quad 42.9 \%$ SAPGGGSKVPQK

$99.0 \% \quad 37.9$

$99.7 \% \quad 42.4$

$98.4 \% \quad 40.4$

$99.7 \% \quad 53.1$

$99.0 \% 34.2$

$99.7 \% \quad 36.4$

$99.7 \% \quad 57.0$

$99.7 \% \quad 54.9$

$95.3 \% \quad 16.9$

$99.7 \% \quad 56.5$

$\begin{array}{lll}97.5 \% & 22.3\end{array}$

$99.7 \% \quad 31.7$

$99.7 \% \quad 48.0$

$99.7 \% \quad 38.6$

$99.7 \% \quad 52.8$

$99.7 \% \quad 49.0$

$99.7 \% \quad 47.3$

$99.7 \% \quad 31.8$

$\begin{array}{lll}99.0 \% & 22.9\end{array}$

$99.7 \% \quad 47.8$

$99.6 \% \quad 23.1$

$99.7 \% \quad 29.2$

$99.7 \% \quad 53.9$

$99.7 \% \quad 50.6$

$\begin{array}{llllll}99.7 \% & 52.7 & 25.0 & 52.7 & 7 & 0\end{array}$

$99.7 \% \quad 42.8 \quad 25.0 \quad 42.8$

$\begin{array}{lllll}99.7 \% & 56.2 & 25.0 & 44.0 & 2\end{array}$

$\begin{array}{llll}99.7 \% & 25.8 & 25.0 & 25.6\end{array}$

$99.7 \% \quad 52.9 \quad 25.0 \quad 52.8$

$\begin{array}{llll}99.7 \% & 34.2 & 25.0 & 27.2\end{array}$

$\begin{array}{llll}99.7 \% & 46.8 & 25.0 & 46.8\end{array}$

$\begin{array}{lllll}99.7 \% & 35.0 & 25.0 & 26.5 & 2\end{array}$

$99.7 \% \quad 41.1 \quad 25.0 \quad 41.1$

42

$99.4 \% 20.5$

$\begin{array}{lll}16 & 42 & 0.06 \%\end{array} \quad 26.0 \%$ GLLNAIVIKETK

$99.7 \% \quad 47.5$

$0.06 \% \quad 26.0 \%$ DNGLLAKPTHGDIIR

$\begin{array}{ll}95.6 \% & 17.7 \\ 99.6 \% & 23.1\end{array}$

$0.00 \% \quad 3.4 \%$ VVLPTFILEPR

$0.02 \% \quad 14.1 \%$ NVQSVSIIDTELK

$0.02 \% \quad 14.1 \%$ NVQSVSIIDTELKVK

$99.7 \% \quad 62.0 \quad 25.1$

$99.7 \% \quad 34.3 \quad 25.0$

$99.6 \% \quad 23.5$
$0.02 \% \quad 14.1 \%$ VVLLHGPPGTGK
1152.68

1134.65

2200.03

1192.62

1561.68

1568.73

2227.22

873.55

1112.61

887.49

1602.78

910.46

1257.67

931.47

1130.61

1021.53

1345.71

985.57

1210.68

1360.68

1419.76

1092.56

1589.82

1181.62

1233.69

954.65

1550.82

1236.65

1066.61

1561.75

1247.70

1676.80

1237.65

1810.98

1687.90

1056.60

1241.72

1125.74

940.62

1298.80

1889.07

1619.89

2001.10

1283.77

1445.78

1672.95

1174.69 
Pachytene checkpoint protein 2 homolog GN=TRIP13 PCH2 HUMAN $48.55 \quad 100.0 \%$ Pachytene checkpoint protein 2 homolog GN=TRIP13 PCH2_HUMAN $48.55 \quad 100.0 \%$ Pachytene checkpoint protein 2 homolog GN=TRIP13 PCH2_HUMAN $48.55 \quad 100.0 \%$ aired amphipathic helix protein Sin3a GN=SIN3A SIN3A HUMAN $145.18100 .0 \%$ Paired amphipathic helix protein Sin3a GN=SIN3A SIN3A_HUMAN $145.18 \quad 100.0 \%$ Paraspeckle component $1 \mathrm{GN}=$ PSPC1 PSPC1_HUMAN $58.74 \quad 100.0 \%$ Paraspeckle component $1 \mathrm{GN}=\mathrm{PSPC} 1 \quad$ PSPC1_HUMAN $58.74 \quad 100.0 \%$ PCI domain-containing protein 2 GN=PCID2 PCID2_HUMAN $46.03 \quad 100.0 \%$ PCI domain-containing protein 2 GN=PCID2 PCID2 HUMAN $46.03 \quad 100.0 \%$

Pentatricopeptide repeat domain-contaning protein 3, mitochondrial GN=PTCD3 $\quad$ PTCD3_HUMAN $78.55 \quad 100.0 \%$

Pentatricopeptide repeat domain-contaning protein 3, mitochondrial GN=PTCD3 $\quad$ PTCD3_HUMAN $78.55 \quad 100.0 \%$

作

Pentatricopeptide repeat domain-containing protein 3, mitochondrial GN=PTCD3 PTCD3_HUMAN 78.55 100.0\%

-PTCD3 PTCD3_HUMAN $78.55 \quad 100.0 \%$ Pericentriolar material 1 protein GN=PCM1 PCM1_HUMAN $228.53 \quad 100.0 \%$ Pericentriolar material 1 protein $\mathrm{GN}=\mathrm{PCM} 1$ PCM1 HUMAN $228.53100 .0 \%$ Peroxiredoxin-1 GN=PRDX1 Peroxiredoxin- 1 GN=PRDX1 Peroxiredoxin-1 GN=PRDX1 Peroxiredoxin-1 GN=PRDX1 Peroxiredoxin-1 GN=PRDX1 Peroxiredoxin-1 GN=PRDX1 Peroxiredoxin-1 GN=PRDX1 Peroxiredoxin-1 GN=PRDX1 Peroxiredoxin-2 GN=PRDX2 Peroxiredoxin-2 GN=PRDX2 Peroxiredoxin-2 GN=PRDX2 Peroxiredoxin-2 GN=PRDX2 Peroxiredoxin-2 GN=PRDX2 Peroxiredoxin-2 GN=PRDX2 Peroxiredoxin- 6 GN=PRDX6 Peroxiredoxin- 6 GN=PRDX 6 Peroxiredoxin-6 GN=PRDX6 Pescadillo homolog GN=PES1 Pescadillo homolog GN=PES1 Pescadillo homolog GN=PES1 PHD finger protein $6 \mathrm{GN}=\mathrm{PHF} 6$ PHD finger protein $6 \mathrm{GN}=\mathrm{PHF} 6$ PRDX1 HUMAN $22.11 \quad 100.0 \%$ PRDX1_HUMAN $22.11 \quad 100.0 \%$ PRDX1 HUMAN $22.11 \quad 100.0 \%$ PRDX1_HUMAN $22.11 \quad 100.0 \%$ PRDX1_HUMAN $22.11 \quad 100.0 \%$ PRDX1_HUMAN $22.11 \quad 100.0 \%$ PRDX1_HUMAN $22.11 \quad 100.0 \%$ PRDX1 HUMAN $22.11 \quad 100.0 \%$ PRDX2_HUMAN $21.89 \quad 100.0 \%$ PRDX2_HUMAN $21.89 \quad 100.0 \%$ PRDX2 HUMAN $21.89 \quad 100.0 \%$ PRDX2_HUMAN $21.89 \quad 100.0 \%$ PRDX2 HUMAN $21.89 \quad 100.0 \%$ PRDX2_HUMAN $21.89 \quad 100.0 \%$ PRDX6_HUMAN $25.04 \quad 100.0 \%$ PRDX6 HUMAN $25.04 \quad 100.0 \%$ PRDX6_HUMAN $25.04 \quad 100.0 \%$ PESC_HUMAN $68.00 \quad 100.0 \%$ PESC HUMAN $68.00 \quad 100.0 \%$ PESC_HUMAN $68.00 \quad 100.0 \%$ PHF6 HUMAN $41.29 \quad 100.0 \%$ PHF6_HUMAN $41.29 \quad 100.0 \%$ Phenylalanine--tRNA ligase beta subunit GN=FARSB SYFB_HUMAN $66.12 \quad 100.0 \%$ Phenylalanine--tRNA ligase beta subunit GN=FARSB SYFB_HUMAN $66.12 \quad 100.0 \%$ Phenylalanine--tRNA ligase beta subunit GN=FARSB SYFB_HUMAN $66.12 \quad 100.0 \%$ Phenylalanine--tRNA ligase beta subunit GN=FARSB SYFB HUMAN $66.12100 .0 \%$ Phenylalanine--tRNA ligase beta subunit GN=FARSB SYFB_HUMAN $66.12 \quad 100.0 \%$ Phenylalanine--tRNA ligase beta subunit GN=FARSB SYFB_HUMAN $66.12 \quad 100.0 \%$ Phosphate carrier protein, mitochondrial GN=SLC25A3 MPCP HUMAN $40.10 \quad 100.0 \%$ Phosphate carrier protein, mitochondrial GN=SLC25A3 $\quad$ MPCP_HUMAN $40.10 \quad 100.0 \%$
$2 \quad 0.02 \% \quad 14.1 \%$ AGTEPSDAIR $0.02 \% \quad 14.1 \%$ VVNAVLTQIDQIKR $0.02 \% \quad 14.1 \%$ LSLLLNDISR $0.01 \% \quad 1.6 \%$ DKSDSPAIQLR $0.01 \% \quad 1.6 \%$ SLLESTYQR $0.00 \% \quad 5.4 \%$ TLAEIAKAELDGTILK $0.00 \% \quad 5.4 \%$ GFVEFAAKPPAR $0.00 \% \quad 4.5 \% \quad$ LQMASPEEK $0.00 \% \quad 4.5 \% \quad$ VTYKYYVGR $0.02 \% \quad 9.6 \%$ VEGTDVTGIEEVVIPK $0.02 \% \quad 9.6 \%$ FIINSYPK

$0.02 \% \quad 9.6 \%$ SPALQVLREMK

$0.02 \% \quad 9.6 \%$ LFDQPGDPLKR

$0.02 \% \quad 9.6 \%$ FIGPDQHR

$0.02 \% \quad 9.6 \%$ SELLNELMDSAK

$0.00 \% \quad 0.8 \% \quad$ FGVESDKR

$0.00 \% \quad 0.8 \%$ ELKQLQEER

$0.03 \% \quad 38.7 \%$ IGHPAPNFK

$0.03 \% \quad 38.7 \%$ QGGLGPMNIPLVSDPKR

$0.03 \% \quad 38.7 \%$ TIAQDYGVLK

$0.03 \% \quad 38.7 \%$ TIAQDYGVLKADEGISFR

$0.03 \% \quad 38.7 \%$ ADEGISFR

$0.03 \% \quad 38.7 \%$ GLFIIDDKGILR

$0.03 \% 38.7 \%$ QITVNDLPVGR

$0.03 \% \quad 38.7 \%$ LVQAFQFTDK

$0.02 \% \quad 39.9 \%$ IGKPAPDFK

$0.02 \% \quad 39.9 \%$ ATAVVDGAFKEVK

$0.02 \% \quad 39.9 \%$ EGGLGPLNIPLLADVTR

$0.02 \% \quad 39.9 \%$ LSEDYGVLKTDEGIAYR

$0.02 \% \quad 39.9 \%$ GLFIIDGKGVLR

$0.02 \% \quad 39.9 \%$ QITVNDLPVGR

$0.01 \% \quad 17.4 \%$ PGGLLLGDVAPNFEANTTVGR

$0.01 \% \quad 17.4 \%$ LAPEFAKR

$0.01 \% \quad 17.4 \%$ VVFVFGPDKK

$0.00 \% \quad 6.3 \%$ GIYPHEPK

$0.00 \% \quad 6.3 \% \quad$ ITHQIVDRPGQQTSVIGR

$0.00 \% \quad 6.3 \%$ LAQEEESEAKR

$0.00 \% \quad 7.1 \%$ TVLQEIKR

$0.00 \% \quad 7.1 \%$ GKVEIDQQQLTQQQLNGN

$0.02 \% \quad 10.9 \%$ DLLFQALGR

$0.02 \% \quad 10.9 \%$ GLQVFKER

$0.02 \% \quad 10.9 \%$ NIFIECTGTDFTKAK

$0.02 \% \quad 10.9 \%$ VGIRETPENLAK

$0.02 \% \quad 10.9 \%$ TTLLPGLLK

$0.02 \% \quad 10.9 \%$ ASEGPAFFPGR

$0.09 \% \quad 23.2 \%$ MQVDPQKYK

$0.09 \% \quad 23.2 \%$ GIFNGFSVTLKEDGVR
$99.7 \% 28.4$

$99.7 \% \quad 41.0$

$99.7 \% \quad 56.0$

$99.7 \% \quad 26.4$

$99.7 \% \quad 35.6$

$99.7 \% \quad 50.2$

$99.7 \% \quad 41.6$

$99.7 \% \quad 24.4$

$99.7 \% \quad 30.6$

$99.7 \% 28.1$

$\begin{array}{ll}97.6 \% & 27.8\end{array}$

$99.7 \% \quad 34.5$

$99.7 \% \quad 43.2$

$99.0 \% \quad 24.0$

$99.7 \% \quad 50$.

$95.8 \% \quad 24.5$

$99.0 \% \quad 40.0$

$99.7 \% \quad 29.9$

$99.7 \% \quad 28.5$

$99.7 \% \quad 47.2$

$99.7 \% 56.5$

$99.0 \% \quad 52.6$

$99.7 \% \quad 56.7$

$99.7 \% \quad 61.0$

$99.7 \% \quad 39.5$

$99.4 \% \quad 23.5$

$99.7 \% \quad 47.7$

$99.7 \% \quad 52.2$

$99.7 \% \quad 46.8$

$99.7 \% \quad 61.0$

$99.7 \% \quad 69.7$

$99.0 \% \quad 34.8$

$99.7 \% \quad 39.6$

$97.1 \% \quad 15.8$

$98.6 \% \quad 19.6$

$\begin{array}{lll}99.7 \% & 40.4\end{array}$

$97.0 \% \quad 22.5$

$99.7 \% \quad 34.6$

$\begin{array}{lll}99.7 \% & 35.5\end{array}$

$99.0 \% 25.5$

$99.5 \% 22.6$

$98.3 \% 21.2$

$99.7 \% \quad 24.8$

$\begin{array}{lll}99.7 \% & 59.4\end{array}$

$99.7 \% \quad 33.8$

$99.7 \% \quad 43.5$
41.0

$\begin{array}{ll}0 & 44.2\end{array}$

$\begin{array}{ll}0 & 21.8\end{array}$

.035 .2

50.2

$\begin{array}{ll}3.0 & 21.4\end{array}$

$\begin{array}{ll}0 & 28.0\end{array}$

$\begin{array}{ll}5.0 & 5.3\end{array}$

$\begin{array}{ll}0 & 26.0\end{array}$

$\begin{array}{ll}.0 & 19.3\end{array}$

\begin{tabular}{ll}
5.0 & 50.1 \\
\hline & 3
\end{tabular}

$0 \quad 17.6$

$\begin{array}{ll}0 & 0.0\end{array}$

\begin{tabular}{ll}
.0 & 27.3 \\
\hline
\end{tabular}

$\begin{array}{ll}28.0 & 28.5 \\ 25.0 & 46.5\end{array}$

$\begin{array}{ll}5.0 & 46.5\end{array}$

50.3

\begin{tabular}{ll}
.0 & 40.8 \\
\hline
\end{tabular}

$\begin{array}{lll}51.0 & 2\end{array}$

0
0 34.9

$\begin{array}{ll}.0 & 34.9 \\ 0 & 52.2\end{array}$

$\begin{array}{ll}5.0 & 43.0\end{array}$

$\begin{array}{ll}25.0 & 46.8\end{array}$

$.0 \quad 51.6$

$\begin{array}{lll}25.0 & 68.7 & 2\end{array}$

\begin{tabular}{ll}
20.5 \\
\hline
\end{tabular}

36.

$\begin{array}{ll}25.0 & 15.8\end{array}$

$\begin{array}{ll}0.0 & 19.6\end{array}$

$\begin{array}{ll}25.0 & 40.4\end{array}$

\begin{tabular}{ll}
11.4 \\
\hline
\end{tabular}

34.6

$\begin{array}{lll} & 25.1 & 4\end{array}$

$\begin{array}{ll}22.4 & 22.6\end{array}$

$\begin{array}{ll}25.0 & 14.5\end{array}$

14
14

$\begin{array}{ccc}1016.50 & 266 & 275 \\ 1596.94 & 276 & 289 \\ 1143.67 & 369 & 378 \\ 1229.65 & 936 & 946 \\ 1096.56 & 1044 & 1052 \\ 1685.97 & 128 & 143 \\ 1289.70 & 199 & 210 \\ 1048.50 & 41 & 49 \\ 1148.61 & 210 & 218 \\ 1684.90 & 46 & 61 \\ 981.54 & 119 & 126 \\ 1271.71 & 351 & 361 \\ 1285.69 & 378 & 388 \\ 969.49 & 447 & 454 \\ 1349.66 & 608 & 619 \\ 937.47 & 52 & 59 \\ 1172.63 & 745 & 753 \\ 980.53 & 8 & 16 \\ 1778.96 & 94 & 110 \\ 1107.60 & 111 & 120 \\ 1983.02 & 111 & 128 \\ 894.43 & 121 & 128 \\ 1359.80 & 129 & 140 \\ 1211.67 & 141 & 151 \\ 1196.63 & 159 & 168 \\ 972.55 & 8 & 16 \\ 1334.73 & 17 & 29 \\ 1734.98 & 93 & 109 \\ 1928.96 & 111 & 127 \\ 1287.78 & 128 & 139 \\ 1211.67 & 140 & 150 \\ 2098.09 & 2 & 22 \\ 931.54 & 57 & 64 \\ 1135.65 & 133 & 142 \\ 940.49 & 42 & 49 \\ 2005.09 & 373 & 390 \\ 1289.63 & 524 & 534 \\ 986.60 & 267 & 274 \\ 2041.03 & 348 & 365 \\ 1032.58 & 9 & 17 \\ 976.56 & 83 & 90 \\ 1744.86 & 250 & 264 \\ 1326.74 & 318 & 329 \\ 955.62 & 452 & 460 \\ 1135.55 & 537 & 547 \\ 1136.58 & 93 & 101 \\ 1738.91 & 102 & 117 \\ & & \end{array}$

Page 92 of Table S-1-1 
Phosphate carrier protein, mitochondrial GN=SLC25A3 MPCP_HUMAN $40.10 \quad 100.0 \%$ Phosphate carrier protein, mitochondrial GN=SLC25A3 MPCP_HUMAN $40.10 \quad 100.0 \%$ Phosphate carrier protein, mitochondrial GN=SLC25A3 MPCP_HUMAN $40.10 \quad 100.0 \%$ Phosphate carrier protein, mitochondrial GN=SLC25A3 MPCP HUMAN $40.10 \quad 100.0^{\circ}$ Phosphate carrier protein, mitochondrial GN=SLC25A3 $\quad$ MPCP_HUMAN $40.10 \quad 100.0 \%$ Phosphate carrier protein, mitochondrial GN=SLC25A3 MPCP_HUMAN $40.10 \quad 100.0 \%$ Phosphate carrier protein, mitochondrial GN=SLC25A3 MPCP_HUMAN $40.10 \quad 100.0 \%$ Phosphate carrier protein, mitochondrial GN=SLC25A3 MPCP_HUMAN $40.10 \quad 100.0 \%$ Phosphatidylinositol 4-kinase alpha GN=PI4KA PI4KA HUMAN $231.33 \quad 100.0 \%$ Phosphatidylinositol 4-kinase alpha GN=PI4KA PI4KA_HUMAN $231.33 \quad 100.0 \%$ Phosphatidylinositol 4-kinase alpha GN=PI4KA PI4KA_HUMAN $231.33 \quad 100.0 \%$ Phosphatidylinositol 4-phosphate 5-kinase type-1 gamma GN=PIP5K1C PI51C_HUMAN $73.26 \quad 100.0 \%$ Phosphatidylinositol 4-phosphate 5-kinase type-1 gamma GN=PIP5KIC PI51C_HUMAN 73.26 100.0\% Phosphatidylinositol 4-phosphate 5-kinase type-1 gamma GN=PIP5K1C PI51C_HUMAN 73.26 100.0\% Phosphatidylinositol 4-phosphate 5-kinase type-1 gamma GN=PIP5K1C PI51C_HUMAN 73.26 100.0\% Phosphatidylinositol 4-phosphate 5-kinase type-1 gamma GN=PIP5K1C PI51C_HUMAN 73.26 $100.0 \%$ Phosphatidylinositol 4-phosphate 5-kinase type-1 gamma GN=PIP5K1C PI51C HUMAN 73.26 100.0\% Phosphatidylserine decarboxylase proenzyme GN=PISD PISD_HUMAN $46.67 \quad 100.0 \%$ Phosphatidylserine decarboxylase proenzyme GN=PISD PISD_HUMAN $46.67 \quad 100.0 \%$ Phosphoacetylglucosamine mutase GN=PGM3 AGM1_HUMAN 59.85 Phosphoacetylglucosamine mutase GN=PGM3 AGM1_HUMAN 59.85 Phosphoenolpyruvate carboxykinase [GTP], mitochondrial GN=PCK2 PCKGM HUMAN 70.73 Phosphoenolpyruvate carboxykinase [GTP], mitochondrial GN=PCK2 PCKGM_HUMAN 70.73 Phosphoenolpyruvate carboxykinase [GTP], mitochondrial GN=PCK2 PCKGM_HUMAN 70.73 Phosphoenolpyruvate carboxykinase [GTP], mitochondrial GN=PCK2 PCKGM_HUMAN 70.73 Phosphoenolpyruvate carboxykinase [GTP], mitochondrial GN=PCK2 PCKGM_HUMAN 70.73 Phosphoenolpyruvate carboxykinase [GTP], mitochondrial GN=PCK2 PCKGM_HUMAN 70.73 Phosphoenolpyruvate carboxykinase [GTP], mitochondrial GN=PCK2 PCKGM_HUMAN 70.73 Phosphoenolpyruvate carboxykinase [GTP], mitochondrial GN=PCK2 PCKGM_HUMAN 70.73 Phosphoenolpyruvate carboxykinase [GTP], mitochondrial GN=PCK2 PCKGM HUMAN 70.73 Phosphoenolpyruvate carboxykinase [GTP], mitochondrial GN=PCK2 PCKGM_HUMAN 70.73 Phosphoenolpyruvate carboxykinase [GTP], mitochondrial GN=PCK2 PCKGM_HUMAN 70.73 Phosphoglycerate kinase $1 \mathrm{GN}=$ PGK1 PGK1_HUMAN 44.62 $100.0 \%$ PGK1_HUMAN $44.62 \quad 100.0 \%$ 1 PGAM1_HUMAN $28.80 \quad 100.0 \%$ PGAM1_HUMAN $28.80 \quad 100.0 \%$ PGP_HUMAN $34.01 \quad 100.0 \%$ PGP HUMAN $34.01 \quad 100.0 \%$ PGP_HUMAN $34.01 \quad 100.0 \%$ PGP HUMAN $34.01 \quad 100.0 \%$ PGP HUMAN $34.01 \quad 100.0 \%$ AP1 KPRA_HUMAN $39.39 \quad 100.0 \%$ $100.0 \%$ $100.0 \%$ $100.0 \%$

8

8

8

6

2

2

$\begin{array}{cc}2 & 3 \\ 2 & 3 \\ 11 & 13\end{array}$

113

$\begin{array}{ll}11 & 13 \\ 11 & 13 \\ 11 & 13\end{array}$

13
13
13

1

11

11

$\begin{array}{ll}11 \\ 11 \\ 11 & 13 \\ 11 & 13\end{array}$

11

11
2

2

2
2
2

5

5

$0.09 \% \quad 23.2 \%$ VRIQTQPGYANTLR

$0.09 \% \quad 23.2 \%$ IQTQPGYANTLR

$0.09 \% \quad 23.2 \%$ IQTQPGYANTLRDAAPK

$0.09 \% \quad 23.2 \%$ MYKEEGLK

$0.09 \% \quad 23.2 \%$ GVAPLWMR

$0.09 \% \quad 23.2 \%$ TVEALYKFVVPKPR

$0.09 \% \quad 23.2 \%$ GSSASLVLK

$0.09 \% \quad 23.2 \%$ GSSASLVLKR

$0.01 \% \quad 1.5 \%$ HVAAIGPR

$0.01 \% \quad 1.5 \%$ SNLDITVGSR

$0.01 \% \quad 1.5 \% \quad$ FKNTEAIGNEVTR

$0.02 \% \quad 12.3 \%$ GVDASGETTYKK

$0.02 \% \quad 12.3 \%$ LLPGYYMNLNQNPR

$0.02 \% \quad 12.3 \%$ FYGLYCVQSGGK

$0.02 \% \quad 12.3 \%$ VVVMNNILPR

$0.02 \% \quad 12.3 \%$ QAQGAQSTSDEKRPVGQK

$0.02 \% \quad 12.3 \%$ ALYSTAMESIQGGAAR

$0.00 \% \quad 6.4 \% \quad$ GVTYSLESFLGPR

$0.00 \% \quad 6.4 \% \quad$ IYFDRDLHTNSPR

$0.01 \% \quad 4.1 \%$ VISTTDAER

$0.01 \% \quad 4.1 \%$ AFVRPSGTEDVVR

$0.04 \% \quad 18.6 \%$ TDPKDVAR

$\begin{array}{llll}0.04 \% & 18.6 \% & 99.0 \% & 26.3\end{array}$

$\begin{array}{lllll}0.04 \% & 18.6 \% & \text { TMYVLPFSMGPVGSPLSR } & 99.7 \% & 54.7 \\ 0.04 \% & 18.6 \% & \text { IGVQLTDSAYVVASMR } & 99.7 \% & 70.3\end{array}$

$0.04 \% \quad 18.6 \%$ LGTPVLQALGDGDFVK

$0.04 \% \quad 18.6 \%$ TLIGHVPDQR

$0.04 \% \quad 18.6 \%$ YVAAAFPSACGK

$0.04 \% \quad 18.6 \%$ RLEGEDSAR

$0.04 \% \quad 18.6 \%$ ETPIGLVPK

$0.04 \% \quad 18.6 \%$ ETPIGLVPKEGALDLSGLR

$0.04 \% \quad 18.6 \%$ EGALDLSGLR

$0.04 \% \quad 18.6 \%$ EVLAELEALER

$0.00 \% \quad 6.2 \%$ LGDVYVNDAFGTAHR

$0.00 \% \quad 6.2 \%$ VLPGVDALSNI

$0.00 \% \quad 12.6 \%$ YADLTEDQLPSCESLKDTIAR

$0.00 \% \quad 12.6 \%$ VLIAAHGNSLR

$0.01 \% \quad 18.1 \%$ LGFITNNSSK

$0.01 \% \quad 18.1 \%$ AVVVGFDPHFSYMK

$0.01 \% \quad 18.1 \%$ FIAGTGCLVR

$0.01 \% \quad 18.1 \%$ AVEMAAQR

$0.01 \% \quad 18.1 \%$ FIFDCVSQEYGINPER

$0.01 \% \quad 18.8 \%$ VFSANSTAACTELAK

$0.01 \% \quad 18.8 \%$ NIIGVIPYFPYSK

$0.01 \% \quad 18.8 \%$ AQSYAERLR

$0.01 \% \quad 18.8 \%$ NATVHPGLELPLMMAK

$\begin{array}{lllll}0.01 \% & 18.8 \% & \text { EKPPITVVGDVGGR } & 99.7 \% & 34.5 \\ 0.02 \% & 19.0 \% & \text { GGLVLFSANSNSSCMELSK } & 99.7 \% & 30.6\end{array}$ $\begin{array}{rr}99.7 \% & 67.2 \\ 99.7 \% & 54.7\end{array}$

$99.7 \% \quad 51.8$

$99.0 \% \quad 26.6$

$99.0 \% \quad 37.2$

$\begin{array}{lll}99.7 \% & 39.2\end{array}$

$99.7 \% \quad 34.0$

$99.0 \% 22.9$

$99.7 \% \quad 35.2$

$99.7 \% \quad 52.8$

$99.7 \% \quad 41.7$

$99.7 \% \quad 48.0$

$99.7 \% \quad 29.8$

$98.8 \% 18.6$

$99.7 \% \quad 50.2$

$\begin{array}{lll}99.4 \% & 20.2\end{array}$

$99.2 \% \quad 21.1$

$99.7 \% \quad 41.8$

$\begin{array}{ll}99.7 \% & 29.0\end{array}$

$\begin{array}{lll}99.7 \% & 39.8\end{array}$

$99.6 \% \quad 29.5$

$96.4 \% \quad 15.4$

$99.6 \% \quad 22.4$

$\begin{array}{ll}99.7 \% & 56.7 \\ 99.7 \% & 40.9\end{array}$

$99.7 \% \quad 50.1$

$99.1 \% \quad 18.9$

$99.7 \% 32.9$

$99.7 \% \quad 36.6$

$97.7 \% 23.0$

$99.6 \% \quad 36.5$

$99.0 \% \quad 40.4$

$\begin{array}{lll}99.7 \% & 32.4\end{array}$

$99.7 \% \quad 49.1$

$99.7 \% \quad 56.5$

$98.3 \% \quad 23.6$

$\begin{array}{lll}99.7 \% & 37.8\end{array}$

$99.7 \% 30.6$

1361.72

1843.97

997.50

929.50

1646.96

861.50

1017.61

820.48

1061.56

1478.76

1255.62

1692.85

1378.65

1154.67

1914.96

1625.80

1425.74

1633.81

991.51

1432.75

901.47

1954.98

1709.89

1629.89

1135.62

1241.60

1032.51

953.57

1965.10

1030.55

1271.68

1634.79

1097.62

2425.16

1150.67

1080.57

1596.79

1093.58

875.44

1973.91

1569.76

1510.83

1093.57

1753.90

1423.79

2016.94

Page 93 of Table S-1-1 
Plectin GN=PLEC

Plectin GN=PLEC

Plectin $\mathrm{GN}=\mathrm{PLEC}$

Plectin GN=PLEC

Plectin GN=PLEC

Plectin GN=PLEC

Plectin GN=PLEC

Plectin GN=PLEC

Plectin GN=PLEC

Plectin GN=PLEC

Plectin GN=PLEC

Plectin GN=PLEC

Plectin GN=PLEC

Plectin GN=PLEC

Plectin $\mathrm{GN}=\mathrm{PLEC}$

Plectin GN=PLEC

Plectin GN=PLEC

Plectin GN=PLEC

Plectin GN=PLEC

Plectin $\mathrm{GN}=\mathrm{PLEC}$

Plectin $\mathrm{GN}=\mathrm{PLEC}$

Plectin GN=PLEC

Plectin GN=PLEC

Plectin $\mathrm{GN}=\mathrm{PLEC}$

Plectin GN=PLEC

PLEC_HUMAN $531.78 \quad 100.0 \%$ PLEC HUMAN $531.78 \quad 100.0 \% \quad 25$ PLEC_HUMAN $531.78 \quad 100.0 \% \quad 25$ PLEC HUMAN $531.78 \quad 100.0 \% \quad 25$ PLEC_HUMAN $531.78 \quad 100.0 \% \quad 25$ PLEC_HUMAN $531.78 \quad 100.0 \% \quad 25$ PLEC HUMAN $531.78 \quad 100.0 \% \quad 25$ PLEC_HUMAN $531.78 \quad 100.0 \% \quad 25$ PLEC_HUMAN $531.78 \quad 100.0 \% \quad 25$ PLEC HUMAN $531.78 \quad 100.0 \% \quad 25$ PLEC_HUMAN $531.78 \quad 100.0 \% \quad 25$ PLEC HUMAN $531.78 \quad 100.0 \% \quad 25$ PLEC_HUMAN $531.78 \quad 100.0 \% \quad 25$ PLEC_HUMAN $531.78 \quad 100.0 \% \quad 25$ PLEC HUMAN $531.78 \quad 100.0 \% \quad 25$ PLEC_HUMAN $531.78 \quad 100.0 \% \quad 25$ PLEC_HUMAN $531.78 \quad 100.0 \% \quad 25$ PLEC_HUMAN $531.78 \quad 100.0 \% \quad 25$ PLEC_HUMAN $531.78 \quad 100.0 \% \quad 25$ PLEC HUMAN $531.78 \quad 100.0 \% \quad 25$ PLEC_HUMAN $531.78 \quad 100.0 \% \quad 25$ PLEC_HUMAN $531.78 \quad 100.0 \% \quad 25$ PLEC HUMAN $531.78 \quad 100.0 \% \quad 25$ PLEC_HUMAN $531.78 \quad 100.0 \% \quad 25$ PLEC HUMAN $531.78 \quad 100.0 \% \quad 25$ Poly [ADP-ribose] polymerase 1 GN=PARP1 PARP1_HUMAN $113.09 \quad 100.0 \% \quad 21$ Poly [ADP-ribose] polymerase 1 GN=PARP1 PARP1_HUMAN $113.09 \quad 100.0 \%$ Poly [ADP-ribose] polymerase $1 \mathrm{GN}=$ PARP1 PARP1_HUMAN $113.09 \quad 100.0 \%$ Poly [ADP-ribose] polymerase 1 GN=PARP1 PARP1_HUMAN $113.09 \quad 100.0 \% \quad 21$ $\begin{array}{ll}0.02 \% & 19.0 \% \text { VQIQESVR } \\ 0.02 \% & 19.0 \% \text { SITVIPYFPYS }\end{array}$

$0.02 \% \quad 19.0 \%$ SIIGVIPYFPYSK

$0.02 \% \quad 19.0 \%$ LLASMMCK

$0.02 \% \quad 19.0 \%$ RAQSFAER

$0.02 \% \quad 19.0 \%$ EKPPITVVGDVGGR

$0.00 \% \quad 6.5 \% \quad$ QVVNFGPGPAK

$0.00 \% \quad 6.5 \%$ CADYVVTGAWSAK

$0.01 \% \quad 3.1 \%$ LLALSGPGGGR

$0.01 \% \quad 3.1 \%$ FKQESTVATER

$0.01 \% \quad 4.4 \%$ AHLTVGQAAAGGSGNLLTER

$0.01 \% \quad 4.4 \%$ VQNEDVQR

$0.01 \% \quad 4.4 \%$ NMSSAGADGRK

$0.00 \% \quad 3.3 \%$ SSPTDKHTLVK

$0.00 \% \quad 3.3 \%$ EASDIILTDDNFTSIVK

$0.00 \% \quad 3.3 \%$ SSLYEGLEKPESR

$\begin{array}{llll}0.01 \% & 9.8 \% & \text { SAAQAAAQTNSNAAGK } \quad 99.7 \% \quad 60.5\end{array}$

$\begin{array}{llllll}0.01 \% & 9.8 \% & \text { SAAQAAAQTNSNAAGKQLR } & 99.7 \% & 40.8\end{array}$

$0.01 \% \quad 9.8 \%$ TDKSSASAPDVDDPEAFPALA $99.1 \% \quad 19.0$

$0.06 \% \quad 5.3 \% \quad$ LLAAGKVPQR

$0.06 \% \quad 5.3 \% \quad$ IKELQNAGDR

$0.06 \% \quad 5.3 \% \quad$ AVVQLKPR

$0.06 \% \quad 5.3 \%$ GTQGAEEVLR

$0.06 \% \quad 5.3 \%$ AQLEPVASPAK

$0.06 \% \quad 5.3 \% \quad$ SIQEELQQLR

$0.06 \% \quad 5.3 \%$ GGAEGELQALR

$0.06 \% \quad 5.3 \%$ QVQVALETAQR

$0.06 \% \quad 5.3 \%$ SAEAELQSK

$0.06 \% \quad 5.3 \%$ SAEAELQSKR

$0.06 \% \quad 5.3 \% \quad$ LRLQAEEVAQQK

$0.06 \% \quad 5.3 \% \quad$ LQAEEVAQQK

$0.06 \% \quad 5.3 \%$ QLAEGTAQQR

$0.06 \% \quad 5.3 \% \quad$ QVEEEILALK

$0.06 \% \quad 5.3 \%$ SLAAEEEAAR

$0.06 \% \quad 5.3 \%$ AQVEQELTTLR

$0.06 \% \quad 5.3 \%$ LKAEATEAAR

$0.06 \% \quad 5.3 \%$ SQVEEELFSVR

$0.06 \% \quad 5.3 \% \quad$ LSVAAQEAAR

$0.06 \% \quad 5.3 \%$ LQEAGILSAEELQR

$42 \quad 0.06 \% \quad 5.3 \%$ LAQGHTTVDELAR

$42 \quad 0.06 \% \quad 5.3 \% \quad$ SLVPAAELLESR

$0.06 \% \quad 5.3 \%$ LTVDEAVR

$42 \quad 0.06 \% \quad 5.3 \% \quad$ LLDAQLSTGGIVDPSK

$42 \quad 0.06 \% \quad 5.3 \% \quad$ NLVDNITGQR

$60 \quad 0.08 \% \quad 23.7 \%$ CSESIPKDSLR

$60 \quad 0.08 \% \quad 23.7 \%$ TAEAGGVTGKGQDGIGSK

$60 \quad 0.08 \% \quad 23.7 \%$ AEKTLGDFAAEYAK

$60 \quad 0.08 \% \quad 23.7 \%$ TLGDFAAEYAK

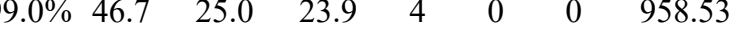

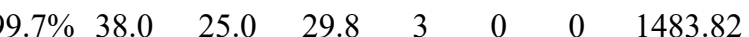

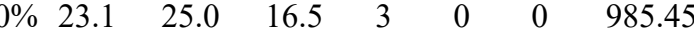

$\begin{array}{llll}99.7 \% & 34.5 & 25.0 & 30.4\end{array}$

$\begin{array}{llll}9.6 \% & 23.4 & 25.0 & 21.8\end{array}$

$99.7 \% \quad 42.3 \quad 25.0 \quad 42.3$

$\begin{array}{llll}9.7 \% & 29.2 & 25.0 & 27.1 \\ 99.7 \% & 50.4 & 25.0 & 32.9\end{array}$

$\begin{array}{llll}99.7 \% & 54.0 & 25.0 & 54.0\end{array}$

$\begin{array}{llll}99.0 \% & 33.8 & 25.0 & 17.8\end{array}$

$\begin{array}{llll}99.5 \% & 22.3 & 25.0 & 22.3\end{array}$

$\begin{array}{llll}99.5 \% & 25.5 & 25.0 & 20.1\end{array}$

$99.7 \% \quad 27.5 \quad 25.0 \quad 27.5$

$5.0 \quad 38.7$

$\begin{array}{ll}6.0 & 60.4\end{array}$

.0 40.8

$\begin{array}{lll}18.7 & 25.0 & 18.7 \\ 23.6 & 25.0 & 15.3\end{array}$

$98.6 \% \quad 23.6 \quad 25.0 \quad 15.3$

$\begin{array}{llll}98.2 \% & 19.2 & 25.0 & 15.5\end{array}$

$\begin{array}{llll}99.7 \% & 32.6 & 25.0 & 25.5\end{array}$

$\begin{array}{llll}99.5 \% & 27.5 & 25.0 & 27.5\end{array}$

$\begin{array}{lllll}99.7 \% & 43.1 & 25.0 & 24.7 & 2\end{array}$

$99.7 \% \quad 40.0 \quad 25.0 \quad 34.8$

$\begin{array}{llll}99.7 \% & 68.9 & 25.0 & 55.0\end{array}$

$\begin{array}{llll}99.7 \% & 24.8 & 25.0 & 21.8\end{array}$

$\begin{array}{llll}99.7 \% & 45.3 & 25.0 & 22.8\end{array}$

$\begin{array}{lllll}99.7 \% & 35.7 & 25.0 & 27.9 & 2\end{array}$

$99.7 \% \quad 50.7 \quad 25.0 \quad 37.8$

$\begin{array}{llll}99.7 \% & 38.5 & 25.0 & 25.7\end{array}$

$99.6 \% \quad 28.4 \quad 25.0 \quad 19.4$

$99.7 \% \quad 32.2 \quad 25.0-22.8$

$\begin{array}{llll}99.7 \% & 28.9 & 25.0 & 23.6\end{array}$

$\begin{array}{llll}99.7 \% & 35.0 & 25.0 & 29.0\end{array}$

$99.7 \% \quad 41.9 \quad 25.0 \quad 38.2$

$\begin{array}{lllll}99.7 \% & 64.9 & 25.0 & 45.3 & 2\end{array}$

$99.7 \% \quad 90.4 \quad 25.0 \quad 90.4$

$\begin{array}{llll}99.7 \% & 41.7 & 25.0 & 38.2\end{array}$

$\begin{array}{lllll}99.7 \% & 40.8 & 25.0 & 39.4 & 3\end{array}$

$\begin{array}{llll}99.0 \% & 26.1 & 25.0 & 18.5\end{array}$

$\begin{array}{lllll}99.7 \% & 51.7 & 25.0 & 42.4 & 2\end{array}$

$\begin{array}{llll}99.5 \% & 22.7 & 25.0 & 22.7\end{array}$

$\begin{array}{lllll}99.7 \% & 47.4 & 25.0 & 41.1\end{array}$

$\begin{array}{lllll}99.7 \% & 60.8 & 25.0 & 60.8 & 2\end{array}$

$\begin{array}{lllll}99.7 \% & 52.3 & 25.0 & 49.1\end{array}$

$\begin{array}{llll}99.7 \% & 44.8 & 25.0 & 44.8\end{array}$
964.50

1423.79

1113.61

1427.66

997.58

1295.66

1923.00

987.49

1093.51

1212.66

1880.95

1494.74

1460.71

1857.95

2103.97

1052.66

1143.61

910.58

1059.54

1110.62

1243.66

1100.57

1242.68

962.48

1118.58

1412.79

1143.60

1101.56

1171.66

1046.5

1287.69

1059.58

1322.66

1015.55

1556.83

1410.73

1284.72

902.49

1613.87

1129.60

1291.63

1632.82

1513.75 1185.58
$03 \quad 115$

$129 \quad 136$

$95 \quad 202$

$6 \quad 16$

$98 \quad 110$

$156 \quad 166$

$317 \quad 336$

$406 \quad 413$

$564 \quad 574$

$768 \quad 778$

$824 \quad 840$

$164 \quad 1176$

$53 \quad 71$

388408

$562 \quad 571$

$809 \quad 818$

$1234 \quad 1243$

$1428 \quad 1438$

$554 \quad 1563$

$1699 \quad 1709$

$1710 \quad 1718$

$1710 \quad 1719$

$1781 \quad 1792$

$1783 \quad 1792$

$1836 \quad 1845$

20592068

$2319 \quad 2329$

$2361 \quad 2371$

$\begin{array}{ll}116 & 3127 \\ \end{array}$

$3270 \quad 3285$

$24 \quad 34$

$88 \quad 105$

$106 \quad 119$

$109 \quad 119$ 
Polyadenylate-binding protein $1 \mathrm{GN}=$ PABPC1 PABP1_HUMAN $70.67 \quad 100.0 \% \quad 33$

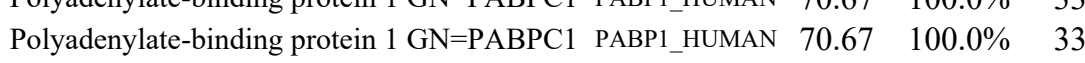
Polyadenylate-binding protein $1 \mathrm{GN}=\mathrm{PABPC} 1 \mathrm{PABP} 1$ HUMAN $70.67 \quad 100.0 \% \quad 33$ Polyadenylate-binding protein $1 \mathrm{GN}=$ PABPC1 PABP1 HUMAN $70.67 \quad 100.0 \%$ Polyadenylate-binding protein $1 \mathrm{GN}=$ PABPC1 PABP1_HUMAN $70.67 \quad 100.0 \%$ Polyadenylate-binding protein $1 \mathrm{GN}=$ PABPC1 PABP1_HUMAN $70.67 \quad 100.0 \% \quad 33$ Polyadenylate-binding protein $1 \mathrm{GN}=\mathrm{PABPC} 1 \mathrm{PABP} 1$ HUMAN $70.67 \quad 100.0 \%$ Polyadenylate-binding protein $1 \mathrm{GN}=\mathrm{PABPC} 1 \mathrm{PABP} 1$ HUMAN $70.67 \quad 100.0 \% \quad 33$ Polyadenylate-binding protein $1 \mathrm{GN}=$ PABPC1 PABP1_HUMAN $70.67 \quad 100.0 \%$ Polyadenylate-binding protein $1 \mathrm{GN}=$ PABPC1 PABP1_HUMAN $70.67 \quad 100.0 \%$ Polyadenylate-binding protein $1 \mathrm{GN}=$ PABPC1 PABP1_HUMAN $70.67 \quad 100.0 \% \quad 33$ Polyadenylate-binding protein $1 \mathrm{GN}=$ PABPC1 PABP1_HUMAN $70.67 \quad 100.0 \%$ Polyadenylate-binding protein $1 \mathrm{GN}=\mathrm{PABPC} 1 \mathrm{PABP} 1$ HUMAN $70.67 \quad 100.0 \% \quad 33$ Polyadenylate-binding protein $1 \mathrm{GN}=$ PABPC1 PABP1_HUMAN $70.67 \quad 100.0 \%$ Polyadenylate-binding protein $1 \mathrm{GN}=\mathrm{PABPC} 1$ PABP1_HUMAN $70.67 \quad 100.0 \%$ Polyadenylate-binding protein $1 \mathrm{GN}=\mathrm{PABPC} 1$ PABP1_HUMAN $70.67 \quad 100.0 \%$ Polyadenylate-binding protein $1 \mathrm{GN}=$ PABPC1 PABP1 HUMAN $70.67 \quad 100.0 \%$ Polyadenylate-binding protein $1 \mathrm{GN}=$ PABPC1 PABP1_HUMAN $70.67 \quad 100.0 \% \quad 33$ Polyadenylate-binding protein $1 \mathrm{GN}=\mathrm{PABPC} 1$ PABP1_HUMAN $70.67 \quad 100.0 \%$ Polyadenylate-binding protein $1 \mathrm{GN}=\mathrm{PABPC} 1$ PABP1_HUMAN $70.67 \quad 100.0 \%$ Polyadenylate-binding protein $1 \mathrm{GN}=\mathrm{PABPC} 1 \mathrm{PABP} 1$ HUMAN $70.67 \quad 100.0 \% \quad 33$ Polyadenylate-binding protein $4 \mathrm{GN}=\mathrm{PABPC} 4$ PABP4 HUMAN $70.78 \quad 100.0 \% \quad 1$ Polyadenylate-binding protein $4 \mathrm{GN}=$ PABPC4 PABP4_HUMAN $70.78 \quad 100.0 \% \quad 1$ Polyadenylate-binding protein $4 \mathrm{GN}=$ PABPC4 PABP4_HUMAN $70.78 \quad 100.0 \%$ Polyadenylate-binding protein $4 \mathrm{GN}=$ PABPC4 PABP4_HUMAN 70.78 Polyadenylate-binding protein $4 \mathrm{GN}=$ PABPC4 PABP4_HUMAN 70.78 Polyadenylate-binding protein $4 \mathrm{GN}=\mathrm{PABPC} 4$ PABP4_HUMAN 70.78 Polyadenylate-binding protein $4 \mathrm{GN}=\mathrm{PABPC} 4$ PABP4_HUMAN 70.78 Polyadenylate-binding protein $4 \mathrm{GN}=\mathrm{PABPC} 4$ PABP4_HUMAN 70.78 Polyadenylate-binding protein $4 \mathrm{GN}=\mathrm{PABPC} 4$ PABP4 HUMAN 70.78 Polyadenylate-binding protein $4 \mathrm{GN}=$ PABPC4 PABP4_HUMAN 70.78 Polyadenylate-binding protein $4 \mathrm{GN}=\mathrm{PABPC} 4$ PABP4_HUMAN 70.7 Polyadenylate-binding protein $4 \mathrm{GN}=\mathrm{PABPC} 4$ PABP4_HUMAN 70.78 Polyadenylate-binding protein $4 \mathrm{GN}=$ PABPC4 PABP4_HUMAN 70.78 Polyadenylate-binding protein $4 \mathrm{GN}=\mathrm{PABPC} 4$ PABP4_HUMAN 70.78 Polyadenylate-binding protein $4 \mathrm{GN}=$ PABPC4 PABP4_HUMAN 70.78 Polyadenylate-binding protein $4 \mathrm{GN}=\mathrm{PABPC} 4$ PABP4_HUMAN 70.7 Polyadenylate-binding protein $4 \mathrm{GN}=\mathrm{PABPC} 4$ PABP4 HUMAN 70.78 Polyadenylate-binding protein $4 \mathrm{GN}=$ PABPC4 PABP4_HUMAN 70.78 Polyadenylate-binding protein $4 \mathrm{GN}=\mathrm{PABPC} 4$ PABP4_HUMAN 70.7 Polyadenylate-binding protein $4 \mathrm{GN}=\mathrm{PABPC} 4$ PABP4_HUMAN 70.78 Polymerase delta-interacting protein 2 GN=POLDIP2 PDIP2_HUMAN 42.03 Polymerase delta-interacting protein 2 GN=POLDIP2 PDIP2 HUMAN 42.0 Polymerase delta-interacting protein 2 GN=POLDIP2 PDIP2_HUMAN 42.03 Polynucleotide 5'-hydroxyl-kinase NOL9 GN=NOL9 NOL9_HUMAN 79.3 Polynucleotide 5'-hydroxyl-kinase NOL9 GN=NOL9 NOL9 HUMAN 79.32 Polynucleotide 5'-hydroxyl-kinase NOL9 GN=NOL9 NOL9_HUMAN 79.32 $\begin{array}{llll}166 & 0.23 \% & 46.7 \% & \text { AKEFTNVYIK }\end{array}$

$45 \quad 166 \quad 0.23 \% \quad 46.7 \%$ FGPALSVK

$45 \quad 166 \quad 0.23 \% \quad 46.7 \%$ GFGFVSFER

$45 \quad 166 \quad 0.23 \% \quad 46.7 \%$ GFGFVSFERHEDAQK

$45 \quad 166 \quad 0.23 \% \quad 46.7 \%$ ITRYQGVNLYVK

$45 \quad 166 \quad 0.23 \% \quad 46.7 \%$ YQGVNLYVK

$45 \quad 166 \quad 0.23 \% \quad 46.7 \%$ NLDDGIDDERLR

$45 \quad 166 \quad 0.23 \% \quad 46.7 \%$ KEFSPFGTITSAK

$45 \quad 166 \quad 0.23 \% \quad 46.7 \%$ EFSPFGTITSAK

$45 \quad 166 \quad 0.23 \% \quad 46.7 \%$ SKGFGFVCFSSPEEATK

$45 \quad 166 \quad 0.23 \% \quad 46.7 \%$ GFGFVCFSSPEEATK

$45 \quad 166 \quad 0.23 \% \quad 46.7 \%$ IVATKPLYVALAQR

$45 \quad 166 \quad 0.23 \% \quad 46.7 \%$ IVATKPLYVALAQRK

$45 \quad 166 \quad 0.23 \% \quad 46.7 \%$ EERQAHLTNQYMQR

$45 \quad 166 \quad 0.23 \% \quad 46.7 \%$ QAHLTNQYMQR

$45 \quad 166 \quad 0.23 \% \quad 46.7 \%$ VANTSTQTMGPRPAAAAAAATPAVR

$45 \quad 166 \quad 0.23 \% \quad 46.7 \%$ TVPQYKYAAGVR

$45 \quad 166 \quad 0.23 \% \quad 46.7 \%$ SKVDEAVAVLQAHQAK

$45 \quad 166 \quad 0.23 \% \quad 46.7 \%$ EAAQKAVNSATGVPTV

$45 \quad 166 \quad 0.23 \% \quad 46.7 \%$ AVNSATGVPTV

$14 \quad 32 \quad 0.04 \% \quad 28.3 \%$ FSPAGPVLSIR

$14 \quad 32 \quad 0.04 \% \quad 28.3 \%$ VCRDMITR

$100.0 \%$ $100.0 \%$ $100.0 \%$ $100.0 \%$ $100.0 \%$ $100.0 \%$ $100.0 \%$ $100.0 \%$ $100.0 \%$ $100.0 \%$ $100.0 \%$ $100.0 \%$ $100.0 \%$ $100.0 \%$ $100.0 \%$ $100.0 \%$ $100.0 \%$ $100.0 \%$ $100.0 \%$ $100.0 \%$ $100.0 \%$ $100.0 \%$ $100.0 \%$ $0.04 \% \quad 28.3 \%$ ALDTMNFDVIK $0.04 \% \quad 28.3 \%$ SGVGNVFIK $0.04 \% \quad 28.3 \%$ NLDKSIDNK $0.04 \% \quad 28.3 \%$ ALYDTFSAFGNILSCK $0.04 \% \quad 28.3 \%$ EREAELGAK $0.04 \% \quad 28.3 \%$ AKEFTNVYIK $0.04 \% \quad 28.3 \%$ ISRYQGVNLYIK $0.04 \% \quad 28.3 \%$ YQGVNLYIK $0.04 \% \quad 28.3 \%$ EFSPFGSITSAK $0.04 \% \quad 28.3 \%$ SKGFGFVCFSSPEEATK $0.04 \% \quad 28.3 \%$ GFGFVCFSSPEEATK $0.04 \% \quad 28.3 \%$ IVGSKPLYVALAQR $0.04 \% \quad 28.3 \%$ IVGSKPLYVALAQRK $0.04 \% \quad 28.3 \%$ KAHLTNQYMQR $0.04 \% \quad 28.3 \%$ AHLTNQYMQR $0.04 \% \quad 28.3 \%$ EAAQKVGAVAAATS $0.01 \% \quad 10.6 \%$ SQTEAVTFLANHDDSR $0.01 \% \quad 10.6 \%$ IFSLSGTLETVR $0.01 \% \quad 10.6 \%$ GVVGREPVLSK $0.01 \% \quad 8.7 \% \quad$ ARPQLILSR $0.01 \% \quad 8.7 \%$ LIGVYTDFAFR $\begin{array}{llllll}99.7 \% & 34.3 & 25.0 & 19.1 & 2 & 0\end{array}$ $\begin{array}{llll}99.7 \% & 35.9 & 25.0 & 30.9\end{array}$ $99.0 \% \quad 40.3 \quad 25.0 \quad 11.9$ $99.7 \% \quad 50.2 \quad 25.0 \quad 37.8$ $99.6 \% \quad 23.6 \quad 25.0 \quad 22.2$ $99.7 \% \quad 44.1 \quad 25.0 \quad 39.1$ $\begin{array}{llll}99.7 \% & 42.1 & 25.0 & 37.7\end{array}$ $\begin{array}{lllll}99.7 \% & 51.8 & 25.0 & 42.7 & 2\end{array}$ $\begin{array}{llll}99.7 \% & 50.0 & 25.0 & 48.7\end{array}$ $99.7 \% \quad 52.6 \quad 25.0 \quad 45.8$ $\begin{array}{llll}99.7 \% & 69.2 & 25.0 & 69.2\end{array}$ $99.7 \% \quad 45.6 \quad 25.0 \quad 45.6$ $99.7 \% \quad 57.1 \quad 25.0 \quad 51.1$ $99.7 \% \quad 33.8 \quad 25.0 \quad 33.8$ $96.1 \% \quad 16.2 \quad 25.0 \quad 14.2$ $99.7 \% \quad 43.5 \quad 25.0 \quad 36.6$ $99.7 \% \quad 48.8 \quad 25.0 \quad 48.8$ $\begin{array}{llll}99.7 \% & 48.4 & 25.0 & 43.6\end{array}$ $\begin{array}{llll}9.7 \% & 40.0 & 25.0 & 40.0\end{array}$ $\begin{array}{llll}98.7 \% & 27.1 & 25.0 & 13.6\end{array}$ $\begin{array}{lll}25.0 & 43.3\end{array}$ $99.7 \% \quad 37.3 \quad 25.0 \quad 26.4$ $99.0 \% \quad 23.1 \quad 25.0 \quad 16.7$ $\begin{array}{lllllll}0.04 \% & 28.3 \% & \text { RSLGYAYVNFQQPADAER } & 99.7 \% & 54.1 & 25.0 & 49.3\end{array}$ $\begin{array}{llllllll}0.04 \% & 28.3 \% & \text { SLGYAYVNFQQPADAER } & 99.7 \% & 52.8 & 25.0 & 52.8 & 11\end{array}$ $\begin{array}{lllllll}0.01 \% & 8.7 \% & \text { TVNCLLVGAIAIPHCVLK } & 99.7 \% & 28.5 & 25.0 & 28.5\end{array}$ $\begin{array}{lllll}99.7 \% & 55.0 & 25.0 & 51.7 & 23\end{array}$

$\begin{array}{lllll}99.7 \% & 64.1 & 25.0 & 31.8 & 2\end{array}$

$99.7 \% \quad 29.6 \quad 25.0 \quad 19.2$

$99.7 \% \quad 49.4 \quad 25.0 \quad 41.6 \quad 3$ $99.7 \% \quad 34.0 \quad 25.0 \quad 13.9$

$99.7 \% \quad 25.5 \quad 25.0 \quad 25.5 \quad 2$ $99.7 \% \quad 40.5 \quad 25.0 \quad 32.1$ $99.7 \% \quad 54.4 \quad 25.0 \quad 54.4$ $\begin{array}{llll}99.7 \% & 69.2 & 25.0 & 69.2\end{array}$ $99.7 \% \quad 45.6 \quad 25.0 \quad 45.6 \quad 8$ $\begin{array}{llll}99.7 \% & 72.6 & 25.0 & 53.7\end{array}$ $96.0 \% \quad 14.6 \quad 25.0 \quad 14.6 \quad 0$ $\begin{array}{llll}99.7 \% & 49.0 & 25.0 & 43.5\end{array}$ $99.1 \% \quad 19.0 \quad 25.0 \quad 18.3$ $\begin{array}{llll}99.7 \% & 45.7 & 25.0 & 45.7\end{array}$ $\begin{array}{llll}99.7 \% & 43.9 & 25.0 & 43.9\end{array}$ $\begin{array}{llll}99.7 \% & 49.0 & 25.0 & 47.5\end{array}$ $\begin{array}{llll}98.3 \% & 19.4 & 25.0 & 15.9\end{array}$ $99.6 \% \quad 22.8 \quad 25.0 \quad 19.9$ $\begin{array}{llll}99.6 \% & 25.1 & 25.0 & 20.7\end{array}$ $\begin{array}{llll}99.7 \% & 35.9 & 25.0 & 30.9\end{array}$
1083.58

1430.69

1412.74

1284.65

1877.87

1662.75

1542.94

1671.03

1803.86

1405.66

2397.23

1352.73

1693.92

1542.81

1015.54

1143.65

1050.52

2085.01

1928.91

1266.64

920.52

1046.55

1806.87

1002.52

1212.66

1453.82

1097.60

1270.63

1877.87

1662.75

1514.91

1643.00

1389.71

1277.61

1273.67

1790.83

1322.73

1140.67

1053.65

1301.69 1978.10

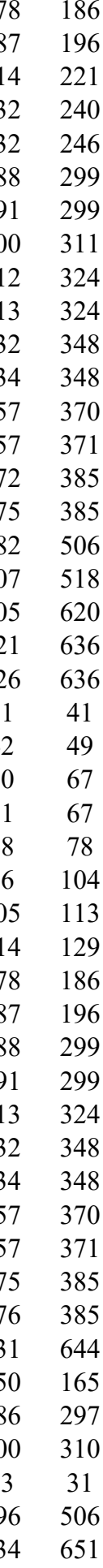

Page 96 of Table S-1-1 

Polypyrimidine tract-binding protein $1 \mathrm{GN}=$ PTBP1 PTBP1_HUMAN $57.22 \quad 100.0 \%$ Polypyrimidine tract-binding protein $1 \mathrm{GN}=$ PTBP1 PTBP1_HUMAN $57.22 \quad 100.0 \%$ Polypyrimidine tract-binding protein $1 \mathrm{GN}=$ PTBP1 PTBP1_HUMAN $57.22 \quad 100.0 \%$ Polypyrimidine tract-binding protein $1 \mathrm{GN}=$ PTBP1 PTBP1_HUMAN $57.22 \quad 100.0 \%$ Pre-mRNA 3'-end-processing factor FIP1 GN=FIP1L1 FIP1_HUMAN $66.53 \quad 100.0 \%$ Pre-mRNA 3'-end-processing factor FIP1 GN=FIP1L1 FIP1_HUMAN $66.53 \quad 100.0 \%$ Pre-mRNA 3'-end-processing factor FIP1 GN=FIP1L1 FIP1_HUMAN $66.53 \quad 100.0 \%$ Pre-mRNA 3'-end-processing factor FIP1 GN=FIP1L1 FIP1 HUMAN $66.53 \quad 100.0 \%$ Pre-mRNA-processing factor 6 GN=PRPF6 PRP6_HUMAN $106.93 \quad 100.0 \%$ Pre-mRNA-processing factor 6 GN=PRPF6 PRP6_HUMAN $106.93 \quad 100.0 \%$ Pre-mRNA-processing factor 6 GN=PRPF6 PRP6_HUMAN $106.93 \quad 100.0 \%$ Pre-mRNA-processing factor 6 GN=PRPF6 PRP6_HUMAN $106.93 \quad 100.0 \%$ Pre-mRNA-processing factor 6 GN=PRPF6 PRP6_HUMAN $106.93 \quad 100.0 \%$ Pre-mRNA-processing factor 6 GN=PRPF6 PRP6_HUMAN $106.93 \quad 100.0 \%$ Pre-mRNA-processing factor 6 GN=PRPF6 PRP6_HUMAN $106.93 \quad 100.0 \%$ Pre-mRNA-processing factor 6 GN=PRPF6 PRP6 HUMAN $106.93100 .0 \%$ Pre-mRNA-processing factor 6 GN=PRPF6 PRP6_HUMAN $106.93 \quad 100.0 \%$ Pre-mRNA-processing factor 6 GN=PRPF6 PRP6_HUMAN $106.93 \quad 100.0 \%$ Pre-mRNA-processing factor 6 GN=PRPF6 PRP6_HUMAN $106.93 \quad 100.0 \%$ Pre-mRNA-processing-splicing factor 8 GN=PRPF8 PRP8_HUMAN $273.61 \quad 100.0 \%$ Pre-mRNA-processing-splicing factor 8 GN=PRPF8 PRP8_HUMAN $273.61 \quad 100.0 \%$ Pre-mRNA-processing-splicing factor 8 GN=PRPF8 PRP8_HUMAN $273.61 \quad 100.0 \%$ Pre-mRNA-processing-splicing factor 8 GN=PRPF8 PRP8_HUMAN $273.61 \quad 100.0 \%$ Pre-mRNA-processing-splicing factor 8 GN=PRPF8 PRP8 HUMAN $273.61 \quad 100.0 \%$ Pre-mRNA-processing-splicing factor 8 GN=PRPF8 PRP8_HUMAN $273.61 \quad 100.0 \%$ Pre-mRNA-processing-splicing factor 8 GN=PRPF8 PRP8_HUMAN $273.61 \quad 100.0 \%$ Pre-mRNA-processing-splicing factor 8 GN=PRPF8 PRP8_HUMAN $273.61 \quad 100.0 \%$ Pre-mRNA-processing-splicing factor 8 GN=PRPF8 PRP8_HUMAN $273.61 \quad 100.0 \% \quad 2$ Pre-mRNA-processing-splicing factor 8 GN=PRPF8 PRP8_HUMAN $273.61 \quad 100.0 \% \quad 29$ Pre-mRNA-processing-splicing factor 8 GN=PRPF8 PRP8_HUMAN $273.61 \quad 100.0 \% \quad 29$ Pre-mRNA-processing-splicing factor 8 GN=PRPF8 PRP8_HUMAN $273.61 \quad 100.0 \%$ Pre-mRNA-processing-splicing factor 8 GN=PRPF8 PRP8_HUMAN $273.61 \quad 100.0 \% \quad 29$ Pre-mRNA-processing-splicing factor 8 GN=PRPF8 PRP8_HUMAN $273.61 \quad 100.0 \% \quad 29$ Pre-mRNA-processing-splicing factor $8 \mathrm{GN}=$ PRPF8 PRP8_HUMAN $273.61 \quad 100.0 \%$ 2 Pre-mRNA-processing-splicing factor 8 GN=PRPF8 PRP8_HUMAN $273.61 \quad 100.0 \% \quad 29$ Pre-mRNA-processing-splicing factor 8 GN=PRPF8 PRP8_HUMAN $273.61 \quad 100.0 \% 29$ Pre-mRNA-processing-splicing factor $8 \mathrm{GN}=$ PRPF8 PRP8 HUMAN $273.61 \quad 100.0 \%$ Pre-mRNA-processing-splicing factor 8 GN=PRPF8 PRP8_HUMAN $273.61 \quad 100.0 \% \quad 29$ Pre-mRNA-processing-splicing factor $8 \mathrm{GN}=$ PRPF8 PRP8_HUMAN $273.61 \quad 100.0 \%$ Pre-mRNA-processing-splicing factor 8 GN=PRPF8 PRP8_HUMAN $273.61 \quad 100.0 \% \quad 29$ Pre-mRNA-processing-splicing factor 8 GN=PRPF8 PRP8_HUMAN $273.61 \quad 100.0 \% \quad 29$ Pre-mRNA-processing-splicing factor 8 GN=PRPF8 PRP8_HUMAN $273.61 \quad 100.0 \% \quad 2$ Pre-mRNA-processing-splicing factor 8 GN=PRPF8 PRP8_HUMAN $273.61 \quad 100.0 \% \quad 29$ Pre-mRNA-processing-splicing factor 8 GN=PRPF8 PRP8_HUMAN $273.61 \quad 100.0 \%$ Pre-mRNA-processing-splicing factor 8 GN=PRPF8 PRP8 HUMAN $273.61 \quad 100.0 \% \quad 29$ $\begin{array}{llll}\text { Pre-mRNA-processing-splicing factor } 8 \text { GN=PRPF8 PRP8_HUMAN } 273.61 & 100.0 \% & 29\end{array}$

$\begin{array}{lll}0.01 \% & 8.7 \% & \text { GIEGTVPYVTTDYNF } \\ 0.01 \% & 8.9 \% & \text { SAGVPSRVIHIR }\end{array}$

$\begin{array}{lll}0.01 \% & 8.9 \% & \text { SAGVPSRVIHI } \\ 0.01 \% & 8.9 \% & \text { HQNVQLPR }\end{array}$

$0.01 \% \quad 8.9 \% \quad$ EGQEDQGLTKDYGNSPLHR $\quad 99.4 \% \quad 24.6$

$0.01 \% \quad 8.9 \%$ VSFSKSTI $\begin{array}{llllll}0.01 \% & 7.9 \% & \text { TGAPQYGSYGTAPVNLNIK } & 99.7 \% & 52.0 \\ 0.01 \% & 7.9 \% & \text { TGGRVYGTTGTK } & 99.5 \% & 21.8\end{array}$ $0.01 \% \quad 7.9 \%$ VYGTTGTKVK $0.01 \% \quad 7.9 \%$ NSTSSQSQTSTASR

$0.03 \% \quad 13.1 \%$ IQQQFSDLKR $0.03 \% \quad 13.1 \%$ LEEVTGKLQVAR $0.03 \% \quad 13.1 \%$ AVVAQAVR $0.03 \% \quad 13.1 \%$ AVVAQAVRHLPQSVR $0.03 \% \quad 13.1 \%$ AAELETDIRAK

$0.03 \% \quad 13.1 \%$ ALEHVPNSVR 0.03\% $13.1 \%$ AAVELEEPEDARIMLSR $99.7 \% 37.4$ $0.03 \% \quad 13.1 \%$ AIYAYALQVFPSKK $0.03 \% \quad 13.1 \%$ ESLEALLQR $0.03 \% \quad 13.1 \%$ SKWLAGDVPAAR $0.03 \% \quad 13.1 \%$ AGLKNIANTLMAK $0.11 \% \quad 11.4 \%$ KWQQLQAK $0.11 \% \quad 11.4 \%$ RALDIPLVK $0.11 \% \quad 11.4 \%$ ALDIPLVK $0.11 \% \quad 11.4 \%$ YYVLNALK $0.11 \% \quad 11.4 \%$ FNTGPVGK $0.11 \% \quad 11.4 \%$ LYLKAEQER $0.11 \% \quad 11.4 \%$ LLILALER $0.11 \% \quad 11.4 \%$ LKEAYSVK $0.11 \% \quad 11.4 \%$ IDLTLLNR $0.11 \% \quad 11.4 \%$ LIVDHNIADYMTAK $0.11 \% \quad 11.4 \%$ FTADEARDLIQR $0.11 \% \quad 11.4 \%$ YLTEHPDPNNENIVGYNNKK $0.11 \% \quad 11.4 \%$ QILMASGSTTFTK $0.11 \% \quad 11.4 \%$ QTDVGITHFR $0.11 \% \quad 11.4 \%$ RQEAIAQNR $0.11 \% \quad 11.4 \%$ TDFKQYQVLK $0.11 \% \quad 11.4 \%$ SGLNQIPNRR $0.11 \% \quad 11.4 \%$ ISLIQIFR

$0.11 \% \quad 11.4 \%$ ANPALYVLR $0.11 \% \quad 11.4 \%$ SLPVEEQPK $0.11 \% \quad 11.4 \%$ SLPVEEQPKQIIVTR $0.11 \% \quad 11.4 \%$ TISSYTAFSR $0.11 \% \quad 11.4 \%$ QTKEQSQLTATQTR $0.11 \% \quad 11.4 \%$ EQSQLTATQTR $0.11 \% \quad 11.4 \%$ AISAANLHLR $0.11 \% \quad 11.4 \%$ KFICISDLR $0.11 \% \quad 11.4 \%$ FICISDLR $\begin{array}{llll}99.7 \% & 30.0 & 25.0 & 27.8\end{array}$ $98.8 \% \quad 17.8$ $98.4 \% \quad 19.0$ $\begin{array}{ll}99.0 \% & 29.1 \\ 99.7 \% & 52.0\end{array}$ $\begin{array}{ll}99.5 \% & 21.8 \\ 99.7 \% & 27.4\end{array}$ $99.7 \% \quad 47.7$ $99.7 \% \quad 43.5$ $\begin{array}{lll}95.4 \% & 13.7\end{array}$ $99.0 \% \quad 52.9$ $99.6 \% 22.6$ $\begin{array}{lll}99.7 \% & 41.8\end{array}$ $99.0 \% \quad 18.6$

991.54

2144.00

868.48

1950.99

1197.62

1053.59

1441.65

1262.69

1342.77

813.49

1630.95

1216.65

1121.61

1944.97

1598.89

1058.58

1270.69

1344.77

1029.58

1024.65

868.55

983.56

819.44

1149.63

940.62

937.54

957.57

1603.82

1434.73

2359.13

1384.71

1173.60

1085.58

1269.68

1154.64

989.61

1016.59

1026.55

1736.99

14.6
55.8

$\begin{array}{llll}99.5 \% & 20.8 & 25.0 & 20.8\end{array}$

$\begin{array}{llll}98.9 \% & 26.0 & 25.0 & 22.6\end{array}$

$\begin{array}{llll}99.7 \% & 51.7 & 25.0 & 38.5\end{array}$

$\begin{array}{llll}99.7 \% & 59.7 & 25.0 & 44.4\end{array}$

$\begin{array}{llll}95.7 \% & 14.9 & 25.0 & 13.9\end{array}$

$99.0 \% \quad 52.4 \quad 25.0 \quad 39.1$

1262.63

1065.62

1151.62 1023.53

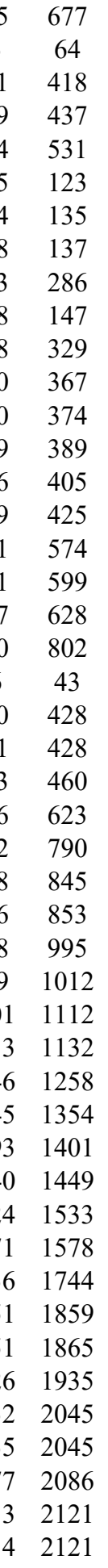


Pre-mRNA-processing-splicing factor 8 GN=PRPF8 PRP8_HUMAN $273.61 \quad 100.0 \% \quad 29$ Pre-mRNA-processing-splicing factor 8 GN=PRPF8 PRP8_HUMAN $273.61 \quad 100.0 \% \quad 29$ Pre-mRNA-splicing factor ATP-dependent RNA helicase DHX15 GN=DHX15 DHX15_HUMAN $90.94 \quad 100.0 \% \quad 14$ Pre-mRNA-splicing factor ATP-denendent RNA helicase DHX15 GN=DHX15 DHX15 HUMAN $90.94 \quad 100.0 \%$ Pre-mRNA-splicing factor ATP-dependent RNA helicase DHX15 GN=DHX15 DHX15_HUMAN $90.94 \quad 100.0 \% \quad 14$ Pre-mRNA-splicing factor ATP-dependent RNA helicase DHX15 GN=DHX15 $\quad$ DHX15_HUMAN $90.94 \quad 100.0 \% \quad 1$ Pre-mRNA-splicing factor ATP-dependent RNA helicase DHX15 GN=DHX15 DHX15_HUMAN $90.94 \quad 100.0 \% \quad 14$ Pre-mRNA-splicing factor ATP-dependent RNA helicase DHX15 GN=DHX15 DHX15_HUMAN $90.94 \quad 100.0 \%$ Pre-mRNA-splicing factor ATP-dependent RNA helicase DHX15 GN=DHX15 DHX15 HUMAN $90.94 \quad 100.0 \%$ Pre-mRNA-splicing factor ATP-dependent RNA helicase DHX15 GN=DHX15 DHX15_HUMAN $90.94 \quad 100.0 \%$ Pre-mRNA-splicing factor ATP-dependent RNA helicase DHX15 GN=DHX15 DHX15_HUMAN $90.94 \quad 100.0 \%$

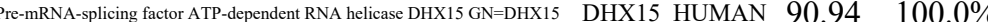
Pre-mRNA-splicing factor ATP-dependent RNA helicase DHX15 GN=DHX15 DHX15_HUMAN $90.94 \quad 100.0 \%$ Pre-mRNA-splicing factor ATP-dependent RNA helicase DHX15 GN=DHX15 DHX15_HUMAN $90.94 \quad 100.0 \%$ Pre-mRNA-splicing factor ATP-dependent RNA helicase DHX15 GN=DHX15 DHX15 HUMAN $90.94 \quad 100.0 \%$ Pre-mRNA-splicing factor ATP-dependent RNA helicase DHX15 GN=DHX15 DHX15_HUMAN $90.94 \quad 100.0 \%$ Probable $28 \mathrm{~S}$ rRNA (cytosine(4447)-C(5))-methyltransferase GN=NOP2 NOP2 HUMAN $89.30100 .0 \%$ Probable 28S rRNA (cytosine(4447)-C(5))-methyltransferase GN=NOP2 NOP2_HUMAN $89.30 \quad 100.0 \%$ Probable 28S rRNA (cytosine(4447)-C(5))-methyltransferase GN=NOP2 NOP2_HUMAN $89.30 \quad 100.0 \%$

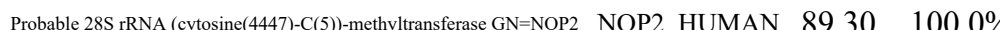
Probable 28S rRNA (cytosine(4447)-C(5))-methyltransferase GN=NOP2 NOP2_HUMAN $89.30 \quad 100.0 \%$ Probable ATP-dependent RNA helicase DDX17 GN=DDX17 DDX17 HUMAN $80.27 \quad 100.0 \%$ Probable ATP-dependent RNA helicase DDX17 GN=DDX17 DDX17_HUMAN $80.27 \quad 100.0 \%$ Probable ATP-dependent RNA helicase DDX17 GN=DDX17 DDX17_HUMAN $80.27 \quad 100.0 \%$ Probable ATP-dependent RNA helicase DDX17 GN=DDX17 DDX17 HUMAN 80.27 Probable ATP-dependent RNA helicase DDX17 GN=DDX17 DDX17_HUMAN 80.27 Probable ATP-dependent RNA helicase DDX17 GN=DDX17 DDX17_HUMAN 80.27 Probable ATP-dependent RNA helicase DDX17 GN=DDX17 DDX17 HUMAN 80.27 Probable ATP-dependent RNA helicase DDX17 GN=DDX17 DDX17_HUMAN 80.27 Probable ATP-dependent RNA helicase DDX17 GN=DDX17 DDX17_HUMAN 80.27 Probable ATP-dependent RNA helicase DDX17 GN=DDX17 DDX17_HUMAN 80.27 Probable ATP-dependent RNA helicase DDX17 GN=DDX17 DDX17_HUMAN 80.27 Probable ATP-dependent RNA helicase DDX17 GN=DDX17 DDX17_HUMAN 80.27 Probable ATP-dependent RNA helicase DDX17 GN=DDX17 DDX17_HUMAN 80.27 Probable ATP-dependent RNA helicase DDX17 GN=DDX17 DDX17_HUMAN 80.27 Probable ATP-dependent RNA helicase DDX17 GN=DDX17 DDX17 HUMAN 80.27 Probable ATP-dependent RNA helicase DDX17 GN=DDX17 DDX17_HUMAN 80.27 Probable ATP-dependent RNA helicase DDX17 GN=DDX17 DDX17 HUMAN 80.2 Probable ATP-dependent RNA helicase DDX17 GN=DDX17 DDX17_HUMAN 80.27 Probable ATP-dependent RNA helicase DDX17 GN=DDX17 DDX17_HUMAN 80.27 Probable ATP-dependent RNA helicase DDX20 GN=DDX20 DDX20 HUMAN 92.24 Probable ATP-dependent RNA helicase DDX20 GN=DDX20 DDX20_HUMAN 92.2 Probable ATP-dependent RNA helicase DDX20 GN=DDX20 DDX20 HUMAN 92.24 Probable ATP-dependent RNA helicase DDX23 GN=DDX23 DDX23 HUMAN 95.59 Probable ATP-dependent RNA helicase DDX23 GN=DDX23 DDX23_HUMAN 95.59 Probable ATP-dependent RNA helicase DDX27 GN=DDX27 DDX27_HUMAN 89.84 Probable ATP-dependent RNA helicase DDX27 GN=DDX27 DDX27_HUMAN 89.84

$\begin{array}{ll}00.0 \% & 12 \\ 100.0 \% & 12\end{array}$

$100.0 \% \quad 12$

$100.0 \% \quad 12$

$100.0 \% \quad 12$

$100.0 \% \quad 12$

$100.0 \% \quad 12$

$100.0 \% \quad 12$

$100.0 \% \quad 12$

$100.0 \% \quad 12$

$100.0 \% \quad 12$

$100.0 \% \quad 12$

$100.0 \% \quad 12$

$100.0 \% \quad 12$

$100.0 \% \quad 12$

$100.0 \% \quad 12$

$100.0 \% \quad 3$

$100.0 \%$

$100.0 \%$

$100.0 \% \quad 2$

$100.0 \% \quad 2$

$100.0 \%$

5
5
5

5

5
5
12

12

12
12
12

0.11\% $11.4 \%$ AQIAGYLYGVSPPDNPQVK

$0.11 \% \quad 11.4 \%$ GYLPSHYER

$0.05 \% \quad 17.6 \%$ ASTNAMLISAGLPPLK

$\begin{array}{ll}99.7 \% & 46.5 \\ 99.7 \% & 35.2\end{array}$

$99.5 \% \quad 24.2$

$99.7 \% \quad 56.9$

$99.7 \% \quad 42.8$

$99.7 \% \quad 45.7$

$99.7 \% \quad 56.0$

$99.7 \% \quad 48.9$

$99.7 \% \quad 52.4$

$99.7 \% \quad 30.1$

$99.7 \% \quad 61.8$

$99.7 \% \quad 54.7$

$99.7 \% \quad 34.7$

$\begin{array}{lll}96.8 \% & 27.0\end{array}$

$99.7 \% \quad 59.3$

$99.7 \% \quad 28.9$

$99.7 \% \quad 63.4$

$99.7 \% \quad 53.9$

$99.7 \% \quad 48.9$

$99.7 \% \quad 42.5$

$99.7 \% \quad 38.5$

$99.7 \% \quad 30.3$

$99.7 \% \quad 48.7$

$\begin{array}{ll}98.8 \% & 22.1\end{array}$

$99.7 \% \quad 39.7$

$99.7 \% \quad 48.4$

$\begin{array}{lll}99.7 \% & 59.3\end{array}$

$0.06 \% \quad 27.2 \%$ GDGPICLVLAPTR

$\begin{array}{lllll}16 & 43 & 0.06 \% & 27.2 \% & \text { GDGPICLVLAPTR } \\ 16 & 43 & 0.06 \% & 27.2 \% & \text { ELAQQVQQVADDYGK }\end{array}$

$99.5 \% \quad 22.0$

$0.06 \% \quad 27.2 \%$ ELAQQVQQVADDYGKCSR

$\begin{array}{llll}16 & 43 & 0.06 \% & 27.2 \% \\ 16 & \text { LKSTCIYGGAPK }\end{array}$

$16 \quad 43 \quad 0.06 \% \quad 27.2 \%$ STCIYGGAPK

$\begin{array}{llll}16 & 43 & 0.06 \% & 27.2 \% \\ 16 & \text { GPQIRDLER }\end{array}$

$16 \quad 43 \quad 0.06 \% \quad 27.2 \%$ GVEICIATPGR

$\begin{array}{llll}16 & 43 & 0.06 \% & 27.2 \% \\ 16 & \text { IVDQIRPDR }\end{array}$

$16 \quad 43 \quad 0.06 \% \quad 27.2 \%$ SGKAPILIATDVASR

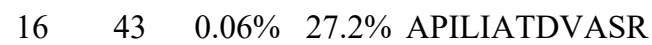

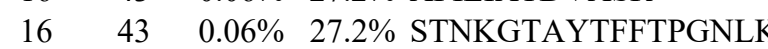

\begin{tabular}{llll}
16 & 43 & $0.06 \%$ & $27.2 \%$ \\
16 & 43 & $0.06 \%$ & $27.2 \%$ \\
\hline
\end{tabular}

$16 \quad 43 \quad 0.06 \% \quad 27.2 \%$ VLEEANQAINPK

$\begin{array}{lllll}16 & 43 & 0.06 \% & 27.2 \% & \text { LMQLVDHRGGGGGGGGR }\end{array}$

$\begin{array}{llll}16 & 43 & 0.06 \% & 27.2 \% \\ 3 & 5 S Q S S S Q Q F S G I G R\end{array}$

$0.01 \% \quad 3.5 \%$ TAQDLSSPR

$0.01 \% \quad 3.5 \%$ VLISTDLTSR

$0.01 \% \quad 3.5 \%$ NNSVSGLSVK

$\begin{array}{ll}99.7 \% & 55.8 \\ 99.7 \% & 57.5\end{array}$

$99.7 \% \quad 57.5$

$94.9 \% \quad 22.9$

$99.7 \% \quad 46.9$

$98.2 \% \quad 18.4$

$99.7 \% \quad 47.2$

$99.7 \% \quad 51.9$

$99.7 \% \quad 52.0$

$99.7 \% \quad 51.8$

$99.7 \% \quad 50.8$

$99.6 \% 23.8$

$99.7 \% \quad 71.2$

$99.7 \% \quad 49.7$

$99.7 \% \quad 38.7$

$99.7 \% \quad 44.7$

$\begin{array}{lllll}0.00 \% & 4.5 \% & \text { QAIPIGLQNRDIIGVAETGSGK } & 99.7 \% & 34.7\end{array}$

$\begin{array}{lllll}0.00 \% & 4.5 \% & \text { AGAKDILVATDVAGR } \quad 99.7 \% & 34.3\end{array}$

$0.00 \% \quad 4.0 \%$ ACIPVGLLGKDICACAATGTGK $97.0 \% \quad 17.2$

$0.00 \% \quad 4.0 \%$ ALQEFDLALR

$99.7 \% \quad 40.0$
$1121.54 \quad 2250 \quad 2258$

1583.88

1445.74

1044.54

1088.60

932.50

1414.73

1428.88

1971.95

1157.69

1285.78

992.48

1604.82

1734.90

1145.55

1059.58

1214.66

1636.83

1390.7

1625.74

1477.75

1360.66

1390.73

1163.57

1368.73

1691.82

2094.99

1294.68

1053.50

1083.59

1172.61

1111.62

1498.86

1226.71

1846.93

1809.01

1325.71

1623.81

1455.68

974.49

1104.63

1004.54

2237.23

1456.81

2233.11

1175.64

$\begin{array}{cc}63 & 2258 \\ 153 & 166 \\ 186 & 194 \\ 195 & 204 \\ 196 & 204 \\ 254 & 265 \\ 451 & 463 \\ 489 & 504 \\ 505 & 515 \\ 505 & 516 \\ 653 & 661 \\ 653 & 666 \\ 692 & 706 \\ 787 & 795 \\ 80 & 91 \\ 92 & 102 \\ 539 & 553 \\ 656 & 669 \\ 670 & 685 \\ 69 & 81 \\ 133 & 143 \\ 144 & 154 \\ 210 & 221 \\ 242 & 254 \\ 255 & 269 \\ 255 & 272 \\ 273 & 284 \\ 275 & 284 \\ 285 & 293 \\ 294 & 304 \\ 342 & 350 \\ 466 & 480 \\ 469 & 480 \\ 512 & 528 \\ 532 & 547 \\ 536 & 547 \\ 548 & 564 \\ 671 & 684 \\ 42 & 50 \\ 362 & 371 \\ 498 & 507 \\ 420 & 441 \\ 712 & 726 \\ 247 & 268 \\ 667 & 676 \\ & \end{array}$

Page 98 of Table S-1-1 
Probable ATP-dependent RNA helicase DDX28 GN=DDX28 DDX28_HUMAN $59.58 \quad 100.0 \%$ Probable ATP-dependent RNA helicase DDX28 GN=DDX28 DDX28_HUMAN $59.58 \quad 100.0 \%$ Probable ATP-dependent RNA helicase DDX28 GN=DDX28 DDX28_HUMAN $59.58 \quad 100.0 \%$ Probable ATP-dependent RNA helicase DDX28 GN=DDX28 DDX28_HUMAN $59.58 \quad 100.0 \%$ Probable ATP-dependent RNA helicase DDX28 GN=DDX28 DDX28_HUMAN $59.58 \quad 100.0 \%$ Probable ATP-dependent RNA helicase DDX31 GN=DDX31 DDX31_HUMAN $94.09 \quad 100.0 \%$ Probable ATP-dependent RNA helicase DDX31 GN=DDX31 DDX31_HUMAN $94.09 \quad 100.0 \%$ Probable ATP-dependent RNA helicase DDX31 GN=DDX31 DDX31_HUMAN $94.09 \quad 100.0 \%$ Probable ATP-dependent RNA helicase DDX31 GN=DDX31 DDX31_HUMAN $94.09 \quad 100.0 \%$ Probable ATP-dependent RNA helicase DDX41 GN=DDX41 DDX41_HUMAN $69.84 \quad 100.0 \%$ Probable ATP-dependent RNA helicase DDX41 GN=DDX41 DDX41_HUMAN $69.84 \quad 100.0 \%$ Probable ATP-dependent RNA helicase DDX5 GN=DDX5 DDX5_HUMAN $69.15 \quad 100.0 \%$ Probable ATP-dependent RNA helicase DDX5 GN=DDX5 DDX5_HUMAN $69.15 \quad 100.0 \%$ Probable ATP-dependent RNA helicase DDX5 GN=DDX5 DDX5_HUMAN $69.15 \quad 100.0 \%$ Probable ATP-dependent RNA helicase DDX5 GN=DDX5 DDX5_HUMAN $69.15 \quad 100.0 \%$ Probable ATP-dependent RNA helicase DDX5 GN=DDX5 DDX5_HUMAN $69.15 \quad 100.0 \%$ Probable ATP-dependent RNA helicase DDX5 GN=DDX5 DDX5 HUMAN $69.15 \quad 100.0 \%$ Probable ATP-dependent RNA helicase DDX5 GN=DDX5 DDX5_HUMAN $69.15 \quad 100.0 \%$ Probable ATP-dependent RNA helicase DDX5 GN=DDX5 DDX5_HUMAN $69.15 \quad 100.0 \%$ Probable ATP-dependent RNA helicase DDX5 GN=DDX5 DDX5_HUMAN $69.15 \quad 100.0 \%$ Probable ATP-dependent RNA helicase DDX5 GN=DDX5 DDX5_HUMAN $69.15 \quad 100.0 \%$ Probable ATP-dependent RNA helicase DDX5 GN=DDX5 DDX5_HUMAN $69.15 \quad 100.0 \%$ Probable ATP-dependent RNA helicase DDX5 GN=DDX5 DDX5_HUMAN $69.15 \quad 100.0 \%$ Probable ATP-dependent RNA helicase DDX5 GN=DDX5 DDX5_HUMAN $69.15 \quad 100.0 \%$ Probable ATP-dependent RNA helicase DDX5 GN=DDX5 DDX5 HUMAN $69.15 \quad 100.0 \%$ Probable ATP-dependent RNA helicase DDX5 GN=DDX5 DDX5_HUMAN $69.15 \quad 100.0 \%$ Probable ATP-dependent RNA helicase DDX5 GN=DDX5 DDX5_HUMAN $69.15 \quad 100.0 \%$ Probable ATP-dependent RNA helicase DDX5 GN=DDX5 DDX5_HUMAN $69.15 \quad 100.0 \%$ Probable ATP-dependent RNA helicase DDX5 GN=DDX5 DDX5_HUMAN $69.15 \quad 100.0 \%$ Probable ATP-dependent RNA helicase DDX5 GN=DDX5 DDX5 HUMAN $69.15 \quad 100.0 \%$ Probable ATP-dependent RNA helicase DDX52 GN=DDX52 DDX52_HUMAN $67.50 \quad 100.0 \%$ Probable ATP-dependent RNA helicase DDX52 GN=DDX52 DDX52_HUMAN $67.50 \quad 100.0 \%$ Probable ATP-dependent RNA helicase DHX40 GN=DHX40 DHX40_HUMAN $88.56 \quad 100.0 \%$ Probable ATP-dependent RNA helicase DHX40 GN=DHX40 DHX40_HUMAN $88.56 \quad 100.0 \%$ Probable C-mannosyltransferase DPY19L1 GN=DPY19L1 D19L1_HUMAN $77.32 \quad 100.0 \%$ Probable C-mannosyltransferase DPY19L1 GN=DPY19L1 D19L1_HUMAN $77.32 \quad 100.0 \%$ Probable cytosolic iron-sulfur protein assembly protein $\mathrm{CIAO1} \mathrm{GN}=\mathrm{CIAO1}$ CIAO1_HUMAN $37.84 \quad 100.0 \%$ Probable cytosolic iron-sulfur protein assembly protein $\mathrm{CIAOI} \mathrm{GN}=\mathrm{CIAO} \quad \mathrm{CIAO}$ _HUMAN $37.84 \quad 100.0 \%$ Probable dimethyladenosine transferase GN=DIMT1 DIM1_HUMAN $35.24 \quad 100.0 \%$ Probable dimethyladenosine transferase GN=DIMT1 DIM1_HUMAN $35.24 \quad 100.0 \%$ Probable dimethyladenosine transferase GN=DIMT1 DIM1_HUMAN $35.24 \quad 100.0 \%$ Probable dimethyladenosine transferase GN=DIMT1 DIM1_HUMAN $35.24 \quad 100.0 \%$ Probable dimethyladenosine transferase GN=DIMT1 DIM1_HUMAN $35.24 \quad 100.0 \%$ Probable dimethyladenosine transferase GN=DIMT1 DIM1_HUMAN $35.24 \quad 100.0 \%$ Probable dimethyladenosine transferase GN=DIMT1 DIM1_HUMAN $35.24 \quad 100.0 \%$ Probable dimethyladenosine transferase GN=DIMT1 DIM1_HUMAN $35.24 \quad 100.0 \%$ Probable dimethyladenosine transferase GN=DIMT1 DIM1_HUMAN $35.24 \quad 100.0 \%$
$0.01 \% \quad 12.6 \%$ GSFADLGLEPR $0.01 \% \quad 12.6 \%$ LLGQPSLDSLPIPAPR $0.01 \% \quad 12.6 \%$ GLVLVPSRELAQQVR $0.01 \% \quad 12.6 \%$ VGIFQSFQK $0.01 \% \quad 12.6 \%$ SLPGLASSVKEPLPQAT $0.01 \% \quad 5.4 \% \quad$ QSIPVLLEGRDALVR $0.01 \% \quad 5.4 \%$ GINILISTPGR $0.01 \% \quad 5.4 \%$ LVCLAAFILQK $0.01 \% \quad 5.4 \%$ SLHLGHVAK $0.00 \% \quad 3.9 \% \quad$ LLQEDSSPLLR $0.00 \% \quad 3.9 \%$ SALVKPVTINVGR $0.09 \% \quad 28.7 \%$ DRGFGAPR $0.09 \% \quad 28.7 \%$ KFGNPGEK $0.09 \% \quad 28.7 \%$ NFYQEHPDLARR $0.09 \% \quad 28.7 \%$ TAQEVETYR $0.09 \% \quad 28.7 \%$ TAQEVETYRR $0.09 \% \quad 28.7 \%$ GDGPICLVLAPTR $0.09 \% \quad 28.7 \%$ ELAQQVQQVAAEYCR $0.09 \% \quad 28.7 \%$ LKSTCIYGGAPK $0.09 \% \quad 28.7 \%$ STCIYGGAPK $0.09 \% \quad 28.7 \%$ GPQIRDLER $0.09 \% \quad 28.7 \%$ GVEICIATPGR $0.09 \% \quad 28.7 \%$ IVDQIRPDR $0.09 \% \quad 28.7 \%$ LMEEIMSEKENK $0.09 \% \quad 28.7 \%$ APILIATDVASR $0.09 \% \quad 28.7 \%$ TGTAYTFFTPNNIK $0.09 \% \quad 28.7 \%$ QVSDLISVLR $0.09 \% \quad 28.7 \%$ EANQAINPK $0.09 \% \quad 28.7 \%$ LLQLVEDR $0.09 \% \quad 28.7 \%$ LLQLVEDRGSGR $0.01 \% \quad 4.3 \%$ ELLASAPTGSGK $0.01 \% \quad 4.3 \%$ AITFFTEDDKPLLR $0.01 \% \quad 3.1 \%$ LGLDILEVVPISK $0.01 \% \quad 3.1 \%$ TSLTSVVLTLK $0.01 \% \quad 4.3 \% \quad$ YSTKPDAVFAGAMPTMASVK $0.01 \% \quad 4.3 \%$ TPLCNLLVK $0.01 \% \quad 5.9 \% \quad$ SVLSEGHQR $0.01 \% \quad 5.9 \%$ LASCSDDRTVR $0.02 \% \quad 31.9 \%$ NPLIINSIIDK $0.02 \% \quad 31.9 \%$ AALRPTDVVLEVGPGTGNMTVK $0.02 \% \quad 31.9 \%$ LVAELHKR $0.02 \% \quad 31.9 \%$ LVAKPGDKLYCR $0.02 \% \quad 31.9 \%$ LSINTQLLAR $0.02 \% \quad 31.9 \%$ NNFRPPPKVESSVVR $0.02 \% \quad 31.9 \%$ SSAVQQLLEK $0.02 \% \quad 31.9 \%$ SSAVQQLLEKNYR $0.02 \% \quad 31.9 \%$ SMDIDDFIR
$99.7 \% \quad 55.8$

$99.7 \% \quad 59.0$

$\begin{array}{cccccccc}99.0 \% & 53.6 & 25.0 & 37.8 & 2 & 0 & 0 & 985.57 \\ 99.7 \% & 57.7 & 25.0 & 48.6 & 6 & 2 & 0 & 1342.74\end{array}$

$\begin{array}{llll}99.7 \% & 57.7 & 25.0 & 48.6\end{array}$

$\begin{array}{llll}99.7 \% & 25.6 & 25.0 & 25.6\end{array}$

$\begin{array}{llll}99.7 \% & 62.3 & 25.0 & 62.3\end{array}$

$\begin{array}{llll}99.7 \% & 38.0 & 25.0 & 38.0\end{array}$

$\begin{array}{llll}99.7 \% & 43.2 & 25.0 & 43.2\end{array}$

$\begin{array}{llll}97.1 \% & 16.0 & 25.0 & 16.0\end{array}$

$\begin{array}{llll}99.7 \% & 31.3 & 25.0 & 26.1\end{array}$

$\begin{array}{llll}99.7 \% & 47.8 & 25.0 & 36.5\end{array}$

$99.0 \% \quad 18.4 \quad 25.0 \quad 18.4$

$\begin{array}{llll}99.7 \% & 38.2 & 25.0 & 38.2\end{array}$

$\begin{array}{llll}99.7 \% & 38.2 & 25.0 & 38.2\end{array}$

$\begin{array}{llll}99.0 \% & 41.1 & 25.0 & 21.0\end{array}$

$99.7 \% \quad 33.9 \quad 25.0 \quad 26.6$

$99.7 \% \quad 48.5 \quad 25.0 \quad 46.4$

$\begin{array}{llll}99.2 \% & 25.3 & 25.0 & 25.3\end{array}$

$\begin{array}{llll}99.7 \% & 57.8 & 25.0 & 40.1\end{array}$

$\begin{array}{llll}99.7 \% & 52.3 & 25.0 & 50.3\end{array}$ $\begin{array}{llll}99.7 \% & 25.9 & 25.0 & 21.6\end{array}$
1096.53

1252.63

1368.73

1792.86

1294.68

1053.50

1083.59

1172.61

1111.62

1480.70

1226.71

1574.79

1129.66

984.51

$\begin{array}{cc}26 & 136 \\ 90 & 205 \\ 06 & 220 \\ 37 & 445 \\ 24 & 540 \\ 60 & 274 \\ 56 & 366 \\ 94 & 504 \\ 37 & 745 \\ 83 & 293 \\ 88 & 400 \\ 3 & 20 \\ 3 & 40 \\ 7 & 68 \\ 9 & 77 \\ 9 & 78 \\ 65 & 177 \\ 78 & 192 \\ 96 & 207 \\ 98 & 207 \\ 08 & 216 \\ 17 & 227 \\ 65 & 273 \\ 32 & 343 \\ 92 & 403 \\ 38 & 451 \\ 52 & 461 \\ 62 & 470 \\ 71 & 478 \\ 71 & 482 \\ 04 & 215 \\ 12 & 525 \\ 75 & 387 \\ 29 & 439 \\ 44 & 563 \\ 44 & 652 \\ 4 & 62 \\ 99 & 219 \\ 1 & 51 \\ 2 & 73 \\ 0 & 97 \\ 63 & 174 \\ 75 & 184 \\ 94 & 208 \\ 44 & 253 \\ 44 & 256 \\ & 300 \\ \end{array}$

1665.88

1395.85

1161.71

2104.01

1057.61

1012.52

1279.6

1239.73

2241.19

965.59

1419.78

1128.67

1725.94

1102.61

1535.82

1111.51 
Probable glutamate--tRNA ligase, mitochondrial GN=EARS2 SYEM_HUMAN $58.69 \quad 100.0 \%$ Probable glutamate--tRNA ligase, mitochondrial GN=EARS2 SYEM_HUMAN $58.69 \quad 100.0 \%$ Probable leucine--tRNA ligase, mitochondrial GN=LARS2 SYLM_HUMAN $101.98 \quad 100.0 \%$ Probable leucine--tRNA ligase, mitochondrial GN=LARS2 SYLM_HUMAN $101.98 \quad 100.0 \%$ Probable leucine--tRNA ligase, mitochondrial GN=LARS2 SYLM_HUMAN $101.98 \quad 100.0 \%$ Probable methyltransferase-like protein 15 GN=METTL15 MET15_HUMAN $46.12 \quad 100.0 \%$ Probable methyltransferase-like protein 15 GN=METTL15 MET15_HUMAN $46.12 \quad 100.0 \%$ Probable rRNA-processing protein EBP2 GN=EBNA1BP2 EBP2_HUMAN $34.85 \quad 100.0 \%$ Probable rRNA-processing protein EBP2 GN=EBNA1BP2 EBP2 HUMAN $34.85 \quad 100.0 \%$ Probable rRNA-processing protein EBP2 GN=EBNA1BP2 EBP2_HUMAN $34.85 \quad 100.0 \%$ Probable rRNA-processing protein EBP2 GN=EBNA1BP2 EBP2_HUMAN $34.85 \quad 100.0 \%$ Probable tRNA N6-adenosine threonylcarbamoyltransferase GN=OSGEP OSGEP_HUMAN $36.43 \quad 100.0 \%$ Probable tRNA N6-adenosine threonylcarbamoyltransferase GN=OSGEP OSGEP_HUMAN $36.43 \quad 100.0 \%$ Probable tRNA N6-adenosine threonylcarbamoyltransferase GN=OSGEP OSGEP_HUMAN $36.43 \quad 100.0 \%$ Probable tRNA N6-adenosine threonylcarbamoyltransferase GN=OSGEP OSGEP_HUMAN $36.43 \quad 100.0 \%$ Probable tRNA N6-adenosine threonylcarbamoyltransferase GN=OSGEP OSGEP_HUMAN $36.43 \quad 100.0 \%$ Probable tRNA pseudouridine synthase 2 GN=TRUB2 TRUB2_HUMAN $36.70 \quad 100.0 \%$ Probable tRNA pseudouridine synthase 2 GN=TRUB2 TRUB2_HUMAN $36.70 \quad 100.0 \%$ Probable ubiquitin carboxyl-terminal hydrolase FAF-X GN=USP9X USP9X_HUMAN $292.28 \quad 100.0 \%$ Probable ubiquitin carboxyl-terminal hydrolase FAF-X GN=USP9X USP9X_HUMAN $292.28 \quad 100.0 \%$ Probable ubiquitin carboxyl-terminal hydrolase FAF-X GN=USP9X USP9X_HUMAN $292.28 \quad 100.0 \%$ Probable ubiquitin carboxyl-terminal hydrolase FAF-X GN=USP9X USP9X_HUMAN $292.28 \quad 100.0 \%$ Probable ubiquitin carboxyl-terminal hydrolase FAF-X GN=USP9X USP9X_HUMAN $292.28 \quad 100.0 \%$ Probable ubiquitin carboxyl-terminal hydrolase FAF-X GN=USP9X USP9X_HUMAN $292.28 \quad 100.0 \%$ Probable ubiquitin carboxyl-terminal hydrolase FAF-X GN=USP9X USP9X_HUMAN $292.28 \quad 100.0 \%$ Procollagen-lysine,2-oxoglutarate 5-dioxygenase 1 GN=PLOD1 PLOD1_HUMAN $83.55 \quad 100.0 \%$ Procollagen-lysine,2-oxoglutarate 5-dioxygenase 1 GN=PLOD1 PLOD1_HUMAN $83.55 \quad 100.0 \%$ Programmed cell death 6-interacting protein GN=PDCD6IP PDC6I_HUMAN $96.03 \quad 100.0 \%$ Programmed cell death 6-interacting protein GN=PDCD6IP PDC6I_HUMAN 96.03 $100.0 \%$ Programmed cell death 6-interacting protein GN=PDCD6IP PDC6I HUMAN $96.03 \quad 100.0 \%$ Prohibitin GN=PHB Prohibitin GN=PHB Prohibitin GN=PHB Prohibitin GN=PHB Prohibitin GN=PHB Prohibitin GN=PHB Prohibitin GN=PHB Prohibitin GN=PHB Prohibitin $\mathrm{GN}=\mathrm{PHB}$ Prohibitin GN=PHB Prohibitin $\mathrm{GN}=\mathrm{PHB}$ Prohibitin $\mathrm{GN}=\mathrm{PHB}$ Prohibitin GN=PHB Prohibitin $\mathrm{GN}=\mathrm{PHB}$ Prohibitin GN=PHB Prohibitin GN=PHB Prohibitin GN=PHB

PHB_HUMAN $29.80 \quad 100.0 \% \quad 21$ PHB HUMAN $29.80 \quad 100.0 \% \quad 21$ PHB_HUMAN $29.80 \quad 100.0 \% \quad 2$ PHB HUMAN $29.80 \quad 100.0 \% \quad 21$ PHB_HUMAN $29.80 \quad 100.0 \% \quad 21$ PHB HUMAN $29.80 \quad 100.0 \% \quad 2$ PHB_HUMAN $29.80 \quad 100.0 \% \quad 21$ PHB_HUMAN $29.80 \quad 100.0 \% \quad 21$ PHB HUMAN $29.80 \quad 100.0 \% \quad 21$ PHB HUMAN $29.80 \quad 100.0 \% \quad 2$ PHB_HUMAN $29.80 \quad 100.0 \% \quad 21$ PHB HUMAN $29.80 \quad 100.0 \% \quad 21$ PHB_HUMAN $29.80 \quad 100.0 \% \quad 2$
$0.01 \% \quad 3.8 \%$ TALYNYIFAK

$0.01 \% \quad 3.8 \% \quad$ NMSQEQVAQK

$0.01 \% \quad 3.3 \% \quad$ ISEADKSKPK

$0.01 \% \quad 3.3 \% \quad$ VYTISDTIAR

$0.01 \% \quad 3.3 \%$ TALINFLVQD

$0.01 \% \quad 5.9 \%$ KIASAIVQAR

$0.01 \% \quad 5.9 \%$ VLSPQDQDVQDNPR

$0.01 \% \quad 10.1 \%$ QAQAAVLAVLPR

$0.01 \% \quad 10.1 \%$ VQTEVLQK

$0.01 \% \quad 10.1 \%$ VQTEVLQKR

$0.01 \% \quad 10.1 \%$ ESYDDVSSFR

$0.01 \% \quad 15.2 \%$ PAVLGFEGSANK

$0.01 \% \quad 15.2 \%$ PAVLGFEGSANKIGVGVVR

$0.01 \% \quad 15.2 \%$ TYVTPPGTGFLPGDTAR

$0.01 \% \quad 15.2 \%$ AGHRTPLSDSGVTQR

$0.01 \% \quad 15.2 \%$ TPLSDSGVTQR

$0.01 \% \quad 6.3 \% \quad$ SPMLITGIR

$0.01 \% \quad 6.3 \%$ AATPQVAAELEK

$0.02 \% \quad 3.2 \%$ VISSVSYYTHR

$0.02 \% \quad 3.2 \%$ VVIQSNDDIASR

$0.02 \% \quad 3.2 \%$ SGGLPLVLSMLTR

$0.02 \% \quad 3.2 \% \quad$ LLLTAIGYGHVR

$0.02 \% \quad 3.2 \%$ ELLAFQTSEK

$0.02 \% \quad 3.2 \%$ VLGGSFADQK

$0.02 \% \quad 3.2 \% \quad$ IIEDCSNSEETVK

$0.01 \% \quad 3.6 \%$ FLGSGGFIGYAPNLSK

$0.01 \% \quad 3.6 \%$ AQFDLAFVVR

$0.01 \% \quad 4.8 \%$ TSEVDLAKPLVK

$0.01 \% \quad 4.8 \%$ TPSNELYKPLRAEGTNFR

$0.01 \% \quad 4.8 \%$ TMQGSEVVNVLK PHB_HUMAN $29.80 \quad 100.0 \% \quad 21$ PHB_HUMAN $29.80 \quad 100.0 \% \quad 21$ PHB_HUMAN $29.80 \quad 100.0 \% \quad 21$ PHB_HUMAN $29.80 \quad 100.0 \% \quad 21$

$0.12 \% \quad 65.1 \%$ AVIFDRFR

$0.12 \% \quad 65.1 \%$ DLQNVNITLR

$0.12 \% \quad 65.1 \%$ ILFRPVASQLPR

$0.12 \% \quad 65.1 \%$ IFTSIGEDYDER

$0.12 \% \quad 65.1 \%$ FVVEKAEQQK

$0.12 \% \quad 65.1 \%$ KAAIISAEGDSK $\begin{array}{llllllll}9.7 \% & 46.4 & 25.0 & 46.3 & 2 & 0 & 0 & 1203.64\end{array}$

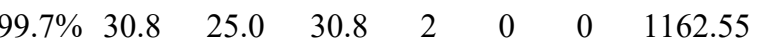
$\begin{array}{llllllll}99.4 \% & 22.4 & 25.0 & 21.7 & 1 & 0 & 0 & 1102.61\end{array}$ $\begin{array}{llllllll}99.7 \% & 38.6 & 25.0 & 33.1 & 1 & 0 & 0 & 1138.61\end{array}$ $\begin{array}{llllllll}99.7 \% & 43.2 & 25.0 & 39.7 & 2 & 0 & 0 & 1133.62\end{array}$

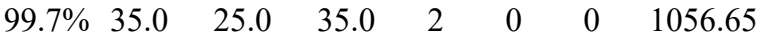

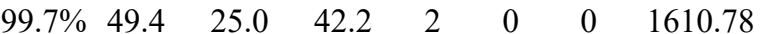
$\begin{array}{llllllll}99.7 \% & 39.7 & 25.0 & 31.9 & 2 & 0 & 0 & 1236.74\end{array}$ $\begin{array}{llllllll}95.8 \% & 21.1 & 25.0 & 11.6 & 1 & 0 & 0 & 944.54\end{array}$ $\begin{array}{llllllll}99.5 \% & 21.4 & 25.0 & 21.4 & 2 & 0 & 0 & 1100.64\end{array}$ $\begin{array}{llllllll}99.7 \% & 37.8 & 25.0 & 37.8 & 2 & 0 & 0 & 1204.51\end{array}$

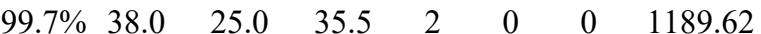

$99.0 \% \quad 22.4$

$0.12 \% \quad 65.1 \%$ NVPVITGSKDLQNVNITLR $99.7 \% \quad 46.5$

$99.7 \% 66$.

$99.7 \% \quad 36.9$

$99.7 \% \quad 57.3$

$0.12 \% \quad 65.1 \%$ IFTSIGEDYDERVLPSITTEILK $99.7 \% 35.3$

$97.6 \% \quad 17.9$

$99.7 \% \quad 33.4$

$99.7 \% \quad 55.5$

$99.7 \% \quad 45.5$

$99.7 \% \quad 47.5$

$99.7 \% \quad 51.5$

$99.0 \% 26.4$

$99.7 \% \quad 45.7$

$99.7 \% \quad 43.9$

$99.7 \% 56.6$

$\begin{array}{ll}99.7 \% & 56.6 \\ & 46.3\end{array}$ 1870.05 1749.88

1581.81 1160.59 987.57

1227.66

1311.67

1316.68

1359.77

1312.77

1165.61

1021.53

1523.69

1627.85

1165.64

1299.75

2093.08

1304.69

$169 \quad 178$

$74 \quad 83$

$104 \quad 113$

$\begin{array}{ll}894 & 903 \\ 234 & 243\end{array}$

$382 \quad 395$

$111 \quad 122$

$180 \quad 187$

$180 \quad 188$

$263 \quad 272$

$2 \quad 20$

$31 \quad 47$

$309 \quad 323$

212

$285 \quad 296$

$\begin{array}{ll}361 & 371 \\ 777 & 788\end{array}$

$1120 \quad 1132$

$157 \quad 1168$

$1436 \quad 1445$

1722

$151 \quad 166$

$635 \quad 644$

$12 \quad 23$

$479 \quad 496$

$\begin{array}{lll}2081.17 & 75 & 93\end{array}$

$\begin{array}{lll}1185.66 & 84 & 93\end{array}$

$\begin{array}{lll}1396.84 & 94 & 105\end{array}$

$\begin{array}{lll}1444.66 & 106 & 117\end{array}$

$2639.38 \quad 106 \quad 128$

$\begin{array}{lll}1213.74 & 118 & 128\end{array}$

$\begin{array}{lll}1661.90 & 129 & 143\end{array}$

$1149.59 \quad 134 \quad 143$

$\begin{array}{lll}1733.92 & 134 & 148\end{array}$

$1062.51 \quad 149 \quad 157$

$\begin{array}{lll}1058.52 & 187 & 195\end{array}$

$\begin{array}{lll}1285.66 & 187 & 197\end{array}$

$\begin{array}{lll}1205.65 & 198 & 207\end{array}$

$\begin{array}{lll}1189.64 & 208 & 219\end{array}$

$1061.55 \quad 209 \quad 219$

$1998.09 \quad 220 \quad 239$ 
Prohibitin GN=PHB Prohibitin GN=PHB Prohibitin GN=PHB Prohibitin GN=PHB Prohibitin-2 GN=PHB2 Prohibitin-2 GN=PHB2 Prohibitin-2 GN=PHB2 Prohibitin-2 GN=PHB2 Prohibitin-2 GN=PHB2 Prohibitin-2 GN=PHB2 Prohibitin-2 GN=PHB2 Prohibitin-2 GN=PHB2 Prohibitin-2 GN=PHB2 Prohibitin-2 GN=PHB2 Prohibitin-2 GN=PHB2 Prohibitin-2 GN=PHB2 Prohibitin-2 GN=PHB2 Prohibitin-2 GN=PHB2 Prohibitin-2 GN=PHB2 Prohibitin-2 GN=PHB2 Prohibitin- 2 GN=PHB2 Prohibitin-2 GN=PHB2 Prohibitin-2 GN=PHB2 Prohibitin-2 GN=PHB2 Prohibitin-2 GN=PHB2 Prohibitin-2 GN=PHB2 Prohibitin-2 GN=PHB2 Prohibitin-2 GN=PHB2 Prohibitin-2 GN=PHB2 Prohibitin-2 GN=PHB2 Prohibitin- 2 GN=PHB2 Prohibitin-2 GN=PHB2 Prohibitin-2 GN=PHB2 Prohibitin-2 GN=PHB2 Prohibitin-2 GN=PHB2

Prolactin-inducible protein GN=PIP Prolactin-inducible protein $\mathrm{GN}=\mathrm{PIP}$ Proliferating cell nuclear antigen $\mathrm{GN}=\mathrm{PCNA}$ PCNA_HUMAN 28.77 Proliferating cell nuclear antigen GN=PCNA PCNA_HUMAN 28.77 Proliferating cell nuclear antigen GN=PCNA PCNA_HUMAN 28.77 Proliferating cell nuclear antigen GN=PCNA PCNA_HUMAN 28.77 Proliferating cell nuclear antigen GN=PCNA PCNA_HUMAN 28.77 Proliferating cell nuclear antigen GN=PCNA PCNA_HUMAN 28.77 Proliferating cell nuclear antigen GN=PCNA PCNA_HUMAN 28.77 Proliferating cell nuclear antigen GN=PCNA PCNA_HUMAN 28.77 Proliferating cell nuclear antigen GN=PCNA PCNA_HUMAN 28.77 Proliferating cell nuclear antigen GN=PCNA PCNA_HUMAN 28.77
PHB HUMAN $29.80 \quad 100.0 \% \quad 21$ PHB_HUMAN $29.80 \quad 100.0 \% \quad 21$ PHB_HUMAN $29.80 \quad 100.0 \% \quad 21$ PHB HUMAN $29.80 \quad 100.0 \% \quad 21$ PHB2_HUMAN $33.30 \quad 100.0 \% \quad 31$ PHB2_HUMAN $33.30 \quad 100.0 \% \quad 31$ PHB2 HUMAN $33.30 \quad 100.0 \% \quad 31$ PHB2_HUMAN $33.30 \quad 100.0 \% \quad 31$ PHB2_HUMAN $33.30 \quad 100.0 \% \quad 31$ PHB2 HUMAN $33.30 \quad 100.0 \% \quad 31$ $\begin{array}{llll} & \\ \text { PHB2_HUMAN } & 33.30 & 100.0 \% & 31\end{array}$ PHB2 HUMAN $33.30 \quad 100.0 \% \quad 31$ $\begin{array}{lll} & \end{array}$ PHB2 HUMAN $33.30 \quad 100.0 \% \quad 31$ PB2_HUMAN $33.30 \quad 100.0 \% \quad 31$ $\begin{array}{llll} & \\ \text { PHB2_HUMAN } & 33.30 & 100.0 \% & 31\end{array}$ PHB2_HUMAN $33.30 \quad 100.0 \% \quad 31$ PHB2 HUMAN $33.30 \quad 100.0 \% \quad 31$ PHB2_HUMAN $33.30 \quad 100.0 \% \quad 31$ PHB2_HUMAN $33.30 \quad 100.0 \% \quad 31$ PHB2 HUMAN $33.30 \quad 100.0 \% \quad 31$ PHB2_HUMAN $33.30 \quad 100.0 \% \quad 31$ PHB2_HUMAN $33.30 \quad 100.0 \% \quad 31$ PHB2 HUMAN $33.30 \quad 100.0 \% \quad 31$ $\begin{array}{ll}100.0 \% & 31 \\ 100.0 \% & 31\end{array}$ $100.0 \%$ $100.0 \% \quad 2$ $100.0 \% \quad 15$ $100.0 \% \quad 15$ $100.0 \% \quad 15$ $100.0 \% \quad 15$ $100.0 \% \quad 15$ $100.0 \% \quad 15$ $100.0 \% \quad 15$ $100.0 \% \quad 15$ $100.0 \% \quad 15$ $100.0 \% \quad 15$ $\begin{array}{llll}0.12 \% & 65.1 \% & \text { NITYLPAGQSVLLQLPQ } \quad 99.7 \% & 51.3\end{array}$

5.0

79.3\% DLAGRLPAGPR $99.7 \% \quad 30.5$

.0

$128 \quad 0.18 \% \quad 79.3 \%$ GMGTALKLLLGAGAVAYGVR $95.1 \% \quad 15.8$ \begin{tabular}{ll}
49.2 \\
\hline
\end{tabular} $99.7 \% \quad 53.2$

0.18\% $79.3 \%$ ESVFTVEGGHR $99.7 \% \quad 55.6$

$47 \quad 128 \quad 0.18 \% \quad 79.3 \%$ IGGVQQDTILAEGLHFR $99.7 \% \quad 47.7$ $99.6 \% \quad 26.9$

$\begin{array}{lllllll}47 & 128 & 0.18 \% & 79.3 \% & \text { ISSPTGSKDLQMVNISLR } & 99.7 \% & 34.4\end{array}$

$47 \quad 128 \quad 0.18 \% \quad 79.3 \%$ DLQMVNISLR $\begin{array}{lllll}34.4 & 3 & 4 & 0 & 1946.04\end{array}$

$\begin{array}{lllll}99.7 \% & 51.7 & 25.0 & 39.9 & 5\end{array}$

$47 \quad 128 \quad 0.18 \% \quad 79.3 \%$ VLSRPNAQELPSMYQR

$47 \quad 128 \quad 0.18 \% \quad 79.3 \%$ LGLDYEER $99.0 \% \quad 45.7$

$47 \quad 128 \quad 0.18 \% \quad 79.3 \%$ VLPSIVNEVLK

$47 \quad 128 \quad 0.18 \% \quad 79.3 \%$ VLPSIVNEVLKSVVAK $99.7 \% \quad 33.9$ $99.7 \% \quad 44.6$ $99.7 \% 66.9$ $99.7 \% \quad 49.9$ $99.0 \% \quad 49.2$ $99.7 \% \quad 44.4$ $99.7 \% \quad 50.1$

$128 \quad 0.18 \% \quad 79.3 \%$ FNASQLITQR

$47 \quad 128 \quad 0.18 \% \quad 79.3 \%$ AQVSLLIR

$47 \quad 128 \quad 0.18 \% \quad 79.3 \%$ AQVSLLIRR

\begin{tabular}{llll}
47 & 128 & $0.18 \%$ & $79.3 \%$ \\
\hline & EYTAAVEAK
\end{tabular} $99.7 \% \quad 58.8$ $99.7 \% \quad 54.1$

$47 \quad 128 \quad 0.18 \% \quad 79.3 \%$ QVAQQEAQR $99.7 \% \quad 54.2$

\begin{tabular}{llll} 
& 128 & $0.18 \%$ & $79.3 \%$ \\
\hline
\end{tabular}

$47 \quad 128 \quad 0.18 \% \quad 79.3 \%$ QKIVQAEGEAEAAK

$47 \quad 128 \quad 0.18 \% \quad 79.3 \%$ IVQAEGEAEAAK

$99.7 \% \quad 55.2$ $99.7 \% \quad 54.8$

\begin{tabular}{llll}
47 & 128 & $0.18 \%$ & $79.3 \%$ \\
\hline
\end{tabular}

$47 \quad 128 \quad 0.18 \% \quad 79.3 \%$ MLGEALSK

$47 \quad 128 \quad 0.18 \% \quad 79.3 \%$ MLGEALSKNPGYIK

$99.0 \% \quad 33.3$

$99.7 \% \quad 55.2$

$99.0 \% \quad 44.0$

$99.7 \% \quad 37.9$

$99.0 \% \quad 27.7$

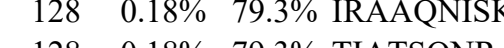

$47 \quad 128 \quad 0.18 \% \quad 79.3 \%$ IYLTADNLVLNLQDESFTR

$128 \quad 0.18 \% \quad 79.3 \%$ GSDSLIKGK

$4 \quad 0.01 \% \quad 15.1 \%$ TVQIAAVVDVIR

$4 \quad 0.01 \% \quad 15.1 \%$ FYTIEILKVE

$43 \quad 0.06 \% \quad 53.3 \%$ LVQGSILK

$43 \quad 0.06 \% \quad 53.3 \%$ LVQGSILKK

$43 \quad 0.06 \% \quad 53.3 \%$ SEGFDTYR

$43 \quad 0.06 \% \quad 53.3 \%$ SEGFDTYRCDR

$99.7 \% \quad 74.6$

$99.7 \% 32.0$

$\begin{array}{ll}99.7 \% & 51.7 \\ 99.7 \% & 41.6\end{array}$

$99.0 \% 36.5$

$99.5 \% \quad 39.2$

$99.0 \% \quad 36.5$

$99.6 \% 24.1$

$43 \quad 0.06 \% \quad 53.3 \%$ CDRNLAMGVNLTSMSK

$99.7 \% \quad 30.1$

$0.06 \% \quad 53.3 \%$ NLAMGVNLTSMSK

$99.7 \% \quad 59.2$

$43 \quad 0.06 \% \quad 53.3 \%$ MPSGEFAR

$99.0 \% \quad 41.5$

\begin{tabular}{lll}
43 & $0.06 \%$ & $53.3 \%$ \\
\hline
\end{tabular}

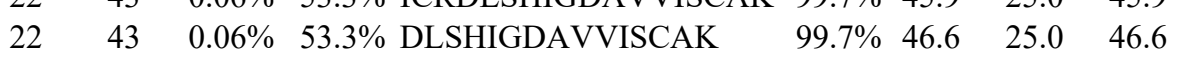

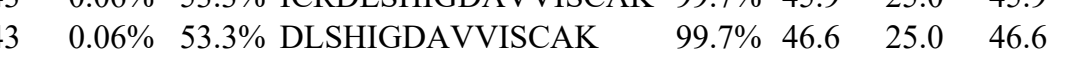

$5.0 \quad 15.8$

15.8

25.0

34.43

$\begin{array}{lll}0 & 36.1 & 5\end{array}$

$\begin{array}{ll}5.0 & 34.0\end{array}$

$\begin{array}{ll}25.0 & 39.4\end{array}$

30.6

\begin{tabular}{ll}
.0 & 30.6 \\
\hline & 38.3
\end{tabular}

$\begin{array}{ll}5.0 & 44.8\end{array}$

$0 \quad 34.6$

38.3
25.0

$\begin{array}{ll}38.0 & 33.6\end{array}$

$\begin{array}{ll}5.0 & 39.9\end{array}$

$0-45$
-0.8

$\begin{array}{lll}0 & 43.6\end{array}$

$\begin{array}{lll}25.0 & 34.5 & 0\end{array}$

$\begin{array}{lll}5.0 & 17.6 & 2\end{array}$

52.6

$\begin{array}{ll}37.3 \\ 25.0 & 22.8\end{array}$

$\begin{array}{ll}.0 & 22.8 \\ 20.3\end{array}$

0

\begin{tabular}{ll}
74.6 \\
\hline
\end{tabular}

$\begin{array}{lll}25.0 & 20.8 \quad 1\end{array}$

$\begin{array}{lll} & & \\ 20.0 & 45.7 & 2\end{array}$

$\begin{array}{ll}5.0 & 26.4\end{array}$

$\begin{array}{ll}25.0 & 12.7\end{array}$

$\begin{array}{lll} & 10.1 & 3\end{array}$

$\begin{array}{lll} & 36.2 & 2\end{array}$

$24.0 \quad 24.1$

$5.0 \quad 30.1$

$\begin{array}{ll}2.0 & 30.1 \\ 25.0 & 56.7\end{array}$

$\begin{array}{ll}25.0 & 57.1\end{array}$

$25.0 \quad 32.0$

$25.0 \quad 45.9$ 
Proliferating cell nuclear antigen GN=PCNA PCNA_HUMAN $28.77 \quad 100.0 \%$ Proliferating cell nuclear antigen GN=PCNA PCNA_HUMAN $28.77 \quad 100.0 \%$ Proliferating cell nuclear antigen GN=PCNA PCNA_HUMAN $28.77 \quad 100.0 \% \quad 15$ Proliferating cell nuclear antigen GN=PCNA PCNA HUMAN $28.77 \quad 100.0 \% \quad 15$ Proliferating cell nuclear antigen GN=PCNA PCNA_HUMAN $28.77 \quad 100.0 \% \quad 15$ Proteasomal ATPase-associated factor $1 \mathrm{GN}=$ PAAF1 PAAF1_HUMAN $42.19 \quad 100.0 \%$ Proteasomal ATPase-associated factor $1 \mathrm{GN}=$ PAAF1 PAAF1_HUMAN $42.19 \quad 100.0 \%$ Proteasomal ATPase-associated factor 1 GN=PAAF1 PAAF1_HUMAN $42.19 \quad 100.0 \%$ Proteasomal ubiquitin receptor ADRM1 GN=ADRM1 ADRM1_HUMAN $42.15 \quad 100.0 \%$ Proteasomal ubiquitin receptor ADRM1 GN=ADRM1 ADRM1_HUMAN $42.15 \quad 100.0 \%$ Proteasome inhibitor PI31 subunit GN=PSMF1 PSMF1_HUMAN $29.82 \quad 100.0 \%$ Proteasome inhibitor PI31 subunit GN=PSMF1 PSMF1 HUMAN $29.82 \quad 100.0^{\circ}$ Proteasome subunit alpha type-3 GN=PSMA3 PSA3_HUMAN $28.43 \quad 100.0 \%$ Proteasome subunit alpha type-3 GN=PSMA3 PSA3_HUMAN $28.43 \quad 100.0 \%$ Proteasome subunit alpha type-4 GN=PSMA4 PSA4 HUMAN $29.48 \quad 100.0 \%$ Proteasome subunit alpha type-4 GN=PSMA4 PSA4_HUMAN $29.48 \quad 100.0 \%$ Proteasome subunit alpha type-4 GN=PSMA4 PSA4 HUMAN $29.48 \quad 100.0^{\circ}$ Proteasome subunit alpha type-4 GN=PSMA4 PSA4_HUMAN $29.48 \quad 100.0 \%$ Proteasome subunit alpha type-4 GN=PSMA4 PSA4_HUMAN $29.48 \quad 100.0 \%$ Proteasome subunit alpha type-4 GN=PSMA4 PSA4 HUMAN $29.48 \quad 100.0 \%$ Proteasome-associated protein ECM29 homolog GN=ECM29 ECM29_HUMAN $204.30 \quad 100.0 \%$ Proteasome-associated protein ECM29 homolog GN=ECM29 ECM29 HUMAN 204.30 100.0\% Proteasome-associated protein ECM29 homolog GN=ECM29 ECM29_HUMAN 204.30 100.0\% Proteasome-associated protein ECM29 homolog GN=ECM29 ECM29_HUMAN $204.30 \quad 100.0 \%$ Proteasome-associated protein ECM29 homolog GN=ECM29 ECM29 HUMAN 204.30 100.0\% Proteasome-associated protein ECM29 homolog GN=ECM29 ECM29_HUMAN $204.30 \quad 100.0 \%$ Proteasome-associated protein ECM29 homolog GN=ECM29 ECM29_HUMAN $204.30 \quad 100.0 \%$ Proteasome-associated protein ECM29 homolog GN=ECM29 ECM29 HUMAN 204.30 $100.0 \%$ Proteasome-associated protein ECM29 homolog GN=ECM29 ECM29_HUMAN $204.30 \quad 100.0 \%$ Protein arginine N-methyltransferase $1 \mathrm{GN}=$ PRMT1 ANM1 HUMAN $41.52 \quad 100.0^{\circ}$ Protein arginine N-methyltransferase $1 \mathrm{GN}=$ PRMT1 ANM1_HUMAN $41.52 \quad 100.0 \%$ Protein arginine N-methyltransferase $1 \mathrm{GN}=$ PRMT1 ANM1_HUMAN $41.52100 .0 \%$ Protein arginine N-methyltransferase $1 \mathrm{GN}=$ PRMT1 ANM1 HUMAN $41.52 \quad 100.0 \%$ Protein arginine N-methyltransferase $1 \mathrm{GN}=$ PRMT1 ANM1_HUMAN $41.52100 .0 \%$ Protein arginine N-methyltransferase $3 \mathrm{GN}=$ PRMT3 ANM3_HUMAN $59.88 \quad 100.0 \%$ Protein arginine N-methyltransferase $3 \mathrm{GN}=$ PRMT3 ANM3 HUMAN $59.88 \quad 100.0 \%$ Protein arginine N-methyltransferase $5 \mathrm{GN}=$ PRMT5 ANM5_HUMAN $72.69100 .0^{\circ}$ Protein arginine N-methyltransferase $5 \mathrm{GN}=$ PRMT5 ANM5 HUMAN $72.69 \quad 100.0 \%$ Protein arginine N-methyltransferase 5 GN=PRMT5 ANM5_HUMAN $72.69 \quad 100.0 \%$ Protein arginine N-methyltransferase 5 GN=PRMT5 ANM5_HUMAN 72.69 Protein arginine N-methyltransferase 5 GN=PRMT5 ANM5 HUMAN 72.69 Protein arginine N-methyltransferase 5 GN=PRMT5 ANM5_HUMAN 72.69 Protein arginine N-methyltransferase $5 \mathrm{GN}=\mathrm{PRMT} 5$ ANM5 HUMAN 72.69 Protein arginine N-methyltransferase 5 GN=PRMT5 ANM5 HUMAN 72.69 Protein arginine N-methyltransferase 5 GN=PRMT5 ANM5_HUMAN 72.6 Protein arginine N-methyltransferase $5 \mathrm{GN}=$ PRMT5 ANM5 HUMAN 72.69 Protein arginine N-methyltransferase 5 GN=PRMT5 ANM5_HUMAN 72.69 $100.0 \% \quad 32$ 22

$0.06 \% \quad 53.3 \%$ FSASGELGNGNIK $99.7 \% 82.6$

$0.06 \% \quad 53.3 \%$ ATPLSSTVTLSMSADVPLVVEYK

$0.06 \% \quad 53.3 \%$ IADMGHLK

$0.06 \% \quad 53.3 \%$ YYLAPKIEDEEGS

$0.01 \% \quad 8.4 \% \quad$ FLAPYTTFSR

$0.01 \% \quad 8.4 \%$ GGILDTAIVDR

$0.01 \% \quad 8.4 \%$ SGAPVLSLLSVR

$0.01 \% \quad 6.6 \%$ GASNKYLVEFR

$0.01 \% \quad 6.6 \%$ SQSAAVTPSSTTSSTR

$0.00 \% \quad 11.8 \%$ TYKNSEELR

$0.00 \% \quad 11.8 \%$ ALIDPSSGLPNRLPPGAVPPGAR

$0.00 \% \quad 9.0 \%$ LYEEGSNKR

$0.00 \% \quad 9.0 \%$ SLADIAREEASNFR

$0.02 \% \quad 24.1 \%$ LLDEVFFSEK

$0.02 \% \quad 24.1 \%$ LLDEVFFSEKIYK

$0.02 \% \quad 24.1 \%$ QAYTQFGGK

$0.02 \% \quad 24.1 \%$ ATCIGNNSAAAVSMLK

$0.02 \% \quad 24.1 \%$ SALALAIKVLNK

$0.02 \% \quad 24.1 \%$ LSAEKVEIATLTR

$0.02 \% \quad 5.9 \% \quad$ LSSTQEGVR

$0.02 \% \quad 5.9 \%$ SASPFNLAEKPK

$0.02 \% \quad 5.9 \% \quad$ KGAAFGFNVIATR

$0.02 \% \quad 5.9 \%$ AGEQLAPFLPQLVPR

$0.02 \% \quad 5.9 \% \quad$ ESSCLALNDLLR

$0.02 \% \quad 5.9 \%$ AQGAIAMASIAK

$0.02 \% \quad 5.9 \%$ AIACVVTACSAELEK

$0.02 \% \quad 5.9 \% \quad$ IVAISCAADILK

$0.02 \% \quad 5.9 \%$ NSLESSGVR

$10 \quad 0.01 \% \quad 13.6 \%$ KVIGIECSSISDYAVK

$10 \quad 0.01 \% \quad 13.6 \%$ VIGIECSSISDYAVK

$10 \quad 0.01 \% \quad 13.6 \%$ ANKLDHVVTIIK

$10 \quad 0.01 \% \quad 13.6 \%$ ATLYVTAIEDR

$10 \quad 0.01 \% \quad 13.6 \%$ QLVTNACLIK

$3 \quad 0.00 \% \quad 4.5 \%$ ALSAEAALAR

$0.00 \% \quad 4.5 \%$ AVIPEAVVEVLDPK

$49 \quad 323 \quad 0.44 \% \quad 41.6 \%$ VSSGRDLNCVPEIADTLGAVAK $\quad 99.7 \% \quad 56.3$

$49 \quad 323 \quad 0.44 \% \quad 41.6 \%$ DLNCVPEIADTLGAVAK $\quad 99.7 \% \quad 52.3$

$49323 \quad 0.44 \% \quad 41.6 \%$ QGFDFLCMPVFHPR

$49323 \quad 0.44 \% \quad 41.6 \%$ REFIQEPAK

$49323 \quad 0.44 \% \quad 41.6 \%$ EFIQEPAK

$49 \quad 323 \quad 0.44 \% \quad 41.6 \%$ EFIQEPAKNRPGPQTR

$49 \quad 323 \quad 0.44 \% \quad 41.6 \%$ NRPGPQTR

$49 \quad 323 \quad 0.44 \% \quad 41.6 \%$ SDLLLSGR

$49 \quad 323 \quad 0.44 \% \quad 41.6 \%$ SDLLLSGRDWNTLIVGK

$49323 \quad 0.44 \% \quad 41.6 \%$ LSPWIRPDSK

$49 \quad 323 \quad 0.44 \% \quad 41.6 \%$ LSPWIRPDSKVEK

$99.0 \% \quad 48.2$

$99.7 \% 33.2$

$97.8 \% \quad 16.3$

$99.7 \% \quad 49.9$

$\begin{array}{llll}99.7 \% & 36.2\end{array}$

$99.7 \% \quad 40.1$

$99.7 \% \quad 60.9$

$99.3 \% 19.8$

$99.7 \% \quad 33.1$

$99.7 \% \quad 53.7$

$99.7 \% \quad 36.4$

$99.7 \% \quad 28.2$

$99.7 \% 52.8$

$99.7 \% \quad 45.5$

$99.7 \% \quad 47.0$

$97.4 \% \quad 24.5$

$99.7 \% 33.5$

$99.7 \% \quad 29.3$

$99.7 \% \quad 28.9$

$99.7 \% \quad 37.9$

$99.7 \% \quad 30.7$

$99.7 \% \quad 54.9$

$99.5 \% 22.1$

$99.7 \% \quad 29.7$

$\begin{array}{lll}99.7 \% & 25.2\end{array}$

$99.7 \% \quad 26.8$

$\begin{array}{lll}99.5 \% & 22.0\end{array}$

$99.7 \% \quad 73.8$

$99.7 \% \quad 36.9$

$99.7 \% \quad 49.0$

$99.7 \% \quad 30.1$

$99.7 \% \quad 50.5$

$99.7 \% 37.1$

$99.0 \% \quad 47.5$

$99.7 \% \quad 30.2$

$99.0 \% \quad 30.2$

$99.0 \% \quad 40.2$
$99.7 \% \quad 29.5$
1984.02

1293.64

2408.26

884.47

1513.71

1202.62

1129.62

1198.72

1283.67

1567.76

1139.57

2252.25

1095.54

1578.79

1226.63

1630.87

999.49

1607.79

1240.80

1430.82

976.51

1288.69

1351.75

1635.92

1390.70

1131.62

1621.79

1273.72

948.47

1768.92

1640.82

1350.81

1251.66

1159.65

972.55

1478.85

2272.16

1785.91

1766.81

1117.60

961.50

1867.98

925.50

860.48

1887.03

1198.66

1554.86

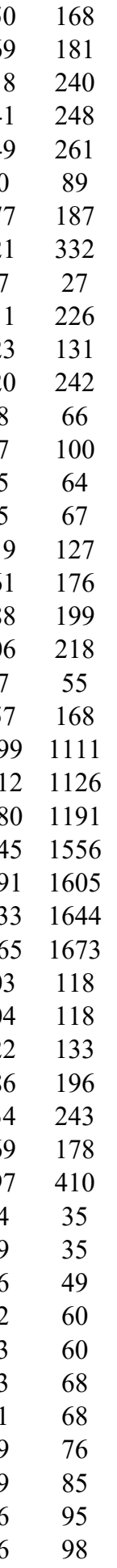

Page 102 of Table S-1-1 
Protein arginine N-methyltransferase 5 GN=PRMT5 ANM5_HUMAN $72.69 \quad 100.0 \% \quad 32$ Protein arginine N-methyltransferase 5 GN=PRMT5 ANM5_HUMAN $72.69 \quad 100.0 \% 32$ Protein arginine N-methyltransferase 5 GN=PRMT5 ANM5_HUMAN $72.69 \quad 100.0 \% 32$ Protein arginine N-methyltransferase 5 GN=PRMT5 ANM5_HUMAN $72.69 \quad 100.0 \% 32$ Protein arginine N-methyltransferase 5 GN=PRMT5 ANM5_HUMAN $72.69 \quad 100.0 \% \quad 32$ Protein arginine N-methyltransferase 5 GN=PRMT5 ANM5_HUMAN $72.69 \quad 100.0 \% \quad 32$ Protein arginine N-methyltransferase 5 GN=PRMT5 ANM5_HUMAN $72.69 \quad 100.0 \% \quad 32$ Protein arginine N-methyltransferase 5 GN=PRMT5 ANM5_HUMAN $72.69 \quad 100.0 \% \quad 32$ Protein arginine N-methyltransferase 5 GN=PRMT5 ANM5_HUMAN $72.69 \quad 100.0 \% 32$ Protein arginine N-methyltransferase 5 GN=PRMT5 ANM5_HUMAN $72.69 \quad 100.0 \% \quad 32$ Protein arginine N-methyltransferase 5 GN=PRMT5 ANM5_HUMAN $72.69 \quad 100.0 \% \quad 32$ Protein arginine N-methyltransferase 5 GN=PRMT5 ANM5_HUMAN $72.69 \quad 100.0 \%$ Protein arginine N-methyltransferase 5 GN=PRMT5 ANM5_HUMAN $72.69 \quad 100.0 \%$ Protein arginine N-methyltransferase 5 GN=PRMT5 ANM5_HUMAN $72.69 \quad 100.0 \% 32$ Protein arginine N-methyltransferase 5 GN=PRMT5 ANM5_HUMAN $72.69 \quad 100.0 \% 32$ Protein arginine N-methyltransferase 5 GN=PRMT5 ANM5_HUMAN $72.69 \quad 100.0 \% \quad 32$ Protein arginine N-methyltransferase 5 GN=PRMT5 ANM5_HUMAN $72.69 \quad 100.0 \% 32$ Protein arginine N-methyltransferase 5 GN=PRMT5 ANM5_HUMAN $72.69 \quad 100.0 \%$ Protein arginine N-methyltransferase 5 GN=PRMT5 ANM5_HUMAN $72.69 \quad 100.0 \% 32$ Protein arginine N-methyltransferase 5 GN=PRMT5 ANM5 HUMAN $72.69 \quad 100.0 \%$ $\begin{array}{llll}\text { Protein arginine N-methyltransferase 5 GN=PRMT5 ANM5_HUMAN } & 72.69 & 100.0 \% & 32\end{array}$ Protein CMSS1 GN=CMSS1 Protein CMSS1 GN=CMSS1 Protein CMSS1 GN=CMSS1 Protein CMSS1 GN=CMSS1 Protein CMSS1 GN=CMSS1 Protein Daple GN $=$ CCDC $88 \mathrm{C}$ Protein Daple GN=CCDC88C Protein Daple GN=CCDC88C Protein Daple GN $=$ CCDC88C Protein Daple GN=CCDC88C Protein Daple GN $=$ CCDC $88 \mathrm{C}$ Protein Daple GN $=\mathrm{CCDC} 88 \mathrm{C}$ Protein Daple GN $=$ CCDC $88 \mathrm{C}$ Protein Daple GN $=$ CCDC88C Protein DEK GN=DEK Protein DEK GN=DEK Protein DEK GN=DEK

Protein flightless-1 homolog GN=FLII Protein flightless-1 homolog GN=FLII Protein flightless-1 homolog GN=FLII Protein FRG1 GN=FRG1 Protein FRG1 GN=FRG1 Protein FRG1 GN=FRG1 Protein KRI1 homolog GN=KRI1 Protein KRI1 homolog GN=KRI1 Protein lin-28 homolog B GN=LIN28B

DAPLE DAPLE HUMAN $228.23 \quad 100.0 \%$ DAPLE HUMAN $228.23 \quad 100.0 \%$ DAPLE HUMAN $228.23 \quad 100.0 \%$ DAPLE_HUMAN $228.23 \quad 100.0 \%$ DAPLE HUMAN $228.23 \quad 100.0 \%$ DAPLE_HUMAN $228.23 \quad 100.0 \%$ DAPLE HUMAN $228.23 \quad 100.0 \%$ DEK_HUMAN $42.68 \quad 100.0 \%$ DEK_HUMAN $42.68 \quad 100.0 \%$ DEK_HUMAN $42.68 \quad 100.0 \%$ FLII_HUMAN $144.76 \quad 100.0 \%$ FLII_HUMAN $144.76 \quad 100.0 \%$ FLII HUMAN $144.76 \quad 100.0 \%$ FRG1_HUMAN $29.17 \quad 100.0 \%$ FRG1_HUMAN $29.17 \quad 100.0 \%$ FRG1_HUMAN $29.17 \quad 100.0 \%$ KRII_HUMAN $82.60 \quad 100.0 \%$ KRI1 HUMAN $82.60 \quad 100.0 \%$ LN28B_HUMAN $27.08 \quad 100.0 \%$
$49 \quad 323 \quad 0.44 \% \quad 41.6 \%$ VPLVAPEDLR $49 \quad 323 \quad 0.44 \% \quad 41.6 \%$ TLCDYSKR

$\begin{array}{llllllll}99.7 \% & 31.9 & 25.0 & 30.1 & 2 & 0 & 0 & 1108.64\end{array}$

$49 \quad 323 \quad 0.44 \% \quad 41.6 \%$ IAVALEIGADL

$49323 \quad 0.44 \% \quad 41.6 \%$ AAILPTSIFLTNK

$49323 \quad 0.44 \% \quad 41.6 \%$ AAILPTSIFLTNKK

$49 \quad 323 \quad 0.44 \% \quad 41.6 \%$ KGFPVLSK

$49323 \quad 0.44 \% \quad 41.6 \%$ DPIKYSQYQQAIYK

$49 \quad 323 \quad 0.44 \% \quad 41.6 \%$ YSQYQQAIYK

$49 \quad 323 \quad 0.44 \% \quad 41.6 \%$ VPEEEKDTNVQVLMVLGAGR

$49323 \quad 0.44 \% \quad 41.6 \%$ DTNVQVLMVLGAGR

$49 \quad 323 \quad 0.44 \% \quad 41.6 \%$ GPLVNASLR

$49323 \quad 0.44 \% \quad 41.6 \%$ GPLVNASLRAAK

$49 \quad 323 \quad 0.44 \% \quad 41.6 \%$ IKLYAVEK

$49323 \quad 0.44 \% \quad 41.6 \%$ DDGVSIPGEYTSFLAPISSSK

$49323 \quad 0.44 \% \quad 41.6 \%$ LYNEVRACR

$49323 \quad 0.44 \% \quad 41.6 \%$ DRDPEAQFEMPYVVR

$49323 \quad 0.44 \% \quad 41.6 \%$ DPEAQFEMPYVVR

$49 \quad 323 \quad 0.44 \% \quad 41.6 \%$ DPMIDNNR

$49323 \quad 0.44 \% \quad 41.6 \%$ QPITVREGQTICVR

$49323 \quad 0.44 \% \quad 41.6 \%$ EGQTICVR

$49323 \quad 0.44 \% \quad 41.6 \%$ EGQTICVRFWR

$11 \quad 0.02 \% \quad 18.6 \%$ SEPKPGLPEDLQK

$11 \quad 0.02 \% \quad 18.6 \%$ LMKDYYSSR

$11 \quad 0.02 \% \quad 18.6 \%$ VVHLGVGTPGR

$11 \quad 0.02 \% \quad 18.6 \%$ QGGLNLSPLK

$18 \quad 0.02 \% \quad 5.3 \% \quad$ VKQENIQLAADAR

$18 \quad 0.02 \% \quad 5.3 \% \quad$ AMLEEQLTAAR DAPLE_HUMAN $228.23 \quad 100.0 \%$
$99.0 \% \quad 54.8$

$0.02 \% \quad 18.6 \%$ SESLKLGLF

$99.7 \% 53.4$

$99.7 \% \quad 48.9$

$99.0 \% \quad 51.3$

$99.7 \% 34.6$

$99.7 \% \quad 53.9$

$99.7 \% \quad 59.0$

$99.7 \% \quad 57.0$

$99.7 \% \quad 58.1$

$99.7 \% \quad 51.5$

$99.0 \% \quad 37.0$

$99.7 \% \quad 63.8$

$99.5 \% \quad 23.6$

$99.7 \% \quad 51.7$

$99.7 \% \quad 57.1$

$99.0 \% \quad 45.8$

$99.7 \% \quad 34.9$

$99.0 \% \quad 41.6$

$99.6 \% \quad 22.9$

$99.7 \% \quad 45.5$

$97.0 \% 19.3$

$99.7 \% \quad 43.6$

$99.7 \% \quad 48.5$

$99.7 \% \quad 31.7$

$99.7 \% \quad 60.9$

$99.7 \% \quad 54.8$

$99.0 \% \quad 42.1$

$97.6 \% \quad 20.2$

$99.4 \% \quad 22.8$

$0.02 \% \quad 5.3 \%$ QSAEYEALIR

$0.02 \% \quad 5.3 \%$ VLTTEREALQQEQR

$0.02 \% \quad 5.3 \%$ TCSTSATTTAPSNS

$\begin{array}{lll}0.02 \% & 5.3 \% & \text { MPTNFVAPTVK } \\ 0.02 \% & 5.3 \% & \text { AFSLASADLLR }\end{array}$

$0.02 \% \quad 5.3 \%$ SGEVATITPVR

$0.01 \% \quad 8.5 \%$ NVGQFSGFPFEK

$0.01 \% \quad 8.5 \%$ SICEVLDLER

$0.01 \% \quad 8.5 \%$ SGVNSELVKR

$0.01 \% \quad 2.9 \%$ SLEGTEAQVFKAK

$0.01 \% \quad 2.9 \%$ ADLTALFLPR

$0.01 \% \quad 2.9 \%$ AVQGAQQPSLYQIR

$0.00 \% \quad 13.6 \%$ YLGINSDGLVVGR

$0.00 \% \quad 13.6 \%$ MALLASNSCFIR

$0.00 \% \quad 13.6 \%$ CNEAGDIEAK

$0.00 \% \quad 3.7 \%$ LLGPTVMLGGCEFSR

$0.00 \% \quad 3.7 \%$ QRLQAFGLNPK

$0.01 \% \quad 14.0 \%$ MGFGFISMINR

\section{AR 99.7}

$98.0 \% 21.2$

$99.7 \% \quad 51.7$

$99.7 \% \quad 51.5$

$99.7 \% \quad 39.0$

$99.7 \% \quad 50.5$

$99.7 \% \quad 53.4$

$99.7 \% \quad 50.0$

$99.7 \% \quad 45.7$

$99.7 \% \quad 37.3$

$99.7 \% \quad 70.2$

$99.3 \% 23.0$

$99.7 \% 27.6$

$99.7 \% \quad 57.7$

$99.2 \% 19.8$

$97.5 \% \quad 16.2$
042.50

2003.09

1388.8

1516.91

875.54

1744.89

1291.63

2184.13

1472.79

926.54

1196.7

963.59

2170.06

1180.59

1851.87

1580.74

990.43

1656.89

962.47

1451.72

1437.76

1162.56

1091.63

1026.59

993.56

1455.79

1232.63

915.53

1179.60

1700.89

1923.91

1204.64

1163.64

1129.62

1356.66

1233.61

1088.61

1407.75

1116.64

1558.83

1362.74

1382.69

1106.48

1636.82

1271.72 1288.62

$\begin{array}{cc}55 & 164 \\ 94 & 201 \\ 02 & 220 \\ 28 & 240 \\ 28 & 241 \\ 41 & 248 \\ 30 & 343 \\ 34 & 343 \\ 49 & 368 \\ 55 & 368 \\ 69 & 377 \\ 69 & 380 \\ 86 & 393 \\ 59 & 479 \\ 80 & 488 \\ 91 & 505 \\ 93 & 505 \\ 27 & 534 \\ 88 & 601 \\ 94 & 601 \\ 94 & 604 \\ 5 & 97 \\ 8 & 106 \\ 05 & 215 \\ 22 & 231 \\ 71 & 279 \\ 94 & 306 \\ 64 & 374 \\ 71 & 878 \\ 81 & 1190 \\ 29 & 1242 \\ 19 & 1537 \\ 24 & 1734 \\ 04 & 1814 \\ 47 & 1957 \\ 26 & 137 \\ 59 & 168 \\ 69 & 178 \\ 22 & 834 \\ 75 & 884 \\ 47 & 1060 \\ 16 & 128 \\ 47 & 158 \\ 59 & 168 \\ 57 & 671 \\ & \end{array}$

Page 103 of Table S-1-1 
Protein lin-28 homolog B GN=LIN28B Protein lin-28 homolog B GN=LIN28B Protein LYRIC GN=MTDH

Protein LYRIC GN=MTDH

Protein LYRIC GN=MTDH

Protein MON2 homolog GN=MON2

Protein MON2 homolog GN=MON2 Protein NipSnap homolog $1 \mathrm{GN}=\mathrm{NIPSNAP1}$ NIPSI_HUMAN $33.31 \quad 100.0 \%$ Protein Njmu-R1 GN=C17orf75 Protein Njmu-R1 GN $=\mathrm{C} 17$ orf 75 Protein pelota homolog $\mathrm{GN}=\mathrm{PELO}$ Protein pelota homolog GN=PELO Protein pelota homolog GN=PELO Protein phosphatase $1 \mathrm{~B}$ GN=PPM1B Protein phosphatase $1 \mathrm{~B}$ GN=PPM1B Protein phosphatase 1B GN=PPM1B Protein phosphatase 1B GN=PPM1B Protein phosphatase $1 \mathrm{~B}$ GN=PPM1B Protein phosphatase $1 \mathrm{~B}$ GN=PPM1B Protein phosphatase $1 \mathrm{~B}$ GN=PPM1B Protein polybromo-1 GN=PBRM1 Protein polybromo- $1 \mathrm{GN}=\mathrm{PBRM} 1$ Protein polybromo- $1 \mathrm{GN}=\mathrm{PBRM} 1$ Protein PRRC2A GN=PRRC2A Protein PRRC2A GN=PRRC2A Protein RFT1 homolog GN=RFT1 Protein RFT1 homolog GN=RFT1 Protein RFT1 homolog GN=RFT1 Protein RRP5 homolog GN=PDCD11 Protein RRP5 homolog GN=PDCD11 Protein RRP5 homolog GN=PDCD1 Protein RRP5 homolog GN=PDCD1 Protein RRP5 homolog GN=PDCD1 Protein RRP5 homolog GN=PDCD11 Protein RRP5 homolog GN=PDCD1 Protein RRP5 homolog GN=PDCD1 Protein RRP5 homolog GN=PDCD1 Protein RRP5 homolog GN=PDCD11 Protein RRP5 homolog GN=PDCD1 Protein RRP5 homolog GN=PDCD1 Protein RRP5 homolog GN=PDCD1 Protein RRP5 homolog GN=PDCD11 Protein RRP5 homolog GN=PDCD1 Protein RRP5 homolog GN=PDCD1 Protein RRP5 homolog GN=PDCD11 Protein RRP5 homolog GN=PDCD11 LYRIC_HUMAN $63.84 \quad 100.0 \%$ MON2_HUMAN $190.36 \quad 100.0 \%$ $\begin{array}{lll}\text { MON2_HUMAN } & 190.36 & 100.0 \% \\ \text { NIPS1_HUMAN } & 33.31 & 100.0 \%\end{array}$ $\begin{array}{rrr}\text { NIPS1_HUMAN } & 33.31 & 100.0 \% \\ \text { NJMU_HUMAN } & 44.62 & 100.0 \%\end{array}$ NJMU_HUMAN $44.62 \quad 100.0 \%$ PELO_HUMAN $43.36 \quad 100.0 \%$ PELO_HUMAN $43.36 \quad 100.0 \%$ PELO_HUMAN $43.36 \quad 100.0 \%$ PPM1B_HUMAN $52.64 \quad 100.0 \%$ PPM1B_HUMAN $52.64 \quad 100.0 \%$ PPM1B HUMAN $52.64 \quad 100.0 \%$ PPM1B_HUMAN $52.64 \quad 100.0 \%$ PPM1B_HUMAN $52.64 \quad 100.0 \%$ PPM1B HUMAN $52.64 \quad 100.0 \%$ PPM1B_HUMAN $52.64 \quad 100.0 \%$ PB1 HUMAN $192.95 \quad 100.0 \%$ PB1_HUMAN $192.95 \quad 100.0 \%$ PB1_HUMAN $192.95 \quad 100.0 \%$ PRC2A_HUMAN $228.87 \quad 100.0 \%$ PRC2A_HUMAN $228.87 \quad 100.0 \%$ RFT1_HUMAN $60.34 \quad 100.0 \%$ RFT1_HUMAN $60.34 \quad 100.0 \%$ RFT1_HUMAN $60.34 \quad 100.0 \%$ RRP5_HUMAN $208.70 \quad 100.0 \%$ RRP5_HUMAN $208.70 \quad 100.0 \%$ RRP5_HUMAN $208.70 \quad 100.0 \%$ RRP5_HUMAN $208.70 \quad 100.0 \%$

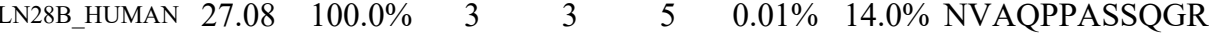

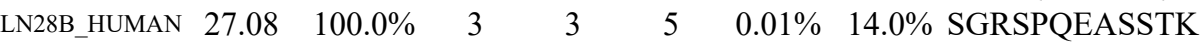

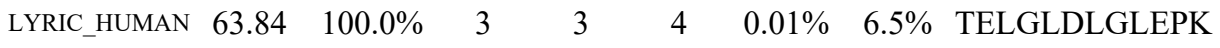

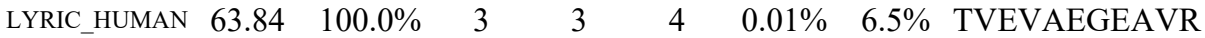
RRP5_HUMAN $208.70 \quad 100.0 \%$ RRP5_HUMAN $208.70 \quad 100.0 \%$ RRP5_HUMAN $208.70 \quad 100.0 \%$ RRP5_HUMAN $208.70 \quad 100.0 \%$ RRP5_HUMAN $208.70 \quad 100.0 \% \quad 18$ RRP5_HUMAN $208.70 \quad 100.0 \% \quad 18$ RRP5_HUMAN $208.70 \quad 100.0 \% \quad 18$ RRP5_HUMAN $208.70 \quad 100.0 \% \quad 18$ RRP5_HUMAN $208.70 \quad 100.0 \% \quad 18$ RRP5_HUMAN $208.70 \quad 100.0 \% \quad 18$ RRP5_HUMAN $208.70 \quad 100.0 \% \quad 18$ RRP5_HUMAN $208.70 \quad 100.0 \% \quad 18$ RRP5_HUMAN $208.70 \quad 100.0 \% \quad 18$ RRP5_HUMAN $208.70 \quad 100.0 \% \quad 18$

$0.00 \% \quad 1.2 \% \quad$ ITQLCLAAIQR

$0.00 \% \quad 1.2 \%$ VLSIGLPVAR

$0.01 \% \quad 7.0 \%$ MGPNIYELR

$0.01 \% \quad 7.0 \% \quad$ IMIPLKISPLQ

$0.00 \% \quad 4.6 \%$ GGNPFLFR

$0.00 \% \quad 4.6 \%$ AIQDTNNLKR

$0.01 \% \quad 9.1 \%$ AKVEVNIPR

$0.02 \% \quad 16.7 \%$ TGFLKIDEYMR

$0.02 \% \quad 16.7 \%$ HIYFINCGDSR

$0.02 \% \quad 16.7 \%$ IQNAGGSVMIQR

$0.02 \% \quad 16.7 \%$ VNGSLAVSR

$0.02 \% \quad 16.7 \%$ NVIEAVYSR

$0.00 \% \quad 1.7 \% \quad$ TPSNLAAAR

$0.00 \% \quad 1.7 \%$ MPISLQQIR

$0.00 \% \quad 1.7 \%$ VVDDEIYYFR

$0.02 \% \quad 5.4 \%$ GSQEVLGHAAR

$0.02 \% \quad 5.4 \%$ LQTLPVSR

$0.02 \% \quad 5.4 \% \quad$ ITDLLPNITR

$0.06 \% \quad 11.3 \%$ ACILCVHPR

$0.06 \% \quad 11.3 \%$ TSIIEAQYLR

$0.06 \% \quad 11.3 \%$ YHDIEPGAVVK

$0.06 \% \quad 11.3 \%$ VLLCDPEAK

$0.06 \% \quad 11.3 \%$ FYNNVQGLVPK

$0.06 \% \quad 11.3 \%$ VVVLNCEPSKER

$0.06 \% 11.3 \%$ VLCLSQSEGR

$0.06 \% \quad 11.3 \%$ IPLLLTSLSFK

$18 \quad 43 \quad 0.06 \% \quad 11.3 \%$ LGPSVVGLAR

$18 \quad 43 \quad 0.06 \% \quad 11.3 \%$ AIFENTLSTYPK
$43 \quad 0.06 \% \quad 11.3 \%$ VIHLSLAPK $\begin{array}{llll}99.7 \% & 29.8 & 25.0 & 29.8\end{array}$

$0.01 \% \quad 9.1 \% \quad$ VKGTNIQENEYVK

$0.01 \% \quad 9.1 \%$ LVDSVKENAGTVR

$0.02 \% \quad 16.7 \%$ SGSTAVGVMISPK

$0.02 \% \quad 16.7 \%$ DNMSIVLVCFSNAPK

$99.0 \% \quad 23.9 \quad 25.0 \quad 23.9$

$99.7 \% \quad 39.1 \quad 25.0 \quad 37.3 \quad 2$

$\begin{array}{llll}98.8 \% & 24.4 & 25.0 & 13.9\end{array}$

$\begin{array}{llll}98.5 \% & 24.5 & 25.0 & 12.8\end{array}$

$\begin{array}{llll}99.7 \% & 37.9 & 25.0 & 37.5\end{array}$

$\begin{array}{llll}99.7 \% & 28.3 & 25.0 & 28.3\end{array}$

$\begin{array}{llll}99.7 \% & 43.2 & 25.0 & 36.9\end{array}$

$\begin{array}{llll}99.7 \% & 60.0 & 25.0 & 53.8\end{array}$

$\begin{array}{llll}99.6 \% & 23.3 & 25.0 & 23.3\end{array}$

$\begin{array}{llll}99.7 \% & 44.1 & 25.0 & 42.0\end{array}$

$99.7 \% \quad 42.0 \quad 25.0 \quad 42.0$

$\begin{array}{llll}99.7 \% & 67.1 & 25.0 & 54.5\end{array}$

$\begin{array}{lllll}99.7 \% & 54.8 & 25.0 & 43.2 & 2\end{array}$

$\begin{array}{llll}99.7 \% & 29.0 & 25.0 & 27.7\end{array}$

$\begin{array}{llll}99.7 \% & 43.5 & 25.0 & 38.1\end{array}$

$\begin{array}{llll}99.6 \% & 28.7 & 25.0 & 15.7\end{array}$

$99.7 \% \quad 25.7 \quad 25.0 \quad 18.3$

$\begin{array}{llll}99.5 \% & 27.8 & 25.0 & 21.3\end{array}$

$\begin{array}{lllllll}0.00 \% & 2.0 \% & \text { LKAEPAAPPAAPSTPAPPPAVPK } & 98.4 \% & 18.9 & 25.0 & 18.9\end{array}$

$\begin{array}{llllllll}0.00 \% & 2.0 \% & \text { AVGTPGGGGGGAVPGISAMSR } & 99.7 \% & 38.3 & 25.0 & 38.3 & 2\end{array}$

$99.7 \% \quad 52.6$

$96.3 \% \quad 26.3$

$0.06 \% \quad 11.3 \%$ LKDGVLAYAR

$0.06 \% \quad 11.3 \%$ TKDGLEVAVLPHNIR

$99.7 \% \quad 31.5 \quad 25.0 \quad 23.9$

$99.7 \% \quad 35.5 \quad 25.0 \quad 30.1$

$99.7 \% \quad 55.0 \quad 25.0 \quad 45.8 \quad 2$

$\begin{array}{llll}99.7 \% & 41.3 & 25.0 & 35.1\end{array}$

$99.6 \% \quad 23.3 \quad 25.0 \quad 19.6 \quad 2$

$99.2 \% \quad 18.8 \quad 25.0 \quad 18.8$

$99.7 \% \quad 47.6 \quad 25.0 \quad 47.6$

$\begin{array}{llll}99.3 \% & 20.0 & 25.0 & 20.0\end{array}$

$99.7 \% \quad 59.4 \quad 25.0 \quad 53.7$

$\begin{array}{llll}99.7 \% & 40.9 & 25.0 & 40.8\end{array}$

$\begin{array}{llll}18 & 43 & 0.06 \% & 11.3 \% \\ 18 & 43 & 0.06 \% & 11.3 \% \text { KPALVSTVEGGQDPK }\end{array}$

$\begin{array}{llll}99.7 \% & 61.9 & 25.0 & 61.9\end{array}$

$\begin{array}{lllll}18 & 43 & 0.06 \% & 11.3 \% & \text { ATVVGPDSSK } \\ 18 & 43 & 0.06 \% & 11.3 \% \text { VTPNEGLTVSFPFGK }\end{array}$

$18 \quad 43 \quad 0.06 \% \quad 11.3 \%$ FAQLEFQLGDAER

$99.7 \% 53.6$

$98.9 \% \quad 20.2 \quad 25.0 \quad 16.9$

$99.7 \% \quad 54.5 \quad 25.0 \quad 54.5 \quad 4$

$\begin{array}{llll}99.7 \% & 45.7 & 25.0 & 45.7\end{array}$

$\begin{array}{lllll}99.7 \% & 61.4 & 25.0 & 50.9 & 3\end{array}$

$99.7 \% \quad 52.6 \quad 25.0 \quad 45.4$

$99.7 \% \quad 25.3 \quad 25.0 \quad 25.3$
$218 \quad 229$

$132 \quad 142$

$247 \quad 261$

$\begin{array}{lc}82 & 92 \\ 469 & 1478\end{array}$

$180 \quad 188$

$274 \quad 284$

$309 \quad 316$

$326 \quad 335$

8395

$161 \quad 169$

332344

$108 \quad 118$

$130 \quad 142$

$143 \quad 153$

$180 \quad 191$

$192 \quad 200$

$286 \quad 300$

361369

$301 \quad 309$

$426 \quad 434$

$1283 \quad 1292$

$504 \quad 526$

$1350 \quad 1370$

$2+12$

$\begin{array}{ll}213 & 220 \\ 221 & 230\end{array}$

$329 \quad 337$

$386 \quad 395$

$437 \quad 446$

$447 \quad 457$

$507 \quad 515$

$561 \quad 571$

$594 \quad 605$

$647 \quad 661$

$692 \quad 701$

$707 \quad 721$

$982 \quad 1000$

$1178 \quad 1188$

$1205 \quad 1214$

$1240 \quad 1254$

$1343 \quad 1352$

$1767 \quad 1779$

$383.72 \quad 1782 \quad 1793$

$\begin{array}{lll}977.61 & 1821 & 1829\end{array}$ 
Protein SDA1 homolog GN=SDAD1 Protein SDA1 homolog GN=SDAD1 Protein SDA1 homolog GN=SDAD1 Protein SDA1 homolog GN=SDAD 1 Protein SDA1 homolog GN=SDAD1 Protein SEC13 homolog GN=SEC13 Protein SEC13 homolog GN=SEC13 Protein SET GN=SET

Protein SET GN=SET

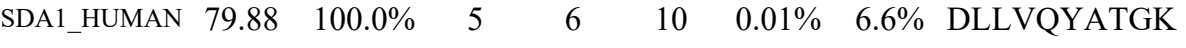
SDA1_HUMAN $79.88 \quad 100.0 \%$ SDA1_HUMAN $79.88 \quad 100.0 \%$ SDA1_HUMAN $79.88 \quad 100.0 \%$ SDA1_HUMAN $79.88 \quad 100.0 \%$ SEC13_HUMAN $35.54 \quad 100.0 \%$ SEC13 HUMAN $35.54 \quad 100.0 \%$ SET_HUMAN $33.49 \quad 100.0 \%$ SET HUMAN $33.49 \quad 100.0 \%$ A1 S61A1_HUMAN $52.27 \quad 100.0 \%$ IA1 S61A1_HUMAN $52.27 \quad 100.0 \%$ $\begin{array}{llll}\text { Protein transport protein Sec61 subunit alpha isoform } 1 \mathrm{GN}=\mathrm{SEC} 61 \mathrm{~A} 1 & \mathrm{~S} 61 \mathrm{~A} 1 \_ \text {HUMAN } & 52.27 & 100.0 \% \\ \text { Protein transport protein Sec61 subunit alpha isoform } 1 \mathrm{GN}=\mathrm{SEC} 61 \mathrm{~A} 1 & \mathrm{~S} 61 \mathrm{~A} 1 \_ \text {HUMAN } & 52.27 & 100.0 \%\end{array}$ Protein unc-45 homolog A GN=UNC45A UN45A_HUMAN $103.08 \quad 100.0 \%$ Protein unc-45 homolog A GN=UNC45A UN45A_HUMAN $103.08 \quad 100.0 \%$ Protein unc-45 homolog A GN=UNC45A UN45A_HUMAN $103.08 \quad 100.0 \%$ Protein VAC14 homolog GN=VAC14 VAC14 HUMAN $87.98 \quad 100.0 \%$ Protein VAC14 homolog GN=VAC14 VAC14_HUMAN $87.98 \quad 100.0 \%$ Protein VAC14 homolog GN=VAC14 VAC14_HUMAN $87.98 \quad 100.0 \%$ Protein virilizer homolog GN=KIAA1429 VIR HUMAN $202.03 \quad 100.0 \%$ Protein virilizer homolog GN=KIAA1429 VIR_HUMAN $202.03 \quad 100.0 \%$ Protein virilizer homolog GN=KIAA1429 VIR HUMAN $202.03 \quad 100.0 \%$ Protein virilizer homolog GN=KIAA1429 VIR_HUMAN $202.03 \quad 100.0 \%$ Protein virilizer homolog GN=KIAA1429 VIR_HUMAN $202.03 \quad 100.0 \%$ Protein VPRBP GN=VPRBP Protein VPRBP GN=VPRBP Protein YIPF5 GN=YIPF5

Protein YIPF5 GN=YIPF5 Pumilio homolog 1 GN=PUM1 Pumilio homolog $1 \mathrm{GN}=\mathrm{PUM} 1$

VPRBP HUMAN $169.01 \quad 100.0 \%$ VPRBP_HUMAN $169.01 \quad 100.0 \%$ YIPF5_HUMAN $27.99 \quad 100.0 \%$ YIPF5 HUMAN $27.99 \quad 100.0 \%$ PUM1_HUMAN $126.47 \quad 100.0 \%$ PUM1 HUMAN $126.47 \quad 100.0 \%$ Puromycin-sensitive aminopeptidase GN=NPEPPS PSA_HUMAN $103.28 \quad 100.0 \%$ Puromycin-sensitive aminopeptidase GN=NPEPPS PSA_HUMAN $103.28 \quad 100.0 \%$ Puromycin-sensitive aminopeptidase GN=NPEPPS PSA_HUMAN $103.28 \quad 100.0 \%$ Puromycin-sensitive aminopeptidase GN=NPEPPS PSA_HUMAN $103.28 \quad 100.0 \%$ Puromycin-sensitive aminopeptidase GN=NPEPPS PSA_HUMAN $103.28 \quad 100.0 \%$ Puromycin-sensitive aminopeptidase GN=NPEPPS PSA_HUMAN $103.28 \quad 100.0 \%$ Puromycin-sensitive aminopeptidase GN=NPEPPS PSA_HUMAN $103.28 \quad 100.0 \%$ Puromycin-sensitive aminopeptidase GN=NPEPPS PSA_HUMAN $103.28 \quad 100.0 \%$ Puromycin-sensitive aminopeptidase GN=NPEPPS PSA_HUMAN $103.28 \quad 100.0 \%$ Puromycin-sensitive aminopeptidase GN=NPEPPS PSA_HUMAN $103.28 \quad 100.0 \%$ Puromycin-sensitive aminopeptidase GN=NPEPPS PSA_HUMAN $103.28100 .0 \%$ Putative ATP-dependent RNA helicase DHX30 GN=DHX30 DHX30_HUMAN $133.94 \quad 100.0 \%$ Putative ATP-dependent RNA helicase DHX30 GN=DHX30 DHX30_HUMAN $133.94 \quad 100.0 \%$ Putative ATP-dependent RNA helicase DHX30 GN=DHX30 DHX30_HUMAN $133.94 \quad 100.0 \%$ Putative ATP-dependent RNA helicase DHX30 GN=DHX30 DHX30_HUMAN $133.94 \quad 100.0 \%$ Putative ATP-dependent RNA helicase DHX30 GN=DHX30 DHX30_HUMAN $133.94 \quad 100.0 \%$ Putative ATP-dependent RNA helicase DHX30 GN=DHX30 DHX30_HUMAN $133.94 \quad 100.0 \%$ $10 \quad 0.01 \% \quad 6.6 \%$ DLLVQYATGKK

$10 \quad 0.01 \% \quad 6.6 \%$ GKPTEASIEAR

$10 \quad 0.01 \% \quad 6.6 \% \quad$ VLTQEDFQKIR

$10 \quad 0.01 \% \quad 6.6 \% \quad$ TNPFSSSTNKEK

$3 \quad 0.00 \% \quad 5.9 \%$ SVKIFDVR

$0.00 \% \quad 5.9 \% \quad$ NGGQILIADLR

$0.00 \% \quad 7.2 \% \quad$ LRQPFFQK

$0.00 \% \quad 7.2 \%$ EFHLNESGDPSSK

$0.02 \% \quad 8.6 \%$ IIEVGDTPKDR

$0.02 \% \quad 8.6 \%$ AFSPTTVNTGR

$0.02 \% \quad 8.6 \%$ GQYNTYPIK

$0.02 \% \quad 8.6 \%$ ETSMVHELNR

$0.01 \% \quad 3.4 \%$ SNGVQLLQR

$0.01 \% \quad 3.4 \%$ ALIPLALEGTDVGQTK

$0.01 \% \quad 3.4 \%$ ALIPLALEGTDVGQTKAAQALAK

$0.01 \% \quad 4.5 \%$ YYACEALYNIVK

$0.01 \% \quad 4.5 \% \quad$ AGLLNTSGTK

$0.01 \% \quad 4.5 \%$ TLESQNLFCCLYR

$0.01 \% \quad 2.9 \%$ TTFEIEISR

$0.01 \% \quad 2.9 \%$ LLELILLDQTVR

$0.01 \% \quad 2.9 \% \quad$ VVTAGSAILQK

$0.01 \% \quad 2.9 \%$ SAVGHVFSLEK

$0.01 \% \quad 2.9 \%$ SEYIEPAKR

$0.00 \% \quad 1.5 \%$ LQKADVVAQSR

$0.00 \% \quad 1.5 \%$ GLGETATVLTK

$0.00 \% \quad 8.2 \%$ QYAGYDYSQQGR

$0.00 \% \quad 8.2 \%$ TLTVLHPLK

$0.01 \% \quad 2.7 \% \quad$ DSLTGSSDLYKR

$0.01 \% \quad 2.7 \%$ SASSASSLFSPSSTLFSSS

$0.03 \% \quad 13.8 \%$ YAAVTQFEATDARR

$0.03 \% \quad 13.8 \%$ ATFDISLVVPKDR

$0.03 \% \quad 13.8 \%$ VYTPVGKAEQGK

$0.03 \% \quad 13.8 \%$ FALEVAAK

$0.03 \% \quad 13.8 \%$ LNLGTVGFYR

$0.03 \% \quad 13.8 \%$ LGLQNDLFSLAR

$0.03 \% \quad 13.8 \%$ AGIISTVEVLK

$0.03 \% \quad 13.8 \%$ SPVYLTVLK

$0.03 \% \quad 13.8 \%$ VLGATLLPDLIQK

$0.03 \% \quad 13.8 \%$ AFFESHPAPSAER

$0.03 \% \quad 13.8 \%$ DAESIHQYLLQR

$0.05 \% \quad 11.7 \%$ NLLNSVIGR

$0.05 \% \quad 11.7 \%$ SVEVEGYGSK

$0.05 \% \quad 11.7 \%$ QLNPESIRPGGPGGLSR

$0.05 \% \quad 11.7 \%$ VIQIATSSSTAK

$0.05 \% \quad 11.7 \%$ IPQLLLER

$0.05 \% \quad 11.7 \%$ CNVIITQPR $\begin{array}{llllllll}99.7 \% & 50.5 & 25.0 & 45.3 & 2 & 0 & 0 & 1107.60\end{array}$

$\begin{array}{llll}99.7 \% & 39.0 & 25.0 & 39.0\end{array}$

$\begin{array}{lllll}99.7 \% & 47.5 & 25.0 & 32.3 & 2\end{array}$

$99.7 \% \quad 41.5 \quad 25.0 \quad 40.9$

$\begin{array}{llll}98.4 \% & 17.4 & 25.0 & 17.4\end{array}$

$99.0 \% \quad 34.8 \quad 25.0 \quad 29.8$

$\begin{array}{llll}99.7 \% & 32.9 & 25.0 & 26.8\end{array}$

$\begin{array}{llll}94.6 \% & 19.7 & 25.0 & 8.9\end{array}$

$\begin{array}{llll}99.7 \% & 27.2 & 25.0 & 27.2\end{array}$

$\begin{array}{llll}99.7 \% & 58.1 & 25.0 & 39.9\end{array}$

$\begin{array}{lllll}99.7 \% & 38.3 & 25.0 & 26.7 & 4\end{array}$

$\begin{array}{llll}95.8 \% & 18.4 & 25.0 & 12.9\end{array}$

$\begin{array}{llll}99.4 \% & 20.9 & 25.0 & 20.9\end{array}$

$\begin{array}{llll}99.7 \% & 30.0 & 25.0 & 23.5\end{array}$

$\begin{array}{llll}99.7 \% & 53.3 & 25.0 & 53.3\end{array}$

$\begin{array}{llll}99.7 \% & 48.0 & 25.0 & 48.0\end{array}$

$99.7 \% \quad 47.9 \quad 25.0 \quad 47.9$

$\begin{array}{llll}99.7 \% & 34.0 & 25.0 & 34.0\end{array}$

$\begin{array}{llll}99.7 \% & 45.2 & 25.0 & 45.2\end{array}$

$98.3 \% \quad 24.9 \quad 25.0 \quad 23.9$

$\begin{array}{llll}99.4 \% & 26.4 & 25.0 & 26.4\end{array}$

$\begin{array}{llll}99.7 \% & 39.2 & 25.0 & 39.2\end{array}$

$\begin{array}{llll}98.8 \% & 20.9 & 25.0 & 20.8\end{array}$

$\begin{array}{llll}98.0 \% & 27.1 & 25.0 & 17.2\end{array}$

$\begin{array}{llll}97.8 \% & 22.1 & 25.0 & 13.5\end{array}$

$\begin{array}{llll}99.7 \% & 32.3 & 25.0 & 18.8\end{array}$

$\begin{array}{llll}99.7 \% & 35.4 & 25.0 & 35.4\end{array}$

$\begin{array}{llll}97.7 \% & 22.3 & 25.0 & 22.1\end{array}$

$\begin{array}{llll}99.7 \% & 31.6 & 25.0 & 31.6\end{array}$

$\begin{array}{llll}99.7 \% & 50.7 & 25.0 & 50.7\end{array}$

$\begin{array}{llll}98.8 \% & 23.3 & 25.0 & 15.0\end{array}$

$\begin{array}{lllll}99.7 \% & 40.5 & 25.0 & 37.0\end{array}$

$\begin{array}{llll}99.3 \% & 25.0 & 25.0 & 16.1\end{array}$

$\begin{array}{llll}98.1 \% & 21.1 & 25.0 & 15.3\end{array}$

$\begin{array}{llll}99.7 \% & 33.2 & 25.0 & 15.5\end{array}$

$\begin{array}{llll}99.7 \% & 56.3 & 25.0 & 42.7\end{array}$

$\begin{array}{llll}99.7 \% & 31.3 & 25.0 & 26.1\end{array}$

$99.7 \% \quad 34.6 \quad 25.0 \quad 34.6$

$\begin{array}{llll}99.7 \% & 37.2 & 25.0 & 37.2\end{array}$

$\begin{array}{llll}99.7 \% & 35.9 & 25.0 & 32.8\end{array}$

$\begin{array}{llll}99.7 \% & 44.1 & 25.0 & 44.1\end{array}$

$\begin{array}{llll}99.7 \% & 34.3 & 25.0 & 21.6\end{array}$

$\begin{array}{llll}99.7 \% & 40.3 & 25.0 & 37.3\end{array}$

$\begin{array}{llll}98.3 \% & 18.7 & 25.0 & 16.5\end{array}$

$\begin{array}{lllll}99.7 \% & 64.2 & 25.0 & 62.0 & 2\end{array}$

$\begin{array}{llll}99.0 \% & 29.6 & 25.0 & 20.5\end{array}$

$\begin{array}{llll}99.7 \% & 52.4 & 25.0 & 35.4\end{array}$
1235.70

1158.61

1376.75

1339.65

963.56

1169.66

1063.60

1446.65

1242.67

1150.59

1083.55

1231.57

1014.57

1625.91

2279.30

1506.73

961.53

1703.79

1095.57

1425.87

1086.65

1173.63

1092.57

1214.69

1089.62

1435.62

1021.64

1341.66

1992.95

1598.79

1460.81

1276.69

848.49

1139.62

1346.74

1129.68

1019.61

1380.85

1445.68

1472.75

985.58

1054.51

1734.92

1205.67

981.61

1100.59

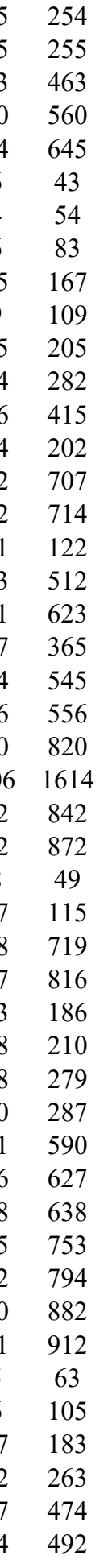



Putative ATP-dependent RNA helicase DHX30 GN=DHX30 DHX30_HUMAN $133.94 \quad 100.0 \%$ Putative ATP-dependent RNA helicase DHX30 GN=DHX30 DHX30 HUMAN $133.94 \quad 100.0^{\circ}$ Putative ATP-dependent RNA helicase DHX30 GN=DHX30 DHX30_HUMAN $133.94 \quad 100.0 \%$ Putative ATP-dependent RNA helicase DHX30 GN=DHX30 DHX30_HUMAN $133.94 \quad 100.0 \%$ Putative ATP-dependent RNA helicase DHX30 GN=DHX30 DHX30_HUMAN $133.94 \quad 100.0 \%$ Putative helicase MOV-10 GN=MOV10 MOV10_HUMAN $113.68 \quad 100.0 \%$ Putative helicase MOV-10 GN=MOV10 MOV10 HUMAN $113.68 \quad 100.0 \%$ Putative helicase MOV-10 GN=MOV10 MOV10_HUMAN $113.68 \quad 100.0 \%$ Putative helicase MOV-10 GN=MOV10 MOV10_HUMAN $113.68 \quad 100.0 \%$ Putative helicase MOV-10 GN=MOV10 MOV10_HUMAN $113.68100 .0 \%$ Putative mitochondrial import inner membrane translocase subunit Tim23B GN=TIMM23B $\quad$ TI23B_HUMAN $21.94 \quad 100.0 \%$ Putative mitcochondral import inner membrane translocase subunit Tim23B GN=TIMM23B $\quad$ TI23B_HUMAN $21.94 \quad 100.0 \%$ TI23B_HUMAN $21.94 \quad 100.0 \%$ Putative oxidoreductase GLYR1 GN=GLYR1 GLYR1_HUMAN $60.56 \quad 100.0 \%$ Putative oxidoreductase GLYR1 GN=GLYR1 GLYR1 HUMAN $60.56100 .0 \%$ Putative oxidoreductase GLYR1 GN=GLYR1 GLYR1_HUMAN $60.56 \quad 100.0 \%$ Putative oxidoreductase GLYR1 GN=GLYR1 GLYR1_HUMAN $60.56 \quad 100.0 \%$ Putative oxidoreductase GLYR1 GN=GLYR1 GLYR1 HUMAN $60.56 \quad 100.0 \%$ Putative oxidoreductase GLYR1 GN=GLYR1 GLYR1_HUMAN $60.56 \quad 100.0 \%$ Putative RNA-binding protein 15 GN=RBM15 RBM15 HUMAN $107.19 \quad 100.0 \%$ Putative RNA-binding protein 15 GN=RBM15 RBM15_HUMAN $107.19 \quad 100.0 \%$ Putative RNA-binding protein 15 GN=RBM15 RBM15_HUMAN $107.19 \quad 100.0 \%$ Putative RNA-binding protein Luc7-like 2 GN=LUC7L2 LC7L2_HUMAN $46.51 \quad 100.0 \%$ Putative RNA-binding protein Luc7-like 2 GN=LUC7L2 LC7L2_HUMAN $46.51 \quad 100.0 \%$ Putative transferase CAF17, mitochondrial GN=IBA57 CAF17_HUMAN $38.16 \quad 100.0 \%$ Putative transferase CAF17, mitochondrial GN=IBA57 CAF17 HUMAN $38.16 \quad 100.0 \%$ Pyridoxal phosphate phosphatase GN=PDXP PLPP_HUMAN $31.70 \quad 100.0 \%$ Pyridoxal phosphate phosphatase GN=PDXP PLPP HUMAN $31.70 \quad 100.0 \%$ Pyridoxal-dependent decarboxylase domain-containing protein 1 GN=PDXDC1 PDXD1_HUMAN $86.71 \quad 100.0 \%$ Pyridoxal-dependent decarboxylase domain-containing protein $1 \mathrm{GN}=\mathrm{PDXDC1}$ PDXD1_HUMAN $86.71 \quad 100.0 \%$ Pyrroline-5-carboxylate reductase 1, mitochondrial GN=PYCR1 P5CR1_HUMAN $33.36 \quad 100.0 \%$ Pyrroline-5-carboxylate reductase 1, mitochondrial GN=PYCR1 P5CR1_HUMAN $33.36 \quad 100.0 \%$ Pyrroline-5-carboxylate reductase 1, mitochondrial GN=PYCR1 P5CR1_HUMAN $33.36 \quad 100.0 \%$ Pyrroline-5-carboxylate reductase 1, mitochondrial GN=PYCR1 P5CR1_HUMAN $33.36 \quad 100.0 \%$ Pyrroline-5-carboxylate reductase 1, mitochondrial GN=PYCR1 P5CR1_HUMAN $33.36 \quad 100.0 \%$ Pyrroline-5-carboxylate reductase 1, mitochondrial GN=PYCR1 P5CR1_HUMAN $33.36100 .0 \%$ Pyrroline-5-carboxylate reductase 1, mitochondrial GN=PYCR1 P5CR1_HUMAN $33.36 \quad 100.0 \%$ Pyrroline-5-carboxylate reductase 1, mitochondrial GN=PYCR1 P5CR1_HUMAN $33.36 \quad 100.0 \%$ Pyrroline-5-carboxylate reductase 1, mitochondrial GN=PYCR1 P5CR1_HUMAN $33.36 \quad 100.0 \%$ Pyrroline-5-carboxylate reductase 1, mitochondrial GN=PYCR1 P5CR1_HUMAN $33.36 \quad 100.0 \%$ Pyrroline-5-carboxylate reductase 1, mitochondrial GN=PYCR1 P5CR1 HUMAN $33.36100 .0 \%$ Pyrroline-5-carboxylate reductase 2 GN=PYCR2 P5CR2_HUMAN $33.64 \quad 100.0 \%$ Pyrroline-5-carboxylate reductase 2 GN=PYCR2 P5CR2_HUMAN $33.64 \quad 100.0 \%$ Pyrroline-5-carboxylate reductase 2 GN=PYCR2 P5CR2_HUMAN $33.64100 .0 \%$ Pyrroline-5-carboxylate reductase 2 GN=PYCR2 P5CR2_HUMAN $33.64 \quad 100.0 \%$

5

(5)

13
13
5

5
3
3

3
3
6

6
6

6
6
6

6

6
6
3

6
3
3

3
3
2

2

2

2
2
2

2

2
2
2

2
2
10
10

2
10
10
10

10

10
10
10

10
10
10

10
10

10

10
10

10

10

14
14
14

4

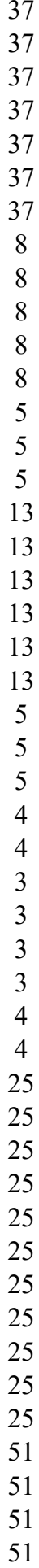

$0.05 \% \quad 11.7 \%$ AIVLAAIFR

$0.05 \% \quad 11.7 \%$ ALLSHDSGSDHLAFVR

$0.05 \% \quad 11.7 \%$ FKPNSVTYR

$0.05 \% \quad 11.7 \%$ SGNILLHK

$0.05 \% \quad 11.7 \%$ ATISLSDSDLLR

$0.01 \% \quad 7.8 \%$ LLTLEVPGVTESRPSVLR

$0.01 \% \quad 7.8 \%$ SLESNPEQLQAMR

$\begin{array}{llll}0.01 \% & 7.8 \% & \text { AHILACAPSNSGADLLCQR } \\ 0.01 \% & 7.8 \% & \text { KGPDGYDPQFITK }\end{array}$

$0.01 \% \quad 7.8 \%$ LDLQQGQNLLQGLSK $99.7 \% \quad 53.6$

$\begin{array}{llllll}0.01 \% & 11.3 \% & \text { YLVQDTDEFILPTGANK } & 99.7 \% & 53.4\end{array}$

$0.01 \% \quad 11.3 \% \quad$ YLVQDTDEFILPTGANKTR $99.7 \% \quad 24.8$

$0.01 \% \quad 11.3 \%$ NVQILNMVTR

$0.02 \% \quad 13.4 \%$ FQQAVDAVEEFLR

$99.7 \% \quad 61.8$

$0.02 \% \quad 13.4 \%$ TAEKCDLFIQEGAR $\quad 99.7 \% \quad 49.9$

$\begin{array}{lll}0.02 \% & 13.4 \% & \text { AAKDLVLGPSGVLQGIRPGK } 99.4 \% 20.6\end{array}$

$0.02 \% \quad 13.4 \%$ DLVLGPSGVLQGIRPGK $\quad 99.7 \% \quad 57.5$

$0.02 \% \quad 13.4 \%$ TSFFLGEVGNAAK

$99.7 \% \quad 45.0$

$\begin{array}{llll}0.02 \% & 13.4 \% & \text { ALDQSDNDMSAVYR } \quad 99.7 \% & 44.9\end{array}$

$0.01 \% \quad 5.1 \%$ SSGAASSAPGGGDGAEYKTLK $\quad 99.7 \% \quad 57.5$

$0.01 \% \quad 5.1 \%$ VRPAYSLEPR

$94.6 \% \quad 14.8$

$\begin{array}{lllll}0.01 \% & 5.1 \% & \text { SSSSSAASDTATSTQRPLR } & 99.7 \% & 32.3\end{array}$

$0.01 \% \quad 6.9 \% \quad$ LAETQEEISAEVAAK $\quad 99.7 \% \quad 52.8$

$0.01 \% \quad 6.9 \% \quad$ NSMPASSFQQQK

$0.00 \% \quad 7.3 \% \quad$ LLTQDEGPALVPGGR

$0.00 \% \quad 7.3 \%$ GCYIGQELTAR

$\begin{array}{rr}96.3 \% & 14.9 \\ 99.2 \% & 23.6\end{array}$

$\begin{array}{ll}99.2 \% & 23.6 \\ 99.3 \% & 24.1\end{array}$

$\begin{array}{llllll}0.00 \% & 10.5 \% & \text { LAGDPSAGDGAAPR } & 99.7 \% & 42.8\end{array}$

$\begin{array}{llll}0.00 \% & 10.5 \% & \text { TPGTGSLAAAVETASGR } & 99.7 \% \quad 73.8\end{array}$

$0.01 \% \quad 3.6 \%$ ILVEDELSSPVVVFR

$99.7 \% \quad 50.0$

$99.7 \% \quad 52.9$

$\begin{array}{rrr}0.01 \% & 3.6 \% & \text { FFQELPGSDPVFK } \\ 0.03 \% & 34.5 \% & \text { GFTAAGVLAAHK }\end{array}$

$99.7 \% \quad 58.3$

$\begin{array}{llllll}0.03 \% & 34.5 \% & \text { IMASSPDMDLATVSALR } & 99.4 \% & 20.7\end{array}$

$\begin{array}{llll}0.03 \% & 34.5 \% & \text { IMASSPDMDLATVSALRK } \quad 99.7 \% \quad 30.9\end{array}$

$0.03 \% \quad 34.5 \%$ KLSAFRPAPR

$0.03 \% \quad 34.5 \%$ LSAFRPAPR

$0.03 \% \quad 34.5 \%$ CMTNTPVVVR

$0.03 \% \quad 34.5 \%$ LGAQALLGAAK

$0.03 \% \quad 34.5 \%$ SLLINAVEASCIR

$\begin{array}{lll}98.8 \% & 23.8\end{array}$

$99.7 \% \quad 32.5$

$\begin{array}{ll}99.7 \% & 36.8 \\ 99.7 \% & 56.8\end{array}$

$99.7 \% \quad 47.7$

$\begin{array}{lllll}0.03 \% & 34.5 \% & \text { ELQSMADQEQVSPAAIKK } & 99.7 \% & 51.7 \\ 0.03 \% & 34.5 \% & \text { VKLDSPAGTALSPSGHTK } & 99.7 \% & 42.8\end{array}$

$\begin{array}{llllll}0.03 \% & 34.5 \% & \text { LDSPAGTALSPSGHTK } \quad 99.7 \% & 26.6\end{array}$

$0.07 \% \quad 40.3 \%$ GFTAAGILSAHK

$99.7 \% \quad 62.6$

$0.07 \% \quad 40.3 \%$ IIASSPEMNLPTVSALR $\quad 99.7 \% \quad 73.1$

$0.07 \% \quad 40.3 \%$ IIASSPEMNLPTVSALRK $\quad 99.7 \% \quad 41.1$

$0.07 \% \quad 40.3 \%$ KMGVNLTR

$99.0 \% 28.6$

1086.64

1225.72

973.62

1724.87

1111.59

881.52

1290.69

1966.13

1502.73

2053.99

1465.73

1654.91

1923.97

2181.12

1187.66

1551.78

1637.80

1976.17

1706.00

1340.68

1584.70

1910.91

1187.65

1909.92

1588.81

1352.63

1522.82

1267.61

1254.61

1545.79

1701.94

1510.76

1142.63

1777.88

1921.97

1142.68

1014.58

1192.58

1012.62

1445.78

1973.00

1765.94

1538.78

1172.64

1814.97

1927.07

Page 106 of Table S-1-1 
Pyrroline-5-carboxylate reductase 2 GN=PYCR2 P5CR2_HUMAN $33.64 \quad 100.0 \% \quad 1$ Pyrroline-5-carboxylate reductase 2 GN=PYCR2 P5CR2_HUMAN $33.64 \quad 100.0 \% \quad 14$ Pyrroline-5-carboxylate reductase 2 GN=PYCR2 P5CR2_HUMAN $33.64 \quad 100.0 \% \quad 14$ Pyrroline-5-carboxylate reductase $2 \mathrm{GN}=\mathrm{PYCR} 2$ P5CR2 HUMAN $33.64 \quad 100.0 \%$ Pyrroline-5-carboxylate reductase 2 GN=PYCR2 P5CR2_HUMAN $33.64 \quad 100.0 \% \quad 14$ Pyrroline-5-carboxylate reductase 2 GN=PYCR2 P5CR2_HUMAN $33.64 \quad 100.0 \% \quad 14$ Pyrroline-5-carboxylate reductase 2 GN=PYCR2 P5CR2_HUMAN $33.64 \quad 100.0 \% \quad 14$ Pyrroline-5-carboxylate reductase 2 GN=PYCR2 P5CR2_HUMAN $33.64 \quad 100.0 \% \quad 14$ Pyrroline-5-carboxylate reductase 2 GN=PYCR2 P5CR2_HUMAN $33.64 \quad 100.0 \% \quad 14$ Pyrroline-5-carboxylate reductase 2 GN=PYCR2 P5CR2_HUMAN $33.64 \quad 100.0 \% \quad 14$ Pyrroline-5-carboxylate reductase $3 \mathrm{GN}=$ PYCRL P5CR3_HUMAN $28.66 \quad 100.0 \%$ Pyrroline-5-carboxylate reductase 3 GN=PYCRL P5CR3 HUMAN $28.66 \quad 100.0 \%$ Pyrroline-5-carboxylate reductase 3 GN=PYCRL P5CR3_HUMAN $28.66 \quad 100.0 \%$ Pyrroline-5-carboxylate reductase 3 GN=PYCRL P5CR3_HUMAN $28.66 \quad 100.0 \%$ Pyrroline-5-carboxylate reductase $3 \mathrm{GN}=$ PYCRL P5CR3 HUMAN $28.66 \quad 100.0 \%$ Pyruate dehydrogenase El component subunit alpha, somatic fom, mitochondral GN=PDHAI ODPA_HUMAN $43.30 \quad 100.0$ 列 ate dehydrogenase E1 component subunit beta, mitochondrial GN=PDHB ODPB HUMAN $39.23 \quad 100.0 \%$ 作 Pyruvate dehydrogenase E1 component subunit beta, mitochondrial GN=PDHB ODPB_HUMAN $39.23 \quad 100.0 \%$ Pyruvate kinase PKM GN=PKN Pyruvate kinase $\mathrm{PKM}$ GN=PKM Pyruvate kinase $P K M$ GN=PKM Pyruvate kinase $\mathrm{PKM}$ GN=PKN Pyruvate kinase $P K M$ GN $=P K M$ Pyruvate kinase $\mathrm{PKM}$ GN=PKN Pyruvate kinase $\mathrm{PKM}$ GN=PKN Pyruvate kinase $\mathrm{PKM}$ GN=PKM Pyruvate kinase $\mathrm{PKM}$ GN=PKM Pyruvate kinase PKM GN=PKM Pyruvate kinase $\mathrm{PKM}$ GN=PKN Pyruvate kinase $\mathrm{PKM}$ GN=PKM Pyruvate kinase PKM GN=PKM Pyruvate kinase $\mathrm{PKM}$ GN=PKN Pyruvate kinase $\mathrm{PKM}$ GN=PKM Pyruvate kinase $P K M$ GN=PKM Pyruvate kinase $P K M$ GN=PKM Pyruvate kinase $\mathrm{PKM}$ GN=PKM Pyruvate kinase PKM GN=PKN ODPA_HUMAN $43.30 \quad 100.0 \%$ ODPA_HUMAN 43.30 $100.0 \%$ 22 22 22 22
22 22 22 22
22

5

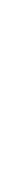

8

8

8
5
5

8
5
5
5

$\begin{array}{cccc}\text { ODPB_HUMAN } & 39.23 & 100.0 \% & 5 \\ \text { KPYM_HUMAN } & 57.94 & 100.0 \% & 25\end{array}$ KPYM HUMAN $57.94 \quad 100.0 \% \quad 25$ KPYM_HUMAN $57.94 \quad 100.0 \% \quad 25$ KPYM_HUMAN $57.94 \quad 100.0 \% \quad 25$ KPYM_HUMAN $57.94 \quad 100.0 \% \quad 25$ KPYM_HUMAN $57.94 \quad 100.0 \% \quad 25$ KPYM_HUMAN $57.94 \quad 100.0 \% \quad 25$ KPYM_HUMAN $57.94 \quad 100.0 \% \quad 25$ KPYM_HUMAN $57.94 \quad 100.0 \% \quad 25$ KPYM HUMAN $57.94 \quad 100.0 \% \quad 25$ KPYM_HUMAN $57.94 \quad 100.0 \% \quad 25$ KPYM_HUMAN $57.94 \quad 100.0 \% \quad 25$ KPYM HUMAN $57.94 \quad 100.0 \% \quad 25$ KPYM_HUMAN $57.94 \quad 100.0 \% \quad 25$ KPYM_HUMAN $57.94 \quad 100.0 \% \quad 25$ KPYM_HUMAN $57.94 \quad 100.0 \% \quad 25$ KPYM_HUMAN $57.94 \quad 100.0 \% \quad 25$ KPYM_HUMAN $57.94 \quad 100.0 \% \quad 25$ KPYM_HUMAN $57.94 \quad 100.0 \% \quad 25$ $0.07 \% \quad 40.3 \%$ HIVVSCAAGVTISSVEKK $\begin{array}{lll}99.7 \% & 39.1\end{array}$ $0.07 \% \quad 40.3 \%$ KLMAFQPAPK $99.7 \% \quad 40.9$ $0.07 \% \quad 40.3 \%$ LMAFQPAPK $\begin{array}{lllll}99.7 \% & 46.6 & 25.0 & 28.9 & 2\end{array}$ $0.07 \% \quad 40.3 \%$ RLAIQLGAQALLGAAK $0.07 \% \quad 40.3 \%$ LAIQLGAQALLGAAK $99.7 \% \quad 43.8$ $0.07 \% \quad 40.3 \%$ SLLINAVEASCIR $0.07 \% \quad 40.3 \%$ ELQSMADQEK $0.07 \% \quad 40.3 \%$ ISPAALKK $\begin{array}{llll}99.7 \% & 59.4 & 25.0 & 59.4\end{array}$ $99.7 \% \quad 47.7 \quad 25.0 \quad 44.7$ $\begin{array}{llll}99.7 \% & 40.7 & 25.0 & 37.9\end{array}$ $\begin{array}{llll}99.0 \% & 33.8 & 25.0 & 26.8\end{array}$

$\begin{array}{llllllll}51 & 0.07 \% & 40.3 \% & \text { VKLESPTVSTLTPSSPGK } & 99.7 \% & 72.7 & 25.0 & 70.5\end{array}$

$10 \quad 0.01 \% \quad 22.3 \%$ RVGFVGAGR $0.01 \% \quad 22.3 \%$ MAGAIAQGLIR $\begin{array}{llll}99.7 \% & 36.3 & 25.0 & 36.3\end{array}$ $99.7 \% \quad 57.5 \quad 25.0 \quad 51.3$

$10 \quad 0.01 \% \quad 22.3 \%$ AGKVEAQHILASAPTDR

$10 \quad 0.01 \% \quad 22.3 \%$ IAAQTLLGTAK

$0.01 \% \quad 22.3 \%$ AATMSAVEAATCR

$18 \quad 0.02 \% \quad 17.7 \%$ LEEGPPVTTVLTR

$18 \quad 0.02 \% \quad 17.7 \%$ AHGFTFTR

$18 \quad 0.02 \% \quad 17.7 \%$ EILAELTGR

$8 \quad 0.02 \% \quad 17.7 \%$ LPCIFICENNR

$18 \quad 0.02 \% \quad 17.7 \%$ YGMGTSVER

$8 \quad 0.02 \% \quad 17.7 \%$ AAASTDYYK

$18 \quad 0.02 \% \quad 17.7 \%$ AAASTDYYKR

$18 \quad 0.02 \% \quad 17.7 \%$ TREEIQEVR

$15 \quad 0.02 \% \quad 19.8 \%$ TYYMSGGLQPVPIVFR

$15 \quad 0.02 \% \quad 19.8 \%$ EGVECEVINMR

$0.02 \% \quad 19.8 \%$ TIRPMDMETIEASVMK

$0.02 \% \quad 19.8 \%$ IMEGPAFNFLDAPAVR

$0.02 \% \quad 19.8 \%$ VTGADVPMPYAK

$0.13 \% \quad 48.4 \%$ NTGIICTIGPASR

$0.13 \% \quad 48.4 \%$ SVETLKEMIK

$\begin{array}{ll}99.7 \% & 30.7 \\ 99.7 \% & 52.5\end{array}$

$99.7 \% \quad 40.5$

$99.7 \% \quad 56.1$

$99.0 \% \quad 25.4$

$99.7 \% \quad 49.1$

$99.7 \% \quad 39.4$

$99.7 \% \quad 54.1$

$99.7 \% \quad 39.4$

$99.7 \% \quad 62.2$

$99.7 \% \quad 34.0$

$99.7 \% \quad 42.4$

$99.7 \% \quad 53.9$

$99.7 \% \quad 32.5$

$99.7 \% \quad 50.0$

$99.7 \% \quad 47.4$

$99.7 \% \quad 53.4$

$99.7 \% \quad 41.9$

$0.13 \% \quad 48.4 \%$ LNFSHGTHEYHAETIK $\quad 99.7 \% \quad 26.4$

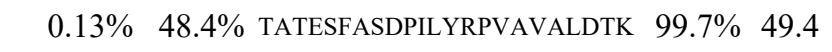

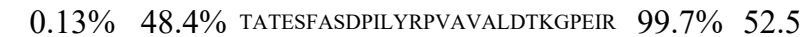

$0.13 \% \quad 48.4 \%$ GSGTAEVELKK

$99.7 \% \quad 49.7$

$0.13 \% \quad 48.4 \%$ IYVDDGLISLQVK

$99.7 \% \quad 52.4$

$0.13 \% \quad 48.4 \%$ IYVDDGLISLQVKQK $\quad 96.9 \% 16.6$

$0.13 \% \quad 48.4 \%$ GADFLVTEVENGGSLGSK $99.7 \% 59.9$

$0.13 \% \quad 48.4 \%$ GADFLVTEVENGGSLGSKK $99.7 \% \quad 53.1$

$0.13 \% \quad 48.4 \%$ KASDVHEVR

$0.13 \% \quad 48.4 \%$ ASDVHEVR

$0.13 \% \quad 48.4 \%$ ASDVHEVRK

$0.13 \% \quad 48.4 \%$ IISKIENHEGVR

$\begin{array}{ll}99.7 \% & 53.1 \\ 99.1 \% & 32.9\end{array}$

$99.0 \% \quad 48.8$

$99.1 \% \quad 32.2$

$99.7 \% \quad 66.7$

$99.0 \% \quad 47.1$

$0.13 \% \quad 48.4 \%$ IENHEGVR

$0.13 \% \quad 48.4 \%$ RFDEILEASDGIMVAR

$99.7 \% \quad 52.0$

$99.7 \% \quad 46.5$

$0.13 \% \quad 48.4 \%$ GDLGIEIPAEK

$99.7 \% \quad 51.3$
1885.02

1130.64

1002.54

1593.98

1437.88

1445.78

1178.54

827.54

1828.01

918.53

1116.62

1763.94

1086.65

1354.61

1411.78

936.47

1001.56

1435.68

999.46

989.46

1145.56

1159.61

1843.94

1335.60

1899.89

1747.88

1264.62

1359.71

1177.65

1883.90

2465.29

3017.59

1118.61

1462.82

1718.97

2036.03

1779.88

1907.97

1040.55

912.45

1040.55

1394.78

953.48

1837.91

1141.61 1828.02 $\begin{array}{cc}0 & 106 \\ 0 & 107 \\ 07 & 116 \\ 08 & 116 \\ 00 & 215 \\ 01 & 215 \\ 52 & 264 \\ 67 & 276 \\ 77 & 284 \\ 90 & 307 \\ 0 & 18 \\ 9 & 29 \\ 0 & 46 \\ 08 & 218 \\ 55 & 267 \\ 6 & 58 \\ 20 & 127 \\ 33 & 141 \\ 16 & 226 \\ 27 & 235 \\ 36 & 244 \\ 36 & 245 \\ 03 & 311 \\ 30 & 145 \\ 59 & 269 \\ 70 & 285 \\ 09 & 324 \\ 25 & 336 \\ 4 & 56 \\ 7 & 66 \\ 4 & 89 \\ 3 & 115 \\ 3 & 120 \\ 26 & 136 \\ 74 & 186 \\ 74 & 188 \\ 87 & 206 \\ 89 & 206 \\ 89 & 207 \\ 47 & 255 \\ 48 & 255 \\ 48 & 256 \\ 67 & 278 \\ 71 & 278 \\ 79 & 294 \\ 95 & 305 \\ & \end{array}$

Page 107 of Table S-1-1 
Pyruvate kinase $\mathrm{PKM}$ GN=PKM Pyruvate kinase $\mathrm{PKM}$ GN=PKM Pyruvate kinase $P K M$ GN=PKM Pyruvate kinase $\mathrm{PKM}$ GN=PKM Pyruvate kinase $\mathrm{PKM}$ GN=PKM Pyruvate kinase $\mathrm{PKM}$ GN=PKM Q5DID0-DECOY

\section{Q5DID0-DECOY}

Rabankyrin-5 GN=ANKFY1

Rabankyrin-5 GN=ANKFY1

Rac GTPase-activating protein $1 \mathrm{GN}=$ RACGAP1 RGAP1 HUMAN $71.03 \quad 100.0 \%$ Rac GTPase-activating protein $1 \mathrm{GN}=\mathrm{RACGAP} 1$ RGAP1 HUMAN $71.03 \quad 100.0 \%$ RAD50-interacting protein $1 \mathrm{GN}=$ RINT1 RINT1_HUMAN $90.64 \quad 100.0 \%$ RAD50-interacting protein $1 \mathrm{GN}=\mathrm{RINT} 1$ RINT1_HUMAN $90.64100 .0 \%$ Ran GTPase-activating protein $1 \mathrm{GN}=\mathrm{RANGAP} 1$ RAGP1_HUMAN $63.54 \quad 100.0 \%$ Ran GTPase-activating protein 1 GN=RANGAP1 RAGP1_HUMAN $63.54 \quad 100.0 \%$ Ran GTPase-activating protein $1 \mathrm{GN}=$ RANGAP1 RAGP1 HUMAN $63.54100 .0 \%$ Ran GTPase-activating protein $1 \mathrm{GN}=$ RANGAP1 RAGP1_HUMAN $63.54 \quad 100.0 \%$ Ran-binding protein $9 \mathrm{GN}=$ RANBP9 $\quad$ RANB9_HUMAN $77.85 \quad 100.0 \%$ Ran-binding protein $9 \mathrm{GN}=\mathrm{RANBP} 9 \quad$ RANB9_HUMAN $77.85 \quad 100.0 \%$ Ran-specific GTPase-activating protein GN=RANBP1 RANG_HUMAN $23.31 \quad 100.0 \%$ Ran-specific GTPase-activating protein GN=RANBP1 RANG_HUMAN $23.31 \quad 100.0 \%$ Ras GTPase-activating-like protein IQGAP1 GN=IQGAP1 IQGA1_HUMAN $189.26100 .0 \%$ Ras GTPase-activating-like protein IQGAP1 GN=IQGAP1 IQGA1_HUMAN $189.26 \quad 100.0 \%$ Ras GTPase-activating-like protein IQGAP1 GN=IQGAP1 IQGA1_HUMAN $189.26100 .0 \%$ Ras GTPase-activating-like protein IQGAP1 GN=IQGAP1 IQGA1_HUMAN $189.26 \quad 100.0 \%$ Ras GTPase-activating-like protein IQGAP1 GN=IQGAP1 IQGA1_HUMAN $189.26 \quad 100.0 \%$ Ras GTPase-activating-like protein IQGAP1 GN=IQGAP1 IQGA1 HUMAN $189.26 \quad 100.0 \%$ Ras GTPase-activating-like protein IQGAP1 GN=IQGAP1 IQGA1_HUMAN $189.26 \quad 100.0 \%$ Ras GTPase-activating-like protein IQGAP1 GN=IQGAP1 IQGA1 HUMAN $189.26 \quad 100.0 \%$ Ras GTPase-activating-like protein IQGAP1 GN=IQGAP1 IQGA1_HUMAN $189.26 \quad 100.0 \%$ Replication factor C subunit $1 \mathrm{GN}=\mathrm{RFC1}$ RFC1_HUMAN $128.26 \quad 100.0 \%$ Replication factor C subunit $1 \mathrm{GN}=\mathrm{RFC1}$ RFC1 HUMAN $128.26 \quad 100.0 \%$ Replication factor C subunit $1 \mathrm{GN}=\mathrm{RFC1} \mathrm{RFC1}{ }_{-} \mathrm{HUMAN} 128.26 \quad 100.0 \%$ Replication factor C subunit $2 \mathrm{GN}=\mathrm{RFC} 2 \quad \mathrm{RFC} 2$ HUMAN $39.16 \quad 100.0 \%$ Replication factor $\mathrm{C}$ subunit $2 \mathrm{GN}=\mathrm{RFC} 2 \mathrm{RFC2}$ HUMAN $39.16 \quad 100.0 \%$ Replication factor C subunit $2 \mathrm{GN}=\mathrm{RFC} 2$ RFC2_HUMAN $39.16 \quad 100.0 \%$ Replication factor $\mathrm{C}$ subunit $2 \mathrm{GN}=\mathrm{RFC} 2 \mathrm{RFC} 2$ HUMAN $39.16 \quad 100.0 \%$ Replication factor C subunit $2 \mathrm{GN}=\mathrm{RFC} 2 \mathrm{RFC2} 2 \mathrm{HUMAN} \quad 39.16 \quad 100.0 \%$ Replication factor C subunit $3 \mathrm{GN}=\mathrm{RFC} 3$ RFC3_HUMAN $40.56 \quad 100.0 \%$ Replication factor C subunit $3 \mathrm{GN}=\mathrm{RFC} 3$ RFC3 HUMAN $40.56 \quad 100.0 \%$ Replication factor C subunit $3 \mathrm{GN}=\mathrm{RFC} 3$ RFC3_HUMAN $40.56 \quad 100.0 \%$ Replication factor $\mathrm{C}$ subunit $3 \mathrm{GN}=\mathrm{RFC} 3 \mathrm{RFC} 3 \mathrm{HUMAN} \quad 40.56 \quad 100.0 \%$ Replication factor C subunit $3 \mathrm{GN}=\mathrm{RFC} 3$ RFC3_HUMAN $40.56 \quad 100.0 \%$ Replication factor C subunit $4 \mathrm{GN}=\mathrm{RFC} 4 \quad \mathrm{RFC} 4$ _HUMAN $39.68 \quad 100.0 \%$ Replication factor C subunit $4 \mathrm{GN}=\mathrm{RFC} 4 \quad \mathrm{RFC} 4$ HUMAN $39.68 \quad 100.0 \%$ Replication factor C subunit 4 GN=RFC4 RFC4_HUMAN $39.68 \quad 100.0 \%$
0

3
3
2

2

2
2
2

2
4
4
4

2

2

2

1

10

1 \\ $\begin{array}{lllll}10 & 15 & 0.02 \% & 6.0 \% & \text { LAAVALINAAIQK } \\ 10 & 15 & 0.02 \% & 6.0 \% & \text { TLQALQIPAAK } \\ 10 & 15 & 0.02 \% & 6.0 \% & \text { LIFQMPQNK }\end{array}$ \\ $\begin{array}{llllll}10 & 15 & 0.02 \% & 6.0 \% & \text { LIFQMPQNK } \\ 10 & 15 & 0.02 \% & 6.0 \% & \text { NKYQELINDIAR }\end{array}$}

$\begin{array}{llllll}10 & 15 & 0.02 \% & 6.0 \% & \text { NKYQELINDIAR } \\ 10 & 15 & 0.02 \% & 6.0 \% & \text { LQQTYAALNSK }\end{array}$

$\begin{array}{llllll}10 & 15 & 0.02 \% & 6.0 \% & \text { LQQTYAALNSK } \\ 10 & 15 & 0.02 \% & 6.0 \% & \text { ATFYGEQVDYYK }\end{array}$

$\begin{array}{ccccc}10 & 15 & 0.02 \% & 6.0 \% & \text { ATFYGEQVDYYK } \\ 3 & 6 & 0.01 \% & 3.0 \% & \text { SSADKIGEVSSPK }\end{array}$

6
6
6

6
6
6
6
6
6
6
8

$\begin{array}{llll}6 & 0.01 \% & 3.0 \% & \text { SSADKIGEVSSPI } \\ 6 & 0.01 \% & 3.0 \% & \text { SYLNREGPK }\end{array}$

$6 \quad 0.01 \% \quad 3.0 \%$ IIDEDGLLNLIR

$10 \quad 0.01 \% \quad 15.8 \%$ EGNVPNIIIAGPPGTGK

$10 \quad 0.01 \% \quad 15.8 \%$ FALACNASDKIIEPIQSR

$10 \quad 0.01 \% \quad 15.8 \%$ LTDAQILTR

$10 \quad 0.01 \% \quad 15.8 \%$ LMNVIEKER

$11 \quad 0.02 \% \quad 16.6 \%$ TVAQSQQLETNSQR

$11 \quad 0.02 \% \quad 16.6 \%$ LILCCNSTSK

$11 \quad 0.02 \% \quad 16.6 \%$ EGLNLPSQLAHR

$\begin{array}{llll}11 & 0.02 \% & 16.6 \% & \text { ALLMCEACR }\end{array}$

$11 \quad 0.02 \% \quad 16.6 \%$ ETANAIVSQQTPQR

$12 \quad 0.02 \% \quad 20.9 \%$ GTSISTKPPLTK

$12 \quad 0.02 \% \quad 20.9 \%$ GVAASAGSSGENKK

$12 \quad 0.02 \% \quad 20.9 \%$ VKNFAQLTVSGSR
$10 \quad 0.01 \% \quad 15.8 \%$ YTKLTDAQILTR $\begin{array}{ll}99.7 \% & 49.1 \\ 99.7 \% & 35.9\end{array}$

1876.97 $\begin{array}{llll}99.7 \% & 27.6 & 25.0 & 25.9\end{array}$

\begin{tabular}{llll}
$99.7 \%$ & 27.6 & 25.0 & 27.6 \\
\hline & 46.8 & 25.0 & 46.8
\end{tabular}

$\begin{array}{lllll}99.7 \% & 46.8 & 25.0 & 46.8 & 3 \\ 99.7 \% & 47.6 & 25.0 & 44.4 & 2\end{array}$

$\begin{array}{llll}99.7 \% & 47.5 & 25.0 & 39.5\end{array}$

$\begin{array}{llll}97.5 \% & 22.9 & 25.0 & 12.6\end{array}$

$\begin{array}{lllll}99.0 \% & 28.5 & 25.0 & 10.9 & 2\end{array}$

$\begin{array}{llll}99.7 \% & 38.5 & 25.0 & 38.5\end{array}$

$99.7 \% \quad 51.4 \quad 25.0 \quad 42.3$

$\begin{array}{lllll}99.7 \% & 36.1 & 25.0 & 36.1 & 3\end{array}$

$\begin{array}{lllll}99.7 \% & 39.5 & 25.0 & 19.8 & 2\end{array}$

$\begin{array}{lllll}99.7 \% & 30.0 & 25.0 & 25.8 & 1\end{array}$

$\begin{array}{llll}99.7 \% & 54.8 & 25.0 & 54.8\end{array}$

$99.7 \% \quad 27.9 \quad 25.0 \quad 27.9$

$\begin{array}{lllll}99.7 \% & 45.2 & 25.0 & 37.1 & 2\end{array}$

$\begin{array}{lllll}99.7 \% & 52.9 & 25.0 & 44.8 & 2\end{array}$

$\begin{array}{llll}99.7 \% & 29.2 & 25.0 & 28.9\end{array}$

$\begin{array}{lllll}99.5 \% & 21.4 & 25.0 & 21.4\end{array}$

$\begin{array}{llll}97.8 \% & 17.2 & 25.0 & 15.9\end{array}$

$\begin{array}{lllll}97.5 \% & 20.3 & 25.0 & 13.4 & 1\end{array}$

$\begin{array}{lllll}99.7 \% & 43.4 & 25.0 & 37.9 & 2\end{array}$

$\begin{array}{llll}99.0 \% & 40.9 & 25.0 & 40.5 \\ 98.5 \% & 17.6 & 25.0 & 17.6\end{array}$

$\begin{array}{llll}99.7 \% & 39.4 & 25.0 & 35.5\end{array}$

$\begin{array}{lllll}99.7 \% & 41.1 & 25.0 & 34.5 & 1\end{array}$

$\begin{array}{lllll}99.7 \% & 33.0 & 25.0 & 27.8 & 2\end{array}$

$\begin{array}{lllll}98.8 \% & 23.5 & 25.0 & 15.1\end{array}$

$\begin{array}{lllll}99.4 \% & 25.1 & 25.0 & 25.1 & 1\end{array}$

$\begin{array}{lllll}99.7 \% & 53.7 & 25.0 & 42.9 & 2\end{array}$

$\begin{array}{lllll}99.7 \% & 47.3 & 25.0 & 47.1\end{array}$

$\begin{array}{lllll}99.7 \% & 37.3 & 25.0 & 30.3 & 3\end{array}$

$\begin{array}{llll}99.1 \% & 18.9 & 25.0 & 18.9\end{array}$

$\begin{array}{llll}99.7 \% & 45.3 & 25.0 & 27.9\end{array}$

$\begin{array}{llll}99.7 \% & 56.8 & 25.0 & 56.8\end{array}$

$\begin{array}{llll}99.7 \% & 47.6 & 25.0 & 42.1\end{array}$

$\begin{array}{lllll}99.7 \% & 61.7 & 25.0 & 53.4 & 2\end{array}$

$98.4 \% \quad 22.7 \quad 25.0 \quad 21.6$

$99.7 \% \quad 51.9 \quad 25.0 \quad 43.9$

$\begin{array}{lllll}99.7 \% & 59.0 & 25.0 & 58.1 & 4\end{array}$

$\begin{array}{lllll}99.7 \% & 36.4 & 25.0 & 33.8 & 1\end{array}$

$\begin{array}{lllll}99.7 \% & 37.9 & 25.0 & 27.2 & 2\end{array}$

$\begin{array}{llll}99.7 \% & 31.2 & 25.0 & 31.2\end{array}$

$\begin{array}{llll}99.7 \% & 35.3 & 25.0 & 32.6\end{array}$

$\begin{array}{lllll}99.7 \% & 29.6 & 25.0 & 20.5 & 2\end{array}$

$\begin{array}{llll}99.7 \% & 57.9 & 25.0 & 48.2 \\ 99.7 \% & 68.9 & 25.0 & 64.3\end{array}$

$\begin{array}{llll}99.7 \% & 68.9 & 25.0 & 64.3\end{array}$

6
0
1
2
0
2
0
0
0
2
0
0
0
0
0
0
0
0
0
0
0
0
0
0
0
0
0
0
0
0
0
0
0
0
0
0
0
0
0
0
0
0
0
0
0
0
0
0
0
0
0
0
0
2
0
0
0
0
0
0
0
0
0
0
0
0
0
0
0
0
0
0
0
0
0
0
0
0
0
0
0
0
0
0
0
0

0

0

0

0

0

0

1114.67

1913.88

1762.84

1574.80

1049.52

1234.65

1524.87

1320.73

1171.68

1692.80

1201.69

1627.83

1289.63

930.56

1309.69

909.48

1660.82

1025.61

1295.80

1153.69

1134.60

1476.78

1236.66

1483.67

1304.67

1063.55

1383.78

1633.89

2033.05

1422.80

1030.59

1131.62

1589.79

1195.58

1334.72

1139.50

1542.79

1229.71

1262.63

1406.78

Page 108 of Table S-1-1 
Replication factor C subunit 4 GN=RFC4 RFC4_HUMAN $39.68 \quad 100.0 \%$ Replication factor C subunit 4 GN=RFC4 RFC4_HUMAN $39.68 \quad 100.0 \%$ Replication factor C subunit 4 GN=RFC4 RFC4_HUMAN $39.68 \quad 100.0 \%$ Replication factor C subunit 4 GN=RFC4 RFC4_HUMAN $39.68 \quad 100.0 \%$ Replication factor C subunit 5 GN=RFC5 RFC5_HUMAN $38.50 \quad 100.0 \%$ Replication factor C subunit 5 GN=RFC5 RFC5_HUMAN $38.50 \quad 100.0 \%$ Replication factor C subunit 5 GN=RFC5 RFC5_HUMAN $38.50 \quad 100.0 \%$ Replication factor C subunit 5 GN=RFC5 RFC5_HUMAN $38.50 \quad 100.0 \%$ Replication factor C subunit 5 GN=RFC5 RFC5_HUMAN $38.50 \quad 100.0 \%$ Replication factor C subunit 5 GN=RFC5 RFC5_HUMAN $38.50 \quad 100.0 \%$ Replication factor C subunit 5 GN=RFC5 RFC5_HUMAN $38.50 \quad 100.0 \%$ Replication factor C subunit 5 GN=RFC5 RFC5_HUMAN $38.50 \quad 100.0 \%$ Replication protein A $70 \mathrm{kDa}$ DNA-binding subunit GN=RPA1 RFA1_HUMAN $68.14 \quad 100.0 \%$ Replication protein A $70 \mathrm{kDa}$ DNA-binding subunit GN=RPA1 RFA1_HUMAN $68.14 \quad 100.0 \%$ Replication protein A $70 \mathrm{kDa}$ DNA-binding subunit GN=RPA1 RFA1_HUMAN $68.14 \quad 100.0 \%$ Required for meiotic nuclear division protein 1 homolog GN=RMND1 RMND1_HUMAN $51.61 \quad 100.0 \%$ Required for meiotic nuclear division protein 1 homolog GN=RMND1 RMND1_HUMAN $51.61 \quad 100.0 \%$ Required for meiotic nuclear division protein 1 homolog GN=RMND1 RMND1_HUMAN $51.61 \quad 100.0 \%$ Ribonuclease P protein subunit p30 GN=RPP30 RPP30_HUMAN $29.32 \quad 100.0 \%$ Ribonuclease P protein subunit p30 GN=RPP30 RPP30_HUMAN $29.32 \quad 100.0 \%$ Ribonuclease P protein subunit p30 GN=RPP30 RPP30_HUMAN $29.32 \quad 100.0 \%$ Ribonuclease P protein subunit p30 GN=RPP30 RPP30_HUMAN $29.32 \quad 100.0 \%$ Ribonuclease P protein subunit p30 GN=RPP30 RPP30_HUMAN $29.32 \quad 100.0 \%$ Ribonuclease P protein subunit p30 GN=RPP30 RPP30_HUMAN $29.32 \quad 100.0 \%$ Ribonuclease P protein subunit p38 GN=RPP38 RPP38_HUMAN $31.84 \quad 100.0 \%$ Ribonuclease P protein subunit p38 GN=RPP38 RPP38_HUMAN $31.84 \quad 100.0 \%$ Ribonuclease P protein subunit p38 GN=RPP38 RPP38_HUMAN $31.84 \quad 100.0 \%$ Ribonuclease P protein subunit p38 GN=RPP38 RPP38_HUMAN $31.84 \quad 100.0 \%$ Ribonucleases P/MRP protein subunit POP1 GN=POP1 POP1_HUMAN $114.71 \quad 100.0 \%$ Ribonucleases P/MRP protein subunit POP1 GN=POP1 POP1_HUMAN $114.71 \quad 100.0 \%$ Ribose-phosphate pyrophosphokinase 1 GN=PRPS1 PRPS1_HUMAN $34.83 \quad 100.0 \%$ Ribose-phosphate pyrophosphokinase 1 GN=PRPS1 PRPS1_HUMAN $34.83 \quad 100.0 \%$ Ribose-phosphate pyrophosphokinase 1 GN=PRPS1 PRPS1_HUMAN $34.83 \quad 100.0 \%$ Ribose-phosphate pyrophosphokinase 1 GN=PRPS1 PRPS1_HUMAN $34.83 \quad 100.0 \%$ Ribose-phosphate pyrophosphokinase 1 GN=PRPS1 PRPS1_HUMAN $34.83 \quad 100.0 \%$ Ribosomal biogenesis protein LAS1L GN=LAS1L LAS1L_HUMAN $83.07 \quad 100.0 \%$ Ribosomal biogenesis protein LAS1L GN=LAS1L LAS1L_HUMAN $83.07 \quad 100.0 \%$ Ribosomal biogenesis protein LAS1L GN=LAS1L LAS1L_HUMAN $83.07 \quad 100.0 \%$ Ribosomal biogenesis protein LAS1L GN=LAS1L LAS1L_HUMAN $83.07 \quad 100.0 \%$ Ribosomal L1 domain-containing protein $1 \mathrm{GN}=$ RSL1D1 RL1D1_HUMAN $54.97 \quad 100.0 \%$ Ribosomal L1 domain-containing protein $1 \mathrm{GN}=$ RSL1D1 RL1D1_HUMAN $54.97 \quad 100.0 \%$ Ribosomal L1 domain-containing protein 1 GN=RSL1D1 RL1D1_HUMAN $54.97 \quad 100.0 \%$ Ribosomal L1 domain-containing protein $1 \mathrm{GN}=$ RSL1D1 RL1D1_HUMAN $54.97 \quad 100.0 \%$ Ribosomal L1 domain-containing protein $1 \mathrm{GN}=$ RSL1D1 RL1D1_HUMAN $54.97 \quad 100.0 \%$ Ribosomal L1 domain-containing protein $1 \mathrm{GN}=$ RSL1D1 RL1D1_HUMAN $54.97 \quad 100.0 \%$ Ribosomal L1 domain-containing protein 1 GN=RSL1D1 RL1D1_HUMAN 54.97 Ribosomal L1 domain-containing protein 1 GN=RSL1D1 RL1D1_HUMAN 54.97

$$
\text { 7 }
$$

$0.02 \% \quad 18.9 \%$ VYAILTHGIFSGPAISR

$0.01 \% \quad 5.6 \% \quad$ SRSGNELPLAVASTADLIR

$0.01 \% \quad 5.6 \%$ SGNELPLAVASTADLIR $0.01 \% \quad 5.6 \%$ FVNLISER

$0.01 \% \quad 5.6 \%$ GLHSQNFTQALLER

$0.04 \% \quad 25.9 \%$ AVDALLTHCK

$0.04 \% \quad 25.9 \%$ LTLPHSIR

$0.04 \% \quad 25.9 \%$ TVSQIISLQTLKK

$0.04 \% \quad 25.9 \%$ LLSSFDFFLTDAR

$\begin{array}{lll}0.04 \% & 25.9 \% & \text { RLLPSLIGR }\end{array}$

$0.04 \% \quad 25.9 \%$ LLPSLIGR

$0.04 \% \quad 25.9 \%$ VPVSVNLLSK

$\begin{array}{llllll}100.0 \% & 14 & 14 & 26 & 0.04 \% & 25.9 \% \text { KVPVSVNLLSK }\end{array}$

$\begin{array}{llllllll}99.7 \% & 44.4 & 25.0 & 40.9 & 1 & 0 & 0 & 1207.66\end{array}$

$\begin{array}{llllllll}98.4 \% & 24.7 & 25.0 & 12.1 & 1 & 0 & 0 & 903.49\end{array}$

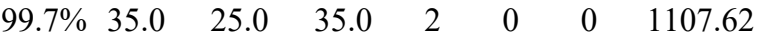

$\begin{array}{llllllll}99.7 \% & 37.9 & 25.0 & 32.0 & 2 & 0 & 0 & 964.51\end{array}$

$\begin{array}{llllllll}99.7 \% & 54.4 & 25.0 & 54.4 & 2 & 0 & 0 & 1048.58\end{array}$

$\begin{array}{llllllll}97.4 \% & 18.8 & 25.0 & 18.8 & 1 & 0 & 0 & 1317.63\end{array}$

$\begin{array}{llllllll}99.7 \% & 31.4 & 25.0 & 29.2 & 2 & 0 & 0 & 1356.73\end{array}$

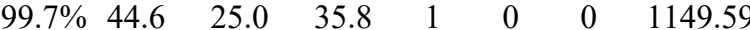

$\begin{array}{llllllll}97.3 \% & 18.2 & 25.0 & 16.2 & 0 & 1 & 0 & 1321.69\end{array}$

$\begin{array}{llllllll}99.7 \% & 58.0 & 25.0 & 45.5 & 4 & 0 & 0 & 1523.79\end{array}$

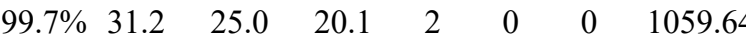

$\begin{array}{llllllll}99.7 \% & 45.6 & 25.0 & 43.8 & 2 & 0 & 0 & 1485.73\end{array}$

$\begin{array}{llllllll}99.0 \% & 24.2 & 25.0 & 24.2 & 1 & 0 & 0 & 1232.66\end{array}$

$\begin{array}{llllllll}99.7 \% & 34.4 & 25.0 & 34.4 & 1 & 0 & 0 & 1282.66\end{array}$

$\begin{array}{llllllll}99.7 \% & 39.0 & 25.0 & 38.2 & 1 & 0 & 0 & 1531.78\end{array}$

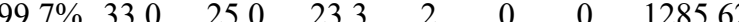

$\begin{array}{llllllll}99.0 \% & 49.5 & 25.0 & 37.2 & 2 & 0 & 0 & 918.54\end{array}$

$\begin{array}{llllllll}97.8 \% & 23.2 & 25.0 & 22.2 & 0 & 1 & 0 & 1723.92\end{array}$

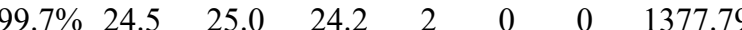

$\begin{array}{llllllll}99.7 \% & 27.4 & 25.0 & 27.4 & 1 & 0 & 0 & 1150.65\end{array}$

$\begin{array}{llllllll}99.4 \% & 29.5 & 25.0 & 12.8 & 1 & 0 & 0 & 1150.67\end{array}$

$\begin{array}{llllllll}99.7 \% & 41.0 & 25.0 & 30.7 & 1 & 0 & 0 & 967.53\end{array}$

$\begin{array}{llllllll}98.6 \% & 18.0 & 25.0 & 17.6 & 1 & 0 & 0 & 1164.70\end{array}$

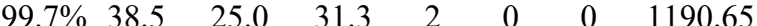

$\begin{array}{llllllll}99.7 \% & 36.7 & 25.0 & 20.4 & 2 & 0 & 0 & 1199.67\end{array}$

$\begin{array}{llllllll}99.7 \% & 30.8 & 25.0 & 19.8 & 2 & 0 & 0 & 1195.56\end{array}$

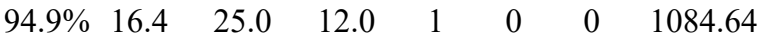

$99.7 \% \quad 47.7 \quad 25.0 \quad 38.2 \quad 2$

$\begin{array}{llll}99.2 \% & 19.7 & 25.0 & 19.7\end{array}$

$99.7 \% \quad 41.0 \quad 25.0 \quad 34.5$

$95.1 \% \quad 22.1 \quad 25.0 \quad 6.7$

$99.7 \% \quad 41.3 \quad 25.0 \quad 37.1$

$\begin{array}{lllll}99.7 \% & 51.5 & 25.0 & 47.2 & 4\end{array}$

$\begin{array}{llll}99.7 \% & 34.5 & 25.0 & 30.0\end{array}$

$\begin{array}{lllll}98.5 \% & 25.5 & 25.0 & 25.5 & 0\end{array}$

$\begin{array}{llll}99.7 \% & 50.9 & 25.0 & 50.9 \\ 99.0 \% & 42.7 & 25.0 & 27.3\end{array}$

$\begin{array}{llll}99.7 \% & 64.7 & 25.0 & 64.5\end{array}$

$\begin{array}{llll}99.7 \% & 50.8 & 25.0 & 46.1\end{array}$

$99.0 \% \quad 26.1 \quad 25.0 \quad 26.1$

$\begin{array}{lllll}99.7 \% & 35.4 & 25.0 & 35.4 & 2\end{array}$

$\begin{array}{llll}99.7 \% & 73.9 & 25.0 & 73.9\end{array}$

$\begin{array}{llll}99.7 \% & 35.8 & 25.0 & 31.1\end{array}$

$\begin{array}{lllll}99.0 \% & 18.8 & 25.0 & 18.8 & 2\end{array}$

$\begin{array}{llll}99.7 \% & 30.7 & 25.0 & 29.1\end{array}$

$\begin{array}{llll}99.7 \% & 33.8 & 25.0 & 33.8\end{array}$ 
Ribosomal L1 domain-containing protein 1 GN=RSL1D1 RL1D1_HUMAN $54.97 \quad 100.0 \%$ Roson L1 domain-containing protein I GN=RSLIDI RLIDI_HUMAN $54.97 \quad 100.0 \%$ Ribosomal L1 domain-containing protein $1 \mathrm{GN}=$ RSL1D1 RL1D1_HUMAN $54.97 \quad 100.0 \%$ Ribosomal L1 domain-containing protein $1 \mathrm{GN}=$ RSL1D1 RL1D1 HUMAN $54.97100 .0 \%$ Ribosomal L1 domain-containing protein $1 \mathrm{GN}=$ RSL1D1 RL1D1_HUMAN $54.97 \quad 100.0 \%$ Ribosomal L1 domain-containing protein 1 GN=RSL1D1 RL1D1_HUMAN $54.97 \quad 100.0 \%$ Ribosomal protein S6 kinase alpha-3 GN=RPS6KA3 KS6A3_HUMAN $83.74 \quad 100.0 \%$ Ribosomal protein S6 kinase alpha-3 GN=RPS6KA3 KS6A3_HUMAN $83.74 \quad 100.0 \%$ Ribosomal protein S6 kinase alpha-3 GN=RPS6KA3 KS6A3 HUMAN $83.74 \quad 100.0 \%$ Ribosomal RNA processing protein 1 homolog A GN=RRP1 RRP1_HUMAN $52.84 \quad 100.0 \%$ Ribosomal RNA processing protein 1 homolog A GN=RRP1 RRP1_HUMAN $52.84 \quad 100.0 \%$ Ribosomal RNA processing protein 1 homolog A GN=RRP1 RRP1_HUMAN $52.84 \quad 100.0 \%$ Ribosomal RNA processing protein 1 homolog A GN=RRP1 RRP1_HUMAN $52.84 \quad 100.0 \%$ Ribosomal RNA processing protein 1 homolog B GN=RRP1B RRP1B_HUMAN $84.43 \quad 100.0 \%$ Ribosomal RNA processing protein 1 homolog B GN=RRP1B RRP1B_HUMAN $84.43 \quad 100.0 \%$ Ribosomal RNA processing protein 1 homolog B GN=RRP1B RRP1B_HUMAN $84.43 \quad 100.0 \%$ Ribosomal RNA processing protein 1 homolog B GN=RRP1B RRP1B HUMAN $84.43 \quad 100.0 \%$ Ribosomal RNA processing protein 1 homolog B GN=RRP1B RRP1B_HUMAN $84.43 \quad 100.0 \%$ Ribosomal RNA processing protein 1 homolog B GN=RRP1B RRP1B_HUMAN $84.43 \quad 100.0 \%$ Ribosomal RNA processing protein 1 homolog B GN=RRP1B RRP1B_HUMAN $84.43 \quad 100.0 \%$ Ribosomal RNA processing protein 1 homolog B GN=RRP1B RRP1B_HUMAN $84.43 \quad 100.0 \%$ Ribosomal RNA processing protein 1 homolog B GN=RRP1B RRP1B_HUMAN $84.43 \quad 100.0 \%$ Ribosomal RNA processing protein 1 homolog B GN=RRP1B RRP1B_HUMAN $84.43 \quad 100.0 \%$ Ribosomal RNA processing protein 1 homolog B GN=RRP1B RRP1B_HUMAN $84.43 \quad 100.0 \%$ Ribosomal RNA processing protein 1 homolog B GN=RRP1B RRP1B HUMAN $84.43 \quad 100.0^{\circ}$ Ribosomal RNA processing protein 1 homolog B GN=RRP1B RRP1B_HUMAN $84.43 \quad 100.0 \%$ Ribosomal RNA processing protein 1 homolog B GN=RRP1B RRP1B_HUMAN $84.43 \quad 100.0 \%$ Ribosome biogenesis protein BMS1 homolog GN=BMS1 BMS1_HUMAN $145.81 \quad 100.0 \%$ Ribosome biogenesis protein BMS1 homolog GN=BMS1 BMS1_HUMAN $145.81 \quad 100.0 \%$ Ribosome biogenesis protein BMS1 homolog GN=BMS1 BMS1_HUMAN $145.81 \quad 100.0 \%$ Ribosome biogenesis protein BMS1 homolog GN=BMS1 BMS1_HUMAN $145.81 \quad 100.0 \%$ Ribosome biogenesis regulatory protein homolog GN=RRS1 RRS1_HUMAN $41.19 \quad 100.0 \%$ Ribosome biogenesis regulatory protein homolog GN=RRS1 RRS1_HUMAN $41.19 \quad 100.0 \%$ Ribosome biogenesis regulatory protein homolog GN=RRS1 RRS1_HUMAN $41.19 \quad 100.0 \%$ Ribosome production factor 2 homolog GN=RPF2 RPF2 HUMAN $35.59100 .0 \%$ Ribosome production factor 2 homolog GN=RPF2 RPF2_HUMAN $35.59 \quad 100.0 \%$ Ribosome production factor 2 homolog GN=RPF2 RPF2_HUMAN $35.59 \quad 100.0 \%$ Ribosome-binding protein $1 \mathrm{GN}=\mathrm{RRBP} 1$ RRBP1 HUMAN $152.47 \quad 100.0 \%$ Ribosome-binding protein $1 \mathrm{GN}=\mathrm{RRBP} 1$ RRBP1_HUMAN $152.47 \quad 100.0 \%$ Ribosome-binding protein $1 \mathrm{GN}=\mathrm{RRBP} 1 \quad$ RRBP1_HUMAN $152.47 \quad 100.0 \%$ RING finger protein $219 \mathrm{GN}=\mathrm{RNF} 219$ RING finger protein $219 \mathrm{GN}=\mathrm{RNF} 219$ RING finger protein $219 \mathrm{GN}=\mathrm{RNF} 219$ RING finger protein $219 \mathrm{GN}=\mathrm{RNF} 219$ RING finger protein $219 \mathrm{GN}=\mathrm{RNF} 219$ RN219 HUMAN $81.12 \quad 100.0 \%$ RN219_HUMAN $81.12 \quad 100.0 \%$ RN219 HUMAN $81.12 \quad 100.0 \%$ RN219_HUMAN $81.12 \quad 100.0 \%$ RN219_HUMAN $81.12 \quad 100.0 \%$ $\begin{array}{llll}\text { RING finger protein } 219 \mathrm{GN}=\mathrm{RNF} 219 & \text { RN219_HUMAN } & 81.12 & 100.0 \% \\ \text { RNA 3'-terminal phosphate cyclase GN=RTCA } & \text { RTCA_HUMAN } & 39.34 & 100.0 \%\end{array}$

(1)

.

3
4
4

4
4

4
4
4
15

4

4
4
14

14
14

14

14
14
14

14
14

14
14

4

4

3

3

3

3
3
3

3

6

6

6
6
6
6
6

$0.04 \% \quad 25.9 \%$ EINDCIGGTVLNISK

\begin{tabular}{ll}
$0.04 \%$ & $25.9 \%$ \\
\hline
\end{tabular}

$0.04 \% \quad 25.9 \%$ TPANEKVEIQK

$0.04 \% 25.9 \%$ SPNPSTPR

$0.00 \% \quad 4.6 \%$ LGAGPDGVEEIKR

$0.00 \% \quad 4.6 \%$ GGELLDKILR

$0.00 \% \quad 4.6 \%$ NQSPVLEPVGR

$0.01 \% \quad 11.9 \%$ VQLPPEIQLAQR

$0.01 \% \quad 11.9 \%$ TKDSLVLNNITR

$\begin{array}{llll}99.7 \% & 40.8 & 25.0 & 37.9\end{array}$

$\begin{array}{lllll} & 99.7 \% & 30.8 & 25.0 & 30.8\end{array}$

$0.01 \% \quad 11.9 \%$ AANVQEPEKK

$0.05 \% \quad 21.0 \%$ APAMQPAEIQFAQR

$0.05 \% \quad 21.0 \%$ VGGKELLADQNLK

$0.05 \% \quad 21.0 \%$ TKDHTLVQTIAR

$\begin{array}{llll}99.7 \% & 56.8 & 25.0 & 51.7\end{array}$

$\begin{array}{llll}99.0 \% & 22.3 & 25.0 & 16.2\end{array}$

$\begin{array}{llll}99.7 \% & 39.6 & 25.0 & 28.6\end{array}$

$0.05 \% \quad 21.0 \%$ GSPTGGAQLLK

$0.05 \% \quad 21.0 \%$ GSPTGGAQLLKR

$0.05 \% \quad 21.0 \%$ AGPGSLELCGLPSQK

$\begin{array}{llll}98.8 \% & 22.5 & 25.0 & 15.3\end{array}$

$\begin{array}{llll}99.7 \% & 54.6 & 25.0 & 42.2\end{array}$

$\begin{array}{llll}99.7 \% & 60.0 & 25.0 & 51.6\end{array}$

$\begin{array}{lllll}99.7 \% & 33.9 & 25.0 & 29.7 & 3\end{array}$

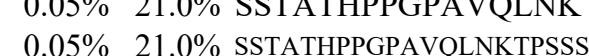

$0.05 \% \quad 21.0 \%$ KVTFGLNR

$0.05 \% \quad 21.0 \%$ TDKSILVSPTGPSR

$0.05 \% \quad 21.0 \%$ SILVSPTGPSR

$\begin{array}{lll}0.05 \% & 21.0 \% & \text { VAFDPEQKPLHGVLK }\end{array}$

$0.05 \% \quad 21.0 \%$ TPTSSPASSPLVAK

$0.01 \% \quad 3.2 \%$ AFAVQSAVR

$0.01 \% \quad 3.2 \%$ STLIQCLIR

$0.01 \% \quad 3.2 \% \quad$ IAATGVVLDLDK

$0.01 \% \quad 3.2 \% \quad$ SSLKGAEGQLQ

$0.00 \% \quad 8.5 \%$ CAGPTPEAELQALAR

$0.00 \% \quad 8.5 \%$ VAKNELNR

$0.00 \% \quad 8.5 \%$ KPQLDVTR

$0.01 \% \quad 12.7 \%$ VLKDVYALK

$0.01 \% \quad 12.7 \%$ NITRPFEDQTSLEFFSK

$0.01 \% \quad 12.7 \%$ NISHDTFGTTYGR

$0.01 \% \quad 2.4 \%$ GNTPATGTTQGK

$0.01 \% \quad 2.4 \%$ EQEITAVQAR

$0.01 \% \quad 2.4 \%$ SIEALLEAGQAR

$0.01 \% \quad 10.1 \%$ NLSLESQIK

$0.01 \% \quad 10.1 \%$ FAVAALQSK

$0.01 \% \quad 10.1 \%$ GSEEDVVSKNQGDSAR

$0.01 \% \quad 10.1 \%$ LCDTSSARQESTSK

$0.01 \% \quad 10.1 \%$ ESSVVQAGGSKK

$0.01 \% \quad 10.1 \%$ KIQSSLSSASPSK

$0.02 \% \quad 19.7 \%$ VEVDGSIMEGGGQILR $\begin{array}{llll}98.6 \% & 21.4 & 25.0 & 21.4\end{array}$

$\begin{array}{llll}98.5 \% & 25.1 & 25.0 & 12.6\end{array}$

$\begin{array}{llll}99.7 \% & 27.7 & 25.0 & 26.0\end{array}$

$99.0 \% \quad 18.5 \quad 25.0 \quad 18.5$

$\begin{array}{llll}99.7 \% & 51.2 & 25.0 & 51.2\end{array}$

$\begin{array}{llll}99.7 \% & 55.7 & 25.0 & 44.9\end{array}$

$\begin{array}{lllll}99.7 \% & 25.6 & 25.0 & 18.8 & 2\end{array}$

$\begin{array}{llll}99.7 \% & 31.4 & 25.0 & 31.4\end{array}$

$\begin{array}{lllll}99.7 \% & 35.8 & 25.0 & 16.9\end{array}$

$\begin{array}{llll}99.1 \% & 26.3 & 25.0 & 26.3\end{array}$

$\begin{array}{llll}98.2 \% & 19.1 & 25.0 & 16.3\end{array}$

$\begin{array}{llll}97.8 \% & 17.2 & 25.0 & 17.2\end{array}$

$\begin{array}{llll}99.1 \% & 19.1 & 25.0 & 19.1\end{array}$

$\begin{array}{llll}97.3 \% & 17.4 & 25.0 & 17.4\end{array}$

$\begin{array}{llll}99.7 \% & 44.6 & 25.0 & 44.6\end{array}$

$\begin{array}{llll}96.2 \% & 15.8 & 25.0 & 14.3\end{array}$

$\begin{array}{llll}99.5 \% & 22.1 & 25.0 & 21.3\end{array}$

$\begin{array}{llll}99.3 \% & 30.3 & 25.0 & 19.8\end{array}$

$\begin{array}{llll}97.1 \% & 21.3 & 25.0 & 12.2\end{array}$

$\begin{array}{llll}99.7 \% & 34.9 & 25.0 & 16.2\end{array}$

$\begin{array}{llll}99.7 \% & 32.5 & 25.0 & 32.5\end{array}$

$\begin{array}{llll}99.7 \% & 37.0 & 25.0 & 37.0\end{array}$

$\begin{array}{llll}99.7 \% & 60.9 & 25.0 & 50.5\end{array}$

$\begin{array}{llll}99.7 \% & 65.9 & 25.0 & 65.9\end{array}$ $\begin{array}{llll}97.8 \% & 17.7 & 25.0 & 15.8\end{array}$

2
0
0
0
0
0
0
0
0
0
0
1
0
0
0
0
1
0
0
0
0
2
0
0
0
0
2
0
0
0
0
0
0
0
0
0
0
0
0
0
0
0
0
0
0
0
0
0
0
0
0
0
0
0
0
0
0
0
0
0
0
0
0

1632.83
977.60
1839.93
1256.68
855.43
1340.72
1113.66
1195.64
1391.80
1373.77
2067.97
1113.59
1557.78
1384.78
1382.78
2185.07
1028.57
1184.67
1513.77
1604.84
2192.13
934.55
1457.80
1113.63
1677.93
1342.72
948.53
1103.62
1214.70
1117.58
1583.78
943.53
956.55
1048.64
2059.01
1468.68
1132.56
1144.60
1257.68
1031.57
934.54
1677.77
1569.72
1176.62
1319.72
1659.84

1632.83
977.60
1839.93
1256.68
855.43
1340.72
1113.66
1195.64
1391.80
1373.77
2067.97
1113.59
1557.78
1384.78
1382.78
2185.07
1028.57
1184.67
1513.77
1604.84
2192.13
934.55
1457.80
1113.63
1677.93
1342.72
948.53
1103.62
1214.70
1117.58
1583.78
943.53
956.55
1048.64
2059.01
1468.68
1132.56
1144.60
1257.68
1031.57
934.54
1677.77
1569.72
1176.62
1319.72
1659.84 $\begin{array}{cc}189 & 207 \\ 193 & 207 \\ 250 & 257 \\ 357 & 373 \\ 375 & 385 \\ 396 & 403 \\ 311 & 323 \\ 498 & 507 \\ 713 & 723 \\ 5 & 16 \\ 204 & 215 \\ 395 & 415 \\ 447 & 456 \\ 2 & 15 \\ 179 & 191 \\ 203 & 214 \\ 239 & 258 \\ 512 & 522 \\ 512 & 523 \\ 575 & 589 \\ 661 & 676 \\ 661 & 682 \\ 683 & 690 \\ 699 & 712 \\ 702 & 712 \\ 713 & 727 \\ 728 & 741 \\ 44 & 52 \\ 96 & 104 \\ 1008 & 1019 \\ 1272 & 1282 \\ 52 & 66 \\ 182 & 189 \\ 279 & 286 \\ 48 & 56 \\ 67 & 83 \\ 253 & 265 \\ 189 & 200 \\ 752 & 761 \\ 959 & 970 \\ 117 & 125 \\ 217 & 225 \\ 284 & 299 \\ 320 & 333 \\ 407 & 418 \\ 710 & 722 \\ 6 & 21 \\ & \\ \text { of } & 5-1-1\end{array}$

Page 110 of Table S-1-1 
RNA 3'-terminal phosphate cyclase GN=RTCA RTCA_HUMAN $39.34 \quad 100.0 \%$ RNA 3'-terminal phosphate cyclase GN=RTCA RTCA_HUMAN $39.34 \quad 100.0 \%$ RNA 3'-terminal phosphate cyclase GN=RTCA RTCA_HUMAN $39.34 \quad 100.0 \%$ RNA 3'-terminal phosphate cyclase GN=RTCA RTCA_HUMAN $39.34 \quad 100.0 \%$ RNA 3'-terminal phosphate cyclase GN=RTCA RTCA_HUMAN $39.34 \quad 100.0 \%$ RNA 3'-terminal phosphate cyclase GN=RTCA RTCA_HUMAN $39.34 \quad 100.0 \%$ RNA 3'-terminal phosphate cyclase-like protein GN=RCL1 RCL1_HUMAN $40.84 \quad 100.0 \%$ RNA 3'-terminal phosphate cyclase-like protein GN=RCL1 RCL1_HUMAN $40.84 \quad 100.0 \%$ RNA 3'-terminal phosphate cyclase-like protein GN=RCL1 RCL1_HUMAN $40.84 \quad 100.0 \%$ RNA 3'-terminal phosphate cyclase-like protein GN=RCL1 RCL1_HUMAN $40.84 \quad 100.0 \%$ RNA pseudouridylate synthase domain-containing protein 3 GN=RPUSD3 RUSD3_HUMAN $38.46 \quad 100.0 \%$ RNA pseudouridylate synthase domain-containing protein 3 GN=RPUSD3 RUSD3_HUMAN $38.46 \quad 100.0 \%$ RNA pseudouridylate synthase domain-containing protein 3 GN=RPUSD3 RUSD3_HUMAN $38.46 \quad 100.0 \%$ RNA pseudouridylate synthase domain-containing protein $3 \mathrm{GN}=\mathrm{RPUSD} 3$ RUSD3_HUMAN $38.46 \quad 100.0 \%$ RNA pseudouridylate synthase domain-containing protein 3 GN=RPUSD3 RUSD3_HUMAN $38.46 \quad 100.0 \%$ RNA pseudouridylate synthase domain-containing protein 3 GN=RPUSD3 RUSD3_HUMAN $38.46 \quad 100.0 \%$ RNA-binding motif protein, $X$ chromosome GN=RBMX RBMX_HUMAN $42.33 \quad 100.0 \%$ RNA-binding motif protein, $X$ chromosome GN=RBMX RBMX_HUMAN $42.33 \quad 100.0 \%$ RNA-binding motif protein, $X$ chromosome GN=RBMX RBMX_HUMAN $42.33 \quad 100.0 \%$ RNA-binding motif protein, $X$ chromosome GN=RBMX RBMX_HUMAN $42.33 \quad 100.0 \%$ RNA-binding motif protein, $X$ chromosome GN=RBMX RBMX_HUMAN $42.33 \quad 100.0 \%$ RNA-binding motif protein, $X$ chromosome GN=RBMX RBMX_HUMAN $42.33 \quad 100.0 \%$ RNA-binding motif protein, $X$ chromosome GN=RBMX RBMX_HUMAN $42.33 \quad 100.0 \%$ RNA-binding motif protein, $X$ chromosome GN=RBMX RBMX_HUMAN $42.33 \quad 100.0 \%$ RNA-binding motif protein, $X$ chromosome GN=RBMX RBMX_HUMAN $42.33 \quad 100.0 \%$ RNA-binding motif protein, $X$ chromosome GN=RBMX RBMX_HUMAN $42.33 \quad 100.0 \%$ RNA-binding motif protein, $X$ chromosome GN=RBMX RBMX_HUMAN $42.33 \quad 100.0 \%$ RNA-binding motif protein, $X$ chromosome GN=RBMX RBMX_HUMAN $42.33 \quad 100.0 \%$ RNA-binding motif protein, $X$ chromosome GN=RBMX RBMX_HUMAN $42.33 \quad 100.0 \%$ RNA-binding motif protein, $X$ chromosome GN=RBMX RBMX HUMAN $42.33 \quad 100.0 \%$ RNA-binding motif protein, $X$ chromosome GN=RBMX RBMX_HUMAN $42.33 \quad 100.0 \% \quad 2$ RNA-binding motif protein, $X$ chromosome GN=RBMX RBMX_HUMAN $42.33 \quad 100.0 \%$ RNA-binding motif protein, $X$ chromosome GN=RBMX RBMX_HUMAN $42.33 \quad 100.0 \% \quad 21$ RNA-binding motif protein, X chromosome GN=RBMX RBMX_HUMAN $42.33 \quad 100.0 \% \quad 2$ RNA-binding motif protein, $X$ chromosome GN=RBMX RBMX_HUMAN $42.33 \quad 100.0 \% \quad 2$ RNA-binding motif protein, $X$ chromosome GN=RBMX RBMX_HUMAN $42.33 \quad 100.0 \%$ RNA-binding motif protein, X chromosome GN=RBMX RBMX_HUMAN $42.33 \quad 100.0 \% \quad 2$ RNA-binding protein $10 \mathrm{GN}=\mathrm{RBM} 10$ RNA-binding protein $10 \mathrm{GN}=\mathrm{RBM} 10$ RNA-binding protein $10 \mathrm{GN}=\mathrm{RBM} 10$ RNA-binding protein $10 \mathrm{GN}=\mathrm{RBM} 10$ RNA-binding protein $10 \mathrm{GN}=\mathrm{RBM} 10$ RNA-binding protein $10 \mathrm{GN}=\mathrm{RBM} 10$ RNA-binding protein $10 \mathrm{GN}=\mathrm{RBM} 10$ RNA-binding protein $10 \mathrm{GN}=\mathrm{RBM} 10$ RNA-binding protein $10 \mathrm{GN}=\mathrm{RBM} 10$ RNA-binding protein $10 \mathrm{GN}=\mathrm{RBM} 10$
RBM10 HUMAN $103.53 \quad 100.0 \% \quad 34$ RBM10_HUMAN $103.53 \quad 100.0 \% \quad 34$ RBM10_HUMAN $103.53 \quad 100.0 \% \quad 34$ RBM10_HUMAN $103.53 \quad 100.0 \% \quad 34$ RBM10_HUMAN $103.53 \quad 100.0 \% \quad 34$ RBM10_HUMAN $103.53 \quad 100.0 \% \quad 34$ RBM10_HUMAN $103.53 \quad 100.0 \% \quad 34$ RBM10_HUMAN $103.53 \quad 100.0 \% \quad 34$ RBM10_HUMAN $103.53 \quad 100.0 \% \quad 34$ RBM10_HUMAN $103.53 \quad 100.0 \% \quad 34$
$0.02 \% \quad 19.7 \%$ VSTALSCLLGLPLR $0.02 \% \quad 19.7 \%$ IKGGIHTADTK $0.02 \% \quad 19.7 \%$ FGFIFNCDIK $0.02 \% \quad 19.7 \%$ AFVAGVLPFK $0.02 \% \quad 19.7 \%$ AFVAGVLPFKVAK $0.02 \% \quad 19.7 \%$ DMAAAAVR

$0.01 \% \quad 11.5 \%$ LVLSTLSGRPVK $0.01 \% \quad 11.5 \%$ GVTNDQVDPSVDVLK $0.01 \% \quad 11.5 \%$ VSPQMANR

$0.01 \% \quad 11.5 \%$ LLLEEIYR

$0.02 \% \quad 22.2 \%$ SGPLGDQPFAGLLPK

$0.02 \% \quad 22.2 \%$ NLSREELVDALR

$0.02 \% \quad 22.2 \%$ ASGKESSGLVLLSSCPQTASR

$0.02 \% \quad 22.2 \%$ VGTVLGQR

$0.02 \% \quad 22.2 \%$ FLLPAENNKPQR

$1 \quad 0.02 \% \quad 22.2 \%$ TLQCLGLRLQ

$69 \quad 0.09 \% \quad 47.1 \%$ LFIGGLNTETNEK

$69 \quad 0.09 \% \quad 47.1 \%$ ALEAVFGKYGR

$69 \quad 0.09 \% \quad 47.1 \%$ IVEVLLMKDR

$0.09 \% \quad 47.1 \%$ GFAFVTFESPADAK

$69 \quad 0.09 \% \quad 47.1 \%$ GFAFVTFESPADAKDAAR

$69 \quad 0.09 \% \quad 47.1 \%$ AIKVEQATKPSFESGR

$69 \quad 0.09 \% \quad 47.1 \%$ VEQATKPSFESGR

$69 \quad 0.09 \% \quad 47.1 \%$ RGPPPPPR

$0.09 \% \quad 47.1 \%$ GGHMDDGGYSMNFNMSSSR

$69 \quad 0.09 \% \quad 47.1 \%$ GRDSYGGPPR

$69 \quad 0.09 \% \quad 47.1 \%$ DSYGGPPR

$69 \quad 0.09 \% \quad 47.1 \%$ DVYLSPRDDGYSTK

$69 \quad 0.09 \% \quad 47.1 \%$ DSYSSRDYPSSR

$69 \quad 0.09 \% \quad 47.1 \%$ DSYESYGNSR

$69 \quad 0.09 \% \quad 47.1 \%$ GPPPSYGGSSR

$69 \quad 0.09 \% \quad 47.1 \%$ GPPPSYGGSSRYDDYSSSR

$69 \quad 0.09 \% \quad 47.1 \%$ YDDYSSSR

$69 \quad 0.09 \% \quad 47.1 \%$ YDDYSSSRDGYGGSR

$69 \quad 0.09 \% \quad 47.1 \%$ DGYGGSRDSYSSSR

$69 \quad 0.09 \% \quad 47.1 \%$ DSYSSSRSDLYSSGR

$69 \quad 0.09 \% \quad 47.1 \%$ SDLYSSGRDR

$154 \quad 0.21 \% \quad 39.2 \%$ TGRYGATDR

$154 \quad 0.21 \% \quad 39.2 \%$ YGATDRSQDDGGENR

$154 \quad 0.21 \% \quad 39.2 \%$ HSPTGPPGFPR

$154 \quad 0.21 \% \quad 39.2 \%$ MLPQAATEDDIRGQLQSHGVQAR

$154 \quad 0.21 \% \quad 39.2 \%$ GQLQSHGVQAR

$154 \quad 0.21 \% \quad 39.2 \%$ GFAFVEFSHLQDATR

$154 \quad 0.21 \% \quad 39.2 \%$ VSMHYSDPKPK

$50 \quad 154 \quad 0.21 \% \quad 39.2 \%$ INEDWLCNK

$50 \quad 154 \quad 0.21 \% \quad 39.2 \%$ INEDWLCNKCGVQNFK

$50 \quad 154 \quad 0.21 \% \quad 39.2 \%$ SEAEQKLPLGTR $\begin{array}{llllllll}99.7 \% & 24.5 & 25.0 & 23.6 & 1 & 0 & 0 & 1499.86\end{array}$ $\begin{array}{llllllll}96.7 \% & 20.1 & 25.0 & 13.1 & 1 & 0 & 0 & 1140.64\end{array}$ $\begin{array}{llllllll}99.5 \% & 25.3 & 25.0 & 19.7 & 2 & 0 & 0 & 1260.61\end{array}$

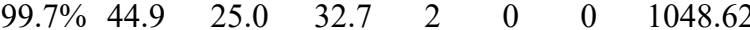
$\begin{array}{llllllll}99.7 \% & 38.0 & 25.0 & 38.0 & 2 & 0 & 0 & 1346.82\end{array}$ $\begin{array}{llllllll}99.0 \% & 40.1 & 25.0 & 26.4 & 2 & 0 & 0 & 804.40\end{array}$

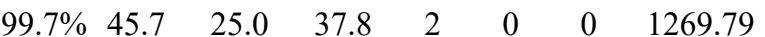
$99.7 \% \quad 45.0 \quad 25.0 \quad 44.3$ $\begin{array}{llll}98.4 \% & 25.7 & 25.0 & 11.2\end{array}$

$\begin{array}{llll}99.0 \% & 30.5 & 25.0 & 22.3\end{array}$

$\begin{array}{lllll}99.7 \% & 48.0 & 25.0 & 48.0 & 2\end{array}$

$\begin{array}{llll}99.7 \% & 36.8 & 25.0 & 27.7\end{array}$

$\begin{array}{llll}99.7 \% & 49.0 & 25.0 & 49.0\end{array}$

$\begin{array}{lllll}99.0 \% & 39.0 & 25.0 & 23.0 & 2\end{array}$

$\begin{array}{llll}99.4 \% & 21.4 & 25.0 & 21.4\end{array}$

$\begin{array}{lllll}99.7 \% & 33.6 & 25.0 & 24.5 & 2\end{array}$

$\begin{array}{llll}99.7 \% & 66.8 & 25.0 & 56.4\end{array}$

$\begin{array}{llll}99.7 \% & 59.6 & 25.0 & 44.8\end{array}$

$\begin{array}{llll}99.7 \% & 31.6 & 25.0 & 31.6\end{array}$

$\begin{array}{llll}99.7 \% & 64.7 & 25.0 & 48.6\end{array}$

$\begin{array}{lllll}99.7 \% & 48.9 & 25.0 & 48.9\end{array}$

$\begin{array}{llll}99.7 \% & 49.3 & 25.0 & 46.7\end{array}$

$\begin{array}{llll}99.7 \% & 56.5 & 25.0 & 52.2\end{array}$

$99.0 \% \quad 49.6 \quad 25.0 \quad 40.6$

$\begin{array}{llll}97.7 \% & 37.8 & 25.0 & 37.8\end{array}$

$\begin{array}{lllll}97.8 \% & 27.7 & 25.0 & 0.8\end{array}$

$\begin{array}{llll}99.0 \% & 34.7 & 25.0 & 27.1\end{array}$

$\begin{array}{llll}99.7 \% & 44.2 & 25.0 & 42.4\end{array}$

$99.7 \% \quad 35.2 \quad 25.0 \quad 35.2$

$99.7 \% \quad 47.6 \quad 25.0 \quad 47.6$

$\begin{array}{llll}98.2 \% & 23.4 & 25.0 & 13.1\end{array}$

$\begin{array}{llll}99.7 \% & 25.5 & 25.0 & 25.5\end{array}$

$\begin{array}{llll}99.0 \% & 37.7 & 25.0 & 37.7\end{array}$

$\begin{array}{llll}98.5 \% & 17.6 & 25.0 & 17.6\end{array}$

$99.7 \% \quad 31.6 \quad 25.0 \quad 31.6$

$\begin{array}{llll}95.0 \% & 14.5 & 25.0 & 14.5\end{array}$

$\begin{array}{llll}99.5 \% & 22.7 & 25.0 & 17.9\end{array}$

$\begin{array}{llll}97.8 \% & 20.5 & 25.0 & 13.9\end{array}$

$\begin{array}{llll}99.7 \% & 35.8 & 25.0 & 35.8\end{array}$

$\begin{array}{llll}98.6 \% & 21.2 & 25.0 & 15.7\end{array}$

$\begin{array}{llll}99.7 \% & 49.9 & 25.0 & 49.9\end{array}$

$\begin{array}{llll}99.1 \% & 18.7 & 25.0 & 18.7\end{array}$

$\begin{array}{llll}99.7 \% & 54.1 & 25.0 & 54.1\end{array}$

$\begin{array}{llll}99.6 \% & 23.2 & 25.0 & 19.8\end{array}$

$\begin{array}{llll}99.7 \% & 50.5 & 25.0 & 33.3\end{array}$

$\begin{array}{llll}99.6 \% & 23.8 & 25.0 & 23.8\end{array}$

$\begin{array}{llll}99.7 \% & 53.7 & 25.0 & 41.5\end{array}$

1269.79
1585.81

902.45

1048.60

1496.81

1414.76

2135.08

829.49

1426.78

1201.67

1435.74

1210.66

1231.71

1486.72

1899.92

1747.93

1435.72

873.51

2097.77

1061.51

848.39

1615.76

1419.61

1177.48

1061.50

2034.88

992.40

1684.68

1493.63

1666.73

1155.54

996.49

1640.69

1149.58

2537.25

1180.62

1724.84

1304.63

1191.55

2024.93

1328.72 
RNA-binding protein $10 \mathrm{GN}=\mathrm{RBM} 10$ RNA-binding protein $10 \mathrm{GN}=\mathrm{RBM} 10$ RNA-binding protein $10 \mathrm{GN}=\mathrm{RBM} 10$ RNA-binding protein $10 \mathrm{GN}=\mathrm{RBM} 10$ RNA-binding protein $10 \mathrm{GN}=\mathrm{RBM} 10$ RNA-binding protein $10 \mathrm{GN}=\mathrm{RBM} 10$ RNA-binding protein $10 \mathrm{GN}=\mathrm{RBM} 10$ RNA-binding protein $10 \mathrm{GN}=\mathrm{RBM} 10$ RNA-binding protein $10 \mathrm{GN}=\mathrm{RBM} 10$ RNA-binding protein $10 \mathrm{GN}=\mathrm{RBM} 10$ RNA-binding protein $10 \mathrm{GN}=\mathrm{RBM} 10$ RNA-binding protein $10 \mathrm{GN}=\mathrm{RBM} 10$ RNA-binding protein $10 \mathrm{GN}=\mathrm{RBM} 10$ RNA-binding protein $10 \mathrm{GN}=\mathrm{RBM} 10$ RNA-binding protein $10 \mathrm{GN}=\mathrm{RBM} 10$ RNA-binding protein $10 \mathrm{GN}=\mathrm{RBM} 10$ RNA-binding protein $10 \mathrm{GN}=\mathrm{RBM} 10$ RNA-binding protein $10 \mathrm{GN}=\mathrm{RBM} 10$ RNA-binding protein $10 \mathrm{GN}=\mathrm{RBM} 10$ RNA-binding protein $10 \mathrm{GN}=\mathrm{RBM} 10$ RNA-binding protein $10 \mathrm{GN}=\mathrm{RBM} 10$ RNA-binding protein $10 \mathrm{GN}=\mathrm{RBM} 10$ RNA-binding protein $10 \mathrm{GN}=\mathrm{RBM} 10$ RNA-binding protein $10 \mathrm{GN}=\mathrm{RBM} 10$ RNA-binding protein $14 \mathrm{GN}=\mathrm{RBM} 14$ RNA-binding protein $14 \mathrm{GN}=\mathrm{RBM} 14$ RNA-binding protein $14 \mathrm{GN}=\mathrm{RBM} 14$ RNA-binding protein $14 \mathrm{GN}=\mathrm{RBM} 14$ RNA-binding protein $14 \mathrm{GN}=\mathrm{RBM} 14$ RNA-binding protein $14 \mathrm{GN}=\mathrm{RBM} 14$ RNA-binding protein $14 \mathrm{GN}=\mathrm{RBM} 14$ RNA-binding protein $14 \mathrm{GN}=\mathrm{RBM} 14$ RNA-binding protein $14 \mathrm{GN}=\mathrm{RBM} 14$ RNA-binding protein $14 \mathrm{GN}=\mathrm{RBM} 14$ RNA-binding protein $14 \mathrm{GN}=\mathrm{RBM} 14$ RNA-binding protein $14 \mathrm{GN}=\mathrm{RBM} 14$ RNA-binding protein $14 \mathrm{GN}=\mathrm{RBM} 14$ RNA-binding protein $14 \mathrm{GN}=\mathrm{RBM} 14$ RNA-binding protein $14 \mathrm{GN}=\mathrm{RBM} 14$ RNA-binding protein $39 \mathrm{GN}=\mathrm{RBM} 39$ RNA-binding protein $39 \mathrm{GN}=\mathrm{RBM} 39$ RNA-binding protein $39 \mathrm{GN}=\mathrm{RBM} 39$ RNA-binding protein $39 \mathrm{GN}=\mathrm{RBM} 39$ RNA-binding protein $4 \mathrm{GN}=\mathrm{RBM} 4$ RNA-binding protein $4 \mathrm{GN}=\mathrm{RBM} 4$ RNA-binding protein $4 \mathrm{GN}=\mathrm{RBM} 4$ RNA-binding protein $4 \mathrm{GN}=\mathrm{RBM} 4$
RBM10_HUMAN $103.53 \quad 100.0 \% \quad 34$ RBM10_HUMAN $103.53 \quad 100.0 \% \quad 34$ RBM10_HUMAN $103.53 \quad 100.0 \% \quad 34$ RBM10_HUMAN $103.53 \quad 100.0 \% \quad 34$ RBM10_HUMAN $103.53 \quad 100.0 \% \quad 34$ RBM10_HUMAN $103.53 \quad 100.0 \% \quad 34$ RBM10_HUMAN $103.53 \quad 100.0 \% \quad 34$ RBM10_HUMAN $103.53 \quad 100.0 \% \quad 34$ RBM10 HUMAN $103.53 \quad 100.0 \% \quad 34$ RBM10_HUMAN $103.53 \quad 100.0 \% \quad 34$ RBM10_HUMAN $103.53 \quad 100.0 \% \quad 34$ RBM10 HUMAN $103.53 \quad 100.0 \% \quad 34$ RBM10_HUMAN $103.53 \quad 100.0 \% \quad 34$ RBM10_HUMAN $103.53 \quad 100.0 \% \quad 34$ RBM10_HUMAN $103.53 \quad 100.0 \% \quad 34$ RBM10_HUMAN $103.53 \quad 100.0 \% \quad 34$ RBM10 HUMAN $103.53 \quad 100.0 \% \quad 34$ RBM10_HUMAN $103.53 \quad 100.0 \% \quad 34$ RBM10_HUMAN $103.53 \quad 100.0 \% \quad 34$ RBM10 HUMAN $103.53 \quad 100.0 \% \quad 34$ RBM10_HUMAN $103.53 \quad 100.0 \% \quad 34$ RBM10_HUMAN $103.53 \quad 100.0 \% \quad 34$ RBM10_HUMAN $103.53 \quad 100.0 \% \quad 34$ RBM10_HUMAN $103.53 \quad 100.0 \% \quad 34$ RBM14_HUMAN $69.49 \quad 100.0 \% \quad 15$ RBM14_HUMAN $69.49 \quad 100.0 \% \quad 15$ RBM14_HUMAN $69.49 \quad 100.0 \% \quad 15$ RBM14 HUMAN $69.49 \quad 100.0 \% \quad 15$ RBM14_HUMAN $69.49 \quad 100.0 \% \quad 15$ RBM14 HUMAN $69.49 \quad 100.0 \% \quad 15$ RBM14_HUMAN $69.49 \quad 100.0 \% \quad 15$ RBM14_HUMAN $69.49 \quad 100.0 \% \quad 15$ RBM14 HUMAN $69.49 \quad 100.0 \% \quad 15$ RBM14_HUMAN $69.49 \quad 100.0 \% \quad 15$ RBM14_HUMAN $69.49 \quad 100.0 \% \quad 15$ RBM14 HUMAN $69.49 \quad 100.0 \% \quad 15$ RBM14_HUMAN $\quad 69.49 \quad 100.0 \% \quad 15$ RBM14 HUMAN $69.49 \quad 100.0 \% \quad 15$ RBM14_HUMAN $69.49 \quad 100.0 \% \quad 15$ RBM39_HUMAN $59.38 \quad 100.0 \% \quad 4$ RBM39 HUMAN $59.38 \quad 100.0 \% \quad 4$ RBM39_HUMAN $59.38 \quad 100.0 \% \quad 4$ RBM39_HUMAN $59.38 \quad 100.0 \% \quad 4$ RBM4 HUMAN $40.31 \quad 100.0 \%$ RBM4_HUMAN $40.31 \quad 100.0 \%$ RBM4 HUMAN $40.31 \quad 100.0 \%$ RBM4_HUMAN $40.31 \quad 100.0 \%$ $\begin{array}{llll}50 & 154 & 0.21 \% & 39.2 \%\end{array}$ LDQQTLPLGGR

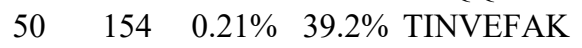

$\begin{array}{llll}50 & 154 & 0.21 \% & 39.2 \% \\ 50 & \text { GTKGPGITGTK }\end{array}$

$\begin{array}{llll}99.7 \% & 51.9 & 25.0 & 51.9\end{array}$

$154 \quad 0.21 \% \quad 39.2 \%$ GPGITGTKGDPTGAGPEASLEPGADSVSMQAFSR

$\begin{array}{llll}50 & 154 & 0.21 \% & 39.2 \%\end{array}$

$\begin{array}{llll}50 & 154 & 0.21 \% & 39.2 \%\end{array}$ TAQQIAKDMER

$50 \quad 154 \quad 0.21 \% \quad 39.2 \%$ NSFQPISSLR

$50 \quad 154 \quad 0.21 \% \quad 39.2 \%$ ESATADAGYAILEK

$50 \quad 154 \quad 0.21 \% \quad 39.2 \%$ GALAERQHTSMDLPK

$50 \quad 154 \quad 0.21 \% \quad 39.2 \%$ HQQLSGLHK

$50 \quad 154 \quad 0.21 \% \quad 39.2 \%$ EKYGIPEPPEPK

$50 \quad 154 \quad 0.21 \% \quad 39.2 \%$ YGIPEPPEPK

$50 \quad 154 \quad 0.21 \% \quad 39.2 \%$ YGIPEPPEPKR

$50 \quad 154 \quad 0.21 \% \quad 39.2 \%$ KYGGISTASVDFEQPTR

$50 \quad 154 \quad 0.21 \% \quad 39.2 \% \quad$ YGGISTASVDFEQPTR

$\begin{array}{lllll}50 & 154 & 0.21 \% & 39.2 \% & \text { YGGISTASVDFEQPTRDGLGSDNIGSR }\end{array}$

$50 \quad 154 \quad 0.21 \% \quad 39.2 \%$ DGLGSDNIGSR

$50 \quad 154 \quad 0.21 \% \quad 39.2 \%$ MLQAMGWKEGSGLGR

$50 \quad 154 \quad 0.21 \% \quad 39.2 \%$ KQGIVTPIEAQTR

$50 \quad 154 \quad 0.21 \% \quad 39.2 \%$ QGIVTPIEAQTR

$\begin{array}{lllll}50 & 154 & 0.21 \% & 39.2 \% & \text { QGIVTPIEAQTRVR }\end{array}$

$50 \quad 154 \quad 0.21 \% \quad 39.2 \%$ VRGSGLGAR

$50 \quad 154 \quad 0.21 \% \quad 39.2 \%$ GSSYGVTSTESYKETLHK

$\begin{array}{llll}50 & 154 & 0.21 \% & 39.2 \% \\ 18 & 30 & 0.04 \% & 24.4 \%\end{array}$

$18 \quad 30 \quad 0.04 \% \quad 24.4 \%$ IFVGNVSAACTSQELR

$\begin{array}{llll}18 & 30 & 0.04 \% & 24.4 \% \\ 18 & \text { INVELSTK }\end{array}$

$18 \quad 30 \quad 0.04 \% \quad 24.4 \%$ INVELSTKGQK

$18 \quad 30 \quad 0.04 \% \quad 24.4 \%$ QPTPPFFGR

$\begin{array}{llll}18 & 30 & 0.04 \% & 24.4 \% \\ 18 & \text { ASYVAPLTAQPATYR }\end{array}$

$\begin{array}{llll}18 & 30 & 0.04 \% & 24.4 \% \\ 18 & \text { AQPSVSLGAAYR }\end{array}$

$\begin{array}{llll}18 & 30 & 0.04 \% & 24.4 \% \\ 18 & \text { AQPSASLGVGYR }\end{array}$

$\begin{array}{llll}18 & 30 & 0.04 \% & 24.4 \% \\ 18 & \text { AQPSASLGVGYRTQPMTAQAASYR }\end{array}$

$\begin{array}{llll}18 & 30 & 0.04 \% & 24.4 \%\end{array}$

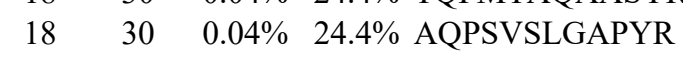

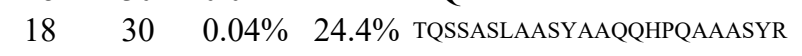

$\begin{array}{llll}18 & 30 & 0.04 \% & 24.4 \%\end{array}$ LAELSDYRR

$18 \quad 30 \quad 0.04 \% \quad 24.4 \%$ RLPDAHSDYAR

$18 \quad 30 \quad 0.04 \% \quad 24.4 \%$ YSGSYNDYLR

$18 \quad 30 \quad 0.04 \% \quad 24.4 \%$ AAQMHSGYQR

$11 \quad 0.02 \% \quad 9.1 \%$ TVFCMQLAAR

$11 \quad 0.02 \% \quad 9.1 \%$ DLEEFFSTVGK

$\begin{array}{llll}11 & 0.02 \% & 9.1 \% & \text { VLGVPIIVQASQAEKNR }\end{array}$

$11 \quad 0.02 \% \quad 9.1 \%$ AAAMANNLQK

$11 \quad 0.02 \% \quad 26.1 \%$ VKLFIGNLPR

$11 \quad 0.02 \% \quad 26.1 \%$ EATEQEIR

$11 \quad 0.02 \% \quad 26.1 \%$ GLDNTEFQGKR

$11 \quad 0.02 \% \quad 26.1 \%$ MHVQLSTSR $\begin{array}{lllll}99.0 \% & 35.8 & 25.0 & 28.4 & 2\end{array}$

$\begin{array}{llll}9.7 \% & 45.7 & 25.0 & 42.7\end{array}$

$\begin{array}{llll}99.7 \% & 49.8 & 25.0 & 49.8\end{array}$

$\begin{array}{llll}99.7 \% & 39.8 & 25.0 & 39.8\end{array}$

$\begin{array}{llll}99.6 \% & 23.1 & 25.0 & 19.5\end{array}$

$\begin{array}{llll}99.7 \% & 56.3 & 25.0 & 49.9\end{array}$

$99.7 \% \quad 28.0 \quad 25.0 \quad 26.3$

$99.7 \% \quad 27.9 \quad 25.0 \quad 26.7$

$\begin{array}{llll}99.7 \% & 38.2 & 25.0 & 25.7\end{array}$

$\begin{array}{llll}97.3 \% & 21.9 & 25.0 & 12.4\end{array}$

$\begin{array}{llll}98.4 \% & 22.3 & 25.0 & 22.3\end{array}$

$\begin{array}{llll}99.7 \% & 37.2 & 25.0 & 35.0\end{array}$

$\begin{array}{llll}99.7 \% & 62.7 & 25.0 & 62.7\end{array}$

$\begin{array}{llll}99.7 \% & 51.8 & 25.0 & 51.8\end{array}$

$\begin{array}{llll}99.7 \% & 48.2 & 25.0 & 41.0\end{array}$

$\begin{array}{llll}99.7 \% & 55.3 & 25.0 & 55.3\end{array}$

$\begin{array}{lllll}99.7 \% & 55.9 & 25.0 & 52.4 & 4\end{array}$

$\begin{array}{llll}99.7 \% & 50.8 & 25.0 & 40.9\end{array}$

$99.1 \% \quad 24.6 \quad 25.0 \quad 24.6$

$\begin{array}{llll}99.1 \% & 27.6 & 25.0 & 15.7\end{array}$

$\begin{array}{llll}99.7 \% & 46.8 & 25.0 & 46.8\end{array}$

$\begin{array}{lllll}99.7 \% & 49.5 & 25.0 & 43.2 & 12\end{array}$

$\begin{array}{llll}99.7 \% & 93.5 & 25.0 & 90.0\end{array}$

$\begin{array}{llll}97.0 \% & 22.4 & 25.0 & 11.1\end{array}$

$99.7 \% \quad 48.1 \quad 25.0 \quad 48.1$

$\begin{array}{lllll}97.9 \% & 21.1 & 25.0 & 14.6\end{array}$

$99.7 \% \quad 59.6 \quad 25.0 \quad 49.1 \quad 2$

$\begin{array}{llll}99.7 \% & 54.6 & 25.0 & 50.5\end{array}$

$\begin{array}{llll}99.7 \% & 43.1 & 25.0 & 39.6\end{array}$

$\begin{array}{llll}99.7 \% & 49.0 & 25.0 & 49.0\end{array}$

$\begin{array}{llll}99.7 \% & 41.9 & 25.0 & 39.5\end{array}$

$\begin{array}{lllll}99.7 \% & 44.8 & 25.0 & 34.8 & 2\end{array}$

$\begin{array}{llll}99.7 \% & 58.4 & 25.0 & 58.4\end{array}$

$99.7 \% \quad 51.0 \quad 25.0 \quad 44.3$

$\begin{array}{llll}99.7 \% & 44.0 & 25.0 & 31.7\end{array}$

$\begin{array}{llll}99.7 \% & 52.4 & 25.0 & 42.2\end{array}$

$\begin{array}{llll}99.7 \% & 37.0 & 25.0 & 31.0\end{array}$

$\begin{array}{llll}99.7 \% & 35.6 & 25.0 & 35.6\end{array}$

$\begin{array}{lllll}99.7 \% & 45.0 & 25.0 & 26.1 & 4\end{array}$

$\begin{array}{llll}99.5 \% & 21.4 & 25.0 & 21.4\end{array}$

$\begin{array}{llll}99.0 \% & 27.1 & 25.0 & 14.8\end{array}$

$\begin{array}{llll}99.7 \% & 37.6 & 25.0 & 32.5\end{array}$

$\begin{array}{llll}99.7 \% & 43.2 & 25.0 & 43.2\end{array}$ $\begin{array}{llll}99.7 \% & 43.3 & 25.0 & 29.4\end{array}$

$\begin{array}{llll}99.6 \% & 22.8 & 25.0 & 19.2\end{array}$

0
0
0
0
0
0
0
0
0
0
0
0
0
0
0
0
0
0
0
0
0
0
0
0
0
0
0
0
0
0
0
0
0
0
0
0
0
0
0
0
0
0
0
0
0
0
0
0
0
0
0
0
0
0
0
0
0
0
0
0
0
0
0
0
0

1197.66

921.50

1016.57

3261.53

3767.82

1290.65

1148.61

1438.71

1669.83

1047.57

1383.72

1126.58

1282.68

1855.92

1727.82

2799.32

1090.51

1620.80

1440.82

1312.72

1567.89

872.51

1973.95

1196.57

1751.87

903.51

1216.69

1046.54

1608.84

1219.64

1205.63

2527.24

1324.63

1245.66

2465.18

1122.59

1300.64

1237.55

1148.53

1196.59

1271.62

1822.05

1031.53

1156.72

975.47

1264.63 1058.54

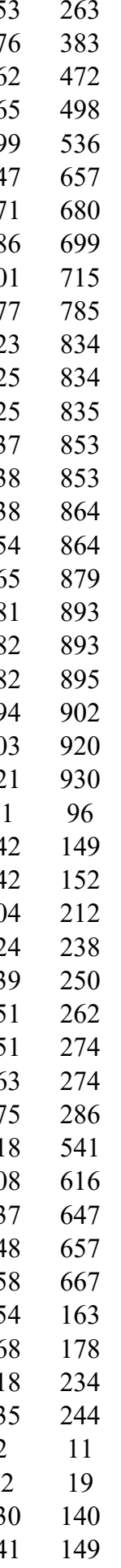

Page 112 of Table S-1-1 
RNA-binding protein $4 \mathrm{GN}=\mathrm{RBM} 4$ RNA-binding protein $4 \mathrm{GN}=\mathrm{RBM} 4$ RNA-binding protein $4 \mathrm{GN}=\mathrm{RBM} 4$ RNA-binding protein $5 \mathrm{GN}=\mathrm{RBM} 5$ RNA-binding protein $5 \mathrm{GN}=\mathrm{RBM} 5$ RNA-binding protein $5 \mathrm{GN}=\mathrm{RBM} 5$ RNA-binding protein $5 \mathrm{GN}=\mathrm{RBM} 5$ RNA-binding protein $5 \mathrm{GN}=\mathrm{RBM} 5$ RNA-binding protein $5 \mathrm{GN}=\mathrm{RBM} 5$ RNA-binding protein $5 \mathrm{GN}=\mathrm{RBM} 5$ RNA-binding protein $5 \mathrm{GN}=\mathrm{RBM} 5$ RNA-binding protein Raly GN=RALY RNA-binding protein Raly GN=RALY RNA-binding protein Raly GN=RALY RNA-binding protein Raly GN=RALY RNA-binding protein Raly GN=RALY RNA-binding protein Raly GN=RALY RNA-binding protein Raly GN=RALY RNA-binding protein Raly GN=RALY $\begin{array}{llll}\text { rRNA 2'-O-methyltransferase fibrillarin GN=FBL RALY_HUMAN } & 32.46 & 100.0 \%\end{array}$ rRNA $2^{2}$-O-methyltransferase fibrillarin GN=FBL FBRL_HUMAN $33.78 \quad 100.0 \%$ rRNA 2'-O-methyltransferase fibrillarin GN=FBL FBRL_HUMAN $33.78 \quad 100.0 \%$ rRNA 2'-O-methyltransferase fibrillarin GN=FBL FBRL_HUMAN $33.78 \quad 100.0 \%$ rRNA 2'-O-methyltransferase fibrillarin GN=FBL FBRL_HUMAN $33.78 \quad 100.0 \%$ rRNA 2'-O-methyltransferase fibrillarin GN=FBL FBRL_HUMAN $33.78 \quad 100.0^{\circ}$ rRNA $2^{2}$-O-methyltransferase fibrillarin GN=FBL FBRL_HUMAN $33.78 \quad 100.0 \%$ rRNA 2'-O-methyltransferase fibrillarin GN=FBL FBRL_HUMAN $33.78 \quad 100.0 \%$ rRNA 2'-O-methyltransferase fibrillarin GN=FBL FBRL_HUMAN $33.78 \quad 100.0 \%$ rRNA $2^{2}$-O-methyltransferase fibrillarin GN=FBL FBRL_HUMAN $33.78 \quad 100.0 \%$ rRNA 2'-O-methyltransferase fibrillarin GN=FBL FBRL HUMAN $33.78 \quad 100.0 \%$ rRNA 2'-O-methyltransferase fibrillarin GN=FBL FBRL_HUMAN $33.78 \quad 100.0 \%$ rRNA methyltransferase 3, mitochondrial GN=RNMTL1 MRM3_HUMAN $47.02 \quad 100.0 \%$ rRNA methyltransferase 3, mitochondrial GN=RNMTL1 MRM3 HUMAN $47.02 \quad 100.0 \%$ rRNA methyltransferase 3, mitochondrial GN=RNMTL1 MRM3_HUMAN $47.02 \quad 100.0 \%$ rRNA methyltransferase 3, mitochondrial GN=RNMTL1 MRM3_HUMAN $47.02 \quad 100.0 \%$ rRNA methyltransferase 3, mitochondrial GN=RNMTL1 MRM3_HUMAN $47.02 \quad 100.0 \%$ rRNA methyltransferase 3, mitochondrial GN=RNMTL1 MRM3_HUMAN $47.02 \quad 100.0 \%$ RRP12-like protein $\mathrm{GN}=\mathrm{RRP} 12$ RRP12-like protein GN=RRP12 RRP12-like protein GN=RRP12 RRP15-like protein GN=RRP15 RRP15-like protein GN=RRP15 RRP15-like protein GN=RRP15 $\begin{array}{lll}\text { S1 RNA-binding domain-containing protein } 1 \text { GN=SRBD1 SRBD1_HUMAN } & 111.78 & 100.0 \%\end{array}$ S1 RNA-binding domain-containing protein 1 GN=SRBD1 SRBD1_HUMAN $111.78 \quad 100.0 \%$ S-adenosylmethionine synthase isoform type-2 GN=MAT2A METK2_HUMAN $43.66 \quad 100.0 \%$ S-adenosylmethionine synthase isoform type-2 GN=MAT2A METK2_HUMAN $43.66 \quad 100.0 \%$
$11 \quad 0.02 \% \quad 26.1 \%$ TAPGMGDQSGCYR

$96.4 \% \quad 16.0 \quad 25.0$

$11 \quad 0.02 \% \quad 26.1 \%$ VADLTEQYNEQYGAVR$$
\begin{array}{lll}
11 & 0.02 \% \quad 26.1 \% & \text { ATAPVPTVGEGYGYGHESELSQASAAAR }
\end{array}
$$
$99.7 \% 72.5$

$99.7 \% \quad 48.4$ $0.01 \% \quad 9.6 \%$ TAQQIAKDMER

$0.01 \% \quad 9.6 \%$ ESAAADAGFALFEK $0.01 \% \quad 9.6 \%$ EKYGIPEPPEPK

$0.01 \% \quad 9.6 \%$ YGIPEPPEPK

$0.01 \% \quad 9.6 \%$ YGIPEPPEPKR

$0.01 \% \quad 9.6 \% \quad$ KCQGITAPIEAQVR

$0.01 \% \quad 9.6 \%$ LKGAGLGAK

$99.7 \% \quad 39.8$

$99.7 \% \quad 45.3$

$99.7 \% \quad 38.2$

$97.3 \% \quad 21.9$

$98.4 \% \quad 22.3$

$99.7 \% 27.5$

$99.6 \% 31.3$

$0.01 \% \quad 9.6 \%$ GSAYGLSGADSYKDAVR

$0.02 \% \quad 21.6 \%$ LQASNVTNKNDPK

$0.02 \% \quad 21.6 \%$ VFIGNLNTALVK

$17 \quad 0.02 \% \quad 21.6 \%$ VFIGNLNTALVKK

$0.02 \% \quad 21.6 \%$ KSDVETIFSK

$0.02 \% \quad 21.6 \%$ SDVETIFSKYGR

$0.02 \% \quad 21.6 \%$ VTVPLVRR

$0.02 \% \quad 21.6 \%$ TNVPVKLFAR

$0.02 \% \quad 21.6 \%$ STAVTTSSAK

$0.05 \% \quad 42.4 \%$ NVMVEPHR

$99.7 \% \quad 48.0$

$99.7 \% \quad 24.5$

$99.1 \% \quad 45.6$

$99.1 \% \quad 33.1$

$99.7 \% \quad 39.3$

$99.7 \% \quad 48.6$

$99.0 \% \quad 35.6$

$99.7 \% 33.6$

$99.7 \% \quad 45.8$

$98.9 \% \quad 23.3$

$0.05 \% \quad 42.4 \%$ GKEDALVTK

$\begin{array}{llll}15 & 40 & 0.05 \% & 42.4 \% \\ 15 & 40 & 0.05 \% & 42.4 \% \text { NLVPGESVYGEK }\end{array}$

$15 \quad 40 \quad 0.05 \% \quad 42.4 \%$ NLVPGESVYGEKR

$\begin{array}{llll}15 & 40 & 0.05 \% & 42.4 \% \\ 15 & \text { VSISEGDDKIEYR }\end{array}$

$\begin{array}{lllll}98.7 \% & 20.5 & 25.0 & 34.4 & 6\end{array}$

$\begin{array}{llll}98.8 \% & 20.5 & 25.0 & 17.4 \\ 99.7 \% & 54.2 & 25.0 & 49.0\end{array}$

$\begin{array}{llll}99.7 \% & 55.6 & 25.0 & 52.7\end{array}$

$15 \quad 40 \quad 0.05 \% \quad 42.4 \%$ LAAAILGGVDQIHIKPGAK

$15 \quad 40 \quad 0.05 \% \quad 42.4 \%$ SGRDLINLAK

$\begin{array}{llll}15 & 40 & 0.05 \% & 42.4 \% \\ 15 & \text { TNIIPVIEDAR }\end{array}$

$\begin{array}{llll}15 & 40 & 0.05 \% & 42.4 \% \\ 15 & \text { IVALNAHTFLR }\end{array}$

$99.7 \% \quad 33.7$

$99.7 \% \quad 27.2$

$99.1 \% \quad 48.8$

$99.7 \% \quad 48.0$

$0.05 \% \quad 42.4 \%$ ANCIDSTASAEAVFASEVKK

$0.05 \% \quad 42.4 \%$ DHAVVVGVYRPPPK

$8 \quad 0.02 \% \quad 15.2 \%$ SPVKVVFPSGEVVEQK

$0.02 \% \quad 15.2 \%$ VVFPSGEVVEQK

$0.02 \% \quad 15.2 \%$ KAPSEASAQEQR

$0.02 \% \quad 15.2 \%$ LSSVMTIVK

$0.02 \% \quad 15.2 \%$ LISDALKAGAVPK

$0.02 \% \quad 15.2 \%$ SAAGAGCSKVLLTK

$0.01 \% \quad 1.5 \% \quad$ FCIQEIEK

$0.01 \% \quad 1.5 \%$ VLATQPGPGR

$0.01 \% \quad 1.5 \%$ VLATQPGPGRGR

$0.01 \% \quad 12.4 \%$ TPESKPTILVK

$0.01 \% \quad 12.4 \%$ GVVQLFNAVQK

$6 \quad 0.01 \% \quad 12.4 \%$ GMDGSTNETASSR

$0.01 \% \quad 2.2 \% \quad$ LFNDDNTIPFIIR

$0.01 \% \quad 2.2 \%$ ITLDLIRVL

$0.03 \% \quad 19.2 \%$ TGMILLAGEITSR

$0.03 \% \quad 19.2 \%$ AAVDYQKVVR

1291.65

1447.75

1510.74

1872.11 
S-adenosylmethionine synthase isoform type-2 GN=MAT2A METK2_HUMAN $43.66 \quad 100.0 \%$ S-adenosylmethionine synthase isoform type-2 GN=MAT2A METK2_HUMAN $43.66 \quad 100.0 \%$ S-adenosylmethionine synthase isoform type-2 GN=MAT2A METK2_HUMAN $43.66 \quad 100.0 \%$ S-adenosylmethionine synthase isoform type-2 GN=MAT2A METK2_HUMAN $43.66 \quad 100.0 \%$ S-adenosylmethionine synthase isoform type-2 GN=MAT2A METK2_HUMAN $43.66 \quad 100.0 \%$ Sarcoplasmic/endoplasmic reticulum calcium ATPase 2 GN=ATP2A2 AT2A2_HUMAN $114.76 \quad 100.0 \%$ Sarcoplasmic/endoplasmic reticulum calcium ATPase 2 GN=ATP2A2 AT2A2_HUMAN $114.76 \quad 100.0 \%$ Sarcoplasmic/endoplasmic reticulum calcium ATPase 2 GN=ATP2A2 AT2A2_HUMAN $114.76 \quad 100.0 \%$ Sarcoplasmic/endoplasmic reticulum calcium ATPase 2 GN=ATP2A2 AT2A2_HUMAN $114.76 \quad 100.0 \%$ Sarcoplasmic/endoplasmic reticulum calcium ATPase 2 GN=ATP2A2 AT2A2_HUMAN $114.76 \quad 100.0 \%$ Sarcoplasmic/endoplasmic reticulum calcium ATPase $2 \mathrm{GN}=\mathrm{ATP} 2 \mathrm{~A} 2$ AT2A2_HUMAN $114.76 \quad 100.0 \%$ Sarcoplasmic/endoplasmic reticulum calcium ATPase 2 GN=ATP2A2 AT2A2_HUMAN $114.76 \quad 100.0 \%$ Sarcoplasmic/endoplasmic reticulum calcium ATPase 2 GN=ATP2A2 AT2A2_HUMAN $114.76 \quad 100.0 \%$ Scaffold attachment factor B1 GN=SAFB SAFB1_HUMAN $102.64 \quad 100.0 \%$ Scaffold attachment factor B1 GN=SAFB SAFB1_HUMAN $102.64 \quad 100.0 \%$ $\mathrm{SCY} 1$-like protein $2 \mathrm{GN}=\mathrm{SCYL} 2$ SCY1-like protein $2 \mathrm{GN}=\mathrm{SCYL} 2$ $\mathrm{SCY} 1-$ like protein $2 \mathrm{GN}=\mathrm{SCYL} 2$ SCY1-like protein $2 \mathrm{GN}=\mathrm{SCYL} 2$ SCY1-like protein $2 \mathrm{GN}=\mathrm{SCYL} 2$ SCY1-like protein $2 \mathrm{GN}=\mathrm{SCYL} 2$ $\mathrm{SCY} 1$-like protein $2 \mathrm{GN}=\mathrm{SCYL} 2$

Secl family domain-cotining Sec1 family domain-containing protein $1 \mathrm{GN}=$ SCFD1 SCFD1_HUMAN $72.38 \quad 100.0 \%$ Sentrin-specific protease $3 \mathrm{GN}=\mathrm{SENP} 3 \quad$ SENP3 HUMAN $65.01 \quad 100.0 \%$ Sentrin-specific protease $3 \mathrm{GN}=$ SENP3 $\quad$ SENP3_HUMAN $65.01 \quad 100.0 \%$ Sentrin-specific protease $3 \mathrm{GN}=$ SENP3 $\quad$ SENP3_HUMAN $65.01 \quad 100.0 \%$ Sentrin-specific protease $3 \mathrm{GN}=$ SENP3 SENP3_HUMAN $65.01 \quad 100.0 \%$ Serine hydroxymethyltransferase, mitochondrial GN=SHMT2 GLYM_HUMAN $55.99 \quad 100.0 \%$ Serine hydroxymethyltransferase, mitochondrial GN=SHMT2 GLYM_HUMAN $55.99 \quad 100.0 \%$ Serine hydroxymethyltransferase, mitochondrial GN=SHMT2 GLYM_HUMAN $55.99 \quad 100.0 \%$ Serine/arginine repetitive matrix protein 2 GN=SRRM2 SRRM2_HUMAN $299.62 \quad 100.0 \%$ Serine/arginine repetitive matrix protein $2 \mathrm{GN}=\mathrm{SRRM} 2 \mathrm{SRRM} 2$ HUMAN $299.62 \quad 100.0 \%$ Serine/arginine repetitive matrix protein $2 \mathrm{GN}=\mathrm{SRRM} 2$ SRRM2_HUMAN $299.62 \quad 100.0 \%$ Serine/arginine repetitive matrix protein $2 \mathrm{GN}=\mathrm{SRRM} 2$ SRRM2_HUMAN $299.62 \quad 100.0 \%$ Serine/arginine repetitive matrix protein 2 GN=SRRM2 SRRM2_HUMAN $299.62 \quad 100.0 \%$ Serine/arginine repetitive matrix protein $2 \mathrm{GN}=$ SRRM2 SRRM2_HUMAN $299.62 \quad 100.0 \%$ Serine/arginine repetitive matrix protein $2 \mathrm{GN}=$ SRRM2 SRRM2_HUMAN $299.62 \quad 100.0 \%$ Serine/arginine repetitive matrix protein 2 GN=SRRM2 SRRM2_HUMAN $299.62 \quad 100.0 \%$ Serine/arginine repetitive matrix protein $2 \mathrm{GN}=\mathrm{SRRM} 2 \mathrm{SRRM} 2$ HUMAN $299.62 \quad 100.0 \%$ Serine/arginine repetitive matrix protein $2 \mathrm{GN}=$ SRRM2 SRRM2_HUMAN $299.62 \quad 100.0 \%$ Serine/arginine repetitive matrix protein $2 \mathrm{GN}=\mathrm{SRRM} 2 \mathrm{SRRM} 2$ HUMAN $299.62 \quad 100.0 \%$ Serine/arginine repetitive matrix protein $2 \mathrm{GN}=$ SRRM2 SRRM2_HUMAN $299.62 \quad 100.0 \%$ Serine/arginine repetitive matrix protein 2 GN=SRRM2 SRRM2_HUMAN $299.62 \quad 100.0 \%$ Serine/arginine repetitive matrix protein 2 GN=SRRM2 SRRM2_HUMAN $299.62 \quad 100.0 \%$ Serine/arginine repetitive matrix protein $2 \mathrm{GN}=\mathrm{SRRM} 2 \mathrm{SRRM} 2$ HUMAN $299.62 \quad 100.0 \%$ Serine/arginine repetitive matrix protein 2 GN=SRRM2 SRRM2_HUMAN $299.62 \quad 100.0 \%$

8

8

8

4

4
3
3

3
3
3

3
3
27

27

27

$0.03 \% \quad 19.2 \%$ NFDLRPGVIVR

$0.03 \% \quad 19.2 \%$ DLDLKKPIYQR

$0.03 \% \quad 10.2 \%$ NMLFSGTNIAAGK

$0.03 \% \quad 10.2 \%$ EFTLEFSR

$0.03 \% \quad 10.2 \%$ SMSVYCTPNKPSR

$0.03 \% \quad 10.2 \%$ VGSTKVPMTSGVK

$0.03 \% \quad 10.2 \%$ IGIFGQDEDVTSK

$0.00 \% \quad 2.6 \%$ NVDSSGNKSVLMER

$0.00 \% \quad 2.6 \%$ ATDLKNLFSK

16

16

16

16

16

$\begin{array}{llll}16 & 0.02 \% & 9.4 \% & \text { SQQPLKPQVHTPV }\end{array}$

$0.00 \% \quad 3.7 \%$ LTSAVSSLPELLEK

$0.01 \% \quad 7.1 \%$ GLVLQLIQSYQR

$0.01 \% \quad 7.1 \%$ YLQAEAVKK

$0.01 \% \quad 6.9 \% \quad$ TGLIDYNQLALTAR

$9 \quad 0.01 \% \quad 6.9 \%$ LIIAGTSAYAR

$0.01 \% \quad 6.9 \% \quad$ AFPMPGFDEH

$105 \quad 0.14 \% \quad 12.9 \%$ SLSGSSPCPK

$105 \quad 0.14 \% \quad 12.9 \%$ SCFESSPDPELK

$105 \quad 0.14 \% \quad 12.9 \%$ SCFESSPDPELKSR

$105 \quad 0.14 \% \quad 12.9 \%$ YSHSGSSSPDTK

$105 \quad 0.14 \% \quad 12.9 \%$ HSLSGSSPGMKDIPR

$105 \quad 0.14 \% \quad 12.9 \%$ GRSECDSSPEPK

$105 \quad 0.14 \% \quad 12.9 \%$ SGSESSVDQKTVAR

$105 \quad 0.14 \% \quad 12.9 \%$ SPSVSSPEPAEK

$105 \quad 0.14 \% \quad 12.9 \%$ SPGMLEPLGSSR

$105 \quad 0.14 \% \quad 12.9 \%$ TSVPENHAQSR

$105 \quad 0.14 \% \quad 12.9 \%$ MSQVPAPVPLMSLR

$105 \quad 0.14 \% \quad 12.9 \%$ TAPAANLASR

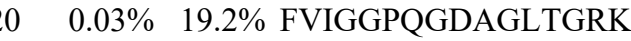

$0.03 \% \quad 10.2 \%$ VGEATETALTCLVEK

$0.03 \% \quad 10.2 \%$ AFTGREFDELNPSAQR

$0.03 \% \quad 10.2 \%$ NYLEPGKECVQPATK

$0.02 \% \quad 9.4 \%$ ASLTLEEKQK

$0.00 \% \quad 3.7 \%$ MLNFNVPHIK

$0.01 \% \quad 7.1 \%$ LKSGGGFGPDPGSGTTVPAR $\quad 99.7 \% \quad 27.5$

$\begin{array}{llllll}0.01 \% & 7.1 \% & \text { SGGGFGPDPGSGTTVPAR } & 99.7 \% & 40.8\end{array}$

$105 \quad 0.14 \% \quad 12.9 \%$ SSTGPEPPAPTPLLAER

$105 \quad 0.14 \% \quad 12.9 \%$ SKDSLVQSCPGSLSLCAGVK

$99.7 \% \quad 51.5$

$99.7 \% \quad 34.0$

$99.7 \% \quad 65.3$

$99.7 \% \quad 47.4$

$99.6 \% \quad 22.9$

$\begin{array}{lll}99.7 \% & 48.2\end{array}$

$99.7 \% \quad 50.8$

$99.7 \% \quad 32.5$

$99.7 \% \quad 48.6$

$99.7 \% \quad 38.4$

$105 \quad 0.14 \% \quad 12.9 \%$ SGSSQELDVKPSASPQE

$105 \quad 0.14 \% \quad 12.9 \%$ AQSGSDSSPEPKAPAPR
$99.7 \% 50.7$

$99.7 \% \quad 36.3$

$99.7 \% \quad 51.8$

$94.5 \% \quad 14.1$

$\begin{array}{llll}97.3 \% & 16.3 \quad 25 .\end{array}$

$99.7 \% \quad 34.2$

$99.6 \% \quad 26.0$

$99.7 \% \quad 28.2$

$99.6 \% \quad 24.6$
1444.75

1572.85

1285.74

1388.79

1323.67

1620.82

1028.50

1526.71

1290.71

1408.70

1837.88

1733.85

1535.75

1136.63

2134.12

1633.82

1995.05

1051.59

1319.67

1146.64

1858.05

1212.66

1486.84

1857.95

1616.77

1417.82

1049.60

1548.84

1135.65

1163.48

1719.89

1019.48

1395.61

1638.74

1252.54

2093.04

1584.78

1348.58

1450.71

1901.92

1681.81

1214.59

1230.61

1225.59

$1541.82 \quad 2208 \quad 2221$

$\begin{array}{lll}971.53 & 2222 & 2231\end{array}$ 
Serine/arginine repetitive matrix protein 2 GN=SRRM2 SRRM2_HUMAN $299.62 \quad 100.0 \% \quad 27$ Serine/arginine repetitive matrix protein 2 GN=SRRM2 SRRM2_HUMAN $299.62 \quad 100.0 \% 27$ Serine/arginine repetitive matrix protein 2 GN=SRRM2 SRRM2_HUMAN $299.62 \quad 100.0 \% 27$ Serine/arginine repetitive matrix protein 2 GN=SRRM2 SRRM2_HUMAN $299.62 \quad 100.0 \% \quad 27$ Serine/arginine repetitive matrix protein 2 GN=SRRM2 SRRM2_HUMAN $299.62 \quad 100.0 \% \quad 27$ Serine/arginine repetitive matrix protein 2 GN=SRRM2 SRRM2_HUMAN $299.62 \quad 100.0 \% \quad 27$ Serine/arginine repetitive matrix protein 2 GN=SRRM2 SRRM2_HUMAN $299.62 \quad 100.0 \% \quad 27$ Serine/arginine repetitive matrix protein $2 \mathrm{GN}=\mathrm{SRRM} 2$ SRRM2_HUMAN $299.62 \quad 100.0 \%$ Serine/arginine repetitive matrix protein $2 \mathrm{GN}=\mathrm{SRRM} 2 \mathrm{SRRM} 2 \mathrm{HUMAN} 299.62 \quad 100.0 \%$ Serine/arginine repetitive matrix protein 2 GN=SRRM2 SRRM2_HUMAN $299.62 \quad 100.0 \% \quad 27$ Serine/arginine repetitive matrix protein 2 GN=SRRM2 SRRM2_HUMAN $299.62 \quad 100.0 \%$ Serine/arginine-rich splicing factor $1 \mathrm{GN}=\mathrm{SRSF} 1 \mathrm{SRSF} 1$ HUMAN $27.75 \quad 100.0 \%$ Serine/arginine-rich splicing factor $1 \mathrm{GN}=\mathrm{SRSF} 1$ SRSF1_HUMAN $27.75 \quad 100.0 \% \quad 12$ Serine/arginine-rich splicing factor $1 \mathrm{GN}=\mathrm{SRSF} 1$ SRSF1_HUMAN $27.75 \quad 100.0 \%$ Serine/arginine-rich splicing factor $1 \mathrm{GN}=\mathrm{SRSF} 1 \quad$ SRSF1_HUMAN $27.75 \quad 100.0 \%$ Serine/arginine-rich splicing factor $1 \mathrm{GN}=\mathrm{SRSF} 1 \quad$ SRSF1_HUMAN $27.75 \quad 100.0 \% \quad 12$ Serine/arginine-rich splicing factor $1 \mathrm{GN}=\mathrm{SRSF} 1$ SRSF1_HUMAN $27.75 \quad 100.0 \%$ Serine/arginine-rich splicing factor $1 \mathrm{GN}=\mathrm{SRSF} 1$ SRSF1_HUMAN $27.75 \quad 100.0 \%$ Serine/arginine-rich splicing factor $1 \mathrm{GN}=\mathrm{SRSF} 1$ SRSF1_HUMAN $27.75 \quad 100.0 \%$ $\begin{array}{llll}\text { Serine/arginine-rich splicing factor } 1 \mathrm{GN}=\text { SRSF1 SRSF1_HUMAN } & 27.75 & 100.0 \% & 12\end{array}$ $\begin{array}{lllll}\text { Serine/arginine-rich splicing factor } 1 \mathrm{GN}=\mathrm{SRSF} 1 & \text { SRSF1_HUMAN } & 27.75 & 100.0 \% & 12\end{array}$ Serine/arginine-rich splicing factor $1 \mathrm{GN}=\mathrm{SRSF} 1$ SRSF1_HUMAN $27.75 \quad 100.0 \%$ Serine/arginine-rich splicing factor $1 \mathrm{GN}=$ SRSF1 SRSF1_HUMAN $27.75 \quad 100.0 \% \quad 12$ Serine/arginine-rich splicing factor $10 \mathrm{GN}=$ SRSF10 SRS10_HUMAN $31.30 \quad 100.0 \%$ Serine/arginine-rich splicing factor $10 \mathrm{GN}=$ SRSF 10 SRS10 HUMAN $31.30 \quad 100.0 \%$ Serine/arginine-rich splicing factor $10 \mathrm{GN}=$ SRSF10 SRS10_HUMAN $31.30 \quad 100.0 \%$ Serine/arginine-rich splicing factor $10 \mathrm{GN}=$ SRSF10 SRS10_HUMAN $31.30 \quad 100.0 \%$ Serine/arginine-rich splicing factor $2 \mathrm{GN}=\mathrm{SRSF} 2$ SRSF2 HUMAN $25.48 \quad 100.0 \%$ Serine/arginine-rich splicing factor $2 \mathrm{GN}=\mathrm{SRSF} 2$ SRSF2_HUMAN $25.48 \quad 100.0 \%$ Serine/arginine-rich splicing factor $2 \mathrm{GN}=\mathrm{SRSF} 2 \mathrm{SRSF} 2 \mathrm{HUMAN} 25.48 \quad 100.0 \%$ Serine/arginine-rich splicing factor $2 \mathrm{GN}=\mathrm{SRSF} 2$ SRSF2_HUMAN $25.48 \quad 100.0 \%$ Serine/arginine-rich splicing factor $2 \mathrm{GN}=\mathrm{SRSF} 2$ SRSF2_HUMAN $25.48 \quad 100.0 \%$ Serine/arginine-rich splicing factor $3 \mathrm{GN}=\mathrm{SRSF} 3 \mathrm{SRSF}_{3}$ HUMAN $19.33 \quad 100.0 \%$ Serine/arginine-rich splicing factor $3 \mathrm{GN}=\mathrm{SRSF} 3$ SRSF3_HUMAN $19.33 \quad 100.0 \%$ Serine/arginine-rich splicing factor $3 \mathrm{GN}=\mathrm{SRSF} 3$ SRSF3 HUMAN $19.33 \quad 100.0 \%$ Serine/arginine-rich splicing factor $3 \mathrm{GN}=\mathrm{SRSF} 3$ SRSF3_HUMAN $19.33 \quad 100.0 \%$ Serine/arginine-rich splicing factor $3 \mathrm{GN}=\mathrm{SRSF} 3$ SRSF3_HUMAN $19.33 \quad 100.0 \%$ Serine/arginine-rich splicing factor $3 \mathrm{GN}=\mathrm{SRSF} 3$ SRSF3 HUMAN $19.33 \quad 100.0 \%$ Serine/arginine-rich splicing factor $3 \mathrm{GN}=\mathrm{SRSF} 3$ SRSF3_HUMAN $19.33 \quad 100.0 \%$ Serine/arginine-rich splicing factor $3 \mathrm{GN}=\mathrm{SRSF} 3 \quad$ SRSF3_HUMAN $19.33 \quad 100.0 \%$ Serine/arginine-rich splicing factor $3 \mathrm{GN}=\mathrm{SRSF} 3$ SRSF3 HUMAN $19.33 \quad 100.0 \%$ Serine/arginine-rich splicing factor $3 \mathrm{GN}=\mathrm{SRSF} 3$ SRSF3_HUMAN $19.33 \quad 100.0 \%$ Serine/arginine-rich splicing factor $4 \mathrm{GN}=\mathrm{SRSF} 4 \mathrm{SRSF} 4$ HUMAN $56.68 \quad 100.0 \%$ Serine/arginine-rich splicing factor $4 \mathrm{GN}=$ SRSF4 SRSF4_HUMAN $56.68 \quad 100.0 \%$ Serine/arginine-rich splicing factor $4 \mathrm{GN}=\mathrm{SRSF} 4$ SRSF4_HUMAN $56.68 \quad 100.0 \%$ Serine/arginine-rich splicing factor $4 \mathrm{GN}=\mathrm{SRSF} 4$ SRSF4 HUMAN $56.68 \quad 100.0 \%$ Serine/arginine-rich splicing factor 5 GN=SRSF5 SRSF5_HUMAN $31.26 \quad 100.0 \%$ $105 \quad 0.14 \% \quad 12.9 \%$ TPAIPTAVNLADSR

0.14\% $12.9 \%$ TPAAAAAMNLASPR

$105 \quad 0.14 \% \quad 12.9 \%$ TAVAPSAVNLADPR

$105 \quad 0.14 \% \quad 12.9 \%$ TPTAPAVNLAGAR

$105 \quad 0.14 \% \quad 12.9 \%$ TPQAPASANLVGPR

$105 \quad 0.14 \% \quad 12.9 \%$ SAHATAPVNIAGSR

$105 \quad 0.14 \% \quad 12.9 \%$ TAAALAPASLTSAR

$105 \quad 0.14 \% \quad 12.9 \%$ MAPALSGANLTSPR

$105 \quad 0.14 \% \quad 12.9 \%$ VPLSAYER

$105 \quad 0.14 \% \quad 12.9 \%$ SPVPSAFSDQSR

$49 \quad 0.07 \% \quad 41.5 \%$ GPAGNNDCR

$49 \quad 0.07 \% \quad 41.5 \%$ IYVGNLPPDIR

$49 \quad 0.07 \% \quad 41.5 \%$ TKDIEDVFYK

$49 \quad 0.07 \% \quad 41.5 \%$ YGAIRDIDLK

$49 \quad 0.07 \% \quad 41.5 \%$ GGGGGGGGGAPR

$49 \quad 0.07 \% \quad 41.5 \%$ GRYGPPSR

$49 \quad 0.07 \% \quad 41.5 \%$ EAGDVCYADVYR

$49 \quad 0.07 \% \quad 41.5 \%$ EAGDVCYADVYRDGTGVVEFVR

$49 \quad 0.07 \% \quad 41.5 \%$ DGTGVVEFVR

$49 \quad 0.07 \% \quad 41.5 \%$ KEDMTYAVR

$49 \quad 0.07 \% \quad 41.5 \%$ FRSHEGETAYIR

$0.07 \% \quad 41.5 \%$ SHEGETAYIR

$0.03 \% \quad 15.3 \%$ YLRPPNTSLFVR

$0.03 \% \quad 15.3 \%$ YGPIVDVYVPLDFYTR

$0.03 \% \quad 15.3 \%$ QIEIQFAQGDR

$0.03 \% \quad 15.3 \%$ QIEIQFAQGDRK

$0.02 \% \quad 17.2 \%$ TSPDTLRR

$0.02 \% \quad 17.2 \%$ VGDVYIPR

$0.02 \% \quad 17.2 \%$ VGDVYIPRDR

$0.02 \% \quad 17.2 \%$ YGRPPDSHHSR

$0.02 \% \quad 17.2 \%$ YGGGGYGRR

$0.03 \% \quad 46.3 \%$ DSCPLDCK

$0.03 \% \quad 46.3 \%$ VYVGNLGNNGNK

$99.7 \% \quad 53.6$

$7 \% \quad 35.9$

$99.7 \% 31$.

$99.7 \% \quad 44.2$

$99.7 \% \quad 41.5$

$99.7 \% \quad 55.3$

$99.7 \% \quad 41.1$

$99.7 \% \quad 45.7$

$99.7 \% \quad 54.0$

$99.0 \% \quad 23.4$

$99.7 \% \quad 38.8$

$99.7 \% \quad 47.5$

$99.7 \% \quad 60.1$

$99.7 \% \quad 47.6$

$99.7 \% \quad 40.3$

$99.7 \% \quad 44.8$

$97.5 \% \quad 24.2$

$99.7 \% \quad 46.2$

$99.7 \% \quad 40.8$

$99.7 \% \quad 38.0$

$99.7 \% \quad 53.8$

$99.7 \% 35.4$

$99.7 \% \quad 48.4$

$99.7 \% \quad 37.4$

$99.7 \% \quad 52.6$

$99.7 \% \quad 40.4$

$99.7 \% \quad 50.5$

$95.5 \% 21.1$

$99.0 \% \quad 63.8$

$99.7 \% \quad 35.3$

$99.7 \% \quad 26.2$

$99.7 \% 25.6$

$99.0 \% 29.1$

$98.5 \% \quad 23.0$

$0.03 \% \quad 46.3 \%$ VYVGNLGNNGNKTELER $99.7 \% \quad 64.3$

$0.03 \% \quad 46.3 \%$ AFGYYGPLR

$99.7 \% \quad 44.5 \quad 25.0 \quad 39.0$

$0.03 \% \quad 46.3 \%$ NPPGFAFVEFEDPRDAADAVR $\quad 99.7 \% \quad 25.0$

$99.7 \% \quad 43.1$

$99.7 \% \quad 39.5$

$99.7 \% 38.1$

$99.0 \% \quad 20.9$

$99.7 \% 38.7$

$99.7 \% \quad 57.7$

$99.7 \% \quad 35.2$

$95.1 \% 18.5$

$98.9 \% \quad 21.8$
$0.00 \% \quad 6.5 \% \quad$ LVEDKPGSR

$0.00 \% \quad 6.5 \% \quad$ SKPNLPSESR

$0.03 \% \quad 29.8 \%$ YSDRFSSR
1425.77

1357.69

1381.74

1238.69

1378.74

1351.71

1300.72

1401.72

1277.61

960.40

1256.70

1257.64

1163.64

856.40

889.46

1417.61

2477.14

1078.55

1112.54

1465.72

1162.55

1462.82

1916.98

1304.66

1432.75

945.51

918.50

1189.63

1308.62

942.45

994.40

1248.63

1876.95

1043.53

1621.76

2320.10

1130.62

1031.55

1123.58

853.43

1579.84

1030.59

1000.54

1114.59

1017.47 
Serine/arginine-rich splicing factor $5 \mathrm{GN}=$ SRSF5 SRSF5_HUMAN $31.26 \quad 100.0 \%$ Serine/arginine-rich splicing factor 5 GN=SRSF5 SRSF5_HUMAN $31.26 \quad 100.0 \%$ Serine/arginine-rich splicing factor 5 GN=SRSF5 SRSF5_HUMAN $31.26 \quad 100.0 \%$ Serine/arginine-rich splicing factor $5 \mathrm{GN}=$ SRSF5 SRSF5_HUMAN $31.26 \quad 100.0 \%$ Serine/arginine-rich splicing factor 5 GN=SRSF5 SRSF5_HUMAN $31.26 \quad 100.0 \%$ Serine/arginine-rich splicing factor $5 \mathrm{GN}=\mathrm{SRSF} 5$ SRSF5 HUMAN $31.26 \quad 100.0 \%$ Serine/arginine-rich splicing factor $5 \mathrm{GN}=$ SRSF5 SRSF5_HUMAN $31.26 \quad 100.0 \%$ Serine/arginine-rich splicing factor $5 \mathrm{GN}=$ SRSF5 SRSF5_HUMAN $31.26 \quad 100.0 \%$ Serine/arginine-rich splicing factor $5 \mathrm{GN}=\mathrm{SRSF} 5$ SRSF5 HUMAN $31.26 \quad 100.0 \%$ Serine/arginine-rich splicing factor $6 \mathrm{GN}=$ SRSF6 SRSF6_HUMAN $39.59 \quad 100.0 \%$ Serine/arginine-rich splicing factor $6 \mathrm{GN}=$ SRSF6 SRSF6_HUMAN $39.59 \quad 100.0 \%$ Serine/arginine-rich splicing factor $6 \mathrm{GN}=\mathrm{SRSF} 6$ SRSF6_HUMAN $39.59100 .0 \%$ Serine/arginine-rich splicing factor 6 GN=SRSF6 SRSF6_HUMAN $39.59100 .0 \%$ Serine/arginine-rich splicing factor $6 \mathrm{GN}=$ SRSF6 SRSF6_HUMAN $39.59 \quad 100.0 \%$ Serine/arginine-rich splicing factor $6 \mathrm{GN}=$ SRSF6 SRSF6_HUMAN $39.59 \quad 100.0 \%$ Serine/arginine-rich splicing factor 6 GN=SRSF6 SRSF6_HUMAN $39.59 \quad 100.0 \%$ Serine/arginine-rich splicing factor $6 \mathrm{GN}=\mathrm{SRSF} 6$ SRSF6 HUMAN $39.59 \quad 100.0 \%$ Serine/arginine-rich splicing factor $7 \mathrm{GN}=$ SRSF7 SRSF7_HUMAN $27.37 \quad 100.0 \%$ Serine/arginine-rich splicing factor $7 \mathrm{GN}=$ SRSF7 SRSF7_HUMAN $27.37 \quad 100.0 \%$ Serine/arginine-rich splicing factor $7 \mathrm{GN}=$ SRSF7 SRSF7_HUMAN $27.37 \quad 100.0 \%$ Serine/arginine-rich splicing factor $7 \mathrm{GN}=$ SRSF7 SRSF7_HUMAN $27.37 \quad 100.0 \%$ Serine/arginine-rich splicing factor $7 \mathrm{GN}=$ SRSF7 $\quad$ SRSF7_HUMAN $27.37 \quad 100.0 \%$ Serine/arginine-rich splicing factor $7 \mathrm{GN}=$ SRSF7 SRSF7_HUMAN $27.37 \quad 100.0 \%$ Serine/arginine-rich splicing factor $7 \mathrm{GN}=$ SRSF7 SRSF7_HUMAN $27.37 \quad 100.0 \%$ Serine/arginine-rich splicing factor $7 \mathrm{GN}=$ SRSF7 SRSF7 HUMAN $27.37 \quad 100.0 \%$ Serine/arginine-rich splicing factor $7 \mathrm{GN}=\mathrm{SRSF} 7$ SRSF7_HUMAN $27.37 \quad 100.0 \%$ Serine/arginine-rich splicing factor $7 \mathrm{GN}=$ SRSF7 SRSF7_HUMAN $27.37 \quad 100.0 \%$ Serine/arginine-rich splicing factor $9 \mathrm{GN}=$ SRSF9 SRSF9_HUMAN $25.54 \quad 100.0 \%$ Serine/arginine-rich splicing factor $9 \mathrm{GN}=$ SRSF9 SRSF9_HUMAN $25.54 \quad 100.0 \%$ Serine/arginine-rich splicing factor $9 \mathrm{GN}=$ SRSF9 SRSF9 HUMAN $25.54 \quad 100.0 \%$ Serine/arginine-rich splicing factor $9 \mathrm{GN}=$ SRSF9 SRSF9_HUMAN $25.54 \quad 100.0 \%$ Serine/arginine-rich splicing factor 9 GN=SRSF9 SRSF9_HUMAN $25.54 \quad 100.0 \%$ Serine/arginine-rich splicing factor $9 \mathrm{GN}=$ SRSF9 SRSF9_HUMAN $25.54 \quad 100.0 \%$ Serine/threonine-protein kinase 38-like GN=STK38L ST38L_HUMAN $54.01 \quad 100.0 \%$ Serine/threonine-protein kinase 38-like GN=STK38L ST38L_HUMAN 54.01 $100.0 \%$ Serine/threonine-protein kinase 38-like GN=STK38L ST38L_HUMAN $54.01 \quad 100.0 \%$ Serine/threonine-protein kinase 38-like GN=STK38L ST38L_HUMAN $54.01 \quad 100.0 \%$ Serine/threonine-protein kinase 38-like GN=STK38L ST38L HUMAN $54.01 \quad 100.0^{\circ}$ Serine/threonine-protein kinase 38-like GN=STK38L ST38L_HUMAN $54.01 \quad 100.0 \%$ Serine/threonine-protein kinase 38-like GN=STK38L ST38L_HUMAN $54.01 \quad 100.0 \%$ Serine/threonine-protein kinase 38-like GN=STK38L ST38L_HUMAN $54.01 \quad 100.0 \%$ Serine/threonine-protein kinase 38-like GN=STK38L ST38L_HUMAN $54.01 \quad 100.0 \%$ Serine/threonine-protein kinase 38-like GN=STK38L ST38L HUMAN 54.01 $100.0 \%$ Serine/threonine-protein kinase MRCK alpha GN=CDC42BPA MRCKA_HUMAN $197.31 \quad 100.0 \%$ Serine/threonine-protein kinase MRCK alpha GN=CDC42BPA MRCKA_HUMAN $197.31 \quad 100.0 \%$ Serine/threonine-protein kinase MRCK alpha GN=CDC42BPA MRCKA_HUMAN $197.31 \quad 100.0 \%$ Serine/threonine-protein kinase MRCK alpha GN=CDC42BPA MRCKA_HUMAN $197.31 \quad 100.0 \%$
$0.03 \% \quad 29.8 \%$ NAPPVRTENR

$0.03 \% \quad 29.8 \%$ TENRLIVENLSSR

$0.03 \% \quad 29.8 \%$ LIVENLSSR

$0.03 \% \quad 29.8 \%$ QAGEVTFADAHRPK

$0.03 \% \quad 29.8 \%$ LNEGVVEFASYGDLK

$0.03 \% \quad 29.8 \%$ LNEGVVEFASYGDLKNAIEK

$0.03 \% \quad 29.8 \%$ SPVPEKSQK

$0.03 \% \quad 29.8 \%$ SKSPASVDR

$0.03 \% \quad 29.8 \%$ SPASVDRQR

$0.10 \% \quad 20.9 \%$ DRDGYSYGSR

$0.10 \% \quad 20.9 \%$ TEYRLIVENLSSR

$0.10 \% \quad 20.9 \%$ LIVENLSSR

$0.10 \% \quad 20.9 \%$ QAGEVTYADAHKER

$0.10 \% \quad 20.9 \%$ TNEGVIEFR

$0.10 \% \quad 20.9 \%$ ALDKLDGTEINGR

$0.10 \% \quad 20.9 \%$ SNSPLPVPPSK

$0.10 \% \quad 20.9 \%$ SNSPLPVPPSKAR

$0.07 \% \quad 39.9 \%$ YGRYGGETK

$0.07 \% \quad 39.9 \%$ VYVGNLGTGAGK

$0.07 \% \quad 39.9 \%$ AFSYYGPLR

$0.07 \% \quad 39.9 \%$ NPPGFAFVEFEDPR

$0.07 \% \quad 39.9 \%$ NPPGFAFVEFEDPRDAEDAVR

$0.07 \% \quad 39.9 \%$ GLDGKVICGSR

$0.07 \% \quad 39.9 \%$ VRVELSTGMPR

$0.07 \% \quad 39.9 \%$ RPFDPNDR

$0.07 \% \quad 39.9 \%$ GHYAYDCHR

$0.02 \% \quad 28.5 \%$ HGLVPFAFVR

$0.02 \% \quad 28.5 \%$ NGYDYGQCR

$0.02 \% \quad 28.5 \%$ SHEGETSYIR

$0.02 \% \quad 28.5 \%$ VYPERSTSYGYSR

$0.02 \% \quad 28.5 \%$ GRDSPYQSR

$0.02 \% \quad 28.5 \%$ GSPHYFSPFRPY

$0.03 \% \quad 20.3 \%$ TRLGLDDFESLK

$0.03 \% \quad 20.3 \%$ LGLDDFESLKVIGR

$0.03 \% \quad 20.3 \%$ DTGHIYAMK

$0.03 \% \quad 20.3 \%$ DIKPDNLLLDAK

$0.03 \% \quad 20.3 \%$ LSDFGLCTGLK

$0.03 \% \quad 20.3 \%$ LSDFGLCTGLKK

$0.03 \% \quad 20.3 \%$ NLTHNPPSDFSFQNMNSK

$0.03 \% \quad 20.3 \%$ ERPAAIPIEIK

$0.03 \% \quad 20.3 \%$ RFEGLTQR

$0.03 \% \quad 20.3 \%$ GSIPTYMK

$0.01 \% \quad 3.6 \%$ GAFGEVAVVK

$0.01 \% \quad 3.6 \%$ VTAGPTSLDLDVNVQR

$0.01 \% \quad 3.6 \%$ GIGTAYEGHVR

$0.01 \% \quad 3.6 \%$ TVFSGSVSIPSITK $\begin{array}{llll}97.7 \% & 21.4 & 25.0 & 16.0\end{array}$

$99.7 \% \quad 37.1$

$99.7 \% \quad 57.7$

$99.7 \% \quad 34.7$

$99.7 \% \quad 38.1$

$99.7 \% \quad 46$.

$98.9 \% \quad 25.9$

$95.3 \% 21$.

$95.8 \% 15.3$

$99.7 \% \quad 39.6$

$99.7 \% \quad 38.7$

$99.7 \% \quad 57.7$

$99.7 \% \quad 51.7$

$99.7 \% \quad 53.4$

$99.7 \% 54.8$

$99.7 \% \quad 40.5$

$96.5 \% \quad 19.2$

$95.7 \% \quad 22.0$

$99.7 \% \quad 56.6$

$\begin{array}{ll}99.7 \% & 37.4\end{array}$

$99.7 \% \quad 53.0$

$99.7 \% \quad 39.9$

$\begin{array}{lll}99.7 \% & 49.8\end{array}$

$99.7 \% \quad 40.8$

$99.0 \% \quad 35.9$

$\begin{array}{lll}99.7 \% & 32.8\end{array}$

$99.7 \% \quad 26.2$

$99.7 \% \quad 52.7$

$99.6 \% 22.6$

$96.5 \% 15.1$

$99.7 \% \quad 41.6$

$99.7 \% \quad 45.9$

$98.2 \% \quad 20.1$

$99.7 \% \quad 58.0$

$99.7 \% \quad 38.8$

$99.7 \% \quad 45.7$

$99.7 \% \quad 54.6$

$99.7 \% \quad 51.7$

$99.7 \% \quad 30.9$

$99.7 \% \quad 31.3$

$99.0 \% \quad 30.2$

$96.8 \% \quad 17.3$

$99.7 \% \quad 35.1$

$99.7 \% \quad 40.2$

$99.7 \% \quad 29.3$

$99.7 \% \quad 39.0$
115

1530.82

1030.59

1526.77

1640.82

2196.12

999.55

946.50

1015.53

1175.51

1579.84

1030.59

1574.76

1064.54

1401.73

1122.62

1349.75

1030.50

1135.61

1719.90

1073.54

1621.76

2378.10

1161.60

1244.68

1016.49

1178.48

1142.65

1132.45

1178.54

1564.74

1065.51

1454.69

1393.73

1561.86

1035.49

1354.76

1210.61

1338.71

2077.94

1236.73

1006.54

896.45

976.55

1684.89

1159.59

1422.78 $\begin{array}{cc}00 & 109 \\ 06 & 118 \\ 10 & 118 \\ 30 & 143 \\ 44 & 158 \\ 44 & 163 \\ 33 & 241 \\ 48 & 256 \\ 50 & 258 \\ 6 & 85 \\ 08 & 120 \\ 12 & 120 \\ 32 & 145 \\ 46 & 154 \\ 62 & 174 \\ 01 & 311 \\ 01 & 313 \\ 4 & 12 \\ 3 & 24 \\ 3 & 29 \\ 0 & 38 \\ 5 & 58 \\ 5 & 65 \\ 6 & 76 \\ 7 & 87 \\ 8 & 105 \\ 13 & 121 \\ 9 & 58 \\ 3 & 81 \\ 72 & 181 \\ 82 & 194 \\ 01 & 209 \\ 10 & 221 \\ 3 & 94 \\ 5 & 98 \\ 11 & 119 \\ 13 & 224 \\ 29 & 239 \\ 29 & 240 \\ 49 & 266 \\ 93 & 403 \\ 45 & 452 \\ 53 & 460 \\ 6 & 95 \\ 18 & 433 \\ & 1090 \\ & \end{array}$

Page 116 of Table S-1-1 
Serine/threonine-protein kinase MRCK alpha GN=CDC42BPA MRCKA_HUMAN $197.31 \quad 100.0 \%$ Serine/threonine-protein kinase mTOR GN=MTOR MTOR_HUMAN $288.90 \quad 100.0 \%$ Serine/threonine-protein kinase mTOR GN=MTOR MTOR_HUMAN $288.90 \quad 100.0 \%$ Serine/threonine-protein kinase mTOR GN=MTOR MTOR_HUMAN $288.90 \quad 100.0 \%$ Serine/threonine-protein kinase mTOR GN=MTOR MTOR_HUMAN $288.90 \quad 100.0 \%$ Serine/threonine-protein kinase mTOR GN=MTOR MTOR_HUMAN $288.90 \quad 100.0 \%$ Serine/threonine-protein kinase mTOR GN=MTOR MTOR_HUMAN $288.90 \quad 100.0 \%$ Serine/threonine-protein kinase Nek7 GN=NEK7 NEK7_HUMAN $34.55 \quad 100.0 \%$ Serine/threonine-protein kinase Nek7 GN=NEK7 NEK7 HUMAN $34.55 \quad 100.0 \%$ Serine/threonine-protein kinase Nek7 GN=NEK7 NEK7_HUMAN $34.55 \quad 100.0 \%$ Serine/threonine-protein kinase RIO1 GN=RIOK1 RIOK1_HUMAN $65.58 \quad 100.0 \%$ Serine/threonine-protein kinase RIO1 GN=RIOK1 RIOK1_HUMAN $65.58 \quad 100.0 \%$ Serine/threonine-protein kinase RIO1 GN=RIOK1 RIOK1_HUMAN $65.58 \quad 100.0 \%$ Serine/threonine-protein kinase RIO1 GN=RIOK1 RIOK1_HUMAN $65.58 \quad 100.0 \%$ Serine/threonine-protein kinase RIO1 GN=RIOK1 RIOK1_HUMAN $65.58 \quad 100.0 \%$ Serine/threonine-protein kinase RIO1 GN=RIOK1 RIOK1_HUMAN $65.58 \quad 100.0 \%$ Serine/threonine-protein kinase RIO1 GN=RIOK1 RIOK1_HUMAN $65.58 \quad 100.0 \%$ Serine/threonine-protein kinase RIO1 GN=RIOK1 RIOK1_HUMAN $65.58 \quad 100.0 \%$ Serine/threonine-protein kinase RIO1 GN=RIOK1 RIOK1_HUMAN $65.58 \quad 100.0 \% \quad 2$ Serine/threonine-protein kinase RIO1 GN=RIOK1 RIOK1_HUMAN $65.58 \quad 100.0 \% \quad 29$ Serine/threonine-protein kinase RIO1 GN=RIOK1 RIOK1_HUMAN $65.58 \quad 100.0 \% \quad 29$ Serine/threonine-protein kinase RIO1 GN=RIOK1 RIOK1 HUMAN $65.58 \quad 100.0 \% \quad 29$ Serine/threonine-protein kinase RIO1 GN=RIOK1 RIOK1_HUMAN $65.58 \quad 100.0 \% \quad 29$ Serine/threonine-protein kinase RIO1 GN=RIOK1 RIOK1_HUMAN $65.58 \quad 100.0 \%$ Serine/threonine-protein kinase RIO1 GN=RIOK1 RIOK1 HUMAN $65.58 \quad 100.0 \%$ Serine/threonine-protein kinase RIO1 GN=RIOK1 RIOK1_HUMAN $65.58 \quad 100.0 \% \quad 29$ Serine/threonine-protein kinase RIO1 GN=RIOK1 RIOK1_HUMAN $65.58 \quad 100.0 \%$ Serine/threonine-protein kinase RIO1 GN=RIOK1 RIOK1_HUMAN $65.58 \quad 100.0 \% \quad 29$ Serine/threonine-protein kinase RIO1 GN=RIOK1 RIOK1_HUMAN $65.58 \quad 100.0 \% \quad 29$ Serine/threonine-protein kinase RIO1 GN=RIOK1 RIOK1 HUMAN $65.58 \quad 100.0 \%$ Serine/threonine-protein kinase RIO1 GN=RIOK1 RIOK1_HUMAN $65.58 \quad 100.0 \% \quad 29$ Serine/threonine-protein kinase RIO1 GN=RIOK1 RIOK1_HUMAN $65.58 \quad 100.0 \% \quad 29$ Serine/threonine-protein kinase RIO1 GN=RIOK1 RIOK1 HUMAN $65.58 \quad 100.0 \%$ Serine/threonine-protein kinase RIO1 GN=RIOK1 RIOK1_HUMAN $65.58 \quad 100.0 \%$ Serine/threonine-protein kinase RIO1 GN=RIOK1 RIOK1_HUMAN $65.58 \quad 100.0 \%$ Serine/threonine-protein kinase RIO1 GN=RIOK1 RIOK1_HUMAN $65.58 \quad 100.0 \% \quad 29$ Serine/threonine-protein kinase RIO1 GN=RIOK1 RIOK1_HUMAN $65.58 \quad 100.0 \% \quad 2$ Serine/threonine-protein kinase RIO1 GN=RIOK1 RIOK1_HUMAN $65.58 \quad 100.0 \%$ Serine/threonine-protein kinase RIO1 GN=RIOK1 RIOK1_HUMAN $65.58 \quad 100.0 \% \quad 29$ Serine/threonine-protein kinase SMG1 GN=SMG1 SMG1_HUMAN $410.50 \quad 100.0 \%$ Serine/threonine-protein kinase SMG1 GN=SMG1 SMG1 HUMAN $410.50 \quad 100.0 \%$ Serine/threonine-protein kinase TBK1 GN=TBK1 TBK1_HUMAN $83.64 \quad 100.0 \%$ Serine/threonine-protein kinase TBK1 GN=TBK1 TBK1_HUMAN $83.64 \quad 100.0 \%$ Serine/threonine-protein phosphatase 6 catalytic subunit GN=PPP6C PPP6_HUMAN $35.14 \quad 100.0 \%$ Serine/threonine-protein phosphatase 6 catalytic subunit GN=PPP6C PPP6_HUMAN $35.14 \quad 100.0 \%$ Serine/threonine-protin $\begin{array}{lll}\text { Serine/threonine-protein phosphatase PGAM5, mitochondrial GN=PGAM5 } & \text { PGAM5 HUMAN } 32.01 \quad 100.0 \%\end{array}$
$0.01 \% \quad 3.6 \%$ SMSASSGLSAR $0.02 \% \quad 2.3 \%$ DASAVSLSESK $0.02 \% \quad 2.3 \% \quad$ LFDAPEAPLPSR

$0.02 \% \quad 2.3 \% \quad$ LFDAPEAPLPSRK

$0.02 \% \quad 2.3 \%$ TLDQSPELR

$0.02 \% \quad 2.3 \%$ TLVLLLGVDPSR

$0.02 \% \quad 2.3 \% \quad$ IQSIAPSLQVITSK

$0.01 \% \quad 13.2 \%$ AACLLDGVPVALKK

$0.01 \% \quad 13.2 \%$ VQIFDLMDAK

$0.01 \% \quad 13.2 \%$ DIKPANVFITATGVVK

$155 \quad 0.21 \% \quad 48.1 \%$ VVPGQFDDADSSDSENRDLK

$99.7 \% \quad 55.2$

$99.7 \% \quad 44.4$

$99.7 \% \quad 37.9$

$99.7 \% \quad 32.0$

$99.7 \% 28.6$

$99.7 \% \quad 40.6$

$99.7 \% \quad 43.2$

$99.7 \% \quad 42.5$

$96.9 \% 23.5$

$99.7 \% \quad 29.2$

$99.2 \% \quad 21.0$

$99.7 \% \quad 50.4$

40

40

40

40

40

40

4

40

40

40
40

40

40
40

40

40
40

40

$155 \quad 0.21 \% \quad 48.1 \%$ GYVWNGGSNPQANRQTSDSSSAK

$155 \quad 0.21 \% \quad 48.1 \%$ MSTPADKVLR

$155 \quad 0.21 \% \quad 48.1 \%$ QKEADMYR

$155 \quad 0.21 \% \quad 48.1 \%$ ATVEQVLDPR

$155 \quad 0.21 \% \quad 48.1 \%$ ATVEQVLDPRTR

$155 \quad 0.21 \% \quad 48.1 \%$ GIITEINGCISTGK

$155 \quad 0.21 \% \quad 48.1 \%$ GIITEINGCISTGKEANVYHASTANGESR

$155 \quad 0.21 \% \quad 48.1 \%$ EANVYHASTANGESR

$155 \quad 0.21 \% \quad 48.1 \%$ HGYCKGNPR

$55 \quad 0.21 \% \quad 48.1 \%$ TWAEKEMR

$\begin{array}{ll}99.7 \% & 36.1 \\ 99.7 \% & 51.4\end{array}$

$99.0 \% \quad 24.8$

$99.7 \% \quad 48.1$

$99.7 \% \quad 36.6$

$99.7 \% \quad 54.7$

$99.7 \% \quad 37.8$

$99.7 \% \quad 54.5$

$\begin{array}{lll}9 & 99.7 \% & 38.8 \\ 48.1 \% & 99.0 \% & 32.7\end{array}$

$\begin{array}{ll}99.0 \% & 32.7 \\ 99.7 \% & 25.6\end{array}$

$155 \quad 0.21 \% \quad 48.1 \%$ LNTAEIPCPEPIMLR

$99.7 \% \quad 57.6$

0.21\% 48.1\% SHVLVMSFIGKDDMPAPLLK $99.7 \% \quad 39.4$

$155 \quad 0.21 \% \quad 48.1 \%$ NVQLSESK

$155 \quad 0.21 \% \quad 48.1 \%$ NVQLSESKAR

$55 \quad 0.21 \% \quad 48.1 \%$ ARELYLQVIQYMR

$155 \quad 0.21 \% \quad 48.1 \%$ ELYLQVIQYMR

$155 \quad 0.21 \% \quad 48.1 \%$ ELYLQVIQYMRR

$155 \quad 0.21 \% \quad 48.1 \%$ KDCANVNDFFMR

$155 \quad 0.21 \% \quad 48.1 \%$ DCANVNDFFMR

$155 \quad 0.21 \% \quad 48.1 \%$ HSVAVMTVR

$55 \quad 0.21 \% \quad 48.1 \%$ ELFEFVTDPSITHENMDAYLSK

$55 \quad 0.21 \% \quad 48.1 \%$ AMEIASQR

$155 \quad 0.21 \% \quad 48.1 \%$ SSQDHVDEEVFKR

$155 \quad 0.21 \% \quad 48.1 \%$ TLNEVKNYER

$99.0 \% \quad 31.5$

$99.7 \% \quad 44.5$

$99.7 \% \quad 33.5$

$99.7 \% \quad 52.1$

$99.7 \% \quad 26.9$

$99.7 \% \quad 32.8$

$99.7 \% \quad 48.6$

$99.7 \% \quad 40.4$

$0.21 \% \quad 48.1 \%$ DLSGVQKVPALLENQVEER

$99.0 \% 51.1$

$99.7 \% 51.8$

$99.7 \% \quad 42.4$

$55 \quad 0.21 \% \quad 48.1 \%$ VPALLENQVEER

$0.00 \% \quad 0.6 \% \quad$ LLAQCSEVQLGK

$0.00 \% \quad 0.6 \%$ GIIPQLFSR

$0.00 \% \quad 3.0 \% \quad$ LFAIEEETTTR

$0.00 \% \quad 3.0 \%$ AITGVVCYACR

$0.01 \% \quad 13.1 \%$ APLDLDKYVEIAR

$0.01 \% \quad 13.1 \%$ QITQVYGFYDECQTK

$0.01 \% \quad 13.1 \%$ VTNEFVHINNLK

$0.02 \% \quad 22.8 \%$ HSQYHVDGSLEKDR

$9.7 \% \quad 45.1$

$99.7 \% \quad 52.5$

$99.7 \% 34.1$

$95.5 \% \quad 14.3$

$99.0 \% \quad 21.6$

$97.9 \% \quad 20.9$

$99.7 \% 57.6$

$99.6 \% 23.5$

$99.7 \% \quad 68.1$

$99.6 \% \quad 21.9$ $\begin{array}{ccc}1053.50 & 1627 & 1637 \\ 1093.54 & 911 & 921 \\ 1312.69 & 1121 & 1132 \\ 1440.78 & 1121 & 1133 \\ 1058.55 & 1162 & 1170 \\ 1282.77 & 1672 & 1683 \\ 1484.87 & 2153 & 2166 \\ 1454.84 & 51 & 64 \\ 1179.61 & 65 & 74 \\ 1672.96 & 161 & 176 \\ 2193.99 & 11 & 30 \\ 1519.70 & 82 & 95 \\ 2411.10 & 82 & 104 \\ 1117.60 & 105 & 114 \\ 1040.48 & 141 & 148 \\ 1127.61 & 156 & 165 \\ 1384.75 & 156 & 167 \\ 1462.76 & 177 & 190 \\ 3049.46 & 177 & 205 \\ 1605.73 & 191 & 205 \\ 1088.51 & 232 & 240 \\ 1050.50 & 245 & 252 \\ 2266.20 & 253 & 271 \\ 1753.90 & 257 & 271 \\ 2198.17 & 272 & 291 \\ 904.47 & 292 & 299 \\ 1131.61 & 292 & 301 \\ 1682.90 & 300 & 312 \\ 1455.77 & 302 & 312 \\ 1627.86 & 302 & 313 \\ 1516.67 & 359 & 370 \\ 1388.57 & 360 & 370 \\ 999.54 & 371 & 379 \\ 2602.20 & 380 & 401 \\ 905.45 & 402 & 409 \\ 1575.74 & 415 & 427 \\ 1265.65 & 433 & 442 \\ 2124.13 & 475 & 493 \\ 1396.74 & 482 & 493 \\ 1345.71 & 1444 & 1455 \\ 1030.60 & 1821 & 1829 \\ 1309.66 & 70 & 80 \\ 1269.61 & 417 & 427 \\ 1502.82 & 2 & 14 \\ 1879.85 & 118 & 132 \\ 1427.76 & 220 & 231 \\ 1670.79 & 105 & 118 \\ & & \end{array}$

Page 117 of Table S-1-1 
Serpin $\mathrm{H} 1 \mathrm{GN}=$ SERPINH1

Serpin H1 GN=SERPINH1

Serpin H1 GN=SERPINH1

Serpin H1 GN=SERPINH1

Serpin H1 GN=SERPINH1

Serpin $\mathrm{H} 1 \mathrm{GN}=$ SERPINH1

Serum albumin GN=ALB

Serum albumin GN=ALB

Serum albumin $\mathrm{GN}=\mathrm{ALB}$

Serum albumin $\mathrm{GN}=\mathrm{ALB}$

Serum albumin GN=ALB

SERPH_HUMAN $46.44 \quad 100.0 \%$

SERPH_HUMAN $46.44 \quad 100.0 \%$

SERPH_HUMAN $46.44 \quad 100.0 \%$

SERPH HUMAN $46.44 \quad 100.0 \%$

SERPH HUMAN $46.44 \quad 100.0 \%$

SERPH_HUMAN $46.44 \quad 100.0 \%$

ALBU HUMAN $69.37 \quad 100.0 \%$

ALBU_HUMAN $69.37 \quad 100.0 \%$

ALBU_HUMAN $69.37 \quad 100.0 \%$

ALBU HUMAN $69.37 \quad 100.0 \%$

ALBU_HUMAN $69.37 \quad 100.0 \%$

SB ACDSB_HUMAN $47.49 \quad 100.0 \%$

$\begin{array}{lll}100.0 & \%\end{array}$

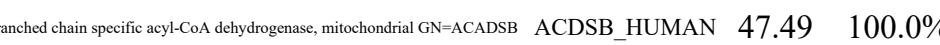

Sideroflexin-1 GN=SFXN1

Sideroflexin-1 GN=SFXN1

Sideroflexin- $1 \mathrm{GN}=\mathrm{SFXN} 1$

Sideroflexin-1 GN=SFXN1

Sideroflexin-1 GN=SFXN1

Sideroflexin-1 GN=SFXN1

Sideroflexin-1 GN=SFXN1

Sideroflexin-1 GN=SFXN1

Sideroflexin-1 GN=SFXN1

Sideroflexin-1 GN=SFXN1

Sideroflexin- 1 GN=SFXN1

Sideroflexin-1 GN=SFXN1

Sideroflexin-2 GN=SFXN2

Sideroflexin-2 GN=SFXN2

Sideroflexin-2 GN=SFXN2

Sideroflexin-2 GN=SFXN2

Sideroflexin-2 GN=SFXN2

Sideroflexin $-2 \mathrm{GN}=\mathrm{SFXN} 2$

Sideroflexin-2 GN=SFXN2

Sideroflexin $4 \mathrm{GN}=\mathrm{SFXN} 4$

Sideroflexin $-4 \mathrm{GN}=\mathrm{SFXN} 4$

Sideroflexin-4 GN=SFXN4

$$
\begin{aligned}
& 19 \\
& 19
\end{aligned}
$$
$0.04 \% \quad 38.5 \%$ YIYDSAFHPDTGEK $0.04 \% \quad 38.5 \%$ QAITQVVVSR $0.04 \% \quad 38.5 \%$ SSMSVTSLEAELQAK $0.04 \% \quad 38.5 \%$ IQESHPELR $0.02 \% \quad 20.2 \%$ RAAAIGITQVVISR $0.02 \% \quad 20.2 \%$ AAAIGITQVVISR $0.02 \% \quad 20.2 \%$ CELPVSYLEPK $0.02 \% \quad 20.2 \%$ YGELEPYVYFNK $0.02 \% \quad 20.2 \%$ YGELEPYVYFNKGL $0.01 \% \quad 9.8 \%$ SLATVHPDSSNLIPK $0.01 \% \quad 9.8 \%$ SYTCKPLER $0.01 \% \quad 9.8 \% \quad$ AVRETLASR $\begin{array}{llllll}99.6 \% & 22.2 & 25.0 & 22.2 & 0 & 2\end{array}$ $99.7 \% \quad 31.6 \quad 25.0 \quad 31.6$ $\begin{array}{lllll}99.7 \% & 36.1 & 25.0 & 36.1 & 1\end{array}$ $\begin{array}{lllllll}0.04 \% & 38.5 \% & \text { AKYIYDSAFHPDTGEK } & 99.7 \% & 27.8 & 25.0 & 27.8\end{array}$

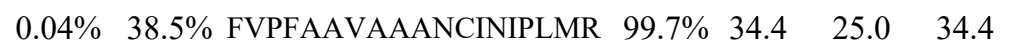
$\begin{array}{lllllll}0.04 \% & 38.5 \% & \text { VGIPVTDENGNR } & 99.7 \% & 50.3 & 25.0 & 47.0\end{array}$

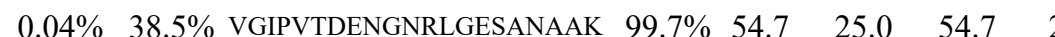
$0.04 \% \quad 38.5 \%$ IQESHPELRR

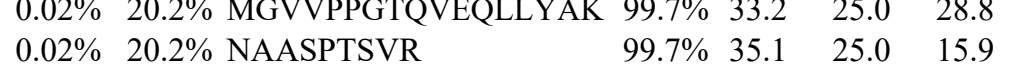
$\begin{array}{llllll}99.7 \% & 39.4 & 25.0 & 25.1 & 4 & 0\end{array}$ $\begin{array}{lllllll}99.7 \% & 28.2 & 25.0 & 20.6 & 2 & 0 & 0\end{array}$ $99.7 \% \quad 60.8 \quad 25.0 \quad 49.9 \quad 3$ $\begin{array}{llll}99.5 \% & 23.2 & 25.0 & 20.6\end{array}$ $\begin{array}{llll}98.8 \% & 20.8 & 25.0 & 19.8\end{array}$ $99.7 \% \quad 31.6 \quad 25.0 \quad 31.6$ $\begin{array}{lllll}99.7 \% & 44.3 & 25.0 & 44.3\end{array}$ $99.7 \% \quad 41.9 \quad 25.0 \quad 39.5$ $\begin{array}{llll}99.4 \% & 20.9 & 25.0 & 20.9\end{array}$ $\begin{array}{llll}99.7 \% & 52.8 & 25.0 & 52.7\end{array}$ $99.7 \% \quad 54.6 \quad 25.0 \quad 51.6 \quad 4$ $99.7 \% \quad 40.9 \quad 25.0 \quad 32.2$ $\begin{array}{lllll}99.7 \% & 46.9 & 25.0 & 36.2 & 6\end{array}$ $99.7 \% \quad 60.1 \quad 25.0 \quad 46.6$ $\begin{array}{lllll}99.7 \% & 27.1 & 25.0 & 17.0 & 18\end{array}$ $\begin{array}{lllll}99.7 \% & 54.3 & 25.0 & 53.4 & 40\end{array}$ $\begin{array}{llll}99.7 \% & 26.0 & 25.0 & 26.0\end{array}$ $\begin{array}{lllll}99.7 \% & 52.5 & 25.0 & 47.8 & 14\end{array}$ $99.0 \% \quad 18.5 \quad 25.0 \quad 18.5$ $\begin{array}{llll}99.7 \% & 52.5 & 25.0 & 39.1\end{array}$ $\begin{array}{lllll}99.7 \% & 68.3 & 25.0 & 57.7 & 2\end{array}$ $\begin{array}{llll}99.7 \% & 67.0 & 25.0 & 62.1\end{array}$ $\begin{array}{llll}99.2 \% & 52.8 & 25.0 & 0.0\end{array}$ $99.7 \% \quad 44.7 \quad 25.0 \quad 38.1$ $\begin{array}{llll}99.7 \% & 73.1 & 25.0 & 70.7\end{array}$ $\begin{array}{llll}99.7 \% & 42.2 & 25.0 & 42.2\end{array}$ $\begin{array}{llll}99.7 \% & 57.7 & 25.0 & 57.7\end{array}$ $\begin{array}{llll}99.7 \% & 81.9 & 25.0 & 80.4\end{array}$ $99.7 \% \quad 43.6 \quad 25.0 \quad 37.4$ $\begin{array}{llll}99.7 \% & 25.5 & 25.0 & 20.3\end{array}$ $\begin{array}{llll}99.7 \% & 33.2 & 25.0 & 28.8\end{array}$

1671.83

1457.75

2073.04

1659.80

1311.60

1224.66

1293.68

1195.59

1443.64

1639.94

1511.84

1138.50

2428.14

1079.55

1418.68

1906.03

1109.54

1304.64

1500.80

1841.87

1642.74

2091.09

1270.64

2112.07

1100.64

1596.78

1108.57

1264.68

1829.98 $\begin{array}{llll}99.4 \% & 24.5 & 25.0 & 24.5\end{array}$ $\begin{array}{llll}99.7 \% & 52.1 & 25.0 & 40.4\end{array}$ $\begin{array}{lllll}99.7 \% & 39.2 & 25.0 & 34.3 & 2\end{array}$ $\begin{array}{llll}99.7 \% & 44.8 & 25.0 & 44.8\end{array}$ $\begin{array}{llll}99.7 \% & 33.6 & 25.0 & 30.2\end{array}$ $\begin{array}{llll}99.7 \% & 30.9 & 25.0 & 25.1\end{array}$ $\begin{array}{lllll}99.6 \% & 27.0 & 25.0 & 15.9 & 2\end{array}$ $99.7 \% \quad 32.0 \quad 25.0 \quad 20.4$

$\begin{array}{cc}19 & 134 \\ 26 & 134 \\ 42 & 152 \\ 53 & 162 \\ 74 & 288 \\ 23 & 132 \\ 33 & 142 \\ 06 & 323 \\ 26 & 137 \\ 05 & 319 \\ 7 & 60 \\ 30 & 148 \\ 34 & 148 \\ 29 & 239 \\ 09 & 319 \\ 94 & 405 \\ 24 & 233 \\ 87 & 298 \\ 38 & 452 \\ 39 & 452 \\ 00 & 508 \\ 1 & 91 \\ 85 & 294 \\ 72 & 384 \\ 09 & 426 \\ 6 & 24 \\ 5 & 35 \\ 6 & 48 \\ 1 & 86 \\ 3 & 86 \\ 79 & 197 \\ 03 & 214 \\ 03 & 223 \\ 24 & 233 \\ 91 & 305 \\ 06 & 314 \\ 06 & 315 \\ 5 & 71 \\ 36 & 144 \\ 19 & 232 \\ 20 & 232 \\ 90 & 300 \\ 09 & 320 \\ 09 & 322 \\ 56 & 106 \\ 45 & 253 \\ & \end{array}$

Page 118 of Table S-1-1 

Spectrin alpha chain, non-erythrocytic $1 \mathrm{GN}=$ SPTAN1 SPTN1_HUMAN $284.54 \quad 100.0 \%$ Spectrin alpha chain, non-erythrocytic $1 \mathrm{GN}=$ SPTAN1 SPTN1_HUMAN $284.54 \quad 100.0 \%$ Spectrin alpha chain, non-erythrocytic 1 GN=SPTAN1 SPTN1_HUMAN $284.54 \quad 100.0 \%$ Spectrin alpha chain, non-erythrocytic $1 \mathrm{GN}=$ SPTAN1 SPTN1_HUMAN $284.54 \quad 100.0 \%$ Spectrin alpha chain, non-erythrocytic 1 GN=SPTAN1 SPTN1_HUMAN $284.54100 .0 \%$ Spectrin alpha chain, non-erythrocytic 1 GN=SPTAN1 SPTN1_HUMAN $284.54 \quad 100.0 \%$ Spectrin alpha chain, non-erythrocytic 1 GN=SPTAN1 SPTN1_HUMAN $284.54 \quad 100.0 \%$ Spectrin beta chain, non-erythrocytic $1 \mathrm{GN}=$ SPTBN1 SPTB2_HUMAN $274.61 \quad 100.0 \%$ Spectrin beta chain, non-erythrocytic $1 \mathrm{GN}=\mathrm{SPTBN} 1 \mathrm{SPTB} 2$ HUMAN $274.61 \quad 100.0 \%$

$\quad 0.01 \% \quad 21.8 \%$ AVLLVGLCDSGK

$10 \quad 0.01 \% \quad 21.8 \%$ LIQQQLEKELNTLR

$\begin{array}{llllllll}97.1 \% & 16.7 & 25.0 & 16.7 & 1 & 0 & 0 & 1231.67\end{array}$

$\begin{array}{llllllll}99.7 \% & 54.3 & 25.0 & 54.1 & 2 & 0 & 0 & 1422.77\end{array}$

$10 \quad 0.01 \% \quad 21.8 \%$ SAAPSTLDSSSTAPAQLGKK $\quad 99.7 \% \quad 52.4$

$10 \quad 0.01 \% \quad 12.3 \%$ ALLQQQPEDDSKR

$10 \quad 0.01 \% \quad 12.3 \%$ YANEVNSDAGAFK

$10 \quad 0.01 \% \quad 12.3 \%$ FETFCLDPSLVTK

$10 \quad 0.01 \% \quad 12.3 \%$ SGLTGYIK

$5 \quad 0.01 \% \quad 3.9 \% \quad$ SPAHLSLIR

$99.7 \% 59.7$

$99.7 \% \quad 51.4$

$99.7 \% \quad 48.4$

$99.0 \% \quad 30.8$

$99.7 \% \quad 35.9$

$0.01 \% \quad 3.9 \%$ GTQGATAGASSELDASK $99.7 \% \quad 97.0$

$0.01 \% \quad 5.1 \% \quad$ NLSFFLTPPCAR

$0.01 \% \quad 5.1 \%$ ALLKDQQPGTFLLR

$0.01 \% \quad 5.1 \%$ ELSAVTFPDIIR

$0.02 \% \quad 11.0 \%$ FLQESNVLYQHNLRR

$0.02 \% \quad 11.0 \%$ IKQFLQSR

$0.02 \% \quad 11.0 \%$ YLEKPMEIAR

$99.7 \% \quad 32.2$

$99.7 \% \quad 34.5$

$99.7 \% 65.6$

$97.5 \% \quad 17.5$

$99.0 \% 35.3$

$99.6 \% \quad 22.5$

$\begin{array}{lll}0.02 \% & 11.0 \% & \text { SQGDMQDLNGN } \\ 0.02 \% & 11.0 \% & \text { KFNILGTNTK }\end{array}$

$0.02 \% \quad 11.0 \%$ AILSTKPPGTFLLR

$0.02 \% \quad 11.0 \%$ TQIQSVEPYTK

$0.02 \% \quad 8.1 \% \quad$ SPDFTNENPLETR

$0.02 \% \quad 8.1 \%$ AVFQANQENLPILK

$0.02 \% \quad 8.1 \%$ AVFQANQENLPILKR

$0.02 \% \quad 8.1 \%$ AAVPDAVGKCR

$0.02 \% \quad 8.1 \%$ SAGIKVIMVTGD

$\begin{array}{lll}0.02 \% & 8.1 \% & \text { LNIPVSQVNPR } \\ 0.02 \% & 8.1 \% & \text { TSPQQKLIIVEGCQR }\end{array}$

$0.00 \% \quad 6.9 \%$ GLGPNLVGVAPSR

$0.00 \% \quad 6.9 \%$ AVYFACYSK

$40 \quad 0.05 \% \quad 6.4 \% \quad$ VLETAEDIQER

$0.05 \% \quad 6.4 \%$ LFGAAEVQR

$17 \quad 40 \quad 0.05 \% \quad 6.4 \% \quad$ TATDEAYKDPSNLQGK

$17 \quad 40 \quad 0.05 \% \quad 6.4 \%$ HQAFEAELSANQSR

$17 \quad 40 \quad 0.05 \% \quad 6.4 \% \quad$ EANQQQQFNR

$17 \quad 40 \quad 0.05 \% \quad 6.4 \% \quad$ GKDLIGVQNLLK

$17 \quad 40 \quad 0.05 \% \quad 6.4 \%$ SQLLGSAHEVQR

$17 \quad 40 \quad 0.05 \% \quad 6.4 \% \quad$ LGESQTLQQFSR

$17 \quad 40 \quad 0.05 \% \quad 6.4 \% \quad$ GVIDMGNSLIER

$17 \quad 40 \quad 0.05 \% \quad 6.4 \%$ GACAGSEDAVK

$17 \quad 40 \quad 0.05 \% \quad 6.4 \%$ GACAGSEDAVKAR

$17 \quad 40 \quad 0.05 \% \quad 6.4 \%$ LSDDNTIGKEEIQQR

$\begin{array}{lllll}17 & 40 & 0.05 \% & 6.4 \% & \text { LLEAQSHFR }\end{array}$

$17 \quad 40 \quad 0.05 \% \quad 6.4 \% \quad$ MQHNLEQQIQAR

$21 \quad 40 \quad 0.05 \% \quad 10.4 \%$ ALAVEGKR

$21 \quad 40 \quad 0.05 \% \quad 10.4 \%$ VLDNAIETEK
$99.7 \% \quad 60.7$

$99.7 \% \quad 25.5$

$99.7 \% 31.9$

$99.7 \% \quad 33.2$

$99.7 \% \quad 38.7$

$99.7 \% \quad 35.7$

$99.3 \% 20.8$

$\begin{array}{ll}97.4 \% & 16.4\end{array}$

$99.7 \% \quad 47.0$

$99.0 \% 20.1$

$99.7 \% \quad 35.5$

$97.4 \% 16.7$

$\begin{array}{lll}99.7 \% & 53.8\end{array}$

$99.7 \% \quad 41.3$

$99.4 \% \quad 24.9$

\begin{tabular}{ll}
$99.7 \% \quad 28.5$ \\
\hline
\end{tabular}

$99.5 \% \quad 22.7$

$99.7 \% \quad 45.3$

$99.7 \% \quad 57.0$

$99.7 \% \quad 63.0$

$99.7 \% \quad 56.8$

$98.8 \% \quad 22.3$

$99.7 \% \quad 37.9$

$99.7 \% \quad 57.3$

$99.7 \% \quad 42.5$

$99.0 \% \quad 19.3$

$99.0 \% 31.5$

$99.7 \% \quad 34.2$
1725.99

1788.90

1916.99

2243.02

1527.78

1385.63

1556.77

838.47

993.58

1550.73

1422.72

1599.92

1360.75

1917.01

1019.60

1249.66

1863.83

1135.65

1513.91

1293.67

1519.70

1584.87

1740.98

1143.59

1854.02

1236.7

1756.94

1236.71

1108.51

1302.65

990.54

1737.83

1587.75

1262.59

1297.78

1324.70

1393.71

1303.67

1064.47

1291.61

1745.87

1100.58

1495.74

843.50

1131.59

$\begin{array}{cc}6 & 77 \\ 38 & 150 \\ 92 & 205 \\ 99 & 227 \\ 09 & 228 \\ 2 & 31 \\ 05 & 417 \\ 92 & 504 \\ 58 & 570 \\ 13 & 620 \\ 43 & 451 \\ 01 & 617 \\ 83 & 494 \\ 89 & 602 \\ 38 & 649 \\ 1 & 85 \\ 6 & 93 \\ 4 & 103 \\ 81 & 197 \\ 83 & 392 \\ 96 & 609 \\ 32 & 642 \\ 28 & 240 \\ 31 & 444 \\ 31 & 445 \\ 97 & 607 \\ 08 & 625 \\ 48 & 658 \\ 93 & 707 \\ 3 & 105 \\ 06 & 114 \\ 8 & 18 \\ 51 & 259 \\ 95 & 610 \\ 14 & 627 \\ 76 & 685 \\ 13 & 824 \\ 26 & 1237 \\ 47 & 1558 \\ 08 & 1619 \\ 20 & 1630 \\ 20 & 1632 \\ 30 & 1844 \\ 79 & 2087 \\ 04 & 2315 \\ 82 & 289 \\ 93 & 302 \\ & \end{array}$


Spectrin beta chain, non-erythrocytic $1 \mathrm{GN}=$ SPTBN1 SPTB2_HUMAN $274.61 \quad 100.0 \% 21$ Spectrin beta chain, non-erythrocytic 1 GN=SPTBN1 SPTB2_HUMAN $274.61 \quad 100.0 \% \quad 21$ Spectrin beta chain, non-erythrocytic $1 \mathrm{GN}=$ SPTBN1 SPTB2_HUMAN $274.61 \quad 100.0 \% \quad 21$ Spectrin beta chain, non-erythrocytic 1 GN=SPTBN1 SPTB2_HUMAN $274.61 \quad 100.0 \% \quad 21$ Spectrin beta chain, non-erythrocytic $1 \mathrm{GN}=$ SPTBN1 SPTB2_HUMAN $274.61 \quad 100.0 \% \quad 21$ Spectrin beta chain, non-erythrocytic $1 \mathrm{GN}=$ SPTBN1 SPTB2_HUMAN $274.61 \quad 100.0 \% \quad 21$ Spectrin beta chain, non-erythrocytic $1 \mathrm{GN}=$ SPTBN1 SPTB2_HUMAN $274.61 \quad 100.0 \%$ Spectrin beta chain, non-erythrocytic $1 \mathrm{GN}=$ SPTBN1 SPTB2_HUMAN $274.61 \quad 100.0 \%$ Spectrin beta chain, non-erythrocytic $1 \mathrm{GN}=$ SPTBN1 SPTB2 HUMAN $274.61 \quad 100.0 \% 2$ Spectrin beta chain, non-erythrocytic 1 GN=SPTBN1 SPTB2_HUMAN $274.61 \quad 100.0 \% \quad 2$ Spectrin beta chain, non-erythrocytic 1 GN=SPTBN1 SPTB2_HUMAN $274.61 \quad 100.0 \%$ Spectrin beta chain, non-erythrocytic $1 \mathrm{GN}=$ SPTBN1 SPTB2 HUMAN $274.61 \quad 100.0 \% 2$ Spectrin beta chain, non-erythrocytic $1 \mathrm{GN}=$ SPTBN1 SPTB2_HUMAN $274.61 \quad 100.0 \% \quad 2$ Spectrin beta chain, non-erythrocytic $1 \mathrm{GN}=$ SPTBN1 SPTB2_HUMAN $274.61 \quad 100.0 \% 2$ Spectrin beta chain, non-erythrocytic $1 \mathrm{GN}=$ SPTBN1 SPTB2_HUMAN $274.61 \quad 100.0 \%$ Spectrin beta chain, non-erythrocytic $1 \mathrm{GN}=$ SPTBN1 SPTB2_HUMAN $274.61 \quad 100.0 \% \quad 2$ Spectrin beta chain, non-erythrocytic $1 \mathrm{GN}=$ SPTBN1 SPTB2 HUMAN $274.61 \quad 100.0 \%$ Spectrin beta chain, non-erythrocytic $1 \mathrm{GN}=$ SPTBN1 SPTB2_HUMAN $274.61 \quad 100.0 \%$ Spectrin beta chain, non-erythrocytic $1 \mathrm{GN}=$ SPTBN1 SPTB2_HUMAN $274.61 \quad 100.0 \%$ Spermatid perinuclear RNA-binding protein GN=STRBP STRBP HUMAN $73.65 \quad 100.0 \%$ Spermatid perinuclear RNA-binding protein GN=STRBP STRBP_HUMAN $73.65 \quad 100.0 \%$ Spermatid perinuclear RNA-binding protein GN=STRBP STRBP_HUMAN $73.65 \quad 100.0 \%$ Spermatid peinger RNA_bindigg podin GN=STRBP STRBP_HUMAN $73.65100 .0 \%$ Spermidine synthase GN=SRN Spermidine synthase GN=SRM Spermidine synthase $\mathrm{GN}=\mathrm{SRM}$ Spermidine synthase GN=SRM Spermidine synthase $\mathrm{GN}=\mathrm{SRM}$ SPEE HUMAN $33.82 \quad 100.0 \%$ SPEE HUMAN $33.82 \quad 100.0 \%$ SPEE_HUMAN $33.82 \quad 100.0 \%$ SPEE HUMAN $33.82 \quad 100.0 \%$ SPEE HUMAN $33.82 \quad 100.0 \%$ Sphingomyelin phosphodiesterase 4 GN=SMPD4 NSMA3_HUMAN $93.35 \quad 100.0 \%$ Sphingomyelin phosphodiesterase 4 GN=SMPD4 NSMA3 HUMAN $93.35 \quad 100.0 \%$ Sphingomyelin phosphodiesterase 4 GN=SMPD4 NSMA3_HUMAN $93.35 \quad 100.0 \%$ Sphingomyelin phosphodiesterase 4 GN=SMPD4 NSMA3_HUMAN $93.35100 .0 \%$ Spindlin-1 GN=SPIN1 Spindlin-1 GN=SPIN1 Spindlin-1 GN=SPIN1 Spindlin-1 GN=SPIN1 Spindlin-1 GN=SPIN1 Spindlin-1 GN=SPIN1

Splicing factor $3 \mathrm{~B}$ subunit $1 \mathrm{GN}=\mathrm{SF} 3 \mathrm{~B} 1$ Splicing factor $3 \mathrm{~B}$ subunit $1 \mathrm{GN}=\mathrm{SF} 3 \mathrm{~B} 1$ Splicing factor $3 \mathrm{~B}$ subunit $1 \mathrm{GN}=\mathrm{SF} 3 \mathrm{~B} 1$ Splicing factor $3 \mathrm{~B}$ subunit $1 \mathrm{GN}=\mathrm{SF} 3 \mathrm{~B} 1$ Splicing factor $3 \mathrm{~B}$ subunit $1 \mathrm{GN}=\mathrm{SF} 3 \mathrm{~B} 1$ Splicing factor $3 \mathrm{~B}$ subunit $1 \mathrm{GN}=\mathrm{SF} 3 \mathrm{~B} 1$ Splicing factor $3 \mathrm{~B}$ subunit $1 \mathrm{GN}=\mathrm{SF} 3 \mathrm{~B} 1$ Splicing factor $3 \mathrm{~B}$ subunit $1 \mathrm{GN}=\mathrm{SF} 3 \mathrm{~B}$ Splicing factor $3 \mathrm{~B}$ subunit $1 \mathrm{GN}=\mathrm{SF} 3 \mathrm{~B}$
SPIN1_HUMAN $29.60 \quad 100.0 \%$ SPIN1_HUMAN $29.60 \quad 100.0 \%$ SPIN1_HUMAN $29.60 \quad 100.0 \%$ SPIN1_HUMAN $29.60 \quad 100.0 \%$ SPIN1_HUMAN $29.60 \quad 100.0 \%$ SPIN1_HUMAN $29.60 \quad 100.0 \%$ SF3B1_HUMAN $145.84 \quad 100.0 \%$ SF3B1_HUMAN $145.84 \quad 100.0 \%$ SF3B1_HUMAN $145.84 \quad 100.0 \%$ SF3B1_HUMAN $145.84 \quad 100.0 \%$ SF3B1_HUMAN $145.84 \quad 100.0 \%$ SF3B1_HUMAN $145.84 \quad 100.0 \%$ SF3B1_HUMAN $145.84 \quad 100.0 \%$ SF3B1 HUMAN $145.84 \quad 100.0 \%$ SF3B1_HUMAN $145.84 \quad 100.0 \%$

6

5

6
6
6
6

5
5
5

5
5
4

5
4
4

4

4

6
6
6

$\begin{array}{ll}6 & 9 \\ 6 & 9 \\ 6 & 9\end{array}$

9

6
6
11

6

11
11
11

11
11
11

11
11
11

11
11

11

40
40
40
40
40
40
40
40
40
40
40
40
40
40
40
4
4
4
4
13
13
13
13
13
8
20
20
20
20
20
20
20
20
20
20
20

$\begin{array}{llll}40 & 0.05 \% & 10.4 \% & 10.4 \% \text { IVSSSDVGHDEYSTQSL }\end{array}$

$40 \quad 0.05 \% \quad 10.4 \%$ YKEVAELTR

$40 \quad 0.05 \% \quad 10.4 \%$ QALQDTLALYK

$40 \quad 0.05 \% \quad 10.4 \%$ VAVVNQIAR

$40 \quad 0.05 \% \quad 10.4 \%$ NRETASELLMR

$40 \quad 0.05 \% \quad 10.4 \%$ SQNIVTDSSSLSAEAIR

$40 \quad 0.05 \% \quad 10.4 \%$ ALVADSHPESER

$0.05 \% \quad 10.4 \%$ DTGNIGQER

$\quad 0.05 \% \quad 10.4 \%$ QLQEDAAR

$40 \quad 0.05 \% \quad 10.4 \%$ SLLDACESR

$\quad 0.05 \% \quad 10.4 \%$ LVDTGDKFR

$\quad 0.05 \% \quad 10.4 \%$ LILEVHQFSR

$\quad 0.05 \% \quad 10.4 \%$ EIGQSVDEVEKLIK

$\quad 0.05 \% \quad 10.4 \%$ TALPAQSAATLPAR

$0.05 \% \quad 10.4 \%$ TQETPSAQMEGFLNR

$0.01 \% \quad 6.3 \% \quad$ ANGLKSCVIVLR

$0.01 \% \quad 6.3 \%$ AIDLMNALMR

$0.01 \% \quad 6.3 \% \quad$ LNQIRPGLQYK

$0.01 \% \quad 6.3 \%$ TAKLHVAVK

$0.02 \% \quad 13.2 \%$ YQDILVFR

$0.02 \% \quad 13.2 \%$ KVLIIGGGDGGVLR

$0.02 \% \quad 13.2 \%$ VLIIGGGDGGVLR

$0.02 \% \quad 13.2 \%$ YYNSDVHR

$0.02 \% \quad 13.2 \%$ AAFVLPEFAR

$0.01 \% \quad 5.3 \%$ YAPDKQAPGSDSQPR

$0.01 \% \quad 5.3 \% \quad$ LFVGFLNR

$0.01 \% \quad 5.3 \% \quad$ ALRTDLVSPK

$0.01 \% \quad 5.3 \% \quad$ YHLTEPGLASR

$0.03 \% \quad 28.2 \%$ SSVGPSKPVSQPR

$0.03 \% \quad 28.2 \%$ GTVLDQVPVNPSLYLIK

$0.03 \% \quad 28.2 \%$ VSALEVLPDR

$0.03 \% \quad 28.2 \%$ VSALEVLPDRVATSR

$0.03 \% \quad 28.2 \%$ ISDAHLADTMIGK

$0.03 \% \quad 7.7 \% \quad$ VVNGAAASQPPSKR

$0.03 \% \quad 7.7 \%$ RWDQTADQTPGATPK

$0.03 \% \quad 7.7 \% \quad$ AKGSETPGATPGSK

$0.03 \% \quad 7.7 \%$ GSETPGATPGSK

$0.03 \% \quad 7.7 \%$ VEGREIISNLAK

$\begin{array}{lll}0.03 \% & 7.7 \% & \text { VRQQAADLISR }\end{array}$

$0.03 \% \quad 7.7 \%$ QQAADLISR

$0.03 \% \quad 7.7 \%$ MTPPIKDLLPR

$0.03 \% \quad 7.7 \%$ VQENCIDLVGR

\begin{tabular}{ccccc} 
99.7\% & 33.8 & 25.0 & 33.8 & 2 \\
$99.4 \%$ & 25.9 & 25.0 & 16.0 & 1 \\
$99.7 \%$ & 32.3 & 25.0 & 32.3 & 0 \\
$98.4 \%$ & 23.5 & 25.0 & 13.7 & 1 \\
\hline $99.7 \%$ & 30.7 & 25.0 & 30.7 & 0 \\
$99.7 \%$ & 30.4 & 25.0 & 28.0 & 1 \\
$99.7 \%$ & 54.2 & 25.0 & 44.0 & 2 \\
$99.7 \%$ & 52.6 & 25.0 & 41.3 & 6 \\
$98.9 \%$ & 27.3 & 25.0 & 13.3 & 2 \\
$99.7 \%$ & 90.7 & 25.0 & 88.4 & 2 \\
$99.7 \%$ & 53.4 & 25.0 & 50.2 & 2 \\
$99.7 \%$ & 32.4 & 25.0 & 20.9 & 2 \\
$99.0 \%$ & 45.5 & 25.0 & 31.4 & 2 \\
$99.7 \%$ & 30.7 & 25.0 & 30.7 & 2 \\
$99.1 \%$ & 18.6 & 25.0 & 18.6 & 1 \\
$99.7 \%$ & 53.7 & 25.0 & 37.7 & 2 \\
$99.7 \%$ & 41.0 & 25.0 & 27.5 & 1 \\
$99.7 \%$ & 55.4 & 25.0 & 55.4 & 2 \\
$99.7 \%$ & 62.5 & 25.0 & 62.5 & 2 \\
$97.5 \%$ & 30.0 & 25.0 & 0.0 & 2 \\
$99.7 \%$ & 47.2 & 25.0 & 39.7 & 2 \\
$99.7 \%$ & 28.0 & 25.0 & 26.6 & 2 \\
$99.7 \%$ & 34.6 & 25.0 & 20.4 & 2 \\
$99.0 \%$ & 27.6 & 25.0 & 22.3 & 2 \\
$99.7 \%$ & 38.1 & 25.0 & 38.1 & 1 \\
$99.7 \%$ & 50.5 & 25.0 & 47.4 & 2 \\
$99.0 \%$ & 43.4 & 25.0 & 38.0 & 2 \\
$99.7 \%$ & 39.7 & 25.0 & 34.4 & 4 \\
$99.7 \%$ & 33.0 & 25.0 & 33.0 & 1 \\
$99.0 \%$ & 42.6 & 25.0 & 37.0 & 2 \\
$99.7 \%$ & 28.6 & 25.0 & 19.1 & 2 \\
$99.1 \%$ & 22.5 & 25.0 & 22.5 & 1 \\
$99.7 \%$ & 50.4 & 25.0 & 48.3 & 3 \\
$99.7 \%$ & 52.0 & 25.0 & 35.7 & 4 \\
$99.6 \%$ & 27.7 & 25.0 & 17.3 & 1 \\
$99.7 \%$ & 42.5 & 25.0 & 36.8 & 2 \\
$99.7 \%$ & 26.2 & 25.0 & 26.2 & 4 \\
$99.7 \%$ & 50.6 & 25.0 & 48.7 & 4 \\
$99.7 \%$ & 26.1 & 25.0 & 21.1 & 2 \\
$99.7 \%$ & 32.8 & 25.0 & 15.4 & 1 \\
$99.7 \%$ & 52.2 & 25.0 & 44.3 & 2 \\
$99.1 \%$ & 20.3 & 25.0 & 17.6 & 2 \\
$99.7 \%$ & 34.4 & 25.0 & 30.8 & 2 \\
$99.7 \%$ & 32.1 & 25.0 & 30.0 & 2 \\
$99.7 \%$ & 40.1 & 25.0 & 25.9 & 1 \\
$99.7 \%$ & 53.5 & 25.0 & 19.5 & 0 \\
95.0 & 25.0 & 53.6 & 2
\end{tabular}

1263.69

969.58

1319.67

1777.89

1310.63

989.46

930.46

1050.49

1050.56

1241.70

1586.86

1367.76

1708.80

1329.77

1147.60

1329.76

966.61

1053.57

1353.82

1225.73

1053.47

1120.61

1616.77

965.56

1099.65

1243.64

1602.75

1325.72

1856.05

1098.62

1612.90

1387.69

1381.75

1671.81

1287.65

1088.52

1328.75

1256.71

1001.54

1280.74

1302.65

$031 \quad 1041$ 
$\begin{array}{lllllllll}\text { Splicing factor 3B subunit } 1 \mathrm{GN}=\mathrm{SF} 3 \mathrm{~B} 1 & \text { SF3B1_HUMAN } 145.84 & 100.0 \% & 11 & 12 & 20 & 0.03 \% & 7.7 \% & \text { RATVNTFGYIAK } \\ \text { Splicing factor 3B subunit } 1 \mathrm{GN}=\mathrm{SF} 3 \mathrm{~B} 1 & \text { SF3B1_HUMAN } 145.84 & 100.0 \% & 11 & 12 & 20 & 0.03 \% & 7.7 \% & \text { ATVNTFGYIAK }\end{array}$ (n) $3 \mathrm{GN}=\mathrm{SF} 3 \mathrm{~B} 3$ icing factor $3 \mathrm{~B}$ subunit $3 \mathrm{GN}=\mathrm{SF} 3 \mathrm{~B} 3$ Splicing factor $3 \mathrm{~B}$ subunit $3 \mathrm{GN}=\mathrm{SF} 3 \mathrm{~B} 3$ Splicing factor $3 \mathrm{~B}$ subunit $3 \mathrm{GN}=\mathrm{SF} 3 \mathrm{~B} 3$

Splicing factor $3 \mathrm{~B}$ subunit $3 \mathrm{GN}=\mathrm{SF} 3 \mathrm{~B} 3$ Splicing factor $3 \mathrm{~B}$ subunit $3 \mathrm{GN}=\mathrm{SF} 3 \mathrm{~B} 3$ Splicing factor $3 \mathrm{~B}$ subunit $3 \mathrm{GN}=\mathrm{SF} 3 \mathrm{~B} 3$ Splicing factor $3 \mathrm{~B}$ subunit $3 \mathrm{GN}=\mathrm{SF} 3 \mathrm{~B} 3$ Splicing factor $3 \mathrm{~B}$ subunit $3 \mathrm{GN}=\mathrm{SF} 3 \mathrm{~B} 3$

Splicing factor $3 \mathrm{~B}$ subunit $3 \mathrm{GN}=\mathrm{SF} 3 \mathrm{~B} 3$ Splicing factor $3 \mathrm{~B}$ subunit $3 \mathrm{GN}=\mathrm{SF} 3 \mathrm{~B} 3$ Splicing factor $3 \mathrm{~B}$ subunit $3 \mathrm{GN}=\mathrm{SF} 3 \mathrm{~B} 3$

Splicing factor $3 \mathrm{~B}$ subunit $3 \mathrm{GN}=\mathrm{SF} 3 \mathrm{~B} 3$ $\begin{array}{lll} & \end{array}$ Splicing factor $\mathrm{U} 2 \mathrm{AF}$ Splicing factor U2AF $35 \mathrm{kDa}$ subunit GN=U2AF1 U2AF1_HUMAN $27.87 \quad 100.0 \%$ Splicing factor U2AF $65 \mathrm{kDa}$ subunit GN=U2AF2 U2AF2 HUMAN $53.50 \quad 100.0 \%$ Splicing factor U2AF $65 \mathrm{kDa}$ subunit GN=U2AF2 U2AF2_HUMAN $53.50 \quad 100.0 \%$ Splicing factor U2AF $65 \mathrm{kDa}$ subunit GN=U2AF2 U2AF2 HUMAN $53.50 \quad 100.0 \%$ Splicing factor U2AF $65 \mathrm{kDa}$ subunit GN=U2AF2 U2AF2_HUMAN $53.50 \quad 100.0 \%$ Splicing factor U2AF $65 \mathrm{kDa}$ subunit GN=U2AF2 U2AF2_HUMAN $53.50 \quad 100.0 \%$ Splicing factor U2AF $65 \mathrm{kD}$ a subunit $\mathrm{GN}=\mathrm{U} 2 \mathrm{AF} 2 \mathrm{U} 2 \mathrm{AF} 2 \mathrm{HUMAN} \quad 53.50 \quad 100.0^{\circ}$ Splicing factor U2AF $65 \mathrm{kDa}$ subunit GN=U2AF2 U2AF2_HUMAN $53.50 \quad 100.0 \%$ Splicing factor, proline- and glutamine-rich GN=SFPQ SFPQ_HUMAN $76.15 \quad 100.0 \%$ Splicing factor, proline- and glutamine-rich GN=SFPQ SFPQ_HUMAN $76.15 \quad 100.0 \%$ Splicing factor, proline- and glutamine-rich GN=SFPQ SFPQ_HUMAN $76.15 \quad 100.0 \%$ Splicing factor, proline- and glutamine-rich $\mathrm{GN}=\mathrm{SFPQ}$ SFPQ HUMAN $76.15100 .0 \%$ Splicing factor, proline- and glutamine-rich GN=SFPQ SFPQ_HUMAN $76.15 \quad 100.0 \%$ $\begin{array}{llll}\text { SRSF protein kinase } 1 \mathrm{GN}=\text { SRPK1 } & \text { SRPK1_HUMAN } & 74.33 \quad 100.0 \%\end{array}$ SRSF protein kinase $1 \mathrm{GN}=$ SRPK1 SRPK1 HUMAN $74.33 \quad 100.0 \%$ Staphylococcal nuclease domain-containing protein $1 \mathrm{GN}=\mathrm{SND} 1$ SND1_HUMAN $102.00 \quad 100.0 \%$ Staphylococcal nuclease domain-containing protein $1 \mathrm{GN}=\mathrm{SND1}$ SND1_HUMAN $102.00 \quad 100.0 \%$ Stomatin-like protein 2, mitochondrial GN=STOML2 STML2_HUMAN $38.53 \quad 100.0 \%$ Stomatin-like protein 2, mitochondrial GN=STOML2 STML2_HUMAN $38.53 \quad 100.0 \%$ Stress-70 protein, mitochondrial GN=HSPA9 GRP75 HUMAN $73.68 \quad 100.0 \%$ Stress-70 protein, mitochondrial GN=HSPA9 GRP75_HUMAN $73.68 \quad 100.0 \%$ Stress-70 protein, mitochondrial GN=HSPA9 GRP75_HUMAN $73.68 \quad 100.0 \%$ Stress-70 protein, mitochondrial GN=HSPA9 GRP75_HUMAN $73.68 \quad 100.0 \%$ Stress-70 protein, mitochondrial GN=HSPA9 GRP75_HUMAN $73.68 \quad 100.0 \%$ Stress-70 protein, mitochondrial GN=HSPA9 GRP75_HUMAN $73.68 \quad 100.0 \%$ Stress-70 protein, mitochondrial GN=HSPA9 GRP75_HUMAN $73.68 \quad 100.0 \%$ Stress-70 protein, mitochondrial GN=HSPA9 GRP75_HUMAN $73.68 \quad 100.0 \%$ Stress-70 protein, mitochondrial GN=HSPA9 GRP75_HUMAN $73.68100 .0 \%$ Stress-70 protein, mitochondrial GN=HSPA9 GRP75_HUMAN $73.68 \quad 100.0 \%$
15

15

$(15$

15
15
15

15

15

15

3

3

0

20
20

20

20
20
20

20
20
20

20

20
$59 \quad 0.08 \% \quad 10.8 \%$ MFLYNLTLQR

$0.08 \% \quad 10.8 \%$ IHQETFGK

$0.08 \% \quad 10.8 \%$ IVPGQFLAVDPK

$0.08 \% \quad 10.8 \%$ IVPGQFLAVDPKGR

$0.08 \% \quad 10.8 \%$ NFGDQPDIR

$59 \quad 0.08 \% \quad 10.8 \%$ FLAVGLVDNTVR

$59 \quad 0.08 \% \quad 10.8 \% \quad$ TVLDPVTGDLSDTR

$59 \quad 0.08 \% \quad 10.8 \%$ TVLDPVTGDLSDTRTR

$59 \quad 0.08 \% \quad 10.8 \%$ SWLSYSYQSR

$59 \quad 0.08 \% \quad 10.8 \%$ AGNGQWASVIR

$59 \quad 0.08 \% \quad 10.8 \%$ SVAGGFVYTYK

$59 \quad 0.08 \% \quad 10.8 \%$ TPVEEVPAAIAPFQGR

$59 \quad 0.08 \% \quad 10.8 \%$ NVSEELDRTPPEVSK

$11 \quad 0.02 \% \quad 18.3 \%$ NPQNSSQSADGLR

$11 \quad 0.02 \% \quad 18.3 \%$ AVIDLNNR

$11 \quad 0.02 \% \quad 18.3 \%$ QYEMGECTR

$11 \quad 0.02 \% \quad 18.3 \%$ GGFCNFMHLKPISR

$13 \quad 0.02 \% \quad 20.2 \%$ GAKEEHGGLIR

$13 \quad 0.02 \% \quad 20.2 \%$ SVDETTQAMAFDGIIFQGQSLK

$13 \quad 0.02 \% \quad 20.2 \%$ AFNLVKDSATGLSK

$13 \quad 0.02 \% \quad 20.2 \%$ SIEIPRPVDGVEVPGCGK

$13 \quad 0.02 \% \quad 20.2 \%$ IFVEFTSVFDCQK

$13 \quad 0.02 \% \quad 20.2 \%$ AMQGLTGRK

$13 \quad 0.02 \% \quad 20.2 \%$ FANRVVVTK

$11 \quad 0.02 \% \quad 7.4 \%$ FATHAAALSVR

$11 \quad 0.02 \% \quad 7.4 \% \quad$ AVVIVDDRGR

$11 \quad 0.02 \% \quad 7.4 \%$ STGKGIVEFASKPAAR

$11 \quad 0.02 \% \quad 7.4 \%$ GIVEFASKPAAR

$11 \quad 0.02 \% \quad 7.4 \%$ FGQGGAGPVGGQGPR

$5 \quad 0.01 \% \quad 3.4 \%$ KVLALQAR

$0.01 \% \quad 3.4 \%$ STAGNFLVNPLEPK

$0.00 \% \quad 2.5 \%$ VADISGDTQKAK

$0.00 \% \quad 2.5 \%$ LGTLSPAFSTR

$\begin{array}{lll}0.00 \% & 6.7 \% & \text { LSLDKVFR }\end{array}$

$\begin{array}{lll}0.00 \% & 6.7 \% & \text { APVPGTPDSLSSGSSR }\end{array}$

$0.07 \% \quad 30.9 \%$ VLENAEGAR

$\quad 0.07 \% \quad 30.9 \%$ TTPSVVAFTADGER

$0.07 \% \quad 30.9 \%$ LVGMPAKR

$0.07 \% \quad 30.9 \%$ QAVTNPNNTFYATK

$48 \quad 0.07 \% \quad 30.9 \%$ QAVTNPNNTFYATKR

$48 \quad 0.07 \% \quad 30.9 \%$ RYDDPEVQK

$48 \quad 0.07 \% \quad 30.9 \%$ NVPFKIVR

$48 \quad 0.07 \% \quad 30.9 \%$ LYSPSQIGAFVLMK

$48 \quad 0.07 \% \quad 30.9 \%$ MKETAENYLGHTAK

$26 \quad 48 \quad 0.07 \% \quad 30.9 \%$ NAVITVPAYFNDSQR

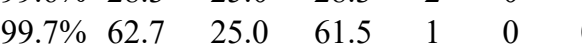

$\begin{array}{llll}99.7 \% & 40.4 & 25.0 & 40.4\end{array}$

$97.7 \% \quad 17.0 \quad 25.0 \quad 15.7$

$99.3 \% \quad 21.6 \quad 25.0 \quad 18.0$

$\begin{array}{llll}96.9 \% & 20.1 & 25.0 & 16.2\end{array}$

$\begin{array}{llll}99.7 \% & 37.8 & 25.0 & 28.7\end{array}$

$\begin{array}{lllll}99.7 \% & 59.1 & 25.0 & 48.3 & 14\end{array}$

$\begin{array}{lllll}99.7 \% & 52.4 & 25.0 & 52.4 & 8\end{array}$

$\begin{array}{llll}99.5 \% & 23.2 & 25.0 & 23.2\end{array}$

$\begin{array}{lllll}99.7 \% & 28.6 & 25.0 & 25.1 & 1\end{array}$

$\begin{array}{llll}99.7 \% & 31.0 & 25.0 & 24.0\end{array}$

$\begin{array}{lllll}99.7 \% & 53.7 & 25.0 & 43.8 & 5\end{array}$

$\begin{array}{lllll}99.7 \% & 55.2 & 25.0 & 49.0 & 8\end{array}$

$99.7 \% \quad 56.5 \quad 25.0 \quad 51.4 \quad 4$

$\begin{array}{lllll}99.7 \% & 49.4 & 25.0 & 49.4 & 4\end{array}$

$96.7 \% \quad 15.8 \quad 25.0 \quad 15.8$

$\begin{array}{llll}99.7 \% & 42.4 & 25.0 & 39.3\end{array}$

$99.6 \% \quad 23.4 \quad 25.0 \quad 23.2$

$99.7 \% \quad 47.9 \quad 25.0 \quad 41.1$

$\begin{array}{lllll}99.7 \% & 54.7 & 25.0 & 54.6 & 1\end{array}$

$\begin{array}{lllll}99.7 \% & 63.2 & 25.0 & 54.0 & 2\end{array}$

$\begin{array}{llll}99.7 \% & 51.8 & 25.0 & 49.4\end{array}$

$\begin{array}{lllll}99.7 \% & 51.4 & 25.0 & 48.5 & 2\end{array}$

$\begin{array}{llll}9.7 \% & 36.7 & 25.0 & 25.5\end{array}$

$\begin{array}{lllll}99.3 \% & 22.8 & 25.0 & 17.4 & 2\end{array}$

$\begin{array}{lllll}99.7 \% & 37.0 & 25.0 & 37.0\end{array}$

$\begin{array}{llll}99.7 \% & 48.0 & 25.0 & 41.9\end{array}$

$\begin{array}{llll}99.7 \% & 29.7 & 25.0 & 29.7\end{array}$

$\begin{array}{lllll}99.7 \% & 32.0 & 25.0 & 32.0 & 2\end{array}$

$\begin{array}{lllll}99.7 \% & 56.4 & 25.0 & 56.4\end{array}$

$\begin{array}{lllll}99.0 \% & 31.4 & 25.0 & 25.2 & 2\end{array}$

$\begin{array}{lllll}99.7 \% & 35.5 & 25.0 & 31.1\end{array}$

$\begin{array}{llll}99.7 \% & 27.3 & 25.0 & 23.1\end{array}$

$\begin{array}{llll}99.7 \% & 26.9 & 25.0 & 24.5\end{array}$

$\begin{array}{llll}99.0 \% & 32.0 & 25.0 & 23.2\end{array}$

$\begin{array}{lllll}99.7 \% & 39.2 & 25.0 & 39.2 & 2\end{array}$

$\begin{array}{llll}99.7 \% & 55.4 & 25.0 & 39.9\end{array}$

$\begin{array}{lllll}99.7 \% & 60.5 & 25.0 & 60.5 & 2\end{array}$

$\begin{array}{llll}99.0 \% & 24.5 & 25.0 & 17.2\end{array}$

$\begin{array}{lllll}99.7 \% & 57.7 & 25.0 & 40.0 & 2\end{array}$

$\begin{array}{lllll}99.7 \% & 59.4 & 25.0 & 47.0 & 2\end{array}$

$\begin{array}{lllll}99.7 \% & 40.1 & 25.0 & 38.2 & 2\end{array}$

$99.0 \% \quad 21.0 \quad 25.0 \quad 20.1$

$\begin{array}{lllll}98.9 \% & 25.4 & 25.0 & 25.4 & 2\end{array}$

$\begin{array}{llll}99.7 \% & 62.8 & 25.0 & 54.3\end{array}$

$\begin{array}{llll}99.7 \% & 51.5 & 25.0 & 51.5\end{array}$

$0 \quad 0$

0

0

0
0
0

1298.69 
Stress-70 protein, mitochondrial GN=HSPA9 GRP75_HUMAN $73.68 \quad 100.0 \% \quad 20$ $\begin{array}{llll}\text { Stress-70 protein, mitochondrial GN=HSPA9 GRP75_HUMAN } & 73.68 & 100.0 \% & 20 \\ \text { Stress-70 protein, mitochondrial GN=HSPA9 GRP75_HUMAN } & 73.68 & 100.0 \% & 20\end{array}$ Stress-70 protein, mitochondrial GN=HSPA9 GRP75_HUMAN $73.68 \quad 100.0 \% \quad 20$ Stress-70 protein, mitochondrial GN=HSPA9 GRP75_HUMAN $73.68 \quad 100.0 \% 20$ Stress-70 protein, mitochondrial GN=HSPA9 GRP75_HUMAN $73.68 \quad 100.0 \% \quad 20$ Stress-70 protein, mitochondrial GN=HSPA9 GRP75_HUMAN $73.68 \quad 100.0 \% \quad 20$ Stress-70 protein, mitochondrial GN=HSPA9 GRP75_HUMAN $73.68 \quad 100.0 \% \quad 20$ Stress-70 protein, mitochondrial GN=HSPA9 GRP75_HUMAN $73.68 \quad 100.0 \% \quad 20$ Stress-70 protein, mitochondrial GN=HSPA9 GRP75 HUMAN $73.68 \quad 100.0 \%$ Stress-70 protein, mitochondrial GN=HSPA9 GRP75_HUMAN $73.68 \quad 100.0 \% \quad 20$ Striatin-interacting protein $1 \mathrm{GN}=$ STRIP1 STRP1_HUMAN $95.58 \quad 100.0 \%$ Striatin-interacting protein $1 \mathrm{GN}=$ STRIP1 STRP1_HUMAN $95.58 \quad 100.0 \%$ Structural maintenance of chromosomes protein 1A GN=SMC1A SMC1A_HUMAN $143.24 \quad 100.0 \%$ Structural maintenance of chromosomes protein 1A GN=SMC1A SMC1A_HUMAN $143.24 \quad 100.0 \%$ Structural maintenance of chromosomes protein $1 \mathrm{~A}$ GN=SMC1A SMC1A_HUMAN $143.24 \quad 100.0 \%$ Structural maintenance of chromosomes protein $1 \mathrm{~A}$ GN=SMC1A SMC1A_HUMAN $143.24 \quad 100.0 \%$ Structural maintenance of chromosomes protein $1 \mathrm{~A}$ GN=SMC1A SMC1A HUMAN $143.24 \quad 100.0 \%$ Structural maintenance of chromosomes protein $1 \mathrm{~A}$ GN=SMC1A SMC1A_HUMAN $143.24 \quad 100.0 \%$ Structural maintenance of chromosomes protein 1A GN=SMC1A SMC1A_HUMAN $143.24 \quad 100.0 \%$ Structural maintenance of chromosomes protein $2 \mathrm{GN}=\mathrm{SMC} 2 \mathrm{SMC} 2 \mathrm{HUMAN} 135.66 \quad 100.0 \%$ Structural maintenance of chromosomes protein 2 GN=SMC2 SMC2_HUMAN $135.66 \quad 100.0 \%$ Structural maintenance of chromosomes protein $2 \mathrm{GN}=\mathrm{SMC} 2 \mathrm{SMC} 2$ HUMAN $135.66 \quad 100.0 \%$ Structural maintenance of chromosomes protein $3 \mathrm{GN}=\mathrm{SMC} 3 \mathrm{SMC3}$ _HUMAN $141.55 \quad 100.0 \%$ Structural maintenance of chromosomes protein $3 \mathrm{GN}=\mathrm{SMC} 3 \mathrm{SMC} 3$ _HUMAN $141.55 \quad 100.0 \%$ Structural maintenance of chromosomes protein $3 \mathrm{GN}=\mathrm{SMC} 3 \mathrm{SMC} 3$ HUMAN $141.55100 .0 \%$ Structural maintenance of chromosomes protein $3 \mathrm{GN}=\mathrm{SMC} 3 \mathrm{SMC} 3$ _HUMAN $141.55 \quad 100.0 \%$ Structural maintenance of chromosomes protein $3 \mathrm{GN}=\mathrm{SMC} 3 \mathrm{SMC} 3$ HUMAN $141.55100 .0 \%$ Structural maintenance of chromosomes protein $3 \mathrm{GN}=\mathrm{SMC} 3 \mathrm{SMC} 3 \mathrm{HUMAN} 141.55100 .0 \%$ Structural maintenance of chromosomes protein $3 \mathrm{GN}=\mathrm{SMC} 3 \mathrm{SMC} 3$ _HUMAN $141.55100 .0 \%$ Structural maintenance of chromosomes protein $4 \mathrm{GN}=\mathrm{SMC} 4 \mathrm{SMC} 4 \mathrm{HUMAN} 147.19100 .0 \%$ Structural maintenance of chromosomes protein $4 \mathrm{GN}=\mathrm{SMC} 4 \mathrm{SMC} 4$ _HUMAN $147.19 \quad 100.0 \%$ Structural maintenance of chromosomes protein $4 \mathrm{GN}=\mathrm{SMC} 4$ SMC4_HUMAN $147.19 \quad 100.0 \%$ Structural maintenance of chromosomes protein $4 \mathrm{GN}=\mathrm{SMC} 4 \mathrm{SMC} 4$ HUMAN $147.19 \quad 100.0 \%$ Structural maintenance of chromosomes protein $4 \mathrm{GN}=\mathrm{SMC} 4 \mathrm{SMC} 4$ _HUMAN $147.19 \quad 100.0 \%$ Structural maintenance of chromosomes protein $4 \mathrm{GN}=\mathrm{SMC} 4$ SMC4_HUMAN $147.19100 .0 \%$ Structural maintenance of chromosomes protein $4 \mathrm{GN}=\mathrm{SMC} 4 \mathrm{SMC} 4$ HUMAN $147.19100 .0^{\circ} \%$ Succinate dehydrogenase [ubiquinone] flavoprotein subunit, mitochondrial GN=SDHA SDHA_HUMAN $72.69 \quad 100.0^{\circ}$

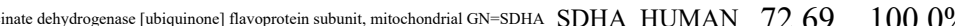
Succinyl-CoA ligase [ADP/GDP-forming] subunit alpha, mitochondrial GN=SUCLG1 SUCA_HUMAN 36.25 100.0\% Succinyl-CoA ligase [ADP/GDP-forming] subunit alpha, mitcochondrial GN=SUCLG1 SUCA_HUMAN 36.25

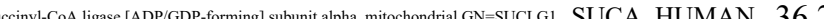
Succinyl-CoA ligase [ADP/GDP-forming] subunit alpha, mitochondrial GN=SUCLG1 SUCA_HUMAN 36.25 Succinyl-CoA ligase [ADP/GDP-forming] subunit alpha, mitochondrial GN=SUCLG1 SUCA_HUMAN 36.25 Th Succinyl-CoA ligase [ADP/GDP-forming] subunit alpha, mitochondrial GN=SUCLG1 SUCA_HUMAN 36.2 Succinyl-CoA ligse [ADP'GDP. for $0.07 \% \quad 30.9 \%$ DAGQISGLNVLR $99.7 \% \quad 42.6$ $0.07 \% \quad 30.9 \%$ STNGDTFLGGEDFDQALLR $99.7 \% \quad 55.6$ $0.07 \% \quad 30.9 \%$ ETGVDLTKDNMALQR

$0.07 \% \quad 30.9 \%$ AQFEGIVTDLIR

$0.07 \% \quad 30.9 \%$ AQFEGIVTDLIRR

$0.07 \% \quad 30.9 \%$ VQQTVQDLFGR

$0.07 \% \quad 30.9 \%$ VQQTVQDLFGRAPSK

$0.07 \% \quad 30.9 \%$ KDSETGENIR

$0.00 \% \quad 2.4 \% \quad$ LLDGLEVTAR

$0.00 \% \quad 2.4 \%$ ILLAAAPTSK

$0.02 \% \quad 7.4 \%$ QIIGPFQR

$0.02 \% \quad 7.4 \%$ TALFEEISR

$99.7 \% \quad 57.5$

$99.7 \% \quad 67.8$

$99.2 \% \quad 23.6$

$99.7 \% \quad 59.2$

$99.7 \% \quad 63.7$

$99.7 \% \quad 43.6$

$99.7 \% \quad 29.3$

$98.2 \% \quad 19.4$

$99.0 \% \quad 29.8$

$99.7 \% \quad 40.1$

$0.02 \% \quad 7.4 \%$ ALQYACGNALVCDNVEDARR $\quad 99.6 \% 23.6$

$0.02 \% \quad 7.4 \%$ TVALDGTLFQK

$0.02 \% \quad 7.4 \%$ SGVISGGASDLKAK

$99.7 \% \quad 34.9$

$99.7 \% \quad 62.0$

$99.2 \% \quad 22.3$

$0.02 \% \quad 7.4 \%$ LNEQQSVLQR

$99.7 \% \quad 48.3$

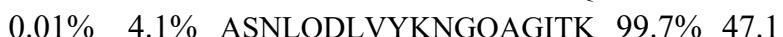

$0.01 \% \quad 4.1 \% \quad$ TVTLGGDVFDPHGTLSGGAR $\quad 99.7 \% \quad 60.7$

$0.01 \% \quad 4.1 \%$ EAEDGAAKVSK

$0.02 \% \quad 7.1 \%$ LALLHEGTGPR

$0.02 \% \quad 7.1 \%$ SNPYYIVKQGK

$0.02 \% \quad 7.1 \%$ ALEYTIYNQELNETR

$99.7 \% \quad 35.2$

$99.7 \% \quad 34.3$

$99.1 \% \quad 22.3$

$99.7 \% \quad 54.1$

$99.7 \% \quad 39.9$

$99.7 \% \quad 48.5$

$99.7 \% 28.6$

$99.7 \% \quad 36.1$

$99.1 \% \quad 20.7$

$99.6 \% 23.7$

$99.7 \% \quad 37.6$

$95.3 \% 15.1$

$99.7 \% \quad 46.8$

$99.7 \% \quad 63.2$

$99.7 \% 43.9$

$99.7 \% \quad 38.2$

$98.0 \% \quad 18.0$

$99.7 \% \quad 33.7$

$99.7 \% \quad 36.6$

$99.7 \% \quad 29.3$

$99.7 \% \quad 32.1$

$0.05 \% \quad 25.7 \%$ QGTFHSQQALEYGTK

$0.05 \% \quad 25.7 \%$ LVGGTTPGK

$\begin{array}{lll}99.6 \% & 22.2\end{array}$

$\begin{array}{llll}0.05 \% & 25.7 \% & \text { GGQTHLGLPVFNTVK } \quad 99.7 \% \quad 47.7\end{array}$

$\begin{array}{ll}0.05 \% & 25.7 \% \\ 0.05 \% & 25.7 \%\end{array}$

$99.7 \% \quad 46.8$ $0.05 \% \quad 25.7 \%$ RMGHAGAIIAGGK $\begin{array}{ccc}1670.92 & 203 & 218 \\ 1242.68 & 207 & 218 \\ 1645.88 & 219 & 234 \\ 2055.96 & 266 & 284 \\ 1690.84 & 293 & 307 \\ 1361.74 & 349 & 360 \\ 1517.84 & 349 & 361 \\ 1290.68 & 395 & 405 \\ 1673.90 & 395 & 409 \\ 1148.55 & 625 & 634 \\ 1086.62 & 129 & 138 \\ 984.61 & 527 & 536 \\ 958.55 & 19 & 26 \\ 1065.56 & 152 & 160 \\ 2295.06 & 608 & 627 \\ 1192.66 & 638 & 648 \\ 1289.71 & 649 & 662 \\ 1214.65 & 1010 & 1019 \\ 2176.06 & 1215 & 1233 \\ 1920.02 & 59 & 76 \\ 1956.98 & 649 & 668 \\ 1104.55 & 923 & 933 \\ 1163.65 & 62 & 72 \\ 1296.69 & 133 & 143 \\ 1856.90 & 222 & 236 \\ 1607.84 & 365 & 378 \\ 1121.56 & 635 & 644 \\ 1173.55 & 662 & 672 \\ 1682.84 & 986 & 999 \\ 1236.60 & 108 & 119 \\ 1162.66 & 205 & 214 \\ 1262.63 & 435 & 445 \\ 1098.59 & 513 & 522 \\ 1213.72 & 597 & 607 \\ 1336.71 & 1107 & 1117 \\ 1242.71 & 1274 & 1285 \\ 1109.56 & 163 & 171 \\ 1139.62 & 172 & 182 \\ 1245.66 & 48 & 57 \\ 1023.53 & 58 & 66 \\ 1694.81 & 67 & 81 \\ 829.48 & 82 & 90 \\ 2378.32 & 82 & 105 \\ 1567.86 & 91 & 105 \\ 1982.00 & 165 & 182 \\ 1724.85 & 167 & 182 \\ 1238.68 & 296 & 308\end{array}$

Page 122 of Table S-1-1 

SUN domain-containing protein $2 \mathrm{GN}=\mathrm{SUN} 2$ SUN2 HUMAN $80.31 \quad 100.0 \%$ SUN domain-containing protein $2 \mathrm{GN}=\mathrm{SUN} 2 \mathrm{SUN} 2$ _HUMAN $80.31 \quad 100.0 \%$ SUN domain-containing protein $2 \mathrm{GN}=\mathrm{SUN} 2$ SUN2 HUMAN $80.31 \quad 100.0 \%$ SUN domain-containing protein 2 GN=SUN2 SUN2_HUMAN $80.31 \quad 100.0 \%$ SUN domain-containing protein 2 GN=SUN2 SUN2_HUMAN $80.31 \quad 100.0 \%$ Superkiller viralicidic activity 2-like 2 GN=SKIV2L2 SK2L2 HUMAN $117.81 \quad 100.0 \%$ Superkiller viralicidic activity 2-like 2 GN=SKIV2L2 SK2L2_HUMAN $117.81 \quad 100.0 \%$

$13 \quad 33 \quad 0.05 \% \quad 25.7 \%$ MGHAGAIIAGGK $23 \quad 36 \quad 0.05 \% \quad 31.1 \%$ GYVAKSPDEAYAIAK $23 \quad 36 \quad 0.05 \% \quad 31.1 \%$ SPDEAYAIAKK $23 \quad 36 \quad 0.05 \% \quad 31.1 \%$ LGSKDVVIK $23 \quad 36 \quad 0.05 \% \quad 31.1 \%$ GKGTFESGLK $23 \quad 36 \quad 0.05 \% \quad 31.1 \%$ GTFESGLKGGVK $23 \quad 36 \quad 0.05 \% \quad 31.1 \%$ IVFSPEEAK $0.05 \% \quad 31.1 \%$ AVSSQMIGK $0.05 \% \quad 31.1 \%$ AVSSQMIGKK $0.05 \% \quad 31.1 \%$ GRICNQVLVCER $0.05 \% \quad 31.1 \%$ ICNQVLVCER $0.05 \% \quad 31.1 \%$ REYYFAITMER $0.05 \% \quad 31.1 \%$ EYYFAITMER $0.05 \% \quad 31.1 \%$ EQALQLAQK $0.05 \% \quad 31.1 \%$ INFDSNSAYR $0.05 \% \quad 31.1 \%$ INFDSNSAYRQK $0.05 \% \quad 31.1 \%$ DLEIKIPVVVR $0.05 \% \quad 31.1 \%$ LQGTRVDDAK $0.05 \% \quad 31.1 \%$ ILACDDLDEAAR $0.05 \% \quad 31.1 \%$ LSEIVTLAK

$0.04 \% \quad 33.6 \%$ KLMSDNGVR $0.04 \% \quad 33.6 \%$ FFVADTANEALEAAK $0.04 \% 33.6 \%$ LNAKEIVLK $0.04 \% 33.6 \%$ GGVHLTKDPNVVC $0.04 \% \quad 33.6 \%$ MAENLGFVGPLK $0.04 \% 33.6 \%$ SQAADQITK $0.04 \% 33.6 \%$ INFDDNAEFR $0.04 \% 33.6 \%$ INFDDNAEFRQK $0.04 \% \quad 33.6 \%$ EAQVYQAFK $0.04 \% \quad 33.6 \%$ ELELKVPLVVR $0.04 \% 33.6 \%$ LEGTNVQEAQK $0.01 \% \quad 6.4 \%$ NRAEASLER $0.01 \% \quad 6.4 \%$ VSQGVEDGPDTKR $0.02 \% \quad 12.4 \%$ DSSPHFQAEQR $0.02 \% \quad 12.4 \%$ IQEELSALR $0.02 \% \quad 12.4 \%$ ILTHVAEMQGK $0.02 \% \quad 12.4 \%$ EAAASLSLTLQK $0.02 \% \quad 12.4 \%$ FRVHGEPAH $0.01 \% \quad 3.9 \%$ EYPFILDAFQR $0.01 \% \quad 3.9 \%$ SFYQFQHYR
$99.7 \% \quad 60.7$ $99.7 \% \quad 57.7$ $99.7 \% \quad 72.4$ $99.7 \% \quad 49.5$ $99.7 \% 56.6$ $99.7 \% \quad 28.5$

$99.7 \% \quad 41.5$ $99.7 \% \quad 32.9$ $0.05 \% \quad 31.1 \%$ IVFSPEEAKAVSSQMIGK $98.4 \% \quad 18.7$ $0.04 \% \quad 33.6 \%$ FFVADTANEALEAAKR $0.04 \% 33.6 \%$ ILNNSGLPITSAIDLEDAAK $0.02 \% \quad 12.4 \%$ YSEDRIGLADYALESGGASVI $\begin{array}{llll}99.7 \% & 53.1 & 25.0 & 51.1\end{array}$

$99.7 \% \quad 28.3 \quad 25.0 \quad 25.6$

$99.7 \% \quad 58.9 \quad 25.0 \quad 58.9$

$99.7 \% \quad 33.0 \quad 25.0 \quad 28.7$

$99.7 \% \quad 31.9 \quad 25.0 \quad 31.9$

$99.7 \% \quad 53.6 \quad 25.0 \quad 35.0 \quad 2$

$99.7 \% \quad 51.9 \quad 25.0 \quad 51.9$

$99.7 \% \quad 33.0 \quad 25.0 \quad 26.5$

$\begin{array}{llll}99.7 \% & 36.4 & 25.0 & 36.4\end{array}$

$98.2 \% \quad 18.6 \quad 25.0 \quad 15.7$

$99.7 \% \quad 40.7 \quad 25.0 \quad 38.5 \quad 2$

$99.7 \% \quad 54.7 \quad 25.0 \quad 37.6$

$\begin{array}{llll}99.7 \% & 27.0 & 25.0 & 22.2\end{array}$

$\begin{array}{lllll}99.7 \% & 94.2 & 25.0 & 83.5 & 2\end{array}$

$\begin{array}{llll}99.7 \% & 30.5 & 25.0 & 30.5\end{array}$

$\begin{array}{llll}99.7 \% & 30.9 & 25.0 & 22.6\end{array}$

$\begin{array}{llll}99.7 \% & 30.4 & 25.0 & 30.4\end{array}$

$\begin{array}{llll}99.7 \% & 38.1 & 25.0 & 38.1\end{array}$

$\begin{array}{llll}99.6 \% & 22.8 & 25.0 & 18.5\end{array}$

$\begin{array}{llll}99.7 \% & 55.7 & 25.0 & 50.2\end{array}$

$\begin{array}{llll}99.7 \% & 40.6 & 25.0 & 33.9\end{array}$

$\begin{array}{llll}99.7 \% & 39.8 & 25.0 & 30.2\end{array}$

$\begin{array}{llll}98.1 \% & 17.2 & 25.0 & 16.8\end{array}$

$\begin{array}{llll}99.7 \% & 59.3 & 25.0 & 54.9\end{array}$

$\begin{array}{llll}99.7 \% & 28.8 & 25.0 & 28.8\end{array}$

$\begin{array}{llll}99.3 \% & 27.9 & 25.0 & 13.8\end{array}$

$\begin{array}{llll}99.7 \% & 45.2 & 25.0 & 27.2\end{array}$

$\begin{array}{llll}99.7 \% & 34.3 & 25.0 & 31.4\end{array}$

$\begin{array}{lllll}99.7 \% & 56.8 & 25.0 & 56.8 & 2\end{array}$

$\begin{array}{llll}99.7 \% & 50.4 & 25.0 & 50.4\end{array}$ $\begin{array}{llll}99.7 \% & 43.7 & 25.0 & 43.7\end{array}$ $\begin{array}{llll}97.6 \% & 16.2 & 25.0 & 16.2\end{array}$ $\begin{array}{llll}99.6 \% & 23.1 & 25.0 & 23.1\end{array}$ $\begin{array}{llll}99.1 \% & 20.3 & 25.0 & 18.3\end{array}$ $\begin{array}{ccc}1098.57 & 297 & 308 \\ 1582.81 & 74 & 88 \\ 1064.53 & 79 & 88 \\ 1192.62 & 79 & 89 \\ 958.59 & 90 & 98 \\ 1023.55 & 107 & 116 \\ 1179.64 & 109 & 120 \\ 1019.54 & 121 & 129 \\ 1937.01 & 121 & 138 \\ 936.48 & 130 & 138 \\ 1048.58 & 130 & 139 \\ 1503.75 & 149 & 160 \\ 1290.63 & 151 & 160 \\ 1494.70 & 165 & 175 \\ 1338.60 & 166 & 175 \\ 1028.57 & 217 & 225 \\ 1186.55 & 275 & 284 \\ 1442.70 & 275 & 286 \\ 1280.79 & 397 & 407 \\ 1102.59 & 408 & 417 \\ 1361.64 & 427 & 438 \\ 973.59 & 443 & 451 \\ 1019.53 & 47 & 55 \\ 1596.79 & 59 & 73 \\ 1752.89 & 59 & 74 \\ 1027.65 & 75 & 83 \\ 1732.97 & 102 & 118 \\ 1154.59 & 119 & 128 \\ 1275.68 & 207 & 218 \\ 961.50 & 219 & 227 \\ 1240.56 & 260 & 269 \\ 1496.71 & 260 & 271 \\ 1083.55 & 339 & 347 \\ 1294.81 & 382 & 392 \\ 1216.62 & 393 & 403 \\ 2055.10 & 404 & 423 \\ 1045.54 & 90 & 98 \\ 1387.68 & 184 & 196 \\ 1301.59 & 265 & 275 \\ 1058.58 & 355 & 363 \\ 1226.66 & 492 & 502 \\ 1231.69 & 506 & 517 \\ 2530.24 & 539 & 562 \\ 1460.86 & 619 & 631 \\ 1049.53 & 709 & 717 \\ 1398.71 & 135 & 145 \\ 1275.59 & 588 & 596\end{array}$ 

SURP and G-patch domain-containing protein 2 GN=SUGP2 SUGP2_HUMAN $120.21 \quad 100.0 \%$ SURP and G-patch domain-containing protein 2 GN=SUGP2 SUGP2 HUMAN $120.21 \quad 100.0 \%$ SURP and G-patch domain-containing protein 2 GN=SUGP2 SUGP2_HUMAN $120.21 \quad 100.0 \%$ SURP and G-patch domain-containing protein 2 GN=SUGP2 SUGP2_HUMAN $120.21 \quad 100.0 \%$ SURP and G-patch domain-containing protein 2 GN=SUGP2 SUGP2_HUMAN $120.21 \quad 100.0 \%$ SURP and G-patch domain-containing protein 2 GN=SUGP2 SUGP2_HUMAN $120.21 \quad 100.0 \%$ Survival motor neuron protein GN=SMN1 SMN_HUMAN $31.85 \quad 100.0 \%$ Survival motor neuron protein GN=SMN1 SMN_HUMAN $31.85 \quad 100.0 \%$ Survival motor neuron protein GN=SMN1 SMN_HUMAN $31.85 \quad 100.0 \%$ SWINN-redated mation $121.91 \quad 100.0 \%$ SMCA5_HUMAN $121.91 \quad 100.0 \%$ SMCA5_HUMAN $121.91 \quad 100.0 \%$

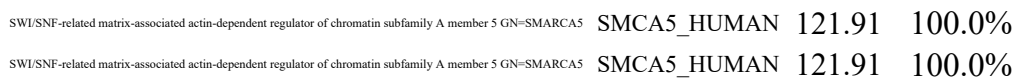

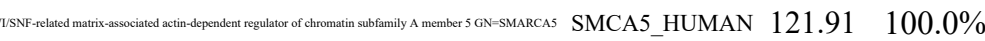

Syntaxin-18 GN=STX18

Syntaxin-18 GN=STX18 SMCA5_HUMAN $121.91 \quad 100.0 \%$ STX18_HUMAN $38.67 \quad 100.0 \%$ STX18 HUMAN $38.67 \quad 100.0 \%$ Syntaxin-binding protein $2 \mathrm{GN}=\mathrm{STXBP} 2$ STXB2_HUMAN $66.45 \quad 100.0 \%$ Syntaxin-binding protein 2 GN=STXBP2 STXB2_HUMAN $66.45 \quad 100.0 \%$ TAR DNA-binding protein 43 GN=TARDBP TADBP_HUMAN $44.74 \quad 100.0 \%$ TAR DNA-binding protein 43 GN=TARDBP TADBP_HUMAN $44.74 \quad 100.0 \%$ $\begin{array}{lll}\text { TAR DNA-binding protein } 43 \mathrm{GN}=\text { TARDBP } \\ \text { TAR DNA-binding protein } 43 \mathrm{GN}=\text { TARDBP TADBP_HUMAN } & 44.74 & 100.0 \%\end{array}$ TAR DNA-binding protein 43 GN=TARDBP TADBP_HUMAN $44.74 \quad 100.0 \%$ TAR DNA-binding protein 43 GN=TARDBP TADBP_HUMAN $44.74 \quad 100.0 \%$ TAR DNA-binding protein 43 GN=TARDBP TADBP_HUMAN $44.74 \quad 100.0 \%$ TAR DNA-binding protein 43 GN=TARDBP TADBP_HUMAN $44.74 \quad 100.0 \%$ TATA-binding protein-associated factor $172 \mathrm{GN}=\mathrm{BTAF} 1$ BTAF1_HUMAN $206.89 \quad 100.0 \%$ TATA-binding protein-associated factor $172 \mathrm{GN}=\mathrm{BTAF} 1$ BTAF1_HUMAN $206.89 \quad 100.0 \%$ TATA-binding protein-associated factor 172 GN=BTAF1 BTAF1_HUMAN $206.89 \quad 100.0 \%$ TATA-binding protein-associated factor 2N GN=TAF15 RBP56_HUMAN $61.83 \quad 100.0 \%$ TATA-binding protein-associated factor 2N GN=TAF15 RBP56_HUMAN $61.83 \quad 100.0 \%$ T-complex protein 1 subunit alpha GN=TCP1 TCPA_HUMAN $60.35 \quad 100.0 \%$ T-complex protein 1 subunit alpha GN=TCP1 TCPA_HUMAN $60.35 \quad 100.0 \%$ T-complex protein 1 subunit alpha GN=TCP1 TCPA_HUMAN $60.35 \quad 100.0 \%$ T-complex protein 1 subunit alpha GN=TCP1 TCPA_HUMAN $60.35 \quad 100.0 \%$ T-complex protein 1 subunit alpha GN=TCP1 TCPA_HUMAN $60.35 \quad 100.0 \%$ T-complex protein 1 subunit alpha GN=TCP1 TCPA_HUMAN $60.35 \quad 100.0 \%$ T-complex protein 1 subunit alpha GN=TCP1 TCPA_HUMAN $60.35 \quad 100.0 \%$
$0.01 \% \quad 3.9 \% \quad$ YCLPFLQPGR $0.01 \% \quad 3.9 \% \quad$ VIQKVEAFEHR $0.01 \% \quad 6.8 \% \quad$ VNLNTIKR

$0.01 \% \quad 6.8 \%$ QAQQAQNVQR $0.01 \% \quad 6.8 \%$ VGGSDEEASGIPSR $0.02 \% \quad 6.7 \%$ QYLPHVAR

$11 \quad 0.02 \% \quad 6.7 \% \quad$ SMFAGVPTMR

$10 \quad 0.01 \% \quad 5.3 \% \quad$ GGVGKLVTLR

$10 \quad 0.01 \% \quad 5.3 \%$ TQGTNQIQK

$10 \quad 0.01 \% \quad 5.3 \% \quad$ APSSLSDAVPQR

$10 \quad 0.01 \% \quad 5.3 \%$ VIEGSLSPKER

$10 \quad 0.01 \% \quad 5.3 \% \quad$ RATTGTQTLLSSGTR

$10 \quad 0.01 \% \quad 5.3 \%$ ATTGTQTLLSSGTR

$5 \quad 0.01 \% \quad 9.9 \%$ AYDKAVASFK

$0.01 \% \quad 9.9 \%$ NTAASLQQWK

$0.01 \% \quad 9.9 \%$ LGPGKPGLK

$16 \quad 0.02 \% \quad 6.2 \% \quad$ SVCLIGDKEQR

$6 \quad 0.02 \% \quad 6.2 \% \quad$ YLVIDEAHR

$16 \quad 0.02 \% \quad 6.2 \% \quad$ MVVLDKLLPK

$0.02 \% \quad 6.2 \%$ VLIFSQMTR

$0.02 \% \quad 6.2 \%$ TAEMNEKLSK

$0.02 \% \quad 6.2 \%$ TIGYKVPR

$0.02 \% \quad 6.2 \% \quad$ ALDTKIGR

$0.00 \% \quad 6.3 \% \quad$ TCSEAIQQLR

$0.00 \% \quad 6.3 \% \quad$ LSKLEPEPNTK

$0.00 \% \quad 5.4 \%$ SQLLIMDR

$0.00 \% \quad 5.4 \%$ NLEQLGGTVTNPGGSGTSSRLEPR

$0.02 \% \quad 17.9 \%$ YRNPVSQCMR

$0.02 \% \quad 17.9 \%$ KMDETDASSAVK

$0.02 \% \quad 17.9 \%$ TSDLIVLGLPWK

$0.02 \% \quad 17.9 \%$ FTEYETQVK

$0.02 \% \quad 17.9 \%$ QSQDEPLR

$0.02 \% \quad 17.9 \%$ QSQDEPLRSR

$\begin{array}{lllll}0.02 \% & 17.9 \% & \text { SGRFGGNPGGFGNQGGFGNSR } & 99.7 \% & 33.9\end{array}$

$0.02 \% \quad 17.9 \%$ FGGNPGGFGNQGGFGNSR

$0.01 \% \quad 1.9 \%$ LFILLDTGTTPVTR

$0.01 \% \quad 1.9 \% \quad$ IAAGQAVEAIVK

$0.01 \% \quad 1.9 \% \quad$ AVTLAVQPR

$0.01 \% \quad 5.6 \%$ GEATVSFDDPPSAK

$\begin{array}{llll}0.6 \% & \text { SGGGYGGDRSSGGGYSGDR } 99.7 \% \quad 27.1\end{array}$

$0.11 \% \quad 52.2 \%$ SQNVMAAASIANIVK

$0.11 \% \quad 52.2 \%$ SSLGPVGLDK

$\begin{array}{ll}99.7 \% & 51.9 \\ 99.7 \% & 98.6\end{array}$

39

$0.11 \% \quad 52.2 \%$ MLVDDIGDVTITNDGATILK

$0.11 \% \quad 52.2 \%$ NADELVKQK

$39 \quad 80 \quad 0.11 \% \quad 52.2 \%$ QKIHPTSVISGYR
$99.0 \% \quad 31.6$

$\begin{array}{llllllll}99.7 \% & 24.0 & 25.0 & 24.0 & 3 & 0 & 0 & 1250.64\end{array}$

$\begin{array}{llll}99.7 \% & 37.0 & 25.0 & 37.0\end{array}$

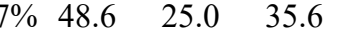

$\begin{array}{llll}99.7 \% & 27.0 & 25.0 & 15.2\end{array}$

$\begin{array}{llll}99.7 \% & 25.8 & 25.0 & 21.6\end{array}$

$\begin{array}{llll}99.7 \% & 31.1 & 25.0 & 22.5\end{array}$

$\begin{array}{llll}99.7 \% & 48.0 & 25.0 & 48.0\end{array}$

$\begin{array}{llll}.7 \% & 27.8 & 25.0 & 26.4\end{array}$

$\begin{array}{lll}25.0 & 20.9\end{array}$

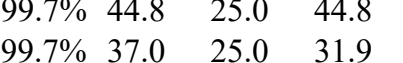

$\begin{array}{llll}99.7 \% & 28.5 & 25.0 & 21.3\end{array}$

$\begin{array}{llll}99.7 \% & 29.3 & 25.0 & 28.5\end{array}$

$\begin{array}{llll}99.7 \% & 56.1 & 25.0 & 24.9\end{array}$

$\begin{array}{llll}99.6 \% & 24.8 & 25.0 & 22.2\end{array}$

$\begin{array}{llll}99.7 \% & 37.1 & 25.0 & 37.1\end{array}$

$\begin{array}{llll}99.7 \% & 56.2 & 25.0 & 49.5\end{array}$

$\begin{array}{llll}98.2 \% & 19.4 & 25.0 & 15.7\end{array}$

$\begin{array}{llll}99.0 \% & 35.4 & 25.0 & 32.2\end{array}$

$\begin{array}{llll}99.0 \% & 29.3 & 25.0 & 22.4\end{array}$

$\begin{array}{llll}9.7 \% & 44.7 & 25.0 & 26.8\end{array}$

$\begin{array}{lll}26.1 & 25.0 & 23.4\end{array}$

$\begin{array}{lll}29.4 & 25.0 & 29.4\end{array}$

$\begin{array}{llll}99.7 \% & 35.7 & 25.0 & 36.5 \\ 95.7 & 25.0 & 32.8\end{array}$

$\begin{array}{llll}99.7 \% & 41.3 & 25.0 & 29.6\end{array}$

$\begin{array}{llll}94.6 \% & 16.5 & 25.0 & 12.9\end{array}$

$\begin{array}{llll}95.4 \% & 14.1 & 25.0 & 14.1\end{array}$

$\begin{array}{llll}99.7 \% & 62.5 & 25.0 & 62.5\end{array}$

$\begin{array}{llll}99.7 \% & 57.3 & 25.0 & 56.8\end{array}$

$\begin{array}{llll}99.7 \% & 31.6 & 25.0 & 21.3\end{array}$

$\begin{array}{ll}25.0 & 50.8\end{array}$

$25.0 \quad 17.6$

$\begin{array}{ll}25.0 & 51.9\end{array}$

$25.0 \quad 89.3$

$25.0 \quad 16.9$

$\begin{array}{llll}99.7 \% & 61.2 & 25.0 & 61.2\end{array}$

$\begin{array}{llll}99.7 \% & 52.0 & 25.0 & 42.4\end{array}$

$\begin{array}{llll}99.7 \% & 30.8 & 25.0 & 21.3\end{array}$

$99.5 \% \quad 21.7 \quad 25.0 \quad 19.3$
1355.74

957.58

1170.60

1360.63

983.54

1096.53

999.63

1017.53

1227.63

1214.67

1549.83

1393.73

1099.58

1146.59

866.55

1304.66

1115.58

1171.71

1094.60

1150.58

933.55

873.52

1205.59

1255.69

975.53

2427.22

1310.61

1281.60

1341.78

1144.55

972.47

1215.61

2026.92

1726.77

1546.88

1169.69

954.57

1420.66

1748.72

2261.19

1516.82

972.54

2120.08

1106.62

1044.57

1485.82

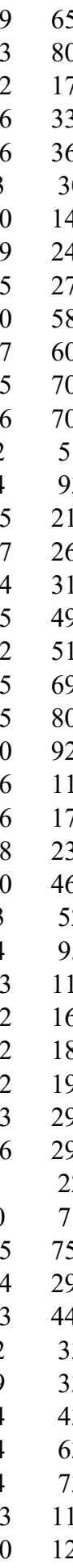


T-complex protein 1 subunit alpha GN=TCP1 TCPA_HUMAN $60.35 \quad 100.0 \% \quad 3$ T-complex protein 1 subunit alpha GN=TCP1 TCPA_HUMAN $60.35 \quad 100.0 \% \quad 30$ T-complex protein 1 subunit alpha GN=TCP1 TCPA_HUMAN $60.35 \quad 100.0 \% \quad 30$ T-complex protein 1 subunit alpha GN=TCP1 TCPA_HUMAN 60.35 T-complex protein 1 subunit alpha GN=TCP1 TCPA_HUMAN 60.35 T-complex protein 1 subunit alpha GN=TCP1 TCPA_HUMAN 60.35 T-complex protein 1 subunit alpha GN=TCP1 TCPA_HUMAN 60.35 T-complex protein 1 subunit alpha GN=TCP1 TCPA_HUMAN 60.3 T-complex protein 1 subunit alpha GN=TCP1 TCPA_HUMAN 60.3 T-complex protein 1 subunit alpha GN=TCP1 TCPA_HUMAN 60.35 T-complex protein 1 subunit alpha GN=TCP1 TCPA_HUMAN 60.3 T-complex protein 1 subunit alpha GN=TCP1 TCPA_HUMAN 60.35 T-complex protein 1 subunit alpha GN=TCP1 TCPA_HUMAN 60.35 T-complex protein 1 subunit alpha GN=TCP1 TCPA_HUMAN 60.35 T-complex protein 1 subunit alpha GN=TCP1 TCPA_HUMAN 60.35 T-complex protein 1 subunit alpha GN=TCP1 TCPA_HUMAN 60.3 T-complex protein 1 subunit alpha GN=TCP1 TCPA HUMAN 60.35 T-complex protein 1 subunit alpha GN=TCP1 TCPA_HUMAN 60.35 T-complex protein 1 subunit alpha GN=TCP1 TCPA_HUMAN 60.35 T-complex protein 1 subunit alpha GN=TCP1 TCPA_HUMAN 60.3 T-complex protein 1 subunit alpha GN=TCP1 TCPA_HUMAN 60.3 T-complex protein 1 subunit alpha GN=TCP1 TCPA_HUMAN 60.3 T-complex protein 1 subunit alpha GN=TCP1 TCPA_HUMAN 60.35 T-complex protein 1 subunit delta $\mathrm{GN}=\mathrm{CCT} 4$ TCPD_HUMAN 57.9 T-complex protein 1 subunit delta GN=CCT4 TCPD HUMAN 57.93 T-complex protein 1 subunit delta GN=CCT4 TCPD_HUMAN 57.93 T-complex protein 1 subunit delta $\mathrm{GN}=\mathrm{CCT} 4$ TCPD_HUMAN 57.9 . T-complex protein 1 subunit delta GN=CCT4 TCPD_HUMAN 57.93 T-complex protein 1 subunit delta GN=CCT4 TCPD_HUMAN 57.93 T-complex protein 1 subunit delta $\mathrm{GN}=\mathrm{CCT} 4$ TCPD HUMAN 57.93 T-complex protein 1 subunit delta GN=CCT4 TCPD_HUMAN 57.93 T-complex protein 1 subunit delta GN=CCT4 TCPD_HUMAN 57.9. T-complex protein 1 subunit delta GN=CCT4 TCPD_HUMAN 57.93 T-complex protein 1 subunit delta GN=CCT4 TCPD_HUMAN 57.93 T-complex protein 1 subunit epsilon GN=CCT5 TCPE HUMAN 59.67 T-complex protein 1 subunit epsilon GN=CCT5 TCPE HUMAN 59.67 T-complex protein 1 subunit epsilon GN=CCT5 TCPE_HUMAN 59.6? T-complex protein 1 subunit epsilon $\mathrm{GN}=\mathrm{CCT} 5$ TCPE HUMAN $59.6^{\circ}$ T-complex protein 1 subunit epsilon GN=CCT5 TCPE_HUMAN 59.67 T-complex protein 1 subunit epsilon GN=CCT5 TCPE_HUMAN 59.6 T-complex protein 1 subunit epsilon GN=CCT5 TCPE HUMAN $59.6^{\circ}$ T-complex protein 1 subunit epsilon GN=CCT5 TCPE_HUMAN 59.6? T-complex protein 1 subunit epsilon GN=CCT5 TCPE HUMAN 59.6 T-complex protein 1 subunit epsilon GN=CCT5 TCPE_HUMAN 59.67 T-complex protein 1 subunit epsilon $\mathrm{GN}=\mathrm{CCT} 5$ TCPE_HUMAN $59.6 ?$ T-complex protein 1 subunit epsilon $\mathrm{GN}=\mathrm{CCT} 5$ TCPE HUMAN $59.6^{6}$ T-complex protein 1 subunit eta $\mathrm{GN}=\mathrm{CCT} 7 \mathrm{TCPH}$ _HUMAN 59.37
$100.0 \% \quad 30$

$100.0 \% \quad 30$

$100.0 \% \quad 30$

$100.0 \% \quad 30$

$100.0 \% \quad 30$

$100.0 \% \quad 30$

$100.0 \% \quad 30$

$100.0 \% \quad 30$

$100.0 \% \quad 30$

$100.0 \% \quad 30$

$100.0 \% \quad 30$

$100.0 \% \quad 30$

$100.0 \% \quad 30$

$100.0 \% \quad 30$

$100.0 \% \quad 30$

$100.0 \% \quad 30$

$100.0 \% \quad 30$

$100.0 \% \quad 30$

$100.0 \% \quad 30$

$100.0 \% \quad 30$

$100.0 \% \quad 11$

$100.0 \% \quad 1$

$100.0 \% \quad 11$

$100.0 \% \quad 11$

$100.0 \% \quad 11$

$100.0 \% \quad 1$

$100.0 \% \quad 11$

$100.0 \% \quad 11$

$100.0 \% \quad 11$

$100.0 \% \quad 11$

$100.0 \% \quad 1$

$100.0 \%$

$100.0 \% \quad 1$

$100.0 \% \quad 1$

$100.0 \%$

$100.0 \%$

$100.0 \%$

$100.0 \%$

$100.0 \%$

$100.0 \%$

$100.0 \%$

$100.0 \%$

$100.0 \%$
$39 \quad 80 \quad 0.11 \% \quad 52.2 \%$ IHPTSVISGYR

$39 \quad 80 \quad 0.11 \% \quad 52.2 \%$ LACKEAVR

$80 \quad 0.11 \% \quad 52.2 \%$ YINENLIVNTDELGRDCLINAAK

$80 \quad 0.11 \% \quad 52.2 \%$ YPVNSVNILK

$0.11 \% 52.2 \%$ IACLDFSLQK

$0.11 \% \quad 52.2 \%$ IACLDFSLQKTK

$99.0 \% \quad 32.1$

$\begin{array}{lll}99.7 \% & 35.4\end{array}$

$25.0-30.4$

\section{$0.11 \% \quad 52.2 \%$ LGVQVVITDPEKLDQIR}

$0.11 \% \quad 52.2 \%$ ESDITKER

$0.11 \% \quad 52.2 \%$ ICDDELILIK

$0.11 \% \quad 52.2 \%$ ICDDELILIKNTK

$80 \quad 0.11 \% \quad 52.2 \%$ TSASIILR

$80 \quad 0.11 \% \quad 52.2 \%$ GANDFMCDEMER

$80 \quad 0.11 \% \quad 52.2 \%$ SLHDALCVVK

$80 \quad 0.11 \% \quad 52.2 \%$ SLHDALCVVKR

$0.11 \% \quad 52.2 \%$ EQLAIAEFAR

$80 \quad 0.11 \% \quad 52.2 \%$ SLLVIPNTLAVNAAQDSTDLVAK

$80 \quad 0.11 \% \quad 52.2 \%$ AFHNEAQVNPER

$80 \quad 0.11 \% \quad 52.2 \%$ AFHNEAQVNPERK

$80 \quad 0.11 \% \quad 52.2 \%$ WIGLDLSNGKPR

$80 \quad 0.11 \% \quad 52.2 \%$ DNKQAGVFEPTIVK

$80 \quad 0.11 \% \quad 52.2 \%$ QAGVFEPTIVK

$0.11 \% \quad 52.2 \%$ SLKFATEAAITILR

$0.11 \% \quad 52.2 \%$ FATEAAITILR

$0.03 \% \quad 26.2 \%$ PENVAPRSGATAGAAGGR

$0.03 \% \quad 26.2 \%$ GAYQDRDKPAQIR

$0.03 \% \quad 26.2 \%$ AVADAIRTSLGPK

$0.03 \% \quad 26.2 \%$ GIHPTIISESFQK

$0.03 \% \quad 26.2 \%$ IGLIQFCLSAPK

$0.03 \% \quad 26.2 \%$ TGCNVLLIQK

$0.03 \% \quad 26.2 \%$ SIHDALCVIR

$0.03 \% \quad 26.2 \%$ ALIAGGGAPEIELALR

$0.03 \% \quad 26.2 \%$ TLSGMESYCVR

$0.03 \% \quad 26.2 \%$ HAQGEKTAGINVR

$0.03 \% \quad 26.2 \%$ SILKIDDVVNTR

$0.04 \% \quad 28.5 \%$ TSLGPNGLDK

$0.04 \% \quad 28.5 \%$ IADGYEQAAR

$0.04 \% \quad 28.5 \%$ TTLGSKVVNSCHR

$0.04 \% 28.5 \%$ DVDFELIKVEGK

$0.04 \% 28.5 \%$ GVIVDKDFSHPQMPK

$0.04 \% \quad 28.5 \%$ IAILTCPFEPPKPK

$0.04 \% 28.5 \%$ WVGGPEIELIAIATGGR

$0.04 \% \quad 28.5 \%$ LGFAGLVQEISFGTTK

$0.04 \% \quad 28.5 \%$ SLHDALCVIR

$0.04 \% \quad 28.5 \%$ EMNPALGIDCLHK

$0.04 \% \quad 28.5 \%$ KQQISLATQMVR

$0.04 \% \quad 28.5 \%$ IDDIRKPGESEE

$0.01 \% \quad 8.1 \%$ LLDVVHPAAK
$25.0 \quad 30.7$

$\begin{array}{llll}99.7 \% & 50.1 & 25.0 & 50.1\end{array}$

$\begin{array}{llll}99.7 \% & 52.3 & 25.0 & 52.3\end{array}$

$\begin{array}{llll}99.0 \% & 50.0 & 25.0 & 33.2\end{array}$

$99.7 \% \quad 54.8 \quad 25.0 \quad 37.9$

$\begin{array}{llll}99.7 \% & 66.5 & 25.0 & 61.6\end{array}$

$99.0 \% \quad 28.4 \quad 25.0 \quad 17.8$

$\begin{array}{llll}99.7 \% & 50.8 & 25.0 & 50.8\end{array}$

$\begin{array}{lllll}99.7 \% & 44.2 & 25.0 & 40.8 & 2\end{array}$

$\begin{array}{llll}99.7 \% & 48.8 & 25.0 & 47.9\end{array}$

$\begin{array}{llll}99.7 \% & 57.5 & 25.0 & 54.9\end{array}$

$\begin{array}{lllll}9.7 \% & 51.4 & 25.0 & 51.4 & 3\end{array}$

$\begin{array}{llll}99.7 \% & 47.7 & 25.0 & 47.7\end{array}$

$\begin{array}{llll}99.7 \% & 49.2 & 25.0 & 39.2\end{array}$

$\begin{array}{llll}99.7 \% & 40.1 & 25.0 & 40.1\end{array}$

$\begin{array}{llll}99.7 \% & 53.9 & 25.0 & 48.8\end{array}$

$\begin{array}{lllll}99.7 \% & 30.3 & 25.0 & 26.9 & 2\end{array}$

$\begin{array}{llll}99.7 \% & 67.7 & 25.0 & 67.7\end{array}$

$\begin{array}{llll}99.7 \% & 62.4 & 25.0 & 51.2\end{array}$

\begin{tabular}{llll}
$99.7 \%$ & 29.9 & 25.0 & 29.9 \\
\hline
\end{tabular}

$\begin{array}{llll}99.6 \% & 23.6 & 25.0 & 23.6\end{array}$

$\begin{array}{llll}99.7 \% & 50.2 & 25.0 & 43.5\end{array}$

$\begin{array}{llll}97.3 \% & 16.3 & 25.0 & 16.3\end{array}$

$\begin{array}{llll}99.7 \% & 49.4 & 25.0 & 49.4\end{array}$

$\begin{array}{llll}99.4 \% & 24.3 & 25.0 & 17.7\end{array}$

$\begin{array}{llll}99.1 \% & 61.0 & 25.0 & 0.0\end{array}$

$\begin{array}{lllll}99.7 \% & 51.0 & 25.0 & 51.0\end{array}$

$\begin{array}{lllll}99.7 \% & 29.9 & 25.0 & 29.9 & 2\end{array}$

$\begin{array}{llll}99.7 \% & 36.0 & 25.0 & 35.0\end{array}$

$\begin{array}{llll}99.7 \% & 32.1 & 25.0 & 19.4\end{array}$

$\begin{array}{llll}99.7 \% & 27.5 & 25.0 & 21.2\end{array}$

$99.7 \% \quad 52.3 \quad 25.0 \quad 44.3$

$99.4 \% \quad 20.4 \quad 25.0 \quad 20.4$

$\begin{array}{llll}99.7 \% & 62.1 & 25.0 & 57.6\end{array}$

$\begin{array}{lllll}99.7 \% & 45.7 & 25.0 & 45.7\end{array}$

$\begin{array}{lllll}99.7 \% & 35.1 & 25.0 & 35.1 & 2\end{array}$

$\begin{array}{llll}99.7 \% & 67.6 & 25.0 & 66.0\end{array}$

$\begin{array}{llll}99.7 \% & 50.0 & 25.0 & 50.0\end{array}$

$\begin{array}{lllll}99.1 \% & 61.0 & 25.0 & 0.0 & 2\end{array}$

$\begin{array}{llll}99.7 \% & 52.8 & 25.0 & 46.5\end{array}$

$\begin{array}{llll}99.7 \% & 36.3 & 25.0 & 36.3\end{array}$

$\begin{array}{llll}96.1 \% & 20.2 & 25.0 & 11.1\end{array}$

$\begin{array}{llll}99.7 \% & 29.1 & 25.0 & 23.8\end{array}$ 
T-complex protein 1 subunit eta GN=CCT7 TCPH HUMAN $59.37 \quad 100.0 \%$ T-complex protein 1 subunit eta GN=CCT7 TCPH_HUMAN $59.37 \quad 100.0 \%$ T-complex protein 1 subunit gamma GN=CCT3 TCPG_HUMAN $60.54 \quad 100.0 \%$ T-complex protein 1 subunit gamma GN=CCT3 TCPG_HUMAN $60.54 \quad 100.0 \%$ T-complex protein 1 subunit gamma GN=CCT3 TCPG_HUMAN $60.54 \quad 100.0 \%$ T-complex protein 1 subunit gamma GN=CCT3 TCPG_HUMAN $60.54 \quad 100.0 \%$ T-complex protein 1 subunit gamma GN=CCT3 TCPG_HUMAN $60.54 \quad 100.0 \%$ T-complex protein 1 subunit gamma GN=CCT3 TCPG_HUMAN $60.54 \quad 100.0 \%$ T-complex protein 1 subunit gamma GN=CCT3 TCPG_HUMAN $60.54 \quad 100.0 \%$ T-complex protein 1 subunit gamma GN=CCT3 TCPG_HUMAN $60.54 \quad 100.0 \%$ T-complex protein 1 subunit gamma GN=CCT3 TCPG_HUMAN $60.54 \quad 100.0 \%$ T-complex protein 1 subunit gamma GN=CCT3 TCPG_HUMAN $60.54 \quad 100.0 \%$ T-complex protein 1 subunit gamma GN=CCT3 TCPG_HUMAN $60.54 \quad 100.0 \%$ T-complex protein 1 subunit gamma GN=CCT3 TCPG_HUMAN $60.54 \quad 100.0 \%$ T-complex protein 1 subunit gamma GN=CCT3 TCPG_HUMAN $60.54 \quad 100.0 \%$ T-complex protein 1 subunit gamma GN=CCT3 TCPG_HUMAN $60.54 \quad 100.0 \%$ T-complex protein 1 subunit gamma GN=CCT3 TCPG_HUMAN $60.54 \quad 100.0 \%$ T-complex protein 1 subunit gamma GN=CCT3 TCPG_HUMAN $60.54 \quad 100.0 \%$ T-complex protein 1 subunit gamma GN=CCT3 TCPG_HUMAN $60.54 \quad 100.0 \%$ T-complex protein 1 subunit theta $\mathrm{GN}=\mathrm{CCT} 8 \mathrm{TCPQ}$ HUMAN $59.62 \quad 100.0 \%$ T-complex protein 1 subunit theta GN=CCT8 TCPQ_HUMAN $59.62 \quad 100.0 \%$ T-complex protein 1 subunit theta $\mathrm{GN}=\mathrm{CCT} 8 \mathrm{TCPQ}$ HUMAN $59.62 \quad 100.0 \%$ T-complex protein 1 subunit zeta GN=CCT6A TCPZ_HUMAN $58.03 \quad 100.0 \%$ T-complex protein 1 subunit zeta GN=CCT6A TCPZ_HUMAN $58.03 \quad 100.0 \%$ T-complex protein 1 subunit zeta GN=CCT6A TCPZ HUMAN $58.03 \quad 100.0 \%$ T-complex protein 1 subunit zeta GN=CCT6A TCPZ_HUMAN $58.03 \quad 100.0 \%$ T-complex protein 1 subunit zeta GN=CCT6A TCPZ_HUMAN $58.03 \quad 100.0 \%$ T-complex protein 1 subunit zeta GN=CCT6A TCPZ_HUMAN $58.03 \quad 100.0 \%$ T-complex protein 1 subunit zeta GN=CCT6A TCPZ_HUMAN $58.03 \quad 100.0 \%$ T-complex protein 1 subunit zeta GN=CCT6A TCPZ HUMAN $58.03 \quad 100.0 \%$ T-complex protein 1 subunit zeta GN=CCT6A TCPZ_HUMAN $58.03 \quad 100.0 \%$ T-complex protein 1 subunit zeta GN=CCT6A TCPZ_HUMAN $58.03 \quad 100.0 \%$ T-complex protein 1 subunit zeta $\mathrm{GN}=\mathrm{CCT} 6 \mathrm{~A}$ TCPZ_HUMAN $58.03 \quad 100.0 \%$ T-complex protein 1 subunit zeta GN=CCT6A TCPZ_HUMAN $58.03 \quad 100.0 \%$ T-complex protein 1 subunit zeta GN=CCT6A TCPZ_HUMAN $58.03 \quad 100.0 \%$ T-complex protein 1 subunit zeta GN=CCT6A TCPZ_HUMAN $58.03 \quad 100.0 \%$ T-complex protein 1 subunit zeta GN=CCT6A TCPZ_HUMAN $58.03 \quad 100.0 \%$ T-complex protein 1 subunit zeta GN=CCT6A TCPZ HUMAN $58.03 \quad 100.0^{\circ}$ Telomere-associated protein RIF1 GN=RIF1 RIF1_HUMAN $274.47 \quad 100.0 \%$ Telomere-associated protein RIF1 GN=RIF1 RIF1_HUMAN $274.47 \quad 100.0 \%$ Telomere-associated protein RIF1 GN=RIF1 RIF1_HUMAN $274.47 \quad 100.0 \%$ Telomere-associated protein RIF1 GN=RIF1 RIF1_HUMAN $274.47 \quad 100.0 \%$ Telomere-associated protein RIF1 GN=RIF1 RIF1_HUMAN $274.47 \quad 100.0 \%$ Telomere-associated protein RIF1 GN=RIF1 RIF1_HUMAN $274.47 \quad 100.0 \%$ Telomere-associated protein RIF1 GN=RIF1 RIF1_HUMAN $274.47 \quad 100.0 \%$ Telomere-associated protein RIF1 GN=RIF1 RIF1_HUMAN $274.47 \quad 100.0 \%$ Telomere-associated protein RIF1 GN=RIF1 RIF1_HUMAN $274.47 \quad 100.0 \%$ $\begin{array}{lll}0.01 \% & 8.1 \% & \text { VQGGALEDSQLVAGVAFKK } \\ 0.01 \% & 8.1 \% & \text { TIPGKQQLLIGAYAK }\end{array}$

$0.01 \%$

$0.07 \% \quad 35.4 \%$ KVQSGNINAAK

$0.07 \% \quad 35.4 \%$ EIQVQHPAAK

$0.07 \% \quad 35.4 \%$ ALDDMISTLK

$0.07 \% \quad 35.4 \%$ ALDDMISTLKK

$0.07 \% \quad 35.4 \%$ WSSLACNIALDAVK

$0.07 \% \quad 35.4 \%$ VEKIPGGIIEDSCVLR

$0.07 \% \quad 35.4 \%$ IPGGIIEDSCVLR

$0.07 \% \quad 35.4 \%$ GVMINKDVTHPR

$0.07 \% \quad 35.4 \%$ IVLLDSSLEYK

$0.07 \% \quad 35.4 \%$ GISDLAQHYLMR

$0.07 \% \quad 35.4 \%$ ANITAIRR

$0.07 \% \quad 35.4 \%$ IGDEYFTFITDCKDPK

$0.07 \% \quad 35.4 \%$ GASKEILSEVER

$0.07 \% \quad 35.4 \%$ NVLLDPQLVPGGGASEMAVAHALTEK

$0.07 \% \quad 35.4 \%$ AVAQALEVIPR

$0.07 \% \quad 35.4 \%$ TLIQNCGASTIR

$0.07 \% \quad 35.4 \%$ TAVETAVLLLR

$0.01 \% \quad 6.4 \%$ AIADTGANVVVTGGK

$0.01 \% \quad 6.4 \% \quad$ FAEAFEAIPR

$0.01 \% \quad 6.4 \% \quad$ LYAVHQEGNK

$0.06 \% \quad 39.2 \%$ TLNPKAEVAR

$0.06 \% 39.2 \%$ AQAALAVNISAAR

$0.06 \% \quad 39.2 \%$ TNLGPKGTMK

$0.06 \% 39.2 \%$ MLVSGAGDIKLTK

$0.06 \% \quad 39.2 \%$ DGNVLLHEMQIQHPTASLIAK

$0.06 \% \quad 39.2 \%$ VATAQDDITGDGTTSNVLIIGELLK

$0.06 \% \quad 39.2 \%$ QADLYISEGLHPR

$0.06 \% \quad 39.2 \%$ IITEGFEAAKEK

$0.06 \% \quad 39.2 \%$ ALQFLEEVKVSR

$0.06 \% \quad 39.2 \%$ EMDRETLIDVAR

$0.06 \% \quad 39.2 \%$ HKSETDTSLIR

$0.06 \% \quad 39.2 \%$ GLVLDHGAR

$0.06 \% 39.2 \%$ GIDPFSLDALSK

$0.06 \% \quad 39.2 \%$ EGIVALRR

$0.06 \% 39.2 \%$ SVTLLIKGPNK

$0.06 \% \quad 39.2 \%$ VLAQNSGFDLQETLVK

$0.08 \% \quad 9.1 \%$ LIEQAPIQMGEEAVR

$0.08 \% \quad 9.1 \%$ LVIPLVVHSAQK

$0.08 \% \quad 9.1 \%$ GATALEMGMPLLLQK

$0.08 \% \quad 9.1 \%$ GASSPYGAPGTPR

$0.08 \% \quad 9.1 \%$ DSFLAQTK

$0.08 \% \quad 9.1 \%$ ILTDHQKEVLK

$0.08 \% \quad 9.1 \%$ SPLHIKDDVLPK

$0.08 \% \quad 9.1 \%$ LIAEQTLQENLIEK

$0.08 \% \quad 9.1 \%$ TLGETSANAETEQNKK
$99.1 \% \quad 19.3 \quad 25.0$

$99.7 \% \quad 58.5$

$99.7 \% \quad 39.5$

$99.7 \% \quad 46.9$

$\begin{array}{lll}99.7 \% & 36.8\end{array}$

$99.7 \% \quad 55.1$

$99.7 \% \quad 45.2$

$99.7 \% \quad 42.8$

$99.7 \% \quad 46.1$

$99.7 \% \quad 53.9$

$99.7 \% \quad 62.6$

$99.0 \% \quad 38.7$

$98.6 \% \quad 19.8$

$99.7 \% \quad 56.5$

$99.7 \% \quad 26.4$

$99.7 \% \quad 59.9$

$99.7 \% \quad 62.5$

$99.7 \% \quad 68.7$

$99.7 \% \quad 71.5$

$99.7 \% \quad 52.6$

$98.3 \% \quad 19.7$

$99.7 \% \quad 39.2$

$99.7 \% \quad 44.8$

$99.0 \% \quad 24.1$

$99.7 \% \quad 56.9$

$99.7 \% \quad 53.0$

$99.7 \% \quad 54.7$

$\begin{array}{lll}99.7 \% & 54.7\end{array}$

$99.7 \% 57$.

$99.7 \% \quad 38.5$

$99.6 \% \quad 25.2$

$99.7 \% \quad 46.0$

$99.7 \% \quad 59.5$

$99.0 \% 27.4$

$99.6 \% \quad 23.8$

$99.7 \% \quad 81.9$

$\begin{array}{lll}99.7 \% & 30.7\end{array}$

$99.7 \% \quad 30.3$

$99.7 \% \quad 33.4$

$99.7 \% \quad 54.5$

$95.5 \% \quad 17.4$

$99.1 \% \quad 23.6$

$99.4 \% \quad 20.8$

$99.7 \% \quad 54.3$

$99.7 \% \quad 41.7$
1600.94

1129.63

1120.61

1106.58

1234.67

1547.79

1784.96

1428.75

1382.72

1279.71

1403.71

914.55

1948.90

1317.70

2633.36

1166.69

1333.69

1185.72

1372.74

1150.59

1158.59

1098.63

1255.71

1046.57

1332.76

2315.22

2544.34

1498.77

1335.72

1418.80

1447.72

1286.67

937.52

1262.66

913.56

1169.73

1761.94

1683.87

1303.81

1604.84

1217.59

909.47

1323.76

1361.78

1641.91

1720.83

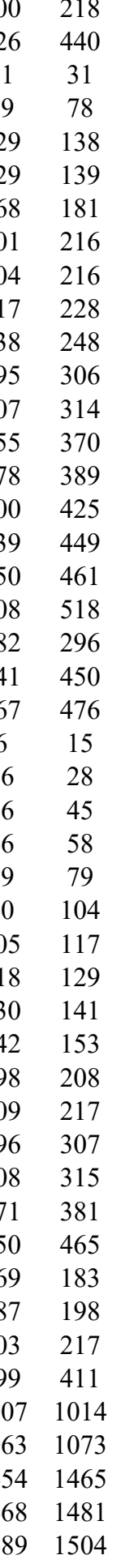

Page 126 of Table S-1-1 
Telomere-associated protein RIF1 GN=RIF1 RIF1 HUMAN $274.47 \quad 100.0 \%$ Telomere-associated protein RIF1 GN=RIF1 RIF1_HUMAN $274.47 \quad 100.0 \%$ Telomere-associated protein RIF1 GN=RIF1 RIF1_HUMAN $274.47 \quad 100.0 \%$ Telomere-associated protein RIF1 GN=RIF1 RIF1_HUMAN $274.47 \quad 100.0 \%$ Telomere-associated protein RIF1 GN=RIF1 RIF1_HUMAN $274.47 \quad 100.0 \%$ Telomere-associated protein RIF1 GN=RIF1 RIF1_HUMAN $274.47 \quad 100.0 \%$ Telomere-associated protein RIF1 GN=RIF1 RIF1_HUMAN $274.47 \quad 100.0 \%$ Telomere-associated protein RIF1 GN=RIF1 RIF1_HUMAN $274.47 \quad 100.0 \%$ Testis-expressed sequence 10 protein GN=TEX10 TEX10 HUMAN $105.68 \quad 100.0 \%$ Testis-expressed sequence 10 protein GN=TEX10 TEX10_HUMAN $105.68 \quad 100.0 \%$ Testis-expressed sequence 10 protein GN=TEX10 TEX10_HUMAN $105.68 \quad 100.0 \%$ Testis-expressed sequence 10 protein GN=TEX10 TEX10 HUMAN $105.68 \quad 100.0 \%$ Testis-expressed sequence 10 protein GN=TEX10 TEX10_HUMAN $105.68 \quad 100.0 \%$ Tetratricopeptide repeat protein $37 \mathrm{GN}=$ TTC37 TTC37_HUMAN $175.49 \quad 100.0 \%$ Tetratricopeptide repeat protein $37 \mathrm{GN}=$ TTC37 TTC37_HUMAN $175.49 \quad 100.0 \%$ Tetratricopeptide repeat protein 37 GN=TTC37 TTC37_HUMAN $175.49 \quad 100.0 \%$ Tetratricopeptide repeat protein $37 \mathrm{GN}=\mathrm{TTC} 37$ TTC37 HUMAN $175.49 \quad 100.0 \%$ TGF-beta-activated kinase 1 and MAP3K7-binding protein $1 \mathrm{GN}=\mathrm{TAB} 1$ TAB1_HUMAN $54.64 \quad 100.0 \%$ TGF-beta-activated kinase 1 and MAP3K7-binding protein $1 \mathrm{GN}=\mathrm{TAB} 1$ TAB1_HUMAN $54.64 \quad 100.0 \%$ TGF-beta-activated kinase 1 and MAP3K7-binding protein $1 \mathrm{GN}=\mathrm{TAB} 1 \mathrm{TAB} 1$ HUMAN $54.64 \quad 100.0 \%$ TGF-beta-activated kinase 1 and MAP3K7-binding protein $1 \mathrm{GN}=\mathrm{TAB} 1$ TAB1_HUMAN $54.64 \quad 100.0 \%$ TGF-beta-activated kinase 1 and MAP3K7-binding protein $1 \mathrm{GN}=\mathrm{TAB} 1 \mathrm{TAB} 1$ HUMAN $54.64100 .0 \%$ TGF-beta-activated kinase 1 and MAP3K7-binding protein $1 \mathrm{GN}=\mathrm{TAB} 1$ TAB1 HUMAN $54.64 \quad 100.0 \%$ TGF-beta-activated kinase 1 and MAP3K7-binding protein 2 GN=TAB2 $\quad$ TAB2_HUMAN $76.49 \quad 100.0 \%$ TGF-beta-activated kinase 1 and MAP3K7 binding protein 2 GN=TAB2 TAB2 HUMAN $76.49 \quad 100.0 \%$ TGF-beta-activated kinase 1 and MAP3K7-binding protein 3 GN=TAB3 $\quad$ TAB3_HUMAN $78.68 \quad 100.0 \%$ TGF-beta-activated kinase 1 and MAP3K7-binding protein $3 \mathrm{GN}=\mathrm{TAB} 3$ TAB3_HUMAN $78.68 \quad 100.0 \%$ THO complex subunit $2 \mathrm{GN}=\mathrm{THOC} 2$ THO complex subunit $2 \mathrm{GN}=\mathrm{THOC} 2$ THO complex subunit $2 \mathrm{GN}=\mathrm{THOC} 2$ THO complex subunit $2 \mathrm{GN}=\mathrm{THOC} 2$ THO complex subunit $2 \mathrm{GN}=\mathrm{THOC} 2$ THO complex subunit $3 \mathrm{GN}=\mathrm{THOC} 3$ THO complex subunit $3 \mathrm{GN}=\mathrm{THOC} 3$ THO complex subunit $3 \mathrm{GN}=\mathrm{THOC} 3$ THO complex subunit 4 GN=ALYREF THO complex subunit $4 \mathrm{GN}=\mathrm{ALYREF}$ THO complex subunit $4 \mathrm{GN}=\mathrm{ALYREF}$ THO complex subunit $4 \mathrm{GN}=\mathrm{ALYREF}$ THO complex subunit 4 GN=ALYREF Threonine--tRNA ligase, mitochondrial GN=TARS2 SYTM_HUMAN $81.04 \quad 100.0 \%$ Thyroid adenoma-associated protein GN=THADA THADA_HUMAN $219.61 \quad 100.0 \%$ Thyroid adenoma-associated protein GN=THADA THADA_HUMAN $219.61 \quad 100.0 \%$ Thyroid hormone receptor-associated protein 3 GN=THRAP3 TR150_HUMAN $108.67 \quad 100.0 \%$ Thyroid hormone receptor-associated protein $3 \mathrm{GN}=\mathrm{THRAP} 3 \mathrm{TR} 150$ HUMAN $108.67 \quad 100.0 \%$ Thyroid hormone receptor-associated protein $3 \mathrm{GN}=$ THRAP3 TR150_HUMAN $108.67 \quad 100.0 \%$ 1HOC2_HUMAN $182.78 \quad 100.0 \%$ THOC2 HUMAN $182.78 \quad 100.0 \%$ THOC2_HUMAN $182.78 \quad 100.0 \%$ THOC2_HUMAN $182.78 \quad 100.0 \%$ THOC3 HUMAN $38.77 \quad 100.0 \%$ $\begin{array}{lll}\text { THOC_HUMAN } & 38.77 & 100.0 \%\end{array}$ THOC4_HUMAN $26.89 \quad 100.0 \%$ THOC4_HUMAN $26.89 \quad 100.0 \%$ THOC4 HUMAN $26.89 \quad 100.0 \%$ THOC4_HUMAN $26.89 \quad 100.0 \%$ THOC4_HUMAN $26.89 \quad 100.0 \%$

5
5

$0.08 \% 9.1 \%$ YAEYSFTSLPVPESNLR

$0.08 \% \quad 9.1 \%$ VTESNLEKAK

$0.08 \% \quad 9.1 \%$ TMELNVGNEASFHGQER

$0.08 \% \quad 9.1 \%$ SQEDEISSPVNKVR

$0.08 \% \quad 9.1 \%$ SHSSNSSPIGK

$0.08 \% \quad 9.1 \%$ TIGDLSTLTASEIK

$0.01 \% \quad 6.5 \%$ NFVELISHQQLSK

$0.01 \% \quad 6.5 \% \quad$ FLQALADGSSR

$0.01 \% \quad 6.5 \% \quad$ AVYTLYQQR

$0.01 \% \quad 6.5 \%$ SQNFDILQSAISK

$0.01 \% \quad 6.5 \%$ VGPEELPVVGQLLR

$0.01 \% \quad 3.0 \%$ SGPGLIGLGIK

$0.01 \% \quad 3.0 \%$ GGYTTALKSFTK

$0.01 \% \quad 3.0 \%$ SNPDQPAVILLLR

$0.01 \% \quad 3.0 \%$ ALELNQRLSSQ

$0.04 \% \quad 15.7 \%$ VLLQAFDVVER

$0.04 \% \quad 15.7 \%$ SFLESIDDALAEK

$0.04 \% \quad 15.7 \%$ YGYTDIDLLSAAK

$0.04 \% \quad 15.7 \%$ QTSLDAVAQAVVDR

$0.04 \% \quad 15.7 \%$ IHSDTFASGGER

$0.04 \% \quad 15.7 \%$ VYPVSVPYSSAQSTSK

$0.01 \% \quad 3.8 \% \quad$ TSSTSSSVNSQTLNR

$0.01 \% \quad 3.8 \%$ AIGNNSATSPR

$0.00 \% \quad 4.6 \%$ QGSHSVAYLPYTASSLSK

$0.00 \% \quad 4.6 \%$ ATTENLLNLVDQEER

$0.02 \% \quad 3.2 \%$ GSPVNALQNK

$0.02 \% \quad 3.2 \%$ CIFSAIDAVYCAR

$0.02 \% \quad 3.2 \% \quad$ FVELVHQQK

$0.02 \% \quad 3.2 \%$ VLNLGQALER

$0.02 \% \quad 3.2 \%$ TPATTPEAR

$0.01 \% \quad 9.4 \%$ YVLGMQELFR

$0.01 \% \quad 9.4 \%$ TLSFSHDGK

$0.01 \% \quad 9.4 \%$ EAGTVKLFGLPNDS

$0.03 \% \quad 28.0 \%$ NRPAPYSRPK

$0.03 \% \quad 28.0 \%$ KAAVHYDR

$0.03 \% \quad 28.0 \%$ SLGTADVHFER

$0.03 \% \quad 28.0 \%$ QYNGVPLDGRPMNIQLVTSQIDAQR

$0.03 \% \quad 28.0 \%$ QQLSAEELDAQLDAYNAR

$0.00 \% \quad 3.6 \%$ SSGAPETLQR

$0.00 \% \quad 3.6 \%$ LVELQNTRVPNAEEIF

$0.00 \% \quad 1.4 \%$ LGENIIPYVADGAK

$0.00 \% \quad 1.4 \%$ NSSTLLFSALITR

$146 \quad 0.20 \% \quad 26.2 \%$ ASESSKPWPDATYGTGSASR

$146 \quad 0.20 \% \quad 26.2 \%$ ASAVSELSPR

$146 \quad 0.20 \% \quad 26.2 \%$ ASAVSELSPRER
$99.7 \% \quad 32.9$ $99.7 \% \quad 51.4$ $99.7 \% \quad 55.7$ $98.6 \% 23.5$

$99.3 \% \quad 20.3$ $\begin{array}{lll}99.7 \% & 50.2\end{array}$

$97.5 \% \quad 16.3$

$99.7 \% 53.2$

$98.1 \% 26.6$

$95.8 \% \quad 15.2$

$99.7 \% \quad 46.4$

$99.7 \% \quad 67.9$

$\begin{array}{ll}99.7 \% & 39.8\end{array}$

$\begin{array}{lll}99.7 \% & 31.7\end{array}$

$97.0 \% \quad 19.0$

$99.7 \% \quad 50.3$

$99.7 \% \quad 41.2$

$99.7 \% \quad 48.5$

$99.7 \% \quad 55.9$

$99.7 \% \quad 56.0$

$99.7 \% \quad 42.8$

$99.7 \% \quad 53.1$

$99.7 \% \quad 40.4$

$99.7 \% \quad 40.7$

$99.7 \% \quad 49.1$

$99.6 \% \quad 22.0$

$\begin{array}{lll}99.7 \% & 30.4\end{array}$

$99.6 \% 25.2$

$99.7 \% \quad 40.7$

$99.7 \% \quad 26.5$

$99.7 \% \quad 43.9$

$99.7 \% \quad 57.3$

$99.7 \% \quad 39.5$

$99.2 \% \quad 20.6$

$99.7 \% \quad 36.8$

$98.8 \% 19.4$

$99.0 \% \quad 33.0$

$99.7 \% \quad 59.0$

$\begin{array}{lll}99.7 \% & 29.9\end{array}$

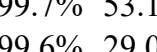

$\begin{array}{lll}99.7 \% & 32.3\end{array}$

$99.7 \% 36.8$

$99.7 \% \quad 60.7$

$99.7 \% \quad 42.8$

$99.7 \% \quad 56.2$

$99.7 \% \quad 37.5$
1972.97

1445.59

1248.67

1118.61

1934.87

1587.80

1100.53

1448.7

1542.83

1164.60

1141.60

1450.75

1505.87

1011.62

1273.68

1435.83

1258.68

1288.73

1437.71

1429.72

1472.77

1276.59

1699.85

1568.75

1087.55

1895.95

1744.87

1027.55

1545.72

1127.62

1112.64

943.48

1255.65

991.48

1447.74

1185.65

959.51

1231.6

2829.43

2034.97

1045.53

1871.99

1459.78

1422.80

2054.94

1016.54

1301.68 
Thyroid hormone receptor-associated protein 3 GN=THRAP3 TR150_HUMAN $108.67 \quad 100.0 \% \quad 28$ Thyroid hormone receptor-associated protein $3 \mathrm{GN}=$ THRAP3 TR150_HUMAN $108.67 \quad 100.0 \% \quad 28$ Thyroid hormone receptor-associated protein $3 \mathrm{GN}=$ THRAP3 TR150_HUMAN $108.67 \quad 100.0 \% \quad 28$ Thyroid hormone receptor-associated protein $3 \mathrm{GN}=\mathrm{THRAP} 3 \mathrm{TR} 150$ HUMAN $108.67 \quad 100.0 \% \quad 28$ Thyroid hormone receptor-associated protein $3 \mathrm{GN}=$ THRAP3 TR150_HUMAN $108.67 \quad 100.0 \% \quad 28$ Thyroid hormone receptor-associated protein $3 \mathrm{GN}=$ THRAP3 TR150_HUMAN $108.67 \quad 100.0 \% \quad 28$ Thyroid hormone receptor-associated protein $3 \mathrm{GN}=$ THRAP3 TR150_HUMAN $108.67 \quad 100.0 \% \quad 28$ Thyroid hormone receptor-associated protein $3 \mathrm{GN}=$ THRAP3 TR150_HUMAN $108.67 \quad 100.0 \% \quad 28$ Thyroid hormone receptor-associated protein $3 \mathrm{GN}=\mathrm{THRAP} 3 \mathrm{TR} 150$ HUMAN $108.67 \quad 100.0 \%$ Thyroid hormone receptor-associated protein $3 \mathrm{GN}=$ THRAP3 TR150_HUMAN $108.67 \quad 100.0 \% \quad 28$ Thyroid hormone receptor-associated protein $3 \mathrm{GN}=$ THRAP3 TR150_HUMAN $108.67 \quad 100.0 \% \quad 28$ Thyroid hormone receptor-associated protein $3 \mathrm{GN}=$ THRAP3 TR150_HUMAN $108.67 \quad 100.0 \% 28$ Thyroid hormone receptor-associated protein $3 \mathrm{GN}=\mathrm{THRAP} 3 \mathrm{TR} 150 \_$HUMAN $108.67 \quad 100.0 \% \quad 28$ Thyroid hormone receptor-associated protein $3 \mathrm{GN}=$ THRAP3 TR150_HUMAN $108.67 \quad 100.0 \% 28$ Thyroid hormone receptor-associated protein 3 GN=THRAP3 TR150_HUMAN $108.67 \quad 100.0 \% \quad 28$ Thyroid hormone receptor-associated protein $3 \mathrm{GN}=$ THRAP3 TR150_HUMAN $108.67 \quad 100.0 \% \quad 28$ Thyroid hormone receptor-associated protein $3 \mathrm{GN}=\mathrm{THRAP} 3 \mathrm{TR} 150$ HUMAN $108.67 \quad 100.0 \%$ Thyroid hormone receptor-associated protein $3 \mathrm{GN}=\mathrm{THRAP} 3$ TR150_HUMAN $108.67 \quad 100.0 \% \quad 28$ Thyroid hormone receptor-associated protein $3 \mathrm{GN}=$ THRAP3 TR150_HUMAN $108.67 \quad 100.0 \% 28$ Thyroid hormone receptor-associated protein $3 \mathrm{GN}=$ THRAP3 TR150_HUMAN $108.67 \quad 100.0 \% \quad 28$ Thyroid hormone receptor-associated protein $3 \mathrm{GN}=$ THRAP3 TR150_HUMAN $108.67 \quad 100.0 \% \quad 28$ Thyroid hormone receptor-associated protein $3 \mathrm{GN}=\mathrm{THRAP} 3 \mathrm{TR} 150$ HUMAN $108.67 \quad 100.0 \%$ Thyroid hormone receptor-associated protein $3 \mathrm{GN}=$ THRAP3 TR150_HUMAN $108.67 \quad 100.0 \% \quad 28$ Thyroid hormone receptor-associated protein $3 \mathrm{GN}=$ THRAP3 TR150_HUMAN $108.67 \quad 100.0 \% \quad 28$ Thyroid hormone receptor-associated protein 3 GN=THRAP3 TR150_HUMAN $108.67 \quad 100.0 \%$ TP53-regulating kinase GN=TP53RK TP53-regulating kinase $\mathrm{GN}=\mathrm{TP} 53 \mathrm{RK}$ TP53-regulating kinase $\mathrm{GN}=\mathrm{TP} 53 \mathrm{RK}$ TP53-regulating kinase $\mathrm{GN}=\mathrm{TP} 53 \mathrm{RK}$ TP53-regulating kinase $\mathrm{GN}=\mathrm{TP} 53 \mathrm{RK}$ TP53-regulating kinase $\mathrm{GN}=\mathrm{TP} 53 \mathrm{RK}$ TraB domain-containing protein GN=TRABD TRABD_HUMAN $42.32 \quad 100.0 \%$ TraB domain-containing protein GN=TRABD TRABD_HUMAN $42.32 \quad 100.0 \%$ Transcription activator BRG1 GN=SMARCA4 SMCA4_HUMAN $184.65 \quad 100.0 \%$ Transcription activator BRG1 GN=SMARCA4 SMCA4_HUMAN $184.65100 .0 \%$ Transcription activator BRG1 GN=SMARCA4 SMCA4_HUMAN $184.65 \quad 100.0 \%$ Transcription activator BRG1 GN=SMARCA4 SMCA4_HUMAN $184.65 \quad 100.0 \%$ Transcription activator BRG1 GN=SMARCA4 SMCA4 HUMAN $184.65 \quad 100.0 \%$ Transcription activator BRG1 GN=SMARCA4 SMCA4_HUMAN $184.65 \quad 100.0 \%$ Transcription activator BRG1 GN=SMARCA4 SMCA4_HUMAN $184.65100 .0 \%$ Transcription activator BRG1 GN=SMARCA4 SMCA4_HUMAN $184.65100 .0 \%$ Transcription activator BRG1 GN=SMARCA4 SMCA4_HUMAN $184.65 \quad 100.0 \%$ Transcription activator BRG1 GN=SMARCA4 SMCA4 HUMAN $184.65100 .0 \%$ Transcription activator BRG1 GN=SMARCA4 SMCA4_HUMAN $184.65 \quad 100.0 \%$ Transcription activator BRG1 GN=SMARCA4 SMCA4_HUMAN $184.65 \quad 100.0 \%$ Transcription activator BRG1 GN=SMARCA4 SMCA4_HUMAN $184.65100 .0 \%$ Transcription activator BRG1 GN=SMARCA4 SMCA4_HUMAN $184.65 \quad 100.0 \%$ PRPK_HUMAN $28.16 \quad 100.0 \%$ PRPK_HUMAN $28.16 \quad 100.0 \%$ PRPK_HUMAN $28.16 \quad 100.0 \%$ PRPK_HUMAN $28.16 \quad 100.0 \%$

6
6
6
2

2

2

$\begin{array}{ll}15 & 17 \\ 15 & 17 \\ 15 & 17\end{array}$

15
15
15

15
15

15
15
15

15
15
15

15
15

$146 \quad 0.20 \% \quad 26.2 \%$ SPALKSPLQSVVVR

$146 \quad 0.20 \% \quad 26.2 \%$ SPLQSVVVR

$146 \quad 0.20 \% \quad 26.2 \%$ SPPSTGSTYGSSQKEESAASGGAAYTK

$146 \quad 0.20 \% \quad 26.2 \%$ EESAASGGAAYTK

$146 \quad 0.20 \% \quad 26.2 \%$ EESAASGGAAYTKR

$146 \quad 0.20 \% \quad 26.2 \%$ GSFSDTGLGDGK

$146 \quad 0.20 \% \quad 26.2 \%$ GSFSDTGLGDGKMK

$146 \quad 0.20 \% \quad 26.2 \%$ MKSDSFAPK

$146 \quad 0.20 \% \quad 26.2 \%$ TDSEKPFR

$146 \quad 0.20 \% \quad 26.2 \%$ ESEFDDEPKFMSK

$146 \quad 0.20 \% \quad 26.2 \%$ VIGANKNQEEEK

$146 \quad 0.20 \% \quad 26.2 \%$ KTEELEEESFPER

$146 \quad 0.20 \% \quad 26.2 \%$ TEELEEESFPER

$146 \quad 0.20 \% \quad 26.2 \%$ GFVPEKNFR

$146 \quad 0.20 \% \quad 26.2 \%$ NFRVTAYK

$146 \quad 0.20 \% \quad 26.2 \%$ VTAYKAVQEK

$146 \quad 0.20 \% \quad 26.2 \%$ LGAKGDFPTGK

$146 \quad 0.20 \% \quad 26.2 \%$ GDFPTGKSSFSITR

$\begin{array}{llll}146 & 0.20 \% & 26.2 \% & \text { SSFSITREAQVNVR }\end{array}$

$146 \quad 0.20 \% \quad 26.2 \%$ MDSFDEDLARPSGLLAQER

$146 \quad 0.20 \% \quad 26.2 \%$ SIFQHIQSAQSQR

$146 \quad 0.20 \% \quad 26.2 \%$ RIDISPSTFR

$146 \quad 0.20 \% \quad 26.2 \%$ IDISPSTFRK

$146 \quad 0.20 \% \quad 26.2 \% \quad$ YKDDPVDLR

$146 \quad 0.20 \% \quad 26.2 \%$ NREEEWDPEYTPK

\begin{tabular}{ll}
$0.01 \%$ & $22.1 \%$ \\
$0.01 \%$ & $22.1 \%$ ATTPADGEEPAPEAEALAAAR \\
\hline 0.0 & $22.1 \%$
\end{tabular} $0.01 \% \quad 22.1 \%$ FLSGLELVK $0.01 \% \quad 22.1 \%$ FLSGLELVKQGAEAR $0.01 \% \quad 22.1 \%$ GYRHPALEAR

$0.01 \% \quad 22.1 \%$ TIGQVLAR

$0.00 \% \quad 5.9 \%$ TVTQLVAEDGSR

$0.00 \% \quad 5.9 \% \quad$ AIAALSFWQK

$0.03 \% \quad 9.8 \%$ GQPLPDHLQMAVQGK

$0.03 \% \quad 9.8 \%$ IQELENLPGSLAGDLR

$0.03 \% \quad 9.8 \%$ RDTALETALNAK

$0.03 \% \quad 9.8 \%$ DTALETALNAK

$0.03 \% \quad 9.8 \%$ LMAEDEEGYRK

$0.03 \% \quad 9.8 \% \quad$ LTQVLNTHYVAPR

$0.03 \% \quad 9.8 \%$ VDLNEEETILIIR

$0.03 \% \quad 9.8 \%$ VLRPFLLR

$0.03 \% \quad 9.8 \%$ CDMSALQR

$0.03 \% \quad 9.8 \%$ IGQQNEVR

$0.03 \% \quad 9.8 \%$ LCTVNSVEEK

$0.03 \% \quad 9.8 \%$ VIQAGMFDQK

$0.03 \% \quad 9.8 \%$ DSDAGSSTPTTSTR

$0.03 \% \quad 9.8 \%$ QLSEVFIQLPSRK

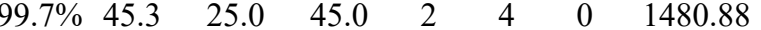
$99.7 \% \quad 59.2$

$99.7 \% \quad 37.3$

$99.7 \% \quad 59.8$

$99.7 \% \quad 58.6$

$99.7 \% 51.1$

$99.7 \% \quad 39.4$

$99.7 \% \quad 31.4$

$99.0 \% \quad 38.5$

$99.7 \% \quad 31.4$

$99.7 \% \quad 43.7$

$99.7 \% \quad 56.2$

$99.7 \% \quad 37.2$

$99.7 \% \quad 40.6$

$95.4 \% \quad 17.8$

$99.7 \% \quad 54.2$

$97.3 \% \quad 25.2$

$\begin{array}{lll}99.6 \% & 25.9\end{array}$

$99.4 \% \quad 20.3$

$\begin{array}{ll}99.7 \% & 49.4\end{array}$

$99.7 \% \quad 56.2$

$99.7 \% \quad 27.2$

$99.7 \% \quad 33.2$

$99.5 \% \quad 26.5$

$99.7 \% \quad 36.1$

$99.7 \% 51.6$

$95.2 \% \quad 16.9$

$99.7 \% \quad 65.1$

$99.5 \% \quad 22.5$

$\begin{array}{lll}97.4 \% & 27.8\end{array}$

$99.7 \% \quad 47.8$

$99.7 \% \quad 30.4$

$99.7 \% \quad 26.5$

$99.7 \% \quad 36.0$

$98.8 \% 26.9$

$99.7 \% \quad 75.6$

$99.7 \% \quad 32.9$

$99.7 \% \quad 74.4$

$99.7 \% \quad 43.2$

$98.2 \% \quad 19.2$

$99.0 \% \quad 21.8$

$\begin{array}{lll}99.0 \% & 38.7\end{array}$

$\begin{array}{lll}97.0 \% & 21.7\end{array}$

$99.7 \% \quad 32.8$

$99.7 \% \quad 61.0$

$99.7 \% \quad 28.3$
984.58

2606.19

1241.56

1397.67

1140.52

1399.65

1010.50

979.48

1588.68

1358.69

1622.75

1494.66

1093.58

998.54

1136.63

1090.59

1499.75

1593.83

2150.02

1529.78

1191.65

1163.64

1120.56

1692.75

2037.97

2323.12

1005.60

1617.90

1169.62

857.52

1275.65

1134.63

1618.84

1724.92

1302.70

1146.60

1340.62

1511.83

1556.85

1013.66

980.43

943.50

1178.57

1136.58

1382.60

1544.88 
Transcription activator BRG1 GN=SMARCA4 SMCA4_HUMAN $184.65 \quad 100.0 \%$ Transcriptional activator protein Pur-alpha GN=PURA PURA_HUMAN $34.91 \quad 100.0 \%$ Transcriptional activator protein Pur-alpha GN=PURA PURA_HUMAN $34.91 \quad 100.0 \%$ Transcriptional activator protein Pur-alpha GN=PURA PURA_HUMAN 34.91 Transcriptional activator protein Pur-alpha GN=PURA PURA_HUMAN $34.91 \quad 100.0 \%$ Transcriptional activator protein Pur-alpha GN=PURA PURA_HUMAN $34.91 \quad 100.0 \%$ Transcriptional activator protein Pur-beta GN=PURB PURB HUMAN $33.24 \quad 100.0 \%$ Transcriptional activator protein Pur-beta GN=PURB PURB_HUMAN $33.24 \quad 100.0 \%$ Transcriptional activator protein Pur-beta GN=PURB PURB HUMAN $33.24 \quad 100.0 \%$ Transcriptional activator protein Pur-beta GN=PURB PURB_HUMAN $33.24 \quad 100.0 \%$ Transducin beta-like protein 3 GN=TBL3 TBL3_HUMAN $89.03 \quad 100.0 \%$ Transducin beta-like protein 3 GN=TBL3 TBL3 HUMAN $89.03 \quad 100.0 \%$ Transducin beta-like protein 3 GN=TBL3 TBL3_HUMAN $89.03 \quad 100.0 \%$ Transducin beta-like protein 3 GN=TBL3 TBL3_HUMAN $89.03 \quad 100.0 \%$ Transducin beta-like protein 3 GN=TBL3 TBL3_HUMAN $89.03 \quad 100.0 \%$ Transferrin receptor protein $1 \mathrm{GN}=\mathrm{TFRC} \quad$ TFR1_HUMAN $84.87 \quad 100.0 \%$ Transferrin receptor protein $1 \mathrm{GN}=\mathrm{TFRC} \quad$ TFR1 HUMAN $84.87 \quad 100.0 \%$ Transformation/transcription domain-associated protein GN=TRRAP TRRAP_HUMAN $437.60 \quad 100.0 \%$ Transformation/transcription domain-associated protein GN=TRRAP TRRAP_HUMAN $437.60 \quad 100.0 \%$ Transformation/transcription domain-associated protein GN=TRRAP TRRAP HUMAN $437.60 \quad 100.0 \%$ Transformation/transcription domain-associated protein GN=TRRAP TRRAP_HUMAN $437.60 \quad 100.0 \%$ Transformation/transcription domain-associated protein GN=TRRAP TRRAP_HUMAN $437.60 \quad 100.0 \%$ Transformation/transcription domain-associated protein GN=TRRAP TRRAP_HUMAN $437.60 \quad 100.0 \%$ Transformation/transcription domain-associated protein GN=TRRAP TRRAP_HUMAN $437.60 \quad 100.0 \%$ 作 Transformer-2 protein homolog alpha GN=TRA2A TRA2A_HUMAN $32.69 \quad 100.0 \%$ Transformer-2 protein homolog alpha GN=TRA2A TRA2A_HUMAN $32.69100 .0 \%$ Transformer-2 protein homolog alpha GN=TRA2A TRA2A HUMAN $32.69 \quad 100.0 \%$ Transformer-2 protein homolog alpha GN=TRA2A TRA2A_HUMAN $32.69 \quad 100.0 \%$ Transformer-2 protein homolog alpha GN=TRA2A TRA2A HUMAN $32.69 \quad 100.0^{\circ}$ Transformer-2 protein homolog alpha GN=TRA2A TRA2A_HUMAN $32.69 \quad 100.0 \%$ Transformer-2 protein homolog alpha GN=TRA2A TRA2A_HUMAN $32.69 \quad 100.0 \%$ Transformer-2 protein homolog alpha GN=TRA2A TRA2A HUMAN $32.69 \quad 100.0 \%$ Transformer-2 protein homolog alpha GN=TRA2A TRA2A_HUMAN $32.69 \quad 100.0 \%$ Transformer-2 protein homolog alpha GN=TRA2A TRA2A_HUMAN $32.69 \quad 100.0 \%$ Transformer- 2 protein homolog alpha GN=TRA2A TRA2A_HUMAN $32.69 \quad 100.0 \%$ Transformer-2 protein homolog alpha GN=TRA2A TRA2A_HUMAN $32.69 \quad 100.0 \%$ Transformer-2 protein homolog beta GN=TRA2B TRA2B HUMAN $33.67 \quad 100.0^{\circ}$ Transformer-2 protein homolog beta GN=TRA2B TRA2B_HUMAN $33.67 \quad 100.0 \%$ Transformer-2 protein homolog beta GN=TRA2B TRA2B_HUMAN $33.67 \quad 100.0 \%$ Transformer-2 protein homolog beta GN=TRA2B TRA2B HUMAN $33.67 \quad 100.0 \%$ Transformer-2 protein homolog beta GN=TRA2B TRA2B_HUMAN $33.67 \quad 100.0 \%$ Transformer-2 protein homolog beta GN=TRA2B TRA2B HUMAN $33.67100 .0 \%$ Transformer-2 protein homolog beta GN=TRA2B TRA2B_HUMAN $33.67 \quad 100.0 \%$ Transformer-2 protein homolog beta GN=TRA2B TRA2B_HUMAN $33.67 \quad 100.0 \%$ Transformer- 2 protein homolog beta GN=TRA2B TRA2B HUMAN $33.67 \quad 100.0 \%$ Translation initiation factor eIF-2B subunit beta GN=EIF2B2 EI2BB_HUMAN $38.99 \quad 100.0 \%$
$0.03 \% \quad 9.8 \%$ ELPEYYELIR $0.02 \% \quad 16.1 \%$ FYLDVKQNAK $0.02 \% \quad 16.1 \%$ IAEVGAGGNKSR $0.02 \% \quad 16.1 \%$ ALKSEFLVR $0.02 \% \quad 16.1 \%$ VSEVKPTYR $0.02 \% \quad 16.1 \%$ NSITVPYKVWAK $0.01 \% \quad 13.1 \%$ GGGEQETQELASK $0.01 \% \quad 13.1 \%$ FYLDVKQNAK $0.01 \% \quad 13.1 \%$ ALKSEFLVR $0.01 \% \quad 13.1 \%$ VSEVKPSYR $0.01 \% \quad 8.4 \% \quad$ FKTNYAVER $0.01 \% \quad 8.4 \%$ VNILEVASGAVLR $0.01 \% \quad 8.4 \%$ SPGLYFLTAGDQGTLR $0.01 \% \quad 8.4 \%$ NTAPDNGPILLQAQTTQR $0.01 \% \quad 8.4 \%$ AALEALLPYTER $0.01 \% \quad 4.0 \%$ SAFSNLFGGEPLSYTR $0.01 \% \quad 4.0 \%$ SSGLPNIPVQTISR $0.02 \% \quad 2.2 \%$ AIETALDCLK $0.02 \% \quad 2.2 \%$ TIPNVIISHR $0.02 \% \quad 2.2 \% \quad$ LGFTPSVTIEQR $0.02 \% \quad 2.2 \%$ GLSVDSAQEVKR $0.02 \% \quad 2.2 \%$ TATGAISAVFGR $0.02 \% \quad 2.2 \% \quad$ LEPAFLSGLR $0.02 \% \quad 2.2 \%$ GLSLQIKPK $0.02 \% \quad 2.2 \% \quad$ VYPQAVYFPIR $0.06 \% \quad 30.1 \%$ SQSKSPTGTPAR $0.06 \% \quad 30.1 \%$ DLREVFSR

$0.06 \% \quad 30.1 \%$ YGPLSGVNVVYDQR $0.06 \% \quad 30.1 \%$ YGPLSGVNVVYDQRTGR $0.06 \% \quad 30.1 \%$ GFAFVYFER

$0.06 \% \quad 30.1 \%$ IDDSKEAMER $0.06 \% \quad 30.1 \%$ ANGMELDGR $0.06 \% \quad 30.1 \%$ ANGMELDGRR $0.06 \% \quad 30.1 \%$ IRVDYSITK $0.06 \% \quad 30.1 \%$ VDYSITKR $0.06 \% \quad 30.1 \%$ RSPSPYYSR $0.06 \% \quad 30.1 \%$ SPSPYYSR $0.06 \% \quad 22.6 \%$ YGPIADVSIVYDQQSR $0.06 \% \quad 22.6 \%$ YGPIADVSIVYDQQSRR $0.06 \% 22.6 \%$ ANGMELDGR

$0.06 \% \quad 22.6 \%$ ANGMELDGRR $0.06 \% \quad 22.6 \%$ IRVDFSITK $0.06 \% \quad 22.6 \%$ GYDDRDYYSR $0.06 \% \quad 22.6 \%$ AAQDRDQIYR $0.06 \% \quad 22.6 \%$ RSPSPYYSR $0.06 \% \quad 22.6 \%$ SPSPYYSR $0.01 \% \quad 10.8 \%$ SSEEMARETLGLLR $\begin{array}{lll}99.7 \% & 31.9\end{array}$ $99.7 \% \quad 27.8$ $99.7 \% \quad 49.5$ $99.7 \% \quad 32.4$ $99.7 \% \quad 37.4$ $99.3 \% \quad 20.6$ $99.7 \% \quad 58.0$ $99.7 \% \quad 27.8$ $99.7 \% \quad 32.4$ $99.7 \% \quad 44.9$ $99.7 \% \quad 38.9$ $99.7 \% \quad 62.7$ $99.7 \% \quad 57.4$ $99.7 \% 59.8$ $97.0 \% \quad 20.4$ $99.7 \% \quad 54.4$ $99.7 \% \quad 37.0$ $99.7 \% \quad 37.4$ $99.1 \% \quad 22.6$ $99.5 \% \quad 24.0$ $99.7 \% \quad 36.2$ $99.7 \% \quad 30.2$ $95.8 \% \quad 17.5$ $99.2 \% \quad 22.3$ $97.9 \% \quad 17.5$ $99.7 \% \quad 34.8$ $\begin{array}{lll}98.5 \% & 20.9\end{array}$ $99.7 \% 51.7$

\section{$\begin{array}{ll}99.7 \% & 30.8 \\ 99.7 \% & 54.0\end{array}$}

$99.7 \% \quad 54.0$

$99.6 \% \quad 27.0$

$\begin{array}{lll}99.7 \% & 39.8\end{array}$

$99.6 \% \quad 22.5$ $99.7 \% \quad 39.5$ $99.0 \% \quad 32.2$ $99.2 \% \quad 26.3$ $99.0 \% \quad 33.0$ $99.7 \% \quad 53.7$ $\begin{array}{lll}99.7 \% & 46.4\end{array}$ $\begin{array}{lll}99.7 \% & 39.8\end{array}$ $99.6 \% \quad 22.5$ $99.7 \% \quad 54.8$ $99.7 \% 28.1$ $99.7 \% \quad 30.7$ $99.2 \% \quad 26.3$ $99.0 \% 33.0$ $99.7 \% \quad 25.2$
1225.66

1158.62

1078.59

1405.78

1333.62

1225.66

1062.63

1064.57

1127.58

1340.79

1695.87

1938.00

1346.73

1745.85

1468.81

1133.59

1149.67

1347.73

1288.69

1150.62

1102.63

983.63

1352.74

1216.63

1021.54

1566.79

1880.96

1135.56

1209.54

962.44

1118.54

1094.62

981.54

1112.55

956.45

1810.90

1967.00

962.44

1118.54

1078.63

1309.54

1235.61

1112.55

956.45

1591.81

$88 \quad 99$



Translation initiation factor eIF-2B subunit beta GN=EIF2B2 EI2BB_HUMAN $38.99 \quad 100.0 \%$ Translation initiation factor eIF-2B subunit delta GN=EIF2B4 EI2BD_HUMAN $57.56 \quad 100.0 \%$ Translation initiation factor elF-2B subunit delta GN=EIF2B4 EI2BD HUMAN $57.56 \quad 100.0 \%$ Translation initiation factor eIF-2B subunit epsilon GN=EIF2B5 EI2BE_HUMAN $80.38 \quad 100.0 \%$ Translation initiation factor elF-2B subunit epsilon GN=EIF2B5 $\quad$ EI2BE_HUMAN $80.38 \quad 100.0 \%$ Translation initiation factor eIF-2B subunit epsilon GN=EIF2B5 EI2BE_HUMAN $80.38 \quad 100.0 \%$ Translation initiation factor eIF-2B subunit epsilon GN=EIF2B5 EI2BE_HUMAN $80.38 \quad 100.0 \%$ Translation initiation factor elF-2B subunit gamma GN=EIF2B3 EI2BG_HUMAN $50.24 \quad 100.0 \%$ Translation initiation factor eIF-2B subunit gamma GN=EIF2B3 EI2BG_HUMAN $50.24 \quad 100.0 \%$ Translational activator GCN1 GN=GCN1L1 GCN1L_HUMAN $292.76 \quad 100.0 \%$ Translational activator GCN1 GN=GCN1L1 GCN1L_HUMAN $292.76 \quad 100.0 \%$ Translational activator GCN1 GN=GCN1L1 GCN1L_HUMAN $292.76 \quad 100.0 \%$ Translational activator GCN1 GN=GCN1L1 GCN1L_HUMAN $292.76 \quad 100.0 \%$ Translational activator GCN1 GN=GCN1L1 GCN1L_HUMAN $292.76 \quad 100.0 \%$ Translational activator GCN1 GN=GCN1L1 GCN1L_HUMAN $292.76 \quad 100.0 \%$ Translational activator GCN1 GN=GCN1L1 GCN1L HUMAN $292.76 \quad 100.0 \%$ Translational activator GCN1 GN=GCN1L1 GCN1L_HUMAN $292.76 \quad 100.0 \%$ Translational activator GCN1 GN=GCN1L1 GCN1L_HUMAN $292.76 \quad 100.0 \%$ Translational activator GCN1 GN=GCN1L1 GCN1L_HUMAN $292.76 \quad 100.0 \%$ Translational activator GCN1 GN=GCN1L1 GCN1L_HUMAN $292.76 \quad 100.0 \%$ Translational activator GCN1 GN=GCN1L1 GCN1L_HUMAN $292.76 \quad 100.0 \%$ Translational activator GCN1 GN=GCN1L1 GCN1L_HUMAN $292.76 \quad 100.0 \%$ Translational activator GCN1 GN=GCN1L1 GCN1L_HUMAN $292.76 \quad 100.0 \%$ Translational activator GCN1 GN=GCN1L1 GCN1L_HUMAN $292.76 \quad 100.0 \%$ Translational activator GCN1 GN=GCN1L1 GCN1L_HUMAN $292.76 \quad 100.0 \%$ Translational activator GCN1 GN=GCN1L1 GCN1L_HUMAN $292.76 \quad 100.0 \%$ Translational activator GCN1 GN=GCN1L1 GCN1L_HUMAN $292.76 \quad 100.0 \%$ Translational activator GCN1 GN=GCN1L1 GCN1L_HUMAN $292.76 \quad 100.0 \%$ Translational activator GCN1 GN=GCN1L1 GCN1L HUMAN $292.76 \quad 100.0 \%$ Translational activator GCN1 GN=GCN1L1 GCN1L_HUMAN $292.76 \quad 100.0 \%$ Translational activator GCN1 GN=GCN1L1 GCN1L_HUMAN $292.76 \quad 100.0 \%$ Translational activator GCN1 GN=GCN1L1 GCN1L_HUMAN $292.76 \quad 100.0 \%$ Translational activator GCN1 GN=GCN1L1 GCN1L_HUMAN $292.76 \quad 100.0 \%$ Translational activator GCN1 GN=GCN1L1 GCN1L_HUMAN $292.76 \quad 100.0 \%$ Translational activator GCN1 GN=GCN1L1 GCN1L_HUMAN $292.76 \quad 100.0 \%$ Translational activator GCN1 GN=GCN1L1 GCN1L_HUMAN $292.76 \quad 100.0 \%$ Translational activator GCN1 GN=GCN1L1 GCN1L_HUMAN $292.76 \quad 100.0^{\circ}$ Translational activator GCN1 GN=GCN1L1 GCN1L_HUMAN $292.76 \quad 100.0 \%$ Translational activator GCN1 GN=GCN1L1 GCN1L_HUMAN $292.76 \quad 100.0 \%$ Translational activator GCN1 GN=GCN1L1 GCN1L_HUMAN $292.76 \quad 100.0 \%$ Translational activator GCN1 GN=GCN1L1 GCN1L_HUMAN $292.76 \quad 100.0 \%$ Translational activator GCN1 GN=GCN1L1 GCN1L HUMAN $292.76 \quad 100.0 \%$ Translational activator GCN1 GN=GCN1L1 GCN1L_HUMAN $292.76 \quad 100.0 \%$ Translational activator GCN1 GN=GCN1L1 GCN1L_HUMAN $292.76 \quad 100.0 \%$ Translational activator GCN1 GN=GCN1L1 GCN1L_HUMAN $292.76 \quad 100.0 \%$ Translational activator GCN1 GN=GCN1L1 GCN1L_HUMAN $292.76 \quad 100.0 \%$
$6.01 \% \quad 10.8 \%$ TVEAFLKEAAR $0.01 \% \quad 10.8 \%$ AVTGTHTLALAAK

$\begin{array}{llllllll}99.7 \% & 53.3 & 25.0 & 51.8 & 2 & 0 & 0 & 1234.68\end{array}$ $99.7 \% \quad 48.9$ $0.00 \% \quad 5.2 \% \quad$ LGLQYSQGLVSGSNAR $0.00 \% \quad 5.2 \%$ VGTAQLALVAR

$0.01 \% \quad 6.8 \%$ AAQIKEHLLK

$0.01 \% \quad 6.8 \% \quad$ IITSELYR $99.7 \% \quad 69.5$ 25.0 -42.2 $\begin{array}{llll}99.7 \% & 64.4 & 25.0 & 51.0\end{array}$ $99.2 \% \quad 21.4 \quad 25.0 \quad 17.8$ $\begin{array}{llll}99.0 \% & 36.5 & 25.0 & 26.1\end{array}$

$0.01 \% \quad 6.8 \%$

$0.01 \% \quad 6.8 \% \quad$ YCALLLPLLK

$0.00 \% \quad 4.9 \%$ KGQDSIEPVPGQK

$0.00 \% \quad 4.9 \%$ SELIPYLVR

$130 \quad 0.18 \% \quad 22.2 \%$ VTTASVKER

$130 \quad 0.18 \% \quad 22.2 \%$ CVAGKDLPEGAVK

$130 \quad 0.18 \% \quad 22.2 \%$ LFCLTLHR

$130 \quad 0.18 \% \quad 22.2 \%$ ALQAAIQQLAEAQPEATAK

$130 \quad 0.18 \% \quad 22.2 \%$ NLLHSLQSSGIGSK

$130 \quad 0.18 \% \quad 22.2 \%$ SALLDFYMK

$130 \quad 0.18 \% \quad 22.2 \%$ YLLDSCAPLLR

$130 \quad 0.18 \% \quad 22.2 \%$ LMDEAVLALR

$130 \quad 0.18 \% \quad 22.2 \%$ QCSDSSAMESLTK

$130 \quad 0.18 \% \quad 22.2 \%$ LSVADSQAEAK

$130 \quad 0.18 \% \quad 22.2 \%$ LTGNKVQQYHR

$130 \quad 0.18 \% \quad 22.2 \%$ ALVAVLLSR

$130 \quad 0.18 \% \quad 22.2 \%$ MKIDPEAFITR

$130 \quad 0.18 \% \quad 22.2 \%$ HLDQIIPR

$130 \quad 0.18 \% \quad 22.2 \%$ SIIQSAQQDSIKK

$130 \quad 0.18 \% \quad 22.2 \%$ GIKEEVQLTSK

$130 \quad 0.18 \% \quad 22.2 \%$ ALGTLVSHVTLR

$130 \quad 0.18 \% \quad 22.2 \%$ LLKPECVLDK

$130 \quad 0.18 \% \quad 22.2 \%$ ASPNTPPGRVDENGPELLPR

$130 \quad 0.18 \% \quad 22.2 \%$ VDENGPELLPR

$63 \quad 130 \quad 0.18 \% \quad 22.2 \%$ QAGAEALSQAVAR

$63 \quad 130 \quad 0.18 \% \quad 22.2 \%$ NAPNDASYDAVR

$63 \quad 130 \quad 0.18 \% \quad 22.2 \%$ LMQQLLESDKYAER

$63 \quad 130 \quad 0.18 \% \quad 22.2 \%$ KGAAYGLAGLVK

$63 \quad 130 \quad 0.18 \% \quad 22.2 \%$ GAAYGLAGLVK

$63 \quad 130 \quad 0.18 \% \quad 22.2 \%$ AVMSNLSAHGVK

$63 \quad 130 \quad 0.18 \% \quad 22.2 \%$ AGSVELLGAMAYCAPK

$63 \quad 130 \quad 0.18 \% \quad 22.2 \%$ QLSSCLPNIVPK

$63 \quad 130 \quad 0.18 \% \quad 22.2 \%$ LTEVLTDSHVK

$63 \quad 130 \quad 0.18 \% \quad 22.2 \%$ LTEVLTDSHVKVQK

$63 \quad 130 \quad 0.18 \% \quad 22.2 \%$ ASLLDPVPEVR

$63 \quad 130 \quad 0.18 \% \quad 22.2 \%$ LMPEIVATASK

$63 \quad 130 \quad 0.18 \% \quad 22.2 \%$ VDIAPHVR

$63 \quad 130 \quad 0.18 \% \quad 22.2 \%$ ALADENEFVR

$63 \quad 130 \quad 0.18 \% \quad 22.2 \%$ ALADENEFVRDTALR

$63 \quad 130 \quad 0.18 \% \quad 22.2 \%$ AIITALGVER

$\begin{array}{llll}63 & 130 & 0.18 \% & 22.2 \% \\ \text { AIITALGVERR }\end{array}$ $\begin{array}{llll}99.7 \% & 36.9 & 25.0 & 36.9\end{array}$

$99.7 \% \quad 44.8 \quad 25.0 \quad 44.0$

$99.7 \% \quad 25.0 \quad 25.0 \quad 25.0$

$99.5 \% \quad 22.6 \quad 25.0 \quad 18.1$

$\begin{array}{llll}97.9 \% & 29.9 & 25.0 & 23.1\end{array}$

$99.0 \% \quad 34.5 \quad 25.0 \quad 26.2$

$\begin{array}{llll}9.7 \% & 40.3 & 25.0 & 40.3\end{array}$

$99.7 \% \quad 54.0 \quad 25.0 \quad 45.7$

$99.7 \% \quad 28.1 \quad 25.0 \quad 28.1$

$99.7 \% \quad 48.7 \quad 25.0 \quad 48.7$

$\begin{array}{llll}99.7 \% & 47.5 & 25.0 & 33.7\end{array}$

$\begin{array}{llll}99.7 \% & 38.6 & 25.0 & 37.3\end{array}$

$99.7 \% \quad 35.5 \quad 25.0 \quad 35.5$

$\begin{array}{llll}99.7 \% & 43.1 & 25.0 & 43.1\end{array}$

$99.7 \% \quad 55.4 \quad 25.0 \quad 42.5$

$99.1 \% \quad 20.3 \quad 25.0 \quad 18.5$

$\begin{array}{llll}99.0 \% & 41.8 & 25.0 & 37.0\end{array}$

$\begin{array}{llll}99.7 \% & 31.5 & 25.0 & 31.5\end{array}$

$\begin{array}{llll}99.7 \% & 48.4 & 25.0 & 27.5\end{array}$

$\begin{array}{llll}99.7 \% & 45.9 & 25.0 & 36.8\end{array}$

$\begin{array}{llll}99.7 \% & 25.5 & 25.0 & 25.5\end{array}$

$99.5 \% \quad 21.5$

$99.7 \% \quad 37.4$

$99.7 \% \quad 48.7$

$\begin{array}{lll}99.7 \% & 26.8\end{array}$

$98.7 \% \quad 19.4$

$99.1 \% \quad 18.9$

$99.7 \% \quad 38.9$

$99.7 \% \quad 49.4$

$\begin{array}{ll}99.7 \% & 50.6 \\ 99.7 \% & 37.7\end{array}$

$99.7 \% \quad 37.7$

$99.7 \% \quad 59.2$

$99.7 \% \quad 32.9$

$99.7 \% \quad 45.0$

$99.7 \% \quad 26.2$

$99.0 \% 25.6$

$99.7 \% \quad 32.1$

$99.7 \% \quad 28.8$

$99.7 \% \quad 45.5$

$99.7 \% \quad 26.0$
1253.72

1649.86

1098.66

1150.69

994.56

2309.17

1203.72

1382.73

1089.63

990.56

1343.70

1059.58

1952.04

1440.78

1103.54

1320.70

1130.62

1443.61

1118.57

1343.72

941.61

1320.70

991.57

1445.80

1231.69

1266.75

1214.68

2116.08

1238.64

1271.67

1292.59

1723.87

1147.68

1019.59

1213.64

1653.80

1355.74

1241.67

1596.90

1195.67

1159.64

906.52

1163.57

1719.87

1042.63

1198.73

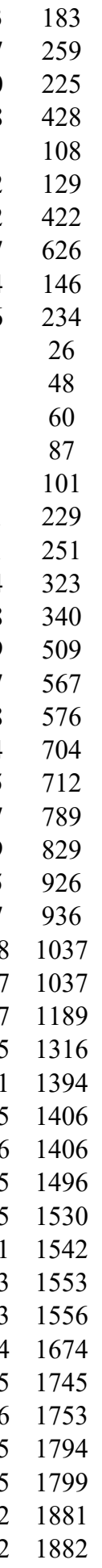

Page 130 of Table S-1-1 
Translational activator GCN1 GN=GCN1L1 GCN1L_HUMAN $292.76 \quad 100.0 \% \quad 55$ Translational activator GCN1 GN=GCN1L1 GCN1L_HUMAN $292.76 \quad 100.0 \% \quad 55$ Translational activator GCN1 GN=GCN1L1 GCN1L_HUMAN $292.76 \quad 100.0 \% \quad 55$ Translational activator GCN1 GN=GCN1L1 GCN1L HUMAN $292.76 \quad 100.0 \%$ Translational activator GCN1 GN=GCN1L1 GCN1L_HUMAN $292.76 \quad 100.0 \% \quad 55$ Translational activator GCN1 GN=GCN1L1 GCN1L_HUMAN $292.76 \quad 100.0 \%$ Translational activator GCN1 GN=GCN1L1 GCN1L_HUMAN $292.76 \quad 100.0 \%$ Translational activator GCN1 GN=GCN1L1 GCN1L_HUMAN $292.76 \quad 100.0 \% \quad 55$ Translational activator GCN1 GN=GCN1L1 GCN1L_HUMAN $292.76 \quad 100.0 \% \quad 55$ Translational activator GCN1 GN=GCN1L1 GCN1L_HUMAN $292.76 \quad 100.0 \% \quad 55$ Translational activator GCN1 GN=GCN1L1 GCN1L_HUMAN $292.76 \quad 100.0 \%$ Translational activator GCN1 GN=GCN1L1 GCN1L_HUMAN $292.76 \quad 100.0 \% \quad 55$ Translational activator GCN1 GN=GCN1L1 GCN1L_HUMAN $292.76 \quad 100.0 \% \quad 55$ Translational activator GCN1 GN=GCN1L1 GCN1L_HUMAN $292.76 \quad 100.0 \%$ Translational activator GCN1 GN=GCN1L1 GCN1L_HUMAN $292.76 \quad 100.0 \% \quad 55$ Translational activator GCN1 GN=GCN1L1 GCN1L_HUMAN $292.76 \quad 100.0 \%$ s Translational activator GCN1 GN=GCN1L1 GCN1L_HUMAN $292.76 \quad 100.0 \% \quad 55$ Translational activator GCN1 GN=GCN1L1 GCN1L_HUMAN $292.76 \quad 100.0 \% \quad 55$ Transmembrane protein 126A GN=TMEM126A T126A_HUMAN $21.53 \quad 100.0 \%$ Transmembrane protein 126A GN=TMEM126A T126A HUMAN $21.53 \quad 100.0 \%$ Transmembrane protein 201 GN=TMEM201 TM201_HUMAN $72.24 \quad 100.0 \%$ Transmembrane protein $201 \mathrm{GN}=$ TMEM201 TM201 HUMAN $72.24 \quad 100.0 \%$ Transmembrane protein 33 GN=TMEM33 TMM33_HUMAN $27.98 \quad 100.0 \%$ Transmembrane protein 33 GN=TMEM33 TMM33_HUMAN $27.98 \quad 100.0 \%$ Transmembrane protein $33 \mathrm{GN}=$ TMEM33 TMM33 HUMAN $27.98 \quad 100.0 \%$ Transmembrane protein 33 GN=TMEM33 TMM33_HUMAN $27.98 \quad 100.0 \%$ Transportin-1 GN=TNPO1

Transportin- $1 \mathrm{GN}=\mathrm{TNPO}$

Transportin-1 GN=TNPO

Transportin- $1 \mathrm{GN}=\mathrm{TNPO}$

Transportin-1 GN=TNPO1

Transportin- 1 GN=TNPO

Transportin-3 GN=TNPO3

Transportin-3 GN=TNPO3

Tricarboxylate transport protein, mitochondrial GN=SLC25A1 TXTP HUMAN $34.01 \quad 100.0 \%$

Tricarboxylate transport protein, mitochondrial GN=SLC25A1 TXTP HUMAN $34.01 \quad 100.0 \%$ Tricarboxylate transport protein, mitochondrial GN=SLC25A1 TXTP_HUMAN $34.01 \quad 100.0 \%$ Tricarboxylate transport protein, mitochondrial GN=SLC25A1 TXTP HUMAN $34.01 \quad 100.0^{\circ} \%$ Tricarboxylate transport protein, mitochondrial GN=SLC25A1 TXTP_HUMAN $34.01 \quad 100.0 \%$ Tricarboxylate transport protein, mitochondrial GN=SLC25A1 TXTP_HUMAN $34.01 \quad 100.0 \%$ Tricarboxylate transport protein, mitochondrial GN=SLC25A1 TXTP HUMAN $34.01 \quad 100.0 \%$ Tricarboxylate transport protein, mitochondrial GN=SLC25A1 TXTP_HUMAN $34.01 \quad 100.0 \%$ Trifunctional enzyme subunit alpha, mitochondrial GN=HADHA ECHA_HUMAN $83.00 \quad 100.0 \%$ Trifunctional enzyme subunit alpha, mitochondrial GN=HADHA ECHA HUMAN $83.00 \quad 100.0 \%$ Trifunctional enzyme subunit alpha, mitochondrial GN=HADHA ECHA_HUMAN 83.00 100.0\% Trifunctional enzyme subunit alpha, mitochondrial GN=HADHA ECHA HUMAN $83.00 \quad 100.0 \%$ Trifunctional enzyme subunit alpha, mitochondrial GN=HADHA ECHA_HUMAN $83.00 \quad 100.0 \%$
$63 \quad 130 \quad 0.18 \% \quad 22.2 \%$ VLAGLYMGR

$63 \quad 130 \quad 0.18 \% \quad 22.2 \%$ SDTQLVVR

$63 \quad 130 \quad 0.18 \% \quad 22.2 \%$ DAVLYFSESLVPTAR

$\begin{array}{lllll}63 & 130 & 0.18 \% & 22.2 \% & \text { LTTPPVNTR }\end{array}$

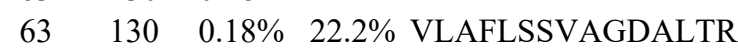

$63 \quad 130 \quad 0.18 \% \quad 22.2 \%$ QAAAIILNIYCSR

$63 \quad 130 \quad 0.18 \% \quad 22.2 \%$ SKADYTSHLR

$63 \quad 130 \quad 0.18 \% \quad 22.2 \%$ SLVSGLIR

$63 \quad 130 \quad 0.18 \% \quad 22.2 \%$ KGVTSILPVLR

$63 \quad 130 \quad 0.18 \% \quad 22.2 \%$ GVTSILPVLR

$63 \quad 130 \quad 0.18 \% \quad 22.2 \%$ EGVLTGSPEQKEEAAK

$63 \quad 130 \quad 0.18 \% \quad 22.2 \%$ LTSADALRPSVVSITGPLIR

$63 \quad 130 \quad 0.18 \% \quad 22.2 \%$ ALQDSNRGVR

$63 \quad 130 \quad 0.18 \% \quad 22.2 \%$ SLALSVAVNVAPGR

$63 \quad 130 \quad 0.18 \% \quad 22.2 \%$ HHIETGGGQLPAK

$63 \quad 130 \quad 0.18 \% \quad 22.2 \%$ AYSDQAIVNLLK

$63 \quad 130 \quad 0.18 \% \quad 22.2 \%$ QGEEVFQSLSK

$63 \quad 130 \quad 0.18 \% \quad 22.2 \%$ LASQADSTEQVDDTILT

$4 \quad 0.01 \% \quad 11.3 \%$ KINQLPEAER

$0.01 \% \quad 11.3 \%$ ALQLSEPGKEIH

$0.00 \% \quad 3.2 \%$ ALLLSHQFK

$0.00 \% \quad 3.2 \%$ ALSLGTIPSLTR

$10 \quad 0.01 \% \quad 19.0 \%$ ALLANALTSALR

$10 \quad 0.01 \% \quad 19.0 \%$ GSNSLPLLR

$10 \quad 0.01 \% \quad 19.0 \%$ SVLDKLSANQQNILK

$10 \quad 0.01 \% \quad 19.0 \%$ LCLQSIAFISR

$11 \quad 0.02 \% \quad 6.9 \% \quad$ SLSGLILK

$11 \quad 0.02 \% \quad 6.9 \% \quad$ SLSGLILKNNVK

$11 \quad 0.02 \% \quad 6.9 \% \quad$ SHAVACVNQFIISR

$\begin{array}{lllll}11 & 0.02 \% & 6.9 \% & \text { QSSFALLGDLTK }\end{array}$

$11 \quad 0.02 \% \quad 6.9 \% \quad$ TLLENTAITIGR

$11 \quad 0.02 \% \quad 6.9 \% \quad$ FSDQFPLPLKER

$0.01 \% \quad 2.7 \% \quad$ IFTELCETFLEK

$0.01 \% \quad 2.7 \%$ GLCEKPLASAAAK

$0.03 \% 24.1 \%$ AKLTHPGK

$0.03 \% \quad 24.1 \%$ TQLQLDER

$0.03 \% \quad 24.1 \%$ SHGVLGLYR

$0.03 \% \quad 24.1 \%$ GLSSLLYGSIPK

$0.03 \% \quad 24.1 \%$ FIHDQTSPNPK

$0.03 \% \quad 24.1 \%$ EQGLKGTYQGLTATVLK

$0.03 \% \quad 24.1 \%$ GTYQGLTATVLK

$0.03 \% \quad 24.1 \%$ MQGLEAHKYR

$0.03 \% \quad 18.9 \%$ TLQEVTQLSQEAQR

$0.03 \% \quad 18.9 \%$ TVLGTPEVLLGALPGAGGTQR

$0.03 \% \quad 18.9 \%$ TVLGTPEVLLGALPGAGGTQRLPK

$0.03 \% \quad 18.9 \%$ MVGVPAALDMMLTGR

$0.03 \% \quad 18.9 \%$ LTAYAMTIPFVR $\begin{array}{lllll}99.7 \% & 40.2 & 25.0 & 38.9 & 2\end{array}$

$99.0 \% \quad 41.0 \quad 25.0 \quad 11.7$

$99.6 \% \quad 23.6 \quad 25.0 \quad 18.4$

$95.7 \% \quad 18.4 \quad 25.0 \quad 11.9$

$99.7 \% \quad 64.0 \quad 25.0 \quad 64.0$

$\begin{array}{lllll}99.7 \% & 43.3 & 25.0 & 43.3 & 4\end{array}$

$\begin{array}{llll}99.7 \% & 29.4 & 25.0 & 24.4\end{array}$

$99.0 \% \quad 33.4 \quad 25.0 \quad 19.1$

$\begin{array}{llll}99.7 \% & 42.1 & 25.0 & 38.6\end{array}$

$\begin{array}{llll}99.1 \% & 22.5 & 25.0 & 22.5\end{array}$

$99.7 \% \quad 51.2$

$7 \% \quad 31.8$

$95.4 \% \quad 20.0$

$98.9 \% \quad 18.0$

$99.7 \% \quad 27.3$

$99.7 \% \quad 73.5$

$99.7 \% \quad 35.5$

$96.8 \% \quad 22.2$

$\begin{array}{lll}99.7 \% & 36.8\end{array}$

$99.7 \% \quad 33.8$

$99.7 \% \quad 27.2$

$99.5 \% \quad 23.7$

$99.7 \% \quad 87.5$

$99.7 \% \quad 43.4$

$99.7 \% \quad 59.2$

$99.7 \% \quad 57.2$

$99.0 \% \quad 25.2$

$99.7 \% \quad 45.5$

$99.7 \% \quad 35.7$

$99.7 \% \quad 50.9$

$99.7 \% \quad 66.5$

$99.7 \% \quad 26.5$

$99.7 \% \quad 30.3$

$99.7 \% \quad 33.0$

$99.0 \% \quad 24.7$

$99.0 \% \quad 37.0$

$99.6 \% \quad 23.0$

$99.7 \% \quad 56.9$

$99.7 \% \quad 45.2$

$99.2 \% \quad 20.8$

$99.7 \% \quad 38.0$

$99.7 \% \quad 26.3$

$99.7 \% 79.4$

$99.7 \% \quad 46.0$

$99.2 \% \quad 19.8$

$99.7 \% \quad 43.6$

\begin{tabular}{ll}
$1997 \quad 2011$ \\
\hline
\end{tabular}

$\begin{array}{lll}1492.79 & 2169 & 2181\end{array}$

$1177.60 \quad 2182 \quad 2191$

$\begin{array}{lll}844.53 & 2192 \quad 2199\end{array}$

$\begin{array}{lll}1182.76 & 2259 & 2269\end{array}$

$\begin{array}{lll}1054.66 & 2260 & 2269\end{array}$

$1672.84 \quad 2270 \quad 2285$

$2066.20 \quad 2293 \quad 2312$

$\begin{array}{lll}1115.59 & 2355 & 2364\end{array}$

$\begin{array}{lll}1353.78 & 2486 & 2499\end{array}$

$\begin{array}{lll}1344.70 & 2538 & 2550\end{array}$

$\begin{array}{lll}1334.73 & 2610 & 2621\end{array}$

$\begin{array}{lll}1251.62 & 2624 & 2634\end{array}$

$\begin{array}{lll}1806.86 & 2655 & 2671\end{array}$

$\begin{array}{lll}1197.66 & 20 & 29\end{array}$

$1321.71 \quad 184 \quad 195$

$\begin{array}{lll}1056.62 & 184 & 192\end{array}$

$1228.73 \quad 452 \quad 463$

$1213.73 \quad 58 \quad 69$

$\begin{array}{lll}956.55 & 135 & 143\end{array}$

$\begin{array}{lll}1670.94 & 144 & 158\end{array}$

$1307.71 \quad 231 \quad 241$

$\begin{array}{lll}830.53 & 74 & 81\end{array}$

$\begin{array}{lll}1285.78 & 74 & 85\end{array}$

$1601.82 \quad 200 \quad 213$

$\begin{array}{lll}1279.69 & 693 & 704\end{array}$

$1301.74 \quad 774 \quad 785$

$\begin{array}{lll}1476.78 & 880 & 891\end{array}$

$\begin{array}{lll}1529.76 & 298 & 309\end{array}$

$1315.70 \quad 509 \quad 521$

$\begin{array}{lll}851.51 & 20 & 27\end{array}$

1002.52

1001.55

1234.70

1283.64

1807.00

1251.69

1248.62

1630.84

2007.12

2345.36

1577.79

1382.75 
Trifunctional enzyme subunit alpha, mitochondrial GN=HADHA ECHA_HUMAN $83.00 \quad 100.0 \%$ Trifunctional enzyme subunit alpha, mitochondrial GN=HADHA ECHA_HUMAN $83.00 \quad 100.0 \%$ Trifunctional enzyme subunit alpha, mitochondrial GN=HADHA ECHA HUMAN $83.00 \quad 100.0 \%$ Trifunctional enzyme subunit alpha, mitochondrial GN=HADHA ECHA_HUMAN $83.00 \quad 100.0 \%$ Trifunctional enzyme subunit alpha, mitochondrial GN=HADHA ECHA_HUMAN $83.00 \quad 100.0 \%$ Trifunctional enzyme subunit beta, mitochondrial GN=HADHB ECHB_HUMAN $51.30 \quad 100.0 \%$ Trifunctional enzyme subunit beta, mitochondrial GN=HADHB ECHB_HUMAN $51.30 \quad 100.0 \%$ Trifunctional enzyme subunit beta, mitochondrial GN=HADHB ECHB HUMAN 51.30 Tifunctionl enzyme subunit beta, mitc Trifunctional enzyme subunit beta, mitochondrial GN=HADHB ECHB_HUMAN 51.30 Trifunctional enzyme subunit beta, mitochondrial GN=HADHB ECHB_HUMAN 51.30 Trifunctional enzyme subunit beta, mitochondrial GN=HADHB ECHB_HUMAN 51.30 Trifunctional enzyme subunit beta, mitochondrial GN=HADHB ECHB_HUMAN 51.30 Trifunctional enzyme subunit beta, mitochondrial GN=HADHB ECHB_HUMAN 51.30 Trifunctional enzyme subunit beta, mitochondrial GN=HADHB ECHB_HUMAN 51.30 Trifunctional enzyme subunit beta, mitochondrial GN=HADHB ECHB HUMAN 51.30 Trifunctional enzyme subunit beta, mitochondrial GN=HADHB ECHB_HUMAN 51.30 Trifunctional enzyme subunit beta, mitochondrial GN=HADHB ECHB_HUMAN 51.30 Trifunctional purine biosynthetic protein adenosine-3 GN=GART PUR2 HUMAN 107.7 Trifunctional purine biosynthetic protein adenosine-3 GN=GART PUR2_HUMAN 107.7 Trifunctional purine biosynthetic protein adenosine-3 GN=GART PUR2_HUMAN 107.77 Trifunctional purine biosynthetic protein adenosine-3 GN=GART PUR2_HUMAN 107.7 Trifunctional purine biosynthetic protein adenosine-3 GN=GART PUR2_HUMAN 107.77 Trifunctional purine biosynthetic protein adenosine-3 GN=GART PUR2 HUMAN 107.77 tRNA (cytosine(34)-C(5))-methyltransferase GN=NSUN2 NSUN2_HUMAN 86.47 tRNA (cytosine(34)-C(5))-methyltransferase GN=NSUN2 NSUN2_HUMAN 86.47 tRNA (cytosine(34)-C(5))-methyltransferase GN=NSUN2 NSUN2 HUMAN 86.47 tRNA (cytosine(34)-C(5))-methyltransferase GN=NSUN2 NSUN2_HUMAN 86.47 tRNA (cytosine(34)-C(5))-methyltransferase GN=NSUN2 NSUN2 HUMAN 86.47 tRNA (cytosine(34)-C(5))-methyltransferase GN=NSUN2 NSUN2_HUMAN 86.47 Tubulin alpha-1B chain GN=TUBA1B Tubulin alpha-1B chain $\mathrm{GN}=\mathrm{TUBA} 1 \mathrm{~B}$ Tubulin alpha-1B chain GN=TUBA1B Tubulin alpha-1B chain GN=TUBA1B Tubulin alpha-1B chain GN=TUBA1B Tubulin alpha-1B chain $\mathrm{GN}=$ TUBA1B Tubulin alpha-1B chain GN=TUBA1B Tubulin alpha-1B chain GN=TUBA1B Tubulin alpha-1B chain GN=TUBA1B

Tubulin alpha-1B chain $\mathrm{GN}=\mathrm{TUBA} 1 \mathrm{~B}$ Tubulin alpha-1B chain GN=TUBA1B Tubulin alpha-1B chain GN=TUBA1B Tubulin alpha-1B chain GN=TUBA1B Tubulin alpha-1B chain GN=TUBA1B Tubulin alpha-1B chain GN=TUBA1B Tubulin alpha-1B chain GN=TUBA1B 政 TBA1B HUMAN $50.15 \quad 100.0 \%$ TBA1B_HUMAN $50.15 \quad 100.0 \%$ TBA1B_HUMAN $50.15 \quad 100.0 \% \quad 19$ TBA1B_HUMAN $50.15 \quad 100.0 \% \quad 19$ TBA1B_HUMAN $50.15 \quad 100.0 \% \quad 19$ TBA1B_HUMAN $50.15 \quad 100.0 \% \quad 19$ TBA1B_HUMAN $50.15 \quad 100.0 \% \quad 19$ TBA1B_HUMAN $50.15 \quad 100.0 \% \quad 19$ TBA1B_HUMAN $50.15 \quad 100.0 \% \quad 19$ TBA1B_HUMAN $50.15 \quad 100.0 \% \quad 19$ TBA1B_HUMAN $50.15 \quad 100.0 \% \quad 19$ TBA1B_HUMAN $50.15 \quad 100.0 \% \quad 19$ TBA1B_HUMAN $50.15 \quad 100.0 \% \quad 19$ TBA1B_HUMAN $50.15 \quad 100.0 \% \quad 19$ TBA1B_HUMAN $50.15 \quad 100.0 \% \quad 19$
$0.03 \% \quad 18.9 \%$ GLYPAPLKIIDVVK

$0.03 \% \quad 18.9 \%$ DTSASAVAVGLKQGK

$0.03 \% \quad 18.9 \%$ VIIVVKDGPGFYTTR

$0.03 \% \quad 18.9 \%$ CLAPMMSEVIR

$0.03 \% \quad 18.9 \%$ ILQEGVDPK

$0.03 \% \quad 18.9 \%$ FGGGNPELLTQMVSK

$0.03 \% \quad 24.5 \%$ TLAKPNIR

$0.03 \% \quad 24.5 \%$ NVVVVDGVR

$0.03 \% 24.5 \%$ AALTGLLHR

$0.03 \% \quad 24.5 \%$ KLMLDLNK

$0.03 \% \quad 24.5 \%$ LSLISKFR

$0.03 \% \quad 24.5 \%$ LAAAFAVSR

$0.03 \% \quad 24.5 \%$ LEQDEYALR

$0.03 \% 24.5 \%$ ALAMGYKPK

$0.03 \% 24.5 \%$ TKVGLPPLEK

$0.03 \% \quad 24.5 \%$ VGLPPLEK

$0.03 \% \quad 24.5 \%$ LVMAAANR

$0.03 \% \quad 24.5 \%$ LVMAAANRLR

$0.03 \% \quad 24.5 \%$ EGGQYGLVAACAAGGQGHAMIVEAYP

$0.01 \% \quad 8.1 \%$ SAGVQCFGPTAEAAQLESSK

$0 \quad 0.01 \% \quad 8.1 \%$ ASGLAAGKGVIVAK

$0.01 \% \quad 8.1 \%$ AIAFLQQPR

$10 \quad 0.01 \% \quad 8.1 \%$ IYSHSLLPVLR

$10 \quad 0.01 \% \quad 8.1 \% \quad$ AFAHITGGGLLENIPR

$10 \quad 0.01 \% \quad 8.1 \%$ AAVAGLDKAER

$11 \quad 0.02 \% \quad 7.0 \%$ ILDMCAAPGSK

$0.02 \% \quad 7.0 \% \quad$ LSSPCIMVVNHDASSIPR

$0.02 \% \quad 7.0 \%$ IATRGAEQLAEGGR

$0.02 \% \quad 7.0 \%$ GAEQLAEGGR

$10.02 \% \quad 7.0 \% \quad$ KLSSETYSQAK

$\begin{array}{llll}11 & 0.02 \% & 7.0 \% & \text { LSSETYSQAK }\end{array}$

$96.8 \% \quad 15.4$

$99.7 \% \quad 39.7$

$99.7 \% \quad 52.7$

$99.7 \% 29.1$

$99.7 \% \quad 28.8$

$99.7 \% \quad 44.0$

$97.3 \% \quad 15.7$

$99.7 \% \quad 57.1$

$99.7 \% 54.9$

$99.0 \% \quad 36.4$

$99.0 \% \quad 40.3$

$99.7 \% \quad 56.1$

$99.7 \% \quad 58.7$

$99.7 \% \quad 33.2$

$98.4 \% \quad 20.6$

$99.0 \% \quad 26.5$

$99.0 \% \quad 44.3$

$96.4 \% \quad 17.9$

$\begin{array}{lll}99.7 \% & 58.4\end{array}$

$99.7 \% \quad 25.3$

$99.7 \% \quad 38.2$

$\begin{array}{lll}98.8 \% & 24.3\end{array}$

$99.1 \% 19.1$

$99.7 \% \quad 36.4$

$99.7 \% \quad 53.9$

$99.7 \% \quad 46.6$

$96.6 \% \quad 17.1$

$99.7 \% \quad 31.3$

$99.7 \% \quad 58.0$

$97.5 \% \quad 18.3 \quad 25.0$

$\begin{array}{lll}99.7 \% & 25.0 \quad 25.0\end{array}$

$207 \quad 0.28 \% \quad 45.5 \%$ TIGGGDDSFNTFFSETGAGK $99.7 \% \quad 76.1$

$207 \quad 0.28 \% \quad 45.5 \%$ TIGGGDDSFNTFFSETGAGKHVPR $99.7 \% \quad 33.5$

$207 \quad 0.28 \% \quad 45.5 \%$ AVFVDLEPTVIDEVR $\quad 99.7 \% \quad 52.4$

$207 \quad 0.28 \% \quad 45.5 \%$ AVFVDLEPTVIDEVRTGTYR $99.7 \% \quad 55.4$

$207 \quad 0.28 \% \quad 45.5 \%$ QLFHPEQLITGKEDAANNYAR $99.7 \% \quad 48.0$

$207 \quad 0.28 \% \quad 45.5 \%$ EDAANNYAR

$207 \quad 0.28 \% \quad 45.5 \%$ LSVDYGKK

$207 \quad 0.28 \% \quad 45.5 \%$ NLDIERPTYTNLNR

$207 \quad 0.28 \% \quad 45.5 \%$ LISQIVSSITASLR

$99.7 \% \quad 33.9$

$99.0 \% 39.9$

$99.7 \% \quad 42.3$

$99.7 \% \quad 69.4$

$99.7 \% \quad 56.1$

$207 \quad 0.28 \% \quad 45.5 \%$ IHFPLATYAPVISAEK

$207 \quad 0.28 \% \quad 45.5 \%$ AYHEQLSVAEITNACFEPANQMVK

$207 \quad 0.28 \% \quad 45.5 \%$ HGKYMACCLLYR

$99.7 \% \quad 45.0$

$99.7 \% \quad 44.5$

$\begin{array}{lll}99.7 \% & 37.7\end{array}$

$99.7 \% \quad 52.5$

$99.7 \% 56.7$

$99.7 \% \quad 56.9$
$207 \quad 0.28 \% \quad 45.5 \%$ GDVVPKDVNAAIATIK

$207 \quad 0.28 \% \quad 45.5 \%$ DVNAAIATIK

$29 \quad 207 \quad 0.28 \% \quad 45.5 \%$ DVNAAIATIKTK
1525.94

1431.78

1664.94

1306.63

998.55

1577.80

912.56

956.55

951.57

974.57

963.60

905.52

1136.56

994.54

1081.66

852.52

845.47

1114.65

2721.28

2194.06

1241.76

1043.60

1297.76

1665.91

1100.61

1162.56

1982.98

1428.76

987.49

1241.64

1113.54

2007.89

2497.17

1701.91

2280.19

2415.21

1023.45

909.50

1718.88

1487.88

1756.96

2766.29

1571.73

1249.55

1610.91

1015.58

1244.72

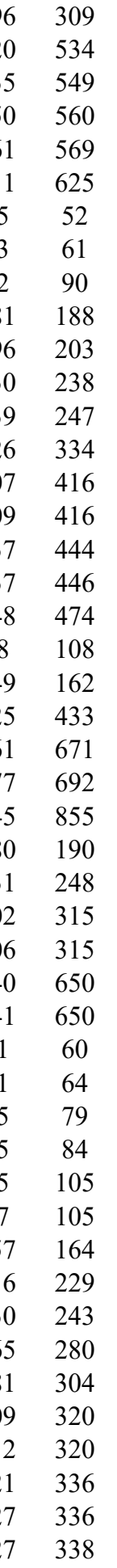

Page 132 of Table S-1-1 
Tubulin alpha-1B chain GN=TUBA1B Tubulin alpha-1B chain GN=TUBA1B Tubulin alpha-1B chain GN=TUBA1B Tubulin beta chain $\mathrm{GN}=\mathrm{TUBB}$ Tubulin beta chain $\mathrm{GN}=$ TUBB Tubulin beta chain GN=TUBB

Tubulin beta chain GN=TUBB Tubulin beta chain GN=TUBB Tubulin beta chain $\mathrm{GN}=\mathrm{TUBB}$

Tubulin beta chain GN=TUBB

Tubulin beta chain $\mathrm{GN}=\mathrm{TUBB}$

Tubulin beta chain $\mathrm{GN}=\mathrm{TUBB}$

Tubulin beta chain GN=TUBB

Tubulin beta chain GN=TUBB

Tubulin beta chain GN=TUBB

Tubulin beta chain GN=TUBB

Tubulin beta chain GN=TUBB

Tubulin beta chain GN=TUBB

Tubulin beta chain GN=TUBB

Tubulin beta chain GN=TUBB

Tubulin beta chain GN=TUBB

Tubulin beta chain GN=TUBB

Tubulin beta chain GN=TUBB

Tubulin beta chain GN=TUBB

Tubulin beta chain $\mathrm{GN}=\mathrm{TUBB}$

Tubulin beta chain GN=TUBB

Tubulin beta chain $\mathrm{GN}=$ TUBB

Tubulin beta chain GN=TUBB

Tubulin beta chain GN=TUBB

Tubulin beta chain $\mathrm{GN}=\mathrm{TUBB}$

Tubulin beta chain GN=TUBB

Tubulin beta-2A chain $\mathrm{GN}=\mathrm{TUBB} 2 \mathrm{~A}$

Tubulin beta-2A chain $\mathrm{GN}=\mathrm{TUBB} 2 \mathrm{~A}$

Tubulin beta- $2 \mathrm{~A}$ chain $\mathrm{GN}=\mathrm{TUBB} 2 \mathrm{~A}$

Tubulin beta- $2 \mathrm{~A}$ chain $\mathrm{GN}=\mathrm{TUBB} 2 \mathrm{~A}$

Tubulin beta- $2 \mathrm{~A}$ chain $\mathrm{GN}=\mathrm{TUBB} 2 \mathrm{~A}$

Tubulin beta- $2 \mathrm{~A}$ chain $\mathrm{GN}=\mathrm{TUBB} 2 \mathrm{~A}$

Tubulin beta- $2 \mathrm{~A}$ chain $\mathrm{GN}=\mathrm{TUBB} 2 \mathrm{~A}$

Tubulin beta- $2 \mathrm{~A}$ chain $\mathrm{GN}=\mathrm{TUBB} 2 \mathrm{~A}$

Tubulin beta- $2 \mathrm{~A}$ chain $\mathrm{GN}=\mathrm{TUBB} 2 \mathrm{~A}$

Tubulin beta- $2 \mathrm{~A}$ chain $\mathrm{GN}=\mathrm{TUBB} 2 \mathrm{~A}$

Tubulin beta- $2 \mathrm{~A}$ chain $\mathrm{GN}=\mathrm{TUBB} 2 \mathrm{~A}$

Tubulin beta- $2 \mathrm{~A}$ chain $\mathrm{GN}=\mathrm{TUBB} 2 \mathrm{~A}$

Tubulin beta- $2 \mathrm{~A}$ chain $\mathrm{GN}=\mathrm{TUBB} 2 \mathrm{~A}$

Tubulin beta- $2 \mathrm{~A}$ chain $\mathrm{GN}=\mathrm{TUBB} 2 \mathrm{~A}$

Tubulin beta- $2 \mathrm{~A}$ chain $\mathrm{GN}=\mathrm{TUBB} 2 \mathrm{~A}$

Tubulin beta-2A chain $\mathrm{GN}=\mathrm{TUBB} 2 \mathrm{~A}$
TBA1B_HUMAN $50.15 \quad 100.0 \% \quad 19$ TBA1B_HUMAN $50.15 \quad 100.0 \% \quad 19$ TBA1B_HUMAN $50.15 \quad 100.0 \% \quad 19$ TBB5_HUMAN $49.67 \quad 100.0 \% \quad 28$ TBB5_HUMAN $49.67 \quad 100.0 \% \quad 28$ TBB5_HUMAN $49.67 \quad 100.0 \% \quad 28$ TBB5_HUMAN $49.67 \quad 100.0 \% \quad 28$ TBB5_HUMAN $49.67 \quad 100.0 \% \quad 28$ TBB5 HUMAN $49.67 \quad 100.0 \% \quad 28$ TBB5_HUMAN $49.67 \quad 100.0 \% \quad 28$ TBB5_HUMAN $49.67 \quad 100.0 \% \quad 28$ TBB5 HUMAN $49.67 \quad 100.0 \% \quad 28$ TBB5_HUMAN $49.67 \quad 100.0 \% \quad 28$ TBB5_HUMAN $49.67 \quad 100.0 \% \quad 28$ TBB5_HUMAN $49.67 \quad 100.0 \% \quad 28$ TBB5_HUMAN $49.67 \quad 100.0 \% \quad 28$ TBB5 HUMAN $49.67 \quad 100.0 \% \quad 28$ TBB5_HUMAN $49.67 \quad 100.0 \% \quad 28$ TBB5_HUMAN $49.67 \quad 100.0 \% \quad 28$ TBB5 HUMAN $49.67 \quad 100.0 \% \quad 28$ TBB5_HUMAN $49.67 \quad 100.0 \% \quad 28$ TBB5_HUMAN $49.67 \quad 100.0 \% \quad 28$ TBB5_HUMAN $49.67 \quad 100.0 \% \quad 28$ TBB5_HUMAN $49.67 \quad 100.0 \% \quad 28$ TBB5 HUMAN $49.67 \quad 100.0 \% \quad 28$ TBB5_HUMAN $49.67 \quad 100.0 \% \quad 28$ TBB5_HUMAN $49.67 \quad 100.0 \% \quad 28$ TBB5 HUMAN $49.67 \quad 100.0 \% \quad 28$ TBB5_HUMAN $49.67 \quad 100.0 \% \quad 28$ TBB5 HUMAN $49.67 \quad 100.0 \% \quad 28$ TBB5_HUMAN $49.67 \quad 100.0 \% \quad 28$ TBB2A_HUMAN $49.91 \quad 100.0 \% \quad 4$ TBB2A HUMAN $49.91 \quad 100.0 \% \quad 4$ TBB2A_HUMAN $49.91 \quad 100.0 \% \quad 4$ TBB2A_HUMAN $49.91 \quad 100.0 \% \quad 4$ TBB2A HUMAN $49.91 \quad 100.0 \%$ TBB2A_HUMAN $49.91 \quad 100.0 \% \quad 4$ TBB2A HUMAN $49.91 \quad 100.0 \% \quad 4$ TBB2A_HUMAN $49.91 \quad 100.0 \%$ TBB2A_HUMAN $49.91 \quad 100.0 \% \quad 4$ TBB2A HUMAN $49.91 \quad 100.0 \%$ TBB2A_HUMAN $49.91 \quad 100.0 \% \quad 4$ TBB2A HUMAN $49.91 \quad 100.0 \% \quad 4$ TBB2A HUMAN $49.91 \quad 100.0 \%$ TBB2A_HUMAN $49.91 \quad 100.0 \%$ TBB2A HUMAN $49.91 \quad 100.0 \% \quad 4$ TBB2A_HUMAN $49.91 \quad 100.0 \%$
$29 \quad 207 \quad 0.28 \% \quad 45.5 \%$ SIQFVDWCPTGFK $99.7 \% 56.1$ $207 \quad 0.28 \% \quad 45.5 \%$ VGINYQ

$29 \quad 207 \quad 0.28 \% \quad 45.5 \%$ VGINYQPPTVVPGGDLAKVQR $\quad 99.7 \% \quad 38.7$

$45 \quad 313 \quad 0.43 \% \quad 53.6 \%$ MREIVHIQAGQCGNQIGAK $\quad 99.2 \% \quad 51.4$

$45 \quad 313 \quad 0.43 \% \quad 53.6 \%$ ISVYYNEATGGK

$99.7 \% 48$.

$313 \quad 0.43 \% \quad 53.6 \%$ ISVYYNEATGGKYVPR

$99.7 \% \quad 43.5$

$\begin{array}{llllll}45 & 313 & 0.43 \% & 53.6 \% & \text { AILVDLEPGTMDSVR } \quad 99.7 \% & 53.3\end{array}$

$45 \quad 313 \quad 0.43 \% \quad 53.6 \%$ GHYTEGAELVDSVLDVVR

$\begin{array}{ll}99.7 \% & 53.3 \\ 99.7 \% & 33.0\end{array}$

$313 \quad 0.43 \% \quad 53.6 \%$ IREEYPDR

$45 \quad 313 \quad 0.43 \% \quad 53.6 \%$ IMNTFSVVPSPK

$45 \quad 313 \quad 0.43 \% \quad 53.6 \%$ FPGQLNADLRK

$45 \quad 313 \quad 0.43 \% \quad 53.6 \%$ KLAVNMVPFPR

$45 \quad 313 \quad 0.43 \% \quad 53.6 \%$ LAVNMVPFPR

$45 \quad 313 \quad 0.43 \% \quad 53.6 \%$ LHFFMPGFAPLTSR

$96.0 \% 20.4$

$99.7 \% \quad 50.1$

$96.0 \% \quad 24.3$

$99.7 \% \quad 62.6$

$99.7 \% \quad 57.1$

$99.7 \% \quad 53.4$

$313 \quad 0.43 \% \quad 53.6 \%$ GSQQYRALTVPELTQQVFDAK $99.7 \% \quad 44.0$

$45 \quad 313 \quad 0.43 \% \quad 53.6 \%$ ALTVPELTQQVFDAK

$45 \quad 313 \quad 0.43 \% \quad 53.6 \%$ ALTVPELTQQVFDAKNMMAACDPR

$99.7 \% \quad 52.0$

$313 \quad 0.43 \% \quad 53.6 \%$ NMMAACDPR

$313 \quad 0.43 \% \quad 53.6 \%$ NMMAACDPRHGR

$313 \quad 0.43 \% \quad 53.6 \%$ HGRYLTVAAVFR

$313 \quad 0.43 \% \quad 53.6 \%$ YLTVAAVFR

$313 \quad 0.43 \% \quad 53.6 \%$ YLTVAAVFRGR

$99.4 \% 27.8$

$99.7 \% \quad 45.5$

$95.6 \% \quad 14.0$

$99.5 \% \quad 21.7$

$99.7 \% \quad 57.6$

$99.7 \% \quad 38.9$

$45 \quad 313 \quad 0.43 \% \quad 53.6 \%$ MSMKEVDEQMLNVQNK $\quad 99.7 \% \quad 56.2$

$45 \quad 313 \quad 0.43 \% \quad 53.6 \%$ EVDEQMLNVQNK

$45 \quad 313 \quad 0.43 \% \quad 53.6 \%$ NSSYFVEWIPNNVK

$99.7 \% \quad 57.9$

$99.7 \% \quad 36.9$

$99.7 \% \quad 50.2$

$99.7 \% \quad 33.3$

$45 \quad 313 \quad 0.43 \% \quad 53.6 \%$ TAVCDIPPRGLK

$313 \quad 0.43 \% \quad 53.6 \%$ MAVTFIGNSTAIQELFK

$313 \quad 0.43 \% \quad 53.6 \%$ MAVTFIGNSTAIQELFKR

$313 \quad 0.43 \% \quad 53.6 \%$ ISEQFTAMFR

$313 \quad 0.43 \% \quad 53.6 \%$ ISEQFTAMFRR

$99.7 \% 56.9$

$99.7 \% 25.5$

$16 \quad 0.02 \% \quad 49.4 \%$ MREIVHIQAGQCGNQIGAK $\quad 99.2 \% \quad 51.4$

$16 \quad 0.02 \% \quad 49.4 \%$ INVYYNEAAGNKYVPR $\quad 99.7 \% \quad 32.2$

$\begin{array}{llllll}16 & 0.02 \% & 49.4 \% & \text { AILVDLEPGTMDSVR } & 99.7 \% & 53.3\end{array}$

16

16

$16 \quad 0.02 \% \quad 49.4 \%$ FPGQLNADLRK

$16 \quad 0.02 \% \quad 49.4 \%$ LAVNMVPFPR

$16 \quad 0.02 \% \quad 49.4 \%$ LHFFMPGFAPLTSR

$16 \quad 0.02 \% \quad 49.4 \%$ ALTVPELTQQMFDSK

$16 \quad 0.02 \% \quad 49.4 \%$ NMMAACDPR

$16 \quad 0.02 \% \quad 49.4 \%$ NMMAACDPRHGR

$16 \quad 0.02 \% \quad 49.4 \%$ YLTVAAIFR

$16 \quad 0.02 \% \quad 49.4 \%$ YLTVAAIFRGR

$\begin{array}{ll}99.7 \% & 53.3 \\ 99.7 \% & 33.0\end{array}$

$96.0 \% \quad 20.4$

$96.0 \% \quad 24.3$

$99.7 \% \quad 62.6$

$99.7 \% \quad 57.1$

$99.7 \% \quad 53.4$

$99.7 \% \quad 44.5$

$99.7 \% \quad 45.5$

$95.6 \% 14.0$

$99.7 \% 29.6$

$99.7 \% \quad 33.8$

$16 \quad 0.02 \% \quad 49.4 \%$ MSMKEVDEQMLNVQNK $99.7 \% \quad 56.2$

$16 \quad 0.02 \% \quad 49.4 \%$ EVDEQMLNVQNK

$99.7 \% \quad 57.9$
1824.99

2110.06

1301.64

1816.92

1631.83

1958.98

1077.53

1319.70

1258.69

1271.73

1159.63

1636.83

2379.23

1659.90

2738.29

1065.43

1415.61

1389.77

1039.59

1252.72

1971.88

1446.69

1696.83

1028.52

1326.72

1869.98

2026.08

1229.60

1401.69

2110.06

1870.94

1631.83

1958.98

1077.53

1258.69

1271.73

1159.63

1636.83

1707.86

1065.43

1415.61

1053.61

1266.73

1971.88

1446.69 
Tubulin beta- $2 \mathrm{~A}$ chain $\mathrm{GN}=\mathrm{TUBB} 2 \mathrm{~A}$ Tubulin beta-2A chain $\mathrm{GN}=\mathrm{TUBB} 2 \mathrm{~A}$ Tubulin beta- $2 \mathrm{~A}$ chain $\mathrm{GN}=\mathrm{TUBB} 2 \mathrm{~A}$ Tubulin beta- $2 \mathrm{~A}$ chain $\mathrm{GN}=\mathrm{TUBB} 2 \mathrm{~A}$ Tubulin beta- $2 \mathrm{~A}$ chain $\mathrm{GN}=\mathrm{TUBB} 2 \mathrm{~A}$ Tubulin beta- $2 \mathrm{~A}$ chain $\mathrm{GN}=\mathrm{TUBB} 2 \mathrm{~A}$

Tubulin beta- $4 \mathrm{~B}$ chain $\mathrm{GN}=\mathrm{TUBB} 4 \mathrm{~B}$ Tubulin beta-4B chain GN=TUBB4B Tubulin beta- $4 \mathrm{~B}$ chain $\mathrm{GN}=\mathrm{TUBB} 4 \mathrm{~B}$ Tubulin beta $-4 \mathrm{~B}$ chain $\mathrm{GN}=\mathrm{TUBB} 4 \mathrm{~B}$ Tubulin beta- $4 \mathrm{~B}$ chain $\mathrm{GN}=\mathrm{TUBB} 4 \mathrm{~B}$ Tubulin beta- $4 \mathrm{~B}$ chain $\mathrm{GN}=\mathrm{TUBB} 4 \mathrm{~B}$ Tubulin beta-4B chain GN=TUBB4B Tubulin beta- $4 \mathrm{~B}$ chain $\mathrm{GN}=\mathrm{TUBB} 4 \mathrm{~B}$

Tubulin beta- $4 \mathrm{~B}$ chain $\mathrm{GN}=\mathrm{TUBB} 4 \mathrm{~B}$

Tubulin beta- $4 \mathrm{~B}$ chain $\mathrm{GN}=\mathrm{TUBB} 4 \mathrm{~B}$

Tubulin beta- $4 \mathrm{~B}$ chain $\mathrm{GN}=\mathrm{TUBB} 4 \mathrm{~B}$

Tubulin beta- $4 \mathrm{~B}$ chain $\mathrm{GN}=\mathrm{TUBB} 4 \mathrm{~B}$

Tubulin beta $-4 \mathrm{~B}$ chain $\mathrm{GN}=\mathrm{TUBB} 4 \mathrm{~B}$

Tubulin beta $-4 \mathrm{~B}$ chain $\mathrm{GN}=\mathrm{TUBB} 4 \mathrm{~B}$

Tubulin beta- $4 \mathrm{~B}$ chain GN=TUBB4B

Tubulin beta- $4 \mathrm{~B}$ chain $\mathrm{GN}=\mathrm{TUBB} 4 \mathrm{~B}$

Tubulin beta $-4 \mathrm{~B}$ chain $\mathrm{GN}=\mathrm{TUBB} 4 \mathrm{~B}$

Tubulin beta $-4 \mathrm{~B}$ chain $\mathrm{GN}=\mathrm{TUBB} 4 \mathrm{~B}$

Tubulin beta- $4 \mathrm{~B}$ chain $\mathrm{GN}=\mathrm{TUBB} 4 \mathrm{~B}$

Tubulin beta-4B chain GN=TUBB4B

Tubulin beta- $4 \mathrm{~B}$ chain $\mathrm{GN}=\mathrm{TUBB} 4 \mathrm{~B}$

Tubulin beta- $4 \mathrm{~B}$ chain $\mathrm{GN}=\mathrm{TUBB} 4 \mathrm{~B}$

Tubulin beta- $4 \mathrm{~B}$ chain $\mathrm{GN}=\mathrm{TUBB} 4 \mathrm{~B}$

Tubulin beta- $4 \mathrm{~B}$ chain $\mathrm{GN}=\mathrm{TUBB} 4 \mathrm{~B}$

Tubulin beta-4B chain $\mathrm{GN}=\mathrm{TUBB} 4 \mathrm{~B}$

Tubulin beta -6 chain GN=TUBB 6

Tubulin beta- 6 chain GN=TUBB 6

Tubulin beta- 6 chain GN=TUBB6

Tubulin beta- 6 chain GN=TUBB 6

Tubulin beta 6 chain $\mathrm{GN}=$ TUBB 6

Tubulin beta -6 chain $\mathrm{GN}=$ TUBB 6

Tubulin beta- 6 chain GN=TUBB 6

Tubulin beta- 6 chain GN=TUBB6

Tubulin beta- 6 chain GN=TUBB 6

Tubulin gamma- 1 chain $\mathrm{GN}=\mathrm{TUBG}$ Tubulin gamma- 1 chain GN=TUBG Tubulin gamma-1 chain $\mathrm{GN}=\mathrm{TUBG}$ Tubulin gamma- 1 chain $\mathrm{GN}=\mathrm{TUBG}$ Tubulin gamma- 1 chain $\mathrm{GN}=\mathrm{TUBG}$ Tubulin gamma- 1 chain $\mathrm{GN}=\mathrm{TUBG}$ Tubulin gamma-1 chain GN=TUBG1

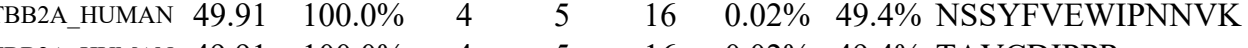
BB2A_HUMAN $49.91 \quad 100.0 \%$ TBB2A_HUMAN $49.91 \quad 100.0 \%$ TBB2A HUMAN $49.91 \quad 100.0 \%$ TBB2A_HUMAN $49.91 \quad 100.0 \%$ TBB2A_HUMAN $49.91 \quad 100.0 \%$ TBB4B HUMAN $49.83 \quad 100.0 \%$ TBB4B_HUMAN $49.83 \quad 100.0 \%$ TBB4B HUMAN $49.83 \quad 100.0 \%$ TBB4B HUMAN $49.83 \quad 100.0 \%$ TBB4B_HUMAN $49.83 \quad 100.0 \%$ TBB4B HUMAN $49.83 \quad 100.0 \%$ TBB4B_HUMAN $49.83 \quad 100.0 \%$ TBB4B_HUMAN $49.83 \quad 100.0 \%$ TBB4B HUMAN $49.83 \quad 100.0 \%$ TBB4B_HUMAN $49.83 \quad 100.0 \%$ TBB4B_HUMAN $49.83 \quad 100.0 \%$ TBB4B HUMAN $49.83 \quad 100.0 \%$ TBB4B_HUMAN $49.83 \quad 100.0 \%$ TBB4B HUMAN $49.83 \quad 100.0 \%$ TBB4B_HUMAN $49.83 \quad 100.0 \%$ TBB4B_HUMAN $49.83 \quad 100.0 \%$ TBB4B HUMAN $49.83 \quad 100.0 \%$ TBB4B_HUMAN $49.83 \quad 100.0 \%$ TBB4B HUMAN $49.83 \quad 100.0 \%$ TBB4B_HUMAN $49.83 \quad 100.0 \%$ TBB4B_HUMAN $49.83 \quad 100.0 \%$ TBB4B HUMAN $49.83 \quad 100.0 \%$ TBB4B_HUMAN $49.83 \quad 100.0 \%$ TBB4B HUMAN $49.83 \quad 100.0 \%$ TBB4B HUMAN $49.83 \quad 100.0 \%$ TBB6_HUMAN $49.86 \quad 100.0 \%$ TBB6 HUMAN $49.86 \quad 100.0 \%$ TBB6_HUMAN $49.86 \quad 100.0 \%$ TBB6 HUMAN $49.86 \quad 100.0 \%$ TBB6_HUMAN $49.86 \quad 100.0 \%$ TBB6_HUMAN $49.86 \quad 100.0 \%$ TBB6 HUMAN $49.86 \quad 100.0 \%$ TBB6_HUMAN $49.86 \quad 100.0 \%$ TBB6_HUMAN $49.86 \quad 100.0 \%$ TBG1_HUMAN $51.17 \quad 100.0 \%$ TBG1_HUMAN $51.17 \quad 100.0 \%$ TBG1_HUMAN $51.17 \quad 100.0 \%$ TBG1_HUMAN $51.17 \quad 100.0 \%$ TBG1_HUMAN $51.17 \quad 100.0 \%$ TBG1_HUMAN $51.17 \quad 100.0 \%$ TBG1_HUMAN $51.17 \quad 100.0 \%$ $0.02 \% \quad 49.4 \%$ TAVCDIPPR

$16 \quad 0.02 \% \quad 49.4 \%$ TAVCDIPPRGLK $99.7 \% \quad 36.9 \quad 25.0 \quad 36.7 \quad 6$ $99.7 \% \quad 50.2 \quad 25.0 \quad 27.9$

$\quad 0.02 \% \quad 49.4 \%$ MSATFIGNSTAIQELFKR

$0.02 \% \quad 49.4 \%$ ISEQFTAMFR

$0.02 \% \quad 49.4 \%$ ISEQFTAMFRR

$99.7 \% \quad 33.3$

$98.4 \% 28.0$

$99.7 \% \quad 56.9$

$99.7 \% \quad 25.5$

$0.06 \% \quad 52.1 \%$ MREIVHLQAGQCGNQIGAK $\quad 99.2 \% \quad 51.4$

$0.06 \% \quad 52.1 \%$ INVYYNEATGGK

$99.7 \% \quad 43.0$

$99.7 \% \quad 56.9$

$99.7 \% \quad 65.0$

$0.06 \% 52.1 \%$ AVLVDLEPGTMDSVR

$0.06 \% \quad 52.1 \%$ GHYTEGAELVDSVLDVVR

$0.06 \% \quad 52.1 \%$ IREEYPDR

$0.06 \% \quad 52.1 \%$ IMNTFSVVPSPK

$0.06 \% 52.1 \%$ FPGQLNADLRK

$0.06 \% \quad 52.1 \%$ KLAVNMVPFPR

$0.06 \% 52.1 \%$ LAVNMVPFPR

$0.06 \% \quad 52.1 \%$ LHFFMPGFAPLTSR

$0.06 \% \quad 52.1 \%$ ALTVPELTQQMFDAK

$0.06 \% \quad 52.1 \%$ NMMAACDPR

$0.06 \% \quad 52.1 \%$ NMMAACDPRHGR

$0.06 \% 52.1 \%$ HGRYLTVAAVFR

$0.06 \% 52.1 \%$ YLTVAAVFR

$0.06 \% \quad 52.1 \%$ YLTVAAVFRGR

$99.7 \% \quad 33.0$

$96.0 \% \quad 20.4$

$99.7 \% \quad 50.1$

$96.0 \% \quad 24.3$

$99.7 \% \quad 62.6$

$99.7 \% 57.1$

$99.7 \% \quad 53.4$

$99.7 \% \quad 44.4$

$99.7 \% \quad 45.5$

$95.6 \% 14.0$

$99.5 \% \quad 21.7$

$99.7 \% \quad 57.6$

$99.7 \% \quad 38.9$

$0.06 \% \quad 52.1 \%$ MSMKEVDEQMLNVQNK $99.7 \% \quad 56.2$

$0.06 \% 52.1 \%$ EVDEQMLNVQNK

$0.06 \% \quad 52.1 \%$ NSSYFVEWIPNNVK

$0.06 \% \quad 52.1 \%$ TAVCDIPPR

$0.06 \% \quad 52.1 \%$ TAVCDIPPRGLK

$99.7 \% \quad 57.9$

$99.7 \% \quad 36.9$

$99.7 \% \quad 50.2$

$99.7 \% \quad 33.3$

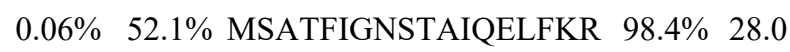

$99.7 \% \quad 56.9$

$99.7 \% \quad 25.5$

$99.7 \% \quad 52.2$

$96.0 \% \quad 24.3$

$99.7 \% \quad 62.6$

$99.7 \% 57.1$

$99.7 \% 53.4$

$99.7 \% \quad 37.5$

$99.7 \% \quad 45.5$

$95.6 \% \quad 14.0$

$\begin{array}{lll}99.7 \% & 36.9\end{array}$

$99.7 \% \quad 35.8$

$99.7 \% \quad 44.2$

$\begin{array}{lll}0.03 \% & 20.0 \% & \text { AVLLDLEPR } \\ 0.03 \% & 20.0 \% & \text { VIHSILNSPYAK }\end{array}$

$0.03 \% \quad 20.0 \%$ RLTQNADCVVVLDNTALNR $\quad 99.7 \% \quad 49.4$

$0.03 \% \quad 20.0 \%$ LTQNADCVVVLDNTALNR $\quad 99.7 \% \quad 40.2$

$0.03 \% \quad 20.0 \%$ LHFLMTGYTPLTTDQSVASVR $99.7 \% 56.8$

$0.03 \% \quad 20.0 \%$ KTTVLDVMR

$0.03 \% \quad 20.0 \%$ TTVLDVMR

$98.5 \% \quad 23.9$

0


Tubulin gamma- 1 chain $\mathrm{GN}=\mathrm{TUBG} 1$ Tubulin gamma- 1 chain $\mathrm{GN}=\mathrm{TUBG}$

Tubulin gamma- 1 chain $\mathrm{GN}=\mathrm{TUBG} 1$

TBCD HUMAN $132.60 \quad 100.0 \%$ Tubulin-specific chaperone D GN=TBCD TBCD_HUMAN $132.60 \quad 100.0 \%$ Tyrosine-protein kinase JAK1 GN=JAK1 JAK1_HUMAN $133.28 \quad 100.0 \%$ Tyrosine-protein kinase JAK1 GN=JAK1 JAK1_HUMAN $133.28 \quad 100.0 \%$ Tyrosine--tRNA ligase, cytoplasmic GN=YARS SYYC_HUMAN $59.15 \quad 100.0 \%$ Tyrosine--tRNA ligase, cytoplasmic GN=YARS SYYC HUMAN $59.15 \quad 100.0 \%$ Tyrosine--tRNA ligase, cytoplasmic GN=YARS SYYC_HUMAN $59.15 \quad 100.0 \%$ Tyrosine--tRNA ligase, cytoplasmic GN=YARS SYYC_HUMAN $59.15 \quad 100.0 \%$ Tyrosine--tRNA ligase, cytoplasmic GN=YARS SYYC HUMAN $59.15 \quad 100.0 \%$ U1 small nuclear ribonucleoprotein A GN=SNRPA SNRPA_HUMAN $31.28 \quad 100.0 \%$ U1 small nuclear ribonucleoprotein A GN=SNRPA SNRPA_HUMAN $31.28 \quad 100.0 \%$ U1 small nuclear ribonucleoprotein A GN=SNRPA SNRPA_HUMAN $31.28 \quad 100.0 \%$ U1 small nuclear ribonucleoprotein A GN=SNRPA SNRPA_HUMAN $31.28 \quad 100.0 \%$ U4/U6 small nuclear ribonucleoprotein Prp31 GN=PRPF31 PRP31_HUMAN 55.46 100.0\% U4/U6 small nuclear ribonucleoprotein Prp31 GN=PRPF31 PRP31_HUMAN 55.46 $100.0 \%$ U4/U6 small nuclear ribonucleoprotein Prp31 GN=PRPF31 PRP31_HUMAN 55.46 $100.0 \%$ U4/U6 small nuclear ribonucleoprotein Prp31 GN=PRPF31 PRP31_HUMAN 55.46 100.0\% U4/U6 small nuclear ribonucleoprotein Prp31 GN=PRPF31 PRP31_HUMAN 55.46 $100.0 \%$ U4/U6 small nuclear ribonucleoprotein Prp31 GN=PRPF31 PRP31_HUMAN 55.46 100.0\% U4/U6 small nuclear ribonucleoprotein Prp31 GN=PRPF31 PRP31_HUMAN $55.46 \quad 100.0 \%$ U4/U6 small nuclear ribonucleoprotein Prp31 GN=PRPF31 PRP31_HUMAN $55.46 \quad 100.0 \%$ U4/U6 small nuclear ribonucleoprotein Prp31 GN=PRPF31 PRP31_HUMAN 55.46 100.0\% U4/U6 small nuclear ribonucleoprotein Prp31 GN=PRPF31 PRP31_HUMAN 55.46 $100.0 \%$ U4/U6 small nuclear ribonucleoprotein Prp31 GN=PRPF31 PRP31_HUMAN 55.46 100.0\% U4/U6 small nuclear ribonucleoprotein Prp31 GN=PRPF31 PRP31_HUMAN $55.46 \quad 100.0 \%$ U4/U6 small nuclear ribonucleoprotein Prp31 GN=PRPF31 PRP31_HUMAN 55.46 $100.0 \%$ U4/U6 small nuclear ribonucleoprotein Prp31 GN=PRPF31 PRP31_HUMAN 55.46 100.0\% U4/U6 small nuclear ribonucleoprotein Prp31 GN=PRPF31 PRP31_HUMAN 55.46 100.0\% U4/U6 small nuclear ribonucleoprotein Prp31 GN=PRPF31 PRP31_HUMAN $55.46 \quad 100.0 \%$ U4/U6 small nuclear ribonucleoprotein Prp31 GN=PRPF31 PRP31_HUMAN 55.46 100.0\% U4/U6 small nuclear ribonucleoprotein Prp31 GN=PRPF31 PRP31_HUMAN $55.46 \quad 100.0 \%$ U4/U6 small nuclear ribonucleoprotein Prp31 GN=PRPF31 PRP31 HUMAN 55.46 100.0\% U4/U6 small nuclear ribonucleoprotein Prp31 GN=PRPF31 PRP31_HUMAN $55.46 \quad 100.0 \%$ U4/U6 small nuclear ribonucleoprotein Prp31 GN=PRPF31 PRP31_HUMAN $55.46 \quad 100.0 \%$ U4/U6.U5 tri-snRNP-associated protein $1 \mathrm{GN}=\mathrm{SART1}$ SNUT1_HUMAN $90.26100 .0 \%$ U4/U6.U5 tri-snRNP-associated protein 1 GN=SART1 SNUT1_HUMAN $90.26 \quad 100.0 \%$ U4/U6.U5 tri-snRNP-associated protein $1 \mathrm{GN}=\mathrm{SART1}$ SNUT1_HUMAN $90.26 \quad 100.0 \%$ U5 small nuclear ribonucleoprotein $200 \mathrm{kDa}$ helicase GN=SNRNP200 U520 HUMAN $244.51 \quad 100.0 \%$ U5 small nuclear ribonucleoprotein $200 \mathrm{kDa}$ helicase GN=SNRNP200 U520_HUMAN $244.51 \quad 100.0 \%$ U5 small nuclear ribonucleoprotein $200 \mathrm{kDa}$ helicase GN=SNRNP200 U520 HUMAN $244.51 \quad 100.0 \%$ U5 small nuclear ribonucleoprotein $200 \mathrm{kDa}$ helicase GN=SNRNP200 U520_HUMAN $244.51 \quad 100.0 \%$ U5 small nuclear ribonucleoprotein $200 \mathrm{kDa}$ helicase GN=SNRNP200 U520_HUMAN $244.51 \quad 100.0 \%$ U5 small nuclear ribonucleoprotein $200 \mathrm{kDa}$ helicase GN=SNRNP200 U520 HUMAN $244.51 \quad 100.0 \%$ U5 small nuclear ribonucleoprotein $200 \mathrm{kDa}$ helicase GN=SNRNP200 U520_HUMAN $244.51 \quad 100.0 \%$ 12 12

(1)

5

5
5
4

4

4
4
21

$\begin{array}{ll}21 & \\ 21 & 29 \\ 21 & 29\end{array}$

21

21
21
21
21

21

21
21
21

21
21
21

21
21
21

$\begin{array}{ll}21 & 29 \\ 21 & 29\end{array}$

21
21
21

$21 \quad 29$

21
21
21

21
21
3

3

3
3
33

3
33
33
33

33
33

33
33
33

33
33
33
33
$0.03 \% \quad 20.0 \%$ KSPYLPSAHR

$0.03 \% \quad 20.0 \%$ SPYLPSAHR

$0.01 \% \quad 1.5 \%$ DAAAVLVSR

$0.01 \% \quad 1.5 \%$ LQQVLTGLR

$0.00 \% \quad 2.5 \%$ EISNLLVATK

$0.00 \% \quad 2.5 \% \quad$ NVLVESEHQVKIGDFGLTK

$0.01 \% \quad 10.2 \%$ LSSVVTQHDSKK

$0.01 \% \quad 10.2 \%$ YLPALGYSKR

$0.01 \% \quad 10.2 \%$ LASAAYPDPSK

$0.01 \% \quad 10.2 \%$ LASAAYPDPSKQKPMAK

$0.01 \% \quad 10.2 \%$ NSEPEEVIPSRLDIR

$0.01 \% \quad 11.0 \%$ GQAFVIFKEVSSATNALR

$0.01 \% \quad 11.0 \%$ EVSSATNALR

$0.01 \% \quad 11.0 \%$ IQYAKTDSDIIAK

$0.01 \% \quad 11.0 \%$ TDSDIIAK

$0.10 \% \quad 40.1 \%$ ASEVMGPVEAAPEYR

$0.10 \% \quad 40.1 \%$ RFPELESLVPNALDYIR

$0.10 \% \quad 40.1 \%$ TVKELGNSLDK

$0.10 \% \quad 40.1 \%$ ELGNSLDKCK

$0.10 \% \quad 40.1 \%$ IYEYVESR

$0.10 \% \quad 40.1 \%$ MSFIAPNLSIIIGASTAAK

$0.10 \% \quad 40.1 \%$ IMGVAGGLTNLSK

$0.10 \% \quad 40.1 \%$ MPACNIMLLGAQR

$0.10 \% \quad 40.1 \%$ MPACNIMLLGAQRK

$0.10 \% \quad 40.1 \%$ VGYELKDEIER

$0.10 \% \quad 40.1 \%$ QVKPLPAPLDGQR

$0.10 \% \quad 40.1 \%$ LGLTEIRK

$0.10 \% \quad 40.1 \%$ VRQTQVNEATK

$0.10 \% \quad 40.1 \%$ QTQVNEATK

$0.10 \% \quad 40.1 \%$ QTQVNEATKAR

$0.10 \% \quad 40.1 \%$ TLQKQSVVYGGK

$0.10 \% \quad 40.1 \%$ QSVVYGGK

$\begin{array}{llllll}0.10 \% & 40.1 \% & 98.6 \% & 24.7 & 25.0 & 14.9\end{array}$

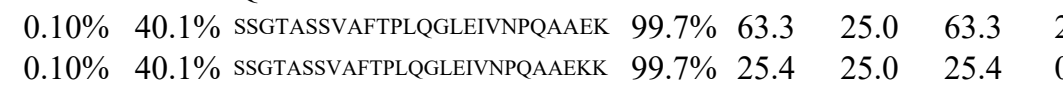

$0.10 \% \quad 40.1 \%$ VAEANQKYFSSMAEFLK

$0.10 \% \quad 40.1 \%$ YFSSMAEFLK

$0.01 \% \quad 4.0 \%$ LQAQSLSTVGPR

$0.01 \% \quad 4.0 \%$ TPYIVLSGSGK

$0.01 \% \quad 4.0 \% \quad$ SMNANTITK

$0.12 \% \quad 17.2 \%$ ANSNLVLQADR

$\begin{array}{lll}0.12 \% & 17.2 \% & \text { CTLSANLVASGELMSSK }\end{array}$

$0.12 \% \quad 17.2 \%$ DIDAFWLQR

$0.12 \% \quad 17.2 \%$ FYDDAIVSQK

$\begin{array}{lll}0.12 \% & 17.2 \% \text { KADEVLEILK }\end{array}$

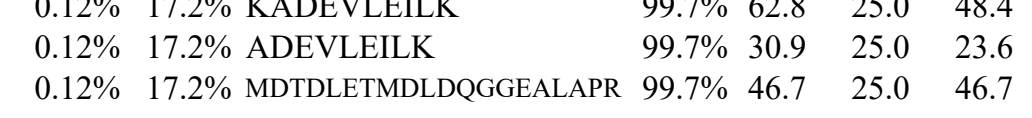

$99.7 \% \quad 33.2 \quad 25.0 \quad 26.7 \quad 2$

$\begin{array}{lllll}99.7 \% & 27.8 & 25.0 & 23.8 & 2\end{array}$

$99.7 \% \quad 50.4 \quad 25.0 \quad 38.5$

$\begin{array}{lllll}99.7 \% & 55.0 & 25.0 & 35.4 & 2\end{array}$

$\begin{array}{llll}99.7 \% & 31.1 & 25.0 & 25.0\end{array}$

$\begin{array}{llll}99.6 \% & 24.6 & 25.0 & 40.7 \\ & 24.5\end{array}$

$\begin{array}{llll}99.7 \% & 58.4 & 25.0 & 49.1\end{array}$

$\begin{array}{llll}94.9 \% & 13.7 & 25.0 & 13.7\end{array}$

$\begin{array}{llll}99.7 \% & 31.5 & 25.0 & 22.8\end{array}$

$\begin{array}{llll}99.7 \% & 43.5 & 25.0 & 40.0\end{array}$

$\begin{array}{rrrr}98.6 \% & 24.3 & 25.0 & 13.8 \\ 99.7 \% & 57.6 & 25.0 & 47.2\end{array}$

$\begin{array}{llll}99.7 \% & 33.0 & 25.0 & 29.5\end{array}$

$\begin{array}{llll}99.7 \% & 52.4 & 25.0 & 25.7\end{array}$

$\begin{array}{llll}97.5 \% & 20.7 & 25.0 & 14.0\end{array}$

$99.7 \% \quad 58.8$

$\begin{array}{llll}99.7 \% & 52.1 & 25.0 & 42.8\end{array}$

$\begin{array}{llll}99.6 \% & 22.6 & 25.0 & 22.6\end{array}$

$\begin{array}{llll}99.0 \% & 59.3 & 25.0 & 43.8\end{array}$

$99.7 \%$ 53.5 $25.0 \quad 45.2 \quad 2$

\begin{tabular}{lllll}
\hline 0 & 39.2 & 25.0 & 33.1 & 2
\end{tabular}

$\begin{array}{lllll}99.7 \% & 54.2 & 25.0 & 43.0 & 3\end{array}$

$\begin{array}{lllll}99.7 \% & 25.4 & 25.0 & 25.4 & 0\end{array}$

$\begin{array}{llll}99.7 \% & 55.0 & 25.0 & 55.0\end{array}$

$\begin{array}{lllll}99.7 \% & 28.4 & 25.0 & 28.4 & 2\end{array}$

$\begin{array}{lllll}99.1 \% & 25.0 & 25.0 & 24.1 & 2\end{array}$

$\begin{array}{llll}99.7 \% & 56.7 & 25.0 & 50.0\end{array}$

$\begin{array}{lllll}99.7 \% & 68.2 & 25.0 & 68.2 & 1 \\ 99.7 \% & 50.6 & 25.0 & 37.7 & 4\end{array}$

$\begin{array}{llll}99.7 \% & 50.6 & 25.0 & 37.7\end{array}$

$\begin{array}{llll}99.7 \% & 50.4 & 25.0 & 50.4\end{array}$

$\begin{array}{lllll}99.7 \% & 62.8 & 25.0 & 48.4 & 2\end{array}$

$\begin{array}{lllll} & 9.7 \% & 30.9 & 25.0 & 23.6 \\ & 99.7 \% & 46.7 & 25.0 & 46.7\end{array}$ $\begin{array}{llll}99.7 \% & 76.0 & 25.0 & 72.7\end{array}$

$\begin{array}{lllll}99.7 \% & 40.8 & 25.0 & 40.8 & 0 \\ 99.2 & 25.0 & 42.2 & 3\end{array}$

0
0
0
0
0
1
0
0
0
2
1
2
0
0
0
0
1
0
0
0
0
0
0
0
0
0
0
1
0
0
2
0
0
0
0
0
0
0
0
0
0
0
0
0
0
0
0
0
0
0
0

1134.57

1155.63

1027.63

1087.64

2113.13

1328.72

1167.65

1119.57

1818.94

1753.91

1938.04

1047.54

1465.79

862.45

1621.75

2032.09

1203.66

1163.57

1058.52

1921.05

1260.70

1490.73

1602.83

1350.69

1418.81

929.58

1273.69

1018.52

1245.65

1307.73

837.45

2602.34

2730.43

1962.96

1222.58

1256.70

1121.62

979.49

1200.63

1767.86

1163.58

1185.58

1157.68

1029.58

2177.97 
5 small nuclear ribonucleoprotein $200 \mathrm{kDa}$ helicase GN=SNRNP200 $\quad$ U520_HUMAN $244.51 \quad 100.0 \% \quad 33$ U5 small nuclear ribonucleoprotein $200 \mathrm{kDa}$ helicase GN=SNRNP200 U520_HUMAN $244.51 \quad 100.0 \% \quad 33$ U5 small nuclear ribonucleoprotein $200 \mathrm{kDa}$ helicase GN=SNRNP200 $\quad$ U520_HUMAN $244.51 \quad 100.0 \% \quad 33$ U5 small nuclear ribonucleoprotein $200 \mathrm{kD}$ a helicase GN=SNRNP200 U520_HUMAN $244.51 \quad 100.0 \%$ U5 small nuclear ribonucleoprotein $200 \mathrm{kDa}$ helicase GN=SNRNP200 U520_HUMAN $244.51 \quad 100.0 \%$ U5 small nuclear ribonucleoprotein $200 \mathrm{kDa}$ helicase GN=SNRNP200 U520_HUMAN $244.51 \quad 100.0 \% \quad 33$ U5 small nuclear ribonucleoprotein $200 \mathrm{kDa}$ helicase GN=SNRNP200 U520_HUMAN $244.51 \quad 100.0 \%$ $\begin{array}{llll}\text { U5 small nuclear ribonucleoprotein } 200 \mathrm{kDa} \text { helicase GN=SNRNP200 } & \text { U520_HUMAN } 244.51 \quad 100.0 \% & 33\end{array}$ U5 small nuclear ribonucleoprotein $200 \mathrm{kDa}$ helicase GN=SNRNP200 U520 HUMAN $244.51 \quad 100.0 \%$ U5 small nuclear ribonucleoprotein $200 \mathrm{kDa}$ helicase GN=SNRNP200 U520_HUMAN $244.51 \quad 100.0 \%$ U5 small nuclear ribonucleoprotein $200 \mathrm{kDa}$ helicase GN=SNRNP200 U520_HUMAN $244.51 \quad 100.0 \% \quad 33$ U5 small nuclear ribonucleoprotein $200 \mathrm{kDa}$ helicase GN=SNRNP200 U520_HUMAN $244.51 \quad 100.0 \% 33$ U5 small nuclear ribonucleoprotein $200 \mathrm{kDa}$ helicase GN=SNRNP200 U520_HUMAN $244.51 \quad 100.0 \%$ U5 small nuclear ribonucleoprotein $200 \mathrm{kDa}$ helicase GN=SNRNP200 U520_HUMAN $244.51 \quad 100.0 \% 33$ U5 small nuclear ribonucleoprotein $200 \mathrm{kDa}$ helicase GN=SNRNP200 U520_HUMAN $244.51 \quad 100.0 \%$ U5 small nuclear ribonucleoprotein $200 \mathrm{kDa}$ helicase GN=SNRNP200 U520_HUMAN $244.51 \quad 100.0 \% \quad 33$ U5 small nuclear ribonucleoprotein $200 \mathrm{kDa}$ helicase GN=SNRNP200 U520_HUMAN $244.51 \quad 100.0 \%$ U5 small nuclear ribonucleoprotein $200 \mathrm{kDa}$ helicase GN=SNRNP200 U520_HUMAN $244.51 \quad 100.0 \% 33$ U5 small nuclear ribonucleoprotein $200 \mathrm{kDa}$ helicase GN=SNRNP200 U520_HUMAN $244.51 \quad 100.0 \% 33$ U5 small nuclear ribonucleoprotein $200 \mathrm{kDa}$ helicase GN=SNRNP200 U520 HUMAN $244.51 \quad 100.0 \%$ U5 small nuclear ribonucleoprotein $200 \mathrm{kDa}$ helicase GN=SNRNP200 U520_HUMAN $244.51 \quad 100.0 \%$ U5 small nuclear ribonucleoprotein $200 \mathrm{kDa}$ helicase GN=SNRNP200 U520 HUMAN $244.51 \quad 100.0 \% 33$ U5 small nuclear ribonucleoprotein $200 \mathrm{kDa}$ helicase GN=SNRNP200 U520_HUMAN $244.51 \quad 100.0 \%$ U5 small nuclear ribonucleoprotein $200 \mathrm{kDa}$ helicase GN=SNRNP200 U520_HUMAN $244.51 \quad 100.0 \% 3$ U5 small nuclear ribonucleoprotein $200 \mathrm{kDa}$ helicase GN=SNRNP200 U520_HUMAN $244.51 \quad 100.0 \%$ U5 small nuclear ribonucleoprotein $200 \mathrm{kDa}$ helicase GN=SNRNP200 U520_HUMAN $244.51 \quad 100.0 \% 33$ U7 snRNA-associated Sm-like protein LSm11 GN=LSM11 LSM11_HUMAN $39.50 \quad 100.0 \%$ U7 snRNA-associated Sm-like protein LSm11 GN=LSM11 LSM11_HUMAN $39.50 \quad 100.0 \%$ UAP56-interacting factor GN=FYTTD1 UIF_HUMAN $35.82 \quad 100.0 \%$ UAP56-interacting factor GN=FYTTD1

UAP56-interacting factor GN=FYTTD1

UAP56-interacting factor GN=FYTTD1

UAP56-interacting factor GN=FYTTD1

UIF $35.82 \quad 100.0 \%$ UIF_HUMAN $35.82 \quad 100.0 \%$ UIF_HUMAN $35.82 \quad 100.0 \%$ UIF HUMAN $35.82 \quad 100.0 \%$ $\begin{array}{llll}\text { UAP56-interacting factor GN=FYTTD1 UIF_HUMAN } & 35.82 & 100.0 \% \\ \text { Ubiquitin carboxyl-terminal hydrolase } 15 \text { GN=USP15 UBP15_HUMAN } & 112.42 & 100.0 \%\end{array}$ Ubiquitin carboxyl-terminal hydrolase 15 GN=USP15 UBP15_HUMAN $112.42 \quad 100.0 \%$ Ubiquitin carboxyl-terminal hydrolase 15 GN=USP15 UBP15_HUMAN $112.42 \quad 100.0 \%$ Ubiquitin carboxyl-terminal hydrolase $15 \mathrm{GN}=$ USP15 UBP15 HUMAN $112.42100 .0^{\circ} \%$ Ubiquitin carboxyl-terminal hydrolase 24 GN=USP24 UBP24_HUMAN $294.37 \quad 100.0 \%$ Ubiquitin carboxyl-terminal hydrolase 24 GN=USP24 UBP24_HUMAN $294.37 \quad 100.0 \%$ Ubiquitin carboxyl-terminal hydrolase 24 GN=USP24 UBP24_HUMAN 294.37 100.0\% Ubiquitin carboxyl-terminal hydrolase 24 GN=USP24 UBP24_HUMAN $294.37 \quad 100.0 \%$ Ubiquitin-40S ribosomal protein S27a GN=RPS27A RS27A HUMAN $17.97 \quad 100.0 \%$ Ubiquitin-40S ribosomal protein S27a GN=RPS27A RS27A_HUMAN $17.97 \quad 100.0 \%$ Ubiquitin-40S ribosomal protein S27a GN=RPS27A RS27A_HUMAN $17.97 \quad 100.0 \%$ Ubiquitin-40S ribosomal protein S27a GN=RPS27A RS27A_HUMAN $17.97 \quad 100.0 \%$ Ubiquitin-associated domain-containing protein 2 GN=UBAC2 UBAC2_HUMAN $38.97 \quad 100.0 \%$
$99.7 \% \quad 47.9$

$99.7 \% \quad 52.0$

$0.12 \% \quad 17.2 \%$ YAQAGFEGFKTLNR

$99.7 \% \quad 55.5$

$99.7 \% \quad 52.8$

$0.12 \% \quad 17.2 \%$ SLVQEMVGSFGK

$\begin{array}{llll}42 & 86 & 0.12 \% & 17.2 \% \\ 42 & 86 & 0.12 \% & 17.2 \% \text { SLVQEMVGSFGKR }\end{array}$

$0.12 \% \quad 17.2 \%$ NIEMTQEDVR

$\begin{array}{lllll}42 & 86 & 0.12 \% & 17.2 \% & \text { FQIMNEIVYEK } \\ 42 & 86 & 0.12 \% & 17.2 \% \text { NQVLVFVHSR }\end{array}$

$99.7 \% \quad 49.8$

$99.7 \% \quad 31.3$

$99.7 \% \quad 54.1$

$99.7 \% \quad 46.2$

$99.7 \% \quad 45.8$

$0.12 \% \quad 17.2 \%$ EGSASTEVLR

$0.12 \% \quad 17.2 \%$ EGSASTEVLRTEAEQCK

$0.12 \% \quad 17.2 \%$ GTQVYSPEK

$0.12 \% \quad 17.2 \%$ TGNFQVTELGR

$0.12 \% \quad 17.2 \%$ VPIPVKESIEEPSAK

$0.12 \% \quad 17.2 \%$ KLPEEVVK

$0.12 \% \quad 17.2 \%$ LYDLNHNEIGELIR

$0.12 \% \quad 17.2 \%$ LELSVHLQPITR

$0.12 \% \quad 17.2 \%$ VVLLTGETSTDLK

$0.12 \% \quad 17.2 \%$ IVALSSSLSNAK

$0.12 \% \quad 17.2 \%$ LLSMAKPVYHAITK

$0.12 \% \quad 17.2 \%$ KPVIVFVPSR

$0.12 \% \quad 17.2 \%$ LTAIDILTTCAADIQR

$0.12 \% \quad 17.2 \%$ MTQNPNYYNLQGISHR

$0.12 \% \quad 17.2 \%$ VPHKLNNPK

$0.12 \% \quad 17.2 \%$ TNLLLQAHLSR

$0.12 \% \quad 17.2 \%$ MQLSAELQSDTEEILSK

$0.12 \% \quad 17.2 \%$ SNSLISIKR

$0.00 \% \quad 5.3 \%$ SAVEDSTLSR

$0.00 \% \quad 5.3 \% \quad$ VDYQQVFTR

$0.02 \% \quad 19.8 \%$ LLQQSGAQQFR

$0.02 \% \quad 19.8 \%$ KNNIPANFTR

$0.02 \% \quad 19.8 \%$ TAVPSFLTKR

$0.02 \% \quad 19.8 \%$ GVPLQFDINSVGK

$0.02 \% \quad 19.8 \%$ FGILKEQR

$0.02 \% \quad 19.8 \%$ ATLTYNKGGSR

$0.01 \% \quad 4.5 \%$ SPGASNFSTLPK

$0.01 \% \quad 4.5 \%$ AFKTQVGR

$0.01 \% \quad 4.5 \%$ STLVCPECAK

$0.01 \% \quad 4.5 \%$ NNTEDKLYNLLLLR

$0.01 \% \quad 1.7 \%$ CLLASTYLAR

$0.01 \% \quad 1.7 \%$ SSIRVEEIIPAAR

$0.01 \% \quad 1.7 \% \quad$ VYDQTNPYTDVR

$0.01 \% \quad 1.7 \%$ VAVATILEK

$\begin{array}{ll}99.7 \% & 25.6 \\ 99.3 \% & 24.9\end{array}$

$99.7 \% \quad 53.1$

$99.7 \% \quad 47.9$

$\begin{array}{lll}98.6 \% & 22.3\end{array}$

$\begin{array}{lll}99.7 \% & 39.7\end{array}$

$99.7 \% \quad 61.0$

$99.7 \% \quad 48.0$

$99.7 \% \quad 60.6$

$96.6 \% \quad 15.5$

$99.7 \% \quad 50.2$

$99.7 \% \quad 45.7$

$\begin{array}{lll}99.7 \% & 51.3\end{array}$

$98.2 \% \quad 16.8$

$99.7 \% \quad 60.0$

$99.7 \% \quad 30.3$

$99.7 \% \quad 52.5$

$99.7 \% \quad 36.1$

$99.7 \% \quad 42.2$

$99.7 \% \quad 37.2$

$99.7 \% \quad 32.9$

$98.8 \% 19.5$

$99.7 \% \quad 37.5$

$99.0 \% 24.1$

$99.7 \% \quad 33.5$

$99.7 \% \quad 47.0$

$95.8 \% 17.1$

$99.4 \% \quad 20.3$

$99.7 \% \quad 29.5$

$99.7 \% \quad 48.9$

$99.6 \% 24.4$

$95.6 \% 16.1$

$99.7 \% \quad 33.2$

$40 \quad 0.05 \% \quad 23.1 \%$ TLTGKTITLEVEPSDTIENVK $99.7 \% 32.2$

$0.05 \% \quad 23.1 \%$ TITLEVEPSDTIENVK

$99.7 \% \quad 51.1$

$\begin{array}{ll}0.05 \% & 23.1 \% \\ 0.05 \% & 23.1 \% \text { TITLEVEPSDTIENV }\end{array}$

$$
\text { K } 99.7
$$

$0.01 \% \quad 7.9 \%$ IGMGATLDIQR $\begin{array}{llll}99.7 \% & 40.3 & 25.0 & 40.3\end{array}$

$\begin{array}{llll}99.7 \% & 49.3 & 25.0 & 39.0\end{array}$
111

1601.8

1943.97

1297.65

1437.75

1234.57

1413.71

1198.67

1048.53

1894.88

1008.50

1221.62

1622.90

941.57

1698.88

1405.82

1375.77

1189.68

1587.89

1141.7

1774.94

1935.91

1046.61

1265.73

1937.94

1017.61

1064.52

1155.58

1275.68

1174.63

1119.65

1373.74

990.57

1167.61

1205.62

906.52

1164.54

1718.94

1167.62

1440.82

1470.69

943.58

2288.22

1787.93

1987.06

1523.78

1174.63 $\begin{array}{cc}70 & 479 \\ 70 & 483 \\ 91 & 509 \\ 46 & 557 \\ 46 & 558 \\ 38 & 647 \\ 01 & 711 \\ 19 & 728 \\ 54 & 763 \\ 54 & 770 \\ 30 & 838 \\ 76 & 986 \\ 44 & 1058 \\ 34 & 1141 \\ 53 & 1166 \\ 84 & 1195 \\ 05 & 1417 \\ 87 & 1498 \\ 39 & 1552 \\ 57 & 1566 \\ 71 & 1586 \\ 64 & 1779 \\ 75 & 1883 \\ 91 & 1901 \\ 02 & 1918 \\ 73 & 2081 \\ 43 & 252 \\ 33 & 341 \\ 7 & 67 \\ 66 & 175 \\ 53 & 262 \\ 73 & 285 \\ 95 & 302 \\ 03 & 313 \\ 29 & 240 \\ 61 & 368 \\ 44 & 453 \\ 00 & 613 \\ 53 & 162 \\ 04 & 1316 \\ 17 & 2028 \\ 36 & 2244 \\ 7 & 27 \\ 2 & 27 \\ 2 & 29 \\ 33 & 42 \\ & 243\end{array}$

Page 136 of Table S-1-1 
Unconventional myosin-Id GN=MYO1D MYO1D_HUMAN $116.21 \quad 100.0 \%$ Unconventional myosin-Id GN=MYO1D MYO1D_HUMAN $116.21 \quad 100.0 \%$ Unconventional myosin-Id GN=MYO1D MYO1D HUMAN $116.21 \quad 100.0 \%$ Unconventional myosin-Id GN=MYO1D MYO1D_HUMAN $116.21 \quad 100.0 \%$ Unconventional myosin-Id GN=MYO1D MYO1D_HUMAN $116.21 \quad 100.0 \%$ Unconventional myosin-Va GN=MYO5A MYO5A_HUMAN $215.41 \quad 100.0 \%$ Unconventional myosin-Va GN=MYO5A MYO5A_HUMAN $215.41 \quad 100.0 \%$ Unconventional myosin-Va GN=MYO5A MYO5A_HUMAN $215.41 \quad 100.0 \%$ Unconventional myosin-Va GN=MYO5A MYO5A_HUMAN $215.41 \quad 100.0 \%$ Unconventional myosin-Va GN=MYO5A MYO5A_HUMAN $215.41 \quad 100.0 \%$ Unconventional myosin-Va GN=MYO5A MYO5A_HUMAN $215.41 \quad 100.0 \%$ Unconventional myosin-Va GN=MYO5A MYO5A_HUMAN $215.41 \quad 100.0 \%$ Unconventional myosin-Va GN=MYO5A MYO5A_HUMAN $215.41 \quad 100.0 \%$ Unconventional myosin-Vb GN=MYO5B MYO5B_HUMAN $213.68 \quad 100.0 \%$ Unconventional myosin-Vb GN=MYO5B MYO5B_HUMAN $213.68 \quad 100.0 \%$ Unconventional myosin-Vb GN=MYO5B MYO5B HUMAN $213.68 \quad 100.0 \%$ Unconventional myosin-Vb GN=MYO5B MYO5B_HUMAN $213.68 \quad 100.0 \%$ Unconventional myosin-Vb GN=MYO5B MYO5B_HUMAN $213.68 \quad 100.0 \%$ Unconventional myosin-Vb GN=MYO5B MYO5B_HUMAN $213.68 \quad 100.0 \%$ Unconventional myosin-Vb GN=MYO5B MYO5B_HUMAN $213.68 \quad 100.0 \%$ Unconventional myosin-Vb GN=MYO5B MYO5B_HUMAN $213.68 \quad 100.0 \%$ Unconventional myosin-Vb GN=MYO5B MYO5B_HUMAN $213.68 \quad 100.0 \%$ Unconventional myosin-Vb GN=MYO5B MYO5B_HUMAN $213.68 \quad 100.0 \%$ Unconventional myosin-Vb GN=MYO5B MYO5B HUMAN $213.68100 .0 \%$ Unconventional myosin-Vb GN=MYO5B MYO5B_HUMAN $213.68 \quad 100.0 \%$ Unconventional myosin-Vb GN=MYO5B MYO5B_HUMAN $213.68 \quad 100.0 \%$ Unconventional myosin-Vb GN=MYO5B MYO5B_HUMAN $213.68 \quad 100.0 \%$ Unconventional myosin-Vb GN=MYO5B MYO5B_HUMAN $213.68 \quad 100.0 \%$ Unconventional myosin-Vb GN=MYO5B MYO5B_HUMAN $213.68 \quad 100.0 \%$ Unconventional myosin-Vb GN=MYO5B MYO5B_HUMAN $213.68 \quad 100.0 \%$ Unhealthy ribosome biogenesis protein 2 homolog GN=URB2 URB2_HUMAN $170.55 \quad 100.0 \%$ Unhealthy ribosome biogenesis protein 2 homolog GN=URB2 URB2 HUMAN $170.55100 .0 \%$ UPF0488 protein C8orf33 GN=C8orf33 CH033_HUMAN $24.99 \quad 100.0 \%$$$
\begin{gathered}
7 \\
11 \\
11
\end{gathered}
$$$$
11
$$ 
UPF0488 protein C8orf33 GN=C8orf33 CH033_HUMAN $24.99 \quad 100.0 \%$ Vacuolar protein sorting-associated protein 26A GN=VPS26A VP26A_HUMAN $38.17 \quad 100.0 \%$ Vacuolar protein sorting-associated protein 26A GN=VPS26A VP26A_HUMAN $38.17 \quad 100.0 \%$ Vacuolar protein sorting-associated protein $35 \mathrm{GN}=\mathrm{VPS} 35$ VPS35_HUMAN $91.71 \quad 100.0 \%$ Vacuolar protein sorting-associated protein $35 \mathrm{GN}=\mathrm{VPS} 35$ VPS35_HUMAN $91.71 \quad 100.0 \%$ Vacuolar protein sorting-associated protein $35 \mathrm{GN}=\mathrm{VPS} 35$ VPS35_HUMAN $91.71 \quad 100.0 \%$ Vacuolar protein sorting-associated protein $35 \mathrm{GN}=$ VPS35 VPS35_HUMAN $91.71 \quad 100.0 \%$ Vacuolar protein sorting-associated protein $35 \mathrm{GN}=\mathrm{VPS} 35$ VPS35_HUMAN $91.71 \quad 100.0 \%$ Vacuolar protein sorting-associated protein 51 homolog GN=VPS51 VPS51_HUMAN $86.04 \quad 100.0 \%$ Vacuolar protein sorting-associated protein 51 homolog GN=VPS51 VPS51_HUMAN $86.04 \quad 100.0 \%$ Very-long-chain (3R)-3-hydroxyacyl-CoA dehydratase $3 \mathrm{GN}=\mathrm{HACD} 3$ HACD3_HUMAN $43.16 \quad 100.0 \%$ Very-long-chain (3R)-3-hydroxyacyl-CoA dehydratase 3 GN=HACD3 HACD3_HUMAN $43.16 \quad 100.0^{\circ}$ Very-long-chain (3R)-3-hydroxyacyl-CoA dehydratase $3 \mathrm{GN}=\mathrm{HACD} 3$ HACD3_HUMAN $43.16 \quad 100.0 \%$ Very-long-chain (3R)-3-hydroxyacyl-CoA dehydratase $3 \mathrm{GN}=\mathrm{HACD} 3$ HACD3_HUMAN $43.16100 .0 \%$ Very-long-chain (3R)-3-hydroxyacyl-CoA dehydratase 3 GN=HACD3 HACD3_HUMAN $43.16 \quad 100.0 \%$ Very-long-chain 3-oxoacyl-CoA reductase GN=HSD17B12 DHB12_HUMAN $34.33 \quad 100.0 \%$ Very-long-chain 3-oxoacyl-CoA reductase GN=HSD17B12 DHB12 HUMAN $34.33 \quad 100.0^{\circ}$ Very-long-chain 3-oxoacyl-CoA reductase GN=HSD17B12 DHB12_HUMAN $34.33 \quad 100.0 \%$ Very-long-chain 3-oxoacyl-CoA reductase GN=HSD17B12 DHB12_HUMAN $34.33 \quad 100.0 \%$ Very-long-chain 3-oxoacyl-CoA reductase GN=HSD17B12 DHB12_HUMAN $34.33 \quad 100.0 \%$ Very-long-chain 3-oxoacyl-CoA reductase GN=HSD17B12 DHB12_HUMAN $34.33 \quad 100.0 \%$ Very-long-chain enoyl-CoA reductase GN=TECR TECR HUMAN $36.04100 .0 \%$ Very-long-chain enoyl-CoA reductase GN=TECR TECR_HUMAN $36.04 \quad 100.0 \%$ Very-long-chain enoyl-CoA reductase GN=TECR TECR_HUMAN $36.04 \quad 100.0 \%$ Vesicle-fusing ATPase $\mathrm{GN}=\mathrm{NSF}$ Vesicle-fusing ATPase GN=NSF Vesicle-fusing ATPase GN=NSF Vesicle-fusing ATPase $\mathrm{GN}=\mathrm{NSF}$ Vesicle-fusing ATPase GN=NSF Vesicle-fusing ATPase $\mathrm{GN}=\mathrm{NSH}$ Vesicle-fusing ATPase GN=NSF Vesicle-fusing ATPase $\mathrm{GN}=\mathrm{NSH}$ Vesicle-fusing ATPase $\mathrm{GN}=\mathrm{NSF}$ Vesicle-fusing ATPase GN=NSF Vesicle-fusing ATPase GN=NSF

Vimentin GN=VIM

Vimentin GN=VIM

Vimentin GN=VIM

Vimentin GN=VIM

Vimentin GN=VIM

Vimentin GN=VIM

Vimentin GN=VIM

Vimentin GN=VIM

Vimentin GN=VIM

Vimentin GN=VIM

Vimentin GN=VIM

Vimentin GN=VIM
NSF HUMAN $82.60 \quad 100.0 \%$ NSF_HUMAN $82.60 \quad 100.0 \%$ NSF_HUMAN $82.60 \quad 100.0 \%$ NSF HUMAN $82.60 \quad 100.0 \%$ NSF_HUMAN $82.60 \quad 100.0 \%$ NSF HUMAN $82.60 \quad 100.0 \%$ NSF_HUMAN $82.60 \quad 100.0 \%$ NSF HUMAN $82.60 \quad 100.0 \%$ NSF HUMAN $82.60 \quad 100.0 \%$ NSF_HUMAN $82.60 \quad 100.0 \%$ NSF HUMAN $82.60 \quad 100.0 \%$ VIME HUMAN $53.65 \quad 100.0 \%$ VIME_HUMAN $53.65 \quad 100.0 \% \quad 28$ VIME HUMAN $53.65 \quad 100.0 \% \quad 28$ VIME_HUMAN $53.65 \quad 100.0 \% \quad 28$ VIME_HUMAN $53.65 \quad 100.0 \% \quad 28$ VIME HUMAN $53.65 \quad 100.0 \% \quad 28$ VIME_HUMAN $53.65 \quad 100.0 \% \quad 28$ VIME HUMAN $53.65 \quad 100.0 \% \quad 28$ VIME HUMAN $53.65 \quad 100.0 \% \quad 28$ VIME_HUMAN $53.65 \quad 100.0 \% \quad 28$ VIME HUMAN $53.65 \quad 100.0 \% \quad 28$ VIME_HUMAN $53.65 \quad 100.0 \% \quad 28$
$0.00 \% \quad 11.4 \%$ AAAYSAQVQPVDGATR $0.01 \% \quad 7.7 \%$ ELALPGELTQSR $0.01 \% \quad 7.7 \% \quad$ LFLAGYDPTPTMR $0.01 \% \quad 7.3 \%$ ILVGTNLVR $0.01 \% \quad 7.3 \% \quad$ LSQLEGVNVER $0.01 \% \quad 7.3 \% \quad$ IPVDTYNNILTVLK $0.01 \% \quad 7.3 \%$ SEDPDQQYLILNTAR $0.01 \% \quad 7.3 \%$ LLKKPDQGR

$0.00 \% \quad 3.5 \% \quad$ AIQDDCQVITAR

$0.00 \% \quad 3.5 \% \quad$ LAQEQGGGDNSLLVR

$0.03 \% \quad 9.7 \% \quad$ QVNITVQK

$0.03 \% \quad 9.7 \%$ QVNITVQKK

$0.03 \% \quad 9.7 \%$ LRLESEGSPETLTNLR

$0.03 \% \quad 9.7 \% \quad$ LESEGSPETLTNLR

$0.03 \% \quad 9.7 \% \quad$ FSFTLPYPVK

$0.02 \% \quad 26.0 \%$ TIAVDFASEDIYDKIK

$0.02 \% \quad 26.0 \%$ MININILSVCK

$0.02 \% \quad 26.0 \%$ MTQLVLPGMVER

$0.02 \% \quad 26.0 \%$ GVFVQSVLPYFVATK

$0.02 \% \quad 26.0 \%$ IRKPTLDKPSPETFVK

$0.02 \% \quad 26.0 \%$ SAIKTVGLQSR

$0.01 \% \quad 9.1 \%$ THPQWYPAR

$0.01 \% \quad 9.1 \%$ SLKDEDVLQK

$0.01 \% \quad 9.1 \%$ LLETLFVHR

$0.04 \% \quad 17.5 \%$ THPSVVPGSIAFSLPQR

$0.04 \% \quad 17.5 \%$ GILLYGPPGCGK

$0.04 \% \quad 17.5 \%$ NFSGAELEGLVR

$0.04 \% \quad 17.5 \%$ AAQSTAMNR

$0.04 \% \quad 17.5 \%$ VLDDGELLVQQTK

$99.7 \% \quad 50.1$

$99.7 \% \quad 56.9$

$99.7 \% \quad 42.4$

$99.7 \% \quad 40.6$

$99.7 \% \quad 50.4$

$96.6 \% \quad 16.8$

$99.7 \% \quad 58.3$

$94.7 \% \quad 14.9$

$99.6 \% 24.4$

$99.7 \% \quad 43.5$

$99.0 \% \quad 43.1$

$97.5 \% \quad 21.5$

$99.7 \% \quad 51.0$

$99.7 \% \quad 62.6$

$99.7 \% \quad 33.0$

$99.7 \% \quad 75.5$

$99.7 \% 57.1$

$98.7 \% \quad 17.8$

$99.7 \% \quad 43.3$

$99.2 \% \quad 26.6$

$99.7 \% \quad 54.7$

$99.7 \% \quad 24.1$

$99.6 \% 23.6$

$97.0 \% \quad 19.1$

$99.7 \% 28.1$

$99.7 \% \quad 38.1$

$99.7 \% \quad 55.7$

$99.7 \% \quad 51.6$

$99.7 \% \quad 72.4$

$0.04 \% \quad 17.5 \%$ NSDRTPLVSVLLEGPPHSGK $99.7 \% \quad 35.4$

$0.04 \% \quad 17.5 \%$ IAEESNFPFIK

$0.04 \% \quad 17.5 \%$ LLDYVPIGPR

$0.04 \% \quad 17.5 \%$ KLLIIGTTSR

$0.04 \% \quad 17.5 \%$ LLIIGTTSR

$0.04 \% \quad 17.5 \%$ FLALLREEGASPLDFD

$0.17 \% \quad 58.4 \%$ SVSSSSYR

$127 \quad 0.17 \% \quad 58.4 \%$ SVSSSSYRR

$127 \quad 0.17 \% \quad 58.4 \%$ RMFGGPGTASRPSSSR

$127 \quad 0.17 \% \quad 58.4 \%$ MFGGPGTASRPSSSR

$99.7 \% \quad 37.2$

$99.7 \% \quad 40.6$

$99.7 \% \quad 41.9$

$99.2 \% \quad 19.3$

$99.7 \% \quad 25.7$

$99.0 \% \quad 29.2$

$99.7 \% \quad 30.9$

$99.7 \% \quad 26.6$

$99.7 \% \quad 25.2$

$95.1 \% \quad 13.6$

$99.0 \% 30.6$

$127 \quad 0.17 \% \quad 58.4 \%$ SYVTTSTR

$127 \quad 0.17 \% \quad 58.4 \%$ SYVTTSTRTYSLGSALRPSTSR

$127 \quad 0.17 \% \quad 58.4 \%$ TYSLGSALRPSTSR

$99.4 \% 20.5$

$99.7 \% 52.9$

$39 \quad 127 \quad 0.17 \% \quad 58.4 \%$ SLYASSPGGVYATR

$127 \quad 0.17 \% \quad 58.4 \%$ SLYASSPGGVYATRSSAVR $99.7 \% \quad 47.8$

$127 \quad 0.17 \% \quad 58.4 \%$ LRSSVPGVR

$99.5 \% 27.7$

39

$\begin{array}{lll}0.17 \% & 58.4 \% \text { LLQDSVDFSLADAINTEFKNTR } & 99.7 \% \quad 50.5\end{array}$
1604.80

1198.65

1294.67

1142.66
1313.71

1497.74

984.62

1243.66

1602.91

1762.86

1054.64

1389.68

1556.80

929.54

1057.64

1814.96

1545.78

1827.94

1320.70

1405.72

1654.92

1856.06

1159.68

1155.57

1174.63

1127.66

1792.97

1231.65

1291.66

949.45

1457.78

2103.12

1101.70

973.60

1792.91

872.41

1028.51

1650.81

1494.71

2390.15

914.46

2391.23

1495.79

1428.71

1928.98

970.58

105

$50 \quad 262$

$218 \quad 226$

$227 \quad 237$

$00 \quad 514$

$660 \quad 668$

$221 \quad 232$

$356 \quad 370$

$77 \quad 85$

$131 \quad 146$

$33 \quad 146$

$10 \quad 319$

$57 \quad 167$

$168 \quad 179$

$224 \quad 238$

$242 \quad 257$

$258 \quad 268$

47

$42 \quad 150$

$51 \quad 67$

$255 \quad 266$

4546

$447 \quad 455$

$30 \quad 549$

$556 \quad 566$

$508 \quad 617$

$639 \quad 648$

$640 \quad 648$

12
13

38

$4 \quad 28$

$4 \quad 36$

36

29

51
51

51
70

2497.26 
Vimentin GN=VIM

Vimentin GN=VIM

Vimentin GN=VIM

Vimentin GN=VIM

Vimentin GN=VIM

Vimentin GN=VIM

Vimentin GN=VIM

Vimentin GN=VIM

Vimentin GN=VIM

Vimentin GN=VIM

Vimentin GN=VIM

Vimentin GN=VIM

Vimentin GN=VIM

Vimentin GN=VIM

Vimentin GN=VIM
Vimentin GN=VIM

VIME HUMAN $53.65 \quad 100.0 \% \quad 28$ VIME HUMAN $53.65 \quad 100.0 \% \quad 28$ VIME_HUMAN $53.65 \quad 100.0 \% \quad 28$ VIME HUMAN $53.65 \quad 100.0 \% \quad 28$ VIME_HUMAN $53.65 \quad 100.0 \% \quad 28$ VIME_HUMAN $53.65 \quad 100.0 \% \quad 28$ VIME HUMAN $53.65 \quad 100.0 \% \quad 28$ VIME_HUMAN $53.65 \quad 100.0 \% \quad 28$ VIME HUMAN $53.65 \quad 100.0 \% \quad 28$ VIME_HUMAN $53.65 \quad 100.0 \% \quad 28$ VIME_HUMAN $53.65 \quad 100.0 \% \quad 28$ VIME HUMAN $53.65 \quad 100.0 \% \quad 28$ VIME_HUMAN $53.65 \quad 100.0 \% \quad 28$ VIME_HUMAN $53.65 \quad 100.0 \% \quad 28$ VIME_HUMAN $53.65 \quad 100.0 \% \quad 28$ VIME_HUMAN $53.65 \quad 100.0 \% \quad 28$ ACl VDAC1_HUMAN $30.77 \quad 100.0 \% \quad 7$ Voltage-dependent anion-selective channel protein $1 \mathrm{GN}=\mathrm{VDACl}$ VDAC1_HUMAN $30.77 \quad 100.0 \%$ Voltage-dependent anion-selective channel protein 1 GN=VDAC1 VDAC1_HUMAN 30.77 Voltage-dependent anion-selective channel protein $1 \mathrm{GN}=\mathrm{VDACl}$ VDAC1_HUMAN 30.77 Voltage-dependent anion-selective channel protein $1 \mathrm{GN}=\mathrm{VDACl}$ VDAC1_HUMAN 30.77 Voltage-dependent anion-selective channel protein $1 \mathrm{GN}=\mathrm{VDAC1}$ VDAC1_HUMAN 30.77 Voltage-dependent anion-selective channel protein $1 \mathrm{GN}=\mathrm{VDAC1}$ VDAC1_HUMAN 30.77 Voltage-dependent anion-selective channel protein $1 \mathrm{GN}=\mathrm{VDACl}$ VDAC1_HUMAN 30.7 Voltage-dependent anion-selective channel protein $2 \mathrm{GN}=\mathrm{VDAC2}$ VDAC2 $\mathrm{HUMAN} 31.5^{\circ}$ Voltage-dependent anion-selective channel protein $2 \mathrm{GN}=\mathrm{VDAC} 2$ VDAC2_HUMAN 31.57 Voltage-dependent anion-selective channel protein $2 \mathrm{GN}=\mathrm{VDAC2}$ VDAC2_HUMAN 31.5 Voltage-dependent anion-selective channel protein $2 \mathrm{GN}=\mathrm{VDAC} 2$ VDAC2 HUMAN 31.57 Voltage-dependent anion-selective channel protein $2 \mathrm{GN}=\mathrm{VDAC2}$ VDAC2_HUMAN 31.5 Voltage-dependent anion-selective channel protein $2 \mathrm{GN}=\mathrm{VDAC} 2$ VDAC2 HUMAN $31.5^{\circ}$ Voltage-dependent anion-selective channel protein $2 \mathrm{GN}=\mathrm{VDAC2}$ VDAC2_HUMAN 31.57 Voltage-dependent anion-selective channel protein $2 \mathrm{GN}=\mathrm{VDAC2}$ VDAC2_HUMAN 31.5 oltage-dependent anion-selective channel protein $2 \mathrm{GN}=\mathrm{VDAC} 2$ VDAC2 HUMAN 31.57 Voltage-dependent anion-selective channel protein $3 \mathrm{GN}=\mathrm{VDAC} 3$ VDAC3_HUMAN 30.66 Voltage-dependent anion-selective channel protein $3 \mathrm{GN}=\mathrm{VDAC} 3$ VDAC3 HUMAN 30.66 Voltage-dependent anion-selective channel protein $3 \mathrm{GN}=\mathrm{VDAC} 3$ VDAC3 HUMAN 30.66 Voltage-dependent anion-selective channel protein $3 \mathrm{GN}=\mathrm{VDAC} 3 \mathrm{VDAC} 3$ HUMAN 30.66 oltage-dependent anion-selective channel protein $3 \mathrm{GN}=\mathrm{VDAC} 3$ VDAC3 HUMAN 30.66 Voltage-dependent anion-selective channel protein 3 GN=VDAC3 VDAC3_HUMAN 30.66 Voltage-dependent anion-selective channel protein $3 \mathrm{GN}=\mathrm{VDAC3}$ VDAC3_HUMAN 30.66 Voltage-dependent anion-selective channel protein $3 \mathrm{GN}=\mathrm{VDAC} 3$ VDAC3_HUMAN 30.66 Voltage-dependent anion-selective channel protein $3 \mathrm{GN}=\mathrm{VDAC} 3$ VDAC3_HUMAN 30.6 Voltage-dependent anion-selective channel protein $3 \mathrm{GN}=\mathrm{VDAC} 3$ VDAC3 HUMAN 30.66 Vollage-d Voltage-dependent anion-selective channel protein $3 \mathrm{GN}=\mathrm{VDAC} 3$ VDAC3_HUMAN 30.6 Willebrand factor A domain-containing protein $8 \mathrm{GN}=\mathrm{VWA} 8 \mathrm{VWA} 8 \mathrm{HUMAN} 214.83$ von Willebrand factor A domain-containing protein $8 \mathrm{GN}=\mathrm{VWA} 8 \mathrm{VWA} 8$ _HUMAN 214.8

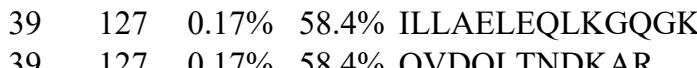

$39 \quad 127 \quad 0.17 \% \quad 58.4 \%$ DVRQQYESVAAK

$39 \quad 127 \quad 0.17 \% \quad 58.4 \%$ QQYESVAAK

$39 \quad 127 \quad 0.17 \% \quad 58.4 \%$ NLQEAEEWYKSK

$39 \quad 127 \quad 0.17 \% \quad 58.4 \%$ FADLSEAANR

$39 \quad 127 \quad 0.17 \% \quad 58.4 \%$ FADLSEAANRNNDALR

$127 \quad 0.17 \% \quad 58.4 \%$ QVQSLTCEVDALKGTNESLER

$127 \quad 0.17 \% \quad 58.4 \%$ KLLEGEESR

$127 \quad 0.17 \% \quad 58.4 \%$ ISLPLPNFSSLNLR

$127 \quad 0.17 \% \quad 58.4 \%$ ETNLDSLPLVDTHSKR

$\begin{array}{llll}127 & 0.17 \% & 58.4 \% & \text { ETNLDSLPLVDTHSKR } \\ 127 & 0.17 \% & 58.4 \% & \text { TLLIKTVETR } \\ 127 & 0.17 \% & 58.4 \% & \text { TVETRDGQVINETSQHHDDLE }\end{array}$

$99.7 \% \quad 41.0$

$99.7 \% \quad 54.9$

$99.7 \% \quad 51.0$

$95.7 \% \quad 15.7$

$99.7 \% \quad 27.7$

$99.3 \% \quad 24.5$

$99.7 \% 37.6$

127

\section{$0.17 \% \quad 58.4 \%$ DGQVINETSQHHDDLE}

$0.02 \% \quad 37.1 \%$ GYGFGLIKLDLK

$0.02 \% \quad 37.1 \%$ VTGSLETKYR

$0.02 \% 37.1 \%$ LTFDSSFSPNTGKK

\section{$99.7 \% \quad 35.9$}

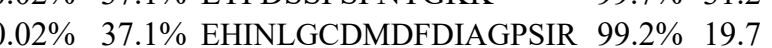

$0.02 \% \quad 37.1 \%$ YQIDPDACFSAK

$99.7 \% \quad 48.5$

$\begin{array}{lll}0.02 \% & 37.1 \% \text { VNNSSLIGLGY } \\ 0.02 \% & 37.1 \% \text { LTLSALLDGK }\end{array}$

$0.05 \% \quad 31.0 \%$ DIFNKGFGFGLVK

$0.05 \% \quad 31.0 \%$ LTFDTTFSPNTGK

$0.05 \% \quad 31.0 \%$ LTFDTTFSPNTGKK

$0.05 \% \quad 31.0 \%$ NNFAVGYR

$0.05 \% \quad 31.0 \%$ YQLDPTASISAK

$0.05 \% \quad 31.0 \%$ VNNSSLIGVGYTQTLRPGVK

$0.05 \% \quad 31.0 \%$ LTLSALVDGK

$99.7 \% \quad 41.7$

$99.7 \% \quad 40.1$

$99.7 \% \quad 41.9$

$99.7 \% \quad 54.5$

$\begin{array}{rr}99.0 \% & 46.9 \\ 99.6 \% & 23.1\end{array}$

$99.7 \% 57.5$

$0.04 \% \quad 45.2 \%$ DVFNKGYGFGMVK

$99.7 \% \quad 44$.

$0.04 \% \quad 45.2 \%$ ASGNLETKYK

$0.04 \% \quad 45.2 \%$ YKVCNYGLTFTQK

$0.04 \% \quad 45.2 \%$ VCNYGLTFTQK

$0.04 \% \quad 45.2 \%$ LTLDTIFVPNTGK

$0.04 \% \quad 45.2 \%$ LTLDTIFVPNTGKK

$0.04 \% \quad 45.2 \%$ LSQNNFALGYK

$0.04 \% \quad 45.2 \%$ YMLDCRTSLSAK

$99.7 \% \quad 68.4$

$99.5 \% \quad 23.4$

$99.7 \% \quad 29.4$

$99.7 \% \quad 32.7$

$99.7 \% \quad 42.2$

$99.7 \% \quad 34.2$

$99.7 \% \quad 51.0$

$99.7 \% \quad 27.4$

$0.04 \% \quad 45.2 \%$ VNNASLIGLGYTQTLRPGVK $\quad 99.7 \% \quad 60.1$ $99.1 \% \quad 61.2$

$99.7 \% \quad 26.4$

$\begin{array}{ccc}0.04 \% & 45.2 \% & \text { LTLSALIDGKN } \\ 0.00 \% & 1.1 \% & \text { VNAGTLAVLQR }\end{array}$

$0.00 \% \quad 1.1 \%$ IILDNLQAK
$99.7 \% 47.1$

$99.4 \% \quad 20.5$
1287.67

1533.85

1393.71

1023.51

1524.73

1093.53

1776.86

2377.17

1527.83

1060.56

1570.90

1824.95

1173.72

2423.11

1836.80

1323.77

1153.62

1528.76

2175.98

1414.63

2103.18

1030.61

1808.00

1441.78

1428.70

1556.80

940.46

1881.01

1293.67

2103.16

1016.60

1780.99

1461.72

1990.84

1110.58

1621.80

1330.65

1418.79

1546.88

1254.65

1444.69

2101.18

1030.61

1828.99

1141.67 1027.61

\begin{tabular}{cc}
0 & 143 \\
0 & 170 \\
3 & 235 \\
1 & 282 \\
4 & 282 \\
3 & 294 \\
5 & 304 \\
5 & 310 \\
2 & 342 \\
9 & 390 \\
2 & 410 \\
1 & 424 \\
5 & 440 \\
1 & 450 \\
6 & 466 \\
1 & 466 \\
1 & 32 \\
4 & 63 \\
7 & 110 \\
1 & 139 \\
5 & 236 \\
7 & 256 \\
7 & 266 \\
7 & 274 \\
7 & 39 \\
8 & 120 \\
8 & 121 \\
8 & 185 \\
0 & 247 \\
6 & 247 \\
8 & 267 \\
8 & 277 \\
8 & 285 \\
6 & 28 \\
5 & 53 \\
4 & 63 \\
2 & 74 \\
4 & 74 \\
7 & 109 \\
7 & 110 \\
4 & 174 \\
5 & 236 \\
7 & 256 \\
7 & 266 \\
7 & 274 \\
56 & 1664 \\
& \\
\hline
\end{tabular}

Page 139 of Table S-1-1 
V-type proton ATPase catalytic subunit A GN=ATP6V1A VATA_HUMAN $68.31 \quad 100.0 \%$ V-type proton ATPase catalytic subunit A GN=ATP6V1A VATA HUMAN $68.31 \quad 100.0 \%$ V-type proton ATPase subunit d 1 GN=ATP6V0D1 VA0D1_HUMAN $40.33 \quad 100.0 \%$ V-type proton ATPase subunit d $1 \mathrm{GN}=\mathrm{ATP} 6 \mathrm{~V} 0 \mathrm{D} 1$ VA0D1_HUMAN $40.33 \quad 100.0^{\circ}$ WD repeat-containing protein 5 GN=WDR5 WDR5_HUMAN $36.59 \quad 100.0 \%$ WD repeat-containing protein 5 GN=WDR5 WDR5_HUMAN $36.59100 .0 \%$ WD repeat-containing protein $5 \mathrm{GN}=$ WDR5 WDR5 HUMAN $36.59100 .0 \%$ WD repeat-containing protein $82 \mathrm{GN}=$ WDR82 WDR82_HUMAN $35.08 \quad 100.0 \%$ WD repeat-containing protein $82 \mathrm{GN}=$ WDR82 WDR82 HUMAN $35.08 \quad 100.0 \%$ WD repeat-containing protein $82 \mathrm{GN}=$ WDR82 WDR82_HUMAN $35.08 \quad 100.0 \%$ X-ray repair cross-complementing protein $5 \mathrm{GN}=\mathrm{XRCC} 5 \mathrm{XRCC5}$ _HUMAN $82.71 \quad 100.0 \%$ X-ray repair cross-complementing protein $5 \mathrm{GN}=\mathrm{XRCC} 5 \mathrm{XRCC} 5$ HUMAN $82.71 \quad 100.0 \%$ X-ray repair cross-complementing protein $5 \mathrm{GN}=\mathrm{XRCC} 5 \mathrm{XRCC} 5$ _HUMAN $82.71 \quad 100.0 \%$ X-ray repair cross-complementing protein $5 \mathrm{GN}=\mathrm{XRCC5}$ XRCC5_HUMAN $82.71 \quad 100.0 \%$ X-ray repair cross-complementing protein $5 \mathrm{GN}=\mathrm{XRCC} 5 \mathrm{XRCC} 5$ HUMAN $82.71 \quad 100.0 \%$ X-ray repair cross-complementing protein $5 \mathrm{GN}=\mathrm{XRCC} 5$ XRCC5_HUMAN $82.71 \quad 100.0 \%$ X-ray repair cross-complementing protein $5 \mathrm{GN}=\mathrm{XRCC} 5 \mathrm{XRCC} 5$ HUMAN $82.71 \quad 100.0 \%$ X-ray repair cross-complementing protein $5 \mathrm{GN}=\mathrm{XRCC} 5$ XRCC5_HUMAN $82.71 \quad 100.0 \%$ X-ray repair cross-complementing protein $5 \mathrm{GN}=\mathrm{XRCC} 5 \mathrm{XRCC5}$ _HUMAN $82.71 \quad 100.0 \%$ X-ray repair cross-complementing protein $5 \mathrm{GN}=\mathrm{XRCC} 5 \mathrm{XRCC} 5$ HUMAN $82.71 \quad 100.0 \%$ X-ray repair cross-complementing protein $5 \mathrm{GN}=\mathrm{XRCC} 5$ XRCC5_HUMAN $82.71 \quad 100.0 \%$ X-ray repair cross-complementing protein $5 \mathrm{GN}=\mathrm{XRCC} 5 \mathrm{XRCC} 5$ HUMAN $82.71 \quad 100.0 \%$ $\mathrm{X}$-ray repair cross-complementing protein $5 \mathrm{GN}=\mathrm{XRCC} 5 \mathrm{XRCC} 5$ HUMAN $82.71 \quad 100.0 \%$ X-ray repair cross-complementing protein $5 \mathrm{GN}=\mathrm{XRCC} 5$ XRCC5_HUMAN $82.71 \quad 100.0 \%$ X-ray repair cross-complementing protein $5 \mathrm{GN}=\mathrm{XRCC} 5$ XRCC5_HUMAN $82.71 \quad 100.0^{\circ}$ X-ray repair cross-complementing protein $5 \mathrm{GN}=\mathrm{XRCC} 5$ XRCC5_HUMAN $82.71 \quad 100.0 \%$ X-ray repair cross-complementing protein $5 \mathrm{GN}=\mathrm{XRCC} 5 \mathrm{XRCC5}$ _HUMAN $82.71 \quad 100.0 \%$ X-ray repair cross-complementing protein $5 \mathrm{GN}=\mathrm{XRCC} 5 \mathrm{XRCC} 5$ HUMAN $82.71 \quad 100.0 \%$ X-ray repair cross-complementing protein $5 \mathrm{GN}=\mathrm{XRCC5}$ XRCC5_HUMAN $82.71 \quad 100.0 \%$ X-ray repair cross-complementing protein $6 \mathrm{GN}=\mathrm{XRCC} 6$ XRCC6 HUMAN 69.85 X-ray repair cross-complementing protein $6 \mathrm{GN}=\mathrm{XRCC} 6$ XRCC6 HUMAN 69.85 $\mathrm{X}$-ray repair cross-complementing protein $6 \mathrm{GN}=\mathrm{XRCC} 6 \mathrm{XRCC} 6 \_$HUMAN 69.85 X-ray repair cross-complementing protein $6 \mathrm{GN}=$ XRCC6 XRCC6 HUMAN 69.8 X-ray repair cross-complementing protein $6 \mathrm{GN}=\mathrm{XRCC6}$ XRCC6_HUMAN 69.85 X-ray repair cross-complementing protein $6 \mathrm{GN}=\mathrm{XRCC} 6$ XRCC6 HUMAN 69.8 X-ray repair cross-complementing protein $6 \mathrm{GN}=\mathrm{XRCC} 6$ XRCC 6 HUMAN 69.85 X-ray repair cross-complementing protein $6 \mathrm{GN}=\mathrm{XRCC6}$ XRCC6_HUMAN 69.85 X-ray repair cross-complementing protein $6 \mathrm{GN}=\mathrm{XRCC} 6$ XRCC6 HUMAN 69.8 X-ray repair cross-complementing protein $6 \mathrm{GN}=\mathrm{XRCC} 6$ XRCC6_HUMAN 69.85 YTH domain-containing family protein $2 \mathrm{GN}=\mathrm{YTHDF} 2$ YTHD2 HUMAN 62.3 YTH domain-containing family protein $2 \mathrm{GN}=$ YTHDF2 YTHD2 HUMAN 62.3 YTH domain-containing protein $1 \mathrm{GN}=$ YTHDC1 YTDC1_HUMAN 84.70 YTH domain-containing protein $1 \mathrm{GN}=$ YTHDC1 YTDC1_HUMAN 84.70 YTH domain-containing protein $1 \mathrm{GN}=$ YTHDC1 1 YTDC1_HUMAN $84.70 \quad 100.0^{\circ}$ YTH domain-containing protein $1 \mathrm{GN}=$ YTHDC1 YTDC1_HUMAN $84.70 \quad 100.0 \%$ YTH domain-containing protein $1 \mathrm{GN}=$ YTHDC1 YTDC1 HUMAN $84.70 \quad 100.0 \%$ Zinc finger $\mathrm{CCCH}$ domain-containing protein $13 \mathrm{GN}=\mathrm{ZC} 3 \mathrm{H} 13$ ZC3HD_HUMAN $196.64 \quad 100.0 \%$
$2 \quad 0.00 \% \quad 3.9 \%$ GVNVSALSR

$0.00 \% \quad 3.9 \%$ TALVANTSNMPVAAR

$0.01 \% \quad 6.0 \% \quad$ LYPEGLAQLAR

$0.01 \% \quad 6.0 \%$ AKIDNYIPIF

$0.01 \% \quad 9.9 \%$ FTLAGHTK

$0.01 \% \quad 9.9 \%$ IWDTASGQCLK

$0.01 \% \quad 9.9 \%$ TLIDDDNPPVSFVK

$0.01 \% \quad 12.8 \%$ MKLTDSVLR

$0.01 \% \quad 12.8 \%$ VVALSMSPVDDTFISGSLDK

$0.01 \% \quad 12.8 \%$ SFDKGPFATFK

$0.06 \% \quad 23.8 \%$ KVITMFVQR

$0.06 \% 23.8 \%$ VITMFVQR

$0.06 \% \quad 23.8 \%$ HIEIFTDLSSR

$0.06 \% \quad 23.8 \%$ SQLDIIIHSLK

$0.06 \% \quad 23.8 \%$ SQLDIIIHSLKK

$0.06 \% \quad 23.8 \%$ GITEQQKEGLEIVK

$0.06 \% \quad 23.8 \%$ LTIGSNLSIR

$0.06 \% \quad 23.8 \%$ IAAYKSILQER

$0.06 \% \quad 23.8 \%$ YGSDIVPFSKVDEEQMK

$0.06 \% \quad 23.8 \%$ CFSVLGFCK

$0.06 \% \quad 23.8 \%$ RFFMGNQVLK

$0.06 \% \quad 23.8 \%$ FFMGNQVLK

$0.06 \% 23.8 \%$ ANPQVGVAFPHIK

$0.06 \% \quad 23.8 \%$ TDTLEDLFPTTKIPNPR

$0.06 \% \quad 23.8 \%$ LFQCLLHR

$0.06 \% \quad 23.8 \%$ SQIPLSKIK

$0.06 \% \quad 23.8 \%$ IKTLFPLIEAK

$0.06 \% \quad 23.8 \%$ TLFPLIEAK

$0.06 \% \quad 23.8 \%$ EEASGSSVTAEEAKK

$0.03 \% \quad 20.2 \%$ DSLIFLVDASK

$0.03 \% \quad 20.2 \%$ NIYVLQELDNPGAK

$0.03 \% \quad 20.2 \%$ NIYVLQELDNPGAKR

$0.03 \% \quad 20.2 \%$ ILELDQFKGQQGQK

$0.03 \% \quad 20.2 \%$ IMLFTNEDNPHGNDSAK

$0.03 \% \quad 20.2 \%$ TFNTSTGGLLLPSDTKR

$0.03 \% \quad 20.2 \%$ CLEKEVAALCR

$0.03 \% \quad 20.2 \%$ IMATPEQVGK

$0.03 \% \quad 20.2 \%$ SDSFENPVLQQHFR

$0.03 \% \quad 20.2 \%$ VEYSEEELKTHISK

$0.00 \% \quad 3.6 \%$ LGSTEVASNVPK

$0.00 \% \quad 3.6 \%$ SYSEDDIHR

$0.02 \% \quad 7.8 \%$ QLVSKPLSSSVSNNKR

$0.02 \% \quad 7.8 \%$ SATEYKNEEYQR

$0.02 \% \quad 7.8 \%$ GISPIVFDR

$0.02 \% \quad 7.8 \%$ SNNHENVSLAK

$0.02 \% \quad 7.8 \%$ TQAVVSGRR

$0.01 \% \quad 2.6 \%$ TGNCLYGNTCR
$99.7 \% \quad 60.5$

$97.9 \% \quad 25.7$

$99.7 \% \quad 40.7$

$99.6 \% 24.8$

$99.0 \% \quad 26.3$

$\begin{array}{lll}99.7 \% & 30.1\end{array}$

$99.7 \% \quad 50.8$

$\begin{array}{lll}99.7 \% & 34.3\end{array}$

$\begin{array}{ll}.7 \% & 49.2\end{array}$

$\begin{array}{ll}99.4 \% & 22.4 \\ 99.7 \% & 62.3\end{array}$

$99.0 \% \quad 55.0$

$99.7 \% \quad 51.6$

$99.7 \% \quad 29.0$

$97.2 \% \quad 15.6$

$99.7 \% \quad 46.0$

$99.7 \% \quad 56.5$

$99.7 \% \quad 27.3$

$99.2 \% \quad 19.4$

$99.7 \% \quad 53.4$

$98.8 \% 24.8$

$99.7 \% \quad 25.6$

$99.7 \% \quad 42.2$

$99.7 \% \quad 38.7$

$99.0 \% \quad 41.8$

$99.0 \% \quad 18.2$

$99.7 \% \quad 35.3$

$99.7 \% \quad 32.4$

$99.7 \% \quad 58.4$

$99.7 \% \quad 62.1$

$99.7 \% \quad 75.9$

$99.7 \% \quad 42.2$

$99.7 \% \quad 54.9$

$99.7 \% \quad 41.2$

$99.7 \% \quad 33.2$

$99.7 \% \quad 44.5$

$96.7 \% \quad 18.1$

$99.7 \% \quad 44.3$

$95.9 \% \quad 14.9$

$99.7 \% \quad 56.3$

$94.8 \% \quad 13.4$

$99.7 \% \quad 42.9$

$99.7 \% \quad 36.3$

$99.7 \% \quad 30.0$

$\begin{array}{lll}99.7 \% & 42.8\end{array}$

$95.1 \% \quad 20.8$

$99.2 \% \quad 26.0$
902.51

1531.79

1230.68

1193.66

874.48

1278.61

1559.80

1062.60

2081.05

1244.63

1121.65

993.56

1317.68

1266.74

1394.84

1571.86

1073.63

1291.74

1971.94

1117.52

1239.67

1083.57

1377.76

1958.02

1086.59

1013.64

1272.79

1031.61

1522.72

1207.66

1573.82

1729.92

1631.88

1918.86

1807.96

1348.67

1089.56

1703.81

1691.85

1201.64

1121.49

1743.97

1517.69

1003.56

1212.60

973.55

1315.55

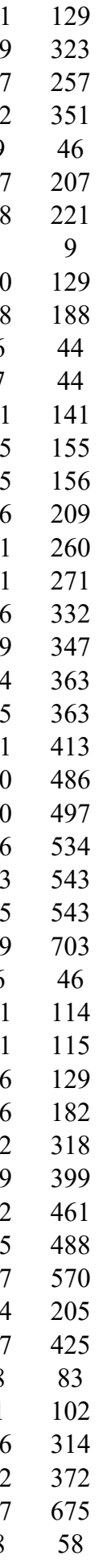

Page 140 of Table S-1-1 
$\begin{array}{lllllllllll}\text { Zinc finger CCCH domain-containing protein } 13 \mathrm{GN}=Z \mathrm{CC} 3 \mathrm{H} 13 & \text { ZC3HD_HUMAN } & 196.64 & 100.0 \% & 4 & 4 & 6 & 0.01 \% & 2.6 \% & \text { EVSPEVVR }\end{array}$

Zinc finger $\mathrm{CCCH}$ domain-containing protein $13 \mathrm{GN}=\mathrm{ZC} 3 \mathrm{H} 13$ ZC3HD_HUMAN $196.64 \quad 100.0 \%$ Zinc finger CCCH domain-containing protein $13 \mathrm{GN}=\mathrm{ZC} 3 \mathrm{H} 13$ ZC3HD_HUMAN $196.64 \quad 100.0 \%$ Zinc finger $\mathrm{CCCH}$ domain-containing protein $18 \mathrm{GN}=\mathrm{ZC} 3 \mathrm{H} 18 \mathrm{ZCH} 18$ HUMAN $106.38 \quad 100.0 \%$ Zinc finger $\mathrm{CCCH}$ domain-containing protein $18 \mathrm{GN}=\mathrm{ZC} 3 \mathrm{H} 18 \mathrm{ZCH} 18 \_\mathrm{HUMAN} 106.38 \quad 100.0 \%$ Zinc finger CCCH-type antiviral protein $1 \mathrm{GN}=\mathrm{ZC} 3 \mathrm{HAV} 1$ ZCCHV_HUMAN $101.43 \quad 100.0 \%$ Zinc finger CCCH-type antiviral protein $1 \mathrm{GN}=$ ZC3HAV1 ZCCHV_HUMAN $101.43 \quad 100.0^{\circ}$ Zinc finger CCCH-type antiviral protein $1 \mathrm{GN}=\mathrm{ZC} 3 \mathrm{HAV} 1 \mathrm{ZCCHV} \_$HUMAN $101.43 \quad 100.0 \%$ Zinc finger CCCH-type antiviral protein $1 \mathrm{GN}=\mathrm{ZC} 3 \mathrm{HAV} 1 \mathrm{ZCCHV}$ HUMAN $101.43 \quad 100.0 \%$ Zinc finger CCHC domain-containing protein $3 \mathrm{GN}=\mathrm{ZCCHC} 3 \mathrm{ZCHC} 3$ _HUMAN $43.62 \quad 100.0 \%$ Zinc finger $\mathrm{CCHC}$ domain-containing protein $3 \mathrm{GN}=\mathrm{ZCCHC} 3 \mathrm{ZCHC} 3$ _HUMAN $43.62 \quad 100.0 \%$ Zinc finger protein $346 \mathrm{GN}=\mathrm{ZNF} 346$ Zinc finger protein $346 \mathrm{GN}=\mathrm{ZNF} 346$ Zinc finger protein $512 \mathrm{GN}=\mathrm{ZNF} 512$ Zinc finger protein $512 \mathrm{GN}=\mathrm{ZNF} 512$ Zinc finger protein $512 \mathrm{GN}=\mathrm{ZNF} 512$ Zinc finger protein $512 \mathrm{GN}=\mathrm{ZNF} 512$ Zinc finger protein $512 \mathrm{GN}=\mathrm{ZNF} 512$ Zinc finger protein $512 \mathrm{GN}=\mathrm{ZNF} 512$ Zinc finger protein $768 \mathrm{GN}=\mathrm{ZNF} 768$ Zinc finger protein $768 \mathrm{GN}=\mathrm{ZNF} 768$ Zinc finger protein $768 \mathrm{GN}=\mathrm{ZNF} 768$
ZN346 HUMAN $32.93 \quad 100.0 \%$

ZN346_HUMAN $32.93 \quad 100.0 \%$ ZN512_HUMAN $64.68 \quad 100.0 \%$ ZN512_HUMAN $64.68 \quad 100.0 \%$ ZN512 HUMAN $64.68 \quad 100.0 \%$ ZN512_HUMAN $64.68 \quad 100.0 \%$ ZN512_HUMAN $64.68 \quad 100.0 \%$ ZN768 HUMAN $60.23 \quad 100.0 \%$ ZN768_HUMAN $60.23 \quad 100.0 \%$ ZN768 HUMAN $60.23 \quad 100.0 \%$ ZN512 HUMAN $64.68 \quad 100.0 \%$
$0.01 \% \quad 2.6 \%$ LLSQVVRPQESR

$0.01 \% \quad 3.0 \% \quad$ SSSYSSYSSR

$99.7 \% \quad 78.3$ $99.7 \% \quad 47.5$

$99.7 \% \quad 62.6$ $95.8 \% \quad 18.6$ $99.7 \% 51.1$ $99.6 \% 23.3$

$0.01 \% \quad 6.0 \%$ ASLEDAPVDDLTR

$0.01 \% \quad 6.0 \%$ ATDLGGTSQAGTSQR

$0.01 \% \quad 6.0 \% \quad$ TVFSPTLPAAR

$0.01 \% \quad 6.0 \%$ SSLGSLQTPEAVTTR

$0.01 \% \quad 6.4 \%$ SAEKLALFLR

$\begin{array}{ll}99.6 \% & 23.3 \\ 99.7 \% & 50.7\end{array}$

$\begin{array}{lllll}0.01 \% & 8.8 \% & \text { LADPAVTDFPAGK } & 99.7 \% & 49.2\end{array}$

$99.7 \% \quad 53.8$

$0.01 \% \quad 8.8 \%$ TVASSLGQIPMQR

$99.7 \% \quad 40.4$

$0.01 \% \quad 14.8 \%$ IKPAATSHVEGSGGVSAK $\quad 99.7 \% \quad 74.2$

$0.01 \% \quad 14.8 \%$ AGLAYHLR

$99.0 \% \quad 71.5$

$\begin{array}{lllll}0.01 \% & 14.8 \% & \text { RQQPGIELPETELSLR } \quad 97.6 \% & 16.4\end{array}$

$96.9 \% \quad 19.6$

$0.01 \% \quad 14.8 \%$ QQPGIELPETELSLR

$99.7 \% \quad 35.9$

$0.01 \% \quad 6.7 \%$ SPGLVPPSPEFAPR

$99.6 \% 21.5$

$0.01 \% \quad 6.7 \%$ AFADSSYLLR

$99.7 \% \quad 49.8$

$99.7 \% \quad 48.2$
1449.69

1159.65

1546.8

1147.68

1531.80

1301.67

1403.73

1758.95

1695.90

900.51

1866.01

1709.91

2857.37

1450.77

1142.58

1285.70 
Peptide index

[3-methy-2-oxobutanoate dehydrogenase [lipoamide] k kinase, mitochondrial GN=BCKDK $\quad$ BCKD_HUMAN $46.36 \quad 100.0 \% \quad 4$ [3-methyl-2-oxobutanoate dehydrogenase [lipoamide]] kinase, mitcochondral GN=BCKDK BCKD_HUMAN $46.36 \quad 100.0 \%$ [3-methy-2-oxobutanoate dehydrogenase [lipoamide] ] kinase, mitochondrial GN=BCKDK BCKD_HUMAN $46.36 \quad 100.0 \%$ [3-methyl-2-oxobutanoate dehydrogenase [lipoamide] k kinase, mitcochondrial GN=BCKDK BCKD_HUMAN $46.36100 .0 \%$ [Pyruvate dehydrogenase (acetyl-transferring]) kinase isozyme 1, mitochondrial GN=PDK1 $\quad$ PDK1_HUMAN $49.25 \quad 100.0 \%$ [yrnvate dehydrogenase (acetyl-transferring)] kinase isozyme 1, mitochondrial GN=PDK1 PDK1_HUMAN 49.25 100.0\% $116 \mathrm{kDa}$ U5 small nuclear ribonucleoprotein component GN=EFTUD2 U5S1_HUMAN $109.44 \quad 100.0 \%$ $116 \mathrm{kDa}$ U5 small nuclear ribonucleoprotein component GN=EFTUD2 U5S1_HUMAN $109.44 \quad 100.0 \%$ $116 \mathrm{kDa}$ U5 small nuclear ribonucleoprotein component GN=EFTUD2 U5S1_HUMAN $109.44100 .0 \%$ $116 \mathrm{kDa}$ U5 small nuclear ribonucleoprotein component GN=EFTUD2 U5S1_HUMAN $109.44 \quad 100.0 \%$ $116 \mathrm{kDa}$ U5 small nuclear ribonucleoprotein component GN=EFTUD2 U5S1_HUMAN $109.44 \quad 100.0 \%$ $116 \mathrm{kDa}$ U5 small nuclear ribonucleoprotein component GN=EFTUD2 U5S1 HUMAN $109.44 \quad 100.0^{\circ}$ $116 \mathrm{kDa}$ U5 small nuclear ribonucleoprotein component GN=EFTUD2 U5S1_HUMAN $109.44 \quad 100.0 \%$ 14-3-3 protein epsilon $\mathrm{GN}=\mathrm{YWHAE}$ 14-3-3 protein epsilon $\mathrm{GN}=\mathrm{YWHAE}$ 14-3-3 protein zeta/delta $\mathrm{GN}=\mathrm{YWHAZ}$ 14-3-3 protein zeta/delta $\mathrm{GN}=\mathrm{YWHAZ}$ 14-3-3 protein zeta/delta $\mathrm{GN}=\mathrm{YWHAZ}$ 14-3-3 protein zeta/delta $\mathrm{GN}=\mathrm{YWHAZ}$ 1433E_HUMAN $29.18 \quad 100.0 \%$ 1433E_HUMAN $29.18 \quad 100.0 \%$ 1433Z_HUMAN $27.75 \quad 100.0 \%$ 1433Z HUMAN $27.75 \quad 100.0 \%$ 1433Z_HUMAN $27.75 \quad 100.0 \%$ 1433Z_HUMAN $27.75 \quad 100.0 \%$ ', $3^{\prime}$-cyclic-nucleotide 3 '-phosphodiesterase GN=CNP CN37_HUMAN $47.58 \quad 100.0 \%$ 2',3'-cyclic-nucleotide 3'-phosphodiesterase GN=CNP CN37_HUMAN $47.58 \quad 100.0 \%$ 2',3'-cyclic-nucleotide 3 '-phosphodiesterase GN=CNP CN37_HUMAN $47.58 \quad 100.0 \%$ 2',3'-cyclic-nucleotide 3 '-phosphodiesterase GN=CNP CN37_HUMAN $47.58 \quad 100.0 \%$ 2',3'-cyclic-nucleotide 3'-phosphodiesterase GN=CNP CN37_HUMAN $47.58 \quad 100.0 \%$ 2',3'-cyclic-nucleotide 3 '-phosphodiesterase GN=CNP CN37 HUMAN $47.58 \quad 100.0 \%$ 2',3'-cyclic-nucleotide 3'-phosphodiesterase GN=CNP CN37_HUMAN $47.58 \quad 100.0 \%$ 2',3'-cyclic-nucleotide 3 '-phosphodiesterase GN=CNP CN37_HUMAN $47.58 \quad 100.0 \%$ $26 \mathrm{~S}$ protease regulatory subunit 10B GN=PSMC6 PRS10_HUMAN $44.17 \quad 100.0 \%$ $26 \mathrm{~S}$ protease regulatory subunit 10B GN=PSMC6 PRS10_HUMAN $44.17 \quad 100.0 \%$ $26 \mathrm{~S}$ protease regulatory subunit 10B GN=PSMC6 PRS10_HUMAN $44.17 \quad 100.0 \%$ $26 \mathrm{~S}$ protease regulatory subunit 10B GN=PSMC6 PRS10_HUMAN $44.17 \quad 100.0 \%$ $26 \mathrm{~S}$ protease regulatory subunit 10B GN=PSMC6 PRS10_HUMAN $44.17 \quad 100.0 \%$ $26 \mathrm{~S}$ protease regulatory subunit 10B GN=PSMC6 PRS10_HUMAN $44.17 \quad 100.0 \%$ $26 \mathrm{~S}$ protease regulatory subunit 10B GN=PSMC6 PRS10_HUMAN $44.17 \quad 100.0 \%$ $26 \mathrm{~S}$ protease regulatory subunit 10B GN=PSMC6 PRS10_HUMAN $44.17 \quad 100.0 \%$ $26 \mathrm{~S}$ protease regulatory subunit 10B GN=PSMC6 PRS10_HUMAN $44.17 \quad 100.0 \%$ $26 \mathrm{~S}$ protease regulatory subunit 10B GN=PSMC6 PRS10_HUMAN $44.17 \quad 100.0 \%$ $26 \mathrm{~S}$ protease regulatory subunit 10B GN=PSMC6 PRS10_HUMAN $44.17 \quad 100.0 \%$ $26 \mathrm{~S}$ protease regulatory subunit $4 \mathrm{GN}=\mathrm{PSMC1}$ PRS4_HUMAN $49.19 \quad 100.0 \%$ 26S protease regulatory subunit 4 GN=PSMC1 PRS4_HUMAN $49.19 \quad 100.0 \%$ $26 \mathrm{~S}$ protease regulatory subunit $4 \mathrm{GN}=\mathrm{PSMC} 1 \mathrm{PRS} 4$ HUMAN $49.19 \quad 100.0 \%$

0.01

\section{$0.01 \% \quad 12.4 \%$ LTPTMMLYAGR}

$0.01 \% \quad 12.4 \%$ YLQQELPVR

$0.01 \% \quad 12.4 \%$ YFLDKTLTSR

$0.01 \% \quad 6.0 \% \quad$ AIYDFTDTVIR

$0.01 \% \quad 6.0 \%$ AVPLAGFGYGLPISR

$0.02 \% \quad 7.5 \%$ STPVTVVLPDTK

$0.02 \% \quad 7.5 \%$ STPVTVVLPDTKGK

$0.02 \% \quad 7.5 \%$ IAVEPVNPSELPK

$0.02 \% \quad 7.5 \%$ EGPLCDELIR

$0.02 \% \quad 7.5 \%$ ILDAVVAQEPLHR

$0.02 \% \quad 7.5 \%$ GGGQIIPTAR

$0.02 \% \quad 7.5 \% \quad$ RVVYSAFLMATPR

$0.00 \% \quad 9.0 \%$ YLAEFATGNDRK

$0.00 \% \quad 9.0 \%$ EAAENSLVAYK

$\begin{array}{lll}0.01 \% & 22.9 \% & \text { LAEQAERYDDMAA } \\ 0.01 \% & 22.9 \% & \text { SVTEQGAELSNEER }\end{array}$

$0.01 \% \quad 22.9 \%$ VVSSIEQKTEGAEK

$0.01 \% \quad 22.9 \%$ YLAEVAAGDDKK

$0.02 \% \quad 21.9 \%$ MVSADAYKITPGAR

$0.02 \% \quad 21.9 \%$ AGQVFLEELGNHK

$3 \quad 0.02 \% \quad 21.9 \%$ QFVPGDEPREK

$0.02 \% \quad 21.9 \%$ RPPGVLHCTTK

$0.02 \% \quad 21.9 \%$ APGAEEYAQQDVLKK

$0.02 \% \quad 21.9 \%$ GEEVGELSR

$0.02 \% \quad 21.9 \%$ GKLYSLGNGR

$0.02 \% \quad 21.9 \%$ AIFTGYYGK

$0.04 \% \quad 36.5 \%$ ALQSVGQIVGEVLK

$0.04 \% \quad 36.5 \%$ VALDMTTLTIMR

$0.04 \% 36.5 \%$ EVIELPLTNPELFQR

$0.04 \% \quad 36.5 \%$ VGIIPPKGCLLYGPPGTGK

$0.04 \% \quad 36.5 \%$ AVASQLDCNFLK

$0.04 \% \quad 36.5 \%$ VVSSSIVDKYIGESAR

$0.04 \% \quad 36.5 \%$ LIREMFNYAR

$0.04 \% \quad 36.5 \%$ FSEGTSADREIQR

$0.04 \% \quad 36.5 \%$ KIHIDLPNEQAR

$0.04 \% \quad 36.5 \%$ IHAGPITK

$0.04 \% \quad 36.5 \%$ HGEIDYEAIVK

$0.02 \% \quad 11.8 \%$ KYEPPVPTR

$0.02 \% \quad 11.8 \%$ GVILYGPPGTGK

$0.02 \% \quad 11.8 \%$ AVANQTSATFLR
$99.0 \% \quad 19.5$

$99.7 \% \quad 30.0$

$99.7 \% \quad 58.8$

$99.7 \% \quad 33.3$

$99.7 \% \quad 45.9$

$99.7 \% \quad 45.8$

$99.6 \% \quad 23.4$

$99.7 \% \quad 51.4$

$99.7 \% \quad 53.5$

$99.5 \% \quad 22.0$

$\begin{array}{lll}99.7 \% & 46.2\end{array}$

$99.7 \% \quad 31.4$

$99.4 \% \quad 22.8$

$99.0 \% \quad 28.6$

$99.7 \% \quad 53.3$

25.0

19.5

$$
\text { K } 99.7
$$

$99.7 \% \quad 64.2$

$99.7 \% \quad 62.6$

$99.7 \% \quad 47.9$

$97.4 \% \quad 15.2$

$99.7 \% \quad 52.5$

$99.7 \% \quad 31.0$

$98.8 \% \quad 20.6$

$99.7 \% \quad 32.7$

$98.3 \% \quad 32.2$

$\begin{array}{lll}99.7 \% & 30.2\end{array}$

$99.7 \% \quad 36.7$

$99.7 \% \quad 45.4$

$\begin{array}{lll}99.7 \% & 63.6\end{array}$

$\begin{array}{lll}99.7 \% & 33.5\end{array}$

$\begin{array}{ll}25.0 & 19.5 \\ 25.0 & 27.0\end{array}$

$\begin{array}{lll}25.0 & 46.4 & 4\end{array}$

\begin{tabular}{ll}
25.0 & 23.4 \\
\hline
\end{tabular}

$\begin{array}{ll}0 & 1 \\ 3 & 0\end{array}$

$\begin{array}{lll}25.0 & 45.9 \quad 2\end{array}$

$25.0 \quad 41.9 \quad 2$

\begin{tabular}{ll}
43.4 \\
\hline
\end{tabular}

51.4

$\begin{array}{ll}5.0 & 48.8\end{array}$

$\begin{array}{ll}25.0 & 18.4\end{array}$

$\begin{array}{ll}25.0 & 38.5\end{array}$

28.8
25.0

$\begin{array}{ll}25.0 & 17.2\end{array}$

\begin{tabular}{ll}
21.4 \\
\hline
\end{tabular}

$\begin{array}{ll}25.0 & 44.5\end{array}$

\begin{tabular}{ll}
30.3 \\
\hline
\end{tabular}

$\begin{array}{ll}25.0 & 64.2\end{array}$

57.2
25.0

$\begin{array}{lll}25.0 & 36.5 & 2\end{array}$

$\begin{array}{lll}0 & 15.2 & 1\end{array}$

$\begin{array}{lll} & 48.1 & 2\end{array}$

21.4

$\begin{array}{ll}25.0 & 16.6\end{array}$

\begin{tabular}{ll}
32.5 \\
\hline
\end{tabular}

$\begin{array}{ll}25.0 & 20.4 \\ 25.0 & 24.7\end{array}$

$25.0 \quad 24.7$

$\begin{array}{lll}25.0 & 25.9 \quad 2\end{array}$

$\begin{array}{lll}25.0 & 45.4 & 1\end{array}$

$\begin{array}{ll}25.0 & 33.5\end{array}$

$\begin{array}{llll}99.7 \% & 34.7 & 25.0 & 32.3\end{array}$

$\begin{array}{lllll}99.7 \% & 59.2 & 25.0 & 50.8 & 2\end{array}$

$\begin{array}{llll}99.7 \% & 42.8 & 25.0 & 42.8\end{array}$

$\begin{array}{lllll}99.6 \% & 23.9 & 25.0 & 23.9 & 0\end{array}$

$\begin{array}{lllll}98.9 \% & 21.8 & 25.0 & 19.5 & 2\end{array}$

$99.7 \% \quad 49.1 \quad 25.0 \quad 49.1$

$\begin{array}{lllll}99.0 \% & 28.7 & 25.0 & 25.2 & 2\end{array}$

$\begin{array}{lllll}99.7 \% & 55.3 & 25.0 & 41.2 & 2\end{array}$

$\begin{array}{llll}99.7 \% & 32.1 & 25.0 & 22.5\end{array}$

$99.0 \% \quad 55.9 \quad 25.0 \quad 0.0$

$\begin{array}{llll}99.7 \% & 60.8 & 25.0 & 57.6\end{array}$

0
0

2255.13
1253.64

1253.64

1243.67

\section{$\sum_{3}$}

start stop

stop

49

$49 \quad 69$

$0 \quad 0$

0

0

$\begin{array}{ll}0 \\ 0 & 0\end{array}$

1313.67

1517.85

1256.71

$0 \quad 1441.83$

$\begin{array}{ll}0 & 1392.77\end{array}$

$\begin{array}{ll}0 & 1201.59\end{array}$

$0 \quad 1460.82$

$0 \quad 969.55$

$\begin{array}{ll}0 & 1510.82\end{array}$

$\begin{array}{ll}0 & 1384.69\end{array}$

0 1194.60

$0 \quad 1933.81$

1548.71
0

$\begin{array}{ll}0 & 1504.79\end{array}$

$0 \quad 1279.65$

$\begin{array}{ll}0 & 1495.76\end{array}$

$0 \quad 1441.74$

$0 \quad 1301.65$

0 1265.68

$\begin{array}{ll}0 & 1646.84\end{array}$

$0 \quad 975.47$

$\begin{array}{ll}0 & 1064.58\end{array}$

$\begin{array}{ll}0 & 1019.52\end{array}$

$\begin{array}{ll}0 & 1440.84\end{array}$

$\begin{array}{lll}0 & 1380.72\end{array}$

$\begin{array}{ll}0 & 1797.97\end{array}$

$\begin{array}{ll}0 & 1924.07\end{array}$

$\begin{array}{ll}0 & 1365.68\end{array}$

0 1709.91

$\begin{array}{ll}0 & 1312.68\end{array}$

$\begin{array}{ll}0 & 1495.71\end{array}$

$\begin{array}{ll}0 & 1433.79\end{array}$

0
0 836.50

$0 \quad 1273.64$

1273.64
1086.59
1158.65

1278.68

\begin{tabular}{cc}
70 & 80 \\
93 & 101 \\
188 & 197 \\
134 & 144 \\
349 & 363 \\
183 & 194 \\
183 & 196 \\
590 & 602 \\
776 & 785 \\
791 & 803 \\
804 & 813 \\
814 & 826 \\
131 & 142 \\
143 & 153 \\
12 & 27 \\
28 & 41 \\
61 & 74 \\
128 & 139 \\
80 & 93 \\
205 & 217 \\
225 & 235 \\
245 & 255 \\
262 & 276 \\
361 & 369 \\
370 & 379 \\
392 & 400 \\
49 & 62 \\
98 & 109 \\
147 & 161 \\
162 & 180 \\
186 & 197 \\
198 & 213 \\
214 & 223 \\
243 & 255 \\
298 & 309 \\
315 & 322 \\
323 & 333 \\
24 & 32 \\
221 & 232 \\
238 & 249 \\
1 & \\
\hline 1 & \\
\hline 1 &
\end{tabular}

Page 1 of Table S-1-2 
26S protease regulatory subunit $4 \mathrm{GN}=$ PSMC1 PRS4_HUMAN $49.19 \quad 100.0 \%$ $26 \mathrm{~S}$ protease regulatory subunit $4 \mathrm{GN}=\mathrm{PSMC1}$ PRS4_HUMAN $49.19 \quad 100.0 \%$ $26 \mathrm{~S}$ protease regulatory subunit $6 \mathrm{~A}$ GN=PSMC3 PRS6A_HUMAN $49.21 \quad 100.0 \%$ $26 \mathrm{~S}$ protease regulatory subunit $6 \mathrm{~A}$ GN=PSMC3 PRS6A_HUMAN $49.21 \quad 100.0 \%$ $26 \mathrm{~S}$ protease regulatory subunit $6 \mathrm{~A}$ GN=PSMC3 PRS6A_HUMAN $49.21 \quad 100.0 \%$ $26 \mathrm{~S}$ protease regulatory subunit $6 \mathrm{~A}$ GN=PSMC3 PRS6A_HUMAN $49.21 \quad 100.0 \%$ $26 \mathrm{~S}$ protease regulatory subunit 6A GN=PSMC3 PRS6A_HUMAN $49.21 \quad 100.0 \%$ $26 \mathrm{~S}$ protease regulatory subunit $6 \mathrm{~A}$ GN=PSMC3 PRS6A_HUMAN $49.21 \quad 100.0 \%$ $26 \mathrm{~S}$ protease regulatory subunit $6 \mathrm{~A}$ GN=PSMC3 PRS6A_HUMAN $49.21 \quad 100.0 \%$ 26S protease regulatory subunit 6B GN=PSMC4 PRS6B_HUMAN $47.37 \quad 100.0 \%$ 26S protease regulatory subunit 6B GN=PSMC4 PRS6B_HUMAN $47.37 \quad 100.0 \%$ $26 \mathrm{~S}$ protease regulatory subunit 6B GN=PSMC4 PRS6B_HUMAN $47.37 \quad 100.0 \%$ $26 \mathrm{~S}$ protease regulatory subunit $6 \mathrm{~B} \mathrm{GN}=\mathrm{PSMC} 4$ PRS6B_HUMAN $47.37 \quad 100.0 \%$ 26S protease regulatory subunit 6B GN=PSMC4 PRS6B_HUMAN $47.37 \quad 100.0 \%$ $26 \mathrm{~S}$ protease regulatory subunit $6 \mathrm{~B}$ GN=PSMC4 PRS6B_HUMAN $47.37 \quad 100.0 \%$ 26S protease regulatory subunit 6B GN=PSMC4 PRS6B_HUMAN $47.37 \quad 100.0 \%$ $26 \mathrm{~S}$ protease regulatory subunit $7 \mathrm{GN}=\mathrm{PSMC} 2$ PRS7 HUMAN $48.64 \quad 100.0 \%$ $26 \mathrm{~S}$ protease regulatory subunit $7 \mathrm{GN}=\mathrm{PSMC} 2 \mathrm{PRS} 7$ HUMAN $48.64 \quad 100.0 \%$ $26 \mathrm{~S}$ protease regulatory subunit $7 \mathrm{GN}=$ PSMC2 PRS7_HUMAN $48.64 \quad 100.0 \%$ $26 \mathrm{~S}$ protease regulatory subunit $7 \mathrm{GN}=$ PSMC2 PRS7_HUMAN $48.64 \quad 100.0 \%$ $26 \mathrm{~S}$ protease regulatory subunit $7 \mathrm{GN}=$ PSMC2 PRS7_HUMAN $48.64 \quad 100.0 \%$ $26 \mathrm{~S}$ protease regulatory subunit $7 \mathrm{GN}=\mathrm{PSMC} 2 \mathrm{PRS} 7$ HUMAN $48.64 \quad 100.0 \%$ $26 \mathrm{~S}$ protease regulatory subunit $7 \mathrm{GN}=\mathrm{PSMC} 2 \mathrm{PRS} 7$ HUMAN $48.64 \quad 100.0 \%$ $26 \mathrm{~S}$ protease regulatory subunit $7 \mathrm{GN}=\mathrm{PSMC} 2 \mathrm{PRS7}$ _HUMAN $48.64 \quad 100.0 \%$ $26 \mathrm{~S}$ protease regulatory subunit $7 \mathrm{GN}=\mathrm{PSMC} 2$ PRS7_HUMAN $48.64 \quad 100.0 \%$ $26 \mathrm{~S}$ protease regulatory subunit $7 \mathrm{GN}=\mathrm{PSMC} 2 \mathrm{PRS7}$ _HUMAN $48.64 \quad 100.0 \%$ $26 \mathrm{~S}$ protease regulatory subunit $7 \mathrm{GN}=\mathrm{PSMC} 2 \mathrm{PRS} 7$ HUMAN $48.64 \quad 100.0 \%$ $26 \mathrm{~S}$ protease regulatory subunit $7 \mathrm{GN}=\mathrm{PSMC} 2 \mathrm{PRS} 7$ HUMAN $48.64 \quad 100.0 \%$ $26 \mathrm{~S}$ protease regulatory subunit $8 \mathrm{GN}=$ PSMC5 PRS8_HUMAN $45.63 \quad 100.0 \%$ $26 \mathrm{~S}$ protease regulatory subunit $8 \mathrm{GN}=$ PSMC5 PRS8 HUMAN $45.63 \quad 100.0 \%$ 26S protease regulatory subunit 8 GN=PSMC5 PRS8_HUMAN $45.63 \quad 100.0 \%$ $26 \mathrm{~S}$ protease regulatory subunit $8 \mathrm{GN}=$ PSMC5 $\mathrm{PRS} 8$ _HUMAN $45.63 \quad 100.0 \%$ $26 \mathrm{~S}$ protease regulatory subunit $8 \mathrm{GN}=\mathrm{PSMC} 5 \mathrm{PRS} 8$ HUMAN $45.63 \quad 100.0 \%$ $26 \mathrm{~S}$ protease regulatory subunit $8 \mathrm{GN}=\mathrm{PSMC} 5$ PRS8_HUMAN $45.63 \quad 100.0 \%$ $26 \mathrm{~S}$ protease regulatory subunit $8 \mathrm{GN}=\mathrm{PSMC} 5 \mathrm{PRS} 8$ _HUMAN $45.63 \quad 100.0 \%$ $26 \mathrm{~S}$ protease regulatory subunit $8 \mathrm{GN}=\mathrm{PSMC} 5 \mathrm{PRS} 8$ HUMAN $45.63 \quad 100.0 \%$ $26 \mathrm{~S}$ protease regulatory subunit $8 \mathrm{GN}=\mathrm{PSMC} 5 \mathrm{PRS} 8$ _HUMAN $45.63 \quad 100.0 \%$ $26 \mathrm{~S}$ protease regulatory subunit $8 \mathrm{GN}=\mathrm{PSMC} 5 \mathrm{PRS} 8 \mathrm{HUMAN} 45.63 \quad 100.0 \%$ $26 \mathrm{~S}$ protease regulatory subunit $8 \mathrm{GN}=\mathrm{PSMC} 5$ PRS8_HUMAN $45.63 \quad 100.0 \%$ $26 \mathrm{~S}$ protease regulatory subunit $8 \mathrm{GN}=\mathrm{PSMC} 5$ PRS8_HUMAN $45.63 \quad 100.0 \%$ $26 \mathrm{~S}$ protease regulatory subunit $8 \mathrm{GN}=\mathrm{PSMC} 5 \mathrm{PRS} 8$ HUMAN $45.63 \quad 100.0 \%$ $26 \mathrm{~S}$ protease regulatory subunit $8 \mathrm{GN}=$ PSMC5 PRS8_HUMAN $45.63 \quad 100.0 \%$ $26 \mathrm{~S}$ proteasome non-ATPase regulatory subunit $1 \mathrm{GN}=\mathrm{PSMD} 1$ PSMD1_HUMAN $105.84 \quad 100.0 \%$ $26 \mathrm{~S}$ proteasome non-ATPase regulatory subunit $1 \mathrm{GN}=$ PSMD1 PSMD1_HUMAN $105.84 \quad 100.0 \%$ 26S proteasome non-ATPase regulatory subunit 1 GN=PSMD1 PSMD1_HUMAN $105.84 \quad 100.0 \%$ $26 \mathrm{~S}$ proteasome non-ATPase regulatory subunit 1 GN=PSMD1 PSMD1 HUMAN $105.84 \quad 100.0 \%$ 26S proteasome non-ATPase regulatory subunit 11 GN=PSMD11 PSD11_HUMAN $47.47 \quad 100.0 \%$
$170.02 \% \quad 11.8 \%$ IFQIHTSR

$0.02 \% \quad 11.8 \%$ KQEGTPEGLYL

$0.02 \% \quad 22.8 \%$ MSTEEIIQR

$0.02 \% \quad 22.8 \%$ LAGPQLVQMFIGDGAK

$0.02 \% \quad 22.8 \%$ VIAATNRVDILDPALLR

$0.02 \% \quad 22.8 \%$ KMNVSPDVNYEELAR

$0.02 \% \quad 22.8 \%$ CTDDFNGAQCK

$0.02 \% \quad 22.8 \%$ AVCVEAGMIALR

$0.02 \% \quad 22.8 \%$ GATELTHEDYMEGILEVQAK

$0.02 \% \quad 14.6 \%$ AVAHHTTAAFIR

$0.02 \% \quad 14.6 \%$ VVGSEFVQK

$0.02 \% \quad 14.6 \%$ VVGSEFVQKYLGEGPR

$0.02 \% \quad 14.6 \%$ FDAQTGADREVQR

$0.02 \% \quad 14.6 \%$ RLIFSTITSK

$0.02 \% \quad 14.6 \%$ LIFSTITSK

$0.02 \% \quad 14.6 \%$ YIVLAKDFEK

$0.05 \% \quad 35.8 \%$ PDYLGADQRK

$0.05 \% \quad 35.8 \%$ ALDEGDIALLK

$0.05 \% \quad 35.8 \%$ TYGQSTYSR

$0.05 \% \quad 35.8 \%$ IINADSEDPKYIINVK

$0.05 \% \quad 35.8 \%$ FVVDLSDQVAPTDIEEGMR

$0.05 \% \quad 35.8 \%$ AVANRTDACFIR

$0.05 \% \quad 35.8 \%$ VIGSELVQKYVGEGAR

$0.05 \% \quad 35.8 \%$ MVRELFEMAR

$0.05 \% \quad 35.8 \%$ ACLIFFDEIDAIGGAR

$0.05 \% \quad 35.8 \%$ FDDGAGGDNEVQR

$0.05 \% \quad 35.8 \%$ LCPNSTGAEIR

$0.05 \% \quad 35.8 \%$ SVCTEAGMFAIR

$0.06 \% \quad 37.4 \%$ LQAQRNELNAK

$0.06 \% \quad 37.4 \%$ FVVDVDKNIDINDVTPNCR

$0.06 \% \quad 37.4 \%$ VALRNDSYTLHK

$0.06 \% \quad 37.4 \%$ GVLLYGPPGTGK

$0.06 \% 37.4 \%$ GVLLYGPPGTGKTLLAR

$0.06 \% \quad 37.4 \%$ AVAHHTDCTFIR

$0.06 \% \quad 37.4 \%$ VSGSELVQK

$\quad 0.06 \% \quad 37.4 \%$ VSGSELVQKFIGEGAR

$0.06 \% 37.4 \%$ MVRELFVMAR

$0.06 \% 37.4 \%$ LEGGSGGDSEVQR

$0.06 \% \quad 37.4 \%$ KIAELMPGASGAEVK

$0.06 \% \quad 37.4 \%$ IAELMPGASGAEVK

$0.06 \% \quad 37.4 \%$ GVCTEAGMYALR

$0.06 \% \quad 37.4 \%$ RVHVTQEDFEMAVAK

$0.01 \% \quad 5.5 \%$ HGGSLGLGLAAMGTAR

$0.01 \% \quad 5.5 \%$ LLHVAVSDVNDDVRR

$0.01 \% \quad 5.5 \%$ AAVESLGFILFR

$0.01 \% \quad 5.5 \%$ VLTMPETCR

$0.01 \% \quad 10.2 \%$ TGQAAELGGLLK $\begin{array}{llll}99.0 \% & 46.8 & 25.0 & 34.5\end{array}$ $95.9 \% \quad 17.2$

$97.0 \% \quad 20.5$

$99.7 \% \quad 56.8$

$99.7 \% 51$.

$99.7 \% \quad 38.7$

$99.7 \% \quad 46.2$

$99.7 \% \quad 57.3$

$9.7 \% \quad 32.5$

$99.7 \% \quad 33.6$

$99.7 \% \quad 49.0$

$99.7 \% \quad 50.1$

$98.1 \% \quad 20.0$

$\begin{array}{lll}99.7 \% & 31.7\end{array}$

$99.7 \% \quad 32.5$

$99.7 \% \quad 37.3$

$99.7 \% \quad 42.2$

$99.7 \% \quad 56.1$

$99.7 \% \quad 43.4$

$99.2 \% \quad 18.5$

$99.7 \% \quad 63.6$

$99.7 \% \quad 32.4$

$99.7 \% \quad 37.0$

$99.7 \% \quad 29.1$

$99.7 \% \quad 69.5$

$99.7 \% \quad 51.9$

$99.7 \% \quad 54.3$

$99.7 \% \quad 61.2$

$99.7 \% \quad 48.1$

$9.7 \% \quad 37.8$

$99.7 \% \quad 31.5$

$99.0 \% \quad 55.9$

$99.7 \% \quad 31.5$

$99.7 \% \quad 36.8$

$99.7 \% \quad 49.0$

$99.7 \% \quad 63.6$

$98.1 \% \quad 16.3$

$99.7 \% \quad 53.1$

$96.4 \% \quad 16.9$

$99.7 \% \quad 50.8$

$99.7 \% \quad 46.4$

$99.7 \% \quad 44.8$

$99.7 \% \quad 35.2$

$99.7 \% \quad 52.5$

$99.7 \% \quad 41.1$

$97.5 \% \quad 16.8$

$99.7 \% \quad 49.6$

\begin{tabular}{|c|c|c|}
\hline \multicolumn{3}{|l|}{13.5} \\
\hline 12.7 & & \\
\hline 56.8 & & \\
\hline 51.1 & & \\
\hline 38.4 & & \\
\hline 46.2 & & \\
\hline 48.4 & & \\
\hline 32.5 & & \\
\hline 33.6 & & \\
\hline 43.5 & & \\
\hline 44.8 & & \\
\hline 17.9 & & \\
\hline 31.7 & & \\
\hline 32.5 & & \\
\hline 34.1 & & \\
\hline 29.8 & & \\
\hline 36.9 & & \\
\hline 32.7 & & \\
\hline 18.5 & & \\
\hline 56.7 & & \\
\hline 32.4 & & \\
\hline 37.0 & & \\
\hline 22.4 & & \\
\hline 67.4 & & \\
\hline 47.7 & & \\
\hline 38.1 & & \\
\hline 54.0 & & \\
\hline 39.4 & & \\
\hline 37.1 & & \\
\hline 21.2 & & \\
\hline 0.0 & & \\
\hline 31.5 & & \\
\hline 36.8 & & \\
\hline 18.6 & & \\
\hline 56.5 & & \\
\hline 16.3 & & \\
\hline 53.1 & & \\
\hline 16.9 & & \\
\hline 40.2 & & \\
\hline 46.4 & & \\
\hline 44.8 & & \\
\hline 34.0 & & \\
\hline 52.5 & & \\
\hline 41.1 & & \\
\hline 16.7 & & \\
\hline 43.0 & & \\
\hline
\end{tabular}

0
0
0
2
2
0
0
2
2
0
2
1
0
0
0
0
0
0
0
0
0
0
2
0
1
0
0
0
0
0
0
0
0
0
0
0

1315.50

1289.67

2250.06

1294.70

992.54

1764.93

1492.71

1165.69

1009.59

1225.68

1162.59

1157.64

1062.49

1831.98

2121.02

1393.70

1704.93

1281.64

1767.87

1379.58

1217.59

1341.63

1284.70

2233.09

1416.76

1158.65

1713.01

1427.68

946.52

1676.90

1267.67

1290.59

1500.81

1388.71

1327.61

1759.88

1468.77

1707.91

1322.75

1106.53

1157.65 
26S proteasome non-ATPase regulatory subunit $11 \mathrm{GN}=$ PSMD11 PSD11_HUMAN $47.47 \quad 100.0 \%$ 26S proteasome non-ATPase regulatory subunit $11 \mathrm{GN}=$ PSMD11 PSD11_HUMAN $47.47 \quad 100.0 \%$ 26S proteasome non-ATPase regulatory subunit 11 GN=PSMD11 PSD11_HUMAN $47.47 \quad 100.0 \%$ 26S proteasome non-ATPase regulatory subunit 13 GN=PSMD13 PSD13_HUMAN $42.95 \quad 100.0 \%$ 26S proteasome non-ATPase regulatory subunit $13 \mathrm{GN}=$ PSMD13 PSD13_HUMAN $42.95 \quad 100.0 \%$ 26S proteasome non-ATPase regulatory subunit 14 GN=PSMD14 PSDE_HUMAN $34.58 \quad 100.0 \%$ 26 proteasome non-ATPase regulatory subunit $14 \mathrm{GN}=$ PSMD14 PSDE_HUMAN $34.58 \quad 100.0 \%$ $26 \mathrm{~S}$ proteasome non-ATPase regulatory subunit $14 \mathrm{GN}=$ PSMD14 PSDE_HUMAN $34.58 \quad 100.0 \%$ $26 \mathrm{~S}$ proteasome non-ATPase regulatory subunit 2 GN=PSMD2 PSMD2_HUMAN $100.20 \quad 100.0 \%$ 26S proteasome non-ATPase regulatory subunit 2 GN=PSMD2 PSMD2_HUMAN $100.20 \quad 100.0 \%$ 26S proteasome non-ATPase regulatory subunit 2 GN=PSMD2 PSMD2_HUMAN $100.20 \quad 100.0 \%$ $26 \mathrm{~S}$ proteasome non-ATPase regulatory subunit $2 \mathrm{GN}=\mathrm{PSMD} 2$ PSMD2_HUMAN $100.20 \quad 100.0 \%$ 26S proteasome non-ATPase regulatory subunit 2 GN=PSMD2 PSMD2_HUMAN $100.20 \quad 100.0 \%$ $26 \mathrm{~S}$ proteasome non-ATPase regulatory subunit 2 GN=PSMD2 PSMD2_HUMAN $100.20 \quad 100.0 \%$ 26S proteasome non-ATPase regulatory subunit 2 GN=PSMD2 PSMD2_HUMAN $100.20 \quad 100.0 \%$ $26 \mathrm{~S}$ proteasome non-ATPase regulatory subunit 2 GN=PSMD2 PSMD2_HUMAN $100.20 \quad 100.0 \%$ $26 \mathrm{~S}$ proteasome non-ATPase regulatory subunit $2 \mathrm{GN}=\mathrm{PSMD} 2$ PSMD2_HUMAN $100.20 \quad 100.0 \%$ 26S proteasome non-ATPase regulatory subunit 3 GN=PSMD3 PSMD3_HUMAN $60.98 \quad 100.0 \%$ 26S proteasome non-ATPase regulatory subunit 3 GN=PSMD3 PSMD3_HUMAN $60.98 \quad 100.0 \%$ 26S proteasome non-ATPase regulatory subunit 3 GN=PSMD3 PSMD3_HUMAN $60.98 \quad 100.0 \%$ 26S proteasome non-ATPase regulatory subunit 3 GN=PSMD3 PSMD3_HUMAN $60.98 \quad 100.0 \%$ 265 proteasome non-ATPase regulatory subunit 3 GN=PSMD3 PSMD3_HUMAN $60.98 \quad 100.0 \%$ 26S proteasome non-ATPase regulatory subunit 3 GN=PSMD3 PSMD3_HUMAN $60.98 \quad 100.0 \%$ 26S proteasome non-ATPase regulatory subunit 3 GN=PSMD3 PSMD3_HUMAN $60.98 \quad 100.0 \%$ $26 \mathrm{~S}$ proteasome non-ATPase regulatory subunit $3 \mathrm{GN}=$ PSMD3 PSMD3_HUMAN $60.98 \quad 100.0 \%$ 26S proteasome non-ATPase regulatory subunit $3 \mathrm{GN}=\mathrm{PSMD} 3$ PSMD3_HUMAN $60.98 \quad 100.0 \%$ 26S proteasome non-ATPase regulatory subunit 3 GN=PSMD3 PSMD3_HUMAN $60.98 \quad 100.0 \%$ 26S proteasome non-ATPase regulatory subunit 3 GN=PSMD3 PSMD3_HUMAN $60.98 \quad 100.0 \%$ 26S proteasome non-ATPase regulatory subunit $3 \mathrm{GN}=$ PSMD3 PSMD3_HUMAN $60.98 \quad 100.0 \%$ 265 proteasome non-ATPase regulatory subunit 3 GN=PSMD3 PSMD3_HUMAN $60.98 \quad 100.0 \%$ 26S proteasome non-ATPase regulatory subunit 3 GN=PSMD3 PSMD3_HUMAN $60.98 \quad 100.0 \%$ 26S proteasome non-ATPase regulatory subunit $3 \mathrm{GN}=$ PSMD3 PSMD3_HUMAN $60.98 \quad 100.0 \%$ $26 \mathrm{~S}$ proteasome non-ATPase regulatory subunit $3 \mathrm{GN}=\mathrm{PSMD} 3$ PSMD3_HUMAN $60.98 \quad 100.0 \%$ 26S proteasome non-ATPase regulatory subunit 3 GN=PSMD3 PSMD3_HUMAN $60.98 \quad 100.0 \%$ 26S proteasome non-ATPase regulatory subunit 3 GN=PSMD3 PSMD3_HUMAN $60.98 \quad 100.0 \%$ 26S proteasome non-ATPase regulatory subunit 3 GN=PSMD3 PSMD3_HUMAN $60.98 \quad 100.0 \%$ 26S proteasome non-ATPase regulatory subunit 3 GN=PSMD3 PSMD3_HUMAN $60.98 \quad 100.0 \%$ $26 \mathrm{~S}$ proteasome non-ATPase regulatory subunit $3 \mathrm{GN}=$ PSMD3 PSMD3_HUMAN $60.98 \quad 100.0 \%$ 26S proteasome non-ATPase regulatory subunit 3 GN=PSMD3 PSMD3_HUMAN $60.98 \quad 100.0 \%$ 26S proteasome non-ATPase regulatory subunit 4 GN=PSMD4 PSMD4_HUMAN $40.74 \quad 100.0 \%$ $26 \mathrm{~S}$ proteasome non-ATPase regulatory subunit 4 GN=PSMD4 PSMD4_HUMAN $40.74 \quad 100.0 \%$ 26S proteasome non-ATPase regulatory subunit 4 GN=PSMD4 PSMD4_HUMAN $40.74 \quad 100.0 \%$ $28 \mathrm{~S}$ ribosomal protein S18b, mitochondrial GN=MRPS18B RT18B_HUMAN $29.40 \quad 100.0 \%$ $28 \mathrm{~S}$ ribosomal protein S18b, mitochondrial GN=MRPS18B RT18B_HUMAN $29.40 \quad 100.0 \%$ $28 \mathrm{~S}$ ribosomal protein S18b, mitochondrial GN=MRPS18B RT18B_HUMAN $29.40 \quad 100.0 \%$ $28 \mathrm{~S}$ ribosomal protein S18b, mitochondrial GN=MRPS18B RT18B_HUMAN $29.40 \quad 100.0 \%$ $28 \mathrm{~S}$ ribosomal protein S2, mitochondrial GN=MRPS2 RT02_HUMAN $33.25 \quad 100.0 \%$
$0.01 \% \quad 10.2 \%$ YVRPFLNSISK $0.01 \% \quad 10.2 \%$ TYHALSNLPK $0.01 \% \quad 10.2 \%$ VVDSLYNKAK $0.01 \% \quad 4.8 \% \quad$ SSDEAVILCK $0.01 \% \quad 4.8 \%$ VLDLQQIK $0.01 \% \quad 7.1 \%$ AVAVVVDPIQSVK $0.01 \% \quad 7.1 \%$ AVAVVVDPIQSVKGK $0.01 \% \quad 7.1 \%$ GKVVIDAFR $0.05 \% \quad 12.8 \%$ SSTTSMTSVPKPLK $0.05 \% \quad 12.8 \%$ CALGVFRK $0.05 \% \quad 12.8 \%$ FGGSGSQVDSAR $0.05 \% \quad 12.8 \%$ SGALLACGIVNSGVR $0.05 \% \quad 12.8 \%$ SETELKDTYAR $0.05 \% \quad 12.8 \%$ AVPLALALISVSNPR $0.05 \% \quad 12.8 \%$ LNILDTLSK $0.05 \% \quad 12.8 \%$ MLVTFDEELRPLPVSVR $0.05 \% \quad 12.8 \%$ VGQAVDVVGQAGKPK $0.08 \% \quad 43.6 \%$ RLNHYVLYK $0.08 \% \quad 43.6 \%$ AVQGFFTSNNATR $0.08 \% \quad 43.6 \%$ ISDDLMQK $0.08 \% \quad 43.6 \%$ RALDLVAAK $0.08 \% \quad 43.6 \%$ ALDLVAAK $0.08 \% \quad 43.6 \%$ VYEFLDKLDVVR $0.08 \% \quad 43.6 \%$ HDADGQATLLNLLLR $0.08 \% \quad 43.6 \%$ NYLHYSLYDQAEK $0.08 \% \quad 43.6 \%$ NYLHYSLYDQAEKLVSK $0.08 \% \quad 43.6 \%$ SVFPEQANNNEWAR $0.08 \% \quad 43.6 \%$ IKAIQLEYSEAR $0.08 \% \quad 43.6 \%$ AIQLEYSEAR $0.08 \% \quad 43.6 \%$ APQHTAVGFK $0.08 \% \quad 43.6 \%$ SLMPYFLLTQAVR $0.08 \% \quad 43.6 \%$ FNQVLDQFGEK $0.08 \% \quad 43.6 \%$ MISLSYSR $0.08 \% \quad 43.6 \%$ ISLADIAQK $0.08 \% \quad 43.6 \%$ LQLDSPEDAEFIVAK $0.08 \% \quad 43.6 \%$ AIRDGVIEASINHEK $0.08 \% \quad 43.6 \%$ EMIDIYSTREPQLA $0.08 \% \quad 43.6 \%$ SYNKDLESAEER $0.02 \% \quad 10.6 \%$ GKITFCTGIR $0.02 \% \quad 10.6 \%$ IIAFVGSPVEDNEKDLVK $0.02 \% \quad 10.6 \%$ NAMGSLASQATK $0.02 \% \quad 20.2 \%$ NKVVGNPCPICR $0.02 \% \quad 20.2 \%$ VVGNPCPICR

$\begin{array}{llll}97.8 \% & 21.7 & 25.0 & 16.6\end{array}$ $\begin{array}{llll}99.3 \% & 19.4 & 25.0 & 19.4\end{array}$ $\begin{array}{llll}99.2 \% & 19.1 & 25.0 & 19.1\end{array}$ $\begin{array}{llll}99.7 \% & 40.7 & 25.0 & 26.7\end{array}$ $\begin{array}{llll}98.0 \% & 27.7 & 25.0 & 21.8\end{array}$ $\begin{array}{llll}99.7 \% & 53.1 & 25.0 & 52.6\end{array}$ $99.7 \% \quad 51.6 \quad 25.0 \quad 51.6$ $\begin{array}{llll}99.5 \% & 21.3 & 25.0 & 19.0\end{array}$ $\begin{array}{llll}99.7 \% & 38.2 & 25.0 & 34.4\end{array}$ $\begin{array}{llll}98.4 \% & 21.7 & 25.0 & 14.6\end{array}$ $\begin{array}{llll}99.7 \% & 54.2 & 25.0 & 46.8\end{array}$ $\begin{array}{llll}99.7 \% & 59.5 & 25.0 & 59.5\end{array}$ $\begin{array}{llll}99.7 \% & 37.3 & 25.0 & 31.5\end{array}$ $\begin{array}{llll}99.7 \% & 47.3 & 25.0 & 47.3\end{array}$ $\begin{array}{llll}99.5 \% & 31.4 & 25.0 & 12.4\end{array}$ $99.7 \% \quad 30.5$ $99.7 \% \quad 37.6$ $\begin{array}{ll}25.0 & 31.4\end{array}$ $\begin{array}{llll}99.7 \% & 55.0 & 25.0 & 55.0\end{array}$ $99.0 \% \quad 52.0 \quad 25.0 \quad 35.6$ $\begin{array}{llll}99.7 \% & 36.0 & 25.0 & 32.3\end{array}$ $99.0 \% \quad 40.2 \quad 25.0 \quad 16.3$ $\begin{array}{llll}99.7 \% & 63.0 & 25.0 & 56.1\end{array}$ $\begin{array}{llll}99.7 \% & 67.7 & 25.0 & 67.7\end{array}$ $99.7 \% \quad 61.0 \quad 25.0 \quad 51.4$ $\begin{array}{llll}99.7 \% & 28.3 & 25.0 & 28.3\end{array}$ $\begin{array}{llll}99.7 \% & 35.3 & 25.0 & 35.3\end{array}$ $99.7 \% \quad 51.1 \quad 25.0 \quad 51.1$ $99.7 \% \quad 71.1 \quad 25.0 \quad 67.4$ $\begin{array}{llll}97.3 \% & 15.9 & 25.0 & 15.9\end{array}$ $\begin{array}{llll}99.7 \% & 58.5 & 25.0 & 49.3\end{array}$ $\begin{array}{llll}99.7 \% & 62.9 & 25.0 & 41.0\end{array}$ $99.0 \% \quad 37.7 \quad 25.0 \quad 30.9$ $\begin{array}{llll}99.7 \% & 58.8 & 25.0 & 19.5\end{array}$ $\begin{array}{llll}99.7 \% & 70.3 & 25.0 & 60.7\end{array}$ $\begin{array}{llll}99.7 \% & 30.9 & 25.0 & 30.9\end{array}$ $\begin{array}{llll}99.7 \% & 27.3 & 25.0 & 27.3\end{array}$ $\begin{array}{llll}99.7 \% & 51.4 & 25.0 & 51.2\end{array}$ $\begin{array}{llll}99.7 \% & 40.7 & 25.0 & 36.1\end{array}$ $\begin{array}{llll}99.7 \% & 65.3 & 25.0 & 61.0\end{array}$ $\begin{array}{lll}99.7 \% & 35.8\end{array}$ $99.7 \% \quad 58.5$ $99.7 \% \quad 41.9$ $99.7 \% \quad 54.2$ $0.02 \% \quad 20.2 \%$ LYQGHLQEESGPPPESMPK $99.7 \% \quad 44.7$

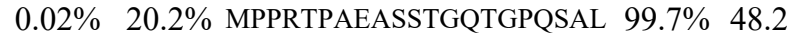
$0.01 \% \quad 19.9 \%$ FMEPYIFGSR
$96.4 \% \quad 14.8$
1323.74

1143.62

1136.63

1121.55

956.58

1324.78

1509.90

1004.59

1463.78

950.52

1167.54

1473.78

1312.64

1520.92

1016.60

2017.08

1452.82

1205.68

1412.69

949.47

956.59

800.49

1495.82

1649.90

1643.77

2071.05

1661.77

1420.78

1179.60

1055.56

1538.84

1324.65

956.49

958.56

1674.86

1651.88

2234.10

1579.76

1440.66

1152.62

1973.06

1178.58

1413.7

1171.57

2140.00

2100.00

1246.59
82
185
419
115
347
152
154
161
97
258
369
456
556
703
712
845
860
115
128
194
209
209
228
256
269
273
287
306
306
325
368
385
416
110
425
439
495
440
455

Page 3 of Table S-1-2 
$28 \mathrm{~S}$ ribosomal protein S2, mitochondrial GN=MRPS2 RT02 HUMAN $33.25 \quad 100.0 \%$ $28 \mathrm{~S}$ ribosomal protein S2, mitochondrial GN=MRPS2 RT02_HUMAN $33.25 \quad 100.0 \%$ $28 \mathrm{~S}$ ribosomal protein S2, mitochondrial GN=MRPS2 RT02_HUMAN $33.25 \quad 100.0 \%$ $28 \mathrm{~S}$ ribosomal protein $\mathrm{S} 2$, mitochondrial GN=MRPS2 RT02 HUMAN $33.25100 .0 \%$ $28 \mathrm{~S}$ ribosomal protein S2, mitochondrial GN=MRPS2 RT02_HUMAN $33.25 \quad 100.0 \%$ $28 \mathrm{~S}$ ribosomal protein S22, mitochondrial GN=MRPS22 RT22_HUMAN $41.28 \quad 100.0 \%$ $28 \mathrm{~S}$ ribosomal protein S22, mitochondrial GN=MRPS22 RT22_HUMAN $41.28 \quad 100.0 \%$ $28 \mathrm{~S}$ ribosomal protein S22, mitochondrial GN=MRPS22 RT22_HUMAN $41.28 \quad 100.0 \%$ $28 \mathrm{~S}$ ribosomal protein S22, mitochondrial GN=MRPS22 RT22 HUMAN $41.28 \quad 100.0 \%$ $28 \mathrm{~S}$ ribosomal protein S22, mitochondrial GN=MRPS22 RT22_HUMAN $41.28 \quad 100.0 \%$ $28 \mathrm{~S}$ ribosomal protein S27, mitochondrial GN=MRPS27 RT27_HUMAN $47.61 \quad 100.0 \%$ $28 \mathrm{~S}$ ribosomal protein S27, mitochondrial GN=MRPS27 RT27 HUMAN $47.61 \quad 100.0 \%$ $28 \mathrm{~S}$ ribosomal protein S27, mitochondrial GN=MRPS27 RT27_HUMAN $47.61 \quad 100.0 \%$ $28 \mathrm{~S}$ ribosomal protein S27, mitochondrial GN=MRPS27 RT27_HUMAN $47.61 \quad 100.0 \%$ $28 \mathrm{~S}$ ribosomal protein S27, mitochondrial GN=MRPS27 RT27_HUMAN $47.61 \quad 100.0 \%$ $28 \mathrm{~S}$ ribosomal protein S29, mitochondrial GN=DAP3 RT29_HUMAN $45.57 \quad 100.0 \%$ $28 \mathrm{~S}$ ribosomal protein $\mathrm{S} 29$, mitochondrial GN=DAP3 RT29 HUMAN $45.57 \quad 100.0 \%$ $28 \mathrm{~S}$ ribosomal protein S29, mitochondrial GN=DAP3 RT29_HUMAN $45.57 \quad 100.0 \%$ $28 \mathrm{~S}$ ribosomal protein $\mathrm{S} 29$, mitochondrial GN=DAP3 RT29_HUMAN $45.57 \quad 100.0 \%$ $28 \mathrm{~S}$ ribosomal protein $\mathrm{S} 29$, mitochondrial GN=DAP3 RT29 HUMAN $45.57 \quad 100.0 \%$ $28 \mathrm{~S}$ ribosomal protein S29, mitochondrial GN=DAP3 RT29_HUMAN $45.57 \quad 100.0 \%$ $28 \mathrm{~S}$ ribosomal protein $\mathrm{S} 29$, mitochondrial GN=DAP3 RT29 HUMAN $45.57 \quad 100.0 \%$ $28 \mathrm{~S}$ ribosomal protein S31, mitochondrial GN=MRPS31 RT31_HUMAN $45.32 \quad 100.0 \%$ $28 \mathrm{~S}$ ribosomal protein S31, mitochondrial GN=MRPS31 RT31_HUMAN $45.32 \quad 100.0 \%$ $28 \mathrm{~S}$ ribosomal protein $\mathrm{S} 35$, mitochondrial GN=MRPS35 RT35 HUMAN $36.85 \quad 100.0 \%$ $28 \mathrm{~S}$ ribosomal protein $\mathrm{S} 35$, mitochondrial GN=MRPS35 RT35_HUMAN $36.85 \quad 100.0 \%$ $28 \mathrm{~S}$ ribosomal protein S35, mitochondrial GN=MRPS35 RT35_HUMAN $36.85 \quad 100.0 \%$ $28 \mathrm{~S}$ ribosomal protein S35, mitochondrial GN=MRPS35 RT35_HUMAN $36.85 \quad 100.0 \%$ $28 \mathrm{~S}$ ribosomal protein $\mathrm{S} 35$, mitochondrial GN=MRPS35 RT35_HUMAN $36.85 \quad 100.0 \%$ $28 \mathrm{~S}$ ribosomal protein $\mathrm{S} 5$, mitochondrial GN=MRPS5 RT05 HUMAN $48.01 \quad 100.0 \%$ $28 \mathrm{~S}$ ribosomal protein $\mathrm{S} 5$, mitochondrial GN=MRPS5 RT05_HUMAN $48.01 \quad 100.0 \%$ $28 \mathrm{~S}$ ribosomal protein S5, mitochondrial GN=MRPS5 RT05_HUMAN $48.01 \quad 100.0 \%$ 28 ribosomal protein S5, mitochondrial GN=MRPS5 RT05 HUMAN $48.01 \quad 100.0 \%$ $28 \mathrm{~S}$ ribosomal protein S5, mitochondrial GN=MRPS5 RT05_HUMAN $48.01 \quad 100.0 \%$ $28 \mathrm{~S}$ ribosomal protein $\mathrm{S} 5$, mitochondrial GN=MRPS5 RT05 HUMAN $48.01 \quad 100.0 \%$ $28 \mathrm{~S}$ ribosomal protein $\mathrm{S} 5$, mitochondrial GN=MRPS5 RT05_HUMAN $48.01 \quad 100.0 \%$ 28S ribosomal protein S9, mitochondrial GN=MRPS9 RT09_HUMAN $45.84 \quad 100.0 \%$ $28 \mathrm{~S}$ ribosomal protein $\mathrm{S} 9$, mitochondrial GN=MRPS9 RT09 HUMAN $45.84 \quad 100.0 \%$ $28 \mathrm{~S}$ ribosomal protein S9, mitochondrial GN=MRPS9 RT09_HUMAN $45.84 \quad 100.0 \%$ $28 \mathrm{~S}$ ribosomal protein S9, mitochondrial GN=MRPS9 RT09_HUMAN $45.84 \quad 100.0 \%$ 2-amino-3-ketobutyrate coenzyme A ligase, mitochondrial $\mathrm{GN}=\mathrm{GCAT} \quad \mathrm{KBL}$ HUMAN $45.29 \quad 100.0 \%$ 2-amino-3-ketobutyrate coenzyme A ligase, mitochondrial GN=GCAT KBL_HUMAN $45.29 \quad 100.0 \%$ 2-amino-3-ketobutyrate coenzyme A ligase, mitochondrial GN=GCAT KBL HUMAN $45.29 \quad 100.0 \%$ 2-amino-3-ketobutyrate coenzyme A ligase, mitochondrial GN=GCAT KBL_HUMAN $45.29 \quad 100.0 \%$ 2-amino-3-ketobutyrate coenzyme A ligase, mitochondrial GN=GCAT KBL_HUMAN $45.29 \quad 100.0 \%$ 作 $\mathrm{GN}=\mathrm{BCKDHB} \quad$ ODBB HUMAN $43.12 \quad 100.0 \%$ 2-oxoisovalerate dehydrogenase subunit beta, mitochondrial $\mathrm{GN}=\mathrm{BCKDHB} \quad \mathrm{ODBB} \_\mathrm{HUMAN} 43.12 \quad 100.0 \%$
$0.01 \% \quad 19.9 \%$ LLFGPTVR $0.01 \% \quad 19.9 \%$ LFQTAITR $0.01 \% \quad 19.9 \%$ RQQVEALYR $0.01 \% \quad 19.9 \%$ QQVEALYR

$0.01 \% \quad 19.9 \%$ LQGQKEPGDQGPAHPPGADMSHSL $0.02 \% \quad 14.2 \%$ MTGLNLQK $0.02 \% \quad 14.2 \%$ LMTQAQLEEATR $0.02 \% \quad 14.2 \%$ FIVVREPSGTLR $0.02 \% \quad 14.2 \%$ MIQVYFPK $0.02 \% \quad 14.2 \%$ DQAAEGINLIK $0.02 \% \quad 13.0 \%$ KLPVSSLTISR $0.02 \% \quad 13.0 \%$ LIDNISSR $0.02 \% \quad 13.0 \%$ NFGASLLLPGLK $0.02 \% \quad 13.0 \%$ VAASPEDIKLCR $0.02 \% \quad 13.0 \%$ EALDVLGAVLK $0.02 \% \quad 18.1 \%$ TFSEACLMVR $0.02 \% \quad 18.1 \%$ NTSFAYPAIR $0.02 \% \quad 18.1 \%$ YLLYGEKGTGK $0.02 \% \quad 18.1 \%$ FDQPLEASTWLK $0.02 \% \quad 18.1 \%$ FLNQIKVQEK $0.02 \% \quad 18.1 \%$ ESTEKGSPLGEVVEQGITR $0.02 \% \quad 18.1 \%$ GSPLGEVVEQGITR $0.01 \% \quad 3.5 \% \quad$ ISFSNIISDMK $0.01 \% \quad 3.5 \% \quad$ ISFSNIISDMKVAR $0.01 \% \quad 13.0 \%$ VKLSSLNLDDHAK $0.01 \% \quad 13.0 \%$ LSSLNLDDHAK $0.01 \% \quad 13.0 \%$ LVGERYCK $0.01 \% \quad 13.0 \%$ TTDVLTIKTDR $0.01 \% \quad 13.0 \%$ NILETLLQMK $0.02 \% \quad 17.7 \%$ GALAETGAGAK $0.02 \% \quad 17.7 \%$ DLNRGQIIGEGR $0.02 \% \quad 17.7 \%$ NGAVQTIAQR $0.02 \% \quad 17.7 \%$ VLVAVGNGK $0.02 \% \quad 17.7 \%$ LIGIKDMYAK $0.02 \% \quad 17.7 \%$ VSGSINMLSLTQGLFR $0.02 \% \quad 17.7 \%$ SVWSNLKR $0.01 \% \quad 10.1 \%$ SLLPEKTVTR $0.01 \% \quad 10.1 \%$ TAKAEAIVYK $0.01 \% \quad 10.1 \%$ AEAIVYKHGSGR $0.01 \% \quad 10.1 \%$ LGKHDVTCTVSGGGR $0.02 \% \quad 20.0 \%$ FICGTQSIHK

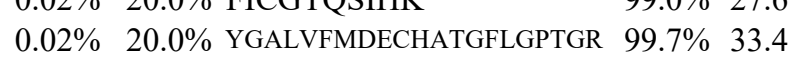
$0.02 \% \quad 20.0 \%$ ALGGASGGYTTGPGPLVSLLR $\quad 99.7 \% \quad 47.2$ $0.02 \% \quad 20.0 \%$ ALDLLMGSNTIVQSMAAK $99.7 \% \quad 60.8$ $0.02 \% \quad 20.0 \%$ GIFVIGFSYPVVPK $0.01 \% \quad 6.1 \%$ SGDLFNCGSLTIR $0.01 \% \quad 6.1 \%$ LGVSCEVIDLR

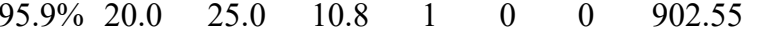
$\begin{array}{llllllll}99.0 \% & 57.0 & 25.0 & 43.3 & 2 & 0 & 0 & 949.55\end{array}$ $\begin{array}{llllllll}98.8 \% & 23.5 & 25.0 & 14.7 & 2 & 0 & 0 & 1162.63\end{array}$ $\begin{array}{llllllll}98.1 \% & 17.2 & 25.0 & 15.6 & 1 & 0 & 0 & 1006.53\end{array}$

$\begin{array}{llll}99.7 \% & 63.5 & 25.0 & 53.3\end{array}$

$\begin{array}{llll}99.5 \% & 27.9 & 25.0 & 26.8\end{array}$

$99.0 \% \quad 29.5 \quad 25.0 \quad 21.0$

$\begin{array}{llll}99.7 \% & 56.8 & 25.0 & 45.4\end{array}$

$\begin{array}{llll}99.7 \% & 30.2 & 25.0 & 27.7\end{array}$

$98.9 \% \quad 34.1 \quad 25.0 \quad 0.0$

$\begin{array}{llll}99.7 \% & 46.1 & 25.0 & 46.1\end{array}$

$99.7 \% \quad 53.6 \quad 25.0 \quad 46.4$

$\begin{array}{llll}99.7 \% & 30.2 & 25.0 & 24.5\end{array}$

$\begin{array}{llll}99.7 \% & 47.7 & 25.0 & 47.7\end{array}$

$99.7 \% \quad 35.9 \quad 25.0 \quad 30.9$

$\begin{array}{llll}98.3 \% & 24.1 & 25.0 & 15.6\end{array}$

$\begin{array}{llll}99.7 \% & 34.4 & 25.0 & 25.9\end{array}$

$99.7 \% \quad 29.7 \quad 25.0 \quad 25.6$

$\begin{array}{lllll}99.7 \% & 41.7 & 25.0 & 36.3\end{array}$

$\begin{array}{llll}99.7 \% & 56.5 & 25.0 & 49.4\end{array}$

$\begin{array}{llll}99.7 \% & 56.6 & 25.0 & 52.7\end{array}$

$\begin{array}{llll}99.7 \% & 40.3 & 25.0 & 39.2\end{array}$

$\begin{array}{llll}99.7 \% & 31.9 & 25.0 & 21.8\end{array}$

$\begin{array}{llll}99.5 \% & 22.3 & 25.0 & 17.9\end{array}$

$\begin{array}{llll}99.0 \% & 18.1 & 25.0 & 18.1\end{array}$

$\begin{array}{llll}99.7 \% & 36.5 & 25.0 & 36.5\end{array}$

$\begin{array}{llll}99.7 \% & 29.7 & 25.0 & 24.7\end{array}$

$\begin{array}{llll}99.7 \% & 44.7 & 25.0 & 36.2\end{array}$

$\begin{array}{llll}99.7 \% & 30.3 & 25.0 & 29.5\end{array}$

$\begin{array}{llll}99.7 \% & 64.2 & 25.0 & 49.0\end{array}$

$\begin{array}{llll}99.7 \% & 25.7 & 25.0 & 24.2\end{array}$

$\begin{array}{llll}99.5 \% & 21.5 & 25.0 & 21.5\end{array}$

$99.7 \% \quad 57.2 \quad 25.0 \quad 57.2$

$\begin{array}{llll}99.0 \% & 26.1 & 25.0 & 15.9\end{array}$

$\begin{array}{llll}99.3 \% & 30.0 & 25.0 & 10.7\end{array}$

$\begin{array}{llll}99.6 \% & 22.9 & 25.0 & 22.9\end{array}$

$\begin{array}{llll}98.1 \% & 21.3 & 25.0 & 14.9\end{array}$

$99.7 \% \quad 27.1 \quad 25.0 \quad 22.6$

$99.0 \% \quad 27.6 \quad 25.0 \quad 11.4$

$25.0 \quad 33.4$

$25.0 \quad 47.1$

$\begin{array}{llll}99.7 \% & 31.8 & 25.0 & 31.8\end{array}$

$\begin{array}{llll}99.7 \% & 58.5 & 25.0 & 52.0\end{array}$

$\begin{array}{llll}99.7 \% & 43.3 & 25.0 & 38.7\end{array}$
2470.14

904.49

1390.70

$181 \quad 188$ $252 \quad 259$ $65 \quad 272$ $273 \quad 296$ 289 1025.55

1171.63 1200.73

917.51

1229.73

1358.71

1127.67

1213.57

1139.58

1228.66

1434.73

1246.72

2016.02

1441.76

1254.64

1596.84

1439.79

1212.62

1024.52

1262.70

1202.68

945.50

1327.71

1057.57

856.53

1167.64

1738.92

989.55

1143.67

1093.63

1287.68

1543.76

1190.60

2315.06

1944.06

1862.97

1522.87

1439.69

1260.66 
S9 ribosomal protein L1, mitochondrial GN=MRPL1 RM01 HUMAN $36.91 \quad 100.0 \%$ 39S ribosomal protein L1, mitochondrial GN=MRPL1 RM01_HUMAN $36.91 \quad 100.0 \%$ 39S ribosomal protein L1, mitochondrial GN=MRPL1 RM01_HUMAN $36.91 \quad 100.0 \%$ 39S ribosomal protein $\mathrm{L} 15$, mitochondrial GN=MRPL15 RM15 HUMAN $33.42 \quad 100.0 \%$ 39S ribosomal protein L15, mitochondrial GN=MRPL15 RM15_HUMAN $33.42 \quad 100.0 \%$ 39S ribosomal protein L15, mitochondrial GN=MRPL15 RM15_HUMAN $33.42 \quad 100.0 \%$ 39S ribosomal protein L15, mitochondrial GN=MRPL15 RM15_HUMAN $33.42 \quad 100.0 \%$ 39S ribosomal protein L15, mitochondrial GN=MRPL15 RM15_HUMAN $33.42 \quad 100.0 \%$ 39S ribosomal protein L15, mitochondrial GN=MRPL15 RM15 HUMAN $33.42 \quad 100.0 \%$ $39 \mathrm{~S}$ ribosomal protein $\mathrm{L} 15$, mitochondrial GN=MRPL15 RM15_HUMAN $33.42 \quad 100.0 \%$ 39S ribosomal protein L15, mitochondrial GN=MRPL15 RM15_HUMAN $33.42 \quad 100.0 \%$ S ribosomal protein $\mathrm{L} 15$, mitochondrial GN=MRPL15 RM15 HUMAN $33.42 \quad 100.0 \%$ 39S ribosomal protein L15, mitochondrial GN=MRPL15 RM15_HUMAN $33.42 \quad 100.0 \%$ 39S ribosomal protein L19, mitochondrial GN=MRPL19 RM19 HUMAN $33.54 \quad 100.0 \%$ 39S ribosomal protein L19, mitochondrial GN=MRPL19 RM19_HUMAN $33.54 \quad 100.0 \%$ 39S ribosomal protein L19, mitochondrial GN=MRPL19 RM19_HUMAN $33.54 \quad 100.0 \%$ 39S ribosomal protein $\mathrm{L} 19$, mitochondrial GN=MRPL19 RM19 HUMAN $33.54 \quad 100.0 \%$ 39S ribosomal protein L19, mitochondrial GN=MRPL19 RM19_HUMAN $33.54 \quad 100.0 \%$ 39S ribosomal protein L2, mitochondrial GN=MRPL2 RM02_HUMAN $33.30 \quad 100.0 \%$ $39 \mathrm{~S}$ ribosomal protein $\mathrm{L} 2$, mitochondrial GN=MRPL2 RM02 HUMAN $33.30 \quad 100.0 \%$ 39S ribosomal protein L2, mitochondrial GN=MRPL2 RM02_HUMAN $33.30 \quad 100.0 \%$ 39S ribosomal protein L2, mitochondrial GN=MRPL2 RM02 HUMAN $33.30 \quad 100.0 \%$ $39 \mathrm{~S}$ ribosomal protein $\mathrm{L} 2$, mitochondrial GN=MRPL2 RM02_HUMAN $33.30 \quad 100.0 \%$ $39 \mathrm{~S}$ ribosomal protein $\mathrm{L} 3$, mitochondrial GN=MRPL3 RM03_HUMAN $38.63 \quad 100.0 \%$ $39 \mathrm{~S}$ ribosomal protein $\mathrm{L} 3$, mitochondrial GN=MRPL3 RM03 HUMAN $38.63 \quad 100.0 \%$ 39S ribosomal protein L37, mitochondrial GN=MRPL37 RM37_HUMAN $48.12 \quad 100.0 \%$ 39S ribosomal protein $\mathrm{L} 37$, mitochondrial GN=MRPL37 RM37_HUMAN $48.12 \quad 100.0 \%$ 39S ribosomal protein L37, mitochondrial GN=MRPL37 RM37_HUMAN $48.12 \quad 100.0 \%$ 39S ribosomal protein $\mathrm{L} 37$, mitochondrial GN=MRPL37 RM37_HUMAN $48.12 \quad 100.0 \%$ $39 \mathrm{~S}$ ribosomal protein $\mathrm{L} 37$, mitochondrial GN=MRPL37 RM37 HUMAN $48.12 \quad 100.0 \%$ $39 \mathrm{~S}$ ribosomal protein $\mathrm{L} 38$, mitochondrial GN=MRPL38 RM38_HUMAN $44.60 \quad 100.0 \%$ 39S ribosomal protein L38, mitochondrial GN=MRPL38 RM38_HUMAN $44.60 \quad 100.0 \%$ 39 r ribosomal protein $\mathrm{L} 39$, mitochondrial GN=MRPL39 RM39 HUMAN $38.71 \quad 100.0 \%$ 39S ribosomal protein L39, mitochondrial GN=MRPL39 RM39_HUMAN $38.71 \quad 100.0 \%$ 39S ribosomal protein L39, mitochondrial GN=MRPL39 RM39_HUMAN $38.71 \quad 100.0 \%$ 39S ribosomal protein L39, mitochondrial GN=MRPL39 RM39_HUMAN $38.71 \quad 100.0 \%$ 39S ribosomal protein L39, mitochondrial GN=MRPL39 RM39_HUMAN $38.71 \quad 100.0 \%$ $39 \mathrm{~S}$ ribosomal protein L39, mitochondrial GN=MRPL39 RM39 HUMAN $38.71 \quad 100.0 \%$ 39S ribosomal protein L44, mitochondrial GN=MRPL44 RM44_HUMAN $37.54 \quad 100.0 \%$ 39S ribosomal protein L44, mitochondrial GN=MRPL44 RM44_HUMAN $37.54 \quad 100.0 \%$ 39S ribosomal protein L44, mitochondrial GN=MRPL44 RM44 HUMAN $37.54 \quad 100.0 \%$ $39 \mathrm{~S}$ ribosomal protein $\mathrm{L} 44$, mitochondrial GN=MRPL44 RM44_HUMAN $37.54 \quad 100.0 \%$ 39S ribosomal protein L44, mitochondrial GN=MRPL44 RM44 HUMAN $37.54 \quad 100.0 \%$ 39S ribosomal protein L44, mitochondrial GN=MRPL44 RM44_HUMAN $37.54 \quad 100.0 \%$ 39S ribosomal protein L45, mitochondrial GN=MRPL45 RM45_HUMAN $35.35 \quad 100.0 \%$ $39 \mathrm{~S}$ ribosomal protein $\mathrm{L} 45$, mitochondrial GN=MRPL 45 RM45 HUMAN $35.35 \quad 100.0 \%$ 39 S ribosomal protein $\mathrm{L} 45$, mitochondrial GN=MRPL45 RM45_HUMAN $35.35 \quad 100.0 \%$
$0.01 \% \quad 6.2 \% \quad$ KFQILDFTSPK $0.01 \% \quad 6.2 \% \quad$ FQILDFTSPK $0.01 \% \quad 6.2 \%$ NSIGRDIPK $0.03 \% \quad 39.9 \%$ VSLANLKPNPGSK $0.03 \% \quad 39.9 \%$ LGFEGGQTPFYIR $0.03 \% \quad 39.9 \%$ YGFNEGHSFRR

$0.03 \% \quad 39.9 \%$ GVTIQPLKR $0.03 \% \quad 39.9 \%$ DYGVQLVEEGADTFTAK $0.03 \% \quad 39.9 \%$ NGGVVTTAFYDPR $0.03 \% \quad 39.9 \%$ SLDIVCKPVPFFLR $0.03 \% \quad 39.9 \%$ GYLADPAKFPEAR $0.03 \% \quad 39.9 \%$ ILKPTDENLLK $0.03 \% \quad 39.9 \%$ ILKPTDENLLKYYTS $0.01 \% \quad 17.5 \%$ FLSPEFIPR $0.01 \% \quad 17.5 \%$ TDPLKFQIER $0.01 \% \quad 17.5 \%$ VTTADPYASGK $0.01 \% \quad 17.5 \%$ VQEIQVVKLEK $0.01 \% \quad 17.5 \%$ RLDDSLLYLR $0.01 \% \quad 14.4 \%$ TKYTITPVK $0.01 \% \quad 14.4 \%$ SADIALVAGGSR $0.01 \% \quad 14.4 \%$ AAGTCGVLLR $0.01 \% \quad 14.4 \%$ AAGTCGVLLRK $0.01 \% \quad 14.4 \%$ SYVKLPSASAQS $0.01 \% \quad 5.2 \%$ MATLSVGGK $0.01 \% \quad 5.2 \%$ LPAYKDLGK

$10 \quad 0.01 \% \quad 13.7 \%$ VYEIPGLEPITFAGK

$10 \quad 0.01 \% \quad 13.7 \%$ TKLIEGLPEK

$10 \quad 0.01 \% \quad 13.7 \%$ SQILKHPSLAR

$10 \quad 0.01 \% \quad 13.7 \%$ ESLLLQVR

$10 \quad 0.01 \% \quad 13.7 \%$ MILFAFGSALAQAR $0.01 \% \quad 7.1 \%$ ANVEEERAAR $0.01 \% \quad 7.1 \%$ VAEGQVTCPYLPPFPAR $0.02 \% \quad 21.6 \%$ HVGKTDPGTVFVMNK $0.02 \% \quad 21.6 \%$ SCAMMMGCVIER $0.02 \% \quad 21.6 \%$ AFKDEYMVNLVR $0.02 \% \quad 21.6 \%$ VALEIFQHSK $0.02 \% \quad 21.6 \%$ YKVDFIEEK $0.02 \% \quad 21.6 \%$ IGDFIDVSEGPLIPR

$10 \quad 0.01 \% \quad 19.3 \%$ LQENFSLDLLK

$10 \quad 0.01 \% \quad 19.3 \%$ TAFVNSCYIK

$\quad 0.01 \% \quad 19.3 \%$ QQLGIEKEAVLLNLK

$10 \quad 0.01 \% \quad 19.3 \%$ LIAEGPGETVLVAEEEAAR

$10 \quad 0.01 \% \quad 19.3 \%$ KLYGFTENR

$10 \quad 0.01 \% \quad 19.3 \%$ LYGFTENR

$0.01 \% \quad 9.2 \%$ EGLIERTER

$0.01 \% \quad 9.2 \%$ TMASQVSIRR

$0.01 \% \quad 9.2 \%$ IKDYDANFK $\begin{array}{llllllll}99.5 \% & 25.3 & 25.0 & 25.3 & 2 & 0 & 0 & 1323.73\end{array}$

$99.7 \% \quad 48.0 \quad 25.0 \quad 38.1$

$\begin{array}{llll}99.3 \% & 29.5 & 25.0 & 11.2\end{array}$

$\begin{array}{llll}99.7 \% & 56.8 & 25.0 & 53.8\end{array}$

$\begin{array}{llll}99.7 \% & 45.6 & 25.0 & 43.7\end{array}$

$\begin{array}{llll}98.4 \% & 19.9 & 25.0 & 15.7\end{array}$

$\begin{array}{llll}99.5 \% & 23.9 & 25.0 & 18.4\end{array}$

$\begin{array}{llll}99.7 \% & 69.2 & 25.0 & 69.2\end{array}$

$99.7 \% \quad 57.2 \quad 25.0 \quad 57.2$

$99.7 \% \quad 31.0 \quad 25.0 \quad 31.0$

$97.9 \% \quad 17.3 \quad 25.0 \quad 15.6$

$99.5 \% \quad 22.5$

$99.7 \% \quad 32.0$

$\begin{array}{lll}99.7 \% & 40.5\end{array}$

$25.0 \quad 19.4$

$\begin{array}{llll}97.3 \% & 18.0 & 25.0 & 15.8\end{array}$

$99.6 \% \quad 25.0 \quad 25.0 \quad 23.4$

$99.7 \% \quad 35.1 \quad 25.0 \quad 19.0$

$99.3 \% \quad 20.4 \quad 25.0 \quad 20.4$

$99.7 \% \quad 27.5$

$99.7 \% \quad 65.2$

$25.0 \quad 23.1$

$99.7 \% \quad 51.6$

$96.1 \% \quad 22.0$

$25.0 \quad 55.6$

$\begin{array}{lll}25.0 & 13.2\end{array}$

$\begin{array}{llll}99.7 \% & 46.0 & 25.0 & 46.0\end{array}$

$99.7 \% \quad 27.2$

$99.7 \% \quad 26.9$

$99.7 \% \quad 39.9$

$99.7 \% \quad 46.9$

$99.7 \% \quad 27.7$

$99.0 \% \quad 50.2$

$99.7 \% \quad 87.4$

$\begin{array}{lll}99.5 \% & 22.3\end{array}$

$99.7 \% \quad 46.5$

$99.7 \% \quad 37.6$

$99.7 \% \quad 48.9$

$95.8 \% \quad 14.6$

$99.4 \% 21.8$

$98.0 \% \quad 21.0$

$99.7 \% \quad 58.5$

$99.7 \% \quad 66.4$

$99.7 \% \quad 41.3$

$96.2 \% \quad 14.8$

$\begin{array}{lll}99.7 \% & 60.7 \\ 99.7 \% & 45.1\end{array}$

$99.0 \% \quad 29.6$

$\begin{array}{ll}99.0 \% & 29.6 \\ 99.7 \% & 29.2\end{array}$

$97.6 \% \quad 18.5$

$98.7 \% \quad 20.4$
$25.0 \quad 20.2$

$25.0 \quad 22.1$

$25.0 \quad 39.9$

$25.0 \quad 42.8$

$25.0 \quad 27.7$

$25.0 \quad 32.8$

$25.0 \quad 83.6$

$25.0 \quad 22.3$

$25.0 \quad 43.3$

$25.0 \quad 37.6$

$25.0 \quad 48.9$

\begin{tabular}{ll}
14.3 \\
\hline
\end{tabular}

$25.0 \quad 19.6$

$25.0 \quad 13.0$

\begin{tabular}{l}
03.6 \\
\hline
\end{tabular}

$5.0 \quad 49.0$

$\begin{array}{ll}5.0 & 35.1\end{array}$

$\begin{array}{ll}25.0 & 14.8\end{array}$

\begin{tabular}{ll}
25.0 & 60.7 \\
\hline
\end{tabular}

$\begin{array}{ll}3.0 & 39.6\end{array}$

$\begin{array}{ll}.0 & 27.4\end{array}$

$\begin{array}{lll}25.0 & 19.8 \quad 2\end{array}$

$25.0 \quad 13.9$

20.4 
39S ribosomal protein L46, mitochondrial GN=MRPL46 RM46_HUMAN $31.71 \quad 100.0 \%$ 3-keto-steroid reductase GN=HSD17B7 3-keto-steroid reductase $\mathrm{GN}=\mathrm{HSD} 17 \mathrm{~B} 7$ $40 \mathrm{~S}$ ribosomal protein $\mathrm{S} 2 \mathrm{GN}=\mathrm{RPS} 2$ $40 \mathrm{~S}$ ribosomal protein $\mathrm{S} 2 \mathrm{GN}=\mathrm{RPS} 2$ $40 \mathrm{~S}$ ribosomal protein $\mathrm{S} 2 \mathrm{GN}=\mathrm{RPS} 2$ $40 \mathrm{~S}$ ribosomal protein $\mathrm{S} 2 \mathrm{GN}=\mathrm{RPS} 2$ $40 \mathrm{~S}$ ribosomal protein $\mathrm{S} 2 \mathrm{GN}=\mathrm{RPS} 2$ $40 \mathrm{~S}$ ribosomal protein $\mathrm{S} 2 \mathrm{GN}=\mathrm{RPS} 2$ $40 \mathrm{~S}$ ribosomal protein $\mathrm{S} 2 \mathrm{GN}=\mathrm{RPS} 2$ $40 \mathrm{~S}$ ribosomal protein $\mathrm{S} 2 \mathrm{GN}=\mathrm{RPS} 2$ $40 \mathrm{~S}$ ribosomal protein $\mathrm{S} 2 \mathrm{GN}=\mathrm{RPS} 2$ $40 \mathrm{~S}$ ribosomal protein $\mathrm{S} 2 \mathrm{GN}=\mathrm{RPS} 2$ $40 \mathrm{~S}$ ribosomal protein $\mathrm{S} 2 \mathrm{GN}=\mathrm{RPS} 2$ $40 \mathrm{~S}$ ribosomal protein $\mathrm{S} 2 \mathrm{GN}=\mathrm{RPS} 2$ $40 \mathrm{~S}$ ribosomal protein $\mathrm{S} 2 \mathrm{GN}=\mathrm{RPS} 2$ $40 \mathrm{~S}$ ribosomal protein $\mathrm{S} 2 \mathrm{GN}=\mathrm{RPS} 2$ $40 \mathrm{~S}$ ribosomal protein $\mathrm{S} 2 \mathrm{GN}=\mathrm{RPS} 2$ $40 \mathrm{~S}$ ribosomal protein $\mathrm{S} 3 \mathrm{GN}=\mathrm{RPS} 3$ $40 \mathrm{~S}$ ribosomal protein $\mathrm{S} 3 \mathrm{GN}=\mathrm{RPS} 3$ $40 \mathrm{~S}$ ribosomal protein $\mathrm{S} 3 \mathrm{GN}=\mathrm{RPS} 3$ $40 \mathrm{~S}$ ribosomal protein $\mathrm{S} 3 \mathrm{GN}=\mathrm{RPS} 3$ $40 \mathrm{~S}$ ribosomal protein $\mathrm{S} 3 \mathrm{GN}=\mathrm{RPS} 3$ $40 \mathrm{~S}$ ribosomal protein $\mathrm{S} 3 \mathrm{GN}=\mathrm{RPS} 3$ $40 \mathrm{~S}$ ribosomal protein $\mathrm{S} 3 \mathrm{GN}=\mathrm{RPS} 3$ $40 \mathrm{~S}$ ribosomal protein $\mathrm{S} 3 \mathrm{GN}=\mathrm{RPS} 3$ $40 \mathrm{~S}$ ribosomal protein $\mathrm{S} 3 \mathrm{GN}=\mathrm{RPS} 3$ $40 \mathrm{~S}$ ribosomal protein $\mathrm{S} 3 \mathrm{GN}=\mathrm{RPS} 3$ $40 \mathrm{~S}$ ribosomal protein $\mathrm{S} 3 \mathrm{GN}=\mathrm{RPS} 3$ $40 \mathrm{~S}$ ribosomal protein $\mathrm{S} 3 \mathrm{GN}=\mathrm{RPS} 3$ $40 \mathrm{~S}$ ribosomal protein $\mathrm{S} 3 \mathrm{GN}=\mathrm{RPS} 3$ $40 \mathrm{~S}$ ribosomal protein $\mathrm{S} 3 \mathrm{GN}=\mathrm{RPS} 3$ $40 \mathrm{~S}$ ribosomal protein $\mathrm{S} 3 \mathrm{GN}=\mathrm{RPS} 3$ $40 \mathrm{~S}$ ribosomal protein $\mathrm{S} 3 \mathrm{GN}=\mathrm{RPS} 3$ $40 \mathrm{~S}$ ribosomal protein $\mathrm{S} 3 \mathrm{GN}=\mathrm{RPS} 3$ $40 \mathrm{~S}$ ribosomal protein $\mathrm{S} 3 \mathrm{GN}=\mathrm{RPS} 3$ $40 \mathrm{~S}$ ribosomal protein $\mathrm{S} 3 \mathrm{GN}=\mathrm{RPS} 3$ $40 \mathrm{~S}$ ribosomal protein $\mathrm{S} 3 \mathrm{GN}=\mathrm{RPS} 3$ $40 \mathrm{~S}$ ribosomal protein $\mathrm{S} 3 \mathrm{GN}=\mathrm{RPS} 3$ $40 \mathrm{~S}$ ribosomal protein $\mathrm{S} 3 \mathrm{GN}=\mathrm{RPS} 3$ $40 \mathrm{~S}$ ribosomal protein $\mathrm{S} 3 \mathrm{GN}=\mathrm{RPS} 3$ $40 \mathrm{~S}$ ribosomal protein $\mathrm{S} 3 \mathrm{GN}=\mathrm{RPS} 3$ $40 \mathrm{~S}$ ribosomal protein $\mathrm{S} 3 \mathrm{GN}=\mathrm{RPS} 3$ $40 \mathrm{~S}$ ribosomal protein $\mathrm{S} 3 \mathrm{GN}=\mathrm{RPS} 3$ $40 \mathrm{~S}$ ribosomal protein $\mathrm{S} 3 \mathrm{a} \mathrm{GN}=\mathrm{RPS} 3 \mathrm{~A}$ $40 \mathrm{~S}$ ribosomal protein $\mathrm{S} 3 \mathrm{a} \mathrm{GN}=\mathrm{RPS} 3 \mathrm{~A}$
DHB7_HUMAN $38.21 \quad 100.0 \%$ DHB7_HUMAN $38.21 \quad 100.0 \%$ RS2_HUMAN $31.33 \quad 100.0 \%$ RS2_HUMAN $31.33 \quad 100.0 \%$ RS2_HUMAN $31.33 \quad 100.0 \% \quad 15$ RS2_HUMAN $31.33 \quad 100.0 \% \quad 15$ RS2 HUMAN $31.33 \quad 100.0 \% \quad 15$ RS2_HUMAN $31.33 \quad 100.0 \% \quad 15$ RS2_HUMAN $31.33 \quad 100.0 \% \quad 15$ RS2 HUMAN $31.33 \quad 100.0 \% \quad 15$ RS2_HUMAN $31.33 \quad 100.0 \% \quad 15$ RS2_HUMAN $31.33 \quad 100.0 \% \quad 15$ RS2 HUMAN $31.33 \quad 100.0 \% \quad 15$ RS2_HUMAN $31.33 \quad 100.0 \% \quad 15$ RS2 HUMAN $31.33 \quad 100.0 \% \quad 15$ RS2_HUMAN $31.33 \quad 100.0 \% \quad 15$ RS2_HUMAN $31.33 \quad 100.0 \% \quad 15$ RS3 HUMAN $26.69 \quad 100.0 \% \quad 26$ RS3_HUMAN $26.69 \quad 100.0 \% \quad 26$ RS3 HUMAN $26.69 \quad 100.0 \% \quad 26$ RS3 HUMAN $26.69 \quad 100.0 \% \quad 26$ RS3 HUMAN $26.69 \quad 100.0 \% \quad 26$ RS3 HUMAN $26.69 \quad 100.0 \% \quad 26$ RS3_HUMAN $26.69 \quad 100.0 \% \quad 26$ RS3_HUMAN $26.69 \quad 100.0 \% \quad 26$ RS3 HUMAN $26.69 \quad 100.0 \% \quad 26$ RS3_HUMAN $26.69 \quad 100.0 \% \quad 26$ RS3 HUMAN $26.69 \quad 100.0 \% \quad 26$ RS3_HUMAN $26.69 \quad 100.0 \% \quad 26$ RS3_HUMAN $26.69 \quad 100.0 \% \quad 26$ RS3 HUMAN $26.69 \quad 100.0 \% \quad 26$ RS3_HUMAN $26.69 \quad 100.0 \% \quad 26$ RS3 HUMAN $26.69 \quad 100.0 \% \quad 26$ RS3 HUMAN $26.69 \quad 100.0 \% \quad 26$ RS3_HUMAN $26.69 \quad 100.0 \% \quad 26$ RS3 HUMAN $26.69 \quad 100.0 \% \quad 26$ RS3_HUMAN $26.69 \quad 100.0 \% \quad 26$ RS3_HUMAN $26.69 \quad 100.0 \% \quad 26$ RS3 HUMAN $26.69 \quad 100.0 \% \quad 26$ RS3_HUMAN $26.69 \quad 100.0 \% \quad 26$ RS3 HUMAN $26.69 \quad 100.0 \% \quad 26$ RS3_HUMAN $26.69 \quad 100.0 \% \quad 26$ RS3_HUMAN $26.69 \quad 100.0 \% \quad 26$ RS3A_HUMAN $29.95 \quad 100.0 \% \quad 29$ RS3A_HUMAN $29.95 \quad 100.0 \% \quad 29$
$0.00 \% \quad 10.4 \%$ SLYSDHELRALDENQR $0.00 \% \quad 10.4 \%$ TLATLSENNMEAK

$0.00 \% \quad 6.7 \%$ YATDLLSVALNR

$0.00 \% \quad 6.7 \% \quad$ VTIQKTDNQAR

$114 \quad 0.17 \% \quad 48.1 \%$ AEDKEWMPVTK

$114 \quad 0.17 \% \quad 48.1 \%$ IMPVQKQTR

$14 \quad 0.17 \% \quad 48.1 \%$ AFVAIGDYNGHVGLGVK

$114 \quad 0.17 \% \quad 48.1 \%$ CSKEVATAIR

$114 \quad 0.17 \% \quad 48.1 \%$ LSIVPVRR

$114 \quad 0.17 \% \quad 48.1 \%$ IGKPHTVPCK

$114 \quad 0.17 \% \quad 48.1 \%$ GTGIVSAPVPK

$114 \quad 0.17 \% \quad 48.1 \%$ GTGIVSAPVPKK

$114 \quad 0.17 \% \quad 48.1 \%$ KLLMMAGIDDCYTSAR

$114 \quad 0.17 \% \quad 48.1 \%$ LLMMAGIDDCYTSAR

$114 \quad 0.17 \% \quad 48.1 \%$ GCTATLGNFAK

$114 \quad 0.17 \% \quad 48.1 \%$ ATFDAISK

$114 \quad 0.17 \% \quad 48.1 \%$ SPYQEFTDHLVK

$114 \quad 0.17 \% \quad 48.1 \%$ SPYQEFTDHLVKTHTR

$114 \quad 0.17 \% \quad 48.1 \%$ VSVQRTQAPAVATT

$105 \quad 0.15 \% \quad 83.5 \%$ KFVADGIFK

$105 \quad 0.15 \% \quad 83.5 \%$ FVADGIFK

$105 \quad 0.15 \% \quad 83.5 \%$ AELNEFLTR

$105 \quad 0.15 \% \quad 83.5 \%$ ELAEDGYSGVEVR

$105 \quad 0.15 \% \quad 83.5 \%$ VTPTRTEIIILATR

$105 \quad 0.15 \% \quad 83.5 \%$ TEIIILATR

$105 \quad 0.15 \% \quad 83.5 \%$ TQNVLGEKGR

$105 \quad 0.15 \% \quad 83.5 \%$ IRELTAVVQK

$105 \quad 0.15 \% \quad 83.5 \%$ ELTAVVQKR

$105 \quad 0.15 \% \quad 83.5 \%$ RFGFPEGSVELYAEK

$105 \quad 0.15 \% \quad 83.5 \%$ FGFPEGSVELYAEK

$105 \quad 0.15 \% \quad 83.5 \%$ GLCAIAQAESLR

$105 \quad 0.15 \% \quad 83.5 \%$ GLCAIAQAESLRYK

$105 \quad 0.15 \% \quad 83.5 \%$ YKLLGGLAVR

$105 \quad 0.15 \% \quad 83.5 \%$ LLGGLAVRR

$105 \quad 0.15 \% \quad 83.5 \%$ RACYGVLR

$105 \quad 0.15 \% \quad 83.5 \%$ FIMESGAK

$105 \quad 0.15 \% \quad 83.5 \%$ FIMESGAKGCEVVVSGK

$105 \quad 0.15 \% \quad 83.5 \%$ GCEVVVSGK

$105 \quad 0.15 \% \quad 83.5 \%$ GCEVVVSGKLR

$105 \quad 0.15 \% \quad 83.5 \%$ FVDGLMIHSGDPVNYYVDTAVR

$105 \quad 0.15 \% \quad 83.5 \%$ QGVLGIKVK

$\begin{array}{llll}105 & 0.15 \% & 83.5 \% & \text { IMLPWDPTGK }\end{array}$

$105 \quad 0.15 \% \quad 83.5 \%$ IMLPWDPTGKIGPK

$105 \quad 0.15 \% \quad 83.5 \%$ DEILPTTPISEQK

$105 \quad 0.15 \% \quad 83.5 \%$ GGKPEPPAMPQPVPTA

$103 \quad 0.15 \% \quad 76.5 \%$ APAMFNIR

$103 \quad 0.15 \% \quad 76.5 \%$ NIGKTLVTR
$98.2 \% \quad 16.3 \quad 25.0$

$99.7 \% \quad 33.2 \quad 25.0-29.5$

$\begin{array}{llll}99.7 \% & 32.1 & 25.0 & 19.9\end{array}$

$99.7 \% \quad 42.9 \quad 25.0 \quad 26.1$

$\begin{array}{llll}99.7 \% & 60.4 & 25.0 & 51.5\end{array}$

$\begin{array}{llll}99.7 \% & 51.2 & 25.0 & 36.6\end{array}$

$99.0 \% \quad 48.5 \quad 25.0 \quad 29.2$

$\begin{array}{llll}99.7 \% & 30.8 & 25.0 & 21.9\end{array}$

$\begin{array}{llll}99.7 \% & 42.9 & 25.0 & 40.6\end{array}$

$99.7 \% \quad 41.7$

$99.7 \% \quad 59.5$

$99.7 \% \quad 59.9$

$99.7 \% \quad 65.0$

$99.0 \% \quad 42.3$

$99.7 \% \quad 57.8$

$99.7 \% \quad 32.8$

$99.7 \% \quad 51.2$

$99.7 \% \quad 35.6$

$99.0 \% \quad 25.4$

$99.7 \% \quad 63.6$

$99.7 \% \quad 60.8$

$99.7 \% \quad 40.2$

$99.7 \% \quad 55.8$

$\begin{array}{lll}99.7 \% & 37.9\end{array}$

$99.7 \% \quad 43.1$

$99.7 \% \quad 48.5$

$99.7 \% \quad 55.2$

$99.7 \% \quad 51.2$

$99.7 \% \quad 65.9$

$99.7 \% \quad 46.7$

$99.7 \% \quad 47.9$

$99.7 \% \quad 29.9$

$98.6 \% \quad 27.0$

$95.6 \% 21.7$

$99.7 \% \quad 46.1$

$99.7 \% \quad 48.2$

$99.7 \% \quad 48.5$

$99.7 \% \quad 38.4$

$99.7 \% \quad 33.8$

$99.7 \% \quad 32.2$

$99.6 \% 25.8$

$99.7 \% \quad 46.0$

$99.7 \% \quad 43.2$

$99.0 \% \quad 51.7$

$99.7 \% \quad 53.5$

1716.91

1134.59

939.61

1136.62

1025.60

1153.69

1844.87

1716.78

1139.55

852.45

1463.72

1958.97

1428.78

1024.58

896.49

1092.57

1423.67

1583.95

1029.63

1101.60

1156.70

1043.62

1728.86

1572.76

1288.67

1579.83

1089.68

954.62

994.53

898.43

1797.89

934.47

1203.65

2484.19

941.61

1173.60

1568.85

1470.77

1573.80

919.48

1001.61 
$40 \mathrm{~S}$ ribosomal protein $\mathrm{S} 3 \mathrm{a} \mathrm{GN}=\mathrm{RPS} 3 \mathrm{~A}$ $40 \mathrm{~S}$ ribosomal protein $\mathrm{S} 3 \mathrm{a} \mathrm{GN}=\mathrm{RPS} 3 \mathrm{~A}$ $40 \mathrm{~S}$ ribosomal protein $\mathrm{S} 3 \mathrm{a} \mathrm{GN}=\mathrm{RPS} 3 \mathrm{~A}$ $40 \mathrm{~S}$ ribosomal protein $\mathrm{S} 3 \mathrm{a} \mathrm{GN}=\mathrm{RPS} 3 \mathrm{~A}$ $40 \mathrm{~S}$ ribosomal protein $\mathrm{S} 3 \mathrm{a} \mathrm{GN}=\mathrm{RPS3A}$ $40 \mathrm{~S}$ ribosomal protein $\mathrm{S} 3 \mathrm{a}$ GN=RPS3A $40 \mathrm{~S}$ ribosomal protein $\mathrm{S} 3 \mathrm{a} \mathrm{GN}=\mathrm{RPS} 3 \mathrm{~A}$ $40 \mathrm{~S}$ ribosomal protein $\mathrm{S} 3 \mathrm{a} \mathrm{GN}=\mathrm{RPS3A} \mathrm{A}$ $40 \mathrm{~S}$ ribosomal protein $\mathrm{S} 3 \mathrm{a} \mathrm{GN}=\mathrm{RPS} 3 \mathrm{~A}$ $40 \mathrm{~S}$ ribosomal protein $\mathrm{S} 3 \mathrm{a} \mathrm{GN}=\mathrm{RPS3A}$ $40 \mathrm{~S}$ ribosomal protein $\mathrm{S} 3 \mathrm{a} \mathrm{GN}=\mathrm{RPS} 3 \mathrm{~A}$ $40 \mathrm{~S}$ ribosomal protein $\mathrm{S} 3 \mathrm{a} \mathrm{GN}=\mathrm{RPS3A}$ 40S ribosomal protein $\mathrm{S} 3 \mathrm{a} \mathrm{GN}=\mathrm{RPS} 3 \mathrm{~A}$ $40 \mathrm{~S}$ ribosomal protein $\mathrm{S} 3 \mathrm{a} \mathrm{GN}=\mathrm{RPS3} \mathrm{A}$ $40 \mathrm{~S}$ ribosomal protein $\mathrm{S} 3 \mathrm{a} \mathrm{GN}=\mathrm{RPS} 3 \mathrm{~A}$ $40 \mathrm{~S}$ ribosomal protein $\mathrm{S} 3 \mathrm{a} \mathrm{GN}=\mathrm{RPS} 3 \mathrm{~A}$ $40 \mathrm{~S}$ ribosomal protein $\mathrm{S} 3 \mathrm{a} \mathrm{GN}=\mathrm{RPS} 3 \mathrm{~A}$ 40S ribosomal protein $\mathrm{S} 3 \mathrm{a} \mathrm{GN}=\mathrm{RPS} 3 \mathrm{~A}$ $40 \mathrm{~S}$ ribosomal protein $\mathrm{S} 3 \mathrm{a} \mathrm{GN}=\mathrm{RPS} 3 \mathrm{~A}$ 40S ribosomal protein $\mathrm{S} 3 \mathrm{a} \mathrm{GN}=\mathrm{RPS} 3 \mathrm{~A}$ $40 \mathrm{~S}$ ribosomal protein $\mathrm{S} 3 \mathrm{a} \mathrm{GN}=\mathrm{RPS} 3 \mathrm{~A}$ $40 \mathrm{~S}$ ribosomal protein $\mathrm{S} 3 \mathrm{a} \mathrm{GN}=\mathrm{RPS} 3 \mathrm{~A}$ $40 \mathrm{~S}$ ribosomal protein $\mathrm{S} 3 \mathrm{a} \mathrm{GN}=\mathrm{RPS} 3 \mathrm{~A}$ $40 \mathrm{~S}$ ribosomal protein $\mathrm{S} 3 \mathrm{a} \mathrm{GN}=\mathrm{RPS3A} \mathrm{A}$ $40 \mathrm{~S}$ ribosomal protein $\mathrm{S} 3 \mathrm{a} \mathrm{GN}=\mathrm{RPS} 3 \mathrm{~A}$ $40 \mathrm{~S}$ ribosomal protein $\mathrm{S} 3 \mathrm{a} \mathrm{GN}=\mathrm{RPS} 3 \mathrm{~A}$ $\begin{array}{lllll}\text { 40S ribosomal protein S3a GN=RPS3A } & \text { RS3A_HUMAN } & 29.95 & 100.0 \% & 29 \\ 40 \text { S ribosomal protein S4, X isoform GN=RPS4X RS4X_HUMAN } & 29.60 & 100.0 \% & 20\end{array}$ 40S ribosomal protein S4, X isoform GN=RPS4X RS4X_HUMAN $29.60 \quad 100.0 \%$ 40S ribosomal protein S4, X isoform GN=RPS4X RS4X_HUMAN $29.60 \quad 100.0 \% \quad 20$ 40S ribosomal protein S4, X isoform GN=RPS4X RS4X_HUMAN $29.60 \quad 100.0 \% \quad 20$ 40 S ribosomal protein S4, X isoform GN=RPS4X RS4X_HUMAN $29.60 \quad 100.0 \% \quad 20$ $40 \mathrm{~S}$ ribosomal protein S4, X isoform GN=RPS4X RS4X_HUMAN $29.60 \quad 100.0 \% \quad 20$ 40 S ribosomal protein S4, X isoform GN=RPS4X RS4X_HUMAN $29.60 \quad 100.0 \% \quad 20$ 40S ribosomal protein S4, X isoform GN=RPS4X RS4X_HUMAN $29.60 \quad 100.0 \% \quad 20$ 40 S ribosomal protein S4, X isoform GN=RPS4X RS4X_HUMAN $29.60 \quad 100.0 \% \quad 20$ 40S ribosomal protein S4, X isoform GN=RPS4X RS4X_HUMAN $29.60 \quad 100.0 \% \quad 20$ $\begin{array}{lllll}40 \text { S ribosomal protein S4, X isoform GN=RPS4X RS4X HUMAN } 29.60 & 100.0 \% & 20\end{array}$ 40S ribosomal protein S4, X isoform GN=RPS4X RS4X_HUMAN $29.60 \quad 100.0 \% \quad 20$ 40S ribosomal protein S4, X isoform GN=RPS4X RS4X_HUMAN $29.60 \quad 100.0 \% \quad 20$ 40S ribosomal protein S4, X isoform GN=RPS4X RS4X_HUMAN $29.60 \quad 100.0 \% \quad 20$ 40S ribosomal protein S4, X isoform GN=RPS4X RS4X_HUMAN $29.60 \quad 100.0 \% \quad 20$ 40S ribosomal protein S4, X isoform GN=RPS4X RS4X_HUMAN $29.60 \quad 100.0 \% \quad 20$ 40S ribosomal protein S4, X isoform GN=RPS4X RS4X_HUMAN $29.60 \quad 100.0 \% \quad 20$ 40S ribosomal protein S4, X isoform GN=RPS4X RS4X_HUMAN $29.60 \quad 100.0 \% \quad 20$ 40S ribosomal protein S4, X isoform GN=RPS4X RS4X_HUMAN $29.60 \quad 100.0 \% \quad 20$ 40S ribosomal protein S4, X isoform GN=RPS4X RS4X_HUMAN $29.60 \quad 100.0 \%$
$49 \quad 103 \quad 0.15 \% \quad 76.5 \%$ TLVTRTQGTK

$\begin{array}{lllll}49 & 103 & 0.15 \% & 76.5 \% & \text { TQGTKIASDGLK }\end{array}$

$49 \quad 103 \quad 0.15 \% \quad 76.5 \%$ IASDGLKGR

$\begin{array}{llllllll}97.2 \% & 21.4 & 25.0 & 15.5 & 1 & 0 & 0 & 1104.64\end{array}$

$\begin{array}{lllll}99.7 \% & 26.0 & 25.0 & 25.5 & 20\end{array}$

$\begin{array}{llll}99.0 \% & 33.2 & 25.0 & 12.1\end{array}$

49

49

49

49

49

49

49

49

49

4

4

49
49

\section{$49 \quad 103 \quad 0.15 \% \quad 76.5 \%$ KPKFELGK}

$49 \quad 103 \quad 0.15 \% \quad 76.5 \%$ FELGKLMELH

$49 \quad 103 \quad 0.15 \% \quad 76.5 \%$ LMELHGEGSSSGK

$49 \quad 103 \quad 0.15 \% \quad 76.5 \%$ LMELHGEGSSSGKATGDETGAK

$49 \quad 103 \quad 0.15 \% \quad 76.5 \%$ ATGDETGAKVER

$49 \quad 103 \quad 0.15 \% \quad 76.5 \%$ VERADGYEPPVQESV

$49 \quad 103 \quad 0.15 \% \quad 76.5 \%$ ADGYEPPVQESV

$25 \quad 54 \quad 0.08 \% \quad 64.6 \%$ LTGVFAPRPSTGPHK

$25 \quad 54 \quad 0.08 \% \quad 64.6 \%$ LRECLPLIIFLR

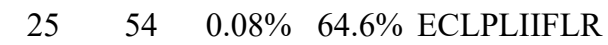

$\begin{array}{llll}25 & 54 & 0.08 \% & 64.6 \% \\ 25 & \text { LKYALTGDEVK }\end{array}$

$\begin{array}{llll}25 & 54 & 0.08 \% & 64.6 \%\end{array}$ YALTGDEVK

$25 \quad 54 \quad 0.08 \% \quad 64.6 \%$ YALTGDEVKK

$25 \quad 54 \quad 0.08 \% \quad 64.6 \%$ TDITYPAGFMDVISIDK

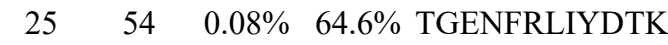

$\begin{array}{lllll}25 & 54 & 0.08 \% & 64.6 \% & \text { LIYDTKGR }\end{array}$

$\begin{array}{llll}25 & 54 & 0.08 \% & 64.6 \% \\ 25 & \text { GIPHLVTHDAR }\end{array}$

$25 \quad 54 \quad 0.08 \% \quad 64.6 \%$ TIRYPDPLIK

$25 \quad 54 \quad 0.08 \% \quad 64.6 \%$ VNDTIQIDLETGK

$\begin{array}{llll}25 & 54 & 0.08 \% & 64.6 \%\end{array}$ FDTGNLCMVTGGANLGR

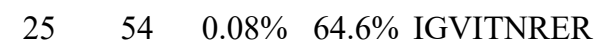

$25 \quad 54 \quad 0.08 \% \quad 64.6 \%$ ERHPGSFDVVHVK

$25 \quad 54 \quad 0.08 \% \quad 64.6 \%$ HPGSFDVVHVK

$25 \quad 54 \quad 0.08 \% \quad 64.6 \%$ HPGSFDVVHVKDANGNSFATR

$25 \quad 54 \quad 0.08 \% \quad 64.6 \%$ DANGNSFATR

$\begin{array}{lllll}25 & 54 & 0.08 \% & 64.6 \% & \text { LSNIFVIGK }\end{array}$

$25 \quad 54 \quad 0.08 \% \quad 64.6 \%$ GNKPWISLPR $\begin{array}{lllll}99.7 \% & 38.8 & 25.0 & 36.7 & 2\end{array}$

$\begin{array}{llll}99.7 \% & 67.3 & 25.0 & 42.0\end{array}$

$\begin{array}{llll}99.7 \% & 49.0 & 25.0 & 41.2\end{array}$

$\begin{array}{llll}99.7 \% & 39.2 & 25.0 & 39.2\end{array}$

$\begin{array}{llll}99.7 \% & 54.7 & 25.0 & 47.3\end{array}$

$\begin{array}{llll}98.8 \% & 18.2 & 25.0 & 18.2\end{array}$

$\begin{array}{llll}99.0 \% & 49.3 & 25.0 & 34.1\end{array}$

$99.0 \% \quad 55.0 \quad 25.0 \quad 41.9$

$\begin{array}{llll}99.7 \% & 26.8 & 25.0 & 26.8\end{array}$

$\begin{array}{llll}99.7 \% & 49.1 & 25.0 & 38.4\end{array}$

$\begin{array}{lllll}99.7 \% & 57.1 & 25.0 & 45.8 & 2\end{array}$

$\begin{array}{lllll}99.0 \% & 26.4 & 25.0 & 23.0 & 4\end{array}$

$\begin{array}{lllll}99.7 \% & 43.9 & 25.0 & 38.8 & 4\end{array}$

$\begin{array}{lllll}99.7 \% & 43.7 & 25.0 & 39.5 & 2\end{array}$

$\begin{array}{llll}99.7 \% & 61.4 & 25.0 & 54.6\end{array}$

$99.7 \% \quad 27.5 \quad 25.0 \quad 27.5$

$\begin{array}{llll}99.0 \% & 24.2 & 25.0 & 20.0\end{array}$

$\begin{array}{llll}99.7 \% & 58.3 & 25.0 & 58.3\end{array}$

$\begin{array}{llll}99.7 \% & 55.4 & 25.0 & 50.3\end{array}$

$\begin{array}{llll}99.7 \% & 39.9 & 25.0 & 39.9\end{array}$

$\begin{array}{lllll}99.7 \% & 54.2 & 25.0 & 45.1 & 6\end{array}$

$\begin{array}{lllll}99.7 \% & 49.6 & 25.0 & 49.6 & 2\end{array}$

$99.3 \% \quad 21.5 \quad 25.0 \quad 17.6$

$\begin{array}{lllll}99.7 \% & 38.4 & 25.0 & 38.4 & 2\end{array}$

$\begin{array}{llll}99.5 \% & 22.2 & 25.0 & 22.0\end{array}$

$\begin{array}{llll}99.7 \% & 64.8 & 25.0 & 55.8\end{array}$

$\begin{array}{lllll}99.7 \% & 38.0 & 25.0 & 26.7 & 2\end{array}$

$\begin{array}{llll}99.7 \% & 51.1 & 25.0 & 39.8\end{array}$

$\begin{array}{lllll}99.7 \% & 26.4 & 25.0 & 26.4 & 4\end{array}$

$99.5 \% \quad 24.5 \quad 25.0 \quad 18.2 \quad 2$

$\begin{array}{llll}99.0 \% & 34.9 & 25.0 & 29.2\end{array}$

$\begin{array}{llll}99.7 \% & 56.1 & 25.0 & 50.5\end{array}$

$99.7 \% \quad 33.4 \quad 25.0 \quad 21.0$

$\begin{array}{lllll}99.7 \% & 49.0 & 25.0 & 46.0 & 2\end{array}$

$\begin{array}{lllll}99.7 \% & 55.3 & 25.0 & 55.3 & 3\end{array}$

$\begin{array}{lllll}99.4 \% & 28.1 & 25.0 & 13.9 & 2\end{array}$

$\begin{array}{llll}99.7 \% & 26.8 & 25.0 & 26.8\end{array}$

$\begin{array}{llll}99.7 \% & 41.4 & 25.0 & 41.4\end{array}$

$\begin{array}{llll}99.7 \% & 47.5 & 25.0 & 47.5\end{array}$

$\begin{array}{lllll}99.7 \% & 59.6 & 25.0 & 53.1 & 2\end{array}$

$\begin{array}{llll}99.7 \% & 60.1 & 25.0 & 57.4\end{array}$

$\begin{array}{llll}99.7 \% & 37.2 & 25.0 & 33.9\end{array}$ $\begin{array}{lllll}99.7 \% & 36.2 & 25.0 & 36.2 & 2\end{array}$

2
0
0
2
2
0
3
3
3
0
0
0
0
0
4
1
0
0
1
0
3
3
2
0
5
5
4
3
3
1
0
0
0
0
0
0
0
0
1
0
0
0
0
0
0
0
0
0
0
1
0
4
2
0
0
0
0
0

2
0
0
2
2
0
3
3
0
0
0
0
4
1
0
1
0
3
2
0
5
4
3
1
0
0
0
0
0
0
1
0
0
0
0
0
0
0
0
0
0
0
0
0
0
0
0
0
0
0
0
0
0

1104.64

1218.67

916.52

1951.98

2080.07

1277.71

1002.55

2578.24

1578.72

998.45

938.49

971.50

1099.60

1345.70

1217.60

1039.51

1515.80

1327.75

1704.85

1832.95

946.57

1921.93

1347.62

2162.00

1233.61

1674.80

1290.58

1564.86

1542.92

1273.73

1236.68

995.50

1123.60

1901.92

1456.74

965.54

1215.66

1215.71

1445.75

1798.82

1057.61

1506.78

1221.64

2255.10

1052.48

990.60

1167.66

Page 7 of Table S-1-2 
$40 \mathrm{~S}$ ribosomal protein $\mathrm{S} 6 \mathrm{GN}=\mathrm{RPS} 6$ $40 \mathrm{~S}$ ribosomal protein $\mathrm{S} 6 \mathrm{GN}=\mathrm{RPS} 6$ $40 \mathrm{~S}$ ribosomal protein $\mathrm{S} 6 \mathrm{GN}=\mathrm{RPS} 6$ $40 \mathrm{~S}$ ribosomal protein $\mathrm{S} 6 \mathrm{GN}=\mathrm{RPS} 6$ $40 \mathrm{~S}$ ribosomal protein $\mathrm{S} 6 \mathrm{GN}=\mathrm{RPS} 6$ $40 \mathrm{~S}$ ribosomal protein $\mathrm{S} 6 \mathrm{GN}=\mathrm{RPS} 6$ $40 \mathrm{~S}$ ribosomal protein $\mathrm{S} 6 \mathrm{GN}=\mathrm{RPS} 6$ $40 \mathrm{~S}$ ribosomal protein $\mathrm{S} 6 \mathrm{GN}=\mathrm{RPS} 6$ $40 \mathrm{~S}$ ribosomal protein $\mathrm{S} 6 \mathrm{GN}=\mathrm{RPS} 6$ $40 \mathrm{~S}$ ribosomal protein $\mathrm{S} 6 \mathrm{GN}=\mathrm{RPS} 6$ $40 \mathrm{~S}$ ribosomal protein $\mathrm{S} 6 \mathrm{GN}=\mathrm{RPS} 6$ $40 \mathrm{~S}$ ribosomal protein $\mathrm{S} 6 \mathrm{GN}=\mathrm{RPS} 6$ $40 \mathrm{~S}$ ribosomal protein $\mathrm{S} 7 \mathrm{GN}=\mathrm{RPS} 7$ $40 \mathrm{~S}$ ribosomal protein $\mathrm{S} 7 \mathrm{GN}=\mathrm{RPS} 7$ $40 \mathrm{~S}$ ribosomal protein $\mathrm{S} 8 \mathrm{GN}=\mathrm{RPS} 8$ $40 \mathrm{~S}$ ribosomal protein $\mathrm{S} 8 \mathrm{GN}=\mathrm{RPS} 8$ $40 \mathrm{~S}$ ribosomal protein $\mathrm{S} 8 \mathrm{GN}=\mathrm{RPS} 8$ $40 \mathrm{~S}$ ribosomal protein $\mathrm{S} 8 \mathrm{GN}=\mathrm{RPS} 8$ $40 \mathrm{~S}$ ribosomal protein $\mathrm{S} 8 \mathrm{GN}=\mathrm{RPS} 8$ $40 \mathrm{~S}$ ribosomal protein $\mathrm{S} 8 \mathrm{GN}=\mathrm{RPS} 8$ $40 \mathrm{~S}$ ribosomal protein $\mathrm{S} 8 \mathrm{GN}=\mathrm{RPS} 8$ $40 \mathrm{~S}$ ribosomal protein $\mathrm{S} 8 \mathrm{GN}=\mathrm{RPS} 8$ $40 \mathrm{~S}$ ribosomal protein $\mathrm{S} 8 \mathrm{GN}=\mathrm{RPS} 8$ $40 \mathrm{~S}$ ribosomal protein $\mathrm{S} 9 \mathrm{GN}=\mathrm{RPS} 9$ $40 \mathrm{~S}$ ribosomal protein $\mathrm{S} 9 \mathrm{GN}=\mathrm{RPS} 9$ $40 \mathrm{~S}$ ribosomal protein SA GN=RPSA 40S ribosomal protein SA GN=RPSA 40 S ribosomal protein SA GN=RPSA $40 \mathrm{~S}$ ribosomal protein SA GN=RPSA $40 \mathrm{~S}$ ribosomal protein $\mathrm{SA}$ GN=RPSA

$4 \mathrm{~F} 2$ cell-surface antigen heavy chain GN=SLC3A2 $4 \mathrm{~F} 2$ _HUMAN $68.00 \quad 100.0 \%$ $4 \mathrm{~F} 2$ cell-surface antigen heavy chain GN=SLC3A2 $\quad 4 \mathrm{~F} 2$ _HUMAN $68.00 \quad 100.0 \%$ $4 \mathrm{~F} 2$ cell-surface antigen heavy chain $\mathrm{GN}=\mathrm{SLC} 3 \mathrm{~A} 2 \quad 4 \mathrm{~F} 2$ HUMAN $68.00 \quad 100.0 \%$ $4 \mathrm{~F} 2$ cell-surface antigen heavy chain GN=SLC3A2 $4 \mathrm{~F} 2$ _HUMAN $68.00 \quad 100.0 \%$ 4F2 cell-surface antigen heavy chain GN=SLC3A2 $4 \mathrm{~F} 2$ HUMAN $68.00 \quad 100.0 \%$ $5^{\prime}-3^{\prime}$ exoribonuclease $2 \mathrm{GN}=\mathrm{XRN} 2$ $5^{\prime}-3^{\prime}$ exoribonuclease $2 \mathrm{GN}=\mathrm{XRN} 2$ $5^{\prime}-3^{\prime}$ exoribonuclease $2 \mathrm{GN}=\mathrm{XRN} 2$ $5^{\prime}-3$ ' exoribonuclease $2 \mathrm{GN}=\mathrm{XRN} 2$ 5'-3' exoribonuclease 2 GN=XRN2 $\begin{array}{llll}5 \text {-AMP-activated protein kinase catalytic subunit alpha-1 GN=PRKAA1 AAPK1_HUMAN } & 64.01 & 100.0 \% \\ 5 \text { 5'AMP-activated protein kinase catalytic subunit alpha-1 GN=PRKAA1 } & \text { AAPK1_HUMAN } 64.01 & 100.0 \%\end{array}$ 5'-AMP-activated protein kinase catalytic subunit alpha-1 GN=PRKAA1 AAPK1_HUMAN $64.01 \quad 100.0 \%$ $60 \mathrm{kDa}$ heat shock protein, mitochondrial GN=HSPD1 CH60_HUMAN $61.06 \quad 100.0 \%$ $60 \mathrm{kDa}$ heat shock protein, mitochondrial GN=HSPD1 CH60_HUMAN $61.06 \quad 100.0 \%$ $60 \mathrm{kDa}$ heat shock protein, mitochondrial GN=HSPD1 CH60_HUMAN $61.06 \quad 100.0 \%$ $60 \mathrm{kDa}$ heat shock protein, mitochondrial GN=HSPD1 CH60_HUMAN $61.06 \quad 100.0 \%$ $60 \mathrm{kDa}$ heat shock protein, mitochondrial GN=HSPD1 CH60_HUMAN $61.06 \quad 100.0 \%$ $\begin{array}{lll} & 100 \%\end{array}$ RS6 HUMAN $28.68 \quad 100.0 \% \quad 12$ $\begin{array}{llll} & \end{array}$ RS7_HUMAN $22.13 \quad 100.0 \% \quad 2$ RS7 HUMAN $22.13 \quad 100.0 \%$ RS8 HUMAN $24.21 \quad 100.0 \%$ RS8 HUMAN $24.21 \quad 100.0 \%$ \begin{tabular}{lll} 
RS8 HUMAN & 24.21 & $100.0 \%$ \\
\hline
\end{tabular} RS8 HUMAN $24.21 \quad 100.0 \%$ RS8_HUMAN $24.21 \quad 100.0 \%$ RS8 HUMAN $24.21 \quad 100.0 \%$ RS9_HUMAN $22.59 \quad 100.0 \%$ RS9 HUMAN $22.59 \quad 100.0 \%$ $\begin{array}{lll}\text { RSSA_HUMAN } & 32.85 & 100.0 \%\end{array}$ RSSA HUMAN $32.85 \quad 100.0 \%$ XRN2_HUMAN $108.59 \quad 100.0 \%$ XRN2 HUMAN $108.59 \quad 100.0 \%$ XRN2_HUMAN $108.59 \quad 100.0 \%$ $100.0 \%$ $0 \% \quad 3$ 18 18 18 18
18 XRN2 HUMAN $108.59 \quad 100.0 \%$
48.6\% MKLNISFPATGCQK

$\begin{array}{llllllll}99.7 \% & 62.4 & 25.0 & 51.7 & 8 & 7 & 0 & 1610.80\end{array}$ $99.7 \% \quad 50.1$ $99.0 \% \quad 52.9$ $0.08 \% \quad 48.6 \%$ LIEVDDER $\begin{array}{llllll}25.0 & 46.0 & 4 & 0 & 0 & 988.49\end{array}$

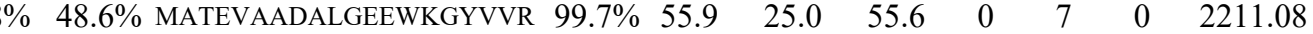
$0.08 \% \quad 48.6 \%$ ISGGNDKQGFPMK $0.08 \% \quad 48.6 \%$ GCIVDANLSVLNLVIVK $0.08 \% \quad 48.6 \%$ GEKDIPGLTDTTVPR $0.08 \% \quad 48.6 \%$ DIPGLTDTTVPR $0.08 \% \quad 48.6 \%$ LFNLSKEDDVR $0.08 \% \quad 48.6 \%$ EDDVRQYVVR $0.08 \% \quad 48.6 \%$ IQRLVTPR $0.08 \% \quad 48.6 \%$ LSSLRASTSK $0.01 \% \quad 11.9 \%$ SFQKIQVR $0.01 \% \quad 11.9 \%$ LTGKDVNFEFPEFQL $0.06 \% \quad 45.7 \%$ KYELGRPAANTK $0.06 \% \quad 45.7 \%$ YELGRPAANTK $0.06 \% \quad 45.7 \%$ TRIIDVVYNASNNELVR $0.06 \% \quad 45.7 \%$ IIDVVYNASNNELVR $0.06 \% \quad 45.7 \%$ NCIVLIDSTPYR $0.06 \% \quad 45.7 \%$ LTPEEEEILNK $0.06 \% \quad 45.7 \%$ ISSLLEEQFQQGK $0.06 \% \quad 45.7 \%$ LLACIASRPGQCGR $0.06 \% \quad 45.7 \%$ ADGYVLEGKELEFYLR $0.01 \% \quad 9.8 \%$ LFEGNALLR $0.01 \% \quad 9.8 \%$ SPYGGGRPGR $0.02 \% \quad 20.3 \%$ SDGIYIINLKR $0.02 \% \quad 20.3 \%$ AIVAIENPADVSVISSR $0.02 \% \quad 20.3 \%$ FAAATGATPIAGR $0.02 \% \quad 20.3 \%$ LLVVTDPR $0.02 \% \quad 20.3 \%$ YVDIAIPCNNK $0.02 \% \quad 10.5 \%$ IKVAEDEAEAAAAAK $0.02 \% \quad 10.5 \%$ VAEDEAEAAAAAK $0.02 \% \quad 10.5 \%$ FTGLSKEELLK $99.7 \% \quad 50.1$ $99.7 \% \quad 76.7$ $99.7 \% \quad 41.5$ $99.7 \% \quad 48.8$ $99.7 \% \quad 49.5$ $99.7 \% \quad 39.7$ $99.0 \% \quad 21.0$ $99.0 \% \quad 26.3$ $99.0 \% \quad 18.4$ $99.7 \% \quad 33.5$ $99.7 \% \quad 45.4$ $99.7 \% \quad 34.0$ $\begin{array}{rr}99.7 \% & 34.0 \\ 99.6 \% & 24.7\end{array}$ $99.7 \% \quad 60.7$ $99.7 \% \quad 60.6$ $99.7 \% \quad 36.3$ $99.7 \% \quad 62.2$ $99.7 \% \quad 37.0$

$99.7 \% \quad 43.5$ $99.7 \% \quad 30.5$ $99.6 \% \quad 23.4$ $99.7 \% \quad 33.3$ $99.7 \% \quad 79.4$ $99.7 \% \quad 64.4$ $99.0 \% \quad 42.7$ $99.7 \% \quad 38.0$ $99.7 \% \quad 39.6$ $99.7 \% \quad 42.4$ $99.7 \% \quad 31.9$ $0.02 \% \quad 10.5 \%$ IGDLQAFQGHGAGNLAGLK $\quad 99.7 \% \quad 36.0$ $0.02 \% \quad 10.5 \%$ ADLLLSTQPGREEGSPLELER $0.01 \% \quad 5.7 \%$ RLLYMAIDGVAPR $0.01 \% \quad 5.7 \% \quad$ NSPGSQVASNPR $\begin{array}{llll}9.7 \% & 36.0 & 25.0 & 36.0 \\ 91.2 & 25.0 & 41.2 & 0\end{array}$ $99.2 \% \quad 25.0$ $99.7 \% \quad 43.6$ $0.01 \% \quad 5.7 \%$ AALEEVYPDLTPEETRR $\quad 99.7 \% \quad 48.5$ $0.01 \% \quad 5.7 \%$ NSLGGDVLFVGK $99.7 \% \quad 28.5$ $0.01 \% \quad 7.7 \%$ DLKPENVLLDAHMNAK $0.01 \% \quad 7.7 \%$ TSCGSPNYAAPEVISGR $99.6 \% \quad 24.3$ $0.01 \% \quad 7.7 \%$ VPFLVAETPR $0.06 \% 35.3 \%$ TVIIEQSWGSPK

$9.7 \% \quad 33.7$ $95.0 \% \quad 13.8$ $99.7 \% \quad 63.0$ $99.7 \% 51.7$ $0.06 \% \quad 35.3 \%$ VTKDGVTVAK $\begin{array}{rr}99.7 \% & 51.7 \\ 99.7 \% & 48.7\end{array}$ $0.06 \% \quad 35.3 \%$ SIAKEGFEK $0.06 \% \quad 35.3 \%$ GANPVEIRR
$25.0 \quad 48.7$

$\begin{array}{llll}99.7 \% & 36.4 & 25.0 & 29.4\end{array}$ $\begin{array}{llll}99.7 \% & 37.6 & 25.0 & 33.2\end{array}$
1378.68

1827.04

1598.84

1284.68

1335.69

1278.64

982.62

1049.59

1005.58

1783.89

1347.74

1219.64

1976.06

1718.91

1450.74

1314.68

1506.78

1558.79

1901.96

1032.58

1003.51

1291.74

1740.95

1203.65

912.55

1306.65

1486.77

1245.60

1264.71

1866.98

2310.19

1474.82

1213.59

1988.99

1205.65

1807.94

1765.82

1128.64

1344.72

1017.59

2560.25

1008.54 1011.57 
$60 \mathrm{kDa}$ heat shock protein, mitochondrial GN=HSPD1 CH60_HUMAN $61.06 \quad 100.0 \% \quad 18$ $60 \mathrm{kDa}$ heat shock protein, mitochondrial GN=HSPD1 CH60_HUMAN $61.06 \quad 100.0 \% \quad 18$ $60 \mathrm{kDa}$ heat shock protein, mitochondrial GN=HSPD1 CH60_HUMAN $61.06 \quad 100.0 \% \quad 18$ $60 \mathrm{kDa}$ heat shock protein, mitochondrial GN=HSPD1 CH60_HUMAN $61.06 \quad 100.0 \% \quad 18$ $60 \mathrm{kDa}$ heat shock protein, mitochondrial GN=HSPD1 CH60_HUMAN $61.06 \quad 100.0 \% \quad 18$ $60 \mathrm{kDa}$ heat shock protein, mitochondrial GN=HSPD1 CH60_HUMAN $61.06 \quad 100.0 \% \quad 18$ $60 \mathrm{kDa}$ heat shock protein, mitochondrial GN=HSPD1 CH60_HUMAN $61.06 \quad 100.0 \% \quad 18$ $60 \mathrm{kDa}$ heat shock protein, mitochondrial GN=HSPD1 CH60_HUMAN $61.06 \quad 100.0 \% \quad 18$ $60 \mathrm{kDa}$ heat shock protein, mitochondrial GN=HSPD1 CH60 HUMAN $61.06 \quad 100.0 \% \quad 18$ $60 \mathrm{kDa}$ heat shock protein, mitochondrial GN=HSPD1 CH60_HUMAN $61.06 \quad 100.0 \% \quad 18$ $60 \mathrm{kDa}$ heat shock protein, mitochondrial GN=HSPD1 CH60_HUMAN $61.06 \quad 100.0 \% \quad 18$ $60 \mathrm{kDa}$ heat shock protein, mitochondrial GN=HSPD1 CH60_HUMAN $61.06 \quad 100.0 \% \quad 18$ $60 \mathrm{kDa}$ heat shock protein, mitochondrial GN=HSPD1 CH60_HUMAN $61.06 \quad 100.0 \% \quad 18$ $60 \mathrm{kDa}$ SS-A/Ro ribonucleoprotein GN=TROVE2 RO60_HUMAN $60.67 \quad 100.0 \%$ $60 \mathrm{kDa}$ SS-A/Ro ribonucleoprotein GN=TROVE2 RO60_HUMAN $60.67 \quad 100.0 \%$ $60 \mathrm{kDa}$ SS-A/Ro ribonucleoprotein GN=TROVE2 RO60_HUMAN $60.67 \quad 100.0 \%$ $60 \mathrm{kDa}$ SS-A/Ro ribonucleoprotein GN=TROVE2 RO60 HUMAN $60.67 \quad 100.0 \%$ 60S acidic ribosomal protein P0 GN=RPLP0 RLA0_HUMAN $34.27 \quad 100.0 \%$ $60 \mathrm{~S}$ acidic ribosomal protein P0 GN=RPLP0 RLA0_HUMAN $34.27 \quad 100.0 \%$ $60 \mathrm{~S}$ acidic ribosomal protein P0 GN=RPLP0 RLA0_HUMAN $34.27 \quad 100.0 \%$ 60S acidic ribosomal protein P0 GN=RPLP0 RLA0_HUMAN $34.27 \quad 100.0 \%$ 60S acidic ribosomal protein P0 GN=RPLP0 RLA0_HUMAN $34.27 \quad 100.0 \% \quad 1$ 60S acidic ribosomal protein P0 GN=RPLP0 RLA0_HUMAN $34.27 \quad 100.0 \% \quad 15$ 60S acidic ribosomal protein P0 GN=RPLP0 RLA0_HUMAN $34.27 \quad 100.0 \% \quad 15$ $60 \mathrm{~S}$ acidic ribosomal protein P0 GN=RPLP0 RLA0_HUMAN $34.27 \quad 100.0 \%$ 60S acidic ribosomal protein P0 GN=RPLP0 RLA0_HUMAN $34.27 \quad 100.0 \% \quad 15$ 60S acidic ribosomal protein P0 GN=RPLP0 RLA0_HUMAN $34.27 \quad 100.0 \% \quad 1$ $60 \mathrm{~S}$ acidic ribosomal protein P0 GN=RPLP0 RLA0_HUMAN $34.27 \quad 100.0 \% \quad 15$ 60S acidic ribosomal protein P0 GN=RPLP0 RLA0_HUMAN $34.27 \quad 100.0 \% \quad 15$ $60 \mathrm{~S}$ acidic ribosomal protein P0 GN=RPLP0 RLA0 HUMAN $34.27 \quad 100.0 \% \quad 15$ 60S acidic ribosomal protein P0 GN=RPLP0 RLA0_HUMAN $34.27 \quad 100.0 \% \quad 15$ $60 \mathrm{~S}$ acidic ribosomal protein P0 GN=RPLP0 RLA0_HUMAN $34.27 \quad 100.0 \% \quad 15$ $60 \mathrm{~S}$ ribosomal protein $\mathrm{L} 10 \mathrm{GN}=\mathrm{RPL} 10 \quad$ RL10 HUMAN $24.60 \quad 100.0 \%$ $60 \mathrm{~S}$ ribosomal protein L10 GN=RPL10 RL10_HUMAN $24.60 \quad 100.0 \%$ $60 \mathrm{~S}$ ribosomal protein $\mathrm{L} 10 \mathrm{GN}=\mathrm{RPL} 10$ $60 \mathrm{~S}$ ribosomal protein $\mathrm{L} 10 \mathrm{GN}=\mathrm{RPL} 10$ $60 \mathrm{~S}$ ribosomal protein $\mathrm{L} 10 \mathrm{GN}=\mathrm{RPL} 1 \mathrm{C}$ $60 \mathrm{~S}$ ribosomal protein $\mathrm{L} 10 \mathrm{GN}=\mathrm{RPL} 10$ $60 \mathrm{~S}$ ribosomal protein $\mathrm{L} 10 \mathrm{GN}=\mathrm{RPL} 10$ $60 \mathrm{~S}$ ribosomal protein $\mathrm{L} 10 \mathrm{GN}=\mathrm{RPL} 1 \mathrm{C}$ $60 \mathrm{~S}$ ribosomal protein $\mathrm{L} 10 \mathrm{GN}=\mathrm{RPL} 10$ $60 \mathrm{~S}$ ribosomal protein $\mathrm{L} 10 \mathrm{GN}=\mathrm{RPL} 10$ $60 \mathrm{~S}$ ribosomal protein $\mathrm{L} 10 \mathrm{GN}=\mathrm{RPL} 10$ $60 \mathrm{~S}$ ribosomal protein $\mathrm{L} 10 \mathrm{GN}=\mathrm{RPL} 10$ 60S ribosomal protein L10a GN=RPL10A RLI0A_HUMAN $24.60 \quad 100.0 \%$ 60 S ribosomal protein L10 GN=RPL10A RL10A_HUMAN $24.83 \quad 100.0 \%$ $60 \mathrm{~S}$ ribosomal protein L10a GN=RPL10A RL10A_HUMAN $24.83 \quad 100.0 \%$

5

$0.06 \% 35.3 \%$ GYISPYFINTSK

$0.06 \% \quad 35.3 \%$ VGLQVVAVK

$0.06 \% \quad 35.3 \%$ VGEVIVTK

$40 \quad 0.06 \% \quad 35.3 \%$ VGEVIVTKDDAMLLK

$0.06 \% 35.3 \%$ LSDGVAVLK

$0.06 \% \quad 35.3 \%$ VGGTSDVEVNEK

$0.06 \% 35.3 \%$ VTDALNATR

$0.06 \% \quad 35.3 \%$ AAVEEGIVLGGGCALLR

$0.06 \% 35.3 \%$ TLKIPAMTIAK

$0.06 \% \quad 35.3 \%$ NAGVEGSLIVEK

$0.06 \% \quad 35.3 \%$ GIIDPTKVVR

$0.01 \% \quad 9.5 \%$ LGLENAEALIR

$0.01 \% \quad 9.5 \% \quad$ LSHLKPSSEGLAIVTK

$0.01 \% \quad 9.5 \%$ ALSVETEKLLK

$0.01 \% \quad 9.5 \%$ ALLQEMPLTALLR

$0.08 \% \quad 51.1 \%$ IIQLLDDYPK

$0.08 \% \quad 51.1 \%$ IIQLLDDYPKCFIVGADNVGSK

$0.08 \% \quad 51.1 \%$ CFIVGADNVGSK

$0.08 \% \quad 51.1 \%$ CFIVGADNVGSKQMQQIR

$0.08 \% 51.1 \%$ GKAVVLMGK

$0.08 \% \quad 51.1 \%$ AVVLMGKNTMMR

$0.08 \% \quad 51.1 \%$ AIRGHLENNPALEK

$0.08 \% \quad 51.1 \%$ GHLENNPALEK

$0.08 \% \quad 51.1 \%$ GNVGFVFTK

$0.08 \% \quad 51.1 \%$ AGAIAPCEVTVPAQNTGLGPEK

$0.08 \% \quad 51.1 \%$ TSFFQALGITTK

$0.08 \% \quad 51.1 \%$ GTIEILSDVQLIK

$0.08 \% \quad 51.1 \%$ VLALSVETDYTFPLAEK

$0.08 \% \quad 51.1 \%$ VLALSVETDYTFPLAEKVK

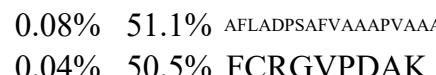

$0.04 \% \quad 50.5 \%$ GVPDAKIR

$0.04 \% 50.5 \%$ IRIFDLGR

$0.04 \% \quad 50.5 \%$ ICANKYMVK

$0.04 \% \quad 50.5 \%$ SCGKDGFHIR

$0.04 \% \quad 50.5 \%$ LHPFHVIR

$0.04 \% \quad 50.5 \%$ INKMLSCAGADR

$0.04 \% \quad 50.5 \%$ MLSCAGADRLQTGMR

$0.04 \% \quad 50.5 \%$ GAFGKPQGTVAR

$0.04 \% \quad 50.5 \%$ VHIGQVIMSIR

$0.04 \% \quad 50.5 \%$ FNADEFEDMVAEKR

$0.04 \% \quad 50.5 \%$ RLIPDGCGVK

$0.04 \% \quad 47.0 \%$ DTLYEAVR

$0.04 \% \quad 47.0 \%$ DTLYEAVREVLHGNQR $0.04 \% \quad 47.0 \%$ FSGTVRLK $\begin{array}{llllllll}99.7 \% & 50.1 & 25.0 & 50.1 & 2 & 0 & 0 & 1389.70\end{array}$

$\begin{array}{llllllll}99.7 \% & 75.8 & 25.0 & 75.8 & 1 & 0 & 0 & 1702.88\end{array}$

$\begin{array}{llllllll}99.7 \% & 33.1 & 25.0 & 33.1 & 0 & 2 & 0 & 1919.07\end{array}$

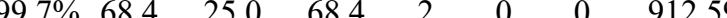

$\begin{array}{llllllll}99.0 \% & 32.7 & 25.0 & 29.3 & 2 & 0 & 0 & 844.51\end{array}$

$\begin{array}{llllllll}99.7 \% & 55.1 & 25.0 & 54.6 & 4 & 3 & 0 & 1630.91\end{array}$

$\begin{array}{llllllll}97.1 \% & 27.0 & 25.0 & 13.5 & 1 & 0 & 0 & 901.54\end{array}$

$\begin{array}{llllllll}99.7 \% & 30.1 & 25.0 & 30.1 & 1 & 0 & 0 & 1233.60\end{array}$

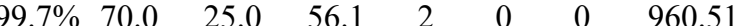

1684.91

1202.72

1215.66

1097.67

1198.68

1679.97

$99.7 \% \quad 58.5 \quad 25.0 \quad 50.1$

$99.7 \% \quad 27.5 \quad 25.0 \quad 27.5$

$99.3 \% \quad 18.9 \quad 25.0 \quad 18.9$

$99.7 \% \quad 62.0 \quad 25.0 \quad 55.0$

$\begin{array}{llll}99.7 \% & 60.3 & 25.0 & 49.9\end{array}$

$\begin{array}{llll}9.7 \% & 56.2 & 25.0 & 56.2\end{array}$

$\begin{array}{llll}99.4 \% & 20.3 & 25.0 & 20.3\end{array}$

$\begin{array}{llll}97.4 \% & 18.9 & 25.0 & 13.3\end{array}$

$\begin{array}{llll}99.7 \% & 41.7 & 25.0 & 41.7\end{array}$

$99.7 \% \quad 50.9 \quad 25.0 \quad 46.9 \quad 2$

$99.7 \% \quad 65.3 \quad 25.0 \quad 44.8$

$\begin{array}{llll}99.7 \% & 34.6 & 25.0 & 29.4\end{array}$

$\begin{array}{llll}99.7 \% & 54.5 & 25.0 & 54.5\end{array}$

$\begin{array}{llll}99.7 \% & 57.5 & 25.0 & 57.5\end{array}$

$\begin{array}{llll}99.7 \% & 66.7 & 25.0 & 49.6\end{array}$

$\begin{array}{lllll}99.7 \% & 53.7 & 25.0 & 53.7 & 4\end{array}$

$\begin{array}{llll}99.7 \% & 47.8 & 25.0 & 47.8\end{array}$

$\begin{array}{lllll}99.7 \% & 57.2 & 25.0 & 57.2 & 2\end{array}$

$\begin{array}{llll}97.6 \% & 19.4 & 25.0 & 14.5\end{array}$

$\begin{array}{llll}95.5 \% & 14.7 & 25.0 & 14.7\end{array}$

$99.0 \% \quad 31.0 \quad 25.0 \quad 13.7$

$\begin{array}{llll}99.7 \% & 40.2 & 25.0 & 39.0\end{array}$

$\begin{array}{llll}99.7 \% & 44.2 & 25.0 & 41.8\end{array}$

$\begin{array}{llll}94.9 \% & 14.1 & 25.0 & 14.1\end{array}$

$99.5 \% \quad 21.5 \quad 25.0 \quad 21.5$

$\begin{array}{llll}99.7 \% & 27.1 & 25.0 & 24.7\end{array}$

$\begin{array}{llll}99.7 \% & 52.0 & 25.0 & 49.6\end{array}$

$\begin{array}{llll}99.7 \% & 32.0 & 25.0 & 32.0\end{array}$

$\begin{array}{llll}99.7 \% & 29.1 & 25.0 & 27.6\end{array}$

$97.3 \% \quad 17.0 \quad 25.0 \quad 14.9$

$99.0 \% \quad 23.8 \quad 25.0 \quad 17.5$

$\begin{array}{llll}99.7 \% & 25.5 & 25.0 & 25.5\end{array}$

$\begin{array}{llll}99.0 \% & 36.5 & 25.0 & 16.9\end{array}$ \begin{tabular}{cc}
222 & 233 \\
222 & 236 \\
251 & 268 \\
293 & 301 \\
345 & 352 \\
345 & 359 \\
397 & 405 \\
406 & 417 \\
421 & 429 \\
430 & 446 \\
471 & 481 \\
482 & 493 \\
517 & 526 \\
53 & 63 \\
185 & 200 \\
217 & 227 \\
271 & 283 \\
17 & 26 \\
17 & 38 \\
27 & 38 \\
27 & 44 \\
49 & 57 \\
51 & 62 \\
64 & 77 \\
67 & 77 \\
84 & 92 \\
113 & 134 \\
135 & 146 \\
150 & 162 \\
248 & 264 \\
248 & 266 \\
267 & 297 \\
22 & 30 \\
25 & 32 \\
31 & 38 \\
70 & 78 \\
79 & 88 \\
91 & 98 \\
99 & 110 \\
102 & 116 \\
117 & 128 \\
129 & 139 \\
176 & 189 \\
189 & 198 \\
8 & 15 \\
& 23 \\
\hline 19
\end{tabular} 
60 S ribosomal protein L10a GN=RPL10A RL10A_HUMAN $24.83 \quad 100.0 \%$ $60 \mathrm{~S}$ ribosomal protein L10a GN=RPL10A RL10A_HUMAN $24.83 \quad 100.0 \%$ $60 \mathrm{~S}$ ribosomal protein L10a GN=RPL10A RL10A_HUMAN $24.83 \quad 100.0 \%$ $60 \mathrm{~S}$ ribosomal protein L10a GN=RPL10A RL10A_HUMAN $24.83 \quad 100.0 \%$ $60 \mathrm{~S}$ ribosomal protein L10a GN=RPL10A RL10A_HUMAN $24.83 \quad 100.0 \%$ $60 \mathrm{~S}$ ribosomal protein L10a GN=RPL10A RL10A_HUMAN $24.83 \quad 100.0 \%$ $60 \mathrm{~S}$ ribosomal protein $\mathrm{L} 13 \mathrm{GN}=\mathrm{RPL} 13$ $60 \mathrm{~S}$ ribosomal protein $\mathrm{L} 13 \mathrm{GN}=\mathrm{RPL} 13$ $60 \mathrm{~S}$ ribosomal protein $\mathrm{L} 13 \mathrm{GN}=\mathrm{RPL} 13$ $60 \mathrm{~S}$ ribosomal protein $\mathrm{L} 13 \mathrm{GN}=\mathrm{RPL} 13$ $60 \mathrm{~S}$ ribosomal protein $\mathrm{L} 13 \mathrm{GN}=\mathrm{RPL} 13$ $60 \mathrm{~S}$ ribosomal protein $\mathrm{L} 13 \mathrm{GN}=\mathrm{RPL} 13$ $60 \mathrm{~S}$ ribosomal protein $\mathrm{L} 13 \mathrm{GN}=\mathrm{RPL} 13$ $60 \mathrm{~S}$ ribosomal protein $\mathrm{L} 13 \mathrm{GN}=\mathrm{RPL} 13$ $60 \mathrm{~S}$ ribosomal protein $\mathrm{L} 13 \mathrm{GN}=\mathrm{RPL} 13$ $60 \mathrm{~S}$ ribosomal protein $\mathrm{L} 13 \mathrm{GN}=\mathrm{RPL} 13$ $60 \mathrm{~S}$ ribosomal protein $\mathrm{L} 13 \mathrm{GN}=\mathrm{RPL} 13$ $60 \mathrm{~S}$ ribosomal protein $\mathrm{L} 13 \mathrm{GN}=\mathrm{RPL} 13$ $60 \mathrm{~S}$ ribosomal protein $\mathrm{L} 13 \mathrm{GN}=\mathrm{RPL} 13$ $60 \mathrm{~S}$ ribosomal protein $\mathrm{L} 13 \mathrm{GN}=\mathrm{RPL} 13$ $60 \mathrm{~S}$ ribosomal protein $\mathrm{L} 13 \mathrm{a} \mathrm{GN}=\mathrm{RPL} 13 \mathrm{~A}$ $60 \mathrm{~S}$ ribosomal protein $\mathrm{L} 13 \mathrm{a} \mathrm{GN}=\mathrm{RPL} 13$ $60 \mathrm{~S}$ ribosomal protein $\mathrm{L} 14 \mathrm{GN}=\mathrm{RPL} 14$ $60 \mathrm{~S}$ ribosomal protein $\mathrm{L} 14 \mathrm{GN}=\mathrm{RPL} 14$ $60 \mathrm{~S}$ ribosomal protein $\mathrm{L} 14 \mathrm{GN}=\mathrm{RPL} 14$ $60 \mathrm{~S}$ ribosomal protein $\mathrm{L} 15 \mathrm{GN}=\mathrm{RPL} 15$ $60 \mathrm{~S}$ ribosomal protein $\mathrm{L} 15 \mathrm{GN}=\mathrm{RPL} 15$ $60 \mathrm{~S}$ ribosomal protein $\mathrm{L} 15 \mathrm{GN}=\mathrm{RPL} 15$ $60 \mathrm{~S}$ ribosomal protein $\mathrm{L} 15 \mathrm{GN}=\mathrm{RPL} 15$ $60 \mathrm{~S}$ ribosomal protein $\mathrm{L} 17 \mathrm{GN}=\mathrm{RPL} 17$ $60 \mathrm{~S}$ ribosomal protein $\mathrm{L} 17 \mathrm{GN}=\mathrm{RPL} 17$ $60 \mathrm{~S}$ ribosomal protein $\mathrm{L} 17 \mathrm{GN}=\mathrm{RPL} 17$ $60 \mathrm{~S}$ ribosomal protein $\mathrm{L} 18 \mathrm{GN}=\mathrm{RPL} 18$ $60 \mathrm{~S}$ ribosomal protein $\mathrm{L} 18 \mathrm{GN}=\mathrm{RPL} 18$ 60 S ribosomal protein $\mathrm{L} 18 \mathrm{GN}=\mathrm{RPL} 18$ $60 \mathrm{~S}$ ribosomal protein $\mathrm{L} 18 \mathrm{a} \mathrm{GN}=\mathrm{RPL} 18 \mathrm{~A}$ $60 \mathrm{~S}$ ribosomal protein $\mathrm{L} 18 \mathrm{a} \mathrm{GN}=\mathrm{RPL} 18$ $60 \mathrm{~S}$ ribosomal protein $\mathrm{L} 19 \mathrm{GN}=\mathrm{RPL} 19$ $60 \mathrm{~S}$ ribosomal protein $\mathrm{L} 19 \mathrm{GN}=\mathrm{RPL} 19$ $60 \mathrm{~S}$ ribosomal protein $\mathrm{L} 19 \mathrm{GN}=\mathrm{RPL} 19$ $60 \mathrm{~S}$ ribosomal protein $\mathrm{L} 19 \mathrm{GN}=\mathrm{RPL} 19$ $60 \mathrm{~S}$ ribosomal protein $\mathrm{L} 19 \mathrm{GN}=\mathrm{RPL} 19$ $60 \mathrm{~S}$ ribosomal protein $\mathrm{L} 19 \mathrm{GN}=\mathrm{RPL} 19$ $60 \mathrm{~S}$ ribosomal protein $\mathrm{L} 19 \mathrm{GN}=\mathrm{RPL} 19$ $60 \mathrm{~S}$ ribosomal protein $\mathrm{L} 19 \mathrm{GN}=\mathrm{RPL} 19$ $60 \mathrm{~S}$ ribosomal protein $\mathrm{L} 21 \mathrm{GN}=\mathrm{RPL} 21$ $60 \mathrm{~S}$ ribosomal protein $\mathrm{L} 21 \mathrm{GN}=\mathrm{RPL} 21$
RL13 HUMAN $24.26 \quad 100.0 \%$ RL13_HUMAN $24.26 \quad 100.0 \%$ RL13 HUMAN $24.26 \quad 100.0 \%$ RL13_HUMAN $24.26 \quad 100.0 \%$ RL13_HUMAN $24.26 \quad 100.0 \%$ RL13 HUMAN $24.26 \quad 100.0 \%$ RL13_HUMAN $24.26 \quad 100.0 \%$ RL13_HUMAN $24.26 \quad 100.0 \%$ RL13_HUMAN $24.26 \quad 100.0 \%$ RL13_HUMAN $24.26 \quad 100.0 \%$ RL13 HUMAN $24.26 \quad 100.0 \%$ RL13_HUMAN $24.26 \quad 100.0 \%$ RL13_HUMAN $24.26 \quad 100.0 \%$ RL13 HUMAN $24.26 \quad 100.0 \%$ RLI3A_HUMAN $23.58 \quad 100.0 \%$ $\begin{array}{ll} & \\ & 100.0 \%\end{array}$ RL14_HUMAN $23.43 \quad 100.0 \%$ RL14_HUMAN $23.43 \quad 100.0 \%$ RL14 HUMAN $23.43 \quad 100.0 \%$ RL15_HUMAN $24.15 \quad 100.0 \%$ RL15_HUMAN $24.15 \quad 100.0 \%$ RL15 HUMAN $24.15 \quad 100.0 \%$ RL15_HUMAN $24.15 \quad 100.0 \%$ RL17 HUMAN $21.40 \quad 100.0 \%$ RL17_HUMAN $21.40 \quad 100.0 \%$ RL17_HUMAN $21.40 \quad 100.0 \%$ RL18 HUMAN $21.64 \quad 100.0 \%$ RL18_HUMAN $21.64 \quad 100.0 \%$ RL18 HUMAN $21.64 \quad 100.0 \%$ RL18A_HUMAN $20.76 \quad 100.0 \%$ RL18A_HUMAN $20.76 \quad 100.0 \%$ RL19_HUMAN $23.47 \quad 100.0 \%$ RL19_HUMAN $23.47 \quad 100.0 \%$ RL19_HUMAN $23.47 \quad 100.0 \%$ RL19 HUMAN $23.47 \quad 100.0 \%$ RL19_HUMAN $23.47 \quad 100.0 \%$ RL19 HUMAN $23.47 \quad 100.0 \%$ RL19_HUMAN $23.47 \quad 100.0 \%$ RL19_HUMAN $23.47 \quad 100.0 \%$ RL21 HUMAN $18.57 \quad 100.0 \%$ RL21_HUMAN $18.57 \quad 100.0 \%$

3

4

3
3
3

3

3

3
3
2

3
2
2

8

$\begin{array}{ll}8 & 8 \\ 8 & 8 \\ 8 & 8 \\ 8 & 8\end{array}$

8

8
8
8

8

8
8
8

8

$\begin{array}{lll}0.04 \% & 47.0 \% & \text { FSVCVLGDQQHCDEAK } \\ 0.04 \% & 47.0 \% & \text { AVDIPHMDIEALKK }\end{array}$

$0.04 \% \quad 47.0 \%$ KYDAFLASESLIK

$0.04 \% \quad 47.0 \%$ ILGPGLNK

$0.04 \% \quad 47.0 \%$ AGKFPSLLTHNENMVAK

$0.04 \% \quad 47.0 \%$ STMGKPQRLY

$0.10 \% \quad 50.2 \%$ RVATWFNQPAR

$0.10 \% \quad 50.2 \%$ VATWFNQPAR

$0.10 \% \quad 50.2 \%$ VATWFNQPARK

$0.10 \% \quad 50.2 \%$ IAPRPASGPIRPIVR

$69 \quad 0.10 \% \quad 50.2 \%$ AGRGFSLEELR

$0.10 \% \quad 50.2 \%$ GFSLEELR

$0.10 \% \quad 50.2 \%$ TIGISVDPR

$69 \quad 0.10 \% \quad 50.2 \%$ NKSTESLQANVQR

$69 \quad 0.10 \% \quad 50.2 \%$ STESLQANVQR

$69 \quad 0.10 \% \quad 50.2 \%$ SKLILFPR

$69 \quad 0.10 \% \quad 50.2 \%$ LILFPRKPSAPK

$69 \quad 0.10 \% \quad 50.2 \%$ LATQLTGPVMPVR

$69 \quad 0.10 \% \quad 50.2 \%$ VITEEEKNFK

$0.10 \% \quad 50.2 \%$ ANARLFGIR

$0.01 \% \quad 9.9 \%$ GQAALDRLK

$0.01 \% \quad 9.9 \%$ MVVPAALKVVR

$0.01 \% \quad 14.9 \%$ LVAIVDVIDQNR

$0.01 \% \quad 14.9 \%$ ADINTKWAATR

$0.01 \% \quad 14.9 \%$ AALLKASPK

$0.02 \% \quad 19.1 \%$ GAYKYIQELWR

$0.02 \% \quad 19.1 \%$ GATYGKPVHHGVNQLK

$0.02 \% \quad 19.1 \%$ SLQSVAEER

$0.02 \% \quad 19.1 \%$ SLQSVAEERAGR

$0.01 \% \quad 17.9 \%$ VRYSLDPENPTK

$0.01 \% \quad 17.9 \%$ ETAQAIKGMHIR

$0.01 \% \quad 17.9 \%$ YLKDVTLQK

$0.01 \% \quad 12.2 \%$ TNSTFNQVVLK

$0.01 \% \quad 12.2 \%$ TNSTFNQVVLKR

$0.01 \% \quad 12.2 \%$ GCGTVLLSGPR

$0.00 \% \quad 10.2 \%$ CHTPPLYR

$0.00 \% \quad 10.2 \%$ FTTKRPNTFF

$4 \quad 0.02 \% \quad 31.6 \%$ RLASSVLR

$\begin{array}{llll}99.0 \% & 32.3 & 25.0 & 22.8\end{array}$

$\begin{array}{lllllll}0.02 \% & 31.6 \% & \text { KVWLDPNETNEIANANSR } & 99.7 \% & 36.0 & 25.0 & 36.0\end{array}$

$\begin{array}{lllllll}0.02 \% & 31.6 \% & \text { VWLDPNETNEIANANSR } & 99.7 \% & 74.1 & 25.0 & 74.1\end{array}$

$\begin{array}{llllllll}0.02 \% & 31.6 \% & \text { VWLDPNETNEIANANSRQQIR } & 98.6 \% & 25.7 & 25.0 & 23.4\end{array}$

$0.02 \% \quad 31.6 \%$ DGLIIRKPVTVHSR

$0.02 \% \quad 31.6 \%$ ILMEHIHK

$0.02 \% \quad 31.6 \%$ LLADQAEAR

$0.02 \% \quad 31.6 \%$ LLADQAEARR

$0.01 \% \quad 18.1 \%$ HGVVPLATYMR

$\begin{array}{lllll}99.5 \% & 21.6 & 25.0 & 21.6 & 0 \\ 99.0 \% & 32.9 & 25.0 & 28.6 & 2\end{array}$

$\begin{array}{lllll}99.7 \% & 59.5 & 25.0 & 51.9 & 2\end{array}$

$\begin{array}{lllll}99.7 \% & 27.9 & 25.0 & 25.7 & 2\end{array}$

$\begin{array}{lllll}98.9 \% & 27.5 & 25.0 & 27.5 & 2\end{array}$
1892.83

1892.83

1595.85

1484.80

811.50

1856.97

1180.61

1345.71

1189.61

1317.71

1599.98

1234.65

950.49

957.54

1474.76

1232.62

973.62

1366.86

1398.78

1236.65

1017.60

971.56

1198.73

1354.77

1246.65

898.57

1426.75

1705.91

1018.52

1302.68

1418.73

1370.72

1107.64

1250.67

1406.78

1116.58

1043.51

1258.66

901.56

2071.02

1942.93

2468.23

1590.94

1020.57

986.53

1142.63

1243.66 2094.01

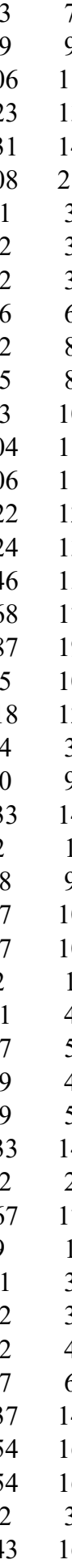

Page 10 of Table S-1-2 

60S ribosomal protein L23a GN=RPL23A RL23A_HUMAN $17.70 \quad 100.0 \%$ $60 \mathrm{~S}$ ribosomal protein $\mathrm{L} 24 \mathrm{GN}=\mathrm{RPL} 24$ $60 \mathrm{~S}$ ribosomal protein $\mathrm{L} 24 \mathrm{GN}=\mathrm{RPL} 24$ $60 \mathrm{~S}$ ribosomal protein $\mathrm{L} 24 \mathrm{GN}=\mathrm{RPL} 24$ $60 \mathrm{~S}$ ribosomal protein $\mathrm{L} 29 \mathrm{GN}=\mathrm{RPL} 29$ $60 \mathrm{~S}$ ribosomal protein $\mathrm{L} 29 \mathrm{GN}=\mathrm{RPL} 29$ $60 \mathrm{~S}$ ribosomal protein $\mathrm{L} 29 \mathrm{GN}=\mathrm{RPL} 29$ $60 \mathrm{~S}$ ribosomal protein $\mathrm{L} 29 \mathrm{GN}=\mathrm{RPL} 29$ $60 \mathrm{~S}$ ribosomal protein $\mathrm{L} 3 \mathrm{GN}=\mathrm{RPL} 3$ $60 \mathrm{~S}$ ribosomal protein $\mathrm{L} 3 \mathrm{GN}=\mathrm{RPL} 3$ $60 \mathrm{~S}$ ribosomal protein $\mathrm{L} 3 \mathrm{GN}=\mathrm{RPL} 3$ $60 \mathrm{~S}$ ribosomal protein $\mathrm{L} 3 \mathrm{GN}=\mathrm{RPL} 3$ $60 \mathrm{~S}$ ribosomal protein $\mathrm{L} 3 \mathrm{GN}=\mathrm{RPL} 3$ $60 \mathrm{~S}$ ribosomal protein $\mathrm{L} 3 \mathrm{GN}=\mathrm{RPL} 3$ $60 \mathrm{~S}$ ribosomal protein $\mathrm{L} 3 \mathrm{GN}=\mathrm{RPL} 3$ $60 \mathrm{~S}$ ribosomal protein $\mathrm{L} 3 \mathrm{GN}=\mathrm{RPL} 3$ $60 \mathrm{~S}$ ribosomal protein $\mathrm{L} 3 \mathrm{GN}=\mathrm{RPL} 3$ $60 \mathrm{~S}$ ribosomal protein $\mathrm{L} 3 \mathrm{GN}=\mathrm{RPL} 3$ $60 \mathrm{~S}$ ribosomal protein $\mathrm{L} 3 \mathrm{GN}=\mathrm{RPL} 3$ $60 \mathrm{~S}$ ribosomal protein $\mathrm{L} 3 \mathrm{GN}=\mathrm{RPL} 3$ $60 \mathrm{~S}$ ribosomal protein $\mathrm{L} 3 \mathrm{GN}=\mathrm{RPL} 3$ $60 \mathrm{~S}$ ribosomal protein $\mathrm{L} 3 \mathrm{GN}=\mathrm{RPL} 3$ $60 \mathrm{~S}$ ribosomal protein $\mathrm{L} 3 \mathrm{GN}=\mathrm{RPL} 3$ $60 \mathrm{~S}$ ribosomal protein $\mathrm{L} 3 \mathrm{GN}=\mathrm{RPL} 3$ $60 \mathrm{~S}$ ribosomal protein $\mathrm{L} 3 \mathrm{GN}=\mathrm{RPL} 3$ $60 \mathrm{~S}$ ribosomal protein $\mathrm{L} 3 \mathrm{GN}=\mathrm{RPL} 3$ $60 \mathrm{~S}$ ribosomal protein $\mathrm{L} 3 \mathrm{GN}=\mathrm{RPL} 3$ $60 \mathrm{~S}$ ribosomal protein $\mathrm{L} 3 \mathrm{GN}=\mathrm{RPL} 3$ $60 \mathrm{~S}$ ribosomal protein $\mathrm{L} 3 \mathrm{GN}=\mathrm{RPL} 3$ $60 \mathrm{~S}$ ribosomal protein $\mathrm{L} 4 \mathrm{GN}=\mathrm{RPL} 4$ $60 \mathrm{~S}$ ribosomal protein $\mathrm{L} 4 \mathrm{GN}=\mathrm{RPL} 4$ $60 \mathrm{~S}$ ribosomal protein $\mathrm{L} 4 \mathrm{GN}=\mathrm{RPL} 4$ $60 \mathrm{~S}$ ribosomal protein $\mathrm{L} 4 \mathrm{GN}=\mathrm{RPL} 4$ $60 \mathrm{~S}$ ribosomal protein $\mathrm{L} 4 \mathrm{GN}=\mathrm{RPL} 4$ $60 \mathrm{~S}$ ribosomal protein $\mathrm{L} 4 \mathrm{GN}=\mathrm{RPL} 4$ $60 \mathrm{~S}$ ribosomal protein $\mathrm{L} 4 \mathrm{GN}=\mathrm{RPL} 4$ $60 \mathrm{~S}$ ribosomal protein $\mathrm{L} 4 \mathrm{GN}=\mathrm{RPL} 4$ $60 \mathrm{~S}$ ribosomal protein $\mathrm{L} 4 \mathrm{GN}=\mathrm{RPL} 4$ $60 \mathrm{~S}$ ribosomal protein $\mathrm{L} 4 \mathrm{GN}=\mathrm{RPL} 4$ $60 \mathrm{~S}$ ribosomal protein $\mathrm{L} 4 \mathrm{GN}=\mathrm{RPL} 4$ $60 \mathrm{~S}$ ribosomal protein $\mathrm{L} 4 \mathrm{GN}=\mathrm{RPL} 4$ $60 \mathrm{~S}$ ribosomal protein $\mathrm{L} 4 \mathrm{GN}=\mathrm{RPL} 4$ $60 \mathrm{~S}$ ribosomal protein $\mathrm{L} 4 \mathrm{GN}=\mathrm{RPL} 4$ $60 \mathrm{~S}$ ribosomal protein $\mathrm{L} 4 \mathrm{GN}=\mathrm{RPL} 4$ $60 \mathrm{~S}$ ribosomal protein $\mathrm{L} 4 \mathrm{GN}=\mathrm{RPL} 4$ $60 \mathrm{~S}$ ribosomal protein $\mathrm{L} 4 \mathrm{GN}=\mathrm{RPL} 4$
RL24_HUMAN $17.78 \quad 100.0 \%$ RL24_HUMAN $17.78 \quad 100.0 \%$ RL24_HUMAN $17.78 \quad 100.0 \%$ RL29_HUMAN $17.75 \quad 100.0 \%$ RL29 HUMAN $17.75 \quad 100.0 \%$ RL29_HUMAN $17.75 \quad 100.0 \%$ RL29 HUMAN $17.75 \quad 100.0 \%$ RL3_HUMAN $46.11 \quad 100.0 \%$ RL3_HUMAN $46.11 \quad 100.0 \%$ RL3 HUMAN $46.11 \quad 100.0 \%$ RL3_HUMAN $46.11 \quad 100.0 \% \quad 21$ RL3_HUMAN $46.11 \quad 100.0 \% \quad 2$ RL3_HUMAN $46.11 \quad 100.0 \% \quad 21$ RL3_HUMAN $46.11 \quad 100.0 \% \quad 21$ RL3 HUMAN $46.11 \quad 100.0 \% \quad 21$ RL3_HUMAN $46.11 \quad 100.0 \% \quad 21$ RL3_HUMAN $46.11 \quad 100.0 \% \quad 21$ RL3 HUMAN $46.11 \quad 100.0 \% \quad 21$ RL3_HUMAN $46.11 \quad 100.0 \% \quad 21$ RL3_HUMAN $46.11 \quad 100.0 \% \quad 21$ RL3_HUMAN $46.11 \quad 100.0 \% \quad 21$ RL3_HUMAN $46.11 \quad 100.0 \% \quad 21$ RL3 HUMAN $46.11 \quad 100.0 \% \quad 21$ RL3_HUMAN $46.11 \quad 100.0 \% \quad 21$ RL3_HUMAN $46.11 \quad 100.0 \% \quad 21$ RL3 HUMAN $46.11 \quad 100.0 \% \quad 21$ RL3_HUMAN $46.11 \quad 100.0 \% \quad 21$ RL3 HUMAN $46.11 \quad 100.0 \% \quad 21$ RL4_HUMAN $47.70 \quad 100.0 \% \quad 24$ RL4_HUMAN $47.70 \quad 100.0 \% \quad 24$ RL4 HUMAN $47.70 \quad 100.0 \% \quad 24$ RL4_HUMAN $47.70 \quad 100.0 \% \quad 24$ RL4_HUMAN $47.70 \quad 100.0 \% \quad 24$ RL4 HUMAN $47.70 \quad 100.0 \% \quad 24$ RL4_HUMAN $47.70 \quad 100.0 \% \quad 24$ RL4 HUMAN $47.70 \quad 100.0 \% \quad 24$ RL4_HUMAN $47.70 \quad 100.0 \% \quad 24$ RL4_HUMAN $47.70 \quad 100.0 \% \quad 24$ RL4 HUMAN $47.70 \quad 100.0 \% \quad 24$ RL4_HUMAN $47.70 \quad 100.0 \% \quad 24$ RL4 HUMAN $\quad 47.70 \quad 100.0 \% \quad 24$ RL4_HUMAN $47.70 \quad 100.0 \% \quad 24$ RL4_HUMAN $47.70 \quad 100.0 \% \quad 24$ RL4 HUMAN $47.70 \quad 100.0 \% \quad 24$ RL4_HUMAN $47.70 \quad 100.0 \% \quad 24$
$0.01 \% \quad 17.9 \%$ EAPAPPKAEAK $0.01 \% \quad 17.9 \%$ LAPDYDALDVANKIGII $0.06 \% \quad 14.0 \%$ CESAFLSK

$0.06 \% \quad 14.0 \%$ AITGASLADIMAK

$0.06 \% \quad 14.0 \%$ AITGASLADIMAKR

$0.04 \% \quad 17.6 \%$ LAYIAHPK

$\begin{array}{llllllll}99.7 \% & 34.7 & 25.0 & 24.9 & 5 & 0 & 0 & 1108.60\end{array}$ $99.7 \% \quad 36.8$

$99.0 \% \quad 20.4$ $99.7 \% \quad 64.7$

$99.7 \% \quad 46.9$ $\begin{array}{lll}99.0 \% & 25.7\end{array}$

$30 \quad 0.04 \% \quad 17.6 \%$ DQTKAQAAAPASVPAQAPK $99.7 \% \quad 26.6$ $0.04 \% \quad 17.6 \%$ AQAAAPASVPAQAPK

0.04\% $17.6 \%$ AQAAAPASVPAQAPKR

$103 \quad 0.15 \% \quad 45.2 \%$ HGSLGFLPR

$103 \quad 0.15 \% \quad 45.2 \%$ DDPSKPVHLTAFLGYK $\begin{array}{lll}99.7 \% & 55.3\end{array}$ $99.7 \% \quad 47.5$ $99.7 \% \quad 58.1$ $99.6 \% \quad 22.6$ $99.0 \% \quad 59.8$

$103 \quad 0.15 \% \quad 45.2 \%$ AGMTHIVR

$103 \quad 0.15 \% \quad 45.2 \%$ AGMTHIVREVDRPGSK

$103 \quad 0.15 \% \quad 45.2 \%$ TVFAEHISDECK

$103 \quad 0.15 \% \quad 45.2 \%$ TVFAEHISDECKR

$103 \quad 0.15 \% \quad 45.2 \%$ VIAHTQMR

$\begin{array}{llll}99.7 \% & 29.3 & 25.0 & 28.5\end{array}$

$99.7 \% \quad 66.1$

$99.7 \% \quad 57.0$

$99.0 \% \quad 35.2$

$103 \quad 0.15 \% \quad 45.2 \%$ AHLMEIQVNGGTVAEK

$103 \quad 0.15 \% \quad 45.2 \%$ ERLEQQVPVNQVFGQDEMIDVIGVTK

$103 \quad 0.15 \% \quad 45.2 \%$ KVACIGAWHPAR

$103 \quad 0.15 \% \quad 45.2 \%$ VACIGAWHPAR

$103 \quad 0.15 \% \quad 45.2 \%$ IYKIGQGYLIK

$103 \quad 0.15 \% \quad 45.2 \%$ IGQGYLIKDGK

$103 \quad 0.15 \% \quad 45.2 \% \quad$ LIKNNASTDYDLSDK

$103 \quad 0.15 \% \quad 45.2 \%$ NNASTDYDLSDK

$103 \quad 0.15 \% \quad 45.2 \%$ KSLLVQTK

$103 \quad 0.15 \% \quad 45.2 \%$ SLLVQTKR

$103 \quad 0.15 \% \quad 45.2 \%$ ALEKIDLK

$103 \quad 0.15 \% \quad 45.2 \%$ IDLKFIDTTSK

$103 \quad 0.15 \% \quad 45.2 \%$ FIDTTSKFGHGR

$103 \quad 0.15 \% \quad 45.2 \%$ AFMGPLKK

$198 \quad 0.29 \% \quad 40.7 \%$ GESSGKNVTLPAVFK

$198 \quad 0.29 \% \quad 40.7 \%$ NVTLPAVFK

$198 \quad 0.29 \% \quad 40.7 \%$ SGQGAFGNMCR

$198 \quad 0.29 \% \quad 40.7 \%$ SGQGAFGNMCRGGR

$99.7 \% \quad 36.5$

$99.7 \% \quad 28.6$

$99.7 \% \quad 49.3$

$97.5 \% \quad 22.7$

$99.7 \% \quad 61.5$

$99.7 \% \quad 31.4$

$99.7 \% \quad 51.3$

$99.0 \% \quad 31.1$

$99.0 \% \quad 38.3$

$99.0 \% \quad 38.7$

$98.0 \% \quad 17.7$

$99.7 \% \quad 47.5$

$99.0 \% \quad 25.0$

$95.7 \% \quad 15.1$

$99.7 \% \quad 27.8$

$\begin{array}{lll}99.7 \% & 59.7\end{array}$

$99.7 \% \quad 44.0$

$198 \quad 0.29 \% \quad 40.7 \%$ YAICSALAASALPALVMSK
$198 \quad 0.29 \% \quad 40.7 \%$ TKEAVLLLK

$198 \quad 0.29 \% \quad 40.7 \%$ EAVLLLKK

$198 \quad 0.29 \% \quad 40.7 \%$ RGPCIIYNEDNGIIK

$198 \quad 0.29 \% \quad 40.7 \%$ GPCIIYNEDNGIIK

$198 \quad 0.29 \% \quad 40.7 \%$ GPCIIYNEDNGIIKAFR

$198 \quad 0.29 \% \quad 40.7 \%$ AFRNIPGITLLNVSK

$198 \quad 0.29 \% \quad 40.7 \%$ NIPGITLLNVSK

$198 \quad 0.29 \% \quad 40.7 \%$ NIPGITLLNVSKLNILK

$198 \quad 0.29 \% \quad 40.7 \%$ FCIWTESAFR

$198 \quad 0.29 \% \quad 40.7 \%$ AASLKSNYNLPMHK

$198 \quad 0.29 \% \quad 40.7 \%$ SNYNLPMHK

$198 \quad 0.29 \% \quad 40.7 \%$ SNYNLPMHKMINTDLSR $\begin{array}{lllll}99.7 \% & 27.7 & 25.0 & 27.7\end{array}$

$25.0 \quad 55.7$

$99.0 \% \quad 55.6 \quad 25.0 \quad 31.3$

$99.7 \% \quad 56.8 \quad 25.0 \quad 46.7$

$99.7 \% \quad 47.7 \quad 25.0 \quad 47.7$

$\begin{array}{llll}99.7 \% & 39.3 & 25.0 & 31.9\end{array}$

$99.7 \% \quad 56.8$

$99.7 \% \quad 44.4$

$99.7 \% \quad 60.5$

$99.7 \% \quad 41.9$

$99.7 \% \quad 33.5$

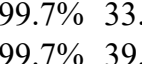

38
1800.97

941.44

1277.68

1433.78

912.53

1849.98

1377.75

1533.85

983.54

1787.93

884.48

1768.91

1435.65

1591.75

955.51

1696.87

2987.51

1365.72

1237.63

1295.77

1191.67

1696.84

1342.58

916.58

944.59

929.57

1280.71

1365.69

907.51

1533.83

988.58

1184.49

1470.63

1953.02

1014.66

913.61

1761.90

1605.79

1980.00

1642.96

1268.76

1850.15

1316.61

1573.82

1103.53 2065.98 
$60 \mathrm{~S}$ ribosomal protein $\mathrm{L} 4 \mathrm{GN}=\mathrm{RPL} 4$ $60 \mathrm{~S}$ ribosomal protein $\mathrm{L} 4 \mathrm{GN}=\mathrm{RPL} 4$ $60 \mathrm{~S}$ ribosomal protein $\mathrm{L} 4 \mathrm{GN}=\mathrm{RPL} 4$ $60 \mathrm{~S}$ ribosomal protein $\mathrm{L} 4 \mathrm{GN}=\mathrm{RPL} 4$ $60 \mathrm{~S}$ ribosomal protein $\mathrm{L} 4 \mathrm{GN}=\mathrm{RPL} 4$ $60 \mathrm{~S}$ ribosomal protein $\mathrm{L} 4 \mathrm{GN}=\mathrm{RPL} 4$ $60 \mathrm{~S}$ ribosomal protein $\mathrm{L} 4 \mathrm{GN}=\mathrm{RPL} 4$ $60 \mathrm{~S}$ ribosomal protein $\mathrm{L} 5 \mathrm{GN}=\mathrm{RPL} 5$ $60 \mathrm{~S}$ ribosomal protein $\mathrm{L} 5 \mathrm{GN}=\mathrm{RPL} 5$ $60 \mathrm{~S}$ ribosomal protein $\mathrm{L} 5 \mathrm{GN}=\mathrm{RPL} 5$ $60 \mathrm{~S}$ ribosomal protein $\mathrm{L} 5 \mathrm{GN}=\mathrm{RPL} 5$ $60 \mathrm{~S}$ ribosomal protein $\mathrm{L} 5 \mathrm{GN}=\mathrm{RPL} 5$ $60 \mathrm{~S}$ ribosomal protein $\mathrm{L} 5 \mathrm{GN}=\mathrm{RPL} 5$ $60 \mathrm{~S}$ ribosomal protein $\mathrm{L} 5 \mathrm{GN}=\mathrm{RPL} 5$ $60 \mathrm{~S}$ ribosomal protein $\mathrm{L} 5 \mathrm{GN}=\mathrm{RPL} 5$ $60 \mathrm{~S}$ ribosomal protein $\mathrm{L} 5 \mathrm{GN}=\mathrm{RPL} 5$ $60 \mathrm{~S}$ ribosomal protein $\mathrm{L} 5 \mathrm{GN}=\mathrm{RPL} 5$ $60 \mathrm{~S}$ ribosomal protein $\mathrm{L} 5 \mathrm{GN}=\mathrm{RPL} 5$ $60 \mathrm{~S}$ ribosomal protein $\mathrm{L} 5 \mathrm{GN}=\mathrm{RPL} 5$ $60 \mathrm{~S}$ ribosomal protein $\mathrm{L} 5 \mathrm{GN}=\mathrm{RPL} 5$ $60 \mathrm{~S}$ ribosomal protein $\mathrm{L} 5 \mathrm{GN}=\mathrm{RPL} 5$ $60 \mathrm{~S}$ ribosomal protein $\mathrm{L} 5 \mathrm{GN}=\mathrm{RPL} 5$ $60 \mathrm{~S}$ ribosomal protein $\mathrm{L} 5 \mathrm{GN}=\mathrm{RPL} 5$ $60 \mathrm{~S}$ ribosomal protein $\mathrm{L} 5 \mathrm{GN}=\mathrm{RPL} 5$ $60 \mathrm{~S}$ ribosomal protein $\mathrm{L} 5 \mathrm{GN}=\mathrm{RPL} 5$ $60 \mathrm{~S}$ ribosomal protein $\mathrm{L} 5 \mathrm{GN}=\mathrm{RPL} 5$ $60 \mathrm{~S}$ ribosomal protein $\mathrm{L} 6 \mathrm{GN}=\mathrm{RPL} 6$ $60 \mathrm{~S}$ ribosomal protein $\mathrm{L} 6 \mathrm{GN}=\mathrm{RPL} 6$ $60 \mathrm{~S}$ ribosomal protein $\mathrm{L} 6 \mathrm{GN}=\mathrm{RPL} 6$ $60 \mathrm{~S}$ ribosomal protein $\mathrm{L} 6 \mathrm{GN}=\mathrm{RPL} 6$ $60 \mathrm{~S}$ ribosomal protein $\mathrm{L} 6 \mathrm{GN}=\mathrm{RPL} 6$ $60 \mathrm{~S}$ ribosomal protein $\mathrm{L} 6 \mathrm{GN}=\mathrm{RPL} 6$ $60 \mathrm{~S}$ ribosomal protein $\mathrm{L} 6 \mathrm{GN}=\mathrm{RPL} 6$ $60 \mathrm{~S}$ ribosomal protein $\mathrm{L} 6 \mathrm{GN}=\mathrm{RPL} 6$ $60 \mathrm{~S}$ ribosomal protein $\mathrm{L} 6 \mathrm{GN}=\mathrm{RPL} 6$ $60 \mathrm{~S}$ ribosomal protein $\mathrm{L} 6 \mathrm{GN}=\mathrm{RPL} 6$ $60 \mathrm{~S}$ ribosomal protein $\mathrm{L} 6 \mathrm{GN}=\mathrm{RPL} 6$ $60 \mathrm{~S}$ ribosomal protein $\mathrm{L} 6 \mathrm{GN}=\mathrm{RPL} 6$ $60 \mathrm{~S}$ ribosomal protein $\mathrm{L} 6 \mathrm{GN}=\mathrm{RPL} 6$ $60 \mathrm{~S}$ ribosomal protein $\mathrm{L} 6 \mathrm{GN}=\mathrm{RPL} 6$ 60S ribosomal protein $\mathrm{L} 6 \mathrm{GN}=\mathrm{RPL} 6$ $60 \mathrm{~S}$ ribosomal protein $\mathrm{L} 6 \mathrm{GN}=\mathrm{RPL} 6$ $60 \mathrm{~S}$ ribosomal protein $\mathrm{L} 6 \mathrm{GN}=\mathrm{RPL} 6$ $60 \mathrm{~S}$ ribosomal protein $\mathrm{L} 6 \mathrm{GN}=\mathrm{RPL} 6$ $60 \mathrm{~S}$ ribosomal protein $\mathrm{L} 6 \mathrm{GN}=\mathrm{RPL} 6$ $60 \mathrm{~S}$ ribosomal protein $\mathrm{L} 6 \mathrm{GN}=\mathrm{RPL} 6$ $60 \mathrm{~S}$ ribosomal protein $\mathrm{L} 7 \mathrm{GN}=\mathrm{RPL} 7$
RL4 HUMAN $47.70 \quad 100.0 \% \quad 24 \quad 38 \quad 198 \quad 0.29 \% \quad 40.7 \%$ MINTDLSR RL4_HUMAN $47.70 \quad 100.0 \% \quad 24 \quad 38 \quad 198 \quad 0.29 \% \quad 40.7 \%$ ILKSPEIQR RL4_HUMAN $47.70 \quad 100.0 \% \quad 24 \quad 38 \quad 198 \quad 0.29 \% \quad 40.7 \%$ IMLKLNPYAK RL4 HUMAN $47.70 \quad 100.0 \% \quad 24 \quad 38 \quad 198 \quad 0.29 \% \quad 40.7 \%$ VDKAAAAAAALQAK RL4_HUMAN $47.70 \quad 100.0 \% \quad 24 \quad 38 \quad 198 \quad 0.29 \% \quad 40.7 \%$ AAAAAAALQAK RL4_HUMAN $47.70 \quad 100.0 \% \quad 24$ RL4 HUMAN $47.70 \quad 100.0 \% \quad 24$ RL5_HUMAN $34.36 \quad 100.0 \% \quad 19$ RL5 HUMAN $34.36 \quad 100.0 \% \quad 19$ RL5_HUMAN $34.36 \quad 100.0 \% \quad 19$ RL5_HUMAN $34.36 \quad 100.0 \% \quad 19$ RL5 HUMAN $34.36 \quad 100.0 \% \quad 19$ RL5_HUMAN $34.36 \quad 100.0 \% \quad 19$ RL5_HUMAN $34.36 \quad 100.0 \% \quad 19$ RL5 HUMAN $34.36 \quad 100.0 \% \quad 19$ RL5_HUMAN $34.36 \quad 100.0 \% \quad 19$ RL5 HUMAN $34.36 \quad 100.0 \% \quad 19$ RL5_HUMAN $34.36 \quad 100.0 \% \quad 19$ RL5_HUMAN $34.36 \quad 100.0 \% \quad 19$ RL5 HUMAN $34.36 \quad 100.0 \% \quad 19$ RL5_HUMAN $34.36 \quad 100.0 \% \quad 19$ RL5 HUMAN $34.36 \quad 100.0 \% \quad 19$ RL5 HUMAN $34.36 \quad 100.0 \% \quad 19$ RL5_HUMAN $34.36 \quad 100.0 \% \quad 19$ RL5 HUMAN $34.36 \quad 100.0 \% \quad 19$ RL5_HUMAN $34.36 \quad 100.0 \% \quad 19$ RL6_HUMAN $32.73 \quad 100.0 \% \quad 20$ RL6 HUMAN $32.73 \quad 100.0 \% \quad 20$ RL6_HUMAN $32.73 \quad 100.0 \% \quad 20$ RL6 HUMAN $32.73 \quad 100.0 \% \quad 20$ RL6_HUMAN $32.73 \quad 100.0 \% \quad 20$ RL6_HUMAN $32.73 \quad 100.0 \% \quad 20$ RL6 HUMAN $32.73 \quad 100.0 \% \quad 20$ RL6_HUMAN $32.73 \quad 100.0 \% \quad 20$ RL6 HUMAN $32.73 \quad 100.0 \% \quad 20$ RL6 HUMAN $32.73 \quad 100.0 \% \quad 20$ RL6_HUMAN $32.73 \quad 100.0 \% \quad 20$ RL6 HUMAN $32.73 \quad 100.0 \% \quad 20$ RL6_HUMAN $32.73 \quad 100.0 \% \quad 20$ RL6_HUMAN $32.73 \quad 100.0 \% \quad 20$ RL6 HUMAN $32.73 \quad 100.0 \% \quad 20$ RL6_HUMAN $32.73 \quad 100.0 \% \quad 20$ RL6 HUMAN $32.73 \quad 100.0 \% \quad 20$ RL6_HUMAN $32.73 \quad 100.0 \% \quad 20$ RL6 HUMAN $32.73 \quad 100.0 \% \quad 20$ RL6 HUMAN $32.73 \quad 100.0 \% \quad 20$ RL7_HUMAN $29.23 \quad 100.0 \% \quad 18$

$0.11 \% \quad 53.2 \%$ EGKTDYYAR

$0.11 \% \quad 53.2 \%$ TTTGNKVFGALK

$0.11 \% \quad 53.2 \%$ GAVDGGLSIPHSTK

$0.11 \% \quad 53.2 \%$ GAVDGGLSIPHSTKR

$0.11 \% \quad 53.2 \%$ EFNAEVHR

$0.11 \% \quad 53.2 \%$ EFNAEVHRK

$0.11 \% \quad 53.2 \%$ KHIMGQNVADYMR

$0.11 \% \quad 53.2 \%$ HIMGQNVADYMR

$0.11 \% \quad 53.2 \%$ YLMEEDEDAYKK

$0.11 \% \quad 53.2 \%$ NSVTPDMMEEMYK

$0.11 \% \quad 53.2 \%$ NSVTPDMMEEMYKK

$0.13 \% \quad 49.0 \%$ EKVLATVTKPVGGDK

$0.13 \% \quad 49.0 \%$ VLATVTKPVGGDK

$0.13 \% \quad 49.0 \%$ KPFSQHVR

$0.13 \% \quad 49.0 \%$ AIPQLQGYLR

$0.13 \% \quad 49.0 \%$ SVFALTNGIYPHK

$28 \quad 92 \quad 0.13 \% \quad 49.0 \%$ SVFALTNGIYPHKLVF $0.07 \% \quad 52.4 \%$ EVPAVPETLK
$99.0 \% \quad 58.7$

$99.7 \% 40.2$

$99.7 \% \quad 36.0$

$99.7 \% \quad 66.4$

$99.7 \% \quad 60$

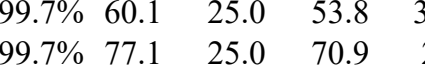

$99.7 \% \quad 36.1 \quad 25.0-36.1$

$\begin{array}{llll}99.7 \% & 36.1 & 25.0 & 36.1 \\ 99.7 \% & 36.2 & 25.0 & 25.3\end{array}$

$99.7 \% \quad 46.7 \quad 25.0 \quad 42.3$

$\begin{array}{ll}25.0 & 42.3 \\ 25.0 & 51.8\end{array}$

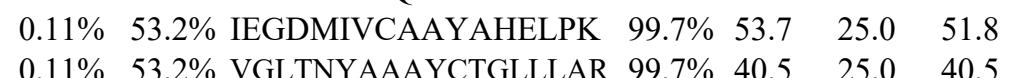

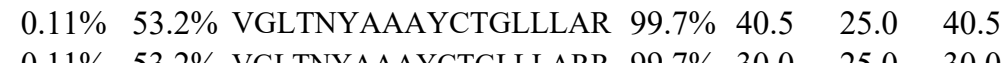

$\begin{array}{lll}0.11 \% & 53.2 \% & \text { VGLTNYAAAYCTGLLLARR } \quad 99.7 \% \quad 30.0\end{array}$

$99.7 \% \quad 51.4$

$0.11 \% \quad 53.2 \%$ VFGALKGAVDGGLSIPHSTK $99.7 \% \quad 37.4$

$25.0 \quad 43.8$

$\begin{array}{lll}99.7 \% & 57.8\end{array}$

$99.7 \% \quad 29.1$

$25.0 \quad 34.7$

$99.6 \% \quad 23.3$

$25.0 \quad 48.4$

$0.11 \% \quad 53.2 \%$ FPGYDSESKEFNAEVHR

$25.0 \quad 23.3$

$\begin{array}{llll}97.7 \% & 21.5 & 25.0 & 14.9\end{array}$

$99.7 \% \quad 29.4$

$97.9 \% \quad 16.1$

$99.7 \% \quad 62.4$

$99.7 \% \quad 57.6$

$99.7 \% 51.3$

$99.7 \% \quad 57.7$

$99.7 \% \quad 45.1$

$99.7 \% \quad 29.3$

$\begin{array}{lll}99.7 \% & 26.3\end{array}$

$99.7 \% \quad 60.7$

$\begin{array}{llll}99.7 \% & 41.3 & 25.0 & 37.9\end{array}$

$0.13 \% \quad 49.0 \%$ VLATVTKPVGGDKNGGTR

$99.7 \% \quad 49.9$

$99.7 \% \quad 39.3$

$99.0 \% \quad 35.9$

$99.7 \% \quad 82.7$

$\begin{array}{ll}99.7 \% & 82.7 \\ 99.7 \% & 61.2\end{array}$

$99.7 \% \quad 58.8$

$97.6 \% \quad 16.2$

$99.0 \% 25$.

$99.7 \% \quad 44.4$

$99.5 \% \quad 23.6$

$99.7 \% \quad 43.3$

$99.7 \% \quad 38.3$

$99.4 \% \quad 27.9$

$\begin{array}{lll}99.7 \% & 32.2\end{array}$

$99.7 \% \quad 44.8$

$99.7 \% \quad 51.2$

$98.9 \% \quad 18.8$

$99.7 \% \quad 27.5$

1083.65

1190.70

1298.74

956.55

1415.75

1124.72

1102.52

1692.89

1932.92

1927.01

2083.11

1236.69

1954.08

1338.70

1494.80

2011.9

1001.48

1129.57

1578.75

1434.66

1533.68

1574.65

1702.75

1497.78

1231.67

1541.89

1284.75

1769.99

1139.54

1267.63

998.55

1525.93

1764.07

1360.76

866.50

994.50

1122.59

1195.60

1454.82

970.56 
$60 \mathrm{~S}$ ribosomal protein $\mathrm{L} 7 \mathrm{GN}=\mathrm{RPL} 7$ $60 \mathrm{~S}$ ribosomal protein $\mathrm{L} 7 \mathrm{GN}=\mathrm{RPL} 7$ $60 \mathrm{~S}$ ribosomal protein $\mathrm{L} 7 \mathrm{GN}=\mathrm{RPL} 7$ $60 \mathrm{~S}$ ribosomal protein $\mathrm{L} 7 \mathrm{GN}=\mathrm{RPL} 7$ $60 \mathrm{~S}$ ribosomal protein $\mathrm{L} 7 \mathrm{GN}=\mathrm{RPL} 7$ $60 \mathrm{~S}$ ribosomal protein $\mathrm{L} 7 \mathrm{GN}=\mathrm{RPL} 7$ $60 \mathrm{~S}$ ribosomal protein $\mathrm{L} 7 \mathrm{GN}=\mathrm{RPL} 7$ $60 \mathrm{~S}$ ribosomal protein $\mathrm{L} 7 \mathrm{GN}=\mathrm{RPL} 7$ $60 \mathrm{~S}$ ribosomal protein $\mathrm{L} 7 \mathrm{GN}=\mathrm{RPL} 7$ $60 \mathrm{~S}$ ribosomal protein $\mathrm{L} 7 \mathrm{GN}=\mathrm{RPL} 7$ $60 \mathrm{~S}$ ribosomal protein $\mathrm{L} 7 \mathrm{GN}=\mathrm{RPL} 7$ $60 \mathrm{~S}$ ribosomal protein $\mathrm{L} 7 \mathrm{GN}=\mathrm{RPL} 7$ $60 \mathrm{~S}$ ribosomal protein $\mathrm{L} 7 \mathrm{GN}=\mathrm{RPL} 7$ $60 \mathrm{~S}$ ribosomal protein $\mathrm{L} 7 \mathrm{GN}=\mathrm{RPL} 7$ $60 \mathrm{~S}$ ribosomal protein $\mathrm{L} 7 \mathrm{GN}=\mathrm{RPL} 7$ $60 \mathrm{~S}$ ribosomal protein $\mathrm{L} 7 \mathrm{GN}=\mathrm{RPL} 7$ $60 \mathrm{~S}$ ribosomal protein $\mathrm{L} 7 \mathrm{GN}=\mathrm{RPL} 7$ $60 \mathrm{~S}$ ribosomal protein $\mathrm{L} 7 \mathrm{a} \mathrm{GN}=\mathrm{RPL} 7 \mathrm{~A}$ $60 \mathrm{~S}$ ribosomal protein $\mathrm{L} 7 \mathrm{a} \mathrm{GN}=\mathrm{RPL} 7 \mathrm{~A}$ $60 \mathrm{~S}$ ribosomal protein $\mathrm{L} 7 \mathrm{a} \mathrm{GN}=\mathrm{RPL} 7 \mathrm{~A}$ $60 \mathrm{~S}$ ribosomal protein $\mathrm{L} 7 \mathrm{a} \mathrm{GN}=\mathrm{RPL} 7 \mathrm{~A}$ $60 \mathrm{~S}$ ribosomal protein $\mathrm{L} 7 \mathrm{a} \mathrm{GN}=\mathrm{RPL} 7 \mathrm{~A}$ $60 \mathrm{~S}$ ribosomal protein $\mathrm{L} 7 \mathrm{a} \mathrm{GN}=\mathrm{RPL} 7 \mathrm{~A}$ $60 \mathrm{~S}$ ribosomal protein $\mathrm{L} 7 \mathrm{a} \mathrm{GN}=\mathrm{RPL} 7 \mathrm{~A}$ $60 \mathrm{~S}$ ribosomal protein $\mathrm{L} 7 \mathrm{a} \mathrm{GN}=\mathrm{RPL} 7 \mathrm{~A}$ $60 \mathrm{~S}$ ribosomal protein $\mathrm{L} 7 \mathrm{a} \mathrm{GN}=\mathrm{RPL} 7 \mathrm{~A}$ $60 \mathrm{~S}$ ribosomal protein $\mathrm{L} 7 \mathrm{a} \mathrm{GN}=\mathrm{RPL} 7 \mathrm{~A}$ $60 \mathrm{~S}$ ribosomal protein $\mathrm{L} 7 \mathrm{a} \mathrm{GN}=\mathrm{RPL} 7 \mathrm{~A}$ $60 \mathrm{~S}$ ribosomal protein $\mathrm{L} 7 \mathrm{a} \mathrm{GN}=\mathrm{RPL} 7 \mathrm{~A}$ $60 \mathrm{~S}$ ribosomal protein $\mathrm{L} 7 \mathrm{a} \mathrm{GN}=\mathrm{RPL} 7 \mathrm{~A}$ $60 \mathrm{~S}$ ribosomal protein $\mathrm{L} 7 \mathrm{a} \mathrm{GN}=\mathrm{RPL} 7 \mathrm{~A}$ $60 \mathrm{~S}$ ribosomal protein $\mathrm{L} 7 \mathrm{a} \mathrm{GN}=\mathrm{RPL} 7 \mathrm{~A}$ 60 S ribosomal protein $\mathrm{L} 7 \mathrm{a} \mathrm{GN}=\mathrm{RPL7A}$ $60 \mathrm{~S}$ ribosomal protein $\mathrm{L} 7 \mathrm{a} \mathrm{GN}=\mathrm{RPL7A}$ $60 \mathrm{~S}$ ribosomal protein $\mathrm{L} 7 \mathrm{a} \mathrm{GN}=\mathrm{RPL} 7 \mathrm{~A}$ 60 S ribosomal protein $\mathrm{L} 7 \mathrm{a} \mathrm{GN}=\mathrm{RPL7A}$ $60 \mathrm{~S}$ ribosomal protein $\mathrm{L} 7 \mathrm{a} \mathrm{GN}=\mathrm{RPL} 7 \mathrm{~A}$ $60 \mathrm{~S}$ ribosomal protein $\mathrm{L} 7 \mathrm{a} \mathrm{GN}=\mathrm{RPL} 7 \mathrm{~A}$ $60 \mathrm{~S}$ ribosomal protein $\mathrm{L} 8 \mathrm{GN}=\mathrm{RPL} 8$ $60 \mathrm{~S}$ ribosomal protein $\mathrm{L} 8 \mathrm{GN}=\mathrm{RPL} 8$ $60 \mathrm{~S}$ ribosomal protein $\mathrm{L} 8 \mathrm{GN}=\mathrm{RPL} 8$ $60 \mathrm{~S}$ ribosomal protein $\mathrm{L} 8 \mathrm{GN}=\mathrm{RPL} 8$ $60 \mathrm{~S}$ ribosomal protein $\mathrm{L} 8 \mathrm{GN}=\mathrm{RPL} 8$ $60 \mathrm{~S}$ ribosomal protein $\mathrm{L} 8 \mathrm{GN}=\mathrm{RPL} 8$ $60 \mathrm{~S}$ ribosomal protein $\mathrm{L} 8 \mathrm{GN}=\mathrm{RPL} 8$ $60 \mathrm{~S}$ ribosomal protein $\mathrm{L} 8 \mathrm{GN}=\mathrm{RPL} 8$ $60 \mathrm{~S}$ ribosomal protein $\mathrm{L} 8 \mathrm{GN}=\mathrm{RPL} 8$
RL7 HUMAN $29.23 \quad 100.0 \% \quad 18 \quad 21 \quad 45 \quad 0.07 \% \quad 52.4 \%$ EVPAVPETLKK RL7_HUMAN $29.23 \quad 100.0 \% \quad 18 \quad 21 \quad 45 \quad 0.07 \% \quad 52.4 \%$ NFAELKIK RL7_HUMAN $29.23 \quad 100.0 \% \quad 18 \quad 21 \quad 45 \quad 0.07 \% \quad 52.4 \%$ KAGNFYVPAEPK RL7_HUMAN $29.23 \quad 100.0 \% \quad 18 \quad 21 \quad 45 \quad 0.07 \% \quad 52.4 \%$ AGNFYVPAEPK RL7_HUMAN $29.23 \quad 100.0 \% \quad 18 \quad 21 \quad 45 \quad 0.07 \% \quad 52.4 \%$ IRGINGVSPK RL7_HUMAN $29.23 \quad 100.0 \% \quad 18 \quad 21 \quad 45 \quad 0.07 \% \quad 52.4 \%$ GINGVSPKVR RL7_HUMAN $29.23 \quad 100.0 \% \quad 18 \quad 21 \quad 45 \quad 0.07 \% \quad 52.4 \%$ LRQIFNGTFVK RL7_HUMAN $29.23 \quad 100.0 \% \quad 18 \quad 21 \quad 45 \quad 0.07 \% \quad 52.4 \%$ QIFNGTFVKLNK $\begin{array}{lllllll}\text { RL7 HUMAN } 29.23 & 100.0 \% & 18 & 21 & 45 & 0.07 \% & 52.4 \% \\ \text { LNKASINMLR }\end{array}$

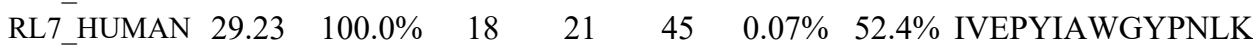
$\begin{array}{lllllll}\text { RL7_HUMAN } 29.23 & 100.0 \% & 18 & 21 & 45 & 0.07 \% & 52.4 \% \\ \text { SVNELIYK }\end{array}$ RL7 HUMAN $29.23 \quad 100.0 \% \quad 18$ RL7_HUMAN $29.23 \quad 100.0 \% \quad 18$ RL7_HUMAN $29.23 \quad 100.0 \% \quad 18$ RL7 HUMAN $29.23 \quad 100.0 \% \quad 18$ RL7_HUMAN $29.23 \quad 100.0 \% \quad 18$ RL7 HUMAN $29.23 \quad 100.0 \% \quad 18$ RL7A_HUMAN $30.00 \quad 100.0 \% \quad 21$ RL7A_HUMAN $30.00 \quad 100.0 \% \quad 21$ RL7A HUMAN $30.00 \quad 100.0 \% \quad 21$ RL7A_HUMAN $30.00 \quad 100.0 \% \quad 21$ RL7A_HUMAN $30.00 \quad 100.0 \% \quad 21$ RL7A_HUMAN $30.00 \quad 100.0 \% \quad 21$ RL7A_HUMAN $30.00 \quad 100.0 \% \quad 21$ RL7A HUMAN $30.00 \quad 100.0 \% \quad 21$ RL7A_HUMAN $30.00 \quad 100.0 \% \quad 21$ RL7A_HUMAN $30.00 \quad 100.0 \% \quad 21$ RL7A_HUMAN $30.00 \quad 100.0 \% \quad 21$ RL7A_HUMAN $30.00 \quad 100.0 \% \quad 21$ RL7A_HUMAN $30.00 \quad 100.0 \% \quad 21$ RL7A_HUMAN $30.00 \quad 100.0 \% \quad 21$ RL7A_HUMAN $30.00 \quad 100.0 \% \quad 21$ RL7A_HUMAN $30.00 \quad 100.0 \% \quad 21$ RL7A_HUMAN $30.00 \quad 100.0 \% \quad 21$ RL7A_HUMAN $30.00 \quad 100.0 \% \quad 21$ RL7A_HUMAN $30.00 \quad 100.0 \% \quad 21$ RL7A_HUMAN $30.00 \quad 100.0 \% \quad 21$ RL7A HUMAN $30.00 \quad 100.0 \% \quad 21$ RL8_HUMAN $28.02 \quad 100.0 \% \quad 12$ RL8_HUMAN $28.02 \quad 100.0 \% \quad 12$ RL8 HUMAN $28.02 \quad 100.0 \% \quad 12$ RL8_HUMAN $28.02 \quad 100.0 \% \quad 12$ RL8 HUMAN $28.02 \quad 100.0 \% \quad 12$ RL8_HUMAN $28.02 \quad 100.0 \% \quad 12$ RL8_HUMAN $28.02 \quad 100.0 \% \quad 12$ RL8 HUMAN $28.02 \quad 100.0 \% \quad 12$ RL8_HUMAN $28.02 \quad 100.0 \% \quad 12$ $\begin{array}{llllllll}98.6 \% & 23.2 & 25.0 & 16.8 & 2 & 0 & 0 & 1210.70\end{array}$ $\begin{array}{llllllll}95.6 \% & 21.0 & 25.0 & 10.1 & 1 & 0 & 0 & 962.57\end{array}$

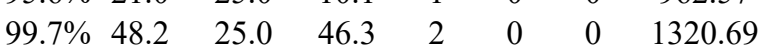

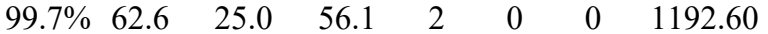
$\begin{array}{llllllll}99.7 \% & 39.2 & 25.0 & 37.8 & 2 & 0 & 0 & 1040.62\end{array}$ $\begin{array}{llllllll}99.6 \% & 26.7 & 25.0 & 17.3 & 2 & 0 & 0 & 1026.61\end{array}$ $\begin{array}{llllllll}99.7 \% & 45.7 & 25.0 & 39.1 & 2 & 1 & 0 & 1322.76\end{array}$ $\begin{array}{llllllll}99.7 \% & 38.1 & 25.0 & 29.6 & 2 & 0 & 0 & 1408.79\end{array}$

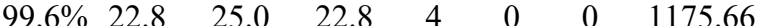

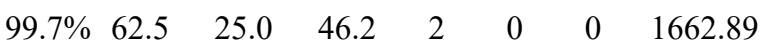
$\begin{array}{llllllll}99.0 \% & 41.8 & 25.0 & 26.6 & 2 & 0 & 0 & 965.53\end{array}$

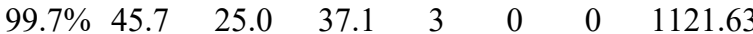
$\begin{array}{llllllll}99.7 \% & 60.0 & 25.0 & 51.5 & 2 & 0 & 0 & 1326.79\end{array}$

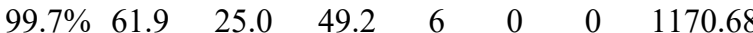

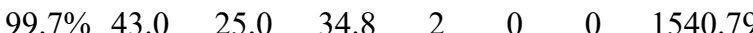
$\begin{array}{llllllll}99.7 \% & 27.5 & 25.0 & 21.8 & 2 & 0 & 0 & 1265.63\end{array}$ 1265.63
2115.98 979.63 $99.7 \% \quad 25.9 \quad 25.0 \quad 25.9$ $99.7 \% \quad 35.2 \quad 25.0 \quad 35.2$ $99.2 \% \quad 19.1 \quad 25.0 \quad 19.1$ $\begin{array}{lllll}99.7 \% & 41.7 & 25.0 & 26.2 & 2\end{array}$ $\begin{array}{llll}98.8 \% & 20.6 & 25.0 & 16.3\end{array}$ $99.7 \% \quad 42.8 \quad 25.0 \quad 40.4$ $\begin{array}{llll}99.7 \% & 61.6 & 25.0 & 52.0\end{array}$ $99.7 \% \quad 49.9 \quad 25.0 \quad 38.0$ $\begin{array}{llll}99.7 \% & 35.0 & 25.0 & 33.8\end{array}$ $\begin{array}{llll}99.7 \% & 43.2 & 25.0 & 38.5\end{array}$ $99.0 \% \quad 46.5 \quad 25.0 \quad 27.6$ $\begin{array}{llll}98.8 \% & 21.5 & 25.0 & 21.5\end{array}$ $99.7 \% \quad 74.6 \quad 25.0 \quad 72.0$ $\begin{array}{llll}99.7 \% & 45.1 & 25.0 & 42.0\end{array}$ $\begin{array}{llll}99.7 \% & 45.3 & 25.0 & 38.3\end{array}$ $99.7 \% \quad 30.0 \quad 25.0 \quad 26.1$ $\begin{array}{llll}98.8 \% & 20.1 & 25.0 & 16.9\end{array}$ 
$60 \mathrm{~S}$ ribosomal protein $\mathrm{L} 8 \mathrm{GN}=\mathrm{RPL} 8$ $60 \mathrm{~S}$ ribosomal protein $\mathrm{L} 8 \mathrm{GN}=\mathrm{RPL} 8$ $60 \mathrm{~S}$ ribosomal protein $\mathrm{L} 9 \mathrm{GN}=\mathrm{RPL} 9$ $60 \mathrm{~S}$ ribosomal protein $\mathrm{L} 9 \mathrm{GN}=\mathrm{RPL} 9$ $60 \mathrm{~S}$ ribosomal protein $\mathrm{L} 8 \mathrm{GN}=\mathrm{RPL} 8$

RL8_HUMAN $28.02 \quad 100.0 \%$ RL8 HUMAN $28.02 \quad 100.0 \%$ RL8_HUMAN $28.02 \quad 100.0 \%$ RL9 HUMAN $21.86 \quad 100.0 \%$ RL9_HUMAN $21.86 \quad 100.0 \%$ F263_HUMAN $59.61 \quad 100.0 \%$ $\begin{array}{llll}\text { 6-phosphofructo-2-kinaseffructose-2,6-isphosphatase 3 GN=PFKFB3 } & \text { F263_HUMAN } & 59.61 & 100.0 \% \\ \text { 6-phosphoffructo-2-kinaseffructose-2,-6-bisphosphatatse 3 } 3 \text { GN=PFFFB3 } & \text { F263_HUMAN } & 59.61 & 100.0 \%\end{array}$ $\begin{array}{llll}\text { 6-phosphofructo-2-kinaseffructose-2,6-6isphosphatase 3 GN=PFKFB3 } & \text { F263_HUMAN } & 59.61 & 100.0 \% \\ \text { 6-phosphogluconolactonase GN=PGLS } & \text { 6PGL_HUMAN } & 27.55 & 100.0 \%\end{array}$ 6-phosphogluconolactonase GN=PGLS 6PGL_HUMAN $27.55 \quad 100.0 \%$ $78 \mathrm{kDa}$ glucose-regulated protein GN=HSPA5 GRP78_HUMAN $72.33 \quad 100.0 \%$ $78 \mathrm{kDa}$ glucose-regulated protein GN=HSPA5 GRP78_HUMAN $72.33 \quad 100.0 \%$ $\begin{array}{lll}78 \mathrm{kDa} \text { glucose-regulated protein GN=HSPA5 GRP78_HUMAN } & 72.33 \quad 100.0 \%\end{array}$ $78 \mathrm{kDa}$ glucose-regulated protein GN=HSPA5 GRP78_HUMAN $72.33 \quad 100.0 \%$ $78 \mathrm{kDa}$ glucose-regulated protein GN=HSPA5 GRP78_HUMAN $72.33 \quad 100.0 \%$ $78 \mathrm{kDa}$ glucose-regulated protein GN=HSPA5 GRP78_HUMAN $72.33 \quad 100.0 \%$ $78 \mathrm{kDa}$ glucose-regulated protein GN=HSPA5 GRP78_HUMAN $72.33 \quad 100.0 \%$ $78 \mathrm{kDa}$ glucose-regulated protein GN=HSPA5 GRP78_HUMAN $72.33 \quad 100.0 \%$ $78 \mathrm{kDa}$ glucose-regulated protein GN=HSPA5 GRP78_HUMAN $72.33 \quad 100.0 \%$ $78 \mathrm{kDa}$ glucose-regulated protein GN=HSPA5 GRP78_HUMAN $72.33 \quad 100.0 \%$ $78 \mathrm{kDa}$ glucose-regulated protein GN=HSPA5 GRP78_HUMAN $72.33 \quad 100.0 \%$ $78 \mathrm{kDa}$ glucose-regulated protein GN=HSPA5 GRP78_HUMAN $72.33 \quad 100.0 \%$ $78 \mathrm{kDa}$ glucose-regulated protein GN=HSPA5 GRP78_HUMAN $72.33 \quad 100.0 \%$ $78 \mathrm{kDa}$ glucose-regulated protein GN=HSPA5 GRP78_HUMAN $72.33 \quad 100.0 \%$ $78 \mathrm{kDa}$ glucose-regulated protein GN=HSPA5 GRP78_HUMAN $72.33 \quad 100.0 \%$ $78 \mathrm{kDa}$ glucose-regulated protein GN=HSPA5 GRP78_HUMAN $72.33 \quad 100.0 \%$ 7-dehydrocholesterol reductase GN=DHCR7 DHCR7_HUMAN $54.49 \quad 100.0 \%$ 7-dehydrocholesterol reductase GN=DHCR7 DHCR7_HUMAN $54.49 \quad 100.0 \%$ 7-dehydrocholesterol reductase GN=DHCR7 DHCR7_HUMAN $54.49100 .0 \%$ 7-dehydrocholesterol reductase GN=DHCR7 DHCR7_HUMAN $54.49 \quad 100.0 \%$ 7-dehydrocholesterol reductase GN=DHCR7 DHCR7_HUMAN $54.49 \quad 100.0 \%$ 7-dehydrocholesterol reductase GN=DHCR7 DHCR7_HUMAN $54.49 \quad 100.0 \%$ Acetolactate synthase-like protein GN=ILVBL ILVBL_HUMAN $67.87 \quad 100.0 \%$ Acetolactate synthase-like protein GN=ILVBL ILVBL_HUMAN $67.87 \quad 100.0 \%$ Acetolactate synthase-like protein GN=ILVBL ILVBL_HUMAN $67.87 \quad 100.0 \%$ Acetolactate synthase-like protein GN=ILVBL ILVBL_HUMAN $67.87 \quad 100.0 \%$ Acetolactate synthase-like protein GN=ILVBL ILVBL_HUMAN $67.87 \quad 100.0 \%$ Acetolactate synthase-like protein GN=ILVBL ILVBL_HUMAN $67.87 \quad 100.0 \%$ Acetyl-CoA acetyltransferase, mitochondrial GN=ACAT1 THIL_HUMAN $45.20 \quad 100.0 \%$ Acetyl-CoA acetyltransferase, mitochondrial GN=ACAT1 THIL_HUMAN $45.20 \quad 100.0 \%$ Acetyl-CoA carboxylase $1 \mathrm{GN}=\mathrm{ACACA} \quad$ ACACA_HUMAN $265.56 \quad 100.0 \%$ Acetyl-CoA carboxylase 1 GN=ACACA ACACA_HUMAN $265.56 \quad 100.0 \%$ Acetyl-CoA carboxylase $1 \mathrm{GN}=\mathrm{ACACA} \quad$ ACACA_HUMAN $265.56100 .0 \%$ Acetyl-CoA carboxylase 1 GN=ACACA ACACA_HUMAN $265.56 \quad 100.0 \%$ Actin, cytoplasmic $1 \mathrm{GN}=\mathrm{ACTB}$ Actin, cytoplasmic $1 \mathrm{GN}=\mathrm{ACTB}$ Actin, cytoplasmic $1 \mathrm{GN}=\mathrm{ACTB}$

ACTB_HUMAN $41.74 \quad 100.0 \%$ ACTB HUMAN $41.74 \quad 100.0 \%$
40.1\% AVVGVVAGG $0.10 \% \quad 40.1 \%$ KVGLIAAR

$0.10 \% \quad 40.1 \%$ VGLIAARR

$99.7 \% \quad 45.8$ $99.0 \% \quad 49.3$ $99.0 \% \quad 34.5$ $99.0 \% \quad 25.7$

$0.01 \% \quad 13.5 \%$ TVIVKGPR

$0.01 \% \quad 13.5 \%$ FLDGIYVSEKGTVQQADE

$0.01 \% \quad 6.5 \% \quad$ PLELTQSR

$0.01 \% \quad 6.5 \%$ IGGDSGLSSR

$0.01 \% \quad 6.5 \% \quad$ NSVTPLASPEPTKKPR

$0.00 \% \quad 10.5 \%$ ELPAAVAPAGPASLAR

$0.00 \% \quad 10.5 \%$ TVIFVATGEGK

$0.05 \% \quad 27.5 \%$ VEIIANDQGNR

$0.05 \% \quad 27.5 \%$ ITPSYVAFTPEGER

$0.05 \% \quad 27.5 \%$ NQLTSNPENTVFDAK

$0.05 \% \quad 27.5 \%$ NQLTSNPENTVFDAKR

$0.05 \% \quad 27.5 \%$ KTKPYIQVDIGGGQTK

$0.05 \% \quad 27.5 \%$ TKPYIQVDIGGGQTK

$0.05 \% \quad 27.5 \%$ TFAPEEISAMVLTK

$99.7 \% \quad 50.4$

$99.0 \% \quad 25.1$

$99.7 \% \quad 58.9$

$99.7 \% \quad 37.4$

$94.9 \% \quad 17.5$

$99.7 \% 55$.

$98.5 \% \quad 29.6$

$99.7 \% \quad 27.4$

$99.7 \% \quad 61.7$

$99.1 \% \quad 21.0$

$99.7 \% \quad 39.3$

$99.7 \% \quad 49.3$

$99.7 \% \quad 55.3$

$0.05 \% \quad 27.5 \%$ VTHAVVTVPAYFNDAQR $\quad 99.7 \% \quad 39.5$

$0.05 \% \quad 27.5 \%$ QATKDAGTIAGLNVMR

$0.05 \% \quad 27.5 \%$ DAGTIAGLNVMR

$0.05 \% \quad 27.5 \%$ IINEPTAAAIAYGLDK

$0.05 \% \quad 27.5 \%$ IINEPTAAAIAYGLDKR

$0.05 \% \quad 27.5 \%$ IEIESFYEGEDFSETLTR

$0.05 \% \quad 27.5 \%$ AKFEELNMDLFR

$0.05 \% \quad 27.5 \%$ SQIFSTASDNQPTVTIK

$0.05 \% \quad 27.5 \%$ ELEEIVQPIISK

$0.02 \% \quad 12.4 \%$ SLDGVTNDR

$99.7 \% \quad 27.2$

$99.7 \% \quad 56.1$

$99.7 \% \quad 69.9$

$99.7 \% \quad 38.8$

$99.7 \% \quad 52.5$

$99.7 \% \quad 55.4$

$99.7 \% \quad 55.1$

$99.7 \% \quad 33.3$

$99.7 \% \quad 54.2$

$0.02 \% \quad 12.4 \%$ SLDGVTNDRTASQGQWGR $\quad 99.7 \% \quad 41.4$

$0.02 \% \quad 12.4 \%$ GYFFPTSAR

$0.02 \% \quad 12.4 \%$ VIECSYTSADGQR

$0.02 \% \quad 12.4 \%$ LLVSGFWGVAR

$99.7 \% \quad 29.9$

$99.7 \% \quad 58.9$

$99.7 \% \quad 53.1$

$99.0 \% \quad 24.1$

$0.02 \% \quad 14.4 \%$ LSGTVGVAAVTAGPGLTNTVTAVK $\quad 99.7 \% \quad 43.7$

$0.02 \% \quad 14.4 \%$ GALQAVDQLSLFRPLCK

$99.6 \% \quad 23.4$

$95.3 \% \quad 17.5$

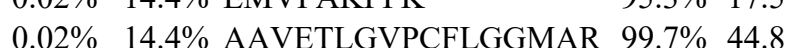

$0.02 \% \quad 14.4 \%$ GLLLSRENEDQVVK

$99.5 \% \quad 25.3$

$99.7 \% \quad 27.5$

$0.02 \% \quad 14.4 \%$ TDFRDGSIAV

$0.01 \% \quad 4.9 \% \quad$ NEQDAYAINSYTR

$0.01 \% \quad 4.9 \% \quad$ LNVTPLAR

$0.01 \% \quad 2.2 \%$ FGGNKVIEK

$99.7 \% 71$.

$99.0 \% \quad 32.7$

$97.3 \% 21.8$

$0.01 \% \quad 2.2 \% \quad$ AIGIGAYLVR

$99.2 \% \quad 28.7$

$0.01 \% \quad 2.2 \%$ TVEL SIPADPANLDSEAK $99.5 \% 22.4$

$0.01 \% \quad 2.2 \%$ GSVLEPEGTVEIKFR

$97.7 \% \quad 20.1$ ACTB_HUMAN $41.74 \quad 100.0 \%$ $\begin{array}{llll}0.28 \% & 52.5 \% & \text { AGFAGDDAPR }\end{array}$

$0.28 \% \quad 52.5 \%$ AVFPSIVGRPR

$0.28 \% 52.5 \%$ HQGVMVGMGQK
$99.7 \% \quad 61.4$

$99.7 \% \quad 56.7$

$99.7 \% \quad 42.0$
1749.07

827.55

855.55

869.56

1998.97

943.52

948.47

1721.95

1490.83

1121.62

1228.63

1566.78

1677.81

1833.91

1732.96

1604.86

1552.79

1887.97

1645.87

1233.63

1659.90

1816.00

2164.99

1512.75

1836.93

1397.79

976.47

1947.93

1045.51

1485.66

1204.68

940.49

2184.22

1916.04

996.55

1748.88

1599.87

1080.53

1544.70

883.54

991.56

1032.62

1869.94

1660.89

976.45

1198.71

1171.57

\begin{tabular}{c}
181 \\
241 \\
242 \\
31 \\
192 \\
9 \\
274 \\
475 \\
72 \\
208 \\
60 \\
74 \\
96 \\
97 \\
138 \\
138 \\
152 \\
181 \\
197 \\
197 \\
213 \\
214 \\
324 \\
336 \\
464 \\
633 \\
22 \\
31 \\
39 \\
207 \\
207 \\
389 \\
404 \\
469 \\
134 \\
1833 \\
174 \\
230 \\
322 \\
599 \\
632 \\
221 \\
311 \\
\hline
\end{tabular}

Page 14 of Table S-1-2 
Actin, cytoplasmic $1 \mathrm{GN}=\mathrm{ACTB}$ Actin, cytoplasmic $1 \mathrm{GN}=\mathrm{ACTB}$ Actin, cytoplasmic $1 \mathrm{GN}=\mathrm{ACTB}$ Actin, cytoplasmic $1 \mathrm{GN}=\mathrm{ACTB}$ Actin, cytoplasmic $1 \mathrm{GN}=\mathrm{ACTB}$ Actin, cytoplasmic $1 \mathrm{GN}=\mathrm{ACTB}$

Actin, cytoplasmic $1 \mathrm{GN}=\mathrm{ACTB}$ Actin, cytoplasmic $1 \mathrm{GN}=\mathrm{ACTB}$ Actin, cytoplasmic $1 \mathrm{GN}=\mathrm{ACTB}$ Actin, cytoplasmic $1 \mathrm{GN}=\mathrm{ACTB}$ Actin, cytoplasmic $1 \mathrm{GN}=\mathrm{ACTB}$ Actin, cytoplasmic $1 \mathrm{GN}=\mathrm{ACTB}$ Actin, cytoplasmic $1 \mathrm{GN}=\mathrm{ACTE}$ Actin, cytoplasmic $1 \mathrm{GN}=\mathrm{ACTB}$ Actin, cytoplasmic $1 \mathrm{GN}=\mathrm{ACTB}$ Actin, cytoplasmic $1 \mathrm{GN}=\mathrm{ACTB}$ Actin, cytoplasmic $1 \mathrm{GN}=\mathrm{ACTB}$ Actin, cytoplasmic $1 \mathrm{GN}=\mathrm{ACTB}$ Actin, cytoplasmic $1 \mathrm{GN}=\mathrm{ACTB}$ Actin, cytoplasmic $1 \mathrm{GN}=\mathrm{ACTB}$ Actin-related protein $2 \mathrm{GN}=\mathrm{ACTR} 2$ Actin-related protein $2 \mathrm{GN}=\mathrm{ACTR} 2$ Actin-related protein $2 \mathrm{GN}=\mathrm{ACTR} 2$ Activating signal cointegrator 1 complex subunit $3 \mathrm{GN}$ Activating signal cointegrator 1 complex subenit $3 \mathrm{GN}=\mathrm{ASC}$ Activating signal cointegrator 1 complex subunit $3 \mathrm{GN}=\mathrm{ASCC} 3$ ASCC3_HUMAN $251.47 \quad 100.0 \%$ Activating signal cointegrator 1 complex subunit $3 \mathrm{GN}=\mathrm{ASCC} 3 \mathrm{ASCC} 3$ HUMAN $251.47 \quad 100.0 \%$ Activating signal cointegrator 1 complex subunit $3 \mathrm{GN}=\mathrm{ASCC} 3 \mathrm{ASCC} 3$ HUMAN $251.47 \quad 100.0 \%$ Activating signal cointegrator 1 complex subunit $3 \mathrm{GN}=\mathrm{ASCC} 3$ ASCC3_HUMAN $251.47 \quad 100.0 \%$ Activating signal cointegrator 1 complex subunit $3 \mathrm{GN}=\mathrm{ASCC} 3 \mathrm{ASCC} 3 \mathrm{HUMAN} 251.47 \quad 100.0 \%$ Activator of $90 \mathrm{kDa}$ heat shock protein ATPase homolog $1 \mathrm{GN}=\mathrm{AHSA} 1$ AHSA1_HUMAN $38.27 \quad 100.0 \%$ Activator of $90 \mathrm{kDa}$ heat shock protein ATPase homolog $1 \mathrm{GN}=\mathrm{AHSA}$ AHSA1_HUMAN $38.27 \quad 100.0 \%$ Activator of $90 \mathrm{kDa}$ heat shock protein ATPase homolog $1 \mathrm{GN}=\mathrm{AHSA} 1$ AHSA1 HUMAN $38.27 \quad 100.0 \%$ Activator of basal transcription $1 \mathrm{GN}=\mathrm{ABT} 1 \mathrm{ABT1}$ HUMAN $31.08 \quad 100.0 \%$ Activator of basal transcription $1 \mathrm{GN}=\mathrm{ABT} 1 \mathrm{ABT1}$ HUMAN $31.08 \quad 100.0 \%$ Acyl-CoA dehydrogenase family member 9 , mitochondrial GN=ACAD9 ACAD9 HUMAN $68.76 \quad 100.0 \%$ Acyl-CoA dehydrogenase family member 9, mitochondrial GN=ACAD9 ACAD9_HUMAN $68.76 \quad 100.0 \%$ Acyl-CoA dehydrogenase family member 9 , mitochondrial GN=ACAD9 ACAD9 HUMAN $68.76 \quad 100.0 \%$ Acyl-CoA dehydrogenase family member 9, mitochondrial GN=ACAD9 ACAD9_HUMAN $68.76 \quad 100.0 \%$ Acyl-coenzyme A thioesterase $1 \mathrm{GN}=$ ACOT1 ACOT1_HUMAN $46.28 \quad 100.0 \%$ Acyl-coenzyme A thioesterase $1 \mathrm{GN}=\mathrm{ACOT} 1$ ACOT1_HUMAN $46.28 \quad 100.0 \%$ Acyl-coenzyme A thioesterase $8 \mathrm{GN}=\mathrm{ACOT} 8$ ACOT8_HUMAN $35.91 \quad 100.0 \%$ Acyl-coenzyme A thioesterase $8 \mathrm{GN}=$ ACOT8 ACOT8_HUMAN $35.91 \quad 100.0 \%$ Acyl-coenzyme A thioesterase 9, mitochondrial GN=ACOT9 ACOT9_HUMAN $49.90 \quad 100.0 \%$ Acyl-coenzyme A thioesterase 9, mitochondrial GN=ACOT9 ACOT9_HUMAN $49.90 \quad 100.0 \%$ Acyl-coenzyme A thioesterase 9, mitochondrial GN=ACOT9 ACOT9_HUMAN $49.90 \quad 100.0 \%$ Acylglycerol kinase, mitochondrial GN=AGK AGK_HUMAN $47.14 \quad 100.0 \%$

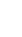

(1)

(1)

8

(1)

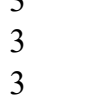

4

4

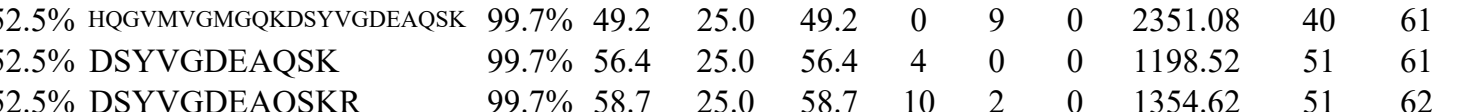

$193 \quad 0.28 \% \quad 52.5 \%$ DSYVGDEAQSK

$193 \quad 0.28 \% \quad 52.5 \%$ DSYVGDEAQSKR

$99.7 \% \quad 58.7$

$193 \quad 0.28 \% \quad 52.5 \%$ VAPEEHPVLLTEAPLNPK $99.7 \% \quad 54.8$

$193 \quad 0.28 \% \quad 52.5 \%$ VAPEEHPVLLTEAPLNPKANR

$193 \quad 0.28 \% \quad 52.5 \%$ LDLAGRDLTDYLMK

$99.7 \% \quad 31.1$

$99.7 \% \quad 52.7$

$99.0 \% 26.2$

$99.7 \% \quad 46.9$

$99.7 \% \quad 62.0$

$\begin{array}{ll}99.7 \% & 29.9 \\ 99.7 \% & 41.7\end{array}$

$193 \quad 0.28 \% \quad 52.5 \%$ GYSFTTTAER

$193 \quad 0.28 \% \quad 52.5 \%$ GYSFTTTAEREIVR

$193 \quad 0.28 \% \quad 52.5 \%$ SYELPDGQVITIGNER $\quad 99.7 \% \quad 64.8$

$193 \quad 0.28 \% \quad 52.5 \%$ SYELPDGQVITIGNERFR $\quad 97.6 \% \quad 18.0$

$193 \quad 0.28 \% \quad 52.5 \%$ DLYANTVLSGGTTMYPGIADR $\quad 99.7 \% \quad 53.7$

$193 \quad 0.28 \% \quad 52.5 \%$ MQKEITALAPSTMK

$193 \quad 0.28 \% \quad 52.5 \%$ EITALAPSTMK

$193 \quad 0.28 \% \quad 52.5 \%$ EITALAPSTMKIK

$193 \quad 0.28 \% \quad 52.5 \%$ IKIIAPPER

$193 \quad 0.28 \% \quad 52.5 \%$ QEYDESGPSIVHR

$193 \quad 0.28 \% \quad 52.5 \%$ QEYDESGPSIVHRK

$0.01 \% \quad 6.4 \%$ KVVVCDNGTGFVK

$0.01 \% \quad 6.4 \%$ VVVCDNGTGFVK

$0.01 \% \quad 6.4 \% \quad$ ILLTEPPMNPTK

$0.02 \% \quad 3.6 \%$ ALAAEMTDYFSR

$0.02 \% \quad 3.6 \%$ RLEPLGIIVK

$0.02 \% \quad 3.6 \%$ SVGDVALSQIVR

$0.02 \% \quad 3.6 \%$ TVAAELAIFR

$0.02 \% \quad 3.6 \%$ VIELTGDVTPDMK

$0.02 \% \quad 3.6 \%$ AGRPQFDDQGK

$0.02 \% \quad 3.6 \%$ VSDSLTDLALK

$0.01 \% \quad 12.4 \%$ ITLKETFLTSPEELYR

$0.01 \% \quad 12.4 \%$ GIPAPEEERTR

$0.01 \% \quad 12.4 \%$ YYFEGIKQTFGYGAR

$0.01 \% \quad 8.8 \%$ NLLSAYGEVGR

$0.01 \% \quad 8.8 \%$ VAASLHNTPMGAR

$0.01 \% \quad 9.0 \%$ AFAKELFLGK

$0.01 \% \quad 9.0 \%$ LASGEHIAAFCLTEPASGSDAASIR

$0.01 \% \quad 9.0 \%$ ILLIFEGTNEILR

$0.01 \% \quad 9.0 \%$ TVETLLLR

$0.01 \% \quad 5.2 \%$ AATLILEPAGR

$0.01 \% \quad 5.2 \%$ GLAPEQPVTLR

$0.00 \% \quad 8.2 \%$ LFGGQIVGQALVAAAK

$0.00 \% \quad 8.2 \%$ VKPQVSESKL

$0.01 \% \quad 6.6 \%$ YLTVQNTVR

$0.01 \% \quad 6.6 \% \quad$ IAFSSTSLLK

$0.01 \% \quad 6.6 \%$ SLEICHPQER

$0.00 \% \quad 3.3 \%$ KATVFLNPAACK
$99.7 \% \quad 64.9$

$99.7 \% \quad 45.6$

$99.7 \% \quad 36.9$

$99.7 \% \quad 36.9$

$99.7 \% \quad 44.1$

$99.7 \% \quad 27.4$

$94.6 \% \quad 15.7$

$99.7 \% \quad 33.0$

$99.7 \% \quad 38.0$

$99.7 \% \quad 47.8$

$99.7 \% \quad 25.4$

$99.7 \% \quad 49.5$

$99.7 \% \quad 52.2$

$99.7 \% \quad 32.4$

$99.7 \% \quad 28.1$

$99.7 \% \quad 27.4$

$99.4 \% \quad 21.1$

$99.7 \% \quad 40.5$

$99.7 \% \quad 50.9$

$99.7 \% \quad 54.5$

$\begin{array}{lll}99.7 \% & 46.9\end{array}$

$99.7 \% \quad 39.6$

$\begin{array}{lll}99.7 \% & 45.7\end{array}$

$99.7 \% \quad 32.3$

$99.0 \% \quad 35.2$

$99.7 \% \quad 45.3$

$99.7 \% \quad 31.1$

$\begin{array}{lll}99.7 \% & 52.6\end{array}$

$99.7 \% \quad 30.1$

$\begin{array}{lll}99.7 \% & 32.7\end{array}$

$99.7 \% \quad 44.9$

$99.7 \% \quad 44.0$

$99.7 \% \quad 27.7$
1354.62

1954.06

2295.25

1623.84

998.49

1744.89

1132.53

1629.82

2566.17

1790.89

2094.06

2231.07

1548.81

1177.61

1402.80

1036.65

1516.70

1644.80

1422.74

1294.65

1353.74

1390.63

1137.74

1243.70

1090.63

1417.72

1218.59

1161.64

1940.04

1254.64

1799.88

1178.62

1324.68

1123.65

2531.22

1530.89

944.58

1111.65

1180.67

1542.90

1114.65

1093.60

1066.61

1268.61

1319.71
61
61
62
113
116
191
191
206
206
210
238
254
256
312
326
326
328
335
372
373
19
19
118
552
562
606
1365
1416
1700
2202
224
316
336
74
133
47
193
433
518
12
35
69
319
112
730

Page 15 of Table S-1-2 
ADP/ATP translocase $1 \mathrm{GN}=\mathrm{SLC} 25 \mathrm{~A}$

ADP/ATP translocase $1 \mathrm{GN}=\mathrm{SLC} 25 \mathrm{~A} 4$

$\mathrm{ADP} / \mathrm{ATP}$ translocase $1 \mathrm{GN}=\mathrm{SLC} 25 \mathrm{~A}$

ADP/ATP translocase $1 \mathrm{GN}=\mathrm{SLC} 25 \mathrm{~A} 4$

ADP/ATP translocase $1 \mathrm{GN}=\mathrm{SLC} 25 \mathrm{~A} 4$

$\mathrm{ADP} / \mathrm{ATP}$ translocase $1 \mathrm{GN}=\mathrm{SLC} 25 \mathrm{~A}^{2}$

ADP/ATP translocase $1 \mathrm{GN}=\mathrm{SLC} 25 \mathrm{~A} 4$

$\mathrm{ADP} / \mathrm{ATP}$ translocase $1 \mathrm{GN}=\mathrm{SLC} 25 \mathrm{~A} 4$

$\mathrm{ADP} / \mathrm{ATP}$ translocase $1 \mathrm{GN}=\mathrm{SLC} 25 \mathrm{~A} 4$

$\mathrm{ADP} / \mathrm{ATP}$ translocase $1 \mathrm{GN}=\mathrm{SLC} 25 \mathrm{~A} 4$

$\mathrm{ADP} / \mathrm{ATP}$ translocase $1 \mathrm{GN}=\mathrm{SLC} 25 \mathrm{~A} 4$

ADP/ATP translocase $1 \mathrm{GN}=\mathrm{SLC} 25 \mathrm{~A} 4$

$\mathrm{ADP} / \mathrm{ATP}$ translocase $1 \mathrm{GN}=\mathrm{SLC} 25 \mathrm{~A}$

$\mathrm{ADP} / \mathrm{ATP}$ translocase $1 \mathrm{GN}=\mathrm{SLC} 25 \mathrm{~A} 4$

ADP/ATP translocase $1 \mathrm{GN}=\mathrm{SLC} 25 \mathrm{~A}^{2}$

$\mathrm{ADP} / \mathrm{ATP}$ translocase $2 \mathrm{GN}=\mathrm{SLC} 25 \mathrm{~A}$

ADP/ATP translocase $2 \mathrm{GN}=\mathrm{SLC} 25 \mathrm{~A} 5$

ADP/ATP translocase $2 \mathrm{GN}=\mathrm{SLC} 25 \mathrm{~A} 5$

ADP/ATP translocase $2 \mathrm{GN}=\mathrm{SLC} 25 \mathrm{~A}$

ADP/ATP translocase $2 \mathrm{GN}=\mathrm{SLC} 25 \mathrm{~A} 5$

$\mathrm{ADP} / \mathrm{ATP}$ translocase $2 \mathrm{GN}=\mathrm{SLC} 25 \mathrm{~A} 5$

$\mathrm{ADP} / \mathrm{ATP}$ translocase $2 \mathrm{GN}=\mathrm{SLC} 25 \mathrm{~A}$

$\mathrm{ADP} / \mathrm{ATP}$ translocase $2 \mathrm{GN}=\mathrm{SLC} 25 \mathrm{~A} 5$

ADP/ATP translocase $2 \mathrm{GN}=\mathrm{SLC} 25 \mathrm{~A}$

ADP/ATP translocase $2 \mathrm{GN}=\mathrm{SLC} 25 \mathrm{~A} 5$

ADP/ATP translocase $2 \mathrm{GN}=\mathrm{SLC} 25 \mathrm{~A} 5$

ADP/ATP translocase $2 \mathrm{GN}=\mathrm{SLC} 25 \mathrm{~A}$

ADP/ATP translocase $2 \mathrm{GN}=\mathrm{SLC} 25 \mathrm{~A} 5$

$\mathrm{ADP} / \mathrm{ATP}$ translocase $2 \mathrm{GN}=\mathrm{SLC} 25 \mathrm{~A}$

ADP/ATP translocase $2 \mathrm{GN}=\mathrm{SLC} 25 \mathrm{~A} 5$

ADP/ATP translocase $2 \mathrm{GN}=\mathrm{SLC} 25 \mathrm{~A} 5$

ADP/ATP translocase $2 \mathrm{GN}=\mathrm{SLC} 25 \mathrm{~A}$

ADP/ATP translocase $2 \mathrm{GN}=\mathrm{SLC} 25 \mathrm{~A} 5$

$\mathrm{ADP} / \mathrm{ATP}$ translocase $2 \mathrm{GN}=\mathrm{SLC} 25 \mathrm{~A} 5$

$\mathrm{ADP} / \mathrm{ATP}$ translocase $2 \mathrm{GN}=\mathrm{SLC} 25 \mathrm{~A} 5$

ADP/ATP translocase $2 \mathrm{GN}=\mathrm{SLC} 25 \mathrm{~A} 5$

ADP/ATP translocase $2 \mathrm{GN}=\mathrm{SLC} 25 \mathrm{~A}$

ADP/ATP translocase $3 \mathrm{GN}=\mathrm{SLC} 25 \mathrm{~A} 6$

ADP/ATP translocase $3 \mathrm{GN}=\mathrm{SLC} 25 \mathrm{~A} 6$

ADP/ATP translocase $3 \mathrm{GN}=\mathrm{SLC} 25 \mathrm{~A} 6$

ADP/ATP translocase $3 \mathrm{GN}=\mathrm{SLC} 25 \mathrm{~A} 6$
ADT1_HUMAN $33.07 \quad 100.0 \%$

ADT1_HUMAN $33.07 \quad 100.0 \%$

ADT1 HUMAN $33.07 \quad 100.0 \%$

ADT1_HUMAN $33.07 \quad 100.0 \%$

ADT1_HUMAN $33.07 \quad 100.0 \%$

ADT1_HUMAN $33.07 \quad 100.0 \%$

ADT1_HUMAN $33.07 \quad 100.0 \%$

ADT1_HUMAN $33.07 \quad 100.0 \%$

ADT1 HUMAN $33.07 \quad 100.0 \%$

ADT1_HUMAN $33.07 \quad 100.0 \%$

ADT1_HUMAN $33.07 \quad 100.0 \%$

ADT1_HUMAN $33.07 \quad 100.0 \%$

ADT1_HUMAN $33.07 \quad 100.0 \%$

ADT1 HUMAN $33.07 \quad 100.0 \%$

ADT1_HUMAN $33.07 \quad 100.0 \%$

ADT2 HUMAN $32.85 \quad 100.0 \%$

ADT2_HUMAN $32.85 \quad 100.0 \%$

ADT2_HUMAN $32.85 \quad 100.0 \%$

ADT2 HUMAN $32.85 \quad 100.0 \% \quad 22$

ADT2_HUMAN $32.85 \quad 100.0 \% \quad 22$

ADT2_HUMAN $32.85 \quad 100.0 \% \quad 22$ ADT2 HUMAN $32.85 \quad 100.0 \% \quad 22$ ADT2_HUMAN $32.85 \quad 100.0 \% \quad 22$ ADT2 HUMAN $32.85 \quad 100.0 \% \quad 22$ ADT2_HUMAN $32.85 \quad 100.0 \% \quad 22$ ADT2_HUMAN $32.85 \quad 100.0 \% \quad 22$ ADT2 HUMAN $32.85 \quad 100.0 \% \quad 22$ ADT2_HUMAN $32.85 \quad 100.0 \% \quad 22$ ADT2_HUMAN $32.85 \quad 100.0 \%$ ADT2_HUMAN $32.85 \quad 100.0 \% \quad 22$ ADT2_HUMAN $32.85 \quad 100.0 \%$ ADT2 HUMAN $32.85 \quad 100.0 \%$ ADT2_HUMAN $32.85 \quad 100.0 \%$ ADT2_HUMAN $32.85 \quad 100.0 \%$ ADT2 HUMAN $32.85 \quad 100.0 \%$ ADT2_HUMAN $32.85 \quad 100.0 \%$ ADT2 HUMAN $32.85 \quad 100.0 \%$ ADT3_HUMAN $32.87 \quad 100.0 \%$ ADT3_HUMAN $32.87 \quad 100.0 \%$ ADT3 HUMAN $32.87 \quad 100.0 \%$ ADT3_HUMAN $32.87 \quad 100.0 \%$
$0.00 \% \quad 3.3 \%$ ATVFLNPAACKGK

$99.6 \% \quad 25.3 \quad 25.0$

$0.01 \% \quad 12.6 \%$ AVILGPPGSGK

$99.6 \% \quad 35.8$

$0.01 \% \quad 12.6 \%$ AVILGPPGSGKGTVCQR

$0.01 \% \quad 12.6 \%$ SLLVPDHVITR

$0.01 \% \quad 5.0 \%$ AFKELPVNAQNYVR

$0.01 \% \quad 5.0 \%$ SRESMIQLF

$0.01 \% \quad 35.9 \%$ TAVAPIER

$0.01 \% \quad 35.9 \%$ TAVAPIERVK

$0.01 \% 35.9 \%$ VKLLLQVQHASK

$0.01 \% \quad 35.9 \%$ LLLQVQHASK

$0.01 \% 35.9 \%$ GIIDCVVR

$0.01 \% \quad 35.9 \%$ GNLANVIR

$0.01 \% \quad 35.9 \%$ YFPTQALNFAFK

$0.01 \% \quad 35.9 \%$ YFPTQALNFAFKDK

$0.01 \% \quad 35.9 \%$ QLFLGGVDR

$0.01 \% \quad 35.9 \%$ TRLAADVGK

$0.01 \% 35.9 \%$ LAADVGKGAAQR

$0.01 \% \quad 35.9 \%$ EFHGLGDCIIK

$0.01 \% \quad 35.9 \%$ AAYFGVYDTAK

$0.01 \% 35.9 \%$ AFFKGAWSNVLR

$0.01 \% \quad 35.9 \%$ GAWSNVLR

$0.10 \% \quad 47.3 \%$ DFLAGGVAAAISK

$0.10 \% \quad 47.3 \%$ TAVAPIER

$0.10 \% \quad 47.3 \%$ TAVAPIERVK

$0.10 \% \quad 47.3 \%$ VKLLLQVQHASK

$0.10 \% \quad 47.3 \%$ LLLQVQHASK

$0.10 \% \quad 47.3 \%$ GIIDCVVR

$0.10 \% \quad 47.3 \%$ IPKEQGVLSFWR

$0.10 \% \quad 47.3 \%$ EQGVLSFWR

$0.10 \% \quad 47.3 \%$ EQGVLSFWRGNLANVIR

$0.10 \% \quad 47.3 \%$ GNLANVIR

$0.10 \% \quad 47.3 \%$ YFPTQALNFAFK

$0.10 \% \quad 47.3 \%$ YFPTQALNFAFKDK

$0.10 \% \quad 47.3 \%$ QIFLGGVDKR

$0.10 \% \quad 47.3 \%$ TRLAADVGK

$0.10 \% \quad 47.3 \%$ LAADVGKAGAER

$0.10 \% \quad 47.3 \%$ EFRGLGDCLVK

$0.10 \% \quad 47.3 \%$ GLGDCLVK

$0.10 \% \quad 47.3 \%$ GLGDCLVKIYK

$0.10 \% \quad 47.3 \%$ AAYFGIYDTAK

$0.10 \% \quad 47.3 \%$ DEGGKAFFK

$0.10 \% \quad 47.3 \%$ AFFKGAWSNVLR

$0.10 \% \quad 47.3 \%$ GAWSNVLR

$0.02 \% \quad 41.3 \%$ DFLAGGIAAAISK

$0.02 \% \quad 41.3 \%$ TAVAPIER

$0.02 \% \quad 41.3 \%$ TAVAPIERVK

$0.02 \% \quad 41.3 \%$ VKLLLQVQHASK $\begin{array}{lll}98.5 \% & 16.9\end{array}$

16.9

$\begin{array}{llll}99.7 \% & 41.2 & 25.0 & 41.2\end{array}$

$\begin{array}{llll}99.6 \% & 24.8 & 25.0 & 24.8\end{array}$

$99.0 \% \quad 32.4 \quad 25.0 \quad 24.6$

$\begin{array}{lllll}99.7 \% & 40.1 & 25.0 & 36.3 & 2\end{array}$

$\begin{array}{llll}99.7 \% & 66.2 & 25.0 & 46.8\end{array}$

$\begin{array}{llll}99.7 \% & 43.1 & 25.0 & 37.7\end{array}$

$99.0 \% \quad 33.5 \quad 25.0 \quad 14.8$

$\begin{array}{llll}99.0 \% & 40.6 & 25.0 & 29.7\end{array}$

$\begin{array}{llll}99.7 \% & 47.2 & 25.0 & 39.1\end{array}$

$99.7 \% \quad 43.7$

$98.4 \% \quad 19.8$

$\begin{array}{lll}99.3 \% & 31.3\end{array}$

$99.7 \% \quad 69.6$

$99.4 \% \quad 24.7$

$\begin{array}{lll}99.7 \% & 56.1\end{array}$

$99.2 \% \quad 26.2$

$99.0 \% \quad 37.4$

$99.7 \% \quad 87.8$

$99.0 \% \quad 32.4$

$99.7 \% \quad 40.1$

$99.7 \% \quad 66.2$

$99.7 \% \quad 43.1$

$\begin{array}{lll}99.0 \% & 33.5\end{array}$

$99.7 \% \quad 41.8$

$99.7 \% \quad 33.8$

$99.3 \% \quad 19.7$

$99.0 \% \quad 40.6$

$99.7 \% \quad 47.2$

$99.7 \% \quad 43.7$

$99.7 \% \quad 33.7$

$99.3 \% \quad 31.3$

$99.7 \% 67$.

$\begin{array}{lll}99.7 \% & 32.8\end{array}$

$99.0 \% \quad 44.8$

$99.7 \% \quad 55.6$

$99.7 \% \quad 59.6$

$99.7 \% \quad 50.4$

$99.2 \% \quad 26.2$

$99.0 \% \quad 37.4$

$99.7 \% \quad 52.5$

$99.0 \% \quad 32.4$

$99.7 \% \quad 40$.

$99.7 \% \quad 66.2$

1136.68

931.50

856.50

1446.74

1689.86

1004.55

930.54

1156.64

1288.64

1205.58

1395.75

902.48

1219.67

856.49

1083.65

1363.84

1136.68

931.50

1459.81

1121.57

1959.06

856.50

1446.74

1689.86

1132.65

930.54

1157.63

1293.66

861.45

1265.69

1219.60

998.49

1395.75

902.48

1233.68

856.49

1083.65

1363.84 
ADP/ATP translocase $3 \mathrm{GN}=\mathrm{SLC} 25 \mathrm{~A} 6$ ADP/ATP translocase $3 \mathrm{GN}=\mathrm{SLC} 25 \mathrm{~A} 6$ ADP/ATP translocase $3 \mathrm{GN}=\mathrm{SLC} 25 \mathrm{AC}$ ADP/ATP translocase $3 \mathrm{GN}=\mathrm{SLC} 25 \mathrm{~A} 6$ ADP/ATP translocase $3 \mathrm{GN}=\mathrm{SLC} 25 \mathrm{~A} 6$ ADP/ATP translocase $3 \mathrm{GN}=\mathrm{SLC} 25 \mathrm{~A} 6$ ADP/ATP translocase $3 \mathrm{GN}=\mathrm{SLC} 25 \mathrm{~A} 6$ ADP/ATP translocase $3 \mathrm{GN}=\mathrm{SLC} 25 \mathrm{~A} 6$ ADP/ATP translocase $3 \mathrm{GN}=\mathrm{SLC} 25 \mathrm{~A} 6$ ADP/ATP translocase $3 \mathrm{GN}=\mathrm{SLC} 25 \mathrm{~A} 6$ ADP/ATP translocase $3 \mathrm{GN}=\mathrm{SLC} 25 \mathrm{~A} 6$ ADP/ATP translocase $3 \mathrm{GN}=\mathrm{SLC} 25 \mathrm{~A} 6$ ADP/ATP translocase $3 \mathrm{GN}=\mathrm{SLC} 25 \mathrm{~A} 6$ ADP/ATP translocase $3 \mathrm{GN}=\mathrm{SLC} 25 \mathrm{~A} 6$ ADP/ATP translocase $3 \mathrm{GN}=\mathrm{SLC} 25 \mathrm{~A} 6$ ADP/ATP translocase $3 \mathrm{GN}=\mathrm{SLC} 25 \mathrm{~A} 6$ AFG3-like protein $2 \mathrm{GN}=\mathrm{AFG} 3 \mathrm{~L} 2$ AFG3-like protein $2 \mathrm{GN}=\mathrm{AFG} 3 \mathrm{~L} 2$ AFG3-like protein $2 \mathrm{GN}=\mathrm{AFG} 3 \mathrm{~L} 2$ AFG3-like protein $2 \mathrm{GN}=\mathrm{AFG} 3 \mathrm{~L} 2$ Aladin $\mathrm{GN}=\mathrm{AAAS}$

Aladin GN=AAAS

Aladin GN=AAAS

Alanine--tRNA ligase, mitochondrial GN=AARS2 SYAM HUMAN $107.34 \quad 100.0 \%$ Alanine--tRNA ligase, mitochondrial GN=AARS2 SYAM_HUMAN $107.34 \quad 100.0 \%$ Alanine--tRNA ligase, mitochondrial GN=AARS2 SYAM_HUMAN $107.34 \quad 100.0 \%$ Aldehyde dehydrogenase family 16 member A1 GN=ALDH16A1 A16A1_HUMAN $85.13 \quad 100.0 \%$ Aldehyde dehydrogenase family 16 member A1 GN=ALDH16A1 A16A1_HUMAN $85.13 \quad 100.0 \%$ Aldehyde dehydrogenase family 16 member Al GN=ALDH16A1 A16A1_HUMAN $85.13 \quad 100.0 \%$ Aldehyde dehydrogenase family 16 member A1 GN=ALDH16A1 A16A1 HUMAN 85.13 100.0\% Aldehyde dehydrogenase family 16 member A1 GN=ALDH16A1 A16A1_HUMAN $85.13 \quad 100.0 \%$ Aldehyde dehydrogenase family 16 member Al GN=ALDH16A1 A16A1_HUMAN $85.13 \quad 100.0 \%$ Aldehyde dehydrogenase $\mathrm{X}$, mitochondrial GN=ALDH1B1 AL1B1_HUMAN $57.21 \quad 100.0 \%$ Aldehyde dehydrogenase $\mathrm{X}$, mitochondrial GN=ALDH1B1 AL1B1_HUMAN $57.21 \quad 100.0 \%$ Alpha-centractin GN $=$ ACTR1A Alpha-centractin GN=ACTR1A Alpha-centractin GN=ACTR1A Alpha-centractin GN=ACTR1A Alpha-centractin GN=ACTR1A Alpha-centractin GN=ACTR1A

Alpha-centractin $\mathrm{GN}=\mathrm{ACTR} 1 \mathrm{~A}$ Alpha-enolase $\mathrm{GN}=\mathrm{ENO} 1$ Alpha-enolase $\mathrm{GN}=\mathrm{ENO} 1$ Alpha-internexin GN=INA Alpha-internexin GN=INA Alpha-internexin GN=INA Alpha-internexin GN=INA
ACTZ_HUMAN $42.62 \quad 100.0 \%$ ACTZ_HUMAN $42.62 \quad 100.0 \%$ ACTZ_HUMAN $42.62 \quad 100.0 \%$ ACTZ HUMAN $42.62 \quad 100.0 \%$ ACTZ_HUMAN $42.62 \quad 100.0 \%$ ACTZ_HUMAN $42.62 \quad 100.0 \%$ ACTZ_HUMAN $42.62 \quad 100.0 \%$ ENOA_HUMAN $47.17 \quad 100.0 \%$ ENOA HUMAN $47.17 \quad 100.0 \%$ AINX_HUMAN $55.39 \quad 100.0 \%$ AINX_HUMAN $55.39 \quad 100.0 \%$ AINX_HUMAN $55.39 \quad 100.0 \%$ AINX_HUMAN $55.39 \quad 100.0 \%$
$13 \quad 0.02 \% \quad 41.3 \%$ LLLQVQHASK $0.02 \% \quad 41.3 \%$ IPKEQGVLSFWR $0.02 \% \quad 41.3 \%$ EQGVLSFWR $\begin{array}{llllllll}99.7 \% & 43.1 & 25.0 & 37.7 & 10 & 0 & 0 & 1136.68\end{array}$

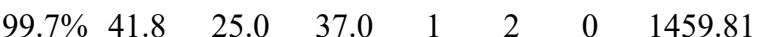
$0.02 \% \quad 41.3 \%$ EQGVLSFWRGNLANVIR $0.02 \% \quad 41.3 \%$ GNLANVIR $0.02 \% \quad 41.3 \%$ YFPTQALNFAFK $0.02 \% \quad 41.3 \%$ YFPTQALNFAFKDK $0.02 \% \quad 41.3 \%$ TRLAADVGK $0.02 \% \quad 41.3 \%$ LAADVGKSGTER $0.02 \% \quad 41.3 \%$ EFRGLGDCLVK $0.02 \% \quad 41.3 \%$ GLGDCLVK $0.02 \% \quad 41.3 \%$ GLGDCLVKITK $0.02 \% \quad 41.3 \%$ AAYFGVYDTAK $0.02 \% \quad 41.3 \%$ DEGGKAFFK $0.02 \% \quad 41.3 \%$ AFFKGAWSNVLR $0.02 \% \quad 41.3 \%$ GAWSNVLR $\begin{array}{llllllll}99.7 \% & 33.8 & 25.0 & 33.8 & 4 & 0 & 0 & 1121.57\end{array}$ 1959.06 $\begin{array}{cccccccc}99.0 \% & 40.6 & 25.0 & 29.7 & 1 & 0 & 0 & 856.50 \\ 99.7 \% & 47.2 & 25.0 & 39.1 & 2 & 0 & 0 & 1446.74\end{array}$

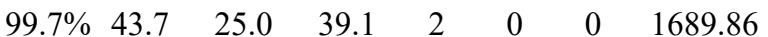
$\begin{array}{llllllll}99.3 \% & 31.3 & 25.0 & 9.6 & 3 & 0 & 0 & 930.54\end{array}$

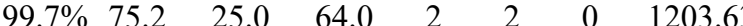

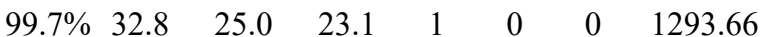
$\begin{array}{llllllll}99.0 \% & 44.8 & 25.0 & 28.7 & 3 & 0 & 0 & 861.45\end{array}$

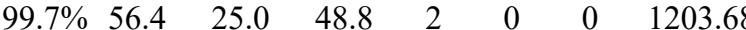
$\begin{array}{llllllll}99.7 \% & 56.1 & 25.0 & 53.5 & 2 & 0 & 0 & 1205.58\end{array}$

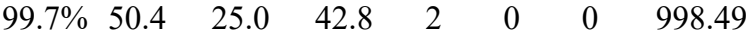

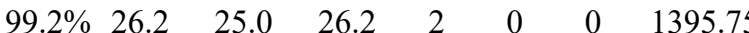
$\begin{array}{llllllll}99.0 \% & 37.4 & 25.0 & 16.7 & 3 & 0 & 0 & 902.48\end{array}$ $\begin{array}{lllllllll}0.01 \% & 5.4 \% & \text { TGRGMGGLFSVGETTAK } & 98.2 \% & 17.1 & 25.0 & 17.1 & 0 & 1\end{array}$ $0.01 \% \quad 5.4 \%$ GMGGLFSVGETTAK $99.6 \% \quad 23.3$ $0.01 \% \quad 5.4 \%$ GAILTGPPGTGKTLLAK $0.01 \% \quad 5.4 \%$ VSEEIFFGR $0.01 \% \quad 6.6 \%$ VYNASSTIVPSLK $0.01 \% \quad 6.6 \% \quad$ ILATTPSAVFR $0.01 \% \quad 6.6 \%$ VQDGKPVILLFR $0.01 \% \quad 3.6 \%$ LVPSASVRPR $0.01 \% \quad 3.6 \%$ AGQEDVLFPVAR $0.01 \% \quad 3.6 \%$ LLAVTGEQAQQAR $0.01 \% \quad 9.1 \%$ LAEVIQKHQR $0.01 \% \quad 9.1 \%$ VAFCGAPEEGR $0.01 \% \quad 9.1 \%$ GLDGAVDMGAR $0.01 \% \quad 9.1 \%$ EALLVANGTPR $0.01 \% \quad 9.1 \%$ AAEAEVELSAR $99.6 \% \quad 25.3$ $99.7 \% \quad 55.7$ $99.7 \% \quad 48.2$ $99.7 \% \quad 62.5$ $99.2 \% \quad 24.8$ $99.6 \% \quad 23.5$ $99.7 \% \quad 50.9$ $99.7 \% \quad 66.3$ $99.6 \% \quad 22.6$ $99.7 \% \quad 34.4$ $99.7 \% \quad 50.1$ $99.7 \% \quad 37.8$ $95.5 \% 21.6$

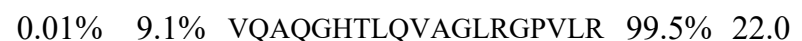
$0.00 \% \quad 4.5 \% \quad$ LAPALATGNTVVMK $0.00 \% \quad 4.5 \%$ TVTIKVPQK $0.02 \% \quad 25.0 \%$ AGFAGDQIPK $0.02 \% \quad 25.0 \%$ YCFPNYVGRPK $0.02 \% \quad 25.0 \%$ VMAGALEGDIFIGPK $0.02 \% \quad 25.0 \%$ IDIAGRDVSR $0.02 \% \quad 25.0 \%$ EGYDFHSSSEFEIVK $0.02 \% \quad 25.0 \%$ AQYYLPDGSTIEIGPSR $0.02 \% \quad 25.0 \%$ TLFSNIVLSGGSTLFK $0.01 \% \quad 6.5 \%$ AVEHINKTIAPALVSK $0.01 \% \quad 6.5 \%$ AGAVEKGVPLYR $0.03 \% \quad 28.7 \%$ LSGAGGAGGFR $\begin{array}{lll}99.7 \% & 54.8\end{array}$ $96.6 \% \quad 23.4$ $99.7 \% 61$. $99.7 \% \quad 41.6$ $98.9 \% \quad 62.8$ $99.7 \% \quad 34.9$ $99.4 \% 21$. $99.7 \% \quad 48.0$ $99.7 \% 44$. $99.7 \% \quad 38.0$ $99.3 \% \quad 23.3$ $99.7 \% 66.4$ $\begin{array}{lllll}0.03 \% & 28.7 \% & \text { SNVASSAACSSASSLGLGLAYR } \quad 99.7 \% \quad 25.8\end{array}$ $0.03 \% \quad 28.7 \%$ RPPASDGLDLSQAAAR $0.03 \% \quad 28.7 \%$ ALEAELAALR
$99.7 \% \quad 63.9$

$99.7 \% \quad 56.1$

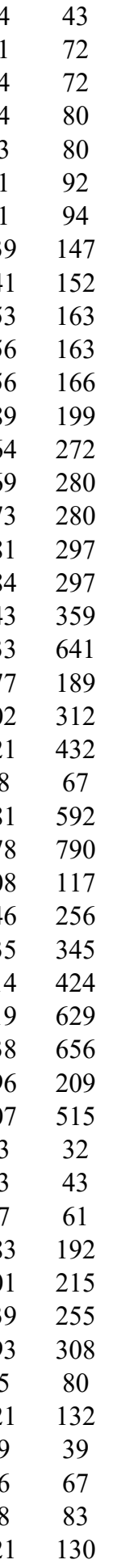

Page 17 of Table S-1-2 
Alpha-internexin GN=INA Alpha-internexin GN=INA Alpha-internexin GN=INA Alpha-internexin GN=INA Alpha-internexin GN=INA Alpha-internexin GN=INA

Alpha-internexin GN=INA Alpha-internexin GN=INA Alpha-internexin GN=INA $\begin{array}{lllllll}\text { AINX HUMAN } 55.39 & 100.0 \% & 12 & 14 & 23 & 0.03 \% & 28.7 \% \\ \text { ALEAELAALRQR }\end{array}$

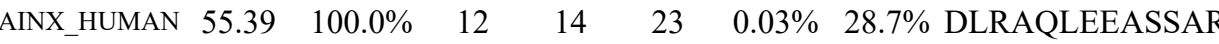
AINX_HUMAN $55.39 \quad 100.0 \% \quad 12$ AINX HUMAN $55.39 \quad 100.0 \% \quad 12$ AINX_HUMAN $55.39 \quad 100.0 \% \quad 12$ AINX_HUMAN $55.39 \quad 100.0 \% \quad 12$ AINX HUMAN $55.39 \quad 100.0 \% \quad 12$ AINX_HUMAN $55.39 \quad 100.0 \% \quad 12$ AINX HUMAN $55.39 \quad 100.0 \% \quad 12$ AIMP1_HUMAN $34.35 \quad 100.0 \%$ AIMP1_HUMAN $34.35 \quad 100.0 \%$ AIMP1_HUMAN $34.35 \quad 100.0 \%$ AIMP1_HUMAN $34.35 \quad 100.0 \%$ AIMP1_HUMAN $34.35 \quad 100.0 \%$ AIMP2 HUMAN $35.35 \quad 100.0 \%$ IMP2_HUMAN $35.35 \quad 100.0 \%$ AIMP2 HUMAN $35.35 \quad 100.0 \%$

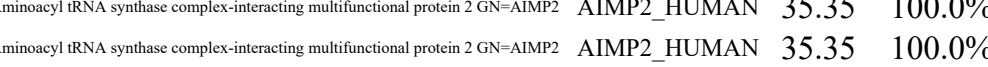
Anaphase-promoting complex subunit $1 \mathrm{GN}=\mathrm{ANAPC1}$ APC1_HUMAN $216.50 \quad 100.0 \%$ Anaphase-promoting complex subunit $1 \mathrm{GN}=$ ANAPC1 APC1_HUMAN $216.50 \quad 100.0 \%$ Anaphase-promoting complex subunit $1 \mathrm{GN}=$ ANAPC1 APC1_HUMAN $216.50 \quad 100.0 \%$ Anaphase-promoting complex subunit $1 \mathrm{GN}=\mathrm{ANAPC} 1$ APC1 HUMAN $216.50 \quad 100.0 \%$ Anaphase-promoting complex subunit $5 \mathrm{GN}=$ ANAPC5 APC5_HUMAN $85.08 \quad 100.0 \%$ Anaphase-promoting complex subunit $5 \mathrm{GN}=$ ANAPC5 APC5_HUMAN $85.08 \quad 100.0 \%$ Anaphase-promoting complex subunit $7 \mathrm{GN}=$ ANAPC7 APC7 HUMAN $66.86 \quad 100.0 \%$ Anaphase-promoting complex subunit $7 \mathrm{GN}=\mathrm{ANAPC} 7 \mathrm{APC} 7$ HUMAN $66.86 \quad 100.0 \%$ Anaphase-promoting complex subunit $7 \mathrm{GN}=$ ANAPC7 APC7_HUMAN $66.86 \quad 100.0 \%$ Anaphase-promoting complex subunit $7 \mathrm{GN}=$ ANAPC7 APC7_HUMAN $66.86 \quad 100.0 \%$ Anaphase-promoting complex subunit $7 \mathrm{GN}=\mathrm{ANAPC} 7$ APC7_HUMAN $66.86 \quad 100.0 \%$ Anaphase-promoting complex subunit $7 \mathrm{GN}=$ ANAPC7 $\mathrm{APC} 7$ HUMAN $66.86 \quad 100.0 \%$ Anaphase-promoting complex subunit $7 \mathrm{GN}=\mathrm{ANAPC} 7$ APC7_HUMAN $66.86 \quad 100.0 \%$ Anaphase-promoting complex subunit 7 GN=ANAPC7 APC7_HUMAN $66.86 \quad 100.0 \%$ Annexin A6 GN=ANXA6 Annexin A6 GN=ANXA6 ANXA6 HUMAN $75.88 \quad 100.0 \%$ ANXA6_HUMAN $75.88 \quad 100.0 \%$ AP 1 complex subunit beta-1 GN=AP1B1 AP1B1_HUMAN $104.64 \quad 100.0 \%$ AP-1 complex subunit beta-1 GN=AP1B1 AP1B1_HUMAN $104.64 \quad 100.0 \%$ AP-1 complex subunit beta-1 GN=AP1B1 AP1B1_HUMAN $104.64 \quad 100.0 \%$ AP-1 complex subunit gamma-1 GN=AP1G1 AP1G1 HUMAN $91.35 \quad 100.0 \%$ AP-1 complex subunit gamma-1 GN=AP1G1 AP1G1_HUMAN $91.35 \quad 100.0 \%$ AP-1 complex subunit gamma-1 GN=AP1G1 AP1G1_HUMAN $91.35 \quad 100.0 \%$ AP-1 complex subunit gamma-1 GN=AP1G1 AP1G1 HUMAN $91.35 \quad 100.0 \%$ AP-1 complex subunit mu-1 GN=AP1M1 AP1M1_HUMAN $48.59 \quad 100.0 \%$ AP-1 complex subunit mu-1 GN=AP1M1 AP1M1 HUMAN $48.59 \quad 100.0 \%$ AP-1 complex subunit mu-1 GN=AP1M1 AP1M1_HUMAN $48.59 \quad 100.0 \%$ AP-1 complex subunit mu-1 GN=AP1M1 AP1M1_HUMAN $48.59 \quad 100.0 \%$ AP-1 complex subunit mu-1 GN=AP1M1 AP1M1_HUMAN $48.59 \quad 100.0 \%$ AP-1 complex subunit mu-1 GN=AP1M1 AP1M1_HUMAN $48.59 \quad 100.0 \%$
$14 \quad 23 \quad 0.03 \% \quad 28.7 \%$ AQLEEASSAR

$\begin{array}{llll}14 & 23 & 0.03 \% & 28.7 \% \\ 14 & \text { DVDGATLAR }\end{array}$

$\begin{array}{llll}14 & 23 & 0.03 \% & 28.7 \% \\ 14 & \text { AQYESLAAK }\end{array}$

$\begin{array}{llll}14 & 23 & 0.03 \% & 28.7 \% \\ 14 & \text { FANLNEQAAR }\end{array}$

$\begin{array}{llll}14 & 23 & 0.03 \% & 28.7 \% \\ 14 & 23 & 0.03 \% & 28.7 \text { TIEIEGLRGANESLER }\end{array}$

$\begin{array}{llll}14 & 23 & 0.03 \% & 28.7 \% \\ 14 & 23 & 0.03 \% & 28.7 \% \\ \text { SNEYEQTLLNVK }\end{array}$

$\begin{array}{llll}14 & 23 & 0.03 \% & 28.7 \% \\ 9 & 17 & 0.02 \% & 17.9 \%\end{array}$

$0.02 \% 17.9 \%$ KQQSIAGSADSKPIDVSR

$0.02 \% \quad 17.9 \%$ QQSIAGSADSKPIDVSR

$0.02 \% \quad 17.9 \%$ IGCIITAR

$0.02 \% \quad 17.9 \%$ TVVSGLVNHVPLEQMQNR

$0.02 \% \quad 17.9 \%$ MVILLCNLKPAK

$0.01 \% \quad 16.2 \%$ LYELKAAVDGLSK

$0.01 \% \quad 16.2 \%$ FSIQTMCPIEGEGNIAR

$0.01 \% \quad 16.2 \%$ FLFSLFGQK

$0.01 \% \quad 16.2 \%$ SCENLAPFNTALK

$0.01 \% \quad 3.0 \%$ FSEQGGTPQNVATSSSLTAHLR

$0.01 \% \quad 3.0 \%$ SPSISNMAALSR

$0.01 \% \quad 3.0 \%$ NFDFEGSLSPVIAPK

$0.01 \% \quad 3.0 \%$ HLYVLAAEPR

$0.00 \% \quad 3.1 \%$ CQVASAASYDQPK

$0.00 \% \quad 3.1 \%$ IRDVVYFQAR

$0.02 \% \quad 15.5 \%$ AISTICSLEK

$0.02 \% \quad 15.5 \%$ GMDVYGYLLAR

$0.02 \% \quad 15.5 \%$ EGRLEDVENLGCR

$0.02 \% \quad 15.5 \%$ AIQLNSNSVQALLLK

$0.02 \% \quad 15.5 \%$ VQEAIIHFR

$0.02 \% \quad 15.5 \%$ ALTQRPDYIK

$0.02 \% \quad 15.5 \%$ EQKYEDGIALLR

$0.02 \% \quad 15.5 \%$ NALANQSDCVLHR

$0.01 \% \quad 3.4 \%$ NKPLFFADKLYK

$0.01 \% \quad 3.4 \%$ GAGTDEKTLTR

$0.00 \% \quad 3.3 \%$ CAIKVEQSAER

$0.00 \% \quad 3.3 \%$ LLSTDPVAAK

$0.00 \% \quad 3.3 \%$ GLEISGTFTR

$0.01 \% \quad 4.0 \%$ SSFREEDNTYR

$0.01 \% \quad 4.0 \%$ KAALCAVHVIR

$0.01 \% \quad 4.0 \% \quad$ AALCAVHVIR

$0.01 \% \quad 4.0 \%$ TVQTDHNAVQR

$0.02 \% \quad 19.6 \%$ ILQEYITQEGHK

$0.02 \% \quad 19.6 \%$ VFLSGMPELR

$11 \quad 0.02 \% \quad 19.6 \%$ LGLNDKVLFDNTGR

$11 \quad 0.02 \% \quad 19.6 \%$ SVELEDVKFHQCVR

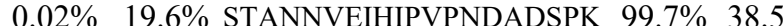

$0.02 \% \quad 19.6 \%$ YITQNGDYQLR $\begin{array}{llllllll}99.5 \% & 23.3 & 25.0 & 18.2 & 2 & 0 & 0 & 1340.76\end{array}$

$\begin{array}{llllllll}99.3 \% & 22.9 & 25.0 & 17.8 & 1 & 0 & 0 & 1445.73\end{array}$

$\begin{array}{llllllll}99.7 \% & 48.6 & 25.0 & 48.6 & 1 & 0 & 0 & 1061.52\end{array}$

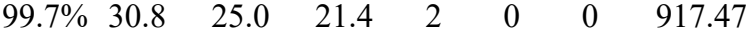

$\begin{array}{llllllll}95.3 \% & 23.5 & 25.0 & 0.0 & 1 & 0 & 0 & 980.50\end{array}$

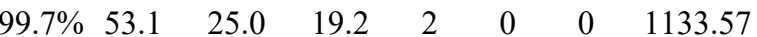

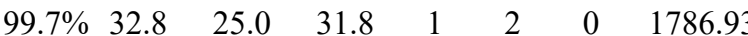

$99.7 \% \quad 24.9 \quad 25.0 \quad 24.9$

$99.7 \% \quad 42.5 \quad 25.0 \quad 42.5$

$\begin{array}{llllllll}99.7 \% & 50.9 & 25.0 & 50.9 & 1 & 0 & 0 & 1620.83 \\ 99.5 \% & 22.8 & 25.0 & 18.7 & 1 & 0 & 0 & 1168.65\end{array}$

$99.5 \% \quad 22.8 \quad 25.0 \quad 18.7$

$\begin{array}{llll}99.7 \% & 26.6 & 25.0 & 26.6\end{array}$

$95.2 \% \quad 15.9 \quad 25.0 \quad 15.9$

$\begin{array}{llll}99.7 \% & 42.9 & 25.0 & 38.0\end{array}$

$99.7 \% \quad 55.0 \quad 25.0 \quad 51.8$

$\begin{array}{llll}94.9 \% & 18.9 & 25.0 & 14.1\end{array}$

$\begin{array}{llll}99.7 \% & 54.7 & 25.0 & 54.7\end{array}$

$\begin{array}{llll}98.7 \% & 17.9 & 25.0 & 17.9\end{array}$

$\begin{array}{lllll}99.6 \% & 24.4 & 25.0 & 20.3\end{array}$

$\begin{array}{llll}99.7 \% & 30.7 & 25.0 & 27.4\end{array}$

$99.7 \% \quad 56.7$

$99.5 \% \quad 25.6$

$99.7 \% \quad 50.3$

$99.3 \% \quad 23.4$

$97.3 \% \quad 18.5$

$99.7 \% \quad 35.9$

$99.7 \% \quad 25.7$

$99.4 \% \quad 22.4$

$99.7 \% \quad 70.9$

$99.7 \% \quad 42.6$

$99.7 \% \quad 48.3$

$99.7 \% \quad 38.5$

$99.7 \% \quad 45.2$

$\begin{array}{lll}99.7 \% & 36.7\end{array}$

$99.7 \% \quad 33.0$
1527.83

1449.74

1886.99

1758.90

903.51

2037.05

1415.81

1406.79

1938.91

1086.60

1464.72

2288.13

1233.63

$149 \quad 16$

$152 \quad 161$

$202 \quad 210$

$\begin{array}{ll}270 & 278 \\ 291 & 300\end{array}$

$323 \quad 338$

$375 \quad 386$

$487 \quad 499$

$137 \quad 154$

166

$188 \quad 205$

$66 \quad 78$

$\begin{array}{ll}199 & 215 \\ & \end{array}$

$305 \quad 317$

285306

$341 \quad 352$

$680 \quad 694$

1424.65

1266.70

1121.59

1257.63

1546.73

1611.94

1112.62

1204.67

1434.76

1497.72

1483.83

1148.59

1290.65

1014.58

1080.57

1403.62

1237.72

1109.62

1268.63

1458.76

1164.6

1561.83

1745.86

2118.05

1370.67$$
\begin{aligned}
& 670 \\
& 7 \\
& 254 \\
& 3 \\
& 3 \\
& 365 \\
& 3 \\
& 468 \\
& 489 \\
& 501 \\
& 599 \\
& 614 \\
& 380 \\
& 529 \\
& 731 \\
& 36 \\
& 156 \\
& 157 \\
& 335 \\
& 130 \\
& 202 \\
& 212 \\
& 230 \\
& 305 \\
& 411
\end{aligned}
$$

$\begin{array}{cc}670 & 682 \\ 710 & 719 \\ 254 & 263 \\ 307 & 317 \\ 318 & 330 \\ 365 & 379 \\ 389 & 397 \\ 468 & 477 \\ 489 & 500 \\ 501 & 513 \\ 599 & 610 \\ 614 & 624 \\ 380 & 390 \\ 529 & 538 \\ 731 & 740 \\ 36 & 46 \\ 156 & 166 \\ 157 & 166 \\ 335 & 345 \\ 130 & 141 \\ 202 & 211 \\ 212 & 225 \\ 230 & 243 \\ 305 & 324 \\ 411 & 421\end{array}$

Page 18 of Table S-1-2 
AP-1 complex subunit mu-1 GN=AP1M1 AP1M1_HUMAN $48.59 \quad 100.0 \%$ AP-2 complex subunit alpha-1 GN=AP2A1 AP2A1_HUMAN $107.55 \quad 100.0 \%$ AP-2 complex subunit alpha-1 GN=AP2A1 AP2A1_HUMAN $107.55 \quad 100.0 \%$ AP-2 complex subunit alpha-1 GN=AP2A1 AP2A1_HUMAN $107.55100 .0 \%$ AP-2 complex subunit alpha-1 GN=AP2A1 AP2A1_HUMAN $107.55 \quad 100.0 \%$ AP-2 complex subunit alpha-2 GN=AP2A2 AP2A2_HUMAN $103.96 \quad 100.0 \%$ AP-2 complex subunit alpha-2 GN=AP2A2 AP2A2_HUMAN $103.96 \quad 100.0 \%$ AP-2 complex subunit alpha-2 GN=AP2A2 AP2A2_HUMAN $103.96 \quad 100.0 \%$ AP-2 complex subunit alpha-2 GN=AP2A2 AP2A2_HUMAN $103.96100 .0 \%$ AP-3 complex subunit mu-1 GN=AP3M1 AP3M1_HUMAN $46.94 \quad 100.0 \%$ AP-3 complex subunit mu-1 GN=AP3M1 AP3M1_HUMAN $46.94 \quad 100.0 \%$ AP-3 complex subunit mu-1 GN=AP3M1 AP3M1_HUMAN $46.94 \quad 100.0 \%$ AP-3 complex subunit mu-1 GN=AP3M1 AP3M1_HUMAN $46.94 \quad 100.0 \%$ Apolipoprotein C-III GN=APOC3

\section{Apolipoprotein C-III GN=APOC3} APOC3_HUMAN $10.85 \quad 100.0 \%$ APOC3_HUMAN $10.85 \quad 100.0 \%$ Apoptosis-inducing factor 1, mitochondrial GN=AIFM1 AIFM1_HUMAN $66.90 \quad 100.0 \%$ Apoptosis-inducing factor 1, mitochondrial GN=AIFM1 AIFM1_HUMAN $66.90 \quad 100.0 \%$ Apoptosis-inducing factor 1, mitochondrial GN=AIFM1 AIFM1_HUMAN $66.90 \quad 100.0 \%$ Apoptosis-inducing factor 1, mitochondrial GN=AIFM1 AIFM1_HUMAN $66.90 \quad 100.0 \%$ Apoptosis-inducing factor 1, mitochondrial GN=AIFM1 AIFM1_HUMAN $66.90 \quad 100.0 \%$ Apoptosis-inducing factor 1, mitochondrial GN=AIFM1 AIFM1_HUMAN $66.90 \quad 100.0 \%$ Apoptosis-inducing factor 1, mitochondrial GN=AIFM1 AIFM1_HUMAN $66.90 \quad 100.0 \%$ Apoptosis-inducing factor 1, mitochondrial GN=AIFM1 AIFM1_HUMAN $66.90 \quad 100.0 \%$ Apoptosis-inducing factor 1, mitochondrial GN=AIFM1 AIFM1_HUMAN $66.90 \quad 100.0 \%$ Apoptosis-inducing factor 1, mitochondrial GN=AIFM1 AIFM1_HUMAN $66.90 \quad 100.0 \%$ Apoptotic chromatin condensation inducer in the nucleus GN=ACIN1 ACINU_HUMAN $151.86 \quad 100.0 \%$ Apoptotic chromatin condensation inducer in the nucleus GN=ACIN1 ACINU_HUMAN $151.86 \quad 100.0 \%$ Apoptotic chromatin condensation inducer in the nucleus GN=ACIN1 ACINU_HUMAN $151.86 \quad 100.0 \%$ Apoptotic chromatin condensation inducer in the nucleus $\mathrm{GN}=\mathrm{ACIN} 1$ ACINU_HUMAN $151.86 \quad 100.0 \%$ Apoptotic chromatin condensation inducer in the nucleus $\mathrm{GN}=\mathrm{ACIN} 1$ ACINU_HUMAN $151.86 \quad 100.0 \%$ $\begin{array}{llll}\text { Apoptotic chromatin condensation inducer in the nucleus } \mathrm{GN}=\mathrm{ACIN} 1 \quad \mathrm{ACINU} \_\mathrm{HUMAN} & 151.86 \quad 100.0 \%\end{array}$ Apoptotic chromatin condensation inducer in the nucleus GN=ACIN1 ACINU_HUMAN $151.86 \quad 100.0 \%$ Apoptotic chromatin condensation inducer in the nucleus GN=ACIN1 ACINU_HUMAN $151.86 \quad 100.0 \%$ Apoptotic chromatin condensation inducer in the nucleus GN=ACIN1 ACINU_HUMAN $151.86 \quad 100.0 \%$ Apoptotic chromatin condensation inducer in the nucleus $\mathrm{GN}=\mathrm{ACIN} 1$ ACINU_HUMAN $151.86 \quad 100.0 \%$ Apoptotic chromatin condensation inducer in the nucleus GN=ACIN1 ACINU_HUMAN $151.86 \quad 100.0 \%$ Apoptotic chromatin condensation inducer in the nucleus GN=ACIN1 ACINU_HUMAN $151.86 \quad 100.0 \%$ Arf-GAP with coiled-coil, ANK repeat and PH domain-contaning protein 2 GN=ACAP2 ACAP2 HUMAN $88.03 \quad 100.0 \%$ Arf-GAP with coiled-coil, ANK repeat and PH domain-containing protein 2 GN=ACAP2 ACAP2_HUMAN $88.03 \quad 100.0 \%$ Arginine--tRNA ligase, cytoplasmic GN=RARS SYRC_HUMAN $75.38 \quad 100.0 \%$ Arginine--tRNA ligase, cytoplasmic GN=RARS SYRC_HUMAN $75.38 \quad 100.0 \%$ Arginine--tRNA ligase, cytoplasmic GN=RARS SYRC_HUMAN $75.38 \quad 100.0 \%$ Arginine--tRNA ligase, cytoplasmic GN=RARS SYRC_HUMAN $75.38 \quad 100.0 \%$ Arginine--tRNA ligase, cytoplasmic GN=RARS SYRC_HUMAN $75.38 \quad 100.0 \%$ Arginine--tRNA ligase, cytoplasmic GN=RARS SYRC_HUMAN $75.38 \quad 100.0 \%$ Arginine--tRNA ligase, cytoplasmic GN=RARS SYRC_HUMAN $75.38 \quad 100.0 \%$ Arginine--tRNA ligase, cytoplasmic GN=RARS SYRC_HUMAN $75.38 \quad 100.0 \%$
$11 \quad 0.02 \% \quad 19.6 \%$ YITQNGDYQLRTQ $0.00 \% \quad 4.7 \%$ GLAVFISDIRNCK $0.00 \% \quad 4.7 \%$ EMGEAFAADIPR $0.00 \% \quad 4.7 \% \quad$ LVECLETVLNK $0.00 \% \quad 4.7 \%$ HLCELLAQQF $0.01 \% \quad 6.1 \%$ GLAVFISDIRNCK $0.01 \% \quad 6.1 \%$ EMAEAFAGEIPK $0.01 \% \quad 6.1 \%$ TVFEALQAPACHENLVK $0.01 \% \quad 6.1 \%$ SDSQLRNADVELQQR $0.01 \% \quad 13.4 \%$ SVVSQSVCDYFFEAQEK $0.01 \% \quad 13.4 \%$ LLDDVSFHPCIR $0.01 \% \quad 13.4 \%$ VSSQNLVAIPVYVK $0.01 \% \quad 13.4 \%$ TIEGITVTVHMPK

$\begin{array}{llllll}0.01 \% & 19.2 \% & \text { TAKDALSSVQESQVAQQAR } & 96.3 \% & 16.8\end{array}$ 0.01\% $19.2 \%$ DALSSVQESQVAQQAR $\quad 99.7 \% \quad 53.0$ $0.03 \% \quad 19.9 \%$ ISGLGLTPEQK $\begin{array}{ll}25.0 & 43.4\end{array}$ $0.03 \% \quad 19.9 \%$ LNDGSQITYEK $0.03 \% \quad 19.9 \%$ CLIATGGTPR $0.03 \% \quad 19.9 \%$ SLSAIDRAGAEVK $0.03 \% \quad 19.9 \%$ ALGTEVIQLFPEK $99.7 \% \quad 47.7 \quad 25.0 \quad 34.6$ $99.7 \% \quad 44.4 \quad 25.0 \quad 32.1$
$0.05 \% \quad 9.4 \%$ GALMLENLQK

$0.05 \% \quad 9.4 \%$ SQEQEVLER

$0.05 \% \quad 9.4 \%$ RLSQPESAEK

$0.05 \% \quad 9.4 \%$ ISVVSATK

$0.05 \% \quad 9.4 \%$ GVPAGNSDTEGGQPGR $0.05 \% \quad 9.4 \%$ GVPAGNSDTEGGQPGRK $0.05 \% \quad 9.4 \%$ WGASTATTQK

$0.05 \% \quad 9.4 \%$ KPSISITTESLK

$0.05 \% \quad 9.4 \%$ VTLGDTLTRR

$0.05 \% \quad 9.4 \%$ SGVSITIDDPVR

$0.05 \% \quad 9.4 \%$ SHCFVTYSTVEEAVATR

$0.00 \% \quad 2.2 \%$ FGPGDQVR

$0.00 \% \quad 2.2 \%$ ASYEKNLPK

$0.05 \% \quad 27.7 \%$ NMINIISR

$\begin{array}{llll}99.7 \% & 50.8 & 25.0 & 39.1\end{array}$

$99.7 \% \quad 45.0 \quad 25.0 \quad 37.4$

$99.7 \% \quad 50.4$

$\begin{array}{llll}98.9 \% & 19.8 & 25.0 & 19.8\end{array}$

$\begin{array}{llll}94.6 \% & 13.3 & 25.0 & 13.3\end{array}$

$0.05 \% \quad 27.7 \%$ AAYPDI

$\begin{array}{lllll}0.05 \% & 27.7 \% & \text { FGDYQCNSAMGISQMLK } & 99.7 \% & 60.2\end{array}$

$0.05 \% \quad 27.7 \%$ EIAENITK

$0.05 \% \quad 27.7 \%$ VIVDFSSPNIAK

$0.05 \% \quad 27.7 \%$ STIIGESISR

$99.0 \% \quad 27.1$

$\begin{array}{ll}99.7 \% & 41.9 \\ 99.7 \% & 50.3\end{array}$

$0.05 \% \quad 27.7 \%$ LFEFAGYDVLR

$99.7 \% \quad 65.7$

0.05\% $\quad 27.7 \%$ AYQCVVLLQGKNPDITK $99.7 \% 29.2$ \begin{tabular}{lllllll}
\hline $.03 \%$ & $19.9 \%$ & VMPNAIVQSVGVSSGK & $99.7 \%$ & 40.6 & 25.0 & 40.6
\end{tabular}
1492.79

1322.60

1317.71

1258.63

1492.79

1308.61

1926.97

1758.87

2022.91

1471.74

1516.87

1425.78

2017.03

1716.85

1142.64

2183.18

1267.62

1045.55

1316.72

1444.80

1948.02

1986.07

1572.84

2104.13

1243.70

1116.61

1117.55

1144.60

804.48

1498.69

1626.78

1050.52

1303.75

1131.65

1258.66

1956.91

875.44

1049.56

960.53

2152.13

1949.86

917.49

1289.71

1062.58

1329.68 1947.04

\begin{tabular}{cc}
11 & 423 \\
12 & 24 \\
42 & 153 \\
80 & 290 \\
68 & 977 \\
12 & 24 \\
42 & 153 \\
81 & 497 \\
64 & 578 \\
22 & 38 \\
27 & 238 \\
64 & 277 \\
04 & 316 \\
42 & 60 \\
45 & 60 \\
99 & 109 \\
59 & 177 \\
45 & 255 \\
56 & 265 \\
66 & 278 \\
25 & 337 \\
25 & 342 \\
59 & 378 \\
63 & 378 \\
89 & 408 \\
77 & 87 \\
04 & 113 \\
28 & 336 \\
08 & 717 \\
24 & 831 \\
32 & 847 \\
32 & 848 \\
51 & 860 \\
61 & 872 \\
71 & 980 \\
87 & 998 \\
050 & 1066 \\
44 & 551 \\
13 & 621 \\
72 & 79 \\
90 & 109 \\
10 & 126 \\
36 & 143 \\
94 & 205 \\
14 & 223 \\
24 & 234 \\
90 & 306 \\
& \\
\hline
\end{tabular}

Page 19 of Table S-1-2 

Aroinine--tRNA ligase, cytoplasmic GN=RARS SYRC HUMAN $75.38 \quad 100.0 \%$ Arginine--tRNA ligase, cytoplasmic GN=RARS SYRC_HUMAN $75.38 \quad 100.0 \%$ Arginine--tRNA ligase, cytoplasmic GN=RARS SYRC HUMAN $75.38 \quad 100.0 \%$ Arginine--tRNA ligase, cytoplasmic GN=RARS SYRC_HUMAN $75.38 \quad 100.0 \%$ Arginine--tRNA ligase, cytoplasmic GN=RARS SYRC_HUMAN $75.38 \quad 100.0 \%$ Armadillo repeat-containing protein $6 \mathrm{GN}=$ ARMC6 ARMC6_HUMAN $54.14 \quad 100.0 \%$ Armadillo repeat-containing protein $6 \mathrm{GN}=$ ARMC6 ARMC6_HUMAN $54.14 \quad 100.0 \%$ Asparagine synthetase [glutamine-hydrolyzing] GN=ASNS ASNS HUMAN $64.37 \quad 100.0 \%$ Asparagine synthetase [glutamine-hydrolyzing] GN=ASNS ASNS_HUMAN $64.37 \quad 100.0 \%$ Asparagine synthetase [glutamine-hydrolyzing] GN=ASNS ASNS_HUMAN $64.37 \quad 100.0 \%$ Asparagine synthetase [glutamine-hydrolyzing] GN=ASNS ASNS_HUMAN $64.37 \quad 100.0 \%$ Asparagine synthetase [glutamine-hydrolyzing] GN=ASNS ASNS_HUMAN $64.37 \quad 100.0 \%$ Asparagine synthetase [glutamine-hydrolyzing] GN=ASNS ASNS HUMAN $64.37 \quad 100.0 \%$ Asparagine synthetase [glutamine-hydrolyzing] GN=ASNS ASNS HUMAN $64.37 \quad 100.0 \%$ Asparagine synthetase [glutamine-hydrolyzing] GN=ASNS ASNS_HUMAN $64.37 \quad 100.0 \%$ Aspartate aminotransferase, mitochondrial $\mathrm{GN}=\mathrm{GOT} 2$ AATM HUMAN $47.52100 .0 \%$ Aspartate aminotransferase, mitochondrial GN=GOT2 AATM_HUMAN $47.52 \quad 100.0 \%$ Aspartate aminotransferase, mitochondrial GN=GOT2 AATM_HUMAN $47.52 \quad 100.0 \%$ Aspartate aminotransferase, mitochondrial GN=GOT2 AATM HUMAN 47.52 $100.0 \%$ Aspartate--tRNA ligase, cytoplasmic GN=DARS SYDC_HUMAN $57.14 \quad 100.0 \%$ Aspartate--tRNA ligase, cytoplasmic GN=DARS SYDC HUMAN $57.14100 .0^{\circ}$ DYRS SYDC_HUMAN $57.14 \quad 100.0$ Ataxin-10 GN=ATXN10

Ataxin-10 GN=ATXN10 Ataxin-10 GN=ATXN10 ATX10_HUMAN $53.49 \quad 100.0 \%$ ATX10 HUMAN $53.49 \quad 100.0 \%$ ATX10_HUMAN $53.49 \quad 100.0 \%$ ATP synthase subunit alpha, mitochondrial GN=ATP5A1 ATPA HUMAN $59.75100 .0^{\circ}$ ATP synthase subunit alpha, mitochondrial GN=ATP5A1 ATPA HUMAN $59.75 \quad 100.0 \%$ ATP synthase subunit alpha, mitochondrial GN=ATP5A1 ATPA_HUMAN $59.75 \quad 100.0 \%$ ATP synthase subunit alpha, mitochondrial GN=ATP5A1 ATPA HUMAN $59.75 \quad 100.0 \%$ ATP synthase subunit alpha, mitochondrial GN=ATP5A1 ATPA_HUMAN $59.75 \quad 100.0 \%$ ATP synthase subunit alpha, mitochondrial GN=ATP5A1 ATPA_HUMAN $59.75 \quad 100.0 \%$ ATP synthase subunit alpha, mitochondrial GN=ATP5A1 ATPA HUMAN $59.75 \quad 100.0 \%$ ATP synthase subunit alpha, mitochondrial GN=ATP5A1 ATPA_HUMAN $59.75 \quad 100.0 \%$ ATP synthase subunit alpha, mitochondrial GN=ATP5A1 ATPA HUMAN $59.75 \quad 100.0 \%$ ATP synthase subunit alpha, mitochondrial GN=ATP5A1 ATPA_HUMAN $59.75 \quad 100.0 \%$ ATP synthase subunit alpha, mitochondrial GN=ATP5A1 ATPA_HUMAN $59.75 \quad 100.0 \%$ ATP synthase subunit alpha, mitochondrial GN=ATP5A1 ATPA HUMAN $59.75 \quad 100.0 \%$ ATP synthase subunit alpha, mitochondrial GN=ATP5A1 ATPA_HUMAN $59.75 \quad 100.0 \%$ ATP synthase subunit alpha, mitochondrial GN=ATP5A1 ATPA_HUMAN $59.75 \quad 100.0 \%$ ATP synthase subunit alpha, mitochondrial GN=ATP5A1 ATPA HUMAN $59.75 \quad 100.0 \%$ ATP synthase subunit alpha, mitochondrial GN=ATP5A1 ATPA_HUMAN $59.75 \quad 100.0 \%$ ATP synthase subunit beta, mitochondrial GN=ATP5B ATPB HUMAN $56.56100 .0^{\circ}$ ATP synthase subunit beta, mitochondrial GN=ATP5B ATPB_HUMAN $56.56 \quad 100.0 \%$ ATP synthase subunit beta, mitochondrial GN=ATP5B ATPB_HUMAN $56.56 \quad 100.0 \%$ ATP synthase subunit beta, mitochondrial GN=ATP5B ATPB HUMAN $56.56 \quad 100.0 \%$ ATP synthase subunit beta, mitochondrial GN=ATP5B ATPB_HUMAN $56.56 \quad 100.0 \%$

17

17

8

8

8
8
8

3
3
3

3

$\begin{array}{ll}3 & 3 \\ 3 & 3 \\ 6 & 2\end{array}$

16
16

$\begin{array}{ll}16 & 2 \\ 16 & 2 \\ 16 & 2\end{array}$

6
6
6

6
6
6

16

$\begin{array}{ll}16 & 21 \\ 16 & 21 \\ 16 & 21\end{array}$

16
16
16

6

16
16
16

16
16
16

16
6
6

16
16
13

3

$33 \quad 0.05 \% \quad 27.7 \%$ IVFVPGCSIPLTIVK $\begin{array}{ll}0.05 \% & 27.7 \% \text { LMDLLGEGLKR }\end{array}$

$0.05 \% \quad 27.7 \%$ LANIDEEMLQK

$0.05 \% \quad 27.7 \%$ MLLCEAVAAVMAK

$0.05 \% \quad 27.7 \%$ GFDILGIKPVQR

$0.01 \% \quad 6.0 \%$ AIAGNDDVKDAIVR

$0.01 \% \quad 6.0 \% \quad$ IIVEGGGAVAALQAMK

$0.03 \% \quad 15.2 \%$ LAVVDPLFGMQPIR

$0.03 \% \quad 15.2 \%$ DTYGVRPLFK

$0.03 \% \quad 15.2 \%$ AMTEDGFLAVCSEAK

$0.03 \% \quad 15.2 \%$ VASVEMVK

$0.03 \% \quad 15.2 \%$ ILFNNAVK

$0.03 \% \quad 15.2 \%$ ELYLFDVLR

$0.03 \% \quad 15.2 \%$ EAFSDGITSVK

$0.03 \% \quad 15.2 \%$ WINATDPSAR

$0.01 \% \quad 11.2 \%$ ASAELALGENSEVLK

$0.01 \% \quad 11.2 \%$ FVTVQTISGTGALR

$0.01 \% \quad 11.2 \%$ DAGMQLQGYR

$0.01 \% \quad 11.2 \%$ TQLVSNLKK

$0.01 \% \quad 8.0 \%$ FAANINKESIVDVEGVVR

$0.01 \% \quad 8.0 \%$ IHDPQLLTER

$0.01 \% \quad 8.0 \% \quad$ VTMLFLGLHNVR

$0.01 \% \quad 6.7 \% \quad$ ALTALFKEQR

$0.01 \% \quad 6.7 \%$ NACIECSVNQNSIR

$0.01 \% \quad 6.7 \%$ LIGNLCYK

$100 \quad 0.15 \% \quad 33.3 \%$ ILGADTSVDLEETGRVLSIGDGIAR

$100 \quad 0.15 \% \quad 33.3 \%$ TGAIVDVPVGEELLGR

$100 \quad 0.15 \% \quad 33.3 \%$ VVDALGNAIDGKGPIGSK

$100 \quad 0.15 \% \quad 33.3 \%$ VGLKAPGIIPR

$100 \quad 0.15 \% \quad 33.3 \%$ ISVREPMQTGIK

$100 \quad 0.15 \% \quad 33.3 \%$ AVDSLVPIGR

$100 \quad 0.15 \% \quad 33.3 \%$ AVDSLVPIGRGQR

$100 \quad 0.15 \% \quad 33.3 \%$ ELIIGDRQTGK

$100 \quad 0.15 \% \quad 33.3 \%$ TSIAIDTIINQK

$100 \quad 0.15 \% \quad 33.3 \%$ TSIAIDTIINQKR

$100 \quad 0.15 \% \quad 33.3 \%$ STVAQLVKR

$100 \quad 0.15 \% \quad 33.3 \%$ HALIIYDDLSK

$100 \quad 0.15 \% \quad 33.3 \%$ EAYPGDVFYLHSR

$100 \quad 0.15 \% \quad 33.3 \%$ EAYPGDVFYLHSRLLER

$100 \quad 0.15 \% \quad 33.3 \%$ GIRPAINVGLSVSR

$100 \quad 0.15 \% \quad 33.3 \%$ LKEIVTNFLAGFEA

$68 \quad 0.10 \% \quad 33.8 \%$ LVLEVAQHLGESTVR

$68 \quad 0.10 \% \quad 33.8 \%$ TIAMDGTEGLVR

$68 \quad 0.10 \% \quad 33.8 \%$ TIAMDGTEGLVRGQK

$68 \quad 0.10 \% \quad 33.8 \%$ VLDSGAPIKIPVGPETLGR

$68 \quad 0.10 \% \quad 33.8 \%$ VVDLLAPYAK $\begin{array}{llll}99.7 \% & 56.6 & 25.0 & 37.3\end{array}$

$\begin{array}{lll}99.7 \% & 32.1 \\ 99.7 \% & 37.4\end{array}$

$99.7 \%-54.8-25.0-47.5$

$99.7 \% \quad 47.7 \quad 25.0 \quad 47.7$

$99.7 \% \quad 64.8 \quad 25.0 \quad 62.0$

$\begin{array}{lllll}99.7 \% & 74.1 & 25.0 & 74.1 & 2\end{array}$

$99.7 \% \quad 55.8 \quad 25.0 \quad 55.5$

$\begin{array}{llll}99.6 \% & 24.3 & 25.0 & 20.9\end{array}$

$\begin{array}{lllll}99.7 \% & 50.0 & 25.0 & 50.0 & 4\end{array}$

$96.1 \% \quad 19.5 \quad 25.0 \quad 11.4 \quad 2$

$\begin{array}{lllll}98.2 \% & 27.5 & 25.0 & 6.1 & 2\end{array}$

$\begin{array}{lllll}99.7 \% & 42.8 & 25.0 & 36.2 & 2\end{array}$

$\begin{array}{llll}99.7 \% & 48.1 & 25.0 & 42.0\end{array}$

$\begin{array}{lllll}99.7 \% & 38.1 & 25.0 & 38.1 & 2\end{array}$

$\begin{array}{llll}99.7 \% & 52.7 & 25.0 & 46.3\end{array}$

$99.7 \% \quad 75.3 \quad 25.0 \quad 72.6$

$\begin{array}{llll}99.7 \% & 36.2 & 25.0 & 36.2\end{array}$

$99.6 \% \quad 24.5 \quad 25.0 \quad 21.3$

$\begin{array}{llll}99.7 \% & 32.1 & 25.0 & 27.0\end{array}$

$\begin{array}{llll}99.7 \% & 27.4 & 25.0 & 27.4\end{array}$

$\begin{array}{llll}99.6 \% & 27.0 & 25.0 & 27.0\end{array}$

$\begin{array}{llll}99.7 \% & 43.2 & 25.0 & 43.2\end{array}$

$\begin{array}{llll}99.7 \% & 62.4 & 25.0 & 62.4\end{array}$

$\begin{array}{llll}98.7 \% & 21.0 & 25.0 & 17.6\end{array}$

$\begin{array}{llll}99.7 \% & 66.5 & 25.0 & 66.5\end{array}$

$\begin{array}{llll}99.7 \% & 52.0 & 25.0 & 50.2\end{array}$

$\begin{array}{lllll}99.7 \% & 57.6 & 25.0 & 57.6 & 2\end{array}$

$\begin{array}{lllll}99.7 \% & 39.0 & 25.0 & 39.0 & 4\end{array}$

$\begin{array}{lllll}99.7 \% & 48.3 & 25.0 & 36.8\end{array}$

$\begin{array}{lllll}99.7 \% & 55.1 & 25.0 & 55.0 & 13\end{array}$

$\begin{array}{llll}99.7 \% & 57.3 & 25.0 & 43.6\end{array}$

$\begin{array}{llll}99.7 \% & 45.4 & 25.0 & 30.5\end{array}$

$\begin{array}{llll}99.7 \% & 56.7 & 25.0 & 55.4\end{array}$

$\begin{array}{lllll}99.7 \% & 59.5 & 25.0 & 59.5 & 8\end{array}$

$\begin{array}{lllll}99.7 \% & 57.4 & 25.0 & 46.9 & 10\end{array}$

$\begin{array}{lllll}99.7 \% & 50.1 & 25.0 & 46.4 & 8\end{array}$

$\begin{array}{llll}99.7 \% & 59.6 & 25.0 & 59.2\end{array}$

$\begin{array}{llll}99.1 \% & 19.7 & 25.0 & 17.9\end{array}$

$\begin{array}{llll}99.7 \% & 39.0 & 25.0 & 39.0\end{array}$

$\begin{array}{lllll}99.7 \% & 59.2 & 25.0 & 59.2 & 2\end{array}$

$\begin{array}{lllll}99.7 \% & 37.1 & 25.0 & 37.1 & 2\end{array}$

$\begin{array}{lllll}99.7 \% & 60.4 & 25.0 & 50.1 & 9\end{array}$

$\begin{array}{llll}97.2 \% & 15.4 & 25.0 & 14.8\end{array}$
$99.7 \% \quad 60.7$

$99.7 \% \quad 41.3$
60.92

1244.70

1303.66

1422.72

1342.78

1456.78

1527.86

1555.87

1195.65

1628.73

862.47

918.54

1167.64

1153.57

1130.56

1530.80

1449.81

1138.53

1030.63

1960.05

1221.66

1399.79

1176.67

1664.75

980.52

2557.35

1624.89

1710.94

1120.72

1358.75

1026.59

1367.78

1229.69

1316.74

1472.84

1001.61

1287.69

1553.74

2065.05

1438.85

1551.84

1650.92

1262.64

1591.81

1919.10

1088.64 $\begin{array}{ll}8 & 395 \\ 2 & 472 \\ 7 & 557\end{array}$

55

$635 \quad 647$

$8 \quad 659$

$407 \quad 422$

$38 \quad 147$

203

$237 \quad 244$

$396 \quad 404$

$468 \quad 478$

$108 \quad 122$

$26 \quad 139$

$71 \quad 180$

$356 \quad 364$

$\begin{array}{ll}104 & 121 \\ 432 & 441\end{array}$

487

87

$0 \quad 103$

$377 \quad 384$

5983

$150 \quad 167$

$183 \quad 194$

$195 \quad 204$

$208 \quad 218$

$219 \quad 230$

$219 \quad 231$

$254 \quad 262$

$306 \quad 316$

$335 \quad 347$

$335 \quad 351$

$403 \quad 416$

$95 \quad 109$

$110 \quad 121$

$110 \quad 124$

$189 \quad 198$

Page 20 of Table S-1-2 
ATP synthase subunit beta, mitochondrial GN=ATP5B ATPB_HUMAN $56.56 \quad 100.0 \% \quad 13$ $\begin{array}{llll}\text { ATP synthase subunit beta, mitochondrial GN=ATP5B ATPB_HUMAN } & 56.56 & 100.0 \% & 13 \\ \text { ATP synthase subunit beta, mitochondrial GN=ATP5B ATPB_HUMAN } & 56.56 & 100.0 \% & 13\end{array}$ ATP synthase subunit beta, mitochondrial GN=ATP5B ATPB_HUMAN $56.56 \quad 100.0 \% \quad 13$ ATP synthase subunit beta, mitochondrial GN=ATP5B ATPB_HUMAN $56.56 \quad 100.0 \%$ ATP synthase subunit beta, mitochondrial GN=ATP5B ATPB_HUMAN $56.56 \quad 100.0 \% \quad 13$ $\begin{array}{llll}\text { ATP synthase subunit beta, mitochondrial GN=ATP5B ATPB_HUMAN } 56.56 & 100.0 \% & 13\end{array}$ ATP synthase subunit beta, mitochondrial GN=ATP5B ATPB_HUMAN $56.56 \quad 100.0 \% \quad 13$ ATP synthase subunit beta, mitochondrial GN=ATP5B ATPB_HUMAN $56.56 \quad 100.0 \%$ ATP synthase subunit gamma, mitochondrial GN=ATP5C1 ATPG_HUMAN $33.00 \quad 100.0 \% \quad 1$ $\begin{array}{lllll}\text { ATP synthase subunit gamma, mitochondrial GN=ATP5C1 } & \text { ATPG_HUMAN } & 33.00 & 100.0 \% & 1\end{array}$ ATP synthase subunit gamma, mitochondrial GN=ATP5C1 ATPG_HUMAN $33.00 \quad 100.0 \%$; ATP synthase subunit gamma, mitochondrial GN=ATP5C1 ATPG_HUMAN $33.00 \quad 100.0 \%$ $\begin{array}{llll}\text { ATP synthase subunit gamma, mitochondrial } \mathrm{GN}=\mathrm{ATP} 5 \mathrm{C} 1 & \mathrm{ATPG} \_ \text {HUMAN } & 33.00 & 100.0 \%\end{array}$ ATP synthase subunit gamma, mitochondrial GN=ATP5C1 ATPG_HUMAN $33.00 \quad 100.0 \% \quad 10$ ATP synthase subunit gamma, mitochondrial GN=ATP5C1 ATPG_HUMAN $33.00 \quad 100.0 \% \quad 10$ $\begin{array}{lllll}\text { ATP synthase subunit gamma, mitochondrial GN=ATP5C1 } & \text { ATPG_HUMAN } & 33.00 & 100.0 \% & 1\end{array}$ ATP synthase subunit gamma, mitochondrial GN=ATP5C1 ATPG_HUMAN $33.00 \quad 100.0 \%$ ATP synthase subunit gamma, mitochondrial GN=ATP5C1 $\quad \mathrm{ATPG}_{-}$HUMAN $33.00 \quad 100.0 \%$ ATP synthase subunit $\mathrm{O}$, mitochondrial GN=ATP5O ATPO_HUMAN $23.28 \quad 100.0 \%$ ATP synthase subunit $\mathrm{O}$, mitochondrial GN=ATP5O ATPO HUMAN $23.28 \quad 100.0 \%$ ATP synthase subunit s-like protein GN=ATP5SL AT5SL_HUMAN $29.27 \quad 100.0 \%$ ATP synthase subunit s-like protein GN=ATP5SL AT5SL_HUMAN $29.27 \quad 100.0 \%$ ATP synthase subunit s-like protein GN=ATP5SL AT5SL_HUMAN $29.27 \quad 100.0 \%$ ATP synthase subunit s-like protein GN=ATP5SL AT5SL_HUMAN $29.27 \quad 100.0 \%$ ATPase family AAA domain-contining protein 3A GN=ATAD3A ATD3A_HUMAN $71.37 \quad 100.0 \%$ ATPase family AAA domain-containing protein 3A GN=ATAD3A ATD3A_HUMAN $71.37 \quad 100.0 \%$ ATPase family AAA domain-containing protein 3A GN=ATAD3A ATD3A_HUMAN $71.37 \quad 100.0 \%$ ATPase family AAA domain-containing protein 3A GN=ATAD3A ATD3A HUMAN 71.37 ATPase family AAA domain-containing protein 3A GN=ATAD3A ATD3A_HUMAN 71.37 ATPase family AAA domain-containing protein 3A GN=ATAD3A ATD3A_HUMAN 71.37 ATPase family AAA domain-containing protein 3A GN=ATAD3A ATD3A_HUMAN 71.37 ATPase family AAA domain-containing protein 3A GN=ATAD3A ATD3A_HUMAN 71.37 ATPase family AAA domain-containing protein 3A GN=ATAD3A ATD3A_HUMAN 71.37 ATPase family AAA domain-containing protein 3A GN=ATAD3A ATD3A_HUMAN 71.37 ATPase family AAA domain-containing protein 3A GN=ATAD3A ATD3A_HUMAN 71.37 ATPase family AAA domain-containing protein 3A GN=ATAD3A ATD3A_HUMAN 71.37 ATPase family AAA domain-containing protein 3A GN=ATAD3A ATD3A_HUMAN 71.37 ATPase family AAA domain-containing protein 3A GN=ATAD3A ATD3A HUMAN 71.37 ATPase family AAA domain-containing protein 3A GN=ATAD3A ATD3A_HUMAN 71.37 ATPase family AAA domain-containing protein 3A GN=ATAD3A ATD3A_HUMAN 71.37 ATPase family AAA domain-containing protein 3A GN=ATAD3A ATD3A_HUMAN 71.37 ATPase family AAA domain-containing protein 3A GN=ATAD3A ATD3A_HUMAN 71.37 ATPase family AAA domain-containing protein 3A GN=ATAD3A ATD3A HUMAN 71.37 ATPase family AAA domain-containing protein 3A GN=ATAD3A ATD3A_HUMAN 71.37 ATPase family AAA domain-containing protein 3A GN=ATAD3A ATD3A_HUMAN 71.37 ATPase family AAA domain-containing protein 3A GN=ATAD3A ATD3A HUMAN 71.37 ATPase family AAA domain-containing protein 3A GN=ATAD3A ATD3A_HUMAN 71.37
$0.10 \% \quad 33.8 \%$ IGLFGGAGVGK $0.10 \% \quad 33.8 \%$ TVLIMELINNVAK

$0.10 \% \quad 33.8 \%$ AHGGYSVFAGVGER $0.10 \% \quad 33.8 \%$ VALVYGQMNEPPGAR $0.10 \% \quad 33.8 \%$ FTQAGSEVSALLGR $0.10 \% \quad 33.8 \%$ AIAELGIYPAVDPLDSTS $0.10 \% \quad 33.8 \%$ IMDPNIVGSEHYDVAR $0.10 \% \quad 33.8 \%$ FLSQPFQVAEVFTGHMGK $0.05 \% \quad 34.6 \%$ IYGLGSLALYEK

$0.05 \% \quad 34.6 \%$ HLLIGVSSDR $0.05 \% \quad 34.6 \%$ GLCGAIHSSIAK $0.05 \% \quad 34.6 \%$ QMKSEVATLTAAGK $0.05 \% \quad 34.6 \%$ SEVATLTAAGK $0.05 \% \quad 34.6 \%$ EVMLVGIGDKIR $0.05 \% \quad 34.6 \%$ THSDQFLVAFK $0.05 \% 34.6 \%$ THSDQFLVAFKEVGR $0.05 \% \quad 34.6 \%$ NASEMIDKLTLTFNR $0.05 \% \quad 34.6 \%$ ELIEIISGAAALD $0.00 \% \quad 9.9 \%$ VAQILKEPK $0.00 \% \quad 9.9 \%$ VAASVLNPYVKR $0.01 \% \quad 15.6 \%$ LGAAVAPEGNQK $0.01 \% \quad 15.6 \%$ LGAAVAPEGNQKK $0.01 \% \quad 15.6 \%$ LKELQSLSLQR $0.01 \% \quad 15.6 \%$ SGPEEQPRDTASPVPA $0.11 \% \quad 37.1 \%$ GLGDRPAPK $0.11 \% \quad 37.1 \%$ TLSEETRQHQAR $0.11 \% \quad 37.1 \%$ AQYQDKLAR $0.11 \% 37.1 \%$ ATVEREMELR $0.11 \% \quad 37.1 \%$ ENADIIREQIR $0.11 \% \quad 37.1 \%$ AAEHRQTVLESIR $0.11 \% \quad 37.1 \%$ QTVLESIR $0.11 \% \quad 37.1 \%$ TAGTLFGEGFR $0.11 \% \quad 37.1 \%$ NATLVAGRFIEAR $0.11 \% \quad 37.1 \%$ LGKPSLVR $0.11 \% 37.1 \%$ ITVLEALR $0.11 \% \quad 37.1 \%$ ITVLEALRHPIQVSR $0.11 \% \quad 37.1 \%$ LLSRPQDALEGVVLSPSLEA $0.11 \% \quad 37.1 \%$ VRDIAIATR $0.11 \% \quad 37.1 \%$ SLYRNILMYGPPGTGK $0.11 \% \quad 37.1 \%$ NILMYGPPGTGK $0.11 \% \quad 37.1 \%$ LALHSGMDYAIMTGGDVAPMGR $0.11 \% \quad 37.1 \%$ LFDWANTSR $0.11 \% 37.1 \%$ MYFDKYVLKPATEGK $0.11 \% \quad 37.1 \%$ LKLAQFDYGR $0.11 \% \quad 37.1 \%$ LAQFDYGR $0.11 \% \quad 37.1 \%$ LAQFDYGRK $0.11 \% \quad 37.1 \%$ LTEGMSGR
$99.7 \% \quad 37.7 \quad 25.0 \quad 30.2 \quad 6$ $99.7 \% \quad 54.8 \quad 25.0 \quad 54.8 \quad 3$ $\begin{array}{lllll}99.7 \% & 54.0 & 25.0 & 53.4 & 2\end{array}$ $99.7 \% \quad 61.5 \quad 25.0 \quad 47.9$ $\begin{array}{llll}99.7 \% & 63.3 & 25.0 & 49.9\end{array}$ $\begin{array}{llll}99.7 \% & 58.6 & 25.0 & 58.6\end{array}$ $99.6 \% \quad 23.4 \quad 25.0 \quad 21.6$ $\begin{array}{llll}99.7 \% & 62.7 & 25.0 & 56.6\end{array}$ $\begin{array}{llll}99.7 \% & 50.0 & 25.0 & 32.6\end{array}$ $\begin{array}{llll}99.7 \% & 66.6 & 25.0 & 66.6\end{array}$ $\begin{array}{llll}98.7 \% & 20.4 & 25.0 & 19.7\end{array}$ $\begin{array}{llll}99.7 \% & 65.5 & 25.0 & 46.6\end{array}$ $\begin{array}{llll}99.7 \% & 56.5 & 25.0 & 46.7\end{array}$ $99.7 \% \quad 50.0 \quad 25.0 \quad 40.1$ $\begin{array}{llll}99.7 \% & 40.2 & 25.0 & 40.2\end{array}$ $99.7 \% \quad 50.4 \quad 25.0 \quad 47.8$ $99.7 \% \quad 31.3 \quad 25.0 \quad 31.3$ $\begin{array}{llll}99.3 \% & 29.4 & 25.0 & 15.2\end{array}$ $\begin{array}{llll}99.3 \% & 19.2 & 25.0 & 19.2\end{array}$ $\begin{array}{llll}99.4 \% & 22.1 & 25.0 & 17.3\end{array}$ $94.9 \% \quad 16.8 \quad 25.0 \quad 11.9$ $99.7 \% \quad 43.9 \quad 25.0 \quad 43.9$ $\begin{array}{llll}99.2 \% & 19.8 & 25.0 & 19.8\end{array}$ $\begin{array}{llll}99.7 \% & 49.1 & 25.0 & 42.0\end{array}$ $\begin{array}{llll}99.7 \% & 54.1 & 25.0 & 51.6\end{array}$ $99.7 \% \quad 48.6 \quad 25.0 \quad 38.7$ $\begin{array}{llll}99.7 \% & 32.5 & 25.0 & 16.8\end{array}$ $\begin{array}{llll}99.7 \% & 33.9 & 25.0 & 25.0\end{array}$ $\begin{array}{llll}99.7 \% & 36.2 & 25.0 & 36.2\end{array}$ $99.0 \% \quad 43.9 \quad 25.0 \quad 24.5$ $\begin{array}{llll}99.7 \% & 58.4 & 25.0 & 58.4\end{array}$ $\begin{array}{llll}99.7 \% & 27.1 & 25.0 & 18.3\end{array}$ $\begin{array}{llll}99.0 \% & 37.1 & 25.0 & 30.0\end{array}$ $99.0 \% \quad 45.7 \quad 25.0 \quad 31.0$ $\begin{array}{llll}99.7 \% & 45.5 & 25.0 & 45.5\end{array}$ $\begin{array}{llll}99.7 \% & 33.2 & 25.0 & 32.1\end{array}$ $\begin{array}{llll}99.7 \% & 44.2 & 25.0 & 36.6\end{array}$ $\begin{array}{llll}99.7 \% & 28.7 & 25.0 & 28.7\end{array}$ $\begin{array}{llll}99.7 \% & 58.5 & 25.0 & 53.8\end{array}$ $\begin{array}{lllll}99.7 \% & 39.0 & 25.0 & 39.0\end{array}$ $\begin{array}{lllll}98.7 \% & 21.5 & 25.0 & 16.3 & 2\end{array}$ $\begin{array}{llll}99.7 \% & 25.7 & 25.0 & 25.7\end{array}$ $\begin{array}{llll}99.7 \% & 41.7 & 25.0 & 41.7\end{array}$ $\begin{array}{lllll}99.0 \% & 46.7 & 25.0 & 46.7 & 2\end{array}$ $\begin{array}{llll}99.7 \% & 37.8 & 25.0 & 37.8\end{array}$ $\begin{array}{llll}99.0 \% & 39.7 & 25.0 & 39.7\end{array}$

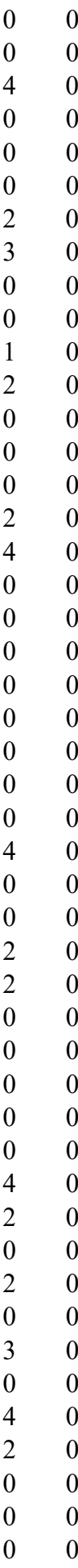
1473.83 1406.68

1601.81

1435.75

1988.03

1815.87

2023.01

1326.73

1096.61

1213.64

1450.76

1047.57

1345.75

1292.66

1733.90

1752.90

1314.72

1025.64

1316.77

1154.62

1282.71

1314.77

1637.78

910.51

1455.73

1092.58

1233.63

1356.72

1509.81

945.54

1155.58

1417.79

869.56

914.57

1732.02

2250.25

1014.61

1766.93

1263.64

2311.05

1109.54

1805.91

1210.66

969.48

1097.57

850.41 $\begin{array}{cc}2 & 212 \\ 13 & 225 \\ 26 & 239 \\ 65 & 279 \\ 11 & 324 \\ 88 & 406 \\ 07 & 422 \\ 63 & 480 \\ 8 & 79 \\ 1 & 100 \\ 01 & 112 \\ 13 & 126 \\ 16 & 126 \\ 27 & 138 \\ 44 & 154 \\ 44 & 158 \\ 63 & 277 \\ 86 & 298 \\ 5 & 73 \\ 4 & 85 \\ 5 & 36 \\ 5 & 37 \\ 47 & 157 \\ 42 & 257 \\ 6 & 44 \\ 66 & 177 \\ 78 & 186 \\ 20 & 229 \\ 50 & 260 \\ 63 & 275 \\ 68 & 275 \\ 76 & 286 \\ 14 & 326 \\ 27 & 334 \\ 39 & 346 \\ 39 & 353 \\ 55 & 375 \\ 76 & 384 \\ 91 & 406 \\ 95 & 406 \\ 13 & 434 \\ 43 & 451 \\ 35 & 549 \\ 52 & 561 \\ 54 & 561 \\ & 576 \\ \end{array}$

Page 21 of Table S-1-2 
ATPase family AAA domain-containing protein 3A GN=ATAD3A ATD3A_HUMAN $71.37 \quad 100.0 \% \quad 24$ ATPase family AAA domain-containing protein 3B GN=ATAD3B ATD3B_HUMAN $72.57 \quad 100.0 \%$ ATPase family AAA domain-containing protein 3B GN=ATAD3B ATD3B_HUMAN $72.57 \quad 100.0 \%$ ATPase family AAA domain-containing protein 3B GN=ATAD3B ATD3B_HUMAN $72.57 \quad 100.0 \%$ ATPase family AAA domain-containing protein 3B GN=ATAD3B ATD3B_HUMAN $72.57 \quad 100.0 \%$ ATPase family AAA domain-containing protein 3B GN=ATAD3B ATD3B_HUMAN $72.57 \quad 100.0 \%$ ATPase family AAA domain-containing protein 3B GN=ATAD3B ATD3B_HUMAN $72.57 \quad 100.0 \%$ ATPase family AAA domain-containing protein 3B GN=ATAD3B ATD3B_HUMAN $72.57 \quad 100.0 \%$ ATPase family AAA domain-containing protein 3B GN=ATAD3B ATD3B_HUMAN $72.57 \quad 100.0 \%$ ATPase family AAA domain-containing protein 3B GN=ATAD3B ATD3B_HUMAN $72.57 \quad 100.0 \%$ ATPase family AAA domain-containing protein 3B GN=ATAD3B ATD3B_HUMAN $72.57 \quad 100.0 \%$ ATPase family AAA domain-containing protein 3B GN=ATAD3B ATD3B_HUMAN $72.57 \quad 100.0 \%$ ATPase family AAA domain-containing protein 3B GN=ATAD3B ATD3B_HUMAN $72.57 \quad 100.0 \%$

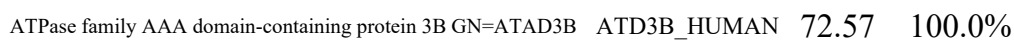
ATPase family AAA domain-containing protein 3B GN=ATAD3B ATD3B_HUMAN $72.57 \quad 100.0 \%$ ATPase family AAA domain-containing protein 3B GN=ATAD3B ATD3B_HUMAN $72.57 \quad 100.0 \%$ ATPase family AAA domain-containing protein 3B GN=ATAD3B ATD3B_HUMAN $72.57 \quad 100.0 \%$ ATPase family AAA domain-containing protein 3B GN=ATAD3B ATD3B_HUMAN $72.57 \quad 100.0 \%$ ATPase family AAA domain-containing protein 3B GN=ATAD3B ATD3B_HUMAN $72.57 \quad 100.0 \%$ ATPase family AAA domain-containing protein 3B GN=ATAD3B ATD3B_HUMAN $72.57 \quad 100.0 \%$ ATPase family AAA domain-containing protein 3B GN=ATAD3B ATD3B_HUMAN $72.57 \quad 100.0 \%$ ATPase family AAA domain-containing protein 3B GN=ATAD3B ATD3B HUMAN $72.57 \quad 100.0 \%$ ATPase family AAA domain-containing protein 3B GN=ATAD3B ATD3B_HUMAN $72.57 \quad 100.0 \%$ ATPase WRNIP1 GN=WRNIP1

ATPase WRNIP1 GN=WRNIP1 ATPase WRNIP1 GN=WRNIP1 WRIP1_HUMAN $72.13 \quad 100.0 \%$ WRIP1_HUMAN $72.13 \quad 100.0 \%$ WRIP1_HUMAN $72.13 \quad 100.0 \%$ drial GN=ABCB10 ABCBA_HUMAN $79.15 \quad 100.0 \%$ ATP-binding cassette sub-family B member 10, mitochondrial GN=ABCB10 ABCBA_HUMAN $79.15 \quad 100.0 \%$ ATP-binding cassette sub-family D member $3 \mathrm{GN}=\mathrm{ABCD} 3 \mathrm{ABCD} 3$ _HUMAN $75.48 \quad 100.0 \%$ ATP-binding cassette sub-family D member $3 \mathrm{GN}=\mathrm{ABCD} 3 \mathrm{ABCD} 3$ _HUMAN $75.48 \quad 100.0 \%$ ATP-binding cassette sub-family D member $3 \mathrm{GN}=\mathrm{ABCD} 3 \mathrm{ABCD} 3$ _HUMAN $75.48 \quad 100.0 \%$ ATP-binding cassette sub-family D member $3 \mathrm{GN}=\mathrm{ABCD} 3 \mathrm{ABCD} 3$ _HUMAN $75.48 \quad 100.0 \%$ ATP-binding cassette sub-family F member $2 \mathrm{GN}=\mathrm{ABCF} 2 \quad \mathrm{ABCF} 2$ HUMAN $71.29 \quad 100.0 \%$ ATP-binding cassette sub-family F member $2 \mathrm{GN}=\mathrm{ABCF} 2 \quad \mathrm{ABCF} 2$ _HUMAN $71.29 \quad 100.0 \%$ ATP-binding cassette sub-family F member $2 \mathrm{GN}=\mathrm{ABCF} 2 \mathrm{ABCF} 2$ HUMAN $71.29 \quad 100.0 \%$ ATP-binding cassette sub-family F member $2 \mathrm{GN}=\mathrm{ABCF} 2 \mathrm{ABCF} 2$ HUMAN $71.29 \quad 100.0 \%$ ATP-binding cassette sub-family F member $2 \mathrm{GN}=\mathrm{ABCF} 2 \mathrm{ABCF} 2$ _HUMAN $71.29 \quad 100.0 \%$ ATP-binding cassette sub-family F member $2 \mathrm{GN}=\mathrm{ABCF} 2 \mathrm{ABCF} 2$ HUMAN $71.29 \quad 100.0 \%$ ATP-binding cassette sub-family F member $2 \mathrm{GN}=\mathrm{ABCF} 2 \quad \mathrm{ABCF} 2$ HUMAN $71.29 \quad 100.0 \%$ ATP-binding cassette sub-family F member $2 \mathrm{GN}=\mathrm{ABCF} 2 \mathrm{ABCF} 2$ HUMAN $71.29 \quad 100.0 \%$ ATP-binding cassette sub-family F member $2 \mathrm{GN}=\mathrm{ABCF} 2 \mathrm{ABCF} 2$ _HUMAN $71.29 \quad 100.0 \%$ ATP-binding cassette sub-family F member $2 \mathrm{GN}=\mathrm{ABCF} 2$ ABCF2_HUMAN $71.29 \quad 100.0 \%$ ATP-binding cassette sub-family F member $2 \mathrm{GN}=\mathrm{ABCF} 2$ ABCF2_HUMAN $71.29 \quad 100.0 \%$ ATP-citrate synthase GN=ACLY ATP-citrate synthase $\mathrm{GN}=\mathrm{ACLY}$ ATP-citrate synthase $\mathrm{GN}=\mathrm{ACLY}$ ATP-citrate synthase GN=ACLY ACLY HUMAN $120.84 \quad 100.0 \%$ ACLY_HUMAN $120.84 \quad 100.0 \%$ ACLY HUMAN $120.84 \quad 100.0 \% \quad 28$ ACLY_HUMAN $120.84 \quad 100.0 \% \quad 28$
$0.11 \% \quad 37.1 \%$ AEGPGRGDEPSPS $0.01 \% \quad 35.3 \%$ GLGDRPAPK $0.01 \% \quad 35.3 \%$ TLSEETRQHQAR $0.01 \% \quad 35.3 \%$ AQYQDKLAR $0.01 \% \quad 35.3 \%$ ATVEREMELR $0.01 \% \quad 35.3 \%$ ENADIIREQIR $0.01 \% \quad 35.3 \%$ QTVLESIR $0.01 \% \quad 35.3 \%$ TAGTLFGEGFR $0.01 \% \quad 35.3 \%$ LGKPSLVR $0.01 \% \quad 35.3 \%$ ITVLEALR $0.01 \% \quad 35.3 \%$ ITVLEALRHPIQVSR $\begin{array}{llll}99.7 \% & 28.1 & 25.0 & 28.1\end{array}$ $\begin{array}{llll}99.7 \% & 49.1 & 25.0 & 42.0\end{array}$ $99.7 \% \quad 54.1 \quad 25.0 \quad 51.6 \quad 2$ $99.7 \% \quad 48.6 \quad 25.0 \quad 38.7$ $\begin{array}{llll}99.7 \% & 32.5 & 25.0 & 16.8\end{array}$ $99.7 \% \quad 33.9 \quad 25.0 \quad 25.0$ $99.0 \% \quad 43.9 \quad 25.0 \quad 24.5$ $99.7 \% \quad 58.4 \quad 25.0 \quad 58.4 \quad 4$ $\begin{array}{lllll}99.0 \% & 37.1 & 25.0 & 30.0\end{array}$ $99.0 \% \quad 45.7 \quad 25.0 \quad 31.0$ $\begin{array}{llll}99.7 \% & 45.5 & 25.0 & 45.5\end{array}$ $\begin{array}{lllllll}0.01 \% & 35.3 \% & \text { LLSRPQDVLEGVVL SPSLEAR } & 99.1 \% & 19.5 & 25.0 & 19.5\end{array}$ $0.01 \% \quad 35.3 \%$ VRDIAIATR $99.7 \% \quad 44.2$ $0.01 \% \quad 35.3 \%$ LALHSGMDYAIMTGGDVAPMGR $99.7 \% \quad 39.0$ $0.01 \% \quad 35.3 \%$ LFDWANTSR $0.01 \% \quad 35.3 \%$ GLLLFMDEADAFLR $0.01 \% 35.3 \%$ ATEEISKDLR $0.01 \% \quad 35.3 \%$ LHFDNCVLKPATEGK $0.01 \% \quad 35.3 \%$ LKLAQFDYGR $0.01 \% \quad 35.3 \%$ LAQFDYGR $0.01 \% \quad 35.3 \%$ LAQFDYGRK $0.01 \% \quad 35.3 \%$ LTEGMSGR $0.01 \% \quad 35.3 \%$ MSCGGGRPFCPPGHPLL $0.01 \% \quad 4.8 \%$ FVTLSATNAK $0.01 \% \quad 4.8 \% \quad$ TNDVRDVIK $0.01 \% \quad 4.8 \%$ AGLNGLQLAVLAR $0.00 \% \quad 2.6 \%$ LSSDTALLGR $0.00 \% \quad 2.6 \%$ STVLSLLLR $0.01 \% \quad 7.6 \%$ AVVDKVFFSR $0.01 \% \quad 7.6 \%$ STHSELLEDYYQSGR $0.01 \% \quad 7.6 \% \quad$ IVLAGREMTR $0.01 \% \quad 7.6 \%$ SGANVLICGPNGCGK $0.03 \% \quad 16.2 \%$ YGLIGLNGIGK $0.03 \% \quad 16.2 \%$ SMLLSAIGKR $0.03 \% \quad 16.2 \%$ EVPIPEHIDIYHLTR $0.03 \% \quad 16.2 \%$ ILHGLGFTPAMQR $0.03 \% \quad 16.2 \%$ YYTGNYDQYVK $0.03 \% \quad 16.2 \%$ LLTGELLPTDGMIR $0.03 \% \quad 16.2 \%$ LLTGELLPTDGMIRK $0.03 \% \quad 16.2 \%$ YGLTGKQQVSPIR $0.03 \% \quad 16.2 \%$ SKLVDEEPQLTK $0.03 \% \quad 16.2 \%$ LVDEEPQLTK $0.03 \% \quad 16.2 \%$ LVDEEPQLTKR $0.14 \% \quad 25.6 \%$ AISEQTGKELLYK $0.14 \% \quad 25.6 \%$ FICTTSAIQNR $0.14 \% \quad 25.6 \%$ GKLGLVGVNLTLDGVK $0.14 \% \quad 25.6 \%$ LGLVGVNLTLDGVK
$98.7 \% \quad 21.5$

$99.7 \% \quad 52.6$

$96.5 \% 24$.

$99.7 \% \quad 37.2$

$99.7 \% \quad 41.7$

$99.0 \% \quad 46.7$

$99.7 \% \quad 37.8$

$99.0 \% \quad 39.7$

$94.7 \% \quad 13.4$

$99.7 \% \quad 38.6$

$98.7 \% \quad 24.1$

$99.7 \% \quad 25.5$

$\begin{array}{lll}99.7 \% & 32.8\end{array}$

$99.7 \% \quad 47.0$

$99.7 \% \quad 52.4$

$99.7 \% \quad 57.5$

$99.5 \% \quad 27.2$

$99.7 \% \quad 57.8$

$99.7 \% \quad 46.8$

$99.6 \% \quad 26.2$

$99.7 \% \quad 24.9$

$99.3 \% \quad 21.7$

$99.7 \% \quad 36.5$

$99.7 \% \quad 72.0$

$99.3 \% \quad 19.7$

$99.7 \% \quad 37.2$

$99.7 \% \quad 57.8$

$99.7 \% \quad 37.7$

$99.7 \% \quad 38.9$

$99.7 \% \quad 53.5$

$99.7 \% \quad 50.7$

$99.7 \% \quad 62.6$

$99.7 \% \quad 59.4$

1109.54

1626.82

1161.6

1728.87

1210.66

969.48

1097.57

850.41

1855.84

1051.58

1059.58

1295.78

1032.57

1001.64

1167.65

1784.81

1145.65

1503.70

1104.64

1091.62

1831.97

1440.78

1413.63

1528.84

1672.93

1446.81

1386.75

1171.62

1327.72

1479.81

1310.65

1582.95

$\begin{array}{lllllllllll}41 & 96 & 0.14 \% & 25 & & \end{array}$


ATP-citrate synthase GN=ACLY ATP-citrate synthase $\mathrm{GN}=\mathrm{ACLY}$ ATP-citrate synthase GN=ACLY ATP-citrate synthase $\mathrm{GN}=\mathrm{ACLY}$ ATP-citrate synthase GN=ACLY ATP-citrate synthase $\mathrm{GN}=\mathrm{ACLY}$ ATP-citrate synthase GN=ACLY ATP-citrate synthase GN=ACLY ATP-citrate synthase GN=ACLY ATP-citrate synthase $\mathrm{GN}=\mathrm{ACLY}$ ATP-citrate synthase $\mathrm{GN}=\mathrm{ACLY}$ ATP-citrate synthase GN=ACLY ATP-citrate synthase $\mathrm{GN}=\mathrm{ACLY}$ ATP-citrate synthase GN=ACLY ATP-citrate synthase GN=ACLY ATP-citrate synthase $\mathrm{GN}=\mathrm{ACLY}$ ATP-citrate synthase GN=ACLY ATP-citrate synthase GN=ACLY ATP-citrate synthase $\mathrm{GN}=\mathrm{ACLY}$ ATP-citrate synthase $\mathrm{GN}=\mathrm{ACLY}$ ATP-citrate synthase GN=ACLY ATP-citrate synthase $\mathrm{GN}=\mathrm{ACLY}$ ATP-citrate synthase GN=ACLY ATP-citrate synthase GN=ACLY

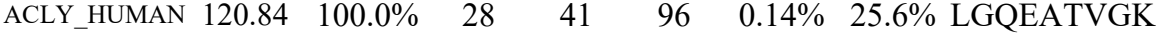
ACLY_HUMAN $120.84 \quad 100.0 \% \quad 28$ ACLY_HUMAN $120.84 \quad 100.0 \% \quad 28$ ACLY_HUMAN $120.84 \quad 100.0 \% \quad 28$ ACLY_HUMAN $120.84 \quad 100.0 \% \quad 28$ ACLY_HUMAN $120.84 \quad 100.0 \% \quad 28$ ACLY HUMAN $120.84 \quad 100.0 \% \quad 28$ ACLY_HUMAN $120.84 \quad 100.0 \% \quad 28$ ACLY HUMAN $120.84 \quad 100.0 \% \quad 28$ ACLY_HUMAN $120.84 \quad 100.0 \% \quad 28$ ACLY_HUMAN $120.84 \quad 100.0 \% \quad 28$ ACLY HUMAN $120.84 \quad 100.0 \% \quad 28$ ACLY_HUMAN $120.84 \quad 100.0 \% \quad 28$ ACLY_HUMAN $120.84 \quad 100.0 \% \quad 28$ ACLY_HUMAN $120.84 \quad 100.0 \% \quad 28$ ACLY_HUMAN $120.84 \quad 100.0 \% \quad 28$ ACLY HUMAN $120.84 \quad 100.0 \% \quad 28$ ACLY_HUMAN $120.84 \quad 100.0 \% \quad 28$ ACLY_HUMAN $120.84 \quad 100.0 \% \quad 28$ ACLY HUMAN $120.84 \quad 100.0 \% \quad 28$ ACLY_HUMAN $120.84 \quad 100.0 \% \quad 28$ ACLY HUMAN $120.84 \quad 100.0 \% \quad 28$ ACLY_HUMAN $120.84 \quad 100.0 \% \quad 28$ ACLY_HUMAN $120.84 \quad 100.0 \% \quad 28$ $\begin{array}{llll} & \end{array}$ ATP-dependent 6-phosphofructokinase, liver type GN=PFKL PFKAL_HUMAN $85.02 \quad 100.0 \% \quad 12$ ATP-dependent 6-phosphofructokinase, liver type GN=PFKL PFKAL_HUMAN $85.02 \quad 100.0 \% \quad 12$ ATP-dependent 6-phosphofructokinase, liver type GN=PFKL PFKAL_HUMAN $85.02 \quad 100.0 \% \quad 12$ ATP-dependent 6-phosphofructokinase, liver type GN=PFKL PFKAL_HUMAN $85.02 \quad 100.0 \% \quad 12$ ATP-dependent 6-phosphofructokinase, liver type GN=PFKL PFKAL HUMAN $85.02 \quad 100.0 \%$ ATP-dependent 6-phosphofructokinase, liver type GN=PFKL PFKAL_HUMAN $85.02 \quad 100.0 \%$ ATP-dependent 6-phosphofructokinase, liver type GN=PFKL PFKAL_HUMAN $85.02 \quad 100.0 \% \quad 12$ ATP-dependent 6-phosphofructokinase, liver type GN=PFKL PFKAL_HUMAN $85.02 \quad 100.0 \%$ ATP-dependent 6-phosphofructokinase, liver type GN=PFKL PFKAL_HUMAN $85.02 \quad 100.0 \% \quad 12$ ATP-dependent 6-phosphofructokinase, liver type GN=PFKL PFKAL_HUMAN $85.02 \quad 100.0 \% \quad 12$ ATP-dependent 6-phosphofructokinase, liver type GN=PFKL PFKAL_HUMAN $85.02 \quad 100.0 \%$ ATP-dependent 6-phosphofructokinase, muscle type GN=PFKM PFKAM_HUMAN $85.18 \quad 100.0 \%$ ATP-dependent 6-phosphofructokinase, muscle type GN=PFKM PFKAM HUMAN $85.18 \quad 100.0 \%$ ATP-dependent 6-phosphofructokinase, muscle type GN=PFKM PFKAM_HUMAN $85.18 \quad 100.0 \%$ ATP-dependent 6-phosphofructokinase, muscle type GN=PFKM PFKAM_HUMAN $85.18 \quad 100.0 \%$ ATP-dependent 6-phosphofructokinase, muscle type GN=PFKM PFKAM HUMAN $85.18 \quad 100.0 \%$ ATP-dependent 6-phosphofructokinase, muscle type GN=PFKM PFKAM_HUMAN $85.18 \quad 100.0 \%$ ATP-dependent 6-phosphofructokinase, muscle type GN=PFKM PFKAM HUMAN $85.18 \quad 100.0 \%$ ATP-dependent 6-phosphofructokinase, platelet type GN=PFKP PFKAP_HUMAN $85.60 \quad 100.0 \%$ ATP-dependent 6-phosphofructokinase, platelet type GN=PFKP PFKAP_HUMAN $85.60 \quad 100.0 \%$ ATP-dependent 6-phosphofructokinase, platelet type GN=PFKP PFKAP_HUMAN $85.60 \quad 100.0 \%$ ATP-dependent 6-phosphofructokinase, platelet type GN=PFKP PFKAP_HUMAN $85.60 \quad 100.0 \%$
$41 \quad 96 \quad 0.14 \% \quad 25.6 \%$ LGQEATVGK

$4196 \quad 0.14 \% \quad 25.6 \%$ LGQEATVGKATGFLK

$41 \quad 96 \quad 0.14 \% \quad 25.6 \%$ EAYPEEAYIADLDAK

$41 \quad 96 \quad 0.14 \% \quad 25.6 \%$ TILSLMTR

$41 \quad 96 \quad 0.14 \% \quad 25.6 \%$ RGGPNYQEGLR

$41 \quad 96 \quad 0.14 \% \quad 25.6 \%$ GGPNYQEGLR

4196

$41 \quad 96$

6

$0.14 \% \quad 25.6 \%$ AKPAMPQDSVPSPR

$0.14 \% \quad 25.6 \%$ SLQGKSTTLFSR

$0.14 \% \quad 25.6 \%$ TIAIIAEGIPEALTR

$0.14 \% \quad 25.6 \%$ TIAIIAEGIPEALTRK

$0.14 \% \quad 25.6 \%$ LYRPGSVAYVSR

$0.14 \% \quad 25.6 \%$ SGGMSNELNNIISR

$0.14 \% \quad 25.6 \%$ NQALKEAGVFVPR

$0.14 \% \quad 25.6 \%$ EAGVFVPR

$0.14 \% \quad 25.6 \%$ AFDSGIIPMEFVNK

$0.14 \% \quad 25.6 \%$ EGKLIMGIGHR

$0.14 \% \quad 25.6 \%$ LIMGIGHR

$0.14 \% \quad 25.6 \%$ SINNPDMR

$0.14 \% \quad 25.6 \%$ VQILKDYVR

$0.05 \% \quad 21.8 \%$ TFVLEVMGR

$0.05 \% \quad 21.8 \%$ LNIIIIAEGAIDR

$0.05 \% \quad 21.8 \%$ GGTPSAFDRILSSK

$0.05 \% \quad 21.8 \%$ LPLMECVQMTK

$0.05 \% \quad 21.8 \%$ GQLESIVENIR

$0.05 \% \quad 21.8 \%$ VFANAPDSACVIGLK

$0.05 \% \quad 21.8 \%$ AVAFSPVTELKK

$0.02 \% \quad 12.4 \%$ VGIFTGAR

$0.02 \% \quad 12.4 \%$ AAYNLVKR

$0.02 \% \quad 12.4 \%$ TFVLEVMGR

$0.02 \% \quad 12.4 \%$ IFANTPDSGCVLGMR

$0.03 \% \quad 23.3 \%$ FLEHLSGAGK

$0.03 \% \quad 23.3 \%$ AACNLLQR

\section{$0.14 \% \quad 25.6 \%$ TASFSESRADEVAPAK}

$0.14 \% \quad 25.6 \%$ SAYDSTMETMNYAQIR

$0.14 \% \quad 25.6 \%$ GVTIIGPATVGGIKPGCFK

$\begin{array}{lll}7.3 & 25.0 & 46.8\end{array}$

$\begin{array}{llll}99.7 \% & 36.5 & 25.0 & 31.7\end{array}$

$\begin{array}{llll}99.7 \% & 46.8 \quad 25.0 & 46.8\end{array}$

$99.0 \% \quad 35.4 \quad 25.0 \quad 22.6$

$\begin{array}{llll}99.7 \% & 30.4 & 25.0 & 20.6\end{array}$

$\begin{array}{llll}99.7 \% & 38.4 & 25.0 & 29.2\end{array}$

$99.7 \% \quad 52.1 \quad 25.0 \quad 52.1$

$\begin{array}{llll}99.7 \% & 55.8 & 25.0 & 55.8\end{array}$

$\begin{array}{llll}99.7 \% & 26.1 & 25.0 & 25.8\end{array}$

$\begin{array}{llll}99.7 \% & 58.3 & 25.0 & 58.3\end{array}$

$99.7 \% \quad 51.8 \quad 25.0 \quad 50.9$

$99.7 \% \quad 43.0$

$\begin{array}{ll}99.7 \% & 41.7 \\ 99.7 \% & 58.9\end{array}$

$99.7 \% \quad 42.5$

$99.7 \% \quad 60.4$

$99.7 \% \quad 44.9$

$99.0 \% \quad 33.3$

$99.7 \% \quad 48.8$

$\begin{array}{ll}99.4 \% & 20.7\end{array}$

$99.0 \% \quad 25.4$

$99.0 \% \quad 27.5$

$98.9 \% \quad 24.5$

$\begin{array}{lllll}0.05 \% & 21.8 \% & \text { AIGVLTSGGDAQGMNAAVR } & 99.7 \% & 43.3\end{array}$

$0.05 \% \quad 21.8 \%$ IMEVIDAITTTAQSHQR

$99.4 \% \quad 55.5 \quad 25.0 \quad 12.2$

$\begin{array}{llll}99.7 \% & 49.2 & 25.0 & 43.8\end{array}$

$99.7 \% \quad 83.2 \quad 25.0 \quad 81.0$

$99.7 \% \quad 58.4 \quad 25.0 \quad 44.5$

$99.7 \% \quad 41.8 \quad 25.0 \quad 41.8$

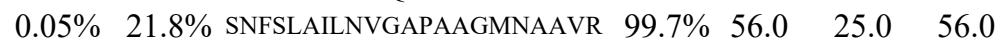

$99.6 \% \quad 24.0 \quad 25.0 \quad 19.9$

$\begin{array}{llll}99.5 \% & 24.1 & 25.0 & 24.1\end{array}$

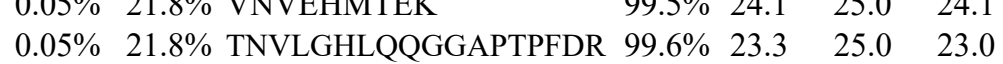

$99.7 \% \quad 55.7$

$99.7 \% \quad 45.6$

$\begin{array}{llllll}0.02 \% & 12.4 \% & \text { AIAVLTSGGDAQGMNAAVR } & 99.7 \% & 66.8\end{array}$

$99.0 \% 39.9$

$99.0 \% \quad 50.0$

$99.7 \% \quad 49.2$

$0.02 \% \quad 12.4 \%$ LGYDTRVTVLGHVQR $\quad 99.7 \% \quad 47.6$

$0.02 \% \quad 12.4 \%$ SGSHTVAVMNVGAPAAGMNAAVR

$\begin{array}{ll}99.7 \% & 37.8 \\ 99.7 \% & 52.0\end{array}$

$\begin{array}{lll}99.7 \% & 39.8\end{array}$

$\begin{array}{ll}99.7 \% & 39.8 \\ 99.7 \% & 43.3\end{array}$

$99.0 \% \quad 34.8$

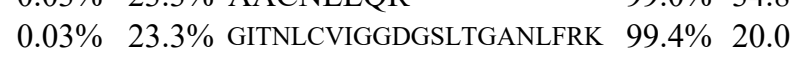

902.49

1519.85

1697.79

934.54

1246.63

1090.53

1665.81

1496.75

1324.72

1880.82

1567.91

1696.00

2314.26

1872.04

1503.78

1367.74

1491.72

1428.80

874.48

1583.78

1226.67

912.51

946.44

1133.67

1787.91

1913.98

1051.56

1410.83

1435.75

1349.66

2144.13

1257.68

1086.52

1907.97

1561.80

1289.75

1801.92

820.47

934.55

1051.56

1713.94

2168.07

1637.78

1058.56

1787.91

945.49

2263.19

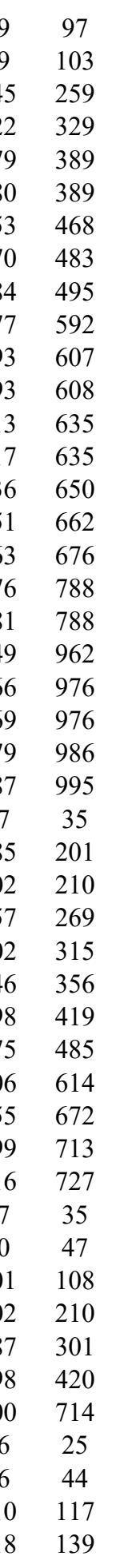

Page 23 of Table S-1-2 
ATP-dependent 6-phosphofructokinase, platelet type GN=PFKP PFKAP_HUMAN $85.60 \quad 100.0 \%$ ATP-dependent 6-phosphofructokinase, platelet type GN=PFKP PFKAP_HUMAN $85.60 \quad 100.0 \%$ ATP-dependent 6-phosphofructokinase, platelet type GN=PFKP PFKAP_HUMAN $85.60 \quad 100.0 \%$ ATP-dependent 6-phosphofructokinase, platelet type GN=PFKP PFKAP_HUMAN $85.60 \quad 100.0 \%$ ATP-dependent 6-phosphofructokinase, platelet type GN=PFKP PFKAP_HUMAN $85.60 \quad 100.0 \%$ ATP-dependent 6-phosphofructokinase, platelet type GN=PFKP PFKAP_HUMAN $85.60 \quad 100.0 \%$ ATP-dependent 6-phosphofructokinase, platelet type GN=PFKP PFKAP_HUMAN $85.60 \quad 100.0 \%$ ATP-dependent 6-phosphofructokinase, platelet type GN=PFKP PFKAP_HUMAN $85.60 \quad 100.0 \%$ ATP-dependent 6-phosphofructokinase, platelet type GN=PFKP PFKAP_HUMAN $85.60 \quad 100.0 \%$ ATP-dependent 6-phosphofructokinase, platelet type GN=PFKP PFKAP_HUMAN $85.60 \quad 100.0 \%$ ATP-dependent 6-phosphofructokinase, platelet type GN=PFKP PFKAP_HUMAN $85.60 \quad 100.0 \%$ ATP-dependent Clp protease ATP-binding subunit clpX-like, mitochondrial GN=CLPX CLPX_HUMAN $69.22 \quad 100.0 \%$ ATP-dependent Clp protease ATP-binding subunit clpX-like, mitcohondrial GN=CLPX CLPX_HUMAN $69.22 \quad 100.0 \%$ ATP-dependent Clp protease ATP-binding subunit clpX-like, mitochondrial GN=CLPX CLPX_HUMAN $69.22 \quad 100.0 \%$ ATP-dependent Clp protease ATP-binding subunit clpX-like, mitochondrial GN=CLPX CLPX_HUMAN $69.22 \quad 100.0 \%$ ATP-dependent Clp protease ATP-binding subunit clpX-like, mitochondrial GN=CLPX CLPX_HUMAN $69.22 \quad 100.0 \%$ ATP-dependent Clp protease ATP-binding subunit clpX-like, mitochondrial GN=CLPX CLPX_HUMAN $69.22 \quad 100.0 \%$ ATP-dependent Clp protease ATP-binding subunit clpX-like, mitochondrial GN=CLPX CLPX_HUMAN $69.22 \quad 100.0 \%$ ATP-dependent Clp protease ATP-binding subunit clpX-like, mitochondrial GN=CLPX CLPX_HUMAN $69.22 \quad 100.0 \%$ ATP-dependent Clp protease proteolytic subunit, mitochondrial GN=CLPP CLPP_HUMAN $30.18 \quad 100.0 \%$ ATP-dependent Clp protease proteolytic subunit, mitochondrial GN=CLPP CLPP_HUMAN $30.18 \quad 100.0 \%$ ATP-dependent RNA helicase A GN=DHX9 DHX9_HUMAN $140.96 \quad 100.0 \%$ ATP-dependent RNA helicase A GN=DHX9 DHX9_HUMAN $140.96 \quad 100.0 \%$ ATP-dependent RNA helicase A GN=DHX9 DHX9_HUMAN $140.96 \quad 100.0 \%$ ATP-dependent RNA helicase A GN=DHX9 DHX9_HUMAN $140.96100 .0 \%$ ATP-dependent RNA helicase A GN=DHX9 DHX9_HUMAN $140.96 \quad 100.0 \%$ ATP-dependent RNA helicase A GN=DHX9 DHX9_HUMAN $140.96100 .0 \%$ ATP-dependent RNA helicase A GN=DHX9 DHX9 HUMAN $140.96 \quad 100.0 \%$ ATP-dependent RNA helicase A GN=DHX9 DHX9_HUMAN $140.96 \quad 100.0 \%$ ATP-dependent RNA helicase A GN=DHX9 DHX9 HUMAN $140.96 \quad 100.0 \%$ ATP-dependent RNA helicase A GN=DHX9 DHX9_HUMAN $140.96 \quad 100.0 \%$ ATP-dependent RNA helicase A GN=DHX9 DHX9_HUMAN $140.96 \quad 100.0 \%$ ATP-dependent RNA helicase A GN=DHX9 DHX9_HUMAN $140.96 \quad 100.0 \%$ ATP-dependent RNA helicase A GN=DHX9 DHX9_HUMAN $140.96 \quad 100.0 \%$ ATP-dependent RNA helicase A GN=DHX9 DHX9_HUMAN $140.96 \quad 100.0 \%$ ATP-dependent RNA helicase A GN=DHX9 DHX9_HUMAN $140.96 \quad 100.0 \%$ ATP-dependent RNA helicase A GN=DHX9 DHX9_HUMAN $140.96 \quad 100.0 \%$ ATP-dependent RNA helicase A GN=DHX9 DHX9 HUMAN $140.96 \quad 100.0 \%$ ATP-dependent RNA helicase A GN=DHX9 DHX9_HUMAN $140.96 \quad 100.0 \%$ ATP-dependent RNA helicase DDX18 GN=DDX18 DDX18_HUMAN $75.41 \quad 100.0 \%$ ATP-dependent RNA helicase DDX18 GN=DDX18 DDX18_HUMAN $75.41 \quad 100.0 \%$ ATP-dependent RNA helicase DDX18 GN=DDX18 DDX18_HUMAN $75.41 \quad 100.0 \%$ ATP-dependent RNA helicase DDX18 GN=DDX18 DDX18 HUMAN $75.41 \quad 100.0 \%$ ATP-dependent RNA helicase DDX18 GN=DDX18 DDX18_HUMAN $75.41 \quad 100.0 \%$ ATP-dependent RNA helicase DDX18 GN=DDX18 DDX18_HUMAN 75.41 $100.0 \%$ ATP-dependent RNA helicase DDX18 GN=DDX18 DDX18_HUMAN $75.41 \quad 100.0 \%$ ATP-dependent RNA helicase DDX3X GN=DDX3X DDX3X_HUMAN $73.25 \quad 100.0 \%$

(14)

14

(1)

13

13

13
13
13

13

18

8

$18 \quad 20$

1820

$\begin{array}{ll}18 & 20 \\ 18 & 20 \\ 18 & 20\end{array}$

$\begin{array}{ll}18 & 20 \\ 18 & 20 \\ 18 & 20\end{array}$

$18 \quad 20$

18

$8 \quad 20$

18
7
7
7

$\begin{array}{ll}7 & 9 \\ 7 & 9 \\ 7 & 9 \\ 7 & 9\end{array}$

7

7
7
18

0.0

0.0

$0.03 \% \quad 23.3 \%$ GGTPSAFDRILA

$0.03 \% \quad 23.3 \%$ SFAGNLNTYKR

$0.03 \% \quad 23.3 \%$ LAIKLPDDQIPK

$0.03 \% \quad 23.3 \%$ SAVRVGIADGHR

$0.03 \% \quad 23.3 \%$ MLAIYDGFDGFAK

$0.03 \% \quad 23.3 \%$ FTTDDSICVLGISKR

$0.03 \% \quad 23.3 \%$ NVIFQPVAELK

$0.03 \% \quad 23.3 \%$ NVIFQPVAELKK

$0.02 \% \quad 16.1 \%$ SIIKEPESAAEAVK

$0.02 \% \quad 16.1 \%$ GGEVLDSSHDDIKLEK

$0.02 \% \quad 16.1 \%$ SNILLLGPTGSGK

$0.02 \% \quad 16.1 \%$ TLLAQTLAK

$0.02 \% \quad 16.1 \%$ DVGGEGVQQGLLK

$0.02 \% \quad 16.1 \%$ LLEGTIVNVPEKNSR

$0.02 \% \quad 16.1 \%$ YLGFGTPSNLGK

$0.02 \% \quad 16.1 \%$ AAAAADLANR

$0.00 \% \quad 9.4 \%$ IMIHQPSGGAR

$0.00 \% \quad 9.4 \%$ GQATDIAIQAEEIMK

$0.12 \% \quad 13.5 \%$ KMTPSYEIR

$0.12 \% \quad 13.5 \%$ MTPSYEIR

$0.12 \% \quad 13.5 \%$ DAQSNAARDFVNYLVR

$0.12 \% \quad 13.5 \%$ DFVNYLVR

$0.12 \% \quad 13.5 \%$ LNQYFQKEK

$0.12 \% \quad 13.5 \%$ LAAQSCALSLVR

$0.12 \% \quad 13.5 \%$ LAQFEPSQR

$0.12 \% \quad 13.5 \%$ AAECNIVVTQPR

$0.12 \% \quad 13.5 \%$ RISAVSVAER

$0.12 \% \quad 13.5 \%$ VAFERGEEPGK

$0.12 \% \quad 13.5 \%$ KVFDPVPVGVTK

$0.12 \% \quad 13.5 \%$ VFDPVPVGVTK

$0.12 \% \quad 13.5 \%$ VRPGFCFHLCSR

$0.12 \% \quad 13.5 \%$ LGGIGQFLAK

$0.12 \% \quad 13.5 \%$ ILAKLPIEPR

$0.12 \% \quad 13.5 \%$ ILTTEGRNALIHK

$0.12 \% \quad 13.5 \%$ QISRPSAAGINLMIGSTR

$0.12 \% \quad 13.5 \%$ YGDGPRPPK

$0.03 \% \quad 11.9 \%$ MVNDAEPDTK

$0.03 \% \quad 11.9 \%$ SIRPLLEGRDLLAAAK

$0.03 \% \quad 11.9 \%$ NGTGVLILSPTR

$0.03 \% \quad 11.9 \%$ SAEAQKLGNGINIIVATPGR

$0.03 \% \quad 11.9 \%$ LGNGINIIVATPGR

$0.03 \% \quad 11.9 \%$ QTMLFSATQTR

$0.03 \% \quad 11.9 \%$ SAQEAYKSYIR

$0.08 \% \quad 26.9 \%$ SSFFSDRGSGSR $\begin{array}{lllll}95.2 \% & 17.5 & 25.0 & 11.9 & 0\end{array}$

$\begin{array}{lllll}99.7 \% & 49.2 & 25.0 & 43.8 & 2\end{array}$

$\begin{array}{llll}99.7 \% & 39.8 & 25.0 & 24.7\end{array}$

$\begin{array}{llll}94.6 \% & 15.9 & 25.0 & 11.8\end{array}$

$99.7 \% \quad 54.0 \quad 25.0 \quad 44.2$

$\begin{array}{llll}99.7 \% & 28.4 & 25.0 & 28.4\end{array}$

$99.7 \% \quad 31.0 \quad 25.0 \quad 31.0$

$\begin{array}{llll}99.7 \% & 32.4 & 25.0 & 32.4\end{array}$

$\begin{array}{llll}98.8 \% & 17.5 & 25.0 & 17.5\end{array}$

$\begin{array}{llll}99.7 \% & 28.9 & 25.0 & 28.9\end{array}$

$\begin{array}{lllll}99.7 \% & 30.3 & 25.0 & 26.0 & 2\end{array}$

$\begin{array}{llll}99.7 \% & 34.9 & 25.0 & 30.0\end{array}$

$\begin{array}{llll}99.3 \% & 24.0 & 25.0 & 16.0\end{array}$

$\begin{array}{lllll}99.7 \% & 82.7 & 25.0 & 81.1 & 2\end{array}$

$\begin{array}{llll}99.7 \% & 35.7 & 25.0 & 26.1\end{array}$

$\begin{array}{lllll}99.7 \% & 38.0 & 25.0 & 38.0 & 2\end{array}$

$\begin{array}{llll}99.7 \% & 26.3 & 25.0 & 26.3\end{array}$

$\begin{array}{llll}99.7 \% & 43.2 & 25.0 & 37.6\end{array}$

$\begin{array}{llll}99.7 \% & 60.3 & 25.0 & 55.2\end{array}$

$\begin{array}{llll}98.6 \% & 17.0 & 25.0 & 17.0\end{array}$

$\begin{array}{llll}99.7 \% & 68.0 & 25.0 & 62.4\end{array}$

$\begin{array}{llll}99.7 \% & 44.3 & 25.0 & 31.5\end{array}$

$\begin{array}{llll}99.0 \% & 32.0 & 25.0 & 30.2\end{array}$

$\begin{array}{llll}99.7 \% & 29.7 & 25.0 & 29.7\end{array}$

$\begin{array}{llll}99.0 \% & 49.0 & 25.0 & 37.2\end{array}$

$\begin{array}{llll}99.4 \% & 29.6 & 25.0 & 10.9\end{array}$

$\begin{array}{llll}99.7 \% & 57.2 & 25.0 & 50.8\end{array}$

$\begin{array}{lllll}99.7 \% & 43.2 & 25.0 & 36.8 & 2\end{array}$

$\begin{array}{lllll}99.7 \% & 56.0 & 25.0 & 50.8 & 4\end{array}$

$\begin{array}{llll}99.7 \% & 48.6 & 25.0 & 38.2\end{array}$

$\begin{array}{llll}98.4 \% & 19.3 & 25.0 & 15.5\end{array}$

$\begin{array}{llll}99.6 \% & 25.1 & 25.0 & 24.8\end{array}$

$\begin{array}{llll}97.6 \% & 20.0 & 25.0 & 17.3\end{array}$

$\begin{array}{llll}99.7 \% & 37.6 & 25.0 & 37.6\end{array}$

$\begin{array}{llll}99.7 \% & 50.8 & 25.0 & 44.5\end{array}$

$\begin{array}{llll}99.7 \% & 25.2 & 25.0 & 25.2\end{array}$

$\begin{array}{llll}98.8 \% & 21.2 & 25.0 & 21.2\end{array}$

$\begin{array}{llll}99.7 \% & 43.0 & 25.0 & 43.0\end{array}$

$\begin{array}{llll}99.7 \% & 33.6 & 25.0 & 33.6\end{array}$

$\begin{array}{llll}99.7 \% & 37.1 & 25.0 & 37.1\end{array}$

$99.0 \% \quad 21.0 \quad 25.0 \quad 17.2$

$\begin{array}{llll}99.7 \% & 34.5 & 25.0 & 25.0\end{array}$

$\begin{array}{llll}99.7 \% & 41.8 & 25.0 & 41.8\end{array}$

$99.7 \% \quad 60.0 \quad 25.0 \quad 60.0$

$\begin{array}{llll}99.7 \% & 63.0 & 25.0 & 44.6\end{array}$

$\begin{array}{llll}99.7 \% & 41.5 & 25.0 & 41.5\end{array}$

$\begin{array}{llll}99.7 \% & 36.6 & 25.0 & 33.8\end{array}$

1051.56

1022.61

1447.77

1270.65

1350.80

1237.68

1447.69

1711.87

1257.72

1385.82

1471.80

1741.86

1256.72

958.59

1299.69

1668.93

1253.65

943.50

1166.61

1633.81

1124.58

996.48

1838.91

1025.54

1197.63

1288.70

1075.55

1357.69

1087.62

1218.61

1285.75

1157.66

1535.74

1003.59

1149.74

1465.85

1888.01

986.51

1119.50

1723.02

1227.71

2009.11

1394.81

1283.64

1315.66 1289.59

Page 24 of Table S-1-2 
ATP-dependent RNA helicase DDX3X GN=DDX3X DDX3X_HUMAN $73.25 \quad 100.0 \% \quad 18 \quad 22 \quad 55 \quad 0.08 \% \quad 26.9 \%$ YTRPTPVQK

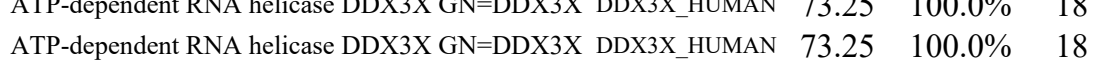
ATP-dependent RNA helicase DDX3X GN=DDX3X DDX3X_HUMAN $73.25 \quad 100.0 \% \quad 18$ ATP-dependent RNA helicase DDX3X GN=DDX3X DDX3X_HUMAN $73.25 \quad 100.0 \% \quad 18$ ATP-dependent RNA helicase DDX3X GN=DDX3X DDX3X_HUMAN $73.25 \quad 100.0 \% \quad 18$ $\begin{array}{llll}\text { ATP-dependent RNA helicase DDX3X GN=DDX3X DDX3X_HUMAN } & 73.25 & 100.0 \% & 18\end{array}$ ATP-dependent RNA helicase DDX3X GN=DDX3X DDX3X_HUMAN $73.25 \quad 100.0 \% \quad 18$ ATP-dependent RNA helicase DDX3X GN=DDX3X DDX3X_HUMAN $73.25 \quad 100.0 \% \quad 18$ ATP-dependent RNA helicase DDX3X GN=DDX3X DDX3X_HUMAN $73.25 \quad 100.0 \% \quad 18$ ATP-dependent RNA helicase DDX3X GN=DDX3X DDX3X_HUMAN $73.25 \quad 100.0 \% \quad 18$ ATP-dependent RNA helicase DDX3X GN=DDX3X DDX3X_HUMAN $73.25 \quad 100.0 \% \quad 18$ ATP-dependent RNA helicase DDX3X GN=DDX3X DDX3X HUMAN $73.25 \quad 100.0 \% \quad 18$ ATP-dependent RNA helicase DDX3X GN=DDX3X DDX3X_HUMAN $73.25 \quad 100.0 \% \quad 18$ ATP-dependent RNA helicase DDX3X GN=DDX3X DDX3X_HUMAN $73.25 \quad 100.0 \% \quad 18$ ATP-dependent RNA helicase DDX3X GN=DDX3X DDX3X_HUMAN $73.25 \quad 100.0 \% \quad 18$ ATP-dependent RNA helicase DDX3X GN=DDX3X DDX3X_HUMAN $73.25 \quad 100.0 \% \quad 18$ ATP-dependent RNA helicase DDX3X GN=DDX3X DDX3X HUMAN $73.25 \quad 100.0 \% \quad 18$ ATP-dependent RNA helicase DDX50 GN=DDX50 DDX50_HUMAN $82.57 \quad 100.0 \% \quad 13$ ATP-dependent RNA helicase DDX50 GN=DDX50 DDX50_HUMAN $82.57 \quad 100.0 \% \quad 13$ ATP-dependent RNA helicase DDX50 GN=DDX50 DDX50_HUMAN $82.57 \quad 100.0 \%$ ATP-dependent RNA helicase DDX50 GN=DDX50 DDX50_HUMAN $82.57 \quad 100.0 \% \quad 13$ ATP-dependent RNA helicase DDX50 GN=DDX50 DDX50_HUMAN $82.57 \quad 100.0 \%$ ATP-dependent RNA helicase DDX50 GN=DDX50 DDX50_HUMAN $82.57 \quad 100.0 \%$ ATP-dependent RNA helicase DDX50 GN=DDX50 DDX50_HUMAN $82.57 \quad 100.0 \% \quad 13$ ATP-dependent RNA helicase DDX50 GN=DDX50 DDX50 HUMAN $82.57 \quad 100.0 \%$ ATP-dependent RNA helicase DDX50 GN=DDX50 DDX50_HUMAN $82.57 \quad 100.0 \% \quad 13$ ATP-dependent RNA helicase DDX50 GN=DDX50 DDX50_HUMAN $82.57 \quad 100.0 \% \quad 1$ ATP-dependent RNA helicase DDX50 GN=DDX50 DDX50 HUMAN $82.57 \quad 100.0 \%$ ATP-dependent RNA helicase DDX50 GN=DDX50 DDX50_HUMAN $82.57 \quad 100.0 \%$ ATP-dependent RNA helicase DDX50 GN=DDX50 DDX50 HUMAN $82.57 \quad 100.0 \%$ ATP-dependent RNA helicase DDX50 GN=DDX50 DDX50_HUMAN $82.57 \quad 100.0 \%$ ATP-dependent RNA helicase DDX50 GN=DDX50 DDX50_HUMAN $82.57 \quad 100.0 \%$ ATP-dependent RNA helicase DDX51 GN=DDX51 DDX51_HUMAN $72.46 \quad 100.0 \%$ ATP-dependent RNA helicase DDX51 GN=DDX51 DDX51_HUMAN $72.46 \quad 100.0 \%$ ATP-dependent RNA helicase DDX54 GN=DDX54 DDX54_HUMAN $98.60 \quad 100.0 \%$ ATP-dependent RNA helicase DDX54 GN=DDX54 DDX54_HUMAN $98.60 \quad 100.0 \%$ ATP-dependent RNA helicase DDX54 GN=DDX54 DDX54_HUMAN $98.60 \quad 100.0 \%$ ATP-dependent zinc metalloprotease YME1L1 GN=YME1L1 YMEL1_HUMAN $86.46 \quad 100.0 \%$ ATP-dependent zinc metalloprotease YME1L1 GN=YME1L1 YMEL1_HUMAN $86.46 \quad 100.0 \%$ Basic leucine zipper and $\mathrm{W} 2$ domain-containing protein $2 \mathrm{GN}=\mathrm{BZW} 2$ BZW2_HUMAN $48.16 \quad 100.0 \%$ Basic leucine zipper and W2 domain-containing protein $2 \mathrm{GN}=\mathrm{BZW} 2$ BZW2 HUMAN $48.16 \quad 100.0 \%$ Basic leucine zipper and W2 domain-containing protein $2 \mathrm{GN}=\mathrm{BZW} 2$ BZW2_HUMAN $48.16 \quad 100.0 \%$ Bcl-2-associated transcription factor $1 \mathrm{GN}=$ BCLAF1 BCLF1_HUMAN $106.13 \quad 100.0 \%$ Bcl-2-associated transcription factor 1 GN=BCLAF1 BCLF1_HUMAN $106.13 \quad 100.0 \%$ Bcl-2-associated transcription factor $1 \mathrm{GN}=\mathrm{BCLAF} 1 \mathrm{BCLF} 1$ HUMAN $106.13 \quad 100.0 \%$ Bcl-2-associated transcription factor $1 \mathrm{GN}=\mathrm{BCLAF} 1 \mathrm{BCLF} 1$ HUMAN $106.13100 .0 \%$ Bcl-2-associated transcription factor $1 \mathrm{GN}=\mathrm{BCLAF} 1$ BCLF1_HUMAN $106.13 \quad 100.0 \%$
$0.08 \% \quad 26.9 \%$ IVEQDTMPPKGVR

$99.3 \% \quad 20.8$

$0.08 \% \quad 26.9 \%$ HTMMFSATFPK

$0.08 \% \quad 26.9 \%$ VGSTSENITQK

$0.08 \% \quad 26.9 \%$ DREEALHQFR

$0.08 \% \quad 26.9 \%$ SGKSPILVATAVAAR

$0.08 \% \quad 26.9 \%$ SPILVATAVAAR

\section{$\begin{array}{lll}98.9 \% & 30.8\end{array}$}

$99.7 \% \quad 59.0$

$99.5 \% \quad 24.0$

$99.7 \% \quad 41.6$

$99.7 \% \quad 56.9$

$0.08 \% \quad 26.9 \%$ TGRVGNLGLATSFFNER

$0.08 \% 26.9 \%$ VGNLGLATSFFNER

$99.1 \% 19.1$

$97.6 \% \quad 22.0$

$0.08 \% \quad 26.9 \%$ DLLDLLVEAK

$0.08 \% \quad 26.9 \%$ DYRQSSGASSSSFSSSR

$0.08 \% \quad 26.9 \%$ QSSGASSSSFSSSR

$0.04 \% \quad 20.1 \%$ EGAFSNFPISEETIK

$0.04 \% \quad 20.1 \%$ GRGVTYLFPIQVK

$0.04 \% \quad 20.1 \%$ GVTYLFPIQVK

$0.04 \% \quad 20.1 \%$ TFGPVYEGKDLIAQAR

$0.04 \% \quad 20.1 \%$ TFSFAIPLIER

$0.04 \% \quad 20.1 \%$ VLVLAPTR

$0.04 \% \quad 20.1 \%$ VLVLAPTRELANQVAK

$99.7 \% \quad 45.7$

$99.7 \% \quad 62.2$

$99.7 \% \quad 28.7$

$\begin{array}{lll}99.6 \% & 24.4\end{array}$

$99.7 \% \quad 58.0$

$99.7 \% \quad 42.0$

$99.7 \% \quad 36.0$

$99.0 \% \quad 52.8$

$99.3 \% \quad 19.0$

$99.7 \% \quad 58.6$

$99.7 \% \quad 52.7$

$99.7 \% \quad 32.8$

$95.5 \% \quad 13.9$

$99.7 \% \quad 38.2$

$0.04 \% \quad 20.1 \%$ TGICICFYQPR

$0.04 \% \quad 20.1 \%$ TGICICFYQPRER

$0.04 \% \quad 20.1 \%$ VGVPSTMDLVK

$99.7 \% \quad 32.4$

$\begin{array}{ll}0.04 \% & 20.1 \% \text { KLSSNAVSQITR }\end{array}$

$0.04 \% \quad 20.1 \%$ LSSNAVSQITR

$0.01 \% \quad 2.9 \%$ LFSTGLAHR

$0.01 \% \quad 2.9 \%$ TGQAFTLLLK

$0.01 \% \quad 3.9 \%$ VADNAQQQYVR

$0.01 \% \quad 3.9 \%$ SRPAPSPESIKR

$0.01 \% \quad 3.9 \%$ VQELQQGAFGR

$0.00 \% \quad 3.2 \% \quad$ LAETQNIAPSFVK

$0.00 \% \quad 3.2 \%$ GILLVGPPGTGK

$0.01 \% \quad 6.7 \%$ EGIAASFAVK

$0.01 \% \quad 6.7 \% \quad$ LLELFPVNR

$0.01 \% \quad 6.7 \% \quad$ ELQKELQER

$0.11 \% \quad 22.5 \%$ KAEGEPQEESPLK

$0.11 \% \quad 22.5 \%$ TIAPQNAPR

$99.7 \% \quad 49.2$

$99.7 \% \quad 39.5$

$99.7 \% \quad 42.0$

$99.4 \% \quad 30.1$

$99.7 \% \quad 65.4$

$99.7 \% \quad 41.4$

$99.7 \% \quad 37.7$

$99.7 \% \quad 43.6$

$97.9 \% \quad 16.9$

$99.6 \% \quad 23.6$

$99.6 \% \quad 26.9$

$98.4 \% \quad 26.8$

$99.7 \% \quad 43.0$

$99.7 \% \quad 43.0$

$99.7 \% \quad 29.2$

$0.11 \% \quad 22.5 \%$ TIAPQNAPRDESR

$0.11 \% \quad 22.5 \%$ GRSSFYPDGGDQETAK

$99.2 \% \quad 26.0$

$99.7 \% \quad 47.7$
1238.55

1357.78

1320.68

1448.77

1887.99

1485.77

1313.60

1163.59

1300.64

1440.85

1168.70

1838.95

1524.78

1128.65

1795.78

1361.59

1668.81

1477.85

1264.73

1764.93

1293.72

868.56

1722.03

1211.67

1013.61

1414.66

1699.80

1145.62

2072.06

1303.73

1175.64

1001.55

1091.65

1291.64

1324.73

1232.64

1417.77

1108.67

992.54

1100.65

1172.63

1441.72

967.53

1454.73

1714.77

1501.64 $\begin{array}{ll}00 & 208 \\ 19 & 230 \\ 65 & 276 \\ 77 & 287 \\ 77 & 288 \\ 95 & 311 \\ 64 & 376 \\ 77 & 387 \\ 08 & 418 \\ 79 & 488 \\ 89 & 503 \\ 92 & 503 \\ 32 & 548 \\ 35 & 548 \\ 55 & 564 \\ 01 & 617 \\ 04 & 617 \\ 36 & 150 \\ 54 & 166 \\ 56 & 166 \\ 67 & 182 \\ 88 & 198 \\ 14 & 221 \\ 14 & 229 \\ 58 & 269 \\ 41 & 450 \\ 85 & 495 \\ 85 & 497 \\ 14 & 524 \\ 33 & 551 \\ 11 & 622 \\ 12 & 622 \\ 51 & 459 \\ 02 & 611 \\ 11 & 521 \\ 22 & 533 \\ 58 & 868 \\ 25 & 237 \\ 74 & 385 \\ 80 & 189 \\ 16 & 224 \\ 57 & 265 \\ 68 & 180 \\ 04 & 312 \\ 04 & 316 \\ 19 & 332 \\ & 332\end{array}$

Page 25 of Table S-1-2 
Bcl-2-associated transcription factor 1 GN=BCLAF1 BCLF1_HUMAN $106.13 \quad 100.0 \% \quad 20$ Bcl-2-associated transcription factor $1 \mathrm{GN}=\mathrm{BCLAF} 1$ BCLF1_HUMAN $106.13 \quad 100.0 \% \quad 20$ Bcl-2-associated transcription factor $1 \mathrm{GN}=\mathrm{BCLAF} 1$ BCLF1_HUMAN $106.13 \quad 100.0 \% \quad 20$ Bcl-2-associated transcription factor $1 \mathrm{GN}=\mathrm{BCLAF} 1$ BCLF1_HUMAN $106.13 \quad 100.0 \% 20$ Bcl-2-associated transcription factor $1 \mathrm{GN}=\mathrm{BCLAF} 1$ BCLF1_HUMAN $106.13 \quad 100.0 \%$ Bcl-2-associated transcription factor $1 \mathrm{GN}=$ BCLAF1 BCLF1_HUMAN $106.13 \quad 100.0 \% 20$ Bcl-2-associated transcription factor $1 \mathrm{GN}=\mathrm{BCLAF} 1$ BCLF1_HUMAN $106.13 \quad 100.0 \% \quad 20$ Bcl-2-associated transcription factor $1 \mathrm{GN}=\mathrm{BCLAF} 1 \mathrm{BCLF} 1$ HUMAN $106.13 \quad 100.0 \%$ Bcl-2-associated transcription factor 1 GN=BCLAF1 BCLF1_HUMAN $106.13 \quad 100.0 \% 20$ Bcl-2-associated transcription factor $1 \mathrm{GN}=\mathrm{BCLAF1}$ BCLF1_HUMAN $106.13 \quad 100.0 \% \quad 20$ Bcl-2-associated transcription factor $1 \mathrm{GN}=\mathrm{BCLAF} 1$ BCLF1_HUMAN $106.13 \quad 100.0 \% \quad 2$ Bcl-2-associated transcription factor $1 \mathrm{GN}=\mathrm{BCLAF} 1 \mathrm{BCLF} 1$ HUMAN $106.13 \quad 100.0 \% 2$ $\begin{array}{lllll}\text { Bcl-2-associated transcription factor } 1 \mathrm{GN}=\mathrm{BCLAF} 1 & \mathrm{BCLF} 1 \text { HUMAN } & 106.13 & 100.0 \% & 2\end{array}$ Bcl-2-associated transcription factor 1 GN=BCLAF1 BCLF1_HUMAN $106.13 \quad 100.0 \% 20$

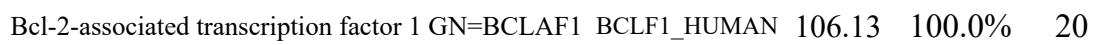
Beta-galactosidase $\mathrm{GN}=\mathrm{GLB}$ Beta-galactosidase $\mathrm{GN}=\mathrm{GLB} 1$ Beta-galactosidase $\mathrm{GN}=\mathrm{GLB} 1$ Beta-galactosidase $\mathrm{GN}=\mathrm{GLB}$ Beta-galactosidase $\mathrm{GN}=\mathrm{GLB}$ Beta-galactosidase $\mathrm{GN}=\mathrm{GLB}$ Beta-galactosidase $\mathrm{GN}=\mathrm{GLB}$ Beta-galactosidase $\mathrm{GN}=\mathrm{GLB} 1$ Beta-galactosidase $\mathrm{GN}=\mathrm{GLB} 1$ Bifunctional glutamate/proline--tRNA ligase GN=EPRS SYEP_HUMAN $170.59100 .0 \%$ Bifunctional glutamate/proline--tRNA ligase GN=EPRS SYEP_HUMAN $170.59100 .0 \%$ Bifunctional glutamate/proline--tRNA ligase GN=EPRS SYEP HUMAN $170.59 \quad 100.0 \%$ Bifunctional glutamate/proline--tRNA ligase GN=EPRS SYEP_HUMAN $170.59100 .0 \%$ Bifunctional glutamate/proline--tRNA ligase GN=EPRS SYEP HUMAN $170.59100 .0^{\circ}$ Bifunctional glutamate/proline--tRNA ligase GN=EPRS SYEP_HUMAN $170.59 \quad 100.0 \%$ Bifunctional glutamate/proline--tRNA ligase GN=EPRS SYEP_HUMAN $170.59 \quad 100.0 \%$ Bifunctional glutamate/proline--tRNA ligase GN=EPRS SYEP HUMAN $170.59 \quad 100.0 \%$ Bifunctional glutamate/proline--tRNA ligase GN=EPRS SYEP_HUMAN $170.59 \quad 100.0 \%$ Bifunctional glutamate/proline--tRNA ligase GN=EPRS SYEP_HUMAN $170.59 \quad 100.0 \%$ Bifunctional glutamate/proline--tRNA ligase GN=EPRS SYEP HUMAN $170.59 \quad 100.0 \%$ Bifunctional glutamate/proline--tRNA ligase GN=EPRS SYEP_HUMAN $170.59 \quad 100.0 \%$ Bifunctional glutamate/proline--tRNA ligase GN=EPRS SYEP HUMAN $170.59100 .0 \%$ Bifinctional methylenetertahydrofolate dechydrogenaseceyclohydrolase, mitochondral GN=MTHFD2 $\quad$ MTDC_HUMAN $37.90 \quad 100.0 \%$ MTDC HUMAN $37.90 \quad 100.0 \%$ MTDC_HUMAN $37.90 \quad 100.0 \%$

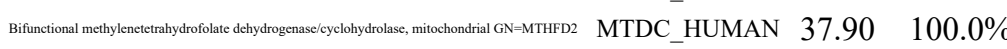
Bifunctional purine biosynthesis protein PURH GN=ATIC PUR9 HUMAN $64.62 \quad 100.0 \%$ Bifunctional purine biosynthesis protein PURH GN=ATIC PUR9_HUMAN $64.62 \quad 100.0 \%$ Bromodomain adjacent to zinc finger domain protein $1 \mathrm{~A}$ GN=BAZ1A BAZ1A_HUMAN $178.71 \quad 100.0 \%$ 列 C-1-tetrahydrofolate synthase, cytoplasmic GN=MTHFD1 C1TC_HUMAN $101.56 \quad 100.0 \%$

.

70.

\section{$0.11 \% \quad 22.5 \%$ FTDEESRVFLLDR}

$0.11 \% \quad 22.5 \%$ SVLADQGKSFATASHR

$0.11 \% \quad 22.5 \%$ NTEEEGLKYK

$0.11 \% \quad 22.5 \%$ LKETGYVVERPSTTK

$0.11 \% \quad 22.5 \%$ ETQSPEQVKSEK

$0.11 \% \quad 22.5 \%$ LKDLFDYSPPLHK

$0.11 \% \quad 22.5 \%$ STFREESPLR

$0.11 \% \quad 22.5 \%$ MIASDSHRPEVK

$0.11 \% 22.5 \%$ LLASTLVHSVK

$0.11 \% \quad 22.5 \%$ SIFDHIKLPQASK

$0.11 \% \quad 22.5 \%$ SAAMTLNER

$0.11 \% \quad 22.5 \%$ SAAMTLNERFTSYQK

$0.11 \% 22.5 \%$ FTSYQKATEEHSTR

$0.11 \% \quad 22.5 \%$ RPKEEEWDPEYTPK

$0.03 \% \quad 18.0 \%$ MFEIDYSR

$0.03 \% \quad 18.0 \%$ DSFLKDGQPFR

$0.03 \% \quad 18.0 \%$ YISGSIHYSR

$9 \quad 0.03 \% \quad 18.0 \%$ TEAVASSLYDILAR

$19 \quad 0.03 \% \quad 18.0 \%$ TVGAALDILCPSGPIK

$9.03 \% \quad 18.0 \%$ SLYPLTFIQVK

$0.03 \% \quad 18.0 \%$ TTLPQDCSNPAPLSSPLNGVHDR

$9 \quad 0.03 \% \quad 18.0 \%$ AYVAVDGIPQGVLER

$19 \quad 0.03 \% \quad 18.0 \%$ AGATLDLLVENMGR

$0.04 \% \quad 9.7 \%$ GSQFGQSCCLR

$0.04 \% \quad 9.7 \% \quad$ LNLNNTVLSK

$\begin{array}{llll}0.04 \% & 9.7 \% & \text { LNLNNTVLSKR }\end{array}$

$0.04 \% \quad 9.7 \%$ KVIDPVAPR

$0.04 \% \quad 9.7 \%$ VIDPVAPR

$0.04 \% \quad 9.7 \% \quad$ NPEVGLKPVWYSPK

$0.04 \% \quad 9.7 \%$ SLYDEVAAQGEVVR

$0.04 \% \quad 9.7 \%$ SLYDEVAAQGEVVRK

$0.04 \% \quad 9.7 \%$ NSEPAGLETPEAK

$0.04 \% \quad 9.7 \%$ VLFDKVASQGEVVR

$0.04 \% \quad 9.7 \%$ AIQGGTSHHLGQNFSK

$0.04 \% \quad 9.7 \%$ RLLSVNIR

$0.04 \% \quad 9.7 \%$ TTARDQDLEPGAPSMGAK

$\begin{array}{ccc}0.01 \% & 11.4 \% & \text { TGIPTLGKNVVVAGR }\end{array}$

$0.01 \% \quad 11.4 \%$ EGAAVIDVGINR

$0.01 \% \quad 11.4 \%$ LVGDVDFEGVR

$0.01 \% \quad 11.4 \%$ LVGDVDFEGVRQK

$0.00 \% \quad 3.7 \%$ VVACNLYPFVK

$0.00 \% \quad 3.7 \%$ TLTPISAAYAR

$0.00 \% \quad 1.9 \%$ GKLSSSFSSR

$0.00 \% \quad 1.9 \%$ LGLHVTPSNVDQVSTPPAAK

$0.03 \% \quad 11.0 \%$ APAEILNGKEISAQIR $\begin{array}{llll} & & & \\ 9 & 57.6 & 25.0 & 57.6\end{array}$

$\begin{array}{llll}95.3 \% & 15.1 & 25.0 & 15.1\end{array}$

$\begin{array}{llll}99.7 \% & 55.8 & 25.0 & 55.7\end{array}$

$99.7 \% \quad 40.0 \quad 25.0 \quad 28.6$

$\begin{array}{llll}96.3 \% & 16.2 & 25.0 & 15.6\end{array}$

$\begin{array}{llll}98.8 \% & 21.2 & 25.0 & 15.9\end{array}$

$97.1 \% \quad 15.9 \quad 25.0 \quad 15.9$

$99.7 \% \quad 31.4 \quad 25.0 \quad 20.6$

$94.9 \% \quad 16.0 \quad 25.0 \quad 13.1$

$\begin{array}{llll}99.4 \% & 21.7 & 25.0 & 17.8\end{array}$

$99.7 \% \quad 35.6 \quad 25.0 \quad 31.6$

$99.7 \% \quad 33.4 \quad 25.0 \quad 27.5$

$99.7 \% \quad 41.0 \quad 25.0 \quad 41.0$

$95.5 \% \quad 14.8 \quad 25.0 \quad 14.8$

$99.7 \% \quad 28.1 \quad 25.0 \quad 28.1$

$98.6 \% \quad 17.4 \quad 25.0 \quad 17.4$

$99.7 \% \quad 36.9 \quad 25.0 \quad 36.9$

$\begin{array}{llll}99.7 \% & 61.1 & 25.0 & 60.4\end{array}$

$99.7 \% \quad 68.8 \quad 25.0 \quad 63.3 \quad 2$

$\begin{array}{llll}99.7 \% & 37.0 & 25.0 & 31.9\end{array}$

$\begin{array}{llll}99.7 \% & 26.6 & 25.0 & 26.6\end{array}$

$\begin{array}{llll}99.7 \% & 43.2 & 25.0 & 41.8\end{array}$

$99.7 \% \quad 51.0 \quad 25.0 \quad 51.0$

$99.7 \% \quad 48.0 \quad 25.0 \quad 44.4$

$99.7 \% \quad 31.2 \quad 25.0 \quad 31.2$

$\begin{array}{llll}99.7 \% & 38.8 & 25.0 & 34.7\end{array}$

$\begin{array}{llll}99.6 \% & 27.2 & 25.0 & 22.8\end{array}$

$\begin{array}{llll}99.4 \% & 22.3 & 25.0 & 19.5\end{array}$

$\begin{array}{llll}99.0 \% & 20.6 & 25.0 & 20.6\end{array}$

$\begin{array}{lllll}98.4 \% & 23.1 & 25.0 & 23.1\end{array}$

$\begin{array}{llll}99.7 \% & 58.2 & 25.0 & 53.4\end{array}$

$\begin{array}{llll}99.7 \% & 28.6 & 25.0 & 28.6\end{array}$

$\begin{array}{llll}99.7 \% & 37.0 & 25.0 & 25.8\end{array}$

$\begin{array}{llll}99.7 \% & 48.4 & 25.0 & 42.1\end{array}$

$\begin{array}{llll}99.6 \% & 23.7 & 25.0 & 23.7\end{array}$

$\begin{array}{llll}97.9 \% & 29.9 & 25.0 & 5.8\end{array}$

$\begin{array}{llll}98.1 \% & 18.6 & 25.0 & 18.6\end{array}$

$\begin{array}{llll}96.8 \% & 15.8 & 25.0 & 14.3\end{array}$

$\begin{array}{llll}99.5 \% & 22.9 & 25.0 & 22.9\end{array}$

$\begin{array}{llll}99.7 \% & 42.3 & 25.0 & 33.7\end{array}$

$99.7 \% 47.6$

$99.7 \% \quad 50.6$

$99.4 \% \quad 22.0$

$99.1 \% \quad 21.2$

$98.9 \% \quad 17.9$

$98.8 \% 21.5$

$99.7 \% \quad 53.0$
1167.71

1483.83

992.48

1746.85

1684.79

1803.86

1060.48

1309.65

1182.59

1508.80

1611.88

1308.76

2476.19

1586.85

1475.75

1299.56

1115.64

1271.74

994.60

866.51

1613.87

1535.77

1663.87

1342.65

1546.86

1681.84

970.62

1860.88

1958.02

1481.88

1213.65

1205.62

1461.77

1309.70

1163.64

1055.55

2031.09 1709.95 $\begin{array}{cc}19 & 335 \\ 40 & 352 \\ 14 & 429 \\ 30 & 439 \\ 61 & 475 \\ 93 & 504 \\ 05 & 517 \\ 25 & 534 \\ 37 & 548 \\ 70 & 580 \\ 87 & 599 \\ 23 & 631 \\ 23 & 637 \\ 32 & 645 \\ 29 & 842 \\ 1 & 38 \\ 9 & 49 \\ 0 & 59 \\ 86 & 299 \\ 84 & 399 \\ 00 & 410 \\ 20 & 442 \\ 43 & 457 \\ 69 & 482 \\ 29 & 339 \\ 26 & 435 \\ 26 & 436 \\ 98 & 506 \\ 99 & 506 \\ 36 & 549 \\ 25 & 838 \\ 25 & 839 \\ 90 & 902 \\ 03 & 916 \\ 33 & 1250 \\ 33 & 1340 \\ 60 & 1477 \\ 78 & 1494 \\ 87 & 201 \\ 67 & 278 \\ 89 & 299 \\ 89 & 301 \\ 8 & 108 \\ 95 & 305 \\ 76 & 1285 \\ 33 & 1552 \\ 2 & 17\end{array}$

Page 26 of Table S-1-2 
C-1-tetrahydrofolate synthase, cytoplasmic GN=MTHFD1 C1TC_HUMAN $101.56 \quad 100.0 \%$ C-1-tetrahydrofolate synthase, cytoplasmic GN=MTHFD1 C1TC_HUMAN $101.56 \quad 100.0 \%$ C-1-tetrahydrofolate synthase, cytoplasmic GN=MTHFD1 C1TC_HUMAN $101.56 \quad 100.0 \%$ C-1-tetrahydrofolate synthase, cytoplasmic GN=MTHFD1 C1TC_HUMAN $101.56 \quad 100.0 \%$ C-1-tetrahydrofolate synthase, cytoplasmic GN=MTHFD1 C1TC_HUMAN $101.56 \quad 100.0 \%$ C-1-tetrahydrofolate synthase, cytoplasmic GN=MTHFD1 C1TC_HUMAN $101.56 \quad 100.0 \%$ C-1-tetrahydrofolate synthase, cytoplasmic GN=MTHFD1 C1TC_HUMAN $101.56 \quad 100.0 \%$ $\mathrm{CAD}$ protein $\mathrm{GN}=\mathrm{CAD}$ $\mathrm{CAD}$ protein $\mathrm{GN}=\mathrm{CAD}$ $\mathrm{CAD}$ protein $\mathrm{GN}=\mathrm{CAD}$ $\mathrm{CAD}$ protein $\mathrm{GN}=\mathrm{CAD}$ $\mathrm{CAD}$ protein $\mathrm{GN}=\mathrm{CAD}$ $\mathrm{CAD}$ protein $\mathrm{GN}=\mathrm{CAD}$ $\mathrm{CAD}$ protein $\mathrm{GN}=\mathrm{CAD}$

$\mathrm{CAD}$ protein $\mathrm{GN}=\mathrm{CAD}$ $\mathrm{CAD}$ protein $\mathrm{GN}=\mathrm{CAD}$ $\mathrm{CAD}$ protein $\mathrm{GN}=\mathrm{CAD}$ $\mathrm{CAD}$ protein $\mathrm{GN}=\mathrm{CAD}$ $\mathrm{CAD}$ protein $\mathrm{GN}=\mathrm{CAD}$ CAD protein $\mathrm{GN}=\mathrm{CAD}$ $\mathrm{CAD}$ protein $\mathrm{GN}=\mathrm{CAD}$ $\mathrm{CAD}$ protein $\mathrm{GN}=\mathrm{CAD}$ $\mathrm{CAD}$ protein $\mathrm{GN}=\mathrm{CAD}$ $\mathrm{CAD}$ protein $\mathrm{GN}=\mathrm{CAD}$ $\mathrm{CAD}$ protein $\mathrm{GN}=\mathrm{CAD}$ $\mathrm{CAD}$ protein $\mathrm{GN}=\mathrm{CAD}$ $\mathrm{CAD}$ protein $\mathrm{GN}=\mathrm{CAD}$ $\mathrm{CAD}$ protein $\mathrm{GN}=\mathrm{CAD}$ $\mathrm{CAD}$ protein $\mathrm{GN}=\mathrm{CAD}$ $\mathrm{CAD}$ protein $\mathrm{GN}=\mathrm{CAD}$ $\mathrm{CAD}$ protein $\mathrm{GN}=\mathrm{CAD}$ $\mathrm{CAD}$ protein $\mathrm{GN}=\mathrm{CAD}$ $\mathrm{CAD}$ protein $\mathrm{GN}=\mathrm{CAD}$ $\mathrm{CAD}$ protein $\mathrm{GN}=\mathrm{CAD}$ $\mathrm{CAD}$ protein $\mathrm{GN}=\mathrm{CAD}$ $\mathrm{CAD}$ protein $\mathrm{GN}=\mathrm{CAD}$ $\mathrm{CAD}$ protein $\mathrm{GN}=\mathrm{CAD}$ $\mathrm{CAD}$ protein $\mathrm{GN}=\mathrm{CAD}$ $\mathrm{CAD}$ protein $\mathrm{GN}=\mathrm{CAD}$ $\mathrm{CAD}$ protein $\mathrm{GN}=\mathrm{CAD}$ $\mathrm{CAD}$ protein $\mathrm{GN}=\mathrm{CAD}$ PYR1_HUMAN $242.98 \quad 100.0 \%$ PYR1_HUMAN $242.98 \quad 100.0 \%$ PYR1_HUMAN $242.98 \quad 100.0 \%$ PYR1_HUMAN $242.98 \quad 100.0 \%$ PYR1_HUMAN $242.98 \quad 100.0 \%$ PYR1_HUMAN $242.98 \quad 100.0 \%$ PYR1_HUMAN $242.98 \quad 100.0 \%$ PYR1_HUMAN $242.98 \quad 100.0 \%$ PYR1_HUMAN $242.98 \quad 100.0 \%$ PYR1_HUMAN $242.98 \quad 100.0 \%$ PYR1_HUMAN $242.98 \quad 100.0 \%$ PYR1_HUMAN $242.98 \quad 100.0 \%$ PYR1 HUMAN $242.98 \quad 100.0 \%$ PYR1_HUMAN $242.98 \quad 100.0 \%$ PYR1_HUMAN $242.98 \quad 100.0 \%$ PYR1_HUMAN $242.98 \quad 100.0 \%$ PYR1_HUMAN $242.98 \quad 100.0 \%$ PYR1_HUMAN $242.98 \quad 100.0 \%$ PYR1_HUMAN $242.98 \quad 100.0 \%$ PYR1_HUMAN $242.98 \quad 100.0 \%$ PYR1_HUMAN $242.98 \quad 100.0 \%$ PYR1_HUMAN $242.98 \quad 100.0 \%$ PYR1_HUMAN $242.98 \quad 100.0 \%$ PYR1_HUMAN $242.98 \quad 100.0 \%$ PYR1_HUMAN $242.98 \quad 100.0 \%$ PYR1_HUMAN $242.98 \quad 100.0 \%$ PYR1_HUMAN $242.98 \quad 100.0 \% \quad 34$ PYR1_HUMAN $242.98 \quad 100.0 \% \quad 34$ PYR1_HUMAN $242.98 \quad 100.0 \% \quad 34$ PYR1_HUMAN $242.98 \quad 100.0 \% \quad 34$ PYR1 HUMAN $242.98 \quad 100.0 \% \quad 34$ PYR1_HUMAN $242.98 \quad 100.0 \% \quad 34$ PYR1_HUMAN $242.98 \quad 100.0 \% \quad 34$ $\begin{array}{rrrr}\text { PYR1_HUMAN } & 242.98 & 100.0 \% & 34 \\ \text { A12 CMC1_HUMAN } & 74.76 & 100.0 \% & 2\end{array}$ Calcium-binding mitochondrial carrier protein Aralarl GN=SLC25A12 CMC1_HUMAN $74.76 \quad 100.0 \%$ Calcium-binding mitochondrial carrier protein Aralarl GN=SLC25A12 CMC1_HUMAN $74.76 \quad 100.0 \%$ Calcium-binding mitochondrial carrier protein Aralarl GN=SLC25A12 CMC1_HUMAN $74.76 \quad 100.0 \%$ Calcium-binding mitochondrial carrier protein Aralar1 GN=SLC25A12 CMC1_HUMAN $74.76 \quad 100.0 \%$ Calcium-binding mitochondrial carrier protein Aralarl GN=SLC25A12 CMC1_HUMAN $74.76 \quad 100.0 \%$ $0.03 \% \quad 11.0 \%$ VVGDVAYDI $0.03 \% \quad 11.0 \%$ TPVPSDIDISR $0.03 \% \quad 11.0 \%$ VLLSALER $0.03 \% \quad 11.0 \%$ YVVVTGITPTPLGEGK $0.03 \% \quad 11.0 \%$ VLDTNDRFLR $0.03 \% \quad 11.0 \%$ YSGLCPHVVVLVATVR $0.11 \% \quad 16.0 \%$ VFNTGGAPR $0.11 \% \quad 16.0 \%$ ILALDCGLK $0.11 \% \quad 16.0 \%$ ILALDCGLKYNQIR $0.11 \% \quad 16.0 \%$ GHNQPCLLVGSGR $0.11 \% \quad 16.0 \%$ EATAGNPGGQTVR $0.11 \% \quad 16.0 \%$ LGYPVLVR $0.11 \% \quad 16.0 \%$ ATGYPLAYVAAK $0.11 \% \quad 16.0 \%$ LALGIPLPELR $0.11 \% \quad 16.0 \%$ NSVTGGTAAFEPSVDYCVVK $0.11 \% \quad 16.0 \%$ SVGEVMGIGR $0.11 \% \quad 16.0 \%$ SFEEAFQK $0.11 \% \quad 16.0 \%$ IIAHAQLLEQHR $0.11 \% \quad 16.0 \%$ GQPLPPDLLQQAK $0.11 \% \quad 16.0 \%$ TPHVLVLGSGVYR $0.11 \% \quad 16.0 \%$ VLGTSPEAIDSAENR $0.11 \% \quad 16.0 \%$ VLGTSPEAIDSAENRFK $0.11 \% \quad 16.0 \%$ LLDTIGISQPQWR $0.11 \% \quad 16.0 \%$ ELSDLESAR $0.11 \% \quad 16.0 \%$ FLSSAAAVSK $0.11 \% \quad 16.0 \%$ EHPVVISK

$0.11 \% \quad 16.0 \%$ TLGVDLVALATR $0.11 \% \quad 16.0 \%$ VPQFSFSR $0.11 \% \quad 16.0 \%$ KNILLTIGSYK $0.11 \% \quad 16.0 \%$ NKSELLPTVR $0.11 \% \quad 16.0 \%$ SELLPTVR $0.11 \% \quad 16.0 \%$ VHVDCMTSQK $0.11 \% \quad 16.0 \%$ KEEILLIK $0.11 \% \quad 16.0 \%$ AHWTPFEGQK $0.11 \% \quad 16.0 \%$ ASDPGLPAEEPKEK $0.11 \% \quad 16.0 \%$ TSSSFAAAMAR $0.11 \% \quad 16.0 \%$ LGGAVLSFSEATSSVQK $0.11 \% \quad 16.0 \%$ YVAPPSLR $0.11 \% \quad 16.0 \%$ VNEISVEVDSDPR $0.11 \% \quad 16.0 \%$ MALLATVLGRF $0.01 \% \quad 12.5 \%$ IAPLAEGALPYNLAELQR $0.01 \% \quad 12.5 \%$ VLRYEGFFGLYR $0.01 \% \quad 12.5 \%$ YEGFFGLYR $0.01 \% \quad 12.5 \%$ GLIPQLIGVAPEK $0.01 \% \quad 12.5 \%$ AIKLTVNDFVR $0.01 \% \quad 12.5 \%$ LTVNDFVR $\begin{array}{llllllll}99.3 \% & 21.1 & 25.0 & 20.5 & 2 & 0 & 0 & 1536.68\end{array}$ $99.7 \% \quad 65.4-25.0-61.5$ $99.7 \% \quad 43.4 \quad 25.0 \quad 41.6 \quad 2$ $99.0 \% \quad 52.2 \quad 25.0 \quad 35.3$ $\begin{array}{llll}99.7 \% & 51.7 & 25.0 & 51.7\end{array}$ $\begin{array}{llll}98.0 \% & 18.9 & 25.0 & 14.6\end{array}$ $99.7 \% \quad 51.1 \quad 25.0 \quad 50.8$ $99.7 \% \quad 61.1 \quad 25.0 \quad 44.3$ $96.9 \% \quad 27.7 \quad 25.0 \quad 8.7$ $\begin{array}{llll}98.5 \% & 23.6 & 25.0 & 20.0\end{array}$ $99.7 \% \quad 34.5 \quad 25.0 \quad 34.5 \quad 2$ $99.7 \% \quad 36.4 \quad 25.0 \quad 36.2$ $99.0 \% \quad 44.5 \quad 25.0 \quad 39.2$ $\begin{array}{llll}99.7 \% & 38.8 & 25.0 & 38.8\end{array}$ $\begin{array}{llll}99.7 \% & 36.5 & 25.0 & 36.5\end{array}$ $\begin{array}{lllll}99.7 \% & 44.5 & 25.0 & 44.5 & 2\end{array}$ $\begin{array}{llll}99.7 \% & 41.6 & 25.0 & 32.7\end{array}$ $99.0 \% \quad 33.3 \quad 25.0 \quad 20.6$ $\begin{array}{llll}99.7 \% & 30.5 & 25.0 & 28.6\end{array}$ $\begin{array}{llll}97.1 \% & 16.6 & 25.0 & 16.6\end{array}$ $\begin{array}{llll}99.3 \% & 19.8 & 25.0 & 19.7\end{array}$ $\begin{array}{llll}99.7 \% & 62.3 & 25.0 & 62.3\end{array}$ $\begin{array}{llll}99.7 \% & 39.4 & 25.0 & 39.4\end{array}$ $\begin{array}{lllll}99.7 \% & 49.9 & 25.0 & 47.3\end{array}$ $99.7 \% \quad 48.2 \quad 25.0 \quad 40.0 \quad 2$ $\begin{array}{llll}97.9 \% & 23.1 & 25.0 & 11.9\end{array}$ $\begin{array}{llll}98.1 \% & 20.4 & 25.0 & 13.8\end{array}$ $\begin{array}{llll}99.7 \% & 57.6 & 25.0 & 49.0\end{array}$ $99.0 \% \quad 35.6 \quad 25.0 \quad 32.0$ $\begin{array}{llll}99.7 \% & 37.5 & 25.0 & 37.5\end{array}$ $99.7 \% \quad 41.5 \quad 25.0 \quad 35.9$ $\begin{array}{llll}99.0 \% & 28.1 & 25.0 & 28.1\end{array}$ $\begin{array}{llll}99.7 \% & 29.8 & 25.0 & 29.8\end{array}$ $\begin{array}{lllll}98.4 \% & 25.1 & 25.0 & 13.2 & 2\end{array}$ $\begin{array}{llll}99.7 \% & 40.0 & 25.0 & 32.8\end{array}$ $\begin{array}{llll}99.7 \% & 42.1 & 25.0 & 40.8\end{array}$ $\begin{array}{lllll}99.7 \% & 59.2 & 25.0 & 57.3 & 4\end{array}$ $\begin{array}{lllll}99.7 \% & 49.5 & 25.0 & 49.5 & 2\end{array}$ $\begin{array}{llll}99.0 \% & 24.1 & 25.0 & 24.1\end{array}$ $99.7 \% \quad 61.6 \quad 25.0 \quad 51.6$ $\begin{array}{llll}99.7 \% & 60.8 & 25.0 & 58.1\end{array}$ $\begin{array}{lllll}99.7 \% & 42.6 & 25.0 & 42.2 & 2\end{array}$ $\begin{array}{llll}99.1 \% & 19.3 & 25.0 & 19.1 \\ 99.7 \% & 48.4 & 25.0 & 46.0\end{array}$ $\begin{array}{lllll}99.0 \% & 50.3 & 25.0 & 0.0 & 2\end{array}$ $\begin{array}{llll}99.7 \% & 42.7 & 25.0 & 42.7\end{array}$ $\begin{array}{llll}99.0 \% & 55.5 & 25.0 & 49.7\end{array}$

1
0
0
0
1
1
0
0
0
2
0
0
0
0
0
0
0
0
0
0
0
2
2
0
0
0
0
0
0
0
0
0
0
0
0
0
0
0
0
0
0
0
0
0
0
0
0
0
0
0
0
0
0
0
0
0
0
0
0
0
0
0
0
1450.72

1199.63

900.55

1630.91

1248.67

1769.97

918.48

1002.57

1676.92

1394.70

1257.62

916.56

1224.66

1191.75

2100.99

1020.5

985.46

1428.81

1404.78

1397.79

1558.77

1833.93

1526.83

1019.50

980.54

908.52

1228.73

967.50

1249.75

1156.67

914.53

1204.55

985.63

1200.58

1467.73

1115.51

1680.88

902.51

1458.7

1207.69

1939.06

1519.81

1151.55

1334.80

1275.74

963.53

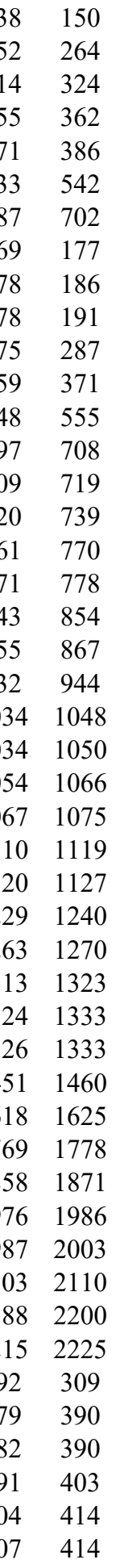

Page 27 of Table S-1-2 
$0.01 \%-12.5 \%$ VSALNVLR

$0.01 \% \quad 12.5 \%$ TRLQVAAR

$0.01 \% \quad 12.5 \%$ AGQTTYSGVIDCFR

$0.01 \% \quad 12.5 \%$ AGQTTYSGVIDCFRK

$0.06 \% \quad 31.0 \%$ YLNIFGESQPNPK

$0.06 \% 31.0 \%$ TVELLSGVVDQTK

$0.06 \% \quad 31.0 \%$ DVEVTKEEFVLAAQK

$0.06 \% \quad 31.0 \%$ MTLADIER

$0.06 \% \quad 31.0 \%$ IAPLEEGTLPFNLAEAQR $99.7 \% \quad 57.7$

$0.06 \% \quad 31.0 \%$ IAPLEEGTLPFNLAEAQRQK $\quad 99.1 \% \quad 18.4$

$0.06 \% \quad 31.0 \%$ ASGDSARPVLLQVAESAYR $99.7 \% \quad 60.2$

$0.06 \% \quad 31.0 \%$ FGLGSVAGAVGATAVYPIDLVK $99.1 \% \quad 23.2$

$0.06 \% \quad 31.0 \%$ STGSFVGELMYK

$0.06 \% \quad 31.0 \%$ VLRYEGFFGLYR

$0.06 \% 31.0 \%$ YEGFFGLYR

$0.06 \% 31.0 \%$ GLLPQLLGVAPEK

$0.06 \% 31.0 \%$ AIKLTVNDFVR

$0.06 \% \quad 31.0 \%$ LTVNDFVR

$0.06 \% \quad 31.0 \%$ VSALSVVR

$0.06 \% 31.0 \%$ DLGFFGIYK

$0.06 \% \quad 31.0 \%$ DLGFFGIYKGAK

$0.06 \% \quad 31.0 \%$ TRLQVAAR

$0.06 \% \quad 31.0 \%$ AGQTTYSGVIDCFR

$0.06 \% \quad 31.0 \%$ AGQTTYSGVIDCFRK

$0.06 \% \quad 31.0 \%$ ILREEGPK

$0.07 \% \quad 18.9 \%$ QLLAGGIAGAVSR

$0.07 \% \quad 18.9 \%$ TSTAPLDRLK

$0.07 \% \quad 18.9 \%$ IMMQVHGSK

$0.07 \% \quad 18.9 \%$ SDKMNIFGGFR

$0.07 \% \quad 18.9 \%$ LLTEEGQKIGTFER

$0.07 \% \quad 18.9 \%$ TGQYSGIYDCAK

$0.07 \% \quad 18.9 \%$ TGQYSGIYDCAKK

$0.07 \% \quad 18.9 \%$ IISKEGIPGLYR

$0.07 \% \quad 18.9 \%$ EGIPGLYR

$0.07 \% \quad 18.9 \%$ GITPNFMK

$0.01 \% \quad 4.9 \% \quad$ LLLSAELYCR

$0.01 \% \quad 4.9 \%$ ASPAAPADGAAPAQPSIR

$0.01 \% \quad 4.9 \%$ RSPGPGPSQSPR

$0.01 \% \quad 4.9 \%$ APAEEEVGPR

\section{$0.01 \% \quad 4.9 \%$ SGCCDDSALAR}

$0.03 \% \quad 28.5 \%$ LFSGDVVLTAR

\section{$99.7 \% \quad 53.7$}

$99.1 \% \quad 19.3$

$99.7 \% \quad 48.4$

$99.0 \% \quad 50.3$

$\begin{array}{lll}99.7 \% & 42.7\end{array}$

$99.0 \% \quad 55.5$

$99.0 \% \quad 51.0$

$99.7 \% \quad 27.3$

$99.7 \% \quad 45.1$

$99.0 \% \quad 34.5$

$99.7 \% \quad 61.1$

$99.7 \% \quad 43.2$

$99.0 \% \quad 37.9$

$99.7 \% \quad 79.1$

$99.7 \% \quad 31.3$

$99.7 \% \quad 36.0$

$99.7 \% \quad 46.2$

$99.7 \% \quad 60.2$

$99.7 \% \quad 56.5$

$99.7 \% \quad 46.5$

$99.7 \% \quad 40.2$

$99.0 \% \quad 24.5$

$98.3 \% \quad 24.6$

$99.7 \% \quad 53.5$

$99.7 \% \quad 54.8$

$98.3 \% \quad 22.2$

$99.7 \% \quad 57.3$

$99.7 \% \quad 39.3$

$99.7 \% \quad 58.5$

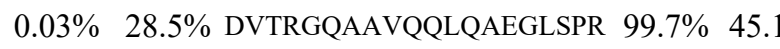

$0.03 \% \quad 28.5 \%$ GQAAVQQLQAEGLSPR $\quad 99.7 \% \quad 61.2$

$0.03 \% \quad 28.5 \%$ EYGGLDVLVNNAGIAFK

$0.03 \% \quad 28.5 \%$ VVNVSSIMSVR

$0.03 \% \quad 28.5 \%$ ALKSCSPELQQK

$\begin{array}{llll}99.7 \% & 52.4 & 25.0 & 52.4 \\ 99.7 \% & 59.3 & 25.0 & 56.0\end{array}$

$\begin{array}{llll}98.7 \% & 19.8 & 25.0 & 17.7\end{array}$

$99.0 \% \quad 39.0 \quad 25.0 \quad 0.0$
914.55

1574.73

1702.82

1506.76

1388.76

1705.90

948.48

1969.04

2225.19

1990.04

2105.16

1318.63

1519.81

1151.55

1334.80

1275.74

963.53

830.51

1059.55

1315.70

914.55

1574.73

1702.82

941.54

1212.71

1101.63

1030.52

1271.62

1620.86

1362.60

1490.69

1345.78

904.49

907.47

1237.66

1647.85

1222.63

1054.52

1211.48

1177.66

2124.12

1652.87

1779.93

1190.66

1388.72

844.53

\begin{tabular}{cc}
66 & 473 \\
44 & 551 \\
52 & 565 \\
52 & 566 \\
4 & 56 \\
7 & 69 \\
46 & 260 \\
85 & 292 \\
93 & 310 \\
93 & 312 \\
13 & 331 \\
32 & 353 \\
61 & 372 \\
81 & 392 \\
84 & 392 \\
93 & 405 \\
06 & 416 \\
09 & 416 \\
68 & 475 \\
76 & 484 \\
76 & 487 \\
46 & 553 \\
54 & 567 \\
54 & 568 \\
69 & 576 \\
97 & 209 \\
10 & 219 \\
20 & 228 \\
29 & 239 \\
78 & 291 \\
21 & 332 \\
21 & 333 \\
34 & 445 \\
38 & 445 \\
46 & 453 \\
7 & 86 \\
92 & 209 \\
68 & 779 \\
64 & 973 \\
20 & 1030 \\
8 & 38 \\
9 & 58 \\
35 & 58 \\
46 & 145 \\
99 & 206 \\
& \\
\hline 9
\end{tabular}

Page 28 of Table S-1-2 
Casein kinase II subunit alpha' GN=CSNK2A2 CSK22_HUMAN $41.21 \quad 100.0 \%$ Casein kinase II subunit alpha' GN=CSNK2A2 CSK22_HUMAN $41.21 \quad 100.0 \%$ Cat eye syndrome critical region protein 5 GN=CECR5 CECR5_HUMAN $46.32 \quad 100.0 \%$ Cat eye syndrome critical region protein $5 \mathrm{GN}=\mathrm{CECR} 5$ CECR5 HUMAN $46.32100 .0^{\circ}$ Cat eye syndrome critical region protein $5 \mathrm{GN}=\mathrm{CECR} 5$ CECR5_HUMAN $46.32 \quad 100.0 \%$ Catenin delta- $1 \mathrm{GN}=\mathrm{CTNND} 1$

Catenin delta-1 GN=CTNND1 CTND1_HUMAN $108.17 \quad 100.0 \%$ CTND1 HUMAN $108.17 \quad 100.0 \%$ CTND1_HUMAN $108.17 \quad 100.0 \%$ CCR4-NOT transcription complex subunit $1 \mathrm{GN}=\mathrm{CNOT1}$ CNOT1 HUMAN $266.94 \quad 100.0 \%$ CCR4-NOT transcription complex subunit $1 \mathrm{GN}=\mathrm{CNOT1}$ CNOT1_HUMAN $266.94 \quad 100.0 \%$ CCR4-NOT transcription complex subunit $1 \mathrm{GN}=\mathrm{CNOT1}$ CNOT1_HUMAN $266.94 \quad 100.0 \%$ Cell cycle and apoptosis regulator protein $2 \mathrm{GN}=$ CCAR2 CCAR2_HUMAN $102.90 \quad 100.0 \%$ Cell cycle and apoptosis regulator protein $2 \mathrm{GN}=\mathrm{CCAR} 2$ CCAR2_HUMAN $102.90 \quad 100.0 \%$ Cell differentiation protein RCD1 homolog GN=RQCD1 RCD1 HUMAN $33.63 \quad 100.0 \%$ Cell differentiation protein RCD1 homolog GN=RQCD1 RCD1_HUMAN $33.63 \quad 100.0 \%$ Cell division control protein 45 homolog GN=CDC45 CDC45_HUMAN $65.57 \quad 100.0 \%$ Cell division control protein 45 homolog $\mathrm{GN}=\mathrm{CDC} 45 \mathrm{CDC} 45$ HUMAN $65.57 \quad 100.0 \%$ Cell division cycle 5-like protein GN=CDC5L CDC5L_HUMAN $92.25 \quad 100.0 \%$ Cell division cycle 5-like protein GN=CDC5L CDC5L_HUMAN $92.25 \quad 100.0 \%$ Cell division cycle protein 23 homolog GN=CDC23 CDC23_HUMAN $68.84 \quad 100.0 \%$ Cell division cycle protein 23 homolog GN=CDC23 CDC23_HUMAN $68.84 \quad 100.0 \%$ Cell growth-regulating nucleolar protein GN=LYAR LYAR HUMAN $43.62 \quad 100.0 \%$ Cell growth-regulating nucleolar protein GN=LYAR LYAR_HUMAN $43.62 \quad 100.0 \%$ Cell growth-regulating nucleolar protein GN=LYAR LYAR_HUMAN $43.62 \quad 100.0 \%$ Cell growth-regulating nucleolar protein GN=LYAR LYAR HUMAN $43.62 \quad 100.0 \%$ Cell growth-regulating nucleolar protein GN=LYAR LYAR_HUMAN $43.62 \quad 100.0 \%$ Cell growth-regulating nucleolar protein GN=LYAR LYAR_HUMAN $43.62 \quad 100.0 \%$ Cell growth-regulating nucleolar protein GN=LYAR LYAR_HUMAN $43.62 \quad 100.0 \%$ Cell growth-regulating nucleolar protein GN=LYAR LYAR_HUMAN $43.62 \quad 100.0 \%$ Cellular tumor antigen p53 GN=TP53 Cellular tumor antigen $\mathrm{p} 53 \mathrm{GN}=\mathrm{TP} 53$ Cellular tumor antigen $\mathrm{p} 53 \mathrm{GN}=\mathrm{TP} 53$ Cellular tumor antigen $\mathrm{p} 53 \mathrm{GN}=\mathrm{TP} 53$ Centromere protein $\mathrm{V}$ GN $=\mathrm{CENPV}$ Centromere protein $\mathrm{V}$ GN $=\mathrm{CENPV}$ Centromere protein $\mathrm{V} \mathrm{GN}=\mathrm{CENPV}$ Centromere protein $\mathrm{V} \mathrm{GN}=\mathrm{CENPV}$ Centromere protein $\mathrm{V}$ GN $=\mathrm{CENPV}$ Centromere protein $\mathrm{V} \mathrm{GN}=\mathrm{CENPV}$ Centromere protein V GN $=\mathrm{CENPV}$ P53 HUMAN $43.65 \quad 100.0 \%$ P53_HUMAN $43.65 \quad 100.0 \%$ P53_HUMAN $43.65 \quad 100.0 \%$ P53 HUMAN $43.65 \quad 100.0 \%$ CENPV_HUMAN $29.95 \quad 100.0 \%$ CENPV_HUMAN $29.95 \quad 100.0 \%$ CENPV_HUMAN $29.95 \quad 100.0 \%$ CENPV_HUMAN $29.95 \quad 100.0 \%$ CENPV HUMAN $29.95 \quad 100.0 \%$ CENPV_HUMAN $29.95 \quad 100.0 \%$ CENPV_HUMAN $29.95 \quad 100.0 \%$ Centromere/kinetochore protein Zw10 homolog GN=ZW10 ZW10_HUMAN $88.83 \quad 100.0 \%$ Centromere/kinetochore protein Zw10 homolog GN=ZW10 ZW10_HUMAN $88.83 \quad 100.0 \%$ Centromere/kinetochore protein Zw10 homolog GN=ZW10 ZW10 HUMAN $88.83 \quad 100.0 \%$ Centromere/kinetochore protein Zw10 homolog GN=ZW10 ZW10_HUMAN $88.83 \quad 100.0 \%$ Charged multivesicular body protein 4b GN=CHMP4B CHM4B_HUMAN $24.95 \quad 100.0 \%$ Charged multivesicular body protein $4 \mathrm{~b}$ GN=CHMP4B CHM4B_HUMAN $24.95 \quad 100.0 \%$ Charged multivesicular body protein 4b GN=CHMP4B CHM4B_HUMAN $24.95 \quad 100.0 \%$
$0.01 \% \quad 3.1 \% \quad$ ARVYAEVNSLR

$0.01 \% \quad 3.1 \% \quad$ VYAEVNSLR

$0.01 \% \quad 7.8 \%$ LVNSQGQLR

$0.01 \% \quad 7.8 \%$ NVVTVDELR

$0.01 \% \quad 7.8 \%$ ATHDGAPELGAGGTR

$0.01 \% \quad 4.0 \%$ GYELLFQPEVVR

$0.01 \% \quad 4.0 \%$ ALSAIADLLTNEHER

$0.01 \% \quad 4.0 \%$ SDFQVNLNNASR

$0.01 \% \quad 1.3 \%$ LAEVGQYEQVK

$0.01 \% \quad 1.3 \% \quad$ NLDEQLSAPK

$0.01 \% \quad 1.3 \%$ NLILSAFPR

$0.00 \% \quad 2.3 \% \quad$ VQTLSNQPLLK

$0.00 \% \quad 2.3 \% \quad$ VVTQNICQYR

$0.00 \% \quad 6.7 \%$ TVATFILQK

$0.00 \% \quad 6.7 \% \quad$ NLQEGQVTDPR

$0.00 \% \quad 3.9 \% \quad$ YVTDVGVLQR

$0.00 \% \quad 3.9 \%$ AFEKAAESTSSR

$0.00 \% \quad 2.1 \%$ TIAPIIGR

$0.00 \% \quad 2.1 \%$ ILLGGYQSR

$0.01 \% \quad 3.5 \%$ AYFDVKEYDR

$0.01 \% \quad 3.5 \% \quad$ VSPLNLSSVTP

$0.02 \% \quad 22.4 \%$ VFFTCNACGESVKK

$0.02 \% \quad 22.4 \%$ IQVEKHVSVCR

$0.02 \% \quad 22.4 \%$ CISEDQKYGGK

$0.02 \% \quad 22.4 \%$ ISELIKRPNVSPK

$0.02 \% \quad 22.4 \%$ VRELLEQISAFDNVPR

$0.02 \% \quad 22.4 \%$ ELLEQISAFDNVPR

$0.02 \% \quad 22.4 \%$ VKDAVEQQGEVK

$0.02 \% \quad 22.4 \%$ ISKNPTFK

$0.02 \% \quad 11.7 \%$ SVTCTYSPALNK

$0.02 \% \quad 11.7 \%$ SVTCTYSPALNKMFCQLAK

$0.02 \% \quad 11.7 \%$ ALPNNTSSSPQPK

$0.02 \% \quad 11.7 \%$ KKPLDGEYFTLQIR

$0.03 \% \quad 34.2 \%$ RSGASGASAAPAASAAAALAPSATR

$0.03 \% \quad 34.2 \%$ SQAVEKPPSEKPR

$0.03 \% \quad 34.2 \%$ LLLDTFEYQGLVK

$0.03 \% \quad 34.2 \%$ GAEHITTYTFNTHK

$0.03 \% \quad 34.2 \%$ CGVQSFYTPR

$0.03 \% 34.2 \%$ SNPGGFGIAPHCLDEGTVR

$0.01 \% \quad 6.7 \% \quad$ NCLVYSIPTNSSK

$0.01 \% \quad 6.7 \% \quad$ NLMTSEIHNTVK

$0.01 \% \quad 6.7 \%$ LGTECFLAQMR

$0.01 \% \quad 6.7 \% \quad$ NFSNMDDEENYSAASK

$0.01 \% \quad 9.8 \%$ AGKGGPTPQEAIQR

$0.01 \% \quad 9.8 \%$ GGPTPQEAIQR

$0.01 \% \quad 9.8 \%$ AALQALKR $\begin{array}{llllllll}99.7 \% & 37.9 & 25.0 & 35.4 & 2 & 0 & 0 & 1277.70\end{array}$

$\begin{array}{llll}99.3 \% & 20.7 & 25.0 & 20.7\end{array}$

$\begin{array}{llll}99.7 \% & 55.9 & 25.0 & 45.5\end{array}$

$99.7 \% \quad 35.2 \quad 25.0 \quad 35.2$

$\begin{array}{llll}99.7 \% & 38.4 & 25.0 & 38.4\end{array}$

$\begin{array}{llll}99.7 \% & 37.9 & 25.0 & 32.4\end{array}$

$98.7 \% \quad 17.6 \quad 25.0 \quad 17.6$

$\begin{array}{llll}99.7 \% & 41.6 & 25.0 & 41.6\end{array}$

$\begin{array}{llll}98.4 \% & 19.1 & 25.0 & 16.5\end{array}$

$99.7 \% \quad 40.9 \quad 25.0 \quad 37.8$

$\begin{array}{llll}99.7 \% & 43.0 & 25.0 & 28.7\end{array}$

$99.7 \% \quad 50.5 \quad 25.0 \quad 50.5$

$\begin{array}{llll}99.0 \% & 24.3 & 25.0 & 24.3\end{array}$

$\begin{array}{llll}99.1 \% & 20.0 & 25.0 & 18.5\end{array}$

$99.7 \% \quad 41.7 \quad 25.0 \quad 41.7$

$\begin{array}{llll}99.1 \% & 25.4 & 25.0 & 25.4\end{array}$

$\begin{array}{llll}99.7 \% & 52.7 & 25.0 & 52.7\end{array}$

$99.7 \% \quad 28.6 \quad 25.0 \quad 28.6$

$99.7 \% \quad 46.0 \quad 25.0 \quad 44.9$

$99.5 \% \quad 24.4 \quad 25.0 \quad 24.4$

$\begin{array}{llll}99.7 \% & 40.3 & 25.0 & 40.3\end{array}$

$\begin{array}{llll}99.7 \% & 58.1 & 25.0 & 55.1\end{array}$

$99.7 \% \quad 40.2 \quad 25.0 \quad 31.8$

$\begin{array}{llll}99.0 \% & 30.0 & 25.0 & 21.5\end{array}$

$\begin{array}{llll}99.7 \% & 49.2 & 25.0 & 49.2\end{array}$

$99.2 \% 21.9$

$99.7 \% \quad 30.5$

$99.7 \% \quad 28.9$

$25.0 \quad 21.9$

$25.0 \quad 25.5$

$\begin{array}{ll}25.0 & 26.5\end{array}$

$\begin{array}{lll}99.7 \% & 52.8\end{array}$

$99.7 \% \quad 40.6$

$99.7 \% \quad 62.0$

$\begin{array}{lll}99.7 \% & 42.4\end{array}$

$99.7 \% \quad 54.0$

$99.7 \% \quad 61.1$

$99.5 \% \quad 23.7$

$99.7 \% \quad 56.0$

$99.7 \% \quad 51.9$

$99.6 \% \quad 27.1$

$99.7 \% \quad 31.7$

$99.7 \% \quad 52.8$

$99.0 \% \quad 32.5$
1050.56

1014.57

1044.57

1409.68

1449.77

1652.86

12

74

153

$332 \quad 346$

$55 \quad 666$

$\begin{array}{lll}1364.66 & 847 \quad 858\end{array}$

1263.66

1114.57

1030.60

1240.73

1280.64

1020.61

1256.62

1149.63

1283.62

840.53

1006.57

1305.6

1113.62

1646.77

1354.73

1284.59

1480.88

1886.01

1630.84

1329.70

934.54

1340.65

2219.07

1340.68

1707.94

2141.11

1985.00

1452.78

1538.85

1619.78

1214.56

1983.93

1482.73

1386.70

1325.63

1821.72

1409.75

1153.60

870.55

20
20
82
161
346
666
725
858
470
1320
2138
123
757
188
292
247
536
91
727
101
597
15
26
61
93
109
109
185
369
132
139
319
333
41
41
65
147
210
228
247
357
424
594
624
28
28
71

Page 29 of Table S-1-2 
Clathrin heavy chain $1 \mathrm{GN}=\mathrm{CLTC}$

Clathrin heavy chain $1 \mathrm{GN}=\mathrm{CLTC}$

Clathrin heavy chain $1 \mathrm{GN}=\mathrm{CLTC}$

Clathrin heavy chain $1 \mathrm{GN}=\mathrm{CLTC}$

Clathrin heavy chain $1 \mathrm{GN}=\mathrm{CLTC}$

Clathrin heavy chain $1 \mathrm{GN}=\mathrm{CLTC}$

Clathrin heavy chain $1 \mathrm{GN}=\mathrm{CLTC}$

Clathrin heavy chain $1 \mathrm{GN}=\mathrm{CLTC}$
Clathrin heavy chain $1 \mathrm{GN}=\mathrm{CLTC}$

CLH1_HUMAN $191.62 \quad 100.0 \%$ CLH1_HUMAN $191.62 \quad 100.0 \%$ CLH1_HUMAN $191.62 \quad 100.0 \%$ CLH1_HUMAN $191.62 \quad 100.0 \%$ CLH1_HUMAN $191.62 \quad 100.0 \%$ CLH1_HUMAN $191.62 \quad 100.0 \%$ CLH1_HUMAN $191.62 \quad 100.0 \%$ CLH1_HUMAN $191.62 \quad 100.0 \%$ CLH1_HUMAN $191.62 \quad 100.0 \%$ 1 CPSF1_HUMAN $160.89 \quad 100.0 \%$ Cleavage and polyadenylation specificity factor subunit $1 \mathrm{GN}=\mathrm{CPSF} 1$ CPSF1_HUMAN $160.89 \quad 100.0 \%$ Cleavage and polyadenylation specificity factor subunit $1 \mathrm{GN}=\mathrm{CPSF} 1$ CPSF1_HUMAN $160.89100 .0 \%$ Cleavage and polyadenylation specificity factor subunit $1 \mathrm{GN}=$ CPSF1 $\quad$ CPSF1_HUMAN $160.89 \quad 100.0 \%$ Cleavage and polyadenylation specificity factor subunit $1 \mathrm{GN}=\mathrm{CPSF} 1$ CPSF1_HUMAN $160.89 \quad 100.0 \%$ Cleavage and polyadenylation specificity factor subunit $1 \mathrm{GN}=\mathrm{CPSF} 1 \quad \mathrm{CPSF} 1$ HUMAN $160.89100 .0 \%$ Cleavage and polyadenylation specificity factor subunit $2 \mathrm{GN}=\mathrm{CPSF} 2 \mathrm{CPSF} 2$ HUMAN $88.49 \quad 100.0 \%$ Cleavage and polyadenylation specificity factor subunit $2 \mathrm{GN}=\mathrm{CPSF} 2 \mathrm{CPSF} 2$ HUMAN $88.49 \quad 100.0 \%$ Cleavage and polyadenylation specificity factor subunit $4 \mathrm{GN}=\mathrm{CPSF} 4$ CPSF4_HUMAN $30.25 \quad 100.0 \%$ Cleavage and polyadenylation specificity factor subunit $4 \mathrm{GN}=\mathrm{CPSF} 4$ CPSF 4 HUMAN $30.25 \quad 100.0 \%$ Cleavage and polyadenylation specificity factor subunit 5 GN=NUDT21 CPSF5 HUMAN $26.23 \quad 100.0 \%$ Cleavage and polyadenylation specificity factor subunit $5 \mathrm{GN}=\mathrm{NUDT} 21$ CPSF5_HUMAN $26.23 \quad 100.0 \%$ Cleavage and polyadenylation specificity factor subunit $6 \mathrm{GN}=\mathrm{CPSF} 6$ CPSF6_HUMAN $59.21 \quad 100.0 \%$ Cleavage and polyadenylation specificity factor subunit $6 \mathrm{GN}=\mathrm{CPSF} 6 \quad \mathrm{CPSF} 6$ HUMAN $59.21 \quad 100.0 \%$ Cleavage and polyadenylation specificity factor subunit $6 \mathrm{GN}=\mathrm{CPSF} 6$ CPSF6_HUMAN $59.21 \quad 100.0 \%$ Cleavage and polyadenylation specificity factor subunit $6 \mathrm{GN}=\mathrm{CPSF} 6$ CPSF6_HUMAN $59.21 \quad 100.0 \%$ Cleavage and polyadenylation specificity factor subunit $6 \mathrm{GN}=$ CPSF 6 CPSF6 HUMAN $59.21 \quad 100.0 \%$ Cleavage and polyadenylation specificity factor subunit $6 \mathrm{GN}=\mathrm{CPSF} 6$ CPSF6_HUMAN $59.21 \quad 100.0 \%$ Cleavage and polyadenylation specificity factor subunit $6 \mathrm{GN}=\mathrm{CPSF} 6 \mathrm{CPSF} 6 \mathrm{HUMAN} 59.21 \quad 100.0 \%$ Coatomer subunit alpha $\mathrm{GN}=\mathrm{COPA}$ Coatomer subunit alpha $\mathrm{GN}=\mathrm{COPA}$ Coatomer subunit alpha $\mathrm{GN}=\mathrm{COPA}$ Coatomer subunit alpha $\mathrm{GN}=\mathrm{COPA}$

COPA_HUMAN $138.35 \quad 100.0 \%$ COPA_HUMAN $138.35 \quad 100.0 \%$ COPA HUMAN $138.35 \quad 100.0 \%$ COPA_HUMAN $138.35 \quad 100.0 \%$
$0.01 \% \quad 6.2 \%$ GVAGPRGQDPVSSPCG

$0.01 \% \quad 5.4 \%$ GGLFTALEKR

$0.03 \% \quad 6.9 \% \quad$ NNLAGAEELFAR

$0.03 \% \quad 6.9 \% \quad$ ALEHFTDLYDIKR

$0.03 \% \quad 5.3 \%$ VLVDSSFGQPTTQGEAR

$0.03 \% \quad 5.3 \%$ VYAVATSTNTPCAR

$0.00 \% \quad 4.5 \%$ QLIIVHGPPEASQDLAECCR

$0.01 \% \quad 10.8 \%$ SSSLIQLTSQNSSPNQQR

$0.02 \% \quad 17.1 \%$ GFALVGVGSEASSK

$0.02 \% \quad 17.1 \%$ TPLSEAEFEEIMNRNR
$0.01 \% \quad 6.2 \% \quad$ ETLLEIQK

$0.01 \% \quad 6.2 \%$ AFDVPDAEAR

$0.04 \% \quad 24.6 \%$ NKQPTPVNIR

$0.04 \% \quad 24.6 \%$ ASMQQQQQLASAR

$0.04 \% 24.6 \%$ LAQQMENRPSVQAALK

$0.04 \% \quad 24.6 \%$ LGKSNIQAR

$0.04 \% \quad 24.6 \%$ EQLDNQLDAYMSK

$0.01 \% \quad 5.4 \%$ GGQAPGFLLR

$0.01 \% \quad 5.4 \%$ FAPGLSCVTYAGDKEER

$0.01 \% \quad 5.4 \%$ GIPTYIYYFPR

$0.00 \% \quad 3.7 \%$ ITFPSSQQEAQNR

$0.00 \% \quad 3.7 \%$ NLIQTLVSGIAPATR

$0.00 \% \quad 3.7 \%$ SLYIRDLL

$0.03 \% \quad 6.9 \% \quad$ KFNALFAQGNYSEAAK

$0.03 \% \quad 6.9 \%$ SVDPTLALSVYLR

$0.03 \% \quad 6.9 \% \quad$ IYIDSNNNPER

$0.03 \% \quad 6.9 \%$ LLYNNVSNFGR

$0.03 \% \quad 6.9 \% \quad$ LASTLVHLGEYQAAVDGAR

$0.03 \% \quad 6.9 \%$ VANVELYYR

$0.03 \% \quad 6.9 \% \quad$ VKQLPLVKPYLR

$0.03 \% \quad 5.3 \%$ CAAMLVYGTR

$0.03 \% \quad 5.3 \%$ ESLAEEHEGLVGEGQR

$0.03 \% \quad 5.3 \%$ EVLLVALGSR

$0.03 \% \quad 5.3 \% \quad$ NVLDGELLNR

$0.00 \% \quad 4.5 \%$ LGLNCAIYATIPVYK

$0.01 \% \quad 10.8 \%$ SGAAVCEFFLK

$0.01 \% \quad 12.8 \%$ GVTQFGNKYIQQTKPLTLER

$0.01 \% \quad 12.8 \%$ LFLVQLQEK

$0.02 \% \quad 17.1 \%$ GFALVGVGSEASSKK

$0.02 \% \quad 17.1 \%$ RELHGQNPVVTPCNK

$0.02 \% \quad 17.1 \%$ QFLSQFEMQSR

$0.02 \% \quad 17.1 \%$ TTQSGQMSGEGKAGPPGGSS

$0.02 \% \quad 17.1 \%$ VLISSLQDCLHGIESK

$99.0 \% \quad 38.8 \quad 25.0 \quad 25.4$

$99.7 \% \quad 40.5$

$99.6 \% \quad 24.6$

$99.7 \% \quad 65.6$

$99.7 \% \quad 31.7$

$99.7 \% \quad 42.9$

$99.7 \% \quad 59.2$

$96.8 \% \quad 24.5$

$99.0 \% \quad 19.5$

$99.7 \% \quad 47.4$

$99.7 \% \quad 46.1$

$99.7 \% \quad 46.5$

$99.7 \% \quad 56.5$

$99.0 \% \quad 23.3$

$99.7 \% \quad 57.4$

$99.7 \% \quad 31.7$

$\begin{array}{lll}99.7 \% & 49.5\end{array}$

$99.7 \% \quad 48.8$

$99.7 \% \quad 40.4$

$99.7 \% \quad 52.7$

$99.7 \% 34.1$

$98.8 \% 21.1$

$99.7 \% \quad 30.2$

$99.7 \% \quad 36.5$

$98.1 \% \quad 17.6$

$99.7 \% \quad 57.6$

$99.7 \% \quad 55.9$

$99.7 \% \quad 47.4$

$99.7 \% \quad 43.5$

$99.7 \% \quad 28.8$

$99.7 \% \quad 26.6$

$99.7 \% \quad 26.9$

$9.7 \% \quad 69.0$

$99.7 \%$

$99.7 \% \quad 76.2$

$99.7 \% \quad 52.8$

$99.5 \% \quad 26.5$

$99.7 \% \quad 58.5$

$99.6 \% 29.4$

$99.6 \% \quad 22.9$

$99.7 \% \quad 34.3$

$99.7 \% \quad 39.9$

$0.03 \% \quad 8.8 \%$ GITGVDLFGTTDAVVK

$0.03 \% \quad 8.8 \%$ QLDFNSSKDVAVMQLR

$0.03 \% \quad 8.8 \% \quad$ ASNLENSTYDLYTIPK

$95.2 \% \quad 14.7$

$99.6 \% \quad 24.1$

$99.7 \% \quad 59.5$ 1090.52

1540.72

1166.66

1462.71

1783.95

986.57

1570.71

1015.57

1899.89

1091.62

1389.72

1505.73

1553.90

992.58

1304.66

1758.88

1433.80

1620.84

1334.63

1296.67

1971.03

1126.59

1453.93

1141.55

1739.82

1791.89

1056.64

1510.73

1142.62

1695.91

2293.11

1228.60

1974.98

2321.26

1117.66

1308.68

1436.77

1748.89

1400.66

1992.90

1951.92

1798.94

1592.85

1850.94

1828.90

1146.63

$\begin{array}{cc}32 & 139 \\ 44 & 453 \\ 36 & 551 \\ 9 & 38 \\ 9 & 51 \\ 5 & 70 \\ 9 & 87 \\ 14 & 226 \\ 0 & 19 \\ 17 & 133 \\ 49 & 758 \\ 67 & 877 \\ 17 & 729 \\ 35 & 749 \\ 68 & 975 \\ 55 & 366 \\ 67 & 382 \\ 69 & 481 \\ 26 & 638 \\ 82 & 892 \\ 16 & 1226 \\ 27 & 1245 \\ 98 & 1406 \\ 42 & 1453 \\ 49 & 158 \\ 67 & 182 \\ 17 & 833 \\ 48 & 857 \\ 33 & 1046 \\ 97 & 1406 \\ 8 & 92 \\ 60 & 579 \\ 6 & 46 \\ 00 & 217 \\ 6 & 35 \\ 74 & 182 \\ 25 & 138 \\ 25 & 139 \\ 47 & 161 \\ 62 & 172 \\ 74 & 194 \\ 07 & 422 \\ 68 & 483 \\ 83 & 198 \\ 43 & 358 \\ 83 & 398 \\ 13 & 423\end{array}$

Page 30 of Table S-1-2 
Coatomer subunit alpha $\mathrm{GN}=\mathrm{COPA}$ Coatomer subunit alpha $\mathrm{GN}=\mathrm{COPA}$ Coatomer subunit alpha $\mathrm{GN}=\mathrm{COPA}$ Coatomer subunit alpha $\mathrm{GN}=\mathrm{COPA}$ Coatomer subunit alpha $\mathrm{GN}=\mathrm{COPA}$ Coatomer subunit beta $\mathrm{GN}=\mathrm{COPB} 1$ Coatomer subunit beta $\mathrm{GN}=\mathrm{COPB} 1$ Coatomer subunit beta $\mathrm{GN}=\mathrm{COPB} 1$ Coatomer subunit beta $\mathrm{GN}=\mathrm{COPB} 1$ Coatomer subunit beta $\mathrm{GN}=\mathrm{COPB} 1$ Coatomer subunit beta $\mathrm{GN}=\mathrm{COPB} 1$ Coatomer subunit beta $\mathrm{GN}=\mathrm{COPB} 1$ Coatomer subunit beta $\mathrm{GN}=\mathrm{COPB} 1$ Coatomer subunit beta $\mathrm{GN}=\mathrm{COPB} 1$ Coatomer subunit beta' $\mathrm{GN}=\mathrm{COPB} 2$ Coatomer subunit beta' $\mathrm{GN}=\mathrm{COPB} 2$ Coatomer subunit delta $\mathrm{GN}=\mathrm{ARCN} 1$ Coatomer subunit delta $\mathrm{GN}=\mathrm{ARCN} 1$ Coatomer subunit delta $\mathrm{GN}=\mathrm{ARCN}$ Coatomer subunit delta $\mathrm{GN}=\mathrm{ARCN} 1$ Coatomer subunit delta $\mathrm{GN}=\mathrm{ARCN} 1$ Coatomer subunit delta $\mathrm{GN}=\mathrm{ARCN} 1$ Coatomer subunit delta $\mathrm{GN}=\mathrm{ARCN} 1$ Coatomer subunit delta $\mathrm{GN}=\mathrm{ARCN} 1$ Coatomer subunit delta GN=ARCN1 Coatomer subunit delta $\mathrm{GN}=\mathrm{ARCN} 1$ Coatomer subunit delta $\mathrm{GN}=\mathrm{ARCN} 1$ Coatomer subunit epsilon $\mathrm{GN}=\mathrm{COPE}$ Coatomer subunit epsilon $\mathrm{GN}=\mathrm{COPE}$ Coatomer subunit gamma- $1 \mathrm{GN}=\mathrm{COPG} 1$ Coatomer subunit gamma- $1 \mathrm{GN}=\mathrm{COPG} 1$ Coatomer subunit gamma-1 GN=COPG1 Coatomer subunit gamma-1 GN=COPG1 COPG1_HUMAN 97.72 100.0\% Coatomer subunit gamma-1 GN=COPG1 COPG1_HUMAN $97.72 \quad 100.0 \%$ Coatomer subunit gamma-2 GN=COPG2 COPG2 HUMAN $97.62 \quad 100.0 \%$ Coatomer subunit gamma-2 GN=COPG2 COPG2_HUMAN $97.62 \quad 100.0 \%$ Coatomer subunit gamma-2 GN=COPG2 COPG2_HUMAN $97.62 \quad 100.0 \%$ Coatomer subunit gamma-2 GN=COPG2 COPG2_HUMAN $97.62 \quad 100.0 \%$ Coatomer subunit gamma-2 GN=COPG2 COPG2_HUMAN $97.62 \quad 100.0 \%$ Coatomer subunit gamma-2 GN=COPG2 COPG2_HUMAN $97.62 \quad 100.0 \%$ Coatomer subunit gamma-2 GN=COPG2 COPG2_HUMAN $97.62 \quad 100.0 \%$ Coatomer subunit gamma-2 GN=COPG2 COPG2_HUMAN $97.62 \quad 100.0 \%$ Coatomer subunit gamma-2 GN=COPG2 COPG2 HUMAN $97.62 \quad 100.0 \%$ Coatomer subunit gamma-2 GN=COPG2 COPG2_HUMAN $97.62 \quad 100.0 \%$ COBW domain-containing protein $1 \mathrm{GN}=\mathrm{CBWD} 1 \mathrm{CBWD} 1$ HUMAN $44.07 \quad 100.0 \%$ COBW domain-containing protein $1 \mathrm{GN}=\mathrm{CBWD} 1 \mathrm{CBWD} 1$ HUMAN $44.07 \quad 100.0 \%$ COBW domain-containing protein $1 \mathrm{GN}=\mathrm{CBWD1}$ CBWD1_HUMAN $44.07 \quad 100.0 \%$
$19 \quad 0.03 \% \quad 8.8 \% \quad$ TLDLPIYVTR COPB2_HUMAN $102.49 \quad 100.0 \%$ COPD HUMAN $57.21 \quad 100.0 \%$ COPD_HUMAN $57.21 \quad 100.0 \%$ COPD HUMAN $57.21 \quad 100.0 \%$ COPD HUMAN $57.21 \quad 100.0 \%$ COPD HUMAN $57.21 \quad 100.0 \%$ COPD_HUMAN $57.21 \quad 100.0 \%$ COPD_HUMAN $57.21 \quad 100.0 \%$ COPD_HUMAN $57.21 \quad 100.0 \%$ COPE HUMAN $34.48 \quad 100.0 \%$ COPE_HUMAN $34.48 \quad 100.0 \%$ COPG1 HUMAN $97.72 \quad 100.0 \%$

11

11

1
1
1

1111

5

(2)
$0.01 \% \quad 2.1 \% \quad$ TYLPSQVSR $0.02 \% \quad 23.1 \%$ LYMVLITTK $0.02 \% \quad 23.1 \%$ KNYCNIQVTK $0.02 \% \quad 23.1 \%$ NYCNIQVTK $0.02 \% \quad 7.4 \%$ SAVLQEAR $\begin{array}{llllllll}99.7 \% & 45.9 & 25.0 & 43.4 & 4 & 0 & 0 & 1190.68\end{array}$

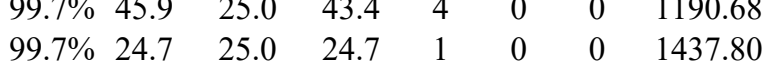
$\begin{array}{llllllll}99.7 \% & 46.6 & 25.0 & 46.6 & 4 & 0 & 0 & 1056.54\end{array}$

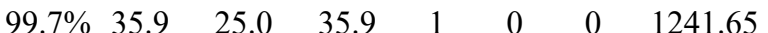
$\begin{array}{llll}99.7 \% & 36.1 & 25.0 & 35.8\end{array}$ $99.3 \% \quad 24.9 \quad 25.0 \quad 17.4 \quad 2$ $\begin{array}{llll}98.9 \% & 20.1 & 25.0 & 16.7\end{array}$ $\begin{array}{lllll}99.6 \% & 25.0 & 25.0 & 25.0 & 2\end{array}$ $\begin{array}{lllll}99.7 \% & 33.5 & 25.0 & 33.5 & 1\end{array}$ $\begin{array}{lllll}99.7 \% & 34.8 & 25.0 & 34.8 & 2\end{array}$ $0.03 \% \quad 12.3 \%$ VLQDLVMDILR $0.03 \% \quad 12.3 \%$ SLGEIPIVESEIKK

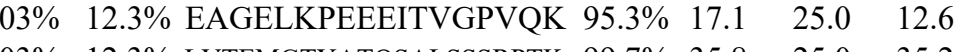

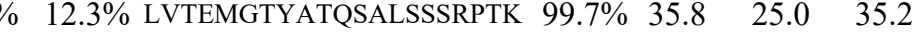
$\begin{array}{lllllll}0.03 \% & 12.3 \% & \text { LVTEMGTYATQSALSSSRPTKK } & 97.3 \% & 17.6 & 25.0 & 17.6 \\ 0.03 \% & 12.3 \% & \text { ALSGYCGFMAANLYAR } & 99.7 \% & 54.8 & 25.0 & 54.8\end{array}$ $0.02 \% \quad 23.1 \%$ VLLAAAVCTK $0.02 \% \quad 23.1 \%$ TRIEGLLAAFPK $0.02 \% \quad 23.1 \%$ NSNILEDLETLR $0.02 \% \quad 23.1 \%$ TFTEMDSHEEKVFR $0.02 \% \quad 23.1 \%$ VAPAPARPSGPSK $0.02 \% \quad 23.1 \%$ LFTAESLIGLKNPEK $0.02 \% \quad 23.1 \%$ SFPVNSDVGVLK $0.02 \% \quad 23.1 \%$ VTQVDGNSPVR $0.01 \% \quad 9.7 \%$ FGVVLDEIKPSSAPELQAVR $0.01 \% \quad 9.7 \%$ YLSQLKDAHR $0.02 \% \quad 7.4 \%$ ELAPAVSVLQLFCSSPK $0.02 \% \quad 7.4 \%$ SIATLAITTLLK $0.02 \% \quad 7.4 \%$ ILHLLGQEGPK $0.02 \% \quad 7.4 \%$ ALQQYTLEPSEKPFDLK $0.02 \% \quad 12.6 \%$ SAVLQEAR $0.02 \% \quad 12.6 \%$ IFNETPINPR $0.02 \% 12.6 \%$ ITDGTMLQAIER $0.02 \% \quad 12.6 \%$ ISYDVVKR $0.02 \% \quad 12.6 \%$ SIATLAITTLLK $0.02 \% \quad 12.6 \%$ ILHLLGKEGPR $0.02 \% \quad 12.6 \%$ TPVPSKYIR $0.02 \% \quad 12.6 \%$ FIFNRVVLENEAVR $0.02 \% \quad 12.6 \%$ AAAVSALAK $0.02 \% \quad 12.6 \%$ SSEPVQLTEAETEYFVR $0.01 \% \quad 10.9 \%$ IPVTIITGYLGAGK $0.01 \% \quad 10.9 \%$ VAVILNEFGEGSALEK $0.01 \% \quad 10.9 \%$ SINGLGQILETQR $\begin{array}{llll}99.5 \% & 23.9 & 25.0 & 22.7\end{array}$ $\begin{array}{lllll}98.5 \% & 17.5 & 25.0 & 17.5 & 2\end{array}$ $99.7 \% \quad 50.8 \quad 25.0 \quad 45.2$ $\begin{array}{llll}99.7 \% & 39.8 & 25.0 & 37.6\end{array}$ $\begin{array}{llll}99.4 \% & 24.2 & 25.0 & 24.2\end{array}$ $99.7 \% \quad 50.3 \quad 25.0 \quad 43.1$ $\begin{array}{llll}99.5 \% & 23.5 & 25.0 & 23.3\end{array}$ $\begin{array}{llll}99.7 \% & 30.8 & 25.0 & 22.3\end{array}$ $99.7 \% \quad 31.0 \quad 25.0 \quad 31.0$ $\begin{array}{llll}97.3 \% & 15.4 & 25.0 & 15.4\end{array}$ $97.1 \% \quad 17.5 \quad 25.0-14.8$ $99.7 \% \quad 35.8 \quad 25.0 \quad 32.4$ $\begin{array}{llll}99.7 \% & 56.3 & 25.0 & 43.5\end{array}$ $\begin{array}{llllll}99.7 \% & 58.1 & 25.0 & 58.1 & 0 & 2\end{array}$ $\begin{array}{lllll}99.7 \% & 33.4 & 25.0 & 25.2 & 0\end{array}$ $\begin{array}{lllll}99.0 \% & 41.4 & 25.0 & 23.3\end{array}$ $\begin{array}{llll}99.7 \% & 45.7 & 25.0 & 45.7\end{array}$ $\begin{array}{lllll}99.7 \% & 50.5 & 25.0 & 50.5 & 8\end{array}$ $\begin{array}{llll}99.6 \% & 25.7 & 25.0 & 23.8\end{array}$ $\begin{array}{llll}99.6 \% & 22.5 & 25.0 & 22.5\end{array}$ $\begin{array}{lllll}99.0 \% & 41.4 & 25.0 & 23.3 & 3\end{array}$ $\begin{array}{llll}99.7 \% & 45.7 & 25.0 & 37.8\end{array}$ $\begin{array}{lllll}99.7 \% & 47.7 & 25.0 & 41.2 & 2\end{array}$ $99.0 \% \quad 47.4 \quad 25.0 \quad 37.8$ $\begin{array}{llll}99.7 \% & 50.5 & 25.0 & 50.5\end{array}$ $99.0 \% \quad 18.3 \quad 25.0 \quad 18.3$ $\begin{array}{llll}99.7 \% & 36.3 & 25.0 & 29.1\end{array}$ $\begin{array}{lllll}99.7 \% & 40.3 & 25.0 & 38.7 & 0\end{array}$ $\begin{array}{llll}97.8 \% & 21.5 & 25.0 & 16.7\end{array}$ $\begin{array}{llll}99.7 \% & 61.2 & 25.0 & 60.9\end{array}$ $\begin{array}{lllll}99.3 \% & 22.6 & 25.0 & 22.6 & 1\end{array}$ $\begin{array}{llll}99.7 \% & 42.2 & 25.0 & 42.2\end{array}$ $99.7 \% \quad 43.7 \quad 25.0 \quad 41.8$

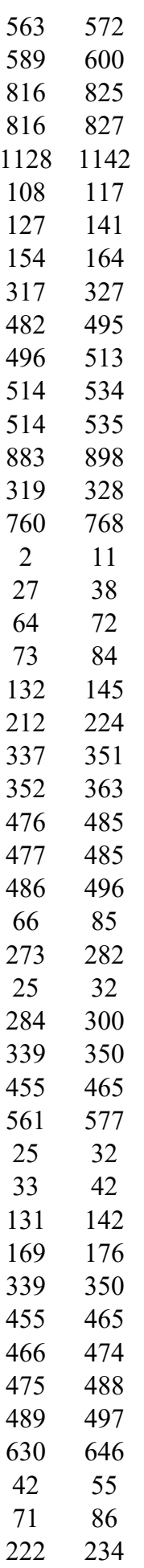

Page 31 of Table S-1-2 
Coiled-coil domain-containing protein $47 \mathrm{GN}=\mathrm{CCDC} 47 \quad \mathrm{CCD} 47$ HUMAN $55.87 \quad 100.0 \%$ Coiled-coil domain-containing protein $47 \mathrm{GN}=\mathrm{CCDC} 47$ CCD47_HUMAN $55.87 \quad 100.0 \%$ Coiled-coil domain-containing protein $47 \mathrm{GN}=\mathrm{CCDC} 47 \quad \mathrm{CCD} 47$ HUMAN $55.87 \quad 100.0 \%$ Coilin GN=COIL

Coilin GN=COIL

COIL HUMAN $62.61 \quad 100.0 \%$ COIL_HUMAN $62.61 \quad 100.0 \%$

Condensin complex subunit $2 \mathrm{GN}=\mathrm{NCAPH}$ CND2_HUMAN $82.57 \quad 100.0 \%$ Condensin complex subunit $2 \mathrm{GN}=\mathrm{NCAPH}$ CND2_HUMAN $82.57 \quad 100.0 \%$ Condensin complex subunit $2 \mathrm{GN}=\mathrm{NCAPH}$ CND2_HUMAN $82.57 \quad 100.0 \%$ Condensin complex subunit $3 \mathrm{GN}=$ NCAPG CND3_HUMAN $114.34100 .0 \%$ Condensin complex subunit $3 \mathrm{GN}=\mathrm{NCAPG}$ CND3_HUMAN $114.34 \quad 100.0 \%$ Condensin-2 complex subunit D3 GN=NCAPD3 CNDD3_HUMAN $168.89 \quad 100.0 \%$ Condensin-2 complex subunit D3 GN=NCAPD3 CNDD3_HUMAN $168.89 \quad 100.0 \%$ Conserved oligomeric Golgi complex subunit $1 \mathrm{GN}=\mathrm{COG} 1$ COG1_HUMAN $108.98 \quad 100.0 \%$ Conserved oligomeric Golgi complex subunit $1 \mathrm{GN}=\mathrm{COG} 1$ COG1_HUMAN $108.98 \quad 100.0 \%$ Constitutive coactivator of PPAR-gamma-like protein 1 GN=FAM120A F120A_HUMAN $121.89 \quad 100.0 \%$ Constitutive coactivator of PPAR-gamma-like protein 1 GN=FAM120A F120A_HUMAN $121.89 \quad 100.0 \%$ Constitutive coactivator of PPAR-gamma-like protein $1 \mathrm{GN}=$ FAM120A F120A_HUMAN $121.89 \quad 100.0 \%$ Constitutive coactivator of PPAR-gamma-like protein $1 \mathrm{GN}=\mathrm{FAM} 120 \mathrm{~A}$ F120A_HUMAN $121.89 \quad 100.0 \%$ COUP transcription factor $2 \mathrm{GN}=\mathrm{NR} 2 \mathrm{~F} 2 \quad$ COT2_HUMAN $45.57 \quad 100.0 \%$ COUP transcription factor $2 \mathrm{GN}=\mathrm{NR} 2 \mathrm{~F} 2$ COT2 HUMAN $45.57 \quad 100.0 \%$ COUP transcription factor $2 \mathrm{GN}=\mathrm{NR} 2 \mathrm{~F} 2 \quad \mathrm{COT} 2$ _HUMAN $45.57 \quad 100.0 \%$ Creatine kinase $\mathrm{B}$-type $\mathrm{GN}=\mathrm{CKB}$

Creatine kinase B-type $\mathrm{GN}=\mathrm{CKB}$

Creatine kinase B-type $\mathrm{GN}=\mathrm{CKB}$

Creatine kinase B-type $\mathrm{GN}=\mathrm{CKB}$

Crk-like protein $\mathrm{GN}=\mathrm{CRKL}$

Crk-like protein $\mathrm{GN}=\mathrm{CRKL}$

Crk-like protein $\mathrm{GN}=\mathrm{CRKL}$

C-terminal-binding protein $1 \mathrm{GN}=\mathrm{CTBP} 1$ CTBP1_HUMAN $47.54 \quad 100.0 \%$ C-terminal-binding protein $1 \mathrm{GN}=\mathrm{CTBP} 1$ CTBP1_HUMAN $47.54 \quad 100.0 \%$ C-terminal-binding protein $1 \mathrm{GN}=\mathrm{CTBP} 1 \quad$ CTBP1_HUMAN $47.54 \quad 100.0 \%$ CTP synthase $1 \mathrm{GN}=\mathrm{CTPS} 1$

CTP synthase $1 \mathrm{GN}=\mathrm{CTPS} 1$ CTP synthase $1 \mathrm{GN}=\mathrm{CTPS} 1$ CTP synthase $1 \mathrm{GN}=\mathrm{CTPS} 1$ CTP synthase $1 \mathrm{GN}=\mathrm{CTPS} 1$ CTP synthase $1 \mathrm{GN}=\mathrm{CTPS} 1$ CTP synthase $1 \mathrm{GN}=\mathrm{CTPS} 1$ CTP synthase $1 \mathrm{GN}=\mathrm{CTPS} 1$ CTP synthase $1 \mathrm{GN}=\mathrm{CTPS} 1$ CTP synthase $1 \mathrm{GN}=\mathrm{CTPS} 1$ CTP synthase $1 \mathrm{GN}=\mathrm{CTPS} 1$ CTP synthase $2 \mathrm{GN}=\mathrm{CTPS} 2$ CTP synthase $2 \mathrm{GN}=\mathrm{CTPS} 2$ CTP synthase $2 \mathrm{GN}=\mathrm{CTPS} 2$ CTP synthase $2 \mathrm{GN}=\mathrm{CTPS} 2$ CTP synthase $2 \mathrm{GN}=\mathrm{CTPS} 2$

$\begin{array}{lll}\text { KCRB_HUMAN } & 42.65 & 100.0 \% \\ \text { KCRB_HUMAN } & 42.65 & 100.0 \%\end{array}$

KCRB_HUMAN $42.65 \quad 100.0 \%$

KCRB HUMAN $42.65 \quad 100.0 \%$

CRKL_HUMAN $33.78 \quad 100.0 \%$

CRKL_HUMAN $33.78 \quad 100.0 \%$

CRKL HUMAN $33.78 \quad 100.0 \%$

PYRG1 HUMAN $66.69 \quad 100.0 \%$

PYRG1_HUMAN $66.69 \quad 100.0 \%$

PYRG1_HUMAN $66.69 \quad 100.0 \%$

PYRG1 HUMAN $66.69 \quad 100.0 \%$

PYRG1_HUMAN $66.69 \quad 100.0 \%$

PYRG1 HUMAN $66.69 \quad 100.0 \%$

PYRG1_HUMAN $66.69 \quad 100.0 \%$

PYRG1_HUMAN $66.69 \quad 100.0 \%$

PYRG1_HUMAN $66.69 \quad 100.0 \%$

PYRG1_HUMAN $66.69 \quad 100.0 \%$

PYRG2 HUMAN $65.68 \quad 100.0 \%$

PYRG2_HUMAN $65.68 \quad 100.0 \%$

PYRG2_HUMAN $65.68 \quad 100.0 \%$

PYRG2_HUMAN $65.68 \quad 100.0 \%$

PYRG2_HUMAN $65.68 \quad 100.0 \%$
$0.01 \% \quad 6.2 \% \quad$ VCCEGMLIQLR

$0.01 \% \quad 6.2 \%$ RQDLLNVLAR

$0.01 \% \quad 6.2 \% \quad$ ARVEENFLK

$0.00 \% \quad 3.3 \% \quad$ VVTDLISLIR

$0.00 \% \quad 3.3 \%$ LVRDNDCLR

$0.00 \% \quad 3.0 \% \quad$ SRVFDLQFSTDSPR

$0.00 \% \quad 3.0 \%$ VFDLQFSTDSPR

$0.00 \% \quad 3.0 \%$ LLASPSSR

$0.01 \% \quad 2.0 \% \quad$ IQAVLALSR

$0.01 \% \quad 2.0 \%$ AVLSCIAPSAK

$0.00 \% \quad 1.9 \%$ NSSAFSYQR

$0.00 \% \quad 1.9 \%$ ASAGHVAVSSPTPETGPLQR

$0.01 \% \quad 2.9 \%$ QALTDFLLAR

$0.01 \% \quad 2.9 \%$ TSVLFGLVTGTENQLAPR

$0.01 \% \quad 4.7 \%$ QTAQQIVSHVQNK

$0.01 \% \quad 4.7 \%$ VAAASGHCGAFSGSDSSR

$0.01 \% \quad 4.7 \%$ GVISTPVIR

$0.01 \% \quad 4.7 \%$ EAALEAAVLNKEE

$0.01 \% \quad 8.0 \%$ SQCALEEYVR

$0.01 \% \quad 8.0 \%$ SQYPNQPTR

$0.01 \% \quad 8.0 \% \quad$ TVSSSVIEQLFFVR

$0.01 \% \quad 9.5 \% \quad$ VLTPELYAELR

$0.01 \% \quad 9.5 \% \quad$ VLTPELYAELRAK

$0.01 \% \quad 9.5 \%$ GGNMKEVFTR

$0.01 \% \quad 9.5 \% \quad$ FCTGLTQIETLFK

$0.01 \% \quad 13.9 \%$ DSSTCPGDYVLSVSENSR

$0.01 \% \quad 13.9 \%$ VSHYIINSLPNRR

$0.01 \% \quad 13.9 \%$ IFDPQNPDENE

$0.01 \% \quad 8.4 \%$ VQSVEQIREVASGAAR

$0.01 \% \quad 8.4 \%$ IRGETLGIIGLGR

$0.01 \% \quad 8.4 \%$ VGQAVALR

$0.05 \% \quad 22.5 \%$ MKYILVTGGVISGIGK

$0.05 \% \quad 22.5 \%$ GIIASSVGTILK

$\begin{array}{llll}99.7 \% & 51.2 & 25.0 & 50.6\end{array}$

$99.7 \% \quad 37.2$

$\begin{array}{lll}99.7 \% & 31.1\end{array}$

$99.7 \% \quad 47.0$

$94.6 \% \quad 14.6$

$99.2 \% \quad 18.6$

$99.7 \% \quad 70.8$

$98.4 \% 18.9$

$99.7 \% \quad 50.2$

$99.7 \% \quad 40.6$

$99.7 \% \quad 45.4$

$\begin{array}{ll}99.7 \% & 26.4\end{array}$

$99.7 \% \quad 47.1$

$99.7 \% \quad 26.1$

$99.7 \% \quad 38.5$

$99.7 \% \quad 37.5$

$99.7 \% \quad 37.4$

$99.7 \% \quad 49.1$

$98.7 \% \quad 19.2$

$97.5 \% \quad 16.3$

$99.7 \% \quad 52.2$

$99.7 \% \quad 32.0$

$99.7 \% \quad 32.9$

$99.7 \% \quad 66.5$

$99.7 \% \quad 33.5$

$99.4 \% \quad 23.1$

$99.4 \% 21.7$

$99.5 \% \quad 21.5$

$95.8 \% \quad 14.2$

$99.0 \% \quad 56.9$

$99.7 \% \quad 52.2$

$99.7 \% \quad 60.8$

$99.0 \% \quad 24.3$

$99.7 \% \quad 37.2$

$99.7 \% \quad 37.3$

$0.05 \% \quad 22.5 \%$ LTKDNNLTTGK

$0.05 \% \quad 22.5 \%$ IYQYVINKER

$0.05 \% \quad 22.5 \%$ ENFCNIHVSLVPQPSSTGEQK

$0.05 \% \quad 22.5 \%$ GLGLSPDLVVCR

$0.05 \% \quad 22.5 \%$ CSNPLDTSVKEK

$0.05 \% \quad 22.5 \%$ RLDLPIER

$0.05 \% \quad 22.5 \%$ FSDSYASVIK

$0.05 \% \quad 22.5 \%$ LCSAHGVLVPGGFGVR

$0.01 \% \quad 13.3 \%$ MKYILVTGGVISGIGK

$0.01 \% \quad 13.3 \%$ GIIASSIGTILK

$10 \quad 0.01 \% \quad 13.3 \%$ ALRGLGLSPDLIVCR

$0 \quad 0.01 \% \quad 13.3 \%$ GLGLSPDLIVCR

$0.01 \% \quad 13.3 \%$ ADGILVPGGFGIR
$99.7 \% 29.6$

$99.7 \% \quad 47.7$

$99.7 \% \quad 31.2$

$99.0 \% \quad 45.2$

$99.7 \% \quad 60.3$

$99.3 \% \quad 22.3$

$\begin{array}{lll}99.7 \% & 52.2\end{array}$

$99.7 \% \quad 45.8$

$99.7 \% \quad 29.8$

$99.7 \% \quad 52.2$

$98.7 \% \quad 28.2$
1378.66

1197.71

1105.60

1128.70

1160.58

1654.82

1411.69

830.47

970.60

1116.61

1059.49

1962.00

1147.65

1903.03

1480.79

1723.75

941.58

1386.71

1254.58

1090.53

1611.87

1303.73

1502.86

1138.57

1557.80

1972.86

1568.87

1317.56

1699.91

1354.82

813.49

1635.95

1158.71

1005.61

1204.65

1325.72

2371.13

1285.69

1377.67

1011.59

1116.56

1625.86

1635.95

1172.73

1639.93

1299.71

1271.71

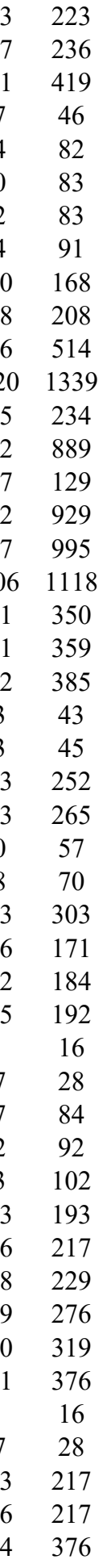

Page 32 of Table S-1-2 
Cyclin-dependent kinase $1 \mathrm{GN}=\mathrm{CDK} 1$

Cyclin-dependent kinase $1 \mathrm{GN}=\mathrm{CDK} 1$

Cyclin-dependent kinase $1 \mathrm{GN}=\mathrm{CDK} 1$

Cyclin-dependent kinase $1 \mathrm{GN}=\mathrm{CDK} 1$

Cyclin-dependent kinase $1 \mathrm{GN}=\mathrm{CDK} 1$

Cyclin-dependent kinase $1 \mathrm{GN}=\mathrm{CDK} 1$

Cyclin-dependent kinase $1 \mathrm{GN}=\mathrm{CDK} 1$

Cyclin-dependent kinase $2 \mathrm{GN}=\mathrm{CDK} 2$

Cyclin-dependent kinase $2 \mathrm{GN}=\mathrm{CDK} 2$

Cyclin-dependent kinase $2 \mathrm{GN}=\mathrm{CDK} 2$

Cyclin-dependent kinase $2 \mathrm{GN}=\mathrm{CDK} 2$

Cyclin-dependent kinase $2 \mathrm{GN}=\mathrm{CDK} 2$

Cyclin-dependent kinase $2 \mathrm{GN}=\mathrm{CDK} 2$

Cyclin-dependent kinase $2 \mathrm{GN}=\mathrm{CDK} 2$

Cyclin-dependent kinase $2 \mathrm{GN}=\mathrm{CDK} 2$

Cyclin-dependent kinase $2 \mathrm{GN}=\mathrm{CDK} 2$

Cyclin-dependent kinase $2 \mathrm{GN}=\mathrm{CDK} 2$

CDK1_HUMAN $34.10 \quad 100.0 \%$ CDK1_HUMAN $34.10 \quad 100.0 \%$ CDK1 HUMAN $34.10 \quad 100.0 \%$ CDK1_HUMAN $34.10 \quad 100.0 \%$ CDK1_HUMAN $34.10 \quad 100.0 \% \quad 15$ CDK1_HUMAN $34.10 \quad 100.0 \% \quad 15$ CDK1_HUMAN $34.10 \quad 100.0 \%$ CDK1_HUMAN $34.10 \quad 100.0 \% \quad 15$ CDK1_HUMAN $34.10 \quad 100.0 \% \quad 15$ CDK1_HUMAN $34.10 \quad 100.0 \% \quad 15$ CDK1 HUMAN $34.10 \quad 100.0 \% \quad 15$ CDK1_HUMAN $34.10 \quad 100.0 \% \quad 15$ CDK1_HUMAN $34.10 \quad 100.0 \% \quad 15$ CDK1_HUMAN $34.10 \quad 100.0 \% \quad 15$ CDK1_HUMAN $34.10 \quad 100.0 \% \quad 15$ CDK2_HUMAN $33.93 \quad 100.0 \%$ CDK2_HUMAN $33.93 \quad 100.0 \%$ CDK2_HUMAN $33.93 \quad 100.0 \%$ CDK2 HUMAN $33.93 \quad 100.0 \%$ CDK2_HUMAN $33.93 \quad 100.0 \%$ CDK2_HUMAN $33.93 \quad 100.0 \%$ CDK2 HUMAN $33.93 \quad 100.0 \%$ CDK2_HUMAN $33.93 \quad 100.0 \%$ CDK2 HUMAN $33.93 \quad 100.0 \%$ CDK2_HUMAN $33.93 \quad 100.0 \%$ Cyclin-dependent-like kinase 5 GN=CDK5 CDK5_HUMAN $33.31 \quad 100.0 \%$ Cyclin-dependent-like kinase $5 \mathrm{GN}=\mathrm{CDK} 5$ CDK5_HUMAN $33.31 \quad 100.0 \%$ Cyclin-dependent-like kinase $5 \mathrm{GN}=\mathrm{CDK} 5$ CDK5_HUMAN $33.31 \quad 100.0 \%$

$10 \quad 0.01 \% \quad 13.3 \%$ TVFKTENSILR

$0.01 \% \quad 13.3 \%$ HRFEVNPNLIK

$0.06 \% \quad 11.2 \%$ LLEDKNGEVQNLAVK

$0.06 \% \quad 11.2 \%$ CLGPLVSK

$\begin{array}{llll}16 & 40 & 0.06 \% & 11.2 \%\end{array}$ TYIQCIAAISR

$\begin{array}{lllll}16 & 40 & 0.06 \% & 11.2 \% & \text { TVSPALISR }\end{array}$

$16 \quad 40 \quad 0.06 \% \quad 11.2 \%$ AADIDQEVKER

$16 \quad 40 \quad 0.06 \% \quad 11.2 \%$ ALTLIAGSPLK

$16 \quad 40 \quad 0.06 \% \quad 11.2 \%$ LGTLSALDILIK

$\begin{array}{llll}16 & 40 & 0.06 \% & 11.2 \% \\ 16 & \text { QSYYSIAK }\end{array}$

$\begin{array}{llll}16 & 40 & 0.06 \% & 11.2 \% \\ 16 & \text { EGPAVVGQFIQDVK }\end{array}$

16

16 $\begin{array}{llll}0.06 \% & 11.2 \% & \text { EGPAV } \\ 40 & 0.06 \% & 11.2 \% & \text { LTLIDPETLLPR }\end{array}$

$40 \quad 0.06 \% \quad 11.2 \%$ LKGYLISGSSYAR

$0.06 \% \quad 11.2 \%$ TLEDPDLNVR

$0.06 \% \quad 11.2 \%$ TLEDPDLNVRR

$0.00 \% \quad 2.8 \% \quad$ LLEDKNGEVQNLAVK

$0.00 \% \quad 2.8 \%$ VPTSPTAIR

$0.00 \% \quad 2.8 \%$ TLIQCLGSVGR

$0.09 \% \quad 44.4 \%$ IGEGTYGVVYK

$0.09 \% \quad 44.4 \%$ HKTTGQVVAMK

$0.09 \% \quad 44.4 \%$ TTGQVVAMKK

$0.09 \% \quad 44.4 \%$ IRLESEEEGVPSTAIR

$0.09 \% \quad 44.4 \%$ LESEEEGVPSTAIR

$0.09 \% \quad 44.4 \%$ EISLLKELR

$0.09 \% \quad 44.4 \%$ DLKPQNLLIDDKGTIK

$0.09 \% \quad 44.4 \%$ LADFGLAR

$0.09 \% \quad 44.4 \%$ SPEVLLGSAR

$0.09 \% \quad 44.4 \%$ WKPGSLASHVK

$0.09 \% \quad 44.4 \%$ NLDENGLDLLSK

$0.09 \% \quad 44.4 \%$ MLIYDPAK

$0.09 \% \quad 44.4 \%$ MLIYDPAKR

$0.09 \% \quad 44.4 \%$ MALNHPYFNDLDNQIK

$0.02 \% \quad 34.9 \%$ IGEGTYGVVYK

$0.02 \% 34.9 \%$ IGEGTYGVVYKAR

$0.02 \% \quad 34.9 \%$ NKLTGEVVALK

$0.02 \% \quad 34.9 \%$ LTGEVVALKK

$0.02 \% \quad 34.9 \%$ IRLDTETEGVPSTAIR

$0.02 \% \quad 34.9 \%$ ELNHPNIVK

$0.02 \% \quad 34.9 \%$ FMDASALTGIPLPLIK

$0.02 \% 34.9 \%$ LADFGLAR

$0.02 \% \quad 34.9 \%$ ALFPGDSEIDQLFR

$0.01 \% \quad 12.0 \%$ IGEGTYGTVFK

$0.01 \% \quad 12.0 \%$ DLKPQNLLINR

$0.01 \% \quad 12.0 \%$ NGELKLADFGLAR
$0.09 \% \quad 44.4 \%$ IGEGTYGVVYKGR

$0.02 \% \quad 34.9 \%$ DLKPQNLLINTEGAIK $\begin{array}{llll}94.9 \% & 13.5 & 25.0 & 13.5\end{array}$

$\begin{array}{llll}99.2 \% & 25.5 & 25.0 & 21.7\end{array}$

$\begin{array}{llll}99.4 \% & 25.3 & 25.0 & 16.3\end{array}$

$\begin{array}{llll}98.1 \% & 26.3 & 25.0 & 7.0\end{array}$

$\begin{array}{llll}99.7 \% & 64.5 & 25.0 & 56.8\end{array}$

$\begin{array}{llll}99.7 \% & 30.3 & 25.0 & 19.6\end{array}$

$99.7 \% \quad 57.9 \quad 25.0 \quad 49.1$

$\begin{array}{lllll}99.7 \% & 59.0 & 25.0 & 58.3 & 4\end{array}$

$\begin{array}{llll}98.3 \% & 23.2 & 25.0 & 18.6\end{array}$

$\begin{array}{llll}98.2 \% & 23.5 & 25.0 & 11.7\end{array}$

$\begin{array}{llll}99.7 \% & 51.5 & 25.0 & 51.5\end{array}$

$\begin{array}{llll}95.5 \% & 14.9 & 25.0 & 14.5\end{array}$

$\begin{array}{llll}99.7 \% & 41.8 & 25.0 & 41.8\end{array}$

$\begin{array}{llll}99.7 \% & 38.5 & 25.0 & 38.4\end{array}$

$\begin{array}{llll}99.1 \% & 24.5 & 25.0 & 19.4\end{array}$

$\begin{array}{llll}99.7 \% & 29.8 & 25.0 & 20.7\end{array}$

$\begin{array}{llll}99.4 \% & 25.3 & 25.0 & 16.3\end{array}$

$\begin{array}{llll}99.7 \% & 32.9 & 25.0 & 24.9\end{array}$

$\begin{array}{llll}99.7 \% & 57.4 & 25.0 & 47.4\end{array}$

$\begin{array}{llll}99.7 \% & 66.9 & 25.0 & 42.0\end{array}$

$\begin{array}{llll}99.7 \% & 67.7 & 25.0 & 26.2\end{array}$

$\begin{array}{llll}99.7 \% & 30.1 & 25.0 & 24.6\end{array}$

$99.7 \% \quad 39.1 \quad 25.0 \quad 31.7$

$\begin{array}{llll}99.7 \% & 49.7 & 25.0 & 39.6\end{array}$

$\begin{array}{llll}99.7 \% & 45.3 & 25.0 & 42.0\end{array}$

$\begin{array}{llll}99.7 \% & 30.8 & 25.0 & 16.1\end{array}$

$\begin{array}{llll}99.7 \% & 41.3 & 25.0 & 41.3\end{array}$

$99.0 \% \quad 37.9 \quad 25.0 \quad 0.0$

$\begin{array}{llll}99.7 \% & 59.3 & 25.0 & 49.1\end{array}$

$\begin{array}{llll}99.7 \% & 29.1 & 25.0 & 27.2\end{array}$

$\begin{array}{llll}99.7 \% & 63.2 & 25.0 & 38.6\end{array}$

$99.0 \% \quad 34.4 \quad 25.0 \quad 26.4$

$\begin{array}{llll}99.7 \% & 40.5 & 25.0 & 28.2\end{array}$

$\begin{array}{llll}99.7 \% & 30.8 & 25.0 & 28.1\end{array}$

$99.7 \% \quad 66.9 \quad 25.0 \quad 42.0$

$\begin{array}{llll}97.3 \% & 16.9 & 25.0 & 16.9\end{array}$

$99.7 \% \quad 31.4 \quad 25.0 \quad 20.4$

$\begin{array}{llll}98.6 \% & 19.0 & 25.0 & 16.8\end{array}$

$\begin{array}{llll}99.7 \% & 39.2 & 25.0 & 28.8\end{array}$

$99.7 \% \quad 31.7 \quad 25.0 \quad 17.9$

$\begin{array}{llll}99.7 \% & 48.7 & 25.0 & 48.7\end{array}$

$\begin{array}{lllll}99.7 \% & 34.9 & 25.0 & 34.9 & 2\end{array}$

$\begin{array}{lllll}99.0 \% & 37.9 & 25.0 & 0.0 & 6\end{array}$

$\begin{array}{llll}99.7 \% & 59.4 & 25.0 & 56.3\end{array}$

$\begin{array}{lllll}99.7 \% & 34.7 & 25.0 & 33.3 & 2\end{array}$

$\begin{array}{llll}99.5 \% & 23.1 & 25.0 & 23.1\end{array}$

$\begin{array}{llll}98.5 \% & 26.1 & 25.0 & 26.1\end{array}$

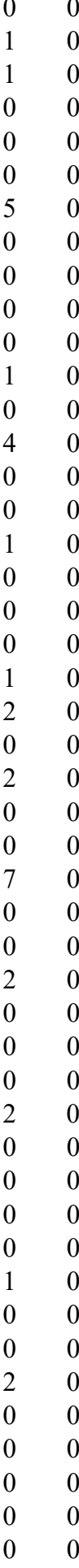

1366.76

1669.91

873.49

1295.68

943.56

1273.64

1083.68

1256.78

959.48

1486.79

1843.97

1380.81

1414.77

1171.60

1327.70

1669.91

941.54

1203.65

1185.62

1398.74

1199.66

1062.60

1785.93

1516.75

1100.67

1811.03

862.48

1028.57

1209.67

1330.69

950.50

1122.60

1932.93

1185.62

1412.75

1171.70

1057.66

1757.94

1063.59

1702.95

1767.00

862.48

1607.81

1171.60

1323.77

1403.76 
Cyclin-dependent-like kinase 5 GN=CDK5 CDK5_HUMAN $33.31 \quad 100.0 \%$ GN=CBS Cystathionine beta-synthase $\mathrm{GN}=\mathrm{CBS}$ Cystathionine beta-synthase $\mathrm{GN}=\mathrm{CBS}$ Cystathionine beta-synthase $\mathrm{GN}=\mathrm{CBS}$ Cystathionine beta-synthase $\mathrm{GN}=\mathrm{CBS}$

Cystathionine beta-synthase $\mathrm{GN}=\mathrm{CBS}$ $100.0 \%$ CBS_HUMAN $60.59 \quad 100.0 \%$ CBS HUMAN $60.59 \quad 100.0 \%$ CBS_HUMAN $60.59 \quad 100.0 \%$ CBS_HUMAN $60.59 \quad 100.0 \%$ CBS HUMAN $60.59 \quad 100.0 \%$ $\begin{array}{lll}\text { Cysteine desulfurase, mitochondrial GN=NFS1 NFS1_HUMAN } 50.20 \quad 100.0 \% & 0.00 \%\end{array}$ Cysteine desulfurase, mitochondrial GN=NFS1 NFS1_HUMAN $50.20 \quad 100.0 \%$ Cysteine desulfurase, mitochondrial GN=NFS1 NFS1_HUMAN $50.20 \quad 100.0 \%$ Cysteine desulfurase, mitochondrial GN=NFS1 NFS1_HUMAN $50.20 \quad 100.0 \%$ Cytochrome b-cl complex subunit 1, mitochondrial GN=UQCRC1 QCR1_HUMAN $52.65 \quad 100.0 \%$ Cytochrome b-c1 complex subunit 1 , mitochondrial GN=UQCRC1 QCR1_HUMAN $52.65 \quad 100.0 \%$ Cytochrome b-c1 complex subunit 1, mitochondrial GN=UQCRC1 QCR1_HUMAN $52.65 \quad 100.0 \%$ Cytochrome b-c1 complex subunit 1, mitochondrial GN=UQCRC1 QCR1_HUMAN 52.65 $100.0 \%$ Cytochrome b-c1 complex subunit 2, mitochondrial GN=UQCRC2 QCR2_HUMAN $48.44 \quad 100.0 \%$ Cytochrome b-c1 complex subunit 2, mitochondrial GN=UQCRC2 QCR2 HUMAN 48.44 100.0\% Cytochrome b-c1 complex subunit 2, mitochondrial GN=UQCRC2 QCR2_HUMAN $48.44 \quad 100.0 \%$ Cytochrome b-c1 complex subunit 2, mitochondrial GN=UQCRC2 QCR2_HUMAN $48.44 \quad 100.0 \%$ Cytochrome b-c1 complex subunit 2, mitochondrial GN=UQCRC2 QCR2_HUMAN $48.44 \quad 100.0 \%$ Cytochrome b-c1 complex subunit 2, mitochondrial GN=UQCRC2 QCR2_HUMAN $48.44 \quad 100.0 \%$ Cytochrome b-c1 complex subunit 2, mitochondrial GN=UQCRC2 QCR2 HUMAN $48.44 \quad 100.0 \%$ Cytochrome b-c1 complex subunit 2, mitochondrial GN=UQCRC2 QCR2_HUMAN $48.44 \quad 100.0 \%$ Cytochrome b-c1 complex subunit 2, mitochondrial GN=UQCRC2 QCR2_HUMAN $48.44 \quad 100.0 \%$ Cytochrome b-c1 complex subunit 2, mitochondrial GN=UQCRC2 QCR2_HUMAN $48.44 \quad 100.0 \%$ Cytochrome b-c1 complex subunit 2, mitochondrial GN=UQCRC2 QCR2_HUMAN $48.44 \quad 100.0 \%$ Cytochrome b-c1 complex subunit 2, mitochondrial GN=UQCRC2 QCR2_HUMAN $48.44 \quad 100.0 \%$ Cytochrome c oxidase assembly protein $\mathrm{COX} 15$ homolog $\mathrm{GN}=\mathrm{COX} 15 \quad \mathrm{COX} 15 \_\mathrm{HUMAN} \quad 46.03 \quad 100.0 \%$ Cytochrome c oxidase assembly protein COX15 homolog GN=COX15 COX15_HUMAN $46.03 \quad 100.0 \%$ Cytoplasmic dynein 1 heavy chain $1 \mathrm{GN}=\mathrm{DYNC} 1 \mathrm{H} 1$ DYHC1_HUMAN $532.41 \quad 100.0 \%$ Cytoplasmic dynein 1 heavy chain $1 \mathrm{GN}=\mathrm{DYNC1} 1 \mathrm{H} 1$ DYHC1_HUMAN $532.41 \quad 100.0 \%$ Cytoplasmic dynein 1 heavy chain $1 \mathrm{GN}=\mathrm{DYNC} 1 \mathrm{H} 1$ DYHC1_HUMAN $532.41 \quad 100.0 \%$ Cytoplasmic dynein 1 heavy chain $1 \mathrm{GN}=\mathrm{DYNC1H} 1$ DYHC1_HUMAN $532.41 \quad 100.0 \%$ Cytoplasmic dynein 1 heavy chain $1 \mathrm{GN}=\mathrm{DYNC1H} 1$ DYHC1_HUMAN $532.41 \quad 100.0 \%$ Cytoplasmic dynein 1 heavy chain $1 \mathrm{GN}=$ DYNC1H1 DYHC1_HUMAN $532.41 \quad 100.0 \%$ Cytoplasmic dynein 1 heavy chain $1 \mathrm{GN}=\mathrm{DYNC1H} 1$ DYHC1_HUMAN $532.41 \quad 100.0 \%$ Cytoplasmic dynein 1 heavy chain $1 \mathrm{GN}=$ DYNC1H1 DYHC1_HUMAN $532.41 \quad 100.0 \%$ Cytoplasmic dynein 1 heavy chain $1 \mathrm{GN}=$ DYNC1H1 DYHC1_HUMAN $532.41 \quad 100.0 \%$ Cytoplasmic dynein 1 heavy chain $1 \mathrm{GN}=\mathrm{DYNC1H} 1$ DYHC1_HUMAN $532.41 \quad 100.0 \%$ Cytoplasmic dynein 1 heavy chain $1 \mathrm{GN}=$ DYNC1H1 DYHC1_HUMAN $532.41 \quad 100.0 \%$ Cytoplasmic dynein 1 heavy chain $1 \mathrm{GN}=$ DYNC1H1 DYHC1_HUMAN $532.41 \quad 100.0 \%$ Cytoplasmic dynein 1 heavy chain $1 \mathrm{GN}=\mathrm{DYNC1H} 1$ DYHC1_HUMAN $532.41 \quad 100.0 \%$ Cytoplasmic dynein 1 heavy chain $1 \mathrm{GN}=$ DYNC1H1 DYHC1_HUMAN $532.41 \quad 100.0 \%$ Cytoplasmic dynein 1 heavy chain $1 \mathrm{GN}=$ DYNC1H1 DYHC1_HUMAN $532.41 \quad 100.0 \%$ Cytoplasmic dynein 1 heavy chain 1 GN=DYNC1H1 DYHC1_HUMAN $532.41 \quad 100.0 \%$ Cytoplasmic dynein 1 heavy chain $1 \mathrm{GN}=\mathrm{DYNC} 1 \mathrm{H} 1$ DYHC1_HUMAN $532.41 \quad 100.0 \%$ Cytoplasmic dynein 1 heavy chain $1 \mathrm{GN}=\mathrm{DYNC} 1 \mathrm{H} 1$ DYHC1_HUMAN $532.41 \quad 100.0 \%$
$4 \quad 0.01 \% \quad 12.0 \%$ LADFGLAR $0.01 \% \quad 12.2 \%$ PSETPQAEVGPTGCPHR

10

$0.01 \% \quad 12.2 \%$ CEFFNAGGSVKDR

$10 \quad 0.01 \% \quad 12.2 \%$ SNDEEAFTFAR

$0.01 \% \quad 12.2 \%$ AAQELQEGQR

$0.01 \% \quad 11.4 \%$ SLEAEGFQVTYLPVQK

$0.01 \% \quad 11.4 \%$ GVGAIYIR

$0.01 \% \quad 11.4 \%$ VRVEALQSGGGQER

$0.01 \% \quad 11.4 \%$ AIGTDEDLAHSSIR

$0.01 \% \quad 11.7 \%$ ADLTEYLSTHYKAPR

$0.01 \% \quad 11.7 \%$ LCTSATESEVAR

$0.01 \% \quad 11.7 \%$ NALVSHLDGTTPVCEDIGR

$0.01 \% \quad 11.7 \%$ IAEVDASVVR

$0.07 \% \quad 34.9 \%$ AGSRYEDFSNLGTTHLLR

$0.07 \% \quad 34.9 \%$ YEDFSNLGTTHLLR

$0.07 \% \quad 34.9 \%$ GASSFKITR

$0.07 \% \quad 34.9 \%$ GIEAVGGKLSVTATR

$0.07 \% \quad 34.9 \%$ WEVADLQPQLK

$0.07 \% \quad 34.9 \%$ AVAFQNPQTHVIENLHAAAYR

$0.07 \% \quad 34.9 \%$ NALANPLYCPDYR

$0.07 \% \quad 34.9 \%$ MALIGLGVSHPVLK

$0.07 \% \quad 34.9 \%$ QVAEQFLNMR

$0.07 \% \quad 34.9 \%$ GSNTTSHLHQAVAK

$0.07 \% \quad 34.9 \%$ TIAQGNLSNTDVQAAK

$0.07 \% \quad 34.9 \%$ SMAASGNLGHTPFVDEL

$0.01 \% \quad 5.4 \%$ YQQFPEFK

$0.01 \% \quad 5.4 \%$ SGLEEKSDSHDIPR

$237 \quad 0.35 \% \quad 14.7 \%$ SNSLAFIK

$237 \quad 0.35 \% \quad 14.7 \%$ TPVIDADKPVSSQLR

$237 \quad 0.35 \% \quad 14.7 \%$ ESPEVLLTLDILK

$237 \quad 0.35 \% \quad 14.7 \%$ LRDQLGTAK

$237 \quad 0.35 \% \quad 14.7 \%$ GAIREYQTQLIQR

$237 \quad 0.35 \% \quad 14.7 \%$ EYQTQLIQR

$237 \quad 0.35 \% \quad 14.7 \%$ VQYPQSQACK

$237 \quad 0.35 \% \quad 14.7 \%$ LKQDGDSFR

$237 \quad 0.35 \% \quad 14.7 \%$ IFTIESTR

$237 \quad 0.35 \% \quad 14.7 \%$ VPLAIVNK

$237 \quad 0.35 \% \quad 14.7 \%$ MVVLSLPR

$237 \quad 0.35 \% \quad 14.7 \%$ FGQMLGSNMTEFHSQISK

$237 \quad 0.35 \% \quad 14.7 \%$ DSAIQQQVANLQMK

$237 \quad 0.35 \% \quad 14.7 \%$ IVQEDRAVESR

$237 \quad 0.35 \% \quad 14.7 \%$ QNLDALLNQLK

$237 \quad 0.35 \% \quad 14.7 \%$ QYASYEFVQR

$237 \quad 0.35 \% \quad 14.7 \%$ INMLVIELK

$237 \quad 0.35 \% \quad 14.7 \%$ HLLPVETQR $\begin{array}{llll}99.0 \% & 37.9 & 25.0 & 0.0\end{array}$

$\begin{array}{llll}9.7 \% & 61.1 & 25.0 & 57.1\end{array}$

$99.0 \% \quad 19.5 \quad 25.0 \quad 19.5$

$\begin{array}{llll}99.0 \% & 42.0 & 25.0 & 28.0\end{array}$

$\begin{array}{llll}94.5 \% & 14.4 & 25.0 & 13.1\end{array}$

$\begin{array}{llll}99.7 \% & 58.3 & 25.0 & 58.3\end{array}$

$99.7 \% \quad 58.6 \quad 25.0 \quad 48.3$

$99.7 \% \quad 48.6 \quad 25.0 \quad 48.5$

$99.0 \% \quad 28.0 \quad 25.0 \quad 20.3$

$\begin{array}{llll}99.7 \% & 35.7 & 25.0 & 35.7\end{array}$

$99.7 \% \quad 33.9 \quad 25.0 \quad 25.8$

$99.7 \% \quad 30.1$

$99.7 \% \quad 53.6$

$99.7 \% \quad 28.7$

$99.7 \% 38.8$

$99.7 \% \quad 27.2$

$99.3 \% \quad 19.5$

$99.7 \% \quad 48.2$

$98.5 \% \quad 24.4$

$99.7 \% \quad 36.3$

$\begin{array}{ll}95.8 \% & 20.0 \\ 99.7 \% & 59.3\end{array}$

$99.7 \% \quad 51.2$

$99.7 \% \quad 55.0$

$99.7 \% \quad 45.9$

$99.7 \% \quad 64.0$

$99.7 \% \quad 59.9$

$99.0 \% \quad 25.0$

$99.7 \% \quad 35.9$

$\begin{array}{lll}98.9 \% & 23.7\end{array}$

$99.7 \% \quad 57.9$

$99.7 \% \quad 33.9$

$99.7 \% \quad 33.2$

$99.7 \% \quad 34.5$

$99.7 \% \quad 51.3$

$99.1 \% \quad 24.2$

$99.7 \% \quad 36.5$

$99.0 \% \quad 31.1$

$99.0 \% \quad 36.7$

$99.0 \% \quad 40.8$

$95.8 \% \quad 14.2$

$99.7 \% \quad 53.1$

$\begin{array}{lll}99.7 \% & 36.3\end{array}$

$99.7 \% \quad 42.8$

$99.5 \% \quad 33.2$

$99.7 \% 38.6$

$99.5 \% \quad 20.9$
862.48

1819.84

939.62

904.46

1486.67

1286.56

1129.56

1808.94

848.50

1485.78

1484.73

1764.89

1323.62

2054.00

1058.58

2037.01

1665.82

966.54

1458.83

1326.7

2350.21

1566.74

1450.85

1235.62

1450.74

1630.84

1761.81

1086.53

1569.75

879.49

1625.89

1469.85

1001.57

1575.86

1178.62

1208.57

1065.53

966.53

853.55

914.55

2073.94

1573.80

1301.68

1269.72

1290.61

1088.64

1092.62

\begin{tabular}{cc}
42 & 149 \\
2 & 18 \\
6 & 83 \\
4 & 91 \\
09 & 121 \\
26 & 336 \\
60 & 369 \\
65 & 180 \\
64 & 271 \\
76 & 289 \\
94 & 407 \\
14 & 228 \\
79 & 390 \\
97 & 415 \\
33 & 442 \\
7 & 84 \\
1 & 84 \\
3 & 101 \\
02 & 116 \\
49 & 159 \\
63 & 183 \\
84 & 196 \\
18 & 231 \\
32 & 241 \\
02 & 315 \\
60 & 375 \\
37 & 453 \\
24 & 131 \\
04 & 217 \\
13 & 120 \\
22 & 136 \\
93 & 305 \\
68 & 576 \\
99 & 611 \\
03 & 611 \\
25 & 634 \\
82 & 690 \\
17 & 724 \\
60 & 767 \\
91 & 998 \\
31 & 1148 \\
29 & 1242 \\
& 1253 \\
\hline 9
\end{tabular}

Page 34 of Table S-1-2 

Cytoplasmic dynein 1 heavy chain $1 \mathrm{GN}=\mathrm{DYNC1H} 1$ DYHC1_HUMAN $532.41 \quad 100.0 \% \quad 66$ Cytoplasmic dynein 1 heavy chain $1 \mathrm{GN}=$ DYNC1H1 DYHC1_HUMAN $532.41 \quad 100.0 \% \quad 66$ Cytoplasmic dynein 1 heavy chain $1 \mathrm{GN}=\mathrm{DYNC1H} 1 \mathrm{DYHC1}$ HUMAN $532.41 \quad 100.0 \%$ $\begin{array}{lllll}\text { Cytoplasmic dynein } 1 \text { heavy chain } 1 \mathrm{GN}=\mathrm{DYNC} 1 \mathrm{H} 1 & \text { DYHC1_HUMAN } & 532.41 & 100.0 \% & 66\end{array}$ Cytoplasmic dynein 1 heavy chain $1 \mathrm{GN}=$ DYNC1H1 DYHC1_HUMAN $532.41 \quad 100.0 \% \quad 66$ Cytoplasmic dynein 1 heavy chain $1 \mathrm{GN}=\mathrm{DYNC} 1 \mathrm{H} 1$ DYHC1_HUMAN $532.41 \quad 100.0 \% \quad 66$ Cytoplasmic dynein 1 heavy chain $1 \mathrm{GN}=\mathrm{DYNC} 1 \mathrm{H} 1$ DYHC1_HUMAN $532.41 \quad 100.0 \% \quad 66$ Cytoplasmic dynein 1 heavy chain $1 \mathrm{GN}=\mathrm{DYNC} 1 \mathrm{H} 1$ DYHC1 HUMAN $532.41 \quad 100.0 \% \quad 66$ Cytoplasmic dynein 1 heavy chain $1 \mathrm{GN}=\mathrm{DYNC} 1 \mathrm{H} 1$ DYHC1_HUMAN $532.41 \quad 100.0 \% \quad 66$ Cytoplasmic dynein 1 heavy chain 1 GN=DYNC1H1 DYHC1_HUMAN $532.41 \quad 100.0 \% \quad 66$ Cytoplasmic dynein 1 heavy chain $1 \mathrm{GN}=\mathrm{DYNC} 1 \mathrm{H} 1$ DYHC1_HUMAN $532.41 \quad 100.0 \% \quad 66$ Cytoplasmic dynein 1 heavy chain $1 \mathrm{GN}=\mathrm{DYNC1H} 1$ DYHC1_HUMAN $532.41 \quad 100.0 \% \quad 66$ Cytoplasmic dynein 1 heavy chain $1 \mathrm{GN}=\mathrm{DYNC} 1 \mathrm{H} 1$ DYHC1_HUMAN $532.41 \quad 100.0 \% \quad 66$ Cytoplasmic dynein 1 heavy chain $1 \mathrm{GN}=\mathrm{DYNC1H} 1$ DYHC1_HUMAN $532.41 \quad 100.0 \% \quad 66$ Cytoplasmic dynein 1 heavy chain $1 \mathrm{GN}=\mathrm{DYNC1H} 1$ DYHC1_HUMAN $532.41 \quad 100.0 \% \quad 66$ Cytoplasmic dynein 1 heavy chain $1 \mathrm{GN}=\mathrm{DYNC1H} 1$ DYHC1_HUMAN $532.41 \quad 100.0 \% \quad 66$ Cytoplasmic dynein 1 heavy chain $1 \mathrm{GN}=\mathrm{DYNC1H} 1$ DYHC1_HUMAN $532.41 \quad 100.0 \% \quad 66$ Cytoplasmic dynein 1 heavy chain $1 \mathrm{GN}=\mathrm{DYNC1H} 1$ DYHC1_HUMAN $532.41 \quad 100.0 \% \quad 66$ Cytoplasmic dynein 1 heavy chain $1 \mathrm{GN}=$ DYNC1H1 DYHC1_HUMAN $532.41 \quad 100.0 \% 66$ Cytoplasmic dynein 1 heavy chain $1 \mathrm{GN}=\mathrm{DYNC} 1 \mathrm{H} 1$ DYHC1_HUMAN $532.41 \quad 100.0 \% \quad 66$ Cytoplasmic dynein 1 heavy chain $1 \mathrm{GN}=\mathrm{DYNC} 1 \mathrm{H} 1$ DYHC1_HUMAN $532.41 \quad 100.0 \% \quad 66$ Cytoplasmic dynein 1 heavy chain $1 \mathrm{GN}=\mathrm{DYNC1H} 1$ DYHC1_HUMAN $532.41 \quad 100.0 \% \quad 66$ Cytoplasmic dynein 1 heavy chain 1 GN=DYNC1H1 DYHC1_HUMAN $532.41 \quad 100.0 \%$ Cytoplasmic dynein 1 heavy chain $1 \mathrm{GN}=\mathrm{DYNC} 1 \mathrm{H} 1$ DYHC1_HUMAN $532.41 \quad 100.0 \%$ Cytoplasmic dynein 1 heavy chain $1 \mathrm{GN}=\mathrm{DYNC1H} 1$ DYHC1_HUMAN $532.41 \quad 100.0 \%$ Cytoplasmic dynein 1 heavy chain $1 \mathrm{GN}=\mathrm{DYNC} 1 \mathrm{H} 1$ DYHC1_HUMAN $532.41 \quad 100.0 \%$ Cytoplasmic dynein 1 heavy chain $1 \mathrm{GN}=\mathrm{DYNC1H} 1$ DYHC1 HUMAN $532.41 \quad 100.0 \%$ Cytoplasmic dynein 1 heavy chain 1 GN=DYNC1H1 DYHC1_HUMAN $532.41 \quad 100.0 \%$ Cytoplasmic dynein 1 heavy chain $1 \mathrm{GN}=\mathrm{DYNC} 1 \mathrm{H} 1$ DYHC1 HUMAN $532.41 \quad 100.0 \%$ Cytoplasmic dynein 1 heavy chain $1 \mathrm{GN}=\mathrm{DYNC} 1 \mathrm{H} 1$ DYHC1_HUMAN $532.41 \quad 100.0 \%$ Cytoplasmic dynein 1 heavy chain $1 \mathrm{GN}=\mathrm{DYNC} 1 \mathrm{H} 1$ DYHC1_HUMAN $532.41 \quad 100.0 \%$ Cytoplasmic dynein 1 heavy chain $1 \mathrm{GN}=\mathrm{DYNC} 1 \mathrm{H} 1$ DYHC1_HUMAN $532.41 \quad 100.0 \%$ Cytoplasmic dynein 1 heavy chain $1 \mathrm{GN}=\mathrm{DYNC1H} 1$ DYHC1_HUMAN $532.41 \quad 100.0 \%$ Cytoplasmic dynein 1 heavy chain $1 \mathrm{GN}=\mathrm{DYNC} 1 \mathrm{H} 1$ DYHC1_HUMAN $532.41 \quad 100.0 \%$ Cytoplasmic dynein 1 heavy chain $1 \mathrm{GN}=\mathrm{DYNC} 1 \mathrm{H} 1$ DYHC1_HUMAN $532.41 \quad 100.0 \%$ Cytoplasmic dynein 1 heavy chain $1 \mathrm{GN}=$ DYNC1H1 DYHC1_HUMAN $532.41 \quad 100.0 \%$ Cytoplasmic dynein 1 heavy chain $1 \mathrm{GN}=\mathrm{DYNC1H} 1$ DYHC1_HUMAN $532.41 \quad 100.0 \%$ Cytoplasmic dynein 1 heavy chain $1 \mathrm{GN}=$ DYNC1H1 DYHC1_HUMAN $532.41 \quad 100.0 \%$ Cytoplasmic dynein 1 heavy chain $1 \mathrm{GN}=$ DYNC1H1 DYHC1_HUMAN $532.41 \quad 100.0 \%$ Cytoplasmic dynein 1 heavy chain $1 \mathrm{GN}=\mathrm{DYNC1H} 1$ DYHC1 HUMAN $532.41 \quad 100.0 \%$ Cytoplasmic dynein 1 heavy chain $1 \mathrm{GN}=\mathrm{DYNC} 1 \mathrm{H} 1$ DYHC1_HUMAN $532.41 \quad 100.0 \%$ Cytoplasmic dynein 1 heavy chain $1 \mathrm{GN}=\mathrm{DYNC1H} 1$ DYHC1 HUMAN $532.41 \quad 100.0 \%$ Cytoplasmic dynein 1 heavy chain $1 \mathrm{GN}=$ DYNC1H1 DYHC1_HUMAN $532.41 \quad 100.0 \%$ Cytoplasmic dynein 1 heavy chain $1 \mathrm{GN}=\mathrm{DYNC} 1 \mathrm{H} 1$ DYHC1_HUMAN $532.41 \quad 100.0 \%$ Cytoplasmic dynein 1 heavy chain $1 \mathrm{GN}=\mathrm{DYNC} 1 \mathrm{H} 1$ DYHC1_HUMAN $532.41 \quad 100.0 \%$ Cytoplasmic dynein 1 heavy chain $1 \mathrm{GN}=\mathrm{DYNC1H} 1$ DYHC1_HUMAN $532.41 \quad 100.0 \%$
$237 \quad 0.35 \% \quad 14.7 \%$ FQSISTEFLALMK

$237 \quad 0.35 \% \quad 14.7 \%$ SPLVMDVLNIQGVQR

$237 \quad 0.35 \% \quad 14.7 \%$ ALGEYLERER

$237 \quad 0.35 \% \quad 14.7 \%$ TPVSITEHPK

$237 \quad 0.35 \% \quad 14.7 \%$ LLAESVTEVEIFGK

$237 \quad 0.35 \% \quad 14.7 \%$ SFEWLSQMR

$237 \quad 0.35 \% \quad 14.7 \%$ CYLTMTQALEAR

$237 \quad 0.35 \% \quad 14.7 \%$ LGGSPFGPAGTGK

$237 \quad 0.35 \% \quad 14.7 \%$ LGGSPFGPAGTGKTESVK

$237 \quad 0.35 \% \quad 14.7 \%$ ALGHQLGR

$237 \quad 0.35 \% \quad 14.7 \%$ TSAPITCELLNK

$237 \quad 0.35 \% \quad 14.7 \%$ SNLPDNLKK

$237 \quad 0.35 \% \quad 14.7 \%$ SLAMTKPDR

$237 \quad 0.35 \% \quad 14.7 \%$ QLIAQVMLYSQGFR

$237 \quad 0.35 \% \quad 14.7 \%$ SVLVSAGNVK

$237 \quad 0.35 \% \quad 14.7 \%$ SVLVSAGNVKR

$237 \quad 0.35 \% \quad 14.7 \%$ IMFEVQDLK

$237 \quad 0.35 \% \quad 14.7 \%$ SIPLDEGEDEAQR

$237 \quad 0.35 \% \quad 14.7 \%$ SIPLDEGEDEAQRR

$237 \quad 0.35 \% \quad 14.7 \%$ GKEDEGEEAASPMLQIQR

$237 \quad 0.35 \% \quad 14.7 \%$ DAATIMQPYFTSNGLVTK

$237 \quad 0.35 \% \quad 14.7 \%$ AELGEYIR

$237 \quad 0.35 \% \quad 14.7 \%$ AELGEYIRR

$237 \quad 0.35 \% \quad 14.7 \%$ VPQIEVETHK

$237 \quad 0.35 \% \quad 14.7 \%$ TMTLFSALR

$237 \quad 0.35 \% \quad 14.7 \%$ TSDQTWVKLER

$237 \quad 0.35 \% \quad 14.7 \%$ IQFVGACNPPTDPGR

$237 \quad 0.35 \% \quad 14.7 \%$ FTQDTQPHYIYSPR

$237 \quad 0.35 \% \quad 14.7 \%$ AATSPALFNR

$237 \quad 0.35 \% \quad 14.7 \%$ SMANPPAAVK

$237 \quad 0.35 \% \quad 14.7 \%$ NYMSNPSYNYEIVNR

$237 \quad 0.35 \% \quad 14.7 \%$ ASLACGPMVK

$237 \quad 0.35 \% \quad 14.7 \%$ TEYLSNADERLR

$237 \quad 0.35 \% \quad 14.7 \%$ TSFLDDAFRK

$237 \quad 0.35 \% \quad 14.7 \%$ VTFVNFTVTR

$237 \quad 0.35 \% \quad 14.7 \%$ SSLQSQCLNEVLK

$237 \quad 0.35 \% \quad 14.7 \%$ LQGEFQLR

$237 \quad 0.35 \% \quad 14.7 \%$ SLLQALNEVK

$237 \quad 0.35 \% \quad 14.7 \%$ SLLQALNEVKGR

$237 \quad 0.35 \% \quad 14.7 \%$ DLFQVAFNR

$237 \quad 0.35 \% \quad 14.7 \%$ GNEIVLSAGSTPR

$237 \quad 0.35 \% \quad 14.7 \%$ IQGLTVEQAEAVVR

$237 \quad 0.35 \% \quad 14.7 \%$ LFLTMEINPK

$237 \quad 0.35 \% \quad 14.7 \%$ IFVFEPPPGVK

$237 \quad 0.35 \% \quad 14.7 \%$ TFSSIPVSR

$237 \quad 0.35 \% \quad 14.7 \%$ KYEFGESDLR

$237 \quad 0.35 \% \quad 14.7 \%$ TLMAQSIYGGR $\begin{array}{lllll}99.7 \% & 48.0 & 25.0 & 39.2 & 2\end{array}$

$99.7 \% \quad 50.1 \quad 25.0 \quad 50.1$

$\begin{array}{llll}95.5 \% & 13.9 & 25.0 & 13.9\end{array}$

$99.7 \% \quad 43.2 \quad 25.0 \quad 43.2$

$99.7 \% \quad 54.0 \quad 25.0 \quad 54.0$

$\begin{array}{llll}99.7 \% & 40.3 & 25.0 & 40.3\end{array}$

$99.7 \% \quad 50.7 \quad 25.0 \quad 50.7$

$\begin{array}{llll}99.7 \% & 53.9 & 25.0 & 45.1\end{array}$

$\begin{array}{llll}99.7 \% & 32.1 & 25.0 & 32.1\end{array}$

$\begin{array}{llll}99.0 \% & 23.8 & 25.0 & 19.2\end{array}$

$\begin{array}{llll}99.7 \% & 30.9 & 25.0 & 26.3\end{array}$

$\begin{array}{llll}97.8 \% & 18.7 & 25.0 & 14.2\end{array}$

$\begin{array}{llll}98.7 \% & 27.9 & 25.0 & 13.4\end{array}$

$99.7 \% \quad 51.8$

$99.7 \% \quad 29.8$

$99.7 \% \quad 44.7$

$97.2 \% \quad 15.2$

$99.7 \% \quad 51.7$

$99.7 \% \quad 36.1$

$\begin{array}{lll}99.7 \% & 37.4\end{array}$

$99.0 \% \quad 26.8$

$99.4 \% \quad 21.0$

$99.7 \% \quad 34.2$

$99.7 \% \quad 50.3$

$99.7 \% \quad 31.4$

$99.7 \% \quad 52.6$

$99.2 \% \quad 19.1$

$99.7 \% \quad 59.9$

$99.7 \% \quad 32.7$

$99.7 \% \quad 58.2$

$99.6 \% \quad 24.2$

$98.1 \% \quad 18.1$

$99.7 \% \quad 35.5$

$99.7 \% \quad 53.5$

$99.7 \% 51.2$

$99.0 \% 31$.

$99.7 \% \quad 56.7$

$99.7 \% \quad 26.8$

$99.7 \% \quad 45.3$

$99.7 \% \quad 57.5$

$99.7 \% \quad 46.6$

$99.7 \% \quad 44.8$

$99.7 \% \quad 37.3$

$99.7 \% \quad 32.2$

$99.7 \% \quad 32.0$

$99.7 \% \quad 38.4$
1684

1235.6

1108.60

1534.84

1199.55

1456.69

1145.60

1689.88

851.48

1346.70

1028.57

1018.54

1669.87

973.57

1129.67

1138.58

1458.67

1614.77

1987.94

1972.97

950.49

1106.60

1179.64

1055.56

1362.70

1628.79

1752.83

1047.56

985.51

1863.83

1049.51

1466.72

1199.61

1183.65

1505.76

990.54

1114.65

1327.77

1109.57

1300.69

1512.84

1205.66

1229.69

993.54

1243.60

1243.60
1196.61 
D-3-phosphoglycerate dehydrogenase GN=PHGDH SERA_HUMAN $56.65 \quad 100.0 \%$ D-3-phosphoglycerate dehydrogenase GN=PHGDH SERA_HUMAN $56.65 \quad 100.0 \%$ D-3-phosphoglycerate dehydrogenase GN=PHGDH SERA HUMAN $56.65 \quad 100.0 \%$ D-3-phosphoglycerate dehydrogenase GN=PHGDH SERA_HUMAN $56.65 \quad 100.0 \%$ D-3-phosphoglycerate dehydrogenase GN=PHGDH SERA_HUMAN $56.65100 .0 \%$ DBIRD complex subunit ZNF326 GN=ZNF326 ZN326_HUMAN $65.65 \quad 100.0 \%$ DBIRD complex subunit ZNF326 GN=ZNF326 ZN326_HUMAN $65.65 \quad 100.0 \%$ DBIRD complex subunit ZNF326 GN=ZNF326 ZN326 HUMAN $65.65100 .0^{\circ}$ DBIRD complex subunit ZNF326 GN=ZNF326 ZN326_HUMAN $65.65 \quad 100.0 \%$ DDB1- and CUL4-associated factor 7 GN=DCAF7 DCAF7_HUMAN $38.93 \quad 100.0 \%$ DD1- and CUL4-associated factor $7 \mathrm{GN}=$ DCAF7 DCAF7 HUMAN $38.93100 .0^{\circ}$ DDRGK domain-containing protein 1 GN=DDRGK1 DDRGK_HUMAN $35.61 \quad 100.0 \%$ DDRGK domain-containing protein $1 \mathrm{GN}=$ DDRGK1 DDRGK_HUMAN $35.61100 .0 \%$ Dedicator of cytokinesis protein 4 GN=DOCK4 DOCK4_HUMAN $225.21 \quad 100.0 \%$ Dedicator of cytokinesis protein $4 \mathrm{GN}=$ DOCK4 DOCK4_HUMAN $225.21 \quad 100.0 \%$ Dedicator of cytokinesis protein $4 \mathrm{GN}=\mathrm{DOCK} 4 \mathrm{DOCK} 4$ HUMAN $225.21 \quad 100.0^{\circ}$ Dedicator of cytokinesis protein 4 GN=DOCK4 DOCK4_HUMAN $225.21 \quad 100.0 \%$ Dedicator of cytokinesis protein 4 GN=DOCK4 DOCK4_HUMAN $225.21 \quad 100.0 \%$ Dedicator of cytokinesis protein $4 \mathrm{GN}=$ DOCK4 DOCK4_HUMAN $225.21 \quad 100.0 \%$ Dedicator of cytokinesis protein 4 GN=DOCK4 DOCK4_HUMAN $225.21 \quad 100.0 \%$ Dedicator of cytokinesis protein $4 \mathrm{GN}=$ DOCK4 DOCK4_HUMAN $225.21 \quad 100.0 \%$ Dedicator of cytokinesis protein 4 GN=DOCK4 DOCK4_HUMAN $225.21 \quad 100.0 \%$ Dedicator of cytokinesis protein $4 \mathrm{GN}=$ DOCK4 DOCK4_HUMAN $225.21 \quad 100.0 \%$ Dedicator of cytokinesis protein $4 \mathrm{GN}=\mathrm{DOCK} 4$ DOCK4 HUMAN $225.21 \quad 100.0 \%$ Dedicator of cytokinesis protein $4 \mathrm{GN}=$ DOCK4 DOCK4_HUMAN $225.21 \quad 100.0 \%$

$237 \quad 0.35 \% \quad 14.7 \%$ VLLTTQGVDMISK

10

$0.01 \% \quad 4.6 \%$ SGFDIKVPR

$0.01 \% \quad 4.6 \%$ RAVGPSSTQLYMVR

$0.01 \% \quad 4.6 \%$ TVLPFSQEFQR

$10 \quad 0.01 \% \quad 4.6 \%$ LGTPQQIAIAR

$10 \quad 0.01 \% \quad 4.6 \% \quad$ CFQPPIHQSLASS

$0.01 \% \quad 3.4 \%$ GGFDIKVPR

$0.01 \% \quad 3.4 \%$ TAIPFTQEPQR

$0.01 \% \quad 3.4 \%$ LGTPQQIAIAR

$0.01 \% \quad 3.4 \% \quad$ SVETDSSTVEHVR

$0.01 \% \quad 3.0 \% \quad$ TTGEVVSGVVSK

$10 \quad 0.01 \% \quad 3.0 \%$ LEAGDYADLVK

$10 \quad 0.01 \% \quad 3.0 \%$ TALAATNPAVR

$10 \quad 0.01 \% \quad 3.0 \%$ TEISDKITSELVSK

$10 \quad 0.01 \% \quad 3.0 \% \quad$ AQNISSNANMLR

$0.04 \% \quad 19.9 \%$ VLISDSLDPCCR

$0.04 \% \quad 19.9 \%$ AGTGVDNVDLEAATR

$\begin{array}{llll}99.7 \% & 39.2 & 25.0 & 38.6\end{array}$

$\begin{array}{llll}99.7 \% & 40.4 & 25.0 & 37.5\end{array}$

$99.3 \% \quad 21.7 \quad 25.0 \quad 17.3$

$\begin{array}{llll}98.9 \% & 22.4 & 25.0 & 16.3\end{array}$

$99.7 \% \quad 60.5 \quad 25.0 \quad 43.2$

$\begin{array}{llll}99.4 \% & 20.0 & 25.0 & 20.0\end{array}$

$99.7 \% \quad 32.1 \quad 25.0 \quad 25.8$

$99.7 \% \quad 30.9$

$99.7 \% \quad 60.5$

$99.7 \% \quad 28.4$

$25.0 \quad 28.9$

$\begin{array}{lll}68.4 & 25.0 & 26.4\end{array}$

$99.7 \% \quad 47.4 \quad 25.0 \quad 30.5$

$98.7 \% \quad 24.6 \quad 25.0 \quad 12.5$

$99.2 \% \quad 26.0 \quad 25.0 \quad 24.7$

$\begin{array}{llll}99.7 \% & 56.9 & 25.0 & 56.9\end{array}$

$\begin{array}{lll}0.01 \% & 7.7 \% & \text { SSLGGRDLYR }\end{array}$

$10 \quad 0.01 \% \quad 7.7 \% \quad$ STNVTVAAAR

$10 \quad 0.01 \% \quad 7.7 \%$ MAFTCSFCK

$10 \quad 0.01 \% \quad 7.7 \% \quad$ ESVLTATSILNNPIVK
$0.04 \% \quad 19.9 \%$ IGREVATR

$0.04 \% \quad 19.9 \%$ GGIVDEGALLR

$99.7 \% \quad 50.6$

$99.7 \% \quad 50.8$

$99.7 \% \quad 62.6$

$98.0 \% \quad 23.6$

$99.7 \% \quad 63.9$

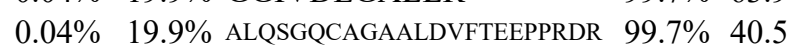

0.04\% 19.9\% CGEEIAVQFVDMVKGK $\quad 99.7 \% \quad 53.2$

$0.04 \% \quad 19.9 \%$ GTIQVITQGTSLK

$0.04 \% \quad 19.9 \%$ DLPLLLFR

$0.01 \% \quad 5.9 \%$ NTFDHPYPTTK

$0.01 \% \quad 5.9 \%$ VNLVSGHVK

$99.7 \% \quad 47.7$

$\begin{array}{lll}99.0 \% & 42.7\end{array}$

$95.2 \% \quad 18.5$

$99.7 \% \quad 56.0$

$99.7 \% \quad 26.6$

$99.7 \% \quad 56.5$

$99.7 \% \quad 31.5$

$99.7 \% \quad 28.7$

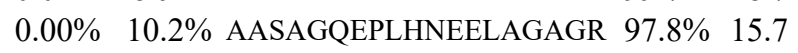

$0.00 \% \quad 10.2 \%$ VAQPGPLEPEEPR

$0.03 \% \quad 7.7 \%$ NACSVQYR

$0.03 \% \quad 7.7 \%$ EYSSVFSHGVSITR

$0.03 \% \quad 7.7 \% \quad$ YLKLPFSK

$0.03 \% \quad 7.7 \%$ GIFLGNNNQAMK

$0.03 \% \quad 7.7 \% \quad$ TVESQLYTNPDSR

$0.03 \% \quad 7.7 \%$ ESGVSLIATVTR

$0.03 \% \quad 7.7 \%$ TSLYLVQSLPGISR

$0.03 \% \quad 7.7 \%$ TLISQCQTR

$0.03 \% \quad 7.7 \% \quad$ KLVDQFFVMK

$0.03 \% \quad 7.7 \%$ NSAPASVSPDGTR

$0.03 \% \quad 7.7 \%$ ERPCSAIYPTPVEPSQR

$\begin{array}{lll}99.7 \% & 33.5\end{array}$

$\begin{array}{lll}99.0 \% & 30.9\end{array}$

$99.7 \% \quad 48.4$

$99.0 \% \quad 20.5$

$99.7 \% \quad 32.9$

$99.7 \% \quad 56.8$

$99.7 \% \quad 55.5$

$99.7 \% \quad 55.9$

$99.7 \% \quad 48.7$

$99.2 \% \quad 18.7$

$99.7 \% \quad 39.7$

$98.3 \% \quad 18.8$

$99.7 \% \quad 35.8$

25.0

$25.0 \quad 50.8$

$25.0 \quad 57.6$

$25.0 \quad 10.7$

$25.0 \quad 44.5$

$25.0 \quad 40.5$

$25.0 \quad 53.2$

$25.0 \quad 47.7$

$25.0 \quad 39.5$

$25.0 \quad 10.9$

$25.0 \quad 45.9$

26.6

$25.0 \quad 56.5$

$25.0 \quad 31.5$

$25.0 \quad 27.3$

$25.0 \quad 15.7$

$25.0 \quad 33.5$

$\begin{array}{ll}25.0 & 30.9\end{array}$

$\begin{array}{ll}25.0 & 48.4\end{array}$

$\begin{array}{ll}.0 & 19.1\end{array}$

$25.0 \quad 27.8$

$25.0 \quad 54.7$

$25.0 \quad 44.8$

51.3

\begin{tabular}{ll}
42.9 \\
\hline
\end{tabular}

$25.0 \quad 18.7$

$\begin{array}{lll}25.0 & 39.7 & 2\end{array}$

$0.03 \% \quad 7.7 \%$ HTTSVSPSPAGR
2055.08

1586.84

1885.94

1018.57

1580.82

1351.70

1167.68

1471.70

988.56

1287.67

1167.68

1445.69

1162.63

1193.61

1084.61

1549.83

1318.65

1434.67

1488.73

901.52

1099.61

2488.19

1809.89

1345.77

986.60

1123.59

989.54

1151.47

1698.96

1320.62

952.56

1877.91

1418.73

997.45

1568.77

995.59

1306.66

1509.72

1232.68

1533.86

1106.56

1254.69

1258.60

1986.97

1196.60 
Dedicator of cytokinesis protein 4 GN=DOCK4 DOCK4_HUMAN $225.21 \quad 100.0 \%$ Dehydrogenase/reductase SDR family member 7B GN=DHRS7B DRS7B_HUMAN $35.12 \quad 100.0 \%$ Dehydrogenase/reductase SDR family member 7B GN=DHRS7B DRS7B_HUMAN $35.12 \quad 100.0 \%$ Dehydrogenase/reductase SDR family member 7B GN=DHRS7B DRS7B_HUMAN $35.12 \quad 100.0 \%$ Dehydrogenase/reductase SDR family member 7B GN=DHRS7B DRS7B_HUMAN $35.12 \quad 100.0 \%$ Dehydrogenase/reductase SDR family member 7B GN=DHRS7B DRS7B_HUMAN $35.12 \quad 100.0 \%$ Delta-1-pyrroline-5-carboxylate synthase GN=ALDH18A1 P5CS_HUMAN 87.30 $100.0 \%$ Delta-1-pyrroline-5-carboxylate synthase GN=ALDH18A1 P5CS_HUMAN 87.30 $100.0 \%$ Delta-1-pyrroline-5-carboxylate synthase GN=ALDH18A1 P5CS_HUMAN 87.30 $100.0 \%$ Delta-1-pyrroline-5-carboxylate synthase GN=ALDH18A1 P5CS_HUMAN 87.30 $100.0 \%$ Delta-1-pyrroline-5-carboxylate synthase GN=ALDH18A1 P5CS_HUMAN $87.30 \quad 100.0 \%$ Delta-1-pyrroline-5-carboxylate synthase GN=ALDH18A1 P5CS_HUMAN $87.30 \quad 100.0 \%$ Delta-1-pyrroline-5-carboxylate synthase GN=ALDH18A1 P5CS_HUMAN $87.30 \quad 100.0 \%$ Delta-1-pyrroline-5-carboxylate synthase GN=ALDH18A1 P5CS_HUMAN $87.30 \quad 100.0 \%$ Delta-1-pyrroline-5-carboxylate synthase GN=ALDH18A1 P5CS HUMAN 87.30 100.0 $\%$ Delta-1-pyrroline-5-carboxylate synthase GN=ALDH18A1 P5CS_HUMAN $87.30 \quad 100.0 \%$ Delta-1-pyrroline-5-carboxylate synthase GN=ALDH18A1 P5CS HUMAN $87.30 \quad 100.0 \%$ Delta-1-pyrroline-5-carboxylate synthase GN=ALDH18A1 P5CS_HUMAN $87.30 \quad 100.0 \%$ Delta-1-pyrroline-5-carboxylate synthase GN=ALDH18A1 P5CS_HUMAN $87.30 \quad 100.0 \%$ Delta-1-pyrroline-5-carboxylate synthase GN=ALDH18A1 P5CS HUMAN $87.30 \quad 100.0 \%$ Delta-1-pyrroline-5-carboxylate synthase GN=ALDH18A1 P5CS_HUMAN 87.30 $100.0 \%$ Delta-1-pyrroline-5-carboxylate synthase GN=ALDH18A1 P5CS_HUMAN $87.30 \quad 100.0 \%$ Delta-1-pyrroline-5-carboxylate synthase GN=ALDH18A1 P5CS_HUMAN $87.30 \quad 100.0 \%$ Delta-1-pyrroline-5-carboxylate synthase GN=ALDH18A1 P5CS_HUMAN $87.30 \quad 100.0 \%$ Delta-1-pyrroline-5-carboxylate synthase GN=ALDH18A1 P5CS HUMAN $87.30 \quad 100.0 \%$ Deoxynucleoside triphosphate triphosphohydrolase SAMHD1 GN=SAMHD1 SAMH1_HUMAN $72.20 \quad 100.0 \%$ Deoxynucleoside triphosphate triphosphohydrolase SAMHDI GN=SAMHD1 SAMH1_HUMAN $72.20 \quad 100.0 \%$ Deoxynucleoside triphosphate triphosphohydrolase SAMHD1 GN=SAMHDI SAMH1_HUMAN $72.20 \quad 100.0 \%$ Deoxynucleoside triphosphate triphosphohydrolase SAMHD1 GN=SAMHDI SAMH1_HUMAN $72.20 \quad 100.0 \%$ Deoxynt SAN=SAMHDI SAMH1_HUMAN $72.20 \quad 100.0 \%$ Deoxyribose-phosphate aldolase GN=DERA DEOC_HUMAN $35.23 \quad 100.0 \%$ Deoxyribose-phosphate aldolase GN=DERA DEOC_HUMAN $35.23 \quad 100.0 \%$ Deoxyribose-phosphate aldolase GN=DERA DEOC_HUMAN $35.23 \quad 100.0 \%$ Deoxyribose-phosphate aldolase GN=DERA DEOC_HUMAN $35.23 \quad 100.0 \%$ Deoxyribose-phosphate aldolase GN=DERA DEOC HUMAN $35.23 \quad 100.0 \%$ Dermcidin GN=DCD Dermcidin GN=DCD Dermcidin $\mathrm{GN}=\mathrm{DCD}$ Dermcidin GN=DCD Dermcidin GN=DCD Desmoplakin GN=DSP Desmoplakin $\mathrm{GN}=\mathrm{DSP}$ Desmoplakin GN=DSP Desmoplakin GN=DSP Desmoplakin GN=DSP Desmoplakin GN=DSP Desmoplakin GN=DSP
DCD_HUMAN $11.28 \quad 100.0 \%$ DCD_HUMAN $11.28 \quad 100.0 \%$ DCD HUMAN $11.28 \quad 100.0 \%$ DCD_HUMAN $11.28 \quad 100.0 \%$ DCD_HUMAN $11.28 \quad 100.0 \%$ DESP HUMAN $331.78 \quad 100.0 \%$ DESP_HUMAN $331.78 \quad 100.0 \%$ DESP HUMAN $331.78 \quad 100.0 \%$ DESP_HUMAN $331.78 \quad 100.0 \%$ DESP_HUMAN $331.78 \quad 100.0 \%$ DESP HUMAN $331.78 \quad 100.0 \%$ DESP_HUMAN $331.78 \quad 100.0 \%$
$0.03 \% \quad 7.7 \%$ TPPPYSVYER

$0.03 \% \quad 18.2 \%$ NAVVVITGATSGLGK

$99.3 \% 21.4$

$0.03 \% \quad 18.2 \%$ NAVVVITGATSGLGKECAK

$0.03 \% \quad 18.2 \%$ VMETNYFGPVALTK

$0.03 \% \quad 18.2 \%$ YGVMDTTTAQGR

$0.03 \% \quad 18.2 \%$ TLAPGLFFSLMASR

$0.07 \% \quad 26.7 \%$ LGSAVVTR

$0.07 \% \quad 26.7 \%$ LGSAVVTRGDECGLALGR

$0.07 \% \quad 26.7 \%$ GDECGLALGR

$0.07 \% \quad 26.7 \%$ LASIVEQVSVLQNQGR

$0.07 \% \quad 26.7 \%$ LRHEILLSQSVR

$0.07 \% \quad 26.7 \%$ EMAIPVLEAR

$0.07 \% \quad 26.7 \%$ NLNGTLHELLR

$99.7 \% \quad 42.5$

25.0

$99.7 \% 46$.

$99.7 \% \quad 64.0$

$99.7 \% \quad 60.8$

$\begin{array}{lll}99.7 \% & 52.7\end{array}$

$99.0 \% \quad 65.9$

$99.7 \% 32.5$

$99.7 \% \quad 33.2$

$99.7 \% \quad 55.0$

$99.7 \% \quad 32.8$

$98.5 \% \quad 21.3$

$99.7 \% \quad 59.7$

$0.07 \% \quad 26.7 \%$ LIDIFYPGDQQSVTFGTK $\quad 99.7 \% \quad 48.0$

$0.07 \% \quad 26.7 \%$ AALWALQGGTSVVIANGTHPK $99.5 \% 24.0$

$0.07 \% \quad 26.7 \%$ VSGHVITDIVEGK

$99.7 \% \quad 49.4$

$99.7 \% \quad 43.2$

$0.07 \% \quad 26.7 \%$ VSGHVITDIVEGKK

$99.7 \% \quad 51.7$

$0.07 \% \quad 26.7 \%$ VGTFFSEVKPAGPTVEQQGEMAR

$0.07 \% \quad 26.7 \%$ LAAPLLKR

$99.0 \% \quad 47.4$

$99.7 \% \quad 43.1$

$99.7 \% \quad 55.1$

$0.07 \% \quad 26.7 \%$ LNSLAIGLR

$0.07 \% \quad 26.7 \%$ MIDLIIPR

$0.07 \% \quad 26.7 \%$ GSSQLVRDIQK

$0.07 \% \quad 26.7 \%$ FASYLTFSPSEVK

$0.07 \% \quad 26.7 \%$ FGLGAEVGISTSR

$0.01 \% \quad 9.6 \%$ GGFEEPVLLK

$0.01 \% \quad 9.6 \%$ SFLYEIVSNKR

$0.01 \% \quad 9.6 \%$ VCEVDNELRICAR

$0.01 \% \quad 9.6 \%$ DKEVGNLYDMFHTR

$0.01 \% \quad 9.6 \%$ YVGETQPTGQIK

$0.01 \% \quad 23.9 \%$ AAGCNIPVASVAAGFPAGQTHLK

$0.01 \% \quad 23.9 \%$ TILATGELGTLTNVYK

$0.01 \% \quad 23.9 \%$ ETVNATFPVAIVMLR

$0.01 \% \quad 23.9 \%$ IGFKPAGGIR

$0.01 \% \quad 23.9 \%$ IGASTLLSDIER

$0.04 \% \quad 46.4 \%$ ENAGEDPGLAR

$0.04 \% \quad 46.4 \%$ SSLLEKGLDGAK

$0.04 \% \quad 46.4 \%$ LGKDAVEDLESVGK

$0.04 \% \quad 46.4 \%$ DAVEDLESVGK

$0.04 \% \quad 46.4 \%$ GAVHDVKDVLDSVL

$0.03 \% \quad 3.6 \% \quad$ LLQLQEQMR

$0.03 \% \quad 3.6 \%$ QLQNIIQATSR

$0.03 \% \quad 3.6 \%$ QVQNLVNK

$0.03 \% \quad 3.6 \%$ LASLEELKR

$0.03 \% \quad 3.6 \%$ SLSEEIKR

$0.03 \% \quad 3.6 \% \quad$ LKNTLTQTTENLR

$0.03 \% \quad 3.6 \%$ RVEEDIQQQK

2091.13

1353.74

1481.83

2481.21

881.59

1673.00

956.59

970.58

1230.68

1475.74

1293.68

1088.60

1355.73

1633.78

1724.81

1320.68

2237.15

1693.94

1660.9

1015.60

1274.70

1128.53

1217.67

1459.76

1161.56

1466.79

1174.63

1271.71

942.54

1058.62

961.53

1531.84

1272.65 

ODP2 HUMAN $69.00 \quad 100.0 \%$

Dihydropyrimidinase-related protein 1 GN=CRMP1 DPYL1_HUMAN $62.18 \quad 100.0 \%$ Dihydropyrimidinase-related protein $1 \mathrm{GN}=\mathrm{CRMP} 1$ DPYL1_HUMAN $62.18 \quad 100.0 \%$ Dihydropyrimidinase-related protein $1 \mathrm{GN}=\mathrm{CRMP1}$ DPYL1_HUMAN $62.18 \quad 100.0 \%$ Dihydropyrimidinase-related protein $1 \mathrm{GN}=\mathrm{CRMP} 1$ DPYL1 HUMAN $62.18 \quad 100.0 \%$ Dimethyladenosine transferase 1, mitochondrial GN=TFB1M TFB1M_HUMAN $39.54 \quad 100.0 \%$ Dimethyladenosine transferase 1, mitochondrial GN=TFB1M TFB1M_HUMAN $39.54 \quad 100.0 \%$ Dimethyladenosine transferase 2, mitochondrial GN=TFB2M TFB2M HUMAN $45.35 \quad 100.0 \%$ Dimethyladenosine transferase 2, mitochondrial GN=TFB2M TFB2M_HUMAN $45.35 \quad 100.0 \%$ DNA mismatch repair protein Msh2 GN=MSH2 MSH2 HUMAN $104.75 \quad 100.0 \%$ DNA mismatch repair protein Msh2 GN=MSH2 MSH2_HUMAN $104.75 \quad 100.0 \%$ DNA mismatch repair protein Msh2 GN=MSH2 MSH2_HUMAN $104.75100 .0 \%$ DNA mismatch repair protein Msh6 GN=MSH6 MSH6 HUMAN $152.79 \quad 100.0 \%$ DNA mismatch repair protein Msh6 GN=MSH6 MSH6_HUMAN $152.79 \quad 100.0 \%$ DNA mismatch repair protein Msh6 GN=MSH6 MSH6_HUMAN $152.79 \quad 100.0 \%$ DNA polymerase delta catalytic subunit GN=POLD1 DPOD1_HUMAN $123.63 \quad 100.0 \%$ DNA polymerase delta catalytic subunit GN=POLD1 DPOD1_HUMAN $123.63 \quad 100.0 \%$ DNA polymerase delta catalytic subunit GN=POLD1 DPOD1_HUMAN $123.63 \quad 100.0 \%$ DNA polymerase delta catalytic subunit GN=POLD1 DPOD1_HUMAN $123.63 \quad 100.0 \%$ DNA polymerase epsilon catalytic subunit A GN=POLE DPOE1_HUMAN $261.52 \quad 100.0 \%$ DNA polymerase epsilon catalytic subunit A GN=POLE DPOE1_HUMAN $261.52 \quad 100.0 \%$ DNA polymerase epsilon catalytic subunit A GN=POLE DPOE1_HUMAN $261.52 \quad 100.0 \%$ DNA polymerase epsilon catalytic subunit A GN=POLE DPOE1_HUMAN $261.52 \quad 100.0 \%$ DNA polymerase epsilon catalytic subunit A GN=POLE DPOE1_HUMAN $261.52 \quad 100.0 \%$ DNA polymerase epsilon catalytic subunit A GN=POLE DPOE1_HUMAN $261.52 \quad 100.0 \%$ DNA polymerase epsilon catalytic subunit A GN=POLE DPOE1 HUMAN $261.52 \quad 100.0 \%$ DNA polymerase epsilon catalytic subunit A GN=POLE DPOE1_HUMAN $261.52 \quad 100.0 \%$ DNA repair protein RAD50 GN=RAD50 RAD50_HUMAN $153.90 \quad 100.0 \%$ DNA repair protein RAD50 GN=RAD50 RAD50_HUMAN $153.90 \quad 100.0 \%$ DNA replication licensing factor MCM3 GN=MCM3 MCM3_HUMAN $90.98 \quad 100.0 \%$ DNA replication licensing factor MCM3 GN=MCM3 MCM3 HUMAN $90.98 \quad 100.0 \%$ DNA replication licensing factor MCM3 GN=MCM3 MCM3_HUMAN $90.98 \quad 100.0 \%$ DNA replication licensing factor MCM3 GN=MCM3 MCM3_HUMAN $90.98 \quad 100.0 \%$ DNA replication licensing factor MCM3 GN=MCM3 MCM3 HUMAN $90.98 \quad 100.0 \%$ DNA replication licensing factor MCM4 GN=MCM4 MCM4_HUMAN $96.56 \quad 100.0 \%$ DNA replication licensing factor MCM4 GN=MCM4 MCM4_HUMAN $96.56 \quad 100.0 \%$ DNA replication licensing factor MCM5 GN=MCM5 MCM5 HUMAN $82.29 \quad 100.0 \%$ DNA replication licensing factor MCM5 GN=MCM5 MCM5_HUMAN $82.29 \quad 100.0 \%$ DNA replication licensing factor MCM5 GN=MCM5 MCM5_HUMAN $82.29 \quad 100.0 \%$ DNA replication licensing factor MCM5 GN=MCM5 MCM5_HUMAN $82.29 \quad 100.0 \%$ DNA replication licensing factor MCM5 GN=MCM5 MCM5_HUMAN $82.29 \quad 100.0 \%$ DNA replication licensing factor MCM5 GN=MCM5 MCM5_HUMAN $82.29 \quad 100.0 \%$ DNA replication licensing factor MCM5 GN=MCM5 MCM5_HUMAN $82.29 \quad 100.0 \%$

ATE

$7 \% 51.6$

$25.0 \quad 12.4$

$0.00 \% \quad 3.9 \% \quad$ YLEKPITMLL

$0.01 \% \quad 7.9 \%$ INCPVYITK

$0.01 \% \quad 7.9 \%$ SAADIIALAR

$0.01 \% \quad 7.9 \%$ NKVFGLQGVSR

$0.01 \% \quad 7.9 \%$ GMYDGPVYEVPATPK

$0.01 \% \quad 6.7 \% \quad$ VVQNVFQFR

$0.01 \% \quad 6.7 \% \quad$ LLELADIDPTLRPR

$0.01 \% \quad 5.6 \%$ SGGVIKPPAMSSR

$0.01 \% \quad 5.6 \%$ SATVIDHLR

$0.00 \% \quad 3.5 \%$ QVGVGYVDSIQR

$0.00 \% \quad 3.5 \% \quad$ LTSLNEEYTK

$0.00 \% \quad 3.5 \%$ NNSFVNEIISR

$0.01 \% \quad 2.8 \%$ SPALSDANKASAR

$0.01 \% \quad 2.8 \%$ QATSISSETKNTLR

$0.01 \% \quad 2.8 \% \quad$ LANLPEEVIQK

$0.01 \% \quad 5.0 \%$ VAGLCSNIRDSSFQSK

$0.01 \% \quad 5.0 \%$ VTGVPLSYLLSR

$0.01 \% \quad 5.0 \%$ LGLTEDQFIR

$99.7 \% \quad 31.6 \quad 25.0 \quad 31.6$

$\begin{array}{llll}99.7 \% & 35.3 & 25.0 & 32.8\end{array}$

$99.7 \% \quad 74.7 \quad 25.0 \quad 60.1$

$\begin{array}{llll}96.3 \% & 20.9 & 25.0 & 20.9\end{array}$

$99.7 \% \quad 48.2 \quad 25.0 \quad 48.2$

$\begin{array}{llll}99.7 \% & 38.7 & 25.0 & 36.2\end{array}$

$99.7 \% \quad 40.8 \quad 25.0 \quad 40.2$

$\begin{array}{llll}99.5 \% & 21.1 & 25.0 & 20.8\end{array}$

$\begin{array}{llll}99.7 \% & 46.3 & 25.0 & 31.0\end{array}$

$99.7 \% \quad 40.1 \quad 25.0 \quad 32.1$

$98.9 \% \quad 18.6 \quad 25.0 \quad 18.6$

$99.7 \% \quad 44.0 \quad 25.0 \quad 44.0$

$99.7 \% \quad 48.6 \quad 25.0 \quad 43.7$

$99.7 \% \quad 41.2 \quad 25.0 \quad 31.2$

$94.9 \% \quad 18.0 \quad 25.0 \quad 11.2$

$98.9 \% \quad 17.9 \quad 25.0 \quad 17.9$

$99.7 \% \quad 28.4 \quad 25.0 \quad 28.4$

$\begin{array}{lllllll}0.01 \% & 5.0 \% & \text { AASDYAGKQAHVELAER } & 98.8 \% & 18.5 & 25.0 & 18.5\end{array}$

$10 \quad 0.01 \% \quad 4.0 \%$ GGVITDEEETSKK

$0 \quad 0.01 \% \quad 4.0 \%$ DSYLPVGSHNLK

$10 \quad 0.01 \% \quad 4.0 \% \quad$ AIPLAIFQAEPTVR

$10 \quad 0.01 \% \quad 4.0 \% \quad$ SSSLQDFDIR

$10 \quad 0.01 \% \quad 4.0 \%$ ASVFVLDTVR

$10 \quad 0.01 \% \quad 4.0 \% \quad$ AETDLKTICR

$10 \quad 0.01 \% \quad 4.0 \%$ LGSSVIYANFNR

$10 \quad 0.01 \% \quad 4.0 \%$ SYVLPEVICR

$0.00 \% \quad 1.5 \%$ WLQDNLTLR

$0.00 \% \quad 1.5 \%$ CSVSSLGFNVH

$0.02 \% \quad 7.3 \%$ TVLIACNVK

$0.02 \% \quad 7.3 \%$ SKDIFDQLAK

$0.02 \% \quad 7.3 \%$ AILCLLLGGVER

$0.02 \% \quad 7.3 \% \quad$ YVLCTAPR

$\begin{array}{llll}99.7 \% & 24.8 & 25.0 & 24.8\end{array}$

$99.6 \% \quad 23.9 \quad 25.0 \quad 21.2$

$\begin{array}{llll}99.7 \% & 42.8 & 25.0 & 39.5\end{array}$

$98.0 \% \quad 28.5 \quad 25.0 \quad 7.4$

$99.7 \% \quad 46.9$

$99.7 \% \quad 25.7$

$99.7 \% \quad 27.3$

$25.0 \quad 40.4$

$25.0 \quad 27.3$

$\begin{array}{lllll}99.6 \% & 27.2 & 25.0 & 21.1\end{array}$

$\begin{array}{llll}98.2 \% & 21.0 & 25.0 & 15.4\end{array}$

$99.7 \% \quad 51.1 \quad 25.0 \quad 47.8$

$\begin{array}{llll}98.1 \% & 25.9 & 25.0 & 10.5\end{array}$

$99.7 \% \quad 49.0 \quad 25.0 \quad 39.6$

$99.7 \% \quad 35.7 \quad 25.0 \quad 30.9$

$\begin{array}{llll}99.0 \% & 35.5 & 25.0 & 32.9\end{array}$

$110.02 \% \quad 7.3 \%$ GSSGVGLTAAVTTDQETGER

$0.01 \% \quad 3.2 \%$ AGIICQLNAR

$.2 \% \quad 83.0$

$0.01 \% \quad 3.2 \%$ TGIVDISILTTGMSATSR

$99.7 \% \quad 65.1$

$0.06 \% \quad 28.3 \%$ IPGIIIAASAVR

$99.7 \% \quad 47.4$

$0.06 \% \quad 28.3 \%$ NTLTNIAMRPGLEGYALPR

$0.06 \% \quad 28.3 \%$ HMQLYCDR

$99.0 \% \quad 32.2$

20

20

20

$0.06 \% \quad 28.3 \%$ SSYIRVLGIQVDTDGSGR

$40 \quad 0.06 \% \quad 28.3 \%$ VLGIQVDTDGSGR

$99.7 \% 34.6$

$0.06 \% \quad 28.3 \%$ SFAGAVSPQEEEEFRR

$95.4 \%-14$

$99.7 \% \quad 50.1$

$20 \quad 40 \quad 0.06 \% \quad 28.3 \%$ LAALPNVYEVISK

1136.62

1621.93

1286.69

1011.56

1320.69

1197.60

1292.66

1287.67

1535.80

1253.71

1768.86

1304.76

1191.64

1815.90

1392.69

1329.68

1525.87

1167.56

1106.62

1206.61

1340.70

1235.65

1158.63

1206.56

1017.58

1164.63

1313.76

979.50

1935.93

1115.60

1822.96

1180.74

2087.11

1122.48

1922.99

1316.68

1838.87

1416.81 


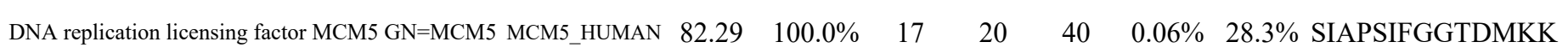

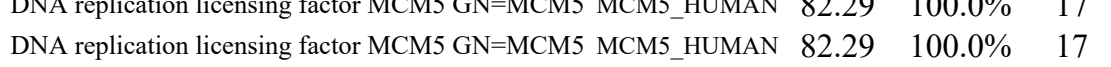
DNA replication licensing factor MCM5 GN=MCM5 MCM5_HUMAN $82.29 \quad 100.0 \% \quad 17$ DNA replication licensing factor MCM5 GN=MCM5 MCM5 HUMAN $82.29 \quad 100.0 \% \quad 17$ $\begin{array}{llll}\text { DNA replication licensing factor MCM5 GN=MCM5 MCM5_HUMAN } & 82.29 & 100.0 \% & 17\end{array}$ DNA replication licensing factor MCM5 GN=MCM5 MCM5_HUMAN $82.29 \quad 100.0 \% \quad 17$ DNA replication licensing factor MCM5 GN=MCM5 MCM5_HUMAN $82.29 \quad 100.0 \% \quad 17$ DNA replication licensing factor MCM5 GN=MCM5 MCM5_HUMAN $82.29 \quad 100.0 \% \quad 17$ DNA replication licensing factor MCM5 GN=MCM5 MCM5_HUMAN 82.29 DNA replication licensing factor MCM5 GN=MCM5 MCM5_HUMAN 82.29 DNA replication licensing factor MCM6 GN=MCM6 MCM6_HUMAN 92.89 DNA replication licensing factor MCM6 GN=MCM6 MCM6_HUMAN 92.89 DNA replication licensing factor MCM6 GN=MCM6 MCM6_HUMAN 92.89 DNA replication licensing factor MCM6 GN=MCM6 MCM6_HUMAN 92.89 DNA replication licensing factor MCM7 GN=MCM7 MCM7_HUMAN 81.31 DNA replication licensing factor MCM7 GN=MCM7 MCM7_HUMAN 81.31 DNA replication licensing factor MCM7 GN=MCM7 MCM7 HUMAN $81.31 \quad 100.0 \%$ DNA replication licensing factor MCM7 GN=MCM7 MCM7_HUMAN $81.31 \quad 100.0 \%$ DNA replication licensing factor MCM7 GN=MCM7 MCM7_HUMAN $81.31 \quad 100.0 \%$ DNA replication licensing factor MCM7 GN=MCM7 MCM7_HUMAN $81.31 \quad 100.0 \%$ DNA replication licensing factor MCM7 GN=MCM7 MCM7_HUMAN $81.31 \quad 100.0 \%$ DNA replication licensing factor MCM7 GN=MCM7 MCM7_HUMAN $81.31 \quad 100.0 \%$ DNA replication licensing factor MCM7 GN=MCM7 MCM7_HUMAN $81.31 \quad 100.0 \%$ DNA replication licensing factor MCM7 GN=MCM7 MCM7_HUMAN $81.31 \quad 100.0 \%$ DNA replication licensing factor MCM7 GN=MCM7 MCM7_HUMAN $81.31 \quad 100.0 \%$ DNA replication licensing factor MCM7 GN=MCM7 MCM7_HUMAN $81.31 \quad 100.0 \%$ DNA replication licensing factor MCM7 GN=MCM7 MCM7_HUMAN $81.31 \quad 100.0 \%$ DNA replication licensing factor MCM7 GN=MCM7 MCM7_HUMAN $81.31 \quad 100.0 \%$ DNA replication licensing factor MCM7 GN=MCM7 MCM7_HUMAN $81.31 \quad 100.0 \%$ DNA replication licensing factor MCM7 GN=MCM7 MCM7 HUMAN $81.31 \quad 100.0 \%$ DNA replication licensing factor MCM7 GN=MCM7 MCM7_HUMAN $81.31 \quad 100.0 \%$ DNA replication licensing factor MCM7 GN=MCM7 MCM7_HUMAN $81.31 \quad 100.0 \%$ DNA topoisomerase $1 \mathrm{GN}=\mathrm{TOP} 1$ DNA topoisomerase $1 \mathrm{GN}=\mathrm{TOP} 1$ DNA topoisomerase $1 \mathrm{GN}=\mathrm{TOP} 1$ DNA topoisomerase $1 \mathrm{GN}=\mathrm{TOP} 1$ DNA topoisomerase $1 \mathrm{GN}=\mathrm{TOP} 1$ DNA topoisomerase $1 \mathrm{GN}=\mathrm{TOP} 1$ TOP1_HUMAN $90.73 \quad 100.0 \%$ TOP1_HUMAN $90.73 \quad 100.0 \%$ TOP1_HUMAN $90.73 \quad 100.0 \%$ TOP1_HUMAN $90.73 \quad 100.0 \%$ TOP1_HUMAN $90.73 \quad 100.0 \%$ TOP1 HUMAN $90.73 \quad 100.0 \%$ DNA topoisomerase 2-alpha GN=TOP2A TOP2A_HUMAN $174.39 \quad 100.0 \%$ DNA topoisomerase 2-alpha GN=TOP2A TOP2A_HUMAN $174.39 \quad 100.0 \%$ DNA topoisomerase 2-alpha GN=TOP2A TOP2A_HUMAN $174.39 \quad 100.0 \%$ DNA topoisomerase 2-alpha GN=TOP2A TOP2A_HUMAN $174.39 \quad 100.0 \%$ DNA topoisomerase 2-alpha GN=TOP2A TOP2A_HUMAN $174.39 \quad 100.0 \%$ DNA topoisomerase 2-alpha GN=TOP2A TOP2A_HUMAN $174.39 \quad 100.0 \%$ DNA topoisomerase 2-alpha GN=TOP2A TOP2A_HUMAN $174.39 \quad 100.0 \%$ DNA topoisomerase 2-alpha GN=TOP2A TOP2A_HUMAN $174.39 \quad 100.0 \%$ DNA topoisomerase 2-alpha GN=TOP2A TOP2A_HUMAN $174.39 \quad 100.0 \%$

24

24

24

8

$\begin{array}{ll}8 & 24 \\ 8 & 24 \\ 18 & -24\end{array}$
24
24
24

24

8
8
8

8
8
18

18
18
18

$\begin{array}{ll}18 & 24 \\ 18 & 24\end{array}$

18
18
18

18

18

18
18
6

6
6
6

6
6
6

6
6
6

6
6
10
10

$0.06 \% \quad 28.3 \%$ AIACLLFGGSRK

$\begin{array}{llll}40 & 0.06 \% & 28.3 \% & \text { RGDINLLMLGD } \\ 40 & 0.06 \% & 28.3 \% & \text { CSPIGVYTSGK }\end{array}$

$40 \quad 0.06 \% \quad 28.3 \%$ GSSAAGLTASVMRDPSSR

$40 \quad 0.06 \% \quad 28.3 \%$ AGITTTLNSR

$40 \quad 0.06 \% \quad 28.3 \%$ CSVLAAANSVFGR

$40 \quad 0.06 \% \quad 28.3 \%$ LSAEAAEKLK

$40 \quad 0.06 \% \quad 28.3 \%$ FAIGSQVSEHSIIKDFTK

$10 \quad 0.01 \% \quad 6.7 \% \quad$ IQETQAELPRGSIPR

$10 \quad 0.01 \% \quad 6.7 \% \quad$ VSGVDGYETEGIRGLR

$10 \quad 0.01 \% \quad 6.7 \% \quad$ HVEEFSPR

$10 \quad 0.01 \% \quad 6.7 \%$ TSILAAANPISGHYDR

$53 \quad 0.08 \% \quad 29.1 \%$ LFADAVQELLPQYKER

$33 \quad 0.08 \% \quad 29.1 \%$ SPQNQYPAELMR

$0.08 \% \quad 29.1 \%$ ADSVGKLVTVR

$0.08 \% \quad 29.1 \%$ SITVLVEGENTR

$0.08 \% \quad 29.1 \%$ IAQPGDHVSVTGIFLPILR

$0.08 \% 29.1 \%$ ALLLLLVGGVDQSPR

$0.08 \% \quad 29.1 \%$ IRGNINICLMGDPGVAK

$0.08 \% \quad 29.1 \%$ GNINICLMGDPGVAK

$0.08 \% \quad 29.1 \%$ SQLLSYIDR

$0.08 \% \quad 29.1 \%$ SQLLSYIDRLAPR

$0.08 \% \quad 29.1 \%$ SQYTTGRGSSGVGLTAAVLR

$0.08 \% 29.1 \%$ GSSGVGLTAAVLR

$0.08 \% \quad 29.1 \%$ AGILTTLNAR

$0.08 \% \quad 29.1 \%$ CSILAAANPAYGR

$0.08 \% \quad 29.1 \%$ SLEQNIQLPAALLSR

$0.08 \% \quad 29.1 \%$ LAQHITYVHQHSR

$0.08 \% \quad 29.1 \%$ TQRPADVIFATVR

$0.08 \% \quad 29.1 \%$ SVRFSEAEQR

$0.02 \% \quad 8.2 \% \quad$ LSPKAEEVATFFAK

$0.02 \% \quad 8.2 \%$ AEEVATFFAK

$0.02 \% \quad 8.2 \%$ CDFTQMSQYFK

$0.02 \% \quad 8.2 \%$ IMPEDIIINCSK

$0.02 \% \quad 8.2 \%$ AVALYFIDKLALR

$0.04 \% \quad 7.7 \%$ EVTFVPGLYK

$\begin{array}{lll}0.04 \% & 7.7 \% & \text { IFDEILVNAADNKQR }\end{array}$

$0.04 \% \quad 7.7 \%$ LCNIFSTK

$0.04 \% \quad 7.7 \%$ AYDIAGSTKDVK

$0.04 \% \quad 7.7 \%$ HVDYVADQIVTK

$0.04 \% \quad 7.7 \%$ SFGSTCQLSEKFIK

$0.04 \% \quad 7.7 \%$ TLAVSGLGVVGR

$0.04 \% \quad 7.7 \%$ QIMENAEINNIIK

$0.04 \% \quad 7.7 \%$ YIFTMLSSLAR
$0.02 \% \quad 8.2 \%$ IANFKIEPPGLFR
$99.7 \% \quad 32.2$

$\begin{array}{llll}99.7 \% & 50.5 & 25.0 & 49.2\end{array}$

$\begin{array}{llll}99.7 \% & 32.7 & 25.0 & 32.7\end{array}$

$\begin{array}{llll}.6 \% & 28.7 & 25.0 & 22.0\end{array}$

$\begin{array}{llll}99.7 \% & 59.5 & 25.0 & 45.0\end{array}$

$\begin{array}{lllll}99.7 \% & 63.7 & 25.0 & 62.8 & 2\end{array}$

$\begin{array}{llll}99.7 \% & 46.2 & 25.0 & 35.3\end{array}$

$99.7 \% \quad 30.6 \quad 25.0 \quad 27.8$

$\begin{array}{llll}99.7 \% & 33.7 & 25.0 & 31.7\end{array}$

$99.7 \% \quad 31.6 \quad 25.0 \quad 26.8$

$\begin{array}{llll}99.0 \% & 29.8 & 25.0 & 29.8\end{array}$

$\begin{array}{llll}99.7 \% & 48.7 & 25.0 & 48.7\end{array}$

$\begin{array}{llll}99.7 \% & 27.9 & 25.0 & 26.1\end{array}$

$\begin{array}{llll}99.7 \% & 40.8 & 25.0 & 40.8\end{array}$

$99.7 \% \quad 64.4 \quad 25.0 \quad 55.7$

$\begin{array}{llll}99.7 \% & 38.8 & 25.0 & 33.6\end{array}$

$99.7 \% \quad 41.1$

$99.7 \% \quad 59.6$

$99.5 \% \quad 23.8$

$\begin{array}{lll}99.7 \% & 49.3\end{array}$

$99.7 \% \quad 37.9$

$99.7 \% \quad 38.9$

$99.7 \% \quad 27.8$

$99.7 \% \quad 64.9$

$\begin{array}{lll}99.7 \% & 59.4\end{array}$

$99.7 \% \quad 67.1$

$99.7 \% \quad 58.8$

$99.5 \% \quad 24.2$

$99.7 \% \quad 44.1$

$\begin{array}{lll}99.7 \% & 29.7\end{array}$

$99.7 \% \quad 33.3$

$99.7 \% \quad 47.7$

$99.7 \% \quad 37.8$

$99.7 \% \quad 32.0$

$99.7 \% \quad 45.3$

$\begin{array}{lll}99.7 \% & 46.2\end{array}$

$98.1 \% \quad 16.2$

$99.7 \% \quad 62.3$

$99.0 \% \quad 31.0$

$99.7 \% \quad 29.6$

$99.7 \% \quad 58.7$

$98.9 \% \quad 28.6$

$99.7 \% \quad 58.7$

$\begin{array}{lll}99.7 \% & 44.0\end{array}$

$99.7 \% \quad 57.1$

0
0
0
3
0
1
0
0
0
2
2
2
0
2
1
0
0
0
0
3
0
2
2
0
0
0
0
3
1
0
0
0
0
0
0
0
0
0
0
0
0
0
0
0
0
0
0
0
0
0
0

1164.62

1292.71

1686.88

1168.57

1749.85

1033.56

1351.68

1059.60

2007.05

1694.92

1707.87

1000.48

1685.86

1920.02

1433.68

1144.67

1317.70

2033.15

1550.93

1843.95

1558.77

1094.58

1531.86

1981.05

1187.67

1029.61

1363.68

1652.93

1589.83

1473.82

1208.60

1537.83

1112.56

1470.60

1501.85

1432.72

1492.89

1152.63

1745.92

982.50

1267.65

1387.72

1631.81

1128.67

1529.80

1301.69 $\begin{array}{cc}38 & 351 \\ 52 & 362 \\ 52 & 363 \\ 72 & 387 \\ 97 & 407 \\ 08 & 425 \\ 72 & 481 \\ 82 & 494 \\ 74 & 583 \\ 83 & 700 \\ 08 & 222 \\ 70 & 285 \\ 08 & 415 \\ 97 & 512 \\ 6 & 91 \\ 21 & 132 \\ 54 & 164 \\ 52 & 263 \\ 64 & 282 \\ 53 & 367 \\ 71 & 387 \\ 73 & 387 \\ 88 & 396 \\ 88 & 400 \\ 01 & 420 \\ 08 & 420 \\ 72 & 481 \\ 82 & 494 \\ 00 & 514 \\ 33 & 545 \\ 54 & 666 \\ 74 & 683 \\ 49 & 262 \\ 53 & 262 \\ 00 & 310 \\ 50 & 362 \\ 77 & 388 \\ 76 & 488 \\ 4 & 83 \\ 4 & 98 \\ 69 & 176 \\ 43 & 254 \\ 25 & 336 \\ 87 & 400 \\ 05 & 478 \\ 512 \\ & 815 \\ & \end{array}$

Page 39 of Table S-1-2 

DNA topoisomerase 2-alpha GN=TOP2A TOP2A_HUMAN $174.39 \quad 100.0 \%$ DNA topoisomerase 2-beta GN=TOP2B TOP2B_HUMAN $183.27 \quad 100.0 \%$ DNA topoisomerase 2-beta GN=TOP2B TOP2B HUMAN $183.27 \quad 100.0 \%$ DNA topoisomerase 2-beta GN=TOP2B TOP2B_HUMAN $183.27 \quad 100.0 \%$ DNA topoisomerase 2-beta GN=TOP2B TOP2B_HUMAN $183.27 \quad 100.0 \%$ DNA topoisomerase 2-beta GN=TOP2B TOP2B_HUMAN $183.27 \quad 100.0 \%$ DNA topoisomerase 2-beta GN=TOP2B TOP2B_HUMAN $183.27 \quad 100.0 \%$ DNA topoisomerase 2-beta GN=TOP2B TOP2B HUMAN $183.27 \quad 100.0 \%$ DNA topoisomerase 2-beta GN=TOP2B TOP2B_HUMAN $183.27 \quad 100.0 \%$ DNA topoisomerase 2-beta GN=TOP2B TOP2B_HUMAN $183.27 \quad 100.0 \%$ DNA topoisomerase 2-beta GN=TOP2B TOP2B_HUMAN $183.27 \quad 100.0 \%$ DNA-binding protein SATB2 GN=SATB2 SATB2_HUMAN $82.56 \quad 100.0 \%$ DNA-binding protein SATB2 GN=SATB2 SATB2_HUMAN $82.56 \quad 100.0 \%$ DNA-dependent protein kinase catalytic subunit GN=PRKDC PRKDC_HUMAN $469.10 \quad 100.0 \%$ DNA-dependent protein kinase catalytic subunit GN=PRKDC PRKDC_HUMAN $469.10 \quad 100.0 \%$ DNA-dependent protein kinase catalytic subunit GN=PRKDC PRKDC_HUMAN $469.10 \quad 100.0 \%$ DNA-dependent protein kinase catalytic subunit GN=PRKDC PRKDC_HUMAN $469.10 \quad 100.0 \%$ DNA-dependent protein kinase catalytic subunit GN=PRKDC PRKDC_HUMAN $469.10 \quad 100.0 \%$ DNA-dependent protein kinase catalytic subunit GN=PRKDC PRKDC_HUMAN $469.10 \quad 100.0 \%$ DNA-dependent protein kinase catalytic subunit GN=PRKDC PRKDC_HUMAN $469.10 \quad 100.0 \%$ DNA-dependent protein kinase catalytic subunit GN=PRKDC PRKDC_HUMAN $469.10 \quad 100.0 \%$ DNA-dependent protein kinase catalytic subunit GN=PRKDC PRKDC_HUMAN $469.10 \quad 100.0 \%$ DNA-dependent protein kinase catalytic subunit GN=PRKDC PRKDC_HUMAN $469.10 \quad 100.0 \%$ DNA-dependent protein kinase catalytic subunit GN=PRKDC PRKDC_HUMAN $469.10 \quad 100.0 \%$ DNA-dependent protein kinase catalytic subunit GN=PRKDC PRKDC_HUMAN $469.10 \quad 100.0 \%$ DNA-dependent protein kinase catalytic subunit GN=PRKDC PRKDC_HUMAN $469.10 \quad 100.0 \%$ DNA-dependent protein kinase catalytic subunit GN=PRKDC PRKDC_HUMAN $469.10 \quad 100.0 \%$ DNA-dependent protein kinase catalytic subunit GN=PRKDC PRKDC_HUMAN $469.10 \quad 100.0 \%$ DNA-dependent protein kinase catalytic subunit GN=PRKDC PRKDC HUMAN $469.10 \quad 100.0 \%$ DNA-dependent protein kinase catalytic subunit GN=PRKDC PRKDC_HUMAN $469.10 \quad 100.0 \%$ DNA-dependent protein kinase catalytic subunit GN=PRKDC PRKDC_HUMAN $469.10 \quad 100.0 \%$ DNA-dependent protein kinase catalytic subunit GN=PRKDC PRKDC HUMAN $469.10 \quad 100.0 \%$ DNA-dependent protein kinase catalytic subunit GN=PRKDC PRKDC_HUMAN $469.10 \quad 100.0 \%$ DNA-dependent protein kinase catalytic subunit GN=PRKDC PRKDC_HUMAN $469.10 \quad 100.0 \%$ DNA-dependent protein kinase catalytic subunit GN=PRKDC PRKDC_HUMAN $469.10 \quad 100.0 \%$ DNA-dependent protein kinase catalytic subunit GN=PRKDC PRKDC_HUMAN $469.10 \quad 100.0 \%$ DNA-dependent protein kinase catalytic subunit GN=PRKDC PRKDC HUMAN $469.10 \quad 100.0 \%$ DNA-dependent protein kinase catalytic subunit GN=PRKDC PRKDC_HUMAN $469.10 \quad 100.0 \%$ DNA-dependent protein kinase catalytic subunit GN=PRKDC PRKDC_HUMAN $469.10 \quad 100.0 \%$ DNA-dependent protein kinase catalytic subunit GN=PRKDC PRKDC HUMAN $469.10 \quad 100.0 \%$ DNA-dependent protein kinase catalytic subunit GN=PRKDC PRKDC_HUMAN $469.10 \quad 100.0 \%$ DNA-dependent protein kinase catalytic subunit GN=PRKDC PRKDC_HUMAN $469.10 \quad 100.0 \%$ DNA-dependent protein kinase catalytic subunit GN=PRKDC PRKDC_HUMAN $469.10 \quad 100.0 \%$ DNA-dependent protein kinase catalytic subunit GN=PRKDC PRKDC_HUMAN $469.10 \quad 100.0 \%$ DNA-dependent protein kinase catalytic subunit GN=PRKDC PRKDC_HUMAN $469.10 \quad 100.0 \%$ DNA-dependent protein kinase catalytic subunit GN=PRKDC PRKDC_HUMAN $469.10 \quad 100.0 \%$ $\begin{array}{llll}27 & 0.04 \% & 7.7 \% & \text { TQMAEVLPSPR }\end{array}$

$16 \quad 0.02 \% \quad 8.0 \%$ EVTFVPGLYK

$16 \quad 0.02 \% \quad 8.0 \% \quad$ IFDEILVNAADNKQR

$16 \quad 0.02 \% \quad 8.0 \% \quad$ LCNIFSTK

$16 \quad 0.02 \% \quad 8.0 \% \quad$ HVDYVVDQVVGK

$16 \quad 0.02 \% \quad 8.0 \%$ AGVSVKPFQVK

$16 \quad 0.02 \% \quad 8.0 \%$ SLAVSGLGVIGR

$16 \quad 0.02 \% \quad 8.0 \% \quad$ QIMENAEINNIIK

$16 \quad 0.02 \% \quad 8.0 \% \quad$ SYDDAESLKTLR

$16 \quad 0.02 \% \quad 8.0 \% \quad$ YAGPEDDAAITLAFSK

$16 \quad 0.02 \% \quad 8.0 \% \quad$ LLFPAVDDNLLK

$16 \quad 0.02 \% \quad 8.0 \%$ DLIQMLVQR

$2 \quad 0.00 \% \quad 2.6 \%$ AKVSQALFAK

$2 \quad 0.00 \% \quad 2.6 \%$ AAPAEIDQR

$471 \quad 0.69 \% \quad 24.1 \%$ LQETLSAADR

$471 \quad 0.69 \% \quad 24.1 \%$ CGAALAGHQLIR

$471 \quad 0.69 \% \quad 24.1 \%$ IAPYSVEIK

$471 \quad 0.69 \% \quad 24.1 \%$ NTCTSVYTKDR

$471 \quad 0.69 \% \quad 24.1 \%$ TQMTSAVREPK

$471 \quad 0.69 \% \quad 24.1 \%$ LPVLAGCLK

$471 \quad 0.69 \% \quad 24.1 \%$ GLSSLLCNFTK

$471 \quad 0.69 \% \quad 24.1 \%$ SMEEDPQTSR

$471 \quad 0.69 \% \quad 24.1 \%$ EIFNFVLK

$471 \quad 0.69 \% \quad 24.1 \%$ AIRPQIDLKR

$471 \quad 0.69 \% \quad 24.1 \%$ AALSALESFLK

$471 \quad 0.69 \% \quad 24.1 \%$ NVDSNNKELSIAIR

$471 \quad 0.69 \% \quad 24.1 \%$ DVDFMYVELIQR

$471 \quad 0.69 \% \quad 24.1 \%$ NCISTVVHQGLIR

$\begin{array}{llll}471 & 0.69 \% & 24.1 \% & \text { ICSKPVVLPK }\end{array}$

$471 \quad 0.69 \% \quad 24.1 \%$ GPESESEDHRASGEVR

$471 \quad 0.69 \% \quad 24.1 \%$ IKYFEGVSPK

$471 \quad 0.69 \% \quad 24.1 \%$ FGKEVAVK

$471 \quad 0.69 \% \quad 24.1 \%$ TSALSDETKNNWEVSALSR

$471 \quad 0.69 \% \quad 24.1 \%$ GFNKVVLK

$471 \quad 0.69 \% \quad 24.1 \%$ NLSSNEAISLEEIR

$471 \quad 0.69 \% \quad 24.1 \%$ VVQMLGSLGGQINK

$471 \quad 0.69 \% \quad 24.1 \%$ NLLTVTSSDEMMK

$471 \quad 0.69 \% \quad 24.1 \%$ SYVAWDREK

$471 \quad 0.69 \% \quad 24.1 \%$ LSFAVPFR

$471 \quad 0.69 \% \quad 24.1 \%$ VTELALTASDR

$471 \quad 0.69 \% \quad 24.1 \%$ VTELALTASDRQTK

$471 \quad 0.69 \% \quad 24.1 \%$ ATQMPEGGQGAPPMYQLYKR

$471 \quad 0.69 \% \quad 24.1 \%$ LACDVDQVTR

$471 \quad 0.69 \% \quad 24.1 \%$ LYSLALHPNAFKR

$471 \quad 0.69 \% \quad 24.1 \%$ LGASLAFNNIYR

$471 \quad 0.69 \% \quad 24.1 \%$ SLGTIQQCCDAIDHLCR

$\begin{array}{llll}117 & 471 & 0.69 \% & 24.1 \% \\ 117 & 471 & 0.69 \% & 24.1 \% \text { FVPLLPGNR }\end{array}$

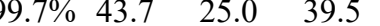

$\begin{array}{llll}98.1 \% & 16.2 & 25.0 & 16.2\end{array}$

$99.7 \% \quad 62.3 \quad 25.0 \quad 59.7$

$99.0 \% \quad 31.0 \quad 25.0 \quad 25.6$

$\begin{array}{llll}99.7 \% & 55.6 & 25.0 & 48.3\end{array}$

$\begin{array}{llll}98.6 \% & 19.9 & 25.0 & 16.9\end{array}$

$99.7 \% \quad 61.2 \quad 25.0 \quad 51.5$

$99.7 \% \quad 44.0 \quad 25.0 \quad 39.6$

$99.7 \% \quad 44.9 \quad 25.0-36.5$

$99.7 \% \quad 48.4 \quad 25.0 \quad 48.4$

$\begin{array}{llll}99.7 \% & 50.2 & 25.0 & 41.0\end{array}$

$99.7 \% \quad 49.6 \quad 25.0 \quad 39.9$

$99.2 \% \quad 19.0 \quad 25.0 \quad 19.0$

$\begin{array}{llll}99.3 \% & 26.5 & 25.0 & 19.6\end{array}$

$99.7 \% \quad 56.8 \quad 25.0 \quad 46.3$

$\begin{array}{llll}99.7 \% & 39.6 & 25.0 & 39.6\end{array}$

$99.3 \% \quad 20.4 \quad 25.0 \quad 18.7$

$\begin{array}{llll}99.7 \% & 28.7 & 25.0 & 28.7\end{array}$

$\begin{array}{llll}99.6 \% & 22.8 & 25.0 & 21.7\end{array}$

$99.7 \% \quad 31.9 \quad 25.0 \quad 31.9$

$\begin{array}{llll}99.7 \% & 48.1 & 25.0 & 33.7\end{array}$

$99.7 \% \quad 29.1 \quad 25.0 \quad 26.0$

$\begin{array}{llll}99.0 \% & 28.3 & 25.0 & 21.7\end{array}$

$\begin{array}{llll}99.7 \% & 34.6 & 25.0 & 33.3\end{array}$

$99.7 \% \quad 54.8 \quad 25.0 \quad 47.6$

$\begin{array}{llll}99.7 \% & 58.1 & 25.0 & 58.1\end{array}$

$\begin{array}{llll}99.7 \% & 57.5 & 25.0 & 53.8\end{array}$

$99.7 \% \quad 62.6 \quad 25.0 \quad 53.9$

$\begin{array}{llll}98.8 \% & 24.0 & 25.0 & 14.3\end{array}$

$\begin{array}{llll}99.7 \% & 47.3 & 25.0 & 47.3\end{array}$

$99.7 \% \quad 31.0 \quad 25.0 \quad 31.0$

$\begin{array}{llll}99.0 \% & 49.7 & 25.0 & 27.2\end{array}$

$99.7 \% \quad 38.4$

$99.0 \% \quad 38.8$

$99.7 \% \quad 52.5$

$99.7 \% \quad 62.9$

$99.7 \% \quad 57.6$

$99.6 \% \quad 28.5$

$99.0 \% \quad 38.1$

$99.7 \% 48$.

$99.7 \% \quad 51.2$

$\begin{array}{ll}99.7 \% & 30.3\end{array}$

$99.7 \% \quad 63.6$

$99.7 \% \quad 28.1$

$99.7 \% \quad 56.3$

$99.7 \% \quad 35.0$

$99.5 \% \quad 21.5$

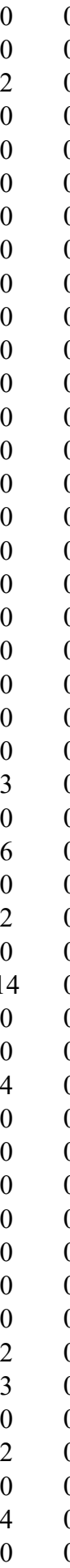

1228.64

1152.63

1745.92

982.50

1357.71

1159.68

1128.67

1529.80

1397.69

1668.81

1357.77

1115.62

1062.63

970.50

1103.57

1266.67

1019.58

1344.62

1247.64

970.58

1239.64

1179.49

1009.57

1209.74

1149.65

1572.83

1543.75

1496.80

1140.68

1741.77

1167.64

877.51

2108.03

904.56

1574.80

1459.79

1500.69

1153.56

936.53

1175.63

1532.83

2239.06

1176.57

1529.86

1338.72

2046.92

2046.92
1012.59 $\begin{array}{cc}05 & 1215 \\ 5 & 104 \\ 05 & 119 \\ 90 & 197 \\ 46 & 357 \\ 68 & 378 \\ 88 & 499 \\ 21 & 533 \\ 42 & 553 \\ 61 & 676 \\ 37 & 848 \\ 93 & 1101 \\ 98 & 507 \\ 25 & 733 \\ 5 & 24 \\ 5 & 36 \\ 00 & 108 \\ 09 & 119 \\ 06 & 216 \\ 17 & 225 \\ 26 & 236 \\ 37 & 246 \\ 47 & 254 \\ 55 & 264 \\ 11 & 321 \\ 51 & 364 \\ 80 & 391 \\ 77 & 489 \\ 90 & 499 \\ 00 & 515 \\ 80 & 689 \\ 10 & 717 \\ 02 & 820 \\ 25 & 832 \\ 39 & 852 \\ 55 & 868 \\ 69 & 881 \\ 82 & 890 \\ 92 & 899 \\ 14 & 924 \\ 14 & 927 \\ 45 & 964 \\ 72 & 981 \\ 63 & 1075 \\ 76 & 1087 \\ 20 & 1136 \\ 94 & 1202 \\ & \end{array}$

Page 40 of Table S-1-2 
DNA-dependent protein kinase catalytic subunit GN=PRKDC PRKDC_HUMAN $469.10 \quad 100.0 \% \quad 92$ DNA-dependent protein kinase catalytic subunit GN=PRKDC PRKDC_HUMAN $469.10 \quad 100.0 \% 92$ DNA-dependent protein kinase catalytic subunit GN=PRKDC PRKDC_HUMAN $469.10 \quad 100.0 \% \quad 92$ DNA-dependent protein kinase catalytic subunit GN=PRKDC PRKDC_HUMAN $469.10 \quad 100.0 \%$ DNA-dependent protein kinase catalytic subunit GN=PRKDC PRKDC_HUMAN $469.10 \quad 100.0 \%$ DNA-dependent protein kinase catalytic subunit GN=PRKDC PRKDC_HUMAN $469.10 \quad 100.0 \%$ DNA-dependent protein kinase catalytic subunit GN=PRKDC PRKDC_HUMAN $469.10 \quad 100.0 \%$ DNA-dependent protein kinase catalytic subunit GN=PRKDC PRKDC_HUMAN $469.10 \quad 100.0 \%$ DNA-dependent protein kinase catalytic subunit GN=PRKDC PRKDC_HUMAN $469.10 \quad 100.0 \%$ DNA-dependent protein kinase catalytic subunit GN=PRKDC PRKDC_HUMAN $469.10 \quad 100.0 \%$ DNA-dependent protein kinase catalytic subunit GN=PRKDC PRKDC_HUMAN $469.10 \quad 100.0 \%$ DNA-dependent protein kinase catalytic subunit GN=PRKDC PRKDC_HUMAN $469.10 \quad 100.0 \%$ DNA-dependent protein kinase catalytic subunit GN=PRKDC PRKDC_HUMAN $469.10 \quad 100.0 \%$ DNA-dependent protein kinase catalytic subunit GN=PRKDC PRKDC_HUMAN $469.10 \quad 100.0 \%$ DNA-dependent protein kinase catalytic subunit GN=PRKDC PRKDC_HUMAN $469.10 \quad 100.0 \%$ DNA-dependent protein kinase catalytic subunit GN=PRKDC PRKDC_HUMAN $469.10 \quad 100.0 \%$ DNA-dependent protein kinase catalytic subunit GN=PRKDC PRKDC_HUMAN $469.10 \quad 100.0 \%$ DNA-dependent protein kinase catalytic subunit GN=PRKDC PRKDC_HUMAN $469.10 \quad 100.0 \%$ DNA-dependent protein kinase catalytic subunit GN=PRKDC PRKDC_HUMAN $469.10 \quad 100.0 \%$ DNA-dependent protein kinase catalytic subunit GN=PRKDC PRKDC_HUMAN $469.10 \quad 100.0 \%$ DNA-dependent protein kinase catalytic subunit GN=PRKDC PRKDC_HUMAN $469.10 \quad 100.0 \%$ DNA-dependent protein kinase catalytic subunit GN=PRKDC PRKDC_HUMAN $469.10 \quad 100.0 \%$ DNA-dependent protein kinase catalytic subunit GN=PRKDC PRKDC_HUMAN $469.10 \quad 100.0 \%$ DNA-dependent protein kinase catalytic subunit GN=PRKDC PRKDC_HUMAN $469.10 \quad 100.0 \%$ DNA-dependent protein kinase catalytic subunit GN=PRKDC PRKDC_HUMAN $469.10 \quad 100.0 \%$ DNA-dependent protein kinase catalytic subunit GN=PRKDC PRKDC_HUMAN $469.10 \quad 100.0 \%$ DNA-dependent protein kinase catalytic subunit GN=PRKDC PRKDC_HUMAN $469.10 \quad 100.0 \%$ DNA-dependent protein kinase catalytic subunit GN=PRKDC PRKDC_HUMAN $469.10 \quad 100.0 \%$ DNA-dependent protein kinase catalytic subunit GN=PRKDC PRKDC_HUMAN $469.10 \quad 100.0 \%$ DNA-dependent protein kinase catalytic subunit GN=PRKDC PRKDC_HUMAN $469.10 \quad 100.0 \%$ DNA-dependent protein kinase catalytic subunit GN=PRKDC PRKDC_HUMAN $469.10 \quad 100.0 \%$ DNA-dependent protein kinase catalytic subunit GN=PRKDC PRKDC_HUMAN $469.10 \quad 100.0 \%$ DNA-dependent protein kinase catalytic subunit GN=PRKDC PRKDC_HUMAN $469.10 \quad 100.0 \%$ DNA-dependent protein kinase catalytic subunit GN=PRKDC PRKDC_HUMAN $469.10 \quad 100.0 \%$ DNA-dependent protein kinase catalytic subunit GN=PRKDC PRKDC_HUMAN $469.10 \quad 100.0 \%$ DNA-dependent protein kinase catalytic subunit GN=PRKDC PRKDC_HUMAN $469.10 \quad 100.0 \%$ DNA-dependent protein kinase catalytic subunit GN=PRKDC PRKDC_HUMAN $469.10 \quad 100.0 \%$ DNA-dependent protein kinase catalytic subunit GN=PRKDC PRKDC_HUMAN $469.10 \quad 100.0 \%$ DNA-dependent protein kinase catalytic subunit GN=PRKDC PRKDC_HUMAN $469.10 \quad 100.0 \%$ DNA-dependent protein kinase catalytic subunit GN=PRKDC PRKDC_HUMAN $469.10 \quad 100.0 \%$ DNA-dependent protein kinase catalytic subunit GN=PRKDC PRKDC_HUMAN $469.10 \quad 100.0 \%$ DNA-dependent protein kinase catalytic subunit GN=PRKDC PRKDC_HUMAN $469.10 \quad 100.0 \%$ DNA-dependent protein kinase catalytic subunit GN=PRKDC PRKDC_HUMAN $469.10 \quad 100.0 \%$ DNA-dependent protein kinase catalytic subunit GN=PRKDC PRKDC_HUMAN $469.10 \quad 100.0 \%$ DNA-dependent protein kinase catalytic subunit GN=PRKDC PRKDC_HUMAN $469.10 \quad 100.0 \%$ DNA-dependent protein kinase catalytic subunit GN=PRKDC PRKDC_HUMAN $469.10 \quad 100.0 \%$ DNA-dependent protein kinase catalytic subunit GN=PRKDC PRKDC_HUMAN $469.10 \quad 100.0 \%$
$0.69 \% \quad 24.1 \%$ TVGALQVLGTEAQSSLLK $0.69 \% \quad 24.1 \%$ CFGTGAAGNR

$\begin{array}{llll}0.69 \% & 24.1 \% & \text { TSPQEGERYNYSK } \\ 471 & 0.69 \% & 24.1 \% & \text { DLCNTHLMR }\end{array}$

$471 \quad 0.69 \% \quad 24.1 \%$ SRLAAVVSACK

$471 \quad 0.69 \% \quad 24.1 \%$ LAAVVSACK

$471 \quad 0.69 \% \quad 24.1 \%$ LAAVVSACKQLHR

$471 \quad 0.69 \% \quad 24.1 \%$ QCLPSLDLSCK

$471 \quad 0.69 \% \quad 24.1 \%$ MVSAVLNGMLDQS

$471 \quad 0.69 \% \quad 24.1 \%$ LNESTFDTQITK

$471 \quad 0.69 \% \quad 24.1 \%$ LNESTFDTQITKK

$471 \quad 0.69 \% \quad 24.1 \%$ ILDVMYSR

$471 \quad 0.69 \% \quad 24.1 \%$ LPKDDVHAK

$471 \quad 0.69 \% \quad 24.1 \%$ INQVFHGSCITEGNELTK

$471 \quad 0.69 \% \quad 24.1 \%$ YNFPVEVEVPMER

$471 \quad 0.69 \% \quad 24.1 \%$ SLGPPQGEEDSVPR

$471 \quad 0.69 \% \quad 24.1 \%$ LGNPIVPLNIR

$471 \quad 0.69 \% \quad 24.1 \%$ LVINTEEVFRPYAK

$471 \quad 0.69 \% \quad 24.1 \%$ SKDFVQVMR

$\begin{array}{llll}471 & 0.69 \% & 24.1 \% & \text { VCLDIIYK }\end{array}$

$471 \quad 0.69 \% \quad 24.1 \%$ LPSNTLDR

$471 \quad 0.69 \% \quad 24.1 \%$ STVLTPMFVETQASQGTLQTR $99.7 \% \quad 51.4$

$471 \quad 0.69 \% \quad 24.1 \%$ TQEGSLSARWPVAGQIR $\quad 98.1 \% \quad 18.6$

$471 \quad 0.69 \% \quad 24.1 \%$ ATQQQHDFTLTQTADGR $99.7 \% \quad 59.4$

$471 \quad 0.69 \% \quad 24.1 \%$ SVGPDFGK

$471 \quad 0.69 \% \quad 24.1 \%$ LGLPGDEVDNKVK

$471 \quad 0.69 \% \quad 24.1 \%$ GAAGRTDLLR

$471 \quad 0.69 \% \quad 24.1 \%$ MKQDAQVVLYR

$471 \quad 0.69 \% \quad 24.1 \%$ QDAQVVLYR

$471 \quad 0.69 \% \quad 24.1 \%$ SYRHGDLPDIQIK

$471 \quad 0.69 \% \quad 24.1 \%$ HGDLPDIQIK

$471 \quad 0.69 \% \quad 24.1 \%$ HSSLITPLQAVAQR

$471 \quad 0.69 \% \quad 24.1 \%$ TLSEKNNITQK

$471 \quad 0.69 \% \quad 24.1 \%$ LLEEALLR

$471 \quad 0.69 \% \quad 24.1 \%$ LLPAELPAKR

$471 \quad 0.69 \% \quad 24.1 \%$ SIGEYDVLR

$471 \quad 0.69 \% \quad 24.1 \%$ GIFTSEIGTK

$471 \quad 0.69 \% \quad 24.1 \%$ QITQSALLAEAR

$471 \quad 0.69 \% \quad 24.1 \%$ QGNLSSQVPLKR

$471 \quad 0.69 \% \quad 24.1 \%$ LLNTWTNRYPDAK

$471 \quad 0.69 \% \quad 24.1 \%$ KQNNFSLAMK

$471 \quad 0.69 \% \quad 24.1 \%$ SRSQGCSEQVLTVLK

$471 \quad 0.69 \% \quad 24.1 \%$ SQGCSEQVLTVLK

$471 \quad 0.69 \% \quad 24.1 \%$ TVSLLDENNVSSYLSK

$471 \quad 0.69 \% \quad 24.1 \%$ ALKLNSNEAR

$471 \quad 0.69 \% \quad 24.1 \%$ NIEKMYER
$99.0 \% \quad 28.5$

$99.7 \% \quad 52.3$

$98.0 \% \quad 24.7$

$99.7 \% \quad 59.7$

$98.2 \% \quad 21.7$

$99.7 \% \quad 36.5$

$99.7 \% \quad 54.1$

$99.7 \% \quad 39.9$

$99.7 \% \quad 30.3$

$99.0 \% \quad 58.0$

$99.7 \% \quad 32.7$

$\begin{array}{lll}99.7 \% & 39.5\end{array}$

$99.7 \% \quad 54.5$

$99.7 \% \quad 66.2$

$99.7 \% \quad 34.0$

$99.7 \% \quad 24.5$

$99.7 \% \quad 30.0$

$99.7 \% \quad 37.2$

$99.7 \% \quad 57.2$

$99.7 \% \quad 56.0$

$99.7 \% \quad 43.5$

$99.0 \% \quad 25.0$
1815.02

1010.45

1558.71

1175.53

1161.64

918.51

1452.81

1320.63

1984.96

1318.59

1396.70

1524.79

1012.51

1022.56

2046.99

1624.77

1467.71

1205.74

1678.92

1109.58

1023.55

915.49

2311.16

1855.98

1917.91

806.40

1383.75

1029.58

1350.72

1091.58

1541.81

1135.61

1520.85

1275.69

956.58

1107.69

1051.54

1052.56

1300.72

1326.75

1591.82

1180.61

1691.87

1448.74

1768.90

1115.62

1082.53 
DNA-dependent protein kinase catalytic subunit GN=PRKDC PRKDC_HUMAN $469.10 \quad 100.0 \% \quad 92 \quad 117 \quad 471 \quad 0.69 \% \quad 24.1 \%$ MYAALGDPK DNA-dependent protein kinase catalytic subunit GN=PRKDC PRKDC_HUMAN $469.10 \quad 100.0 \% \quad 92 \quad 117 \quad 471 \quad 0.69 \% \quad 24.1 \%$ APGLGAFRR DNA-dependent protein kinase catalytic subunit GN=PRKDC PRKDC_HUMAN $469.10 \quad 100.0 \%$ DNA-dependent protein kinase catalytic subunit GN=PRKDC PRKDC_HUMAN $469.10 \quad 100.0 \%$ DNA-dependent protein kinase catalytic subunit GN=PRKDC PRKDC_HUMAN $469.10 \quad 100.0 \%$ DNA-dependent protein kinase catalytic subunit GN=PRKDC PRKDC_HUMAN $469.10 \quad 100.0 \%$ DNA-dependent protein kinase catalytic subunit GN=PRKDC PRKDC_HUMAN $469.10 \quad 100.0 \%$ DNA-dependent protein kinase catalytic subunit GN=PRKDC PRKDC_HUMAN $469.10 \quad 100.0 \%$ DNA-dependent protein kinase catalytic subunit GN=PRKDC PRKDC_HUMAN $469.10 \quad 100.0 \%$ DNA-dependent protein kinase catalytic subunit GN=PRKDC PRKDC_HUMAN $469.10 \quad 100.0 \%$ DNA-dependent protein kinase catalytic subunit GN=PRKDC PRKDC_HUMAN $469.10 \quad 100.0 \%$ DNA-dependent protein kinase catalytic subunit GN=PRKDC PRKDC_HUMAN $469.10 \quad 100.0 \%$ DNA-directed RNA polymerase I subunit RPA1 GN=POLR1A RPA1_HUMAN $194.81 \quad 100.0 \%$ DNA-directed RNA polymerase I subunit RPA1 GN=POLR1A RPA1_HUMAN $194.81 \quad 100.0 \%$ DNA-directed RNA polymerase I subunit RPA34 GN=CD3EAP RPA34_HUMAN $54.99 \quad 100.0 \%$ DNA-directed RNA polymerase I subunit RPA34 GN=CD3EAP RPA34_HUMAN $54.99 \quad 100.0 \%$ DNA-directed RNA polymerase I subunit RPA34 GN=CD3EAP RPA34 HUMAN $54.99 \quad 100.0 \%$ DNA-directed RNA polymerase I subunit RPA34 GN=CD3EAP RPA34_HUMAN $54.99 \quad 100.0 \%$ DNA-directed RNA polymerase II subunit RPB1 GN=POLR2A RPB1_HUMAN $217.18 \quad 100.0 \%$ DNA-directed RNA polymerase II subunit RPB1 GN=POLR2A RPB1_HUMAN $217.18 \quad 100.0 \%$ DNA-directed RNA polymerases I and III subunit RPACI GN=POLRIC RPAC1_HUMAN $39.25 \quad 100.0 \%$ DNA-directed RNA polymerases I and III subunit RPACI GN=POLRIC RPAC1_HUMAN $39.25 \quad 100.0 \%$ DNA-directed RNA polymerases I and III subunit RPACI GN=POLRIC RPAC1_HUMAN $39.25 \quad 100.0 \%$ DNA-directed RNA polymerases I and III subunit RPACI GN=POLRIC RPAC1_HUMAN $39.25 \quad 100.0 \%$ DnaJ homolog subfamily A member $1 \mathrm{GN}=$ DNAJA1 DNJA1_HUMAN $44.87 \quad 100.0 \%$ DnaJ homolog subfamily A member 1 GN=DNAJA1 DNJA1_HUMAN $44.87 \quad 100.0 \%$ DnaJ homolog subfamily A member 1 GN=DNAJA1 DNJA1_HUMAN $44.87 \quad 100.0 \%$ DnaJ homolog subfamily A member 1 GN=DNAJA1 DNJA1_HUMAN $44.87 \quad 100.0 \%$ DnaJ homolog subfamily A member 1 GN=DNAJA1 DNJA1_HUMAN $44.87 \quad 100.0 \%$ DnaJ homolog subfamily A member 2 GN=DNAJA2 DNJA2 HUMAN $45.75 \quad 100.0 \%$ DnaJ homolog subfamily A member 2 GN=DNAJA2 DNJA2_HUMAN $45.75 \quad 100.0 \%$ DnaJ homolog subfamily A member 2 GN=DNAJA2 DNJA2_HUMAN $45.75 \quad 100.0 \%$ DnaJ homolog subfamily A member 3, mitochondrial GN=DNAJA3 DNJA3 HUMAN $52.49 \quad 100.0 \%$ DnaJ homolog subfamily A member 3, mitochondrial GN=DNAJA3 DNJA3_HUMAN $52.49 \quad 100.0 \%$ DnaJ homolog subfamily A member 3, mitochondrial GN=DNAJA3 DNJA3_HUMAN $52.49 \quad 100.0 \%$ DnaJ homolog subfamily A member 3, mitochondrial GN=DNAJA3 DNJA3_HUMAN $52.49 \quad 100.0 \%$ DnaJ homolog subfamily A member 3, mitochondrial GN=DNAJA3 DNJA3_HUMAN $52.49 \quad 100.0 \%$ DnaJ homolog subfamily A member 3, mitochondrial GN=DNAJA3 DNJA3 HUMAN $52.49 \quad 100.0 \%$ Dnas homolog subfamily A member 3, mitochondrial GN=DNAJA3 DNJA3_HUMAN $52.49 \quad 100.0 \%$ DnaJ homolog subfamily A member 3, mitochondrial GN=DNAJA3 DNJA3_HUMAN $52.49 \quad 100.0 \%$ DnaJ homolog subfamily C member $10 \mathrm{GN}=$ DNAJC10 DJC10_HUMAN $91.08 \quad 100.0 \%$ DnaJ homolog subfamily C member $10 \mathrm{GN}=$ DNAJC10 DJC10_HUMAN $91.08 \quad 100.0 \%$ DnaJ homolog subfamily C member $10 \mathrm{GN}=$ DNAJC10 DJC10 HUMAN $91.08 \quad 100.0 \%$ DnaJ homolog subfamily C member $10 \mathrm{GN}=$ DNAJC10 DJC10_HUMAN $91.08 \quad 100.0 \%$ DnaJ homolog subfamily C member $10 \mathrm{GN}=$ DNAJC10 DJC10_HUMAN $91.08 \quad 100.0 \%$ DnaJ homolog subfamily C member $10 \mathrm{GN}=$ DNAJC10 DJC10_HUMAN $91.08 \quad 100.0 \%$ DnaJ homolog subfamily C member $10 \mathrm{GN}=$ DNAJC10 DJC10_HUMAN $91.08 \quad 100.0 \%$

2
4
4
4

4

2

4

5
5
5

5
5
3

5
3

3

3
3
8
8

8
8
8

8

8
8
8
8

8

8
8
8
14

8
14
14

14

$471 \quad 0.69 \% \quad 24.1 \%$ LSDFNDITNMLLLK

$\begin{array}{lll}0.69 \% & 24.1 \% & \text { NELEIPGQYDGR }\end{array}$

$471 \quad 0.69 \% \quad 24.1 \%$ TYSVVPMTSR

$471 \quad 0.69 \% \quad 24.1 \%$ GANRTETVTSFR

$471 \quad 0.69 \% \quad 24.1 \%$ TETVTSFR

$471 \quad 0.69 \% \quad 24.1 \%$ VPADLLKR

$471 \quad 0.69 \% \quad 24.1 \%$ MSTSPEAFLALR

$471 \quad 0.69 \% \quad 24.1 \%$ AQEPESGLSEETQVK

$471 \quad 0.69 \% \quad 24.1 \%$ CLMDQATDPNILGR

$0.00 \% \quad 1.1 \%$ GLTDKVGR

$0.00 \% \quad 1.1 \%$ DLDNAGELGR

$0.01 \% \quad 8.8 \% \quad$ FSCPPNFTAKPPASESPR

$0.01 \% \quad 8.8 \%$ FCAFGGNPPVTGPR

$0.01 \% \quad 8.8 \%$ SALAPNLLTSGK

$0.01 \% \quad 8.8 \%$ SALAPNLLTSGKK

$0.00 \% \quad 1.4 \% \quad$ YSPTSPTYSPTTPK

$0.00 \% \quad 1.4 \% \quad$ YSPTSPTYSPTSPK

$0.01 \% \quad 14.2 \%$ VVLGEFGVR

$0.01 \% \quad 14.2 \%$ ILLAEVPTMAVEK

$0.01 \% \quad 14.2 \%$ DSSDPNELYVNHKVYTR

$0.01 \% \quad 14.2 \%$ FSPVATASYR

$0.01 \% \quad 14.9 \%$ QISQAYEVLSDAK

$0.01 \% \quad 14.9 \%$ ELYDKGGEQAIK

$0.01 \% \quad 14.9 \%$ NVICDKCEGR

$0.01 \% \quad 14.9 \%$ TIVITSHPGQIVK

$0.01 \% \quad 14.9 \%$ CVLNEGMPIYR

$0.01 \% \quad 8.7 \%$ ELYDRYGEQGLR

$0.01 \% \quad 8.7 \%$ NVLCSACSGQGGK

$0.01 \% \quad 8.7 \% \quad$ ILEVHVDKGMK

$0.04 \% \quad 19.2 \%$ GGPTVDPEELFR

$0.04 \% \quad 19.2 \%$ GVNKEFTVNIMDTCER

$0.04 \% \quad 19.2 \%$ CGGRGSIIISPCVVCR

$0.04 \% \quad 19.2 \%$ GSIIISPCVVCR

$0.04 \% \quad 19.2 \%$ VMIPVPAGVEDGQTVR

$0.04 \% \quad 19.2 \%$ EIFITFRVQK

$0.04 \% \quad 19.2 \%$ MGGKGIPR

$0.04 \% \quad 19.2 \%$ INSYGYGDHYIHIK

$0.06 \% \quad 16.5 \%$ DFAKEVDGLLR

$0.06 \% \quad 16.5 \%$ IGAVNCGDDRMLCR

$0.06 \% \quad 16.5 \%$ MKGVNSYPSLFIFR

$0.06 \% \quad 16.5 \%$ GVNSYPSLFIFR

$0.06 \% \quad 16.5 \%$ SGMAPVKYHGDR

$0.06 \% \quad 16.5 \%$ GGDCLTSQTR

$0.06 \% \quad 16.5 \%$ ILYDILAFAK
$99.7 \% \quad 46.9$

$95.6 \% \quad 20.5$

$99.7 \% \quad 49.2$

$98.7 \% \quad 28.4$

$99.0 \% \quad 30.0$

$99.7 \% \quad 36.0$

$99.7 \% \quad 47.5$

$99.0 \% \quad 26.7$

$99.0 \% 59.0$

$99.7 \% \quad 58.6$

$99.7 \% \quad 40.3$

$99.7 \% \quad 57.0$

$99.0 \% \quad 32.4$

$99.5 \% \quad 23.4$

$98.7 \% \quad 18.9$

$\begin{array}{lll}99.7 \% & 47.0\end{array}$

$99.7 \% \quad 33.9$

$99.7 \% \quad 33.6$

$\begin{array}{lll}99.2 \% & 24.8\end{array}$

$99.7 \% \quad 44.7$

$99.7 \% \quad 38.8$

$99.7 \% \quad 54.0$

$\begin{array}{lll}99.5 \% & 20.9\end{array}$

$99.7 \% \quad 51.1$

$99.7 \% \quad 66.5$

$99.7 \% \quad 32.2$

$99.7 \% \quad 35.1$

$99.7 \% \quad 60.6$

$99.7 \% \quad 41.1$

$99.7 \% \quad 33.7$

$99.7 \% \quad 69.9$

$98.2 \% \quad 16.9$

$99.7 \% \quad 43.6$

$99.7 \% \quad 29.0$

$\begin{array}{lll}99.6 \% & 25.2\end{array}$

$\begin{array}{lll}99.7 \% & 50.0\end{array}$

$99.7 \% \quad 56.5$

$99.7 \% \quad 31.0$

$99.0 \% \quad 29.0$

$99.1 \% \quad 23.5$

$99.7 \% \quad 36.4$

$99.7 \% \quad 44.4$

$99.4 \% \quad 22.7$

$99.7 \% \quad 48.9$

$99.7 \% \quad 51.9$

$99.7 \% \quad 40.0$

$99.7 \% \quad 46.1$
965.48

944.54

1652.86

1390.66

876.50

1140.57

1338.68

940.47

911.57

1322.68

1631.78

1619.75

845.48

1059.51

1989.95

1476.71

1171.67

1299.76

1526.74

1512.72

975.56

1429.80

2036.97

1098.56

1451.74

1350.69

1250.56

1392.82

1351.65

1498.73

1337.59

1268.70

1316.65

1928.88

1790.88

1360.71

1667.88

1280.74

815.46

1679.82

1262.67

1636.74

1674.87

1399.74

1317.64

1094.49

1166.68 


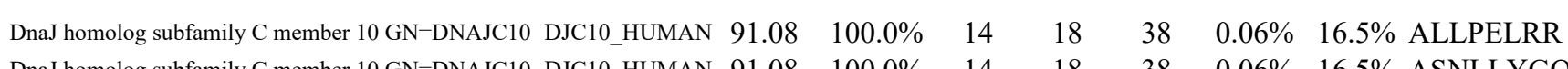
DnaJ homolog subfamily C member $10 \mathrm{GN}=$ DNAJC10 DJC10_HUMAN $91.08 \quad 100.0 \%$ DnaJ homolog subfamily C member $10 \mathrm{GN}=$ DNAJC10 DJC10 HUMAN $91.08 \quad 100.0 \%$ DnaJ homolog subfamily C member $10 \mathrm{GN}=$ DNAJC10 DJC10_HUMAN $91.08 \quad 100.0 \%$ DnaJ homolog subfamily C member $10 \mathrm{GN}=$ DNAJC10 DJC10_HUMAN $91.08 \quad 100.0 \%$ DnaJ homolog subfamily C member $10 \mathrm{GN}=$ DNAJC10 DJC10 HUMAN $91.08 \quad 100.0 \%$ DnaJ homolog subfamily C member 11 GN=DNAJC11 DJC11_HUMAN $63.28 \quad 100.0 \%$ DnaJ homolog subfamily C member 11 GN=DNAJC11 DJC11 HUMAN $63.28 \quad 100.0 \%$ DnaJ homolog subfamily C member 11 GN=DNAJC11 DJC11_HUMAN $63.28 \quad 100.0 \%$ DnaJ homolog subfamily C member 11 GN=DNAJC11 DJC11_HUMAN $63.28 \quad 100.0 \%$ DnaJ homolog subfamily C member 11 GN=DNAJC11 DJC11 HUMAN 63.28 DnaJ homolog subfamily C member 11 GN=DNAJC11 DJC11_HUMAN $63.28 \quad 100.0 \%$ DnaJ homolog subfamily C member $11 \mathrm{GN}=$ DNAJC11 DJC11_HUMAN $63.28 \quad 100.0 \%$ DnaJ homolog subfamily C member $11 \mathrm{GN}=$ DNAJC11 DJC11_HUMAN $63.28 \quad 100.0 \%$ DnaJ homolog subfamily C member $11 \mathrm{GN}=$ DNAJC11 DJC11_HUMAN $63.28 \quad 100.0 \%$ DnaJ homolog subfamily C member 11 GN=DNAJC11 DJC11_HUMAN $63.28 \quad 100.0 \%$ DnaJ homolog subfamily C member $11 \mathrm{GN}=$ DNAJC11 DJC11_HUMAN $63.28 \quad 100.0 \%$ DnaJ homolog subfamily C member 13 GN=DNAJC13 DJC13_HUMAN $254.42 \quad 100.0 \%$ DnaJ homolog subfamily C member 13 GN=DNAJC13 DJC13 HUMAN $254.42 \quad 100.0 \%$ DnaJ homolog subfamily C member 13 GN=DNAJC13 DJC13_HUMAN $254.42 \quad 100.0 \%$ DnaJ homolog subfamily C member 13 GN=DNAJC13 DJC13_HUMAN $254.42 \quad 100.0 \%$ DnaJ homolog subfamily C member 13 GN=DNAJC13 DJC13_HUMAN $254.42 \quad 100.0 \%$ DnaJ homolog subfamily C member 13 GN=DNAJC13 DJC13_HUMAN $254.42 \quad 100.0 \%$ DnaJ homolog subfamily C member 13 GN=DNAJC13 DJC13 HUMAN $254.42 \quad 100.0 \%$ DnaJ homolog subfamily C member 13 GN=DNAJC13 DJC13_HUMAN $254.42 \quad 100.0 \%$ DnaJ homolog subfamily C member 13 GN=DNAJC13 DJC13_HUMAN $254.42 \quad 100.0 \%$ DnaJ homolog subfamily C member $13 \mathrm{GN}=$ DNAJC13 DJC13 HUMAN $254.42 \quad 100.0 \%$ DnaJ homolog subfamily C member 9 GN=DNAJC9 DNJC9_HUMAN $29.91 \quad 100.0 \%$ DnaJ homolog subfamily C member 9 GN=DNAJC9 DNJC9 HUMAN $29.91 \quad 100.0 \%$ Dolichol-phosphate mannosyltransferase subunit 1 GN=DPM1 DPM1_HUMAN $29.64 \quad 100.0 \%$ Dolichol-phosphate mannosyltransferase subunit 1 GN=DPM1 DPM1_HUMAN $29.64 \quad 100.0 \%$ Dolichol-phosphate mannosyltransferase subunit $1 \mathrm{GN}=\mathrm{DPM} 1$ DPM1 HUMAN $29.64 \quad 100.0 \%$ Dolichy-diphosphooligosaccharide-proteting glycosyltransferase 48 kDa subunit GN=DDOST OST48_HUMAN $50.80 \quad 100.0 \%$ Dolichy-diphosphooligosaccharide-protetin glycosyltransferase 48 kDa subunit GN=DDOST OST48_HUMAN $50.80 \quad 100.0^{\circ}$ Whowgosaccharide-protetin glyycosyltransferase 48 kDa subunit GN=DDOST OST48_HUMAN $50.80 \quad 100.0 \%$ Dolichyl-diphosphooligosaccharide-protein glycosyltransferase subunit I GN=RPNI RPN1_HUMAN $68.57 \quad 100.0 \%$ Dolichyl-diphosphooligosaccharide-protetin glycosyltransferase subunit $1 \mathrm{GN}=\mathrm{RPN}$ I RPN1_HUMAN $68.57 \quad 100.0 \%$ $\begin{array}{lll}0 & 100.0 \%\end{array}$ Double-stranded RNA-specific adenosine deaminase GN=ADAR DSRAD_HUMAN $136.07 \quad 100.0 \%$
$0.06 \% \quad 16.5 \%$ ASNLLYGQLK

$0.06 \% \quad 16.5 \%$ AGKVDCQAYAQTCQK

$0.06 \% \quad 16.5 \%$ VDCQAYAQTCQK

$0.06 \% \quad 16.5 \%$ NFQEEQINTR

$0.06 \% \quad 16.5 \%$ NFQEEQINTRDAK

$0.06 \% \quad 16.5 \%$ AIAALISEKLETLR

$0.03 \% \quad 20.6 \%$ EASSEELKAAYR

$0.03 \% \quad 20.6 \%$ AIYDIYGKR

$0.03 \% \quad 20.6 \%$ CFVTTNCALQFSSR

$0.03 \% \quad 20.6 \%$ GIRPGLTTVLAR

$0.03 \% \quad 20.6 \%$ AGFFGTVVEYGAER

$0.03 \% \quad 20.6 \%$ AGFFGTVVEYGAERK

$0.03 \% \quad 20.6 \%$ HSVLGAAVSVGVPQGVSLK

$0.03 \% \quad 20.6 \%$ ESAATDVLQK

$0.03 \% \quad 20.6 \%$ VIDVTVPLQCLVK

$0.03 \% \quad 20.6 \%$ DSKLILTEASK

$0.03 \% \quad 20.6 \%$ LILTEASK

$0.02 \% \quad 5.9 \%$ GQGTEFNLTFR

$0.02 \% \quad 5.9 \%$ AGFLAFTQLPK

$0.02 \% \quad 5.9 \%$ AIIEEGDKEIATK

$0.02 \% \quad 5.9 \%$ MQELALSEGALPR

$0.02 \% \quad 5.9 \% \quad$ IVDGPDPENIILILK

$0.02 \% \quad 5.9 \%$ TQSILFNR

$0.02 \% \quad 5.9 \% \quad$ SEETNQQEVANSLAK

$0.02 \% \quad 5.9 \% \quad$ LGGYLAEEQATPENPTIRK

$0.02 \% \quad 5.9 \%$ VIHALSENELCVR

$0.02 \% \quad 5.9 \%$ SLQYGEQVNEILCR

$0.00 \% \quad 8.5 \%$ VYSVLSDREQR

$0.00 \% \quad 8.5 \% \quad$ ISLEDIQAFEK

$0.01 \% \quad 9.2 \%$ QKEGNFDIVSGTR

$0.01 \% \quad 9.2 \%$ EGNFDIVSGTR

$0.01 \% \quad 9.2 \%$ LGGNEIVSFLK

$0.01 \% \quad 12.3 \%$ TLVLLDNLNVR

$0.01 \% \quad 12.3 \%$ SSLNPILFR

$0.01 \% \quad 12.3 \%$ NTLLIAGLQAR

$0.01 \% \quad 12.3 \%$ YSQTGNYELAVALSR

$0.01 \% \quad 12.3 \%$ WVFKEEGVLR

$0.02 \% \quad 13.3 \%$ VTAEVVLAHLGGGSTSR

$0.02 \% \quad 13.3 \%$ ATSFLLALEPELEAR

$0.02 \% \quad 13.3 \%$ YDYQRQPDSGISSIR

$0.02 \% \quad 13.3 \%$ QPDSGISSIR

$0.02 \% \quad 13.3 \%$ NIEIDSPYEISR

$0.02 \% \quad 13.3 \%$ DISTLNSGKK

$0.02 \% \quad 13.3 \%$ SAVEAERLVAGK

$99.0 \% 19.0$

$99.7 \% \quad 54.7$

$99.7 \% \quad 46.3$

$99.7 \% \quad 51.7$

$\begin{array}{llll}99.7 \% & 36.8\end{array}$

$99.7 \% \quad 39.7$

$99.7 \% \quad 54.6$

$99.7 \% \quad 49.4$

$99.7 \% \quad 70.1$

$\begin{array}{lll}99.7 \% & 25.8\end{array}$

$99.7 \% \quad 52.6$

$96.5 \% \quad 17.0$

$99.7 \% \quad 34.5$

$99.5 \% \quad 23.6$

$99.6 \% \quad 24.5$

$99.7 \% \quad 38.7$

$99.0 \% \quad 32.0$

$\begin{array}{lll}99.7 \% & 45.0\end{array}$

$99.7 \% \quad 49.2$

$99.7 \% \quad 48.2$

$99.7 \% \quad 55.7$

$99.7 \% \quad 35.9$

$99.0 \% \quad 36.9$

$99.7 \% \quad 57.2$

$99.7 \% \quad 33.8$

$99.7 \% \quad 36.3$

$99.7 \% \quad 47.4$

$98.5 \% \quad 20.1$

$99.7 \% \quad 48.7$

$99.7 \% \quad 35.6$

$99.7 \% \quad 56.1$

$99.7 \% \quad 40.1$

$99.7 \% \quad 30.1$

$99.7 \% \quad 40.1$

$99.7 \% \quad 68.6$

$99.7 \% \quad 71.7$

$99.5 \% 24$.

$99.7 \% \quad 48$.

$99.7 \% \quad 64.4$

$99.6 \% 24.4$

$95.8 \% \quad 22.0$

$99.7 \% \quad 56.4$

$98.9 \% \quad 21.8$

$\begin{array}{ll}99.7 \% & 43.7\end{array}$

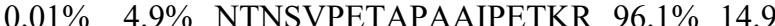

$0.01 \% \quad 4.9 \% \quad$ YLNTNPVGGLLEYAR

$99.7 \% \quad 57.3$
967.60

1106.62

1727.78

1471.63

1278.61

1592.77

1527.91

1353.66

1098.59

1690.77

1253.77

1502.73

1630.82

1805.03

1061.55

1483.86

1204.68

874.52

1269.62

1192.67

1416.76

1414.74

1648.95

978.54

1647.78

2087.08

1539.79

1708.83

1351.70

1292.67

1450.73

1194.58

1176.66

1269.75

1046.60

1169.70

1671.83

1262.69

1653.89

1659.90

1784.86

1059.54

1435.71

1062.58

1229.68

1895.98

1679.88

$\begin{array}{cc}85 & 492 \\ 93 & 502 \\ 23 & 737 \\ 26 & 737 \\ 57 & 766 \\ 57 & 769 \\ 70 & 783 \\ 4 & 35 \\ 6 & 84 \\ 35 & 248 \\ 49 & 260 \\ 28 & 341 \\ 28 & 342 \\ 46 & 364 \\ 25 & 434 \\ 85 & 497 \\ 98 & 508 \\ 01 & 508 \\ 3 & 73 \\ 40 & 450 \\ 87 & 599 \\ 00 & 612 \\ 60 & 1374 \\ 75 & 1382 \\ 66 & 1580 \\ 89 & 1607 \\ 72 & 2084 \\ 69 & 2182 \\ 5 & 75 \\ 08 & 118 \\ 35 & 147 \\ 37 & 147 \\ 41 & 251 \\ 7 & 57 \\ 90 & 198 \\ 40 & 250 \\ 83 & 297 \\ 98 & 307 \\ 9 & 65 \\ 6 & 80 \\ 64 & 278 \\ 69 & 278 \\ 80 & 391 \\ 08 & 517 \\ 65 & 576 \\ 68 & 385 \\ 22 & 736 \\ & \end{array}$

Page 43 of Table S-1-2 
Double-stranded RNA-specific adenosine deaminase GN=ADAR DSRAD_HUMAN $136.07 \quad 100.0 \%$ Double-stranded RNA-specific adenosine deaminase GN=ADAR DSRAD_HUMAN $136.07 \quad 100.0 \%$ Dual specificity mitogen-activated protein kinase kinase 2 GN=MAP2K2 $\mathrm{MP} 2 \mathrm{~K} 2 \_$HUMAN $44.43 \quad 100.0 \%$ Dual specificity mitogen-activated protein kinase kinase 2 GN=MAP2K2 $\quad$ MP2K2_HUMAN $44.43 \quad 100.0 \%$ Dual specificity mitogen-activated protein kinase kinase 3 GN=MAP2K3 $\quad$ MP2K3_HUMAN $39.32 \quad 100.0 \%$ Dual specificity mitogen-activated protein kinase kinase 3 GN=MAP2K3 MP2K3_HUMAN $39.32 \quad 100.0 \%$ Dual specificity mitogen-activated protein kinase kinase 7 GN=MAP2K7 MP2K7_HUMAN $47.49 \quad 100.0 \%$ Dual specificity mitogen-activated protein kinase kinase 7 GN=MAP2K7 MP2K7_HUMAN $47.49 \quad 100.0 \%$ Dynactin subunit $1 \mathrm{GN}=\mathrm{DCTN} 1$ Dynactin subunit $1 \mathrm{GN}=\mathrm{DCTN} 1$ Dynamin-2 GN=DNM2

Dynamin -2 GN=DNM2

Dynamin-2 GN=DNM2

Dynamin-2 GN=DNM2

DCTN1 HUMAN $141.70 \quad 100.0 \%$ DCTN1_HUMAN $141.70 \quad 100.0 \%$ DYN2_HUMAN $98.07 \quad 100.0 \%$ DYN2 HUMAN $98.07 \quad 100.0 \%$ DYN2_HUMAN $98.07 \quad 100.0 \%$ DYN2_HUMAN $98.07 \quad 100.0 \%$ Dynamin-like $120 \mathrm{kDa}$ protein, mitochondrial GN=OPA1 OPA1_HUMAN $111.63 \quad 100.0 \%$ Dynamin-like $120 \mathrm{kDa}$ protein, mitochondrial GN=OPA1 OPA1_HUMAN $111.63 \quad 100.0 \%$ Dynamin-like $120 \mathrm{kDa}$ protein, mitochondrial GN=OPA1 OPA1 HUMAN $111.63100 .0 \%$ Dynein assembly factor 5, axonemal GN=DNAAF5 DAAF5_HUMAN $93.52 \quad 100.0 \%$ Dynein assembly factor 5, axonemal GN=DNAAF5 DAAF5_HUMAN $93.52 \quad 100.0 \%$ Dynein assembly factor 5 , axonemal GN=DNAAF5 DAAF5_HUMAN $93.52 \quad 100.0 \%$ Dynein assembly factor 5, axonemal GN=DNAAF5 DAAF5_HUMAN $93.52 \quad 100.0 \%$ Dynein assembly factor 5, axonemal GN=DNAAF5 DAAF5_HUMAN $93.52 \quad 100.0 \%$ Dynein assembly factor 5, axonemal GN=DNAAF5 DAAF5_HUMAN $93.52 \quad 100.0 \%$ Dynein assembly factor 5, axonemal GN=DNAAF5 DAAF5_HUMAN $93.52 \quad 100.0 \%$ E3 SUMO-protein ligase RanBP2 GN=RANBP2 RBP2_HUMAN $358.20 \quad 100.0 \%$ E3 SUMO-protein ligase RanBP2 GN=RANBP2 RBP2_HUMAN $358.20 \quad 100.0 \%$ E3 SUMO-protein ligase RanBP2 GN=RANBP2 RBP2_HUMAN $358.20 \quad 100.0 \%$ E3 SUMO-protein ligase RanBP2 GN=RANBP2 RBP2_HUMAN $358.20 \quad 100.0 \%$ E3 SUMO-protein ligase RanBP2 GN=RANBP2 RBP2_HUMAN $358.20 \quad 100.0 \%$ E3 SUMO-protein ligase RanBP2 GN=RANBP2 RBP2 HUMAN $358.20 \quad 100.0 \%$ E3 SUMO-protein ligase RanBP2 GN=RANBP2 RBP2_HUMAN $358.20 \quad 100.0 \%$ E3 SUMO-protein ligase RanBP2 GN=RANBP2 RBP2_HUMAN $358.20 \quad 100.0 \%$ E3 ubiquitin-protein ligase HUWE1 GN=HUWE1 HUWE1_HUMAN $481.89 \quad 100.0 \%$ E3 ubiquitin-protein ligase HUWE1 GN=HUWE1 HUWE1_HUMAN $481.89 \quad 100.0 \%$ E3 ubiquitin-protein ligase HUWE1 GN=HUWE1 HUWE1_HUMAN $481.89 \quad 100.0 \%$ E3 ubiquitin-protein ligase HUWE1 GN=HUWE1 HUWE1_HUMAN $481.89 \quad 100.0 \%$ E3 ubiquitin-protein ligase HUWE1 GN=HUWE1 HUWE1_HUMAN $481.89 \quad 100.0 \%$ E3 ubiquitin-protein ligase HUWE1 GN=HUWE1 HUWE1_HUMAN $481.89 \quad 100.0 \%$ E3 ubiquitin-protein ligase HUWE1 GN=HUWE1 HUWE1_HUMAN $481.89 \quad 100.0 \%$ E3 ubiquitin-protein ligase HUWE1 GN=HUWE1 HUWE1_HUMAN $481.89 \quad 100.0 \%$ E3 ubiquitin-protein ligase HUWE1 GN=HUWE1 HUWE1_HUMAN $481.89 \quad 100.0 \%$ E3 ubiquitin-protein ligase HUWE1 GN=HUWE1 HUWE1_HUMAN $481.89 \quad 100.0 \%$ E3 ubiquitin-protein ligase HUWE1 GN=HUWE1 HUWE1_HUMAN $481.89 \quad 100.0 \%$ E3 ubiquitin-protein ligase HUWE1 GN=HUWE1 HUWE1_HUMAN $481.89 \quad 100.0 \%$ E3 ubiquitin-protein ligase MYCBP2 GN=MYCBP2 MYCB2_HUMAN $510.08 \quad 100.0 \%$ E3 ubiquitin-protein ligase MYCBP2 GN=MYCBP2 MYCB2_HUMAN $510.08 \quad 100.0 \%$ E3 ubiquitin-protein ligase TRIM21 GN=TRIM21 RO52_HUMAN $54.17 \quad 100.0 \%$
$0.01 \% \quad 4.9 \% \quad$ VLIGENEKAER $0.01 \% \quad 4.9 \%$ MGFTEVTPVTGASLRR $0.00 \% \quad 5.3 \% \quad$ DVKPSNILVNSR $0.00 \% \quad 5.3 \%$ LNQPGTPTR $0.00 \% \quad 8.1 \%$ ISCMSKPPAPNPTPPR $0.00 \% \quad 8.1 \%$ HAQSGTIMAVKR

$0.00 \% \quad 5.5 \%$ LCDFGISGR $0.00 \% \quad 5.5 \%$ TSGVLSQPHLPFFR $0.01 \% \quad 2.4 \%$ ASLASLPPLHVAK $0.01 \% \quad 2.4 \%$ LSHEGPGSELPAGALYR $0.01 \% \quad 4.7 \%$ SSVLENFVGRDFLPR $0.01 \% \quad 4.7 \%$ GISPVPINLR $0.01 \% \quad 4.7 \%$ EVDPQGLR $0.01 \% \quad 4.7 \%$ GYIGVVNR $0.01 \% \quad 3.4 \%$ IQQIIEGKLFPMK $0.01 \% \quad 3.4 \%$ ALGYFAVVTGK $0.01 \% \quad 3.4 \%$ QQLTNTEVR $0.02 \% \quad 9.8 \%$ LLPGLEADSKPGR $0.02 \% \quad 9.8 \%$ CLSDPAEGCR $0.02 \% \quad 9.8 \%$ ALAVHLLDLGLRR $0.02 \% \quad 9.8 \%$ SVDDVLSHFAQR $0.02 \% \quad 9.8 \%$ LFDDVPQVR $0.02 \% \quad 9.8 \%$ TPSASGLLVLASAMR $0.02 \% \quad 9.8 \%$ ACLQPSQDPQMR $0.02 \% \quad 3.0 \%$ YIASVQGSTPSPR $0.02 \% \quad 3.0 \% \quad$ IIDDSDSNLSVVK $0.02 \% \quad 3.0 \%$ SGSSFVHQASFK $0.02 \% \quad 3.0 \% \quad$ FGTSETSKAPK $0.02 \% \quad 3.0 \%$ FGISEPGNQEK $0.02 \% \quad 3.0 \%$ STSGEGFQFGK $0.02 \% \quad 3.0 \%$ IAVAVLEETTR $0.02 \% \quad 3.0 \%$ NSDIEQSSDSKVK $0.05 \% \quad 3.7 \%$ TPTEAPADCR $0.05 \% \quad 3.7 \%$ TLTSIVHLER $0.05 \% \quad 3.7 \%$ GLQSFVQCQPFER $0.05 \% \quad 3.7 \%$ ADGTATAPPPR $0.05 \% \quad 3.7 \%$ STASALTKLLTK $0.05 \% \quad 3.7 \%$ SAATSGAGSTTSGVVSGSLGSR $0.05 \% \quad 3.7 \%$ IVNQPSSLFGSK $0.05 \% \quad 3.7 \%$ HADHSSLTLGSGSSTTR $0.05 \% \quad 3.7 \%$ AGSSTPGDAPPAVAEVQGR $0.05 \% \quad 3.7 \%$ DSAVAISGADSR $0.05 \% \quad 3.7 \%$ TNIFQIQR

$0.05 \% \quad 3.7 \%$ LGSSGLGSASSIQAAVR $0.00 \% \quad 0.4 \%$ IGSGYSGTVR $0.00 \% \quad 0.4 \%$ ALSVVSTVVR $0.01 \% \quad 4.0 \%$ GGGSVCPVCR

1
0
0
1
1
0
2
2
2
1
1
2
0
0
0
0
0
1
0
0
0
0
0
0
2
0
0
0
0
0
0
0
0
0
0
0
0
0
0
0
0
0
0
0
0
0
0
0
0
0
0
0
0
0
0
0
0
0
0
0
0
0
0
0
0

1544.89

1125.63

1352.75

1164.48

1446.89

1373.68

1473.81

1430.65

1362.70

1404.72

1281.62

1152.59

1205.58

1144.53

1201.68

1436.69

1117.49

1168.67

1595.76

1053.53

1233.74

1896.93

1276.69

1713.82

1766.87

1148.55

1019.56

1560.83

996.51

1030.63 1048.47 
E3 ubiquitin-protein ligase TRIM21 GN=TRIM21 RO52_HUMAN $54.17 \quad 100.0 \%$ E3 ubiquitin-protein ligase TRIP12 GN=TRIP12 TRIPC_HUMAN $220.44 \quad 100.0 \%$ E3 ubiquitin-protein ligase TRIP12 GN=TRIP12 TRIPC_HUMAN $220.44 \quad 100.0 \%$ E3 ubiquitin-protein ligase UBR4 GN=UBR4 UBR4 HUMAN $573.84 \quad 100.0 \%$ E3 ubiquitin-protein ligase UBR4 GN=UBR4 UBR4_HUMAN $573.84 \quad 100.0 \%$ E3 ubiquitin-protein ligase UBR4 GN=UBR4 UBR4_HUMAN $573.84 \quad 100.0 \%$ E3 ubiquitin-protein ligase UBR4 GN=UBR4 UBR4_HUMAN $573.84 \quad 100.0 \%$ E3 UFM1-protein ligase $1 \mathrm{GN}=\mathrm{UFL} 1$ E3 UFM1-protein ligase $1 \mathrm{GN}=\mathrm{UFL} 1$ E3 UFM1-protein ligase $1 \mathrm{GN}=\mathrm{UFL} 1$ E3 UFM1-protein ligase $1 \mathrm{GN}=\mathrm{UFL} 1$ E3 UFM1-protein ligase $1 \mathrm{GN}=\mathrm{UFL} 1$ EH domain-containing protein $1 \mathrm{GN}=$ EHD1 EHD1_HUMAN $60.63 \quad 100.0 \%$ EH domain-containing protein $1 \mathrm{GN}=$ EHD1 EHD1_HUMAN $60.63 \quad 100.0 \%$ EH domain-containing protein $1 \mathrm{GN}=$ EHD1 EHD1_HUMAN $60.63 \quad 100.0 \%$ EH domain-containing protein $1 \mathrm{GN}=$ EHD1 EHD1_HUMAN $60.63 \quad 100.0 \%$ ELAV-like protein $1 \mathrm{GN}=$ ELAVL1 ELAV-like protein $1 \mathrm{GN}=$ ELAVL1 ELAV-like protein $1 \mathrm{GN}=\mathrm{ELAVL} 1$ ELAV-like protein $1 \mathrm{GN}=$ ELAVL1 ELAV-like protein $1 \mathrm{GN}=\mathrm{ELAVL} 1$ ELAV-like protein $1 \mathrm{GN}=$ ELAVL1 ELAV-like protein $1 \mathrm{GN}=\mathrm{ELAVL} 1$ ELAV-like protein $1 \mathrm{GN}=\mathrm{ELAVL}$ ELAV-like protein $1 \mathrm{GN}=\mathrm{ELAVL} 1$ ELAV-like protein $1 \mathrm{GN}=\mathrm{ELAVL} 1$ ELAV-like protein $1 \mathrm{GN}=\mathrm{ELAVL} 1$ ELAV-like protein $1 \mathrm{GN}=\mathrm{ELAVL} 1$ ELAV-like protein $2 \mathrm{GN}=$ ELAVL2 ELAV-like protein $2 \mathrm{GN}=\mathrm{ELAVL} 2$ ELAV-like protein $2 \mathrm{GN}=\mathrm{ELAVL} 2$ ELAV-like protein $2 \mathrm{GN}=\mathrm{ELAVL} 2$ ELAV-like protein $2 \mathrm{GN}=\mathrm{ELAVL} 2$

ELAV1_HUMAN $36.09 \quad 100.0 \%$ ELAV1_HUMAN $36.09 \quad 100.0 \%$ ELAV1_HUMAN $36.09 \quad 100.0 \%$ ELAV1 HUMAN $36.09 \quad 100.0 \%$ ELAV1_HUMAN $36.09 \quad 100.0 \%$ ELAV1 HUMAN $36.09 \quad 100.0 \%$ ELAV1_HUMAN $36.09 \quad 100.0 \%$ ELAV1_HUMAN $36.09 \quad 100.0 \%$ ELAV1 HUMAN $36.09 \quad 100.0 \%$ ELAV1_HUMAN $36.09 \quad 100.0 \%$ ELAV1_HUMAN $36.09 \quad 100.0 \%$ ELAV1_HUMAN $36.09 \quad 100.0 \%$ ELAV2_HUMAN $39.51 \quad 100.0 \%$ ELAV2 HUMAN $39.51 \quad 100.0 \%$ ELAV2_HUMAN $39.51 \quad 100.0 \%$ ELAV2_HUMAN $39.51 \quad 100.0 \%$ ELAV2 HUMAN $39.51 \quad 100.0 \%$ Electron transfer flavoprotein subunit alpha, mitochondrial GN=ETFA ETFA_HUMAN $35.08 \quad 100.0 \%$ Electron transfer flavoprotein subunit alpha, mitochondrial GN=ETFA ETFA_HUMAN $35.08 \quad 100.0 \%$ Electron transfer flavoprotein subunit alpha, mitochondrial GN=ETFA ETFA_HUMAN $35.08 \quad 100.0 \%$ Electron transfer flavoprotein subunit alpha, mitochondrial GN=ETFA ETFA_HUMAN $35.08 \quad 100.0 \%$ Electron transfer flavoprotein subunit alpha, mitochondrial GN=ETFA ETFA HUMAN $35.08 \quad 100.0 \%$ Electron transfer flavoprotein subunit alpha, mitochondrial GN=ETFA ETFA_HUMAN $35.08 \quad 100.0 \%$ Electron transfer flavoprotein subunit alpha, mitochondrial GN=ETFA ETFA_HUMAN $35.08 \quad 100.0 \%$ Flectron transfer flavoprotein subunit alpha, mitochondrial GN=ETFA ETFA HUMAN $35.08 \quad 100.0 \%$ Electron transfer flavoprotein subunit alpha, mitochondrial GN=ETFA ETFA_HUMAN $35.08 \quad 100.0 \%$ Electron transfer flavoprotein subunit beta GN=ETFB ETFB HUMAN $27.84 \quad 100.0 \%$ Electron transfer flavoprotein subunit beta GN=ETFB ETFB_HUMAN $27.84 \quad 100.0 \%$ Electron transfer flavoprotein subunit beta GN=ETFB ETFB_HUMAN $27.84 \quad 100.0 \%$ ELMO domain-containing protein 2 GN=ELMOD2 ELMD2_HUMAN $34.96 \quad 100.0 \%$ ELMO domain-containing protein 2 GN=ELMOD2 ELMD2_HUMAN $34.96 \quad 100.0 \%$
$0.01 \% \quad 4.0 \% \quad$ IHAEFVQQK

$0.00 \% \quad 1.2 \% \quad$ LSTQSNSNNIEPAR

$0.00 \% \quad 1.2 \%$ SVYHLEDIVR

$0.01 \% \quad 0.8 \%$ IQIGTQAIER

$0.01 \% \quad 0.8 \%$ TINLYYNNR

$0.01 \% \quad 0.8 \%$ TVQAIVELK

$0.01 \% \quad 0.8 \%$ TSVQPTFTASQYR

$0.01 \% \quad 8.4 \%$ TYDLPGNFLTQALTQR

$0.01 \% \quad 8.4 \%$ AVFVPDIYSR

$0.01 \% \quad 8.4 \%$ LGIPDAVSYIK

$0.01 \% \quad 8.4 \%$ SVFMSSTTSASGTGR

$0.01 \% \quad 8.4 \%$ ELQELSSSIKDLVLK

$0.01 \% \quad 8.8 \%$ HLIEQDFPGMR

$0.01 \% \quad 8.8 \%$ LNAFGNAFLNR

$0.01 \% \quad 8.8 \%$ LLDTVDDMLANDIAR

$0.01 \% \quad 8.8 \%$ SKLPNTVLGK

$0.07 \% \quad 40.5 \%$ TNLIVNYLPQNMTQDELR

$0.07 \% \quad 40.5 \%$ SLFSSIGEVESAK

$0.07 \% \quad 40.5 \%$ AINTLNGLR

$0.07 \% \quad 40.5 \%$ AINTLNGLRLQSK

$0.07 \% \quad 40.5 \%$ TMTQKDVEDMFSR

$0.07 \% \quad 40.5 \%$ VLVDQTTGLSR

$0.07 \% \quad 40.5 \%$ GVAFIRFDK

$0.07 \% \quad 40.5 \%$ FAANPNQNK

$0.07 \% \quad 40.5 \%$ NVALLSQLYHSPARR

$0.07 \% \quad 40.5 \%$ FGGPVHHQAQR

$0.07 \% \quad 40.5 \%$ VIRDFNTNK

$0.07 \% \quad 40.5 \%$ LGDKILQVSFK

$0.01 \% \quad 15.3 \%$ AINTLNGLR

$0.01 \% \quad 15.3 \%$ DANLYVSGLPK

$0.01 \% \quad 15.3 \%$ ILVDQVTGISR

$0.01 \% \quad 15.3 \%$ TNQAILSQLYQSPNR

$0.01 \% \quad 15.3 \%$ VIRDFNTNK

$0.02 \% 37.5 \%$ LGGEVSCLVAGTK

$0.02 \% \quad 37.5 \%$ VLVAQHDVYK

$0.02 \% \quad 37.5 \%$ QFNYTHICAGASAFGK

$0.02 \% \quad 37.5 \%$ LEVAPISDIIAIK

$99.7 \% \quad 47.2$

$\begin{array}{ll}99.7 \% & 47.2 \\ 99.5 \% & 24.5\end{array}$

$99.7 \% \quad 38.1$

$99.7 \% \quad 29.3$

$97.7 \% 16$.

$99.7 \% \quad 37.1$

$99.7 \% \quad 54.2$

$99.5 \% \quad 21.3$

$96.5 \% \quad 17.5$

$99.7 \% 72.0$

$99.7 \% \quad 25.4$

$99.7 \% \quad 45.4$

$99.7 \% \quad 61.3$

$99.7 \% \quad 56.7$

$99.7 \% \quad 27.0$

$\begin{array}{ll}9.7 \% & 32.8\end{array}$

$\begin{array}{lll}99.7 \% & 61.2\end{array}$

$99.7 \% \quad 53.8$

$99.7 \% \quad 49.0$

$99.7 \% \quad 40.3$

$99.7 \% \quad 72.9$

$99.7 \% \quad 37.2$

$99.7 \% \quad 32.6$

$99.4 \% \quad 20.1$

$97.8 \% \quad 22.2$

$99.7 \% \quad 41.3$

$99.7 \% \quad 43.0$

$99.7 \% \quad 53.8$

$99.7 \% \quad 31.5$

$99.7 \% \quad 50.7$

$99.7 \% \quad 52.2$

$99.7 \% \quad 41.3$

$99.7 \% \quad 64.2$

$99.7 \% \quad 42.0$

$97.3 \% \quad 18.7$

$99.6 \% \quad 25.2$

AIKSPDTFVR $97.8 \% \quad 15.9$

$0.02 \% \quad 37.5 \%$ TIYAGNALCTVK

$99.7 \% \quad 54.7$

$0.02 \% \quad 37.5 \%$ GTSFDAAATSGGSASSEK $99.6 \% 99.0$

$0.02 \% \quad 37.5 \%$ LLYDLADQLHAAVGASR $98.9 \% 22.0$

$0.02 \% \quad 37.5 \%$ AAVDAGFVPNDMQVGQTGK $\quad 99.7 \% \quad 48.6$

$0.01 \% \quad 11.8 \%$ LGPLQVAR

$0.01 \% \quad 11.8 \%$ EIDGGLETLR

$0.01 \% \quad 11.8 \%$ LSVISVEDPPQR

$0.01 \% \quad 7.5 \%$ IFDTYVGAQR

$0.01 \% \quad 7.5 \%$ THRIENSLTYSK $\begin{array}{llll}99.0 \% & 43.2 & 25.0 & 37.7\end{array}$

$\begin{array}{llll}99.7 \% & 37.3 & 25.0 & 35.4\end{array}$

$99.7 \% \quad 55.2 \quad 25.0 \quad 53.2$

$99.7 \% \quad 57.7 \quad 25.0 \quad 48.3$

$\begin{array}{llll}99.7 \% & 30.8 & 25.0 & 30.8\end{array}$
1099.59

1530.75

1230.65

1128.64

1170.59

1000.60

1485.73

1837.94

1166.62

1175.67

1475.68

1701.96

1342.66

1236.65

1674.84

1056.64

2162.09

1353.69

971.56

1427.83

1587.71

1188.66

1052.59

1003.50

1724.96

1233.62

1106.60

1247.74

971.56

1176.63

1200.69

1732.90

1106.60

1290.67

1171.65

1771.82

1381.83

2184.23

1310.68

1630.72

1812.96

1904.92

853.53

1102.57

1339.72

1169.60

1448.75 
ELMO domain-containing protein 2 GN=ELMOD2 ELMD2_HUMAN $34.96 \quad 100.0 \%$ Elongation factor 1-alpha $1 \mathrm{GN}=\mathrm{EEF} 1 \mathrm{~A} 1$ EF1A1_HUMAN $50.14 \quad 100.0 \%$ Elongation factor 1-alpha $1 \mathrm{GN}=\mathrm{EEF} 1 \mathrm{~A} 1 \quad$ EF1A1_HUMAN $50.14 \quad 100.0 \%$ Elongation factor 1-alpha $1 \mathrm{GN}=\mathrm{EEF} 1 \mathrm{~A} 1 \quad$ EF1A1_HUMAN $50.14 \quad 100.0 \%$ Elongation factor 1-alpha $1 \mathrm{GN}=\mathrm{EEF} 1 \mathrm{~A} 1$ EF1A1_HUMAN $50.14 \quad 100.0 \%$ Elongation factor 1-alpha $1 \mathrm{GN}=\mathrm{EEF} 1 \mathrm{~A} 1$ EF1A1_HUMAN $50.14 \quad 100.0 \%$ Elongation factor 1-alpha $1 \mathrm{GN}=\mathrm{EEF} 1 \mathrm{~A} 1 \quad$ EF1A1_HUMAN $50.14 \quad 100.0 \%$ Elongation factor 1-alpha $1 \mathrm{GN}=\mathrm{EEF} 1 \mathrm{~A} 1 \quad$ EF1A1_HUMAN $50.14 \quad 100.0 \% \quad 1$ Elongation factor 1-alpha $1 \mathrm{GN}=\mathrm{EEF} 1 \mathrm{~A} 1 \quad$ EF1A1_HUMAN $50.14 \quad 100.0 \%$ Elongation factor 1-alpha 1 GN=EEF1A1 EF1A1_HUMAN $50.14 \quad 100.0 \%$ Elongation factor 1-alpha $1 \mathrm{GN}=\mathrm{EEF} 1 \mathrm{~A} 1 \quad$ EF1A1_HUMAN $50.14 \quad 100.0 \% \quad 1$ Elongation factor 1-alpha 1 GN=EEF1A1 EF1A1_HUMAN $50.14 \quad 100.0 \%$ Elongation factor 1-alpha $1 \mathrm{GN}=\mathrm{EEF} 1 \mathrm{~A} 1 \quad$ EF1A1_HUMAN $50.14 \quad 100.0 \%$ Elongation factor 1-alpha $1 \mathrm{GN}=\mathrm{EEF} 1 \mathrm{~A} 1 \quad$ EF1A1_HUMAN $50.14 \quad 100.0 \%$ Elongation factor 1-alpha $1 \mathrm{GN}=\mathrm{EEF} 1 \mathrm{~A} 1 \quad$ EF1A1_HUMAN $50.14 \quad 100.0 \%$ Elongation factor 1-alpha $1 \mathrm{GN}=\mathrm{EEF} 1 \mathrm{~A} 1 \quad$ EF1A1_HUMAN $50.14 \quad 100.0 \% \quad 1$ Elongation factor 1-delta GN=EEF1D Elongation factor 1-delta GN=EEF1D Elongation factor 1-gamma GN=EEF1G Elongation factor 1-gamma GN=EEF1G Elongation factor 1-gamma GN=EEF1G Elongation factor 1-gamma GN=EEF1G Elongation factor 1-gamma $\mathrm{GN}=\mathrm{EEF} 1 \mathrm{G}$ Elongation factor 1-gamma $\mathrm{GN}=\mathrm{EEF} 1 \mathrm{G}$ Elongation factor 1-gamma GN=EEF1G Elongation factor 1-gamma GN=EEF1G Elongation factor 1-gamma GN=EEF1G Elongation factor $2 \mathrm{GN}=\mathrm{EEF} 2$ Elongation factor $2 \mathrm{GN}=\mathrm{EEF} 2$ Elongation factor $2 \mathrm{GN}=\mathrm{EEF} 2$ Elongation factor $2 \mathrm{GN}=\mathrm{EEF} 2$ Elongation factor $2 \mathrm{GN}=\mathrm{EEF} 2$ Elongation factor $2 \mathrm{GN}=\mathrm{EEF} 2$ Elongation factor $2 \mathrm{GN}=\mathrm{EEF} 2$ Elongation factor $2 \mathrm{GN}=\mathrm{EEF} 2$ Elongation factor $2 \mathrm{GN}=\mathrm{EEF} 2$ Elongation factor $2 \mathrm{GN}=\mathrm{EEF} 2$ Elongation factor $2 \mathrm{GN}=\mathrm{EEF} 2$ Elongation factor $2 \mathrm{GN}=\mathrm{EEF} 2$ Elongation factor $2 \mathrm{GN}=\mathrm{EEF} 2$ EF2_HUMAN $95.34 \quad 100.0 \% \quad 13$ Elongation factor Tu, mitochondrial GN=TUFM EFTU_HUMAN $49.54 \quad 100.0 \%$ Elongation factor Tu, mitochondrial GN=TUFM EFTU_HUMAN $49.54 \quad 100.0 \%$ Elongation factor Tu, mitochondrial GN=TUFM EFTU_HUMAN $49.54 \quad 100.0 \%$ Elongation factor Tu, mitochondrial GN=TUFM EFTU_HUMAN $49.54 \quad 100.0 \%$ Elongation factor Tu, mitochondrial GN=TUFM EFTU_HUMAN $49.54 \quad 100.0 \% \quad 2$ Elongation factor Tu, mitochondrial GN=TUFM EFTU_HUMAN $49.54 \quad 100.0 \% \quad 2$

EF1D_HUMAN $31.12 \quad 100.0 \%$ EF1G_HUMAN $50.12 \quad 100.0 \%$ EF1G HUMAN $50.12 \quad 100.0 \%$ $\begin{array}{lll} & 50.12 & 100.0 \%\end{array}$ $\begin{array}{lll}\text { EF1G_HUMAN } & 50.12 & 100.0 \%\end{array}$ EF1G_HUMAN $50.12 \quad 100.0 \%$ EF1G HUMAN $50.12 \quad 100.0 \%$ EF1G_HUMAN $50.12 \quad 100.0 \%$ EF1G_HUMAN $50.12 \quad 100.0 \%$ EF2_HUMAN $95.34 \quad 100.0 \%$ $\begin{array}{lll} & 100.0 \% & 13\end{array}$ EF2_HUMAN $95.34 \quad 100.0 \% \quad 13$ EF2_HUMAN $95.34 \quad 100.0 \% \quad 13$ EF2 HUMAN $95.34 \quad 100.0 \% \quad 13$ EF2_HUMAN $95.34 \quad 100.0 \% \quad 13$ EF2_HUMAN $95.34 \quad 100.0 \% \quad 13$ EF2_HUMAN $95.34 \quad 100.0 \% \quad 13$ EF2_HUMAN $95.34 \quad 100.0 \% \quad 13$ EF2 HUMAN $95.34 \quad 100.0 \% \quad 13$ EF2_HUMAN $95.34 \quad 100.0 \% \quad 13$ $\begin{array}{llll}\text { EF2_HUMAN } & 95.34 & 100.0 \% & 13 \\ \text { EF2_HUMAN } & 95.34 & 100.0 \% & 13\end{array}$

20

20

20

20

20

20

20

20

1520

3
3
13

9

13

13

$9 \begin{array}{lll}9 & 13 \\ 9 & 13\end{array}$

9

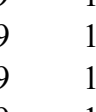

913

13

13

\begin{tabular}{lllll}
14 & 36 & $0.05 \%$ & $17.4 \%$ STLTDSLVCK \\
& 14 & 36 & $0.05 \%$ & $17.4 \%$ FAAKGEGQLGPAER \\
14 & 36 & $0.05 \%$ & $17.4 \%$ VFSGLVSTGLK \\
\hline 3 & 14 & 36 & $0.05 \%$ & $17.4 \%$ VFSGLVSTGLKVR
\end{tabular}

$\begin{array}{lllll}14 & 36 & 0.05 \% & 17.4 \% \text { STLTDSLVCK } \\ 14 & 36 & 0.05 \% & 17.4 \% \text { FAAKGEGQLGPAER } \\ 14 & 36 & 0.05 \% & 17.4 \% \text { VFSGLVSTGLK } \\ 14 & 36 & 0.05 \% & 17.4 \% \text { VFSGLVSTGLKVR }\end{array}$

$\begin{array}{llll}14 & 36 & 0.05 \% & 17.4 \% \\ 14 & 36 & 0.05 \% & 17.4 \%\end{array}$

$\begin{array}{lllll}14 & 36 & 0.05 \% & 17.4 \% & \text { KEDLYLKPIQR } \\ 14 & 36 & 0.05 \% & 17.4 \% \text { VAVEAKNPADLPK }\end{array}$

$\begin{array}{llll}14 & 36 & 0.05 \% & 17.4 \% \\ 14 & 36 & 0.05 \% & 17.4 \% \text { VAVEAKNPADSYRETVSEESNVLCLSK }\end{array}$

$14 \quad 36 \quad 0.05 \% \quad 17.4 \%$ GGGQIIPTAR

$\begin{array}{llll}14 & 36 & 0.05 \% & 17.4 \% \\ 14 & 36 & 0.05 \% & 17.4 \% \text { CLYASVLLTAQPR }\end{array}$

$14 \quad 36 \quad 0.05 \% \quad 17.4 \%$ CLYASVLTAQPR

$14 \quad 36 \quad 0.05 \% \quad 17.4 \%$ GHVFEESQVAGTPMFVVK

$14 \quad 36 \quad 0.05 \% \quad 17.4 \%$ AYLPVNESFGFTADLR

$31 \quad 116 \quad 0.17 \% \quad 46.9 \%$ ILAEGGGAKFK

$\begin{array}{llll}31 & 116 & 0.17 \% & 46.9 \% \\ 31 & 116 & 0.17 \% & \text { KYEEIDNAPEER }\end{array}$

$31 \quad 116 \quad 0.17 \% \quad 46.9 \%$ YEEIDNAPEERAR

$31 \quad 116 \quad 0.17 \% \quad 46.9 \%$ ARGITINAAHVEYSTAAR

$31 \quad 116 \quad 0.17 \% \quad 46.9 \%$ GITINAAHVEYSTAAR

$31 \quad 116 \quad 0.17 \% \quad 46.9 \%$ HYAHTDCPGHADYVK

$31 \quad 116 \quad 0.17 \% \quad 46.9 \%$ QIGVEHVVVYVNK
$99.7 \% \quad 30.5$

$99.7 \% \quad 54.0$

$99.7 \% \quad 48.4$

$99.4 \% 28.4$

$99.6 \% \quad 24.5$

$99.7 \% \quad 52.1$

$99.0 \% \quad 35.1$

$99.7 \% \quad 53.2$

$99.0 \% \quad 41.2$

$99.0 \% \quad 47.3$

$99.7 \% \quad 59.1$

$99.7 \% 39.8$

$97.3 \% \quad 22.3$

$99.7 \% \quad 43.4$

$99.7 \% \quad 42.6$

$99.7 \% \quad 44.0$

$99.7 \% \quad 42.0$

$99.7 \% \quad 50.0$

$99.7 \% \quad 52.6$

$99.7 \% \quad 74.2$

$99.7 \% \quad 43.4$

$99.7 \% \quad 55.9$

$99.7 \% \quad 48.2$

$99.0 \% \quad 45.5$

$99.7 \% \quad 57.8$

$99.7 \% \quad 35.7$

$99.6 \% \quad 26.6$

$99.7 \% \quad 59.3$

$99.7 \% \quad 42.7$

$\begin{array}{lll}99.7 \% & 33.6\end{array}$

$99.7 \% \quad 53.4$

$99.7 \% \quad 49.4$

$97.9 \% \quad 17.7$

$99.7 \% \quad 57.4$

$98.5 \% \quad 17.8$

$99.7 \% \quad 31.4$

$99.7 \% \quad 32.3$

$99.7 \% \quad 54.5$

$99.7 \% \quad 30.6$

$99.7 \% \quad 76.7$

$99.7 \% \quad 49.0$

$99.7 \% \quad 52.4$

$99.7 \% \quad 37.1$

$99.7 \% \quad 38.0$

$\begin{array}{rr}99.7 \% & 57.6 \\ 99.7 \% & 31.5\end{array}$

$99.7 \% \quad 28.3$

$\begin{array}{ccc}1054.54 & 47 & 55 \\ 1588.88 & 6 & 20 \\ 1120.60 & 21 & 30 \\ 1139.54 & 42 & 51 \\ 1871.01 & 130 & 146 \\ 1314.74 & 135 & 146 \\ 870.54 & 147 & 154 \\ 1600.85 & 167 & 179 \\ 967.55 & 173 & 180 \\ 975.55 & 248 & 255 \\ 1025.61 & 256 & 266 \\ 2531.38 & 267 & 290 \\ 1046.59 & 387 & 395 \\ 3027.39 & 396 & 423 \\ 1316.74 & 428 & 439 \\ 914.57 & 431 & 439 \\ 2185.05 & 60 & 83 \\ 1439.71 & 124 & 136 \\ 1693.94 & 15 & 30 \\ 1347.74 & 18 & 30 \\ 1118.68 & 138 & 147 \\ 1375.83 & 138 & 149 \\ 1245.69 & 202 & 212 \\ 938.48 & 213 & 220 \\ 1241.65 & 286 & 295 \\ 1572.82 & 401 & 414 \\ 1052.59 & 429 & 437 \\ 1091.58 & 2 & 10 \\ 1123.57 & 33 & 42 \\ 1430.74 & 236 & 249 \\ 1107.64 & 416 & 426 \\ 1362.81 & 416 & 428 \\ 1402.81 & 439 & 449 \\ 1351.76 & 507 & 519 \\ 2498.21 & 573 & 594 \\ 969.55 & 717 & 726 \\ 1534.82 & 727 & 739 \\ 1378.71 & 728 & 739 \\ 1977.97 & 768 & 785 \\ 1799.90 & 786 & 801 \\ 1090.63 & 80 & 90 \\ 1492.69 & 91 & 102 \\ 1591.73 & 92 & 104 \\ 1901.00 & 103 & 120 \\ 1673.86 & 105 & 120 \\ 1770.77 & 121 & 135 \\ 1483.83 & 170 & 182 \\ & & \end{array}$

Page 46 of Table S-1-2 
Elongation factor Tu, mitochondrial GN=TUFM EFTU_HUMAN $49.54 \quad 100.0 \% \quad 21$ Elongation factor Tu, mitochondrial GN=TUFM EFTU_HUMAN $49.54 \quad 100.0 \%$ Elongation factor Tu, mitochondrial GN=TUFM EFTU_HUMAN $49.54 \quad 100.0 \% \quad 21$ Elongation factor Tu, mitochondrial GN=TUFM EFTU HUMAN $49.54 \quad 100.0 \% 21$ Elongation factor Tu, mitochondrial GN=TUFM EFTU_HUMAN $49.54 \quad 100.0 \% \quad 21$ Elongation factor $\mathrm{Tu}$, mitochondrial GN=TUFM EFTU_HUMAN $49.54 \quad 100.0 \% \quad 2$ Elongation factor Tu, mitochondrial GN=TUFM EFTU_HUMAN $49.54 \quad 100.0 \%$ Elongation factor Tu, mitochondrial GN=TUFM EFTU_HUMAN $49.54 \quad 100.0 \% \quad 21$ Elongation factor $\mathrm{Tu}$, mitochondrial GN=TUFM EFTU HUMAN $49.54 \quad 100.0 \%$ Elongation factor Tu, mitochondrial GN=TUFM EFTU_HUMAN $49.54 \quad 100.0 \%$ Elongation factor $\mathrm{Tu}$, mitochondrial GN=TUFM EFTU_HUMAN $49.54 \quad 100.0 \% \quad 2$ Elongation factor $\mathrm{Tu}$, mitochondrial GN=TUFM EFTU_HUMAN $49.54 \quad 100.0 \%$ Elongation factor Tu, mitochondrial GN=TUFM EFTU_HUMAN $49.54 \quad 100.0 \% \quad 2$ Elongation factor Tu, mitochondrial GN=TUFM EFTU_HUMAN $49.54 \quad 100.0 \% \quad 2$ Emerin $\mathrm{GN}=\mathrm{EMD}$ Emerin $\mathrm{GN}=\mathrm{EMD}$ Emerin $\mathrm{GN}=\mathrm{EMD}$ Emerin $\mathrm{GN}=\mathrm{EMD}$ Emerin GN=EMD

Emerin GN=EMD Emerin $\mathrm{GN}=\mathrm{EMD}$ Endoplasmin GN=HSP90B

Endoplasmin GN=HSP90B1 EN EMC3 EMC3_HUMAN $29.95 \quad 100.0 \%$ Erlin-1 GN=ERLIN 1 Erlin-1 GN=ERLIN 1 Erlin-1 GN=ERLIN 1 Erlin-1 GN=ERLIN 1 Erlin-1 GN=ERLIN1 Erlin-1 GN=ERLIN1 Erlin-1 GN=ERLIN 1 Erlin-1 GN=ERLIN 1 Erlin-1 GN=ERLIN1 Erlin-1 GN=ERLIN 1 Erlin-1 GN=ERLIN 1 Erlin-2 GN=ERLIN 2 Erlin-2 GN=ERLIN2 Erlin-2 GN=ERLIN2 Erlin-2 GN=ERLIN2 Erlin-2 GN=ERLIN2 Erlin-2 GN=ERLIN 2 Erlin-2 GN=ERLIN2 Erlin-2 GN=ERLIN2 Erlin-2 GN=ERLIN2 Erlin-2 GN=ERLIN 2 Erlin-2 GN=ERLIN2
EMD HUMAN $28.99 \quad 100.0 \%$ EMD_HUMAN $28.99 \quad 100.0 \%$ EMD HUMAN $28.99 \quad 100.0 \%$ EMD HUMAN $28.99 \quad 100.0 \%$ EMD_HUMAN $28.99 \quad 100.0 \%$ EMD HUMAN $28.99 \quad 100.0 \%$ EMD_HUMAN $28.99 \quad 100.0 \%$ ENPL HUMAN $92.47 \quad 100.0 \%$ ENPL_HUMAN $92.47 \quad 100.0 \%$ EMC3 HUMAN $29.95 \quad 100.0 \%$ ERLN1_HUMAN $38.93 \quad 100.0 \%$ ERLN1_HUMAN $38.93 \quad 100.0 \%$ ERLN1_HUMAN $38.93 \quad 100.0 \%$ ERLN1_HUMAN $38.93 \quad 100.0 \%$ ERLN1_HUMAN $38.93 \quad 100.0 \%$ ERLN1_HUMAN $38.93 \quad 100.0 \%$ ERLN1_HUMAN $38.93 \quad 100.0 \%$ ERLN1 HUMAN $38.93 \quad 100.0 \%$ ERLN1_HUMAN $38.93 \quad 100.0 \%$ ERLN1 HUMAN $38.93 \quad 100.0 \%$ ERLN1 HUMAN $38.93 \quad 100.0 \%$ ERLN2_HUMAN $37.84 \quad 100.0 \%$ ERLN2 HUMAN $37.84 \quad 100.0 \%$ ERLN2_HUMAN $37.84 \quad 100.0 \%$ ERLN2_HUMAN $37.84 \quad 100.0 \%$ ERLN2 HUMAN $37.84 \quad 100.0 \%$ ERLN2_HUMAN $37.84 \quad 100.0 \%$ ERLN2 HUMAN $37.84 \quad 100.0 \%$ ERLN2 HUMAN $37.84 \quad 100.0 \%$ ERLN2_HUMAN $37.84 \quad 100.0 \%$ ERLN2 HUMAN $37.84 \quad 100.0 \%$ ERLN2_HUMAN $37.84 \quad 100.0 \% \quad 16$

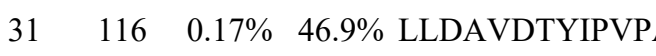
$99.7 \% \quad 56.0$ $16 \quad 0.17 \% \quad 46.9 \%$ DLEKPFLLPVEAVYSVPGR $116 \quad 0.17 \% \quad 46.9 \%$ GTVVTGTLER

$116 \quad 0.17 \% \quad 46.9 \%$ KGDECELLGHSK

$116 \quad 0.17 \% \quad 46.9 \%$ TVVTGIEMFHK

$116 \quad 0.17 \% \quad 46.9 \%$ TVVTGIEMFHKSLER

$116 \quad 0.17 \% \quad 46.9 \%$ SLERAEAGDNLGALVR

$116 \quad 0.17 \% \quad 46.9 \%$ AEAGDNLGALVR

$116 \quad 0.17 \% \quad 46.9 \%$ GLVMVKPGSIKPHQK

$116 \quad 0.17 \% \quad 46.9 \%$ VEAQVYILSK

$116 \quad 0.17 \% \quad 46.9 \%$ VEAQVYILSKEEGGR $6.17 \% \quad 46.9 \%$ QPMILEKGQR

$116 \quad 0.17 \% \quad 46.9 \%$ TIGTGLVTNTLAMTEEEK

$99.1 \% \quad 18.5$

$\begin{array}{ll}9.7 \% & 64.7 \\ 99.7 \% & 48.5\end{array}$

$99.7 \% \quad 59.5$

$98.6 \% \quad 20.2$

$99.7 \% \quad 56.4$

$99.7 \% \quad 83.0$

$99.4 \% 19.7$

$99.7 \% \quad 62.8$

$99.7 \% \quad 60.3$

$96.8 \% \quad 16.8$

$0.04 \% \quad 33.9 \%$ YNIPHGPVVGSTR

$0.04 \% \quad 33.9 \%$ KIFEYETQR

$0.04 \% \quad 33.9 \%$ KEDALLYQSK

$0.04 \% \quad 33.9 \%$ GYNDDYYEESYFTTR

$0.04 \% 33.9 \%$ TYGEPESAGPSR

$0.04 \% 33.9 \%$ DSAYQSITHYRPVSASR

$0.04 \% 33.9 \%$ APGAGLGQDR

$0.01 \% \quad 3.0 \%$ GVVDSDDLPLNVSR

$0.01 \% \quad 3.0 \%$ EAESSPFVER

$0.00 \% \quad 11.9 \%$ LTQEQVSDSQVLIR

$99.6 \% 23.1$

$\begin{array}{lll}99.7 \% & 49.7\end{array}$

$99.7 \% \quad 61.9$

$99.7 \% \quad 49.8$

$99.7 \% \quad 62.2$

$99.7 \% \quad 53.8$

$99.7 \% \quad 37.7$

$99.7 \% \quad 45.2$

$99.7 \% \quad 47.3$

$99.7 \% \quad 30.4$

$99.7 \% \quad 56.7$

$0.00 \% \quad 11.9 \%$ SIYSLILGQDNAADQSR

$0.02 \% \quad 35.0 \%$ SVQTTLQTDEVK

$0.02 \% \quad 35.0 \%$ DLNLMAPGLTIQAVR

$0.02 \% \quad 35.0 \%$ NFELMEAEKTK

$0.02 \% \quad 35.0 \%$ TKLLIAAQK

$0.02 \% \quad 35.0 \%$ VVEKEAETER

$0.02 \% \quad 35.0 \%$ AVIEAEKIAQVAK

$0.02 \% \quad 35.0 \%$ ISEIEDAAFLAR

$0.02 \% \quad 35.0 \%$ ISEIEDAAFLAREK

$0.02 \% \quad 35.0 \%$ ADAEYYAAHK

$0.02 \% \quad 35.0 \%$ YSDIRTGR

$99.7 \% \quad 58.1$

$0.06 \% 37.8 \%$ SVQTTLQTDEVK

$0.06 \% 37.8 \%$ VTKPNIPEAIR

$0.06 \% 37.8 \%$ VTKPNIPEAIRR

$0.06 \% \quad 37.8 \%$ NYELMESEKTK

$0.06 \% 37.8 \%$ TKLLIAAQK

$0.06 \% 37.8 \%$ VVEKEAETER

$99.7 \% \quad 39.8$

$0.06 \% \quad 37.8 \%$ ALIEAEKVAQVAEI

$\begin{array}{lll}0.06 \% & 37.8 \% \text { KISEIEDAAFLAR }\end{array}$

$0.06 \% \quad 37.8 \%$ ISEIEDAAFLAR $\begin{array}{llll}9.7 \% & 55.4 & 25.0 & 45.3\end{array}$

$99.7 \% \quad 44.0 \quad 25.0 \quad 25.3$

$\begin{array}{lllll}99.7 \% & 25.6 & 25.0 & 25.6 & 2\end{array}$

$\begin{array}{llll}99.7 \% & 33.7 & 25.0 & 33.7\end{array}$

$\begin{array}{llll}99.7 \% & 58.5 & 25.0 & 47.6\end{array}$

$99.7 \% \quad 65.6 \quad 25.0 \quad 57.0$

$99.7 \% \quad 57.4 \quad 25.0 \quad 55.7$

$\begin{array}{llll}99.7 \% & 30.1 & 25.0 & 30.1\end{array}$

$\begin{array}{llll}98.8 \% & 18.2 & 25.0 & 18.2\end{array}$

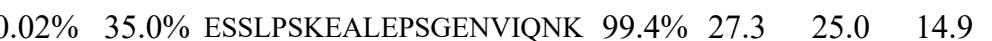

$\begin{array}{llll}99.7 \% & 58.1 & 25.0 & 51.8\end{array}$

$99.4 \% \quad 21.5 \quad 25.0 \quad 21.5$

$99.6 \% \quad 23.4 \quad 25.0 \quad 22.3$

$\begin{array}{llll}99.7 \% & 41.6 & 25.0 & 39.7\end{array}$

$99.7 \% 25.6 \quad 25.0 \quad 25.6$

$\begin{array}{llll}99.7 \% & 33.7 & 25.0 & 33.7\end{array}$

$\begin{array}{llll}99.7 \% & 71.3 & 25.0 & 71.3\end{array}$

$\begin{array}{lllll}99.7 \% & 63.3 & 25.0 & 57.3 & 2\end{array}$

$99.7 \% \quad 65.6 \quad 25.0 \quad 57.0-4$

$\begin{array}{llll}99.7 \% & 57.4 & 25.0 & 55.7\end{array}$
1542.85

2129.16

1032.57

1372.65

1261.66

1746.92

1670.88

1185.62

1618.95

1149.65

1677.88

1199.66

1907.96

2263.19

1396.73

1213.62

1194.6

1922.77

1250.56

1937.95

941.48

1485.75

1150.54

1615.87

1850.92

1348.70

1627.88

1339.66

985.64

1189.6

1369.81

1334.70

1591.83

1138.52

967.50

2256.14

1348.70

1237.73

1393.83

1371.65

985.64

1189.61

2061.12

1306.70

1462.79

1334.70

1591.83

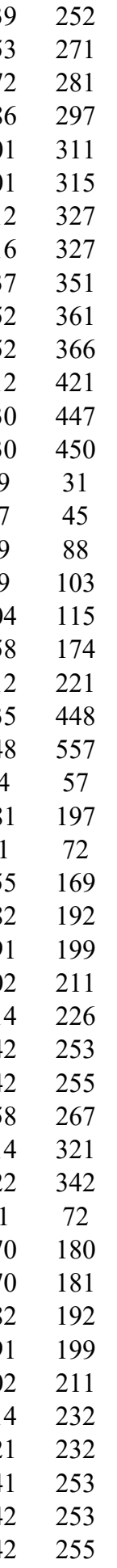

Page 47 of Table S-1-2 
Erlin-2 GN=ERLIN2

Erlin-2 GN=ERLIN2

Erlin-2 GN=ERLIN2

Erlin-2 GN=ERLIN2

Erlin-2 GN=ERLIN2

Erythrocyte band 7 integral membrane protein GN=STOM STOM HUMAN $31.73 \quad 100.0 \%$

Erythrocyte band 7 integral membrane protein GN=STOM STOM_HUMAN $31.73 \quad 100.0 \%$

Eukaryotic initiation factor 4A-I GN=EIF4A1 IF4A1_HUMAN $46.16 \quad 100.0 \%$ Eukaryotic initiation factor 4A-I GN=EIF4A1 IF4A1 HUMAN $46.16 \quad 100.0 \%$ Eukaryotic initiation factor 4A-I GN=EIF4A1 IF4A1_HUMAN $46.16 \quad 100.0 \%$ Eukaryotic initiation factor 4A-I GN=EIF4A1 IF4A1_HUMAN $46.16 \quad 100.0 \%$ Eukaryotic initiation factor 4A-I GN=EIF4A1 IF4A1_HUMAN $46.16 \quad 100.0 \%$ Eukaryotic initiation factor 4A-I GN=EIF4A1 IF4A1_HUMAN $46.16 \quad 100.0 \%$ Eukaryotic initiation factor 4A-I GN=EIF4A1 IF4A1_HUMAN $46.16 \quad 100.0 \%$ Eukaryotic initiation factor 4A-I GN=EIF4A1 IF4A1_HUMAN $46.16 \quad 100.0 \%$ Eukaryotic initiation factor 4A-III GN=EIF4A3 IF4A3_HUMAN $46.87 \quad 100.0 \%$ Eukaryotic initiation factor 4A-III GN=EIF4A3 IF4A3 HUMAN $46.87 \quad 100.0 \%$ Eukaryotic initiation factor 4A-III GN=EIF4A3 IF4A3_HUMAN $46.87 \quad 100.0 \%$ Eukaryotic initiation factor 4A-III GN=EIF4A3 IF4A3_HUMAN $46.87 \quad 100.0 \%$ Eukaryotic initiation factor 4A-III GN=EIF4A3 IF4A3_HUMAN $46.87 \quad 100.0 \%$ Eukaryotic initiation factor 4A-III GN=EIF4A3 IF4A3_HUMAN $46.87 \quad 100.0 \%$ Eukaryotic translation initiation factor 2 subunit 1 GN=EIF2S1 IF2A HUMAN $36.11 \quad 100.0 \%$ Eukaryotic translation initiation factor 2 subunit $1 \mathrm{GN}=$ EIF2S1 IF2A_HUMAN $36.11 \quad 100.0 \%$ Eukaryotic translation initiation factor 2 subunit 1 GN=EIF2S1 IF2A_HUMAN $36.11 \quad 100.0 \%$ Eukaryotic translation initiation factor 3 subunit A GN=EIF3A EIF3A_HUMAN $166.57 \quad 100.0 \%$ Eukaryotic translation initiation factor 3 subunit A GN=EIF3A EIF3A_HUMAN $166.57 \quad 100.0 \%$ Eukaryotic translation initiation factor 3 subunit A GN=EIF3A EIF3A_HUMAN $166.57 \quad 100.0 \%$ Eukaryotic translation initiation factor 3 subunit A GN=EIF3A EIF3A_HUMAN $166.57 \quad 100.0 \%$ Eukaryotic translation initiation factor 3 subunit A GN=EIF3A EIF3A_HUMAN $166.57 \quad 100.0 \%$ Eukaryotic translation initiation factor 3 subunit A GN=EIF3A EIF3A HUMAN $166.57 \quad 100.0 \%$ Eukaryotic translation initiation factor 3 subunit A GN=EIF3A EIF3A_HUMAN $166.57 \quad 100.0 \%$ Eukaryotic translation initiation factor 3 subunit A GN=EIF3A EIF3A_HUMAN $166.57 \quad 100.0 \%$ Eukaryotic translation initiation factor 3 subunit A GN=EIF3A EIF3A_HUMAN $166.57 \quad 100.0 \%$ Eukaryotic translation initiation factor 3 subunit A GN=EIF3A EIF3A_HUMAN $166.57 \quad 100.0 \%$ Eukaryotic translation initiation factor 3 subunit A GN=EIF3A EIF3A_HUMAN $166.57 \quad 100.0 \%$ Eukaryotic translation initiation factor 3 subunit A GN=EIF3A EIF3A_HUMAN $166.57 \quad 100.0 \%$ Eukaryotic translation initiation factor 3 subunit A GN=EIF3A EIF3A_HUMAN $166.57 \quad 100.0 \%$ Eukaryotic translation initiation factor 3 subunit A GN=EIF3A EIF3A_HUMAN $166.57 \quad 100.0 \%$ Eukaryotic translation initiation factor 3 subunit A GN=EIF3A EIF3A_HUMAN $166.57 \quad 100.0 \%$ Eukaryotic translation initiation factor 3 subunit A GN=EIF3A EIF3A_HUMAN $166.57 \quad 100.0 \%$ Eukaryotic translation initiation factor 3 subunit A GN=EIF3A EIF3A_HUMAN $166.57 \quad 100.0 \%$ Eukaryotic translation initiation factor 3 subunit A GN=EIF3A EIF3A_HUMAN $166.57 \quad 100.0 \%$ Eukaryotic translation initiation factor 3 subunit B GN=EIF3B EIF3B_HUMAN $92.48 \quad 100.0 \%$ Eukaryotic translation initiation factor 3 subunit $\mathrm{B}$ GN=EIF3B EIF3B_HUMAN $92.48 \quad 100.0 \%$ Eukaryotic translation initiation factor 3 subunit B GN=EIF3B EIF3B_HUMAN $92.48 \quad 100.0 \%$ Eukaryotic translation initiation factor 3 subunit B GN=EIF3B EIF3B_HUMAN $92.48 \quad 100.0 \%$ Eukaryotic translation initiation factor 3 subunit B GN=EIF3B EIF3B_HUMAN $92.48 \quad 100.0 \%$
$41 \quad 0.06 \% \quad 37.8 \%$ AKADAECYTAMK $0.06 \% 37.8 \%$ ADAECYTAMK $0.06 \% \quad 37.8 \%$ LTPEYLQLMK

$99.7 \% \quad 48.9 \quad 25.0 \quad 48.9$ $99.7 \% \quad 42.6 \quad 25.0 \quad 35.7 \quad 2$ $0.06 \% \quad 37.8 \%$ IYFGKDIPNMFMDSAGSVSK $0.06 \% 37.8 \%$ DIPNMFMDSAGSVSK $0.01 \% \quad 6.9 \% \quad$ LLAQTTLR

$0.01 \% \quad 6.9 \%$ VIAAEGEMNASR $99.7 \% \quad 40.9$ $99.7 \% \quad 32.3$ $99.0 \% 31.1$ $99.5 \% 25.1$ $0.05 \% \quad 22.9 \%$ GIYAYGFEKPSAIQQR $99.7 \% \quad 56.5$ $0.05 \% \quad 22.9 \%$ AILPCIKGYDVIAQAQSGTGK $97.9 \% \quad 47.1$ $0.05 \% \quad 22.9 \%$ GYDVIAQAQSGTGK $99.7 \% \quad 46.1$ $0.05 \% \quad 22.9 \%$ AEVQKLQMEAPHIIVGTP $0.05 \% \quad 22.9 \%$ MFVLDEADEMLSR $0.05 \% \quad 22.9 \%$ VLITTDLLAR

$0.05 \% \quad 22.9 \%$ GVAINMVTEEDKR $0.02 \% \quad 15.6 \%$ GIYAYGFEKPSAIQQR $0.02 \% \quad 15.6 \%$ GRDVIAQSQSGTGK $0.02 \% \quad 15.6 \%$ KLDYGQHVVAGTPGR $0.02 \% \quad 15.6 \%$ LDYGQHVVAGTPGR $0.02 \% \quad 15.6 \%$ VLISTDVWAR $0.02 \% \quad 15.6 \%$ KGVAINFVK $0.01 \% \quad 9.2 \%$ SKTVYSILR

$0.01 \% \quad 9.2 \%$ RLTPQAVK $0.01 \% \quad 9.2 \%$ VVTDTDETELAR $0.07 \% \quad 13.5 \%$ PAYFQRPENALKR $0.07 \% \quad 13.5 \%$ ANEFLEVGK $0.07 \% \quad 13.5 \%$ YLELCVDLRK $0.07 \% \quad 13.5 \%$ SGNALFHASTLHR $0.07 \% \quad 13.5 \%$ NLTQDEMQR $0.07 \% \quad 13.5 \%$ VLLATLSIPITPER $0.07 \% \quad 13.5 \%$ VLLATLSIPITPERTDIAR $0.07 \% \quad 13.5 \%$ LLDMDGIIVEK $0.07 \% \quad 13.5 \%$ RLATLLGLQAPPTR $0.07 \% \quad 13.5 \%$ LATLLGLQAPPTR $0.07 \% \quad 13.5 \%$ IGLINDMVR $0.07 \% \quad 13.5 \%$ LTSLVPFVDAFQLER $0.07 \% \quad 13.5 \%$ TLSFGSDLNYATR $0.07 \% \quad 13.5 \%$ NQLTAMSSVLAK $0.07 \% \quad 13.5 \%$ ILQEHEQIKK $0.07 \% \quad 13.5 \%$ RLEEIPLIK $0.07 \% \quad 13.5 \%$ MLEDRDLFVMR $0.07 \% \quad 13.5 \%$ RLGDSSLSR $99.7 \% \quad 45.6$ $99.7 \% \quad 48.1$ $99.7 \% \quad 60.4$ $99.7 \% \quad 60.1$ $99.7 \% \quad 50.9$ $99.7 \% \quad 56.5$ $99.7 \% \quad 48.7$ $99.7 \% \quad 30.0$ $\begin{array}{lll}99.7 \% & 34.8\end{array}$ $99.7 \% \quad 41.3$ $99.7 \% \quad 30.9$ $96.5 \% \quad 14.9$ $99.0 \% \quad 21.5$ $99.7 \% \quad 44.3$ $99.5 \% \quad 28.3$ $99.5 \% \quad 26.9$ $\begin{array}{lll}98.5 \% & 23.8\end{array}$ $99.7 \% \quad 55.6$ $99.7 \% \quad 26.5$ $99.7 \% \quad 35.5$

$99.7 \% \quad 31.7$ $\begin{array}{lll}99.7 \% & 38.4\end{array}$ $98.2 \% \quad 22.2$ $99.7 \% \quad 34.2$ $99.7 \% \quad 52.2$ $99.7 \% \quad 41.8$ $\begin{array}{lll}99.7 \% & 48.2\end{array}$ $\begin{array}{lll}99.7 \% & 50.3\end{array}$ $97.9 \% \quad 15.8$ $\begin{array}{lll}99.3 \% & 26.3\end{array}$ $99.7 \% \quad 36.0$ $99.7 \% \quad 30.3$ $0.05 \% \quad 12.8 \%$ SDSRAQAVSEDAGGNEGR $\quad 99.0 \% \quad 18.1$ $0.05 \% \quad 12.8 \%$ AQAVSEDAGGNEGR $99.7 \% \quad 47.1$

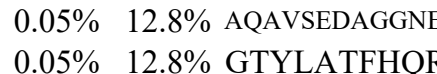
$0.05 \% \quad 12.8 \%$ FSHQGVQLIDFSPCER $\begin{array}{ll}99.7 \% & 54.0\end{array}$ $99.7 \% \quad 49.0$ $99.7 \% \quad 29.8$

0
0
2
0
0
0
0
0
1
0
2
2
4
0
0
0
1
0
2
2
2
2
0
0
0
0
0
0
0
0
0
0
0
0
0
0
1
0
0
0
0
0
0
0
0
0
0
0
0
0
0
0
0
0
0
0
0
0
0
0
0
0
0
0

1358.61 1159.48 1251.67

2239.04

1598.72

915.56

1263.60

1827.94

2190.16

1394.69

2174.18

1618.87

1555.71

1114.68

1461.74

1827.94

1403.72

1597.84

1469.75

1159.65

975.60

1066.63

912.56

1348.66

1589.85

1006.52

1308.70

1410.72

1134.52

1522.92

2079.22

1245.68

1506.9

1350.81

1030.57

1734.94

1444.71

1262.68

1265.72

1110.69

1440.70

990.53

1805.80

1360.61

2084.96

1193.61 1919.91

$\begin{array}{cc}56 & 267 \\ 58 & 267 \\ 76 & 285 \\ 95 & 314 \\ 00 & 314 \\ 45 & 152 \\ 21 & 232 \\ 6 & 61 \\ 2 & 82 \\ 9 & 82 \\ 42 & 161 \\ 47 & 161 \\ 78 & 190 \\ 25 & 334 \\ 70 & 382 \\ 2 & 67 \\ 5 & 88 \\ 52 & 166 \\ 53 & 166 \\ 30 & 339 \\ 74 & 382 \\ 05 & 113 \\ 83 & 190 \\ 77 & 288 \\ 2 & 14 \\ 5 & 23 \\ 4 & 63 \\ 86 & 298 \\ 09 & 317 \\ 22 & 335 \\ 22 & 340 \\ 41 & 351 \\ 54 & 367 \\ 55 & 367 \\ 68 & 376 \\ 55 & 469 \\ 90 & 502 \\ 21 & 532 \\ 24 & 633 \\ 03 & 711 \\ 53 & 763 \\ 77 & 885 \\ 17 & 134 \\ 21 & 134 \\ 21 & 141 \\ 46 & 355 \\ 71 & 386\end{array}$

Page 48 of Table S-1-2 

Eukaryotic translation initiation factor 3 subunit B GN=EIF3B EIF3B_HUMAN $92.48 \quad 100.0 \%$ Eukaryotic translation initiation factor 3 subunit B GN=EIF3B EIF3B_HUMAN $92.48 \quad 100.0 \%$ Eukaryotic translation initiation factor 3 subunit B GN=EIF3B EIF3B HUMAN $92.48 \quad 100.0^{\circ}$ Eukaryotic translation initiation factor 3 subunit B GN=EIF3B EIF3B_HUMAN $92.48 \quad 100.0 \%$ Eukaryotic translation initiation factor 3 subunit B GN=EIF3B EIF3B_HUMAN $92.48 \quad 100.0 \%$ Eukaryotic translation initiation factor 3 subunit D GN=EIF3D EIF3D_HUMAN $63.97 \quad 100.0 \%$ Eukaryotic translation initiation factor 3 subunit D GN=EIF3D EIF3D_HUMAN $63.97 \quad 100.0 \%$ Eukaryotic translation initiation factor 3 subunit D GN=EIF3D EIF3D HUMAN $63.97100 .0^{\circ}$ Eukaryotic translation initiation factor 3 subunit D GN=EIF3D EIF3D_HUMAN $63.97 \quad 100.0 \%$ Eukaryotic translation initiation factor 3 subunit D GN=EIF3D EIF3D_HUMAN $63.97 \quad 100.0 \%$ Eukaryotic translation initiation factor 3 subunit D GN=EIF3D EIF3D HUMAN $63.97 \quad 100.0 \%$ Eukaryotic translation initiation factor 3 subunit E GN=EIF3E EIF3E_HUMAN $52.22 \quad 100.0 \%$ Eukaryotic translation initiation factor 3 subunit $\mathrm{E}$ GN=EIF3E EIF3E_HUMAN $52.22 \quad 100.0 \%$ Eukaryotic translation initiation factor 3 subunit E GN=EIF3E EIF3E_HUMAN $52.22 \quad 100.0 \%$ Eukaryotic translation initiation factor 3 subunit E GN=EIF3E EIF3E_HUMAN $52.22 \quad 100.0 \%$ Eukaryotic translation initiation factor 3 subunit $\mathrm{E}$ GN=EIF3E EIF3E_HUMAN $52.22 \quad 100.0^{\circ}$ Eukaryotic translation initiation factor 3 subunit E GN=EIF3E EIF3E_HUMAN $52.22 \quad 100.0 \%$ Eukaryotic translation initiation factor 3 subunit E GN=EIF3E EIF3E_HUMAN $52.22 \quad 100.0 \%$ Eukaryotic translation initiation factor 3 subunit $\mathrm{E}$ GN=EIF3E EIF3E HUMAN $52.22 \quad 100.0 \%$ Eukaryotic translation initiation factor 3 subunit E GN=EIF3E EIF3E_HUMAN $52.22 \quad 100.0 \%$ Eukaryotic translation initiation factor 3 subunit E GN=EIF3E EIF3E HUMAN $52.22 \quad 100.0 \%$ Eukaryotic translation initiation factor 3 subunit E GN=EIF3E EIF3E_HUMAN $52.22 \quad 100.0 \%$ Eukaryotic translation initiation factor 3 subunit E GN=EIF3E EIF3E_HUMAN $52.22 \quad 100.0 \%$ Eukaryotic translation initiation factor 3 subunit $\mathrm{E}$ GN=EIF3E EIF3E HUMAN $52.22 \quad 100.0 \%$ Eukaryotic translation initiation factor 3 subunit F GN=EIF3F EIF3F_HUMAN $37.56 \quad 100.0 \%$ Eukaryotic translation initiation factor 3 subunit F GN=EIF3F EIF3F_HUMAN $37.56 \quad 100.0 \%$ Eukaryotic translation initiation factor 3 subunit G GN=EIF3G EIF3G_HUMAN $35.61 \quad 100.0 \%$ Eukaryotic translation initiation factor 3 subunit G GN=EIF3G EIF3G_HUMAN $35.61 \quad 100.0 \%$ Eukaryotic translation initiation factor 3 subunit G GN=EIF3G EIF3G HUMAN $35.61 \quad 100.0 \%$ Eukaryotic translation initiation factor 3 subunit G GN=EIF3G EIF3G_HUMAN $35.61 \quad 100.0 \%$ Eukaryotic translation initiation factor 3 subunit $\mathrm{H}$ GN=EIF3H EIF3H_HUMAN $39.93 \quad 100.0 \%$ Eukaryotic translation initiation factor 3 subunit $\mathrm{H}$ GN=EIF3H EIF3H HUMAN $39.93 \quad 100.0 \%$ Eukaryotic translation initiation factor 3 subunit $\mathrm{H}$ GN=EIF3H EIF3H_HUMAN $39.93 \quad 100.0 \%$ Eukaryotic translation initiation factor 3 subunit I GN=EIF3I EIF3I HUMAN $36.50 \quad 100.0 \%$ Eukaryotic translation initiation factor 3 subunit I GN=EIF3I EIF3I_HUMAN $36.50 \quad 100.0 \%$ Eukaryotic translation initiation factor 3 subunit I GN=EIF3I EIF3I_HUMAN $36.50 \quad 100.0 \%$ Eukaryotic translation initiation factor 3 subunit I GN=EIF3I EIF3I HUMAN $36.50 \quad 100.0 \%$ Eukaryotic translation initiation factor 3 subunit I GN=EIF3I EIF3I_HUMAN $36.50 \quad 100.0 \%$ Eukaryotic translation initiation factor 3 subunit I GN=EIF3I EIF3I_HUMAN $36.50 \quad 100.0 \%$ Eukaryotic translation initiation factor 3 subunit I GN=EIF3I EIF3I HUMAN $36.50 \quad 100.0 \%$ Eukaryotic translation initiation factor 3 subunit I GN=EIF3I EIF3I_HUMAN $36.50 \quad 100.0 \%$ Eukaryotic translation initiation factor 3 subunit I GN=EIF3I EIF3I HUMAN $36.50 \quad 100.0 \%$ Eukaryotic translation initiation factor 3 subunit I GN=EIF3I EIF3I_HUMAN $36.50 \quad 100.0 \%$ Eukaryotic translation initiation factor 3 subunit I GN=EIF3I EIF3I_HUMAN $36.50 \quad 100.0 \%$ Eukaryotic translation initiation factor 3 subunit I GN=EIF3I EIF3I HUMAN $36.50 \quad 100.0 \%$ Eukaryotic translation initiation factor 3 subunit L GN=EIF3L EIF3L_HUMAN $66.73 \quad 100.0 \%$
$0.05 \% \quad 12.8 \%$ VTLMQLPTR

$0.05 \% \quad 12.8 \%$ VTLMQLPTRQEIR

$0.05 \% \quad 12.8 \%$ GTQGVVTNFEIFR

$0.05 \% \quad 12.8 \%$ FAVLHGEAPR

$0.05 \% \quad 12.8 \%$ ISVSFYHVK

$0.05 \% \quad 12.8 \%$ TMMEDFRK

$0.03 \% \quad 12.2 \%$ NMLQFNLQILPK

$0.03 \% \quad 12.2 \%$ IFHTVTTTDDPVIR

$0.03 \% \quad 12.2 \%$ IFHTVTTTDDPVIRK

$0.03 \% \quad 12.2 \%$ SVYSWDIVVQR

$0.03 \% \quad 12.2 \%$ NLAMEATYINHN

$0.03 \% \quad 12.2 \%$ LGDDIDLIVR

$0.05 \% \quad 31.7 \%$ NLYSDDIPHALR

$99.7 \% 31.8$

$99.3 \% \quad 21.9$

$99.7 \% \quad 57.6$

$99.7 \% \quad 43.5$

$99.7 \% \quad 31.5$

$\begin{array}{lll}99.0 \% & 27.0\end{array}$

$99.7 \% \quad 58.3$

$99.7 \% \quad 58.5$

$99.7 \% \quad 32.0$

$99.7 \% \quad 49.1$

$\begin{array}{lll}99.7 \% & 44.7\end{array}$

$99.7 \% \quad 44.3$

$99.5 \% \quad 23.5$

$0.05 \% \quad 31.7 \%$ TTVVAQLKQLQAETEPIVK $99.7 \% 56.6$

$0.05 \% \quad 31.7 \%$ QLQAETEPIVK

$0.05 \% \quad 31.7 \%$ MFEDPETTR

$0.05 \% \quad 31.7 \%$ MLFDYLADK

$0.05 \% \quad 31.7 \%$ VLVPATDR

$99.7 \% \quad 46.1$

$99.7 \% \quad 39.5$

$96.8 \% \quad 25.9$

$99.0 \% \quad 24.2$

$0.05 \% \quad 31.7 \%$ LKETIDNNSVSSPLQSLQQR $\quad 99.7 \% \quad 54.8$

$0.05 \% \quad 31.7 \%$ YLTTAVITNKDVR

$99.7 \% \quad 61.3$

$\begin{array}{llllll}0.05 \% & 31.7 \% & \text { LGHVVMGNNAVSPYQQVIEK } \quad 99.7 \% & 48.8\end{array}$

$0.05 \% \quad 31.7 \%$ LGHVVMGNNAVSPYQQVIEKTK $99.7 \% \quad 25.5$

$0.05 \% \quad 31.7 \%$ SLSFRSQMLAMNIEK

$0.05 \% \quad 31.7 \%$ SQMLAMNIEK

$0.05 \% \quad 31.7 \%$ SEAPNWATQDSGFY

$0.01 \% \quad 8.1 \%$ AYVSTLMGVPGR

$98.4 \% \quad 19.3$

$99.7 \% \quad 38.9$

$99.7 \% \quad 35.8$

$\begin{array}{lll}99.6 \% & 26.3\end{array}$

$0.01 \% \quad 8.1 \%$ VIGLSSDLQQVGGASAR

$0.01 \% \quad 11.2 \%$ CPYKDTLGPMQK

$0.01 \% \quad 11.2 \%$ TGKYVPPSLR

$0.01 \% \quad 11.2 \%$ YVPPSLRDGASR

$0.01 \% \quad 11.2 \%$ GFAFISFHR

$\begin{array}{lllll}0.01 \% & 6.3 \% & \text { KEGTGSTATSSSSTAGAAGK } & 99.7 \% & 78.3\end{array}$

$0.01 \% \quad 6.3 \% \quad$ EGTGSTATSSSSTAGAAGK $\quad 99.7 \% \quad 66.4$

$0.01 \% \quad 6.3 \% \quad$ EGTGSTATSSSSTAGAAGKGK

$0.06 \% \quad 34.8 \%$ MKPILLQGHER

$0.06 \% \quad 34.8 \%$ SITQIKYNR

$0.06 \% \quad 34.8 \%$ LWDCETGKQLALLK

$0.06 \% 34.8 \%$ SGEVLVNVKEHSR

$0.06 \% 34.8 \%$ QINDIQLSR

$0.06 \% 34.8 \%$ DMTMFVTASK

$0.06 \% 34.8 \%$ DMTMFVTASKDNTAK

$0.06 \% 34.8 \%$ DNTAKLFDSTTLEHQK

$0.06 \% \quad 34.8 \%$ LFDSTTLEHQK

$0.06 \% \quad 34.8 \%$ LFDSTTLEHQKTFR

$0.06 \% \quad 34.8 \%$ GHFGPINSVAFHPDGK

$\begin{array}{lll}0.06 \% & 22.3 \% & \text { TVSDLIDQKVYELQASR }\end{array}$ $\begin{array}{ll}99.7 \% & 26.8 \\ 99.7 \% & 35.5\end{array}$

$99.7 \% \quad 47.1$

$99.7 \% \quad 29.3$

$99.7 \% \quad 60.6$

$99.7 \% \quad 50.9$

$99.7 \% \quad 40.2$

$99.7 \% \quad 50.8$

$98.9 \% \quad 18.4$

$99.7 \% \quad 44.2$

$99.7 \% \quad 29.5$

$99.7 \% 53$.

$99.7 \% \quad 45.1$
$99.7 \% \quad 27.8$

$\begin{array}{ll}0 & 19.7\end{array}$

0
57.6

$\begin{array}{ll}0 & 39.7\end{array}$

$.0 \quad 25.6$

25.0
27.0

0
53.0

\begin{tabular}{ll}
25.0 & 48.5 \\
\hline &
\end{tabular}

32.0

$\begin{array}{ll}0 & 42.2\end{array}$

$\begin{array}{ll}.0 & 44.7\end{array}$

$\begin{array}{ll}25.0 & 44.3\end{array}$

$25.0 \quad 17.8$

\begin{tabular}{ll}
56.6 \\
\hline
\end{tabular}

$25.0 \quad 34.6$

$25.0 \quad 26.4$

$\begin{array}{ll}.0 & 13.9\end{array}$

$\begin{array}{ll}0 & 24.2\end{array}$

$\begin{array}{ll}54.0 & 54.8\end{array}$

$25.0 \quad 60.3$

$25.0 \quad 47.9$

\begin{tabular}{ll}
25.5 \\
\hline
\end{tabular}

$25.0 \quad 19.3$

$25.0 \quad 33.6$

\begin{tabular}{ll}
35.8 \\
\hline
\end{tabular}

$\begin{array}{ll}25.0 & 18.7 \\ 25.0 & 67.1\end{array}$

$\begin{array}{ll}67.0 & 67 \\ 25.0 & 14.1\end{array}$

$\begin{array}{ll}5.0 & 24.2\end{array}$

$\begin{array}{ll}24.0 & 10.3\end{array}$

$\begin{array}{ll}.0 & 33.9\end{array}$

$\begin{array}{ll}25.0 & 78.1\end{array}$

$\begin{array}{ll}5.0 & 62.2\end{array}$

$25.0 \quad 26.8$

\begin{tabular}{ll}
31.3 \\
\hline
\end{tabular}

$25.0 \quad 38.2$

$25.0 \quad 26.5$

$25.0 \quad 53.2$

$25.0 \quad 16.3$

$25.0 \quad 39.4$

$25.0 \quad 45.2$

$25.0 \quad 18.4$

$25.0 \quad 34.7$

$25.0 \quad 27.5$

$25.0 \quad 27.8$

$\begin{array}{ll}.0 & 51.0\end{array}$

$\begin{array}{ll}17 & 41 \\ 15 & 39\end{array}$

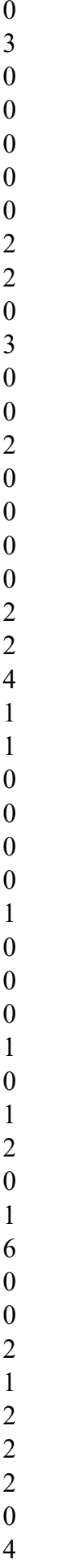

1584.89

1467.76

1096.59

1079.59

1057.48

1458.81

1614.85

1742.94

1351.70

2310.08

1128.63

1413.71

2096.20

1255.69

1125.49

1115.54

870.50

2257.18

1493.83

2199.12

2412.27

1754.89

1164.58

1572.66

1250.66

1657.89

1453.68

1117.64

1317.69

1081.56

1755.84

1627.74

1812.86

1321.74

1122.63

1674.89

1453.78

1086.59

1130.52

1659.77

1847.91

1318.66

1722.88

1679.83

1276.54 1965.03

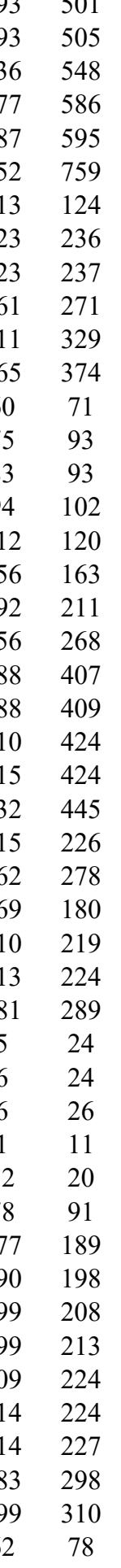



Eukaryotic translation initiation factor 3 subunit L GN=EIF3L EIF3L_HUMAN $66.73 \quad 100.0 \%$ Eukaryotic translation initiation factor 3 subunit L GN=EIF3L EIF3L_HUMAN $66.73 \quad 100.0 \%$ Eukaryotic translation initiation factor 3 subunit L GN=EIF3L EIF3L_HUMAN 66.73 Eukaryotic translation initiation factor 3 subunit L GN=EIF3L EIF3L_HUMAN $66.73 \quad 100.0 \%$ Eukaryotic translation initiation factor 3 subunit L GN=EIF3L EIF3L_HUMAN $66.73 \quad 100.0 \%$ Eukaryotic translation initiation factor 3 subunit L GN=EIF3L EIF3L_HUMAN $66.73 \quad 100.0 \%$ Eukaryotic translation initiation factor 3 subunit L GN=EIF3L EIF3L_HUMAN $66.73 \quad 100.0 \%$ Eukaryotic translation initiation factor 3 subunit $\mathrm{L}$ GN=EIF3L EIF3L HUMAN $66.73 \quad 100.0 \%$ Eukaryotic translation initiation factor 3 subunit L GN=EIF3L EIF3L_HUMAN $66.73 \quad 100.0 \%$ Eukaryotic translation initiation factor 4 gamma $1 \mathrm{GN}=\mathrm{EIF} 4 \mathrm{G} 1 \quad$ IF4G1_HUMAN $175.49 \quad 100.0 \%$ Eukaryotic translation initiation factor 4 gamma $1 \mathrm{GN}=\mathrm{EIF} 4 \mathrm{G} 1 \quad$ IF4G1 HUMAN $175.49 \quad 100.0 \%$ Eukaryotic translation initiation factor 4 gamma 1 GN=EIF4G1 IF4G1_HUMAN $175.49 \quad 100.0 \%$ Eukaryotic translation initiation factor 4 gamma $2 \mathrm{GN}=\mathrm{EIF} 4 \mathrm{G} 2$ IF4G2 HUMAN $102.37 \quad 100.0 \%$ Eukaryotic translation initiation factor 4 gamma 2 GN=EIF4G2 IF4G2_HUMAN $102.37 \quad 100.0 \%$ Eukaryotic translation initiation factor 4 gamma 2 GN=EIF4G2 IF4G2_HUMAN $102.37 \quad 100.0 \%$ Eukaryotic translation initiation factor 4 gamma $2 \mathrm{GN}=\mathrm{EIF} 4 \mathrm{G} 2$ IF4G2 HUMAN $102.37 \quad 100.0 \%$ Eukaryotic translation initiation factor 4B GN=EIF4B IF4B_HUMAN $69.15 \quad 100.0 \%$ Eukaryotic translation initiation factor 4B GN=EIF4B IF4B_HUMAN $69.15 \quad 100.0 \%$ Eukaryotic translation initiation factor $4 \mathrm{~B}$ GN=EIF4B IF4B HUMAN $69.15 \quad 100.0 \%$ Eukaryotic translation initiation factor 4B GN=EIF4B IF4B_HUMAN $69.15 \quad 100.0 \%$ Eukaryotic translation initiation factor 4B GN=EIF4B IF4B HUMAN $69.15 \quad 100.0 \%$ Eukaryotic translation initiation factor 4B GN=EIF4B IF4B_HUMAN $69.15 \quad 100.0 \%$ Eukaryotic translation initiation factor 4B GN=EIF4B IF4B_HUMAN $69.15 \quad 100.0 \%$ Eukaryotic translation initiation factor 4B GN=EIF4B IF4B HUMAN $69.15 \quad 100.0 \%$ Eukaryotic translation initiation factor 4B GN=EIF4B IF4B_HUMAN $69.15 \quad 100.0 \%$ Eukaryotic translation initiation factor 4B GN=EIF4B IF4B_HUMAN $69.15 \quad 100.0 \%$ Eukaryotic translation initiation factor 4B GN=EIF4B IF4B HUMAN $69.15 \quad 100.0 \%$ Eukaryotic translation initiation factor 4B GN=EIF4B IF4B_HUMAN $69.15 \quad 100.0 \%$ Eukaryotic translation initiation factor 4B GN=EIF4B IF4B HUMAN $69.15 \quad 100.0 \%$ Eukaryotic translation initiation factor 4B GN=EIF4B IF4B_HUMAN $69.15 \quad 100.0 \%$ Eukaryotic translation initiation factor 4B GN=EIF4B IF4B_HUMAN $69.15 \quad 100.0 \%$ Eukaryotic translation initiation factor 4B GN=EIF4B IF4B HUMAN $69.15 \quad 100.0 \%$ Eukaryotic translation initiation factor 4B GN=EIF4B IF4B_HUMAN $69.15 \quad 100.0 \%$ Eukaryotic translation initiation factor 4B GN=EIF4B IF4B_HUMAN $69.15 \quad 100.0 \%$ Eukaryotic translation initiation factor 4B GN=EIF4B IF4B HUMAN $69.15 \quad 100.0 \%$ Eukaryotic translation initiation factor 4B GN=EIF4B IF4B_HUMAN $69.15 \quad 100.0 \%$ Exocyst complex component $4 \mathrm{GN}=\mathrm{EXOC} 4$ EXOC4_HUMAN $110.50 \quad 100.0 \%$ Exocyst complex component 4 GN=EXOC4 EXOC4_HUMAN $110.50 \quad 100.0 \%$ Exocyst complex component $8 \mathrm{GN}=$ EXOC8 EXOC8_HUMAN $81.80 \quad 100.0 \%$ Exocyst complex component 8 GN=EXOC8 EXOC8_HUMAN $81.80 \quad 100.0 \%$ Exosome complex component MTR3 GN=EXOSC6 EXOS6_HUMAN $28.24 \quad 100.0 \%$ Exosome complex component MTR3 GN=EXOSC6 EXOS6 HUMAN $28.24 \quad 100.0 \%$ Exosome complex component MTR3 GN=EXOSC6 EXOs6_HUMAN $28.24 \quad 100.0 \%$ Exosome complex component MTR3 GN=EXOSC6 EXOS6_HUMAN $28.24 \quad 100.0 \%$ Exosome complex component MTR3 GN=EXOSC6 EXOS6_HUMAN $28.24 \quad 100.0 \%$ Exosome complex component MTR3 GN=EXOSC6 EXOS6_HUMAN $28.24 \quad 100.0 \%$

$\begin{array}{llll}15 & 39 & 0.06 \% & 22.3 \% \\ 15 & \text { VSSDVIDQK }\end{array}$

15

15

15

15

15

11

3

3

3
3
4

3

4
4
4

4

$\begin{array}{cc}4 & 4 \\ 20 & 25 \\ 20 & 25\end{array}$

20
20
20

0

0

20
20

20

20

20

20
20

0

20

7
7
7

$0.06 \% \quad 22.3 \%$ KSEEEIDFLR

$0.06 \% 22.3 \%$ SEEEIDFLR

$0.06 \% 22.3 \%$ QLEVYTSGGDPESVAGEYGR

$0.06 \% 22.3 \%$ VLENIELNKK

$0.06 \% 22.3 \%$ VFANILLYIQR

$0.06 \% \quad 22.3 \%$ IDESIHLQLR

$0.06 \% \quad 22.3 \%$ VFSDEVQQQAQLSTIR

$0.06 \% \quad 22.3 \%$ SFLKLYTTMPVAK

$\begin{array}{lll}0.01 \% & 2.8 \% & \text { ITKPGSIDSNNQLFAPGGR } \\ 0.01 \% & 2.8 \% & \text { FSALQQAVPTESTDNRR }\end{array}$

$\begin{array}{lll}0.01 \% & 2.8 \% & \text { HGVESTLER }\end{array}$

$0.01 \% \quad 4.7 \%$ TAGNSEFLGK

$0.01 \% \quad 4.7 \% \quad$ KAFLDNGPK

$0.01 \% \quad 4.7 \%$ TQTPPLGQTPQLGLK

$0.01 \% \quad 4.7 \% \quad$ SYLAQFAAR

$186 \quad 0.27 \% \quad 31.9 \%$ APPIDRSILPTAPR

$186 \quad 0.27 \% \quad 31.9 \%$ SILPTAPR

$186 \quad 0.27 \% \quad 31.9 \%$ AAREPNIDR

$186 \quad 0.27 \% \quad 31.9 \%$ GLNISAVR

$186 \quad 0.27 \% \quad 31.9 \%$ GLNISAVRLPR

$186 \quad 0.27 \% \quad 31.9 \%$ LPREPSNPER

$186 \quad 0.27 \% \quad 31.9 \%$ ARPATDSFDDYPPR

$186 \quad 0.27 \% \quad 31.9 \%$ DYDRGYDSR

$186 \quad 0.27 \% \quad 31.9 \%$ AFGSGYRR

$186 \quad 0.27 \% \quad 31.9 \%$ STPKEDDSSASTSQSTR

$186 \quad 0.27 \% \quad 31.9 \%$ AASIFGGAKPVDTAAR

$186 \quad 0.27 \% \quad 31.9 \%$ AASIFGGAKPVDTAARER

$186 \quad 0.27 \% \quad 31.9 \%$ QLDEPKLER

$186 \quad 0.27 \% \quad 31.9 \%$ SRTGSESSQTGTSTTSSR

$186 \quad 0.27 \% \quad 31.9 \%$ TGSESSQTGTSTTSSRNAR

$186 \quad 0.27 \% \quad 31.9 \%$ SSNPPARSQSSDTEQQSPTSGGGK $\quad 99.7 \% \quad 54.8$

$186 \quad 0.27 \% \quad 31.9 \%$ SQSSDTEQQSPTSGGGK

$186 \quad 0.27 \% \quad 31.9 \%$ VAPAQPSEEGPGR

$186 \quad 0.27 \% \quad 31.9 \%$ SAPEPKKPEENPASK

$186 \quad 0.27 \% \quad 31.9 \%$ KPEENPASKFSSASK

$0.00 \% \quad 2.9 \%$ DASVPLIDVTNLPTPR

$0.00 \% \quad 2.9 \%$ STTQVADSGYQR

$0.00 \% \quad 3.3 \%$ RFEEGVGKPAK

$0.00 \% \quad 3.3 \%$ LIRVNPESTTSVV

$0.02 \% \quad 20.6 \%$ GSAYLEAGGTK

$0.02 \% \quad 20.6 \%$ VLCAVSGPR

$\begin{array}{lll}46.2 & 25.0 & 39.3\end{array}$

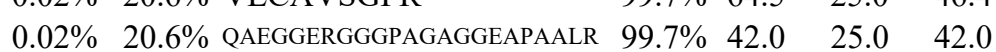

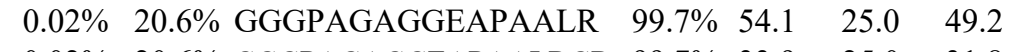

$\begin{array}{lllllll}0.02 \% & 20.6 \% & \text { GGGPAGAGGEAPAALRGR } & 99.7 \% & 33.9 & 25.0 & 31.8\end{array}$

990.51

1029.53

1265.64

1137.54

2113.97

1199.70

1349.79

1223.67

1848.95

1498.83

1972.02

1919.96

1027.52

1023.51

989.54

1578.89

1026.54

1503.86

854.51

1041.54

829.49

1195.73

1194.62

1607.75

1146.48

913.46

1783.79

1531.82

1816.97

1127.61

1816.83

1914.87

2390.08

1680.73

1294.64

1608.82

1606.81

1707.93

1312.61

1217.66

1414.79

1053.52

1993.02

958.51

2035.99

1308.67

1521.79

Page 50 of Table S-1-2 
Exosome complex component MTR3 GN=EXOSC6 EXOS6_HUMAN $28.24 \quad 100.0 \%$ Exosome complex component RRP4 GN=EXOSC2 EXOS2_HUMAN $32.79 \quad 100.0 \%$ Exosome complex component RRP4 GN=EXOSC2 EXOS2_HUMAN $32.79 \quad 100.0 \%$ Exosome complex component RRP4 GN=EXOSC2 EXOS2 HUMAN 32.79 Exosome complex component RRP41 GN=EXOSC4 EXOS4_HUMAN $26.38 \quad 100.0 \%$ Exosome complex component RRP41 GN=EXOSC4 EXOS4_HUMAN $26.38 \quad 100.0 \%$ Exosome complex component RRP43 GN=EXOSC8 EXOS8 HUMAN $30.04 \quad 100.0 \%$ Exosome complex component RRP43 GN=EXOSC8 EXOS8_HUMAN $30.04 \quad 100.0 \%$ Exosome complex component RRP43 GN=EXOSC8 EXOS8_HUMAN $30.04 \quad 100.0 \%$ Exosome complex exonuclease RRP44 GN=DIS3 RRP44_HUMAN $109.01 \quad 100.0 \%$ Exosome complex exonuclease RRP44 GN=DIS3 RRP44_HUMAN $109.01 \quad 100.0 \%$ Exportin-1 GN=XPO1 Exportin-1 GN=XPO1 Exportin-1 GN=XPO1 Exportin-1 GN=XPO1 Exportin-1 GN=XPO1 Exportin-1 GN=XPO1 Exportin-1 GN=XPO1 Exportin-1 GN=XPO1 Exportin-1 GN=XPO1 Exportin-1 GN=XPO1 Exportin-1 GN=XPO1 Exportin-2 GN=CSE1L Exportin-2 GN=CSE1L Exportin-2 GN $=\mathrm{CSE} 1 \mathrm{~L}$ Exportin $-2 \mathrm{GN}=\mathrm{CSE} 1 \mathrm{~L}$ Exportin-2 GN=CSE1L Exportin-2 GN=CSE1L Exportin-2 GN=CSE1L Exportin-2 GN=CSE1L Exportin-2 GN=CSE1L Exportin-2 GN=CSE1L Exportin-2 GN $=$ CSE1L Exportin-2 GN=CSE1I Exportin-2 GN=CSE1L Exportin-2 GN=CSE1L Exportin-2 GN=CSE1L Exportin-2 GN=CSE1I Exportin-7 GN=XPO7 Exportin-7 GN=XPO7

Exportin-7 GN=XPO7 Exportin- $\mathrm{T}$ GN=XPOT Exportin- $\mathrm{T}$ GN=XPOT Exportin- $\mathrm{T}$ GN=XPOT Exportin- $\mathrm{T}$ GN $=\mathrm{XPOT}$ XPO1_HUMAN $123.39 \quad 100.0 \%$ XPO1_HUMAN $123.39 \quad 100.0 \%$ XPO1_HUMAN $123.39 \quad 100.0 \%$ XPO1_HUMAN $123.39 \quad 100.0 \%$ XPO1_HUMAN $123.39 \quad 100.0 \%$ XPO1_HUMAN $123.39 \quad 100.0 \%$ XPO1_HUMAN $123.39 \quad 100.0 \%$ XPO1_HUMAN $123.39 \quad 100.0 \%$ XPO1_HUMAN $123.39 \quad 100.0 \%$ XPO1_HUMAN $123.39 \quad 100.0 \%$ XPO1_HUMAN $123.39 \quad 100.0 \%$ XPO2 HUMAN $110.42 \quad 100.0 \%$ XPO2_HUMAN $110.42 \quad 100.0 \%$ XPO2 HUMAN $110.42 \quad 100.0 \%$ XPO2_HUMAN $110.42 \quad 100.0 \%$ XPO2 HUMAN $110.42 \quad 100.0 \%$ XPO2 HUMAN $110.42 \quad 100.0 \%$ XPO2_HUMAN $110.42 \quad 100.0 \%$ XPO2 HUMAN $110.42 \quad 100.0 \%$ XPO2_HUMAN $110.42 \quad 100.0 \%$ XPO2_HUMAN $110.42 \quad 100.0 \%$ XPO2 HUMAN $110.42 \quad 100.0 \%$ XPO2_HUMAN $110.42 \quad 100.0 \%$ XPO2_HUMAN $110.42 \quad 100.0 \%$ XPO2_HUMAN $110.42 \quad 100.0 \%$ XPO2_HUMAN $110.42 \quad 100.0 \%$ XPO2 HUMAN $110.42 \quad 100.0 \%$ XPO7_HUMAN $123.91 \quad 100.0 \%$ XPO7_HUMAN $123.91 \quad 100.0 \%$ XPO7_HUMAN $123.91 \quad 100.0 \%$ XPOT_HUMAN $109.97 \quad 100.0 \%$ XPOT_HUMAN $109.97 \quad 100.0 \%$ XPOT_HUMAN $109.97 \quad 100.0 \%$ XPOT HUMAN $109.97 \quad 100.0 \%$ $100.0 \%$ F-actin-capping protein subunit alpha-1 GN=CAPZA1 CAZA1_HUMAN $32.92 \quad 100.0 \%$

3

$0.02 \% \quad 20.6 \%$ LYPVLQQSLVR $0.01 \% \quad 13.0 \%$ YIGEVGDIVVGR $0.01 \% \quad 13.0 \%$ LGQGVLVQVSPSLVKR $0.01 \% \quad 13.0 \%$ NCIISLVTQR

$0.00 \% \quad 13.1 \%$ ALAVVYGPHEIRGSR

$0.00 \% \quad 13.1 \%$ ALVNCQYSSATFSTGER

$0.01 \% \quad 13.8 \%$ TTTVNIGSISTADGSALVK

$0.01 \% \quad 13.8 \%$ LGNTTVICGVK

$0.01 \% \quad 13.8 \%$ KLMDEVIK

$0.01 \% \quad 2.5 \%$ AVHEDIVAVELLPK

$0.01 \% \quad 2.5 \%$ NLEIKTDTAK

$0.04 \% \quad 12.0 \%$ TSSDPTCVEKEK

$0.04 \% \quad 12.0 \%$ TSESLCQNNMVILK

$0.04 \% \quad 12.0 \%$ LLSEEVFDFSSGQITQVK

$0.04 \% \quad 12.0 \%$ QLYLPMLFK

$0.04 \% \quad 12.0 \%$ QLYLPMLFKVR

$0.04 \% \quad 12.0 \%$ MAKPEEVLVVENDQGEVVR $99.4 \% 27.2$

$0.04 \% \quad 12.0 \%$ NVDILKDPETVK

$0.04 \% \quad 12.0 \%$ AVGHPFVIQLGR

$0.04 \% \quad 12.0 \%$ IYLDMLNVYK

$0.04 \% \quad 12.0 \%$ NVPAAREPEVLSTMAIIVNK

$0.04 \% \quad 12.0 \%$ EPEVLSTMAIIVNK

$0.06 \% \quad 16.2 \%$ TLDPDPAIR

$0.06 \% \quad 16.2 \%$ TLDPDPAIRRPAEK

$0.06 \% \quad 16.2 \%$ ANIVHLMLSSPEQIQK

$0.06 \% \quad 16.2 \%$ TAHSLFKR

$0.06 \% \quad 16.2 \%$ NLFEDQNTLTSICEK

$0.06 \% \quad 16.2 \%$ VIVPNMEFR

$0.06 \% \quad 16.2 \%$ AADEEAFEDNSEEYIRR

$0.06 \% \quad 16.2 \%$ DLEGSDIDTRR

$0.06 \% \quad 16.2 \%$ RAACDLVR

$0.06 \% \quad 16.2 \%$ ADGIKYIMIFR

$0.06 \% \quad 16.2 \%$ TGNIPALVR

$0.06 \% \quad 16.2 \%$ LLQAFLER

$0.06 \% \quad 16.2 \%$ KICAVGITK

$0.06 \% \quad 16.2 \%$ ICAVGITK

$0.06 \% \quad 16.2 \%$ EHDPVGQMVNNPK

$0.06 \% \quad 16.2 \%$ IHLAQSLHK

$0.01 \% \quad 3.1 \%$ ALVEFTNSPDCLSK

$0.01 \% \quad 3.1 \%$ VLQLMNLTDSR

$0.01 \% \quad 3.1 \%$ TTFYTALGR

$0.01 \% \quad 3.7 \%$ ALAYFEQLK

$0.01 \% \quad 3.7 \% \quad$ NTLIKDTMR

$0.01 \% \quad 3.7 \%$ ASALQDMMR

$0.01 \% \quad 3.7 \%$ SRTAYLFSR

$0.00 \% \quad 9.4 \%$ LLLNNDNLLR

$0.00 \% \quad 9.4 \%$ AYVKDHYSNGFCTVYAK $94.8 \% \quad 13.5$
$99.7 \%$ 49.9

$99.7 \% \quad 27.8$

$99.7 \% 32$.

$95.5 \% \quad 17.6$

$99.7 \% 51.1$

$99.7 \% \quad 47.3$

$98.2 \% \quad 28.8$

$99.7 \% \quad 59.0$

$99.7 \% \quad 27.3$

$97.7 \% \quad 23.4$

$99.7 \% \quad 39.1$

$9.7 \% \quad 60.5$

$95.9 \% \quad 14.3$

$99.7 \% \quad 35.2$

$99.7 \% \quad 48.8$

$99.7 \% \quad 32.0$

$99.6 \% 23.7$

$99.5 \% \quad 21.4$

$96.9 \% \quad 15.0$

$99.5 \% \quad 22.0$

$97.2 \% \quad 19.2$

$99.7 \% \quad 56.9$

$99.7 \% \quad 28.0$

$99.7 \% \quad 44.0$

$96.8 \% \quad 26.3$

$98.2 \% \quad 22.1$

$99.7 \% \quad 40.3$

$99.0 \% \quad 57.2$

$99.7 \% \quad 42.8$

$99.0 \% \quad 24.5$

$99.7 \% \quad 58.2$

$99.7 \% \quad 33.8$

$98.1 \% \quad 16.6$

$99.7 \% \quad 42.7$

$99.7 \% \quad 49$.

$99.7 \% \quad 42.8$

$97.1 \% \quad 23.5$

$99.7 \% \quad 48.0$

$99.7 \% \quad 29.3$

$98.0 \% \quad 20.1$
1276.69

1680.02

1203.65

1624.89

1890.87

1834.98

1161.63

975.55

1532.87

1132.62

1380.63

1636.80

2027.03

1152.65

1423.81

2157.09

1370.75

1293.74

1271.67

2168.17

1543.84

997.53

1578.86

807.97

959.54

1811.85

1104.59

2043.89

276.6

960.50

1326.72

940.56

989.58

989.58

861.49

1480.69

1046.61

1580.76

1289.69

1029.54

1082.59

1091.59

1022.48

1100.58

1197.70

2022.94 
F-actin-capping protein subunit beta GN=CAPZB CAPZB_HUMAN $31.35 \quad 100.0 \%$ F-actin-capping protein subunit beta GN=CAPZB CAPZB_HUMAN $31.35 \quad 100.0 \%$ F-actin-capping protein subunit beta GN=CAPZB CAPZB_HUMAN $31.35 \quad 100.0 \%$ Far upstream element-binding protein 2 GN=KHSRP FUBP2_HUMAN $73.12 \quad 100.0 \%$ Far upstream element-binding protein 2 GN=KHSRP FUBP2_HUMAN $73.12 \quad 100.0 \%$ Far upstream element-binding protein 2 GN=KHSRP FUBP2_HUMAN $73.12 \quad 100.0 \%$ Far upstream element-binding protein 2 GN=KHSRP FUBP2_HUMAN $73.12 \quad 100.0 \%$ Far upstream element-binding protein 2 GN=KHSRP FUBP2_HUMAN $73.12 \quad 100.0 \%$ Far upstream element-binding protein $3 \mathrm{GN}=\mathrm{FUBP} 3$ FUBP3 HUMAN $61.64100 .0 \%$ Far upstream element-binding protein $3 \mathrm{GN}=\mathrm{FUBP} 3$ FUBP3_HUMAN $61.64 \quad 100.0 \%$ Far upstream element-binding protein 3 GN=FUBP3 FUBP3_HUMAN $61.64 \quad 100.0 \%$ FAST kinase domain-containing protein 2 GN=FASTKD2 FAKD2 HUMAN $81.47 \quad 100.0 \%$ FAST kinase domain-containing protein 2 GN=FASTKD2 FAKD2_HUMAN $81.47 \quad 100.0 \%$ FAST kinase domain-containing protein $2 \mathrm{GN}=$ FASTKD2 FAKD2_HUMAN $81.47 \quad 100.0 \%$ FAST kinase domain-containing protein 3 GN=FASTKD3 FAKD3_HUMAN $75.69 \quad 100.0 \%$ FAST kinase domain-containing protein 3 GN=FASTKD3 FAKD3_HUMAN $75.69 \quad 100.0 \%$ FAST kinase domain-containing protein 5 GN=FASTKD5 FAKD5 HUMAN $86.58 \quad 100.0 \%$ FAST kinase domain-containing protein 5 GN=FASTKD5 FAKD5_HUMAN $86.58 \quad 100.0 \%$ Fatty acid synthase GN=FASN Fatty acid synthase GN=FASN Fatty acid synthase GN=FASI Fatty acid synthase GN=FASN Fatty acid synthase GN=FASN Fatty acid synthase GN=FASN Fatty acid synthase GN=FASN Fatty acid synthase GN=FASN Fatty acid synthase GN=FASN Fatty acid synthase GN=FASN Fatty acid synthase GN=FASN Fatty acid synthase GN=FASN Fatty acid synthase GN=FASN Fatty acid synthase GN=FASN Fatty acid synthase GN=FASN Fatty acid synthase GN=FASN Fatty acid synthase GN=FASN Fatty acid synthase GN=FASN Fibronectin $\mathrm{GN}=\mathrm{FN}$ Fibronectin $\mathrm{GN}=\mathrm{FN} 1$ Fibronectin $\mathrm{GN}=\mathrm{FN} 1$ Filamin-A GN=FLNA Filamin-A GN=FLNA Filamin-A GN=FLNA Filamin-A GN=FLNA Filamin-A GN=FLNA Filamin-A GN=FLNA Filamin-A GN=FLNA Filamin-A GN=FLNA
FAS_HUMAN $273.43 \quad 100.0 \%$ FAS HUMAN $273.43 \quad 100.0 \%$ FAS_HUMAN $273.43 \quad 100.0 \%$ FAS HUMAN $273.43 \quad 100.0 \%$ FAS HUMAN $273.43 \quad 100.0 \%$ FAS HUMAN $273.43 \quad 100.0 \%$ FAS HUMAN $273.43 \quad 100.0 \%$ FAS_HUMAN $273.43 \quad 100.0 \%$ FAS HUMAN $273.43 \quad 100.0 \%$ FAS HUMAN $273.43 \quad 100.0 \%$ FAS_HUMAN $273.43 \quad 100.0 \%$ FAS HUMAN $273.43 \quad 100.0 \%$ FAS_HUMAN $273.43 \quad 100.0 \%$ FAS_HUMAN $273.43 \quad 100.0 \%$ FAS HUMAN $273.43 \quad 100.0 \%$ FAS_HUMAN $273.43 \quad 100.0 \%$ FAS HUMAN $273.43 \quad 100.0 \%$ FAS HUMAN $273.43 \quad 100.0 \%$ FINC_HUMAN $262.62 \quad 100.0 \%$ FINC HUMAN $262.62 \quad 100.0 \%$ FINC_HUMAN $262.62 \quad 100.0 \%$ FLNA_HUMAN $280.73 \quad 100.0 \%$ FLNA_HUMAN $280.73 \quad 100.0 \%$ FLNA_HUMAN $280.73 \quad 100.0 \% \quad 25$ FLNA HUMAN $280.73 \quad 100.0 \% \quad 25$ FLNA_HUMAN $280.73 \quad 100.0 \% \quad 25$ FLNA_HUMAN $280.73 \quad 100.0 \% \quad 25$ FLNA HUMAN $280.73 \quad 100.0 \% \quad 25$ FLNA_HUMAN $280.73 \quad 100.0 \% \quad 25$
$0.01 \% \quad 12.3 \%$ SGSGTMNLGGSLTR $0.01 \% \quad 12.3 \%$ $0.01 \% \quad 12.3 \%$ STLNEIYFGK $\begin{array}{lllll}99.7 \% & 57.6 & 25.0 & 48.0 & 3\end{array}$ $\begin{array}{lllll}98.8 \% & 21.8 & 25.0 & 18.5\end{array}$ $0.01 \% \quad 10.1 \%$ IGGDAATTVNNSTPDFGFGGQKR $0.01 \% \quad 10.1 \%$ SVSLTGAPESVQK $0.01 \% \quad 10.1 \%$ GGETIKQLQER $0.01 \% \quad 10.1 \%$ IGGGIDVPVPR $0.01 \% \quad 10.1 \%$ AINQQTGAFVEISR $0.01 \% \quad 6.8 \%$ RPLDDGVGNQLGALVHQR $0.01 \% \quad 6.8 \%$ GGETIKQLQER $0.01 \% \quad 6.8 \%$ GVPQQIEVAR $0.01 \% \quad 5.5 \%$ VAVLCVSR $0.01 \% \quad 5.5 \%$ SAYCLGSSHPR $0.01 \% \quad 5.5 \%$ TKIYSVEALPVAAVNVQSTQ $0.01 \% \quad 2.7 \%$ IGLTNLLGAR $0.01 \% \quad 2.7 \%$ ELVEYLQR $0.01 \% \quad 2.6 \%$ ASTLQLGSPR $0.01 \% \quad 2.6 \%$ EATPAENVAK $0.05 \% \quad 8.4 \%$ AGLYGLPR $0.05 \% \quad 8.4 \%$ FDASFFGVHPK $0.05 \% \quad 8.4 \%$ LGMLSPEGTCK $0.05 \% \quad 8.4 \%$ SEGVVAVLLTK $0.05 \% \quad 8.4 \%$ VGDPQELNGITR $0.05 \% \quad 8.4 \%$ ALCATRQEPLLIGSTK $0.05 \% \quad 8.4 \%$ LQVVDQPLPVR $0.05 \% \quad 8.4 \%$ TGTVSLEVR $0.05 \% \quad 8.4 \%$ VYQWDDPDPR $0.05 \% \quad 8.4 \%$ HGLYLPTR $0.05 \% \quad 8.4 \%$ RQQEQQVPILEK $0.05 \% \quad 8.4 \%$ AALQEELQLCK $0.05 \% \quad 8.4 \%$ GLVQALQTK $0.05 \% \quad 8.4 \%$ VVVQVLAEEPEAVLK $0.05 \% \quad 8.4 \%$ QGVQVQVSTSNISSLEGAR $0.05 \% \quad 8.4 \%$ EDGLAQQQTQLNLR $0.05 \% \quad 8.4 \%$ SLLVNPEGPTLMR $0.05 \% \quad 8.4 \%$ LSIPTYGLQCTR $0.01 \% \quad 1.7 \%$ ISCTIANR

$0.01 \% \quad 1.7 \%$ LGVRPSQGGEAPR

$0.01 \% \quad 1.7 \% \quad$ SSPVVIDASTAIDAPSNLR $0.10 \% \quad 12.6 \%$ IQQNTFTR

$0.10 \% \quad 12.6 \%$ AYGPGIEPTGNMVK $0.10 \% \quad 12.6 \%$ VTVLFAGQHIAK

$0.10 \% \quad 12.6 \%$ SPFEVYVDKSQGDASK $0.10 \% \quad 12.6 \%$ VTAQGPGLEPSGNIANK $0.10 \% \quad 12.6 \%$ SPYTVTVGQACNPSACR $0.10 \% \quad 12.6 \%$ GAGSGELKVTVK $0.10 \% \quad 12.6 \%$ AWGPGLEGGVVGK
$99.5 \% \quad 22.1$

$99.7 \% \quad 55.7$

$99.7 \% \quad 48.0$

$97.2 \% 15$.

$99.7 \% \quad 60.2$

$99.7 \% \quad 74.5$

$96.0 \% \quad 14.7$

$97.2 \% \quad 15.1$

$99.7 \% \quad 35.5$

$99.0 \% \quad 48.3$

$99.7 \% \quad 25.5$

$99.7 \% \quad 59.7$

$99.7 \% \quad 61.2$

$99.0 \% \quad 36.7$

$99.7 \% \quad 55.5$

$99.7 \% \quad 28.3$

$99.0 \% \quad 34.8$

$\begin{array}{lll}99.7 \% & 36.7\end{array}$

$99.7 \% \quad 29.5$

$99.7 \% \quad 52.4$

$99.7 \% \quad 59.2$

$99.7 \% \quad 35.1$

$99.7 \% \quad 48.3$

$99.7 \% \quad 46.9$

$\begin{array}{lll}98.7 \% & 17.3\end{array}$

$99.0 \% \quad 22.3$

$99.3 \% \quad 19.0$

$99.7 \% \quad 48$.

$\begin{array}{lll}99.7 \% & 42.0\end{array}$

$99.7 \% \quad 63.4$

$99.7 \% \quad 60.6$

$99.7 \% \quad 57.2$

$99.7 \% \quad 37.1$

$99.7 \% \quad 35.5$

$\begin{array}{lll}96.7 \% & 25.7\end{array}$

$99.7 \% \quad 34.0$

$99.7 \% \quad 49.5$

$99.0 \% \quad 22.8$

$99.1 \% \quad 20.4$

$97.9 \% \quad 15.9$

$98.0 \% \quad 16.1$

$99.7 \% \quad 41.5$

$99.7 \% \quad 32.5$

0
0
0
2
0
0
0
0
0
1
0
0
0
0
0
0
0
0
0
0
0
0
0
0
0
0
0
0
0
2
0
0
0
0
0
0
0
0
1
0
0
0
0
0
0
0
0
0
0
0
0
0
0
0
0
0
0
0
0
0
0
0
0
0

1246.65

1171.60

2310.11

1302.69

1258.68

1079.62

1533.80

1945.04

1258.68

1096.61

903.51

1234.56

2118.14

1027.63

1049.56

1029.57

1029.52

846.48

1251.62

1208.57

1115.67

1298.67

1757.96

1263.74

961.53

1290.58

956.53

1495.82

1302.67

957.57

1622.94

1960.01

1613.82

1426.77

1408.73

934.48

1323.71

1913.00

1007.53

1449.70

1283.75

1756.84

1652.86

1867.84

1145.65 1226.65

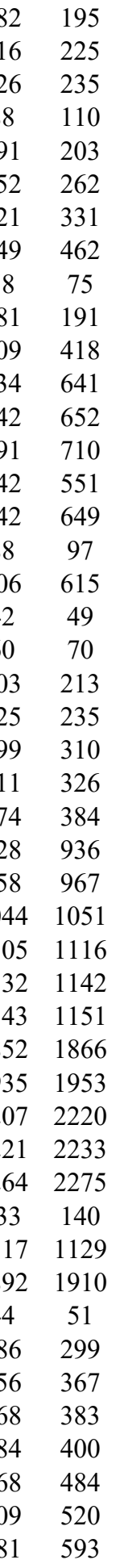

Page 52 of Table S-1-2 
Filamin-A GN=FLNA

Filamin-A GN=FLNA

Filamin-A GN=FLNA

Filamin-A GN=FLNA

Filamin-A GN=FLNA

Filamin-A GN=FLNA

Filamin-A GN=FLNA

Filamin-A GN=FLNA

Filamin-A GN=FLNA

Filamin-A GN=FLNA

Filamin-A GN=FLNA

Filamin-A GN=FLNA

Filamin-A GN=FLNA

Filamin-A GN=FLNA

Filamin-A GN=FLNA

Filamin-A GN=FLNA

Filamin-A GN=FLNA

Flap endonuclease $1 \mathrm{GN}=\mathrm{FEN} 1$

Flap endonuclease $1 \mathrm{GN}=\mathrm{FEN} 1$

Fragile X mental retardation protein 1 GN=FMR1 FMR1_HUMAN Fragile X mental retardation protein 1 GN=FMR1 FMR1_HUMAN $71.17 \quad 100.0 \%$ Fragile X mental retardation protein $1 \mathrm{GN}=\mathrm{FMR} 1$ FMR1 HUMAN $71.17 \quad 100.0 \%$ Fragile X mental retardation protein $1 \mathrm{GN}=$ FMR1 FMR1_HUMAN $71.17 \quad 100.0 \%$ Fragile X mental retardation protein 1 GN=FMR1 FMR1_HUMAN $71.17 \quad 100.0 \%$ Fragile X mental retardation protein $1 \mathrm{GN}=\mathrm{FMR} 1$ FMR1_HUMAN $71.17 \quad 100.0 \%$ Fragile X mental retardation protein 1 GN=FMR1 FMR1_HUMAN $71.17 \quad 100.0 \%$ Fragile X mental retardation syndrome-related protein 2 GN=FXR2 FXR2_HUMAN $74.22 \quad 100.0 \%$ Fragile X mental retardation syndrome-related protein 2 GN=FXR2 FXR2 HUMAN $74.22 \quad 100.0 \%$ Fragile X mental retardation syndrome-related protein 2 GN=FXR2 FXR2_HUMAN $74.22 \quad 100.0 \%$ Fragile X mental retardation syndrome-related protein $2 \mathrm{GN}=\mathrm{FXR} 2 \mathrm{FXR} 2 \mathrm{HUMAN} 74.22 \quad 100.0 \%$ Fragile X mental retardation syndrome-related protein 2 GN=FXR2 $\quad$ FXR2_HUMAN 74.22 $100.0 \%$ Fragile X mental retardation syndrome-related protein 2 GN=FXR2 FXR2_HUMAN $74.22 \quad 100.0 \%$ Fragile X mental retardation syndrome-related protein 2 GN=FXR2 FXR2 HUMAN $74.22 \quad 100.0 \%$ Fructose-bisphosphate aldolase A GN=ALDOA ALDOA_HUMAN $39.42 \quad 100.0 \%$ Fructose-bisphosphate aldolase A GN=ALDOA ALDOA_HUMAN $39.42 \quad 100.0 \%$ Fructose-bisphosphate aldolase A GN=ALDOA ALDOA_HUMAN $39.42 \quad 100.0 \%$ Fructose-bisphosphate aldolase A GN=ALDOA ALDOA_HUMAN $39.42 \quad 100.0 \%$ Galactokinase $\mathrm{GN}=\mathrm{GALK} 1$

Galactokinase $\mathrm{GN}=\mathrm{GALK} 1$

Galactokinase $\mathrm{GN}=\mathrm{GALK} 1$

Galactokinase $\mathrm{GN}=\mathrm{GALK} 1$

Galactokinase $\mathrm{GN}=\mathrm{GALK} 1$

Galactokinase $\mathrm{GN}=\mathrm{GALK} 1$

GALK1 HUMAN $42.27 \quad 100.0 \%$

GALK1_HUMAN $42.27 \quad 100.0 \%$

GALK1_HUMAN $42.27 \quad 100.0 \%$

GALK1_HUMAN $42.27 \quad 100.0 \%$

GALK1_HUMAN $42.27 \quad 100.0 \%$

GALK1_HUMAN $42.27 \quad 100.0 \%$

Gamma-tubulin complex component 3 GN=TUBGCP3 GCP3_HUMAN $103.57 \quad 100.0 \%$ Gamma-tubulin complex component 3 GN=TUBGCP3 GCP3_HUMAN $103.57 \quad 100.0 \%$ Gem-associated protein $2 \mathrm{GN}=$ GEMIN2 GEMI2_HUMAN $31.59 \quad 100.0 \%$ Gem-associated protein 2 GN=GEMIN2 GEMI2_HUMAN $31.59 \quad 100.0 \%$
$0.10 \% \quad 12.6 \%$ VKAEGPGLSR

$99.5 \% \quad 24.8$

25.0

$0.10 \% \quad 12.6 \%$ TGVELGKPTHFTVNAK

$99.7 \% \quad 30.4$

$99.7 \% \quad 61.2$

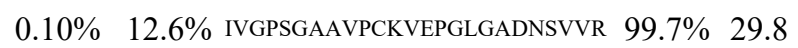

$0.10 \% \quad 12.6 \%$ AFGPGLQGGSAGSPAR

$99.7 \% \quad 55.3$

$97.1 \% \quad 16.0$

$0.10 \% \quad 12.6 \%$ AHVVPCFDASK

$0.10 \% \quad 12.6 \%$ EATTEFSVDAR

$99.7 \% \quad 36.3$

$99.7 \% \quad 40.2$

$0.10 \% \quad 12.6 \%$ GAGTGGLGLAVEGPSEAK $\quad 99.7 \% \quad 52.5$

$0.10 \% \quad 12.6 \%$ ANLPQSFQVDTSK

$99.7 \% \quad 45.2$

$0.10 \% \quad 12.6 \%$ AGVAPLQVK

$0.10 \% \quad 12.6 \%$ YGGDEIPFSPYR

$0.10 \% \quad 12.6 \%$ KGEITGEVR

$0.10 \% \quad 12.6 \%$ SSFTVDCSK

$0.10 \% \quad 12.6 \%$ AGNNMLLVGVHGPR

$99.7 \% \quad 33.2$

$95.2 \% \quad 21.3$

$\begin{array}{lll}98.5 \% & 18.0\end{array}$

$99.7 \% \quad 32.0$

$99.7 \% \quad 32.6$

$99.7 \% \quad 38.7$

$98.3 \% \quad 18.4$

$\begin{array}{lll}99.0 \% & 24.0\end{array}$

$98.0 \% \quad 17.8$

$97.7 \% \quad 20.4$

$99.7 \% \quad 45.6$

$99.7 \% \quad 56.4$

$0.02 \% \quad 15.3 \%$ SVNPNKPATKDTFHK

$0.02 \% \quad 15.3 \%$ NEEASKQLESSR

$0.02 \% \quad 15.3 \%$ SFLEFAEDVIQVPR

$0.02 \% \quad 15.3 \%$ LIQEIVDKSGVVR

$98.1 \% \quad 27.2$

$\begin{array}{lll}99.0 \% & 34.8\end{array}$

$0.02 \% \quad 15.3 \%$ LQIDEQLR

$0.02 \% \quad 15.3 \%$ EKPDSVDGQQPLVNGVP

$0.02 \% \quad 12.6 \%$ LRPVNPNPLATK

$0.02 \% \quad 12.6 \%$ ASLLGDMHFR

$0.02 \% \quad 12.6 \%$ SYLEFSEDSVQVPR

$0.02 \% \quad 12.6 \%$ VIQEIVDKSGVVR

$0.02 \% \quad 12.6 \%$ LQIDEQLR

$0.02 \% \quad 12.6 \%$ AGYSTDESSSSSLHATR

$0.02 \% \quad 12.6 \%$ GPPPAPRPTSR

$0.01 \% \quad 13.2 \%$ IVAPGKGILAADESTGSIAK

$0.01 \% \quad 13.2 \%$ ALQASALK

$0.01 \% \quad 13.2 \%$ AAQEEYVKR

$0.01 \% \quad 13.2 \%$ ALANSLACQGK

$0.01 \% \quad 16.1 \%$ SLETSLVPLSDPK

$0.01 \% \quad 16.1 \%$ LAVLITNSNVR

$0.01 \% \quad 16.1 \%$ HSLASSEYPVR

$0.01 \% \quad 16.1 \%$ ALGKESLR

$0.01 \% \quad 16.1 \%$ EVQLEELEAAR

$0.01 \% \quad 16.1 \%$ TAQAAAALR

$0.00 \% \quad 3.0 \%$ VSSYATLFAQALPR

$0.00 \% \quad 3.0 \%$ ATNAQFDSPEILR

$0.00 \% \quad 8.6 \%$ SQQLDSNVTMPK

$0.00 \% \quad 8.6 \% \quad$ YFDQRDLADEPS
$99.7 \% \quad 55.4$

$99.7 \% \quad 35.3$

$95.1 \% \quad 19.3$

$99.7 \% \quad 46.5$

$99.0 \% \quad 34.8$

$99.7 \% \quad 33.7$

$99.7 \% \quad 25.0$

$99.7 \% \quad 31.5$

$\begin{array}{lll}96.8 \% & 27.0\end{array}$

$99.7 \% \quad 40.5$

$99.7 \% \quad 49.5$

$99.7 \% \quad 34.7$

$99.7 \% \quad 42.1$

$99.7 \% \quad 54.0$

$98.2 \% \quad 23.9$

$99.7 \% \quad 31.8$

$99.7 \% \quad 41.3$

$99.6 \% \quad 24.4$

$99.7 \% \quad 41.7$

$99.1 \% \quad 25.4$
$99.7 \% \quad 58.3$
1013.57

1698.92

1533.82

2449.29

1429.72

1230.59

1225.57

1108.61

1570.81

1434.72

882.54

1400.65

988.54

1030.45

1450.76

1088.57

1367.78

942.57

1683.88

1377.66

1649.85

1455.85

1841.04

1014.56

1778.89

1319.78

1146.57

1655.79

1441.84

1014.56

1755.78

1132.62

1898.06

801.48

1093.56

1132.58

1385.75

1199.71

1245.62

873.52

1286.66

872.49

1523.82

1461.73

1347.66

1455.64

$\begin{array}{cc}85 & 700 \\ 75 & 884 \\ 85 & 900 \\ 59 & 973 \\ 08 & 1032 \\ 72 & 1087 \\ 52 & 1162 \\ 73 & 1283 \\ 84 & 1294 \\ 82 & 1399 \\ 65 & 1477 \\ 78 & 1486 \\ 22 & 1633 \\ 01 & 1809 \\ 76 & 2584 \\ 85 & 2598 \\ 99 & 2607 \\ 01 & 211 \\ 45 & 252 \\ 14 & 128 \\ 02 & 213 \\ 77 & 290 \\ 03 & 315 \\ 76 & 393 \\ 35 & 442 \\ 16 & 632 \\ 22 & 133 \\ 91 & 200 \\ 87 & 300 \\ 13 & 325 \\ 79 & 386 \\ 07 & 423 \\ 91 & 501 \\ 3 & 42 \\ 05 & 312 \\ 23 & 331 \\ 32 & 342 \\ 05 & 217 \\ 18 & 228 \\ 29 & 239 \\ 49 & 256 \\ 57 & 267 \\ 88 & 296 \\ 11 & 124 \\ 07 & 619 \\ 26 & 137 \\ 69 & 280 \\ & \end{array}$

Page 53 of Table S-1-2 
Gem-associated protein 4 GN=GEMIN4 GEMI4_HUMAN $120.04 \quad 100.0 \%$ Gem-associated protein 4 GN=GEMIN4 GEMI4_HUMAN $120.04 \quad 100.0 \%$ General transcription factor 3C polypeptide $1 \mathrm{GN}=\mathrm{GTF} 3 \mathrm{C} 1 \quad \mathrm{TF} 3 \mathrm{C} 1 \_$HUMAN $238.88 \quad 100.0 \%$ General transcription factor 3C polypeptide $1 \mathrm{GN}=\mathrm{GTF} 3 \mathrm{Cl} 1 \mathrm{TF} 3 \mathrm{C} 1$ HUMAN $238.88 \quad 100.0 \%$ General transcription factor 3C polypeptide $1 \mathrm{GN}=\mathrm{GTF} 3 \mathrm{Cl} 1 \mathrm{TF} 3 \mathrm{C} 1$ _HUMAN $238.88 \quad 100.0 \%$ General transcription factor $3 \mathrm{C}$ polypeptide $1 \mathrm{GN}=\mathrm{GTF} 3 \mathrm{Cl} 1 \mathrm{TF} 3 \mathrm{C} 1 \_$HUMAN $238.88 \quad 100.0 \%$ General transcription factor 3C polypeptide $1 \mathrm{GN}=\mathrm{GTF} 3 \mathrm{Cl} 1$ TF3C1_HUMAN $238.88 \quad 100.0 \%$ General transcription factor $3 \mathrm{C}$ polypeptide $1 \mathrm{GN}=\mathrm{GTF} 3 \mathrm{C} 1 \quad \mathrm{TF} 3 \mathrm{C} 1 \_$HUMAN $238.88 \quad 100.0 \%$ General transcription factor $3 \mathrm{C}$ polypeptide $1 \mathrm{GN}=\mathrm{GTF} 3 \mathrm{C} 1 \mathrm{TF} 3 \mathrm{C} 1$ HUMAN $238.88 \quad 100.0 \%$ General transcription factor $3 \mathrm{C}$ polypeptide $1 \mathrm{GN}=\mathrm{GTF} 3 \mathrm{C} 1 \quad \mathrm{TF} 3 \mathrm{C} 1 \_H U M A N \quad 238.88 \quad 100.0 \%$ General transcription factor 3C polypeptide $2 \mathrm{GN}=\mathrm{GTF} 3 \mathrm{C} 2$ TF3C2_HUMAN $100.68 \quad 100.0 \%$ General transcription factor $3 \mathrm{C}$ polypeptide $2 \mathrm{GN}=\mathrm{GTF} 3 \mathrm{C} 2$ TF3C2 HUMAN $100.68 \quad 100.0 \%$ General transcription factor $3 \mathrm{C}$ polypeptide $2 \mathrm{GN}=\mathrm{GTF} 3 \mathrm{C} 2$ TF3C2_HUMAN $100.68 \quad 100.0 \%$ General transcription factor 3C polypeptide $5 \mathrm{GN}=\mathrm{GTF} 3 \mathrm{C} 5$ TF3C5 HUMAN $59.57 \quad 100.0 \%$ General transcription factor $3 \mathrm{C}$ polypeptide $5 \mathrm{GN}=\mathrm{GTF} 3 \mathrm{C} 5 \mathrm{TF} 3 \mathrm{C} 5 \mathrm{HUMAN} 59.57 \quad 100.0 \%$ General transcription factor $3 \mathrm{C}$ polypeptide $5 \mathrm{GN}=\mathrm{GTF} 3 \mathrm{C} 5$ TF3C5_HUMAN $59.57 \quad 100.0 \%$ General transcription factor $3 \mathrm{C}$ polypeptide $5 \mathrm{GN}=\mathrm{GTF} 3 \mathrm{C} 5 \mathrm{TF} 3 \mathrm{C} 5$ HUMAN $59.57 \quad 100.0 \%$ General transcription factor 3C polypeptide 5 GN=GTF3C5 TF3C5_HUMAN $59.57 \quad 100.0 \%$ General vesicular transport factor p115 GN=USO1 USO1_HUMAN $107.90 \quad 100.0 \%$ General vesicular transport factor p115 GN=USO1 USO1_HUMAN $107.90 \quad 100.0 \%$ General vesicular transport factor p115 GN=USO1 USO1_HUMAN $107.90 \quad 100.0 \%$ General vesicular transport factor p115 GN=USO1 USO1_HUMAN $107.90 \quad 100.0 \%$ Girdin $\mathrm{GN}=\mathrm{CCDC} 88 \mathrm{~A}$ Girdin $\mathrm{GN}=\mathrm{CCDC} 88 \mathrm{~A}$ Girdin $\mathrm{GN}=\mathrm{CCDC} 88 \mathrm{~A}$ Girdin $\mathrm{GN}=\mathrm{CCDC} 88 \mathrm{~A}$ Girdin $\mathrm{GN}=\mathrm{CCDC} 88 \mathrm{~A}$ Girdin $\mathrm{GN}=\mathrm{CCDC} 88 \mathrm{~A}$ Girdin $\mathrm{GN}=\mathrm{CCDC} 88 \mathrm{~A}$ GRDN_HUMAN $216.05 \quad 100.0 \%$ GRDN_HUMAN $216.05 \quad 100.0 \%$ GRDN HUMAN $216.05 \quad 100.0 \%$ GRDN_HUMAN $216.05 \quad 100.0 \%$ GRDN HUMAN $216.05 \quad 100.0 \%$ GRDN HUMAN $216.05 \quad 100.0 \%$ GRDN_HUMAN $216.05 \quad 100.0 \%$ Glioma tumor suppressor candidate region gene 2 protein GN=GLTSCR2 GSCR2_HUMAN $54.39 \quad 100.0 \%$ Glutamine--fructose-6-phosphate aminotransferase [isomerizing] 1 GN=GFPT1 $\quad$ GFPT1_HUMAN $78.81 \quad 100.0 \%$ 作 lutamine--fructose-6-phosphate aminotransferase [isomerizing] 1 GN=GFPT1 GFPT1_HUMAN $78.81 \quad 100.0 \%$ Glutamine--tRNA ligase GN=QARS Glutamine--tRNA ligase $\mathrm{GN}=\mathrm{QAR} S$ Glutamine--tRNA ligase $\mathrm{GN}=\mathrm{QARS}$ Glutamine--tRNA ligase $\mathrm{GN}=\mathrm{QARS}$ Glutamine--tRNA ligase $\mathrm{GN}=\mathrm{QARS}$ Glutamine--tRNA ligase GN=QARS Glutamine--tRNA ligase $\mathrm{GN}=\mathrm{QARS}$ tutaminyl-peptide cyclotransferase-like protein GN=QPCTL QPCTL HUMAN $42.93 \quad 100.0 \%$ Glutaminyl-peptide cyclotransferase-like protein GN=QPCTL QPCTL_HUMAN $42.93 \quad 100.0 \%$ Glutaminyl-peptide cyclotransferase-like protein GN=QPCTL QPCTL_HUMAN $42.93 \quad 100.0 \%$ Glutaminyl-peptide cyclotransferase-like protein GN=QPCTL QPCTL HUMAN $42.93 \quad 100.0 \%$ Glutaminyl-peptide cyclotransferase-like protein GN=QPCTL QPCTL_HUMAN $42.93 \quad 100.0 \%$ SYQ HUMAN $87.80 \quad 100.0 \%$ SYQ_HUMAN $87.80 \quad 100.0 \%$ SYQ HUMAN $87.80 \quad 100.0 \%$ SYQ_HUMAN $87.80 \quad 100.0 \%$ SYQ HUMAN $87.80 \quad 100.0 \%$ SYQ HUMAN $87.80 \quad 100.0 \%$ SYQ HUMAN $87.80 \quad 100.0 \%$ $0 \%$

$4 \quad 0.01 \% \quad 2.0 \%$ GLTQIQSR $0.01 \% \quad 2.0 \% \quad$ LLETVIDVSTADR $0.02 \% \quad 4.3 \%$ LYQYMLNAGLAK $0.02 \% \quad 4.3 \%$ GISQAEIR

$0.02 \% \quad 4.3 \% \quad$ NLSEEGLLR

$0.02 \% \quad 4.3 \%$ TTVIQDGIKK

$0.02 \% \quad 4.3 \%$ NAVIVDTTICDPHYNLAR

$0.02 \% \quad 4.3 \%$ IASNVLNTK

$0.02 \% \quad 4.3 \%$ SYQSFQTFR

$0.02 \% \quad 4.3 \% \quad$ NLNPNDSIVVNSCQMK

$0.00 \% \quad 3.2 \%$ SKAELLLLK

$0.00 \% \quad 3.2 \%$ RPYEPINSIKR

$0.00 \% \quad 3.2 \%$ GLASPLGHR

$0.01 \% \quad 12.5 \%$ MLPTLGGEEGVSR

$0.01 \% \quad 12.5 \%$ FSTSSLLLR

$0.01 \% \quad 12.5 \%$ EGYNNPPISGENLIGLSR

$0.01 \% \quad 12.5 \%$ STYNYSLPITVKK

$0.01 \% \quad 12.5 \%$ SKRPALFSSSAK

$0.01 \% \quad 7.0 \%$ GVMGGQSAGPQHTEAETIQK

$0.01 \% \quad 7.0 \%$ VLVSPTNPPGATSSCQK

$0.01 \% \quad 7.0 \%$ LGFISKHELYSR

$0.01 \% \quad 7.0 \%$ SSQTSGTNEQSSAIVSAR

$0.01 \% \quad 5.1 \%$ LQQENMNLLSDAR

$0.01 \% \quad 5.1 \%$ TSELSEAPQK

$0.01 \% \quad 5.1 \%$ SLGHEVNELTSSR

$0.01 \% \quad 5.1 \%$ ILEQENEHLNQTVSSLR

$0.01 \% \quad 5.1 \%$ LEVSYQGLDIENQR

$0.01 \% \quad 5.1 \% \quad$ NLEELKISSK

$0.01 \% \quad 5.1 \%$ QTVSLQEQNTTLQTQNAK

$0.00 \% \quad 4.2 \%$ DVLAHQVPNAK

$0.00 \% \quad 4.2 \%$ LRVQQAALR

$0.01 \% \quad 7.2 \%$ AVQTLQMELQQIMK

$0.01 \% \quad 7.2 \%$ GALTVGITNTVGSSISR

$0.01 \% \quad 7.2 \%$ CQNALQQVVAR

$0.01 \% \quad 7.2 \%$ GYDVDFPR

$0.02 \% \quad 8.1 \%$ ETLKNSALSAQLR

$0.02 \% \quad 8.1 \%$ NSALSAQLR

$0.02 \% \quad 8.1 \%$ LSFLVSYIASK

$0.02 \% \quad 8.1 \%$ AINFNFGYAK

$0.02 \% \quad 8.1 \%$ ANNGICFLR

$0.02 \% \quad 8.1 \%$ GKFSEGEATLR

$0.02 \% \quad 8.1 \%$ AMAVLESLR

$0.03 \% \quad 13.1 \%$ TEELPLGR

$0.03 \% \quad 13.1 \%$ ELRVPLIGSLPEAR

$0.03 \% \quad 13.1 \%$ VPLIGSLPEAR

$0.03 \% \quad 13.1 \%$ VVGQLDPQR

$0.03 \% \quad 13.1 \%$ TPGSPGNLQVR $\begin{array}{llllllll}97.0 \% & 24.2 & 25.0 & 9.4 & 1 & 0 & 0 & 902.51\end{array}$

$\begin{array}{llllllll}99.7 \% & 45.5 & 25.0 & 44.0 & 3 & 0 & 0 & 1431.77\end{array}$

$\begin{array}{llllllll}99.7 \% & 33.9 & 25.0 & 33.9 & 1 & 0 & 0 & 1384.73\end{array}$

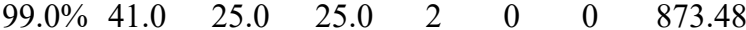

$\begin{array}{llllllll}99.7 \% & 31.1 & 25.0 & 21.6 & 2 & 0 & 0 & 1030.55\end{array}$

$\begin{array}{llll}98.0 \% & 21.4 & 25.0 & 12.8\end{array}$

$\begin{array}{llll}7 \% & 38.4 & 25.0 & 37.2\end{array}$

$\begin{array}{llll}99.7 \% & 32.8 & 25.0 & 28.2\end{array}$

$99.7 \% \quad 25.7 \quad 25.0 \quad 25.7$

$99.7 \% \quad 56.8 \quad 25.0 \quad 56.8$

$\begin{array}{llll}98.4 \% & 17.3 & 25.0 & 17.3\end{array}$

$99.0 \% \quad 21.4 \quad 25.0 \quad 18.2$

$99.7 \% \quad 28.8 \quad 25.0 \quad 28.8$

$99.7 \% \quad 44.4 \quad 25.0 \quad 38.4$

$99.7 \% \quad 43.0 \quad 25.0 \quad 43.0$

$99.7 \% \quad 42.9$

$99.7 \% 33.8$

$99.7 \% \quad 31.4$

$25.0 \quad 42.9$

31.6

$.0 \% \quad 20.0$

$99.7 \% 33.9$

$99.7 \% \quad 57.1$

$99.7 \% \quad 34.4$

$99.7 \% \quad 37.0$

$99.7 \% \quad 28.1$

$97.6 \% \quad 16.8$

$99.7 \% \quad 36.2$

$99.7 \% \quad 27.1$

$\begin{array}{lll}99.7 \% & 36.8\end{array}$

$97.9 \% \quad 16.9$

$99.7 \% \quad 39.6$

$99.7 \% \quad 80.8$

$99.7 \% \quad 52.2$

$\begin{array}{lll}97.7 \% & 21.3\end{array}$

$97.0 \% \quad 21.9$

$99.7 \% \quad 51.2$

$99.7 \% 47$.

$99.7 \% \quad 52.2$

$99.7 \% \quad 38.0$

$99.7 \% \quad 43.4$

$99.7 \% \quad 35.8$

$99.0 \% 23$.

$99.7 \% \quad 53.1$

$99.7 \% \quad 46.5$

$99.5 \% \quad 24.2$

$99.7 \% \quad 55.0$

1102.65

2072.02

959.55

1163.55

1832.86

1014.66

1372.77

907.51

1345.68

1023.58

1929.97

1513.83

1278.72

2041.96

1742.87

1449.78

1809.86

1531.75

1089.54

1428.71

2010.03

1663.83

1160.65

2032.03

1191.65

1054.65

1660.88

1632.89

1286.66

968.45

1430.80

959.53

1227.70

1144.58

1064.53

1194.61

989.54

914.49

1549.91

1151.68

1011.56

1125.60 

Guanine nucleotide-binding protein-like $3 \mathrm{GN}=\mathrm{GNL3}$ GNL3_HUMAN $61.99 \quad 100.0 \%$ $\mathrm{H} / \mathrm{ACA}$ ribonucleoprotein complex subunit $1 \mathrm{GN}=\mathrm{GAR} 1 \mathrm{GAR} 1$ HUMAN $22.35 \quad 100.0 \%$ H/ACA ribonucleoprotein complex subunit $1 \mathrm{GN}=\mathrm{GAR} 1$ GAR1_HUMAN $22.35 \quad 100.0 \%$ H/ACA ribonucleoprotein complex subunit $4 \mathrm{GN}=\mathrm{DKC1}$ DKC1_HUMAN $57.68 \quad 100.0 \%$ $\mathrm{H} / \mathrm{ACA}$ ribonucleoprotein complex subunit $4 \mathrm{GN}=\mathrm{DKC} 1 \mathrm{DKC} 1$ HUMAN $57.68 \quad 100.0 \%$ $\mathrm{H} / \mathrm{ACA}$ ribonucleoprotein complex subunit $4 \mathrm{GN}=\mathrm{DKC1} \mathrm{DKC1}{ }_{-} \mathrm{HUMAN} 57.68 \quad 100.0 \%$ $\mathrm{H} / \mathrm{ACA}$ ribonucleoprotein complex subunit $4 \mathrm{GN}=\mathrm{DKC1} \mathrm{DKC} 1$ HUMAN $57.68100 .0 \%$ $\mathrm{H} / \mathrm{ACA}$ ribonucleoprotein complex subunit $4 \mathrm{GN}=\mathrm{DKC1}$ DKC1_HUMAN $57.68 \quad 100.0 \%$ HCLS1-associated protein X-1 GN=HAX1 HAX1_HUMAN $31.62 \quad 100.0 \%$ HCLS1-associated protein X-1 GN=HAX1 HAX1 HUMAN $31.62 \quad 100.0 \%$ HCLS1-associated protein X-1 GN=HAX1 HAX1_HUMAN $31.62 \quad 100.0 \%$ HCLS1-associated protein X-1 GN=HAX1 HAX1_HUMAN $31.62 \quad 100.0 \%$ HCLS1-associated protein X-1 GN=HAX1 HAX1_HUMAN $31.62 \quad 100.0 \%$ HEAT repeat-containing protein $1 \mathrm{GN}=$ HEATR1 HEAT1_HUMAN $242.38 \quad 100.0 \%$ HEAT repeat-containing protein $1 \mathrm{GN}=$ HEATR1 HEAT1 HUMAN $242.38 \quad 100.0 \%$ HEAT repeat-containing protein $1 \mathrm{GN}=$ HEATR1 HEAT1_HUMAN $242.38 \quad 100.0 \%$ HEAT repeat-containing protein 1 GN=HEATR1 HEAT1_HUMAN $242.38 \quad 100.0 \%$ HEAT repeat-containing protein $1 \mathrm{GN}=$ HEATR1 HEAT1_HUMAN $242.38 \quad 100.0 \%$ HEAT repeat-containing protein 1 GN=HEATR1 HEAT1_HUMAN $242.38 \quad 100.0 \%$ HEAT repeat-containing protein $1 \mathrm{GN}=$ HEATR1 HEAT1 HUMAN $242.38 \quad 100.0 \%$ HEAT repeat-containing protein $1 \mathrm{GN}=$ HEATR1 HEAT1_HUMAN $242.38 \quad 100.0 \%$ HEAT repeat-containing protein $1 \mathrm{GN}=$ HEATR1 HEAT1_HUMAN $242.38 \quad 100.0 \%$ Heat shock $70 \mathrm{kDa}$ protein $1 \mathrm{~A} / 1 \mathrm{~B}$ GN=HSPA1A HSP71 HUMAN $70.05 \quad 100.0 \%$ Heat shock $70 \mathrm{kDa}$ protein $1 \mathrm{~A} / 1 \mathrm{~B}$ GN=HSPA1A HSP71_HUMAN $70.05 \quad 100.0 \%$ Heat shock $70 \mathrm{kDa}$ protein $1 \mathrm{~A} / 1 \mathrm{~B}$ GN=HSPA1A HSP71_HUMAN $70.05 \quad 100.0 \%$ Heat shock $70 \mathrm{kDa}$ protein 1A/1B GN=HSPA1A HSP71_HUMAN $70.05 \quad 100.0 \%$ Heat shock $70 \mathrm{kDa}$ protein $1 \mathrm{~A} / 1 \mathrm{~B}$ GN=HSPA1A HSP71_HUMAN $70.05 \quad 100.0 \%$ Heat shock $70 \mathrm{kDa}$ protein 1A/1B GN=HSPA1A HSP71 HUMAN $70.05100 .0 \%$ Heat shock $70 \mathrm{kDa}$ protein 1A/1B GN=HSPA1A HSP71_HUMAN $70.05 \quad 100.0 \%$ Heat shock $70 \mathrm{kDa}$ protein 1A/1B GN=HSPA1A HSP71_HUMAN $70.05 \quad 100.0 \%$ Heat shock $70 \mathrm{kDa}$ protein 1A/1B GN=HSPA1A HSP71_HUMAN $70.05 \quad 100.0 \%$ Heat shock $70 \mathrm{kDa}$ protein 1A/1B GN=HSPA1A HSP71_HUMAN $70.05 \quad 100.0 \%$

$0.02 \% \quad 14.0 \%$ LLLLGAGESGK

3

$0.03 \% \quad 33.4 \%$ DETNYGIPQR

$0.03 \% \quad 33.4 \%$ VWQVTIGTR

$0.02 \% \quad 6.6 \% \quad$ ELPTVVFR

$0.02 \% \quad 6.6 \%$ VGVIGFPNVGK

$0.02 \% \quad 24.7 \%$ IFGGVLESDAR

$0.02 \% \quad 24.7 \%$ ITKPDGIVEER

$0.02 \% \quad 4.3 \%$ LLESKYPR

$0.02 \% \quad 4.3 \%$ LIGVANQK

$0.02 \% \quad 4.3 \%$ LDDTYSFQVINK

$0.02 \% \quad 4.3 \%$ VVESGGPEILK

$0.02 \% \quad 4.3 \%$ GLVGNPLPSVR

$0.02 \% \quad 4.3 \% \quad$ LVPDLLAIVQR

$0.02 \% \quad 4.3 \% \quad$ VLLPAIKK

$0.12 \% \quad 30.9 \%$ VEIIANDQGNR

$0.12 \% \quad 30.9 \%$ VQVSYKGETK
$0.03 \% 33.4 \%$ LTRDETNYGIPQR

$0.03 \% \quad 33.4 \%$ FVGHTKDVLSVAFSSDNR $\quad 99.7 \% \quad 44.6$

$0.03 \% \quad 33.4 \%$ DVLSVAFSSDNR

$0.03 \% \quad 33.4 \%$ DVLSVAFSSDNRQIVSGSR $99.7 \% \quad 47.5$

$0.03 \% \quad 33.4 \%$ YTVQDESHSEWVSCVR $\quad 99.7 \% \quad 34.0$

$0.03 \% \quad 33.4 \%$ TNHIGHTGYLNTVTVSPDGSLCASGGK $\quad 99.7 \% \quad 60.9$

$0.03 \% \quad 33.4 \%$ IIVDELKQEVISTSSK $\quad 99.7 \% \quad 44.2$

$0.02 \% \quad 6.6 \%$ SGFNLEELEKNNAQSIR $\quad 99.7 \% \quad 51.1$

$0.01 \% \quad 14.3 \%$ VVLLGEFLHPCEDDIVCK $99.7 \% \quad 27.2$

$0.01 \% \quad 14.3 \%$ FYIDPYKLLPLQR

$0.01 \% \quad 11.1 \%$ SQQSAGKEYVGIVR

$\begin{array}{lll}99.3 \% & 21.2\end{array}$

$0.02 \% \quad 24.7 \%$ DSMLKYPDSHQPR

$\begin{array}{lll}99.7 \% & 44.1\end{array}$

$0.02 \% \quad 4.3 \%$ ITSEMGSASQANIR

$99.7 \% \quad 48.9$

$\begin{array}{llll}98.5 \% & 29.6 & 25.0 & 22.9\end{array}$

$0.12 \% \quad 30.9 \%$ TTPSYVAFTDTER

$99.7 \% \quad 45.3$

$\begin{array}{lllll}0.12 \% & 30.9 \% & \text { LIGDAAKNQVALNPQNTVFDAK } & 99.7 \% & 47.8\end{array}$

$\begin{array}{lllll}0.12 \% & 30.9 \% & \text { NQVALNPQNTVFDAK } & 99.7 \% & 47.7\end{array}$

$0.12 \% \quad 30.9 \%$ NQVALNPQNTVFDAKR $\quad 99.7 \% \quad 58.1$

$0.12 \% \quad 30.9 \%$ AFYPEEISSMVLTK

$0.12 \% \quad 30.9 \%$ QATKDAGVIAGLNVLR $\quad 99.7 \% \quad 54.0$ $\begin{array}{llll}99.7 \% & 57.6 & 25.0 & 45.8\end{array}$

$\begin{array}{llll}99.7 \% & 39.1\end{array}$ $99.7 \% \quad 48$.

$25.0 \quad 31.0$

$\begin{array}{llll}99.7 \% & 53.5 & 25.0 & 42.8\end{array}$

$99.0 \% \quad 41.5 \quad 25.0 \quad 28.4$

$\begin{array}{llll}99.7 \% & 49.0 & 25.0 & 38.8\end{array}$

$99.6 \% 22.8$

$99.7 \% \quad 49.9$

$99.7 \% \quad 55.4$

$99.0 \% \quad 21.3$

$\begin{array}{lll}99.7 \% & 31.4\end{array}$

$99.7 \% \quad 29.9$

$99.7 \% \quad 26.0$

$99.7 \% \quad 46.3$

$99.7 \% 26.3$

$99.0 \% \quad 30.8$

$99.0 \% \quad 30.7$

$99.4 \% \quad 20.2$

$99.7 \% \quad 32.5$

$99.7 \% \quad 34.3$

$\begin{array}{lll}99.7 \% & 36.8\end{array}$

$99.7 \% \quad 49.5$

$\begin{array}{llll}99.7 \% & 73.3 & 25.0 & 71.8\end{array}$

$25.0 \quad 45.3$

$25.0 \quad 47.8$

$\begin{array}{llll}99.7 \% & 58.1 & 25.0 & 58.1\end{array}$

$99.7 \% \quad 55.2$

$25.0 \quad 35.0$

43

1562.79

1192.56

1979.00

1309.64

2037.04

1981.87

2743.31

1789.00

1059.59

960.55

1086.63

1948.97

2143.06

1665.94

1521.80

1395.73

1003.59

1268.59

983.55

981.49

1573.74

1163.61

2750.36

1256.68

1005.57

842.51

1442.72

1127.63

1108.65

1236.77

1464.71

943.56

881.62

1228.63

1487.70

2156.09

2327.24

1658.85

1814.95

1138.61

1630.80 $\begin{array}{llllllll}99.7 \% & 54.0 & 25.0 & 47.3 & 3 & 4 & 0 & 1625.93 \\ 99.7 \% & 62.4 & 25.0 & 54.8 & 2 & 0 & 0 & 1197.70\end{array}$ 

Heat shock $70 \mathrm{kDa}$ protein 1A/1B GN=HSPA1A HSP71_HUMAN $70.05 \quad 100.0 \% \quad 23$ Heat shock $70 \mathrm{kDa}$ protein 1A/1B GN=HSPA1A HSP71_HUMAN $70.05 \quad 100.0 \%$ at shock $70 \mathrm{kDa}$ protein $1 \mathrm{~A} / 1 \mathrm{~B}$ GN=HSPA1A HSP71 HUMAN $70.05 \quad 100.0 \%$ Heat shock $70 \mathrm{kDa}$ protein $1 \mathrm{~A} / 1 \mathrm{~B}$ GN=HSPA1A HSP71_HUMAN $70.05 \quad 100.0 \%$ Heat shock $70 \mathrm{kDa}$ protein $1 \mathrm{~A} / 1 \mathrm{~B}$ GN=HSPA1A HSP71_HUMAN $70.05 \quad 100.0 \%$ Heat shock $70 \mathrm{kDa}$ protein 1A/1B GN=HSPA1A HSP71_HUMAN $70.05 \quad 100.0 \%$ Heat shock $70 \mathrm{kDa}$ protein 1A/1B GN=HSPA1A HSP71_HUMAN $70.05 \quad 100.0 \%$ Heat shock $70 \mathrm{kDa}$ protein $1 \mathrm{~A} / 1 \mathrm{~B}$ GN=HSPA1A HSP71 HUMAN $70.05 \quad 100.0 \%$ Heat shock $70 \mathrm{kDa}$ protein $1 \mathrm{~A} / 1 \mathrm{~B}$ GN=HSPA1A HSP71_HUMAN $70.05 \quad 100.0 \%$ Heat shock $70 \mathrm{kDa}$ protein 1A/1B GN=HSPA1A HSP71_HUMAN $70.05 \quad 100.0 \% \quad 2$ Heat shock $70 \mathrm{kDa}$ protein $1 \mathrm{~A} / 1 \mathrm{~B}$ GN=HSPA1A HSP71 HUMAN $70.05 \quad 100.0 \%$ Heat shock $70 \mathrm{kDa}$ protein $1 \mathrm{~A} / 1 \mathrm{~B}$ GN=HSPA1A HSP71_HUMAN $70.05 \quad 100.0 \% \quad 23$ Heat shock cognate $71 \mathrm{kDa}$ protein GN=HSPA8 HSP7C_HUMAN $70.90 \quad 100.0 \%$ Heat shock cognate $71 \mathrm{kDa}$ protein GN=HSPA8 HSP7C_HUMAN $70.90 \quad 100.0 \% \quad 19$ Heat shock cognate $71 \mathrm{kDa}$ protein GN=HSPA8 HSP7C_HUMAN $70.90 \quad 100.0 \% \quad 19$ Heat shock cognate $71 \mathrm{kDa}$ protein GN=HSPA8 HSP7C HUMAN $70.90 \quad 100.0 \%$ Heat shock cognate $71 \mathrm{kDa}$ protein GN=HSPA8 HSP7C_HUMAN $70.90 \quad 100.0 \%$ Heat shock cognate $71 \mathrm{kDa}$ protein GN=HSPA8 HSP7C_HUMAN $70.90 \quad 100.0 \%$ Heat shock cognate $71 \mathrm{kDa}$ protein GN=HSPA8 HSP7C HUMAN $70.90 \quad 100.0 \%$ Heat shock cognate $71 \mathrm{kDa}$ protein GN=HSPA8 HSP7C_HUMAN $70.90 \quad 100.0 \%$ Heat shock cognate $71 \mathrm{kDa}$ protein GN=HSPA8 HSP7C_HUMAN $70.90 \quad 100.0 \%$ Heat shock cognate $71 \mathrm{kDa}$ protein GN=HSPA8 HSP7C_HUMAN $70.90 \quad 100.0 \%$ Heat shock cognate $71 \mathrm{kDa}$ protein GN=HSPA8 HSP7C_HUMAN $70.90 \quad 100.0 \%$ Heat shock cognate $71 \mathrm{kDa}$ protein GN=HSPA8 HSP7C HUMAN $70.90 \quad 100.0 \%$ Heat shock cognate $71 \mathrm{kDa}$ protein GN=HSPA8 HSP7C_HUMAN $70.90 \quad 100.0 \%$ Heat shock cognate $71 \mathrm{kDa}$ protein GN=HSPA8 HSP7C_HUMAN $70.90 \quad 100.0 \%$ Heat shock cognate $71 \mathrm{kDa}$ protein GN=HSPA8 HSP7C HUMAN $70.90 \quad 100.0 \%$ Heat shock cognate $71 \mathrm{kDa}$ protein GN=HSPA8 HSP7C_HUMAN $70.90 \quad 100.0 \%$ Heat shock cognate $71 \mathrm{kDa}$ protein GN=HSPA8 HSP7C HUMAN $70.90 \quad 100.0 \%$ Heat shock cognate $71 \mathrm{kDa}$ protein GN=HSPA8 HSP7C_HUMAN $70.90 \quad 100.0 \%$ Heat shock cognate $71 \mathrm{kDa}$ protein GN=HSPA8 HSP7C_HUMAN $70.90 \quad 100.0 \%$ Heat shock cognate $71 \mathrm{kDa}$ protein GN=HSPA8 HSP7C HUMAN $70.90 \quad 100.0 \%$ Heat shock cognate $71 \mathrm{kDa}$ protein GN=HSPA8 HSP7C_HUMAN $70.90 \quad 100.0 \%$ Heat shock cognate $71 \mathrm{kDa}$ protein GN=HSPA8 HSP7C_HUMAN $70.90 \quad 100.0 \%$ Heat shock cognate $71 \mathrm{kDa}$ protein GN=HSPA8 HSP7C_HUMAN $70.90 \quad 100.0 \%$ Heat shock protein $105 \mathrm{kDa}$ GN=HSPH1 HS105_HUMAN $96.87 \quad 100.0 \%$ Heat shock protein $105 \mathrm{kDa}$ GN=HSPH1 HS105 HUMAN $96.87 \quad 100.0 \%$ Heat shock protein $105 \mathrm{kDa}$ GN=HSPH1 HS105_HUMAN $96.87 \quad 100.0 \%$ Heat shock protein $105 \mathrm{kDa}$ GN=HSPH1 HS105_HUMAN $96.87 \quad 100.0 \%$ Heat shock protein $75 \mathrm{kDa}$, mitochondrial GN=TRAP1 TRAP1_HUMAN $80.11 \quad 100.0 \%$ Heat shock protein $75 \mathrm{kDa}$, mitochondrial GN=TRAP1 TRAP1_HUMAN $80.11 \quad 100.0 \%$ Heat shock protein $75 \mathrm{kDa}$, mitochondrial GN=TRAP1 TRAP1 HUMAN $80.11 \quad 100.0 \%$ Heat shock protein $75 \mathrm{kDa}$, mitochondrial GN=TRAP1 TRAP1_HUMAN $80.11 \quad 100.0 \%$ Heat shock protein $75 \mathrm{kDa}$, mitochondrial GN=TRAP1 TRAP1_HUMAN $80.11 \quad 100.0 \%$ Heat shock protein $75 \mathrm{kDa}$, mitochondrial GN=TRAP1 TRAP1_HUMAN $80.11 \quad 100.0 \%$ Heat shock protein $75 \mathrm{kDa}$, mitochondrial GN=TRAP1 TRAP1_HUMAN $80.11 \quad 100.0 \%$

\section{$0.12 \% \quad 30.9 \%$ ARFEELCSDLFR}

$0.12 \% \quad 30.9 \%$ FEELCSDLFR

$0.12 \% \quad 30.9 \%$ STLEPVEK

$0.12 \% \quad 30.9 \%$ AQIHDLVLVGGSTR

$0.12 \% \quad 30.9 \%$ LLQDFFNGR

$0.12 \% \quad 30.9 \%$ LLQDFFNGRDLNK

$0.12 \% \quad 30.9 \%$ ITITNDKGR

$0.12 \% \quad 30.9 \%$ LSKEEIER

$0.12 \% \quad 30.9 \%$ NALESYAFNMK

$0.12 \% \quad 30.9 \%$ GGSGSGPTIEEVD

$0.11 \% \quad 34.4 \%$ VEIIANDQGNR

$0.11 \% \quad 34.4 \%$ TTPSYVAFTDTER

$0.11 \% \quad 34.4 \%$ VQVEYKGETK

$0.11 \% \quad 34.4 \%$ SFYPEEVSSMVLTK

$0.11 \% \quad 34.4 \%$ MKEIAEAYLGK

$0.11 \% 34.4 \%$ DAGTIAGLNVLR

$0.11 \% \quad 34.4 \%$ IINEPTAAAIAYGLDK

$0.11 \% \quad 34.4 \%$ ARFEELNADLFR

$0.11 \% \quad 34.4 \%$ SQIHDIVLVGGSTR

$0.11 \% \quad 34.4 \%$ LLQDFFNGKELNK

$0.11 \% \quad 34.4 \%$ ITITNDKGR

$0.11 \% \quad 34.4 \%$ LSKEDIER

$0.11 \% \quad 34.4 \%$ NSLESYAFNMK

$0.01 \% \quad 5.5 \%$ SVLDAAQIVGLNCLR

$0.01 \% \quad 5.5 \%$ GCALQCAILSPAFK

$0.02 \% \quad 14.8 \%$ AFLDALQNQAEASSK

$0.02 \% \quad 14.8 \%$ YTLHYKTDAPLNIR

$0.02 \% \quad 14.8 \%$ GVVDSEDIPLNLSR

$0.02 \% \quad 14.8 \%$ FFEDYGLFMR
$0.12 \% \quad 30.9 \%$ AQIHDLVLVGGSTRIPK

$0.12 \% \quad 30.9 \%$ VSAKNALESYAFNMK

$0.11 \% \quad 34.4 \%$ TTPSYVAFTDTERLIGDAAK

$0.11 \% \quad 34.4 \%$ NQVAMNPTNTVFDAK

$\begin{array}{lll}0.11 \% & 34.4 \% \text { NQVAMNPTNTVFDAKR }\end{array}$

$0.11 \% \quad 34.4 \%$ TVTNAVVTVPAYFNDSQR $99.7 \% \quad 52.0$

$\begin{array}{lllll}0.11 \% & 34.4 \% & \text { TVTNAVVTVPAYFNDSQRQATK } & 99.6 \% & 24.8\end{array}$

$0.11 \% \quad 34.4 \%$ QATKDAGTIAGLNVLR

$0.11 \% \quad 34.4 \%$ IINEPTAAAIAYGLDKK

$0.11 \% 34.4 \%$ STAGDTHLGGEDFDNR

$0.11 \% \quad 34.4 \%$ LDKSQIHDIVLVGGSTR

$0.11 \% 34.4 \%$ SQIHDIVLVGGSTRIPK

$0.01 \% \quad 5.5 \% \quad$ NQQITHANNTVSNFKR

$0.01 \% \quad 5.5 \%$ GCALQCAILSPAFKVR

$0.02 \% \quad 14.8 \%$ FIRGVVDSEDIPLNLSR

$0.02 \% \quad 14.8 \%$ YESSALPSGQLTSLSEYASR

$0.02 \% \quad 14.8 \%$ NIYYLCAPNR $\begin{array}{lll}99.7 \% & 49.9\end{array}$

$99.7 \% \quad 53.5$

$99.7 \% \quad 69.9$

$99.7 \% \quad 60.9$

$99.7 \% \quad 52.5$

$99.7 \% \quad 52.4$

$99.7 \% \quad 30.1$

$99.7 \% \quad 54.1$

$99.7 \% \quad 29.4$

$99.7 \% \quad 35.8$

$99.7 \% \quad 47.0$

$99.0 \% \quad 61.5$

$99.7 \% 72.6$

$99.5 \% \quad 22.7$

$99.7 \% \quad 34.8$

$99.7 \% \quad 52.2$

$99.5 \% \quad 22.0$

$99.7 \% \quad 72.9$

$99.7 \% \quad 45.8$

$99.1 \% 28.0$

$99.1 \% \quad 47.9$

$\begin{array}{lll}99.7 \% & 50.7\end{array}$

$99.7 \% \quad 30.2$
1687.90

1542.74

1315.60

902.48

1465.81

1804.04

1109.57

1579.82

1017.57

1003.54

1672.84

1303.60

1204.53

1228.63

1487.70

2156.09

1665.79

1821.89

1180.62

1632.78

1252.66

1982.00

2410.24

1627.91

1199.67

1659.90

1787.99

1691.73

1480.75

1838.0

1481.81

1820.04

1565.83

1017.57

989.53

1319.59

1871.95

1628.88

1535.77

1790.94

1592.79

1704.91

1930.04

1513.79

1324.60

2146.03 1283.62

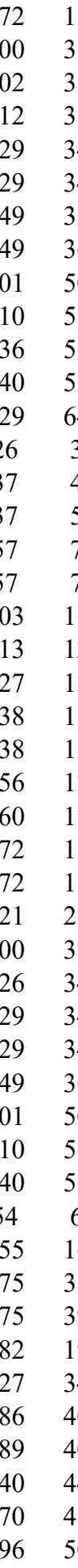



Heat shock protein $75 \mathrm{kDa}$, mitochondrial GN=TRAP1 TRAP1_HUMAN $80.11 \quad 100.0 \%$ $\begin{array}{lll}\text { Heat shock protein beta-1 GN=HSPB1 HSPB1_HUMAN } 22.78 & 100.0 \%\end{array}$ Heat shock protein beta-1 GN=HSPB1 HSPB1_HUMAN $22.78 \quad 100.0 \%$ Heat shock protein HSP 90-alpha GN=HSP90AA1 HS90A_HUMAN $84.66 \quad 100.0 \%$ Heat shock protein HSP 90-alpha GN=HSP90AA1 HS90A_HUMAN $84.66 \quad 100.0 \%$ Heat shock protein HSP 90-alpha GN=HSP90AA1 HS90A_HUMAN $84.66 \quad 100.0 \%$ Heat shock protein HSP 90-alpha GN=HSP90AA1 HS90A_HUMAN $84.66 \quad 100.0 \%$ Heat shock protein HSP 90-alpha GN=HSP90AA1 HS90A HUMAN $84.66100 .0 \%$ Heat shock protein HSP 90-alpha GN=HSP90AA1 HS90A_HUMAN $84.66 \quad 100.0 \%$ Heat shock protein HSP 90-alpha GN=HSP90AA1 HS90A_HUMAN $84.66 \quad 100.0 \%$ Heat shock protein HSP 90-alpha GN=HSP90AA1 HS90A_HUMAN $84.66100 .0 \%$ Heat shock protein HSP 90-alpha GN=HSP90AA1 HS90A_HUMAN $84.66 \quad 100.0 \%$ Heat shock protein HSP 90-alpha GN=HSP90AA1 HS90A_HUMAN $84.66 \quad 100.0 \%$ Heat shock protein HSP 90-alpha GN=HSP90AA1 HS90A_HUMAN $84.66 \quad 100.0 \%$ Heat shock protein HSP 90-alpha GN=HSP90AA1 HS90A_HUMAN $84.66 \quad 100.0 \%$ Heat shock protein HSP 90-alpha GN=HSP90AA1 HS90A HUMAN $84.66 \quad 100.0 \%$ Heat shock protein HSP 90-alpha GN=HSP90AA1 HS90A_HUMAN $84.66 \quad 100.0 \%$ Heat shock protein HSP 90-alpha GN=HSP90AA1 HS90A_HUMAN $84.66 \quad 100.0 \%$ Heat shock protein HSP 90-alpha GN=HSP90AA1 HS90A_HUMAN $84.66 \quad 100.0 \%$ Heat shock protein HSP 90-alpha GN=HSP90AA1 HS90A_HUMAN $84.66 \quad 100.0 \%$ Heat shock protein HSP 90-alpha GN=HSP90AA1 HS90A_HUMAN $84.66 \quad 100.0 \%$ Heat shock protein HSP 90-alpha GN=HSP90AA1 HS90A_HUMAN $84.66 \quad 100.0 \%$ Heat shock protein HSP 90-alpha GN=HSP90AA1 HS90A_HUMAN $84.66 \quad 100.0 \%$ Heat shock protein HSP 90-beta GN=HSP90AB1 HS90B HUMAN 83.27 Heat shock protein HSP 90-beta GN=HSP90AB1 HS90B_HUMAN 83.27 Heat shock protein HSP 90-beta GN=HSP90AB1 HS90B_HUMAN 83.27 Heat shock protein HSP 90-beta GN=HSP90AB1 HS90B_HUMAN 83.27 Heat shock protein HSP 90-beta GN=HSP90AB1 HS90B_HUMAN 83.27 Heat shock protein HSP 90-beta GN=HSP90AB1 HS90B HUMAN 83.27 Heat shock protein HSP 90-beta GN=HSP90AB1 HS90B_HUMAN 83.27 Heat shock protein HSP 90-beta GN=HSP90AB1 HS90B_HUMAN 83.27 Heat shock protein HSP 90-beta GN=HSP90AB1 HS90B_HUMAN 83.27 Heat shock protein HSP 90-beta GN=HSP90AB1 HS90B_HUMAN 83.27 Heat shock protein HSP 90-beta GN=HSP90AB1 HS90B_HUMAN 83.27 Heat shock protein HSP 90-beta GN=HSP90AB1 HS90B_HUMAN 83.27 Heat shock protein HSP 90-beta GN=HSP90AB1 HS90B_HUMAN 83.27 Heat shock protein HSP 90-beta GN=HSP90AB1 HS90B_HUMAN 83.27 Heat shock protein HSP 90-beta GN=HSP90AB1 HS90B_HUMAN 83.27 Heat shock protein HSP 90-beta GN=HSP90AB1 HS90B_HUMAN 83.27 Heat shock protein HSP 90-beta GN=HSP90AB1 HS90B_HUMAN 83.27 Heat shock protein HSP 90-beta GN=HSP90AB1 HS90B_HUMAN 83.27 Heat shock protein HSP 90-beta GN=HSP90AB1 HS90B_HUMAN 83.27 Heat shock protein HSP 90-beta GN=HSP90AB1 HS90B_HUMAN 83.27 Heat shock protein HSP 90-beta GN=HSP90AB1 HS90B_HUMAN 83.27 Heat shock protein HSP 90-beta GN=HSP90AB1 HS90B_HUMAN 83.27 Heat shock protein HSP 90-beta GN=HSP90AB1 HS90B_HUMAN 83.27

20

11

11

(11

1

11

0

0

10

10
10

10

10

10

10
10

$100.0 \% \quad 35$

$100.0 \% \quad 35$

$100.0 \% \quad 35$

$100.0 \% \quad 35$

$100.0 \% \quad 35$

$100.0 \% \quad 35$

$100.0 \% \quad 35$

$100.0 \% \quad 35$

$100.0 \% \quad 35$

$100.0 \% \quad 35$

$100.0 \% \quad 35$

$100.0 \% \quad 35$

$100.0 \% \quad 35$

$100.0 \% \quad 35$

$100.0 \% \quad 35$

$100.0 \% \quad 35$

$100.0 \% \quad 35$

$100.0 \% \quad 35$

$100.0 \% \quad 35$

$100.0 \% \quad 35$

$100.0 \% \quad 35$

$100.0 \% \quad 35$

$100.0 \% \quad 35$

20

1120
$0.02 \% \quad 14.8 \%$ TQEERAQLLQPTLEINPR $0.02 \% \quad 14.8 \%$ AQLLQPTLEINPR

$\begin{array}{ll}99.7 \% & 47.4 \\ 99.7 \% & 59.5\end{array}$

$99.7 \% \quad 59.5$

$97.7 \% \quad 20.6$

$00 \% \quad 16.6 \%$ AQLGGPEAAKSDETAAK $99.4 \% 24.8$

$99.1 \% \quad 51.7$

$99.1 \% \quad 53.8$

$99.7 \% \quad 62.3$

$99.7 \% \quad 55.0$

$99.7 \% \quad 34.8$

$99.7 \% \quad 63.2$

$99.7 \% \quad 51.9$

$99.7 \% \quad 57.3$

$99.7 \% \quad 33.5$

$99.7 \% \quad 36.5$

$99.0 \% \quad 40.9$

$99.1 \% \quad 47.9$

$0.03 \% \quad 26.2 \%$ NNIKLYVR

$0.03 \% \quad 26.2 \%$ GVVDSEDLPLNISR

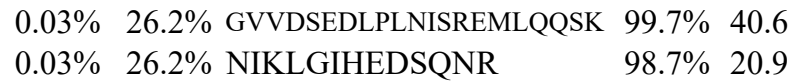

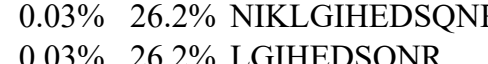

$0.03 \% \quad 26.2 \%$ LGIHEDSQNRK

$\begin{array}{lll}99.6 \% & 26.1\end{array}$

$97.3 \% \quad 16.9$

$\begin{array}{llllll}0.03 \% & 26.2 \% & \text { YYTSASGDEMVSLKDYCTR } & 99.7 \% & 46.0\end{array}$

$0.03 \% \quad 26.2 \%$ DQVANSAFVER

$99.7 \% \quad 50.5$

$0.03 \% \quad 26.2 \%$ HLEINPDHSIIETLR

$157 \quad 0.23 \% \quad 38.1 \%$ ELKIDIIPNPQER

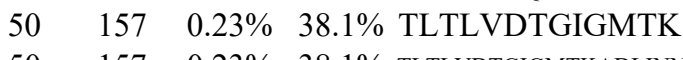

$99.1 \% 24$.

$99.7 \% \quad 35.3$

$99.7 \% \quad 43.6$

$99.7 \% \quad 44.8$

$99.1 \% \quad 51.7$

$57 \quad 0.23 \% \quad 38.1 \%$ TLTLVDTGIGMTKADLINNLGTIAK $99.1 \% 53.8$

$157 \quad 0.23 \% \quad 38.1 \%$ ADLINNLGTIAK

$157 \quad 0.23 \% \quad 38.1 \%$ ADHGEPIGRGTK

$50 \quad 157 \quad 0.23 \% \quad 38.1 \%$ VILHLKEDQTEYLEER

$50 \quad 157 \quad 0.23 \% \quad 38.1 \%$ HSQFIGYPITLYLEK

$50 \quad 157 \quad 0.23 \% \quad 38.1 \%$ EKYIDQEELNK

$50 \quad 157 \quad 0.23 \% \quad 38.1 \%$ YIDQEELNK

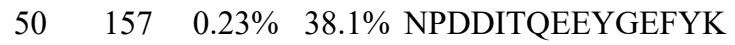

$50 \quad 157 \quad 0.23 \% \quad 38.1 \%$ HFSVEGQLEFR

$50 \quad 157 \quad 0.23 \% \quad 38.1 \%$ ALLFIPRR

$50 \quad 157 \quad 0.23 \% \quad 38.1 \%$ RAPFDLFENK

$50 \quad 157 \quad 0.23 \% \quad 38.1 \%$ APFDLFENK

$50 \quad 157 \quad 0.23 \% \quad 38.1 \%$ APFDLFENKK

$50 \quad 157 \quad 0.23 \% \quad 38.1 \%$ NNIKLYVR

$50 \quad 157 \quad 0.23 \% \quad 38.1 \%$ GVVDSEDLPLNISR

$50 \quad 157 \quad 0.23 \% \quad 38.1 \%$ GVVDSEDLPLNISREMLQQSK

$50 \quad 157 \quad 0.23 \% \quad 38.1 \%$ FYEAFSKNLK

$50 \quad 157 \quad 0.23 \% \quad 38.1 \%$ NLKLGIHEDSTNR

$50 \quad 157 \quad 0.23 \% \quad 38.1 \%$ LGIHEDSTNR

$50 \quad 157 \quad 0.23 \% \quad 38.1 \%$ LGIHEDSTNRR

\section{$\begin{array}{lll}99.7 \% & 62.3\end{array}$}

$99.5 \% \quad 29.3$

$99.7 \% \quad 55.0$

$97.2 \% \quad 29.9$

$99.7 \% \quad 34.8$

$99.7 \% \quad 63.2$

$99.7 \% \quad 56.2$

$99.7 \% \quad 57.3$

$99.0 \% 29$.

$99.7 \% \quad 33.1$

$99.7 \% \quad 31.4$

$99.6 \% \quad 27.0$

$99.0 \% \quad 40.9$

$99.1 \% \quad 47.9$

$99.7 \% \quad 40.6$

$99.7 \% \quad 40.2$

$99.7 \% \quad 55.6$

$99.7 \% \quad 59.1$

$99.5 \% 21.0$
2136.14

1492.85

1905.99

1643.82

1349.73

2589.42

1242.71

2015.04

1408.70

1151.56

1833.78

1348.66

1264.64

1108.54

1019.60

1513.79

2374.19

1523.79

1168.57

1296.67

2245.97

1235.60

1727.82

1786.94

1564.87

1194.65

1349.73

2589.42

1242.71

1237.63

2015.04

1808.96

1408.70

1151.56

1847.80

1348.66

985.63

1236.64

1080.54

1208.63

1019.60

1513.79

2374.19

1246.65

1496.78

1141.56

1297.66
$635 \quad 647$

$\begin{array}{ll}2 & 188 \\ 89 & 205\end{array}$

$88 \quad 100$

112

$186 \quad 201$

$282 \quad 292$

$284 \quad 292$

$328 \quad 338$

$346 \quad 355$

$347 \quad 355$

$359 \quad 366$

$387 \quad 400$

$387 \quad 407$

$444 \quad 456$

447
456
477

$465 \quad 483$

$616 \quad 631$

$633 \quad 647$

$70 \quad 82$

$83 \quad 95$

$83 \quad 107$

$96 \quad 107$

$169 \quad 180$

$181 \quad 196$

$\begin{array}{ll}205 & 219 \\ 274 & 284\end{array}$

$276 \quad 284$

$292 \quad 306$

$320 \quad 330$

$\begin{array}{ll}331 & 338 \\ 338 & 347\end{array}$

$339 \quad 347$

$339 \quad 348$

$351 \quad 358$

$\begin{array}{ll}379 & 392 \\ 379 & 399\end{array}$

429438

$436 \quad 448$

$439 \quad 448$

Page 58 of Table S-1-2 
Heat shock protein HSP 90-beta GN=HSP90AB1 HS90B_HUMAN $83.27 \quad 100.0 \% \quad 35$ Heat shock protein HSP 90-beta GN=HSP90AB1 HS90B_HUMAN $83.27 \quad 100.0 \% \quad 35$ Heat shock protein HSP 90-beta GN=HSP90AB1 HS90B_HUMAN $83.27 \quad 100.0 \% \quad 35$ Heat shock protein HSP 90-beta GN=HSP90AB1 HS90B HUMAN $83.27 \quad 100.0 \%$ Heat shock protein HSP 90-beta GN=HSP90AB1 HS90B_HUMAN $83.27 \quad 100.0 \%$ Heat shock protein HSP 90-beta GN=HSP90AB1 HS90B_HUMAN $83.27 \quad 100.0 \% 3$ Heat shock protein HSP 90-beta GN=HSP90AB1 HS90B_HUMAN $83.27 \quad 100.0 \%$ Heat shock protein HSP 90-beta GN=HSP90AB1 HS90B_HUMAN $83.27 \quad 100.0 \%$ Heat shock protein HSP 90-beta GN=HSP90AB1 HS90B HUMAN $83.27 \quad 100.0 \% \quad 35$ Heat shock protein HSP 90-beta GN=HSP90AB1 HS90B_HUMAN $83.27 \quad 100.0 \% \quad 35$ Heat shock protein HSP 90-beta GN=HSP90AB1 HS90B_HUMAN $83.27 \quad 100.0 \%$ Heat shock protein HSP 90-beta GN=HSP90AB1 HS90B HUMAN $83.27 \quad 100.0 \%$ Helicase-like transcription factor GN=HLTF HLTF_HUMAN $113.93 \quad 100.0 \%$ Helicase-like transcription factor GN=HLTF HLTF_HUMAN $113.93 \quad 100.0 \%$ Hermansky-Pudlak syndrome 6 protein GN=HPS6 HPS6_HUMAN $82.98 \quad 100.0 \%$ Hermansky-Pudlak syndrome 6 protein GN=HPS6 HPS6_HUMAN $82.98 \quad 100.0 \%$ Hermansky-Pudlak syndrome 6 protein GN=HPS6 HPS6 HUMAN $82.98 \quad 100.0 \%$ Heterochromatin protein 1-binding protein $3 \mathrm{GN}=\mathrm{HP} 1 \mathrm{BP} 3 \mathrm{HP} 1 \mathrm{~B} 3$ _HUMAN $61.21 \quad 100.0 \%$ Heterochromatin protein 1-binding protein $3 \mathrm{GN}=\mathrm{HP} 1 \mathrm{BP} 3 \mathrm{HP} 1 \mathrm{~B} 3$ _HUMAN $61.21 \quad 100.0 \%$ Heterochromatin protein 1-binding protein $3 \mathrm{GN}=\mathrm{HP} 1 \mathrm{BP} 3 \mathrm{HP} 1 \mathrm{~B} 3$ HUMAN $61.21 \quad 100.0 \%$ Heterochromatin protein 1-binding protein $3 \mathrm{GN}=\mathrm{HP} 1 \mathrm{BP} 3 \mathrm{HP} 1 \mathrm{~B} 3$ _HUMAN $61.21 \quad 100.0 \%$ Heterochromatin protein 1-binding protein $3 \mathrm{GN}=\mathrm{HP} 1 \mathrm{BP} 3 \mathrm{HP1B} 3$ HUMAN $61.21 \quad 100.0 \%$ Heterochromatin protein 1-binding protein $3 \mathrm{GN}=\mathrm{HP} 1 \mathrm{BP} 3 \mathrm{HP} 1 \mathrm{~B} 3$ _HUMAN $61.21 \quad 100.0 \%$ Heterochromatin protein 1-binding protein $3 \mathrm{GN}=\mathrm{HP} 1 \mathrm{BP} 3 \mathrm{HP} 1 \mathrm{~B} 3$ _HUMAN $61.21 \quad 100.0 \%$ Heterochromatin protein 1-binding protein $3 \mathrm{GN}=\mathrm{HP} 1 \mathrm{BP} 3 \mathrm{HP} 1 \mathrm{~B} 3$ HUMAN $61.21-100.0 \%$ Heterochromatin protein 1-binding protein $3 \mathrm{GN}=\mathrm{HP} 1 \mathrm{BP} 3 \mathrm{HP} 1 \mathrm{~B} 3$ _HUMAN $61.21 \quad 100.0 \%$ Heterogeneous nuclear ribonucleoprotein A/B GN=HNRNPAB ROAA_HUMAN $36.23 \quad 100.0 \%$ Heterogeneous nuclear ribonucleoprotein $\mathrm{A} / \mathrm{B}$ GN=HNRNPAB ROAA HUMAN $36.23 \quad 100.0 \%$ Heterogeneous nuclear ribonucleoprotein A/B GN=HNRNPAB ROAA_HUMAN $36.23 \quad 100.0 \%$ Heterogeneous nuclear ribonucleoprotein $\mathrm{A} / \mathrm{B}$ GN=HNRNPAB ROAA HUMAN $36.23 \quad 100.0 \%$ Heterogeneous nuclear ribonucleoprotein A/B GN=HNRNPAB ROAA_HUMAN $36.23 \quad 100.0 \%$ Heterogeneous nuclear ribonucleoprotein A/B GN=HNRNPAB ROAA_HUMAN $36.23 \quad 100.0 \%$ Heterogeneous nuclear ribonucleoprotein $\mathrm{A} 0 \mathrm{GN}=\mathrm{HNRNPA0} \mathrm{ROA} 0$ HUMAN $30.84 \quad 100.0 \%$ Heterogeneous nuclear ribonucleoprotein A0 GN=HNRNPA0 ROA0_HUMAN $30.84 \quad 100.0 \%$ Heterogeneous nuclear ribonucleoprotein A0 GN=HNRNPA0 ROA0_HUMAN $30.84 \quad 100.0 \%$ Heterogeneous nuclear ribonucleoprotein A0 GN=HNRNPA0 ROA0_HUMAN $30.84 \quad 100.0 \%$ Heterogeneous nuclear ribonucleoprotein A0 GN=HNRNPA0 ROA0_HUMAN 30.84 Heterogeneous nuclear ribonucleoprotein $\mathrm{Al}$ GN=HNRNPA1 ROA1_HUMAN 38.75 Heterogeneous nuclear ribonucleoprotein A1 GN=HNRNPA1 ROA1_HUMAN 38.75 Heterogeneous nuclear ribonucleoprotein A1 GN=HNRNPA1 ROA1_HUMAN 38.75 Heterogeneous nuclear ribonucleoprotein A1 GN=HNRNPA1 ROA1_HUMAN 38.75 Heterogeneous nuclear ribonucleoprotein A1 GN=HNRNPA1 ROA1_HUMAN 38.75 Heterogeneous nuclear ribonucleoprotein A1 GN=HNRNPA1 ROA1_HUMAN 38.7 Heterogeneous nuclear ribonucleoprotein A1 GN=HNRNPA1 ROA1_HUMAN 38.75 Heterogeneous nuclear ribonucleoprotein A1 GN=HNRNPA1 ROA1_HUMAN 38.75 Heterogeneous nuclear ribonucleoprotein A1 GN=HNRNPA1 ROA1_HUMAN 38.7 Heterogeneous nuclear ribonucleoprotein A3 GN=HNRNPA3 ROA3_HUMAN 39.60

3

3

9

$157 \quad 0.23 \% \quad 38.1 \%$ YHTSQSGDEM

$99.7 \% \quad 56.2$

$99.7 \% \quad 43.1$

25.0

56.2

$157 \quad 0.23 \% \quad 38.1 \%$ EQVANSAFVER

$157 \quad 0.23 \% \quad 38.1 \%$ EQVANSAFVERVR

$157 \quad 0.23 \% \quad 38.1 \%$ AKFENLCK

$157 \quad 0.23 \% \quad 38.1 \%$ LMKEILDK

$157 \quad 0.23 \% \quad 38.1 \%$ AQALRDNSTMGYMMAK

$157 \quad 0.23 \% \quad 38.1 \%$ DNSTMGYMMAK

$157 \quad 0.23 \% \quad 38.1 \%$ DNSTMGYMMAKK

$157 \quad 0.23 \% \quad 38.1 \%$ KHLEINPDHPIVETLR

$\begin{array}{lll}98.9 \% & 18.3\end{array}$

$\begin{array}{lll}95.5 \% & 15.3\end{array}$

$99.0 \% 25.9$

$157 \quad 0.23 \% \quad 38.1 \%$ HLEINPDHPIVETLR

$99.4 \% \quad 43.3$

$99.7 \% \quad 26.0$

$99.7 \% \quad 27.0$

$99.7 \% \quad 53.0$

$\begin{array}{lllll}0.00 \% & 2.8 \% & \text { VILDEGHAIRNPNAQQTK } & 99.0 \% & 18.3\end{array}$

$0.00 \% \quad 2.8 \%$ INEIRTLIDL

$0.01 \% \quad 4.8 \%$ LLSDLSAFGGAAR

$0.01 \% \quad 4.8 \%$ TLEPSGEASTSLGR

$0.01 \% \quad 4.8 \%$ KVLGGITAGK

$0.03 \% \quad 12.8 \%$ SGASVVAIRK

$0.03 \% \quad 12.8 \%$ YIIHKYPSLELER

$0.03 \% \quad 12.8 \%$ GKGASGSFVVVQK

$0.03 \% \quad 12.8 \%$ GASGSFVVVQK

$0.03 \% \quad 12.8 \%$ LCEPKEASYSLIR

$0.03 \% \quad 12.8 \%$ EASYSLIR

$0.03 \% \quad 12.8 \%$ KYVSQYYPK

$0.03 \% \quad 12.8 \%$ AVERGQLEQITGK

$0.03 \% \quad 12.8 \%$ GQLEQITGK

$0.03 \% \quad 13.9 \%$ DLKDYFTK

$0.03 \% \quad 13.9 \%$ FGEVVDCTIK

$99.7 \% \quad 44.3$

$99.7 \% \quad 56.2$

$99.7 \% \quad 43.0$

$99.5 \% \quad 20.7$

$99.7 \% \quad 60.5$

$99.7 \% \quad 27.3$

$99.7 \% \quad 59.3$

$99.7 \% \quad 39.4$

$99.7 \% \quad 29.7$

$99.0 \% \quad 37.6$

$99.7 \% \quad 57.5$

$99.7 \% \quad 53.3$

$99.3 \% \quad 21.1$

$\begin{array}{lll}95.5 \% & 16.1\end{array}$

$99.1 \% \quad 47.2$

$0.03 \% \quad 13.9 \%$ FGEVVDCTIKMDPNTGR $99.7 \% \quad 37.5$

$0.03 \% \quad 13.9 \%$ VAQPKEVYQQQQYGSGGR $\quad 99.7 \% \quad 49.3$

$0.03 \% \quad 13.9 \%$ EVYQQQQYGSGGR

$99.7 \% \quad 43.8$

$\begin{array}{lllll}0.03 \% & 13.9 \% & \text { EVYQQQQYGSGGRGNR } & 99.4 \% & 21.3\end{array}$

$0.03 \% \quad 21.0 \%$ LFIGGLNVQTSESGLR

$99.7 \% 73.6$

$0.03 \% \quad 21.0 \%$ AEIIADKQSGK

$99.7 \% \quad 38.8$

$0.03 \% \quad 21.0 \%$ GFGFVYFQNHDAADKAAVVK $\quad 99.7 \% \quad 35.4$

$0.03 \% \quad 21.0 \%$ AVPKEDIYSGGGGGGSR $\quad 99.7 \% \quad 44.6$

$0.03 \% \quad 21.0 \%$ EDIYSGGGGGGSR

$0.10 \% \quad 31.5 \%$ SESPKEPEQLR

$0.10 \% \quad 31.5 \%$ LFIGGLSFETTDESLR

$0.10 \% \quad 31.5 \%$ EDSQRPGAHLTVK

$97.4 \% \quad 15.7$

$99.7 \% \quad 45.8$

$99.7 \% \quad 48.8$

$99.7 \% \quad 36.8$

$0.10 \% \quad 31.5 \%$ EDSQRPGAHLTVKK

$99.7 \% \quad 33.2$

$99.6 \% \quad 26.0$

$0.10 \% \quad 31.5 \%$ IEVIEIMTDR

$99.7 \% 31.6$

$0.10 \% \quad 31.5 \%$ YHTVNGHNCEVR

$99.7 \% \quad 31.1$

$0.10 \% \quad 31.5 \%$ SSGPYGGGGQYFAKPR $\quad 99.7 \% \quad 59.7$

$0.10 \% \quad 31.5 \%$ NQGGYGGSSSSSSYGSGR $\quad 99.7 \% \quad 70.6$

$0.02 \% \quad 9.3 \%$ EDSVKPGAHLTVK
2192.94

1160.58

2391.18

1249.62

1504.79

1009.51

989.57

1787.82

1264.50

1376.60

1911.04

1782.95

2004.06

1199.70

1277.68

1404.70

943.59

987.59

1660.91

1263.71

1078.59

1565.80

938.49

1175.61

1428.78

973.53

1029.53

1167.57

1938.91

2023.00

1499.69

1826.85

1690.9

1159.63

2184.09

1606.78

1211.53

1299.65

1784.91

1437.74

1565.84

1234.64

2281.15

1485.67

1628.78

1694.70

1380.75

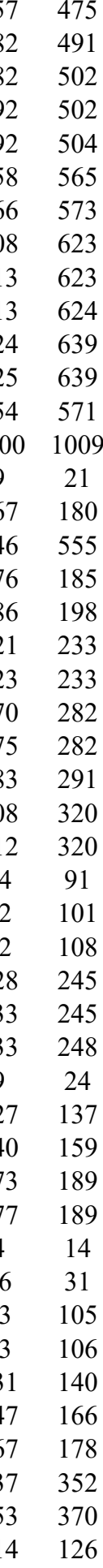

Page 59 of Table S-1-2 
Heterogeneous nuclear ribonucleoprotein $\mathrm{A} 3 \mathrm{GN}=\mathrm{HNRNPA} 3$ ROA3_HUMAN $39.60 \quad 100.0 \%$ Heterogeneous nuclear ribonucleoprotein D0 GN=HNRNPD HNRPD_HUMAN $38.43 \quad 100.0 \%$ Heterogeneous nuclear ribonucleoprotein D0 GN=HNRNPD HNRPD_HUMAN $38.43 \quad 100.0 \%$ Heterogeneous nuclear ribonucleoprotein D0 GN=HNRNPD HNRPD_HUMAN $38.43 \quad 100.0 \%$ Heterogeneous nuclear ribonucleoprotein D0 GN=HNRNPD HNRPD_HUMAN $38.43 \quad 100.0 \%$ Heterogeneous nuclear ribonucleoprotein D0 GN=HNRNPD HNRPD_HUMAN $38.43 \quad 100.0 \%$ Heterogeneous nuclear ribonucleoprotein D0 GN=HNRNPD HNRPD_HUMAN $38.43 \quad 100.0 \%$ Heterogeneous nuclear ribonucleoprotein D-like GN=HNRNPDL HNRDL_HUMAN $46.44 \quad 100.0 \%$ Heterogeneous nuclear ribonucleoprotein D-like GN=HNRNPDL HNRDL_HUMAN $46.44 \quad 100.0 \%$ Heterogeneous nuclear ribonucleoprotein D-like GN=HNRNPDL HNRDL_HUMAN $46.44 \quad 100.0 \%$ Heterogeneous nuclear ribonucleoprotein D-like GN=HNRNPDL HNRDL_HUMAN $46.44 \quad 100.0 \%$ Heterogeneous nuclear ribonucleoprotein D-like GN=HNRNPDL HNRDL_HUMAN $46.44 \quad 100.0 \%$ Heterogeneous nuclear ribonucleoprotein D-like GN=HNRNPDL HNRDL_HUMAN $46.44 \quad 100.0 \%$ Heterogeneous nuclear ribonucleoprotein F GN=HNRNPF HNRPF_HUMAN $45.67 \quad 100.0 \%$ Heterogeneous nuclear ribonucleoprotein F GN=HNRNPF HNRPF_HUMAN $45.67 \quad 100.0 \%$ Heterogeneous nuclear ribonucleoprotein F GN=HNRNPF HNRPF_HUMAN $45.67 \quad 100.0 \%$ Heterogeneous nuclear ribonucleoprotein F GN=HNRNPF HNRPF_HUMAN $45.67 \quad 100.0 \%$ Heterogeneous nuclear ribonucleoprotein F GN=HNRNPF HNRPF_HUMAN $45.67 \quad 100.0 \%$ Heterogeneous nuclear ribonucleoprotein F GN=HNRNPF HNRPF_HUMAN $45.67 \quad 100.0 \%$ Heterogeneous nuclear ribonucleoprotein F GN=HNRNPF HNRPF_HUMAN $45.67 \quad 100.0 \%$ Heterogeneous nuclear ribonucleoprotein $\mathrm{H}$ GN=HNRNPH1 HNRH1_HUMAN $49.23 \quad 100.0 \%$ Heterogeneous nuclear ribonucleoprotein $\mathrm{H}$ GN=HNRNPH1 HNRH1_HUMAN $49.23 \quad 100.0 \%$ Heterogeneous nuclear ribonucleoprotein H GN=HNRNPH1 HNRH1_HUMAN $49.23 \quad 100.0 \%$ Heterogeneous nuclear ribonucleoprotein H GN=HNRNPH1 HNRH1_HUMAN $49.23 \quad 100.0 \%$ Heterogeneous nuclear ribonucleoprotein $\mathrm{H}$ GN=HNRNPH1 HNRH1_HUMAN $49.23 \quad 100.0 \%$ Heterogeneous nuclear ribonucleoprotein $\mathrm{H}$ GN=HNRNPH1 HNRH1_HUMAN $49.23 \quad 100.0 \%$ Heterogeneous nuclear ribonucleoprotein H GN=HNRNPH1 HNRH1_HUMAN $49.23 \quad 100.0 \%$ Heterogeneous nuclear ribonucleoprotein $\mathrm{H}$ GN=HNRNPH1 HNRH1_HUMAN $49.23 \quad 100.0 \%$ Heterogeneous nuclear ribonucleoprotein $\mathrm{H}$ GN=HNRNPH1 HNRH1_HUMAN $49.23 \quad 100.0 \%$ Heterogeneous nuclear ribonucleoprotein $\mathrm{H}$ GN=HNRNPH1 HNRH1_HUMAN $49.23 \quad 100.0 \%$ Heterogeneous nuclear ribonucleoprotein H GN=HNRNPH1 HNRH1_HUMAN $49.23 \quad 100.0 \%$ Heterogeneous nuclear ribonucleoprotein H GN=HNRNPH1 HNRH1_HUMAN $49.23 \quad 100.0 \%$ Heterogeneous nuclear ribonucleoprotein $\mathrm{H} 3 \mathrm{GN}=\mathrm{HNRNPH} 3$ HNRH3_HUMAN $36.93 \quad 100.0 \%$ Heterogeneous nuclear ribonucleoprotein $\mathrm{H} 3 \mathrm{GN}=\mathrm{HNRNPH} 3$ HNRH3_HUMAN $36.93 \quad 100.0 \%$ Heterogeneous nuclear ribonucleoprotein $\mathrm{H} 3 \mathrm{GN}=\mathrm{HNRNPH} 3$ HNRH3_HUMAN $36.93 \quad 100.0 \%$ Heterogeneous nuclear ribonucleoprotein $\mathrm{H} 3 \mathrm{GN}=\mathrm{HNRNPH} 3$ HNRH3_HUMAN $36.93 \quad 100.0 \%$ Heterogeneous nuclear ribonucleoprotein K GN=HNRNPK HNRPK_HUMAN $50.98 \quad 100.0 \%$ Heterogeneous nuclear ribonucleoprotein K GN=HNRNPK HNRPK_HUMAN $50.98 \quad 100.0 \%$ Heterogeneous nuclear ribonucleoprotein K GN=HNRNPK HNRPK_HUMAN $50.98 \quad 100.0 \%$ Heterogeneous nuclear ribonucleoprotein K GN=HNRNPK HNRPK_HUMAN $50.98 \quad 100.0 \%$ Heterogeneous nuclear ribonucleoprotein K GN=HNRNPK HNRPK_HUMAN $50.98 \quad 100.0 \%$ Heterogeneous nuclear ribonucleoprotein K GN=HNRNPK HNRPK_HUMAN $50.98 \quad 100.0 \%$ Heterogeneous nuclear ribonucleoprotein K GN=HNRNPK HNRPK_HUMAN $50.98 \quad 100.0 \%$ Heterogeneous nuclear ribonucleoprotein K GN=HNRNPK HNRPK_HUMAN $50.98 \quad 100.0 \%$ Heterogeneous nuclear ribonucleoprotein K GN=HNRNPK HNRPK_HUMAN $50.98 \quad 100.0 \%$ $\begin{array}{llll}\text { Heterogeneous nuclear ribonucleoprotein K GN=HNRNPK HNRPK_HUMAN } & 50.98 & 100.0 \% \\ \text { Heterogeneous nuclear ribonucleoprotein K GN=HNRNPK HNRPK_HUMAN } & 50.98 & 100.0 \%\end{array}$

17

7

17

$\begin{array}{ll}7 & 22 \\ 7 & 22 \\ 7 & 22\end{array}$

$17-22$

(1)

$0.02 \% \quad 9.3 \% \quad$ SSGSPYGGGYGSGGGSGGYGSR $\quad 99.7 \% \quad 59.7$ $0.02 \% \quad 16.6 \%$ IDASKNEEDEGHSNSSPR $0.02 \% \quad 16.6 \%$ DLKDYFSK

$0.02 \% \quad 16.6 \%$ FGEVVDCTLK

$0.02 \% \quad 16.6 \%$ FGEVVDCTLKLDPITGR

$0.02 \% \quad 16.6 \%$ IFVGGLSPDTPEEK

$0.02 \% \quad 16.6 \%$ IFVGGLSPDTPEEKIR

$0.02 \% \quad 15.2 \%$ QLAPLLPSLAPSSAR

$0.02 \% \quad 15.2 \%$ DLTEYLSR

$0.02 \% \quad 15.2 \%$ FGEVVDCTIK

$0.02 \% \quad 15.2 \%$ FGEVVDCTIKTDPVTGR

$0.02 \% \quad 15.2 \%$ GFCFITYTDEEPVKK

$0.02 \% \quad 15.2 \%$ VAQPKEVYR

$\begin{array}{lll}99.7 \% & 43.8\end{array}$

$96.7 \% \quad 15.5$

$99.1 \% \quad 47.2$

$99.7 \% \quad 34.5$

$99.7 \% \quad 59.0$

$99.4 \% \quad 26.0$

$98.3 \% 19.0$

$99.0 \% 25.6$

$99.1 \% \quad 47.2$

$99.7 \% \quad 59.5$

$99.7 \% \quad 46.6$

$98.8 \% \quad 22.3$

22.2\% HSGPNSADSANDGFVR $\quad 99.7 \% \quad 53.0$

$0.02 \% \quad 22.2 \%$ HSGPNSADSANDGFVRLR $\quad 99.7 \% 36.8$

$0.02 \% \quad 22.2 \%$ ITGEAFVQFASQELAEK $\quad 99.7 \% \quad 44.7$

$0.02 \% \quad 22.2 \%$ YIEVFKSSQEEVR

$99.7 \% \quad 59.2$

$\begin{array}{lllll}0.02 \% & 22.2 \% & \text { FMSVQRPGPYDRPGTAR } & 98.3 \% & 16.9\end{array}$

$0.02 \% \quad 22.2 \%$ ATENDIYNFFSPLNPVR

$0.02 \% \quad 22.2 \%$ VHIEIGPDGR

$0.09 \% \quad 27.8 \%$ GLPWSCSADEVQR

$0.09 \% \quad 27.8 \%$ FFSDCKIQNGAQGIR

$99.7 \% \quad 42.3$

$99.7 \% 36.6$

$99.7 \% \quad 33.4$

$\begin{array}{lll}98.7 \% & 29.9\end{array}$

$0.09 \% \quad 27.8 \%$ IQNGAQGIR

$\begin{array}{llll}0.09 \% & 27.8 \% & \text { HTGPNSPDTANDGFVR } \quad 99.7 \% & 61.9\end{array}$

$0.09 \% \quad 27.8 \%$ HTGPNSPDTANDGFVRLR $\quad 99.7 \% \quad 30.2$

$\begin{array}{lllll}0.09 \% & 27.8 \% & \text { STGEAFVQFASQEIAEK } \quad 99.7 \% & 43.3\end{array}$

$0.09 \% \quad 27.8 \%$ STGEAFVQFASQEIAEKALK $96.7 \% \quad 15.4$

$0.09 \% \quad 27.8 \%$ IGHRYIEIFK

$99.7 \% 29.8$

$99.6 \% \quad 23.3$

$0.09 \% \quad 27.8 \%$ YIEIFKSSR

$99.7 \% \quad 51.5$

$\begin{array}{llllll}0.09 \% & 27.8 \% & \text { YGDGGSTFQSTTGHCVHMR } & 99.7 \% & 51.5 \\ 0.09 \% & 27.8 \% & \text { ATENDIYNFFSPLNPVR } & 99.7 \% & 60.8\end{array}$

$0.09 \% \quad 27.8 \%$ VHIEIGPDGR

$0.02 \% \quad 16.2 \%$ HNGPNDASDGTVR

$0.02 \% \quad 16.2 \%$ STGEAFVQFASK

$0.02 \% \quad 16.2 \%$ ATENDIANFFSPLNPIR

$0.02 \% \quad 16.2 \%$ DGMDNQGGYGSVGR

$0.07 \% \quad 32.0 \%$ RPAEDMEEEQAFKR

$0.07 \% \quad 32.0 \%$ SRNTDEMVELR

$\begin{array}{lll}99.7 \% & 42.3\end{array}$

$99.7 \% \quad 31.8$

$99.7 \% \quad 61.7$

$99.7 \% \quad 39.6$

$99.7 \% \quad 54.5$

$99.7 \% \quad 57.2$

$99.7 \% \quad 42.7$

$99.7 \% \quad 59.1$

$0.07 \% \quad 32.0 \%$ NTDEMVELR

$\begin{array}{ll}99.7 \% & 49.7\end{array}$

$\begin{array}{llll}0.07 \% & 32.0 \% & \text { TDYNASVSVPDSSGPER } \quad 99.7 \% \quad 65.7\end{array}$

$0.07 \% \quad 32.0 \%$ LLIHQSLAGGIIGVK

$0.07 \% \quad 32.0 \%$ LFQECCPHSTDR

$0.07 \% \quad 32.0 \%$ IILDLISESPIK

$0.07 \% \quad 32.0 \%$ IILDLISESPIKGR

$0.07 \% \quad 32.0 \%$ RDYDDMSPR

$99.7 \% \quad 39.0$

$99.7 \% 59.6$

$99.7 \% \quad 44.6$

$99.7 \% \quad 27.3$

$99.0 \% \quad 43.0$

59.7

43.8

15.5

0.0

$\begin{array}{ll}0 & 52.5\end{array}$

$\begin{array}{ll}0 & 22.8\end{array}$

\begin{tabular}{ll}
19.0 \\
\hline
\end{tabular}

15.8

$\begin{array}{ll}0.0 & 0.0\end{array}$

54.6

$\begin{array}{ll}25.0 & 44.9\end{array}$

$\begin{array}{ll}5.0 & 15.3\end{array}$

\begin{tabular}{ll}
52.7 \\
\hline
\end{tabular}

34.0

$\begin{array}{ll}.0 & 42.4 \\ 25.0 & 54.5\end{array}$

\begin{tabular}{ll}
54.5 \\
\hline
\end{tabular}

$\begin{array}{ll}.0 & 16.9\end{array}$

$\begin{array}{ll}5.0 & 60.8\end{array}$

$25.0 \quad 41.0$

$25.0 \quad 36.6$

$\begin{array}{ll}27.0 & 27.8\end{array}$

23.0

54.0
.0

$\begin{array}{ll}30.0 & 30.2\end{array}$

$\begin{array}{ll}3.0 & 43.3\end{array}$

$\begin{array}{ll}25.0 & 15.2\end{array}$

\begin{tabular}{ll}
29.4 \\
\hline
\end{tabular}

$\begin{array}{ll}5.0 & 23.3\end{array}$

$\begin{array}{ll} & 51.5\end{array}$

$25.0 \quad 60.8$

$25.0 \quad 41.0$

$25.0 \quad 25.4$

$25.0 \quad 56.2$

$\begin{array}{ll}25.0 & 39.6\end{array}$

$25.0 \quad 54.5$

$25.0 \quad 57.2$

$\begin{array}{ll}0.0 & 29.4\end{array}$

$\begin{array}{ll}5.0 & 43.7\end{array}$

$\begin{array}{lll}45.0 & 49.3 \quad 2\end{array}$

$\begin{array}{lll}25.0 & 65.7 & 2\end{array}$

$\begin{array}{lll}5.0 & 39.0 & 0 \\ 5.0 & 45.2 & 2\end{array}$

$\begin{array}{ccc}1910.79 & 355 & 376 \\ 1971.86 & 68 & 85 \\ 1015.51 & 112 & 119 \\ 1167.57 & 120 & 129 \\ 1919.99 & 120 & 136 \\ 1488.76 & 184 & 197 \\ 1757.94 & 184 & 199 \\ 1520.88 & 37 & 51 \\ 996.50 & 163 & 170 \\ 1167.57 & 171 & 180 \\ 1893.94 & 171 & 187 \\ 1833.87 & 275 & 289 \\ 1089.61 & 307 & 315 \\ 1630.72 & 99 & 114 \\ 1899.91 & 99 & 116 \\ 1867.94 & 151 & 167 \\ 1613.82 & 180 & 192 \\ 1934.97 & 201 & 217 \\ 1996.98 & 300 & 316 \\ 1092.58 & 317 & 326 \\ 1504.69 & 17 & 29 \\ 1740.85 & 30 & 44 \\ 956.53 & 36 & 44 \\ 1684.77 & 99 & 114 \\ 1953.95 & 99 & 116 \\ 1841.89 & 151 & 167 \\ 2154.11 & 151 & 170 \\ 1275.72 & 176 & 185 \\ 1142.62 & 180 & 188 \\ 2097.89 & 276 & 294 \\ 1996.98 & 300 & 316 \\ 1092.58 & 317 & 326 \\ 1339.60 & 7 & 19 \\ 1271.63 & 56 & 67 \\ 1918.97 & 206 & 222 \\ 1428.58 & 288 & 301 \\ 1735.81 & 22 & 35 \\ 1349.65 & 36 & 46 \\ 1106.51 & 38 & 46 \\ 2121.02 & 67 & 86 \\ 1780.80 & 70 & 86 \\ 1518.94 & 149 & 163 \\ 1549.65 & 180 & 191 \\ 1340.80 & 208 & 219 \\ 1553.93 & 208 & 221 \\ 1154.49 & 278 & 286 \\ 998.39 & 279 & 286 \\ & & \end{array}$

Page 60 of Table S-1-2 
Heterogeneous nuclear ribonucleoprotein K GN=HNRNPK HNRPK_HUMAN $50.98 \quad 100.0 \% \quad 17$ Heterogeneous nuclear ribonucleoprotein K GN=HNRNPK HNRPK_HUMAN $50.98 \quad 100.0 \% \quad 17$ Heterogeneous nuclear ribonucleoprotein K GN=HNRNPK HNRPK_HUMAN $50.98 \quad 100.0 \% \quad 17$ Heterogeneous nuclear ribonucleoprotein K GN=HNRNPK HNRPK_HUMAN $50.98 \quad 100.0 \% \quad 17$ $\begin{array}{llll}\text { Heterogeneous nuclear ribonucleoprotein K GN=HNRNPK HNRPK_HUMAN } & 50.98 & 100.0 \% & 17\end{array}$ Heterogeneous nuclear ribonucleoprotein K GN=HNRNPK HNRPK_HUMAN $50.98 \quad 100.0 \% \quad 17$ Heterogeneous nuclear ribonucleoprotein L GN=HNRNPL HNRPL_HUMAN $64.13 \quad 100.0 \% \quad 12$ Heterogeneous nuclear ribonucleoprotein L GN=HNRNPL HNRPL_HUMAN $64.13 \quad 100.0 \% \quad 12$ Heterogeneous nuclear ribonucleoprotein L GN=HNRNPL HNRPL HUMAN $64.13 \quad 100.0 \%$ Heterogeneous nuclear ribonucleoprotein L GN=HNRNPL HNRPL_HUMAN $64.13 \quad 100.0 \% \quad 12$ Heterogeneous nuclear ribonucleoprotein L GN=HNRNPL HNRPL_HUMAN $64.13 \quad 100.0 \% \quad 12$ Heterogeneous nuclear ribonucleoprotein L GN=HNRNPL HNRPL_HUMAN $64.13 \quad 100.0 \% \quad 12$ $\begin{array}{llll}\text { Heterogeneous nuclear ribonucleoprotein L GN=HNRNPL HNRPL_HUMAN } & 64.13 & 100.0 \% & 12\end{array}$ Heterogeneous nuclear ribonucleoprotein L GN=HNRNPL HNRPL_HUMAN $64.13 \quad 100.0 \%$ $\begin{array}{llll}\text { Heterogeneous nuclear ribonucleoprotein L GN=HNRNPL HNRPL_HUMAN } & 64.13 & 100.0 \% & 12\end{array}$ Heterogeneous nuclear ribonucleoprotein L GN=HNRNPL HNRPL_HUMAN $64.13 \quad 100.0 \% \quad 12$ Heterogeneous nuclear ribonucleoprotein L GN=HNRNPL HNRPL_HUMAN $64.13 \quad 100.0 \% \quad 12$ Heterogeneous nuclear ribonucleoprotein L GN=HNRNPL HNRPL_HUMAN $64.13 \quad 100.0 \% \quad 12$ Heterogeneous nuclear ribonucleoprotein M GN=HNRNPM HNRPM_HUMAN $77.52 \quad 100.0 \% \quad 54$ Heterogeneous nuclear ribonucleoprotein M GN=HNRNPM HNRPM_HUMAN $77.52 \quad 100.0 \% 54$ Heterogeneous nuclear ribonucleoprotein M GN=HNRNPM HNRPM_HUMAN $77.52 \quad 100.0 \% \quad 54$ Heterogeneous nuclear ribonucleoprotein M GN=HNRNPM HNRPM_HUMAN $77.52 \quad 100.0 \% \quad 54$ Heterogeneous nuclear ribonucleoprotein M GN=HNRNPM HNRPM_HUMAN $77.52 \quad 100.0 \% \quad 54$ Heterogeneous nuclear ribonucleoprotein M GN=HNRNPM HNRPM_HUMAN $77.52 \quad 100.0 \% \quad 54$ Heterogeneous nuclear ribonucleoprotein M GN=HNRNPM HNRPM_HUMAN $77.52 \quad 100.0 \% \quad 54$ Heterogeneous nuclear ribonucleoprotein M GN=HNRNPM HNRPM_HUMAN $77.52 \quad 100.0 \% \quad 54$ Heterogeneous nuclear ribonucleoprotein M GN=HNRNPM HNRPM_HUMAN $77.52 \quad 100.0 \% \quad 54$ Heterogeneous nuclear ribonucleoprotein M GN=HNRNPM HNRPM_HUMAN $77.52 \quad 100.0 \% \quad 54$ Heterogeneous nuclear ribonucleoprotein M GN=HNRNPM HNRPM_HUMAN $77.52 \quad 100.0 \% \quad 54$ Heterogeneous nuclear ribonucleoprotein M GN=HNRNPM HNRPM_HUMAN $77.52 \quad 100.0 \% \quad 54$ Heterogeneous nuclear ribonucleoprotein M GN=HNRNPM HNRPM_HUMAN $77.52 \quad 100.0 \% \quad 54$ Heterogeneous nuclear ribonucleoprotein M GN=HNRNPM HNRPM_HUMAN $77.52 \quad 100.0 \% \quad 54$ Heterogeneous nuclear ribonucleoprotein M GN=HNRNPM HNRPM HUMAN $77.52 \quad 100.0 \% \quad 54$ Heterogeneous nuclear ribonucleoprotein M GN=HNRNPM HNRPM_HUMAN $77.52 \quad 100.0 \% \quad 54$ Heterogeneous nuclear ribonucleoprotein M GN=HNRNPM HNRPM_HUMAN $77.52 \quad 100.0 \% \quad 54$ Heterogeneous nuclear ribonucleoprotein M GN=HNRNPM HNRPM_HUMAN $77.52 \quad 100.0 \% \quad 54$ Heterogeneous nuclear ribonucleoprotein M GN=HNRNPM HNRPM_HUMAN $77.52 \quad 100.0 \% \quad 54$ Heterogeneous nuclear ribonucleoprotein M GN=HNRNPM HNRPM HUMAN $77.52 \quad 100.0 \% \quad 54$ Heterogeneous nuclear ribonucleoprotein M GN=HNRNPM HNRPM_HUMAN $77.52 \quad 100.0 \% \quad 54$ Heterogeneous nuclear ribonucleoprotein M GN=HNRNPM HNRPM_HUMAN $77.52 \quad 100.0 \% \quad 54$ Heterogeneous nuclear ribonucleoprotein M GN=HNRNPM HNRPM_HUMAN $77.52 \quad 100.0 \% \quad 54$ Heterogeneous nuclear ribonucleoprotein M GN=HNRNPM HNRPM_HUMAN $77.52 \quad 100.0 \% \quad 54$ Heterogeneous nuclear ribonucleoprotein M GN=HNRNPM HNRPM_HUMAN $77.52 \quad 100.0 \% \quad 54$ Heterogeneous nuclear ribonucleoprotein M GN=HNRNPM HNRPM_HUMAN $77.52 \quad 100.0 \%$ Heterogeneous nuclear ribonucleoprotein M GN=HNRNPM HNRPM_HUMAN $77.52 \quad 100.0 \% \quad 54$ Heterogeneous nuclear ribonucleoprotein M GN=HNRNPM HNRPM_HUMAN $77.52 \quad 100.0 \%$ Heterogeneous nuclear ribonucleoprotein M GN=HNRNPM HNRPM_HUMAN $77.52 \quad 100.0 \% \quad 54$

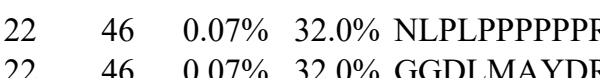

$99.7 \% \quad 25.9 \quad 25.0 \quad 25.0$

$99.7 \% \quad 40.0 \quad 25.0 \quad 37.2$

$0.07 \% \quad 32.0 \%$ GGDLMAYDRR

$\begin{array}{llll}99.7 \% & 32.5 & 25.0 & 20.5\end{array}$

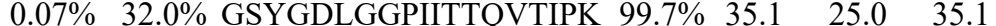

$0.07 \% \quad 32.0 \%$ DLAGSIIGK

$0.07 \% \quad 32.0 \%$ DLAGSIIGKGGQR

$\begin{array}{llll}99.3 \% & 33.2 & 25.0 & 9.0\end{array}$

$\begin{array}{llll}99.7 \% & 64.2 & 25.0 & 57.8\end{array}$

$99.7 \% \quad 60.4 \quad 25.0 \quad 57.6$

$\begin{array}{llll}99.7 \% & 40.5 & 25.0 & 26.4\end{array}$

$0.06 \% \quad 25.8 \%$ ISRPGDSDDSR

$\begin{array}{ll}99.7 \% & 83.7\end{array}$

$99.7 \% \quad 63.5$

$0.06 \% \quad 25.8 \%$ ASLNGADIYSGCCTLK

$0.06 \% 25.8 \%$ IEYAKPTR

$0.06 \% 25.8 \%$ MGPPVGGHR

$99.0 \% \quad 31.0$

$99.7 \% \quad 32.4$

$99.7 \% \quad 51.3$

$0.06 \% 25.8 \%$ VFNVFCLYGNVEK

$99.7 \% \quad 31.0$

$99.7 \% \quad 65.0$

$99.7 \% \quad 54.2$

$99.5 \% \quad 21.3$

$99.7 \% \quad 42.7$

$99.7 \% \quad 33.8$

$99.7 \% \quad 61.6$

$0.06 \% \quad 25.8 \%$ NPNC

$0.06 \% \quad 25.8 \%$ LCFSTAQHAS

$91361 \quad 0.53 \% \quad 64.2 \%$ GGNRFEPYANPTK

$91 \quad 361 \quad 0.53 \% \quad 64.2 \%$ AFITNIPFDVK

$99.7 \% \quad 57.1$

$99.7 \% \quad 45.9$

$99.0 \% \quad 38.1$

$99.7 \% \quad 32.8$

$98.6 \% 28.0$

$99.7 \% \quad 51.8$

$99.7 \% \quad 63.1$

$99.7 \% \quad 59.7$

$99.7 \% \quad 33.6$

$99.0 \% \quad 35.7$

$91361 \quad 0.53 \% \quad 64.2 \%$ ADILEDKDGK

$91 \quad 361 \quad 0.53 \% \quad 64.2 \%$ MDERALPK

$91361 \quad 0.53 \% \quad 64.2 \%$ GIGMGNIGPAGMGMEGIGFGINK $\quad 99.7 \% \quad 57.2$

$91361 \quad 0.53 \% \quad 64.2 \%$ MGGMEGPFGGGMENMGR

$9.7 \% 51.0$

$99.7 \% \quad 63.7$

$91 \quad 361 \quad 0.53 \% \quad 64.2 \%$ FGSGMNMGR

$91 \quad 361 \quad 0.53 \% \quad 64.2 \%$ FGSGMNMGRINEILSNALK

$91 \quad 361 \quad 0.53 \% \quad 64.2 \%$ INEILSNALK

$91361 \quad 0.53 \% \quad 64.2 \%$ INEILSNALKR

$99.7 \% 65.6$

$99.7 \% 53.9$

$\begin{array}{lllllll}91 & 361 & 0.53 \% & 64.2 \% & \text { GEIIAKQGGGGGGGSVPGIER } & 99.7 \% & 33.3\end{array}$

$91361 \quad 0.53 \% \quad 64.2 \%$ QGGGGGGGSVPGIER

$91361 \quad 0.53 \% \quad 64.2 \%$ QGGGGGGGSVPGIERMGPGIDR

$91361 \quad 0.53 \% \quad 64.2 \%$ MGPGIDRLGGAGMER

$91 \quad 361 \quad 0.53 \% \quad 64.2 \%$ MGAGLGHGMDR

$99.7 \% 43$.

$99.7 \% \quad 59.6$

$99.7 \% \quad 28.3$

$91 \quad 361 \quad 0.53 \% \quad 64.2 \%$ MGAGLGHGMDRVGSEIER

$91361 \quad 0.53 \% \quad 64.2 \%$ VGSEIERMGLVMDR

$91 \quad 361 \quad 0.53 \% \quad 64.2 \%$ MGLVMDRMGSVER

$91 \quad 361 \quad 0.53 \% \quad 64.2 \%$ MGSVERMGSGIER

$91 \quad 361 \quad 0.53 \% \quad 64.2 \%$ MGPLGLDHMASSIER

$91 \quad 361 \quad 0.53 \% \quad 64.2 \%$ MGQTMERIGSGVER $\begin{array}{ll}99.7 \% & 33.5 \\ 99.7 \% & 33.4\end{array}$

$99.5 \% \quad 20.8$

$99.7 \% \quad 33.3$

$99.7 \% \quad 58.6$

$99.7 \% \quad 41.9$

0
0
0
0
0
0
0
2
0
0
0
0
0
3
2
0
0
0
1
0
0
1
0
2
0
0
6
0
0
0
0
0
0
0
3
0
0
1
1
0
0
0
0
0
0
0
0
0
0
0
0
0
0
0
0
0
0
0
0

1013.44

1153.54

1917.03

873.50

1271.71

1298.61

1204.56

1865.88

1729.79

977.54

907.46

1588.78

1899.86

1634.81

1362.68

1263.64

1121.50

1450.71

1264.69

1768.87

1996.01

909.45

1719.99

994.58

1426.76

1434.81

1193.63

1103.56

959.50

2178.05

1778.66

956.41

2084.03

1114.65

1270.75

1895.99

1284.63

2026.97

1516.74

1117.49

1887.88

1591.79

1512.70

1424.66

1613.78

1550.74 $\begin{array}{cc} & 316 \\ 17 & 325 \\ 17 & 326 \\ 78 & 396 \\ 97 & 405 \\ 97 & 409 \\ 7 & 59 \\ 79 & 189 \\ 30 & 246 \\ 49 & 264 \\ 65 & 272 \\ 45 & 353 \\ 99 & 411 \\ 17 & 434 \\ 35 & 448 \\ 82 & 493 \\ 69 & 579 \\ 80 & 589 \\ 7 & 69 \\ 3 & 83 \\ 5 & 110 \\ 5 & 112 \\ 13 & 120 \\ 28 & 143 \\ 35 & 143 \\ 02 & 214 \\ 20 & 232 \\ 22 & 232 \\ 33 & 242 \\ 78 & 285 \\ 23 & 345 \\ 46 & 362 \\ 63 & 371 \\ 63 & 381 \\ 72 & 381 \\ 72 & 382 \\ 83 & 403 \\ 89 & 403 \\ 89 & 410 \\ 04 & 418 \\ 19 & 429 \\ 19 & 436 \\ 30 & 443 \\ 37 & 449 \\ 44 & 456 \\ 57 & 471 \\ & 485 \\ \end{array}$

Page 61 of Table S-1-2 
Heterogeneous nuclear ribonucleoprotein M GN=HNRNPM HNRPM_HUMAN $77.52 \quad 100.0 \% \quad 54$ Heterogeneous nuclear ribonucleoprotein M GN=HNRNPM HNRPM_HUMAN $77.52 \quad 100.0 \%$ Heterogeneous nuclear ribonucleoprotein M GN=HNRNPM HNRPM_HUMAN $77.52 \quad 100.0 \% \quad 54$ Heterogeneous nuclear ribonucleoprotein M GN=HNRNPM HNRPM_HUMAN $77.52 \quad 100.0 \%$ Heterogeneous nuclear ribonucleoprotein M GN=HNRNPM HNRPM_HUMAN $77.52 \quad 100.0 \% \quad 54$ Heterogeneous nuclear ribonucleoprotein M GN=HNRNPM HNRPM_HUMAN $77.52 \quad 100.0 \%$ Heterogeneous nuclear ribonucleoprotein M GN=HNRNPM HNRPM_HUMAN $77.52 \quad 100.0 \%$ Heterogeneous nuclear ribonucleoprotein M GN=HNRNPM HNRPM_HUMAN $77.52 \quad 100.0 \%$ Heterogeneous nuclear ribonucleoprotein M GN=HNRNPM HNRPM_HUMAN $77.52 \quad 100.0 \%$ Heterogeneous nuclear ribonucleoprotein M GN=HNRNPM HNRPM_HUMAN $77.52 \quad 100.0 \%$ Heterogeneous nuclear ribonucleoprotein M GN=HNRNPM HNRPM_HUMAN $77.52 \quad 100.0 \%$ Heterogeneous nuclear ribonucleoprotein M GN=HNRNPM HNRPM_HUMAN $77.52 \quad 100.0^{\circ}$ Heterogeneous nuclear ribonucleoprotein M GN=HNRNPM HNRPM_HUMAN $77.52 \quad 100.0 \%$ Heterogeneous nuclear ribonucleoprotein M GN=HNRNPM HNRPM_HUMAN $77.52 \quad 100.0 \%$ Heterogeneous nuclear ribonucleoprotein M GN=HNRNPM HNRPM_HUMAN $77.52 \quad 100.0 \%$ Heterogeneous nuclear ribonucleoprotein M GN=HNRNPM HNRPM_HUMAN $77.52 \quad 100.0 \%$ Heterogeneous nuclear ribonucleoprotein M GN=HNRNPM HNRPM_HUMAN $77.52100 .0 \%$ Heterogeneous nuclear ribonucleoprotein M GN=HNRNPM HNRPM_HUMAN 77.52 $100.0 \%$ Heterogeneous nuclear ribonucleoprotein M GN=HNRNPM HNRPM_HUMAN $77.52 \quad 100.0 \%$ 管 Heterogeneous nuclear ribonucleoprotein M GN=HNRNPM HNRPM_HUMAN 77.52 $100.0 \%$ Heterogeneous nuclear ribonucleoprotein M GN=HNRNPM HNRPM HUMAN 77.52 100.0\% Heterogeneous nuclear ribonucleoprotein M GN=HNRNPM HNRPM_HUMAN $77.52 \quad 100.0 \%$ Heterogeneous nuclear ribonucleoprotein M GN=HNRNPM HNRPM_HUMAN $77.52 \quad 100.0 \%$ Heterogeneous nuclear ribonucleoprotein M GN=HNRNPM HNRPM_HUMAN $77.52 \quad 100.0 \%$ Heterogeneous nuclear ribonucleoprotein Q GN=SYNCRIP HNRPQ_HUMAN $69.60 \quad 100.0 \%$ Heterogeneous nuclear ribonucleoprotein Q GN=SYNCRIP HNRPQ_HUMAN $69.60 \quad 100.0 \%$ Heterogeneous nuclear ribonucleoprotein Q GN=SYNCRIP HNRPQ_HUMAN $69.60 \quad 100.0 \%$ Heterogeneous nuclear ribonucleoprotein Q GN=SYNCRIP HNRPQ_HUMAN $69.60 \quad 100.0 \%$ Heterogeneous nuclear ribonucleoprotein Q GN=SYNCRIP HNRPQ HUMAN $69.60 \quad 100.0 \%$ Heterogeneous nuclear ribonucleoprotein Q GN=SYNCRIP $\quad$ HNRPQ_HUMAN $69.60 \quad 100.0 \%$ Heterogeneous nuclear ribonucleoprotein Q GN=SYNCRIP HNRPQ_HUMAN $69.60 \quad 100.0 \%$ (100.0\% $\begin{array}{llll}\text { Heterogeneous nuclear ribonucleoprotein Q GN=SYNCRIP } & \text { HNRPQ_HUMAN } 69.60 \quad 100.0 \%\end{array}$ Heterogeneous nuclear ribonucleoprotein Q GN=SYNCRIP HNRPQ_HUMAN $69.60 \quad 100.0 \%$ Heterogeneous nuclear ribonucleoprotein Q GN=SYNCRIP HNRPQ_HUMAN $69.60 \quad 100.0 \%$ Heterogeneous nuclear ribonucleoprotein R GN=HNRNPR HNRPR_HUMAN $70.94 \quad 100.0 \%$ Heterogeneous nuclear ribonucleoprotein R GN=HNRNPR HNRPR_HUMAN $70.94 \quad 100.0 \%$ Heterogeneous nuclear ribonucleoprotein R GN=HNRNPR HNRPR_HUMAN $70.94 \quad 100.0 \%$ Heterogeneous nuclear ribonucleoprotein R GN=HNRNPR HNRPR_HUMAN $70.94 \quad 100.0 \%$ Heterogeneous nuclear ribonucleoprotein R GN=HNRNPR HNRPR_HUMAN $70.94 \quad 100.0 \%$ Heterogeneous nuclear ribonucleoprotein R GN=HNRNPR HNRPR_HUMAN $70.94 \quad 100.0 \%$ Heterogeneous nuclear ribonucleoprotein R GN=HNRNPR HNRPR HUMAN $70.94100 .0 \%$ Heterogeneous nuclear ribonucleoprotein R GN=HNRNPR HNRPR_HUMAN $70.94 \quad 100.0 \%$ Heterogeneous nuclear ribonucleoprotein R GN=HNRNPR HNRPR_HUMAN $70.94 \quad 100.0 \%$ Heterogeneous nuclear ribonucleoprotein $\mathrm{R}$ GN=HNRNPR HNRPR_HUMAN $70.94 \quad 100.0 \%$ Heterogeneous nuclear ribonucleoprotein R GN=HNRNPR HNRPR_HUMAN $70.94 \quad 100.0 \%$

91

91

(1)

(1)

4

4

44

54

$361 \quad 0.53 \% \quad 64.2 \%$ MAAPIDRVGQTIER

$361 \quad 0.53 \% \quad 64.2 \%$ VGQTIERMGSGVER

$361 \quad 0.53 \% \quad 64.2 \%$ MGPAIERMGLSMER

$361 \quad 0.53 \% \quad 64.2 \%$ MGLSMERMVPAGMGAG

$\begin{array}{llll}361 & 0.53 \% & 64.2 \% & \text { MVPAGMGAGLER }\end{array}$

$361 \quad 0.53 \% \quad 64.2 \%$ MATGLERMGANNLER

$361 \quad 0.53 \% \quad 64.2 \%$ MGANNLER

$361 \quad 0.53 \% \quad 64.2 \%$ MGANNLERMGLER

$1361 \quad 0.53 \% \quad 64.2 \%$ MGLERMGANSLER

$91361 \quad 0.53 \% \quad 64.2 \%$ MGANSLER

$91 \quad 361 \quad 0.53 \% \quad 64.2 \%$ MGANSLERMGLER

$91 \quad 361 \quad 0.53 \% \quad 64.2 \%$ MGANSLERMGPAMGPALGAGIE

$91 \quad 361 \quad 0.53 \% \quad 64.2 \%$ MGPAMGPALGAGIER

$91 \quad 361 \quad 0.53 \% \quad 64.2 \%$ MGLAMGGGGGASFDR

$91 \quad 361 \quad 0.53 \% \quad 64.2 \%$ MGLAMGGGGGASFDRAIEMER

$\begin{array}{llll}961 & 0.53 \% & 64.2 \% & \text { GNFGGSFAGSFG }\end{array}$

$\begin{array}{llll}961 & 0.53 \% & 64.2 \% & \text { KACQIFVR } \\ 91 & 361 & 0.53 \% & 64.2 \%\end{array}$

$361 \quad 0.53 \% \quad 64.2 \%$ FESPEVAER

$361 \quad 0.53 \% \quad 64.2 \%$ EIDVRIDR

$11 \quad 0.02 \% \quad 16.4 \%$ SAFLCGVMK

$11 \quad 0.02 \% \quad 16.4 \%$ ALLERTGYTLDVTTGQR

$11 \quad 0.02 \% \quad 16.4 \%$ TGYTLDVTTGQR

$11 \quad 0.02 \% \quad 16.4 \%$ TGYTLDVTTGQRK

$11 \quad 0.02 \% \quad 16.4 \%$ LMMDPLTGLNR

$11 \quad 0.02 \% \quad 16.4 \%$ GYAFVTFCTK

$11 \quad 0.02 \% \quad 16.4 \%$ EAAQEAVKLYNNHEIR

$11 \quad 0.02 \% \quad 16.4 \%$ LYNNHEIR

$11 \quad 0.02 \% \quad 16.4 \%$ LFVGSIPK

$0.02 \% \quad 16.4 \%$ NLANTVTEEILEK

$0.09 \% \quad 17.7 \%$ SAFLCGVMK

$\begin{array}{rr}99.7 \% & 42.5 \\ 99.0 \% & 58.3\end{array}$

$99.7 \% \quad 60.4$

$99.6 \% \quad 25.5$

$94.8 \% \quad 22.5$

$99.7 \% \quad 35.5$

$0.09 \% \quad 17.7 \%$ ALLERTGYTLDVTTGQR

$0.09 \% \quad 17.7 \%$ TGYTLDVTTGQR

$64 \quad 0.09 \% \quad 17.7 \%$ TGYTLDVTTGQRK

$0.09 \% \quad 17.7 \%$ DLYEDELVPLFEK

$0.09 \% \quad 17.7 \%$ GYAFITFCGK

$0.09 \% \quad 17.7 \%$ LFVGSIPK

$99.7 \% \quad 25.4$

$\begin{array}{ll}99.7 \% & 56.2 \\ 99.7 \% & 59.0\end{array}$

$95.8 \% \quad 14.5$

$99.7 \% \quad 39.3$

$99.7 \% \quad 39.0$

$\begin{array}{ll}99.0 \% & 34.6 \\ 99.0 \% & 31.0\end{array}$

$\begin{array}{ll}99.7 \% & 47.6\end{array}$

$99.7 \% \quad 35.5$

$99.7 \% \quad 25.4$

$99.7 \% \quad 56.2$

$99.7 \% \quad 59.0$

$99.7 \% \quad 49.4$

$\begin{array}{ll}99.7 \% & 58.3\end{array}$

$99.0 \% \quad 31.0$

$0.09 \% \quad 17.7 \%$ GFCFLEYEDHKSAAQAR

$0.09 \% \quad 17.7 \%$ NLATTVTEEILEK

$0.09 \% \quad 17.7 \%$ SFSEFGKLER

$\begin{array}{ll}99.7 \% & 48.0 \\ 99.7 \% & 63.6\end{array}$

$99.7 \% \quad 39.6$

$99.7 \% \quad 30.6$
$0.09 \% \quad 17.7 \%$ STAYEDYYYHPPPR
1839.88

1141.51

1556.82

1518.77

1521.72

1577.76

2040.93

1188.59

1563.74

1678.80

904.43

1522.71

1479.70

877.42

1463.71

2334.10

1459.70

1399.61

2128.96

2034.95

2163.05

1021.56

1663.81

1063.51

1015.55

1012.50

1894.00

1311.65

1439.75

1260.64

1193.57

1884.96

1058.54

860.52

2042.94

1473.78

1012.50

1894.00

1311.65

1439.75

1609.80

1163.56

860.52

2028.92

1460.78

1199.61

1758.78 
Heterogeneous nuclear ribonucleoprotein U GN=HNRNPU HNRPU_HUMAN $90.59 \quad 100.0 \% \quad 23$ Heterogeneous nuclear ribonucleoprotein U GN=HNRNPU HNRPU_HUMAN $90.59 \quad 100.0 \% \quad 23$ Heterogeneous nuclear ribonucleoprotein U GN=HNRNPU HNRPU_HUMAN $90.59 \quad 100.0 \% \quad 23$ Heterogeneous nuclear ribonucleoprotein $\mathrm{U}$ GN=HNRNPU HNRPU HUMAN $90.59 \quad 100 \%$ Heterogeneous nuclear ribonucleoprotein U GN=HNRNPU HNRPU_HUMAN $90.59 \quad 100.0 \% \quad 23$ Heterogeneous nuclear ribonucleoprotein U GN=HNRNPU HNRPU_HUMAN $90.59 \quad 100.0 \%$ Heterogeneous nuclear ribonucleoprotein U GN=HNRNPU HNRPU_HUMAN $90.59 \quad 100.0 \% \quad 23$ Heterogeneous nuclear ribonucleoprotein U GN=HNRNPU HNRPU_HUMAN $90.59 \quad 100.0 \%$ Heterogeneous nuclear ribonucleoprotein U GN=HNRNPU HNRPU HUMAN $90.59 \quad 100.0 \%$ Heterogeneous nuclear ribonucleoprotein U GN=HNRNPU HNRPU_HUMAN $90.59 \quad 100.0 \% \quad 23$ Heterogeneous nuclear ribonucleoprotein U GN=HNRNPU HNRPU_HUMAN $90.59 \quad 100.0 \% \quad 23$ Heterogeneous nuclear ribonucleoprotein U GN=HNRNPU HNRPU_HUMAN $90.59 \quad 100.0 \% \quad 23$ Heterogeneous nuclear ribonucleoprotein U GN=HNRNPU HNRPU_HUMAN $90.59 \quad 100.0 \%$ Heterogeneous nuclear ribonucleoprotein U GN=HNRNPU HNRPU_HUMAN $90.59 \quad 100.0 \% \quad 23$ Heterogeneous nuclear ribonucleoprotein U GN=HNRNPU HNRPU_HUMAN $90.59 \quad 100.0 \% 23$ Heterogeneous nuclear ribonucleoprotein U GN=HNRNPU HNRPU_HUMAN $90.59 \quad 100.0 \% \quad 23$ Heterogeneous nuclear ribonucleoprotein U GN=HNRNPU HNRPU HUMAN $90.59 \quad 100.0 \%$ Heterogeneous nuclear ribonucleoprotein U GN=HNRNPU HNRPU_HUMAN $90.59 \quad 100.0 \% \quad 23$ Heterogeneous nuclear ribonucleoprotein U GN=HNRNPU HNRPU_HUMAN $90.59 \quad 100.0 \% \quad 23$ Heterogeneous nuclear ribonucleoprotein U GN=HNRNPU HNRPU_HUMAN $90.59 \quad 100.0 \% \quad 23$ Heterogeneous nuclear ribonucleoprotein U GN=HNRNPU HNRPU_HUMAN $90.59 \quad 100.0 \% \quad 23$ Heterogeneous nuclear ribonucleoprotein U GN=HNRNPU HNRPU_HUMAN $90.59 \quad 100.0 \% \quad 23$ Heterogeneous nuclear ribonucleoprotein U GN=HNRNPU HNRPU_HUMAN $90.59 \quad 100.0 \% \quad 23$ Heterogeneous nuclear ribonucleoprotein U-like protein 1 GN=HNRNPUL1 HNRL1_HUMAN $95.74 \quad 100.0 \% \quad 12$ Hetergeneous nuclear ibon Heterogeneous nuclear ribonucleoprotein U-like protein 1 GN=HNRNPUL1 $\quad$ HNRL1_HUMAN $95.74 \quad 100.0 \% \quad 12$ Heterogeneous nuclear ribonucleoprotein U-like protein 1 GN=HNRNPUL1 $\quad$ HNRL1_HUMAN $95.74 \quad 100.0 \% 12$ Heterogeneous nuclear ribonucleoprotein U-like protein 1 GN=HNRNPUL1 HNRL1_HUMAN $95.74 \quad 100.0 \% 12$ $\begin{array}{llll}\text { Heterogeneous nuclear ribonucleoprotein U-like protein } 1 \text { GN=HNRNPUL1 HNRL1_HUMAN } & 95.74 & 100.0 \% & 12\end{array}$ Heterogeneous nuclear ribonucleoprotein U-like protein 1 GN=HNRNPUL1 HNRL1_HUMAN $95.74 \quad 100.0 \%$ Heterogeneous nuclear ribonucleoprotein U-like protein 1 GN=HNRNPUL1 HNRL1_HUMAN $95.74 \quad 100.0 \%$ Heterogeneous nuclear ribonucleoprotein U-like protein 1 GN=HNRNPUL1 HNRL1_HUMAN $95.74 \quad 100.0 \% \quad 12$ 作 Heterogeneous nuclear ribonucleoprotein U-like protein 1 GN=HNRNPUL1 HNRL1_HUMAN $95.74 \quad 100.0 \%$ Heterogeneous nuclear ribonucleoprotein U-like protein $1 \mathrm{GN}=$ HNRNPUL1 $\quad$ HNRL1_HUMAN $95.74 \quad 100.0 \% \quad 12$ Heterogeneous nuclear ribonucleoproteins A2/B1 GN=HNRNPA2B1 $\quad$ ROA2_HUMAN $37.43 \quad 100.0 \% \quad 14$ $\begin{array}{lllll}\text { Heterogeneous nuclear ribonucleoproteins A2/B1 GN=HNRNPA2B1 } & \text { ROA2_HUMAN } & 37.43 & 100.0 \% & 14\end{array}$ Heterogeneous nuclear ribonucleoproteins $\mathrm{A} 2 / \mathrm{B} 1 \mathrm{GN}=\mathrm{HNRNPA} 2 \mathrm{~B} 1 \quad \mathrm{ROA} 2$ HUMAN $37.43 \quad 100.0 \%$ Heterogeneous nuclear ribonucleoproteins A2/B1 GN=HNRNPA2B1 ROA2_HUMAN $37.43 \quad 100.0 \% \quad 14$ $\begin{array}{lllll}\text { Heterogeneous nuclear ribonucleoproteins A2/B1 GN=HNRNPA2B1 } & \text { ROA2_HUMAN } 37.43 \quad 100.0 \% & 14\end{array}$ $\begin{array}{lllll}\text { Heterogeneous nuclear ribonucleoproteins A2/B1 GN=HNRNPA2B1 } & \text { ROA2 HUMAN } 37.43 \quad 100.0 \% & 14\end{array}$ Heterogeneous nuclear ribonucleoproteins A2/B1 GN=HNRNPA2B1 ROA2_HUMAN $37.43 \quad 100.0 \% \quad 14$ Heterogeneous nuclear ribonucleoproteins A2/B1 GN=HNRNPA2B1 $\quad$ ROA2_HUMAN $37.43 \quad 100.0 \% \quad 14$ Heterogeneous nuclear ribonucleoproteins A2/B1 GN=HNRNPA2B1 ROA2_HUMAN $37.43 \quad 100.0 \% \quad 14$ $\begin{array}{lllll}\text { Heterogeneous nuclear ribonucleoproteins A2/B1 GN=HNRNPA2B1 } & \text { ROA2_HUMAN } & 37.43 & 100.0 \% & 14\end{array}$ $\begin{array}{lllll} & 10\end{array}$ Heterogeneous nuclear ribonucleoproteins A2/B1 GN=HNRNPA2B1 ROA2_HUMAN $37.43 \quad 100.0 \% \quad 14$ $\begin{array}{lllllll}37 & 178 & 0.26 \% & 24.7 \% & \text { EAAGKSSGPTSLFAVTVAPPGAR } & 99.5 \% & 22.8\end{array}$ 178

\section{$\begin{array}{llllll} & 0.26 \% & 24.7 \% & \text { SSGPTSLFAVTVAPPGAR } & 99.7 \% & 39.8\end{array}$}

$178 \quad 0.26 \% \quad 24.7 \%$ KAEGGGGGGRPGAPAAGDGK $\quad 99.7 \% \quad 30.3$

$178 \quad 0.26 \% \quad 24.7 \%$ AEGGGGGGRPGAPAAGDGK $99.7 \% \quad 26.9$

$178 \quad 0.26 \% \quad 24.7 \%$ AEGGGGGGRPGAPAAGDGKTEQK

$178 \quad 0.26 \% \quad 24.7 \%$ GYFEYIEENKYSR

$178 \quad 0.26 \% \quad 24.7 \%$ VTEKIPVR

$178 \quad 0.26 \% \quad 24.7 \%$ DIDIHEVR

$178 \quad 0.26 \% \quad 24.7 \%$ NGQDLGVAFK

$178 \quad 0.26 \% \quad 24.7 \%$ NGQDLGVAFKISK

$99.7 \% \quad 46.3$

$99.7 \% \quad 58.8$

$99.0 \% \quad 45.4$

$99.0 \% \quad 49.4$

$99.7 \% \quad 55.1$

$99.7 \% \quad 64.5$

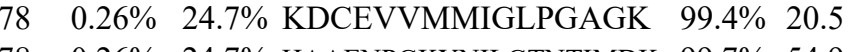

$178 \quad 0.26 \% \quad 24.7 \%$ MMVAGFKK

$178 \quad 0.26 \% \quad 24.7 \%$ QMADTGKLNTLLQR

$178 \quad 0.26 \% \quad 24.7 \%$ APQCLGKFIEIAAR

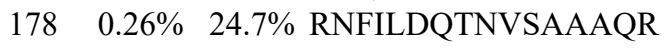

$178 \quad 0.26 \% \quad 24.7 \%$ NFILDQTNVSAAAQR

$178 \quad 0.26 \% \quad 24.7 \%$ NFILDQTNVSAAAQRR

$178 \quad 0.26 \% \quad 24.7 \%$ KMCLFAGFQR

$178 \quad 0.26 \% \quad 24.7 \%$ MCLFAGFQR

$178 \quad 0.26 \% \quad 24.7 \%$ MCLFAGFQRK

$178 \quad 0.26 \% \quad 24.7 \%$ AEVEGKDLPEHAVLK

$178.26 \% \quad 24.7 \%$ DLPEHAVLK

$36 \quad 0.05 \% \quad 15.9 \%$ GYFEHREDR

$0.05 \% \quad 15.9 \%$ HLPSTEPDPHVVR

$99.0 \% \quad 33.7$

$99.7 \% \quad 57.6$

$99.7 \% \quad 58.0$

$99.7 \% \quad 41.5$

$99.7 \% \quad 60.0$

$99.7 \% \quad 34.6$

$\begin{array}{lll}99.7 \% & 26.1\end{array}$

$99.7 \% \quad 43.4$

$97.8 \% 18.2$

$99.7 \% \quad 39.3$

$99.4 \% \quad 24.4$

$94.7 \% \quad 15.4$

$99.7 \% \quad 33.7$

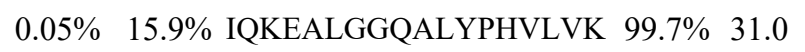

$0.05 \% \quad 15.9 \%$ EALGGQALYPHVLVK

$0.05 \% \quad 15.9 \%$ NCAVEFNFGQR

$0.05 \% \quad 15.9 \%$ YNILGTNAIMDK

$0.05 \% \quad 15.9 \%$ LIQIAARK

$0.05 \% \quad 15.9 \%$ NYILDQTNVYGSAQR

$0.05 \% \quad 15.9 \%$ MRPFEGFQR

$0.05 \% \quad 15.9 \%$ AIVICPTDEDLKDR

$99.7 \% \quad 35.1$

$99.7 \% \quad 60.6$

$99.7 \% \quad 39.2$

$96.0 \% \quad 15.3$

$99.7 \% \quad 66.4$

$98.1 \% \quad 22.3$

$99.4 \% \quad 19.9$

$0.05 \% \quad 15.9 \%$ TDEEGKDVPDHAVLEMK

$0.05 \% \quad 15.9 \%$ NPPGASTYNK

$15 \quad 0.17 \% \quad 39.7 \%$ TLETVPLER

$15 \quad 0.17 \% \quad 39.7 \%$ LFIGGLSFETTEESLR

$99.7 \% \quad 27.0$

$99.7 \% \quad 40.5$

$99.7 \% \quad 44.5$

0.17\% 39.7\% AVAREESGKPGAHVTVK $99.7 \% \quad 32.0$

$115 \quad 0.17 \% \quad 39.7 \%$ EESGKPGAHVTVK

$115 \quad 0.17 \% \quad 39.7 \%$ EESGKPGAHVTVKK

$15 \quad 0.17 \% \quad 39.7 \%$ YHTINGHNAEVR

$115 \quad 0.17 \% \quad 39.7 \%$ ALSRQEMQEVQSSR

$115 \quad 0.17 \% \quad 39.7 \%$ SGRGGNFGFGDSR

$115 \quad 0.17 \% \quad 39.7 \%$ GGNFGFGDSR

$\begin{array}{llll}99.7 \% & 34.8 & 25.0 & 27.0\end{array}$

$96.7 \% \quad 17.9$

$99.7 \% \quad 30.3$

$99.7 \% \quad 61.5$

$99.7 \% \quad 45.1$

$99.7 \% \quad 61.1$

$15 \quad 0.17 \% \quad 39.7 \%$ GGGGNFGPGPGSNFR

15
$99.7 \% \quad 60.5$

$99.7 \% \quad 47.0$

$\begin{array}{ccc}2171.15 & 182 & 204 \\ 1714.91 & 187 & 204 \\ 1666.83 & 215 & 234 \\ 1538.73 & 216 & 234 \\ 2024.97 & 216 & 238 \\ 1697.78 & 256 & 268 \\ 941.58 & 340 & 347 \\ 996.51 & 353 & 360 \\ 1048.54 & 424 & 433 \\ 1376.75 & 424 & 436 \\ 1736.84 & 495 & 510 \\ 2203.08 & 517 & 536 \\ 911.48 & 537 & 544 \\ 1588.85 & 545 & 558 \\ 1573.85 & 559 & 572 \\ 1803.95 & 575 & 590 \\ 1647.84 & 576 & 590 \\ 1803.95 & 576 & 591 \\ 1257.62 & 592 & 601 \\ 1129.53 & 593 & 601 \\ 1257.62 & 593 & 602 \\ 1634.88 & 621 & 635 \\ 1021.57 & 627 & 635 \\ 1208.54 & 182 & 190 \\ 1483.77 & 271 & 283 \\ 1964.13 & 358 & 375 \\ 1594.90 & 361 & 375 \\ 1341.60 & 376 & 386 \\ 1352.69 & 450 & 461 \\ 912.60 & 491 & 498 \\ 1741.85 & 501 & 515 \\ 1167.57 & 518 & 526 \\ 1644.83 & 528 & 541 \\ 1912.90 & 546 & 562 \\ 1048.51 & 722 & 731 \\ 1057.59 & 4 & 12 \\ 1798.92 & 23 & 38 \\ 1735.95 & 96 & 112 \\ 1338.70 & 100 & 112 \\ 1466.80 & 100 & 113 \\ 1410.69 & 174 & 185 \\ 1648.81 & 187 & 200 \\ 1313.60 & 201 & 213 \\ 1013.44 & 204 & 213 \\ 2372.06 & 204 & 228 \\ 1377.63 & 214 & 228 \\ 2270.99 & 214 & 238 \\ & & \end{array}$

Page 63 of Table S-1-2 

$\begin{array}{lllll}\text { Heterogeneous nuclear ribonucleoproteins A2/B1 GN=HNRNPA2B1 } & \text { ROA2 HUMAN } & 37.43 & 100.0 \% & 14\end{array}$ Heterogeneous nuclear ribonucleoproteins $\mathrm{C} 1 / \mathrm{C} 2 \mathrm{GN}=$ HNRNPC HNRPC_HUMAN $33.67 \quad 100.0 \%$ Heterogeneous nuclear ribonucleoproteins $\mathrm{C} 1 / \mathrm{C} 2 \mathrm{GN}=\mathrm{HNRNPC}$ HNRPC HUMAN $33.67 \quad 100.0 \%$ Heterogeneous nuclear ribonucleoproteins $\mathrm{C} 1 / \mathrm{C} 2 \mathrm{GN}=\mathrm{HNRNPC}$ HNRPC_HUMAN $33.67 \quad 100.0 \% \quad 14$ Heterogeneous nuclear ribonucleoproteins $\mathrm{Cl} / \mathrm{C} 2 \mathrm{GN}=\mathrm{HNRNPC}$ HNRPC_HUMAN $33.67 \quad 100.0 \% \quad 1$ Heterogeneous nuclear ribonucleoproteins $\mathrm{C} 1 / \mathrm{C} 2 \mathrm{GN}=\mathrm{HNRNPC}$ HNRPC HUMAN $33.67 \quad 100.0 \% \quad 14$ Heterogeneous nuclear ribonucleoproteins $\mathrm{C} 1 / \mathrm{C} 2 \mathrm{GN}=\mathrm{HNRNPC}$ HNRPC_HUMAN $33.67 \quad 100.0 \% \quad 14$ Heterogeneous nuclear ribonucleoproteins $\mathrm{C} 1 / \mathrm{C} 2 \mathrm{GN}=\mathrm{HNRNPC}$ HNRPC HUMAN $33.67 \quad 100.0 \%$ Heterogeneous nuclear ribonucleoproteins $\mathrm{Cl} / \mathrm{C} 2 \mathrm{GN}=\mathrm{HNRNPC}$ HNRPC_HUMAN $33.67 \quad 100.0 \% \quad 14$ Heterogeneous nuclear ribonucleoproteins $\mathrm{Cl} / \mathrm{C} 2 \mathrm{GN}=\mathrm{HNRNPC}$ HNRPC_HUMAN $33.67 \quad 100.0 \% \quad 14$ Heterogeneous nuclear ribonucleoproteins $\mathrm{Cl} / \mathrm{C} 2 \mathrm{GN}=\mathrm{HNRNPC}$ HNRPC HUMAN $33.67 \quad 100.0 \%$ Heterogeneous nuclear ribonucleoproteins $\mathrm{C} 1 / \mathrm{C} 2 \mathrm{GN}=\mathrm{HNRNPC}$ HNRPC_HUMAN $33.67 \quad 100.0 \% \quad 14$ Heterogeneous nuclear ribonucleoproteins $\mathrm{C} 1 / \mathrm{C} 2 \mathrm{GN}=\mathrm{HNRNPC}$ HNRPC HUMAN $33.67 \quad 100.0 \% \quad 1$ Heterogeneous nuclear ribonucleoproteins $\mathrm{C} 1 / \mathrm{C} 2 \mathrm{GN}=\mathrm{HNRNPC}$ HNRPC HUMAN $33.67 \quad 100.0 \%$ Heterogeneous nuclear ribonucleoproteins $\mathrm{C} 1 / \mathrm{C} 2 \mathrm{GN}=\mathrm{HNRNPC}$ HNRPC_HUMAN $33.67 \quad 100.0 \% \quad 14$ Histone deacetylase $1 \mathrm{GN}=\mathrm{HDAC} 1$ Histone deacetylase $1 \mathrm{GN}=\mathrm{HDAC}$ Histone deacetylase $1 \mathrm{GN}=\mathrm{HDAC} 1$ Histone H1.2 GN=HIST1H1C Histone H1.2 GN=HIST1H1C Histone H1.2 GN=HIST1H1C Histone $\mathrm{H} 1.2 \mathrm{GN}=\mathrm{HIST} 1 \mathrm{H} 1 \mathrm{C}$ Histone H1.2 GN=HIST1H1C Histone H1.2 GN=HIST1H1C Histone H1.2 GN=HIST1H1C Histone H1.2 GN=HIST1H1C Histone $\mathrm{H} 1.2 \mathrm{GN}=\mathrm{HIST} 1 \mathrm{H} 1 \mathrm{C}$ Histone H1.2 GN=HIST1H1C Histone H1.2 GN=HIST1H1C Histone $\mathrm{H} 1.2 \mathrm{GN}=\mathrm{HIST} 1 \mathrm{H} 1 \mathrm{C}$ Histone H1.2 GN=HIST1H1C Histone $\mathrm{H} 1.5 \mathrm{GN}=\mathrm{HIST} 1 \mathrm{H} 1 \mathrm{~B}$ Histone H1.5 GN=HIST1H1B Histone $\mathrm{H} 1.5 \mathrm{GN}=\mathrm{HIST} 1 \mathrm{H} 1 \mathrm{~B}$ Histone $\mathrm{H} 1.5 \mathrm{GN}=\mathrm{HIST} 1 \mathrm{H} 1 \mathrm{P}$ Histone H1.5 GN=HIST1H1P Histone $\mathrm{H} 1.5 \mathrm{GN}=\mathrm{HIST} 1 \mathrm{H} 1 \mathrm{~B}$ Histone $\mathrm{H} 1 \mathrm{x}$ GN=H1FX Histone $\mathrm{H} 1 \mathrm{x}$ GN=H1FX Histone $\mathrm{H} 1 \mathrm{x} \mathrm{GN}=\mathrm{H} 1 \mathrm{FX}$ Histone $\mathrm{H} 1 \mathrm{x}$ GN=H1FX Histone $\mathrm{H} 1 \mathrm{x} \mathrm{GN}=\mathrm{H} 1 \mathrm{FX}$ Histone $\mathrm{H} 1 \mathrm{x}$ GN=H1FX Hornerin $\mathrm{GN}=\mathrm{HRNR}$ Hornerin GN $=\mathrm{HRNR}$ Hornerin GN=HRNR HDAC1_HUMAN $55.10 \quad 100.0 \%$ HDAC1_HUMAN $55.10 \quad 100.0 \%$ H12 HUMAN $21.37 \quad 100.0 \% \quad 13$ H12_HUMAN $21.37 \quad 100.0 \% \quad 13$ H12 HUMAN $21.37 \quad 100.0 \% \quad 13$ H12 HUMAN $21.37 \quad 100.0 \% \quad 13$ H12_HUMAN $21.37 \quad 100.0 \% \quad 13$ H12 HUMAN $21.37 \quad 100.0 \% \quad 13$ H12_HUMAN $21.37 \quad 100.0 \% \quad 13$ H12_HUMAN $21.37 \quad 100.0 \% \quad 13$ H12 HUMAN $21.37 \quad 100.0 \% \quad 13$ H12_HUMAN $21.37 \quad 100.0 \% \quad 13$ H12 HUMAN $21.37 \quad 100.0 \% \quad 13$ H12_HUMAN $21.37 \quad 100.0 \% \quad 13$ H12_HUMAN $21.37 \quad 100.0 \% \quad 13$ H15 HUMAN $22.58 \quad 100.0 \%$ H15_HUMAN $22.58 \quad 100.0 \% \quad 2$ H15 HUMAN $22.58 \quad 100.0 \%$ H15 HUMAN $22.58 \quad 100.0 \%$ H15_HUMAN $22.58 \quad 100.0 \%$ H15 HUMAN $22.58 \quad 100.0 \%$ H1X_HUMAN $22.49 \quad 100.0 \%$ H1X_HUMAN $22.49 \quad 100.0 \%$ H1X_HUMAN $22.49 \quad 100.0 \%$ H1X_HUMAN $22.49 \quad 100.0 \%$ H1X HUMAN $22.49 \quad 100.0 \%$ HORN_HUMAN $282.37 \quad 100.0 \%$ HORN HUMAN $282.37 \quad 100.0 \%$ HORN_HUMAN $282.37 \quad 100.0 \%$
HDAC1 HUMAN $55.10 \quad 100.0 \% \quad 3$ H1X_HUMAN $22.49 \quad 100.0 \%$

7

115

$62 \quad 0.0$

$\begin{array}{cccc}7 & 0.01 \% & 6.2 \% & \text { YGEYFPGTGDLRDIGAGK } \\ 318 & 0.46 \% & 39.4 \% & \text { SETAPAAPAAAPPAEK }\end{array}$

$318 \quad 0.46 \% \quad 39.4 \%$ KASGPPVSELITK

$318 \quad 0.46 \% \quad 39.4 \%$ ASGPPVSELITK

$318 \quad 0.46 \% \quad 39.4 \%$ ERSGVSLAALK

$318 \quad 0.46 \% \quad 39.4 \%$ SGVSLAALK

$318 \quad 0.46 \% \quad 39.4 \%$ SGVSLAALKK

$318 \quad 0.46 \% \quad 39.4 \%$ KALAAAGYDVEK

$318 \quad 0.46 \% \quad 39.4 \%$ ALAAAGYDVEK

$318 \quad 0.46 \% \quad 39.4 \%$ ALAAAGYDVEKNNSR

$318 \quad 0.46 \% \quad 39.4 \%$ LGLKSLVSK

$318 \quad 0.46 \% \quad 39.4 \%$ SLVSKGTLVQTK

$318 \quad 0.46 \% \quad 39.4 \%$ GTLVQTKGTGASGSFK

$318 \quad 0.46 \% \quad 39.4 \%$ GTGASGSFKLNK

$0.01 \% \quad 24.3 \%$ ATGPPVSELITK

$0.01 \% \quad 24.3 \%$ ALAAGGYDVEKNNSR

$0.01 \% \quad 24.3 \%$ LGLKSLVSK

$0.01 \% \quad 24.3 \%$ SLVSKGTLVQTK

$0.01 \% \quad 24.3 \%$ GTLVQTKGTGASGSFK

$0.01 \% \quad 24.3 \%$ GTGASGSFKLNK

$0.04 \% \quad 20.7 \%$ NQPGKYSQLVVETIR

$0.04 \% \quad 20.7 \%$ YSQLVVETIR

$0.04 \% \quad 20.7 \%$ YSQLVVETIRR

$\begin{array}{ll}0.04 \% & 20.7 \% \\ \text { ALVQNDTLLQVK }\end{array}$

$0.04 \% \quad 20.7 \%$ RGAPAAATAPAPTAHK

$0.04 \% \quad 20.7 \%$ GAPAAATAPAPTAHK

$0.03 \% \quad 1.9 \%$ GSGSGQSPSGQHGTGFGR $\quad 99.7 \% \quad 55.8$

$\begin{array}{lllll}0.03 \% & 1.9 \% & \text { QSLGGSPSSGQHGTGFR } & 99.3 \% & 19.3\end{array}$

$\begin{array}{lllll}0.03 \% & 1.9 \% & \text { GPYESGSGHSSGLGHR } & 99.7 \% & 35.2\end{array}$ $\begin{array}{ll}99.7 \% & 58.1 \\ 99.7 \% & 60.5\end{array}$

$99.7 \% \quad 57.8$

$99.7 \% \quad 48.3$

$99.7 \% \quad 54.8$

$99.7 \% \quad 44.3$

$99.7 \% \quad 37.4$

$99.2 \% \quad 25.1$

$99.7 \% \quad 59.9$

$99.3 \% \quad 19.7$

$99.7 \% \quad 67.4$

$\begin{array}{lll}98.3 \% & 18.9\end{array}$

$99.1 \% \quad 23.3$

$99.7 \% \quad 31.9$

$\begin{array}{lll}99.6 \% & 22.8\end{array}$

$99.7 \% \quad 30.7$

$99.7 \% \quad 40.4$

$94.8 \% \quad 23.5$

$99.7 \% \quad 61.1$

$99.7 \% \quad 60.3$

$96.5 \% \quad 21.9$

$99.7 \% \quad 62.8$

$99.7 \% \quad 63.4$

$99.7 \% \quad 54.0$

$99.7 \% 65.3$

$98.8 \% \quad 39.3$

$99.7 \% \quad 61.8$

$99.7 \% \quad 59.6$

$99.7 \% \quad 60.2$

$99.7 \% \quad 57.0$

$\begin{array}{lll}98.8 \% & 39.3\end{array}$

$99.7 \% \quad 61.8$

$99.7 \% \quad 59.6$

$99.7 \% \quad 60.2$

$99.7 \% \quad 33.2$

$99.7 \% \quad 49.2$

$99.7 \% \quad 35.2$

$99.7 \% \quad 61.8$

$99.7 \% \quad 31.9$
2968.24

1316.79

1444.89

1123.60

995.50

1343.68

1247.66

1329.66

1670.84

2525.30

1698.91

2068.12

1811.96

943.57

1415.77

1442.66

1374.63

1915.92

1478.75

1326.76

1198.67

1130.65

845.51

973.60

1235.66

1107.57

1578.79

944.61

1260.75

1538.82

1166.62

1212.68

1564.77

944.61

1260.75

1538.82

1166.62

1731.94

1207.67

1363.77

1341.77

1487.81

1331.71

1747.77

1947.90 1584.72

350
350
29
30
39
39
42
50
61
64
89
89
92
151
151
216
89
212
218
17
46
46
1011
63
1053
63



Ig kappa chain V-I region Lay OS=Homo sapiens KV113_HUMAN $11.83 \quad 100.0 \%$ Ig kappa chain V-I region Lay OS=Homo sapiens KV113_HUMAN $11.83 \quad 100.0 \%$ Ig kappa chain V-II region RPMI 6410 OS=Homo sapiens KV206_HUMAN $14.71 \quad 100.0 \%$ Ig kappa chain V-II region RPMI 6410 OS=Homo sapiens KV206_HUMAN $14.71 \quad 100.0 \%$ Ig kappa chain V-II region RPMI 6410 OS=Homo sapiens KV206_HUMAN $14.71 \quad 100.0 \%$ Importin subunit alpha-1 GN=KPNA2 Importin subunit alpha-1 GN=KPNA2 Importin subunit alpha-1 GN=KPNA2 Importin subunit alpha-1 GN=KPNA2 Importin subunit alpha-1 GN=KPNA2 Importin subunit alpha-5 GN=KPNA1 Importin subunit alpha- $5 \mathrm{GN}=\mathrm{KPNA} 1$ Importin subunit beta- $1 \mathrm{GN}=\mathrm{KPNB} 1$ Importin subunit beta-1 GN=KPNB Importin subunit beta- $1 \mathrm{GN}=\mathrm{KPNB} 1$ Importin subunit beta-1 GN=KPNB1 Importin subunit beta-1 GN=KPNB Importin subunit beta- $1 \mathrm{GN}=\mathrm{KPNB} 1$ Importin-11 GN=IPO11 Importin-11 GN=IPO11 Importin-4 GN=IPO4 Importin- $4 \mathrm{GN}=\mathrm{IPO} 4$ Importin- $4 \mathrm{GN}=\mathrm{IPO} 4$ Importin-4 GN=IPO Importin-5 GN=IPO5 Importin-5 GN=IPO5 Importin-5 GN=IPO IMA1_HUMAN $57.86 \quad 100.0 \%$ IMA1_HUMAN $57.86 \quad 100.0 \%$ IMA1_HUMAN $57.86 \quad 100.0 \%$ IMA1_HUMAN $57.86 \quad 100.0 \%$ IMA1_HUMAN $57.86 \quad 100.0 \%$ IMA5_HUMAN $60.22 \quad 100.0 \%$ IMA5 HUMAN $60.22 \quad 100.0 \%$ IMB1_HUMAN $97.17 \quad 100.0 \%$ IMB1_HUMAN $97.17 \quad 100.0 \%$ IMB1_HUMAN $97.17 \quad 100.0 \%$ IMB1_HUMAN $97.17 \quad 100.0 \%$ IMB1_HUMAN $97.17 \quad 100.0 \%$ IMB1 HUMAN $97.17 \quad 100.0 \%$ IPO11_HUMAN $112.54 \quad 100.0 \%$ IPO11 HUMAN $112.54 \quad 100.0 \%$ IPO4_HUMAN $118.72 \quad 100.0 \%$ IPO4_HUMAN $118.72 \quad 100.0 \%$ IPO4 HUMAN $118.72 \quad 100.0 \%$ IPO4_HUMAN $118.72 \quad 100.0 \%$ IPO5 HUMAN $123.63 \quad 100.0 \%$ IPO5_HUMAN $123.63 \quad 100.0 \%$ IPO5_HUMAN $123.63 \quad 100.0 \%$

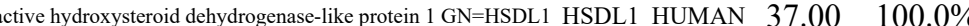
Inactive hydroxysteroid dehydrogenase-like protein $1 \mathrm{GN}=$ HSDL1 HSDL1_HUMAN $37.00 \quad 100.0 \%$ Inactive hydroxysteroid dehydrogenase-like protein $1 \mathrm{GN}=$ HSDL1 HSDL1_HUMAN $37.00100 .0 \%$ (100.0\% Insulin receptor substrate $4 \mathrm{GN}=\mathrm{IRS}$ Insulin receptor substrate $4 \mathrm{GN}=\mathrm{IRS} 4$ Insulin receptor substrate $4 \mathrm{GN}=\mathrm{IRS} 4$ Insulin receptor substrate $4 \mathrm{GN}=\mathrm{IRS}$ Insulin receptor substrate $4 \mathrm{GN}=\mathrm{IRS} 4$ Insulin receptor substrate $4 \mathrm{GN}=\mathrm{IRS} 4$ IRS4_HUMAN $133.77 \quad 100.0 \%$ IRS4 HUMAN $133.77 \quad 100.0 \%$ IRS4 HUMAN $133.77 \quad 100.0 \%$ IRS4 HUMAN $133.77 \quad 100.0 \%$ IRS4 HUMAN $133.77 \quad 100.0 \%$ IRS4_HUMAN $133.77 \quad 100.0 \%$

$0.01 \% \quad 9.6 \%$ TFESLVDFSK $0.01 \% \quad 9.6 \%$ LLVPYLMEAIR $0.01 \% \quad 9.6 \%$ TGEGFYKYK $0.02 \% \quad 23.9 \%$ LAGCTVFITGASR $0.02 \% \quad 23.9 \%$ AAKDGANIVIAAK $\begin{array}{llll}0.02 \% & 23.9 \% & \text { LLGTIYTAAEEIEAVGGK } 99.7 \% & 44.6\end{array}$ $0.02 \% \quad 23.9 \%$ TAIHTAAMDMLGGPGIESOCR $\quad 96.5 \% \quad 26.1$ $0.02 \% \quad 23.9 \%$ KVDIIADAAYSIFQKPK $0.02 \% \quad 23.9 \%$ SGAVEETFR

$0.02 \% \quad 23.9 \%$ LMNQMNARL

2232.02

1907.06

995.48

$0.01 \% \quad 25.0 \%$ DIQMTQSPSSLSVSVGDR

$99.7 \% \quad 41$.

$99.7 \% \quad 25.7$

1090.55

$0.01 \% \quad 25.0 \%$ LLIYGASTR

$0.09 \% \quad 18.0 \%$ LIYKVSNR

$0.09 \% \quad 18.0 \%$ FSGSGSGTDFTLK

$99.0 \% \quad 34.1$

$99.0 \% \quad 36.0$

$99.1 \% \quad 51.7$

$0.09 \% \quad 18.0 \%$ FSGSGSGTDFTLKISR $\quad 98.9 \% \quad 32.2$

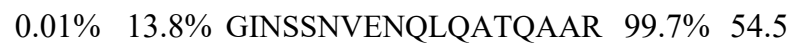

$0.01 \% \quad 13.8 \%$ EKQPPIDNIIR

$99.7 \% \quad 29.2$

$0.01 \% \quad 13.8 \%$ NKNPAPPIDAVEQILPTLVR

$0.01 \% \quad 13.8 \%$ TGVVPQLVK

$98.9 \% \quad 18.5$

$99.0 \% \quad 20.1$

$0.01 \% \quad 13.8 \%$ LLGASELPIVTPALR

$0.00 \% \quad 4.7 \%$ NAVWALSNLCR

$0.00 \% \quad 4.7 \%$ IVQVALNGLENILR

$0.03 \% \quad 9.0 \%$ AAVENLPTFLVELSR

$0.03 \% \quad 9.0 \%$ VLANPGNSQVAR

$0.03 \% \quad 9.0 \% \quad$ LAATNALLNSLEFTK

$0.03 \% \quad 9.0 \%$ VAALQNLVK

$0.03 \% \quad 9.0 \% \quad$ LLETTDRPDGHQNNLR

$0.03 \% \quad 9.0 \%$ SSAYESLMEIVK

$0.00 \% \quad 2.6 \%$ VAPHALSEEEKTTLR

$0.00 \% \quad 2.6 \%$ ALLTFYHVTK

$10 \quad 0.01 \% \quad 3.8 \%$ ATEQLQIVLR

$10 \quad 0.01 \% \quad 3.8 \% \quad$ LLPPLLQIVCK

$0.01 \% \quad 3.8 \%$ EVMPLLLAYLK

$0.01 \% \quad 3.8 \%$ LAELCGVLK

$99.7 \% \quad 48.0$

$98.3 \% \quad 23.2$

$99.7 \% \quad 49.2$

$99.7 \% \quad 75.7$

$99.7 \% \quad 54.9$

$99.7 \% \quad 60.6$

$99.7 \% \quad 40.1$

$99.7 \% \quad 31.4$

$99.7 \% \quad 60.5$

$99.3 \% \quad 23.0$

$99.7 \% \quad 28.4$

$99.7 \% \quad 47.6$

$97.5 \% \quad 17.9$

$99.7 \% \quad 30.4$

$99.2 \% \quad 33.4$

$99.7 \% \quad 58.1$

$0.02 \% \quad 4.0 \% \quad$ SLVEIADTVPK

$9.2 \% \quad 19.3$

$0.02 \% \quad 4.0 \%$ VAAAESMPLLLECAR
$0.01 \% \quad 11.8 \%$ ADLIKQYGR

$0.01 \% \quad 11.8 \%$ WAVVSGATDGIGK

$0.01 \% \quad 11.8 \%$ GLNIILISR

$0.01 \% \quad 11.8 \%$ AYLDHFSR

$0.02 \% \quad 7.6 \%$ ALCADEYRAR

$0.02 \% \quad 7.6 \%$ RFVTPSEPVAHSR

$0.02 \% \quad 7.6 \%$ LAPSPARPR

$0.02 \% \quad 7.6 \%$ SYFGKLTQSK

$0.02 \% \quad 7.6 \%$ SQSFFAAAR

$\begin{array}{lllll}0.02 \% & 7.6 \% & \text { GAQDVAGGSNPGAHNPSANLAR } & 98.1 \% & 18.7\end{array}$

$99.7 \% \quad 44.3$

$99.7 \% \quad 52.3$

$\begin{array}{lll}99.7 \% & 46.5\end{array}$

$99.0 \% 23.1$

$98.9 \% \quad 18.4$

$99.7 \% \quad 30.6$

$99.1 \% 21.2$

$99.7 \% \quad 33.4$

$99.7 \%$ 1 $\begin{array}{cc}193 & 202 \\ 222 & 232 \\ 306 & 314 \\ 8 & 20 \\ 30 & 42 \\ 50 & 67 \\ 199 & 219 \\ 220 & 236 \\ 307 & 315 \\ 410 & 418 \\ 1 & 18 \\ 46 & 54 \\ 72 & 79 \\ 87 & 99 \\ 87 & 102 \\ 84 & 101 \\ 107 & 117 \\ 239 & 258 \\ 292 & 300 \\ 301 & 315 \\ 231 & 241 \\ 439 & 452 \\ 28 & 42 \\ 43 & 54 \\ 192 & 206 \\ 235 & 243 \\ 510 & 525 \\ 526 & 537 \\ 77 & 91 \\ 147 & 156 \\ 24 & 33 \\ 391 & 401 \\ 435 & 445 \\ 793 & 801 \\ 239 & 249 \\ 458 & 475 \\ 721 & 735 \\ 60 & 68 \\ 69 & 81 \\ 91 & 99 \\ 223 & 230 \\ 330 & 339 \\ 398 & 410 \\ 436 & 444 \\ 614 & 623 \\ 1177 & 1198 \\ & \end{array}$

Page 65 of Table S-1-2 

Integrator complex subunit $1 \mathrm{GN}=\mathrm{INTS} 1 \quad$ INT1_HUMAN $244.30 \quad 100.0 \%$ Integrator complex subunit $1 \mathrm{GN}=\mathrm{INTS} 1$ INT1_HUMAN $244.30 \quad 100.0 \%$ Integrator complex subunit $1 \mathrm{GN}=\mathrm{INTS} 1$ INT1_HUMAN $244.30 \quad 100.0 \%$ Integrator complex subunit $1 \mathrm{GN}=\mathrm{INTS} 1 \quad$ INT1_HUMAN $244.30 \quad 100.0 \%$ Integrator complex subunit $11 \mathrm{GN}=\mathrm{CPSF} 3 \mathrm{~L}$ INT11_HUMAN $67.66 \quad 100.0 \%$ Integrator complex subunit $11 \mathrm{GN}=\mathrm{CPSF} 3 \mathrm{~L}$ INT11_HUMAN $67.66 \quad 100.0 \%$ Interferon-inducible double-stranded RNA-dependent protein kinase activator A GN=PRKRA PRKRA_HUMAN 34.41 $100.0 \%$ Interleukin enhancer-binding factor $2 \mathrm{GN}=\mathrm{ILF} 2$ ILF2_HUMAN $43.06 \quad 100.0 \%$ Interleukin enhancer-binding factor 2 GN=ILF2 ILF2_HUMAN $43.06 \quad 100.0 \%$ Interleukin enhancer-binding factor 2 GN=ILF2 ILF2 HUMAN $43.06 \quad 100.0 \%$ Interleukin enhancer-binding factor 2 GN=ILF2 ILF2_HUMAN $43.06 \quad 100.0 \%$

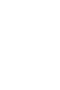

.

5

2

8

\section{$\begin{array}{ccccc}0.02 \% & 7.6 \% & \text { GDNQAGGAAAAAAAPEPPPRSR } & 99.3 \% & 20.8 \\ 0.12 \% & 45.2 \% & \text { LYIGNLNESVTPADLEK } & 99.7 \% & 67.6\end{array}$}

\section{$0.12 \% \quad 45.2 \%$ ISYSGQFLVK \\ $0.12 \% \quad 45.2 \%$ AIETFSGKVELQGK \\ $0.12 \% \quad 45.2 \%$ RLEIEHSVPK}

$0.12 \% \quad 45.2 \%$ LNGHQLENHALK

$0.12 \% \quad 45.2 \%$ VSYIPDEQIAQGPENGR

$0.12 \% \quad 45.2 \%$ QGSPVAAGAPAK

$0.12 \% \quad 45.2 \%$ QGSPVAAGAPAKQQQVDIPLR

$0.12 \% \quad 45.2 \%$ QQQVDIPLR

$0.12 \% \quad 45.2 \%$ LLVPTQYVGAIIGK

$0.12 \% \quad 45.2 \%$ AISVHSTPEGCSSACK

$0.12 \% \quad 45.2 \%$ MILEIMHK

$0.12 \% \quad 45.2 \%$ TADEVPLKILAHNNFVGR

$0.12 \% \quad 45.2 \%$ ILAHNNFVGR

$0.12 \% \quad 45.2 \%$ ITISSLQDLTLYNPER

$0.12 \% \quad 45.2 \%$ GQHIKQLSR

$0.12 \% \quad 45.2 \%$ FASASIKIAPPETPDSK

$0.12 \% \quad 45.2 \%$ IAPPETPDSKVR

$0.12 \% \quad 45.2 \%$ MVIITGPPEAQFK

$0.12 \% \quad 45.2 \%$ MVIITGPPEAQFKAQGR

$0.12 \% \quad 45.2 \%$ TVNELQNLTAAEVVVPR

$0.12 \% \quad 45.2 \%$ DQTPDENDQVIVK

$0.12 \% \quad 45.2 \%$ IIGHFYASQMAQR

$0.02 \% \quad 19.9 \%$ VAYIPDEMAAQQNPLQQPR

$0.02 \% \quad 19.9 \%$ LLVPTQFVGAIIGK

$0.02 \% \quad 19.9 \%$ SITILSTPEGTSAACK

$0.02 \% \quad 19.9 \%$ ILAHNNFVGR

$0.02 \% \quad 19.9 \%$ IAPAEAPDAK

$0.02 \% \quad 19.9 \%$ IAPAEAPDAKVR

$0.02 \% \quad 19.9 \%$ MVIITGPPEAQFK

$0.02 \% \quad 19.9 \%$ MVIITGPPEAQFKAQGR

$0.02 \% \quad 19.9 \%$ TVNELQNLSSAEVVVPR

$0.02 \% \quad 19.9 \%$ ALQSGPPQSR

$0.01 \% \quad 2.4 \% \quad$ LAEAAVAEKR

$0.01 \% \quad 2.4 \%$ TFVDNIQTAFNTR

$0.01 \% \quad 2.4 \%$ LVIFNELSSAR

$0.01 \% \quad 2.4 \%$ SFQNQIAAIQR

$\begin{array}{lll}0.01 \% & 2.4 \% & \text { LPLFDSVR }\end{array}$

$0.00 \% \quad 3.7 \%$ VTPLGAGQDVGR

$0.00 \% \quad 3.7 \%$ VLIPVFALGR

$0.00 \% \quad 6.1 \%$ AAEAAINILK

$0.00 \% \quad 6.1 \%$ NAAEKFLAK

$0.05 \% \quad 25.9 \%$ VKPAPDETSFSEALLK

$\begin{array}{lllll}0.05 \% & 25.9 \% & \text { VKPAPDETSFSEALLKR } & 97.0 \% & 14.9\end{array}$

$0.05 \% \quad 25.9 \%$ NQDLAPNSAEQASILSLVTK $\quad 99.7 \% \quad 51.0$

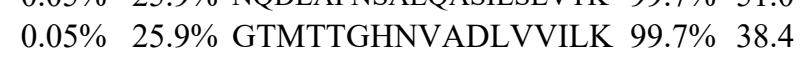

$99.7 \% 58.9$

$99.7 \% \quad 29.1$

$99.0 \% \quad 20.8$

$\begin{array}{lll}99.7 \% & 31.9 \\ 99.7 \% & 45.6 \\ 9\end{array}$

$9.7 \% \quad 50.3$

$99.7 \% \quad 51.6$

$99.7 \% \quad 58.3$

$96.2 \% \quad 19.2$

$99.7 \% \quad 38.7$

$99.7 \% \quad 28.3$

$98.8 \% \quad 21.0$

$99.7 \% \quad 38.7$

$99.2 \% \quad 25.0$

$\begin{array}{lll}99.7 \% & 62.5 \\ 99.7 \% & 58.8\end{array}$

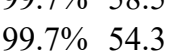

$99.7 \% \quad 42.2$

$99.0 \% \quad 64.6$

$99.7 \% \quad 52.9$

$99.7 \% \quad 38.7$

$96.7 \% \quad 16.5$

$99.7 \% \quad 49.8$

$99.7 \% \quad 62.5$

$\begin{array}{llll}99.7 \% & 45.1\end{array}$

$\begin{array}{llll}99.7 \% & 29.9\end{array}$

$\begin{array}{lll}99.7 \% & 56.7 \\ 99.7 \% & 49.9 & 2\end{array}$

$\begin{array}{lll}99.7 \% & 49.9 \\ 99.7 \% & 29.7\end{array}$

$99.7 \% \quad 38.0$

$97.7 \% \quad 17.5$

$\begin{array}{llll}99.7 \% & 26.1\end{array}$

$\begin{array}{lll}99.7 \% & 30.0\end{array}$

$\begin{array}{lll}99.7 \% & 47.3\end{array}$

$99.7 \% \quad 29.9$

$25.0 \quad 39.8$

$25.0 \quad 19.2$

$25.0 \quad 32.6$

$\begin{array}{ll}25.0 & 14.9\end{array}$

$25.0 \quad 51.0$ $25.0 \quad 37.1$
Page 66 of Table S-1-2 
Interleukin enhancer-binding factor $2 \mathrm{GN}=\mathrm{ILF} 2$ ILF2_HUMAN $43.06 \quad 100.0 \%$ Interleukin enhancer-binding factor $2 \mathrm{GN}=\mathrm{ILF} 2 \mathrm{ILF} 2$ _HUMAN $43.06 \quad 100.0 \%$ Interleukin enhancer-binding factor 2 GN=ILF2 ILF2_HUMAN $43.06 \quad 100.0 \%$ Interleukin enhancer-binding factor $2 \mathrm{GN}=\mathrm{ILF} 2 \mathrm{ILF} 2 \mathrm{HUMAN} 43.06 \quad 100.0 \%$ Interleukin enhancer-binding factor $3 \mathrm{GN}=\mathrm{ILF} 3 \mathrm{ILF} 3$ _HUMAN $95.34 \quad 100.0 \%$ Interleukin enhancer-binding factor $3 \mathrm{GN}=\mathrm{ILF} 3 \mathrm{ILF} 3$ _HUMAN $95.34 \quad 100.0 \%$ Interleukin enhancer-binding factor $3 \mathrm{GN}=\mathrm{ILF} 3$ ILF3_HUMAN $95.34100 .0 \%$ Interleukin enhancer-binding factor $3 \mathrm{GN}=\mathrm{ILF} 3 \mathrm{ILF} 3$ _HUMAN $95.34 \quad 100.0 \%$ Interleukin enhancer-binding factor $3 \mathrm{GN}=\mathrm{ILF} 3 \mathrm{ILF} 3$ HUMAN $95.34100 .0 \%$ Interleukin enhancer-binding factor $3 \mathrm{GN}=\mathrm{ILF} 3 \mathrm{ILF} 3$ _HUMAN $95.34 \quad 100.0 \%$ Interleukin enhancer-binding factor 3 GN=ILF3 ILF3_HUMAN $95.34 \quad 100.0 \%$ Interleukin enhancer-binding factor $3 \mathrm{GN}=\mathrm{ILF} 3 \mathrm{ILF} 3$ HUMAN 95.34 Interleukin enhancer-binding factor $3 \mathrm{GN}=\mathrm{ILF} 3 \mathrm{ILF} 3$ _HUMAN $95.34 \quad 100.0 \%$ Interleukin enhancer-binding factor $3 \mathrm{GN}=\mathrm{ILF} 3$ ILF3_HUMAN $95.34 \quad 100.0 \%$ Interleukin enhancer-binding factor $3 \mathrm{GN}=\mathrm{ILF} 3 \mathrm{ILF} 3$ HUMAN $95.34 \quad 100.0 \%$ Interleukin enhancer-binding factor $3 \mathrm{GN}=\mathrm{ILF} 3 \mathrm{ILF} 3$ _HUMAN $95.34 \quad 100.0 \%$ Interleukin enhancer-binding factor $3 \mathrm{GN}=\mathrm{ILF} 3 \mathrm{ILF} 3$ HUMAN $95.34 \quad 100.0 \%$ Interleukin enhancer-binding factor 3 GN=ILF3 ILF3_HUMAN $95.34 \quad 100.0 \%$ Isocitrate dehydrogenase [NAD] subunit apha, mitochondrial GN=IDH3A IDH3A_HUMAN $39.59 \quad 100.0 \%$ Isocitrate dehydrogenase [NAD] subunit alpha, mitochondrial GN=IDH3A IDH3A_HUMAN $39.59100 .0 \%$ Isocitrate dehydrogenase [NAD] subunit alpha, mitochondrial GN=IDH3A IDH3A_HUMAN $39.59 \quad 100.0 \%$ Isocitrate dehydrogenase [NAD] subunit alpha, mitochondrial GN=IDH3A IDH3A_HUMAN $39.59 \quad 100.0 \%$ Isocitrate dehydrogenase [NAD] subunit alpha, mitochondrial GN=IDH3A IDH3A_HUMAN $39.59 \quad 100.0 \%$ Isocitrate dehydrogenase [NAD] subunit alpha, mitochondrial GN=IDH3A IDH3A_HUMAN $39.59 \quad 100.0 \%$ Isocitrate dehydrogenase [NAD] subunit alpha, mitochondrial GN=IDH3A IDH3A_HUMAN $39.59 \quad 100.0 \%$ Isocitrate dehydrogenase [NAD] subunit alpha, mitochondrial GN=IDH3A IDH3A_HUMAN $39.59 \quad 100.0 \%$ Isocitrate dehydrogenase $[\mathrm{NAD}]$ subunit alpha, mitochondrial GN=IDH3A IDH3A_HUMAN $39.59 \quad 100.0 \%$ Isocitrate dehydrogenase $[\mathrm{NAD}]$ subunit beta, mitochondrial GN=IDH3B IDH3B HUMAN $42.18 \quad 100.0 \%$ Isocitrate dehydrogenase $[\mathrm{NAD}]$ subunit beta, mitochondrial GN=IDH3B IDH3B_HUMAN $42.18 \quad 100.0 \%$ Isocitrate dehydrogenase [NAD] subunit beta, mitochondrial GN=IDH3B IDH3B HUMAN $42.18100 .0 \%$ Isocitrate dehydrogenase $[\mathrm{NAD}]$ subunit beta, mitochondrial GN=IDH3B IDH3B_HUMAN $42.18 \quad 100.0 \%$ Isocitrate dehydrogenase $[\mathrm{NAD}]$ subunit beta, mitochondrial GN=IDH3B IDH3B_HUMAN $42.18 \quad 100.0 \%$ Isocitrate dehydrogenase [NAD] subunit beta, mitochondrial GN=IDH3B IDH3B_HUMAN $42.18 \quad 100.0 \%$ Isocitrate dehydrogenase $[\mathrm{NAD}]$ subunit beta, mitochondrial GN=IDH3B IDH3B_HUMAN $42.18 \quad 100.0 \%$ Isocitrate dehydrogenase $[\mathrm{NAD}]$ subunit beta, mitochondrial GN=IDH3B IDH3B_HUMAN $42.18 \quad 100.0 \%$ Isocitrate dehydrogenase $[\mathrm{NAD}]$ subunit beta, mitochondrial GN=IDH3B $\quad$ IDH3B HUMAN $42.18 \quad 100.0 \%$ Isocitrate dehydrogenase $[\mathrm{NAD}]$ subunit beta, mitochondrial GN=IDH3B IDH3B_HUMAN $42.18 \quad 100.0 \%$ Isocitrate dehydrogenase $[\mathrm{NAD}]$ subunit gamma mitochondrial GN=IDH3G IDH3G_HUMAN $42.79100 .0 \%$ Isocitrate dehydrogenase $[\mathrm{NAD}]$ subunit gamma, mitochondrial $\mathrm{GN}=[\mathrm{DH} 3 \mathrm{G}$ IDH3G_HUMAN $42.79 \quad 100.0 \%$ Isocitrate dehydrogenase $[\mathrm{NAD}]$ subunit gamma, mitochondrial GN=IDH3G IDH3G_HUMAN $42.79 \quad 100.0 \%$ Isocitrate dehydrogenase [NADP], mitochondrial GN=IDH2 IDHP HUMAN $50.91 \quad 100.0 \%$ Isocitrate dehydrogenase [NADP], mitochondrial GN=IDH2 IDHP_HUMAN $50.91 \quad 100.0 \%$ Isocitrate dehydrogenase [NADP], mitochondrial GN=IDH2 IDHP HUMAN $50.91 \quad 100.0 \%$ Isocitrate dehydrogenase [NADP], mitochondrial GN=IDH2 IDHP_HUMAN $50.91 \quad 100.0 \%$ Isocitrate dehydrogenase [NADP], mitochondrial GN=IDH2 IDHP_HUMAN $50.91 \quad 100.0 \%$ Isocitrate dehydrogenase [NADP], mitochondrial GN=IDH2 IDHP_HUMAN $50.91 \quad 100.0 \%$ Isocitrate dehydrogenase [NADP], mitochondrial GN=IDH2 IDHP_HUMAN $50.91 \quad 100.0 \%$
$10 \quad 31 \quad 0.05 \% \quad 25.9 \%$ ILPTLEAVAALGNK $10 \quad 31 \quad 0.05 \% \quad 25.9 \%$ ILITTVPPNLR

$10 \quad 31 \quad 0.05 \% \quad 25.9 \%$ WFEENASQSTVK

$\begin{array}{llll}10 & 31 & 0.05 \% & 25.9 \% \\ & & \text { QPLALNVAYR }\end{array}$

$22 \quad 59 \quad 0.09 \% \quad 16.8 \%$ IFVNDDRHVMAK

2259

22

22

22

2

2

22

22

22

2

4

\begin{tabular}{ll}
42 \\
4 & 22 \\
\hline &
\end{tabular}

$9 \quad 12$

1

$90.09 \% \quad 16.8 \%$ VLAGETLSVNDPPDVLDR $0.09 \% \quad 16.8 \%$ CLAALASLR 0.09\% $16.8 \%$ SIGTANRPMGAGEALRR $0.09 \% \quad 16.8 \%$ QQREDITQSAQHALR $0.09 \% \quad 16.8 \%$ LAAFGQLHK $0.09 \% \quad 16.8 \%$ VLGMDPLPSK $0.09 \% \quad 16.8 \%$ VLGMDPLPSKMPK $0.09 \% \quad 16.8 \%$ LNQLKPGLQYK $0.09 \% \quad 16.8 \%$ TAKLHVAVK $0.09 \% \quad 16.8 \%$ VLQDMGLPTGAEGR $0.09 \% \quad 16.8 \%$ AYAALAALEK $0.09 \% \quad 16.8 \%$ NADHSMNYQYR $0.03 \% 24.6 \%$ MGLKGPLK $0.03 \% 24.6 \%$ TPIAAGHPSMNLLLR $0.03 \% 24.6 \%$ SNVTAVHKANIMR $0.03 \% \quad 24.6 \%$ MSDGLFLQK $0.03 \% \quad 24.6 \%$ IEAACFATIKDGK $0.03 \% 24.6 \%$ SLTKDLGGNAK $0.03 \% \quad 24.6 \%$ CSDFTEEICR $0.03 \% \quad 24.6 \%$ CSDFTEEICRR $0.04 \% 21.0 \%$ SLPGYMTR $0.04 \% \quad 21.0 \%$ HNNLDLVIIR $0.04 \% \quad 21.0 \%$ GVIECLKIVTR $0.04 \% \quad 21.0 \%$ FAFDYATK $0.04 \% \quad 21.0 \%$ FAFDYATKK $0.04 \% \quad 21.0 \%$ TRDMGGYSTTTDFIK $0.04 \% \quad 21.0 \%$ DMGGYSTTTDFIK $0.04 \% \quad 21.0 \%$ SVIGHLQTK $0.04 \% \quad 21.0 \%$ SVIGHLQTKGS $0.01 \% \quad 9.7 \%$ TSLDLYANVIHCK $0.01 \% \quad 9.7 \%$ IAEYAFKLAQESGR $0.01 \% \quad 9.7 \%$ LGDGLFLQCCR

$0.04 \% \quad 24.1 \%$ CATITPDEAR $0.04 \% \quad 24.1 \%$ NILGGTVFREPIICK $0.04 \% \quad 24.1 \%$ ATDFVADRAGTFK $0.04 \% \quad 24.1 \%$ LIDDMVAQVLK $0.04 \% 24.1 \%$ SSGGFVWACK $0.04 \% \quad 24.1 \%$ TIEAEAAHGTVTR $0.04 \% \quad 24.1 \%$ GKLDGNQDLIR $\begin{array}{llllllll}9.7 \% & 61.0 & 25.0 & 59.1 & 4 & 0 & 0 & 1409.84\end{array}$ $\begin{array}{lll}0 & 0 & 1236.77\end{array}$ $\begin{array}{llllllll}99.7 \% & 50.0 & 25.0 & 48.1 & 2 & 0 & 0 & 1425.66\end{array}$

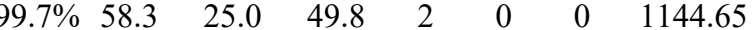
$\begin{array}{llllllll}99.7 \% & 33.2 & 25.0 & 31.7 & 3 & 7 & 0 & 1460.73\end{array}$ 1909.99

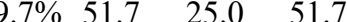
$0.03 \% \quad 24.6 \%$ IAEFAFEYAR $\begin{array}{llll}99.7 \% & 50.2 & 25.0 & 38.2\end{array}$ $\begin{array}{llll}99.7 \% & 33.0 & 25.0 & 33.0\end{array}$ $99.7 \% \quad 61.6 \quad 25.0 \quad 60.3$ $99.7 \% \quad 36.3 \quad 25.0 \quad 28.0$ $99.7 \% \quad 30.0 \quad 25.0 \quad 30.0$ $97.7 \% \quad 16.1 \quad 25.0 \quad 16.1$ $99.7 \% \quad 47.7 \quad 25.0 \quad 36.7$ $99.7 \% \quad 29.3 \quad 25.0 \quad 29.3$ $99.7 \% \quad 55.8 \quad 25.0 \quad 51.5$ $99.7 \% \quad 51.1 \quad 25.0 \quad 41.5$ $98.1 \% \quad 16.9 \quad 25.0 \quad 16.9$ $98.5 \% \quad 25.9 \quad 25.0 \quad 14.7$

$99.7 \% \quad 27.0$ $\begin{array}{llll}99.7 \% & 66.4 & 25.0 & 62.1\end{array}$ $99.7 \% \quad 30.3 \quad 25.0 \quad 29.5$ $\begin{array}{llll}98.1 \% & 23.5 & 25.0 & 11.7\end{array}$ $\begin{array}{lllll}99.7 \% & 48.3 & 25.0 & 48.3 & 2\end{array}$ $99.7 \% \quad 33.6 \quad 25.0 \quad 25.5$ $\begin{array}{llll}99.7 \% & 58.3 & 25.0 & 53.6\end{array}$ $\begin{array}{llll}98.7 \% & 20.6 & 25.0 & 18.9\end{array}$ $98.7 \% \quad 17.9 \quad 25.0 \quad 17.7$ $\begin{array}{llll}99.7 \% & 32.0 & 25.0 & 32.0\end{array}$ $99.7 \% \quad 48.4 \quad 25.0 \quad 39.4$ $\begin{array}{llll}99.0 \% & 24.9 & 25.0 & 24.9\end{array}$ $\begin{array}{llll}99.5 \% & 24.9 & 25.0 & 17.4\end{array}$

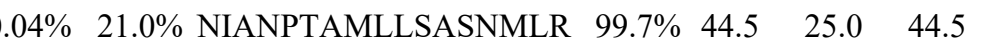

$\begin{array}{lllll}99.3 \% & 23.1 & 25.0 & 21.5 & 1 \\ 99.7 \% & 46.9 & 25.0 & 46.9 & 4\end{array}$

$\begin{array}{llll}99.7 \% & 46.9 & 25.0 & 46.9 \\ 99.7 \% & 26.0 & 25.0 & 26.0\end{array}$

$\begin{array}{llll}99.7 \% & 49.4 & 25.0 & 41.4\end{array}$

$\begin{array}{llll}99.7 \% & 53.7 & 25.0 & 53.7\end{array}$

$\begin{array}{llll}99.7 \% & 43.1 & 25.0 & 43.1\end{array}$

$\begin{array}{llll}99.7 \% & 47.3 & 25.0 & 47.3\end{array}$

$\begin{array}{llll}99.7 \% & 37.0 & 25.0 & 34.5\end{array}$

$\begin{array}{lllll}99.7 \% & 52.3 & 25.0 & 52.3 & 2\end{array}$

$\begin{array}{lllll}99.7 \% & 45.0 & 25.0 & 38.2\end{array}$

$\begin{array}{llll}99.7 \% & 58.2 & 25.0 & 52.1\end{array}$

$\begin{array}{lllll}99.7 \% & 50.9 & 25.0 & 42.8 & 2\end{array}$

$\begin{array}{llll}99.7 \% & 86.4 & 25.0 & 78.0\end{array}$

$\begin{array}{llll}99.7 \% & 36.0 & 25.0 & 27.9\end{array}$
2166.14 974.55

$210 \quad 221$

$260 \quad 269$

$183 \quad 200$

$183 \quad 202$

$203 \quad 211$

$258 \quad 27$

$1780.91 \quad 309 \quad 323$

984.56

1056.58

1412.76

1301.76

966.61

1443.73

1020.57

1414.58

843.51

1590.88

1216.60

1440.77

1054.52

1423.73

1103.61

1316.52

1472.63

940.46

1206.70

1287.75

962.46

1090.56

1848.93

1692.79

1451.64

982.57

1126.62

1533.77

1582.82

1338.63

1133.53

1716.95

1398.70

1244.69

1098.50

1355.69

1228.66

$324 \quad 332$

$\begin{array}{ll}333 & 345\end{array}$

$409 \quad 419$

$452 \quad 460$

461474

$578 \quad 587$

$884 \quad 894$

$101 \quad 115$

$179 \quad 188$

$206 \quad 214$

$327 \quad 339$

$340 \quad 350$

$351 \quad 360$

351361

$147 \quad 154$

$155 \quad 164$

$181 \quad 191$

$200 \quad 207$

$200 \quad 208$ 
Isocitrate dehydrogenase [NADP], mitochondrial GN=IDH2 IDHP_HUMAN $50.91 \quad 100.0 \%$ Isocitrate dehydrogenase [NADP], mitochondrial GN=IDH2 IDHP_HUMAN $50.91 \quad 100.0 \%$ Isoleucine--tRNA ligase, cytoplasmic GN=IARS SYIC_HUMAN $144.50 \quad 100.0 \%$ Isoleucine--tRNA ligase, cytoplasmic GN=IARS SYIC_HUMAN $144.50 \quad 100.0 \%$ Isoleucine--tRNA ligase, cytoplasmic GN=IARS SYIC_HUMAN $144.50 \quad 100.0 \%$ Isoleucine--tRNA ligase, cytoplasmic GN=IARS SYIC_HUMAN $144.50 \quad 100.0 \%$ Isoleucine--tRNA ligase, cytoplasmic GN=IARS SYIC_HUMAN $144.50 \quad 100.0 \%$ Isoleucine--tRNA ligase, mitochondrial GN=IARS2 SYIM_HUMAN $113.79 \quad 100.0 \%$ Isoleucine--tRNA ligase, mitochondrial GN=IARS2 SYIM_HUMAN $113.79 \quad 100.0 \%$ Isoleucine--tRNA ligase, mitochondrial GN=IARS2 SYIM_HUMAN $113.79 \quad 100.0 \%$ Isoleucine--tRNA ligase, mitochondrial GN=IARS2 SYIM_HUMAN $113.79 \quad 100.0 \%$ Isoleucine--tRNA ligase, mitochondrial GN=IARS2 SYIM_HUMAN $113.79 \quad 100.0 \%$ Isovaleryl-CoA dehydrogenase, mitochondrial GN=IVD IVD_HUMAN $46.32 \quad 100.0 \%$ Isovaleryl-CoA dehydrogenase, mitochondrial GN=IVD IVD_HUMAN $46.32 \quad 100.0 \%$ Junction plakoglobin GN=JUP Junction plakoglobin $\mathrm{GN}=\mathrm{JUP}$ Junction plakoglobin GN=JUP Katanin p60 ATPase-containing subunit A1 GN=KATNA1 KTNA1_HUMAN $55.97 \quad 100.0 \%$ Katanin p60 ATPase-containing subunit A1 GN=KATNA1 KTNA1_HUMAN $55.97 \quad 100.0 \%$ Ketosamine-3-kinase GN=FN3KRP $\quad$ KT3K_HUMAN $34.41 \quad 99.9 \%$ Ketosamine-3-kinase GN=FN3KRP KT3K_HUMAN $34.41 \quad 99.9 \%$ KHDR1_HUMAN $48.23 \quad 100.0 \%$ KHDR1_HUMAN $48.23 \quad 100.0 \%$ $\begin{array}{llll}\text { KH domain-containing, RNA-binding, signal transduction-associated protein } 1 \text { GN=KHDRBSI } & \text { KHDR1_HUMAN } & 48.23 & 100.0 \% \\ \text { Kinetochore-associated protein } 1 \mathrm{GN}=\mathrm{KNTC} 1 & \mathrm{KNTC1} \text { HUMAN } 250.76 & 100.0 \%\end{array}$ Kinetochore-associated protein $1 \mathrm{GN}=\mathrm{KNTC1} \mathrm{KNTC1}$ HUMAN $250.76 \quad 100.0 \%$ Kinetochore-associated protein $1 \mathrm{GN}=\mathrm{KNTC1}$ KNTC1_HUMAN $250.76 \quad 100.0 \%$ Kinetochore-associated protein $1 \mathrm{GN}=\mathrm{KNTC1}$ KNTC1_HUMAN $250.76 \quad 100.0 \%$ Kinetochore-associated protein $1 \mathrm{GN}=\mathrm{KNTC1}$ KNTC1_HUMAN $250.76 \quad 100.0 \%$ KRR1 small subunit processome component homolog GN=KRR1 KRR1_HUMAN $43.67 \quad 100.0 \%$ KRR1 small subunit processome component homolog GN=KRR1 KRR1_HUMAN $43.67 \quad 100.0 \%$ KRR1 small subunit processome component homolog GN=KRR1 KRR1_HUMAN $43.67 \quad 100.0 \%$ KRR1 small subunit processome component homolog GN=KRR1 KRR1_HUMAN $43.67 \quad 100.0 \%$ KRR1 small subunit processome component homolog GN=KRR1 KRR1_HUMAN $43.67 \quad 100.0 \%$ KRR1 small subunit processome component homolog GN=KRR1 KRR1_HUMAN $43.67 \quad 100.0 \%$ L-2-hydroxyglutarate dehydrogenase, mitochondrial GN=L2HGDH L2HDH_HUMAN $50.32 \quad 100.0 \%$ L-2-hydroxyglutarate dehydrogenase, mitochondrial GN=L2HGDH L2HDH_HUMAN $50.32 \quad 100.0 \%$ L-2-hydroxyglutarate dehydrogenase, mitochondrial GN=L2HGDH L2HDH_HUMAN $50.32 \quad 100.0 \%$ Lactadherin GN=MFGE8 Lactadherin GN=MFGE8 Lactadherin GN=MFGE8 amina-associated polypeptide 2, isoform alpha GN=TMPO LAP2A_HUMAN $75.49 \quad 100.0 \%$ Lamina-associated polypeptide 2, isoform alpha GN=TMPO LAP2A_HUMAN $75.49 \quad 100.0 \%$ Lamina-associated polypeptide 2, isoform alpha GN=TMPO LAP2A_HUMAN $75.49 \quad 100.0 \%$ Lamin-B receptor $\mathrm{GN}=\mathrm{LBR}$ Lamin-B receptor $\mathrm{GN}=\mathrm{LBR}$ Lamin- $\mathrm{B}$ receptor $\mathrm{GN}=\mathrm{LBR}$ Lamin-B receptor $\mathrm{GN}=\mathrm{LBR}$ MFGM HUMAN $43.12 \quad 100.0 \%$ MFGM_HUMAN $43.12 \quad 100.0 \%$ $\begin{array}{lll}\text { MFGM_HUMAN } & 43.12 & 100.0 \% \\ \text { MFGM_HUMAN } & 43.12 & 100.0 \%\end{array}$ LBR_HUMAN $70.71 \quad 100.0 \%$ LBR_HUMAN $70.71 \quad 100.0 \%$ LBR_HUMAN $70.71 \quad 100.0 \%$ LBR_HUMAN $70.71 \quad 100.0 \%$
$0.04 \% \quad 24.1 \%$ VCVETVESGAMTK

$0.04 \% \quad 24.1 \%$ DLAGCIHGLSNVK

$0.01 \% \quad 4.0 \%$ MGITEYNNQCR

$0.01 \% \quad 4.0 \% \quad$ LYLINSPVVR

$0.01 \% \quad 4.0 \%$ FLIQNVLR

$0.01 \% \quad 4.0 \%$ EVINRIQK

$0.01 \% \quad 4.0 \%$ TQLKGSELEITLTR

$0.02 \% \quad 5.9 \%$ TALAEAELEYNPEHVSR

$0.02 \% \quad 5.9 \% \quad$ SIYVKFPLLKPSPK

$0.02 \% \quad 5.9 \%$ FPLLKPSPK

$0.02 \% \quad 5.9 \%$ AVLEEGTDVVIK

$0.02 \% \quad 5.9 \%$ TKDEYLINSQTTEHIVK

$0.00 \% \quad 4.5 \% \quad$ FLQEHLAPK

$0.00 \% \quad 4.5 \%$ TDLAAVPASR

$0.01 \% \quad 6.3 \%$ LAEPSQLLK

$0.01 \% \quad 6.3 \%$ NLALCPANHAPLQEAAVIPR

$0.00 \% \quad 5.3 \%$ GVLMVGPPGTGK

$0.00 \% \quad 5.3 \%$ TTFFNVSSSTLTSK

$0.00 \% \quad 7.4 \%$ TNTVKVPKPIK

$0.00 \% \quad 7.4 \%$ GGGQEERPFVAR

$0.01 \% \quad 5.6 \%$ SGSMDPSGAHPSVR

$0.01 \% \quad 5.6 \%$ ILGPQGNTIKR

$0.01 \% \quad 2.9 \% \quad$ LSEDSVSVLVLR

$0.01 \% \quad 2.9 \%$ HKPGSTPEPIAAEVR

$0.01 \% \quad 2.9 \%$ LGISFQPVFR

$0.01 \% \quad 2.9 \% \quad$ SSTLINKEITK

$0.01 \% \quad 2.9 \%$ IQNSSGTDYPDIHAAAK

$0.02 \% \quad 15.0 \%$ GLLEESSFATLFPK

$0.02 \% \quad 15.0 \%$ KTFDPYIIIR

$0.02 \% \quad 15.0 \%$ TFDPYIIIR

$0.02 \% \quad 15.0 \%$ SVSFEQAVR

$0.02 \% \quad 15.0 \%$ ILQDDVACDIIK

$0.02 \% \quad 15.0 \%$ LGALTAEEIALK

$0.01 \% \quad 7.8 \%$ LIVAVEQEEIPR

$0.01 \% \quad 7.8 \%$ SIDGMQYPIVIK

$0.01 \% \quad 7.8 \%$ FIPEITISDILR

$99.7 \% \quad 37.5$

$\begin{array}{ll}99.7 \% & 37.5 \\ 99.7 \% & 36.8\end{array}$

$99.7 \% \quad 38.9$

$99.0 \% \quad 21.6$

$\begin{array}{lll}95.8 \% & 22.8\end{array}$

$99.4 \% \quad 24.3$

$\begin{array}{ll}99.7 \% & 52.9 \\ 98.6 \% & 24.3\end{array}$

$98.6 \% \quad 26.4$

$99.7 \% \quad 52.0$

$\begin{array}{lll}99.7 \% & 27.8\end{array}$

$99.7 \% \quad 29.6$

$\begin{array}{lll}99.7 \% & 27.8\end{array}$

$\begin{array}{ll}99.4 \% & 25.8 \\ 98.4 \% & 16.8\end{array}$

$99.0 \% \quad 20.1$

$99.7 \% \quad 38.3$

$97.3 \% \quad 16.1$

$98.7 \% \quad 26.1$

$99.7 \% \quad 29.5$

$99.7 \% \quad 56.3$

$99.7 \% \quad 56.1$

$99.6 \% \quad 23.6$

$99.7 \% \quad 33.0$

$99.2 \% \quad 25.6$

$99.7 \% \quad 34.5$

$99.7 \% \quad 31.3$

$99.7 \% \quad 27.6$

$99.5 \% \quad 25.3$

$99.7 \% \quad 45.7$

$\begin{array}{lll}99.7 \% & 56.8\end{array}$

$99.7 \% \quad 51.7$

$99.3 \% \quad 26.4$

$99.7 \% \quad 34.0$

$99.7 \% \quad 48.0$

0.01\% $10.3 \%$ NAVHVNLFETPVEAQYVR $\quad 96.8 \% \quad 15.3$

$0.01 \% \quad 10.3 \%$ NFGSVQFVASYK

$0.01 \% \quad 10.3 \%$ NLFETPILAR

$0.02 \% \quad 7.1 \%$ YGVNPGPIVGTTR

$0.02 \% \quad 7.1 \%$ SSTPLPTISSSAENTR

$99.6 \% 29.1$

$99.7 \% \quad 43.4$

$99.7 \% \quad 46.6$

$99.7 \% \quad 59.3$

$0.02 \% \quad 7.1 \%$ AYEAAASALQIATHTAFVAK

$0.05 \% \quad 14.1 \%$ KFADGEVVR

$0.05 \% \quad 14.1 \%$ SASASHQADIKEAR

$0.05 \% \quad 14.1 \%$ LTPLILKPFGNSISR

$0.05 \% \quad 14.1 \%$ TFEVTPIR
$99.7 \%$

$99.7 \% \quad 52.1$

$99.3 \% \quad 22.2$

$99.0 \% \quad 33.4$
33.4

36.0

$\begin{array}{ll}0 & 38.3\end{array}$

$\begin{array}{ll}17.4 \\ .0 & 10.2\end{array}$

20.6

52.9

$\begin{array}{ll}0.0 & 24.3\end{array}$

26.4

$\begin{array}{ll}45.0 & 45.2\end{array}$

\begin{tabular}{ll}
23.9 \\
\hline
\end{tabular}

$25.0 \quad 22.8$

$\begin{array}{ll}0 & 18.0\end{array}$

$\begin{array}{ll}.0 & 16.5\end{array}$

$\begin{array}{ll}.0 & 16.8\end{array}$

$\begin{array}{ll}.0 & 21.1\end{array}$

$\begin{array}{ll}0 & 20.0\end{array}$

$\begin{array}{ll}38.0 & 38.0\end{array}$

$\begin{array}{ll}0 & 16.1\end{array}$

\begin{tabular}{ll}
13.5 \\
\hline
\end{tabular}

\begin{tabular}{ll}
28.2 \\
\hline
\end{tabular}

$\begin{array}{ll}0 & 45.2\end{array}$

$\begin{array}{ll}.0 & 44.0\end{array}$

$25.0 \quad 23.6$

$25.0 \quad 28.6$

\begin{tabular}{ll}
21.9 \\
\hline
\end{tabular}

$25.0 \quad 33.4$

$25.0 \quad 29.1$

\begin{tabular}{ll}
27.6 \\
\hline
\end{tabular}

$25.0 \quad 17.6$

$25.0 \quad 37.5$

$\begin{array}{ll}25.0 & 40.0\end{array}$

\begin{tabular}{ll}
32.5 \\
\hline
\end{tabular}

22.8
25.0

$25.0 \quad 32.2$

$25.0 \quad 44.7$

$\begin{array}{ll}0 & 15.3\end{array}$

$25.0 \quad 29.1$

\begin{tabular}{ll}
24.7 \\
\hline
\end{tabular}

$\begin{array}{ll}0 & 46.3\end{array}$

$5.0 \quad 52.6$

$\begin{array}{ll}52.6 & 40.6\end{array}$

$25.0 \quad 39.6$

$25.0 \quad 52.1$

$25.0 \quad 22.2$

$25.0 \quad 33.4$
1385.59

1173.70

1002.61

999.59

1588.89

1928.93

1616.98

1026.63

1272.70

2019.04

1082.60

1000.54

998.59

2029.04

2155.14

1112.61

1519.76

1224.77

1302.66

1400.62

1196.71

1316.74

1588.84

1163.66

1233.71

1787.86

1538.81

1265.73

1137.63

1022.53

1402.73

1228.71

1395.78

1379.72

1416.81

2086.07

1346.67

1173.66

1330.71

1647.82

2034.07

1020.55

1470.73

1655.98

962.53

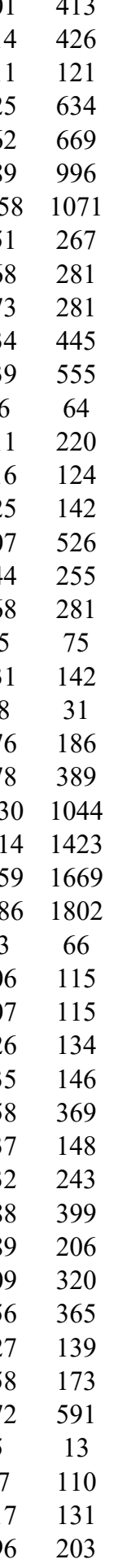

Page 68 of Table S-1-2 
Lamin-B1 GN=LMNB Lamin-B1 GN=LMNB Lamin-B1 GN=LMNB1 Lamin-B1 GN=LMNB Lamin-B1 GN=LMNB Lamin-B1 GN=LMNB Lamin-B1 GN=LMNB Lamin-B1 GN=LMNB Lamin-B1 GN=LMNB Lamin-B1 GN=LMNB Lamin-B1 GN=LMNB Lamin-B1 GN=LMNB Lamin-B1 GN=LMNB Lamin-B1 GN=LMNB Lamin-B1 GN=LMNB Lamin-B1 GN=LMNB1 Lamin-B1 GN=LMNB Lamin-B1 GN=LMNB Lamin-B1 GN=LMNB Lamin-B1 GN=LMNB Lamin-B1 GN=LMNB Lamin-B1 GN=LMNB Lamin-B1 GN=LMNB Lamin-B1 GN=LMNB1 Lamin-B1 GN=LMNB1 Lamin-B1 GN=LMNB Lamin-B2 GN=LMNB Lamin-B2 GN=LMNB? Lamin-B2 GN=LMNB2 Lamin-B2 GN=LMNB Lamin-B2 GN=LMNB Lamin-B2 GN=LMNB Lamin-B2 GN=LMNB2 Lamin-B2 GN=LMNB2 Lamin-B2 GN=LMNB Lamin-B2 GN=LMNB2 Lamin-B2 GN=LMNB2 Lamin-B2 GN=LMNB2 Lamin-B2 GN=LMNB2 Lamin-B2 GN=LMNB2 Lamin-B2 GN=LMNB2

LBR HUMAN $70.71 \quad 100.0 \%$ LBR_HUMAN $70.71 \quad 100.0 \%$ LBR_HUMAN $70.71 \quad 100.0 \%$ LMNB1 HUMAN $66.41 \quad 100.0 \% \quad 29$ LMNB1_HUMAN $66.41 \quad 100.0 \% \quad 29$ LMNB1_HUMAN $66.41 \quad 100.0 \% \quad 29$ LMNB1_HUMAN $66.41 \quad 100.0 \% \quad 29$ LMNB1_HUMAN $66.41 \quad 100.0 \% \quad 29$ LMNB1 HUMAN $66.41 \quad 100.0 \% \quad 29$ LMNB1_HUMAN $66.41 \quad 100.0 \% \quad 29$ LMNB1_HUMAN $66.41 \quad 100.0 \% \quad 29$ LMNB1_HUMAN $66.41 \quad 100.0 \% \quad 29$ LMNB1_HUMAN $66.41 \quad 100.0 \% \quad 29$ LMNB1_HUMAN $66.41 \quad 100.0 \% \quad 29$ LMNB1_HUMAN $66.41 \quad 100.0 \% \quad 29$ LMNB1_HUMAN $66.41 \quad 100.0 \% \quad 29$ LMNB1_HUMAN $66.41 \quad 100.0 \% \quad 29$ LMNB1_HUMAN $66.41 \quad 100.0 \% \quad 29$ LMNB1_HUMAN $66.41 \quad 100.0 \% \quad 29$ LMNB1_HUMAN $66.41 \quad 100.0 \% \quad 29$ LMNB1_HUMAN $66.41 \quad 100.0 \% \quad 29$ LMNB1_HUMAN $66.41 \quad 100.0 \% \quad 29$ LMNB1_HUMAN $66.41 \quad 100.0 \% \quad 29$ LMNB1_HUMAN $66.41 \quad 100.0 \% \quad 29$ LMNB1 HUMAN $66.41 \quad 100.0 \% \quad 29$ LMNB1_HUMAN $66.41 \quad 100.0 \% \quad 29$ LMNB1_HUMAN $66.41 \quad 100.0 \% \quad 29$ LMNB1_HUMAN $66.41 \quad 100.0 \% \quad 29$ LMNB1_HUMAN $66.41 \quad 100.0 \% \quad 29$ LMNB1_HUMAN $66.41 \quad 100.0 \% \quad 29$ LMNB1_HUMAN $66.41 \quad 100.0 \% \quad 29$ LMNB1_HUMAN $66.41 \quad 100.0 \% \quad 29$ LMNB2 HUMAN $67.69 \quad 100.0 \% \quad 14$ $\begin{array}{llll}\text { LMNB2_HUMAN } & 67.69 & 100.0 \% & 14\end{array}$ LMNB2 HUMAN $67.69 \quad 100.0 \% \quad 14$ LMNB2 HUMAN $67.69 \quad 100.0 \% \quad 14$ LMNB2_HUMAN $67.69 \quad 100.0 \% \quad 14$ LMNB2 HUMAN $67.69 \quad 100.0 \% \quad 14$ LMNB2_HUMAN $67.69 \quad 100.0 \% \quad 14$ LMNB2_HUMAN $67.69 \quad 100.0 \% \quad 14$ LMNB2 HUMAN $67.69 \quad 100.0 \% \quad 14$ LMNB2_HUMAN $67.69 \quad 100.0 \% \quad 14$ LMNB2 HUMAN $67.69 \quad 100.0 \% \quad 14$ LMNB2 HUMAN $67.69 \quad 100.0 \% \quad 14$ LMNB2_HUMAN $67.69 \quad 100.0 \% \quad 14$ LMNB2 HUMAN $67.69 \quad 100.0 \% \quad 14$ LMNB2_HUMAN $67.69 \quad 100.0 \% \quad 14$
$37 \quad 0.05 \% \quad 14.1 \%$ VVEGTPLIDGR $0.05 \% \quad 14.1 \%$ NDLSPASSGNAVYDFFIGR

$37 \quad 0.05 \% \quad 14.1 \%$ NPSDPKLAHLK

$\begin{array}{llll}99.7 \% & 58.5 & 25.0 & 55.9\end{array}$ $99.7 \% \quad 55.7$ $95.2 \% \quad 14.4$ $99.7 \% \quad 42.3$ $99.6 \% \quad 25.7$ $\begin{array}{lll}97.2 \% & 26.0\end{array}$

$40 \quad 107 \quad 0.16 \% \quad 44.7 \%$ AGGPTTPLSPTR

$40 \quad 107 \quad 0.16 \% \quad 44.7 \%$ AGGPTTPLSPTRLSR

$107 \quad 0.16 \% \quad 44.7 \%$ LQEKEELR

$99.7 \% \quad 54.7$

$99.7 \% \quad 63.2$

$99.7 \% \quad 34.9$

$99.3 \% \quad 35.9$

$99.7 \% \quad 58.9$

$99.7 \% \quad 29.3$

$99.7 \% \quad 36.5$

$99.7 \% \quad 59.7$

$99.7 \% \quad 58.7$

$99.7 \% \quad 44.1$

$99.7 \% \quad 28.6$

$\begin{array}{lll}99.1 \% & 21.7\end{array}$

$96.5 \% \quad 14.9$

$99.7 \% \quad 57.0$

$97.9 \% \quad 16.3$

$99.7 \% \quad 29.1$

$99.7 \% \quad 68.4$ $\begin{array}{llll}99.7 \% & 35.5 & 25.0 & 32.4\end{array}$ $\begin{array}{llll}99.7 \% & 36.1 & 25.0 & 31.1\end{array}$ $\begin{array}{llll}99.7 \% & 39.1 & 25.0 & 33.0\end{array}$ $\begin{array}{llll}99.0 \% & 35.1 & 25.0 & 25.6\end{array}$ $\begin{array}{llll}99.7 \% & 56.7 & 25.0 & 47.1\end{array}$ $99.7 \% \quad 41.4 \quad 25.0 \quad 36.1$ $\begin{array}{llll}99.7 \% & 26.5 & 25.0 & 23.4\end{array}$ $\begin{array}{llll}99.7 \% & 27.6 & 25.0 & 27.6\end{array}$ $\begin{array}{llll}99.7 \% & 46.1 & 25.0 & 38.4\end{array}$ $\begin{array}{llll}99.2 \% & 19.7 & 25.0 & 19.7\end{array}$ $\begin{array}{llll}97.2 \% & 26.0 & 25.0 & 5.7\end{array}$ $99.5 \% \quad 25.9 \quad 25.0 \quad 23.8$ $\begin{array}{llll}99.7 \% & 45.6 & 25.0 & 41.8\end{array}$ $\begin{array}{llll}97.1 \% & 15.3 & 25.0 & 15.3\end{array}$ $\begin{array}{llll}98.6 \% & 21.7 & 25.0 & 15.9\end{array}$ $\begin{array}{llll}99.7 \% & 57.0 & 25.0 & 32.1\end{array}$ $\begin{array}{llll}99.2 \% & 29.0 & 25.0 & 25.0\end{array}$ $\begin{array}{lllll}99.7 \% & 42.2 & 25.0 & 42.2 & 2\end{array}$ $\begin{array}{lllll}99.5 \% & 23.0 & 25.0 & 17.5 & 2\end{array}$ $\begin{array}{llll}99.7 \% & 55.8 & 25.0 & 44.0\end{array}$ $\begin{array}{llll}99.0 \% & 35.1 & 25.0 & 25.6\end{array}$ $\begin{array}{llll}99.7 \% & 56.7 & 25.0 & 47.1\end{array}$ $\begin{array}{llll}99.7 \% & 48.7 \quad 25.0 & 48.5\end{array}$

\begin{tabular}{ccc}
1155.64 & 280 & 290 \\
2029.96 & 354 & 372 \\
1219.68 & 514 & 524 \\
1154.62 & 15 & 26 \\
1510.83 & 15 & 29 \\
1044.57 & 30 & 37 \\
2331.18 & 52 & 71 \\
1251.62 & 80 & 90 \\
1407.72 & 80 & 91 \\
1046.52 & 92 & 100 \\
999.62 & 101 & 109 \\
1702.86 & 110 & 123 \\
1202.64 & 124 & 134 \\
1293.68 & 135 & 145 \\
1173.65 & 146 & 157 \\
1158.67 & 182 & 191 \\
1030.58 & 183 & 191 \\
1756.94 & 183 & 197 \\
1525.73 & 198 & 209 \\
1400.60 & 210 & 220 \\
1556.70 & 210 & 221 \\
1651.83 & 259 & 271 \\
1512.70 & 277 & 290 \\
2371.09 & 277 & 297 \\
1733.92 & 298 & 312 \\
1446.78 & 300 & 312 \\
1818.96 & 300 & 315 \\
974.48 & 380 & 387 \\
1215.66 & 380 & 389 \\
1476.73 & 475 & 487 \\
1787.93 & 517 & 532 \\
1570.85 & 529 & 542 \\
1124.61 & 9 & 20 \\
1480.82 & 9 & 23 \\
1044.57 & 24 & 31 \\
1426.83 & 46 & 57 \\
1237.61 & 74 & 84 \\
1393.71 & 74 & 85 \\
1088.57 & 86 & 94 \\
1059.54 & 119 & 128 \\
1088.56 & 152 & 161 \\
1599.87 & 152 & 166 \\
1060.57 & 220 & 228 \\
1752.93 & 292 & 306 \\
\hline & 374 & 381 \\
\hline & 397 & 410
\end{tabular}

Page 69 of Table S-1-2 
Lamin-B2 GN=LMNB2 Lamin-B2 GN=LMNB2 La-related protein $1 \mathrm{GN}=\mathrm{LARP} 1$ La-related protein $1 \mathrm{GN}=$ LARP1 La-related protein $1 \mathrm{GN}=\mathrm{LARP} 1$ La-related protein $1 \mathrm{GN}=\mathrm{LARP} 1$ La-related protein $1 \mathrm{GN}=\mathrm{LARP} 1$

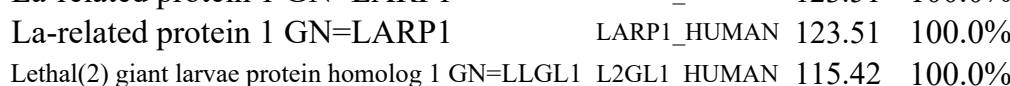
Lethal(2) giant larvae protein homolog 1 GN=LLGL1 L2GL1_HUMAN $115.42 \quad 100.0 \%$ Leucine-rich PPR motif-containing protein, mitochondrial GN=LRPPRC LPPRC_HUMAN $157.91 \quad 100.0 \%$ Leucine-rich PPR motif-containing protein, mitochondrial GN=LRPPRC LPPRC_HUMAN $157.91 \quad 100.0 \%$ Leucine-rich PPR motif-containing protein, mitochondrial GN=LRPPRC LPPRC_HUMAN $157.91 \quad 100.0 \%$ Leucine-rich PPR motif-containing protein, mitochondrial GN=LRPPRC LPPRC_HUMAN $157.91 \quad 100.0 \%$ Leucine-rich PPR motif-containing protein, mitochondrial GN=LRPPRC LPPRC_HUMAN $157.91 \quad 100.0 \%$ Leucine-rich PPR motif-containing protein, mitochondrial GN=LRPPRC LPPRC_HUMAN $157.91 \quad 100.0 \%$ Leucine-rich PPR motif-containing protein, mitochondrial GN=LRPPRC LPPRC_HUMAN $157.91 \quad 100.0 \%$ Leucine-rich PPR motif-containing protein, mitochondrial GN=LRPPRC LPPRC_HUMAN $157.91 \quad 100.0 \%$ Leucine-rich PPR motif-containing protein, mitochondrial GN=LRPPRC LPPRC_HUMAN $157.91 \quad 100.0 \%$ Leucine-rich repeat-containing protein $40 \mathrm{GN}=\mathrm{LRRC} 40$ LRC40_HUMAN $68.25 \quad 100.0 \%$ Leucine-rich repeat-containing protein $40 \mathrm{GN}=\mathrm{LRRC} 40$ LRC40_HUMAN $68.25 \quad 100.0 \%$ Leucine-rich repeat-containing protein $40 \mathrm{GN}=\mathrm{LRRC} 40$ LRC40_HUMAN $68.25 \quad 100.0 \%$ Leucine-rich repeat-containing protein $40 \mathrm{GN}=\mathrm{LRRC} 40$ LRC40_HUMAN $68.25 \quad 100.0 \%$ Leucine-rich repeat-containing protein $40 \mathrm{GN}=\mathrm{LRRC40}$ LRC40_HUMAN $68.25 \quad 100.0 \%$ Leucine-rich repeat-containing protein $40 \mathrm{GN}=$ LRRC40 LRC40_HUMAN $68.25 \quad 100.0 \%$ Leucine-rich repeat-containing protein $40 \mathrm{GN}=\mathrm{LRRC} 40$ LRC40_HUMAN $68.25 \quad 100.0 \%$ Leucine-rich repeat-containing protein $40 \mathrm{GN}=$ LRRC40 LRC40_HUMAN $68.25 \quad 100.0 \%$ Leucine-rich repeat-containing protein $40 \mathrm{GN}=\mathrm{LRRC40}$ LRC40_HUMAN $68.25 \quad 100.0 \%$ LINE-1 retrotransposable element ORF1 protein GN=L1RE1 LORF1_HUMAN $40.06 \quad 100.0 \%$ LINE-1 retrotransposable element ORF1 protein GN=L1RE1 LORF1_HUMAN $40.06 \quad 100.0 \%$ Lipopolysaccharide-responsive and beige-like anchor protein GN=LRBA LRBA_HUMAN $319.11 \quad 100.0 \%$ Lipopolysaccharide-responsive and beige-like anchor protein GN=LRBA LRBA_HUMAN $319.11 \quad 100.0 \%$ Lipopolysaccharide-responsive and beige-like anchor protein GN=LRBA LRBA_HUMAN $319.11 \quad 100.0 \%$ Lipopolysaccharide-responsive and beige-like anchor protein GN=LRBA LRBA_HUMAN $319.11 \quad 100.0 \%$ L-lactate dehydrogenase A chain GN=LDHA LDHA_HUMAN $36.69 \quad 100.0 \%$ L-lactate dehydrogenase A chain GN=LDHA LDHA_HUMAN $36.69 \quad 100.0 \%$ L-lactate dehydrogenase A chain GN=LDHA LDHA_HUMAN $36.69 \quad 100.0 \%$ L-lactate dehydrogenase A chain GN=LDHA LDHA_HUMAN $36.69 \quad 100.0 \%$ L-lactate dehydrogenase A chain GN=LDHA LDHA_HUMAN $36.69 \quad 100.0 \%$ L-lactate dehydrogenase A chain GN=LDHA LDHA_HUMAN $36.69 \quad 100.0 \%$ L-lactate dehydrogenase A chain GN=LDHA LDHA_HUMAN $36.69 \quad 100.0 \%$ L-lactate dehydrogenase A chain GN=LDHA LDHA_HUMAN $36.69 \quad 100.0 \%$ L-lactate dehydrogenase A chain GN=LDHA LDHA_HUMAN $36.69 \quad 100.0 \%$ L-lactate dehydrogenase A chain GN=LDHA LDHA_HUMAN $36.69 \quad 100.0 \% \quad 2$ L-lactate dehydrogenase A chain GN=LDHA LDHA_HUMAN $36.69 \quad 100.0 \% 26$ L-lactate dehydrogenase A chain GN=LDHA LDHA_HUMAN $36.69 \quad 100.0 \% \quad 26$ $\begin{array}{llll}\text { L-lactate dehydrogenase A chain GN=LDHA LDHA_HUMAN } 36.69 & 100.0 \% & 26\end{array}$
$39 \quad 0.06 \% \quad 26.3 \%$ QVLEGEEIAYKFTPK $0.06 \% \quad 26.3 \%$ TVLVNADGEEVA

$0.02 \% \quad 6.5 \% \quad$ SVQPQSHKPQPTR

$0.02 \% \quad 6.5 \%$ KFDGVEGPR

$0.02 \% \quad 6.5 \%$ QHYQKETESAPGSPR

$0.02 \% \quad 6.5 \% \quad$ SLPTTVPESPNYR

$0.02 \% \quad 6.5 \% \quad$ TPQLKDSSQTSR

$0.02 \% \quad 6.5 \%$ FYPVVKEGR

$0.00 \% \quad 2.2 \%$ SADDSLSGVVR

$0.00 \% \quad 2.2 \%$ APVVAIAVLDGR

$0.03 \% \quad 7.6 \%$ EKDIQEESTFSSR

$0.03 \% \quad 7.6 \%$ SGGLGGSHALLLLR

$0.03 \% \quad 7.6 \%$ LIASYCNVGDIEGASK

$0.03 \% \quad 7.6 \%$ NVQGIIEILK

$0.03 \% \quad 7.6 \%$ SNTLPISLQSIR

$0.03 \% \quad 7.6 \%$ SSLLLGFRR

$0.03 \% \quad 7.6 \%$ KIIETPGIR

$0.03 \% \quad 7.6 \%$ TVLDQQQTPSR

$0.03 \% \quad 7.6 \%$ SYVSEKDVTSAK

$0.02 \% \quad 16.6 \%$ IAGQDLRAGFK

$0.02 \% \quad 16.6 \%$ LQSLTDDLR

$0.02 \% \quad 16.6 \%$ ILPEEITNLR

$0.02 \% \quad 16.6 \%$ LNLSSNELKSLPAEINR

$0.02 \% \quad 16.6 \%$ FLPEFPSCSLLK

$0.02 \% \quad 16.6 \%$ SVPDEIILLR

$0.02 \% \quad 16.6 \%$ FLALEGNPLR

$0.02 \% \quad 16.6 \%$ SNIVTSINFSK

$0.02 \% \quad 16.6 \%$ LQTINLSFNR

$0.00 \% \quad 7.1 \%$ QANVQIQEIQR

$0.00 \% \quad 7.1 \%$ LTADLSAETLQAR

$0.01 \% \quad 1.7 \%$ SAAAIALPPIAK

$0.01 \% \quad 1.7 \%$ ATDAQLCLESSPK

$0.01 \% \quad 1.7 \%$ VANEAEFILSR

$0.01 \% \quad 1.7 \%$ VGVGTSFGLPQTR

$100 \quad 0.15 \% \quad 50.6 \%$ DQLIYNLLK

$100 \quad 0.15 \% \quad 50.6 \%$ DQLIYNLLKEEQTPQNK

$100 \quad 0.15 \% \quad 50.6 \%$ LKGEMMDLQHGSLFLR

$100 \quad 0.15 \% \quad 50.6 \%$ GEMMDLQHGSLFLR

$100 \quad 0.15 \% \quad 50.6 \%$ IVSGKDYNVTANSK

$100 \quad 0.15 \% \quad 50.6 \%$ DYNVTANSK

$100 \quad 0.15 \% \quad 50.6 \%$ LVIITAGAR

$100 \quad 0.15 \% \quad 50.6 \%$ LVIITAGARQQEGESR

$100 \quad 0.15 \% \quad 50.6 \%$ QQEGESRLNLVQR

$100 \quad 0.15 \% \quad 50.6 \%$ NVNIFKFIIPNVVK

$100 \quad 0.15 \% \quad 50.6 \%$ FIIPNVVK

$100 \quad 0.15 \% \quad 50.6 \%$ NRVIGSGCNLDSAR $\begin{array}{llll}99.7 \% & 45.0 & 25.0 & 40.8\end{array}$

$\begin{array}{llll}99.7 \% & 80.9 & 25.0 & 80.9\end{array}$

$\begin{array}{llll}97.8 \% & 23.3 & 25.0 & 14.0\end{array}$

$99.7 \% \quad 35.6 \quad 25.0 \quad 28.5$

$96.9 \% \quad 17.1 \quad 25.0 \quad 16.1$

$\begin{array}{llll}99.7 \% & 28.2 & 25.0 & 28.2\end{array}$

$99.7 \% \quad 58.9 \quad 25.0 \quad 57.4$

$99.7 \% \quad 32.2 \quad 25.0 \quad 31.0$

$99.7 \% \quad 37.4 \quad 25.0 \quad 31.1$

$99.7 \% \quad 46.6 \quad 25.0 \quad 46.6$

$99.7 \% \quad 61.5 \quad 25.0 \quad 52.9$

$99.7 \% \quad 58.6 \quad 25.0 \quad 52.3$

$99.7 \% \quad 54.6 \quad 25.0 \quad 54.6$

$\begin{array}{llll}99.7 \% & 29.8 & 25.0 & 28.9\end{array}$

$99.7 \% \quad 61.8 \quad 25.0 \quad 47.1$

$94.6 \% \quad 19.5 \quad 25.0 \quad 9.5$

$99.7 \% \quad 33.3 \quad 25.0 \quad 27.2$

$\begin{array}{llll}99.7 \% & 46.8 & 25.0 & 38.5\end{array}$

$99.7 \% \quad 57.2$

$99.5 \% \quad 28.6$

$96.6 \% \quad 24.9$

$98.2 \% \quad 16.5$

$99.4 \% 20.7$

$\begin{array}{lll}98.9 \% & 24.2\end{array}$

$99.7 \% \quad 32.2$

$99.7 \% \quad 39.5$

$99.7 \% \quad 56.7$

$99.7 \% \quad 33.7$

$\begin{array}{lll}99.7 \% & 55.2\end{array}$

$99.7 \% \quad 82.1$

$99.7 \% \quad 29.4$

$99.7 \% \quad 62.4$

$99.7 \% \quad 35.0$

$99.7 \% \quad 40.8$

$99.0 \% \quad 32.9$

$99.7 \% \quad 43.7$

$\begin{array}{ll}95.3 \% & 14.5\end{array}$

$99.7 \% \quad 44.8$

$99.7 \% \quad 47.4$

$99.7 \% \quad 49.2$

$99.7 \% \quad 60.3$

$99.7 \% \quad 49.7$

$99.7 \% 34.8$

$99.7 \% \quad 47.1$

$99.0 \% \quad 26.4$

$99.7 \% \quad 64.0$
1519.74

1489.79

1004.52

1714.81

1460.74

1347.69

1094.60

1105.55

1180.70

1555.72

1350.79

1696.82

1126.68

1328.75

1048.63

1026.63

1272.65

1313.66

1175.65

1060.56

1197.68

1898.03

1437.74

1154.68

1129.64

1209.65

1205.66

1326.71

1388.74

1122.69

1419.68

1248.66

1318.71

1119.64

2074.08

1906.95

1633.78

1495.78

1011.47

1906.04

913.58

1727.94

1556.81

1644.98

929.58

1518.74 $\begin{array}{cc}86 & 500 \\ 42 & 555 \\ 86 & 198 \\ 67 & 375 \\ 09 & 523 \\ 66 & 778 \\ 88 & 799 \\ 00 & 808 \\ 14 & 724 \\ 88 & 799 \\ 5 & 77 \\ 15 & 128 \\ 03 & 218 \\ 54 & 463 \\ 30 & 541 \\ 42 & 550 \\ 09 & 917 \\ 29 & 1139 \\ 27 & 1338 \\ 7 & 17 \\ 4 & 102 \\ 42 & 151 \\ 02 & 218 \\ 57 & 268 \\ 03 & 312 \\ 38 & 347 \\ 24 & 434 \\ 97 & 506 \\ 92 & 202 \\ 49 & 261 \\ 13 & 224 \\ 25 & 437 \\ 95 & 1905 \\ 83 & 2195 \\ 6 & 14 \\ 6 & 22 \\ 8 & 73 \\ 0 & 73 \\ 7 & 90 \\ 2 & 90 \\ 2 & 99 \\ 1 & 99 \\ 1 & 106 \\ 00 & 112 \\ 13 & 126 \\ 19 & 126 \\ 56 & 169\end{array}$

Page 70 of Table S-1-2 
L-lactate dehydrogenase A chain GN=LDHA LDHA_HUMAN $36.69 \quad 100.0 \% \quad 26$ L-lactate dehydrogenase A chain GN=LDHA LDHA_HUMAN $36.69 \quad 100.0 \% \quad 26$ L-lactate dehydrogenase A chain GN=LDHA LDHA_HUMAN $36.69 \quad 100.0 \% \quad 26$ L-lactate dehydrogenase A chain GN=LDHA LDHA HUMAN $36.69 \quad 100.0 \%$ L-lactate dehydrogenase A chain GN=LDHA LDHA_HUMAN $36.69 \quad 100.0 \% \quad 26$ L-lactate dehydrogenase A chain GN=LDHA LDHA_HUMAN $36.69 \quad 100.0 \% \quad 26$ L-lactate dehydrogenase A chain GN=LDHA LDHA_HUMAN $36.69 \quad 100.0 \% \quad 26$ L-lactate dehydrogenase A chain GN=LDHA LDHA_HUMAN $36.69 \quad 100.0 \% \quad 26$ L-lactate dehydrogenase A chain GN=LDHA LDHA_HUMAN $36.69 \quad 100.0 \% \quad 26$ L-lactate dehydrogenase A chain GN=LDHA LDHA_HUMAN $36.69 \quad 100.0 \% \quad 26$ L-lactate dehydrogenase A chain GN=LDHA LDHA_HUMAN $36.69 \quad 100.0 \% \quad 26$ L-lactate dehydrogenase A chain GN=LDHA LDHA_HUMAN $36.69 \quad 100.0 \% \quad 26$ L-lactate dehydrogenase A chain GN=LDHA LDHA_HUMAN $36.69 \quad 100.0 \% \quad 26$ L-lactate dehydrogenase B chain GN=LDHB LDHB_HUMAN $36.64 \quad 100.0 \%$ L-lactate dehydrogenase B chain GN=LDHB LDHB_HUMAN $36.64 \quad 100.0 \% \quad 15$ L-lactate dehydrogenase B chain GN=LDHB LDHB_HUMAN $36.64 \quad 100.0 \% \quad 15$ L-lactate dehydrogenase B chain GN=LDHB LDHB HUMAN $36.64 \quad 100.0 \%$ L-lactate dehydrogenase B chain GN=LDHB LDHB_HUMAN $36.64 \quad 100.0 \% \quad 15$ $\begin{array}{llll}\text { L-lactate dehydrogenase B chain GN=LDHB LDHB_HUMAN } & 36.64 & 100.0 \% & 1\end{array}$ L-lactate dehydrogenase B chain GN=LDHB LDHB_HUMAN $36.64 \quad 100.0 \% \quad 15$ L-lactate dehydrogenase B chain GN=LDHB LDHB_HUMAN $36.64 \quad 100.0 \% \quad 15$ L-lactate dehydrogenase B chain GN=LDHB LDHB_HUMAN $36.64 \quad 100.0 \% \quad 15$ $\begin{array}{llll}\text { L-lactate dehydrogenase B chain GN=LDHB LDHB_HUMAN } & 36.64 & 100.0 \% & 15\end{array}$ L-lactate dehydrogenase B chain GN=LDHB LDHB_HUMAN $36.64 \quad 100.0 \% \quad 15$ L-lactate dehydrogenase B chain GN=LDHB LDHB HUMAN $36.64 \quad 100.0 \%$ L-lactate dehydrogenase B chain GN=LDHB LDHB_HUMAN $36.64 \quad 100.0 \% \quad 15$ L-lactate dehydrogenase B chain GN=LDHB LDHB_HUMAN $36.64 \quad 100.0 \% \quad 15$ L-lactate dehydrogenase B chain GN=LDHB LDHB_HUMAN $36.64 \quad 100.0 \%$ L-lactate dehydrogenase B chain GN=LDHB LDHB_HUMAN $36.64 \quad 100.0 \%$ L-lactate dehydrogenase B chain GN=LDHB LDHB HUMAN $36.64 \quad 100.0 \%$ L-lactate dehydrogenase B chain GN=LDHB LDHB_HUMAN $36.64 \quad 100.0 \% \quad 15$ Long-chain fatty acid transport protein 4 GN=SLC27A4 S27A4_HUMAN $72.07 \quad 100.0 \%$ Long-chain fatty acid transport protein $4 \mathrm{GN}=$ SLC27A4 S27A4_HUMAN $72.07 \quad 100.0 \%$ Long-chain-fatty-acid--CoA ligase $3 \mathrm{GN}=$ ACSL3 ACSL3_HUMAN $80.42 \quad 100.0 \%$ Long-chain-fatty-acid--CoA ligase $3 \mathrm{GN}=$ ACSL3 ACSL3_HUMAN $80.42 \quad 100.0 \%$ Long-chain-fatty-acid--CoA ligase $3 \mathrm{GN}=$ ACSL3 ACSL3_HUMAN $80.42 \quad 100.0 \%$ Long-chain-fatty-acid--CoA ligase $3 \mathrm{GN}=$ ACSL3 ACSL3_HUMAN $80.42 \quad 100.0 \%$ Long-chain-fatty-acid--CoA ligase $3 \mathrm{GN}=$ ACSL 3 ACSL3 HUMAN $80.42 \quad 100.0 \%$ Lupus La protein $\mathrm{GN}=\mathrm{SSB}$ Lupus La protein $\mathrm{GN}=\mathrm{SSB}$

Lupus La protein $\mathrm{GN}=\mathrm{SSB}$

LA_HUMAN $46.84 \quad 100.0 \%$ LA HUMAN $46.84 \quad 100.0 \%$ LA HUMAN $46.84 \quad 100.0 \%$ Lys-63-specific deubiquitinase BRCC36 GN=BRCC3 BRCC3_HUMAN $36.07 \quad 100.0 \%$ Lys-63-specific deubiquitinase BRCC36 GN=BRCC3 BRCC3 HUMAN $36.07 \quad 100.0 \%$ Lys-63-specific deubiquitinase BRCC36 GN=BRCC3 BRCC3_HUMAN $36.07 \quad 100.0 \%$ Lys-63-specific deubiquitinase BRCC36 GN=BRCC3 BRCC3_HUMAN $36.07 \quad 100.0 \%$ Lysine--tRNA ligase $\mathrm{GN}=\mathrm{KARS}$ Lysine--tRNA ligase GN=KARS

SYK_HUMAN $68.05 \quad 100.0 \%$
$38 \quad 100 \quad 0.15 \% \quad 50.6 \%$ VIGSGCNLDSAR $38 \quad 100 \quad 0.15 \% \quad 50.6 \%$ VIGSGCNLDSARFR $38 \quad 100 \quad 0.15 \% \quad 50.6 \%$ FRYLMGER $38 \quad 100 \quad 0.15 \% \quad 50.6 \%$ TLHPDLGTDK

$38 \quad 100 \quad 0.15 \% \quad 50.6 \%$ EVHKQVVESAYEVIK $38 \quad 100 \quad 0.15 \% \quad 50.6 \%$ QVVESAYEVIK $38 \quad 100 \quad 0.15 \% \quad 50.6 \%$ QVVESAYEVIKLK $38 \quad 100 \quad 0.15 \% \quad 50.6 \%$ RVHPVSTMIK $38 \quad 100 \quad 0.15 \% \quad 50.6 \%$ VHPVSTMIK $38 \quad 100 \quad 0.15 \% \quad 50.6 \%$ VTLTSEEEAR $38 \quad 100 \quad 0.15 \% \quad 50.6 \%$ VTLTSEEEARLK $38 \quad 100 \quad 0.15 \% \quad 50.6 \%$ SADTLWGIQK $38 \quad 100 \quad 0.15 \% \quad 50.6 \%$ SADTLWGIQKELQF

(1)

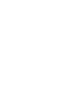

$89 \quad 0.13 \% \quad 47.6 \%$ EKLIAPVAEEEATVPNNK

$89 \quad 0.13 \% \quad 47.6 \%$ LIAPVAEEEATVPNNK

$89 \quad 0.13 \% \quad 47.6 \%$ ITVVGVGQVGMACAISILGK

$89 \quad 0.13 \% \quad 47.6 \%$ GEMMDLQHGSLFLQTPK

$89 \quad 0.13 \% \quad 47.6 \%$ IVADKDYSVTANSK

$89 \quad 0.13 \% \quad 47.6 \%$ IVVVTAGVR

$89 \quad 0.13 \% \quad 47.6 \%$ IVVVTAGVRQQEGESR

$89 \quad 0.13 \% \quad 47.6 \%$ QQEGESRLNLVQR

$89 \quad 0.13 \% \quad 47.6 \%$ NVNVFKFIIPQIVK

$89 \quad 0.13 \% \quad 47.6 \%$ FIIPQIVK

$89 \quad 0.13 \% \quad 47.6 \%$ HRVIGSGCNLDSAR

$89 \quad 0.13 \% \quad 47.6 \%$ VIGSGCNLDSAR

$89 \quad 0.13 \% \quad 47.6 \%$ VIGSGCNLDSARFR

$89 \quad 0.13 \% \quad 47.6 \%$ FRYLMAEK

$89 \quad 0.13 \% \quad 47.6 \%$ MVVESAYEVIK

$89 \quad 0.13 \% \quad 47.6 \%$ MVVESAYEVIKLK

$89 \quad 0.13 \% \quad 47.6 \%$ GLTSVINQK

$89 \quad 0.13 \% \quad 47.6 \%$ LKDDEVAQLK

$0.00 \% \quad 3.1 \%$ TVPILFASTVR

$0.00 \% \quad 3.1 \%$ ILSFVYPIR

$0.01 \% \quad 8.3 \%$ LKDIVSLVPR

$0.01 \% \quad 8.3 \% \quad$ IGYSSPQTLADQSSK

$0.01 \% \quad 8.3 \% \quad$ NTPLCDSFVFR

$0.01 \% \quad 8.3 \%$ LLLCGGAPLSATTQR

$0.01 \% \quad 8.3 \% \quad$ THYQADIER

$0.02 \% \quad 6.4 \% \quad$ LTTDFNVIVEALSK

$0.02 \% \quad 6.4 \%$ AKDANNGNLQLR

$0.02 \% \quad 6.4 \%$ DANNGNLQLR

$0.01 \% \quad 14.6 \%$ TVAEKVDAVR

$0.01 \% \quad 14.6 \%$ VLYTCFQSIQAQK

$0.01 \% \quad 14.6 \%$ VCLESAVELPK

$0.01 \% \quad 14.6 \%$ IHSLTHLDSVTK

$0.01 \% \quad 7.9 \%$ RGDIIGVQGNPGK

$0.01 \% \quad 7.9 \% \quad$ YLDLILNDFVR
$99.7 \% \quad 62.2$

$99.6 \% 24.5$

$99.0 \% \quad 30.0$

$99.3 \% \quad 20.9$

$99.7 \% \quad 57.7$

$\begin{array}{lll}99.7 \% & 58.8\end{array}$

$99.7 \% \quad 60.0$

$99.7 \% \quad 33.3$

$95.4 \% \quad 16.1$

$99.7 \% \quad 63.1$

$99.7 \% \quad 57.3$

$99.7 \% \quad 50.2$

$99.7 \% \quad 26.4$

$9.7 \% \quad 43.3$

$99.7 \% \quad 47.2$

$99.7 \% \quad 48.3$

$99.7 \% \quad 56.5$

$99.7 \% \quad 66.1$

$99.7 \% \quad 42.7$

$99.7 \% \quad 34.8$

$\begin{array}{lll}99.7 \% & 58.5\end{array}$

$99.0 \% \quad 18.6$

$99.7 \% \quad 48.8$

$99.7 \% \quad 62.2$

$99.6 \% \quad 24.5$

$99.0 \% \quad 34.2$

$99.7 \% \quad 56.0$

$99.7 \% \quad 61.6$

$99.7 \% \quad 59.7$

$99.7 \% \quad 54.9$

$99.7 \% \quad 40.4$

$99.7 \% \quad 34.3$

$99.7 \% \quad 38.9$

$99.7 \% \quad 43.3$

$97.6 \% \quad 20.7$

$99.7 \% \quad 64.6$

$97.7 \% 18.6$

$99.7 \% \quad 39.5$

$99.7 \% \quad 41.5$

$99.7 \% \quad 45.8$

$99.7 \% \quad 53.8$

$99.7 \% \quad 51.1$

$99.7 \% \quad 42.4$

$\begin{array}{lll}97.5 \% & 18.0\end{array}$

$99.7 \% \quad 46.2$

$99.7 \% \quad 52.1$
248.60

1551.77

1087.54

1096.56

1757.94

1264.68

1505.86

1167.67

1011.57

1134.56

1375.74

1118.58

1635.84

1952.03

1694.90

1989.09

1963.93

1510.77

913.58

1727.94

1556.81

1659.00

957.61

1541.76

1248.60

1551.77

1057.55

1283.66

1508.84

959.55

1158.64

1203.71

1107.66

1139.71

1581.78

1355.64

1557.84

1132.54

1549.85

1313.69

1114.56

1087.61

1585.80

1244.66

1350.74

1310.72

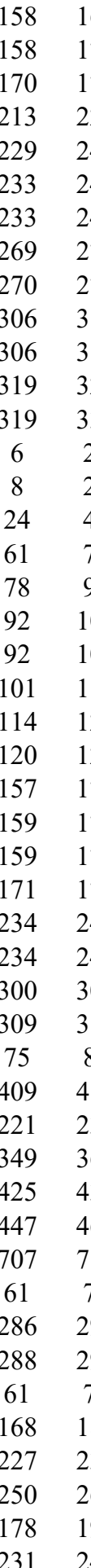

1380.75 
Lysine--tRNA ligase GN=KARS Lysine--tRNA ligase GN=KARS

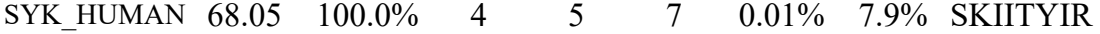
SYK_HUMAN $68.05 \quad 100.0 \%$ GT1 MAGT1_HUMAN $38.04 \quad 100.0 \%$ MAGT1_HUMAN $38.04 \quad 100.0 \%$ $\begin{array}{llll}\text { Magnesium transporter protein 1 GN=MAGT1 } & \text { MAGT1_HUMAN } & 38.04 & 100.0 \% \\ \text { Malectin GN=MLEC } & \text { MLEC_HUMAN } & 32.23 & 100.0 \% \\ \text { Malectin GN=MLEC } & \text { MLEC_HUMAN } & 32.23 & 100.0 \% \\ \text { Malectin GN=MLEC } & \text { MLEC_HUMAN } & 32.23 & 100.0 \%\end{array}$ $\begin{array}{llll}\text { Magnesium transporter protein 1 GN=MAGT1 } & \text { MAGT1_HUMAN } & 38.04 & 100.0 \% \\ \text { Malectin GN=MLEC } & \text { MLEC_HUMAN } & 32.23 & 100.0 \% \\ \text { Malectin GN=MLEC } & \text { MLEC_HUMAN } & 32.23 & 100.0 \% \\ \text { Malectin GN=MLEC } & \text { MLEC_HUMAN } & 32.23 & 100.0 \%\end{array}$ $\begin{array}{llll}\text { Magnesium transporter protein 1 GN=MAGT1 } & \text { MAGT1_HUMAN } & 38.04 & 100.0 \% \\ \text { Malectin GN=MLEC } & \text { MLEC_HUMAN } & 32.23 & 100.0 \% \\ \text { Malectin GN=MLEC } & \text { MLEC_HUMAN } & 32.23 & 100.0 \% \\ \text { Malectin GN=MLEC } & \text { MLEC_HUMAN } & 32.23 & 100.0 \%\end{array}$ Malectin GN=MLEC Manganese-transporting ATPase 13A1 GN=ATP13A1 AT131_HUMAN $132.96 \quad 100.0 \%$ Manganese-transporting ATPase 13A1 GN=ATP13A1 AT131 HUMAN $132.96 \quad 100.0 \%$ Mannose-1-phosphate guanyltransferase alpha GN=GMPPA GMPPA_HUMAN $46.29 \quad 100.0 \%$ Mannose-1-phosphate guanyltransferase alpha GN=GMPPA GMPPA_HUMAN $46.29 \quad 100.0 \%$ Matrin-3 GN=MATR3

Matrin-3 GN=MATR3

Matrin-3 GN=MATR3

Matrin-3 GN=MATR3

Matrin-3 GN=MATR3

Matrin-3 GN=MATR3

Matrin-3 GN=MATR3

Matrin-3 GN=MATR3

Matrin-3 GN=MATR3

Matrin-3 GN=MATR3

Matrin-3 GN=MATR3

MAX gene-associated pr MAX gene-associated protein GN=MGA $\quad$ MGAP_HUMAN $331.84 \quad 100.0 \%$ MAX gene-associated protein GN=MGA MGAP_HUMAN $331.84 \quad 100.0 \%$ MAX gene-associated protein GN=MGA MGAP_HUMAN $331.84 \quad 100.0 \%$ MAX gene-associated protein GN=MGA MGAP_HUMAN $331.84 \quad 100.0 \%$ Medium-chain specific acyl-CoA dehydrogenase, mitochondrial GN=ACADM ACADM_HUMAN $46.59 \quad 100.0 \%$ Medium-chain specific acyl-CoA dehydrogenase, mitochondrial GN=ACADM ACADM_HUMAN $46.59 \quad 100.0 \%$ Medium-chain specific acyl-CoA dehydrogenase, mitochondrial GN=ACADM ACADM_HUMAN 46.59 100.0\% Medium-chain specific acyl-CoA dehydrogenase, mitochondrial GN=ACADM ACADM_HUMAN $46.59 \quad 100.0 \%$ Medium-chain specific acyl-CoA dehydrogenase, mitochondrial GN=ACADM ACADM_HUMAN $46.59 \quad 100.0 \%$ Melanoma-associated antigen D2 GN=MAGED2 MAGD2_HUMAN $64.96 \quad 100.0 \%$ Melanoma-associated antigen D2 GN=MAGED2 MAGD2_HUMAN $64.96 \quad 100.0 \%$ Methionine--tRNA ligase, cytoplasmic GN=MARS SYMC_HUMAN $101.12 \quad 100.0 \%$ Methionine--tRNA ligase, cytoplasmic GN=MARS SYMC_HUMAN $101.12 \quad 100.0 \%$ Methionine--tRNA ligase, cytoplasmic GN=MARS SYMC_HUMAN $101.12 \quad 100.0 \%$ Methionine--tRNA ligase, cytoplasmic GN=MARS SYMC_HUMAN $101.12 \quad 100.0 \%$ Methionine--tRNA ligase, cytoplasmic GN=MARS SYMC_HUMAN $101.12 \quad 100.0 \%$ Methionine--tRNA ligase, cytoplasmic GN=MARS SYMC_HUMAN $101.12 \quad 100.0 \%$ Methionine--tRNA ligase, cytoplasmic GN=MARS SYMC_HUMAN $101.12 \quad 100.0 \%$ Methionine--tRNA ligase, cytoplasmic GN=MARS SYMC_HUMAN $101.12 \quad 100.0 \%$ Methionine--tRNA ligase, cytoplasmic GN=MARS SYMC_HUMAN $101.12 \quad 100.0 \%$ Methionine--tRNA ligase, cytoplasmic GN=MARS SYMC_HUMAN $101.12 \quad 100.0 \%$ Methionine--tRNA ligase, cytoplasmic GN=MARS SYMC_HUMAN $101.12 \quad 100.0 \%$ Methionine--tRNA ligase, mitochondrial GN=MARS2 SYMM_HUMAN $66.59 \quad 100.0 \%$ Methionine--tRNA ligase, mitochondrial GN=MARS2 SYMM_HUMAN $66.59 \quad 100.0 \%$
$0.01 \% \quad 7.9 \%$ MLVVGGIDRVYEIGR

$\begin{array}{lll}0.01 \% & 5.7 \% & \text { RGDTYELQVR }\end{array}$

$0.01 \% \quad 5.7 \%$ GFSAEQIAR

$0.01 \% \quad 12.7 \%$ ASDYGMKLPILR

$0.01 \% \quad 12.7 \%$ SNPEDQILYQTER

$0.01 \% \quad 12.7 \%$ FAEVYFAQSQQK

$0.00 \% \quad 2.1 \%$ SIDGSIVLPLAR

$0.00 \% \quad 2.1 \%$ LGDASIAAPFTSK

$0.01 \% \quad 5.7 \% \quad$ AVILIGGPQK

$0.01 \% \quad 5.7 \% \quad$ VEGTPSDPNPNDPR

$0.03 \% \quad 16.1 \%$ TEEGPTLSYGR

$0.03 \% \quad 16.1 \%$ TEEGPTLSYGRDGR

$0.03 \% \quad 16.1 \%$ MGRGPGPLQER

$0.03 \% \quad 16.1 \%$ GAPPSSNIEDFHGLLPK

$0.03 \% \quad 16.1 \%$ GNLGAGNGNLQGPR

$0.03 \% \quad 16.1 \%$ VVHIMDFQR

$0.03 \% \quad 16.1 \%$ FDQKQELGR

$0.03 \% \quad 16.1 \%$ VIHLSNLPHSGYSDSAVLK

$0.03 \% \quad 16.1 \%$ IGPYQPNVPVGIDYVIPK

$0.03 \% \quad 16.1 \%$ LCSLFYTNEEVAK

$0.03 \% \quad 16.1 \%$ NTHCSSLPHYQK

$0.03 \% \quad 2.5 \% \quad$ VVNANQNASPNVPGKR

$0.03 \% \quad 2.5 \%$ QAQQQQQQQQGSRPPGLSK

$0.03 \% \quad 2.5 \%$ GLPFYAGLSPAGK

$0.03 \% \quad 2.5 \%$ TTGITTPVASVAFPK

$0.03 \% \quad 2.5 \% \quad$ ISNPSAFSIVPR

$0.01 \% \quad 15.7 \%$ ANWYFLLAR

$0.01 \% \quad 15.7 \%$ SDPDPKAPANK

$0.01 \% \quad 15.7 \%$ AFTGFIVEADTPGIQIGR

$0.01 \% \quad 15.7 \%$ TRPVVAAGAVGLAQR

$0.01 \% \quad 15.7 \%$ IYQIYEGTSQIQR

$0.00 \% \quad 5.5 \%$ ALEVSEDVKVSK

$\begin{array}{llllll}0.00 \% & 5.5 \% & \text { LQSSQEPEAPPPRDVALLQGR } & 99.7 \% & 27.6\end{array}$

$0.03 \% \quad 13.0 \%$ MRLFVSDGVPGCLPVLAAAGR $95.8 \% 14.5$

$0.03 \% \quad 13.0 \%$ LFVSDGVPGCLPVLAAAGR $99.7 \% 50.6$

$0.03 \% \quad 13.0 \%$ KGEDVLGSVR

$0.03 \% \quad 13.0 \%$ ALTHIDHSLSR

$0.03 \% \quad 13.0 \%$ QPQPSPAEGR

$0.03 \% \quad 13.0 \%$ ITQDIFQQLLK

$0.03 \% \quad 13.0 \%$ ITQDIFQQLLKR

$0.03 \% \quad 13.0 \%$ GFVLQDTVEQLR

$0.03 \% \quad 13.0 \%$ TLPGSDWTPNAQFITR

$0.03 \% \quad 13.0 \%$ SWLRDGLKPR

$0.03 \% \quad 13.0 \%$ NNSELLNNLGNFINR

$0.00 \% \quad 3.2 \%$ LGVSASER

$0.00 \% \quad 3.2 \%$ LGPETGLLFPR
$99.0 \% \quad 31.5 \quad 25.0 \quad 31.5$

$99.5 \% \quad 24.3$

$99.7 \% \quad 27.8$

$99.7 \% 51.4$

$\begin{array}{lll}99.7 \% & 25.4\end{array}$

$94.6 \% \quad 16.2$

$99.5 \% \quad 22.7$

$\begin{array}{lll}99.7 \% & 49.0\end{array}$

$99.7 \% 37.1$

$94.6 \% 17.3$

$99.2 \% \quad 22.2$

$99.7 \% \quad 63.4$

$99.7 \% \quad 29.2$

$99.5 \% \quad 24.9$

$\begin{array}{ll}99.7 \% & 46.5\end{array}$

$99.7 \% \quad 38.8$

$98.2 \% \quad 19.4$

$99.7 \% \quad 41.5$

$99.7 \% \quad 49.5$

$99.7 \% \quad 29.0$

$\begin{array}{ll}99.7 \% & 60.5 \\ 99.7 \% & 49.8\end{array}$

$98.7 \% \quad 18.9$

$99.7 \% \quad 34.2$

$99.7 \% \quad 30.8$

$\begin{array}{ll}99.7 \% & 30.8 \\ 99.7 \% & 61.6\end{array}$

$\begin{array}{ll}99.7 \% & 50.6 \\ 99.7 \% & 30.8\end{array}$

$99.7 \% \quad 26.2$

$99.7 \% \quad 42.3$

$99.7 \% \quad 35.9$

$99.7 \% \quad 39.3$

$99.7 \% \quad 61.0$

$99.7 \% \quad 35.1$

$96.7 \% \quad 17.0$

$99.7 \% \quad 61.7$

$99.0 \% \quad 35.4$

$\begin{array}{lll}99.7 \% & 38.4\end{array}$
1676.92

1236.63

978.50

1363.74

1592.76

1445.71

1240.73

1277.67

995.63

1494.68

1209.57

1537.72

1213.61

1778.91

1324.67

1144.59

1120.57

2037.08

1969.08

1573.76

1471.67

1664.88

2122.08

1277.69

1489.83

1287.71

1153.62

1139.57

1891.99

1465.86

1598.82

1303.71

2288.20

2202.15

1899.02

1059.58

1249.66

1066.53

1346.77

1502.87

1404.75

1803.90

1227.70

1731.88

818.44

1199.68

$\begin{array}{cc}48 & 255 \\ 06 & 320 \\ 50 & 159 \\ 60 & 168 \\ 9 & 90 \\ 1 & 103 \\ 27 & 138 \\ 86 & 797 \\ 51 & 963 \\ 4 & 13 \\ 53 & 366 \\ 50 & 160 \\ 50 & 163 \\ 53 & 263 \\ 71 & 287 \\ 74 & 387 \\ 99 & 407 \\ 88 & 496 \\ 97 & 515 \\ 81 & 798 \\ 05 & 817 \\ 18 & 829 \\ 99 & 614 \\ 72 & 990 \\ 49 & 1461 \\ 63 & 1677 \\ 08 & 2219 \\ 98 & 206 \\ 07 & 217 \\ 18 & 235 \\ 80 & 294 \\ 96 & 408 \\ 8 & 59 \\ 62 & 282 \\ 1 & 21 \\ 3 & 21 \\ 09 & 118 \\ 20 & 130 \\ 05 & 214 \\ 65 & 375 \\ 65 & 376 \\ 77 & 388 \\ 68 & 483 \\ 84 & 493 \\ 42 & 656 \\ 39 & 546 \\ 69 & 579 \\ & \end{array}$

Page 72 of Table S-1-2 
Methylosome protein $50 \mathrm{GN}=$ WDR77 Methylosome protein $50 \mathrm{GN}=$ WDR77 Methylosome protein $50 \mathrm{GN}=$ WDR77 Methylosome protein $50 \mathrm{GN}=\mathrm{WDR} 77$ Methylosome protein $50 \mathrm{GN}=$ WDR77 Methylosome protein $50 \mathrm{GN}=$ WDR77 Methylosome protein $50 \mathrm{GN}=$ WDR77 Methylosome protein $50 \mathrm{GN}=$ WDR77 Methylosome protein $50 \mathrm{GN}=$ WDR77 Methylosome protein $50 \mathrm{GN}=\mathrm{WDR} 77$ Methylosome protein $50 \mathrm{GN}=\mathrm{WDR} 77$ Methylosome protein $50 \mathrm{GN}=\mathrm{WDR} 77$ $\begin{array}{lll}\text { Methylosome protein } 50 \mathrm{GN}=\text { WDR77 } & \text { MEP50_HUMAN } & 36.72 \\ \text { Methylosome subunit pICln GN=CLNS1A ICLN_HUMAN } & 26.22\end{array}$ Pethy Methylosome subunit pICln GN=CLNS1A ICLN_HUMAN $26.22 \quad 100.0 \%$ Methylosome subunit pICln GN=CLNS1A ICLN_HUMAN $26.22 \quad 100.0 \%$ Methylosome subunit pICln GN=CLNS1A ICLN_HUMAN $26.22 \quad 100.0 \%$ Methylosome subunit pICln GN=CLNS1A ICLN_HUMAN $26.22 \quad 100.0 \%$ Methylthioribose-1-phosphate isomerase GN=MRI1 MTNA_HUMAN $39.15 \quad 100.0 \%$ Methylthioribose-1-phosphate isomerase GN=MRI1 MTNA_HUMAN $39.15 \quad 100.0 \%$ Methylthioribose-1-phosphate isomerase GN=MRI1 MTNA_HUMAN $39.15 \quad 100.0 \%$ Methylthioribose-1-phosphate isomerase GN=MRI1 MTNA_HUMAN $39.15 \quad 100.0 \%$ Methylthioribose-1-phosphate isomerase GN=MRI1 MTNA_HUMAN $39.15 \quad 100.0 \%$ Methylthioribose-1-phosphate isomerase GN=MRI1 MTNA_HUMAN $39.15 \quad 100.0 \%$ Methylthioribose-1-phosphate isomerase GN=MRI1 MTNA_HUMAN $39.15 \quad 100.0 \%$ Methyltransferase-like protein 13 GN=METTL13 MET13_HUMAN $78.77 \quad 100.0 \%$ Methyltransferase-like protein $13 \mathrm{GN}=$ METTL13 MET13_HUMAN $78.77 \quad 100.0 \%$ Methyltransferase-like protein 17, mitochondrial GN=METTL17 MET17_HUMAN $50.73 \quad 100.0 \%$ Methyltransferase-like protein 17, mitochondrial GN=METTL17 MET17 HUMAN $50.73 \quad 100.0 \%$ MICOS complex subunit MIC27 GN=APOOL MIC27_HUMAN $29.16 \quad 100.0 \%$ MICOS complex subunit MIC27 GN=APOOL MIC27_HUMAN $29.16 \quad 100.0 \%$ MICOS complex subunit MIC27 GN=APOOL MIC27_HUMAN $29.16 \quad 100.0 \%$ MICOS complex subunit MIC27 GN=APOOL MIC27_HUMAN $29.16 \quad 100.0 \%$ MICOS complex subunit MIC27 GN=APOOL MIC27_HUMAN $29.16 \quad 100.0 \%$ MICOS complex subunit MIC27 GN=APOOL MIC27_HUMAN $29.16 \quad 100.0 \%$ MICOS complex subunit MIC60 GN=IMMT MIC60_HUMAN $83.68100 .0 \%$ MICOS complex subunit MIC60 GN=IMMT MIC60 HUMAN $83.68 \quad 100.0 \%$ MICOS complex subunit MIC60 GN=IMMT MIC60_HUMAN $83.68 \quad 100.0 \%$ MICOS complex subunit MIC60 GN=IMMT MIC60_HUMAN $83.68 \quad 100.0 \%$ MICOS complex subunit MIC60 GN=IMMT MIC60_HUMAN $83.68 \quad 100.0 \%$ MICOS complex subunit MIC60 GN=IMMT MIC60_HUMAN $83.68 \quad 100.0 \%$ MICOS complex subunit MIC60 GN=IMMT MIC60_HUMAN $83.68 \quad 100.0 \%$ MICOS complex subunit MIC60 GN=IMMT MIC60_HUMAN $83.68 \quad 100.0 \%$ MICOS complex subunit MIC60 GN=IMMT MIC60_HUMAN $83.68 \quad 100.0 \%$ MICOS complex subunit MIC60 GN=IMMT MIC60_HUMAN $83.68 \quad 100.0 \%$ Microtubule-associated protein 1B GN=MAP1B MAP1B_HUMAN $270.63 \quad 100.0 \%$

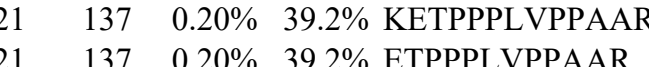

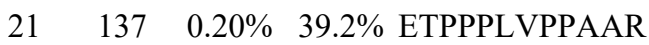

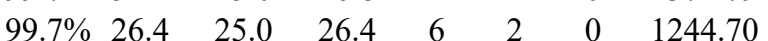

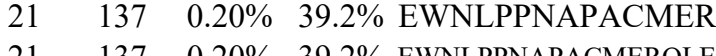
$99.7 \% \quad 49.4$

$37 \quad 0.20 \% \quad 39.2 \%$ EWNLPPNAPACMERQLEAAR $\quad 98.9 \% \quad 20.5$

$137 \quad 0.20 \% \quad 39.2 \%$ YRSDGALLLGASSLSGR $\quad 99.7 \% \quad 59.7$

$137 \quad 0.20 \% \quad 39.2 \%$ SDGALLLGASSLSGR

$99.7 \% \quad 62.5$

$137 \quad 0.20 \% \quad 39.2 \%$ FCKYEHDDIVSTVSVLSSGTQAVSGSK $99.5 \% \quad 97.3$

$137 \quad 0.20 \% \quad 39.2 \%$ YEHDDIVSTVSVLSSGTQAVSGSK $\quad 99.7 \% \quad 52.3$

$137 \quad 0.20 \% \quad 39.2 \%$ VWDLAQQVVLSSYR

$99.7 \% \quad 61.8$

$137 \quad 0.20 \% \quad 39.2 \%$ AHAAQVTCVAASPHK

$99.7 \% \quad 57.0$

$99.7 \% \quad 60.6$

$137 \quad 0.20 \% \quad 39.2 \%$ DSVFLSCSEDNR

$99.7 \% \quad 46.3$

$\begin{array}{llll}137 & 0.20 \% & 39.2 \% & \text { DSVFLSCSED } \\ 137 & 0.20 \% & 39.2 \% & \text { SQAHRDFVR }\end{array}$

$26 \quad 0.04 \% \quad 31.2 \%$ SFPPPGPAEGLLR

$99.7 \% \quad 41.0$

$99.7 \% \quad 49.4$

$0.04 \% \quad 31.2 \%$ QQPDTEAVLNGK

$99.7 \% \quad 39.2$

$\begin{array}{lllll}0.04 \% & 31.2 \% & \text { QQPDTEAVLNGKGLGTGTLYIAESR } & 99.7 \% & 33.1\end{array}$

$0.04 \% \quad 31.2 \%$ GLGTGTLYIAESR

$99.7 \% 78.4$

$0.04 \% \quad 31.2 \%$ DRSDCLGEHLYVMVNAK $99.5 \% 21.6$

$0.04 \% \quad 31.2 \%$ LEGMLSQSVSSQYNMAGVR $99.7 \% \quad 60.8$

$0.01 \% \quad 19.2 \%$ GSLQILDQLLLPK

$0.01 \% \quad 19.2 \%$ YEAVGSVHQAWEAIR

$99.7 \% \quad 42.6$

$0.01 \% \quad 19.2 \%$ AARDLADVAAR

$0.01 \% \quad 19.2 \%$ DLADVAAR

$0.01 \% \quad 19.2 \%$ GVSAVVVGADR

$0.01 \% \quad 19.2 \%$ VGTYQLAIVAK

$0.01 \% \quad 19.2 \%$ TALTTTISSR

$0.00 \% \quad 4.3 \% \quad$ YTLHVVDSPTVKPSR

$0.00 \% \quad 4.3 \%$ LATPELLETAQALER

$0.00 \% \quad 4.0 \%$ LDGGFAAVSR

$0.00 \% \quad 4.0 \% \quad$ FSMVILAR

$99.6 \% \quad 24.0$

$98.2 \% \quad 27.6$

$97.7 \% \quad 26.3$

$99.7 \% \quad 48.1$

$99.7 \% \quad 27.6$

$99.7 \% \quad 25.7$

$\begin{array}{lll}99.7 \% & 24.9\end{array}$

$99.7 \% \quad 62.2$

$99.7 \% \quad 43.6$

$99.0 \% \quad 25.8$

$\begin{array}{llll}0.01 \% & 33.2 \% & \text { YVEEQPGHLQMGFASIR } \quad 98.9 \% \quad 22.5\end{array}$

$0.01 \% \quad 33.2 \%$ MGVITVSGLAGLVSAR

$99.7 \% \quad 49.4$

$0.01 \% 33.2 \%$ VYATSQQIFGAVK

$99.7 \% \quad 42.9$

$0.01 \% \quad 33.2 \%$ SSKEESLPKPK

$99.7 \% \quad 28.7$

$0.01 \% \quad 33.2 \%$ LGSSSEIEVPAKTTHVLK $99.0 \% \quad 20.0$

$0.01 \% 33.2 \%$ HSVPLPTELSSEAK

$0.03 \% \quad 14.2 \%$ YSTSGSSGLTTGK

$0.03 \% \quad 14.2 \%$ ERPPEEVAAR

$0.03 \% \quad 14.2 \%$ TVEGALKER

$0.03 \% \quad 14.2 \%$ EVAGAKPHITAAEGK

$0.03 \% \quad 14.2 \%$ VVSQYHELVVQAR

$98.8 \% \quad 18.9$

$99.7 \% \quad 52.4$

$99.7 \% \quad 44.8$

$99.7 \% \quad 52.0$

$99.1 \% \quad 24.0$

$99.7 \% \quad 54.6$

$95.7 \% \quad 18.4$

$0.03 \% \quad 14.2 \%$ AFDSAVAK

$\begin{array}{lll}99.7 \% & 52.8\end{array}$

$0.03 \% \quad 14.2 \%$ GVYSEETLR

$0.03 \% \quad 14.2 \%$ GVYSEETLRAR

$0.03 \% \quad 14.2 \%$ FVNQLKGESR

$99.4 \% \quad 24.4$

$99.6 \% \quad 23.1$

$99.7 \% \quad 29.5$

$99.7 \% \quad 43.4$

$0.01 \% \quad 1.5 \%$ AIGNIELGIR

1547.77

1428.61

2326.1

1115.57

1337.72

1299.65

2618.34

1337.71

2022.94

2088.97

1437.87

1715.85

1128.61

830.44

1029.57

1162.68

1050.58

1698.92

1654.90

992.52

936.53

1961.95

1546.86

1411.76

1229.67

1896.04

1494.78

1245.60

1153.60

1002.56

1478.80

1527.83

808.42

1872.00

1053.52

1280.66

1177.63 1055.62 
Microtubule-associated protein 1B GN=MAP1B MAP1B_HUMAN $270.63 \quad 100.0 \%$ Microtubule-associated protein 1B GN=MAP1B MAP1B_HUMAN $270.63 \quad 100.0 \%$ Midasin GN=MDN1

Midasin GN=MDN1

Midasin GN=MDN1

Midasin GN=MDN1

Midasin GN=MDN1

Midasin GN=MDN1 MDN1_HUMAN $632.83 \quad 100.0 \%$ MDN1_HUMAN $632.83 \quad 100.0 \%$ MDN1_HUMAN $632.83 \quad 100.0 \%$ MDN1_HUMAN $632.83 \quad 100.0 \%$ MDN1 HUMAN $632.83 \quad 100.0 \%$ MDN1_HUMAN $632.83 \quad 100.0 \%$ 2 AL1L2 HUMAN $101.75 \quad 100.0 \%$

Mitochondrial 10-formyltetrahydrofolate dehydrogenase GN=ALDHIL2 AL1L2_HUMAN $101.75 \quad 100.0 \%$ Mitochondrial 2-oxoglutarate/malate carrier protein GN=SLC25A11 M2OM_HUMAN $34.06 \quad 100.0 \%$ Mitochondrial 2-oxoglutarate/malate carrier protein GN=SLC25A11 M2OM_HUMAN $34.06 \quad 100.0 \%$ Mitochondrial 2-oxoglutarate/malate carrier protein GN=SLC25A11 $\quad$ M2OM_HUMAN $34.06 \quad 100.0 \%$ Mitochondrial 2-oxoglutarate/malate carrier protein GN=SLC25A11 M2OM_HUMAN $34.06 \quad 100.0 \%$ Mitochondrial 2-oxoglutarate/malate carrier protein GN=SLC25A11 M2OM_HUMAN $34.06 \quad 100.0 \%$ Mitochondrial 2-oxoglutarate/malate carrier protein GN=SLC25A11 M2OM_HUMAN $34.06 \quad 100.0 \%$ Mitochondrial 2-oxoglutarate/malate carrier protein GN=SLC25A11 M2OM HUMAN $34.06 \quad 100.0 \%$ Mitochondrial 2-oxoglutarate/malate carrier protein GN=SLC25A11 M2OM_HUMAN $34.06 \quad 100.0 \%$ Mitochondrial carnitine/acylcarnitine carrier protein GN=SLC25A20 MCAT_HUMAN $32.95 \quad 100.0 \%$ Mitochondrial carnitine/acylcarnitine carrier protein GN=SLC25A20 MCAT_HUMAN $32.95 \quad 100.0 \%$ Mitochondrial carnitine/acylcarnitine carrier protein GN=SLC25A20 MCAT_HUMAN $32.95 \quad 100.0 \%$ Mitochondrial carnitine/acylcarnitine carrier protein GN=SLC25A20 MCAT_HUMAN $32.95 \quad 100.0 \%$ Mitochondrial carnitine/acylcarnitine carrier protein GN=SLC25A20 MCAT_HUMAN $32.95 \quad 100.0 \%$ Mitochondrial dicarboxylate carrier GN=SLC25A10 DIC_HUMAN $31.28 \quad 100.0 \%$ Mitochondrial dicarboxylate carrier GN=SLC25A10 DIC HUMAN $31.28 \quad 100.0 \%$ Mitochondrial dicarboxylate carrier GN=SLC25A10 DIC_HUMAN $31.28 \quad 100.0 \%$ Mitochondrial dicarboxylate carrier GN=SLC25A10 DIC_HUMAN $31.28 \quad 100.0 \%$ Mitochondrial dicarboxylate carrier GN=SLC25A10 DIC HUMAN $31.28 \quad 100.0 \%$ Mitochondrial dicarboxylate carrier GN=SLC25A10 DIC_HUMAN $31.28 \quad 100.0 \%$ Mitochondrial dicarboxylate carrier GN=SLC25A10 DIC HUMAN $31.28 \quad 100.0 \%$ Mitochondrial dicarboxylate carrier GN=SLC25A10 DIC_HUMAN $31.28 \quad 100.0 \%$ Mitochondrial dicarboxylate carrier GN=SLC25A10 DIC_HUMAN $31.28 \quad 100.0 \%$ Mitochondrial dicarboxylate carrier GN=SLC25A10 DIC HUMAN $31.28 \quad 100.0 \%$ Mitochondrial glutamate carrier $1 \mathrm{GN}=\mathrm{SLC} 25 \mathrm{~A} 22 \mathrm{GHC} 1$ _HUMAN $34.47 \quad 100.0 \%$ Mitochondrial glutamate carrier 1 GN=SLC25A22 GHC1 HUMAN $34.47 \quad 100.0 \%$ Mitochondrial glutamate carrier $1 \mathrm{GN}=\mathrm{SLC} 25 \mathrm{~A} 22 \mathrm{GHC} 1$ HUMAN $34.47 \quad 100.0 \%$ Mitochondrial glutamate carrier $1 \mathrm{GN}=\mathrm{SLC} 25 \mathrm{~A} 22$ GHC1_HUMAN $34.47 \quad 100.0 \%$ Mitochondrial glutamate carrier $1 \mathrm{GN}=\mathrm{SLC} 25 \mathrm{~A} 22 \mathrm{GHC} 1$ HUMAN $34.47 \quad 100.0 \%$ Mitochondrial glutamate carrier $1 \mathrm{GN}=\mathrm{SLC} 25 \mathrm{~A} 22 \mathrm{GHC1}$ _HUMAN $34.47 \quad 100.0 \%$ Mitochondrial glutamate carrier $1 \mathrm{GN}=\mathrm{SLC} 25 \mathrm{~A} 22$ GHC1_HUMAN $34.47 \quad 100.0 \%$ Mitochondrial glutamate carrier $1 \mathrm{GN}=\mathrm{SLC} 25 \mathrm{~A} 22 \mathrm{GHC} 1$ HUMAN $34.47 \quad 100.0 \%$ Mitochondrial glutamate carrier $1 \mathrm{GN}=\mathrm{SLC} 25 \mathrm{~A} 22 \mathrm{GHC} 1$ _HUMAN $34.47 \quad 100.0 \%$ Mitochondrial glutamate carrier 1 GN=SLC25A22 GHC1 HUMAN $34.47 \quad 100.0 \%$ Mitochondrial import inner membrane translocase subunit TIM44 GN=TIMM44 TIM44_HUMAN $51.36 \quad 100.0 \%$ Mitochondrial import inner membrane translocase subunit TIM44 GN=TIMM44 TIM44_HUMAN $51.36 \quad 100.0 \%$ 作 Mitochondrial import inner membrane translocase subunit TIM50 GN=TIMM50 TIM50_HUMAN $39.65 \quad 100.0 \%$
$0.01 \% \quad 1.5 \%$ SVGNTIDPVILFQK $0.01 \% \quad 1.5 \%$ DLTGQVPTPVVK $0.01 \% \quad 1.3 \% \quad$ LFLESSDANPVR $0.01 \% \quad 1.3 \% \quad$ LLEKVEGTVR

$10 \quad 0.01 \% \quad 1.3 \%$ GMIDGSTPTITPNPNFR

$10 \quad 0.01 \% \quad 1.3 \% \quad$ DGQILVYCLNR

$10 \quad 0.01 \% \quad 1.3 \%$ TDSQLQGQVLFR

$10 \quad 0.01 \% \quad 1.3 \% \quad$ LNAALATPAK

$0.01 \% \quad 3.5 \%$ NGLVLFGNDGKALTVR

$0.01 \% \quad 3.5 \%$ GVINIIPGSGGIAGQR

$0.03 \% \quad 30.3 \%$ LGIYTVLFER

$0.03 \% \quad 30.3 \%$ LTGADGTPPGFLLK

$0.03 \% \quad 30.3 \%$ AVIGMTAGATGAFVGTPAEVALIR

$0.03 \% \quad 30.3 \%$ MTADGRLPADQR

$0.03 \% \quad 30.3 \%$ GYKNVFNALIR

$0.03 \% \quad 30.3 \%$ NVFNALIR

$0.03 \% \quad 30.3 \%$ AVVVNAAQLASYSQSK

$0.03 \% \quad 30.3 \%$ GFTPYYAR

$0.01 \% \quad 11.3 \%$ EGITGLYR

$0.01 \% \quad 11.3 \%$ KLYQEFGIR

$0.01 \% \quad 11.3 \%$ RVSELSAPR

$0.01 \% \quad 11.3 \%$ VSELSAPR

$0.01 \% \quad 11.3 \%$ GFNAVMIR

$0.03 \% \quad 43.9 \%$ VHLQTQQEVK

$0.03 \% \quad 43.9 \%$ QMTYSLTR

$0.03 \% \quad 43.9 \%$ GSQGPLPFHEK

$0.03 \% \quad 43.9 \%$ VLLGSVSGLAGGFVGTPADLVNVR

$0.03 \% \quad 43.9 \%$ MQNDVKLPQGQR

$0.03 \% \quad 43.9 \%$ NYAHALDGLYR

$0.03 \% \quad 43.9 \%$ LFSGATMASSR

$0.03 \% \quad 43.9 \%$ GALVTVGQLSCYDQAK

$0.03 \% \quad 43.9 \%$ GEYQGVFHCAVETAK

$0.03 \% \quad 43.9 \%$ LGPLAFYK

$0.03 \% \quad 35.3 \%$ VYTSMSDCLIK

$0.03 \% \quad 35.3 \%$ SEGYFGMYR

$0.03 \% \quad 35.3 \%$ GAAVNLTLVTPEK

$0.03 \% \quad 35.3 \%$ LAANDFFR

$0.03 \% \quad 35.3 \%$ IQLQDAGR

$0.03 \% \quad 35.3 \%$ ILAaqgQLSAQgGapPSVEAPAaPRPTATQLTR

$0.03 \% 35.3 \%$ GLGATLLR

$0.03 \% \quad 35.3 \%$ TRLQSLQR

$0.03 \% \quad 35.3 \%$ GVNEDTYSGILDCAR

$0.03 \% \quad 35.3 \%$ GVNEDTYSGILDCARK

$0.00 \% \quad 5.8 \% \quad$ ILDIDNVDLAMGK

$0.00 \% \quad 5.8 \%$ LLDISASSTEQIL

$0.03 \% \quad 22.7 \%$ RAPDQAAEIGSR

$\begin{array}{lllll}0.03 \% & 22.7 \% & \text { AQGPQQQPGSEGPSYAK } & 99.7 \% & 52.9\end{array}$

$99.7 \% \quad 36.8$

$99.7 \% \quad 28.5$

$99.7 \% \quad 54.1$

$97.0 \% \quad 18.8$

$99.7 \% \quad 30.6$

$99.7 \% \quad 36.8$

$98.7 \% 28.6$

$99.7 \% \quad 44.0$

$99.6 \% \quad 23.3$

$99.7 \% \quad 58.3$

$99.7 \% \quad 46.8$

$99.7 \% \quad 51.6$

$99.7 \% 27.9$

$99.3 \% \quad 19.4$

$97.9 \% \quad 22.2$

$9.7 \% \quad 61.5$

$96.8 \% \quad 16.7$

$99.0 \% \quad 41.0$

$99.6 \% \quad 27.8$

$99.7 \% \quad 30.4$

$96.3 \% \quad 18.5$

$99.0 \% \quad 39.1$

$99.7 \% \quad 49.2$

$99.0 \% \quad 23.6$

$99.7 \% \quad 29.2$

$99.7 \% \quad 46.2$

$\begin{array}{lll}99.7 \% & 50.1\end{array}$

$99.7 \% \quad 63.8$

$99.7 \% \quad 69.8$

$\begin{array}{lll}99.7 \% & 48.8\end{array}$

$97.1 \% \quad 16.3$

$99.7 \% \quad 43.8$

$99.7 \% \quad 32.5$

$99.7 \% \quad 47.7$

$99.0 \% \quad 53.0$

$99.0 \% 58.5$

$99.7 \% \quad 91.8$

$99.0 \% \quad 27.0$

$99.0 \% \quad 24.1$

$99.7 \% \quad 63.7$

$99.7 \% \quad 29.1$

$99.7 \% \quad 45.0$

$\begin{array}{lll}99.7 \% & 33.7\end{array}$

$99.7 \% \quad 54.8$

$\begin{array}{ll}12 & 19\end{array}$
$100.0 \% \quad 9$
1253.71

1347.69

1143.67

1833.88

1350.68

1391.73

969.57

1673.93

1508.85

1210.68

1386.76

2289.23

1330.65

1294.73

946.55

1635.87

974.47

908.48

1153.64

1014.57

858.47

907.48

1209.66

1015.49

1196.61

2298.28

1429.72

1292.64

1143.55

1709.85

1695.78

908.52

1316.62

1109.47

1312.75

953.48

900.49

3256.74

800.50

1001.59

1669.75

1797.84

1432.74

1389.75

1270.65

1729.81 

Mitochondrial import inner membrane translocase subunit TIM50 GN=TIMM50 TIM50_HUMAN $39.65 \quad 100.0 \%$ 作 hondral import inner membrane translocase subunit TIM50 GN=TIMM50 TIM50_HUMAN $39.65 \quad 100.0 \%$ Mitochondrial import inner membrane translocase subunit TIM50 GN=TIMM50 TIM50_HUMAN $39.65 \quad 100.0 \%$ Mitochondrial import inner membrane translocase subunit TIM50 GN=TIMM50 TIM50 HUMAN $39.65 \quad 100.0 \%$ Mitochondrial import receptor subunit TOM40 homolog GN=TOMM40 TOM40_HUMAN 37.89 Mitochondrial import receptor subunit TOM 40 homolog GN=TOMM40 TOM40_HUMAN 37.89 Mitochondrial import receptor subunit TOM 40 homolog GN=TOMM40 TOM40_HUMAN 37.89 Mitochondrial inner membrane protein OXA1L GN=OXA1L OXA1L_HUMAN 48.55 Mitochondrial inner membrane protein OXA1L GN=OXA1L OXA1L HUMAN 48.55 Mitochondrial inner membrane protein OXA1L GN=OXA1L OXA1L_HUMAN 48.5 Mitochondrial inner membrane protein OXA1L GN=OXA1L OXA1L_HUMAN 48.55 Mitochondrial inner membrane protein OXA1L GN=OXAIL OXA1L_HUMAN 48.55 Mitochondrial inner membrane protein OXA1L GN=OXA1L OXA1L_HUMAN 48.55 Mitochondrial inner membrane protein OXA1L GN=OXA1L OXA1L_HUMAN 48.55 Mitochondrial inner membrane protein OXA1L GN=OXA1L OXA1L_HUMAN 48.55 Mitochondrial Rho GTPase 2 GN=RHOT2 MIRO2_HUMAN 68.12 Mitochondrial Rho GTPase $2 \mathrm{GN}=\mathrm{RHOT} 2 \mathrm{MIRO} 2 \mathrm{HUMAN} 68.12$ Mitochondrial Rho GTPase 2 GN=RHOT2 MIRO2_HUMAN $68.12 \quad 100.0 \%$ Mitochondrial ribonuclease P protein 1 GN=TRMT10C MRRP1_HUMAN $47.35100 .0 \%$ Mitochondrial ribonuclease P protein 1 GN=TRMT10C MRRP1_HUMAN $47.35 \quad 100.0 \%$ Mitochondrial ribonuclease P protein $1 \mathrm{GN}=$ TRMT10C MRRP1_HUMAN $47.35100 .0 \%$ Mitochondrial thiamine pyrophosphate carrier GN=SLC25A19 TPC HUMAN 35.51 100.0\% Mitochondrial thiamine pyrophosphate carrier GN=SLC25A19 TPC_HUMAN $35.51 \quad 100.0 \%$ Mitochondrial thiamine pyrophosphate carrier GN=SLC25A19 TPC_HUMAN $35.51 \quad 100.0 \%$ Mitochondrial thiamine pyrophosphate carrier GN=SLC25A19 TPC HUMAN $35.51 \quad 100.0 \%$ Mitochondrial thiamine pyrophosphate carrier GN=SLC25A19 TPC_HUMAN $35.51 \quad 100.0 \%$ Mitochondrial thiamine pyrophosphate carrier GN=SLC25A19 TPC HUMAN $35.51 \quad 100.0 \%$ Mitochondrial thiamine pyrophosphate carrier GN=SLC25A19 TPC_HUMAN $35.51 \quad 100.0 \%$ Mitochondrial thiamine pyrophosphate carrier GN=SLC25A19 TPC_HUMAN $35.51 \quad 100.0 \%$ Mitogen-activated protein kinase kinase kinase $7 \mathrm{GN}=$ MAP3K7 M3K7 HUMAN $67.20 \quad 100.0 \%$ Mitogen-activated protein kinase kinase kinase 7 GN=MAP3K7 M3K7_HUMAN $67.20 \quad 100.0 \%$ Mitogen-activated protein kinase kinase kinase 7 GN=MAP3K7 M3K7_HUMAN 67.20 $100.0 \%$ Mitogen-activated protein kinase kinase kinase $7 \mathrm{GN}=$ MAP3K 7 M3K7 HUMAN 67.20 $100.0 \%$ Mitogen-activated protein kinase kinase kinase 7 GN=MAP3K7 M3K7_HUMAN $67.20 \quad 100.0 \%$ Mitogen-activated protein kinase kinase kinase $7 \mathrm{GN}=\mathrm{MAP} 3 \mathrm{~K} 7 \mathrm{M3K} 7$ HUMAN $67.20 \quad 100.0 \%$ MOB kinase activator $2 \mathrm{GN}=\mathrm{MOB} 2$ MOB kinase activator $2 \mathrm{GN}=\mathrm{MOB} 2$ MOB kinase activator $2 \mathrm{GN}=\mathrm{MOB} 2$ MOB kinase activator $2 \mathrm{GN}=\mathrm{MOB} 2$ MOB kinase activator $2 \mathrm{GN}=\mathrm{MOB} 2$ MOB kinase activator $2 \mathrm{GN}=\mathrm{MOB} 2$ MOB kinase activator $2 \mathrm{GN}=\mathrm{MOB} 2$ $\mathrm{MOB}$ kinase activator $2 \mathrm{GN}=\mathrm{MOB} 2$

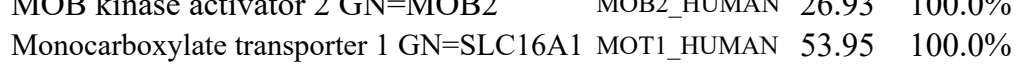

(2)

8

8

8

3

3

3

3

3

8

8
8

8

8
8

8

8
8

6

6

6

6
6

6 $\begin{array}{lll}\text { MOB2_HUMAN } & 26.93 & 100.0 \%\end{array}$ MOB2_HUMAN $26.93 \quad 100.0 \%$ MOB2_HUMAN $26.93 \quad 100.0 \%$ MOB2 HUMAN $26.93 \quad 100.0 \%$ MOB2_HUMAN $26.93 \quad 100.0 \%$

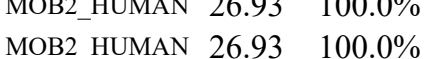
MOB2_HUMAN $26.93 \quad 100.0 \%$
12

12

12

12

4

4

4

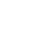

19
$0.05 \% \quad 28.3 \%$ KAYLEPEHTK

$0.05 \% \quad 28.3 \%$ AYLEPEHTK

$0.05 \% \quad 28.3 \%$ AYLEPEHTKAR

$0.05 \% \quad 28.3 \%$ ITDFQFKELVVLPR

$0.05 \% \quad 28.3 \%$ CTAPQYVDFVMSSVQK

$0.05 \% \quad 28.3 \%$ LVTDEDVFPTK

$\begin{array}{lll}0.05 \% & 28.3 \% & \text { LVTDEDVFPTKYGR }\end{array}$

$0.05 \% \quad 28.3 \%$ EFPSSFESLVR

$0.01 \% \quad 6.4 \%$ DLHDANTDLIGR $\begin{array}{llll}98.1 \% & 16.2 & 25.0 & 16.2\end{array}$ $\begin{array}{llll}97.8 \% & 17.1 & 25.0 & 15.4\end{array}$ $\begin{array}{lllll}99.0 \% & 27.0 & 25.0 & 27.0 & 2\end{array}$ $\begin{array}{llll}99.7 \% & 34.7 & 25.0 & 21.7\end{array}$ $\begin{array}{llll}99.7 \% & 27.0 & 25.0 & 25.7\end{array}$ $\begin{array}{llll}99.7 \% & 60.0 & 25.0 & 59.4\end{array}$ $\begin{array}{llll}97.4 \% & 15.9 & 25.0 & 15.5\end{array}$ $\begin{array}{llll}99.7 \% & 44.2 & 25.0 & 44.2\end{array}$ $\begin{array}{llll}99.7 \% & 60.7 & 25.0 & 60.7\end{array}$ $\begin{array}{llll}99.7 \% & 46.8 & 25.0 & 46.8\end{array}$ $\begin{array}{llll}99.7 \% & 58.9 & 25.0 & 47.9\end{array}$ $\begin{array}{llll}99.7 \% & 28.6 & 25.0 & 28.5\end{array}$ $\begin{array}{llll}99.7 \% & 27.6 & 25.0 & 26.6\end{array}$ $\begin{array}{lllll}99.7 \% & 28.7 & 25.0 & 28.7 & 2\end{array}$ $\begin{array}{llll}99.0 \% & 32.7 & 25.0 & 21.8\end{array}$ $\begin{array}{llll}99.6 \% & 27.4 & 25.0 & 16.5\end{array}$ $\begin{array}{llll}99.0 \% & 30.2 & 25.0 & 12.6\end{array}$ $\begin{array}{llll}99.7 \% & 26.6 & 25.0 & 26.6\end{array}$ $99.7 \% \quad 51.1 \quad 25.0 \quad 40.2$ $\begin{array}{llll}99.7 \% & 36.9 & 25.0 & 30.3\end{array}$ $\begin{array}{llll}99.7 \% & 42.2 & 25.0 & 33.3\end{array}$ $\begin{array}{llll}99.6 \% & 26.4 & 25.0 & 26.4\end{array}$ $\begin{array}{llll}99.7 \% & 49.6 & 25.0 & 38.5\end{array}$ $\begin{array}{llll}99.5 \% & 24.0 & 25.0 & 24.0\end{array}$ $\begin{array}{llll}99.4 \% & 21.0 & 25.0 & 21.0\end{array}$ $\begin{array}{llll}94.6 \% & 17.3 & 25.0 & 11.6\end{array}$ $\begin{array}{llll}99.7 \% & 31.4 & 25.0 & 28.3\end{array}$ $\begin{array}{llll}96.9 \% & 19.1 & 25.0 & 12.7\end{array}$ $\begin{array}{llll}95.2 \% & 14.1 & 25.0 & 14.1\end{array}$ $\begin{array}{llll}99.7 \% & 61.2 & 25.0 & 55.5\end{array}$ $\begin{array}{llll}99.7 \% & 38.5 & 25.0 & 38.5\end{array}$ $\begin{array}{llll}99.7 \% & 31.2 & 25.0 & 31.2\end{array}$ $\begin{array}{llll}98.2 \% & 18.7 & 25.0 & 18.7\end{array}$ $\begin{array}{llll}96.2 \% & 15.2 & 25.0 & 15.2\end{array}$ $\begin{array}{llll}99.7 \% & 37.1 & 25.0 & 37.1\end{array}$ $\begin{array}{llll}99.7 \% & 61.5 & 25.0 & 61.5\end{array}$ $\begin{array}{llll}99.7 \% & 44.9 & 25.0 & 44.7\end{array}$ $\begin{array}{llll}97.4 \% & 25.0 & 25.0 & 25.0\end{array}$ $\begin{array}{llll}98.8 \% & 18.0 & 25.0 & 18.0\end{array}$ $\begin{array}{llll}99.4 \% & 26.6 & 25.0 & 14.7\end{array}$ $\begin{array}{llll}99.7 \% & 29.7 & 25.0 & 29.7\end{array}$ $\begin{array}{llll}99.7 \% & 47.9 & 25.0 & 47.9\end{array}$ $\begin{array}{llll}99.7 \% & 37.5 & 25.0 & 37.5\end{array}$ $\begin{array}{llll}99.7 \% & 42.8 & 25.0 & 38.7\end{array}$ $\begin{array}{lllll}99.7 \% & 54.8 & 25.0 & 54.8 & 3\end{array}$ $\begin{array}{llll}99.7 \% & 39.8 & 25.0 & 39.8\end{array}$ $99.7 \% \quad 34.0 \quad 25.0 \quad 28.9$
185

1316.64

946.54

1430.70

1700.88

1564.84

1235.67

1828.88

1575.80

1341.66

1416.80

1208.59

1127.54

1255.64

954.61

1201.65

914.51

1203.58

1140.70

1375.69

1109.61

1253.59

1019.52

2043.00

1102.65

1226.68

1629.83

934.46

1054.52

1873.94

1269.68

1113.58

1748.07

1489.79

1239.53

1874.95

1521.76

1283.77

1215.64

1087.54

1314.68

1704.97

1859.87

1263.65

1639.83

1297.64

1339.66

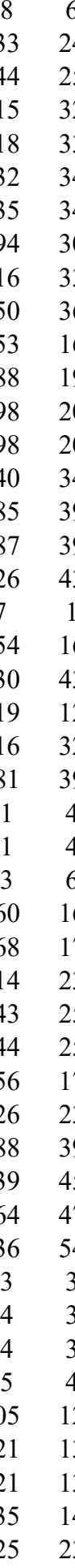

Page 75 of Table S-1-2 
Monocarboxylate transporter $1 \mathrm{GN}=$ SLC16A1 MOT1_HUMAN $53.95 \quad 100.0 \%$ Monofunctional C1-tetrahydrofolate synthase, mitochondrial GN=MTHFDIL C1TM_HUMAN $105.79 \quad 100.0 \%$ Monofunctional Cl-tetrahydrofolate synthase, mitochondrial GN=MTHFDIL C1TM_HUMAN $105.79 \quad 100.0 \%$ 等 Monofunctional C1-tetrahydrofolate synthase, mitochondrial GN=MTHFDIL C1TM_HUMAN $105.79 \quad 100.0 \%$ Monofunctional Cl-tetrahydrofolate synthase, mitochondrial GN=MTHFDIL C1TM_HUMAN $105.79 \quad 100.0 \%$ finctional Cl-tetrahydrofolate synthase, mitochondrial GN=MTHFDIL C1TM HUMAN $105.79 \quad 100.0 \%$ CI-tetrahydrofolate synthase, mitochondrial GN=MTHFDIL C1TM HUMAN $105.79 \quad 100.0 \%$ Cl-tertahydrofolate synthase, mitochondrial GN=MTHFDIL C1TM_HUMAN $105.79 \quad 100.0 \%$ mRNA export factor $\mathrm{GN}=\mathrm{RAE}$ mRNA export factor $\mathrm{GN}=\mathrm{RAE} 1$ mRNA export factor $\mathrm{GN}=\mathrm{RAE}$ mRNA export factor $\mathrm{GN}=\mathrm{RAE} 1$ mRNA export factor $\mathrm{GN}=\mathrm{RAE}$ mRNA turnover protein 4 homolog $\mathrm{GN}=\mathrm{MRTO} 4 \mathrm{MR}$ mRNA turnover protein 4 homolog GN=MRTO4 MRT4_HUMAN $27.56 \quad 100.0 \%$ Multifunctional protein ADE2 GN=PAICS PUR6_HUMAN $47.08 \quad 100.0 \%$ Multifunctional protein ADE2 GN=PAICS PUR6 HUMAN $47.08 \quad 100.0 \%$ Multifunctional protein ADE2 GN=PAICS PUR6_HUMAN $47.08 \quad 100.0 \%$ Multifunctional protein ADE2 GN=PAICS PUR6 HUMAN $47.08 \quad 100.0 \%$ Multifunctional protein ADE2 GN=PAICS PUR6_HUMAN $47.08 \quad 100.0 \%$ Myb-binding protein 1A GN=MYBBP1A MBB1A_HUMAN $148.86 \quad 100.0 \%$ Myb-binding protein 1A GN=MYBBP1A MBB1A_HUMAN $148.86 \quad 100.0 \%$ Myb-binding protein 1A GN=MYBBP1A MBB1A_HUMAN $148.86 \quad 100.0 \%$ Myb-binding protein 1A GN=MYBBP1A MBB1A_HUMAN $148.86 \quad 100.0 \%$ Myb-binding protein 1A GN=MYBBP1A MBB1A_HUMAN $148.86 \quad 100.0 \%$ Myb-binding protein 1A GN=MYBBP1A MBB1A_HUMAN $148.86 \quad 100.0 \%$ Myb-binding protein 1A GN=MYBBP1A MBB1A HUMAN $148.86 \quad 100.0 \%$ Myb-binding protein 1A GN=MYBBP1A MBB1A_HUMAN $148.86 \quad 100.0 \%$ Myb-binding protein 1A GN=MYBBP1A MBB1A_HUMAN $148.86 \quad 100.0 \%$ Myb-binding protein 1A GN=MYBBP1A MBB1A_HUMAN $148.86 \quad 100.0 \%$ Myb-binding protein 1A GN=MYBBP1A MBB1A_HUMAN $148.86 \quad 100.0 \%$ Myb-binding protein 1A GN=MYBBP1A MBB1A_HUMAN $148.86 \quad 100.0 \%$ Myb-binding protein 1A GN=MYBBP1A MBB1A_HUMAN $148.86 \quad 100.0 \%$ Myb-binding protein 1A GN=MYBBP1A MBB1A_HUMAN $148.86 \quad 100.0 \%$ Myeloid leukemia factor $2 \mathrm{GN}=\mathrm{MLF} 2$ Myeloid leukemia factor $2 \mathrm{GN}=\mathrm{MLF} 2$ Myosin-10 GN=MYH10

Myosin-10 GN=MYH10 Myosin-10 GN=MYH10 Myosin-10 GN=MYH10 Myosin-10 GN=MYH10 Myosin-10 GN=MYH10 Myosin-10 GN=MYH10 Myosin-10 GN=MYH10 MLF2_HUMAN $28.15 \quad 100.0 \%$ MLF2_HUMAN $28.15 \quad 100.0 \%$ MYH10_HUMAN $229.01 \quad 100.0 \%$ MYH10 HUMAN $229.01 \quad 100.0 \%$ MYH10_HUMAN $229.01 \quad 100.0 \%$ MYH10_HUMAN $229.01 \quad 100.0 \%$ MYH10_HUMAN $229.01 \quad 100.0 \%$ MYH10_HUMAN $229.01 \quad 100.0 \%$ MYH10 HUMAN $229.01 \quad 100.0 \%$ MYH10_HUMAN $229.01 \quad 100.0 \%$
0.0 2 22 $0.03 \% \quad 10.8 \%$ ASGLVPNVVVLVATVR $0.03 \% \quad 10.8 \%$ TIAQAVYGAK

$0.03 \% \quad 10.8 \%$ TIAQAVYGAKDIELSPEAQAK $0.03 \% \quad 10.8 \%$ DIELSPEAQAK

$0.03 \% \quad 10.8 \%$ IDRYTQQGFGNLPICMAK $0.03 \% \quad 10.8 \%$ DFILPISDVR $0.02 \% \quad 13.9 \%$ CWEVQDSGQTIPK $0.02 \% \quad 13.9 \%$ SSNPMMVLQLPER $0.02 \% \quad 13.9 \%$ GLIVYQLENQPSEFR $0.02 \% \quad 13.9 \%$ GLIVYQLENQPSEFRR $0.02 \% \quad 13.9 \%$ NAAEELKPR $0.00 \% \quad 8.4 \%$ GEVGLLFTNR $0.00 \% \quad 8.4 \%$ QLGLPTALKR $0.01 \% \quad 17.4 \%$ VLLQSKDQITAGNAAR $0.01 \% \quad 17.4 \%$ IATGSFLKR $0.01 \% \quad 17.4 \%$ VVVLMGSTSDLGHCEK $0.01 \% \quad 17.4 \%$ VTSAHKGPDETLR $0.01 \% \quad 17.4 \%$ IKAEYEGDGIPTVFVAVAGR $0.03 \% \quad 9.6 \% \quad$ LVGSVNLFSDENVPR $0.03 \% \quad 9.6 \%$ SSSSKQEQDLLHK $0.03 \% \quad 9.6 \%$ IFTHHLCR $0.03 \% \quad 9.6 \%$ AGALHAQVER $0.03 \% \quad 9.6 \%$ VYSTALSSFLTK $0.03 \% \quad 9.6 \%$ VYSTALSSFLTKR $0.03 \% \quad 9.6 \%$ HQACLLLQK $0.03 \% \quad 9.6 \%$ EIPSATQSPISK $0.03 \% \quad 9.6 \% \quad$ AKVPAQANGTPTTK $0.03 \% \quad 9.6 \%$ SPAPGAPTR $0.03 \% \quad 9.6 \%$ SPLSALAR $0.03 \% \quad 9.6 \%$ LSLVIRSPSLLQSGAK $0.03 \% \quad 9.6 \%$ SPSLLQSGAK $0.03 \% \quad 9.6 \%$ SPSLLQSGAKK $0.01 \% \quad 8.5 \% \quad$ VYQETSEMR $0.01 \% \quad 8.5 \%$ LAIQGPEDSPSR $0.04 \% \quad 8.4 \%$ TGLEDPERYLFVDR $0.04 \% \quad 8.4 \%$ AMVNKDDIQK $0.04 \% \quad 8.4 \%$ QLLQANPILESFGNAK 0.04\% $\quad 8.4 \%$ AQTKEQADFAVEALAK $0.04 \% \quad 8.4 \%$ EQADFAVEALAK $0.04 \% \quad 8.4 \%$ NTNPNFVR $0.04 \% \quad 8.4 \%$ CNGVLEGIR $0.04 \% \quad 8.4 \%$ YEILTPNAIPK
$99.7 \% 31.9$ $99.0 \% \quad 29.0$ $99.7 \% \quad 40.1$ $99.0 \% 37.1$ $98.0 \% \quad 18.9$ $99.7 \% \quad 54.9$ $99.7 \% \quad 37.2$ $99.7 \% \quad 42.7$ $99.7 \% \quad 26.5$ $99.1 \% \quad 20.4$ $97.8 \% \quad 26.5$ $99.7 \% \quad 47.9$ $99.7 \% \quad 46.7$ $99.7 \% \quad 40.5$ $99.7 \% \quad 47.3$ $99.7 \% \quad 27.8$ $96.6 \% \quad 20.0$ $99.7 \% \quad 57.2$ $99.7 \% \quad 27.1$ $97.6 \% \quad 15.5$ $96.5 \% \quad 14.7$

$99.7 \% \quad 40.4$ $99.7 \% \quad 58.1$ $97.0 \% \quad 22.4$ $98.6 \% 27$. $\begin{array}{lll}99.7 \% & 27.1\end{array}$ $99.7 \% \quad 31.0$ $99.7 \% \quad 27.0$ $99.7 \% \quad 32.4$ $99.7 \% \quad 39.7$ $\begin{array}{lll}99.7 \% & 40.8\end{array}$ $99.7 \% \quad 51.8$ $99.0 \% \quad 37.5$ $\begin{array}{lll}99.5 \% & 23.7\end{array}$ $99.7 \% \quad 31.3$ $94.9 \% \quad 14.1$ $99.7 \% \quad 34.0$ $99.7 \% \quad 42.8$ $99.7 \% \quad 26.6$ $99.7 \% \quad 46.5$ $99.7 \% \quad 49.2$ $99.2 \% \quad 25.5$ $99.7 \% \quad 63.0$ $94.7 \% \quad 15.4$ $99.7 \% \quad 32.6$ $99.7 \% \quad 53.4$
1021.57 2203.16

1200.61

2112.04

1174.65

1547.72

1501.75

1792.92

1949.02

1027.55

1105.60

1096.68

1684.93

992.59

1731.84

1410.73

2092.11

1645.85

1486.75

1083.55

1051.56

1316.71

1472.81

1110.61

1257.67

1383.76

853.45

814.48

1669.00

987.55

1115.64

1142.51

1269.64

1709.85

1161.59

1742.94

1719.89

1291.65

961.48

1017.51

1258.70

$\begin{array}{cc}60 & 479 \\ 06 & 213 \\ 53 & 367 \\ 98 & 405 \\ 76 & 585 \\ 30 & 745 \\ 71 & 880 \\ 71 & 891 \\ 81 & 891 \\ 92 & 909 \\ 26 & 935 \\ 8 & 80 \\ 60 & 172 \\ 91 & 205 \\ 91 & 206 \\ 57 & 365 \\ 8 & 107 \\ 55 & 164 \\ 1 & 46 \\ 03 & 111 \\ 68 & 283 \\ 99 & 311 \\ 12 & 331 \\ 32 & 246 \\ 62 & 874 \\ 78 & 885 \\ 97 & 906 \\ 77 & 988 \\ 77 & 989 \\ 28 & 1036 \\ 56 & 1167 \\ 18 & 1231 \\ 32 & 1240 \\ 90 & 1297 \\ 02 & 1317 \\ 08 & 1317 \\ 08 & 1318 \\ 20 & 128 \\ 30 & 241 \\ 5 & 18 \\ 9 & 78 \\ 17 & 232 \\ 11 & 426 \\ 15 & 426 \\ 70 & 677 \\ 01 & 709 \\ 28 & 738 \\ & \end{array}$

Page 76 of Table S-1-2 
Myosin-10 GN=MYH10

Myosin-10 GN=MYH10

Myosin-10 GN=MYH10

Myosin-10 GN=MYH10

Myosin-10 GN=MYH10

Myosin-10 GN=MYH10

Myosin-10 GN=MYH10

Myosin-10 GN=MYH10

Myosin- 9 GN=MYH9

Myosin-9 GN=MYH9

Myosin-9 GN=MYH9

Myosin-9 GN=MYH9

Myosin-9 GN=MYH9

Myosin- 9 GN=MYH9

Myosin-9 GN=MYH9

Myosin-9 GN=MYH9

$\mathrm{N}$-acetyltransferase $10 \mathrm{GN}=\mathrm{NAT} 10$

$\mathrm{N}$-acetyltransferase $10 \mathrm{GN}=\mathrm{NAT} 10$

$\mathrm{N}$-acetyltransferase $10 \mathrm{GN}=\mathrm{NAT} 10$

$\mathrm{N}$-acetyltransferase $10 \mathrm{GN}=\mathrm{NAT} 10$

$\mathrm{N}$-acylneuraminate cytidylyltransferase GN=CMAS NEUA_HUMAN $48.38 \quad 100.0 \%$ $\mathrm{N}$-acylneuraminate cytidylyltransferase GN=CMAS NEUA HUMAN $48.38 \quad 100.0 \%$

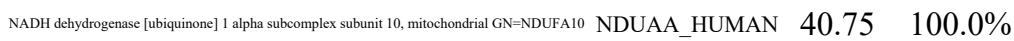

NADH dehydrogenase [ubiquinone] 1 alpha subcomplex subunit 10, mitochondral GN=NDUFA 10 NDUAA_HUMAN $40.75 \quad 100.0 \%$

NDH dechydrogenase [ubiquinone] 1 alpha subcomplex subunit 10, mitochondral GN=NDUFA10 NDUAA_HUMAN $40.75 \quad 100.0 \%$

NADH dehydrogenase [ubiquinone] I alpha subcomplex subunit 10, mitochondral GN=NDUFA10 NDUAA_HUMAN $40.75 \quad 100.0 \%$

NADH dehydrogenase [ubiquinone] 1 alpha subcomplex subunit 10, mitochondrial GN=NDUFA10 NDUAA_HUMAN $40.75 \quad 100.0 \%$

MADH dehydrogenase [ubizininone] 1 I lpha subcomplex subunit 10, mitochondrial GN=NDUFA I0 NDUAA_HUMAN $40.75 \quad 100.0 \%$

NADH dehydrogenase [ubiquinone] I alpha subcomplex subunit , mitochondral GN=NDUFA9 NDUA9_HUMAN $42.51 \quad 100.0 \%$

ADH dehydrogenase [ubiquinone] I lapha subcomplex subunit 9 , mitochondrial GN=NDUFA9 NDUA9_HUMAN $42.51 \quad 100.0 \%$

$\begin{array}{lll}\text { NADH dehydrogenase [ubiquinone] 1 alpha subcomplex subunit } 9 \text {, mitochondral GN=NDUFA9 NDUA9_HUMAN } 42.51 & 100.0 \%\end{array}$

DH dehydrogenase e ubiquinonel 1 lapha subcomplex subunit 9, mitcochondral GN=NDUFA9 NDUA9_HUMAN $42.51 \quad 100.0 \%$

NADH dehydrogenase [ubiquinone] 1 alpha subcomplex subunit 9 , mitochondrial GN=NDUFA9 NDUA9_HUMAN $42.51 \quad 100.0 \%$

NADH dehydrogenase [ubiquinone] iron-sulfur protein 2, mitochondrial GN=NDUFS2 NDUS2_HUMAN $52.55 \quad 100.0 \%$

NADH dehydrogenase [ubiquinone] iron-sulfur protein 2, mitochondrial GN=NDUFS2 NDUS2_HUMAN $52.55 \quad 100.0 \%$ NADH-ubiquinone oxidoreductase 75 kDa subunit, mitochondrial GN=NDUFS1 NDUS1_HUMAN $79.47 \quad 100.0 \%$ NADH-ubiquinone oxidoreductase 75 kDa subunit, mitochondrial GN=NDUFS1 NDUS1_HUMAN $79.47 \quad 100.0 \%$ NADH-ubiquinone oxidoreductase $75 \mathrm{kDa}$ subunit, mitochondrial GN=NDUFS1 NDUS1_HUMAN $79.47 \quad 100.0 \%$ NADH-ubiquinone oxidoreductase 75 kDa subunit, mitochondrial GN=NDUFS1 NDUS1_HUMAN $79.47 \quad 100.0 \%$ DDH-ubiquinone oxidoreductase $75 \mathrm{kDa}$ subunit, mitochondrial GN=NDUFS1 NDUS1_HUMAN $79.47 \quad 100.0 \%$ NADPH:adrenodoxin oxidoreductase, mitochondrial GN=FDXR ADRO_HUMAN $53.84 \quad 100.0 \%$ NADPH:adrenodoxin oxidoreductase, mitochondrial GN=FDXR ADRO_HUMAN $53.84 \quad 100.0 \%$ N-alpha-acetyltransferase $10 \mathrm{GN}=\mathrm{NAA10}$ NAA10_HUMAN $26.46 \quad 100.0 \%$ N-alpha-acetyltransferase 10 GN=NAA10 NAA10_HUMAN $26.46 \quad 100.0 \%$ $\mathrm{N}$-alpha-acetyltransferase $10 \mathrm{GN}=\mathrm{NAA} 10$ NAA10_HUMAN $26.46 \quad 100.0 \%$ N-alpha-acetyltransferase 15 , NatA auxiliary subunit GN=NAA15 NAA15_HUMAN $101.28 \quad 100.0 \%$ $\begin{array}{lllll}16 & 24 & 0.04 \% & 8.4 \% & \text { ALELDPNLYR }\end{array}$

$\begin{array}{lllll}16 & 24 & 0.04 \% & 8.4 \% & \text { ALAYDKLEK }\end{array}$

$16 \quad 24 \quad 0.04 \% \quad 8.4 \%$ ASRDEIFAQSK

$\begin{array}{lllll}16 & 24 & 0.04 \% & 8.4 \% & \text { TTLQVDTLNAELAAER }\end{array}$

$0.04 \% \quad 8.4 \%$ FKATISALEAK

$0.04 \% \quad 8.4 \%$ ATISALEAK

$0.04 \% \quad 8.4 \%$ IGQLEEQLEQEAKER

$0.04 \% \quad 8.4 \%$ GGPISFSSSR

$0.01 \% \quad 5.3 \% \quad$ VIQYLAYVASSHK

$0.01 \% \quad 5.3 \%$ QLLQANPILEAFGNAK

$0.01 \% \quad 5.3 \% \quad$ VSHLLGINVTDFTR

$0.01 \% \quad 5.3 \%$ EQADFAIEALAK

$0.01 \% \quad 5.3 \% \quad$ NTNPNFVR

$0.01 \% \quad 5.3 \%$ CNGVLEGIR

$0.01 \% \quad 5.3 \%$ ANLQIDQINTDLNLER

$0.01 \% \quad 5.3 \%$ IAQLEEQLDNETKER

$0.01 \% \quad 4.5 \%$ QSILNSLSR

$0.01 \% \quad 4.5 \%$ IAVHPDYQGMGYGSR

$0.01 \% \quad 4.5 \%$ LDYLGVSYGLTPR

$0.01 \% \quad 4.5 \%$ AGFVPVYLR

$0.00 \% \quad 7.1 \%$ GVEKPPHLAALILAR

$0.00 \% \quad 7.1 \%$ VGLSGAPADACSTAQK

$0.02 \% \quad 9.9 \% \quad$ SRVITVDGNICTGK

$0.02 \% \quad 9.9 \%$ VITVDGNICTGK

$0.02 \% \quad 9.9 \%$ VITVDGNICTGKGK

$0.02 \% \quad 9.9 \%$ LQSWLYSSR

$0.02 \% \quad 9.9 \% \quad$ KVVEDIEYLK

$0.02 \% \quad 9.9 \%$ VVEDIEYLK

$0.02 \% \quad 15.4 \%$ YVVNHLGR

$0.02 \% \quad 15.4 \%$ MGSQVIIPYR

$0.02 \% \quad 15.4 \%$ TVKQPVYVVDVSK

$0.02 \% \quad 15.4 \%$ QPVYVVDVSK

$0.02 \% \quad 15.4 \%$ GIVNAVKDPDANGK

$0.02 \% \quad 15.4 \%$ WLSAEIEDVKPAK

$0.01 \% \quad 4.1 \%$ LVMELSGEMVR

$0.01 \% \quad 4.1 \%$ IIAQCLNK

$0.02 \% \quad 10.6 \%$ FEAPLFNAR

$0.02 \% \quad 10.6 \%$ ILQDIASGSHPFSQVLK

$0.02 \% \quad 10.6 \%$ NDGAAILAAVSSIAQK

$0.02 \% \quad 10.6 \%$ IASQVAALDLGYKPGVEAIR

$0.02 \% \quad 10.6 \%$ SATYVNTEGRAQQTK

$0.00 \% \quad 5.5 \%$ TATEKPGPAEAAR

$0.00 \% \quad 5.5 \%$ LAVTRLEGVDEATR

$0.01 \% \quad 17.0 \%$ LGLAQKLMDQASR

$0.01 \% \quad 17.0 \%$ YYADGEDAYAMKR

$0.01 \% \quad 17.0 \%$ HVVLGAIENKVESK

$0.04 \% \quad 14.8 \%$ FAEHGETLAMK

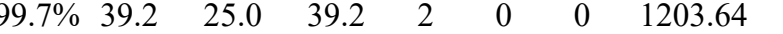

1050.58

1251.63

1744.91

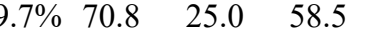

$\begin{array}{llll}97.4 \% & 23.2 & 25.0 & 10.1\end{array}$

$99.6 \% \quad 27.6 \quad 25.0 \quad 18.0$

$99.4 \% \quad 21.0 \quad 25.0 \quad 21.0$

$\begin{array}{llll}99.7 \% & 45.4 & 25.0 & 40.6\end{array}$

$97.9 \% \quad 26.8 \quad 25.0 \quad 26.8$

$99.7 \% \quad 44.5 \quad 25.0 \quad 44.5$

$99.7 \% \quad 25.0 \quad 25.0 \quad 23.2$

$98.5 \% \quad 70.8 \quad 25.0 \quad 0.0$

$\begin{array}{llll}94.7 \% & 15.4 & 25.0 & 13.2\end{array}$

$99.7 \% \quad 32.6 \quad 25.0 \quad 26.5$

$99.7 \% \quad 46.8 \quad 25.0 \quad 45.6$

$\begin{array}{llll}99.6 \% & 24.7 & 25.0 & 24.7\end{array}$

$99.5 \% \quad 25.7-25.0-18.0$

$99.7 \% \quad 30.6 \quad 25.0 \quad 30.6$

$99.7 \% \quad 34.1 \quad 25.0 \quad 27.6$

$99.7 \% \quad 29.2 \quad 25.0 \quad 24.2$

$\begin{array}{llll}98.9 \% & 17.8 & 25.0 & 17.8\end{array}$

$\begin{array}{llll}99.7 \% & 32.7 & 25.0 & 32.7\end{array}$

$\begin{array}{llll}99.7 \% & 25.3 & 25.0 & 25.3\end{array}$

$\begin{array}{llll}99.7 \% & 53.9 & 25.0 & 43.2\end{array}$

$99.7 \% \quad 47.5 \quad 25.0 \quad 43.8$

$\begin{array}{llll}98.8 \% & 27.3 & 25.0 & 19.8\end{array}$

$98.1 \% \quad 27.1 \quad 25.0 \quad 27.1$

$\begin{array}{llll}99.7 \% & 29.6 & 25.0 & 24.1\end{array}$

$99.0 \% \quad 36.5 \quad 25.0 \quad 27.2$

$99.7 \% \quad 36.9 \quad 25.0 \quad 35.9$

$\begin{array}{llll}99.7 \% & 43.4 & 25.0 & 43.4\end{array}$

$\begin{array}{llll}98.8 \% & 22.0 & 25.0 & 18.4\end{array}$

$\begin{array}{llll}99.7 \% & 38.7 & 25.0 & 38.7\end{array}$

$\begin{array}{llll}99.7 \% & 45.6 & 25.0 & 40.0\end{array}$

$99.7 \% \quad 40.3 \quad 25.0 \quad 40.3$

$\begin{array}{llll}99.0 \% & 33.2 & 25.0 & 14.7\end{array}$

$\begin{array}{llll}96.9 \% & 17.8 & 25.0 & 13.3\end{array}$

$99.7 \% \quad 30.4 \quad 25.0 \quad 30.4$

$\begin{array}{llll}99.7 \% & 56.9 & 25.0 & 50.8\end{array}$

$\begin{array}{llll}99.7 \% & 34.9 & 25.0 & 34.9\end{array}$

$\begin{array}{llll}99.7 \% & 45.9 & 25.0 & 45.9\end{array}$

$\begin{array}{llll}97.7 \% & 15.5 & 25.0 & 15.5\end{array}$

$\begin{array}{lllll}99.2 \% & 18.8 & 25.0 & 18.8\end{array}$

$99.7 \% \quad 32.4 \quad 25.0 \quad 30.1$

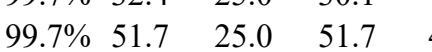

$\begin{array}{llll}99.7 \% & 26.8 & 25.0 & 26.8\end{array}$

$\begin{array}{llll}99.7 \% & 48.9 & 25.0 & 44.2\end{array}$
903.51

1799.91

994.50

1478.80

1726.95

1571.85

1305.67

961.48

1017.51

1869.97

1815.91

1017.57

1666.76

1453.77

1021.58

1584.96

1532.74

1519.79

1276.66

1461.77

1139.58

1235.69

1107.59

957.53

1163.62

1461.83

1133.62

1397.74

1485.79

1279.64

959.53

1064.55

1840.00

1528.83

2071.15

1653.82

1298.67

1529.83

1430.78

1568.67

1522.86

1233.59

Page 77 of Table S-1-2 
-alpha-acetyltransferase 15 , NatA auxiliary subunit GN=NAA15 NAA15 HUMAN $101.28 \quad 100.0 \%$ N-alpha-acetyltransferase 15 , NatA auxiliary subunit GN=NAA15 NAA15_HUMAN $101.28 \quad 100.0 \%$ N-alpha-acetyltransferase 15 , NatA auxiliary subunit GN=NAA15 NAA15_HUMAN $101.28 \quad 100.0 \%$ $\mathrm{N}$-alpha-acetyltransferase 15, NatA auxiliary subunit GN=NAA15 NAA15_HUMAN $101.28 \quad 100.0 \%$ N-alpha-acetyltransferase 15 , NatA auxiliary subunit GN=NAA15 NAA15_HUMAN $101.28 \quad 100.0 \%$ N-alpha-acetyltransferase 15 , NatA auxiliary subunit GN=NAA15 NAA15_HUMAN $101.28100 .0 \%$ N-alpha-acetyltransferase 15 , NatA auxiliary subunit GN=NAA15 NAA15 HUMAN $101.28 \quad 100.0 \%$ N-alpha-acetyltransferase 15 , NatA auxiliary subunit GN=NAA15 NAA15_HUMAN $101.28 \quad 100.0 \%$ $\mathrm{N}$-alpha-acetyltransferase 15 , NatA auxiliary subunit GN=NAA15 NAA15 HUMAN $101.28100 .0 \%$ $\mathrm{N}$-alpha-acetyltransferase 15 , NatA auxiliary subunit GN=NAA15 NAA15_HUMAN $101.28 \quad 100.0 \%$ N-alpha-acetyltransferase 15, NatA auxiliary subunit GN=NAA15 NAA15_HUMAN $101.28 \quad 100.0 \%$ Neuroblastoma-amplified sequence GN=NBAS NBAS_HUMAN $268.58 \quad 100.0 \%$ Neuroblastoma-amplified sequence GN=NBAS NBAS_HUMAN $268.58 \quad 100.0 \%$ Neurofilament light polypeptide GN=NEFL NFL HUMAN $61.52 \quad 100.0 \%$ Neurofilament light polypeptide GN=NEFL NFL_HUMAN $61.52 \quad 100.0 \%$ Neurofilament medium polypeptide GN=NEFM NFM_HUMAN $102.47 \quad 100.0 \%$ Neurofilament medium polypeptide GN=NEFM NFM HUMAN $102.47 \quad 100.0 \%$ Neurofilament medium polypeptide GN=NEFM NFM_HUMAN $102.47 \quad 100.0 \%$ Neurofilament medium polypeptide GN=NEFM NFM_HUMAN $102.47 \quad 100.0 \%$ Neutral alpha-glucosidase AB GN=GANAB GANAB_HUMAN $106.88 \quad 100.0 \%$ Neutral alpha-glucosidase AB GN=GANAB GANAB_HUMAN $106.88 \quad 100.0 \%$ Neutral alpha-glucosidase AB GN=GANAB GANAB_HUMAN $106.88 \quad 100.0 \%$ Neutral alpha-glucosidase AB GN=GANAB GANAB_HUMAN $106.88 \quad 100.0 \%$ NF-kappa-B-repressing factor GN=NKRF NKRF_HUMAN $77.67 \quad 100.0 \%$ NF-kappa-B-repressing factor GN=NKRF NKRF HUMAN $77.67 \quad 100.0 \%$ NF-kappa-B-repressing factor GN=NKRF NKRF_HUMAN $77.67 \quad 100.0 \%$ NF-kappa-B-repressing factor GN=NKRF NKRF_HUMAN $77.67 \quad 100.0 \%$ NF-kappa-B-repressing factor GN=NKRF NKRF_HUMAN $77.67 \quad 100.0 \%$ Nicalin GN=NCLN

Nicalin GN=NCLN

Nicalin GN=NCLN

Nicalin GN=NCLN

Nicalin $\mathrm{GN}=\mathrm{NCLN}$ NCLN_HUMAN $62.97 \quad 100.0 \%$ NCLN_HUMAN $62.97 \quad 100.0 \%$ NCLN_HUMAN $62.97 \quad 100.0 \%$ NCLN_HUMAN $62.97 \quad 100.0 \%$ NCLN HUMAN $62.97 \quad 100.0 \%$ Non-POU domain-containing octamer-binding protein GN=NONO NONO_HUMAN $54.23 \quad 100.0 \%$ Non-POU domain-containing octamer-binding protein GN=NONO NONO_HUMAN $54.23 \quad 100.0 \%$ Non-POU domain-containing octamer-binding protein GN=NONO NONO_HUMAN $54.23 \quad 100.0 \%$ Non-POU domain-containing octamer-binding protein GN=NONO NONO_HUMAN $54.23 \quad 100.0 \%$ Non-POU domain-containing octamer-binding protein GN=NONO NONO HUMAN $54.23 \quad 100.0 \%$ Nuclear cap-binding protein subunit $1 \mathrm{GN}=\mathrm{NCBP} 1$ NCBP1_HUMAN $91.84 \quad 100.0 \%$ Nuclear cap-binding protein subunit $1 \mathrm{GN}=\mathrm{NCBP} 1 \mathrm{NCBP} 1$ _HUMAN $91.84 \quad 100.0 \%$ Nuclear cap-binding protein subunit $1 \mathrm{GN}=\mathrm{NCBP} 1 \mathrm{NCBP} 1$ HUMAN $91.84 \quad 100.0 \%$ Nuclear cap-binding protein subunit $1 \mathrm{GN}=\mathrm{NCBP} 1 \mathrm{NCBP} 1 \_$HUMAN $91.84 \quad 100.0 \%$ Nuclear cap-binding protein subunit $1 \mathrm{GN}=\mathrm{NCBP} 1 \mathrm{NCBP} 1$ HUMAN $91.84 \quad 100.0 \%$ Nuclear mitotic apparatus protein $1 \mathrm{GN}=\mathrm{NUMA} 1$ NUMA1_HUMAN $238.26 \quad 100.0 \%$ Nuclear mitotic apparatus protein 1 GN=NUMA1 NUMA1_HUMAN $238.26 \quad 100.0 \%$ Nuclear mitotic apparatus protein 1 GN=NUMA1 NUMA1_HUMAN $238.26100 .0 \%$ Nuclear mitotic apparatus protein 1 GN=NUMA1 NUMA1_HUMAN $238.26 \quad 100.0 \%$

15

15

15

15

15

.

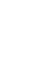

3
3

3
3

5
5
5
5

5
5

5
5

5
5
5

5
22
22

22

$24 \quad 0.04 \% \quad 14.8 \%$ YQLLQLRPAQR $0.04 \% \quad 14.8 \%$ LEDAADVYR

$0.04 \% \quad 14.8 \%$ ALKPANMLER

$0.04 \% \quad 14.8 \%$ RLPLNFLSGEK

$0.04 \% \quad 14.8 \%$ GCPPVFNTLR

$0.04 \% \quad 14.8 \%$ LFNTAVCESK

$0.04 \% \quad 14.8 \%$ LFNTAVCESKDLSDTVR

$0.04 \% \quad 14.8 \%$ NFNETFLKR

$0.04 \% \quad 14.8 \%$ NSDSLPHRLSAAK

$0.04 \% \quad 14.8 \%$ MVYYLDPSSQKR

$0.04 \% \quad 14.8 \%$ AIELATTLDESLTNR

$0.00 \% \quad 1.0 \%$ SAKDDFTSIIGK

$0.00 \% \quad 1.0 \%$ SLTYLRPLQGQK

$0.00 \% \quad 6.1 \%$ SAYSSYSAPVSSSLSVR

$0.00 \% \quad 6.1 \%$ SAYGGLQTSSYLMSTR

$0.01 \% \quad 5.1 \%$ VSGSPSSGFR

$0.01 \% \quad 5.1 \%$ GSPSTVSSSYKR

$0.01 \% \quad 5.1 \% \quad$ LTEAAEQNKEAIR

$0.01 \% \quad 5.1 \%$ HLREYQDLLNVK

$0.01 \% \quad 5.5 \% \quad$ SIRPGLSPYR

$0.01 \% \quad 5.5 \%$ YRVPDVLVADPPIAR

$0.01 \% \quad 5.5 \%$ GLLEFEHQRAPR

$0.01 \% \quad 5.5 \%$ LSFQHDPETSVLVLR

$0.01 \% \quad 9.4 \%$ HLSTCDGQNPPKK

$0.01 \% \quad 9.4 \%$ DASGQPIFNASAK

$0.01 \% \quad 9.4 \%$ HAAADEALKILQK

$10 \quad 0.01 \% \quad 9.4 \%$ GAVEDVISRNEIQGR

$0.01 \% \quad 9.4 \%$ SESHTDLTFSR

$0.01 \% \quad 10.1 \%$ NAVLNTEAR

$0.01 \% \quad 10.1 \%$ TMAAEVLSR

$0.01 \% \quad 10.1 \%$ LLDFSYEQYQK

$0.01 \% \quad 10.1 \%$ AMAAVPQDVVR

\begin{tabular}{llll}
$0.01 \%$ & $10.1 \%$ & $99.7 \%$ & 60.7 \\
\hline
\end{tabular}

$0.04 \% \quad 10.6 \%$ FACHSASLTVR

$0.04 \% \quad 10.6 \%$ AVVIVDDRGRPSGK

$0.04 \% \quad 10.6 \%$ GIVEFSGKPAAR

$0.04 \% \quad 10.6 \%$ GIVEFSGKPAARK

$0.04 \% \quad 10.6 \%$ AAPGAEFAPNKR

$0.01 \% \quad 7.3 \% \quad$ FVIEENLHCIIK

$0.01 \% \quad 7.3 \%$ KTCAAQLVSYPGK

$0.01 \% \quad 7.3 \%$ TCAAQLVSYPGK

$0.01 \% \quad 7.3 \%$ ILDIVPPTFSALCPANPTCIYK

$0.01 \% \quad 7.3 \%$ ATNDEIFSILK

$0.07 \% \quad 12.4 \%$ VEMLETERGQQEAK

$0.07 \% \quad 12.4 \%$ HQVEQLSSSLK

$0.07 \% \quad 12.4 \%$ DSAQTSVTQAQR

$\begin{array}{lllll}24 & 49 & 0.07 \% & 12.4 \% & \text { DSAQTSVTQAQR } \\ 24 & 49 & 0.07 \% & 12.4 \% & \text { AADALEEQQR }\end{array}$ $\begin{array}{ll}98.9 \% & 17.9 \\ 99.7 \% & 51.9\end{array}$

$99.6 \% \quad 28.3$

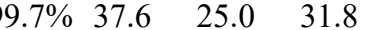

$98.7 \% \quad 23.9 \quad 25.0 \quad 13.4$

$\begin{array}{llll}98.3 \% & 26.4 & 25.0 & 12.5\end{array}$

$\begin{array}{llll}97.9 \% & 22.0 & 25.0 & 11.7\end{array}$

$\begin{array}{llll}99.7 \% & 43.3 & 25.0 & 35.1\end{array}$

$\begin{array}{llll}99.7 \% & 29.2 & 25.0 & 23.1\end{array}$

$99.7 \% \quad 39.1 \quad 25.0 \quad 31.4$

$99.7 \% \quad 66.4 \quad 25.0 \quad 60.4$

$\begin{array}{llll}98.1 \% & 20.5 & 25.0 & 14.0\end{array}$

$\begin{array}{llll}95.6 \% & 19.8 & 25.0 & 19.8\end{array}$

$97.0 \% \quad 14.9 \quad 25.0 \quad 14.9$

$99.7 \% \quad 45.2 \quad 25.0 \quad 45.2$

$\begin{array}{llll}99.7 \% & 33.9 & 25.0 & 25.7\end{array}$

$\begin{array}{llll}99.7 \% & 31.8 & 25.0 & 31.8\end{array}$

$\begin{array}{llll}98.8 \% & 21.4 & 25.0 & 21.2\end{array}$

$\begin{array}{llll}99.7 \% & 24.9 & 25.0 & 24.9\end{array}$

$\begin{array}{llll}99.7 \% & 25.5 & 25.0 & 21.1\end{array}$

$\begin{array}{llll}99.6 \% & 24.2 & 25.0 & 24.2\end{array}$

$\begin{array}{llll}94.7 \% & 19.0 & 25.0 & 11.8\end{array}$

$\begin{array}{llll}96.4 \% & 15.5 & 25.0 & 15.5\end{array}$

$\begin{array}{llll}98.7 \% & 25.6 & 25.0 & 21.8\end{array}$

$\begin{array}{llll}99.7 \% & 33.7 & 25.0 & 33.3\end{array}$

$\begin{array}{llll}99.7 \% & 31.3 & 25.0 & 31.3\end{array}$

$\begin{array}{llll}99.7 \% & 44.0 & 25.0 & 41.2\end{array}$

$\begin{array}{llll}99.5 \% & 21.5 & 25.0 & 20.3\end{array}$

$\begin{array}{llll}97.6 \% & 17.9 & 25.0 & 16.8\end{array}$

$\begin{array}{llll}98.6 \% & 22.8 & 25.0 & 15.6\end{array}$

$\begin{array}{llll}99.7 \% & 60.7 & 25.0 & 60.7\end{array}$

$\begin{array}{llll}95.8 \% & 14.5 & 25.0 & 14.3\end{array}$

$\begin{array}{llll}99.7 \% & 52.2 & 25.0 & 51.0\end{array}$

$\begin{array}{llll}99.6 \% & 28.9 & 25.0 & 23.7 \\ 99.7 \% & 25.8 & 25.0 & 25.8\end{array}$

$\begin{array}{llll}99.7 \% & 58.1 & 25.0 & 54.9\end{array}$

$\begin{array}{llll}99.6 \% & 24.8 & 25.0 & 22.4\end{array}$

$99.7 \% \quad 52.4 \quad 25.0 \quad 52.4$

$\begin{array}{llll}99.7 \% & 34.9 & 25.0 & 33.5\end{array}$

$99.7 \% \quad 55.4 \quad 25.0 \quad 55.4$

$99.7 \% \quad 47.6 \quad 25.0 \quad 46.2$

$\begin{array}{llll}99.7 \% & 35.2 & 25.0 & 35.2\end{array}$

$\begin{array}{llll}99.7 \% & 32.8 & 25.0 & 29.8\end{array}$

$\begin{array}{llll}99.7 \% & 29.0 & 25.0 & 29.0\end{array}$

$\begin{array}{lllll}99.7 \% & 37.8 & 25.0 & 37.4 & 2\end{array}$

$\begin{array}{lllll}99.7 \% & 60.8 & 25.0 & 54.6 & 2\end{array}$

$\begin{array}{llll}99.7 \% & 55.6 & 25.0 & 45.1\end{array}$

Page 78 of Table $S-1-2$ 
Nuclear mitotic apparatus protein 1 GN=NUMA1 NUMA1_HUMAN $238.26 \quad 100.0 \% \quad 22$ Nuclear mitotic apparatus protein 1 GN=NUMA1 NUMA1_HUMAN $238.26 \quad 100.0 \% \quad 22$ Nuclear mitotic apparatus protein 1 GN=NUMA1 NUMA1_HUMAN $238.26 \quad 100.0 \% \quad 22$ Nuclear mitotic apparatus protein $1 \mathrm{GN}=$ NUMA1 NUMA1_HUMAN $238.26 \quad 100.0 \%$ Nuclear mitotic apparatus protein 1 GN=NUMA1 NUMA1_HUMAN $238.26 \quad 100.0 \% \quad 22$ Nuclear mitotic apparatus protein 1 GN=NUMA1 NUMA1_HUMAN $238.26 \quad 100.0 \% \quad 22$ Nuclear mitotic apparatus protein 1 GN=NUMA1 NUMA1_HUMAN $238.26 \quad 100.0 \% \quad 22$ Nuclear mitotic apparatus protein 1 GN=NUMA1 NUMA1_HUMAN $238.26 \quad 100.0 \% \quad 22$ Nuclear mitotic apparatus protein 1 GN=NUMA1 NUMA1_HUMAN $238.26 \quad 100.0 \% \quad 22$ Nuclear mitotic apparatus protein $1 \mathrm{GN}=\mathrm{NUMA} 1$ NUMA1_HUMAN $238.26 \quad 100.0 \% \quad 22$ Nuclear mitotic apparatus protein 1 GN=NUMA1 NUMA1_HUMAN $238.26 \quad 100.0 \% \quad 22$ Nuclear mitotic apparatus protein 1 GN=NUMA1 NUMA1_HUMAN $238.26 \quad 100.0 \% \quad 22$ Nuclear mitotic apparatus protein 1 GN=NUMA1 NUMA1_HUMAN $238.26 \quad 100.0 \% \quad 22$ Nuclear mitotic apparatus protein 1 GN=NUMA1 NUMA1_HUMAN $238.26 \quad 100.0 \% \quad 22$ Nuclear mitotic apparatus protein 1 GN=NUMA1 NUMA1_HUMAN $238.26 \quad 100.0 \% \quad 22$ Nuclear mitotic apparatus protein 1 GN=NUMA1 NUMA1_HUMAN $238.26 \quad 100.0 \%$ Nuclear mitotic apparatus protein 1 GN=NUMA1 NUMA1_HUMAN $238.26 \quad 100.0 \%$ Nuclear mitotic apparatus protein 1 GN=NUMA1 NUMA1_HUMAN $238.26 \quad 100.0 \%$ Nuclear pore complex protein Nup107 GN=NUP107 NU107_HUMAN $106.38 \quad 100.0 \%$ Nuclear pore complex protein Nup107 GN=NUP107 NU107_HUMAN $106.38 \quad 100.0 \%$ Nuclear pore complex protein Nup107 GN=NUP107 NU107_HUMAN $106.38 \quad 100.0 \%$ Nuclear pore complex protein Nup107 GN=NUP107 NU107 HUMAN $106.38 \quad 100.0 \%$ Nuclear pore complex protein Nup133 GN=NUP133 NU133_HUMAN $128.98 \quad 100.0 \%$ Nuclear pore complex protein Nup133 GN=NUP133 NU133_HUMAN $128.98 \quad 100.0 \%$ Nuclear pore complex protein Nup133 GN=NUP133 NU133_HUMAN $128.98 \quad 100.0 \%$ Nuclear pore complex protein Nup133 GN=NUP133 NU133_HUMAN $128.98 \quad 100.0 \%$ Nuclear pore complex protein Nup205 GN=NUP205 NU205_HUMAN $227.93 \quad 100.0 \%$ Nuclear pore complex protein Nup205 GN=NUP205 NU205_HUMAN $227.93 \quad 100.0 \%$ Nuclear pore complex protein Nup205 GN=NUP205 NU205_HUMAN $227.93 \quad 100.0 \%$ Nuclear pore complex protein Nup205 GN=NUP205 NU205 HUMAN $227.93 \quad 100.0 \%$ Nuclear pore complex protein Nup205 GN=NUP205 NU205_HUMAN $227.93 \quad 100.0 \%$ Nuclear pore complex protein Nup205 GN=NUP205 NU205_HUMAN $227.93 \quad 100.0 \%$ Nuclear pore complex protein Nup205 GN=NUP205 NU205_HUMAN $227.93 \quad 100.0 \%$ Nuclear pore complex protein Nup205 GN=NUP205 NU205_HUMAN $227.93 \quad 100.0 \%$ Nuclear pore complex protein Nup205 GN=NUP205 NU205_HUMAN $227.93 \quad 100.0 \%$ Nuclear pore complex protein Nup205 GN=NUP205 NU205_HUMAN $227.93 \quad 100.0 \%$ Nuclear pore complex protein Nup205 GN=NUP205 NU205_HUMAN $227.93 \quad 100.0 \%$ Nuclear pore complex protein Nup205 GN=NUP205 NU205_HUMAN $227.93 \quad 100.0 \%$ Nuclear pore complex protein Nup205 GN=NUP205 NU205_HUMAN $227.93 \quad 100.0 \%$ Nuclear pore complex protein Nup205 GN=NUP205 NU205_HUMAN $227.93 \quad 100.0 \%$ Nuclear pore complex protein Nup205 GN=NUP205 NU205_HUMAN $227.93 \quad 100.0 \%$ Nuclear pore complex protein Nup205 GN=NUP205 NU205_HUMAN $227.93 \quad 100.0 \%$ Nuclear pore complex protein Nup205 GN=NUP205 NU205_HUMAN $227.93 \quad 100.0 \%$ Nuclear pore complex protein Nup85 GN=NUP85 NUP85_HUMAN $75.02 \quad 100.0 \%$ Nuclear pore complex protein Nup85 GN=NUP85 NUP85_HUMAN $75.02 \quad 100.0 \%$ Nuclear pore complex protein Nup85 GN=NUP85 NUP85_HUMAN $75.02 \quad 100.0 \%$ Nuclear pore complex protein Nup85 GN=NUP85 NUP85_HUMAN $75.02 \quad 100.0 \%$
$49 \quad 0.07 \% \quad 12.4 \%$ CISELKAETR $\begin{array}{lllll}0.07 \% & 12.4 \% & \text { LQQLGEAHQAETEVLRR } & 99.7 \% & 33.3\end{array}$ $0.07 \% \quad 12.4 \%$ VAGIESHSELQISR $0.07 \% \quad 12.4 \%$ ALQQVQEKEVR $0.07 \% \quad 12.4 \%$ LADDLSTLQEK $0.07 \% \quad 12.4 \%$ ELVKEPAR $0.07 \% \quad 12.4 \%$ GRAQADLALEK $0.07 \% \quad 12.4 \%$ AQADLALEK $0.07 \% \quad 12.4 \%$ LLQAETASNSAR $0.07 \% \quad 12.4 \%$ HLCQQLQAEQAAAEKR $0.07 \% \quad 12.4 \%$ ELGELIPLRQK $0.07 \% \quad 12.4 \%$ AHGLLAEENRGLGER $0.07 \% \quad 12.4 \%$ YVQELAAVR $0.07 \% \quad 12.4 \%$ TTQIINITMTK $0.07 \% \quad 12.4 \%$ KLDVEEPDSANSSFYSTR $0.07 \% \quad 12.4 \%$ SAPASQASLR $0.07 \% \quad 12.4 \%$ SQAGVSSGAPPGR $0.07 \% \quad 12.4 \%$ IATTTASAATAAAIGATPR $0.01 \% \quad 5.0 \%$ SGFGEISSPVIR

$0.01 \% \quad 5.0 \%$ SGFGEISSPVIREAEVTR $0.01 \% \quad 5.0 \%$ VLLQASQDENFGNTTPR $0.01 \% \quad 5.0 \%$ EADLDVATITK

$0.01 \% \quad 4.8 \%$ RGPLAGLGPGSTPR $0.01 \% \quad 4.8 \%$ GLPLGSAVSS

$\begin{array}{lll}0.01 \% & 4.8 \% & \text { LGSFPVRGTPMATR }\end{array}$ $0.06 \% \quad 10.3 \%$ RQPEAVHLLDK $0.06 \% \quad 10.3 \%$ ASTEGVAIQGQQGTR $0.06 \% \quad 10.3 \%$ FTDELMEQGLTYK $0.06 \% \quad 10.3 \%$ EVSDLIKECR $0.06 \% \quad 10.3 \%$ DLPSADSVQYR $0.06 \% \quad 10.3 \%$ KADNVVNIAR $0.06 \% \quad 10.3 \%$ YLYHGNTNPELAFESAK $0.06 \% \quad 10.3 \%$ ILCCISCNSNIQIK $0.06 \% \quad 10.3 \%$ LVGDFTHDQSISQK $0.06 \% \quad 10.3 \%$ KPVSTTNLQDPGVLGCPR $0.06 \% \quad 10.3 \%$ SVSGFLHFDTATK $0.06 \% \quad 10.3 \%$ LTAPEDVFSK $0.06 \% \quad 10.3 \%$ ALYTYESK $0.06 \% \quad 10.3 \%$ IQQGALELLR $0.06 \% \quad 10.3 \%$ QCLGLLSR $0.06 \% \quad 10.3 \%$ RLQDSFASETNLDFR $0.06 \% \quad 10.3 \%$ KLLDIEGLYSK $0.02 \% \quad 11.6 \%$ DVDVYSQILR $0.02 \% \quad 11.6 \%$ IDEELTGKSR $0.02 \% \quad 11.6 \%$ EADASPASAGICR $0.02 \% \quad 11.6 \%$ VSLELHIERIPLNTEQK
$99.7 \% \quad 68.2$ $99.7 \% \quad 51.9$ $99.7 \% \quad 54.6$ $\begin{array}{lll}99.0 \% & 23.1\end{array}$ $99.7 \% \quad 37.2$ $99.4 \% \quad 23.5$ $99.7 \% \quad 57.7$

$99.5 \% \quad 21.3$ $\begin{array}{lll}97.8 \% & 21.5\end{array}$ $99.6 \% \quad 24.0$ $99.7 \% \quad 48.9$ $99.7 \% \quad 61.8$ $\begin{array}{lll}99.7 \% & 34.2\end{array}$ $99.7 \% \quad 40.7$ $\begin{array}{ll}99.7 \% & 35.8 \\ 99.7 \% & 33.9\end{array}$ $99.7 \% \quad 35.1$ $\begin{array}{ll}99.7 \% & 59.4 \\ 99.7 \% & 53.4\end{array}$ $99.7 \% \quad 53.4$ $99.3 \% \quad 21.2$ $\begin{array}{lll}99.7 \% & 41.8\end{array}$ $\begin{array}{lll}99.0 \% & 35.5\end{array}$ $99.4 \% \quad 19.8$ $\begin{array}{lll}98.9 \% & 27.1\end{array}$ $99.7 \% \quad 62.8$ $99.7 \% \quad 56.2$ $99.7 \% \quad 32.5$ $99.7 \% \quad 51.5$ $99.7 \% \quad 48.2$ $99.7 \% \quad 39.0$ $99.7 \% \quad 64.0$ $99.7 \% \quad 49.1$ $99.7 \% \quad 24.7$ $99.7 \% \quad 41.4$ $99.5 \% \quad 23.2$ $\begin{array}{lll}97.0 \% & 20.7\end{array}$ $99.7 \% \quad 50.5$ $99.0 \% \quad 39.1$ $99.7 \% \quad 36.4$ $99.7 \% \quad 32.9$ $99.7 \% 54.4$ $98.5 \% \quad 17.3$ $99.7 \% \quad 55.9$ $99.6 \% \quad 22.7$ $\begin{array}{ll}23.0 \\ 29.0 & 29.7\end{array}$ $\begin{array}{ll}25.0 & 63.7\end{array}$

$25.0 \quad 42.2$

$25.0 \quad 44.3$

$25.0 \quad 15.7$

$25.0 \quad 31.0$

$25.0 \quad 17.3$

$25.0 \quad 50.8$

$25.0 \quad 21.3$

$25.0 \quad 12.1$

$25.0 \quad 22.5$

$25.0 \quad 32.0$

$25.0 \quad 51.6$

$25.0 \quad 34.2$

$25.0 \quad 21.4$

$25.0 \quad 40.7$

$25.0 \quad 35.8$

$25.0 \quad 28.2$

$25.0 \quad 35.1$

$25.0 \quad 59.4$

$25.0 \quad 53.4$

$25.0 \quad 19.9$

$25.0 \quad 41.8$

$25.0 \quad 27.2$

$25.0 \quad 19.8$

$25.0 \quad 19.7$

$25.0 \quad 52.8$

$25.0 \quad 56.2$

$25.0 \quad 39.6$

$25.0 \quad 45.3$

$25.0 \quad 39.0$

$25.0 \quad 54.9$

$25.0 \quad 48.5$

$25.0 \quad 24.7$

$\begin{array}{ll}25.0 & 41.4\end{array}$

$25.0 \quad 19.8$

$\begin{array}{ll}25.0 & 12.2\end{array}$

$25.0 \quad 47.1$

\begin{tabular}{ll}
21.9 \\
\hline
\end{tabular}

\begin{tabular}{ll}
36.4 \\
\hline
\end{tabular}

\begin{tabular}{ll}
26.4 \\
\hline
\end{tabular}

\begin{tabular}{ll}
47.5 \\
\hline
\end{tabular}

$25.0 \quad 17.3$

$25.0 \quad 53.5$
1206.61 1978.05

1525.80

1327.73

1232.64

941.54

1171.64

958.52

1260.65

1880.94

1295.77

1621.84

1048.58

1263.70

2044.95

987.52

1170.59

1715.93

1248.66

1934.00

1889.94

1175.62

1335.75

1840.03

1028.50

1489.79

1305.73

1502.76

1590.74

1248.63

1250.60

1099.62

1953.93

1722.83

1574.78

1939.01

1409.71

1106.57

974.48

1140.67

946.51

1798.87

1278.73

1207.63

1147.60

1304.59 2019.12 
Nuclear pore complex protein Nup85 GN=NUP85 NUP85_HUMAN $75.02 \quad 100.0 \%$ Nuclear pore complex protein Nup85 GN=NUP85 NUP85_HUMAN $75.02 \quad 100.0 \%$ Nuclear pore complex protein Nup85 GN=NUP85 NUP85_HUMAN $75.02 \quad 100.0 \%$ Nuclear pore complex protein Nup88 GN=NUP88 NUP88_HUMAN $83.54 \quad 100.0 \%$ Nuclear pore complex protein Nup88 GN=NUP88 NUP88_HUMAN $83.54 \quad 100.0 \%$ Nuclear pore complex protein Nup93 GN=NUP93 NUP93_HUMAN $93.49 \quad 100.0 \%$ Nuclear pore complex protein Nup93 GN=NUP93 NUP93_HUMAN $93.49 \quad 100.0 \%$ Nuclear pore complex protein Nup93 GN=NUP93 NUP93_HUMAN $93.49 \quad 100.0 \%$ Nuclear pore complex protein Nup93 GN=NUP93 NUP93 HUMAN $93.49 \quad 100.0 \%$ Nuclear pore complex protein Nup93 GN=NUP93 NUP93_HUMAN $93.49 \quad 100.0 \%$ Nuclear pore complex protein Nup93 GN=NUP93 NUP93_HUMAN $93.49 \quad 100.0 \%$ Nuclear pore complex protein Nup93 GN=NUP93 NUP93_HUMAN $93.49 \quad 100.0 \%$ Nuclear pore complex protein Nup93 GN=NUP93 NUP93_HUMAN $93.49 \quad 100.0 \%$ Nuclear pore complex protein Nup93 GN=NUP93 NUP93_HUMAN $93.49 \quad 100.0 \%$ Nuclear pore complex protein Nup93 GN=NUP93 NUP93_HUMAN $93.49 \quad 100.0 \%$ Nuclear pore complex protein Nup93 GN=NUP93 NUP93_HUMAN $93.49 \quad 100.0 \%$ Nuclear pore complex protein Nup93 GN=NUP93 NUP93 HUMAN $93.49 \quad 100.0 \%$ Nuclear pore complex protein Nup93 GN=NUP93 NUP93_HUMAN $93.49 \quad 100.0 \%$ Nuclear pore complex protein Nup93 GN=NUP93 NUP93_HUMAN $93.49 \quad 100.0 \%$ Nuclear pore complex protein Nup93 GN=NUP93 NUP93_HUMAN $93.49 \quad 100.0 \%$ Nuclear pore complex protein Nup93 GN=NUP93 NUP93_HUMAN $93.49 \quad 100.0 \%$ Nuclear pore complex protein Nup93 GN=NUP93 NUP93_HUMAN $93.49 \quad 100.0 \%$ Nuclear pore complex protein Nup93 GN=NUP93 NUP93_HUMAN $93.49 \quad 100.0 \%$ Nuclear pore complex protein Nup93 GN=NUP93 NUP93_HUMAN $93.49 \quad 100.0 \%$ Nuclear pore membrane glycoprotein $210 \mathrm{GN}=\mathrm{NUP} 210$ PO210_HUMAN $205.11 \quad 100.0 \%$ Nuclear pore membrane glycoprotein $210 \mathrm{GN}=\mathrm{NUP} 210 \quad$ PO210_HUMAN $205.11 \quad 100.0 \%$ Nuclear RNA export factor $1 \mathrm{GN}=\mathrm{NXF} 1 \quad \mathrm{NXF1}$ _HUMAN $70.19 \quad 100.0 \%$ Nuclear RNA export factor $1 \mathrm{GN}=\mathrm{NXF} 1 \quad \mathrm{NXF1}$ _HUMAN $70.19 \quad 100.0 \%$ Nuclease-sensitive element-binding protein $1 \mathrm{GN}=$ YBX1 YBOX1_HUMAN $35.92 \quad 100.0 \%$ Nuclease-sensitive element-binding protein $1 \mathrm{GN}=$ YBX1 YBOX1_HUMAN $35.92 \quad 100.0 \%$ Nuclease-sensitive element-binding protein $1 \mathrm{GN}=$ YBX1 YBOX1_HUMAN $35.92 \quad 100.0 \%$ Nuclease-sensitive element-binding protein $1 \mathrm{GN}=$ YBX1 YBOX1_HUMAN $35.92 \quad 100.0 \%$ Nuclease-sensitive element-binding protein $1 \mathrm{GN}=\mathrm{YBX} 1$ YBOX1_HUMAN $35.92 \quad 100.0 \%$ Nuclease-sensitive element-binding protein $1 \mathrm{GN}=$ YBX1 YBOX1_HUMAN $35.92 \quad 100.0 \%$ Nuclease-sensitive element-binding protein $1 \mathrm{GN}=\mathrm{YBX} 1$ YBOX1_HUMAN $35.92 \quad 100.0 \%$ Nuclease-sensitive element-binding protein $1 \mathrm{GN}=$ YBX1 YBOX1_HUMAN $35.92 \quad 100.0 \%$ Nuclease-sensitive element-binding protein $1 \mathrm{GN}=$ YBX1 YBOX1_HUMAN $35.92 \quad 100.0 \%$ Nuclease-sensitive element-binding protein $1 \mathrm{GN}=\mathrm{YBX} 1$ YBOX1_HUMAN $35.92 \quad 100.0 \%$ Nuclease-sensitive element-binding protein $1 \mathrm{GN}=$ YBX1 YBOX1_HUMAN $35.92 \quad 100.0 \%$ Nuclease-sensitive element-binding protein $1 \mathrm{GN}=$ YBX1 YBOX1_HUMAN $35.92 \quad 100.0 \%$ Nucleolar complex protein 2 homolog GN=NOC2L NOC2L_HUMAN $84.92 \quad 100.0 \%$ Nucleolar complex protein 2 homolog GN=NOC2L NOC2L_HUMAN $84.92 \quad 100.0 \%$ Nucleolar complex protein 2 homolog GN=NOC2L NOC2L_HUMAN $84.92 \quad 100.0 \%$ Nucleolar complex protein 2 homolog GN=NOC2L NOC2L_HUMAN $84.92 \quad 100.0 \%$ Nucleolar complex protein 2 homolog GN=NOC2L NOC2L_HUMAN $84.92 \quad 100.0 \%$ Nucleolar complex protein 2 homolog GN=NOC2L NOC2L_HUMAN $84.92 \quad 100.0 \%$ Nucleolar complex protein 3 homolog GN=NOC3L NOC3L_HUMAN $92.55 \quad 100.0 \%$
$11 \quad 0.02 \% \quad 11.6 \%$ IPLNTEQK

(1)

19
19
19

$0.07 \% \quad 25.5 \%$ AVYCIIGR

$0.03 \% \quad 8.5 \%$ GILRPLSTR
$0.02 \% \quad 11.6 \%$ FADAASLLLSLMTSR

$0.02 \% \quad 11.6 \%$ AIIREGSLEGS

$\begin{array}{llll}97.6 \% & 23.1 & 25.0 & 11.7\end{array}$ $\begin{array}{lllll}99.7 \% & 48.2 & 25.0 & 48.2 & 2\end{array}$ $99.7 \% \quad 60.0 \quad 25.0 \quad 54.1 \quad 2$

$\begin{array}{lllllll}0.01 \% & 3.6 \% & \text { LRGPSGGGEEPALSQYQR } & 99.7 \% & 37.4 & 25.0 & 29.9\end{array}$ $0.01 \% \quad 3.6 \%$ SVANPAFLK

$0.07 \% \quad 25.5 \%$ NLQEIQQAGER $\begin{array}{llll}99.5 \% & 21.7 & 25.0 & 21.7\end{array}$

$0.07 \% \quad 25.5 \%$ NLQEIQQAGERLR

\begin{tabular}{llll}
$99.7 \%$ & 29.5 & 25.0 & 27.2 \\
\hline
\end{tabular}

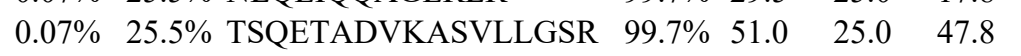

$0.07 \% \quad 25.5 \%$ DNALLSAIEESR

$0.07 \% \quad 25.5 \%$ SSLDNIEMAYAR

$\begin{array}{llll}99.7 \% & 40.0 & 25.0 & 39.2\end{array}$

$\begin{array}{llll}99.7 \% & 61.7 & 25.0 & 59.2\end{array}$

$0.07 \% \quad 25.5 \%$ QMTDVLLTPATDALK

$99.5 \% \quad 24.5$

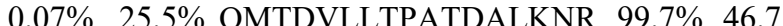

$0.07 \% \quad 25.5 \%$ CGDLLAASQVVNR

$0.07 \% \quad 25.5 \%$ LSPATENKLR

$99.7 \% \quad 65.3$

$99.7 \% \quad 70.2$

$99.0 \% \quad 46.4$

$0.07 \% \quad 25.5 \%$ SSGQSAQLLSHEPGDPPCLR $\quad 99.7 \% \quad 38.0$

$0.07 \% \quad 25.5 \%$ FTSDTKPIINK

$0.07 \% \quad 25.5 \%$ VASVAENKGLFEEAAK

$0.07 \% \quad 25.5 \%$ LKNMALSIAER

$0.07 \% \quad 25.5 \%$ LKLVPLNQESVEER

$0.07 \% \quad 25.5 \%$ LVPLNQESVEER

$0.07 \% \quad 25.5 \%$ LKGTSPSSSSRPQR

$0.07 \% \quad 25.5 \%$ TLITFAGMIPYR

$0.07 \% \quad 25.5 \%$ LVQMEVLMN

$0.01 \% \quad 1.3 \%$ VGQALELPLR

$0.01 \% \quad 1.3 \%$ AVDPTSGQLYGLAR

$0.00 \% \quad 4.0 \% \quad$ YNPYTTRPNR

$0.00 \% \quad 4.0 \% \quad$ AQFFVEDASTASALK

$0.03 \% \quad 47.8 \%$ VIATKVLGTVK

$0.03 \% \quad 47.8 \%$ VLGTVKWFNVR

$0.03 \% \quad 47.8 \%$ NGYGFINR

$0.03 \% \quad 47.8 \%$ NDTKEDVFVHQTAIK

$\begin{array}{lll}98.8 \% & 25.0 \\ 2 & 2.0\end{array}$

$97.7 \% \quad 15.7$

$\begin{array}{lll}99.7 \% & 35.1 \\ & 99.1\end{array}$

$99.3 \% \quad 20.2$

$99.7 \% \quad 40.8$

$97.5 \% \quad 17.9$

$99.7 \% \quad 61.7$

$\begin{array}{llll}99.7 \% & 37.8\end{array}$

$99.7 \% \quad 47.2$

$99.7 \% \quad 40.8$

$99.3 \% \quad 22.5$

$99.7 \% \quad 52.4$

$99.1 \% \quad 44.5$

$99.7 \% \quad 35.8$

$99.0 \% \quad 50.5$

$99.7 \% \quad 28.7$

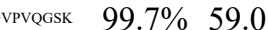

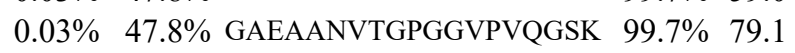

$0.03 \% \quad 47.8 \%$ YAADRNHYR

$98.4 \% \quad 18.7$

$0.03 \% \quad 47.8 \%$ NYQONYONSESGEKNEGSESAPEGQAQQR $\quad 99.7 \% \quad 54.0$

$0.03 \% \quad 47.8 \%$ NEGSESAPEGQAQQR

$99.7 \% 61.6$

$94.6 \% \quad 17.8$

$99.5 \% 20.6$

$\begin{array}{ll}0.03 \% & 47.8 \% \text { RPENPKPQDGKETK }\end{array}$

$99.7 \% 57.0$

$\begin{array}{lll}0.03 \% & 47.8 \% & \text { AADPPAENSSAPEAEQG } \\ 0.03 \% & 8.5 \% & \text { SPDKPGGSPSASR }\end{array}$

$\begin{array}{lll}0.03 \% & 8.5 \% & \text { SPDKPGGSPSASR } \\ 0.03 \% & 8.5 \% & \text { NSVPVTVAMVER }\end{array}$

$0.03 \% \quad 8.5 \%$ LFHEVVQAFR

$0.03 \% \quad 8.5 \%$ LSNVNLQEK

$0.03 \% \quad 8.5 \%$ VQENSAYICSR

$0.02 \% \quad 7.6 \%$ DLSSSEPVHAK $\begin{array}{llll}99.7 \% & 33.1 & 25.0 & 31.2\end{array}$

$99.7 \% \quad 25.2 \quad 25.0 \quad 25.1$

$99.7 \% \quad 38.7 \quad 25.0 \quad 21.0$

$99.7 \% \quad 40.0 \quad 25.0 \quad 40.0$

$\begin{array}{lllll}95.2 \% & 17.0 & 25.0 & 12.1\end{array}$

$99.7 \% \quad 57.7 \quad 25.0 \quad 52.0 \quad 2$
1131.60

1901.95

946.54

1285.65

1554.83

1761.93

1317.66

1369.64

1616.86

1903.00

1402.71

1128.64

951.51

2136.01

1263.69

1662.87

1261.69

1653.92

1412.74

1487.79

1398.75

1092.54

1095.65

1447.75

1281.63

1584.79

1128.74

1318.76

940.46

1744.89

3472.67

1695.87

1165.55

3257.40

1587.70

1129.56

1623.85

1897.80

1242.61

1301.69

1245.67

1044.57

1326.61

1012.63

1169.58 \begin{tabular}{cc}
42 & 449 \\
53 & 567 \\
46 & 656 \\
3 & 100 \\
40 & 548 \\
2 & 42 \\
2 & 44 \\
1 & 67 \\
07 & 118 \\
76 & 187 \\
29 & 243 \\
99 & 245 \\
28 & 340 \\
63 & 372 \\
89 & 396 \\
05 & 524 \\
1 & 611 \\
12 & 627 \\
63 & 673 \\
17 & 730 \\
19 & 730 \\
63 & 776 \\
91 & 802 \\
11 & 819 \\
49 & 558 \\
59 & 1272 \\
2 & 81 \\
59 & 173 \\
4 & 64 \\
9 & 69 \\
0 & 77 \\
8 & 92 \\
02 & 137 \\
19 & 137 \\
38 & 146 \\
57 & 185 \\
71 & 185 \\
92 & 199 \\
91 & 304 \\
55 & 324 \\
9 & 61 \\
45 & 156 \\
69 & 178 \\
08 & 516 \\
77 & 587 \\
85 & 693 \\
13 & 123 \\
& \\
& \\
\hline
\end{tabular}

Page 80 of Table S-1-2 
Nucleolar complex protein 3 homolog GN=NOC3L NOC3L_HUMAN $92.55 \quad 100.0 \%$ Nucleolar complex protein 3 homolog GN=NOC3L NOC3L_HUMAN $92.55 \quad 100.0 \%$ Nucleolar complex protein 3 homolog GN=NOC3L NOC3L_HUMAN $92.55 \quad 100.0 \%$ Nucleolar complex protein 3 homolog GN=NOC3L NOC3L_HUMAN $92.55 \quad 100.0 \%$ Nucleolar complex protein 3 homolog GN=NOC3L NOC3L_HUMAN $92.55 \quad 100.0 \%$ Nucleolar complex protein 4 homolog GN=NOC4L NOC4L_HUMAN $58.47 \quad 100.0 \%$ Nucleolar complex protein 4 homolog GN=NOC4L NOC4L_HUMAN $58.47 \quad 100.0 \%$ Nucleolar complex protein 4 homolog GN=NOC4L NOC4L_HUMAN $58.47 \quad 100.0 \%$ Nucleolar GTP-binding protein $1 \mathrm{GN}=\mathrm{GTPBP} 4$ NOG1_HUMAN $73.97 \quad 100.0 \%$ Nucleolar GTP-binding protein $1 \mathrm{GN}=$ GTPBP4 NOG1_HUMAN $73.97 \quad 100.0 \%$ Nucleolar GTP-binding protein $1 \mathrm{GN}=$ GTPBP4 NOG1_HUMAN $73.97 \quad 100.0 \%$ Nucleolar GTP-binding protein $1 \mathrm{GN}=$ GTPBP4 NOG1_HUMAN $73.97 \quad 100.0 \%$ Nucleolar GTP-binding protein $1 \mathrm{GN}=$ GTPBP4 NOG1_HUMAN $73.97 \quad 100.0 \%$ Nucleolar GTP-binding protein $1 \mathrm{GN}=$ GTPBP4 NOG1_HUMAN $73.97 \quad 100.0 \%$ Nucleolar MIF4G domain-containing protein $1 \mathrm{GN}=\mathrm{NOM} 1$ NOM1_HUMAN $96.26 \quad 100.0 \%$ Nucleolar MIF4G domain-containing protein $1 \mathrm{GN}=\mathrm{NOM} 1 \mathrm{NOM} 1$ _HUMAN $96.26 \quad 100.0 \%$ Nucleolar pre-ribosomal-associated protein 1 GN=URB1 NPA1P_HUMAN $254.39 \quad 100.0 \%$ Nucleolar pre-ribosomal-associated protein 1 GN=URB1 NPA1P_HUMAN $254.39 \quad 100.0 \%$ Nucleolar pre-ribosomal-associated protein 1 GN=URB1 NPA1P_HUMAN $254.39 \quad 100.0 \%$ Nucleolar protein $56 \mathrm{GN}=\mathrm{NOP} 56$ Nucleolar protein $56 \mathrm{GN}=\mathrm{NOP} 56$ Nucleolar protein $56 \mathrm{GN}=\mathrm{NOP} 56$ Nucleolar protein $56 \mathrm{GN}=\mathrm{NOP} 56$ Nucleolar protein $56 \mathrm{GN}=\mathrm{NOP} 56$ Nucleolar protein $56 \mathrm{GN}=\mathrm{NOP} 56$ Nucleolar protein $56 \mathrm{GN}=\mathrm{NOP} 56$ Nucleolar protein $56 \mathrm{GN}=\mathrm{NOP} 56$ Nucleolar protein $56 \mathrm{GN}=\mathrm{NOP} 56$ Nucleolar protein $58 \mathrm{GN}=\mathrm{NOP} 58$ Nucleolar protein $58 \mathrm{GN}=\mathrm{NOP} 58$ Nucleolar protein $58 \mathrm{GN}=\mathrm{NOP} 58$ Nucleolar protein $58 \mathrm{GN}=\mathrm{NOP} 58$ Nucleolar protein $58 \mathrm{GN}=\mathrm{NOP} 58$ Nucleolar protein $58 \mathrm{GN}=\mathrm{NOP} 58$ Nucleolar protein $58 \mathrm{GN}=\mathrm{NOP} 58$ Nucleolar protein $58 \mathrm{GN}=\mathrm{NOP} 58$ Nucleolar protein $58 \mathrm{GN}=\mathrm{NOP} 58$ Nucleolar protein $58 \mathrm{GN}=\mathrm{NOP} 58$ Nucleolar RNA helicase 2 GN=DDX21 Nucleolar RNA helicase 2 GN=DDX2 Nucleolar RNA helicase 2 GN=DDX21 Nucleolar RNA helicase 2 GN=DDX2 1 Nucleolar RNA helicase 2 GN=DDX2 Nucleolar RNA helicase 2 GN=DDX21 Nucleolar RNA helicase 2 GN=DDX21 Nucleolar RNA helicase 2 GN=DDX2 Nucleolar RNA helicase 2 GN=DDX21
NOP56 HUMAN $66.05 \quad 100.0 \%$ NOP56_HUMAN $66.05 \quad 100.0 \%$ NOP56_HUMAN $66.05 \quad 100.0 \%$ NOP56_HUMAN $66.05 \quad 100.0 \%$ NOP56_HUMAN $66.05 \quad 100.0 \%$ NOP56 HUMAN $66.05 \quad 100.0 \%$ NOP56_HUMAN $66.05 \quad 100.0 \%$ NOP56_HUMAN $66.05 \quad 100.0 \%$ NOP56_HUMAN $66.05 \quad 100.0 \%$ NOP58_HUMAN $59.58 \quad 100.0 \%$ NOP58_HUMAN $59.58 \quad 100.0 \%$ NOP58_HUMAN $59.58 \quad 100.0 \%$ NOP58_HUMAN $59.58 \quad 100.0 \%$ NOP58_HUMAN $59.58 \quad 100.0 \%$ NOP58_HUMAN $59.58 \quad 100.0 \%$ NOP58_HUMAN $59.58 \quad 100.0 \%$ NOP58_HUMAN $59.58 \quad 100.0 \%$ NOP58_HUMAN $59.58 \quad 100.0 \%$ NOP58_HUMAN $59.58 \quad 100.0 \%$ DDX21_HUMAN $87.35 \quad 100.0 \%$ DDX21_HUMAN $87.35 \quad 100.0 \%$ DDX21_HUMAN $87.35 \quad 100.0 \%$ DDX21_HUMAN $87.35 \quad 100.0 \% \quad 22$ DDX21_HUMAN $87.35 \quad 100.0 \% \quad 22$ DDX21_HUMAN $87.35 \quad 100.0 \% \quad 22$ DDX21_HUMAN $87.35 \quad 100.0 \% \quad 22$ DDX21_HUMAN $87.35 \quad 100.0 \% \quad 22$ DDX21_HUMAN $87.35 \quad 100.0 \% \quad 22$
$1 \quad 0.02 \% \quad 7.6 \% \quad$ IRPLTEAEK

$11-0.02 \% \quad 7.6 \%$ SNVVSLI

$11 \quad 0.02 \% \quad 7.6 \% \quad$ SPLLPAVLEGLAK

$\begin{array}{llll}96.0 \% & 21.1 & 25.0 & 10.5\end{array}$ $99.4 \% \quad 21.7 \quad 25.0 \quad 21.7$

$0.02 \% \quad 7.6 \%$ YSSEVATESPLDFTK

$99.4 \% \quad 20.5$

$99.7 \% \quad 33.0$

$0.02 \% \quad 7.6 \%$ YSSEVATESPLDFTKYLK

$0.01 \% \quad 5.6 \%$ RLEAVLASR

$0.01 \% \quad 5.6 \%$ ELALSALLK

$0.01 \% \quad 5.6 \%$ REPTVSSFYVK

$0.02 \% \quad 11.2 \%$ ITVVPSAKDFIDLTLSK

$0.02 \% \quad 11.2 \%$ NLVDNVAKDYVR

$0.02 \% \quad 11.2 \%$ TLLLCGYPNVGK

$0.02 \% \quad 11.2 \%$ ADVDVQPYAFTTK

$0.02 \% \quad 11.2 \%$ TVLEKEMR

$0.02 \% \quad 11.2 \%$ DVSGLRDVK

$0.01 \% \quad 3.3 \%$ SGAEEASGHRQDTEER

$0.01 \% \quad 3.3 \%$ TRPSAAATAAAR

$0.01 \% \quad 1.4 \%$ TLYTLVTKR

$0.01 \% \quad 1.4 \% \quad$ IYEAQPEISR

$0.01 \% \quad 1.4 \%$ LCQPSSQEPAKR

$0.03 \% \quad 18.7 \%$ VLLGVGDPK

$0.03 \% \quad 18.7 \%$ AQLGLGHSYSR

$0.03 \% \quad 18.7 \%$ IINDNATYCR

$0.03 \% \quad 18.7 \%$ AKAILDASR

$96.1 \% \quad 14.6$

$99.7 \% \quad 47.4$

$99.7 \% \quad 47.9$

$99.7 \% \quad 31.9$

$99.7 \% \quad 37.7$

$99.7 \% \quad 51.3$

$\begin{array}{lll}99.7 \% & 59.7\end{array}$

$99.7 \% \quad 38.9$

$97.0 \% \quad 19.4$

$99.7 \% \quad 34.9$

$99.7 \% \quad 44.8$

$99.5 \% \quad 21.8$

$\begin{array}{lll}98.8 \% & 21.2\end{array}$

$99.7 \% \quad 38.0$

$\begin{array}{lll}99.6 \% & 26.3\end{array}$

$99.7 \% \quad 45.3$

$99.7 \% \quad 49.6$

$99.7 \% \quad 51.2$

$99.1 \% \quad 21.4$

$0.03 \% \quad 18.7 \%$ MSQVAPSLSALIGEAVGAR $\quad 99.7 \% \quad 68.9$

$0.03 \% \quad 18.7 \%$ LIAHAGSLTNLAK

$0.03 \% \quad 18.7 \%$ YPASTVQILGAEK

$0.03 \% \quad 18.7 \%$ YGLIFHSTFIGR

$0.03 \% \quad 18.7 \%$ EAMVQAEEAAAEITR

$0.04 \% \quad 24.0 \%$ LGGVIKEK

$0.04 \% \quad 24.0 \%$ SQMDGLIPGVEPR

$0.04 \% \quad 24.0 \%$ EMAAMCLGLAHSLSR

$0.04 \% \quad 24.0 \%$ IISDNLTYCK

$0.04 \% \quad 24.0 \%$ LSELLPEEVEAEVK

$0.04 \% \quad 24.0 \%$ TQLYEYLQNR

$0.04 \% \quad 24.0 \%$ LIAHAGSLLNLAK

$0.04 \% \quad 24.0 \%$ HAASTVQILGAEK

$0.04 \% \quad 24.0 \%$ YGLIYHASLVGQTSPK

$0.04 \% \quad 24.0 \%$ TYDPSGDSTLPTCSK

$99.7 \% \quad 61.8$

$99.7 \% \quad 64.3$

$99.7 \% \quad 40.5$

$99.7 \% \quad 81.7$

$96.9 \% \quad 22.3$

$99.7 \% \quad 41.4$

$99.7 \% \quad 60.7$

$\begin{array}{lll}99.7 \% & 37.8\end{array}$

$99.7 \% \quad 40.5$

$99.7 \% \quad 49.8$

$99.7 \% \quad 52.8$

$99.7 \% \quad 66.7$

$99.7 \% \quad 60.0$

$99.7 \% 47$.

$99.7 \% \quad 39.7$

$0.10 \% \quad 30.0 \%$ KAEPSEVDMNSPK

$0.10 \% \quad 30.0 \%$ EGAFSNFPISEETIK

$0.10 \% \quad 30.0 \%$ GRGVTFLFPIQAK

$0.10 \% \quad 30.0 \%$ GVTFLFPIQAK

$0.10 \% \quad 30.0 \%$ TFHHVYSGKDLIAQAR

$0.10 \% \quad 30.0 \%$ TGTGKTFSFAIPLIEK

$0.10 \% \quad 30.0 \%$ GRAPQVLVLAPTR

$0.10 \% \quad 30.0 \%$ APQVLVLAPTR
$99.7 \% \quad 37.9$

$99.7 \% \quad 51.5$

$99.7 \% \quad 26.6$

$98.8 \% \quad 18.5$

$99.7 \% \quad 54.4$

$99.7 \% \quad 59.5$
$99.7 \% 28.7$
1056.60

1108.64

1307.79

1673.79

2078.03

1014.61

957.60

1312.69

1847.05

1405.74

1334.71

1454.72

1005.54

988.54

1758.76

1143.62

1094.66

1205.62

1400.70

897.54

1188.61

1239.58

944.55

1872.98

1308.76

1376.74

1410.75

1618.77

843.53

1414.70

1646.78

1226.61

1584.84

1327.66

1320.80

1324.72

1733.92

1628.71

1447.67

2040.01

1668.81

1433.83

1220.70

1842.96

1709.95

1377.83

1164.71 $\begin{array}{cc}75 & 283 \\ 27 & 336 \\ 12 & 524 \\ 79 & 793 \\ 79 & 796 \\ 7 & 25 \\ 16 & 124 \\ 22 & 232 \\ 9 & 25 \\ 04 & 115 \\ 70 & 181 \\ 91 & 203 \\ 18 & 525 \\ 76 & 584 \\ 14 & 129 \\ 60 & 171 \\ 78 & 186 \\ 00 & 409 \\ 99 & 1910 \\ 1 & 99 \\ 44 & 154 \\ 03 & 212 \\ 41 & 249 \\ 89 & 307 \\ 08 & 320 \\ 21 & 333 \\ 48 & 359 \\ 23 & 437 \\ 4 & 101 \\ 21 & 133 \\ 34 & 148 \\ 97 & 206 \\ 22 & 235 \\ 69 & 278 \\ 98 & 310 \\ 11 & 323 \\ 38 & 353 \\ 27 & 441 \\ 1 & 73 \\ 14 & 131 \\ 85 & 199 \\ 03 & 215 \\ 05 & 215 \\ 16 & 231 \\ 32 & 247 \\ 58 & 270 \\ 60 & 270 \\ & \end{array}$

Page 81 of Table S-1-2 
Nucleolar RNA helicase $2 \mathrm{GN}=\mathrm{DDX} 2$ Nucleolar RNA helicase 2 GN=DDX2 Nucleolar RNA helicase $2 \mathrm{GN}=\mathrm{DDX} 2$ Nucleolar RNA helicase $2 \mathrm{GN}=\mathrm{DDX} 2$ Nucleolar RNA helicase 2 GN=DDX2 Nucleolar RNA helicase $2 \mathrm{GN}=\mathrm{DDX} 2$

Nucleolar RNA helicase 2 GN=DDX2 Nucleolar RNA helicase 2 GN=DDX21 Nucleolar RNA helicase 2 GN=DDX2 Nucleolar RNA helicase 2 GN=DDX21 Nucleolar RNA helicase 2 GN=DDX2 Nucleolar RNA helicase $2 \mathrm{GN}=\mathrm{DDX} 2$ Nucleolar RNA helicase 2 GN=DDX21 Nucleolin $\mathrm{GN}=\mathrm{NCL}$

Nucleolin GN=NCL

Nucleolin $\mathrm{GN}=\mathrm{NCL}$

Nucleolin $\mathrm{GN}=\mathrm{NCL}$

Nucleolin $\mathrm{GN}=\mathrm{NCL}$

Nucleolin $\mathrm{GN}=\mathrm{NCL}$

Nucleolin $\mathrm{GN}=\mathrm{NCL}$

Nucleolin GN=NCL

Nucleolin $\mathrm{GN}=\mathrm{NCL}$

Nucleolin GN=NCL

Nucleolin $\mathrm{GN}=\mathrm{NCL}$

Nucleolin $\mathrm{GN}=\mathrm{NCL}$

Nucleolin GN=NCL

Nucleolin GN=NCL

Nucleolin $\mathrm{GN}=\mathrm{NCL}$

Nucleophosmin GN=NPM1

Nucleophosmin GN=NPM

Nucleophosmin GN=NPM1

Nucleophosmin GN=NPM

Nucleophosmin GN=NPM

Nucleophosmin GN=NPM1

Nucleophosmin GN=NPM]

Nucleophosmin GN=NPM

Nucleophosmin GN=NPM

Nucleophosmin GN=NPM

Nucleophosmin GN=NPM1

Nucleophosmin GN=NPM

Nucleoporin NDC1 GN=NDC1

Nucleoporin NDC1 GN=NDC1

Nucleoporin NDC1 GN=NDC1

Nucleoporin NDC1 GN=NDC1 $\begin{array}{lll} & 0\end{array}$ DDX21 HUMAN $87.35 \quad 100.0 \% \quad 22$ $\begin{array}{llll} & \end{array}$ DDX21 HUMAN $87.35 \quad 100.0 \% \quad 22$ DDX21_HUMAN $87.35 \quad 100.0 \% \quad 22$ DDX21_HUMAN $87.35 \quad 100.0 \% \quad 22$ DDX21_HUMAN $87.35 \quad 100.0 \% \quad 22$ DDX21_HUMAN $87.35 \quad 100.0 \% \quad 22$ DDX21_HUMAN $87.35 \quad 100.0 \% \quad 22$ DDX21_HUMAN $87.35 \quad 100.0 \% \quad 22$ NUCL_HUMAN $76.62 \quad 100.0 \% \quad 15$ NUCL HUMAN $76.62 \quad 100.0 \% \quad 15$ NUCL_HUMAN $76.62 \quad 100.0 \% \quad 15$ NUCL HUMAN $76.62 \quad 100.0 \% \quad 15$ NUCL_HUMAN $76.62 \quad 100.0 \% \quad 15$ NUCL_HUMAN $76.62 \quad 100.0 \% \quad 15$ NUCL HUMAN $76.62 \quad 100.0 \% \quad 15$ NUCL_HUMAN $76.62 \quad 100.0 \% \quad 15$ NUCL_HUMAN $76.62 \quad 100.0 \% \quad 15$ NUCL_HUMAN $76.62 \quad 100.0 \% \quad 15$ NUCL_HUMAN $76.62 \quad 100.0 \% \quad 15$ NUCL_HUMAN $76.62 \quad 100.0 \% \quad 15$ NUCL_HUMAN $76.62 \quad 100.0 \% \quad 15$ NUCL_HUMAN $76.62 \quad 100.0 \% \quad 15$ NUCL HUMAN $76.62 \quad 100.0 \% \quad 15$ NPM_HUMAN $32.58 \quad 100.0 \% \quad 12$ NPM HUMAN $32.58 \quad 100.0 \% \quad 12$ NPM_HUMAN $32.58 \quad 100.0 \% \quad 12$ NPM_HUMAN $32.58 \quad 100.0 \% \quad 12$ NPM HUMAN $32.58 \quad 100.0 \% \quad 12$ NPM_HUMAN $32.58 \quad 100.0 \% \quad 12$ NPM HUMAN $32.58 \quad 100.0 \% \quad 12$ NPM HUMAN $32.58 \quad 100.0 \% \quad 12$ NPM_HUMAN $32.58 \quad 100.0 \% \quad 12$ NPM HUMAN $32.58 \quad 100.0 \% \quad 12$ NPM_HUMAN $32.58 \quad 100.0 \% \quad 12$ NPM_HUMAN $32.58 \quad 100.0 \% \quad 12$ NDC1_HUMAN $76.31 \quad 100.0 \%$ NDC1_HUMAN $76.31 \quad 100.0 \% \quad 4$ NDC1_HUMAN $76.31 \quad 100.0 \% \quad 4$ NDC1_HUMAN $76.31 \quad 100.0 \% \quad 4$ $\begin{array}{lll}\text { U188_HUMAN } & 196.05 & 100.0 \%\end{array}$ 66
$0.10 \% \quad 30.0 \%$ STYEQVDLIGKK

$0.10 \% \quad 30.0 \%$ TAITVEHLAIK

$0.10 \% \quad 30.0 \%$ AAVIGDVIR

$0.10 \% \quad 30.0 \%$ NGSFGVLVATNVAAR

$0.10 \% \quad 30.0 \%$ DVESYIHR

$0.10 \% \quad 30.0 \%$ IGVPSATEIIK

$0.10 \% \quad 30.0 \%$ WQLSVATEQPELEGPR

$0.10 \% \quad 30.0 \%$ EGYGGFRGQR

$0.10 \% \quad 30.0 \%$ SFSKAFGQ

$0.11 \% \quad 19.4 \%$ KVAVATPAK

$0.11 \% \quad 19.4 \%$ VAVATPAKK

$0.11 \% \quad 19.4 \%$ TVTPAKAVTTPGK

0.11\% 19.4\% GATPGKALVATPGK

$0.11 \% \quad 19.4 \%$ ALVATPGKK

$0.11 \% \quad 19.4 \%$ SAPELKTGISDVFAK

$0.11 \%$ 19.4\% TGISDVFAK

$0.11 \% \quad 19.4 \%$ NDLAVVDVR

$0.11 \% \quad 19.4 \%$ VFGNEIKLEKPK

$0.11 \% \quad 19.4 \%$ SISLYYTGEK

0.11\% 19.4\% AIRLELQGPR

$0.11 \% \quad 19.4 \%$ SQPSKTLFVK

$0.11 \% \quad 19.4 \%$ GLSEDTTEETLKESFDGSVR

$0.11 \% \quad 19.4 \%$ GFGFVDFNSEEDAK

$0.09 \% \quad 37.4 \%$ VDNDENEHQLSLR

0.09\% $37.4 \%$ MSVQPTVSL

$0.09 \% \quad 37.4 \%$ SAPGGGSKVPQK

$0.09 \% \quad 37.4 \%$ TPKGPSSVEDIK

$0.09 \% \quad 37.4 \%$ GPSSVEDIK

$0.09 \% \quad 37.4 \%$ GPSSVEDIKAK

$0.09 \% \quad 37.4 \%$ MQASIEKGGSLPK

0.09\% $37.4 \%$ GGSLPKVEAK

$0.09 \% \quad 37.4 \%$ FINYVKNCFR

$0.09 \% \quad 37.4 \%$ MTDQEAIQDLWQWRK

$0.02 \% \quad 7.1 \%$ LILYQEAAATNGR

$0.02 \% \quad 7.1 \%$ VSSSYPVEPK

$0.02 \% \quad 7.1 \% \quad$ KLNSPEETAFQTPK

$0.02 \% \quad 7.1 \%$ ISGSLVDTSYK

$0.00 \% \quad 1.9 \%$ VQRPPSAASAAPSSSK

$0.00 \% \quad 1.9 \%$ GAPSSPATGVLPSPQGK

$0.01 \% \quad 5.2 \%$ AICQFFLQGR
2008.92

1211.67

1252.64

1380.74

1195.70

913.55

1475.80

1018.50

1127.67

1839.92

1126.54

871.43

884.56

884.56

1270.74

1267.74

884.56

1562.84

937.50

1919.02

1000.54

1401.81

1160.58

1152.68

1134.65

2200.03

1561.68

1568.73

2227.22

873.55

1112.61

1257.67

931.47

1130.61

1345.71

985.57

1210.68

1360.68

1963.93

1419.76

1092.56

1589.82

1169.60

1540.81

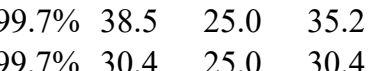

$\begin{array}{llll}99.7 \% & 30.4 & 25.0 & 30.4\end{array}$

$\begin{array}{llll}99.7 \% & 37.8 & 25.0 & 33.0 \\ 99.7 \% & 41.0 & 25.0 & 25.4\end{array}$ $\begin{array}{cc}86 & 304 \\ 87 & 304 \\ 07 & 318 \\ 92 & 402 \\ 92 & 403 \\ 07 & 417 \\ 24 & 432 \\ 85 & 499 \\ 17 & 524 \\ 63 & 573 \\ 03 & 718 \\ 19 & 728 \\ 76 & 783 \\ 1 & 79 \\ 2 & 80 \\ 7 & 109 \\ 11 & 124 \\ 17 & 125 \\ 19 & 333 \\ 25 & 333 \\ 25 & 342 \\ 34 & 342 \\ 71 & 382 \\ 58 & 467 \\ 52 & 561 \\ 68 & 577 \\ 78 & 597 \\ 11 & 624 \\ 3 & 45 \\ 1 & 101 \\ 35 & 142 \\ 43 & 154 \\ 37 & 248 \\ 40 & 248 \\ 40 & 250 \\ 51 & 263 \\ 58 & 267 \\ 64 & 273 \\ 68 & 277 \\ 78 & 292 \\ 80 & 392 \\ 93 & 402 \\ 03 & 416 \\ 18 & 628 \\ 18 & 1533 \\ 05 & 1721 \\ & 11\end{array}$

Page 82 of Table S-1-2 
Nucleoporin-like protein 2 GN=NUPL2 NUPL2_HUMAN $44.87 \quad 100.0 \%$ Nucleosome assembly protein 1-like 1 GN=NAP1L1 NP1L1_HUMAN $45.38 \quad 100.0 \%$ Nucleosome assembly protein 1-like 1 GN=NAP1L1 NP1L1_HUMAN $45.38 \quad 100.0 \%$ Ornithine aminotransferase, mitochondrial GN=OAT OAT_HUMAN $48.54 \quad 100.0 \%$ Ornithine aminotransferase, mitochondrial GN=OAT OAT_HUMAN $48.54 \quad 100.0 \%$ Ornithine aminotransferase, mitochondrial GN=OAT OAT_HUMAN $48.54 \quad 100.0 \%$ Ornithine aminotransferase, mitochondrial GN=OAT OAT_HUMAN $48.54 \quad 100.0 \%$ Ornithine aminotransferase, mitochondrial GN=OAT OAT_HUMAN $48.54 \quad 100.0 \%$ Ornithine aminotransferase, mitochondrial GN=OAT OAT HUMAN $48.54 \quad 100.0 \%$ Ornithine aminotransferase, mitochondrial GN=OAT OAT_HUMAN $48.54 \quad 100.0 \%$ Ornithine aminotransferase, mitochondrial GN=OAT OAT_HUMAN $48.54 \quad 100.0 \%$ Ornithine aminotransferase, mitochondrial GN=OAT OAT HUMAN $48.54 \quad 100.0 \%$ Ornithine aminotransferase, mitochondrial GN=OAT OAT_HUMAN $48.54 \quad 100.0 \%$ Ornithine aminotransferase, mitochondrial GN=OAT OAT_HUMAN $48.54 \quad 100.0 \%$ Ornithine aminotransferase, mitochondrial GN=OAT OAT_HUMAN $48.54 \quad 100.0 \%$ Oxysterol-binding protein-related protein $8 \mathrm{GN}=$ OSBPL8 OSBL8_HUMAN $101.20 \quad 100.0 \%$ Oxysterol-binding protein-related protein $8 \mathrm{GN}=\mathrm{OSBPL} 8$ OSBL8 HUMAN $101.20 \quad 100.0 \%$ Pachytene checkpoint protein 2 homolog GN=TRIP13 PCH2_HUMAN $48.55 \quad 100.0 \%$ Pachytene checkpoint protein 2 homolog GN=TRIP13 PCH2_HUMAN $48.55 \quad 100.0 \%$ Pachytene checkpoint protein 2 homolog GN=TRIP13 PCH2_HUMAN $48.55 \quad 100.0 \%$ Pachytene checkpoint protein 2 homolog GN=TRIP13 PCH2_HUMAN $48.55 \quad 100.0 \%$ Pachytene checkpoint protein 2 homolog GN=TRIP13 PCH2 HUMAN $48.55 \quad 100.0 \%$ Pachytene checkpoint protein 2 homolog GN=TRIP13 PCH2_HUMAN $48.55 \quad 100.0 \%$ Pachytene checkpoint protein 2 homolog GN=TRIP13 PCH2_HUMAN $48.55 \quad 100.0 \%$ Pantothenate kinase $4 \mathrm{GN}=\mathrm{PANK} 4$ Pantothenate kinase $4 \mathrm{GN}=\mathrm{PANK} 4$ Paraspeckle component $1 \mathrm{GN}=\mathrm{PSPC} 1$ Paraspeckle component $1 \mathrm{GN}=\mathrm{PSPC} 1$ Paraspeckle component $1 \mathrm{GN}=\mathrm{PSPC}$ Paraspeckle component $1 \mathrm{GN}=\mathrm{PSPC} 1$ Paraspeckle component $1 \mathrm{GN}=\mathrm{PSPC} 1$ PANK4 HUMAN $85.99 \quad 100.0 \%$ PANK4_HUMAN $85.99 \quad 100.0 \%$ PSPC1_HUMAN $58.74 \quad 100.0 \%$ PSPC1 HUMAN $58.74 \quad 100.0 \%$ PSPC1_HUMAN $58.74 \quad 100.0 \%$ PSPC1 HUMAN $58.74 \quad 100.0 \%$ PSPC1_HUMAN $58.74 \quad 100.0 \%$ CI domain-containing protein $2 \mathrm{GN}=$ PCID2 PCID2_HUMAN $46.03 \quad 100.0 \%$ PCI domain-containing protein $2 \mathrm{GN}=\mathrm{PCID} 2$ PCID2_HUMAN $46.03 \quad 100.0 \%$ PCI domain-containing protein 2 GN=PCID2 PCID2_HUMAN $46.03 \quad 100.0 \%$ Pentatricopeptide repeat domain-containing protein 3, mitochondrial $\mathrm{GN}=\mathrm{PTCD} 3 \quad \mathrm{PTCD} 3$ HUMAN $78.55 \quad 100.0 \%$ Pentatricopeptide repeat domain-containing protein 3, mitochondrial GN=PTCD3 $\quad$ PTCD3_HUMAN $78.55 \quad 100.0 \%$ $\begin{array}{lll}\text { Pentatricopeptide repeat domain-containing protein 3, mitochondrial GN=PTCD3 } & \text { PTCD3_HUMAN } 78.55 \quad 100.0 \%\end{array}$ G

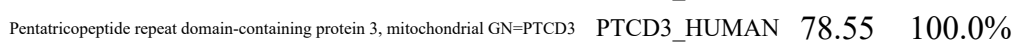
Pentarticopeppide repeat doman-containing protein 3, mitochondrial GN=PTCD3 PTCD3_HUMAN 78.55 $100.0 \%$ Peroxiredoxin-6 GN=PRDX6 Peroxiredoxin- 6 GN=PRDX6 Peroxiredoxin- 6 GN=PRDX6 PTCD3 HUMAN $78.55 \quad 100.0 \%$ PRDX6_HUMAN $25.04 \quad 100.0 \%$ PRDX6 HUMAN $25.04 \quad 100.0 \%$ PRDX6_HUMAN $25.04 \quad 100.0 \%$ Peroxisomal 2,4-dienoyl-CoA reductase GN=DECR2 DECR2_HUMAN $30.78 \quad 100.0 \%$ Peroxisomal 24-dienoyl-CoA reductase GN=DECR2 DECR2 HUMAN $30.78-100.0^{\circ}$ Pescadillo homolog GN=PES1
$0.01 \% \quad 5.2 \% \quad$ YSNVIQPSSFSK

$0.00 \% \quad 5.1 \% \quad$ VNALKNLQVK

$0.00 \% \quad 5.1 \%$ FYEEVHDLER

$0.06 \% \quad 25.1 \%$ KTVQGPPTSDDIFER

$0.06 \% \quad 25.1 \%$ TVQGPPTSDDIFER

$0.06 \% \quad 25.1 \%$ SQVDKLTLTSR

$0.06 \% \quad 25.1 \%$ VLPMNTGVEAGETACK

$0.06 \% \quad 25.1 \%$ IVFAAGNFWGR

$0.06 \% \quad 25.1 \%$ HQVLFIADEIQTGLAR

$0.06 \% \quad 25.1 \%$ LPSDVVTAVR

$0.06 \% \quad 25.1 \%$ GKGLLNAIVIK

$0.06 \% \quad 25.1 \%$ GLLNAIVIK

$0.06 \% \quad 25.1 \%$ GLLNAIVIKETK

$0.06 \% \quad 25.1 \%$ LRDNGLLAKPTHGDIIR

$0.06 \% \quad 25.1 \%$ DNGLLAKPTHGDIIR

$0.00 \% \quad 3.4 \%$ GEAVGSITQPLPSSYLIIR

$0.00 \% \quad 3.4 \%$ VVLPTFILEPR

$0.02 \% \quad 16.2 \%$ NVQSVSIIDTELK

$0.02 \% \quad 16.2 \%$ NVQSVSIIDTELKVK

$0.02 \% \quad 16.2 \%$ VVLLHGPPGTGK

$0.02 \% \quad 16.2 \%$ ALAQKLTIR

$0.02 \% \quad 16.2 \%$ AGTEPSDAIR

$0.02 \% \quad 16.2 \%$ VVNAVLTQIDQIKR

$0.02 \% \quad 16.2 \%$ LSLLLNDISR

$0.00 \% \quad 4.0 \%$ QQPFAYGTLTVR

$0.00 \% \quad 4.0 \% \quad$ AVSAVLESDPYFGFEEAKR

$0.01 \% \quad 12.0 \%$ TLAEIAKAELDGTILK

$0.01 \% \quad 12.0 \%$ FATHGAALTVK

$0.01 \% \quad 12.0 \%$ AVVVVDDRGR

$0.01 \% \quad 12.0 \%$ GFVEFAAKPPAR

$0.01 \% \quad 12.0 \%$ FAQPGTFEFEYASR

$0.01 \% \quad 9.0 \%$ LQMASPEEK

$0.01 \% \quad 9.0 \%$ AIDSSNLKDDYSTAQR

$0.01 \% \quad 9.0 \%$ QNPFPPLSTVC

$0.02 \% \quad 9.7 \%$ VEGTDVTGIEEVVIPK

$0.02 \% \quad 9.7 \%$ SPALQVLR

$0.02 \% \quad 9.7 \%$ SPALQVLREMK

$0.02 \% \quad 9.7 \%$ LFDQPGDPLKR

$0.02 \% \quad 9.7 \% \quad$ FIGPDQHR

$0.02 \% \quad 9.7 \%$ SAYESQPIR

$0.02 \% \quad 9.7 \%$ SELLNELMDSAK

$0.01 \% \quad 18.3 \%$ PGGLLLGDVAPNFEANTTVGR

$0.01 \% \quad 18.3 \%$ DFTPVCTTELGR

$0.01 \% \quad 18.3 \%$ LAPEFAKR

$0.00 \% \quad 6.5 \% \quad$ LGGPQASLSTK

$0.00 \% \quad 6.5 \% \quad$ LGGPQASLSTKVTASPLQR

$0.00 \% \quad 3.7 \%$ LFEGLKFFLNR $\begin{array}{llllllll}99.7 \% & 37.0 & 25.0 & 37.0 & 2 & 0 & 0 & 1356.68\end{array}$

$\begin{array}{llllllll}95.8 \% & 15.1 & 25.0 & 15.1 & 1 & 0 & 0 & 1126.69\end{array}$

$\begin{array}{llllllll}99.7 \% & 39.3 & 25.0 & 36.3 & 2 & 0 & 0 & 1336.62\end{array}$

$\begin{array}{llllllll}98.8 \% & 21.1 & 25.0 & 21.1 & 0 & 1 & 0 & 1689.84\end{array}$

$\begin{array}{llllllll}99.7 \% & 60.5 & 25.0 & 47.9 & 3 & 0 & 0 & 1561.75\end{array}$

$\begin{array}{llllllll}99.7 \% & 55.9 & 25.0 & 48.5 & 4 & 4 & 0 & 1247.70\end{array}$

1676.80

$\begin{array}{llllllll}99.7 \% & 51.6 & 25.0 & 51.6 & 4 & 0 & 0 & 1237.65\end{array}$

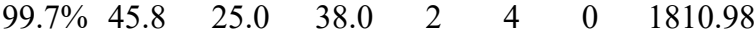

$\begin{array}{llllllll}99.7 \% & 48.3 & 25.0 & 46.2 & 4 & 0 & 0 & 1056.60\end{array}$

$\begin{array}{llllllll}99.7 \% & 28.2 & 25.0 & 28.2 & 2 & 0 & 0 & 1125.74\end{array}$

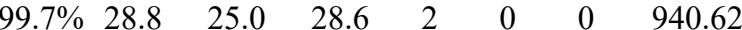

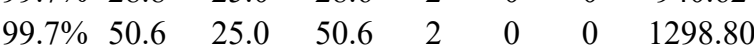

$\begin{array}{llllllll}99.5 \% & 23.4 & 25.0 & 23.4 & 0 & 2 & 0 & 1889.07\end{array}$

$\begin{array}{llllllll}99.7 \% & 48.0 & 25.0 & 48.0 & 0 & 2 & 0 & 1619.89\end{array}$

1619.89
2001.10

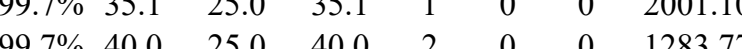

$\begin{array}{llllllll}99.7 \% & 55.8 & 25.0 & 50.7 & 2 & 0 & 0 & 1445.78\end{array}$

$\begin{array}{llllllll}99.7 \% & 33.5 & 25.0 & 33.5 & 2 & 0 & 0 & 1672.95\end{array}$

$\begin{array}{llllllll}99.4 \% & 20.0 & 25.0 & 19.9 & 1 & 0 & 0 & 1174.69\end{array}$

$99.7 \% \quad 28.6 \quad 25.0 \quad 28.6$

$99.7 \% \quad 26.5 \quad 25.0 \quad 25.1$

$\begin{array}{llll}99.7 \% & 49.4 & 25.0 & 49.4\end{array}$

$99.7 \% \quad 50.5 \quad 25.0 \quad 32.6$

$99.5 \% \quad 24.6 \quad 25.0 \quad 18.7$

$98.0 \% 22.3$

$99.7 \% \quad 34.5$

$99.7 \% \quad 37.9$

$99.7 \% \quad 35.2$

$99.7 \% \quad 36.3$

$99.7 \% \quad 31.4$

$99.6 \% \quad 24.9$

$99.7 \% \quad 44.0$

$99.7 \% \quad 27.5$

$99.7 \% \quad 37.9$

$99.0 \% \quad 51.4$

$99.7 \% \quad 36.5$

$\begin{array}{lll}99.7 \% & 29.8\end{array}$

$\begin{array}{lll}99.0 \% & 24.8\end{array}$

$99.7 \% \quad 30.5$

$99.7 \% \quad 59.2$

$\begin{array}{rr}99.7 \% & 89.4 \\ 99.7 \% & 36.5\end{array}$

$98.5 \% 26.5$

$99.7 \% \quad 27.6$

$95.1 \% \quad 13.8$

$99.7 \% \quad 28.1$ \begin{tabular}{c}
65 \\
87 \\
104 \\
46 \\
46 \\
113 \\
151 \\
180 \\
271 \\
372 \\
383 \\
383 \\
386 \\
413 \\
413 \\
246 \\
433 \\
81 \\
83 \\
185 \\
199 \\
275 \\
289 \\
378 \\
504 \\
591 \\
143 \\
161 \\
194 \\
210 \\
278 \\
49 \\
209 \\
399 \\
61 \\
358 \\
361 \\
388 \\
454 \\
565 \\
619 \\
22 \\
53 \\
336 \\
\\
230 \\
\hline
\end{tabular}

Page 83 of Table S-1-2 
Pescadillo homolog GN=PES1 PHD finger protein $6 \mathrm{GN}=\mathrm{PHF} 6$ PHD finger protein $6 \mathrm{GN}=\mathrm{PHF} 6$ PHD finger protein $6 \mathrm{GN}=\mathrm{PHF} 6$ Phenylalanine--tRNA ligase alpha subunit GN=FARSA SYFA_HUMAN $57.56 \quad 100.0 \%$ Phenylalanine--tRNA ligase alpha subunit GN=FARSA SYFA_HUMAN $57.56 \quad 100.0 \%$ Phenylalanine--tRNA ligase beta subunit GN=FARSB SYFB_HUMAN $66.12 \quad 100.0 \%$ $\begin{array}{lll}\text { Phenylalanine--tRNA ligase beta subunit GN=FARSB SYFB_HUMAN } 66.12 & 100.0 \%\end{array}$ Phenylalanine--tRNA ligase beta subunit GN=FARSB SYFB HUMAN $66.12 \quad 100.0 \%$ Phenylalanine--tRNA ligase beta subunit GN=FARSB SYFB_HUMAN $66.12 \quad 100.0 \%$ Phenylalanine--tRNA ligase beta subunit GN=FARSB SYFB_HUMAN $66.12 \quad 100.0 \%$ Phenylalanine--tRNA ligase beta subunit GN=FARSB SYFB_HUMAN $66.12 \quad 100.0 \%$ Phenylalanine--tRNA ligase beta subunit GN=FARSB SYFB_HUMAN $66.12 \quad 100.0 \%$ Phosphate carrier protein, mitochondrial GN=SLC25A3 MPCP_HUMAN $40.10 \quad 100.0 \%$ Phosphate carrier protein, mitochondrial GN=SLC25A3 MPCP_HUMAN $40.10 \quad 100.0 \%$ Phosphate carrier protein, mitochondrial GN=SLC25A3 $\quad$ MPCP_HUMAN $40.10 \quad 100.0 \%$ Phosphate carrier protein, mitochondrial GN=SLC25A3 MPCP HUMAN $40.10 \quad 100.0 \%$ $\begin{array}{lll}\text { Phosphate carrier protein, mitochondrial GN=SLC25A3 } & \text { MPCP_HUMAN } 40.10 \quad 100.0 \%\end{array}$ Phosphate carrier protein, mitochondrial GN=SLC25A3 $\quad$ MPCP_HUMAN $40.10 \quad 100.0 \%$ Phosphate carrier protein, mitochondrial GN=SLC25A3 MPCP_HUMAN $40.10 \quad 100.0 \%$ Phosphate carrier protein, mitochondrial GN=SLC25A3 $\quad$ MPCP_HUMAN $40.10 \quad 100.0 \%$ $\begin{array}{lll}\text { Phosphate carrier protein, mitochondrial GN=SLC25A3 } & \text { MPCP_HUMAN } 40.10 \quad 100.0 \%\end{array}$ Phosphate carrier protein, mitochondrial GN=SLC25A3 $\quad$ MPCP_HUMAN $40.10 \quad 100.0 \%$ Phosphatidylinositol 4-phosphate 5-kinase type-1 gamma GN=PIP5K1C PI51C_HUMAN 73.26 $100.0 \%$ Phosphatidylinositol 4-phosphate 5-kinase type-1 gamma GN=PIPSK1C PI51C_HUMAN $73.26 \quad 100.0 \%$ Phosphatidylinositol 4-phosphate 5-kinase type-1 gamma GN=PIPSK1C PI51C_HUMAN 73.26 $100.0 \%$ Phosphatidylinositol 4-phosphate 5-kinase type-1 gamma GN=PIP5KIC PI51C_HUMAN 73.26 $100.0 \%$ Phosphatidylinositol 4-phosphate 5-kinase type-1 gamma GN=PIPSK1C PI51C_HUMAN 73.26 $100.0 \%$ Phosphatidylinositol 4-phosphate 5-kinase type-1 gamma GN=PIP5K1C PI51C_HUMAN 73.26 $100.0 \%$ Phosphatidylinositol 4-phosphate 5-kinase type-1 gamma GN=PIP5K1C PI51C HUMAN 73.26 $100.0 \%$ Phosphatidylserine decarboxylase proenzyme GN=PISD PISD_HUMAN $46.67 \quad 100.0 \%$ Phosphatidylserine decarboxylase proenzyme GN=PISD PISD_HUMAN $46.67 \quad 100.0 \%$ Phosphoacetylglucosamine mutase GN=PGM3 AGM1_HUMAN $59.85 \quad 100.0 \%$ Phosphoacetylglucosamine mutase GN=PGM3 AGM1_HUMAN $59.85 \quad 100.0 \%$ Phosphoenolpyruvate carboxykinase [GTP], mitochondrial GN=PCK2 $\quad$ PCKGM_HUMAN $70.73 \quad 100.0 \%$ Phosphoenolpyruvate carboxykinase [GTP], mitochondrial GN=PCK2 $\quad$ PCKGM_HUMAN $70.73 \quad 100.0 \%$ $\begin{array}{llll}\text { Phosphoenolpyruvate carboxykinase [GTP], mitochondrial GN=PCK2 } & \text { PCKGM_HUMAN } 70.73 \quad 100.0 \%\end{array}$ Phosphoenolpyruvate carboxykinase [GTP], mitochondrial GN=PCK2 $\quad$ PCKGM_HUMAN $70.73 \quad 100.0 \%$ Phosphoenolpyruvate carboxykinase [GTP], mitochondrial GN=PCK2 $\quad$ PCKGM_HUMAN $70.73 \quad 100.0 \%$ Phosphoenolpyruvate carboxykinase [GTP], mitochondrial GN=PCK2 $\quad$ PCKGM_HUMAN $70.73 \quad 100.0 \%$ Phosphoenolpyruvate carboxykinase [GTP], mitochondrial GN=PCK2 PCKGM_HUMAN $70.73 \quad 100.0 \%$ Phosphoenolpyruvate carboxykinase [GTP], mitochondrial GN=PCK2 PCKGM_HUMAN $70.73 \quad 100.0 \%$ Phosphoenolpyruvate carboxykinase [GTP], mitochondrial GN=PCK2 PCKGM_HUMAN 70.73 100.0\% Phosphoenolpyruvate carboxykinase [GTP], mitochondrial GN=PCK2 $\quad$ PCKGM_HUMAN $70.73 \quad 100.0 \%$ Phosphoglycerate kinase $1 \mathrm{GN}=$ PGK1 PGK1_HUMAN $44.62 \quad 100.0 \%$ Phosphoglycerate kinase 1 GN=PGK1 PGK1_HUMAN $44.62 \quad 100.0 \%$ Phosphoglycerate mutase 1 GN=PGAM1 PGAM1_HUMAN $28.80 \quad 100.0 \%$
$0.00 \% \quad 3.7 \% \quad$ LAQEEESEAKR $0.01 \% \quad 9.0 \%$ CGFCHVGEEENEAR $0.01 \% \quad 9.0 \%$ TVLQEIKR $0.01 \% \quad 9.0 \%$ TYHYHCGVQDK $0.01 \% \quad 5.5 \%$ SLQALGEVIEAELR $0.01 \% \quad 5.5 \%$ LDAEPRPPPTQEAA $0.02 \% \quad 12.4 \%$ DLLFQALGR $0.02 \% \quad 12.4 \%$ AAGASDVVLYK $0.02 \% \quad 12.4 \%$ GLQVFKER $0.02 \% \quad 12.4 \%$ NIFIECTGTDFTK $0.02 \% \quad 12.4 \%$ VGIRETPENLAK $0.02 \% \quad 12.4 \%$ TTLLPGLLK $0.02 \% \quad 12.4 \%$ ASEGPAFFPGR

$0.12 \% \quad 23.2 \%$ MQVDPQKYK

$0.12 \% \quad 23.2 \%$ GIFNGFSVTLKEDGVR $0.12 \% \quad 23.2 \%$ VRIQTQPGYANTLR $0.12 \% \quad 23.2 \%$ IQTQPGYANTLR $0.12 \% \quad 23.2 \%$ IQTQPGYANTLRDAAPK $0.12 \% \quad 23.2 \%$ MYKEEGLK $0.12 \% \quad 23.2 \%$ GVAPLWMR $0.12 \% \quad 23.2 \%$ TVEALYKFVVPKPR $0.12 \% \quad 23.2 \%$ GSSASLVLK $0.12 \% \quad 23.2 \%$ GSSASLVLKR $0.03 \% \quad 12.7 \%$ GVDASGETTYKK $0.03 \% \quad 12.7 \%$ LLPGYYMNLNQNPR $0.03 \% \quad 12.7 \%$ FYGLYCVQSGGK $0.03 \% \quad 12.7 \%$ FYGLYCVQSGGKNIR $0.03 \% \quad 12.7 \%$ VVVMNNILPR $0.03 \% \quad 12.7 \%$ QAQGAQSTSDEKRPVGQK $0.00 \% \quad 6.4 \%$ GVTYSLESFLGPR $0.00 \% \quad 6.4 \% \quad$ IYFDRDLHTNSPR $0.01 \% \quad 5.0 \% \quad$ YLEEVMKVPVYCTK $0.01 \% \quad 5.0 \%$ AFVRPSGTEDVVR $0.04 \% \quad 17.5 \%$ AVDERFPGCMQGR $0.04 \% \quad 17.5 \%$ TMYVLPFSMGPVGSPLSR $0.04 \% \quad 17.5 \%$ IGVQLTDSAYVVASMR $0.04 \% \quad 17.5 \%$ LGTPVLQALGDGDFVK $0.04 \% \quad 17.5 \%$ TLIGHVPDQR $0.04 \% \quad 17.5 \%$ YVAAAFPSACGK $0.04 \% \quad 17.5 \%$ FDSEGRLR $0.04 \% \quad 17.5 \%$ ETPIGLVPK $0.04 \% \quad 17.5 \%$ ETPIGLVPKEGALDLSGLR $0.04 \% \quad 17.5 \%$ EGALDLSGLR $0.00 \% \quad 7.7 \%$ LGDVYVNDAFGTAHR $0.00 \% \quad 7.7 \%$ ALESPERPFLAILGGAK $0.01 \% \quad 13.0 \%$ YADLTEDQLPSCESLKDTIAR $\quad 99.7 \% \quad 34.9$
$99.7 \% \quad 42.1$

8.0

$\begin{array}{llll}99.7 \% & 90.4 & 25.0 & 81.2\end{array}$

$\begin{array}{llll}99.6 \% & 22.5 & 25.0 & 22.5\end{array}$

$99.7 \% \quad 33.7 \quad 25.0 \quad 17.9$

$\begin{array}{llll}99.7 \% & 34.1 & 25.0 & 34.1\end{array}$

$99.0 \% \quad 23.8 \quad 25.0 \quad 20.0$

$\begin{array}{llll}99.7 \% & 37.4 & 25.0 & 37.2\end{array}$

$\begin{array}{llll}98.3 \% & 16.7 & 25.0 & 16.7\end{array}$

$\begin{array}{llll}99.7 \% & 25.7 & 25.0 & 25.7\end{array}$

$\begin{array}{llll}99.7 \% & 55.9 & 25.0 & 41.4\end{array}$

$\begin{array}{llll}99.7 \% & 43.7 & 25.0 & 32.9\end{array}$

$99.7 \% \quad 49.6 \quad 25.0 \quad 49.6$

$\begin{array}{llll}99.7 \% & 56.4 & 25.0 & 49.8\end{array}$

$99.7 \% \quad 66.2 \quad 25.0-52.2$

$99.0 \% \quad 29.1$

$99.0 \% \quad 34.7$

$99.7 \% \quad 37.9$

$\begin{array}{lll}99.7 \% & 39.7\end{array}$

$99.7 \% \quad 58.3$

$99.7 \% \quad 55.3$

$99.7 \% \quad 33.2$

$99.7 \% \quad 43.5$

$96.7 \% \quad 15.3$

$99.4 \% 24.3$

$99.7 \% \quad 26.4$

$99.7 \% \quad 32.4$

$99.7 \% \quad 49.4$

$\begin{array}{lll}98.2 \% & 22.3\end{array}$

$94.8 \% \quad 13.7$

$99.7 \% \quad 45.4$

$97.4 \% \quad 15.9$

$\begin{array}{lll}99.7 \% & 60.0\end{array}$

$99.5 \% \quad 29.0$

$99.7 \% \quad 44.2$

$95.8 \% \quad 18.0$

$99.7 \% \quad 41.6$

$95.2 \% \quad 17.4$

$96.4 \% \quad 16.7$

$\begin{array}{lll}99.7 \% & 32.3\end{array}$

$99.7 \% \quad 51.9$

$99.7 \% \quad 38.4$

$99.2 \% \quad 19.8$
Page 84 of Table S-1-2 
Phosphoglycerate mutase $1 \mathrm{GN}=$ PGAM1 PGAM1_HUMAN $28.80 \quad 100.0 \%$ Phosphoglycerate mutase $1 \mathrm{GN}=$ PGAM1 PGAM1_HUMAN $28.80 \quad 100.0 \%$ Phosphoglycolate phosphatase GN=PGP PGP_HUMAN $34.01 \quad 100.0 \%$ Phosphoglycolate phosphatase GN=PGP PGP HUMAN $34.01 \quad 100.0 \%$ Phosphoglycolate phosphatase GN=PGP PGP_HUMAN $34.01 \quad 100.0 \%$ Phosphoribosyl pyrophosphate synthase-associated protein 1 GN=PRPSAP1 KPRA_HUMAN $39.39100 .0 \%$ Phosphoribosyl pyrophosphate synthase-associated protein 1 GN=PRPSAP1 KPRA_HUMAN $39.39100 .0 \%$ Phosphoribosyl pyrophosphate synthase-associated protein 1 GN=PRPSAP1 KPRA_HUMAN $39.39100 .0 \%$ Phosphoribosyl pyrophosphate synthase-associated protein 1 GN=PRPSAP1 KPRA HUMAN $39.39100 .0 \%$ Phosphoribosyl pyrophosphate synthase-associated protein 2 GN=PRPSAP2 KPRB_HUMAN $40.93 \quad 100.0 \%$ Phosphoribosyl pyrophosphate synthase-associated protein 2 GN=PRPSAP2 KPRB_HUMAN $40.93 \quad 100.0 \%$ KPRB HUMAN $40.93 \quad 100.0 \%$ sphoribosyl pyrophosphate synthase-associated protein 2 GN=PRPSAP2 KPRB_HUMAN $40.93 \quad 100.0 \%$ Pinin GN=PNN Pinin $\mathrm{GN}=\mathrm{PNN}$ Pinin $\mathrm{GN}=\mathrm{PNN}$ PININ_HUMAN $81.61 \quad 100.0 \%$ PININ HUMAN $81.61 \quad 100.0 \%$ PININ_HUMAN $81.61 \quad 100.0 \%$

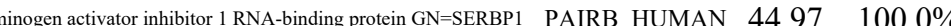
$\begin{array}{lll} & \end{array}$ PAIRB HUMAN $44.97 \quad 100.0 \%$ Plectin $\mathrm{GN}=\mathrm{PLEC}$ Plectin GN=PLEC Plectin GN=PLEC Plectin GN=PLEC Plectin GN=PLEC Plectin GN=PLEC Plectin GN=PLEC Plectin GN=PLEC Plectin GN=PLEC Plectin GN=PLEC Plectin GN=PLEC Plectin GN=PLEC Plectin GN=PLEC Plectin GN=PLEC Plectin GN=PLEC Plectin GN=PLEC Plectin GN=PLEC

Plectin GN=PLEC Plectin GN=PLEC Poly [ADP-ribose] polymerase $1 \mathrm{GN}=\mathrm{PARP} 1 \mathrm{PARP} 1$ HUMAN $113.09 \quad 100.0 \%$ Poly [ADP-ribose] polymerase $1 \mathrm{GN}=$ PARP1 PARP1_HUMAN $113.09 \quad 100.0 \%$ Poly [ADP-ribose] polymerase $1 \mathrm{GN}=$ PARP1 PARP1_HUMAN $113.09 \quad 100.0 \%$ Poly [ADP-ribose] polymerase $1 \mathrm{GN}=$ PARP1 PARP1_HUMAN $113.09 \quad 100.0 \%$ Poly [ADP-ribose] polymerase $1 \mathrm{GN}=$ PARP1 PARP1_HUMAN $113.09 \quad 100.0 \%$ Poly [ADP-ribose] polymerase $1 \mathrm{GN}=$ PARP1 PARP1 HUMAN $113.09 \quad 100.0 \%$ Poly [ADP-ribose] polymerase $1 \mathrm{GN}=$ PARP1 PARP1_HUMAN $113.09 \quad 100.0 \%$ Poly [ADP-ribose] polymerase $1 \mathrm{GN}=$ PARP1 PARP1_HUMAN $113.09 \quad 100.0 \%$ Poly [ADP-ribose] polymerase $1 \mathrm{GN}=$ PARP1 PARP1_HUMAN $113.09 \quad 100.0 \%$ Poly [ADP-ribose] polymerase 1 GN=PARP1 PARP1_HUMAN $113.09 \quad 100.0 \%$
$0.01 \% \quad 13.0 \%$ RVLIAAHGNSLR

$0.01 \% \quad 13.0 \%$ VLIAAHGNSLR

$0.01 \% \quad 11.2 \%$ LGFITNNSSK

$0.01 \% \quad 11.2 \%$ FIAGTGCLVR

$0.01 \% \quad 11.2 \%$ FIFDCVSQEYGINPER

$0.01 \% \quad 14.6 \%$ NIIGVIPYFPYSK

$0.01 \% \quad 14.6 \%$ AQSYAERLR

$0.01 \% \quad 14.6 \%$ NATVHPGLELPLMMAK

$0.01 \% \quad 14.6 \%$ EKPPITVVGDVGGR

$0.01 \% \quad 11.7 \%$ VQIQESVR

$10 \quad 0.01 \% \quad 11.7 \%$ SIIGVIPYFPYSK

$0.01 \% \quad 11.7 \%$ LLASMMCK

$0.01 \% \quad 11.7 \%$ EKPPITVVGDVGGR

$0.02 \% \quad 4.6 \%$ LLALSGPGGGR

$0.02 \% \quad 4.6 \% \quad$ IFGLLMGTLQK

$0.02 \% \quad 4.6 \%$ FKQESTVATER

$99.7 \% \quad 39.4$

$\begin{array}{ll}99.7 \% & 39.4 \\ 99.7 \% & 37.2\end{array}$

$99.7 \% 36$.

$99.7 \% \quad 43.0$

$99.7 \% \quad 41.7$

$96.6 \% \quad 18.2$

$99.7 \% \quad 34.8$

$99.7 \% \quad 43.9$

$99.0 \% 41$.

$99.7 \% \quad 44.8$

$99.0 \% \quad 24.0$

$99.7 \% \quad 43.9$

$99.7 \% \quad 43.0$

$99.7 \% \quad 37.6$

$99.7 \% \quad 59.6$

$0.01 \% \quad 4.7 \% \quad$ SAAQAAAQTNSNAAGK $\quad 99.7 \% \quad 65.6$

$0.01 \% \quad 4.7 \%$ SAAQAAAQTNSNAAGKQLR

$0.05 \% \quad 4.5 \%$ VPDVQDGVR

$0.05 \% \quad 4.5 \%$ AVVQLKPR

$0.05 \% \quad 4.5 \%$ AQLEPVASPAK

$0.05 \% \quad 4.5 \% \quad$ SIQEELQQLR

$0.05 \% \quad 4.5 \%$ GGAEGELQALR

$0.05 \% \quad 4.5 \%$ QVQVALETAQR

$0.05 \% \quad 4.5 \%$ SAEAELQSKR

$0.05 \% \quad 4.5 \% \quad$ LRLQAEEVAQQK

$0.05 \% \quad 4.5 \%$ LRAETEQGEQQR

$0.05 \% \quad 4.5 \%$ QVEEEILALK

$0.05 \% \quad 4.5 \%$ LKAEATEAAR

$0.05 \% \quad 4.5 \%$ SQVEEELFSVR

$0.05 \% \quad 4.5 \% \quad$ LSVAAQEAAR

$0.05 \% \quad 4.5 \%$ LRQLAEEDLAQQR

$0.05 \% \quad 4.5 \%$ LQEAGILSAEELQR

$0.05 \% \quad 4.5 \%$ LAQGHTTVDELAR

$0.05 \% \quad 4.5 \%$ SLVPAAELLESR

$0.05 \% \quad 4.5 \%$ LTVDEAVR

$0.05 \% \quad 4.5 \% \quad$ LLDAQLSTGGIVDPSK

$0.07 \% \quad 20.0 \%$ CSESIPKDSLR

$0.07 \% \quad 20.0 \%$ TAEAGGVTGKGQDGIGSK

$0.07 \% \quad 20.0 \%$ AEKTLGDFAAEYAK

$0.07 \% \quad 20.0 \%$ TLGDFAAEYAK

$0.07 \% \quad 20.0 \%$ TLGDFAAEYAKSNR

$0.07 \% \quad 20.0 \%$ NREELGFRPEYSASQLK

$0.07 \% \quad 20.0 \%$ ILTLGKLSR

$0.07 \% \quad 20.0 \%$ LGGKLTGTANK

$0.07 \% \quad 20.0 \%$ VVSEDFLQDVSASTK

$20 \quad 51 \quad 0.07 \% \quad 20.0 \%$ AEPVEVVAPR $\begin{array}{ll}99.7 \% & 49.8 \\ 99.0 \% & 22.8\end{array}$

$99.0 \% \quad 22.0$

$99.7 \% \quad 34.2$

$99.7 \% \quad 59.2$

$99.7 \% \quad 42.4$

$99.7 \% \quad 39.3$

$99.7 \% \quad 42.9$

$99.6 \% \quad 22.6$

$99.2 \% 33.8$

$99.7 \% \quad 33.3$

$99.1 \% \quad 20.2$

$99.7 \% \quad 54.0$

$99.7 \% \quad 62.7$

$99.6 \% \quad 26.5$

$99.7 \% \quad 67.8$

$99.7 \% \quad 36.8$

$99.7 \% \quad 40.2$

$99.0 \% \quad 32.5$

$99.7 \% \quad 54.8$

$99.7 \% \quad 31.2$

$99.7 \% \quad 35.6$

$99.7 \% \quad 43.8$

$99.7 \% \quad 69.2$

$99.7 \% \quad 55.9$

$98.1 \% \quad 21.9$

$99.7 \% \quad 35.5$

$99.7 \% \quad 46.4$

$99.7 \% \quad 64.0$

$99.7 \% \quad 45.5$ $\begin{array}{lll} & 39.4 & 2\end{array}$

$\begin{array}{ll}.0 & 26.5 \\ .0 & 22.2\end{array}$

$\begin{array}{ll}0 & 40.3\end{array}$

\begin{tabular}{ll}
41.7 \\
\hline
\end{tabular}

$25.0 \quad 12.9$

$25.0 \quad 34.8$

$\begin{array}{ll} & 43.6\end{array}$

$25.0 \quad 21.1$

$25.0 \quad 35.5$

$25.0 \quad 15.7$

$25.0 \quad 43.6$

\begin{tabular}{l}
39.4 \\
\hline
\end{tabular}

\begin{tabular}{ll}
37.6 \\
\hline
\end{tabular}

$\begin{array}{lll}46.0 & 46.0 \quad 6\end{array}$

$\begin{array}{lll} & 65.6 & 4\end{array}$

$\begin{array}{ll}57.0 & 47.7\end{array}$

20.0
25.0

$25.0 \quad 18.6$

$\begin{array}{lll}25.0 & 32.1 & 2\end{array}$

$\begin{array}{ll}5.0 & 44.2\end{array}$

$25.0 \quad 30.2$

$25.0 \quad 32.4$

$25.0 \quad 35.8$

$25.0 \quad 22.6$

$25.0 \quad 22.1$

$25.0 \quad 31.3$

$25.0 \quad 17.4$

$25.0 \quad 37.7$

$25.0 \quad 26.5$

$25.0 \quad 67.1$

$25.0 \quad 33.5$

$25.0 \quad 30.9$

$25.0 \quad 17.9$

$25.0 \quad 54.8$

$25.0 \quad 31.2$

$25.0 \quad 32.7$

$25.0 \quad 43.8$

$25.0 \quad 69.2$

$\begin{array}{lll}25.0 & 50.1 \quad 2\end{array}$

$25.0 \quad 20.4$

$\begin{array}{ll}25.0 & 33.3\end{array}$

$25.0 \quad 40.5$

$20-51 \quad 0.0$

1236.70

1295.66

1460.71

1857.95

984.51

910.58

1110.62

1243.66

1100.57

1242.68

1118.58

1412.79

1444.71

1171.66

1059.58

1322.66

1015.55

1569.83

1556.83

1410.73

1284.72

902.49

1613.87

1291.63

1632.82

1513.75

1185.58

1542.75

2024.02

1000.65

1059.62

1624.81

1066.59

Page 85 of Table S-1-2 
Poly [ADP-ribose] polymerase 1 GN=PARP1 PARP1_HUMAN $113.09 \quad 100.0 \%$ Poly [ADP-ribose] polymerase 1 GN=PARP1 PARP1_HUMAN $113.09 \quad 100.0 \%$ Poly [ADP-ribose] polymerase 1 GN=PARP1 PARP1_HUMAN $113.09 \quad 100.0 \%$ Poly [ADP-ribose] polymerase 1 GN=PARP1 PARP1_HUMAN $113.09 \quad 100.0 \%$ Poly [ADP-ribose] polymerase 1 GN=PARP1 PARP1_HUMAN $113.09 \quad 100.0 \%$ Poly [ADP-ribose] polymerase 1 GN=PARP1 PARP1_HUMAN $113.09 \quad 100.0 \%$ Poly [ADP-ribose] polymerase 1 GN=PARP1 PARP1_HUMAN $113.09 \quad 100.0 \%$ Poly [ADP-ribose] polymerase 1 GN=PARP1 PARP1_HUMAN $113.09 \quad 100.0 \%$ Poly(A) RNA polymerase, mitochondrial GN=MTPAP PAPD1_HUMAN $66.17 \quad 100.0 \%$ Poly(A) RNA polymerase, mitochondrial GN=MTPAP PAPD1_HUMAN $66.17 \quad 100.0 \%$ Poly(A) RNA polymerase, mitochondrial GN=MTPAP PAPD1_HUMAN $66.17 \quad 100.0 \%$ Poly(A) RNA polymerase, mitochondrial GN=MTPAP PAPD1 HUMAN $66.17 \quad 100.0^{\circ}$ Poly(rC)-binding protein $1 \mathrm{GN}=\mathrm{PCBP} 1 \quad$ PCBP1_HUMAN $37.50 \quad 100.0 \%$ Poly(rC)-binding protein $1 \mathrm{GN}=\mathrm{PCBP} 1$ Poly(rC)-binding protein $1 \mathrm{GN}=\mathrm{PCBP} 1$ Poly(rC)-binding protein $1 \mathrm{GN}=\mathrm{PCBP} 1$ Poly(rC)-binding protein $1 \mathrm{GN}=\mathrm{PCBP} 1$ Poly $(\mathrm{rC})$-binding protein $1 \mathrm{GN}=\mathrm{PCBP} 1$ Poly(rC)-binding protein $2 \mathrm{GN}=\mathrm{PCBP} 2$ Poly(rC)-binding protein $2 \mathrm{GN}=\mathrm{PCBP} 2$ Poly $(\mathrm{rC})$-binding protein $2 \mathrm{GN}=\mathrm{PCBP} 2$ Poly(rC)-binding protein $2 \mathrm{GN}=\mathrm{PCBP} 2$ PCBP1_HUMAN $37.50 \quad 100.0 \%$ PCBP1_HUMAN $37.50 \quad 100.0 \%$ PCBP1_HUMAN $37.50 \quad 100.0 \%$ PCBP1 HUMAN $37.50 \quad 100.0 \%$ PCBP1_HUMAN $37.50 \quad 100.0 \%$ PCBP2_HUMAN $38.58 \quad 100.0 \%$ PCBP2_HUMAN $38.58 \quad 100.0 \%$

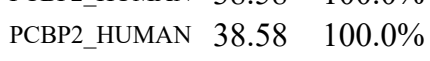
PCBP2_HUMAN $38.58 \quad 100.0 \%$ Poly(U)-binding-splicing factor PUF60 GN=PUF60 PUF60_HUMAN $59.88 \quad 100.0 \%$ Poly(U)-binding-splicing factor PUF60 GN=PUF60 PUF60_HUMAN $59.88 \quad 100.0 \%$ Poly(U)-binding-splicing factor PUF60 GN=PUF60 PUF60_HUMAN $59.88 \quad 100.0 \%$ Poly(U)-binding-splicing factor PUF60 GN=PUF60 PUF60_HUMAN $59.88 \quad 100.0 \%$ Poly(U)-binding-splicing factor PUF60 GN=PUF60 PUF60_HUMAN $59.88 \quad 100.0 \%$ Poly(U)-binding-splicing factor PUF60 GN=PUF60 PUF60_HUMAN $59.88 \quad 100.0 \%$ Poly(U)-binding-splicing factor PUF60 GN=PUF60 PUF60_HUMAN $59.88 \quad 100.0 \%$ Polyadenylate-binding protein $1 \mathrm{GN}=\mathrm{PABPC} 1$ PABP1_HUMAN $70.67 \quad 100.0 \%$ Polyadenylate-binding protein $1 \mathrm{GN}=$ PABPC1 PABP1_HUMAN $70.67 \quad 100.0 \%$ Polyadenylate-binding protein 1 GN=PABPC1 PABP1_HUMAN $70.67 \quad 100.0 \%$ Polyadenylate-binding protein $1 \mathrm{GN}=$ PABPC1 PABP1_HUMAN $70.67 \quad 100.0 \%$ Polyadenylate-binding protein $1 \mathrm{GN}=$ PABPC1 PABP1_HUMAN $70.67 \quad 100.0 \%$ Polyadenylate-binding protein $1 \mathrm{GN}=$ PABPC1 PABP1_HUMAN $70.67 \quad 100.0 \%$ Polyadenylate-binding protein 1 GN=PABPC1 PABP1_HUMAN $70.67 \quad 100.0 \%$ Polyadenylate-binding protein 1 GN=PABPC1 PABP1_HUMAN $70.67 \quad 100.0 \%$ Polyadenylate-binding protein $1 \mathrm{GN}=\mathrm{PABPC} 1$ PABP1_HUMAN $70.67 \quad 100.0 \%$ Polyadenylate-binding protein $1 \mathrm{GN}=\mathrm{PABPC} 1$ PABP1_HUMAN $70.67 \quad 100.0 \%$ Polyadenylate-binding protein $1 \mathrm{GN}=$ PABPC1 PABP1_HUMAN $70.67 \quad 100.0 \%$ Polyadenylate-binding protein $1 \mathrm{GN}=\mathrm{PABPC} 1$ PABP1_HUMAN $70.67 \quad 100.0 \%$ Polyadenylate-binding protein 1 GN=PABPC1 PABP1_HUMAN $70.67 \quad 100.0 \%$ Polyadenylate-binding protein 1 GN=PABPC1 PABP1_HUMAN $70.67 \quad 100.0 \%$ Polyadenylate-binding protein $1 \mathrm{GN}=$ PABPC1 PABP1_HUMAN $70.67 \quad 100.0 \%$ Polyadenylate-binding protein 1 GN=PABPC1 PABP1_HUMAN $70.67 \quad 100.0 \%$ Polyadenylate-binding protein $1 \mathrm{GN}=$ PABPC1 PABP1_HUMAN $70.67 \quad 100.0 \%$ Polyadenylate-binding protein $1 \mathrm{GN}=$ PABPC1 PABP1_HUMAN $70.67 \quad 100.0 \%$

20

2

20

4

7

4
7
7

7

6

2

2

$\begin{array}{ll}7 & 9 \\ 7 & 9 \\ 7 & 9\end{array}$

9

7

9

$\begin{array}{cc}7 & 9 \\ 34 & 47\end{array}$

$\begin{array}{ll}34 & 47 \\ 4 & 47 \\ 4 & 47\end{array}$

447

$\begin{array}{ll}4 & 47 \\ 4 & 47 \\ 4 & 47\end{array}$

34
34
34

$\begin{array}{ll}34 & 47 \\ 34 & 47 \\ 34 & 47\end{array}$

44

34
34
34

34

34
34
34

34
34
34

34

34
$\begin{array}{llll}51 & 0.07 \% & 20.0 \% & \text { VFSATLGLVDIVK } \\ 51 & 0.07 \% & 20.0 \% & \text { LTVNPGTK }\end{array}$

$0.07 \% \quad 20.0 \%$ SKLPKPVQDLIK

$0.07 \% \quad 20.0 \%$ MIFDVESMKK

$0.07 \% \quad 20.0 \%$ KPPLLNNADSVQAK

$0.07 \% \quad 20.0 \%$ TTNFAGILSQGLR

$0.07 \% \quad 20.0 \%$ IAPPEAPVTGYMFGK

$0.07 \% \quad 20.0 \%$ GIYFADMVSK

$0.01 \% \quad 10.0 \%$ FSHQASGFQCDLTTNNR

$0.01 \% \quad 10.0 \%$ SPPILPTLDSLK

$0.01 \% \quad 10.0 \%$ TLADAEDKCVIEGNNCTFVR

$0.01 \% \quad 10.0 \%$ NVSQSQLQK

$0.04 \% \quad 22.8 \%$ INISEGNCPER

$0.04 \% \quad 22.8 \%$ LVVPATQCGSLIGK

$0.04 \% \quad 22.8 \%$ ESTGAQVQVAGDMLPNSTER

$0.04 \% 22.8 \%$ AITIAGVPQSVTECVK

$0.04 \% \quad 22.8 \%$ QGANINEIR

$0.04 \% \quad 22.8 \%$ IANPVEGSSGR

$0.01 \% \quad 15.9 \%$ INISEGNCPER

$0.01 \% \quad 15.9 \%$ IITLAGPTNAIFK

$0.01 \% \quad 15.9 \%$ LVVPASQCGSLIGK

$0.01 \% \quad 15.9 \%$ ESTGAQVQVAGDMLPNSTER

$6 \quad 0.02 \% \quad 15.9 \%$ LGLPPLTPEQQEALQK

$0.02 \% \quad 15.9 \%$ YAMEQSIK

$6 \quad 0.02 \% \quad 15.9 \%$ VYVGSIYYELGEDTIR

$0.02 \% \quad 15.9 \%$ SCTLARDPTTGK

$\begin{array}{lll}6 & 0.02 \% & 15.9 \% \text { GYGFIEYEK }\end{array}$

$16 \quad 0.02 \% \quad 15.9 \%$ KQESTVMVLR

$16 \quad 0.02 \% \quad 15.9 \%$ VVAEVYDQERFDNSDLSA 99.7

$172 \quad 0.25 \% \quad 48.3 \%$ FSPAGPILSIR

$172 \quad 0.25 \% \quad 48.3 \%$ VCRDMITR

$\begin{array}{llllll} & 0.25 \% & 48.3 \% & \text { RSLGYAYVNFQQPADAER } & 99.7 \% & 57.5\end{array}$

$172 \quad 0.25 \% \quad 48.3 \%$ SLGYAYVNFQQPADAER $99.7 \% \quad 53.2$

$172 \quad 0.25 \% \quad 48.3 \%$ ALDTMNFDVIK

$172 \quad 0.25 \% \quad 48.3 \%$ ALDTMNFDVIKGKPVR

$172 \quad 0.25 \% \quad 48.3 \%$ KSGVGNIFIK

$172 \quad 0.25 \% \quad 48.3 \%$ SGVGNIFIK

$172 \quad 0.25 \% \quad 48.3 \%$ SGVGNIFIKNLDK

$172 \quad 0.25 \% \quad 48.3 \%$ ALYDTFSAFGNILSCK

$172 \quad 0.25 \% \quad 48.3 \%$ GYGFVHFETQEAAER

$172 \quad 0.25 \% \quad 48.3 \%$ EREAELGAR

$\begin{array}{llll}172 & 0.25 \% & 48.3 \% & \text { AKEFTNVYIK } \\ 172 & 0.25 \% & 48.3 \% & \text { FGPALSVK }\end{array}$

$\begin{array}{llll}172 & 0.25 \% & 48.3 \% & \text { GFGFVSFER }\end{array}$

$47 \quad 172 \quad 0.25 \% \quad 48.3 \%$ GFGFVSFERHEDAQK

$47 \quad 172 \quad 0.25 \% \quad 48.3 \%$ ITRYQGVNLYVK

\begin{abstract}
$\begin{array}{lllll}47 & 172 & 0.25 \% & 48.3 \% & \text { ITRYQGVNLYVK } \\ 47 & 172 & 0.25 \% & 48.3 \% \text { YQGVNLYVK }\end{array}$
\end{abstract}
$99.7 \% \quad 56.9$

$99.7 \% \quad 50.5$

$\begin{array}{ll}98.9 \% & 21.4\end{array}$

$99.7 \% 61.4$

$97.6 \% \quad 16.2$

$\begin{array}{lll}99.7 \% & 82.8\end{array}$

$\begin{array}{ll}99.7 \% & 48.7 \\ 97.3 \% & 27.3\end{array}$

$\begin{array}{ll}99.7 \% & 34.4\end{array}$

$99.0 \% \quad 43.1$

$\begin{array}{lll}99.7 \% & 37.1\end{array}$

$99.4 \% 22.9$

$\begin{array}{llll}99.7 \% & 37.1 & 25.0 & 26 . \\ 99.4 \% & 22.9 & 25.0 & 22.9 \\ 99.7 \% & 44.3 & 25.0 & 44.3 \\ 99.7 \% & 48.9 & 25.0 & 40.7\end{array}$

Page 86 of Table S-1-2 
Polyadenylate-binding protein 1 GN=PABPC1 PABP1_HUMAN $70.67 \quad 100.0 \% \quad 34$ Polyadenylate-binding protein $1 \mathrm{GN}=\mathrm{PABPC} 1 \mathrm{PABP} 1$ HUMAN $70.67 \quad 100.0 \% \quad 34$ Polyadenylate-binding protein $1 \mathrm{GN}=$ PABPC1 PABP1_HUMAN $70.67 \quad 100.0 \% \quad 34$ Polyadenylate-binding protein $1 \mathrm{GN}=\mathrm{PABPC} 1 \mathrm{PABP} 1 \mathrm{HUMAN} \quad 70.67 \quad 100.0 \% \quad 3$ $\begin{array}{lllll}\text { Polyadenylate-binding protein } 1 \mathrm{GN}=\text { PABPC1 PABP1_HUMAN } & 70.67 & 100.0 \% & 34\end{array}$ Polyadenylate-binding protein $1 \mathrm{GN}=$ PABPC1 PABP1_HUMAN $70.67 \quad 100.0 \% \quad 34$ Polyadenylate-binding protein $1 \mathrm{GN}=$ PABPC1 PABP1_HUMAN $70.67 \quad 100.0 \% \quad 34$ $\begin{array}{lllll}\text { Polyadenylate-binding protein } 1 \mathrm{GN}=\text { PABPC1 } & \text { PABP1_HUMAN } & 70.67 & 100.0 \% & 34\end{array}$ Polyadenylate-binding protein $1 \mathrm{GN}=\mathrm{PABPC} 1 \mathrm{PABP} 1 \mathrm{HUMAN} \quad 70.67 \quad 100.0 \% \quad 34$ Polyadenylate-binding protein $1 \mathrm{GN}=$ PABPC1 PABP1_HUMAN $70.67 \quad 100.0 \% \quad 34$ Polyadenylate-binding protein $1 \mathrm{GN}=$ PABPC1 PABP1_HUMAN $70.67 \quad 100.0 \%$ Polyadenylate-binding protein $1 \mathrm{GN}=\mathrm{PABPC} 1 \mathrm{PABP} 1$ HUMAN $70.67 \quad 100.0 \%$ Polyadenylate-binding protein $1 \mathrm{GN}=\mathrm{PABPC} 1 \mathrm{PABP} 1$ HUMAN $70.67 \quad 100.0 \%$ Polyadenylate-binding protein $1 \mathrm{GN}=$ PABPC1 PABP1_HUMAN $70.67 \quad 100.0 \%$ Polyadenylate-binding protein $1 \mathrm{GN}=$ PABPC1 PABP1_HUMAN $70.67 \quad 100.0 \%$ Polyadenylate-binding protein $1 \mathrm{GN}=$ PABPC1 PABP1_HUMAN $70.67 \quad 100.0 \%$ Polyadenylate-binding protein $4 \mathrm{GN}=\mathrm{PABPC} 4$ PABP4_HUMAN $70.78 \quad 100.0 \%$ Polyadenylate-binding protein $4 \mathrm{GN}=\mathrm{PABPC} 4$ PABP4_HUMAN $70.78 \quad 100.0 \%$ Polyadenylate-binding protein $4 \mathrm{GN}=\mathrm{PABPC} 4$ PABP4_HUMAN $70.78 \quad 100.0 \%$ Polyadenylate-binding protein $4 \mathrm{GN}=$ PABPC4 PABP4_HUMAN $70.78 \quad 100.0 \%$ Polyadenylate-binding protein $4 \mathrm{GN}=$ PABPC4 PABP4_HUMAN $70.78 \quad 100.0 \%$ Polyadenylate-binding protein $4 \mathrm{GN}=$ PABPC4 PABP4_HUMAN $70.78 \quad 100.0 \%$ Polyadenylate-binding protein $4 \mathrm{GN}=$ PABPC4 PABP4_HUMAN $70.78 \quad 100.0 \%$ Polyadenylate-binding protein $4 \mathrm{GN}=$ PABPC4 PABP4_HUMAN $70.78 \quad 100.0 \%$ Polyadenylate-binding protein $4 \mathrm{GN}=$ PABPC4 PABP4 HUMAN $70.78 \quad 100.0 \%$ Polyadenylate-binding protein $4 \mathrm{GN}=$ PABPC4 PABP4_HUMAN $70.78 \quad 100.0 \%$ Polyadenylate-binding protein $4 \mathrm{GN}=\mathrm{PABPC} 4$ PABP4_HUMAN $70.78 \quad 100.0 \%$ Polyadenylate-binding protein $4 \mathrm{GN}=$ PABPC4 PABP4_HUMAN $70.78 \quad 100.0 \%$ Polyadenylate-binding protein $4 \mathrm{GN}=$ PABPC4 PABP4_HUMAN $70.78 \quad 100.0 \%$ Polyadenylate-binding protein $4 \mathrm{GN}=$ PABPC4 PABP4 HUMAN $70.78 \quad 100.0 \%$ Polyadenylate-binding protein $4 \mathrm{GN}=$ PABPC4 PABP4_HUMAN $70.78 \quad 100.0 \%$ Polyadenylate-binding protein $4 \mathrm{GN}=\mathrm{PABPC} 4$ PABP4_HUMAN $70.78 \quad 100.0 \%$ Polyadenylate-binding protein $4 \mathrm{GN}=\mathrm{PABPC} 4$ PABP4_HUMAN $70.78 \quad 100.0 \%$ Polyadenylate-binding protein $4 \mathrm{GN}=$ PABPC4 PABP4_HUMAN $70.78 \quad 100.0 \%$ Polyadenylate-binding protein $4 \mathrm{GN}=\mathrm{PABPC} 4$ PABP4_HUMAN $70.78 \quad 100.0 \%$ Polymerase delta-interacting protein 2 GN=POLDIP2 PDIP2_HUMAN $42.03 \quad 100.0 \%$ Polymerase delta-interacting protein 2 GN=POLDIP2 PDIP2_HUMAN $42.03 \quad 100.0 \%$ Polymerase delta-interacting protein 2 GN=POLDIP2 PDIP2 HUMAN $42.03 \quad 100.0 \%$ Polymerase delta-interacting protein 3 GN=POLDIP3 PDIP3_HUMAN $46.09 \quad 100.0 \%$ Polymerase delta-interacting protein 3 GN=POLDIP3 PDIP3_HUMAN $46.09 \quad 100.0 \%$ Polynucleotide 5'-hydroxyl-kinase NOL9 GN=NOL9 NOL9 HUMAN 79.32 $100.0 \%$ Polynucleotide 5'-hydroxyl-kinase NOL9 GN=NOL9 NOL9_HUMAN 79.32 $100.0 \%$ Polynucleotide 5'-hydroxyl-kinase NOL9 GN=NOL9 NOL9 HUMAN $79.32 \quad 100.0 \%$ Pre-mRNA 3'-end-processing factor FIP1 GN=FIP1L1 FIP1_HUMAN $66.53 \quad 100.0 \%$ Pre-mRNA 3'-end-processing factor FIP1 GN=FIP1L1 FIP1_HUMAN $66.53 \quad 100.0 \%$ Pre-mRNA-processing factor 6 GN=PRPF6 PRP6_HUMAN $106.93 \quad 100.0 \%$ Pre-mRNA-processing factor 6 GN=PRPF6 PRP6_HUMAN $106.93 \quad 100.0 \%$

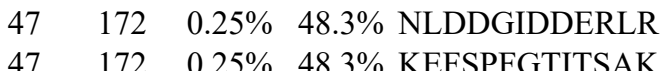
$99.7 \% \quad 61.5 \quad 25.0 \quad 57.8$

$172 \quad 0.25 \% \quad 48.3 \%$ EFSPFGTITSAK

$99.7 \% \quad 59.1$

$99.7 \% \quad 34.7$

25.0

50.

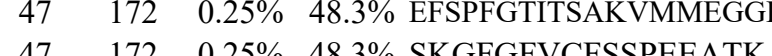

$47 \quad 172 \quad 0.25 \% \quad 48.3 \%$ GFGFVCFSSPEEATK

$99.7 \% \quad 50.9$

$99.7 \% \quad 50.4$

$47 \quad 172 \quad 0.25 \% \quad 48.3 \%$ GFGFVCFSSPEEATKAVTEMNGR $\quad 97.5 \% \quad 25.3$

$47 \quad 172 \quad 0.25 \% \quad 48.3 \%$ IVATKPLYVALAQR

$47 \quad 172 \quad 0.25 \% \quad 48.3 \%$ IVATKPLYVALAQRK

$99.7 \% \quad 57.7$

$99.7 \% \quad 34.7$

$99.4 \% \quad 20.9$

$99.7 \% \quad 54.9$

$47 \quad 172 \quad 0.25 \% \quad 48.3 \%$ QAHLTNQYMQR

$\begin{array}{lllllll}47 & 172 & 0.25 \% & 48.3 \% & \text { VANTSTQTMGPRPAAAAAAATPAVR } & 99.7 \% & 52.2 \\ 47 & 172 & 0.25 \% & 48.3 \% & \text { TVPQYKYAAGVR } & 99.7 \% & 58.2\end{array}$

$47 \quad 172 \quad 0.25 \% \quad 48.3 \%$ SKVDEAVAVLQAHQAK

$47 \quad 172 \quad 0.25 \% \quad 48.3 \%$ EAAQKAVNSATGVPTV

$47 \quad 172 \quad 0.25 \% \quad 48.3 \%$ AVNSATGVPTV

$\begin{array}{llll}16 & 37 & 0.05 \% & 27.6 \% \\ 16 & 37 & \text { FSPAGPVLSIR }\end{array}$

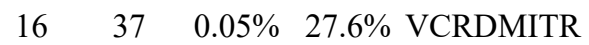

$99.7 \% \quad 65.3$

$99.6 \% \quad 24.4$

$99.7 \% \quad 38.3$

$99.7 \% \quad 39.5$

$97.7 \% \quad 24.2$

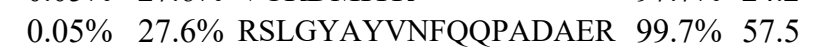

$0.05 \% \quad 27.6 \%$ SLGYAYVNFQQPADAER $\quad 99.7 \% \quad 53.2$

$0.05 \% \quad 27.6 \%$ ALDTMNFDVIK

$0.05 \% \quad 27.6 \%$ ALYDTFSAFGNILSCK

$99.7 \% \quad 56.9$

$99.7 \% \quad 82.8$

$99.7 \% \quad 34.4$

$99.7 \% \quad 26.2$

$99.7 \% \quad 31.4$

$0.05 \% \quad 27.6 \%$ GFGFVSYEKHEDANK

$0.05 \% \quad 27.6 \%$ ISRYQGVNLYIK

$0.05 \% \quad 27.6 \%$ YQGVNLYIK

$0.05 \% \quad 27.6 \%$ EFSPFGSITSAK

$99.7 \% \quad 40.7$

$99.7 \% \quad 56.3$

$0.05 \% \quad 27.6 \%$ SKGFGFVCFSSPEEATK $\quad 99.7 \% \quad 50.9$

$0.05 \% \quad 27.6 \%$ GFGFVCFSSPEEATK $\quad 99.7 \% \quad 50.4$

$0.05 \% \quad 27.6 \%$ GFGFVCFSSPEEATKAVTEMNGR $\quad 97.5 \% \quad 25.3$

$0.05 \% \quad 27.6 \%$ IVGSKPLYVALAQR

$0.05 \% \quad 27.6 \%$ IVGSKPLYVALAQRK

$99.7 \% \quad 58.9$

$99.7 \% \quad 32.8$

$\begin{array}{lll}99.7 \% & 54.3\end{array}$

$99.5 \% \quad 23.8$

$\begin{array}{lll}99.7 \% & 32.5\end{array}$

$0.05 \% \quad 27.6 \%$ AHLTNQYMQR

$0.05 \% \quad 27.6 \%$ EAAQKVGAVAAATS

$0.01 \% \quad 10.6 \%$ SQTEAVTFLANHDDSR

$0.01 \% \quad 10.6 \%$ IFSLSGTLETVR

$99.7 \% \quad 64.4$

$99.7 \% \quad 63.4$

$99.6 \% \quad 26.3$

$99.7 \% \quad 25.3$

$\begin{array}{lll}0.00 \% & 6.7 \% & \text { KQQTTVPQKPR }\end{array}$

$0.00 \% \quad 6.7 \%$ VVQNDAYTAPALPSSIR

$0.01 \% \quad 6.1 \%$ ARPQLILSR

$0.01 \% \quad 6.1 \%$ LIGVYTDFAFR

$\begin{array}{ll}98.1 \% & 21.6 \\ 99.7 \% & 36.4\end{array}$

$\begin{array}{ll}99.7 \% & 36.4 \\ 99.7 \% & 27.3\end{array}$

$0.01 \% \quad 6.1 \%$ GIEGTVPYVTTDYNFKLPGASEK $\quad 99.7 \% \quad 44.1$

$0.00 \% \quad 5.4 \%$ TGAPQYGSYGTAPVNLNIK $\quad 99.7 \% \quad 49.0$

$0.00 \% \quad 5.4 \% \quad$ ANENSNIQVLSER

$\begin{array}{ll}99.7 \% & 49.0 \\ 99.7 \% & 52.3\end{array}$

$99.7 \% 26.7$

$0.03 \% \quad 9.8 \% \quad$ IQQQFSDLKR

$99.7 \% \quad 41.2$

$25.0 \quad 34.7$

$\begin{array}{ll}25.0 & 48.2 \\ 25.0 & 50.4\end{array}$

$25.0 \quad 23.2$

$25.0 \quad 57.7$

$25.0 \quad 31.4$

$25.0 \quad 20.9$

$25.0 \quad 51.8$

$25.0 \quad 52.2$

$25.0 \quad 54.6$

$25.0 \quad 65.3$

$25.0 \quad 23.5$

$25.0 \quad 35.6$

$25.0 \quad 36.8$

$25.0 \quad 8.7$

$25.0 \quad 48.7$

$25.0 \quad 53.2$

$25.0 \quad 55.5$

$25.0 \quad 82.5$

$25.0 \quad 25.1$

$25.0 \quad 24.5$

$25.0 \quad 31.4$

$25.0 \quad 33.6$

$25.0 \quad 51.3$

$25.0 \quad 48.2$

$25.0 \quad 50.4$

$25.0 \quad 23.2$

$25.0 \quad 35.9$

$25.0 \quad 32.8$

$25.0 \quad 54.3$

$25.0 \quad 18.8$

$\begin{array}{ll}0 & 32.5\end{array}$

$\begin{array}{ll}0.0 & 64.4\end{array}$

50.0

$\begin{array}{ll}0 & 18.4\end{array}$

$5.0 \quad 25.3$

$25.0 \quad 21.6$

$25.0 \quad 31.6$

$25.0 \quad 27.0$

$25.0 \quad 43.6$

$25.0 \quad 46.0$

$25.0 \quad 45.6$

$25.0 \quad 25.9$

$0.03 \% \quad 9.8 \%$ LEEVTGKLQVAR 
Pre-mRNA-processing factor 6 GN=PRPF6 PRP6_HUMAN $106.93 \quad 100.0 \%$ Pre-mRNA-processing factor 6 GN=PRPF6 PRP6_HUMAN $106.93 \quad 100.0 \%$ Pre-mRNA-processing factor 6 GN=PRPF6 PRP6_HUMAN $106.93 \quad 100.0 \%$ Pre-mRNA-processing factor $6 \mathrm{GN}=$ =PRPF6 PRP6_HUMAN $106.93 \quad 100.0 \%$ Pre-mRNA-processing factor 6 GN=PRPF6 PRP6_HUMAN $106.93 \quad 100.0 \%$ Pre-mRNA-processing factor 6 GN=PRPF6 PRP6_HUMAN $106.93 \quad 100.0 \%$ Pre-mRNA-processing-splicing factor 8 GN=PRPF8 PRP8_HUMAN $273.61 \quad 100.0 \%$ Pre-mRNA-processing-splicing factor 8 GN=PRPF8 PRP8_HUMAN $273.61 \quad 100.0 \%$ Pre-mRNA-processing-splicing factor 8 GN=PRPF8 PRP8 HUMAN $273.61 \quad 100.0 \%$ Pre-mRNA-processing-splicing factor 8 GN=PRPF8 PRP8_HUMAN $273.61 \quad 100.0 \%$ Pre-mRNA-processing-splicing factor $8 \mathrm{GN}=$ =PRPF8 PRP8_HUMAN $273.61 \quad 100.0 \%$ Pre-mRNA-processing-splicing factor $8 \mathrm{GN}=$ PRPF8 PRP8_HUMAN $273.61 \quad 100.0 \%$ Pre-mRNA-processing-splicing factor 8 GN=PRPF8 PRP8_HUMAN $273.61 \quad 100.0 \%$ Pre-mRNA-processing-splicing factor $8 \mathrm{GN}=$ PRPF8 PRP8_HUMAN $273.61 \quad 100.0 \%$ Pre-mRNA-processing-splicing factor $8 \mathrm{GN}=$ =PRPF8 PRP8_HUMAN $273.61 \quad 100.0 \%$ Pre-mRNA-processing-splicing factor 8 GN=PRPF8 PRP8_HUMAN $273.61 \quad 100.0 \%$ Pre-mRNA-processing-splicing factor $8 \mathrm{GN}=$ =PRPF PRP8 HUMAN $273.61 \quad 100.0 \%$ Pre-mRNA-processing-splicing factor 8 GN=PRPF8 PRP8_HUMAN $273.61 \quad 100.0 \%$ Pre-mRNA-processing-splicing factor 8 GN=PRPF8 PRP8_HUMAN $273.61 \quad 100.0 \%$ Pre-mRNA-processing-splicing factor 8 GN=PRPF8 PRP8_HUMAN $273.61 \quad 100.0 \%$ Pre-mRNA-processing-splicing factor 8 GN=PRPF8 PRP8_HUMAN $273.61 \quad 100.0 \%$ Pre-mRNA-processing-splicing factor 8 GN=PRPF8 PRP8_HUMAN $273.61 \quad 100.0 \%$ Pre-mRNA-processing-splicing factor 8 GN=PRPF8 PRP8_HUMAN $273.61 \quad 100.0 \%$ Pre-mRNA-processing-splicing factor 8 GN=PRPF8 PRP8_HUMAN $273.61 \quad 100.0 \%$ Pre-mRNA-processing-splicing factor $8 \mathrm{GN}=$ PRPF8 PRP8_HUMAN $273.61 \quad 100.0 \%$ Pre-mRNA-processing-splicing factor 8 GN=PRPF8 PRP8_HUMAN $273.61 \quad 100.0 \%$ Pre-mRNA-processing-splicing factor $8 \mathrm{GN}=$ PRPF8 PRP8_HUMAN $273.61 \quad 100.0 \%$ Pre-mRNA-processing-splicing factor 8 GN=PRPF8 PRP8_HUMAN $273.61 \quad 100.0 \%$ Pre-mRNA-processing-splicing factor 8 GN=PRPF8 PRP8_HUMAN $273.61 \quad 100.0 \%$ Pre-mRNA-splicing factor ATP-dependent RNA helicase DHX15 GN=DHX15 DHX15_HUMAN $90.94 \quad 100.0 \%$ Pre-mRNA-splicing factor ATP-dependent RNA helicase DHX15 GN=DHX15 DHX15_HUMAN $90.94 \quad 100.0 \%$ Pre-mRNA-splicing factor ATP-dependent RNA helicase DHX15 GN=DHX15 DHX15_HUMAN $90.94 \quad 100.0 \%$ Pre-mRNA-splicing factor ATP-dependent RNA helicase DHX15 GN=DHX15 DHX15 HUMAN $90.94 \quad 100.0 \%$ Pre-mRNA-splicing factor ATP-dependent RNA helicase DHX15 GN=DHX15 DHX15_HUMAN $90.94 \quad 100.0 \%$ Pre-mRNA-splicing factor ATP-dependent RNA helicase DHX15 GN=DHX15 DHX15_HUMAN $90.94 \quad 100.0 \%$ Pre-mRNA-splicing factor ATP-dependent RNA helicase DHX15 GN=DHX15 DHX15_HUMAN $90.94 \quad 100.0 \%$ Pre-mRNA-splicing factor ATP-dependent RNA helicase DHX15 GN=DHX15 DHX15_HUMAN $90.94 \quad 100.0 \%$ Pre-mRNA-splicing factor ATP-dependent RNA helicase DHX15 GN=DHX15 DHX15_HUMAN $90.94 \quad 100.0 \%$ Pre-mRNA-splicing factor ATP-dependent RNA helicase DHX15 GN=DHX15 DHX15_HUMAN $90.94 \quad 100.0 \%$ Pre-mRNA-splicing factor ATP-dependent RNA helicase DHX15 GN=DHX15 DHX15_HUMAN $90.94 \quad 100.0 \%$ Probable 28S rRNA (cytosine(4447)-C(5))-methyltransferase GN=NOP2 NOP2 HUMAN $89.30 \quad 100.0 \%$ Probable 28S rRNA (cytosine(4447)-C(5))-methyltransferase GN=NOP2 NOP2_HUMAN $89.30 \quad 100.0 \%$ Probable 28S rRNA (cytosine(4447)-C(5))-methyltransferase GN=NOP2 NOP2 HUMAN $89.30 \quad 100.0 \%$ Probable $28 \mathrm{~S}$ rRNA (cytosine(4447)-C(5))-methyltransferase GN=NOP2 NOP2 HUMAN $89.30 \quad 100.0 \%$ Probable 28S rRNA (cytosine(4447)-C(5))-methyltransferase GN=NOP2 NOP2_HUMAN $89.30 \quad 100.0 \%$ Probable 28S rRNA (cytosine(4447)-C(5))-methyltransferase GN=NOP2 NOP2_HUMAN $89.30 \quad 100.0 \%$ Probable 28S rRNA (cytosine(4447)-C(5))-methyltransferase GN=NOP2 NOP2_HUMAN $89.30 \quad 100.0 \%$ $\begin{array}{lllll}10 & 20 & 0.03 \% & 9.8 \% & \text { AVVAQAVR } \\ 10 & 20 & 0.03 \% & 9.8 \% & \text { AVVAQAVRH } \\ 10 & 20 & 0.03 \% & 9.8 \% & \text { AAELETDIRAK }\end{array}$

10

10

10

10

$23-24$

23

23

3

23

23

23
23

23

23

23
23
23

23

23

23

23

23

23
23
11

1

11
11
11

11
11
11

11

11
8

8
8
8

8
8
8

$\begin{array}{ll}8 & 9 \\ 8 & 9\end{array}$

$0.08 \% \quad 9.7 \%$ GYLPSHYER
$9.8 \%$ AAELETDIRAK

$0.03 \% \quad 9.8 \%$ AIYAYALQVFPSKK

$0.03 \% \quad 9.8 \%$ AGLKNIANTLMAK

$0.08 \% \quad 9.7 \%$ ALNMAIPGGPK

$0.08 \% \quad 9.7 \%$ RALDIPLVK

$0.08 \% \quad 9.7 \% \quad$ YYVLNALK

$0.08 \% \quad 9.7 \%$ LVVDSHVQYR

$0.08 \% \quad 9.7 \%$ FNTGPVGK

$0.08 \% \quad 9.7 \%$ LYLKAEQER

$0.08 \% \quad 9.7 \%$ LKEAYSVK

$0.08 \% \quad 9.7 \%$ IDLTLLNR

$0.08 \% \quad 9.7 \%$ LIVDHNIADYMTAK

$0.08 \% \quad 9.7 \%$ FTADEARDLIQR

$0.08 \% \quad 9.7 \%$ QILMASGSTTFTK

$0.08 \% \quad 9.7 \%$ IKIGLNSK

$0.08 \% \quad 9.7 \%$ QTDVGITHFR

$0.08 \% \quad 9.7 \%$ SGMSHEEDQLIPNLYR

$0.08 \% \quad 9.7 \%$ TDFKQYQVLK

$0.08 \% \quad 9.7 \%$ ANPALYVLR

$0.08 \% \quad 9.7 \% \quad$ SLPVEEQPK

$0.08 \% \quad 9.7 \%$ SLPVEEQPKQIIVTR

$0.08 \% \quad 9.7 \%$ TISSYTAFSR

$0.08 \% \quad 9.7 \%$ EQSQLTATQTR

$0.08 \% \quad 9.7 \%$ AISAANLHLR

$0.08 \% \quad 9.7 \% \quad$ FICISDLR

$0.04 \% \quad 14.7 \%$ ASTNAMLISAGLPPLK

$0.04 \% \quad 14.7 \%$ HQSFVLVGETGSGK

$0.04 \% \quad 14.7 \%$ RVAAMSVAQR

$0.04 \% \quad 14.7 \%$ YMTDGMLLR

$0.04 \% \quad 14.7 \%$ YGVIILDEAHER

$0.04 \% \quad 14.7 \%$ IRVESLLVTAISK

$0.04 \% \quad 14.7 \%$ SNLGSVVLQLK

$0.04 \% \quad 14.7 \%$ SNLGSVVLQLKK

$0.04 \% \quad 14.7 \%$ SLMSADNVRQQLSR

$0.04 \% \quad 14.7 \%$ QLDRIIAK

$0.04 \% \quad 14.7 \%$ LQSKEYSQY

$0.02 \% \quad 11.8 \%$ GAETELVR

$0.02 \% \quad 11.8 \%$ FLPAVSDENSKR

$0.02 \% \quad 11.8 \%$ GISAGAVQTAGK

$0.02 \% \quad 11.8 \%$ KGPQSLFNAPR

$0.02 \% \quad 11.8 \%$ SVVGNLHR

$0.02 \% \quad 11.8 \%$ LVPTGLDFGQEGFTR

$0.02 \% \quad 11.8 \%$ GADSELSTVPSVTK
1084.58

1024.65

983.56

1215.65

819.44

1149.63

937.54

957.57

1603.82

$\begin{array}{llll}99.0 \% & 36.5 & 25.0 & 29.5\end{array}$

$\begin{array}{llll}99.5 \% & 27.7 & 25.0 & 27.7\end{array}$

$\begin{array}{llll}99.6 \% & 30.5 & 25.0 & 14.8\end{array}$

$\begin{array}{llll}99.7 \% & 46.5 & 25.0 & 42.3\end{array}$

$\begin{array}{llll}97.4 \% & 16.9 & 25.0 & 14.7\end{array}$

$99.7 \% \quad 50.5 \quad 25.0 \quad 44.2$

$99.7 \% \quad 31.6 \quad 25.0 \quad 31.6$

$\begin{array}{llll}99.7 \% & 32.6 & 25.0 & 23.8\end{array}$

$\begin{array}{llll}99.7 \% & 30.0 & 25.0 & 29.9\end{array}$

$99.7 \% \quad 40.4 \quad 25.0 \quad 33.5$

$99.7 \% \quad 51.2 \quad 25.0 \quad 50.7 \quad 2$

$\begin{array}{llll}99.4 \% & 19.9 & 25.0 & 19.9\end{array}$

$\begin{array}{lllll}99.7 \% & 43.4 & 25.0 & 31.2 & 2\end{array}$

$\begin{array}{lllll}99.7 \% & 59.0 & 25.0 & 47.0 & 4\end{array}$

$\begin{array}{llll}98.8 \% & 25.3 & 25.0 & 15.0\end{array}$

$\begin{array}{lllll}99.6 \% & 25.1 & 25.0 & 23.0 & 2\end{array}$

$\begin{array}{llll}99.7 \% & 36.2 & 25.0 & 36.2\end{array}$

$\begin{array}{lllll}99.7 \% & 46.9 & 25.0 & 46.9 & 2\end{array}$

$\begin{array}{lllll}99.7 \% & 30.4 & 25.0 & 18.3 & 3\end{array}$

$\begin{array}{llll}99.7 \% & 27.3 & 25.0 & 20.9\end{array}$

$\begin{array}{lllll}99.7 \% & 49.3 & 25.0 & 43.6 & 3\end{array}$

$\begin{array}{lllll}99.7 \% & 34.7 & 25.0 & 34.7 & 2\end{array}$

$\begin{array}{lllll}99.7 \% & 65.2 & 25.0 & 57.5 & \end{array}$

$\begin{array}{lllll}99.7 \% & 35.9 & 25.0 & 35.9 & 4\end{array}$

$\begin{array}{llll}97.9 \% & 17.8 & 25.0 & 15.8\end{array}$

$\begin{array}{llll}99.0 \% & 30.8 & 25.0 & 20.2\end{array}$

$\begin{array}{lllll}99.7 \% & 25.5 & 25.0 & 22.6 & 2\end{array}$

$\begin{array}{llll}99.0 \% & 35.0 & 25.0 & 21.9\end{array}$

$\begin{array}{lllll}99.7 \% & 38.4 & 25.0 & 31.3 & 2\end{array}$

$\begin{array}{llll}99.7 \% & 58.8 & 25.0 & 55.2\end{array}$

$\begin{array}{llll}99.7 \% & 44.7 & 25.0 & 37.2\end{array}$

$\begin{array}{llll}99.0 \% & 30.1 & 25.0 & 21.3\end{array}$

$\begin{array}{llll}99.7 \% & 51.6 & 25.0 & 51.6\end{array}$

$\begin{array}{llll}99.7 \% & 40.2 & 25.0 & 36.3\end{array}$

1434.73

1384.71

872.56

1173.60

1904.88

1269.68

1016.59

1026.55

1736.99

1132.56

1262.63

1065.62

1023.53

1121.5

1599.88

1445.74

1088.60

1099.53

1414.73

1428.88

1157.69

1285.78

1604.82

956.59

1145.55

874.46

1362.70

1059.58

1214.66

881.50

1636.83

1390.71

Page 88 of Table S-1-2 
Pobable 28S rRNA (cytosine(4447)-C(5))-methyltransferase GN=NOP2 NOP2 HUMAN 89.30 $100.0 \%$ Probable arginine--tRNA ligase, mitochondrial GN=RARS2 SYRM_HUMAN $65.51 \quad 100.0 \%$ Probable arginine--tRNA ligase, mitochondrial GN=RARS2 SYRM_HUMAN $65.51 \quad 100.0 \%$ Probable arginine--tRNA ligase, mitochondrial GN=RARS2 SYRM HUMAN $65.51 \quad 100.0 \%$ Probable ATP-dependent RNA helicase DDX17 GN=DDX17 DDX17_HUMAN $80.27 \quad 100.0 \%$ Probable ATP-dependent RNA helicase DDX17 GN=DDX17 DDX17_HUMAN $80.27 \quad 100.0 \%$ Probable ATP-dependent RNA helicase DDX17 GN=DDX17 DDX17_HUMAN $80.27 \quad 100.0 \%$ Probable ATP-dependent RNA helicase DDX17 GN=DDX17 DDX17_HUMAN $80.27 \quad 100.0 \%$ Probable ATP-dependent RNA helicase DDX17 GN=DDX17 DDX17 HUMAN 80.27 Probable ATP-dependent RNA helicase DDX17 GN=DDX17 DDX17_HUMAN 80.27 Probable ATP-dependent RNA helicase DDX17 GN=DDX17 DDX17_HUMAN 80.27 Probable ATP-dependent RNA helicase DDX17 GN=DDX17 DDX17_HUMAN 80.27 Probable ATP-dependent RNA helicase DDX17 GN=DDX17 DDX17_HUMAN 80.27 Probable ATP-dependent RNA helicase DDX17 GN=DDX17 DDX17_HUMAN 80.27 Probable ATP-dependent RNA helicase DDX17 GN=DDX17 DDX17_HUMAN 80.27 Probable ATP-dependent RNA helicase DDX17 GN=DDX17 DDX17_HUMAN $80.2^{2}$ Probable ATP-dependent RNA helicase DDX17 GN=DDX17 DDX17 HUMAN 80.27 Probable ATP-dependent RNA helicase DDX17 GN=DDX17 DDX17_HUMAN 80.27 Probable ATP-dependent RNA helicase DDX17 GN=DDX17 DDX17_HUMAN 80.27 Probable ATP-dependent RNA helicase DDX17 GN=DDX17 DDX17_HUMAN 80.27 Probable ATP-dependent RNA helicase DDX17 GN=DDX17 DDX17_HUMAN 80.27 Probable ATP-dependent RNA helicase DDX17 GN=DDX17 DDX17_HUMAN 80.27 Probable ATP-dependent RNA helicase DDX17 GN=DDX17 DDX17_HUMAN 80.27 Probable ATP-dependent RNA helicase DDX17 GN=DDX17 DDX17_HUMAN 80.2 Probable ATP-dependent RNA helicase DDX17 GN=DDX17 DDX17 HUMAN 80.2 Probable ATP-dependent RNA helicase DDX20 GN=DDX20 DDX20_HUMAN 92.24 Probable ATP-dependent RNA helicase DDX20 GN=DDX20 DDX20_HUMAN 92.24 Probable ATP-dependent RNA helicase DDX23 GN=DDX23 DDX23 HUMAN 95.5 Probable ATP-dependent RNA helicase DDX23 GN=DDX23 DDX23_HUMAN 95.5 Probable ATP-dependent RNA helicase DDX28 GN=DDX28 DDX28 HUMAN 59.58 Probable ATP-dependent RNA helicase DDX28 GN=DDX28 DDX28_HUMAN 59.58 Probable ATP-dependent RNA helicase DDX28 GN=DDX28 DDX28_HUMAN 59.5 Probable ATP-dependent RNA helicase DDX28 GN=DDX28 DDX28_HUMAN 59.58 Probable ATP-dependent RNA helicase DDX28 GN=DDX28 DDX28_HUMAN 59.58 Probable ATP-dependent RNA helicase DDX28 GN=DDX28 DDX28_HUMAN 59.58 Probable ATP-dependent RNA helicase DDX28 GN=DDX28 DDX28 HUMAN 59.5 Probable ATP-dependent RNA helicase DDX28 GN=DDX28 DDX28_HUMAN 59.58 Probable ATP-dependent RNA helicase DDX28 GN=DDX28 DDX28 HUMAN 59.5 Probable ATP-dependent RNA helicase DDX28 GN=DDX28 DDX28_HUMAN 59.58 Probable ATP-dependent RNA helicase DDX28 GN=DDX28 DDX28_HUMAN 59.58 Probable ATP-dependent RNA helicase DDX5 GN=DDX5 DDX5 HUMAN 69.15 Probable ATP-dependent RNA helicase DDX5 GN=DDX5 DDX5_HUMAN 69.15 Probable ATP-dependent RNA helicase DDX5 GN=DDX5 DDX5_HUMAN 69.15 Probable ATP-dependent RNA helicase DDX5 GN=DDX5 DDX5 HUMAN 69.1 Probable ATP-dependent RNA helicase DDX5 GN=DDX5 DDX5_HUMAN 69.1 Probable ATP-dependent RNA helicase DDX5 GN=DDX5 DDX5_HUMAN 69.15 Probable ATP-dependent RNA helicase DDX5 GN=DDX5 DDX5_HUMAN 69.15
$100.0 \%$

$100.0 \% \quad 13$

$100.0 \% \quad 13$

$100.0 \% \quad 13$ $100.0 \% \quad 13$ $100.0 \% \quad 13$ $100.0 \% \quad 13$ $100.0 \%$ $100.0 \%$ $100.0 \%$ $100.0 \%$ $100.0 \% \quad 13$ $100.0 \% \quad 13$ $100.0 \% \quad 13$ $100.0 \% \quad 13$ $100.0 \% \quad 13$ $100.0 \% \quad 13$ $100.0 \%$ $100.0 \%$ $100.0 \% \quad 2$ $100.0 \%$ $100.0 \%$ $100.0 \%$ $100.0 \%$ $100.0 \%$ $100.0 \%$ $100.0 \%$ $100.0 \%$ $100.0 \%$ $100.0 \%$ $100.0 \%$ $100.0 \%$ $100.0 \% \quad 2$ $100.0 \% \quad 2$ $100.0 \% \quad 2$ $100.0 \% \quad 21$ $100.0 \% \quad 21$
$0.02 \% \quad 11.8 \%$ TQASSSFQDSSQPAGK $0.01 \% \quad 5.5 \%$ AIACQLSR $5.5 \%$ TVLQQVIEDGSK $0.01 \% \quad 5.5 \%$ IVVEFSSPNVAK $0.05 \% \quad 28.0 \%$ APLPDLYPFGTMR $0.05 \% \quad 28.0 \%$ NFYVEHPEVAR $0.05 \% \quad 28.0 \%$ LTPYEVDELRR $0.05 \% \quad 28.0 \%$ DMVGIAQTGSGK $0.05 \% \quad 28.0 \%$ GDGPICLVLAPTR $0.05 \% \quad 28.0 \%$ ELAQQVQQVADDYGK $0.05 \% \quad 28.0 \%$ LKSTCIYGGAPK $0.05 \% \quad 28.0 \%$ STCIYGGAPK $0.05 \% \quad 28.0 \%$ GPQIRDLER $0.05 \% \quad 28.0 \%$ GVEICIATPGR

$0.05 \% \quad 28.0 \%$ KIVDQIRPDR $0.05 \% \quad 28.0 \%$ IVDQIRPDR $0.05 \% \quad 28.0 \%$ QLAEDFLR $0.05 \% \quad 28.0 \%$ SGKAPILIATDVASR $0.05 \% \quad 28.0 \%$ APILIATDVASR $0.05 \% \quad 28.0 \%$ STNKGTAYTFFTPGNLK $0.05 \% \quad 28.0 \%$ GTAYTFFTPGNLK $0.05 \% \quad 28.0 \%$ ELIKVLEEANQAINPK $0.05 \% \quad 28.0 \%$ VLEEANQAINPK $\begin{array}{lll}0.05 \% & 28.0 \% & \text { LMQLVDHRGGGGG } \\ 0.05 \% & 28.0 \% & \text { SSQSSSQQFSGIGR }\end{array}$ $0.01 \% \quad 2.3 \%$ TAQDLSSPR $0.01 \% \quad 2.3 \%$ VLISTDLTSR $0.00 \% \quad 4.2 \%$ AQPLSLEELLAK $0.00 \% \quad 4.2 \%$ QAIPIGLQNRDIIGVAETGSGK $0.03 \% \quad 23.7 \%$ SPDEPLPVVR $0.03 \% \quad 23.7 \%$ RPELNQPAR $0.03 \% \quad 23.7 \%$ AQQEAPAVR $0.03 \% \quad 23.7 \%$ GSFADLGLEPR $0.03 \% \quad 23.7 \%$ LLGQPSLDSLPIPAPR $0.03 \% \quad 23.7 \%$ GLVLVPSRELAQQVR $0.03 \% \quad 23.7 \%$ AVAQPLGR $0.03 \% \quad 23.7 \%$ VASPDAVTTITSSK $0.03 \% \quad 23.7 \%$ LQGQMPALMR $0.03 \% \quad 23.7 \%$ VGIFQSFQK $0.03 \% \quad 23.7 \%$ SLPGLASSVKEPLPQAT $0.11 \% 30.8 \%$ FGNPGEKLVK $0.11 \% \quad 30.8 \%$ NFYQEHPDLARR $0.11 \% \quad 30.8 \%$ TAQEVETYR $0.11 \% \quad 30.8 \%$ TAQEVETYRR $0.11 \% \quad 30.8 \%$ GDGPICLVLAPTR $0.11 \% \quad 30.8 \%$ ELAQQVQQVAAEYCR $0.11 \% \quad 30.8 \%$ LKSTCIYGGAPK
$99.7 \% \quad 56.4$ $99.0 \% \quad 42.0$ $99.7 \% \quad 44.8$ $99.7 \% \quad 46.5$ $97.9 \% 21.5$ $99.7 \% \quad 36.3$ $99.6 \% \quad 26.4$ $99.7 \% \quad 51.8$ $99.7 \% 33.0$ $99.7 \% \quad 51.4$ $\begin{array}{lll}99.7 \% & 57.8\end{array}$ $99.7 \% \quad 63.3$ $99.2 \% \quad 25.8$ $99.7 \% \quad 61.9$ $99.3 \% \quad 24.5$ $98.3 \% 19$. $99.0 \% \quad 28.6$ $99.7 \% \quad 63.5$ $99.7 \% \quad 60.8$ $99.7 \% \quad 42.0$ $99.7 \% \quad 28.8$ $99.7 \% \quad 61.1$ $99.7 \% \quad 51.1$

\section{$\begin{array}{lll}99.4 \% & 20.7\end{array}$} $99.7 \% \quad 68.0$ $99.7 \% \quad 42.5$ $99.7 \% \quad 40.0$ $99.4 \% \quad 20.0$ $\begin{array}{ll}96.0 \% & 14.5 \\ 95.7 \% & 15.4\end{array}$ $95.7 \% \quad 15.4$ $\begin{array}{lll}99.7 \% & 40.7\end{array}$ $\begin{array}{lll}99.7 \% & 29.5\end{array}$ $\begin{array}{lll}99.7 \% & 40.8\end{array}$ $99.7 \% \quad 35.3$ $\begin{array}{lll}99.7 \% & 31.2\end{array}$ $99.0 \% \quad 26.9$ $99.7 \% \quad 41.5$ $99.2 \% \quad 25.4$ $99.7 \% \quad 48.0$ $99.7 \% \quad 56.4$ $99.7 \% \quad 40.0$ $99.7 \% \quad 33.8$ $\begin{array}{lll}99.7 \% & 53.7\end{array}$ $99.7 \% \quad 30.7$ $99.7 \% \quad 33.0$ $\begin{array}{lll}99.7 \% & 57.3\end{array}$ $99.7 \% \quad 57.8$
1316.7

1289.7

1477.75

1360.66

1390.73

1163.57

1368.73

1691.82

1294.68

1053.50

1083.59

1172.61

1239.72

1111.62

991.52

1498.86

1226.71

1846.93

1416.72

1809.01

1325.71

1623.81

1455.68

974.49

1104.63

1311.75

2237.23

1108.60

1080.59

969.51

1161.59

1673.96

1664.98

811.48

1376.73

1144.60

1053.57

1694.93

1088.61

1545.76

1096.53

1252.63

1368.73

1792.86 1294.68 
Probable ATP-dependent RNA helicase DDX5 GN=DDX5 DDX5_HUMAN $69.15 \quad 100.0 \% \quad 21$ $\begin{array}{lllll}\text { Probable ATP-dependent RNA helicase DDX5 GN=DDX5 } & \text { DDX5_HUMAN } & 69.15 & 100.0 \% & 21 \\ \text { Probable ATP-dependent RNA helicase DDX5 GN=DDX5 } & \text { DDX5_HUMAN } & 69.15 & 100.0 \% & 21\end{array}$ Probable ATP-dependent RNA helicase DDX5 GN=DDX5 DDX5_HUMAN $69.15 \quad 100.0 \% \quad 21$ Probable ATP-dependent RNA helicase DDX5 GN=DDX5 DDX5 HUMAN $69.15 \quad 100.0 \%$ Probable ATP-dependent RNA helicase DDX5 GN=DDX5 DDX5_HUMAN $69.15 \quad 100.0 \% \quad 2$ Probable ATP-dependent RNA helicase DDX5 GN=DDX5 DDX5_HUMAN $69.15 \quad 100.0 \% \quad 2$ Probable ATP-dependent RNA helicase DDX5 GN=DDX5 DDX5_HUMAN $69.15 \quad 100.0 \% \quad 2$ Probable ATP-dependent RNA helicase DDX5 GN=DDX5 DDX5_HUMAN $69.15 \quad 100.0 \%$ Probable ATP-dependent RNA helicase DDX5 GN=DDX5 DDX5_HUMAN $69.15 \quad 100.0 \%$ Probable ATP-dependent RNA helicase DDX5 GN=DDX5 DDX5_HUMAN $69.15 \quad 100.0 \%$ Probable ATP-dependent RNA helicase DDX5 GN=DDX5 DDX5_HUMAN $69.15 \quad 100.0 \%$ Probable ATP-dependent RNA helicase DDX5 GN=DDX5 DDX5 HUMAN $69.15 \quad 100.0 \%$ Probable ATP-dependent RNA helicase DDX5 GN=DDX5 DDX5_HUMAN $69.15 \quad 100.0 \%$ Probable ATP-dependent RNA helicase DDX5 GN=DDX5 DDX5_HUMAN $69.15 \quad 100.0 \%$ Probable ATP-dependent RNA helicase DDX52 GN=DDX52 DDX52_HUMAN $67.50 \quad 100.0 \%$ Probable ATP-dependent RNA helicase DDX52 GN=DDX52 DDX52_HUMAN $67.50 \quad 100.0 \%$ Probable ATP-dependent RNA helicase DDX56 GN=DDX56 DDX56 HUMAN $61.59 \quad 100.0 \%$ Probable ATP-dependent RNA helicase DDX56 GN=DDX56 DDX56_HUMAN $61.59 \quad 100.0 \%$ Probable ATP-dependent RNA helicase DHX40 GN=DHX40 DHX40_HUMAN $88.56 \quad 100.0 \%$ Probable ATP-dependent RNA helicase DHX40 GN=DHX40 DHX40_HUMAN $88.56 \quad 100.0 \%$ Probable C-mannosyltransferase DPY19L1 GN=DPY19L1 D19L1_HUMAN $77.32 \quad 100.0 \%$ Probable C-mannosyltransferase DPY19L1 GN=DPY19L1 D19L1_HUMAN $77.32 \quad 100.0 \%$ Probable cytosolic iron-sulfur protein assembly protein CIAOI GN=CIAOI CIAO1_HUMAN $37.84 \quad 100.0 \%$ $\begin{array}{llll}\text { Probable cytosolic iron-sulfur protein assembly protein } \mathrm{CIAOI} \mathrm{GN}=\mathrm{CIAO} \quad \text { CIAO1_HUMAN } 37.84 & 100.0 \%\end{array}$ PIAOI HUMAN $37.84 \quad 100.0 \%$ Probable dimethyladenosine transferase GN=DIMT1 DIM1_HUMAN $35.24 \quad 100.0 \%$ Probable dimethyladenosine transferase GN=DIMT1 DIM1_HUMAN $35.24 \quad 100.0 \%$ Probable dimethyladenosine transferase GN=DIMT1 DIM1_HUMAN $35.24 \quad 100.0 \%$ Probable dimethyladenosine transferase GN=DIMT1 DIM1_HUMAN $35.24 \quad 100.0 \%$ Probable dimethyladenosine transferase GN=DIMT1 DIM1 HUMAN $35.24 \quad 100.0 \%$ Probable dimethyladenosine transferase GN=DIMT1 DIM1_HUMAN $35.24 \quad 100.0 \%$ Probable dimethyladenosine transferase GN=DIMT1 DIM1_HUMAN $35.24 \quad 100.0 \%$ Probable dimethyladenosine transferase GN=DIMT1 DIM1_HUMAN $35.24 \quad 100.0 \%$ Probable dimethyladenosine transferase GN=DIMT1 DIM1_HUMAN $35.24 \quad 100.0 \%$ Probable glutamate--tRNA ligase, mitochondrial GN=EARS2 SYEM_HUMAN $58.69 \quad 100.0 \%$ Probable glutamate--tRNA ligase, mitochondrial GN=EARS2 SYEM_HUMAN $58.69 \quad 100.0 \%$ Probable leucine--tRNA ligase, mitochondrial GN=LARS2 SYLM_HUMAN $101.98 \quad 100.0 \%$ Probable leucine--tRNA ligase, mitochondrial GN=LARS2 SYLM_HUMAN $101.98 \quad 100.0 \%$ Probable methyltransferase-like protein 15 GN=METTL15 MET15_HUMAN $46.12 \quad 100.0 \%$ Probable methyltransferase-like protein 15 GN=METTL15 MET15_HUMAN $46.12 \quad 100.0 \%$ Probable rRNA-processing protein EBP2 GN=EBNA1BP2 EBP2 HUMAN $34.85 \quad 100.0 \%$ Probable rRNA-processing protein EBP2 GN=EBNA1BP2 EBP2_HUMAN $34.85 \quad 100.0 \%$ Probable tRNA N6-adenosine threonylcarbamoyltransferase GN=OSGEP OSGEP HUMAN $36.43 \quad 100.0 \%$ Probable tRNA N6-adenosine threonylcarbamoyltransferase GN=OSGEP OSGEP HUMAN $36.43 \quad 100.0 \%$ Probable tRNA N6-adenosine threonylcarbamoyltransferase GN=OSGEP OSGEP_HUMAN $36.43 \quad 100.0 \%$ Probable tRNA N6-adenosine threonylarbamoyltransferse GN=OSGEP OSGEP HUMAN $36.43 \quad 100.0 \%$ Probable tRNA N6-adenosine threonylcarbamoyltransferase GN=OSGEP OSGEP_HUMAN $36.43 \quad 100.0 \%$

9

2
2
2

2

$77 \quad 0.11 \% \quad 30.8 \%$ STCIYGGAPK$$
2
$$

$0.11 \% 30.8 \%$ GPQIRDLER

$0.11 \% \quad 30.8 \%$ GVEICIATPGR

$0.11 \% 30.8 \%$ LIDFLECGK

$0.11 \% \quad 30.8 \%$ KIVDQIRPDR

$0.11 \% \quad 30.8 \%$ IVDQIRPDR

$0.11 \% \quad 30.8 \%$ TIVFVETKR

$0.11 \% \quad 30.8 \%$ QVSDLISVLR

$0.11 \% \quad 30.8 \%$ LLQLVEDR

$\begin{array}{llll}0.01 \% & 4.3 \% & \text { TPLCNLLVK }\end{array}$

$0.01 \% \quad 10.6 \%$ SVLSEGHQR

$0.03 \% \quad 30.0 \%$ NPLIINSIIDK

$0.03 \% \quad 30.0 \%$ VVACELDPR

$0.03 \% 30.0 \%$ LVAELHKR

$$
\begin{aligned}
& 18 \\
& 18 \\
& 18
\end{aligned}
$$

$0.03 \% \quad 30.0 \%$ SSAVQQLLEK
$0.11 \% \quad 30.8 \%$ LMEEIMSEKENK

$0.11 \% \quad 30.8 \%$ APILIATDVASR

$0.11 \% \quad 30.8 \%$ TGTAYTFFTPNNIK

$0.11 \% 30.8 \%$ QVSDLISVLREANQAINPK

$0.11 \% 30.8 \%$ LLQLVEDRGSGR

$0.01 \% \quad 4.3 \%$ ELLASAPTGSGK

$0.01 \% \quad 4.3 \%$ AITFFTEDDKPLLR

$0.00 \% \quad 4.8 \%$ GLVLVPTKELAR

$0.00 \% \quad 4.8 \%$ VANVSAAEDSVSQR

$0.00 \% \quad 3.1 \%$ LGLDILEVVPISK

$0.00 \% \quad 3.1 \%$ TSLTSVVLTLK

$0.01 \% \quad 10.6 \%$ SVAWAPSGNLLATCSR

$0.01 \% \quad 10.6 \%$ LASCSDDRTVR

$0.03 \% \quad 30.0 \%$ LQVLVGDVLK

$0.03 \% \quad 30.0 \%$ LVAKPGDKLYCR

$0.03 \% \quad 30.0 \%$ LSINTQLLAR

$0.03 \% \quad 30.0 \%$ NNFRPPPKVESSVVR

$0.03 \% \quad 30.0 \%$ SMDIDDFIR

$0.00 \% \quad 3.8 \%$ TALYNYIFAK

$0.00 \% \quad 3.8 \%$ NMSQEQVAQK

$0.00 \% \quad 2.2 \% \quad$ VYTISDTIAR

$0.00 \% \quad 2.2 \%$ TALINFLVQD

$0.00 \% \quad 5.9 \%$ KIASAIVQAR

$0.00 \% \quad 5.9 \% \quad$ VLSPQDQDVQDNPR

$0.01 \% \quad 7.2 \%$ QAQAAVLAVLPR

$0.01 \% \quad 7.2 \%$ ESYDDVSSFR

$0.01 \% \quad 14.9 \%$ RTYVTPPGTGFLPGDTAR

$\begin{array}{lll}0.01 \% & 14.9 \% & \text { TYVTPPGTGFLPGDTAR } \\ 0.01 \% & 14.9 \% \text { ISNDPSPGYNIEQMAKR }\end{array}$

$0.01 \% \quad 14.9 \%$ AGHRTPLSDSGVTQR

$0.01 \% \quad 14.9 \%$ TPLSDSGVTQR $\begin{array}{ll}99.7 \% & 63.3 \\ 99.2 \% & 25.8\end{array}$

$99.7 \% \quad 61.9$

$99.7 \% \quad 43.4$

$99.3 \% \quad 24.5$

$\begin{array}{lll}98.3 \% & 19.1\end{array}$

$99.7 \% \quad 31.5$

$98.6 \% \quad 17.5$

$99.7 \% \quad 60.8$

$99.7 \% \quad 43.2$

$99.7 \% \quad 50.0$

$9.2 \% 21$.

$99.0 \% \quad 53.8$

$99.7 \% \quad 51.9$

$99.7 \% \quad 30.5$

$99.7 \% \quad 32.8$

$99.7 \% \quad 37.0$

$99.7 \% \quad 67.7$

$99.7 \% \quad 36.5$

$99.7 \% \quad 44.0$

$\begin{array}{ll}99.7 \% & 25.4 \\ 99.7 \% & 35.0\end{array}$

$99.5 \% \quad 24.0$

$99.7 \% \quad 47.6$

$99.4 \% \quad 20.3$

$99.7 \% \quad 27.9$

$99.1 \% \quad 28.1$

$\begin{array}{lll}99.0 \% & 31.7\end{array}$

$99.7 \% \quad 58.7$

$\begin{array}{lll}99.5 \% & 22.6\end{array}$

$99.7 \% \quad 62.4$

$99.6 \% \quad 26.1$

$\begin{array}{lll}99.7 \% & 51.2\end{array}$

$98.3 \% \quad 21.2$

$\begin{array}{lll}94.8 \% & 17.4\end{array}$

$99.5 \% \quad 21.8$

$99.7 \% \quad 26.8$

$99.7 \% \quad 33.9$

$98.0 \% \quad 16.1$

$99.7 \% \quad 57.6$

$99.7 \% \quad 58.3$

$99.7 \% \quad 30.7$

$96.6 \% 16.1$

$99.2 \% \quad 22.0$

$99.7 \% \quad 35.9$

$99.7 \% \quad 51.3$

1083.59

1172.6

1094.56
1239.72

1111.62

1480.70

1092.64

1226.7

1574.79

1129.66

2095.15

985.57

1342.74

1130.61

1665.88

1295.80

1432.70

1395.85

1161.71

2104.01

1057.6

1012.52

1689.84

1279.6

1239.73

1058.53

965.59

1083.68

1419.78

1128.67

1725.94

1102.61

1111.51

1203.64

1162.55

1138.61

1133.62

1056.65 
Probable tRNA pseudouridine synthase 2 GN=TRUB2 TRUB2_HUMAN $36.70 \quad 100.0 \%$ Probable tRNA pseudouridine synthase 2 GN=TRUB2 TRUB2_HUMAN $36.70 \quad 100.0 \%$ Probable tRNA pseudouridine synthase 2 GN=TRUB2 TRUB2_HUMAN $36.70 \quad 100.0 \%$ Probable ubiquitin carboxyl-terminal hydrolase FAF-X GN=USP9X USP9X HUMAN $292.28 \quad 100.0 \%$ Probable ubiquitin carboxyl-terminal hydrolase FAF-X GN=USP9X USP9X_HUMAN $292.28 \quad 100.0 \%$ Probable ubiquitin carboxyl-terminal hydrolase FAF-X GN=USP9X USP9X_HUMAN $292.28 \quad 100.0 \%$ Probable ubiquitin carboxyl-terminal hydrolase FAF-X GN=USP9X USP9X HUMAN $292.28 \quad 100.0 \%$ Probable ubiquitin carboxyl-terminal hydrolase FAF-X GN=USP9X USP9X_HUMAN $292.28 \quad 100.0 \%$ Probable ubiquitin carboxyl-terminal hydrolase FAF-X GN=USP9X USP9X HUMAN $292.28 \quad 100.0 \%$ Probable ubiquitin carboxyl-terminal hydrolase FAF-X GN=USP9X USP9X_HUMAN $292.28 \quad 100.0 \%$ Procollagen-lysine,2-oxoglutarate 5-dioxygenase 1 GN=PLOD1 PLOD1_HUMAN $83.55 \quad 100.0 \%$ Procollagen-lysine 2-oxoglutarate 5-dioxygenase 1 GN=PLOD1 PLOD1_HUMAN 83.55 $100.0^{\circ}$ Programmed cell death 6-interacting protein GN=PDCD6IP PDC6I_HUMAN 96.03 $100.0 \%$ Programmed cell death 6-interacting protein GN=PDCD6IP PDC6I_HUMAN $96.03 \quad 100.0 \%$ Prohibitin GN=PHB Prohibitin GN=PHB Prohibitin $\mathrm{GN}=\mathrm{PHB}$ Prohibitin GN=PHB Prohibitin $\mathrm{GN}=\mathrm{PHB}$ Prohibitin $\mathrm{GN}=\mathrm{PHB}$ Prohibitin GN=PHB Prohibitin $\mathrm{GN}=\mathrm{PHB}$ Prohibitin $\mathrm{GN}=\mathrm{PHB}$ Prohibitin $\mathrm{GN}=\mathrm{PHB}$ Prohibitin $\mathrm{GN}=\mathrm{PHB}$ Prohibitin GN=PHB Prohibitin $\mathrm{GN}=\mathrm{PHB}$ Prohibitin $\mathrm{GN}=\mathrm{PHB}$ Prohibitin GN=PHB Prohibitin $\mathrm{GN}=\mathrm{PHB}$ Prohibitin GN=PHB Prohibitin-2 GN=PHB2 Prohibitin-2 GN=PHB2 Prohibitin-2 GN=PHB2 Prohibitin-2 GN=PHB2 Prohibitin-2 GN=PHB2 Prohibitin-2 GN=PHB2 Prohibitin-2 GN=PHB2 Prohibitin-2 GN=PHB2 Prohibitin $-2 \mathrm{GN}=\mathrm{PHB} 2$ Prohibitin-2 GN=PHB2 Prohibitin-2 GN=PHB2 Prohibitin $-2 \mathrm{GN}=\mathrm{PHB} 2$ Prohibitin-2 GN=PHB2 Prohibitin-2 GN=PHB2 Prohibitin $-2 \mathrm{GN}=\mathrm{PHB} 2$ Prohibitin-2 GN=PHB2
$0.01 \% \quad 9.1 \%$ DTVELQLLK

$0.01 \% \quad 9.1 \%$ SPMLITGIR

$0.01 \% \quad 9.1 \%$ AATPQVAAELEK

$0.02 \% \quad 3.0 \%$ VPGQEETVK

$0.02 \% \quad 3.0 \%$ VISSVSYYTHR

$0.02 \% \quad 3.0 \%$ VVIQSNDDIASR

$0.02 \% \quad 3.0 \%$ NNFLPNADMETR

$0.02 \% \quad 3.0 \%$ ELLAFQTSEK

$0.02 \% \quad 3.0 \%$ VLGGSFADQK

$0.02 \% \quad 3.0 \% \quad$ IIEDCSNSEETVK

$0.00 \% \quad 3.6 \%$ FLGSGGFIGYAPNLSK

$0.00 \% \quad 3.6 \%$ AQFDLAFVVR

$0.01 \% \quad 2.4 \%$ EVFPVLAAK

$0.01 \% \quad 2.4 \%$ TMQGSEVVNVLK

$0.13 \% \quad 60.7 \%$ AVIFDRFR

$0.13 \% \quad 60.7 \%$ NVPVITGSKDLQNVNITLR PHB HUMAN $29.80 \quad 100.0 \% \quad 17$ PHB_HUMAN $29.80 \quad 100.0 \% \quad 17$ PHB_HUMAN $29.80 \quad 100.0 \% \quad 17$ PHB_HUMAN $29.80 \quad 100.0 \% \quad 17$ PHB HUMAN $29.80 \quad 100.0 \% \quad 17$ PHB_HUMAN $29.80 \quad 100.0 \% \quad 17$ PHB HUMAN $29.80 \quad 100.0 \% \quad 17$ PHB_HUMAN $29.80 \quad 100.0 \% \quad 17$ PHB_HUMAN $29.80 \quad 100.0 \% \quad 17$ PHB HUMAN $29.80 \quad 100.0 \% \quad 17$ PHB_HUMAN $29.80 \quad 100.0 \% \quad 17$ PHB_HUMAN $29.80 \quad 100.0 \% \quad 17$ PHB HUMAN $29.80 \quad 100.0 \% \quad 17$ PHB_HUMAN $29.80 \quad 100.0 \% \quad 17$ PHB HUMAN $29.80 \quad 100.0 \% \quad 17$ PHB HUMAN $29.80 \quad 100.0 \% \quad 17$ PHB2_HUMAN $33.30 \quad 100.0 \% \quad 26$ PHB2 HUMAN $33.30 \quad 100.0 \% \quad 26$ PHB2_HUMAN $33.30 \quad 100.0 \% \quad 26$ PHB2_HUMAN $33.30 \quad 100.0 \% \quad 26$ PHB2 HUMAN $33.30 \quad 100.0 \% \quad 26$ PHB2_HUMAN $33.30 \quad 100.0 \% \quad 26$ PHB2 HUMAN $33.30 \quad 100.0 \% \quad 26$ PHB2_HUMAN $33.30 \quad 100.0 \% \quad 26$ PHB2_HUMAN $33.30 \quad 100.0 \% \quad 26$ PHB2 HUMAN $33.30 \quad 100.0 \% \quad 26$ PHB2_HUMAN $33.30 \quad 100.0 \% \quad 26$ PHB2 HUMAN $33.30 \quad 100.0 \% \quad 26$ PHB2 HUMAN $33.30 \quad 100.0 \% \quad 26$ PHB2_HUMAN $33.30 \quad 100.0 \% \quad 26$ PHB2 HUMAN $33.30 \quad 100.0 \% \quad 26$ PHB2_HUMAN $33.30 \quad 100.0 \% \quad 26$

$0.13 \% \quad 60.7 \%$ DLQNVNITLR

$0.13 \% \quad 60.7 \%$ ILFRPVASQLPR

$0.13 \% \quad 60.7 \%$ IFTSIGEDYDER

$0.13 \% \quad 60.7 \%$ SVVARFDAGELITQR

$0.13 \% \quad 60.7 \%$ FDAGELITQR

$0.13 \% \quad 60.7 \%$ FDAGELITQRELVSR

$0.13 \% \quad 60.7 \%$ QVSDDLTER

$0.13 \% \quad 60.7 \%$ QVAQQEAERAR

$0.13 \% \quad 60.7 \%$ FVVEKAEQQK

$0.13 \% \quad 60.7 \%$ AAIISAEGDSK

$41 \quad 125 \quad 0.18 \% \quad 70.9 \%$ DLAGRLPAGPR

$41 \quad 125 \quad 0.18 \% \quad 70.9 \%$ LLLGAGAVAYGVR

$125 \quad 0.18 \% \quad 70.9 \%$ ESVFTVEGGHR

$41 \quad 125 \quad 0.18 \% \quad 70.9 \%$ IGGVQQDTILAEGLHFR

$41 \quad 125 \quad 0.18 \% \quad 70.9 \%$ ISSPTGSKDLQMVNISLR

$41 \quad 125 \quad 0.18 \% \quad 70.9 \%$ DLQMVNISLR

$5 \quad 0.18 \% \quad 70.9 \%$ VLSRPNAQELPSMYQR

$41 \quad 125 \quad 0.18 \% \quad 70.9 \%$ LGLDYEER

$41 \quad 125 \quad 0.18 \% \quad 70.9 \%$ VLPSIVNEVLK

$41 \quad 125 \quad 0.18 \% \quad 70.9 \%$ VLPSIVNEVLKSVVAK

$41 \quad 125 \quad 0.18 \% \quad 70.9 \%$ SVVAKFNASQLITQR
$99.7 \% \quad 43.7 \quad 25.0 \quad 40.6$

$99.7 \% \quad 57.7 \quad 25.0 \quad 51.4 \quad 4$

$99.7 \% \quad 50.5 \quad 25.0 \quad 43.7$

$99.7 \% \quad 50.2$

$99.7 \% \quad 49.2$

$25.0 \quad 38.9$

$99.7 \% \quad 34.8 \quad 25.0-25.6$

$99.7 \% \quad 27.0 \quad 25.0 \quad 23.3 \quad 4$

$99.7 \% \quad 53.3 \quad 25.0 \quad 42.3$

$99.7 \% \quad 47.4 \quad 25.0 \quad 42.3 \quad 4$

$99.7 \% \quad 69.2$

$\begin{array}{llllllll}0.13 \% & 60.7 \% & \text { KLEAAEDIAYQLSR } & 99.7 \% & 58.9\end{array}$

$\begin{array}{lll}25.0 & 66.9\end{array}$

$99.7 \% \quad 61.3$

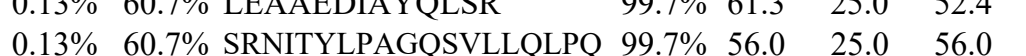

$25.0 \quad 58.9$

\section{$26 \quad 87$

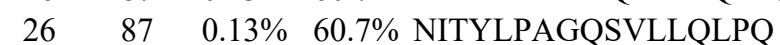

$\begin{array}{llll}99.7 \% & 37.3 & 25.0 & 31.9\end{array}$

$\begin{array}{lllll}99.7 \% & 58.8 & 25.0 & 51.9\end{array}$

$99.7 \%$ 65.7 $25.0 \quad 55.2$

$99.7 \% \quad 56.2$

$\begin{array}{llll}99.7 \% & 56.4 & 25.0 & 51.1\end{array}$

$99.7 \% \quad 58.0 \quad 25.0 \quad 40.7 \quad 6$

$.7 \% \quad 52.9$

$99.0 \% \quad 59.6$

$25.0 \quad 52.9$

$41 \quad 125 \quad 0.18 \% \quad 70.9 \%$ LGLDYEERVLPSIVNEVLK

$99.7 \% \quad 28.5$

$99.7 \% \quad 33.1$

$\begin{array}{lll}99.7 \% & 50.9\end{array}$

$99.7 \% \quad 63.8$

$99.0 \% \quad 44.0$

$99.7 \% \quad 45.5$

$99.7 \% \quad 47.5$
$28 \quad 36$ $204 \quad 212$ $321 \quad 329$ $361 \quad 371$ $777 \quad 788$

$021.53 \quad 1713 \quad 1722$

$\begin{array}{lll}1523.69 & 2289 & 2301\end{array}$

$\begin{array}{lll}1627.85 & 151 & 166\end{array}$

$1165.64 \quad 635 \quad 644$

$973.57 \quad 240 \quad 248$

$1304.69 \quad 542 \quad 553$

1023.57

2081.17

1185.66

1396.84

1444.66

1661.90

1149.59

1733.92

1062.51

1285.66

1205.65

1061.55

1998.09

1606.84

1478.75

2098.17

1855.03

1122.64

1259.75

1217.59

1853.99

1946.04

1188.64

1888.97

994.48

2186.21

1210.74

1695.04

1661.93

1177.63

899.57

055.67

981.49 


\section{Prohibitin-2 $\mathrm{GN}=\mathrm{PHB} 2$
Prolactin-inducible protein GN=PIP}

Prolactin-inducible protein GN=PIP $\begin{array}{cccc}\text { Priferating cell nuclear antigen GN=PCNA PCNA_HUMAN } & 28.77 & 100.0 \% & 14 \\ \text { Proliferating cell nuclear antigen GN=PCNA PCNA_HUMAN } & 28.77 & 100.0 \% & 14\end{array}$ Proliferating cell nuclear antigen GN=PCNA PCNA_HUMAN $28.77 \quad 100.0 \% \quad 14$ Proliferating cell nuclear antigen GN=PCNA PCNA_HUMAN $28.77 \quad 100.0 \% \quad 14$ Proliferating cell nuclear antigen GN=PCNA PCNA HUMAN $28.77 \quad 100.0 \%$ Proliferating cell nuclear antigen GN=PCNA PCNA_HUMAN $28.77 \quad 100.0 \%$ Proliferating cell nuclear antigen GN=PCNA PCNA_HUMAN $28.77 \quad 100.0 \%$ Proliferating cell nuclear antigen GN=PCNA PCNA_HUMAN 28.77 Proliferating cell nuclear antigen GN=PCNA PCNA_HUMAN $28.77 \quad 100.0 \%$ Proliferating cell nuclear antigen GN=PCNA PCNA HUMAN $28.77 \quad 100.0 \%$ Proliferating cell nuclear antigen GN=PCNA PCNA_HUMAN $28.77 \quad 100.0 \%$ Proliferating cell nuclear antigen GN=PCNA PCNA_HUMAN $28.77 \quad 100.0 \%$ Proliferating cell nuclear antigen GN=PCNA PCNA_HUMAN 28.77 Proliferating cell nuclear antigen GN=PCNA PCNA_HUMAN 28.77 Proteasomal ATPase-associated factor $1 \mathrm{GN}=$ PAAF1 PAAF1_HUMAN 42.19 Proteasomal ATPase-associated factor $1 \mathrm{GN}=\mathrm{PAAF} 1$ PAAF1 HUMAN 42.16 Proteasomal ubiquitin receptor ADRM1 GN=ADRM1 ADRM1_HUMAN 42.1: Proteasomal ubiquitin receptor ADRM1 GN=ADRM1 ADRM1_HUMAN 42.15 Proteasomal ubiquitin receptor ADRM1 GN=ADRM1 ADRM1_HUMAN $42.15 \quad 100.0 \%$ Proteasome inhibitor PI31 subunit GN=PSMF1 PSMF1_HUMAN $29.82 \quad 100.0 \%$ Proteasome inhibitor PI31 subunit GN=PSMF1 PSMF1_HUMAN $29.82 \quad 100.0 \%$ Proteasome subunit alpha type-4 GN=PSMA4 PSA4_HUMAN $29.48 \quad 100.0 \%$ Proteasome subunit alpha type-4 GN=PSMA4 PSA4 HUMAN $29.48 \quad 100.0 \%$ Proteasome subunit alpha type-4 GN=PSMA4 PSA4_HUMAN $29.48 \quad 100.0 \%$ Proteasome subunit alpha type-4 GN=PSMA4 PSA4_HUMAN $29.48 \quad 100.0 \%$ Proteasome subunit alpha type-4 GN=PSMA4 PSA4 HUMAN $29.48 \quad 100.0 \%$ Proteasome subunit alpha type-4 GN=PSMA4 PSA4_HUMAN $29.48 \quad 100.0 \%$ Proteasome subunit alpha type-4 GN=PSMA4 PSA4_HUMAN $29.48 \quad 100.0 \%$ Proteasome-associated protein ECM29 homolog GN=ECM29 ECM29 HUMAN 204.30 100.0\% Proteasome-associated protein ECM29 homolog GN=ECM29 ECM29_HUMAN $204.30 \quad 100.0 \%$ Proteasome-associated protein ECM29 homolog GN=ECM29 ECM29 HUMAN $204.30100 .0 \%$ Proteasome-associated protein ECM29 homolog GN=ECM29 ECM29_HUMAN 204.30 100.0\% Proteasome-associated protein ECM29 homolog GN=ECM29 ECM29_HUMAN $204.30 \quad 100.0 \%$ Protein arginine N-methyltransferase 1 GN=PRMT1 ANM1_HUMAN $41.52 \quad 100.0 \%$ Protein arginine N-methyltransferase $1 \mathrm{GN}=$ PRMT1 ANM1_HUMAN $41.52 \quad 100.0 \%$

$\begin{array}{llllll}25 & 0.18 \% & 70.9 \% & \text { EYTAAVEAKQVAQQEAQR } & 99.7 \% & 69.1 \\ 125 & 0.18 \% & 70.9 \% & \text { QVAQQEAQRAQFLVEK } & 99.7 \% & 52.7\end{array}$

$0.18 \% 70.9 \%$ QVAQQEAQRAQFLVEK

125

$0.18 \% 70.9 \%$ IVQAEGEAEAAK

$99.7 \% \quad 51.7$

$99.7 \% \quad 68.2$

125

$0.18 \% \quad 70.9 \%$ IVQAEGEAEAAKMLGEALSK

$99.3 \% 19.3$

$98.7 \% \quad 30.0$

0.18\% 70.9\% MLGEALSKNPGYIK

$125 \quad 0.18 \% \quad 70.9 \%$ NPGYIKLR

$125 \quad 0.18 \% \quad 70.9 \%$ IRAAQNISK

$99.7 \% \quad 48.5$

$99.0 \% \quad 40.4$

$99.6 \% \quad 30.4$

$5 \quad 0.18 \% \quad 70.9 \%$ IYLTADNLVLNLQDESFTR

$0.01 \% \quad 15.1 \%$ TVQIAAVVDVIR

$0.01 \% \quad 15.1 \%$ FYTIEILKVE

$0.06 \% \quad 46.0 \%$ LVQGSILK

$0.06 \% \quad 46.0 \%$ LVQGSILKK

$0.06 \% \quad 46.0 \%$ SEGFDTYR

$0.06 \% \quad 46.0 \%$ SEGFDTYRCDR

$\begin{array}{ll}99.7 \% & 69.7 \\ 99.7 \% & 75.7\end{array}$

$99.7 \% \quad 40.2$

$98.9 \% \quad 30.1$

$99.7 \% \quad 54.0$

$99.0 \% \quad 38.6$

$99.7 \% \quad 34.5$

$0.06 \% \quad 46.0 \%$ CDRNLAMGVNLTSMSK $\quad 99.7 \% \quad 45.2$

$0.06 \% \quad 46.0 \%$ NLAMGVNLTSMSK

$99.7 \% \quad 58.6$

$99.0 \% \quad 40.3$

$0.06 \% \quad 46.0 \%$ ICRDLSHIGDAVVISCAK $\quad 99.7 \% \quad 44.1$

$\begin{array}{lllll}0.06 \% & 46.0 \% & \text { DLSHIGDAVVISCAK } \quad 99.7 \% & 59.0\end{array}$

$0.06 \% \quad 46.0 \%$ DLSHIGDAVVISCAKDGVK $\quad 99.7 \% \quad 60.0$

$0.06 \% \quad 46.0 \%$ FSASGELGNGNIK

$99.7 \% \quad 65.8$

$0.06 \% \quad 46.0 \%$ ATPLSSTVTLSMSADVPLVVEYK $\quad 99.7 \% \quad 50.0$

$0.06 \% \quad 46.0 \%$ IADMGHLK

$0.06 \% \quad 46.0 \%$ YYLAPKIEDEEGS

$0.00 \% \quad 5.9 \%$ GGILDTAIVDR

$0.00 \% \quad 5.9 \%$ SGAPVLSLLSVR

$0.01 \% \quad 8.6 \%$ GASNKYLVEFR

$10 \quad 0.01 \% \quad 8.6 \%$ VPQCPSGR

$10 \quad 0.01 \% \quad 8.6 \%$ SQSAAVTPSSTTSSTR

$0.00 \% \quad 11.8 \%$ TYKNSEELR

$0.00 \% \quad 11.8 \%$ ALIDPSSGLPNRLPPGAVPPGAR

PGAR $99.6 \% 24.6$

$13 \quad 0.02 \% \quad 27.2 \%$ YDSRTTIFSPEGR

$3 \quad 0.02 \% \quad 27.2 \%$ TTIFSPEGR

$3 \quad 0.02 \% \quad 27.2 \%$ LLDEVFFSEK

$0.02 \% \quad 27.2 \%$ QAYTQFGGK

$3 \quad 0.02 \% \quad 27.2 \%$ ATCIGNNSAAAVSMLK

$0.02 \% \quad 27.2 \%$ VLNKTMDVSK

$3 \quad 0.02 \% \quad 27.2 \%$ LSAEKVEIATLTR

$0.01 \% \quad 3.4 \%$ SASPFNLAEKPK

$0.01 \% \quad 3.4 \%$ AGEQLAPFLPQLVPR

$0.01 \% \quad 3.4 \%$ ESSCLALNDLLR

$0.01 \% \quad 3.4 \%$ AQGAIAMASIAK

$0.01 \% \quad 3.4 \%$ IVAISCAADILK

$0.01 \% \quad 14.7 \%$ KVIGIECSSISDYAVK

$0.01 \% \quad 14.7 \%$ ATLYVTAIEDR
$99.0 \% \quad 45.3$

$99.7 \% \quad 52.5$

$99.7 \% \quad 33.2$

$99.7 \% \quad 44.6$

$99.7 \% \quad 41.2$

$99.0 \% \quad 40.1$

$99.7 \% 53.4$

$99.6 \% 26.5$

$99.7 \% \quad 30.6$

$99.7 \% \quad 52.2$

$99.5 \% \quad 26.0$

$99.7 \% \quad 56.8$

$99.0 \% \quad 19.2$

$99.7 \% \quad 36.4$

$96.5 \% \quad 18.0$

$99.7 \% \quad 37.5$

$95.6 \% \quad 22.4$

$98.9 \% \quad 30.2$

$99.7 \% \quad 54.7$

$99.7 \% \quad 34.7$

$99.7 \% \quad 70.0$
43.52

$\begin{array}{ll}4.0 & 44.3\end{array}$

\begin{tabular}{ll}
54.7 \\
\hline
\end{tabular}

$\begin{array}{lll}.0 & 19.3 \quad 0\end{array}$

.0
8.9

\begin{tabular}{ll}
0 & 45.5 \\
\hline
\end{tabular}

$\begin{array}{ll}.0 & 13.8\end{array}$

$\begin{array}{ll}25.0 & 69.7\end{array}$

$\begin{array}{ll}65.0 & 63.4\end{array}$

$\begin{array}{ll}5.0 & 36.9\end{array}$

$\begin{array}{lll}25.0 & 6.1 & 2\end{array}$

$\begin{array}{lll}.0 & 23.1 & 3\end{array}$

$\begin{array}{lll}.0 & 38.5 & 2\end{array}$

\begin{tabular}{ll}
.0 & 29.9 \\
\hline & 45.2
\end{tabular}

$\begin{array}{ll}25.0 & 57.2\end{array}$

$\begin{array}{ll}5.0 & 31.9\end{array}$

$\begin{array}{ll}25.0 & 44.1\end{array}$

$5.0 \quad 59.0$

$\begin{array}{ll}25.0 & 58.2\end{array}$

$5.0 \quad 59.4$

$\begin{array}{lll}5.0 & 50.0 & 2\end{array}$

$\begin{array}{lll}25.0 & 37.9 & 2\end{array}$

$\begin{array}{lll}5.0 & 52.5 & 2\end{array}$

$\begin{array}{ll}23.0 & 23.8\end{array}$

$\begin{array}{lll} & 43.0\end{array}$

\begin{tabular}{ll}
.0 & 24.7 \\
\hline & 38.1
\end{tabular}

$5.0 \quad 53.1$

$\begin{array}{ll}5.0 & 18.0\end{array}$

$25.0 \quad 24.6$

$\begin{array}{ll}5.0 & 22.1\end{array}$

$\begin{array}{ll}26.0 & 26.4\end{array}$

$\begin{array}{ll}5.0 & 48.5\end{array}$

$25.0 \quad 22.0$

$5.0 \quad 54.4$

$\begin{array}{lll}5.0 & 19.2 \quad 2\end{array}$

$\begin{array}{lll}5.0 & 36.4 & 2\end{array}$

$25.0 \quad 15.0$

$\begin{array}{lll}25.0 & 34.2 & 2\end{array}$

$\begin{array}{ll}25.0 & 15.1\end{array}$

$\begin{array}{ll}25.0 & 24.4\end{array}$

$\begin{array}{lll}25.0 & 54.7 & 2\end{array}$

$\begin{array}{ll}25.0 & 34.7\end{array}$

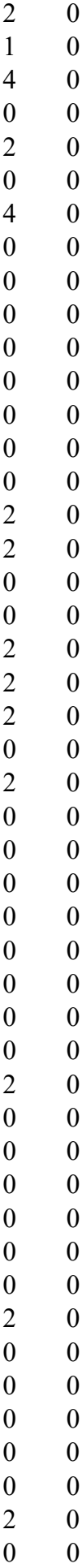

2020.01

1872.99

1471.78

1215.62

2061.05

864.45

1520.81

960.56

1000.59

2225.15

1283.77

1254.70

857.55

985.64

974.42

1405.58

1796.85

1381.68

910.41

2014.02

1584.81

1984.02

1293.64

2424.26

884.47

1513.71

1129.62

1198.72

1283.67

900.44

1567.76

1139.57

2252.25

1528.74

1007.52

1226.63

999.49

1623.78

1150.61

1430.82

1288.69

1635.92

1390.70

1131.62

1273.72

1768.92 1251.66

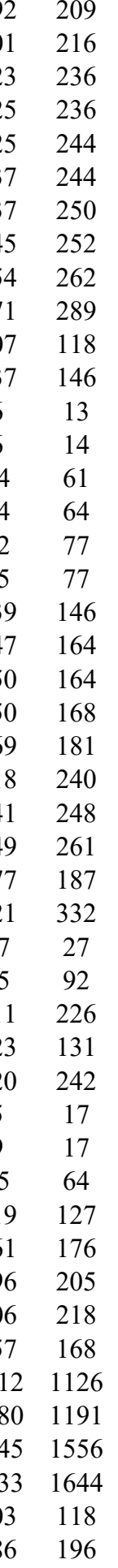


Protein arginine N-methyltransferase $1 \mathrm{GN}=$ PRMT1 ANM1_HUMAN $41.52 \quad 100.0 \%$ Protein arginine N-methyltransferase $1 \mathrm{GN}=$ PRMT1 ANM1_HUMAN $41.52 \quad 100.0 \%$ Protein arginine N-methyltransferase 3 GN=PRMT3 ANM3_HUMAN $59.88 \quad 100.0 \%$ Protein arginine N-methyltransferase $3 \mathrm{GN}=$ PRMT3 ANM3 HUMAN $59.88 \quad 100.0 \%$ Protein arginine N-methyltransferase 5 GN=PRMT5 ANM5_HUMAN $72.69 \quad 100.0 \%$ Protein arginine N-methyltransferase 5 GN=PRMT5 ANM5_HUMAN $72.69 \quad 100.0 \%$ Protein arginine N-methyltransferase 5 GN=PRMT5 ANM5_HUMAN $72.69 \quad 100.0 \%$ Protein arginine N-methyltransferase 5 GN=PRMT5 ANM5_HUMAN $72.69 \quad 100.0 \%$ Protein arginine N-methyltransferase 5 GN=PRMT5 ANM5_HUMAN $72.69 \quad 100.0 \%$ Protein arginine N-methyltransferase 5 GN=PRMT5 ANM5_HUMAN $72.69 \quad 100.0 \%$ Protein arginine N-methyltransferase 5 GN=PRMT5 ANM5_HUMAN $72.69 \quad 100.0 \%$ Protein arginine N-methyltransferase $5 \mathrm{GN}=$ PRMT5 ANM5 HUMAN $72.69100 .0 \%$ Protein arginine N-methyltransferase 5 GN=PRMT5 ANM5_HUMAN $72.69 \quad 100.0 \%$ Protein arginine N-methyltransferase 5 GN=PRMT5 ANM5_HUMAN $72.69 \quad 100.0 \%$ Protein arginine N-methyltransferase 5 GN=PRMT5 ANM5_HUMAN $72.69 \quad 100.0 \%$ Protein arginine N-methyltransferase 5 GN=PRMT5 ANM5_HUMAN $72.69 \quad 100.0 \%$ Protein arginine N-methyltransferase $5 \mathrm{GN}=$ PRMT5 ANM5 HUMAN $72.69100 .0 \%$ Protein arginine N-methyltransferase 5 GN=PRMT5 ANM5_HUMAN $72.69 \quad 100.0 \%$ Protein arginine N-methyltransferase 5 GN=PRMT5 ANM5_HUMAN $72.69 \quad 100.0 \%$ Protein arginine N-methyltransferase 5 GN=PRMT5 ANM5 HUMAN $72.69 \quad 100.0 \%$ Protein arginine N-methyltransferase 5 GN=PRMT5 ANM5_HUMAN $72.69 \quad 100.0 \%$ Protein arginine N-methyltransferase 5 GN=PRMT5 ANM5 HUMAN $72.69 \quad 100.0 \%$ Protein arginine N-methyltransferase 5 GN=PRMT5 ANM5_HUMAN $72.69 \quad 100.0 \%$ Protein arginine N-methyltransferase 5 GN=PRMT5 ANM5_HUMAN $72.69 \quad 100.0 \%$ Protein arginine N-methyltransferase 5 GN=PRMT5 ANM5 HUMAN $72.69 \quad 100.0 \%$ Protein arginine N-methyltransferase 5 GN=PRMT5 ANM5_HUMAN $72.69 \quad 100.0 \%$ Protein arginine N-methyltransferase 5 GN=PRMT5 ANM5_HUMAN $72.69 \quad 100.0 \%$ Protein arginine N-methyltransferase $5 \mathrm{GN}=$ PRMT5 ANM5 HUMAN $72.69 \quad 100.0 \%$ Protein arginine N-methyltransferase 5 GN=PRMT5 ANM5_HUMAN $72.69 \quad 100.0 \%$ Protein arginine N-methyltransferase $5 \mathrm{GN}=$ PRMT5 ANM5 HUMAN $72.69 \quad 100.0 \%$ Protein arginine N-methyltransferase 5 GN=PRMT5 ANM5_HUMAN $72.69 \quad 100.0 \%$ Protein arginine N-methyltransferase 5 GN=PRMT5 ANM5_HUMAN $72.69 \quad 100.0 \%$ Protein arginine N-methyltransferase $5 \mathrm{GN}=$ =PRMT5 ANM5 HUMAN $72.69 \quad 100.0 \%$ Protein arginine N-methyltransferase 5 GN=PRMT5 ANM5_HUMAN $72.69 \quad 100.0 \%$ Protein arginine N-methyltransferase $5 \mathrm{GN}=$ PRMT5 ANM5 HUMAN $72.69 \quad 100.0 \%$ Protein arginine N-methyltransferase $5 \mathrm{GN}=$ =PRMT5 ANM5_HUMAN $72.69 \quad 100.0 \%$ Protein arginine N-methyltransferase 5 GN=PRMT5 ANM5_HUMAN $72.69 \quad 100.0 \%$ Protein arginine N-methyltransferase $5 \mathrm{GN}=$ PRMT5 ANM5 HUMAN $72.69 \quad 100.0 \%$ Protein $\mathrm{CMSS} 1 \mathrm{GN}=\mathrm{CMSS} 1$ Protein $\mathrm{CMSS} 1 \mathrm{GN}=\mathrm{CMSS} 1$ Protein CMSS1 GN=CMSS1 Protein CMSS1 GN=CMSS1 Protein CMSS1 GN=CMSS1 Protein Daple GN=CCDC88C Protein Daple GN=CCDC88C Protein Daple GN=CCDC88C Protein Daple GN=CCDC88C

DAPLE_HUMAN $228.23 \quad 100.0 \%$
$0.01 \% \quad 14.7 \%$ QLVTNACLIK $0.01 \% \quad 14.7 \%$ TGEEIFGTIGMRPNAK $0.01 \% \quad 4.5 \%$ ALSAEAALAR $0.01 \% \quad 4.5 \%$ AVIPEAVVEVLDPK

$99.7 \% 27.9$ $95.6 \% \quad 16.1$ $99.7 \% \quad 70.8$ $99.7 \% \quad 30.8$

$336 \quad 0.49 \% \quad 49.1 \%$ VSSGRDLNCVPEIADTLGAVAK $\quad 99.7 \% \quad 56.2$

$336 \quad 0.49 \% \quad 49.1 \%$ DLNCVPEIADTLGAVAK

$336 \quad 0.49 \% \quad 49.1 \%$ QGFDFLCMPVFHPR

$336 \quad 0.49 \% \quad 49.1 \%$ REFIQEPAK

$336 \quad 0.49 \% \quad 49.1 \%$ EFIQEPAK

$48 \quad 336 \quad 0.49 \% \quad 49.1 \%$ EFIQEPAKNRPGPQTR

$48 \quad 336 \quad 0.49 \% \quad 49.1 \%$ SDLLLSGR

$336 \quad 0.49 \% \quad 49.1 \%$ SDLLLSGRDWNTLIVGK

$336 \quad 0.49 \% \quad 49.1 \%$ LSPWIRPDSK

$336 \quad 0.49 \% \quad 49.1 \%$ LSPWIRPDSKVEK

$336 \quad 0.49 \% \quad 49.1 \%$ VPLVAPEDLR

$336 \quad 0.49 \% \quad 49.1 \%$ VPLVAPEDLRDDIIENAPTTHTEEYSGEEK

$336 \quad 0.49 \% \quad 49.1 \%$ TLCDYSKR

$\begin{array}{ll}99.7 \% & 54.1 \\ 99.7 \% & 41.3\end{array}$

$99.7 \% \quad 38.5$

$99.0 \% \quad 47.5$

$99.7 \% \quad 46.8$

$99.0 \% \quad 35.7$

$97.6 \% 17.6$

$99.7 \% \quad 46.5$

$99.7 \% \quad 50.1$

$336 \quad 0.49 \% \quad 49.1 \%$ IAVALEIGADLPSNHVIDR $\quad 99.7 \% \quad 60.6$

$336 \quad 0.49 \% \quad 49.1 \%$ WLGEPIKAAILPTSIFLTNK $99.7 \% 32.4$

$336 \quad 0.49 \% \quad 49.1 \%$ AAILPTSIFLTNK

$336 \quad 0.49 \% \quad 49.1 \%$ AAILPTSIFLTNKK

$336 \quad 0.49 \% \quad 49.1 \%$ KGFPVLSK

$48 \quad 336 \quad 0.49 \% \quad 49.1 \%$ DPIKYSQYQQAIYK

$48 \quad 336 \quad 0.49 \% \quad 49.1 \%$ YSQYQQAIYK

$99.7 \% \quad 60.2$

$99.7 \% \quad 49.7$

$99.0 \% \quad 48.8$

$99.7 \% \quad 57.9$

$99.7 \% \quad 56.5$

$336 \quad 0.49 \% \quad 49.1 \%$ VPEEEKDTNVQVLMVLGAGR $99.7 \% \quad 52.2$

$336 \quad 0.49 \% \quad 49.1 \%$ DTNVQVLMVLGAGR

$336 \quad 0.49 \% \quad 49.1 \%$ GPLVNASLR

$336 \quad 0.49 \% \quad 49.1 \%$ GPLVNASLRAAK

$336 \quad 0.49 \% \quad 49.1 \%$ IKLYAVEK

$99.7 \% \quad 63.7$

$99.7 \% \quad 60.9$

$99.7 \% \quad 49.2$

$99.0 \% \quad 38.0$

$336 \quad 0.49 \% \quad 49.1 \%$ DDGVSIPGEYTSFLAPISSSK $\quad 99.7 \% \quad 43.9$

$336 \quad 0.49 \% \quad 49.1 \%$ LYNEVRACR

$336 \quad 0.49 \% \quad 49.1 \%$ DRDPEAQFEMPYVVR

$99.3 \% \quad 23.7$

$99.7 \% \quad 49.5$

$99.7 \% \quad 34.6$

$336 \quad 0.49 \% \quad 49.1 \%$ DPEAQFEMPYVVR

$99.7 \% 29.5$

$\begin{array}{lll}99.0 \% & 28.7\end{array}$

$99.6 \% 23.0$

$99.0 \% \quad 38.2$

$99.2 \% \quad 22.8$

$99.7 \% \quad 34.4$

$99.7 \% \quad 33.7$
$99.7 \% \quad 50.2$

$99.7 \% \quad 40.4$

$97.5 \% \quad 19.5$

$99.7 \% \quad 36.4$

$99.7 \% \quad 59.2$

$99.7 \% \quad 42.0$

DAPLE HUMAN $228.23 \quad 100.0 \%$

DAPLE HUMAN $228.23 \quad 100.0 \%$ CMS1 HUMAN $31.89 \quad 100.0 \%$ HUMAN $31.89 \quad 100.0 \%$

$12 \quad 0.02 \% \quad 15.8 \%$ QGGLNLSPLK

$2 \quad 0.02 \% \quad 15.8 \%$ SESLKLGLF

$16 \quad 0.02 \% \quad 3.8 \%$ VKQENIQLAADAR

$16 \quad 0.02 \% \quad 3.8 \%$ AMLEEQLTAAR

$\begin{array}{lllll}16 & 0.02 \% & 3.8 \% & \text { TCSTSATTTAPSNSTPIAR } & 99.7 \% \quad 52.5\end{array}$
1736.86

972.55

1478.85

2272.16

1785.91

1766.81

1117.60

961.50

1867.98

860.48

1887.03

1198.66

1554.86

1108.64

3367.62

1042.50

2003.09

2212.27

1388.81

1516.91

875.54

1744.89

1291.63

2184.13

1472.79

926.54

1196.71

963.59

2170.06

1180.59

1851.87

1580.74

2535.21

974.44

1656.89

962.47

1451.72

1437.76

1247.73

1091.63

1026.59

993.56

1455.79

1232.63

1204.57

1923.91 $\begin{array}{cc}34 & 243 \\ 17 & 332 \\ 69 & 178 \\ 97 & 410 \\ 4 & 35 \\ 9 & 35 \\ 6 & 49 \\ 2 & 60 \\ 3 & 60 \\ 3 & 68 \\ 9 & 76 \\ 9 & 85 \\ 6 & 95 \\ 6 & 98 \\ 55 & 164 \\ 55 & 184 \\ 94 & 201 \\ 02 & 220 \\ 21 & 240 \\ 28 & 240 \\ 28 & 241 \\ 41 & 248 \\ 30 & 343 \\ 34 & 343 \\ 49 & 368 \\ 55 & 368 \\ 69 & 377 \\ 69 & 380 \\ 86 & 393 \\ 59 & 479 \\ 80 & 488 \\ 91 & 505 \\ 93 & 505 \\ 06 & 526 \\ 27 & 534 \\ 88 & 601 \\ 94 & 601 \\ 94 & 604 \\ 5 & 97 \\ 04 & 215 \\ 05 & 215 \\ 22 & 231 \\ 71 & 279 \\ 94 & 306 \\ 64 & 374 \\ 43 & 1253 \\ 19 & 1537\end{array}$

Page 93 of Table S-1-2 
Protein Daple GN $=\mathrm{CCDC} 88 \mathrm{C}$ Protein Daple GN=CCDC88C Protein DEK GN=DEK

Protein DEK GN=DEK

Protein DEK GN=DEK

Protein DEK GN=DEK

Protein DENND6A GN=DENND6A

Protein DENND6A GN=DENND6A

Protein flightless- 1 homolog GN=FLII

Protein flightless- 1 homolog GN=FLII

Protein flightless- 1 homolog GN=FLII

Protein KRI1 homolog GN=KRI1

Protein KRI1 homolog GN=KRI1

Protein lin-28 homolog B GN=LIN28B

Protein lin-28 homolog B GN=LIN28B

Protein lin-28 homolog B GN=LIN28B

Protein LSM14 homolog A GN=LSM14A LS14A_HUMAN 50.53 Protein LSM14 homolog A GN=LSM14A LS14A_HUMAN $50.53 \quad 100.0 \%$ Protein LSM14 homolog A GN=LSM14A LS14A_HUMAN $50.53 \quad 100.0 \%$ Protein LYRIC GN=MTDH Protein LYRIC GN=MTDH Protein LYRIC GN=MTDH

Protein MON2 homolog GN=MON2 Protein MON2 homolog GN=MON2 Protein Njmu-R1 GN $=\mathrm{C} 17$ orf 75

Protein Njmu-R1 GN=C17orf75

Protein pelota homolog GN=PELO

Protein pelota homolog GN=PELO

Protein pelota homolog $\mathrm{GN}=\mathrm{PELO}$

Protein pelota homolog GN=PELO

Protein pelota homolog GN=PELO

Protein pelota homolog $\mathrm{GN}=\mathrm{PELO}$

Protein phosphatase $1 \mathrm{~B}$ GN $=$ PPM1B

Protein phosphatase $1 \mathrm{~B}$ GN $=\mathrm{PPM} 1 \mathrm{~B}$

Protein phosphatase $1 \mathrm{~B}$ GN $=\mathrm{PPM} 1 \mathrm{~B}$

Protein phosphatase 1B GN=PPM1B

Protein phosphatase $1 \mathrm{~B}$ GN=PPM1B

Protein phosphatase $1 \mathrm{~B}$ GN=PPM1B

Protein PRRC2C GN=PRRC2C

Protein PRRC2C GN=PRRC2C

Protein RFT1 homolog GN=RFT1

Protein RFT1 homolog GN=RFT1

Protein RRP5 homolog GN=PDCD1]

Protein RRP5 homolog GN=PDCD11

Protein RRP5 homolog GN=PDCD11 ON_ HUMAN $190.36 \quad 100.0 \%$

$228.23 \quad 100.0 \%$ DAPLE_HUMAN $228.23 \quad 100.0 \%$ DEK_HUMAN $42.68 \quad 100.0 \%$ DEK HUMAN $42.68 \quad 100.0 \%$ DEK_HUMAN $42.68 \quad 100.0 \%$ DEK_HUMAN $42.68 \quad 100.0 \%$ DEN6A HUMAN $69.58 \quad 100.0 \%$ DEN6A_HUMAN $69.58 \quad 100.0 \%$ FLII HUMAN $144.76 \quad 100.0 \%$ FLII_HUMAN $144.76 \quad 100.0 \%$ FII_HUMAN $144.76 \quad 100.0 \%$ KRI1_HUMAN $82.60 \quad 100.0 \%$ KRI1_HUMAN $82.60 \quad 100.0 \%$ LN28B HUMAN $27.08 \quad 100.0 \%$ LN28B HUMAN $27.08 \quad 100.0 \%$ LN28B HUMAN $27.08 \quad 100.0 \%$ LYRIC_HUMAN $63.84 \quad 100.0 \%$ LYRIC_HUMAN $63.84 \quad 100.0 \%$ MON2_HUMAN $190.36 \quad 100.0 \%$ NIPS1_HUMAN $33.31 \quad 100.0 \%$ NJMU_HUMAN $44.62 \quad 99.6 \%$ NJMU HUMAN $44.62 \quad 99.6 \%$ PELO_HUMAN $43.36 \quad 100.0 \%$ PELO HUMAN $43.36 \quad 100.0 \%$ PELO_HUMAN $43.36 \quad 100.0 \%$ PELO_HUMAN $43.36 \quad 100.0 \%$ PELO HUMAN $43.36 \quad 100.0 \%$ PELO_HUMAN $43.36 \quad 100.0 \%$ PPM1B HUMAN $52.64 \quad 100.0 \%$ PPM1B HUMAN $52.64 \quad 100.0 \%$ PPM1B_HUMAN $52.64 \quad 100.0 \%$ PPM1B HUMAN $52.64 \quad 100.0 \%$ PPM1B_HUMAN $52.64 \quad 100.0 \%$ PPM1B_HUMAN $52.64 \quad 100.0 \%$ PRC2C HUMAN $316.91 \quad 100.0 \%$ PRC2C_HUMAN $316.91 \quad 100.0 \%$ RFT1_HUMAN $60.34 \quad 100.0 \%$ RFT1_HUMAN $60.34 \quad 100.0 \%$ RRP5_HUMAN $208.70 \quad 100.0 \%$ RRP5 HUMAN $208.70 \quad 100.0 \%$ RRP5_HUMAN $208.70 \quad 100.0 \%$ $\begin{array}{lll}99.7 \% & 38.2\end{array}$

$0.02 \% \quad 3.8 \% \quad$ AFSLASADLLR

$0.02 \% \quad 3.8 \%$ SGEVATITPVR

$0.02 \% \quad 12.3 \%$ LLYNRPGTVSSLKK

$0.02 \% \quad 12.3 \%$ NVGQFSGFPFEK

$0.02 \% \quad 12.3 \%$ SICEVLDLER

$0.02 \% \quad 12.3 \%$ SGVNSELVKR

$0.00 \% \quad 4.4 \%$ IGDLKPTGEIPKQVK

$0.00 \% \quad 4.4 \% \quad$ RPSEAQSVILRR

$0.01 \% \quad 2.9 \%$ SLEGTEAQVFKAK

$0.01 \% \quad 2.9 \%$ ADLTALFLPR

$0.01 \% \quad 2.9 \%$ AVQGAQQPSLYQIR

$0.00 \% \quad 3.7 \%$ LLGPTVMLGGCEFSR

$0.00 \% \quad 3.7 \%$ QRLQAFGLNPK

$0.01 \% \quad 14.8 \%$ MGFGFISMINR

$0.01 \% \quad 14.8 \%$ NVAQPPASSQGR

$0.01 \% \quad 14.8 \%$ QEAESQPCTSTLPR

$0.01 \% \quad 7.1 \%$ SLKTQLSQGR

$0.01 \% \quad 7.1 \% \quad$ SPVSTRPLPSASQK

$0.01 \% \quad 7.1 \%$ EFADFEYRK

$0.01 \% \quad 5.5 \%$ TVEVAEGEAVR

$0.01 \% \quad 5.5 \%$ TVEVAEGEAVRTPQSVTAK

$0.01 \% \quad 5.5 \%$ TISTSDPAEVLVK

$0.00 \% \quad 1.2 \%$ ITQLCLAAIQR

$0.00 \% \quad 1.2 \%$ VLSIGLPVAR

$0.01 \% \quad 7.0 \%$ MGPNIYELR

$0.01 \% \quad 7.0 \%$ IMIPLKISPLQ

$0.00 \% \quad 4.6 \%$ GGNPFLFR

$0.00 \% \quad 4.6 \%$ AIQDTNNLKR

$0.02 \% \quad 17.1 \%$ VQTESSTGSVGSNRVR

$0.02 \% \quad 17.1 \%$ VKGTNIQENEYVK

$0.02 \% \quad 17.1 \%$ GTNIQENEYVK

$0.02 \% \quad 17.1 \%$ AKVEVNIPR

$0.02 \% \quad 17.1 \%$ YSLKEALCDPTVASR

$0.02 \% \quad 17.1 \%$ LVDSVKENAGTVR

$0.03 \% \quad 16.3 \%$ SGSTAVGVMISPK

$0.03 \% \quad 16.3 \%$ IQNAGGSVMIQR

$0.03 \% \quad 16.3 \%$ VNGSLAVSR

$99.7 \% \quad 57.3$

$97.4 \% 20.4$

$99.7 \% \quad 32.5$

$99.7 \% \quad 57.3$

$99.7 \% 52$.

$99.2 \% \quad 21.8$

$99.3 \% \quad 19.5$

$99.7 \% \quad 30.3$

$99.7 \% \quad 39.5$

$99.7 \% \quad 57.2$

$99.7 \% \quad 50.5$

$94.8 \% \quad 16.2$

$99.5 \% \quad 24.0$

$99.7 \% \quad 32.3$

$99.6 \% \quad 28.9$

$99.7 \% \quad 35.5$

$99.7 \% \quad 27.5$

$99.7 \% \quad 30.2$

$99.7 \% \quad 46.1$

$94.9 \% \quad 17.1$

$99.7 \% \quad 30.7$

$99.7 \% \quad 28.7$

$99.7 \% \quad 52.9$

$99.7 \% \quad 34.1$

$94.6 \% \quad 22.1$

$96.7 \% \quad 14.8$

$99.7 \% \quad 31.3$

$99.7 \% \quad 37.2$

$\begin{array}{lll}99.5 \% & 21.8\end{array}$

$99.7 \% \quad 53.3$

$94.8 \% \quad 13.4$

$99.7 \% 71.1$

$99.7 \% \quad 41.0$

$99.7 \% \quad 65.9$

$99.7 \% \quad 38.0$

$99.7 \% \quad 57.5$

$0.03 \% \quad 16.3 \%$ ILSAENIPNLPPGGGLAGKR

$0.03 \% \quad 16.3 \%$ NVIEAVYSR

$0.00 \% \quad 0.8 \% \quad$ SSSQIPAQPSVAK

$0.00 \% \quad 0.8 \%$ NADLNAQTVVK

$0.01 \% \quad 3.9 \%$ GSQEVLGHAAR

$0.01 \% \quad 3.9 \% \quad$ ITDLLPNITR

$0.05 \% \quad 11.5 \%$ ACILCVHPR

$0.05 \% \quad 11.5 \%$ LKDGVLAYAR

$0.05 \% \quad 11.5 \%$ TSIIEAQYLR $\begin{array}{llll}97.1 \% & 16.6 & 25.0 & 16.6\end{array}$

$\begin{array}{lllll}99.7 \% & 52.0 & 25.0 & 49.1 & 4\end{array}$

$99.1 \% \quad 25.0 \quad 25.0 \quad 18.3$

$\begin{array}{lllll}99.6 \% & 27.2 & 25.0 & 23.6 & 2\end{array}$

$\begin{array}{llll}99.7 \% & 50.8 & 25.0 & 50.8\end{array}$

$\begin{array}{llll}99.7 \% & 35.9 & 25.0 & 22.1\end{array}$

$99.6 \% \quad 27.7 \quad 25.0 \quad 20.0 \quad 2$

$\begin{array}{llll}99.7 \% & 34.5 & 25.0 & 34.5\end{array}$

$\begin{array}{llll}99.7 \% & 56.9 & 25.0 & 49.2\end{array}$
1129.6

1575.92

1356.66

1233.61

1088.61

1622.95

1411.81

1407.75

1116.64

1558.83

1636.82

1271.72

1272.62

1211.61

1603.74

1117.63

1454.80

1204.56

1159.60

1972.03

1359.74

1286.73

1024.65

1108.55

1268.77

907.48

1172.64

1663.84

1521.79

1294.63

1025.61

1709.85

1387.75

1249.65

1273.67

902.51

1694.82

1974.11

1050.56

1299.69

1172.63

1124.58

1155.67

1125.57

1105.64

1193.65 
Protein RRP5 homolog GN=PDCD11 Protein RRP5 homolog GN=PDCD11 Protein RRP5 homolog GN=PDCD1 Protein RRP5 homolog GN=PDCD1 Protein RRP5 homolog GN=PDCD11 Protein RRP5 homolog GN=PDCD1 Protein RRP5 homolog GN=PDCD11 Protein RRP5 homolog GN=PDCD11 Protein RRP5 homolog GN=PDCD11 Protein RRP5 homolog GN=PDCD11 Protein RRP5 homolog GN=PDCD1 Protein RRP5 homolog GN=PDCD11 Protein RRP5 homolog GN=PDCD11 Protein RRP5 homolog GN=PDCD11 Protein RRP5 homolog GN=PDCD11 Protein RRP5 homolog GN=PDCD1 Protein SDA1 homolog GN=SDAD1 Protein SDA1 homolog GN=SDAD1 Protein SDA1 homolog GN=SDAD 1 Protein SDA1 homolog GN=SDAD1 Protein $\mathrm{SEC} 13$ homolog GN=SEC13 Protein SEC13 homolog GN=SEC13 Protein TBRG4 GN=TBRG4

Protein TBRG4 GN=TBRG4 Protein SDA1 homolog GN=SDAD1

RRP5 HUMAN $208.70 \quad 100.0 \% \quad 19$ RRP5_HUMAN $208.70 \quad 100.0 \% \quad 19$ RRP5_HUMAN $208.70 \quad 100.0 \% \quad 19$ RRP5 HUMAN $208.70 \quad 100.0 \%$ RRP5_HUMAN $208.70 \quad 100.0 \%$ RRP5_HUMAN $208.70 \quad 100.0 \%$ RRP5 HUMAN $208.70 \quad 100.0 \%$ RRP5_HUMAN $208.70 \quad 100.0 \%$ RRP5 HUMAN $208.70 \quad 100.0 \%$ RRP5 HUMAN $208.70 \quad 100.0 \%$ RRP5_HUMAN $208.70 \quad 100.0 \%$ RRP5 HUMAN $208.70 \quad 100.0 \%$ RRP5_HUMAN $208.70 \quad 100.0 \%$ RRP5 HUMAN $208.70 \quad 100.0 \%$ RRP5 HUMAN $208.70 \quad 100.0 \%$ RRP5_HUMAN $208.70 \quad 100.0 \%$ SDA1_HUMAN $79.88 \quad 100.0 \%$ SDA1_HUMAN $79.88 \quad 100.0 \%$ SDA1_HUMAN $79.88 \quad 100.0 \%$ SDA1_HUMAN $79.88 \quad 100.0 \%$ SDA1_HUMAN $79.88 \quad 100.0 \%$ SEC13 HUMAN $35.54 \quad 100.0 \%$ SEC13_HUMAN $35.54 \quad 100.0 \%$ TBRG4_HUMAN $70.74 \quad 100.0 \%$ TBRG4 HUMAN $70.74 \quad 100.0 \%$ A1 S61A1_HUMAN $52.27 \quad 100.0 \%$ A1 S61A1_HUMAN $52.27 \quad 100.0 \%$ \begin{tabular}{llll} 
Protein transport protein Sec61 subunit alpha isoform $1 \mathrm{GN}=\mathrm{GEC} 61 \mathrm{~A} 1$ & $\mathrm{~S} 61 \mathrm{~A} 1$ _HUMAN & 52.27 & $100.0 \%$ \\
Protein transport protein Sec61 subunit alpha isoform $1 \mathrm{GN}=\mathrm{SEC} 61 \mathrm{~A} 1$ & $\mathrm{~S} 61 \mathrm{~A} 1$ _HUMAN & 52.27 & $100.0 \%$ \\
\hline Protein transport protein Sec61 subunit alpha isoform $1 \mathrm{GN}=\mathrm{SEC} 61 \mathrm{~A} 1$ & $\mathrm{~S} 61 \mathrm{~A} 1$ HUMAN & 52.27 & $100.0 \%$
\end{tabular} \begin{tabular}{llll} 
Protein transport protein Sec61 subunit alpha isoform $1 \mathrm{GN}=\mathrm{GEC} 61 \mathrm{~A} 1$ & $\mathrm{~S} 61 \mathrm{~A} 1$ _HUMAN & 52.27 & $100.0 \%$ \\
Protein transport protein Sec61 subunit alpha isoform $1 \mathrm{GN}=\mathrm{SEC} 61 \mathrm{~A} 1$ & $\mathrm{~S} 61 \mathrm{~A} 1$ _HUMAN & 52.27 & $100.0 \%$ \\
\hline Protein transport protein Sec61 subunit alpha isoform $1 \mathrm{GN}=\mathrm{SEC} 61 \mathrm{~A} 1$ & $\mathrm{~S} 61 \mathrm{~A} 1$ HUMAN & 52.27 & $100.0 \%$
\end{tabular} $\begin{array}{llll}\text { Protein transport protein Sec61 subunit alpha isoform } 1 \mathrm{GN}=\mathrm{GEC} 61 \mathrm{~A} 1 & \mathrm{~S} 61 \mathrm{~A} 1 \text { _HUMAN } & 52.27 & 100.0 \% \\ \text { Protein transport protein Sec61 subunit alpha isoform } 1 \mathrm{GN}=\mathrm{SEC} 61 \mathrm{~A} 1 & \mathrm{~S} 61 \mathrm{~A} 1 \text { _HUMAN } & 52.27 & 100.0 \% \\ \text { Protein transport protein Sec61 subunit alpha isoform } 1 \mathrm{GN}=\mathrm{SEC} 61 \mathrm{~A} 1 & \mathrm{~S} 61 \mathrm{~A} 1 \text { HUMAN } & 52.27 & 100.0 \% \\ \text { Protein unc-45 homolog A GN=UNC45A } & \text { UN45A_HUMAN } & 103.08 & 100.0 \%\end{array}$ Protein unc-45 homolog A GN=UNC45A UN45A_HUMAN $103.08 \quad 100.0 \%$ Puromycin-sensitive aminopeptidase GN=NPEPPS PSA HUMAN $103.28 \quad 100.0 \%$ Puromycin-sensitive aminopeptidase GN=NPEPPS PSA_HUMAN $103.28 \quad 100.0 \%$ Puromycin-sensitive aminopeptidase GN=NPEPPS PSA HUMAN $103.28 \quad 100.0 \%$ Puromycin-sensitive aminopeptidase GN=NPEPPS PSA_HUMAN $103.28 \quad 100.0 \%$ Puromycin-sensitive aminopeptidase GN=NPEPPS PSA_HUMAN $103.28 \quad 100.0 \%$ Puromycin-sensitive aminopeptidase GN=NPEPPS PSA HUMAN $103.28100 .0 \%$ Puromycin-sensitive aminopeptidase GN=NPEPPS PSA_HUMAN $103.28 \quad 100.0 \%$ Puromycin-sensitive aminopeptidase GN=NPEPPS PSA_HUMAN $103.28100 .0 \%$ Puromycin-sensitive aminopeptidase GN=NPEPPS PSA_HUMAN $103.28100 .0 \%$ Putative ATP-dependent RNA helicase DHX30 GN=DHX30 DHX30_HUMAN $133.94 \quad 100.0 \%$ Putative ATP-dependent RNA helicase DHX30 GN=DHX30 DHX30 HUMAN $133.94 \quad 100.0 \%$ Putative ATP-dependent RNA helicase DHX30 GN=DHX30 DHX30_HUMAN $133.94 \quad 100.0 \%$ Putative ATP-dependent RNA helicase DHX30 GN=DHX30 DHX30_HUMAN $133.94 \quad 100.0 \%$ Putative ATP-dependent RNA helicase DHX30 GN=DHX30 DHX30_HUMAN $133.94 \quad 100.0 \%$ Putative ATP-dependent RNA helicase DHX30 GN=DHX30 DHX30_HUMAN $133.94 \quad 100.0 \%$

19
19
19

6

6
6

6

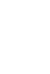

6

2

2

5
2
2

2

9
9

9
9

9
9
9

9

9
12
12

$35 \quad 0.05 \% \quad 11.5 \%$ YHDIEPGAVVK

(1)

11.5\% VLLCDPEAK

$0.05 \% \quad 11.5 \%$ FYNNVQGLVPK

$0.05 \% \quad 11.5 \%$ VVVLNCEPSKER

$0.05 \% \quad 11.5 \%$ TKDGLEVAVLPHNIR

$0.05 \% \quad 11.5 \%$ VLCLSQSEGR

$0.05 \% \quad 11.5 \%$ KPALVSTVEGGQDPK

$\begin{array}{lll}0.05 \% & 11.5 \% & \text { TTEPGVTGLLLAV } \\ 0.05 \% & 11.5 \% & \text { IPLLLTSLSFK }\end{array}$

$0.05 \% \quad 11.5 \%$ VTPNEGLTVSFPFGK

$0.05 \% \quad 11.5 \%$ LGPSVVGLAR

$0.05 \% \quad 11.5 \%$ YGAFLLRR

$0.05 \% \quad 11.5 \%$ ALECLPSKEHVDVIAK

$0.05 \% \quad 11.5 \%$ FAQLEFQLGDAER

$0.05 \% \quad 11.5 \%$ FAQLEFQLGDAERAK

$0.05 \% \quad 11.5 \%$ VIHLSLAPK

$0.01 \% \quad 6.6 \%$ DLLVQYATGK

$0.01 \% \quad 6.6 \%$ DLLVQYATGKK

$0.01 \% \quad 6.6 \%$ GKPTEASIEAR

$0.01 \% \quad 6.6 \%$ VLTQEDFQKIR

$0.01 \% \quad 6.6 \%$ TNPFSSSTNKEK

$0.00 \% \quad 5.9 \% \quad$ SVKIFDVR

$0.00 \% \quad 5.9 \% \quad$ NGGQILIADLR

$0.00 \% \quad 3.3 \%$ VLVMLAAQSR

$0.00 \% \quad 3.3 \%$ LSFHQTQVSQR

$0.03 \% \quad 8.6 \%$ IIEVGDTPK

$0.03 \% \quad 8.6 \%$ IIEVGDTPKDR

$0.03 \% \quad 8.6 \%$ AFSPTTVNTGR

$0.03 \% \quad 8.6 \%$ GQYNTYPIK

$0.03 \% \quad 8.6 \%$ ETSMVHELNR

$0.01 \% \quad 2.7 \%$ SNGVQLLQR

$0.01 \% \quad 2.7 \%$ ALIPLALEGTDVGQTK

$0.03 \% \quad 11.4 \%$ SKYTTPSGEVR

$0.03 \% \quad 11.4 \%$ YAAVTQFEATDARR

$0.03 \% \quad 11.4 \%$ LGLQNDLFSLAR

$0.03 \% \quad 11.4 \%$ AGIISTVEVLK

$0.03 \% \quad 11.4 \%$ SPVYLTVLK

$0.03 \% \quad 11.4 \%$ VLGATLLPDLIQK

$0.03 \% \quad 11.4 \%$ LSVEGFAVDK

$0.03 \% \quad 11.4 \%$ AFFESHPAPSAER

$0.03 \% \quad 11.4 \%$ DAESIHQYLLQR

$0.04 \% \quad 10.5 \%$ NLLNSVIGR

$0.04 \% \quad 10.5 \%$ SVEVEGYGSK

$0.04 \% \quad 10.5 \%$ VIQIATSSSTAK

$30 \quad 0.04 \% \quad 10.5 \%$ IPQLLLER

$0.04 \% \quad 10.5 \%$ CNVIITQPR

$0.04 \% \quad 10.5 \%$ RISAVSVAQR $\begin{array}{llllllll}99.7 \% & 29.2 & 25.0 & 29.2 & 1 & 0 & 0 & 1278.68\end{array}$

$\begin{array}{llllllll}99.7 \% & 54.3 & 25.0 & 54.3 & 1 & 0 & 0 & 1429.75\end{array}$

$\begin{array}{llllllll}99.5 \% & 23.2 & 25.0 & 23.2 & 0 & 2 & 0 & 1661.93\end{array}$

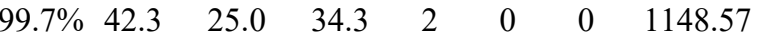

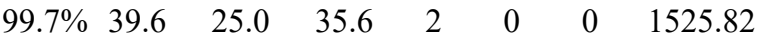

1824.01

1231.77

$\begin{array}{llll}99.7 \% & 38.5 & 25.0 & 38.5\end{array}$

$\begin{array}{llll}99.7 \% & 52.0 & 25.0 & 50.8\end{array}$

$\begin{array}{llll}99.7 \% & 35.0 & 25.0 & 30.6\end{array}$

$95.6 \% \quad 16.6 \quad 25.0 \quad 16.1$

$99.3 \% \quad 20.4 \quad 25.0 \quad 18.7$

$\begin{array}{llll}99.7 \% & 65.9 & 25.0 & 48.3\end{array}$

$99.7 \% \quad 31.8 \quad 25.0 \quad 30.1$

$98.0 \% \quad 17.8 \quad 25.0 \quad 17.8$

$99.7 \% \quad 41.7 \quad 25.0 \quad 40.0$

$99.7 \% \quad 35.2 \quad 25.0 \quad 27.0$

$\begin{array}{llll}99.7 \% & 44.7 \quad 25.0 & 35.6\end{array}$

$99.7 \% \quad 34.5$

$98.7 \% \quad 19.8$

$99.0 \% \quad 28.6$

$99.2 \% \quad 26.4$

$99.7 \% \quad 58.4$

$99.7 \% \quad 32.6$

$99.7 \% \quad 27.0$

$99.7 \% \quad 47.7$

$99.7 \% \quad 35.4$

$99.7 \% \quad 25.7$

$95.3 \% \quad 14.2$

$\begin{array}{lll}99.7 \% & 25.2\end{array}$

$99.7 \% \quad 58.6$

$99.7 \% \quad 35.8$

$99.6 \% \quad 24.9$

$99.7 \% \quad 55.1$

$99.7 \% \quad 32.4$

$99.7 \% \quad 25.5$

$99.7 \% \quad 32.5$

$95.7 \% \quad 20.1$

$\begin{array}{lll}99.7 \% & 26.7\end{array}$

$\begin{array}{lll}99.7 \% & 55.3\end{array}$

$99.7 \% \quad 55.0$

$99.7 \% \quad 32.7$

$99.7 \% \quad 44.9$

$\begin{array}{lll}98.9 \% & 22.6\end{array}$

$99.7 \% \quad 40.0$

$99.7 \% \quad 44.6$

1592.83

968.59

995.58

1808.96

1523.75

1722.88

977.61

1107.60

1235.70

1158.61

1376.75

1339.65

963.56

1169.66

1087.63

1330.69

971.54

1242.67

1150.59

1083.55

1231.57

1014.57

1625.91

1224.62

1598.79

1346.74

1129.68

1019.61

1380.85

1064.56

1445.68

1472.75

985.58

1054.51

1205.67

981.61

1100.59

1086.64 
Putative ATP-dependent RNA helicase DHX30 GN=DHX30 DHX30_HUMAN $133.94 \quad 100.0 \%$ Putative ATP-dependent RNA helicase DHX30 GN=DHX30 DHX30_HUMAN $133.94 \quad 100.0 \%$ Putative ATP-dependent RNA helicase DHX30 GN=DHX30 DHX30 HUMAN $133.94 \quad 100.0 \%$ Putative ATP-dependent RNA helicase DHX30 GN=DHX30 DHX30_HUMAN $133.94 \quad 100.0 \%$ Putative ATP-dependent RNA helicase DHX30 GN=DHX30 DHX30_HUMAN $133.94 \quad 100.0 \%$ Putative ATP-dependent RNA helicase DHX57 GN=DHX57 DHX57_HUMAN $155.61100 .0 \%$ Putative ATP-dependent RNA helicase DHX57 GN=DHX57 DHX57_HUMAN $155.61 \quad 100.0 \%$ Putative helicase MOV-10 GN=MOV10 MOV10 HUMAN $113.68 \quad 100.0 \%$ Putative helicase MOV-10 GN=MOV10 MOV10_HUMAN $113.68 \quad 100.0 \%$ Putative helicase MOV-10 GN=MOV10 MOV10_HUMAN $113.68 \quad 100.0 \%$ Putative helicase MOV-10 GN=MOV10 MOV10_HUMAN $113.68 \quad 100.0 \%$ Putative helicase MOV-10 GN=MOV10 MOV10_HUMAN $113.68 \quad 100.0 \%$ Putative helicase MOV-10 GN=MOV10 MOV10_HUMAN $113.68 \quad 100.0 \%$ Putative helicase MOV-10 GN=MOV10 MOV10_HUMAN $113.68 \quad 100.0 \%$ Putative methyltransferase C9orf114 GN=C9orf114 CI114_HUMAN $42.01 \quad 100.0 \%$ Putative methyltransferase C9orf114 GN=C9orf114 CI114 HUMAN $42.01 \quad 100.0 \%$ Putative oxidoreductase GLYR1 GN=GLYR1 GLYR1_HUMAN $60.56 \quad 100.0 \%$ Putative oxidoreductase GLYR1 GN=GLYR1 GLYR1_HUMAN $60.56 \quad 100.0 \%$ Putative oxidoreductase GLYR1 GN=GLYR1 GLYR1_HUMAN $60.56 \quad 100.0 \%$ Putative oxidoreductase GLYR1 GN=GLYR1 GLYR1_HUMAN $60.56 \quad 100.0 \%$ Putative oxidoreductase GLYR1 GN=GLYR1 GLYR1_HUMAN $60.56 \quad 100.0 \%$ Putative oxidoreductase GLYR1 GN=GLYR1 GLYR1_HUMAN $60.56 \quad 100.0 \%$ Putative RNA-binding protein 15 GN=RBM15 RBM15_HUMAN $107.19 \quad 100.0 \%$ Putative RNA-binding protein 15 GN=RBM15 RBM15_HUMAN $107.19 \quad 100.0 \%$ Putative RNA-binding protein Luc7-like 2 GN=LUC7L2 LC7L2_HUMAN $46.51 \quad 100.0 \%$ Putative RNA-binding protein Luc7-like 2 GN=LUC7L2 LC7L2_HUMAN $46.51 \quad 100.0 \%$ Putative RNA-binding protein Luc7-like 2 GN=LUC7L2 LC7L2_HUMAN $46.51 \quad 100.0 \%$ $\begin{array}{llll}\text { Pyridoxal-dependent decarboxylase domain-containing protein 1 GN=PDXDC1 } & \text { PDXD1_HUMAN } & 86.71 & 100.0 \%\end{array}$ Pyrroline-5-carboxylate reductase 1, mitochondrial GN=PYCR1 P5CR1_HUMAN $33.36 \quad 100.0 \%$ Pyrroline-5-carboxylate reductase 1, mitochondrial GN=PYCR1 P5CR1_HUMAN $33.36 \quad 100.0 \%$ Pyrroline-5-carboxylate reductase 1, mitochondrial GN=PYCR1 P5CR1_HUMAN $33.36 \quad 100.0 \%$ $\begin{array}{llll}\text { Pyrroline-5-carboxylate reductase 1, mitochondrial GN=PYCR1 P5CR1_HUMAN } 33.36 & 100.0 \%\end{array}$ Pyrroline-5-carboxylate reductase 1, mitochondrial GN=PYCR1 P5CR1_HUMAN $33.36 \quad 100.0 \%$ Pyrroline-5-carboxylate reductase 1, mitochondrial GN=PYCR1 P5CR1_HUMAN $33.36 \quad 100.0 \%$ Pyrroline-5-carboxylate reductase 1, mitochondrial GN=PYCR1 P5CR1_HUMAN $33.36 \quad 100.0 \%$ Pyrroline-5-carboxylate reductase 1, mitochondrial GN=PYCR1 P5CR1_HUMAN $33.36 \quad 100.0 \%$ Pyrroline-5-carboxylate reductase 1, mitochondrial GN=PYCR1 P5CR1_HUMAN $33.36 \quad 100.0 \%$ Pyrroline-5-carboxylate reductase 1, mitochondrial GN=PYCR1 P5CR1_HUMAN $33.36 \quad 100.0 \%$ Pyrroline-5-carboxylate reductase 2 GN=PYCR2 P5CR2_HUMAN $33.64100 .0 \%$ Pyrroline-5-carboxylate reductase 2 GN=PYCR2 P5CR2_HUMAN $33.64 \quad 100.0 \%$ Pyrroline-5-carboxylate reductase $2 \mathrm{GN}=\mathrm{PYCR} 2$ P5CR2 HUMAN $33.64100 .0 \%$ Pyrroline-5-carboxylate reductase 2 GN=PYCR2 P5CR2_HUMAN $33.64 \quad 100.0 \%$ Pyrroline-5-carboxylate reductase 2 GN=PYCR2 P5CR2_HUMAN $33.64 \quad 100.0 \%$ Pyrroline-5-carboxylate reductase 2 GN=PYCR2 P5CR2_HUMAN $33.64100 .0 \%$ Pyrroline-5-carboxylate reductase 2 GN=PYCR2 P5CR2_HUMAN $33.64 \quad 100.0 \%$

(1)

8

8
8
8

7

7
7
7

7

2
6
6

6
6

6
6
6

6
6
6
2

6
2
2

2
3
3

3

3
2
2

913

$\begin{array}{ll}9 & 13 \\ 9 & 13\end{array}$

$\begin{array}{ll}9 & 13 \\ 9 & 13 \\ 9 & 13\end{array}$

13

$\begin{array}{ll}9 & 13 \\ 9 & 13 \\ 9 & 13 \\ 9 & 13\end{array}$

13
13
13
13

9

9
15
15
15

15
15
15

15
15
15

15
15
15
$30 \quad 0.04 \% \quad 10.5 \%$ AIFQQPPVGVR

$30 \quad 0.04 \% \quad 10.5 \%$ TPLENLVLQAK

$30 \quad 0.04 \% \quad 10.5 \%$ AIVLAAIFR

$\quad 0.04 \% \quad 10.5 \%$ ALLSHDSGSDHLAFVR

$0.04 \% \quad 10.5 \%$ SGNILLHK

$0.04 \% \quad 10.5 \%$ ATISLSDSDLLR

$0.00 \% \quad 1.5 \%$ ISAISVAER

$0.00 \% \quad 1.5 \%$ IISTIVKLVTTQ

$0.02 \% \quad 8.8 \%$ ITGNPVVTNRIEEGERPDR

$0.02 \% \quad 8.8 \%$ DVPLLPSDVKLK

$0.02 \% \quad 8.8 \%$ SLESNPEQLQAMR

$0.02 \% \quad 8.8 \% \quad$ SVGVISPYR

$0.02 \% \quad 8.8 \%$ SVGVISPYRK

$0.02 \% \quad 8.8 \% \quad$ LDLQQGQNLLQGLSK

$0.00 \% \quad 5.9 \% \quad$ TYLAGQIAR

$0.00 \% \quad 5.9 \%$ GSDVASAQLPNFR

$0.04 \% \quad 13.2 \%$ FQQAVDAVEEFLR

$0.04 \% \quad 13.2 \%$ TAEKCDLFIQEGAR

$0.04 \% \quad 13.2 \%$ DLVLGPSGVLQGIRPGK $99.7 \% \quad 46.0$

$0.04 \% \quad 13.2 \%$ TSFFLGEVGNAAK

$\begin{array}{llllll}0.04 \% & 13.2 \% & \text { AKALDQSDNDMSAVYR } & 99.7 \% & 34.1\end{array}$

$\begin{array}{lllllll}0.04 \% & 13.2 \% & \text { ALDQSDNDMSAVYR } & 99.7 \% & 58.2\end{array}$

$\begin{array}{llllll}0.00 \% & 4.1 \% & \text { SSGAASSAPGGGDGAEYKTLK } & 99.6 \% & 24.2\end{array}$

$0.00 \% \quad 4.1 \% \quad$ SSSSSAASDTATSTQRPLR $98.6 \% \quad 18.8$

$0.01 \% \quad 9.7 \%$ AMLDQLMGTSR

$0.01 \% \quad 9.7 \%$ LAETQEEISAEVAAK

$0.01 \% \quad 9.7 \% \quad$ NSMPASSFQQQK

$0.01 \% \quad 3.6 \% \quad$ ILVEDELSSPVVVFR

$0.01 \% \quad 3.6 \%$ FFQELPGSDPVFK

$0.04 \% \quad 38.2 \%$ GFTAAGVLAAHK

$99.7 \% \quad 27.1 \quad 25.0 \quad 18.8$

$25.0 \quad 23.8$

$\begin{array}{llll}\% & 58.9 & 25.0 & 55.0\end{array}$

$\begin{array}{llll}98.8 \% & 26.2 & 25.0 & 24.2\end{array}$

$\begin{array}{lllll}99.7 \% & 48.2 & 25.0 & 48.0 & 2\end{array}$

$99.7 \% \quad 30.5$

$99.7 \% \quad 61.7$

$\begin{array}{lllll}0.04 \% & 38.2 \% & \text { IMASSPDMDLATVSALRK } & 98.7 \% & 28.7\end{array}$

$0.04 \% \quad 38.2 \%$ LSAFRPAPR

$0.04 \% \quad 38.2 \%$ CMTNTPVVVR

$0.04 \% \quad 38.2 \%$ LGAQALLGAAK

$0.04 \% \quad 38.2 \%$ MLLHSEQHPGQLK

$0.04 \% \quad 38.2 \%$ SLLINAVEASCIR

$99.7 \% \quad 37.3$

$99.7 \% \quad 53.4$

$99.7 \% \quad 61.4$

$97.1 \% \quad 15.6$

$99.7 \% 59.9$

$0.04 \% \quad 38.2 \%$ ELQSMADQEQVSPAAIKK $\quad 99.7 \% 35.3$

$\begin{array}{llll}0.04 \% & 38.2 \% & \text { VKLDSPAGTALSPSGHTK } 99.7 \% & 31.4\end{array}$

$0.04 \% \quad 38.2 \%$ LDSPAGTALSPSGHTK

$0.07 \% \quad 40.3 \%$ GFTAAGILSAHK

$99.7 \% \quad 35.1$

$99.7 \% \quad 54.8$

$0.07 \% \quad 40.3 \%$ IIASSPEMNLPTVSALR

$0.07 \% \quad 40.3 \%$ IIASSPEMNLPTVSALRK

$\begin{array}{lllll}0.07 \% & 40.3 \% & \text { HIVVSCAAGVTISSVEK } & 99.7 \% & 58.5 \\ 0.07 \% & 40.3 \% & \text { HIVVSCAAGVTISSVEKK } & 99.7 \% & 46.2\end{array}$

$0.07 \% \quad 40.3 \%$ KLMAFQPAPK

$\begin{array}{llll}99.7 \% & 46.2 & 25.0 & 46.2 \\ 99.7 \% & 42.9 & 25.0 & 29.4\end{array}$

$\begin{array}{cccc}0 & 1211.69 & 715 & 725 \\ 0 & 1225.72 & 814 & 824 \\ 0 & 973.62 & 886 & 894 \\ 0 & 1724.87 & 926 & 941 \\ 0 & 881.52 & 1052 & 1059 \\ 0 & 1290.69 & 1116 & 1127 \\ 0 & 945.54 & 604 & 612 \\ 0 & 1315.82 & 1375 & 1386 \\ 0 & 2152.11 & 261 & 279 \\ 0 & 1323.79 & 480 & 491 \\ 0 & 1502.73 & 496 & 508 \\ 0 & 2053.99 & 548 & 566 \\ 0 & 977.54 & 826 & 834 \\ 0 & 1105.64 & 826 & 835 \\ 0 & 1654.91 & 953 & 967 \\ 0 & 992.55 & 94 & 102 \\ 0 & 1361.68 & 293 & 305 \\ 0 & 1551.78 & 79 & 91 \\ 0 & 1637.80 & 299 & 312 \\ 0 & 1706.00 & 339 & 355 \\ 0 & 1340.68 & 423 & 435 \\ 0 & 1783.83 & 534 & 549 \\ 0 & 1584.70 & 536 & 549 \\ 0 & 1910.91 & 153 & 173 \\ 0 & 1909.92 & 871 & 889 \\ 0 & 1238.59 & 9 & 19 \\ 0 & 1588.81 & 108 & 122 \\ 0 & 1352.63 & 175 & 186 \\ 0 & 1701.94 & 379 & 393 \\ 0 & 1510.76 & 394 & 406 \\ 0 & 1142.63 & 18 & 29 \\ 0 & 1905.98 & 30 & 47 \\ 0 & 1014.58 & 108 & 116 \\ 0 & 1192.58 & 120 & 129 \\ 0 & 1012.62 & 205 & 215 \\ 0 & 1517.79 & 216 & 228 \\ 0 & 1445.78 & 252 & 264 \\ 0 & 1989.00 & 267 & 284 \\ 0 & 1765.94 & 290 & 307 \\ 0 & 1538.78 & 292 & 307 \\ 0 & 1172.64 & 18 & 29 \\ 0 & 1798.97 & 30 & 46 \\ 0 & 1943.06 & 30 & 47 \\ 0 & 918.52 & 47 & 54 \\ 0 & 1756.93 & 90 & 106 \\ 0 & 1885.02 & 90 & 107 \\ 0 & 1130.64 & 107 & 116 \\ & & & \end{array}$

Page 96 of Table S-1-2 
Pyrroline-5-carboxylate reductase 2 GN=PYCR2 P5CR2_HUMAN $33.64 \quad 100.0 \% \quad 15$ $\begin{array}{llll}\text { Pyrroline-5-carboxylate reductase } 2 \text { GN=PYCR2 P5CR2_HUMAN } & 33.64 & 100.0 \% & 15\end{array}$ $\begin{array}{llll}\text { Pyrroline-5-carboxylate reductase } 2 \text { GN=PYCR2 P5CR2_HUMAN } 33.64 & 100.0 \% & 15\end{array}$ Pyrroline-5-carboxylate reductase 2 GN=PYCR2 P5CR2_HUMAN $33.64 \quad 100.0 \% \quad 15$ Pyrroline-5-carboxylate reductase 2 GN=PYCR2 P5CR2_HUMAN $33.64 \quad 100.0 \% \quad 15$ Pyrroline-5-carboxylate reductase 2 GN=PYCR2 P5CR2_HUMAN $33.64 \quad 100.0 \% \quad 15$ Pyrroline-5-carboxylate reductase 2 GN=PYCR2 P5CR2_HUMAN $33.64 \quad 100.0 \% \quad 15$ $\begin{array}{lllll}\text { Pyrroline-5-carboxylate reductase } 2 \text { GN=PYCR2 P5CR2_HUMAN } 33.64 & 100.0 \% & 15\end{array}$ Pyrroline-5-carboxylate reductase $3 \mathrm{GN}=$ PYCRL P5CR3 HUMAN $28.66 \quad 100.0 \% \quad 6$ Pyrroline-5-carboxylate reductase 3 GN=PYCRL P5CR3_HUMAN $28.66 \quad 100.0 \%$ Pyrroline-5-carboxylate reductase 3 GN=PYCRL P5CR3_HUMAN $28.66 \quad 100.0 \%$ Pyrroline-5-carboxylate reductase 3 GN=PYCRL P5CR3_HUMAN $28.66 \quad 100.0 \%$ Pyrroline-5-carboxylate reductase $3 \mathrm{GN}=$ PYCRL P5CR3_HUMAN $28.66 \quad 100.0 \%$ Pyrroline-5-carboxylate reductase 3 GN=PYCRL P5CR3_HUMAN $28.66 \quad 100.0 \%$

Pyruvate dehydrogenase El component subunit alpha, somatic form, mitcochondrial GN=PDHAI ODPA_HUMAN $43.30 \quad 100.0 \%$ Pyunate dehydrogenase El component subunit alpha, somatic form, mitochondral GN-PDHAI ODPA_HUMAN $43.30 \quad 100.0 \%$ 列 ODPA_HUMAN $43.30 \quad 100.0 \%$ ODPA_HUMAN $43.30 \quad 100.0 \%$ ODPA HUMAN $43.30 \quad 100.0 \%$ ODPA_HUMAN $43.30 \quad 100.0 \%$ ODPA_HUMAN $43.30 \quad 100.0 \%$ ODPB_HUMAN $39.23 \quad 100.0 \%$ ODPB_HUMAN $39.23 \quad 100.0 \%$ ODPB HUMAN $39.23 \quad 100.0 \%$ ODPB_HUMAN $39.23 \quad 100.0 \%$ KPYM_HUMAN $57.94 \quad 100.0 \%$ KPYM HUMAN $57.94 \quad 100.0 \%$ KPYM_HUMAN $57.94 \quad 100.0 \% \quad 24$ KPYM HUMAN $57.94 \quad 100.0 \% \quad 24$ KPYM_HUMAN $57.94 \quad 100.0 \% \quad 24$ KPYM_HUMAN $57.94 \quad 100.0 \% \quad 24$ KPYM HUMAN $57.94 \quad 100.0 \% \quad 24$ KPYM_HUMAN $57.94 \quad 100.0 \% \quad 24$ KPYM_HUMAN $57.94 \quad 100.0 \% \quad 24$ KPYM_HUMAN $57.94 \quad 100.0 \% \quad 24$ KPYM_HUMAN $57.94 \quad 100.0 \% \quad 24$ KPYM HUMAN $57.94 \quad 100.0 \% \quad 24$ KPYM_HUMAN $57.94 \quad 100.0 \% \quad 24$ KPYM_HUMAN $57.94 \quad 100.0 \% \quad 24$ KPYM_HUMAN $57.94 \quad 100.0 \% \quad 24$ KPYM_HUMAN $57.94 \quad 100.0 \% \quad 24$ KPYM HUMAN $57.94 \quad 100.0 \% \quad 24$ KPYM_HUMAN $57.94 \quad 100.0 \% \quad 24$ KPYM_HUMAN $57.94 \quad 100.0 \% \quad 24$ KPYM HUMAN $57.94 \quad 100.0 \% \quad 24$ KPYM_HUMAN $57.94 \quad 100.0 \% \quad 24$
Pyruvate kinase $\mathrm{PKM}$ GN=PKI

Pyruvate kinase $P K M$ GN=PKM
Pyruvate kinase $P K M$ GN=PKM
$0.07 \% \quad 40.3 \%$ RLAIQLGAQALLGAAK

$0.07 \% \quad 40.3 \%$ LAIQLGAQALLGAAK

$99.7 \% \quad 48.4$

$99.7 \% \quad 59.2$

$99.7 \% \quad 40.5$

$99.7 \% \quad 59.9$

$\begin{array}{lll}0.07 \% & 40.3 \% & \text { ELQSMADQEK }\end{array}$

$0.07 \% \quad 40.3 \%$ ISPAALKK

$0.07 \% \quad 40.3 \%$ LESPTVSTLTPSSPGK

$0.02 \% \quad 27.0 \%$ RVGFVGAGR

$0.02 \% \quad 27.0 \%$ MAGAIAQGLIR

$0.02 \% \quad 27.0 \%$ AGKVEAQHILASAPTDR

$0.02 \% \quad 27.0 \%$ IAAQTLLGTAK

$0.02 \% \quad 27.0 \%$ MLLHEGQHPAQLR

$0.02 \% \quad 27.0 \%$ AATMSAVEAATCR

$0.02 \% \quad 16.9 \%$ LEEGPPVTTVLTR

$0.02 \% \quad 16.9 \%$ AHGFTFTR

$0.02 \% \quad 16.9 \%$ EILAELTGR

$0.02 \% \quad 16.9 \%$ YGMGTSVER

$0.02 \% \quad 16.9 \%$ AAASTDYYK

$0.02 \% \quad 16.9 \%$ AAASTDYYKR

$0.02 \% \quad 16.9 \%$ RGDFIPGLR

$0.02 \% \quad 16.9 \%$ TREEIQEVR

$0.02 \% \quad 15.3 \%$ EGVECEVINMR

$0.02 \% \quad 15.3 \%$ TIRPMDMETIEASVMK

$0.02 \% \quad 15.3 \%$ IMEGPAFNFLDAPAVR

$0.02 \% \quad 15.3 \%$ VTGADVPMPYAK

$0.14 \% \quad 52.4 \%$ NTGIICTIGPASR

$0.14 \% 52.4 \%$ SVETLKEMIK

$99.7 \% \quad 55.4$

$99.0 \% 32.6$

$99.7 \% \quad 49.3$

$99.7 \% \quad 38.7$

$99.7 \% \quad 62.5$

$99.6 \% \quad 23.6$

$99.7 \% \quad 72.2$

$98.7 \% \quad 25.2$

$\begin{array}{lll}99.7 \% & 59.1\end{array}$

$99.7 \% 55.6$

$98.2 \% \quad 18.8$

$99.7 \% \quad 54.1$

$99.7 \% \quad 48.1$

$99.7 \% \quad 32.0$

$99.7 \% \quad 46.0$

$99.0 \% \quad 24.4$

$99.7 \% \quad 34.1$

$99.7 \% \quad 61.2$

$99.7 \% \quad 29.8$

$99.7 \% \quad 52.9$

$99.7 \% \quad 50.2$

$99.7 \% \quad 58.2$

$99.7 \% \quad 63.5$

$99.7 \% \quad 29.6$

$0.14 \% \quad 52.4 \%$ TATESFASDPILYRPVAVALDTK $\quad 99.7 \% \quad 31.1$

$0.14 \% \quad 52.4 \%$ GSGTAEVELKK

$0.14 \% \quad 52.4 \%$ ITLDNAYMEK

$0.14 \% \quad 52.4 \%$ IYVDDGLISLQVK

$99.7 \% \quad 53.6$

$99.7 \% \quad 44.5$

$99.7 \% \quad 50.2$

$0.14 \% \quad 52.4 \%$ IYVDDGLISLQVKQK

$99.7 \% \quad 56.3$

$0.14 \% \quad 52.4 \%$ QKGADFLVTEVENGGSLGSK $\quad 99.7 \% \quad 47.0$

$0.14 \% \quad 52.4 \%$ GADFLVTEVENGGSLGSK $99.7 \% 58.0$

$\begin{array}{lllll}0.14 \% & 52.4 \% & \text { GADFLVTEVENGGSLGSKK } & 99.7 \% & 61.7\end{array}$

$0.14 \% \quad 52.4 \%$ KGVNLPGAAVDLPAVSEK $\quad 97.5 \% \quad 15.5$

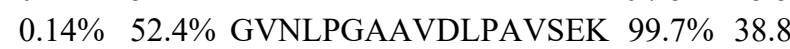

$0.14 \% \quad 52.4 \%$ IISKIENHEGVR

$99.7 \% \quad 58.6$

$0.14 \% \quad 52.4 \%$ RFDEILEASDGIMVAR $\quad 99.7 \% \quad 54.2$

$0.14 \% \quad 52.4 \%$ GDLGIEIPAEK

$99.7 \% \quad 39.7$

$0.14 \% \quad 52.4 \%$ GDLGIEIPAEKVFLAQK $\quad 99.5 \% 22.5$

$\begin{array}{lllll}0.14 \% & 52.4 \% & \text { AGKPVICATQMLESMIK } & 99.7 \% & 35.2\end{array}$

$0.14 \% \quad 52.4 \%$ GDYPLEAVR

$99.7 \% \quad 55.4$

$0.14 \% \quad 52.4 \%$ EAEAAIYHLQLFEELRR $\quad 99.7 \% \quad 26.5$

$\begin{array}{llll}0.14 \% & 52.4 \% & \text { LAPITSDPTEATAVGAVEASFK } \quad 99.7 \% \quad 38.4\end{array}$
$0.14 \% \quad 52.4 \%$ LNFSHGTHEYHAETIK

\begin{tabular}{|c|c|c|c|c|c|c|c|c|c|c|}
\hline 22 & 49 & $0.07 \%$ & $40.3 \%$ LMAFOPAPK & $99.7 \%$ & 48.4 & 25.0 & 40.1 & 4 & 0 & 0 \\
\hline 22 & 49 & $0.07 \%$ & $40.3 \%$ RLAIOLGAOALLGAAK & $99.7 \%$ & 59.2 & 25.0 & 59.2 & 2 & 2 & 0 \\
\hline 22 & 49 & $0.07 \%$ & $40.3 \%$ LAIQLGAQALLGAAK & $99.7 \%$ & 40.5 & 25.0 & 40.5 & 3 & 0 & 0 \\
\hline 22 & 49 & $0.07 \%$ & $40.3 \%$ SLLINAVEASCIR & $99.7 \%$ & $\begin{array}{l}40.5 \\
59.9\end{array}$ & 25.0 & $\begin{array}{l}40.5 \\
59.9\end{array}$ & 6 & 0 & 0 \\
\hline 22 & 49 & $0.07 \%$ & $40.3 \%$ TRELOSMADOEK & $99.7 \%$ & 47.2 & 25.0 & 33.8 & 1 & 0 & 0 \\
\hline 22 & 49 & $0.07 \%$ & $40.3 \%$ ELQSMADQEK & $99.7 \%$ & 55.4 & 25.0 & 43.0 & 4 & 0 & 0 \\
\hline 22 & 49 & $0.07 \%$ & $40.3 \%$ ISPAALKK & $99.0 \%$ & 32.6 & 25.0 & 24.9 & 2 & 0 & 0 \\
\hline 22 & 49 & $0.07 \%$ & $40.3 \%$ LESPTVSTLTPSSPGK & $99.7 \%$ & 49.3 & 25.0 & 37.7 & 2 & 0 & 0 \\
\hline 7 & 12 & $0.02 \%$ & $27.0 \%$ RVGFVGAGR & $99.7 \%$ & 387 & 25.0 & 36.4 & 2 & 0 & 0 \\
\hline 7 & 12 & $0.02 \%$ & $27.0 \%$ MAGAIAQGLIR & $99.7 \%$ & 62.5 & 25.0 & $\begin{array}{l}30.4 \\
53.8\end{array}$ & 2 & 0 & 0 \\
\hline 7 & 12 & $002 \%$ & $270 \%$ AGKVEAOHUL ASAPTDR & $996 \%$ & 236 & 250 & 206 & 0 & 2 & 0 \\
\hline 7 & 12 & $0.02 \%$ & $270 \%$ IAAOTLLGTAK & $997 \%$ & 722 & 25.0 & 717 & 2 & 0 & 0 \\
\hline 7 & 12 & $0.02 \%$ & $27.0 \%$ MLLHEGQHPAQLR & $98.7 \%$ & 25.2 & 25.0 & 15.9 & 0 & 1 & 0 \\
\hline 7 & $\begin{array}{l}12 \\
12\end{array}$ & $\begin{array}{l}0.02 \% \\
0.02 \%\end{array}$ & $27.0 \%$ AATMSAVEAATCR & $\begin{array}{l}90.1 \% \\
99.7 \%\end{array}$ & $\begin{array}{l}25.2 \\
59.1\end{array}$ & $\begin{array}{l}25.0 \\
25.0\end{array}$ & $\begin{array}{l}15.9 \\
51.3\end{array}$ & 3 & $\begin{array}{l}1 \\
0\end{array}$ & 0 \\
\hline 9 & 16 & $0.02 \%$ & $16.9 \%$ LEEGPPVTTVLTR & $997 \%$ & 556 & 250 & 556 & 2 & 0 & 0 \\
\hline 9 & 16 & $0.02 \%$ & $16.9 \%$ AHGFTFTR & $98.2 \%$ & 18.8 & 25.0 & 15.2 & 2 & 0 & 0 \\
\hline 9 & 16 & $0.02 \%$ & $16.9 \%$ EILAELTGR & $99.7 \%$ & $\begin{array}{l}10.0 \\
54.1\end{array}$ & 25.0 & 46.7 & 2 & 0 & 0 \\
\hline 9 & 16 & $0.02 \%$ & $16.9 \%$ YGMGTSVER & $997 \%$ & 481 & 25.0 & 460 & 3 & 0 & 0 \\
\hline 9 & 16 & $0.02 \%$ & $16.9 \%$ AAASTDYYK & $99.7 \%$ & 32.0 & 25.0 & 26.2 & 2 & 0 & 0 \\
\hline 9 & 16 & $0.02 \%$ & $16.9 \%$ AAASTDYYKR & $99.7 \%$ & 46.0 & 25.0 & 45.9 & 2 & 0 & 0 \\
\hline 9 & 16 & $0.02 \%$ & $16.9 \%$ RGDFIPGLR & $99.0 \%$ & 24.4 & 25.0 & 14.6 & 1 & 0 & 0 \\
\hline 9 & 16 & $0.02 \%$ & $16.9 \%$ TREEIOEVR & $997 \%$ & 34.1 & 25.0 & 20.4 & 2 & 0 & 0 \\
\hline 6 & 12 & $0.02 \%$ & $15.3 \%$ EGVECEVINMR & $99.7 \%$ & $\begin{array}{l}34.1 \\
61.2\end{array}$ & 25.0 & $\begin{array}{l}20.4 \\
54.7\end{array}$ & $\begin{array}{l}2 \\
4\end{array}$ & 0 & 0 \\
\hline 6 & 12 & $0.02 \%$ & $15.3 \%$ TIRPMDMETIEASVMK & $99.7 \%$ & 29.8 & 25.0 & 29.8 & 0 & 2 & 0 \\
\hline 6 & 12 & $0.02 \%$ & $15.3 \%$ IMEGPAFNFLDAPAVR & $997 \%$ & 529 & 250 & 519 & 2 & 0 & 0 \\
\hline 6 & 12 & $0.02 \%$ & 15.3\% VTGADVPMPYAK & $99.7 \%$ & 50.2 & $\begin{array}{l}25.0 \\
25.0\end{array}$ & 44.8 & 4 & 0 & 0 \\
\hline 33 & 94 & $014 \%$ & $524 \%$ NTGUCTIGPASR & $997 \%$ & 582 & 250 & 582 & 14 & 0 & 0 \\
\hline $\begin{array}{l}53 \\
33\end{array}$ & $\begin{array}{l}94 \\
94\end{array}$ & $\begin{array}{l}0.14 \% \\
0.14 \%\end{array}$ & $52.4 \%$ SVETLKEMIK & $99.7 \%$ & $\begin{array}{l}50.2 \\
63.5\end{array}$ & $\begin{array}{l}25.0 \\
25.0\end{array}$ & $\begin{array}{l}50.2 \\
52.5\end{array}$ & $\begin{array}{c}14 \\
4\end{array}$ & 0 & 0 \\
\hline 33 & 94 & $0.14 \%$ & $52.4 \%$ LNFSHGTHEYHAETIK & $99.7 \%$ & 29.6 & $\begin{array}{l}25.0 \\
25.0\end{array}$ & 29.6 & 0 & 2 & 0 \\
\hline 33 & 94 & $0.14 \%$ & $52.4 \%$ TATESFASDPILYRPVAVALDTK & $99.7 \%$ & 31.1 & 25.0 & 31.1 & 0 & 2 & 0 \\
\hline 33 & 94 & $\begin{array}{l}0.1470 \\
0.14 \%\end{array}$ & $52.4 \%$ GSGTAEVELKK & $99.7 \%$ & $\begin{array}{l}51.1 \\
53.6\end{array}$ & $\begin{array}{l}25.0 \\
25.0\end{array}$ & $\begin{array}{l}31.1 \\
39.6\end{array}$ & 4 & $\begin{array}{l}2 \\
0\end{array}$ & 0 \\
\hline 33 & 94 & $0.14 \%$ & $52.4 \%$ ITLDNAYMEK & $99.7 \%$ & 44.5 & 25.0 & 43.5 & 2 & 0 & 0 \\
\hline $\begin{array}{l}53 \\
33\end{array}$ & $\begin{array}{l}94 \\
94\end{array}$ & $\begin{array}{l}0.14 \% \\
0.14 \%\end{array}$ & $\begin{array}{l}52.4 \% \text { 11LDNA YIMER } \\
52.4 \% \text { IYYDDGLISLOVK }\end{array}$ & $\begin{array}{l}99.1 \% \\
99.7 \%\end{array}$ & $\begin{array}{l}44.5 \\
502\end{array}$ & $\begin{array}{l}25.0 \\
25.0\end{array}$ & $\begin{array}{l}45.5 \\
50.2\end{array}$ & $\begin{array}{l}2 \\
5\end{array}$ & 0 & 0 \\
\hline 33 & 94 & $0.14 \%$ & $524 \%$ IYVDDGLISLOVKOK & $997 \%$ & 56.2 & 250 & 56.3 & 2 & 0 & 0 \\
\hline 33 & 94 & $0.14 \%$ & $52.4 \%$ QKGADFLVTEVENGGSLGSK & $99.7 \%$ & 47.0 & 25.0 & 47.0 & 0 & 2 & 0 \\
\hline 33 & 94 & $0.14 \%$ & $52.4 \%$ GADFLVTEVENGGSLGSK & $99.7 \%$ & 58.0 & $\begin{array}{l}25.0 \\
25.0\end{array}$ & 54.2 & 4 & $\begin{array}{l}2 \\
0\end{array}$ & 0 \\
\hline 33 & 94 & $0.14 \%$ & $524 \%$ GADFLVTEVENGGSLGSKK & $997 \%$ & 617 & 25.0 & 56.1 & 1 & 2 & 0 \\
\hline 33 & 94 & $0.14 \%$ & $52.4 \%$ KGVNLPGAAVDLPAVSEK & $97.5 \%$ & 15.5 & 25.0 & 15.5 & 0 & 1 & 0 \\
\hline 33 & $\begin{array}{l}94 \\
94\end{array}$ & 0.1470 & $52.4 \%$ GVNLPGAAVDLPAVSEK & $99.7 \%$ & $\begin{array}{l}15.5 \\
38.8\end{array}$ & $\begin{array}{l}25.0 \\
25.0\end{array}$ & $\begin{array}{l}15.5 \\
33.5\end{array}$ & 2 & $\begin{array}{l}1 \\
0\end{array}$ & 0 \\
\hline 33 & 94 & $0.14 \%$ & $52.4 \%$ IISKIENHEGVR & $997 \%$ & 58.6 & 25.0 & 54.3 & 2 & 2 & 0 \\
\hline 33 & 94 & $0.14 \%$ & $524 \%$ RFDEILEASDGIMVAR & $997 \%$ & 542 & 25.0 & 472 & 4 & 4 & 0 \\
\hline 33 & 94 & $\begin{array}{l}0.1470 \\
0.14 \%\end{array}$ & $52.4 \%$ GDLGIEIPAEK & $99.7 \%$ & $\begin{array}{l}34.2 \\
39.7\end{array}$ & $\begin{array}{l}25.0 \\
25.0\end{array}$ & $\begin{array}{l}4 / .2 \\
27.9\end{array}$ & $\begin{array}{l}4 \\
4\end{array}$ & $\begin{array}{l}4 \\
0\end{array}$ & 0 \\
\hline 33 & 94 & $0.14 \%$ & $524 \%$ GDLGIEIPAEKVFLAOK & $99.5 \%$ & 22.5 & 250 & 179 & 2 & 0 & 0 \\
\hline 33 & 94 & $0.14 \%$ & $524 \%$ AGKPVICATOMLESMIK & $997 \%$ & 352 & 25.0 & 352 & 1 & 6 & 0 \\
\hline 33 & 94 & $\begin{array}{l}0.1470 \\
0.14 \%\end{array}$ & $52.4 \%$ GDYPLEAVR & $99.7 \%$ & $\begin{array}{l}55.2 \\
55.4\end{array}$ & $\begin{array}{l}25.0 \\
25.0\end{array}$ & $\begin{array}{l}53.2 \\
48.0\end{array}$ & $\begin{array}{l}1 \\
2\end{array}$ & 0 & 0 \\
\hline 33 & 94 & $0.14 \%$ & $52.4 \%$ EAEAAIYHLQLFEELRR & $99.7 \%$ & 26.5 & 25.0 & 25.9 & 0 & 2 & 0 \\
\hline 33 & $\begin{array}{l}94 \\
94\end{array}$ & $\begin{array}{l}0.14 \% \\
0.14 \%\end{array}$ & $\begin{array}{l}52.4 \% \text { EAEAAT } \\
52.4 \% \text { LAPITSDPTEATAVGAVEASFK }\end{array}$ & $99.1 \%$ & $\begin{array}{l}20.5 \\
38.4\end{array}$ & $\begin{array}{l}25.0 \\
25.0\end{array}$ & $\begin{array}{l}25.9 \\
38.4\end{array}$ & 2 & $\begin{array}{l}2 \\
2\end{array}$ & 0 \\
\hline
\end{tabular}

Page 97 of Table S-1-2 
Pyruvate kinase $\mathrm{PKM}$ GN=PKM Pyruvate kinase $\mathrm{PKM}$ GN=PKM Pyruvate kinase $\mathrm{PKM}$ GN=PKM Q96DT5-DECOY

\section{Q96DT5-DECOY}

Rabankyrin-5 GN=ANKFY

Rabankyrin-5 GN=ANKFY

Rac GTPase-activating protein $1 \mathrm{GN}=$ RACGAP1 RGAP1_HUMAN $71.03 \quad 100.0 \%$ Rac GTPase-activating protein $1 \mathrm{GN}=$ RACGAP1 RGAP1 HUMAN $71.03 \quad 100.0^{\circ}$ Ran GTPase-activating protein $1 \mathrm{GN}=$ RANGAP1 RAGP1_HUMAN $63.54 \quad 100.0 \%$ Ran GTPase-activating protein 1 GN=RANGAP1 RAGP1_HUMAN $63.54 \quad 100.0 \%$ Ran GTPase-activating protein $1 \mathrm{GN}=$ RANGAP1 RAGP1 HUMAN $63.54100 .0 \%$ Ran GTPase-activating protein 1 GN=RANGAP1 RAGP1_HUMAN $63.54 \quad 100.0 \%$ Ran GTPase-activating protein $1 \mathrm{GN}=$ RANGAP1 RAGP1_HUMAN $63.54 \quad 100.0 \%$ Ran GTPase-activating protein 1 GN=RANGAP1 RAGP1_HUMAN $63.54 \quad 100.0 \%$ Ras GTPase-activating-like protein IQGAP1 GN=IQGAP1 IQGA1_HUMAN $189.26 \quad 100.0 \%$ Ras GTPase-activating-like protein IQGAP1 GN=IQGAP1 IQGA1 HUMAN $189.26 \quad 100.0 \%$ Ras GTPase-activating-like protein IQGAP1 GN=IQGAP1 IQGA1_HUMAN $189.26 \quad 100.0 \%$ Ras GTPase-activating-like protein IQGAP1 GN=IQGAP1 IQGA1_HUMAN $189.26 \quad 100.0 \%$ Ras GTPase-activating-like protein IQGAP1 GN=IQGAP1 IQGA1_HUMAN $189.26 \quad 100.0 \%$ Ras GTPase-activating-like protein IQGAP1 GN=IQGAP1 IQGA1_HUMAN $189.26 \quad 100.0 \%$ Ras GTPase-activating-like protein IQGAP1 GN=IQGAP1 IQGA1_HUMAN $189.26 \quad 100.0 \%$ Ras GTPase-activating-like protein IQGAP1 GN=IQGAP1 IQGA1_HUMAN $189.26 \quad 100.0 \%$ Ras GTPase-activating-like protein IQGAP1 GN=IQGAP1 IQGA1_HUMAN $189.26 \quad 100.0 \%$ Ras GTPase-activating-like protein IQGAP1 GN=IQGAP1 IQGA1_HUMAN $189.26 \quad 100.0 \%$ Regulator of nonsense transcripts 1 GN=UPF1 RENT1_HUMAN $124.35100 .0 \%$ Regulator of nonsense transcripts 1 GN=UPF1 RENT1_HUMAN $124.35100 .0 \%$ Regulator of nonsense transcripts $1 \mathrm{GN}=\mathrm{UPF} 1$ RENT1_HUMAN $124.35 \quad 100.0 \%$ Replication factor C subunit $1 \mathrm{GN}=\mathrm{RFC1}$ RFC1_HUMAN $128.26 \quad 100.0 \%$ Replication factor $\mathrm{C}$ subunit $1 \mathrm{GN}=\mathrm{RFC} 1 \mathrm{RFC1}$ HUMAN $128.26 \quad 100.0 \%$ Replication factor C subunit $2 \mathrm{GN}=\mathrm{RFC} 2 \quad \mathrm{RFC} 2$ HUMAN $39.16 \quad 100.0 \%$ Replication factor C subunit $2 \mathrm{GN}=\mathrm{RFC} 2$ RFC2_HUMAN $39.16 \quad 100.0 \%$ Replication factor $\mathrm{C}$ subunit $2 \mathrm{GN}=\mathrm{RFC} 2 \mathrm{RFC} 2$ HUMAN $39.16 \quad 100.0 \%$ Replication factor C subunit $2 \mathrm{GN}=\mathrm{RFC} 2 \mathrm{RFC2}$ HUMAN $39.16 \quad 100.0 \%$ Replication factor $\mathrm{C}$ subunit $2 \mathrm{GN}=\mathrm{RFC} 2 \mathrm{RFC} 2 \mathrm{HUMAN} 39.16 \quad 100.0 \%$ Replication factor C subunit $3 \mathrm{GN}=\mathrm{RFC} 3$ RFC3_HUMAN $40.56 \quad 100.0 \%$ Replication factor C subunit $3 \mathrm{GN}=\mathrm{RFC} 3 \quad \mathrm{RFC} 3$ _HUMAN $40.56 \quad 100.0 \%$ Replication factor $\mathrm{C}$ subunit $3 \mathrm{GN}=\mathrm{RFC} 3 \mathrm{RFC} 3 \mathrm{HUMAN} 40.56 \quad 100.0 \%$ Replication factor C subunit $3 \mathrm{GN}=\mathrm{RFC} 3 \quad \mathrm{RFC} 3$ _HUMAN $40.56 \quad 100.0 \%$ Replication factor C subunit $3 \mathrm{GN}=\mathrm{RFC} 3$ RFC3_HUMAN $40.56 \quad 100.0 \%$ Replication factor $\mathrm{C}$ subunit $3 \mathrm{GN}=\mathrm{RFC} 3 \mathrm{RFC} 3$ HUMAN $40.56 \quad 100.0 \%$ Replication factor $\mathrm{C}$ subunit $4 \mathrm{GN}=\mathrm{RFC} 4 \quad \mathrm{RFC} 4$ _HUMAN $39.68 \quad 100.0 \%$ Replication factor $\mathrm{C}$ subunit $4 \mathrm{GN}=\mathrm{RFC} 4 \mathrm{RFC} 4$ HUMAN $39.68 \quad 100.0 \%$ Replication factor C subunit $4 \mathrm{GN}=\mathrm{RFC} 4 \quad \mathrm{RFC} 4$ _HUMAN $39.68 \quad 100.0 \%$ Replication factor C subunit $4 \mathrm{GN}=\mathrm{RFC} 4 \quad \mathrm{RFC} 4$ _HUMAN $39.68 \quad 100.0 \%$ Replication factor $\mathrm{C}$ subunit $4 \mathrm{GN}=\mathrm{RFC} 4 \mathrm{RFC} 4 \mathrm{HUMAN} 39.68 \quad 100.0 \%$ Replication factor $\mathrm{C}$ subunit $4 \mathrm{GN}=\mathrm{RFC} 4 \quad \mathrm{RFC} 4$ _HUMAN $39.68 \quad 100.0 \%$
$0.14 \% 52.4 \%$ CCSGAIIVLTK

$0.14 \% \quad 52.4 \%$ APIIAVTRNPQTAR

$0.14 \% \quad 52.4 \%$ VNFAMNVGK

$0.00 \% \quad 0.0 \%$ HFIARMSMPGGR

$0.00 \% \quad 0.0 \% \quad$ SSNQIAQR

$0.01 \% \quad 2.8 \%$ GSHTDAPDTATGNCLLQR

$0.01 \% \quad 2.8 \%$ AIDENNEPTACFLIR

$0.01 \% \quad 4.1 \%$ SIGSAVDQGNESIVAK

$0.01 \% \quad 4.1 \%$ TPSSSSLSQR

$0.02 \% \quad 14.7 \%$ TQVAGGQLSFKGK

$0.02 \% \quad 14.7 \%$ QVEVINFGDCLVR

$0.02 \% \quad 14.7 \%$ SKGAVAIADAIR

$0.02 \% \quad 14.7 \%$ SSVLIAQQTDTSDPEKVVSAFLK

$0.02 \% \quad 14.7 \%$ AFNSSSFNSNTFLTR

$0.02 \% \quad 14.7 \%$ HSLLQTLYKV

$0.03 \% \quad 6.2 \% \quad$ LGNFFSPK

$0.03 \% \quad 6.2 \%$ ALQSPALGLR

$0.03 \% \quad 6.2 \% \quad$ LAAVALINAAIQK

$0.03 \% \quad 6.2 \% \quad$ TLQALQIPAAK

$0.03 \% \quad 6.2 \% \quad$ NKITLQDVVSHSK

$0.03 \% \quad 6.2 \%$ LIFQMPQNK

$0.03 \% \quad 6.2 \%$ TILLNTKR

$0.03 \% \quad 6.2 \%$ RLIVDVIR

$0.03 \% \quad 6.2 \%$ LQQTYAALNSK

$0.03 \% \quad 6.2 \% \quad$ ATFYGEQVDYYK

$0.01 \% \quad 4.1 \%$ TVLQRPLSLIQGPPGTGK

$0.01 \% \quad 4.1 \%$ AGLSQSLFER

$0.01 \% \quad 4.1 \%$ AGAKPDQIGIITPYEGQR

$0.00 \% \quad 1.9 \%$ SSADKIGEVSSPK

$0.00 \% \quad 1.9 \%$ SYLNREGPK

$0.02 \% \quad 15.8 \%$ EGNVPNIIIAGPPGTGK

$0.02 \% \quad 15.8 \%$ FALACNASDKIIEPIQSR

$0.02 \% \quad 15.8 \%$ YTKLTDAQILTR

$0.02 \% \quad 15.8 \%$ LTDAQILTR

$0.02 \% \quad 15.8 \%$ LMNVIEKER

$0.02 \% \quad 19.4 \%$ LDYHKEQAAQLR

$0.02 \% \quad 19.4 \%$ TVAQSQQLETNSQR

$0.02 \% \quad 19.4 \%$ TMEKYMSTCR

$0.02 \% \quad 19.4 \%$ LILCCNSTSK

$0.02 \% \quad 19.4 \%$ ALLMCEACR

$0.02 \% \quad 19.4 \%$ ETANAIVSQQTPQR

$0.02 \% \quad 16.8 \%$ GTSISTKPPLTK

$0.02 \% \quad 16.8 \%$ TSTILAAAR

$0.02 \% \quad 16.8 \%$ ELFGPELFR

$0.02 \% \quad 16.8 \%$ VKNFAQLTVSGSR

$0.02 \% \quad 16.8 \%$ IIEPLTSR

$0.02 \% \quad 16.8 \%$ AITFLQSATR $\begin{array}{llllllll}99.7 \% & 57.5 & 25.0 & 49.5 & 2 & 0 & 0 & 1221.63\end{array}$

1507.87

979.50

1359.68

903.46

1913.88

1762.84

1574.80

1049.52

1320.73

1548.78

1171.68

2463.30

1692.80

1201.69

909.48

1025.61

1295.80

1153.69

1468.81

1118.60

958.60

983.64

1236.66

1483.67

1862.09

1107.58

1914.0

1304.67

1063.55

1633.89

2033.05

1422.80

1030.59

1131.62

1471.77

1589.79

1306.56

1195.58

1123.51

1542.79

1229.71

903.53

1107.58

1406.78

928.55

$\begin{array}{llll}99.7 \% & 38.2 & 25.0 & 38.2\end{array}$

$\begin{array}{llll}99.0 \% & 34.4 & 25.0 & 19.6\end{array}$

$\begin{array}{llll}99.7 \% & 37.3 & 25.0 & 32.2\end{array}$

1107.62 
Replication factor C subunit 5 GN=RFC5 RFC5_HUMAN $38.50 \quad 100.0 \%$ $\begin{array}{llll}\text { Replication factor C subunit } 5 \mathrm{GN}=\mathrm{RFC} 5 & \mathrm{RFC5} \text { _HUMAN } & 38.50 & 100.0 \%\end{array}$ Replication factor C subunit $5 \mathrm{GN}=\mathrm{RFC} 5 \mathrm{RFC5}$ _HUMAN $38.50 \quad 100.0 \%$ Replication factor C subunit $5 \mathrm{GN}=\mathrm{RFC} 5$ RFC5_HUMAN $38.50 \quad 100.0 \%$ Replication factor C subunit $5 \mathrm{GN}=\mathrm{RFC} 5$ RFC5_HUMAN $38.50 \quad 100.0 \%$ Replication factor C subunit 5 GN=RFC5 RFC5_HUMAN $38.50 \quad 100.0 \%$ Replication factor C subunit $5 \mathrm{GN}=\mathrm{RFC} 5$ RFC5_HUMAN $38.50 \quad 100.0 \%$ Replication factor C subunit 5 GN=RFC5 RFC5_HUMAN $38.50 \quad 100.0 \%$ Replication protein A $70 \mathrm{kDa}$ DNA-binding subunit GN=RPA1 RFA1_HUMAN $68.14 \quad 100.0 \%$ Replication protein A $70 \mathrm{kDa}$ DNA-binding subunit GN=RPA1 RFA1_HUMAN $68.14 \quad 100.0 \%$ Required for meiotic nuclear division protein 1 homolog GN=RMND1 RMND1_HUMAN $51.61 \quad 100.0 \%$ Required for meiotic nuclear division protein 1 homolog GN=RMND1 RMND1_HUMAN $51.61 \quad 100.0 \%$ Required for meiotic nuclear division protein 1 homolog GN=RMND1 RMND1_HUMAN $51.61 \quad 100.0 \%$ Ribonuclease H2 subunit A GN=RNASEH2A RNH2A_HUMAN $33.40 \quad 100.0 \%$ Ribonuclease H2 subunit A GN=RNASEH2A RNH2A_HUMAN $33.40 \quad 100.0 \%$ Ribonuclease P protein subunit p30 GN=RPP30 RPP30_HUMAN $29.32 \quad 100.0 \%$ Ribonuclease P protein subunit p30 GN=RPP30 RPP30 HUMAN $29.32 \quad 100.0 \%$ Ribonuclease P protein subunit p30 GN=RPP30 RPP30_HUMAN $29.32 \quad 100.0 \%$ Ribonuclease P protein subunit p30 GN=RPP30 RPP30_HUMAN $29.32 \quad 100.0 \%$ Ribonuclease P protein subunit p38 GN=RPP38 RPP38_HUMAN $31.84 \quad 100.0 \%$ Ribonuclease P protein subunit p38 GN=RPP38 RPP38_HUMAN $31.84 \quad 100.0 \%$ Ribonuclease P protein subunit p38 GN=RPP38 RPP38_HUMAN $31.84 \quad 100.0 \%$ Ribonuclease P protein subunit p38 GN=RPP38 RPP38_HUMAN $31.84 \quad 100.0 \%$ Ribonucleases P/MRP protein subunit POP1 GN=POP1 POP1_HUMAN $114.71 \quad 100.0 \%$ Ribonucleases P/MRP protein subunit POP1 GN=POP1 POP1_HUMAN $114.71 \quad 100.0 \%$ Ribonucleases P/MRP protein subunit POP1 GN=POP1 POP1_HUMAN $114.71 \quad 100.0 \%$ Ribonucleases P/MRP protein subunit POP1 GN=POP1 POP1_HUMAN $114.71 \quad 100.0 \%$ Ribose-phosphate pyrophosphokinase 1 GN=PRPS1 PRPS1_HUMAN $34.83 \quad 100.0 \%$ Ribose-phosphate pyrophosphokinase 1 GN=PRPS1 PRPS1_HUMAN $34.83 \quad 100.0 \%$ Ribose-phosphate pyrophosphokinase 1 GN=PRPS1 PRPS1_HUMAN $34.83 \quad 100.0 \%$ Ribose-phosphate pyrophosphokinase 1 GN=PRPS1 PRPS1_HUMAN $34.83 \quad 100.0 \%$ Ribose-phosphate pyrophosphokinase 1 GN=PRPS1 PRPS1_HUMAN $34.83 \quad 100.0 \%$ Ribose-phosphate pyrophosphokinase 2 GN=PRPS2 PRPS2_HUMAN $34.77 \quad 100.0 \%$ Ribose-phosphate pyrophosphokinase 2 GN=PRPS2 PRPS2_HUMAN $34.77 \quad 100.0 \%$ Ribose-phosphate pyrophosphokinase 2 GN=PRPS2 PRPS2_HUMAN $34.77 \quad 100.0 \%$ Ribose-phosphate pyrophosphokinase 2 GN=PRPS2 PRPS2_HUMAN $34.77 \quad 100.0 \%$ Ribose-phosphate pyrophosphokinase 2 GN=PRPS2 PRPS2_HUMAN $34.77 \quad 100.0 \%$ Ribosomal biogenesis protein LAS1L GN=LAS1L LAS1L_HUMAN $83.07 \quad 100.0 \%$ Ribosomal biogenesis protein LAS1L GN=LAS1L LAS1L_HUMAN $83.07 \quad 100.0 \%$ Ribosomal biogenesis protein LAS1L GN=LAS1L LAS1L_HUMAN $83.07 \quad 100.0 \%$ Ribosomal biogenesis protein LAS1L GN=LAS1L LAS1L_HUMAN $83.07 \quad 100.0 \%$ Ribosomal L1 domain-containing protein 1 GN=RSL1D1 RL1D1_HUMAN $54.97 \quad 100.0 \%$ Ribosomal L1 domain-containing protein 1 GN=RSL1D1 RL1D1_HUMAN $54.97 \quad 100.0 \%$ Ribosomal L1 domain-containing protein $1 \mathrm{GN}=$ RSL1D1 RL1D1_HUMAN $54.97 \quad 100.0 \%$ Ribosomal L1 domain-containing protein $1 \mathrm{GN}=$ RSL1D1 RL1D1_HUMAN $54.97 \quad 100.0 \%$ Ribosomal L1 domain-containing protein 1 GN=RSL1D1 RL1D1_HUMAN 54.97 Ribosomal L1 domain-containing protein 1 GN=RSL1D1 RL1D1_HUMAN 54.97 $0.02 \% \quad 24.4 \%$ IIPALQSR

$10 \quad 16 \quad 0.02 \% \quad 24.4 \%$ FGPLTPELMVPR

$\begin{array}{llll}10 & 16 & 0.02 \% & 24.4 \% \\ 10 & \text { ALVTLSSGDMR }\end{array}$

$10 \quad 16 \quad 0.02 \% \quad 24.4 \%$ ALNILQSTNMAFGK

$\begin{array}{llll}10 & 16 & 0.02 \% & 24.4 \% \\ 3 & \text { NITELKTLK }\end{array}$

$0.01 \% \quad 4.4 \%$ AAGPSLSHTSGGTQSK

$0.01 \% \quad 4.4 \%$ DSLVDIIGICK

$0.01 \% \quad 7.6 \%$ DAANILVMGVENSAK

$0.01 \% \quad 7.6 \%$ EGDPGTIFFFR

$0.01 \% \quad 7.6 \%$ IGELFALR

$0.00 \% \quad 9.4 \%$ LQQSFPGIEVTVK

$0.00 \% \quad 9.4 \%$ ITSYFLNEGSQARPR

$0.01 \% \quad 16.8 \%$ LTIIVSDPSHCNVLR

$0.01 \% \quad 16.8 \%$ LYDVVAVFPK

$0.01 \% \quad 16.8 \%$ AALLHGETR

$0.01 \% \quad 16.8 \%$ KTAFGIISTVK

$0.01 \% \quad 14.5 \%$ TSLNNPYIIR

$0.01 \% \quad 14.5 \%$ QLAIGVNEVTR

$0.01 \% \quad 14.5 \%$ NTTDFVDEVR

$0.01 \% \quad 14.5 \%$ QASVTLQPLK

$0.01 \% \quad 5.3 \% \quad$ NQPTNVTLSSGFVADR

$0.01 \% \quad 5.3 \%$ SSNSLVFQTLPR

$0.01 \% \quad 5.3 \%$ EACLSILGHFPR

$0.01 \% \quad 5.3 \%$ GLVLLRPPASLQYR

$0.02 \% \quad 20.4 \%$ IFSGSSHQDLSQK

$0.02 \% \quad 20.4 \%$ VTAVIPCFPYAR

$0.02 \% \quad 20.4 \%$ NCTIVSPDAGGAK

$0.02 \% \quad 20.4 \%$ MVLVGDVKDR

$0.02 \% \quad 20.4 \%$ VYAILTHGIFSGPAISR

$0.01 \% \quad 21.1 \%$ PNIVLFSGSSHQDLSQR

$0.01 \% \quad 21.1 \%$ VADRLGLELGK

$0.01 \% \quad 21.1 \%$ VTAVIPCFPYAR

$0.01 \% \quad 21.1 \%$ MVLVGDVKDR

$0.01 \% \quad 21.1 \%$ VYAILTHGIFSGPAISR

$0.01 \% \quad 4.9 \%$ SGNELPLAVASTADLIR

$0.01 \% \quad 4.9 \% \quad$ FVNLISER

$0.01 \% \quad 4.9 \% \quad$ FVNLISERK

$0.01 \% \quad 4.9 \%$ ALSHKELYER

$0.04 \% \quad 25.5 \%$ KAVDALLTHCK

$0.04 \% \quad 25.5 \%$ AVDALLTHCK

$0.04 \% \quad 25.5 \%$ AVDALLTHCKSR

$0.04 \% \quad 25.5 \%$ LTLPHSIR

$0.04 \% \quad 25.5 \%$ TVSQIISLQTLKK

$0.04 \% \quad 25.5 \%$ LLSSFDFFLTDAR $\begin{array}{llllllll}99.7 \% & 32.2 & 25.0 & 29.3 & 1 & 0 & 0 & 964.51\end{array}$

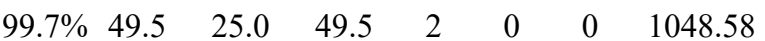

$\begin{array}{llllllll}97.7 \% & 18.2 & 25.0 & 18.2 & 1 & 0 & 0 & 1317.63\end{array}$

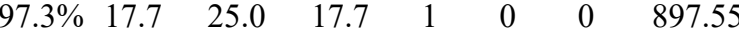

$\begin{array}{llllllll}99.7 \% & 31.4 & 25.0 & 30.2 & 3 & 0 & 0 & 1356.73\end{array}$

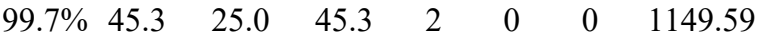

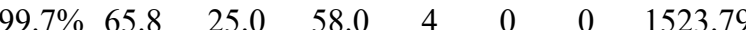

$\begin{array}{llllllll}99.7 \% & 26.4 & 25.0 & 22.2 & 2 & 0 & 0 & 1059.64\end{array}$

$99.7 \% \quad 31.0 \quad 25.0 \quad 29.8$

$\begin{array}{llll}99.3 \% & 23.4 & 25.0 & 23.4\end{array}$

$\begin{array}{llll}99.7 \% & 57.8 & 25.0 & 57.8\end{array}$

$99.7 \% \quad 35.1 \quad 25.0 \quad 28.0$

$99.0 \% \quad 54.4 \quad 25.0 \quad 42.0$

$95.3 \% \quad 14.4 \quad 25.0 \quad 14.4$

$99.6 \% \quad 23.0 \quad 25.0 \quad 23.0$

$\begin{array}{llll}98.5 \% & 19.8 & 25.0 & 19.8\end{array}$

$99.5 \% \quad 25.7 \quad 25.0 \quad 25.4$

$\begin{array}{llll}99.7 \% & 36.2 & 25.0 & 31.5\end{array}$

$96.9 \% \quad 17.5 \quad 25.0 \quad 15.3$

$\begin{array}{llll}99.7 \% & 40.3 & 25.0 & 35.4\end{array}$

$99.7 \% \quad 49.5 \quad 25.0 \quad 31.1$

$\begin{array}{llll}99.7 \% & 28.4 & 25.0 & 26.7\end{array}$

$\begin{array}{llll}99.6 \% & 25.6 & 25.0 & 19.5\end{array}$

$99.7 \% \quad 25.1$

$25.0 \quad 25$.

$\begin{array}{llll}99.7 \% & 63.6 & 25.0 & 50.9\end{array}$

$\begin{array}{llll}99.7 \% & 37.3 & 25.0 & 36.6\end{array}$

$\begin{array}{llll}94.7 \% & 14.3 & 25.0 & 14.3\end{array}$

$\begin{array}{llll}99.7 \% & 49.7 & 25.0 & 49.2\end{array}$

$\begin{array}{llll}99.7 \% & 35.2 & 25.0 & 34.6\end{array}$

$99.7 \% \quad 41.8 \quad 25.0 \quad 31.3$

$\begin{array}{llll}99.7 \% & 39.6 & 25.0 & 35.1\end{array}$

$\begin{array}{lllll}99.7 \% & 46.1 & 25.0 & 46.1 & 2\end{array}$

$99.7 \% \quad 41.5 \quad 25.0 \quad 41.5$

$99.7 \% \quad 34.0 \quad 25.0 \quad 21.1$

$\begin{array}{llll}99.7 \% & 35.2 & 25.0 & 34.6\end{array}$

$99.7 \% \quad 39.6 \quad 25.0 \quad 35.1$

$99.7 \% \quad 46.1 \quad 25.0 \quad 46.1 \quad 2$

$\begin{array}{llll}99.7 \% & 53.9 & 25.0 & 53.9\end{array}$

$\begin{array}{llll}99.0 \% & 40.3 & 25.0 & 22.8\end{array}$

$\begin{array}{llll}96.5 \% & 19.2 & 25.0 & 15.8\end{array}$

$\begin{array}{lllll}95.6 \% & 14.4 & 25.0 & 13.9\end{array}$

$\begin{array}{llll}99.7 \% & 31.8 & 25.0 & 31.8\end{array}$

$\begin{array}{llll}99.7 \% & 39.6 & 25.0 & 34.0\end{array}$

$\begin{array}{llll}99.3 \% & 23.2 & 25.0 & 17.0\end{array}$

$96.8 \% \quad 16.0 \quad 25.0 \quad 16.0$

$\begin{array}{llll}99.7 \% & 41.1 & 25.0 & 41.1\end{array}$

$99.7 \% \quad 83.8 \quad 25.0 \quad 83.6$ 103 151 161 174

1232.66

1531.78

1285.62

918.54

1445.80

1738.89

1723.92

150.65

967.53

1164.70

1190.65

1199.67

1195.56

1084.64

1705.85

1348.72

1399.72

1582.94

1433.70

1393.73

1289.62

1147.61

1802.00

1884.96

1170.68

1393.73

1147.61

1802.00

1726.93

977.54

1105.64

1245.66

1255.68

1127.59

1370.72

936.56

1458.89

1531.78
265
168

314

314
205

220

353

353
268

268

77

236

23

112
185

185
251

15

126

843

0031016

$6 \quad 18$

$85 \quad 96$

$164 \quad 176$

$205 \quad 214$

$244 \quad 260$

$2 \quad 18$

$19 \quad 29$

$85 \quad 96$

$205 \quad 214$

$244 \quad 260$

96

122

259

38
39

39

82

125 

Ribosomal L1 domain-containing protein 1 GN=RSL1D1 RL1D1_HUMAN $54.97 \quad 100.0 \%$ Ribosomal L1 domain-containing protein 1 GN=RSL1D1 RL1D1 HUMAN $54.97 \quad 100.0 \%$ Ribosomal L1 domain-containing protein $1 \mathrm{GN}=$ RSL1D1 RL1D1_HUMAN $54.97100 .0^{\circ}$ Ribosomal L1 domain-containing protein $1 \mathrm{GN}=$ RSL1D1 RL1D1_HUMAN $54.97 \quad 100.0 \%$ Ribosomal L1 domain-containing protein $1 \mathrm{GN}=$ RSL1D1 RL1D1_HUMAN $54.97 \quad 100.0 \%$ Ribosom 1 L1 domin-containg protin 1 GN=RSL1D1 RL1D1_HUMAN $54.97 \quad 100.0 \%$ Ribosomal L1 domain-containing protein $1 \mathrm{GN}=\mathrm{RSL} 1 \mathrm{D} 1$ RL1D1_HUMAN $54.97 \quad 100.0 \%$ Ribosomal protein S6 kinase alpha-3 GN=RPS6KA3 KS6A3 HUMAN $83.74 \quad 100.0 \%$ Ribosomal protein S6 kinase alpha-3 GN=RPS6KA3 KS6A3_HUMAN $83.74 \quad 100.0 \%$ Ribosomal RNA processing protein 1 homolog A GN=RRP1 RRP1_HUMAN $52.84 \quad 100.0 \%$ Ribosomal RNA processing protein 1 homolog A GN=RRP1 RRP1_HUMAN $52.84 \quad 100.0 \%$ Ribosomal RNA processing protein 1 homolog A GN=RRP1 RRP1_HUMAN $52.84 \quad 100.0 \%$ Ribosomal RNA processing protein 1 homolog A GN=RRP1 RRP1_HUMAN $52.84 \quad 100.0 \%$ Ribosomal RNA processing protein 1 homolog B GN=RRP1B RRP1B_HUMAN $84.43 \quad 100.0 \%$ Ribosomal RNA processing protein 1 homolog B GN=RRP1B RRP1B_HUMAN $84.43 \quad 100.0 \%$ Ribosomal RNA processing protein 1 homolog B GN=RRP1B RRP1B HUMAN $84.43 \quad 100.0 \%$ Ribosomal RNA processing protein 1 homolog B GN=RRP1B RRP1B_HUMAN $84.43 \quad 100.0 \%$ Ribosomal RNA processing protein 1 homolog B GN=RRP1B RRP1B_HUMAN $84.43 \quad 100.0 \%$ Ribosomal RNA processing protein 1 homolog B GN=RRP1B RRP1B_HUMAN $84.43 \quad 100.0 \%$ Ribosomal RNA processing protein 1 homolog B GN=RRP1B RRP1B_HUMAN $84.43 \quad 100.0 \%$ Ribosomal RNA processing protein 1 homolog B GN=RRP1B RRP1B_HUMAN $84.43 \quad 100.0 \%$ Ribosomal RNA processing protein 1 homolog B GN=RRP1B RRP1B_HUMAN $84.43 \quad 100.0 \%$ Ribosomal RNA processing protein 1 homolog B GN=RRP1B RRP1B_HUMAN $84.43 \quad 100.0 \%$ Ribosomal RNA processing protein 1 homolog B GN=RRP1B RRP1B_HUMAN $84.43 \quad 100.0 \%$ Ribosomal RNA processing protein 1 homolog B GN=RRP1B RRP1B_HUMAN $84.43 \quad 100.0 \%$ Ribosome biogenesis protein BMS1 homolog GN=BMS1 BMS1_HUMAN $145.81 \quad 100.0 \%$ Ribosome biogenesis protein BMS1 homolog GN=BMS1 BMS1_HUMAN $145.81 \quad 100.0 \%$ Ribosome production factor 2 homolog GN=RPF2 RPF2_HUMAN $35.59 \quad 100.0 \%$ Ribosome production factor 2 homolog GN=RPF2 RPF2 HUMAN $35.59 \quad 100.0 \%$ Ribosome production factor 2 homolog GN=RPF2 RPF2_HUMAN $35.59 \quad 100.0 \%$ Ribosome-binding protein 1 GN=RRBP1 RRBP1_HUMAN $152.47 \quad 100.0 \%$ Ribosome-binding protein $1 \mathrm{GN}=\mathrm{RRBP} 1$ RRBP1 HUMAN $152.47 \quad 100.0 \%$ RING finger protein $219 \mathrm{GN}=\mathrm{RNF} 219 \quad$ RN219_HUMAN $81.12 \quad 100.0 \%$ RING finger protein 219 GN=RNF219 RN219_HUMAN $81.12 \quad 100.0 \%$ RING finger protein 219 GN=RNF219 RN219_HUMAN $81.12 \quad 100.0 \%$ RING finger protein $219 \mathrm{GN}=\mathrm{RNF} 219 \quad$ RN219_HUMAN $81.12 \quad 100.0 \%$ RING finger protein $219 \mathrm{GN}=\mathrm{RNF} 219 \quad$ RN219 HUMAN $81.12 \quad 100.0 \%$ RNA 3'-terminal phosphate cyclase GN=RTCA RTCA_HUMAN $39.34 \quad 100.0 \%$ RNA 3'-terminal phosphate cyclase GN=RTCA RTCA_HUMAN $39.34 \quad 100.0 \%$ RNA 3'-terminal phosphate cyclase GN=RTCA RTCA_HUMAN $39.34 \quad 100.0 \%$ RNA 3'-terminal phosphate cyclase GN=RTCA RTCA_HUMAN $39.34 \quad 100.0 \%$ RNA 3'-terminal phosphate cyclase GN=RTCA RTCA HUMAN $39.34 \quad 100.0 \%$ RNA 3'-terminal phosphate cyclase-like protein GN=RCL1 RCL1_HUMAN $40.84 \quad 100.0 \%$ RNA 3'-terminal phosphate cyclase-like protein GN=RCL1 RCL1_HUMAN $40.84 \quad 100.0 \%$ RNA 3'-terminal phosphate cyclase-like protein GN=RCL1 RCL1_HUMAN $40.84 \quad 100.0^{\circ}$ RNA binding protein fox-1 homolog 2 GN=RBFOX2 RFOX2_HUMAN $41.37 \quad 100.0 \%$

(1)

(1)

(1)

13

13

13

12

2

12
12
12

2
2

2
3
3

3
3
3

5

5
3
3

$\begin{array}{ll}3 & 3 \\ 3 & 3 \\ 3 & 3\end{array}$

$\begin{array}{llllllll}99.7 \% & 43.3 & 25.0 & 43.3 & 3 & 0 & 0 & 1024.66\end{array}$ $\begin{array}{llll}99.0 \% & 29.2 & 25.0 & 20.2\end{array}$ $\begin{array}{llll}99.7 \% & 38.7 & 25.0 & 38.7\end{array}$ $\begin{array}{llll}99.6 \% & 25.0 & 25.0 & 25.0\end{array}$ $\begin{array}{llll}99.7 \% & 64.9 & 25.0 & 54.1\end{array}$ $\begin{array}{llll}99.7 \% & 42.2 & 25.0 & 39.1\end{array}$ $99.7 \% \quad 57.6 \quad 25.0 \quad 56.2$ $\begin{array}{llll}97.4 \% & 19.3 & 25.0 & 19.3\end{array}$ $\begin{array}{llll}96.7 \% & 20.6 & 25.0 & 11.5\end{array}$ $99.6 \% \quad 24.2 \quad 25.0 \quad 24.2$ $99.7 \% \quad 59.8 \quad 25.0 \quad 45.9$ $99.7 \% \quad 49.6 \quad 25.0 \quad 49.0$ $0.01 \% \quad 10.8 \%$ LAGNEQVTR $0.01 \% \quad 10.8 \%$ TKDSLVLNNITR $0.01 \% \quad 10.8 \%$ GVGADPEARAEAGEQPGTAER $0.01 \% \quad 10.8 \%$ ALLRDQPR $0.05 \% \quad 19.4 \%$ APAMQPAEIQFAQR $\begin{array}{lll}95.2 \% & 18.7\end{array}$ $99.7 \% \quad 59.8$

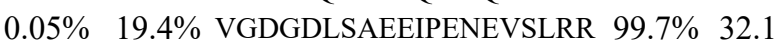
$0.05 \% \quad 19.4 \%$ VFCVEEEDSESSLQKR $0.05 \% \quad 19.4 \%$ GSPTGGAQLLK $0.05 \% \quad 19.4 \%$ GSPTGGAQLLKR $0.05 \% \quad 19.4 \%$ AGPGSLELCGLPSQK $0.05 \% \quad 19.4 \%$ SSTATHPPGPAVQLNK $0.05 \% \quad 19.4 \%$ SSTATHPPGPAVQLNKTPSSSK $0.05 \% \quad 19.4 \%$ KVTFGLNR $0.05 \% \quad 19.4 \%$ SILVSPTGPSR $0.05 \% \quad 19.4 \%$ VAFDPEQKPLHGVLK $0.05 \% \quad 19.4 \%$ TPTSSPASSPLVAK $0.00 \% \quad 1.6 \%$ AFAVQSAVR $0.00 \% \quad 1.6 \%$ SSLKGAEGQLQ $0.01 \% \quad 11.8 \%$ VLKDVYALK $0.01 \% \quad 11.8 \%$ KSDCSLFMFGSHNK $0.01 \% \quad 11.8 \%$ NISHDTFGTTYGR $0.01 \% \quad 1.6 \%$ EQEITAVQAR $0.01 \% \quad 1.6 \%$ SIEALLEAGQAR $0.02 \% \quad 9.2 \%$ NLSLESQIK $0.02 \% \quad 9.2 \%$ FAVAALQSK $0.02 \% \quad 9.2 \%$ GSEEDVVSKNQGDSAR $0.02 \% \quad 9.2 \% \quad$ KQPGSSTSSSSHLAKPSSSR $0.02 \% \quad 9.2 \% \quad$ KIQSSLSSASPSK $0.01 \% \quad 14.5 \%$ VEVDGSIMEGGGQILR $0.01 \% \quad 14.5 \%$ VSTALSCLLGLPLR $0.01 \% \quad 14.5 \%$ FGFIFNCDIK $0.01 \% \quad 14.5 \%$ AFVAGVLPFK $0.01 \% \quad 14.5 \%$ AFVAGVLPFKVAK $0.01 \% \quad 9.4 \%$ LVLSTLSGRPVK $0.01 \% \quad 9.4 \%$ GVTNDQVDPSVDVLK $0.01 \% \quad 9.4 \%$ LLLEEIYR $0.01 \% \quad 9.5 \%$ RLHVSNIPFR
$25.0 \quad 32.1$

$98.6 \% \quad 26.3$

$\begin{array}{llll}99.7 \% & 55.7 & 25.0 & 54.2\end{array}$

$99.7 \% \quad 54.8 \quad 25.0 \quad 51.5$

$\begin{array}{lllll}99.7 \% & 40.5 & 25.0 & 38.7 & 2\end{array}$

$\begin{array}{llll}98.7 \% & 20.6 & 25.0 & 20.6 \\ 99.0 \% & 37.7 & 25.0 & 37.7\end{array}$

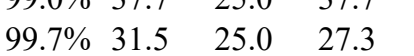

$99.2 \% \quad 20.1 \quad 25.0 \quad 20.1$

$\begin{array}{llll}99.7 \% & 57.5 & 25.0 & 56.7\end{array}$

$\begin{array}{llll}99.7 \% & 58.3 & 25.0 & 50.0\end{array}$

$\begin{array}{llll}99.7 \% & 34.5 & 25.0 & 18.3\end{array}$

$\begin{array}{llll}99.7 \% & 28.5 & 25.0 & 23.9\end{array}$

$97.7 \% \quad 15.6 \quad 25.0 \quad 15.6$

$\begin{array}{llll}99.7 \% & 48.2 & 25.0 & 48.2\end{array}$

$\begin{array}{llll}99.7 \% & 28.5 & 25.0 & 28.5\end{array}$

$\begin{array}{llll}99.7 \% & 43.2 & 25.0 & 23.5\end{array}$

$\begin{array}{llll}99.7 \% & 36.0 & 25.0 & 17.2\end{array}$

$\begin{array}{llll}99.7 \% & 28.6 & 25.0 & 19.4\end{array}$

$\begin{array}{llll}99.7 \% & 43.4 & 25.0 & 43.4\end{array}$

$99.3 \% \quad 19.8$

$99.7 \% \quad 54.2$

$99.7 \% \quad 48.4$

$99.7 \% \quad 33.4$

$99.7 \% \quad 35.2$

$99.7 \% \quad 31.9$

$99.7 \% \quad 46.4$

$99.7 \% \quad 41.9$

$99.7 \% \quad 50.6$

$\begin{array}{lll}99.0 \% & 29.1\end{array}$

$99.7 \% \quad 35.1$
868.56

1055.65

2103.09

1632.83

1839.93

1256.68

1238.65

1113.66

1195.64

987.52

1373.77

2067.97

968.56

1557.78

2185.07

1941.89

1028.57

1184.67

1513.77

1604.84

2192.13

934.55

1113.63

1677.93

1342.72

948.53

1117.58

1048.64

1657.75

1468.68

1144.60

1257.68

1031.57

934.54

1677.77

2016.01

1319.72

1675.83

1499.86

1260.61

1048.62

1346.82

1269.79

1585.81

1048.60 1238.71

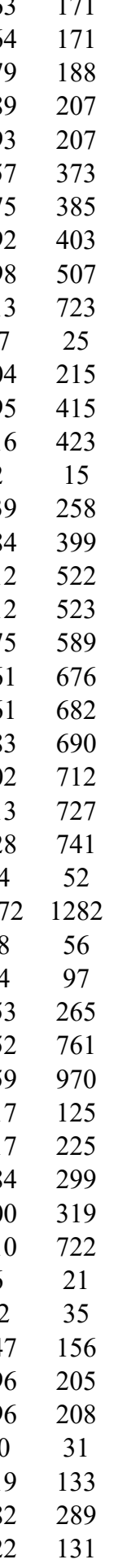

Page 100 of Table S-1-2 
RNA binding protein fox-1 homolog $2 \mathrm{GN}=\mathrm{RBFOX} 2$ RFOX2 HUMAN $41.37 \quad 100.0 \%$ RNA binding protein fox-1 homolog 2 GN=RBFOX2 RFOX2_HUMAN $41.37 \quad 100.0 \%$ RNA pseudouridylate synthase domain-containing protein 3 GN=RPUSD3 $\quad$ RUSD3_HUMAN $38.46 \quad 100.0 \%$ 作 RNA pseudouridylate synthase domain-containing protein 3 GN=RPUSD3 RUSD3_HUMAN $38.46 \quad 100.0 \%$ RNA pseudouridylate synthase domain-containing protein 3 GN=RPUSD3 RUSD3_HUMAN $38.46 \quad 100.0 \%$ RNA pseudouridylate synthase domain-containing protein 3 GN=RPUSD3 RUSD3 HUMAN $38.46 \quad 100.0 \%$ RNA pseudouridylate synthase domain-containing protein 3 GN=RPUSD3 RUSD3_HUMAN $38.46 \quad 100.0 \%$ RNA pseudouridylate synthase domain-containing protein 3 GN=RPUSD3 RUSD3 HUMAN $38.46 \quad 100.0 \%$ RNA-binding motif protein, $X$ chromosome GN=RBMX RBMX_HUMAN $42.33 \quad 100.0 \%$ RNA-binding motif protein, $X$ chromosome GN=RBMX RBMX_HUMAN $42.33 \quad 100.0 \%$ RNA-binding motif protein, $X$ chromosome GN=RBMX RBMX HUMAN $42.33 \quad 100.0 \%$ RNA-binding motif protein, $X$ chromosome GN=RBMX RBMX_HUMAN $42.33 \quad 100.0 \%$ RNA-binding motif protein, $\mathrm{X}$ chromosome GN=RBMX RBMX_HUMAN $42.33 \quad 100.0 \%$ RNA-binding motif protein, $X$ chromosome GN=RBMX RBMX_HUMAN $42.33 \quad 100.0 \%$ RNA-binding motif protein, $X$ chromosome GN=RBMX RBMX_HUMAN $42.33 \quad 100.0 \%$ RNA-binding motif protein, $X$ chromosome GN=RBMX RBMX_HUMAN $42.33 \quad 100.0^{\circ}$ RNA-binding motif protein, $X$ chromosome GN=RBMX RBMX_HUMAN $42.33 \quad 100.0 \%$ RNA-binding motif protein, $X$ chromosome GN=RBMX RBMX_HUMAN $42.33 \quad 100.0 \%$ RNA-binding motif protein, $X$ chromosome GN=RBMX RBMX HUMAN $42.33 \quad 100.0 \%$ RNA-binding motif protein, $X$ chromosome GN=RBMX RBMX_HUMAN $42.33 \quad 100.0 \%$ RNA-binding motif protein, $X$ chromosome GN=RBMX RBMX_HUMAN $42.33 \quad 100.0 \%$ RNA-binding motif protein, $X$ chromosome GN=RBMX RBMX_HUMAN $42.33 \quad 100.0 \%$ RNA-binding motif protein, $X$ chromosome GN=RBMX RBMX_HUMAN $42.33 \quad 100.0 \%$ RNA-binding motif protein, $X$ chromosome GN=RBMX RBMX_HUMAN $42.33 \quad 100.0 \%$ RNA-binding motif protein, $X$ chromosome GN=RBMX RBMX_HUMAN $42.33 \quad 100.0 \%$ RNA-binding motif protein, $X$ chromosome GN=RBMX RBMX_HUMAN $42.33 \quad 100.0 \% \quad 2$ RNA-binding motif protein, $X$ chromosome GN=RBMX RBMX_HUMAN $42.33 \quad 100.0 \% \quad 20$ RNA-binding motif protein, X chromosome GN=RBMX RBMX_HUMAN $42.33 \quad 100.0 \% \quad 20$ RNA-binding protein $10 \mathrm{GN}=\mathrm{RBM} 10$ RNA-binding protein $10 \mathrm{GN}=\mathrm{RBM} 10$ RNA-binding protein $10 \mathrm{GN}=\mathrm{RBM} 10$ RNA-binding protein $10 \mathrm{GN}=\mathrm{RBM} 10$ RNA-binding protein $10 \mathrm{GN}=\mathrm{RBM} 10$ RNA-binding protein $10 \mathrm{GN}=\mathrm{RBM} 10$ RNA-binding protein $10 \mathrm{GN}=\mathrm{RBM} 10$ RNA-binding protein $10 \mathrm{GN}=\mathrm{RBM} 10$ RNA-binding protein $10 \mathrm{GN}=\mathrm{RBM} 10$ RNA-binding protein $10 \mathrm{GN}=\mathrm{RBM} 10$ RNA-binding protein $10 \mathrm{GN}=\mathrm{RBM} 10$ RNA-binding protein $10 \mathrm{GN}=\mathrm{RBM} 10$ RNA-binding protein $10 \mathrm{GN}=\mathrm{RBM} 10$ RNA-binding protein $10 \mathrm{GN}=\mathrm{RBM} 10$ RNA-binding protein $10 \mathrm{GN}=\mathrm{RBM} 10$ RNA-binding protein $10 \mathrm{GN}=\mathrm{RBM} 10$ RNA-binding protein $10 \mathrm{GN}=\mathrm{RBM} 10$ RNA-binding protein $10 \mathrm{GN}=\mathrm{RBM} 10$

RBM10 HUMAN $103.53 \quad 100.0 \% \quad 27$ RBM10_HUMAN $103.53 \quad 100.0 \% \quad 27$ RBM10_HUMAN $103.53 \quad 100.0 \% \quad 27$ RBM10 HUMAN $103.53 \quad 100.0 \% \quad 27$ RBM10_HUMAN $103.53 \quad 100.0 \% \quad 27$ RBM10_HUMAN $103.53 \quad 100.0 \% \quad 27$ RBM10_HUMAN $103.53 \quad 100.0 \% \quad 27$ RBM10_HUMAN $103.53 \quad 100.0 \% \quad 27$ RBM10 HUMAN $103.53 \quad 100.0 \% \quad 27$ RBM10_HUMAN $103.53 \quad 100.0 \% \quad 27$ RBM10_HUMAN $103.53 \quad 100.0 \% \quad 27$ RBM10 HUMAN $103.53 \quad 100.0 \% \quad 27$ RBM10_HUMAN $103.53 \quad 100.0 \% \quad 27$ RBM10 HUMAN $103.53 \quad 100.0 \% \quad 27$ RBM10 HUMAN $103.53 \quad 100.0 \% \quad 27$ RBM10_HUMAN $103.53 \quad 100.0 \% \quad 27$ RBM10 HUMAN $103.53 \quad 100.0 \% \quad 27$ RBM10_HUMAN $103.53 \quad 100.0 \% \quad 27$
$0.01 \% \quad 9.5 \%$ GFGFVTFENSAD

$96.4 \% 15.9$
$97.1 \% \quad 21.2$

$98.3 \% 26.7$

$98.6 \% \quad 20.8$

$99.7 \% \quad 61.7$

$99.7 \% 34.9$

$99.3 \% \quad 19.0$

$99.7 \% \quad 34.5$

$96.7 \% \quad 17.6$

$99.7 \% \quad 33.9$

$99.7 \% \quad 34.0$

$99.3 \% \quad 21.7$

$96.7 \% \quad 17.2$

$99.7 \% \quad 35.5$

$99.7 \% \quad 42.4$

$99.7 \% \quad 62.5$

$99.7 \% \quad 24.4$

$99.7 \% \quad 60.7$

$99.1 \% 21.0$

$99.7 \% 58.6$

$99.7 \% \quad 61.0$

$99.7 \% \quad 57.3$

$99.7 \% \quad 29.0$

$99.7 \% \quad 53.8$

$99.7 \% 25.6$

$99.7 \% \quad 72.9$

$99.7 \% \quad 29.6$

$99.7 \% \quad 29.1$

$\begin{array}{lll}94.5 \% & 13.3\end{array}$

$99.7 \% 37.0$

$99.5 \% \quad 20.6$ $0.01 \% \quad 9.5 \%$ KIEVNNATAR

$0.02 \% 24.8 \%$ SGPLGDQPFAGLLPK

$0.02 \% \quad 24.8 \%$ NLSREELVDALR

$0.02 \% \quad 24.8 \%$ ASGKESSGLVLLSSCPQTASR

$0.02 \% \quad 24.8 \%$ VGTVLGQR

$0.02 \% \quad 24.8 \%$ FLLPAENNKPQR

$0.02 \% \quad 24.8 \%$ QVLDEALLR

$0.02 \% \quad 24.8 \%$ TLQCLGLRLQ

$0.13 \% \quad 55.0 \%$ LFIGGLNTETNEK

$0.13 \% \quad 55.0 \%$ ALEAVFGKYGR

$0.13 \% \quad 55.0 \%$ GFAFVTFESPADAK

$\begin{array}{ll}0.13 \% & 55.0 \% \\ 0.13 \% & 55.0 \%\end{array}$

$0.13 \% \quad 55.0 \%$ AIKVEQATKPSFESG

$0.13 \% \quad 55.0 \%$ RGPPPPPR $99.7 \% \quad 35.4$

$99.7 \% \quad 51.6$

$99.7 \% \quad 38.1$

$99.7 \% \quad 47.3$

$99.0 \% \quad 47.9$

$99.7 \% \quad 35.3$

$99.4 \% \quad 38.4$

$99.7 \% \quad 30.4$

$99.7 \% \quad 64.7$

$99.7 \% \quad 48.7$

$99.7 \% \quad 64.0$

$99.7 \% \quad 57.4$

$99.7 \% \quad 50.1$

$99.7 \% \quad 44.5$

$99.0 \% \quad 50.1$

$0.13 \% \quad 55.0 \%$ GGHMDDGGYSMNFNMSSSR $\quad 99.7 \% \quad 56.0$

$0.13 \% \quad 55.0 \%$ SSSGMGGRAPVSR

$0.13 \% \quad 55.0 \%$ GRDSYGGPPR

$0.13 \% \quad 55.0 \%$ DSYGGPPR

$0.13 \% \quad 55.0 \%$ DVYLSPRDDGYSTK

$0.13 \% \quad 55.0 \%$ DSYSSRDYPSSR

$0.13 \% \quad 55.0 \%$ DYGHSSSRDDYPSR

$0.13 \% \quad 55.0 \%$ DSYESYGNSR

$0.13 \% \quad 55.0 \%$ SAPPTRGPPPSYGGSSR

$0.13 \% \quad 55.0 \%$ YDDYSSSRDGYGGSR

$0.13 \% \quad 55.0 \%$ DGYGGSRDSYSSSR

$0.13 \% \quad 55.0 \%$ SDLYSSGRDR

$0.13 \% \quad 55.0 \%$ GLPPSMER

1496.81

2135.08

829.49

1426.78

1056.60

1201.67

1435.74

1210.66

1486.72

1899.92

1747.93

1435.72

873.51

2081.77

1248.61

1061.51

1615.76

1419.61

1641.69

1177.48

1670.82

1684.68

1493.63

1155.54

2537.25

1724.84

1304.63

1191.55

2024.93

1328.72

1197.66

3261.53

2550.14

1290.65

1148.6

1438.71

1669.83

1210.62

1047.57

1383.72

$144 \quad 0.21 \% \quad 32.7 \%$ EKYGIPEPPEPK

$144 \quad 0.21 \% \quad 32.7 \%$ YGIPEPPEPKR
1115.62

1414.76

848.39

902.44

1640.69

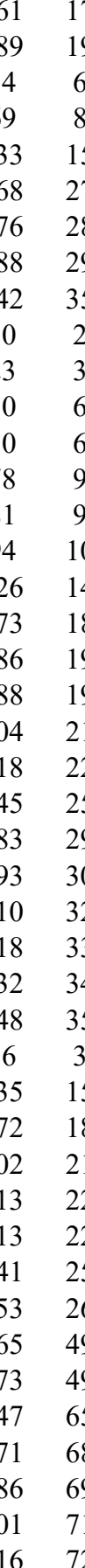
1282.68 
RNA-binding protein $10 \mathrm{GN}=\mathrm{RBM} 10$ RNA-binding protein $10 \mathrm{GN}=\mathrm{RBM} 10$ RNA-binding protein $10 \mathrm{GN}=\mathrm{RBM} 10$ RNA-binding protein $10 \mathrm{GN}=\mathrm{RBM} 10$ RNA-binding protein $10 \mathrm{GN}=\mathrm{RBM} 10$ RNA-binding protein $10 \mathrm{GN}=\mathrm{RBM} 10$ RNA-binding protein $10 \mathrm{GN}=\mathrm{RBM} 10$ RNA-binding protein $10 \mathrm{GN}=\mathrm{RBM} 10$ RNA-binding protein $10 \mathrm{GN}=\mathrm{RBM} 10$ RNA-binding protein $14 \mathrm{GN}=\mathrm{RBM} 14$ RNA-binding protein $14 \mathrm{GN}=\mathrm{RBM} 14$ RNA-binding protein $14 \mathrm{GN}=\mathrm{RBM} 14$ RNA-binding protein $14 \mathrm{GN}=\mathrm{RBM} 14$ RNA-binding protein $14 \mathrm{GN}=\mathrm{RBM} 14$ RNA-binding protein $14 \mathrm{GN}=\mathrm{RBM} 14$ RNA-binding protein $14 \mathrm{GN}=\mathrm{RBM} 14$ RNA-binding protein $14 \mathrm{GN}=\mathrm{RBM} 14$ RNA-binding protein $14 \mathrm{GN}=\mathrm{RBM} 14$ RNA-binding protein $14 \mathrm{GN}=\mathrm{RBM} 14$ RNA-binding protein $14 \mathrm{GN}=\mathrm{RBM} 14$ RNA-binding protein $14 \mathrm{GN}=\mathrm{RBM} 14$ RNA-binding protein $14 \mathrm{GN}=\mathrm{RBM} 14$ RNA-binding protein $14 \mathrm{GN}=\mathrm{RBM} 14$ RNA-binding protein $14 \mathrm{GN}=\mathrm{RBM} 14$ RNA-binding protein $28 \mathrm{GN}=\mathrm{RBM} 28$ RNA-binding protein $28 \mathrm{GN}=\mathrm{RBM} 28$ RNA-binding protein $39 \mathrm{GN}=\mathrm{RBM} 39$ RNA-binding protein $39 \mathrm{GN}=\mathrm{RBM} 39$ RNA-binding protein $39 \mathrm{GN}=\mathrm{RBM} 39$ RNA-binding protein $39 \mathrm{GN}=\mathrm{RBM} 39$ RNA-binding protein $4 \mathrm{GN}=\mathrm{RBM} 4$ RNA-binding protein $4 \mathrm{GN}=\mathrm{RBM} 4$ RNA-binding protein $4 \mathrm{GN}=\mathrm{RBM} 4$ RNA-binding protein $4 \mathrm{GN}=\mathrm{RBM} 4$ RNA-binding protein $4 \mathrm{GN}=\mathrm{RBM} 4$ RNA-binding protein $4 \mathrm{GN}=\mathrm{RBM} 4$ RNA-binding protein Raly GN=RALY RNA-binding protein Raly GN=RALY RNA-binding protein Raly GN=RALY RNA-binding protein Raly GN=RALY

RNA-binding protein Raly GN=RALY rRNA $2^{2}$-O-methyltransferase fibrillarin GN=FBL FBRL_HUMAN $33.78 \quad 100.0 \%$ rRNA 2'-O-methyltransferase fibrillarin GN=FBL FBRL HUMAN $33.78 \quad 100.0 \%$ rRNA 2'-O-methyltransferase fibrillarin GN=FBL FBRL_HUMAN $33.78 \quad 100.0 \%$ rRNA 2'-O-methyltransferase fibrillarin GN=FBL FBRL_HUMAN $33.78 \quad 100.0 \%$ rRNA $2^{2}$-O-methyltransferase fibrillarin GN=FBL FBRL_HUMAN $33.78 \quad 100.0 \%$ rRNA 2'-O-methyltransferase fibrillarin GN=FBL FBRL_HUMAN $33.78 \quad 100.0 \%$
RBM10_HUMAN $103.53 \quad 100.0 \% \quad 27$ RBM10_HUMAN $103.53 \quad 100.0 \% \quad 27$ $\begin{array}{llll} & 103.53 & 100.0 \% & 27\end{array}$ RBM10_HUMAN $103.53 \quad 100.0 \% \quad 27$ RBM10_HUMAN $103.53 \quad 100.0 \% \quad 27$ RBM10_HUMAN $103.53 \quad 100.0 \% \quad 27$ RBM10_HUMAN $103.53 \quad 100.0 \% \quad 27$ RBM10 HUMAN $103.53 \quad 100.0 \% \quad 27$ RBM14_HUMAN $\quad 69.49 \quad 100.0 \% \quad 15$ RBM14_HUMAN $69.49 \quad 100.0 \% \quad 15$ RBM14 HUMAN $69.49 \quad 100.0 \% \quad 15$ RBM14_HUMAN $69.49 \quad 100.0 \% \quad 15$ RBM14_HUMAN $69.49 \quad 100.0 \% \quad 15$ RBM14 HUMAN $69.49 \quad 100.0 \% \quad 15$ RBM14_HUMAN $69.49 \quad 100.0 \% \quad 15$ RBM14_HUMAN $69.49 \quad 100.0 \% \quad 15$ RBM14_HUMAN $69.49 \quad 100.0 \% \quad 15$ RBM14_HUMAN $69.49 \quad 100.0 \% \quad 15$ RBM14 HUMAN $69.49 \quad 100.0 \% \quad 15$ RBM14_HUMAN $69.49 \quad 100.0 \% \quad 15$ RBM14_HUMAN $69.49 \quad 100.0 \% \quad 15$ $\begin{array}{llll} & 100.0 \% & 15\end{array}$ RBM28_HUMAN $85.74 \quad 100.0 \%$ RBM39_HUMAN $59.38 \quad 100.0 \%$ RBM39 HUMAN $59.38 \quad 100.0 \%$ RBM39_HUMAN $59.38 \quad 100.0 \%$ RBM39 HUMAN $59.38 \quad 100.0 \%$ RBM4_HUMAN $40.31 \quad 100.0 \%$ RBM4_HUMAN $40.31 \quad 100.0 \%$ RBM4_HUMAN $40.31 \quad 100.0 \%$ RBM4_HUMAN $40.31 \quad 100.0 \%$ RBM4_HUMAN $40.31 \quad 100.0 \%$ RBM4 HUMAN $40.31 \quad 100.0 \%$ RALY_HUMAN $32.46 \quad 100.0 \%$ RALY HUMAN $32.46 \quad 100.0 \%$ RALY_HUMAN $32.46 \quad 100.0 \%$ RALY HUMAN $32.46 \quad 100.0 \%$ RALY_HUMAN $32.46 \quad 100.0 \%$ $\begin{array}{ll}0 \% & 11 \\ 0 & 0\end{array}$ 11 11
11 11
11

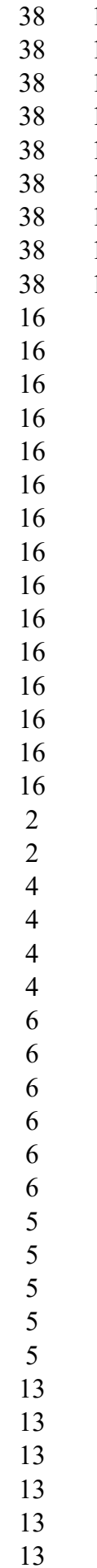

$99.7 \% \quad 34.9$ $99.7 \% \quad 50.4$ $0.21 \% \quad 32.7 \%$ YGGISTASVDFEQPTR $99.7 \% \quad 43.8$

$44 \quad 0.21 \% \quad 32.7 \%$ DGLGSDNIGSR

$44 \quad 0.21 \% \quad 32.7 \%$ MLQAMGWKEGSGLGR $\begin{array}{ll}0.21 \% & 32.7 \% \text { KQGIVTPIEAQTR }\end{array}$

$99.7 \% \quad 37.2$ $99.7 \% \quad 50.2$ $99.7 \% \quad 51.8$

$144 \quad 0.21 \% \quad 32.7 \%$ QGIVTPIEAQTR $99.3 \% \quad 23.6$ $99.7 \% 57.6$ $99.7 \% \quad 37.4$ $99.7 \% \quad 50.4$ $99.7 \% \quad 28.0$ $99.1 \% \quad 20.8$ $99.7 \% \quad 40.6$ $99.7 \% \quad 53.7$ $99.7 \% \quad 49.6$ $0.21 \% \quad 32.7 \%$ TMVTRFNEAQ $0.04 \% \quad 24.7 \%$ INVELSTKGQK $0.04 \% \quad 24.7 \%$ KGPGLAVQSGDK $0.04 \% \quad 24.7 \%$ QPTPPFFGR $0.04 \% \quad 24.7 \%$ ASYVAPLTAQPATYR $0.04 \% \quad 24.7 \%$ AQPSVSLGAAYR $0.04 \% \quad 24.7 \%$ AQPSASLGVGYR $0.04 \% \quad 24.7 \%$ AQPSASLGVGYRTQPMTAQAASYR $99.7 \% 53.4$ $0.04 \% \quad 24.7 \%$ TQPMTAQAASYR $0.04 \% \quad 24.7 \%$ AQPSVSLGAPYR $99.7 \% \quad 51.6$ $99.7 \% \quad 67.7$

$0.04 \% \quad 24.7 \%$ TQSSASLAASYAAQQHPQAAASYR $\quad 99.7 \% \quad 68.2$ $0.04 \% \quad 24.7 \%$ LAELSDYRR $0.04 \% \quad 24.7 \%$ RLPDAHSDYAR $0.04 \% \quad 24.7 \%$ LPDAHSDYAR $0.04 \% \quad 24.7 \%$ YSGSYNDYLR $0.00 \% \quad 2.6 \%$ LLLSATSGEK $0.00 \% \quad 2.6 \%$ QQLSSEQVSR $0.01 \% \quad 7.6 \%$ YRSPYSGPK $0.01 \% \quad 7.6 \%$ TVFCMQLAAR $0.01 \% \quad 7.6 \%$ DLEEFFSTVGK $0.01 \% \quad 7.6 \%$ AAAMANNLQK $0.02 \% \quad 23.4 \%$ GLDNTEFQGKR $0.02 \% \quad 23.4 \%$ MHVQLSTSR $25.0 \quad 68.2$ $\begin{array}{llll}99.7 \% & 28.0 & 25.0 & 21.9\end{array}$ $99.0 \% \quad 19.5$ $99.7 \% \quad 28.5$ $99.7 \% \quad 58.2$ $95.9 \% \quad 16.6$ $99.7 \% \quad 49.8$ $98.3 \% \quad 16.6$ $99.7 \% \quad 54.2$ $99.7 \% \quad 44.3$ $99.7 \% \quad 63.7$ $99.7 \% \quad 41.0$ $\begin{array}{lll}99.7 \% & 33.2\end{array}$ $96.1 \% \quad 14.7$

$0.02 \% \quad 23.4 \%$ TAPGMGDQSGCYR $99.7 \% \quad 73.7$ $0.02 \% \quad 23.4 \%$ VADLTEQYNEQYGAVR $0.02 \% \quad 23.4 \%$ ATAPVPTVGEGYGYGHESELSQASAAAR $0.02 \% \quad 23.4 \%$ NSLYDMAR $0.02 \% \quad 15.7 \%$ LQASNVTNKNDPK $0.02 \% \quad 15.7 \%$ VFIGNLNTALVK $0.02 \% \quad 15.7 \%$ KSDVETIFSK $0.02 \% \quad 15.7 \%$ SDVETIFSKYGR $0.02 \% \quad 15.7 \%$ TNVPVKLFAR $0.05 \% \quad 42.4 \%$ NVMVEPHRHEGVFICR $0.05 \% \quad 42.4 \%$ GKEDALVTK $0.05 \% \quad 42.4 \%$ NLVPGESVYGEK $0.05 \% \quad 42.4 \%$ NLVPGESVYGEKR $0.05 \% \quad 42.4 \%$ VSISEGDDKIEYR $\begin{array}{llll}99.7 \% & 43.2 & 25.0 & 43.2\end{array}$ $99.0 \% \quad 27.9 \quad 25.0 \quad 22.4$ $99.7 \% \quad 28.1 \quad 25.0 \quad 22.4$ $\begin{array}{llll}98.9 \% & 34.6 & 25.0 & 0.0\end{array}$ $99.7 \% \quad 41.1 \quad 25.0 \quad 28.4$ $\begin{array}{llll}99.7 \% & 34.4 & 25.0 & 34.0\end{array}$ $\begin{array}{llll}99.6 \% & 24.8 & 25.0 & 24.8\end{array}$ $\begin{array}{llll}99.3 \% & 20.4 & 25.0 & 20.3\end{array}$ $99.7 \% \quad 29.4 \quad 25.0 \quad 22.3$ $99.6 \% \quad 24.6 \quad 25.0 \quad 23.9$ $99.7 \% \quad 54.1$ $99.7 \% \quad 62.2$ $0.05 \% \quad 42.4 \%$ LAAAILGGVDQIHIKPGAK $99.7 \% \quad 28.7$
1727.82

2799.32

1090.5

1620.80

1440.82

1312.72

1973.95

1196.57

1751.87

1216.69

1156.63

1046.54

1608.84

1219.64

1205.63

2527.24

1324.63

1245.66

2465.18

1122.59

1300.64

1144.54

1237.55

1018.58

1161.59

1054.53

1196.59

1271.62

1031.53

1264.63

1058.54

1399.57

1855.88

2776.32

969.45

1428.74

1288.76

1153.61

1401.70

1144.68

1995.96

960.54

1291.65

1447.75

1510.74 1872.11 \begin{tabular}{cc}
37 & 853 \\
38 & 853 \\
38 & 864 \\
54 & 864 \\
65 & 879 \\
81 & 893 \\
82 & 893 \\
03 & 920 \\
21 & 930 \\
81 & 96 \\
42 & 152 \\
53 & 164 \\
04 & 212 \\
24 & 238 \\
39 & 250 \\
51 & 262 \\
51 & 274 \\
63 & 274 \\
75 & 286 \\
18 & 541 \\
08 & 616 \\
637 & 647 \\
38 & 647 \\
48 & 657 \\
06 & 515 \\
09 & 718 \\
95 & 103 \\
54 & 163 \\
68 & 178 \\
335 & 244 \\
30 & 140 \\
41 & 149 \\
52 & 164 \\
83 & 198 \\
14 & 341 \\
42 & 349 \\
5 & 17 \\
23 & 34 \\
35 & 44 \\
36 & 47 \\
60 & 169 \\
85 & 100 \\
01 & 109 \\
10 & 121 \\
\hline 0 & 122 \\
\hline
\end{tabular}

Page 102 
rRNA 2'-O-methyltransferase fibrillarin GN=FBL FBRL_HUMAN $33.78 \quad 100.0 \%$ rRNA 2'-O-methyltransferase fibrillarin GN=FBL FBRL_HUMAN $33.78 \quad 100.0 \%$ rRNA 2'-O-methyltransferase fibrillarin GN=FBL FBRL_HUMAN $33.78 \quad 100.0 \%$ rRNA 2'-O-methyltransferase fibrillarin GN=FBL FBRL HUMAN $33.78 \quad 100.0 \%$ rRNA 2'-O-methyltransferase fibrillarin GN=FBL FBRL_HUMAN $33.78 \quad 100.0 \%$ rRNA methyltransferase 3, mitochondrial GN=RNMTL1 MRM3_HUMAN $47.02 \quad 100.0 \%$ rRNA methyltransferase 3, mitochondrial GN=RNMTL1 MRM3_HUMAN $47.02 \quad 100.0 \%$ rRNA methyltransferase 3, mitochondrial GN=RNMTL1 MRM3_HUMAN $47.02 \quad 100.0 \%$ rRNA methyltransferase 3, mitochondrial GN=RNMTL1 MRM3_HUMAN $47.02 \quad 100.0 \%$ rRNA methyltransferase 3, mitochondrial GN=RNMTL1 MRM3_HUMAN $47.02 \quad 100.0 \%$ rRNA methyltransferase 3, mitochondrial GN=RNMTL1 MRM3_HUMAN $47.02 \quad 100.0 \%$ RRP12-like protein GN=RRP12 RRP12-like protein $\mathrm{GN}=\mathrm{RRP} 12$ RRP15-like protein GN=RRP15 RRP15-like protein $\mathrm{GN}=\mathrm{RRP} 15$ RRP15-like protein $\mathrm{GN}=\mathrm{RRP} 15$ RRP12 HUMAN $143.71 \quad 100.0 \%$ RRP12_HUMAN $143.71 \quad 100.0 \%$ RRP15_HUMAN $31.48 \quad 100.0 \%$ RRP15_HUMAN $31.48 \quad 100.0 \%$ RRP15_HUMAN $31.48 \quad 100.0 \%$ RUS1 family protein C16orf58 GN=C16orf58 RUS1_HUMAN $51.02 \quad 100.0 \%$ RUS1 family protein C16orf58 GN=C16orf58 RUS1_HUMAN $51.02 \quad 100.0 \%$ S1 RNA-binding domain-containing protein 1 GN=SRBD1 SRBD1_HUMAN $111.78 \quad 100.0 \%$ S1 RNA-binding domain-containing protein $1 \mathrm{GN}=$ SRBD1 SRBD1_HUMAN $111.78 \quad 100.0 \%$ S-adenosylmethionine synthase isoform type-2 GN=MAT2A METK2_HUMAN $43.66 \quad 100.0 \%$ S-adenosylmethionine synthase isoform type-2 GN=MAT2A METK2_HUMAN $43.66 \quad 100.0 \%$ S-adenosylmethionine synthase isoform type-2 GN=MAT2A METK2_HUMAN $43.66 \quad 100.0 \%$ S-adenosylmethionine synthase isoform type-2 GN=MAT2A METK2_HUMAN $43.66 \quad 100.0 \%$ Sarcoplasmic/endoplasmic reticulum calcium ATPase 2 GN=ATP2A2 AT2A2_HUMAN $114.76 \quad 100.0 \%$ Sarcoplasmic/endoplasmic reticulum calcium ATPase $2 \mathrm{GN}=\mathrm{ATP} 2 \mathrm{~A} 2 \mathrm{AT} 2 \mathrm{~A} 2$ _HUMAN $114.76 \quad 100.0 \%$ Sarcoplasmic/endoplasmic reticulum calcium ATPase $2 \mathrm{GN}=\mathrm{ATP} 2 \mathrm{~A} 2$ AT2A2_HUMAN $114.76 \quad 100.0 \%$ Sarcoplasmic/endoplasmic reticulum calcium ATPase 2 GN=ATP2A2 AT2A2_HUMAN $114.76 \quad 100.0 \%$ Sarcoplasmic/endoplasmic reticulum calcium ATPase 2 GN=ATP2A2 AT2A2_HUMAN $114.76 \quad 100.0 \%$ Sarcoplasmic/endoplasmic reticulum calcium ATPase 2 GN=ATP2A2 AT2A2_HUMAN $114.76 \quad 100.0 \%$ Sarcoplasmic/endoplasmic reticulum calcium ATPase $2 \mathrm{GN}=\mathrm{ATP} 2 \mathrm{~A} 2$ AT2A2_HUMAN $114.76 \quad 100.0 \%$ $\begin{array}{llll}\text { Scaffold attachment factor B1 GN=SAFB SAFB1_HUMAN } 102.64 & 100.0 \%\end{array}$ Scaffold attachment factor B1 GN=SAFB SAFB1_HUMAN $102.64 \quad 100.0 \%$ $\mathrm{SCY} 1$-like protein $2 \mathrm{GN}=\mathrm{SCYL} 2$ $\mathrm{SCY} 1$-like protein $2 \mathrm{GN}=\mathrm{SCYL} 2$ SCY1-like protein $2 \mathrm{GN}=\mathrm{SCYL} 2$ SCY1-like protein $2 \mathrm{GN}=\mathrm{SCYL} 2$ SCY1-like protein $2 \mathrm{GN}=\mathrm{SCYL} 2$ $\mathrm{SCY} 1-$ like protein $2 \mathrm{GN}=\mathrm{SCYL} 2$ SCYL2_HUMAN $103.71 \quad 100.0 \%$ SCYL2_HUMAN $103.71 \quad 100.0 \%$ SCYL2_HUMAN $103.71 \quad 100.0 \%$ SCYL2_HUMAN $103.71 \quad 100.0 \%$ SCYL2 HUMAN $103.71 \quad 100.0 \%$ SCYL2_HUMAN $103.71 \quad 100.0 \%$ Sec1 family domain-containing protein $1 \mathrm{GN}=$ SCFD1 SCFD1_HUMAN $72.38 \quad 100.0 \%$ Sec1 family domain-containing protein $1 \mathrm{GN}=$ SCFD1 SCFD1_HUMAN $72.38 \quad 100.0 \%$ Sec1 family domain-containing protein $1 \mathrm{GN}=$ SCFD1 SCFD1_HUMAN $72.38 \quad 100.0 \%$ Sentrin-specific protease $3 \mathrm{GN}=\mathrm{SENP} 3$ SENP3_HUMAN $65.01 \quad 100.0 \%$ Sentrin-specific protease $3 \mathrm{GN}=\mathrm{SENP} 3$ Septin-9 GN=SEPT9

Septin-9 GN=SEPT9

SENP3_HUMAN $65.01 \quad 100.0 \%$ SEPT9_HUMAN $65.40 \quad 100.0 \%$ SEPT9_HUMAN $65.40 \quad 100.0 \%$

8

2
3
3

3
3
3
2

2

2
2
2

$\begin{array}{ll}2 & 2 \\ 2 & 2 \\ 4 & 6\end{array}$

6

6

6

9
9
9

9
9
9

9
9
9

7
7
7

9
9
2
2

2
2
7

7
7
7

6
6
6
6

7

7
4
4
4
2
2
2
2
3

(4)

$24 \quad 0.04$

$3 \quad 0.00 \% \quad 1.4 \%$ FCIQEIEK

$1.4 \%$ VLATQPGPGR

$0.01 \% \quad 12.4 \%$ TPESKPTILVK

$0.01 \% \quad 12.4 \%$ GVVQLFNAVQK

$0.01 \% \quad 12.4 \%$ GMDGSTNETASSR

$0.00 \% \quad 4.3 \%$ AFTVKPEGR

$0.00 \% \quad 4.3 \%$ CIVSVAGGATR

$0.01 \% \quad 2.2 \%$ LFNDDNTIPFIIR

$0.01 \% \quad 2.2 \%$ ITLDLIRVL

$0.02 \% \quad 11.1 \%$ TGMILLAGEITSR

$0.02 \% \quad 11.1 \%$ YLDEDTIYHLQPSGR

$0.02 \% \quad 11.1 \%$ FVIGGPQGDAGLTGR

$0.02 \% \quad 11.1 \%$ FVIGGPQGDAGLTGRK

$0.03 \% \quad 9.7 \%$ NMLFSGTNIAAGK

$0.03 \% \quad 9.7 \%$ VGEATETALTCLVEK

$0.03 \% \quad 9.7 \%$ SMSVYCTPNKPSR

$0.03 \% \quad 9.7 \%$ IGIFGQDEDVTSK

$0.03 \% \quad 9.7 \%$ AFTGREFDELNPSAQR

$0.03 \% \quad 9.7 \%$ KAEIGIAMGSGTAVAK

$0.03 \% \quad 9.7 \%$ NYLEPGKECVQPATK

$0.00 \% \quad 2.6 \% \quad$ NVDSSGNKSVLMER

$0.00 \% \quad 2.6 \%$ ATDLKNLFSK

$\begin{array}{lll}0.02 \% & 7.3 \% & \text { STVTKVTADVTSAVMGNPVTR } \\ 0.02 \% & 7.3 \% & \text { VTADVTSAVMGNPVTR }\end{array}$

$\begin{array}{llll}0.02 \% & 7.3 \% & \text { VTADVTSAVMGNPVTR } \\ 0.02 \% & 7.3 \% & \text { DQIIDSLKR }\end{array}$

$0.02 \% \quad 7.3 \%$ SQFFKGLPK

$0.02 \% \quad 7.3 \% \quad$ NACLQTSSLAVR

$\begin{array}{llllllll}0.02 \% & 7.3 \% & \text { SQQPLKPQVHTPVATVK } & 98.2 \% & 21.3 & 25.0 & 15.2 & 0\end{array}$

$\begin{array}{llllllll}0.01 \% & 8.7 \% & \text { SKLEDIANAALAASAVTQVAK } & 99.7 \% & 31.4 & 25.0 & 31.4 & 0\end{array}$

$\begin{array}{llllllll}0.01 \% & 8.7 \% & \text { LTSAVSSLPELLEK } & 99.7 \% & 52.6 & 25.0 & 37.1 & 2\end{array}$

$\begin{array}{llllllll}0.01 \% & 8.7 \% & \text { MASAPASYGSTTTKPMGLLSR } & 99.7 \% & 35.5 & 25.0 & 35.5 & 0 \\ 0.01 \% & 5.6 \% & \text { LKSGGGFGPDPGSGTTVPAR } & 99.5 \% & 26.0 & 25.0 & 26.0 & 0\end{array}$

$\begin{array}{llllllll}0.01 \% & 5.6 \% & \text { LKSGGGFGPDPGSGTTVPAR } & 99.5 \% & 26.0 & 25.0 & 26.0 & 0 \\ 0.01 \% & 5.6 \% & \text { GLVLQLIQSYQR } & 99.7 \% & 56.3 & 25.0 & 47.2 & 2\end{array}$

$\begin{array}{lll}0.00 \% & 3.6 \% & \text { DAGLKQAPASR }\end{array}$

$0.00 \% \quad 3.6 \%$ VVNIVPVIAK

$0.01 \% \quad 6.8 \%$ TGLIDYNQLALTAR $\begin{array}{lllll}98.2 \% & 27.6 & 25.0 & 23.6 & 1 \\ 99.0 \% & 19.1 & 25.0 & 19.1 & 1\end{array}$

$\begin{array}{lllll}99.0 \% & 19.1 & 25.0 & 19.1 & 1 \\ 99.7 \% & 57.2 & 25.0 & 57.2 & 2\end{array}$ $\begin{array}{llll}97.8 \% & 16.0 & 25.0 & 16.0\end{array}$

$\begin{array}{llll}9.7 \% & 28.4 & 25.0 & 28.4\end{array}$

$99.7 \% \quad 43.2 \quad 25.0 \quad 31.1$

$\begin{array}{llll}99.7 \% & 53.1 & 25.0 & 48.1\end{array}$

\begin{tabular}{llll}
\hline $.6 \%$ & 47.2 & 25.0 & 37.8
\end{tabular}

$\begin{array}{llll}99.7 \% & 46.1 & 25.0 & 40.0\end{array}$

$\begin{array}{llll}99.9 \% & 19.0 & 25.0 & 15.0\end{array}$

$\begin{array}{llll}9.7 \% & 60.0 & 25.0 & 60.0\end{array}$

$\begin{array}{llll}99.7 \% & 35.1 & 25.0 & 26.4\end{array}$

$99.7 \% \quad 62.0 \quad 25.0 \quad 54.2$

$\begin{array}{cccc}99.7 \% & 45.2 & 25.0 & 45.2 \\ 99.4 \% & 20.9 & 25.0 & 20.9\end{array}$

$\begin{array}{llll}99.7 \% & 83.4 & 25.0 & 73.0\end{array}$

$\begin{array}{lllll}99.7 \% & 30.9 & 25.0 & 30.9 & 2\end{array}$

$\begin{array}{rrrr}99.4 \% & 49.3 & 25.0 & 49.3 \\ 99.5 & 25.0 & 21.5\end{array}$

$\begin{array}{llll}99.7 \% & 60.7 & 25.0 & 57.9\end{array}$

$\begin{array}{llll}99.7 \% & 36.4 & 25.0 & 16.9 \\ 95.0 & 36.4\end{array}$

$\begin{array}{llll}97.2 \% & 23.5 & 25.0 & 23.5\end{array}$

$\begin{array}{llll}99.7 \% & 38.7 & 25.0 & 30.4\end{array}$ Serine hydroxymethyltransferase, mitochondrial GN=SHMT2 GLYM_HUMAN $55.99 \quad 100.0 \%$

$\begin{array}{ccccc}98.8 \% & 36.6 & 25.0 & 0.0 & 3 \\ 99.7 \% & 46.4 & 25.0 & 39.1 & 4\end{array}$

$4.7 \%$

$\begin{array}{cccccccc}25.0 & 57.2 & 2 & 0 & 0 & 1548.84 & 201 & 214\end{array}$

Page 103 of Table S-1-2 

(100.0\% Serine racemase $\mathrm{GN}=\mathrm{SRR}$ Serine racemase $\mathrm{GN}=\mathrm{SRR}$ Serine racemase $\mathrm{GN}=\mathrm{SRR}$ SRR_HUMAN $36.57 \quad 100.0 \%$ SRR HUMAN $36.57 \quad 100.0 \%$ SRR_HUMAN $36.57 \quad 100.0 \%$ Serine/arginine repetitive matrix protein 2 GN=SRRM2 SRRM2_HUMAN $299.62 \quad 100.0 \%$ Serine/arginine repetitive matrix protein 2 GN=SRRM2 SRRM2_HUMAN $299.62 \quad 100.0 \%$ Serine/arginine repetitive matrix protein 2 GN=SRRM2 SRRM2_HUMAN $299.62 \quad 100.0 \%$ Serine/arginine repetitive matrix protein 2 GN=SRRM2 SRRM2_HUMAN $299.62 \quad 100.0 \%$ Serine/arginine repetitive matrix protein $2 \mathrm{GN}=$ SRRM2 SRRM2_HUMAN $299.62 \quad 100.0 \%$ Serine/arginine repetitive matrix protein 2 GN=SRRM2 SRRM2_HUMAN $299.62 \quad 100.0 \%$ Serine/arginine repetitive matrix protein $2 \mathrm{GN}=$ SRRM2 SRRM2_HUMAN $299.62 \quad 100.0 \%$ Serine/arginine repetitive matrix protein $2 \mathrm{GN}=\mathrm{SRRM} 2 \mathrm{SRRM} 2$ HUMAN $299.62 \quad 100.0 \%$ Serine/arginine repetitive matrix protein $2 \mathrm{GN}=$ SRRM2 SRRM2_HUMAN $299.62 \quad 100.0 \%$ Serine/arginine repetitive matrix protein 2 GN=SRRM2 SRRM2_HUMAN $299.62 \quad 100.0 \%$ Serine/arginine repetitive matrix protein 2 GN=SRRM2 SRRM2_HUMAN $299.62 \quad 100.0 \%$ Serine/arginine repetitive matrix protein $2 \mathrm{GN}=\mathrm{SRRM} 2 \mathrm{SRRM} 2$ HUMAN $299.62 \quad 100.0 \%$ Serine/arginine repetitive matrix protein $2 \mathrm{GN}=$ SRRM2 SRRM2_HUMAN $299.62 \quad 100.0 \%$ Serine/arginine repetitive matrix protein 2 GN=SRRM2 SRRM2_HUMAN $299.62 \quad 100.0 \%$ Serine/arginine repetitive matrix protein $2 \mathrm{GN}=$ SRRM2 SRRM2_HUMAN $299.62 \quad 100.0 \%$ Serine/arginine repetitive matrix protein 2 GN=SRRM2 SRRM2_HUMAN $299.62 \quad 100.0 \%$ Serine/arginine repetitive matrix protein $2 \mathrm{GN}=\mathrm{SRRM} 2 \mathrm{SRRM} 2$ HUMAN $299.62 \quad 100.0 \%$ Serine/arginine repetitive matrix protein $2 \mathrm{GN}=\mathrm{SRRM} 2 \mathrm{SRRM} 2$ HUMAN $299.62 \quad 100.0 \%$ Serine/arginine repetitive matrix protein 2 GN=SRRM2 SRRM2_HUMAN $299.62 \quad 100.0 \%$ Serine/arginine repetitive matrix protein 2 GN=SRRM2 SRRM2_HUMAN $299.62 \quad 100.0 \%$ Serine/arginine repetitive matrix protein 2 GN=SRRM2 SRRM2_HUMAN $299.62 \quad 100.0 \%$ Serine/arginine repetitive matrix protein $2 \mathrm{GN}=\mathrm{SRRM} 2$ SRRM2_HUMAN $299.62 \quad 100.0 \%$ Serine/arginine repetitive matrix protein 2 GN=SRRM2 SRRM2_HUMAN $299.62 \quad 100.0 \%$ Serine/arginine repetitive matrix protein $2 \mathrm{GN}=$ SRRM2 SRRM2_HUMAN $299.62 \quad 100.0 \%$ Serine/arginine repetitive matrix protein $2 \mathrm{GN}=$ SRRM2 SRRM2 HUMAN $299.62 \quad 100.0 \%$ Serine/arginine-rich splicing factor $1 \mathrm{GN}=\mathrm{SRSF} 1$ SRSF1_HUMAN $27.75 \quad 100.0 \%$ Serine/arginine-rich splicing factor $1 \mathrm{GN}=$ SRSF1 SRSF1_HUMAN $27.75 \quad 100.0 \%$ Serine/arginine-rich splicing factor $1 \mathrm{GN}=\mathrm{SRSF} 1 \mathrm{SRSF} 1$ HUMAN $27.75 \quad 100.0^{\circ}$ Serine/arginine-rich splicing factor $1 \mathrm{GN}=\mathrm{SRSF} 1$ SRSF1_HUMAN $27.75 \quad 100.0 \%$ Serine/arginine-rich splicing factor $1 \mathrm{GN}=\mathrm{SRSF} 1$ SRSF1 HUMAN $27.75 \quad 100.0 \%$ Serine/arginine-rich splicing factor $1 \mathrm{GN}=\mathrm{SRSF} 1$ SRSF1_HUMAN $27.75 \quad 100.0 \%$ Serine/arginine-rich splicing factor $1 \mathrm{GN}=\mathrm{SRSF} 1$ SRSF1_HUMAN $27.75 \quad 100.0 \%$ Serine/arginine-rich splicing factor $1 \mathrm{GN}=\mathrm{SRSF} 1$ SRSF1_HUMAN $27.75 \quad 100.0 \%$ Serine/arginine-rich splicing factor $1 \mathrm{GN}=\mathrm{SRSF} 1$ SRSF1_HUMAN $27.75 \quad 100.0 \%$ Serine/arginine-rich splicing factor $1 \mathrm{GN}=\mathrm{SRSF} 1$ SRSF1_HUMAN $27.75 \quad 100.0 \%$ Serine/arginine-rich splicing factor $1 \mathrm{GN}=\mathrm{SRSF} 1$ SRSF1_HUMAN $27.75 \quad 100.0 \%$ Serine/arginine-rich splicing factor $1 \mathrm{GN}=\mathrm{SRSF} 1$ SRSF1_HUMAN $27.75 \quad 100.0 \%$ Serine/arginine-rich splicing factor $1 \mathrm{GN}=\mathrm{SRSF} 1$ SRSF1_HUMAN $27.75 \quad 100.0 \%$ Serine/arginine-rich splicing factor $10 \mathrm{GN}=$ SRSF10 SRS10_HUMAN $31.30 \quad 100.0 \%$ Serine/arginine-rich splicing factor $10 \mathrm{GN}=$ SRSF10 SRS10_HUMAN $31.30 \quad 100.0 \%$ Serine/arginine-rich splicing factor $10 \mathrm{GN}=$ SRSF10 SRS10 HUMAN $31.30 \quad 100.0 \%$ Serine/arginine-rich splicing factor $10 \mathrm{GN}=\mathrm{SRSF} 10$ SRS10_HUMAN $31.30 \quad 100.0 \%$
$0.01 \% \quad 6.8 \% \quad$ LIIAGTSAYAR

$0.01 \% \quad 6.8 \%$

$0.01 \% \quad 12.1 \%$ SLVPDALER

$99.7 \% \quad 40.6$

$97.8 \% \quad 16.3$

$95.6 \% \quad 18.7$

$0.01 \% \quad 12.1 \%$ AVVTHSSGNHGQALTYAAK $99.0 \% \quad 19.1$

$0.01 \% \quad 12.1 \%$ QAERPASYQSVSV

$116 \quad 0.17 \% \quad 12.2 \%$ SSTGPEPPAPTPLLAER

$116 \quad 0.17 \% \quad 12.2 \%$ SLSGSSPCPK

$116 \quad 0.17 \% \quad 12.2 \%$ SCFESSPDPELKSR

$99.7 \% \quad 32.7$

$\begin{array}{lll}99.7 \% & 46.1\end{array}$

$99.7 \% \quad 33.2$

$99.7 \% \quad 37.9$

$\begin{array}{llllll}116 & 0.17 \% & 12.2 \% & \text { SKDSLVQSCPGSLSLCAGVK } & 99.7 \% & 27.0\end{array}$

$116 \quad 0.17 \% \quad 12.2 \%$ AGMSSNQSISSPVLDAVPR $99.7 \% \quad 47.3$

$116 \quad 0.17 \% \quad 12.2 \%$ HSLSGSSPGMKDIPR

$97.3 \% \quad 17.8$

$16 \quad 0.17 \% \quad 12.2 \%$ SGSESSVDQKTVAR

$99.7 \% \quad 61.7$

$116 \quad 0.17 \% \quad 12.2 \%$ SGSSQELDVKPSASPQER $99.7 \% \quad 49.4$

$116 \quad 0.17 \% \quad 12.2 \%$ AQSGSDSSPEPKAPAPR

$116 \quad 0.17 \% \quad 12.2 \%$ SPSVSSPEPAEK

$116 \quad 0.17 \% \quad 12.2 \%$ SPGMLEPLGSSR

$116 \quad 0.17 \% \quad 12.2 \%$ TSVPENHAQSR

$116 \quad 0.17 \% \quad 12.2 \%$ MSQVPAPVPLMSLR

$116 \quad 0.17 \% \quad 12.2 \%$ TAPAANLASR

$116 \quad 0.17 \% \quad 12.2 \%$ IPAASAAAMNLASAR

$116 \quad 0.17 \% \quad 12.2 \%$ TPAIPTAVNLADSR

$116 \quad 0.17 \% \quad 12.2 \%$ TAVAPSAVNLADPR

$116 \quad 0.17 \% \quad 12.2 \%$ TAVAPSAVNLADPRTPTAPAVNLAGAR

$116 \quad 0.17 \% \quad 12.2 \%$ TPTAPAVNLAGAR

$116 \quad 0.17 \% \quad 12.2 \%$ TPQAPASANLVGPR

$116 \quad 0.17 \% \quad 12.2 \%$ SAHATAPVNIAGSR

$116 \quad 0.17 \% \quad 12.2 \%$ TAAALAPASLTSAR

$116 \quad 0.17 \% \quad 12.2 \%$ MAPALSGANLTSPR

$116 \quad 0.17 \% \quad 12.2 \%$ VPLSAYER

$116 \quad 0.17 \% \quad 12.2 \%$ SPVPSAFSDQSR

$\begin{array}{ll}99.6 \% & 23.3 \\ 99.7 \% & 29.6\end{array}$

$97.8 \% \quad 26.5$

$99.6 \% \quad 24.8$

$99.7 \% \quad 28.5$

$\begin{array}{lll}99.7 \% & 29.9\end{array}$

$99.7 \% \quad 58.7$

$99.7 \% \quad 34.0$

$99.7 \% \quad 38.7$

$99.7 \% \quad 50.4$

$99.7 \% \quad 49.6$

$99.7 \% \quad 51.9$

$99.7 \% \quad 36.2$

$99.7 \% \quad 54.6$

$99.7 \% \quad 41.5$

$99.0 \% \quad 48.7$

$99.7 \% \quad 42.9$

14

14

$(14$

14

$52 \quad 0.08 \% \quad 41.1 \%$ GPAGNNDCRIYVGNLPPDIR

$52 \quad 0.08 \% \quad 41.1 \%$ IYVGNLPPDIR

$52 \quad 0.08 \% \quad 41.1 \%$ TKDIEDVFYK

$0.08 \% \quad 41.1 \%$ DIEDVFYK

$52 \quad 0.08 \% \quad 41.1 \%$ YGAIRDIDLK

$52 \quad 0.08 \% \quad 41.1 \%$ DGYDYDGYRLR

$52 \quad 0.08 \% \quad 41.1 \%$ GRYGPPSR

$52 \quad 0.08 \% \quad 41.1 \%$ EAGDVCYADVYR

$52 \quad 0.08 \% \quad 41.1 \%$ DGTGVVEFVR

$52 \quad 0.08 \% \quad 41.1 \%$ KEDMTYAVR

$52 \quad 0.08 \% \quad 41.1 \%$ EDMTYAVR

$52 \quad 0.08 \% \quad 41.1 \%$ FRSHEGETAYIR

$52 \quad 0.08 \% \quad 41.1 \%$ SHEGETAYIR

$20 \quad 0.03 \% \quad 15.3 \% \quad$ YLRPPNTSLFVR

$20 \quad 0.03 \% \quad 15.3 \%$ YGPIVDVYVPLDFYTR

$20 \quad 0.03 \% \quad 15.3 \%$ QIEIQFAQGDR

$20 \quad 0.03 \% \quad 15.3 \%$ QIEIQFAQGDRK
$99.7 \% \quad 54.6$

$99.0 \% \quad 27.6$

$99.7 \% \quad 31.0$

$99.7 \% \quad 27.7$

$99.0 \% \quad 30.8$

$99.7 \% \quad 52.4$

$99.7 \% \quad 45.5$

$99.7 \% \quad 57.2$

$99.0 \% 30.6$

$99.7 \% \quad 46.8$

$99.7 \% \quad 53.4$

$99.7 \% \quad 34.2$

$99.7 \% \quad 52.4$

$99.7 \% \quad 60.0$

$99.7 \% \quad 43.9$
1135.65

871.50

999.55

1911.97

1421.70

1719.89

1019.48

1638.74

2093.04

1931.95

1584.78

1450.71

1901.92

1681.81

1214.59

1230.61

1225.59

1541.82

971.53

1430.74

1425.77

1381.74

2601.41

1238.69

1378.74

1351.71

1300.72

1401.72

934.50

1277.61

2198.08

1256.70

1257.64

1028.49

1163.64

1392.62

889.46

1417.61

1078.55

1112.54

984.45

1465.72

1162.55

1462.82

1916.98

304.66

1432.75

$\begin{array}{cc}0 & 230 \\ 7 & 425 \\ 6 & 74 \\ 8 & 96 \\ 8 & 340 \\ 7 & 373 \\ 8 & 787 \\ 1 & 884 \\ 21 & 1040 \\ 94 & 1412 \\ 57 & 1471 \\ 17 & 1530 \\ 39 & 1556 \\ 14 & 1630 \\ 27 & 1738 \\ 32 & 2143 \\ 70 & 2180 \\ 08 & 2221 \\ 22 & 2231 \\ 32 & 2246 \\ 47 & 2260 \\ 75 & 2288 \\ 75 & 2301 \\ 89 & 2301 \\ 29 & 2342 \\ 43 & 2356 \\ 57 & 2370 \\ 71 & 2384 \\ 85 & 2392 \\ 49 & 2460 \\ & 28 \\ 8 & 28 \\ 9 & 38 \\ 1 & 38 \\ 9 & 48 \\ 5 & 85 \\ 0 & 117 \\ 33 & 154 \\ 5 & 164 \\ 5 & 173 \\ 6 & 173 \\ 0 & 191 \\ 0 & 99 \\ 0 & 91 \\ & \\ 30\end{array}$

Page 104 of Table S-1-2 
Serine/arginine-rich splicing factor $2 \mathrm{GN}=\mathrm{SRSF} 2$ SRSF2_HUMAN $25.48 \quad 100.0 \%$ Serine/arginine-rich splicing factor 2 GN=SRSF2 SRSF2_HUMAN $25.48 \quad 100.0 \%$ Serine/arginine-rich splicing factor $2 \mathrm{GN}=\mathrm{SRSF} 2$ SRSF2_HUMAN $25.48 \quad 100.0 \%$ Serine/arginine-rich splicing factor $3 \mathrm{GN}=$ SRSF3 SRSF3_HUMAN $19.33 \quad 100.0 \%$ Serine/arginine-rich splicing factor $3 \mathrm{GN}=\mathrm{SRSF} 3$ SRSF3_HUMAN $19.33 \quad 100.0 \%$ Serine/arginine-rich splicing factor $3 \mathrm{GN}=\mathrm{SRSF} 3$ SRSF3_HUMAN $19.33 \quad 100.0 \%$ Serine/arginine-rich splicing factor 5 GN=SRSF5 SRSF5_HUMAN $31.26 \quad 100.0 \%$ Serine/arginine-rich splicing factor 5 GN=SRSF5 SRSF5_HUMAN $31.26 \quad 100.0 \%$ Serine/arginine-rich splicing factor $5 \mathrm{GN}=\mathrm{SRSF} 5$ SRSF5 HUMAN $31.26 \quad 100.0 \%$ Serine/arginine-rich splicing factor 5 GN=SRSF5 SRSF5_HUMAN $31.26 \quad 100.0 \%$ Serine/arginine-rich splicing factor 5 GN=SRSF5 SRSF5_HUMAN $31.26 \quad 100.0 \%$ Serine/arginine-rich splicing factor $6 \mathrm{GN}=\mathrm{SRSF} 6$ SRSF6_HUMAN $39.59100 .0 \%$ Serine/arginine-rich splicing factor 6 GN=SRSF6 SRSF6_HUMAN $39.59 \quad 100.0 \%$ Serine/arginine-rich splicing factor $6 \mathrm{GN}=$ SRSF6 SRSF6 HUMAN $39.59100 .0 \%$ Serine/arginine-rich splicing factor 6 GN=SRSF6 SRSF6_HUMAN $39.59 \quad 100.0 \%$ Serine/arginine-rich splicing factor 6 GN=SRSF6 SRSF6_HUMAN $39.59 \quad 100.0 \%$ Serine/arginine-rich splicing factor $6 \mathrm{GN}=\mathrm{SRSF} 6$ SRSF6 HUMAN $39.59 \quad 100.0 \%$ Serine/arginine-rich splicing factor 6 GN=SRSF6 SRSF6_HUMAN $39.59 \quad 100.0 \%$ Serine/arginine-rich splicing factor $6 \mathrm{GN}=$ SRSF6 SRSF6_HUMAN $39.59 \quad 100.0 \%$ Serine/arginine-rich splicing factor 7 GN=SRSF7 SRSF7_HUMAN $27.37 \quad 100.0 \%$ Serine/arginine-rich splicing factor $7 \mathrm{GN}=\mathrm{SRSF} 7$ SRSF7_HUMAN $27.37 \quad 100.0 \%$ Serine/arginine-rich splicing factor $7 \mathrm{GN}=\mathrm{SRSF} 7 \mathrm{SRSF} 7$ HUMAN $27.37 \quad 100.0 \%$ Serine/arginine-rich splicing factor $7 \mathrm{GN}=$ SRSF7 SRSF7_HUMAN $27.37 \quad 100.0 \%$ Serine/arginine-rich splicing factor 7 GN=SRSF7 SRSF7_HUMAN $27.37 \quad 100.0 \%$ Serine/arginine-rich splicing factor $7 \mathrm{GN}=$ SRSF7 SRSF7_HUMAN $27.37 \quad 100.0 \%$ Serine/arginine-rich splicing factor 7 GN=SRSF7 SRSF7_HUMAN $27.37 \quad 100.0 \%$ Serine/arginine-rich splicing factor $7 \mathrm{GN}=$ SRSF7 SRSF7_HUMAN $27.37 \quad 100.0 \%$ Serine/arginine-rich splicing factor $7 \mathrm{GN}=$ SRSF7 SRSF7_HUMAN $27.37 \quad 100.0 \%$ Serine/arginine-rich splicing factor 9 GN=SRSF9 SRSF9_HUMAN $25.54 \quad 100.0 \%$ Serine/arginine-rich splicing factor $9 \mathrm{GN}=$ SRSF9 SRSF9 HUMAN $25.54 \quad 100.0 \%$ Serine/arginine-rich splicing factor 9 GN=SRSF9 SRSF9_HUMAN $25.54 \quad 100.0 \%$ Serine/arginine-rich splicing factor 9 GN=SRSF9 SRSF9_HUMAN $25.54 \quad 100.0 \%$ Serine/threonine-protein kinase 38-like GN=STK38L ST38L HUMAN $54.01 \quad 100.0 \%$ Serine/threonine-protein kinase 38-like GN=STK38L ST38L_HUMAN $54.01 \quad 100.0 \%$ Serine/threonine-protein kinase 38-like GN=STK38L ST38L_HUMAN $54.01 \quad 100.0 \%$ Serine/threonine-protein kinase 38-like GN=STK38L ST38L_HUMAN $54.01 \quad 100.0 \%$ Serine/threonine-protein kinase 38-like GN=STK38L ST38L_HUMAN 54.01 $100.0 \%$ Serine/threonine-protein kinase 38-like GN=STK38L ST38L_HUMAN $54.01 \quad 100.0 \%$ Serine/threonine-protein kinase 38-like GN=STK38L ST38L_HUMAN $54.01 \quad 100.0 \%$ Serine/threonine-protein kinase 38-like GN=STK38L ST38L_HUMAN $54.01 \quad 100.0 \%$ Serine/threonine-protein kinase 38-like GN=STK38L ST38L_HUMAN $54.01 \quad 100.0 \%$ Serine/threonine-protein kinase 38-like GN=STK38L ST38L_HUMAN $54.01 \quad 100.0 \%$ Serine/threonine-protein kinase $4 \mathrm{GN}=\mathrm{STK} 4 \mathrm{STK} 4$ HUMAN $55.63 \quad 100.0 \%$ Serine/threonine-protein kinase 4 GN=STK4 STK4_HUMAN $55.63 \quad 100.0 \%$ Serine/threonine-protein kinase ATR GN=ATR ATR_HUMAN $301.37 \quad 100.0 \%$ Serine/threonine-protein kinase ATR GN=ATR ATR HUMAN $301.37 \quad 100.0 \%$ Serine/threonine-protein kinase ATR GN=ATR ATR_HUMAN $301.37 \quad 100.0 \%$
$0.01 \% \quad 9.5 \%$ VGDVYIPR

$0.01 \% \quad 9.5 \%$ YGRPPDSHHSR

$0.01 \% \quad 20.1 \%$ AFGYYGPLR

$0.01 \% \quad 20.1 \%$ NPPGFAFVEFEDPR

$0.01 \% \quad 20.1 \%$ VRVELSNGEK

$0.02 \% \quad 18.4 \%$ YSDRFSSR

$0.02 \% \quad 18.4 \%$ TENRLIVENLSSR

$0.02 \% \quad 18.4 \%$ LIVENLSSR

$0.02 \% \quad 18.4 \%$ QAGEVTFADAHRPK

$0.02 \% \quad 18.4 \%$ LNEGVVEFASYGDLK

$0.10 \% \quad 20.9 \%$ DRDGYSYGSR

$0.10 \% \quad 20.9 \%$ TEYRLIVENLSSR

$0.10 \% \quad 20.9 \%$ LIVENLSSR

$0.10 \% \quad 20.9 \%$ QAGEVTYADAHKER

$0.10 \% \quad 20.9 \%$ TNEGVIEFR

$0.10 \% \quad 20.9 \%$ ALDKLDGTEINGR

$0.10 \% \quad 20.9 \%$ SNSPLPVPPSK

$0.10 \% \quad 20.9 \%$ SNSPLPVPPSKAR

$0.08 \% 32.4 \%$ VYVGNLGTGAGK

$0.08 \% \quad 32.4 \%$ VYVGNLGTGAGKGELER

$0.08 \% 32.4 \%$ AFSYYGPLR

$0.08 \% \quad 32.4 \%$ NPPGFAFVEFEDPR

$\begin{array}{lll}0.08 \% & 32.4 \% & \text { NPPGFAFVEFEDPRD } \\ 0.08 \% & 32.4 \% & \text { GLDGKVICGSR }\end{array}$

$\begin{array}{lll}0.08 \% & 32.4 \% \text { VRVELSTGMPR }\end{array}$

$0.08 \% \quad 32.4 \%$ VELSTGMPR

$0.08 \% \quad 32.4 \%$ RPFDPNDR

$0.01 \% \quad 18.6 \%$ HGLVPFAFVR

$0.01 \% \quad 18.6 \%$ NGYDYGQCR

$0.01 \% \quad 18.6 \%$ SHEGETSYIR

$0.01 \% \quad 18.6 \%$ GSPHYFSPFRPY

$0.03 \% \quad 18.1 \%$ LGLDDFESLK

$0.03 \% 18.1 \%$ LGLDDFESLKVIGR

$0.03 \% \quad 18.1 \%$ DIKPDNLLLDAK

$0.03 \% \quad 18.1 \%$ LSDFGLCTGLK

$0.03 \% \quad 18.1 \%$ LSDFGLCTGLKK

$99.0 \% \quad 48.2$

$99.7 \% \quad 39.9$

$\begin{array}{lll}99.7 \% & 29.4\end{array}$

$99.7 \% \quad 32.0$

$99.7 \% \quad 44.7$

$99.7 \% \quad 31.6$

$97.0 \% \quad 22.6$

$99.7 \% \quad 41.1$

$99.7 \% \quad 55.9$

$99.7 \% \quad 31.1$

$99.7 \% \quad 62.8$

$\begin{array}{lll}99.7 \% & 38.7\end{array}$

$99.7 \% \quad 39.7$

$99.7 \% \quad 55.9$

$99.7 \% \quad 59.5$

$99.7 \% \quad 62.6$

$99.7 \% \quad 48.8$

$99.7 \% \quad 39.6$

$\begin{array}{lll}95.4 \% & 16.7\end{array}$

$99.7 \% \quad 49.9$

$99.7 \% 56.0$

$99.7 \% \quad 50.1$

$\begin{array}{lll}99.7 \% & 44.7\end{array}$

$\begin{array}{ll}99.7 \% & 30.9\end{array}$

$\begin{array}{lll}99.7 \% & 56.9\end{array}$

$99.7 \% \quad 45.9$

$99.7 \% \quad 47.2$

$98.5 \% \quad 21.0$

$99.7 \% \quad 30.2$

$99.7 \% \quad 34.9$

$98.4 \% \quad 17.0$

$97.7 \% \quad 16.7$

$99.7 \% \quad 48.2$

$99.7 \% \quad 58.7$

$99.7 \% \quad 43.7$

$99.7 \% \quad 58.2$

$99.7 \% \quad 49.9$

$0.03 \% \quad 18.1 \%$ NLTHNPPSDFSFQNMNSK $99.7 \% \quad 53.5$

$0.03 \% \quad 18.1 \%$ NLTHNPPSDFSFQNMNSKR

$0.03 \% \quad 18.1 \%$ ERPAAIPIEIK

$0.03 \% \quad 18.1 \%$ RFEGLTQR

$0.03 \% \quad 18.1 \%$ GSIPTYMK

$\begin{array}{ll}98.9 \% & 18.3 \\ 99.7 \% & 33.7\end{array}$

$99.0 \% 32.8$

$99.0 \% \quad 20.6$

$0.00 \% \quad 6.2 \% \quad$ LADFGVAGQLTDTMAKR

$0.00 \% \quad 6.2 \% \quad$ ATATQLLQHPFVR

$0.01 \% \quad 1.0 \%$ ASPAASALIR

$0.01 \% \quad 1.0 \%$ LGQLLLSAK

$0.01 \% \quad 1.0 \%$ LAELYVER
$99.5 \% \quad 24.8$

$99.4 \% \quad 29.6$

$99.7 \% 33.6$

$99.0 \% \quad 52.7$

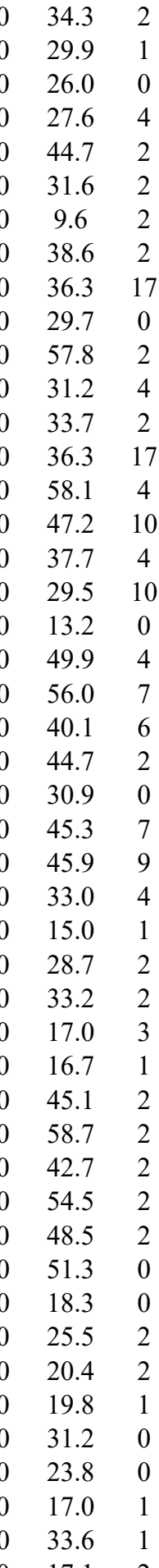

$.0 \quad 17.1$
18.50

1189.63

1308.62

1043.53

1621.76

1130.62

1017.47

1530.82

1030.59

1526.77

1640.82

1175.51

1579.84

1030.59

1574.76

1064.54

1401.73

1122.62

1349.75

1135.61

1719.90

1073.54

1621.76

2378.10

1161.60

1244.68

989.51

1016.49

1142.65

1132.45

1178.54

1454.69

1136.58

1561.86

1354.76

1210.61

1338.71

2077.94

2250.04

1236.73

1006.54

896.45

1793.92

1481.82

956.55

942.60

992.54
47
49
102
37
57
85
92
118
118
143
158
85
120
120
145
154
174
311
313
24
29
38
58
65
76
87
87
105
58
81
181
221
94
98
224
239
240
266
267
403
452
460
181
1959

Page 105 of Table S-1-2 

Serine/threonine-protein kinase MRCK alpha GN=CDC42BPA MRCKA_HUMAN $197.31 \quad 100.0 \%$ Serine/threonine-protein kinase mTOR GN=MTOR MTOR_HUMAN $288.90 \quad 100.0 \%$ Serine/threonine-protein kinase mTOR GN=MTOR MTOR_HUMAN $288.90 \quad 100.0 \%$ Serine/threonine-protein kinase mTOR GN=MTOR MTOR_HUMAN $288.90 \quad 100.0 \%$ Serine/threonine-protein kinase mTOR GN=MTOR MTOR_HUMAN $288.90 \quad 100.0 \%$ Serine/threonine-protein kinase mTOR GN=MTOR MTOR_HUMAN $288.90 \quad 100.0 \%$ Serine/threonine-protein kinase mTOR GN=MTOR MTOR_HUMAN $288.90 \quad 100.0 \%$ Serine/threonine-protein kinase mTOR GN=MTOR MTOR_HUMAN $288.90 \quad 100.0 \%$ Serine/threonine-protein kinase RIO1 GN=RIOK1 RIOK1_HUMAN $65.58 \quad 100.0 \%$ Serine/threonine-protein kinase RIO1 GN=RIOK1 RIOK1_HUMAN $65.58 \quad 100.0 \%$ Serine/threonine-protein kinase RIO1 GN=RIOK1 RIOK1_HUMAN $65.58 \quad 100.0 \%$ Serine/threonine-protein kinase RIO1 GN=RIOK1 RIOK1_HUMAN $65.58 \quad 100.0 \%$ Serine/threonine-protein kinase RIO1 GN=RIOK1 RIOK1_HUMAN $65.58 \quad 100.0 \%$ Serine/threonine-protein kinase RIO1 GN=RIOK1 RIOK1 HUMAN $65.58 \quad 100.0 \%$ Serine/threonine-protein kinase RIO1 GN=RIOK1 RIOK1_HUMAN $65.58 \quad 100.0 \%$ Serine/threonine-protein kinase RIO1 GN=RIOK1 RIOK1_HUMAN $65.58 \quad 100.0 \%$ Serine/threonine-protein kinase RIO1 GN=RIOK1 RIOK1_HUMAN $65.58 \quad 100.0 \%$ Serine/threonine-protein kinase RIO1 GN=RIOK1 RIOK1_HUMAN $65.58 \quad 100.0 \%$ Serine/threonine-protein kinase RIO1 GN=RIOK1 RIOK1_HUMAN $65.58 \quad 100.0 \%$ Serine/threonine-protein kinase RIO1 GN=RIOK1 RIOK1_HUMAN $65.58 \quad 100.0 \%$ Serine/threonine-protein kinase RIO1 GN=RIOK1 RIOK1_HUMAN $65.58 \quad 100.0 \%$ Serine/threonine-protein kinase RIO1 GN=RIOK1 RIOK1_HUMAN $65.58 \quad 100.0 \%$ Serine/threonine-protein kinase RIO1 GN=RIOK1 RIOK1_HUMAN $65.58 \quad 100.0 \%$ Serine/threonine-protein kinase RIO1 GN=RIOK1 RIOK1_HUMAN $65.58 \quad 100.0 \%$ Serine/threonine-protein kinase RIO1 GN=RIOK1 RIOK1_HUMAN $65.58 \quad 100.0 \%$ Serine/threonine-protein kinase RIO1 GN=RIOK1 RIOK1_HUMAN $65.58 \quad 100.0 \%$ Serine/threonine-protein kinase RIO1 GN=RIOK1 RIOK1 HUMAN $65.58 \quad 100.0 \%$ Serine/threonine-protein kinase RIO1 GN=RIOK1 RIOK1_HUMAN $65.58 \quad 100.0 \%$ Serine/threonine-protein kinase RIO1 GN=RIOK1 RIOK1_HUMAN $65.58 \quad 100.0 \%$ Serine/threonine-protein kinase RIO1 GN=RIOK1 RIOK1 HUMAN $65.58 \quad 100.0 \%$ Serine/threonine-protein kinase RIO1 GN=RIOK1 RIOK1_HUMAN $65.58 \quad 100.0 \% \quad 24$ Serine/threonine-protein kinase RIO1 GN=RIOK1 RIOK1_HUMAN $65.58 \quad 100.0 \%$ Serine/threonine-protein kinase SMG1 GN=SMG1 SMG1_HUMAN $410.50 \quad 100.0 \%$ Serine/threonine-protein kinase SMG1 GN=SMG1 SMG1_HUMAN $410.50 \quad 100.0 \%$ GNPPRSD 2A5D HUMAN $69.99 \quad 100.0 \%$ SD 2A5D_HUMAN $69.99 \quad 100.0 \%$ 2AAA HUMAN $65.31 \quad 100.0 \%$ 2AAA HUMAN $65.31 \quad 100.0 \%$

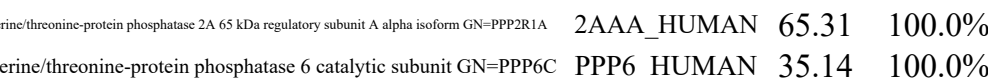
Serine/threonine-protein phosphatase 6 catalytic subunit GN=PPP6C PPP6_HUMAN $35.14 \quad 100.0 \%$ Serine/threonine-protein phosphatase 6 catalytic subunit GN=PPP6C PPP6_HUMAN $35.14 \quad 100.0 \%$ Serine/threonine-protein phosphatase 6 catalytic subunit GN=PPP6C PPP6_HUMAN $35.14 \quad 100.0 \%$ Serine/threonine-protein phosphatase PGAM5, mitochondrial GN=PGAM5 $\quad$ PGAM5_HUMAN $32.01 \quad 100.0 \%$

$0.01 \% \quad 2.5 \%$ GAFGEVAVVK $0.01 \% \quad 2.5 \%$ LADFGSCLK $0.01 \% \quad 2.5 \%$ TVFSGSVSIPSITK $0.01 \% \quad 2.5 \%$ SMSASSGLSAR $0.02 \% \quad 3.4 \%$ DASAVSLSESK $0.02 \% \quad 3.4 \%$ LFDAPEAPLPSR $0.02 \% \quad 3.4 \%$ TLDQSPELR $0.02 \% \quad 3.4 \%$ SGQGDALASGPVETGPMKK $0.02 \% \quad 3.4 \%$ TLVLLLGVDPSR

$0.02 \% \quad 3.4 \%$ GNNLQDTLR

$3 \quad 0.02 \% \quad 3.4 \%$ IQSIAPSLQVITSK $99.4 \% \quad 19.9$ $99.7 \% \quad 28.0$ $99.7 \% \quad 28.8$ $99.7 \% \quad 52.0$ $\begin{array}{llll}99.6 \% & 29.7\end{array}$ $99.6 \% 26.5$

\section{$99.7 \% \quad 26.7$} $99.7 \% \quad 43.4$ $94.9 \% \quad 20.0$ $99.7 \% \quad 53.8$ $99.7 \% \quad 45.7$

$161 \quad 0.24 \% \quad 40.1 \%$ GYVWNGGSNPQANR

$161 \quad 0.24 \% \quad 40.1 \%$ GYVWNGGSNPQANRQTSDSSSAK

$161 \quad 0.24 \% \quad 40.1 \%$ MSTPADKVLR

$161 \quad 0.24 \% \quad 40.1 \%$ ATVEQVLDPR

$\begin{array}{llll}161 & 0.24 \% & 40.1 \% & \text { ATVEQVLDPRTR }\end{array}$

$161 \quad 0.24 \% \quad 40.1 \%$ GIITEINGCISTGK

$99.7 \% \quad 57.4$

$99.7 \% \quad 48.7$

$99.7 \% \quad 37.5$

$99.7 \% \quad 59.3$

$161 \quad 0.24 \% \quad 40.1 \%$ GIITEINGCISTGKEANVYHASTANGESR $\quad 99.7 \% \quad 47.7$

$161 \quad 0.24 \% \quad 40.1 \%$ EANVYHASTANGESR

$99.7 \% \quad 55.9$

$161 \quad 0.24 \% \quad 40.1 \%$ NLIRLNTAEIPCPEPIMLR $99.6 \% \quad 24.1$

$161 \quad 0.24 \% \quad 40.1 \%$ LNTAEIPCPEPIMLR

$99.7 \% \quad 62.6$

$161 \quad 0.24 \% \quad 40.1 \%$ SHVLVMSFIGKDDMPAPLLK $99.7 \% \quad 46.5$

$161 \quad 0.24 \% \quad 40.1 \%$ NVQLSESKAR

$161 \quad 0.24 \% \quad 40.1 \%$ ARELYLQVIQYMR

$161 \quad 0.24 \% \quad 40.1 \%$ ELYLQVIQYMR

$161 \quad 0.24 \% \quad 40.1 \%$ ELYLQVIQYMRR

$161 \quad 0.24 \% \quad 40.1 \%$ KDCANVNDFFMR

$161 \quad 0.24 \% \quad 40.1 \%$ DCANVNDFFMR

$161 \quad 0.24 \% \quad 40.1 \%$ HSVAVMTVR

$161 \quad 0.24 \% \quad 40.1 \%$ ELFEFVTDPSITHENMDAYLSK

$161 \quad 0.24 \% \quad 40.1 \%$ AMEIASQR

$161 \quad 0.24 \% \quad 40.1 \%$ SSQDHVDEEVFKR

$161 \quad 0.24 \% \quad 40.1 \%$ TLNEVKNYER

$161 \quad 0.24 \% \quad 40.1 \%$ DLSGVQKVPALLENQVEER

$161 \quad 0.24 \% \quad 40.1 \%$ VPALLENQVEER

$0.00 \% \quad 0.5 \%$ SIEVQLLR

$0.00 \% \quad 0.5 \% \quad$ LLAQCSEVQLGK

$0.00 \% \quad 4.0 \% \quad$ FLESPDFQPNIAK

$0.00 \% \quad 4.0 \%$ VLPIMFPALYR

$0.01 \% \quad 6.5 \%$ LSTIALALGVER

$0.01 \% \quad 6.5 \%$ TSACGLFSVCYPR

$0.01 \% \quad 6.5 \%$ VLAMSGDPNYLHR

$0.01 \% \quad 16.7 \%$ APLDLDKYVEIAR

$0.01 \% \quad 16.7 \%$ QITQVYGFYDECQTK

$0.01 \% \quad 16.7 \%$ TIERNQEIPHK

$0.01 \% \quad 16.7 \%$ VTNEFVHINNLK

$0.04 \% \quad 26.6 \%$ NVESGEEELASK $\begin{array}{llll}99.7 \% & 56.0 & 25.0 & 51.2\end{array}$

$99.6 \% \quad 23.4$

$99.7 \% \quad 60.2$

$99.5 \% \quad 22.6$

$99.7 \% \quad 40.9$

$99.7 \% \quad 58.3$

$99.7 \% \quad 42.0$

$99.7 \% \quad 27.5$

$99.0 \% 39$.

$99.7 \% \quad 62.8$

$99.7 \% \quad 32.9$

$99.7 \% \quad 51.8$

$99.7 \% \quad 60.8$

$98.4 \% \quad 27.4$

$99.7 \% \quad 43.1$

$97.5 \% \quad 20.0$

$99.7 \% \quad 48.0$

$99.7 \% \quad 69.2$

$99.7 \% \quad 45.7$

$99.7 \% \quad 35.6$

$99.7 \% \quad 57.8$

$99.7 \% \quad 43.4$

$97.9 \% \quad 17.1$

$99.7 \% 45$.

$99.7 \% \quad 51.6$
976.55

1010.50

1422.78

1053.50

1093.54

1312.69

1058.55

1845.90

1282.77

1030.53

1484.87

1519.70

2411.10

1117.60

1127.61

1384.75

1462.76

3049.46

1605.73

2266.20

1753.90

2230.16

1131.61

1698.90

1455.77

1627.86

1532.66

1404.57

999.54

2602.20

905.45

1575.74

1265.65

2124.13

1396.74

957.57

1345.71

1505.76

1319.75

1242.74

1517.69

1472.73

1502.82

1879.85

1364.73

1427.76

1291.60

$\begin{array}{cc} & \\ 86 & 95 \\ 217 & 225 \\ 1606 & 1619 \\ 1627 & 1637 \\ 911 & 921 \\ 1121 & 1132 \\ 1162 & 1170 \\ 1239 & 1257 \\ 1672 & 1683 \\ 1897 & 1905 \\ 2153 & 2166 \\ 82 & 95 \\ 82 & 104 \\ 105 & 114 \\ 156 & 165 \\ 156 & 167 \\ 177 & 190 \\ 177 & 205 \\ 191 & 205 \\ 253 & 271 \\ 257 & 271 \\ 272 & 291 \\ 292 & 301 \\ 300 & 312 \\ 302 & 312 \\ 302 & 313 \\ 359 & 370 \\ 360 & 370 \\ 371 & 379 \\ 380 & 401 \\ 402 & 409 \\ 415 & 427 \\ 433 & 442 \\ 475 & 493 \\ 482 & 493 \\ 1288 & 1295 \\ 1444 & 1455 \\ 220 & 232 \\ 442 & 452 \\ 35 & 46 \\ 145 & 157 \\ 486 & 498 \\ 2 & 14 \\ 118 & 132 \\ 178 & 188 \\ 220 & 231 \\ 77 & 88 \\ & \end{array}$

106 of Table $S-1-2$ 
Sideroflexin-1 GN=SFXN1

Sideroflexin-1 GN=SFXN1 Sideroflexin $1 \mathrm{GN}=\mathrm{SFXN} 1$ Sideroflexin-1 GN=SFXN1 Sideroflexin-1 GN=SFXN1 Sideroflexin-1 GN=SFXN1 Sideroflexin-1 GN=SFXN1 Sideroflexin-1 GN=SFXN1 Sideroflexin-1 GN=SFXN1 Sideroflexin-1 GN=SFXN1 Sideroflexin-1 GN=SFXN1 Sideroflexin-2 GN=SFXN2 Sideroflexin-2 GN $=$ SFXN2 Sideroflexin-2 GN=SFXN2 Sideroflexin $-2 \mathrm{GN}=\mathrm{SFXN} 2$ Sideroflexin-2 GN=SFXN2
16 SFXN1 HUMAN $35.62 \quad 100.0 \%$ SFXN1_HUMAN $35.62 \quad 100.0 \%$ SFXN1_HUMAN $35.62 \quad 100.0 \%$ SFXN1 HUMAN $35.62 \quad 100.0 \%$ SFXN1_HUMAN $35.62 \quad 100.0 \%$ SFXN1_HUMAN $35.62 \quad 100.0 \%$ SFXN1_HUMAN $35.62 \quad 100.0 \%$ SFXN1_HUMAN $35.62 \quad 100.0 \%$ SFXN2 HUMAN $36.23 \quad 100.0 \%$ SFXN2_HUMAN $36.23 \quad 100.0 \%$ SFXN2_HUMAN $36.23 \quad 100.0 \%$ SFXN2_HUMAN $36.23 \quad 100.0 \%$ SFXN2_HUMAN $36.23 \quad 100.0 \%$ $0.17 \% \quad 7.6 \%$ VPQVSTPTLVEVSR
$0.04 \% \quad 26.6 \%$ HSQYHVDGSLEKDR $0.04 \% \quad 26.6 \%$ TLTPLGREQAELTGLR $0.04 \% \quad 26.6 \%$ EQAELTGLR

$0.04 \% \quad 26.6 \%$ LASLGLKFNK

$0.04 \% \quad 26.6 \%$ AIETTDIISR

$0.04 \% \quad 26.6 \%$ TLGDTGFMPPDKITR

$0.00 \% \quad 8.5 \%$ IYGFYDECKR

$0.00 \% \quad 8.5 \% \quad$ YGQFSGLNPGGRPITPPR $0.01 \% \quad 11.0 \%$ IVQMTEAEVR

$0.01 \% \quad 11.0 \%$ IYGFYDECKR

$0.01 \% \quad 11.0 \%$ YQYGGLNSGRPVTPPR

$0.01 \% \quad 11.7 \%$ GAVWGATLNKDATK

$0.01 \% \quad 11.7 \%$ IYDLNKPEAEPK

$0.01 \% \quad 11.7 \%$ CVLPEEDSGELAKPK

$0.02 \% \quad 16.0 \%$ SAGLAFSLYQAMAK

$99.7 \% \quad 41.7 \quad 25.0 \quad 33.4 \quad 0$ $99.4 \% \quad 21.1 \quad 25.0 \quad 21.1$ $99.7 \% \quad 49.3 \quad 25.0 \quad 35.9$ $99.7 \% \quad 30.1 \quad 25.0 \quad 30.1$ $99.7 \% \quad 63.7 \quad 25.0 \quad 54.2$ $\begin{array}{llll}99.7 \% & 28.3 & 25.0 & 25.4\end{array}$ $\begin{array}{llll}98.8 \% & 26.8 & 25.0 & 22.3\end{array}$ $\begin{array}{llll}99.7 \% & 47.6 & 25.0 & 43.0\end{array}$ $\begin{array}{llll}98.8 \% & 26.8 & 25.0 & 22.3\end{array}$ $99.6 \% \quad 24.4 \quad 25.0 \quad 22.5$ $\begin{array}{llll}99.7 \% & 28.2 & 25.0 & 28.2\end{array}$ $99.7 \% \quad 35.1 \quad 25.0 \quad 26.1 \quad 2$ $\begin{array}{llll}99.7 \% & 32.2 & 25.0 & 27.7\end{array}$ $99.7 \% \quad 45.5 \quad 25.0 \quad 45.5$

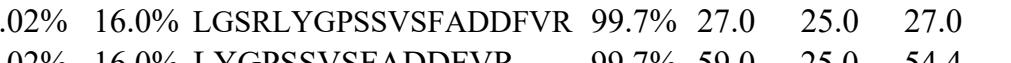
$0.02 \% \quad 16.0 \%$ SYTVGVMMMHR $0.02 \% \quad 16.0 \%$ GVVEVTHDLQK $0.02 \% \quad 16.0 \%$ DTQSGSLLFIGR $0.17 \% \quad 7.6 \%$ CASLQKFGER 0.17\% 7.6\% YICENQDSISSK $0.17 \% \quad 7.6 \%$ KVPQVSTPTLVEVSR 7.17\% CCTESLVNR $0.01 \% \quad 17.4 \%$ ATYLPQLTTEK $0.01 \% \quad 17.4 \%$ ASSTCPLTFENVK $0.01 \% \quad 17.4 \%$ YAIGSLNEGR $0.01 \% \quad 17.4 \%$ LLEAGKPFIK $0.01 \% \quad 17.4 \%$ YYASEIAGQTTSK $0.01 \% \quad 17.4 \%$ IGTIYEGASNIQLNTIAK $0.04 \% \quad 39.4 \%$ ANHFFTVTDPR

$0.04 \% 39.4 \%$ NILLTNEQLESAR

$\begin{array}{llll}99.7 \% & 49.2 & 25.0 & 47.5\end{array}$ $99.7 \% \quad 41.0 \quad 25.0 \quad 30.4$ $99.7 \% \quad 61.9 \quad 25.0 \quad 57.2$ $\begin{array}{llll}99.7 \% & 47.1 & 25.0 & 38.3\end{array}$ $\begin{array}{llll}99.7 \% & 30.6 & 25.0 & 19.6\end{array}$ $99.7 \% \quad 62.1 \quad 25.0 \quad 59.8$ $99.7 \% \quad 34.0 \quad 25.0 \quad 34.0$ $\begin{array}{lllll}99.7 \% & 45.8 & 25.0 & 45.8\end{array}$ $99.5 \% \quad 22.2 \quad 25.0 \quad 22.2$ $99.2 \% \quad 21.6 \quad 25.0 \quad 18.8$ $99.7 \% \quad 52.4 \quad 25.0 \quad 41.5$ $95.7 \% \quad 20.2 \quad 25.0 \quad 12.0$ $99.7 \% \quad 82.6 \quad 25.0 \quad 78.5$ $99.7 \% \quad 74.4 \quad 25.0 \quad 74.4$ $99.7 \% \quad 43.5 \quad 25.0 \quad 36.1 \quad 2$ $99.7 \% \quad 79.8 \quad 25.0 \quad 70.3$

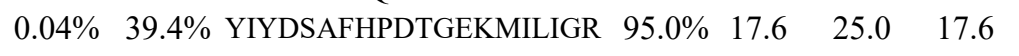
$0.04 \% \quad 39.4 \%$ HVSPLIGR $\begin{array}{llll}99.0 \% & 40.1 & 25.0 & 34.5\end{array}$ $\begin{array}{lllllll}0.04 \% & 39.4 \% & \text { FVPFAAVAAANCINIPLMR } & 99.7 \% & 28.8 & 25.0 & 28.8\end{array}$ $\begin{array}{lllllll}0.04 \% & 39.4 \% & \text { VGIPVTDENGNR } & 99.7 \% & 60.3 & 25.0 & 54.2\end{array}$

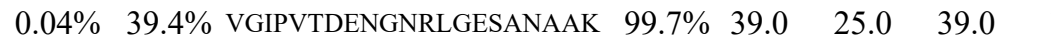
$0.04 \% \quad 39.4 \%$ QAITQVVVSR $0.04 \% \quad 39.4 \%$ SSMSVTSLEAELQAK $99.7 \% \quad 77.2 \quad 25.0 \quad 72.3$ $\begin{array}{llll}99.7 \% & 50.4 & 25.0 & 50.4\end{array}$ $99.7 \% \quad 51.5 \quad 25.0 \quad 42.8$ $0.04 \% \quad 39.4 \%$ IQESHPELR $0.04 \% \quad 39.4 \%$ IQESHPELRR $\begin{array}{llll}99.5 \% & 21.4 & 25.0 & 21.4\end{array}$ $\begin{array}{lllllll}0.02 \% & 17.4 \% & \text { MGVVPPGTQVEQLLYAK } & 99.7 \% & 28.4 & 25.0 & 25.6\end{array}$ $0.02 \% \quad 17.4 \%$ RAAAIGITQVVISR $0.02 \% \quad 17.4 \%$ AAAIGITQVVISR $0.02 \% \quad 17.4 \%$ CELPVSYLEPK $0.02 \% \quad 17.4 \%$ YGELEPYVYFNK $\begin{array}{llll}99.7 \% & 34.7 & 25.0 & 34.7\end{array}$ $\begin{array}{lllll}99.7 \% & 60.1 & 25.0 & 50.6 & 2\end{array}$ $99.7 \% \quad 41.7 \quad 25.0 \quad 37.0$ $\begin{array}{lllll}99.7 \% & 36.0 & 25.0 & 36.0 & 2\end{array}$

3
2
0
0
0
4
0
2
2
0
0
3
0
0
0
2
2
0
2
0
0
0
0
0
0
0
0
0
0
39
0
0
0
0
0
0
0
0
0
0
0
0
0
0
0
0
1
0
0
0
0
0
0
0
0
0
0
0
0
0
0
0
0
0
0
1754.98

1016.54

1090.66

1118.61

1648.84

1350.61

1914.00

1175.61

1350.61

1761.90

1431.76

1416.74

1671.83

1457.75

2073.04

1659.80

1311.60

1224.66

1293.68

1195.59

1443.64

1639.94

1511.84

1138.50

1264.68

1453.70

1079.55

1115.68

1418.68

1906.03

1304.64

1500.80

2342.15

878.52

2091.09

1270.64

2112.07

1100.64

1580.78

1108.57

1264.68

1845.98

1454.88

1298.78

1334.67 1521.73

$\begin{array}{cc}5 & 118 \\ 9 & 134 \\ 6 & 134 \\ 5 & 144 \\ 3 & 162 \\ 4 & 288 \\ 3 & 142 \\ 6 & 323 \\ 6 & 35 \\ 2 & 141 \\ 4 & 319 \\ 0 & 73 \\ 6 & 137 \\ 5 & 319 \\ 7 & 60 \\ 0 & 148 \\ 4 & 148 \\ 9 & 239 \\ 9 & 319 \\ 4 & 405 \\ 4 & 233 \\ 7 & 298 \\ 8 & 452 \\ 9 & 452 \\ 0 & 508 \\ 0 & 170 \\ 7 & 269 \\ 5 & 294 \\ 6 & 365 \\ 2 & 384 \\ 9 & 426 \\ 5 & 35 \\ 6 & 48 \\ 3 & 92 \\ 1 & 178 \\ 9 & 197 \\ 3 & 214 \\ 3 & 223 \\ 4 & 233 \\ 1 & 305 \\ 6 & 314 \\ 66 & 315 \\ 5 & 71 \\ 9 & 232 \\ 0 & 232 \\ 0 & 300 \\ 9 & 320 \\ & \\ & \\ 6\end{array}$

Page 107 of Table S-1-2 
Sideroflexin-2 GN=SFXN2 Sideroflexin-4 GN=SFXN4 Sideroflexin- $4 \mathrm{GN}=\mathrm{SFXN} 4$ Sideroflexin-4 GN=SFXN4 Sideroflexin-4 GN=SFXN4 Sideroflexin- $4 \mathrm{GN}=$ SFXN4

SFXN4 HUMAN $38.00 \quad 100.0 \%$ Signal recognition particle receptor subunit beta GN=SRPRB SRPRB_HUMAN $29.70 \quad 100.0 \%$ Signal recognition particle receptor subunit beta GN=SRPRB SRPRB_HUMAN $29.70 \quad 100.0 \%$ Signal recognition particle receptor subunit beta GN=SRPRB SRPRB_HUMAN $29.70 \quad 100.0 \%$ Signal recognition particle receptor subunit beta GN=SRPRB SRPRB_HUMAN $29.70 \quad 100.0 \%$ Signal recognition particle subunit SRP68 GN=SRP68 SRP68_HUMAN $70.73 \quad 100.0 \%$ Signal recognition particle subunit SRP68 GN=SRP68 SRP68_HUMAN $70.73 \quad 100.0 \%$ Signal recognition particle subunit SRP68 GN=SRP68 SRP68_HUMAN $70.73 \quad 100.0 \%$ Signal recognition particle subunit SRP68 GN=SRP68 SRP68_HUMAN $70.73 \quad 100.0 \%$ Signal recognition particle subunit SRP68 GN=SRP68 SRP68_HUMAN $70.73 \quad 100.0 \%$ Signal recognition particle subunit SRP68 GN=SRP68 SRP68 HUMAN $70.73 \quad 100.0 \%$ Signal recognition particle subunit SRP68 GN=SRP68 SRP68_HUMAN $70.73 \quad 100.0 \%$ Signal transducer and activator of transcription 1-alpha/beta GN=STAT1 STAT1_HUMAN $87.34 \quad 100.0 \%$ Signal transducer and activator of transcription 1-alpha/beta GN=STAT1 STAT1_HUMAN $87.34 \quad 100.0 \%$ Signal transducer and activator of transcription 3 GN=STAT3 STAT3_HUMAN $88.07 \quad 100.0 \%$ Signal transducer and activator of transcription 3 GN=STAT3 STAT3_HUMAN $88.07 \quad 100.0 \%$ Signal transducer and activator of transcription $3 \mathrm{GN}=$ STAT3 STAT3_HUMAN $88.07 \quad 100.0 \%$ Sister chromatid cohesion protein PDS5 homolog A GN=PDS5A PDS5A_HUMAN $150.84 \quad 100.0 \%$ Sister chromatid cohesion protein PDS5 homolog A GN=PDS5A PDS5A_HUMAN $150.84 \quad 100.0 \%$ SNW domain-containing protein $1 \mathrm{GN}=\mathrm{SNW} 1 \mathrm{SNW} 1$ HUMAN $61.50 \quad 100.0 \%$ SNW domain-containing protein $1 \mathrm{GN}=\mathrm{SNW} 1 \mathrm{SNW} 1$ HUMAN $61.50 \quad 100.0 \%$ SNW domain-containing protein $1 \mathrm{GN}=\mathrm{SNW} 1$ SNW1_HUMAN $61.50 \quad 100.0 \%$ Sodium/potassium-transporting ATPase subunit alpha-1 GN=ATP1A1 AT1A1_HUMAN $112.90 \quad 100.0 \%$ Sodium/potassium-transporting ATPase subunit alpha-1 GN=ATP1A1 AT1A1_HUMAN $112.90 \quad 100.0 \%$ Sodium/potassium-transporting ATPase subunit alpha-1 GN=ATP1A1 AT1A1_HUMAN $112.90 \quad 100.0 \%$ Sodium/potassium-transporting ATPase subunit alpha-1 GN=ATP1A1 AT1A1_HUMAN $112.90 \quad 100.0 \%$ Sodium/potassium-transporting ATPase subunit alpha-1 GN=ATP1A1 AT1A1_HUMAN $112.90 \quad 100.0 \%$ Sodium/potassium-transporting ATPase subunit alpha-1 GN=ATP1A1 AT1A1_HUMAN $112.90 \quad 100.0 \%$ Solute carrier family 25 member $33 \mathrm{GN}=$ SLC25A33 S2533_HUMAN $35.38 \quad 100.0 \%$ Solute carrier family 25 member $33 \mathrm{GN}=$ SLC25A33 S2533_HUMAN $35.38 \quad 100.0 \%$ Solute carrier family 25 member $40 \mathrm{GN}=$ SLC25A40 S2540_HUMAN $38.13 \quad 100.0 \%$ Solute carrier family 25 member $40 \mathrm{GN}=$ SLC25A40 S2540_HUMAN $38.13 \quad 100.0 \%$ Spectrin alpha chain, non-erythrocytic 1 GN=SPTAN1 SPTN1_HUMAN $284.54 \quad 100.0 \%$ Spectrin alpha chain, non-erythrocytic 1 GN=SPTAN1 SPTN1_HUMAN $284.54 \quad 100.0 \%$ Spectrin alpha chain, non-erythrocytic $1 \mathrm{GN}=$ SPTAN1 SPTN1_HUMAN $284.54 \quad 100.0 \%$ Spectrin alpha chain, non-erythrocytic 1 GN=SPTAN1 SPTN1_HUMAN $284.54 \quad 100.0 \%$ Spectrin alpha chain, non-erythrocytic $1 \mathrm{GN}=$ SPTAN1 SPTN1_HUMAN $284.54 \quad 100.0 \%$ Spectrin alpha chain, non-erythrocytic 1 GN=SPTAN1 SPTN1_HUMAN $284.54 \quad 100.0 \%$ Spectrin alpha chain, non-erythrocytic 1 GN=SPTAN1 SPTN1_HUMAN $284.54 \quad 100.0 \%$ Spectrin alpha chain, non-erythrocytic 1 GN=SPTAN1 SPTN1_HUMAN $284.54 \quad 100.0 \%$ Spectrin alpha chain, non-erythrocytic $1 \mathrm{GN}=$ SPTAN1 SPTN1_HUMAN $284.54 \quad 100.0 \%$
$15 \quad 0.02 \% \quad 17.4 \%$ YGELEPYVYFNKGL $0.02 \% \quad 17.5 \%$ DAVPAFIEPNVR $0.02 \% \quad 17.5 \%$ SLATVHPDSSNLIPK $0.02 \% \quad 17.5 \%$ SYTCKPLER $0.02 \% \quad 17.5 \%$ AVRETLASR $0.02 \% \quad 17.5 \%$ IQSPTEETEIFYHR $0.02 \% \quad 21.8 \%$ AVLLVGLCDSGK $0.02 \% \quad 21.8 \%$ AIVFVVDSAAFQR $0.02 \% \quad 21.8 \%$ LIQQQLEKELNTLR $0.02 \% \quad 21.8 \%$ SAAPSTLDSSSTAPAQLG $0.02 \% \quad 21.8 \%$ SAAPSTLDSSSTAPAQLGKK $0.02 \% \quad 13.7 \%$ VEEISPNIR $0.02 \% \quad 13.7 \%$ ALLQQQPEDDSK $0.02 \% \quad 13.7 \%$ ALLQQQPEDDSKR $0.02 \% \quad 13.7 \%$ YANEVNSDAGAFK $0.02 \% \quad 13.7 \%$ FETFCLDPSLVTK $0.02 \% \quad 13.7 \%$ SGLTGYIK $0.01 \% \quad 3.2 \%$ NLSFFLTPPCAR $0.01 \% \quad 3.2 \%$ ELSAVTFPDIIR $0.01 \% \quad 3.8 \%$ IKQFLQSR $0.01 \% \quad 3.8 \%$ KFNILGTNTK $0.01 \% \quad 3.8 \%$ TQIQSVEPYTK $0.01 \% \quad 2.2 \%$ STLIPILHQK $0.01 \% \quad 2.2 \%$ AAVGQESPGGLEAGNAKAPK $0.01 \% \quad 6.9 \%$ AADKLAPAQYIR $0.01 \% \quad 6.9 \%$ GYTIPLDKR $0.01 \% \quad 6.9 \%$ TSNEVQYDQRLFNQSK $0.02 \% \quad 6.7 \%$ AVAGDASESALLK $0.02 \% \quad 6.7 \%$ AAVPDAVGKCR $0.02 \% \quad 6.7 \%$ SAGIKVIMVTGDHPITAK $0.02 \% \quad 6.7 \% \quad$ LNIPVSQVNPR $0.02 \% \quad 6.7 \%$ TSPQQKLIIVEGCQR $0.02 \% \quad 6.7 \% \quad$ LIIVEGCQR $0.00 \% \quad 6.9 \%$ SILEKEGPK $0.00 \% \quad 6.9 \%$ GLGPNLVGVAPSR $0.00 \% \quad 7.1 \% \quad$ LQAQNNPLPK $0.00 \% \quad 7.1 \%$ FGAVTVISPLELIR $0.05 \% \quad 4.8 \%$ VLETAEDIQER $0.05 \% \quad 4.8 \% \quad$ LFGAAEVQR $0.05 \% \quad 4.8 \%$ EANQQQQFNR $0.05 \% \quad 4.8 \%$ GKDLIGVQNLLK $0.05 \% \quad 4.8 \%$ SQLLGSAHEVQR $0.05 \% \quad 4.8 \%$ LGESQTLQQFSR $0.05 \% \quad 4.8 \%$ GVIDMGNSLIER $0.05 \% \quad 4.8 \%$ GACAGSEDAVKAR $0.05 \% \quad 4.8 \%$ LSDDNTIGKEEIQQR $\begin{array}{llll}99.7 \% & 29.2 & 25.0 & 29.2\end{array}$ $99.7 \% \quad 36.9 \quad 25.0 \quad 31.6$ $\begin{array}{lllll}99.7 \% & 31.0 & 25.0 & 30.9 & 4\end{array}$ $\begin{array}{llll}99.7 \% & 32.7 & 25.0 & 28.0\end{array}$ $\begin{array}{llll}99.7 \% & 28.8 & 25.0 & 24.0\end{array}$ $\begin{array}{llll}98.8 \% & 17.8 & 25.0 & 17.8\end{array}$ $\begin{array}{llll}99.6 \% & 23.1 & 25.0 & 23.1\end{array}$ $\begin{array}{lllll}99.7 \% & 66.0 & 25.0 & 66.0\end{array}$ $\begin{array}{llll}99.6 \% & 27.2 & 25.0 & 22.8\end{array}$

$\begin{array}{lllll}99.7 \% & 68.6 & 25.0 & 67.0 & 2\end{array}$ $\begin{array}{lllll}99.7 \% & 46.7 & 25.0 & 43.7 & 2 \\ 99.7 \% & 58.1 & 25.0 & 58.0 & 0\end{array}$ $\begin{array}{llll}94.9 \% & 14.4 & 25.0 & 14.4\end{array}$ $\begin{array}{llll}99.5 \% & 24.5 & 25.0 & 24.5\end{array}$ $\begin{array}{llll}99.7 \% & 57.8 & 25.0 & 53.9\end{array}$ $\begin{array}{llll}99.7 \% & 55.5 & 25.0 & 48.3\end{array}$ $99.7 \% \quad 40.5 \quad 25.0 \quad 31.3$ $\begin{array}{llll}99.0 \% & 36.1 & 25.0 & 25.5\end{array}$ $\begin{array}{llll}99.7 \% & 31.9 & 25.0 & 30.1\end{array}$ $\begin{array}{llll}99.7 \% & 48.9 & 25.0 & 38.8\end{array}$ $\begin{array}{llll}99.0 \% & 29.3 & 25.0 & 15.5\end{array}$ $\begin{array}{llll}99.7 \% & 33.0 & 25.0 & 28.5\end{array}$ $\begin{array}{llll}99.7 \% & 36.4 & 25.0 & 26.4\end{array}$ $\begin{array}{llll}99.7 \% & 39.5 & 25.0 & 39.5\end{array}$ $\begin{array}{llll}98.4 \% & 17.3 & 25.0 & 17.3\end{array}$ $\begin{array}{llll}99.7 \% & 35.7 & 25.0 & 35.7\end{array}$ $\begin{array}{llll}95.1 \% & 22.5 & 25.0 & 5.2\end{array}$ $\begin{array}{llll}97.2 \% & 16.0 & 25.0 & 14.8\end{array}$ $\begin{array}{llll}99.7 \% & 38.8 & 25.0 & 38.7\end{array}$ $\begin{array}{llll}99.1 \% & 20.6 & 25.0 & 18.0\end{array}$

$99.2 \% 18.6$ $99.5 \% \quad 21.8$ $\begin{array}{lll}98.7 \% & 24.6\end{array}$ $99.2 \% \quad 19.1$ $99.2 \% \quad 23.7$ $99.7 \% \quad 33.1$ $99.7 \% \quad 45.9$ $\begin{array}{lll}99.1 \% & 35.4\end{array}$ $99.7 \% \quad 60.0$ $99.7 \% \quad 56.9$ $\begin{array}{lll}98.4 \% & 20.4\end{array}$ $99.7 \% \quad 31.0$ $99.7 \% \quad 60.5$ $99.7 \% \quad 57.8$ $99.7 \% \quad 56.3$ $99.7 \% \quad 44.3$ $99.7 \% \quad 40.0$

$\begin{array}{cccc}0 & 1691.83 & 309 & 322 \\ 0 & 1327.70 & 19 & 30 \\ 0 & 1578.85 & 92 & 106 \\ 0 & 1153.57 & 156 & 164 \\ 0 & 1002.57 & 245 & 253 \\ 0 & 1749.84 & 322 & 335 \\ 0 & 1231.67 & 66 & 77 \\ 0 & 1422.77 & 138 & 150 \\ 0 & 1725.99 & 192 & 205 \\ 0 & 1788.90 & 209 & 227 \\ 0 & 1916.99 & 209 & 228 \\ 0 & 2243.02 & 2 & 31 \\ 0 & 1056.57 & 237 & 245 \\ 0 & 1371.68 & 405 & 416 \\ 0 & 1527.78 & 405 & 417 \\ 0 & 1385.63 & 492 & 504 \\ 0 & 1556.77 & 558 & 570 \\ 0 & 838.47 & 613 & 620 \\ 0 & 1422.72 & 483 & 494 \\ 0 & 1360.75 & 638 & 649 \\ 0 & 1019.60 & 86 & 93 \\ 0 & 1135.65 & 383 & 392 \\ 0 & 1293.67 & 632 & 642 \\ 0 & 1149.70 & 718 & 727 \\ 0 & 1851.96 & 1299 & 1318 \\ 0 & 1316.73 & 167 & 178 \\ 0 & 1062.59 & 259 & 267 \\ 0 & 1956.94 & 401 & 416 \\ 0 & 1231.65 & 446 & 458 \\ 0 & 1143.59 & 597 & 607 \\ 0 & 1838.02 & 608 & 625 \\ 0 & 1236.71 & 648 & 658 \\ 0 & 1756.94 & 693 & 707 \\ 0 & 1087.59 & 699 & 707 \\ 0 & 1000.57 & 80 & 88 \\ 0 & 1236.71 & 93 & 105 \\ 0 & 1122.63 & 43 & 52 \\ 0 & 1514.89 & 153 & 166 \\ 0 & 1302.65 & 8 & 18 \\ 0 & 990.54 & 251 & 259 \\ 0 & 1262.59 & 676 & 685 \\ 0 & 1297.78 & 813 & 824 \\ 0 & 1324.70 & 1226 & 1237 \\ 0 & 1393.71 & 1547 & 1558 \\ 0 & 1303.67 & 1608 & 1619 \\ 0 & 1291.61 & 1620 & 1632 \\ 0 & 1745.87 & 1830 & 1844\end{array}$


Spectrin alpha chain, non-erythrocytic 1 GN=SPTAN1 SPTN1_HUMAN $284.54 \quad 100.0 \% \quad 10$ $\begin{array}{llll}\text { Spectrin beta chain, non-erythrocytic } 1 \text { GN=SPTBN1 SPTB2_HUMAN } 274.61 & 100.0 \% & 22\end{array}$ Spectrin beta chain, non-erythrocytic $1 \mathrm{GN}=$ SPTBN1 SPTB2_HUMAN $274.61 \quad 100.0 \% \quad 22$ Spectrin beta chain, non-erythrocytic $1 \mathrm{GN}=$ SPTBN1 SPTB2_HUMAN $274.61 \quad 100.0 \% \quad 22$ Spectrin beta chain, non-erythrocytic $1 \mathrm{GN}=$ SPTBN1 SPTB2_HUMAN $274.61 \quad 100.0 \% \quad 22$ Spectrin beta chain, non-erythrocytic $1 \mathrm{GN}=$ SPTBN1 SPTB2_HUMAN $274.61 \quad 100.0 \% \quad 22$ Spectrin beta chain, non-erythrocytic $1 \mathrm{GN}=$ SPTBN1 SPTB2_HUMAN $274.61 \quad 100.0 \% \quad 22$ Spectrin beta chain, non-erythrocytic $1 \mathrm{GN}=$ SPTBN1 SPTB2_HUMAN $274.61 \quad 100.0 \% \quad 22$ Spectrin beta chain, non-erythrocytic $1 \mathrm{GN}=$ SPTBN1 SPTB2 HUMAN $274.61 \quad 100.0 \%$ Spectrin beta chain, non-erythrocytic $1 \mathrm{GN}=$ SPTBN1 SPTB2_HUMAN $274.61 \quad 100.0 \% \quad 22$ Spectrin beta chain, non-erythrocytic $1 \mathrm{GN}=$ SPTBN1 SPTB2_HUMAN $274.61 \quad 100.0 \% 22$ Spectrin beta chain, non-erythrocytic $1 \mathrm{GN}=$ SPTBN1 SPTB2_HUMAN $274.61 \quad 100.0 \%$ Spectrin beta chain, non-erythrocytic $1 \mathrm{GN}=$ SPTBN1 SPTB2_HUMAN $274.61 \quad 100.0 \% \quad 22$ Spectrin beta chain, non-erythrocytic $1 \mathrm{GN}=$ SPTBN1 SPTB2_HUMAN $274.61 \quad 100.0 \% \quad 22$ Spectrin beta chain, non-erythrocytic $1 \mathrm{GN}=$ SPTBN1 SPTB2_HUMAN $274.61 \quad 100.0 \%$ Spectrin beta chain, non-erythrocytic $1 \mathrm{GN}=\mathrm{SPTBN} 1$ SPTB2_HUMAN $274.61 \quad 100.0 \%$ Spectrin beta chain, non-erythrocytic 1 GN=SPTBN1 SPTB2_HUMAN $274.61 \quad 100.0 \%$ Spectrin beta chain, non-erythrocytic 1 GN=SPTBN1 SPTB2_HUMAN $274.61 \quad 100.0 \%$ Spectrin beta chain, non-erythrocytic $1 \mathrm{GN}=$ SPTBN1 SPTB2_HUMAN $274.61 \quad 100.0 \%$ Spectrin beta chain, non-erythrocytic $1 \mathrm{GN}=$ SPTBN1 SPTB2_HUMAN $274.61 \quad 100.0 \%$ Spectrin beta chain, non-erythrocytic $1 \mathrm{GN}=$ SPTBN1 SPTB2_HUMAN $274.61 \quad 100.0 \%$ Spectrin beta chain, non-erythrocytic $1 \mathrm{GN}=$ SPTBN1 SPTB2_HUMAN $274.61 \quad 100.0 \%$ Spectrin beta chain, non-eryhteytic 1 GN=SPTBN1 SPTB2 HUMAN 274.61 100 Spermidine synthase GN=SRM Spermidine synthase GN=SRM Spermidine synthase $\mathrm{GN}=\mathrm{SRM}$ Spermidine synthase GN=SRM Spermidine synthase GN=SRM Spermidine synthase $\mathrm{GN}=\mathrm{SRM}$ SPEE HUMAN $33.82 \quad 100.0 \%$ SPEE HUMAN $33.82 \quad 100.0 \%$ SPEE_HUMAN $33.82 \quad 100.0 \%$ SPEE HUMAN $33.82 \quad 100.0 \%$ SPEE HUMAN $33.82 \quad 100.0 \%$ SPEE_HUMAN $33.82 \quad 100.0 \%$ 作 4 GN=SMPD4 NSMA3 HUMAN $93.35 \quad 100.0 \%$ Sphingomyelin phosphodiesterase 4 GN=SMPD4 NSMA3_HUMAN $93.35 \quad 100.0 \%$ Sphingomyelin phosphodiesterase 4 GN=SMPD4 NSMA3_HUMAN $93.35 \quad 100.0 \%$ Sphingomyelin phosphodiesterase 4 GN=SMPD4 NSMA3 HUMAN $93.35100 .0 \%$ Spindlin-1 GN=SPIN1 Spindlin-1 GN=SPIN1

Spindlin-1 GN=SPIN1

Spindlin-1 GN=SPIN1

Spindlin-1 GN=SPIN1

Spindlin-1 GN=SPIN1

Splicing factor $3 \mathrm{~B}$ subunit $1 \mathrm{GN}=\mathrm{SF} 3 \mathrm{~B} 1$

Splicing factor $3 \mathrm{~B}$ subunit $1 \mathrm{GN}=\mathrm{SF} 3 \mathrm{~B} 1$

Splicing factor $3 \mathrm{~B}$ subunit $1 \mathrm{GN}=\mathrm{SF} 3 \mathrm{~B} 1$

Splicing factor $3 \mathrm{~B}$ subunit $1 \mathrm{GN}=\mathrm{SF} 3 \mathrm{~B} 1$

Splicing factor $3 \mathrm{~B}$ subunit $1 \mathrm{GN}=\mathrm{SF} 3 \mathrm{~B} 1$

Splicing factor $3 \mathrm{~B}$ subunit $1 \mathrm{GN}=\mathrm{SF} 3 \mathrm{~B} 1$

Splicing factor $3 \mathrm{~B}$ subunit $1 \mathrm{GN}=\mathrm{SF} 3 \mathrm{~B}$

Splicing factor $3 \mathrm{~B}$ subunit $1 \mathrm{GN}=\mathrm{SF} 3 \mathrm{~B} 1$ SPIN1_HUMAN $29.60 \quad 100.0 \%$ SPIN1_HUMAN $29.60 \quad 100.0 \%$ SPIN1_HUMAN $29.60 \quad 100.0 \%$ SPIN1 HUMAN $29.60 \quad 100.0 \%$ SPIN1_HUMAN $29.60 \quad 100.0 \%$ SF3B1_HUMAN $145.84 \quad 100.0 \%$ SF3B1 HUMAN $145.84 \quad 100.0 \%$ SF3B1_HUMAN $145.84 \quad 100.0 \%$ SF3B1_HUMAN $145.84 \quad 100.0 \%$ SF3B1 HUMAN $145.84 \quad 100.0 \%$ SF3B1_HUMAN $145.84 \quad 100.0 \%$ SF3B1_HUMAN $145.84 \quad 100.0 \%$ SF3B1_HUMAN $145.84 \quad 100.0 \%$
SPIN1_HUMAN $29.60 \quad 100.0 \%$ $\begin{array}{llll}35 & 0.05 \% & 4.8 \% & \text { MQHNLEQQIQAR } \\ 37 & 0.05 \% & 10.6 \% & \text { VLDNAIETEK }\end{array}$

$24 \quad 37$

24

24 24

24

6

6

6

4

5
5
5

5

5
8
8

8
8

8
8

8
8
8

8
8
8

8
8
8

8
8
8

8
8
8

8
8
8
$0.05 \% \quad 10.6 \%$ VLDNAIETEK $0.05 \% \quad 10.6 \%$ ETWLSENQR $0.05 \% \quad 10.6 \%$ VQAVVAVAR $0.05 \% \quad 10.6 \%$ ELEAENYHDIKR $0.05 \% \quad 10.6 \%$ AFEDEMSGR

$0.05 \% \quad 10.6 \%$ YKEVAELTR

$0.05 \% \quad 10.6 \%$ QALQDTLALYK

$0.05 \% \quad 10.6 \%$ VAVVNQIAR

$0.05 \% \quad 10.6 \%$ NRETASELLMR

$0.05 \% \quad 10.6 \%$ FMELLEPLNER

$0.05 \% \quad 10.6 \%$ ALVADSHPESER

$0.05 \% \quad 10.6 \%$ SLLDACESR

$0.05 \% \quad 10.6 \%$ LVDTGDKFR

$0.05 \% \quad 10.6 \%$ LILEVHQFSR

$0.05 \% \quad 10.6 \%$ EIGQSVDEVEK

$0.02 \% \quad 17.5 \%$ YQDILVFR

$0.02 \% \quad 17.5 \%$ VLIIGGGDGGVLR

$0.02 \% \quad 17.5 \%$ FLPGMAIGYSSSK

$0.02 \% \quad 17.5 \%$ YYNSDVHR

$0.02 \% \quad 17.5 \%$ AAFVLPEFAR

$0.01 \% \quad 5.3 \%$ LFVGFLNR

$0.01 \% \quad 5.3 \% \quad$ ALRTDLVSPK

$0.01 \% \quad 5.3 \% \quad$ YHLTEPGLASR

$0.04 \% \quad 28.2 \%$ SSVGPSKPVSQPR

$0.04 \% \quad 28.2 \%$ VSALEVLPDR

$0.02 \% \quad 6.8 \%$ VEGREIISNLAK

$0.02 \% \quad 6.8 \% \quad$ VRQQAADLISR

$0.02 \% \quad 6.8 \%$ QQAADLISR

$0.02 \% \quad 6.8 \% \quad$ VQENCIDLVGR

$0.02 \% \quad 6.8 \%$ RATVNTFGYIAK $0.05 \% \quad 10.6 \%$ FATDGEGYKPCDPQVIR $0.05 \% \quad 10.6 \%$ ILSSDDYGKDLTSVMR

$99.3 \% \quad 20.3 \quad 25.0 \quad 18.4$ $\begin{array}{llll}99.7 \% & 27.7 & 25.0 & 27.7\end{array}$ $99.5 \% \quad 21.2$ $99.7 \% \quad 43.3$ $98.9 \% \quad 23.1$ $99.7 \% \quad 27.3$ $\begin{array}{lll}98.0 \% & 21.2\end{array}$ $99.3 \% 19.1$

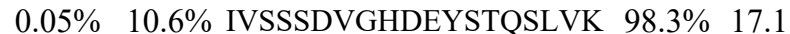

$0.05 \% \quad 10.6 \%$ IVSSSDVGHDEYSTQSLVKK $99.7 \% 40.3$

$0.05 \% \quad 10.6 \%$ SQNIVTDSSSLSAEAIR

$0.05 \% \quad 10.6 \%$ TALPAQSAATLPAR

$0.05 \% \quad 10.6 \%$ TQETPSAQMEGFLNR

$0.02 \% \quad 17.5 \%$ KVLIIGGGDGGVLR

$0.01 \% \quad 5.3 \% \quad$ YAPDKQAPGSDSQPR

$0.04 \% \quad 28.2 \%$ SRADAGHAGVSANMMK

$0.04 \% \quad 28.2 \%$ GTVLDQVPVNPSLYLIK

$0.04 \% \quad 28.2 \%$ VSALEVLPDRVATSR

$0.04 \% \quad 28.2 \%$ ISDAHLADTMIGK

$0.02 \% \quad 6.8 \% \quad$ VVNGAAASQPPSKR

$0.02 \% \quad 6.8 \%$ RWDQTADQTPGATPK

$0.02 \% \quad 6.8 \%$ MLQYCLQGLFHPAR
$25.0 \quad 29.8$

$\begin{array}{lll}55.7 & 25.0 & 45.5\end{array}$

$\begin{array}{llll}99.7 \% & 54.5 & 25.0 & 46.0\end{array}$

$98.3 \% \quad 22.6 \quad 25.0 \quad 12.7$

$99.7 \% \quad 32.8 \quad 25.0 \quad 31.1$

$99.0 \%$ \#\#\#\# 25.0 \#\#\#\# 2

$99.7 \% \quad 51.4 \quad 25.0 \quad 51.4$

$\begin{array}{llll}99.5 \% & 23.0 & 25.0 & 23.0\end{array}$

$\begin{array}{llll}98.6 \% & 20.9 & 25.0 & 15.4\end{array}$

$99.7 \% \quad 42.5 \quad 25.0 \quad 36.5$

$\begin{array}{llll}98.6 \% & 20.1 & 25.0 & 15.8\end{array}$

$99.7 \% \quad 65.1 \quad 25.0 \quad 65.1$

$99.7 \% \quad 53.3 \quad 25.0 \quad 52.5$

$99.0 \% \quad 33.0 \quad 25.0 \quad 33.0$

$99.7 \% \quad 41.6 \quad 25.0 \quad 41.6$

$\begin{array}{llll}99.7 \% & 54.3 & 25.0 & 49.4\end{array}$

$\begin{array}{llll}99.7 \% & 36.3 & 25.0 & 29.5\end{array}$

$99.0 \% \quad 41.6 \quad 25.0 \quad 41.6$

$\begin{array}{llll}99.7 \% & 44.8 & 25.0 & 44.8\end{array}$

$\begin{array}{llll}99.7 \% & 26.6 & 25.0 & 26.6\end{array}$

$99.0 \% \quad 28.0 \quad 25.0 \quad 19.9$

$\begin{array}{llll}99.7 \% & 26.7 & 25.0 & 24.7\end{array}$

$\begin{array}{llll}99.6 \% & 25.1 & 25.0 & 25.1\end{array}$

$\begin{array}{llll}99.5 \% & 22.0 & 25.0 & 22.0\end{array}$

$\begin{array}{llll}99.7 \% & 54.0 & 25.0 & 33.9\end{array}$

$\begin{array}{llll}99.6 \% & 34.7 & 25.0 & 13.4\end{array}$

$\begin{array}{llll}99.7 \% & 63.7 & 25.0 & 53.9\end{array}$

$\begin{array}{llll}99.6 \% & 24.8 & 25.0 & 24.8\end{array}$

$\begin{array}{llll}99.7 \% & 49.9 & 25.0 & 49.9\end{array}$

$\begin{array}{llll}99.7 \% & 37.6 & 25.0 & 37.6\end{array}$

$97.8 \% \quad 17.9 \quad 25.0 \quad 17.1$

$\begin{array}{llll}99.4 \% & 21.3 & 25.0 & 20.9\end{array}$

$\begin{array}{llll}99.7 \% & 43.3 & 25.0 & 40.9\end{array}$

$\begin{array}{llll}99.7 \% & 39.0 & 25.0 & 25.1\end{array}$

$\begin{array}{lllll}99.7 \% & 50.5 & 25.0 & 45.3 & 2\end{array}$

$\begin{array}{llll}95.1 \% & 22.7 & 25.0 & 11.4\end{array}$

$\begin{array}{llll}98.8 \% & 17.8 & 25.0 & 17.7\end{array}$ $\begin{array}{lll}8 & 8 & 15\end{array}$

$\begin{array}{ll}3 & 0 \\ 0 & 0 \\ 0 & 0 \\ 0 & 0 \\ 2 & 0 \\ 1 & 0 \\ 2 & 0 \\ 0 & 0 \\ 1 & 0 \\ 2 & 0 \\ 0 & 0 \\ 0 & 0 \\ 0 & 0 \\ 0 & 0 \\ 0 & 0 \\ 0 & 0 \\ 0 & 0 \\ 0 & 0 \\ 0 & 0 \\ 0 & 0 \\ 0 & 0 \\ 0 & 0 \\ 0 & 0 \\ 0 & 0 \\ 2 & 0 \\ 0 & 0 \\ 0 & 0 \\ 0 & 0 \\ 0 & 0 \\ 0 & 0 \\ 1 & 0 \\ 0 & 0 \\ 0 & 0 \\ 0 & 0 \\ 5 & 0 \\ 5 & 0 \\ 0 & 0 \\ 0 & 0 \\ 0 & 0 \\ 0 & 0 \\ 0 & 0 \\ 0 & 0 \\ 0 & 0 \\ 0 & 0 \\ 0\end{array}$

1131.59

1162.55

912.56

1516.74

1952.92

1815.88

1057.43

2050.99

2179.09

1108.60

1263.69

969.58

1319.67

1406.70

1777.89

1310.63

1050.49

1050.56

1241.70

1232.60

1367.76

1724.79

1053.57

1353.82

1225.73

1357.68

1053.47

1120.61

1616.77

965.56

1099.65

1243.64

1634.74

1325.72

1856.05

1098.62

1612.90

1371.69

1381.75

1671.81

1328.75

1256.71

1001.54

1302.65

1340.73

Page 109 of Table S-1-2 
Splicing factor 3B subunit $3 \mathrm{GN}=\mathrm{SF} 3 \mathrm{~B} 3 \quad$ SF3B3_HUMAN $135.58 \quad 100.0 \%$ Splicing factor 3B subunit $3 \mathrm{GN}=$ SF3B3 SF3B3_HUMAN $135.58 \quad 100.0 \%$ Splicing factor 3B subunit $3 \mathrm{GN}=\mathrm{SF} 3 \mathrm{~B} 3 \quad$ SF3B3 HUMAN $135.58 \quad 100.0 \%$ Splicing factor 3B subunit $3 \mathrm{GN}=$ SF3B3 SF3B3_HUMAN $135.58 \quad 100.0 \%$ Splicing factor 3B subunit $3 \mathrm{GN}=\mathrm{SF} 3 \mathrm{~B} 3 \quad$ SF3B3_HUMAN $135.58 \quad 100.0 \%$ Splicing factor 3B subunit $3 \mathrm{GN}=$ SF3B3 SF3B3_HUMAN $135.58 \quad 100.0 \%$ Splicing factor 3B subunit $3 \mathrm{GN}=\mathrm{SF} 3 \mathrm{~B} 3 \quad$ SF3B3_HUMAN $135.58 \quad 100.0 \%$ Splicing factor 3B subunit $3 \mathrm{GN}=\mathrm{SF} 3 \mathrm{~B} 3 \quad$ SF3B3_HUMAN $135.58 \quad 100.0 \%$ Splicing factor 3B subunit $3 \mathrm{GN}=$ SF3B3 $\quad$ SF3B3_HUMAN $135.58 \quad 100.0 \%$ Splicing factor 3B subunit $3 \mathrm{GN}=\mathrm{SF} 3 \mathrm{~B} 3 \quad$ SF3B3_HUMAN $135.58 \quad 100.0 \%$ Splicing factor U2AF $35 \mathrm{kDa}$ subunit GN=U2AF1 U2AF1_HUMAN $27.87 \quad 100.0 \%$ Splicing factor U2AF $35 \mathrm{kDa}$ subunit GN=U2AF1 U2AF1_HUMAN $27.87 \quad 100.0 \%$ Splicing factor U2AF $35 \mathrm{kDa}$ subunit GN=U2AF1 U2AF1_HUMAN $27.87 \quad 100.0 \%$ Splicing factor U2AF $35 \mathrm{kDa}$ subunit GN=U2AF1 U2AF1_HUMAN $27.87 \quad 100.0 \%$ Splicing factor U2AF $65 \mathrm{kDa}$ subunit GN=U2AF2 U2AF2_HUMAN $53.50 \quad 100.0 \%$ Splicing factor U2AF $65 \mathrm{kDa}$ subunit GN=U2AF2 U2AF2 HUMAN $53.50 \quad 100.0 \%$ Splicing factor U2AF $65 \mathrm{kDa}$ subunit GN=U2AF2 U2AF2_HUMAN $53.50 \quad 100.0 \%$ Splicing factor U2AF $65 \mathrm{kDa}$ subunit GN=U2AF2 U2AF2_HUMAN $53.50 \quad 100.0 \%$ Splicing factor U2AF $65 \mathrm{kDa}$ subunit GN=U2AF2 U2AF2 HUMAN $53.50 \quad 100.0 \%$ Splicing factor U2AF $65 \mathrm{kDa}$ subunit GN=U2AF2 U2AF2_HUMAN $53.50 \quad 100.0 \%$ Splicing factor U2AF $65 \mathrm{kDa}$ subunit GN=U2AF2 U2AF2 HUMAN $53.50 \quad 100.0 \%$ Splicing factor U2AF $65 \mathrm{kDa}$ subunit GN=U2AF2 U2AF2_HUMAN $53.50 \quad 100.0 \%$ Splicing factor, proline- and glutamine-rich GN=SFPQ SFPQ_HUMAN $76.15 \quad 100.0 \%$ Splicing factor, proline- and glutamine-rich GN=SFPQ SFPQ HUMAN $76.15 \quad 100.0 \%$ Splicing factor, proline- and glutamine-rich GN=SFPQ SFPQ_HUMAN $76.15 \quad 100.0 \%$ Splicing factor, proline- and glutamine-rich GN=SFPQ SFPQ_HUMAN $76.15 \quad 100.0 \%$ Splicing factor, proline- and glutamine-rich GN=SFPQ SFPQ HUMAN $76.15 \quad 100.0 \%$ Splicing factor, proline- and glutamine-rich GN=SFPQ SFPQ_HUMAN $76.15 \quad 100.0 \%$ Stomatin-like protein 2, mitochondrial GN=STOML2 STML2_HUMAN $38.53 \quad 100.0 \%$ Stomatin-like protein 2, mitochondrial GN=STOML2 STML2_HUMAN $38.53 \quad 100.0 \%$ Stress-70 protein, mitochondrial GN=HSPA9 GRP75_HUMAN $73.68 \quad 100.0 \%$ Stress-70 protein, mitochondrial GN=HSPA9 GRP75_HUMAN $73.68 \quad 100.0 \%$ Stress-70 protein, mitochondrial GN=HSPA9 GRP75_HUMAN $73.68 \quad 100.0 \%$ Stress-70 protein, mitochondrial GN=HSPA9 GRP75_HUMAN $73.68 \quad 100.0 \%$ Stress-70 protein, mitochondrial GN=HSPA9 GRP75_HUMAN $73.68 \quad 100.0 \%$ Stress-70 protein, mitochondrial GN=HSPA9 GRP75_HUMAN $73.68 \quad 100.0 \%$ Stress-70 protein, mitochondrial GN=HSPA9 GRP75_HUMAN $73.68 \quad 100.0 \%$ Stress-70 protein, mitochondrial GN=HSPA9 GRP75_HUMAN $73.68 \quad 100.0 \%$ Stress-70 protein, mitochondrial GN=HSPA9 GRP75_HUMAN $73.68 \quad 100.0 \%$ Stress-70 protein, mitochondrial GN=HSPA9 GRP75_HUMAN $73.68 \quad 100.0 \%$ Stress-70 protein, mitochondrial GN=HSPA9 GRP75_HUMAN $73.68 \quad 100.0 \%$ Stress-70 protein, mitochondrial GN=HSPA9 GRP75 HUMAN $73.68 \quad 100.0 \%$ Stress-70 protein, mitochondrial GN=HSPA9 GRP75_HUMAN $73.68 \quad 100.0 \%$ Stress-70 protein, mitochondrial GN=HSPA9 GRP75_HUMAN $73.68 \quad 100.0 \%$ Stress-70 protein, mitochondrial GN=HSPA9 GRP75_HUMAN $73.68 \quad 100.0 \%$ Stress-70 protein, mitochondrial GN=HSPA9 GRP75_HUMAN $73.68 \quad 100.0 \%$

6

6
9
9

9

8
8
8

8
8
8

8

8
8
6

8
6
6
6

6
6
6

6
6
6

6
2
2

2
2
18

18
18
18

$18 \quad 26$

18
18
18

18
18
8

8

18
18
18
18

8
8

18
18

$0.01 \% \quad 9.3 \%$ APVPGTPDSLSSGSSR $0.08 \% \quad 30.5 \%$ VLENAEGAR

$\begin{array}{lll}99.7 \% & 45.7\end{array}$

$99.7 \% \quad 67.1$

$99.7 \% \quad 59.1$

$99.7 \% \quad 67.9$

$99.7 \% \quad 65.4$

$99.7 \% \quad 31.5$

$99.7 \% \quad 31.3$

$99.7 \% \quad 54.8$

$\begin{array}{ll}99.7 \% & 47.7 \\ 99.7 \% & 44.6\end{array}$

$99.7 \% \quad 44.3$ $0.08 \% \quad 30.5 \%$ QATKDAGQISGLNVLR

$0.08 \% \quad 30.5 \%$ DAGQISGLNVLR

$99.7 \% \quad 36.1$ $\begin{array}{lllll}0.08 \% & 30.5 \% & \text { STNGDTFLGGEDFDQALLR } & 99.7 \% & 64.2\end{array}$ $\begin{array}{lll}0.08 \% & 30.5 \% & \text { ETGVDLTKDNMALQR }\end{array}$ $0.08 \% \quad 30.5 \%$ AQFEGIVTDLIR

$99.7 \% \quad 56.2$

$0.08 \% \quad 30.5 \%$ AQFEGIVTDLIRR

$\begin{array}{ll}99.7 \% & 53.5 \\ 99.6 \% & 24.0\end{array}$

$\begin{array}{lllll}0.08 \% & 30.5 \% & \text { AMQDAEVSKSDIGEVILVGGMTR } & 99.7 \% & 33.6\end{array}$

1681.89
1699.85

1373.64

914.51

1173.47

1663.82

1166.63

2402.15

1450.79

1908.99

1619.78

961.52

1033.62

1368.58

1235.65

1143.63

1099.62

1618.89

1245.70

1341.67

2014.08

1514.74

958.50

1450.72

1568.77

1724.87

1149.55

1553.84

1694.85

1670.92

1242.68

1645.88

2055.96

1690.84

1361.74

1517.84 2438.19 
Stress-70 protein, mitochondrial GN=HSPA9 GRP75_HUMAN $73.68 \quad 100.0 \%$ Stress-70 protein, mitochondrial GN=HSPA9 GRP75_HUMAN $73.68 \quad 100.0 \%$ Structural maintenance of chromosomes protein 1A GN=SMC1A SMC1A_HUMAN $143.24 \quad 100.0 \%$ Structural maintenance of chromosomes protein $1 \mathrm{~A}$ GN=SMC1A SMC1A_HUMAN $143.24 \quad 100.0 \%$ Structural maintenance of chromosomes protein $1 \mathrm{~A}$ GN=SMC1A SMC1A_HUMAN $143.24 \quad 100.0 \%$ Structural maintenance of chromosomes protein $1 \mathrm{~A}$ GN=SMC1A SMC1A_HUMAN $143.24 \quad 100.0 \%$ Structural maintenance of chromosomes protein $2 \mathrm{GN}=\mathrm{SMC} 2 \mathrm{SMC} 2$ HUMAN $135.66 \quad 100.0 \%$ Structural maintenance of chromosomes protein $2 \mathrm{GN}=\mathrm{SMC} 2 \mathrm{SMC2}$ _HUMAN $135.66 \quad 100.0 \%$ Structural maintenance of chromosomes protein $2 \mathrm{GN}=\mathrm{SMC} 2 \mathrm{SMC} 2 \mathrm{HUMAN} 135.66100 .0 \%$ Structural maintenance of chromosomes protein $3 \mathrm{GN}=\mathrm{SMC} 3 \mathrm{SMC} 3$ _HUMAN $141.55 \quad 100.0 \%$ Structural maintenance of chromosomes protein $3 \mathrm{GN}=\mathrm{SMC} 3 \mathrm{SMC} 3$ HUMAN $141.55 \quad 100.0 \%$ Structural maintenance of chromosomes protein $3 \mathrm{GN}=\mathrm{SMC} 3 \mathrm{SMC} 3$ _HUMAN $141.55100 .0 \%$ Structural maintenance of chromosomes protein $3 \mathrm{GN}=\mathrm{SMC} 3 \mathrm{SMC} 3$ _HUMAN $141.55 \quad 100.0 \%$ Structural maintenance of chromosomes protein $3 \mathrm{GN}=\mathrm{SMC} 3 \mathrm{SMC} 3$ HUMAN $141.55 \quad 100.0 \%$ Structural maintenance of chromosomes protein $3 \mathrm{GN}=\mathrm{SMC} 3 \mathrm{SMC} 3$ _HUMAN $141.55 \quad 100.0 \%$ Structural maintenance of chromosomes protein $3 \mathrm{GN}=\mathrm{SMC} 3 \mathrm{SMC} 3$ _HUMAN $141.55 \quad 100.0 \%$ Structural maintenance of chromosomes protein $4 \mathrm{GN}=\mathrm{SMC} 4 \mathrm{SMC} 4$ HUMAN $147.19 \quad 100.0 \%$ Structural maintenance of chromosomes protein 4 GN=SMC4 SMC4_HUMAN $147.19 \quad 100.0 \%$ Structural maintenance of chromosomes protein $4 \mathrm{GN}=\mathrm{SMC} 4$ SMC4_HUMAN $147.19 \quad 100.0 \%$ Structural maintenance of chromosomes protein $4 \mathrm{GN}=\mathrm{SMC} 4 \mathrm{SMC} 4$ HUMAN $147.19 \quad 100.0 \%$ Structural maintenance of chromosomes protein $4 \mathrm{GN}=\mathrm{SMC} 4$ SMC4_HUMAN $147.19 \quad 100.0 \%$ Structural maintenance of chromosomes protein $4 \mathrm{GN}=\mathrm{SMC} 4 \mathrm{SMC} 4$ HUMAN $147.19 \quad 100.0 \%$ Structural maintenance of chromosomes protein 4 GN=SMC4 SMC4_HUMAN $147.19 \quad 100.0 \%$ Succinyl-COA ligase [ADP/GDP-forming] subunit alpha, mitochondrial GN=SUCLG1 SUCA_HUMAN $36.25 \quad 100.0 \%$ GUCLGI SUCA_HUMAN $36.25 \quad 100.0 \%$ Succinyl-CoA ligase [ADP/GDP-forming] subunit alpha, mitochondrial GN=SUCLGI SUCA_HUMAN $36.25 \quad 100.0 \%$ Succinyl-CoA ligase [ADP/GDP-forming] subunit alpha, mitcochondrial GN=SUCLG1 SUCA_HUMAN $36.25 \quad 100.0^{\circ}$ Succinyl-CoA ligase [ADP/GDP-forming] subunit alpha, mitochondrial GN=SUCLG1 SUCA HUMAN $36.25 \quad 100.0 \%$ Succinyl-CoA ligase [ADP/GDP-forming] subunit apha, mitochondrial GN=SUCLGI SUCA_HUMAN $36.25 \quad 100.0 \%$ Succinyl-CoA ligase [ADP/GDP-forming] subunit alpha, mitochondrial GN=SUCLGI SUCA HUMAN 36.25 $100.0 \%$ Succinyl-COA ligase [ADP/GDP-forming] subunit alpha, mitochondrial GN=SUCLGI SUCA_HUMAN $36.25 \quad 100.0 \%$ Succinyl-CoA ligase [ADP/GDP-forming] subunit alpha, mitochondrial GN=SUCLG1 SUCA_HUMAN $36.25 \quad 100.0 \%$ Succinyl-CoA ligase [ADP/GDP-forming] subunit alpha, mitochondrial GN=SUCLGI SUCA_HUMAN $36.25 \quad 100.0 \%$ Succinyl-CoA ligase [ADP/GDP-forming] subunit alpha, mitochondrial GN=SUCLG1 SUCA_HUMAN $36.25 \quad 100.0 \%$ Succinyl-CoA ligase [ADP-forming] subunit beta, mitochondrial GN=SUCLA2 SUCB1_HUMAN $50.32 \quad 100.0 \%$ Succinyl-CoA ligase [ADP-forming] subunit beta, mitochondrial GN=SUCLA2 SUCB1_HUMAN $50.32 \quad 100.0 \%$ Succinyl-CoA ligase [ADP-forming] subunit beta, mitochondrial GN=SUCLA2 SUCB1_HUMAN $50.32 \quad 100.0 \%$ Succinyl-COA ligase [ADP-forming] subunit teta mitochondrial GN=SUCLA2 SUCB1_HUMAN $50.32 \quad 100.0 \%$ Succinyl-COA ligase [ADP-forming] subunit beta, mitochondrial GN=SUCLA2 SUCB1_HUMAN $50.32 \quad 100.0 \%$ Succinyl-CoA ligase [ADP-forming] subunit beta, mitochondrial GN=SUCLA2 SUCB1_HUMAN $50.32 \quad 100.0 \%$ Succinyl-CoA ligase [ADP-forming] subunit beta, mitochondrial GN=SUCLA2 SUCB1 HUMAN $50.32 \quad 100.0 \%$ Succinyl-COA ligase [ADP-forming] subunit beta, mitochondrial GN=SUCLA2 SUCB1_HUMAN $50.32 \quad 100.0 \%$ Succinyl-CoA ligase [ADP-forming] subumit beta, mitochondrial GN=SUCLA2 SUCB1 HUMAN $50.32100 .0^{\circ}$ Succinyl-CoA ligase [ADP-forming] subunit beta, mitochondrial GN=SUCLA2 SUCB1_HUMAN $50.32 \quad 100.0 \%$ Succinyl-COA ligase [ADP-forming] subunit beta, mitochondrial GN=SUCLA2 SUCB1_HUMAN $50.32 \quad 100.0 \%$

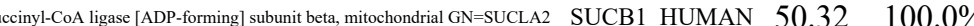
Succinyl-CoA ligase [ADP-forming] subunit beta, mitochondrial GN=SUCLA2 SUCB1_HUMAN $50.32 \quad 100.0 \%$

(3)

(n)

3

3
7

$\begin{array}{lll}0.01 \% & 3.7 \% & \text { TALFEEISR }\end{array}$

$0.01 \% \quad 3.7 \% \quad$ TVALDGTLFQK

$0.01 \% \quad 3.7 \%$ SGVISGGASDLKAK

$99.7 \%$

$99.7 \% \quad 26.2$

$99.7 \% \quad 37.0$

$99.7 \% \quad 52.3$

$99.7 \% \quad 65.1$

$0.01 \% \quad 4.4 \%$ ASNLQDLVYKNGQAGITK $99.7 \% \quad 34.4$

$99.6 \% \quad 25.0$

$0.01 \% \quad 4.4 \%$ SLEDALAEAQRVNTK

$\begin{array}{ll}99.7 \% & 35.0\end{array}$

$0.02 \% \quad 7.1 \%$ LALLHEGTGPR

$0.02 \% \quad 7.1 \%$ SNPYYIVKQGK

$0.02 \% \quad 7.1 \%$ ALEYTIYNQELNETR

$0.02 \% \quad 7.1 \%$ LAQATQERTDLYAK

$0.02 \% \quad 7.1 \%$ SMEVSTQLAR

$0.02 \% \quad 7.1 \%$ GALTGGYYDTR

$0.02 \% \quad 7.1 \%$ ALDQFVNFSEQKEK

$0.02 \% \quad 5.5 \%$ FSCIIGPNGSGK

$0.02 \% \quad 5.5 \%$ TACRDNTSVYHISGK

$0.02 \% \quad 5.5 \%$ TFKDVGNLLR

$0.02 \% \quad 5.5 \%$ SNNIINETTTR

$0.02 \% \quad 5.5 \%$ GKVLDAIIQEK

$0.02 \% \quad 5.5 \%$ VLDAIIQEK

$0.02 \% \quad 5.5 \%$ SVAVNPKEIASK

$0.05 \% \quad 27.7 \%$ QHLYVDKNTK

$0.05 \% \quad 27.7 \%$ IICQGFTGK

$0.05 \% \quad 27.7 \%$ QGTFHSQQALEYGTK

$0.05 \% \quad 27.7 \%$ LVGGTTPGK

$\begin{array}{llll}99.7 \% & 37.8 & 25.0 & 32.8\end{array}$

$\begin{array}{llll}99.7 \% & 38.7 & 25.0 & 29.9\end{array}$

$99.7 \% \quad 29.7 \quad 25.0 \quad 29.7$

$\begin{array}{llll}99.7 \% & 40.5 & 25.0 & 40.5\end{array}$

$\begin{array}{llll}99.7 \% & 50.9 & 25.0 & 44.0\end{array}$

$\begin{array}{llll}99.7 \% & 38.2 & 25.0 & 38.2\end{array}$

$\begin{array}{llll}99.7 \% & 37.2 & 25.0 & 31.8\end{array}$

$99.5 \% \quad 22.0 \quad 25.0 \quad 22.0$

$99.2 \% \quad 24.0 \quad 25.0 \quad 15.8$

$\begin{array}{llll}97.9 \% & 20.6 & 25.0 & 20.6\end{array}$

$99.7 \% 53.6$

$\begin{array}{llll}99.7 \% & 31.3 & 25.0 & 20.0\end{array}$

$\begin{array}{llll}98.8 \% & 20.9 & 25.0 & 15.8\end{array}$

$95.4 \% \quad 15.0 \quad 25.0 \quad 13.9$

$99.7 \% \quad 38.3 \quad 25.0 \quad 35.4$

$\begin{array}{llll}99.7 \% & 32.2 & 25.0 & 30.9\end{array}$

$96.1 \% \quad 16.7 \quad 25.0 \quad 16.4$

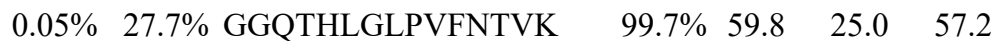

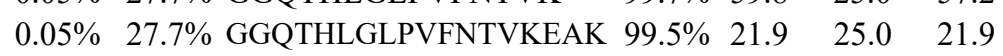

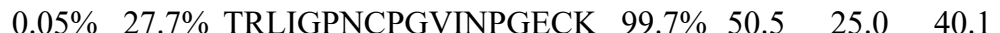

$0.05 \% \quad 27.7 \%$ LIGPNCPGVINPGECK

$0.05 \% \quad 27.7 \%$ RMGHAGAIIAGGK

$0.05 \% \quad 27.7 \%$ MGHAGAIIAGGK

$99.7 \% \quad 54.4 \quad 25.0 \quad 51.7$

$\begin{array}{llll}99.7 \% & 40.8 & 25.0 & 40.8\end{array}$

$99.7 \% \quad 61.0 \quad 25.0 \quad 60.7$

$0.05 \% \quad 27.7 \%$ MGHAGAIIAGGKGGAK

$0.04 \% \quad 27.2 \%$ SPDEAYAIAK

$0.04 \% \quad 27.2 \%$ LGSKDVVIK

$0.04 \% \quad 27.2 \%$ GTFESGLKGGVK

$0.04 \% \quad 27.2 \%$ IVFSPEEAK

$99.4 \% \quad 21.3$

$99.7 \% \quad 65.2$

$99.7 \% \quad 53.9$

$99.7 \% \quad 39.8$

$\begin{array}{lll}98.8 \% & 17.8\end{array}$

$0.04 \% \quad 27.2 \%$ AVSSQMIGKK

$0.04 \% \quad 27.2 \%$ GRICNQVLVCER

$0.04 \% \quad 27.2 \%$ ICNQVLVCER

$0.04 \% \quad 27.2 \%$ REYYFAITMER

0.04\% 27.2\% EYYFAITMER

$0.04 \% \quad 27.2 \%$ EQALQLAQK

$0.04 \% \quad 27.2 \%$ INFDSNSAYR

$0.04 \% \quad 27.2 \%$ INFDSNSAYRQK

\section{K $97.6 \%$}

$\begin{array}{llll}99.7 \% & 34.6 & 25.0 & 29.2\end{array}$

$\begin{array}{llll}99.7 \% & 28.7 & 25.0 & 28.7\end{array}$

$\begin{array}{llll}99.7 \% & 67.7 & 25.0 & 66.2\end{array}$

$\begin{array}{llll}99.7 \% & 35.0 & 25.0 & 31.4\end{array}$

$\begin{array}{llll}99.7 \% & 25.2 & 25.0 & 25.2\end{array}$

$\begin{array}{lllll}99.7 \% & 41.6 & 25.0 & 29.1 & 2\end{array}$

$\begin{array}{lllll}99.7 \% & 52.3 & 25.0 & 52.3 & 2\end{array}$

$\begin{array}{llll}99.7 \% & 31.1 & 25.0 & 26.1\end{array}$ $\begin{array}{ccc}1290.68 & 395 & 405 \\ 1673.90 & 395 & 409 \\ 1161.63 & 27 & 38 \\ 1065.56 & 152 & 160 \\ 1192.66 & 638 & 648 \\ 1289.71 & 649 & 662 \\ 1920.02 & 59 & 76 \\ 1644.86 & 298 & 312 \\ 1956.98 & 649 & 668 \\ 1163.65 & 62 & 72 \\ 1296.69 & 133 & 143 \\ 1856.90 & 222 & 236 \\ 1607.84 & 365 & 378 \\ 1121.56 & 635 & 644 \\ 1173.55 & 662 & 672 \\ 1682.84 & 986 & 999 \\ 1236.60 & 108 & 119 \\ 1708.81 & 188 & 202 \\ 1162.66 & 205 & 214 \\ 1262.63 & 435 & 445 \\ 1213.72 & 597 & 607 \\ 1028.60 & 599 & 607 \\ 1242.71 & 1274 & 1285 \\ 1245.66 & 48 & 57 \\ 1023.53 & 58 & 66 \\ 1694.81 & 67 & 81 \\ 829.48 & 82 & 90 \\ 1567.86 & 91 & 105 \\ 1896.03 & 91 & 108 \\ 1982.00 & 165 & 182 \\ 1724.85 & 167 & 182 \\ 1238.68 & 296 & 308 \\ 1098.57 & 297 & 308 \\ 1411.75 & 297 & 312 \\ 1064.53 & 79 & 88 \\ 958.59 & 90 & 98 \\ 1179.64 & 109 & 120 \\ 1019.54 & 121 & 129 \\ 1921.01 & 121 & 138 \\ 1048.58 & 130 & 139 \\ 1503.75 & 149 & 160 \\ 1290.63 & 151 & 160 \\ 1494.70 & 165 & 175 \\ 1322.61 & 166 & 175 \\ 1028.57 & 217 & 225 \\ 1186.55 & 275 & 284 \\ 1442.70 & 275 & 286\end{array}$

Page 111 of Table S-1-2 
SUN domain-containing protein $1 \mathrm{GN}=\mathrm{SUN} 1$ SUN1_HUMAN $90.06 \quad 99.9 \%$ SUN domain-containing protein $1 \mathrm{GN}=\mathrm{SUN} 1$ SUN1_HUMAN $90.06 \quad 99.9 \%$ SUN domain-containing protein $2 \mathrm{GN}=\mathrm{SUN} 2$ SUN2 HUMAN $80.31 \quad 100.0 \%$ SUN domain-containing protein 2 GN=SUN2 SUN2_HUMAN $80.31 \quad 100.0 \%$ SUN domain-containing protein $2 \mathrm{GN}=\mathrm{SUN} 2$ SUN2_HUMAN $80.31 \quad 100.0 \%$ SUN domain-containing protein 2 GN=SUN2 SUN2_HUMAN $80.31 \quad 100.0 \%$ SUN domain-containing protein 2 GN=SUN2 SUN2_HUMAN $80.31 \quad 100.0 \%$ SUN domain-containing protein 2 GN=SUN2 SUN2 HUMAN $80.31 \quad 100.0 \%$ SUN domain-containing protein 2 GN=SUN2 SUN2_HUMAN $80.31 \quad 100.0 \%$ SUN domain-containing protein 2 GN=SUN2 SUN2_HUMAN $80.31 \quad 100.0 \%$ SUN domain-containing protein $2 \mathrm{GN}=\mathrm{SUN} 2$ SUN2 HUMAN $80.31 \quad 100.0 \%$ Superkiller viralicidic activity 2-like 2 GN=SKIV2L2 SK2L2_HUMAN $117.81 \quad 100.0 \%$ Superkiller viralicidic activity 2-like 2 GN=SKIV2L2 SK2L2_HUMAN $117.81 \quad 100.0 \%$ Superkiller viralicidic activity 2-like 2 GN=SKIV2L2 SK2L2_HUMAN $117.81 \quad 100.0 \%$ Superkiller viralicidic activity 2-like 2 GN=SKIV2L2 SK2L2_HUMAN $117.81 \quad 100.0 \%$ Suppressor of SWI4 1 homolog GN=PPAN SSF1 HUMAN $53.19 \quad 100.0 \%$ Suppressor of SWI4 1 homolog GN=PPAN SSF1_HUMAN $53.19 \quad 100.0 \%$ Suppressor of SWI4 1 homolog GN=PPAN SSF1_HUMAN $53.19 \quad 100.0 \%$ Suppressor of SWI4 1 homolog GN=PPAN SSF1_HUMAN $53.19100 .0 \%$ Surfeit locus protein $6 \mathrm{GN}=\mathrm{SURF} 6$ Surfeit locus protein $6 \mathrm{GN}=\mathrm{SURF} 6$ SURF6_HUMAN $41.45 \quad 100.0 \%$ SURP and G-patch domain-containing protein 2 GN=SUGP2 SUGP2_HUMAN $120.21 \quad 100.0 \%$ SURP and G-patch domain-containing protein 2 GN=SUGP2 SUGP2 HUMAN $120.21 \quad 100.0 \%$ SURP and G-patch domain-containing protein 2 GN=SUGP2 SUGP2_HUMAN $120.21 \quad 100.0 \%$ Survival motor neuron protein GN=SMN1 SMN_HUMAN $31.85 \quad 100.0 \%$ Survival motor neuron protein GN=SMN1 SMN_HUMAN $31.85 \quad 100.0 \%$ Survival motor neuron protein GN=SMN1 SMN_HUMAN $31.85 \quad 100.0 \%$ SMCA5 HUMAN $121.91 \quad 100.0 \%$ SMCA5_HUMAN $121.91 \quad 100.0 \%$ SMCA5_HUMAN $121.91 \quad 100.0 \%$ SMCA5 HUMAN $121.91 \quad 100.0 \%$

4

4

4
4
3

3

2

4
4
4
4
3

4

$30 \quad 0.04 \% \quad 27.2 \%$ DLEIKIPVVVR

$0.04 \% \quad 27.2 \%$ LSEIVTLAK

$0.03 \% \quad 26.4 \%$ KLMSDNGVR

$0.03 \% \quad 26.4 \%$ FFVADTANEALEAAK

$20 \quad 0.03 \% \quad 26.4 \%$ LNAKEIVLK

$20 \quad 0.03 \% \quad 26.4 \%$ GGVHLTKDPNVVGQLAK

$20 \quad 0.03 \% \quad 26.4 \%$ QMIGYNLATK

$20 \quad 0.03 \% \quad 26.4 \%$ MAENLGFVGPLK

20

20

$0.03 \% \quad 26.4 \%$ INFDDNAEFR

$0.03 \% \quad 26.4 \%$ INFDDNAEFRQK

$0.03 \% \quad 26.4 \%$ EAQVYQAFK

$\begin{array}{ll}99.7 \% & 32.9 \\ 99.7 \% & 55.8\end{array}$

$\begin{array}{ll}99.7 \% & 55.8 \\ 99.7 \% & 43.5\end{array}$

$99.7 \% \quad 39.0$

99.6\% \#\#\#\#

$96.7 \% \quad 20.9$

$99.6 \% \quad 22.7$

$99.7 \% \quad 44.9$

$99.7 \% \quad 56.7$

$99.7 \% \quad 54.0$

$99.7 \% \quad 34.4$

$99.7 \% \quad 27.6$

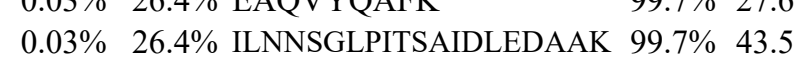

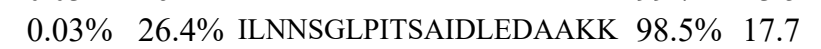

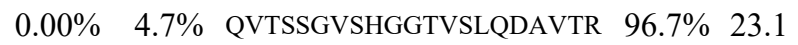

$\begin{array}{llllll}0.00 \% & 4.7 \% & \text { TQRVDDPQDVFKPTTSR } & 96.6 \% & 17.0\end{array}$

$0.04 \% \quad 20.1 \%$ YSQGDDDGSSSSGGSSVAGSQSTLFKDSPLR $\quad 99.7 \% 95.6$

$0.04 \% \quad 20.1 \%$ KATEDFLGSSSGYSSEDDYVGYSDVDQQSSSSR $\quad 99.7 \% \quad 38.6$

$0.04 \% \quad 20.1 \%$ DSSPHFQAEQR

$0.04 \% \quad 20.1 \%$ IQEELSALR

$0.04 \% \quad 20.1 \%$ ILTHVAEMQGK

$0.04 \% \quad 20.1 \%$ EAAASLSLTLQK

$99.7 \% \quad 47.1$

$99.7 \% \quad 46.5$

$99.7 \% \quad 41.7$

$99.7 \% \quad 42.4$

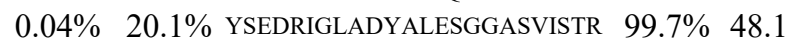

$0.04 \% \quad 20.1 \%$ IGLADYALESGGASVISTR $99.7 \% \quad 54.8$

$0.04 \% \quad 20.1 \%$ IRPTAVTLEHVPK

$0.01 \% \quad 3.2 \%$ AAKEYPFILDAFQR

$0.01 \% \quad 3.2 \% \quad$ EYPFILDAFQR

$0.01 \% \quad 3.2 \% \quad$ SFYQFQHYR

$0.01 \% \quad 3.2 \%$ YCLPFLQPGR

$0.01 \% \quad 9.9 \% \quad$ NLEAYAANPHSFVFTR

$0.01 \% \quad 9.9 \%$ VMEPLTASR

$0.01 \% \quad 9.9 \%$ VNLNTIKR

$0.01 \% \quad 9.9 \%$ VGGSDEEASGIPSR

$0.01 \% \quad 6.9 \% \quad$ SLGEKSPAASGAR

$0.01 \% \quad 6.9 \% \quad$ ILPQDLERAGLV

$0.01 \% \quad 3.4 \%$ GGVGKLVTLR

$0.01 \% \quad 3.4 \% \quad$ APSSLSDAVPQR

$0.01 \% \quad 3.4 \%$ RATTGTQTLLSSGTR

$0.01 \% \quad 3.4 \%$ ATTGTQTLLSSGTR

$0.01 \% \quad 9.9 \%$ AYDKAVASFK

$0.01 \% \quad 9.9 \%$ NTAASLQQWK

$0.01 \% \quad 9.9 \%$ LGPGKPGLK

$0.02 \% \quad 4.5 \%$ SVCLIGDKEQR

$0.02 \% \quad 4.5 \%$ YLVIDEAHR

$0.02 \% \quad 4.5 \%$ MVVLDKLLPK

$0.02 \% \quad 4.5 \%$ VLIFSQMTR

$0.02 \% \quad 4.5 \%$ ALDTKIGR $\begin{array}{llll}99.7 \% & 54.5 & 25.0 & 54.8\end{array}$

$\begin{array}{llll}99.7 \% & 32.9 & 25.0 & 25.6\end{array}$

$\begin{array}{llll}99.7 \% & 33.8 & 25.0 & 27.6\end{array}$

$\begin{array}{llll}99.5 \% & 22.8 & 25.0 & 21.6\end{array}$

$99.7 \% \quad 28.0 \quad 25.0 \quad 28.0$

$\begin{array}{llll}99.7 \% & 33.5 & 25.0 & 31.7\end{array}$

$99.0 \% \quad 32.9 \quad 25.0 \quad 25.0$

$99.7 \% \quad 28.8$

$99.7 \% \quad 33.7$

$98.8 \% \quad 21.1$

$99.7 \% \quad 27.4$

$99.7 \% \quad 32.1$

$99.2 \% \quad 20.6$

$99.7 \% \quad 46.0$

$99.7 \% \quad 43.1$

$\begin{array}{lll}99.7 \% & 50.1\end{array}$

$99.5 \% \quad 24.2$

$99.7 \% \quad 50.5$

$99.1 \% \quad 28.6$

$99.6 \% \quad 26.1$

$99.7 \% \quad 31.8$

$99.0 \% \quad 34.4$
1280.79

1361.64

973.59

1019.53

1596.79

1027.65

1732.97

1138.59

1275.68

1240.56

1496.71

1083.55

2055.10

2183.19

2086.05

1990.00

3079.37

3553.50

1301.59

1058.58

1242.65

1231.69

2530.24

1879.98

1460.86

1668.87

1398.71

1275.59

1250.64

1836.90

1003.52

957.58

1360.63

1230.64

1323.76

999.63

1227.63

1549.83

1393.73

1099.58

1146.59

866.55

1304.66

1115.58

1171.71

1094.60

873.52 $\begin{array}{cc}97 & 407 \\ 27 & 438 \\ 43 & 451 \\ 7 & 55 \\ 9 & 73 \\ 5 & 83 \\ 02 & 118 \\ 19 & 128 \\ 07 & 218 \\ 60 & 269 \\ 60 & 271 \\ 39 & 347 \\ 04 & 423 \\ 04 & 424 \\ 10 & 130 \\ 56 & 372 \\ 1 & 41 \\ 22 & 154 \\ 65 & 275 \\ 55 & 363 \\ 92 & 502 \\ 06 & 517 \\ 39 & 562 \\ 44 & 562 \\ 19 & 631 \\ 32 & 145 \\ 35 & 145 \\ 88 & 596 \\ 49 & 658 \\ 1 & 36 \\ 3 & 61 \\ 72 & 179 \\ 56 & 369 \\ 9 & 81 \\ 50 & 361 \\ 39 & 248 \\ 70 & 581 \\ 95 & 709 \\ 96 & 709 \\ 2 & 51 \\ 4 & 93 \\ 05 & 213 \\ 57 & 267 \\ 04 & 312 \\ 85 & 494 \\ 02 & 510 \\ 20 & 927 \\ & \end{array}$

Page 112 of Table S-1-2 
Syntaxin-binding protein $2 \mathrm{GN}=\mathrm{STXBP} 2$ STXB2_HUMAN $66.45 \quad 100.0 \%$ $\begin{array}{lllll}\text { Syntaxin-binding protein } 2 \mathrm{GN}=\mathrm{STXBP} 2 & \text { STXB2_HUMAN } & 66.45 & 100.0 \% \\ \text { Syntaxin-binding protein } 3 \mathrm{GN}=\mathrm{STXBP} 3 & \text { STXB3_HUMAN } & 67.77 & 100.0 \%\end{array}$ Syntaxin-binding protein $3 \mathrm{GN}=$ STXBP3 3 STXB3_HUMAN $67.77 \quad 100.0 \%$ TAR DNA-binding protein 43 GN=TARDBP TADBP_HUMAN $44.74 \quad 100.0 \%$ TAR DNA-binding protein 43 GN=TARDBP TADBP_HUMAN $44.74 \quad 100.0 \%$ TAR DNA-binding protein $43 \mathrm{GN}=$ TARDBP TADBP HUMAN $44.74 \quad 100.0 \%$ TAR DNA-binding protein 43 GN=TARDBP TADBP_HUMAN $44.74 \quad 100.0 \%$ TAR DNA-binding protein 43 GN=TARDBP TADBP_HUMAN $44.74 \quad 100.0 \%$ TAR DNA-binding protein 43 GN=TARDBP TADBP_HUMAN $44.74 \quad 100.0 \%$ TATA-binding protein-associated factor $172 \mathrm{GN}=\mathrm{BTAF} 1$ BTAF1_HUMAN $206.89 \quad 100.0 \%$ TATA-binding protein-associated factor $172 \mathrm{GN}=\mathrm{BTAF} 1$ BTAF1_HUMAN $206.89 \quad 100.0 \%$ TATA-binding protein-associated factor $172 \mathrm{GN}=\mathrm{BTAF} 1$ BTAF1_HUMAN $206.89 \quad 100.0 \%$ TATA-binding protein-associated factor 2N GN=TAF15 RBP56_HUMAN $61.83 \quad 100.0 \%$ TATA-binding protein-associated factor 2N GN=TAF15 RBP56 HUMAN $61.83 \quad 100.0 \%$ T-complex protein 1 subunit alpha GN=TCP1 TCPA_HUMAN $60.35 \quad 100.0 \%$ T-complex protein 1 subunit alpha GN=TCP1 TCPA_HUMAN $60.35 \quad 100.0 \%$ T-complex protein 1 subunit alpha GN=TCP1 TCPA_HUMAN $60.35 \quad 100.0 \%$ T-complex protein 1 subunit alpha GN=TCP1 TCPA_HUMAN $60.35 \quad 100.0 \%$ T-complex protein 1 subunit alpha GN=TCP1 TCPA HUMAN $60.35 \quad 100.0 \%$ T-complex protein 1 subunit alpha GN=TCP1 TCPA_HUMAN $60.35 \quad 100.0 \%$ T-complex protein 1 subunit alpha GN=TCP1 TCPA_HUMAN $60.35 \quad 100.0 \%$ T-complex protein 1 subunit alpha GN=TCP1 TCPA_HUMAN 60.3 T-complex protein 1 subunit alpha GN=TCP1 TCPA_HUMAN 60.35 T-complex protein 1 subunit alpha GN=TCP1 TCPA_HUMAN 60.35 T-complex protein 1 subunit alpha GN=TCP1 TCPA_HUMAN 60.35 T-complex protein 1 subunit alpha GN=TCP1 TCPA_HUMAN 60.35 T-complex protein 1 subunit alpha GN=TCP1 TCPA HUMAN 60.35 T-complex protein 1 subunit alpha GN=TCP1 TCPA_HUMAN 60.35 T-complex protein 1 subunit alpha GN=TCP1 TCPA_HUMAN 60.35 T-complex protein 1 subunit alpha GN=TCP1 TCPA_HUMAN 60.35 T-complex protein 1 subunit alpha GN=TCP1 TCPA_HUMAN 60.35 T-complex protein 1 subunit alpha GN=TCP1 TCPA_HUMAN 60.35 T-complex protein 1 subunit alpha GN=TCP1 TCPA_HUMAN 60.35 T-complex protein 1 subunit alpha GN=TCP1 TCPA_HUMAN 60.3 T-complex protein 1 subunit alpha GN=TCP1 TCPA HUMAN 60.35 T-complex protein 1 subunit alpha GN=TCP1 TCPA_HUMAN 60.35 T-complex protein 1 subunit alpha GN=TCP1 TCPA_HUMAN 60.35 T-complex protein 1 subunit alpha GN=TCP1 TCPA HUMAN 60.3 T-complex protein 1 subunit alpha GN=TCP1 TCPA_HUMAN 60.35 T-complex protein 1 subunit alpha GN=TCP1 TCPA HUMAN 60.3 T-complex protein 1 subunit alpha GN=TCP1 TCPA_HUMAN 60.35 T-complex protein 1 subunit alpha GN=TCP1 TCPA_HUMAN 60.3 T-complex protein 1 subunit alpha GN=TCP1 TCPA HUMAN 60.35 T-complex protein 1 subunit alpha GN=TCP1 TCPA_HUMAN 60.35

$0.02 \% \quad 17.6 \%$ FGGNPGGFGNQGGFGNSR

$98.5 \% \quad 23.8$

$0.01 \% \quad 2.0 \% \quad$ LFILLDTGTTPVTR

$0.01 \% \quad 2.0 \%$ IAAGQAVEAIVK

$0.01 \% \quad 2.0 \% \quad$ NTIDINNFDGK

$99.7 \% \quad 80.1$

$0.01 \% \quad 5.6 \%$ GEATVSFDDPPSAK

$0.01 \% \quad 5.6 \%$ SGGGYGGDRSSGGGYSGDR $99.7 \% \quad 46.9$

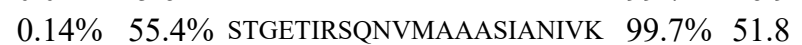

$0.14 \% \quad 55.4 \%$ SQNVMAAASIANIVK

$\begin{array}{lll}99.7 \% & 85.2\end{array}$

$0.14 \% \quad 55.4 \%$ SSLGPVGLDK

$99.5 \% \quad 46.9$

$0.14 \% \quad 55.4 \%$ MLVDDIGDVTITNDGATILK $99.7 \% \quad 59.9$

$0.14 \% \quad 55.4 \%$ LLEVEHPAAK

$0.14 \% \quad 55.4 \%$ QKIHPTSVISGYR

$0.14 \% \quad 55.4 \%$ IHPTSVISGYR

$99.7 \% 53.6$

$99.7 \% \quad 38.6$

$0.14 \% \quad 55.4 \%$ YINENLIVNTDELGR

$99.7 \% \quad 32.0$

$99.7 \% \quad 47.5$

$0.14 \% \quad 55.4 \%$ YINENLIVNTDELGRDCLINAAK $99.6 \% 29.6$

$0.14 \% \quad 55.4 \%$ DCLINAAK

$0.14 \% \quad 55.4 \%$ YPVNSVNILK

$99.0 \% \quad 40.4$

$99.7 \% \quad 42.2$

$99.7 \% \quad 57.6$

$0.14 \% \quad 55.4 \%$ IACLDFSLQK

$0.14 \% \quad 55.4 \%$ IACLDFSLQKTK

$99.7 \% \quad 41.0$

$0.14 \% \quad 55.4 \%$ LGVQVVITDPEKLDQIR $\quad 99.7 \% \quad 56.6$

$0.14 \% \quad 55.4 \%$ ILATGANVILTTGGIDDMCLK

$99.7 \% \quad 52.1$

$0.14 \% \quad 55.4 \%$ ICDDELILIK

$0.14 \% 55.4 \%$ ICDDELILIKNTK

$0.14 \% \quad 55.4 \%$ TSASIILR

$0.14 \% \quad 55.4 \%$ GANDFMCDEMER

$0.14 \% 55.4 \%$ SLHDALCVVK

$0.14 \% \quad 55.4 \%$ SLHDALCVVKR

$99.7 \% \quad 50.6$

$99.7 \% \quad 72.7$

$99.0 \% \quad 39.6$

$99.7 \% \quad 63.5$

$99.7 \% \quad 44.8$

$99.7 \% \quad 54.1$

$99.7 \% \quad 45.1$

$0.14 \% \quad 55.4 \%$ EQLAIAEFAR

$\begin{array}{ll}0.14 \% & 55.4 \% \\ 0.14 \% & 55.4 \%\end{array}$

$0.14 \% \quad 55.4 \%$ AFHNEAQVNPER

$0.14 \% 55.4 \%$ AFHNEAQVNPERK

$0.14 \% \quad 55.4 \%$ WIGLDLSNGKPR

$0.14 \% \quad 55.4 \%$ DNKQAGVFEPTIVK

$0.14 \% \quad 55.4 \%$ QAGVFEPTIVK

$\begin{array}{lllllll}100.0 \% & 33 & 46 & 96 & 0.14 \% & 55.4 \% & \text { SLKFATEAAITILR }\end{array}$

1144.55

1251.67

1726.77

1546.88

1169.69

1250.60

1420.66

1748.72

2261.19

1516.82

972.54

2104.08

1106.62

1485.82

1229.66

1762.90

2648.34

904.46

1146.65

1194.62

1423.76

1923.09

2192.13

1231.66

1574.85

860.52

1490.53

1141.60

1297.70

1147.61

2353.30

1680.86

1411.67

1539.77

1355.74

1545.83

1188.66 1533.90 
$\begin{array}{lllll}\text { T-complex protein } 1 \text { subunit alpha GN=TCP1 TCPA_HUMAN } & 60.35 & 100.0 \% & 33\end{array}$

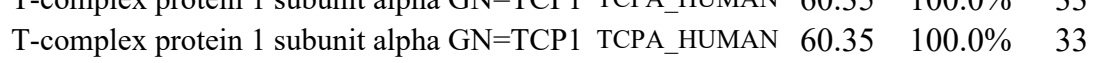
T-complex protein 1 subunit alpha GN=TCP1 TCPA_HUMAN $60.35 \quad 100.0 \% \quad 33$ T-complex protein 1 subunit delta GN=CCT4 TCPD HUMAN $57.93 \quad 100.0 \%$ T-complex protein 1 subunit delta GN=CCT4 TCPD_HUMAN $57.93 \quad 100.0 \% \quad 10$ T-complex protein 1 subunit delta GN=CCT4 TCPD_HUMAN $57.93 \quad 100.0 \% \quad 10$ T-complex protein 1 subunit delta GN=CCT4 TCPD_HUMAN $57.93 \quad 100.0 \% \quad 10$ $\begin{array}{lllll}\text { T-complex protein } 1 \text { subunit delta GN=CCT4 } & \text { TCPD_HUMAN } & 57.93 & 100.0 \% & 1\end{array}$ T-complex protein 1 subunit delta GN=CCT4 TCPD HUMAN $57.93 \quad 100.0 \%$ T-complex protein 1 subunit delta GN=CCT4 TCPD_HUMAN $57.93 \quad 100.0 \%$ T-complex protein 1 subunit delta GN=CCT4 TCPD_HUMAN $57.93 \quad 100.0 \%$ T-complex protein 1 subunit delta GN=CCT4 TCPD_HUMAN $57.93 \quad 100.0 \%$ T-complex protein 1 subunit delta GN=CCT4 TCPD_HUMAN $57.93 \quad 100.0 \%$ T-complex protein 1 subunit epsilon GN=CCT5 TCPE_HUMAN $59.67 \quad 100.0 \%$ T-complex protein 1 subunit epsilon $\mathrm{GN}=\mathrm{CCT} 5$ TCPE_HUMAN $59.67 \quad 100.0 \%$ T-complex protein 1 subunit epsilon GN=CCT5 TCPE_HUMAN $59.67 \quad 100.0 \%$ T-complex protein 1 subunit epsilon $\mathrm{GN}=\mathrm{CCT} 5$ TCPE HUMAN $59.67 \quad 100.0 \%$ T-complex protein 1 subunit epsilon GN=CCT5 TCPE_HUMAN $59.67 \quad 100.0 \%$ T-complex protein 1 subunit epsilon GN=CCT5 TCPE_HUMAN $59.67 \quad 100.0 \%$ T-complex protein 1 subunit epsilon GN=CCT5 TCPE_HUMAN $59.67 \quad 100.0 \%$ T-complex protein 1 subunit epsilon GN=CCT5 TCPE_HUMAN $59.67 \quad 100.0 \%$ T-complex protein 1 subunit epsilon GN=CCT5 TCPE HUMAN $59.67 \quad 100.0 \%$ T-complex protein 1 subunit epsilon GN=CCT5 TCPE_HUMAN $59.67 \quad 100.0 \%$ T-complex protein 1 subunit epsilon GN=CCT5 TCPE_HUMAN $59.67 \quad 100.0 \%$ T-complex protein 1 subunit epsilon GN=CCT5 TCPE HUMAN $59.67 \quad 100.0 \%$ T-complex protein 1 subunit epsilon GN=CCT5 TCPE_HUMAN $59.67 \quad 100.0 \%$ T-complex protein 1 subunit epsilon GN=CCT5 TCPE_HUMAN $59.67 \quad 100.0 \%$ T-complex protein 1 subunit epsilon GN=CCT5 TCPE_HUMAN $59.67 \quad 100.0 \%$ T-complex protein 1 subunit epsilon GN=CCT5 TCPE_HUMAN $59.67 \quad 100.0 \%$ T-complex protein 1 subunit eta $\mathrm{GN}=\mathrm{CCT} 7 \mathrm{TCPH}$ _HUMAN $59.37 \quad 100.0 \%$ T-complex protein 1 subunit eta $\mathrm{GN}=\mathrm{CCT} 7 \mathrm{TCPH}$ HHUMAN $59.37 \quad 100.0 \%$ T-complex protein 1 subunit gamma GN=CCT3 TCPG_HUMAN $60.54 \quad 100.0 \%$ T-complex protein 1 subunit gamma GN=CCT3 TCPG_HUMAN $60.54 \quad 100.0 \%$ T-complex protein 1 subunit gamma GN=CCT3 TCPG_HUMAN $60.54 \quad 100.0 \%$ T-complex protein 1 subunit gamma GN=CCT3 TCPG_HUMAN $60.54 \quad 100.0 \%$ T-complex protein 1 subunit gamma GN=CCT3 TCPG_HUMAN $60.54 \quad 100.0 \%$ T-complex protein 1 subunit gamma GN=CCT3 TCPG_HUMAN $60.54 \quad 100.0 \%$ T-complex protein 1 subunit gamma GN=CCT3 TCPG_HUMAN $60.54 \quad 100.0 \%$ T-complex protein 1 subunit gamma GN=CCT3 TCPG_HUMAN $60.54 \quad 100.0 \%$ T-complex protein 1 subunit gamma GN=CCT3 TCPG_HUMAN $60.54 \quad 100.0 \%$ T-complex protein 1 subunit gamma $\mathrm{GN}=\mathrm{CCT} 3 \mathrm{TCPG}$ HUMAN $60.54 \quad 100.0 \%$ T-complex protein 1 subunit gamma GN=CCT3 TCPG_HUMAN $60.54 \quad 100.0 \%$ T-complex protein 1 subunit gamma GN=CCT3 TCPG HUMAN $60.54 \quad 100.0 \%$ T-complex protein 1 subunit gamma GN=CCT3 TCPG_HUMAN $60.54 \quad 100.0 \%$ T-complex protein 1 subunit gamma GN=CCT3 TCPG_HUMAN $60.54 \quad 100.0 \%$ T-complex protein 1 subunit gamma GN=CCT3 TCPG_HUMAN $60.54 \quad 100.0 \% \quad 2$ $\begin{array}{lllll}\mathrm{T} \text {-complex protein } 1 \text { subunit gamma } \mathrm{GN}=\mathrm{CCT} 3 & \mathrm{TCPG} \_ \text {HUMAN } & 60.54 & 100.0 \% & 21\end{array}$

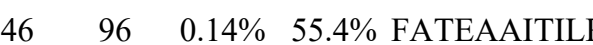

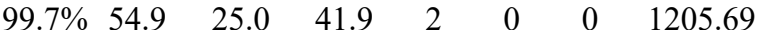

$0.14 \% \quad 55.4 \%$ DDKHGSYEDAVHSGALND $\quad 99.7 \% \quad 43.6$

$0.14 \% \quad 55.4 \%$ HGSYEDAVHSGALND

$99.7 \% \quad 38.4$

$0.04 \% \quad 23.0 \%$ PENVAPRSGATAGAAGGR $\quad 99.7 \% \quad 47.6$

$0.04 \% \quad 23.0 \%$ GAYQDRDKPAQIR

$0.04 \% \quad 23.0 \%$ FSNISAAKAVADAIR

$99.7 \% \quad 32.8$

$99.7 \% \quad 29.8$

$99.7 \% \quad 41.7$

$99.7 \% \quad 51.2$

$98.8 \% 26.6$

$99.1 \% \quad 48.7$

$99.7 \% \quad 55.1$

$99.7 \% \quad 30.5$

$99.7 \% \quad 27.9$

$99.0 \% \quad 27.9$

$97.3 \% \quad 15.3$

$99.7 \% \quad 46.4$

$99.7 \% \quad 51.5$

$99.7 \% \quad 33.6$

$99.7 \% \quad 67.6$

$\begin{array}{llll}99.7 \% & 32.3\end{array}$

$99.7 \% \quad 29.5$

$99.7 \% \quad 49.6$

$99.7 \% \quad 52.9$

$99.0 \% \quad 39.9$

$99.1 \% \quad 48.7$

$99.7 \% \quad 55.2$

$99.7 \% \quad 33.3$

$99.7 \% \quad 51.0$

$99.7 \% \quad 38.1$

$99.4 \% 22.4$

$\begin{array}{ll}99.7 \% & 27.2 \\ 99.7 \% & 41.9\end{array}$

$0.05 \% \quad 31.6 \%$ IDDIRKPGESEE

$0.01 \% \quad 4.1 \%$ ATISNDGATILK

$0.01 \% \quad 4.1 \%$ LLDVVHPAAK

$99.7 \% \quad 36.8$

$0.09 \% \quad 35.0 \%$ EIQVQHPAAK

$0.09 \% \quad 35.0 \%$ ALDDMISTLK

$0.09 \% \quad 35.0 \%$ ALDDMISTLKK

$0.09 \% \quad 35.0 \%$ WSSLACNIALDAVK

$0.09 \% \quad 35.0 \%$ MVQFEENGRK

$0.09 \% \quad 35.0 \%$ VEKIPGGIIEDSCVLR

$0.09 \% \quad 35.0 \%$ IPGGIIEDSCVLR

$0.09 \% \quad 35.0 \%$ GVMINKDVTHPR

$0.09 \% \quad 35.0 \%$ IVLLDSSLEYK

$0.09 \% \quad 35.0 \%$ IVLLDSSLEYKK

$0.09 \% \quad 35.0 \%$ GISDLAQHYLMR

$0.09 \% \quad 35.0 \%$ ANITAIRR

$0.09 \% \quad 35.0 \%$ GASKEILSEVER

$0.09 \% \quad 35.0 \%$ EILSEVER

$0.09 \% \quad 35.0 \%$ NLQDAMQVCR
$99.7 \% \quad 44.5$

$99.7 \% \quad 49.7$

$99.7 \% \quad 56.3$

$99.7 \% \quad 40.4$

$99.7 \% \quad 60.4$

$99.7 \% \quad 59.6$

$99.7 \% \quad 44.9$

$99.7 \% \quad 51.2$

$99.7 \% \quad 32.2$

$99.7 \% \quad 48.5$

$99.0 \% \quad 30.8$

$99.7 \% \quad 65.8$

$99.0 \% \quad 40.2$

$99.7 \% \quad 61.7$ $\begin{array}{ll}0 & 46.8\end{array}$

$\begin{array}{ll}.0 & 32.8\end{array}$

\begin{tabular}{ll}
29.8 \\
\hline
\end{tabular}

$25.0 \quad 36.9$

$25.0 \quad 51.2$

$25.0 \quad 11.7$

$25.0 \quad 0.0$

$25.0 \quad 55.1$

$25.0 \quad 30.5$

$25.0 \quad 27.9$

$25.0 \quad 17.1$

$25.0 \quad 15.3$

$25.0 \quad 38.8$

$25.0 \quad 40.8$

$25.0 \quad 33.6$

$25.0 \quad 58.2$

$25.0 \quad 32.3$

$25.0 \quad 29.5$

$\begin{array}{ll}.0 & 49.6\end{array}$

$25.0 \quad 48.0$

$25.0 \quad 23.2$

$25.0 \quad 0.0$

$25.0 \quad 48.4$

24.5
25.0

$25.0 \quad 49.0$

$25.0 \quad 32.2$

$25.0 \quad 17.6$

$25.0 \quad 26.9$

$25.0 \quad 41.9$

$25.0 \quad 32.0$

$25.0 \quad 35.3$

$\begin{array}{ll}5.0 & 47.9\end{array}$

$\begin{array}{ll}0.0 & 52.8\end{array}$

\begin{tabular}{ll}
.0 & 39.5 \\
\hline
\end{tabular}

56.9

$25.0 \quad 51.5$

$25.0 \quad 38.8$

$25.0 \quad 48.4$

$25.0 \quad 32.2$

$25.0 \quad 46.6$

$\begin{array}{ll}25.0 & 24.7\end{array}$

$25.0 \quad 58.5$

$25.0 \quad 15.2$

$25.0 \quad 51.7$

2
0
2
2
2
0
0
0
0
0
0
0
0
0
0
0
1
0
0
0
2
0
4
0
0
0
0
0
0
0
0
0
0
0
4
0
0
0
0
0
0
0
0
0
0
0
0
0
0
2
0
0
0
0
0
0
0
0
0
0

1929.82

1571.67

1638.83

1517.78

1533.84

1298.74

1346.75

1145.63

1183.63

1550.89

1318.58

1380.73

874.51

1628.89

1001.53

1093.53

1458.75

1391.74

1713.86

1610.90

1667.90

1377.70

989.54

1183.63

1497.72

1402.78

1290.68

1387.67

1203.66

1062.63

2179.06

1120.61

1106.58

1234.67

1547.79

1237.60

1784.96

1428.75

1366.73

1279.7

1407.81

1419.71

914.55

1317.70

974.52

1234.57 $\begin{array}{cc}16 & 526 \\ 39 & 556 \\ 42 & 556 \\ 2 & 19 \\ 2 & 34 \\ 5 & 49 \\ 3 & 55 \\ 46 & 257 \\ 93 & 302 \\ 04 & 413 \\ 20 & 435 \\ 42 & 452 \\ 84 & 496 \\ 8 & 35 \\ 8 & 42 \\ 0 & 59 \\ 33 & 142 \\ 71 & 183 \\ 03 & 214 \\ 27 & 241 \\ 48 & 261 \\ 53 & 368 \\ 71 & 381 \\ 93 & 400 \\ 01 & 410 \\ 84 & 496 \\ 14 & 525 \\ 15 & 525 \\ 30 & 541 \\ 6 & 67 \\ 8 & 77 \\ 9 & 68 \\ 9 & 78 \\ 29 & 138 \\ 29 & 139 \\ 68 & 181 \\ 82 & 191 \\ 01 & 216 \\ 04 & 216 \\ 17 & 228 \\ 38 & 248 \\ 38 & 249 \\ 95 & 306 \\ 07 & 314 \\ 78 & 389 \\ 82 & 389 \\ 90 & 399\end{array}$

Page 114 of Table S-1-2 


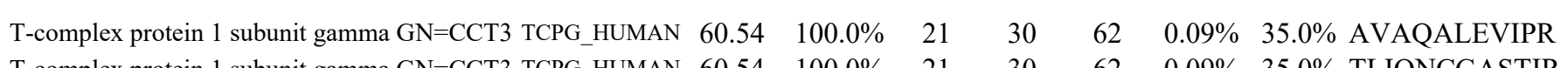
T-complex protein 1 subunit gamma GN=CCT3 TCPG_HUMAN $60.54 \quad 100.0 \%$ T-complex protein 1 subunit gamma GN=CCT3 TCPG_HUMAN $60.54 \quad 100.0 \%$ T-complex protein 1 subunit gamma GN=CCT3 TCPG_HUMAN $60.54 \quad 100.0 \%$ T-complex protein 1 subunit theta GN=CCT8 TCPQ_HUMAN $59.62 \quad 100.0 \%$ T-complex protein 1 subunit theta GN=CCT8 TCPQ_HUMAN $59.62 \quad 100.0 \%$ T-complex protein 1 subunit theta GN=CCT8 TCPQ_HUMAN $59.62 \quad 100.0 \%$ T-complex protein 1 subunit theta GN=CCT8 TCPQ HUMAN $59.62 \quad 100.0 \%$ T-complex protein 1 subunit theta GN=CCT8 TCPQ_HUMAN $59.62 \quad 100.0 \%$ T-complex protein 1 subunit theta GN=CCT8 TCPQ_HUMAN $59.62 \quad 100.0 \%$ T-complex protein 1 subunit theta GN=CCT8 TCPQ_HUMAN $59.62 \quad 100.0 \%$ T-complex protein 1 subunit theta GN=CCT8 TCPQ_HUMAN $59.62 \quad 100.0 \%$ T-complex protein 1 subunit zeta GN=CCT6A TCPZ_HUMAN $58.03 \quad 100.0 \%$ T-complex protein 1 subunit zeta GN=CCT6A TCPZ_HUMAN $58.03 \quad 100.0 \%$ T-complex protein 1 subunit zeta GN=CCT6A TCPZ_HUMAN $58.03 \quad 100.0 \%$ T-complex protein 1 subunit zeta GN=CCT6A TCPZ HUMAN $58.03 \quad 100.0 \%$ T-complex protein 1 subunit zeta GN=CCT6A TCPZ_HUMAN $58.03 \quad 100.0 \%$ T-complex protein 1 subunit zeta GN=CCT6A TCPZ_HUMAN $58.03 \quad 100.0 \%$ T-complex protein 1 subunit zeta GN=CCT6A TCPZ_HUMAN $58.03 \quad 100.0 \%$ T-complex protein 1 subunit zeta GN=CCT6A TCPZ_HUMAN $58.03 \quad 100.0 \%$ T-complex protein 1 subunit zeta GN=CCT6A TCPZ_HUMAN $58.03 \quad 100.0 \%$ T-complex protein 1 subunit zeta GN=CCT6A TCPZ_HUMAN $58.03 \quad 100.0 \%$ T-complex protein 1 subunit zeta GN=CCT6A TCPZ_HUMAN $58.03 \quad 100.0 \%$ T-complex protein 1 subunit zeta GN=CCT6A TCPZ HUMAN $58.03 \quad 100.0 \%$ T-complex protein 1 subunit zeta GN=CCT6A TCPZ_HUMAN $58.03 \quad 100.0 \%$ T-complex protein 1 subunit zeta GN=CCT6A TCPZ_HUMAN $58.03 \quad 100.0 \%$ T-complex protein 1 subunit zeta GN=CCT6A TCPZ_HUMAN $58.03 \quad 100.0 \%$ T-complex protein 1 subunit zeta GN=CCT6A TCPZ_HUMAN $58.03 \quad 100.0 \%$ T-complex protein 1 subunit zeta GN=CCT6A TCPZ HUMAN $58.03 \quad 100.0 \%$ T-complex protein 1 subunit zeta GN=CCT6A TCPZ_HUMAN $58.03 \quad 100.0 \%$ Telomere-associated protein RIF1 GN=RIF1 RIF1_HUMAN $274.47 \quad 100.0 \%$ Telomere-associated protein RIF1 GN=RIF1 RIF1_HUMAN $274.47 \quad 100.0 \%$ Telomere-associated protein RIF1 GN=RIF1 RIF1_HUMAN $274.47 \quad 100.0 \%$ Telomere-associated protein RIF1 GN=RIF1 RIF1_HUMAN $274.47 \quad 100.0 \%$ Telomere-associated protein RIF1 GN=RIF1 RIF1_HUMAN $274.47 \quad 100.0 \%$ Telomere-associated protein RIF1 GN=RIF1 RIF1_HUMAN $274.47 \quad 100.0 \%$ Telomere-associated protein RIF1 GN=RIF1 RIF1 HUMAN $274.47 \quad 100.0 \%$ Telomere-associated protein RIF1 GN=RIF1 RIF1_HUMAN $274.47 \quad 100.0 \%$ Telomere-associated protein RIF1 GN=RIF1 RIF1_HUMAN $274.47 \quad 100.0 \%$ Telomere-associated protein RIF1 GN=RIF1 RIF1_HUMAN $274.47 \quad 100.0 \%$ Telomere-associated protein RIF1 GN=RIF1 RIF1_HUMAN $274.47 \quad 100.0 \%$ Testis-expressed sequence 10 protein GN=TEX10 TEX10 HUMAN $105.68 \quad 100.0 \%$ Testis-expressed sequence 10 protein GN=TEX10 TEX10_HUMAN $105.68 \quad 100.0 \%$ Testis-expressed sequence 10 protein GN=TEX10 TEX10_HUMAN $105.68 \quad 100.0 \%$ Testis-expressed sequence 10 protein GN=TEX10 TEX10 HUMAN $105.68 \quad 100.0 \%$ Tetratricopeptide repeat protein 37 GN=TTC37 TTC37_HUMAN $175.49 \quad 100.0 \%$
$0.09 \% \quad 35.0 \%$ TAVETAVLLLR

$0.09 \% \quad 35.0 \%$ IDDIVSGHK

$0.09 \% \quad 35.0 \%$ IDDIVSGHKK

$0.02 \% \quad 19.2 \%$ HFSGLEEAVYR

$0.02 \% \quad 19.2 \%$ NLRDIDEVSSLLR

$0.02 \% \quad 19.2 \%$ QYGNEVFLAK

$0.02 \% \quad 19.2 \%$ ETEGDVTSVKDAK

$0.02 \% \quad 19.2 \%$ AIADTGANVVVTGGK

$0.02 \% \quad 19.2 \%$ LVPGGGATEIELAK

$99.7 \% \quad 66.0-25.0 \quad 58.2$

$99.7 \% \quad 83.1 \quad 25.0 \quad 72.2$

$99.7 \% \quad 44.5 \quad 25.0 \quad 33.9$

$98.0 \% \quad 23.4 \quad 25.0 \quad 11.1$

$99.0 \% \quad 19.7 \quad 25.0 \quad 19.7$

$99.7 \% \quad 29.6 \quad 25.0 \quad 28.0$

$\begin{array}{llll}96.6 \% & 21.2 & 25.0 & 11.8\end{array}$

$99.6 \% \quad 28.5 \quad 25.0 \quad 20.7$

$99.7 \% \quad 63.0 \quad 25.0 \quad 54.7$

$99.7 \% \quad 39.2$

$0.02 \% \quad 19.2 \%$ QITSYGETCPGLEQYAIKK $96.9 \% \quad 15.7$

$0.02 \% \quad 19.2 \%$ FAEAFEAIPR

$0.07 \% \quad 36.3 \%$ TLNPKAEVAR

$0.07 \% \quad 36.3 \%$ AQAALAVNISAAR

$0.07 \% \quad 36.3 \%$ MLVSGAGDIK

$0.07 \% \quad 36.3 \%$ MLVSGAGDIKLTK

$99.7 \% \quad 61.8$

$99.7 \% \quad 59.6$

$99.7 \% \quad 53.7$

$99.5 \% \quad 27.4$

$99.7 \% 73.2$

$0.07 \% \quad 36.3 \%$ DGNVLLHEMQIQHPTASLIAK $\quad 99.7 \% \quad 51.2$

$0.07 \% \quad 36.3 \%$ QADLYISEGLHPR

$0.07 \% \quad 36.3 \%$ IITEGFEAAK

$0.07 \% \quad 36.3 \%$ IITEGFEAAKEK

$0.07 \% \quad 36.3 \%$ ALQFLEEVKVSR

$0.07 \% \quad 36.3 \%$ EMDRETLIDVAR

$0.07 \% \quad 36.3 \%$ SETDTSLIR

$0.07 \% \quad 36.3 \%$ GLVLDHGAR

$0.07 \% \quad 36.3 \%$ VCGDSDKGFVVINQK

$0.07 \% \quad 36.3 \%$ GIDPFSLDALSK

$0.07 \% \quad 36.3 \%$ EGIVALRR

$0.07 \% \quad 36.3 \%$ SVTLLIKGPNK

$0.07 \% \quad 36.3 \%$ GPNKHTLTQIK

$0.07 \% \quad 36.3 \%$ VLAQNSGFDLQETLVK

$0.05 \% \quad 6.0 \%$ GATALEMGMPLLLQK

$0.05 \% \quad 6.0 \%$ RQTFITLEK

$0.05 \% \quad 6.0 \%$ SPLHIKDDVLPK

$0.05 \% \quad 6.0 \% \quad$ LIAEQTLQENLIEK

$0.05 \% \quad 6.0 \%$ TLGETSANAETEQNKK

$0.05 \% \quad 6.0 \%$ DSFDNCSLGESSK

$0.05 \% \quad 6.0 \% \quad$ IGISDISSLSEK

$99.7 \% \quad 60.0$

$99.4 \% \quad 37.8$

$99.7 \% 70.1$

$99.7 \% \quad 64.4$

$99.7 \% \quad 38.3$

$99.7 \% \quad 45.9$

$99.7 \% \quad 46.3$

$99.7 \% \quad 47.0$

$98.5 \% \quad 28.6$

$98.3 \% \quad 22.3$

$99.7 \% \quad 40.3$

$97.6 \% \quad 16.5$

$99.7 \% \quad 56.3$

$99.7 \% \quad 42.0$

$96.6 \% \quad 21.2$

$97.9 \% \quad 16.9$

$99.7 \% \quad 57.6$

$99.7 \% \quad 32.3$

$99.7 \% \quad 45.7$

$99.7 \% \quad 53.4$

$0.05 \% \quad 6.0 \% \quad$ TMELNVGNEASFHGQER

$0.05 \% \quad 6.0 \%$ SQEDEISSPVNKVR

$0.05 \% \quad 6.0 \% \quad$ TIGDLSTLTASEIK

$0.05 \% \quad 6.0 \%$ GLEEIPVFDISEK

$0.01 \% \quad 4.4 \%$ LQNATPTNFK

$0.01 \% \quad 4.4 \%$ AVYTLYQQR

$0.01 \% \quad 4.4 \%$ SLQATALR

$0.01 \% \quad 4.4 \%$ VGPEELPVVGQLLR

$0.01 \% \quad 2.1 \%$ SNPDQPAVILLLR $\begin{array}{ll}99.5 \% & 22.2 \\ 99.7 \% & 43.0\end{array}$

$99.7 \% \quad 41.2$

$98.1 \% \quad 25.3$

$99.7 \% \quad 33.3$

$99.7 \% \quad 53.7$

$99.0 \% \quad 25.8$

$99.7 \% \quad 47.0$

$99.7 \% \quad 36.3$
1333.69

1185.72

983.52

1111.61

1307.64

1529.83

1168.60

1378.67

1372.74

1354.76

2186.08

1150.59

1098.63

1255.71

1006.52

1348.75

2315.22

1498.77

1078.58

1335.72

1418.80

1447.72

1021.52

937.52

1665.83

1262.66

913.56

1169.73

1236.71

1761.94

1604.84

1135.65

1361.78

1641.91

1720.83

1445.59

1248.67

1918.87

1587.80

1448.78

1475.76

1133.60

1141.60

859.50

1505.87

1435.83 $\begin{array}{cc}39 & 449 \\ 50 & 461 \\ 08 & 518 \\ 19 & 527 \\ 19 & 528 \\ 1 & 31 \\ 53 & 165 \\ 72 & 181 \\ 26 & 238 \\ 82 & 296 \\ 08 & 421 \\ 22 & 440 \\ 41 & 450 \\ 6 & 15 \\ 6 & 28 \\ 6 & 55 \\ 6 & 58 \\ 9 & 79 \\ 05 & 117 \\ 18 & 127 \\ 18 & 129 \\ 30 & 141 \\ 42 & 153 \\ 00 & 208 \\ 09 & 217 \\ 81 & 295 \\ 96 & 307 \\ 08 & 315 \\ 71 & 381 \\ 78 & 388 \\ 50 & 465 \\ 03 & 217 \\ 18 & 1226 \\ 54 & 1465 \\ 68 & 1481 \\ 89 & 1504 \\ 87 & 1699 \\ 00 & 1711 \\ 16 & 1932 \\ 89 & 2202 \\ 29 & 2342 \\ 70 & 2382 \\ 5 & 34 \\ 05 & 513 \\ 91 & 598 \\ 52 & 865 \\ 55 & 1367\end{array}$

Page 115 of Table S-1-2 
THO complex subunit $2 \mathrm{GN}=\mathrm{THOC}$

THO complex subunit $2 \mathrm{GN}=\mathrm{THOC} 2$

THO complex subunit $2 \mathrm{GN}=\mathrm{THOC} 2$

THO complex subunit $2 \mathrm{GN}=\mathrm{THOC} 2$

THO complex subunit $2 \mathrm{GN}=\mathrm{THOC} 2$

THO complex subunit $3 \mathrm{GN}=\mathrm{THOC} 3$

THO complex subunit $3 \mathrm{GN}=\mathrm{THOC} 3$

THO complex subunit $3 \mathrm{GN}=$ THOC 3

THO complex subunit $4 \mathrm{GN}=\mathrm{ALYREF}$

THO complex subunit $4 \mathrm{GN}=\mathrm{ALYREF}$

THO complex subunit $4 \mathrm{GN}=\mathrm{ALYREF}$

THOC2_HUMAN $182.78 \quad 100.0 \%$ THOC2 HUMAN $182.78 \quad 100.0 \%$ THOC2_HUMAN $182.78 \quad 100.0 \%$ THOC2 HUMAN $182.78 \quad 100.0 \%$ THOC2 HUMAN $182.78 \quad 100.0 \%$ THOC3_HUMAN $38.77 \quad 100.0 \%$ THOC3 HUMAN $38.77 \quad 100.0 \%$ THOC3_HUMAN $38.77 \quad 100.0 \%$ THOC4_HUMAN $26.89 \quad 100.0 \%$ THOC4 HUMAN $26.89 \quad 100.0 \%$ THOC4_HUMAN $26.89 \quad 100.0 \%$ $\begin{array}{ll} & \end{array}$ THUMP domain-containing protein 3 GN=THUMPD3 THUM3_HUMAN $57.00 \quad 100.0 \%$ THUMP domain-containing protein 3 GN=THUMPD3 THUM3_HUMAN $57.00 \quad 100.0 \%$ Thyroid hormone receptor-associated protein $3 \mathrm{GN}=\mathrm{THRAP} 3 \mathrm{TR} 150$ HUMAN $108.67 \quad 100.0 \%$ Thyroid hormone receptor-associated protein 3 GN=THRAP3 TR150_HUMAN $108.67 \quad 100.0 \%$ Thyroid hormone receptor-associated protein $3 \mathrm{GN}=$ THRAP3 TR150_HUMAN $108.67 \quad 100.0 \%$ Thyroid hormone receptor-associated protein $3 \mathrm{GN}=$ THRAP3 TR150_HUMAN $108.67 \quad 100.0 \%$ Thyroid hormone receptor-associated protein $3 \mathrm{GN}=$ THRAP3 TR150_HUMAN $108.67 \quad 100.0 \%$ Thyroid hormone receptor-associated protein $3 \mathrm{GN}=\mathrm{THRAP} 3 \mathrm{TR} 150$ HUMAN $108.67 \quad 100.0 \%$ Thyroid hormone receptor-associated protein $3 \mathrm{GN}=$ THRAP3 TR150_HUMAN $108.67 \quad 100.0 \%$ Thyroid hormone receptor-associated protein $3 \mathrm{GN}=$ THRAP3 TR150_HUMAN $108.67 \quad 100.0 \%$ Thyroid hormone receptor-associated protein $3 \mathrm{GN}=\mathrm{THRAP} 3 \mathrm{TR} 150$ HUMAN $108.67 \quad 100.0 \%$ Thyroid hormone receptor-associated protein $3 \mathrm{GN}=$ THRAP3 TR150_HUMAN $108.67 \quad 100.0 \%$ Thyroid hormone receptor-associated protein $3 \mathrm{GN}=$ THRAP3 TR150 HUMAN $108.67 \quad 100.0 \%$ Thyroid hormone receptor-associated protein $3 \mathrm{GN}=$ THRAP3 TR150_HUMAN $108.67 \quad 100.0 \%$ Thyroid hormone receptor-associated protein 3 GN=THRAP3 TR150_HUMAN $108.67 \quad 100.0 \%$ 作 3 GN=THRAP3 TR150 HUMAN $108.67 \quad 100.0 \%$ Thyroid hormone receptor-associated protein $3 \mathrm{GN}=\mathrm{THRAP} 3 \mathrm{TR} 150 \_$HUMAN $108.67 \quad 100.0 \%$
$0.01 \% \quad 2.1 \% \quad$ VVYQPGYPK $0.01 \% \quad 2.1 \%$ ALELNQRLSSQ $0.00 \% \quad 5.4 \%$ AAAQYYLGNFR $0.00 \% \quad 5.4 \%$ SALNDVTAAR $0.06 \% \quad 26.6 \%$ VLLQAFDVVER $0.06 \% 26.6 \%$ SFLESIDDALAEK $0.06 \% \quad 26.6 \%$ LSQLGLDAGK $0.06 \% \quad 26.6 \%$ QVGIICGQESTR $0.06 \% \quad 26.6 \%$ QVGIICGQESTRR $0.06 \% \quad 26.6 \%$ YGYTDIDLLSAAK $0.06 \% \quad 26.6 \%$ QTSLDAVAQAVVDR $0.06 \% \quad 26.6 \%$ IHSDTFASGGER $0.06 \% \quad 26.6 \%$ HEDMTLLVR $0.06 \% 26.6 \%$ NFGYPLGEMSQPTPSPAPAAGGR $0.06 \% \quad 26.6 \%$ VYPVSVPYSSAQSTSK $0.01 \% \quad 5.3 \%$ GTSSLSQQTPR $0.01 \% \quad 5.3 \%$ TSSTSSSVNSQTLNR $0.01 \% \quad 5.3 \% \quad$ AIGNNSATSPR $0.02 \% \quad 3.1 \%$ GSPVNALQNK $0.02 \% \quad 3.1 \% \quad$ LTKENVKPSGR $0.02 \% \quad 3.1 \%$ FLQLCIFPR $0.02 \% \quad 3.1 \% \quad$ FVELVHQQK $0.02 \% \quad 3.1 \%$ VLNLGQALER $0.01 \% \quad 9.4 \%$ YVLGMQELFR $0.01 \% \quad 9.4 \%$ TLSFSHDGK $0.01 \% \quad 9.4 \%$ EAGTVKLFGLPNDS $19 \quad 0.03 \% \quad 21.0 \%$ SLGTADVHFER

0.03\% $21.0 \%$ QYNGVPLDGRPMNIQLVTSQIDAQR $97.8 \% \quad 15$

$19 \quad 0.03 \% \quad 21.0 \%$ QQLSAEELDAQLDAYNAR $99.7 \% \quad 43.2$

$0.01 \% \quad 6.7 \%$ AGEKHCFTSNEAAR

$0.01 \% \quad 6.7 \%$ STLAYGMLR

$0.01 \% \quad 6.7 \%$ AANNIASLLTK

$139 \quad 0.20 \% \quad 23.2 \%$ ASESSKPWPDATYGTGSASR $99.7 \% \quad 42.0$

$139 \quad 0.20 \% \quad 23.2 \%$ ASAVSELSPR

$139 \quad 0.20 \% \quad 23.2 \%$ ASAVSELSPRER

$139 \quad 0.20 \% \quad 23.2 \%$ SPALKSPLQSVVVR

$139 \quad 0.20 \% \quad 23.2 \%$ SPLQSVVVR

$139 \quad 0.20 \% \quad 23.2 \%$ SPLQSVVVRR

$139 \quad 0.20 \% \quad 23.2 \%$ SPPSTGSTYGSSQKEESAASGGAAYTK

$139 \quad 0.20 \% \quad 23.2 \%$ EESAASGGAAYTK

$139 \quad 0.20 \% \quad 23.2 \%$ EESAASGGAAYTKR

$139 \quad 0.20 \% \quad 23.2 \%$ GSFSDTGLGDGK

$139 \quad 0.20 \% \quad 23.2 \%$ GSFSDTGLGDGKMK

$139 \quad 0.20 \% \quad 23.2 \%$ MKSDSFAPK

$139 \quad 0.20 \% \quad 23.2 \%$ VIGANKNQEEEK

$139 \quad 0.20 \% \quad 23.2 \%$ KTEELEEESFPER

$139 \quad 0.20 \% \quad 23.2 \%$ GFVPEKNFR
$99.7 \% \quad 28.0$

$99.7 \% \quad 49.4$

$\begin{array}{llll}99.4 \% & 20.4 & 25.0 & 20.4\end{array}$

$99.7 \% \quad 48.1$

$99.7 \% \quad 58.3$

$99.7 \% \quad 39.3$

$\begin{array}{lll}95.8 \% & 20.2\end{array}$

$99.2 \% \quad 24.7$

$99.7 \% \quad 51.4$

$99.7 \% \quad 46.3$

$\begin{array}{lll}99.7 \% & 39.4\end{array}$

$99.7 \% 58.4$

$96.7 \% \quad 19.5$

$.7 \% \quad 54.7$

$99.3 \% \quad 21.8$

$97.3 \% \quad 15.8$

$99.7 \% 29.7$

$99.7 \% \quad 48.8$

$99.4 \% \quad 25.8$

$88.8 \%-19.1$

$99.7 \% \quad 54.1$

$99.7 \% \quad 30.6$

$99.7 \% \quad 51.2$

$99.7 \% \quad 52.0$

$99.5 \% \quad 29.5$

$99.7 \% \quad 56.5$

$99.7 \% \quad 55.8$

$99.7 \% \quad 57.4$

$99.7 \% \quad 48.7$

$99.7 \% \quad 39.2$

$99.7 \% \quad 31.5$

$99.7 \% \quad 42.8$

$99.7 \% \quad 62.7$

$99.7 \% \quad 40.0$

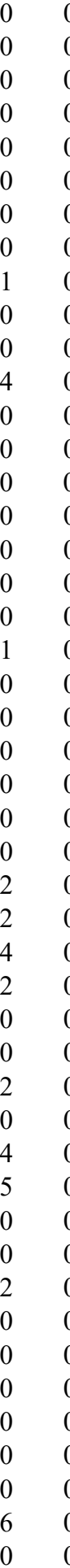

$050.56 \quad 1508 \quad 1516$

$\begin{array}{lll}258.68 & 1554 & 1564\end{array}$

$\begin{array}{lll}1273.63 & 124 & 134\end{array}$

$\begin{array}{lll}1017.53 & 135 & 144\end{array}$

$1288.73 \quad 105 \quad 115$

$\begin{array}{lll}1437.71 & 116 & 128\end{array}$

$\begin{array}{lll}1001.56 & 218 & 227\end{array}$

$\begin{array}{lll}1347.67 & 230 & 241\end{array}$

$1503.77 \quad 230 \quad 242$

$1429.72 \quad 250 \quad 262$

$1472.77 \quad 320 \quad 333$

$\begin{array}{lll}1276.59 & 337 & 348\end{array}$

$1113.57 \quad 355 \quad 363$

$2302.09 \quad 364 \quad 386$

$1699.85 \quad 387 \quad 402$

1161.59

1568.75

1087.55

1027.55

1228.70

1193.65

1127.62

1112.64

1255.65

991.48

1447.74

1231.61

2829.43

2034.97

1577.7

1011.53

1115.64

2054.94

1016.54

1301.68

1480.88

984.58

1140.68

2606.19

1241.56

1397.67

1140.52

1399.65

1010.50

1358.69

1622.75

1093.58 
Thyroid hormone receptor-associated protein 3 GN=THRAP3 TR150_HUMAN $108.67 \quad 100.0 \% \quad 24$ Thyroid hormone receptor-associated protein 3 GN=THRAP3 TR150_HUMAN $108.67 \quad 100.0 \% 24$ Thyroid hormone receptor-associated protein $3 \mathrm{GN}=$ THRAP3 TR150_HUMAN $108.67 \quad 100.0 \% 24$ Thyroid hormone receptor-associated protein $3 \mathrm{GN}=\mathrm{THR}$ AP3 TR150 HUMAN $108.67 \quad 100.0 \%$ Thyroid hormone receptor-associated protein $3 \mathrm{GN}=$ THRAP3 TR150_HUMAN $108.67 \quad 100.0 \% 24$ Thyroid hormone receptor-associated protein $3 \mathrm{GN}=$ THRAP3 TR150_HUMAN $108.67 \quad 100.0 \% \quad 2$ Thyroid hormone receptor-associated protein $3 \mathrm{GN}=$ THRAP3 TR150_HUMAN $108.67 \quad 100.0 \%$ Thyroid hormone receptor-associated protein 3 GN=THRAP3 TR150_HUMAN $108.67 \quad 100.0 \% \quad 2$ Thyroid hormone receptor-associated protein $3 \mathrm{GN}=\mathrm{THRAP} 3 \mathrm{TR} 150$ HUMAN $108.67 \quad 100.0 \%$ Thyroid transcription factor 1-associated protein $26 \mathrm{GN}=\mathrm{CCDC} 59$ TAP26_HUMAN $28.67 \quad 100.0 \%$ Thyroid transcription factor 1-associated protein $26 \mathrm{GN}=\mathrm{CCDC} 59$ TAP26_HUMAN $28.67 \quad 100.0 \%$ TP53-regulating kinase GN=TP53RK PRPK HUMAN $28.16 \quad 100.0 \%$ TP53-regulating kinase GN=TP53RK TP53-regulating kinase $\mathrm{GN}=\mathrm{TP} 53 \mathrm{RK}$ TP53-regulating kinase $\mathrm{GN}=\mathrm{TP} 53 \mathrm{RK}$ PRPK_HUMAN $28.16 \quad 100.0 \%$ PRPK HUMAN $28.16 \quad 100.0 \%$ PRPK HUMAN $28.16 \quad 100.0 \%$ Transcription activator BRG1 GN=SMARCA4 SMCA4_HUMAN $184.65100 .0 \%$ Transcription activator BRG1 GN=SMARCA4 SMCA4 HUMAN $184.65100 .0 \%$ Transcription activator BRG1 GN=SMARCA4 SMCA4_HUMAN $184.65 \quad 100.0 \%$ Transcription activator BRG1 GN=SMARCA4 SMCA4_HUMAN $184.65 \quad 100.0 \%$ Transcription activator BRG1 GN=SMARCA4 SMCA4_HUMAN $184.65100 .0 \%$ Transcription activator BRG1 GN=SMARCA4 SMCA4_HUMAN $184.65100 .0 \%$ Transcription activator BRG1 GN=SMARCA4 SMCA4_HUMAN $184.65100 .0^{\circ}$ Transcription activator BRG1 GN=SMARCA4 SMCA4_HUMAN $184.65 \quad 100.0 \%$ Transcription activator BRG1 GN=SMARCA4 SMCA4_HUMAN $184.65 \quad 100.0 \%$ Transcription activator BRG1 GN=SMARCA4 SMCA4 HUMAN $184.65 \quad 100.0^{\circ}$ Transcription activator BRG1 GN=SMARCA4 SMCA4_HUMAN $184.65 \quad 100.0 \%$ Transcription initiation factor TFIID subunit 4 GN=TAF4 TAF4_HUMAN $110.11 \quad 100.0 \%$ Transcription initiation factor TFIID subunit $4 \mathrm{GN}=\mathrm{TAF} 4 \mathrm{TAF} 4$ HUMAN $110.11 \quad 100.0 \%$ Transcription initiation factor TFIID subunit 4 GN=TAF4 TAF4_HUMAN $110.11 \quad 100.0 \%$ Transcriptional activator protein Pur-alpha GN=PURA PURA HUMAN $34.91100 .0 \%$ Transcriptional activator protein Pur-alpha GN=PURA PURA_HUMAN $34.91 \quad 100.0 \%$ Transcriptional activator protein Pur-alpha GN=PURA PURA_HUMAN $34.91 \quad 100.0 \%$ Transcriptional activator protein Pur-alpha GN=PURA PURA HUMAN $34.91 \quad 100.0 \%$ Transcriptional activator protein Pur-beta GN=PURB PURB_HUMAN $33.24 \quad 100.0 \%$ Transcriptional activator protein Pur-beta GN=PURB PURB HUMAN $33.24 \quad 100.0 \%$ Transcriptional activator protein Pur-beta GN=PURB PURB_HUMAN 33.24 100.0\% Transcriptional activator protein Pur-beta GN=PURB PURB_HUMAN 33.24 100.0\% Transducin beta-like protein $3 \mathrm{GN}=\mathrm{TBL} 3$ TBL3 HUMAN $89.03 \quad 100.0^{\circ}$ Transducin beta-like protein 3 GN=TBL3 TBL3_HUMAN $89.03 \quad 100.0 \%$ Transducin beta-like protein 3 GN=TBL3 TBL3_HUMAN $89.03 \quad 100.0 \%$ Transducin beta-like protein $3 \mathrm{GN}=$ TBL3 TBL3 HUMAN $89.03 \quad 100.0 \%$ Transducin beta-like protein 3 GN=TBL3 TBL3_HUMAN $89.03 \quad 100.0 \%$ Transferrin receptor protein $1 \mathrm{GN}=$ TFRC TFR1 HUMAN $84.87 \quad 100.0^{\circ}$ Transferrin receptor protein $1 \mathrm{GN}=$ TFRC $\quad$ TFR1_HUMAN $84.87 \quad 100.0 \%$ Transferrin receptor protein $1 \mathrm{GN}=$ TFRC $\quad$ TFR1_HUMAN $84.87 \quad 100.0 \%$ Transformation/transcription domain-associated protein GN=TRRAP TRRAP HUMAN $437.60 \quad 100.0 \%$ $\begin{array}{lll}\text { Transformation/transcription domain-associated protein GN=TRRAP TRRAP_HUMAN } 437.60 & 100.0 \%\end{array}$ $\begin{array}{llll}32 & 139 & 0.20 \% & 23.2 \% \\ 3 & \text { NFRVTAYK }\end{array}$

$39 \quad 0.20 \% \quad 23.2$

$139 \quad 0.20 \% \quad 23.2 \%$ LGAKGDFPTGK

$139 \quad 0.20 \% \quad 23.2 \%$ GDFPTGKSSFSITR

$99.0 \% \quad 23.3$

$99.7 \% \quad 28.9$

$139 \quad 0.20 \% \quad 23.2 \%$ MDSFDEDLARPSGLLAQER

$139 \quad 0.20 \% \quad 23.2 \%$ SIFQHIQSAQSQR

$139 \quad 0.20 \% \quad 23.2 \%$ IDISPSTFRK

$139 \quad 0.20 \% \quad 23.2 \%$ YKDDPVDLR

$139 \quad 0.20 \% \quad 23.2 \%$ NREEEWDPEYTPK

$0.00 \% \quad 7.9 \%$ GEGVSTVGYR

$0.00 \% \quad 7.9 \%$ HLYLAEEER

$99.7 \% \quad 51.8$

$99.7 \% \quad 62.8$

$98.7 \% \quad 26.9$

$99.5 \% \quad 26.3$

$99.7 \% \quad 30.8$

$99.7 \% \quad 49.4$

$\begin{array}{lll}97.1 \% & 20.4\end{array}$

$\begin{array}{llll} & \end{array}$

$0.01 \% \quad 21.3 \%$ FLSGLELVKQGAEAR

$0.01 \% \quad 21.3 \%$ TPQGLSNLAK

$0.01 \% \quad 21.3 \%$ TIGQVLAR

$0.02 \% \quad 7.4 \% \quad$ IQELENLPGSLAGDLR

$0.02 \% \quad 7.4 \%$ RDTALETALNAK

$0.02 \% \quad 7.4 \%$ DTALETALNAK

$0.02 \% \quad 7.4 \%$ GLQSYYAVAHAVTER

$0.02 \% \quad 7.4 \%$ VDLNEEETILIIR

$0.02 \% \quad 7.4 \%$ CDMSALQR

$0.02 \% \quad 7.4 \%$ LCTVNSVEEK

$0.02 \% \quad 7.4 \%$ VIQAGMFDQK

$0.02 \% \quad 7.4 \%$ DSDAGSSTPTTSTR

$0.02 \% \quad 7.4 \%$ QLSEVFIQLPSRK

$0.02 \% \quad 7.4 \%$ ELPEYYELIR

$0.01 \% \quad 3.7 \%$ GAAGAVTQSLSR

$0.01 \% \quad 3.7 \%$ ALSAVSAQAAAAQK

$0.01 \% \quad 3.7 \%$ ILATNSELVGTLTR

$0.01 \% \quad 16.8 \%$ FYLDVKQNAK

$0.01 \% \quad 16.8 \%$ ALKSEFLVR

$0.01 \% \quad 16.8 \%$ LIDDYGVEEEPAELPEGTSLTVDNK

$0.01 \% \quad 16.8 \%$ VSEVKPTYR

$0.01 \% \quad 13.1 \%$ GGGEQETQELASK

$0.01 \% \quad 13.1 \%$ FYLDVKQNAK

$0.01 \% \quad 13.1 \%$ ALKSEFLVR

$0.01 \% \quad 13.1 \%$ VSEVKPSYR

$0.01 \% \quad 8.7 \% \quad$ FKTNYAVER

$0.01 \% \quad 8.7 \%$ VNILEVASGAVLR

$0.01 \% \quad 8.7 \% \quad$ SPGLYFLTAGDQGTLR

$0.01 \% \quad 8.7 \%$ NTAPDNGPILLQAQTTQR

$0.01 \% \quad 8.7 \%$ GTQLLSSGSDGLVK

$0.01 \% \quad 5.9 \%$ SAFSNLFGGEPLSYTR

$0.01 \% \quad 5.9 \% \quad$ SSGLPNIPVQTISR

$0.01 \% \quad 5.9 \%$ GFVEPDHYVVVGAQR

$0.02 \% \quad 2.1 \%$ AIETALDCLK

$0.02 \% \quad 2.1 \%$ TIPNVIISHR $\begin{array}{llll}99.7 \% & 60.7 & 25.0 & 60.7\end{array}$

$\begin{array}{llll}99.7 \% & 32.6 & 25.0 & 25.8\end{array}$

$\begin{array}{lllll}98.9 \% & 34.0 & 25.0 & 11.0\end{array}$

$\begin{array}{llll}99.7 \% & 45.8 & 25.0 & 45.8\end{array}$

$99.4 \% \quad 27.6 \quad 25.0 \quad 14.1$

$99.7 \% \quad 75.9 \quad 25.0 \quad 58.5$

$\begin{array}{llll}98.8 \% & 20.9 & 25.0 & 20.9\end{array}$

$99.7 \% \quad 52.6$

$96.6 \% \quad 16.2$

$97.0 \% \quad 23.3$

$99.7 \% 44$.

$99.7 \% \quad 47.5$

$97.8 \% \quad 16.2$

$99.7 \% \quad 34.3$

$\begin{array}{lll}99.7 \% & 30.1\end{array}$

$99.7 \% \quad 47.6$

$99.7 \% \quad 35.6$

$99.7 \% \quad 31.6$

$98.8 \% 26.7$

$99.7 \% \quad 52.3$

$99.7 \% \quad 35.3$

$99.7 \% \quad 50.7$

$99.7 \% \quad 31.6$

$98.8 \% \quad 26.7$

$99.7 \% \quad 30.6$

$99.7 \% \quad 30.3$

$99.7 \% \quad 65.2$

$\begin{array}{lll}99.7 \% & 48.8\end{array}$

$99.7 \% \quad 63.2$

$94.8 \% \quad 17.6$

$99.7 \% \quad 46.8$

$99.5 \% \quad 23.5$

$99.4 \% \quad 23.4$

$99.7 \% \quad 36.9$

$99.7 \% \quad 31.5$
998.54

1136.63

1090.59

1499.75

2150.02

1529.78

1163.64

1120.56

1692.75

1024.51

1159.57

2037.97

1617.90

1028.57

857.52

1724.92

1302.70

1146.60

1664.84

1556.85

980.43

1178.57

1136.58

1382.60

1544.88

1324.68

1117.60

1286.71

1487.84

1225.66

1062.63

2889.40

1078.59

1333.62

1225.66

1062.63

1064.57

1127.58

1340.79

1695.87

1938.00

1361.73

1745.85

1468.81

1672.84

1133.59

1149.67 $\begin{array}{cc}20 & 527 \\ 23 & 532 \\ 48 & 558 \\ 52 & 565 \\ 73 & 591 \\ 09 & 621 \\ 79 & 688 \\ 10 & 718 \\ 64 & 876 \\ 9 & 28 \\ 5 & 103 \\ 6 & 26 \\ 2 & 46 \\ 35 & 144 \\ 45 & 152 \\ 82 & 397 \\ 26 & 437 \\ 27 & 437 \\ 27 & 741 \\ 54 & 966 \\ 98 & 1005 \\ 04 & 1213 \\ 28 & 1237 \\ 16 & 1429 \\ 80 & 1492 \\ 93 & 1502 \\ 03 & 414 \\ 04 & 817 \\ 52 & 865 \\ 3 & 82 \\ 42 & 150 \\ 05 & 230 \\ 46 & 254 \\ 5 & 37 \\ 6 & 55 \\ 18 & 126 \\ 47 & 255 \\ 1 & 19 \\ 7 & 59 \\ 57 & 272 \\ 59 & 476 \\ 75 & 588 \\ 7 & 22 \\ 26 & 339 \\ 95 & 409 \\ 42 & 951 \\ 97 & 1006\end{array}$

Page 117 of Table S-1-2 

Transformer- 2 protein homolog beta GN=TRA2B TRA2B_HUMAN $33.67 \quad 100.0 \%$ Transformer-2 protein homolog beta GN=TRA2B TRA2B_HUMAN $33.67 \quad 100.0 \%$ Transformer-2 protein homolog beta GN=TRA2B TRA2B HUMAN $33.67 \quad 100.0 \%$ Transformer- 2 protein homolog beta GN=TRA2B TRA2B_HUMAN $33.67 \quad 100.0 \%$ Transformer-2 protein homolog beta GN=TRA2B TRA2B_HUMAN $33.67 \quad 100.0 \%$ Transformer-2 protein homolog beta GN=TRA2B TRA2B HUMAN $33.67 \quad 100.0 \%$ Transformer-2 protein homolog beta GN=TRA2B TRA2B_HUMAN $33.67 \quad 100.0 \%$ Transformer-2 protein homolog beta GN=TRA2B TRA2B_HUMAN $33.67 \quad 100.0 \%$ Translation initiation factor elF-2B subunit alpha GN=EIF2B1 EI2BA_HUMAN $33.71 \quad 100.0 \%$ Translation initiation factor eIF-2B subunit alpha GN=EIF2B1 EI2BA_HUMAN $33.71 \quad 100.0 \%$ Translation initiation factor eIF-2B subunit alpha GN=EIF2B1 EI2BA HUMAN $33.71 \quad 100.0 \%$ Translation initiation factor eIF-2B subunit beta GN=EIF2B2 EI2BB_HUMAN $38.99 \quad 100.0 \%$ Translation initiation factor eIF-2B subunit beta GN=EIF2B2 EI2BB_HUMAN $38.99 \quad 100.0 \%$ Translation initiation factor eIF-2B subunit beta GN=EIF2B2 EI2BB HUMAN $38.99 \quad 100.0 \%$ Translation initiation factor eIF-2B subunit delta GN=EIF2B4 EI2BD_HUMAN $57.56 \quad 100.0 \%$ Translation initiation factor eIF-2B subunit delta GN=EIF2B4 EI2BD HUMAN $57.56 \quad 100.0 \%$ Translation initiation factor elF-2B subunit epsilon GN=EIF2B5 EI2BE_HUMAN $80.38 \quad 100.0 \%$ Translation initiation factor elF-2B subunit epsilon GN=EIF2B5 EI2BE_HUMAN $80.38 \quad 100.0 \%$ Translational activator GCN1 GN=GCN1L1 GCN1L_HUMAN $292.76 \quad 100.0 \%$ Translational activator GCN1 GN=GCN1L1 GCN1L_HUMAN $292.76 \quad 100.0 \%$ Translational activator GCN1 GN=GCN1L1 GCN1L_HUMAN $292.76 \quad 100.0 \%$ Translational activator GCN1 GN=GCN1L1 GCN1L_HUMAN $292.76 \quad 100.0 \%$ Translational activator GCN1 GN=GCN1L1 GCN1L_HUMAN $292.76 \quad 100.0 \%$ Translational activator GCN1 GN=GCN1L1 GCN1L HUMAN $292.76 \quad 100.0 \%$ Translational activator GCN1 GN=GCN1L1 GCN1L_HUMAN $292.76 \quad 100.0 \%$ Translational activator GCN1 GN=GCN1L1 GCN1L_HUMAN $292.76 \quad 100.0 \%$ Translational activator GCN1 GN=GCN1L1 GCN1L_HUMAN $292.76 \quad 100.0 \%$ Translational activator GCN1 GN=GCN1L1 GCN1L_HUMAN $292.76 \quad 100.0 \%$ Translational activator GCN1 GN=GCN1L1 GCN1L_HUMAN $292.76 \quad 100.0 \%$ Translational activator GCN1 GN=GCN1L1 GCN1L_HUMAN $292.76 \quad 100.0 \%$ Translational activator GCN1 GN=GCN1L1 GCN1L_HUMAN $292.76 \quad 100.0 \%$ Translational activator GCN1 GN=GCN1L1 GCN1L HUMAN $292.76 \quad 100.0 \%$ Translational activator GCN1 GN=GCN1L1 GCN1L_HUMAN $292.76 \quad 100.0 \%$

$13 \quad 0.02 \% \quad 2.1 \%$ EVTSPNSTVR $0.02 \% \quad 2.1 \% \quad$ SLTLNVVNR $0.02 \% \quad 2.1 \%$ GLSVDSAQEVKR $0.02 \% \quad 2.1 \%$ TATGAISAVFGR $0.02 \% \quad 2.1 \%$ GLSLQIKPK $0.02 \% \quad 2.1 \%$ VVAVSPQMR

$0.04 \% \quad 22.7 \%$ YGPLSGVNVVYDQR

$0.04 \% \quad 22.7 \%$ YGPLSGVNVVYDQRTGR $0.04 \% \quad 22.7 \%$ GFAFVYFER

$0.04 \% \quad 22.7 \%$ IDDSKEAMER

$0.04 \% \quad 22.7 \%$ ANGMELDGRR

$0.04 \% \quad 22.7 \%$ IRVDYSITK

$0.04 \% \quad 22.7 \%$ RSPSPYYSR

$0.04 \% \quad 22.7 \%$ SPSPYYSR

$0.07 \% \quad 22.6 \%$ YGPIADVSIVYDQQSR

$0.07 \% \quad 22.6 \%$ YGPIADVSIVYDQQSRR

$0.07 \% 22.6 \%$ ANGMELDGRR

$0.07 \% \quad 22.6 \%$ IRVDFSITK

$0.07 \% \quad 22.6 \%$ GYDDRDYYSR

$0.07 \% 22.6 \%$ AAQDRDQIYR

$0.07 \% \quad 22.6 \%$ RSPSPYYSR

$0.07 \% \quad 22.6 \%$ SPSPYYSR

$0.01 \% \quad 12.1 \%$ DKGETIQGLR

$0.01 \% \quad 12.1 \%$ FSVYVTESQPDLSGKK

$0.01 \% \quad 12.1 \%$ IGTNQMAVCAK

$0.01 \% \quad 10.3 \%$ SDESDQQESLHK

$0.01 \% \quad 10.3 \%$ TVEAFLKEAAR

$0.01 \% \quad 10.3 \%$ AVTGTHTLALAAK

$0.00 \% \quad 5.4 \%$ VSLFSHLPQYSR

$0.00 \% \quad 5.4 \%$ LGLQYSQGLVSGSNAR

$0.00 \% \quad 2.5 \%$ AAQIKEHLLK

$0.00 \% \quad 2.5 \% \quad$ IITSELYR

$111 \quad 0.16 \% \quad 17.1 \%$ AADTQVSETLKR

$111 \quad 0.16 \% \quad 17.1 \%$ LFCLTLHR

$111 \quad 0.16 \% \quad 17.1 \%$ ALQAAIQQLAEAQPEATAK

$111 \quad 0.16 \% \quad 17.1 \%$ NLLHSLQSSGIGSK

$111 \quad 0.16 \% \quad 17.1 \%$ YLLDSCAPLLR

$111 \quad 0.16 \% \quad 17.1 \%$ LMDEAVLALR

$111 \quad 0.16 \% \quad 17.1 \%$ QCSDSSAMESLTK

$111 \quad 0.16 \% \quad 17.1 \%$ LSVADSQAEAK

$111 \quad 0.16 \% \quad 17.1 \%$ ALVAVLLSR

$111 \quad 0.16 \% \quad 17.1 \%$ HLDQIIPR

$111 \quad 0.16 \% \quad 17.1 \%$ SIIQSAQQDSIK

$111 \quad 0.16 \% \quad 17.1 \%$ SIIQSAQQDSIKK

$111 \quad 0.16 \% \quad 17.1 \%$ GIKEEVQLTSK

$111 \quad 0.16 \% \quad 17.1 \%$ ALGTLVSHVTLR

$111 \quad 0.16 \% \quad 17.1 \%$ ASPNTPPGRVDENGPELLPR $99.7 \% \quad 31.2$

$97.2 \% \quad 22.0$

$99.7 \% \quad 41.5$

$99.7 \% \quad 43.5$

$99.7 \% \quad 56.0$

$99.6 \% \quad 23.5$

$99.7 \% \quad 37.5$

$99.7 \% 58.0$

$\begin{array}{ll}99.6 \% & 26.2 \\ 99.7 \% & 54.9\end{array}$

$99.7 \% \quad 71.2$

$99.5 \% \quad 22.9$

$99.7 \% \quad 49.1$

$99.7 \% \quad 35.2$

$99.0 \% \quad 28.3$

$99.7 \% \quad 61.0$

$99.7 \% \quad 48.0$

$99.5 \% \quad 22.9$

$99.7 \% \quad 51.9$

$\begin{array}{lll}99.7 \% & 32.9\end{array}$

$99.7 \% \quad 48.5$

$99.7 \% \quad 35.2$

$99.0 \% \quad 28.3$

$99.7 \% \quad 44.1$

$99.7 \% \quad 31.7$

$99.7 \% \quad 32.3$

$99.7 \% \quad 38.2$

$99.7 \% \quad 60.9$

$99.7 \% \quad 43.4$

$98.1 \% \quad 18.7$

$99.7 \% \quad 70.7$

$99.6 \% \quad 24.7$

$99.0 \% \quad 35.5$

$99.4 \% \quad 25.8$

$99.0 \% \quad 28.6$

$99.7 \% \quad 47.9$

$99.7 \% \quad 50.7$

$\begin{array}{lll}99.7 \% & 49.7\end{array}$

$99.7 \% \quad 58.2$

$99.7 \% \quad 36.7$

$99.7 \% \quad 54.3$

$99.7 \% \quad 64.3$

$99.0 \% \quad 37.1$

$99.5 \% \quad 26.1$

$99.5 \% \quad 20.5$

$99.7 \% \quad 46.3$

$9.7 \% \quad 59.8$

50

1193.55

1118.54

1094.62

1112.55

956.45

1810.90

1967.00

1118.54

1078.63

1309.54

1235.61

1112.55

956.45

1116.60

1784.91

1192.58

1402.61

1234.68

1253.72

1433.75

1649.86

1150.69

994.56

1318.70

1059.58

1952.04

1440.78

1320.70

1130.62

1443.61

1118.57

941.61

991.57

1317.70

1445.80

1231.69

1266.75 2116.08 $\begin{array}{cc}48 & 1257 \\ 39 & 1447 \\ 49 & 2060 \\ 63 & 2074 \\ 18 & 2726 \\ 74 & 3582 \\ 42 & 155 \\ 42 & 158 \\ 61 & 169 \\ 70 & 179 \\ 80 & 189 \\ 90 & 198 \\ 59 & 267 \\ 60 & 267 \\ 41 & 156 \\ 41 & 157 \\ 79 & 188 \\ 89 & 197 \\ 29 & 238 \\ 52 & 261 \\ 63 & 271 \\ 64 & 271 \\ 7 & 46 \\ 48 & 163 \\ 10 & 220 \\ 00 & 111 \\ 73 & 183 \\ 47 & 259 \\ 77 & 188 \\ 10 & 225 \\ 9 & 108 \\ 22 & 129 \\ 2 & 13 \\ 3 & 60 \\ 9 & 87 \\ 8 & 101 \\ 41 & 251 \\ 14 & 323 \\ 28 & 340 \\ 99 & 509 \\ 68 & 576 \\ 05 & 712 \\ 77 & 788 \\ 77 & 789 \\ 19 & 829 \\ 15 & 926 \\ & 1037\end{array}$

Page 118 of Table S-1-2 
Translational activator GCN1 GN=GCN1L1 GCN1L_HUMAN $292.76 \quad 100.0 \% \quad 43$ $\begin{array}{llll}\text { Translational activator GCN1 GN=GCN1L1 GCN1L_HUMAN } 292.76 & 100.0 \% & 43\end{array}$ Translational activator GCN1 GN=GCN1L1 GCN1L_HUMAN $292.76 \quad 100.0 \% \quad 43$ Translational activator GCN1 GN=GCN1L1 GCN1L HUMAN $292.76 \quad 100.0 \%$ Translational activator GCN1 GN=GCN1L1 GCN1L_HUMAN $292.76 \quad 100.0 \% \quad 43$ Translational activator GCN1 GN=GCN1L1 GCN1L_HUMAN $292.76 \quad 100.0 \% \quad 4$ Translational activator GCN1 GN=GCN1L1 GCN1L_HUMAN $292.76 \quad 100.0 \%$ Translational activator GCN1 GN=GCN1L1 GCN1L_HUMAN $292.76 \quad 100.0 \% \quad 43$ Translational activator GCN1 GN=GCN1L1 GCN1L HUMAN $292.76 \quad 100.0 \%$ Translational activator GCN1 GN=GCN1L1 GCN1L_HUMAN $292.76 \quad 100.0 \%$ Translational activator GCN1 GN=GCN1L1 GCN1L_HUMAN $292.76 \quad 100.0 \% \quad 43$ Translational activator GCN1 GN=GCN1L1 GCN1L_HUMAN $292.76 \quad 100.0 \% \quad 43$ Translational activator GCN1 GN=GCN1L1 GCN1L_HUMAN $292.76 \quad 100.0 \% \quad 43$ Translational activator GCN1 GN=GCN1L1 GCN1L_HUMAN $292.76 \quad 100.0 \% \quad 43$ Translational activator GCN1 GN=GCN1L1 GCN1L_HUMAN $292.76 \quad 100.0 \% \quad 43$ Translational activator GCN1 GN=GCN1L1 GCN1L_HUMAN $292.76 \quad 100.0 \%$ Translational activator GCN1 GN=GCN1L1 GCN1L HUMAN $292.76 \quad 100.0 \%$ Translational activator GCN1 GN=GCN1L1 GCN1L_HUMAN $292.76 \quad 100.0 \%$ Translational activator GCN1 GN=GCN1L1 GCN1L_HUMAN $292.76 \quad 100.0 \%$ Translational activator GCN1 GN=GCN1L1 GCN1L HUMAN $292.76 \quad 100.0 \%$ Translational activator GCN1 GN=GCN1L1 GCN1L_HUMAN $292.76 \quad 100.0 \% \quad 43$ Translational activator GCN1 GN=GCN1L1 GCN1L_HUMAN $292.76 \quad 100.0 \%$ Translational activator GCN1 GN=GCN1L1 GCN1L_HUMAN $292.76 \quad 100.0 \%$ Translational activator GCN1 GN=GCN1L1 GCN1L_HUMAN $292.76 \quad 100.0 \% \quad 4$ Translational activator GCN1 GN=GCN1L1 GCN1L HUMAN $292.76 \quad 100.0 \%$ $\begin{array}{llll}\text { Translational activator GCN1 GN=GCN1L1 GCN1L_HUMAN } 292.76 & 100.0 \% & 43\end{array}$ Translational activator GCN1 GN=GCN1L1 GCN1L_HUMAN $292.76 \quad 100.0 \%$ Translational activator GCN1 GN=GCN1L1 GCN1L_HUMAN $292.76 \quad 100.0 \%$ Transmembrane protein 201 GN=TMEM201 TM201_HUMAN $72.24 \quad 100.0 \%$ Transmembrane protein 201 GN=TMEM201 TM201 HUMAN $72.24 \quad 100.0 \%$ Transportin-1 GN=TNPO1 Transportin- $1 \mathrm{GN}=\mathrm{TNPO}$

Transportin- $1 \mathrm{GN}=\mathrm{TNPO}$ Transportin-1 GN=TNPO Transportin- $1 \mathrm{GN}=\mathrm{TNPO}$ Transportin-3 GN=TNPO3 Transportin-3 GN=TNPO3 TNPO3 HUMAN $104.20 \quad 100.0 \%$ Tricarboxylate transport protein, mitochondrial GN=SLC25A1 TXTP HUMAN $34.01 \quad 100.0 \%$ Tricarboxylate transport protein, mitochondrial GN=SLC25A1 TXTP HUMAN $34.01 \quad 100.0 \%$ Tricarboxylate transport protein, mitochondrial GN=SLC25A1 TXTP_HUMAN $34.01 \quad 100.0 \%$ Tricarboxylate transport protein, mitochondrial GN=SLC25A1 TXTP HUMAN $34.01 \quad 100.0 \%$ Tricarboxylate transport protein, mitochondrial GN=SLC25A1 TXTP HUMAN $34.01 \quad 100.0 \%$ Tricarboxylate transport protein, mitochondrial GN=SLC25A1 TXTP_HUMAN $34.01 \quad 100.0 \%$ Trifunctional enzyme subunit alpha, mitochondrial GN=HADHA ECHA HUMAN $83.00 \quad 100.0 \%$ Trifunctional enzyme subunit alpha, mitochondrial GN=HADHA ECHA_HUMAN $83.00 \quad 100.0 \%$
$50 \quad 111 \quad 0.16 \% \quad 17.1 \%$ VDENGPELLPR

$50 \quad 111 \quad 0.16 \% \quad 17.1 \%$ QAGAEALSQAVAR

$50 \quad 111 \quad 0.16 \% \quad 17.1 \%$ LMEIYQEK

$50 \quad 111 \quad 0.16 \% \quad 17.1 \%$ VISESPPDQWEAR

$50 \quad 111 \quad 0.16 \% \quad 17.1 \%$ NAPNDASYDAVR

$50 \quad 111 \quad 0.16 \% \quad 17.1 \%$ KGAAYGLAGLVK

$50 \quad 111 \quad 0.16 \% \quad 17.1 \%$ GAAYGLAGLVK

$50 \quad 111 \quad 0.16 \% \quad 17.1 \%$ AVMSNLSAHGVK

$50 \quad 111 \quad 0.16 \% \quad 17.1 \%$ AGSVELLGAMAYCAPK

$50 \quad 111 \quad 0.16 \% \quad 17.1 \%$ QLSSCLPNIVPK

$50 \quad 111 \quad 0.16 \% \quad 17.1 \%$ LTEVLTDSHVK

$50 \quad 111 \quad 0.16 \% \quad 17.1 \%$ LTEVLTDSHVKVQK

$50 \quad 111 \quad 0.16 \% \quad 17.1 \%$ ASLLDPVPEVR

$50 \quad 111 \quad 0.16 \% \quad 17.1 \%$ VDIAPHVR

$50 \quad 111 \quad 0.16 \% \quad 17.1 \%$ ALADENEFVR

$50 \quad 111 \quad 0.16 \% \quad 17.1 \%$ ALADENEFVRDTALR

$50 \quad 111 \quad 0.16 \% \quad 17.1 \%$ AIITALGVERR

$50 \quad 111 \quad 0.16 \% \quad 17.1 \%$ VLAGLYMGR

$50 \quad 111 \quad 0.16 \% \quad 17.1 \%$ SDTQLVVR

$50 \quad 111 \quad 0.16 \% \quad 17.1 \%$ LTTPPVNTR

$50 \quad 111 \quad 0.16 \% \quad 17.1 \%$ VLAFLSSVAGDALTR

$50 \quad 111 \quad 0.16 \% \quad 17.1 \%$ QAAAIILNIYCSR

$50 \quad 111 \quad 0.16 \% \quad 17.1 \%$ ADYTSHLR

$50 \quad 111 \quad 0.16 \% \quad 17.1 \%$ SLVSGLIR

$50 \quad 111 \quad 0.16 \% \quad 17.1 \%$ EGVLTGSPEQKEEAAK

$50 \quad 111 \quad 0.16 \% \quad 17.1 \%$ LTSADALRPSVVSITGPLIR

$50 \quad 111 \quad 0.16 \% \quad 17.1 \%$ AYSDQAIVNLLK

$50 \quad 111 \quad 0.16 \% \quad 17.1 \%$ QGEEVFQSLSK

$5 \quad 0.01 \% \quad 3.6 \%$ ALLLSHQFK

$0.01 \% \quad 3.6 \%$ EADQTHAQNFSSAVK

$0.01 \% \quad 6.8 \%$ SLSGLILKNNVK

$0.01 \% \quad 6.8 \% \quad$ ATVGILITTIASK

$0.01 \% \quad 6.8 \%$ OSSFALLGDLTK

$0.01 \% \quad 6.8 \% \quad$ TLLENTAITIGR

$0.01 \% \quad 6.8 \% \quad$ FSDQFPLPLKER

$0.00 \% \quad 2.3 \%$ GLCEKPLASAAAK

$0.00 \% \quad 2.3 \%$ GTALVLAR

$0.04 \% \quad 21.9 \%$ TQLQLDER

$0.04 \% \quad 21.9 \%$ YRGIGDCVR

$0.04 \% \quad 21.9 \%$ SHGVLGLYR

$0.04 \% \quad 21.9 \%$ GLSSLLYGSIPK

$0.04 \% \quad 21.9 \%$ VKFIHDQTSPNPK

$0.04 \% \quad 21.9 \%$ FIHDQTSPNPK

$0.04 \% \quad 21.9 \%$ EQGLKGTYQGLTATVLK

$0.04 \% \quad 21.9 \%$ GTYQGLTATVLK

$0.04 \% \quad 22.4 \%$ INSPNSKVNTLSK

$0.04 \% \quad 22.4 \%$ TLQEVTQLSQEAQR
$99.6 \% \quad 22.9$

$99.7 \% \quad 63.2$

$99.0 \% \quad 31.4$

$99.7 \% \quad 44.7$

$99.3 \% \quad 20.5$

$99.7 \% \quad 30.2$

$99.7 \% \quad 39.6$

$99.7 \% \quad 57.4$

$99.7 \% \quad 65.9$

$99.7 \% \quad 34.3$

$99.7 \% \quad 47.9$

$99.7 \% \quad 28.3$

$99.7 \% \quad 44.7$

$99.0 \% \quad 21.9$

$99.7 \% \quad 50.8$

$99.5 \% \quad 25.0$

$99.4 \% \quad 26.7$

$99.7 \% \quad 44.3$

$\begin{array}{lll}99.0 \% & 42.7\end{array}$

$99.2 \% \quad 20.0$

$99.7 \% \quad 85.4$

$99.7 \% 71.6$

$99.0 \% \quad 51.2$

$99.0 \% \quad 35.7$

$99.7 \% \quad 58.0$

$96.9 \% \quad 16.0$

$99.7 \% \quad 66.2$

$99.7 \% \quad 43.0$

$99.7 \% \quad 30.9$

$99.7 \% \quad 32.8$

$99.7 \% \quad 42.0$

$99.0 \% \quad 23.2$

$99.7 \% \quad 54.1$

$99.7 \% \quad 56.5$

$97.8 \% \quad 18.7$

$99.7 \% \quad 31.1$

$99.0 \% \quad 26.8$

$99.0 \% \quad 36.3$

$99.2 \% \quad 25.9$

$99.7 \% \quad 38.6$

$99.7 \% \quad 61.1$

$99.7 \% \quad 31.7$

$99.7 \% \quad 45.5$

$99.5 \% \quad 27.8$

$\begin{array}{lll}99.7 \% & 50.8\end{array}$

$99.7 \% \quad 50.2$

$99.7 \% \quad 58.7$ $\begin{array}{ll}.0 & 50.7\end{array}$

$\begin{array}{ll}0 & 25.2\end{array}$

$\begin{array}{ll}0 & 44.2\end{array}$

$\begin{array}{ll}0 & 20.5\end{array}$

$\begin{array}{ll}.0 & 23.9\end{array}$

$25.0 \quad 27.0$

$25.0 \quad 51.6$

$\begin{array}{ll}25.0 & 65.9\end{array}$

$25.0 \quad 27.6$

$25.0 \quad 34.0$

$25.0 \quad 28.3$

$25.0 \quad 42.0$

$25.0 \quad 21.9$

$25.0 \quad 47.3$

$25.0 \quad 19.0$

$25.0 \quad 17.8$

$25.0 \quad 38.8$

$25.0 \quad 17.0$

$25.0 \quad 18.3$

$25.0 \quad 81.4$

$25.0 \quad 71.6$

$25.0 \quad 43.1$

$25.0 \quad 15.8$

$25.0 \quad 56.5$

$25.0 \quad 16.0$

$25.0 \quad 36.3$

$25.0 \quad 27.2$

$25.0 \quad 25.9$

$25.0 \quad 31.8$

$25.0 \quad 42.0$

$25.0 \quad 23.2$

$25.0 \quad 47.6$

$25.0 \quad 43.5$

$25.0 \quad 15.9$

$25.0 \quad 18.0$

$25.0 \quad 20.2$

$25.0 \quad 23.3$

$25.0 \quad 38.6$

$25.0 \quad 42.3$

$25.0 \quad 31.7$

$25.0 \quad 29.8$

$25.0 \quad 27.8$

$25.0 \quad 44.5$

$25.0 \quad 50.2$
14

0
0
0
0
0
0
0
0
0
0
0
2
0
0
0
4
0
0
0
0
0
0
0
0
0
0
1
0
0
0
0
0
0
0
0
0
0
0
0
0
0
0
0
0
0
0
0
0
0
0
0
0
0
0
0
0
0

$\begin{array}{ccc}1238.64 & 1027 & 1037 \\ 1271.67 & 1177 & 1189 \\ 1053.53 & 1201 & 1208 \\ 1513.73 & 1222 & 1234 \\ 1292.59 & 1305 & 1316 \\ 1147.68 & 1395 & 1406 \\ 1019.59 & 1396 & 1406 \\ 1213.64 & 1485 & 1496 \\ 1653.80 & 1515 & 1530 \\ 1355.74 & 1531 & 1542 \\ 1241.67 & 1543 & 1553 \\ 1596.90 & 1543 & 1556 \\ 1195.67 & 1664 & 1674 \\ 906.52 & 1746 & 1753 \\ 1163.57 & 1785 & 1794 \\ 1719.87 & 1785 & 1799 \\ 1198.73 & 1872 & 1882 \\ 979.54 & 1885 & 1893 \\ 917.51 & 1894 & 1901 \\ 998.56 & 2084 & 2092 \\ 1519.85 & 2093 & 2107 \\ 1492.79 & 2169 & 2181 \\ 962.47 & 2184 & 2191 \\ 844.53 & 2192 & 2199 \\ 1672.84 & 2270 & 2285 \\ 2066.20 & 2293 & 2312 \\ 1334.73 & 2610 & 2621 \\ 1251.62 & 2624 & 2634 \\ 1056.62 & 184 & 192 \\ 1632.76 & 195 & 209 \\ 1285.78 & 74 & 85 \\ 1287.79 & 116 & 128 \\ 1279.69 & 693 & 704 \\ 1301.74 & 774 & 785 \\ 1476.78 & 880 & 891 \\ 1315.70 & 509 & 521 \\ 800.50 & 564 & 571 \\ 1002.52 & 51 & 58 \\ 1095.54 & 64 & 72 \\ 1001.55 & 77 & 85 \\ 1234.70 & 86 & 97 \\ 1510.80 & 148 & 160 \\ 1283.64 & 150 & 160 \\ 1807.00 & 174 & 190 \\ 1251.69 & 179 & 190 \\ 1401.77 & 54 & 66 \\ 1630.84 & 112 & 125 \\ & & \end{array}$

Page 119 of Table S-1-2 
Trifunctional enzyme subunit alpha, mitochondrial GN=HADHA ECHA_HUMAN $83.00 \quad 100.0 \% \quad 13$ Trifunctional enzyme subunit alpha, mitochondrial GN=HADHA ECHA_HUMAN $83.00 \quad 100.0 \% \quad 13$ Trifunctional enzyme subunit alpha, mitochondrial GN=HADHA ECHA_HUMAN $83.00 \quad 100.0 \%$ Trifunctional enzyme subunit alpha, mitochondrial GN=HADHA ECHA_HUMAN $83.00 \quad 100.0 \%$; Trifunctional enzyme subunit alpha, mitochondrial GN=HADHA ECHA_HUMAN $83.00 \quad 100.0 \%$ Trifunctional enzyme subunit alpha, mitochondrial GN=HADHA ECHA_HUMAN $83.00 \quad 100.0 \%$ $\begin{array}{llll}\text { Trifunctional enzyme subunit alpha, mitochondrial GN=HADHA } & \text { ECHA_HUMAN } & 83.00 & 100.0 \%\end{array}$ Trifunctional enzyme subunit alpha, mitochondrial GN=HADHA ECHA_HUMAN $83.00 \quad 100.0 \%$ Trifunctional enzyme subunit alpha, mitochondrial GN=HADHA ECHA HUMAN $83.00 \quad 100.0 \%$ Trifunctional enzyme subunit alpha, mitochondrial GN=HADHA ECHA_HUMAN $83.00 \quad 100.0 \%$ Trifunctional enzyme subunit alpha, mitochondrial GN=HADHA ECHA_HUMAN $83.00 \quad 100.0 \%$ Trifunctional enzyme subunit beta, mitochondrial GN=HADHB ECHB_HUMAN $51.30 \quad 100.0 \%$ Trifunctional enzyme subunit beta, mitochondrial GN=HADHB ECHB_HUMAN $51.30 \quad 100.0 \%$ $\begin{array}{llll}\text { Trifunctional enzyme subunit beta, mitochondrial GN=HADHB } & \text { ECHB_HUMAN } & 51.30 & 100.0 \%\end{array}$ Trifunctional enzyme subunit beta, mitochondrial GN=HADHB ECHB_HUMAN $51.30 \quad 100.0 \%$ $\begin{array}{llll}\text { Trifunctional enzyme subunit beta, mitochondrial GN=HADHB ECHB_HUMAN } & 51.30 & 100.0 \% & 1\end{array}$ Trifunctional enzyme subunit beta, mitochondrial GN=HADHB ECHB HUMAN $51.30 \quad 100.0 \%$ Trifunctional enzyme subunit beta, mitochondrial GN=HADHB ECHB_HUMAN $51.30 \quad 100.0 \%$ Trifunctional enzyme subunit beta, mitochondrial GN=HADHB ECHB_HUMAN $51.30 \quad 100.0 \%$ Trifunctional enzyme subunit beta, mitochondrial GN=HADHB ECHB_HUMAN $51.30 \quad 100.0 \%$ $\begin{array}{llll}\text { Trifunctional enzyme subunit beta, mitochondrial GN=HADHB ECHB_HUMAN } & 51.30 & 100.0 \% & 1\end{array}$ Trifunctional enzyme subunit beta, mitochondrial GN=HADHB ECHB HUMAN $51.30 \quad 100.0 \%$ Trifunctional enzyme subunit beta, mitochondrial GN=HADHB ECHB_HUMAN $51.30 \quad 100.0 \%$ Trifunctional purine biosynthetic protein adenosine-3 GN=GART PUR2_HUMAN $107.77 \quad 100.0 \%$ Trifunctional purine biosynthetic protein adenosine-3 GN=GART PUR2 HUMAN $107.77 \quad 100.0 \%$ Trifunctional purine biosynthetic protein adenosine-3 GN=GART PUR2_HUMAN $107.77 \quad 100.0 \%$ Trifunctional purine biosynthetic protein adenosine-3 GN=GART PUR2_HUMAN $107.77 \quad 100.0 \%$ TRMT1-like protein GN=TRMT1L TRM1L_HUMAN $81.75 \quad 100.0 \%$ TRMT1-like protein GN=TRMT1L TRM1L_HUMAN $81.75 \quad 100.0 \%$ tRNA (cytosine(34)-C(5))-methyltransferase GN=NSUN2 NSUN2 HUMAN $86.47 \quad 100.0 \%$ tRNA (cytosine(34)-C(5))-methyltransferase GN=NSUN2 NSUN2_HUMAN $86.47 \quad 100.0 \%$ tRNA (cytosine(34)-C(5))-methyltransferase GN=NSUN2 NSUN2_HUMAN $86.47 \quad 100.0 \%$ tRNA (cytosine(34)-C(5))-methyltransferase GN=NSUN2 NSUN2 HUMAN $86.47 \quad 100.0 \%$ tRNA-splicing ligase RtcB homolog GN=RTCB RTCB_HUMAN $55.21 \quad 100.0 \%$ tRNA-splicing ligase RtcB homolog GN=RTCB RTCB_HUMAN $55.21 \quad 100.0 \%$ Tryptophan--tRNA ligase, cytoplasmic GN=WARS SYWC_HUMAN $53.17 \quad 100.0 \%$ Tryptophan--tRNA ligase, cytoplasmic GN=WARS SYWC_HUMAN $53.17 \quad 100.0 \%$ Tubulin alpha-1B chain GN=TUBA1B Tubulin alpha-1B chain $\mathrm{GN}=\mathrm{TUBA} 1 \mathrm{~B}$ Tubulin alpha-1B chain $\mathrm{GN}=$ TUBA1B

Tubulin alpha-1B chain $\mathrm{GN}=\mathrm{TUBA} 1 \mathrm{~B}$ Tubulin alpha-1B chain GN=TUBA1B Tubulin alpha-1B chain GN=TUBA1B Tubulin alpha-1B chain GN=TUBA1B Tubulin alpha-1B chain GN=TUBA1B Tubulin alpha-1B chain GN=TUBA1B Tubulin alpha-1B chain GN=TUBA1B

.

2
4

4

4

4

4

2

2

19
$\begin{array}{llll}\text { TBA1B_HUMAN } & 50.15 & 100.0 \% & 19\end{array}$

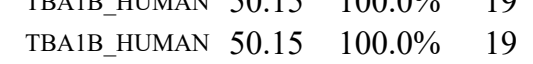

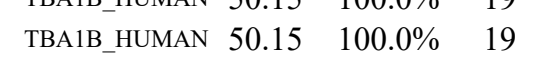

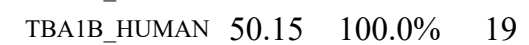
TBA1B_HUMAN $50.15 \quad 100.0 \% \quad 19$ TBA1B_HUMAN $50.15 \quad 100.0 \% \quad 19$

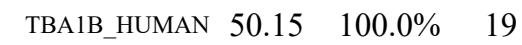
TBA1B_HUMAN $50.15 \quad 100.0 \% \quad 19$

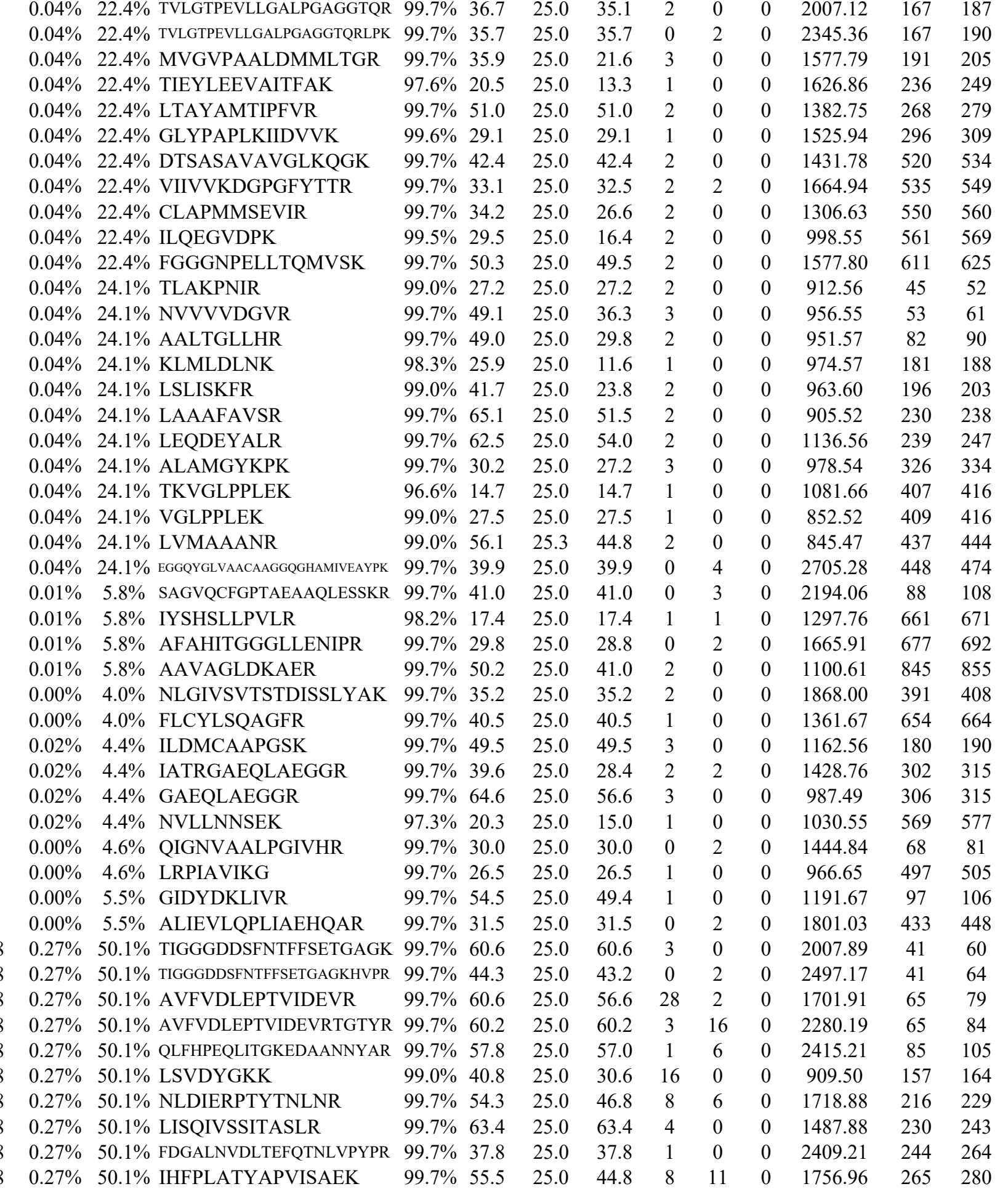


Tubulin alpha- $1 \mathrm{~B}$ chain $\mathrm{GN}=\mathrm{TUBA} 1 \mathrm{~B}$ Tubulin alpha- $1 \mathrm{~B}$ chain $\mathrm{GN}=\mathrm{TUBA} 1 \mathrm{~B}$ Tubulin alpha-1B chain GN=TUBA1B Tubulin alpha-1B chain GN=TUBA1B Tubulin alpha- $1 \mathrm{~B}$ chain $\mathrm{GN}=\mathrm{TUBA} 1 \mathrm{~B}$ Tubulin alpha-1B chain GN=TUBA1B

Tubulin alpha-1B chain GN=TUBA1B

Tubulin alpha-1B chain GN=TUBA1B

Tubulin alpha-1B chain $\mathrm{GN}=\mathrm{TUBA} \mathrm{B}$

Tubulin beta chain GN=TUBB

Tubulin beta chain $\mathrm{GN}=\mathrm{TUBB}$

Tubulin beta chain $\mathrm{GN}=\mathrm{TUBB}$

Tubulin beta chain GN=TUBB

Tubulin beta chain $\mathrm{GN}=\mathrm{TUBB}$

Tubulin beta chain GN=TUBB

Tubulin beta chain $\mathrm{GN}=\mathrm{TUBB}$

Tubulin beta chain $\mathrm{GN}=\mathrm{TUBB}$

Tubulin beta chain GN=TUBB

Tubulin beta chain GN=TUBB

Tubulin beta chain $\mathrm{GN}=\mathrm{TUBB}$

Tubulin beta chain GN=TUBB

Tubulin beta chain $\mathrm{GN}=\mathrm{TUBB}$

Tubulin beta chain GN=TUBB

Tubulin beta chain GN=TUBB

Tubulin beta chain GN=TUBB

Tubulin beta chain GN=TUBB

Tubulin beta chain $\mathrm{GN}=\mathrm{TUBB}$

Tubulin beta chain $\mathrm{GN}=\mathrm{TUBB}$

Tubulin beta chain GN=TUBB

Tubulin beta chain $\mathrm{GN}=\mathrm{TUBB}$

Tubulin beta chain GN=TUBB

Tubulin beta chain GN=TUBB

Tubulin beta chain $\mathrm{GN}=\mathrm{TUBB}$

Tubulin beta chain GN=TUBB

Tubulin beta chain GN=TUBB

Tubulin beta chain GN=TUBB

Tubulin beta chain GN=TUBB

Tubulin beta chain $\mathrm{GN}=\mathrm{TUBB}$

Tubulin beta chain GN=TUBB

Tubulin beta-2A chain $\mathrm{GN}=\mathrm{TUBB} 2 \mathrm{~A}$

Tubulin beta- $2 \mathrm{~A}$ chain $\mathrm{GN}=\mathrm{TUBB} 2 \mathrm{~A}$

Tubulin beta- $2 \mathrm{~A}$ chain $\mathrm{GN}=\mathrm{TUBB} 2 \mathrm{~A}$

Tubulin beta- $2 \mathrm{~A}$ chain $\mathrm{GN}=\mathrm{TUBB} 2 \mathrm{~A}$

Tubulin beta- $2 \mathrm{~A}$ chain $\mathrm{GN}=\mathrm{TUBB} 2 \mathrm{~A}$

Tubulin beta- $2 \mathrm{~A}$ chain $\mathrm{GN}=\mathrm{TUBB} 2 \mathrm{~A}$

Tubulin beta- $2 \mathrm{~A}$ chain $\mathrm{GN}=\mathrm{TUBB} 2 \mathrm{~A}$

Tubulin beta-2A chain $\mathrm{GN}=\mathrm{TUBB} 2 \mathrm{~A}$
TBA1B_HUMAN $50.15 \quad 100.0 \% \quad 19$ TBA1B_HUMAN $50.15 \quad 100.0 \% \quad 19$ TBA1B_HUMAN $50.15 \quad 100.0 \% \quad 19$ TBA1B HUMAN $50.15 \quad 100.0 \% \quad 19$ TBA1B_HUMAN $50.15 \quad 100.0 \% \quad 19$ TBA1B_HUMAN $50.15 \quad 100.0 \% \quad 19$ TBA1B HUMAN $50.15 \quad 100.0 \% \quad 19$ TBA1B_HUMAN $50.15 \quad 100.0 \% \quad 19$ TBA1B HUMAN $50.15 \quad 100.0 \% \quad 19$ TBB5_HUMAN $49.67 \quad 100.0 \% \quad 30$ TBB5 HUMAN $49.67 \quad 100.0 \% \quad 30$ TBB5 HUMAN $49.67 \quad 100.0 \% \quad 30$ TBB5_HUMAN $49.67 \quad 100.0 \% \quad 30$ TBB5_HUMAN $49.67 \quad 100.0 \% \quad 30$ TBB5 HUMAN $49.67 \quad 100.0 \% \quad 30$ TBB5_HUMAN $49.67 \quad 100.0 \% \quad 30$ TBB5 HUMAN $49.67 \quad 100.0 \% \quad 30$ TBB5_HUMAN $49.67 \quad 100.0 \% \quad 30$ TBB5_HUMAN $49.67 \quad 100.0 \% \quad 30$ TBB5 HUMAN $49.67 \quad 100.0 \% \quad 30$ TBB5_HUMAN $49.67 \quad 100.0 \% \quad 30$ TBB5 HUMAN $49.67 \quad 100.0 \% \quad 30$ TBB5 HUMAN $49.67 \quad 100.0 \% \quad 30$ TBB5_HUMAN $49.67 \quad 100.0 \% \quad 30$ TBB5 HUMAN $49.67 \quad 100.0 \% \quad 30$ TBB5_HUMAN $49.67 \quad 100.0 \% \quad 30$ TBB5_HUMAN $49.67 \quad 100.0 \% \quad 30$ TBB5 HUMAN $49.67 \quad 100.0 \% \quad 30$ TBB5_HUMAN $49.67 \quad 100.0 \% \quad 30$ TBB5 HUMAN $49.67 \quad 100.0 \% \quad 30$ TBB5_HUMAN $49.67 \quad 100.0 \% \quad 30$ TBB5_HUMAN $49.67 \quad 100.0 \% \quad 30$ TBB5 HUMAN $49.67 \quad 100.0 \% \quad 30$ TBB5_HUMAN $49.67 \quad 100.0 \% \quad 30$ TBB5 HUMAN $49.67 \quad 100.0 \% \quad 30$ TBB5 HUMAN $49.67 \quad 100.0 \% \quad 30$ TBB5_HUMAN $49.67 \quad 100.0 \% \quad 30$ TBB5 HUMAN $49.67 \quad 100.0 \% \quad 30$ TBB5_HUMAN $49.67 \quad 100.0 \% \quad 30$ TBB2A_HUMAN $49.91 \quad 100.0 \%$ TBB2A HUMAN $49.91 \quad 100.0 \%$ TBB2A_HUMAN $49.91 \quad 100.0 \%$ TBB2A HUMAN $49.91 \quad 100.0 \%$ TBB2A HUMAN $49.91 \quad 100.0 \%$ TBB2A_HUMAN $49.91 \quad 100.0 \%$ TBB2A HUMAN $49.91 \quad 100.0 \%$ TBB2A_HUMAN $49.91 \quad 100.0 \%$
$188 \quad 0.27 \% \quad 50.1 \%$ AYHEQLSVAEITNACFEPANQMVK $99.7 \% \quad 52.4$ $99.7 \% \quad 31.0$ $25.0 \quad 52.4$ $188 \quad 0.27 \% \quad 50.1 \%$ YMACCLLYR $188 \quad 0.27 \% \quad 50.1 \%$ GDVVPKDVNAAIATIK $188 \quad 0.27 \% \quad 50.1 \%$ DVNAAIATIK $188 \quad 0.27 \% \quad 50.1 \%$ DVNAAIATIKTK $99.7 \% \quad 41.8$ $25.0 \quad 36.1$ $188 \quad 0.27 \% \quad 50.1 \%$ SIQFVDWCPTGFK $99.7 \% \quad 60.9$ $99.7 \% \quad 53.9$

$88 \quad 0.27 \% \quad 50.1 \%$ VGINYQPPTVVPGGDLAK $99.7 \% \quad 49.4$

$188 \quad 0.27 \% \quad 50.1 \%$ VGINYQPPTVVPGGDLAKVQR $\quad 99.7 \% \quad 47.1$

$325 \quad 0.47 \% \quad 65.1 \%$ MREIVHIQAGQCGNQIGAK $99.1 \% \quad 50.7$

$325 \quad 0.47 \% \quad 65.1 \%$ ISVYYNEATGGK $99.7 \% \quad 57.8$

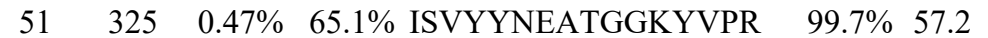

$\begin{array}{lllllll}51 & 325 & 0.47 \% & 65.1 \% & \text { AILVDLEPGTMDSVR } & 99.7 \% & 60.9\end{array}$

$\begin{array}{lllllll}51 & 325 & 0.47 \% & 65.1 \% & \text { SGPFGQIFRPDNFVFGQSGAGNNWAK } & 99.7 \% & 62.4\end{array}$

$51325 \quad 0.47 \% \quad 65.1 \%$ GHYTEGAELVDSVLDVVR $99.7 \% \quad 39.9$

$\begin{array}{lllllll}51 & 325 & 0.47 \% & 65.1 \% & \text { GHYTEGAELVDSVLDVVRK } & 99.7 \% & 43.9\end{array}$

$51325 \quad 0.47 \% \quad 65.1 \%$ EAESCDCLOGFOLTHSLGGGTGSGMGTLLISK $\quad 99.1 \% \quad 49.5$

$51 \quad 325 \quad 0.47 \% \quad 65.1 \%$ IMNTFSVVPSPK

$51 \quad 325 \quad 0.47 \% \quad 65.1 \%$ FPGQLNADLRK

$51325 \quad 0.47 \% \quad 65.1 \%$ KLAVNMVPFPR

$51 \quad 325 \quad 0.47 \% \quad 65.1 \%$ LAVNMVPFPR

$51 \quad 325 \quad 0.47 \% \quad 65.1 \%$ LHFFMPGFAPLTSR

$99.7 \% \quad 59.9$

$99.3 \% \quad 36.3$

$99.7 \% \quad 46.9$

$99.7 \% \quad 63.8$

$99.7 \% \quad 57.4$

$5 \quad 0.47 \% \quad 65.1 \%$ LHFFMPGFAPLTSRGSQQYR $\quad 98.9 \% \quad 18.1$

$\begin{array}{lllllll}51 & 325 & 0.47 \% & 65.1 \% & \text { GSQQYRALTVPELTQQVFDAK } & 99.7 \% & 32.7\end{array}$

$51325 \quad 0.47 \% \quad 65.1 \%$ ALTVPELTQQVFDAK $\quad 99.7 \% \quad 48.5$

$\begin{array}{llllllll}51 & 325 & 0.47 \% & 65.1 \% & \text { ALTVPELTQQVFDAKNMMAACDPR } & 99.7 \% & 41.9\end{array}$

$\begin{array}{llll}51 & 325 & 0.47 \% & 65.1 \%\end{array}$

$51 \quad 325 \quad 0.47 \% \quad 65.1 \%$ HGRYLTVAAVFR

$51325 \quad 0.47 \% \quad 65.1 \%$ YLTVAAVFR

$51325 \quad 0.47 \% \quad 65.1 \%$ YLTVAAVFRGR

$99.7 \%$

$99.7 \% \quad 25.2$

$99.7 \% \quad 59.5$

$99.7 \% \quad 46.1$

$\begin{array}{llllllll}5 & 325 & 0.47 \% & 65.1 \% & \text { MSMKEVDEQMLNVQNK } & 99.7 \% & 42.6\end{array}$

$51325 \quad 0.47 \% \quad 65.1 \%$ EVDEQMLNVQNK

$51325 \quad 0.47 \% \quad 65.1 \%$ NSSYFVEWIPNNVK

$51325 \quad 0.47 \% \quad 65.1 \%$ TAVCDIPPR

$51325 \quad 0.47 \% \quad 65.1 \%$ TAVCDIPPRGLK

$99.7 \% \quad 63.5$

$99.7 \% \quad 46.9$

$99.7 \% \quad 36.2$

0.47\% $\quad 65.1 \%$ MAVTFIGNSTAIQELFK $\quad 99.7 \% \quad 60.6$

$25 \quad 0.47 \% \quad 65.1 \%$ MAVTFIGNSTAIQELFKR

$\begin{array}{ll}99.7 \% & 60.6 \\ 99.7 \% & 49.8\end{array}$

$99.7 \% \quad 62.0$

$99.5 \% \quad 22.3$

$\begin{array}{lll}0.47 \% & 65.1 \% & \text { ISEQHTAMFR }\end{array}$

$\begin{array}{lllll}0.03 \% & 47.4 \% & \text { MREIVHIQAGQCGNQIGAK } & 99.1 \% & 50.7 \\ 0.03 \% & 47.4 \% & \text { AILVDLEPGTMDSVR } & 99.7 \% & 60.9\end{array}$

$0.03 \% \quad 47.4 \%$ AILVDLEPGTMDSVR

$\begin{array}{lll}99.7 \% & 62.4\end{array}$

$0.03 \% \quad 47.4 \%$ GHYTEGAELVDSVLDVVR $99.7 \% \quad 39.9$

$0.03 \% \quad 47.4 \%$ GHYTEGAELVDSVLDVVRK $99.7 \% \quad 43.9$

$0.03 \% \quad 47.4 \%$ FPGQLNADLRK

$99.3 \% \quad 36.3$

$99.7 \% \quad 46.9$

$99.7 \% \quad 63.8$

$0.03 \% \quad 47.4 \%$ LAVNMVPFPR
2750.29

1587.72

1249.55

1610.91

1015.58

1244.72

1584.75

1824.99

2208.21

2126.06

1301.64

1816.92

1615.84

2798.34

1958.98

2087.08

3327.53

1319.70

1258.69

1271.73

1143.63

1620.84

2356.17

2379.23

1659.90

2738.29

1065.43

1389.77

1039.59

1252.72

1971.88

1446.69

1696.83

1028.52

1326.72

1885.97

2026.08

1229.60

1401.69

2126.06

1615.84

2798.34

1958.98

2087.08

1258.69

1271.73

1143.63 
Tubulin beta- $2 \mathrm{~A}$ chain $\mathrm{GN}=\mathrm{TUBB} 2 \mathrm{~A}$ Tubulin beta- $2 \mathrm{~A}$ chain $\mathrm{GN}=\mathrm{TUBB} 2 \mathrm{~A}$ Tubulin beta- $2 \mathrm{~A}$ chain $\mathrm{GN}=\mathrm{TUBB} 2 \mathrm{~A}$ Tubulin beta- $2 \mathrm{~A}$ chain $\mathrm{GN}=\mathrm{TUBB} 2$ Tubulin beta- $2 \mathrm{~A}$ chain $\mathrm{GN}=\mathrm{TUBB} 2 \mathrm{~A}$ Tubulin beta- $2 \mathrm{~A}$ chain $\mathrm{GN}=\mathrm{TUBB} 2 \mathrm{~A}$

Tubulin beta-2A chain $\mathrm{GN}=\mathrm{TUBB} 2$ Tubulin beta- $2 \mathrm{~A}$ chain $\mathrm{GN}=\mathrm{TUBB} 2 \mathrm{~A}$ Tubulin beta- $2 \mathrm{~A}$ chain $\mathrm{GN}=\mathrm{TUBB} 2$ Tubulin beta- $2 \mathrm{~A}$ chain $\mathrm{GN}=\mathrm{TUBB} 2 \mathrm{~A}$ Tubulin beta- $2 \mathrm{~A}$ chain $\mathrm{GN}=\mathrm{TUBB} 2 \mathrm{~A}$ Tubulin beta-2A chain $\mathrm{GN}=\mathrm{TUBB} 2$ Tubulin beta- $2 \mathrm{~A}$ chain $\mathrm{GN}=\mathrm{TUBB} 2 \mathrm{~A}$ Tubulin beta- $2 \mathrm{~A}$ chain $\mathrm{GN}=\mathrm{TUBB} 2 \mathrm{~A}$

Tubulin beta- $4 \mathrm{~A}$ chain $\mathrm{GN}=\mathrm{TUBB} 4 \mathrm{~A}$

Tubulin beta-4A chain $\mathrm{GN}=\mathrm{TUBB} 4 \mathrm{~A}$

Tubulin beta-4A chain $\mathrm{GN}=\mathrm{TUBB} 4 \mathrm{~A}$

Tubulin beta- $4 \mathrm{~A}$ chain $\mathrm{GN}=\mathrm{TUBB} 4 \mathrm{~A}$

Tubulin beta- $4 \mathrm{~A}$ chain $\mathrm{GN}=\mathrm{TUBB} 4 \mathrm{~A}$

Tubulin beta-4A chain $\mathrm{GN}=\mathrm{TUBB} 4$

Tubulin beta- $4 \mathrm{~A}$ chain $\mathrm{GN}=\mathrm{TUBB} 4 \mathrm{~A}$

Tubulin beta-4A chain $\mathrm{GN}=\mathrm{TUBB} 4$

Tubulin beta- $4 \mathrm{~A}$ chain $\mathrm{GN}=\mathrm{TUBB} 4 \mathrm{~A}$

Tubulin beta-4A chain $\mathrm{GN}=\mathrm{TUBB} 4 \mathrm{~A}$

Tubulin beta-4A chain $\mathrm{GN}=\mathrm{TUBB} 4$

Tubulin beta- $4 \mathrm{~A}$ chain $\mathrm{GN}=\mathrm{TUBB} 4 \mathrm{~A}$

Tubulin beta-4A chain $\mathrm{GN}=\mathrm{TUBB} 4 \mathrm{~A}$

Tubulin beta-4A chain $\mathrm{GN}=\mathrm{TUBB} 4$

Tubulin beta- $4 \mathrm{~A}$ chain $\mathrm{GN}=\mathrm{TUBB} 4 \mathrm{~A}$

Tubulin beta-4A chain $\mathrm{GN}=\mathrm{TUBB} 4$

Tubulin beta- $4 \mathrm{~A}$ chain $\mathrm{GN}=\mathrm{TUBB} 4 \mathrm{~A}$

Tubulin beta- $4 \mathrm{~A}$ chain $\mathrm{GN}=\mathrm{TUBB} 4 \mathrm{~A}$

Tubulin beta-4A chain $\mathrm{GN}=\mathrm{TUBB} 4$

Tubulin beta- $4 \mathrm{~A}$ chain $\mathrm{GN}=\mathrm{TUBB} 4 \mathrm{~A}$

Tubulin beta- $4 \mathrm{~A}$ chain $\mathrm{GN}=\mathrm{TUBB} 4 \mathrm{~A}$

Tubulin beta- $4 \mathrm{~A}$ chain $\mathrm{GN}=\mathrm{TUBB} 4 \mathrm{~A}$

Tubulin beta- $4 \mathrm{~B}$ chain $\mathrm{GN}=\mathrm{TUBB} 4 \mathrm{E}$

Tubulin beta- $4 \mathrm{~B}$ chain $\mathrm{GN}=\mathrm{TUBB} 4 \mathrm{~B}$

Tubulin beta- $4 \mathrm{~B}$ chain $\mathrm{GN}=\mathrm{TUBB} 4 \mathrm{~B}$

Tubulin beta- $4 \mathrm{~B}$ chain $\mathrm{GN}=\mathrm{TUBB} 4 \mathrm{~B}$

Tubulin beta- $4 \mathrm{~B}$ chain $\mathrm{GN}=\mathrm{TUBB} 4 \mathrm{H}$

Tubulin beta- $4 \mathrm{~B}$ chain GN=TUBB4P

Tubulin beta- $4 \mathrm{~B}$ chain $\mathrm{GN}=\mathrm{TUBB} 4 \mathrm{E}$

Tubulin beta- $4 \mathrm{~B}$ chain $\mathrm{GN}=\mathrm{TUBB} 4 \mathrm{~B}$

Tubulin beta- $4 \mathrm{~B}$ chain $\mathrm{GN}=\mathrm{TUBB} 4 \mathrm{~B}$

Tubulin beta- $4 \mathrm{~B}$ chain $\mathrm{GN}=\mathrm{TUBB} 4 \mathrm{E}$

Tubulin beta-4B chain $\mathrm{GN}=\mathrm{TUBB} 4 \mathrm{~B}$
BB2A_HUMAN $49.91 \quad 100.0 \%$ BB2A HUMAN $49.91 \quad 100.0 \%$ TBB2A_HUMAN $49.91 \quad 100.0 \%$ TBB2A HUMAN $49.91 \quad 100.0 \%$ TBB2A_HUMAN $49.91 \quad 100.0 \%$ TBB2A_HUMAN $49.91 \quad 100.0 \%$ TBB2A HUMAN $49.91 \quad 100.0 \%$ TBB2A_HUMAN $49.91 \quad 100.0 \%$ TBB2A HUMAN $49.91 \quad 100.0 \%$ TBB2A HUMAN $49.91 \quad 100.0 \%$ TBB2A_HUMAN $49.91 \quad 100.0 \%$ TBB2A HUMAN $49.91 \quad 100.0 \%$ TBB2A_HUMAN $49.91 \quad 100.0 \%$ TBB2A HUMAN $49.91 \quad 100.0 \%$ TBB4A HUMAN $49.59 \quad 100.0 \%$ TBB4A_HUMAN $49.59 \quad 100.0 \%$ TBB4A HUMAN $49.59 \quad 100.0 \%$ TBB4A HUMAN $49.59 \quad 100.0 \%$ TBB4A_HUMAN $49.59 \quad 100.0 \%$ TBB4A_HUMAN $49.59 \quad 100.0 \%$ TBB4A_HUMAN $49.59 \quad 100.0 \%$ TBB4A HUMAN $49.59 \quad 100.0 \%$ TBB4A_HUMAN $49.59 \quad 100.0 \%$ TBB4A_HUMAN $49.59 \quad 100.0 \%$ TBB4A HUMAN $49.59 \quad 100.0 \%$ TBB4A_HUMAN $49.59 \quad 100.0 \%$ TBB4A HUMAN $49.59 \quad 100.0 \%$ TBB4A HUMAN $49.59 \quad 100.0 \%$ TBB4A_HUMAN $49.59 \quad 100.0 \%$ TBB4A_HUMAN $49.59 \quad 100.0 \%$ TBB4A HUMAN $49.59 \quad 100.0 \%$ TBB4A_HUMAN $49.59 \quad 100.0 \%$ TBB4A_HUMAN $49.59 \quad 100.0 \%$ TBB4A_HUMAN $49.59 \quad 100.0 \%$ TBB4A_HUMAN $49.59 \quad 100.0 \%$ TBB4A HUMAN $49.59 \quad 100.0 \%$ TBB4B_HUMAN $49.83 \quad 100.0 \%$ TBB4B HUMAN $49.83 \quad 100.0 \%$ TBB4B_HUMAN $49.83 \quad 100.0 \%$ TBB4B_HUMAN $49.83 \quad 100.0 \%$ TBB4B HUMAN $49.83 \quad 100.0 \%$ TBB4B_HUMAN $49.83 \quad 100.0 \%$ TBB4B HUMAN $49.83 \quad 100.0 \%$ TBB4B HUMAN $49.83 \quad 100.0 \%$ TBB4B_HUMAN $49.83 \quad 100.0 \%$ TBB4B HUMAN $49.83 \quad 100.0 \%$ TBB4B_HUMAN $49.83 \quad 100.0 \%$
$18 \quad 0.03 \% \quad 47.4 \%$ LHFFMPGFAPLTSR $99.7 \% \quad 57.4$ $0.03 \% \quad 47.4 \%$ LHFFMPGFAPLTSRGSQQ $0.03 \% \quad 47.4 \%$ ALTVPELTQQMFDSK $98.9 \% 18.1$ $0.03 \% \quad 47.4 \%$ NMMAACDPR $0.03 \% \quad 47.4 \%$ HGRYLTVAAIFR $0.03 \% \quad 47.4 \%$ YLTVAAIFR $0.03 \% \quad 47.4 \%$ YLTVAAIFRGR $0.03 \% \quad 47.4 \%$ MSMKEVDEQMLNVQNK $0.03 \% \quad 47.4 \%$ EVDEQMLNVQNK $0.03 \% \quad 47.4 \%$ NSSYFVEWIPNNVK $0.03 \% \quad 47.4 \%$ TAVCDIPPR $0.03 \% \quad 47.4 \%$ TAVCDIPPRGLK $0.03 \% \quad 47.4 \%$ ISEQFTAMFR $0.03 \% \quad 47.4 \%$ ISEQFTAMFRR $99.7 \% \quad 39.6$ $99.7 \% \quad 35.2$ $99.7 \% \quad 43.3$ $\begin{array}{lll}99.7 \% & 54.8\end{array}$ $99.7 \% \quad 31.3$ $99.7 \% \quad 42.6$ $99.7 \% \quad 32.2$ $99.7 \% \quad 63.5$ $99.7 \% \quad 46.9$ $99.7 \% \quad 36.2$ $99.7 \% \quad 62.0$ $99.5 \% \quad 22.3$

$0.00 \% \quad 53.6 \%$ MREIVHLQAGQCGNQIGAK $99.1 \% 50.7$

$0.00 \% \quad 53.6 \%$ AVLVDLEPGTMDSVR $\quad 99.7 \% \quad 65.1$

$0.00 \% \quad 53.6 \%$ SGPFGQIFRPDNFVFGQSGAGNNWAK $\quad 99.7 \% \quad 62.4$

$0.00 \% \quad 53.6 \%$ EAESCDCLQGFQLTHSLGGGTGSGMGTLLISK

$0.00 \% \quad 53.6 \%$ IMNTFSVVPSPK

$0.00 \% \quad 53.6 \%$ FPGQLNADLRK

$0.00 \% \quad 53.6 \%$ KLAVNMVPFPR

$0.00 \% \quad 53.6 \%$ LAVNMVPFPR

$0.00 \% \quad 53.6 \%$ LHFFMPGFAPLTSR

$99.1 \% \quad 49.5$

$99.7 \% \quad 59.9$

$99.3 \% \quad 36.3$

$99.7 \% \quad 46.9$

$99.7 \% \quad 63.8$

$99.7 \% \quad 57.4$

$0.00 \% \quad 53.6 \%$ LHFFMPGFAPLTSRGSQQYR $\quad 98.9 \% \quad 18.1$

$0.00 \% \quad 53.6 \%$ ALTVPELTQQMFDAK

$0.00 \% \quad 53.6 \%$ NMMAACDPR

$0.00 \% \quad 53.6 \%$ HGRYLTVAAVFR

$0.00 \% \quad 53.6 \%$ YLTVAAVFR

$0.00 \% \quad 53.6 \%$ YLTVAAVFRGR

$0.00 \% \quad 53.6 \%$ NSSYFVEWIPNNVK

$0.00 \% \quad 53.6 \%$ TAVCDIPPR

$0.00 \% \quad 53.6 \%$ TAVCDIPPRGLK

$99.7 \% \quad 47.3$

$99.7 \% \quad 35.2$

$99.7 \% \quad 25.2$

$99.7 \% \quad 59.5$

$99.7 \% \quad 46.1$

$99.7 \% \quad 63.5$

$99.7 \% \quad 46.9$

$99.7 \% \quad 36.2$

0.00\% 53.6\% MAATFIGNSTAIQELFK $\quad 99.1 \% \quad 76.6$

$0.00 \% \quad 53.6 \%$ MAATFIGNSTAIQELFKR

$0.00 \% \quad 53.6 \%$ ISEQFTAMFR

$99.2 \% \quad 54.3$

$99.7 \% \quad 62.0$

$0.00 \% \quad 53.6 \%$ ISEQFTAMFRR

$99.5 \% 22.3$

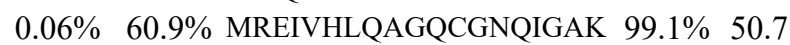

$0.06 \% \quad 60.9 \%$ INVYYNEATGGK

$99.7 \% \quad 61.6$

$0.06 \% \quad 60.9 \%$ INVYYNEATGGKYVPR

$99.7 \% \quad 58.5$

$0.06 \% \quad 60.9 \%$ AVLVDLEPGTMDSVR

$99.7 \% \quad 65.1$

$0.06 \% \quad 60.9 \%$ SGPFGQIFRPDNFVFGQSGAGNNWAK $\quad 99.7 \% \quad 62.4$

$0.06 \% \quad 60.9 \%$ GHYTEGAELVDSVLDVVR $99.7 \% \quad 39.9$

$0.06 \% \quad 60.9 \%$ GHYTEGAELVDSVLDVVRK $99.7 \% \quad 43.9$

$0.06 \% \quad 60.9 \%$ EAESCDCLQGFQLTHSLGGGTGSGMGTLLISK $\quad 99.1 \% \quad 49.5$

$0.06 \% \quad 60.9 \%$ IMNTFSVVPSPK

$0.06 \% \quad 60.9 \%$ FPGQLNADLRK

$99.7 \% \quad 59.9$

$99.3 \% \quad 36.3$

$99.7 \% \quad 46.9$

$0.06 \% \quad 60.9 \%$ KLAVNMVPFPR

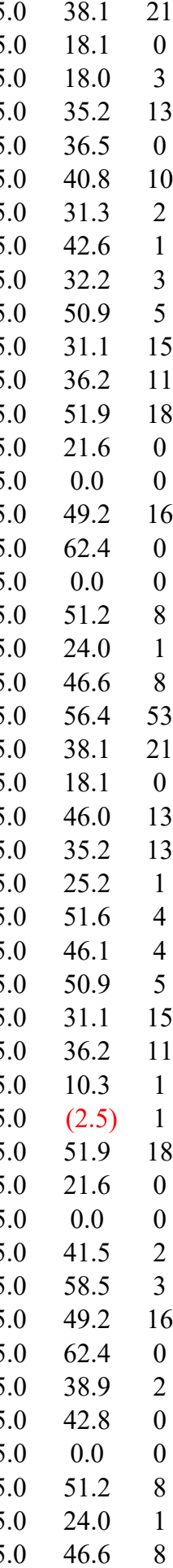

1620.84

2356.17

1707.86

1065.43

1403.79

1053.61

1266.73

1971.88

1446.69

1696.83

1028.52

1326.72

1229.60

1401.69

2126.06

1601.82

2798.34

3327.53

1319.70

1258.69

1271.73

1143.63

1620.84

2356.17

1691.87

1065.43

1389.77

1039.59

1252.72

1696.83

1028.52

1326.72

1857.94

2014.04

1229.60

1401.69

2126.06

1328.65

1843.93

1601.82

2798.34

1958.98

2087.08

3327.53

1319.70

1258.69

1271.73 $\begin{array}{cc}63 & 276 \\ 63 & 282 \\ 83 & 297 \\ 98 & 306 \\ 07 & 318 \\ 10 & 318 \\ 10 & 320 \\ 21 & 336 \\ 25 & 336 \\ 37 & 350 \\ 51 & 359 \\ 51 & 362 \\ 81 & 390 \\ 81 & 391 \\ 1 & 19 \\ 3 & 77 \\ 8 & 103 \\ 23 & 154 \\ 63 & 174 \\ 42 & 252 \\ 52 & 262 \\ 53 & 262 \\ 63 & 276 \\ 63 & 282 \\ 83 & 297 \\ 98 & 306 \\ 07 & 318 \\ 10 & 318 \\ 10 & 320 \\ 37 & 350 \\ 51 & 359 \\ 51 & 362 \\ 63 & 379 \\ 63 & 380 \\ 81 & 390 \\ 81 & 391 \\ 1 & 19 \\ 7 & 58 \\ 7 & 62 \\ 3 & 77 \\ 8 & 103 \\ 04 & 121 \\ 04 & 122 \\ 23 & 154 \\ 63 & 174 \\ 42 & 252 \\ & 262 \\ \end{array}$ 
Tubulin beta- $4 \mathrm{~B}$ chain $\mathrm{GN}=\mathrm{TUBB} 4 \mathrm{~B}$ Tubulin beta- $4 \mathrm{~B}$ chain $\mathrm{GN}=T$ TUBB4B Tubulin beta- $4 \mathrm{~B}$ chain $\mathrm{GN}=\mathrm{TUBB} 4 \mathrm{~B}$ Tubulin beta- $4 \mathrm{~B}$ chain $\mathrm{GN}=\mathrm{TUBB} 4 \mathrm{~B}$ Tubulin beta- $4 \mathrm{~B}$ chain $\mathrm{GN}=\mathrm{TUBB} 4 \mathrm{~B}$ Tubulin beta- $4 \mathrm{~B}$ chain $\mathrm{GN}=\mathrm{TUBB} 4 \mathrm{~B}$

Tubulin beta- $4 \mathrm{~B}$ chain $\mathrm{GN}=\mathrm{TUBB} 4 \mathrm{~B}$ Tubulin beta- $4 \mathrm{~B}$ chain $\mathrm{GN}=\mathrm{TUBB} 4 \mathrm{~B}$ Tubulin beta- $4 \mathrm{~B}$ chain $\mathrm{GN}=\mathrm{TUBB} 4 \mathrm{~B}$ Tubulin beta- $4 \mathrm{~B}$ chain $\mathrm{GN}=\mathrm{TUBB} 4 \mathrm{~B}$ Tubulin beta- $4 \mathrm{~B}$ chain $\mathrm{GN}=\mathrm{TUBB} 4 \mathrm{~B}$ Tubulin beta- $4 \mathrm{~B}$ chain $\mathrm{GN}=\mathrm{TUBB} 4 \mathrm{~B}$ Tubulin beta-4B chain $\mathrm{GN}=\mathrm{TUBB} 4 \mathrm{~B}$ Tubulin beta- $4 \mathrm{~B}$ chain $\mathrm{GN}=\mathrm{TUBB} 4 \mathrm{~B}$

Tubulin beta- $4 \mathrm{~B}$ chain $\mathrm{GN}=\mathrm{TUBB} 4 \mathrm{~B}$

Tubulin beta- 6 chain $\mathrm{GN}=$ TUBB 6

Tubulin beta- 6 chain GN=TUBB6

Tubulin beta- 6 chain GN=TUBB 6

Tubulin beta -6 chain GN=TUBB 6

Tubulin beta- 6 chain GN=TUBB 6

Tubulin beta- 6 chain GN=TUBB6

Tubulin beta- 6 chain GN=TUBB 6

Tubulin beta 6 chain GN=TUBB 6

Tubulin beta- 6 chain GN=TUBB6

Tubulin beta- 6 chain GN=TUBB 6

Tubulin beta- 6 chain GN=TUBB6

Tubulin gamma- 1 chain $\mathrm{GN}=\mathrm{TUBG} 1$

Tubulin gamma- 1 chain $\mathrm{GN}=\mathrm{TUBG}$

Tubulin gamma- 1 chain $\mathrm{GN}=\mathrm{TUBG}$

Tubulin gamma-1 chain GN=TUBG1

Tubulin gamma- 1 chain GN=TUBG1

Tubulin gamma- 1 chain $\mathrm{GN}=$ TUBG 1

Tubulin gamma- 1 chain $\mathrm{GN}=\mathrm{TUBG} 1$

Tubulin gamma- 1 chain GN=TUBG1

Tubulin gamma- 1 chain $\mathrm{GN}=\mathrm{TUBG} 1$

Tubulin-specific chaperone D GN=TBCI

Tubulin-specific chaperone D GN=TBCD TBCD_HUMAN $132.60 \quad 100.0 \%$

Tubulin-specific chaperone D GN=TBCD TBCD_HUMAN $132.60 \quad 100.0 \%$

Tubulin-specific chaperone D GN=TBCD TBCD_HUMAN $132.60 \quad 100.0 \%$

Tyrosine--tRNA ligase, cytoplasmic GN=YARS SYYC_HUMAN $59.15 \quad 100.0 \%$

Tyrosine--tRNA ligase, cytoplasmic GN=YARS SYYC_HUMAN $59.15 \quad 100.0 \%$

Tyrosine--tRNA ligase, cytoplasmic GN=YARS SYYC_HUMAN $59.15 \quad 100.0 \%$ Tyrosine--tRNA ligase, cytoplasmic GN=YARS SYYC_HUMAN $59.15 \quad 100.0 \%$ Tyrosine--tRNA ligase, cytoplasmic GN=YARS SYYC_HUMAN $59.15 \quad 100.0 \%$ Tyrosine--tRNA ligase, cytoplasmic GN=YARS SYYC_HUMAN $59.15 \quad 100.0 \%$ Tyrosine--tRNA ligase, cytoplasmic GN=YARS SYYC_HUMAN $59.15 \quad 100.0 \%$ Tyrosine--tRNA ligase, cytoplasmic GN=YARS SYYC_HUMAN $59.15 \quad 100.0 \%$

TBG1_HUMAN $51.17 \quad 100.0 \%$

TBG1 HUMAN $51.17 \quad 100.0 \%$
$42 \quad 0.06 \% \quad 60.9 \%$ LAVNMVPFPR

$0.06 \% \quad 60.9 \%$ LHFFMPGFAPLTSR

$99.7 \% 63.8$

$99.7 \% \quad 57.4$

25.0

$\begin{array}{lll}0.06 \% & 60.9 \% & \text { LHFFMPGFAPLTSRGSQQ } \\ 0.06 \% & 60.9 \% & \text { ALTVPELTQQMFDAK }\end{array}$

$98.9 \% \quad 18.1$

$99.7 \% \quad 47.3$

$99.7 \% 35.2$

$0.06 \% \quad 60.9 \%$ NMMAACDPR

$0.06 \% \quad 60.9 \%$ HGRYLTVAAVFR

$0.06 \% \quad 60.9 \%$ YLTVAAVFR

$0.06 \% \quad 60.9 \%$ YLTVAAVFRGR

$99.7 \% \quad 25.2$

$99.7 \% \quad 59.5$

$99.7 \% \quad 46.1$

$0.06 \% \quad 60.9 \%$ MSMKEVDEQMLNVQNK $99.7 \% \quad 42.6$

$0.06 \% \quad 60.9 \%$ EVDEQMLNVQNK

$0.06 \% \quad 60.9 \%$ NSSYFVEWIPNNVK

$99.7 \% \quad 32.2$

$99.7 \% \quad 63.5$

$99.7 \% \quad 46.9$

$\begin{array}{lll}0.06 \% & 60.9 \% & \text { TAVCDIPPRGLK }\end{array}$

$0.06 \% \quad 60.9 \%$ ISEQFTAMFR

$0.06 \% \quad 60.9 \%$ ISEQFTAMFRR

$0.01 \% \quad 28.7 \%$ INVYYNESSSQKYVPR

$0.01 \% \quad 28.7 \%$ AALVDLEPGTMDSVR

$0.01 \% \quad 28.7 \%$ FPGQLNADLRK

$0.01 \% \quad 28.7 \%$ KLAVNMVPFPR

$0.01 \% \quad 28.7 \%$ LAVNMVPFPR

$99.7 \% \quad 36.2$

$99.7 \% \quad 62.0$

$99.5 \% 22.3$

$99.7 \% \quad 28.7$

$99.7 \% 40.8$

$99.3 \% \quad 36.3$

$\begin{array}{lll}99.7 \% & 46.9\end{array}$

$99.7 \% \quad 63.8$

$99.7 \% \quad 57.4$

$0.01 \% \quad 28.7 \%$ LHFFMPGFAPLTSR

$98.9 \% \quad 18.1$

$0.01 \% \quad 28.7 \%$ LHFFMPGFAPLTSRGSQQY

$0.01 \% \quad 28.7 \%$ NMMAACDPR

$99.7 \% \quad 60.5$

$99.7 \% \quad 35.2$

$99.7 \% \quad 63.5$

$0.01 \% \quad 28.7 \%$ NSSYFVEWIPNNVK

$\begin{array}{ll}99.4 \% & 30.7 \\ 99.7 \% & 46.8\end{array}$

$99.7 \% \quad 49.9$

$0.03 \% \quad 19.7 \%$ AVLLDLEPR

$0.03 \% \quad 19.7 \%$ VIHSILNSPYAK

$\begin{array}{ll}99.7 \% & 49.9 \\ 99.7 \% & 52.4\end{array}$

$\begin{array}{lllll}0.03 \% & 19.7 \% & \text { RLTQNADCVVVLDNTALNR } & 99.7 \% & 52.4 \\ 0.03 \% & 19.7 \% & 99.7 \% & 45.7\end{array}$

$\begin{array}{lllll}0.03 \% & 19.7 \% & \text { LTQNADCVVVLDNTALNR } & 99.7 \% & 45.7 \\ 0.03 \% & 19.7 \% & \text { LHFLMTGYTPLTTDQSVASVR } & 99.7 \% & 55.3\end{array}$

$0.03 \% \quad 19.7 \%$ KTTVLDVMR

$0.03 \% \quad 19.7 \%$ TTVLDVMR

$0.03 \% \quad 19.7 \%$ NVMVSTGRDR

$0.03 \% \quad 19.7 \%$ SPYLPSAHR

$0.01 \% \quad 3.4 \%$ DAAAVLVSR

$0.01 \% \quad 3.4 \%$ LGLTFLKPK

$0.01 \% \quad 3.4 \%$ LQQVLTGLR

$0.01 \% \quad 3.4 \%$ SQPELIEAHTCER

$0.04 \% \quad 29.9 \%$ EYTLDVYR

$0.04 \% \quad 29.9 \%$ LSSVVTQHDSKK

$0.04 \% \quad 29.9 \%$ YLPALGYSK

$0.04 \% \quad 29.9 \%$ YLPALGYSKR

$99.7 \% \quad 33.4$

$96.1 \% \quad 21.3$

$97.8 \% \quad 21.7$

$99.7 \% \quad 31.2$

$99.7 \% \quad 54.6$

$99.5 \% \quad 25.2$

$99.7 \% \quad 30.6$

$99.7 \% \quad 31.3$

$99.0 \% 31.4$

$99.7 \% \quad 30.0$

$95.3 \% \quad 20.9$

$99.7 \% \quad 37.5$

0.04\% 29.9\% AFCEPGNVENNGVLSFIK 99.7\% 50.3

$0.04 \% \quad 29.9 \%$ NSVEVALNK

$99.7 \% \quad 36.5$

$99.7 \% \quad 51.8$

$0.04 \% \quad 29.9 \%$ LASAAYPDPSK

$\begin{array}{ll}99.6 \% & 22.5\end{array}$
1620.84

2356.17

1691.87

1065.43

1389.77

1039.59

1252.72

1971.88

1446.69

1696.83

1028.52

1326.72

1229.60

1401.69

1946.96

1573.79

1258.69

1271.73

1143.63

1620.84

2356.17

1719.87

1065.43

1696.83

2014.04

1025.60

1341.75

2172.12

2016.02

2353.19

1062.60

934.50

1134.57

1027.53

901.51

1016.65

1027.63

1569.73

1058.52

1328.72

1011.55

1167.65

1994.96

973.53

1119.57

1818.94

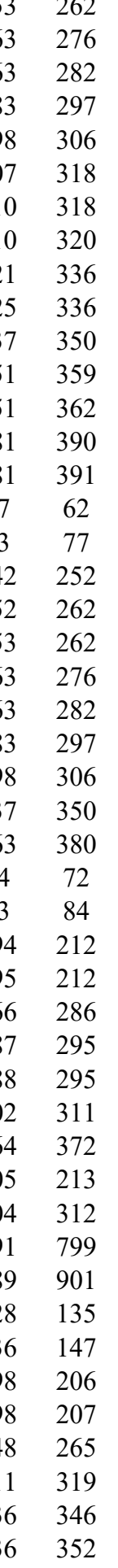

Page 123 of Table S-1-2 
Tyrosine--tRNA ligase, cytoplasmic GN=YARS SYYC_HUMAN $59.15 \quad 100.0 \% \quad 15$

U1 small nuclear ribonucleoprotein A GN=SNRPA SNRPA_HUMAN $31.28 \quad 100.0 \%$

U1 small nuclear ribonucleoprotein A GN=SNRPA SNRPA HUMAN $31.28 \quad 100.0 \%$

U1 small nuclear ribonucleoprotein A GN=SNRPA SNRPA_HUMAN $31.28 \quad 100.0 \%$

U1 small nuclear ribonucleoprotein A GN=SNRPA SNRPA_HUMAN $31.28 \quad 100.0 \%$

1 small nuclear ribonucleoprotein A GN=SNRPA SNRPA HUMAN $31.28 \quad 100.0 \%$

U1 small nuclear ribonucleoprotein A GN=SNRPA SNRPA_HUMAN $31.28 \quad 100.0 \%$

U4/U6 small nuclear ribonucleoprotein Prp31 GN=PRPF31 PRP31 HUMAN 55.46 100.0\%

U4/U6 small nuclear ribonucleoprotein Prp31 GN=PRPF31 PRP31 HUMAN 55.46 100.0\%

U4/U6 small nuclear ribonucleoprotein Prp31 GN=PRPF31 PRP31_HUMAN $55.46 \quad 100.0 \%$

U4/U6 small nuclear ribonucleoprotein Prp31 GN=PRPF31 PRP31 HUMAN 55.46 100.0\%

U4/U6 small nuclear ribonucleoprotein Prp31 GN=PRPF31 PRP31_HUMAN $55.46 \quad 100.0 \%$

U4/U6 small nuclear ribonucleoprotein Prp31 GN=PRPF31 PRP31_HUMAN $55.46 \quad 100.0 \%$

44/U6 small nuclear ribonucleoprotein Prp31 GN=PRPF31 PRP31_HUMAN 55.46 100.0\%

U4/U6 small nuclear ribonucleoprotein Prp31 GN=PRPF31 PRP31_HUMAN 55.46 $100.0 \%$

U4/U6 small nuclear ribonucleoprotein Prp31 GN=PRPF31 PRP31_HUMAN $55.46100 .0 \%$

U4/U6 small nuclear ribonucleoprotein Prp31 GN=PRPF31 PRP31 HUMAN 55.46 100.0\%

U4/U6 small nuclear ribonucleoprotein Prp31 GN=PRPF31 PRP31_HUMAN 55.46 100.0\%

44/U6 small nuclear ribonucleoprotein Prp31 GN=PRPF31 PRP31 HUMAN 55.46 100.0\%

U4/U6 small nuclear ribonucleoprotein Prp31 GN=PRPF31 PRP31_HUMAN 55.46 $100.0 \%$

U4/U6 small nuclear ribonucleoprotein Prp31 GN=PRPF31 PRP31_HUMAN $55.46100 .0 \%$

U4/U6 small nuclear ribonucleoprotein Prp31 GN=PRPF31 PRP31 HUMAN 55.46 100.0\%

U4/U6 small nuclear ribonucleoprotein Prp31 GN=PRPF31 PRP31_HUMAN 55.46 $100.0 \%$

U4/U6 small nuclear ribonucleoprotein Prp31 GN=PRPF31 PRP31 HUMAN 55.46 100.0\%

U4/U6 small nuclear ribonucleoprotein Prp31 GN=PRPF31 PRP31_HUMAN 55.46 100.0\%

U4/U6 small nuclear ribonucleoprotein Prp31 GN=PRPF31 PRP31_HUMAN $55.46 \quad 100.0 \%$

U46 small nuclear ribonucleoprotein Prp31 GN=PRPF31 PRP31_HUMAN $55.46 \quad 100.0 \%$

U4/U6 small nuclear ribonucleoprotein Prp31 GN=PRPF31 PRP31_HUMAN $55.46 \quad 100.0 \%$

U4/U6 small nuclear ribonucleoprotein Prp31 GN=PRPF31 PRP31 HUMAN 55.46 100.0\%

U4/U6 small nuclear ribonucleoprotein Prp4 GN=PRPF4 PRP4 HUMAN 58.45 100.0\% U4/U6 small nuclear ribonucleoprotein Prp4 GN=PRPF4 PRP4_HUMAN 58.45 $100.0 \%$ U4/U6 small nuclear ribonucleoprotein Prp4 GN=PRPF4 PRP4_HUMAN $58.45100 .0 \%$ U5 small nuclear ribonucleoprotein $200 \mathrm{kDa}$ helicase GN=SNRNP200 U520_HUMAN $244.51 \quad 100.0 \%$ U5 small nuclear ribonucleoprotein $200 \mathrm{kDa}$ helicase GN=SNRNP200 U520_HUMAN $244.51 \quad 100.0 \%$ 45 small nuclear ribonucleoprotein $200 \mathrm{kDa}$ helicase GN=SNRNP200 U520 HUMAN $244.51 \quad 100.0 \%$ U5 small nuclear ribonucleoprotein $200 \mathrm{kDa}$ helicase GN=SNRNP200 U520_HUMAN $244.51 \quad 100.0 \%$ U5 small nuclear ribonucleoprotein $200 \mathrm{kDa}$ helicase GN=SNRNP200 U520 HUMAN $244.51 \quad 100.0 \%$ U5 small nuclear ribonucleoprotein $200 \mathrm{kDa}$ helicase GN=SNRNP200 U520 HUMAN $244.51 \quad 100.0 \%$ U5 small nuclear ribonucleoprotein $200 \mathrm{kDa}$ helicase GN=SNRNP200 U520_HUMAN $244.51 \quad 100.0 \%$ U5 small nuclear ribonucleoprotein $200 \mathrm{kDa}$ helicase GN=SNRNP200 U520 HUMAN $244.51 \quad 100.0 \%$

$\begin{array}{llll}16 & 24 & 0.04 \% & 29.9 \% \\ 16 & 24 & 0.04 \% & 29.9 \%\end{array}$

1624

$16 \quad 24$

$16 \quad 24$

$16 \quad 24$

$16 \quad 24$

1624

6

6

6

37

37

37
37

37
37
37

37

37
2

2

37
37

37
37
37

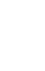

22
22
22

22

22
22

22

22
22

22
22
22

22

22

32

3
3
3

3
32
32

32
32
32

32
32

32
32
32

32
32

$0.04 \% \quad 29.9 \%$ IDVGEAEPR

$0.04 \% \quad 29.9 \%$ GQPDEELKPK

$0.02 \% \quad 27.0 \%$ EVSSATNALR

$0.12 \% \quad 43.9 \%$ ELGNSLDKCK

$0.12 \% \quad 43.9 \%$ HRIYEYVESR

$0.12 \% \quad 43.9 \%$ IYEYVESR

$0.12 \% \quad 43.9 \%$ LGLTEIRK

$0.12 \% \quad 43.9 \%$ YFSSMAEFLK

$0.00 \% \quad 6.3 \% \quad$ LHKEIPETTR

$0.00 \% \quad 6.3 \% \quad$ FLGTTCYDR

$0.11 \% \quad 14.3 \%$ DIDAFWLQR

$0.11 \% \quad 14.3 \%$ FYDDAIVSQK

$0.11 \% \quad 14.3 \%$ KADEVLEILK

$0.11 \% \quad 14.3 \%$ ADEVLEILK
$0.04 \% \quad 29.9 \%$ NSEPEEVIPSRLDIR

$0.04 \% \quad 29.9 \%$ TVVSGLVQFVPK

$0.04 \% \quad 29.9 \%$ QVEPLDPPAGSAPGEHVFVK $99.3 \%$

$98.1 \% \quad 18.2$

$\begin{array}{lllll}0.02 \% & 27.0 \% & \text { GQAFVIFKEVSSATNALR } & 99.4 \% & 20.0\end{array}$

$0.02 \% \quad 27.0 \%$ IQYAKTDSDIIAK

$99.7 \% \quad 65.8$

$99.7 \% \quad 63.8$

$0.02 \% \quad 27.0 \%$ KAVQGGGATPVVGAVQGPVPGMPPMTQAPR $\quad 99.7 \% 33.6$

$0.02 \% \quad 27.0 \%$ AVQGGGATPVVGAVQGPVPGMPPMTQAPR $\quad 97.1 \% \quad 15.0$

$0.02 \% \quad 27.0 \%$ DALQGFKITQNNAMK

$0.12 \% \quad 43.9 \%$ ASEVMGPVEAAPEYR

$0.12 \% \quad 43.9 \%$ RFPELESLVPNALDYIR

$0.12 \% \quad 43.9 \%$ TVKELGNSLDK

$99.5 \% \quad 24.7$

$99.7 \% \quad 63.0$

$95.5 \% \quad 15.0$

$99.7 \% \quad 53.5$

$99.7 \% \quad 36.6$

$99.7 \% \quad 41.5$

$99.0 \% \quad 47.0$

$0.12 \% \quad 43.9 \%$ MSFIAPNL SIIIGASTAAK $\quad 99.7 \% \quad 60.5$

$0.12 \% \quad 43.9 \%$ IMGVAGGLTNLSK

$0.12 \% \quad 43.9 \%$ MPACNIMLLGAQR

$0.12 \% \quad 43.9 \%$ MPACNIMLLGAQRK

$99.7 \% \quad 63.9$

$99.7 \% \quad 62.6$

$99.7 \% \quad 43.6$

$\begin{array}{llll}0.12 \% & 43.9 \% & \text { CTLAARVDSFHESTEGK } \quad 99.7 \% & 29.5\end{array}$

$0.12 \% \quad 43.9 \%$ VDSFHESTEGK

$0.12 \% \quad 43.9 \%$ VGYELKDEIER

$0.12 \% \quad 43.9 \%$ QVKPLPAPLDGQR

$0.12 \% \quad 43.9 \%$ VRQTQVNEATK

$0.12 \% \quad 43.9 \%$ QTQVNEATKAR

$0.12 \% \quad 43.9 \%$ TLQKQSVVYGGK

$99.7 \% \quad 40.2$

$99.7 \% \quad 55.6$

$99.7 \% \quad 30.6$

$99.0 \% \quad 63.9$

$99.7 \% \quad 57.4$

$99.7 \% \quad 51.7$

$99.7 \% \quad 49.4$

$0.12 \% \quad 43.9 \%$ SSGTASSVAFTPLQGLEIVNPQAAEK $\quad 99.7 \% \quad 43.2$

$\begin{array}{llll}0.12 \% & 43.9 \% & \text { SSGTASSVAFTPLQGLEIVNPQAAEKK } \quad 99.7 \% \quad 38.0\end{array}$

$0.12 \% \quad 43.9 \%$ VAEANQKYFSSMAEFLK

$0.00 \% \quad 6.3 \%$ GHNTNVGAIVFHPK

$0.11 \% \quad 14.3 \%$ ANSNLVLQADR

$0.11 \% \quad 14.3 \%$ YAQAGFEGFK

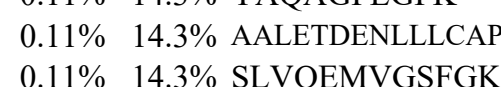

$\begin{array}{lll}0.11 \% & 14.3 \% & \text { SLVQEMVGSFGK } \\ 0.11 \% & 14.3 \% & \text { SLVQEMVGSFGKR }\end{array}$

$\begin{array}{ll}99.7 \% & 47.2 \\ 99.7 \% & 40.2\end{array}$

$\begin{array}{ll}99.7 \% & 40.2 \\ 99.2 \% & 20.6\end{array}$

$99.5 \% \quad 24.4$

$99.4 \% \quad 24.2$

$99.7 \% \quad 56.4$

$99.7 \% \quad 43.2$

$99.7 \% \quad 56.3$

$99.7 \% \quad 58.3$

$98.4 \% \quad 20.0$

$\begin{array}{lll}99.7 \% & 53.8\end{array}$

$\begin{array}{ll}99.7 \% & 53.7 \\ 99.7 \% & 57.1\end{array}$

$\begin{array}{lll}99.7 \% & 57.1 & 25.0 \\ 99.7 \% & 52.0 & 25.0\end{array}$

$\begin{array}{lll}99.7 \% & 57.1 & 25.0 \\ 99.7 \% & 52.0 & 25.0\end{array}$

1753.91

985.50

1273.75

1933.95

2074.06

1140.59

1938.04

1047.54

1465.79

2887.49

2759.40

1678.86

1621.75

2032.09

1203.66

1163.57

1351.68

1058.52

1921.05

1260.70

1490.73

1602.83

1907.89

1235.55

1350.69

1418.81

929.58

1273.69

1245.65

1307.73

2602.34

2730.43

1978.96

1238.58

1223.67

1490.79

1132.51

1200.63

1163.58

1185.58

1157.68

1029.58

1117.53

1943.97

1281.65

1437.75 
U5 small nuclear ribonucleoprotein $200 \mathrm{kDa}$ helicase GN=SNRNP200 U520_HUMAN $244.51 \quad 100.0 \% 32$ U5 small nuclear ribonucleoprotein $200 \mathrm{kDa}$ helicase GN=SNRNP200 U520_HUMAN $244.51 \quad 100.0 \%$ U5 small nuclear ribonucleoprotein $200 \mathrm{kDa}$ helicase GN=SNRNP200 U520_HUMAN $244.51 \quad 100.0 \%$ U5 small nuclear ribonucleoprotein $200 \mathrm{kDa}$ helicase GN=SNRNP200 U520_HUMAN $244.51 \quad 100.0 \%$ U5 small nuclear ribonucleoprotein $200 \mathrm{kDa}$ helicase GN=SNRNP200 U520_HUMAN $244.51 \quad 100.0 \% \quad 32$ U5 small nuclear ribonucleoprotein $200 \mathrm{kDa}$ helicase GN=SNRNP200 U520_HUMAN $244.51 \quad 100.0 \% \quad 32$ U5 small nuclear ribonucleoprotein $200 \mathrm{kDa}$ helicase GN=SNRNP200 U520_HUMAN $244.51 \quad 100.0 \%$ U5 small nuclear ribonucleoprotein $200 \mathrm{kDa}$ helicase GN=SNRNP200 U520_HUMAN $244.51 \quad 100.0 \%$ U5 small nuclear ribonucleoprotein $200 \mathrm{kDa}$ helicase GN=SNRNP200 U520_HUMAN $244.51 \quad 100.0 \%$ U5 small nuclear ribonucleoprotein $200 \mathrm{kDa}$ helicase GN=SNRN200 U520_HUMAN $244.51 \quad 100.0 \%$ U5 small nuclear ribonucleoprotein $200 \mathrm{kDa}$ helicase GN=SNRNP200 U520_HUMAN $244.51 \quad 100.0 \% \quad 32$ U5 small nuclear ribonucleoprotein $200 \mathrm{kDa}$ helicase GN=SNRNP200 U520_HUMAN $244.51 \quad 100.0 \%$ U5 small nuclear ribonucleoprotein $200 \mathrm{kDa}$ helicase GN=SNRNP200 U520_HUMAN $244.51 \quad 100.0 \%$ U5 small nuclear ribonucleoprotein $200 \mathrm{kDa}$ helicase GN=SNRNP200 U520_HUMAN $244.51 \quad 100.0 \%$ U5 small nuclear ribonucleoprotein $200 \mathrm{kDa}$ helicase GN=SNRNP200 U520_HUMAN $244.51 \quad 100.0 \% \quad 32$ U5 small nuclear ribonucleoprotein $200 \mathrm{kDa}$ helicase GN=SNRNP200 U520_HUMAN $244.51 \quad 100.0 \%$ U5 small nuclear ribonucleoprotein $200 \mathrm{kDa}$ helicase GN=SNRNP200 U520 HUMAN $244.51 \quad 100.0 \% \quad 32$ U5 small nuclear ribonucleoprotein $200 \mathrm{kDa}$ helicase GN=SNRNP200 U520_HUMAN $244.51 \quad 100.0 \% \quad 32$ U5 small nuclear ribonucleoprotein $200 \mathrm{kDa}$ helicase GN=SNRNP200 U520_HUMAN $244.51 \quad 100.0 \%$ U5 small nuclear ribonucleoprotein $200 \mathrm{kDa}$ helicase GN=SNRNP200 U520_HUMAN $244.51 \quad 100.0 \%$ U5 small nuclear ribonucleoprotein $200 \mathrm{kDa}$ helicase GN=SNRNP200 U520_HUMAN $244.51 \quad 100.0 \%$ U5 small nuclear ribonucleoprotein $200 \mathrm{kDa}$ helicase GN=SNRNP200 U520_HUMAN $244.51 \quad 100.0 \%$ U5 small nuclear ribonucleoprotein $200 \mathrm{kDa}$ helicase GN=SNRNP200 U520_HUMAN $244.51 \quad 100.0 \%$ U7 snRNA-associated Sm-like protein LSm11 GN=LSM11 LSM11_HUMAN $39.50 \quad 100.0 \%$ U7 snRNA-associated Sm-like protein LSm11 GN=LSM11 LSM11 HUMAN $39.50 \quad 100.0 \%$ UAP56-interacting factor GN=FYTTD1 UIF_HUMAN $35.82 \quad 100.0 \%$ UAP56-interacting factor GN=FYTTD1 UIF HUMAN $35.82 \quad 100.0 \%$ UAP56-interacting factor GN=FYTTD1 UIF_HUMAN $35.82 \quad 100.0 \%$ UAP56-interacting factor GN=FYTTD1 UIF_HUMAN $35.82 \quad 100.0 \%$ UAP56-interacting factor GN=FYTTD1 UIF HUMAN $35.82 \quad 100.0 \%$ UAP56-interacting factor GN=FYTTD1 UIF_HUMAN $35.82 \quad 100.0 \%$ Ubiquitin carboxyl-terminal hydrolase 15 GN=USP15 UBP15_HUMAN $112.42 \quad 100.0 \%$ Ubiquitin carboxyl-terminal hydrolase $15 \mathrm{GN}=\mathrm{USP} 15$ UBP15_HUMAN $112.42 \quad 100.0 \%$ Ubiquitin carboxyl-terminal hydrolase 24 GN=USP24 UBP24_HUMAN $294.37 \quad 100.0 \%$ Ubiquitin carboxyl-terminal hydrolase 24 GN=USP24 UBP24_HUMAN $294.37 \quad 100.0 \%$ Ubiquitin-40S ribosomal protein S27a GN=RPS27A RS27A_HUMAN $17.97 \quad 100.0 \%$ Ubiquitin-40S ribosomal protein S27a GN=RPS27A RS27A_HUMAN $17.97 \quad 100.0 \%$ Ubiquitin-40S ribosomal protein S27a GN=RPS27A RS27A HUMAN $17.97 \quad 100.0 \%$ Ubiquitin-40S ribosomal protein S27a GN=RPS27A RS27A_HUMAN $17.97 \quad 100.0 \%$ Ubiquitin-40S ribosomal protein S27a GN=RPS27A RS27A_HUMAN $17.97 \quad 100.0 \%$ Ubiquitin-like modifier-activating enzyme $1 \mathrm{GN}=$ UBA1 UBA1_HUMAN $117.85 \quad 100.0 \%$ Ubiquitin-like modifier-activating enzyme 1 GN=UBA1 UBA1_HUMAN $117.85 \quad 100.0 \%$ Ubiquitin-like modifier-activating enzyme 1 GN=UBA1 UBA1 HUMAN $117.85100 .0 \%$ Ubiquitin-protein ligase E3A GN=UBE3A UBE3A_HUMAN $100.69 \quad 100.0 \%$ Ubiquitin-protein ligase E3A GN=UBE3A UBE3A_HUMAN $100.69 \quad 100.0 \%$ Uncharacterized protein $\mathrm{C} 17$ orf $85 \mathrm{GN}=\mathrm{C} 17$ orf85 CQ085 HUMAN $70.59 \quad 100.0 \%$ Uncharacterized protein $\mathrm{C} 17$ orf85 GN=C17orf85 CQ085_HUMAN $70.59 \quad 100.0 \%$

6

6

2

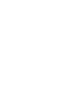

2

2
5
5

5
5

5
5
5

5
5
3

$\begin{array}{llll}75 & 0.11 \% & 14.3 \% & \text { NIEMTQEDVR } \\ 75 & 0.11 \% & 14.3 \% & \text { FQIMNEIVYEK }\end{array}$ $0.11 \% \quad 14.3 \%$ NQVLVFVHSR $0.11 \% \quad 14.3 \%$ EGSASTEVLR $0.11 \% \quad 14.3 \%$ GTQVYSPEK $0.11 \% \quad 14.3 \%$ KTGNFQVTELGR $0.11 \% \quad 14.3 \%$ TGNFQVTELGR $0.11 \% \quad 14.3 \%$ VPIPVKESIEEPSAK $0.11 \% \quad 14.3 \%$ ESIEEPSAK $0.11 \% \quad 14.3 \%$ LYDLNHNEIGELIR $0.11 \% \quad 14.3 \%$ LELSVHLQPITR $0.11 \% \quad 14.3 \%$ MLLQSSEGR $0.11 \% \quad 14.3 \%$ VVLLTGETSTDLK $0.11 \% \quad 14.3 \%$ VVLLTGETSTDLKLLGK $0.11 \% \quad 14.3 \%$ YISSQIERPIR $0.11 \% \quad 14.3 \%$ IVALSSSLSNAK $0.11 \% \quad 14.3 \%$ KPVIVFVPSR $0.11 \% \quad 14.3 \%$ KPVIVFVPSRK $0.11 \% \quad 14.3 \%$ LTAIDILTTCAADIQR $0.11 \% \quad 14.3 \%$ CVIMCQGSK $0.11 \% \quad 14.3 \%$ MTQNPNYYNLQGISHR $0.11 \% 14.3 \%$ TNLLLQAHLSR

$0.11 \% \quad 14.3 \%$ SNSLISIKR

$0.00 \% \quad 5.3 \% \quad$ SAVEDSTLSR $0.00 \% \quad 5.3 \%$ VDYQQVFTR $0.02 \% \quad 21.4 \%$ LVGATATSSPPPKAR $0.02 \% \quad 21.4 \%$ LLQQSGAQQFR $0.02 \% \quad 21.4 \%$ KNNIPANFTR $0.02 \% \quad 21.4 \%$ GVPLQFDINSVGK $3 \quad 0.02 \% \quad 21.4 \%$ FGILKEQR $3 \quad 0.02 \% \quad 21.4 \%$ ATLTYNKGGSR $0.01 \% \quad 2.2 \%$ SPGASNFSTLPK $0.01 \% \quad 2.2 \%$ STLVCPECAK $0.00 \% \quad 0.7 \%$ SSSGFVGLR $0.00 \% \quad 0.7 \%$ VAVATILEK

$\begin{array}{ll}99.5 \% & 29.8\end{array}$ $99.7 \% \quad 58.7$ $99.7 \% \quad 44.2$ $99.7 \% \quad 45.4$ $95.7 \% \quad 17.9$ $\begin{array}{lll}94.9 \% & 20.9\end{array}$ $99.7 \% \quad 66.9$ $99.7 \% \quad 44.1$ $99.6 \% 29.4$ $99.7 \% \quad 35.9$ $99.7 \% \quad 48.0$ $98.7 \% \quad 19.4$ $99.7 \% \quad 39.1$ $99.3 \% \quad 19.1$ $98.0 \% \quad 21.6$ $99.7 \% \quad 79.5$ $99.7 \% \quad 44.7$ $98.4 \% \quad 19.4$ $\begin{array}{lll}99.7 \% & 81.7\end{array}$ $99.4 \% \quad 29.4$ $\begin{array}{lll}99.4 \% & 20.5\end{array}$ $99.7 \% \quad 60.1$ $99.7 \% \quad 48.0$ $99.6 \% \quad 24.0$ $99.4 \% \quad 21.0$ $99.0 \% \quad 23.1$ $99.7 \% \quad 46.2$ $99.7 \% 36.8$ $99.7 \% \quad 39.8$ $98.4 \% 24.8$ $99.7 \% \quad 30.8$ $99.7 \% \quad 69.1$ $99.4 \% \quad 20.2$ $99.5 \% \quad 25.8$ $96.9 \% \quad 17.2$

$0.07 \% \quad 28.8 \%$ TLTGKTITLEVEPSDTIENVK $98.5 \% 25.2$ $0.07 \% \quad 28.8 \%$ TITLEVEPSDTIENVK $0.07 \% \quad 28.8 \%$ TITLEVEPSDTIENVKAK $0.07 \% \quad 28.8 \%$ IQDKEGIPPDQQR $0.07 \% \quad 28.8 \%$ TLSDYNIQK $99.7 \% \quad 57.9$ $99.7 \% \quad 28.0$ $99.7 \% \quad 34.4$ $99.6 \% \quad 30.5$

$0.01 \% \quad 4.2 \% \quad$ SLVASLAEPDFVVTDFAK $\quad 99.7 \% \quad 30.4$ $0.01 \% \quad 4.2 \% \quad$ LKSDTAAAAVR $0.01 \% \quad 4.2 \% \quad$ LAGTQPLEVLEAVQR $0.00 \% \quad 3.1 \%$ IGDSSQGDNNLQK $0.00 \% \quad 3.1 \%$ NLVNDDDAIVAASK $0.00 \% \quad 3.2 \% \quad$ SEVNLAQR $0.00 \% \quad 3.2 \%$ ADSVSSSNIKNR $\begin{array}{llll}99.7 \% & 30.4 & 25.0 & 30.4\end{array}$ $\begin{array}{llll}99.7 \% & 58.2 & 25.0 & 58.2\end{array}$ $\begin{array}{llll}99.5 \% & 22.4 & 25.0 & 22.4\end{array}$ $\begin{array}{lllll}99.7 \% & 45.6 & 25.0 & 37.7 & 2\end{array}$ $98.0 \% \quad 22.7 \quad 25.0 \quad 17.9$ $99.4 \% \quad 23.6 \quad 25.0 \quad 23.2$
1234.57 1429.70 1198.67

1048.53

1008.50

1349.72

1221.62

1622.90

989.48

1698.88

1405.82

1020.51

1375.77

1787.05

1361.75

1189.68

1141.71

1269.80

1774.94

1082.48

1935.91

1265.73

1017.61

1064.52

1155.58

1452.82

1275.68

1174.63

1373.74

990.57

1167.61

1205.62

1164.54

909.48

943.58

2288.22

1787.93

1987.06

1523.78

1081.55

1909.00

1102.62

1623.91

1375.65

1444.73

916.48

1277.64 $\begin{array}{cc}38 & 647 \\ 01 & 711 \\ 19 & 728 \\ 54 & 763 \\ 30 & 838 \\ 75 & 986 \\ 76 & 986 \\ 44 & 1058 \\ 50 & 1058 \\ 53 & 1166 \\ 84 & 1195 \\ 67 & 1375 \\ 05 & 1417 \\ 05 & 1421 \\ 76 & 1486 \\ 87 & 1498 \\ 57 & 1566 \\ 57 & 1567 \\ 71 & 1586 \\ 02 & 1710 \\ 64 & 1779 \\ 91 & 1901 \\ 73 & 2081 \\ 43 & 252 \\ 33 & 341 \\ 8 & 22 \\ 7 & 67 \\ 66 & 175 \\ 73 & 285 \\ 95 & 302 \\ 03 & 313 \\ 29 & 240 \\ 44 & 453 \\ 84 & 1692 \\ 36 & 2244 \\ 7 & 27 \\ 2 & 27 \\ 2 & 29 \\ 0 & 42 \\ 5 & 63 \\ 05 & 322 \\ 27 & 537 \\ 79 & 693 \\ 14 & 226 \\ 60 & 373 \\ 00 & 107 \\ 42 & 453 \\ & \end{array}$

Page 125 of Table S-1-2 
Uncharacterized protein C3orf17 GN=C3orf17 CC017_HUMAN $64.55 \quad 100.0 \%$ Uncharacterized protein $\mathrm{C} 3$ orf $17 \mathrm{GN}=\mathrm{C} 3$ orf17 $\quad$ CC017_HUMAN $64.55 \quad 100.0 \%$ Uncharacterized protein $\mathrm{C} 3$ orf $17 \mathrm{GN}=\mathrm{C} 3$ orf17 $\quad$ CC017_HUMAN $64.55 \quad 100.0 \%$ Unconventional myosin-Ic GN=MYO1C MYO1C_HUMAN $121.68 \quad 100.0 \%$ Unconventional myosin-Ic GN=MYO1C MYO1C_HUMAN $121.68 \quad 100.0 \%$ Unconventional myosin-Va GN=MYO5A MYO5A_HUMAN $215.41 \quad 100.0 \%$ Unconventional myosin-Va GN=MYO5A MYO5A_HUMAN $215.41 \quad 100.0 \%$ Unconventional myosin-Va GN=MYO5A MYO5A_HUMAN $215.41 \quad 100.0 \%$ Unconventional myosin-Va GN=MYO5A MYO5A_HUMAN $215.41 \quad 100.0 \%$ Unconventional myosin-Va GN=MYO5A MYO5A_HUMAN $215.41 \quad 100.0 \%$ Unconventional myosin-Va GN=MYO5A MYO5A_HUMAN $215.41 \quad 100.0 \%$ Unconventional myosin-Va GN=MYO5A MYO5A_HUMAN $215.41 \quad 100.0 \%$ Unconventional myosin-Vb GN=MYO5B MYO5B_HUMAN $213.68 \quad 100.0 \%$ Unconventional myosin-Vb GN=MYO5B MYO5B_HUMAN $213.68 \quad 100.0 \%$ Unconventional myosin-Vb GN=MYO5B MYO5B_HUMAN $213.68 \quad 100.0 \%$ Unconventional myosin-Vb GN=MYO5B MYO5B_HUMAN $213.68 \quad 100.0 \%$ Unconventional myosin-Vb GN=MYO5B MYO5B_HUMAN $213.68 \quad 100.0 \%$ Unconventional myosin-Vb GN=MYO5B MYO5B_HUMAN $213.68 \quad 100.0 \%$ Unconventional myosin-Vb GN=MYO5B MYO5B_HUMAN $213.68 \quad 100.0 \%$ Unconventional myosin-Vb GN=MYO5B MYO5B_HUMAN $213.68 \quad 100.0 \%$ Unconventional myosin-Vb GN=MYO5B MYO5B_HUMAN $213.68 \quad 100.0 \%$ Unconventional myosin-Vb GN=MYO5B MYO5B_HUMAN $213.68 \quad 100.0 \%$ Unconventional myosin-Vb GN=MYO5B MYO5B_HUMAN $213.68 \quad 100.0 \%$ Unconventional myosin-Vb GN=MYO5B MYO5B_HUMAN $213.68 \quad 100.0 \%$ UPF0488 protein $\mathrm{C} 8$ orf33 $\mathrm{GN}=\mathrm{C} 8$ orf33 $\mathrm{CH} 033$ HUMAN $24.99 \quad 100.0 \%$ UPF0488 protein C8orf33 GN=C8orf33 CH033_HUMAN $24.99 \quad 100.0 \%$ UPF0488 protein C8orf33 GN=C8orf33 CH033_HUMAN $24.99 \quad 100.0 \%$ Uridine-cytidine kinase $2 \mathrm{GN}=\mathrm{UCK} 2 \quad$ UCK2_HUMAN $29.30 \quad 100.0 \%$ Uridine-cytidine kinase 2 GN=UCK2 UCK2_HUMAN $29.30 \quad 100.0 \%$ Uridine-cytidine kinase-like 1 GN=UCKL1 UCKL1_HUMAN $61.14 \quad 100.0 \%$ Uridine-cytidine kinase-like $1 \mathrm{GN}=\mathrm{UCKL} 1$ UCKL1_HUMAN $61.14 \quad 100.0 \%$ Vacuolar protein sorting-associated protein 26A GN=VPS26A VP26A_HUMAN $38.17 \quad 100.0 \%$ Vacuolar protein sorting-associated protein 26A GN=VPS26A VP26A HUMAN $38.17 \quad 100.0 \%$ Vacuolar protein sorting-associated protein 26A GN=VPS26A VP26A_HUMAN $38.17 \quad 100.0 \%$ Vacuolar protein sorting-associated protein 33B GN=VPS33B VP33B_HUMAN $70.59 \quad 100.0 \%$ Vacuolar protein sorting-associated protein 33B GN=VPS33B VP33B HUMAN $70.59 \quad 100.0 \%$ Vacuolar protein sorting-associated protein $35 \mathrm{GN}=\mathrm{VPS} 35$ VPS35_HUMAN $91.71 \quad 100.0 \%$ Vacuolar protein sorting-associated protein $35 \mathrm{GN}=$ VPS35 VPS35 HUMAN $91.71 \quad 100.0 \%$ Vacuolar protein sorting-associated protein $35 \mathrm{GN}=\mathrm{VPS} 35$ VPS35_HUMAN $91.71 \quad 100.0 \%$ Vacuolar protein sorting-associated protein $35 \mathrm{GN}=$ VPS35 VPS35_HUMAN $91.71 \quad 100.0 \%$ Vecular protein sorting-associated protein 51 homolog GN=VPS51 VPS51 HUMAN $86.04 \quad 100.0 \%$ Vacuolar protein sorting-associated protein 51 homolog GN=VPS51 VPS51_HUMAN $86.04 \quad 100.0 \%$ Vacuolar protein sorting-associated protein 52 homolog GN=VPS52 VPS52 HUMAN $82.22 \quad 99.9 \%$ Vacuolar protein sorting-associated protein 52 homolog GN=VPS52 VPS52_HUMAN $82.22 \quad 99.9 \%$ Very-long-chain (3R)-3-hydroxyacyl-CoA dehydratase $3 \mathrm{GN}=\mathrm{HACD} 3$ HACD3_HUMAN $43.16 \quad 100.0 \%$ Very-long-chain (3R)-3-hydroxyacyl-CoA dehydratase $3 \mathrm{GN}=\mathrm{HACD} 3 \mathrm{HACD} 3$ HUMAN $43.16100 .0 \%$ Very-long-chain (3R)-3-hydroxyacyl-CoA dehydratase 3 GN=HACD3 HACD3_HUMAN $43.16 \quad 100.0 \%$
$0.00 \% \quad 5.8 \%$ ASEETLLGISK $0.00 \% \quad 5.8 \%$ HLEAQGTSLPK

$0.00 \% \quad 5.8 \%$ EIQQFSQGTRK

$0.00 \% \quad 3.4 \%$ LFISTRLGTDEISPR

$96.3 \% \quad 15.3$

$95.0 \% \quad 19.5$

$99.7 \% \quad 31.7$

$0.00 \% \quad 3.4 \%$ VLQALGSEPIQYAVPVVKYDR

$0.01 \% \quad 4.2 \%$ LGNADNFNYTK

$0.01 \% \quad 4.2 \%$ ACGVLETIR

$0.01 \% \quad 4.2 \%$ AGQVAYLEK

$0.01 \% \quad 4.2 \% \quad$ AATIVLQSYLR

$0.01 \% \quad 4.2 \%$ SAPEVTAPGAPAYR

$0.01 \% \quad 4.2 \%$ IEASLQHEITR

$0.01 \% \quad 4.2 \%$ HADYLNDDQKVR

$0.04 \% \quad 7.5 \%$ DEKNQSIIVSGESGAGK

$0.04 \% \quad 7.5 \%$ VLASSPIMEAIGNAK

$0.04 \% \quad 7.5 \%$ YIQIGFDKR

$0.04 \% \quad 7.5 \% \quad$ KLVTTSETYVK

$0.04 \% \quad 7.5 \%$ TMSLQQVINAR

$0.04 \% \quad 7.5 \%$ ACGVLETIR

$0.04 \% \quad 7.5 \%$ AGQVAYLEK

$0.04 \% \quad 7.5 \%$ LNVGMENKVVQLQR

$0.04 \% \quad 7.5 \%$ AAMDMTVFLK

$0.04 \% \quad 7.5 \%$ TQIVSADQRR

$0.04 \% \quad 7.5 \%$ AQDLEAAQALAQSER

$0.04 \% \quad 7.5 \%$ TIQAQLQER

$0.01 \% \quad 17.5 \%$ AHPLGDEGGTASKK

$0.01 \% \quad 17.5 \%$ QKEQAIGAIR

$0.01 \% \quad 17.5 \%$ AAAYSAQVQPVDGATR

$0.00 \% \quad 7.7 \%$ QVVILSQDSFYR

$0.00 \% \quad 7.7 \%$ YADVIIPR

$0.00 \% \quad 3.1 \%$ LADIVVPR

$0.00 \% \quad 3.1 \%$ QITGVSILR

$0.01 \% \quad 14.1 \%$ ELALPGELTQSR

$0.01 \% \quad 14.1 \%$ LFLAGYDPTPTMR

$0.01 \% \quad 14.1 \%$ TNFHQRFESPESQASAEQPEM

$0.00 \% \quad 4.9 \% \quad$ AGLLTEQAPGDTLTAVESK

$0.00 \% \quad 4.9 \%$ VDGEYDLKVPR

$0.01 \% \quad 6.2 \% \quad$ ILVGTNLVR

$0.01 \% \quad 6.2 \% \quad$ LSQLEGVNVER

$0.01 \% \quad 6.2 \% \quad$ IPVDTYNNILTVLK

$0.01 \% \quad 6.2 \% \quad$ SEDPDQQYLILNTAR

$0.00 \% \quad 3.6 \%$ AIQDDCQVITAR

$0.00 \% \quad 3.6 \%$ RLAQEQGGGDNSLLVR

$0.00 \% \quad 3.6 \%$ AADDSKEVESFQQLLNAR

$0.00 \% \quad 3.6 \%$ VLSQPQLR

$0.04 \% \quad 9.9 \%$ QVNITVQK

$0.04 \% \quad 9.9 \%$ QVNITVQKK

$0.04 \% \quad 9.9 \%$ LRLESEGSPETLTNLR $\begin{array}{llll}99.7 \% & 33.4 & 25.0 & 33.4\end{array}$

$99.7 \% \quad 51.7$

$99.0 \% \quad 36.9$

$99.7 \% \quad 52.2$

$99.7 \% \quad 50.4$

$99.7 \% 27$.

$96.3 \% \quad 16.8$

$98.8 \% \quad 22.0$

$99.7 \% \quad 37.0$

$\begin{array}{lll}98.9 \% & 22.0\end{array}$

$99.7 \% \quad 28.8$

$99.7 \% \quad 37.3$

$99.7 \% \quad 36.6$

$99.0 \% \quad 36.9$

$99.7 \% \quad 52.2$

$99.7 \% \quad 29.3$

$99.7 \% \quad 28.6$

$99.7 \% \quad 33.7$

$99.7 \% \quad 64.6$

$99.2 \% \quad 25.2$

$94.9 \% \quad 13.9$

$99.7 \% \quad 30.9$

$99.7 \% \quad 47.0$

$99.7 \% \quad 35.6$

$99.0 \% \quad 40.6$

$99.0 \% \quad 45.0$

$97.9 \% \quad 23.9$

$99.7 \% \quad 42.3$

$99.7 \% \quad 50.6$

$99.7 \% \quad 51.7$

$9.7 \% \quad 47.0$

$99.0 \% \quad 25.4$

$\begin{array}{lll}99.7 \% & 40.5\end{array}$

$99.7 \% \quad 65.8$

$97.9 \% \quad 16.6$

$99.7 \% \quad 49.6$

$99.7 \% \quad 56.4$

$9.7 \% 26.5$

$99.0 \% \quad 42.8$

$96.0 \% \quad 15.6$

$99.7 \% \quad 42.3$
180.6

1321.69

1704.93

2345.29

1256.59

1018.54

978.53

1234.72

1386.70

1296.69

1473.71

1718.86

1500.81

1139.62

1268.71

1260.67

1018.54

978.53

1643.89

1126.56

1173.63

1600.79

1086.59

1367.69

1113.64

1604.80

1454.76

946.54

882.54

986.60

1313.71

1497.74

2466.06

1900.99

1290.67

984.62

1243.66

1602.91

1762.86

1389.68

1712.90

2020.99

940.56

929.54

1057.64

1814.96 $\begin{array}{cc}68 & 278 \\ 05 & 415 \\ 68 & 478 \\ 95 & 909 \\ 10 & 930 \\ 79 & 289 \\ 83 & 691 \\ 52 & 760 \\ 39 & 849 \\ 33 & 1246 \\ 97 & 1407 \\ 19 & 1530 \\ 53 & 169 \\ 96 & 210 \\ 23 & 231 \\ 80 & 390 \\ 91 & 401 \\ 80 & 688 \\ 50 & 758 \\ 19 & 932 \\ 39 & 1148 \\ 66 & 1275 \\ 34 & 1448 \\ 96 & 1804 \\ 7 & 70 \\ 34 & 143 \\ 83 & 198 \\ 5 & 66 \\ 03 & 210 \\ 74 & 281 \\ 93 & 401 \\ 4 & 105 \\ 50 & 262 \\ 07 & 327 \\ 40 & 458 \\ 97 & 507 \\ 18 & 226 \\ 27 & 237 \\ 04 & 417 \\ 00 & 514 \\ 21 & 232 \\ 55 & 370 \\ 79 & 596 \\ 91 & 698 \\ 7 & 84 \\ 7 & 85 \\ 31 & 146\end{array}$

Page 126 of Table S-1-2 
Vesicle-fusing ATPase GN=NSH

Vesicle-fusing ATPase GN=NSF

Vesicle-fusing ATPase GN=NSF

Vesicle-fusing ATPase $\mathrm{GN}=\mathrm{NSF}$

Vesicle-fusing ATPase $\mathrm{GN}=\mathrm{NSH}$

Vesicle-fusing ATPase $\mathrm{GN}=\mathrm{NSF}$

Vesicle-fusing ATPase GN=NSF

Vesicle-fusing ATPase $\mathrm{GN}=\mathrm{NSS}$

Vesicle-fusing ATPase $\mathrm{GN}=\mathrm{NSF}$

Vesicle-fusing ATPase $\mathrm{GN}=\mathrm{NSH}$

esicle-fusing ATPase $\mathrm{GN}=\mathrm{NS}$

Vesicle-fusing ATPase GN=NSF

Vesicle-fusing ATPase $\mathrm{GN}=\mathrm{NS}$

Vimentin GN=VIM

Vimentin GN=VIM

Vimentin $\mathrm{GN}=\mathrm{VIM}$

Vimentin GN=VIM

Vimentin GN=VIN

Vimentin $\mathrm{GN}=\mathrm{VIM}$

Vimentin GN=VIN

Vimentin GN=VIN

Vimentin GN=VIM

Vimentin GN=VIN

Vimentin GN=VIM

Vimentin GN=VIM

Vimentin GN=VIM

Vimentin GN=VIM

Vimentin GN=VIM

Vimentin $\mathrm{GN}=\mathrm{VIM}$

Vimentin GN=VIM

Vimentin GN=VIM

Vimentin GN=VIM

Vimentin GN=VIM
NSF_HUMAN $82.60 \quad 100.0 \%$ NSF_HUMAN $82.60 \quad 100.0 \%$ NSF HUMAN $82.60 \quad 100.0 \%$ NSF HUMAN $82.60 \quad 100.0 \%$ NSF HUMAN $82.60 \quad 100.0 \%$ NSF HUMAN $82.60 \quad 100.0 \%$ NSF_HUMAN $82.60 \quad 100.0 \%$ NSF HUMAN $82.60 \quad 100.0 \%$ NSF HUMAN $82.60 \quad 100.0 \%$ NSF_HUMAN $82.60 \quad 100.0 \%$ NSF HUMAN $82.60 \quad 100.0 \%$ NSF_HUMAN $82.60 \quad 100.0 \%$ NSF_HUMAN $82.60 \quad 100.0 \%$ VIME_HUMAN $53.65 \quad 100.0 \%$ VIME_HUMAN $53.65 \quad 100.0 \% \quad 23$ VIME_HUMAN $53.65 \quad 100.0 \% \quad 23$ VIME HUMAN $53.65 \quad 100.0 \% \quad 23$ VIME_HUMAN $53.65 \quad 100.0 \% \quad 23$ VIME HUMAN $53.65 \quad 100.0 \% \quad 23$ VIME_HUMAN $53.65 \quad 100.0 \% \quad 23$ VIME_HUMAN $53.65 \quad 100.0 \% \quad 23$ VIME HUMAN $53.65 \quad 100.0 \% \quad 23$ VIME_HUMAN $53.65 \quad 100.0 \% \quad 23$ VIME HUMAN $53.65 \quad 100.0 \% \quad 23$ VIME_HUMAN $53.65 \quad 100.0 \% \quad 23$ VIME_HUMAN $53.65 \quad 100.0 \% \quad 23$ VIME_HUMAN $53.65 \quad 100.0 \% \quad 23$ VIME_HUMAN $53.65 \quad 100.0 \% \quad 23$ VIME HUMAN $53.65 \quad 100.0 \% \quad 23$ VIME HUMAN $53.65 \quad 100.0 \% \quad 23$ VIME_HUMAN $53.65 \quad 100.0 \% \quad 23$ VIME HUMAN $53.65 \quad 100.0 \% \quad 23$ VIME_HUMAN $53.65 \quad 100.0 \% \quad 23$
$0.04 \% \quad 9.9 \% \quad$ LESEGSPETLTNLR $0.04 \% \quad 9.9 \%$ LESEGSPETLTNLRK $0.04 \% \quad 9.9 \%$ FSFTLPYPVK

$0.03 \% \quad 31.7 \%$ ISYSLFTALR

$0.03 \% \quad 31.7 \%$ SYAEELAK

$0.03 \% \quad 31.7 \%$ TIAVDFASEDIYDKIK

$0.03 \% \quad 31.7 \%$ MININILSVCK

$0.03 \% \quad 31.7 \%$ MTQLVLPGMVER

$0.03 \% \quad 31.7 \%$ GVFVQSVLPYFVATK

$0.03 \% \quad 31.7 \%$ IRKPTLDKPSPETFVK

$0.03 \% \quad 31.7 \%$ KPTLDKPSPETFVK

$0.03 \% \quad 31.7 \%$ SAIKTVGLQSR

$0.01 \% \quad 6.2 \%$ THPQWYPAR

$0.01 \% \quad 6.2 \% \quad$ SLKDEDVLQK

$0.04 \% \quad 20.2 \%$ THPSVVPGSIAFSLPQR

$0.04 \% \quad 20.2 \%$ THPSVVPGSIAFSLPQRK

$0.04 \% \quad 20.2 \%$ GILLYGPPGCGK

$0.04 \% \quad 20.2 \%$ MLNAREPK

$0.04 \% \quad 20.2 \%$ VVNGPEILNKYVGESEANIR

$0.04 \% \quad 20.2 \%$ NFSGAELEGLVR

$0.04 \% \quad 20.2 \%$ VLDDGELLVQQTK

$0.04 \% \quad 20.2 \%$ NSDRTPLVSVLLEGPPHSGK

$0.04 \% \quad 20.2 \%$ IAEESNFPFIK

$0.04 \% \quad 20.2 \%$ LLDYVPIGPR

$0.04 \% \quad 20.2 \%$ KLLIIGTTSR

$0.04 \% \quad 20.2 \%$ LLIIGTTSR

$0.04 \% \quad 20.2 \%$ FLALLREEGASPLDFD

$0.20 \% \quad 51.1 \%$ RMFGGPGTASRPSSSR

$137 \quad 0.20 \% \quad 51.1 \%$ MFGGPGTASRPSSSR

$137 \quad 0.20 \% \quad 51.1 \%$ SYVTTSTR

$137 \quad 0.20 \% \quad 51.1 \%$ SYVTTSTRTYSLGSALRPSTS

$137 \quad 0.20 \% \quad 51.1 \%$ TYSLGSALRPSTSR

$137 \quad 0.20 \% \quad 51.1 \%$ SLYASSPGGVYATR

$137 \quad 0.20 \% \quad 51.1 \%$ SLYASSPGGVYATRSSAV

$137 \quad 0.20 \% \quad 51.1 \%$ LRSSVPGVR

$137 \quad 0.20 \% \quad 51.1 \%$ LLQDSVDFSLADAINTEFKNTR

$137 \quad 0.20 \% \quad 51.1 \%$ QVDQLTNDKAR

$137 \quad 0.20 \% \quad 51.1 \%$ QDVDNASLAR

$137 \quad 0.20 \% \quad 51.1 \%$ KVESLQEEIAFLK

$137 \quad 0.20 \% \quad 51.1 \%$ DVRQQYESVAAK

$137 \quad 0.20 \% \quad 51.1 \%$ QQYESVAAK

$137 \quad 0.20 \% \quad 51.1 \%$ FADLSEAANR

RNNDALR

$137 \quad 0.20 \% \quad 51.1 \%$ QVQSLTCEVDALKGTNESLER

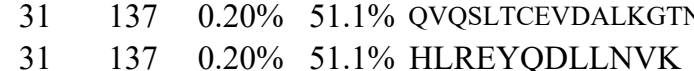

$31 \quad 137 \quad 0.20 \% \quad 51.1 \%$ MALDIEIATYR

$31 \quad 137 \quad 0.20 \% \quad 51.1 \%$ KLLEGEESR $99.6 \% \quad 28.5$

$\begin{array}{lll}99.7 \% & 31.7\end{array}$

$99.7 \% \quad 45.0$

$96.6 \% \quad 15.7$

$\begin{array}{lll}99.7 \% & 58.3\end{array}$

$99.7 \% \quad 56.9$

$99.7 \% 35$.

$99.7 \% \quad 41.3$

$99.7 \% \quad 26.6$

$99.6 \% \quad 23.9$

$99.7 \% \quad 49.1$

$98.7 \% \quad 17.4$

$99.7 \% \quad 26.2$

$\begin{array}{lll}95.0 \% & 17.7\end{array}$

$99.4 \% 20.2$

$97.6 \% \quad 16.8$

$\begin{array}{lll}99.3 \% & 27.1\end{array}$

$99.7 \% \quad 60.2$

$99.7 \% \quad 59.8$

$99.7 \% \quad 30.7$

$99.7 \% \quad 41.2$

$99.7 \% \quad 34.6$

$99.7 \% \quad 32.8$

$\begin{array}{lll}99.7 \% & 28.7\end{array}$

$\begin{array}{lll}99.7 \% & 45.8\end{array}$

$99.5 \% 20.6$

$99.7 \% \quad 25.1$

$99.0 \% \quad 37.1$

$97.8 \% \quad 16.2$

$\begin{array}{lll}99.7 \% & 45.0\end{array}$

$99.7 \% \quad 59.7$

$\begin{array}{ll}99.7 \% & 35.2 \\ 99.7 \% & 27.9\end{array}$

$99.7 \% \quad 56.2$

$99.7 \% 35.1$

$99.7 \% \quad 64.8$

$99.7 \% \quad 25.8$

$99.7 \% 31.0$

$\begin{array}{ll}99.7 \% & 43.2\end{array}$

$99.7 \% \quad 54.3$

$99.7 \% \quad 60.0$

$\begin{array}{ll}99.7 \% & 24.9 \\ 99.7 \% & 58.8\end{array}$

$99.7 \% \quad 44.3$
1673.87

1198.65

1170.65

910.45

1827.94

1304.71

1373.73

1654.92

1856.06

1586.88

1159.68

1155.57

1174.63

1792.97

1921.07

1231.65

958.51

2201.16

1291.66

1457.78

2103.12

1294.67

1142.66

1101.70

973.60

1792.91

1650.81

1510.71

914.46

2391.23

1495.79

1428.7

1928.98

970.58

2497.26

1287.67

1088.53

1533.85

1393.71

1023.51

1093.53

1776.86

2377.17

1527.83

1295.67

1060.56

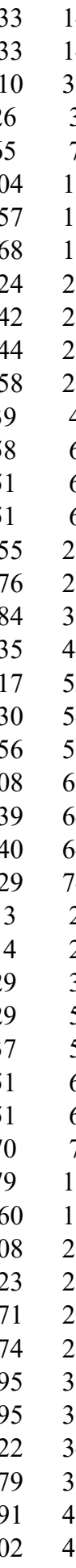


$\begin{array}{llll}137 & 0.20 \% & 51.1 \% & \text { ISLPLPNFSSLNLR } \\ 137 & 0.20 \% & 51.1 \% & \text { TVETRDGQVINETSQHHDD }\end{array}$

$99.7 \% \quad 62.2$ $0.02 \% \quad 30.4 \%$ GYGFGLIKLDLK $0.02 \% \quad 30.4 \%$ VTGSLETKYR $0.02 \% \quad 30.4 \%$ LTFDSSFSPNTGKK $0.02 \% \quad 30.4 \%$ YQIDPDACFSAK

$0.02 \% \quad 30.4 \%$ VNNSSLIGLGYTQTLKPGIK 99. $0.02 \% \quad 30.4 \%$ LTLSALLDGK \begin{tabular}{ll}
$0.02 \%$ & $30.4 \%$ \\
$0.05 \%$ & $49.7 \%$ DILSALLDGKNVNAGGHK \\
\hline
\end{tabular} $0.05 \% \quad 49.7 \%$ GFGFGLVKLDVK

$0.05 \% \quad 49.7 \%$ SCSGVEFSTSGSSNTDTGK

$0.05 \% \quad 49.7 \%$ LTFDTTFSPNTGK

$0.05 \% \quad 49.7 \%$ LTFDTTFSPNTGKK

$0.05 \% \quad 49.7 \%$ NNFAVGYR

$99.7 \% \quad 51.4$

$99.7 \% \quad 46.1$

$99.7 \% \quad 41.7$

$99.7 \% \quad 49.2$

$97.9 \% \quad 17.4$

$99.7 \% \quad 53.5$

$0.05 \% \quad 49.7 \%$ TGDFQLHTNVNDGTEFGGSIYQK

$0.05 \% \quad 49.7 \%$ FGIAAKYQLDPTASISAK 99.

$0.05 \% \quad 49.7 \%$ YQLDPTASISAK

$0.05 \% \quad 49.7 \%$ LTLSALVDGK

$99.7 \% \quad 41.6$

$0.05 \% \quad 49.7 \%$ LTLSALVDGKSINAGGHK $99.7 \% 31.4$

$0.05 \% \quad 49.7 \%$ SINAGGHKVGLALELEA $\quad 99.7 \% \quad 39.4$

$\begin{array}{lllll}0.05 \% & 43.1 \% & \text { DVFNKGYGFGMVK } \quad 99.7 \% & 28.2\end{array}$

$0.05 \% \quad 43.1 \%$ SCSGVEFSTSGHAYTDTGK $99.7 \% \quad 48.0$

$0.05 \% \quad 43.1 \%$ ASGNLETKYK

$0.05 \% \quad 43.1 \%$ YKVCNYGLTFTQK

$0.05 \% \quad 43.1 \%$ VCNYGLTFTQK

$0.05 \% \quad 43.1 \%$ LTLDTIFVPNTGK

$0.05 \% \quad 43.1 \%$ LTLDTIFVPNTGKK

$0.05 \% \quad 43.1 \%$ SKLSQNNFALGYK

$0.05 \% \quad 43.1 \%$ LSQNNFALGYK

$0.05 \% \quad 43.1 \%$ YMLDCRTSLSAK

$96.3 \% \quad 16.7 \quad 25.0 \quad 16.7$

$99.7 \% \quad 40.8 \quad 25.0 \quad 37.2$

$99.7 \% \quad 56.1 \quad 25.0 \quad 54.7$

$\begin{array}{lllll}99.7 \% & 43.3 & 25.0 & 43.3 & 2\end{array}$

$99.2 \% \quad 19.9 \quad 25.0 \quad 19.9$

$99.7 \% \quad 65.4 \quad 25.0 \quad 58.3$

$99.7 \% \quad 50.6$

$99.7 \% \quad 48.2$

$0.05 \% \quad 43.1 \%$ VNNASLIGLGYTQTLRPGVK $\quad 99.7 \% \quad 38.7$

$0.05 \% \quad 43.1 \%$ LTLSALIDGK

$0.00 \% \quad 1.4 \%$ VNAGTLAVLQR

$0.00 \% \quad 1.4 \%$ RGELEPQLGSPQQKPK

$0.01 \% \quad 7.3 \%$ GVNVSALSR

$99.0 \% \quad 55.2$

$99.7 \% \quad 46.6$

$94.7 \% \quad 13.4$

$99.7 \% \quad 44.1$

$\begin{array}{lll}0.01 \% & 7.3 \% & \text { VGSHITGGDIYGIVSENSLIK } \\ 0.01 \% & 7.3 \% & \text { TALVANTSNMPVAAR }\end{array}$

$\begin{array}{lll}0.01 \% & 7.3 \% & \text { TALVANTSNMPVA } \\ 0.00 \% & 6.0 \% & \text { LYPEGLAQLAR }\end{array}$

$\begin{array}{lll}0.00 \% & 6.0 \% & \text { AKIDNYIPIF }\end{array}$

$0.01 \% \quad 8.3 \%$ VFASLPQVER

$0.01 \% \quad 8.3 \%$ YAPSGFYIASGDVSGK

$0.01 \% \quad 8.3 \%$ IAVVGEGREK

$0.01 \% \quad 8.3 \%$ LYSILGTTLKDEGK

$0.01 \% \quad 9.9 \%$ FTLAGHTK $\begin{array}{lll}99.7 \% & 27.4\end{array}$

$99.7 \% 35.3$

$99.3 \% \quad 19.5$

$\begin{array}{lll}99.7 \% & 33.1\end{array}$

$99.7 \% \quad 34.2$

$99.1 \% \quad 21.6$

$99.7 \% \quad 33.6$

$99.0 \% \quad 27.7$

\subsection{0}


WD repeat-containing protein 5 GN=WDR5 WDR5_HUMAN $36.59 \quad 100.0 \%$ WD repeat-containing protein 5 GN=WDR5 WDR5_HUMAN $36.59 \quad 100.0 \%$ WD repeat-containing protein $82 \mathrm{GN}=$ WDR82 WDR82_HUMAN $35.08 \quad 100.0 \%$ WD repeat-containing protein $82 \mathrm{GN}=$ WDR82 WDR82_HUMAN $35.08 \quad 100.0 \%$ WD repeat-containing protein $82 \mathrm{GN}=$ WDR82 WDR82_HUMAN $35.08 \quad 100.0 \%$ WD repeat-containing protein $82 \mathrm{GN}=$ WDR82 WDR82_HUMAN $35.08 \quad 100.0 \%$ WD repeat-containing protein $82 \mathrm{GN}=$ WDR82 WDR82_HUMAN $35.08 \quad 100.0 \%$ X-ray repair cross-complementing protein $5 \mathrm{GN}=\mathrm{XRCC} 5$ XRCC5_HUMAN $82.71 \quad 100.0 \%$ X-ray repair cross-complementing protein $5 \mathrm{GN}=\mathrm{XRCC} 5 \mathrm{XRCC} 5$ HUMAN $82.71 \quad 100.0 \%$ X-ray repair cross-complementing protein $5 \mathrm{GN}=\mathrm{XRCC} 5$ XRCC5_HUMAN $82.71 \quad 100.0 \%$ X-ray repair cross-complementing protein $5 \mathrm{GN}=\mathrm{XRCC} 5 \mathrm{XRCC5} 5 \mathrm{HUMAN} \quad 82.71 \quad 100.0 \%$ X-ray repair cross-complementing protein $5 \mathrm{GN}=\mathrm{XRCC} 5$ XRCC5_HUMAN $82.71 \quad 100.0 \%$ X-ray repair cross-complementing protein $5 \mathrm{GN}=\mathrm{XRCC} 5 \mathrm{XRCC} 5$ _HUMAN $82.71 \quad 100.0 \%$ X-ray repair cross-complementing protein $5 \mathrm{GN}=\mathrm{XRCC} 5$ XRCC5_HUMAN $82.71 \quad 100.0 \%$ X-ray repair cross-complementing protein $5 \mathrm{GN}=\mathrm{XRCC} 5$ XRCC5_HUMAN $82.71 \quad 100.0 \%$ X-ray repair cross-complementing protein $5 \mathrm{GN}=\mathrm{XRCC} 5$ XRCC5_HUMAN $82.71 \quad 100.0 \%$ X-ray repair cross-complementing protein $5 \mathrm{GN}=\mathrm{XRCC} 5 \mathrm{XRCC5}$ _HUMAN $82.71 \quad 100.0 \%$ X-ray repair cross-complementing protein $5 \mathrm{GN}=\mathrm{XRCC} 5 \mathrm{XRCC5}$ _HUMAN $82.71 \quad 100.0 \%$ X-ray repair cross-complementing protein $5 \mathrm{GN}=\mathrm{XRCC} 5 \mathrm{XRCC} 5$ HUMAN $82.71 \quad 100.0 \%$ X-ray repair cross-complementing protein $5 \mathrm{GN}=\mathrm{XRCC} 5 \mathrm{XRCC} 5$ HUMAN $82.71 \quad 100.0 \%$ X-ray repair cross-complementing protein $6 \mathrm{GN}=\mathrm{XRCC6}$ XRCC6_HUMAN $69.85 \quad 100.0 \%$ X-ray repair cross-complementing protein $6 \mathrm{GN}=\mathrm{XRCC} 6 \mathrm{XRCC} 6 \_$HUMAN $69.85 \quad 100.0 \%$ X-ray repair cross-complementing protein $6 \mathrm{GN}=$ XRCC6 XRCC6_HUMAN $69.85 \quad 100.0 \%$ X-ray repair cross-complementing protein $6 \mathrm{GN}=\mathrm{XRCC6}$ XRCC6_HUMAN $69.85 \quad 100.0 \%$ X-ray repair cross-complementing protein $6 \mathrm{GN}=\mathrm{XRCC} 6$ XRCC6 HUMAN 69.85 $\mathrm{X}$-ray repair cross-complementing protein $6 \mathrm{GN}=\mathrm{XRCC} 6 \mathrm{XRCC} 6$ _HUMAN 69.85 X-ray repair cross-complementing protein $6 \mathrm{GN}=\mathrm{XRCC} 6 \mathrm{XRCC6} 6$ HUMAN 69.85 X-ray repair cross-complementing protein $6 \mathrm{GN}=\mathrm{XRCC} 6 \mathrm{XRCC} 6$ HUMAN 69.85 X-ray repair cross-complementing protein $6 \mathrm{GN}=\mathrm{XRCC} 6$ XRCC6_HUMAN 69.85 X-ray repair cross-complementing protein $6 \mathrm{GN}=\mathrm{XRCC} 6$ XRCC6 HUMAN 69.85 X-ray repair cross-complementing protein $6 \mathrm{GN}=\mathrm{XRCC} 6$ XRCC6_HUMAN 69.85 $\mathrm{X}$-ray repair cross-complementing protein $6 \mathrm{GN}=\mathrm{XRCC} 6 \mathrm{XRCC6} 6 \mathrm{HUMAN} 69.85$ YTH domain-containing family protein $2 \mathrm{GN}=$ YTHDF2 YTHD2_HUMAN 62.33 YTH domain-containing family protein $2 \mathrm{GN}=$ YTHDF2 YTHD2_HUMAN 62.33 YTH domain-containing protein $1 \mathrm{GN}=$ YTHDC1 YTDC1_HUMAN 84.70 YTH domain-containing protein $1 \mathrm{GN}=$ YTHDC1 YTDC1 HUMAN 84.71 YTH domain-containing protein $1 \mathrm{GN}=$ YTHDC1 YTDC1_HUMAN $84.70 \quad 100.0 \%$ YTH domain-containing protein $1 \mathrm{GN}=$ YTHDC1 YTDC1_HUMAN $84.70 \quad 100.0 \%$ Zinc finger CCCH domain-containing protein $13 \mathrm{GN}=\mathrm{ZC} 3 \mathrm{H} 13$ ZC3HD_HUMAN $196.64100 .0 \%$ Zinc finger CCCH domain-containing protein $13 \mathrm{GN}=\mathrm{ZC} 3 \mathrm{H} 13$ ZC3HD_HUMAN $196.64100 .0 \%$ Zinc finger $\mathrm{CCCH}$ domain-containing protein $13 \mathrm{GN}=\mathrm{ZC} 3 \mathrm{H} 13 \mathrm{ZC} 3 \mathrm{HD} \_\mathrm{HUMAN} 196.64 \quad 100.0 \%$ Zinc finger CCCH domain-containing protein $13 \mathrm{GN}=\mathrm{ZC} 3 \mathrm{H} 13$ ZC3HD_HUMAN $196.64100 .0 \%$ Zinc finger CCCH domain-containing protein $13 \mathrm{GN}=\mathrm{ZC} 3 \mathrm{H} 13$ ZC3HD HUMAN $196.64 \quad 100.0 \%$ Zinc finger $\mathrm{CCCH}$ domain-containing protein $18 \mathrm{GN}=\mathrm{ZC} 3 \mathrm{H} 18 \mathrm{ZCH} 18$ _HUMAN $106.38 \quad 100.0 \%$ Zinc finger CCCH domain-containing protein $18 \mathrm{GN}=\mathrm{ZC} 3 \mathrm{H} 18 \mathrm{ZCH} 18$ _HUMAN $106.38 \quad 100.0 \%$ Zinc finger CCCH-type antiviral protein $1 \mathrm{GN}=\mathrm{ZC} 3 \mathrm{HAV} 1 \mathrm{ZCCHV}$ HUMAN $101.43 \quad 100.0 \%$

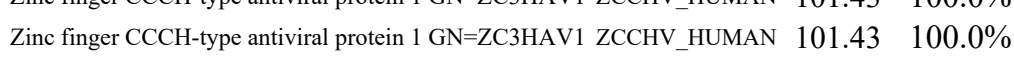

$0.01 \% \quad 9.9 \% \quad$ IWDTASGQCLK

$0.01 \% \quad 9.9 \%$ TLIDDDNPPVSFVK

$0.02 \% \quad 22.7 \%$ MKLTDSVLR $99.7 \% 58.2$

$99.7 \% \quad 33.0$

$\begin{array}{lllll}0.02 \% & 22.7 \% & \text { YTHAANTVVYSSNKIDDTIR } & 99.6 \% & 23.9\end{array}$

$99.6 \% \quad 23.5$

$0.02 \% \quad 22.7 \%$ YLSLHDNKYIR

$\begin{array}{ll}0.02 \% & 22.7 \% \text { VVALSMSPVDDTFIS } \\ 0.02 \% & 22.7 \% \text { SFDKGPFATFK }\end{array}$

$0.04 \% \quad 13.8 \%$ KVITMFVQR

$0.04 \% \quad 13.8 \%$ VITMFVQR

$0.04 \% \quad 13.8 \%$ HIEIFTDLSSR

$0.04 \% \quad 13.8 \%$ HIEIFTDLSSRFSK

$0.04 \% \quad 13.8 \%$ GITEQQKEGLEIVK

$0.04 \% \quad 13.8 \%$ LTIGSNLSIR

$0.04 \% \quad 13.8 \%$ CFSVLGFCK

$0.04 \% \quad 13.8 \%$ RFFMGNQVLK

$0.04 \% \quad 13.8 \%$ FFMGNQVLK

$0.04 \% 13.8 \%$ LFQCLLHR

$0.04 \% \quad 13.8 \%$ SQIPLSKIK

$0.04 \% \quad 13.8 \%$ IKTLFPLIEAK

$0.04 \% \quad 13.8 \%$ ALQEKVEIK

$0.04 \% \quad 22.7 \%$ DSLIFLVDASK

$0.04 \% \quad 22.7 \%$ NIYVLQELDNPGAK

$0.04 \% \quad 22.7 \%$ NIYVLQELDNPGAKR

$0.04 \% \quad 22.7 \%$ ILELDQFKGQQGQK

$99.7 \% \quad 53.6$

$99.4 \% \quad 25.2$

$99.7 \% \quad 33.1$

$99.0 \% \quad 60.2$

$99.7 \% \quad 44.7$

$99.7 \% \quad 27.0$

$99.7 \% \quad 27.0$

$99.7 \% \quad 61.2$

$99.7 \% \quad 45.5$

$99.4 \% \quad 30.9$

$99.7 \% \quad 25.0$

$99.0 \% \quad 35.6$

$99.4 \% \quad 20.0$

$99.7 \% \quad 31.8$

$99.5 \% \quad 34.6$

$99.7 \% \quad 62.8$

$99.7 \% \quad 48.8$

$99.7 \% \quad 37.6$

$99.7 \% \quad 33.2$

$0.04 \% \quad 22.7 \%$ IMLFTNEDNPHGNDSAK $\quad 99.7 \% \quad 39.4$

$99.7 \% \quad 24.9$

$0.04 \% \quad 22.7 \%$ ALKPPPIKLYR

$0.04 \% \quad 22.7 \%$ TFNTSTGGLLLPSDTKR

$0.04 \% \quad 22.7 \%$ CLEKEVAALCR

$0.04 \% \quad 22.7 \%$ IMATPEQVGK

$99.7 \% \quad 61.1$

$99.7 \% \quad 44.8$

$99.7 \% \quad 29.0$

$0.04 \% \quad 22.7 \%$ FTYRSDSFENPVLQQHFR $\quad 99.7 \% \quad 42.4$

$0.04 \% \quad 22.7 \%$ SDSFENPVLQQHFR

$0.04 \% \quad 22.7 \%$ VEYSEEELKTHISK

$0.01 \% \quad 3.6 \%$ LGSTEVASNVPK

$0.01 \% \quad 3.6 \%$ SYSEDDIHR

$0.01 \% \quad 6.6 \%$ QLVSKPLSSSVSNNKR

$0.01 \% \quad 6.6 \%$ SATEYKNEEYQR

$0.01 \% \quad 6.6 \%$ GISPIVFDR

$0.01 \% \quad 6.6 \% \quad$ SNNHENVSLAK

$0.01 \% \quad 3.5 \%$ LGPSTGSTAETQCR

$0.01 \% \quad 3.5 \%$ TSAVSSPLLDQQR

$0.01 \% \quad 3.5 \% \quad$ TPSPSYQR

$0.01 \% \quad 3.5 \%$ LLSQVVRPQESR

$0.01 \% \quad 3.5 \%$ ASLLSNLGPCCK

$0.00 \% \quad 3.0 \%$ SSSYSSYSSR

$\begin{array}{lll}0.00 \% & 3.0 \% & \text { TLSGSGSGSGS } \\ 0.01 \% & 4.4 \% & \text { KFTYLGSQDR }\end{array}$

$0.01 \% \quad 4.4 \%$ ATDLGGTSQAGTSQR
$98.9 \% \quad 22.4$

$99.6 \% \quad 24.9$

$99.7 \% \quad 63.7$

$99.6 \% \quad 23.9$

$99.7 \% \quad 38.4$

$99.3 \% \quad 23.5$

$99.7 \% \quad 30.1$

$99.7 \% \quad 28.8$

$99.7 \% \quad 50.0$

$99.7 \% \quad 38.2$

$98.3 \% 25.6$

$99.3 \% \quad 19.8$

$99.7 \% \quad 50.9$

$99.7 \% \quad 34.3$

$99.7 \% 26.6$

$99.7 \% \quad 69.5$ \begin{tabular}{ll}
.0 & 58.2 \\
\hline .0 & 24.7
\end{tabular}

$.0 \quad 23.9$

19.6
53.6

53.6

$25.0 \quad 15.7$

$25.0 \quad 32.3$

$\begin{array}{ll} & 54.5\end{array}$

$.0 \quad 35.2$

27.0

$\begin{array}{ll}0 & 27.0\end{array}$

\begin{tabular}{ll}
58.0 \\
\hline
\end{tabular}

$\begin{array}{ll}25.0 & 41.2\end{array}$

$25.0 \quad 9.3$

$\begin{array}{ll}25.0 & 20.2\end{array}$

\begin{tabular}{ll}
26.9 \\
\hline
\end{tabular}

$\begin{array}{ll}0 & 20.0\end{array}$

$\begin{array}{ll}3.0 & 31.3\end{array}$

$25.0 \quad 12.6$

$25.0 \quad 58.9$

$\begin{array}{ll}0.0 & 48.8\end{array}$

\begin{tabular}{ll}
36.7 \\
\hline
\end{tabular}

$\begin{array}{ll}33.0 & 33.2\end{array}$

$\begin{array}{ll}0 & 35.5\end{array}$

$\begin{array}{ll}.0 & 24.9\end{array}$

\begin{tabular}{ll}
60.2 \\
\hline
\end{tabular}

$\begin{array}{ll}25.0 & 44.8\end{array}$

$\begin{array}{ll} & 16.6\end{array}$

$\begin{array}{ll}0.0 & 42.4\end{array}$

21.4
25.0

$\begin{array}{ll}25.0 & 22.0\end{array}$

55.6

22.7
25.0

\begin{tabular}{ll}
38.4 \\
\hline
\end{tabular}

$25.0 \quad 23.5$

$25.0 \quad 25.0$

0.0
28.8

$25.0 \quad 50.0$

$25.0 \quad 31.6$

$25.0 \quad 13.8$

$\begin{array}{ll}5.0 & 19.8\end{array}$

$\begin{array}{ll}5.0 & 50.9\end{array}$

30.6
25.0

$\begin{array}{ll}5.0 & 66.6\end{array}$

$\begin{array}{ll}.0 & 20.5\end{array}$
1559.80

1062.60

2268.13

1421.75

2097.04

1244.63

1121.65

993.56

1317.68

1679.88

1571.86

1073.63

1117.52

1239.67

1083.57

1086.59

1013.64

1272.79

1057.63

1207.66

1573.82

1729.92

1631.88

1918.86

1295.82

1807.96

1348.67

1089.56

2271.09

1703.81

1691.85

1201.64

1121.49

1743.97

1517.69

1003.56

1212.60

1464.67

1401.73

935.46

1411.80

1319.64

1110.47

1707.74

1214.62

1449.69

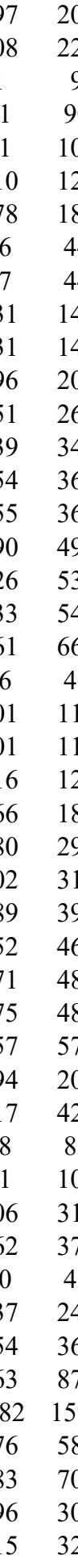


Zinc finger CCCH-type antiviral protein $1 \mathrm{GN}=Z \mathrm{ZC} 3 \mathrm{HAV} 1 \mathrm{ZCCHV}$ HUMAN $101.43 \quad 100.0 \%$ Zinc finger $\mathrm{CCHC}$ domain-containing protein $3 \mathrm{GN}=\mathrm{ZCCHC} 3 \quad \mathrm{ZCHC} 3$ _HUMAN $43.62 \quad 100.0 \%$ Zinc finger CCHC domain-containing protein $3 \mathrm{GN}=\mathrm{ZCCHC} 3 \mathrm{ZCHC} 3$ _HUMAN $43.62 \quad 100.0 \%$ Zinc finger $\mathrm{CCHC}$ domain-containing protein $3 \mathrm{GN}=\mathrm{ZCCHC} 3 \mathrm{ZCHC} 3 \mathrm{HUMAN} 43.62100 .0 \%$ Zinc finger protein $346 \mathrm{GN}=\mathrm{ZNF} 346$ Zinc finger protein $346 \mathrm{GN}=\mathrm{ZNF} 346$ Zinc finger protein $346 \mathrm{GN}=\mathrm{ZNF} 346$ Zinc finger protein $512 \mathrm{GN}=\mathrm{ZNF} 512$ Zinc finger protein $512 \mathrm{GN}=\mathrm{ZNF} 512$ Zinc finger protein $512 \mathrm{GN}=\mathrm{ZNF} 512$ Zinc finger protein $512 \mathrm{GN}=\mathrm{ZNF} 512$ Zinc finger protein $512 \mathrm{GN}=\mathrm{ZNF} 512$ Zinc finger protein $768 \mathrm{GN}=\mathrm{ZNF} 768$ Zinc finger protein $768 \mathrm{GN}=\mathrm{ZNF} 768$

ZN346_HUMAN $32.93 \quad 100.0 \%$ ZN346_HUMAN $32.93 \quad 100.0 \%$ ZN346 HUMAN $32.93 \quad 100.0 \%$ ZN512_HUMAN $64.68 \quad 100.0 \%$ ZN512 HUMAN $64.68 \quad 100.0 \%$ ZN512_HUMAN $64.68 \quad 100.0 \%$ ZN512_HUMAN $64.68 \quad 100.0 \%$ ZN512 HUMAN $64.68 \quad 100.0 \%$ ZN768_HUMAN $60.23 \quad 100.0 \%$ ZN768_HUMAN $60.23 \quad 100.0 \%$

$6 \quad 0.01 \% \quad 4.4 \%$ SSLGSLQTPEAVTTR $0.01 \% \quad 8.7 \%$ SAEKLALFLR

$\begin{array}{ll}99.1 \% & 25.9 \\ 99.7 \% & 28.3\end{array}$

$99.7 \% \quad 28.3$

$99.2 \% 18.9$

$0.01 \% \quad 8.7 \% \quad$ AVHNSVAAQLTGVAGH $\quad 99.7 \% \quad 43.6$ $0.01 \% \quad 13.9 \%$ YLAIHGMETLKGETK

$0.01 \% \quad 13.9 \%$ LADPAVTDFPAGK

$99.4 \% \quad 25.2$

$99.7 \% \quad 44.0$

$99.7 \% \quad 43.2$

$0.01 \% \quad 13.9 \%$ TVASSLGQIPMQR

$\begin{array}{lllll}0.01 \% & 10.4 \% & \text { LGAVPATSGPTTFKQQR } & 98.2 \% & 17.8\end{array}$

$0.01 \% \quad 10.4 \%$ IKPAATSHVEGSGGVSAK $99.7 \% \quad 28.2$

$0.01 \% \quad 10.4 \%$ AGLAYHLR

$0.01 \% \quad 10.4 \%$ RQQPGIELPETELSLR

$99.0 \% \quad 26.2$

$\begin{array}{lll}97.5 \% & 25.7\end{array}$

$98.7 \% \quad 17.3$

$0.01 \% \quad 10.4 \%$ QQPGIELPETELSLR

$\begin{array}{ll}99.7 \% & 50.6 \\ 99.7 \% & 39.4\end{array}$
$0.01 \% \quad 8.7 \%$ GHAFAQCPK
1546.8

1147.68

1015.48

1531.80

1690.88

1301.67

1403.73

1758.95

1695.90

900.51

1866.01

1709.9

1142.58

1285.70
400

$\begin{array}{llll}3 & 0.00 \% & 4.1 \% & \text { AFADSSYLLR } \\ 3 & 0.00 \% & 4.1 \% & \text { FGQSSVLAIHAR }\end{array}$
386 228

$\begin{array}{ll}380 & 388 \\ 389 & 404\end{array}$

$104 \quad 118$

$270 \quad 282$

$83 \quad 100$

$300 \quad 307$

$507 \quad 522$

$508 \quad 522$

\begin{tabular}{ll}
325 & 334 \\
438 & 449 \\
\hline
\end{tabular} 
Peptide index $\begin{array}{lllll}\text { [3-methyl-2-oxobutanoate dehydrogenase [lipoamide]] kinase, mitochondrial GN=BCKDK } & \text { BCKD_HUMAN } & 46.36 & 100.0 \% & 3 \\ \text { [3-methyl-2-oxobutanoate dehydrogenase [lipoamide] k kinase, mitochondrial GN=BCKDK } & \text { BCKD_HUMAN } & 46.36 & 100.0 \% & 3\end{array}$ $\begin{array}{llll}0.01 \% & 7.3 \% & \text { LTPTMMLYAGR } \\ 6 & 0.01 \% & 7.3 \% & \text { YLQQELPVR }\end{array}$

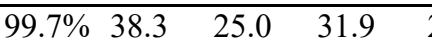

$99.7 \% \quad 60.5$

$99.7 \% \quad 33.6$

$99.7 \% \quad 36.0$

$99.7 \% \quad 37.4$

$99.7 \% \quad 35.2$

$99.6 \% \quad 26.7$

$99.7 \% \quad 33.5$

$99.7 \% \quad 47.2$

$\begin{array}{lll}0.01 \% & 3.5 \% & \text { GGGQIIPTAR } \\ 0.01 \% & 9.0 \% & \text { YLAEFATGNDRK }\end{array}$

$0.01 \% \quad 9.0 \%$ EAAENSLVAYK

$0.02 \% \quad 22.9 \%$ LAEQAERYDDMAACMK

$0.02 \% \quad 22.9 \%$ SVTEQGAELSNEER

$0.02 \% \quad 22.9 \%$ VVSSIEQKTEGAEK

$0.02 \% \quad 22.9 \%$ YLAEVAAGDDKK

$0.03 \% \quad 16.6 \%$ MVSADAYKITPGAR

$0.03 \% \quad 16.6 \%$ AGQVFLEELGNHK

$0.03 \% \quad 16.6 \%$ APGAEEYAQQDVLKK

$0.03 \% \quad 16.6 \%$ GEEVGELSR

$0.03 \% \quad 16.6 \%$ GKLYSLGNGR

$0.03 \% \quad 16.6 \%$ AIFTGYYGK

$0.04 \% \quad 24.2 \%$ VALDMTTLTIMR

$0.04 \% \quad 24.2 \%$ AVASQLDCNFLK

$0.04 \% \quad 24.2 \%$ VVSSSIVDKYIGESAR

$0.04 \% \quad 24.2 \%$ LIREMFNYAR

$0.04 \% \quad 24.2 \%$ FSEGTSADREIQR

$0.04 \% \quad 24.2 \%$ KIHIDLPNEQAR

$0.04 \% \quad 24.2 \%$ IHAGPITK

$0.04 \% \quad 24.2 \%$ HGEIDYEAIVK

$0.02 \% \quad 10.0 \%$ KYEPPVPTR

$0.02 \% \quad 10.0 \%$ GVILYGPPGTGK

$0.02 \% \quad 10.0 \%$ AVANQTSATFLR

$0.02 \% \quad 10.0 \%$ KQEGTPEGLYL

$0.00 \% \quad 4.3 \% \quad$ MSTEEIIQR

$0.00 \% \quad 4.3 \% \quad$ LVRDAFALAK

$0.03 \% \quad 13.2 \%$ EFLHAQEEVKR

$0.03 \% \quad 13.2 \%$ AVAHHTTAAFIR

$0.03 \% \quad 13.2 \%$ VVGSEFVQK

$0.03 \% \quad 13.2 \%$ FDAQTGADREVQR

$0.03 \% \quad 13.2 \%$ RLIFSTITSK

$0.03 \% \quad 13.2 \%$ LIFSTITSK

$0.03 \% \quad 17.3 \%$ PDYLGADQRK

$0.03 \% \quad 17.3 \%$ ALDEGDIALLK

\section{$99.7 \%$}

$99.7 \% \quad 68.5$

$99.7 \% \quad 63.2$

$99.7 \% \quad 50.5$

$99.7 \% \quad 51.5$

$99.7 \% \quad 53.0$

$99.6 \% \quad 25.9$

$99.7 \% \quad 43.8$

$99.7 \% \quad 32.4$

$98.7 \% \quad 26.2$

$99.7 \% \quad 48.8$

$99.7 \% \quad 59.5$

$99.7 \% \quad 57.8$

$99.7 \% \quad 28.6$

$99.3 \% \quad 23.2$

$99.7 \% \quad 31.4$

$99.0 \% \quad 26.7$

$99.7 \% \quad 64.2$

$99.7 \% \quad 32.2$

$99.1 \% \quad 57.0$

$99.7 \% \quad 68.5$

$99.7 \% \quad 40.3$

$99.4 \% \quad 28.4$

$99.0 \% \quad 27.9$

$98.1 \% \quad 22.9$

$99.7 \% \quad 35.2$

$99.7 \% \quad 50.1$

$99.3 \% \quad 22.7$

$99.7 \% \quad 33.0$

$99.7 \% \quad 33.3$

$99.7 \% \quad 34.4$

$99.7 \% \quad 58.7$

$\begin{array}{lll}25.0 & 31.9 & 2 \\ 25.0 & 46.1 & 3 \\ 25.0 & 26.5 & 1 \\ 25.0 & 35.3 & 2 \\ 25.0 & 37.4 & 2 \\ 25.0 & 31.7 & 1 \\ 25.0 & 26.7 & 3 \\ 25.0 & 33.4 & 1 \\ 25.0 & 47.2 & 2 \\ 25.0 & 32.7 & 0 \\ 25.0 & 63.2 & 2 \\ 25.0 & 60.9 & 2 \\ 25.0 & 37.6 & 2 \\ 25.0 & 51.5 & 2 \\ 25.0 & 50.6 & 2 \\ 25.0 & 25.1 & 0 \\ 25.0 & 27.0 & 3 \\ 25.0 & 25.7 & 2 \\ 25.0 & 14.1 & 1 \\ 25.0 & 48.8 & 4 \\ 25.0 & 53.9 & 2 \\ 25.0 & 57.8 & 2 \\ 25.0 & 26.3 & 1 \\ 25.0 & 21.6 & 2 \\ 25.0 & 31.4 & 0 \\ 25.0 & 26.7 & 2 \\ 25.0 & 58.0 & 2 \\ 25.0 & 19.2 & 3 \\ 25.0 & 0.0 & 4 \\ 25.0 & 61.5 & 6 \\ 25.0 & 39.5 & 2 \\ 25.0 & 16.2 & 1 \\ 25.0 & 17.0 & 1 \\ 25.0 & 14.6 & 1 \\ 25.0 & 35.2 & 2 \\ 25.0 & 37.9 & 2 \\ 25.0 & 18.5 & 1 \\ 25.0 & 32.6 & 2 \\ 25.0 & 33.3 & 2 \\ 25.0 & 27.0 & 2 \\ 25.0 & 45.0 & 2 \\ & & \\ 25\end{array}$

\begin{tabular}{cccc}
\hline 0 & 1253.64 & 70 & 80 \\
0 & 1145.63 & 93 & 101 \\
0 & 1243.67 & 188 & 197 \\
0 & 1256.71 & 183 & 194 \\
0 & 1441.83 & 183 & 196 \\
0 & 1201.59 & 776 & 785 \\
0 & 969.55 & 804 & 813 \\
0 & 1384.69 & 131 & 142 \\
0 & 1194.60 & 143 & 153 \\
0 & 1901.82 & 12 & 27 \\
0 & 1548.71 & 28 & 41 \\
0 & 1504.79 & 61 & 74 \\
0 & 1279.65 & 128 & 139 \\
0 & 1479.76 & 80 & 93 \\
0 & 1441.74 & 205 & 217 \\
0 & 1646.84 & 262 & 276 \\
0 & 975.47 & 361 & 369 \\
0 & 1064.58 & 370 & 379 \\
0 & 1019.52 & 392 & 400 \\
0 & 1380.72 & 98 & 109 \\
0 & 1365.68 & 186 & 197 \\
0 & 1709.91 & 198 & 213 \\
0 & 1312.68 & 214 & 223 \\
0 & 1495.71 & 243 & 255 \\
0 & 1433.79 & 298 & 309 \\
0 & 836.50 & 315 & 322 \\
0 & 1273.64 & 323 & 333 \\
0 & 1086.59 & 24 & 32 \\
0 & 1158.65 & 221 & 232 \\
0 & 1278.68 & 238 & 249 \\
0 & 1234.63 & 430 & 440 \\
0 & 1106.55 & 36 & 44 \\
0 & 1103.66 & 267 & 276 \\
0 & 1385.72 & 71 & 81 \\
0 & 1294.70 & 218 & 229 \\
0 & 992.54 & 230 & 238 \\
0 & 1492.71 & 275 & 287 \\
0 & 1165.69 & 342 & 351 \\
0 & 1009.59 & 343 & 351 \\
0 & 1162.59 & 2 & 11 \\
0 & 1157.64 & 24 & 34 \\
& & & \\
0 & &
\end{tabular}

Page 1 of Table S-1-3 
$26 \mathrm{~S}$ protease regulatory subunit 7 GN=PSMC2 PRS7_HUMAN $48.64 \quad 100.0 \%$ $26 \mathrm{~S}$ protease regulatory subunit $7 \mathrm{GN}=\mathrm{PSMC} 2$ PRS7_HUMAN $48.64 \quad 100.0 \%$ $26 \mathrm{~S}$ protease regulatory subunit $7 \mathrm{GN}=$ PSMC2 PRS7_HUMAN $48.64 \quad 100.0 \%$ $26 \mathrm{~S}$ protease regulatory subunit $7 \mathrm{GN}=\mathrm{PSMC} 2 \mathrm{PRS} 7 \mathrm{HUMAN} 48.64100 .0 \%$ $26 \mathrm{~S}$ protease regulatory subunit $7 \mathrm{GN}=$ PSMC2 PRS7_HUMAN $48.64 \quad 100.0 \%$ $26 \mathrm{~S}$ protease regulatory subunit $8 \mathrm{GN}=$ PSMC5 PRS8_HUMAN $45.63 \quad 100.0 \%$ $26 \mathrm{~S}$ protease regulatory subunit $8 \mathrm{GN}=$ PSMC5 PRS8_HUMAN $45.63 \quad 100.0 \%$ $26 \mathrm{~S}$ protease regulatory subunit $8 \mathrm{GN}=$ PSMC5 PRS8_HUMAN $45.63 \quad 100.0 \%$ $26 \mathrm{~S}$ protease regulatory subunit $8 \mathrm{GN}=$ PSMC5 PRS8_HUMAN $45.63100 .0 \%$ $26 \mathrm{~S}$ protease regulatory subunit $8 \mathrm{GN}=$ PSMC5 PRS8_HUMAN $45.63 \quad 100.0 \%$ $26 \mathrm{~S}$ protease regulatory subunit $8 \mathrm{GN}=$ PSMC5 PRS8_HUMAN $45.63 \quad 100.0 \%$ $26 \mathrm{~S}$ protease regulatory subunit $8 \mathrm{GN}=$ PSMC5 PRS8_HUMAN $45.63100 .0 \%$ 26S proteasome non-ATPase regulatory subunit $1 \mathrm{GN}=$ PSMD1 PSMD1_HUMAN $105.84 \quad 100.0 \%$ 26S proteasome non-ATPase regulatory subunit 1 GN=PSMD1 PSMD1_HUMAN $105.84 \quad 100.0 \%$ $26 \mathrm{~S}$ proteasome non-ATPase regulatory subunit $13 \mathrm{GN}=\mathrm{PSMD} 13$ PSD13_HUMAN $42.95 \quad 100.0 \%$ 26S proteasome non-ATPase regulatory subunit $13 \mathrm{GN}=$ PSMD13 PSD13_HUMAN $42.95 \quad 100.0 \%$ $26 \mathrm{~S}$ proteasome non-ATPase regulatory subunit $13 \mathrm{GN}=\mathrm{PSMD} 13$ PSD13 HUMAN $42.95 \quad 100.0 \%$ 26S proteasome non-ATPase regulatory subunit $14 \mathrm{GN}=$ PSMD14 PSDE_HUMAN $34.58 \quad 100.0 \%$ 26S proteasome non-ATPase regulatory subunit $14 \mathrm{GN}=$ PSMD14 PSDE_HUMAN $34.58 \quad 100.0 \%$ 26 proteasome non-ATPase regulatory subunit 14 GN=PSMD14 PSDE_HUMAN $34.58 \quad 100.0 \%$ 26S proteasome non-ATPase regulatory subunit 2 GN=PSMD2 PSMD2_HUMAN $100.20 \quad 100.0 \%$ $26 \mathrm{~S}$ proteasome non-ATPase regulatory subunit 2 GN=PSMD2 PSMD2_HUMAN $100.20 \quad 100.0 \%$ $26 \mathrm{~S}$ proteasome non-ATPase regulatory subunit 2 GN=PSMD2 PSMD2_HUMAN $100.20 \quad 100.0 \%$ 26S proteasome non-ATPase regulatory subunit 2 GN=PSMD2 PSMD2_HUMAN $100.20 \quad 100.0 \%$ 26S proteasome non-ATPase regulatory subunit 2 GN=PSMD2 PSMD2_HUMAN $100.20 \quad 100.0 \%$ 26S proteasome non-ATPase regulatory subunit $3 \mathrm{GN}=\mathrm{PSMD} 3 \mathrm{PSMD} 3$ _HUMAN $60.98 \quad 100.0 \%$ 26S proteasome non-ATPase regulatory subunit 3 GN=PSMD3 PSMD3_HUMAN $60.98 \quad 100.0 \%$ 26S proteasome non-ATPase regulatory subunit 3 GN=PSMD3 PSMD3_HUMAN $60.98 \quad 100.0 \%$ 26S proteasome non-ATPase regulatory subunit 3 GN=PSMD3 PSMD3_HUMAN $60.98 \quad 100.0 \%$ 26 proteasome non-ATPase regulatory subunit 3 GN=PSMD3 PSMD3_HUMAN $60.98 \quad 100.0 \%$ 26S proteasome non-ATPase regulatory subunit 3 GN=PSMD3 PSMD3_HUMAN $60.98 \quad 100.0 \%$ 26S proteasome non-ATPase regulatory subunit 3 GN=PSMD3 PSMD3_HUMAN $60.98 \quad 100.0 \%$ 26S proteasome non-ATPase regulatory subunit 3 GN=PSMD3 PSMD3_HUMAN $60.98 \quad 100.0 \%$ 26S proteasome non-ATPase regulatory subunit 3 GN=PSMD3 PSMD3_HUMAN $60.98 \quad 100.0 \%$ 26S proteasome non-ATPase regulatory subunit 3 GN=PSMD3 PSMD3_HUMAN $60.98 \quad 100.0 \%$ $26 \mathrm{~S}$ proteasome non-ATPase regulatory subunit $3 \mathrm{GN}=$ PSMD3 PSMD3_HUMAN $60.98 \quad 100.0 \%$ 26S proteasome non-ATPase regulatory subunit 3 GN=PSMD3 PSMD3_HUMAN $60.98 \quad 100.0 \%$ $26 \mathrm{~S}$ proteasome non-ATPase regulatory subunit $3 \mathrm{GN}=$ PSMD3 $3 S M D 3$ HUMAN $60.98 \quad 100.0 \%$ 26S proteasome non-ATPase regulatory subunit $3 \mathrm{GN}=$ PSMD3 PSMD3_HUMAN $60.98 \quad 100.0 \%$ 26S proteasome non-ATPase regulatory subunit 4 GN=PSMD4 PSMD4_HUMAN $40.74 \quad 100.0 \%$ 265 proteasome non-ATPase regulatory subunit 4 GN=PSMD4 PSMD4_HUMAN $40.74 \quad 100.0 \%$ 26S proteasome non-ATPase regulatory subunit 4 GN=PSMD4 PSMD4_HUMAN $40.74 \quad 100.0 \%$ $28 \mathrm{~S}$ ribosomal protein $\mathrm{S} 18 \mathrm{~b}$, mitochondrial GN=MRPS18B RT18B_HUMAN $29.40 \quad 100.0 \%$ $28 \mathrm{~S}$ ribosomal protein S18b, mitochondrial GN=MRPS18B RT18B_HUMAN $29.40 \quad 100.0 \%$ $28 \mathrm{~S}$ ribosomal protein S18b, mitochondrial GN=MRPS18B RT18B_HUMAN $29.40 \quad 100.0 \%$ $28 \mathrm{~S}$ ribosomal protein S18b, mitochondrial GN=MRPS18B RT18B_HUMAN $29.40 \quad 100.0 \%$ $28 \mathrm{~S}$ ribosomal protein S18b, mitochondrial GN=MRPS18B RT18B_HUMAN $29.40 \quad 100.0 \%$
$4 \quad 0.03 \% \quad 17.3 \%$ TYGQSTYSR $0.03 \% \quad 17.3 \%$ AVANRTDACFIR $0.03 \% \quad 17.3 \%$ MVRELFEMAR $0.03 \% \quad 17.3 \%$ LCPNSTGAEIR $0.03 \% \quad 17.3 \%$ SVCTEAGMFAIR $0.06 \% \quad 20.4 \%$ LQAQRNELNAK $0.06 \% 20.4 \%$ VALRNDSYTLHK $0.06 \% \quad 20.4 \%$ GVLLYGPPGTGK $0.06 \% \quad 20.4 \%$ AVAHHTDCTFIR $0.06 \% 20.4 \%$ VSGSELVQK $0.06 \% \quad 20.4 \%$ LEGGSGGDSEVQR $0.06 \% \quad 20.4 \%$ IAELMPGASGAEVK $0.01 \% \quad 2.4 \%$ QDVYDLLK $0.01 \% \quad 2.4 \%$ LLHVAVSDVNDDVRR $0.01 \% \quad 7.2 \% \quad$ SSDEAVILCK $0.01 \% \quad 7.2 \%$ QLTFEEIAK $0.01 \% \quad 7.2 \% \quad$ VLDLQQIK $0.01 \% \quad 7.1 \%$ AVAVVVDPIQSVK $0.01 \% \quad 7.1 \%$ AVAVVVDPIQSVKGK $0.01 \% \quad 7.1 \%$ GKVVIDAFR $0.05 \% \quad 6.4 \% \quad$ SSTTSMTSVPKPLK $0.05 \% \quad 6.4 \%$ CALGVFRK $0.05 \% \quad 6.4 \%$ FGGSGSQVDSAR $0.05 \% \quad 6.4 \%$ LNILDTLSK $0.05 \% \quad 6.4 \%$ VGQAVDVVGQAGKPK $0.07 \% \quad 24.9 \%$ RLNHYVLYK $0.07 \% \quad 24.9 \%$ AVQGFFTSNNATR $0.07 \% \quad 24.9 \%$ ISDDLMQK $0.07 \% \quad 24.9 \%$ RALDLVAAK $0.07 \% \quad 24.9 \%$ ALDLVAAK $0.07 \% \quad 24.9 \%$ NYLHYSLYDQAEK $0.07 \% \quad 24.9 \%$ SVFPEQANNNEWAR $0.07 \% \quad 24.9 \%$ IKAIQLEYSEAR $0.07 \% \quad 24.9 \%$ AIQLEYSEAR $0.07 \% \quad 24.9 \%$ FNQVLDQFGEK $0.07 \% \quad 24.9 \%$ MISLSYSR $0.07 \% \quad 24.9 \%$ ISLADIAQK $0.07 \% \quad 24.9 \%$ AIRDGVIEASINHEK $0.07 \% \quad 24.9 \%$ SYNKDLESAEER $0.03 \% \quad 9.8 \%$ LQAQQDAVNIVCHSK $0.03 \% \quad 9.8 \%$ GKITFCTGIR $0.03 \% \quad 9.8 \%$ NAMGSLASQATK $0.01 \% \quad 20.2 \%$ NKVVGNPCPICR $0.01 \% \quad 20.2 \%$ VVGNPCPICR

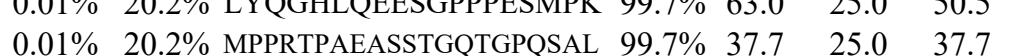

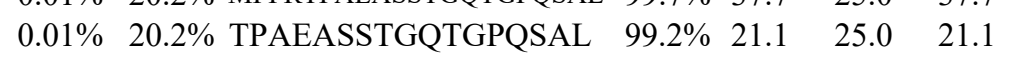

$\begin{array}{llllllll}99.7 \% & 29.1 & 25.0 & 29.1 & 2 & 0 & 0 & 1062.49\end{array}$

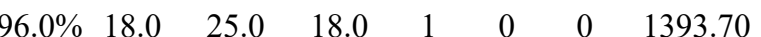

$99.2 \% \quad 19.9 \quad 25.0 \quad 19.9$

$99.7 \% \quad 37.6 \quad 25.0 \quad 29.6$

$\begin{array}{llll}99.7 \% & 51.8 & 25.0 & 42.3\end{array}$

$\begin{array}{llll}99.7 \% & 44.3 & 25.0 & 37.0\end{array}$

$\begin{array}{llll}99.7 \% & 34.0 & 25.0 & 25.1\end{array}$

$99.1 \% \quad 57.0 \quad 25.0 \quad 0.0 \quad 4$

$\begin{array}{llll}99.7 \% & 31.4 & 25.0 & 29.8\end{array}$

$99.7 \% \quad 37.4 \quad 25.0 \quad 22.1$

$99.7 \% \quad 61.3 \quad 25.0 \quad 59.2 \quad 4$

$\begin{array}{lllll}99.7 \% & 38.8 & 25.0 & 27.1\end{array}$

$98.8 \% \quad 26.9 \quad 25.0 \quad 22.1$

$99.7 \% \quad 43.2 \quad 25.0 \quad 43.2$

$\begin{array}{llll}99.7 \% & 59.3 & 25.0 & 32.5\end{array}$

$\begin{array}{llll}99.7 \% & 37.5 & 25.0 & 26.9\end{array}$

$99.0 \% \quad 25.8 \quad 25.0 \quad 17.3$

$\begin{array}{llll}99.7 \% & 59.3 & 25.0 & 57.4\end{array}$

$\begin{array}{llll}99.7 \% & 28.3 & 25.0 & 28.3\end{array}$

$\begin{array}{llll}99.6 \% & 25.4 & 25.0 & 25.4\end{array}$

$\begin{array}{llll}99.7 \% & 44.2 & 25.0 & 43.5\end{array}$

$99.0 \% \quad 23.4 \quad 25.0 \quad 17.9$

$\begin{array}{llll}99.7 \% & 72.7 & 25.0 & 62.6\end{array}$

$\begin{array}{llll}99.5 \% & 27.7 & 25.0 & 19.4\end{array}$

$\begin{array}{llll}99.7 \% & 74.2 & 25.0 & 68.0\end{array}$

$\begin{array}{llll}99.7 \% & 36.2 & 25.0 & 32.7\end{array}$

$\begin{array}{llll}99.7 \% & 69.4 & 25.0 & 69.4\end{array}$

$\begin{array}{llll}99.0 \% & 36.8 & 25.0 & 23.9\end{array}$

$\begin{array}{lllll}99.7 \% & 31.6 & 25.0 & 22.7 & 2\end{array}$

$99.0 \% \quad 59.1 \quad 25.0 \quad 31.3 \quad 2$

$\begin{array}{llll}99.7 \% & 51.1 & 25.0 & 43.2\end{array}$

$\begin{array}{llll}99.7 \% & 44.8 & 25.0 & 44.2\end{array}$

$99.7 \% \quad 51.0 \quad 25.0 \quad 51.0$

$\begin{array}{llll}99.7 \% & 70.7 & 25.0 & 66.1\end{array}$

$\begin{array}{llll}99.7 \% & 46.5 & 25.0 & 34.4\end{array}$

$\begin{array}{llll}99.0 \% & 44.2 & 25.0 & 38.1\end{array}$

$\begin{array}{llll}99.0 \% & 38.3 & 25.0 & 7.1\end{array}$

$99.7 \% \quad 35.6 \quad 25.0 \quad 32.0$

$\begin{array}{llll}99.7 \% & 37.7 & 25.0 & 30.6\end{array}$

$\begin{array}{llll}96.7 \% & 16.3 & 25.0 & 16.3\end{array}$

$\begin{array}{llll}99.7 \% & 42.6 & 25.0 & 42.6\end{array}$

$\begin{array}{llll}99.7 \% & 63.3 & 25.0 & 57.8\end{array}$

$\begin{array}{lllll}99.7 \% & 43.2 & 25.0 & 43.2\end{array}$

$\begin{array}{llll}99.5 \% & 26.2 & 25.0 & 21.2\end{array}$

0
0
0
0
0
0
0
0
0
0
0
0
0
0
0
0
0
0
0
0
0
0
0
0
0
0
0
0
0
0
0
0
0
0
0
0
0
0
0
0
0
0
0
0
0
0
0
0
0
0
0
0
0
0
0
0

1416.76

1158.65

1427.68

946.52

1290.59

1372.71

993.53

1707.91

1121.55

1078.58

956.58

1324.78

1509.90

1004.59

1463.78

950.52

1167.54

1016.60

1452.82

1205.68

1412.69

949.47

956.59

800.49

1643.77

1661.77

1420.78

1179.60

1324.65

956.49

958.56

1651.88

1440.66

1710.86

1152.62

1178.58

1413.71

1171.57

2140.00

2100.00

1602.76 
$28 \mathrm{~S}$ ribosomal protein $\mathrm{S} 22$, mitochondrial GN=MRPS22 RT22_HUMAN $41.28 \quad 100.0 \%$ $28 \mathrm{~S}$ ribosomal protein S22, mitochondrial GN=MRPS22 RT22_HUMAN $41.28 \quad 100.0 \%$ $28 \mathrm{~S}$ ribosomal protein S22, mitochondrial GN=MRPS22 RT22_HUMAN $41.28 \quad 100.0 \%$ $28 \mathrm{~S}$ ribosomal protein S22, mitochondrial GN=MRPS22 RT22 HUMAN $41.28 \quad 100.0 \%$ $28 \mathrm{~S}$ ribosomal protein S22, mitochondrial GN=MRPS22 RT22_HUMAN $41.28 \quad 100.0 \%$ $28 \mathrm{~S}$ ribosomal protein S27, mitochondrial GN=MRPS27 RT27_HUMAN $47.61 \quad 100.0 \%$ $28 \mathrm{~S}$ ribosomal protein S27, mitochondrial GN=MRPS27 RT27_HUMAN $47.61 \quad 100.0 \%$ $28 \mathrm{~S}$ ribosomal protein S27, mitochondrial GN=MRPS27 RT27_HUMAN $47.61 \quad 100.0 \%$ $28 \mathrm{~S}$ ribosomal protein S27, mitochondrial GN=MRPS27 RT27 HUMAN $47.61 \quad 100.0 \%$ $28 \mathrm{~S}$ ribosomal protein S27, mitochondrial GN=MRPS27 RT27_HUMAN $47.61 \quad 100.0 \%$ $28 \mathrm{~S}$ ribosomal protein S29, mitochondrial GN=DAP3 RT29_HUMAN $45.57 \quad 100.0 \%$ $28 \mathrm{~S}$ ribosomal protein $\mathrm{S} 29$, mitochondrial GN=DAP3 RT29 HUMAN $45.57 \quad 100.0 \%$ $28 \mathrm{~S}$ ribosomal protein $\mathrm{S} 29$, mitochondrial GN=DAP3 RT29_HUMAN $45.57 \quad 100.0 \%$ $28 \mathrm{~S}$ ribosomal protein S29, mitochondrial GN=DAP3 RT29_HUMAN $45.57 \quad 100.0 \%$ $28 \mathrm{~S}$ ribosomal protein S29, mitochondrial GN=DAP3 RT29_HUMAN $45.57 \quad 100.0 \%$ $28 \mathrm{~S}$ ribosomal protein S29, mitochondrial GN=DAP3 RT29_HUMAN $45.57 \quad 100.0 \%$ $28 \mathrm{~S}$ ribosomal protein $\mathrm{S} 29$, mitochondrial GN=DAP3 RT29 HUMAN $45.57 \quad 100.0 \%$ $28 \mathrm{~S}$ ribosomal protein S35, mitochondrial GN=MRPS35 RT35_HUMAN $36.85 \quad 100.0 \%$ $28 \mathrm{~S}$ ribosomal protein S35, mitochondrial GN=MRPS35 RT35_HUMAN $36.85 \quad 100.0 \%$ $28 \mathrm{~S}$ ribosomal protein $\mathrm{S} 35$, mitochondrial GN=MRPS35 RT35 HUMAN $36.85 \quad 100.0 \%$ $28 \mathrm{~S}$ ribosomal protein S35, mitochondrial GN=MRPS35 RT35_HUMAN $36.85 \quad 100.0 \%$ $28 \mathrm{~S}$ ribosomal protein $\mathrm{S} 35$, mitochondrial GN=MRPS35 RT35 HUMAN $36.85 \quad 100.0 \%$ $28 \mathrm{~S}$ ribosomal protein $\mathrm{S} 5$, mitochondrial GN=MRPS5 RT05_HUMAN $48.01 \quad 100.0 \%$ $28 \mathrm{~S}$ ribosomal protein S5, mitochondrial GN=MRPS5 RT05_HUMAN $48.01 \quad 100.0 \%$ $28 \mathrm{~S}$ ribosomal protein $\mathrm{S} 5$, mitochondrial GN=MRPS5 RT05 HUMAN $48.01 \quad 100.0 \%$ $28 \mathrm{~S}$ ribosomal protein S5, mitochondrial GN=MRPS5 RT05_HUMAN $48.01 \quad 100.0 \%$ $28 \mathrm{~S}$ ribosomal protein S5, mitochondrial GN=MRPS5 RT05_HUMAN $48.01 \quad 100.0 \%$ $28 \mathrm{~S}$ ribosomal protein S5, mitochondrial GN=MRPS5 RT05_HUMAN $48.01 \quad 100.0 \%$ $28 \mathrm{~S}$ ribosomal protein S9, mitochondrial GN=MRPS9 RT09_HUMAN $45.84 \quad 100.0 \%$ $28 \mathrm{~S}$ ribosomal protein $\mathrm{S} 9$, mitochondrial GN=MRPS9 RT09 HUMAN $45.84 \quad 100.0 \%$ $28 \mathrm{~S}$ ribosomal protein S9, mitochondrial GN=MRPS9 RT09_HUMAN $45.84 \quad 100.0 \%$ $28 \mathrm{~S}$ ribosomal protein S9, mitochondrial GN=MRPS9 RT09_HUMAN $45.84 \quad 100.0 \%$ $28 \mathrm{~S}$ ribosomal protein $\mathrm{S} 9$, mitochondrial GN=MRPS9 RT09_HUMAN $45.84100 .0 \%$ 2-oxoisovalerate dehydrogenase subunit beta, mitochondrial GN=BCKDHB ODBB_HUMAN $43.12 \quad 100.0 \%$ 2oxoisovalerate dehydrogenase subunit beta, mitochondrial GN=BCKDHB ODBB_HUMAN $43.12 \quad 100.0 \%$ 39S ribosomal protein L15, mitochondrial GN=MRPL15 RM15_HUMAN $33.42 \quad 100.0 \%$ 39S ribosomal protein L15, mitochondrial GN=MRPL15 RM15_HUMAN $33.42 \quad 100.0 \%$ 39S ribosomal protein $\mathrm{L} 15$, mitochondrial GN=MRPL15 RM15 HUMAN $33.42 \quad 100.0 \%$ 39S ribosomal protein L15, mitochondrial GN=MRPL15 RM15_HUMAN $33.42 \quad 100.0 \%$ 39S ribosomal protein L15, mitochondrial GN=MRPL15 RM15_HUMAN $33.42 \quad 100.0 \%$ 39S ribosomal protein $\mathrm{L} 15$, mitochondrial GN=MRPL15 RM15 HUMAN $33.42 \quad 100.0 \%$ 39S ribosomal protein L19, mitochondrial GN=MRPL19 RM19_HUMAN $33.54 \quad 100.0 \%$ 39S ribosomal protein $\mathrm{L} 19$, mitochondrial GN=MRPL19 RM19 HUMAN $33.54 \quad 100.0 \%$ 39S ribosomal protein L19, mitochondrial GN=MRPL19 RM19_HUMAN $33.54 \quad 100.0 \%$ 39S ribosomal protein L19, mitochondrial GN=MRPL19 RM19_HUMAN $33.54 \quad 100.0 \%$ 39S ribosomal protein $\mathrm{L} 2$, mitochondrial GN=MRPL2 RM02_HUMAN $33.30 \quad 100.0 \%$ $39 \mathrm{~S}$ ribosomal protein $\mathrm{L} 2$, mitochondrial GN=MRPL2 RM02_HUMAN $33.30 \quad 100.0 \%$
$15 \quad 0.03 \% \quad 14.2 \%$ MTGLNLQK $0.03 \% \quad 14.2 \%$ LMTQAQLEEATR $0.03 \% \quad 14.2 \%$ FIVVREPSGTLR $0.03 \% \quad 14.2 \%$ MIQVYFPK $0.03 \% \quad 14.2 \%$ DQAAEGINLIK $0.02 \% \quad 12.1 \%$ KLPVSSLTISR $0.02 \% \quad 12.1 \%$ LIDNISSR $0.02 \% \quad 12.1 \%$ VELQQGLR $0.02 \% \quad 12.1 \%$ VAASPEDIKLCR $0.02 \% \quad 12.1 \%$ EALDVLGAVLK $0.03 \% \quad 17.3 \%$ TFSEACLMVR $0.03 \% \quad 17.3 \%$ NTSFAYPAIR $0.03 \% \quad 17.3 \%$ NCRDLLQSSYNK $0.03 \% \quad 17.3 \%$ FLNQIKVQEK $0.03 \% \quad 17.3 \%$ GSPLGEVVEQGITR $0.03 \% \quad 17.3 \%$ VRNATDAVGIVLK $0.03 \% \quad 17.3 \%$ NATDAVGIVLK $0.02 \% \quad 12.4 \%$ EGNLELLK $0.02 \% \quad 12.4 \%$ VKLSSLNLDDHAK $0.02 \% \quad 12.4 \%$ LSSLNLDDHAK $0.02 \% \quad 12.4 \%$ LVGERYCK $0.02 \% \quad 12.4 \%$ TTDVLTIKTDR $0.03 \% \quad 12.1 \%$ GALAETGAGAK $0.03 \% \quad 12.1 \%$ DLNRGQIIGEGR $0.03 \% \quad 12.1 \%$ GQIIGEGR $0.03 \% \quad 12.1 \%$ NGAVQTIAQR $0.03 \% \quad 12.1 \%$ GAAGFSIGK $0.03 \% \quad 12.1 \%$ LIGIKDMYAK $0.02 \% \quad 12.1 \%$ HPEQIFPR $0.02 \% \quad 12.1 \%$ SLLPEKTVTR $0.02 \% \quad 12.1 \%$ TAKAEAIVYK $0.02 \% \quad 12.1 \%$ AEAIVYKHGSGR $0.02 \% \quad 12.1 \%$ LGKHDVTCTVSGGGR $0.01 \% \quad 6.1 \%$ SGDLFNCGSLTIR $0.01 \% \quad 6.1 \%$ LGVSCEVIDLR $0.02 \% \quad 23.6 \%$ VSLANLKPNPGSK $0.02 \% \quad 23.6 \%$ YGFNEGHSFRR $0.02 \% \quad 23.6 \%$ GVTIQPLKR $0.02 \% \quad 23.6 \%$ NGGVVTTAFYDPR $0.02 \% \quad 23.6 \%$ GYLADPAKFPEAR $0.02 \% \quad 23.6 \%$ ILKPTDENLLK $0.02 \% \quad 13.7 \%$ FLSPEFIPR $0.02 \% \quad 13.7 \%$ VTTADPYASGK $0.02 \% \quad 13.7 \%$ GLGATFILR $0.02 \% \quad 13.7 \%$ VQEIQVVKLEK $0.01 \% \quad 14.1 \%$ TKYTITPVK $0.01 \% \quad 14.1 \%$ SADIALVAGGSR

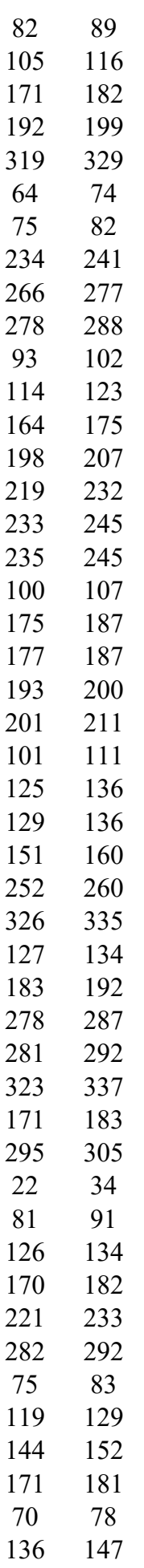


S ribosomal protein L2, mitochondrial GN=MRPL2 RM02 HUMAN $33.30 \quad 100.0 \%$ 39S ribosomal protein L2, mitochondrial GN=MRPL2 RM02_HUMAN $33.30 \quad 100.0 \%$ 39S ribosomal protein L3, mitochondrial GN=MRPL3 RM03_HUMAN $38.63 \quad 100.0 \%$ S ribosomal protein $\mathrm{L} 3$, mitochondrial GN=MRPL3 RM03 HUMAN $38.63-100.0^{\circ}$ 39S ribosomal protein L3, mitochondrial GN=MRPL3 RM03_HUMAN $38.63 \quad 100.0 \%$ 39S ribosomal protein L37, mitochondrial GN=MRPL37 RM37_HUMAN $48.12 \quad 100.0 \%$ $39 \mathrm{~S}$ ribosomal protein $\mathrm{L} 37$, mitochondrial GN=MRPL37 RM37 HUMAN $48.12 \quad 100.0 \%$ 39S ribosomal protein L38, mitochondrial GN=MRPL38 RM38_HUMAN $44.60 \quad 100.0 \%$ 39S ribosomal protein $\mathrm{L} 38$, mitochondrial GN=MRPL38 RM38 HUMAN $44.60 \quad 100.0^{\circ}$ $39 \mathrm{~S}$ ribosomal protein L38, mitochondrial GN=MRPL38 RM38_HUMAN $44.60 \quad 100.0 \%$ 39S ribosomal protein L39, mitochondrial GN=MRPL39 RM39_HUMAN $38.71 \quad 100.0 \%$ 39S ribosomal protein L39, mitochondrial GN=MRPL39 RM39 HUMAN $38.71 \quad 100.0 \%$ 39S ribosomal protein L39, mitochondrial GN=MRPL39 RM39_HUMAN $38.71 \quad 100.0 \%$ 39S ribosomal protein L39, mitochondrial GN=MRPL39 RM39_HUMAN $38.71 \quad 100.0 \%$ 39S ribosomal protein L44, mitochondrial GN=MRPL44 RM44_HUMAN $37.54 \quad 100.0 \%$ 39S ribosomal protein L44, mitochondrial GN=MRPL44 RM44_HUMAN $37.54 \quad 100.0 \%$ 39S ribosomal protein L46, mitochondrial GN=MRPL46 RM46 HUMAN $31.71 \quad 100.0 \%$ 39S ribosomal protein L46, mitochondrial GN=MRPL46 RM46_HUMAN $31.71 \quad 100.0 \%$ $40 \mathrm{~S}$ ribosomal protein $\mathrm{S} 2 \mathrm{GN}=\mathrm{RPS} 2$ $40 \mathrm{~S}$ ribosomal protein $\mathrm{S} 2 \mathrm{GN}=\mathrm{RPS} 2$ $40 \mathrm{~S}$ ribosomal protein $\mathrm{S} 2 \mathrm{GN}=\mathrm{RPS} 2$ $40 \mathrm{~S}$ ribosomal protein $\mathrm{S} 2 \mathrm{GN}=\mathrm{RPS} 2$ $40 \mathrm{~S}$ ribosomal protein $\mathrm{S} 2 \mathrm{GN}=\mathrm{RPS} 2$ $40 \mathrm{~S}$ ribosomal protein $\mathrm{S} 2 \mathrm{GN}=\mathrm{RPS} 2$ $40 \mathrm{~S}$ ribosomal protein $\mathrm{S} 2 \mathrm{GN}=\mathrm{RPS} 2$ $40 \mathrm{~S}$ ribosomal protein $\mathrm{S} 2 \mathrm{GN}=\mathrm{RPS} 2$ $40 \mathrm{~S}$ ribosomal protein $\mathrm{S} 2 \mathrm{GN}=\mathrm{RPS} 2$ $40 \mathrm{~S}$ ribosomal protein $\mathrm{S} 2 \mathrm{GN}=\mathrm{RPS} 2$ $40 \mathrm{~S}$ ribosomal protein $\mathrm{S} 2 \mathrm{GN}=\mathrm{RPS} 2$ $40 \mathrm{~S}$ ribosomal protein $\mathrm{S} 2 \mathrm{GN}=\mathrm{RPS} 2$ $40 \mathrm{~S}$ ribosomal protein $\mathrm{S} 2 \mathrm{GN}=\mathrm{RPS} 2$ $40 \mathrm{~S}$ ribosomal protein $\mathrm{S} 2 \mathrm{GN}=\mathrm{RPS} 2$ $40 \mathrm{~S}$ ribosomal protein $\mathrm{S} 2 \mathrm{GN}=\mathrm{RPS} 2$ $40 \mathrm{~S}$ ribosomal protein $\mathrm{S} 3 \mathrm{GN}=\mathrm{RPS} 3$ $40 \mathrm{~S}$ ribosomal protein $\mathrm{S} 3 \mathrm{GN}=\mathrm{RPS} 3$ $40 \mathrm{~S}$ ribosomal protein $\mathrm{S} 3 \mathrm{GN}=\mathrm{RPS} 3$ $40 \mathrm{~S}$ ribosomal protein $\mathrm{S} 3 \mathrm{GN}=\mathrm{RPS} 3$ $40 \mathrm{~S}$ ribosomal protein $\mathrm{S} 3 \mathrm{GN}=\mathrm{RPS} 3$ $40 \mathrm{~S}$ ribosomal protein $\mathrm{S} 3 \mathrm{GN}=\mathrm{RPS} 3$ $40 \mathrm{~S}$ ribosomal protein $\mathrm{S} 3 \mathrm{GN}=\mathrm{RPS} 3$ $40 \mathrm{~S}$ ribosomal protein $\mathrm{S} 3 \mathrm{GN}=\mathrm{RPS} 3$ $40 \mathrm{~S}$ ribosomal protein $\mathrm{S} 3 \mathrm{GN}=\mathrm{RPS} 3$ $40 \mathrm{~S}$ ribosomal protein $\mathrm{S} 3 \mathrm{GN}=\mathrm{RPS} 3$ $40 \mathrm{~S}$ ribosomal protein $\mathrm{S} 3 \mathrm{GN}=\mathrm{RPS} 3$ $40 \mathrm{~S}$ ribosomal protein $\mathrm{S} 3 \mathrm{GN}=\mathrm{RPS} 3$ $40 \mathrm{~S}$ ribosomal protein $\mathrm{S} 3 \mathrm{GN}=\mathrm{RPS} 3$ $40 \mathrm{~S}$ ribosomal protein $\mathrm{S} 3 \mathrm{GN}=\mathrm{RPS} 3$ RS2 HUMAN $31.33 \quad 100.0 \%$ RS2 HUMAN $31.33 \quad 100.0 \%$ RS2_HUMAN $31.33 \quad 100.0 \%$ RS2 HUMAN $31.33 \quad 100.0 \% \quad 15$ RS2_HUMAN $31.33 \quad 100.0 \% \quad 15$ RS2_HUMAN $31.33 \quad 100.0 \% \quad 15$ RS2 HUMAN $31.33 \quad 100.0 \% \quad 15$ RS2_HUMAN $31.33 \quad 100.0 \% \quad 15$ RS2_HUMAN $31.33 \quad 100.0 \% \quad 15$ RS2 HUMAN $31.33 \quad 100.0 \% \quad 15$ RS2_HUMAN $31.33 \quad 100.0 \% \quad 15$ RS2 HUMAN $31.33 \quad 100.0 \% \quad 15$ RS2_HUMAN $31.33 \quad 100.0 \% \quad 15$ RS2_HUMAN $31.33 \quad 100.0 \% \quad 15$ RS2 HUMAN $31.33 \quad 100.0 \% \quad 15$ RS3_HUMAN $26.69 \quad 100.0 \% \quad 20$ RS3 HUMAN $26.69 \quad 100.0 \% \quad 20$ RS3 HUMAN $26.69 \quad 100.0 \% \quad 20$ RS3_HUMAN $26.69 \quad 100.0 \% \quad 20$ RS3 HUMAN $26.69 \quad 100.0 \% \quad 20$ RS3_HUMAN $26.69 \quad 100.0 \% \quad 20$ RS3_HUMAN $26.69 \quad 100.0 \% \quad 20$ RS3 HUMAN $26.69 \quad 100.0 \% \quad 20$ RS3_HUMAN $26.69 \quad 100.0 \% \quad 20$ RS3 HUMAN $26.69 \quad 100.0 \% \quad 20$ RS3_HUMAN $26.69 \quad 100.0 \% \quad 20$ RS3_HUMAN $26.69 \quad 100.0 \% \quad 20$ RS3 HUMAN $26.69 \quad 100.0 \% \quad 20$ RS3_HUMAN $26.69 \quad 100.0 \% \quad 20$
$0.01 \% \quad 14.1 \%$ AAGTCGVLLR $0.01 \% \quad 14.1 \%$ SYVKLPSASAQS $0.01 \% \quad 8.6 \%$ MATLSVGGK

$0.01 \% \quad 8.6 \%$ RPGAVATGDIGR $0.01 \% \quad 8.6 \%$ LPAYKDLGK $0.01 \% \quad 4.3 \%$ TKLIEGLPEK

$0.01 \% \quad 4.3 \%$ ESLLLQVR

$0.01 \% \quad 5.8 \%$ ANVEEERAAR

$0.01 \% \quad 5.8 \%$ LRTASVPLDAVR

$0.01 \% \quad 5.8 \%$ TASVPLDAVR

$0.01 \% \quad 10.7 \%$ HVGKTDPGTVFVMNK

$0.01 \% \quad 10.7 \%$ TDPGTVFVMNK

$0.01 \% \quad 10.7 \%$ AFKDEYMVNLVR

$0.01 \% \quad 10.7 \%$ YKVDFIEEK

$0.01 \% \quad 5.7 \%$ TAFVNSCYI

$0.01 \% \quad 5.7 \% \quad$ KLYGFTENR

$0.01 \% \quad 10.4 \%$ SLYSDHELRALDENQR

$0.01 \% \quad 10.4 \%$ TLATLSENNMEAK

$0.18 \% \quad 43.3 \%$ AEDKEWMPVTK

$0.18 \% \quad 43.3 \%$ IMPVQKQTR

$0.18 \% \quad 43.3 \%$ CSKEVATAIR

$0.18 \% \quad 43.3 \%$ EVATAIRGAIILAK

$0.18 \% \quad 43.3 \%$ LSIVPVRR

$0.18 \% \quad 43.3 \%$ IGKPHTVPCK

$0.18 \% \quad 43.3 \%$ GTGIVSAPVPK

$0.18 \% \quad 43.3 \%$ GTGIVSAPVPKK

$0.18 \% \quad 43.3 \%$ KLLMMAGIDDCYTSAR $0.18 \% \quad 43.3 \%$ LLMMAGIDDCYTSAR

$0.18 \% \quad 43.3 \%$ GCTATLGNFAK

$0.18 \% \quad 43.3 \%$ ATFDAISK

$0.18 \% \quad 43.3 \%$ SPYQEFTDHLVK

$0.18 \% \quad 43.3 \%$ VSVQRTQAPAVATT

$0.18 \% \quad 43.3 \%$ TQAPAVATT

$0.16 \% \quad 60.1 \%$ KFVADGIFK

$0.16 \% \quad 60.1 \%$ FVADGIFK

$0.16 \% \quad 60.1 \%$ AELNEFLTR

$0.16 \% \quad 60.1 \%$ ELAEDGYSGVEVR

$0.16 \% \quad 60.1 \%$ VTPTRTEIIILATR

$0.16 \% \quad 60.1 \%$ TEIIILATR

$0.16 \% \quad 60.1 \%$ TQNVLGEKGR

$0.16 \% \quad 60.1 \%$ IRELTAVVQK

$0.16 \% \quad 60.1 \%$ ELTAVVQKR

$0.16 \% \quad 60.1 \%$ GLCAIAQAESLR

$0.16 \% \quad 60.1 \%$ GLCAIAQAESLRYK

$0.16 \% \quad 60.1 \%$ YKLLGGLAVR

$0.16 \% \quad 60.1 \%$ LLGGLAVRR

$0.16 \% \quad 60.1 \%$ FIMESGAK $\begin{array}{lllll}9.7 \% & 66.8 & 25.0 & 51.8 & 2\end{array}$

$\begin{array}{llll}99.7 \% & 35.2 & 25.0 & 26.9\end{array}$

$\begin{array}{llll}99.7 \% & 34.0 & 25.0 & 23.6\end{array}$

$\begin{array}{llll}98.6 \% & 24.9 & 25.0 & 15.1\end{array}$

$\begin{array}{llll}97.2 \% & 19.9 & 25.0 & 14.9\end{array}$

$99.7 \% \quad 47.0 \quad 25.0 \quad 39.7$

$99.0 \% \quad 47.6 \quad 25.0 \quad 31.9$

$99.3 \% \quad 23.4 \quad 25.0 \quad 19.8$

$94.9 \% \quad 15.0 \quad 25.0 \quad 14.8$

$\begin{array}{llll}99.7 \% & 31.4 & 25.0 & 21.6\end{array}$

$\begin{array}{llll}99.0 \% & 20.1 & 25.0 & 20.1\end{array}$

$\begin{array}{llll}97.3 \% & 17.3 & 25.0 & 17.3\end{array}$

$\begin{array}{llll}97.3 \% & 17.2 & 25.0 & 17.2\end{array}$

$99.6 \% \quad 27.9 \quad 25.0 \quad 20.5$

$\begin{array}{llll}99.7 \% & 29.5 & 25.0 & 25.7\end{array}$

$\begin{array}{llll}99.7 \% & 39.4 & 25.0 & 39.4\end{array}$

$95.4 \% \quad 19.2 \quad 25.0-17.0$

$\begin{array}{llll}99.7 \% & 58.1 & 25.0 & 58.1\end{array}$

$\begin{array}{llll}99.7 \% & 55.8 & 25.0 & 37.8\end{array}$

$99.7 \% \quad 44.0 \quad 25.0 \quad 33.0$

$\begin{array}{llll}99.7 \% & 41.1 & 25.0 & 27.2\end{array}$

$\begin{array}{llll}99.3 \% & 21.5 & 25.0 & 21.5\end{array}$

$\begin{array}{llll}99.0 \% & 46.4 & 25.0 & 37.2\end{array}$

$\begin{array}{llll}99.7 \% & 39.8 & 25.0 & 30.4\end{array}$

$\begin{array}{llll}99.7 \% & 48.5 & 25.0 & 48.5\end{array}$

$\begin{array}{llll}99.7 \% & 55.1 & 25.0 & 49.2\end{array}$

$\begin{array}{llll}99.7 \% & 47.8 & 25.0 & 46.7\end{array}$

$\begin{array}{llll}99.7 \% & 49.2 & 25.0 & 49.2\end{array}$

$\begin{array}{llll}99.7 \% & 59.9 & 25.0 & 52.6\end{array}$

$\begin{array}{llll}99.0 \% & 44.2 & 25.0 & 26.3\end{array}$

$\begin{array}{llll}99.7 \% & 44.8 & 25.0 & 42.4\end{array}$

$\begin{array}{lllll}99.7 \% & 32.4 & 25.0 & 32.4 & 4\end{array}$

$\begin{array}{llll}99.4 \% & 23.4 & 25.0 & 23.4\end{array}$

$\begin{array}{lllll}97.8 \% & 21.0 & 25.0 & 15.1 & 2\end{array}$

$\begin{array}{llll}99.0 \% & 23.4 & 25.0 & 17.7\end{array}$

$\begin{array}{llll}99.7 \% & 56.3 & 25.0 & 42.4\end{array}$

$\begin{array}{llll}99.7 \% & 65.7 & 25.0 & 54.5\end{array}$

$99.1 \% \quad 24.2 \quad 25.0 \quad 24.2$

$\begin{array}{llll}99.7 \% & 54.5 & 25.0 & 50.3\end{array}$

$\begin{array}{llll}99.7 \% & 37.3 & 25.0 & 22.5\end{array}$

$\begin{array}{llll}99.7 \% & 48.3 & 25.0 & 42.8\end{array}$

$\begin{array}{lllll}99.7 \% & 51.2 & 25.0 & 38.1 & 2\end{array}$

$\begin{array}{llll}99.7 \% & 67.8 & 25.0 & 55.0\end{array}$

$99.7 \% \quad 61.9 \quad 25.0 \quad 61.4$

$\begin{array}{lllll}99.7 \% & 43.2 & 25.0 & 33.7 & 5\end{array}$

$\begin{array}{llll}99.7 \% & 33.9 & 25.0 & 24.0\end{array}$

$99.0 \% \quad 35.1 \quad 25.0 \quad 10.6$

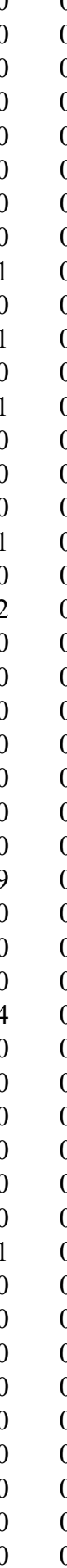

1237.64

879.46

1169.64

1004.58

1127.67

957.57

1144.57

1297.76

1028.57

1645.84

1208.60

1500.75

1170.60

1202.59

1127.58

1945.94

1437.69

1333.65

1116.62

1134.59

1425.88

939.61

1136.62

1025.60

1153.69

1876.86

1748.77

1139.55

852.45

1463.72

1428.78

859.45

1024.58

896.49

1092.57

1423.67

1583.95

1029.63

1101.60

1156.70

1043.62

1288.67

1579.83

1089.68

954.62

898.43 $\begin{array}{cc}09 & 218 \\ 94 & 305 \\ 42 & 150 \\ 39 & 250 \\ 04 & 312 \\ 26 & 135 \\ 16 & 223 \\ 15 & 124 \\ 25 & 136 \\ 27 & 136 \\ 9 & 83 \\ 3 & 83 \\ 57 & 168 \\ 35 & 243 \\ 0 & 99 \\ 03 & 311 \\ 2 & 97 \\ 91 & 203 \\ 5 & 65 \\ 09 & 117 \\ 43 & 152 \\ 46 & 159 \\ 60 & 167 \\ 74 & 183 \\ 01 & 211 \\ 01 & 212 \\ 12 & 227 \\ 13 & 227 \\ 28 & 238 \\ 39 & 246 \\ 64 & 275 \\ 80 & 293 \\ 85 & 293 \\ 0 & 18 \\ 1 & 18 \\ 9 & 27 \\ 8 & 40 \\ 1 & 54 \\ 6 & 54 \\ 5 & 64 \\ 6 & 75 \\ 8 & 76 \\ 5 & 106 \\ 5 & 108 \\ 07 & 116 \\ 09 & 117 \\ 25 & 132 \\ & \end{array}$

Page 4 of Table S-1-3 
$40 \mathrm{~S}$ ribosomal protein $\mathrm{S} 3 \mathrm{GN}=\mathrm{RPS} 3$ $40 \mathrm{~S}$ ribosomal protein $\mathrm{S} 3 \mathrm{GN}=\mathrm{RPS} 3$ $40 \mathrm{~S}$ ribosomal protein $\mathrm{S} 3 \mathrm{GN}=\mathrm{RPS} 3$ $40 \mathrm{~S}$ ribosomal protein $\mathrm{S} 3 \mathrm{GN}=\mathrm{RPS} 3$ $40 \mathrm{~S}$ ribosomal protein $\mathrm{S} 3 \mathrm{GN}=\mathrm{RPS} 3$ $40 \mathrm{~S}$ ribosomal protein $\mathrm{S} 3 \mathrm{GN}=\mathrm{RPS} 3$ $40 \mathrm{~S}$ ribosomal protein $\mathrm{S} 3 \mathrm{a} \mathrm{GN}=\mathrm{RPS} 3 \mathrm{~A}$ $40 \mathrm{~S}$ ribosomal protein $\mathrm{S} 3 \mathrm{a} \mathrm{GN}=\mathrm{RPS} 3 \mathrm{~A}$ $40 \mathrm{~S}$ ribosomal protein $\mathrm{S} 3 \mathrm{a} \mathrm{GN}=\mathrm{RPS} 3 \mathrm{~A}$ $40 \mathrm{~S}$ ribosomal protein $\mathrm{S} 3 \mathrm{a} \mathrm{GN}=\mathrm{RPS} 3 \mathrm{~A}$ $40 \mathrm{~S}$ ribosomal protein $\mathrm{S} 3 \mathrm{a} \mathrm{GN}=\mathrm{RPS} 3 \mathrm{~A}$ $40 \mathrm{~S}$ ribosomal protein $\mathrm{S} 3 \mathrm{a} \mathrm{GN}=\mathrm{RPS} 3 \mathrm{~A}$ $40 \mathrm{~S}$ ribosomal protein $\mathrm{S} 3 \mathrm{a} \mathrm{GN}=\mathrm{RPS} 3 \mathrm{~A}$ $40 \mathrm{~S}$ ribosomal protein $\mathrm{S} 3 \mathrm{a} \mathrm{GN}=\mathrm{RPS} 3 \mathrm{~A}$ $40 \mathrm{~S}$ ribosomal protein $\mathrm{S} 3 \mathrm{a} \mathrm{GN}=\mathrm{RPS} 3 \mathrm{~A}$ $40 \mathrm{~S}$ ribosomal protein $\mathrm{S} 3 \mathrm{a} \mathrm{GN}=\mathrm{RPS} 3 \mathrm{~A}$ $40 \mathrm{~S}$ ribosomal protein $\mathrm{S} 3 \mathrm{a} \mathrm{GN}=\mathrm{RPS} 3 \mathrm{~A}$ $40 \mathrm{~S}$ ribosomal protein $\mathrm{S} 3 \mathrm{a} \mathrm{GN}=\mathrm{RPS} 3 \mathrm{~A}$ $40 \mathrm{~S}$ ribosomal protein $\mathrm{S} 3 \mathrm{a} \mathrm{GN}=\mathrm{RPS} 3 \mathrm{~A}$ $40 \mathrm{~S}$ ribosomal protein $\mathrm{S} 3 \mathrm{a} \mathrm{GN}=\mathrm{RPS} 3 \mathrm{~A}$ $40 \mathrm{~S}$ ribosomal protein $\mathrm{S} 3 \mathrm{a} \mathrm{GN}=\mathrm{RPS} 3 \mathrm{~A}$ $40 \mathrm{~S}$ ribosomal protein $\mathrm{S} 3 \mathrm{a} \mathrm{GN}=\mathrm{RPS} 3 \mathrm{~A}$ $40 \mathrm{~S}$ ribosomal protein $\mathrm{S} 3 \mathrm{a} \mathrm{GN}=\mathrm{RPS} 3 \mathrm{~A}$ $40 \mathrm{~S}$ ribosomal protein $\mathrm{S} 3 \mathrm{a} \mathrm{GN}=\mathrm{RPS} 3 \mathrm{~A}$ $40 \mathrm{~S}$ ribosomal protein $\mathrm{S} 3 \mathrm{a} \mathrm{GN}=\mathrm{RPS} 3 \mathrm{~A}$ $40 \mathrm{~S}$ ribosomal protein $\mathrm{S} 3 \mathrm{a} \mathrm{GN}=\mathrm{RPS} 3 \mathrm{~A}$ $40 \mathrm{~S}$ ribosomal protein $\mathrm{S} 3 \mathrm{a} \mathrm{GN}=\mathrm{RPS} 3 \mathrm{~A}$ $40 \mathrm{~S}$ ribosomal protein $\mathrm{S} 3 \mathrm{a} \mathrm{GN}=\mathrm{RPS} 3 \mathrm{~A}$ $40 \mathrm{~S}$ ribosomal protein $\mathrm{S} 3 \mathrm{a} \mathrm{GN}=\mathrm{RPS} 3 \mathrm{~A}$ $40 \mathrm{~S}$ ribosomal protein $\mathrm{S} 3 \mathrm{a} \mathrm{GN}=\mathrm{RPS} 3 \mathrm{~A}$
RS3 HUMAN $26.69 \quad 100.0 \% \quad 20$ RS3_HUMAN $26.69 \quad 100.0 \% \quad 20$ RS3_HUMAN $26.69 \quad 100.0 \% \quad 20$ RS3 HUMAN $26.69 \quad 100.0 \% \quad 20$ RS3_HUMAN $26.69 \quad 100.0 \% \quad 20$ RS3_HUMAN $26.69 \quad 100.0 \% \quad 20$ RS3A HUMAN $29.95 \quad 100.0 \% \quad 24$ RS3A_HUMAN $29.95 \quad 100.0 \% \quad 24$ RS3A HUMAN $29.95 \quad 100.0 \% \quad 24$ RS3A_HUMAN $29.95 \quad 100.0 \% \quad 24$ RS3A_HUMAN $29.95 \quad 100.0 \% \quad 24$ RS3A HUMAN $29.95 \quad 100.0 \% \quad 24$ RS3A_HUMAN $29.95 \quad 100.0 \% \quad 24$ RS3A_HUMAN $29.95 \quad 100.0 \% \quad 24$ RS3A_HUMAN $29.95 \quad 100.0 \% \quad 24$ RS3A_HUMAN $29.95 \quad 100.0 \% \quad 24$ RS3A HUMAN $29.95 \quad 100.0 \% \quad 24$ RS3A_HUMAN $29.95 \quad 100.0 \% \quad 24$ RS3A_HUMAN $29.95 \quad 100.0 \% \quad 24$ RS3A HUMAN $29.95 \quad 100.0 \% \quad 24$ RS3A_HUMAN $29.95 \quad 100.0 \% \quad 24$ RS3A HUMAN $29.95 \quad 100.0 \% \quad 24$ RS3A_HUMAN $29.95 \quad 100.0 \% \quad 24$ RS3A_HUMAN $29.95 \quad 100.0 \% \quad 24$ RS3A HUMAN $29.95 \quad 100.0 \% \quad 24$ RS3A_HUMAN $29.95 \quad 100.0 \% \quad 24$ RS3A_HUMAN $29.95 \quad 100.0 \% \quad 24$ RS3A_HUMAN $29.95 \quad 100.0 \% \quad 24$ RS3A_HUMAN $29.95 \quad 100.0 \% \quad 24$ RS3A HUMAN $29.95 \quad 100.0 \% \quad 24$ $100.0 \% \quad 19$ $100.0 \% \quad 19$ $100.0 \% \quad 19$ $100.0 \% \quad 19$ $100.0 \% \quad 19$ $100.0 \% \quad 19$ $100.0 \% \quad 19$ $100.0 \% \quad 19$ $100.0 \% \quad 19$ $100.0 \% \quad 19$ $100.0 \% \quad 19$ $100.0 \% \quad 19$ $100.0 \% \quad 19$ $100.0 \% \quad 19$ $100.0 \% \quad 19$ $100.0 \% \quad 19$ $100.0 \% \quad 19$
$0.17 \% \quad 66.3 \%$ TLVTRTQGTK

$0.17 \% \quad 66.3 \%$ IASDGLKGR

$0.17 \% \quad 66.3 \%$ FKLITEDVQGK

$0.17 \% \quad 66.3 \%$ LITEDVQGK

$0.17 \% \quad 66.3 \%$ TTDGYLLR

\begin{tabular}{lll}
$0.17 \%$ & $66.3 \%$ & LFCVGFTK \\
\hline
\end{tabular}

$0.17 \% \quad 66.3 \%$ KMMEIMTR

$0.17 \% \quad 66.3 \%$ LIPDSIGKDIEK

66.3\% KPKFELGK

\section{$\begin{array}{ll}60.1 \% & \text { FIMESGAKGCEV } \\ 16 \% & 60.1 \% \text { GCEVVVSGK }\end{array}$ \\ $0.16 \% \quad 60.1 \%$ GCEVVVSGKLR \\ $0.16 \% \quad 60.1 \%$ QGVLGIKVK \\ $0.16 \% \quad 60.1 \%$ DEILPTTPISEQK

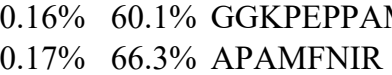

$0.17 \% \quad 66.3 \%$ NIGKTLVTR

$0.17 \% \quad 66.3 \%$ TQGTKIASDGLK

$0.17 \% \quad 66.3 \%$ NCLTNFHGMDLTR

$0.17 \% \quad 66.3 \%$ KTSYAQHQQVR

$0.17 \% \quad 66.3 \%$ TSYAQHQQVR

$0.17 \% \quad 66.3 \%$ EVQTNDLKEVVNK

$0.17 \% \quad 66.3 \%$ ACQSIYPLHDVFVR

$99.7 \% 57.5$

$99.7 \% \quad 46.9$

$99.7 \% \quad 58.9$

$99.7 \% 33.6$

$99.7 \% \quad 39.3$

$\begin{array}{lll}25.0 & 21.0\end{array}$

$\begin{array}{llll}99.7 \% & 45.1 & 25.0 & 36.6\end{array}$

$\begin{array}{llll}99.7 \% & 39.5 & 25.0 & 38.9\end{array}$

$99.7 \% \quad 28.8 \quad 25.0 \quad 27.5$

$99.7 \% \quad 31.4 \quad 25.0 \quad 21.9$

$\begin{array}{lllll}99.7 \% & 46.1 & 25.0 & 34.7 & 4\end{array}$

$99.7 \% \quad 63.9 \quad 25.0 \quad 35.5$

$\begin{array}{llll}99.7 \% & 56.5 & 25.0 & 42.2\end{array}$

$99.7 \% \quad 60.6 \quad 25.0 \quad 58.6$

$99.0 \% \quad 55.1 \quad 25.0 \quad 30.6$

$99.0 \% \quad 45.9 \quad 25.0 \quad 37.6$

$99.1 \% \quad 19.2 \quad 25.0 \quad 19.2$

$\begin{array}{llll}99.7 \% & 52.3 & 25.0 & 40.9\end{array}$

$\begin{array}{llll}99.7 \% & 64.2 & 25.0 & 58.8\end{array}$

$99.0 \% \quad 36.0 \quad 25.0 \quad 3.2$

$\begin{array}{llll}99.7 \% & 73.0 & 25.0 & 64.5\end{array}$

$99.7 \% \quad 38.1 \quad 25.0 \quad 28.0$

$\begin{array}{llll}99.4 \% & 23.3 & 25.0 & 21.9\end{array}$

$\begin{array}{llll}98.9 \% & 19.7 & 25.0 & 18.4\end{array}$

$\begin{array}{llllll} & 25.0 & 32.2\end{array}$

$\begin{array}{llll}99.7 \% & 68.8 & 25.0 & 67.6\end{array}$

$0.17 \% \quad 66.3 \%$ LMELHGEGSSSGKATGDETC

$99.7 \% \quad 33.0$

$99.7 \% \quad 60.4$

$99.7 \% \quad 28.6$

$99.7 \% \quad 32.7$

$99.1 \% \quad 19.5$

$99.7 \% \quad 52.2$

$99.7 \% \quad 35.7$

$99.7 \% \quad 53.8$

$99.7 \% \quad 37.8$

$99.0 \% \quad 37.4$

$97.0 \% \quad 21.5$

$99.7 \% \quad 53.4$

$94.8 \% \quad 24.4$

$99.7 \% \quad 58.2$

$0.09 \% \quad 60.8 \%$ VNDTIQIDLETGK

$99.7 \% \quad 35.5$

$99.7 \% \quad 30.0$

$\begin{array}{ll}99.7 \% & 35.9 \\ 99.7 \% & 35.0\end{array}$

$0.09 \% \quad 60.8 \%$ ERHPGSFDVVHVK

$0.09 \% \quad 60.8 \%$ HPGSFDVVHVKDANG

$99.7 \% \quad 65.1$

$99.7 \% \quad 63$.
1218.67

916.52

1277.71

1002.55

1594.71

938.49

971.50

1099.60

1345.70

1217.60

1055.50

1515.80

1327.75

1704.85

946.57

1921.93

1331.63

2162.00

1233.61

1674.80

1290.58

1564.86

1236.68

995.50

1123.60

1456.74

965.54

1078.58

1215.66

1215.71

1445.75

1798.82

1057.61

1506.78

1221.64

2255.10

1052.48

990.60

141
141
143
187
227
243
42
51
56
63
65
94
94
107
136
144
145
162
162
174
187
199
213
227
240
240
249
252
264
264
37
62
62
63
106
108
122
145
155
168
191
200
211
230


40S ribosomal protein S4, X isoform GN=RPS4X RS4X_HUMAN $29.60 \quad 100.0 \% \quad 19 \quad 21 \quad 45 \quad 0.09 \% \quad 60.8 \%$ GNKPWISLPR 40S ribosomal protein S4, X isoform GN=RPS4X RS4X_HUMAN $29.60 \quad 100.0 \% \quad 19 \quad 21 \quad 45 \quad 0.09 \% \quad 60.8 \%$ GIRLTIAEER 40S ribosomal protein $\mathrm{S} 5 \mathrm{GN}=\mathrm{RPS} 5$ $40 \mathrm{~S}$ ribosomal protein $\mathrm{S} 5 \mathrm{GN}=\mathrm{RPS} 5$ 40S ribosomal protein $\mathrm{S} 5 \mathrm{GN}=\mathrm{RPS} 5$ $40 \mathrm{~S}$ ribosomal protein $\mathrm{S} 5 \mathrm{GN}=\mathrm{RPS} 5$ 40S ribosomal protein $\mathrm{S} 6 \mathrm{GN}=\mathrm{RPS} 6$ $40 \mathrm{~S}$ ribosomal protein $\mathrm{S} 6 \mathrm{GN}=\mathrm{RPS} 6$ $40 \mathrm{~S}$ ribosomal protein $\mathrm{S} 6 \mathrm{GN}=\mathrm{RPS} 6$ $40 \mathrm{~S}$ ribosomal protein $\mathrm{S} 6 \mathrm{GN}=\mathrm{RPS} 6$ $40 \mathrm{~S}$ ribosomal protein $\mathrm{S} 6 \mathrm{GN}=\mathrm{RPS} 6$ $40 \mathrm{~S}$ ribosomal protein $\mathrm{S} 6 \mathrm{GN}=\mathrm{RPS} 6$ $40 \mathrm{~S}$ ribosomal protein $\mathrm{S} 6 \mathrm{GN}=\mathrm{RPS} 6$ $40 \mathrm{~S}$ ribosomal protein $\mathrm{S} 6 \mathrm{GN}=\mathrm{RPS} 6$ $40 \mathrm{~S}$ ribosomal protein $\mathrm{S} 6 \mathrm{GN}=\mathrm{RPS} 6$ $40 \mathrm{~S}$ ribosomal protein $\mathrm{S} 6 \mathrm{GN}=\mathrm{RPS} 6$ $40 \mathrm{~S}$ ribosomal protein $\mathrm{S} 6 \mathrm{GN}=\mathrm{RPS} 6$ $40 \mathrm{~S}$ ribosomal protein $\mathrm{S} 6 \mathrm{GN}=\mathrm{RPS} 6$ $40 \mathrm{~S}$ ribosomal protein $\mathrm{S} 7 \mathrm{GN}=\mathrm{RPS} 7$ $40 \mathrm{~S}$ ribosomal protein $\mathrm{S} 7 \mathrm{GN}=\mathrm{RPS} 7$ $40 \mathrm{~S}$ ribosomal protein $\mathrm{S} 7 \mathrm{GN}=\mathrm{RPS} 7$ 40S ribosomal protein $\mathrm{S} 7 \mathrm{GN}=\mathrm{RPS} 7$ $40 \mathrm{~S}$ ribosomal protein $\mathrm{S} 7 \mathrm{GN}=\mathrm{RPS} 7$ $40 \mathrm{~S}$ ribosomal protein $\mathrm{S} 8 \mathrm{GN}=\mathrm{RPS} 8$ $40 \mathrm{~S}$ ribosomal protein $\mathrm{S} 8 \mathrm{GN}=\mathrm{RPS} 8$ $40 \mathrm{~S}$ ribosomal protein $\mathrm{S} 8 \mathrm{GN}=\mathrm{RPS} 8$ $40 \mathrm{~S}$ ribosomal protein $\mathrm{S} 8 \mathrm{GN}=\mathrm{RPS} 8$ $40 \mathrm{~S}$ ribosomal protein $\mathrm{S} 8 \mathrm{GN}=\mathrm{RPS} 8$ $40 \mathrm{~S}$ ribosomal protein $\mathrm{S} 8 \mathrm{GN}=\mathrm{RPS} 8$ $40 \mathrm{~S}$ ribosomal protein $\mathrm{S} 9 \mathrm{GN}=\mathrm{RPS}$ 9 $40 \mathrm{~S}$ ribosomal protein $\mathrm{S} 9 \mathrm{GN}=\mathrm{RPS} 9$ $40 \mathrm{~S}$ ribosomal protein $\mathrm{S} 9 \mathrm{GN}=\mathrm{RPS} 9$ $40 \mathrm{~S}$ ribosomal protein $\mathrm{S} 9 \mathrm{GN}=\mathrm{RPS} 9$ $40 \mathrm{~S}$ ribosomal protein $\mathrm{S} 9 \mathrm{GN}=\mathrm{RPS} 9$ $40 \mathrm{~S}$ ribosomal protein $\mathrm{S} 9 \mathrm{GN}=\mathrm{RPS} 9$ $40 \mathrm{~S}$ ribosomal protein $\mathrm{S} 9 \mathrm{GN}=\mathrm{RPS} 9$ $40 \mathrm{~S}$ ribosomal protein $\mathrm{SA} \mathrm{GN}=\mathrm{RPSA}$ 40S ribosomal protein $\mathrm{SA} \mathrm{GN=RPSA}$ $40 \mathrm{~S}$ ribosomal protein $\mathrm{SA}$ GN=RPSA $40 \mathrm{~S}$ ribosomal protein $\mathrm{SA}$ GN=RPSA RS5_HUMAN $22.88 \quad 100.0 \%$ RS5_HUMAN $22.88 \quad 100.0 \%$ RS5_HUMAN $22.88 \quad 100.0 \%$ RS6_HUMAN $28.68 \quad 100.0 \%$ RS6_HUMAN $28.68 \quad 100.0 \%$ RS6 HUMAN $28.68 \quad 100.0 \%$ RS6_HUMAN $28.68 \quad 100.0 \% \quad 12$ RS6_HUMAN $28.68 \quad 100.0 \% \quad 12$ RS6 HUMAN $28.68 \quad 100.0 \% \quad 12$ RS6_HUMAN $28.68 \quad 100.0 \% \quad 12$ RS6_HUMAN $28.68 \quad 100.0 \% \quad 12$ RS6_HUMAN $28.68 \quad 100.0 \% \quad 12$ RS6_HUMAN $28.68 \quad 100.0 \% \quad 12$ RS6 HUMAN $28.68 \quad 100.0 \% \quad 12$ RS6_HUMAN $28.68 \quad 100.0 \% \quad 12$ RS7_HUMAN $22.13 \quad 100.0 \%$ RS7 HUMAN $22.13 \quad 100.0 \%$ RS7_HUMAN $22.13 \quad 100.0 \%$ RS7 HUMAN $22.13 \quad 100.0 \%$ RS7_HUMAN $22.13 \quad 100.0 \%$ RS8_HUMAN $24.21 \quad 100.0 \%$ RS8 HUMAN $24.21 \quad 100.0 \%$ RS8_HUMAN $24.21 \quad 100.0 \%$ RS8_HUMAN $24.21 \quad 100.0 \%$ RS8 HUMAN $24.21 \quad 100.0 \%$ RS8_HUMAN $24.21 \quad 100.0 \%$ RS9 HUMAN $22.59 \quad 100.0 \%$ RS9 HUMAN $22.59 \quad 100.0 \%$ RS9 HUMAN $22.59 \quad 100.0 \%$ RS9_HUMAN $22.59 \quad 100.0 \%$ RS9_HUMAN $22.59 \quad 100.0 \%$ RS9 HUMAN $22.59 \quad 100.0 \%$ RS9 HUMAN $22.59 \quad 100.0 \%$ RSSA_HUMAN $32.85 \quad 100.0 \%$ RSSA_HUMAN $32.85 \quad 100.0 \%$ RSSA_HUMAN $32.85 \quad 100.0 \%$ RSSA HUMAN $32.85 \quad 100.0 \%$ 4F2 cell-surface antigen heavy chain $\mathrm{GN}=\mathrm{SLC} 3 \mathrm{~A} 2 \quad 4 \mathrm{~F} 2$ HUMAN $68.00 \quad 100.0 \%$ $4 \mathrm{~F} 2$ cell-surface antigen heavy chain GN=SLC3A2 $4 \mathrm{~F} 2$ _HUMAN $68.00 \quad 100.0 \%$ $4 \mathrm{~F} 2$ cell-surface antigen heavy chain $\mathrm{GN}=\mathrm{SLC} 3 \mathrm{~A} 2 \mathrm{~F} 2 \mathrm{HUMAN} 68.00 \quad 100.0^{\circ} \%$ 5'-AMP-activated protein kinase catalytic subunit alpha-1 GN=PRKAA1 AAPK1_HUMAN $64.01 \quad 100.0 \%$ 5'-AMP-activated protein kinase catalytic subunit alpha-1 GN=PRKAA1 AAPK1_HUMAN $64.01 \quad 100.0 \%$ 5-methylcytosine rRNA methyltransferase NSUN4 GN=NSUN4 NSUN4_HUMAN $43.09 \quad 100.0 \%$ 5-methylcytosine rRNA methyltransferase NSUN4 GN=NSUN4 NSUN4_HUMAN $43.09 \quad 100.0 \%$

$0.03 \% \quad 30.4 \%$ RLFEGNALLR
$0.01 \% \quad 12.7 \%$ AQCPIVER

$0.01 \% \quad 12.7 \%$ QAVDVSPLR

$0.01 \% \quad 12.7 \%$ QAVDVSPLRR

$0.01 \% \quad 12.7 \%$ EAAFRNIK

$0.07 \% \quad 37.3 \%$ MKLNISFPATGCQK

$0.07 \% \quad 37.3 \%$ LNISFPATGCQK

$0.07 \% \quad 37.3 \%$ LIEVDDER

$0.07 \% \quad 37.3 \%$ LIEVDDERK

$0.07 \% \quad 37.3 \%$ ISGGNDKQGFPMK

$0.07 \% \quad 37.3 \%$ DIPGLTDTTVPR

$0.07 \% \quad 37.3 \%$ DIPGLTDTTVPRR

$0.07 \% \quad 37.3 \%$ LFNLSKEDDVR

$0.07 \% \quad 37.3 \%$ EDDVRQYVVR

$0.07 \% \quad 37.3 \%$ IQRLVTPR

$0.07 \% \quad 37.3 \%$ NKEEAAEYAK

$0.07 \% \quad 37.3 \%$ LSSLRASTSK

$0.01 \% \quad 21.6 \%$ SFQKIQVR

$0.01 \% \quad 21.6 \%$ HVVFIAQR

$0.01 \% \quad 21.6 \%$ RILPKPTR

$0.01 \% \quad 21.6 \%$ LIKVHLDK

$0.01 \% \quad 21.6 \%$ VETFSGVYKK

$0.05 \% \quad 31.2 \%$ KYELGRPAANTK

$0.05 \% \quad 31.2 \%$ YELGRPAANTK

$0.05 \% \quad 31.2 \%$ IIDVVYNASNNELVR

$0.05 \% \quad 31.2 \%$ LTPEEEEILNK

$0.05 \% \quad 31.2 \%$ ISSLLEEQFQQGK

$0.05 \% \quad 31.2 \%$ LLACIASRPGQCGR

$0.03 \% \quad 30.4 \%$ SRLDQELK

$0.03 \% \quad 30.4 \%$ LFEGNALLR

$0.03 \% \quad 30.4 \%$ IGVLDEGK

$0.03 \% \quad 30.4 \%$ QVVNIPSFIVR

$0.03 \% \quad 30.4 \%$ LDSQKHIDFSLR

$0.03 \% \quad 30.4 \%$ SPYGGGRPGR

$0.03 \% \quad 14.6 \%$ SDGIYIINLKR

$0.03 \% \quad 14.6 \%$ FAAATGATPIAGR

$0.03 \% \quad 14.6 \%$ LLVVTDPR

$0.03 \% \quad 14.6 \%$ YVDIAIPCNNK

$0.02 \% \quad 4.1 \%$ IKVAEDEAEAAAAAK

$0.02 \% \quad 4.1 \%$ VAEDEAEAAAAAK

$0.02 \% \quad 4.1 \% \quad$ FTGLSKEELLK

$0.01 \% \quad 4.8 \%$ TSCGSPNYAAPEVISGR

$0.01 \% \quad 4.8 \%$ VPFLVAETPR

$0.01 \% \quad 5.7 \%$ TLALLQTGCCR

$0.01 \% \quad 5.7 \%$ NLAANDLSPSR
1167.66

1157.66

972.49

984.55

1140.65

948.53

1610.80

1335.67

988.49

1116.59

1378.68

1284.68

1440.78

1335.69

1278.64

982.62

1152.55

1049.59

1005.58

969.56

980.64

965.61

1157.62

1347.74

1219.64

1718.91

1314.68

1506.78

1558.79

988.54

1188.68

1032.58

830.46

1271.75

1458.77

1003.51

1291.74

1203.65

912.55

1306.65

1486.77

1245.60

1264.71

1765.82

$\begin{array}{llllllll}98.4 \% & 18.1 & 25.0 & 18.1 & 1 & 0 & 0 & 1128.64 \\ 99.7 \% & 57.0 & 25.0 & 40.5 & 2 & 0 & 0 & 1292.65\end{array}$

$\begin{array}{llllllll}98.4 \% & 18.1 & 25.0 & 18.1 & 1 & 0 & 0 & 1128.64 \\ 99.7 \% & 57.0 & 25.0 & 40.5 & 2 & 0 & 0 & 1292.65\end{array}$

$\begin{array}{llllllll}99.7 \% & 39.5 & 25.0 & 26.8 & 2 & 0 & 0 & 1157.59\end{array}$

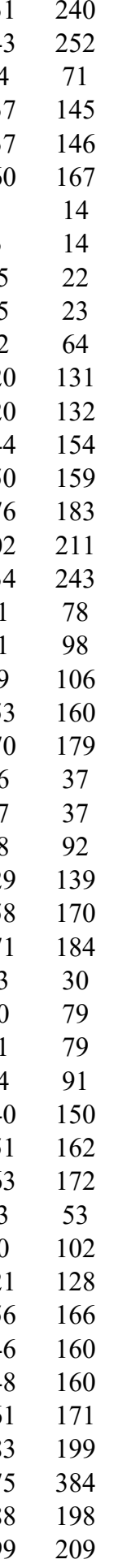

Page 6 of Table S-1-3 
$60 \mathrm{kDa}$ heat shock protein, mitochondrial GN=HSPD1 CH60_HUMAN $61.06 \quad 100.0 \%$ $60 \mathrm{kDa}$ heat shock protein, mitochondrial GN=HSPD1 CH60 HUMAN $61.06 \quad 100.0 \%$ $60 \mathrm{kDa}$ heat shock protein, mitochondrial GN=HSPD1 CH60_HUMAN $61.06 \quad 100.0 \% \quad 13$ $60 \mathrm{kDa}$ heat shock protein, mitochondrial GN=HSPD1 $\mathrm{CH} 60$ HUMAN $61.06 \quad 100.0 \%$ $60 \mathrm{kDa}$ heat shock protein, mitochondrial GN=HSPD1 $\mathrm{CH} 60 \_$HUMAN $61.06 \quad 100.0 \%$ $60 \mathrm{kDa}$ heat shock protein, mitochondrial GN=HSPD1 CH60_HUMAN $61.06 \quad 100.0 \% \quad 13$ $60 \mathrm{kDa}$ heat shock protein, mitochondrial GN=HSPD1 CH60_HUMAN $61.06 \quad 100.0 \%$ $60 \mathrm{kDa}$ heat shock protein, mitochondrial GN=HSPD1 CH60_HUMAN $61.06 \quad 100.0 \%$ $60 \mathrm{kDa}$ heat shock protein, mitochondrial GN=HSPD1 CH60 HUMAN 61.06 $60 \mathrm{kDa}$ he shock protin, $60 \mathrm{kDa}$ heat shock protein, mitochondrial GN=HSPD1 CH60_HUMAN 61.06 $60 \mathrm{kDa}$ heat shock protein, mitochondrial GN=HSPD1 CH60 HUMAN 61.06 $60 \mathrm{kDa}$ heat shock protein, mitochondrial GN=HSPD1 CH60_HUMAN 61.06 $60 \mathrm{~S}$ acidic ribosomal protein $\mathrm{P} 0 \mathrm{GN}=\mathrm{RPLP0}$ RLA0 HUMAN 34.27 $60 \mathrm{~S}$ acidic ribosomal protein P0 GN=RPLP0 RLA0 HUMAN $34.2^{7}$ $60 \mathrm{~S}$ acidic ribosomal protein $\mathrm{P} 0 \mathrm{GN}=\mathrm{RPLP0}$ RLA0_HUMAN 34.2 $60 \mathrm{~S}$ acidic ribosomal protein P0 GN=RPLP0 RLA0 HUMAN 34.27 $60 \mathrm{~S}$ acidic ribosomal protein P0 GN=RPLP0 RLA0_HUMAN 34.27 $60 \mathrm{~S}$ acidic ribosomal protein $\mathrm{P0}$ GN=RPLP0 RLA0_HUMAN $34.2^{2}$ $60 \mathrm{~S}$ acidic ribosomal protein $\mathrm{P} 0 \mathrm{GN}=\mathrm{RPLP0}$ RLA0 HUMAN 34.27 $60 \mathrm{~S}$ acidic ribosomal protein $\mathrm{P} 0 \mathrm{GN}=\mathrm{RPLP0}$ RLA0_HUMAN 34.2 $60 \mathrm{~S}$ acidic ribosomal protein $\mathrm{P} 0 \mathrm{GN}=\mathrm{RPLP0}$ RLA0 HUMAN 34 $60 \mathrm{~S}$ acidic ribosomal protein $\mathrm{P} 0 \mathrm{GN}=\mathrm{RPLP0}$ RLA0 HUMAN 34.27 $60 \mathrm{~S}$ acidic ribosomal protein P0 GN=RPLP0 RLA0_HUMAN 34.27 $60 \mathrm{~S}$ ribosomal protein $\mathrm{L} 10 \mathrm{GN}=\mathrm{RPL} 10$ $60 \mathrm{~S}$ ribosomal protein $\mathrm{L} 10 \mathrm{GN}=\mathrm{RPL} 10$ $60 \mathrm{~S}$ ribosomal protein $\mathrm{L} 10 \mathrm{GN}=\mathrm{RPL} 10$ $60 \mathrm{~S}$ ribosomal protein $\mathrm{L} 10 \mathrm{GN}=\mathrm{RPL} 10$ $60 \mathrm{~S}$ ribosomal protein $\mathrm{L} 10 \mathrm{GN}=\mathrm{RPL} 1 \mathrm{C}$ $60 \mathrm{~S}$ ribosomal protein $\mathrm{L} 10 \mathrm{GN}=\mathrm{RPL} 10$

RL10_HUMAN 24.60 RL10 HUMAN 24.60 RL10 HUMAN 24.60 RL10_HUMAN 24.60 RL10 HUMAN 24.60 $100.0 \% \quad 13$ $100.0 \% \quad 13$ $100.0 \% \quad 13$ $100.0 \% \quad 13$ $100.0 \% \quad 13$ $100.0 \% \quad 1$ $100.0 \% \quad 11$ $100.0 \% \quad 11$ $100.0 \% \quad 11$ $100.0 \% \quad 11$ $100.0 \% \quad 1$ $100.0 \% \quad 1$ $100.0 \% \quad 11$ $100.0 \% \quad 1$ $100.0 \% \quad 1$ $100.0 \%$ $100.0 \%$ $100.0 \%$ $100.0 \%$ $100.0 \%$ $100.0 \%$ $100.0 \%$ $100.0 \%$ $100.0 \%$ $100.0 \%$ $100.0 \%$ $100.0 \%$ $100.0 \%$ $100.0 \%$ $100.0 \%$ $100.0 \%$ $\begin{array}{llll}\text { RL13_HUMAN } & 24.26 & 100.0 \% & 13 \\ \text { RL13_HUMAN } & 24.26 & 100.0 \% & 13 \\ \text { RL13_HUMAN } & 24.26 & 100.0 \% & 13\end{array}$ $\begin{array}{llll}\text { RL13_HUMAN } & 24.26 & 100.0 \% & 13 \\ \text { RL13_HUMAN } & 24.26 & 100.0 \% & 13 \\ \text { RL13 HUMAN } & 24.26 & 100.0 \% & 13\end{array}$ $\begin{array}{llll}\text { RL13_HUMAN } & 24.26 & 100.0 \% & 13\end{array}$ RL13_HUMAN $24.26 \quad 100.0 \%$ RL13_HUMAN $24.26 \quad 100.0 \% \quad 13$ RL13_HUMAN $24.26 \quad 100.0 \% \quad 13$ RL13 HUMAN $24.26 \quad 100.0 \% \quad 13$ RL13_HUMAN $24.26 \quad 100.0 \% \quad 13$ $60 \mathrm{~S}$ ribosomal protein $\mathrm{L} 13 \mathrm{GN}=\mathrm{RPL} 13$
$60 \mathrm{~S}$ ribosomal protein $\mathrm{L} 13 \mathrm{GN}=\mathrm{RPL} 13$

7
7

$0.05 \% \quad 24.8 \%$ TVIIEQSWGSPK

$0.05 \% \quad 24.8 \%$ VTKDGVTVAK

$0.05 \% \quad 24.8 \%$ LVQDVANNTNEEAGDGTTTATVLAR

$0.05 \% \quad 24.8 \%$ SIAKEGFEK

$0.05 \% \quad 24.8 \%$ GANPVEIRR

$0.05 \% \quad 24.8 \%$ GYISPYFINTSK

$0.05 \% \quad 24.8 \%$ LKVGLQVVAVK

$0.05 \% \quad 24.8 \%$ VGLQVVAVK

$0.05 \% \quad 24.8 \%$ VGEVIVTKDDAMLLK

$0.05 \% \quad 24.8 \%$ VTDALNATR

$0.05 \% \quad 24.8 \%$ IGIEIIKR

$0.05 \% \quad 24.8 \%$ NAGVEGSLIVEK

$0.05 \% \quad 24.8 \%$ GIIDPTKVVR

$0.06 \% \quad 35.3 \%$ IIQLLDDYPK

$0.06 \% 35.3 \%$ CFIVGADNVGSK

$0.06 \% \quad 35.3 \%$ CFIVGADNVGSKQMQQIR

$0.06 \% 35.3 \%$ GKAVVLMGK

$0.06 \% \quad 35.3 \%$ AVVLMGKNTMMR

$0.06 \% 35.3 \%$ AIRGHLENNPALEK

$0.06 \% 35.3 \%$ GHLENNPALEK

$0.06 \% \quad 35.3 \%$ GNVGFVFTK

$0.06 \% \quad 35.3 \%$ AGAIAPCEVTVPAQNTGLGPEK

$0.06 \% \quad 35.3 \%$ TSFFQALGITTK

$0.06 \% 35.3 \%$ GTIEILSDVQLIK

$0.03 \% \quad 29.0 \%$ GVPDAKIR

$0.03 \% \quad 29.0 \%$ IRIFDLGR

$0.03 \% \quad 29.0 \%$ MLSCAGADRLQTGMR

$0.03 \% \quad 29.0 \%$ GAFGKPQGTVAR

$0.03 \% \quad 29.0 \%$ VHIGQVIMSIR

$0.03 \% \quad 29.0 \%$ RLIPDGCGVK

$0.04 \% \quad 30.4 \%$ VSRDTLYEAVR

$0.04 \% \quad 30.4 \%$ FSGTVRLK

$0.04 \% \quad 30.4 \%$ FSVCVLGDQQHCDEAK

$0.04 \% 30.4 \%$ KYDAFLASESLIK

$0.04 \% \quad 30.4 \%$ ILGPGLNK

$0.04 \% \quad 30.4 \%$ STMGKPQRLY

$0.01 \% \quad 15.2 \%$ AAKVLEQLTGQTPVFSK

$0.01 \% \quad 15.2 \%$ GAKAEEILEK

$0.14 \% \quad 40.8 \%$ RVATWFNQPAR

$0.14 \% \quad 40.8 \%$ VATWFNQPAR

$0.14 \% \quad 40.8 \%$ VATWFNQPARK

$0.14 \% \quad 40.8 \%$ AGRGFSLEELR

$0.14 \% \quad 40.8 \%$ GFSLEELR

$0.14 \% \quad 40.8 \%$ TIGISVDPR

$0.14 \% \quad 40.8 \%$ TIGISVDPRR

$0.14 \% \quad 40.8 \%$ NKSTESLQANVQR

$0.14 \% \quad 40.8 \%$ STESLQANVQR $\begin{array}{llllllll}99.7 \% & 63.6 & 25.0 & 54.7 & 2 & 0 & 0 & 1344.72\end{array}$

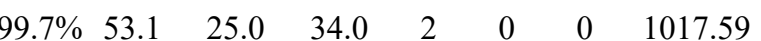
$99.7 \% \quad 33.4$ $99.7 \% \quad 56.4-25.0 \quad 17.3$ $\begin{array}{llll}99.7 \% & 52.8 & 25.0 & 52.4\end{array}$ $\begin{array}{llll}99.7 \% & 36.1 & 25.0 & 36.1\end{array}$ $\begin{array}{lllll}99.7 \% & 65.2 & 25.0 & 65.0 & 2\end{array}$ $\begin{array}{lllll}99.7 \% & 29.4 & 25.0 & 29.4 & 2\end{array}$ $99.7 \% \quad 75.3 \quad 25.0 \quad 59.6$ $\begin{array}{llll}99.0 \% & 26.0 & 25.0 & 16.3\end{array}$ $\begin{array}{llll}99.7 \% & 67.0 & 25.0 & 54.6\end{array}$ $99.7 \% \quad 45.6 \quad 25.0 \quad 37.5 \quad 2$ $\begin{array}{llll}99.7 \% & 63.0 & 25.0 & 48.4\end{array}$ $\begin{array}{llll}99.7 \% & 57.3 & 25.0 & 57.3\end{array}$ $\begin{array}{llll}99.2 \% & 22.0 & 25.0 & 19.1 \\ 99.7 \% & 31.3 & 25.0 & 22.3\end{array}$ $\begin{array}{llll}99.7 \% & 35.6 & 25.0 & 35.6\end{array}$ $\begin{array}{llll}99.7 \% & 57.2 & 25.0 & 47.9\end{array}$ $\begin{array}{llll}99.7 \% & 58.2 & 25.0 & 41.2\end{array}$ $\begin{array}{lllll}99.7 \% & 39.9 & 25.0 & 35.1 & 2\end{array}$ $\begin{array}{llll}99.7 \% & 44.4 & 25.0 & 44.2\end{array}$ $\begin{array}{llll}99.7 \% & 59.5 & 25.0 & 59.5\end{array}$ $\begin{array}{lllll}99.7 \% & 54.2 & 25.0 & 49.5 & 2\end{array}$ $99.0 \% \quad 24.0 \quad 25.0 \quad 24.0$ $\begin{array}{llll}99.0 \% & 26.7 & 25.0 & 15.8\end{array}$ $\begin{array}{llll}94.6 \% & 24.8 & 25.0 & 13.9\end{array}$ $\begin{array}{llll}99.7 \% & 57.4 & 25.0 & 46.7\end{array}$ $\begin{array}{lllll}99.7 \% & 27.7 & 25.0 & 27.7 & 2\end{array}$ $\begin{array}{llll}99.7 \% & 38.3 & 25.0 & 29.4\end{array}$ $\begin{array}{llll}99.4 \% & 23.2 & 25.0 & 21.7\end{array}$ $\begin{array}{llll}97.0 \% & 27.0 & 25.0 & 8.7\end{array}$ $\begin{array}{llll}99.7 \% & 38.2 & 25.0 & 38.2\end{array}$ $\begin{array}{lllll}99.7 \% & 56.4 & 25.0 & 52.5 & 4\end{array}$ $\begin{array}{lllll}99.0 \% & 28.3 & 25.0 & 16.0 & 3\end{array}$ $99.7 \% \quad 28.6 \quad 25.0 \quad 28.6$ $\begin{array}{lllll}99.7 \% & 67.9 & 25.0 & 67.9 & 1\end{array}$ $\begin{array}{llll}99.7 \% & 42.7 & 25.0 & 32.7\end{array}$ $99.7 \% \quad 46.1 \quad 25.0 \quad 38.2$ $\begin{array}{lllll}99.7 \% & 73.9 & 25.0 & 61.0 & 4\end{array}$ $\begin{array}{llll}99.6 \% & 34.5 & 25.0 & 16.9\end{array}$ $\begin{array}{ccccc}97.6 \% & 29.7 & 25.0 & 2.3 & 1\end{array}$ $\begin{array}{lllll}99.0 \% & 34.2 & 25.0 & 28.4 & 2\end{array}$ $\begin{array}{lllll}99.7 \% & 37.8 & 25.0 & 27.0 & 13\end{array}$ $\begin{array}{lllll}99.3 \% & 40.0 & 25.0 & 10.8 & 1\end{array}$ $\begin{array}{llll}99.7 \% & 75.2 & 25.0 & 64.5\end{array}$ $\begin{array}{llll}99.7 \% & 74.2 & 25.0 & 62.8\end{array}$ 
$60 \mathrm{~S}$ ribosomal protein $\mathrm{L} 13 \mathrm{GN}=\mathrm{RPL} 13$ $60 \mathrm{~S}$ ribosomal protein $\mathrm{L} 13 \mathrm{GN}=\mathrm{RPL} 13$ $60 \mathrm{~S}$ ribosomal protein $\mathrm{L} 13 \mathrm{GN}=\mathrm{RPL} 13$ $60 \mathrm{~S}$ ribosomal protein $\mathrm{L} 13 \mathrm{GN}=\mathrm{RPL} 13$ 60 S ribosomal protein L13a GN=RPL13A RL13 HUMAN 24.26 $60 \mathrm{~S}$ ribosomal protein L13a GN=RPL13A RL13A_HUMAN 23.58 $60 \mathrm{~S}$ ribosomal protein L13a GN=RPL13A RL13A_HUMAN 23.58 60S ribosomal protein L13a GN=RPL13A RL13A_HUMAN 23.58 $60 \mathrm{~S}$ ribosomal protein L13a GN=RPL13A RL13A_HUMAN 23.58 $60 \mathrm{~S}$ ribosomal protein $\mathrm{L} 15 \mathrm{GN}=\mathrm{RPL} 15$ $60 \mathrm{~S}$ ribosomal protein $\mathrm{L} 15 \mathrm{GN}=\mathrm{RPL} 15$ $60 \mathrm{~S}$ ribosomal protein $\mathrm{L} 15 \mathrm{GN}=\mathrm{RPL} 15$ $60 \mathrm{~S}$ ribosomal protein $\mathrm{L} 17 \mathrm{GN}=\mathrm{RPL} 17$ $60 \mathrm{~S}$ ribosomal protein $\mathrm{L} 17 \mathrm{GN}=\mathrm{RPL} 17$ $60 \mathrm{~S}$ ribosomal protein $\mathrm{L} 17 \mathrm{GN}=\mathrm{RPL} 17$ $60 \mathrm{~S}$ ribosomal protein $\mathrm{L} 17 \mathrm{GN}=\mathrm{RPL} 17$ 60 S ribosomal protein $\mathrm{L} 17 \mathrm{GN}=\mathrm{RPL} 17$ $60 \mathrm{~S}$ ribosomal protein $\mathrm{L} 18 \mathrm{GN}=\mathrm{RPL} 18$ $60 \mathrm{~S}$ ribosomal protein $\mathrm{L} 18 \mathrm{GN}=\mathrm{RPL} 18$ $60 \mathrm{~S}$ ribosomal protein $\mathrm{L} 18 \mathrm{GN}=\mathrm{RPL} 18$ $60 \mathrm{~S}$ ribosomal protein $\mathrm{L} 18 \mathrm{GN}=\mathrm{RPL} 18$ $60 \mathrm{~S}$ ribosomal protein $\mathrm{L} 18 \mathrm{GN}=\mathrm{RPL} 18$ $60 \mathrm{~S}$ ribosomal protein $\mathrm{L} 18 \mathrm{GN}=\mathrm{RPL} 18$ $60 \mathrm{~S}$ ribosomal protein $\mathrm{L} 18 \mathrm{GN}=\mathrm{RPL} 18$ RL15_HUMAN $24.15 \quad 100.0 \%$ RL15_HUMAN $24.15 \quad 100.0 \%$ RL15 HUMAN $24.15 \quad 100.0 \%$ RL17_HUMAN $21.40 \quad 100.0 \%$ RL17_HUMAN $21.40 \quad 100.0 \%$ RL17 HUMAN $21.40 \quad 100.0 \%$ RL17_HUMAN $21.40 \quad 100.0 \%$ RL17 HUMAN $21.40 \quad 100.0 \%$ RL18_HUMAN $21.64 \quad 100.0 \%$ RL18_HUMAN $21.64 \quad 100.0 \%$ RL18 HUMAN $21.64 \quad 100.0 \%$ RL18_HUMAN $21.64 \quad 100.0 \%$ RL18_HUMAN $21.64 \quad 100.0 \%$ RL18_HUMAN $21.64 \quad 100.0 \%$ RL18_HUMAN $21.64 \quad 100.0 \%$ 60 ribosomal protein L18a GN=RPL18A RL18A_HUMAN $20.76 \quad 100.0 \%$ 60S ribosomal protein L18a GN=RPL18A RL18A_HUMAN $20.76 \quad 100.0 \%$ $60 \mathrm{~S}$ ribosomal protein L18a GN=RPL18A RL18A_HUMAN $20.76 \quad 100.0 \%$ $60 \mathrm{~S}$ ribosomal protein L18a GN=RPL18A RL18A_HUMAN $20.76 \quad 100.0 \%$ 60S ribosomal protein L18a GN=RPL18A RL18A_HUMAN $20.76 \quad 100.0 \%$ $60 \mathrm{~S}$ ribosomal protein $\mathrm{L} 19 \mathrm{GN}=\mathrm{RPL} 19$ $60 \mathrm{~S}$ ribosomal protein $\mathrm{L} 19 \mathrm{GN}=\mathrm{RPL} 19$ $60 \mathrm{~S}$ ribosomal protein $\mathrm{L} 19 \mathrm{GN}=\mathrm{RPL} 19$ $60 \mathrm{~S}$ ribosomal protein $\mathrm{L} 21 \mathrm{GN}=\mathrm{RPL} 21$ $60 \mathrm{~S}$ ribosomal protein $\mathrm{L} 21 \mathrm{GN}=\mathrm{RPL} 21$ $60 \mathrm{~S}$ ribosomal protein $\mathrm{L} 21 \mathrm{GN}=\mathrm{RPL} 21$ 60S ribosomal protein L23a GN=RPL23A RL23A_HUMAN $17.70 \quad 100.0 \%$ $60 \mathrm{~S}$ ribosomal protein $\mathrm{L} 24 \mathrm{GN}=\mathrm{RPL} 24$ $60 \mathrm{~S}$ ribosomal protein $\mathrm{L} 24 \mathrm{GN}=\mathrm{RPL} 24$ $60 \mathrm{~S}$ ribosomal protein $\mathrm{L} 24 \mathrm{GN}=\mathrm{RPL} 24$ 60 S ribosomal protein $\mathrm{L} 24 \mathrm{GN}=\mathrm{RPL} 24$ $\begin{array}{llll}60 \mathrm{~S} \text { ribosomal protein L24 GN=RPL24 } & \text { RL22_HUMAN } & 17.78 & 100.0 \% \\ 60 \text { S ribosomal protein L27a GN=RPL27A } & \text { RL27A HUMAN } & 16.56 & 100.0 \%\end{array}$ 60 S ribosomal protein L27a GN=RPL27A RL27A_HUMAN $16.56 \quad 100.0 \%$ $60 \mathrm{~S}$ ribosomal protein L27a GN=RPL27A RL27A_HUMAN $16.56 \quad 100.0 \%$ $60 \mathrm{~S}$ ribosomal protein $\mathrm{L} 29 \mathrm{GN}=\mathrm{RPL} 29$ 60 S ribosomal protein $\mathrm{L} 29 \mathrm{GN}=\mathrm{RPL} 29$ RL24_HUMAN $17.78 \quad 100.0 \%$ RL24_HUMAN $17.78 \quad 100.0 \%$ RL24_HUMAN $17.78 \quad 100.0 \%$ RL24_HUMAN $17.78 \quad 100.0 \%$

RL19_HUMAN $23.47 \quad 100.0 \%$ RL19_HUMAN $23.47 \quad 100.0 \%$ RL19_HUMAN $23.47 \quad 100.0 \%$ RL21_HUMAN $18.57 \quad 100.0 \%$ $100.0 \%$ $100.0 \%$ $0.0 \%$ 2
$0.14 \% \quad 40.8 \%$ VITEEEKNFK

$0.14 \% \quad 40.8 \%$ ANARLFGIR

$\begin{array}{lll}10 & 0.02 \% & 22.2 \% \\ 10 & 0.02 \% & 22.2 \%\end{array}$

$10 \quad 0.02 \% \quad 22.2 \%$ GQAALDRLK

$10 \quad 0.02 \% \quad 22.2 \%$ VFDGIPPPYDKK

$10 \quad 0.02 \% \quad 22.2 \%$ MVVPAALK

$10 \quad 0.02 \% \quad 22.2 \%$ MVVPAALKVVR

$0.02 \% \quad 10.3 \%$ AKQGYVIYR

$0.02 \% \quad 10.3 \%$ SLQSVAEER

$9 \quad 0.02 \% \quad 10.3 \%$ SLQSVAEERAGR

$\begin{array}{lll}0.02 \% & 23.4 \% \text { VRYSLDPENPTK }\end{array}$

$9 \quad 0.02 \% \quad 23.4 \%$ YSLDPENPTK

$0.02 \% \quad 23.4 \%$ ETAQAIKGMHIR

$0.02 \% \quad 23.4 \%$ YLKDVTLQK

$0.02 \% \quad 23.4 \%$ SAEFLLHMLK

$0.03 \% \quad 35.6 \%$ TNSTFNQVVLK

$0.03 \% \quad 35.6 \%$ TAVVVGTITDDVR

$\begin{array}{llllllll}99.7 \% & 37.7 & 25.0 & 37.7 & 7 & 0 & 0 & 1398.78\end{array}$

$\begin{array}{llllllll}99.7 \% & 54.0 & 25.0 & 37.9 & 4 & 0 & 0 & 1236.65\end{array}$

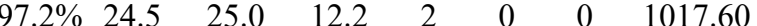

$96.1 \% \quad 19.2 \quad 25.0 \quad 14.5$

$99.7 \% \quad 47.4 \quad 25.0 \quad 29.4$

$97.9 \% \quad 24.5 \quad 25.0 \quad 24.3$

$\begin{array}{llll}95.3 \% & 15.4 & 25.0 & 15.4\end{array}$

$99.7 \% \quad 36.4 \quad 25.0 \quad 36.4$

$\begin{array}{llll}98.7 \% & 20.1 & 25.0 & 18.3\end{array}$

$\begin{array}{llll}99.7 \% & 54.7 & 25.0 & 42.3\end{array}$

$99.7 \% \quad 29.9 \quad 25.0 \quad 26.3$

$\begin{array}{lllll}99.7 \% & 43.3 & 25.0 & 41.1 & 2\end{array}$

$\begin{array}{llll}99.7 \% & 39.8 & 25.0 & 37.7\end{array}$

$99.6 \% \quad 27.5 \quad 25.0 \quad 24.1$

$99.7 \% \quad 42.3 \quad 25.0 \quad 35.8 \quad 2$

$99.1 \% \quad 23.1 \quad 25.0 \quad 23.1$

$\begin{array}{llll}99.7 \% & 60.6 & 25.0 & 47.2\end{array}$

$\begin{array}{llll}99.7 \% & 67.6 & 25.0 & 60.6\end{array}$

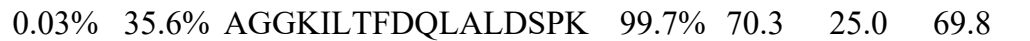

$0.03 \% \quad 35.6 \%$ ILTFDQLALDSPK

$0.03 \% 35.6 \%$ GCGTVLLSGPR

$0.03 \% \quad 35.6 \%$ GCGTVLLSGPRK

$0.03 \% \quad 35.6 \%$ APGTPHSHTKPYVR

$0.03 \% \quad 26.1 \%$ CHTPPLYR

$0.03 \% \quad 26.1 \%$ MRIFAPNHVVAK

$0.03 \% \quad 26.1 \%$ IFAPNHVVAK

$0.03 \% \quad 26.1 \%$ AHSIQIMKVEEIAASK

$0.03 \% \quad 26.1 \%$ FTTKRPNTFF

$0.01 \% \quad 9.2 \%$ RLASSVLR

$0.01 \% \quad 9.2 \%$ LLADQAEAR

$0.01 \% \quad 9.2 \%$ LLADQAEARR

$0.02 \% \quad 18.1 \%$ HGVVPLATYMR

$99.7 \% \quad 84.3$

$99.7 \% \quad 56.3$

$99.7 \% \quad 50.4$

$99.1 \% \quad 23.6$

$97.7 \% \quad 23.1$

$99.7 \% \quad 30.0$

$99.7 \% \quad 33.5$

$99.7 \% \quad 40.3$

$99.7 \% \quad 35.8$

$99.0 \% \quad 29.2$

$99.7 \% \quad 59.3$

$97.0 \% \quad 20.6$

$99.7 \% \quad 43.6$

$0.02 \% \quad 18.1 \%$ VYNVTQHAVGIVVNK

$99.7 \% \quad 55.5$

$0.02 \% \quad 18.1 \%$ VYNVTQHAVGIVVNKQVK

$0.01 \% \quad 14.1 \%$ EAPAPPKAEAK

$0.01 \% \quad 14.1 \%$ VNTLIRPDGEK

$0.06 \% \quad 28.7 \%$ MKVELCSFSGYK

$0.06 \% \quad 28.7 \%$ CESAFLSK

$0.06 \% 28.7 \%$ AITGASLADIMAK

$0.06 \% \quad 28.7 \%$ AITGASLADIMAKR

$0.06 \% \quad 28.7 \%$ TAMAAAKAPTK

$0.03 \% \quad 14.9 \%$ NKTGAAPIIDVVR

$0.03 \% \quad 14.9 \%$ TGAAPIIDVVR

$0.03 \% \quad 14.9 \%$ SGYYKVLGK

$0.06 \% \quad 30.8 \%$ AMSARAEAIK

$0.06 \% \quad 30.8 \%$ AEAIKALVKPK
$99.2 \% 24.6$

$99.7 \% \quad 34.8$

$99.7 \% \quad 45.3$

$99.0 \% \quad 26.1$

$99.7 \% \quad 67.0$

$99.7 \% \quad 70.7$

$99.7 \% \quad 47.0$

$99.7 \% \quad 54.5$

$99.7 \% \quad 45.4$

$96.7 \% \quad 17.5$

$99.5 \% \quad 32.1$

$99.7 \% \quad 43.3$
1592.74

971.56

1375.73

828.50

1182.74

1097.61

1018.52

1302.68

1418.73

1163.56

1354.73

1107.64

1204.64

1250.67

1345.73

1773.97

1460.80

1116.58

1244.68

1547.81

1043.51

1398.77

1095.63

1754.95

1258.66

901.56

986.53

1142.63

1243.66

1640.91

1996.13

1108.60

1241.69

1448.69

941.44

1277.68

1417.78

1060.58

1353.79

1111.65

1014.56

1047.56

1167.75 
60 ribosomal protein $\mathrm{L} 29 \mathrm{GN}=\mathrm{RPL} 29$ $60 \mathrm{~S}$ ribosomal protein $\mathrm{L} 29 \mathrm{GN}=\mathrm{RPL} 29$ 60 S ribosomal protein $\mathrm{L} 29 \mathrm{GN}=\mathrm{RPL} 29$ $60 \mathrm{~S}$ ribosomal protein $\mathrm{L} 29 \mathrm{GN}=\mathrm{RPL} 29$ $60 \mathrm{~S}$ ribosomal protein $\mathrm{L} 29 \mathrm{GN}=\mathrm{RPL} 29$ $60 \mathrm{~S}$ ribosomal protein $\mathrm{L} 3 \mathrm{GN}=\mathrm{RPL} 3$ $60 \mathrm{~S}$ ribosomal protein $\mathrm{L} 3 \mathrm{GN}=\mathrm{RPL} 3$ $60 \mathrm{~S}$ ribosomal protein $\mathrm{L} 3 \mathrm{GN}=\mathrm{RPL} 3$ $60 \mathrm{~S}$ ribosomal protein $\mathrm{L} 3 \mathrm{GN}=\mathrm{RPL} 3$ $60 \mathrm{~S}$ ribosomal protein $\mathrm{L} 3 \mathrm{GN}=\mathrm{RPL} 3$ $60 \mathrm{~S}$ ribosomal protein $\mathrm{L} 3 \mathrm{GN}=\mathrm{RPL} 3$ $60 \mathrm{~S}$ ribosomal protein $\mathrm{L} 3 \mathrm{GN}=\mathrm{RPL} 3$ $60 \mathrm{~S}$ ribosomal protein $\mathrm{L} 3 \mathrm{GN}=\mathrm{RPL} 3$ $60 \mathrm{~S}$ ribosomal protein $\mathrm{L} 3 \mathrm{GN}=\mathrm{RPL} 3$ $60 \mathrm{~S}$ ribosomal protein $\mathrm{L} 3 \mathrm{GN}=\mathrm{RPL} 3$ $60 \mathrm{~S}$ ribosomal protein $\mathrm{L} 3 \mathrm{GN}=\mathrm{RPL} 3$ $60 \mathrm{~S}$ ribosomal protein $\mathrm{L} 3 \mathrm{GN}=\mathrm{RPL} 3$ $60 \mathrm{~S}$ ribosomal protein $\mathrm{L} 3 \mathrm{GN}=\mathrm{RPL} 3$ $60 \mathrm{~S}$ ribosomal protein $\mathrm{L} 4 \mathrm{GN}=\mathrm{RPL} 4$ $60 \mathrm{~S}$ ribosomal protein $\mathrm{L} 4 \mathrm{GN}=\mathrm{RPL} 4$ $60 \mathrm{~S}$ ribosomal protein $\mathrm{L} 4 \mathrm{GN}=\mathrm{RPL} 4$ $60 \mathrm{~S}$ ribosomal protein $\mathrm{L} 4 \mathrm{GN}=\mathrm{RPL} 4$ $60 \mathrm{~S}$ ribosomal protein $\mathrm{L} 4 \mathrm{GN}=\mathrm{RPL} 4$ $60 \mathrm{~S}$ ribosomal protein $\mathrm{L} 4 \mathrm{GN}=\mathrm{RPL} 4$ $60 \mathrm{~S}$ ribosomal protein $\mathrm{L} 4 \mathrm{GN}=\mathrm{RPL} 4$ $60 \mathrm{~S}$ ribosomal protein $\mathrm{L} 4 \mathrm{GN}=\mathrm{RPL} 4$ $60 \mathrm{~S}$ ribosomal protein $\mathrm{L} 4 \mathrm{GN}=\mathrm{RPL} 4$ $60 \mathrm{~S}$ ribosomal protein $\mathrm{L} 4 \mathrm{GN}=\mathrm{RPL} 4$ $60 \mathrm{~S}$ ribosomal protein $\mathrm{L} 4 \mathrm{GN}=\mathrm{RPL} 4$ $60 \mathrm{~S}$ ribosomal protein $\mathrm{L} 4 \mathrm{GN}=\mathrm{RPL} 4$ $60 \mathrm{~S}$ ribosomal protein $\mathrm{L} 4 \mathrm{GN}=\mathrm{RPL} 4$ $60 \mathrm{~S}$ ribosomal protein $\mathrm{L} 4 \mathrm{GN}=\mathrm{RPL} 4$ $60 \mathrm{~S}$ ribosomal protein $\mathrm{L} 4 \mathrm{GN}=\mathrm{RPL} 4$ $60 \mathrm{~S}$ ribosomal protein $\mathrm{L} 4 \mathrm{GN}=\mathrm{RPL} 4$ $60 \mathrm{~S}$ ribosomal protein $\mathrm{L} 5 \mathrm{GN}=\mathrm{RPL} 5$ $60 \mathrm{~S}$ ribosomal protein $\mathrm{L} 5 \mathrm{GN}=\mathrm{RPL} 5$ $60 \mathrm{~S}$ ribosomal protein $\mathrm{L} 5 \mathrm{GN}=\mathrm{RPL} 5$ $60 \mathrm{~S}$ ribosomal protein $\mathrm{L} 5 \mathrm{GN}=\mathrm{RPL} 5$ $60 \mathrm{~S}$ ribosomal protein $\mathrm{L} 5 \mathrm{GN}=\mathrm{RPL} 5$ $60 \mathrm{~S}$ ribosomal protein $\mathrm{L} 5 \mathrm{GN}=\mathrm{RPL} 5$ $60 \mathrm{~S}$ ribosomal protein $\mathrm{L} 5 \mathrm{GN}=\mathrm{RPL} 5$ $60 \mathrm{~S}$ ribosomal protein $\mathrm{L} 5 \mathrm{GN}=\mathrm{RPL} 5$ $60 \mathrm{~S}$ ribosomal protein $\mathrm{L} 5 \mathrm{GN}=\mathrm{RPL} 5$ $60 \mathrm{~S}$ ribosomal protein $\mathrm{L} 5 \mathrm{GN}=\mathrm{RPL} 5$ $60 \mathrm{~S}$ ribosomal protein $\mathrm{L} 5 \mathrm{GN}=\mathrm{RPL} 5$ $60 \mathrm{~S}$ ribosomal protein $\mathrm{L} 5 \mathrm{GN}=\mathrm{RPL} 5$ $60 \mathrm{~S}$ ribosomal protein $\mathrm{L} 5 \mathrm{GN}=\mathrm{RPL} 5$
RL29_HUMAN $17.75 \quad 100.0 \%$ RL29 HUMAN $17.75 \quad 100.0 \%$ RL29_HUMAN $17.75 \quad 100.0 \%$ RL29_HUMAN $17.75 \quad 100.0 \%$ RL29_HUMAN $17.75 \quad 100.0 \%$ RL3_HUMAN $46.11 \quad 100.0 \%$ RL3 HUMAN $46.11 \quad 100.0 \%$ RL3_HUMAN $46.11 \quad 100.0 \%$ RL3 HUMAN $46.11 \quad 100.0 \%$ RL3_HUMAN $46.11 \quad 100.0 \% \quad 13$ RL3_HUMAN $46.11 \quad 100.0 \% \quad 13$ RL3 HUMAN $46.11 \quad 100.0 \% \quad 13$ RL3_HUMAN $46.11 \quad 100.0 \% \quad 13$ RL3_HUMAN $46.11 \quad 100.0 \% \quad 13$ RL3 HUMAN $46.11 \quad 100.0 \% \quad 13$ RL3_HUMAN $46.11 \quad 100.0 \% \quad 13$ RL3 HUMAN $46.11 \quad 100.0 \% \quad 13$ RL3_HUMAN $46.11 \quad 100.0 \% \quad 13$ RL4_HUMAN $47.70 \quad 100.0 \% \quad 16$ RL4 HUMAN $47.70 \quad 100.0 \% \quad 16$ RL4_HUMAN $47.70 \quad 100.0 \% \quad 16$ RL4_HUMAN $47.70 \quad 100.0 \% \quad 16$ RL4_HUMAN $47.70 \quad 100.0 \% \quad 16$ RL4_HUMAN $47.70 \quad 100.0 \% \quad 16$ RL4 HUMAN $47.70 \quad 100.0 \% \quad 16$ RL4_HUMAN $47.70 \quad 100.0 \% \quad 16$ RL4_HUMAN $47.70 \quad 100.0 \% \quad 16$ RL4 HUMAN $47.70 \quad 100.0 \% \quad 16$ RL4_HUMAN $47.70 \quad 100.0 \% \quad 16$ RL4 HUMAN $47.70 \quad 100.0 \% \quad 16$ RL4_HUMAN $47.70 \quad 100.0 \% \quad 16$ RL4_HUMAN $47.70 \quad 100.0 \% \quad 16$ RL4 HUMAN $47.70 \quad 100.0 \% \quad 16$ RL4_HUMAN $47.70 \quad 100.0 \% \quad 16$ RL5_HUMAN $34.36 \quad 100.0 \% \quad 14$ RL5 HUMAN $34.36 \quad 100.0 \% \quad 14$ RL5_HUMAN $34.36 \quad 100.0 \% \quad 14$ RL5 HUMAN $34.36 \quad 100.0 \% \quad 14$ RL5_HUMAN $34.36 \quad 100.0 \% \quad 14$ RL5_HUMAN $34.36 \quad 100.0 \% \quad 14$ RL5 HUMAN $34.36 \quad 100.0 \% \quad 14$ RL5_HUMAN $34.36 \quad 100.0 \% \quad 14$ RL5 HUMAN $34.36 \quad 100.0 \% \quad 14$ RL5 HUMAN $34.36 \quad 100.0 \% \quad 14$ RL5_HUMAN $34.36 \quad 100.0 \% \quad 14$ RL5 HUMAN $34.36 \quad 100.0 \% \quad 14$ RL5_HUMAN $34.36 \quad 100.0 \% \quad 14$
$0.06 \% \quad 30.8 \%$ ALVKPKEVKPK $0.06 \% 30.8 \%$ LAYIAHPK

$96.4 \% \quad 16.1 \quad 25.0$ $99.0 \% \quad 29.4$

$0.06 \% \quad 30.8 \%$ DQTKAQAAAPASVPAQAPK $\quad 99.7 \% \quad 32.9$

$0.06 \% \quad 30.8 \%$ AQAAAPASVPAQAPK

$0.06 \% \quad 30.8 \%$ AQAAAPASVPAQAPKR

$0.15 \% \quad 29.3 \%$ HGSLGFLPR

$0.15 \% \quad 29.3 \%$ AGMTHIVR

$0.15 \% \quad 29.3 \%$ TVFAEHISDECKR

$0.15 \% \quad 29.3 \%$ VIAHTQMR

$0.15 \% \quad 29.3 \%$ AHLMEIQVNGGTVAEK

$0.15 \% \quad 29.3 \%$ VACIGAWHPAR

$0.15 \% \quad 29.3 \%$ IYKIGQGYLIK

$0.15 \% \quad 29.3 \%$ IGQGYLIK

$0.15 \% \quad 29.3 \%$ IGQGYLIKDGK

$0.15 \% \quad 29.3 \%$ NNASTDYDLSDK

$0.15 \% \quad 29.3 \%$ SLLVQTKR

$0.15 \% \quad 29.3 \%$ IDLKFIDTTSK

$0.15 \% \quad 29.3 \%$ AFMGPLKK

$134 \quad 0.28 \% \quad 27.9 \%$ SGQGAFGNMCR

$134 \quad 0.28 \% \quad 27.9 \%$ SGQGAFGNMCRGGR

$134 \quad 0.28 \% \quad 27.9 \%$ TKEAVLLLK

$134 \quad 0.28 \% \quad 27.9 \%$ EAVLLLKK

$134 \quad 0.28 \% \quad 27.9 \%$ RGPCIIYNEDNGIIK

$134 \quad 0.28 \% \quad 27.9 \%$ GPCIIYNEDNGIIK

$134 \quad 0.28 \% \quad 27.9 \%$ NIPGITLLNVSK

$134 \quad 0.28 \% \quad 27.9 \%$ LAPGGHVGR

$134 \quad 0.28 \% \quad 27.9 \%$ AASLKSNYNLPMHK

$134 \quad 0.28 \% \quad 27.9 \%$ SNYNLPMHK

$134 \quad 0.28 \% \quad 27.9 \%$ MINTDLSR

$134 \quad 0.28 \% \quad 27.9 \%$ ILKSPEIQR

$134 \quad 0.28 \% \quad 27.9 \%$ IMLKLNPYAK

$134 \quad 0.28 \% \quad 27.9 \%$ VDKAAAAAAALQAK

$134 \quad 0.28 \% \quad 27.9 \%$ AAAAAAALQAK

$134 \quad 0.28 \% \quad 27.9 \%$ AAAAAAALQAKSDEK

$49 \quad 0.10 \% \quad 38.0 \%$ EGKTDYYAR

$49 \quad 0.10 \% \quad 38.0 \%$ VTNRDIICQIAYAR

$49 \quad 0.10 \% \quad 38.0 \%$ TTTGNKVFGALK

$49 \quad 0.10 \% \quad 38.0 \%$ GAVDGGLSIPHSTK

$49 \quad 0.10 \% \quad 38.0 \%$ GAVDGGLSIPHSTKR

$49 \quad 0.10 \% \quad 38.0 \%$ EFNAEVHR

$49 \quad 0.10 \% \quad 38.0 \%$ EFNAEVHRK

$49 \quad 0.10 \% \quad 38.0 \%$ KHIMGQNVADYMR

$49 \quad 0.10 \% \quad 38.0 \%$ HIMGQNVADYMR

$49 \quad 0.10 \% \quad 38.0 \%$ YLMEEDEDAYKK

$49 \quad 0.10 \% \quad 38.0 \%$ NSVTPDMMEEMYK

$49 \quad 0.10 \% \quad 38.0 \%$ NSVTPDMMEEMYKK $\begin{array}{lllll}99.7 \% & 55.5 & 25.0 & 54.6 & 13\end{array}$

$\begin{array}{lllll}99.7 \% & 47.2 & 25.0 & 47.2 & 2\end{array}$

$99.7 \% \quad 61.7 \quad 25.0 \quad 50.4 \quad 25$

$99.0 \% \quad 55.0 \quad 25.0 \quad 45.2$

$\begin{array}{llll}99.5 \% & 25.1 & 25.0 & 22.2\end{array}$

$\begin{array}{llll}99.0 \% & 32.0 & 25.0 & 27.0\end{array}$

$\begin{array}{llll}98.9 \% & 24.0 & 25.0 & 24.0\end{array}$

$\begin{array}{llll}98.9 \% & 19.6 & 25.0 & 19.6\end{array}$

$\begin{array}{llll}96.7 \% & 16.5 & 25.0 & 16.2\end{array}$

$99.0 \% \quad 30.0 \quad 25.0 \quad 20.0$

$\begin{array}{llll}99.7 \% & 69.1 & 25.0 & 62.5\end{array}$

$99.7 \% \quad 65.9 \quad 25.0 \quad 65.9$

$99.0 \% \quad 40.2 \quad 25.0 \quad 34.6 \quad 3$

$99.7 \% \quad 62.2 \quad 25.0 \quad 55.3$

$\begin{array}{llll}98.6 \% & 21.8 & 25.0 & 17.1\end{array}$

$\begin{array}{llll}99.7 \% & 59.5 & 25.0 & 59.5\end{array}$

$\begin{array}{llll}99.7 \% & 43.1 & 25.0 & 41.5\end{array}$

$\begin{array}{llll}99.7 \% & 42.2 & 25.0 & 31.0\end{array}$

$\begin{array}{llll}99.0 \% & 57.5 & 25.0 & 39.5\end{array}$

$\begin{array}{llll}99.7 \% & 47.6 & 25.0 & 47.0\end{array}$

$\begin{array}{lllll}99.7 \% & 56.3 & 25.0 & 56.3 & 4\end{array}$

$\begin{array}{llll}97.8 \% & 17.3 & 25.0 & 17.3\end{array}$

$\begin{array}{llll}95.4 \% & 15.6 & 25.0 & 15.6\end{array}$

$\begin{array}{llll}99.7 \% & 30.5 & 25.0 & 30.5\end{array}$

$\begin{array}{lllll}99.7 \% & 34.5 & 25.0 & 32.7\end{array}$

$\begin{array}{lllll}99.0 \% & 55.1 & 25.0 & 40.3 & 17\end{array}$

$\begin{array}{llll}99.7 \% & 37.3 & 25.0 & 33.9\end{array}$

$\begin{array}{llll}99.5 \% & 34.8 & 25.0 & 14.0\end{array}$

$\begin{array}{llll}99.7 \% & 74.1 & 25.0 & 63.4\end{array}$

$99.7 \% \quad 75.9 \quad 25.0 \quad 65.7$

$\begin{array}{llll}99.7 \% & 62.1 & 25.0 & 62.1\end{array}$

$\begin{array}{llll}99.7 \% & 52.5 & 25.0 & 35.9\end{array}$

$\begin{array}{llll}99.7 \% & 47.7 & 25.0 & 47.7\end{array}$

$99.7 \% \quad 41.9 \quad 25.0 \quad 37.9$

$99.7 \% \quad 70.9 \quad 25.0 \quad 64.1$

$\begin{array}{llll}99.7 \% & 30.7 & 25.0 & 28.4\end{array}$

$\begin{array}{llll}98.2 \% & 24.1 & 25.0 & 14.0\end{array}$

$\begin{array}{llll}99.7 \% & 31.5 & 25.0 & 21.3\end{array}$

$\begin{array}{llll}98.7 \% & 19.9 & 25.0 & 18.9\end{array}$

$99.7 \% \quad 66.4 \quad 25.0 \quad 52.9$

$\begin{array}{llll}99.7 \% & 44.0 & 25.0 & 44.0\end{array}$

$\begin{array}{lllll}99.7 \% & 69.8 & 25.0 & 69.8 & 2\end{array}$

$\begin{array}{lllll}99.7 \% & 48.3 & 25.0 & 48.3 & 4\end{array}$

$\begin{array}{llll}99.7 \% & 49.5 & 25.0 & 45.3\end{array}$
912.53

1849.98

1377.75

1533.85

983.54

884.48

1591.75

955.51

1696.87

1237.63

1295.77

891.53

1191.67

1342.58

944.59

1280.71

907.51

1184.49

1454.64

1014.66

913.61

1761.90

1605.79

1268.76

863.48

1589.81

1103.53

949.48

1083.65

1190.70

1298.74

956.55

1415.75

1102.52

1692.89

1236.69

1338.70

1494.80

1001.48

1129.57

1578.75

1434.66

1533.68

1574.65

1702.75

1497.78

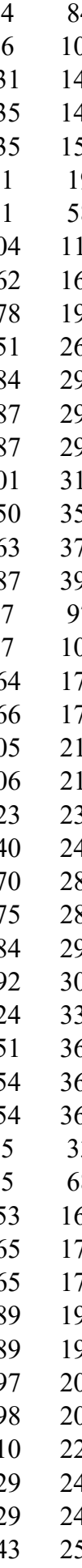


$60 \mathrm{~S}$ ribosomal protein $\mathrm{L} 5 \mathrm{GN}=\mathrm{RPL} 5$ $60 \mathrm{~S}$ ribosomal protein $\mathrm{L} 6 \mathrm{GN}=\mathrm{RPL} 6$ $60 \mathrm{~S}$ ribosomal protein $\mathrm{L} 6 \mathrm{GN}=\mathrm{RPL} 6$ $60 \mathrm{~S}$ ribosomal protein $\mathrm{L} 6 \mathrm{GN}=\mathrm{RPL} 6$ $60 \mathrm{~S}$ ribosomal protein $\mathrm{L} 6 \mathrm{GN}=\mathrm{RPL} 6$ $60 \mathrm{~S}$ ribosomal protein $\mathrm{L} 6 \mathrm{GN}=\mathrm{RPL} 6$ $60 \mathrm{~S}$ ribosomal protein $\mathrm{L} 6 \mathrm{GN}=\mathrm{RPL} 6$ $60 \mathrm{~S}$ ribosomal protein $\mathrm{L} 6 \mathrm{GN}=\mathrm{RPL} 6$ $60 \mathrm{~S}$ ribosomal protein $\mathrm{L} 6 \mathrm{GN}=\mathrm{RPL} 6$ $60 \mathrm{~S}$ ribosomal protein $\mathrm{L} 6 \mathrm{GN}=\mathrm{RPL} 6$ $60 \mathrm{~S}$ ribosomal protein $\mathrm{L} 6 \mathrm{GN}=\mathrm{RPL} 6$ $60 \mathrm{~S}$ ribosomal protein $\mathrm{L} 6 \mathrm{GN}=\mathrm{RPL} 6$ $60 \mathrm{~S}$ ribosomal protein $\mathrm{L} 6 \mathrm{GN}=\mathrm{RPL} 6$ $60 \mathrm{~S}$ ribosomal protein $\mathrm{L} 6 \mathrm{GN}=\mathrm{RPL} 6$ $60 \mathrm{~S}$ ribosomal protein $\mathrm{L} 6 \mathrm{GN}=\mathrm{RPL} 6$ $60 \mathrm{~S}$ ribosomal protein $\mathrm{L} 6 \mathrm{GN}=\mathrm{RPL} 6$ $60 \mathrm{~S}$ ribosomal protein $\mathrm{L} 6 \mathrm{GN}=\mathrm{RPL} 6$ $60 \mathrm{~S}$ ribosomal protein $\mathrm{L} 6 \mathrm{GN}=\mathrm{RPL} 6$ $60 \mathrm{~S}$ ribosomal protein $\mathrm{L} 7 \mathrm{GN}=\mathrm{RPL} 7$ $60 \mathrm{~S}$ ribosomal protein $\mathrm{L} 7 \mathrm{GN}=\mathrm{RPL} 7$ $60 \mathrm{~S}$ ribosomal protein $\mathrm{L} 7 \mathrm{GN}=\mathrm{RPL} 7$ $60 \mathrm{~S}$ ribosomal protein $\mathrm{L} 7 \mathrm{GN}=\mathrm{RPL} 7$ $60 \mathrm{~S}$ ribosomal protein $\mathrm{L} 7 \mathrm{GN}=\mathrm{RPL} 7$ $60 \mathrm{~S}$ ribosomal protein $\mathrm{L} 7 \mathrm{GN}=\mathrm{RPL} 7$ $60 \mathrm{~S}$ ribosomal protein $\mathrm{L} 7 \mathrm{GN}=\mathrm{RPL} 7$ $60 \mathrm{~S}$ ribosomal protein $\mathrm{L} 7 \mathrm{GN}=\mathrm{RPL} 7$ $60 \mathrm{~S}$ ribosomal protein $\mathrm{L} 7 \mathrm{GN}=\mathrm{RPL} 7$ $60 \mathrm{~S}$ ribosomal protein $\mathrm{L} 7 \mathrm{GN}=\mathrm{RPL} 7$ $60 \mathrm{~S}$ ribosomal protein $\mathrm{L} 7 \mathrm{GN}=\mathrm{RPL} 7$ $60 \mathrm{~S}$ ribosomal protein $\mathrm{L} 7 \mathrm{GN}=\mathrm{RPL} 7$ $60 \mathrm{~S}$ ribosomal protein $\mathrm{L} 7 \mathrm{GN}=\mathrm{RPL} 7$ $60 \mathrm{~S}$ ribosomal protein $\mathrm{L} 7 \mathrm{GN}=\mathrm{RPL} 7$ $60 \mathrm{~S}$ ribosomal protein $\mathrm{L} 7 \mathrm{GN}=\mathrm{RPL} 7$ $60 \mathrm{~S}$ ribosomal protein $\mathrm{L} 7 \mathrm{GN}=\mathrm{RPL} 7$ $60 \mathrm{~S}$ ribosomal protein $\mathrm{L} 7 \mathrm{GN}=\mathrm{RPL} 7$ $60 \mathrm{~S}$ ribosomal protein $\mathrm{L} 7 \mathrm{a} \mathrm{GN}=\mathrm{RPL} 7 \mathrm{~A}$ $60 \mathrm{~S}$ ribosomal protein $\mathrm{L} 7 \mathrm{a} \mathrm{GN}=\mathrm{RPL} 7 \mathrm{~A}$ $60 \mathrm{~S}$ ribosomal protein $\mathrm{L} 7 \mathrm{a} \mathrm{GN}=\mathrm{RPL} 7 \mathrm{~A}$ $60 \mathrm{~S}$ ribosomal protein $\mathrm{L} 7 \mathrm{a} \mathrm{GN}=\mathrm{RPL} 7 \mathrm{~A}$ $60 \mathrm{~S}$ ribosomal protein $\mathrm{L} 7 \mathrm{a} \mathrm{GN}=\mathrm{RPL} 7 \mathrm{~A}$ $60 \mathrm{~S}$ ribosomal protein $\mathrm{L} 7 \mathrm{a} \mathrm{GN}=\mathrm{RPL} 7 \mathrm{~A}$ $60 \mathrm{~S}$ ribosomal protein $\mathrm{L} 7 \mathrm{a} \mathrm{GN}=\mathrm{RPL} 7 \mathrm{~A}$ $60 \mathrm{~S}$ ribosomal protein $\mathrm{L} 7 \mathrm{a} \mathrm{GN}=\mathrm{RPL} 7 \mathrm{~A}$ $60 \mathrm{~S}$ ribosomal protein $\mathrm{L} 7 \mathrm{a} \mathrm{GN}=\mathrm{RPL} 7 \mathrm{~A}$ $60 \mathrm{~S}$ ribosomal protein $\mathrm{L} 7 \mathrm{a} \mathrm{GN}=\mathrm{RPL} 7 \mathrm{~A}$ $60 \mathrm{~S}$ ribosomal protein $\mathrm{L} 7 \mathrm{a} \mathrm{GN}=\mathrm{RPL} 7 \mathrm{~A}$ $60 \mathrm{~S}$ ribosomal protein $\mathrm{L} 7 \mathrm{a} \mathrm{GN}=\mathrm{RPL} 7 \mathrm{~A}$ $\begin{array}{lllllll}\text { RL5_HUMAN } 34.36 & 100.0 \% & 14 & 26 & 49 & 0.10 \% & 38.0 \% \\ \text { ENPVYEKKPK }\end{array}$ $\begin{array}{lllllll}\text { RL6_HUMAN } 32.73 & 100.0 \% & 17 & 24 & 86 & 0.18 \% & 40.6 \% \\ \text { AGEKVEKPDTK }\end{array}$ RL6_HUMAN $32.73 \quad 100.0 \% \quad 17$ $\begin{array}{lll}\text { RL6 HUMAN } 32.73 \quad 100.0 \% & 17\end{array}$ RL6_HUMAN $32.73 \quad 100.0 \% \quad 17$ RL6_HUMAN $32.73 \quad 100.0 \% \quad 17$ RL6 HUMAN $32.73 \quad 100.0 \% \quad 17$

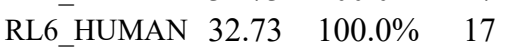
RL6 HUMAN $32.73 \quad 100.0 \% \quad 17$ RL6_HUMAN $32.73 \quad 100.0 \% \quad 17$ RL6_HUMAN $32.73 \quad 100.0 \% \quad 17$ RL6 HUMAN $32.73 \quad 100.0 \% \quad 17$ RL6_HUMAN $32.73 \quad 100.0 \% \quad 17$ RL6_HUMAN $32.73 \quad 100.0 \% \quad 17$ RL6_HUMAN $32.73 \quad 100.0 \% \quad 17$ RL6_HUMAN $32.73 \quad 100.0 \% \quad 17$ $\begin{array}{lll}\text { RL6 HUMAN } 32.73 \quad 100.0 \% & 17\end{array}$ RL6_HUMAN $32.73 \quad 100.0 \% \quad 17$ RL7_HUMAN $29.23 \quad 100.0 \% \quad 17$ RL7 HUMAN $29.23 \quad 100.0 \% \quad 17$ RL7_HUMAN $29.23 \quad 100.0 \% \quad 17$ RL7 HUMAN $29.23 \quad 100.0 \% \quad 17$ RL7_HUMAN $29.23 \quad 100.0 \% \quad 17$ RL7_HUMAN $29.23 \quad 100.0 \% \quad 17$ RL7 HUMAN $29.23 \quad 100.0 \% \quad 17$

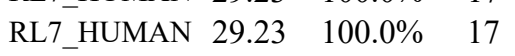
RL7_HUMAN $29.23 \quad 100.0 \% \quad 17$ RL7 HUMAN $29.23 \quad 100.0 \% \quad 17$

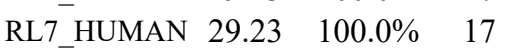
RL7 HUMAN $29.23 \quad 100.0 \% \quad 17$ RL7_HUMAN $29.23 \quad 100.0 \% \quad 17$ RL7_HUMAN $29.23 \quad 100.0 \% \quad 17$ RL7 HUMAN $29.23 \quad 100.0 \% \quad 17$ RL7_HUMAN $29.23 \quad 100.0 \% \quad 17$ RL7_HUMAN $29.23 \quad 100.0 \% \quad 17$ $\begin{array}{llll}\text { RL7A_HUMAN } & 30.00 & 100.0 \% & 18\end{array}$ RL7A_HUMAN $30.00 \quad 100.0 \% \quad 18$ RL7A_HUMAN $30.00 \quad 100.0 \% \quad 18$ RL7A_HUMAN $30.00 \quad 100.0 \% \quad 18$ RL7A_HUMAN $30.00 \quad 100.0 \% \quad 18$

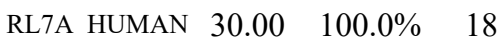

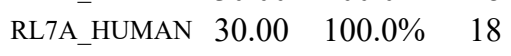
$\begin{array}{llll}\text { RL7A_HUMAN } & 30.00 & 100.0 \% & 18\end{array}$

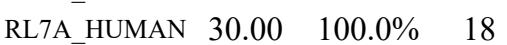
RL7A_HUMAN $30.00 \quad 100.0 \% \quad 18$ $\begin{array}{llll}\text { RL7A_HUMAN } & 30.00 & 100.0 \% & 18\end{array}$

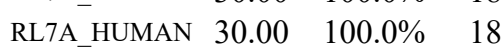

$\begin{array}{llll}99.7 \% & 34.4 & 25.0 & 18.8\end{array}$ $\begin{array}{llll}99.7 \% & 39.5 & 25.0 & 32.7\end{array}$ $0.18 \% \quad 40.6 \%$ EKVLATVTKPVGGDK $\begin{array}{llll}96.6 \% & 15.9 & 25.0 & 15.9\end{array}$ $\begin{array}{llll}99.7 \% & 64.4 & 25.0 & 62.4\end{array}$

$0.18 \% \quad 40.6 \%$ VLATVTKPVGGDK $99.7 \% \quad 41.8$ $\begin{array}{lll}99.7 \% & 38.8\end{array}$ $99.7 \% 37.3$ $99.0 \% \quad 31.5$ $99.7 \% \quad 53.2$ $97.2 \% \quad 20.9$ $99.0 \% \quad 39.5$ $99.7 \% 39.8$ $97.1 \% \quad 18.1$ $99.7 \% \quad 58.3$ $99.7 \% \quad 57.2$ $99.7 \% \quad 31.5$ $97.2 \% \quad 19.1$

$99.7 \% \quad 50.7$ $99.3 \% \quad 22.5$ $99.3 \% \quad 25.1$ $97.4 \% \quad 18.0$ $99.7 \% \quad 62.5$ $99.7 \% \quad 48.5$ $99.7 \% \quad 34.6$ $95.9 \% 18$ $99.7 \% \quad 34.2$ $94.9 \% \quad 16.6$ $99.7 \% \quad 61.9$ $99.7 \% \quad 34.7$ $98.6 \% \quad 24.2$ $99.7 \% \quad 45.9$ $99.7 \% \quad 40.4$ $99.7 \% \quad 61.8$ $99.7 \% \quad 30.9$ $25.0-28.2$ $\begin{array}{llll}99.5 \% & 25.1 & 25.0 & 25.1\end{array}$ $\begin{array}{llll}96.9 \% & 16.8 & 25.0 & 16.8\end{array}$ $\begin{array}{llll}95.2 \% & 15.2 & 25.0 & 15.2\end{array}$ $\begin{array}{llll}99.7 \% & 39.5 & 25.0 & 24.7\end{array}$ $\begin{array}{llll}96.2 \% & 19.4 & 25.0 & 13.5\end{array}$ $\begin{array}{llll}99.7 \% & 35.2 & 25.0 & 35.2\end{array}$ $\begin{array}{llll}99.7 \% & 64.4 & 25.0 & 53.6\end{array}$ $\begin{array}{llll}99.7 \% & 50.7 & 25.0 & 38.2\end{array}$ $\begin{array}{llll}99.0 \% & 36.9 & 25.0 & 19.6\end{array}$ $\begin{array}{llll}98.9 \% & 23.9 & 25.0 & 23.9\end{array}$ $99.7 \% \quad 70.1 \quad 25.0 \quad 69.8$ $\begin{array}{llll}99.7 \% & 71.2 & 25.0 & 69.7\end{array}$ $\begin{array}{ccc}1231.67 & 249 & 258 \\ 1201.64 & 2 & 12 \\ 1541.89 & 86 & 100 \\ 1284.75 & 88 & 100 \\ 1769.99 & 88 & 105 \\ 1139.54 & 115 & 123 \\ 1267.63 & 115 & 124 \\ 998.55 & 131 & 138 \\ 1360.76 & 189 & 200 \\ 866.50 & 193 & 200 \\ 994.50 & 211 & 218 \\ 1122.59 & 211 & 219 \\ 1195.60 & 238 & 246 \\ 1454.82 & 248 & 260 \\ 970.56 & 252 & 260 \\ 1399.84 & 261 & 272 \\ 1158.66 & 263 & 272 \\ 1446.77 & 273 & 285 \\ 1082.61 & 10 & 19 \\ 1210.70 & 10 & 20 \\ 962.57 & 24 & 31 \\ 1320.69 & 77 & 88 \\ 1192.60 & 78 & 88 \\ 1040.62 & 95 & 104 \\ 1026.61 & 97 & 106 \\ 1322.76 & 114 & 124 \\ 1053.57 & 116 & 124 \\ 1408.79 & 116 & 127 \\ 1175.66 & 125 & 134 \\ 965.53 & 149 & 156 \\ 1121.63 & 149 & 157 \\ 1326.79 & 166 & 177 \\ 1170.68 & 167 & 177 \\ 1540.79 & 201 & 212 \\ 2115.98 & 224 & 242 \\ 979.63 & 11 & 20 \\ 851.53 & 12 & 20 \\ 979.63 & 12 & 21 \\ 1073.64 & 26 & 34 \\ 945.54 & 27 & 34 \\ 1326.79 & 27 & 37 \\ 1216.63 & 38 & 48 \\ 1372.73 & 38 & 49 \\ 902.53 & 90 & 97 \\ 1334.79 & 126 & 137 \\ 1345.73 & 138 & 150 \\ 1473.83 & 138 & 151\end{array}$

Page 10 of Table S-1-3 
$60 \mathrm{~S}$ ribosomal protein $\mathrm{L} 7 \mathrm{a} \mathrm{GN}=\mathrm{RPL} 7 \mathrm{~A}$ $60 \mathrm{~S}$ ribosomal protein $\mathrm{L} 7 \mathrm{a} \mathrm{GN}=\mathrm{RPL} 7 \mathrm{~A}$ $60 \mathrm{~S}$ ribosomal protein $\mathrm{L} 7 \mathrm{a} \mathrm{GN}=\mathrm{RPL7A}$ $60 \mathrm{~S}$ ribosomal protein $\mathrm{L} 7 \mathrm{a} \mathrm{GN}=\mathrm{RPL} 7 \mathrm{~A}$ $60 \mathrm{~S}$ ribosomal protein $\mathrm{L} 8 \mathrm{GN}=\mathrm{RPL} 8$ $60 \mathrm{~S}$ ribosomal protein $\mathrm{L} 8 \mathrm{GN}=\mathrm{RPL} 8$ $60 \mathrm{~S}$ ribosomal protein $\mathrm{L} 8 \mathrm{GN}=\mathrm{RPL} 8$ $60 \mathrm{~S}$ ribosomal protein $\mathrm{L} 8 \mathrm{GN}=\mathrm{RPL} 8$ $60 \mathrm{~S}$ ribosomal protein $\mathrm{L} 8 \mathrm{GN}=\mathrm{RPL} 8$ $60 \mathrm{~S}$ ribosomal protein $\mathrm{L} 8 \mathrm{GN}=\mathrm{RPL} 8$ $60 \mathrm{~S}$ ribosomal protein $\mathrm{L} 8 \mathrm{GN}=\mathrm{RPL} 8$ $60 \mathrm{~S}$ ribosomal protein $\mathrm{L} 8 \mathrm{GN}=\mathrm{RPL} 8$ $60 \mathrm{~S}$ ribosomal protein $\mathrm{L} 8 \mathrm{GN}=\mathrm{RPL} 8$ $60 \mathrm{~S}$ ribosomal protein $\mathrm{L} 8 \mathrm{GN}=\mathrm{RPL} 8$ $60 \mathrm{~S}$ ribosomal protein $\mathrm{L} 8 \mathrm{GN}=\mathrm{RPL} 8$ $60 \mathrm{~S}$ ribosomal protein $\mathrm{L} 9 \mathrm{GN}=\mathrm{RPL} 9$ $60 \mathrm{~S}$ ribosomal protein $\mathrm{L} 9 \mathrm{GN}=\mathrm{RPL} 9$ $60 \mathrm{~S}$ ribosomal protein $\mathrm{L} 9 \mathrm{GN}=\mathrm{RPL} 9$ $60 \mathrm{~S}$ ribosomal protein $\mathrm{L} 7 \mathrm{a} \mathrm{GN}=\mathrm{RPL7A}$ $60 \mathrm{~S}$ ribosomal protein $\mathrm{L} 7 \mathrm{a} \mathrm{GN}=\mathrm{RPL7A}$

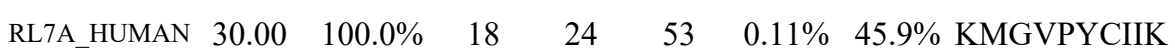

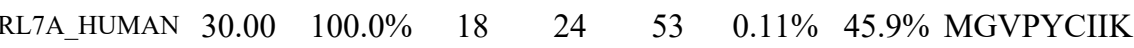

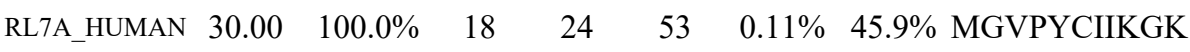
RL7A_HUMAN $30.00 \quad 100.0 \% \quad 18$ RL7A_HUMAN $30.00 \quad 100.0 \% \quad 18$ RL7A_HUMAN $30.00 \quad 100.0 \% \quad 18$ RL8 HUMAN $28.02 \quad 100.0 \% \quad 11$ RL8_HUMAN $28.02 \quad 100.0 \% \quad 11$ RL8 HUMAN $28.02 \quad 100.0 \% \quad 11$ RL8_HUMAN $28.02 \quad 100.0 \% \quad 11$ RL8_HUMAN $28.02 \quad 100.0 \% \quad 11$ RL8 HUMAN $28.02 \quad 100.0 \% \quad 11$ RL8_HUMAN $28.02 \quad 100.0 \% \quad 11$ RL8_HUMAN $28.02 \quad 100.0 \% \quad 11$ RL8 HUMAN $28.02 \quad 100.0 \% \quad 11$ RL8_HUMAN $28.02 \quad 100.0 \% \quad 11$ RL8 HUMAN $28.02 \quad 100.0 \% \quad 11$ RL9_HUMAN $21.86 \quad 100.0 \% \quad 3$ RL9_HUMAN $21.86 \quad 100.0 \% \quad 3$ RL9 HUMAN $21.86 \quad 100.0 \%$ 33 F263_HUMAN $59.61 \quad 100.0 \%$ $\begin{array}{llll} & 100.0 \%\end{array}$ $78 \mathrm{kDa}$ glucose-regulated protein GN=HSPA5 GRP78_HUMAN $72.33 \quad 100.0 \%$ $78 \mathrm{kDa}$ glucose-regulated protein GN=HSPA5 GRP78_HUMAN $72.33 \quad 100.0 \%$ $78 \mathrm{kDa}$ glucose-regulated protein GN=HSPA5 GRP78_HUMAN $72.33 \quad 100.0 \%$ $78 \mathrm{kDa}$ glucose-regulated protein GN=HSPA5 GRP78_HUMAN $72.33 \quad 100.0 \%$ $78 \mathrm{kDa}$ glucose-regulated protein GN=HSPA5 GRP78_HUMAN $72.33 \quad 100.0 \%$ 7-dehydrocholesterol reductase GN=DHCR7 DHCR7_HUMAN $54.49 \quad 100.0 \%$ 7-dehydrocholesterol reductase GN=DHCR7 DHCR7_HUMAN $54.49 \quad 100.0 \%$ 7-dehydrocholesterol reductase GN=DHCR7 DHCR7 HUMAN $54.49 \quad 100.0 \%$ 7-dehydrocholesterol reductase GN=DHCR7 DHCR7_HUMAN $54.49 \quad 100.0 \%$ 7-dehydrocholesterol reductase GN=DHCR7 DHCR7_HUMAN $54.49 \quad 100.0 \%$ Acetolactate synthase-like protein GN=ILVBL ILVBL_HUMAN $67.87 \quad 100.0 \%$ Acetolactate synthase-like protein GN=ILVBL ILVBL_HUMAN $67.87 \quad 100.0 \%$ Acetyl-CoA acetyltransferase, mitochondrial GN=ACAT1 THIL_HUMAN $45.20 \quad 100.0 \%$ Acetyl-CoA acetyltransferase, mitochondrial GN=ACAT1 THIL_HUMAN $45.20 \quad 100.0 \%$ Acetyl-CoA acetyltransferase, mitochondrial GN=ACAT1 THIL_HUMAN $45.20 \quad 100.0 \%$ Acetyl-CoA acetyltransferase, mitochondrial GN=ACAT1 THIL HUMAN $45.20 \quad 100.0 \%$ Actin, cytoplasmic $1 \mathrm{GN}=\mathrm{ACTB}$ Actin, cytoplasmic $1 \mathrm{GN}=\mathrm{ACTB}$ Actin, cytoplasmic $1 \mathrm{GN}=\mathrm{ACTB}$ Actin, cytoplasmic $1 \mathrm{GN}=\mathrm{ACTB}$ Actin, cytoplasmic $1 \mathrm{GN}=\mathrm{ACTB}$ Actin, cytoplasmic $1 \mathrm{GN}=\mathrm{ACTB}$ Actin, cytoplasmic $1 \mathrm{GN}=\mathrm{ACTB}$ Actin, cytoplasmic $1 \mathrm{GN}=\mathrm{ACTB}$ Actin, cytoplasmic $1 \mathrm{GN}=\mathrm{ACTB}$ ACTB_HUMAN $41.74 \quad 100.0 \%$ ACTB_HUMAN $41.74 \quad 100.0 \%$ ACTB_HUMAN $41.74 \quad 100.0 \% \quad 19$ ACTB_HUMAN $41.74 \quad 100.0 \% \quad 19$ ACTB_HUMAN $41.74 \quad 100.0 \% \quad 19$ ACTB_HUMAN $41.74 \quad 100.0 \% \quad 19$ ACTB_HUMAN $41.74 \quad 100.0 \% \quad 19$ ACTB_HUMAN $41.74 \quad 100.0 \% \quad 19$ ACTB_HUMAN $41.74 \quad 100.0 \%$
$0.11 \% \quad 45.9 \%$ TCTTVAFTQVNSEDKGALAK $99.7 \% \quad 70.2$

$99.7 \% \quad 33.1$

$99.7 \% \quad 29.8$

$99.7 \% \quad 39.4$

$99.7 \% \quad 33.3$

$99.7 \% \quad 53.6$

$97.5 \% 19.7$

$99.7 \% \quad 73.1$

$0.10 \% \quad 32.3 \%$ DIIHDPGRGAPLAK

$99.7 \% \quad 60.0$

16

16
16

$99.7 \% \quad 74.6$

$0.10 \% \quad 32.3 \%$ AVVGVVAGGGR

16

16

$0.10 \% \quad 32.3 \%$ AVVGVVAGGGRIDKPILK

$40.10 \% \quad 32.3 \%$ KVGLIAAR

$0.10 \% \quad 32.3 \%$ VGLIAARR

$99.0 \% \quad 55.0$

$99.0 \% \quad 38.1$

$99.0 \% \quad 46.1$

$99.7 \% \quad 46.6$

$0.01 \% \quad 19.3 \%$ TICSHVQNMIK

$99.7 \% 70.3$

$99.7 \% 72.4$

$98.5 \% \quad 20.4$

$99.7 \% \quad 64.2$

$0.01 \% \quad 5.0 \%$ NSVTPLASPEPTKKPR

$0.04 \% \quad 9.6 \%$ NQLTSNPENTVFDAK

$99.7 \% \quad 55.7$

$0.04 \% \quad 9.6 \% \quad$ TKPYIQVDIGGGQTK

$0.04 \% \quad 9.6 \%$ QATKDAGTIAGLNV

$\begin{array}{llll}96.0 \% & 16.1 & 25.0\end{array}$

$0.04 \% \quad 9.6 \%$ DAGTIAGLNVMR

$0.04 \% \quad 9.6 \%$ SQIFSTASDNQPTVTIK

$0.02 \% \quad 9.1 \%$ SLDGVTNDR

$0.02 \% \quad 9.1 \%$ GYFFPTSAR

$0.02 \% \quad 9.1 \%$ VIECSYTSADGQR

$99.7 \% \quad 48.7$

$99.7 \% \quad 75.1$

$99.7 \% \quad 44.7$

$99.7 \% \quad 29.5$

$99.7 \% 71.1$

$0.02 \% \quad 9.1 \%$ VIECSYTSADGQRHHSK

$0.02 \% \quad 9.1 \%$ YTAAVPYR

$0.01 \% \quad 3.8 \%$ GLLLSRENEDQVVK

$0.01 \% \quad 3.8 \%$ TDFRDGSIAV

$0.02 \% \quad 9.8 \%$ EVVIVSATR

$0.02 \% \quad 9.8 \%$ LGSIAIQGAIEK

$0.02 \% \quad 9.8 \%$ NEQDAYAINSYTR

$0.02 \% \quad 9.8 \% \quad$ LNVTPLAR

$123 \quad 0.26 \% \quad 38.1 \%$ AGFAGDDAPR

$123 \quad 0.26 \% \quad 38.1 \%$ AVFPSIVGRPR

$123 \quad 0.26 \% \quad 38.1 \%$ HQGVMVGMGQK

$\begin{array}{ll}99.7 \% & 27.2 \\ 99.0 \% & 37.8\end{array}$

$99.0 \% \quad 26.2$

$99.7 \% \quad 40.8$

$99.7 \% \quad 51.6$

$95.5 \% \quad 42.6$

$99.7 \% \quad 82.0$

$99.0 \% \quad 43.2$

$99.7 \% \quad 66.6$

$99.7 \% \quad 49.3$

$99.7 \% \quad 69.0$

$123 \quad 0.26 \% \quad 38.1 \%$ HQGVMVGMGQKDSYVGDEAQSK

$123 \quad 0.26 \% \quad 38.1 \%$ DSYVGDEAQSK

$99.7 \% 51.2$

$99.7 \% 53.6$

$123 \quad 0.26 \% \quad 38.1 \%$ DSYVGDEAQSKR

$\begin{array}{ll}99.7 \% & 53.6 \\ 99.7 \% & 42.0\end{array}$

$99.0 \% \quad 22.8$

$99.7 \% \quad 35.4$

1281.67

2141.05

1458.66

1064.56

1076.58

1405.72

1319.74

1459.80

1688.82

1816.92

1668.95

941.55

1749.07

827.55

855.55

869.56

1330.66

1998.97

948.47

1721.95

1677.81

1604.86

1661.86

1233.63

1836.93

976.47

1045.51

1485.66

1974.91

940.49

1599.87

1080.53

973.57

1199.70

1544.70

883.54

976.45

1198.71

1171.57

2351.08

1198.52

1354.62

$123 \quad 0.26 \% \quad 38.1 \%$ DLTDYLMK

1954.06

998.49

1744.89 
Actin, cytoplasmic $1 \mathrm{GN}=\mathrm{ACTB}$ Actin, cytoplasmic $1 \mathrm{GN}=\mathrm{ACTB}$ Actin, cytoplasmic $1 \mathrm{GN}=\mathrm{ACTB}$ Actin, cytoplasmic $1 \mathrm{GN}=\mathrm{ACTB}$ Actin, cytoplasmic $1 \mathrm{GN}=\mathrm{ACTB}$ Actin, cytoplasmic $1 \mathrm{GN}=\mathrm{ACTB}$ Actin, cytoplasmic $1 \mathrm{GN}=\mathrm{ACTB}$ Actin, cytoplasmic $1 \mathrm{GN}=\mathrm{ACTB}$ Actin, cytoplasmic $1 \mathrm{GN}=\mathrm{ACTB}$ Actin, cytoplasmic $1 \mathrm{GN}=\mathrm{ACTB}$ Actin-related protein $2 \mathrm{GN}=\mathrm{ACTR} 2$ Actin-related protein $2 \mathrm{GN}=\mathrm{ACTR} 2$ Actin-related protein $2 \mathrm{GN}=\mathrm{ACTR} 2$ Actin-related protein $2 \mathrm{GN}=\mathrm{ACTR} 2$

Actin-related protein $2 \mathrm{GN}=\mathrm{ACTR} 2$ Activator of basal transcription $1 \mathrm{GN}=\mathrm{Al}$ Activator of basal transcription $1 \mathrm{GN}=\mathrm{ABT} 1 \mathrm{ABT1} H \mathrm{HUAN} 31.08$ Acyl-CoA dehydrogenase family member 9, mitochondrial $\mathrm{GN}=\mathrm{ACAD} 9$ ACAD9_HUMAN $68.76 \quad 100.0 \%$ Acyl-CoA dehydrogenase family member 9 , mitochondrial GN=ACAD9 ACAD9_HUMAN $68.76 \quad 100.0 \%$ Acyl-CoA dehydrogenase family member 9, mitochondrial GN=ACAD9 ACAD9_HUMAN $68.76 \quad 100.0 \%$ Acyl-CoA dehydrogenase family member 9, mitochondrial GN=ACAD9 ACAD9_HUMAN $68.76 \quad 100.0 \%$ Acyl-CoA dehydrogenase family member 9 , mitochondrial GN=ACAD9 ACAD9 HUMAN $68.76 \quad 100.0 \%$ Acyl-CoA dehydrogenase family member 9 , mitochondrial GN=ACAD9 ACAD9_HUMAN $68.76 \quad 100.0 \%$ Acyl-coenzyme A thioesterase $1 \mathrm{GN}=$ ACOT1 ACOT1_HUMAN $46.28 \quad 100.0 \%$ Acyl-coenzyme A thioesterase $1 \mathrm{GN}=\mathrm{ACOT} 1$ ACOT1_HUMAN $46.28 \quad 100.0 \%$ Acyl-coenzyme A thioesterase 9, mitochondrial GN=ACOT9 ACOT9_HUMAN $49.90 \quad 100.0 \%$ Acyl-coenzyme A thioesterase 9, mitochondrial GN=ACOT9 ACOT9_HUMAN $49.90 \quad 100.0 \%$ Acilca Adenosylhomocysteinase $\mathrm{GN}=\mathrm{AHCY}$ Adenosylhomocysteinase $\mathrm{GN}=\mathrm{AHCY}$ Adenosylhomocysteinase $\mathrm{GN}=\mathrm{AHCY}$ SAHH_HUMAN $47.72 \quad 100.0 \%$ SAHH HUMAN $47.72 \quad 100.0 \%$ SAHH_HUMAN $47.72 \quad 100.0 \%$ Adenylate kinase 2, mitochondrial GN=AK2 KAD2_HUMAN $26.48 \quad 100.0 \%$ Adenylate kinase 2, mitochondrial GN=AK2 KAD2 HUMAN $26.48 \quad 100.0 \%$ Adenylate kinase 4, mitochondrial GN=AK4 KAD4_HUMAN $25.27 \quad 100.0 \%$ Adenylate kinase 4, mitochondrial GN=AK4 KAD4_HUMAN $25.27 \quad 100.0 \%$ ADP/ATP translocase $1 \mathrm{GN}=\mathrm{SLC} 25 \mathrm{~A} 4$ $\mathrm{ADP} / \mathrm{ATP}$ translocase $1 \mathrm{GN}=\mathrm{SLC} 25 \mathrm{~A} 4$ ADP/ATP translocase $1 \mathrm{GN}=\mathrm{SLC} 25 \mathrm{~A} 4$ ADP/ATP translocase $1 \mathrm{GN}=\mathrm{SLC} 25 \mathrm{~A} 4$ $\mathrm{ADP} / \mathrm{ATP}$ translocase $1 \mathrm{GN}=\mathrm{SLC} 25 \mathrm{~A} 4$ ADP/ATP translocase $1 \mathrm{GN}=\mathrm{SLC} 25 \mathrm{~A} 4$ ADP/ATP translocase $1 \mathrm{GN}=\mathrm{SLC} 25 \mathrm{~A} 4$ $\mathrm{ADP} / \mathrm{ATP}$ translocase $1 \mathrm{GN}=\mathrm{SLC} 25 \mathrm{~A} 4$ ADP/ATP translocase $1 \mathrm{GN}=\mathrm{SLC} 25 \mathrm{~A} 4$ $\mathrm{ADP} / \mathrm{ATP}$ translocase $1 \mathrm{GN}=\mathrm{SLC} 25 \mathrm{~A} 4$ ADP/ATP translocase $1 \mathrm{GN}=\mathrm{SLC} 25 \mathrm{~A} 4$ ADP/ATP translocase $1 \mathrm{GN}=\mathrm{SLC} 25 \mathrm{~A} 4$
ADT1_HUMAN $33.07 \quad 100.0 \%$ ADT1_HUMAN $33.07 \quad 100.0 \%$ ADT1_HUMAN $33.07 \quad 100.0 \%$ ADT1_HUMAN $33.07 \quad 100.0 \%$ ADT1_HUMAN $33.07 \quad 100.0 \%$ ADT1_HUMAN $33.07 \quad 100.0 \%$ ADT1_HUMAN $33.07 \quad 100.0 \%$ ADT1_HUMAN $33.07 \quad 100.0 \%$ ADT1_HUMAN $33.07 \quad 100.0 \%$ ADT1_HUMAN $33.07 \quad 100.0 \%$ ADT1_HUMAN $33.07 \quad 100.0 \%$ ADT1_HUMAN $33.07 \quad 100.0 \%$ $\begin{array}{llll}32 & 123 & 0.26 \% & 38.1 \% \\ 32 & 123 & 0.26 \% & 38.1 \%\end{array}$

32

$\begin{array}{llll}32 & 123 & 0.26 \% & 38.1 \% \\ 3 & 123 & 0.26 \% & 38.1 \%\end{array}$

$32 \quad 123 \quad 0.26 \% \quad 38.1 \%$ IKIIAPPER

$32 \quad 123 \quad 0.26 \% \quad 38.1 \%$ IIAPPERK

$32 \quad 123 \quad 0.26 \% \quad 38.1 \%$ QEYDESGPSIVHR

$32 \quad 123 \quad 0.26 \% \quad 38.1 \%$ QEYDESGPSIVHRK

$9 \quad 0.02 \% \quad 12.2 \%$ KVVVCDNGTGFVK

$9 \quad 0.02 \% \quad 12.2 \%$ VVVCDNGTGFVK

$9 \quad 0.02 \% \quad 12.2 \%$ ILLTEPPMNPTK

$9 \quad 0.02 \% \quad 12.2 \%$ GYAFNHSADFETVR

$0.02 \% \quad 12.2 \%$ ELKQLYLER

$5 \quad 0.01 \% \quad 8.8 \% \quad$ NLLSAYGEVGR

$0.01 \% \quad 8.8 \% \quad$ VAASLHNTPMGAR

$0.01 \% \quad 7.9 \%$ AFAKELFLGK

$0.01 \% \quad 7.9 \%$ VAMNILNSGR

$0.01 \% \quad 7.9 \%$ LIEMTAEYACTR

$0.01 \% \quad 7.9 \%$ TVETLLLR

$0.01 \% \quad 7.9 \%$ VSQQILEK

$0.01 \% \quad 7.9 \%$ VSQQILEKR

$0.01 \% \quad 5.2 \% \quad$ AATLILEPAGR

$0.01 \% \quad 5.2 \%$ GLAPEQPVTLR

$0.01 \% \quad 6.6 \% \quad$ YLTVQNTVR

$0.01 \% \quad 6.6 \%$ IAFSSTSLLK

$0.01 \% \quad 6.6 \%$ SLEICHPQER

$0.01 \% \quad 7.6 \%$ GISEETTTGVHNLYK

$0.01 \% \quad 7.6 \%$ SKFDNLYGCR

$0.01 \% \quad 7.6 \%$ IILLAEGR

$0.00 \% \quad 12.1 \%$ AVLLGPPGAGKGTQ

$0.00 \% \quad 12.1 \%$ AMVASGSELGKK

$0.01 \% \quad 12.6 \%$ AVILGPPGSGKGTVCQR

$0.01 \% \quad 12.6 \%$ SLLVPDHVITR

$0.01 \% \quad 31.2 \%$ TAVAPIER

$0.01 \% \quad 31.2 \%$ TAVAPIERVK

$0.01 \% 31.2 \%$ VKLLLQVQHASK

$0.01 \% \quad 31.2 \%$ LLLQVQHASK

$0.01 \% \quad 31.2 \%$ GIIDCVVRIPK

$0.01 \% \quad 31.2 \%$ TRLAADVGK

$0.01 \% \quad 31.2 \%$ LAADVGKGAAQR

$0.01 \% 31.2 \%$ EFHGLGDCIIK

$0.01 \% \quad 31.2 \%$ AAYFGVYDTAK

$0.01 \% \quad 31.2 \%$ GADIMYTGTVDCWR

$0.01 \% \quad 31.2 \%$ AFFKGAWSNVLR

$0.01 \% \quad 31.2 \%$ GAWSNVLR $\begin{array}{llllllll}99.7 \% & 66.1 & 25.0 & 64.6 & 12 & 0 & 0 & 1132.53\end{array}$

1629.82

1790.89

1564.81

1161.62

1418.79

1036.65

923.57

1516.70

1644.80

1422.74

1294.65

1353.74

1613.73

1191.67

1178.62

1324.68

1123.65

1090.57

1457.68

944.58

944.54

1100.64

1111.65

1180.67

1093.60

1066.61

1268.61

1648.82

1259.58

884.56

1589.91

1177.62

1696.92

1249.73

856.49

1083.65

1363.84

1136.68

1269.74

930.54

1156.64

1288.64

1205.58

1660.71

1395.75

$\begin{array}{llll}99.7 \% & 54.0 & 25.0 & 54.0\end{array}$

$\begin{array}{llll}99.7 \% & 28.5 & 25.0 & 28.5\end{array}$

$\begin{array}{llll}99.0 \% & 46.6 & 25.0 & 26.4\end{array}$

902.48 
ADP/ATP translocase $2 \mathrm{GN}=\mathrm{SLC} 25 \mathrm{~A} 5$ $\mathrm{ADP} / \mathrm{ATP}$ translocase $2 \mathrm{GN}=\mathrm{SLC} 25 \mathrm{~A} 5$ $\mathrm{ADP} / \mathrm{ATP}$ translocase $2 \mathrm{GN}=\mathrm{SLC} 25 \mathrm{~A} 5$ $\mathrm{ADP} / \mathrm{ATP}$ translocase $2 \mathrm{GN}=\mathrm{SLC} 25 \mathrm{~A}$ ADP/ATP translocase $2 \mathrm{GN}=\mathrm{SLC} 25 \mathrm{~A} 5$ $\mathrm{ADP} / \mathrm{ATP}$ translocase $2 \mathrm{GN}=\mathrm{SLC} 25 \mathrm{~A} 5$ $\mathrm{ADP} / \mathrm{ATP}$ translocase $2 \mathrm{GN}=\mathrm{SLC} 25 \mathrm{~A} 5$ $\mathrm{ADP} / \mathrm{ATP}$ translocase $2 \mathrm{GN}=\mathrm{SLC} 25 \mathrm{~A} 5$ $\mathrm{ADP} / \mathrm{ATP}$ translocase $2 \mathrm{GN}=\mathrm{SLC} 25 \mathrm{~A} 5$ ADP/ATP translocase $2 \mathrm{GN}=\mathrm{SLC} 25 \mathrm{~A} 5$ ADP/ATP translocase $2 \mathrm{GN}=\mathrm{SLC} 25 \mathrm{~A} 5$ ADP/ATP translocase $2 \mathrm{GN}=\mathrm{SLC} 25 \mathrm{~A} 5$ ADP/ATP translocase $2 \mathrm{GN}=\mathrm{SLC} 25 \mathrm{~A} 5$ $\mathrm{ADP} / \mathrm{ATP}$ translocase $2 \mathrm{GN}=\mathrm{SLC} 25 \mathrm{~A} 5$ ADP/ATP translocase $2 \mathrm{GN}=\mathrm{SLC} 25 \mathrm{~A} 5$ $\mathrm{ADP} / \mathrm{ATP}$ translocase $2 \mathrm{GN}=\mathrm{SLC} 25 \mathrm{~A} 5$ $\mathrm{ADP} / \mathrm{ATP}$ translocase $2 \mathrm{GN}=\mathrm{SLC} 25 \mathrm{~A} 5$ ADP/ATP translocase $2 \mathrm{GN}=\mathrm{SLC} 25 \mathrm{~A} 5$ $\mathrm{ADP} / \mathrm{ATP}$ translocase $2 \mathrm{GN}=\mathrm{SLC} 25 \mathrm{~A} 5$ ADP/ATP translocase $3 \mathrm{GN}=\mathrm{SLC} 25 \mathrm{~A} 6$ $\mathrm{ADP} / \mathrm{ATP}$ translocase $3 \mathrm{GN}=\mathrm{SLC} 25 \mathrm{~A} 6$ $\mathrm{ADP} / \mathrm{ATP}$ translocase $3 \mathrm{GN}=\mathrm{SLC} 25 \mathrm{~A} 6$ ADP/ATP translocase $3 \mathrm{GN}=\mathrm{SLC} 25 \mathrm{~A} 6$ $\mathrm{ADP} / \mathrm{ATP}$ translocase $3 \mathrm{GN}=\mathrm{SLC} 25 \mathrm{~A} 6$ $\mathrm{ADP} / \mathrm{ATP}$ translocase $3 \mathrm{GN}=\mathrm{SLC} 25 \mathrm{~A} 6$ $\mathrm{ADP} / \mathrm{ATP}$ translocase $3 \mathrm{GN}=\mathrm{SLC} 25 \mathrm{~A} 6$ ADP/ATP translocase $3 \mathrm{GN}=\mathrm{SLC} 25 \mathrm{~A} 6$ $\mathrm{ADP} / \mathrm{ATP}$ translocase $3 \mathrm{GN}=\mathrm{SLC} 25 \mathrm{~A} 6$ $\mathrm{ADP} / \mathrm{ATP}$ translocase $3 \mathrm{GN}=\mathrm{SLC} 25 \mathrm{~A} 6$ $\mathrm{ADP} / \mathrm{ATP}$ translocase $3 \mathrm{GN}=\mathrm{SLC} 25 \mathrm{~A} 6$ ADP/ATP translocase $3 \mathrm{GN}=\mathrm{SLC} 25 \mathrm{~A} 6$ $\mathrm{ADP} / \mathrm{ATP}$ translocase $3 \mathrm{GN}=\mathrm{SLC} 25 \mathrm{~A} 6$ ADP/ATP translocase $3 \mathrm{GN}=\mathrm{SLC} 25 \mathrm{~A} 6$ ADP/ATP translocase $3 \mathrm{GN}=\mathrm{SLC} 25 \mathrm{~A} 6$ AFG3-like protein $2 \mathrm{GN}=\mathrm{AFG} 3 \mathrm{~L} 2$

AFG3-like protein $2 \mathrm{GN}=\mathrm{AFG} 3 \mathrm{~L} 2$

A-kinase anchor protein 8-like GN=AKAP8L AKP8L HUMAN 71.65

A-kinase anchor protein 8 -like $\mathrm{GN}=\mathrm{AKAP} 8 \mathrm{~L}$

Aladin GN=AAAS

Aladin $\mathrm{GN}=\mathrm{AAAS}$

Alanine--tRNA ligase, Alanine--tRNA ligase, mitochondrial GN=AARS2 SYAM_HUMAN $107.34 \quad 100.0 \%$ Alanine--tRNA ligase, mitochondrial GN=AARS2 SYAM HUMAN $107.34 \quad 100.0 \%$ Alanine--tRNA ligase, mitochondrial GN=AARS2 SYAM_HUMAN $107.34 \quad 100.0 \%$ Alanine--tRNA ligase, mitochondrial GN=AARS2 SYAM_HUMAN $107.34 \quad 100.0 \%$ Aldehyde dehydrogenase family 16 member Al GN=ALDH16A1 A16A1_HUMAN $85.13 \quad 100.0 \%$ Aldehyde dehydrogenase family 16 member Al GN=ALDH16A1 A16A1_HUMAN $85.13 \quad 100.0 \%$
$50 \quad 0.11 \% \quad 45.3 \%$ DFLAGGVAAAISK $0.11 \% \quad 45.3 \%$ TAVAPIER $0.11 \% \quad 45.3 \%$ TAVAPIERVK $0.11 \% \quad 45.3 \%$ VKLLLQVQHASK $0.11 \% \quad 45.3 \%$ LLLQVQHASK $0.11 \% \quad 45.3 \%$ GIIDCVVRIPK $0.11 \% \quad 45.3 \%$ EQGVLSFWR $0 \quad 0.11 \% \quad 45.3 \%$ QIFLGGVDKR $0.11 \% \quad 45.3 \%$ TRLAADVGK $0.11 \% \quad 45.3 \%$ LAADVGKAGAER $50 \quad 0.11 \% \quad 45.3 \%$ EFRGLGDCLVK $50 \quad 0.11 \% \quad 45.3 \%$ GLGDCLVKIYK $50 \quad 0.11 \% \quad 45.3 \%$ AAYFGIYDTAK $50 \quad 0.11 \% \quad 45.3 \%$ KGTDIMYTGTLDCWR $50 \quad 0.11 \% \quad 45.3 \%$ GTDIMYTGTLDCWR

$50 \quad 0.11 \% \quad 45.3 \%$ GTDIMYTGTLDCWRK $50 \quad 0.11 \% \quad 45.3 \%$ DEGGKAFFK

$50 \quad 0.11 \% \quad 45.3 \%$ AFFKGAWSNVLR

$50 \quad 0.11 \% \quad 45.3 \%$ GAWSNVLR

$12 \quad 0.03 \% \quad 37.6 \%$ DFLAGGIAAAISK

$12 \quad 0.03 \% \quad 37.6 \%$ TAVAPIER

$12 \quad 0.03 \% \quad 37.6 \%$ TAVAPIERVK

$12 \quad 0.03 \% \quad 37.6 \%$ VKLLLQVQHASK

$12 \quad 0.03 \% \quad 37.6 \%$ LLLQVQHASK

$12 \quad 0.03 \% \quad 37.6 \%$ EQGVLSFWR

$12 \quad 0.03 \% \quad 37.6 \%$ TRLAADVGK

$12 \quad 0.03 \% \quad 37.6 \%$ LAADVGKSGTER

$2 \quad 0.03 \% \quad 37.6 \%$ EFRGLGDCLVK

$0.03 \% \quad 37.6 \%$ GLGDCLVKITK

$2 \quad 0.03 \% \quad 37.6 \%$ AAYFGVYDTAK

$12 \quad 0.03 \% \quad 37.6 \%$ GADIMYTGTVDCWR

$12 \quad 0.03 \% \quad 37.6 \%$ DEGGKAFFK

$0.03 \% \quad 37.6 \%$ AFFKGAWSNVLR

$0.03 \% \quad 37.6 \%$ GAWSNVLR

$0.01 \% \quad 3.3 \%$ TGRGMGGLFSVGETTAK

$0.01 \% \quad 3.3 \%$ VSEEIFFGR

$0.01 \% \quad 2.9 \% \quad$ IQFVCSLCK

$0.01 \% \quad 2.9 \% \quad$ SILNNKLISK

$0.01 \% \quad 4.4 \%$ VYNASSTIVPSLK

$0.01 \% \quad 4.4 \%$ ILATTPSAVFR

$0 \quad 0.02 \% \quad 5.8 \% \quad$ LVPSASVRPR

$10 \quad 0.02 \% \quad 5.8 \% \quad$ AGQEDVLFPVAR

$10 \quad 0.02 \% \quad 5.8 \%$ SLDEVYPDPVR

$10 \quad 0.02 \% \quad 5.8 \% \quad$ LLAVTGEQAQQAR

$10 \quad 0.02 \% \quad 5.8 \% \quad$ ELGQSLAQEVK

$0.01 \% \quad 5.2 \% \quad$ LAEVIQKHQR

$0.01 \% \quad 5.2 \%$ VAFCGAPEEGR

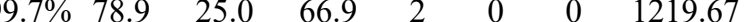

856.49

1083.65

1363.84

1136.68

1269.74

1121.57

$99.0 \% \quad 22.6$

$99.7 \% \quad 57.2$

$96.9 \% \quad 23.0$

$99.0 \% \quad 31.7$

$99.7 \% 70.3$

$99.7 \% \quad 35.5$

$99.7 \% \quad 43.3$

$99.7 \% \quad 63.2$

$99.6 \% \quad 25.3$

$99.7 \% \quad 69.1$

$99.7 \% \quad 37.0$

$99.7 \% \quad 48.4$

$99.7 \% \quad 28.5$

$99.0 \% \quad 46.6$

$99.7 \% \quad 66.4$

$99.0 \% \quad 36.5$

$99.7 \% \quad 36.5$

$99.7 \% \quad 68.2$

$99.7 \% \quad 47.4$

$99.7 \% \quad 57.2$

$99.0 \% \quad 31.7$

$99.7 \% \quad 69.1$

$99.7 \% \quad 35.5$

$99.7 \% \quad 54.0$

$99.7 \% \quad 49.5$

$99.7 \% \quad 54.0$

$99.7 \% \quad 48.4$

$99.7 \% \quad 28.5$

$99.0 \% \quad 46.6$

$95.9 \% \quad 17.8$

$99.7 \% \quad 64.6$

$98.5 \% \quad 22.7$

$99.7 \% \quad 40.7$

$99.7 \% \quad 39.4$

$99.7 \% \quad 47.6$

$99.3 \% 23.5$

$99.7 \% \quad 47.7$

$99.5 \% 28.6$

$99.7 \% \quad 73.8$

$95.2 \% \quad 23.5$

$99.7 \% \quad 30.4$

$99.7 \% \quad 42.2$

\subsection{5}

930.54

1157.63

1293.66

1265.69

1219.60

1832.83

1704.74

1816.84

998.49

1395.75

902.48

1233.68

856.49

1083.65

1363.84

1136.68

1121.57

930.54

1203.63

1293.66

1203.68

1205.58

1660.71

998.49

1395.75

902.48

1684.83

1083.55

1154.57

1129.69

1378.76

1175.68

1081.65

1301.68

1289.64

1384.75

1201.64

1221.71

1192.54 

HLDH16A1 A16A1_HUMAN $85.13 \quad 100.0 \%$ Alpha-centractin GN=ACTR1A Alpha-centractin GN=ACTR1A Alpha-centractin GN=ACTR1A Alpha-enolase $\mathrm{GN}=\mathrm{ENO} 1$

Alpha-enolase GN=ENO1 Alpha-enolase GN=ENO1 Alpha-enolase $\mathrm{GN}=\mathrm{ENO}$ Alpha-internexin GN=INA Alpha-internexin GN=INA Alpha-internexin GN=INA Alpha-internexin GN=INA Alpha-internexin GN=INA Alpha-internexin GN=INA Alpha-internexin GN=INA ACTZ HUMAN $42.62 \quad 100.0 \%$ ACTZ_HUMAN $42.62 \quad 100.0 \%$ ENOA_HUMAN $47.17 \quad 100.0 \%$ ENOA HUMAN $47.17 \quad 100.0 \%$ ENOA HUMAN $47.17 \quad 100.0 \%$ AINX_HUMAN $55.39 \quad 100.0 \%$ AINX_HUMAN $55.39 \quad 100.0 \%$ AINX HUMAN $55.39 \quad 100.0 \%$ AINX_HUMAN $55.39 \quad 100.0 \%$ AINX HUMAN $55.39 \quad 100.0 \%$ AINX_HUMAN $55.39 \quad 100.0 \%$ AINX_HUMAN $55.39 \quad 100.0 \%$ ACTZ_HUMAN $42.62 \quad 100.0 \%$ AIMP1 HUMAN $34.35 \quad 100.0 \%$ PIMP1_HUMAN $34.35 \quad 100.0 \%$ AIMP1_HUMAN $34.35 \quad 100.0 \%$ AIMP1 HUMAN $34.35 \quad 100.0 \%$ AIMP1_HUMAN $34.35 \quad 100.0 \%$ AIMP1 HUMAN $34.35 \quad 100.0 \%$ AIMP2_HUMAN $35.35 \quad 100.0 \%$ AIMP2_HUMAN $35.35 \quad 100.0 \%$ $100.0 \%$ $100.0 \%$ $100.0 \%$ $100.0 \%$ $100.0 \%$ $100.0 \%$ $100.0 \%$ $100.0 \%$ $100.0 \%$ $100.0 \%$ $100.0 \%$ $100.0 \%$ $100.0 \%$ $100.0 \%$ $100.0 \%$ $100.0 \%$ $100.0 \%$ $100.0 \%$

$100.0 \%$ $100.0 \%$ $100.0 \%$ $100.0 \%$ APOC3_HUMAN $10.85 \quad 100.0 \%$ ENOA_HUMAN $47.17 \quad 100.0 \%$
$0.01 \% \quad 5.2 \%$ GAAACDLVQR $0.01 \% \quad 5.2 \%$ EALLVANGTPR $0.02 \% \quad 8.2 \%$ AGFAGDQIPK $0.02 \% \quad 8.2 \% \quad$ YCFPNYVGRPK $0.02 \% \quad 8.2 \%$ IDIAGRDVSR $0.03 \% \quad 9.9 \%$ AVEHINKTIAPALVSK $0.03 \% \quad 9.9 \%$ TIAPALVSK $0.03 \% \quad 9.9 \%$ AGAVEKGVPLYR $0.03 \% \quad 9.9 \%$ VNQIGSVTESLQACK $0.03 \% \quad 15.8 \%$ LSGAGGAGGFR $0.03 \% \quad 15.8 \%$ RPPASDGLDLSQAAAR $0.03 \% \quad 15.8 \%$ ALEAELAALR $0.03 \% \quad 15.8 \%$ AQLEEASSAR $0.03 \% \quad 15.8 \%$ DVDGATLAR $0.03 \% \quad 15.8 \%$ FANLNEQAAR $0.03 \% \quad 15.8 \%$ SNIEETTISSQKI $0.03 \% \quad 21.5 \%$ AILQATLREEK $0.03 \% \quad 21.5 \%$ KQQSIAGSADSKPIDVSR $0.03 \% 21.5 \%$ QQSIAGSADSKPIDVSR $0.03 \% \quad 21.5 \%$ IGCIITAR $0.03 \% \quad 21.5 \%$ TVVSGLVNHVPLEQMQNR $0.03 \% \quad 21.5 \%$ MVILLCNLKPAK $0.01 \% \quad 11.9 \%$ LYELKAAVDGLSK $0.01 \% \quad 11.9 \%$ VLSTVHTHSSVK $0.01 \% \quad 11.9 \%$ SCENLAPFNTALK $0.01 \% \quad 1.8 \%$ SPSISNMAALSR $0.01 \% \quad 1.8 \%$ FNISSHNQSPKR $0.01 \% \quad 1.8 \%$ HLYVLAAEPR $0.02 \% \quad 12.5 \%$ YTMALQQK $0.02 \% \quad 12.5 \%$ AISTICSLEK

$\quad 0.02 \% \quad 12.5 \%$ EGRLEDVENLGCR

$10 \quad 0.02 \% \quad 12.5 \%$ VQEAIIHFR

$10 \quad 0.02 \% \quad 12.5 \%$ ALTQRPDYIK

$10 \quad 0.02 \% \quad 12.5 \%$ EQKYEDGIALLR

$10 \quad 0.02 \% \quad 12.5 \%$ NALANQSDCVLHR

$0.00 \% \quad 1.9 \% \quad$ KQALYEYAR

$0.00 \% \quad 1.9 \%$ QALYEYAR

$0.01 \% \quad 9.2 \%$ ILQEYITQEGHK

$0.01 \% \quad 9.2 \% \quad$ SVELEDVKFHQCVR

$0.01 \% \quad 9.2 \% \quad$ YITQNGDYQLR

$0.01 \% \quad 9.2 \% \quad$ YITQNGDYQLRTQ

$0.01 \% \quad 3.7 \%$ LSKFDSER

$0.01 \% \quad 3.7 \%$ SGIYETRC

$0.01 \% \quad 2.7 \%$ NASELFPAVVK

$0.01 \% \quad 2.7 \%$ ALKDPNQLIR

$0.01 \% \quad 2.7 \% \quad$ IAPDVLRK

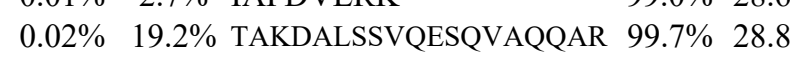

$99.7 \% \quad 48.9$ $99.7 \% \quad 37.1$ $99.7 \% \quad 56.1$ $99.7 \% 33.1$ $99.7 \% 31.6$ $99.7 \% \quad 31.4$ $97.8 \% 20$. $99.7 \% \quad 30.5$ $\begin{array}{lll}98.5 \% & 35.4\end{array}$ $99.7 \% \quad 71.5$ $99.7 \% \quad 47.5$ $99.7 \% \quad 64.1$ $99.7 \% \quad 63.2$ $99.5 \% \quad 27.5$ $99.7 \% \quad 63.2$ $99.7 \% \quad 69.6$ $99.7 \% \quad 31.2$

$\begin{array}{lll}99.7 \% & 44.9\end{array}$ $\begin{array}{lll}99.7 \% & 47.4\end{array}$ $99.7 \% \quad 38.6$ $99.0 \% 27.6$ $99.7 \% \quad 35.6$ $99.7 \% \quad 41.0$ $99.7 \% \quad 59.4$ $97.9 \% 18.4$ $98.8 \% 27.4$ $99.0 \% \quad 26.0$ $99.7 \% \quad 30.5$

$99.1 \% 26.7$ $97.3 \% 16.9$ $96.3 \% 21.5$ $99.4 \% \quad 25.3$ $99.7 \% \quad 65.8$ $97.5 \% \quad 19.2$

$99.0 \% \quad 22.6$ $98.9 \% 29.1$ $99.3 \% 22.6$ $99.7 \% \quad 47.0$ $99.7 \% \quad 49.5$ $96.4 \% \quad 20.4$ $99.0 \% 32.8$ $99.7 \% 33.9$ $96.6 \% 18.1$ $\begin{array}{ll}96.6 \% & 18 . \\ 99.0 \% & 28.6\end{array}$ Apolipoprotein C-III GN=APOC3

1140.64

1003.52

1400.68

1101.60

1690.99

899.56

1259.71

1633.82

949.49

1624.84

1056.60

1061.52

917.47

1133.57

1449.74

1271.73

1886.99

1758.90

903.51

2037.05

1415.81

1406.79

1294.71

1464.72

1233.63

1414.72

1168.65

982.50

1121.59

1546.73

1112.62

1204.67

1434.76

1497.72

1141.60

1013.51

1458.76

1745.86

1370.67

1599.78

981.50

985.44

1174.65

1167.68

911.57 2017.03

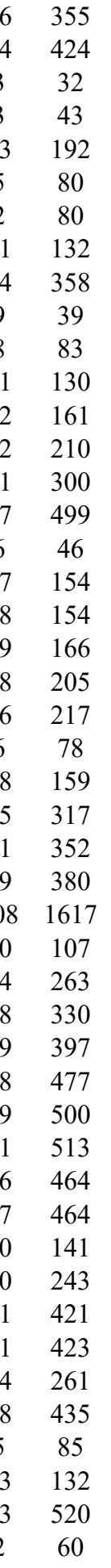

Page 14 of Table S-1-3 
Arginine--tRNA ligase, cytoplasmic GN=RARS SYRC_HUMAN $75.38 \quad 100.0 \%$ Arginine--tRNA ligase, cytoplasmic GN=RARS SYRC_HUMAN $75.38 \quad 100.0 \%$ Arginine--tRNA ligase, cytoplasmic GN=RARS SYRC HUMAN $75.38 \quad 100.0 \%$ Arginine--tRNA ligase, cytoplasmic GN=RARS SYRC_HUMAN $75.38 \quad 100.0 \%$ Asparagine synthetase [glutamine-hydrolyzing] GN=ASNS ASNS_HUMAN $64.37 \quad 100.0 \%$ Asparagine synthetase [glutamine-hydrolyzing] GN=ASNS ASNS HUMAN $64.37 \quad 100.0 \%$ Asparagine synthetase [glutamine-hydrolyzing] GN=ASNS ASNS_HUMAN $64.37 \quad 100.0 \%$ Asparagine synthetase [glutamine-hydrolyzing] GN=ASNS ASNS HUMAN $64.37 \quad 100.0 \%$ Asparagine synthetase [glutamine-hydrolyzing] GN=ASNS ASNS_HUMAN $64.37 \quad 100.0 \%$ Asparagine synthetase [glutamine-hydrolyzing] GN=ASNS ASNS_HUMAN $64.37 \quad 100.0 \%$ Aspartate aminotransferase, mitochondrial GN=GOT2 AATM HUMAN $47.52 \quad 100.0^{\circ}$ Aspartate aminotransferase, mitochondrial GN=GOT2 AATM_HUMAN $47.52 \quad 100.0 \%$ Aspartate aminotransferase, mitochondrial GN=GOT2 AATM_HUMAN $47.52 \quad 100.0 \%$ Ataxin-10 GN=ATXN10 Ataxin-10 GN=ATXN10 ATX10 HUMAN $53.49 \quad 100.0 \%$ Ataxin-10 GN=ATXN10 ATX10_HUMAN $53.49 \quad 100.0 \%$ ATX10 HUMAN $53.49 \quad 100.0 \%$ ATP synthase subunit alpha, mitochondrial GN=ATP5A1 ATPA_HUMAN $59.75 \quad 100.0 \%$ ATP synthase subunit alpha, mitochondrial GN=ATP5A1 ATPA_HUMAN $59.75 \quad 100.0 \%$ ATP synthase subunit alpha, mitochondrial GN=ATP5A1 ATPA HUMAN $59.75 \quad 100.0 \%$ ATP synthase subunit alpha, mitochondrial GN=ATP5A1 ATPA_HUMAN $59.75 \quad 100.0 \%$ ATP synthase subunit alpha, mitochondrial GN=ATP5A1 ATPA_HUMAN $59.75 \quad 100.0 \%$ ATP synthase subunit alpha, mitochondrial GN=ATP5A1 ATPA_HUMAN $59.75 \quad 100.0 \%$ ATP synthase subunit alpha, mitochondrial GN=ATP5A1 ATPA_HUMAN $59.75 \quad 100.0 \%$ ATP synthase subunit alpha, mitochondrial GN=ATP5A1 ATPA_HUMAN $59.75 \quad 100.0 \%$ ATP synthase subunit alpha, mitochondrial GN=ATP5A1 ATPA_HUMAN $59.75 \quad 100.0 \%$

$0.01 \% \quad 7.3 \%$ SATEQSGTGIR

$99.7 \% \quad 53.5$

1106.54

$0.08 \% \quad 8.7 \% \quad$ VTDLKAALEQR

$99.7 \% \quad 43.3$

1243.70

$0.08 \% \quad 8.7 \%$ GALMLENLQK

$99.7 \% \quad 57.0$

1116.6

$0.08 \% \quad 8.7 \%$ SQEQEVLER

$0.08 \% \quad 8.7 \%$ SLSPGVSR

$96.0 \% \quad 23.6$

$99.1 \% 21.2$

1117.55

$0.08 \% \quad 8.7 \%$ KISVVSATK

$99.7 \% \quad 52.4$

$\begin{array}{lllllll}0.08 \% & 8.7 \% & \text { GVPAGNSDTEGGQPGR } & 99.7 \% & 52.4 \\ 0.08 \% & 8.7 \% & \text { GVPAGNSDTEGGQPGRK } & 99.1 \% & 24.2\end{array}$

$0.08 \% \quad 8.7 \%$ WGASTATTQK

$0.08 \% \quad 8.7 \%$ KPSISITTESLK

$99.7 \% \quad 48.7$

$99.7 \% \quad 37.7$

$99.7 \% \quad 42.2$

$95.3 \% \quad 19.2$

$99.7 \% \quad 54.5$

$99.0 \% \quad 45.1$

$99.7 \% \quad 44.0$

$99.0 \% \quad 19.2$

$98.3 \% \quad 22.2$

$99.7 \% \quad 55.7$ $96.2 \% 22.4$

$0.01 \% \quad 3.7 \%$ GGVEEGPTVLI

$0.03 \% \quad 10.5 \%$ EIAENITK

$0.03 \% \quad 10.5 \%$ STIIGESISR

$0.03 \% \quad 10.5 \%$ AYQCVVLLQGK

$\begin{array}{ll}96.2 \% & 22.4 \\ 99.7 \% & 35.1\end{array}$

$0.03 \% \quad 10.5 \%$ SDGGYTYDTSDLAA $99.5 \% \quad 30.0$

$\begin{array}{ll}0.03 \% & 10.5 \% \\ 0.03 \% & 11.1 \%\end{array}$

$0.03 \% \quad 11.1 \%$ DTYGVRPLFK

$99.7 \% \quad 46.3$

$99.7 \% \quad 41.8$

$0.03 \% \quad 11.1 \%$ AMTEDGFLAVCSEAK

$0.03 \% \quad 11.1 \%$ ILFNNAVK

$0.03 \% \quad 11.1 \%$ EAFSDGITSVK

$0.03 \% \quad 11.1 \%$ TKEGYYYR

$0.03 \% \quad 11.1 \%$ WINATDPSAR

$0.01 \% \quad 7.9 \%$ ASAELALGENSEVLK

$0.01 \% \quad 7.9 \%$ DAGMQLQGYR

$0.01 \% \quad 7.9 \%$ TQLVSNLKK

$0.01 \% \quad 6.7 \% \quad$ ALTALFKEQR

$0.01 \% \quad 6.7 \% \quad$ NACIECSVNQNSIR

$0.01 \% \quad 6.7 \% \quad$ LIGNLCYK

$90 \quad 0.19 \% \quad 27.3 \%$ ILGADTSVDLEETGR

$99.7 \% \quad 59.4$

$99.0 \% \quad 35.8$

$99.7 \% \quad 55.2$

$99.0 \% \quad 24.2$

$99.7 \% \quad 35.0$

$99.7 \% \quad 66.6$

$99.7 \% \quad 48.9$

$98.4 \% \quad 21.6$

$99.7 \% \quad 30.7$

$99.7 \% \quad 63.0$

$98.8 \% \quad 21.0$

$99.7 \% \quad 46.5$

$99.7 \% \quad 53.2$

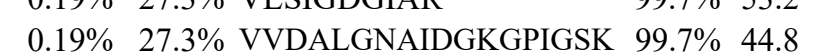

$99.7 \% \quad 41.3$

$99.7 \% \quad 53.3$

$99.7 \% \quad 47.8$

$99.7 \% \quad 32.2$

$99.7 \% \quad 39.9$

$99.7 \% \quad 53.2$

$0.19 \% \quad 27.3 \%$ AVDSLVPIGRGQR

$0.19 \% \quad 27.3 \%$ ELIIGDRQTGK $0.19 \% \quad 27.3 \%$ TSIAIDTIINQK

$\begin{array}{cc}45 & 60 \\ 99 & 109 \\ 256 & 265 \\ 266 & 278 \\ 519 & 529 \\ 77 & 87 \\ 104 & 113 \\ 328 & 336 \\ 655 & 662 \\ 823 & 831 \\ 832 & 847 \\ 832 & 848 \\ 851 & 860 \\ 861 & 872 \\ 971 & 979 \\ 971 & 980 \\ 987 & 998 \\ 210 & 1217 \\ 22 & 32 \\ 22 & 33 \\ 136 & 143 \\ 214 & 223 \\ 290 & 300 \\ 378 & 395 \\ 462 & 472 \\ 547 & 557 \\ 138 & 147 \\ 148 & 162 \\ 237 & 244 \\ 468 & 478 \\ 512 & 519 \\ 541 & 550 \\ 108 & 122 \\ 171 & 180 \\ 356 & 364 \\ 28 & 37 \\ 90 & 103 \\ 377 & 384 \\ 59 & 73 \\ 74 & 83 \\ 150 & 167 \\ 172 & 182 \\ 183 & 194 \\ 195 & 204 \\ 195 & 207 \\ 208 & 218 \\ 219 & 230 \\ & \end{array}$

Page 15 of Table S-1-3 

ATP synthase subunit alpha, mitochondrial GN=ATP5A1 ATPA_HUMAN $59.75 \quad 100.0 \% \quad 16 \quad 19 \quad 90 \quad 0.19 \% \quad 27.3 \%$ TSIAIDTIINQKR ATP synthase subunit alpha, mitochondrial GN=ATP5A1 ATPA_HUMAN $59.75 \quad 100.0 \%$ ATP synthase subunit alpha, mitochondrial GN=ATP5A1 ATPA_HUMAN $59.75 \quad 100.0 \%$ ATP synthase subunit alpha, mitochondrial GN=ATP5A1 ATPA_HUMAN $59.75 \quad 100.0 \%$ ATP synthase subunit alpha, mitochondrial GN=ATP5A1 ATPA_HUMAN $59.75 \quad 100.0 \%$ ATP synthase subunit alpha, mitochondrial GN=ATP5A1 ATPA_HUMAN 59.75 ATP synthase subunit beta, mitochondrial GN=ATP5B ATPB_HUMAN 56.56 ATP synthase subunit beta, mitochondrial GN=ATP5B ATPB HUMAN 56.56 ATP synthase subunit beta, mitochondrial GN=ATP5B ATPB_HUMAN 56.56 ATP synthase subunit beta, mitochondrial GN=ATP5B ATPB_HUMAN 56.56 ATP synthase subunit beta, mitochondrial GN=ATP5B ATPB_HUMAN 56.56 ATP synthase subunit beta, mitochondrial GN=ATP5B ATPB_HUMAN 56.56 ATP synthase subunit beta, mitochondrial GN=ATP5B ATPB_HUMAN 56.56 ATP synthase subunit gamma, mitochondrial GN=ATP5C1 ATPG_HUMAN 33.00 ATP synthase subunit gamma, mitochondrial GN=ATP5C1 ATPG_HUMAN 33.00 ATP synthase subunit gamma, mitochondrial GN=ATP5C1 ATPG HUMAN 33.00 ATP synthase subunit gamma, mitochondrial GN=ATP5C1 ATPG_HUMAN 33.00 ATP synthase subunit gamma, mitochondrial GN=ATP5C1 ATPG_HUMAN 33.00 ATP synthase subunit gamma, mitochondrial GN=ATP5C1 ATPG HUMAN 33.00 ATP synthase subunit gamma, mitochondrial GN=ATP5C1 ATPG_HUMAN 33.00 ATP synthase subunit $\mathrm{O}$, mitochondrial GN=ATP5O ATPO_HUMAN 23.28 ATP synthase subunit $\mathrm{O}$, mitochondrial GN=ATP5O ATPO HUMAN 23.28 ATP synthase subunit O, mitochondrial GN=ATP5O ATPO_HUMAN 23.28 ATP synthase subunit $\mathrm{O}$, mitochondrial GN=ATP5O ATPO HUMAN 23.28 ATP synthase subunit s-like protein GN=ATP5SL AT5SL_HUMAN 29.27 ATP synthase subunit s-like protein GN=ATP5SL AT5SL_HUMAN 29.27 ATPase family AAA domain-containing protein $3 \mathrm{~A}$ GN=ATAD3A ATD3A HUMAN 71.37 ATPase family AAA domain-containing protein $3 \mathrm{~A}$ GN=ATAD3A ATD3A_HUMAN 71.37 ATPase family AAA domain-containing protein $3 \mathrm{~A}$ GN=ATAD3A ATD3A HUMAN 71.37 ATPase family AAA domain-containing protein 3A GN=ATAD3A ATD3A_HUMAN 71.37 ATPase family AAA domain-containing protein 3A GN=ATAD3A ATD3A_HUMAN 71.3 ATPase family AAA domain-containing protein 3A GN=ATAD3A ATD3A_HUMAN 71.37 ATPase family AAA domain-containing protein 3A GN=ATAD3A ATD3A_HUMAN 71.37 ATPase family AAA domain-containing protein 3A GN=ATAD3A ATD3A_HUMAN 71.37 ATPase family AAA domain-containing protein 3A GN=ATAD3A ATD3A_HUMAN 71.37 ATPase family AAA domain-containing protein 3A GN=ATAD3A ATD3A_HUMAN 71.37 ATPase family AAA domain-containing protein 3A GN=ATAD3A ATD3A_HUMAN 71.37 ATPase family AAA domain-containing protein 3A GN=ATAD3A ATD3A_HUMAN 71.37 ATPase family AAA domain-containing protein 3A GN=ATAD3A ATD3A_HUMAN 71.37 ATPase family AAA domain-containing protein 3A GN=ATAD3A ATD3A_HUMAN 71.37 ATPase family AAA domain-containing protein $3 \mathrm{~A}$ GN=ATAD3A ATD3A_HUMAN 71.37 ATPase family AAA domain-containing protein 3A GN=ATAD3A ATD3A_HUMAN 71.37 ATPase family AAA domain-containing protein 3A GN=ATAD3A ATD3A_HUMAN 71.3 ATPase family AAA domain-containing protein 3A GN=ATAD3A ATD3A_HUMAN 71.37 ATPase family AAA domin-containing protein 3 A GN=ATAD3A ATD3A_HUMAN 7137 ATPase WRNIP1 GN=WRNIP1
$99.7 \% \quad 67.4$ $95.3 \% 20.8$

$99.0 \% \quad 45.4$ $99.7 \% \quad 53.5$ $99.7 \% \quad 69.4$ $99.7 \% \quad 62.3$ $99.7 \% \quad 27.5$ $99.7 \% \quad 36.2$ $99.7 \% \quad 44.7$

$99.7 \% \quad 34.7$

$99.7 \% \quad 42.3$

$99.7 \% \quad 57.1$

$99.7 \% \quad 77.3$

$\begin{array}{lll}98.4 \% & 21.5\end{array}$

$99.7 \% \quad 51.6$

$99.7 \% \quad 52.6$

$99.7 \% \quad 58.0$

$99.0 \% 25.6$

$99.7 \% \quad 72.4$

$99.7 \% 55.1$

$99.6 \% \quad 27.7$

$99.7 \% \quad 33.9$

$99.7 \% \quad 51.2$

$99.7 \% \quad 27.0$

$99.7 \% \quad 38.4$

$99.2 \% \quad 24.7$

$99.7 \% \quad 27.1$

$99.7 \% \quad 34.9$

$99.7 \% \quad 34.8$

$99.7 \% \quad 54.2$

$99.5 \% \quad 32.5$

$99.7 \% \quad 34.0$

$99.7 \% \quad 26.2$

$99.0 \% \quad 43.1$

$99.7 \% \quad 67.2$

$99.4 \% \quad 26.3$

$99.0 \% \quad 53.3$

$99.0 \% \quad 49.9$

$99.7 \% \quad 42.1$

$99.7 \% \quad 68.6$

$98.3 \% \quad 30.7$

$99.7 \% \quad 45.2$

$99.0 \% \quad 50.1$

$99.7 \% \quad 37.9$

$99.0 \% \quad 40.0$

$99.7 \% \quad 36.9$

$99.6 \% 31.4$
845.51

1001.61

1287.69

1553.74

1438.85

1650.92

1278.64

1088.64

975.56

1406.68

1601.81

1815.87

1326.73

1096.61

1213.64

1450.76

1047.57

1329.76

1292.66

1025.64

1160.67

1316.77

1146.61

1314.77

1637.78

910.51

1455.73

1092.58

1233.63

1356.72

1509.81

945.54

1155.58

1417.79

1014.61

1263.64

1161.61

1210.66

969.48

1097.57

$0.12 \% \quad 26.3 \%$ AEGPGRGDEPSPS

$0.01 \% \quad 4.7 \%$ AVGQDTLLR
1001.61

869.56

914.57

850.41

$\begin{array}{cc}19 & 231 \\ 53 & 261 \\ 54 & 261 \\ 54 & 262 \\ 66 & 316 \\ 35 & 347 \\ 03 & 416 \\ 5 & 109 \\ 10 & 121 \\ 89 & 198 \\ 02 & 212 \\ 26 & 239 \\ 65 & 279 \\ 07 & 422 \\ 8 & 79 \\ 1 & 100 \\ 01 & 112 \\ 13 & 126 \\ 16 & 126 \\ 27 & 138 \\ 44 & 154 \\ 5 & 73 \\ 4 & 84 \\ 4 & 85 \\ 1 & 100 \\ 47 & 157 \\ 42 & 257 \\ 6 & 44 \\ 66 & 177 \\ 78 & 186 \\ 20 & 229 \\ 50 & 260 \\ 63 & 275 \\ 68 & 275 \\ 76 & 286 \\ 14 & 326 \\ 27 & 334 \\ 39 & 346 \\ 76 & 384 \\ 95 & 406 \\ 69 & 478 \\ 52 & 561 \\ 54 & 561 \\ 54 & 562 \\ 69 & 576 \\ 22 & 634 \\ 45 & 253\end{array}$

$\begin{array}{lll}1255.56 & 622 & 634 \\ 972.55 & 245 & 253\end{array}$ 
$\begin{array}{lllllllll}\text { WRIP1_HUMAN } & 72.13 & 100.0 \% & 3 & 3 & 6 & 0.01 \% & 4.7 \% & \text { FVTLSATNAK }\end{array}$ WRIP1_HUMAN $72.13 \quad 100.0 \%$ ATPase WRNIP1 GN=WRNIP

ATP-binding cassette sub-family D member $3 \mathrm{GN}=\mathrm{ABCD} 3 \quad \mathrm{ABCD} 3$ _HUMAN $75.48 \quad 100.0 \%$ ATP-binding cassette sub-family D member $3 \mathrm{GN}=\mathrm{ABCD} 3 \quad \mathrm{ABCD} 3$ _HUMAN $75.48 \quad 100.0 \%$ ATP-binding cassette sub-family D member $3 \mathrm{GN}=\mathrm{ABCD} 3 \mathrm{ABCD} 3$ _HUMAN $75.48 \quad 100.0 \%$ ATP-binding cassette sub-family D member $3 \mathrm{GN}=\mathrm{ABCD} 3 \mathrm{ABCD} 3$ _HUMAN $75.48 \quad 100.0 \%$ ATP-binding cassette sub-family F member $2 \mathrm{GN}=\mathrm{ABCF} 2 \mathrm{ABCF} 2$ HUMAN $71.29 \quad 100.0 \%$ ATP-binding cassette sub-family F member $2 \mathrm{GN}=\mathrm{ABCF} 2 \mathrm{ABCF} 2$ HUMAN $71.29 \quad 100.0 \%$ ATP-binding cassette sub-family F member 2 GN=ABCF2 ABCF2_HUMAN $71.29 \quad 100.0 \%$ ATP-binding cassette sub-family F member 2 GN=ABCF2 ABCF2_HUMAN $71.29 \quad 100.0 \%$ ATP-binding cassette sub-family F member $2 \mathrm{GN}=\mathrm{ABCF} 2 \mathrm{ABCF} 2$ _HUMAN $71.29 \quad 100.0 \%$ ATP-binding cassette sub-family F member 2 GN=ABCF2 ABCF2_HUMAN $71.29 \quad 100.0 \%$ ATP-binding cassette sub-family F member $2 \mathrm{GN}=\mathrm{ABCF} 2 \quad \mathrm{ABCF} 2$ HUMAN $71.29 \quad 100.0 \%$ ATP-binding cassette sub-family F member 2 GN=ABCF2 ABCF2_HUMAN $71.29 \quad 100.0 \%$ ATP-citrate synthase $\mathrm{GN}=\mathrm{ACLY}$ ATP-citrate synthase $\mathrm{GN}=\mathrm{ACLY}$ ATP-citrate synthase GN=ACLY ATP-citrate synthase GN=ACLY ATP-citrate synthase GN=ACLY ATP-citrate synthase GN=ACLY ATP-citrate synthase GN=ACLY ATP-citrate synthase GN=ACLY ATP-citrate synthase GN=ACLY ATP-citrate synthase GN=ACLY ATP-citrate synthase $\mathrm{GN}=\mathrm{ACLY}$ ATP-citrate synthase GN=ACLY ATP-citrate synthase GN=ACLY ATP-citrate synthase GN=ACLY ATP-citrate synthase GN=ACLY ATP-citrate synthase $\mathrm{GN}=\mathrm{ACLY}$ ATP-citrate synthase GN=ACLY ATP-citrate synthase GN=ACLY ATP-citrate synthase $\mathrm{GN}=\mathrm{ACLY}$ ACLY_HUMAN $120.84 \quad 100.0 \%$ ACLY_HUMAN $120.84 \quad 100.0 \%$ ACLY HUMAN $120.84 \quad 100.0 \%$ ACLY_HUMAN $120.84 \quad 100.0 \%$ ACLY_HUMAN $120.84 \quad 100.0 \%$ ACLY HUMAN $120.84 \quad 100.0 \%$ ACLY_HUMAN $120.84 \quad 100.0 \%$ ACLY_HUMAN $120.84 \quad 100.0 \%$ ACLY_HUMAN $120.84 \quad 100.0 \%$ ACLY_HUMAN $120.84 \quad 100.0 \%$ ACLY_HUMAN $120.84 \quad 100.0 \%$ ACLY_HUMAN $120.84 \quad 100.0 \%$ ACLY_HUMAN $120.84 \quad 100.0 \%$ ACLY_HUMAN $120.84 \quad 100.0 \%$ ACLY_HUMAN $120.84 \quad 100.0 \%$ ACLY HUMAN $120.84 \quad 100.0 \%$ ACLY_HUMAN $120.84 \quad 100.0 \%$ ACLY_HUMAN $120.84 \quad 100.0 \%$ ACLY_HUMAN $120.84 \quad 100.0 \%$ ATP-dependent 6-phosphofructokinase, liver type GN=PFKL PFKAL_HUMAN $85.02 \quad 100.0 \%$ ATP-dependent 6-phosphofructokinase, liver type GN=PFKL PFKAL_HUMAN $85.02 \quad 100.0 \%$ ATP-dependent 6-phosphofructokinase, liver type GN=PFKL PFKAL_HUMAN 85.02 $100.0 \%$ ATP-dependent 6-phosphofructokinase, liver type GN=PFKL PFKAL_HUMAN $85.02 \quad 100.0 \%$ ATP-dependent 6-phosphofructokinase, liver type GN=PFKL PFKAL_HUMAN $85.02 \quad 100.0 \%$ ATP-dependent 6-phosphofructokinase, muscle type GN=PFKM PFKAM_HUMAN $85.18 \quad 100.0 \%$ ATP-dependent 6-phosphofructokinase, muscle type GN=PFKM PFKAM_HUMAN $85.18 \quad 100.0 \%$ ATP-dependent 6-phosphofructokinase, muscle type GN=PFKM PFKAM_HUMAN $85.18 \quad 100.0 \%$ ATP-dependent 6-phosphofructokinase, muscle type GN=PFKM PFKAM_HUMAN $85.18 \quad 100.0 \%$ ATP-dependent 6-phosphofructokinase, muscle type GN=PFKM PFKAM_HUMAN $85.18 \quad 100.0 \%$ ATP-dependent 6-phosphofructokinase, platelet type GN=PFKP PFKAP_HUMAN $85.60 \quad 100.0 \%$ ATP-dependent 6-phosphofructokinase, platelet type GN=PFKP PFKAP_HUMAN $85.60 \quad 100.0 \%$ ATP-dependent 6-phosphofructokinase, platelet type GN=PFKP PFKAP_HUMAN $85.60 \quad 100.0 \%$ ATP-dependent 6-phosphofructokinase, platelet type GN=PFKP PFKAP_HUMAN $85.60 \quad 100.0 \%$
$0.01 \% \quad 4.7 \%$ SIEVYSAYNNVK

$0.01 \% \quad 6.8 \% \quad$ AAFSKYLTAR

$0.01 \% \quad 6.8 \%$ AVVDKVFFSR

$0.01 \% \quad 6.8 \% \quad$ IVLAGREMTR

$0.01 \% \quad 6.8 \%$ SGANVLICGPNGCGK

$0.05 \% \quad 11.4 \%$ YGLIGLNGIGK

$0.05 \% \quad 11.4 \%$ SMLLSAIGKR

$0.05 \% \quad 11.4 \%$ ILHGLGFTPAMQR

$0.05 \% \quad 11.4 \%$ YYTGNYDQYVK

$0.05 \% \quad 11.4 \%$ YGLTGKQQVSPIR

$0.05 \% \quad 11.4 \%$ SKLVDEEPQLTK

$0.05 \% \quad 11.4 \%$ LVDEEPQLTK

$0.05 \% \quad 11.4 \%$ LVDEEPQLTKR

$0.11 \% \quad 19.0 \%$ AISEQTGKELLYK

$0.11 \% \quad 19.0 \%$ FICTTSAIQNR

$0.11 \% \quad 19.0 \%$ LGQEATVGK

$0.11 \% \quad 19.0 \%$ LGQEATVGKATGFLK

$0.11 \% \quad 19.0 \%$ SGASLKLTLLNPK

$0.11 \% \quad 19.0 \%$ TILSLMTR

$0.11 \% \quad 19.0 \%$ RGGPNYQEGLR

$0.11 \% \quad 19.0 \%$ GGPNYQEGLR

$0.11 \% \quad 19.0 \%$ TASFSESRADEVAPAK

$0.11 \% \quad 19.0 \%$ AKPAMPQDSVPSPR

$0.11 \% \quad 19.0 \%$ SLQGKSTTLFSR

$0.11 \% \quad 19.0 \%$ AIVWGMQTR

$0.11 \% \quad 19.0 \%$ SAYDSTMETMNYAQIR

$0.11 \% \quad 19.0 \%$ IGNTGGMLDNILASK

$0.11 \% \quad 19.0 \%$ LYRPGSVAYVSR

$0.11 \% \quad 19.0 \%$ SGGMSNELNNIISR

$0.11 \% \quad 19.0 \%$ YQDTPGVK

$\quad 0.11 \% \quad 19.0 \%$ NQALKEAGVFVPR

$0.11 \% \quad 19.0 \%$ VQILKDYVR

$0.03 \% \quad 8.0 \% \quad$ AIGVLTSGGDAQGMNAAVR

$0.03 \% \quad 8.0 \%$ TFVLEVMGR

$0.03 \% \quad 8.0 \%$ GGTPSAFDRILSSK

$0.03 \% \quad 8.0 \%$ AVAFSPVTELKK

$0.03 \% \quad 8.0 \%$ TLSMDKGF

$0.01 \% \quad 7.1 \%$ VGIFTGAR

$0.01 \% \quad 7.1 \%$ AAYNLVKR

$0.01 \% \quad 7.1 \%$ TFVLEVMGR

$0.01 \% \quad 7.1 \%$ LGYDTRVTVLGHVQR

$0.01 \% \quad 7.1 \%$ IFANTPDSGCVLGMR

$10 \quad 0.02 \% \quad 8.8 \%$ FLEHLSGAGK

$10 \quad 0.02 \% \quad 8.8 \%$ AIGVLTSGGDAQGMNAAVR

$10 \quad 0.02 \% \quad 8.8 \% \quad$ AACNLLQR

$10 \quad 0.02 \% \quad 8.8 \%$ TFVLEVMGR $\begin{array}{llllllll}99.7 \% & 44.1 & 25.0 & 44.1 & 2 & 0 & 0 & 1386.69\end{array}$

$\begin{array}{llllllll}99.6 \% & 27.0 & 25.0 & 22.5 & 1 & 0 & 0 & 1127.62\end{array}$

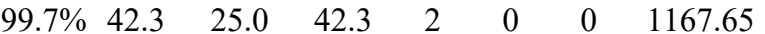

$\begin{array}{llllllll}99.7 \% & 31.3 & 25.0 & 26.9 & 2 & 0 & 0 & 1145.65\end{array}$

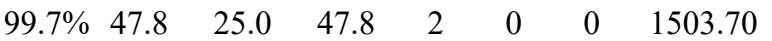

$\begin{array}{llllllll}99.7 \% & 51.4 & 25.0 & 39.2 & 4 & 0 & 0 & 1104.64\end{array}$

$\begin{array}{llllllll}99.7 \% & 35.9 & 25.0 & 33.7 & 2 & 0 & 0 & 1091.62\end{array}$

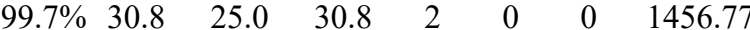

$\begin{array}{llllllll}99.7 \% & 43.8 & 25.0 & 43.8 & 2 & 0 & 0 & 1413.63\end{array}$

$\begin{array}{llllllll}99.7 \% & 45.5 & 25.0 & 42.5 & 2 & 2 & 0 & 1446.81\end{array}$

$\begin{array}{llllllll}99.7 \% & 58.1 & 25.0 & 51.9 & 2 & 0 & 0 & 1386.75\end{array}$

$\begin{array}{llllllll}99.7 \% & 35.1 & 25.0 & 18.9 & 4 & 0 & 0 & 1171.62\end{array}$

$\begin{array}{llllllll}99.7 \% & 40.6 & 25.0 & 32.7 & 2 & 0 & 0 & 1327.72\end{array}$

$\begin{array}{llllllll}99.7 \% & 44.6 & 25.0 & 44.6 & 2 & 0 & 0 & 1479.81\end{array}$

$\begin{array}{llllllll}99.7 \% & 58.9 & 25.0 & 51.7 & 2 & 0 & 0 & 1310.65\end{array}$

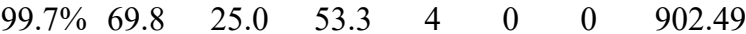

$\begin{array}{llllllll}99.7 \% & 32.1 & 25.0 & 32.1 & 1 & 1 & 0 & 1519.85\end{array}$

$\begin{array}{llllllll}99.7 \% & 29.8 & 25.0 & 26.4 & 1 & 0 & 0 & 1341.81\end{array}$

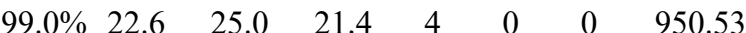

$\begin{array}{llllllll}97.5 \% & 22.0 & 25.0 & 14.1 & 1 & 0 & 0 & 1246.63\end{array}$

$\begin{array}{llllllll}99.7 \% & 37.5 & 25.0 & 29.6 & 2 & 0 & 0 & 1090.53\end{array}$

$\begin{array}{llllllll}99.7 \% & 46.2 & 25.0 & 46.2 & 2 & 2 & 0 & 1665.81\end{array}$

$\begin{array}{llllllll}99.7 \% & 45.2 & 25.0 & 45.2 & 4 & 1 & 0 & 1480.76\end{array}$

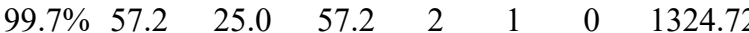

$\begin{array}{llllllll}99.7 \% & 41.1 & 25.0 & 33.5 & 2 & 0 & 0 & 1061.56\end{array}$

$\begin{array}{llllllll}99.7 \% & 32.2 & 25.0 & 32.2 & 2 & 0 & 0 & 1912.81\end{array}$

$\begin{array}{llllllll}99.7 \% & 31.7 & 25.0 & 31.7 & 2 & 0 & 0 & 1519.78\end{array}$

$\begin{array}{llllllll}99.7 \% & 33.3 & 25.0 & 25.6 & 0 & 3 & 0 & 1367.74\end{array}$

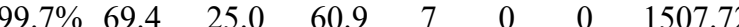

$\begin{array}{llllllll}99.0 \% & 27.0 & 25.0 & 15.5 & 1 & 0 & 0 & 907.45\end{array}$

$\begin{array}{llllllll}99.7 \% & 49.0 & 25.0 & 48.5 & 2 & 2 & 0 & 1428.80\end{array}$

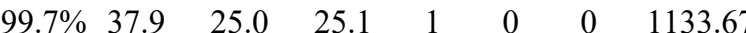

1787.91

$\begin{array}{llllllll}99.7 \% & 38.1 & 25.0 & 33.1 & 2 & 0 & 0 & 1051.56\end{array}$

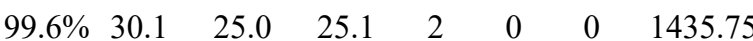

$\begin{array}{llllllll}99.7 \% & 41.8 & 25.0 & 39.9 & 2 & 1 & 0 & 1289.75\end{array}$

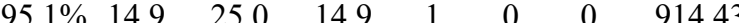

$99.0 \% \quad 30.5 \quad 25.0 \quad 23.8$

$99.0 \% \quad 41.3 \quad 25.0 \quad 41.3$

$99.7 \% \quad 38.1 \quad 25.0 \quad 33.1$

$99.7 \% \quad 31.0 \quad 25.0 \quad 31.0$

$\begin{array}{llll}98.8 \% & 27.7 & 25.0 & 23.3\end{array}$

$\begin{array}{llll}99.7 \% & 34.5 & 25.2 & 27.2\end{array}$

$\begin{array}{lllll}99.7 \% & 70.0 & 25.0 & 70.0 & 3\end{array}$

$99.0 \% \quad 32.9 \quad 25.0 \quad 2.1 \quad 2$

$99.7 \% \quad 38.1 \quad 25.0 \quad 33.1$

914.43
820.47

934.55

1051.56

1713.94

1653.77

1058.56

1787.91

945.49

1051.56 


(1)

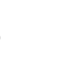

3

3
15
15

$\begin{array}{ll}5 & 19 \\ 5 & 19 \\ 5 & 19\end{array}$

15
15
15
$99.5 \% 25.0$

$99.7 \% \quad 42.4$ $99.7 \% \quad 31.9$

$99.7 \% \quad 68.8$

$\begin{array}{ll}99.7 \% \quad 53.6 & 0.7\end{array}$

$99.5 \% 27.1$

$99.7 \% \quad 61.5$

$99.7 \% \quad 35.9$

$99.7 \% \quad 67.3$

$99.3 \% \quad 23.2$

$99.7 \% \quad 59.6$

$99.7 \% \quad 41.3$

$99.0 \% \quad 51.9$

$99.7 \% \quad 37.2$

$98.2 \% \quad 25.5$

$99.7 \% \quad 61.5$

$99.7 \% \quad 52.4$

$99.7 \% \quad 54.2$

$99.7 \% \quad 54.0$

$99.7 \% \quad 59.2$

$99.7 \% \quad 46.0$

$99.7 \% \quad 31.6$

$99.3 \% \quad 21.3$

$99.7 \% \quad 64.3$

$\begin{array}{lll}99.7 \% & 29.8\end{array}$

$98.0 \% \quad 26.0$

$99.7 \% \quad 27.2$

$99.7 \% \quad 37.4$

$99.7 \% \quad 40.3$

$99.1 \% \quad 20.4$

$99.7 \% \quad 36.7$

$99.5 \% \quad 25.0$

$99.7 \% \quad 32.7$

$99.7 \% \quad 61.8$

$99.7 \% \quad 35.2$

$98.4 \% \quad 18.2$

$99.3 \% 24.5$

$98.2 \% \quad 26.1$

$99.7 \% \quad 54.4$

$99.7 \% 61.5$

$99.7 \% \quad 60.9$

$99.7 \% \quad 62.4$

$\begin{array}{lll}99.7 \% & 36.8\end{array}$

$99.7 \% \quad 61.5$

$99.7 \% \quad 31.0$

$99.7 \% \quad 66.3$
1306.66

1299.69

1253.65

943.50

1166.61

1633.8

1124.58

1025.54

1186.59

1197.63

1288.70

1075.55

1357.69

1087.62

931.52

1285.75

1157.66

1535.74

1003.59

1149.74

917.54

1465.85

1260.69

986.51

1360.68

1111.68

1165.60

1227.71

1283.64

1315.66

1232.55

1289.59

1089.61

1238.55

1320.68

1448.77

1180.63

1485.77

1163.59

1300.64 1440.85 
ATP-dependent RNA helicase DDX3X GN=DDX3X DDX3X_HUMAN $73.25 \quad 100.0 \%$ ATP-dependent RNA helicase DDX3X GN=DDX3X DDX3X_HUMAN $73.25 \quad 100.0 \%$ ATP-dependent RNA helicase DDX3X GN=DDX3X DDX3X_HUMAN $73.25 \quad 100.0 \%$ ATP-dependent RNA helicase DDX50 GN=DDX50 DDX50_HUMAN $82.57 \quad 100.0 \%$ ATP-dependent RNA helicase DDX50 GN=DDX50 DDX50_HUMAN $82.57 \quad 100.0 \%$ ATP-dependent RNA helicase DDX50 GN=DDX50 DDX50 HUMAN $82.57 \quad 100.0 \%$ ATP-dependent RNA helicase DDX50 GN=DDX50 DDX50_HUMAN $82.57 \quad 100.0 \%$ ATP-dependent RNA helicase DDX50 GN=DDX50 DDX50 HUMAN $82.57 \quad 100.0 \%$ ATP-dependent RNA helicase DDX50 GN=DDX50 DDX50_HUMAN $82.57 \quad 100.0 \%$ ATP-dependent RNA helicase DDX50 GN=DDX50 DDX50_HUMAN $82.57 \quad 100.0 \%$ ATP-dependent RNA helicase DDX51 GN=DDX51 DDX51_HUMAN $72.46 \quad 100.0 \%$ ATP-dependent RNA helicase DDX51 GN=DDX51 DDX51_HUMAN $72.46 \quad 100.0 \%$ ATP-dependent RNA helicase DDX54 GN=DDX54 DDX54_HUMAN $98.60 \quad 100.0 \%$ ATP-dependent RNA helicase DDX54 GN=DDX54 DDX54 HUMAN $98.60 \quad 100.0 \%$ ATP-dependent RNA helicase DDX54 GN=DDX54 DDX54_HUMAN $98.60 \quad 100.0 \%$ ATP-dependent RNA helicase DDX54 GN=DDX54 DDX54 HUMAN $98.60100 .0 \%$ Bcl-2-associated transcription factor $1 \mathrm{GN}=\mathrm{BCLAF1}$ BCLF1_HUMAN $106.13 \quad 100.0 \%$ Bcl-2-associated transcription factor $1 \mathrm{GN}=\mathrm{BCLAF} 1$ BCLF1_HUMAN $106.13 \quad 100.0 \%$ Bcl-2-associated transcription factor $1 \mathrm{GN}=\mathrm{BCLAF} 1 \mathrm{BCLF} 1$ HUMAN $106.13100 .0 \%$ Bcl-2-associated transcription factor $1 \mathrm{GN}=\mathrm{BCLAF} 1$ BCLF1_HUMAN $106.13 \quad 100.0 \%$ Bcl-2-associated transcription factor $1 \mathrm{GN}=\mathrm{BCLAF} 1 \mathrm{BCLF} 1$ HUMAN $106.13 \quad 100.0 \%$ Bcl-2-associated transcription factor $1 \mathrm{GN}=$ BCLAF1 BCLF1_HUMAN $106.13100 .0 \%$ Bcl-2-associated transcription factor $1 \mathrm{GN}=\mathrm{BCLAF} 1$ BCLF1_HUMAN $106.13 \quad 100.0 \%$ Bcl-2-associated transcription factor $1 \mathrm{GN}=\mathrm{BCLAF} 1 \mathrm{BCLF} 1$ HUMAN $106.13100 .0 \%$ Bcl-2-associated transcription factor $1 \mathrm{GN}=\mathrm{BCLAF} 1 \mathrm{BCLF} 1$ HUMAN $106.13 \quad 100.0 \%$ Bcl-2-associated transcription factor $1 \mathrm{GN}=$ BCLAF1 BCLF1_HUMAN $106.13100 .0 \%$ Bcl-2-associated transcription factor $1 \mathrm{GN}=$ BCLAF1 BCLF1_HUMAN $106.13 \quad 100.0 \%$ Bcl-2-associated transcription factor $1 \mathrm{GN}=\mathrm{BCLAF} 1$ BCLF1_HUMAN $106.13 \quad 100.0 \%$ Bcl-2-associated transcription factor $1 \mathrm{GN}=\mathrm{BCLAF} 1 \mathrm{BCLF} 1$ HUMAN $106.13 \quad 100.0 \%$ Bcl-2-associated transcription factor $1 \mathrm{GN}=\mathrm{BCLAF} 1 \mathrm{BCLF} 1$ HUMAN $106.13 \quad 100.0 \%$ Bcl-2-associated transcription factor $1 \mathrm{GN}=\mathrm{BCLAF1}$ BCLF1_HUMAN $106.13 \quad 100.0 \%$ Bcl-2-associated transcription factor $1 \mathrm{GN}=\mathrm{BCLAF} 1 \mathrm{BCLF} 1$ HUMAN $106.13100 .0 \%$ Bcl-2-associated transcription factor $1 \mathrm{GN}=\mathrm{BCLAF} 1 \mathrm{BCLF} 1$ HUMAN $106.13 \quad 100.0 \%$ Bcl-2-associated transcription factor $1 \mathrm{GN}=\mathrm{BCLAF1}$ BCLF1_HUMAN $106.13 \quad 100.0 \%$ Beta-adrenergic receptor kinase $1 \mathrm{GN}=\mathrm{ADRBK} 1$ ARBK1_HUMAN $79.58 \quad 100.0 \%$ Beta-adrenergic receptor kinase $1 \mathrm{GN}=$ ADRBK1 ARBK1_HUMAN $79.58 \quad 100.0 \%$ Beta-galactosidase $\mathrm{GN}=\mathrm{GLB}$ Beta-galactosidase $\mathrm{GN}=\mathrm{GLB}$ Beta-galactosidase $\mathrm{GN}=\mathrm{GLB}$

Beta-galactosidase $\mathrm{GN}=\mathrm{GLB}$ BGAL_HUMAN $76.08 \quad 100.0 \%$ BGAL_HUMAN $76.08 \quad 100.0 \%$ BGAL_HUMAN $76.08 \quad 100.0 \%$ BGAL HUMAN $76.08 \quad 100.0 \%$ Bifunctional glutamate/proline--tRNA ligase GN=EPRS SYEP_HUMAN $170.59 \quad 100.0 \%$ Bifunctional glutamate/proline--tRNA ligase GN=EPRS SYEP HUMAN $170.59 \quad 100.0 \%$ Bifunctional glutamate/proline--tRNA ligase GN=EPRS SYEP_HUMAN $170.59 \quad 100.0 \%$ Bifunctional glutamate/proline--tRNA ligase GN=EPRS SYEP_HUMAN $170.59 \quad 100.0 \%$ Bifunctional glutamate/proline--tRNA ligase GN=EPRS SYEP HUMAN $170.59 \quad 100.0 \%$ Bifunctional glutamate/proline--tRNA ligase GN=EPRS SYEP_HUMAN $170.59 \quad 100.0 \%$
19

19

6

(6)

4

4
4
4

4

18
18
18

18

18
18
18

18
18

18

18
18

18

4
4
4

4

4
9
9

9

9
9

9
9

$\begin{array}{llll}49 & 0.10 \% & 21.3 \% & \text { SPILVATAVAAR } \\ 49 & 0.10 \% & 21.3 \% \text { GLDISNVK }\end{array}$

$0.10 \% \quad 21.3 \%$ DYRQSSGASSSSFSSSR

$99.7 \% \quad 72.9$

$99.0 \% 27.2$

$99.7 \% \quad 46.1 \quad 25.0 \quad 18.1$

$0.10 \% \quad 21.3 \%$ QSSGASSSSFSSSR

$0.02 \% \quad 8.7 \%$ RVSSLDTSTHK

$10 \quad 0.02 \% \quad 8.7 \% \quad$ VLVLAPTR

$10 \quad 0.02 \% \quad 8.7 \%$ NGIDILVGTPGR

$10 \quad 0.02 \% \quad 8.7 \% \quad$ VLVATNVAAR

$10 \quad 0.02 \% \quad 8.7 \% \quad$ VGVPSTMDLVK

$10 \quad 0.02 \% \quad 8.7 \% \quad$ KLSSNAVSQITR

$10 \quad 0.02 \% \quad 8.7 \% \quad$ LSSNAVSQITR

$0.01 \% \quad 2.9 \% \quad$ LFSTGLAHR

$0.01 \% \quad 2.9 \%$ TGQAFTLLLK

$0.02 \% \quad 5.2 \%$ CSTLIVTDLAAR

$0.02 \% \quad 5.2 \% \quad$ VADNAQQQYVR

$0.02 \% \quad 5.2 \% \quad$ SRPAPSPESIKR

$0.02 \% \quad 5.2 \%$ VQELQQGAFGR

$0.11 \% \quad 18.7 \%$ KAEGEPQEESPLK

$0.11 \% \quad 18.7 \%$ TIAPQNAPR

$0.11 \% \quad 18.7 \%$ TIAPQNAPRDESR

$0.11 \% \quad 18.7 \%$ GRSSFYPDGGDQETAK

$0.11 \% \quad 18.7 \%$ SSFYPDGGDQETAK

$0.11 \% \quad 18.7 \%$ SSFYPDGGDQETAKTGK

$0.11 \% \quad 18.7 \%$ SVLADQGKSFATASHR

$0.11 \% \quad 18.7 \%$ NTEEEGLKYK

$0.11 \% \quad 18.7 \%$ LKETGYVVERPSTTK

$0.11 \% \quad 18.7 \%$ ETQSPEQVKSEK

$0.11 \% \quad 18.7 \%$ STFREESPLR

$0.11 \% \quad 18.7 \%$ MAPVPLDDSNRPASLTK

$0.11 \% \quad 18.7 \%$ SAAMTLNER

$0.11 \% \quad 18.7 \%$ SAAMTLNERFTSYQK

$0.11 \% \quad 18.7 \%$ FTSYQKATEEHSTR

$0.11 \% \quad 18.7 \%$ IDISPSTLR

$0.11 \% \quad 18.7 \%$ IDISPSTLRK

$0.11 \% \quad 18.7 \%$ RPKEEEWDPEYTPK

$0.01 \% \quad 3.5 \% \quad$ ISDLGLACDFSK

$0.01 \% \quad 3.5 \%$ GAQEVKESPFFR

$0.01 \% \quad 5.8 \%$ MFEIDYSR

$0.01 \% \quad 5.8 \%$ DSFLKDGQPFR

$0.01 \% \quad 5.8 \% \quad$ YISGSIHYSR

$0.01 \% \quad 5.8 \%$ FAYGKVTLEK

$18 \quad 0.04 \% \quad 7.4 \%$ GSQFGQSCCLR

$18 \quad 0.04 \% \quad 7.4 \% \quad$ LNLNNTVLSK

$0.04 \% \quad 7.4 \%$ VIDPVAPR

$0.04 \% \quad 7.4 \%$ GDIIQLQR

$0.04 \% \quad 7.4 \%$ SLYDEVAAQGEVVR

$0.04 \% \quad 7.4 \%$ NSEPAGLETPEAK $\begin{array}{llll}99.7 \% & 45.7 & 25.0 & 44.5\end{array}$

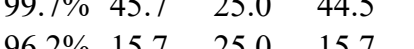

$99.0 \% \quad 53.4 \quad 25.0 \quad 48.8$

$99.7 \% \quad 62.4 \quad 25.0 \quad 62.4$

$99.7 \% \quad 46.2 \quad 25.0 \quad 42.2$

$\begin{array}{llll}99.7 \% & 41.2 & 25.0 & 39.1\end{array}$

$99.5 \% \quad 23.6 \quad 25.0 \quad 23.6$

$99.7 \% \quad 51.1 \quad 25.0 \quad 43.5 \quad 2$

$\begin{array}{llll}99.7 \% & 39.5 & 25.0 & 32.7\end{array}$

$\begin{array}{lllll}99.7 \% & 40.8 & 25.0 & 33.9 & 2\end{array}$

$\begin{array}{llll}99.7 \% & 44.5 & 25.0 & 36.7\end{array}$

$99.7 \% \quad 54.1 \quad 25.0 \quad 48.1$

$\begin{array}{llll}99.7 \% & 28.8 & 25.0 & 27.0\end{array}$

$\begin{array}{llll}99.7 \% & 35.5 & 25.0 & 33.2\end{array}$

$\begin{array}{llll}98.9 \% & 29.7 & 25.0 & 25.2\end{array}$

$\begin{array}{llll}99.7 \% & 39.3 & 25.0 & 27.9\end{array}$

$\begin{array}{llll}99.6 \% & 30.0 & 25.0 & 22.5\end{array}$

$\begin{array}{llll}99.7 \% & 32.8 & 25.0 & 32.8\end{array}$

$\begin{array}{llll}99.7 \% & 56.7 & 25.0 & 42.0\end{array}$

$\begin{array}{llll}99.7 \% & 47.2 & 25.0 & 46.2\end{array}$

$\begin{array}{lllll}99.7 \% & 65.0 & 25.0 & 65.0 & 1\end{array}$

$\begin{array}{llll}95.9 \% & 15.3 & 25.0 & 15.3\end{array}$

$\begin{array}{llll}99.7 \% & 33.1 & 25.0 & 32.2\end{array}$

$\begin{array}{llll}96.6 \% & 16.9 & 25.0 & 16.5\end{array}$

$\begin{array}{llll}99.7 \% & 37.2 & 25.0 & 22.8\end{array}$

$99.7 \% \quad 26.6 \quad 25.0 \quad 26.6$

$\begin{array}{llll}99.7 \% & 27.2 & 25.0 & 27.2\end{array}$

$\begin{array}{llll}98.3 \% & 27.6 & 25.0 & 21.9\end{array}$

$\begin{array}{llll}99.7 \% & 32.4 & 25.0 & 24.3\end{array}$

$\begin{array}{lllll}98.7 \% & 18.7 & 25.0 & 18.7 & 0\end{array}$

$\begin{array}{lllll}99.7 \% & 58.4 & 25.0 & 58.4\end{array}$

$\begin{array}{llll}99.0 \% & 19.8 & 25.0 & 19.8\end{array}$

$\begin{array}{llll}98.9 \% & 19.3 & 25.0 & 19.3\end{array}$

$\begin{array}{lllll}99.7 \% & 36.2 & 25.0 & 36.2 & 2\end{array}$

$\begin{array}{lllll}99.7 \% & 58.5 & 25.0 & 58.5 & 2\end{array}$

$\begin{array}{llll}99.7 \% & 39.0 & 25.0 & 33.4\end{array}$

$\begin{array}{lllll}99.7 \% & 36.4 & 25.0 & 36.4 & 2\end{array}$

$\begin{array}{lllll}99.7 \% & 40.2 & 25.0 & 34.0 & 2\end{array}$

$\begin{array}{lllll}95.5 \% & 15.6 & 25.0 & 15.6\end{array}$

$\begin{array}{lllll}99.0 \% & 36.3 & 25.0 & 14.1 & 2\end{array}$

$\begin{array}{lllll}99.7 \% & 65.9 & 25.0 & 64.0 & 2 \\ 99.7 \% & 53.0 & 25.0 & 46.0 & 2\end{array}$ $\begin{array}{llll}98.5 \% & 19.5 & 25.0 & 19.5\end{array}$

10

1230.64

868.56

1211.67

1013.61

1145.62

1303.73

1175.64

1001.55

1091.65

1319.70

1291.64

1324.73

1232.64

1441.72

967.53

1454.73

1714.77

1501.64

1787.81

1674.86

1210.60

1707.93

1389.69

1221.62

1827.93

992.48

1762.84

1684.79

1001.56

1129.66

1803.86

1325.64

1394.71

1060.48

1309.65

1182.59

1155.64

1299.56

1115.64

866.51

942.54

1535.77

1342.65 
$0.02 \% \quad 16.9 \%$ EGAAVIDVGINR

$0.02 \% \quad 16.9 \%$ VHDPVTAKPK

$0.02 \% \quad 16.9 \%$ LVGDVDFEGVR

$0.02 \% \quad 16.9 \%$ LVGDVDFEGVRQK

$0.02 \% \quad 16.9 \%$ SKELGVATN

$0.01 \% \quad 7.6 \%$ VVACNLYPFVK

$0.01 \% \quad 7.6 \%$ TLTPISAAYAR

$0.01 \% \quad 7.6 \%$ SLFSNVVTK

$0.01 \% \quad 7.6 \%$ NGQVIGIGAGQQSR

$0.00 \% \quad 2.4 \%$ SVEGYYQESGR

\begin{tabular}{llll}
\hline & 20.5 & 25.0 & 20.5
\end{tabular}

$99.7 \% 59.6$

$\begin{array}{llll}99.3 \% & 21.3\end{array}$

$99.7 \% \quad 74.9$

$99.7 \% \quad 55.0$

$96.7 \% 19.1$

$98.6 \% 18.2$

$96.2 \% \quad 18.1$

$98.3 \% 24.4$

$99.7 \% \quad 62.4$

$\begin{array}{llll}98.9 \% & 28.5\end{array}$

$0.00 \% \quad 2.4 \%$ SSSIIGSSSASHTSQATSGANSK

$0.00 \% \quad 1.2 \%$ VVSTSLDCLQK

$0.00 \% \quad 1.2 \%$ ALMEAVSHAK

$0.01 \% \quad 1.3 \% \quad$ APLDASDSGR

$0.01 \% \quad 1.3 \%$ GKLSSSFSSR

$0.04 \% \quad 7.1 \%$ GDLNDCFIPCTPK

$0.04 \% \quad 7.1 \%$ VVGDVAYDEAKER

$0.04 \% \quad 7.1 \%$ TPVPSDIDISR

$0.04 \% \quad 7.1 \%$ VLLSALER

$0.04 \% \quad 7.1 \%$ VLDTNDRFLR

$0.04 \% \quad 7.1 \%$ GALALAQAVQR

$0.06 \% \quad 5.7 \%$ VFNTGGAPR

$0.06 \% \quad 5.7 \%$ LGYPVLVR

$0.06 \% \quad 5.7 \%$ ATGYPLAYVAAK

$0.06 \% \quad 5.7 \%$ SVGEVMGIGR

$0.06 \% \quad 5.7 \%$ SFEEAFQK

$0.06 \% \quad 5.7 \%$ ELSDLESAR

$0.06 \% \quad 5.7 \%$ VPQFSFSR

$0.06 \% \quad 5.7 \%$ SELLPTVR

$0.06 \% \quad 5.7 \%$ RLSSFVTK

$0.06 \% \quad 5.7 \%$ ASDPGLPAEEPKEK

$0.06 \% \quad 5.7 \%$ TSSSFAAAMAR

$0.06 \% \quad 5.7 \%$ YVAPPSLR

$0.06 \% \quad 5.7 \%$ VNEISVEVDSDPR

$0.01 \% \quad 11.1 \%$ YEGFFGLYR

$0.01 \% \quad 11.1 \%$ AIKLTVNDFVR

$0.01 \% \quad 11.1 \%$ LTVNDFVR

$0.01 \% \quad 11.1 \%$ LQVAGEITTGPR

$0.01 \% \quad 11.1 \%$ VSALNVLR

$0.01 \% \quad 11.1 \%$ TRLQVAAR

$0.01 \% \quad 11.1 \%$ AGQTTYSGVIDCFR

$0.01 \% \quad 11.1 \%$ AGQTTYSGVIDCFRK

$0.01 \% \quad 11.1 \%$ FKSPSVAVVQPK

$\begin{array}{lll}97.9 \% & 20.3\end{array}$

$99.7 \% \quad 30.4$

$99.7 \% \quad 38.0$

$99.2 \% \quad 22.5$

$99.7 \% \quad 30.1$

$99.7 \% \quad 45.3$

$\begin{array}{lll}99.7 \% & 29.9\end{array}$

$\begin{array}{lll}99.0 \% & 37.8\end{array}$

$97.9 \% \quad 24.7$

$99.7 \% \quad 56.6$

$99.2 \% \quad 22.7$

$\begin{array}{lll}97.1 \% & 19.6\end{array}$

$99.7 \% \quad 28.9$

$99.7 \% \quad 35.8$

$99.0 \% \quad 27.0$

$99.7 \% \quad 34.2$

$99.0 \% 25.6$

$97.2 \% \quad 16.6$

$99.0 \% \quad 25.1$

$99.7 \% \quad 31.0$

$99.7 \% \quad 58.8$

$96.6 \% \quad 19.6$

$99.7 \% \quad 58.3$

$99.7 \% \quad 32.1$

$99.7 \% \quad 32.9$

$99.0 \% \quad 50.8$

$99.7 \% \quad 60.2$

$99.0 \% \quad 37.8$

$\begin{array}{lll}97.8 \% & 28.3\end{array}$

$99.7 \% 50.9$

$99.7 \% \quad 27.8$

1546.86

1681.84

1860.88

1481.88

1213.65

1091.62

1205.62

1461.77

918.49

1309.70

1163.64

994.56

1384.73

1274.56

2152.01

1249.65

1056.55

988.47

1055.55

1536.68

1450.72

1199.63

900.55

1248.67

1097.64

918.48

916.56

1224.66

1004.52

985.46

1019.50

967.50

914.53

937.55

1467.73

1099.52

902.51

1458.7

1151.55

1275.74

963.53

1241.69

871.54

914.55

1574.73

1702.82 1286.75 


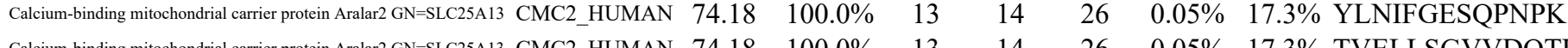
Calcium-binding mitochondrial carrier protein Aralar2 GN=SLC25A13 CMC2_HUMAN $74.18 \quad 100.0 \% \quad 13 \quad 14 \quad 26 \quad 0.05 \% \quad 17.3 \%$ TVELLSGVVDQTK Calcium-binding mitochondrial carrier protein Aralar2 GN=SLC25A13 CMC2_HUMAN $74.18 \quad 100.0 \%$ Clcium-binding mitochondrial carrier protein Aralar2 GN=SLC25A13 CMC2 HUMAN $74.18 \quad 100.0 \%$ Calcium-binding mitochondrial carrier protein Aralar2 GN=SLC25A13 $\quad$ CMC2_HUMAN $74.18 \quad 100.0 \%$ Calcium-binding mitochondrial carrier protein Aralar2 GN=SLC25A13 CMC2_HUMAN $74.18 \quad 100.0 \%$ Calcium-binding mitochondrial carrier protein Aralar2 GN=SLC25A13 CMC2_HUMAN $74.18 \quad 100.0 \%$ Calcium-binding mitochondrial carrier protein Aralar2 GN=SLC25A13 CMC2_HUMAN $74.18 \quad 100.0 \%$ Calcium-binding mitochondrial carrier protein Aralar2 GN=SLC25A13 $\mathrm{CMC} 2$ HUMAN $74.18 \quad 100.0^{\circ} \%$ Calcium-binding mitochondrial carrier protein Aralar2 GN=SLC25A13 CMC2_HUMAN $74.18 \quad 100.0 \%$ Calcium-binding mitochondrial carrier protein Aralar2 $\mathrm{GN}=\mathrm{SLC} 25 \mathrm{~A} 13 \mathrm{CMC} 2$ _HUMAN $74.18 \quad 100.0 \%$ Calcium-binding mitochondrial carrier protein Aralar2 GN=SLC25A13 CMC2 HUMAN $74.18 \quad 100.0^{\circ}$ Calcium-binding mitochondrial carrier protein Aralar2 $\mathrm{GN}=\mathrm{SLC} 25 \mathrm{~A} 13 \mathrm{CMC} 2$ HUMAN $74.18 \quad 100.0 \%$ Calcium-binding mitochondrial carrier protein SCaMC-1 GN=SLC25A24 SCMC1_HUMAN 53.36 Calcium-binding mitochondrial carrier protein SCaMC-1 GN=SLC25A24 SCMC1 HUMAN 53.36 Calcium-binding mitochondrial carrier protein SCaMC-1 GN=SLC25A24 SCMC1_HUMAN 53.36 Calcium-binding mitochondrial carrier protein SCaMC-1 GN=SLC25A24 SCMC1_HUMAN 53.36 Calcium-binding mitochondrial carrier protein SCaMC-1 GN=SLC25A24 SCMC1_HUMAN 53.36 Calcium-binding mitochondrial carrier protein SCaMC-1 GN=SLC25A24 SCMC1_HUMAN 53.36 Calcium-binding mitochondrial carrier protein SCaMC-1 GN=SLC25A24 SCMC1_HUMAN 53.36 Calcium-binding mitochondrial carrier protein SCaMC-1 GN=SLC25A24 SCMC1_HUMAN 53.3 Calcium-binding mitochondrial carrier protein SCaMC-1 GN=SLC25A24 SCMC1_HUMAN 53.36 Calcium-binding mitochondrial carrier protein SCaMC-1 GN=SLC25A24 SCMC1_HUMAN 53.3 Calcium-binding mitochondrial carrier protein SCaMC-1 GN=SLC25A24 SCMC1_HUMAN 53.36 Calcium-binding mitochondrial carrier protein SCaMC-1 GN=SLC25A24 SCMC1_HUMAN 53.36 Calmodulin-regulated spectrin-associated protein 3 GN=CAMSAP3 CAMP3_HUMAN 134.75 Calmodulin-regulated spectrin-associated protein 3 GN=CAMSAP3 CAMP3_HUMAN 134.75

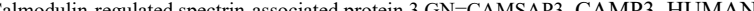
$\begin{array}{lll} & \end{array}$ Codulin-regulated spectrin-associated protein $3 \mathrm{GN}=\mathrm{CAMSAP} 3$ CAMP3 HUMAN $134.75 \quad 100.0 \%$ Calmodulin-regulated spectrin-associated protein 3 GN=CAMSAP3 CAMP3_HUMAN $134.75 \quad 100.0 \%$ Calmodulin-regulated spectrin-associated protein 3 GN=CAMSAP3 CAMP3_HUMAN $134.75 \quad 100.0 \%$ . cAMP-dependent protein kinase catalytic subunit beta GN=PRKACB $\quad$ KAPCB_HUMAN $40.62 \quad 100.0 \%$ cAMP-dependent protein kinase catalytic subunit beta GN=PRKACB KAPCB_HUMAN $40.62 \quad 100.0 \%$ Carbonyl reductase [NADPH] 1 GN=CBR1 CBR1_HUMAN $30.37 \quad 100.0 \%$ Carbonyl reductase [NADPH] 1 GN=CBR1 CBR1_HUMAN $30.37 \quad 100.0 \%$ Carbonyl reductase [NADPH] $1 \mathrm{GN}=\mathrm{CBR} 1$ CBR1 HUMAN $30.37 \quad 100.0 \%$ Carbonyl reductase [NADPH] 1 GN=CBR1 CBR1_HUMAN $30.37 \quad 100.0 \%$ Casein kinase II subunit alpha' GN=CSNK2A2 CSK22_HUMAN $41.21 \quad 100.0 \%$ Casein kinase II subunit alpha' GN=CSNK2A2 CSK22_HUMAN $41.21 \quad 100.0 \%$ Casein kinase II subunit alpha' GN=CSNK2A2 CSK22_HUMAN $41.21 \quad 100.0 \%$ Cat eye syndrome critical region protein $5 \mathrm{GN}=\mathrm{CECR} 5$ CECR5 HUMAN $46.32 \quad 100.0 \%$ Cat eye syndrome critical region protein $5 \mathrm{GN}=$ CECR5 CECR5_HUMAN $46.32 \quad 100.0 \%$ Cat eye syndrome critical region protein $5 \mathrm{GN}=\mathrm{CECR} 5$ CECR5_HUMAN $46.32 \quad 100.0 \%$ CCR4-NOT transcription complex subunit $1 \mathrm{GN}=\mathrm{CNOT} 1$ CNOT1 HUMAN $266.94 \quad 100.0 \%$ CCR4-NOT transcription complex subunit $1 \mathrm{GN}=\mathrm{CNOT} 1$ CNOT1_HUMAN $266.94 \quad 100.0 \%$
$14 \quad 26 \quad 0.05 \% \quad 17.3 \%$ STGSFVGELMYK

$14 \quad 26 \quad 0.05 \% \quad 17.3 \%$ YEGFFGLYR

$14 \quad 26 \quad 0.05 \% \quad 17.3 \%$ AIKLTVNDFVR

$14 \quad 26 \quad 0.05 \% \quad 17.3 \%$ LTVNDFVR

$14 \quad 26 \quad 0.05 \% \quad 17.3 \%$ LQVAGEITTGPR

$\begin{array}{lllll}14 & 26 & 0.05 \% & 17.3 \% & \text { VSALSVVR }\end{array}$

$14 \quad 26 \quad 0.05 \% \quad 17.3 \%$ TRLQVAAR

$14 \quad 26 \quad 0.05 \% \quad 17.3 \%$ AGQTTYSGVIDCFR

$14 \quad 26 \quad 0.05 \% \quad 17.3 \%$ AGQTTYSGVIDCFRK

$17 \quad 42 \quad 0.09 \% \quad 21.4 \%$ QLLAGGIAGAVSR

$17 \quad 42 \quad 0.09 \% \quad 21.4 \%$ TSTAPLDRLK

$\begin{array}{llll}17 & 42 & 0.09 \% & 21.4 \% \\ 17 & \text { IMMQVHGSK }\end{array}$

$17 \quad 42 \quad 0.09 \% \quad 21.4 \%$ SDKMNIFGGFR

$17 \quad 42 \quad 0.09 \% \quad 21.4 \%$ LLTEEGQKIGTFER

$17 \quad 42 \quad 0.09 \% \quad 21.4 \%$ TGQYSGIYDCAK

$17 \quad 42 \quad 0.09 \% \quad 21.4 \%$ ILKHEGLGAFYK

$17 \quad 42 \quad 0.09 \% \quad 21.4 \%$ HEGLGAFYK

$17 \quad 42 \quad 0.09 \% \quad 21.4 \%$ IISKEGIPGLYR

$17 \quad 42 \quad 0.09 \% \quad 21.4 \%$ EGIPGLYR

$0.09 \% \quad 21.4 \%$ GITPNFMK

$\begin{array}{lll}0.04 \% & 7.0 \% & \text { ASPAAPADGAAPAQPSIR }\end{array}$

$0.04 \% \quad 7.0 \%$ SVSSDSLGPPRPAPAR

$0.04 \% \quad 7.0 \%$ SAFLQVQPR

$0.04 \% \quad 7.0 \%$ RSPGPGPSQSPR

$0.04 \% \quad 7.0 \%$ SPGPGPSQSPR

$\begin{array}{lll}0.04 \% & 7.0 \% & \text { FSPSQVPVQTR }\end{array}$

$0.04 \% \quad 7.0 \%$ APAEEEVGPR

$0.04 \% \quad 7.0 \%$ SGCCDDSALAR

$0.01 \% \quad 5.1 \%$ TLGTGSFGR

$0.01 \% \quad 5.1 \%$ KVEAPFIPK

$0.03 \% \quad 16.6 \%$ LFSGDVVLTAR

$0.03 \% \quad 16.6 \%$ GQAAVQQLQAEGLSPR

$0.03 \% \quad 16.6 \%$ VVNVSSIMSVR

$0.03 \% \quad 16.6 \%$ IGVTVLSR

$0.01 \% \quad 6.3 \%$ ARVYAEVNSLR

$0.01 \% \quad 6.3 \% \quad$ VYAEVNSLR

$0.01 \% \quad 6.3 \%$ LIDTVKDPVSK

$0.02 \% \quad 7.8 \%$ LVNSQGQLR

$0.02 \% \quad 7.8 \%$ NVVTVDELR

$0.02 \% \quad 7.8 \%$ ATHDGAPELGAGGTR

$0.01 \% \quad 0.9 \% \quad$ LAEVGQYEQVK

$0.01 \% \quad 0.9 \% \quad$ NLDEQLSAPK
$14 \quad 26 \quad 0.05 \% \quad 17.3 \%$ ILREEGPK

$17 \quad 42 \quad 0.09 \% \quad 21.4 \%$ TGQYSGIYDCAKK $\begin{array}{llllllll}99.7 \% & 62.0 & 25.0 & 62.0 & 2 & 0 & 0 & 1506.76\end{array}$

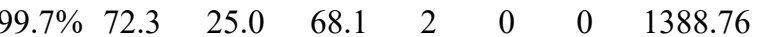

$\begin{array}{llllllll}99.0 \% & 45.3 & 25.0 & 36.5 & 2 & 0 & 0 & 948.48\end{array}$

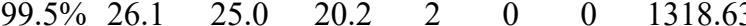

$\begin{array}{llllllll}99.7 \% & 32.1 & 25.0 & 30.1 & 1 & 0 & 0 & 1151.55\end{array}$

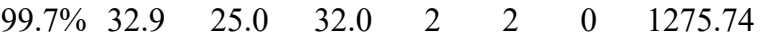

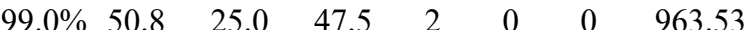

$\begin{array}{llllllll}99.7 \% & 60.2 & 25.0 & 47.0 & 2 & 0 & 0 & 1241.69\end{array}$

$\begin{array}{llllllll}99.0 \% & 45.5 & 25.0 & 40.5 & 2 & 0 & 0 & 830.51\end{array}$

$\begin{array}{llllllll}97.8 \% & 28.3 & 25.0 & 8.6 & 1 & 0 & 0 & 914.55\end{array}$

$\begin{array}{llllllll}99.7 \% & 50.9 & 25.0 & 50.9 & 2 & 0 & 0 & 1574.73\end{array}$

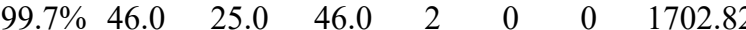

$\begin{array}{llllllll}99.0 \% & 35.5 & 25.0 & 29.2 & 2 & 0 & 0 & 941.54\end{array}$

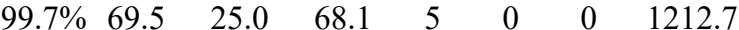

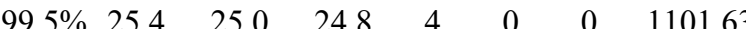

$\begin{array}{llllllll}99.7 \% & 33.9 & 25.0 & 28.6 & 4 & 0 & 0 & 1030.52\end{array}$

$\begin{array}{llllllll}99.7 \% & 28.7 & 25.0 & 27.8 & 3 & 2 & 0 & 1271.62\end{array}$

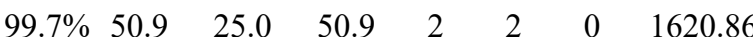

$\begin{array}{llllllll}99.7 \% & 64.6 & 25.0 & 64.6 & 4 & 0 & 0 & 1362.60\end{array}$

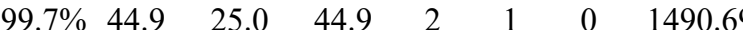

$\begin{array}{llllllll}99.6 \% & 27.5 & 25.0 & 24.3 & 0 & 1 & 0 & 1375.77\end{array}$

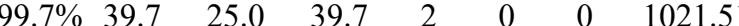

$\begin{array}{llllllll}99.7 \% & 37.5 & 25.0 & 37.5 & 3 & 4 & 0 & 1345.78\end{array}$

$\begin{array}{llllllll}99.0 \% & 32.0 & 25.0 & 24.6 & 2 & 0 & 0 & 904.49\end{array}$

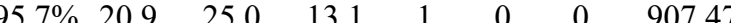

1647.85

1593.83

1045.58

$\begin{array}{llll}99.7 \% & 31.7 & 25.0 & 22.8\end{array}$

$99.7 \% \quad 51.3 \quad 25.0 \quad 42.6$

$\begin{array}{llll}99.7 \% & 44.5 & 25.0 & 38.8\end{array}$

$99.7 \% \quad 51.6 \quad 25.0 \quad 46.8$

$\begin{array}{llll}99.7 \% & 31.8 & 25.0 & 28.7\end{array}$

$\begin{array}{llll}99.7 \% & 62.1 & 25.0 & 49.3\end{array}$

$99.7 \% \quad 51.5 \quad 25.0 \quad 51.5$

$\begin{array}{llll}99.7 \% & 34.5 & 25.0 & 27.4\end{array}$

$99.7 \% \quad 49.6 \quad 25.0 \quad 43.8$

$99.7 \% \quad 56.8 \quad 25.0 \quad 47.6$

$\begin{array}{lllll}99.7 \% & 61.7 & 25.0 & 60.1\end{array}$

$99.7 \% \quad 73.7 \quad 25.0 \quad 67.7$

$\begin{array}{llll}98.8 \% & 35.7 & 25.0 & 0.0\end{array}$

$99.7 \% \quad 39.0$

$99.7 \% \quad 52.5$

$99.6 \% \quad 27.5$

25.0

39.0

$99.7 \% \quad 52.8 \quad 25.0$

$\begin{array}{llll}9.7 \% & 55.3 & 25.0 & 53.2\end{array}$

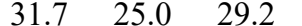

$\begin{array}{llll}96.7 \% & 20.8 & 25.0 & 16.4\end{array}$ \begin{tabular}{cc}
44 & 56 \\
57 & 69 \\
285 & 292 \\
361 & 372 \\
384 & 392 \\
406 & 416 \\
409 & 416 \\
456 & 467 \\
468 & 475 \\
546 & 553 \\
554 & 567 \\
554 & 568 \\
569 & 576 \\
197 & 209 \\
210 & 219 \\
220 & 228 \\
229 & 239 \\
278 & 291 \\
321 & 332 \\
321 & 333 \\
334 & 345 \\
337 & 345 \\
434 & 445 \\
438 & 445 \\
446 & 453 \\
192 & 209 \\
429 & 444 \\
635 & 643 \\
768 & 779 \\
769 & 779 \\
313 & 823 \\
364 & 973 \\
020 & 1030 \\
49 & 57 \\
310 & 318 \\
28 & 38 \\
433 & 58 \\
135 & 145 \\
199 & 206 \\
10 & 20 \\
12 & 20 \\
98 & 108 \\
74 & 82 \\
153 & 161 \\
& 346 \\
\hline 32
\end{tabular}

Page 21 of Table S-1-3 
Cell cycle and apoptosis regulator protein $2 \mathrm{GN}=\mathrm{CCAR} 2$ CCAR2_HUMAN $102.90 \quad 100.0 \%$ Cell cycle and apoptosis regulator protein $2 \mathrm{GN}=\mathrm{CCAR} 2$ CCAR2_HUMAN $102.90 \quad 100.0 \%$ Cell division cycle 5-like protein $\mathrm{GN}=\mathrm{CDC} 5 \mathrm{~L} \quad \mathrm{CDC} 5 \mathrm{~L} \_$HUMAN $92.25 \quad 100.0 \%$ Cell division cycle 5-like protein GN=CDC5L CDC5L_HUMAN $92.25 \quad 100.0 \%$ Cell division cycle protein 23 homolog GN=CDC23 CDC23_HUMAN $68.84 \quad 100.0 \%$ Cell division cycle protein 23 homolog $\mathrm{GN}=\mathrm{CDC} 23 \mathrm{CDC} 23$ _HUMAN $68.84 \quad 100.0 \%$ Cell division cycle protein 23 homolog $\mathrm{GN}=\mathrm{CDC} 23$ CDC23_HUMAN $68.84 \quad 100.0 \%$ Cell division cycle protein 23 homolog GN=CDC23 CDC23_HUMAN $68.84 \quad 100.0 \%$ Cell growth-regulating nucleolar protein GN=LYAR LYAR HUMAN $43.62 \quad 100.0 \%$ Cell growth-regulating nucleolar protein GN=LYAR LYAR_HUMAN $43.62 \quad 100.0 \%$ Cell growth-regulating nucleolar protein GN=LYAR LYAR_HUMAN $43.62 \quad 100.0 \%$ Cell growth-regulating nucleolar protein GN=LYAR LYAR_HUMAN $43.62 \quad 100.0 \%$ Cell growth-regulating nucleolar protein GN=LYAR LYAR_HUMAN $43.62 \quad 100.0 \%$ Cell growth-regulating nucleolar protein GN=LYAR LYAR_HUMAN $43.62 \quad 100.0 \%$ Cellular tumor antigen $533 \mathrm{GN}=\mathrm{TP} 53$ Cellular tumor antigen p53 GN=TP53 Cellular tumor antigen p53 GN=TP53 Centromere protein $\mathrm{V}$ GN $=\mathrm{CENPV}$ Centromere protein $\mathrm{V}$ GN $=\mathrm{CENPV}$ Centromere protein $\mathrm{V}$ GN $=\mathrm{CENPV}$ Centromere protein $\mathrm{V}$ GN $=\mathrm{CENPV}$ Centromere protein $\mathrm{V} \mathrm{GN}=\mathrm{CENPV}$ P53_HUMAN $43.65 \quad 100.0 \%$ P53_HUMAN $43.65 \quad 100.0 \%$ P53 HUMAN $43.65 \quad 100.0 \%$ CENPV_HUMAN $29.95 \quad 100.0 \%$ CENPV_HUMAN $29.95 \quad 100.0 \%$ CENPV HUMAN $29.95 \quad 100.0 \%$ CENPV_HUMAN $29.95 \quad 100.0 \%$ CENPV HUMAN $29.95 \quad 100.0 \%$ Centromere/kinetochore protein Zw10 homolog GN=ZW10 ZW10_HUMAN $88.83 \quad 100.0 \%$ Centromere/kinetochore protein Zw10 homolog GN=ZW10 ZW10_HUMAN $88.83 \quad 100.0 \%$ Centromere/kinetochore protein Zw10 homolog GN=ZW10 ZW10_HUMAN $88.83 \quad 100.0 \%$ Charged multivesicular body protein $4 \mathrm{~b}$ GN=CHMP4B CHM4B_HUMAN $24.95 \quad 100.0 \%$ Charged multivesicular body protein $4 \mathrm{~b}$ GN=CHMP4B CHM4B_HUMAN $24.95 \quad 100.0 \%$ Charged multivesicular body protein $4 \mathrm{~b}$ GN=CHMP4B CHM4B_HUMAN $24.95 \quad 100.0 \%$ Chloride channel CLIC-like protein $1 \mathrm{GN}=\mathrm{CLCC} 1$ CLCC1_HUMAN $62.02 \quad 100.0 \%$ Chloride channel CLIC-like protein $1 \mathrm{GN}=\mathrm{CLCC} 1 \mathrm{CLCC} 1$ HUMAN $62.02 \quad 100.0 \%$ Chloride channel CLIC-like protein $1 \mathrm{GN}=\mathrm{CLCC1}$ CLCC1_HUMAN $62.02 \quad 100.0 \%$ Chloride channel CLIC-like protein $1 \mathrm{GN}=\mathrm{CLCC1}$ CLCC1_HUMAN $62.02 \quad 100.0 \%$ Chloride channel CLIC-like protein $1 \mathrm{GN}=\mathrm{CLCC} 1 \mathrm{CLCC} 1$ HUMAN $62.02 \quad 100.0 \%$ Chloride channel CLIC-like protein $1 \mathrm{GN}=\mathrm{CLCC1}$ CLCC1_HUMAN $62.02 \quad 100.0 \%$ Chromatin target of PRMT1 protein GN=CHTOP CHTOP_HUMAN $26.40 \quad 100.0 \%$ Chromatin target of PRMT1 protein GN=CHTOP CHTOP_HUMAN $26.40 \quad 100.0 \%$ Chromatin target of PRMT1 protein GN=CHTOP CHTOP_HUMAN $26.40 \quad 100.0 \%$ Chromatin target of PRMT1 protein GN=CHTOP CHTOP HUMAN $26.40 \quad 100.0 \%$ Chromatin target of PRMT1 protein GN=CHTOP CHTOP_HUMAN $26.40 \quad 100.0 \%$ Chromobox protein homolog $8 \mathrm{GN}=\mathrm{CBX} 8 \mathrm{CBX} 8$ HUMAN $43.40 \quad 100.0 \%$ Chromobox protein homolog $8 \mathrm{GN}=\mathrm{CBX} 8 \mathrm{CBX} 8$ HUMAN $43.40 \quad 100.0 \%$ Chromodomain-helicase-DNA-binding protein 1-like GN=CHDIL CHD1L_HUMAN $100.99 \quad 100.0 \%$ Chromodomain-helicase-DNA-binding protein 1-like GN=CHD1L CHD1L_HUMAN $100.99 \quad 100.0 \%$ Clathrin heavy chain $1 \mathrm{GN}=\mathrm{CLTC}$ Clathrin heavy chain $1 \mathrm{GN}=\mathrm{CLTC}$ Clathrin heavy chain $1 \mathrm{GN}=\mathrm{CLTC}$

CLH1_HUMAN $191.62 \quad 100.0 \%$ CLH1_HUMAN $191.62 \quad 100.0 \%$ CLH1 HUMAN $191.62 \quad 100.0 \%$ 6 CPSF6_HUMAN $59.21 \quad 100.0 \%$
$0.01 \% \quad 2.3 \% \quad$ VQTLSNQPLLK

$0.01 \% \quad 2.3 \%$ VVTQNICQYR

$0.01 \% \quad 2.1 \%$ AAGIEIQK

$0.01 \% \quad 2.1 \%$ ILLGGYQSR

$0.01 \% \quad 6.0 \%$ AYFDVKEYDR

$0.01 \% \quad 6.0 \%$ AYFLYMYSR

$0.01 \% \quad 6.0 \%$ AYAVGDVEK

$0.01 \% \quad 6.0 \%$ YLAQYYFK

$0.02 \% \quad 15.0 \%$ VFFTCNACGESVK

$0.02 \% \quad 15.0 \%$ VFFTCNACGESVKK

$0.02 \% \quad 15.0 \%$ IQVEKHVSVCR

$0.02 \% \quad 15.0 \%$ CISEDQKYGGK

$0.02 \% \quad 15.0 \%$ ISELIKRPNVSPK

$0.02 \% \quad 15.0 \%$ ISKNPTFK

$0.02 \% \quad 8.7 \%$ TYQGSYGFR

$0.02 \% \quad 8.7 \% \quad$ SVTCTYSPALNK

$0.02 \% \quad 8.7 \%$ ALPNNTSSSPQPK

$0.03 \% \quad 29.1 \%$ SGASGASAAPAASAAAALAPSATR

$0.03 \% \quad 29.1 \%$ SQAVEKPPSEKPR

$0.03 \% \quad 29.1 \%$ GAEHITTYTFNTHK

$0.03 \% \quad 29.1 \%$ CGVQSFYTPR

$0.03 \% \quad 29.1 \%$ SNPGGFGIAPHCLDEGTVR

$0.01 \% \quad 4.1 \%$ CQDVIVAAR

$0.01 \% \quad 4.1 \% \quad$ NLMTSEIHNTVK

$0.01 \% \quad 4.1 \% \quad$ YQEEVPVYVPK

$0.01 \% \quad 14.7 \%$ GGPTPQEAIQR

$0.01 \% \quad 14.7 \%$ AALQALKR

$0.01 \% \quad 14.7 \%$ EALENANTNTEVLK

$0.02 \% \quad 12.2 \%$ ETLLEIQK

$0.02 \% \quad 12.2 \%$ LAFAQHQAEVAK

$0.02 \% \quad 12.2 \%$ MEPLNNVCAK

$0.02 \% \quad 12.2 \%$ AQLKSEAAGSPDQGSTYSPAR

$0.02 \% \quad 12.2 \%$ SEAAGSPDQGSTYSPAR

$0.02 \% \quad 12.2 \%$ GVAGPRGQDPVSSPCG

$0.07 \% \quad 24.6 \%$ NKQPTPVNIR

$0.07 \% \quad 24.6 \%$ ASMQQQQQLASAR

$0.07 \% \quad 24.6 \%$ LAQQMENRPSVQAALK

$0.07 \% \quad 24.6 \%$ LGKSNIQAR

$0.07 \% \quad 24.6 \%$ EQLDNQLDAYMSK

$0.01 \% \quad 4.9 \% \quad$ SPQDLASTSR

$0.01 \% \quad 4.9 \%$ LAVDTFPAR

$0.01 \% \quad 2.2 \%$ SFEQLVNLQK

$0.01 \% \quad 2.2 \%$ GGLFTALEKR

$0.02 \% \quad 1.9 \%$ TGQIKEVER

$0.02 \% \quad 1.9 \% \quad$ IYIDSNNNPER

$0.02 \% \quad 1.9 \% \quad$ LLYNNVSNFGR

$0.03 \% \quad 12.9 \%$ GFALVGVGSEASSK $\begin{array}{llllllll}99.7 \% & 38.7 & 25.0 & 29.8 & 2 & 0 & 0 & 1240.73\end{array}$

1280.64

$99.7 \% \quad 35.3 \quad 25.0 \quad 25.0 \quad 2$

$\begin{array}{lllll}99.3 \% & 23.2 & 25.0 & 23.2 & 2\end{array}$

$\begin{array}{llll}99.7 \% & 28.0 & 25.0 & 28.0\end{array}$

$98.8 \% \quad 18.9 \quad 25.0 \quad 18.9$

$\begin{array}{lllll}99.0 \% & 24.5 & 25.0 & 16.9 & 2\end{array}$

$99.7 \% \quad 38.9 \quad 25.0 \quad 38.5$

$95.7 \% \quad 18.9 \quad 25.0 \quad 15.7$

$99.3 \% \quad 21.0 \quad 25.0 \quad 21.0$

$\begin{array}{llll}96.5 \% & 20.9 & 25.0 & 13.3\end{array}$

$99.5 \% \quad 24.1 \quad 25.0 \quad 24.1$

$\begin{array}{llll}99.0 \% & 25.8 & 25.0 & 19.7\end{array}$

$\begin{array}{llll}99.6 \% & 25.2 & 25.0 & 25.2\end{array}$

$\begin{array}{llll}99.7 \% & 46.0 & 25.0 & 46.0\end{array}$

$99.7 \% 28.6 \quad 25.0-24.8$

$\begin{array}{llll}99.7 \% & 65.8 & 25.0 & 64.8\end{array}$

$\begin{array}{llll}99.3 \% & 28.8 & 25.0 & 28.8\end{array}$

$\begin{array}{llll}99.7 \% & 36.5 & 25.0 & 34.9\end{array}$

$\begin{array}{llll}99.7 \% & 65.1 & 25.0 & 59.2\end{array}$

$\begin{array}{llll}99.7 \% & 60.8 & 25.0 & 57.6\end{array}$

$\begin{array}{llll}99.7 \% & 45.9 & 25.0 & 23.5\end{array}$

$\begin{array}{lllll}99.7 \% & 66.8 & 25.0 & 66.3\end{array}$

$99.7 \% \quad 42.4 \quad 25.0 \quad 42.4$

$\begin{array}{llll}99.7 \% & 36.9 & 25.0 & 30.0\end{array}$

$\begin{array}{llll}99.0 \% & 36.9 & 25.0 & 14.9\end{array}$

$\begin{array}{llll}99.7 \% & 57.8 & 25.0 & 57.8\end{array}$

$99.0 \% \quad 35.6 \quad 25.0 \quad 31.7 \quad 2$

$99.1 \% \quad 24.6 \quad 25.0 \quad 21.1$

$\begin{array}{llll}96.7 \% & 17.9 & 25.0 & 15.3\end{array}$

$99.7 \% \quad 40.7$

$99.7 \% \quad 35.0$

$99.7 \% \quad 60.4$

$99.4 \% 21.9$

$99.7 \% 76.2$

$99.7 \% \quad 34.6$

$99.7 \% \quad 46.6$

$99.7 \% \quad 70.4$

$99.7 \% \quad 58.3$

$98.8 \% \quad 24.5$

$99.7 \% \quad 40.7$

$99.7 \% \quad 51.8$

$98.9 \% \quad 22.1$

$99.7 \% \quad 38.5$

$99.7 \% \quad 44.8$

$99.7 \% \quad 50.8$
829.48

1006.57

1305.61

$193 \quad 200$

$719 \quad 727$

1213.57

951.48

1095.55

1518.67

1646.77

1354.73

1284.59

1480.88

934.54

1078.50

1340.65

1340.68

1985.00

1452.78

1619.78

1214.56

1983.93

1031.53

1402.70

1350.69

1153.60

870.55

1545.78

973.56

1312.70

1175.55

2121.02

1680.75

1540.72

1166.66

1462.71

1783.95

986.57

1570.71

1061.52

989.54

1205.65

1091.62

1059.58

1334.63

1296.67

1308.68
$92 \quad 101$

$14 \quad 122$

467

$\begin{array}{cc}522 \\ 2 & 14\end{array}$

$2 \quad 15$

$\begin{array}{ll}16 & 26 \\ 51 & 61\end{array}$

$81 \quad 93$

$362 \quad 369$

$102 \quad 110$

$121 \quad 132$

$307 \quad 319$

$\begin{array}{ll}18 & 41 \\ 53 & 65\end{array}$

$197 \quad 210$

$219 \quad 228$

$404 \quad 412$

$413 \quad 424$

719

$18 \quad 28$

$\begin{array}{ll}64 & 71 \\ 9 & 107\end{array}$

$132 \quad 139$

$235 \quad 246$

$247 \quad 256$

1535
$19 \quad 535$

$536 \quad 55$

$79 \quad 87$

$214 \quad 226$

$110 \quad 119$

$275 \quad 283$

$591 \quad 600$

$749 \quad 758$

$738 \quad 746$

$882 \quad 892$

$1216 \quad 1226$ 
Coatomer subunit beta $\mathrm{GN}=\mathrm{COPB} 1$

Coatomer subunit beta' $\mathrm{GN}=\mathrm{COPB} 2$

Coatomer subunit beta' $\mathrm{GN}=\mathrm{COPB} 2$

Coatomer subunit delta $\mathrm{GN}=\mathrm{ARCN} 1$

Coatomer subunit delta $\mathrm{GN}=\mathrm{ARCN} 1$

Coatomer subunit delta $\mathrm{GN}=\mathrm{ARCN} 1$

Coatomer subunit delta $\mathrm{GN}=\mathrm{ARCN} 1$

Coatomer subunit delta $\mathrm{GN}=\mathrm{ARCN} 1$

Coatomer subunit delta $\mathrm{GN}=\mathrm{ARCN} 1$

Coatomer subunit delta $\mathrm{GN}=\mathrm{ARCN} 1$

Coatomer subunit delta $\mathrm{GN}=\mathrm{ARCN} 1$

COPA_HUMAN $138.35 \quad 100.0 \%$

COPA HUMAN $138.35 \quad 100.0 \%$

COPA_HUMAN $138.35 \quad 100.0 \%$ COPA_HUMAN $138.35 \quad 100.0 \%$ COPA_HUMAN $138.35 \quad 100.0 \%$ COPB_HUMAN $107.15 \quad 100.0 \%$ COPB_HUMAN $107.15 \quad 100.0 \%$ COPB_HUMAN $107.15 \quad 100.0 \%$ COPB2_HUMAN $102.49 \quad 100.0 \%$ COPB2 HUMAN $102.49 \quad 100.0 \%$ COPD_HUMAN $57.21 \quad 100.0 \%$ COPD_HUMAN $57.21 \quad 100.0 \%$ COPD HUMAN $57.21 \quad 100.0 \%$ COPD_HUMAN $57.21 \quad 100.0 \%$ COPD HUMAN $57.21 \quad 100.0 \%$ COPD_HUMAN $57.21 \quad 100.0 \%$ COPD_HUMAN $57.21 \quad 100.0 \%$ COPD HUMAN $57.21 \quad 100.0 \%$ Coatomer subunit gamma-1 GN=COPG1 COPG1_HUMAN $97.72 \quad 100.0 \%$ Coatomer subunit gamma-1 GN=COPG1 COPG1_HUMAN $97.72 \quad 100.0 \%$ Coatomer subunit gamma-2 GN=COPG2 COPG2_HUMAN $97.62 \quad 100.0 \%$ Coatomer subunit gamma-2 GN=COPG2 COPG2_HUMAN $97.62 \quad 100.0 \%$ Coatomer subunit gamma-2 GN=COPG2 COPG2_HUMAN $97.62 \quad 100.0 \%$ Coatomer subunit gamma-2 GN=COPG2 COPG2_HUMAN $97.62 \quad 100.0 \%$ Coatomer subunit gamma-2 GN=COPG2 COPG2_HUMAN $97.62 \quad 100.0 \%$ Coiled-coil domain-containing protein $137 \mathrm{GN}=\mathrm{CCDC} 137 \quad \mathrm{CC} 137$ HUMAN $33.23 \quad 100.0 \%$ Coiled-coil domain-containing protein $137 \mathrm{GN}=\mathrm{CCDC} 137 \quad \mathrm{CC} 137$ _HUMAN $33.23 \quad 100.0 \%$ Coiled-coil domain-containing protein $47 \mathrm{GN}=\mathrm{CCDC} 47$ CCD47_HUMAN $55.87 \quad 100.0 \%$ Coiled-coil domain-containing protein $47 \mathrm{GN}=\mathrm{CCDC} 47$ CCD47_HUMAN $55.87 \quad 100.0 \%$ Condensin complex subunit $1 \mathrm{GN}=\mathrm{NCAPD} 2$ CND1_HUMAN $157.19 \quad 100.0 \%$ Condensin complex subunit $1 \mathrm{GN}=\mathrm{NCAPD} 2$ CND1 HUMAN $157.19100 .0 \%$ Condensin complex subunit $1 \mathrm{GN}=\mathrm{NCAPD} 2 \mathrm{CND} 1$ HUUMAN $157.19 \quad 100.0 \%$ Condensin complex subunit $3 \mathrm{GN}=\mathrm{NCAPG}$ CND3_HUMAN $114.34 \quad 100.0 \%$ Condensin complex subunit $3 \mathrm{GN}=\mathrm{NCAPG}$ CND3_HUMAN $114.34100 .0 \%$ Condensin-2 complex subunit D3 GN=NCAPD3 CNDD3_HUMAN $168.89 \quad 100.0 \%$ Condensin-2 complex subunit D3 GN=NCAPD3 CNDD3_HUMAN $168.89100 .0 \%$ Constitutive coactivator of PPAR-gamma-like protein $1 \mathrm{GN}=\mathrm{FAM} 120 \mathrm{~A}$ F120A_HUMAN $121.89 \quad 100.0 \%$ Constitutive coactivator of PPAR-gamma-like protein 1 GN=FAM120A F120A_HUMAN $121.89 \quad 100.0 \%$ Constitutive coactivator of PPAR-gamma-like protein 1 GN=FAM120A F120A_HUMAN $121.89100 .0 \%$

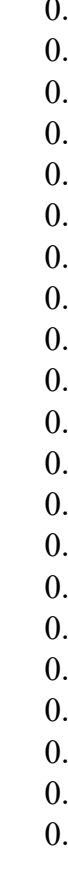



GN=COPRS COPRS_HUMAN $20.07 \quad 100.0 \%$ (20) COUP transcription factor $2 \mathrm{GN}=\mathrm{NR} 2 \mathrm{~F} 2$ Creatine kinase B-type $\mathrm{GN}=\mathrm{CKB}$ Creatine kinase $\mathrm{B}$-type $\mathrm{GN}=\mathrm{CKB}$

Crk-like protein $\mathrm{GN}=\mathrm{CRKL}$

Crk-like protein $\mathrm{GN}=\mathrm{CRKL}$

COT2_HUMAN 45.57 KCRB_HUMAN $42.65 \quad 100.0 \%$ KCRB_HUMAN $42.65 \quad 100.0 \%$ CRKL_HUMAN $33.78 \quad 100.0 \%$ CRKL_HUMAN $33.78 \quad 100.0 \%$ Crooked neck-like protein $1 \mathrm{GN}=\mathrm{CRNKL} 1$ CRNL1 HUMAN $100.45 \quad 100.0 \%$ Crooked neck-like protein $1 \mathrm{GN}=\mathrm{CRNKL1}$ CRNL1_HUMAN $100.45 \quad 100.0 \%$ C-terminal-binding protein $1 \mathrm{GN}=\mathrm{CTBP} 1 \quad$ CTBP1_HUMAN $47.54 \quad 100.0 \%$ C-terminal-binding protein $1 \mathrm{GN}=\mathrm{CTBP} 1$ CTBP1 HUMAN $47.54 \quad 100.0 \%$ CTP synthase $1 \mathrm{GN}=\mathrm{CTPS} 1$ CTP synthase $1 \mathrm{GN}=\mathrm{CTPS} 1$ CTP synthase $1 \mathrm{GN}=\mathrm{CTPS} 1$ CTP synthase $1 \mathrm{GN}=\mathrm{CTPS} 1$ CTP synthase $1 \mathrm{GN}=\mathrm{CTPS} 1$ CTP synthase $1 \mathrm{GN}=\mathrm{CTPS} 1$ CTP synthase $1 \mathrm{GN}=\mathrm{CTPS} 1$

\section{CTP synthase $1 \mathrm{GN}=\mathrm{CTPS} 1$} PYRG1_HUMAN $66.69 \quad 100.0 \%$ PYRG1_HUMAN $66.69 \quad 100.0 \%$ PYRG1_HUMAN $66.69 \quad 100.0 \%$ PYRG1_HUMAN $66.69 \quad 100.0 \%$ PYRG1 HUMAN $66.69 \quad 100.0 \%$ PYRG1_HUMAN $66.69 \quad 100.0 \%$ PYRG1_HUMAN $66.69 \quad 100.0 \%$ PYRG1_HUMAN $66.69 \quad 100.0 \%$ Cullin-associated NEDD8-dissociated protein 1 GN=CAND1 CAND1_HUMAN $136.38 \quad 100.0 \%$ Cullin-associated NEDD8-dissociated protein 1 GN=CAND1 CAND1_HUMAN $136.38 \quad 100.0 \%$ Cullin-associated NEDD8-dissociated protein $1 \mathrm{GN}=$ CAND1 CAND1_HUMAN $136.38 \quad 100.0 \%$ Cullin-associated NEDD8-dissociated protein $1 \mathrm{GN}=$ CAND1 CAND1_HUMAN $136.38 \quad 100.0 \%$ Cullin-associated NEDD8-dissociated protein $1 \mathrm{GN}=$ CAND1 CAND1_HUMAN $136.38100 .0 \%$ Cullin-associated NEDD8-dissociated protein 1 GN=CAND1 CAND1_HUMAN $136.38 \quad 100.0 \%$ Cullin-associated NEDD8-dissociated protein $1 \mathrm{GN}=$ CAND1 CAND1_HUMAN $136.38 \quad 100.0 \%$ Cullin-associated NEDD8-dissociated protein 2 GN=CAND2 CAND2_HUMAN $135.26 \quad 100.0 \%$ Cullin-associated NEDD8-dissociated protein 2 GN=CAND2 CAND2_HUMAN $135.26 \quad 100.0 \%$ Cyclin-dependent kinase $1 \mathrm{GN}=\mathrm{CDK} 1$ Cyclin-dependent kinase $1 \mathrm{GN}=\mathrm{CDK} 1$ Cyclin-dependent kinase $1 \mathrm{GN}=\mathrm{CDK} 1$ Cyclin-dependent kinase $1 \mathrm{GN}=\mathrm{CDK} 1$ Cyclin-dependent kinase $1 \mathrm{GN}=\mathrm{CDK} 1$ Cyclin-dependent kinase $1 \mathrm{GN}=\mathrm{CDK} 1$ Cyclin-dependent kinase $1 \mathrm{GN}=\mathrm{CDK} 1$ Cyclin-dependent kinase $1 \mathrm{GN}=\mathrm{CDK} 1$ Cyclin-dependent kinase $1 \mathrm{GN}=\mathrm{CDK} 1$ Cyclin-dependent kinase $1 \mathrm{GN}=\mathrm{CDK} 1$ Cyclin-dependent kinase $1 \mathrm{GN}=\mathrm{CDK} 1$ Cyclin-dependent kinase $1 \mathrm{GN}=\mathrm{CDK} 1$ Cyclin-dependent kinase $1 \mathrm{GN}=\mathrm{CDK} 1$ Cyclin-dependent kinase $2 \mathrm{GN}=\mathrm{CDK} 2$ Cyclin-dependent kinase $2 \mathrm{GN}=\mathrm{CDK} 2$ Cyclin-dependent kinase $2 \mathrm{GN}=\mathrm{CDK} 2$ Cyclin-dependent kinase $2 \mathrm{GN}=\mathrm{CDK} 2$ Cyclin-dependent kinase $2 \mathrm{GN}=\mathrm{CDK} 2$

\begin{tabular}{|c|c|}
\hline $0.01 \%$ & $13.6 \%$ GTQSIPNDSPAR \\
\hline $0.01 \%$ & 13.6\% MVFETGQFDDAED \\
\hline $0.01 \%$ & $4.6 \%$ SQCALEEYVR \\
\hline $0.01 \%$ & $4.6 \%$ SQYPNQPTR \\
\hline $0.01 \%$ & $5.5 \%$ VLTPELYAELR \\
\hline $0.01 \%$ & $5.5 \%$ GGNMKEVFTR \\
\hline $0.00 \%$ & 9.6\% DSSTCPGDYVLSVSENSR \\
\hline $0.00 \%$ & 9.6\% VGMIPVPYVEK \\
\hline $0.01 \%$ & $2.4 \%$ GIEDIIVSK \\
\hline $0.01 \%$ & 2.4\% AIYELAISQPR \\
\hline $0.01 \%$ & $4.3 \%$ IGSGFDNIDIK \\
\hline $0.01 \%$ & $4.3 \%$ VGQAVALR \\
\hline $0.04 \%$ & $14.6 \%$ GIIASSVGTILK \\
\hline $0.04 \%$ & $14.6 \%$ LTKDNNLTTGK \\
\hline $0.04 \%$ & 14.6\% IYQYVINKER \\
\hline $0.04 \%$ & $14.6 \%$ GLGLSPDLVVCR \\
\hline $0.04 \%$ & $14.6 \%$ CSNPLDTSVKEK \\
\hline $0.04 \%$ & $14.6 \%$ RLDLPIER \\
\hline $0.04 \%$ & $14.6 \%$ FSDSYASVIK \\
\hline $0.04 \%$ & $14.6 \%$ TLFQTKNSVMR \\
\hline $0.06 \%$ & $6.0 \%$ CLGPLVSK \\
\hline $0.06 \%$ & $6.0 \%$ TYIQCIAAISR \\
\hline $0.06 \%$ & $6.0 \%$ TVSPALISR \\
\hline $0.06 \%$ & 6.0\% AADIDQEVKER \\
\hline $0.06 \%$ & $6.0 \%$ ALTLIAGSPLK \\
\hline $0.06 \%$ & 6.0\% LKGYLISGSSYAR \\
\hline $0.06 \%$ & $6.0 \%$ TLEDPDLNVRR \\
\hline $0.01 \%$ & $1.6 \%$ VPTSPTAIR \\
\hline $0.01 \%$ & $1.6 \%$ TLIQCLGSVGR \\
\hline $0.07 \%$ & $32.3 \%$ IGEGTYGVVYK \\
\hline $0.07 \%$ & 32.3\% IGEGTYGVVYKGR \\
\hline $0.07 \%$ & 32.3\% HKTTGQVVAMK \\
\hline $0.07 \%$ & 32.3\% TTGQVVAMK \\
\hline $0.07 \%$ & 32.3\% TTGQVVAMKK \\
\hline $0.07 \%$ & 32.3\% IRLESEEEGVPSTAIR \\
\hline $0.07 \%$ & 32.3\% LESEEEGVPSTAIR \\
\hline $0.07 \%$ & 32.3\% DLKPQNLLIDDKGTIK \\
\hline $0.07 \%$ & $32.3 \%$ LADFGLAR \\
\hline $0.07 \%$ & 32.3\% SPEVLLGSAR \\
\hline $0.07 \%$ & 32.3\% NLDENGLDLLSK \\
\hline $0.07 \%$ & $32.3 \%$ MLIYDPAK \\
\hline $0.07 \%$ & $32.3 \%$ MLIYDPAKR \\
\hline $0.01 \%$ & 13.8\% IGEGTYGVVYK \\
\hline $0.01 \%$ & $13.8 \%$ IGEGTYGVVYKAR \\
\hline $0.01 \%$ & $13.8 \%$ NKLTGEVVALK \\
\hline $0.01 \%$ & $13.8 \%$ LADFGLAR \\
\hline $0.01 \%$ & 13.8\% APEILLGCK \\
\hline
\end{tabular}

$\begin{array}{llll}33.0 & 25.0 & 32.4 & 4\end{array}$

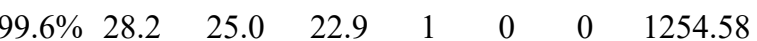

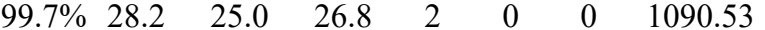
$\begin{array}{llllllll}99.7 \% & 33.4 & 25.0 & 29.4 & 2 & 0 & 0 & 1303.73\end{array}$ $\begin{array}{llllllll}99.7 \% & 40.2 & 25.0 & 28.4 & 2 & 0 & 0 & 1138.57\end{array}$

1972.86 1247.67

973.56 $\begin{array}{llll}9.4 \% & 25.5 & 25.0 & 17.0\end{array}$ $25.0 \quad 18.4$ $99.7 \% \quad 32.4 \quad 25.0 \quad 18.2$ $99.0 \% \quad 62.2 \quad 25.0 \quad 43.4$ $\begin{array}{llll}99.7 \% & 56.2 & 25.0 & 51.2\end{array}$ $\begin{array}{llll}95.0 \% & 18.3 & 25.0 & 12.3\end{array}$ $\begin{array}{llll}99.7 \% & 44.2 & 25.0 & 41.3\end{array}$ $99.7 \% \quad 43.2 \quad 25.0 \quad 43.2 \quad 3$ $99.7 \% \quad 28.0 \quad 25.0 \quad 25.6$ $\begin{array}{llll}99.0 \% & 45.2 & 25.0 & 29.8\end{array}$ $\begin{array}{llll}99.7 \% & 66.1 & 25.0 & 40.7\end{array}$ $\begin{array}{llll}99.4 \% & 24.5 & 25.0 & 20.6\end{array}$ $99.0 \% \quad 36.8 \quad 25.2 \quad 13.0 \quad 2$ $99.7 \% \quad 72.1 \quad 25.0 \quad 71.4$ $96.5 \% \quad 21.9 \quad 25.0 \quad 11.8$ $\begin{array}{lllll}99.7 \% & 30.8 & 25.0 & 26.4 & 2\end{array}$ $99.7 \% \quad 65.4 \quad 25.0 \quad 54.4$ $\begin{array}{llll}99.7 \% & 31.3 & 25.0 & 31.3\end{array}$ $99.1 \% \quad 24.8 \quad 25.0 \quad 17.1$ $\begin{array}{llll}99.7 \% & 32.6 & 25.0 & 25.0\end{array}$ $\begin{array}{lllll}99.7 \% & 43.0 & 25.0 & 39.9 & 2\end{array}$ $\begin{array}{llll}99.7 \% & 76.6 & 25.0 & 43.5\end{array}$ $99.7 \% \quad 75.1 \quad 25.0 \quad 32.1$ $\begin{array}{llll}99.7 \% & 36.5 & 25.0 & 36.2\end{array}$ $\begin{array}{llll}99.7 \% & 46.5 & 25.0 & 38.2\end{array}$ $\begin{array}{llll}99.7 \% & 45.3 & 25.0 & 37.5\end{array}$ $\begin{array}{llll}99.7 \% & 56.7 & 25.0 & 51.3\end{array}$ $\begin{array}{llll}99.7 \% & 48.9 & 25.0 & 45.7\end{array}$ $\begin{array}{llll}98.7 \% & 19.9 & 25.0 & 19.9\end{array}$ $\begin{array}{llll}98.9 \% & 35.9 & 25.0 & 0.0\end{array}$ $\begin{array}{lllll}99.7 \% & 57.2 & 25.0 & 48.3 & 2\end{array}$ $\begin{array}{llll}99.7 \% & 54.0 & 25.0 & 40.6\end{array}$ $\begin{array}{llll}98.2 \% & 24.8 & 25.0 & 13.0\end{array}$ $\begin{array}{lllll}99.7 \% & 45.8 & 25.0 & 25.9\end{array}$ $\begin{array}{lllll}99.7 \% & 76.6 & 25.0 & 43.5 & 2\end{array}$ $\begin{array}{llll}99.7 \% & 34.2 & 25.0 & 34.2\end{array}$ $\begin{array}{lllll}99.3 \% & 36.2 & 25.0 & 15.0 & 2\end{array}$ $\begin{array}{llll}98.9 \% & 35.9 & 25.0 & 0.0\end{array}$ $\begin{array}{llll}95.1 \% & 18.3 & 25.0 & 18.3\end{array}$

\begin{tabular}{cc}
58 & 69 \\
172 & 184 \\
341 & 350 \\
351 & 359 \\
33 & 43 \\
243 & 252 \\
40 & 57 \\
170 & 180 \\
467 & 475 \\
561 & 671 \\
98 & 108 \\
185 & 192 \\
17 & 28 \\
82 & 92 \\
93 & 102 \\
206 & 217 \\
218 & 229 \\
269 & 276 \\
310 & 319 \\
455 & 465 \\
71 & 78 \\
233 & 243 \\
374 & 382 \\
578 & 588 \\
631 & 641 \\
970 & 982 \\
014 & 1024 \\
227 & 235 \\
236 & 246 \\
10 & 20 \\
10 & 22 \\
23 & 33 \\
25 & 33 \\
25 & 34 \\
35 & 50 \\
37 & 50 \\
128 & 143 \\
144 & 151 \\
171 & 180 \\
255 & 266 \\
267 & 274 \\
267 & 275 \\
10 & 20 \\
10 & 22 \\
133 & 33 \\
170 & 170 \\
& \\
\hline 178
\end{tabular}


D-3-phosphoglycerate dehydrogenase GN=PHGDH SERA HUMAN $56.65 \quad 100.0 \%$

D-3-phosphoglycerate dehydrogenase GN=PHGDH SERA_HUMAN $56.65 \quad 100.0 \%$

D-3-phosphoglycerate dehydrogenase GN=PHGDH SERA HUMAN $56.65100 .0 \%$

D-3-phosphoglycerate dehydrogenase GN=PHGDH SERA_HUMAN $56.65 \quad 100.0 \%$

D-3-phosphoglycerate dehydrogenase GN=PHGDH SERA_HUMAN $56.65 \quad 100.0 \%$

D-3-phosphoglycerate dehydrogenase GN=PHGDH SERA HUMAN $56.65100 .0 \%$ DBIRD complex subunit ZNF326 GN=ZNF326 ZN326_HUMAN $65.65 \quad 100.0 \%$ DBIRD complex subunit ZNF326 GN=ZNF326 ZN326_HUMAN $65.65 \quad 100.0 \%$ DBIRD complex subunit ZNF326 GN=ZNF326 ZN326 HUMAN $65.65 \quad 100.0 \%$ DDB1 - and CUL4-associated factor 7 GN=DCAF7 DCAF7_HUMAN $38.93 \quad 100.0 \%$ DDB1- and CUL4-associated factor 7 GN=DCAF7 DCAF7 HUMAN $38.93 \quad 100.0 \%$ DDB1- and CUL4-associated factor 7 GN=DCAF7 DCAF7_HUMAN $38.93 \quad 100.0 \%$ DDRGK domain-containing protein 1 GN=DDRGK1 DDRGK_HUMAN $35.61 \quad 100.0 \%$ DDRGK domain-containing protein $1 \mathrm{GN}=$ DDRGK1 DDRGK HUMAN $35.61 \quad 100.0 \%$ Dedicator of cytokinesis protein $11 \mathrm{GN}=$ DOCK11 DOC11_HUMAN $237.68 \quad 100.0 \%$ Dedicator of cytokinesis protein $11 \mathrm{GN}=$ DOCK11 DOC11_HUMAN $237.68100 .0 \%$ Dedicator of cytokinesis protein 4 GN=DOCK4 DOCK4_HUMAN $225.21 \quad 100.0 \%$ Dedicator of cytokinesis protein $4 \mathrm{GN}=$ DOCK4 DOCK4_HUMAN $225.21 \quad 100.0 \%$ Dedicator of cytokinesis protein $4 \mathrm{GN}=$ DOCK4 DOCK4 HUMAN $225.21 \quad 100.0 \%$ Dedicator of cytokinesis protein $4 \mathrm{GN}=$ DOCK4 DOCK4_HUMAN $225.21 \quad 100.0 \%$ Dedicator of cytokinesis protein 4 GN=DOCK4 DOCK4_HUMAN $225.21 \quad 100.0 \%$ Dedicator of cytokinesis protein $4 \mathrm{GN}=$ DOCK4 DOCK4_HUMAN $225.21 \quad 100.0 \%$ Dedicator of cytokinesis protein 4 GN=DOCK4 DOCK4_HUMAN $225.21 \quad 100.0 \%$ Dedicator of cytokinesis protein $4 \mathrm{GN}=$ DOCK4 DOCK4_HUMAN $225.21 \quad 100.0 \%$ Dedicator of cytokinesis protein $4 \mathrm{GN}=$ DOCK4 DOCK4_HUMAN $225.21 \quad 100.0 \%$ Dehydrogenase/reductase SDR family member 7B GN=DHRS7B DRS7B_HUMAN $35.12 \quad 100.0 \%$ Dehydrogenase/reductase SDR family member 7B GN=DHRS7B DRS7B HUMAN $35.12100 .0 \%$ Delta-1-pyrroline-5-carboxylate synthase GN=ALDH18A1 P5CS_HUMAN $87.30 \quad 100.0 \%$

$0.02 \% \quad 4.5 \%$ SGFDIKVPR

$0.02 \% \quad 4.5 \%$ RAVGPSSTQLYMVR

$0.02 \% \quad 4.5 \%$ LGTPQQIAIAR

$0.02 \% \quad 4.5 \% \quad$ EGDLLTKER

$0.02 \% \quad 4.5 \%$ CFQPPIHQSLASS

$0.01 \% \quad 4.2 \%$ GGFDIKVPR

$0.01 \% \quad 4.2 \%$ TAIPFTQEPQR

$0.01 \% \quad 4.2 \% \quad$ LGTPQQIAIAR

$0.01 \% \quad 4.2 \% \quad$ EGDLLTKER

$0.01 \% \quad 4.2 \%$ SVETDSSTVEHVR

$0.01 \% \quad 2.9 \%$ TTGEVVSGVVSK

$0.01 \% \quad 2.9 \%$ QQTSLFIAR

$0.01 \% \quad 2.9 \%$ GKPAAPGGAGNTGTK

$0.01 \% \quad 2.9 \%$ TALAATNPAVR

$0.01 \% \quad 2.9 \% \quad$ AQNISSNANMLR

$0.06 \% \quad 12.8 \%$ VLISDSLDPCCR

$0.06 \% \quad 12.8 \%$ AGTGVDNVDLEAATR

$0.06 \% \quad 12.8 \%$ TLGILGLGR

$0.06 \% \quad 12.8 \%$ IGREVATR

$0.06 \% \quad 12.8 \%$ GGIVDEGALLR

$0.06 \% 12.8 \%$ GTIQVITQGTSLK

$0.01 \% \quad 5.0 \%$ SSLGGRDLYR

$0.01 \% \quad 5.0 \%$ STNVTVAAAR

$0.01 \% \quad 5.0 \%$ MAFTCSFCK

$0.01 \% \quad 11.1 \%$ NTFDHPYPTTK

$0.01 \% \quad 11.1 \%$ VNLVSGHVK

$99.7 \% \quad 50.7$

$98.9 \% \quad 21.3$

$99.7 \% \quad 56.0$

$99.0 \% 25.7$

$98.8 \% \quad 25.3$

$99.7 \% \quad 32.7$

$99.7 \% \quad 33.8$

$99.7 \% \quad 56.0$

$99.0 \% \quad 25.7$

$99.7 \% \quad 47.2$

$99.7 \% \quad 42.2$

$99.7 \% \quad 29.6$

$99.7 \% \quad 28.6$

$\begin{array}{lll}98.2 \% & 25.7\end{array}$

$99.7 \% \quad 43.8$

$99.7 \% \quad 50.6$

$99.7 \% \quad 62.6$

$99.7 \% \quad 59.0$

$96.9 \% \quad 24.9$

$99.7 \% \quad 66.8$

$99.7 \% 71.1$

$97.3 \% \quad 20.7$

$99.7 \% \quad 65.5$

$99.7 \% \quad 29.7$

$99.7 \% \quad 41.6$

$99.7 \% 39.9$

$0.01 \% \quad 11.1 \%$ AGGGRDMFASVGADGSVR $97.9 \% \quad 17.5$

$\begin{array}{lllll}0.01 \% & 10.2 \% & \text { AASAGQEPLHNEELAGAGR } & 99.7 \% & 28.4\end{array}$

$0.01 \% \quad 10.2 \%$ VAQPGPLEPEEPR

$0.01 \% \quad 1.0 \%$ SYASTPELRK

$0.01 \% \quad 1.0 \%$ LTGLSEISLR

$0.03 \% \quad 5.0 \% \quad$ NACSVQYR

$0.03 \% \quad 5.0 \%$ GIFLGNNNQAMK

$0.03 \% \quad 5.0 \%$ TVESQLYTNPDSR

$0.03 \% \quad 5.0 \%$ SGNFKQVEAK

$0.03 \% \quad 5.0 \%$ ESGVSLIATVTR

$0.03 \% \quad 5.0 \%$ TLISQCQTR

$0.03 \% \quad 5.0 \%$ NSAPASVSPDGTR

$0.03 \% \quad 5.0 \%$ SDPNLSAPEK

$0.03 \% \quad 5.0 \%$ HTTSVSPSPAGR

$0.02 \% \quad 8.3 \%$ NAVVVITGATSGLGK

$0.02 \% \quad 8.3 \% \quad$ YGVMDTTTAQGR

$0.04 \% \quad 10.7 \%$ LGSAVVTR
$99.7 \% \quad 34.5$

$99.7 \% \quad 34.4$

$99.7 \% \quad 46.4$

$97.4 \% \quad 26.5$

$99.7 \% \quad 40.1$

$99.7 \% \quad 60$.

$94.8 \% \quad 19.2$

$99.7 \% \quad 47.3$

$99.7 \% \quad 47.5$

$99.7 \% \quad 56.3$

$99.2 \% \quad 23.9$

$99.7 \% \quad 31.7$

$99.7 \% \quad 32.2$

$99.7 \% \quad 64.8$

$99.0 \% \quad 38.1$
854.53

854.53

1586.84

1885.94

1018.57

1580.82

1167.68

1060.56

1471.70

988.56

1287.67

1167.68

1060.56

1445.69

1162.63

1063.59

1283.67

1084.61

1318.65

1434.67

1488.73

899.57

901.52

1099.61

1345.77

1123.59

989.54

1151.47

1320.62

952.56

1709.80

1877.91

1418.73

1151.61

1088.63

997.45

1306.66

1509.72

1107.58

1232.68

1106.56

1258.60

1057.52

1196.60

1386.80

1299.60

802.48 
Delta-1-pyrroline-5-carboxylate synthase GN=ALDH18A1 P5CS_HUMAN $87.30 \quad 100.0 \%$ Delta-1-pyrroline-5-carboxylate synthase GN=ALDH18A1 P5CS_HUMAN 87.30 $\quad 100.0 \%$ Delta-1-pyrroline-5-carboxylate synthase GN=ALDH18A1 P5CS_HUMAN $87.30 \quad 100.0 \%$ Delta-1-pyrroline-5-carboxylate synthase GN=ALDH18A1 P5CS HUMAN 87.30 $100.0 \%$ Delta-1-pyrroline-5-carboxylate synthase GN=ALDH18A1 P5CS_HUMAN $87.30 \quad 100.0 \%$ Delta-1-pyrroline-5-carboxylate synthase GN=ALDH18A1 P5CS_HUMAN 87.30 $100.0 \%$ Delta-1-pyrroline-5-carboxylate synthase GN=ALDH18A1 P5CS_HUMAN $87.30 \quad 100.0 \%$ Delta-1-pyrroline-5-carboxylate synthase GN=ALDH18A1 P5CS_HUMAN 87.30 $100.0 \%$ Deoxynucleoside triphosphate triphosphohydrolase SAMHDI GN=SAMHDI SAMH1 HUMAN $72.20 \quad 100.0 \%$ Deoxynucleoside triphosphate triphosphohydrolase SAMHD1 GN=SAMHDI SAMH1_HUMAN $72.20 \quad 100.0 \%$ Deoxynucleoside triphosphate triphosphohydrolase SAMHDI GN=SAMHD1 SAMH1_HUMAN $72.20 \quad 100.0 \%$ Deoxynucleoside triphosphate triphosphohydrolase SAMHDI GN=SAMHD1 SAMH1_HUMAN $72.20 \quad 100.0 \%$ Deoxynucleoside triphosphate triphosphohydrolase SAMHD1 GN=SAMHDI SAMH1_HUMAN $72.20 \quad 100.0 \%$ Deoxynucleoside triphosphate triphosphohydrolase SAMHD1 GN=SAMHD1 SAMH1_HUMAN $72.20 \quad 100.0 \%$ Developmentally-regulated GTP-binding protein 1 GN=DRG1 DRG1_HUMAN $40.54 \quad 100.0 \%$ Developmentally-regulated GTP-binding protein 1 GN=DRG1 DRG1_HUMAN $40.54 \quad 100.0 \%$ Developmentally-regulated GTP-binding protein $1 \mathrm{GN}=\mathrm{DRG} 1 \mathrm{DRG1}$ HUMAN $40.54 \quad 100.0 \%$ Dihydropyrimidinase-related protein $1 \mathrm{GN}=$ CRMP1 DPYL1_HUMAN $62.18 \quad 100.0 \%$ Dihydropyrimidinase-related protein $1 \mathrm{GN}=\mathrm{CRMP} 1$ DPYL1_HUMAN $62.18 \quad 100.0 \%$ Dihydropyrimidinase-related protein $1 \mathrm{GN}=\mathrm{CRMP1}$ DPYL1_HUMAN $62.18 \quad 100.0 \%$ Dihydropyrimidinase-related protein $1 \mathrm{GN}=\mathrm{CRMP} 1$ DPYL1_HUMAN $62.18 \quad 100.0 \%$ Dihydropyrimidinase-related protein $4 \mathrm{GN}=$ DPYSL4 DPYL4_HUMAN $61.88 \quad 100.0 \%$ Dihydropyrimidinase-related protein 4 GN=DPYSL4 DPYL4_HUMAN $61.88 \quad 100.0 \%$ Dimethyladenosine transferase 1, mitochondrial GN=TFB1M TFB1M_HUMAN $39.54 \quad 100.0 \%$ Dimethyladenosine transferase 1, mitochondrial GN=TFB1M TFB1M_HUMAN $39.54 \quad 100.0 \%$ Dimethyladenosine transferase 2, mitochondrial GN=TFB2M TFB2M_HUMAN $45.35 \quad 100.0 \%$ Dimethyladenosine transferase 2, mitochondrial GN=TFB2M TFB2M_HUMAN $45.35 \quad 100.0 \%$ Dimethyladenosine transferase 2, mitochondrial GN=TFB2M TFB2M_HUMAN $45.35 \quad 100.0 \%$ DNA mismatch repair protein Msh6 GN=MSH6 MSH6_HUMAN $152.79 \quad 100.0 \%$ DNA mismatch repair protein Msh6 GN=MSH6 MSH6 HUMAN $152.79 \quad 100.0 \%$ DNA polymerase delta catalytic subunit GN=POLD1 DPOD1_HUMAN $123.63 \quad 100.0 \%$ DNA polymerase delta catalytic subunit GN=POLD1 DPOD1_HUMAN $123.63 \quad 100.0 \%$ DNA repair protein RAD50 GN=RAD50 RAD50_HUMAN $153.90 \quad 100.0 \%$ DNA repair protein RAD50 GN=RAD50 RAD50_HUMAN $153.90 \quad 100.0 \%$ DNA replication licensing factor MCM3 GN=MCM3 MCM3 HUMAN $90.98 \quad 100.0 \%$ DNA replication licensing factor MCM3 GN=MCM3 MCM3_HUMAN $90.98 \quad 100.0 \%$ DNA replication licensing factor MCM3 GN=MCM3 MCM3_HUMAN $90.98 \quad 100.0 \%$ DNA replication licensing factor MCM3 GN=MCM3 MCM3 HUMAN $90.98 \quad 100.0 \%$ DNA replication licensing factor MCM3 GN=MCM3 MCM3_HUMAN $90.98 \quad 100.0 \%$ DNA replication licensing factor MCM3 GN=MCM3 MCM3_HUMAN $90.98 \quad 100.0 \%$ DNA replication licensing factor MCM3 GN=MCM3 MCM3_HUMAN $90.98 \quad 100.0 \%$ DNA replication licensing factor MCM4 GN=MCM4 MCM4_HUMAN $96.56 \quad 100.0 \%$ DNA replication licensing factor MCM4 GN=MCM4 MCM4 HUMAN $96.56 \quad 100.0 \%$ DNA replication licensing factor MCM4 GN=MCM4 MCM4_HUMAN $96.56 \quad 100.0 \%$ DNA replication licensing factor MCM5 GN=MCM5 MCM5_HUMAN $82.29 \quad 100.0 \%$ DNA replication licensing factor MCM5 GN=MCM5 MCM5_HUMAN $82.29 \quad 100.0 \%$ DNA replication licensing factor MCM5 GN=MCM5 MCM5_HUMAN $82.29 \quad 100.0 \%$
$17 \quad 0.04 \% \quad 10.7 \%$ LRHEILLSQSVR $0.04 \% \quad 10.7 \%$ NLNGTLHELLR $0.04 \% \quad 10.7 \%$ VSGHVITDIVEGK $0.04 \% \quad 10.7 \%$ VSGHVITDIVEGKK $0.04 \% \quad 10.7 \%$ LAAPLLKR $0.04 \% \quad 10.7 \%$ MIDLIIPR

$0.04 \% \quad 10.7 \%$ GSSQLVRDIQK $0.04 \% \quad 10.7 \%$ FASYLTFSPSEVK $0.02 \% \quad 9.0 \%$ RGGFEEPVLLK $0.02 \% \quad 9.0 \%$ GGFEEPVLLK $0.02 \% \quad 9.0 \% \quad$ IIDTPQFQR $0.02 \% \quad 9.0 \%$ SFLYEIVSNKR $0.02 \% \quad 9.0 \%$ VCEVDNELRICAR $0.02 \% \quad 9.0 \% \quad$ YVGETQPTGQIK

$0.01 \% \quad 9.3 \% \quad$ IAEIEAEMAR $0.01 \% \quad 9.3 \%$ GGGGGGPGEGFDVAK $0.01 \% \quad 9.3 \%$ GRQVIAVAR $0.01 \% \quad 5.2 \%$ INCPVYITK $0.01 \% \quad 5.2 \%$ SAADIIALAR $0.01 \% \quad 5.2 \%$ NKVFGLQGVSR $0.01 \% \quad 5.2 \%$ VFGLQGVSR $0.01 \% \quad 3.5 \%$ GAPAVVISQGR $0.01 \% \quad 3.5 \%$ LAEIHGVPR $0.01 \% \quad 5.5 \% \quad$ IEQPFKLVEK $0.01 \% \quad 5.5 \%$ VVQNVFQFR $0.01 \% \quad 7.8 \%$ SGGVIKPPAMSSR $0.01 \% \quad 7.8 \%$ ELLDQLQQK $0.01 \% \quad 7.8 \%$ SATVIDHLR $0.01 \% \quad 2.0 \%$ SPALSDANKASAR $0.01 \% \quad 2.0 \% \quad$ QATSISSETKNTLR $0.00 \% \quad 2.0 \%$ GQQVKVVSQLLR $0.00 \% \quad 2.0 \% \quad$ IFEPILGEGR $0.01 \% \quad 1.5 \%$ WLQDNLTLR $0.03 \% \quad 9.7 \%$ LIVNVNDLR $0.03 \% \quad 9.7 \%$ GGYTSGTFR $0.03 \% \quad 9.7 \%$ TVLIACNVK $0.03 \% \quad 9.7 \%$ DAQPSFSAEDIAK $0.03 \% \quad 9.7 \%$ SKDIFDQLAK $0.03 \% \quad 9.7 \% \quad$ YVLCTAPR $0.03 \% \quad 9.7 \%$ GSSGVGLTAAVTTDQETGER $0.02 \% \quad 3.2 \%$ IAEPSVCGR $0.02 \% \quad 3.2 \%$ AVPIRVNPR $0.02 \% \quad 3.2 \%$ AGIICQLNAR $0.04 \% \quad 14.2 \%$ VLGIQVDTDGSGR $0.04 \% \quad 14.2 \%$ SFAGAVSPQEEEEFRR $0.01 \% \quad 1.5 \%$ CSVSSLGFNVH

$19 \quad 0.04 \% \quad 14.2 \%$ SIAPSIFGGTDMKK
$99.4 \% 22.3$

$99.7 \% \quad 57$.

$99.6 \% \quad 24.7$

$99.7 \% 36.3$

$99.0 \% \quad 36.7$

$99.0 \% 34.0$

$99.7 \% 36.5$

$99.7 \% 47.1$

$99.6 \% 31$.

$99.5 \% \quad 31.9$

$99.7 \% \quad 44.3$

$99.7 \% \quad 48.4$

$97.8 \% 25.4$

$\begin{array}{lll}99.5 \% & 28.7\end{array}$

$99.7 \% 53.5$

$99.7 \% \quad 38.0$

$99.7 \% \quad 35.7$

$99.7 \% \quad 46.9$

$99.7 \% \quad 66.2$

$97.8 \% 17.6$

$99.7 \% 34$.

$99.7 \% 54$.

$99.7 \% \quad 37.0$

$\begin{array}{lll}99.7 \% & 36.2\end{array}$

$99.7 \% \quad 43.3$

$99.6 \% \quad 28.3$

$98.6 \% \quad 27.1$

$99.7 \% \quad 52.2$

$99.7 \% \quad 64.1$

$99.7 \% \quad 31.4$

$98.8 \% 21.0$

$99.2 \% \quad 20.1$

$98.3 \% \quad 24.3$

$99.7 \% \quad 52.4$

$99.4 \% \quad 23.5$

$99.4 \% \quad 23.2$

$95.3 \% \quad 23.4$

$99.7 \% \quad 28$.

$99.7 \% \quad 48.8$

$99.0 \% \quad 42.6$

$97 \% 60.5$

$\begin{array}{ll}99.7 \% & 46.4\end{array}$

$97.8 \% \quad 17.7$

$99.7 \% \quad 62.4$

$99.7 \% \quad 52.6$

$97.4 \% \quad 16.9$

$99.7 \% \quad 34.6$
50.4

$\begin{array}{ll}0 & 24.7\end{array}$

36.3

$\begin{array}{ll}.0 & 36.0\end{array}$

$\begin{array}{lll}.0 & 21.7 & 2\end{array}$

$\begin{array}{lll} & 23.9 & 3\end{array}$

.047 .1

$\begin{array}{ll}0.0 & 18.0\end{array}$

\begin{tabular}{ll}
5.0 & 16.0 \\
\hline
\end{tabular}

34.4
25.0

$\begin{array}{ll}0 & 47.4\end{array}$

\begin{tabular}{l}
24.6 \\
\hline
\end{tabular}

\begin{tabular}{ll}
22.6 \\
\hline
\end{tabular}

$\begin{array}{ll}25.0 & 48\end{array}$

\begin{tabular}{ll}
35.7 \\
\hline
\end{tabular}

\begin{tabular}{ll}
.0 & 39.4 \\
\hline
\end{tabular}

$\begin{array}{lll}25.0 & 53.7 & 2\end{array}$

$\begin{array}{ll}53.7 & 17.6\end{array}$

$\begin{array}{ll}.0 & 28.2 \\ 0 & 50.5\end{array}$

$\begin{array}{ll}0 & 50.5 \\ & 32.7\end{array}$

23.0

$\begin{array}{ll}36.0 & 36.8\end{array}$

38.1
28.0

13.1
25.0

\begin{tabular}{ll}
.0 & 56.4 \\
\hline
\end{tabular}

$\begin{array}{ll}25.0 & 27.5\end{array}$

$\begin{array}{ll}25.0 & 19.4\end{array}$

$\begin{array}{ll}25.0 & 14.4\end{array}$

\begin{tabular}{ll}
51.5 \\
\hline
\end{tabular}

20.2
25.0

$\begin{array}{ll}20.0 & 20.5\end{array}$

$\begin{array}{ll}28.0 & 10.4\end{array}$

$\begin{array}{ll}25.0 & 28.1\end{array}$

$\begin{array}{lll}25.0 & 33.6 & 2\end{array}$

$\begin{array}{lll}25.0 & 60.5 & 3\end{array}$

$5.0 \quad 36.1$

$\begin{array}{ll}25.0 & 36.1 \\ 25.0 & 17.7\end{array}$

17.

$\begin{array}{lll}25.0 & 52.6 & 3\end{array}$
1450.85

1279.71

1353.74

1481.83

881.59

986.57

1230.68

1475.74

1244.70

1088.60

1117.60

1355.73

1633.78

1320.68

1132.57

1261.58

969.60

1107.59

1000.58

1204.68

962.54

1054.60

991.57

1230.71

1136.62

1302.68

1114.61

1011.56

1287.67

1535.80

1354.82

1130.62

1158.63

1206.56

1055.62

945.44

1017.58

1378.65

1164.63

979.50

1935.93

988.49

1021.63

1115.60

1316.68

1838.87

1467.75 $\begin{array}{cc}27 & 138 \\ 2 & 212 \\ 35 & 347 \\ 35 & 348 \\ 18 & 425 \\ 1 & 558 \\ 9 & 569 \\ 0 & 662 \\ 6 & 66 \\ 7 & 66 \\ 35 & 143 \\ 5 & 305 \\ 40 & 352 \\ 56 & 467 \\ & 17 \\ 7 & 61 \\ 32 & 140 \\ 46 & 254 \\ 59 & 268 \\ 86 & 496 \\ 38 & 496 \\ 41 & 451 \\ 38 & 496 \\ 38 & 247 \\ 48 & 256 \\ 58 & 170 \\ 37 & 295 \\ 32 & 340 \\ 4 & 26 \\ 25 & 338 \\ 50 & 561 \\ 69 & 978 \\ 17 & 1025 \\ 02 & 1312 \\ 7 & 55 \\ 49 & 257 \\ 58 & 266 \\ 71 & 283 \\ 2 & 301 \\ 57 & 364 \\ 72 & 391 \\ 22 & 330 \\ 96 & 404 \\ 91 & 610 \\ 99 & 308 \\ 38 & 324 \\ & 351\end{array}$

Page 27 of Table S-1-3 
DNA replication licensing factor MCM5 GN=MCM5 MCM5_HUMAN $82.29 \quad 100.0 \%$ DNA replication licensing factor MCM5 GN=MCM5 MCM5_HUMAN $82.29 \quad 100.0 \%$ DNA replication licensing factor MCM5 GN=MCM5 MCM5_HUMAN $82.29 \quad 100.0 \%$ DNA replication licensing factor MCM5 GN=MCM5 MCM5 HUMAN $82.29 \quad 100.0 \%$ DNA replication licensing factor MCM5 GN=MCM5 MCM5_HUMAN $82.29 \quad 100.0 \%$ DNA replication licensing factor MCM5 GN=MCM5 MCM5_HUMAN $82.29 \quad 100.0 \%$ DNA replication licensing factor MCM6 GN=MCM6 MCM6_HUMAN $92.89 \quad 100.0 \%$ DNA replication licensing factor MCM6 GN=MCM6 MCM6_HUMAN $92.89 \quad 100.0 \%$ DNA replication licensing factor MCM6 GN=MCM6 MCM6 HUMAN $92.89 \quad 100.0 \%$ DNA replication licensing factor MCM6 GN=MCM6 MCM6_HUMAN $92.89 \quad 100.0 \%$ DNA replication licensing factor MCM7 GN=MCM7 MCM7_HUMAN $81.31 \quad 100.0 \%$ DNA replication licensing factor MCM7 GN=MCM7 MCM7_HUMAN $81.31 \quad 100.0 \%$ DNA replication licensing factor MCM7 GN=MCM7 MCM7_HUMAN $81.31 \quad 100.0 \%$ DNA replication licensing factor MCM7 GN=MCM7 MCM7_HUMAN $81.31 \quad 100.0 \%$ DNA replication licensing factor MCM7 GN=MCM7 MCM7_HUMAN $81.31 \quad 100.0 \%$ DNA replication licensing factor MCM7 GN=MCM7 MCM7_HUMAN $81.31 \quad 100.0 \%$ DNA replication licensing factor MCM7 GN=MCM7 MCM7 HUMAN $81.31 \quad 100.0 \%$ DNA replication licensing factor MCM7 GN=MCM7 MCM7_HUMAN $81.31 \quad 100.0 \%$ DNA replication licensing factor MCM7 GN=MCM7 MCM7_HUMAN $81.31 \quad 100.0 \%$ DNA replication licensing factor $\mathrm{MCM} 7 \mathrm{GN}=\mathrm{MCM} 7 \mathrm{MCM} 7$ HUMAN $81.31 \quad 100.0^{\circ}$ DNA replication licensing factor MCM7 GN=MCM7 MCM7_HUMAN $81.31 \quad 100.0 \%$ DNA topoisomerase $1 \mathrm{GN}=\mathrm{TOP} 1 \quad$ TOP1 HUMAN $90.73 \quad 100.0 \%$ DNA topoisomerase $1 \mathrm{GN}=\mathrm{TOP} 1$ DNA topoisomerase $1 \mathrm{GN}=\mathrm{TOP} 1$ TOP1_HUMAN $90.73 \quad 100.0 \%$ TOP1_HUMAN $90.73 \quad 100.0 \%$ DA topoisomerase 2-alpha GN=TOP2A TOP2A HUMAN $174.39 \quad 100.0 \%$ DNA topoisomerase 2-alpha GN=TOP2A TOP2A_HUMAN $174.39 \quad 100.0 \%$ DNA topoisomerase 2-alpha GN=TOP2A TOP2A_HUMAN $174.39 \quad 100.0 \%$ DNA topoisomerase 2-alpha GN=TOP2A TOP2A_HUMAN $174.39 \quad 100.0 \%$ DNA topoisomerase 2-alpha GN=TOP2A TOP2A_HUMAN $174.39 \quad 100.0 \%$ DNA topoisomerase 2-alpha GN=TOP2A TOP2A HUMAN $174.39100 .0 \%$ DNA topoisomerase 2-beta GN=TOP2B TOP2B_HUMAN $183.27 \quad 100.0 \%$ DNA topoisomerase 2-beta GN=TOP2B $\quad$ TOP2B_HUMAN $183.27 \quad 100.0 \%$ DNA topoisomerase 2-beta GN=TOP2B TOP2B_HUMAN $183.27 \quad 100.0 \%$ DNA topoisomerase 2-beta GN=TOP2B TOP2B_HUMAN $183.27 \quad 100.0 \%$ DNA topoisomerase 2-beta GN=TOP2B TOP2B_HUMAN $183.27 \quad 100.0 \%$ DNA topoisomerase 2-beta GN=TOP2B TOP2B_HUMAN $183.27 \quad 100.0 \%$ DNA-dependent protein kinase catalytic subunit GN=PRKDC PRKDC_HUMAN $469.10 \quad 100.0 \%$ DNA-dependent protein kinase catalytic subunit GN=PRKDC PRKDC HUMAN $469.10 \quad 100.0 \%$ DNA-dependent protein kinase catalytic subunit GN=PRKDC PRKDC_HUMAN $469.10 \quad 100.0 \%$ DNA-dependent protein kinase catalytic subunit GN=PRKDC PRKDC_HUMAN $469.10 \quad 100.0 \%$ DNA-dependent protein kinase catalytic subunit GN=PRKDC PRKDC_HUMAN $469.10 \quad 100.0 \%$ DNA-dependent protein kinase catalytic subunit GN=PRKDC PRKDC_HUMAN $469.10 \quad 100.0 \%$ DNA-dependent protein kinase catalytic subunit GN=PRKDC PRKDC HUMAN $469.10 \quad 100.0 \%$ DNA-dependent protein kinase catalytic subunit GN=PRKDC PRKDC_HUMAN $469.10 \quad 100.0 \%$ DNA-dependent protein kinase catalytic subunit GN=PRKDC PRKDC_HUMAN $469.10 \quad 100.0 \%$ DNA-dependent protein kinase catalytic subunit GN=PRKDC PRKDC HUMAN $469.10 \quad 100.0 \%$ DNA-dependent protein kinase catalytic subunit GN=PRKDC PRKDC_HUMAN $469.10 \quad 100.0 \%$

.

3

6

6

6

4

4

4
54
54

54

54
54
54

54

$0.04 \% \quad 14.2 \%$ AIACLLFGGSR

$0.04 \% 14.2 \%$ CSPIGVYTSGK

$0.04 \% \quad 14.2 \%$ GSSAAGLTASVMRDPSSR

$0.04 \% \quad 14.2 \%$ AGITTTLNSR

$0.04 \% \quad 14.2 \%$ LSAEAAEKLK

$0.01 \% \quad 5.9 \% \quad$ FLLDTNKSR

$0.01 \% \quad 5.9 \%$ IQETQAELPRGSIPR

$0.01 \% \quad 5.9 \%$ VSGVDGYETEGIRGLR

$0.01 \% \quad 5.9 \%$ HVEEFSPR

$0.08 \% \quad 17.4 \%$ SPQNQYPAELMR

$0.08 \% \quad 17.4 \%$ ADSVGKLVTVR

$0.08 \% \quad 17.4 \%$ SITVLVEGENTR

$39 \quad 0.08 \% \quad 17.4 \%$ GNINICLMGDPGVAK

$0.08 \% \quad 17.4 \%$ SQLLSYIDR

$0.08 \% \quad 17.4 \%$ SQYTTGRGSSGVGLTAAVLR

$0.08 \% \quad 17.4 \%$ GSSGVGLTAAVLR

$0.08 \% \quad 17.4 \%$ AGILTTLNAR

$0.08 \% \quad 17.4 \%$ CSILAAANPAYGR

$0.08 \% \quad 17.4 \%$ TQRPADVIFATVR

$0.08 \% \quad 17.4 \%$ SVRFSEAEQR

$0.01 \% \quad 4.3 \%$ AEEVATFFAK

$0.01 \% \quad 4.3 \%$ CDFTQMSQYFK

$0.01 \% \quad 4.3 \% \quad$ IMPEDIIINCSK

$0.03 \% \quad 3.9 \%$ LCNIFSTK

$0.03 \% \quad 3.9 \%$ AYDIAGSTKDVK

$0.03 \% \quad 3.9 \%$ TLAVSGLGVVGR

$0.03 \% \quad 3.9 \%$ DKYGVFPLR

$0.03 \% \quad 3.9 \% \quad$ IVGLQYKK

$0.03 \% \quad 3.9 \%$ TQMAEVLPSPR

$0.02 \% \quad 3.9 \% \quad$ LCNIFSTK

$0.02 \% \quad 3.9 \%$ HVDYVVDQVVGK

$0.02 \% \quad 3.9 \%$ AGVSVKPFQVK

$0.02 \% \quad 3.9 \%$ SLAVSGLGVIGR

$9 \quad 0.02 \% \quad 3.9 \%$ IVGLQYKK

$\quad 0.02 \% \quad 3.9 \%$ SYDDAESLKTLR

$66 \quad 227 \quad 0.48 \% \quad 13.0 \%$ LQETLSAADR

$66 \quad 227 \quad 0.48 \% \quad 13.0 \%$ CGAALAGHQLIR

$\begin{array}{lllll}66 & 227 & 0.48 \% & 13.0 \% & \text { LPVLAGCLK }\end{array}$

$66 \quad 227 \quad 0.48 \% \quad 13.0 \%$ YAVPSAGLR

$66 \quad 227 \quad 0.48 \% \quad 13.0 \%$ NVDSNNKELSIAIR

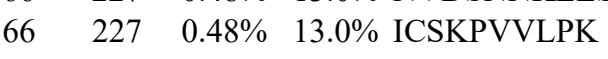

$66 \quad 227 \quad 0.48 \% \quad 13.0 \%$ GPESESEDHRASGEVR

$\begin{array}{lllll}66 & 227 & 0.48 \% & 13.0 \% & \text { IKYFEGVSPK }\end{array}$

$66 \quad 227 \quad 0.48 \% \quad 13.0 \%$ FGKEVAVK

$\begin{array}{llll}66 & 227 & 0.48 \% & 13.0 \% \text { GFNKVVLK }\end{array}$

$66 \quad 227 \quad 0.48 \% \quad 13.0 \%$ NLLTVTSSDEMMK $\begin{array}{llllllll}99.7 \% & 66.3 & 25.0 & 65.6 & 4 & 0 & 0 & 1164.62\end{array}$

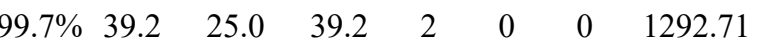

$\begin{array}{llllllll}99.7 \% & 32.3 & 25.0 & 26.6 & 2 & 0 & 0 & 1168.57\end{array}$

1749.85

1033.56

1059.60

1093.60

1694.92

1707.87

1000.48

1449.68

1144.67

1317.70

1574.77

1094.58

1981.05

1187.67

1029.61

1363.68

1473.82

1208.60

1112.56

1470.60

1448.71

982.50

1267.65

1128.67

1094.60

948.59

1228.64

982.50

1357.71

1159.68

1128.67

948.59

1397.69

1103.57

1266.67

970.58

933.52

1572.83

1140.68

1741.77

1167.64

877.51

904.56

$\begin{array}{llll}99.0 \% & 30.1 & 25.0 & 22.4\end{array}$

$\begin{array}{llll}99.7 \% & 47.9 & 25.0 & 42.4\end{array}$

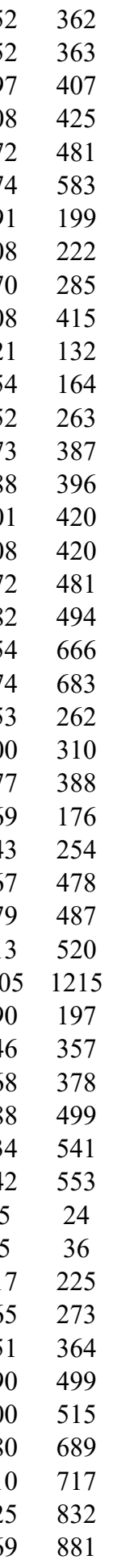

Page 28 of Table S-1-3 
DNA-dependent protein kinase catalytic subunit GN=PRKDC PRKDC_HUMAN $469.10 \quad 100.0 \% \quad 54$ DNA-dependent protein kinase catalytic subunit GN=PRKDC PRKDC_HUMAN $469.10 \quad 100.0 \% \quad 54$ DNA-dependent protein kinase catalytic subunit GN=PRKDC PRKDC_HUMAN $469.10 \quad 100.0 \% \quad 54$ DNA-dependent protein kinase catalytic subunit GN=PRKDC PRKDC_HUMAN $469.10 \quad 100.0 \% \quad 54$ DNA-dependent protein kinase catalytic subunit GN=PRKDC PRKDC_HUMAN $469.10 \quad 100.0 \% \quad 54$ DNA-dependent protein kinase catalytic subunit GN=PRKDC PRKDC_HUMAN $469.10 \quad 100.0 \% \quad 54$ DNA-dependent protein kinase catalytic subunit GN=PRKDC PRKDC_HUMAN $469.10 \quad 100.0 \% \quad 54$ DNA-dependent protein kinase catalytic subunit GN=PRKDC PRKDC_HUMAN $469.10 \quad 100.0 \% \quad 5$ DNA-dependent protein kinase catalytic subunit GN=PRKDC PRKDC HUMAN $469.10 \quad 100.0 \%$ DNA-dependent protein kinase catalytic subunit GN=PRKDC PRKDC_HUMAN $469.10 \quad 100.0 \% \quad 54$ DNA-dependent protein kinase catalytic subunit GN=PRKDC PRKDC_HUMAN $469.10 \quad 100.0 \%$ DNA-dependent protein kinase catalytic subunit GN=PRKDC PRKDC_HUMAN $469.10 \quad 100.0 \%$ DNA-dependent protein kinase catalytic subunit GN=PRKDC PRKDC_HUMAN $469.10 \quad 100.0 \%$ DNA-dependent protein kinase catalytic subunit GN=PRKDC PRKDC_HUMAN $469.10 \quad 100.0 \%$ DNA-dependent protein kinase catalytic subunit GN=PRKDC PRKDC_HUMAN $469.10 \quad 100.0 \%$ DNA-dependent protein kinase catalytic subunit GN=PRKDC PRKDC_HUMAN 469.10 $100.0 \%$ DNA-dependent protein kinase catalytic subunit GN=PRKDC PRKDC HUMAN $469.10 \quad 100.0 \%$ DNA-dependent protein kinase catalytic subunit GN=PRKDC PRKDC_HUMAN $469.10 \quad 100.0 \%$ DNA-dependent protein kinase catalytic subunit GN=PRKDC PRKDC_HUMAN $469.10 \quad 100.0 \%$ DNA-dependent protein kinase catalytic subunit GN=PRKDC PRKDC_HUMAN $469.10 \quad 100.0 \%$ DNA-dependent protein kinase catalytic subunit GN=PRKDC PRKDC_HUMAN $469.10 \quad 100.0 \%$ DNA-dependent protein kinase catalytic subunit GN=PRKDC PRKDC_HUMAN $469.10 \quad 100.0 \%$ DNA-dependent protein kinase catalytic subunit GN=PRKDC PRKDC_HUMAN $469.10 \quad 100.0 \%$ DNA-dependent protein kinase catalytic subunit GN=PRKDC PRKDC_HUMAN $469.10 \quad 100.0 \%$ DNA-dependent protein kinase catalytic subunit GN=PRKDC PRKDC_HUMAN $469.10 \quad 100.0 \%$ DNA-dependent protein kinase catalytic subunit GN=PRKDC PRKDC_HUMAN $469.10 \quad 100.0 \%$ DNA-dependent protein kinase catalytic subunit GN=PRKDC PRKDC_HUMAN $469.10 \quad 100.0 \%$ DNA-dependent protein kinase catalytic subunit GN=PRKDC PRKDC_HUMAN $469.10 \quad 100.0 \%$ DNA-dependent protein kinase catalytic subunit GN=PRKDC PRKDC_HUMAN $469.10 \quad 100.0 \%$ DNA-dependent protein kinase catalytic subunit GN=PRKDC PRKDC HUMAN 469.10 $100.0 \%$ DNA-dependent protein kinase catalytic subunit GN=PRKDC PRKDC_HUMAN $469.10 \quad 100.0 \%$ DNA-dependent protein kinase catalytic subunit GN=PRKDC PRKDC_HUMAN $469.10 \quad 100.0 \%$ DNA-dependent protein kinase catalytic subunit GN=PRKDC PRKDC HUMAN $469.10 \quad 100.0 \%$ DNA-dependent protein kinase catalytic subunit GN=PRKDC PRKDC_HUMAN $469.10 \quad 100.0 \%$ DNA-dependent protein kinase catalytic subunit GN=PRKDC PRKDC_HUMAN $469.10 \quad 100.0 \%$ DNA-dependent protein kinase catalytic subunit GN=PRKDC PRKDC_HUMAN $469.10 \quad 100.0 \%$ DNA-dependent protein kinase catalytic subunit GN=PRKDC PRKDC_HUMAN $469.10 \quad 100.0 \%$ DNA-dependent protein kinase catalytic subunit GN=PRKDC PRKDC HUMAN $469.10 \quad 100.0 \%$ DNA-dependent protein kinase catalytic subunit GN=PRKDC PRKDC_HUMAN $469.10 \quad 100.0 \%$ DNA-dependent protein kinase catalytic subunit GN=PRKDC PRKDC_HUMAN $469.10 \quad 100.0 \%$ DNA-dependent protein kinase catalytic subunit GN=PRKDC PRKDC HUMAN 469.10 100.0\% DNA-dependent protein kinase catalytic subunit GN=PRKDC PRKDC_HUMAN $469.10 \quad 100.0 \%$ DNA-dependent protein kinase catalytic subunit GN=PRKDC PRKDC_HUMAN $469.10 \quad 100.0 \%$ DNA-directed RNA polymerase I subunit RPA1 GN=POLR1A RPA1_HUMAN $194.81 \quad 100.0 \%$ DNA-directed RNA polymerase I subunit RPA1 GN=POLR1A RPA1_HUMAN $194.81 \quad 100.0 \%$ DNA-directed RNA polymerase I subunit RPA34 GN=CD3EAP RPA34 HUMAN $54.99 \quad 100.0 \%$ DNA-directed RNA polymerase I subunit RPA34 GN=CD3EAP RPA34_HUMAN $54.99 \quad 100.0 \%$

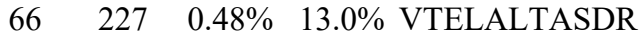
$66 \quad 227 \quad 0.48 \% \quad 13.0 \%$ VTELALTASDRQTK

$\begin{array}{lllll}66 & 227 & 0.48 \% & 13.0 \% & \text { LACDVDQVTR }\end{array}$

$66 \quad 227 \quad 0.48 \% \quad 13.0 \%$ FVPLLPGNR

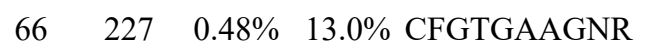

$66 \quad 227 \quad 0.48 \% \quad 13.0 \%$ TSPQEGERYNYSK

$66 \quad 227 \quad 0.48 \% \quad 13.0 \%$ DLCNTHLMR

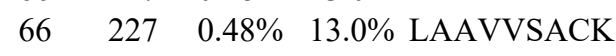

$\begin{array}{llll}66 & 227 & 0.48 \% & 13.0 \% \\ 6 & \text { GIAPGDER }\end{array}$

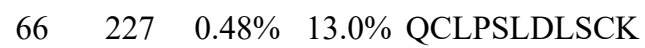

$\begin{array}{lllll}66 & 227 & 0.48 \% & 13.0 \% & \text { FNNYVDCMKK }\end{array}$

$66 \quad 227 \quad 0.48 \% \quad 13.0 \%$ LNESTFDTQITK

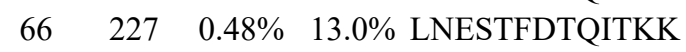

$66 \quad 227 \quad 0.48 \% \quad 13.0 \%$ ILDVMYSR

$\begin{array}{llll}66 & 227 & 0.48 \% & 13.0 \% \\ 66 & \text { LPKDDVHAK }\end{array}$

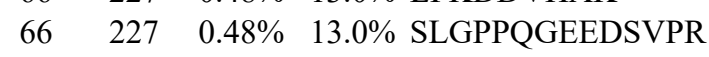

$66 \quad 227 \quad 0.48 \% \quad 13.0 \%$ SKDFVQVMR

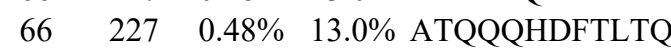

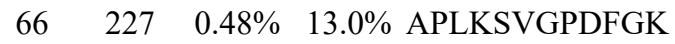

$66 \quad 227 \quad 0.48 \% \quad 13.0 \%$ LGLPGDEVDNKVK

$66 \quad 227 \quad 0.48 \% \quad 13.0 \%$ GAAGRTDLLR

$\begin{array}{lllll}66 & 227 & 0.48 \% & 13.0 \% & \text { MKQDAQVVLYR }\end{array}$

$66 \quad 227 \quad 0.48 \% \quad 13.0 \%$ HGDLPDIQIK

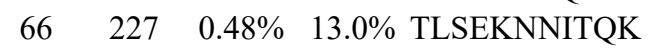

$\begin{array}{llll}66 & 227 & 0.48 \% & 13.0 \% \\ 6 & \text { LLEEALLR }\end{array}$

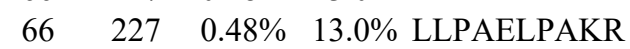

$66 \quad 227 \quad 0.48 \% \quad 13.0 \%$ SIGEYDVLR

$66 \quad 227 \quad 0.48 \% \quad 13.0 \%$ GIFTSEIGTK

$\begin{array}{lllll}66 & 227 & 0.48 \% & 13.0 \% & \text { QITQSALLAEAR }\end{array}$

$\begin{array}{lllll}66 & 227 & 0.48 \% & 13.0 \% & \text { QGNLSSQVPLKR }\end{array}$

$\begin{array}{lllll}66 & 227 & 0.48 \% & 13.0 \% & \text { KQNNFSLAMK }\end{array}$

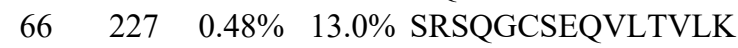

$66 \quad 227 \quad 0.48 \% \quad 13.0 \%$ SQGCSEQVLTVLK

$66 \quad 227 \quad 0.48 \% \quad 13.0 \%$ ALKLNSNEAR

$\begin{array}{llll}66 & 227 & 0.48 \% & 13.0 \%\end{array}$

$66 \quad 227 \quad 0.48 \% \quad 13.0 \%$ MYAALGDPK

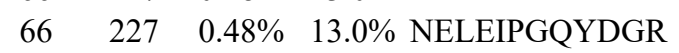

$\begin{array}{llll}66 & 227 & 0.48 \% & 13.0 \%\end{array}$

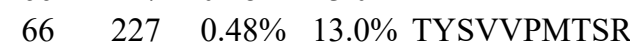

$66 \quad 227 \quad 0.48 \% \quad 13.0 \%$ GANRTETVTSFR

$\begin{array}{llll}66 & 227 & 0.48 \% & 13.0 \%\end{array}$

$\begin{array}{lllll}66 & 227 & 0.48 \% & 13.0 \% & \text { VPADLLKR }\end{array}$

$66 \quad 227 \quad 0.48 \% \quad 13.0 \%$ AQEPESGLSEETQVK

$2 \quad 0.00 \% \quad 1.1 \%$ SPGTQEMLR

$2 \quad 0.00 \% \quad 1.1 \%$ DLDNAGELGR

$6 \quad 0.01 \% \quad 5.3 \% \quad$ FCAFGGNPPVTGPR

$6 \quad 0.01 \% \quad 5.3 \%$ SALAPNLLTSGK $\begin{array}{llll}99.7 \% & 50.3 & 25.0 & 49.7\end{array}$

$99.7 \% \quad 66.4 \quad 25.0 \quad 52.5$

$\begin{array}{llll}99.0 \% & 19.3 & 25.0 & 19.3\end{array}$

$99.7 \% \quad 48.1 \quad 25.0 \quad 48.1$

$\begin{array}{llll}99.7 \% & 29.4 & 25.0 & 29 .\end{array}$

$99.7 \% \quad 40.7 \quad 25.0$

$99.7 \% \quad 42.1 \quad 25.0$

$96.5 \% \quad 17.5 \quad 25.0$

$99.7 \% \quad 45.6 \quad 25.0$

$99.7 \% \quad 31.0 \quad 25.0$

$99.7 \% \quad 54.6 \quad 25.0$

$99.0 \% \quad 43.7$

$99.0 \% \quad 28.2$

$99.7 \% \quad 63.3$

$99.7 \% \quad 48.7$

$99.7 \% 53.5$

$99.0 \% \quad 20.6$

$99.7 \% \quad 40.2$

$99.1 \% \quad 30.5$

$99.7 \% \quad 68.0$

$99.7 \% \quad 59.9$

$99.3 \% \quad 26.9$

$99.0 \% \quad 52.0$

$99.7 \% \quad 31.9$

$99.7 \% \quad 39.8$

$99.7 \% \quad 47.4$

$99.7 \% \quad 56.2$

$99.7 \% \quad 42.8$

$99.7 \% \quad 27.7$

$\begin{array}{lll}99.7 \% & 26.0\end{array}$

$99.7 \% \quad 51.7$

$99.7 \% \quad 39.1$

$99.0 \% \quad 34.9$

$99.7 \% \quad 39.5$

$99.7 \% \quad 30.2$

$99.0 \% 39.4$

$99.7 \% \quad 45.5$

$99.7 \% \quad 28.9$

$99.0 \% 27.6$

$99.0 \% \quad 25.0$

$99.7 \% \quad 29.4$

$96.5 \% 21.3$

$99.2 \% \quad 22.1$

$99.7 \% \quad 47.4$

$99.7 \% \quad 42.0$
117
175.63

532.83

176.57

1010.45
1558.71

1159.53

918.51

814.41

1320.63

1318.59

1396.70

1524.79

996.52

1022.56

1467.71

1109.58

1917.91

1215.67

1383.75

1029.58

1350.72

1135.61

1275.69

$\begin{array}{lll}956.58 & 2892 & 2899\end{array}$

107.69

$\begin{array}{lll}1051.54 & 2932 & 2940\end{array}$

29412950

$\begin{array}{lll}1300.72 & 2951 & 2962\end{array}$

$\begin{array}{lll}326.75 & 3148 & 3159\end{array}$

$\begin{array}{lll}1180.61 & 3248 & 3257\end{array}$

$1691.87 \quad 3288 \quad 3302$

$\begin{array}{lll}1448.74 & 3290 & 3302\end{array}$

$\begin{array}{lll}1115.62 & 3453 & 3462\end{array}$

$1082.53 \quad 3605 \quad 3612$

$3613 \quad 3621$

$\begin{array}{lll}1390.66 & 3697 & 3708\end{array}$

$876.50 \quad 3726 \quad 3733$

$\begin{array}{lll}1140.57 & 3790 & 3799\end{array}$

$\begin{array}{lll}1338.68 & 3861 & 3872\end{array}$

$940.47 \quad 3865 \quad 3872$

$\begin{array}{lll}911.57 & 3878 & 3885\end{array}$

$\begin{array}{lll}631.78 & 4091 & 4105\end{array}$

$\begin{array}{lll}1018.50 & 1114 & 1122\end{array}$

$1059.51 \quad 1376 \quad 1385$

$\begin{array}{lll}1476.71 & 149 & 162\end{array}$

$1171.67 \quad 163 \quad 174$ 
DNA-directed RNA polymerase I subunit RPA34 GN=CD3EAP RPA34_HUMAN $54.99 \quad 100.0 \%$ DNA-directed RNA polymerase II subunit RPB3 GN=POLR2C RPB3_HUMAN $31.44 \quad 100.0 \%$ DNA-directed RNA polymerase II subunit RPB3 GN=POLR2C RPB3_HUMAN $31.44 \quad 100.0 \%$ DNA-directed RNA polymerases I and III subunit RPAC1 GN=POLRIC RPAC1_HUMAN $39.25 \quad 100.0 \%$ DNA-directed RNA polymerases I and III subunit RPACI GN=POLRIC RPAC1_HUMAN $39.25 \quad 100.0 \%$ DnaJ homolog subfamily A member 1 GN=DNAJA1 DNJA1_HUMAN $44.87 \quad 100.0 \%$ DnaJ homolog subfamily A member 1 GN=DNAJA1 DNJA1_HUMAN $44.87 \quad 100.0 \%$ DnaJ homolog subfamily A member 1 GN=DNAJA1 DNJA1_HUMAN $44.87 \quad 100.0 \%$ DnaJ homolog subfamily A member $1 \mathrm{GN}=$ DNAJA1 DNJA1_HUMAN $44.87 \quad 100.0 \%$ DnaJ homolog subfamily A member 2 GN=DNAJA2 DNJA2_HUMAN $45.75 \quad 100.0 \%$ DnaJ homolog subfamily A member 2 GN=DNAJA2 DNJA2_HUMAN $45.75 \quad 100.0 \%$ DnaJ homolog subfamily A member 2 GN=DNAJA2 DNJA2_HUMAN 45.75 DnaJ homolog subfamily A member 3, mitochondrial GN=DNAJA3 DNJA3_HUMAN $52.49 \quad 100.0 \%$ DnaJ homolog subfamily A member 3, mitochondrial GN=DNAJA3 DNJA3_HUMAN $52.49 \quad 100.0 \%$ DnaJ homolog subfamily A member 3 , mitochondrial GN=DNAJA3 DNJA3_HUMAN $52.49 \quad 100.0 \%$ DnaJ homolog subfamily A member 3, mitochondrial GN=DNAJA3 DNJA3_HUMAN $52.49 \quad 100.0 \%$ DnaJ homolog subfamily C member $10 \mathrm{GN}=$ DNAJC10 DJC10_HUMAN $91.08 \quad 100.0 \%$ DnaJ homolog subfamily C member $10 \mathrm{GN}=$ DNAJC10 DJC10_HUMAN $91.08 \quad 100.0 \%$ DnaJ homolog subfamily $\mathrm{C}$ member $10 \mathrm{GN}=$ DNAJC10 DJC10_HUMAN $91.08 \quad 100.0 \%$ DnaJ homolog subfamily C member $10 \mathrm{GN}=$ DNAJC10 DJC10_HUMAN $91.08 \quad 100.0 \%$ DnaJ homolog subfamily C member $10 \mathrm{GN}=$ DNAJC10 DJC10_HUMAN $91.08 \quad 100.0 \%$ DnaJ homolog subfamily C member 10 GN=DNAJC10 DJC10_HUMAN $91.08 \quad 100.0 \%$ DnaJ homolog subfamily C member $10 \mathrm{GN}=$ DNAJC10 DJC10_HUMAN $91.08 \quad 100.0 \%$ DnaJ homolog subfamily C member 10 GN=DNAJC10 DJC10_HUMAN $91.08 \quad 100.0 \%$ DnaJ homolog subfamily $C$ member $10 \mathrm{GN}=$ DNAJC10 DJC10_HUMAN $91.08 \quad 100.0 \%$ DnaJ homolog subfamily C member $10 \mathrm{GN}=$ DNAJC10 DJC10_HUMAN $91.08 \quad 100.0 \%$ DnaJ homolog subfamily C member 11 GN=DNAJC11 DJC11_HUMAN $63.28 \quad 100.0 \%$ DnaJ homolog subfamily C member 11 GN=DNAJC11 DJC11_HUMAN $63.28 \quad 100.0 \%$ DnaJ homolog subfamily C member 11 GN=DNAJC11 DJC11_HUMAN $63.28 \quad 100.0 \%$ DnaJ homolog subfamily C member 11 GN=DNAJC11 DJC11 HUMAN $63.28 \quad 100.0 \%$ DnaJ homolog subfamily C member 13 GN=DNAJC13 DJC13_HUMAN $254.42 \quad 100.0 \%$ DnaJ homolog subfamily C member 13 GN=DNAJC13 DJC13_HUMAN $254.42 \quad 100.0 \%$ DnaJ homolog subfamily C member 13 GN=DNAJC13 DJC13_HUMAN $254.42 \quad 100.0 \%$ DnaJ homolog subfamily C member 13 GN=DNAJC13 DJC13_HUMAN $254.42 \quad 100.0 \%$ DnaJ homolog subfamily C member $13 \mathrm{GN}=$ DNAJC13 DJC13_HUMAN $254.42 \quad 100.0 \%$ Dolichol-phosphate mannosyltransferase subunit 1 GN=DPM1 DPM1_HUMAN $29.64 \quad 100.0 \%$ Dolichol-phosphate mannosyltransferase subunit 1 GN=DPM1 DPM1_HUMAN $29.64 \quad 100.0 \%$ Dolichol-phosphate mannosyltransferase subunit 1 GN=DPM1 DPM1_HUMAN $29.64 \quad 100.0 \%$ Dolichol-phosphate mannosyltransferase subunit 1 GN=DPM1 DPM1_HUMAN $29.64 \quad 100.0 \%$ Dolichol-phosphate mannosyltransferase subunit 1 GN=DPM1 DPM1_HUMAN $29.64 \quad 100.0 \%$ Dolichy-diphosphooligosaccharide--protein glycosyltransferase 48 kDa subunit GN=DDOST OST48_HUMAN $50.80 \quad 100.0 \%$ $\begin{array}{lll} & \\ \text { OST48_HUMAN } & 50.80 & 100.0 \%\end{array}$ OST OS HUMAN $50.80 \quad 100.0 \%$ RPN1_HUMAN $68.57 \quad 100.0 \%$ NPN1_HUMAN $68.57 \quad 100.0 \%$ RPN1_HUMAN $68.57 \quad 100.0 \%$ $100.0 \%$
$6 \quad 0.01 \% \quad 5.3 \% \quad$ SALAPNLLTSGKK $0.00 \% \quad 6.2 \% \quad$ PYANQPTVR $0.00 \% \quad 6.2 \%$ DLISNSPR $0.01 \% \quad 5.5 \% \quad$ VVLGEFGVR $0.01 \% \quad 5.5 \% \quad$ FSPVATASYR $0.02 \% \quad 11.8 \%$ QISQAYEVLSDAK $0.02 \% \quad 11.8 \%$ NVICDKCEGR $0.02 \% \quad 11.8 \%$ TIVITSHPGQIVK $0.02 \% \quad 11.8 \%$ CVLNEGMPIYR $0.01 \% \quad 8.0 \%$ ELYDRYGEQGLR $0.01 \% \quad 8.0 \%$ NVLCSACSGQGGK $0.01 \% \quad 8.0 \% \quad$ VIEPGCVR $0.02 \% \quad 9.2 \%$ GSIIISPCVVCR $0.02 \% \quad 9.2 \%$ EIFITFRVQK $0.02 \% \quad 9.2 \%$ MGGKGIPR $0.02 \% \quad 9.2 \%$ INSYGYGDHYIHIK $0.06 \% \quad 11.9 \%$ IGAVNCGDDRMLCR $0.06 \% \quad 11.9 \%$ SGMAPVKYHGDR $0.06 \% \quad 11.9 \%$ GGDCLTSQTR $0.06 \% \quad 11.9 \%$ TLLKNDHIQVGR $0.06 \% 11.9 \%$ ALLPELRR $0.06 \% \quad 11.9 \%$ ASNLLYGQLK $0.06 \% 11.9 \%$ AGKVDCQAYAQTCQK $0.06 \% \quad 11.9 \%$ VDCQAYAQTCQK $0.06 \% \quad 11.9 \%$ NFQEEQINTR $0.06 \% \quad 11.9 \%$ NFQEEQINTRDAK $0.01 \% \quad 7.9 \%$ EASSEELKAAYR $0.01 \% \quad 7.9 \%$ AIYDIYGKR $0.01 \% \quad 7.9 \%$ GIRPGLTTVLAR $0.01 \% \quad 7.9 \%$ DSKLILTEASK $0.01 \% \quad 2.2 \%$ GQGTEFNLTFR $0.01 \% \quad 2.2 \%$ SNLIWNFK $0.01 \% \quad 2.2 \%$ TQSILFNR $0.01 \% \quad 2.2 \%$ SEETNQQEVANSLAK $0.01 \% \quad 2.2 \% \quad$ LSVHALSR $0.02 \% \quad 17.3 \%$ LGLGTAYIHGMK $0.02 \% \quad 17.3 \%$ QKEGNFDIVSGTR $0.02 \% \quad 17.3 \%$ EGNFDIVSGTR $0.02 \% \quad 17.3 \%$ EVLEKLIEK $0.02 \% \quad 17.3 \%$ LGGNEIVSFLK $0.01 \% \quad 7.7 \%$ SSLNPILFR $\begin{array}{lll}0.01 \% & 7.7 \% & \text { NTLLIAGLQAR }\end{array}$ $0.01 \% \quad 7.7 \% \quad$ YSQTGNYELAVALSR $0.02 \% \quad 8.1 \%$ YDYQRQPDSGISSIR $0.02 \% \quad 8.1 \%$ NIEIDSPYEISR $0.02 \% \quad 8.1 \%$ DISTLNSGKK $0.02 \% \quad 8.1 \%$ SAVEAERLVAGK
$99.7 \% \quad 57.9$

$99.7 \% \quad 47.8$

$99.7 \% \quad 32.2$

$99.7 \% \quad 55.4$

$99.7 \% \quad 38.2$

$99.4 \% 25.9$

$99.7 \% \quad 67.3$

$99.0 \% \quad 45.2$

$99.7 \% \quad 53.8$

$99.7 \% \quad 29.5$

$\begin{array}{lll}98.9 \% & 26.2\end{array}$

$99.4 \% \quad 21.2$

$99.7 \% \quad 39.9$

$\begin{array}{lll}95.2 \% & 16.5\end{array}$

$\begin{array}{lll}99.0 \% & 30.7\end{array}$

$99.7 \% \quad 38.3$

$99.0 \% \quad 22.0$

$99.7 \% \quad 54.5$

$99.7 \% \quad 57.7$

$99.7 \% \quad 44.8$

$99.7 \% \quad 67.5$

$99.7 \% \quad 40.7$

$99.7 \% \quad 56.5$

$99.7 \% \quad 46.7$

$99.7 \% \quad 32.6$

$99.7 \% \quad 30.1$

$99.7 \% \quad 42.2$

$99.0 \% \quad 28.1$

$99.0 \% \quad 26.3$

$99.7 \% \quad 61.9$

$\begin{array}{lll}99.0 \% & 34.8\end{array}$

$99.7 \% \quad 30.8$

$99.7 \% \quad 46.6$

$99.7 \% \quad 53.2$

$\begin{array}{lll}94.7 \% & 17.8\end{array}$

$99.7 \% \quad 46.0$

$99.7 \% \quad 44.9$

$99.7 \% \quad 81$.

$99.7 \% \quad 62.9$

$99.7 \% \quad 33.1$

$99.7 \% \quad 58.6$

$98.6 \% \quad 23.1$

$99.7 \% \quad 55.0$

6.4

5.8

5.8

$25.0 \quad 54.3$

$\begin{array}{ll}0 & 44.9\end{array}$

$\begin{array}{ll}06.5 & 2\end{array}$

$\begin{array}{lll}5.0 & 55.4 & 2\end{array}$

\begin{tabular}{ll}
5.0 & 25.9 \\
\hline
\end{tabular}

\begin{tabular}{ll}
67.3 \\
\hline
\end{tabular}

\begin{tabular}{ll}
40.0 \\
\hline
\end{tabular}

.0 28.6

$25.0 \quad 17.3$

$25.0 \quad 21.2$

$\begin{array}{ll}0 & 39.9\end{array}$

$\begin{array}{ll}.0 & 16.5\end{array}$

$\begin{array}{ll}.0 & 10.4\end{array}$

38.3

$\begin{array}{ll}0 & 22.0 \\ & \end{array}$

$\begin{array}{ll}0 & 48.0\end{array}$

$25.0 \quad 57.7$

$\begin{array}{lll}25.0 & 44.1 & 2\end{array}$

$\begin{array}{lll}0 & 49.3 & 2\end{array}$

$\begin{array}{lll} & 26.7 & 2\end{array}$

$\begin{array}{lll}26.0 & 46.3 \quad 2\end{array}$

$\begin{array}{lll}38.0 & 2\end{array}$

.0 20.0

$\begin{array}{ll}30.0 & 30.1\end{array}$

$\begin{array}{lll}25 & 35.4 \quad 2\end{array}$

$\begin{array}{lll}5.0 & 28.1 \quad 1\end{array}$

$\begin{array}{ll}.0 & 26.3\end{array}$

$5.0 \quad 58.7$

\begin{tabular}{ll}
25.0 & 28.0 \\
\hline 5.0 & 30.8
\end{tabular}

$\begin{array}{lll}25.0 & 30.8 & 2\end{array}$

$\begin{array}{ll}58.0 & 38.3 \\ 25.0 & 41.7\end{array}$

$\begin{array}{ll}0 & 41.7\end{array}$

$\begin{array}{ll}.0 & 15.8 \\ 37.6 & 30.5\end{array}$

\begin{tabular}{ll}
0 & 37.6 \\
\hline & 30.5
\end{tabular}

$\begin{array}{ll}.0 & 62 . \\ .0 & 62.9\end{array}$

\begin{tabular}{ll}
62.0 & 62.9 \\
\hline
\end{tabular}

$\begin{array}{lll} & 27.7 & 0 \\ .0 & 49.0 & 2\end{array}$

$\begin{array}{lll}.0 & 49.0 & 2 \\ 5.0 & 15.3 & 2\end{array}$

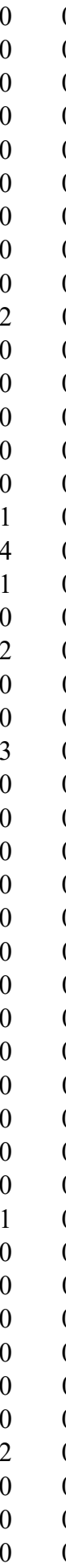

1045.54

901.47

975.56

1098.56

1451.74

1250.56

1392.82

1351.65

1498.73

1337.59

929.49

1360.71

1280.74

815.46

1679.82

1636.74

1317.64

1094.49

1393.79

967.60

1106.62

1727.78

1471.63

1278.61

1592.77

1353.66

1098.59

1253.77

1204.68

1269.62

1021.55

978.54

1647.78

882.52

1260.68

1450.73

1194.58

1100.66

1176.66

1046.60

1169.70

1671.83

1784.86

1435.71

1062.58

1229.68

175
10
126
22
234
59
140
296
312
75
152
310
293
335
395
409
194
220
276
400
492
502
737
737
766
769
35
84
260
508
73
576
779
1382
1580
1588
107
147
147
201
251
198
250
297

Page 30 of Table S-1-3 

Dual specificity protein kinase CLK2 GN=CLK2 CLK2_HUMAN $60.09 \quad 100.0 \%$ Dual specificity protein kinase CLK2 GN=CLK2 CLK2 HUMAN $60.09 \quad 100.0 \%$ Dynamin-2 GN=DNM2

Dynamin-2 GN=DNM2 DYN2_HUMAN $98.07 \quad 100.0 \%$ Dynamin -2 GN=DNM2 Dynein assembly factor 5, axonemal GN=DNAAF5 DAAF5_HUMAN $93.52 \quad 100.0 \%$ Dynein assembly factor 5, axonemal GN=DNAAF5 DAAF5_HUMAN $93.52 \quad 100.0 \%$ Dynein assembly factor 5, axonemal GN=DNAAF5 DAAF5_HUMAN $93.52 \quad 100.0 \%$ Dynein assembly factor 5, axonemal GN=DNAAF5 DAAF5_HUMAN $93.52 \quad 100.0 \%$ E3 ubiquitin-protein ligase HUWE1 GN=HUWE1 HUWE1_HUMAN $481.89 \quad 100.0 \%$ E3 ubiquitin-protein ligase HUWE1 GN=HUWE1 HUWE1_HUMAN $481.89 \quad 100.0 \%$ E3 ubiquitin-protein ligase HUWE1 GN=HUWE1 HUWE1 HUMAN $481.89 \quad 100.0 \%$ E3 ubiquitin-protein ligase HUWE1 GN=HUWE1 HUWE1_HUMAN $481.89 \quad 100.0 \%$ E3 ubiquitin-protein ligase TRIM21 GN=TRIM21 RO52_HUMAN $54.17 \quad 100.0 \%$ E3 ubiquitin-protein ligase TRIM21 GN=TRIM21 RO52 HUMAN $54.17 \quad 100.0 \%$ E3 ubiquitin-protein ligase TRIM21 GN=TRIM21 RO52_HUMAN $54.17 \quad 100.0 \%$ E3 ubiquitin-protein ligase TRIP12 GN=TRIP12 TRIPC_HUMAN $220.44 \quad 100.0 \%$ E3 ubiquitin-protein ligase TRIP12 GN=TRIP12 TRIPC_HUMAN $220.44 \quad 100.0 \%$ E3 ubiquitin-protein ligase UBR4 GN=UBR4 UBR4_HUMAN $573.84 \quad 100.0 \%$ E3 ubiquitin-protein ligase UBR4 GN=UBR4 UBR4 HUMAN $573.84 \quad 100.0 \%$ E3 ubiquitin-protein ligase UBR4 GN=UBR4 UBR4_HUMAN $573.84 \quad 100.0 \%$ E3 UFM1-protein ligase $1 \mathrm{GN}=$ UFL1 UFL1_HUMAN $89.60 \quad 100.0 \%$ E3 UFM1-protein ligase $1 \mathrm{GN}=\mathrm{UFL} 1$ E3 UFM1-protein ligase $1 \mathrm{GN}=\mathrm{UFL} 1$ ELAV-like protein $1 \mathrm{GN}=\mathrm{ELAVL} 1$ ELAV-like protein $1 \mathrm{GN}=\mathrm{ELAVL} 1$ ELAV-like protein $1 \mathrm{GN}=\mathrm{ELAVL}$ ELAV-like protein $1 \mathrm{GN}=\mathrm{ELAVL}$ ELAV-like protein $1 \mathrm{GN}=\mathrm{ELAVL}$ : ELAV-like protein $1 \mathrm{GN}=$ ELAVL1 ELAV-like protein $1 \mathrm{GN}=\mathrm{ELAVL}$ : ELAV-like protein $1 \mathrm{GN}=\mathrm{ELAVL}$ ELAV-like protein $1 \mathrm{GN}=\mathrm{ELAVL} 1$ ELAV-like protein $1 \mathrm{GN}=\mathrm{ELAVL} 1$ ELAV-like protein $2 \mathrm{GN}=\mathrm{ELAVL} 2$ ELAV-like protein $2 \mathrm{GN}=\mathrm{ELAVL}$ ELAV-like protein $2 \mathrm{GN}=$ ELAVL2 ELAV-like protein $2 \mathrm{GN}=\mathrm{ELAVL}$ UFL1_HUMAN $89.60 \quad 100.0 \%$ UFL1_HUMAN $89.60 \quad 100.0 \%$ ELAV1_HUMAN $36.09 \quad 100.0 \%$ ELAV1_HUMAN $36.09 \quad 100.0 \%$ ELAV1_HUMAN $36.09 \quad 100.0 \%$ ELAV1 HUMAN $36.09 \quad 100.0 \%$ ELAV1_HUMAN $36.09 \quad 100.0 \%$ ELAV1_HUMAN $36.09 \quad 100.0 \%$ ELAV1_HUMAN $36.09 \quad 100.0 \%$ ELAV1_HUMAN $36.09 \quad 100.0 \%$ ELAV1 HUMAN $36.09 \quad 100.0 \%$ ELAV1_HUMAN $36.09 \quad 100.0 \%$ ELAV2_HUMAN $39.51 \quad 100.0 \%$ ELAV2 HUMAN $39.51 \quad 100.0 \%$ ELAV2_HUMAN $39.51 \quad 100.0 \%$ ELAV2 HUMAN $39.51 \quad 100.0 \%$ lectron transfer flavoprotein subunit alpha, mitochondrial GN=ETFA ETFA_HUMAN $35.08 \quad 100.0 \%$ Electron transfer flavoprotein subunit alpha, mitochondrial GN=ETFA ETFA_HUMAN $35.08 \quad 100.0 \%$ Electron transfer flavoprotein subunit alpha, mitochondrial GN=ETFA ETFA HUMAN $35.08 \quad 100.0 \%$

$0.01 \% \quad 10.5 \%$ QLSVVVPSYNEEK $0.01 \% \quad 10.5 \%$ MGIFSSRGEK $0.01 \% \quad 10.5 \%$ AHLEKESIAQR $0.01 \% \quad 5.3 \%$ DVKPSNILVNSR $0.01 \% \quad 5.3 \%$ LNQPGTPTR $0.01 \% \quad 3.2 \%$ LEINVLEK

$0.01 \% \quad 3.2 \% \quad$ ILGPIPSR $0.02 \% \quad 3.0 \%$ GISPVPINLR $0.02 \% \quad 3.0 \%$ EVDPQGLR $0.02 \% \quad 3.0 \%$ GYIGVVNR $0.01 \% \quad 4.7 \% \quad$ LLPGLEADSKPGR $0.01 \% \quad 4.7 \%$ CLSDPAEGCR $0.01 \% \quad 4.7 \% \quad$ LLPALAAR $0.01 \% \quad 4.7 \% \quad$ LFDDVPQVR $0.01 \% \quad 1.3 \%$ SHHAASTTTAPTPAAR $0.01 \% \quad 1.3 \%$ SAATSGAGSTTSGVVSGSLGS $0.01 \% \quad 1.3 \%$ IVNQPSSLFGSK $0.01 \% \quad 1.3 \%$ TNIFQIQR $0.01 \% \quad 6.1 \%$ GGGSVCPVCR $0.01 \% \quad 6.1 \%$ QLANMVNNLK $0.01 \% \quad 6.1 \%$ IHAEFVQQK $0.01 \% \quad 1.2 \% \quad$ SSFLASLNPK $0.01 \% \quad 1.2 \% \quad$ LSTQSNSNNIEPAR $0.01 \% \quad 0.6 \%$ IQIGTQAIER $0.01 \% \quad 0.6 \% \quad$ SLLASLHTSR $0.01 \% \quad 0.6 \%$ TSVQPTFTASQYR $0.01 \% \quad 4.7 \% \quad$ AVFVPDIYSR $0.01 \% \quad 4.7 \% \quad$ SVFMSSTTSASGTGR $0.01 \% \quad 4.7 \% \quad$ FFADDTQAALTK $0.07 \% \quad 30.4 \%$ SLFSSIGEVESAK $0.07 \% \quad 30.4 \%$ AINTLNGLR $0.07 \% \quad 30.4 \%$ AINTLNGLRLQSK $0.07 \% \quad 30.4 \%$ TMTQKDVEDMFSR $0.07 \% \quad 30.4 \%$ VLVDQTTGLSR $0.07 \% \quad 30.4 \%$ GVAFIRFDK $0.07 \% \quad 30.4 \%$ FAANPNQNK $0.07 \% \quad 30.4 \%$ FGGPVHHQAQR $0.07 \% \quad 30.4 \%$ VIRDFNTNK $0.07 \% \quad 30.4 \%$ LGDKILQVSFK $0.01 \% \quad 11.1 \%$ AINTLNGLR $0.01 \% \quad 11.1 \%$ DANLYVSGLPK $0.01 \% \quad 11.1 \%$ ILVDQVTGISR $0.01 \% \quad 11.1 \%$ VIRDFNTNK $0.03 \% 24.6 \%$ LGGEVSCLVAGTK $0.03 \% \quad 24.6 \%$ VLVAQHDVYK $0.03 \% \quad 24.6 \%$ TIYAGNALCTVK

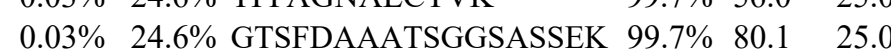

$99.7 \% \quad 46.9$ $99.2 \% \quad 23.5$ $\begin{array}{lll}99.7 \% & 40.8\end{array}$ $99.7 \% \quad 29.7$ $99.0 \% \quad 20.0$ $\begin{array}{lll}99.0 \% & 28.9\end{array}$ $99.0 \% \quad 26.0$ $99.7 \% 33$. $99.0 \% \quad 37.8$ $99.0 \% 39.1$ $99.7 \% \quad 44.7$ $99.7 \% \quad 37.6$ $98.9 \% \quad 19.4$ $99.7 \% \quad 38.2$ $95.4 \% \quad 15.7$

\section{$99.7 \% \quad 31.7$} $99.5 \% \quad 27.5$ $99.0 \% \quad 46.2$ $99.4 \% 23$. $99.7 \% \quad 41.8$ $99.1 \% \quad 24.0$ $99.7 \% \quad 31.9$ $99.7 \% \quad 39.4$ $99.7 \% \quad 32.5$ $98.0 \% \quad 19.1$ $98.2 \% \quad 19.3$ $\begin{array}{lll}98.7 \% & 20.8\end{array}$ $99.7 \% \quad 55.0$ $\begin{array}{lll}99.7 \% & 63.3\end{array}$ $99.7 \% \quad 63.1$ $99.7 \% \quad 56.9$ $99.7 \% \quad 52.1$ $\begin{array}{lll}99.7 \% & 38.3\end{array}$ $99.7 \% \quad 79.4$ $99.5 \% \quad 24.9$ $\begin{array}{lll}99.7 \% & 32.8\end{array}$ $99.7 \% \quad 30.7$ $99.7 \% \quad 34.1$ $99.7 \% \quad 39.8$ $99.7 \% \quad 56.9$ $99.7 \% \quad 40.1$ $99.7 \% \quad 52.2$ $99.7 \% \quad 34.1$ $99.7 \% \quad 85.0$ $99.7 \% \quad 36.5$ $99.7 \% 56.0$
1576.78

1896.93

1276.69

1019.56

1048.47

1144.61

1099.59

1063.58

1530.75

1128.64

1084.61

1485.73

1166.62

1475.68

1327.65

1353.69

971.56

1427.83

1619.70

1188.66

1052.59

1003.50

1233.62

1106.60

1247.74

971.56

1176.63

1200.69

1106.60

1290.67

1171.65

1310.68 1630.72 $\begin{array}{cc}6 & 78 \\ 19 & 158 \\ 8 & 208 \\ 4 & 205 \\ 39 & 397 \\ 7 & 214 \\ 6 & 403 \\ 4 & 123 \\ 2 & 199 \\ 0 & 237 \\ 4 & 46 \\ 4 & 93 \\ 7 & 124 \\ 4 & 262 \\ 84 & 1099 \\ 44 & 1865 \\ 56 & 2267 \\ 98 & 3305 \\ 6 & 55 \\ 8 & 77 \\ 78 & 186 \\ 39 & 1048 \\ 53 & 1066 \\ 54 & 2363 \\ 27 & 2536 \\ 45 & 3857 \\ 12 & 251 \\ 9 & 533 \\ 50 & 571 \\ 8 & 50 \\ 7 & 85 \\ 7 & 89 \\ 6 & 128 \\ 37 & 147 \\ 18 & 156 \\ 33 & 191 \\ 77 & 217 \\ 75 & 283 \\ 0 & 320 \\ 6 & 104 \\ 24 & 134 \\ 66 & 166 \\ 7 & 315 \\ 7 & 59 \\ 6 & 85 \\ 17 & 158 \\ 70 & 187 \\ & \end{array}$ 

Electron transfer flavoprotein subunit beta GN=ETFB ETFB_HUMAN $27.84 \quad 100.0 \%$ Electron transfer flavoprotein subunit beta GN=ETFB ETFB_HUMAN $27.84 \quad 100.0 \%$ ELMO domain-containing protein 2 GN=ELMOD2 ELMD2_HUMAN $34.96 \quad 100.0 \%$ ELMO domain-containing protein 2 GN=ELMOD2 ELMD2_HUMAN $34.96 \quad 100.0 \%$ ELMO domain-containing protein $2 \mathrm{GN}=$ ELMOD2 ELMD2 HUMAN $34.96 \quad 100.0 \%$ Elongation factor 1-alpha $1 \mathrm{GN}=\mathrm{EEF} 1 \mathrm{~A} 1$ EF1A1_HUMAN $50.14 \quad 100.0 \%$ Elongation factor 1-alpha $1 \mathrm{GN}=\mathrm{EEF} 1 \mathrm{~A} 1 \quad$ EF1A1_HUMAN $50.14 \quad 100.0 \%$ Elongation factor 1-alpha $1 \mathrm{GN}=\mathrm{EEF} 1 \mathrm{~A} 1$ EF1A1_HUMAN $50.14 \quad 100.0 \%$ Elongation factor 1-alpha $1 \mathrm{GN}=\mathrm{EEF} 1 \mathrm{~A} 1 \quad$ EF1A1_HUMAN $50.14 \quad 100.0 \%$ Elongation factor 1-alpha $1 \mathrm{GN}=\mathrm{EEF} 1 \mathrm{~A} 1 \quad$ EF1A1_HUMAN $50.14 \quad 100.0 \%$ Elongation factor 1-alpha $1 \mathrm{GN}=\mathrm{EEF} 1 \mathrm{~A} 1 \quad$ EF1A1_HUMAN $50.14 \quad 100.0 \%$ Elongation factor 1-alpha $1 \mathrm{GN}=\mathrm{EEF} 1 \mathrm{~A} 1 \quad$ EF1A1_HUMAN $50.14 \quad 100.0 \%$ Elongation factor 1-alpha $1 \mathrm{GN}=\mathrm{EEF} 1 \mathrm{~A} 1 \quad$ EF1A1_HUMAN $50.14 \quad 100.0 \%$ Elongation factor 1-alpha $1 \mathrm{GN}=\mathrm{EEF} 1 \mathrm{~A} 1 \quad$ EF1A1_HUMAN $50.14 \quad 100.0 \%$ Elongation factor 1-alpha $1 \mathrm{GN}=\mathrm{EEF} 1 \mathrm{~A} 1 \quad$ EF1A1_HUMAN $50.14 \quad 100.0 \%$ Elongation factor 1-alpha $1 \mathrm{GN}=\mathrm{EEF} 1 \mathrm{~A} 1$ EF1A1_HUMAN $50.14 \quad 100.0 \%$ Elongation factor 1-delta GN=EEF1D Elongation factor 1-delta GN=EEF1D Elongation factor 1-delta GN=EEF1D Elongation factor 1-delta GN=EEF1D Elongation factor 1-gamma $\mathrm{GN}=\mathrm{EEF} 1 \mathrm{G}$ Elongation factor 1-gamma $\mathrm{GN}=\mathrm{EEF} 1 \mathrm{G}$ Elongation factor 1-gamma $\mathrm{GN}=\mathrm{EEF} 1 \mathrm{G}$ Elongation factor 1-gamma GN=EEF1G Elongation factor 1-gamma GN=EEF1G Elongation factor $2 \mathrm{GN}=\mathrm{EEF} 2$ Elongation factor $2 \mathrm{GN}=\mathrm{EEF} 2$ Elongation factor $2 \mathrm{GN}=\mathrm{EEF} 2$ Elongation factor $2 \mathrm{GN}=\mathrm{EEF} 2$ Elongation factor $2 \mathrm{GN}=\mathrm{EEF} 2$ Elongation factor $2 \mathrm{GN}=\mathrm{EEF} 2$ Elongation factor $2 \mathrm{GN}=\mathrm{EEF} 2$ Elongation factor $2 \mathrm{GN}=\mathrm{EEF} 2$ Elongation factor $2 \mathrm{GN}=\mathrm{EEF} 2$ EF1D_HUMAN $31.12 \quad 100.0 \%$ EF1D HUMAN $31.12 \quad 100.0 \%$ EF1D HUMAN $31.12 \quad 100.0 \%$ EF1D_HUMAN $31.12 \quad 100.0 \%$ EF1G_HUMAN $50.12 \quad 100.0 \%$ EF1G_HUMAN $50.12 \quad 100.0 \%$ EF1G_HUMAN $50.12 \quad 100.0 \%$ EF1G HUMAN $50.12 \quad 100.0 \%$ EF1G_HUMAN $50.12 \quad 100.0 \%$ EF2 HUMAN $95.34 \quad 100.0 \%$ EF2 HUMAN $95.34 \quad 100.0 \%$ EF2 HUMAN $95.34 \quad 100.0 \%$ EF2 HUMAN $95.34 \quad 100.0 \%$ EF2_HUMAN $95.34 \quad 100.0 \%$ EF2 HUMAN $95.34 \quad 100.0 \%$ EF2 HUMAN $95.34 \quad 100.0 \%$ EF2_HUMAN $95.34 \quad 100.0 \%$ EF2 HUMAN $95.34 \quad 100.0 \%$ Elongation factor Tu, mitochondrial GN=TUFM EFTU_HUMAN $49.54 \quad 100.0 \%$ Elongation factor Tu, mitochondrial GN=TUFM EFTU_HUMAN $49.54 \quad 100.0 \%$ Elongation factor Tu, mitochondrial GN=TUFM EFTU_HUMAN $49.54 \quad 100.0 \%$ Elongation factor Tu, mitochondrial GN=TUFM EFTU_HUMAN $49.54 \quad 100.0 \%$ Elongation factor Tu, mitochondrial GN=TUFM EFTU HUMAN $49.54 \quad 100.0 \%$ Elongation factor Tu, mitochondrial GN=TUFM EFTU_HUMAN $49.54 \quad 100.0 \%$ Elongation factor Tu, mitochondrial GN=TUFM EFTU_HUMAN $49.54 \quad 100.0 \%$ Elongation factor Tu, mitochondrial GN=TUFM EFTU HUMAN $49.54 \quad 100.0 \%$ Elongation factor Tu, mitochondrial GN=TUFM EFTU_HUMAN $49.54 \quad 100.0 \%$

$0.01 \% \quad 15.7 \%$ TALAMGADR

$0.01 \% \quad 15.7 \%$ EIDGGLETLR

$6 \quad 0.01 \% \quad 15.7 \%$ LSVISVEDPPQR

$6 \quad 0.01 \% \quad 7.5 \%$ IFDTYVGAQR

$6 \quad 0.01 \% \quad 7.5 \% \quad$ THRIENSLTYSK

$6 \quad 0.01 \% \quad 7.5 \% \quad$ IENSLTYSK

$14 \quad 114 \quad 0.24 \% \quad 22.3 \%$ THINIVVIGHVDSGK

$14 \quad 114 \quad 0.24 \% \quad 22.3 \%$ STTTGHLIYK

$14 \quad 114 \quad 0.24 \% \quad 22.3 \%$ FEKEAAEMGK

$14 \quad 114 \quad 0.24 \% \quad 22.3 \%$ EHALLAYTLGVK

$14 \quad 114 \quad 0.24 \% \quad 22.3 \%$ QLIVGVNK

$14 \quad 114 \quad 0.24 \% \quad 22.3 \%$ EVSTYIKK

$14 \quad 114 \quad 0.24 \% \quad 22.3 \%$ LPLQDVYK

$14 \quad 114 \quad 0.24 \% \quad 22.3 \%$ IGGIGTVPVGR

$14 \quad 114 \quad 0.24 \% \quad 22.3 \%$ LEDGPKFLK

$14 \quad 114 \quad 0.24 \% \quad 22.3 \%$ DMRQTVAVGVIK

$114 \quad 0.24 \% \quad 22.3 \%$ QTVAVGVIK

$0.01 \% \quad 20.6 \%$ SLAGSSGPGASSGTSGDHGELVVR

$0.01 \% \quad 20.6 \%$ IASLEVENQSLR

$0.01 \% \quad 20.6 \%$ ATAPQTQHVSPMR

$0.01 \% \quad 20.6 \%$ LVPVGYGIR

$16 \quad 0.03 \% \quad 12.8 \%$ ALIAAQYSGAQVR

$6 \quad 0.03 \% \quad 12.8 \%$ AVLGEVKLCEK

$16 \quad 0.03 \% \quad 12.8 \%$ MAQFDAKK

$16 \quad 0.03 \% \quad 12.8 \%$ STFVLDEFKR

$16 \quad 0.03 \% \quad 12.8 \%$ KLDPGSEETQTLVR

$38 \quad 0.08 \% \quad 9.3 \% \quad$ VNFTVDQIR

$0.08 \% \quad 9.3 \% \quad$ STLTDSLVCK

$38 \quad 0.08 \% \quad 9.3 \% \quad$ FAAKGEGQLGPAER

$0.08 \% \quad 9.3 \%$ GEGQLGPAER

$\begin{array}{lll}0.08 \% & 9.3 \% & \text { VFSGLVSTGLK }\end{array}$

$0.08 \% \quad 9.3 \%$ VAVEAKNPADLPK

$0.08 \% \quad 9.3 \%$ GGGQIIPTAR

$38 \quad 0.08 \% \quad 9.3 \% \quad$ RCLYASVLTAQPR

$38 \quad 0.08 \% \quad 9.3 \% \quad$ CLYASVLTAQPR

$103 \quad 0.22 \% \quad 34.7 \%$ TTLTAAITK

$103 \quad 0.22 \% \quad 34.7 \%$ ILAEGGGAKFK

$103 \quad 0.22 \% \quad 34.7 \%$ KYEEIDNAPEER

$103 \quad 0.22 \% \quad 34.7 \%$ YEEIDNAPEERAR

$103 \quad 0.22 \% \quad 34.7 \%$ ARGITINAAHVEYSTAAR

$\begin{array}{lll}103 & 0.22 \% & 34.7 \% \\ 103 & 0.22 \% & 34.7 \%\end{array}$

$103 \quad 0.22 \% \quad 34.7 \%$ HYAHTDCPGHADYVK

$103 \quad 0.22 \% \quad 34.7 \%$ QIGVEHVVVYVNK

$103 \quad 0.22 \% \quad 34.7 \%$ GTVVTGTLER
$99.7 \% 48.6$ $96.6 \% \quad 17.4$

$99.3 \% \quad 26.6$

$99.5 \% \quad 26.7$

$99.7 \% \quad 38.1$

$\begin{array}{lll}99.7 \% & 44.3\end{array}$

$99.7 \% \quad 61.5$

$99.7 \% \quad 29.7$

$98.5 \% \quad 19.5$

$99.7 \% \quad 69.9$

$99.7 \% \quad 51.7$

$99.7 \% \quad 31.0$

$99.7 \% \quad 63.0$

$99.0 \% \quad 32.6$

$99.0 \% \quad 60.5$

$99.0 \% \quad 35.9$

$99.7 \% \quad 75.2$

$99.7 \% \quad 34.0$

$99.7 \% \quad 34.8$

$99.7 \% \quad 44.5$

$\begin{array}{lll}99.7 \% & 47.0\end{array}$

$99.7 \% \quad 49.2$

$99.6 \% 28.4$

$95.4 \% 18.5$

$99.7 \% \quad 71.5$

$99.7 \% \quad 58.0$

$99.0 \% \quad 34.1$

$99.7 \% \quad 37.6$

$99.7 \% \quad 31.2$

$99.7 \% \quad 72.7$

$99.7 \% \quad 45.1$

$99.5 \% \quad 27.8$

$99.7 \% \quad 32.6$

$99.7 \% \quad 29.7$

$99.7 \% \quad 37.9$

$99.6 \% \quad 26.7$

$99.7 \% \quad 32.0$

$99.7 \% \quad 67.9$

$99.7 \% \quad 61.6$

$99.7 \% \quad 44.6$

$99.7 \% \quad 50.4$

$99.7 \% \quad 42.2$

$99.7 \% \quad 33.4$

$99.7 \% \quad 66.7$

$99.7 \% \quad 33.9$

$99.7 \% \quad 64.3$

$99.7 \% \quad 66$.
1169.60

1448.75

1054.54

1588.88

1120.60

1139.54

1314.74

870.54

967.55

975.55

1025.61

1046.59

1316.74

914.57

2185.05

1358.73

1439.71

973.58

1347.74

1245.69

938.48

1241.65

1572.82

1091.58

1123.57

1430.74

1013.50

1107.64

1351.76

969.55

1534.82

1378.71

919.55

1090.63

1492.69

1591.73

1901.00

1673.86

1770.77

1483.83

1032.57

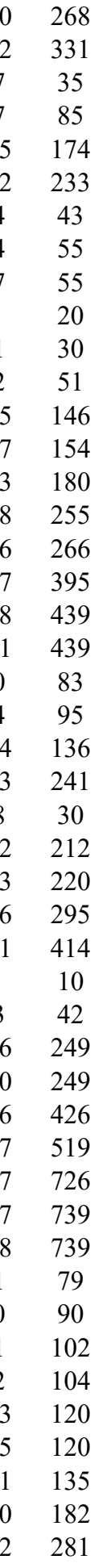

Page 32 of Table S-1-3 
Elongation factor Tu, mitochondrial GN=TUFM EFTU HUMAN $49.54 \quad 100.0 \%$ Elongation factor Tu, mitochondrial GN=TUFM EFTU HUMAN $49.54 \quad 100.0 \%$ Elongation factor Tu, mitochondrial GN=TUFM EFTU_HUMAN $49.54 \quad 100.0 \%$ Elongation factor Tu, mitochondrial GN=TUFM EFTU HUMAN $49.54 \quad 100.0 \%$ Elongation factor Tu, mitochondrial GN=TUFM EFTU_HUMAN $49.54 \quad 100.0 \%$ Elongation factor Tu, mitochondrial GN=TUFM EFTU HUMAN $49.54 \quad 100.0 \%$ Elongation factor Tu, mitochondrial GN=TUFM EFTU HUMAN $49.54 \quad 100.0 \%$ Emerin GN=EMD Emerin GN=EMD

Emerin GN=EMD

Emerin GN=EMD

Emerin GN=EMD

Emerin $\mathrm{GN}=\mathrm{EMD}$

Emerin $\mathrm{GN}=\mathrm{EMD}$

Emerin $\mathrm{GN}=\mathrm{EMD}$

Enoyl-CoA hydratase, mitochondrial GN=ECHS1 ECHM HUMAN 31.39

Enoyl-CoA hydratase, mitochondrial GN=ECHS1 ECHM HUMAN 31.39

Erlin-1 GN=ERLIN1

Erlin-1 GN=ERLIN 1

Erlin-1 GN=ERLIN

Erlin-1 GN=ERLIN 1

Erlin-1 GN=ERLIN1

Erlin-1 GN=ERLIN1

Erlin-1 GN=ERLIN]

Erlin-1 GN=ERLIN 1

Erlin-1 GN=ERLIN1

Erlin-2 GN=ERLIN2

Erlin-2 GN=ERLIN2

Erlin-2 GN=ERLIN2

Erlin-2 GN=ERLIN2

Erlin-2 GN=ERLIN2

Erlin-2 GN=ERLIN2

Erlin-2 GN=ERLIN 2

Erlin-2 GN=ERLIN 2

Erlin-2 GN=ERLIN

Erlin-2 GN=ERLIN2

Erlin-2 GN=ERLIN2

Eukaryotic initiation factor $4 \mathrm{~A}-\mathrm{I} \mathrm{GN}=\mathrm{EIF} 4 \mathrm{~A} 1 \mathrm{IF} 4 \mathrm{~A} 1$ HUMAN $46.16 \quad 100.0 \%$ Eukaryotic initiation factor 4A-I GN=EIF4A1 IF4A1_HUMAN $46.16 \quad 100.0 \%$ Eukaryotic initiation factor 4A-I GN=EIF4A1 IF4A1_HUMAN $46.16 \quad 100.0 \%$ Eukaryotic initiation factor 4A-I GN=EIF4A1 IF4A1 HUMAN $46.16 \quad 100.0 \%$ Eukaryotic initiation factor 4A-I GN=EIF4A1 IF4A1_HUMAN $46.16 \quad 100.0 \%$ Eukaryotic initiation factor 4A-III GN=EIF4A3 IF4A3 HUMAN $46.87100 .0 \%$ Eukaryotic initiation factor 4A-III GN=EIF4A3 IF4A3_HUMAN $46.87 \quad 100.0 \%$ Eukaryotic initiation factor 4A-III GN=EIF4A3 IF4A3_HUMAN $46.87 \quad 100.0 \%$ Eukaryotic initiation factor 4A-III GN=EIF4A3 IF4A3 HUMAN $46.87 \quad 100.0 \%$ Eukaryotic initiation factor 4A-III GN=EIF4A3 IF4A3_HUMAN $46.87 \quad 100.0 \%$
$103 \quad 0.22 \% \quad 34.7 \%$ AEAGDNLGALVR

$103 \quad 0.22 \% \quad 34.7 \%$ GLVMVKPGSIKPHQK

$103 \quad 0.22 \% \quad 34.7 \%$ VEAQVYILSK

$103 \quad 0.22 \% \quad 34.7 \%$ VEAQVYILSKEEGGR

$23 \quad 0.05 \% \quad 34.3 \%$ RYNIPHGPVVGSTR

$23 \quad 0.05 \% \quad 34.3 \%$ YNIPHGPVVGSTR

$23 \quad 0.05 \% \quad 34.3 \%$ KIFEYETQR

$23 \quad 0.05 \% \quad 34.3 \%$ KEDALLYQSK

$0.05 \% \quad 34.3 \%$ GYNDDYYEESYFTTR

$0.05 \% \quad 34.3 \%$ TYGEPESAGPSR

$0.05 \% \quad 34.3 \%$ DSAYQSITHYRPVSASR

$0.05 \% \quad 34.3 \%$ APGAGLGQDR

$0.01 \% \quad 11.0 \%$ NNTVGLIQLNRPK

$99.7 \% \quad 80.7$

$96.3 \% 16.1$

$99.7 \% \quad 72.2$

$99.7 \% 77.0$

$98.4 \% \quad 18.9$

$99.7 \% \quad 28.5$

$99.7 \% \quad 48.3$

$99.7 \% \quad 45.8$

$99.7 \% \quad 64.2$

$99.7 \% \quad 73.7$

$99.7 \% \quad 40.1$

$99.7 \% 39.8$

$99.7 \% \quad 54.2$

$0.01 \% \quad 11.0 \%$ SLAMEMVLTGDRISAQDAK $\quad 98.0 \% \quad 24.0$

$0.02 \% \quad 25.1 \%$ SVQTTLQTDEVK

$0.02 \% \quad 25.1 \%$ NFELMEAEKTK

$0.02 \% \quad 25.1 \%$ TKLLIAAQK

$0.02 \% \quad 25.1 \%$ AVIEAEKIAQVAK

$0.02 \% \quad 25.1 \%$ ISEIEDAAFLAR

$0.02 \% \quad 25.1 \%$ ISEIEDAAFLAREK

$0.02 \% \quad 25.1 \%$ ADAEYYAAHK

$99.7 \% \quad 74.3 \quad 25.0 \quad 65.6$

$\begin{array}{llll}99.7 \% & 43.2 & 25.0 & 22.5\end{array}$

$99.7 \% \quad 32.2$

$99.7 \% \quad 65.6$

$99.7 \% 93$.

$99.7 \% \quad 61.5$

$99.7 \% \quad 40.0$

$\begin{array}{lllll}0.02 \% & 25.1 \% & \text { ADAEYYAAHKYATSNK } & 99.7 \% & 36.9\end{array}$

$0.02 \% \quad 25.1 \%$ EALEPSGENVIQNK

$0.07 \% \quad 26.8 \%$ SVQTTLQTDEVK

$0.07 \% \quad 26.8 \%$ VTKPNIPEAIRR

$0.07 \% \quad 26.8 \%$ NYELMESEKTK

$0.07 \% \quad 26.8 \%$ TKLLIAAQK

$0.07 \% \quad 26.8 \%$ VAQVAEITYGQK

$0.07 \% \quad 26.8 \%$ KISEIEDAAFLAR

$0.07 \% \quad 26.8 \%$ ISEIEDAAFLAR

$0.07 \% \quad 26.8 \%$ ISEIEDAAFLAREK

$0.07 \% \quad 26.8 \%$ AKADAECYTAMK

$0.07 \% \quad 26.8 \%$ ADAECYTAMK

$0.07 \% \quad 26.8 \%$ LTPEYLQLMK

$0.04 \% \quad 15.0 \%$ GIYAYGFEKPSAIQQR

$0.04 \% \quad 15.0 \%$ GYDVIAQAQSGTGK

$0.04 \% \quad 15.0 \%$ DVIMREFR

$0.04 \% \quad 15.0 \%$ VLITTDLLAR

$0.04 \% \quad 15.0 \%$ GVAINMVTEEDKR

$0.02 \% \quad 15.3 \%$ GIYAYGFEKPSAIQQR

$0.02 \% \quad 15.3 \%$ GRDVIAQSQSGTGK

$0.02 \% \quad 15.3 \%$ ELAVQIQK

$99.4 \% \quad 23.5$

$\begin{array}{lll}99.7 \% & 74.3\end{array}$

$96.7 \% \quad 17.8$

$99.7 \% \quad 48.2$

$99.7 \% \quad 32.2$

$99.7 \% \quad 69.1$

$99.7 \% \quad 63.0$

$99.7 \% 93.1$

$99.7 \% \quad 61.5$

$99.7 \% \quad 50.1$

$99.7 \% \quad 58.1$

$99.3 \% \quad 25.0$

$99.7 \% \quad 67.7$

$\begin{array}{lll}98.9 \% & 25.2\end{array}$

$99.7 \% \quad 62.2$

$99.7 \% \quad 43.8$

$99.7 \% \quad 31.7$

$99.7 \% \quad 62.7$

$\begin{array}{lllll}99.0 \% & 47.0 & 25.0 & 38.3 & 2\end{array}$

$0.02 \% \quad 15.3 \%$ KLDYGQHVVAGTPGR

$\begin{array}{llll}99.7 \% & 45.2 & 25.0 & 45.2\end{array}$

$\begin{array}{ccc}1372.65 & 286 & 297 \\ 1277.66 & 301 & 311 \\ 1670.88 & 312 & 327 \\ 1185.62 & 316 & 327 \\ 1618.95 & 337 & 351 \\ 1149.65 & 352 & 361 \\ 1677.88 & 352 & 366 \\ 1552.83 & 18 & 31 \\ 1396.73 & 19 & 31 \\ 1213.62 & 37 & 45 \\ 1194.64 & 79 & 88 \\ 1922.77 & 89 & 103 \\ 1250.56 & 104 & 115 \\ 1937.95 & 158 & 174 \\ 941.48 & 212 & 221 \\ 1466.84 & 44 & 56 \\ 2068.01 & 186 & 204 \\ 1348.70 & 61 & 72 \\ 1339.66 & 182 & 192 \\ 985.64 & 191 & 199 \\ 1369.81 & 214 & 226 \\ 1334.70 & 242 & 253 \\ 1591.83 & 242 & 255 \\ 1138.52 & 258 & 267 \\ 1802.83 & 258 & 273 \\ 1527.77 & 329 & 342 \\ 1348.70 & 61 & 72 \\ 1393.83 & 170 & 181 \\ 1371.65 & 182 & 192 \\ 985.64 & 191 & 199 \\ 1306.70 & 221 & 232 \\ 1462.79 & 241 & 253 \\ 1334.70 & 242 & 253 \\ 1591.83 & 242 & 255 \\ 1358.61 & 256 & 267 \\ 1159.48 & 258 & 267 \\ 1251.67 & 276 & 285 \\ 1827.94 & 46 & 61 \\ 1394.69 & 69 & 82 \\ 1065.55 & 312 & 319 \\ 1114.68 & 325 & 334 \\ 1461.74 & 370 & 382 \\ 1827.94 & 52 & 67 \\ 1403.72 & 75 & 88 \\ 928.55 & 117 & 124 \\ 1597.84 & 152 & 166 \\ 1159.65 & 330 & 339 \\ & & \end{array}$

Page 33 of Table S-1-3 
$0.01 \% \quad 9.2 \% \quad$ SKTVYSILR

$0.01 \% \quad 9.2 \%$ RLTPQAVK

$0.01 \% \quad 9.2 \% \quad$ VVTDTDETELAR

$0.05 \% \quad 7.7 \%$ PAYFQRPENALKR

$0.05 \% \quad 7.7 \%$ ANEFLEVGK

$0.05 \% \quad 7.7 \% \quad$ YLELCVDLRK

$0.05 \% \quad 7.7 \% \quad$ NLTQDEMQR

$0.05 \% \quad 7.7 \%$ IGLINDMVR

$0.05 \% \quad 7.7 \%$ NQLTAMSSVLAK

$0.05 \% \quad 7.7 \% \quad$ LESLNIQR

$0.05 \% \quad 7.7 \%$ RLEEIPLIK

$0.05 \% \quad 7.7 \%$ RLGDSSLSR

$0.05 \% \quad 7.7 \%$ GLDDDRGPR

$0.05 \% \quad 7.7 \%$ NMDDDRLSR

$0.02 \% \quad 7.3 \%$ AQAVSEDAGGNEGR

$0.02 \% \quad 7.3 \%$ AQAVSEDAGGNEGRAAEAEPR

$0.02 \% \quad 7.3 \%$ GTYLATFHQR

$0.02 \% \quad 7.3 \%$ VTLMQLPTR

$0.02 \% \quad 7.3 \%$ FAVLHGEAPR

$0.02 \% \quad 7.3 \%$ ISVSFYHVK

$0.01 \% \quad 7.1 \%$ IFHTVTTTDDPVIR

$0.01 \% \quad 7.1 \%$ IFHTVTTTDDPVIRK

$0.01 \% \quad 7.1 \%$ LGDDIDLIVR

$0.01 \% \quad 7.1 \%$ GAVIATELKNNSYK

$0.05 \% \quad 13.0 \%$ RTTVVAQLK

$0.05 \% \quad 13.0 \%$ TTVVAQLK

$0.05 \% \quad 13.0 \%$ QLQAETEPIVK

$0.05 \% \quad 13.0 \%$ MFEDPETTR

$0.05 \% \quad 13.0 \%$ MFEDPETTRQMQSTR

$0.05 \% \quad 13.0 \%$ YLTTAVITNK

$0.05 \% \quad 13.0 \%$ YLTTAVITNKDVR

$0.05 \% \quad 13.0 \%$ SQMLAMNIEK

$0.01 \% \quad 8.1 \%$ AYVSTLMGVPGR

$0.01 \% \quad 8.1 \%$ VIGLSSDLQQVGGASAR

$0.01 \% \quad 11.6 \%$ ELAEQLGLSTGEK

$0.01 \% \quad 11.6 \%$ TGKYVPPSLR

$0.01 \% \quad 11.6 \%$ YVPPSLRDGASR

$0.01 \% \quad 11.6 \%$ GFAFISFHR

$0.08 \% \quad 33.2 \%$ MKPILLQGHER

$0.08 \% \quad 33.2 \%$ SITQIKYNR

$0.08 \% 33.2 \%$ HVLTGSADNSCR

$0.08 \% \quad 33.2 \%$ SGEVLVNVKEHSR

$0.08 \% \quad 33.2 \%$ QINDIQLSR

$0.08 \% \quad 33.2 \%$ DMTMFVTASK

$0.08 \% 33.2 \%$ DMTMFVTASKDNTAK

$0.08 \% \quad 33.2 \%$ LFDSTTLEHQK

$0.08 \% \quad 33.2 \%$ GHFGPINSVAFHPDGK $\begin{array}{llllllll}96.2 \% & 15.8 & 25.0 & 15.8 & 1 & 0 & 0 & 1066.63\end{array}$

$98.5 \% \quad 24.9$

$99.7 \% \quad 69.5$

$99.5 \% 24.6$

$99.6 \% \quad 27.2$

$96.6 \% 26.7$

$99.7 \% 29.3$

$99.5 \% 27.1$

$99.7 \% 29.1$

$98.9 \% \quad 28.5$

$99.6 \% \quad 29.4$

$99.7 \% \quad 41.0$

$96.1 \% \quad 15.8$

$98.0 \% \quad 17.9$

$99.7 \% \quad 61.6$

$99.7 \% \quad 46.9$

$99.7 \% \quad 45.7$

$99.7 \% \quad 37.8$

$99.7 \% \quad 51.9$

$96.3 \% 22.6$

$99.7 \% \quad 54.0$

$99.4 \% \quad 24.7$

$99.7 \% \quad 50.5$

$\begin{array}{lll}97.4 \% & 24.8\end{array}$

$99.4 \% \quad 22.6$

$99.0 \% \quad 31.6$

$99.7 \% \quad 50.3$

$99.7 \% \quad 36.7$

$99.0 \% \quad 22.9$

$99.7 \% \quad 30.1$

$99.7 \% \quad 65.4$

$99.7 \% \quad 58.2$

$99.5 \% \quad 26.4$

$99.7 \% 76.7$

$98.8 \% 19$.

$95.5 \% \quad 17.3$

$98.7 \% \quad 23.7$

$99.7 \% \quad 36.1$

$99.7 \% \quad 31.8$

$99.7 \% \quad 39.9$

$99.7 \% \quad 53.3$

$99.7 \% \quad 60.5$

$99.6 \% \quad 59.7$

$99.7 \% \quad 47.7$

$99.7 \% \quad 56.8$

$99.7 \% \quad 68.2$

$98.6 \% \quad 20.1$
912.56

1348.66

1589.85

1006.52

1308.70

1134.52

1046.57

1278.67

972.55

1110.69

990.53

1000.48

1121.50

1360.61

2084.96

1193.61

1058.60

1096.59

1079.59

1614.85

1742.94

1128.63

1507.81

1015.63

859.52

1255.69

1125.49

1872.82

1123.64

1493.83

1180.57

1266.65

1657.89

1374.71

1117.64

1317.69

1081.56

1321.74

1122.63

1316.60

1453.78

1086.59

1130.52

1659.77

1318.66 1679.83 $\begin{array}{cc}05 & 113 \\ 83 & 190 \\ 77 & 288 \\ 2 & 14 \\ 5 & 23 \\ 4 & 63 \\ 99 & 317 \\ 68 & 376 \\ 21 & 532 \\ 82 & 589 \\ 03 & 711 \\ 77 & 885 \\ 72 & 1080 \\ 42 & 1150 \\ 21 & 134 \\ 21 & 141 \\ 46 & 355 \\ 93 & 501 \\ 77 & 586 \\ 87 & 595 \\ 23 & 236 \\ 23 & 237 \\ 65 & 374 \\ 18 & 431 \\ 4 & 82 \\ 5 & 82 \\ 3 & 93 \\ 4 & 102 \\ 4 & 108 \\ 56 & 265 \\ 56 & 268 \\ 15 & 424 \\ 15 & 226 \\ 62 & 278 \\ 81 & 193 \\ 10 & 219 \\ 13 & 224 \\ 81 & 289 \\ 1 & 11 \\ 2 & 20 \\ 6 & 77 \\ 77 & 189 \\ 90 & 198 \\ 99 & 208 \\ 99 & 213 \\ 14 & 224 \\ 83 & 298\end{array}$ 
Eukaryotic translation initiation factor 3 subunit I GN=EIF3I EIF3I_HUMAN $36.50 \quad 100.0 \%$ Eukaryotic translation initiation factor 3 subunit $\mathrm{L}$ GN=EIF3L EIF3L_HUMAN $66.73 \quad 100.0 \%$ Eukaryotic translation initiation factor 3 subunit L GN=EIF3L EIF3L_HUMAN $66.73 \quad 100.0 \%$ Eukaryotic translation initiation factor 3 subunit L GN=EIF3L EIF3L_HUMAN $66.73 \quad 100.0 \%$ Eukaryotic translation initiation factor 3 subunit L GN=EIF3L EIF3L_HUMAN $66.73 \quad 100.0 \%$ Eukaryotic translation initiation factor 3 subunit L GN=EIF3L EIF3L_HUMAN $66.73 \quad 100.0 \%$ Eukaryotic translation initiation factor 3 subunit L GN=EIF3L EIF3L_HUMAN $66.73 \quad 100.0 \%$ Eukaryotic translation initiation factor 3 subunit $\mathrm{L}$ GN=EIF3L EIF3L_HUMAN $66.73 \quad 100.0 \%$ Eukaryotic translation initiation factor 3 subunit L GN=EIF3L EIF3L_HUMAN $66.73 \quad 100.0 \%$ Eukaryotic translation initiation factor 4B GN=EIF4B IF4B_HUMAN $69.15 \quad 100.0 \%$ Eukaryotic translation initiation factor 4B GN=EIF4B IF4B_HUMAN $69.15 \quad 100.0 \%$ Eukaryotic translation initiation factor 4B GN=EIF4B IF4B HUMAN $69.15100 .0 \%$ Eukaryotic translation initiation factor 4B GN=EIF4B IF4B_HUMAN $69.15 \quad 100.0 \%$ Eukaryotic translation initiation factor 4B GN=EIF4B IF4B_HUMAN $69.15 \quad 100.0 \%$ Eukaryotic translation initiation factor 4B GN=EIF4B IF4B_HUMAN $69.15 \quad 100.0 \%$ Eukaryotic translation initiation factor 4B GN=EIF4B IF4B_HUMAN $69.15 \quad 100.0 \%$ Eukaryotic translation initiation factor 4B GN=EIF4B IF4B HUMAN $69.15100 .0 \%$ Eukaryotic translation initiation factor 4B GN=EIF4B IF4B_HUMAN $69.15 \quad 100.0 \%$ Eukaryotic translation initiation factor 4B GN=EIF4B IF4B_HUMAN $69.15 \quad 100.0 \%$ Eukaryotic translation initiation factor 4B GN=EIF4B IF4B_HUMAN $69.15 \quad 100.0 \%$ Eukaryotic translation initiation factor 4B GN=EIF4B IF4B_HUMAN $69.15 \quad 100.0 \%$ Eukaryotic translation initiation factor 4B GN=EIF4B IF4B HUMAN $69.15 \quad 100.0 \%$ Eukaryotic translation initiation factor 4B GN=EIF4B IF4B_HUMAN $69.15 \quad 100.0 \%$ Eukaryotic translation initiation factor 4B GN=EIF4B IF4B_HUMAN $69.15 \quad 100.0 \%$ Eukaryotic translation initiation factor $4 \mathrm{~B} \mathrm{GN}=\mathrm{EIF} 4 \mathrm{~B}$ IF4B HUMAN $69.15 \quad 100.0 \%$ Eukaryotic translation initiation factor 4B GN=EIF4B IF4B_HUMAN $69.15 \quad 100.0 \%$ Eukaryotic translation initiation factor 4B GN=EIF4B IF4B_HUMAN $69.15 \quad 100.0 \%$ Eukaryotic translation initiation factor 4B GN=EIF4B IF4B_HUMAN $69.15 \quad 100.0 \%$ Exocyst complex component $4 \mathrm{GN}=\mathrm{EXOC} 4$ EXOC4_HUMAN $110.50 \quad 100.0 \%$ Exocyst complex component $4 \mathrm{GN}=\mathrm{EXOC} 4$ EXOC4 HUMAN $110.50100 .0 \%$ Exosome complex component MTR3 GN=EXOSC6 EXOS6_HUMAN $28.24 \quad 100.0 \%$ Exosome complex component MTR3 GN=EXOSC6 EXOS6_HUMAN $28.24 \quad 100.0 \%$ Exosome complex component MTR3 GN=EXOSC6 EXOS6_HUMAN $28.24 \quad 100.0 \%$ Exosome complex component MTR3 GN=EXOSC6 EXOS6_HUMAN $28.24 \quad 100.0 \%$ Exosome complex component MTR3 GN=EXOSC6 EXOS6_HUMAN $28.24 \quad 100.0 \%$ Exosome complex component MTR3 GN=EXOSC6 EXOS6_HUMAN $28.24 \quad 100.0 \%$ Exosome complex exonuclease RRP44 GN=DIS3 RRP44_HUMAN $109.01 \quad 100.0 \%$ Exosome complex exonuclease RRP44 GN=DIS3 RRP44 HUMAN $109.01 \quad 100.0 \%$ Exosome complex exonuclease RRP44 GN=DIS3 RRP44_HUMAN $109.01 \quad 100.0 \%$ Exportin-1 GN=XPO1

Exportin-1 GN=XPO1 Exportin-1 GN=XPO1 Exportin-2 GN=CSE1L Exportin-2 GN=CSE1L Exportin-2 GN=CSE1L Exportin-2 GN=CSE1L Exportin-2 GN=CSE1L XPO1_HUMAN $123.39 \quad 100.0 \%$ XPO1_HUMAN $123.39 \quad 100.0 \%$ XPO1_HUMAN $123.39 \quad 100.0 \%$ XPO2 HUMAN $110.42 \quad 100.0 \%$ XPO2_HUMAN $110.42 \quad 100.0 \%$ XPO2_HUMAN $110.42 \quad 100.0 \%$ XPO2_HUMAN $110.42 \quad 100.0 \%$ XPO2_HUMAN $110.42 \quad 100.0 \%$
$0.08 \% \quad 33.2 \%$ SYSSGGEDGYVR

$0.04 \% \quad 12.2 \%$ VSGGPSLEQR

$0.04 \% \quad 12.2 \%$ KSEEEIDFLR

$0.04 \% \quad 12.2 \%$ SEEEIDFLR

$0.04 \% \quad 12.2 \%$ SEEEIDFLRSNPK

$0.04 \% \quad 12.2 \%$ VLENIELNKK

$0.04 \% \quad 12.2 \%$ IDESIHLQLR

$0.04 \% \quad 12.2 \%$ VFSDEVQQQAQLSTIR

$0.04 \% \quad 12.2 \%$ LYTTMPVAK

$188 \quad 0.40 \% \quad 29.8 \%$ SILPTAPR

$188 \quad 0.40 \% \quad 29.8 \%$ AAREPNIDR

$188 \quad 0.40 \% \quad 29.8 \%$ GLNISAVR

$188 \quad 0.40 \% \quad 29.8 \%$ LPREPSNPER

$188 \quad 0.40 \% \quad 29.8 \%$ ARPATDSFDDYPPR

$188 \quad 0.40 \% \quad 29.8 \%$ SWSSRDDYSR

$188 \quad 0.40 \% \quad 29.8 \%$ STPKEDDSSASTSQSTR

$188 \quad 0.40 \% \quad 29.8 \%$ AASIFGGAKPVDTAAR

$188 \quad 0.40 \% \quad 29.8 \%$ AASIFGGAKPVDTAARER

$188 \quad 0.40 \% \quad 29.8 \%$ QLDEPKLER

$188 \quad 0.40 \% \quad 29.8 \%$ SSNPPARSQSSDTEQQSPTSGGGK $\quad 99.7 \% \quad 48.8$

$\begin{array}{lllllll}188 & 0.40 \% & 29.8 \% & \text { SQSSDTEQQSPTSGGGK } & 99.7 \% & 69.7\end{array}$

$188 \quad 0.40 \% \quad 29.8 \%$ SQSSDTEQQSPTSGGGKVAPAQPSEEGPGR $\quad 99.7 \% \quad 54.3$

$188 \quad 0.40 \% \quad 29.8 \%$ VAPAQPSEEGPGR

$188 \quad 0.40 \% \quad 29.8 \%$ SAPEPKKPEENPASK

$188 \quad 0.40 \% \quad 29.8 \%$ KPEENPASKFSSASK

$99.7 \% \quad 53.0$

$99.7 \% \quad 46.7$

$99.7 \% \quad 56.7$

$0.01 \% \quad 3.0 \%$ KFLDTSHYSTAGSSSVR

$0.01 \% \quad 3.0 \%$ STTQVADSGYQR

$1 \quad 0.02 \% \quad 20.2 \%$ GSAYLEAGGTK

$94.6 \% 14.2$

$99.7 \% 34.8$

$99.7 \% \quad 48.0$

$0.02 \% \quad 20.2 \%$ GGGPAGAGGEAPAALR $\quad 99.7 \% \quad 67.7$

$0.02 \% \quad 20.2 \%$ GGGPAGAGGEAPAALRGR $\quad 99.7 \% \quad 40.1$

$0.02 \% \quad 20.2 \%$ LGLEGCQR

$0.02 \% \quad 20.2 \%$ LYPVLQQSLVR

$0.01 \% \quad 3.2 \%$ RGTTVYLCEK

$0.01 \% \quad 3.2 \%$ GALTLSSPEVR

$0.01 \% \quad 3.2 \%$ NLEIKTDTAK

$0.01 \% \quad 3.2 \%$ TSESLCQNNMVILK

$0.01 \% \quad 3.2 \%$ AVGHPFVIQLGR

$0.01 \% \quad 3.2 \%$ LISGWVSR

$0.05 \% \quad 7.9 \%$ TLDPDPAIR

$0.05 \% \quad 7.9 \%$ VIVPNMEFR

$0.05 \% \quad 7.9 \%$ DLEGSDIDTRR

$0.05 \% \quad 7.9 \%$ TGNIPALVR

$0.05 \% \quad 7.9 \%$ LLQAFLER 
Exportin-2 GN=CSE1L Exportin-2 GN=CSE1L Exportin-2 GN=CSE1L Exportin-5 GN=XPO5 Exportin-5 GN=XPO5 Exportin- $\mathrm{T}$ GN $=$ XPOT

\section{Exportin- $\mathrm{T} \mathrm{GN}=\mathrm{XPOT}$} Far upstream element-binding protein $2 \mathrm{GN}=$ KHSRP FUBP2_HUMAN $73.12 \quad 100.0 \%$ Far upstream element-binding protein 2 GN=KHSRP FUBP2_HUMAN $73.12 \quad 100.0 \%$ Far upstream element-binding protein 2 GN=KHSRP FUBP2_HUMAN $73.12 \quad 100.0 \%$ Far upstream element-binding protein 2 GN=KHSRP FUBP2_HUMAN $73.12 \quad 100.0 \%$ Far upstream element-binding protein $3 \mathrm{GN}=$ FUBP3 FUBP3_HUMAN $61.64 \quad 100.0 \%$ Far upstream element-binding protein $3 \mathrm{GN}=$ FUBP3 FUBP3_HUMAN $61.64 \quad 100.0 \%$ Far upstream element-binding protein $3 \mathrm{GN}=\mathrm{FUBP} 3$ FUBP3_HUMAN $61.64 \quad 100.0 \%$ Far upstream element-binding protein 3 GN=FUBP3 FUBP3_HUMAN $61.64 \quad 100.0 \%$ FAST kinase domain-containing protein 2 GN=FASTKD2 FAKD2 HUMAN $81.47 \quad 100.0 \%$ FAST kinase domain-containing protein 2 GN=FASTKD2 FAKD2_HUMAN $81.47 \quad 100.0 \%$ FAST kinase domain-containing protein 2 GN=FASTKD2 FAKD2_HUMAN $81.47 \quad 100.0 \%$ FAST kinase domain-containing protein 3 GN=FASTKD3 FAKD3_HUMAN $75.69 \quad 100.0 \%$ FAST kinase domain-containing protein 3 GN=FASTKD3 FAKD3_HUMAN $75.69 \quad 100.0 \%$ FAST kinase domain-containing protein 5 GN=FASTKD5 FAKD5_HUMAN $86.58 \quad 100.0 \%$ FAST kinase domain-containing protein 5 GN=FASTKD5 FAKD5_HUMAN $86.58 \quad 100.0 \%$ Fatty acyl-CoA reductase $1 \mathrm{GN}=$ FAR 1 Fatty acyl-CoA reductase $1 \mathrm{GN}=\mathrm{FAR} 1$ Filamin-A GN=FLNA Filamin-A GN=FLNA

Filamin-A GN=FLNA Filamin-A GN=FLNA Filamin-A GN=FLNA Filamin-A GN=FLNA Filamin-A GN=FLNA Filamin-A GN=FLNA Filamin-A GN=FLNA Filamin-A GN=FLNA Fragile X mental retardation syndrome-related protein $2 \mathrm{GN}=\mathrm{FXR} 2 \quad \mathrm{FXR} 2$ HUMAN $74.22 \quad 100.0 \%$ Fragile X mental retardation syndrome-related protein 2 GN=FXR2 FXR2_HUMAN $74.22 \quad 100.0 \%$ Fragile X mental retardation syndrome-related protein 2 GN=FXR2 FXR2 HUMAN $74.22 \quad 100.0 \%$ Fragile X mental retardation syndrome-related protein 2 GN=FXR2 $\quad$ FXR2_HUMAN $74.22 \quad 100.0 \%$ Fragile X mental retardation syndrome-related protein 2 GN=FXR2 FXR2_HUMAN 74.22 $100.0 \%$ Fructose-bisphosphate aldolase A GN=ALDOA ALDOA_HUMAN $39.42 \quad 100.0 \%$ Fructose-bisphosphate aldolase A GN=ALDOA ALDOA_HUMAN $39.42 \quad 100.0 \%$ Fructose-bisphosphate aldolase A GN=ALDOA ALDOA_HUMAN $39.42 \quad 100.0 \%$ Galactokinase $\mathrm{GN}=\mathrm{GALK} 1$ Galactokinase $\mathrm{GN}=\mathrm{GALK} 1$ Galactokinase GN=GALK1 Galactokinase $\mathrm{GN}=\mathrm{GALK} 1$ _t $59.36 \quad 100.0 \%$ FLNA_HUMAN $280.73 \quad 100.0 \%$ FLNA_HUMAN $280.73 \quad 100.0 \%$ FLNA_HUMAN $280.73 \quad 100.0 \%$ FLNA_HUMAN $280.73 \quad 100.0 \%$ FLNA HUMAN $280.73 \quad 100.0 \%$ FLNA_HUMAN $280.73 \quad 100.0 \%$ FLNA_HUMAN $280.73 \quad 100.0 \%$ FLNA_HUMAN $280.73 \quad 100.0 \%$ FLNA_HUMAN $280.73 \quad 100.0 \%$ FLNA_HUMAN $280.73 \quad 100.0 \%$ $0.0 \% \quad 10$ \begin{tabular}{ll}
$0 \%$ & 4 \\
\hline & 4
\end{tabular} \begin{tabular}{ll}
$0.0 \%$ & 4 \\
\hline & 4 \\
0 & 3
\end{tabular} GALK1_HUMAN $42.27 \quad 100.0 \%$ GALK1_HUMAN $42.27 \quad 100.0 \%$ GALK1_HUMAN $42.27 \quad 100.0 \%$ GALK1_HUMAN $42.27 \quad 100.0 \%$ $\begin{array}{llllllll}99.7 \% & 27.2 & 25.0 & 26.9 & 1 & 3 & 0 & 1480.69\end{array}$

$\begin{array}{llllllll}99.7 \% & 32.5 & 25.0 & 30.4 & 2 & 0 & 0 & 1046.61\end{array}$

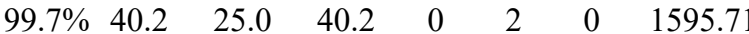

$\begin{array}{llllllll}99.0 \% & 32.9 & 25.0 & 18.5 & 1 & 0 & 0 & 863.47\end{array}$

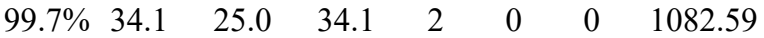

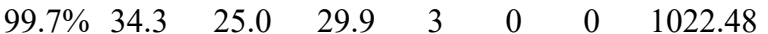

$\begin{array}{llll}99.7 \% & 35.5 & 25.0 & 28.4\end{array}$

$99.7 \% \quad 61.3 \quad 25.0 \quad 46.3$

$99.7 \% \quad 32.8 \quad 25.0 \quad 17.7$

$\begin{array}{lllll}99.7 \% & 72.2 & 25.0 & 64.2 & 2\end{array}$

$99.7 \% \quad 77.3 \quad 25.0 \quad 70.1 \quad 2$

$\begin{array}{llll}99.7 \% & 32.8 & 25.0 & 17.7\end{array}$

$99.7 \% \quad 53.7 \quad 25.0 \quad 46.3$

$\begin{array}{llll}99.7 \% & 47.2 & 25.0 & 33.6\end{array}$

$\begin{array}{lllll}96.5 \% & 23.3 & 25.0 & 10.5 & 2\end{array}$

$99.7 \% \quad 27.8 \quad 25.0 \quad 25.0$

$\begin{array}{llll}99.0 \% & 42.6 & 25.0 & 34.5\end{array}$

$\begin{array}{llll}99.7 \% & 38.9 & 25.0 & 37.2\end{array}$

$99.7 \% \quad 43.0 \quad 25.0 \quad 24.2$

$\begin{array}{llll}99.0 \% & 37.2 & 25.0 & 24.7\end{array}$

$99.7 \% \quad 58.9 \quad 25.0 \quad 41.2$

$\begin{array}{llll}99.7 \% & 35.2 & 25.0 & 28.8\end{array}$

$99.7 \% \quad 38.7 \quad 25.0 \quad 29.2 \quad 2$

$99.7 \% \quad 45.1 \quad 25.0 \quad 45.1$

$0.01 \% \quad 2.6 \%$ EATPAENVAK

$0.01 \% \quad 4.1 \% \quad$ VNSVYVLVR

$0.01 \% \quad 4.1 \% \quad$ IIAINSELTQPK

CR

$99.7 \% 30.8$

$0.07 \% \quad 4.8 \%$ TGVAVNKPAEFTVDAK

$0.07 \% \quad 4.8 \%$ AFGPGLQGGSAGSPAR

$0.07 \% \quad 4.8 \%$ CSGPGLER

$0.07 \% \quad 4.8 \%$ EATTEFSVDAR

$99.7 \% \quad 65.9$

$96.6 \% \quad 21.2$

$99.7 \% \quad 43.7$

$99.7 \% \quad 30.7$

$0.07 \% \quad 4.8 \%$ ALTQTGGPHVK

99.7

$0.07 \% \quad 4.8 \% \quad$ ANLPQSFQVDTSK

$0.07 \% \quad 4.8 \%$ AGVAPLQVK

$0.07 \% \quad 4.8 \%$ TPCEEILVK

$0.03 \% \quad 8.9 \%$ LRPVNPNPLATK

$0.03 \% \quad 8.9 \%$ ASLLGDMHFR

$0.03 \% \quad 8.9 \%$ VIQEIVDKSGVVR

$0.03 \% \quad 8.9 \%$ LQIDEQLR

$0.03 \% \quad 8.9 \%$ AGYSTDESSSSSLHATR

$0.01 \% \quad 9.6 \%$ GILAADESTGSIAKR

$0.01 \% \quad 9.6 \%$ AAQEEYVKR

$0.01 \% \quad 9.6 \%$ ALANSLACQGK

$0.02 \% \quad 10.5 \%$ GHALLIDCR

$0.02 \% \quad 10.5 \%$ LAVLITNSNVR

$0.02 \% \quad 10.5 \%$ HSLASSEYPVR

$0.02 \% \quad 10.5 \%$ HSLASSEYPVRR

\section{$99.7 \% \quad 53.5$}

$99.1 \% \quad 23.2$

$99.7 \% \quad 30.0$

$99.7 \% \quad 42.1$

$96.8 \% \quad 18.9$

$99.7 \% \quad 68.9$

$\begin{array}{lll}96.0 \% & 20.7\end{array}$

$99.7 \% \quad 31.7$

$99.7 \% \quad 46.5$

$99.7 \% \quad 51.5$

$99.7 \% \quad 36.1$

$99.7 \% \quad 52.8$

$98.3 \% \quad 36.1$

$99.7 \% \quad 43.6$

$98.1 \% \quad 18.3$
$926 \quad 93$

$209 \quad 222$

$400 \quad 407$

$\begin{array}{lll}992.48 & 72 & 80\end{array}$

191203

$1258.68 \quad 252 \quad 262$

$1079.62 \quad 321 \quad 331$

$\begin{array}{lll}1533.80 & 449 & 462\end{array}$

1258.68

1204.60

931.57

1096.61

1177.61

903.51

1234.56

1027.63

1049.56

1029.57

1029.52

1048.61

1326.76

1867.84

1646.87

1429.72

875.40

1225.57

1108.61

1570.81

1434.72

882.54

1088.57

1319.78

1162.57

1441.84

1014.56

1755.78

1488.80

1093.56

1132.58

1054.55

1199.71

1245.62

1401.72 $\begin{array}{ll}449 & 462 \\ 181 & 191\end{array}$

$251 \quad 262$

$263 \quad 271$

409418

359368

$634 \quad 641$

652
$642-551$

551

$88 \quad 97$

$606 \quad 615$

$37 \quad 45$

$79 \quad 90$

$468 \quad 484$

$\begin{array}{cc}685 & 700 \\ 1072 & 1087\end{array}$

$072 \quad 1087$

$\begin{array}{ll}165 & 1172 \\ 273 & 1283\end{array}$

$1284 \quad 1294$

$\begin{array}{ll}1382 & 1399\end{array}$

$\begin{array}{ll}2599 & 2607\end{array}$

$122 \quad 133$

191200

$313 \quad 325$

$379 \quad 386$

$407 \quad 423$

2943

$323 \quad 331$

$332 \quad 342$

$196 \quad 204$

$218 \quad 228$

$229 \quad 240$ 
$0.01 \% \quad 7.8 \%$ FYQASTSELYGK $0.01 \% \quad 7.8 \%$ VAFDELVR

$0.00 \% \quad 8.6 \%$ SQQLDSNVTMPK

$0.00 \% \quad 8.6 \% \quad$ YFDQRDLADEPS

$0.00 \% \quad 2.0 \%$ GLTQIQSR

$0.00 \% \quad 2.0 \% \quad$ LLETVIDVSTADR

$0.02 \% \quad 11.9 \%$ MLPTLGGEEGVSR

$0.02 \% \quad 11.9 \%$ FSTSSLLLR

$11 \quad 0.02 \% \quad 11.9 \%$ ANISVHPDKLK

$0.02 \% \quad 11.9 \%$ IYQVLDFR

$0.02 \% \quad 11.9 \%$ LKDSVYIFR

$0.02 \% \quad 11.9 \%$ SKRPALFSSSAK

$99.7 \% \quad 50.8$

$99.3 \% \quad 33.9$

$99.7 \% \quad 54.3$

$99.0 \% \quad 33.6$

$99.7 \% \quad 37.5$

$\begin{array}{lll}99.7 \% & 42.3\end{array}$

$94.7 \% \quad 20.2$

$99.7 \% \quad 35.9$

$99.7 \% \quad 60.9$

$99.7 \% \quad 58.0$

$95.1 \% \quad 15.2$

$99.0 \% \quad 43.6$

$99.7 \% \quad 43.1$

$\begin{array}{lll}95.5 \% & 15.5\end{array}$

$0.01 \% \quad 3.6 \%$ VLVSPTNPPGATSSCQK $\quad 99.7 \% \quad 61.4$

$\begin{array}{lllll}0.01 \% & 3.6 \% & \text { SSQTSGTNEQSSAIVSAR } & 99.7 \% & 61.0\end{array}$

$0.01 \% \quad 2.7 \%$ LQQENMNLLSDAR

$0.01 \% \quad 2.7 \%$ TSELSEAPQK

$0.01 \% \quad 2.7 \% \quad$ NLEELKISSK

$99.7 \% \quad 30.8$

$99.7 \% \quad 61.4$

$99.7 \% \quad 31.7$

GRDN_HUMAN $216.05 \quad 100.0 \%$ GRDN HUMAN $216.05 \quad 100.0 \%$

$0.01 \% \quad 2.7 \%$ QTVSLQEQNTTLQTQNAK

$0.01 \% \quad 4.2 \%$ DVLAHQVPNAK

$0.01 \% \quad 4.2 \% \quad$ LRVQQAALR

$0.01 \% \quad 4.2 \%$ AHYEAEIKNSQEAQK

$0.01 \% \quad 4.2 \%$ STSEENIGIK

$0.01 \% \quad 4.0 \%$ GSPLLIGVR

$0.01 \% \quad 4.0 \% \quad$ CQNALQQVVAR

$0.01 \% \quad 4.0 \%$ GYDVDFPR

$10 \quad 0.02 \% \quad 5.2 \%$ AINFNFGYAK

$10 \quad 0.02 \% \quad 5.2 \% \quad$ ANNGICFLR

$10 \quad 0.02 \% \quad 5.2 \% \quad$ GKFSEGEATLR

$10 \quad 0.02 \% \quad 5.2 \% \quad$ LAWGQPVGLR

$16 \quad 0.03 \% \quad 16.8 \%$ TEELPLGR

$16 \quad 0.03 \% \quad 16.8 \%$ VPLIGSLPEAR

$16 \quad 0.03 \% \quad 16.8 \%$ VVGQLDPQR

$16 \quad 0.03 \% \quad 16.8 \%$ TPGSPGNLQVR

$16 \quad 0.03 \% \quad 16.8 \%$ TPGSPGNLQVRK

$\begin{array}{lll}0.03 \% & 16.8 \% & 16.8 \% \\ 0.03 & \text { KFLEATLR }\end{array}$

$0.03 \% \quad 16.8 \%$ HLAQLMESIPHSPGPTR

$0.04 \% \quad 18.2 \%$ IISNASCTTNCLAPLAK

$0.04 \% \quad 18.2 \%$ DGRGALQNIIPASTGAAK

$0.04 \% \quad 18.2 \%$ GALQNIIPASTGAAK

$0.04 \% \quad 18.2 \%$ VPTANVSVVDLTCR

$0.04 \% \quad 18.2 \%$ VVDLMAHMASKE

$0.01 \% \quad 9.1 \%$ ICDEITGRVPK

$0.01 \% \quad 9.1 \%$ KALGITLIK

$0.01 \% \quad 9.1 \%$ LQGPQTSAEVYR

$0.01 \% \quad 3.9 \%$ GIVGVENVAELKK
$99.7 \% \quad 45.8$

$99.3 \% 20.9$

$99.0 \% \quad 24.2$

$99.3 \% \quad 22.5$

$99.7 \% \quad 49.9$

$99.7 \% \quad 71.2$

$99.0 \% 32.6$

$99.7 \% \quad 48.0$

$99.7 \% \quad 41.9$

$99.7 \% 57.6$

$99.7 \% \quad 50.3$

$\begin{array}{lll}96.1 \% & 22.3\end{array}$

$99.7 \% \quad 47.6$

$99.7 \% \quad 38.0$

$99.7 \% \quad 63.1$

$99.7 \% \quad 34.3$

$99.0 \% \quad 38.8$

$99.7 \% \quad 29.1$

$99.7 \% \quad 80.3$

$99.7 \% \quad 59.2$

$99.7 \% \quad 52.0$

$99.7 \% \quad 71.2$

$99.7 \% 65.1$

$99.4 \% 26.8$

$97.0 \% \quad 19.0$

$99.7 \% 36.6$

$99.7 \% \quad 49.3$
872.49

991.52

1393.66

948.51

1347.66

1455.64

902.51

1431.77

1361.67

1023.58

1221.70

1053.57

1140.64

1278.72

1742.87

1809.86

1531.75

1089.54

1160.65

2032.03

1191.65

1054.65

1745.85

1077.54

911.57

1286.66

968.45

1144.58

1064.53

1194.61

1096.63

914.49

1151.68

1011.56

1125.60

1253.70

977.58

1886.95

1833.92

1739.94

1411.79

1530.79

1330.65

1287.67

956.65

1348.69 1355.79

$\begin{array}{cc}88 & 296 \\ 41 & 149 \\ 50 & 161 \\ 49 & 356 \\ 26 & 137 \\ 69 & 280 \\ 22 & 229 \\ 57 & 469 \\ 9 & 51 \\ 9 & 87 \\ 71 & 281 \\ 15 & 322 \\ 88 & 396 \\ 61 & 472 \\ 89 & 305 \\ 65 & 782 \\ 91 & 303 \\ 39 & 448 \\ 99 & 808 \\ 89 & 1106 \\ 33 & 143 \\ 51 & 359 \\ 18 & 532 \\ 85 & 594 \\ 04 & 212 \\ 20 & 630 \\ 83 & 690 \\ 83 & 292 \\ 93 & 301 \\ 93 & 403 \\ 30 & 639 \\ 9 & 66 \\ 0 & 80 \\ 4 & 92 \\ 06 & 116 \\ 06 & 117 \\ 17 & 124 \\ 42 & 258 \\ 46 & 162 \\ 98 & 215 \\ 01 & 215 \\ 35 & 248 \\ 24 & 335 \\ 03 & 113 \\ 14 & 122 \\ 99 & 310 \\ & 30 \\ & \end{array}$

Page 37 of Table S-1-3 

$\mathrm{H} / \mathrm{ACA}$ ribonucleoprotein complex subunit $4 \mathrm{GN}=\mathrm{DKC1}$ DKC1_HUMAN $57.68100 .0 \%$ $\mathrm{H} / \mathrm{ACA}$ ribonucleoprotein complex subunit $4 \mathrm{GN}=\mathrm{DKC1} \mathrm{DKC1}$ _HUMAN $57.68 \quad 100.0 \%$ $\mathrm{H} / \mathrm{ACA}$ ribonucleoprotein complex subunit $4 \mathrm{GN}=\mathrm{DKC} 1 \mathrm{DKC1}$ HUMAN $57.68100 .0 \%$ $\mathrm{H} / \mathrm{ACA}$ ribonucleoprotein complex subunit $4 \mathrm{GN}=\mathrm{DKC1} \mathrm{DKC1}$ _HUMAN $57.68 \quad 100.0 \%$ HCLS1-associated protein X-1 GN=HAX1 HAX1_HUMAN $31.62 \quad 100.0 \%$ HCLS1-associated protein X-1 GN=HAX1 HAX1_HUMAN $31.62 \quad 100.0 \%$ HCLS1-associated protein X-1 GN=HAX1 HAX1_HUMAN $31.62 \quad 100.0 \%$ HCLS1-associated protein X-1 GN=HAX1 HAX1_HUMAN $31.62100 .0 \%$ HEAT repeat-containing protein $1 \mathrm{GN}=$ HEATR1 HEAT1_HUMAN $242.38 \quad 100.0 \%$ HEAT repeat-containing protein 1 GN=HEATR1 HEAT1_HUMAN $242.38 \quad 100.0 \%$ HEAT repeat-containing protein $1 \mathrm{GN}=$ HEATR1 HEAT1_HUMAN $242.38100 .0 \%$ HEAT repeat-containing protein $1 \mathrm{GN}=$ HEATR1 HEAT1_HUMAN $242.38 \quad 100.0 \%$

$6 \quad 0.01 \% \quad 3.9 \%$ VIFLENYR $0.01 \% \quad 3.9 \%$ NIAASGKFSSDR $0.01 \% \quad 1.9 \%$ KGIQFLQEK $0.01 \% \quad 1.9 \%$ MQALTYLQR $0.01 \% \quad 1.9 \%$ AASSSSPGSPVASSPSR $0.01 \% \quad 3.6 \%$ ALGQLISK

$0.01 \% \quad 3.6 \%$ TLTEPCPLASESR $0.01 \% \quad 7.9 \%$ HVANTLSVYR $0.01 \% \quad 7.9 \%$ NPKPATVFSHK $0.01 \% \quad 7.9 \%$ SLCVSTPGHR $0.01 \% \quad 5.0 \%$ STLSNQLLGR $0.01 \% \quad 5.0 \%$ DPNTQSVGNPQR $0.01 \% \quad 7.4 \%$ ELAGHTGYLSCCR $0.01 \% \quad 7.4 \%$ LFVSGACDASAK $0.01 \% \quad 7.4 \%$ ELPGHTGYLSCCR $0.01 \% \quad 7.4 \%$ TFVSGACDASIK $0.01 \% \quad 8.8 \%$ LLLLGAGESGK $0.01 \% \quad 8.8 \%$ LKIDFGEAAR $0.01 \% \quad 8.8 \%$ IDFGEAAR $0.01 \% \quad 8.8 \%$ DGGVQACFSR $0.01 \% \quad 6.1 \%$ LLLLGTGESGK $0.01 \% \quad 6.1 \%$ DAQAAREFILK $0.04 \% \quad 24.6 \%$ LTRDETNYGIPQR $\begin{array}{lllll}10 & 19 & 0.04 \% & 24.6 \% & \text { LTRDETNYGIPQ } \\ 10 & 19 & 0.04 \% & 24.6 \% & \text { DETNYGIPQR }\end{array}$ $10 \quad 19 \quad 0.04 \% \quad 24.6 \%$ LWDLTTGTTTR $10 \quad 19 \quad 0.04 \% \quad 24.6 \%$ DVLSVAFSSDNR $10 \quad 19 \quad 0.04 \% \quad 24.6 \%$ LWNTLGVCK

$10 \quad 19 \quad 0.04 \% \quad 24.6 \%$ YTVQDESHSEWVSCVR $\begin{array}{llll}10 & 19 & 0.04 \% & 24.6 \% \\ 10 & 19 & 0.04 \% & 24.6 \% \\ & \end{array}$ $10 \quad 19 \quad 0.04 \% \quad 24.6 \%$ VWQVTIGTR $0.04 \% \quad 6.9 \% \quad$ KLVLILNK $0.04 \% \quad 6.9 \%$ ELPTVVFR $0.04 \% \quad 6.9 \% \quad$ LLGGFQETCSK $0.04 \% \quad 6.9 \%$ VGVIGFPNVGK $0.03 \% \quad 10.3 \%$ SQQSAGKEYVGIVR $0.03 \% \quad 10.3 \%$ LHNAIEGGTQLSR $0.03 \% \quad 10.3 \%$ LVMKDSAVNAICYGAK $0.03 \% \quad 10.3 \%$ DSAVNAICYGAK $0.03 \% \quad 10.3 \%$ APQVVAEAAK $0.01 \% \quad 11.5 \%$ GFFGFPGPR $0.01 \% \quad 11.5 \%$ IFGGVLESDAR $0.01 \% \quad 11.5 \%$ ITKPDGIVEER $0.01 \% \quad 11.5 \%$ ITKPDGIVEERR $0.01 \% \quad 1.8 \%$ LLESKYPR $0.01 \% \quad 1.8 \%$ VVESGGPEILK $0.01 \% \quad 1.8 \%$ GLVGNPLPSVR $0.01 \% \quad 1.8 \%$ TLATTLAPR 
Heat shock $70 \mathrm{kDa}$ protein 1A/1B GN=HSPA1A HSP71_HUMAN $70.05 \quad 100.0 \% \quad 1$ . Da protein 1A/1B GN=HSPA1A HSP71_HUMAN 70.05 at shock $70 \mathrm{kDa}$ protein $1 \mathrm{~A} / \mathrm{B}$ GN=HSPA1A HSP7_HUMAN 70.05 Heat shock $70 \mathrm{kDa}$ protein 1A/1B GN=HSPA1A HSP71_HUMAN 70.05 Heat shock $70 \mathrm{kDa}$ protein 1A/1B GN=HSPA1A HSP71_HUMAN 70.05 Heat shock $70 \mathrm{kDa}$ protein 1A/1B GN=HSPA1A HSP71_HUMAN 70.05 Heat shock $70 \mathrm{kDa}$ protein $1 \mathrm{~A} / 1 \mathrm{~B}$ GN=HSPA1A HSP71_HUMAN 70.05 Heat shock $70 \mathrm{kDa}$ protein 1A/1B GN=HSPA1A HSP71 HUMAN 70.05 Heat shock $70 \mathrm{kDa}$ protein 1A/1B GN=HSPA1A HSP71_HUMAN 70.05 Heat shock $70 \mathrm{kDa}$ protein 1A/1B GN=HSPA1A HSP71_HUMAN 70.05 Heat shock $70 \mathrm{kDa}$ protein 1A/1B GN=HSPA1A HSP71_HUMAN 70.05 Heat shock $70 \mathrm{kDa}$ protein 1A/1B GN=HSPA1A HSP71_HUMAN 70.05 Heat shock $70 \mathrm{kDa}$ protein 1A/1B GN=HSPA1A HSP71_HUMAN 70.05 Heat shock $70 \mathrm{kDa}$ protein $1 \mathrm{~A} / 1 \mathrm{~B}$ GN=HSPA1A HSP71_HUMAN 70.05 Heat shock cognate $71 \mathrm{kDa}$ protein GN=HSPA8 HSP7C_HUMAN 70.90 Heat shock cognate $71 \mathrm{kDa}$ protein GN=HSPA8 HSP7C HUMAN 70.90 Heat shock cognate $71 \mathrm{kDa}$ protein GN=HSPA8 HSP7C_HUMAN 70.90 Heat shock cognate $71 \mathrm{kDa}$ protein GN=HSPA8 HSP7C_HUMAN 70.90 Heat shock cognate $71 \mathrm{kDa}$ protein GN=HSPA8 HSP7C_HUMAN 70.90 Heat shock cognate $71 \mathrm{kDa}$ protein GN=HSPA8 HSP7C_HUMAN 70.90 Heat shock cognate $71 \mathrm{kDa}$ protein GN=HSPA8 HSP7C HUMAN 70.90 Heat shock cognate $71 \mathrm{kDa}$ protein GN=HSPA8 HSP7C_HUMAN 70.90 Heat shock cognate $71 \mathrm{kDa}$ protein GN=HSPA8 HSP7C_HUMAN 70.90 Heat shock cognate $71 \mathrm{kDa}$ protein GN=HSPA8 HSP7C HUMAN 70.90 Heat shock protein $75 \mathrm{kDa}$, mitochondrial GN=TRAP1 TRAP1_HUMAN 80.11 Heat shock protein $75 \mathrm{kDa}$, mitochondrial GN=TRAP1 TRAP1_HUMAN 80.1 Heat shock protein $75 \mathrm{kDa}$, mitochondrial GN=TRAP1 TRAP1_HUMAN 80.1 Heat shock protein $75 \mathrm{kDa}$, mitochondrial GN=TRAP1 TRAP1_HUMAN 80.1 Heat shock protein HSP 90-alpha GN=HSP90AA1 HS90A HUMAN 84.66 Heat shock protein HSP 90-alpha GN=HSP90AA1 HS90A_HUMAN 84.66 Heat shock protein HSP 90-alpha GN=HSP90AA1 HS90A_HUMAN 84.66 Heat shock protein HSP 90-alpha GN=HSP90AA1 HS90A_HUMAN 84.66 Heat shock protein HSP 90-alpha GN=HSP90AA1 HS90A_HUMAN 84.66 Heat shock protein HSP 90-alpha GN=HSP90AA1 HS90A HUMAN 84.66 Heat shock protein HSP 90-alpha GN=HSP90AA1 HS90A_HUMAN 84.66 Heat shock protein HSP 90-alpha GN=HSP90AA1 HS90A_HUMAN 84.66 Heat shock protein HSP 90-alpha GN=HSP90AA1 HS90A HUMAN 84.66 Heat shock protein HSP 90-alpha GN=HSP90AA1 HS90A_HUMAN 84.66 Heat shock protein HSP 90-alpha GN=HSP90AA1 HS90A_HUMAN 84.66 Heat shock protein HSP 90-alpha GN=HSP90AA1 HS90A_HUMAN 84.66 Heat shock protein HSP 90-alpha GN=HSP90AA1 HS90A_HUMAN 84.66 Heat shock protein HSP 90-alpha GN=HSP90AA1 HS90A HUMAN 84.66 Heat shock protein HSP 90-alpha GN=HSP90AA1 HS90A_HUMAN 84.66 Heat shock protein HSP 90-alpha GN=HSP90AA1 HS90A_HUMAN 84.66 Heat shock protein HSP 90-beta GN=HSP90AB1 HS90B_HUMAN 83.27 Heat shock protein HSP 90-beta GN=HSP90AB1 HS90B_HUMAN 83.27 $\begin{array}{ll}100.0 \% & 15 \\ 100.0 \% & 15\end{array}$

$100.0 \% \quad 15$

$100.0 \% \quad 15$

$100.0 \% \quad 15$

$100.0 \% \quad 15$

$100.0 \% \quad 15$

$100.0 \% \quad 15$

$100.0 \% \quad 15$

$100.0 \% \quad 15$

$100.0 \% \quad 15$

$100.0 \% \quad 15$

$100.0 \% \quad 15$

$100.0 \% \quad 15$

$100.0 \% \quad 8$

$100.0 \%$

$100.0 \%$

$100.0 \%$

$100.0 \%$

$100.0 \%$

$100.0 \%$

$100.0 \%$

$100.0 \%$

$100.0 \%$

$100.0 \%$

$100.0 \%$

$100.0 \%$

$100.0 \%$

$100.0 \%$

$100.0 \%$

$100.0 \%$

$100.0 \%$

$100.0 \%$

$100.0 \%$

$100.0 \%$

$100.0 \%$

$100.0 \%$

$100.0 \%$

$100.0 \%$

$100.0 \%$ $100.0 \%$

$100.0 \%$

$100.0 \%$ $100.0 \%$ $100.0 \% \quad 25$ $100.0 \% \quad 25$
$46 \quad 0.10 \% \quad 21.1 \%$ TTPSYVAFTDTER

$99.7 \% \quad 64.5$ $99.7 \% \quad 68.5$

$0.10 \% \quad 21.1 \%$ NQVALNPQNTVFDAK

$\begin{array}{rr}99.7 \% & 68.5 \\ 99.7 \% & 61.4\end{array}$

$99.7 \% \quad 43.7$

$0.10 \% \quad 21.1 \%$ VQVSYKGETK

$0.10 \% \quad 21.1 \%$ QATKDAGVIAGLNVLR

$0.10 \% \quad 21.1 \%$ DAGVIAGLNVLR

$0.10 \% \quad 21.1 \%$ STLEPVEK

$0.10 \% \quad 21.1 \%$ AQIHDLVLVGGSTR

$0.10 \% \quad 21.1 \%$ LLQDFFNGR

$0.10 \% \quad 21.1 \%$ LLQDFFNGRDLNK

$0.10 \% \quad 21.1 \%$ ITITNDKGR

$0.10 \% \quad 21.1 \%$ LSKEEIER

$0.10 \% \quad 21.1 \%$ VSAKNALESYAFNMK

$0.10 \% \quad 21.1 \%$ NALESYAFNMK

$0.10 \% \quad 21.1 \%$ GGSGSGPTIEEVD

$0.09 \% \quad 15.0 \%$ TTPSYVAFTDTER

$99.7 \% \quad 44.9$

$99.7 \% \quad 62.3$

$95.7 \% \quad 22.7$

$99.7 \% \quad 70.3$

$99.7 \% 35.1$

$99.1 \% 21.9$

$99.7 \% \quad 41.5$

$99.0 \% \quad 47.7$

$98.7 \% \quad 18.4$

$99.7 \% \quad 67.4$

$99.7 \% \quad 37.7$

$99.7 \% \quad 64.5$

$99.7 \% \quad 63.3$

$\begin{array}{lll}0.09 \% & 15.0 \% \\ 0.09 \% & 15.0 \%\end{array}$

$0.09 \% \quad 15.0 \%$ VQVEYKGETK

$0.09 \% \quad 15.0 \%$ MKEIAEAYLGK

$0.09 \% \quad 15.0 \%$ QATKDAGTIAGLNVLR

$0.09 \% \quad 15.0 \%$ DAGTIAGLNVLR

$0.09 \% \quad 15.0 \%$ SQIHDIVLVGGSTR

$0.09 \% \quad 15.0 \%$ ITITNDKGR

$0.09 \% \quad 15.0 \%$ LSKEDIER

$0.01 \% \quad 6.7 \%$ AFLDALQNQAEASSK

$0.01 \% \quad 6.7 \% \quad$ TDAPLNIR

$0.01 \% \quad 6.7 \% \quad$ GVVDSEDIPLNLSR

$0.01 \% \quad 6.7 \% \quad$ ELLQESALIR

$0.03 \% \quad 22.3 \%$ TLTIVDTGIGMTK

$0.03 \% \quad 22.3 \%$ ADLINNLGTIAK

$0.03 \% \quad 22.3 \%$ EKYIDQEELNK

$0.03 \% \quad 22.3 \%$ YIDQEELNK

$0.03 \% \quad 22.3 \%$ NPDDITNEEYGEFYK

$0.03 \% \quad 22.3 \%$ HFSVEGQLEFR

$0.03 \% \quad 22.3 \%$ RAPFDLFENR

$0.03 \% \quad 22.3 \%$ APFDLFENR

$0.03 \% \quad 22.3 \%$ NNIKLYVR

$0.03 \% \quad 22.3 \%$ GVVDSEDLPLNISR

$0.03 \% \quad 22.3 \%$ EMLQQSKILK

$0.03 \% \quad 22.3 \%$ NIKLGIHEDSQNR

$0.03 \% \quad 22.3 \%$ LGIHEDSQNR

$\begin{array}{ll}99.5 \% & 23.3 \\ 99.7 \% & 50.7\end{array}$

$99.7 \% \quad 55.0$

$99.7 \% \quad 62.9$

$99.7 \% \quad 73.0$

$99.7 \% \quad 60.0$

$99.7 \% \quad 41.5$

$99.0 \% \quad 59.4$

$99.7 \% \quad 81.8$

$95.2 \% \quad 20.0$

$99.1 \% \quad 60.5$

$99.7 \% \quad 72.5$

$99.1 \% 70.8$

$99.7 \% \quad 65.4$

$99.7 \% \quad 39.7$

$99.7 \% \quad 43.2$

$99.7 \% \quad 67.9$

$\begin{array}{lll}99.7 \% & 38.2\end{array}$

$99.6 \% \quad 28.7$

$99.7 \% \quad 50.4$

$99.0 \% \quad 44.8$

$99.1 \% \quad 60.5$

$97.4 \% \quad 18.0$

$95.0 \% \quad 17.7$

$99.7 \% \quad 27.4$

0.03\% 22.3\% YYTSASGDEMVSLKDYCTR $99.7 \% \quad 37.4$

$\begin{array}{ll}99.7 \% & 53.5 \\ 94.8 \% & 14.4\end{array}$

$0.03 \% \quad 22.3 \%$ DQVANSAFVER

$0.19 \% \quad 31.9 \%$ IDIIPNPQER

$0.19 \% \quad 31.9 \%$ TLTLVDTGIGMTK

$99.7 \% \quad 30.3$

$99.1 \% 70.8$
1658.85

1814.95

1138.6

1625.93

1197.70

902.48

1465.81

1109.57

1579.82

1017.57

1003.54

1688.83

1287.60

1204.53

1487.70

1649.80

1821.89

1180.62

1252.66

1627.91

1199.67

1481.81

1017.57

989.53

1592.79

899.49

1513.79

1171.67

1349.73

1242.71

1408.70

1151.56

1833.78

1348.66

1264.64

1108.54

1019.60

1513.79

1217.69

1523.79

1168.57

2261.97

1235.60

1759.81

1194.65

1349.73 
Heat shock protein HSP 90-beta GN=HSP90AB1 HS90B_HUMAN $83.27 \quad 100.0 \% \quad 25$ Heat shock protein HSP 90-beta GN=HSP90AB1 HS90B_HUMAN $83.27 \quad 100.0 \% \quad 25$ Heat shock protein HSP 90-beta GN=HSP90AB1 HS90B_HUMAN $83.27 \quad 100.0 \% \quad 25$ Heat shock protein HSP 90-beta GN=HSP90AB1 HS90B_HUMAN 83.27 Heat shock protein HSP 90-beta GN=HSP90AB1 HS90B_HUMAN 83.27 Heat shock protein HSP 90-beta GN=HSP90AB1 HS90B_HUMAN 83.27 Heat shock protein HSP 90-beta GN=HSP90AB1 HS90B_HUMAN 83.27 Heat shock protein HSP 90-beta GN=HSP90AB1 HS90B_HUMAN 83.27 Heat shock protein HSP 90-beta GN=HSP90AB1 HS90B HUMAN 83.27 Heat shock protein HSP 90-beta GN=HSP90AB1 HS90B_HUMAN 83.27 Heat shock protein HSP 90-beta GN=HSP90AB1 HS90B_HUMAN 83.27 Heat shock protein HSP 90-beta GN=HSP90AB1 HS90B_HUMAN 83.2? Heat shock protein HSP 90-beta GN=HSP90AB1 HS90B_HUMAN 83.27 Heat shock protein HSP 90-beta GN=HSP90AB1 HS90B_HUMAN 83.27 Heat shock protein HSP 90-beta GN=HSP90AB1 HS90B_HUMAN 83.27 Heat shock protein HSP 90-beta GN=HSP90AB1 HS90B_HUMAN 83.27 Heat shock protein HSP 90-beta GN=HSP90AB1 HS90B HUMAN 83.27 Heat shock protein HSP 90-beta GN=HSP90AB1 HS90B_HUMAN 83.27 Heat shock protein HSP 90-beta GN=HSP90AB1 HS90B_HUMAN 83.27 Heat shock protein HSP 90-beta GN=HSP90AB1 HS90B_HUMAN 83.27 Heat shock protein HSP 90-beta GN=HSP90AB1 HS90B_HUMAN 83.27 Heat shock protein HSP 90-beta GN=HSP90AB1 HS90B_HUMAN 83.27 Heat shock protein HSP 90-beta GN=HSP90AB1 HS90B HUMAN 83.27 Hermansky-Pudlak syndrome 6 protein GN=HPS6 HPS6_HUMAN 82.98 Hermansky-Pudlak syndrome 6 protein GN=HPS6 HPS6 HUMAN 82.98 Hermansky-Pudlak syndrome 6 protein GN=HPS6 HPS6_HUMAN 82.98 Heterochromatin protein 1-binding protein $3 \mathrm{GN}=\mathrm{HP} 1 \mathrm{BP} 3 \mathrm{HP} 1 \mathrm{~B} 3$ _HUMAN 61.2 Heterochromatin protein 1-binding protein $3 \mathrm{GN}=\mathrm{HP} 1 \mathrm{BP} 3 \mathrm{HP} 1 \mathrm{~B} 3$ HUMAN 61.2 Heterochromatin protein 1-binding protein $3 \mathrm{GN}=\mathrm{HP} 1 \mathrm{BP} 3 \mathrm{HP} 1 \mathrm{~B} 3$ _HUMAN 61.2 Heterochromatin protein 1-binding protein $3 \mathrm{GN}=\mathrm{HP} 1 \mathrm{BP} 3 \mathrm{HP} 1 \mathrm{~B} 3$ HUMAN 61.2 Heterochromatin protein 1-binding protein $3 \mathrm{GN}=\mathrm{HP} 1 \mathrm{BP} 3 \mathrm{HP} 1 \mathrm{~B} 3$ _HUMAN 61.21 Heterochromatin protein 1-binding protein $3 \mathrm{GN}=\mathrm{HP} 1 \mathrm{BP} 3 \mathrm{HP} 1 \mathrm{~B} 3$ _HUMAN 61.21 Heterochromatin protein 1-binding protein $3 \mathrm{GN}=\mathrm{HP} 1 \mathrm{BP} 3 \mathrm{HP} 1 \mathrm{~B} 3$ _HUMAN 61.21 Heterochromatin protein 1-binding protein $3 \mathrm{GN}=\mathrm{HP} 1 \mathrm{BP} 3$ HP1B3_HUMAN 61.21 Heterogeneous nuclear ribonucleoprotein A/B GN=HNRNPAB ROAA_HUMAN 36.23 Heterogeneous nuclear ribonucleoprotein A/B GN=HNRNPAB ROAA HUMAN 36.23 Heterogeneous nuclear ribonucleoprotein A/B GN=HNRNPAB ROAA_HUMAN 36.2 . Heterogeneous nuclear ribonucleoprotein $\mathrm{A} / \mathrm{B}$ GN=HNRNPAB ROAA_HUMAN 36.2 Heterogeneous nuclear ribonucleoprotein A/B GN=HNRNPAB ROAA_HUMAN 36.23 Heterogeneous nuclear ribonucleoprotein A/B GN=HNRNPAB ROAA_HUMAN 36.23 Heterogeneous nuclear ribonucleoprotein A0 GN=HNRNPA0 ROA0 HUMAN 30.84 Heterogeneous nuclear ribonucleoprotein A0 GN=HNRNPA0 ROA0_HUMAN 30.84 Heterogeneous nuclear ribonucleoprotein A0 GN=HNRNPA0 ROA0 HUMAN 30.84 Heterogeneous nuclear ribonucleoprotein A0 GN=HNRNPA0 ROA0 HUMAN 30.84 Heterogeneous nuclear ribonucleoprotein A1 GN=HNRNPA1 ROA1_HUMAN 38.7 . Heterogeneous nuclear ribonucleoprotein A1 GN=HNRNPA1 ROA1_HUMAN 38.7 Heterogeneous nuclear ribonucleoprotein A1 GN=HNRNPA1 ROA1_HUMAN 38.75
$100.0 \% \quad 25$ $100.0 \% \quad 25$ $100.0 \% \quad 25$ $100.0 \% \quad 25$ $100.0 \% \quad 25$ $100.0 \% \quad 25$ $100.0 \% \quad 25$ $100.0 \% \quad 25$ $100.0 \% \quad 25$ $100.0 \% \quad 25$ $100.0 \% \quad 25$ $100.0 \% \quad 25$ $100.0 \% \quad 25$ $100.0 \% \quad 25$ $100.0 \% \quad 25$ $100.0 \% \quad 25$ $100.0 \% \quad 25$ $100.0 \% \quad 25$ $100.0 \% \quad 25$ $100.0 \% \quad 25$ $100.0 \% \quad 3$ $100.0 \%$ $100.0 \%$ $100.0 \%$ $100.0 \%$ $100.0 \%$ $100.0 \%$ $100.0 \%$ $100.0 \%$ $100.0 \%$ $100.0 \%$ $100.0 \%$ $100.0 \%$ $100.0 \%$ $100.0 \%$ $100.0 \%$ $100.0 \%$ $100.0 \%$ $100.0 \%$ $100.0 \%$ $100.0 \%$ $100.0 \%$ $100.0 \%$ $100.0 \%$

5
5
5
5

5

$89 \quad 0.19 \% \quad 31.9 \%$ ADLINNLGTIAK

$89 \quad 0.19 \% \quad 31.9 \%$ EKYIDQEELNK

$0.19 \% \quad 31.9 \%$ YIDQEELNK

$99 \quad 0.19 \% \quad 31.9 \%$ NPDDITQEEYGEFYK

$89 \quad 0.19 \% \quad 31.9 \%$ HFSVEGQLEFR

$0.19 \% \quad 31.9 \%$ ALLFIPRR

$89 \quad 0.19 \% \quad 31.9 \%$ RAPFDLFENK

$8.19 \% \quad 31.9 \%$ APFDLFENK

$89 \quad 0.19 \% \quad 31.9 \%$ APFDLFENKK

$89 \quad 0.19 \% \quad 31.9 \%$ NNIKLYVR

$89 \quad 0.19 \% \quad 31.9 \%$ GVVDSEDLPLNISR

$89 \quad 0.19 \% \quad 31.9 \%$ EMLQQSKILK

$89 \quad 0.19 \% \quad 31.9 \%$ FYEAFSKNLK

$89 \quad 0.19 \% \quad 31.9 \%$ NLKLGIHEDSTNR

$89 \quad 0.19 \% \quad 31.9 \%$ LGIHEDSTNR

$89 \quad 0.19 \% \quad 31.9 \%$ LGIHEDSTNRR

$0.19 \% \quad 31.9 \%$ YHTSQSGDEMTSLSEYVSR

$89 \quad 0.19 \% \quad 31.9 \%$ SIYYITGESK

$0.19 \% \quad 31.9 \%$ EQVANSAFVER

$0.19 \% \quad 31.9 \%$ EFDGKSLVSVTK

$0.19 \% \quad 31.9 \%$ AKFENLCK

$0.19 \% \quad 31.9 \%$ AQALRDNSTMGYMMAK

$0.01 \% \quad 4.8 \%$ LLSDLSAFGGAAR

$0.01 \% \quad 4.8 \%$ TLEPSGEASTSLGR

$0.01 \% \quad 4.8 \%$ KVLGGITAGK

$0.04 \% \quad 9.8 \%$ SGASVVAIRK

$0.04 \% \quad 9.8 \%$ GKGASGSFVVVQK

$0.04 \% \quad 9.8 \%$ GASGSFVVVQK

$0.04 \% \quad 9.8 \% \quad$ KYVSQYYPK

$0.04 \% \quad 9.8 \% \quad$ YVSQYYPK

$21 \quad 0.04 \% \quad 9.8 \% \quad$ AVERGQLEQITGK

$0.04 \% \quad 9.8 \%$ GQLEQITGK

$0.04 \% \quad 9.8 \%$ TRPSSTVIK

$0.04 \% \quad 13.9 \%$ DLKDYFTK

$0.04 \% \quad 13.9 \%$ FGEVVDCTIK

$99.7 \% \quad 65.4$

$99.7 \% \quad 30.3$

$99.7 \% \quad 39.7$

$99.7 \% \quad 43.2$

$99.7 \% \quad 64.3$

$99.7 \% \quad 38.2$

$99.0 \% 34.8$

$99.7 \% \quad 38.6$

$99.7 \% \quad 47.9$

$99.7 \% 32.8$

$99.0 \% \quad 44.8$

$99.1 \% \quad 60.5$

$97.4 \% \quad 18.0$

$99.7 \% \quad 39.3$

$99.7 \% \quad 46.1$

$99.7 \% \quad 42.3$

$99.3 \% 23.7$

$99.7 \% \quad 73$.

$99.7 \% \quad 43.5$

$99.7 \% \quad 57.8$

$99.3 \% \quad 23.5$

$98.2 \% \quad 18.7$

$\begin{array}{lll}99.6 \% & 25.9\end{array}$

$\begin{array}{lll}99.7 \% & 53.3\end{array}$

$99.7 \% \quad 60.5$

$98.7 \% \quad 22.1$

$99.7 \% \quad 38.1$

$99.7 \% \quad 59.5$

$99.7 \% \quad 50.2$

$99.7 \% \quad 37.4$

$97.5 \% \quad 17.0$

$99.7 \% \quad 49.9$

$\begin{array}{lll}98.9 \% & 22.7\end{array}$

$\begin{array}{lll}98.3 \% & 29.1\end{array}$

$95.3 \% \quad 15.2$

$99.2 \% \quad 48.9$

$\begin{array}{lllll}0.04 \% & 13.9 \% & \text { FGEVVDCTIKMDPNTGR } & 99.7 \% & 37.8\end{array}$

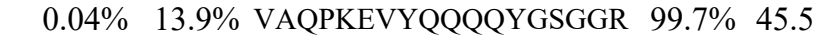

$0.04 \% \quad 13.9 \%$ EVYQQQQYGSGGR

$99.7 \% \quad 72.2$

$0.04 \% \quad 13.9 \%$ EVYQQQQYGSGGRGNR

$0.03 \% \quad 14.1 \%$ AEIIADKQSGK

$\begin{array}{ll}99.6 \% & 27.4 \\ 99.7 \% & 39.8\end{array}$

$\begin{array}{lllll}0.03 \% & 14.1 \% \text { GFGFVYFQNHDAADK } \quad 95.8 \% & 15.6\end{array}$

$0.03 \% \quad 14.1 \%$ AVPKEDIYSGGGGGGSR

$0.03 \% \quad 14.1 \%$ EDIYSGGGGGGSR

$0.14 \% \quad 25.3 \%$ SESPKEPEQLR

$0.14 \% \quad 25.3 \%$ VDGRVVEPK

$0.14 \% \quad 25.3 \%$ EDSQRPGAHLTVK

1835.81

1277.68

1404.70

943.59

1263.71

1078.59

1175.61

1047.51

1428.78

973.53

988.58

1029.53

1167.57

1954.90

2023.00

1499.69

1826.85

1159.63

1715.78

1606.78

1211.53

1299.65

998.56

1437.74 
Heterogeneous nuclear ribonucleoprotein A1 GN=HNRNPA1 ROA1_HUMAN $38.75 \quad 100.0 \%$ Heterogeneous nuclear ribonucleoprotein A1 GN=HNRNPA1 ROA1_HUMAN $38.75 \quad 100.0 \%$ Heterogeneous nuclear ribonucleoprotein A1 GN=HNRNPA1 ROA1_HUMAN $38.75 \quad 100.0 \%$ Heterogeneous nuclear ribonucleoprotein A1 GN=HNRNPA1 ROA1_HUMAN 38.75 Heterogeneous nuclear ribonucleoprotein A1 GN=HNRNPA1 ROA1_HUMAN 38.75 Heterogeneous nuclear ribonucleoprotein A1 GN=HNRNPA1 ROA1_HUMAN 38.75 Heterogeneous nuclear ribonucleoprotein $\mathrm{A} 3 \mathrm{GN}=\mathrm{HNRNPA} 3$ ROA3_HUMAN 39.60 Heterogeneous nuclear ribonucleoprotein A3 GN=HNRNPA3 ROA3_HUMAN 39.60 Heterogeneous nuclear ribonucleoprotein A3 GN=HNRNPA3 ROA3_HUMAN 39.60 Heterogeneous nuclear ribonucleoprotein A3 GN=HNRNPA3 ROA3_HUMAN 39.60 Heterogeneous nuclear ribonucleoprotein A3 GN=HNRNPA3 ROA3_HUMAN 39.60 Heterogeneous nuclear ribonucleoprotein D-like GN=HNRNPDL HNRDL_HUMAN 46.44 Heterogeneous nuclear ribonucleoprotein D-like GN=HNRNPDL HNRDL_HUMAN 46.44 Heterogeneous nuclear ribonucleoprotein D-like GN=HNRNPDL HNRDL_HUMAN 46.44 Heterogeneous nuclear ribonucleoprotein D-like GN=HNRNPDL HNRDL_HUMAN 46.44 Heterogeneous nuclear ribonucleoprotein D-like GN=HNRNPDL HNRDL_HUMAN 46.44 Heterogeneous nuclear ribonucleoprotein F GN=HNRNPF HNRPF_HUMAN 45.67 Heterogeneous nuclear ribonucleoprotein F GN=HNRNPF HNRPF_HUMAN 45.67 Heterogeneous nuclear ribonucleoprotein F GN=HNRNPF HNRPF_HUMAN 45.67 Heterogeneous nuclear ribonucleoprotein F GN=HNRNPF HNRPF_HUMAN 45.67 Heterogeneous nuclear ribonucleoprotein F GN=HNRNPF HNRPF_HUMAN 45.67 Heterogeneous nuclear ribonucleoprotein H GN=HNRNPH1 HNRH1 HUMAN 49.23 oneous nuclear ribonucleoprotein $\mathrm{H}$ GN=HNRNPH1 HNRH1_HUMAN 49.23 Heterogeneous nuclear ribonucleoprotein H GN=HNRNPH1 HNRH1_HUMAN 49.2 Heterogeneous nuclear ribonucleoprotein $\mathrm{H}$ GN=HNRNPH1 HNRH1_HUMAN 49.23 Heterogeneous nuclear ribonucleoprotein H GN=HNRNPH1 HNRH1_HUMAN 49.23 Heterogeneous nuclear ribonucleoprotein $\mathrm{H}$ GN=HNRNPH1 HNRH1_HUMAN 49.23 Heterogeneous nuclear ribonucleoprotein $\mathrm{H} 3 \mathrm{GN}=\mathrm{HNRNPH3}$ HNRH3_HUMAN 36.93 Heterogeneous nuclear ribonucleoprotein $\mathrm{H} 3 \mathrm{GN}=\mathrm{HNRNPH} 3 \mathrm{HNRH} 3$ HUMAN 36.93 Heterogeneous nuclear ribonucleoprotein $\mathrm{H3}$ GN=HNRNPH3 HNRH3_HUMAN 36.93 Heterogeneous nuclear ribonucleoprotein $\mathrm{H} 3$ GN=HNRNPH3 HNRH3_HUMAN 36.93 Heterogeneous nuclear ribonucleoprotein $\mathrm{H} 3 \mathrm{GN}=\mathrm{HNRNPH} 3$ HNRH3_HUMAN 36.93 Heterogeneous nuclear ribonucleoprotein K GN=HNRNPK HNRPK_HUMAN 50.98 Heterogeneous nuclear ribonucleoprotein K GN=HNRNPK HNRPK_HUMAN 50.98 Heterogeneous nuclear ribonucleoprotein K GN=HNRNPK HNRPK_HUMAN 50.98 Heterogeneous nuclear ribonucleoprotein K GN=HNRNPK HNRPK_HUMAN 50.98 Heterogeneous nuclear ribonucleoprotein $\mathrm{K}$ GN=HNRNPK HNRPK_HUMAN 50.98 Heterogeneous nuclear ribonucleoprotein K GN=HNRNPK HNRPK_HUMAN 50.98 Heterogeneous nuclear ribonucleoprotein K GN=HNRNPK HNRPK_HUMAN 50.98 Heterogeneous nuclear ribonucleoprotein K GN=HNRNPK HNRPK_HUMAN 50.98 Heterogeneous nuclear ribonucleoprotein K GN=HNRNPK HNRPK_HUMAN 50.98 Heterogeneous nuclear ribonucleoprotein K GN=HNRNPK HNRPK_HUMAN 50.98 Heterogeneous nuclear ribonucleoprotein $\mathrm{K}$ GN=HNRNPK HNRPK_HUMAN 50.98 Heterogeneous nuclear ribonucleoprotein K GN=HNRNPK HNRPK_HUMAN 50.98 Heterogeneous nuclear ribonucleoprotein $\mathrm{K}$ GN=HNRNPK HNRPK HUMAN 50.98 Heterogeneous nuclear ribonucleoprotein L GN=HNRNPL HNRPL_HUMAN 64.13
$100.0 \%$

$100.0 \%$

$100.0 \%$

$100.0 \%$ $100.0 \%$

$100.0 \%$

$100.0 \%$

$100.0 \%$

$00.0 \%$

$00.0 \%$

$100.0 \%$

$100.0 \%$

$00.0 \%$

$100.0 \%$

$100.0 \%$

$100.0 \%$

$100.0 \%$

$100.0 \%$

$100.0 \%$

$100.0 \%$

$100.0 \%$

$100.0 \%$ $100.0 \%$

$100.0 \%$ $100.0 \%$ $100.0 \%$ $100.0 \%$ $100.0 \%$ $100.0 \%$ $100.0 \% \quad 13$ $100.0 \% \quad 13$ $100.0 \% \quad 13$ $100.0 \% \quad 13$ $100.0 \% \quad 13$ $100.0 \% \quad 13$ $100.0 \%$ $100.0 \% \quad 13$ $100.0 \% \quad 13$ $100.0 \% \quad 13$ $100.0 \% \quad 13$ $100.0 \%$
$0.14 \% \quad 25.3 \%$ IEVIEIMTDR

$0.14 \% \quad 25.3 \%$ IEVIEIMTDRGSGK

$\begin{array}{llllllll}99.7 \% & 31.2 & 25.0 & 25.3 & 2 & 1 & 0 & 1565.84\end{array}$

$\begin{array}{llllllll}99.7 \% & 46.9 & 25.0 & 39.8 & 2 & 0 & 0 & 1234.64\end{array}$

$9.7 \%-46.9-25.0-39.8$
-0.0

$0.14 \% \quad 25.3 \%$ YHTVNGHNCEVR

$99.7 \% \quad 27.8 \quad 25.0 \quad 27.8$

$0.14 \% \quad 25.3 \%$ SSGPYGGGGQYFAKPR

$99.7 \% \quad 69.6$

$0.14 \% \quad 25.3 \%$ NQGGYGGSSSSSSYGSGR $99.7 \% \quad 67.9$

$97.8 \% 24.0$

$0.03 \% \quad 16.4 \%$ VDGRVVEPK

$99.4 \% \quad 23.1$

$0.03 \% \quad 16.4 \%$ EDSVKPGAHLTVKK

$98.9 \% \quad 25.4$

$0.03 \% \quad 16.4 \%$ YHTINGHNCEVKK

$99.4 \% \quad 27.2$

$0.03 \% \quad 16.4 \%$ SSGSPYGGGYGSGGGS

$\begin{array}{lll}99.7 \% & 84.4\end{array}$

$99.2 \% \quad 48.9$

$\begin{array}{lllll}0.03 \% & 12.6 \% & \text { FGEVVDCTIKTDPVTGR } & 99.7 \% & 61.4\end{array}$

$0.03 \% \quad 12.6 \%$ GFCFITYTDEEPVKK

$0.03 \% \quad 12.6 \%$ YHQIGSGKCEIK

$99.7 \% \quad 49.5$

$97.5 \% \quad 19.3$

$95.4 \% \quad 15.7$

$0.02 \% \quad 11.8 \%$ HSGPNSADSANDGFVR $\quad 99.7 \% \quad 62.9$

$0.02 \% \quad 11.8 \%$ HSGPNSADSANDGFVRLR

$99.2 \% \quad 20.5$

$99.7 \% \quad 62.0$

$99.2 \% \quad 24.5$

$99.7 \% \quad 56.3$

$99.7 \% \quad 35.9$

$99.7 \% \quad 32.4$

$0.07 \% \quad 16.3 \%$ FFSDCKIQNGAQGIR

$0.07 \% \quad 16.3 \%$ IQNGAQGIR

$0.07 \% \quad 16.3 \%$ HTGPNSPDTANDGFVR

$0.07 \% \quad 16.3 \%$ IGHRYIEIFK

$99.7 \% \quad 59.5$

$99.7 \% \quad 29.2$

$99.4 \% \quad 26.0$

$0.07 \% \quad 16.3 \%$ YIEIFKSSR

$\begin{array}{lllll}99.6 \% & 27.0 & 25.0 & 19.6 & 2\end{array}$

$0.07 \% \quad 16.3 \%$ VHIEIGPDGR

$\begin{array}{lll}0.02 \% & 16.8 \% \text { HNGPNDASDGTVR } \\ 0.02 \% & 16.8 \% \text { STGEAFVQFASK }\end{array}$

$0.02 \% \quad 16.8 \%$ EIAENALGK

$0.02 \% \quad 16.8 \%$ VHIDIGADGR

$0.02 \% \quad 16.8 \%$ DGMDNQGGYGSVGR

$0.07 \% \quad 21.4 \%$ RPAEDMEEEQAFKR

$0.07 \% \quad 21.4 \%$ SRNTDEMVELR

$0.07 \% \quad 21.4 \%$ NTDEMVELR

$99.7 \% \quad 56.3$

$99.6 \% \quad 26.4$

$99.7 \% \quad 70.3$

$99.7 \% \quad 39.1$

$99.2 \% \quad 20.9$

$99.7 \% \quad 62.1$

$99.7 \% \quad 49.5$

$99.7 \% \quad 46.1$

$99.7 \% \quad 63.0$

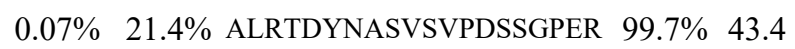

$0.07 \% \quad 21.4 \%$ TDYNASVSVPDSSGPER $\quad 99.7 \% \quad 58.4$

$0.07 \% \quad 21.4 \%$ LFQECCPHSTDR

$0.07 \% \quad 21.4 \%$ VVLIGGKPDR

$0.07 \% \quad 21.4 \%$ RDYDDMSPR

$0.07 \% \quad 21.4 \%$ DYDDMSPR

$0.07 \% \quad 21.4 \%$ GGDLMAYDR

$0.07 \% \quad 21.4 \%$ GGDLMAYDRR

$0.07 \% \quad 21.4 \%$ DLAGSIIGK

$99.7 \% \quad 46.6$

$99.7 \% \quad 40.9$

$99.5 \% \quad 25.0$

$99.0 \% \quad 28.4$

$99.7 \% 52.5$

$97.7 \% \quad 23.4$

$99.7 \% \quad 41.9$

$99.7 \% \quad 63.2$

$99.7 \% \quad 69.4$

1547.81

1485.67

1628.78

1694.70

998.56

1793.99

1508.84

1599.77

1910.79

1167.57

1893.94

1833.87

1419.71

1089.61

1630.72

1899.91

1613.82

1721.83

1092.58

1740.85

956.53

1684.77

1275.72

1142.62

2097.89

1092.58

1339.60

1271.63

944.50

1052.55

1428.58

1735.81

1349.65

1106.51

2121.02

1780.80

1549.65

1053.64

1154.49

998.39

1013.44

1153.54

$\begin{array}{lllll}9.7 \% & 69.4 & 25.0 & 67.4 & 4\end{array}$

$\begin{array}{lllll}17 & 32 & 0.07 \% & 21.4 \% & \text { DLAGSIIGKGGQR } \\ 12 & 31 & 0.07 \% & 23.6 \% & \text { YYGGGSEGGRAPK }\end{array}$

$\begin{array}{cc}3 & 106 \\ 31 & 140 \\ 31 & 144 \\ 67 & 178 \\ 37 & 352 \\ 53 & 370 \\ 00 & 108 \\ 10 & 126 \\ 14 & 127 \\ 88 & 200 \\ 55 & 376 \\ 71 & 180 \\ 71 & 187 \\ 75 & 289 \\ 95 & 306 \\ 07 & 315 \\ 9 & 114 \\ 9 & 116 \\ 80 & 192 \\ 86 & 200 \\ 17 & 326 \\ 30 & 44 \\ 36 & 44 \\ 99 & 114 \\ 76 & 185 \\ 80 & 188 \\ 76 & 294 \\ 17 & 326 \\ 7 & 19 \\ 56 & 67 \\ 58 & 76 \\ 23 & 232 \\ 88 & 301 \\ 22 & 35 \\ 36 & 46 \\ 38 & 46 \\ 97 & 86 \\ 97 & 409 \\ 70 & 86 \\ 80 & 191 \\ 92 & 201 \\ 78 & 286 \\ 79 & 286 \\ 17 & 325 \\ & 326 \\ & \end{array}$

Page 41 of Table S-1-3 

Heterogeneous nuclear ribonucleoprotein L GN=HNRNPL HNRPL HUMAN $64.13 \quad 100.0 \%$ Heterogeneous nuclear ribonucleoprotein L GN=HNRNPL HNRPL_HUMAN $64.13 \quad 100.0 \%$

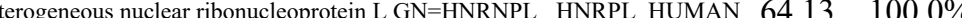
Heterogeneous nuclear ribonucleoprotein L GN=HNRNPL HNRPL_HUMAN $64.13 \quad 100.0 \%$ Heterogeneous nuclear ribonucleoprotein L GN=HNRNPL HNRPL_HUMAN $64.13 \quad 100.0 \%$ Heterogeneous nuclear ribonucleoprotein L GN=HNRNPL HNRPL_HUMAN $64.13 \quad 100.0 \%$ Heterogeneous nuclear ribonucleoprotein L GN=HNRNPL HNRPL_HUMAN $64.13 \quad 100.0 \%$ Heterogeneous nuclear ribonucleoprotein L GN=HNRNPL HNRPL HUMAN $64.13 \quad 100.0 \%$ Heterogeneous nuclear ribonucleoprotein L GN=HNRNPL HNRPL_HUMAN $64.13 \quad 100.0 \%$ Heterogeneous nuclear ribonucleoprotein M GN=HNRNPM HNRPM_HUMAN $77.52 \quad 100.0 \%$ teterogeneous nuclear ribonucleoprotein M GN=HNRNPM HNRPM HUMAN 77.52 $100.0 \%$ Heterogeneous nuclear ribonucleoprotein M GN=HNRNPM HNRPM_HUMAN $77.52 \quad 100.0 \%$ Heterogeneous nuclear ribonucleoprotein M GN=HNRNPM HNRPM_HUMAN 77.52 Heterogeneous nuclear ribonucleoprotein M GN=HNRNPM HNRPM HUMAN 77.52 Heterogeneous nuclear ribonucleoprotein M GN=HNRNPM HNRPM_HUMAN 77.52 Heterogeneous nuclear ribonucleoprotein M GN=HNRNPM HNRPM_HUMAN 77.52 Heterogeneous nuclear ribonucleoprotein M GN=HNRNPM HNRPM_HUMAN 77.52 Heterogeneous nuclear ribonucleoprotein M GN=HNRNPM HNRPM_HUMAN 77.52 Heterogeneous nuclear ribonucleoprotein M GN=HNRNPM HNRPM HUMAN 77.52 Heterogeneous nuclear ribonucleoprotein M GN=HNRNPM HNRPM_HUMAN 77.52 Heterogeneous nuclear ribonucleoprotein M GN=HNRNPM HNRPM_HUMAN 77.52 Heterogeneous nuclear ribonucleoprotein M GN=HNRNPM HNRPM_HUMAN 77.52 Heterogeneous nuclear ribonucleoprotein M GN=HNRNPM HNRPM_HUMAN 77.52 Heterogeneous nuclear ribonucleoprotein M GN=HNRNPM HNRPM_HUMAN 77.52 Heterogeneous nuclear ribonucleoprotein M GN=HNRNPM HNRPM_HUMAN 77.52 Heterogeneous nuclear ribonucleoprotein M GN=HNRNPM HNRPM_HUMAN 77.52 Heterogeneous nuclear ribonucleoprotein M GN=HNRNPM HNRPM_HUMAN 77.52 Heterogeneous nuclear ribonucleoprotein M GN=HNRNPM HNRPM_HUMAN 77.52 Heterogeneous nuclear ribonucleoprotein M GN=HNRNPM HNRPM_HUMAN 77.52 Heterogeneous nuclear ribonucleoprotein M GN=HNRNPM HNRPM_HUMAN 77.52 Heterogeneous nuclear ribonucleoprotein M GN=HNRNPM HNRPM_HUMAN 77.52 Heterogeneous nuclear ribonucleoprotein M GN=HNRNPM HNRPM HUMAN 77.52 Heterogeneous nuclear ribonucleoprotein M GN=HNRNPM HNRPM_HUMAN 77.52 Heterogeneous nuclear ribonucleoprotein M GN=HNRNPM HNRPM_HUMAN 77.52 Heterogeneous nuclear ribonucleoprotein M GN=HNRNPM HNRPM HUMAN 77.52 Heterogeneous nuclear ribonucleoprotein M GN=HNRNPM HNRPM_HUMAN 77.52 Heterogeneous nuclear ribonucleoprotein M GN=HNRNPM HNRPM_HUMAN 77.52 Heterogeneous nuclear ribonucleoprotein M GN=HNRNPM HNRPM_HUMAN 77.52 Heterogeneous nuclear ribonucleoprotein M GN=HNRNPM HNRPM_HUMAN 77.52 Heterogeneous nuclear ribonucleoprotein M GN=HNRNPM HNRPM HUMAN 77.52 Heterogeneous nuclear ribonucleoprotein M GN=HNRNPM HNRPM_HUMAN 77.52 Heterogeneous nuclear ribonucleoprotein M GN=HNRNPM HNRPM_HUMAN 77.52

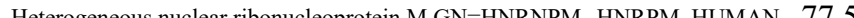
Heterogeneous nuclear ribonucleoprotein M GN=HNRNPM HNRPM_HUMAN 77.52 Heterogeneous nuclear ribonucleoprotein M GN=HNRNPM HNRPM HUMAN 77.52 Heterogeneous nuclear ribonucleoprotein M GN=HNRNPM HNRPM_HUMAN 77.52
$100.0 \%$
$100.0 \%$

12

12

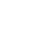

12

(1)

68

$\begin{array}{ll}1 & 12 \\ 1 & 68 \\ 1 & 68\end{array}$

68

1

41

41

$11 \quad 0.07 \% \quad 23.6 \%$ ISRPGDSDDSR $99.5 \% \quad 30.1$ $1 \quad 0.07 \% \quad 23.6 \%$ ASLNGADIYSGCCTLK $0.07 \% \quad 23.6 \%$ IEYAKPTR

$0.07 \% \quad 23.6 \%$ MGPPVGGHR

$99.7 \% \quad 34.6$

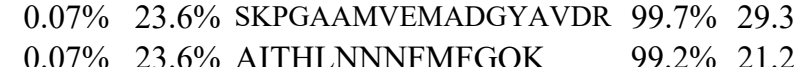

$0.07 \% \quad 23.6 \%$

$0.07 \% \quad 23.6 \%$ NNRFSTPEQAAK

$0.07 \% \quad 23.6 \%$ NPNGPYPYTLK

$31 \quad 0.07 \% \quad 23.6 \%$ LCFSTAQHAS

$68 \quad 237 \quad 0.50 \% \quad 54.2 \%$ GGNRFEPYANPTK

$\begin{array}{llll}68 & 237 & 0.50 \% & 54.2 \% \\ 68 & 237 & 0.50 \% & 54.2 \% \text { AAEVEFK }\end{array}$

$68 \quad 237 \quad 0.50 \% \quad 54.2 \%$ AAEVLNKHSLSGRPLK

$\begin{array}{llll}68 & 237 & 0.50 \% & 54.2 \%\end{array}$ HSLSGRPLK

$68 \quad 237 \quad 0.50 \% \quad 54.2 \%$ LGSTVFVANLDYK

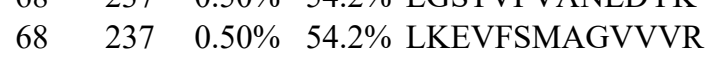

$\begin{array}{llll}68 & 237 & 0.50 \% & 54.2 \% \\ 68 & \text { ADILEDKDGK }\end{array}$

$68 \quad 237 \quad 0.50 \% \quad 54.2 \%$ MDERALPK

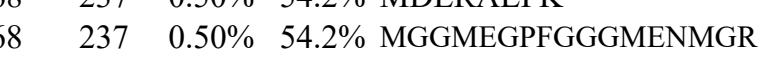

$68 \quad 237 \quad 0.50 \% \quad 54.2 \%$ FGSGMNMGR

$68 \quad 237 \quad 0.50 \% \quad 54.2 \%$ INEILSNALK

$\begin{array}{llll}68 & 237 & 0.50 \% & 54.2 \%\end{array}$ INEILSNALKR

$68 \quad 237 \quad 0.50 \% \quad 54.2 \%$ GEIIAKQGGGGGGGSVPGIER

$68 \quad 237 \quad 0.50 \% \quad 54.2 \%$ QGGGGGGGSVPGIER

$\begin{array}{lllll}68 & 237 & 0.50 \% & 54.2 \% & \text { QGGGGGGGSVPGIERMGPGIDR } \\ 68 & 237 & 0.50 \% & 54.2 \% \text { MGPGIDRLGGAGMER }\end{array}$

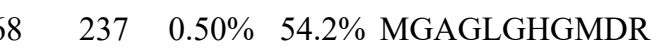

$\begin{array}{lllll}68 & 237 & 0.50 \% & 54.2 \% & \text { MGAGLGHGMDRVGSEIER } \\ 68 & 237 & 0.50 \% & 54.2 \% & \text { VGSEIERMGLVMDR }\end{array}$

$68 \quad 237 \quad 0.50 \% \quad 54.2 \%$ MGSVERMGSGIER

$237 \quad 0.50 \% \quad 54.2 \%$ MGPLGLDHMASSIER

$237 \quad 0.50 \% \quad 54.2 \%$ MGQTMERIGSGVER

$\begin{array}{lllll}68 & 237 & 0.50 \% & 54.2 \% & \text { IGSGVERMGAGMGFGLER } \\ 68 & 237 & 0.50 \% & 54.2 \% \text { MGAGMGFGLER }\end{array}$

$68 \quad 237 \quad 0.50 \% \quad 54.2 \%$ MAAPIDRVGQTIER

$68 \quad 237 \quad 0.50 \% \quad 54.2 \%$ VGQTIERMGSGVER

$68 \quad 237 \quad 0.50 \% \quad 54.2 \%$ MGSGVERMGPAIER

$68 \quad 237 \quad 0.50 \% \quad 54.2 \%$ MVPAGMGAGLER

$68 \quad 237 \quad 0.50 \% \quad 54.2 \%$ MGPVMDRMATGLER

$\begin{array}{llll}68 & 237 & 0.50 \% & 54.2 \% \\ 68 & \text { MATGLERMGANNLER }\end{array}$

$68 \quad 237 \quad 0.50 \% \quad 54.2 \%$ MGANNLER

$68 \quad 237 \quad 0.50 \% \quad 54.2 \%$ MGANNLERMGLER

$68 \quad 237 \quad 0.50 \% \quad 54.2 \%$ MGLERMGANSLER

$68 \quad 237 \quad 0.50 \% \quad 54.2 \%$ MGANSLER

$\begin{array}{llll}68 & 237 & 0.50 \% & 54.2 \% \\ 68 & 237 & 0.50 \% & 54.2 \%\end{array}$

68 $237 \quad 0.50 \% \quad 54.2 \%$ MGPAMGPALGAGIER

$68 \quad 237 \quad 0.50 \% \quad 54.2 \%$ MGLAMGGGGGASFDR \begin{tabular}{llll}
$99.7 \%$ & 29.3 & 25.0 & 29.3 \\
\hline & 21.2 & 25.0 & 21.2
\end{tabular}

$99.7 \% \quad 52.5 \quad 25.0 \quad 43.2$

$99.7 \% \quad 36.2 \quad 25.0 \quad 36.2$

$99.7 \% \quad 43.2 \quad 25.0 \quad 43.2$

$\begin{array}{llll}99.7 \% & 36.2 & 25.0 & 29.5\end{array}$

$\begin{array}{llll}99.0 \% & 43.0 & 25.0 & 25.0\end{array}$

$99.5 \% \quad 25.1 \quad 25.0 \quad 25.1$

$\begin{array}{llll}97.1 \% & 25.0 & 25.0 & 11.6\end{array}$

$99.7 \% \quad 35.4 \quad 25.0 \quad 35.4$

$\begin{array}{llll}99.7 \% & 67.3 & 25.0 & 64.6\end{array}$

$\begin{array}{llll}99.7 \% & 32.8 & 25.0 & 30.6\end{array}$

$\begin{array}{cccc}98.4 \% & 29.3 & 25.0 & 8.2\end{array}$

$\begin{array}{llll}99.7 \% & 33.9 & 25.0 & 33.9\end{array}$

$\begin{array}{llll}99.7 \% & 57.8 & 25.0 & 48.9\end{array}$

$\begin{array}{llll}99.7 \% & 59.8 & 25.0 & 44.6\end{array}$

$\begin{array}{llll}99.7 \% & 49.7 & 25.0 & 37.0\end{array}$

$\begin{array}{llll}99.7 \% & 40.6 & 25.0 & 40.6\end{array}$

$\begin{array}{llll}99.7 \% & 76.2 & 25.0 & 64.2\end{array}$

$\begin{array}{llll}99.7 \% & 44.2 & 25.0 & 44.2\end{array}$

$\begin{array}{llll}99.7 \% & 35.0 & 25.0 & 35.0\end{array}$

$\begin{array}{llll}99.7 \% & 34.5 & 25.0 & 34.5\end{array}$

$\begin{array}{llll}9.6 \% & 25.9 & 25.0 & 25.9\end{array}$

$\begin{array}{llll}99.4 \% & 22.3 & 25.0 & 22.3\end{array}$

$99.7 \% \quad 54.9 \quad 25.0 \quad 54.9$

$\begin{array}{llll}99.7 \% & 35.7 & 25.0 & 35.7\end{array}$

$\begin{array}{llll}9.7 \% & 58.1 & 25.0 & 58.1\end{array}$

$\begin{array}{lllll}99.7 \% & 75.1 & 25.0 & 51.5 & 2\end{array}$

$\begin{array}{llll}9.7 \% & 61.0 & 25.0 & 50.0\end{array}$

$\begin{array}{llll}99.6 \% & 26.4 & 25.0 & 24.8\end{array}$

$\begin{array}{llll}99.4 \% & 22.2 & 25.0 & 20.1\end{array}$

$99.7 \% \quad 60.4 \quad 25.0 \quad 52.5$

$\begin{array}{llll}99.7 \% & 30.9 & 25.0 & 21.7\end{array}$

$\begin{array}{llll}99.3 \% & 23.2 & 25.0 & 23.2\end{array}$

$\begin{array}{llll}99.0 \% & 64.3 & 25.0 & 56.0\end{array}$

$\begin{array}{llll}99.7 \% & 31.2 & 25.0 & 28.2\end{array}$

$\begin{array}{llll}99.7 \% & 43.2 & 25.0 & 29.0\end{array}$

$\begin{array}{llll}99.0 \% & 70.8 & 25.0 & 53.8\end{array}$

$\begin{array}{lllll}99.7 \% & 32.5 & 25.0 & 26.0 & 2\end{array}$

$\begin{array}{llll}99.7 \% & 67.4 & 25.0 & 56.1\end{array}$

$\begin{array}{llll}99.7 \% & 68.5 & 25.0 & 36.8\end{array}$ 
Heterogeneous nuclear ribonucleoprotein M GN=HNRNPM HNRPM_HUMAN $77.52 \quad 100.0 \%$ Heterger $77.52 \quad 100.0 \%$ Heterogeneous nuclear ribonucleoprotein M GN=HNRNPM HNRPM_HUMAN $77.52 \quad 100.0 \%$ Heterogeneous nuclear ribonucleoprotein M GN=HNRNPM HNRPM HUMAN $77.52 \quad 100.0 \%$ Heterogeneous nuclear ribonucleoprotein Q GN=SYNCRIP HNRPQ_HUMAN $69.60 \quad 100.0 \%$ Heterogeneous nuclear ribonucleoprotein Q GN=SYNCRIP HNRPQ_HUMAN $69.60 \quad 100.0 \%$ Heterogeneous nuclear ribonucleoprotein Q GN=SYNCRIP $\quad$ HNRPQ_HUMAN $69.60 \quad 100.0 \%$ Heterogeneous nuclear ribonucleoprotein Q GN=SYNCRIP HNRPQ_HUMAN $69.60 \quad 100.0 \%$ Heterogeneous nuclear ribonucleoprotein Q GN=SYNCRIP HNRPQ HUMAN $69.60100 .0 \%$ Heterogeneous nuclear ribonucleoprotein Q GN=SYNCRIP HNRPQ_HUMAN $69.60 \quad 100.0 \%$ Heterogeneous nuclear ribonucleoprotein Q GN=SYNCRIP HNRPQ_HUMAN $69.60 \quad 100.0 \%$ Heterogeneous nuclear ribonucleoprotein R GN=HNRNPR HNRPR_HUMAN $70.94 \quad 100.0^{\circ}$ Heterogeneous nuclear ribonucleoprotein R GN=HNRNPR HNRPR_HUMAN $70.94 \quad 100.0 \%$ Heterogeneous nuclear ribonucleoprotein R GN=HNRNPR HNRPR_HUMAN $70.94 \quad 100.0 \%$ Heterogeneous nuclear ribonucleoprotein R GN=HNRNPR HNRPR_HUMAN $70.94 \quad 100.0 \%$ Heterogeneous nuclear ribonucleoprotein R GN=HNRNPR HNRPR_HUMAN $70.94 \quad 100.0 \%$ Heterogeneous nuclear ribonucleoprotein $\mathrm{R}$ GN=HNRNPR HNRPR HUMAN $70.94100 .0 \%$ Heterogeneous nuclear ribonucleoprotein R GN=HNRNPR HNRPR_HUMAN $70.94 \quad 100.0 \%$ Heterogeneous nuclear ribonucleoprotein R GN=HNRNPR HNRPR_HUMAN 70.94 100.0\% terogeneous nuclear ribonucleoprotein U GN=HNRNPU HNRPU_HUMAN $90.59-100.0 \%$ Heterogeneous nuclear ribonucleoprotein U GN=HNRNPU HNRPU_HUMAN $90.59 \quad 100.0 \%$ Heterogeneous nuclear ribonucleoprotein U GN=HNRNPU HNRPU_HUMAN $90.59100 .0 \%$ Heterogeneous nuclear ribonucleoprotein U GN=HNRNPU HNRPU_HUMAN $90.59 \quad 100.0 \%$ Heterogeneous nuclear ribonucleoprotein U GN=HNRNPU HNRPU_HUMAN $90.59100 .0 \%$ Heterogeneous nuclear ribonucleoprotein $\mathrm{U}$ GN=HNRNPU HNRPU HUMAN 90.55 Heterogeneous nuclear ribonucleoprotein U GN=HNRNPU HNRPU_HUMAN 90.59 Heterogeneous nuclear ribonucleoprotein U GN=HNRNPU HNRPU_HUMAN 90.59 Heterogeneous nuclear ribonucleoprotein U GN=HNRNPU HNRPU_HUMAN 90.59 Heterogeneous nuclear ribonucleoprotein U GN=HNRNPU HNRPU_HUMAN 90.59 Heterogeneous nuclear ribonucleoprotein U GN=HNRNPU HNRPU HUMAN 90.59 Heterogeneous nuclear ribonucleoprotein U GN=HNRNPU HNRPU_HUMAN 90.59 Heterogeneous nuclear ribonucleoprotein U GN=HNRNPU HNRPU_HUMAN 90.59 Heterogeneous nuclear ribonucleoprotein U GN=HNRNPU HNRPU HUMAN 90.59 Heterogeneous nuclear ribonucleoprotein U GN=HNRNPU HNRPU_HUMAN 90.59 Heterogeneous nuclear ribonucleoprotein U GN=HNRNPU HNRPU HUMAN 90.59 Herogeneons actor ido Heterogeneous nuclear ribonucleoprotein U-like protein 1 GN=HNRNPUL1 HNRL1_HUMAN 95.74 $\begin{array}{lll} & \end{array}$ Heterogeneous nuclear ribonucleoprotein U-like protein 1 GN=HNRNPUL1 HNRL1_HUMAN $95.74 \quad 100.0 \%$ Heterogeneous nuclear ribonucleoprotein U-like protein 1 GN=HNRNPUL1 HNRL1_HUMAN $95.74 \quad 100.0 \%$ 作 Heterogeneous nuclear ribonucleoproteins A2/B1 GN=HNRNPA2B1 ROA2 HUMAN $37.43100 .0 \%$ Heterogeneous nuclear ribonucleoproteins A2/B1 GN=HNRNPA2B1 ROA2 HUMAN $37.43 \quad 100.0 \%$ Hetrogeneous nuclear ribonucleoproteins A2/B1 GN=HNRNPA2B1 ROA2_HUMAN $37.43 \quad 100.0 \%$ Heterogeneous nuclear ribonucleoproteins A2/B1 GN=HNRNPA2B1 ROA2 HUMAN $37.43 \quad 100.0 \%$ Heterogeneous nuclear ribonucleoproteins A2/B1 GN=HNRNPA2B1 ROA2_HUMAN $37.43 \quad 100.0 \%$
68 68

(n)

2

2
2 $\begin{array}{llll}237 & 0.50 \% & 54.2 \% & \text { GNFGGSFAGSFG } \\ 237 & 0.50 \% & 54.2 \% & \text { KACQIFVR } \\ 237 & 0.50 \% & 54.2 \% & \text { GCGVVKFESPI }\end{array}$

$237 \quad 0.50 \% \quad 54.2 \%$ GCGVVKFESPEVAER

$237 \quad 0.50 \% \quad 54.2 \%$ EIDVRIDR

$0.01 \% \quad 10.0 \%$ SAFLCGVMK

$\begin{array}{lll}0.01 \% & 10.0 \% \text { ALLERTGYTLDV }\end{array}$

$\begin{array}{lll}0.01 \% & 10.0 \% & \text { TGYTLDVTTGQR } \\ 0.01 \% & 10.0 \% & \text { TGYTLDVTTGQRK }\end{array}$

$7 \quad 0.01 \% \quad 10.0 \%$ GYAFVTFCTK

$0.01 \% \quad 10.0 \%$ LFVGSIPK

$0.01 \% \quad 10.0 \%$ GFCFLEYEDHKTAAQAR

$43 \quad 0.09 \% \quad 10.9 \%$ SAFLCGVMK

$43 \quad 0.09 \% \quad 10.9 \%$ ALLERTGYTLDVTTGQR

$43 \quad 0.09 \% \quad 10.9 \%$ TGYTLDVTTGQR

$43 \quad 0.09 \% \quad 10.9 \%$ TGYTLDVTTGQRK

$43 \quad 0.09 \% \quad 10.9 \%$ GYAFITFCGK

$43 \quad 0.09 \% \quad 10.9 \%$ LFVGSIPK

$43 \quad 0.09 \% \quad 10.9 \%$ SFSEFGKLER

$43 \quad 0.09 \% \quad 10.9 \%$ STAYEDYYYHPPPR

$0.18 \% \quad 15.8 \%$ KAEGGGGGGRPGAPAAGDGK

$87 \quad 0.18 \% \quad 15.8 \%$ AEGGGGGGRPGAPAAGDGKTEQK

$87 \quad 0.18 \% \quad 15.8 \%$ GYFEYIEENKYSR

$87 \quad 0.18 \% \quad 15.8 \%$ VTEKIPVR

$87 \quad 0.18 \% \quad 15.8 \%$ DIDIHEVR

$87 \quad 0.18 \% \quad 15.8 \%$ NGQDLGVAFK

$87 \quad 0.18 \% \quad 15.8 \%$ NGQDLGVAFKISK

$87 \quad 0.18 \% \quad 15.8 \%$ MMVAGFKK

$87 \quad 0.18 \% \quad 15.8 \%$ QMADTGKLNTLLQR

$87 \quad 0.18 \% \quad 15.8 \%$ RNFILDQTNVSAAAQR

$87 \quad 0.18 \% \quad 15.8 \%$ NFILDQTNVSAAAQR

$0.18 \% \quad 15.8 \%$ KMCLFAGFQR

$87 \quad 0.18 \% \quad 15.8 \%$ MCLFAGFQR

$87 \quad 0.18 \% \quad 15.8 \%$ MCLFAGFQRK

$87 \quad 0.18 \% \quad 15.8 \%$ AEVEGKDLPEHAVLK

$87 \quad 0.18 \% \quad 15.8 \%$ DLPEHAVLK

$20 \quad 0.04 \% \quad 7.4 \%$ HLPSTEPDPHVVR

$20 \quad 0.04 \% \quad 7.4 \%$ NCAVEFNFGQR

$20 \quad 0.04 \% \quad 7.4 \% \quad$ NYILDQTNVYGSAQR

$20 \quad 0.04 \% \quad 7.4 \%$ AIVICPTDEDLKDR

$20 \quad 0.04 \% \quad 7.4 \% \quad$ NPPGASTYNK

$103 \quad 0.22 \% \quad 35.1 \%$ TLETVPLER

$103 \quad 0.22 \% \quad 35.1 \%$ AVAREESGKPGAHVTVK

$19 \quad 103 \quad 0.22 \% \quad 35.1 \%$ EESGKPGAHVTVK

$19 \quad 103 \quad 0.22 \% \quad 35.1 \%$ YHTINGHNAEVR

$19 \quad 103 \quad 0.22 \% \quad 35.1 \%$ YHTINGHNAEVRK

$19 \quad 103 \quad 0.22 \% \quad 35.1 \%$ ALSRQEMQEVQSSR

$19 \quad 103 \quad 0.22 \% \quad 35.1 \%$ QEMQEVQSSR $\begin{array}{llll}99.7 \% & 39.3 & 25.0 & 39.3\end{array}$

$\begin{array}{llllll}25.0 & 39.3 & 0 & 2 & 0 & 2034.95\end{array}$

$\begin{array}{lllll}99.7 \% & 55.5 & 25.0 & 55.5 & 2\end{array}$

$\begin{array}{llll}94.7 \% & 23.6 & 25.0 & 0.0\end{array}$

$\begin{array}{llll}99.4 \% & 21.4 & 25.0 & 21.4\end{array}$

$\begin{array}{llll}9.6 \% & 25.7 & 25.0 & 25.7\end{array}$

$\begin{array}{llll}99.7 \% & 63.7 & 25.0 & 57.4\end{array}$

$\begin{array}{llll}99.7 \% & 46.7 & 25.0 & 39.2\end{array}$

$\begin{array}{llll}98.7 \% & 27.2 & 25.0 & 13.3\end{array}$

$\begin{array}{llll}94.7 \% & 15.2 & 25.0 & 15.2\end{array}$

$99.4 \% \quad 21.4 \quad 25.0 \quad 21.4$

$\begin{array}{lll}98.6 \% & 25.7\end{array}$

$99.7 \% \quad 67.2$

$99.7 \% \quad 63.7$

$99.7 \% \quad 47.3$

$98.7 \% \quad 27.2$

$99.5 \% \quad 27.2$

$99.7 \% \quad 43.5$

$99.7 \% \quad 31.4$

$99.7 \% \quad 53.8$

$99.0 \% 31.1$

$99.0 \% \quad 44.4$

$99.7 \% \quad 55.0$

$99.7 \% \quad 36.8$

$99.0 \% \quad 27.0$

$99.7 \% \quad 31.5$

$97.7 \% \quad 21.6$

$99.7 \% \quad 76.5$

$99.4 \% \quad 23.5$

$99.7 \% \quad 40.6$

$99.7 \% \quad 34.1$

$99.7 \% \quad 35.4$

$99.4 \% \quad 24.4$

$99.0 \% \quad 27.4$

$99.7 \% \quad 69.6$

$\begin{array}{lll}99.7 \% & 55.7\end{array}$

$\begin{array}{lll}99.4 \% & 23.8\end{array}$

$99.3 \% \quad 23.3$

$\begin{array}{lll}99.7 \% & 43.5\end{array}$

$\begin{array}{lll}99.7 \% & 31.8\end{array}$

$\begin{array}{lll}99.7 \% & 30.4\end{array}$

$\begin{array}{ll}99.2 \% & 21.3 \\ 98.7 \% & 19.1\end{array}$

$99.7 \% \quad 65.1$

$99.7 \% \quad 47.1$
021.56

1663.81

1015.55

1012.50

1894.00

1311.65

1439.75

1193.57

860.52

2042.94

1012.50

1894.00

1311.65

1439.75

1163.56

860.52

1199.61

1758.78

1666.83

2024.97

1697.78

941.58

996.51

1048.54

1376.75

911.48

1588.85

1803.95

1647.84

1273.62

1145.52

1257.62

1634.88

1021.57

1483.77

1341.60

1741.85

1644.83

1048.51

1057.59

1735.95

1338.70

1410.69

1538.78

1648.81

1221.55

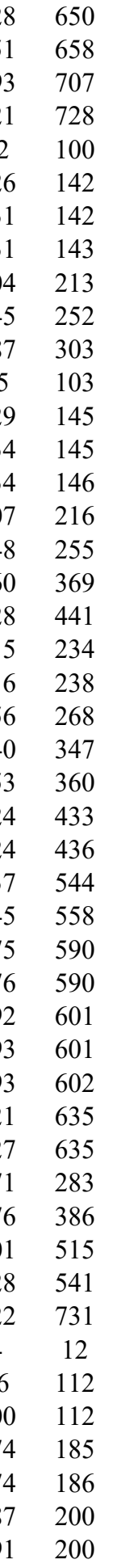

Page 43 of Table S-1-3 

Heterogeneous nuclear ribonucleoproteins A2/B1 GN=HNRNPA2B1 $\quad$ ROA2_HUMAN $37.43 \quad 100.0 \%$ $\begin{array}{llll} & \end{array}$ Heterogeneous nuclear ribonucleoproteins A2/B1 GN=HNRNPA2B1 $\quad$ ROA2_HUMAN $37.43 \quad 100.0 \% \quad 1$ $\begin{array}{lllll}\text { Heterogeneous nuclear ribonucleoproteins A2/B1 GN=HNRNPA2B1 } & \text { ROA2_HUMAN } 37.43 \quad 100.0 \% \quad 13\end{array}$ $\begin{array}{lllll}\text { Heterogeneous nuclear ribonucleoproteins A2/B1 GN=HNRNPA2B1 } & \text { ROA2_HUMAN } 37.43 \quad 100.0 \% \quad 13\end{array}$ Heterogeneous nuclear ribonucleoproteins $\mathrm{Cl} / \mathrm{C} 2 \mathrm{GN}=\mathrm{HNRNPC}$ HNRPC_HUMAN $33.67 \quad 100.0 \% 10$ Heterogeneous nuclear ribonucleoproteins $\mathrm{C} 1 / \mathrm{C} 2 \mathrm{GN}=\mathrm{HNRNPC}$ HNRPC_HUMAN $33.67 \quad 100.0 \% \quad 10$ Heterogeneous nuclear ribonucleoproteins $\mathrm{C} 1 / \mathrm{C} 2 \mathrm{GN}=\mathrm{HNRNPC}$ HNRPC HUMAN $33.67 \quad 100.0 \% \quad 1$ Heterogeneous nuclear ribonucleoproteins $\mathrm{C} 1 / \mathrm{C} 2 \mathrm{GN}=$ HNRNPC HNRPC_HUMAN $33.67 \quad 100.0 \% \quad 10$ Heterogeneous nuclear ribonucleoproteins $\mathrm{Cl} / \mathrm{C} 2 \mathrm{GN}=\mathrm{HNRNPC}$ HNRPC_HUMAN $33.67 \quad 100.0 \% \quad 1$ Heterogeneous nuclear ribonucleoproteins $\mathrm{C} 1 / \mathrm{C} 2 \mathrm{GN}=\mathrm{HNRNPC}$ HNRPC HUMAN $33.67 \quad 100.0 \%$ Heterogeneous nuclear ribonucleoproteins $\mathrm{C} 1 / \mathrm{C} 2 \mathrm{GN}=\mathrm{HNRNPC}$ HNRPC_HUMAN $33.67 \quad 100.0 \%$ Heterogeneous nuclear ribonucleoproteins $\mathrm{Cl} / \mathrm{C} 2 \mathrm{GN}=\mathrm{HNRNPC}$ HNRPC_HUMAN $33.67 \quad 100.0 \%$ Heterogeneous Histone deacetylase $1 \mathrm{GN}=\mathrm{HDAC}$ Histone deacetylase $1 \mathrm{GN}=\mathrm{HDAC} 1$ Histone deacetylase $1 \mathrm{GN}=\mathrm{HD}$ Histone H1.2 GN=HIST1H1C Histone $\mathrm{H} 1.2 \mathrm{GN}=\mathrm{HIST} 1 \mathrm{H} 1 \mathrm{C}$ Histone H1.2 GN=HIST1H1C Histone $\mathrm{H} 1.2 \mathrm{GN}=\mathrm{HIST} 1 \mathrm{H} 1 \mathrm{C}$
Histone $\mathrm{H} 1.2 \mathrm{GN}=\mathrm{HIST} 1 \mathrm{H} 1 \mathrm{C}$ Histone H1.2 GN=HIST1H1C Histone H1.2 GN=HIST1H1C Histone H1.2 GN=HIST1H1C Histone H1.2 GN=HIST1H1C Histone H1.2 GN=HIST1H1C Histone H1.2 GN=HIST1H1C Histone $\mathrm{H} 1.2 \mathrm{GN}=\mathrm{HIST} 1 \mathrm{H} 1 \mathrm{C}$ Histone H1.2 GN=HIST1H1C Histone $\mathrm{H} 1.5 \mathrm{GN}=\mathrm{HIST} 1 \mathrm{H} 1 \mathrm{~B}$ Histone H1.5 GN=HIST1H1B Histone H1.5 GN=HIST1H1B Histone $\mathrm{H} 1.5 \mathrm{GN}=\mathrm{HIST} 1 \mathrm{H} 1 \mathrm{~B}$ Histone $\mathrm{H} 1.5 \mathrm{GN}=\mathrm{HIST} 1 \mathrm{H} 1 \mathrm{~B}$ Histone $\mathrm{H} 1.5 \mathrm{GN}=\mathrm{HIST} 1 \mathrm{H} 1 \mathrm{~B}$ Histone $\mathrm{H} 1 \mathrm{x} \mathrm{GN}=\mathrm{H} 1 \mathrm{FX}$ Histone $\mathrm{H} 1 \mathrm{x}$ GN=H1FX Histone $\mathrm{H} 1 \mathrm{x} \mathrm{GN}=\mathrm{H} 1 \mathrm{FX}$ Histone $\mathrm{H} 1 \mathrm{x}$ GN=H1FX Histone $\mathrm{H} 1 \mathrm{x}$ GN=H1FX Histone $\mathrm{H} 1 \mathrm{x}$ GN=H1FX Hornerin $\mathrm{GN}=\mathrm{HRNR}$ Hornerin GN $=\mathrm{HRNR}$ Hornerin GN=HRNR

$\begin{array}{llll}\text { HDAC1_HUMAN } & 55.10 & 100.0 \% & 3 \\ \text { HDAC1_HUMAN } & 55.10 & 100.0 \% & 3\end{array}$ $\begin{array}{llll}\text { H12_HUMAN } & 21.37 & 100.0 \% & 13\end{array}$ $\begin{array}{llll}\text { H12_HUMAN } & 21.37 & 100.0 \% & 13\end{array}$ H12 HUMAN $21.37 \quad 100.0 \% \quad 13$ H12_HUMAN $21.37 \quad 100.0 \% \quad 13$ H12_HUMAN $21.37 \quad 100.0 \% \quad 13$ H12 HUMAN $21.37 \quad 100.0 \% \quad 13$ H12_HUMAN $21.37 \quad 100.0 \% \quad 13$ H12_HUMAN $21.37 \quad 100.0 \% \quad 13$ H12 HUMAN $21.37 \quad 100.0 \% \quad 13$ H12_HUMAN $21.37 \quad 100.0 \% \quad 13$ H12 HUMAN $21.37 \quad 100.0 \% \quad 13$ H12_HUMAN $21.37 \quad 100.0 \% \quad 13$ H12_HUMAN $21.37 \quad 100.0 \% \quad 13$ H15 HUMAN $22.58 \quad 100.0 \% \quad 2$ H15_HUMAN $22.58 \quad 100.0 \% \quad 2$ H15 HUMAN $22.58 \quad 100.0 \% \quad 2$ H15 HUMAN $22.58 \quad 100.0 \%$ H15_HUMAN $22.58 \quad 100.0 \% \quad 2$ H15 HUMAN $22.58 \quad 100.0 \%$ H1X_HUMAN $22.49 \quad 100.0 \%$ H1X_HUMAN $22.49 \quad 100.0 \%$ H1X HUMAN $22.49 \quad 100.0 \%$ H1X_HUMAN $22.49 \quad 100.0 \%$ H1X HUMAN $22.49 \quad 100.0 \%$ H1X_HUMAN $22.49 \quad 100.0 \%$ HORN_HUMAN $282.37 \quad 100.0 \%$ HORN_HUMAN $282.37 \quad 100.0 \%$ HORN_HUMAN $282.37 \quad 100.0 \%$
$19 \quad 103 \quad 0.22 \% \quad 35.1 \%$ SGRGGNFGFGDSR

$19 \quad 103 \quad 0.22 \% \quad 35.1 \%$ GGNFGFGDSR

$19 \quad 103 \quad 0.22 \% \quad 35.1 \%$ GGGGNFGPGPGSNFR

$99.7 \% \quad 40.0$

$99.7 \% 64.8$

$99.7 \% \quad 52.0$

$\begin{array}{lllllll}19 & 103 & 0.22 \% & 35.1 \% & \text { GGGGNFGPGPGNFRGGSDGYGSGR } & 99.7 \% & 63.8\end{array}$

19

19

10

10

1032

10

10

10

10
10
10

10

10
4

$\begin{array}{lllllll}103 & 0.22 \% & 35.1 \% & \text { GGGGNFGPGPGSNFRGGSDGYGSGR } & 99.7 \% & 63.8 \\ 103 & 0.22 \% & 35.1 \% & \text { SGNFGGSRMGGPYGGGNYGGGSGGSGGYGGR } & 99.7 \% & 70.3\end{array}$

$03 \quad 0.22 \% \quad 35.1 \%$ NMGGPYGGGNYGPGGSGGSGGYGGR

$0.07 \% \quad 21.2 \%$ VFIGNLNTLVVK

$20.07 \% \quad 21.2 \%$ VFIGNLNTLVVKK

$0.07 \% \quad 21.2 \%$ KSDVEAIFSK

$0.07 \% \quad 21.2 \%$ SDVEAIFSK

$32 \quad 0.07 \% \quad 21.2 \%$ SDVEAIFSKYGK

$0.07 \% \quad 21.2 \%$ YGKIVGCSVHK

$0.07 \% \quad 21.2 \%$ GFAFVQYVNER

$0.07 \% \quad 21.2 \%$ VPPPPPIAR

$32 \quad 0.07 \% \quad 21.2 \%$ QKVDSLLENLEK

$32 \quad 0.07 \% \quad 21.2 \%$ VDSLLENLEK

$6 \quad 0.01 \% \quad 6.9 \% \quad$ SIRPDNMSEYSK

$6 \quad 0.01 \% \quad 6.9 \% \quad$ YGEYFPGTGDLR

$6 \quad 0.01 \% \quad 6.9 \% \quad$ ISICSSDKR

$296 \quad 0.62 \% \quad 39.4 \%$ SETAPAAPAAAPPAEK

$296 \quad 0.62 \% \quad 39.4 \%$ KASGPPVSELITK

$296 \quad 0.62 \% \quad 39.4 \%$ ASGPPVSELITK

$296 \quad 0.62 \% \quad 39.4 \%$ ERSGVSLAALK

$296 \quad 0.62 \% \quad 39.4 \%$ SGVSLAALK

$296 \quad 0.62 \% \quad 39.4 \%$ SGVSLAALKK

$296 \quad 0.62 \% \quad 39.4 \%$ KALAAAGYDVEK

$296 \quad 0.62 \% \quad 39.4 \%$ ALAAAGYDVEK

$296 \quad 0.62 \% \quad 39.4 \%$ ALAAAGYDVEKNNSR

$296 \quad 0.62 \% \quad 39.4 \%$ LGLKSLVSK

$296 \quad 0.62 \% \quad 39.4 \%$ SLVSKGTLVQTK

$296 \quad 0.62 \% \quad 39.4 \%$ GTLVQTKGTGASGSFK

$296 \quad 0.62 \% \quad 39.4 \%$ GTGASGSFKLNK

$0.01 \% \quad 24.3 \%$ ATGPPVSELITK

$0.01 \% \quad 24.3 \%$ ALAAGGYDVEKNNSR

$0.01 \% \quad 24.3 \%$ LGLKSLVSK

$0.01 \% \quad 24.3 \%$ SLVSKGTLVQTK

$0.01 \% \quad 24.3 \%$ GTGASGSFKLNK

$0.05 \% \quad 22.1 \%$ YSQLVVETIR

$0.05 \% \quad 22.1 \%$ YSQLVVETIRR

$0.05 \% \quad 22.1 \%$ TYLKYSIK

$0.05 \% \quad 22.1 \%$ ALVQNDTLLQVK

$\begin{array}{ll}99.7 \% & 50.0 \\ 99.7 \% & 65.1\end{array}$

$99.4 \% \quad 21.2$

$99.7 \% \quad 57.2$

$99.7 \% \quad 50.7$

$99.7 \% \quad 70.2$

$99.7 \% \quad 37.5$

$99.7 \% \quad 70.5$

$99.7 \% \quad 35.7$

$99.3 \% \quad 27.9$

$98.3 \% \quad 19.5$

$99.7 \% \quad 53.8$

$\begin{array}{llll}99.7 \% & 35.3\end{array}$

$\begin{array}{lll}99.5 \% & 30.1\end{array}$

$99.0 \% \quad 41.2$

$99.7 \% \quad 68.3$

$99.7 \% \quad 60.2$

$99.3 \% \quad 27.5$

$99.7 \% \quad 55.3$

$99.7 \% \quad 69.3$

$99.7 \% \quad 63.4$

$99.7 \% \quad 67.2$

$99.7 \% 72.9$

$96.4 \% \quad 26.8$

$99.7 \% \quad 66.7$

$99.7 \% \quad 64.6$

$99.7 \% \quad 49.6$

$99.0 \% \quad 25.3$

$99.7 \% \quad 51.2$

$\begin{array}{lll}96.4 \% & 26.8\end{array}$

$99.7 \% \quad 66.7$

$99.7 \% \quad 64.6$

$99.7 \% \quad 49.6$

$99.7 \% \quad 66.0$

$99.7 \% \quad 31.9$

$95.2 \% \quad 19.7$

$99.7 \% \quad 60.9$

$0.05 \% \quad 22.1 \%$ RGAPAAATAPAPTAHK

$0.05 \% \quad 22.1 \%$ GAPAAATAPAPTAHK

$99.5 \% \quad 25.3$

$0.04 \% \quad 2.4 \%$ GSGSGQSPSSGQHGTGFGR

$98.8 \% \quad 23.3$

$0.04 \% \quad 2.4 \% \quad$ YGQQGSGSGQSPSR

$99.7 \% \quad 32.7$

20
$0.01 \% \quad 24.3 \%$ GTLVQTKGTGASGSFK $\begin{array}{ccc}1313.60 & 201 & 213 \\ 1013.44 & 204 & 213 \\ 1377.63 & 214 & 228 \\ 2270.99 & 214 & 238 \\ 2968.24 & 318 & 350 \\ 2205.90 & 326 & 350 \\ 1316.79 & 18 & 29 \\ 1444.89 & 18 & 30 \\ 1123.60 & 30 & 39 \\ 995.50 & 31 & 39 \\ 1343.68 & 31 & 42 \\ 1247.66 & 40 & 50 \\ 1329.66 & 51 & 61 \\ 943.57 & 143 & 151 \\ 1415.77 & 205 & 216 \\ 1159.62 & 207 & 216 \\ 1426.66 & 78 & 89 \\ 1374.63 & 201 & 212 \\ 1065.54 & 405 & 413 \\ 1478.75 & 2 & 17 \\ 1326.76 & 34 & 46 \\ 1198.67 & 35 & 46 \\ 1130.65 & 53 & 63 \\ 845.51 & 55 & 63 \\ 973.60 & 55 & 64 \\ 1235.66 & 64 & 75 \\ 1107.57 & 65 & 75 \\ 1578.79 & 65 & 79 \\ 944.61 & 82 & 90 \\ 1260.75 & 86 & 97 \\ 1538.82 & 91 & 106 \\ 1166.62 & 98 & 109 \\ 1212.68 & 38 & 49 \\ 1564.77 & 68 & 82 \\ 944.61 & 85 & 93 \\ 1260.75 & 89 & 100 \\ 1538.82 & 94 & 109 \\ 1166.62 & 101 & 112 \\ 1207.67 & 48 & 57 \\ 1363.77 & 48 & 58 \\ 1015.58 & 87 & 94 \\ 1341.77 & 95 & 106 \\ 1487.81 & 128 & 143 \\ 1331.71 & 129 & 143 \\ 1747.77 & 430 & 448 \\ 1395.62 & 649 & 662 \\ 1947.90 & 992 & 1011 \\ & & \end{array}$

Page 44 of Table S-1-3 
Ig kappa chain V-I region Lay OS=Homo sapiens KV113_HUMAN $11.83 \quad 100.0 \%$ Ig kappa chain V-I region Lay OS=Homo sapiens KV113 HUMAN $11.83 \quad 100.0 \%$ Ig kappa chain V-II region RPMI 6410 OS=Homo sapiens KV206_HUMAN $14.71 \quad 100.0 \%$ Ig kappa chain V-II region RPMI 6410 OS=Homo sapiens KV206_HUMAN $14.71 \quad 100.0 \%$ Ig kappa chain V-II region RPMI 6410 OS=Homo sapiens KV206 HUMAN $14.71 \quad 100.0 \%$ Importin subunit alpha- $1 \mathrm{GN}=\mathrm{KPNA} 2$ Importin subunit alpha-1 GN=KPNA2 Importin subunit beta-1 GN=KPNB1 Importin subunit beta-1 GN=KPNB1 Importin subunit beta-1 GN=KPNB1 Importin subunit beta-1 $\mathrm{GN}=\mathrm{KPNB} 1$ Importin subunit beta-1 GN=KPNB1

Importin- $4 \mathrm{GN}=\mathrm{IPO} 4$

Importin-4 GN=IPO4

Importin-4 GN=IPO4

Importin-5 GN=IPO5

Importin-5 GN=IPO5

IMA1_HUMAN $57.86 \quad 100.0 \%$ IMA1_HUMAN $57.86 \quad 100.0 \%$ IMB1_HUMAN $97.17 \quad 100.0 \%$ IMB1_HUMAN $97.17 \quad 100.0 \%$ IMB1_HUMAN $97.17 \quad 100.0 \%$ IMB1_HUMAN $97.17 \quad 100.0 \%$ IMB1_HUMAN $97.17 \quad 100.0 \%$ IPO4_HUMAN $118.72 \quad 100.0 \%$ IPO4_HUMAN $118.72 \quad 100.0 \%$ IPO4 HUMAN $118.72 \quad 100.0 \%$ IPO5_HUMAN $123.63 \quad 100.0 \%$ IPO5_HUMAN $123.63 \quad 100.0 \%$ 作 Inactive hydroxysteroid dehydrogenase-like protein 1 GN=HSDL1 HSDL1_HUMAN $37.00 \quad 100.0 \%$ Inactive hydroxysteroid dehydrogenase-like protein $1 \mathrm{GN}=$ HSDL1 HSDL1_HUMAN $37.00 \quad 100.0 \%$ Inactive hydroxysteroid dehydrogenase-like protein 1 GN=HSDL1 HSDL1_HUMAN $37.00 \quad 100.0 \%$ Inactive hydroxysteroid dehydrogenase-like protein $1 \mathrm{GN}=$ HSDL1 HSDL1_HUMAN $37.00 \quad 100.0 \%$ Insulin receptor substrate $4 \mathrm{GN}=\mathrm{IRS} 4$ Insulin receptor substrate $4 \mathrm{GN}=\mathrm{IRS} 4$ Insulin receptor substrate $4 \mathrm{GN}=\mathrm{IRS} 4$ Insulin receptor substrate $4 \mathrm{GN}=\mathrm{IRS} 4$ Insulin receptor substrate $4 \mathrm{GN}=\mathrm{IRS} 4$ Insulin receptor substrate $4 \mathrm{GN}=\mathrm{IRS} 4$ Insulin receptor substrate $4 \mathrm{GN}=\mathrm{IRS} 4$ Insulin receptor substrate $4 \mathrm{GN}=\mathrm{IRS} 4$ IRS4 HUMAN $133.77 \quad 100.0 \%$ IRS4_HUMAN $133.77 \quad 100.0 \%$ IRS4_HUMAN $133.77 \quad 100.0 \%$ IRS4 HUMAN $133.77 \quad 100.0 \%$ IRS4_HUMAN $133.77 \quad 100.0 \%$ IRS4 HUMAN $133.77 \quad 100.0 \%$ IRS4 HUMAN $133.77 \quad 100.0 \%$ IRS4_HUMAN $133.77 \quad 100.0 \%$ 作 1 IF2B1 HUMAN $63.48 \quad 100.0 \%$ Insulin-like growth factor 2 mRNA-binding protein 1 GN=IGF2BP1 $\quad$ IF2B1_HUMAN $63.48 \quad 100.0 \%$ Insulin-like growth factor 2 mRNA-binding protein 1 GN=IGF2BP1 IF2B1_HUMAN $63.48 \quad 100.0 \%$ Insulin-like growth factor 2 mRNA-binding protein $1 \mathrm{GN}=I \mathrm{GF} 2 \mathrm{BP} 1 \quad$ IF2B1_HUMAN $63.48 \quad 100.0 \%$ Insulin-like growth factor 2 mRNA-binding protein 1 GN=IGF2BP1 IF2B1_HUMAN $63.48 \quad 100.0 \%$ Insulin-like growth factor 2 mRNA-binding protein 1 GN=IGF2BP1 IF2B1_HUMAN $63.48 \quad 100.0 \%$ Insulin-like growth factor 2 mRNA-binding protein $1 \mathrm{GN}=I$ GF2BP1 $\quad$ IF2B1_HUMAN $63.48 \quad 100.0 \%$ Insulin-like growth factor 2 mRNA-binding protein 1 GN=IGF2BP1 IF2B1_HUMAN $63.48 \quad 100.0 \%$ Insulin-like growth factor 2 mRNA-binding protein $1 \mathrm{GN}=I \mathrm{GF} 2 \mathrm{BP} 1 \quad$ IF2B1 HUMAN $63.48 \quad 100.0 \%$ Insulin-like growth factor 2 mRNA-binding protein 1 GN=IGF2BP1 $\quad$ IF2B1_HUMAN $63.48 \quad 100.0 \%$

$0.02 \% \quad 10.5 \%$ LAGCTVFITGASR

$0.02 \% \quad 10.5 \%$ AAKDGANIVIAAK

$0.02 \% \quad 10.5 \%$ SGAVEETFR

$0.02 \% \quad 10.5 \%$ LMNQMNARL

$0.02 \% \quad 25.0 \%$ DIQMTQSPSSLSVSVGDR $0.02 \% \quad 25.0 \%$ LLIYGASTR

$50 \quad 0.11 \% \quad 18.0 \%$ LIYKVSNR

$50 \quad 0.11 \% \quad 18.0 \%$ FSGSGSGTDFTLK

$50 \quad 0.11 \% \quad 18.0 \%$ FSGSGSGTDFTLKISR

$0.01 \% \quad 3.8 \%$ EKQPPIDNIIR

$0.01 \% \quad 3.8 \%$ TGVVPQLVK

$0.03 \% \quad 6.5 \%$ VLANPGNSQVAR

$0.03 \% \quad 6.5 \%$ WLAIDANAR

$0.03 \% \quad 6.5 \%$ VAALQNLVK

$0.03 \% \quad 6.5 \% \quad$ LLETTDRPDGHQNNLR

$0.03 \% \quad 6.5 \%$ TLATWATKELR

$0.02 \% \quad 2.8 \%$ ATEQLQIVLR

$0.02 \% \quad 2.8 \% \quad$ VVPSYMQAVNR

$0.02 \% \quad 2.8 \% \quad$ LAELCGVLK

$0.02 \% \quad 1.9 \%$ VCDIAAELAR

$0.02 \% \quad 1.9 \% \quad$ SLVEIADTVPK

$0.02 \% \quad 16.4 \%$ ADLIKQYGR

$0.02 \% \quad 16.4 \%$ WAVVSGATDGIGK

$0.02 \% \quad 16.4 \%$ AYAEELASR

$0.02 \% \quad 16.4 \%$ GLNIILISR

$0.02 \% \quad 16.4 \%$ VYAHHAVSTLGISK

$0.04 \% \quad 6.8 \%$ ALCADEYRAR

$0.04 \% \quad 6.8 \%$ RFVTPSEPVAHSR

$0.04 \% \quad 6.8 \% \quad$ FVTPSEPVAHSR

$0.04 \% \quad 6.8 \%$ SYFGKLTQSK

$0.04 \% \quad 6.8 \%$ SQSFFAAAR

$0.04 \% \quad 6.8 \%$ GAQDVAGGSNPGAHNPSANLAR $\quad 99.7 \% \quad 38.0$

$0.04 \% \quad 6.8 \%$ GDNQAGGAAAAAAAPEPPPR $99.3 \% \quad 24.9$

$0.04 \% \quad 6.8 \% \quad$ GDNQAGGAAAAAAAPEPPPRSR $\quad 98.8 \% \quad 18.8$

$0.09 \% \quad 25.5 \%$ ISYSGQFLVK

$0.09 \% \quad 25.5 \%$ AIETFSGKVELQGK

$0.09 \% \quad 25.5 \%$ RLEIEHSVPK

$0.09 \% \quad 25.5 \%$ GGFGSRGQPR

$0.09 \% \quad 25.5 \%$ QGSPVAAGAPAK

$0.09 \% \quad 25.5 \%$ QQQVDIPLR

$0.09 \% \quad 25.5 \%$ AISVHSTPEGCSSACK

$0.09 \% \quad 25.5 \%$ ILAHNNFVGR

$0.09 \% \quad 25.5 \%$ GQHIKQLSR

$0.09 \% \quad 25.5 \%$ IAPPETPDSK $\begin{array}{ll}99.7 \% & 28.8 \\ 99.7 \% & 39.7\end{array}$

$\begin{array}{lll}98.1 \% & 20.9\end{array}$

$99.7 \% \quad 78.1$

$96.0 \% \quad 17.4$

$99.7 \% \quad 59.1$

$94.8 \% \quad 18.4$

$99.3 \% \quad 40.6$

$98.0 \% \quad 17.5$

$99.2 \% \quad 53.1$

$99.0 \% \quad 33.9$

$99.7 \% \quad 32.7$

$98.3 \% \quad 21.9$

$\begin{array}{ll}99.7 \% & 64.4 \\ 99.7 \% & 35.1\end{array}$

$99.7 \% \quad 31.3$

$99.7 \% \quad 28.4$

$99.7 \% \quad 31.3$

$99.2 \% \quad 19.5$

$99.7 \% \quad 48.4$

$99.7 \% \quad 54.4$

$99.7 \% \quad 66.5$

$99.7 \% \quad 47.5$

$\begin{array}{lll}99.7 \% & 39.5\end{array}$

$99.7 \% \quad 63.0$

$99.0 \% 23.4$

$99.1 \% 21.5$

$98.9 \% \quad 24.0$

$99.7 \% \quad 41.8$

$99.7 \% \quad 35.0$

$\begin{array}{ll}98.8 \% & 18.8 \\ 99.7 \% & 31.2\end{array}$

$99.7 \% \quad 60.0$

$99.6 \% \quad 29.3$

$95.1 \% 21.6$

$99.7 \% \quad 52.9$

$99.7 \% \quad 58.3$

$99.7 \% \quad 67.4$

$99.7 \% \quad 37.1$

$99.3 \% \quad 21.2$

$94.6 \% 17.4$
1172.58

1092.54

1352.70

1241.72

995.48

1090.55

1922.91

993.57

992.59

1303.62

1659.83

1322.74

940.58

1225.66

1029.55

955.59

1878.94

1289.72

1170.68

1263.65

1002.57

1117.57

1171.66

1063.59

1260.66

1009.49

998.64

1482.81

1224.58

1482.78

1326.68

1158.62

984.49

2060.99

1788.86

2032.00

1141.63

1506.82

1207.68

1018.52

1053.57

1096.61

1690.75

1140.63

1066.61

1054.54 3202 314
-20 $30 \quad 42$ $\begin{array}{ll}307 & 315 \\ 410 & 418\end{array}$ $\begin{array}{ll}1 & 18 \\ 46 & 54\end{array}$ $72 \quad 79$ $87 \quad 99$ $87 \quad 102$ $107 \quad 117$ $292 \quad 300$ $43 \quad 54$ $235 \quad 243$

$510 \quad 525$

$860 \quad 870$

$24 \quad 33$

$751 \quad 761$

$793 \quad 801$

$109 \quad 118$

$239 \quad 249$

$60 \quad 68$

$69 \quad 81$

$82 \quad 90$

$274 \quad 287$

$398 \quad 410$

$399 \quad 410$

$1177 \quad 1198$

$1199 \quad 1218$

$1199 \quad 1220$

$27 \quad 36$

$53 \quad 66$

$\begin{array}{ll}67 & 76 \\ 169 & 178\end{array}$

$169 \quad 178$

$91 \quad 199$

$243 \quad 258$

290
$5 \quad 433$

$441 \quad 450$ 
$\begin{array}{lllllllll}\text { Insulin-like growth factor } 2 \text { mRNA-binding protein } 1 \text { GN=IGF2BP1 } & \text { IF2B1_HUMAN } & 63.48 & 100.0 \% & 14 & 18 & 43 & 0.09 \% & 25.5 \% \\ \text { IAPPETPDSKVR }\end{array}$ $\begin{array}{llllllllll}\text { Insulin-like growth factor } 2 \text { mRNA-binding protein } 1 \mathrm{GN}=I G F 2 B P 1 & \text { IF2B1_HUMAN } & 63.48 & 100.0 \% & 14 & 18 & 43 & 0.09 \% & 25.5 \% & \text { DQTPDENDQVIVK }\end{array}$ Insulin-like growth factor 2 mRNA-binding protein 1 GN=IGF2BP1 IF2B1_HUMAN $63.48 \quad 100.0 \%$ Insulin-like growth factor 2 mRNA-binding protein 1 GN=IGF2BP1 $\quad$ IF2B1_HUMAN $63.48 \quad 100.0 \%$ Insulin-like growth factor 2 mRNA-binding protein 3 GN=IGF2BP3 IF2B3_HUMAN $63.71 \quad 100.0 \%$ Insulin-like growth factor 2 mRNA-binding protein 3 GN=IGF2BP3 IF2B3_HUMAN $63.71 \quad 100.0 \%$ Insulin-like growth factor 2 mRNA-binding protein 3 GN=IGF2BP3 $\quad$ IF2B3_HUMAN $63.71 \quad 100.0 \%$ Insulin-like growth factor 2 mRNA-binding protein 3 GN=IGF2BP3 $\quad$ IF2B3_HUMAN $63.71 \quad 100.0 \%$ Insulin-like growth factor 2 mRNA-binding protein 3 GN=IGF2BP3 IF2B3_HUMAN $63.71 \quad 100.0 \%$ Integrator complex subunit $1 \mathrm{GN}=\mathrm{INTS} 1 \quad$ INT1_HUMAN $244.30 \quad 100.0 \%$ Integrator complex subunit $1 \mathrm{GN}=\mathrm{INTS} 1 \quad$ INT1_HUMAN $244.30 \quad 100.0 \%$ Integrator complex subunit $1 \mathrm{GN}=\mathrm{INTS} 1 \quad$ INT1_HUMAN $244.30 \quad 100.0 \%$ Integrator complex subunit $1 \mathrm{GN}=\mathrm{INTS} 1 \quad$ INT1_HUMAN $244.30 \quad 100.0 \%$ Interferen-inducible double-stranded RNA-dependent protein kinase activator A GN=PRKRA PRKRA_HUMAN $34.41 \quad 100.0 \%$

$\begin{array}{llll}\text { Interferen-inducible double-stranded RNA-dependent protein kinase activator A GN=PRKRA } & \text { PRKRA_HUMAN } 34.41 & 100.0 \% \\ \text { Interleukin enhancer-binding factor } 2 \text { GN=ILF2 } & \text { ILF2 HUMAN } & 43.06 & 100.0 \%\end{array}$ Interleukin enhancer-binding factor $2 \mathrm{GN}=\mathrm{ILF} 2 \mathrm{ILF} 2 \mathrm{HUMAN} 43.06 \quad 100.0 \%$ Interleukin enhancer-binding factor 2 GN=ILF2 ILF2_HUMAN $43.06 \quad 100.0 \%$ Interleukin enhancer-binding factor 2 GN=ILF2 ILF2_HUMAN $43.06 \quad 100.0 \%$ Interleukin enhancer-binding factor 2 GN=ILF2 ILF2_HUMAN $43.06 \quad 100.0 \%$ Interleukin enhancer-binding factor 2 GN=ILF2 ILF2_HUMAN $43.06 \quad 100.0 \%$ Interleukin enhancer-binding factor $3 \mathrm{GN}=\mathrm{ILF} 3$ ILF3_HUMAN $95.34 \quad 100.0 \%$ Interleukin enhancer-binding factor 3 GN=ILF3 ILF3_HUMAN $95.34 \quad 100.0 \%$ Interleukin enhancer-binding factor $3 \mathrm{GN}=\mathrm{ILF} 3 \mathrm{ILF} 3$ HUMAN $95.34 \quad 100.0 \%$ Interleukin enhancer-binding factor $3 \mathrm{GN}=\mathrm{ILF} 3 \mathrm{ILF} 3$ HUMAN $95.34100 .0 \%$ Interleukin enhancer-binding factor 3 GN=ILF3 ILF3_HUMAN $95.34 \quad 100.0 \%$ Interleukin enhancer-binding factor $3 \mathrm{GN}=\mathrm{ILF} 3 \mathrm{ILF} 3$ _HUMAN $95.34 \quad 100.0 \%$ Interleukin enhancer-binding factor $3 \mathrm{GN}=\mathrm{ILF} 3 \mathrm{ILF} 3$ _HUMAN $95.34 \quad 100.0 \%$ Interleukin enhancer-binding factor $3 \mathrm{GN}=\mathrm{ILF} 3 \mathrm{ILF} 3$ _HUMAN $95.34 \quad 100.0 \%$ Interleukin enhancer-binding factor $3 \mathrm{GN}=\mathrm{ILF} 3 \mathrm{ILF} 3$ HUMAN $95.34100 .0 \%$ Interleukin enhancer-binding factor 3 GN=ILF3 ILF3_HUMAN $95.34 \quad 100.0 \%$ Isocitrate dehydrogenase [NAD] subunit alpha, mitochondrial GN=IDH3A IDH3A_HUMAN $39.59 \quad 100.0 \%$ Isocitrate dehydrogenase [NAD] subunit alpha, mitochondrial GN=IDH3A IDH3A_HUMAN $39.59100 .0 \%$ Isocitrate dehydrogenase $[\mathrm{NAD}]$ subunit alpha, mitochondrial GN=IDH3A IDH3A_HUMAN $39.59 \quad 100.0 \%$ Isocitrate dehydrogenase $[\mathrm{NAD}]$ subunit alpha, mitochondrial GN=IDH3A IDH3A_HUMAN $39.59 \quad 100.0 \%$ Isocitrate dehydrogenase [NAD] subunit alpha, mitochondrial GN=IDH3A IDH3A_HUMAN $39.59100 .0 \%$ Isocitrate dehydrogenase [NAD] subunit alpha, mitochondrial GN=IDH3A IDH3A_HUMAN $39.59 \quad 100.0 \%$ Isocitrate dehydrogenase [NAD] subunit alpha, mitochondrial GN=IDH3A IDH3A_HUMAN $39.59 \quad 100.0 \%$ Isocitrate dehydrogenase [NAD] subunit alpha, mitochondrial GN=IDH3A IDH3A_HUMAN $39.59 \quad 100.0 \%$ Isocitrate dehydrogenase [NAD] subunit beta, mitochondrial GN=IDH3B IDH3B_HUMAN $42.18 \quad 100.0 \%$ Isocitrate dehydrogenase [NAD] subunit beta, mitochondrial GN=IDH3B IDH3B_HUMAN $42.18 \quad 100.0 \%$ Isocitrate dehydrogenase $[\mathrm{NAD}]$ subunit beta, mitochondrial GN=IDH3B IDH3B_HUMAN $42.18 \quad 100.0 \%$ Isocitrate dehydrogenase [NAD] subunit beta, mitochondrial GN=IDH3B IDH3B_HUMAN $42.18 \quad 100.0 \%$ Isocitrate dehydrogenase [NAD] subunit beta, mitochondrial GN=IDH3B IDH3B_HUMAN $42.18 \quad 100.0 \%$ Isocitrate dehydrogenase $[\mathrm{NAD}]$ subunit beta, mitochondrial GN=IDH3B IDH3B_HUMAN $42.18 \quad 100.0 \%$ Isocitrate dehydrogenase [NAD] subunit beta, mitochondrial GN=IDH3B IDH3B_HUMAN $42.18 \quad 100.0 \%$ Isocitrate dehydrogenase $[\mathrm{NAD}]$ subunit beta, mitochondrial GN=IDH3B $\mathrm{IDH3B} \_$HUMAN $42.18 \quad 100.0 \%$
$0.09 \% \quad 25.5 \%$ IIGHFYASQMAQR

$0.09 \% \quad 25.5 \%$ IRDILAQVK

$10 \quad 0.02 \% \quad 8.3 \% \quad$ SITILSTPEGTSAACK

$10 \quad 0.02 \% \quad 8.3 \%$ ILAHNNFVGR

$10 \quad 0.02 \% \quad 8.3 \% \quad$ IAPAEAPDAK

$10 \quad 0.02 \% \quad 8.3 \%$ IAPAEAPDAKVR

$10 \quad 0.02 \% \quad 8.3 \% \quad$ ALQSGPPQSR

$0.02 \% \quad 1.9 \% \quad$ LAEAAVAEKR

$0.02 \% \quad 1.9 \% \quad$ SFQNQIAAIQR

$0.02 \% \quad 1.9 \%$ AAAVQADDVEVLK

$0.02 \% \quad 1.9 \%$ LPLFDSVR

$0.01 \% \quad 6.1 \%$ AAEAAINILK

$0.01 \% \quad 6.1 \%$ NAAEKFLAK

$0.02 \% \quad 15.4 \%$ VKPAPDETSFSEALLK

$0.02 \% \quad 15.4 \%$ ILITTVPPNLR

$0.02 \% \quad 15.4 \%$ VLQSALAAIR

$0.02 \% \quad 15.4 \%$ WFEENASQSTVK

$0.02 \% \quad 15.4 \%$ QPLALNVAYR

$0.02 \% \quad 15.4 \%$ QPLALNVAYRR

$0.09 \% \quad 13.2 \%$ IFVNDDRHVMAK

$0.09 \% \quad 13.2 \%$ CLAALASLR

$0.09 \% \quad 13.2 \%$ SIGTANRPMGAGEALRR

$0.09 \% \quad 13.2 \%$ QQREDITQSAQHALR

$0.09 \% \quad 13.2 \%$ LAAFGQLHK

$0.09 \% \quad 13.2 \%$ LNQLKPGLQYK

$0.09 \% \quad 13.2 \%$ TAKLHVAVK

$0.09 \% \quad 13.2 \%$ VLQDMGLPTGAEGR

$0.09 \% \quad 13.2 \%$ HGKNPVMELNEK

$0.09 \% \quad 13.2 \%$ AYAALAALEK

$0.03 \% \quad 22.7 \%$ MGLKGPLK

$0.03 \% \quad 22.7 \%$ LITEGASKR

$0.03 \% \quad 22.7 \%$ IAEFAFEYAR

$0.03 \% \quad 22.7 \%$ SNVTAVHKANIMR

$0.03 \% \quad 22.7 \%$ MSDGLFLQK

$0.03 \% \quad 22.7 \%$ IEAACFATIKDGK

$0.03 \% 22.7 \%$ SLTKDLGGNAK

$0.03 \% \quad 22.7 \%$ CSDFTEEICR

$0.05 \% \quad 15.3 \%$ HNNLDLVIIR

$0.05 \% \quad 15.3 \%$ GVIECLKIVTR

$0.05 \% \quad 15.3 \%$ FAFDYATK

$0.05 \% \quad 15.3 \%$ FAFDYATKK

$0.05 \% \quad 15.3 \%$ TRDMGGYSTTTDFIK

$0.05 \% \quad 15.3 \%$ DMGGYSTTTDFIK

$0.05 \% \quad 15.3 \%$ SVIGHLQTK
$0.05 \% \quad 15.3 \%$ IAKFAFDYATK $\begin{array}{llllllll} & 26.8 & 25.0 & 24.0 & 2 & 2 & 0 & 1309.71\end{array}$

$\begin{array}{llllllll}99.7 \% & 51.6 & 25.0 & 47.1 & 1 & 0 & 0 & 1500.72\end{array}$

$99.7 \% \quad 48.5$

$99.7 \% \quad 34.2$

$99.7 \% \quad 54.8$

$99.7 \% 37$.

$98.1 \% \quad 18.2$

$99.7 \% \quad 44.5$

$99.6 \% \quad 29.4$

$99.7 \% \quad 61.8$

$99.3 \% \quad 27.4$

$99.7 \% \quad 37.8$

$99.0 \% \quad 23.3$

$\begin{array}{lll}99.7 \% & 43.5\end{array}$

$99.1 \% \quad 24.8$

$99.2 \% \quad 19.9$

$99.7 \% \quad 35.2$

$99.7 \% \quad 66.7$

$99.7 \% \quad 63.7$

$99.7 \% \quad 33.8$

$98.1 \% \quad 20.9$

$99.7 \% \quad 30.2$

$99.7 \% \quad 49.3$

$95.8 \% \quad 16.8$

$99.7 \% \quad 47.5$

$99.7 \% \quad 37.9$

$\begin{array}{lll}99.7 \% & 43.5\end{array}$

$96.7 \% \quad 17.0$

$99.7 \% \quad 70.8$

$95.4 \% \quad 15.9$

$99.7 \% \quad 50.4$

$99.0 \% \quad 31.8$

$99.5 \% \quad 36.5$

$99.7 \% \quad 72.4$

$99.0 \% \quad 27.4$

$99.5 \% \quad 28.2$

$99.7 \% \quad 50.5$

$97.7 \% \quad 24.4$

$99.7 \% \quad 61.2$

$99.7 \% \quad 46.3$

$99.7 \% \quad 53.8$

$99.7 \% \quad 33.0$

$98.7 \% 26.7$

$99.7 \% \quad 39.8$

$99.7 \% \quad 29.4$

$99.7 \% \quad 68.6$

$99.1 \% \quad 20.4$
1521.76

055.66

1635.83

1140.63

982.52

1237.69

1040.55

1057.60

1275.68

1328.71

946.54

1013.60

991.56

1731.92

1236.77

1041.64

1425.66

1144.65

1300.75

1460.73

974.55

1756.92

1780.91

984.56

1301.76

966.61

1459.72

1411.70

1020.57

843.51

974.56

1216.60

1440.77

1054.52

1423.73

1103.61

1316.52

1206.70

1287.75

1274.68

962.46

1090.56

1708.79

1435.64

982.57 $\begin{array}{cc}41 & 452 \\ 26 & 538 \\ 39 & 551 \\ 53 & 561 \\ 43 & 258 \\ 81 & 290 \\ 41 & 450 \\ 41 & 452 \\ 68 & 577 \\ 2 & 101 \\ 77 & 587 \\ 83 & 695 \\ 36 & 1043 \\ 1 & 100 \\ 83 & 191 \\ 4 & 59 \\ 75 & 185 \\ 97 & 206 \\ 10 & 221 \\ 60 & 269 \\ 60 & 270 \\ 6 & 17 \\ 03 & 211 \\ 58 & 274 \\ 09 & 323 \\ 24 & 332 \\ 09 & 419 \\ 52 & 460 \\ 61 & 474 \\ 24 & 535 \\ 78 & 587 \\ 3 & 100 \\ 70 & 178 \\ 79 & 188 \\ 93 & 205 \\ 06 & 214 \\ 27 & 339 \\ 40 & 350 \\ 51 & 360 \\ 55 & 164 \\ 81 & 191 \\ 97 & 207 \\ 00 & 207 \\ 00 & 208 \\ 60 & 374 \\ 62 & 374 \\ 75 & 383\end{array}$

Page 46 of Table S-1-3 

Isocitrate dehydrogenase [NADP], mitochondrial GN=IDH2 IDHP_HUMAN $50.91 \quad 100.0 \%$ Isocitrate dehydrogenase [NADP], mitochondrial GN=IDH2 IDHP HUMAN $50.91 \quad 100.0 \%$ Isocitrate dehydrogenase [NADP], mitochondrial GN=IDH2 IDHP_HUMAN $50.91 \quad 100.0 \%$ Isocitrate dehydrogenase [NADP], mitochondrial GN=IDH2 IDHP_HUMAN $50.91 \quad 100.0 \%$ Isocitrate dehydrogenase [NADP], mitochondrial GN=IDH2 IDHP_HUMAN $50.91 \quad 100.0 \%$ Isoleucine--tRNA ligase, cytoplasmic GN=IARS SYIC_HUMAN $144.50 \quad 100.0 \%$ Isoleucine--tRNA ligase, cytoplasmic GN=IARS SYIC_HUMAN $144.50 \quad 100.0 \%$ Isoleucine--tRNA ligase, cytoplasmic GN=IARS SYIC_HUMAN $144.50 \quad 100.0 \%$ Isovaleryl-CoA dehydrogenase, mitochondrial GN=IVD IVD_HUMAN $46.32 \quad 100.0 \%$ Isovaleryl-CoA dehydrogenase, mitochondrial GN=IVD IVD HUMAN $46.32100 .0 \%$ Junction plakoglobin GN=JUP Junction plakoglobin $\mathrm{GN}=\mathrm{JUP}$ Junction plakoglobin GN=JUP PLAK_HUMAN $81.75 \quad 100.0 \%$ PLAK_HUMAN $81.75 \quad 100.0 \%$ PLAK HUMAN $81.75 \quad 100.0 \%$ Katanin p60 ATPase-containing subunit A1 GN=KATNA1 KTNA1_HUMAN $55.97 \quad 100.0 \%$ Katanin p60 ATPase-containing subunit A1 GN=KATNA1 KTNA1_HUMAN $55.97 \quad 100.0 \%$ Kelch-like ECH-associated protein 1 GN=KEAP1 KEAP1_HUMAN $69.66 \quad 100.0 \%$ Kelch-like ECH-associated protein 1 GN=KEAP1 KEAP1_HUMAN $69.66 \quad 100.0 \%$ Ketosamine-3-kinase GN=FN3KRP Ketosamine-3-kinase GN=FN3KRP KT3K HUMAN $34.41 \quad 100.0 \%$ KT3K_HUMAN $34.41 \quad 100.0 \%$ KHDR1_HUMAN $48.23 \quad 100.0 \%$

KH domain-conamas 1 we

Kinesin- 1 heavy chain GN=KIF5B R1_HUMAN $48.23 \quad 100.0 \%$ KINH_HUMAN $109.69 \quad 100.0 \%$ KINH_HUMAN $109.69 \quad 100.0 \%$

Kinetochore-associated protein $1 \mathrm{GN}=\mathrm{KNTC1}$ KNTC1_HUMAN $250.76 \quad 100.0 \%$ Kinetochore-associated protein $1 \mathrm{GN}=\mathrm{KNTC1}$ KNTC1_HUMAN $250.76 \quad 100.0 \%$ Kinetochore-associated protein $1 \mathrm{GN}=\mathrm{KNTC1}$ KNTC1_HUMAN $250.76 \quad 100.0 \%$ KRR1 small subunit processome component homolog GN=KRR1 KRR1_HUMAN $43.67 \quad 100.0 \%$ KRR1 small subunit processome component homolog GN=KRR1 KRR1_HUMAN $43.67 \quad 100.0 \%$ KRR1 small subunit processome component homolog GN=KRR1 KRR1_HUMAN $43.67 \quad 100.0 \%$ L-2-hydroxyglutarate dehydrogenase, mitochondrial GN=L2HGDH L2HDH_HUMAN $50.32 \quad 100.0 \%$ L-2-hydroxyglutarate dehydrogenase, mitochondrial GN=L2HGDH L2HDH HUMAN $50.32 \quad 100.0 \%$ Lamina-associated polypeptide 2, isoform alpha GN=TMPO LAP2A_HUMAN $75.49 \quad 100.0 \%$ Lamina-associated polypeptide 2, isoform alpha GN=TMPO LAP2A_HUMAN $75.49 \quad 100.0 \%$ . Lamin-B receptor $\mathrm{GN}=\mathrm{LBR}$ Lamin-B receptor $\mathrm{GN}=\mathrm{LBR}$ Lamin-B receptor $\mathrm{GN}=\mathrm{LBR}$ Lamin-B receptor $\mathrm{GN}=\mathrm{LBR}$ Lamin-B receptor $\mathrm{GN}=\mathrm{LBR}$ Lamin-B1 GN=LMNB LBR_HUMAN $70.71 \quad 100.0 \%$ LBR HUMAN $70.71 \quad 100.0 \%$ LBR_HUMAN $70.71 \quad 100.0 \%$ LBR_HUMAN $70.71 \quad 100.0 \%$ LBR HUMAN $70.71 \quad 100.0 \%$ LMNB1_HUMAN $66.41 \quad 100.0 \%$

$0.05 \% \quad 15.3 \%$ SVIGHLQTKGS $0.01 \% \quad 11.7 \%$ SLPGVVTR $0.01 \% \quad 11.7 \%$ IAEYAFKLAQESGR $0.01 \% \quad 11.7 \%$ LGDGLFLQCCR

$19 \quad 0.04 \% \quad 18.6 \%$ CATITPDEAR

$19 \quad 0.04 \% \quad 18.6 \%$ ATDFVADRAGTFK $19 \quad 0.04 \% \quad 18.6 \%$ LIDDMVAQVLK $19 \quad 0.04 \% \quad 18.6 \%$ TIEAEAAHGTVTR $19 \quad 0.04 \% \quad 18.6 \%$ GKLDGNQDLIR $19 \quad 0.04 \% \quad 18.6 \%$ VCVETVESGAMTK $0.04 \% \quad 18.6 \%$ DLAGCIHGLSNVK $0.01 \% \quad 2.3 \%$ MGITEYNNQCR $0.01 \% \quad 2.3 \%$ SDTPLIYK $0.01 \% \quad 2.3 \% \quad$ LYLINSPVVR $0.01 \% \quad 4.5 \%$ FLQEHLAPK $0.01 \% \quad 4.5 \%$ TDLAAVPASR $0.01 \% \quad 4.0 \% \quad$ AAMIVNQLSK $0.01 \% \quad 4.0 \% \quad$ LVQNCLWTLR $0.01 \% \quad 4.0 \% \quad$ LNYGIPAIVK $0.01 \% \quad 4.3 \%$ GVLMVGPPGTGK $0.01 \% \quad 4.3 \%$ IYIPLPSAK $0.01 \% \quad 3.0 \% \quad$ LADLQVPR $0.01 \% \quad 3.0 \%$ SALGITVHQGR $0.01 \% \quad 7.8 \%$ SYDTDQGRVFVK $0.01 \% \quad 7.8 \%$ GGGQEERPFVAR $0.01 \% \quad 5.6 \%$ SGSMDPSGAHPSVR $0.01 \% \quad 5.6 \%$ ILGPQGNTIKR $0.01 \% \quad 2.5 \% \quad$ LFVQDLATR $0.01 \% \quad 2.5 \%$ GGGAFVQNSQPVAVR $0.01 \% \quad 1.9 \% \quad$ IQQAIENVDFSTAK $0.01 \% \quad 1.9 \%$ CLTEALPENR $0.01 \% \quad 1.9 \%$ IQNSSGTDYPDIHAAAK $0.01 \% \quad 6.6 \%$ DLIKLLAR $0.01 \% \quad 6.6 \%$ SVSFEQAVR $0.01 \% \quad 6.6 \% \quad$ KVVLDTMK $0.01 \% \quad 4.8 \%$ GLQNGVPGLR $0.01 \% \quad 4.8 \%$ SIDGMQYPIVIK $0.03 \% \quad 5.9 \%$ NRPPLPAGTNSK $0.03 \% \quad 5.9 \% \quad$ YGVNPGPIVGTTR $0.03 \% \quad 5.9 \%$ SSTPLPTISSSAENTR $0.03 \% \quad 8.6 \%$ KFADGEVVR $0.03 \% \quad 8.6 \%$ SASASHQADIKEAR $0.03 \% \quad 8.6 \% \quad$ YNGEPEHIER $0.03 \% \quad 8.6 \%$ TFEVTPIR $0.03 \% \quad 8.6 \%$ VVEGTPLIDGRR $0.11 \% \quad 31.4 \%$ AGGPTTPLSPTR

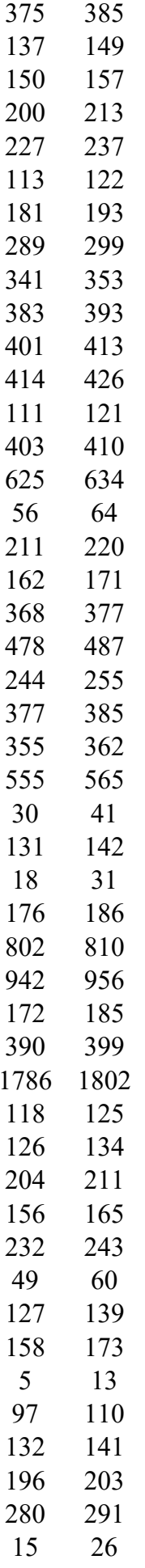

Page 47 of Table S-1-3 
Lamin-B1 GN=LMNB1 Lamin-B1 GN=LMNB Lamin-B1 GN=LMNB1 Lamin-B1 GN=LMNB Lamin-B1 GN=LMNB1 Lamin-B1 GN=LMNB1 Lamin-B1 GN=LMNB1 Lamin-B1 GN=LMNB1 Lamin-B1 GN=LMNB Lamin-B1 GN=LMNB1 Lamin-B1 GN=LMNB1 Lamin-B1 GN=LMNB Lamin-B1 GN=LMNB1 Lamin-B1 GN=LMNB Lamin-B1 GN=LMNB1 Lamin-B1 GN=LMNB1 Lamin-B1 GN=LMNB1 Lamin-B2 GN=LMNB2 Lamin-B2 GN=LMNB2 Lamin-B2 GN=LMNB2 Lamin-B2 GN=LMNB2 Lamin-B2 GN=LMNB2 Lamin-B2 GN=LMNB2 Lamin-B2 GN=LMNB2 Lamin-B2 GN=LMNB2 La-related protein $1 \mathrm{GN}=\mathrm{LARP} 1$ La-related protein $1 \mathrm{GN}=\mathrm{LARP} 1$ La-related protein $1 \mathrm{GN}=\mathrm{LARP} 1$ La-related protein $1 \mathrm{GN}=\mathrm{LARP}$ La-related protein $1 \mathrm{GN}=\mathrm{LARP} 1$ La-related protein $1 \mathrm{GN}=\mathrm{LARP} 1$ La-related protein $1 \mathrm{GN}=\mathrm{LARP} 1$ Lamin-B1 GN=LMNB1 Lamin-B1 GN=LMNB1 Lamin-B2 GN=LMNB2

LMNB1_HUMAN $66.41 \quad 100.0 \% \quad 20 \quad 22 \quad 54 \quad 0.11 \% \quad 31.4 \%$ AGGPTTPLSPTRLSR LMNB1_HUMAN $66.41 \quad 100.0 \% \quad 20$ LMNB1_HUMAN $\quad 66.41 \quad 100.0 \% \quad 20$ LMNB1_HUMAN $\quad 66.41 \quad 100.0 \% \quad 20$ LMNB1_HUMAN $66.41 \quad 100.0 \% \quad 20$ LMNB1_HUMAN $66.41 \quad 100.0 \% \quad 20$ LMNB1 HUMAN $66.41 \quad 100.0 \% \quad 20$ LMNB1_HUMAN $66.41 \quad 100.0 \% \quad 20$ LMNB1_HUMAN $66.41 \quad 100.0 \% \quad 20$ LMNB1_HUMAN $\quad 66.41 \quad 100.0 \% \quad 20$ LMNB1_HUMAN $66.41 \quad 100.0 \% \quad 20$ LMNB1_HUMAN $\quad 66.41 \quad 100.0 \% \quad 20$ LMNB1_HUMAN $66.41 \quad 100.0 \% \quad 20$ LMNB1_HUMAN $66.41 \quad 100.0 \% \quad 20$ LMNB1_HUMAN $\quad 66.41 \quad 100.0 \% \quad 20$ LMNB1_HUMAN $66.41 \quad 100.0 \% \quad 20$ LMNB1_HUMAN $66.41 \quad 100.0 \% \quad 20$ $\begin{array}{lll}\text { LMNB1_HUMAN } & 66.41 & 100.0 \%\end{array}$ LMNB1_HUMAN $66.41 \quad 100.0 \% \quad 20$ LMNB2 HUMAN $67.69 \quad 100.0 \% \quad 7$ LMNB2_HUMAN $67.69 \quad 100.0 \%$ LMNB2_HUMAN $67.69 \quad 100.0 \%$ LMNB2_HUMAN $67.69 \quad 100.0 \%$ LMNB2_HUMAN $67.69 \quad 100.0 \%$ LMNB2 HUMAN $67.69 \quad 100.0 \% \quad 7$ LMNB2_HUMAN $67.69 \quad 100.0 \% \quad 7$ LMNB2_HUMAN $67.69 \quad 100.0 \%$ LMNB2_HUMAN $67.69 \quad 100.0 \%$ LARP1_HUMAN $123.51 \quad 100.0 \%$ LARP1 HUMAN $123.51 \quad 100.0 \%$ LARP1_HUMAN $123.51 \quad 100.0 \%$ LARP1_HUMAN $123.51 \quad 100.0 \%$ LARP1 HUMAN $123.51 \quad 100.0 \%$ LARP1_HUMAN $123.51 \quad 100.0 \%$ LARP1_HUMAN $123.51 \quad 100.0 \%$ LPPRC_HUMAN $157.91 \quad 100.0 \%$ RC LPPRC_HUMAN $157.91 \quad 100.0 \%$ RC LPPRC_HUMAN $157.91 \quad 100.0 \%$ C LPPRC_HUMAN $157.91 \quad 100.0 \%$ C LPPRC_HUMAN $157.91 \quad 100.0 \%$ LPPRC_HUMAN $157.91 \quad 100.0 \%$ RC LPPRC_HUMAN $157.91 \quad 100.0 \%$ C LPPRC_HUMAN $157.91 \quad 100.0 \%$ $\begin{array}{llll}\text { Leucine-rich repeat-containing protein } 40 \mathrm{GN}=\text { LRRC40 } & \text { LRC40_HUMAN } & 68.25 & 100.0 \% \\ \text { Leucine-rich repeat-containing protein } 40 \mathrm{GN}=\mathrm{LRRC} 40 & \text { LRC40 HUMAN } & 68.25 & 100.0 \%\end{array}$ Leucine-rich repeat-containing protein $40 \mathrm{GN}=$ LRRC40 LRC40_HUMAN $68.25 \quad 100.0 \%$ Leucine-rich repeat-containing protein $40 \mathrm{GN}=\mathrm{LRRC} 40$ LRC40_HUMAN $68.25 \quad 100.0 \%$ $0.11 \% \quad 31.4 \%$ ALYETELADAR $0.11 \% 31.4 \%$ ALDDTARER $0.11 \% \quad 31.4 \%$ AKLQIELGK $0.11 \% \quad 31.4 \%$ CKAEHDQLLLNYAK $0.11 \% 31.4 \%$ LREYEAALNSK $0.11 \% \quad 31.4 \%$ DAALATALGDKK $0.11 \% 31.4 \%$ KQLADETLLK $0.11 \% \quad 31.4 \%$ QLADETLLK $0.11 \% \quad 31.4 \%$ SMYEEEINETR $0.11 \% 31.4 \%$ EQHDAQVR $0.11 \% 31.4 \%$ LYKEELEQTYHAK $0.11 \% 31.4 \%$ LSSEMNTSTVNSAR $0.11 \% 31.4 \%$ IESLSSQLSNLQK $0.11 \% \quad 31.4 \%$ IQELEDLLAK $0.11 \% 31.4 \%$ LLEGEEER $0.11 \% \quad 31.4 \%$ LLEGEEERLK $0.11 \% \quad 31.4 \%$ IGDTSVSYKYTSR $0.06 \% \quad 15.2 \%$ AGGPATPLSPTR $0.06 \% \quad 15.2 \%$ ALYESELADARR $0.06 \% \quad 15.2 \%$ EGELTVAQGR $0.06 \% \quad 15.2 \%$ GLESDVAELR $0.06 \% \quad 15.2 \%$ RLVEVDSSR $0.06 \% \quad 15.2 \%$ LLEGEEER $0.06 \% \quad 15.2 \%$ LLEGEEERLK $0.06 \% \quad 15.2 \%$ ATSSSSGSLSATGR $0.06 \% \quad 15.2 \%$ TVLVNADGEEVAMR $0.04 \% \quad 6.4 \%$ KFDGVEGPR $0.04 \% \quad 6.4 \%$ AVTPVPTKTEEVSNLK $0.04 \% \quad 6.4 \% \quad$ SLPTTVPESPNYR $0.04 \% \quad 6.4 \% \quad$ SLPTTVPESPNYRNTR $0.04 \% \quad 6.4 \%$ TPQLKDSSQTSR $0.04 \% \quad 6.4 \% \quad$ FYPVVKEGR $0.04 \% \quad 6.4 \%$ TLDAKMPR $0.03 \% \quad 7.0 \%$ EKDIQEESTFSSR $0.03 \% \quad 7.0 \%$ SGGLGGSHALLLLR $0.03 \% \quad 7.0 \%$ LIASYCNVGDIEGASK $0.03 \% \quad 7.0 \% \quad$ SSLLLGFRR $0.03 \% \quad 7.0 \% \quad$ IIETPGIRAR $0.03 \% \quad 7.0 \%$ TVLDQQQTPSR $0.03 \% \quad 7.0 \%$ VIEEQLEPAVEK $0.03 \% \quad 7.0 \%$ SYVSEKDVTSAK $0.01 \% \quad 6.8 \% \quad$ SVPDEIILLR $0.01 \% \quad 6.8 \%$ FLALEGNPLR $0.01 \% \quad 6.8 \%$ SNIVTSINFSK $0.01 \% \quad 6.8 \%$ LQTINLSFNR $0.11 \% \quad 31.4 \%$ ALYETELADARR $\begin{array}{llllllll}99.5 \% & 24.6 & 25.0 & 22.1 & 1 & 1 & 0 & 1510.83\end{array}$

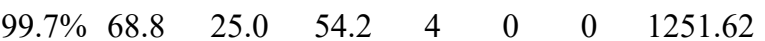
$\begin{array}{llllllll}99.7 \% & 52.8 & 25.0 & 48.1 & 2 & 1 & 0 & 1407.72\end{array}$

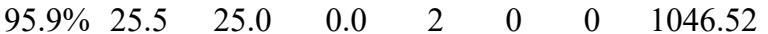
$\begin{array}{llllllll}99.7 \% & 52.7 & 25.0 & 41.6 & 6 & 0 & 0 & 999.62\end{array}$

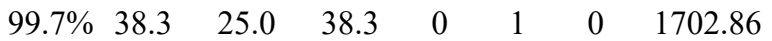
$\begin{array}{llllllll}99.7 \% & 47.4 & 25.0 & 29.5 & 2 & 0 & 0 & 1293.68\end{array}$ $\begin{array}{llllllll}99.7 \% & 65.6 & 25.0 & 49.5 & 6 & 0 & 0 & 1173.65\end{array}$

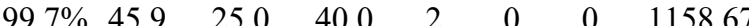
$\begin{array}{llllllll}99.7 \% & 31.0 & 25.0 & 28.3 & 1 & 0 & 0 & 1030.58\end{array}$ $\begin{array}{llllllll}99.7 \% & 56.4 & 25.0 & 56.4 & 2 & 0 & 0 & 1400.60\end{array}$ $\begin{array}{llllllll}95.2 \% & 27.5 & 25.0 & 18.0 & 1 & 0 & 0 & 982.47\end{array}$ $\begin{array}{llllllll}99.7 \% & 38.0 & 25.0 & 38.0 & 0 & 2 & 0 & 1651.83\end{array}$ $\begin{array}{llllllll}99.7 \% & 35.4 & 25.0 & 35.4 & 1 & 0 & 0 & 1496.70\end{array}$ $\begin{array}{llll}99.7 \% & 46.4 & 25.0 & 40.5\end{array}$ $\begin{array}{lllll}99.4 \% & 36.8 & 25.0 & 14.8 & 2\end{array}$ $99.0 \% \quad 52.2 \quad 25.0 \quad 44.1$ $99.7 \% \quad 43.6 \quad 25.0 \quad 35.9$ $\begin{array}{lllll}99.3 \% & 27.9 & 25.0 & 23.5 & 0\end{array}$ $\begin{array}{llll}99.7 \% & 45.6 & 25.0 & 39.9\end{array}$ $99.3 \% \quad 22.6 \quad 25.0 \quad 22.6$ $\begin{array}{llll}99.7 \% & 58.4 & 25.0 & 33.5\end{array}$ $\begin{array}{llll}99.7 \% & 77.7 & 25.0 & 58.7\end{array}$ $\begin{array}{lllll}99.7 \% & 39.1 & 25.0 & 28.8 & 2\end{array}$ $\begin{array}{llll}99.0 \% & 52.2 & 25.0 & 44.1\end{array}$ $\begin{array}{lllll}99.7 \% & 43.6 & 25.0 & 35.9 & 2\end{array}$ $\begin{array}{lllll}99.7 \% & 61.2 & 25.0 & 61.2 & 6\end{array}$ $99.7 \% \quad 71.1 \quad 25.0 \quad 71.1$ $\begin{array}{lllll}99.7 \% & 35.4 & 25.0 & 25.9 & 2\end{array}$ $\begin{array}{llll}99.5 \% & 23.9 & 25.0 & 23.2\end{array}$ $\begin{array}{llll}99.7 \% & 34.9 & 25.0 & 34.3\end{array}$ $\begin{array}{lllll}97.8 \% & 23.9 & 25.0 & 23.9 & 1\end{array}$ $\begin{array}{llll}99.7 \% & 33.9 & 25.0 & 33.9\end{array}$ $\begin{array}{llll}99.4 \% & 21.7 & 25.0 & 21.7\end{array}$ $\begin{array}{llll}99.0 \% & 30.0 & 25.0 & 20.2\end{array}$ $\begin{array}{llll}99.7 \% & 50.8 & 25.0 & 47.6\end{array}$ $\begin{array}{lllll}99.7 \% & 44.3 & 25.0 & 37.8 & 2\end{array}$ $\begin{array}{lllll}99.7 \% & 52.9 & 25.0 & 52.9 & 2\end{array}$ $\begin{array}{llll}97.5 \% & 22.3 & 25.0 & 15.2\end{array}$ $\begin{array}{llll}96.7 \% & 18.1 & 25.0 & 16.6\end{array}$ $\begin{array}{llll}99.7 \% & 48.0 & 25.0 & 38.2\end{array}$ $\begin{array}{lllll}99.7 \% & 64.8 & 25.0 & 64.4 & 2\end{array}$ $\begin{array}{llll}99.7 \% & 54.8 & 25.0 & 54.8\end{array}$ $\begin{array}{llll}99.7 \% & 32.7 & 25.0 & 27.2\end{array}$ $\begin{array}{lllll}99.7 \% & 42.5 & 25.0 & 28.0 & 2\end{array}$ $\begin{array}{lllll}99.7 \% & 44.4 & 25.0 & 40.8\end{array}$ $\begin{array}{llll}99.7 \% & 31.8 & 25.0 & 24.6\end{array}$

\begin{tabular}{|c|c|c|c|c|c|c|c|c|c|c|c|}
\hline 22 & 54 & $0.11 \%$ & 31.4\% AGGPTTPLSPTRLSR & $99.5 \%$ & 24.6 & 25.0 & 22.1 & 1 & 1 & 0 & 1510.83 \\
\hline 22 & 54 & $0.11 \%$ & 31.4\% ALYETELADAR & $99.7 \%$ & 68.8 & 25.0 & 54.2 & 4 & 0 & 0 & 1251.62 \\
\hline & 54 & $0.11 \%$ & $31.4 \%$ ALYETELADARR & $99.7 \%$ & 52.8 & 25.0 & 48.1 & 2 & 0 & 0 & 1407.72 \\
\hline & 54 & $0.11 \%$ & $31.4 \%$ ALDDTARER & $95.9 \%$ & 25.5 & 25.0 & 0.0 & 2 & 0 & 0 & 1046.52 \\
\hline & 54 & $0.11 \%$ & 31.4\% AKLQIELGK & $99.7 \%$ & 52.7 & 25.0 & 41.6 & 6 & 0 & 0 & 999.62 \\
\hline & 54 & $0.11 \%$ & $31.4 \%$ CKAEHDQLLLNYAK & $99.7 \%$ & 38.3 & 25.0 & 38.3 & 0 & 1 & 0 & 1702.86 \\
\hline & 54 & $0.11 \%$ & $31.4 \%$ LREYEAALNSK & $99.7 \%$ & 47.4 & 25.0 & 29.5 & 2 & 0 & 0 & 1293.68 \\
\hline & 54 & $0.11 \%$ & $31.4 \%$ DAALATALGDKK & $99.7 \%$ & 65.6 & 25.0 & 49.5 & 6 & 0 & 0 & 1173.65 \\
\hline & 54 & $0.11 \%$ & $31.4 \%$ KQLADETLLK & $99.7 \%$ & 45.9 & 25.0 & 40.0 & 2 & 0 & 0 & 1158.67 \\
\hline & 54 & $0.11 \%$ & $31.4 \%$ QLADETLLK & $99.7 \%$ & 31.0 & 25.0 & 28.3 & 1 & 0 & 0 & 1030.58 \\
\hline & 54 & $0.11 \%$ & $31.4 \%$ SMYEEEINETR & $99.7 \%$ & 56.4 & 25.0 & 56.4 & 2 & 0 & 0 & 1400.60 \\
\hline & 54 & $0.11 \%$ & $31.4 \%$ EQHDAQVR & $95.2 \%$ & 27.5 & 25.0 & 18.0 & 1 & 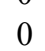 & 0 & 982.47 \\
\hline & 54 & $0.11 \%$ & $31.4 \%$ LYKEELEQTYHAK & $99.7 \%$ & 38.0 & 25.0 & 38.0 & 0 & 2 & 0 & 1651.83 \\
\hline & 54 & $0.11 \%$ & $31.4 \%$ LSSEMNTSTVNSAR & $99.7 \%$ & 35.4 & 25.0 & 35.4 & 1 & 0 & 0 & 1496.70 \\
\hline & 54 & $0.11 \%$ & $31.4 \%$ IESLSSQLSNLQK & $99.7 \%$ & 46.4 & 25.0 & 40.5 & 2 & 0 & 0 & 1446.78 \\
\hline & 54 & $0.11 \%$ & $31.4 \%$ IQELEDLLAK & $99.4 \%$ & 36.8 & 25.0 & 14.8 & 2 & 0 & 0 & 1171.66 \\
\hline & 54 & $0.11 \%$ & $31.4 \%$ LLEGEEER & $99.0 \%$ & 52.2 & 25.0 & 44.1 & 2 & 0 & 0 & 974.48 \\
\hline & 54 & $0.11 \%$ & $31.4 \%$ LLEGEEERLK & $99.7 \%$ & 43.6 & 25.0 & 35.9 & 2 & 0 & 0 & 1215.66 \\
\hline & 54 & $0.11 \%$ & $31.4 \%$ IGDTSVSYKYTSR & $99.3 \%$ & 27.9 & 25.0 & 23.5 & 0 & 2 & 0 & 1476.73 \\
\hline & 27 & $0.06 \%$ & $15.2 \%$ AGGPATPLSPTR & $99.7 \%$ & 45.6 & 25.0 & 39.9 & 8 & 0 & 0 & 1124.61 \\
\hline & 27 & $0.06 \%$ & $15.2 \%$ ALYESELADARR & $99.3 \%$ & 22.6 & 25.0 & 22.6 & 1 & 0 & 0 & 1393.71 \\
\hline & 27 & $0.06 \%$ & $15.2 \%$ EGELTVAOGR & $99.7 \%$ & 58.4 & 25.0 & 33.5 & 4 & 0 & 0 & 1059.54 \\
\hline 0 & 27 & $0.06 \%$ & $15.2 \%$ GLESDVAELR & $99.7 \%$ & 77.7 & 25.0 & 58.7 & 2 & 0 & 0 & 1088.56 \\
\hline 8 & 27 & $0.06 \%$ & $15.2 \%$ RLVEVDSSR & $99.7 \%$ & 39.1 & 25.0 & 28.8 & 2 & 0 & 0 & 1060.57 \\
\hline 8 & 27 & $0.06 \%$ & $15.2 \%$ LLEGEEER & $99.0 \%$ & 52.2 & 25.0 & 44.1 & 2 & 0 & 0 & 974.48 \\
\hline 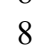 & 27 & $0.06 \%$ & $15.2 \%$ LLEGEEERLK & $99.7 \%$ & 43.6 & 25.0 & 35.9 & 2 & 0 & 0 & 1215.66 \\
\hline$\delta$ & 27 & $0.06 \%$ & $15.2 \%$ ATSSSSGSLSATGR & $99.7 \%$ & 61.2 & 25.0 & 61.2 & 6 & 0 & 0 & 1268.61 \\
\hline 8 & 27 & $0.06 \%$ & $15.2 \%$ TVLVNADGEEVAMR & $99.7 \%$ & 71.1 & 25.0 & 71.1 & 4 & 0 & 0 & 1519.74 \\
\hline . & 17 & $0.04 \%$ & $6.4 \%$ KFDGVEGPR & $99.7 \%$ & 35.4 & 25.0 & 25.9 & 2 & 0 & 0 & 1004.52 \\
\hline 8 & 17 & $0.04 \%$ & $6.4 \%$ AVTPVPTKTEEVSNLK & $99.5 \%$ & 23.9 & 25.0 & 23.2 & 0 & 2 & 0 & 1712.94 \\
\hline 8 & 17 & $0.04 \%$ & $6.4 \%$ SLPTTVPESPNYR & $99.7 \%$ & 34.9 & 25.0 & 34.3 & 2 & 0 & 0 & 1460.74 \\
\hline 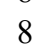 & 17 & $0.04 \%$ & $6.4 \%$ SLPTTVPESPNYRNTR & $97.8 \%$ & 23.9 & 25.0 & 23.9 & 1 & 0 & 0 & 1831.93 \\
\hline 8 & 17 & $0.04 \%$ & $6.4 \%$ TPQLKDSSQTSR & $99.7 \%$ & 33.9 & 25.0 & 33.9 & 4 & 3 & 0 & 1347.69 \\
\hline 8 & 17 & $0.04 \%$ & $6.4 \%$ FYPVVKEGR & $99.4 \%$ & 21.7 & 25.0 & 21.7 & 2 & 0 & 0 & 1094.60 \\
\hline 8 & 17 & $0.04 \%$ & $6.4 \%$ TLDAKMPR & $99.0 \%$ & 30.0 & 25.0 & 20.2 & 1 & 0 & 0 & 931.50 \\
\hline 8 & 13 & $0.03 \%$ & $7.0 \%$ EKDIOEESTFSSR & $99.7 \%$ & 50.8 & 25.0 & 47.6 & 1 & 0 & 0 & 1555.72 \\
\hline 8 & 13 & $0.03 \%$ & $7.0 \%$ SGGLGGSHALLLLR & $99.7 \%$ & 44.3 & 25.0 & 37.8 & 2 & 0 & 0 & 1350.79 \\
\hline 8 & 13 & $0.03 \%$ & $7.0 \%$ LIASYCNVGDIEGASK & $99.7 \%$ & 52.9 & 25.0 & 52.9 & 2 & 0 & 0 & 1696.82 \\
\hline 8 & 13 & $0.03 \%$ & $7.0 \%$ SSLLLGFRR & $97.5 \%$ & 22.3 & 25.0 & 15.2 & 1 & 0 & 0 & 1048.63 \\
\hline 8 & 13 & $0.03 \%$ & $7.0 \%$ IIETPGIRAR & $96.7 \%$ & 18.1 & 25.0 & 16.6 & 1 & 0 & 0 & 1125.67 \\
\hline 8 & 13 & $0.03 \%$ & $7.0 \%$ TVLDQQQTPSR & $99.7 \%$ & 48.0 & 25.0 & 38.2 & 2 & 0 & 0 & 1272.65 \\
\hline 8 & 13 & $0.03 \%$ & $7.0 \%$ VIEEQLEPAVEK & $99.7 \%$ & 64.8 & 25.0 & 64.4 & 2 & 0 & 0 & 1383.74 \\
\hline 8 & 13 & $0.03 \%$ & $7.0 \%$ SYVSEKDVTSAK & $99.7 \%$ & 54.8 & 25.0 & 54.8 & 2 & 0 & 0 & 1313.66 \\
\hline 4 & 7 & $0.01 \%$ & $6.8 \%$ SVPDEIILLR & $99.7 \%$ & 32.7 & 25.0 & 27.2 & 1 & 0 & 0 & 1154.68 \\
\hline 4 & 7 & $0.01 \%$ & $6.8 \%$ FLALEGNPLR & $99.7 \%$ & 42.5 & 25.0 & 28.0 & 2 & 0 & 0 & 1129.64 \\
\hline T & 7 & $0.01 \%$ & $6.8 \%$ SNIVTSINFSK & $99.7 \%$ & 44.4 & 25.0 & 40.8 & 2 & 0 & 0 & 1209.65 \\
\hline & 7 & $0.01 \%$ & $6.8 \%$ LQTINLSFNR & $99.7 \%$ & 31.8 & 25.0 & 24.6 & 2 & 0 & 0 & 1205.66 \\
\hline
\end{tabular}

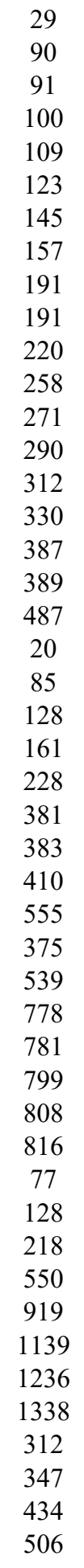


\begin{tabular}{lllllllll} 
LINE-1 retrotransposable element ORF1 protein GN=L1RE1 LORF1_HUMAN & 40.06 & $100.0 \%$ & 2 & 2 & 4 & $0.01 \%$ & $7.1 \%$ & QANVQIQEIQR \\
\hline LINE-1 retrotransposable element ORF1 protein GN=L1RE1 LORF1_HUMAN & 40.06 & $100.0 \%$ & 2 & 2 & 4 & $0.01 \%$ & $7.1 \%$ & LTADLSAETLL
\end{tabular} L-lactate dehydrogenase A chain GN=LDHA LDHA_HUMAN $36.69 \quad 100.0 \%$ L-lactate dehydrogenase A chain GN=LDHA LDHA_HUMAN 36.69 L-lactate dehydrogenase A chain GN=LDHA LDHA_HUMAN 36.69 L-lactate dehydrogenase A chain GN=LDHA LDHA_HUMAN 36.69

L-lactate dehydrogenase A chain GN=LDHA LDHA_HUMAN 36.69 L-lactate dehydrogenase A chain GN=LDHA LDHA_HUMAN 36.69 L-lactate dehydrogenase A chain GN=LDHA LDHA HUMAN 36.69 L-lactate dehydrogenase A chain GN=LDHA LDHA_HUMAN 36.69 L-lactate dehydrogenase A chain GN=LDHA LDHA_HUMAN 36.69 L-lactate dehydrogenase A chain GN=LDHA LDHA_HUMAN 36.69 L-lactate dehydrogenase A chain GN=LDHA LDHA_HUMAN 36.69 L-lactate dehydrogenase A chain GN=LDHA LDHA_HUMAN 36.69 L-lactate dehydrogenase A chain GN=LDHA LDHA_HUMAN 36.69 L-lactate dehydrogenase A chain GN=LDHA LDHA_HUMAN 36.69 L-lactate dehydrogenase A chain GN=LDHA LDHA_HUMAN 36.69 L-lactate dehydrogenase A chain GN=LDHA LDHA_HUMAN 36.69 L-lactate dehydrogenase A chain GN=LDHA LDHA_HUMAN 36.69 L-lactate dehydrogenase A chain GN=LDHA LDHA_HUMAN 36.69 L-lactate dehydrogenase B chain GN=LDHB LDHB_HUMAN 36.64 L-lactate dehydrogenase B chain GN=LDHB LDHB_HUMAN 36.64 L-lactate dehydrogenase B chain GN=LDHB LDHB_HUMAN 36.64 L-lactate dehydrogenase B chain GN=LDHB LDHB_HUMAN 36.64 L-lactate dehydrogenase B chain GN=LDHB LDHB_HUMAN 36.64 L-lactate dehydrogenase B chain GN=LDHB LDHB_HUMAN 36.64 L-lactate dehydrogenase B chain GN=LDHB LDHB_HUMAN 36.64

L-lactate dehydrogenase B chain GN=LDHB LDHB_HUMAN 36.64 L-lactate dehydrogenase B chain GN=LDHB LDHB_HUMAN 36.64 L-lactate dehydrogenase B chain GN=LDHB LDHB_HUMAN 36.64 L-lactate dehydrogenase B chain GN=LDHB LDHB_HUMAN 36.64 L-lactate dehydrogenase B chain GN=LDHB LDHB_HUMAN 36.64 L-lactate dehydrogenase B chain GN=LDHB LDHB_HUMAN 36.64 L-lactate dehydrogenase B chain GN=LDHB LDHB_HUMAN 36.64 L-lactate dehydrogenase B chain GN=LDHB LDHB_HUMAN 36.64 L-lactate dehydrogenase B chain GN=LDHB LDHB_HUMAN 36.64 Long-chain-fatty-acid--CoA ligase $3 \mathrm{GN}=$ ACSL3 ACSL3_HUMAN 80.42 Long-chain-fatty-acid--CoA ligase $3 \mathrm{GN}=$ ACSL3 ACSL3_HUMAN 80.42 Long-chain-fatty-acid--CoA ligase 3 GN=ACSL3 ACSL3_HUMAN 80.42 Long-chain-fatty-acid--CoA ligase 3 GN=ACSL3 ACSL3_HUMAN 80.42 Lupus La protein $\mathrm{GN}=\mathrm{SSB}$ Lupus La protein $\mathrm{GN}=\mathrm{SSB}$ pre 36 GRCC3 BRCC3 HUMAN $36.07 \quad 100.0 \%$ Lys-63-specific deubiquitinase BRCC36 GN=BRCC3 BRCC3_HUMAN $36.07 \quad 100.0 \%$ Lysine--tRNA ligase GN=KARS Lysine--tRNA ligase $\mathrm{GN}=\mathrm{KARS}$ Lysine--tRNA ligase GN=KARS LA HUMAN $46.84 \quad 100.0 \%$ LA_HUMAN $46.84 \quad 100.0 \%$

$100.0 \% \quad 18$

$100.0 \% \quad 18$

$00.0 \% \quad 18$

$100.0 \% \quad 18$

$100.0 \% \quad 18$

$100.0 \% \quad 18$

$100.0 \% \quad 18$

$00.0 \% \quad 18$

$100.0 \% \quad 18$

$100.0 \% \quad 18$

$00.0 \% \quad 18$

$100.0 \% \quad 18$

$100.0 \% \quad 18$

$100.0 \% \quad 18$

$100.0 \% \quad 18$

$00.0 \% \quad 18$

$100.0 \% \quad 13$

$100.0 \% \quad 13$

$0.0 \% \quad 13$ $100.0 \%$ $100.0 \% \quad 13$ $100.0 \% \quad 13$ $00.0 \% \quad 13$ $100.0 \% \quad 13$

$00.0 \% \quad 13$

$100.0 \% \quad 13$ $100.0 \%$

$100.0 \% \quad 4$ $.0 \%$ SYK_HUMAN $68.05 \quad 100.0 \%$ SYK HUMAN $68.05 \quad 100.0 \%$ SYK_HUMAN $68.05 \quad 100.0 \%$
$0.01 \% \quad 7.1 \%$ LTADLSAETLQAR

$0.18 \% \quad 37.3 \%$ DQLIYNLLK

$0.18 \% \quad 37.3 \%$ IVSGKDYNVTANSK

$0.18 \% \quad 37.3 \%$ DYNVTANSK

$0.18 \% \quad 37.3 \%$ LVIITAGAR

$0.18 \% \quad 37.3 \%$ LVIITAGARQQEGESR

$0.18 \% 37.3 \%$ QQEGESRLNLVQR

$0.18 \% \quad 37.3 \%$ FIIPNVVK

$0.18 \% 37.3 \%$ NRVIGSGCNLDSAR

$0.18 \% \quad 37.3 \%$ VIGSGCNLDSAR

$0.18 \% \quad 37.3 \%$ VIGSGCNLDSARFR

$0.18 \% \quad 37.3 \%$ FRYLMGER

$0.18 \% \quad 37.3 \%$ EVHKQVVESAYEVIK

$0.18 \% \quad 37.3 \%$ QVVESAYEVIK

$0.18 \% \quad 37.3 \%$ QVVESAYEVIKLK

$0.18 \% \quad 37.3 \%$ RVHPVSTMIK

$0.18 \% \quad 37.3 \%$ VTLTSEEEAR

$0.18 \% \quad 37.3 \%$ VTLTSEEEARLK

$0.18 \% \quad 37.3 \%$ SADTLWGIQK

$0.16 \% 37.4 \%$ EKLIAPVAEEEATVPNNK

$0.16 \% 37.4 \%$ LIAPVAEEEATVPNNK

$0.16 \% \quad 37.4 \%$ IVADKDYSVTANSK

$0.16 \% \quad 37.4 \%$ IVVVTAGVR

$0.16 \% \quad 37.4 \%$ IVVVTAGVRQQEGESR

$0.16 \% \quad 37.4 \%$ QQEGESRLNLVQR

$0.16 \% \quad 37.4 \%$ FIIPQIVK

$0.16 \% \quad 37.4 \%$ HRVIGSGCNLDSAR

$0.16 \% \quad 37.4 \%$ VIGSGCNLDSAR

$0.16 \% \quad 37.4 \%$ VIGSGCNLDSARFR

$0.16 \% \quad 37.4 \%$ FRYLMAEK

$0.16 \% \quad 37.4 \%$ MVVESAYEVIK

$0.16 \% \quad 37.4 \%$ MVVESAYEVIKLK

$0.16 \% \quad 37.4 \%$ IHPVSTMVK

$0.16 \% \quad 37.4 \%$ GLTSVINQK

$0.16 \% 37.4 \%$ LKDDEVAQLK

$0.01 \% \quad 7.4 \%$ AKPVNSKPDSAYR

$0.01 \% \quad 7.4 \%$ LKDIVSLVPR

$0.01 \% \quad 7.4 \%$ IGYSSPQTLADQSSK

$0.01 \% \quad 7.4 \%$ LLLCGGAPLSATTQR

$0.01 \% \quad 2.9 \%$ AKDANNGNLQLR

$0.01 \% \quad 2.9 \%$ DANNGNLQLR

$0.01 \% \quad 7.3 \%$ TVAEKVDAVR

$0.01 \% \quad 7.3 \%$ VLYTCFQSIQAQK

$0.01 \% \quad 4.9 \%$ RGDIIGVQGNPGK

$0.01 \% \quad 4.9 \% \quad$ SKIITYIR

$0.01 \% \quad 4.9 \%$ QLFEEQAK $\begin{array}{llllll}99.7 \% & 42.2 & 25.0 & 36.3 & 2 & 0\end{array}$

$\begin{array}{llllll}99.7 \% & 64.9 & 25.0 & 60.0 & 2 & 0\end{array}$

$97.3 \% \quad 28.5$

$99.7 \% \quad 60.6$

$99.7 \% \quad 48.5$

$99.7 \% \quad 72.8$

$99.7 \% \quad 50.3$

$99.0 \% \quad 20.0$

$98.7 \% \quad 24.4$

$99.7 \% \quad 76.8$

$99.7 \% \quad 68.4$

$\begin{array}{lll}98.9 \% & 22.7\end{array}$

$\begin{array}{lll}99.0 \% & 29.4\end{array}$

$99.7 \% \quad 56.2$

$99.7 \% \quad 66.2$

$99.7 \% \quad 65.5$

$99.4 \% 24.8$

$99.7 \% \quad 62.7$

$99.7 \% \quad 65.9$

$99.7 \% \quad 36.7$

$\begin{array}{lll}99.7 \% & 43.3\end{array}$

$99.7 \% \quad 53.4$

$99.7 \% \quad 68.3$

$99.7 \% \quad 77.9$

$99.7 \% \quad 41.7$

$99.0 \% \quad 20.0$

$99.0 \% \quad 21.2$

$99.7 \% \quad 46.5$

$99.7 \% \quad 68.4$

$98.9 \% \quad 22.7$

$99.0 \% \quad 44.0$

$99.7 \% \quad 62.0$

$99.7 \% \quad 52.9$

$95.2 \% \quad 18.3$

$99.7 \% \quad 61.4$

$99.7 \% \quad 53.2$

$\begin{array}{lll}94.8 \% & 20.0\end{array}$

$99.7 \% \quad 33.9$

$99.7 \% \quad 58$

$99.7 \% \quad 39.8$

$99.1 \% \quad 24.3$

$99.7 \% \quad 46.6$

$99.7 \% \quad 56.5$

$99.7 \% \quad 57.5$

$99.7 \% \quad 37.8$

$95.9 \% 20.6$

$99.0 \% \quad 29.5$
1388.74

1119.64

1495.78

1011.47

913.58

1727.94

1556.81

929.58

1518.74

1248.60

1551.77

1071.54

1757.94

1264.68

1505.86

1167.67

1134.56

1375.74

1118.58

1952.03

1694.90

1510.77

913.58

1727.94

1556.81

957.61

1541.76

1248.60

1551.77

1057.55

1267.66

1524.83

1011.57

959.55

1158.64

1432.75

1139.71

1581.78

1557.84

1313.69

1114.56

1087.61

1585.80

1310.72

993.6

992.50 $\begin{array}{cc}92 & 202 \\ 49 & 261 \\ 6 & 14 \\ 7 & 90 \\ 2 & 90 \\ 1 & 99 \\ 1 & 106 \\ 00 & 112 \\ 19 & 126 \\ 56 & 169 \\ 58 & 169 \\ 58 & 171 \\ 70 & 177 \\ 29 & 243 \\ 33 & 243 \\ 33 & 245 \\ 69 & 278 \\ 06 & 315 \\ 06 & 317 \\ 19 & 328 \\ 6 & 23 \\ 8 & 23 \\ 8 & 91 \\ 2 & 100 \\ 2 & 107 \\ 01 & 113 \\ 20 & 127 \\ 57 & 170 \\ 59 & 170 \\ 59 & 172 \\ 71 & 178 \\ 34 & 244 \\ 34 & 246 \\ 71 & 279 \\ 00 & 308 \\ 09 & 318 \\ 7 & 69 \\ 21 & 230 \\ 49 & 363 \\ 47 & 461 \\ 86 & 297 \\ 88 & 297 \\ 1 & 70 \\ 68 & 180 \\ 78 & 190 \\ 10 & 517\end{array}$

Page 49 of Table S-1-3 
Magnesium transporter protein 1 GN=MAGT1 MAGT1_HUMAN $38.04 \quad 100.0 \%$ C Malectin GN $=$ MLEC

Malectin GN=MLEC MLEC_HUMAN 32.23 MLEC HUMAN 32.23 Mannose-1-phosphate guanyltransferase alpha GN=GMPPA GMPPA_HUMAN $46.29 \quad 100.0 \%$ Mannose-1-phosphate guanyltransferase alpha GN=GMPPA GMPPA_HUMAN $46.29 \quad 100.0 \%$ Mannose-1-phosphate guanyltransferase alpha GN=GMPPA GMPPA_HUMAN $46.29 \quad 100.0 \%$ Mannose-1-phosphate guanyltransferase alpha GN=GMPPA GMPPA_HUMAN $46.29 \quad 100.0 \%$ Matrin-3 GN=MATR3

Matrin-3 GN=MATR3

Matrin-3 GN=MATR3

Matrin-3 GN=MATR3

Matrin-3 GN=MATR3

Matrin-3 GN=MATR3

Matrin-3 GN=MATR3 MATR3 HUMAN $94.63 \quad 100.0 \%$ MATR3_HUMAN $94.63 \quad 100.0 \%$ MATR3_HUMAN $94.63 \quad 100.0 \%$ MATR3 HUMAN $94.63 \quad 100.0 \%$ MATR__HUMAN $94.63 \quad 100.0 \%$ MATR3 HUMAN $94.63 \quad 100.0 \%$ MATR3 HUMAN $94.63 \quad 100.0 \%$ (100.0\% Medium-chain specific acyl-CoA dehydrogenase, mitochondrial GN=ACADM ACADM HUMAN $46.59 \quad 100.0 \%$ Medium-chain specific acyl-COA dehydrogenase, mitochondrial GN=ACADM ACADM_HUMAN $46.59 \quad 100.0 \%$ Melanoma-associated antigen D2 GN=MAGED2 MAGD2_HUMAN $64.96 \quad 100.0 \%$ Melanoma-associated antigen D2 GN=MAGED2 MAGD2_HUMAN $64.96 \quad 100.0 \%$ Methionine--tRNA ligase, cytoplasmic GN=MARS SYMC HUMAN $101.12 \quad 100.0 \%$ Methionine--tRNA ligase, cytoplasmic GN=MARS SYMC_HUMAN $101.12 \quad 100.0 \%$ Methionine--tRNA ligase, cytoplasmic GN=MARS SYMC_HUMAN $101.12 \quad 100.0 \%$ Methionine--tRNA ligase, cytoplasmic GN=MARS SYMC HUMAN $101.12 \quad 100.0 \%$ Methionine--tRNA ligase, cytoplasmic GN=MARS SYMC_HUMAN $101.12 \quad 100.0 \%$ Methylosome protein $50 \mathrm{GN}=$ WDR77 MEP50 HUMAN $36.72 \quad 100.0 \%$ Methylosome protein $50 \mathrm{GN}=\mathrm{WDR} 7$ ? Methylosome protein $50 \mathrm{GN}=$ WDR77 Methylosome protein $50 \mathrm{GN}=$ WDR77 Methylosome protein $50 \mathrm{GN}=$ WDR77 Methylosome protein $50 \mathrm{GN}=$ WDR77 Methylosome protein $50 \mathrm{GN}=$ WDR77 MEP50 HUMAN 36.72 (100. MEP50_HUMAN $36.72 \quad 100.0 \%$ MEP50 HUMAN $36.72 \quad 100.0 \%$ MEP50_HUMAN $36.72 \quad 100.0 \%$ MEP50_HUMAN $36.72 \quad 100.0 \%$ MEP50_HUMAN $36.72 \quad 100.0 \%$ Methylosome subunit pICln GN=CLNS1A ICLN_HUMAN $26.22 \quad 100.0 \%$ Methylosome subunit pICln GN=CLNS1A ICLN HUMAN $26.22 \quad 100.0 \%$ Methylosome subunit pICln GN=CLNS1A ICLN_HUMAN $26.22 \quad 100.0 \%$ Methylosome subunit pICln GN=CLNS1A ICLN_HUMAN $26.22 \quad 100.0 \%$ Methylthioribose-1-phosphate isomerase GN=MRI1 MTNA_HUMAN $39.15 \quad 100.0 \%$ Methylthioribose-1-phosphate isomerase GN=MRI1 MTNA_HUMAN $39.15 \quad 100.0 \%$ Methylthioribose-1-phosphate isomerase GN=MRI1 MTNA_HUMAN $39.15 \quad 100.0 \%$ Methylthioribose-1-phosphate isomerase GN=MRI1 MTNA_HUMAN $39.15 \quad 100.0 \%$ Methylthioribose-1-phosphate isomerase GN=MRI1 MTNA_HUMAN $39.15 \quad 100.0 \%$ MICOS complex subunit MIC27 GN=APOOL MIC27 HUMAN $29.16 \quad 100.0 \%$ MICOS complex subunit MIC27 GN=APOOL MIC27_HUMAN $29.16 \quad 100.0 \%$ MICOS complex subunit MIC60 GN=IMMT MIC60_HUMAN $83.68 \quad 100.0 \%$ MICOS complex subunit MIC60 GN=IMMT MIC60 HUMAN $83.68 \quad 100.0 \%$ MICOS complex subunit MIC60 GN=IMMT MIC60_HUMAN $83.68 \quad 100.0 \%$
$0.01 \% \quad 5.7 \% \quad$ RGDTYELQVR $0.01 \% \quad 5.7 \%$ GFSAEQIAR $0.01 \% \quad 8.6 \% \quad$ SNPEDQILYQTER $0.01 \% \quad 8.6 \%$ FAEVYFAQSQQK $0.01 \% \quad 10.5 \%$ AVILIGGPQK $0.01 \% \quad 10.5 \%$ SAGSALYASR $0.01 \% \quad 10.5 \%$ GNVYIHPTAK $0.01 \% \quad 10.5 \%$ VEGTPSDPNPNDPR $0.03 \% \quad 8.0 \% \quad$ SFQQSSLSR $0.03 \% \quad 8.0 \%$ TEEGPTLSYGR $0.03 \% \quad 8.0 \%$ TEEGPTLSYGRDGR $0.03 \% \quad 8.0 \%$ GNLGAGNGNLQGPR $0.03 \% \quad 8.0 \%$ FDQKQELGR $0.03 \% \quad 8.0 \% \quad$ LCSLFYTNEEVAK $0.03 \% \quad 8.0 \%$ FLNKLAEER $0.01 \% \quad 10.7 \%$ SDPDPKAPANK $0.01 \% \quad 10.7 \%$ ALDEATKYALER $0.01 \% \quad 10.7 \%$ NTYYASIAK $0.01 \% \quad 10.7 \%$ IYQIYEGTSQIQR $0.01 \% \quad 3.5 \%$ ALEVSEDVKVSK $0.01 \% \quad 3.5 \%$ ALLSLRSPK $0.01 \% \quad 6.2 \% \quad$ KGEDVLGSVR $0.01 \% \quad 6.2 \% \quad$ QPQPSPAEGR $0.01 \% \quad 6.2 \% \quad$ SWLRDGLKPR $0.01 \% \quad 6.2 \% \quad$ LENDQIESLRQR $0.01 \% \quad 6.2 \%$ QLAVAEGKPPEAPK $0.18 \% \quad 19.3 \%$ KETPPPLVPPAAR $0.18 \% \quad 19.3 \%$ ETPPPLVPPAAR $0.18 \% \quad 19.3 \%$ YRSDGALLLGASSLSGR $0.18 \% \quad 19.3 \%$ SDGALLLGASSLSGR $0.18 \% \quad 19.3 \%$ AHAAQVTCVAASPHK $0.18 \% \quad 19.3 \%$ DSVFLSCSEDNR $0.18 \% \quad 19.3 \%$ SQAHRDFVR $0.03 \% \quad 25.7 \%$ QQPDTEAVLNGK $0.03 \% \quad 25.7 \%$ GLGTGTLYIAESR $0.03 \% \quad 25.7 \%$ DRSDCLGEHLYVN

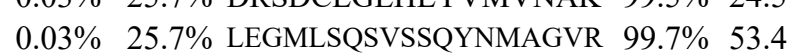
$0.02 \% \quad 11.7 \%$ AARDLADVAAR $0.02 \% \quad 11.7 \%$ DLADVAAR $0.02 \% \quad 11.7 \%$ GVSAVVVGADR $0.02 \% \quad 11.7 \%$ VGTYQLAIVAK $0.02 \% \quad 11.7 \%$ TALTTTISSR $0.00 \% \quad 9.3 \%$ SSKEESLPKPK $0.00 \% \quad 9.3 \%$ HSVPLPTELSSEAK $0.03 \% \quad 8.7 \%$ YSTSGSSGLTTGK $0.03 \% \quad 8.7 \%$ ERPPEEVAAR $0.03 \% \quad 8.7 \%$ TVEGALKER
$99.4 \% \quad 30.0$

$99.7 \% 70.7$

$99.4 \% \quad 22.4$

$99.7 \% \quad 45.1$

$\begin{array}{lll}94.8 \% & 20.7\end{array}$

$99.4 \% \quad 23.0$

$99.7 \% \quad 49.3$

$96.2 \% \quad 17.0$

$99.7 \% \quad 69.1$

$99.7 \% \quad 55.1$

$98.3 \% \quad 26.2$

$99.7 \% \quad 32.8$

$99.7 \% \quad 49.0$

$95.3 \% \quad 16.5$

$98.9 \% \quad 22.6$

$99.7 \% \quad 37.4$

$99.7 \% \quad 51.3$

$99.1 \% \quad 28.0$

$99.7 \% \quad 57.3$

$99.7 \% \quad 71.2$

$99.7 \% \quad 70.0$

$\begin{array}{lll}99.7 \% & 64.8\end{array}$

$99.7 \% \quad 43.8$

$99.7 \% \quad 69.3$

$99.7 \% \quad 64.3$

$\begin{array}{ll}99.7 \% & 53.4 \\ 99.7 \% & 48.1\end{array}$

$98.4 \% \quad 26.5$

$99.7 \% \quad 52.1$

$99.7 \% \quad 38.5$

$99.7 \% \quad 45.7$

$97.4 \% \quad 17.0$

$98.7 \% \quad 26.3$

$99.7 \% \quad 61.6$

$99.7 \% \quad 32.9$

$99.7 \% \quad 44.2$
1236.63

1592.76

445.71

995.63

982.50

1099.59

1494.68

1039.52

1209.57

1537.72

1324.67

1120.57

1573.76

1119.62

1139.57

1379.72

1030.52

1598.82

1303.71

984.62

1059.58

1066.53

1227.70

1500.78

1434.80

1372.79

1244.70

1722.91

1403.75

1547.77

1428.61

1115.57

1299.65

1337.71

2022.94

2088.97

1128.61

830.44

1029.57

1162.68

1050.58

1229.67

1494.78

1245.60

1153.60 1002.56 $\begin{array}{cc}50 & 159 \\ 60 & 168 \\ 91 & 103 \\ 27 & 138 \\ 4 & 13 \\ 50 & 259 \\ 85 & 294 \\ 53 & 366 \\ 4 & 12 \\ 50 & 160 \\ 50 & 163 \\ 74 & 387 \\ 88 & 496 \\ 05 & 817 \\ 33 & 841 \\ 07 & 217 \\ 95 & 306 \\ 50 & 358 \\ 96 & 408 \\ 48 & 59 \\ 41 & 249 \\ 09 & 118 \\ 05 & 214 \\ 84 & 493 \\ 05 & 816 \\ 82 & 895 \\ 3 & 15 \\ 4 & 15 \\ 36 & 52 \\ 38 & 52 \\ 65 & 179 \\ 80 & 191 \\ 93 & 301 \\ 19 & 30 \\ 31 & 43 \\ 69 & 85 \\ 88 & 206 \\ 99 & 109 \\ 02 & 109 \\ 39 & 249 \\ 60 & 270 \\ 51 & 360 \\ 86 & 196 \\ 19 & 232 \\ 33 & 45 \\ 96 & 205 \\ 76 & 284 \\ & \end{array}$

Page 50 of Table S-1-3 
MICOS complex subunit MIC60 GN=IMMT MIC60_HUMAN $83.68 \quad 100.0 \%$ MICOS complex subunit MIC60 GN=IMMT MIC60_HUMAN $83.68 \quad 100.0 \%$ MICOS complex subunit MIC60 GN=IMMT MIC60_HUMAN $83.68 \quad 100.0 \%$ Microtubule-associated protein 1B GN=MAP1B MAP1B HUMAN $270.63100 .0 \%$ Microtubule-associated protein 1B GN=MAP1B MAP1B_HUMAN $270.63 \quad 100.0 \%$ Microtubule-associated protein 1B GN=MAP1B MAP1B_HUMAN $270.63 \quad 100.0 \%$ Mitochondrial 2-oxoglutarate/malate carrier protein GN=SLC25A11 M2OM_HUMAN $34.06 \quad 100.0 \%$ Mitochondrial 2-oxoglutarate/malate carrier protein GN=SLC25A11 M2OM_HUMAN $34.06 \quad 100.0 \%$ Mitochondrial 2-oxoglutarate/malate carrier protein GN=SLC25A11 M2OM HUMAN $34.06 \quad 100.0 \%$ Mitochondrial 2-oxoglutarate/malate carrier protein GN=SLC25A11 M2OM_HUMAN $34.06 \quad 100.0 \%$ Mitochondrial carnitine/acylcarnitine carrier protein GN=SLC25A20 MCAT_HUMAN $32.95 \quad 100.0 \%$ Mitochondrial carnitine/acylcarnitine carrier protein GN=SLC25A20 MCAT_HUMAN 32.9 Mitochondrial carnitine/acylcarnitine carrier protein GN=SLC25A20 MCAT_HUMAN 32.95 Mitochondrial dicarboxylate carrier GN=SLC25A10 DIC HUMAN 31.2 Mitochondrial dicarboxylate carrier GN=SLC25A10 DIC_HUMAN 31.28 Mitochondrial dicarboxylate carrier GN=SLC25A10 DIC_HUMAN 31.28 Mitochondrial dicarboxylate carrier GN=SLC25A10 DIC HUMAN 31.28 Mitochondrial dicarboxylate carrier GN=SLC25A10 DIC_HUMAN 31.28 Mitochondrial dicarboxylate carrier GN=SLC25A10 DIC_HUMAN 31.28 Mitochondrial dicarboxylate carrier GN=SLC25A10 DIC HUMAN 31.28 Mitochondrial dicarboxylate carrier GN=SLC25A10 DIC_HUMAN 31.28 Mitochondrial dicarboxylate carrier GN=SLC25A10 DIC HUMAN 31.28 Mitochondrial dicarboxylate carrier GN=SLC25A10 DIC_HUMAN 31.28 Mitochondrial glutamate carrier $1 \mathrm{GN}=\mathrm{SLC} 25 \mathrm{~A} 22$ GHC1_HUMAN 34.47 Mitochondrial glutamate carrier $1 \mathrm{GN}=\mathrm{SLC} 25 \mathrm{~A} 22$ GHC1_HUMAN 34.47 Mitochondrial glutamate carrier $1 \mathrm{GN}=$ SLC25A22 GHC1_HUMAN 34.47 Mitochondrial glutamate carrier $1 \mathrm{GN}=\mathrm{SLC} 25 \mathrm{~A} 22 \mathrm{GHC1}$ _HUMAN 34.47 Mitochondrial glutamate carrier $1 \mathrm{GN}=\mathrm{SLC} 25 \mathrm{~A} 22 \mathrm{GHC} 1$ HUMAN 34.47 Mitochondrial glutamate carrier $1 \mathrm{GN}=$ SLC25A22 GHC1_HUMAN 34.47 Mitochondrial glutamate carrier 1 GN=SLC25A22 GHC1 HUMAN 34.47 Mitochondrial import inner membrane translocase subunit TIM50 GN=TIMM50 TIM50 HUMAN 39.65 Mitochondrial import inner membrane translocase subunit TIM50 GN=TIMM50 TIM50_HUMAN 39.65 作 Mitchondrial import inner membrane translocase subunit TIM50 GN=TIMM50 TIM50_HUMAN 39.65 Mitochondrial import inner membrane translocase subunit TIM50 GN=TIMM50 TIM50_HUMAN 39.65 Mitochondrial import inner membrane translocase subunit TIM50 GN=TIMM50 TIM50 HUMAN 39.65 Mitochondrial import inner membrane translocase subunit TIM50 GN=TIMM50 TIM50_HUMAN 39.65 作 Mitochondrial inner membrane protein OXA1L GN=OXA1L OXA1L_HUMAN 48.55 Mitochondrial inner membrane protein OXA1L GN=OXA1L OXA1L_HUMAN 48.55 Mitochondrial inner membrane protein OXA1L GN=OXA1L OXA1L_HUMAN 48.5 Mitochondrial inner membrane protein OXA1L GN=OXA1L OXA1L_HUMAN 48.5 Mitochondrial inner membrane protein OXA1L GN=OXA1L OXA1L HUMAN 48.5 Mitochondrial Rho GTPase 2 GN=RHOT2 MIRO2_HUMAN 68.12 Mitochondrial Rho GTPase 2 GN=RHOT2 MIRO2_HUMAN 68.12 Mitochondrial thiamine pyrophosphate carrier GN=SLC25A19 TPC HUMAN 35.5 Mitochondrial thiamine pyrophosphate carrier GN=SLC25A19 TPC_HUMAN 35.51
$0.03 \% \quad 8.7 \% \quad$ VVSQYHELVVQAR $0.03 \% \quad 8.7 \%$ GVYSEETLRAR $0.03 \% \quad 8.7 \% \quad$ FVNQLKGESR $0.01 \% \quad 1.3 \%$ DLTGQVPTPVVK $0.01 \% \quad 1.3 \%$ AAKPTTTPEVK $0.01 \% \quad 1.3 \% \quad$ AVLDALLEGK $0.02 \% \quad 15.6 \%$ MQLSGEGAKTR $0.02 \% \quad 15.6 \%$ LTGADGTPPGFLLK $0.02 \% \quad 15.6 \%$ NVFNALIR $0.02 \% \quad 15.6 \%$ AVVVNAAQLASYSQSK $0.01 \% \quad 5.7 \%$ EGITGLYR

$0.01 \% \quad 5.7 \%$ RVSELSAPR

$0.01 \% \quad 5.7 \% \quad$ VSELSAPR $0.05 \% \quad 38.3 \%$ VHLQTQQEVK

$0.05 \% \quad 38.3 \%$ QMTYSLTR $0.05 \% 38.3 \%$ GSQGPLPFHEK $0.05 \% \quad 38.3 \%$ MQNDVKLPQGQR $0.05 \% \quad 38.3 \%$ NYAHALDGLYR $0.05 \% \quad 38.3 \%$ LFSGATMASSR

$0.05 \% \quad 38.3 \%$ GALVTVGQLSCYDQAK $0.05 \% 38.3 \%$ GEYQGVFHCAVETAK $0.05 \% \quad 38.3 \%$ LGPLAFYK

$0.05 \% \quad 38.3 \%$ NFGIKVPS $0.03 \% \quad 22.3 \%$ VYTSMSDCLIK $0.03 \% \quad 22.3 \%$ SEGYFGMYR $0.03 \% \quad 22.3 \%$ GAAVNLTLVTPEK $0.03 \% \quad 22.3 \%$ LAANDFFR

$0.03 \% \quad 22.3 \%$ IQLQDAGR $0.03 \% \quad 22.3 \%$ GLGATLLR $0.03 \% \quad 22.3 \%$ GVNEDTYSGILDCAR $0.04 \% \quad 21.0 \%$ RAPDQAAEIGSR $\begin{array}{lll}0.04 \% & 21.0 \% & \text { AQGPQQQPGSEGPSYAK } 99.7 \% \quad 48.4\end{array}$ $0.04 \% \quad 21.0 \%$ AQGPQQQPGSEGPSYAKK $97.9 \% 17.4$ $0.04 \% \quad 21.0 \%$ DISCLNRDPAR $0.04 \% \quad 21.0 \%$ VVVVDCKK $0.04 \% \quad 21.0 \%$ QSRLEQEEQQR $0.04 \% \quad 21.0 \%$ SNKQNLFLGSLTSR $0.04 \% \quad 21.0 \%$ QNLFLGSLTSR $0.02 \% \quad 8.7 \%$ LAGDHIEYYK $0.02 \% \quad 8.7 \% \quad$ ASSEMALYQK $0.02 \% \quad 8.7 \%$ TVLKIPQR $0.02 \% \quad 8.7 \%$ MRNQLELAAR $0.02 \% \quad 8.7 \% \quad$ NQLELAAR $0.01 \% \quad 3.2 \%$ ILLLGEAQVGK $0.01 \% \quad 3.2 \%$ VPIILVGNK $0.01 \% \quad 5.6 \%$ HAVGTMYR $0.01 \% \quad 5.6 \%$ LQVGGFEHAR
$99.7 \% \quad 57.6$

$98.6 \% \quad 24.9$

$\begin{array}{lll}99.7 \% & 38.3\end{array}$

$99.0 \% \quad 22.8$

$99.5 \% \quad 26.3$

$97.5 \% 17.8$

$99.7 \% \quad 34.6$

$99.7 \% \quad 36.2$

$95.9 \% \quad 22.4$

$99.7 \% \quad 58.0$

$99.0 \% \quad 22.0$

$97.5 \% \quad 22.2$

$99.7 \% \quad 39.7$

$99.0 \% \quad 44$

$99.5 \% \quad 27.8$

$99.7 \% 28.4$

$99.7 \% \quad 47.9$

$99.7 \% \quad 69.4$

$99.7 \% \quad 68.6$

$99.7 \% \quad 32.8$

$96.9 \% \quad 21.1$

$96.1 \% \quad 22.9$

$99.7 \% \quad 56.4$

$97.7 \% \quad 27.8$

$99.7 \% \quad 52.9$

$99.0 \% \quad 50.8$

$99.0 \% \quad 47.9$

$99.0 \% \quad 26.4$

$99.7 \% \quad 57.9$

$99.7 \% \quad 48.6$

$98.3 \% \quad 22.2$

$99.0 \% \quad 30.1$

$99.3 \% 29.6$

$99.7 \% \quad 43.8$

$99.7 \% \quad 53.2$

$99.7 \% \quad 48.4$

$99.7 \% \quad 27.4$

$98.5 \% \quad 27.0$

$99.7 \% \quad 36.3$

$99.0 \% \quad 42.3$

$99.7 \% \quad 44.5$

$96.6 \% 26.6$

$95.5 \% 15.7$

$99.7 \% \quad 28.6$
152

1177.63

1253.71

1142.64

1028.60

1177.60

1386.76

946.55

1635.87

908.48

1014.57

858.47

1209.66

999.49

1196.61

1429.72

1292.64

1143.55

1709.85

1695.78

908.52

861.48

1316.62

1109.47

1312.75

953.48

900.49

800.50

1669.75

1270.65

1729.81

1857.9

1316.64

946.54

1430.70

1564.84

1235.67

1208.59

1127.54

954.61

1201.65

914.51

1140.70

952.62

934.46

1113.58 
Mitochondrial-processing peptidase subunit beta GN=PMPCB MPPB HUMAN $54.37 \quad 100.0 \%$ Mitochondrial-processing peptidase subunit beta GN=PMPCB MPPB_HUMAN $54.37 \quad 100.0 \%$ Mitogen-activated protein kinase kinase kinase 7 GN=MAP3K7 M3K7_HUMAN $67.20 \quad 100.0 \%$ Mitogen-activated protein kinase kinase kinase $7 \mathrm{GN}=$ MAP3K7 M3K7 HUMAN 67.20 $100.0^{\circ}$ MOB kinase activator $2 \mathrm{GN}=\mathrm{MOB} 2$ MOB kinase activator $2 \mathrm{GN}=\mathrm{MOB} 2$ MOB kinase activator $2 \mathrm{GN}=\mathrm{MOB} 2$ MOB2_HUMAN $26.93 \quad 100.0 \%$ MOB2_HUMAN $26.93 \quad 100.0 \%$ MOB2 HUMAN $26.93 \quad 100.0 \%$ MOB2_HUMAN $26.93 \quad 100.0 \%$ MOB kinase activator $2 \mathrm{GN}=\mathrm{MOB} 2$ MOT1_HUMAN $53.95 \quad 100.0 \%$ Monocarboxylate transporter $1 \mathrm{GN}=\mathrm{SLC} 16 \mathrm{~A} 1 \mathrm{MO}$ MOC1_HUMAN $53.95 \quad 100.0 \%$ $\begin{array}{llll}\text { Monocarboxylate transporter } 1 \mathrm{GN}=\mathrm{SLC16A1} & \text { MOT1_HUMAN } & 53.95 & 100.0 \% \\ \text { Monocarboxylate transporter } 1 \mathrm{GN}=\mathrm{SLC} 16 \mathrm{~A} 1 \text { MOT1_HUMAN } & 53.95 & 100.0 \%\end{array}$ Monfunctional Cl-tetrahydrofolate synthase, mitchondrial GN=MTHFDIL CITM HUMAN $105.79 \quad 100.0 \%$

Monofunctional Cl-tetrahydrofolate synthase, mitochondrial GN=MTHFDIL C1TM_HUMAN $105.79 \quad 100.0 \%$

Monofunctional Cl-tetrahydrofolate synthase, mitochondrial GN=MTHFDIL C1TM HUMAN 105.79 100.0\% MNTHFDIL C1TM HUMAN $105.79 \quad 100.0 \%$ Multifunctional protein ADE2 GN=PAICS PUR6_HUMAN $47.08 \quad 100.0 \%$ Multifunctional protein ADE2 GN=PAICS PUR6 HUMAN $47.08 \quad 100.0 \%$ Myb-binding protein 1A GN=MYBBP1A MBB1A_HUMAN $148.86 \quad 100.0 \%$ Myb-binding protein 1A GN=MYBBP1A MBB1A_HUMAN $148.86 \quad 100.0 \%$ Myb-binding protein 1A GN=MYBBP1A MBB1A_HUMAN $148.86 \quad 100.0 \%$ Myb-binding protein 1A GN=MYBBP1A MBB1A_HUMAN $148.86 \quad 100.0 \%$ Myb-binding protein 1A GN=MYBBP1A MBB1A_HUMAN $148.86 \quad 100.0 \%$ Myb-binding protein 1A GN=MYBBP1A MBB1A_HUMAN $148.86 \quad 100.0 \%$ Myb-binding protein 1A GN=MYBBP1A MBB1A_HUMAN $148.86 \quad 100.0 \%$ Myb-binding protein 1A GN=MYBBP1A MBB1A_HUMAN $148.86 \quad 100.0 \%$ Myb-binding protein 1A GN=MYBBP1A MBB1A_HUMAN $148.86 \quad 100.0 \%$ Myb-binding protein 1A GN=MYBBP1A MBB1A_HUMAN $148.86 \quad 100.0 \%$ Myb-binding protein 1A GN=MYBBP1A MBB1A_HUMAN $148.86 \quad 100.0 \%$ Myb-binding protein 1A GN=MYBBP1A MBB1A_HUMAN $148.86 \quad 100.0 \%$ Myb-binding protein 1A GN=MYBBP1A MBB1A HUMAN $148.86 \quad 100.0 \%$ Myb-binding protein 1A GN=MYBBP1A MBB1A_HUMAN $148.86 \quad 100.0 \%$ Myb-binding protein 1A GN=MYBBP1A MBB1A_HUMAN $148.86 \quad 100.0 \%$ Myb-binding protein 1A GN=MYBBP1A MBB1A_HUMAN $148.86 \quad 100.0 \%$ Myb-binding protein 1A GN=MYBBP1A MBB1A_HUMAN $148.86 \quad 100.0 \%$ Myosin-10 GN=MYH10

Myosin-10 GN=MYH10

Myosin-10 GN=MYH10

Myosin-10 GN=MYH10

Myosin-10 GN=MYH10

Myosin-10 GN=MYH10

Myosin-10 GN=MYH10

Myosin-10 GN=MYH10

Myosin-10 GN=MYH10

Myosin-10 GN=MYH10

Myosin-9 GN=MYHC

Myosin-9 GN=MYHC

Myosin-9 GN=MYH9
MYH10_HUMAN $229.01 \quad 100.0 \%$ MYH10 HUMAN $229.01 \quad 100.0 \%$ MYH10_HUMAN $229.01 \quad 100.0 \%$ MYH10 HUMAN $229.01 \quad 100.0 \%$ MYH10_HUMAN $229.01 \quad 100.0 \%$ MYH10_HUMAN $229.01 \quad 100.0 \%$ MYH10 HUMAN $229.01 \quad 100.0 \%$ MYH10_HUMAN $229.01 \quad 100.0 \%$ MYH10 HUMAN $229.01 \quad 100.0 \%$ MYH10 HUMAN $229.01 \quad 100.0 \%$ MYH9_HUMAN $226.54 \quad 100.0 \%$ MYH9 HUMAN $226.54 \quad 100.0 \%$ MYH9_HUMAN $226.54 \quad 100.0 \%$
$0.01 \% \quad 5.7 \% \quad$ STQAATQVVLNVPETR $0.01 \% \quad 5.7 \% \quad$ LCTSVTESEVAR

$0.01 \% \quad 4.8 \%$ MSADMSEIEAR

$99.4 \% 28.4$

$0.01 \% \quad 4.8 \% \quad$ SIQDLTVTGTEPGQVSSR $\quad 99.7 \% \quad 67.5$

$0.02 \% \quad 10.1 \%$ KAYLEPEHTK

$0.02 \% \quad 10.1 \%$ AYLEPEHTK

$0.02 \% \quad 10.1 \%$ LVTDEDVFPTK

$0.02 \% \quad 10.1 \%$ LVTDEDVFPTKYGR

$0.01 \% \quad 7.0 \%$ DLHDANTDLIGR

$0.01 \% \quad 7.0 \%$ DLHDANTDLIGRHPK

$0.01 \% \quad 7.0 \%$ ESKEEETSIDVAGKPNEVTK

$0.01 \% \quad 3.7 \%$ AVIELLEK

$0.01 \% \quad 3.7 \%$ VRLSVLER

$0.01 \% \quad 3.7 \%$ VLDTNDRFLR

$0.01 \% \quad 3.7 \%$ TIAQAVYGAK

$0.01 \% \quad 6.6 \%$ VLLQSKDQITAGNAAR

$0.01 \% \quad 6.6 \%$ ACGNFGIPCELR

$0.06 \% \quad 12.9 \%$ LITGLGVGR

$0.06 \% \quad 12.9 \%$ LVKDQEALMK

$0.06 \% \quad 12.9 \%$ HYGEHVCTAK

$0.06 \% \quad 12.9 \%$ KPTSQIPETK

$0.06 \% \quad 12.9 \%$ SSSSKQEQDLLHK

$0.06 \% \quad 12.9 \%$ IFTHHLCR

$0.06 \% \quad 12.9 \%$ YCHDLGER

$0.06 \% 12.9 \%$ AGALHAQVER

$0.06 \% \quad 12.9 \%$ HQACLLLQK

$0.06 \% \quad 12.9 \%$ TLSMREVR

$0.06 \% \quad 12.9 \%$ TLGVQRPK

$0.06 \% \quad 12.9 \%$ KSEDGTPAEDGTPAATGGSQPPSMGR

$0.06 \% \quad 12.9 \%$ AKVPAQANGTPTTK

$0.06 \% \quad 12.9 \%$ SPAPGAPTR

$0.06 \% 12.9 \%$ SPLSALAR

$0.06 \% \quad 12.9 \%$ SPSLLQSGAK

$0.06 \% \quad 12.9 \%$ SPSLLQSGAKK

$0.04 \% \quad 4.9 \% \quad$ AMVNKDDIQK

$0.04 \% \quad 4.9 \%$ EQADFAVEALAK

$0.04 \% \quad 4.9 \% \quad$ NTNPNFVR

$0.04 \% \quad 4.9 \% \quad$ CNGVLEGIR

$0.04 \% \quad 4.9 \% \quad$ ALELDPNLYR

$19 \quad 0.04 \% \quad 4.9 \% \quad$ ALAYDKLEK

$0.04 \% \quad 4.9 \%$ ASRDEIFAQSK

$0.04 \% \quad 4.9 \% \quad$ FKATISALEAK

$0.04 \% \quad 4.9 \% \quad$ ATISALEAK

$9 \quad 0.04 \% \quad 4.9 \% \quad$ QLEEAEEEATRANASR

$6 \quad 0.01 \% \quad 3.3 \% \quad$ NTDQASMPDNTAAQK

$0.01 \% \quad 3.3 \%$ TVGQLYKEQLAK

$0.01 \% \quad 3.3 \%$ NTNPNFVR $\begin{array}{lll}23.6 & 25.0 & 12.6\end{array}$

$\begin{array}{lllll}99.7 \% & 37.9 & 25.0 & 29.1\end{array}$

$\begin{array}{lllll}99.7 \% & 67.2 & 25.0 & 62.9 & 2\end{array}$

$\begin{array}{llll}95.8 \% & 15.9 & 25.0 & 15.9\end{array}$

$\begin{array}{llll}98.7 \% & 18.8 & 25.0 & 18.8\end{array}$

$\begin{array}{llll}99.7 \% & 39.0 & 25.0 & 39.0\end{array}$

$\begin{array}{llll}98.5 \% & 29.6 & 25.0 & 9.1\end{array}$

$99.0 \% \quad 28.9 \quad 25.0 \quad 22.6$

$\begin{array}{llll}97.9 \% & 24.7 & 25.0 & 12.6\end{array}$

$99.7 \% \quad 49.6 \quad 25.0 \quad 45.1$

$99.7 \% \quad 66.0 \quad 25.0 \quad 66.0$

$99.7 \% \quad 53.3 \quad 25.0 \quad 52.6$

$\begin{array}{llll}99.7 \% & 58.9 & 25.0 & 46.8\end{array}$

$\begin{array}{llll}98.3 \% & 25.6 & 25.0 & 16.2\end{array}$

$\begin{array}{llll}97.6 \% & 20.5 & 25.0 & 15.9\end{array}$

$96.0 \% \quad 19.2 \quad 25.0 \quad 14.7$

$\begin{array}{llll}97.6 \% & 20.4 & 25.0 & 17.1\end{array}$

$99.0 \% \quad 34.6 \quad 25.0 \quad 33.3$

$\begin{array}{llll}95.5 \% & 20.5 & 25.0 & 16.5\end{array}$

$\begin{array}{llll}98.6 \% & 27.2 & 25.0 & 13.3\end{array}$

$\begin{array}{llll}99.5 \% & 28.1 & 25.0 & 19.5\end{array}$

$\begin{array}{llll}97.9 \% & 25.3 & 25.0 & 12.0\end{array}$

$\begin{array}{llll}98.1 \% & 17.7 & 25.0 & 17.7\end{array}$

$\begin{array}{llll}99.2 \% & 20.5 & 25.0 & 20.5\end{array}$

$\begin{array}{llll}97.3 \% & 16.8 & 25.0 & 16.8\end{array}$

$99.7 \% \quad 38.0 \quad 25.0 \quad 31.4$

$\begin{array}{llll}99.0 \% & 34.7 & 25.0 & 19.9\end{array}$

$99.7 \% \quad 32.2 \quad 25.0 \quad 23.5$

$\begin{array}{llll}99.4 \% & 26.2 & 25.0 & 17.8\end{array}$

$\begin{array}{llll}99.1 \% & 25.7 & 25.0 & 16.1\end{array}$

$\begin{array}{llll}99.7 \% & 44.0 & 25.0 & 44.0\end{array}$

$\begin{array}{llll}96.9 \% & 21.2 & 25.0 & 15.6\end{array}$

$99.7 \% \quad 40.3 \quad 25.0 \quad 28.3$

$\begin{array}{llll}99.7 \% & 48.9 & 25.0 & 48.9\end{array}$

$\begin{array}{llll}96.1 \% & 20.8 & 25.0 & 12.1\end{array}$

$99.7 \% \quad 35.8 \quad 25.0 \quad 34.5$

$99.7 \% \quad 33.2 \quad 25.0 \quad 17.1$

$\begin{array}{llll}98.7 \% & 20.4 & 25.0 & 18.2\end{array}$

$\begin{array}{llll}99.7 \% & 37.8 & 25.0 & 37.8\end{array}$

$\begin{array}{llll}99.7 \% & 43.8 & 25.0 & 43.8\end{array}$

$99.7 \% \quad 41.0 \quad 25.0 \quad 33.2$

$\begin{array}{llll}96.9 \% & 21.2 & 25.0 & 15.6\end{array}$

0
0
0
0
2
0
0
0
2
2
0
1
1
4
0
0
0
0
0
0
2
2
0
0
0
0
0
1
0
0
2
0
0
0
0
0
0
0
0
0
0
0
0
0
0
0
0
0
1
0
0
0
0
0
0
0
0
0
0
0
0
0
0
0
0
0
0
0
0

0
0
0
0
0
0
0
0
0
0
0
0
0
0
0
0
0
0
0
0
0
0
0
0
0
0
0
0
0
0
0
0
0
0
0
0
0
0
0
0
0
0
0
0
0
0
0
0
0
0
0
0
0
0
0
0
0

1351.65

1239.53

1874.95

1215.64

1087.54

1263.65

1639.83

1339.66

1701.87

2190.08

914.56

971.60

1248.67

1021.57

1684.93

1393.64

885.55

1174.65

1201.54

1128.63

1486.75

1083.55

1049.45

1051.56

1110.61

991.54

898.55

2517.12

1383.76

853.45

814.48

987.55

1115.64

1161.59

1291.65

961.48

1017.5

1203.64

1050.58

1251.63

1178.68

903.51

1803.85

1591.70

1377.77

961.48

Page 52 
Myosin-9 GN=MYH9

Myosin-9 GN=MYH9

Myosin-9 GN=MYH9

$\mathrm{N}$-acetyltransferase $10 \mathrm{GN}=\mathrm{NAT} 10$

$\mathrm{N}$-acetyltransferase $10 \mathrm{GN}=\mathrm{NAT} 10$

$\mathrm{N}$-acetyltransferase $10 \mathrm{GN}=\mathrm{NAT} 10$

$\mathrm{N}$-acetyltransferase $10 \mathrm{GN}=\mathrm{NAT} 10$

N-acylneuraminate cytidylyltransferase GN=CMAS NEUA_HUMAN $48.38 \quad 100.0^{\circ}$

NADH dehydrogenase [ubiquinone] 1 alpha subcomplex subunit 10, mitochondrial GN=NDUFA10 NDUAA_HUMAN $40.75 \quad 100.0 \%$

NADH dehydrogenase [ubiquinone] 1 alpha subcomplex subunit 10, mitochondral GN=NDUFA10 NDUAA_HUMAN $40.75 \quad 100.0 \%$

NADH dehydrogenase [ubiquinone] 1 alpha subcomplex subunit 10, mitochondrial GN=NDUFA10 NDUAA_HUMAN $40.75 \quad 100.0 \%$

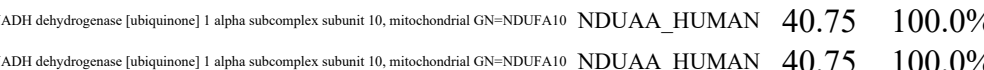

NADH dehydrogenase [ubiquinone] I alpha subcomplex subunit 10, mitochondral GN=NDUFA 10 NDUAA_HUMAN $40.75 \quad 100.0 \%$

NADH dehydrogenase [ubiquinone] I alpha subcomplex subunit 10, mitochondrial GN=NDUFAI0 NDUAA_HUMAN $40.75 \quad 100.0 \%$

NADH dehydrogenase [ubiquinone] I lapha subcomplex subunit 10, mitochondral GN=NDUFA10 NDUAA HUMAN $40.75 \quad 100.0 \%$

NADH dehydrogenase [ubiquinone] 1 alpha subcomplex subunit 9 , mitochondrial GN=NDUFA9 NDUA9_HUMAN $42.51 \quad 100.0 \%$

$\mathrm{NADH}$ dehydrogenase [ubiquinone] 1 alpha subcomplex subunit 9 , mitochondrial GN=NDUFA9 NDUA9_HUMAN $42.51 \quad 100.0 \%$

NADH dehydrogenase [ubiquinone] 1 alpha subcomplex subunit, mitochondral GN=NDUFA9 NDUA9_HUMAN $42.51 \quad 100.0 \%$

NADH dehydrogenase [ubiquinone] 1 alpha subcomplex subunit 9 , mitochondrial GN=NDUFA9 NDUA9_HUMAN $42.51 \quad 100.0 \%$

NADH dehydrogenase [ubiquinone] 1 alpha subcomplex subunit, mitochondrial GN=NDUFA9 NDUA9_HUMAN $42.51 \quad 100.0 \%$

NADH dehydrogenase [ubiquinone] iron-sulfur protein 2, mitochondrial GN=NDUFS2 NDUS2_HUMAN $52.55 \quad 100.0 \%$ NADH dehydrogenase [ubiquinone] iron-sulfur protein 2, mitochondrial GN=NDUFS2 NDUS2_HUMAN $52.55 \quad 100.0 \%$ NADH-ubiquinone oxidoreductase 75 kDa subunit, mitochondrial GN=NDUFS1 NDUS1_HUMAN $79.47 \quad 100.0 \%$

NADH-ubiquinone oxidoreductase $75 \mathrm{kDa}$ subunit, mitochondrial GN=NDUFS1 NDUS1_HUMAN $79.47 \quad 100.0 \%$ $\mathrm{N}$-alpha-acetyltransferase $10 \mathrm{GN}=\mathrm{NAA} 10$ NAA10_HUMAN $26.46 \quad 100.0 \%$ $\mathrm{N}$-alpha-acetyltransferase $10 \mathrm{GN}=\mathrm{NAA} 10$ NAA10_HUMAN $26.46 \quad 100.0 \%$ N-alpha-acetyltransferase $10 \mathrm{GN}=\mathrm{NAA} 10$ NAA10_HUMAN $26.46 \quad 100.0 \%$ $\mathrm{N}$-alpha-acetyltransferase $10 \mathrm{GN}=\mathrm{NAA} 10$ NAA10 HUMAN $26.46 \quad 100.0 \%$ $\mathrm{N}$-alpha-acetyltransferase 15 , NatA auxiliary subunit GN=NAA15 NAA15_HUMAN $101.28 \quad 100.0 \%$ N-alpha-acetyltransferase 15 , NatA auxiliary subunit GN=NAA15 NAA15_HUMAN $101.28 \quad 100.0 \%$ $\mathrm{N}$-alpha-acetyltransferase 15 , NatA auxiliary subunit GN=NAA15 NAA15_HUMAN $101.28 \quad 100.0 \%$ $\mathrm{N}$-alpha-acetyltransferase 15 , NatA auxiliary subunit GN=NAA15 NAA15_HUMAN $101.28 \quad 100.0 \%$ N-alpha-acetyltransferase 15 , NatA auxiliary subunit GN=NAA15 NAA15_HUMAN $101.28 \quad 100.0 \%$ N-alpha-acetyltransferase 15 , NatA auxiliary subunit GN=NAA15 NAA15_HUMAN $101.28 \quad 100.0 \%$ N-alpha-acetyltransferase 15 , NatA auxiliary subunit GN=NAA15 NAA15_HUMAN $101.28100 .0 \%$ N-alpha-acetyltransferase 15 , NatA auxiliary subunit GN=NAA15 NAA15_HUMAN $101.28 \quad 100.0 \%$ Nascent polypeptide-associated complex subunit alpha, muscle-specific form GN=NACA NACAM_HUMAN $205.42 \quad 100.0 \%$ NAfic form GN=NACA NACAM_HUMAN $205.42 \quad 100.0 \%$ polypeptide GN=NEFM NFM_HUMAN $102.47 \quad 100.0 \%$ Neurofilament medium polypeptide GN=NEFM NFM_HUMAN $102.47 \quad 100.0 \%$ NF-kappa-B-repressing factor GN=NKRF NKRF HUMAN $77.67 \quad 100.0 \%$ NF-kappa-B-repressing factor GN=NKRF NKRF_HUMAN $77.67 \quad 100.0 \%$ NF-kappa-B-repressing factor GN=NKRF NKRF_HUMAN $77.67 \quad 100.0 \%$ Nicalin GN=NCLN Nicalin $\mathrm{GN}=\mathrm{NCLN}$
$0.01 \% \quad 3.3 \% \quad$ CNGVLEGIR $0.01 \% \quad 3.3 \%$ ALELDSNLYR $0.01 \% \quad 3.3 \%$ VKLQEMEGTVK $0.01 \% \quad 4.2 \%$ QSILNSLSR $0.01 \% \quad 4.2 \%$ IAVHPDYQGMGYGSR $0.01 \% \quad 4.2 \%$ AGFVPVYLR $0.01 \% \quad 4.2 \%$ AIEEQMVAAK $0.01 \% \quad 6.0 \%$ GAATSVSNPR $0.01 \% \quad 6.0 \%$ VGLSGAPADACSTAQK $0.03 \% \quad 15.5 \%$ SRVITVDGNICTGK $0.03 \% \quad 15.5 \%$ VITVDGNICTGK $0.03 \% \quad 15.5 \%$ VITVDGNICTGKGK $0.03 \% \quad 15.5 \%$ LQSWLYSSR $0.03 \% \quad 15.5 \%$ QCVDHYNEVK $0.03 \% \quad 15.5 \%$ KVVEDIEYLK $0.03 \% \quad 15.5 \%$ VVEDIEYLK $0.03 \% \quad 15.5 \%$ QDNRTLYHLR $0.03 \% \quad 10.6 \%$ YVVNHLGR $0.03 \% \quad 10.6 \%$ MGSQVIIPYR $0.03 \% \quad 10.6 \%$ TVKQPVYVVDVSK $0.03 \% \quad 10.6 \%$ QPVYVVDVSK $0.03 \% \quad 10.6 \%$ SFAFVGPSR $0.02 \% \quad 4.1 \%$ LVMELSGEMVR $0.02 \% \quad 4.1 \%$ IIAQCLNK $0.01 \% \quad 2.6 \%$ FEAPLFNAR $0.01 \% \quad 2.6 \%$ SATYVNTEGR $0.02 \% \quad 21.7 \%$ LGLAQKLMDQASR $0.02 \% \quad 21.7 \%$ YYADGEDAYAMKR $0.02 \% \quad 21.7 \%$ DLTQMADELRR $0.02 \% \quad 21.7 \%$ HVVLGAIENKVESK $0.04 \% \quad 9.5 \%$ FAEHGETLAMK $0.04 \% \quad 9.5 \%$ LEDAADVYR $0.04 \% \quad 9.5 \%$ ALKPANMLER $0.04 \% \quad 9.5 \%$ GCPPVFNTLR $0.04 \% \quad 9.5 \%$ IAIEIYLK

$0.04 \% \quad 9.5 \%$ NFNETFLKR $0.04 \% \quad 9.5 \%$ NSDSLPHRLSAAK $0.04 \% \quad 9.5 \%$ MVYYLDPSSQKR $0.00 \% \quad 1.4 \%$ SPASDTYIVFGEAK $0.00 \% \quad 1.4 \%$ IEDLSQQAQLAAAEK $0.01 \% \quad 2.4 \%$ VSGSPSSGFR $0.01 \% \quad 2.4 \%$ GSPSTVSSSYKR $0.01 \% \quad 5.9 \%$ HLSTCDGQNPPKK $0.01 \% \quad 5.9 \%$ DASGQPIFNASAK $0.01 \% \quad 5.9 \%$ GAVEDVISRNEIQGR $0.01 \% \quad 6.0 \%$ MQQYDLQGQPYGTR $0.01 \% \quad 6.0 \%$ NAVLNTEAR
$99.7 \%$

$99.1 \% \quad 20.3$

$99.7 \% \quad 32.2$

$99.6 \% 25.8$

$99.7 \% 33$.

$99.1 \% \quad 24.3$

$99.5 \% \quad 27.5$

$99.7 \% \quad 29.7$

$99.7 \% \quad 41.3$

$99.7 \% \quad 59.2$

$99.7 \% 34.1$

$99.6 \% \quad 29.8$

$\begin{array}{lll}96.3 \% & 18.7\end{array}$

$99.7 \% \quad 36.9$

$99.7 \% \quad 44.9$

$99.4 \% \quad 22.5$

$99.0 \% 39.1$

$99.7 \% \quad 38.6$

$99.7 \% \quad 40.7$

$99.7 \% \quad 33.5$

$98.3 \% \quad 23.2$

$99.7 \% \quad 58.6$

$99.0 \% \quad 34.7$

$96.7 \% 17.1$

$99.7 \% \quad 30.6$

$96.9 \% \quad 17.0$

$99.7 \% \quad 54.4$

$95.4 \% \quad 16.5$

$97.5 \% \quad 18.5$

$99.7 \% \quad 31.0$

$99.7 \% \quad 40.5$

$98.0 \% \quad 23.5$

$98.5 \% \quad 22.1$

$98.6 \% \quad 19.6$

$99.7 \% \quad 45.8$

$99.7 \% \quad 39.4$

$99.7 \% \quad 46.8$

$99.7 \% \quad 48.9$

$99.7 \% \quad 40.8$

$99.1 \% \quad 20.7$

$99.7 \% \quad 32.8$

$99.5 \% 30.1$

$99.7 \% \quad 34.7$

$99.7 \% \quad 65.0$

$99.7 \% \quad 32.5$

$98.0 \% \quad 23.6$
1261.68

1017.57

1666.76

1021.58

1089.56

959.49

1532.74

1519.79

1276.66

1461.77

1139.58

1291.57

1235.69

1107.59

1315.69

957.53

1163.62

1461.83

1133.62

967.50

1263.64

959.53

1064.55

1097.52

1446.77

1552.67

1347.67

1522.86

1233.59

1051.51

1142.64

1160.59

962.59

1168.61

1395.73

1502.73

1484.73

1614.83

980.48

1255.63

1481.72

1305.64

1642.85

1684.78

987.52 
Nuclear mitotic apparatus protein 1 GN=NUMA1 NUMA1_HUMAN $238.26 \quad 100.0 \%$ Nuclear mitotic apparatus protein 1 GN=NUMA1 NUMA1_HUMAN $238.26 \quad 100.0 \%$ Nuclear mitotic apparatus protein 1 GN=NUMA1 NUMA1_HUMAN $238.26 \quad 100.0 \%$ Nuclear mitotic apparatus protein 1 GN=NUMA1 NUMA1_HUMAN $238.26 \quad 100.0 \%$ Nuclear mitotic apparatus protein 1 GN=NUMA1 NUMA1_HUMAN $238.26 \quad 100.0 \%$ Nuclear mitotic apparatus protein 1 GN=NUMA1 NUMA1_HUMAN $238.26 \quad 100.0 \%$ Nuclear mitotic apparatus protein 1 GN=NUMA1 NUMA1_HUMAN $238.26 \quad 100.0 \%$ Nuclear mitotic apparatus protein 1 GN=NUMA1 NUMA1_HUMAN $238.26 \quad 100.0 \%$ Nuclear mitotic apparatus protein 1 GN=NUMA1 NUMA1_HUMAN $238.26 \quad 100.0 \%$ Nuclear mitotic apparatus protein 1 GN=NUMA1 NUMA1_HUMAN $238.26 \quad 100.0 \%$ Nuclear mitotic apparatus protein 1 GN=NUMA1 NUMA1_HUMAN $238.26 \quad 100.0 \%$ Nuclear mitotic apparatus protein 1 GN=NUMA1 NUMA1_HUMAN $238.26 \quad 100.0 \%$ Nuclear pore complex protein Nup107 GN=NUP107 NU107_HUMAN $106.38 \quad 100.0 \%$ Nuclear pore complex protein Nup107 GN=NUP107 NU107_HUMAN $106.38 \quad 100.0 \%$ Nuclear pore complex protein Nup160 GN=NUP160 NU160_HUMAN $162.13 \quad 100.0 \%$ Nuclear pore complex protein Nup160 GN=NUP160 NU160_HUMAN $162.13 \quad 100.0 \%$ Nuclear pore complex protein Nup205 GN=NUP205 NU205_HUMAN $227.93 \quad 100.0 \%$ Nuclear pore complex protein Nup205 GN=NUP205 NU205_HUMAN $227.93 \quad 100.0 \%$ Nuclear pore complex protein Nup205 GN=NUP205 NU205_HUMAN $227.93 \quad 100.0 \%$ Nuclear pore complex protein Nup205 GN=NUP205 NU205_HUMAN $227.93 \quad 100.0 \%$ Nuclear pore complex protein Nup205 GN=NUP205 NU205_HUMAN $227.93 \quad 100.0 \%$ Nuclear pore complex protein Nup205 GN=NUP205 NU205_HUMAN $227.93 \quad 100.0 \%$ Nuclear pore complex protein Nup205 GN=NUP205 NU205_HUMAN $227.93 \quad 100.0 \%$ Nuclear pore complex protein Nup205 GN=NUP205 NU205_HUMAN $227.93 \quad 100.0 \%$ Nuclear pore complex protein Nup205 GN=NUP205 NU205_HUMAN $227.93 \quad 100.0 \%$ Nuclear pore complex protein Nup205 GN=NUP205 NU205_HUMAN $227.93 \quad 100.0 \%$ Nuclear pore complex protein Nup205 GN=NUP205 NU205_HUMAN $227.93 \quad 100.0 \%$ Nuclear pore complex protein Nup205 GN=NUP205 NU205_HUMAN $227.93 \quad 100.0 \%$ Nuclear pore complex protein Nup205 GN=NUP205 NU205_HUMAN $227.93 \quad 100.0 \%$ Nuclear pore complex protein Nup205 GN=NUP205 NU205_HUMAN $227.93 \quad 100.0 \%$ Nuclear pore complex protein Nup85 GN=NUP85 NUP85_HUMAN $75.02 \quad 100.0 \%$ Nuclear pore complex protein Nup85 GN=NUP85 NUP85_HUMAN $75.02 \quad 100.0 \%$ Nuclear pore complex protein Nup85 GN=NUP85 NUP85_HUMAN $75.02 \quad 100.0 \%$

$0.05 \% \quad 10.6 \%$ FACHSASLTVR

$0.05 \% \quad 10.6 \%$ AVVIVDDRGRPSGK

$0.05 \% \quad 10.6 \%$ GIVEFSGKPAAR

$0.05 \% \quad 10.6 \%$ GIVEFSGKPAARK

$0.05 \% \quad 10.6 \%$ AAPGAEFAPNKR

$0.01 \% \quad 3.0 \% \quad$ KTCAAQLVSYPGK

$0.01 \% \quad 3.0 \%$ TCAAQLVSYPGK

$0.01 \% \quad 3.0 \%$ ATNDEIFSILK

$0.07 \% \quad 9.5 \%$ VEMLETERGQQEAK

$0.07 \% \quad 9.5 \%$ HQVEQLSSSLK

$0.07 \% \quad 9.5 \%$ DSAQTSVTQAQR

$0.07 \% \quad 9.5 \%$ AADALEEQQR

$0.07 \% \quad 9.5 \%$ CISELKAETR

$0.07 \% \quad 9.5 \%$ VAGIESHSELQISR

$0.07 \% \quad 9.5 \%$ ALQQVQEKEVR

$0.07 \% \quad 9.5 \%$ ELVKEPAR

$0.07 \% \quad 9.5 \%$ GRAQADLALEK

$0.07 \% \quad 9.5 \%$ LLQAETASNSAR

$0.07 \% \quad 9.5 \%$ ELGELIPLRQK

$0.07 \% \quad 9.5 \% \quad$ YVQELAAVR

$0.07 \% \quad 9.5 \%$ AVQAQGGESQQEAQR

$0.07 \% \quad 9.5 \%$ TTQIINITMTK

$0.07 \% \quad 9.5 \% \quad$ SAPASQASLR

$0.07 \% \quad 9.5 \%$ SQAGVSSGAPPGR

$0.07 \% \quad 9.5 \%$ IATTTASAATAAAIGATPR

$\begin{array}{lll}0.01 \% & 3.0 \% & \text { VLLQASQDENFGNT } \\ 0.01 \% & 3.0 \% & \text { EADLDVATITK }\end{array}$

$\begin{array}{lll}0.01 \% & 3.0 \% & \text { EADLDVATITK } \\ 0.01 \% & 1.4 \% & \text { SFVELSGAER }\end{array}$

$0.01 \% \quad 1.4 \%$ CYLVTGEGQK

$0.05 \% \quad 7.4 \%$ RQPEAVHLLDK

$0.05 \% \quad 7.4 \%$ ASTEGVAIQGQQGTR

$0.05 \% \quad 7.4 \%$ EVSDLIKECR

$0.05 \% \quad 7.4 \%$ QYIATIHSR

$0.05 \% \quad 7.4 \%$ LPGLQATVR

$0.05 \% \quad 7.4 \%$ DLPSADSVQYR

$0.05 \% \quad 7.4 \%$ KADNVVNIAR

$0.05 \% \quad 7.4 \% \quad$ ILCCISCNSNIQIK

$0.05 \% \quad 7.4 \%$ LVGDFTHDQSISQK

$0.05 \% \quad 7.4 \%$ LTAPEDVFSK

$0.05 \% \quad 7.4 \%$ IQQGALELLR

$0.05 \% \quad 7.4 \%$ QCLGLLSR

$0.05 \% \quad 7.4 \% \quad$ FGGSDRLR

$0.05 \% \quad 7.4 \%$ LLDIEGLYSK

$0.01 \% \quad 6.6 \%$ DVDVYSQILR

$0.01 \% \quad 6.6 \%$ EADASPASAGICR

$0.01 \% \quad 6.6 \%$ VSLELHIER
$98.0 \% \quad 23.2 \quad 25.0$

$99.3 \% \quad 26.8 \quad 25.0$

$\begin{array}{lll}98.6 \% & 20.0 \quad 25.0\end{array}$

$99.7 \% \quad 50.0 \quad 25.0$

$\begin{array}{lll}99.4 \% & 22.5 & 25.0\end{array}$

$\begin{array}{lll}99.7 \% & 52.4 \quad 25.0\end{array}$

$99.3 \% \quad 23.6 \quad 25.0$

$\begin{array}{lll}99.7 \% & 54.7 \quad 25.0\end{array}$

$99.7 \% \quad 41.4 \quad 25.0$

$99.7 \% \quad 46.7 \quad 25.0$

$99.3 \% \quad 21.7 \quad 25.0$

$99.7 \% \quad 56.0 \quad 25.0$

$\begin{array}{lll}99.7 \% & 49.3 & 25.0\end{array}$

$99.7 \% \quad 38.8$

$\begin{array}{lll}99.7 \% & 42.7\end{array}$

$99.7 \% \quad 39.6$

$99.0 \% \quad 29.3$

$\begin{array}{lll}99.7 \% & 29.1\end{array}$

$99.7 \% \quad 76.3$

$95.7 \% \quad 16.9$

$98.2 \% \quad 26.2$

$99.7 \% \quad 64.6$

$99.7 \% \quad 72.4$

$99.7 \% \quad 37.0$

$99.7 \% \quad 42.7$

\section{PR 99.7}

$99.7 \% \quad 81.1$

$99.7 \% \quad 43.2$

$99.7 \% \quad 56.5$

$95.1 \% \quad 15.1$

$94.8 \% \quad 15.3$

$99.7 \% \quad 62.5$

$99.7 \% \quad 33.0$

$99.7 \% \quad 30.5$

$99.3 \% \quad 24.5$

$99.7 \% \quad 47.5$

$99.7 \% \quad 63.8$

$99.7 \% \quad 50.5$

$99.7 \% \quad 63.9$

$98.8 \% \quad 20.1$

$99.7 \% \quad 53.2$

$99.0 \% \quad 30.3$

$98.6 \% \quad 24.0$

$99.7 \% \quad 48.1$

$99.7 \% \quad 41.2$

$99.7 \% \quad 55.9$

$99.7 \% \quad 26.9$
1172.61

1248.62

1468.82

1231.68

1359.77

1228.64

1422.74

1294.65

1250.66

1647.80

1255.66

1291.62

1130.54

1206.61

1525.80

1327.73

941.54

1171.64

1260.65

1295.77

1048.58

1586.75

1263.70

987.52

1170.59

1715.93

1889.94

1175.62

1094.55

1154.55

1305.73

1502.76

1248.63

1088.58

954.57

1250.60

1099.62

1722.83

1574.78

1106.57

1140.67

946.51

907.47

1150.64

1207.63

1304.59

1095.62 $\begin{array}{cc}15 & 125 \\ 43 & 153 \\ 77 & 190 \\ 91 & 202 \\ 91 & 203 \\ 57 & 468 \\ 30 & 342 \\ 31 & 342 \\ 12 & 522 \\ 36 & 449 \\ 51 & 561 \\ 32 & 643 \\ 25 & 734 \\ 35 & 744 \\ 56 & 869 \\ 84 & 894 \\ 36 & 943 \\ 14 & 1024 \\ 71 & 1282 \\ 05 & 1415 \\ 76 & 1484 \\ 74 & 1588 \\ 11 & 1821 \\ 40 & 1849 \\ 87 & 1899 \\ 90 & 2108 \\ 2 & 48 \\ 27 & 637 \\ 4 & 53 \\ 16 & 925 \\ 1 & 41 \\ 0 & 84 \\ 16 & 225 \\ 05 & 313 \\ 22 & 330 \\ 72 & 582 \\ 92 & 901 \\ 19 & 932 \\ 33 & 946 \\ 52 & 1461 \\ 66 & 1575 \\ 14 & 1721 \\ 22 & 1729 \\ 79 & 1988 \\ 0 & 69 \\ 19 & 231 \\ 33 & 441 \\ & \end{array}$

Page 54 of Table S-1-3 
Nuclear pore complex protein Nup85 GN=NUP85 NUP85_HUMAN $75.02 \quad 100.0 \%$ Nuclear pore complex protein Nup88 GN=NUP88 NUP88_HUMAN $83.54 \quad 100.0 \%$ Nuclear pore complex protein Nup88 GN=NUP88 NUP88_HUMAN $83.54 \quad 100.0 \%$ Nuclear pore complex protein Nup93 GN=NUP93 NUP93 HUMAN $93.49 \quad 100.0 \%$ Nuclear pore complex protein Nup93 GN=NUP93 NUP93_HUMAN $93.49 \quad 100.0 \%$ Nuclear pore complex protein Nup93 GN=NUP93 NUP93_HUMAN $93.49 \quad 100.0 \%$ Nuclear pore complex protein Nup93 GN=NUP93 NUP93_HUMAN $93.49100 .0 \%$ Nuclear pore complex protein Nup93 GN=NUP93 NUP93_HUMAN $93.49 \quad 100.0 \%$ Nuclear pore complex protein Nup93 GN=NUP93 NUP93 HUMAN $93.49 \quad 100.0 \%$ Nuclear pore complex protein Nup93 GN=NUP93 NUP93_HUMAN $93.49 \quad 100.0 \%$ Nuclear pore complex protein Nup93 GN=NUP93 NUP93_HUMAN $93.49 \quad 100.0 \%$ Nuclear pore complex protein Nup93 GN=NUP93 NUP93 HUMAN $93.49 \quad 100.0 \%$ Nuclease-sensitive element-binding protein $1 \mathrm{GN}=$ YBX1 YBOX1_HUMAN $35.92 \quad 100.0 \%$ Nuclease-sensitive element-binding protein $1 \mathrm{GN}=\mathrm{YBX} 1$ YBOX1_HUMAN $35.92 \quad 100.0 \%$ Nuclease-sensitive element-binding protein $1 \mathrm{GN}=\mathrm{YBX} 1 \mathrm{YBOX} 1$ HUMAN $35.92 \quad 100.0 \%$ Nuclease-sensitive element-binding protein $1 \mathrm{GN}=$ YBX1 YBOX1_HUMAN $35.92 \quad 100.0 \%$ Nuclease-sensitive element-binding protein $1 \mathrm{GN}=\mathrm{YBX} 1$ YBOX1 HUMAN $35.92 \quad 100.0 \%$ Nuclease-sensitive element-binding protein $1 \mathrm{GN}=$ YBX1 YBOX1_HUMAN $35.92 \quad 100.0 \%$ Nuclease-sensitive element-binding protein $1 \mathrm{GN}=\mathrm{YBX} 1$ YBOX1_HUMAN $35.92 \quad 100.0 \%$ Nucleolar complex protein 2 homolog GN=NOC2L NOC2L_HUMAN $84.92 \quad 100.0 \%$ Nucleolar complex protein 2 homolog GN=NOC2L NOC2L_HUMAN $84.92 \quad 100.0 \%$ Nucleolar complex protein 2 homolog GN=NOC2L NOC2L_HUMAN $84.92 \quad 100.0 \%$ Nucleolar complex protein 2 homolog GN=NOC2L NOC2L_HUMAN $84.92 \quad 100.0 \%$ Nucleolar complex protein 2 homolog GN=NOC2L NOC2L_HUMAN $84.92 \quad 100.0 \%$ Nucleolar complex protein 2 homolog GN=NOC2L NOC2L HUMAN $84.92 \quad 100.0 \%$ Nucleolar complex protein 3 homolog GN=NOC3L NOC3L_HUMAN $92.55 \quad 100.0 \%$ Nucleolar complex protein 3 homolog GN=NOC3L NOC3L_HUMAN $92.55 \quad 100.0 \%$ Nucleolar complex protein 3 homolog GN=NOC3L NOC3L HUMAN $92.55100 .0 \%$ Nucleolar complex protein 4 homolog GN=NOC4L NOC4L_HUMAN $58.47 \quad 100.0 \%$ Nucleolar complex protein 4 homolog GN=NOC4L NOC4L HUMAN $58.47 \quad 100.0^{\circ}$ Nucleolar GTP-binding protein $1 \mathrm{GN}=$ GTPBP4 NOG1_HUMAN $73.97 \quad 100.0 \%$ Nucleolar GTP-binding protein $1 \mathrm{GN}=$ GTPBP4 NOG1_HUMAN $73.97 \quad 100.0 \%$ Nucleolar GTP-binding protein $1 \mathrm{GN}=\mathrm{GTPBP} 4$ NOG1_HUMAN $73.97100 .0 \%$ Nucleolar MIF4G domain-containing protein 1 GN=NOM1 NOM1_HUMAN $96.26 \quad 100.0 \%$ Nucleolar MIF4G domain-containing protein $1 \mathrm{GN}=\mathrm{NOM} 1$ NOM1_HUMAN $96.26 \quad 100.0 \%$ Nucleolar protein $56 \mathrm{GN}=\mathrm{NOP} 56$ Nucleolar protein $56 \mathrm{GN}=\mathrm{NOP} 56$ Nucleolar protein $56 \mathrm{GN}=\mathrm{NOP} 56$ Nucleolar protein $56 \mathrm{GN}=\mathrm{NOP} 56$ Nucleolar protein $56 \mathrm{GN}=\mathrm{NOP} 56$ Nucleolar protein $58 \mathrm{GN}=\mathrm{NOP} 58$ Nucleolar protein $58 \mathrm{GN}=\mathrm{NOP} 58$ Nucleolar protein $58 \mathrm{GN}=\mathrm{NOP} 58$ Nucleolar protein $58 \mathrm{GN}=\mathrm{NOP} 58$ Nucleolar protein $58 \mathrm{GN}=\mathrm{NOP} 58$ Nucleolar protein $58 \mathrm{GN}=\mathrm{NOP} 58$ Nucleolar protein $58 \mathrm{GN}=\mathrm{NOP} 58$

$0.5 \%$
0.58

NOP58_HUMAN $59.58 \quad 100.0 \%$
$98.6 \% 20.4$

$99.7 \% 33.6$

$99.7 \% \quad 39.4$

$99.7 \% \quad 38.5$

$99.0 \% \quad 24.8$

$99.7 \% \quad 45.5$

$99.7 \% \quad 43.5$

$99.7 \% \quad 32.3$

$99.6 \% 25.0$

$99.7 \% \quad 31.5$

$99.7 \% \quad 29.0$

$99.7 \% \quad 45.4$

$99.7 \% \quad 53.0$

$97.9 \% \quad 26.0$

$99.7 \% \quad 42.2$

$99.7 \% \quad 37.4$

$99.7 \% \quad 46.4$

$99.7 \% \quad 51.2$

$99.7 \% \quad 37.9$

$99.7 \% \quad 68.8$

$98.6 \% \quad 18.6$

$95.3 \% \quad 19.0$

$99.0 \% \quad 42.1$

$99.7 \% 55.6$

$99.7 \% \quad 50.3$

$99.7 \% \quad 47.3$

$99.7 \% \quad 55.1$

$99.7 \% \quad 66.2$
$0.01 \% \quad 6.6 \%$ AIIREGSLEGS

$99.7 \% 70.0$

$0.01 \% \quad 3.6 \%$ LRGPSGGGEEPALSQYQR

$0.01 \% \quad 3.6 \%$ SVANPAFLK

$.7 \% \quad 58.5$

$99.5 \% \quad 31.1$

$99.7 \% \quad 57.2$

$\%$ NLQEIQQAGER

$\begin{array}{lll}99.7 \% & 41.7\end{array}$

$0.05 \% \quad 11.4 \%$ NLQEIQQAGERLR

$\begin{array}{llll}99.7 \% & 53.2\end{array}$

$0.05 \% \quad 11.4 \%$ CGDLLAASQVVNR

$0.05 \% \quad 11.4 \%$ LSPATENKLR

$0.05 \% \quad 11.4 \%$ AVYCIIGR

$0.05 \% \quad 11.4 \%$ LKNMALSIAER

$0.05 \% \quad 11.4 \%$ LVPLNQESVEER

$0.05 \% \quad 11.4 \%$ LVQMEVLMN

$0.02 \% \quad 31.5 \%$ VIATKVLGTVK

$0.02 \% \quad 31.5 \%$ NGYGFINR

$99.7 \% \quad 64.1$

$\begin{array}{lll}99.7 \% & 57.9\end{array}$

$99.0 \% 39.4$

$99.7 \% \quad 38.7$

$99.7 \% \quad 59.1$

$99.7 \% 28.6$

$99.1 \% \quad 37.2$

$99.0 \% \quad 33.3$

$99.7 \% \quad 27.9$

$0.02 \% \quad 31.5 \%$ NDTKEDVFVHQTAIK

$0.02 \% \quad 31.5 \%$ GAEAANVTGPGGVPVQGSK

$0.02 \% \quad 31.5 \%$ NEGSESAPEGQAQQR

$99.7 \% \quad 61.9$

$99.7 \% \quad 26.6$

$0.02 \% \quad 31.5 \%$ RPENPKPQDGKETK

$\begin{array}{ll}0.02 \% & 31.5 \% \\ 0.03 \% & 8.4 \% \text { AADPPAENSSAPEAEQ }\end{array}$

$0.03 \% \quad 8.4 \%$ NSVPVTVAMVER

$0.03 \% \quad 8.4 \%$ LFHEVVQAFR

$0.03 \% \quad 8.4 \% \quad$ LSNVNLQEK

$0.03 \% \quad 8.4 \%$ QVQQLLGK

$0.03 \% \quad 8.4 \%$ VQENSAYICSR

$0.01 \% \quad 2.9 \%$ DLSSSEPVHAK

$0.01 \% \quad 2.9 \% \quad$ IRPLTEAEK

$0.01 \% \quad 2.9 \% \quad$ IRPLTEAEKSTK

$0.01 \% \quad 3.9 \%$ RLEAVLASR

$0.01 \% \quad 3.9 \%$ REPTVSSFYVK

$0.01 \% \quad 5.4 \% \quad$ NLVDNVAKDYVR

$0.01 \% \quad 5.4 \%$ ADVDVQPYAFTTK

$0.01 \% \quad 5.4 \% \quad$ DVSGLRDVK

$0.01 \% \quad 3.3 \%$ SGAEEASGHRQDTEER

$0.01 \% \quad 3.3 \%$ TRPSAAATAAAR

$0.02 \% \quad 10.4 \%$ VLLGVGDPK

$0.02 \% \quad 10.4 \%$ IINDNATYCR

$0.02 \% \quad 10.4 \%$ LIAHAGSLTNLAK

$0.02 \% \quad 10.4 \%$ YPASTVQILGAEK

$0.02 \% \quad 10.4 \%$ STPKEETVNDPEEAGHR

$0.05 \% \quad 20.8 \%$ EAHEPLAVADAK

$0.05 \% \quad 20.8 \%$ LGGVIKEK

$0.05 \% \quad 20.8 \%$ SQMDGLIPGVEPR

$0.05 \% \quad 20.8 \%$ IISDNLTYCK

$0.05 \% \quad 20.8 \%$ TQLYEYLQNR

$0.05 \% \quad 20.8 \%$ LIAHAGSLLNLAK

1

1901.95

946.54

1285.65

1554.83

1761.93

1402.71

1128.64

951.51

1261.69

1412.74

1128.74

940.46

1744.89

1695.87

1587.70

1623.85

1897.80

1242.6

1301.69

1245.67

1044.57

913.55

1326.6

1169.58

1056.60

1372.78

1014.61

1312.69

1405.74

1454.72

988.54

1758.76

1143.62

897.54

1239.58

1308.76

1376.74

1895.87

1250.64

843.53

1414.70

1226.61

1327.66

1320.80 $0.05 \% \quad 20.8 \%$ HAASTVQILGAEK

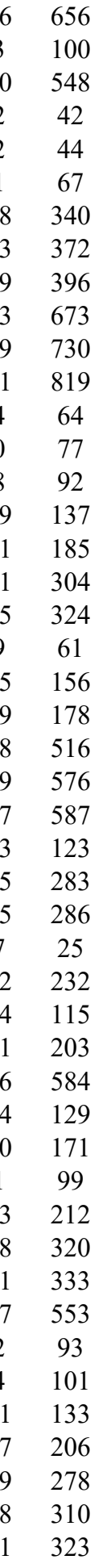

Page 55 of Table S-1-3 
Nucleolar protein $58 \mathrm{GN}=\mathrm{NOP} 58$ Nucleolar protein $58 \mathrm{GN}=\mathrm{NOP} 58$ Nucleolar RNA helicase 2 GN=DDX21 1 Nucleolar RNA helicase 2 GN=DDX2 1 Nucleolar RNA helicase 2 GN=DDX2 Nucleolar RNA helicase 2 GN=DDX21 Nucleolar RNA helicase 2 GN=DDX2 Nucleolar RNA helicase 2 GN=DDX2 Nucleolar RNA helicase 2 GN=DDX2 Nucleolar RNA helicase 2 GN=DDX2 1 Nucleolar RNA helicase 2 GN=DDX2 1 Nucleolar RNA helicase 2 GN=DDX21 Nucleolar RNA helicase 2 GN=DDX21 Nucleolar transcription factor $1 \mathrm{GN}=\mathrm{UBT}$

Nucleolar transcripti
Nucleolin GN=NCL

Nucleolin $\mathrm{GN}=\mathrm{NCL}$

Nucleolin GN=NCL

Nucleolin $\mathrm{GN}=\mathrm{NCL}$

Nucleolin $\mathrm{GN}=\mathrm{NCL}$

Nucleolin GN=NCL

Nucleolin $\mathrm{GN}=\mathrm{NCL}$

Nucleolin GN $=\mathrm{NCL}$

Nucleolin GN=NCL

Nucleolin GN=NCL

Nucleophosmin GN=NPM1

Nucleophosmin GN=NPM

Nucleophosmin GN=NPM1

Nucleophosmin GN=NPM1

Nucleophosmin GN=NPM

Nucleophosmin GN=NPM1

Nucleophosmin GN=NPM

Nucleophosmin GN=NPM

Nucleophosmin GN=NPM1

Nucleophosmin GN=NPM

Nucleoporin NDC1 GN=NDC1

Nucleoporin NDC1 GN=NDC1 Nucleoporin NUP188 homolog GN=NUP188 NU188_HUMAN $196.05 \quad 100.0 \%$ Nucleoporin-like protein 2 GN=NUPL2 NUPL2_HUMAN $44.87 \quad 100.0 \%$ Nucleoporin-like protein 2 GN=NUPL2 NUPL2_HUMAN $44.87 \quad 100.0 \%$ Origin recognition complex subunit $5 \mathrm{GN}=\mathrm{ORC5}$ ORC5_HUMAN $50.29 \quad 100.0 \%$ Origin recognition complex subunit $5 \mathrm{GN}=\mathrm{ORC} 5$ ORC5 HUMAN $50.29 \quad 100.0 \%$ Origin recognition complex subunit $5 \mathrm{GN}=\mathrm{ORC} 5$ ORC5_HUMAN $50.29 \quad 100.0 \%$ Ornithine aminotransferase, mitochondrial GN=OAT OAT_HUMAN $48.54 \quad 100.0 \%$ Ornithine aminotransferase, mitochondrial $\mathrm{GN}=\mathrm{OAT}$ OAT HUMAN $48.54 \quad 100.0 \%$ Ornithine aminotransferase, mitochondrial GN=OAT OAT_HUMAN $48.54 \quad 100.0 \%$
NOP58_HUMAN $59.58 \quad 100.0 \%$ DDX21_HUMAN $87.35 \quad 100.0 \%$ DDX21_HUMAN $87.35 \quad 100.0 \%$ DDX21_HUMAN $87.35 \quad 100.0 \%$ DDX21_HUMAN $87.35 \quad 100.0 \%$ DDX21 HUMAN $87.35 \quad 100.0 \%$ $\begin{array}{lll}\text { UBF1_HUMAN } & 89.41 & 100.0 \%\end{array}$ NUCL_HUMAN $76.62 \quad 100.0 \%$ NUCL_HUMAN $76.62 \quad 100.0 \%$ NUCL_HUMAN $76.62 \quad 100.0 \%$ NUCL_HUMAN $76.62 \quad 100.0 \%$ NUCL_HUMAN $76.62 \quad 100.0 \%$ NUCL_HUMAN $76.62 \quad 100.0 \%$ NUCL_HUMAN $76.62 \quad 100.0 \%$ NPM_HUMAN $32.58 \quad 100.0 \%$ NPM_HUMAN $32.58 \quad 100.0 \%$ NPM_HUMAN $32.58 \quad 100.0 \%$ NPM HUMAN $32.58 \quad 100.0 \%$ NPM_HUMAN $32.58 \quad 100.0 \%$ $\begin{array}{lll}\text { NPM_HUMAN } 32.58 & 100.0 \%\end{array}$ NPM_HUMAN $32.58 \quad 100.0 \%$ NPM HUMAN $32.58 \quad 100.0 \%$ NDC1 HUMAN $76.31 \quad 100.0 \%$ NDC1_HUMAN $76.31 \quad 100.0 \%$ $0 \%$ 2 3 3 7 1 1 (1) 11

(1)

11

11

11

1

2

2

2
10
10

0

$\begin{array}{ll}10 & 10 \\ 10 & 10 \\ 10 & 10 \\ 10 & 10\end{array}$

10

10
10
10

$\begin{array}{ll}10 & 10 \\ 10 & 10 \\ 10 & 10\end{array}$

10
10
10
10

10

10

10
10
10
10

10
10

0

10
10
10

$10 \quad 14$

2

\begin{tabular}{|c|c|c|c|c|c|}
\hline $05 \%$ & 20.8\% YGLIYHASLVGQTSPK & $99.7 \%$ & 51.2 & 25.0 & 42.8 \\
\hline $0.05 \%$ & 20.8\% TYDPSGDSTLPTCSK & $99.7 \%$ & 47.1 & 25.0 & 47.1 \\
\hline $0.07 \%$ & 13.5\% KAEPSEVDMNSPK & $99.7 \%$ & 43.5 & 25.0 & 43.5 \\
\hline $0.07 \%$ & 13.5\% VTKNEEPSEEEIDAPKPK & $99.7 \%$ & 47.3 & 25.0 & 47.3 \\
\hline $0.07 \%$ & $13.5 \%$ GRAPQVLVLAPTR & $99.7 \%$ & 48.0 & 25.0 & 48.0 \\
\hline $0.07 \%$ & 13.5\% APQVLVLAPTR & $99.7 \%$ & 53.5 & 25.0 & 53.5 \\
\hline $0.07 \%$ & 13.5\% NGIDILVGTPGR & $99.7 \%$ & 62.4 & 25.0 & 62.4 \\
\hline $0.07 \%$ & 13.5\% STYEQVDLIGK & $99.7 \%$ & 28.9 & 25.0 & 28.9 \\
\hline $0.07 \%$ & 13.5\% STYEQVDLIGKK & $99.7 \%$ & 45.0 & 25.0 & 36.6 \\
\hline $0.07 \%$ & $13.5 \%$ AAVIGDVIR & $99.7 \%$ & 40.3 & 25.0 & 30.8 \\
\hline $0.07 \%$ & 13.5\% IGVPSATEIIK & $97.6 \%$ & 23.5 & 25.0 & 13.4 \\
\hline $0.07 \%$ & $13.5 \%$ EGYGGFRGQR & $99.3 \%$ & 27.5 & 25.0 & 16.5 \\
\hline $0.07 \%$ & $13.5 \%$ SFSKAFGQ & $96.7 \%$ & 17.3 & 25.0 & 15.8 \\
\hline $0.00 \%$ & $2.8 \%$ KPLTPYFR & $96.0 \%$ & 21.0 & 25.0 & 11.9 \\
\hline $0.00 \%$ & $2.8 \%$ FREDHPDLIQNAK & $98.5 \%$ & 23.4 & 25.0 & 22.1 \\
\hline $0.11 \%$ & $13.8 \%$ VAVATPAKK & $99.6 \%$ & 28.7 & 25.0 & 22.6 \\
\hline $0.11 \%$ & 13.8\% TVTPAKAVTTPGK & $99.3 \%$ & 25.2 & 25.0 & 20.3 \\
\hline $0.11 \%$ & 13.8\% GATPGKALVATPGK & $99.7 \%$ & 45.7 & 25.0 & 43.6 \\
\hline $0.11 \%$ & 13.8\% ALVATPGKK & $99.5 \%$ & 27.7 & 25.0 & 20.1 \\
\hline $0.11 \%$ & $13.8 \%$ TGISDVFAK & $99.7 \%$ & 39.1 & 25.0 & 31.8 \\
\hline $0.11 \%$ & $13.8 \%$ NDLAVVDVR & $99.7 \%$ & 31.6 & 25.0 & 31.6 \\
\hline $0.11 \%$ & $13.8 \%$ SISLYYTGEK & $99.7 \%$ & 48.5 & 25.0 & 43.3 \\
\hline $0.11 \%$ & $13.8 \%$ ATFIKVPQNQNGK & $99.7 \%$ & 31.9 & 25.0 & 31.6 \\
\hline $0.11 \%$ & 13.8\% AIRLELQGPR & $99.7 \%$ & 39.9 & 25.0 & 36.0 \\
\hline $0.11 \%$ & $13.8 \%$ SQPSKTLFVK & $99.5 \%$ & 24.3 & 25.0 & 24.3 \\
\hline $0.11 \%$ & $25.2 \%$ VDNDENEHQLSLR & $99.7 \%$ & 30.4 & 25.0 & 30.4 \\
\hline $0.11 \%$ & $25.2 \%$ LLSISGKR & $99.0 \%$ & 48.7 & 25.0 & 36.9 \\
\hline $0.11 \%$ & 25.2\% SAPGGGSKVPQK & $99.7 \%$ & 55.3 & 25.0 & 52.9 \\
\hline $0.11 \%$ & 25.2\% TPKGPSSVEDIK & $99.5 \%$ & 23.7 & 25.0 & 19.6 \\
\hline $0.11 \%$ & 25.2\% GPSSVEDIK & $99.7 \%$ & 54.2 & 25.0 & 47.5 \\
\hline $0.11 \%$ & $25.2 \%$ GPSSVEDIKAK & $99.7 \%$ & 69.7 & 25.0 & 56.0 \\
\hline $0.11 \%$ & 25.2\% MQASIEKGGSLPK & $99.7 \%$ & 57.9 & 25.0 & 47.7 \\
\hline $0.11 \%$ & 25.2\% GGSLPKVEAK & $99.6 \%$ & 30.0 & 25.0 & 17.6 \\
\hline $0.11 \%$ & $25.2 \%$ VEAKFINYVK & $99.7 \%$ & 36.9 & 25.0 & 36.5 \\
\hline $0.11 \%$ & $25.2 \%$ FINYVKNCFR & $99.7 \%$ & 46.0 & 25.0 & 43.0 \\
\hline $0.01 \%$ & $3.6 \%$ VSSSYPVEPK & $99.7 \%$ & 31.9 & 25.0 & 30.6 \\
\hline $0.01 \%$ & $3.6 \%$ KLNSPEETAFQTPK & $95.5 \%$ & 15.7 & 25.0 & 15.7 \\
\hline $0.01 \%$ & $1.9 \%$ VQRPPSAASAAPSSSK & $99.7 \%$ & 47.8 & 25.0 & 47.8 \\
\hline $0.01 \%$ & 1.9\% GAPSSPATGVLPSPQGK & $99.7 \%$ & 47.8 & 25.0 & 47.8 \\
\hline $0.01 \%$ & $5.2 \%$ AICQFFLQGR & $98.0 \%$ & 34.9 & 25.0 & 18.0 \\
\hline $0.01 \%$ & $5.2 \%$ YSNVIQPSSFSK & $99.7 \%$ & 52.9 & 25.0 & 48.0 \\
\hline $0.01 \%$ & $6.0 \%$ TYVTQTLLK & $99.7 \%$ & 32.7 & 25.0 & 32.7 \\
\hline $0.01 \%$ & $6.0 \%$ NIEPHLKK & $97.3 \%$ & 18.6 & 25.0 & 16.4 \\
\hline $0.01 \%$ & $6.0 \%$ CTVSLDFIR & $99.6 \%$ & 26.9 & 25.0 & 23.9 \\
\hline $0.06 \%$ & 18.2\% TVQGPPTSDDIFER & $99.7 \%$ & 32.5 & 25.0 & 32.5 \\
\hline $0.06 \%$ & $18.2 \%$ SQVDKLTLTSR & $99.7 \%$ & 58.0 & 25.0 & 46.9 \\
\hline $0.06 \%$ & 18.2\% VLPMNTGVEAGETACK & $99.7 \%$ & 72.2 & 25.0 & 69.6 \\
\hline
\end{tabular}


Ornithine aminotransferase, mitochondrial GN=OAT OAT_HUMAN $48.54 \quad 100.0 \%$ Ornithine aminotransferase, mitochondrial GN=OAT OAT_HUMAN $48.54 \quad 100.0 \%$ Ornithine aminotransferase, mitochondrial GN=OAT OAT_HUMAN $48.54 \quad 100.0 \%$ Ornithine aminotransferase, mitochondrial GN=OAT OAT HUMAN $48.54 \quad 100.0 \%$ Pachytene checkpoint protein 2 homolog GN=TRIP13 PCH2_HUMAN $48.55 \quad 100.0 \%$ Pachytene checkpoint protein 2 homolog GN=TRIP13 PCH2_HUMAN $48.55 \quad 100.0 \%$ Pachytene checkpoint protein 2 homolog GN=TRIP13 PCH2_HUMAN $48.55 \quad 100.0 \%$ Pachytene checkpoint protein 2 homolog GN=TRIP13 PCH2_HUMAN $48.55 \quad 100.0 \%$ Pantothenate kinase $4 \mathrm{GN}=\mathrm{PANK} 4$ Pantothenate kinase $4 \mathrm{GN}=\mathrm{PANK} 4$ Paraspeckle component $1 \mathrm{GN}=\mathrm{PSPC} 1$ Paraspeckle component $1 \mathrm{GN}=\mathrm{PSPC} 1$ Paraspeckle component $1 \mathrm{GN}=\mathrm{PSPC} 1$ PANK4 HUMAN $85.99 \quad 100.0 \%$ PANK4 HUMAN $85.99 \quad 100.0 \%$ PSPC1_HUMAN $58.74 \quad 100.0 \%$ PSPC1_HUMAN $58.74 \quad 100.0 \%$ PSPC1_HUMAN $58.74 \quad 100.0 \%$ PCI domain-containing protein 2 GN=PCID2 PCID2_HUMAN $46.03 \quad 100.0 \%$ PCI domain-containing protein $2 \mathrm{GN}=$ PCID2 PCID2_HUMAN $46.03 \quad 100.0 \%$ PCI domain-containing protein 2 GN=PCID2 PCID2_HUMAN $46.03 \quad 100.0 \%$ Pentatricopeptide repeat domain-containing protein 3, mitochondrial GN=PTCD3 PTCD3 HUMAN 78.55 100.0\%

$\begin{array}{lll}\text { Pentatricopeptide repeat domain-containing protein 3, mitochondrial GN=PTCD3 } & \text { PTCD3_HUMAN } 78.55 \quad 100.0 \%\end{array}$ Pentatricopeptide repeat domain-containing protein 3, mitochondrial GN=PTCD3 $\quad$ PTCD3_HUMAN 78.55 $100.0 \%$ Pentatricopeptide repeat domain-containing protein $3, \mathrm{~m}$
Peroxiredoxin- $1 \mathrm{GN}=\mathrm{PRDX} 1$ Peroxiredoxin- 1 GN=PRDX1 Peroxiredoxin- 6 GN=PRDX6 Peroxiredoxin- 6 GN=PRDX6 PTCD3 HUMAN $78.55 \quad 100.0 \%$ PRDX1_HUMAN $22.11 \quad 100.0 \%$ PRDX1_HUMAN $22.11 \quad 100.0 \%$ PRDX6_HUMAN $25.04 \quad 100.0 \%$ PRDX6_HUMAN $25.04 \quad 100.0 \%$ Peroxisomal 2,4-dienoyl-CoA reductase GN=DECR2 DECR2_HUMAN $30.78 \quad 100.0 \%$ Peroxisomal 2,4-dienoyl-CoA reductase GN=DECR2 DECR2_HUMAN $30.78 \quad 100.0 \%$ Peroxisomal membrane protein PEX16 GN=PEX16 PEX16_HUMAN $38.63100 .0 \%$ Peroxisomal membrane protein PEX16 GN=PEX16 PEX16_HUMAN $38.63 \quad 100.0 \%$ Pescadillo homolog GN=PES1 Pescadillo homolog GN=PES1 PHD finger protein $6 \mathrm{GN}=\mathrm{PHF} 6$ PHD finger protein $6 \mathrm{GN}=\mathrm{PHF} 6$ PESC_HUMAN $68.00 \quad 100.0 \%$ PESC_HUMAN $68.00 \quad 100.0 \%$ PHF6_HUMAN $41.29 \quad 100.0 \%$ PHF6_HUMAN $41.29 \quad 100.0 \%$ Phenylalanine--tRNA ligase beta subunit GN=FARSB SYFB_HUMAN $66.12 \quad 100.0 \%$ Phenylalanine--tRNA ligase beta subunit GN=FARSB SYFB_HUMAN $66.12 \quad 100.0 \%$ Phenylalanine--tRNA ligase beta subunit GN=FARSB SYFB_HUMAN $66.12 \quad 100.0 \%$ Phenylalanine--tRNA ligase beta subunit GN=FARSB SYFB_HUMAN $66.12 \quad 100.0 \%$ Phosphate carrier protein, mitochondrial GN=SLC25A3 MPCP_HUMAN $40.10 \quad 100.0 \%$ Phosphate carrier protein, mitochondrial GN=SLC25A3 MPCP HUMAN $40.10 \quad 100.0 \%$ Phosphate carrier protein, mitochondrial GN=SLC25A3 $\quad$ MPCP_HUMAN $40.10 \quad 100.0 \%$ Phosphate carrier protein, mitochondrial GN=SLC25A3 MPCP_HUMAN $40.10 \quad 100.0 \%$ Phosphate carrier protein, mitochondrial GN=SLC25A3 MPCP_HUMAN $40.10 \quad 100.0 \%$ Phosphate carrier protein, mitochondrial GN=SLC25A3 $\mathrm{MPCP}+\mathrm{HUMAN} \quad 40.10 \quad 100.0 \%$ Phosphate carrier protein, mitochondrial GN=SLC25A3 MPCP HUMAN $40.10100 .0^{\circ}$, Phosphate carrier protein, mitochondrial GN=SLC25A3 MPCP_HUMAN $40.10 \quad 100.0 \%$ Phosphate carrier protein, mitochondrial GN=SLC25A3 $\quad$ MPCP_HUMAN $40.10 \quad 100.0 \%$ Phosphatidylinositol 4-phosphate 5-kinase type-1 gamma GN=PIP5K1C PI51C_HUMAN 73.26 $100.0 \%$ Phosphatidylinositol 4-phosphate 5-kinase type-1 gamma GN=PIP5K1C PI51C_HUMAN $73.26 \quad 100.0 \%$
$30 \quad 0.06 \% \quad 18.2 \%$ LPSDVVTAVR

$30 \quad 0.06 \% \quad 18.2 \%$ GKGLLNAIVI

$30 \quad 0.06 \% \quad 18.2 \%$ GLLNAIVIKETK

$30 \quad 0.06 \% \quad 18.2 \%$ DNGLLAKPTHGDIIR

$0.01 \% \quad 9.7 \% \quad$ NVQSVSIIDTELK

$0.01 \% \quad 9.7 \%$ ALAQKLTIR

$0.01 \% \quad 9.7 \%$ AGTEPSDAIR

$0.01 \% \quad 9.7 \% \quad$ LSLLLNDISR

$0.01 \% \quad 3.4 \%$ AVASQPDSVDAAER

$0.01 \% \quad 3.4 \%$ QQPFAYGTLTVR

$0.01 \% \quad 6.3 \%$ FATHGAALTVK

$0.01 \% \quad 6.3 \% \quad$ AVVVVDDRGR

$0.01 \% \quad 6.3 \%$ GFVEFAAKPPAR

$0.01 \% \quad 9.3 \%$ LQMASPEEK

$0.01 \% \quad 9.3 \%$ VFANNADQQLVK

$0.01 \% \quad 9.3 \% \quad$ AIDSSNLKDDYSTAQR

$0.02 \% \quad 5.2 \%$ SPALQVLR

$0.02 \% \quad 5.2 \% \quad$ LFDQPGDPLKR

$0.02 \% \quad 5.2 \%$ FIGPDQHR

$0.02 \% \quad 5.2 \%$ SAYESQPIR

$0.01 \% \quad 10.1 \%$ IGHPAPNFK

$0.01 \% \quad 10.1 \%$ QITVNDLPVGR

$0.00 \% \quad 8.0 \% \quad$ LAPEFAKR

$0.00 \% \quad 8.0 \%$ VVFVFGPDKK

$0.01 \% \quad 6.5 \%$ LGGPQASLSTK

$0.01 \% \quad 6.5 \%$ VTASPLQR

$0.01 \% \quad 6.0 \%$ GFSYLLAGR

$0.01 \% \quad 6.0 \% \quad$ TLQNTPSLHSR

$0.00 \% \quad 3.2 \%$ GIYPHEPK

$0.00 \% \quad 3.2 \%$ LAQEEESEAKR

$0.00 \% \quad 8.8 \%$ CGFCHVGEEENEAR

$0.00 \% \quad 8.8 \%$ GKVEIDQQQLTQQQLNGN

$0.01 \% \quad 6.3 \%$ DLLFQALGR

$0.01 \% \quad 6.3 \%$ GLQVFKER

$0.01 \% \quad 6.3 \%$ TTLLPGLLK

$0.01 \% \quad 6.3 \%$ ASEGPAFFPGR

$0.12 \% \quad 15.5 \%$ MQVDPQKYK

$0.12 \% \quad 15.5 \%$ VRIQTQPGYANTLR

$0.12 \% \quad 15.5 \%$ IQTQPGYANTLR

$0.12 \% \quad 15.5 \%$ IQTQPGYANTLRDAAPK

$0.12 \% \quad 15.5 \%$ MYKEEGLK

$0.12 \% \quad 15.5 \%$ GVAPLWMR

$0.12 \% \quad 15.5 \%$ EKGSSASLVLK

$0.12 \% \quad 15.5 \%$ GSSASLVLK

$0.12 \% \quad 15.5 \%$ GSSASLVLKR

$0.03 \% \quad 7.8 \%$ GVDASGETTYKK

$0.03 \% \quad 7.8 \%$ FYGLYCVQSGGK $\begin{array}{llll}99.7 \% & 59.7 & 25.0 & 50.9\end{array}$

$\begin{array}{llll}99.7 \% & 32.5 & 25.0 & 32.5\end{array}$

$\begin{array}{lllll}99.7 \% & 45.4 & 25.0 & 45.4 & 2\end{array}$

$\begin{array}{llll}99.7 \% & 33.7 & 25.0 & 33.7\end{array}$

$\begin{array}{llll}99.7 \% & 70.4 & 25.0 & 66.3\end{array}$

$98.5 \% \quad 19.0 \quad 25.0 \quad 17.5$

$99.2 \% \quad 28.0 \quad 25.0 \quad 21.2$

$\begin{array}{lllll}99.7 \% & 46.4 & 25.0 & 39.1 & 2\end{array}$

$99.5 \% \quad 24.9 \quad 25.0 \quad 22.1$

$\begin{array}{llll}99.7 \% & 44.5 & 25.0 & 43.7\end{array}$

$\begin{array}{llll}99.7 \% & 50.7 & 25.0 & 50.7\end{array}$

$99.5 \% \quad 27.4 \quad 25.0 \quad 24.4$

$\begin{array}{llll}99.7 \% & 27.5 & 25.0 & 27.5\end{array}$

$\begin{array}{llll}99.7 \% & 34.4 & 25.0 & 31.1\end{array}$

$99.1 \% \quad 25.8 \quad 25.0 \quad 23.0$

$\begin{array}{llll}96.2 \% & 17.7 & 25.0 & 15.1\end{array}$

$\begin{array}{llll}99.0 \% & 55.8 & 25.0 & 46.5\end{array}$

$\begin{array}{llll}99.7 \% & 35.5 & 25.0 & 33.1\end{array}$

$99.0 \% \quad 34.8 \quad 25.0 \quad 27.1$

$\begin{array}{llll}99.7 \% & 32.3 & 25.0 & 26.3\end{array}$

$\begin{array}{llll}99.7 \% & 32.5 & 25.0 & 32.5\end{array}$

$\begin{array}{llll}99.7 \% & 48.8 & 25.0 & 48.0\end{array}$

$\begin{array}{llll}99.0 \% & 37.3 & 25.0 & 19.6\end{array}$

$\begin{array}{llll}99.3 \% & 23.4 & 25.0 & 19.4\end{array}$

$99.7 \% \quad 33.0 \quad 25.0 \quad 33.0$

$\begin{array}{llll}99.0 \% & 31.5 & 25.0 & 13.7\end{array}$

$\begin{array}{llll}99.7 \% & 38.4 & 25.0 & 30.8\end{array}$

$\begin{array}{llll}99.7 \% & 35.1 & 25.0 & 31.2\end{array}$

$\begin{array}{llll}95.6 \% & 16.4 & 25.0 & 16.4\end{array}$

$\begin{array}{llll}99.7 \% & 39.2 & 25.0 & 33.4\end{array}$

$\begin{array}{llll}99.1 \% & 20.0 & 25.0 & 20.0\end{array}$

$\begin{array}{llll}99.6 \% & 27.2 & 25.0 & 27.2\end{array}$

$\begin{array}{llll}99.7 \% & 39.5 & 25.0 & 20.4\end{array}$

$99.0 \% \quad 35.1 \quad 25.0 \quad 28.0$

$\begin{array}{llll}98.4 \% & 18.7 & 25.0 & 18.2\end{array}$

$99.7 \% \quad 52.0 \quad 25.0 \quad 40.9$

$\begin{array}{llll}99.7 \% & 42.1 & 25.0 & 26.8\end{array}$

$99.7 \% \quad 38.6 \quad 25.0 \quad 32.8$

$\begin{array}{llll}99.7 \% & 63.0 & 25.0 & 54.0\end{array}$

$\begin{array}{llll}99.7 \% & 51.0 & 25.0 & 50.5\end{array}$

$\begin{array}{llll}99.0 \% & 40.0 & 25.0 & 24.3\end{array}$

$\begin{array}{llll}99.0 \% & 31.6 & 25.0 & 13.5\end{array}$

$\begin{array}{llll}98.5 \% & 22.5 & 25.0 & 15.4\end{array}$

$\begin{array}{llll}99.7 \% & 31.1 & 25.0 & 19.8\end{array}$

$99.7 \% \quad 58.4 \quad 25.0 \quad 45.5$

$\begin{array}{llll}99.7 \% & 28.6 & 25.0 & 27.6\end{array}$

$\begin{array}{llll}99.7 \% & 58.2 & 25.0 & 49.9\end{array}$

0
0
0
3
0
0
0
0
0
0
0
0
0
0
0
0
0
0
1
0
0
2
0
0
0
0
0
0
0
0
0
0
0
0
0
0
0
0
0
0
0
0
0
0
0
0
0
0
0
0
0
0
0
0
0
0
0
0
0
0
0
0
0
0
0
0
0
0
0
0
0
0
0
0
0
0
0
0
0
0
0
0
0
0
0
0
0

1125.74

1298.80

1619.89

1445.78

1013.65

1016.50

1143.67

1415.68

1380.73

1115.62

1085.61

1289.70

1048.50

1346.71

1783.85

883.54

1285.69

969.49

1050.52

980.53

1211.67

931.54

1135.65

1058.58

871.50

983.53

1253.66

940.49

1289.63

1693.67

2041.03

1032.58

976.56

955.62

1135.55

1136.58

1616.89

1361.72

1843.97

997.50

929.50

1118.64

861.50

1017.61

1255.62

1378.65

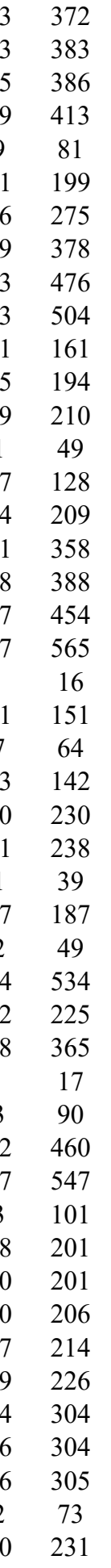

Page 57 of Table S-1-3 

Prosphatidylinositol 4-phosphate 5-kinase type-1 gamma GN=PIP5K1C PI51C_HUMAN 73.26 $100.0 \%$ Phosphoacetylglucosamine mutase GN=PGM3 AGM1_HUMAN $59.85 \quad 100.0 \%$ Phosphoacetylglucosamine mutase GN=PGM3 AGM1_HUMAN $59.85 \quad 100.0 \%$ Phosphoacetylglucosamine mutase GN=PGM3 AGM1_HUMAN $59.85 \quad 100.0 \%$ Phosphoacetylglucosamine mutase GN=PGM3 AGM1_HUMAN $59.85 \quad 100.0 \%$ Phosphoenolpyruvate carboxykinase [GTP], mitochondrial GN=PCK2 PCKGM_HUMAN $70.73 \quad 100.0 \%$ Phosphoenolpyruvate carboxykinase [GTP], mitochondrial GN=PCK2 $\quad$ PCKGM_HUMAN $70.73 \quad 100.0 \%$ Phosphoenolpyruvate carboxykinase [GTP], mitochondrial GN=PCK2 PCKGM HUMAN $70.73 \quad 100.0 \%$ Plo 2 PCKGM_HUMAN $70.73 \quad 100.0 \%$ Phosphoglycerate mutase 1 GN=PGAM1 PGAM1_HUMAN $28.80 \quad 100.0 \%$ Phosphoglycerate mutase 1 GN=PGAM1 PGAM1_HUMAN $28.80 \quad 100.0 \%$ Phosphoglycolate phosphatase GN=PGP PGP_HUMAN $34.01 \quad 100.0 \%$ Phosphoglycolate phosphatase GN=PGP PGP_HUMAN $34.01 \quad 100.0 \%$

Phosphoribosyl pyrophosphate synthase-associated protein 2 GN=PRPSAP2 KPRB_HUMAN $40.93 \quad 100.0 \%$

Phosphoribosyl pyrophosphate synthase-associated protein 2 GN=PRPSAP2 KPRB_HUMAN $40.93 \quad 100.0 \%$

$\begin{array}{llll} & \end{array}$

Phosphoribosyl pyrophosphate synthase-associated protein 2 GN=PRPSAP2 KPRB HUMAN $40.93 \quad 100.0 \%$ Phosphoribosyl pyrophosphate synthase-associated protein 2 GN=PRPSAP2 KPRB_HUMAN $40.93 \quad 100.0 \%$ Phosphoserine aminotransferase GN=PSAT1 SERC HUMAN $40.42 \quad 100.0 \%$ Phosphoserine aminotransferase GN=PSAT1 SERC_HUMAN $40.42 \quad 100.0 \%$ Phosphoserine aminotransferase GN=PSAT1 SERC HUMAN $40.42 \quad 100.0 \%$ Pinin GN $=$ PNN

Pinin GN=PNN

Plakophilin-2 GN=PKP2 Plakophilin-2 GN=PKP2 PININ HUMAN $81.61 \quad 100.0 \%$ PININ_HUMAN $81.61 \quad 100.0 \%$ PKP2 HUMAN $97.42 \quad 100.0 \%$ PKP2_HUMAN $97.42 \quad 100.0 \%$ PAIRB_HUMAN $44.97 \quad 100.0 \%$ PAIRB HUMAN $44.97 \quad 100.0 \%$ PLEC_HUMAN $531.78 \quad 100.0 \%$ PLEC HUMAN $531.78 \quad 100.0 \%$

$\begin{array}{rr}\text { PLEC_HUMAN } 531.78 & 100.0 \% \\ 1 \text { PARP1_HUMAN } 113.09 & 100.0 \%\end{array}$

Plectin GN=PLEC

Plectin GN=PLEC

Plectin GN=PLEC

Poly [ADP-ribose] polymerase $1 \mathrm{GN}=$ PARP1 PARP1_HUMAN $113.09 \quad 100.0 \%$ Poly [ADP-ribose] polymerase $1 \mathrm{GN}=$ PARP1 PARP1_HUMAN $113.09 \quad 100.0 \%$ Poly [ADP-ribose] polymerase $1 \mathrm{GN}=$ PARP1 PARP1_HUMAN $113.09100 .0 \%$ Poly [ADP-ribose] polymerase 1 GN=PARP1 PARP1_HUMAN $113.09 \quad 100.0 \%$ Poly [ADP-ribose] polymerase 1 GN=PARP1 PARP1_HUMAN $113.09 \quad 100.0 \%$ Poly [ADP-ribose] polymerase $1 \mathrm{GN}=$ PARP1 PARP1_HUMAN $113.09100 .0 \%$ Poly [ADP-ribose] polymerase $1 \mathrm{GN}=$ PARP1 PARP1_HUMAN $113.09 \quad 100.0 \%$ Poly [ADP-ribose] polymerase 1 GN=PARP1 PARP1_HUMAN $113.09 \quad 100.0 \%$ Poly [ADP-ribose] polymerase 1 GN=PARP1 PARP1_HUMAN $113.09 \quad 100.0 \%$ Poly [ADP-ribose] polymerase $1 \mathrm{GN}=$ PARP1 PARP1_HUMAN $113.09 \quad 100.0 \%$ Poly [ADP-ribose] polymerase $1 \mathrm{GN}=$ PARP1 PARP1 HUMAN $113.09100 .0 \%$ Poly [ADP-ribose] polymerase $1 \mathrm{GN}=$ PARP1 PARP1_HUMAN $113.09 \quad 100.0 \%$ Poly [ADP-ribose] polymerase 1 GN=PARP1 PARP1_HUMAN $113.09 \quad 100.0 \%$ Poly(A) RNA polymerase, mitochondrial GN=MTPAP PAPD1 HUMAN $66.17 \quad 100.0 \%$ Poly(A) RNA polymerase, mitochondrial GN=MTPAP PAPD1_HUMAN $66.17 \quad 100.0 \%$
$3 \quad 0.03 \% \quad 7.8 \% \quad$ VVVMNNILPR $99.7 \% \quad 30.3$

$0.03 \% \quad 7.8 \%$ QAQGAQSTSDEKRPVGQK

$0.02 \% \quad 7.8 \%$ MGLLAVLR

$0.02 \% \quad 7.8 \%$ ATIEGYYQKLSK

$0.02 \% \quad 7.8 \%$ VISTTDAER

$0.02 \% \quad 7.8 \%$ AFVRPSGTEDVVR

$0.03 \% \quad 6.9 \% \quad$ AVDERFPGCMQGR

$0.03 \% \quad 6.9 \% \quad$ YVAAAFPSACGK

$0.03 \% \quad 6.9 \% \quad$ ETPIGLVPK

$0.03 \% \quad 6.9 \%$ EGALDLSGLR

$0.01 \% \quad 10.6 \%$ HYGGLTGLNKAE

$0.00 \% \quad 7.2 \%$ GETAVPGAPEALR

$0.00 \% \quad 7.2 \%$ LGFITNNSSK

$0.03 \% \quad 13.8 \%$ VQVYQEPNRETR

$0.03 \% \quad 13.8 \%$ VQIQESVR

$0.03 \% \quad 13.8 \%$ LLASMMCK

$0.03 \% \quad 13.8 \%$ AQSFAERLR

$0.03 \% \quad 13.8 \%$ EKPPITVVGDVGGR

$0.01 \% \quad 7.8 \%$ QVVNFGPGPAK

$0.01 \% \quad 7.8 \%$ FGTINIVHPK

$0.01 \% \quad 7.8 \% \quad$ SKMNIPFR

$0.02 \% \quad 3.1 \%$ LLALSGPGGGR

$0.02 \% \quad 3.1 \%$ FKQESTVATER

$0.01 \% \quad 2.2 \%$ IQEQVQQTLAR

$0.01 \% \quad 2.2 \%$ SEIVGVSR

$99.7 \% \quad 46.6$

$99.0 \% \quad 42.6$

$95.2 \% \quad 14.9$

$99.7 \% \quad 41.4$

$99.7 \% \quad 43.5$

$95.0 \% 15.1$

$99.7 \% \quad 42.9$

$95.8 \% \quad 15.3$

$99.7 \% \quad 46.7$

$\begin{array}{llll}99.7 \% & 47.2 & 25.0 & 47.2\end{array}$

$\begin{array}{llll}95.8 \% & 20.1 & 25.0 & 13.4\end{array}$

$99.4 \% \quad 28.1 \quad 25.0 \quad 16.3$

$95.4 \% \quad 18.0 \quad 25.0 \quad 15.4$

$99.0 \% \quad 64.1 \quad 25.0 \quad 49.1 \quad 4$

$\begin{array}{llll}99.0 \% & 29.0 & 25.0 & 29.0\end{array}$

$\begin{array}{llll}99.6 \% & 29.3 & 25.0 & 20.1\end{array}$

$\begin{array}{llll}99.7 \% & 40.6 & 25.0 & 40.6\end{array}$

$\begin{array}{llll}98.1 \% & 20.9 & 25.0 & 20.4\end{array}$

$\begin{array}{lllll}99.7 \% & 33.5 & 25.0 & 30.4 & 2\end{array}$

$\begin{array}{llll}98.7 \% & 21.5 & 25.0 & 21.5\end{array}$

$99.7 \% \quad 38.0 \quad 25.0 \quad 35.0$

$99.7 \% \quad 50.2 \quad 25.0 \quad 38.1$

$99.7 \% \quad 36.8 \quad 25.0 \quad 27.1$

$99.0 \% \quad 41.6$

$\begin{array}{llll}0.01 \% & 4.7 \% & \text { SAAQAAAQTNSNAAGK } \quad 99.7 \% \quad 70.8\end{array}$

$\begin{array}{llll}0.01 \% & 4.7 \% & \text { SAAQAAAQTNSNAAGKQLR } \quad 99.7 \% \quad 29.7\end{array}$

$0.01 \% \quad 0.6 \%$ QVQVALETAQR

$0.01 \% \quad 0.6 \%$ LSVAAQEAAR

$99.7 \% \quad 47.7$

$99.7 \% \quad 64.1$

$97.7 \% \quad 24.7$

$99.7 \% \quad 48.8$

$0.07 \% \quad 14.4 \%$ CSESIPKDSLR

$99.7 \% \quad 53.9$

$0.07 \% \quad 14.4 \%$ TAEAGGVTGKGQDGIGSK

$0.07 \% \quad 14.4 \%$ AEKTLGDFAAEYAK

$0.07 \% \quad 14.4 \%$ TLGDFAAEYAK

$0.07 \% \quad 14.4 \%$ TLGDFAAEYAKSNR

$0.07 \% \quad 14.4 \%$ KGDEVDGVDEVAK

$0.07 \% \quad 14.4 \%$ ILTLGKLSR

$0.07 \% \quad 14.4 \%$ LGGKLTGTANK

$0.07 \% \quad 14.4 \%$ VVSEDFLQDVSASTK

$0.07 \% \quad 14.4 \%$ AEPVEVVAPR

$0.07 \% \quad 14.4 \%$ LTVNPGTK

$0.07 \% \quad 14.4 \%$ MIFDVESMKK

$0.07 \% \quad 14.4 \%$ KPPLLNNADSVQAK

$0.07 \% \quad 14.4 \%$ GIYFADMVSK

$0.01 \% \quad 4.8 \%$ TVLIHCPEK

$0.01 \% \quad 4.8 \% \quad$ NVSQSQLQK

$99.7 \% \quad 62.3$

$99.7 \% \quad 55.2$

$99.7 \% \quad 66.8$

$99.7 \% \quad 33.7$

$99.7 \% \quad 46.7$

$99.7 \% \quad 36.5$

$99.7 \% \quad 58.7$

$99.7 \% \quad 48.7$

$96.2 \% \quad 21.1 \quad 25.0$

$\begin{array}{lll}99.7 \% & 34.0\end{array}$

$99.7 \% 29.8$

$99.7 \% \quad 41.6$

$99.7 \% \quad 32.7$

$99.7 \% \quad 33.0$
1170.67

872.54

1400.74

991.51

1432.75

1522.69

1241.60

953.57

1030.55

1630.85

1150.67

1267.66

1080.57

1518.77

958.53

985.45

1077.58

1423.79

1113.6

1125.6

992.53

997.58

1295.66

1313.72

846.47

1460.71

1857.95

1242.68

1015.55

902.49

1291.63

1632.82

1513.75

1185.58

1542.75

1360.66

1000.65

1059.62

1624.81

1066.59

829.48

1227.6

1494.83

1146.55

1096.58

1031.55 
Poly(A) RNA polymerase, mitochondrial GN=MTPAP PAPD1_HUMAN $66.17 \quad 100.0 \%$ Poly(rC)-binding protein $1 \mathrm{GN}=\mathrm{PCBP} 1$ Poly(rC)-binding protein $1 \mathrm{GN}=\mathrm{PCBP} 1$ Poly(rC)-binding protein $1 \mathrm{GN}=\mathrm{PCBP}$ Poly(rC)-binding protein $1 \mathrm{GN}=\mathrm{PCBP} 1$ Poly $(\mathrm{rC})$-binding protein $1 \mathrm{GN}=\mathrm{PCBP} 1$ Poly $(\mathrm{rC})$-binding protein $1 \mathrm{GN}=\mathrm{PCBP} 1$ Poly $(\mathrm{rC})$-binding protein $2 \mathrm{GN}=\mathrm{PCBP} 2$ Poly $(\mathrm{rC})$-binding protein $2 \mathrm{GN}=\mathrm{PCBP} 2$ Poly $(\mathrm{rC})$-binding protein $2 \mathrm{GN}=\mathrm{PCBP} 2$ Poly(rC)-binding protein $2 \mathrm{GN}=\mathrm{PCBP} 2$ Poly(U)-binding-splicing factor PUF60 GN=PUF60 PUF60HUMAN 38.58 Poly(U)-binding-splicing factor PUF60 GN=PUF60 PUF60_HUMAN 59.88 Poly(U)-binding-splicing factor PUF60 GN=PUF60 PUF60_HUMAN 59.88 Poly(U)-binding-splicing factor PUF60 GN=PUF60 PUF60_HUMAN 59.88 Poly(U)-binding-splicing factor PUF60 GN=PUF60 PUF60_HUMAN 59.88 Polyadenylate-binding protein $1 \mathrm{GN}=\mathrm{PABPC} 1$ PABP1_HUMAN 70.67 Polyadenylate-binding protein $1 \mathrm{GN}=$ PABPC1 PABP1_HUMAN 70.67 Polyadenylate-binding protein $1 \mathrm{GN}=\mathrm{PABPC} 1$ PABP1_HUMAN 70.67 Polyadenylate-binding protein $1 \mathrm{GN}=\mathrm{PABPC} 1$ PABP1_HUMAN $70.6^{\circ}$ Polyadenylate-binding protein $1 \mathrm{GN}=\mathrm{PABPC} 1$ PABP1_HUMAN 70.67 Polyadenylate-binding protein $1 \mathrm{GN}=\mathrm{PABPC} 1$ PABP1_HUMAN 70.6 Polyadenylate-binding protein $1 \mathrm{GN}=$ PABPC1 PABP1_HUMAN 70.67 Polyadenylate-binding protein $1 \mathrm{GN}=\mathrm{PABPC} 1$ PABP1_HUMAN 70.6 Polyadenylate-binding protein $1 \mathrm{GN}=\mathrm{PABPC} 1$ PABP1_HUMAN 70.6 Polyadenylate-binding protein $1 \mathrm{GN}=\mathrm{PABPC} 1$ PABP1_HUMAN 70.67 Polyadenylate-binding protein $1 \mathrm{GN}=\mathrm{PABPC} 1$ PABP1_HUMAN 70.6 ? Polyadenylate-binding protein $1 \mathrm{GN}=\mathrm{PABPC} 1 \mathrm{PABP} 1 \mathrm{HUMAN} 70.6$ Polyadenylate-binding protein $1 \mathrm{GN}=\mathrm{PABPC} 1 \mathrm{PABP} 1$ HUMAN $70.6 \%$ Polyadenylate-binding protein $1 \mathrm{GN}=\mathrm{PABPC} 1$ PABP1 HUMAN 70.6 ? Polyadenylate-binding protein $1 \mathrm{GN}=\mathrm{PABPC} 1$ PABP1_HUMAN 70.67 Polyadenylate-binding protein $1 \mathrm{GN}=\mathrm{PABPC} 1$ PABP1_HUMAN 70.6 ? Polyadenylate-binding protein $1 \mathrm{GN}=\mathrm{PABPC} 1$ PABP1_HUMAN 70.67 Polyadenylate-binding protein $1 \mathrm{GN}=\mathrm{PABPC} 1 \mathrm{PABP} 1$ HUMAN 70.67 Polyadenylate-binding protein $1 \mathrm{GN}=\mathrm{PABPC} 1 \mathrm{PABP} 1 \mathrm{HUMAN} 70.6$ Polyadenylate-binding protein $1 \mathrm{GN}=\mathrm{PABPC} 1$ PABP1_HUMAN 70.67 Polyadenylate-binding protein $1 \mathrm{GN}=\mathrm{PABPC} 1$ PABP1_HUMAN 70.6 Polyadenylate-binding protein $1 \mathrm{GN}=\mathrm{PABPC} 1 \mathrm{PABP} 1 \mathrm{HUMAN} 70.6 ?$ Polyadenylate-binding protein $1 \mathrm{GN}=$ PABPC1 PABP1_HUMAN 70.67 Polyadenylate-binding protein $1 \mathrm{GN}=\mathrm{PABPC} 1$ PABP1_HUMAN 70.6? Polyadenylate-binding protein $1 \mathrm{GN}=\mathrm{PABPC} 1 \mathrm{PABP} 1$ HUMAN 70.6 Polyadenylate-binding protein $1 \mathrm{GN}=\mathrm{PABPC} 1$ PABP1_HUMAN 70.67 Polyadenylate-binding protein $4 \mathrm{GN}=\mathrm{PABPC} 4$ PABP4 HUMAN 70.78 Polyadenylate-binding protein $4 \mathrm{GN}=\mathrm{PABPC} 4$ PABP4_HUMAN 70.78 Polyadenylate-binding protein $4 \mathrm{GN}=\mathrm{PABPC} 4$ PABP4_HUMAN 70.78 Polyadenylate-binding protein $4 \mathrm{GN}=\mathrm{PABPC} 4$ PABP4 HUMAN 70.78 Polyadenylate-binding protein $4 \mathrm{GN}=$ PABPC4 PABP4_HUMAN 70.78
$00.0 \%$

$100.0 \%$

$100.0 \%$

$100.0 \%$

$100.0 \%$

$100.0 \%$

$100.0 \%$

$100.0 \%$

$100.0 \%$

$100.0 \%$

$100.0 \%$

$100.0 \%$

$100.0 \%$

$100.0 \%$

$100.0 \%$

$100.0 \% \quad 26$

$100.0 \% \quad 26$

$100.0 \% \quad 26$

$100.0 \% \quad 26$ $100.0 \% \quad 26$ $100.0 \% \quad 26$ $100.0 \% \quad 26$ $100.0 \% \quad 26$ $100.0 \% \quad 26$ $100.0 \% \quad 26$ $100.0 \% \quad 26$ $100.0 \% \quad 26$ $100.0 \% \quad 26$ $100.0 \% \quad 26$ $100.0 \% \quad 26$ $100.0 \% \quad 26$ $100.0 \% \quad 26$ $100.0 \% \quad 26$ $100.0 \% \quad 26$ $100.0 \% \quad 26$ $100.0 \% \quad 26$ $100.0 \% \quad 26$ $100.0 \% \quad 26$ $100.0 \% \quad 26$ $100.0 \% \quad 26$ $100.0 \% \quad 26$ $100.0 \%$ $100.0 \%$ $100.0 \%$ $100.0 \%$ $100.0 \%$
$0.01 \% \quad 4.8 \% \quad$ NLLESLKGNR $0.05 \% \quad 21.1 \%$ INISEGNCPER $99.7 \% \quad 35$. $99.7 \% \quad 54.3$ $\begin{array}{lll}99.7 \% & 30.9\end{array}$ $0.05 \% \quad 21.1 \%$ LVVPATQCGSLIGK $99.7 \% \quad 60.2$

$0.05 \% \quad 21.1 \%$ ESTGAQVQV $0.05 \% \quad 21.1 \%$ QGANINEIR

$0.05 \% \quad 21.1 \%$ IANPVEGSSGR

$0.05 \% \quad 21.1 \%$ LSSEKGMGCS

$0.02 \% \quad 15.3 \%$ INISEGNCPER

$\begin{array}{lll}98.8 \% & 23.2\end{array}$

$99.7 \% \quad 62.2$

$99.5 \% \quad 23.7$

$99.7 \% \quad 54.3$

$99.7 \% \quad 49.8$

$0.02 \% \quad 15.3 \%$ LVVPASQCGSLIGK

$99.7 \% \quad 60.2$

$99.5 \% \quad 28.0$

$99.0 \% 39.4$

$99.4 \% 23.1$

$99.5 \% \quad 27.7$

$99.7 \% \quad 51.6$

$95.6 \% 15.4$

$96.0 \% \quad 22.7$

$\begin{array}{llll}11 & 0.02 \% & 8.4 \% & \text { AIQALNGR }\end{array}$

$120 \quad 0.25 \% \quad 38.7 \%$ VCRDMITR

$97.6 \% 17.5$

$120 \quad 0.25 \% \quad 38.7 \%$ SLGYAYVNFQQPADAER $\quad 99.7 \% \quad 62.8$

$120 \quad 0.25 \% \quad 38.7 \%$ ALDTMNFDVIK

$120 \quad 0.25 \% \quad 38.7 \%$ KSGVGNIFIK

$120 \quad 0.25 \% \quad 38.7 \%$ SGVGNIFIK

$120 \quad 0.25 \% \quad 38.7 \%$ SGVGNIFIKNLDK

$120 \quad 0.25 \% \quad 38.7 \%$ GYGFVHFETQEAAER

$120 \quad 0.25 \% \quad 38.7 \%$ EREAELGAR

$120 \quad 0.25 \% \quad 38.7 \%$ AKEFTNVYIK

$120 \quad 0.25 \% \quad 38.7 \%$ EFTNVYIK

$120 \quad 0.25 \% \quad 38.7 \%$ FGPALSVK

$120 \quad 0.25 \% \quad 38.7 \%$ GFGFVSFER

$120 \quad 0.25 \% \quad 38.7 \%$ ITRYQGVNLYVK

$\begin{array}{llll}120 & 0.25 \% & 38.7 \% & \text { YQGVNLYVK }\end{array}$

$\begin{array}{lll}120 & 0.25 \% & 38.7 \% \\ 120 & 0.25 \% & 38.7 \%\end{array}$

$120 \quad 0.25 \% \quad 38.7 \%$ KEFSPFGTITSAK

$120 \quad 0.25 \% \quad 38.7 \%$ EFSPFGTITSAK

$120 \quad 0.25 \% \quad 38.7 \%$ SKGFGFVCFSSPEEATK

$120 \quad 0.25 \% \quad 38.7 \%$ IVATKPLYVALAQR

$\begin{array}{llll}120 & 0.25 \% & 38.7 \% & \text { IVATKPLYVALAQRK }\end{array}$

$120 \quad 0.25 \% \quad 38.7 \%$ QAHLTNQYMQR

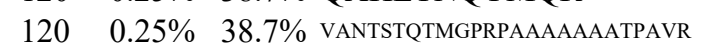

$99.7 \% \quad 62.1$

$99.4 \% \quad 23.8$

$99.7 \% \quad 70.7$

$99.7 \% 72.3$

$99.7 \% \quad 41.1$

$99.7 \% \quad 57.7$

$99.7 \% \quad 35.4$

$94.7 \% \quad 21.9$

$99.0 \% \quad 42.4$

$99.7 \% \quad 53.7$

$99.7 \% \quad 43.2$

$99.7 \% \quad 44.8$

$99.7 \% \quad 45.7$

$99.7 \% \quad 72.2$

$99.7 \% \quad 43.2$

$99.3 \% \quad 21.1$

$99.7 \% \quad 64.2$

$99.3 \% \quad 21.3$

$99.7 \% \quad 71.8$

$120 \quad 0.25 \% \quad 38.7 \%$ TVPQYKYAAGVR

$\begin{array}{rr}99.7 \% & 49.5 \\ 99.7 \% & 63.0\end{array}$

$\begin{array}{ll}99.7 \% & 63.0 \\ 99.7 \% & 33.8\end{array}$

$20 \quad 0.25 \% \quad 38.7 \%$ SKVDEAVAVLQAHQAK

$120 \quad 0.25 \% \quad 38.7 \%$ AVNSATGVPTV

$99.4 \% \quad 23.6$

$\begin{array}{lll}96.0 \% & 22.7\end{array}$

$\begin{array}{llll}12 & 29 & 0.06 \% & 21.7 \% \\ & 29 & \text { VCRDMITR }\end{array}$

$97.6 \% \quad 17.5$

$\begin{array}{lll}0.06 \% & 21.7 \% & \text { RSLGYAYVNFQQPADAER } \\ 0.06 \% & 21.7 \% & \text { SLGYAYVNFQQPADAER }\end{array}$

$0.06 \% \quad 21.7 \%$ ALDTMNFDVIK

$0.06 \% \quad 21.7 \%$ SGVGNVFIK

1404.78

1740.80

1030.53

1212.66

1013.53

818.48

1045.51

1453.82

1083.58

1430.69

1412.74

1284.65

1877.87

1542.94

1671.03

1405.66

2397.23

1352.73

1693.92

1015.54

1050.52

2085.01

1928.91

1266.64

920.52 
Polyadenylate-binding protein 4 GN=PABPC4 PABP4_HUMAN $70.78 \quad 100.0 \%$ Polyadenylate-binding protein 4 GN=PABPC4 PABP4_HUMAN $70.78 \quad 100.0 \%$ Polyadenylate-binding protein 4 GN=PABPC4 PABP4_HUMAN $70.78 \quad 100.0 \%$ Polyadenylate-binding protein 4 GN=PABPC4 PABP4 HUMAN $70.78 \quad 100.0 \%$ Polyadenylate-binding protein 4 GN=PABPC4 PABP4_HUMAN $70.78 \quad 100.0 \%$ Polyadenylate-binding protein 4 GN=PABPC4 PABP4_HUMAN $70.78 \quad 100.0 \%$ Polyadenylate-binding protein 4 GN=PABPC4 PABP4_HUMAN $70.78 \quad 100.0 \%$ Polyadenylate-binding protein 4 GN=PABPC4 PABP4_HUMAN $70.78 \quad 100.0 \%$ Polyadenylate-binding protein $4 \mathrm{GN}=$ PABPC4 PABP4 HUMAN $70.78 \quad 100.0 \%$ Polyadenylate-binding protein 4 GN=PABPC4 PABP4_HUMAN $70.78 \quad 100.0 \%$ Polyadenylate-binding protein 4 GN=PABPC4 PABP4_HUMAN $70.78 \quad 100.0 \%$ Polymerase delta-interacting protein $2 \mathrm{GN}=$ POLDIP2 PDIP2 HUMAN $42.03 \quad 100.0 \%$ Polymerase delta-interacting protein 2 GN=POLDIP2 PDIP2_HUMAN $42.03 \quad 100.0 \%$ Polymerase delta-interacting protein 2 GN=POLDIP2 PDIP2_HUMAN $42.03 \quad 100.0 \%$ Polymerase delta-interacting protein $2 \mathrm{GN}=$ POLDIP2 PDIP2_HUMAN $42.03 \quad 100.0 \%$ Polymerase delta-interacting protein 2 GN=POLDIP2 PDIP2_HUMAN $42.03 \quad 100.0 \%$ Polypyrimidine tract-binding protein $1 \mathrm{GN}=\mathrm{PTBP} 1$ PTBP1 HUMAN $57.22 \quad 100.0 \%$ Polypyrimidine tract-binding protein $1 \mathrm{GN}=\mathrm{PTBP} 1$ PTBP1_HUMAN $57.22 \quad 100.0 \%$ Pre-mRNA 3'-end-processing factor FIP1 GN=FIP1L1 FIP1_HUMAN $66.53 \quad 100.0 \%$ Pre-mRNA 3'-end-processing factor FIP1 GN=FIP1L1 FIP1 HUMAN $66.53 \quad 100.0 \%$ Pre-mRNA-processing factor 19 GN=PRPF19 PRP19_HUMAN $55.18 \quad 100.0 \%$ Pre-mRNA-processing factor 19 GN=PRPF19 PRP19 HUMAN $55.18 \quad 100.0 \%$ Pre-mRNA-processing factor 6 GN=PRPF6 PRP6_HUMAN $106.93 \quad 100.0 \%$ Pre-mRNA-processing factor 6 GN=PRPF6 PRP6_HUMAN $106.93 \quad 100.0 \%$ Pre-mRNA-processing factor 6 GN=PRPF6 PRP6_HUMAN $106.93 \quad 100.0 \%$ Pre-mRNA-processing factor 6 GN=PRPF6 PRP6_HUMAN $106.93 \quad 100.0 \%$ Pre-mRNA-processing factor 6 GN=PRPF6 PRP6_HUMAN $106.93 \quad 100.0 \%$ Pre-mRNA-processing-splicing factor $8 \mathrm{GN}=$ PRPF8 PRP8_HUMAN $273.61 \quad 100.0 \%$ Pre-mRNA-processing-splicing factor 8 GN=PRPF8 PRP8_HUMAN $273.61 \quad 100.0 \%$ Pre-mRNA-processing-splicing factor 8 GN=PRPF8 PRP8 HUMAN $273.61 \quad 100.0 \%$ Pre-mRNA-processing-splicing factor 8 GN=PRPF8 PRP8_HUMAN $273.61 \quad 100.0 \%$ Pre-mRNA-processing-splicing factor 8 GN=PRPF8 PRP8_HUMAN $273.61 \quad 100.0 \%$ Pre-mRNA-processing-splicing factor $8 \mathrm{GN}=$ PRPF8 PRP8 HUMAN $273.61 \quad 100.0 \%$ Pre-mRNA-processing-splicing factor $8 \mathrm{GN}=$ PRPF8 PRP8_HUMAN $273.61 \quad 100.0 \%$ Pre-mRNA-processing-splicing factor 8 GN=PRPF8 PRP8_HUMAN $273.61 \quad 100.0 \%$ Pre-mRNA-processing-splicing factor 8 GN=PRPF8 PRP8_HUMAN $273.61 \quad 100.0 \%$ Pre-mRNA-processing-splicing factor 8 GN=PRPF8 PRP8_HUMAN $273.61 \quad 100.0 \%$ Pre-mRNA-processing-splicing factor 8 GN=PRPF8 PRP8 HUMAN $273.61 \quad 100.0 \%$ Pre-mRNA-splicing factor ATP-dependent RNA helicase DHX15 GN=DHX15 DHX15_HUMAN $90.94 \quad 100.0 \%$ Pre-mRNA-splicing factor ATP-dependent RNA helicase DHX15 GN=DHX15 DHX15_HUMAN $90.94 \quad 100.0 \%$ Pre-mRNA-splicing factor ATP-dependent RNA helicase DHX15 GN=DHX15 DHX15 HUMAN $90.94 \quad 100.0 \%$ Pre-mRNA-splicing factor ATP-dependent RNA helicase DHX15 GN=DHX15 DHX15_HUMAN $90.94 \quad 100.0 \%$ Pre-mRNA-splicing factor ATP-dependent RNA helicase DHX15 GN=DHX15 DHX15 HUMAN $90.94 \quad 100.0 \%$ Pre-mRNA-splicing factor ATP-dependent RNA helicase DHX15 GN=DHX15 DHX15 HUMAN $90.94 \quad 100.0 \%$ Pre-mRNA-splicing factor ATP-dependent RNA helicase DHX15 GN=DHX15 DHX15_HUMAN $90.94 \quad 100.0 \%$ pre-rRNA processing protein FTSJ3 GN=FTSJ3 SPB1_HUMAN $96.56 \quad 100.0 \%$ pre-rRNA processing protein FTSJ3 GN=FTSJ3 SPB1_HUMAN $96.56 \quad 100.0 \%$

5
5
5

5
5
2

5
2

\begin{tabular}{|c|c|c|c|c|}
\hline $0.06 \%$ & $21.7 \%$ SGVGNVFIKNLDK & $99.7 \% \quad 34.0$ & 25.0 & 18.4 \\
\hline $0.06 \%$ & 21.7\% AKEFTNVYIK & $99.7 \% \quad 35.4$ & 25.0 & 31.2 \\
\hline $0.06 \%$ & $21.7 \%$ EFTNVYIK & $94.7 \% \quad 21.9$ & 25.0 & 9.4 \\
\hline $0.06 \%$ & 21.7\% ISRYQGVNLYIK & $99.7 \% \quad 43.2$ & 25.0 & 30.5 \\
\hline $0.06 \%$ & 21.7\% YQGVNLYIK & $99.7 \% \quad 53.2$ & 25.0 & 45.0 \\
\hline $0.06 \%$ & 21.7\% EFSPFGSITSAK & $99.7 \% \quad 47.2$ & 25.0 & 47.2 \\
\hline $0.06 \%$ & 21.7\% SKGFGFVCFSSPEEATK & $99.3 \% \quad 21.1$ & 25.0 & 19.5 \\
\hline $0.06 \%$ & 21.7\% IVGSKPLYVALAQR & $99.4 \% \quad 43.4$ & 25.0 & 8.9 \\
\hline $0.06 \%$ & 21.7\% KAHLTNQYMQR & $99.7 \% \quad 33.5$ & 25.0 & 33.5 \\
\hline $0.06 \%$ & 21.7\% AHLTNQYMQR & $99.7 \% \quad 27.5$ & 25.0 & 27.5 \\
\hline $0.06 \%$ & 21.7\% EAAQKVGAVAAATS & $99.7 \% \quad 65.1$ & 25.0 & 65.1 \\
\hline $0.02 \%$ & 17.4\% VLETVGVFEVPK & $99.7 \% \quad 48.7$ & 25.0 & 40.1 \\
\hline $0.02 \%$ & 17.4\% LYDRDVASAAPEK & $97.8 \% \quad 17.3$ & 25.0 & 17.3 \\
\hline $0.02 \%$ & 17.4\% SQTEAVTFLANHDDSR & $99.7 \% \quad 73.2$ & 25.0 & 72.3 \\
\hline $0.02 \%$ & 17.4\% IFSLSGTLETVR & $99.7 \% \quad 59.3$ & 25.0 & 43.9 \\
\hline $0.02 \%$ & 17.4\% GVVGREPVLSK & $99.7 \% \quad 31.2$ & 25.0 & 24.4 \\
\hline $0.00 \%$ & $5.8 \%$ SAGVPSRVIHIR & $96.2 \% \quad 15.9$ & 25.0 & 15.9 \\
\hline $0.00 \%$ & $5.8 \%$ EGQEDQGLTKDYGNSPLHR & $99.7 \% \quad 31.5$ & 25.0 & 31.5 \\
\hline $0.00 \%$ & 2.4\% RANENSNIQVLSER & $99.7 \% \quad 42.4$ & 25.0 & 34.8 \\
\hline $0.00 \%$ & 2.4\% ANENSNIQVLSER & $99.7 \% \quad 53.1$ & 25.0 & 50.8 \\
\hline $0.00 \%$ & $4.6 \%$ LQDKATVLTTER & $99.7 \% \quad 39.4$ & 25.0 & 32.8 \\
\hline $0.00 \%$ & $4.6 \%$ TLQLDNNFEVK & $99.5 \% \quad 24.2$ & 25.0 & 24.2 \\
\hline $0.03 \%$ & $5.5 \%$ IQQQFSDLKR & $99.7 \% \quad 41.5$ & 25.0 & 29.6 \\
\hline $0.03 \%$ & $5.5 \%$ AVVAQAVR & $99.0 \% \quad 61.4$ & 25.0 & 55.7 \\
\hline $0.03 \%$ & $5.5 \%$ ESLEALLQR & $99.7 \% \quad 47.8$ & 25.0 & 20.4 \\
\hline $0.03 \%$ & 5.5\% SKWLAGDVPAAR & $99.7 \% \quad 37.8$ & 25.0 & 35.8 \\
\hline $0.03 \%$ & 5.5\% AGLKNIANTLMAK & $\begin{array}{lll}95.1 \% & 16.7\end{array}$ & 25.0 & 16.7 \\
\hline $0.05 \%$ & $4.5 \%$ RALDIPLVK & $96.9 \% \quad 20.9$ & 25.0 & 14.0 \\
\hline $0.05 \%$ & $4.5 \%$ FNTGPVGK & $99.0 \% \quad 32.7$ & 25.0 & 21.9 \\
\hline $0.05 \%$ & $4.5 \%$ LLILALER & $99.0 \% \quad 33.0$ & 25.0 & 12.6 \\
\hline $0.05 \%$ & 4.5\% QILMASGSTTFTK & $99.7 \% \quad 36.7$ & 25.0 & 30.1 \\
\hline $0.05 \%$ & $4.5 \%$ IKIGLNSK & $94.5 \% \quad 16.4$ & 25.0 & 13.5 \\
\hline $0.05 \%$ & 4.5\% QTDVGITHFR & $99.7 \% \quad 29.4$ & 25.0 & 26.1 \\
\hline $0.05 \%$ & $4.5 \%$ ANPALYVLR & $99.6 \% 26.6$ & 25.0 & 22.9 \\
\hline $0.05 \%$ & 4.5\% SLPVEEQPK & $98.1 \% \quad 20.6$ & 25.0 & 15.8 \\
\hline $0.05 \%$ & 4.5\% EQSQLTATQTR & $99.7 \% \quad 47.9$ & 25.0 & 40.2 \\
\hline $0.05 \%$ & $4.5 \%$ AISAANLHLR & $99.7 \% \quad 39.4$ & 25.0 & 30.4 \\
\hline $0.05 \%$ & 4.5\% GYLPSHYER & $99.3 \% \quad 23.1$ & 25.0 & 19.3 \\
\hline $0.04 \%$ & 9.1\% HRLDLGEDYPSGK & $99.7 \% \quad 40.8$ & 25.0 & 32.8 \\
\hline $0.04 \%$ & 9.1\% HQSFVLVGETGSGK & $99.7 \% \quad 46.1$ & 25.0 & 46.1 \\
\hline $0.04 \%$ & 9.1\% YGVIILDEAHER & $99.7 \% \quad 44.1$ & 25.0 & 40.0 \\
\hline $0.04 \%$ & 9.1\% SNLGSVVLQLK & $99.7 \% \quad 65.1$ & 25.0 & 61.8 \\
\hline $0.04 \%$ & 9.1\% SNLGSVVLQLKK & $99.7 \% \quad 45.6$ & 25.0 & 45.6 \\
\hline $0.04 \%$ & 9.1\% TCTDIKPEWLVK & $\begin{array}{lll}99.7 \% & 37.7\end{array}$ & 25.0 & 24.0 \\
\hline $0.04 \%$ & 9.1\% LQSKEYSQY & $99.3 \% \quad 23.0$ & 25.0 & 23.0 \\
\hline $0.02 \%$ & $2.1 \%$ TSVTDFLR & $99.0 \% \quad 50.5$ & 25.0 & 41.5 \\
\hline $0.02 \%$ & $2.1 \%$ AANPVDFLSK & $99.5 \% \quad 26.1$ & 25.0 & 22.2 \\
\hline
\end{tabular}



Probable ATP-dependent RNA helicase DDX17 GN=DDX17 DDX17_HUMAN $80.27 \quad 100.0 \%$ Probable ATP-dependent RNA helicase DDX17 GN=DDX17 DDX17 HUMAN $80.27 \quad 100.0^{\circ}$ Probable ATP-dependent RNA helicase DDX17 GN=DDX17 DDX17_HUMAN $80.27 \quad 100.0 \%$ Probable ATP-dependent RNA helicase DDX17 GN=DDX17 DDX17_HUMAN $80.27 \quad 100.0 \%$ Probable ATP-dependent RNA helicase DDX17 GN=DDX17 DDX17 HUMAN $80.27100 .0 \%$ Probable ATP-dependent RNA helicase DDX17 GN=DDX17 DDX17_HUMAN $80.27 \quad 100.0 \%$ Probable ATP-dependent RNA helicase DDX17 GN=DDX17 DDX17 HUMAN $80.27 \quad 100.0 \%$ Probable ATP-dependent RNA helicase DDX17 GN=DDX17 DDX17_HUMAN $80.27 \quad 100.0 \%$ Probable ATP-dependent RNA helicase DDX17 GN=DDX17 DDX17_HUMAN $80.27 \quad 100.0 \%$ Probable ATP-dependent RNA helicase DDX17 GN=DDX17 DDX17_HUMAN $80.27 \quad 100.0 \%$ Probable ATP-dependent RNA helicase DDX17 GN=DDX17 DDX17_HUMAN $80.27 \quad 100.0 \%$ Probable ATP-dependent RNA helicase DDX17 GN=DDX17 DDX17_HUMAN $80.27 \quad 100.0 \%$ Probable ATP-dependent RNA helicase DDX20 GN=DDX20 DDX20 HUMAN $92.24 \quad 100.0 \%$ Probable ATP-dependent RNA helicase DDX20 GN=DDX20 DDX20_HUMAN $92.24 \quad 100.0 \%$ Probable ATP-dependent RNA helicase DDX20 GN=DDX20 DDX20 HUMAN $92.24100 .0^{\circ}$ Probable ATP-dependent RNA helicase DDX28 GN=DDX28 DDX28_HUMAN $59.58 \quad 100.0 \%$ Probable ATP-dependent RNA helicase DDX28 GN=DDX28 DDX28_HUMAN $59.58 \quad 100.0 \%$ Probable ATP-dependent RNA helicase DDX28 GN=DDX28 DDX28 HUMAN $59.58 \quad 100.0 \%$ Probable ATP-dependent RNA helicase DDX28 GN=DDX28 DDX28_HUMAN $59.58 \quad 100.0 \%$ Probable ATP-dependent RNA helicase DDX28 GN=DDX28 DDX28 HUMAN $59.58100 .0 \%$ Probable ATP-dependent RNA helicase DDX28 GN=DDX28 DDX28_HUMAN $59.58100 .0 \%$ Probable ATP-dependent RNA helicase DDX28 GN=DDX28 DDX28_HUMAN $59.58 \quad 100.0 \%$ Probable ATP-dependent RNA helicase DDX28 GN=DDX28 DDX28 HUMAN $59.58 \quad 100.0 \%$ Probable ATP-dependent RNA helicase DDX41 GN=DDX41 DDX41_HUMAN $69.84 \quad 100.0 \%$ Probable ATP-dependent RNA helicase DDX41 GN=DDX41 DDX41_HUMAN $69.84 \quad 100.0 \%$ Probable ATP-dependent RNA helicase DDX5 GN=DDX5 DDX5 HUMAN $69.15100 .0 \%$ Probable ATP-dependent RNA helicase DDX5 GN=DDX5 DDX5_HUMAN $69.15 \quad 100.0 \%$ Probable ATP-dependent RNA helicase DDX5 GN=DDX5 DDX5 HUMAN $69.15 \quad 100.0 \%$ Probable ATP-dependent RNA helicase DDX5 GN=DDX5 DDX5_HUMAN $69.15 \quad 100.0 \%$ Probable ATP-dependent RNA helicase DDX5 GN=DDX5 DDX5_HUMAN $69.15 \quad 100.0 \%$ Probable ATP-dependent RNA helicase DDX5 GN=DDX5 DDX5 HUMAN $69.15 \quad 100.0 \%$ Probable ATP-dependent RNA helicase DDX5 GN=DDX5 DDX5_HUMAN $69.15 \quad 100.0 \%$

$\begin{array}{llll}10 & 16 & 0.03 \% & 12.2 \% \\ 10 & 16 & 0.03 \% & \text { GAETELVR }\end{array}$ $\begin{array}{llll}10 & 16 & 0.03 \% & 12.2 \%\end{array}$

$\begin{array}{llll}10 & 16 & 0.03 \% & 12.2 \%\end{array}$

$10 \quad 16 \quad 0.03 \% \quad 12.2 \%$ GISAGAVQTAGK

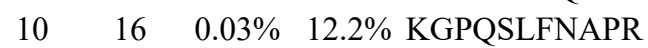

$10 \quad 16 \quad 0.03 \% \quad 12.2 \%$ IQDIVGILR

$10 \quad 16 \quad 0.03 \% \quad 12.2 \%$ DLAQALINR

$\begin{array}{llll}10 & 16 & 0.03 \% & 12.2 \% \\ 10 & 16 & 0.03 \% & 12.2 \%\end{array}$

\begin{tabular}{llll}
10 & 16 & $0.03 \%$ & $12.2 \%$ \\
\hline & TQASSSFQDSSQPAGK
\end{tabular}

$0.02 \% \quad 9.2 \% \quad$ AIACQLSR

$0.02 \% \quad 9.2 \%$ TVLQQVIEDGSK

$0.02 \% \quad 9.2 \% \quad$ IVVEFSSPNVAK

$0.02 \% \quad 9.2 \%$ AAQEFFQR

$0.02 \% \quad 9.2 \%$ GDTGVFLQYTHAR

$0.05 \% \quad 19.3 \%$ NFYVEHPEVAR

$0.05 \% \quad 19.3 \%$ LTPYEVDELRR

$0.05 \% \quad 19.3 \%$ DMVGIAQTGSGK

$0.05 \% \quad 19.3 \%$ LKSTCIYGGAPK

$0.05 \% \quad 19.3 \%$ STCIYGGAPK

$0.05 \% \quad 19.3 \%$ GPQIRDLER

$0.05 \% \quad 19.3 \%$ GVEICIATPGR

$0.05 \% \quad 19.3 \%$ SGKAPILIATDVASR

$0.05 \% \quad 19.3 \%$ APILIATDVASR

$0.05 \% \quad 19.3 \%$ STNKGTAYTFFTPGNLK

$0.05 \% \quad 19.3 \%$ VLEEANQAINPK

$0.05 \% \quad 19.3 \%$ LMQLVDHRGGGGGGGGR

$0.05 \% \quad 19.3 \%$ SSQSSSQQFSGIGR

$0.01 \% \quad 3.5 \%$ TAQDLSSPR

$0.01 \% \quad 3.5 \%$ VLISTDLTSR

$0.01 \% \quad 3.5 \%$ NNSVSGLSVK

$0.03 \% \quad 14.8 \%$ SPDEPLPVVR

$0.03 \% \quad 14.8 \%$ RPELNQPAR

$0.03 \% \quad 14.8 \%$ AQQEAPAVR

$0.03 \% \quad 14.8 \%$ AVAQPLGR

$0.03 \% \quad 14.8 \%$ VASPDAVTTITSSK

$0.03 \% \quad 14.8 \%$ LQGQMPALMR

$0.03 \% \quad 14.8 \%$ VGIFQSFQK

$0.03 \% \quad 14.8 \%$ DILLCTDIASR

$0.01 \% \quad 3.9 \% \quad$ LLQEDSSPLLR

$0.01 \% \quad 3.9 \%$ SALVKPVTINVGR

$0.13 \% \quad 20.7 \%$ FGNPGEKLVK

$0.13 \% \quad 20.7 \%$ NFYQEHPDLAR

$0.13 \% \quad 20.7 \%$ NFYQEHPDLARR

$\begin{array}{lll}0.13 \% & 20.7 \% \text { TAQEVETYR }\end{array}$

$63 \quad 0.13 \% \quad 20.7 \%$ TAQEVETYRR

$63 \quad 0.13 \% \quad 20.7 \%$ LKSTCIYGGAPK

$0.13 \% \quad 20.7 \%$ STCIYGGAPK $\begin{array}{llllllll}96.2 \% & 23.6 & 25.0 & 10.6 & 1 & 0 & 0 & 874.46\end{array}$

$\begin{array}{llllllll}99.7 \% & 37.2 & 25.0 & 35.7 & 2 & 0 & 0 & 1362.70\end{array}$

$\begin{array}{llllllll}97.0 \% & 23.8 & 25.0 & 12.1 & 1 & 0 & 0 & 800.45\end{array}$

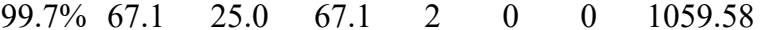

$\begin{array}{llllllll}99.6 \% & 30.8 & 25.0 & 19.9 & 1 & 1 & 0 & 1214.66\end{array}$

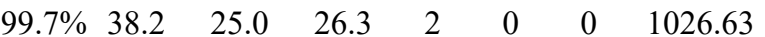

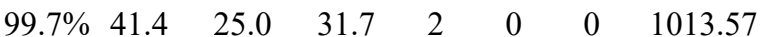

$\begin{array}{llllllll}99.7 \% & 68.4 & 25.0 & 62.4 & 2 & 0 & 0 & 1390.71\end{array}$

$\begin{array}{llllllll}99.7 \% & 57.9 & 25.0 & 57.9 & 2 & 0 & 0 & 1625.74\end{array}$

$\begin{array}{llllllll}99.0 \% & 41.1 & 25.0 & 27.6 & 2 & 0 & 0 & 918.48\end{array}$

$\begin{array}{llllllll}99.7 \% & 57.0 & 25.0 & 48.2 & 2 & 0 & 0 & 1316.71\end{array}$

$\begin{array}{llllllll}99.7 \% & 61.8 & 25.0 & 50.9 & 2 & 0 & 0 & 1289.71\end{array}$

$\begin{array}{llllllll}97.2 \% & 17.2 & 25.0 & 16.5 & 1 & 0 & 0 & 996.49\end{array}$

$\begin{array}{llllllll}99.7 \% & 30.4 & 25.0 & 30.4 & 1 & 0 & 0 & 1464.72\end{array}$

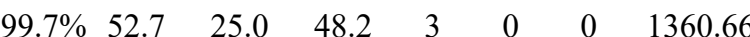

$\begin{array}{llllllll}99.5 \% & 25.3 & 25.0 & 22.4 & 2 & 0 & 0 & 1390.73\end{array}$

$99.7 \% \quad 55.3 \quad 25.0 \quad 48.1 \quad 2 \quad 00001163.57$

$\begin{array}{llllllll}99.7 \% & 51.1 & 25.0 & 47.2 & 6 & 0 & 0 & 1294.68\end{array}$

$\begin{array}{llllllll}99.7 \% & 53.2 & 25.0 & 43.1 & 8 & 0 & 0 & 1053.50\end{array}$

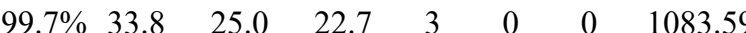

$\begin{array}{llllllll}99.7 \% & 45.5 & 25.0 & 27.0 & 4 & 0 & 0 & 1172.61\end{array}$

$\begin{array}{llllllll}99.7 \% & 47.5 & 25.0 & 41.4 & 3 & 1 & 0 & 1498.86\end{array}$

$\begin{array}{llllllll}99.7 \% & 64.0 & 25.0 & 64.0 & 4 & 0 & 0 & 1226.71\end{array}$

1226.71
1846.93

1325.71

1623.81

1455.68

974.49

1104.63

1004.54

1108.60

1080.59

969.51

811.48

1376.73

1144.60

1053.57

1276.66

1270.70

1353.82

1088.6

1389.65

1545.76

1096.53

1252.63

1294.68

$\begin{array}{llll}99.3 \% & 21.8 & 25.0 & 21.8\end{array}$

$\begin{array}{llll}99.7 \% & 51.1 & 25.0 & 47.2\end{array}$ $\begin{array}{llll}99.7 \% & 53.2 & 25.0 & 43.1\end{array}$

30
42
63
91
102
251
331
669
685
15
111
138
229
469
143
154
221
284
284
293
304
480
480
528
547
564
684
50
371
507
37
81
120
228
357
436
445
459
293
400
43
67
68
77

Page 61 of Table S-1- 3 
Probable ATP-dependent RNA helicase DDX5 GN=DDX5 DDX5_HUMAN $69.15 \quad 100.0 \% \quad 1$ Probable ATP-dectent RNA helica DDX5 GN=DDX5 DDX5_HUMAN $69.15 \quad 100.0 \%$ Probable ATP-dependent RNA helicase DDX5 GN=DDX5 DDX5_HUMAN $69.15 \quad 100.0 \%$ Probable ATP-dependent RNA helicase DDX5 GN=DDX5 DDX5 HUMAN $69.15 \quad 100.0 \%$ Probable ATP-dependent RNA helicase DDX5 GN=DDX5 DDX5_HUMAN $69.15 \quad 100.0 \%$ Probable ATP-dependent RNA helicase DDX5 GN=DDX5 DDX5_HUMAN $69.15 \quad 100.0 \%$ Probable ATP-dependent RNA helicase DDX5 GN=DDX5 DDX5_HUMAN $69.15 \quad 100.0 \%$ Probable ATP-dependent RNA helicase DDX5 GN=DDX5 DDX5_HUMAN $69.15 \quad 100.0 \%$ Probable ATP-dependent RNA helicase DDX5 GN=DDX5 DDX5_HUMAN 69.15 Probable ATP-dependent RNA helicase DDX56 GN=DDX56 DDX56_HUMAN 61.59 Probable ATP-dependent RNA helicase DDX56 GN=DDX56 DDX56_HUMAN 61.59 Probable cytosolic iron-sulfur protein assembly protein CIAO1 GN=CIAO1 CIAO1_HUMAN 37.84 Probable cytosolic iron-sulfur protein assembly protein CIAO1 GN=CIAO1 CIAO1_HUMAN 37.84 Probable cytosolic iron-sulfur protein assembly protein CIAO1 GN=CIAO1 CIAO1_HUMAN 37.84 Probable dimethyladenosine transferase GN=DIMT1 DIM1_HUMAN $35.24 \quad 100.0 \%$ Probable dimethyladenosine transferase GN=DIMT1 DIM1_HUMAN $35.24 \quad 100.0 \%$ Probable dimethyladenosine transferase GN=DIMT1 DIM1 HUMAN $35.24 \quad 100.0 \%$ Probable dimethyladenosine transferase GN=DIMT1 DIM1_HUMAN $35.24 \quad 100.0 \%$ Probable dimethyladenosine transferase GN=DIMT1 DIM1_HUMAN $35.24 \quad 100.0 \%$ Probable dimethyladenosine transferase GN=DIMT1 DIM1 HUMAN $35.24 \quad 100.0 \%$ Probable methyltransferase-like protein 15 GN=METTL15 MET15_HUMAN $46.12 \quad 100.0 \%$ Probable methyltransferase-like protein 15 GN=METTL15 MET15 HUMAN $46.12 \quad 100.0 \%$ Probable rRNA-processing protein EBP2 GN=EBNA1BP2 EBP2_HUMAN $34.85 \quad 100.0 \%$ Probable rRNA-processing protein EBP2 GN=EBNA1BP2 EBP2_HUMAN $34.85 \quad 100.0 \%$ Probable rRNA-processing protein EBP2 GN=EBNA1BP2 EBP2 HUMAN $34.85 \quad 100.0 \%$ Probable rRNA-processing protein EBP2 GN=EBNA1BP2 EBP2_HUMAN $34.85 \quad 100.0 \%$ Probable tRNA N6-adenosine threonylcarbamoyltransferase GN=OSGEP OSGEP_HUMAN $36.43 \quad 100.0 \%$ Probable tRNA N6-adenosine threonylcarbamoyltransferase GN=OSGEP OSGEP HUMAN $36.43 \quad 100.0 \%$ Probable tRNA N6-adenosine threonylcarbamoyltransferase GN=OSGEP OSGEP_HUMAN $36.43 \quad 100.0 \%$ Probable tRNA pseudouridine synthase $1 \mathrm{GN}=$ TRUB1 TRUB1 HUMAN $37.25 \quad 100.0 \%$ Probable tRNA pseudouridine synthase 1 GN=TRUB1 TRUB1_HUMAN $37.25 \quad 100.0 \%$ Probable tRNA pseudouridine synthase 2 GN=TRUB2 TRUB2_HUMAN $36.70 \quad 100.0 \%$ Probable tRNA pseudouridine synthase 2 GN=TRUB2 TRUB2_HUMAN $36.70 \quad 100.0 \%$ Programmed cell death 6-interacting protein GN=PDCD6IP PDC6I_HUMAN 96.03 $100.0 \%$ Programmed cell death 6-interacting protein GN=PDCD6IP PDC6I_HUMAN $96.03 \quad 100.0 \%$

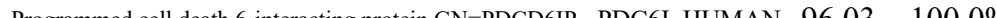
Prohibitin $\mathrm{GN}=\mathrm{PHB}$ Prohibitin GN=PHB Prohibitin $\mathrm{GN}=\mathrm{PHB}$ Prohibitin GN=PHB Prohibitin GN=PHB Prohibitin $\mathrm{GN}=\mathrm{PHB}$ Prohibitin $\mathrm{GN}=\mathrm{PHB}$ Prohibitin $\mathrm{GN}=\mathrm{PHB}$ Prohibitin $\mathrm{GN}=\mathrm{PHB}$ Prohibitin GN=PHB Prohibitin GN=PHB

PHB HUMAN $29.80 \quad 100.0 \% \quad 15$

18

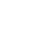

4

(1)

3

3

3
2
2
2

2
2
3

2
3
3

4

4

$\begin{array}{ll}15 & 19 \\ 15 & 19 \\ 15 & 19\end{array}$

$\begin{array}{ll}5 & 19 \\ 5 & 19 \\ 5 & 19 \\ 5 & 19\end{array}$

$\begin{array}{ll}19 \\ 15 & 19\end{array}$

$\begin{array}{ll}15 & 19 \\ 15 & 19\end{array}$

19
19
19

\section{$\begin{array}{lllll}19 & 55 & 0.12 \% & 50.4 \% & \text { VLPSITTEILK } \\ 19 & 55 & 0.12 \% & 50.4 \% \text { SVVARFDAGELITQR }\end{array}$

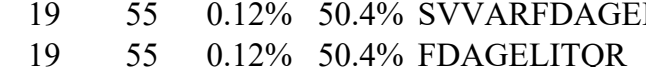

$\begin{array}{lllll}19 & 55 & 0.12 \% & 50.4 \% & \text { FDAGELITQR } \\ 19 & 55 & 0.12 \% & 50.4 \% & \text { FDAGELITQRELVSR }\end{array}$

$1955 \quad 0.12 \% \quad 50.4 \%$ QVSDDLTER PHB_HUMAN $29.80 \quad 100.0 \% \quad 15$ $\begin{array}{llllll}99.7 \% & 33.8 & 25.0 & 22.7 & 3 & 0\end{array}$

$99.7 \% \quad 45.5 \quad 25.0 \quad 27.0 \quad 4$

$\begin{array}{lllll}99.7 \% & 39.7 & 25.0 & 37.0 & 4\end{array}$

$\begin{array}{llll}99.7 \% & 33.6 & 25.0 & 33.6\end{array}$

$99.7 \% \quad 64.0 \quad 25.0 \quad 64.0 \quad 4$

$\begin{array}{llll}99.7 \% & 55.2 & 25.0 & 52.2\end{array}$

$99.0 \% \quad 59.2 \quad 25.0 \quad 40.7$

$\begin{array}{llll}99.7 \% & 47.4 & 25.0 & 44.0\end{array}$

$99.7 \% \quad 45.0 \quad 25.0 \quad 38.5$

$\begin{array}{lllll}99.7 \% & 74.0 & 25.0 & 71.6 & 2\end{array}$

$\begin{array}{llll}99.1 \% & 22.0 & 25.0 & 22.0\end{array}$

$\begin{array}{lllll}99.7 \% & 38.5 & 25.0 & 27.6 & 2\end{array}$

$\begin{array}{llll}98.4 \% & 23.0 & 25.0 & 19.5\end{array}$

$\begin{array}{llll}99.7 \% & 41.4 & 25.0 & 36.8\end{array}$

$\begin{array}{llll}99.7 \% & 33.3 & 25.0 & 23.0\end{array}$

$99.6 \% \quad 33.7 \quad 25.0 \quad 16.2$

$\begin{array}{llll}99.7 \% & 34.4 & 25.0 & 32.6\end{array}$

$\begin{array}{lllll}99.7 \% & 50.7 & 25.0 & 41.0 & 4\end{array}$

$\begin{array}{llll}98.0 \% & 17.8 & 25.0 & 17.8\end{array}$

$\begin{array}{llll}99.7 \% & 37.2 & 25.0 & 32.3\end{array}$

$\begin{array}{llll}99.7 \% & 56.2 & 25.0 & 54.8\end{array}$

$\begin{array}{llll}99.7 \% & 51.1 & 25.0 & 42.5\end{array}$

$\begin{array}{llll}99.0 \% & 34.2 & 25.0 & 12.4\end{array}$

$\begin{array}{llll}99.4 \% & 24.7 & 25.0 & 23.4\end{array}$

$\begin{array}{lllll}99.7 \% & 43.6 & 25.0 & 43.6 & 2\end{array}$

$\begin{array}{llll}97.8 \% & 18.9 & 25.0 & 17.1\end{array}$

$\begin{array}{llll}99.6 \% & 30.9 & 25.0 & 23.6\end{array}$

$\begin{array}{lllll}99.7 \% & 51.5 & 25.0 & 25.6 & 2\end{array}$

$\begin{array}{llll}99.7 \% & 57.6 & 25.0 & 57.6\end{array}$

$\begin{array}{llll}99.7 \% & 65.9 & 25.0 & 61.6\end{array}$

$\begin{array}{lllll}99.7 \% & 40.2 & 25.0 & 27.5 & 2\end{array}$

$\begin{array}{llll}99.6 \% & 29.5 & 25.0 & 23.9\end{array}$

$95.7 \% \quad 15.9 \quad 25.0 \quad 15.9$

$\begin{array}{llll}99.7 \% & 49.2 & 25.0 & 45.1\end{array}$

$\begin{array}{llll}99.7 \% & 31.2 & 25.0 & 31.2\end{array}$

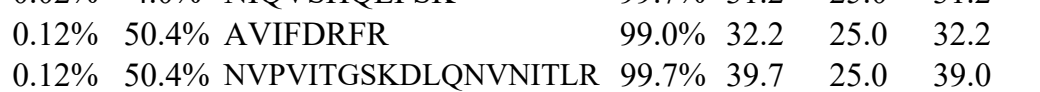

$\begin{array}{llll}99.7 \% & 72.0 & 25.0 & 62.6\end{array}$

$99.7 \% \quad 41.0 \quad 25.0 \quad 41.0 \quad 2$

$99.7 \% \quad 70.4 \quad 25.0 \quad 63.6 \quad 4$

$\begin{array}{lllll}99.4 \% & 26.2 & 25.0 & 19.0 & 2\end{array}$

$99.7 \% \quad 68.8 \quad 25.0 \quad 60.9 \quad 2$

$\begin{array}{lllll}99.7 \% & 73.2 & 25.0 & 60.2 \quad 4\end{array}$

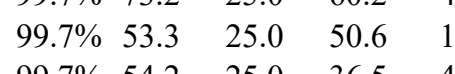

$\begin{array}{llll}99.7 \% & 54.2 & 25.0 & 36.5 \\ 99.4 \% & 29.9 & 25.0 & 14.4\end{array}$ $\begin{array}{ccc}1083.59 & 208 & 216 \\ 1172.61 & 217 & 227 \\ 1094.56 & 228 & 236 \\ 1295.65 & 242 & 252 \\ 1092.64 & 344 & 352 \\ 1226.71 & 392 & 403 \\ 1129.66 & 452 & 461 \\ 985.57 & 471 & 478 \\ 1342.74 & 471 & 482 \\ 1126.62 & 74 & 84 \\ 1432.70 & 115 & 128 \\ 1147.65 & 1 & 10 \\ 1012.52 & 54 & 62 \\ 1279.61 & 209 & 219 \\ 1239.73 & 41 & 51 \\ 1058.53 & 81 & 89 \\ 1083.68 & 107 & 116 \\ 1419.78 & 163 & 174 \\ 1128.67 & 175 & 184 \\ 1725.94 & 194 & 208 \\ 1056.65 & 234 & 243 \\ 1610.78 & 382 & 395 \\ 1236.74 & 111 & 122 \\ 944.54 & 180 & 187 \\ 1100.64 & 180 & 188 \\ 1204.51 & 263 & 272 \\ 1061.62 & 190 & 198 \\ 1581.81 & 309 & 323 \\ 1160.59 & 313 & 323 \\ 941.55 & 39 & 49 \\ 1086.65 & 126 & 137 \\ 987.57 & 204 & 212 \\ 1227.66 & 285 & 296 \\ 1299.75 & 12 & 23 \\ 1304.69 & 542 & 553 \\ 1316.66 & 628 & 638 \\ 1023.57 & 36 & 43 \\ 2081.17 & 75 & 93 \\ 1185.66 & 84 & 93 \\ 1396.84 & 94 & 105 \\ 1444.66 & 106 & 117 \\ 1213.74 & 118 & 128 \\ 1661.90 & 129 & 143 \\ 1149.59 & 134 & 143 \\ 1733.92 & 134 & 148 \\ 1062.51 & 149 & 157 \\ 1285.66 & 187 & 197 \\ & & \end{array}$

Page 62 of Table S-1-3 
Prohibitin GN=PHB Prohibitin GN=PHB Prohibitin GN=PHB Prohibitin GN=PHB Prohibitin-2 GN=PHB2 Prohibitin-2 GN=PHB2 Prohibitin-2 GN=PHB2 Prohibitin-2 GN=PHB2 Prohibitin-2 GN=PHB2 Prohibitin-2 GN=PHB2 Prohibitin-2 GN=PHB2 Prohibitin-2 GN=PHB2 Prohibitin-2 GN=PHB2 Prohibitin-2 GN=PHB2 Prohibitin-2 GN=PHB2 Prohibitin-2 GN=PHB2 Prohibitin-2 GN=PHB2 Prohibitin-2 GN=PHB2 Prohibitin-2 GN=PHB2

Prohibitin-2 GN=PHB2

Prohibitin-2 GN=PHB2

Prohibitin-2 GN=PHB2

Proliferating cell wuclear angen $\mathrm{CN}=\mathrm{PCNA}$ Proliferating cell nuclear antigen GN=PCNA PCNA_HUMAN 28.77 Proliferating cell nuclear antigen GN=PCNA PCNA_HUMAN 28.77 Proliferating cell nuclear antigen GN=PCNA PCNA_HUMAN 28.77 Proliferating cell nuclear antigen GN=PCNA PCNA_HUMAN 28.77 Proliferating cell nuclear antigen GN=PCNA PCNA_HUMAN 28.77 Proliferating cell nuclear antigen GN=PCNA PCNA_HUMAN 28.77 Proliferating cell nuclear antigen GN=PCNA PCNA_HUMAN 28.77 Proliferating cell nuclear antigen GN=PCNA PCNA_HUMAN 28.77 Proliferating cell nuclear antigen GN=PCNA PCNA_HUMAN 28.77 Proline-, glutamic acid-and leucine-rich protein 1 GN=PELP1 PELP1_HUMAN 119.70 Proline-, glutamic acid- and leucine-rich protein 1 GN=PELP1 PELP1_HUMAN 119.70 Propionyl-CoA carboxylase alpha chain, mitochondrial GN=PCCA PCCA_HUMAN 80.06 Propionyl-CoA carboxylase alpha chain, mitochondrial GN=PCCA PCCA_HUMAN 80.06 Proteasomal ATPase-associated factor 1 GN=PAAF1 PAAF1_HUMAN 42.19 Proteasomal ATPase-associated factor $1 \mathrm{GN}=$ PAAF1 PAAF1_HUMAN 42.19 Proteasomal ATPase-associated factor $1 \mathrm{GN}=$ PAAF1 PAAF1_HUMAN 42.19 Proteasomal ubiquitin receptor ADRM1 GN=ADRM1 ADRM1_HUMAN 42.15 Proteasomal ubiquitin receptor ADRM1 GN=ADRM1 ADRM1_HUMAN 42.1 Proteasomal ubiquitin receptor ADRM1 GN=ADRM1 ADRM1_HUMAN $42.15 \quad 100.0 \%$ Proteasome subunit alpha type-4 GN=PSMA4 PSA4 HUMAN $29.48 \quad 100.0 \%$ Proteasome subunit alpha type-4 GN=PSMA4 PSA4_HUMAN $29.48 \quad 100.0 \%$ Proteasome subunit alpha type-4 GN=PSMA4 PSA4_HUMAN $29.48 \quad 100.0 \%$ Proteasome subunit alpha type-4 GN=PSMA4 PSA4 HUMAN $29.48 \quad 100.0 \%$ Proteasome subunit alpha type-4 GN=PSMA4 PSA4_HUMAN $29.48 \quad 100.0 \%$
$19 \quad 55 \quad 0.12 \% \quad 50.4 \%$ FVVEKAEQQK

$19 \quad 55 \quad 0.12 \% \quad 50.4 \%$ AAIISAEGDSK

$19 \quad 55 \quad 0.12 \% \quad 50.4 \%$ KLEAAEDIAYQLSR

$19 \quad 55 \quad 0.12 \% \quad 50.4 \%$ LEAAEDIAYQLSR

$\begin{array}{llll}28 & 84 & 0.18 \% & 51.8 \% \\ 28 & \text { DLAGRLPAGPR }\end{array}$

$28 \quad 84 \quad 0.18 \% \quad 51.8 \%$ LLLGAGAVAYGVR

$0.18 \% \quad 51.8 \%$ ESVFTVEGGHR

$0.18 \% \quad 51.8 \%$ DLQMVNISLR

$0.18 \% \quad 51.8 \%$ VLSRPNAQELPSMYQR

$0.18 \% \quad 51.8 \%$ LGLDYEER

$0.18 \% \quad 51.8 \%$ SVVAKFNASQLITQR

$0.18 \% \quad 51.8 \%$ FNASQLITQR

$0.18 \% \quad 51.8 \%$ AQVSLLIR

$0.18 \% \quad 51.8 \%$ AQVSLLIRR

$0.18 \% \quad 51.8 \%$ EYTAAVEAK

$0.18 \% \quad 51.8 \%$ EYTAAVEAKQVAQQEAQR

$0.18 \% \quad 51.8 \%$ QVAQQEAQRAQFLVEK

$0.18 \% \quad 51.8 \%$ QKIVQAEGEAEAAK

$0.18 \% \quad 51.8 \%$ IVQAEGEAEAAK

$0.18 \% \quad 51.8 \%$ MLGEALSK

$0.18 \% \quad 51.8 \%$ MLGEALSKNPGYIK

$0.18 \% \quad 51.8 \%$ IRAAQNISK

$0.06 \% \quad 35.6 \%$ LVQGSILKK

$0.06 \% \quad 35.6 \%$ SEGFDTYR

$0.06 \% \quad 35.6 \%$ SEGFDTYRCDR

$0.06 \% 35.6 \%$ NLAMGVNLTSMSK

$0.06 \% 35.6 \%$ MPSGEFAR

$100.0 \% \quad 10$

$100.0 \% \quad 10$

$00.0 \% \quad 10$

$100.0 \% \quad 10$

$00.0 \% \quad 10$

$100.0 \%$

$100.0 \%$

$100.0 \%$

$00.0 \%$

$100.0 \%$

$0 \% \quad 3$

3

8

$\begin{array}{ll}0 \\ \% & 8 \\ 0 & 8\end{array}$

$0.06 \% \quad 35.6 \%$ DLSHIGDAVVISCAK

$0.06 \% \quad 35.6 \%$ FSASGELGNGNIK

$0.06 \% \quad 35.6 \%$ IADMGHLK

$0.06 \% \quad 35.6 \%$ YYLAPKIEDEEGS

$0.00 \% \quad 2.6 \%$ TGSAVAPVHPPNR

$0.00 \% \quad 2.6 \%$ GSPDGSLQTGKPSAPK

$0.00 \% \quad 2.9 \%$ AMGEQAVALAR

$0.00 \% \quad 2.9 \%$ VTEDTSSVLR

$0.01 \% \quad 7.9 \% \quad$ FLAPYTTFSR

$0.01 \% \quad 7.9 \%$ SITCLDISSR

$0.01 \% \quad 7.9 \%$ GGILDTAIVDR

$0.02 \% \quad 8.6 \%$ GASNKYLVEFR

$0.02 \% \quad 8.6 \%$ VPQCPSGR

$0.02 \% \quad 8.6 \% \quad$ SQSAAVTPSSTTSSTR

$0.04 \% \quad 28.7 \%$ TTIFSPEGR

$0.04 \% \quad 28.7 \%$ LLDEVFFSEK

$0.04 \% \quad 28.7 \%$ QAYTQFGGK

$0.04 \% \quad 28.7 \%$ ATCIGNNSAAAVSMLK

$0.04 \% \quad 28.7 \%$ SALALAIKVLNK $\begin{array}{llllllll}99.7 \% & 47.0 & 25.0 & 37.0 & 4 & 0 & 0 & 1205.65\end{array}$ $\begin{array}{lllllll}99.7 \% & 64.7 & 25.0 & 56.8 & 4 & 0 & 0\end{array}$ $\begin{array}{lllllll}99.7 \% & 34.5 & 25.0 & 27.8 & 4 & 2 & 0\end{array}$

$99.7 \% \quad 55.6 \quad 25.0 \quad 51.7 \quad$

$\begin{array}{lllll}99.7 \% & 32.9 & 25.0 & 29.4 & 2\end{array}$

$99.7 \% \quad 75.3 \quad 25.0 \quad 64.1$

$\begin{array}{llll}99.7 \% & 67.0 & 25.0 & 50.2\end{array}$

$\begin{array}{llll}99.7 \% & 62.5 & 25.0 & 47.3\end{array}$

$\begin{array}{llll}99.7 \% & 38.8 & 25.0 & 35.8\end{array}$

$\begin{array}{llll}99.0 \% & 60.3 & 25.0 & 46.3\end{array}$

$\begin{array}{llll}99.7 \% & 32.4 & 25.0 & 28.5\end{array}$

$\begin{array}{llll}99.7 \% & 65.7 & 25.0 & 58.7\end{array}$

$\begin{array}{llll}99.0 \% & 35.8 & 25.0 & 26.0\end{array}$

$\begin{array}{llll}99.7 \% & 56.7 & 25.0 & 50.4\end{array}$

$\begin{array}{llll}99.7 \% & 56.3 & 25.0 & 51.8\end{array}$

$\begin{array}{lll}99.7 \% & 50.1\end{array}$

$9.7 \% \quad 37.7$

$99.7 \% \quad 67.8$

$99.7 \% \quad 75.6$

$99.0 \% \quad 41.0$

$99.7 \% \quad 71.3$

$99.7 \% \quad 45.9$

$99.4 \% \quad 40.7$

$99.0 \% \quad 27.7$

$99.7 \% \quad 26.0$

$99.7 \% \quad 69.8$

$\begin{array}{lll}99.0 \% & 31.8\end{array}$ $\begin{array}{ll}99.7 \% & 53.7\end{array}$

$99.7 \% \quad 70.8$

$99.0 \% \quad 40.3$

$99.7 \% \quad 48.4$

$98.6 \% \quad 18.1$

$99.0 \% \quad 21.5$

$99.7 \% \quad 53.7$

$95.8 \% \quad 22.4$

$99.3 \% \quad 22.6$

$99.7 \% \quad 53.5$

$99.7 \% \quad 60.5$

$99.7 \% \quad 46.7$

$99.0 \% \quad 19.3$

$99.7 \% \quad 61.9$

$99.7 \% \quad 37.3$

$99.7 \% \quad 36.5$

$96.7 \% 20.9$

$\begin{array}{ll}99.7 \% & 62.1\end{array}$

$99.7 \% \quad 33.2$
1061.55

1606.84

1478.75

1122.64

1259.75

1217.59

1188.64

1904.96

994.48

1661.93

1177.63

899.57

1055.67

981.49

2020.01

1872.99

1471.78

1215.62

864.45

1536.81

1000.59

985.64

974.42

1405.58

1397.68

894.41

2014.02

1584.81

1293.64

884.47

1513.71

1302.69

1526.78

1116.58

1106.57

1202.62

1151.57

1129.62

1283.67

900.44

1567.76

1007.52

1226.63

999.49

1607.79

1240.80 $\begin{array}{cc}98 & 207 \\ 09 & 219 \\ 40 & 253 \\ 41 & 253 \\ 7 & 17 \\ 5 & 37 \\ 8 & 48 \\ 8 & 107 \\ 08 & 123 \\ 24 & 131 \\ 43 & 157 \\ 48 & 157 \\ 58 & 165 \\ 58 & 166 \\ 92 & 200 \\ 92 & 209 \\ 01 & 216 \\ 23 & 236 \\ 25 & 236 \\ 37 & 244 \\ 37 & 250 \\ 54 & 262 \\ 6 & 14 \\ 4 & 61 \\ 4 & 64 \\ 5 & 77 \\ 39 & 146 \\ 47 & 164 \\ 50 & 164 \\ 69 & 181 \\ 41 & 248 \\ 49 & 261 \\ 9 & 61 \\ 80 & 495 \\ 15 & 325 \\ 54 & 663 \\ 0 & 89 \\ 4 & 103 \\ 77 & 187 \\ 7 & 27 \\ 5 & 92 \\ 11 & 226 \\ 9 & 17 \\ 5 & 64 \\ 19 & 127 \\ 61 & 176 \\ 88 & 199\end{array}$

Page 63 of Table S-1-3 
Protein arginine N-methyltransferase $5 \mathrm{GN}=$ PRMT5 ANM5 HUMAN $72.69 \quad 100.0 \%$

Protein CMSS1 GN=CMSS1

Protein CMSS1 GN=CMSS1

Protein $\mathrm{CMSS} 1 \mathrm{GN}=\mathrm{CMSS} 1$

Protein CMSS1 GN=CMSS1

Protein Daple GN $=$ CCDC88C Protein Daple GN $=\mathrm{CCDC} 88 \mathrm{C}$ Protein Daple GN=CCDC88C Protein Daple GN $=$ CCDC $88 \mathrm{C}$ Protein Daple GN=CCDC88C Protein Daple GN=CCDC88C Protein DEK GN=DEK Protein DEK GN=DEK

Protein DEK GN=DEK Protein DEK GN=DEK

Protein EFR3 homolog A GN=EFR3A Protein EFR3 homolog A GN=EFR3A Protein flightless -1 homolog GN=FLII Protein flightless- 1 homolog GN=FLII Protein lin-28 homolog B GN=LIN28B CMS1_HUMAN $31.89 \quad 100.0 \%$ CMS1_HUMAN $31.89 \quad 100.0 \%$ CMS1_HUMAN $31.89 \quad 100.0 \%$ CMS1_HUMAN $31.89 \quad 100.0 \%$ DAPLE HUMAN $228.23 \quad 100.0 \%$ DAPLE_HUMAN $228.23 \quad 100.0 \%$ DAPLE_HUMAN $228.23 \quad 100.0 \%$ DAPLE HUMAN $228.23 \quad 100.0 \%$ DAPLE_HUMAN $228.23 \quad 100.0 \%$ DAPLE HUMAN $228.23 \quad 100.0 \%$ DEK_HUMAN $42.68 \quad 100.0 \%$ DEK_HUMAN $42.68 \quad 100.0 \%$ DEK_HUMAN $42.68 \quad 100.0 \%$ DEK_HUMAN $42.68 \quad 100.0 \%$ EFR3A HUMAN $92.93 \quad 100.0 \%$ EFR3A HUMAN $92.93 \quad 100.0 \%$ FLII_HUMAN $144.76 \quad 100.0 \%$ FLII_HUMAN $144.76 \quad 100.0 \%$ LN28B_HUMAN $27.08 \quad 100.0 \%$

$17 \quad 0.04 \% \quad 28.7 \%$ VLNKTMDVSK $0.04 \% \quad 28.7 \%$ LSAE

$17-0.0$

$0.04 \% 28.7 \%$ VEIATLTR

$0.01 \% \quad 2.8 \%$ LSSTQEGVR

$0.01 \% \quad 2.8 \%$ SASPFNLAEKPK

$0.01 \% \quad 2.8 \%$ TLMSSGQMAPSSSNK

$0.01 \% \quad 2.8 \%$ AIACVVTACSAELEK

$0.01 \% \quad 6.4 \%$ ANKLDHVVTIIK

$0.01 \% \quad 6.4 \% \quad$ ATLYVTAIEDR

$128 \quad 0.27 \% \quad 23.7 \%$ REFIQEPAK

$128 \quad 0.27 \% \quad 23.7 \%$ EFIQEPAK

$128 \quad 0.27 \% \quad 23.7 \%$ EFIQEPAKNRPGPQTR

$128 \quad 0.27 \% \quad 23.7 \%$ SDLLLSGR

$128 \quad 0.27 \% \quad 23.7 \%$ LSPWIRPDSKVEK

$128 \quad 0.27 \% \quad 23.7 \%$ VPLVAPEDLR

$128 \quad 0.27 \% \quad 23.7 \%$ TLCDYSKR

$128 \quad 0.27 \% \quad 23.7 \%$ AAILPTSIFLTNK

$128 \quad 0.27 \% \quad 23.7 \%$ AAILPTSIFLTNKK

$128 \quad 0.27 \% \quad 23.7 \%$ KGFPVLSK

$128 \quad 0.27 \% \quad 23.7 \%$ DPIKYSQYQQAIYK

$128 \quad 0.27 \% \quad 23.7 \%$ YSQYQQAIYK

$128 \quad 0.27 \% \quad 23.7 \%$ GPLVNASLR

$128 \quad 0.27 \% \quad 23.7 \%$ GPLVNASLRAAK

$128 \quad 0.27 \% \quad 23.7 \%$ IKLYAVEK

$128 \quad 0.27 \% \quad 23.7 \%$ LYNEVRACR

$128 \quad 0.27 \% \quad 23.7 \%$ DRDPEAQFEMPYVVR

$128 \quad 0.27 \% \quad 23.7 \%$ DPMIDNNR

$128 \quad 0.27 \% \quad 23.7 \%$ EGQTICVR

$10 \quad 0.02 \% \quad 12.5 \%$ SEPKPGLPEDLQK

$10 \quad 0.02 \% \quad 12.5 \%$ RVVHLGVGTPGR

$10 \quad 0.02 \% \quad 12.5 \%$ VVHLGVGTPGR

$10 \quad 0.02 \% \quad 12.5 \%$ QGGLNLSPLK

$13 \quad 0.03 \% \quad 3.6 \%$ VKQENIQLAADAR

$0.03 \% \quad 3.6 \%$ ALDKELAR

$0.03 \% \quad 3.6 \%$ QSAEYEALIR

$0.03 \% \quad 3.6 \%$ TNALAMGENQR

$0.03 \% \quad 3.6 \%$ TCSTSATTTAPSNSTPIAR

$0.03 \% \quad 3.6 \%$ MPTNFVAPTVK

$0.01 \% \quad 12.0 \%$ NVGQFSGFPFEK

$0.01 \% \quad 12.0 \%$ SICEVLDLER

$0.01 \% \quad 12.0 \%$ SGVNSELVKR

$0.01 \% \quad 12.0 \%$ LLASANLEEVTMK

$0.01 \% \quad 2.4 \%$ LQVLGTNSFVK

$0.01 \% \quad 2.4 \%$ TEIRIAGIR

$0.01 \% \quad 2.1 \%$ SLEGTEAQVFKAK

$0.01 \% \quad 2.1 \%$ AVQGAQQPSLYQIR

$0.01 \% \quad 12.0 \%$ NVAQPPASSQGR
1430.82

902.53

976.51

1288.69

1525.70

1621.79

$\begin{array}{llll}99.7 \% & 37.7 & 25.0 & 37.7\end{array}$

$99.7 \% \quad 56.3 \quad 25.0 \quad 53.5$

$\begin{array}{llll}99.3 \% & 20.9 & 25.0 & 20.9\end{array}$

$99.7 \% \quad 46.8 \quad 25.0 \quad 46.8$

$\begin{array}{llll}99.7 \% & 47.2 & 25.0 & 32.9\end{array}$

$\begin{array}{lllll}99.0 \% & 37.7 & 25.0 & 19.4 & 20\end{array}$

$\begin{array}{llll}99.7 \% & 39.3 & 25.0 & 34.2\end{array}$

$\begin{array}{llll}99.0 \% & 39.2 & 25.0 & 17.9\end{array}$

$99.7 \% \quad 31.5 \quad 25.0 \quad 30.1$

$\begin{array}{llll}99.7 \% & 42.7 & 25.0 & 42.7\end{array}$

$\begin{array}{llll}99.0 \% & 37.7 & 25.0 & 24.5\end{array}$

$\begin{array}{llll}99.7 \% & 56.1 & 25.0 & 56.1\end{array}$

$99.7 \% \quad 48.4 \quad 25.0 \quad 48.4$

$\begin{array}{llll}99.0 \% & 55.4 & 25.0 & 35.0\end{array}$

$\begin{array}{llll}99.7 \% & 45.8 & 25.0 & 42.0\end{array}$

$\begin{array}{lllll}99.7 \% & 63.5 & 25.0 & 63.5 & 16\end{array}$

$99.7 \% \quad 63.3 \quad 25.0 \quad 54.8$

$\begin{array}{llll}99.7 \% & 45.3 & 25.0 & 34.5\end{array}$

$99.0 \% \quad 38.0 \quad 25.0 \quad 24.8$

$\begin{array}{llll}99.4 \% & 24.4 & 25.0 & 24.4\end{array}$

$\begin{array}{llll}99.7 \% & 26.5 & 25.0 & 25.5\end{array}$

$\begin{array}{llll}99.0 \% & 24.2 & 25.0 & 19.6\end{array}$

$\begin{array}{lllll}99.0 \% & 38.0 & 25.0 & 35.6\end{array}$

$\begin{array}{lllll}99.2 \% & 24.9 & 25.0 & 17.1 & 2\end{array}$

$\begin{array}{llll}99.7 \% & 32.5 & 25.0 & 29.4\end{array}$

$\begin{array}{llll}99.7 \% & 50.2 & 25.0 & 50.2\end{array}$

$\begin{array}{lllll}99.7 \% & 29.9 & 25.0 & 26.8 & 4\end{array}$

$\begin{array}{llll}99.7 \% & 68.2 & 25.0 & 62.9\end{array}$

$99.0 \% \quad 42.0 \quad 25.0 \quad 22.2$

$\begin{array}{llll}97.8 \% & 27.6 & 25.0 & 17.5\end{array}$

$\begin{array}{llll}99.7 \% & 35.1 & 25.0 & 35.1\end{array}$

$\begin{array}{lllll}99.7 \% & 36.3 & 25.0 & 35.3\end{array}$

$\begin{array}{lllll}99.6 \% & 27.1 & 25.0 & 27.1 & 2\end{array}$

$\begin{array}{llll}99.7 \% & 35.8 & 25.0 & 35.8\end{array}$

$\begin{array}{llll}99.7 \% & 63.3 & 25.0 & 47.4\end{array}$

$99.7 \% \quad 49.2 \quad 25.0 \quad 38.7$

$\begin{array}{llll}99.7 \% & 31.3 & 25.0 & 27.2\end{array}$

$\begin{array}{llll}99.6 \% & 27.3 & 25.0 & 27.3\end{array}$

$\begin{array}{llll}99.3 \% & 24.2 & 25.0 & 18.8\end{array}$

$\begin{array}{lllll}99.7 \% & 68.0 & 25.0 & 68.0 & 2\end{array}$

$\begin{array}{llll}99.7 \% & 51.0 & 25.0 & 47.5\end{array}$

$\begin{array}{llll}99.7 \% & 28.1 & 25.0 & 25.3\end{array}$
1251.66

1117.60

961.50

1867.98

860.48

1554.86

1108.64

1042.50

1388.8

1516.91

875.54

1744.89

1291.63

926.54

1196.71

963.59

1180.59

1867.86

974.44

962.47

1437.76

1247.73

1091.63

1026.59

1455.79

915.53

1179.60

1204.57

1923.91

1204.64

1356.66

1233.61

1088.61

1434.75

1205.69

1028.62

1407.75

1558.83

1211.61 
Protein lin-28 homolog B GN=LIN28B $\quad$ LN28B_HUMAN $27.08 \quad 100.0 \%$ Protein LSM14 homolog A GN=LSM14A LS14A_HUMAN $50.53 \quad 100.0 \%$ Protein LSM14 homolog A GN=LSM14A LS14A_HUMAN $50.53 \quad 100.0 \%$ Protein LSM14 homolog A GN=L SM14A LS14A HUMAN $50.53100 .0^{\circ}$ Protein LYRIC GN=MTDH Protein LYRIC GN=MTDH

Protein pelota homolog GN=PELO Protein pelota homolog GN=PELO Protein pelota homolog $\mathrm{GN}=\mathrm{PELO}$ Protein pelota homolog GN=PELO Protein pelota homolog GN=PELO Protein pelota homolog GN=PELO Protein pelota homolog GN=PELO Protein pelota homolog GN=PELO Protein phosphatase $1 \mathrm{~B}$ GN=PPM1B Protein phosphatase $1 \mathrm{~B}$ GN=PPM1B Protein phosphatase $1 \mathrm{~B}$ GN=PPM1B Protein phosphatase 1B GN=PPM1B Protein phosphatase 1B GN=PPM1B Protein polybromo-1 GN=PBRM1 Protein polybromo- 1 GN=PBRM1 Protein polybromo-1 GN=PBRM1 Protein PRRC2A GN=PRRC2A Protein PRRC2A GN=PRRC2A Protein PRRC2A GN=PRRC2A Protein RRP5 homolog GN=PDCD1 Protein RRP5 homolog GN=PDCD11 Protein RRP5 homolog GN=PDCD1 Protein RRP5 homolog GN=PDCD1 Protein RRP5 homolog GN=PDCD11 Protein RRP5 homolog GN=PDCD1 Protein RRP5 homolog GN=PDCD1 Protein RRP5 homolog GN=PDCD1 Protein SDA1 homolog GN=SDAD1 Protein SDA1 homolog GN=SDAD1 Protein SDA1 homolog GN=SDAD1 Protein SDA1 homolog GN=SDAD 1 Protein SDA1 homolog GN=SDAD1 Protein SDA1 homolog GN=SDAD1 Protein SEC13 homolog GN=SEC13 Protein SEC13 homolog GN=SEC13 Protein SET GN=SET Protein SET GN=SET LYRIC_HUMAN $63.84 \quad 100.0 \%$ PELO_HUMAN $43.36 \quad 100.0 \%$ PELO_HUMAN $43.36 \quad 100.0 \%$ PELO HUMAN $43.36 \quad 100.0 \%$ PELO_HUMAN $43.36 \quad 100.0 \%$ PELO_HUMAN $43.36 \quad 100.0 \%$ PELO HUMAN $43.36 \quad 100.0 \%$ PELO_HUMAN $43.36 \quad 100.0 \%$ PPM1B_HUMAN $52.64 \quad 100.0 \%$ PPM1B_HUMAN $52.64 \quad 100.0 \%$ PPM1B HUMAN $52.64 \quad 100.0 \%$ PPM1B_HUMAN $52.64 \quad 100.0 \%$ PPM1B_HUMAN $52.64 \quad 100.0 \%$ PB1 HUMAN $192.95 \quad 100.0 \%$ PB1_HUMAN $192.95 \quad 100.0 \%$ PB1 HUMAN $192.95 \quad 100.0 \%$ PRC2A_HUMAN $228.87 \quad 100.0 \%$ PRC2A_HUMAN $228.87 \quad 100.0 \%$ PRC2A_HUMAN $228.87 \quad 100.0 \%$ RRP5_HUMAN $208.70 \quad 100.0 \%$ RRP5_HUMAN $208.70 \quad 100.0 \%$ RRP5 HUMAN $208.70 \quad 100.0 \%$ RRP5_HUMAN $208.70 \quad 100.0 \%$ RRP5 HUMAN $208.70 \quad 100.0 \%$ RRP5_HUMAN $208.70 \quad 100.0 \%$ RRP5_HUMAN $208.70 \quad 100.0 \%$ RRP5 HUMAN $208.70 \quad 100.0 \%$ SDA1_HUMAN $79.88 \quad 100.0 \%$ SDA1_HUMAN $79.88 \quad 100.0 \%$ SDA1_HUMAN $79.88 \quad 100.0 \%$ SDA1_HUMAN $79.88 \quad 100.0 \%$ SDA1 HUMAN $79.88 \quad 100.0 \%$ SDA1_HUMAN $79.88 \quad 100.0 \%$ SEC13_HUMAN $35.54 \quad 100.0 \%$ SEC13 HUMAN $35.54 \quad 100.0 \%$ SET_HUMAN $33.49 \quad 100.0 \%$ SET HUMAN $33.49 \quad 100.0 \%$ S61A1_HUMAN $52.27 \quad 100.0 \%$ S61A1_HUMAN $52.27 \quad 100.0 \%$ A1 S61A1 HUMAN $52.27 \quad 100.0 \%$ 1A1 S61A1_HUMAN $52.27 \quad 100.0 \%$
LYRIC_HUMAN $63.84 \quad 100.0 \%$ PELO_HUMAN $43.36 \quad 100.0 \%$
$12.0 \%$ EVGGGHGCTSPI $0.01 \% \quad 7.1 \%$ SLKTQLSQGR $0.01 \% \quad 7.1 \%$ SPVSTRPLPSASQK $0.01 \% \quad 7.1 \%$ EFADFEYRK $0.01 \% \quad 4.1 \%$ TVEVAEGEAVR $0.01 \% \quad 4.1 \%$ TISTSDPAEVLVK $0.03 \% \quad 19.0 \%$ KVQTESSTGSVGSNR $6 \quad 0.03 \% \quad 19.0 \%$ VQTESSTGSVGSNRVR $6 \quad 0.03 \% \quad 19.0 \%$ VKGTNIQENEYVK $0.03 \% \quad 19.0 \%$ GTNIQENEYVK $0.03 \% \quad 19.0 \%$ AKVEVNIPR $0.03 \% \quad 19.0 \%$ FYEQVVQAIQR $0.03 \% \quad 19.0 \%$ TDNKLLLENR $0.03 \% \quad 19.0 \%$ LVDSVKENAGTVR $0.04 \% \quad 11.3 \%$ SGSTAVGVMISPK $0.04 \% \quad 11.3 \%$ HIYFINCGDSR $0.04 \% \quad 11.3 \%$ IQNAGGSVMIQR $0.04 \% \quad 11.3 \%$ VNGSLAVSR $0.04 \% \quad 11.3 \%$ NVIEAVYSR $0.01 \% \quad 1.5 \%$ TPSNLAAAR $0.01 \% \quad 1.5 \%$ MPISLQQIR $0.01 \% \quad 1.5 \% \quad$ VGDCVFIK $0.01 \% \quad 1.7 \%$ QSSSEISLAVER $0.01 \% \quad 1.7 \%$ GVGSGGQGPPPPRR $0.01 \% \quad 1.7 \%$ LIPGPLSPVAR $0.04 \% \quad 4.7 \%$ ACILCVHPR $0.04 \% \quad 4.7 \%$ LKDGVLAYAR $0.04 \% \quad 4.7 \%$ TSIIEAQYLR $0.04 \% \quad 4.7 \% \quad$ VLLCDPEAK $0.04 \% \quad 4.7 \% \quad$ VVVLNCEPSKER $0.04 \% \quad 4.7 \% \quad$ KPALVSTVEGGQDPK $0.04 \% \quad 4.7 \%$ LGPSVVGLAR $0.04 \% \quad 4.7 \% \quad$ AIFENTLSTYPK $0.03 \% \quad 8.3 \%$ TVNVITTACFSK $0.03 \% \quad 8.3 \%$ DLLVQYATGK $0.03 \% \quad 8.3 \%$ DLLVQYATGKK $0.03 \% \quad 8.3 \% \quad$ GKPTEASIEAR $0.03 \% \quad 8.3 \% \quad$ VLTQEDFQKIR $0.03 \% \quad 8.3 \% \quad$ TNPFSSSTNKEK $0.01 \% \quad 5.9 \% \quad$ SVKIFDVR

$0.01 \% \quad 5.9 \%$ NGGQILIADLR $0.01 \% \quad 7.2 \% \quad$ LRQPFFQK $0.01 \% \quad 7.2 \%$ EFHLNESGDPSSK

$9 \quad 0.04 \% \quad 8.6 \%$ IIEVGDTPK

$19 \quad 0.04 \% \quad 8.6 \% \quad$ IIEVGDTPKDR

$19 \quad 0.04 \% \quad 8.6 \% \quad$ AFSPTTVNTGR $19 \quad 0.04 \% \quad 8.6 \%$ GQYNTYPIK $\begin{array}{lllll}98.4 \% & 18.9 & 25.0 & 17.5 & 0\end{array}$ $\begin{array}{llll}99.7 \% & 36.1 & 25.0 & 28.8\end{array}$ $\begin{array}{llll}99.4 \% & 23.5 & 25.0 & 23.5\end{array}$ $\begin{array}{llll}99.7 \% & 31.5 & 25.0 & 23.9\end{array}$ $\begin{array}{llll}99.7 \% & 74.0 & 25.0 & 64.4\end{array}$ $\begin{array}{llll}99.7 \% & 35.6 & 25.0 & 23.8\end{array}$ $99.7 \% \quad 33.0 \quad 25.0 \quad 28.9$ $\begin{array}{llll}97.3 \% & 17.5 & 25.0 & 17.4\end{array}$ $\begin{array}{llll}99.3 \% & 23.8 & 25.0 & 23.8\end{array}$ $\begin{array}{llll}99.7 \% & 34.2 & 25.0 & 31.3\end{array}$ $\begin{array}{llll}99.7 \% & 36.1 & 25.0 & 26.5\end{array}$ $\begin{array}{llll}99.7 \% & 64.6 & 25.0 & 49.3\end{array}$ $\begin{array}{llll}99.6 \% & 26.3 & 25.0 & 26.3\end{array}$ $\begin{array}{llll}99.7 \% & 48.4 & 25.0 & 42.9\end{array}$ $\begin{array}{llll}99.7 \% & 52.4 & 25.0 & 38.8\end{array}$ $99.7 \% \quad 41.2 \quad 25.0 \quad 41.2 \quad 2$ $99.7 \% \quad 77.9 \quad 25.0 \quad 57.2$ $\begin{array}{llll}99.7 \% & 43.6 & 25.0 & 32.3\end{array}$ $\begin{array}{llll}99.7 \% & 42.0 & 25.0 & 39.3\end{array}$ $\begin{array}{llll}99.7 \% & 37.5 & 25.0 & 20.0\end{array}$ $\begin{array}{llll}98.7 \% & 25.1 & 25.0 & 15.2\end{array}$ $\begin{array}{llll}96.8 \% & 25.9 & 25.0 & 9.8\end{array}$ $\begin{array}{llll}99.7 \% & 64.7 & 25.0 & 59.0\end{array}$ $96.6 \% \quad 18.0 \quad 25.0 \quad 17.7$ $\begin{array}{llll}95.7 \% & 15.2 & 25.0 & 15.2\end{array}$ $99.7 \% \quad 35.6 \quad 25.0 \quad 27.4$ $99.7 \% \quad 44.3 \quad 25.0 \quad 37.4$ $\begin{array}{llll}99.7 \% & 46.4 & 25.0 & 40.6\end{array}$ $\begin{array}{lllll}99.7 \% & 33.0 & 25.0 & 33.0\end{array}$ $\begin{array}{llll}99.7 \% & 49.6 & 25.0 & 49.6\end{array}$ $\begin{array}{llll}99.7 \% & 35.4 & 25.0 & 35.4\end{array}$ $\begin{array}{llll}99.7 \% & 58.4 & 25.0 & 54.9\end{array}$ $\begin{array}{lllll}99.7 \% & 41.0 & 25.0 & 38.9 & 2\end{array}$ $\begin{array}{lllll}99.7 \% & 42.8 & 25.0 & 32.0 & 2\end{array}$ $\begin{array}{llll}99.7 \% & 32.3 & 25.0 & 27.4\end{array}$ $\begin{array}{llll}99.7 \% & 48.4 & 25.0 & 48.4\end{array}$ $\begin{array}{lllll}99.7 \% & 34.5 & 25.0 & 24.6\end{array}$ $\begin{array}{lllll}99.7 \% & 29.1 & 25.0 & 26.4 & 2\end{array}$ $\begin{array}{llll}99.6 \% & 26.7 & 25.0 & 26.7\end{array}$ $\begin{array}{llll}98.8 \% & 21.1 & 25.0 & 20.2\end{array}$ $\begin{array}{llll}99.7 \% & 54.1 & 25.0 & 54.1\end{array}$ $99.0 \% \quad 29.6 \quad 25.0 \quad 19.0$ $\begin{array}{llll}99.7 \% & 27.4 & 25.0 & 26.4\end{array}$ $\begin{array}{llll}95.6 \% & 25.0 & 25.0 & 15.3\end{array}$ $\begin{array}{llll}99.7 \% & 60.8 & 25.0 & 44.9\end{array}$ $\begin{array}{llll}99.7 \% & 52.1 & 25.0 & 39.8\end{array}$ $\begin{array}{llll}99.5 \% & 26.2 & 25.0 & 19.7\end{array}$

1305.66

1318.70

1119.69

1125.57

1105.64

1193.65

1044.54

1429.75

1525.82

968.59

1383.72

1340.69

1107.60

1235.70

1158.61

1376.75

1339.65

963.56

1169.66

1063.60

1446.65

971.54

1242.67

1150.59 1083.55 
$\begin{array}{lll} & \end{array}$ Protein virilizer homolog GN=KIAA1429 VIR_HUMAN $202.03 \quad 100.0 \%$ Protein virilizer homolog GN=KIAA1429 VIR_HUMAN $202.03 \quad 100.0 \%$ Protein virilizer homolog GN=KIAA1429 VIR HUMAN $202.03 \quad 100.0 \%$ Puromycin-sensitive aminopeptidase GN=NPEPPS PSA_HUMAN $103.28 \quad 100.0 \%$ Puromycin-sensitive aminopeptidase GN=NPEPPS PSA_HUMAN $103.28 \quad 100.0 \%$ Puromycin-sensitive aminopeptidase GN=NPEPPS PSA_HUMAN $103.28 \quad 100.0 \%$ Puromycin-sensitive aminopeptidase GN=NPEPPS PSA_HUMAN $103.28 \quad 100.0 \%$ Puromycin-sensitive aminopeptidase GN=NPEPPS PSA HUMAN $103.28100 .0 \%$ Puromycin-sensitive aminopeptidase GN=NPEPPS PSA_HUMAN $103.28 \quad 100.0 \%$ Puromycin-sensitive aminopeptidase GN=NPEPPS PSA_HUMAN $103.28 \quad 100.0 \%$ Puromycin-sensitive aminopeptidase GN=NPEPPS PSA HUMAN $103.28100 .0 \%$ Putative ATP-dependent RNA helicase DHX30 GN=DHX30 DHX30_HUMAN $133.94 \quad 100.0 \%$ Putative ATP-dependent RNA helicase DHX30 GN=DHX30 DHX30_HUMAN $133.94 \quad 100.0 \%$ Putative ATP-dependent RNA helicase DHX30 GN=DHX30 DHX30_HUMAN $133.94 \quad 100.0 \%$ Putative ATP-dependent RNA helicase DHX30 GN=DHX30 DHX30_HUMAN $133.94 \quad 100.0 \%$ Putative ATP-dependent RNA helicase DHX30 GN=DHX30 DHX30_HUMAN $133.94100 .0 \%$ Putative ATP-dependent RNA helicase DHX30 GN=DHX30 DHX30_HUMAN $133.94 \quad 100.0 \%$ Putative ATP-dependent RNA helicase DHX30 GN=DHX30 DHX30_HUMAN $133.94 \quad 100.0 \%$ Putative ATP-dependent RNA helicase DHX30 GN=DHX30 DHX30_HUMAN $133.94 \quad 100.0 \%$ Putative ATP-dependent RNA helicase DHX30 GN=DHX30 DHX30_HUMAN $133.94 \quad 100.0 \%$ Putative ATP-dependent RNA helicase DHX30 GN=DHX30 DHX30 HUMAN $133.94 \quad 100.0 \%$ Putative ATP-dependent RNA helicase DHX30 GN=DHX30 DHX30_HUMAN $133.94 \quad 100.0 \%$ Putative ATP-dependent RNA helicase DHX30 GN=DHX30 DHX30_HUMAN $133.94 \quad 100.0 \%$ Putative ATP-dependent RNA helicase DHX30 GN=DHX30 DHX30_HUMAN $133.94 \quad 100.0 \%$ Putative ATP-dependent RNA helicase DHX30 GN=DHX30 DHX30_HUMAN $133.94 \quad 100.0 \%$ Putative ATP-dependent RNA helicase DHX30 GN=DHX30 DHX30_HUMAN $133.94 \quad 100.0 \%$ Putative ATP-dependent RNA helicase DHX33 GN=DHX33 DHX33_HUMAN 78.88 100.0\% Putative ATP-dependent RNA helicase DHX33 GN=DHX33 DHX33_HUMAN 78.88 $100.0 \%$ Putative ATP-dependent RNA helicase DHX33 GN=DHX33 DHX33 HUMAN 78.88 100.0\% Putative ATP-dependent RNA helicase DHX57 GN=DHX57 DHX57_HUMAN $155.61 \quad 100.0 \%$ Putative ATP-dependent RNA helicase DHX57 GN=DHX57 DHX57_HUMAN $155.61 \quad 100.0 \%$ Putative helicase MOV-10 GN=MOV10 MOV10_HUMAN $113.68 \quad 100.0 \%$ Putative helicase MOV-10 GN=MOV10 MOV10_HUMAN $113.68 \quad 100.0 \%$ Putative oxidoreductase GLYR1 GN=GLYR1 GLYR1_HUMAN $60.56 \quad 100.0 \%$ Putative oxidoreductase GLYR1 GN=GLYR1 GLYR1_HUMAN $60.56 \quad 100.0 \%$ Putative oxidoreductase GLYR1 GN=GLYR1 GLYR1_HUMAN $60.56 \quad 100.0 \%$ Putative oxidoreductase GLYR1 GN=GLYR1 GLYR1 HUMAN $60.56 \quad 100.0 \%$ Putative RNA-binding protein Luc7-like 2 GN=LUC7L2 LC7L2_HUMAN $46.51 \quad 100.0 \%$ Putative RNA-binding protein Luc7-like 2 GN=LUC7L2 LC7L2_HUMAN $46.51 \quad 100.0 \%$ Putative transferase CAF17, mitochondrial GN=IBA57 CAF17_HUMAN $38.16 \quad 100.0 \%$ Putative transferase CAF17, mitochondrial GN=IBA57 CAF17_HUMAN $38.16 \quad 100.0 \%$ Pyridoxal phosphate phosphatase GN=PDXP PLPP HUMAN $31.70 \quad 100.0 \%$ Pyridoxal phosphate phosphatase GN=PDXP PLPP_HUMAN $31.70 \quad 100.0 \%$ Pyrroline-5-carboxylate reductase 1, mitochondrial GN=PYCR1 P5CR1_HUMAN $33.36 \quad 100.0 \%$ Pyrroline-5-carboxylate reductase 1, mitochondrial GN=PYCR1 P5CR1_HUMAN $33.36 \quad 100.0 \%$ Pyrroline-5-carboxylate reductase 1, mitochondrial GN=PYCR1 P5CR1_HUMAN $33.36 \quad 100.0 \%$ $0.01 \% \quad 1.6 \%$ SEYIEPAKR $0.03 \% \quad 9.0 \%$ SKYTTPSGEVR $0.03 \% \quad 9.0 \% \quad$ YAAVTQFEATDARR

$0.03 \% \quad 9.0 \%$ AEQGKFALEVAAK $0.03 \% \quad 9.0 \%$ FALEVAAK

$0.03 \% \quad 9.0 \%$ AGIISTVEVLK

$0.03 \% \quad 9.0 \%$ SPVYLTVLK

$0.03 \% \quad 9.0 \%$ AFFESHPAPSAER

$0.03 \% \quad 9.0 \%$ DAESIHQYLLQR

$0.07 \% \quad 12.0 \%$ NLLNSVIGR

$0.07 \% \quad 12.0 \%$ SVEVEGYGSK

$0.07 \% \quad 12.0 \%$ ALTQFPLPK

$0.07 \% \quad 12.0 \%$ VIQIATSSSTAK

$0.07 \% \quad 12.0 \%$ NLMQFHTVGTK

$0.07 \% \quad 12.0 \%$ IPQLLLER

$0.07 \% \quad 12.0 \%$ CNVIITQPR

$0.07 \% \quad 12.0 \%$ RISAVSVAQR

$0.07 \% \quad 12.0 \%$ ISAVSVAQR

$0.07 \% \quad 12.0 \%$ AIFQQPPVGVR

$0.07 \% \quad 12.0 \%$ TPLENLVLQAK

$0.07 \% \quad 12.0 \%$ AIVLAAIFR

$0.07 \% \quad 12.0 \%$ DPFSSSLQNR

$0.07 \% \quad 12.0 \%$ ALLSHDSGSDHLAFVR

$0.07 \% \quad 12.0 \%$ SGNILLHK

$0.01 \% \quad 4.0 \% \quad$ FRPGSGPPSR

$0.01 \% \quad 4.0 \%$ GQLLAQLR

$0.01 \% \quad 4.0 \%$ RVAAISLATR

$0.01 \% \quad 1.4 \%$ VANIICTQPR

$0.01 \% \quad 1.4 \%$ ISAISVAER

$0.01 \% \quad 2.3 \%$ SLESNPEQLQAMR

$0.01 \% \quad 2.3 \% \quad$ SVGVISPYRK

$0.03 \% \quad 9.0 \%$ IVNPPKDLK

$0.03 \% \quad 9.0 \%$ TAEKCDLFIQEGAR

$0.03 \% \quad 9.0 \%$ TSFFLGEVGNAAK

$0.03 \% \quad 9.0 \%$ ALDQSDNDMSAVYR

$0.01 \% \quad 6.6 \% \quad$ AMLDQLMGTSR

$0.01 \% \quad 6.6 \%$ LAETQEEISAEVAAK

$0.00 \% \quad 7.3 \%$ LLTQDEGPALVPGGR

$0.00 \% \quad 7.3 \%$ GCYIGQELTAR

$0.01 \% \quad 8.5 \%$ AVPGAPELLER

$0.01 \% \quad 8.5 \%$ LAGDPSAGDGAAPR

$0.04 \% \quad 32.6 \%$ GFTAAGVLAAHK

$0.04 \% \quad 32.6 \%$ LSAFRPAPR

$0.04 \% \quad 32.6 \%$ CMTNTPVVVR
$99.2 \% \quad 21.1 \quad 25.0$

$99.7 \%$

$99.7 \% \quad 39.5$

$99.1 \% \quad 20.9$

$98.4 \% 22.1$

$99.0 \% \quad 28.6$

$99.7 \% 34$.

$97.6 \% \quad 21.3$

$99.7 \% \quad 30.5$

$99.7 \% \quad 59.8$

$99.7 \% \quad 38.2$

$99.7 \% \quad 29.6$

$99.3 \% \quad 23.9$

$99.7 \% \quad 58.0$

$99.7 \% \quad 34.9$

$99.0 \% \quad 30.6$

$\begin{array}{lll}99.7 \% & 40.7\end{array}$

$98.8 \% 28.4$

$99.7 \% \quad 64.1$

$99.5 \% \quad 26.8$

$99.7 \% \quad 48.5$

$99.7 \% \quad 32.1$

$99.7 \% \quad 32.5$

$99.7 \% \quad 32.5$

$99.0 \% \quad 32.9$

$95.1 \% 22.8$

$99.0 \% 36$.

$99.7 \% \quad 35.5$

$99.7 \% 41.1$

$99.7 \% \quad 40.6$

$99.7 \% \quad 35.5$

$99.5 \% \quad 25.9$

$97.1 \% 23$.

$99.7 \% \quad 54$

$99.7 \% \quad 66.8$

$99.7 \% \quad 66.2$

$99.7 \% \quad 35.5$

$99.7 \% \quad 60.9$

$99.7 \% \quad 37.5$

$99.7 \% \quad 48.7$

$99.6 \% \quad 28$.

$99.7 \% \quad 60.3$

$99.7 \% \quad 58.3$

$99.3 \% 27.6$

$99.7 \% \quad 49.8$
1231.57

1095.57

1086.65

1092.57

1224.62

1598.79

1361.74

848.49

1129.68

1019.61

1445.68

1472.75

985.58

1054.51

1014.60

1205.67

1275.65

981.61

1100.59

1086.64

930.54

1211.69

1225.72

973.62

1150.55

1724.87

881.52

1057.55

898.55

1057.65

1171.63

945.54

1502.73

1105.64

1023.62

1637.80

1340.68

1584.70

1238.59

1588.81

1522.82

1267.61

1151.64

1254.61

1142.63

1014.58

1176.59 $\begin{array}{cc}06 & 415 \\ 57 & 365 \\ 46 & 556 \\ 06 & 1614 \\ 62 & 172 \\ 73 & 186 \\ 75 & 287 \\ 80 & 287 \\ 28 & 638 \\ 45 & 753 \\ 70 & 882 \\ 01 & 912 \\ 5 & 63 \\ 6 & 105 \\ 38 & 246 \\ 52 & 263 \\ 64 & 274 \\ 67 & 474 \\ 84 & 492 \\ 93 & 502 \\ 94 & 502 \\ 15 & 725 \\ 14 & 824 \\ 86 & 894 \\ 09 & 918 \\ 26 & 941 \\ 52 & 1059 \\ 3 & 22 \\ 1 & 88 \\ 29 & 138 \\ 93 & 602 \\ 04 & 612 \\ 96 & 508 \\ 26 & 835 \\ 6 & 34 \\ 99 & 312 \\ 23 & 435 \\ 36 & 549 \\ 9 & 19 \\ 08 & 122 \\ 98 & 212 \\ 58 & 268 \\ 6 & 46 \\ 29 & 142 \\ 8 & 29 \\ 08 & 116 \\ 20 & 129\end{array}$

Page 66 of Table S-1-3 
Pyrroline-5-carboxylate reductase 1, mitochondrial GN=PYCR1 P5CR1_HUMAN $33.36 \quad 100.0 \%$ Pyrroline-5-carboxylate reductase 1, mitochondrial GN=PYCR1 P5CR1_HUMAN $33.36 \quad 100.0 \%$ Pyrroline-5-carboxylate reductase 1, mitochondrial GN=PYCR1 P5CR1_HUMAN $33.36 \quad 100.0 \%$ Pyrroline-5-carboxylate reductase 1, mitochondrial GN=PYCR1 P5CR1_HUMAN $33.36 \quad 100.0 \%$ Pyrroline-5-carboxylate reductase 1, mitochondrial GN=PYCR1 P5CR1_HUMAN $33.36 \quad 100.0 \%$ Pyrroline-5-carboxylate reductase 2 GN=PYCR2 P5CR2_HUMAN $33.64100 .0 \%$ Pyrroline-5-carboxylate reductase 2 GN=PYCR2 P5CR2_HUMAN $33.64 \quad 100.0 \%$ Pyrroline-5-carboxylate reductase 2 GN=PYCR2 P5CR2_HUMAN $33.64 \quad 100.0 \%$ Pyrroline-5-carboxylate reductase 2 GN=PYCR2 P5CR2_HUMAN $33.64 \quad 100.0 \%$ Pyrroline-5-carboxylate reductase 2 GN=PYCR2 P5CR2_HUMAN $33.64 \quad 100.0 \%$ Pyrroline-5-carboxylate reductase 2 GN=PYCR2 P5CR2_HUMAN $33.64 \quad 100.0 \%$ Pyrroline-5-carboxylate reductase 2 GN=PYCR2 P5CR2_HUMAN $33.64 \quad 100.0 \%$ Pyrroline-5-carboxylate reductase 2 GN=PYCR2 P5CR2_HUMAN $33.64 \quad 100.0 \%$ Pyrroline-5-carboxylate reductase 2 GN=PYCR2 P5CR2_HUMAN $33.64100 .0 \%$ Pyrroline-5-carboxylate reductase 2 GN=PYCR2 P5CR2_HUMAN $33.64 \quad 100.0 \%$ Pyrroline-5-carboxylate reductase 3 GN=PYCRL P5CR3_HUMAN $28.66 \quad 100.0 \%$ Pyrroline-5-carboxylate reductase $3 \mathrm{GN}=$ PYCRL P5CR3 HUMAN $28.66 \quad 100.0 \%$ Pyrroline-5-carboxylate reductase 3 GN=PYCRL P5CR3_HUMAN $28.66 \quad 100.0 \%$ Pyrroline-5-carboxylate reductase 3 GN=PYCRL P5CR3_HUMAN $28.66100 .0 \%$

Pyvate dehydrogenase El component subunit alpha, somatic fom, mitochondrial GN=PDHAI ODPA_HUMAN $43.30 \quad 100.0 \%$

gN=pDAI ODPA_HUMAN $43.30 \quad 100.0 \%$

列 GN=PDHB ODPB HUMAN $39.23 \quad 100.0 \%$ $\begin{array}{lll} & \end{array}$ Pyruvate kinase $\mathrm{PKM}$ GN=PKN Pyruvate kinase $P K M$ GN=PKN Pyruvate kinase $\mathrm{PKM}$ GN=PKM Pyruvate kinase $\mathrm{PKM}$ GN=PKM Pyruvate kinase PKM GN=PKM Pyruvate kinase $\mathrm{PKM}$ GN=PKM Pyruvate kinase $\mathrm{PKM}$ GN=PKN Pyruvate kinase $\mathrm{PKM}$ GN=PKM Pyruvate kinase $P K M$ GN=PKM Pyruvate kinase $\mathrm{PKM}$ GN=PKM Pac GTPase-activating protein $1 \mathrm{GN}=\mathrm{RACGAP} 1 \mathrm{RGAP} 1$ HUMAN $71.03 \quad 100.0 \%$ Rac GTPase-activating protein 1 GN=RACGAP1 RGAP1_HUMAN $71.03 \quad 100.0 \%$ Rac GTPase-activating protein 1 GN=RACGAP1 RGAP1_HUMAN $71.03 \quad 100.0 \%$ Rac GTPase-activating protein $1 \mathrm{GN}=$ RACGAP1 RGAP1_HUMAN $71.03 \quad 100.0 \%$ Ran GTPase-activating protein 1 GN=RANGAP1 RAGP1_HUMAN $63.54 \quad 100.0 \%$ Ran GTPase-activating protein $1 \mathrm{GN}=$ RANGAP1 RAGP1 HUMAN $63.54100 .0 \%$ Ran GTPase-activating protein $1 \mathrm{GN}=$ RANGAP1 RAGP1_HUMAN $63.54 \quad 100.0 \%$ Ras GTPase-activating-like protein IQGAP1 GN=IQGAP1 IQGA1_HUMAN $189.26 \quad 100.0 \%$ Ras GTPase-activating-like protein IQGAP1 GN=IQGAP1 IQGA1_HUMAN $189.26 \quad 100.0 \%$ Ras GTPase-activating-like protein IQGAP1 GN=IQGAP1 IQGA1_HUMAN $189.26 \quad 100.0 \%$
$0.04 \% \quad 32.6 \%$ LGAQALLGAAK $0.04 \% 32.6 \%$ MLLHSEQHPGQLK

$0.04 \% \quad 32.6 \%$ SLLINAVEASCIR

$.7 \% \quad 76.4$

$99.5 \% 27.0$

$99.7 \% \quad 69.8$

$0.04 \% \quad 32.6 \%$ ELQSMADQEQVSPAAIKK $99.7 \% 38.2$

$0.04 \% \quad 32.6 \%$ VKLDSPAGTALSPSGHTK

$0.06 \% \quad 25.0 \%$ GFTAAGILSAHK

$0.06 \% \quad 25.0 \%$ KMGVNLTR

$99.7 \%$ \% 57.3

$97.0 \% \quad 23.8$

$0.06 \% \quad 25.0 \%$ HIVVSCAAGVTISSVEK $\quad 99.7 \% \quad 47.0$

$0.06 \% \quad 25.0 \%$ HIVVSCAAGVTISSVEKK $99.7 \% \quad 38.8$

$0.06 \% \quad 25.0 \%$ KLMAFQPAPK

$0.06 \% \quad 25.0 \%$ LMAFQPAPK

$0.06 \% \quad 25.0 \%$ SLLINAVEASCIR

$0.06 \% \quad 25.0 \%$ TRELQSMADQEK

$0.06 \% \quad 25.0 \%$ ELQSMADQEK

$0.06 \% \quad 25.0 \%$ ISPAALKK

$0.02 \% \quad 16.1 \%$ RVGFVGAGR

$\quad 0.02 \% \quad 16.1 \%$ MAGAIAQGLIR

$10 \quad 0.02 \% \quad 16.1 \%$ IAAQTLLGTAK

$10 \quad 0.02 \% \quad 16.1 \%$ AATMSAVEAATCR

$0.02 \% \quad 9.2 \% \quad$ AHGFTFTR

$10 \quad 0.02 \% \quad 9.2 \% \quad$ YGMGTSVER

$10 \quad 0.02 \% \quad 9.2 \% \quad$ AAASTDYYK

$10 \quad 0.02 \% \quad 9.2 \% \quad$ AAASTDYYKR

$10 \quad 0.02 \% \quad 9.2 \%$ TREEIQEVR

$11 \quad 0.02 \% \quad 10.9 \%$ EGVECEVINMR

$0.02 \% \quad 10.9 \%$ TIRPMDMETIEASVMK

$0.02 \% \quad 10.9 \%$ VTGADVPMPYAK

$0.10 \% \quad 21.1 \%$ LDIDSPPITAR

$0.10 \% \quad 21.1 \%$ NTGIICTIGPASR

$0.10 \% \quad 21.1 \%$ SVETLKEMIK

$0.10 \% \quad 21.1 \%$ GSGTAEVELKK

$0.10 \% \quad 21.1 \%$ ITLDNAYMEK

$0.10 \% \quad 21.1 \%$ IISKIENHEGVR

$0.10 \% \quad 21.1 \%$ GDLGIEIPAEK

$0.10 \% \quad 21.1 \%$ GDYPLEAVR

$0.10 \% \quad 21.1 \%$ CCSGAIIVLTK

$0.10 \% \quad 21.1 \%$ APIIAVTRNPQTAR

$0.01 \% \quad 7.9 \%$ SALDVKLK

$0.01 \% \quad 7.9 \%$ SIGSAVDQGNESIVAK

$0.01 \% \quad 7.9 \%$ VAQSPHTKMDVANLAK

$0.01 \% \quad 7.9 \%$ TPSSSSLSQR

$0.02 \% \quad 6.0 \% \quad$ TQVAGGQLSFKGK

$0.02 \% \quad 6.0 \%$ SKGAVAIADAIR

$0.02 \% \quad 6.0 \%$ HSLLQTLYKV

$0.02 \% \quad 3.1 \%$ LGNFFSPK

$0.02 \% \quad 3.1 \%$ ALESGDVNTVWK

$0.02 \% \quad 3.1 \%$ TLQALQIPAAK
$25.0 \quad 33.8$

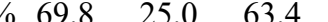

$\begin{array}{llll}99.7 \% & 57.2 & 25.0 & 45.8\end{array}$

$\begin{array}{llll}99.7 \% & 50.3 & 25.0 & 40.7\end{array}$

$\begin{array}{llll}99.0 \% & 44.7 & 25.0 & 35.7\end{array}$

$99.7 \% \quad 42.7$

$99.7 \% \quad 68.6$

$99.7 \% \quad 58.9$

$99.7 \% \quad 67.3$

$96.7 \% \quad 17.0$

$99.2 \% \quad 19.5$

$99.4 \% \quad 23.2$

$99.7 \% \quad 50.2$

$99.7 \% \quad 41.4$

$99.7 \% \quad 63.9$

$99.3 \% \quad 22.0$

$99.7 \% \quad 59.4$

$99.7 \% \quad 61.0$

$99.7 \% \quad 72.1$

$99.7 \% \quad 47.8$

$99.7 \% \quad 59.4$

$99.7 \% \quad 58.8$

$99.7 \% \quad 58.9$

$99.7 \% \quad 43.6$

$99.7 \% \quad 61.8$

$99.7 \% \quad 68.8$

$99.7 \% \quad 43.3$

$99.0 \% \quad 26.2$

$99.7 \% \quad 49.4$

$99.2 \% \quad 21.2$

$99.7 \% \quad 35.5$

$99.7 \% \quad 33.1$

$\begin{array}{lll}99.7 \% & 34.1\end{array}$

$99.7 \% \quad 33.7$

$99.0 \% \quad 49.7$

$99.7 \% \quad 38.3$

$98.9 \% \quad 22.6$
1445.78

1973.00

1765.94

1172.64

934.51

1756.93

1885.02

1130.64

1002.54

1445.78

1435.68

1194.53

827.54

918.53

1116.62

1086.65

1338.61

936.47

1015.45

989.46

1145.56

1159.61

1335.60

1899.89

1264.62

1197.65

1359.71

1177.65

1118.61

1197.58

1394.78

1141.61

1019.52

1221.63

1507.87

873.54

1574.80

1725.90

1049.52

1320.73

1171.68

1201.69

909.48

1318.66

1153.69

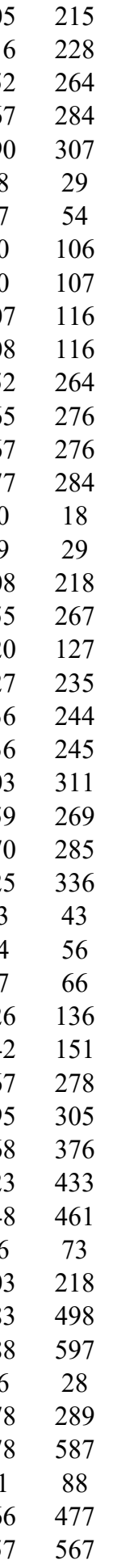

Page 67 of Table S-1-3 
Ras GTPase-activating-like protein IQGAP1 GN=IQGAP1 IQGA1_HUMAN $189.26 \quad 100.0 \%$ Ras GTPase-activating-like protein IQGAP1 GN=IQGAP1 IQGA1_HUMAN $189.26 \quad 100.0 \%$ Regulator of nonsense transcripts 1 GN=UPF1 RENT1_HUMAN $124.35 \quad 100.0 \%$ Regulator of nonsense transcripts 1 GN=UPF1 RENT1_HUMAN $124.35 \quad 100.0 \%$ Regulator of nonsense transcripts 1 GN=UPF1 RENT1_HUMAN $124.35 \quad 100.0 \%$ Replication factor C subunit $1 \mathrm{GN}=\mathrm{RFC} 1 \quad$ RFC1_HUMAN $128.26 \quad 100.0 \%$ Replication factor C subunit $1 \mathrm{GN}=\mathrm{RFC1}$ RFC1_HUMAN $128.26 \quad 100.0 \%$ Replication factor C subunit $2 \mathrm{GN}=\mathrm{RFC} 2 \mathrm{RFC} 2$ HUMAN $39.16 \quad 100.0 \%$ Replication factor $\mathrm{C}$ subunit $2 \mathrm{GN}=\mathrm{RFC} 2 \mathrm{RFC} 2 \mathrm{HUMAN} 39.16 \quad 100.0 \%$ Replication factor C subunit 2 GN=RFC2 RFC2_HUMAN $39.16 \quad 100.0 \%$ Replication factor C subunit $3 \mathrm{GN}=\mathrm{RFC} 3$ RFC3_HUMAN $40.56 \quad 100.0 \%$ Replication factor $\mathrm{C}$ subunit $3 \mathrm{GN}=\mathrm{RFC} 3$ RFC3_HUMAN $40.56 \quad 100.0 \%$ $\begin{array}{llll}\text { Replication factor C subunit } 3 \mathrm{GN}=\mathrm{RFC} 3 & \mathrm{RFC} 3 \text { _HUMAN } & 40.56 & 100.0 \%\end{array}$ Replication factor $\mathrm{C}$ subunit $3 \mathrm{GN}=\mathrm{RFC} 3 \quad \mathrm{RFC} 3$ _HUMAN $40.56 \quad 100.0 \%$ Replication factor C subunit $3 \mathrm{GN}=\mathrm{RFC} 3 \quad \mathrm{RFC} 3$ _HUMAN $40.56 \quad 100.0 \%$ Replication factor C subunit $3 \mathrm{GN}=\mathrm{RFC} 3$ RFC3_HUMAN $40.56 \quad 100.0 \%$ Replication factor $\mathrm{C}$ subunit $3 \mathrm{GN}=\mathrm{RFC} 3 \mathrm{RFC} 3$ HUMAN $40.56 \quad 100.0 \%$ Replication factor C subunit 4 GN=RFC4 RFC4_HUMAN $39.68 \quad 100.0 \%$ Replication factor C subunit $4 \mathrm{GN}=\mathrm{RFC} 4 \quad$ RFC4_HUMAN $39.68 \quad 100.0 \%$ Replication factor C subunit 4 GN=RFC4 RFC4_HUMAN $39.68 \quad 100.0 \%$ Replication factor C subunit 4 GN=RFC4 RFC4_HUMAN $39.68 \quad 100.0 \%$ Replication factor $\mathrm{C}$ subunit $4 \mathrm{GN}=\mathrm{RFC} 4 \mathrm{RFC} 4 \mathrm{HUMAN} 39.68 \quad 100.0 \%$ Replication factor C subunit 4 GN=RFC4 RFC4_HUMAN $39.68 \quad 100.0 \%$ Replication factor C subunit 4 GN=RFC4 RFC4_HUMAN $39.68 \quad 100.0 \%$ Replication factor C subunit $4 \mathrm{GN}=\mathrm{RFC} 4 \quad \mathrm{RFC} 4$ HUMAN $39.68 \quad 100.0 \%$ Replication factor C subunit 4 GN=RFC4 RFC4_HUMAN $39.68 \quad 100.0 \%$ Replication factor C subunit $5 \mathrm{GN}=\mathrm{RFC} 5$ RFC5_HUMAN $38.50 \quad 100.0 \%$ Replication factor C subunit 5 GN=RFC5 RFC5_HUMAN $38.50 \quad 100.0 \%$ Replication factor C subunit 5 GN=RFC5 RFC5_HUMAN $38.50 \quad 100.0 \%$ Replication factor C subunit $5 \mathrm{GN}=\mathrm{RFC} 5 \mathrm{RFC5}$ HUMAN $38.50 \quad 100.0 \%$ Replication factor C subunit 5 GN=RFC5 RFC5_HUMAN $38.50 \quad 100.0 \%$ Ribonuclease P protein subunit p30 GN=RPP30 RPP30_HUMAN $29.32 \quad 100.0 \%$ Ribonuclease P protein subunit p30 GN=RPP30 RPP30 HUMAN $29.32 \quad 100.0 \%$ Ribonuclease P protein subunit p30 GN=RPP30 RPP30_HUMAN $29.32 \quad 100.0 \%$ Ribonuclease P protein subunit $\mathrm{p} 30 \mathrm{GN}=\mathrm{RPP} 30$ RPP30 HUMAN $29.32 \quad 100.0 \%$ Ribonuclease P protein subunit p30 GN=RPP30 RPP30_HUMAN $29.32 \quad 100.0 \%$ Ribonuclease P protein subunit p38 GN=RPP38 RPP38_HUMAN $31.84 \quad 100.0 \%$ Ribonuclease P protein subunit p38 GN=RPP38 RPP38 HUMAN $31.84 \quad 100.0 \%$ Ribonuclease P protein subunit p38 GN=RPP38 RPP38_HUMAN $31.84 \quad 100.0 \%$ Ribonuclease P protein subunit $\mathrm{p} 38 \mathrm{GN}=\mathrm{RPP} 38$ RPP38_HUMAN $31.84 \quad 100.0 \%$ Ribonuclease P protein subunit p38 GN=RPP38 RPP38_HUMAN $31.84 \quad 100.0 \%$ Ribonuclease P protein subunit p38 GN=RPP38 RPP38_HUMAN $31.84 \quad 100.0 \%$ Ribonuclease P protein subunit $\mathrm{p} 38 \mathrm{GN}=\mathrm{RPP} 38$ RPP38 HUMAN $31.84 \quad 100.0 \%$ Ribonuclease P protein subunit p38 GN=RPP38 RPP38_HUMAN $31.84 \quad 100.0 \%$ Ribose-phosphate pyrophosphokinase $1 \mathrm{GN}=$ PRPS1 PRPS1_HUMAN $34.83 \quad 100.0 \%$ Ribose-phosphate pyrophosphokinase $1 \mathrm{GN}=$ PRPS1 PRPS1_HUMAN $34.83 \quad 100.0 \%$ Ribose-phosphate pyrophosphokinase 1 GN=PRPS1 PRPS1_HUMAN $34.83 \quad 100.0 \%$
$0.02 \% \quad 3.1 \% \quad$ LIFQMPQNK $0.02 \% \quad 3.1 \% \quad$ LQQTYAALNSK

$0.01 \% \quad 3.2 \%$ TVTSATIVYHLAR $0.01 \% \quad 3.2 \%$ AGLSQSLFER

$0.01 \% \quad 3.2 \%$ AYQHGGVTGLSQY

$0.01 \% \quad 2.2 \% \quad$ SSADKIGEVSSPK

$0.01 \% \quad 2.2 \%$ AALLSGPPGVGK

$0.02 \% \quad 5.9 \%$ TTSILCLAR

$0.02 \% \quad 5.9 \% \quad$ YTKLTDAQILTR

$0.02 \% \quad 5.9 \% \quad$ LTDAQILTR

$0.04 \% \quad 21.9 \%$ LDYHKEQAAQLR

$0.04 \% \quad 21.9 \%$ ELYGVGVEK

$19 \quad 0.04 \% \quad 21.9 \%$ TVAQSQQLETNSQR

$19 \quad 0.04 \% \quad 21.9 \%$ TMEKYMSTCR

$0.04 \% \quad 21.9 \%$ LILCCNSTSK

$9 \quad 0.04 \% \quad 21.9 \%$ ALLMCEACR

$19 \quad 0.04 \% \quad 21.9 \%$ ETANAIVSQQTPQR

$0.04 \% \quad 22.9 \%$ GTSISTKPPLTK

$17 \quad 0.04 \% \quad 22.9 \%$ GTSISTKPPLTKDR

$0.04 \% \quad 22.9 \%$ TSTILAAAR

$0.04 \% \quad 22.9 \%$ VLELNASDER

$0.04 \% 22.9 \%$ VKNFAQLTVSGSR

$0.04 \% \quad 22.9 \%$ IIEPLTSR

$0.04 \% \quad 22.9 \%$ ISDEGIAYLVK

$0.04 \% \quad 22.9 \%$ VSEGDLRK

$0.04 \% \quad 22.9 \%$ AITFLQSATR

$0.03 \% \quad 11.8 \%$ TSTILACAK

$0.03 \% \quad 11.8 \%$ GPILSFASTR

$0.03 \% \quad 11.8 \%$ ALVTLSSGDMR

$0.03 \% \quad 11.8 \%$ ALVTLSSGDMRR

$0.03 \% \quad 11.8 \%$ NITELKTLK

$0.01 \% \quad 20.5 \%$ LTIIVSDPSHCNVLR

$0.01 \% \quad 20.5 \%$ LYDVVAVFPK

$0.01 \% \quad 20.5 \%$ RPPINVAIDR

$0.01 \% \quad 20.5 \%$ AALLHGETR

$0.01 \% \quad 20.5 \%$ KTAFGIISTVK

$0.03 \% \quad 24.0 \%$ TSLNNPYIIR

$0.03 \% \quad 24.0 \%$ KQLAIGVNEVTR

$0.03 \% \quad 24.0 \%$ QLAIGVNEVTR

$0.03 \% \quad 24.0 \%$ ELLLVLVCK

$0.03 \% \quad 24.0 \%$ IAPVIGLK

$0.03 \% \quad 24.0 \%$ CVLALAFKK

$0.03 \% \quad 24.0 \%$ NTTDFVDEVR

$0.03 \% \quad 24.0 \%$ QASVTLQPLK

$0.02 \% \quad 12.6 \%$ PNIKIFSGSSHQDLSQK

$0.02 \% \quad 12.6 \%$ IFSGSSHQDLSQK

$0.02 \% \quad 12.6 \%$ NCTIVSPDAGGAK
$98.9 \% \quad 28.0$

$99.7 \% \quad 51.4$

$99.7 \% \quad 49.4$

$99.7 \% \quad 48.0$

$99.2 \% \quad 22.8$

$99.7 \% \quad 29.3$

$99.7 \% \quad 32.6$

$99.7 \% 35$.

$99.7 \% \quad 55.2$

$99.7 \% \quad 49.4$

$99.7 \% \quad 40.8$

$99.2 \% 21.1$

$99.7 \% \quad 73.3$

$99.7 \% \quad 31.3$

$99.7 \% \quad 52.3$

$99.7 \% \quad 49.8$

$99.7 \% \quad 52.4$

$99.7 \% \quad 32.7$

$\begin{array}{lll}99.4 \% & 23.8\end{array}$

$99.7 \% \quad 43.0$

$99.7 \% \quad 39.3$

$99.7 \% \quad 65.5$

$99.0 \% \quad 40.2$

$99.7 \% \quad 60.1$

$95.9 \% 27.1$

$99.7 \% \quad 48.2$

$99.7 \% 35$.

$99.7 \% \quad 48.5$

$99.7 \% \quad 33.7$

$95.2 \% \quad 21.5$

$99.7 \% \quad 30.4$

$99.7 \% \quad 27.9$

$99.4 \% 21.2$

$99.7 \% \quad 43.2$

$99.7 \% \quad 31.9$

$98.7 \% \quad 20.4$

$99.7 \% \quad 58.5$

$99.3 \% 27.5$

$99.7 \% \quad 42.3$

$99.7 \% \quad 39.3$

$98.4 \% \quad 19.4$

$99.7 \% \quad 45.1$

$99.7 \% \quad 53.8$

$99.7 \% \quad 35.4$

$99.6 \% \quad 26.5$

$99.7 \% \quad 34.3$

$99.7 \% \quad 50.5$

0

$0 \quad 49.4$

$0 \quad 28.9$

22.8

$\begin{array}{ll}0 & 27.1 \\ & \end{array}$

28.9

045

45.1
.0

34.5
25.0

$25.0 \quad 21.1$

62.0

\begin{tabular}{ll}
3.0 & 31.3 \\
\hline
\end{tabular}

$\begin{array}{ll}.0 & 49.8 \\ & 44.2\end{array}$

$\begin{array}{ll}25.0 & 44.2 \\ 25.0 & 19.2\end{array}$

\begin{tabular}{ll}
23.0 \\
\hline
\end{tabular}

$\begin{array}{ll}23.0 & 29.7\end{array}$

38.7

\begin{tabular}{ll}
0 & 65.5 \\
\hline
\end{tabular}

5.8
-0.9

$\begin{array}{lll}5.0 & 50.9 & 2\end{array}$

$\begin{array}{lll}7.9 & 1 \\ 25.0 & 46.8 & 2\end{array}$

35.

$\begin{array}{ll}35.0 & 43.0\end{array}$

$\begin{array}{lll}.0 & 28.0 & 2\end{array}$

$\begin{array}{ll}25.0 & 15.5\end{array}$

$\begin{array}{ll}.0 & 20.9 \\ 25.0 & 25.7\end{array}$

\begin{tabular}{ll}
25.0 & 25.7 \\
\hline
\end{tabular}

$25.0-21.2$

\begin{tabular}{ll}
28.0 & 28.2 \\
\hline & 21.4
\end{tabular}

\begin{tabular}{ll}
.0 & 21.4 \\
\hline & 1
\end{tabular}

$\begin{array}{lll}5.0 & 52.9 & 2\end{array}$

$25.0 \quad 25.2$

$25.0 \quad 31.6 \quad 2$

$\begin{array}{lll}25.0 & 39.3 & 2\end{array}$

$\begin{array}{lll}25.0 & 37.3 & 2\end{array}$

$\begin{array}{lll}25.0 & 45.6 & 2\end{array}$

$\begin{array}{lll}25.0 & 25.1 & 2\end{array}$

$25.0 \quad 26.5 \quad 0$

$25.0 \quad 34.3$

$\begin{array}{ll}5.0 & 34.3 \\ 26.1\end{array}$

0
0

$\begin{array}{ll}0 & 123 \\ 0 & 143\end{array}$

$0 \quad 1431.8$

1107.5

1380.65

1066.63

1034.57

1422.80

1030.59

1471.77

993.53

1589.79

1306.56

1195.58

1139.50

1542.79

1229.71

1500.84

903.53

1145.58

1406.78

928.55

1207.66

903.49

1107.62

964.51

1048.58

1149.59

1321.69

1059.64

1723.92

1150.65

1150.67

967.53

1164.70

1190.65

1327.77

1199.67

1086.66

810.54

1049.62

1195.56

1084.64

1885.98

1433.70 1289.62 
Ribose-phosphate pyrophosphokinase 1 GN=PRPS1 PRPS1_HUMAN $34.83 \quad 100.0 \%$ Ribose-phosphate pyrophosphokinase 2 GN=PRPS2 PRPS2_HUMAN $34.77 \quad 100.0 \%$ Ribose-phosphate pyrophosphokinase 2 GN=PRPS2 PRPS2_HUMAN $34.77 \quad 100.0 \%$ Ribose-phosphate pyrophosphokinase $2 \mathrm{GN}=$ PRPS2 PRPS2_HUMAN $34.77 \quad 100.0 \%$ Ribosomal biogenesis protein LAS1L GN=LAS1L LAS1L_HUMAN $83.07 \quad 100.0 \%$ Ribosomal biogenesis protein LAS1L GN=LAS1L LAS1L_HUMAN $83.07 \quad 100.0 \%$ Ribosomal biogenesis protein LAS1L GN=LAS1L LAS1L_HUMAN $83.07 \quad 100.0 \%$ Ribosomal biogenesis protein LAS1L GN=LAS1L LAS1L_HUMAN $83.07 \quad 100.0 \%$ Ribosomal L1 domain-containing protein 1 GN=RSL1D1 RL1D1_HUMAN $54.97 \quad 100.0 \%$ Ribosomal L1 domain-containing protein 1 GN=RSL1D1 RL1D1_HUMAN $54.97 \quad 100.0 \%$ Ribosomal L1 domain-containing protein $1 \mathrm{GN}=$ RSL1D1 RL1D1_HUMAN $54.97 \quad 100.0 \%$ Ribosomal L1 domain-containing protein 1 GN=RSL1D1 RL1D1_HUMAN $54.97 \quad 100.0 \%$ Ribosomal L1 domain-containing protein $1 \mathrm{GN}=$ RSL1D1 RL1D1_HUMAN $54.97 \quad 100.0 \%$ Ribosomal L1 domain-containing protein 1 GN=RSL1D1 RL1D1_HUMAN $54.97 \quad 100.0 \%$ Ribosomal L1 domain-containing protein $1 \mathrm{GN}=$ RSL1D1 RL1D1_HUMAN $54.97 \quad 100.0 \%$ Ribosomal L1 domain-containing protein 1 GN=RSL1D1 RL1D1_HUMAN $54.97 \quad 100.0 \%$ Ribosomal protein S6 kinase alpha-3 GN=RPS6KA3 KS6A3_HUMAN $83.74 \quad 100.0 \%$ Ribosomal protein S6 kinase alpha-3 GN=RPS6KA3 KS6A3_HUMAN $83.74 \quad 100.0 \%$ Ribosomal protein S6 kinase alpha-3 GN=RPS6KA3 KS6A3_HUMAN $83.74 \quad 100.0 \%$ Ribosomal RNA processing protein 1 homolog A GN=RRP1 RRP1_HUMAN $52.84 \quad 100.0 \%$ Ribosomal RNA processing protein 1 homolog A GN=RRP1 RRP1_HUMAN $52.84 \quad 100.0 \%$ Ribosomal RNA processing protein 1 homolog B GN=RRP1B RRP1B_HUMAN $84.43 \quad 100.0 \%$ Ribosomal RNA processing protein 1 homolog B GN=RRP1B RRP1B_HUMAN $84.43 \quad 100.0 \%$ Ribosomal RNA processing protein 1 homolog B GN=RRP1B RRP1B_HUMAN $84.43 \quad 100.0 \%$ Ribosomal RNA processing protein 1 homolog B GN=RRP1B RRP1B_HUMAN $84.43 \quad 100.0 \%$ Ribosomal RNA processing protein 1 homolog B GN=RRP1B RRP1B_HUMAN $84.43 \quad 100.0 \%$ Ribosomal RNA processing protein 1 homolog B GN=RRP1B RRP1B_HUMAN $84.43 \quad 100.0 \%$ Ribosomal RNA processing protein 1 homolog B GN=RRP1B RRP1B_HUMAN $84.43 \quad 100.0 \%$ Ribosome biogenesis protein BMS1 homolog GN=BMS1 BMS1_HUMAN $145.81 \quad 100.0 \%$ Ribosome biogenesis protein BMS1 homolog GN=BMS1 BMS1 HUMAN $145.81 \quad 100.0 \%$ Ribosome production factor 2 homolog GN=RPF2 RPF2_HUMAN $35.59 \quad 100.0 \%$ Ribosome production factor 2 homolog GN=RPF2 RPF2_HUMAN $35.59 \quad 100.0 \%$ Ribosome production factor 2 homolog GN=RPF2 RPF2_HUMAN $35.59 \quad 100.0 \%$ RING finger protein $219 \mathrm{GN}=\mathrm{RNF} 219 \quad$ RN219_HUMAN $81.12 \quad 100.0 \%$ RING finger protein $219 \mathrm{GN}=\mathrm{RNF} 219 \quad$ RN219_HUMAN $81.12 \quad 100.0 \%$ RING finger protein 219 GN=RNF219 RN219_HUMAN $81.12 \quad 100.0 \%$ RING finger protein $219 \mathrm{GN}=\mathrm{RNF} 219 \quad$ RN219_HUMAN $81.12 \quad 100.0 \%$ RING finger protein 219 GN=RNF219 RN219_HUMAN $81.12 \quad 100.0 \%$ RNA 3'-terminal phosphate cyclase GN=RTCA RTCA_HUMAN $39.34 \quad 100.0 \%$ RNA 3'-terminal phosphate cyclase GN=RTCA RTCA_HUMAN $39.34 \quad 100.0 \%$ RNA 3'-terminal phosphate cyclase-like protein GN=RCL1 RCL1 HUMAN $40.84 \quad 100.0 \%$ RNA 3'-terminal phosphate cyclase-like protein GN=RCL1 RCL1_HUMAN $40.84 \quad 100.0 \%$ RNA 3'-terminal phosphate cyclase-like protein GN=RCL1 RCL1_HUMAN $40.84 \quad 100.0 \%$ RNA 3'-terminal phosphate cyclase-like protein GN=RCL1 RCL1_HUMAN $40.84 \quad 100.0 \%$ RNA pseudouridylate synthase domain-containing protein 3 GN=RPUSD3 RUSD3_HUMAN $38.46 \quad 100.0 \%$ RNA pseudouridylate synthase domain-containing protein 3 GN=RPUSD3 RUSD3_HUMAN $38.46 \quad 100.0 \%$ RNA pseudouridylate synthase domain-containing protein $3 \mathrm{GN}=\mathrm{RPUSD} 3$ RUSD3_HUMAN $38.46 \quad 100.0 \%$
$0.02 \% \quad 12.6 \%$ MVLVGDVKDR $0.01 \% \quad 11.9 \%$ PNIVLFSGSSHQDLSQR $0.01 \% \quad 11.9 \%$ VADRLGLELGK $0.01 \% \quad 11.9 \%$ MVLVGDVKDR $0.01 \% \quad 3.5 \% \quad$ FVNLISER $0.01 \% \quad 3.5 \% \quad$ FVNLISERK $0.01 \% \quad 3.5 \% \quad$ AWNNPSPR $0.01 \% \quad 3.5 \%$ VECVLAELK $0.03 \% \quad 15.5 \%$ AVDALLTHCK $0.03 \% \quad 15.5 \%$ LTLPHSIR $0.03 \% \quad 15.5 \%$ TVSQIISLQTLKK $0.03 \% \quad 15.5 \%$ RLLPSLIGR $0.03 \% \quad 15.5 \%$ LLPSLIGR $0.03 \% \quad 15.5 \%$ VPVSVNLLSK $0.03 \% \quad 15.5 \%$ EINDCIGGTVLNISK $0.03 \% \quad 15.5 \%$ TPANEKVEIQK $0.01 \% \quad 3.9 \%$ GGELLDKILR $0.01 \% \quad 3.9 \%$ ICDFGFAK $0.01 \% \quad 3.9 \% \quad$ NQSPVLEPVGR $0.01 \% \quad 4.6 \% \quad$ LAGNEQVTR $0.01 \% \quad 4.6 \%$ TKDSLVLNNITR $0.04 \% \quad 10.6 \%$ APAMQPAEIQFAQR $0.04 \% \quad 10.6 \%$ GSPTGGAQLLK $0.04 \% \quad 10.6 \%$ SSTATHPPGPAVQLNK $0.04 \% \quad 10.6 \%$ SSTATHPPGPAVQLNKTPSSSK $0.04 \% \quad 10.6 \%$ KVTFGLNR $0.04 \% \quad 10.6 \%$ SILVSPTGPSR $0.04 \% \quad 10.6 \%$ TPTSSPASSPLVAK $0.01 \% \quad 1.6 \%$ AFAVQSAVR $0.01 \% \quad 1.6 \%$ SSLKGAEGQLQ $0.01 \% \quad 10.5 \%$ VLKDVYALK $0.01 \% \quad 10.5 \%$ THLASDDLYK $0.01 \% \quad 10.5 \%$ NISHDTFGTTYGR $0.03 \% \quad 7.7 \%$ NLSLESQIK $0.03 \% \quad 7.7 \%$ FAVAALQSK $0.03 \% \quad 7.7 \%$ GSEEDVVSKNQGDSAR $0.03 \% \quad 7.7 \%$ SLDLDGLSK $0.03 \% \quad 7.7 \%$ KIQSSLSSASPSK $0.01 \% \quad 6.6 \%$ VEVDGSIMEGGGQILR $0.01 \% \quad 6.6 \%$ DMAAAAVR $0.01 \% \quad 12.6 \%$ LVLSTLSGRPVK $0.01 \% \quad 12.6 \%$ GVTNDQVDPSVDVLK $0.01 \% \quad 12.6 \%$ VLKPIQLTDPGK $0.01 \% \quad 12.6 \%$ LLLEEIYR $0.02 \% \quad 13.7 \%$ ASGKESSGLVLLSSCPQTASR $0.02 \% \quad 13.7 \%$ VGTVLGQR $0.02 \% \quad 13.7 \%$ QVLDEALLR $\begin{array}{llll}99.7 \% & 53.3 & 25.0 & 48.3\end{array}$ $\begin{array}{llll}99.7 \% & 38.7 & 25.0 & 35.9\end{array}$ $\begin{array}{llll}99.7 \% & 40.5 & 25.0 & 24.6\end{array}$ $\begin{array}{llll}99.7 \% & 53.3 & 25.0 & 48.3\end{array}$ $\begin{array}{llll}99.0 \% & 36.3 & 25.0 & 34.2\end{array}$ $99.7 \% \quad 32.6 \quad 25.0 \quad 25.5$ $99.0 \% \quad 32.2 \quad 25.0 \quad 25.9$ $\begin{array}{llll}99.7 \% & 33.8 & 25.0 & 22.5\end{array}$ $\begin{array}{llll}99.7 \% & 46.9 & 25.0 & 43.2\end{array}$ $\begin{array}{llll}98.9 \% & 21.6 & 25.0 & 21.6\end{array}$ $\begin{array}{llll}99.7 \% & 30.7 & 25.0 & 30.7\end{array}$ $\begin{array}{llll}99.5 \% & 25.6 & 25.0 & 20.0\end{array}$ $\begin{array}{llll}95.8 \% & 17.1 & 25.0 & 15.7\end{array}$ $\begin{array}{llll}99.6 \% & 25.6 & 25.0 & 25.6\end{array}$ $\begin{array}{llll}99.7 \% & 46.8 & 25.0 & 40.6\end{array}$ $\begin{array}{llll}99.7 \% & 41.5 & 25.0 & 33.2\end{array}$ $99.7 \% \quad 42.0 \quad 25.0 \quad 27.2$ $\begin{array}{llll}95.3 \% & 26.0 & 25.0 & 0.0\end{array}$ $\begin{array}{llll}99.7 \% & 31.1 & 25.0 & 28.4\end{array}$ $\begin{array}{llll}99.7 \% & 49.1 & 25.0 & 36.4\end{array}$ $\begin{array}{lllll}99.7 \% & 48.0 & 25.0 & 48.0\end{array}$ $\begin{array}{llll}99.7 \% & 57.3 & 25.0 & 53.8\end{array}$ $\begin{array}{llll}99.7 \% & 32.2 & 25.0 & 17.7\end{array}$ $\begin{array}{llll}99.2 \% & 21.8 & 25.0 & 21.8\end{array}$ $\begin{array}{llll}97.0 \% & 18.8 & 25.0 & 18.8\end{array}$ $\begin{array}{llll}99.0 \% & 34.2 & 25.0 & 34.2\end{array}$ $\begin{array}{llll}99.7 \% & 32.4 & 25.0 & 28.7\end{array}$ $\begin{array}{llll}99.7 \% & 58.3 & 25.0 & 58.3\end{array}$ $99.7 \% \quad 43.1 \quad 25.0 \quad 28.2 \quad 3$ $\begin{array}{llll}99.7 \% & 37.2 & 25.0 & 21.6\end{array}$ $\begin{array}{llll}97.9 \% & 25.0 & 25.0 & 12.9\end{array}$ $\begin{array}{llll}99.7 \% & 32.0 & 25.0 & 32.0\end{array}$ $\begin{array}{llll}99.7 \% & 72.1 & 25.0 & 72.1\end{array}$ $\begin{array}{llll}95.0 \% & 19.1 & 25.0 & 11.9\end{array}$ $99.7 \% \quad 52.9 \quad 25.0 \quad 34.2$ $\begin{array}{llll}99.3 \% & 20.7 & 25.0 & 20.7\end{array}$ $\begin{array}{llll}99.7 \% & 34.7 & 25.0 & 29.3\end{array}$ $\begin{array}{llll}99.7 \% & 52.7 & 25.0 & 50.2\end{array}$ $99.7 \% \quad 47.0 \quad 25.0 \quad 47.0$ $\begin{array}{llll}99.0 \% & 39.7 & 25.0 & 24.9\end{array}$ $\begin{array}{llll}99.7 \% & 50.1 & 25.0 & 46.6\end{array}$ $\begin{array}{lllll}99.7 \% & 52.9 & 25.0 & 45.1 & 2\end{array}$ $\begin{array}{llll}97.6 \% & 17.1 & 25.0 & 17.1\end{array}$ $\begin{array}{llll}99.0 \% & 48.8 & 25.0 & 47.6\end{array}$ $\begin{array}{llll}99.7 \% & 45.4 & 25.0 & 40.1 \\ 99.0 \% & 47.1 & 25.0 & 24.2\end{array}$ $\begin{array}{llll}99.3 \% & 38.0 & 25.0 & 9.6\end{array}$

$\begin{array}{ccc}1131.62 & 205 & 214 \\ 1884.96 & 2 & 18 \\ 1170.68 & 19 & 29 \\ 1131.62 & 205 & 214 \\ 977.54 & 122 & 129 \\ 1105.64 & 122 & 130 \\ 941.46 & 296 & 303 \\ 1060.57 & 304 & 312 \\ 1127.59 & 39 & 48 \\ 936.56 & 82 & 89 \\ 1458.89 & 125 & 137 \\ 1024.66 & 163 & 171 \\ 868.56 & 164 & 171 \\ 1055.65 & 179 & 188 \\ 1632.83 & 193 & 207 \\ 1256.68 & 375 & 385 \\ 1113.66 & 498 & 507 \\ 957.45 & 559 & 566 \\ 1195.64 & 713 & 723 \\ 987.52 & 17 & 25 \\ 1373.77 & 204 & 215 \\ 1573.78 & 2 & 15 \\ 1028.57 & 512 & 522 \\ 1604.84 & 661 & 676 \\ 2192.13 & 661 & 682 \\ 934.55 & 683 & 690 \\ 1113.63 & 702 & 712 \\ 1342.72 & 728 & 741 \\ 948.53 & 44 & 52 \\ 1117.58 & 1272 & 1282 \\ 1048.64 & 48 & 56 \\ 1162.57 & 228 & 237 \\ 1468.68 & 253 & 265 \\ 1031.57 & 117 & 125 \\ 934.54 & 217 & 225 \\ 1677.77 & 284 & 299 \\ 947.50 & 561 & 569 \\ 1319.72 & 710 & 722 \\ 1675.83 & 6 & 21 \\ 804.40 & 209 & 216 \\ 1269.79 & 20 & 31 \\ 1585.81 & 119 & 133 \\ 1308.79 & 176 & 187 \\ 1048.60 & 282 & 289 \\ 2135.08 & 133 & 153 \\ 829.49 & 268 & 275 \\ 1056.60 & 288 & 296\end{array}$


RNA pseudouridylate synthase domain-containing protein 3 GN=RPUSD3 RUSD3_HUMAN $38.46 \quad 100.0 \%$ RNA-binding motif protein, $\mathrm{X}$ chromosome GN=RBMX RBMX_HUMAN $42.33 \quad 100.0 \%$ RNA-binding motif protein, $X$ chromosome GN=RBMX RBMX_HUMAN $42.33 \quad 100.0 \%$ RNA-binding motif protein, $X$ chromosome GN=RBMX RBMX_HUMAN $42.33 \quad 100.0 \%$ RNA-binding motif protein, $X$ chromosome GN=RBMX RBMX_HUMAN $42.33 \quad 100.0 \%$ RNA-binding motif protein, $X$ chromosome GN=RBMX RBMX_HUMAN $42.33 \quad 100.0 \%$ RNA-binding motif protein, $X$ chromosome GN=RBMX RBMX_HUMAN $42.33 \quad 100.0 \%$ RNA-binding motif protein, $X$ chromosome GN=RBMX RBMX_HUMAN $42.33 \quad 100.0 \%$ RNA-binding motif protein, $X$ chromosome GN=RBMX RBMX_HUMAN $42.33 \quad 100.0 \%$ RNA-binding motif protein, $X$ chromosome GN=RBMX RBMX_HUMAN $42.33 \quad 100.0 \%$ RNA-binding motif protein, X chromosome GN=RBMX RBMX_HUMAN $42.33 \quad 100.0 \%$ RNA-binding motif protein, $X$ chromosome GN=RBMX RBMX_HUMAN 42.33 RNA-binding motif protein, $X$ chromosome GN=RBMX RBMX_HUMAN 42.33 RNA-binding motif protein, $X$ chromosome GN=RBMX RBMX_HUMAN 42.33 RNA-binding motif protein, $X$ chromosome GN=RBMX RBMX_HUMAN $42.33 \quad 100.0 \%$ RNA-binding motif protein, $X$ chromosome GN=RBMX RBMX HUMAN $42.33100 .0 \%$ RNA-binding protein $10 \mathrm{GN}=\mathrm{RBM} 10$ RNA-binding protein $10 \mathrm{GN}=\mathrm{RBM} 10$ RNA-binding protein $10 \mathrm{GN}=\mathrm{RBM} 10$ RNA-binding protein $10 \mathrm{GN}=\mathrm{RBM} 10$ RNA-binding protein $10 \mathrm{GN}=\mathrm{RBM} 10$ RNA-binding protein $10 \mathrm{GN}=\mathrm{RBM} 10$ RNA-binding protein $10 \mathrm{GN}=\mathrm{RBM} 10$ RNA-binding protein $10 \mathrm{GN}=\mathrm{RBM} 10$ RNA-binding protein $10 \mathrm{GN}=\mathrm{RBM} 10$ RNA-binding protein $10 \mathrm{GN}=\mathrm{RBM} 10$ RNA-binding protein $10 \mathrm{GN}=\mathrm{RBM} 10$ RNA-binding protein $10 \mathrm{GN}=\mathrm{RBM} 10$ RNA-binding protein $10 \mathrm{GN}=\mathrm{RBM} 10$ RNA-binding protein $10 \mathrm{GN}=\mathrm{RBM} 10$ RNA-binding protein $10 \mathrm{GN}=\mathrm{RBM} 10$ RNA-binding protein $10 \mathrm{GN}=\mathrm{RBM} 10$ RNA-binding protein $10 \mathrm{GN}=\mathrm{RBM} 10$ RNA-binding protein $10 \mathrm{GN}=\mathrm{RBM} 10$ RNA-binding protein $10 \mathrm{GN}=\mathrm{RBM} 10$ RNA-binding protein $14 \mathrm{GN}=\mathrm{RBM} 14$ RNA-binding protein $14 \mathrm{GN}=\mathrm{RBM} 14$ RNA-binding protein $14 \mathrm{GN}=\mathrm{RBM} 14$ RNA-binding protein $14 \mathrm{GN}=\mathrm{RBM} 14$ RNA-binding protein $14 \mathrm{GN}=\mathrm{RBM} 14$ RNA-binding protein $14 \mathrm{GN}=\mathrm{RBM} 14$ RNA-binding protein $14 \mathrm{GN}=\mathrm{RBM} 14$ RNA-binding protein $14 \mathrm{GN}=\mathrm{RBM} 14$ RNA-binding protein $14 \mathrm{GN}=\mathrm{RBM} 14$ RNA-binding protein $14 \mathrm{GN}=\mathrm{RBM} 14$ RNA-binding protein $14 \mathrm{GN}=\mathrm{RBM} 14$
RBM10_HUMAN $103.53 \quad 100.0 \%$ RBM10_HUMAN $103.53 \quad 100.0 \%$ RBM10_HUMAN $103.53 \quad 100.0 \%$ RBM10_HUMAN $103.53 \quad 100.0 \%$ RBM10_HUMAN $103.53 \quad 100.0 \%$ RBM10_HUMAN $103.53 \quad 100.0 \%$ RBM10_HUMAN $103.53 \quad 100.0 \%$ RBM10_HUMAN $103.53 \quad 100.0 \%$ RBM10_HUMAN $103.53 \quad 100.0 \%$ RBM10_HUMAN $103.53 \quad 100.0 \%$ RBM10_HUMAN $103.53 \quad 100.0 \%$ RBM10_HUMAN $103.53 \quad 100.0 \%$ RBM10 HUMAN $103.53 \quad 100.0 \% \quad 19$ RBM10_HUMAN $103.53 \quad 100.0 \% \quad 19$ RBM10_HUMAN $103.53 \quad 100.0 \% \quad 19$ RBM10_HUMAN $103.53 \quad 100.0 \% \quad 19$ RBM10_HUMAN $103.53 \quad 100.0 \% \quad 19$ RBM10_HUMAN $103.53 \quad 100.0 \% \quad 19$ RBM10_HUMAN $103.53 \quad 100.0 \% \quad 19$ RBM14_HUMAN $69.49 \quad 100.0 \% \quad 11$ RBM14_HUMAN $69.49 \quad 100.0 \% \quad 11$ RBM14_HUMAN $69.49 \quad 100.0 \% \quad 11$ RBM14_HUMAN $69.49 \quad 100.0 \% \quad 11$ RBM14_HUMAN $\quad 69.49 \quad 100.0 \% \quad 11$ RBM14_HUMAN $69.49 \quad 100.0 \% \quad 11$ RBM14_HUMAN $69.49 \quad 100.0 \% \quad 11$ RBM14_HUMAN $69.49 \quad 100.0 \% \quad 11$ RBM14_HUMAN $69.49 \quad 100.0 \% \quad 11$ RBM14_HUMAN $69.49 \quad 100.0 \% \quad 11$ RBM14_HUMAN $69.49 \quad 100.0 \%$
$0.02 \% \quad 13.7 \%$ TLQCLGLRLQ $0.12 \% \quad 43.0 \%$ LFIGGLNTETNEK $0.12 \% \quad 43.0 \%$ ALEAVFGKYGR $0.12 \% \quad 43.0 \%$ IVEVLLMKDR $0.12 \% \quad 43.0 \%$ AIKVEQATKPSFESGR $0.12 \% \quad 43.0 \%$ VEQATKPSFESGR

$0.12 \% \quad 43.0 \%$ RGPPPPPR

$0.12 \% \quad 43.0 \%$ GGHMDDGGYSMNFNMSSSR $0.12 \% \quad 43.0 \%$ GRDSYGGPPR

$0.12 \% \quad 43.0 \%$ DSYGGPPR $0.12 \% \quad 43.0 \%$ DVYLSPRDDGYSTK $0.12 \% \quad 43.0 \%$ DSYSSRDYPSSR $57 \quad 0.12 \% \quad 43.0 \%$ DYGHSSSRDDYPSR $0.12 \% \quad 43.0 \%$ DSYESYGNSR

$0.12 \% \quad 43.0 \%$ SAPPTRGPPPSYGGSSR $0.12 \% \quad 43.0 \%$ GPPPSYGGSSR

$57 \quad 0.12 \% \quad 43.0 \%$ DGYGGSRDSYSSSR

$116 \quad 0.24 \% \quad 23.9 \%$ YGATDRSQDDGGENR

$116 \quad 0.24 \% \quad 23.9 \%$ HSPTGPPGFPR

$116 \quad 0.24 \% \quad 23.9 \%$ VSMHYSDPKPK

$116 \quad 0.24 \% \quad 23.9 \%$ INEDWLCNK

$116 \quad 0.24 \% \quad 23.9 \%$ SEAEQKLPLGTR

$116 \quad 0.24 \% \quad 23.9 \%$ LDQQTLPLGGR

$\begin{array}{lll}116 & 0.24 \% & 23.9 \% \\ 116 & 0.24 \% & 23.9 \%\end{array}$

$116 \quad 0.24 \% \quad 23.9 \%$ TAQQIAKDMER

$\begin{array}{lll}116 & 0.24 \% & 23.9 \% \\ 116 & 0.24 \% & 23.9 \%\end{array}$

$116 \quad 0.24 \% \quad 23.9 \%$ ESATADAGYAILEK

$116 \quad 0.24 \% \quad 23.9 \%$ GALAERQHTSMDLPK

$116 \quad 0.24 \% \quad 23.9 \%$ EKYGIPEPPEPK

$116 \quad 0.24 \% \quad 23.9 \%$ YGGISTASVDFEQPTR

$116 \quad 0.24 \% \quad 23.9 \%$ DGLGSDNIGSR

$\begin{array}{lll}116 & 0.24 \% & 23.9 \% \\ 116 & 0.24 \% & 23.9 \%\end{array}$

$116 \quad 0.24 \% \quad 23.9 \%$ KQGIVTPIEAQTR

$116 \quad 0.24 \% \quad 23.9 \%$ QGIVTPIEAQTR

$116 \quad 0.24 \% \quad 23.9 \%$ GSSYGVTSTESYKETLHK

$116 \quad 0.24 \% \quad 23.9 \%$ TMVTRFNEAQ

$22 \quad 0.05 \% \quad 18.1 \%$ IFVGNVSAACTSQELR

$0.05 \% \quad 18.1 \%$ AAIAQLNGKEVK

$0.05 \% \quad 18.1 \%$ INVELSTKGQK

$22 \quad 0.05 \% \quad 18.1 \%$ ASYVAPLTAQPATYR

$0.05 \% \quad 18.1 \%$ AQPSVSLGAAYR

$0.05 \% \quad 18.1 \%$ AQPSASLGVGYR

$0.05 \% \quad 18.1 \%$ AQPSASLGVGYRTQPMTAQAASYR

$0.05 \% \quad 18.1 \%$ TQPMTAQAASYR

$0.05 \% \quad 18.1 \%$ AQPSVSLGAPYR

$0.05 \% \quad 18.1 \%$ LAELSDYRR

$0.05 \% \quad 18.1 \%$ YSGSYNDYLR $\begin{array}{lllll}99.7 \% & 34.5 & 25.0 & 24.4 & 2\end{array}$

$\begin{array}{lllll}99.7 \% & 48.4 & 25.0 & 39.8 & 2\end{array}$

$99.7 \% \quad 63.0 \quad 25.0 \quad 52.9 \quad 2$

$99.7 \% \quad 33.8 \quad 25.0 \quad 33.8$

$\begin{array}{lllll}99.7 \% & 66.0 & 25.0 & 66.0 & 2\end{array}$

$\begin{array}{llll}99.7 \% & 56.6 & 25.0 & 51.3\end{array}$

$99.0 \% \quad 56.9 \quad 25.0 \quad 49.6$

$99.7 \% \quad 51.4$

$98.5 \% 31.9$

$99.0 \% \quad 27.3$

$99.7 \% \quad 35.5$

$99.7 \% \quad 35.6$

$99.2 \% \quad 20.3$

$99.7 \% \quad 46.8$

$98.7 \% \quad 19.9$

$99.7 \% \quad 37.0$

$99.7 \% \quad 44.9$

$99.3 \% \quad 23.1$

$99.0 \% 25.4$

$98.6 \% \quad 19.5$

$99.7 \% \quad 55.5$

$99.7 \% \quad 56.0$

$99.7 \% 70.5$

$99.0 \% \quad 46.7$

$99.7 \% \quad 50.1$

$99.7 \% \quad 32.2$

$99.7 \% \quad 67.6$

$99.7 \% \quad 28.3$

$99.7 \% \quad 42.3$

$99.7 \% \quad 69.6$

$\begin{array}{lll}99.7 \% & 51.7\end{array}$

$99.7 \% \quad 45.2$

$99.7 \% \quad 61.4$

$99.7 \% \quad 49.6$

$99.3 \% 21.3$

$\begin{array}{lll}99.7 \% & 54.2\end{array}$

$99.7 \% \quad 84.3$

$95.3 \% \quad 16.5$

$99.7 \% \quad 45.4$

$99.7 \% \quad 64.2$

$99.7 \% \quad 55.8$

$99.7 \% \quad 68.4$

$99.7 \% \quad 28.4$

$99.7 \% \quad 47.2$

$99.7 \% \quad 60.1$

$99.7 \% \quad 32.8$

$99.7 \% \quad 52.1$
1201.67

1435.74

1210.66

1231.71

1747.93

1435.72

873.51

2065.78

1061.51

848.39

1615.76

1419.61

1641.69

1177.48

1670.82

1061.50

1493.63

1640.69

1149.58

1304.63

1191.55

1328.72

1197.66

921.50

1290.65

1148.61

1438.71

1669.83

1383.72

1727.82

1090.51

1620.80

1440.82

1312.72

1973.95

1196.57

1751.87

1241.72

1216.69

1608.84

1219.64

1205.63

2527.24

1340.63

1245.66

1122.59

1237.55

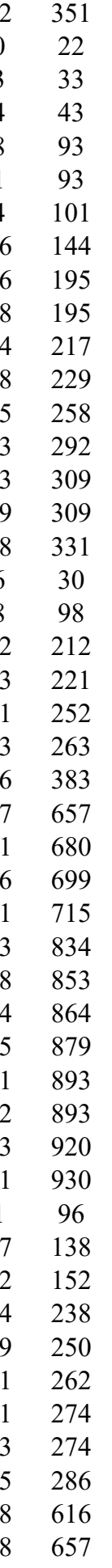

Page 70 of Table S-1-3 
RNA-binding protein $25 \mathrm{GN}=\mathrm{RBM} 25$ RNA-binding protein $25 \mathrm{GN}=\mathrm{RBM} 25$ RNA-binding protein $28 \mathrm{GN}=\mathrm{RBM} 28$ RNA-binding protein $28 \mathrm{GN}=\mathrm{RBM} 28$ RNA-binding protein $39 \mathrm{GN}=\mathrm{RBM} 39$ RNA-binding protein $39 \mathrm{GN}=\mathrm{RBM} 39$ RNA-binding protein $39 \mathrm{GN}=\mathrm{RBM} 39$ RNA-binding protein $4 \mathrm{GN}=\mathrm{RBM} 4$ RNA-binding protein $4 \mathrm{GN}=\mathrm{RBM} 4$ RNA-binding protein $4 \mathrm{GN}=\mathrm{RBM} 4$ RNA-binding protein $4 \mathrm{GN}=\mathrm{RBM} 4$ RNA-binding protein $4 \mathrm{GN}=\mathrm{RBM} 4$ RNA-binding protein $4 \mathrm{GN}=\mathrm{RBM} 4$ RNA-binding protein $7 \mathrm{GN}=\mathrm{RBM} 7$

RNA-binding protein $7 \mathrm{GN}=\mathrm{RBM} 7$

RNA-binding protein Raly GN=RALY

RNA-binding protein Raly GN=RALY

RNA-binding protein Raly GN=RALY

RNA-binding protein Raly GN=RALY

RNA-binding protein Raly GN=RALY $\begin{array}{llll}\text { rRNA 2'-O-methyltransferase fibrillarin GN=FBL FBRL_HUMAN } & 33.78 & 100.0 \%\end{array}$ rRNA 2'-O-methyltransferase fibrillarin GN=FBL FBRL_HUMAN $33.78 \quad 100.0 \%$ rRNA 2'-O-methyltransferase fibrillarin GN=FBL FBRL_HUMAN $33.78 \quad 100.0 \%$ rRNA 2'-O-methyltransferase fibrillarin GN=FBL FBRL_HUMAN $33.78 \quad 100.0 \%$ rRNA 2'-O-methyltransferase fibrillarin GN=FBL FBRL_HUMAN $33.78 \quad 100.0 \%$ rRNA $2^{\prime}$-O-methyltransferase fibrillarin GN=FBL FBRL_HUMAN $33.78 \quad 100.0 \%$ rRNA 2'-O-methyltransferase fibrillarin GN=FBL FBRL_HUMAN $33.78 \quad 100.0 \%$ rRNA 2'-O-methyltransferase fibrillarin GN=FBL FBRL_HUMAN $33.78 \quad 100.0 \%$ rRNA 2'-O-methyltransferase fibrillarin GN=FBL FBRL_HUMAN $33.78 \quad 100.0 \%$ rRNA methyltransferase 3, mitochondrial GN=RNMTL1 MRM3 HUMAN $47.02 \quad 100.0 \%$ rRNA methyltransferase 3, mitochondrial GN=RNMTL1 MRM3_HUMAN $47.02 \quad 100.0 \%$ rRNA methyltransferase 3, mitochondrial GN=RNMTL1 MRM3_HUMAN $47.02 \quad 100.0 \%$ rRNA methyltransferase 3, mitochondrial GN=RNMTL1 MRM3_HUMAN $47.02 \quad 100.0 \%$ rRNA methyltransferase 3, mitochondrial GN=RNMTL1 MRM3_HUMAN $47.02 \quad 100.0 \%$ rRNA methyltransferase 3, mitochondrial GN=RNMTL1 MRM3_HUMAN $47.02 \quad 100.0 \%$ RRP12-like protein GN=RRP12 RRP12_HUMAN $143.71 \quad 100.0 \%$ RRP12-like protein $\mathrm{GN}=\mathrm{RRP} 12$ RRP12-like protein GN=RRP12 RRP15-like protein GN=RRP15 RRP15-like protein GN=RRP15 RRP15-like protein GN=RRP15 RRP12_HUMAN $143.71 \quad 100.0 \%$ RRP12 HUMAN $143.71 \quad 100.0 \%$ RRP15_HUMAN $31.48 \quad 100.0 \%$ RRP15_HUMAN $31.48 \quad 100.0 \%$ RRP15 HUMAN $31.48 \quad 100.0 \%$ S-adenosylmethionine synthase isoform type-2 GN=MAT2A METK2_HUMAN $43.66 \quad 100.0 \%$ S-adenosylmethionine synthase isoform type-2 GN=MAT2A METK2_HUMAN $43.66 \quad 100.0 \%$ S-adenosylmethionine synthase isoform type-2 GN=MAT2A METK2_HUMAN $43.66 \quad 100.0 \%$ Sarcoplasmic/endoplasmic reticulum calcium ATPase $2 \mathrm{GN}=\mathrm{ATP} 2 \mathrm{~A} 2$ AT2A2_HUMAN $114.76 \quad 100.0 \%$ Sarcoplasmic/endoplasmic reticulum calcium ATPase $2 \mathrm{GN}=\mathrm{ATP} 2 \mathrm{~A} 2$ AT2A2_HUMAN $114.76 \quad 100.0 \%$
$0.01 \% \quad 1.8 \% \quad$ LGASNSPGQPNSVK $0.01 \% \quad 1.8 \%$ LGASNSPGQPNSVKR $0.01 \% \quad 2.8 \%$ NLYLAREGLIR $0.01 \% \quad 2.8 \%$ QQLSSEQVSR $0.01 \% \quad 5.7 \%$ TVFCMQLAAR $0.01 \% \quad 5.7 \%$ AAAMANNLQK $0.01 \% \quad 5.7 \%$ TGIDLGTTGR $0.02 \% \quad 16.2 \%$ GLDNTEFQGKR $0.02 \% \quad 16.2 \%$ MHVQLSTSR $0.02 \% \quad 16.2 \%$ LRTAPGMGDQSGCYR $0.02 \% \quad 16.2 \%$ TAPGMGDQSGCYR $0.02 \% \quad 16.2 \%$ VADLTEQYNEQYGAVR $0.02 \% \quad 16.2 \%$ NSLYDMAR $0.01 \% \quad 9.0 \%$ TMDNMTSSAQIIQR $0.01 \% \quad 9.0 \% \quad$ SFSSPENFQR $0.03 \% \quad 17.3 \%$ LQASNVTNKNDPK $0.03 \% \quad 17.3 \%$ VFIGNLNTALVK $0.03 \% \quad 17.3 \%$ KSDVETIFSK $0.03 \% \quad 17.3 \%$ VTVPLVRR $0.03 \% \quad 17.3 \%$ TNVPVKLFAR $0.08 \% \quad 27.7 \%$ HEGVFICR $0.08 \% \quad 27.7 \%$ GKEDALVTK $0.08 \% \quad 27.7 \%$ NLVPGESVYGEK $0.08 \% \quad 27.7 \%$ NLVPGESVYGEKR $0.08 \% \quad 27.7 \%$ VSISEGDDKIEYR $0.08 \% \quad 27.7 \%$ SGRDLINLAK $0.08 \% \quad 27.7 \%$ TNIIPVIEDAR $0.08 \% \quad 27.7 \%$ IVALNAHTFLR $0.08 \% \quad 27.7 \%$ DHAVVVGVYRPPPK $0.05 \% \quad 13.6 \%$ KAPSEASAQEQR $0.05 \% \quad 13.6 \%$ LSSVMTIVK $0.05 \% \quad 13.6 \%$ RLISDALK $0.05 \% \quad 13.6 \%$ LISDALKAGAVPK $0.05 \% \quad 13.6 \%$ SAAGAGCSKVLLTK $0.05 \% \quad 13.6 \%$ AGMGAHFR $0.01 \% \quad 2.0 \%$ FCIQEIEK $0.01 \% \quad 2.0 \%$ RAVLETIR $0.01 \% \quad 2.0 \%$ VLATQPGPGR $0.01 \% \quad 11.7 \%$ GVVQLFNAVQK $0.01 \% \quad 11.7 \%$ AKLISTVSK $0.01 \% \quad 11.7 \%$ GMDGSTNETASSR $0.01 \% \quad 9.9 \%$ TGMILLAGEITSR $0.01 \% \quad 9.9 \%$ FVIGGPQGDAGLTGR $0.01 \% \quad 9.9 \%$ DLDLKKPIYQR $0.03 \% \quad 8.3 \%$ NMLFSGTNIAAGK $0.03 \% \quad 8.3 \%$ AMGVVVATGVNTEIGK $0.03 \% \quad 8.3 \%$ SMSVYCTPNKPSR

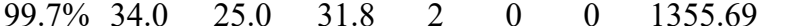
$99.7 \% \quad 39.5$ $\begin{array}{llll}99.7 \% & 48.7 & 25.0 & 41.8\end{array}$ $\begin{array}{llll}99.7 \% & 49.6 & 25.0 & 36.9\end{array}$ $99.7 \% \quad 29.9 \quad 25.0 \quad 23.6$ $\begin{array}{lllll}99.7 \% & 37.5 & 25.0 & 37.5 & 2\end{array}$ $\begin{array}{llll}99.7 \% & 30.2 & 25.0 & 28.9\end{array}$

$96.0 \% \quad 19.2 \quad 25.0 \quad 13.7$ $\begin{array}{llll}99.1 \% & 20.0 & 25.0 & 20.0\end{array}$ $\begin{array}{llll}99.7 \% & 56.3 & 25.0 & 52.0\end{array}$ $\begin{array}{llll}98.8 \% & 22.9 & 25.0 & 17.0\end{array}$ $\begin{array}{llll}99.7 \% & 41.7 & 25.0 & 41.7\end{array}$ $\begin{array}{llll}99.7 \% & 38.8 & 25.0 & 38.8\end{array}$ $\begin{array}{lllll}99.7 \% & 32.1 & 25.0 & 24.0 & 2\end{array}$ $\begin{array}{llll}99.0 \% & 32.6 & 25.0 & 0.0\end{array}$

$\begin{array}{llll}99.7 \% & 42.2 & 25.0 & 33.3\end{array}$

$\begin{array}{llll}99.0 \% & 25.6 & 25.0 & 16.4\end{array}$

$\begin{array}{llll}99.4 \% & 22.7 & 25.0 & 21.2\end{array}$

$99.0 \% \quad 29.5 \quad 25.0 \quad 23.2$

$\begin{array}{llll}99.7 \% & 27.4 & 25.0 & 27.4\end{array}$

$\begin{array}{llll}96.4 \% & 17.4 & 25.0 & 14.8\end{array}$

$\begin{array}{llll}99.7 \% & 66.7 & 25.0 & 54.0\end{array}$

$99.7 \% \quad 71.0 \quad 25.0 \quad 67.3$

$\begin{array}{llll}99.7 \% & 35.3 & 25.0 & 25.3\end{array}$

$\begin{array}{llll}99.0 \% & 38.7 & 25.0 & 0.0\end{array}$

$\begin{array}{llll}99.7 \% & 47.8 & 25.0 & 37.9\end{array}$

$\begin{array}{llll}99.7 \% & 36.3 & 25.0 & 33.7\end{array}$

$\begin{array}{llll}99.7 \% & 49.0 & 25.0 & 31.2\end{array}$

$\begin{array}{llll}99.7 \% & 54.1 & 25.0 & 47.4\end{array}$

$\begin{array}{llll}96.5 \% & 26.0 & 25.0 & 7.8\end{array}$

$99.7 \% \quad 55.6 \quad 25.0 \quad 41.0$

$99.5 \% \quad 25.7 \quad 25.0 \quad 22.4$

$\begin{array}{llll}99.0 \% & 45.1 & 25.0 & 30.2\end{array}$

$98.6 \% \quad 22.25 .0 \quad 16.5$

$\begin{array}{llll}96.5 \% & 26.8 & 25.0 & 6.5\end{array}$

$99.7 \% \quad 31.9 \quad 25.0 \quad 23.5$

$\begin{array}{llll}99.7 \% & 51.5 & 25.0 & 44.4\end{array}$

$\begin{array}{llll}99.1 \% & 21.9 & 25.0 & 19.4\end{array}$

$\begin{array}{llll}99.7 \% & 66.2 & 25.0 & 66.2\end{array}$

$\begin{array}{lllll}99.7 \% & 73.0 & 25.0 & 69.9 & 2\end{array}$

$99.7 \% \quad 71.8 \quad 25.0 \quad 65.6$

$95.0 \% \quad 17.1 \quad 25.0 \quad 14.5$

$\begin{array}{lllll}99.7 \% & 45.5 & 25.0 & 36.8 & 2\end{array}$

$\begin{array}{lllll}99.7 \% & 48.4 & 25.0 & 37.0\end{array}$ $\begin{array}{llll}99.7 \% & 33.2 & 25.0 & 33.2\end{array}$
1511.79

1317.76

1161.59

1196.59

1031.53

990.52

1264.63

1058.54

1684.75

1415.57

1855.88

969.45

1627.74

1198.55

1428.74

1288.76

1153.61

939.61

1144.68

1017.49

960.54

1291.65

1447.75

1510.74

1086.63

1240.69

1254.73

1533.85

1301.64

977.57

915.56

1282.77

1362.74

846.40

1066.52

957.58

995.56

1202.69

946.59

1312.54

1377.74

1444.75

1388.79

1323.67

1561.83 1526.71

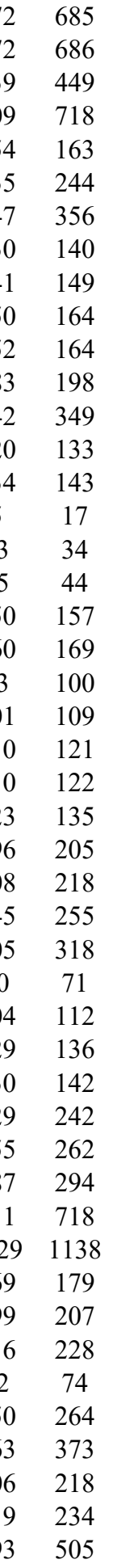



replasmic/endoplasmic reticulum calcium ATPase 2 GN=ATP2A2 AT2A2_HUMAN $114.76 \quad 100.0 \%$ Scaffold attachment factor B1 GN=SAFB SAFB1_HUMAN $102.64 \quad 100.0 \%$ Scaffold attachment factor B1 GN=SAFB SAFB1_HUMAN $102.64 \quad 100.0 \%$ SCY1-like protein $2 \mathrm{GN}=\mathrm{SCYL} 2$ SCY1-like protein $2 \mathrm{GN}=\mathrm{SCYL} 2$ SCY1-like protein $2 \mathrm{GN}=\mathrm{SCYL} 2$ SCY1-like protein $2 \mathrm{GN}=\mathrm{SCYL} 2$ SCY1-like protein $2 \mathrm{GN}=\mathrm{SCYL} 2$ SCY1-like protein $2 \mathrm{GN}=\mathrm{SCYL} 2$ Sentrin-specific protease $3 \mathrm{GN}=\mathrm{SENP} 3$ Sentrin-specific protease $3 \mathrm{GN}=\mathrm{SENP} 3$ Sentrin-specific protease $3 \mathrm{GN}=\mathrm{SENP} 3$ SCYL2 HUMAN $103.71 \quad 100.0 \%$ SCYL2_HUMAN $103.71 \quad 100.0 \%$ SCYL2 HUMAN $103.71 \quad 100.0 \%$ SCYL2_HUMAN $103.71 \quad 100.0 \%$ SCYL2_HUMAN $103.71 \quad 100.0 \%$ SCYL2 HUMAN $103.71 \quad 100.0 \%$ SENP3_HUMAN $65.01 \quad 100.0 \%$ SENP3_HUMAN $65.01 \quad 100.0 \%$ SENP3_HUMAN $65.01 \quad 100.0 \%$ Serine hydroxymethyltransferase, mitochondrial GN=SHMT2 GLYM_HUMAN $55.99 \quad 100.0 \%$ Serine hydroxymethyltransferase, mitochondrial GN=SHMT2 GLYM HUMAN $55.99 \quad 100.0 \%$ Serine/arginine repetitive matrix protein $2 \mathrm{GN}=$ SRRM2 SRRM2_HUMAN $299.62 \quad 100.0 \%$ Serine/arginine repetitive matrix protein 2 GN=SRRM2 SRRM2_HUMAN $299.62 \quad 100.0 \%$ Serine/arginine repetitive matrix protein $2 \mathrm{GN}=\mathrm{SRRM} 2 \mathrm{SRRM} 2 \mathrm{HUMAN} 299.62 \quad 100.0 \%$ Serine/arginine repetitive matrix protein 2 GN=SRRM2 SRRM2_HUMAN $299.62 \quad 100.0 \%$ Serine/arginine repetitive matrix protein $2 \mathrm{GN}=$ SRRM2 SRRM2 HUMAN $299.62 \quad 100.0 \%$ Serine/arginine repetitive matrix protein $2 \mathrm{GN}=\mathrm{SRRM} 2 \mathrm{SRRM} 2$ HUMAN $299.62 \quad 100.0 \%$ Serine/arginine repetitive matrix protein $2 \mathrm{GN}=$ SRRM2 SRRM2_HUMAN $299.62 \quad 100.0 \%$ Serine/arginine repetitive matrix protein $2 \mathrm{GN}=$ SRRM2 SRRM2_HUMAN $299.62100 .0 \%$ Serine/arginine repetitive matrix protein 2 GN=SRRM2 SRRM2_HUMAN $299.62 \quad 100.0 \%$ Serine/arginine repetitive matrix protein $2 \mathrm{GN}=$ SRRM2 SRRM2_HUMAN $299.62 \quad 100.0 \%$ Serine/arginine repetitive matrix protein $2 \mathrm{GN}=$ SRRM2 SRRM2_HUMAN $299.62100 .0 \%$ Serine/arginine repetitive matrix protein 2 GN=SRRM2 SRRM2_HUMAN $299.62 \quad 100.0 \%$ Serine/arginine repetitive matrix protein $2 \mathrm{GN}=\mathrm{SRRM} 2 \mathrm{SRRM} 2$ HUMAN $299.62 \quad 100.0 \%$ Serine/arginine repetitive matrix protein 2 GN=SRRM2 SRRM2_HUMAN $299.62 \quad 100.0 \%$ Serine/arginine repetitive matrix protein 2 GN=SRRM2 SRRM2_HUMAN $299.62 \quad 100.0 \%$ Serine/arginine repetitive matrix protein $2 \mathrm{GN}=$ SRRM2 SRRM2_HUMAN $299.62 \quad 100.0 \%$ Serine/arginine-rich splicing factor 1 GN=SRSF1 SRSF1_HUMAN $27.75 \quad 100.0 \%$ Serine/arginine-rich splicing factor $1 \mathrm{GN}=$ SRSF1 SRSF1_HUMAN $27.75 \quad 100.0 \%$ Serine/arginine-rich splicing factor $1 \mathrm{GN}=\mathrm{SRSF} 1$ SRSF1_HUMAN $27.75 \quad 100.0 \%$ Serine/arginine-rich splicing factor $1 \mathrm{GN}=$ SRSF1 SRSF1_HUMAN $27.75 \quad 100.0 \%$ Serine/arginine-rich splicing factor $1 \mathrm{GN}=\mathrm{SRSF} 1$ SRSF1 HUMAN $27.75 \quad 100.0 \%$ Serine/arginine-rich splicing factor $1 \mathrm{GN}=\mathrm{SRSF} 1$ SRSF1_HUMAN $27.75 \quad 100.0 \%$ Serine/arginine-rich splicing factor $1 \mathrm{GN}=$ SRSF1 SRSF1_HUMAN $27.75 \quad 100.0 \%$ Serine/arginine-rich splicing factor $1 \mathrm{GN}=$ SRSF1 SRSF1_HUMAN $27.75 \quad 100.0 \%$ Serine/arginine-rich splicing factor $1 \mathrm{GN}=\mathrm{SRSF} 1$ SRSF1_HUMAN $27.75 \quad 100.0 \%$ Serine/arginine-rich splicing factor 1 GN=SRSF1 SRSF1 HUMAN $27.75 \quad 100.0 \%$ Serine/arginine-rich splicing factor $1 \mathrm{GN}=\mathrm{SRSF} 1$ SRSF1_HUMAN $27.75 \quad 100.0 \%$ Serine/arginine-rich splicing factor $1 \mathrm{GN}=\mathrm{SRSF} 1$ SRSF1_HUMAN $27.75 \quad 100.0 \%$ Serine/arginine-rich splicing factor $10 \mathrm{GN}=$ SRSF10 SRS10 HUMAN $31.30 \quad 100.0 \%$ Serine/arginine-rich splicing factor $10 \mathrm{GN}=$ SRSF10 SRS10_HUMAN $31.30 \quad 100.0 \%$

$3 \quad 0.03 \% \quad 8.3 \% \quad$ IGIFGQDEDVTSK $0.03 \% \quad 8.3 \%$ KAEIGIAMGSGTAVAK $0.03 \% \quad 8.3 \%$ AEIGIAMGSGTAVAK $0.03 \% \quad 8.3 \%$ NYLEPGKECVQPATK $0.01 \% \quad 2.6 \%$ NVDSSGNKSVLMER $0.01 \% \quad 2.6 \%$ ATDLKNLFSK

$0.03 \% \quad 7.9 \% \quad$ VTADVTSAVMGNPVTR $0.03 \% \quad 7.9 \%$ DQIIDSLKR

$0.03 \% \quad 7.9 \%$ SQFFKGLPK

$0.03 \% \quad 7.9 \%$ NACLQTSSLAVR

$0.03 \% \quad 7.9 \% \quad$ ASLTLEEKQK

$99.7 \% \quad 57.8$ $99.5 \% \quad 25.5$ $99.7 \% \quad 37.0$ $98.7 \% \quad 25.9$ $99.7 \% \quad 51.4$ $99.5 \% 34$.

$99.7 \% 57.6$ $99.4 \% 27.3$ $99.7 \% \quad 46.4$ $99.7 \% \quad 34.3$

$\begin{array}{llll} & 95.7 \% & 34.3\end{array}$

$\begin{array}{llllll}0.01 \% & 5.1 \% & \text { LKSGGGFGPDPGSGTTVPAR } & 99.6 \% & 26.4\end{array}$

$0.01 \% \quad 5.1 \%$ SGGGFGPDPGSGTTVPAR

$0.01 \% \quad 5.1 \% \quad$ YLQAEAVKK

$0.01 \% \quad 4.0 \% \quad$ LIIAGTSAYAR

$0.01 \% \quad 4.0 \%$ SAITPGGLR

$0.14 \% \quad 7.3 \% \quad$ SLSGSSPCPK

$0.14 \% \quad 7.3 \%$ SCFESSPDPELKSR

$0.14 \% \quad 7.3 \%$ SSSPVTELASR

$0.14 \% \quad 7.3 \%$ SGSESSVDQKTVAR

$0.14 \% \quad 7.3 \%$ AQSGSDSSPEPKAPAPR

$0.14 \% \quad 7.3 \%$ SPSVSSPEPAEK

$0.14 \% \quad 7.3 \%$ TSVPENHAQSR

$0.14 \% \quad 7.3 \%$ TAPAANLASR

$0.14 \% \quad 7.3 \%$ TAVAPSAVNLADPR

$0.14 \% \quad 7.3 \%$ TPTAPAVNLAGAR

$0.14 \% \quad 7.3 \%$ TPQAPASANLVGPR

$0.14 \% \quad 7.3 \%$ SAHATAPVNIAGSR

$0.14 \% \quad 7.3 \%$ TAAALAPASLTSAR

$0.14 \% \quad 7.3 \%$ MAPALSGANLTSPR

$0.14 \% \quad 7.3 \%$ VPLSAYER

$0.14 \% \quad 7.3 \%$ SPVPSAFSDQSR

$0.09 \% \quad 37.5 \%$ IYVGNLPPDIR

$0.09 \% \quad 37.5 \%$ TKDIEDVFYK

$0.09 \% \quad 37.5 \%$ DIEDVFYK

$0.09 \% \quad 37.5 \%$ YGAIRDIDLK

$0.09 \% \quad 37.5 \%$ DGYDYDGYRLR

$0.09 \% \quad 37.5 \%$ GRYGPPSR

$0.09 \% \quad 37.5 \%$ EAGDVCYADVYR

$0.09 \% \quad 37.5 \%$ DGTGVVEFVR

$0.09 \% \quad 37.5 \%$ KEDMTYAVR

$0.09 \% \quad 37.5 \%$ EDMTYAVR

$0.09 \% \quad 37.5 \%$ FRSHEGETAYIR

$0.09 \% \quad 37.5 \%$ SHEGETAYIR

$0.03 \% \quad 9.2 \% \quad$ YLRPPNTSLFVR

$0.03 \% \quad 9.2 \%$ QIEIQFAQGDR

1319.67

1146.64

1858.05

1857.95

1616.77

1049.60

1135.65

871.50

1019.48

1638.74

1133.58

1450.71

1681.81

1214.59

1225.59

971.53

1381.74

1238.69

1378.74

1351.71

1300.72

1401.72

934.50

1277.6

1256.70

1257.64

1028.49

1163.64

1392.62

889.46

1417.61

1078.55

1112.54

984.45

1465.72

1162.55

1462.82

1304.66 

Serine/arginine-rich splicing factor $2 \mathrm{GN}=\mathrm{SRSF} 2 \mathrm{SRSF} 2$ HUMAN $25.48 \quad 100.0 \%$ Serine/arginine-rich splicing factor $2 \mathrm{GN}=\mathrm{SRSF} 2$ SRSF2_HUMAN $25.48 \quad 100.0 \%$ Serine/arginine-rich splicing factor $2 \mathrm{GN}=\mathrm{SRSF} 2$ SRSF2_HUMAN $25.48 \quad 100.0 \%$ Serine/arginine-rich splicing factor $3 \mathrm{GN}=\mathrm{SRSF} 3$ SRSF3_HUMAN $19.33 \quad 100.0 \%$ Serine/arginine-rich splicing factor $3 \mathrm{GN}=\mathrm{SRSF} 3 \mathrm{SRSF} 3$ HUMAN $19.33 \quad 100.0 \%$ Serine/arginine-rich splicing factor 5 GN=SRSF5 SRSF5_HUMAN $31.26 \quad 100.0 \%$ Serine/arginine-rich splicing factor $5 \mathrm{GN}=\mathrm{SRSF} 5$ SRSF5 HUMAN $31.26 \quad 100.0 \%$ Serine/arginine-rich splicing factor $5 \mathrm{GN}=\mathrm{SRSF} 5$ SRSF5_HUMAN $31.26 \quad 100.0 \%$ Serine/arginine-rich splicing factor 6 GN=SRSF6 SRSF6_HUMAN $39.59 \quad 100.0 \%$ Serine/arginine-rich splicing factor 6 GN=SRSF6 SRSF6_HUMAN $39.59100 .0 \%$ Serine/arginine-rich splicing factor 6 GN=SRSF6 SRSF6_HUMAN $39.59 \quad 100.0 \%$ Serine/arginine-rich splicing factor $6 \mathrm{GN}=\mathrm{SRSF} 6$ SRSF6 HUMAN $39.59 \quad 100.0 \%$ Serine/arginine-rich splicing factor 6 GN=SRSF6 SRSF6_HUMAN $39.59 \quad 100.0 \%$ Serine/arginine-rich splicing factor 6 GN=SRSF6 SRSF6_HUMAN $39.59 \quad 100.0 \%$ Serine/arginine-rich splicing factor $6 \mathrm{GN}=$ SRSF6 SRSF6 HUMAN $39.59100 .0 \%$ Serine/arginine-rich splicing factor $7 \mathrm{GN}=\mathrm{SRSF} 7$ SRSF7_HUMAN $27.37 \quad 100.0 \%$ Serine/arginine-rich splicing factor $7 \mathrm{GN}=$ SRSF7 SRSF7_HUMAN $27.37 \quad 100.0 \%$ Serine/arginine-rich splicing factor $7 \mathrm{GN}=$ SRSF7 SRSF7_HUMAN $27.37 \quad 100.0 \%$ Serine/arginine-rich splicing factor $7 \mathrm{GN}=\mathrm{SRSF} 7$ SRSF7_HUMAN $27.37 \quad 100.0 \%$ Serine/arginine-rich splicing factor $7 \mathrm{GN}=\mathrm{SRSF} 7$ SRSF7 HUMAN $27.37 \quad 100.0 \%$ Serine/arginine-rich splicing factor 7 GN=SRSF7 SRSF7_HUMAN $27.37 \quad 100.0 \%$ Serine/arginine-rich splicing factor 9 GN=SRSF9 SRSF9_HUMAN $25.54 \quad 100.0 \%$ Serine/arginine-rich splicing factor $9 \mathrm{GN}=$ SRSF9 SRSF9 HUMAN $25.54 \quad 100.0 \%$ Serine/arginine-rich splicing factor 9 GN=SRSF9 SRSF9_HUMAN $25.54 \quad 100.0 \%$ Serine/threonine-protein kinase 38-like GN=STK38L ST38L_HUMAN $54.01 \quad 100.0 \%$ Serine/threonine-protein kinase 38-like GN=STK38L ST38L_HUMAN $54.01 \quad 100.0 \%$ Serine/threonine-protein kinase 38-like GN=STK38L ST38L_HUMAN $54.01 \quad 100.0 \%$ Serine/threonine-protein kinase 38-like GN=STK38L ST38L HUMAN $54.01 \quad 100.0 \%$ Serine/threonine-protein kinase 38-like GN=STK38L ST38L_HUMAN $54.01 \quad 100.0 \%$ Serine/threonine-protein kinase 38-like GN=STK38L ST38L_HUMAN $54.01 \quad 100.0 \%$ Serine/threonine-protein kinase 38-like GN=STK38L ST38L HUMAN $54.01 \quad 100.0 \%$ Serine/threonine-protein kinase MARK2 GN=MARK2 MARK2_HUMAN $87.91 \quad 100.0 \%$ Serine/threonine-protein kinase MARK2 GN=MARK2 MARK2_HUMAN $87.91 \quad 100.0 \%$ Serine/threonine-protein kinase MARK2 GN=MARK2 MARK2_HUMAN $87.91 \quad 100.0 \%$ Serine/threonine-protein kinase MARK2 GN=MARK2 MARK2_HUMAN $87.91 \quad 100.0 \%$ Serine/threonine-protein kinase mTOR GN=MTOR MTOR_HUMAN $288.90 \quad 100.0 \%$ Serine/threonine-protein kinase mTOR GN=MTOR MTOR_HUMAN $288.90 \quad 100.0 \%$ Serine/threonine-protein kinase RIO1 GN=RIOK1 RIOK1_HUMAN $65.58 \quad 100.0 \%$ Serine/threonine-protein kinase RIO1 GN=RIOK1 RIOK1_HUMAN $65.58 \quad 100.0 \%$ Serine/threonine-protein kinase RIO1 GN=RIOK1 RIOK1_HUMAN $65.58 \quad 100.0 \%$ Serine/threonine-protein kinase RIO1 GN=RIOK1 RIOK1_HUMAN $65.58 \quad 100.0 \%$ Serine/threonine-protein kinase RIO1 GN=RIOK1 RIOK1_HUMAN $65.58 \quad 100.0 \%$ Serine/threonine-protein kinase RIO1 GN=RIOK1 RIOK1_HUMAN $65.58 \quad 100.0 \%$ Serine/threonine-protein kinase RIO1 GN=RIOK1 RIOK1_HUMAN $65.58 \quad 100.0 \%$ Serine/threonine-protein kinase RIO1 GN=RIOK1 RIOK1_HUMAN $65.58 \quad 100.0 \%$ $0.02 \% \quad 13.1 \%$ TSPDTLRR $0.02 \% \quad 13.1 \%$ VGDVYIPR $0.02 \% \quad 13.1 \%$ VGDVYIPRDR $0.02 \% \quad 13.1 \%$ YGRPPDSHHSR $0.01 \% \quad 11.6 \%$ AFGYYGPLR $0.01 \% \quad 11.6 \%$ VRVELSNGEK $0.03 \% \quad 9.9 \% \quad$ TENRLIVENLSSR $0.03 \% \quad 9.9 \%$ LIVENLSSR $0.03 \% \quad 9.9 \%$ QAGEVTFADAHRPK $0.11 \% \quad 19.8 \%$ DRDGYSYGSR $0.11 \% \quad 19.8 \%$ LIVENLSSR $0.11 \% \quad 19.8 \%$ QAGEVTYADAHKER $0.11 \% \quad 19.8 \%$ TNEGVIEFR $0.11 \% \quad 19.8 \%$ ALDKLDGTEINGR $0.11 \% \quad 19.8 \%$ SNSPLPVPPSK $0.11 \% \quad 19.8 \%$ SNSPLPVPPSKAR $0.11 \% \quad 20.2 \%$ VYVGNLGTGAGK $0.11 \% \quad 20.2 \%$ VYVGNLGTGAGKGELER $0.11 \% \quad 20.2 \%$ AFSYYGPLR $0.11 \% \quad 20.2 \%$ GLDGKVICGSR $0.11 \% \quad 20.2 \%$ VRVELSTGMPR $0.11 \% \quad 20.2 \%$ VELSTGMPR $0.02 \% \quad 14.0 \%$ NGYDYGQCR $0.02 \% \quad 14.0 \%$ SHEGETSYIR $0.02 \% \quad 14.0 \%$ GSPHYFSPFRPY $0.04 \% \quad 14.9 \%$ DIKPDNLLLDAK $0.04 \% \quad 14.9 \%$ LSDFGLCTGLK $0.04 \% \quad 14.9 \%$ LSDFGLCTGLKK $0.04 \% \quad 14.9 \%$ NLTHNPPSDFSFQNMNSK $0.04 \% \quad 14.9 \%$ ERPAAIPIEIK $0.04 \% \quad 14.9 \%$ RFEGLTQR $0.04 \% \quad 14.9 \%$ GSIPTYMK $0.01 \% \quad 6.7 \% \quad$ FLILNPSKR $0.01 \% \quad 6.7 \% \quad$ VPASPLPGLER $0.01 \% \quad 6.7 \% \quad$ TTPTPSTNSVLSTSTNR $0.01 \% \quad 6.7 \% \quad$ ASTASASAAVSAARPR $0.01 \% \quad 0.8 \%$ DASAVSLSESK

$0.01 \% \quad 0.8 \%$ TLDQSPELR

$120 \quad 0.25 \% \quad 29.0 \%$ GYVWNGGSNPQANR

$120 \quad 0.25 \% \quad 29.0 \%$ GYVWNGGSNPQANRQTSDSSSAK

$120 \quad 0.25 \% \quad 29.0 \%$ MSTPADKVLR

$120 \quad 0.25 \% \quad 29.0 \%$ ATVEQVLDPR

$120 \quad 0.25 \% \quad 29.0 \%$ ATVEQVLDPRTR

$120 \quad 0.25 \% \quad 29.0 \%$ MILFKMLTR

$120 \quad 0.25 \% \quad 29.0 \%$ GIITEINGCISTGK

$120 \quad 0.25 \% \quad 29.0 \%$ EANVYHASTANGESR $\begin{array}{llllllll}99.7 \% & 46.5 & 25.0 & 44.6 & 2 & 2 & 0 & 1432.75\end{array}$

945.51

918.50

1189.63

1308.62

1043.53

1130.62

1530.82

1030.59

1526.77

1175.51

1030.59

1574.76

1064.54

1401.73

1122.62

1349.75

1135.61

1719.90

1073.54

1161.60

1244.68

1005.50

1132.45

1178.54

1454.69

1354.76

1210.6

1338.71

2093.93

1236.73

1006.54

896.45

1087.66

1135.65

1763.88

1473.78

1093.54

1058.55

1519.70

2411.10

1133.60

1127.61

1384.75

1168.66

1462.76

$\begin{array}{llll}99.7 \% & 31.7 & 25.0 & 30.6\end{array}$

$\begin{array}{llll}99.7 \% & 72.5 & 25.0 & 65.0\end{array}$

$\begin{array}{llll}99.7 \% & 67.5 & 25.0 & 66.5\end{array}$

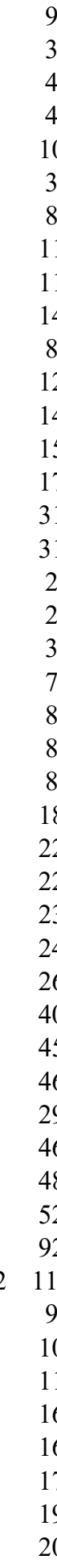



Serine/threonine-protein kinase RIO1 GN=RIOK1 RIOK1_HUMAN $65.58 \quad 100.0 \% \quad 17$ Serine/threonine-protein kinase RIO1 GN=RIOK1 RIOK1_HUMAN $65.58 \quad 100.0 \% \quad 17$ Serine/threonine-protein kinase RIO1 GN=RIOK1 RIOK1_HUMAN $65.58 \quad 100.0 \% \quad 17$ Serine/threonine-protein kinase RIO1 GN=RIOK1 RIOK1_HUMAN $65.58 \quad 100.0 \% \quad 17$ Serine/threonine-protein kinase RIO1 GN=RIOK1 RIOK1_HUMAN $65.58 \quad 100.0 \% \quad 17$ Serine/threonine-protein kinase RIO1 GN=RIOK1 RIOK1_HUMAN $65.58 \quad 100.0 \%$ Serine/threonine-protein kinase RIO1 GN=RIOK1 RIOK1_HUMAN $65.58 \quad 100.0 \% \quad 17$ Serine/threonine-protein kinase RIO1 GN=RIOK1 RIOK1_HUMAN $65.58 \quad 100.0 \%$

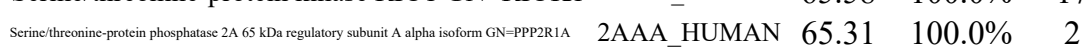
$\begin{array}{llll} & \text { 2AAA_HUMAN } & 65.31 & 100.0 \%\end{array}$ Serine/threonine-protein phosphatase 6 catalytic subunit GN=PPP6C PPP6_HUMAN $35.14 \quad 100.0 \%$ Serine/threonine-protein phosphatase PGAM5, mitochondrial GN=PGAM5 PGAM5_HUMAN $32.01 \quad 100.0 \%$ Serine/threonine-protein phosphatase PGAM5, mitochondrial GN=PGAM5 $\quad$ PGAM5 HUMAN $32.01 \quad 100.0 \%$ Serine/threonine-protein phosphatase PGAM5, mitochondrial GN=PGAM5 $\quad$ PGAM5_HUMAN $32.01 \quad 100.0 \%$ 列 Serine/threonine-protein phosphatase PGAM5, mitochondrial GN=PGAM5 PGAM5_HUMAN $32.01 \quad 100.0 \%$ Serine/threonine-protein phosphatase PP1-alpha catalytic subunit GN=PPPICA PP1A_HUMAN $37.51 \quad 100.0 \%$

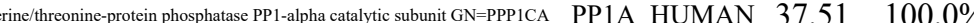
Serine/threonine-protein phosphatase PPI-beta catalytic subunit GN=PPPICB PP1B_HUMAN $37.19 \quad 100.0 \%$ Serine/threonine-protein phosphatase PPI-beta catalytic subunit GN=PPPICB PP1B HUMAN $37.19 \quad 100.0 \%$ Serine/threonine-protein phosphatase PPI-beta catalytic subunit GN=PPPICB PP1B HUMAN $37.19 \quad 100.0 \%$ Serine/threonine-protein phosphatase PPI-beta catalytic subunit GN=PPPICB PP1B_HUMAN $37.19 \quad 100.0 \%$ Serine/threonine protein phosphatase $\mathrm{PP} 1$-gamma catalytic subunit GN=PPPICC PP1G_HUMAN 36.99 Serine/threonine-protein phosphatase PP1-gamma catalytic subunit GN=PPPICC PP1G_HUMAN 36.99 PP1G_HUMAN $36.99 \quad 100.0 \%$ Serine-threonine kinase receptor-associated protein GN=STRAP STRAP_HUMAN $38.44 \quad 100.0 \%$ Serine-threonine kinase receptor-associated protein GN=STRAP STRAP HUMAN $38.44 \quad 100.0 \%$ Serpin $\mathrm{H} 1 \mathrm{GN}=$ SERPINH1 Serpin $\mathrm{H} 1 \mathrm{GN}=$ SERPINH1 Serpin $\mathrm{H} 1 \mathrm{GN}=$ SERPINH1 Serum albumin $\mathrm{GN}=\mathrm{ALB}$ Serum albumin $\mathrm{GN}=\mathrm{ALB}$ Serum albumin $\mathrm{GN}=\mathrm{ALB}$ Serum albumin $\mathrm{GN}=\mathrm{ALB}$ Serum albumin $\mathrm{GN}=\mathrm{ALB}$ Serum albumin $\mathrm{GN}=\mathrm{ALB}$

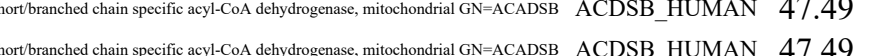
Shortbranched chain specific ayyl-CoA dehydrogenase, mitochondrial GN=ACADSB ACDSB_HUMAN $47.49 \quad 100.0$ 政 $\begin{array}{llll}23 & 120 & 0.25 \% & 29.0 \% \\ & & \text { TWAEKEMR }\end{array}$ $23 \quad 120 \quad 0.25 \% \quad 29.0 \%$ NVQLSESKAR $23 \quad 120 \quad 0.25 \% \quad 29.0 \%$ KDCANVNDFFMR $23 \quad 120 \quad 0.25 \% \quad 29.0 \%$ DCANVNDFFMR $23 \quad 120 \quad 0.25 \% \quad 29.0 \%$ HSVAVMTVR $23 \quad 120 \quad 0.25 \% \quad 29.0 \%$ AMEIASQR

$23 \quad 120 \quad 0.25 \% \quad 29.0 \%$ SSQDHVDEEVFKR $23 \quad 120 \quad 0.25 \% \quad 29.0 \%$ TLNEVKNYER $23 \quad 120 \quad 0.25 \% \quad 29.0 \%$ VPALLENQVEER

$2 \quad 0.00 \% \quad 3.9 \% \quad$ LAGGDWFTSR

$2 \quad 0.00 \% \quad 3.9 \% \quad$ VLAMSGDPNYLHR

$4 \quad 0.01 \% \quad 8.9 \% \quad$ QITQVYGFYDECQTK $0.01 \% \quad 8.9 \%$ VTNEFVHINNLK $14 \quad 0.03 \% \quad 19.4 \%$ NVESGEEELASK $4 \quad 0.03 \% \quad 19.4 \%$ EQAELTGLR $14 \quad 0.03 \% \quad 19.4 \%$ LASLGLKFNK $14 \quad 0.03 \% \quad 19.4 \%$ AIETTDIISR $14 \quad 0.03 \% \quad 19.4 \%$ TLGDTGFMPPDKITR $0.01 \% \quad 7.6 \% \quad$ IYGFYDECKR $0.01 \% \quad 7.6 \%$ AHQVVEDGYEFFAKR $0.01 \% \quad 15.6 \%$ IVQMTEAEVR $0.01 \% \quad 15.6 \%$ IYGFYDECKR $0.01 \% \quad 15.6 \%$ AHQVVEDGYEFFAKR $0.01 \% \quad 15.6 \%$ YQYGGLNSGRPVTPPR $0.01 \% \quad 12.7 \%$ GSKPGKNVQLQENEIR $0.01 \% \quad 12.7 \%$ NVQLQENEIR $0.01 \% \quad 12.7 \%$ IYGFYDECKR $0.01 \% \quad 12.7 \%$ AHQVVEDGYEFFAKR $0.01 \% \quad 7.7 \%$ IYDLNKPEAEPK $0.01 \% \quad 7.7 \%$ CVLPEEDSGELAKPK

$11 \quad 0.02 \% \quad 8.1 \%$ SYTVGVMMMHR

$11 \quad 0.02 \% \quad 8.1 \%$ GVVEVTHDLQK

$11 \quad 0.02 \% \quad 8.1 \% \quad$ DTQSGSLLFIGR

$86 \quad 0.18 \% \quad 10.7 \%$ LVNEVTEFAK

$86 \quad 0.18 \% \quad 10.7 \%$ CASLQKFGER

$86 \quad 0.18 \% \quad 10.7 \%$ YICENQDSISSK

$86 \quad 0.18 \% \quad 10.7 \%$ KVPQVSTPTLVEVSR

$86 \quad 0.18 \% \quad 10.7 \%$ CCTESLVNR

$86 \quad 0.18 \% \quad 10.7 \%$ QTALVELVK

$10 \quad 0.02 \% \quad 13.2 \%$ ATYLPQLTTEK

$10 \quad 0.02 \% \quad 13.2 \%$ ASSTCPLTFENVK

$10 \quad 0.02 \% \quad 13.2 \%$ YAIGSLNEGR

$10 \quad 0.02 \% \quad 13.2 \%$ LLEAGKPFIK

$10 \quad 0.02 \% \quad 13.2 \%$ YYASEIAGQTTSK

$24 \quad 0.05 \% \quad 31.7 \%$ WDQSTFIGR

$24 \quad 0.05 \% \quad 31.7 \%$ ANHFFTVTDPR

$24 \quad 0.05 \% \quad 31.7 \%$ NILLTNEQLESAR

1109.54

1472.73

1879.85

1427.76

1291.60

1016.54

1090.66

1118.61

1664.83

1350.61

1795.88

1175.61

1350.61

1795.88

1761.90

1796.96

1242.64

1350.61

1795.88

1416.74

1671.83

1311.60

1224.66

1293.68

1149.62

1195.59

1443.64

1639.94

1138.50

1000.60

1264.68

1453.70

1079.55

1115.68

1418.68

1109.54

1304.64

1500.80 
Sideroflexin-1 GN=SFXN1 Sideroflexin-1 GN=SFXN1 Sideroflexin-1 GN=SFXN1 Sideroflexin-1 GN=SFXN1 Sideroflexin-1 GN=SFXN1 Sideroflexin-1 GN=SFXN1 Sideroflexin-1 GN=SFXN1 Sideroflexin-2 GN=SFXN2 Sideroflexin-2 GN=SFXN2 Sideroflexin- 4 GN=SFXN4 Sideroflexin- $4 \mathrm{GN}=\mathrm{SFXN} 4$ Sideroflexin- 4 GN=SFXN4 Sideroflexin-4 GN=SFXN4 Signal recognition particle receptor sub GN=SRPRB SRPRB_HUMAN $29.70 \quad 100.0 \%$ Signal recognition particle subunit SRP68 GN=SRP68 SRP68_HUMAN $70.73 \quad 100.0 \%$ Signal recognition particle subunit SRP68 GN=SRP68 SRP68_HUMAN $70.73 \quad 100.0 \%$ Signal recognition particle subunit SRP72 GN=SRP72 SRP72_HUMAN 74.61 $100.0 \%$ Signal recognition particle subunit SRP72 GN=SRP72 SRP72_HUMAN $74.61 \quad 100.0 \%$ Signal transducer and activator of transcription $3 \mathrm{GN}=$ STAT3 STAT3_HUMAN $88.07 \quad 100.0 \%$ Signal transducer and activator of transcription 3 GN=STAT3 STAT3_HUMAN $88.07 \quad 100.0 \%$ Signal transducer and activator of transcription 3 GN=STAT3 STAT3_HUMAN $88.07 \quad 100.0 \%$ Sodium/potassium-transporting ATPase subunit alpha-1 GN=ATP1A1 AT1A1_HUMAN $112.90 \quad 100.0 \%$ Sodium/potassium-transporting ATPase subunit alpha-1 GN=ATP1A1 AT1A1_HUMAN $112.90 \quad 100.0 \%$ Sodium/potassium-transporting ATPase subunit alpha-1 GN=ATP1A1 AT1A1_HUMAN $112.90 \quad 100.0 \%$ Sodium/potassium-transporting ATPase subunit alpha-1 GN=ATP1A1 AT1A1_HUMAN $112.90 \quad 100.0 \%$ Sodium/potassium-transporting ATPase subunit alpha-1 GN=ATP1A1 AT1A1_HUMAN $112.90 \quad 100.0 \%$ Sodium/potassium-transporting ATPase subunit alpha-1 GN=ATP1A1 AT1A1_HUMAN $112.90 \quad 100.0 \%$ Sodium/potassium-transporting ATPase subunit alpha-1 GN=ATP1A1 AT1A1_HUMAN $112.90 \quad 100.0 \%$ Spectrin alpha chain, non-erythrocytic 1 GN=SPTAN1 SPTN1_HUMAN $284.54 \quad 100.0 \%$ Spectrin alpha chain, non-erythrocytic $1 \mathrm{GN}=$ SPTAN1 SPTN1_HUMAN $284.54 \quad 100.0 \%$ Spectrin alpha chain, non-erythrocytic $1 \mathrm{GN}=$ SPTAN1 SPTN1_HUMAN $284.54 \quad 100.0 \%$ Spectrin alpha chain, non-erythrocytic $1 \mathrm{GN}=$ SPTAN1 SPTN1_HUMAN $284.54 \quad 100.0 \%$ Spectrin beta chain, non-erythrocytic $1 \mathrm{GN}=$ SPTBN1 SPTB2_HUMAN $274.61 \quad 100.0 \%$ Spectrin beta chain, non-erythrocytic $1 \mathrm{GN}=$ SPTBN1 SPTB2_HUMAN $274.61 \quad 100.0 \%$ Spermidine synthase GN=SRM Spermidine synthase $\mathrm{GN}=\mathrm{SRM}$ Spermidine synthase $\mathrm{GN}=\mathrm{SRM}$ Spermidine synthase $\mathrm{GN}=\mathrm{SRM}$ SPEE HUMAN $33.82 \quad 100.0 \%$ SPEE_HUMAN $33.82 \quad 100.0 \%$ SPEE HUMAN $33.82 \quad 100.0 \%$ SPEE_HUMAN $33.82 \quad 100.0 \%$ Sphingomyelin phosphodiesterase 4 GN=SMPD4 NSMA3_HUMAN $93.35 \quad 100.0 \%$ Sphingomyelin phosphodiesterase 4 GN=SMPD4 NSMA3_HUMAN $93.35100 .0 \%$ Sphingomyelin phosphodiesterase 4 GN=SMPD4 NSMA3_HUMAN $93.35 \quad 100.0 \%$ Sphingomyelin phosphodiesterase 4 GN=SMPD4 NSMA3_HUMAN $93.35100 .0 \%$ Sphingomyelin phosphodiesterase 4 GN=SMPD4 NSMA3_HUMAN $93.35 \quad 100.0 \%$ Spindlin-1 GN=SPIN1

Spindlin-1 GN=SPIN1 Spindlin-1 GN=SPIN1
$24 \quad 0.05 \% \quad 31.7 \%$ YIYDSAFHPDTGEK

$0.05 \% \quad 31.7 \%$ HVSPLIGR

$0.05 \% \quad 31.7 \%$ VGIPVTDENGNR

$0.05 \% \quad 31.7 \%$ QAITQVVVSR

$0.05 \% \quad 31.7 \%$ SSMSVTSLEAELQAK

$0.05 \% \quad 31.7 \%$ IQESHPELR

$0.05 \% \quad 31.7 \%$ IQESHPELRR

$0.01 \% \quad 4.4 \%$ RAAAIGITQVVISR

$0.01 \% \quad 4.4 \%$ AAAIGITQVVISR

$0.03 \% \quad 14.8 \%$ DAVPAFIEPNVR

$0.03 \% \quad 14.8 \%$ SLATVHPDSSNLIPK

$0.03 \% \quad 14.8 \%$ SYTCKPLER

$0.03 \% \quad 14.8 \%$ IQSPTEETEIFYHR

$0.01 \% \quad 7.4 \%$ SAAPSTLDSSSTAPAQLGK

$0.01 \% \quad 7.4 \%$ SAAPSTLDSSSTAPAQLGKK

$0.01 \% \quad 6.9 \%$ AAEKQVPGGGGGGGSGGGGGSGGGGSGGGR

$0.01 \% \quad 6.9 \%$ ALLQQQPEDDSKR

$0.01 \% \quad 3.9 \%$ SPAHLSLIR

$0.01 \% \quad 3.9 \%$ GTQGATAGASSELDASK

$0.01 \% \quad 3.8 \%$ IKQFLQSR

$0.01 \% \quad 3.8 \%$ KFNILGTNTK

$0.01 \% \quad 3.8 \%$ TQIQSVEPYTK

$10 \quad 0.02 \% \quad 7.7 \% \quad$ SPDFTNENPLETR

$10 \quad 0.02 \% \quad 7.7 \%$ AVAGDASESALLK

$10 \quad 0.02 \% \quad 7.7 \%$ AAVPDAVGKCR

$10 \quad 0.02 \% \quad 7.7 \% \quad$ LNIPVSQVNPR

$10 \quad 0.02 \% \quad 7.7 \% \quad$ TSPQQKLIIVEGCQR

$0.02 \% \quad 7.7 \%$ LIIVEGCQR

$10 \quad 0.02 \% \quad 7.7 \%$ ADIGVAMGIAGSDVSK

$0.01 \% \quad 1.9 \%$ VLETAEDIQER

$0.01 \% \quad 1.9 \%$ LFGAAEVQR

$0.01 \% \quad 1.9 \% \quad$ LGESQTLQQFSR

$0.01 \% \quad 1.9 \%$ LSDDNTIGKEEIQQR

$0.01 \% \quad 0.9 \%$ VAVVNQIAR

$0.01 \% \quad 0.9 \% \quad$ ALVADSHPESER

$0.02 \% \quad 13.9 \%$ YQDILVFR

$0.02 \% \quad 13.9 \%$ VLIIGGGDGGVLR

$0.02 \% \quad 13.9 \%$ FLPGMAIGYSSSK

$0.02 \% \quad 13.9 \%$ YYNSDVHR

$10 \quad 0.02 \% \quad 6.2 \% \quad$ YAPDKQAPGSDSQPR

$\quad 0.02 \% \quad 6.2 \% \quad$ LFVGFLNR

$10 \quad 0.02 \% \quad 6.2 \% \quad$ ALRTDLVSPK

$10 \quad 0.02 \% \quad 6.2 \% \quad$ LAQLITQAK

$10 \quad 0.02 \% \quad 6.2 \% \quad$ DDFLGSFCR

23

23

23

$0.05 \% \quad 21.8 \%$ SSVGPSKPVSQPR $\begin{array}{llllllll}7 & 80.2 & 25.0 & 72.9 & 1 & 0 & 0 & 1642.74\end{array}$

878.52

$\begin{array}{llllllll}99.7 \% & 39.0 & 25.0 & 36.6 & 2 & 0 & 0 & 1270.64\end{array}$

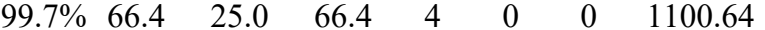

$\begin{array}{llllllll}99.7 \% & 26.7 & 25.0 & 26.7 & 1 & 0 & 0 & 1596.78\end{array}$

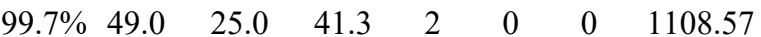

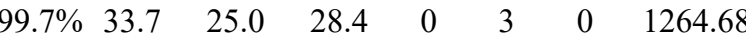

$\begin{array}{llllllll}99.3 \% & 24.4 & 25.0 & 24.4 & 0 & 2 & 0 & 1454.88\end{array}$

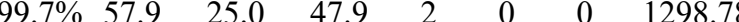

$\begin{array}{llllllll}99.7 \% & 35.6 & 25.0 & 31.1 & 4 & 0 & 0 & 1327.70\end{array}$

$\begin{array}{llllllll}99.7 \% & 27.3 & 25.0 & 25.3 & 4 & 0 & 0 & 1578.85\end{array}$

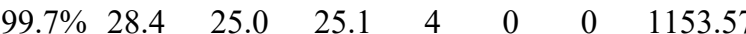

$99.7 \% \quad 26.5$

1749.84

1788.90

1916.99

2243.02

1527.78

993.58

1550.73

1019.60

1135.65

1293.67

1519.70

1231.65

1143.59

1236.71

1756.94

1087.59

1490.75

1302.65

990.54

1393.71

1745.87

969.58

1310.63

1053.57

$99.0 \% \quad 44.2$

$\begin{array}{llll}99.7 \% & 57.4 & 25.0 & 55.5\end{array}$

$\begin{array}{llll}99.7 \% & 29.7 & 25.0 & 28.3\end{array}$

$\begin{array}{llll}99.0 \% & 34.2 & 25.0 & 34.2\end{array}$

$\begin{array}{llll}99.7 \% & 55.0 & 25.0 & 55.0\end{array}$

$\begin{array}{llll}99.0 \% & 37.2 & 25.0 & 36.7\end{array}$

$\begin{array}{llll}99.5 \% & 26.5 & 25.0 & 22.0\end{array}$

$99.7 \% \quad 58.5 \quad 25.0 \quad 50.7$

$\begin{array}{llll}99.0 \% & 19.3 & 25.0 & 19.3\end{array}$

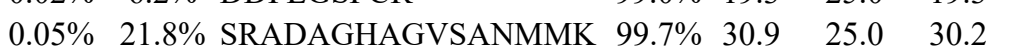

$99.7 \% \quad 64.2$

$99.7 \% \quad 53.9$ 


\section{Spindlin-1 GN=SPIN1}

Spindlin-1 GN=SPIN1

Splicing factor $3 \mathrm{~B}$ subunit $1 \mathrm{GN}=\mathrm{SF} 3 \mathrm{~B} 1$

Splicing factor $3 \mathrm{~B}$ subunit $1 \mathrm{GN}=\mathrm{SF} 3 \mathrm{~B} 1$

Splicing factor $3 B$ subunit $1 \mathrm{GN}=\mathrm{SF} 3 \mathrm{~B} 1$

Splicing factor $3 \mathrm{~B}$ subunit $1 \mathrm{GN}=\mathrm{SF} 3 \mathrm{~B} 1$

Splicing factor $3 \mathrm{~B}$ subunit $1 \mathrm{GN}=\mathrm{SF} 3 \mathrm{~B}$

Splicing factor $3 B$ subunit $1 \mathrm{GN}=\mathrm{SF} 3 \mathrm{~B} 1$

Splicing factor $3 \mathrm{~B}$ subunit $1 \mathrm{GN}=\mathrm{SF} 3 \mathrm{~B} 1$

Splicing factor $3 B$ subunit $1 \mathrm{GN}=\mathrm{SF} 3 \mathrm{~B} 1$

Splicing factor $3 \mathrm{~B}$ subunit $1 \mathrm{GN}=\mathrm{SF} 3 \mathrm{~B} 1$

Splicing factor $3 \mathrm{~B}$ subunit $1 \mathrm{GN}=\mathrm{SF} 3 \mathrm{~B} 1$

Splicing factor $3 \mathrm{~B}$ subunit $1 \mathrm{GN}=\mathrm{SF} 3 \mathrm{~B} 1$

Splicing factor $3 \mathrm{~B}$ subunit $3 \mathrm{GN}=\mathrm{SF} 3 \mathrm{~B} 3$

Splicing factor $3 \mathrm{~B}$ subunit $3 \mathrm{GN}=\mathrm{SF} 3 \mathrm{~B} 3$

Splicing factor $3 \mathrm{~B}$ subunit $3 \mathrm{GN}=\mathrm{SF} 3 \mathrm{~B} 3$

Splicing factor $3 \mathrm{~B}$ subunit $3 \mathrm{GN}=\mathrm{SF} 3 \mathrm{~B} 3$

Splicing factor $3 \mathrm{~B}$ subunit $3 \mathrm{GN}=\mathrm{SF} 3 \mathrm{~B} 3$

Splicing factor $3 \mathrm{~B}$ subunit $3 \mathrm{GN}=\mathrm{SF} 3 \mathrm{~B} 3$

Splicing factor $3 \mathrm{~B}$ subunit $3 \mathrm{GN}=\mathrm{SF} 3 \mathrm{~B} 3$

ing factor U2AF $35 \mathrm{kDa}$ subunit GN=U2AF1 U2AF1_HUMAN $27.87 \quad 100.0 \%$

Splicing factor U2AF $65 \mathrm{kDa}$ subunit GN=U2AF2 U2AF2_HUMAN $53.50 \quad 100.0 \%$ Splicing factor U2AF $65 \mathrm{kDa}$ subunit GN=U2AF2 U2AF2_HUMAN $53.50 \quad 100.0 \%$ Splicing factor U2AF $65 \mathrm{kDa}$ subunit GN=U2AF2 U2AF2 HUMAN $53.50 \quad 100.0 \%$ Splicing factor U2AF $65 \mathrm{kDa}$ subunit GN=U2AF2 U2AF2_HUMAN $53.50 \quad 100.0 \%$ Splicing factor U2AF $65 \mathrm{kDa}$ subunit GN=U2AF2 U2AF2_HUMAN $53.50 \quad 100.0 \%$ Splicing factor, proline- and glutamine-rich GN=SFPQ SFPQ_HUMAN $76.15 \quad 100.0 \%$ Splicing factor, proline- and glutamine-rich GN=SFPQ SFPQ_HUMAN $76.15 \quad 100.0 \%$ Splicing factor, proline- and glutamine-rich GN=SFPQ SFPQ HUMAN $76.15 \quad 100.0 \%$ Splicing factor, proline- and glutamine-rich GN=SFPQ SFPQ_HUMAN $76.15 \quad 100.0 \%$ Splicing factor, proline- and glutamine-rich GN=SFPQ SFPQ_HUMAN $76.15 \quad 100.0 \%$ Splicing factor, proline- and glutamine-rich GN=SFPQ SFPQ HUMAN 76.15 100.0\% SRSF protein kinase $1 \mathrm{GN}=\mathrm{SRPK} 1$ SRSF protein kinase $1 \mathrm{GN}=\mathrm{SRPK} 1$

SRSF protein kinase $1 \mathrm{GN}=\mathrm{SRPK} 1$ SRPK1_HUMAN $74.33 \quad 100.0 \%$ SRPK1 HUMAN $74.33 \quad 100.0 \%$ SRPK1_HUMAN $74.33 \quad 100.0 \%$ Stress-70 protein, mitochondrial GN=HSPA9 GRP75_HUMAN $73.68 \quad 100.0 \%$ Stress-70 protein, mitochondrial GN=HSPA9 GRP75_HUMAN $73.68 \quad 100.0 \%$ Stress-70 protein, mitochondrial GN=HSPA9 GRP75_HUMAN $73.68 \quad 100.0 \%$ Stress-70 protein, mitochondrial GN=HSPA9 GRP75_HUMAN $73.68 \quad 100.0 \%$ Stress-70 protein, mitochondrial GN=HSPA9 GRP75_HUMAN $73.68 \quad 100.0 \%$ Stress-70 protein, mitochondrial GN=HSPA9 GRP75_HUMAN $73.68 \quad 100.0 \%$ Stress-70 protein, mitochondrial GN=HSPA9 GRP75_HUMAN $73.68 \quad 100.0 \%$ Stress-70 protein, mitochondrial GN=HSPA9 GRP75_HUMAN $73.68 \quad 100.0 \%$ Stress-70 protein, mitochondrial GN=HSPA9 GRP75_HUMAN $73.68 \quad 100.0 \%$ Stress-70 protein, mitochondrial GN=HSPA9 GRP75_HUMAN $73.68 \quad 100.0 \%$ Stress-70 protein, mitochondrial GN=HSPA9 GRP75_HUMAN $73.68 \quad 100.0 \%$
$0.05 \% \quad 21.8 \%$ VSALEVLPDRVATSR

$0.05 \% \quad 21.8 \%$ ISDAHLADTMIGK

$0.04 \% \quad 7.3 \% \quad$ VVNGAAASQPPSK

$99.7 \% \quad 32.8$

$99.7 \% \quad 68.9$

$98.9 \% \quad 24.9$

$0.04 \% \quad 7.3 \%$ TDRGGDSIGETPTPGASK $97.0 \% \quad 23.9$

$0.04 \% \quad 7.3 \%$ GGDSIGETPTPGASK

$0.04 \% \quad 7.3 \%$ VEGREIISNLAK

$0.04 \% \quad 7.3 \%$ GKGLAAFLK

$0.04 \% \quad 7.3 \%$ VGAAEIISR

$0.04 \% \quad 7.3 \% \quad$ VRQQAADLISR

$0.04 \% \quad 7.3 \%$ QQAADLISR

$0.04 \% \quad 7.3 \% \quad$ VQENCIDLVGR

$0.04 \% \quad 7.3 \%$ RATVNTFGYIAK

$0.04 \% \quad 7.3 \%$ ATVNTFGYIAK

$0.04 \% \quad 6.2 \%$ NFGDQPDIR

$0.04 \% \quad 6.2 \% \quad$ FLAVGLVDNTVR

$0.04 \% \quad 6.2 \% \quad$ TVLDPVTGDLSDTR

$0.04 \% \quad 6.2 \%$ TVLDPVTGDLSDTRTR

$0.04 \% \quad 6.2 \%$ MQGQEAVLAMSSR

$0.04 \% \quad 6.2 \% \quad$ SVAGGFVYTYK

$0.04 \% \quad 6.2 \% \quad$ NVSEELDRTPPEVSK

$0.01 \% \quad 9.2 \%$ NPQNSSQSADGLR

$0.01 \% \quad 9.2 \%$ QYEMGECTR

$0.02 \% \quad 11.2 \%$ GAKEEHGGLIR

$0.02 \% \quad 11.2 \%$ AFNLVKDSATGLSK

$0.02 \% \quad 11.2 \%$ AMQGLTGRK

$0.02 \% \quad 11.2 \%$ FANRVVVTK

$0.02 \% \quad 11.2 \%$ YCDPDSYHRR

$0.02 \% \quad 8.8 \%$ RPGEKTYTQR

$0.02 \% \quad 8.8 \%$ FATHAAALSVR

$0.02 \% \quad 8.8 \% \quad$ AVVIVDDRGR

$0.02 \% \quad 8.8 \%$ STGKGIVEFASKPAAR

$0.02 \% \quad 8.8 \%$ GIVEFASKPAAR

$0.02 \% \quad 8.8 \% \quad$ FGQGGAGPVGGQGPR

$0.01 \% \quad 4.9 \% \quad$ KVLALQAR

$0.01 \% \quad 4.9 \%$ LAAEATEWQR

$0.01 \% \quad 4.9 \% \quad$ ATAAECLRHPWLNS

$0.09 \% \quad 20.9 \%$ VLENAEGAR

$0.09 \% \quad 20.9 \%$ TTPSVVAFTADGER

$0.09 \% \quad 20.9 \%$ QAVTNPNNTFYATK

$0.09 \% \quad 20.9 \%$ QAVTNPNNTFYATKR

$0.09 \% \quad 20.9 \%$ RYDDPEVQK

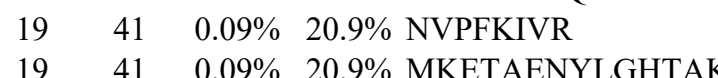

$19 \quad 41 \quad 0.09 \% \quad 20.9 \%$ NAVITVPAYFNDSQR

$19 \quad 41 \quad 0.09 \% \quad 20.9 \%$ QATKDAGQISGLNVLR

$19 \quad 41 \quad 0.09 \% \quad 20.9 \%$ DAGQISGLNVLR

$19 \quad 41 \quad 0.09 \% \quad 20.9 \%$ ETGVDLTKDNMALQR $\begin{array}{llll}99.7 \% & 37.8 & 25.0 & 37.8\end{array}$

$99.7 \% \quad 28.1 \quad 25.0 \quad 28.1$

$95.7 \% \quad 16.9 \quad 25.0 \quad 16.9$

$\begin{array}{lllll}99.7 \% & 50.5 & 25.0 & 24.7 & 2\end{array}$

$99.7 \% \quad 39.5 \quad 25.0 \quad 39.5$

$\begin{array}{llll}99.7 \% & 45.7 & 25.0 & 28.5\end{array}$

$\begin{array}{lllll}99.7 \% & 53.5 & 25.0 & 51.1 & 2\end{array}$

$99.7 \% \quad 34.8 \quad 25.0 \quad 28.7$

$99.7 \% \quad 66.9 \quad 25.0 \quad 64.7$

$98.0 \% \quad 25.1 \quad 25.0 \quad 13.1$

$99.7 \% \quad 68.5 \quad 25.0 \quad 61.9$

$99.7 \% \quad 70.8 \quad 25.0 \quad 70.8 \quad 8$

$\begin{array}{llll}99.3 \% & 21.5 & 25.0 & 20.7\end{array}$

$\begin{array}{llll}99.7 \% & 43.5 & 25.0 & 43.5\end{array}$

$\begin{array}{llll}99.7 \% & 45.7 & 25.0 & 28.5\end{array}$

$99.7 \% \quad 36.0 \quad 25.0 \quad 35.8$

$\begin{array}{llll}99.7 \% & 68.9 & 25.0 & 68.9\end{array}$

$99.7 \% \quad 30.8 \quad 25.0 \quad 29.2$

$99.7 \% \quad 35.9 \quad 25.0 \quad 21.7$

$\begin{array}{llll}99.7 \% & 45.9 & 25.0 & 45.9\end{array}$

$99.7 \% \quad 35.7 \quad 25.0 \quad 17.6$

$\begin{array}{llll}99.7 \% & 33.0 & 25.0 & 25.5\end{array}$

$\begin{array}{llll}96.2 \% & 16.2 & 25.0 & 16.2\end{array}$

$\begin{array}{llll}97.5 \% & 17.8 & 25.0 & 16.6\end{array}$

$99.7 \% \quad 29.8 \quad 25.0 \quad 25.1 \quad 2$

$\begin{array}{llll}99.7 \% & 33.4 & 25.0 & 27.5\end{array}$

$\begin{array}{llll}99.7 \% & 35.8 & 25.0 & 34.6\end{array}$

$\begin{array}{llll}99.6 \% & 26.7 & 25.0 & 26.7\end{array}$

$\begin{array}{llll}99.7 \% & 58.7 & 25.0 & 51.0\end{array}$

$\begin{array}{llll}99.0 \% & 24.7 & 25.0 & 17.0\end{array}$

$\begin{array}{llll}99.7 \% & 48.8 & 25.0 & 45.1\end{array}$

$\begin{array}{llll}99.7 \% & 43.5 & 25.0 & 43.5\end{array}$

$\begin{array}{llll}99.7 \% & 65.1 & 25.0 & 55.4\end{array}$

$99.7 \% \quad 73.6 \quad 25.0 \quad 69.3$

$\begin{array}{llll}99.7 \% & 75.0 & 25.0 & 63.3\end{array}$

$\begin{array}{llll}99.7 \% & 57.7 & 25.0 & 55.9\end{array}$

$\begin{array}{llll}98.8 \% & 23.7 & 25.0 & 16.5\end{array}$

$\begin{array}{llll}98.8 \% & 20.5 & 25.0 & 17.7\end{array}$

$\begin{array}{llll}95.1 \% & 14.7 & 25.0 & 14.7\end{array}$

$\begin{array}{llll}99.7 \% & 50.9 & 25.0 & 49.3\end{array}$

$\begin{array}{lllll}99.7 \% & 68.8 & 25.0 & 66.2 & 2\end{array}$

$\begin{array}{llll}99.7 \% & 57.5 & 25.0 & 33.0\end{array}$

$\begin{array}{llll}99.7 \% & 36.6 & 25.0 & 34.4\end{array}$
1225.65

1745.83

1373.65

1328.75

904.56

915.53

1256.71

1001.54

1302.65

1340.73

1184.63

1061.50

1303.74

1488.75

1745.90

1407.67

1191.60

1699.85

1373.64

1173.47

1166.63

1450.79

961.52

1033.62

1368.58

1235.65

1143.63

1099.62

1618.89

1245.70

1341.67

898.58

1174.59

1625.79

958.50

1450.72

1568.77

1724.87

1149.55

972.60

1592.77

1694.85

1670.92

1242.68

1690.84 $\begin{array}{cc}08 & 122 \\ 23 & 135 \\ 83 & 195 \\ 16 & 333 \\ 19 & 333 \\ 91 & 602 \\ 40 & 748 \\ 44 & 852 \\ 47 & 957 \\ 49 & 957 \\ 31 & 1041 \\ 75 & 1086 \\ 76 & 1086 \\ 60 & 268 \\ 04 & 615 \\ 77 & 690 \\ 77 & 692 \\ 06 & 718 \\ 19 & 929 \\ 92 & 1206 \\ 4 & 66 \\ 57 & 165 \\ 8 & 78 \\ 87 & 300 \\ 45 & 453 \\ 54 & 462 \\ 63 & 472 \\ 87 & 296 \\ 66 & 376 \\ 00 & 409 \\ 10 & 425 \\ 14 & 425 \\ 67 & 681 \\ 4 & 11 \\ 31 & 240 \\ 42 & 655 \\ 7 & 85 \\ 6 & 99 \\ 08 & 121 \\ 08 & 122 \\ 27 & 135 \\ 39 & 146 \\ 74 & 187 \\ 88 & 202 \\ 03 & 218 \\ 07 & 218 \\ 93 & 307\end{array}$

Page 76 of Table S-1-3 
Stress-70 protein, mitochondrial GN=HSPA9 GRP75_HUMAN $73.68 \quad 100.0 \% \quad 1$ $\begin{array}{lll} & \end{array}$ Stress-70 protein, mitochondrial GN=HSPA9 GRP75_HUMAN $73.68 \quad 100.0 \%$ Striatin-interacting protein $1 \mathrm{GN}=$ STRIP1 STRP1_HUMAN $95.58 \quad 100.0 \%$ Striatin-interacting protein $1 \mathrm{GN}=$ STRIP1 STRP1_HUMAN $95.58 \quad 100.0 \%$ Structural maintenance of chromosomes protein $1 \mathrm{~A}$ GN=SMC1A SMC1A_HUMAN $143.24 \quad 100.0 \%$ Structural maintenance of chromosomes protein $1 \mathrm{~A}$ GN=SMC1A SMC1A_HUMAN $143.24 \quad 100.0 \%$ Structural maintenance of chromosomes protein $1 \mathrm{~A}$ GN=SMC1A SMC1A_HUMAN $143.24100 .0 \%$ Structural maintenance of chromosomes protein $1 \mathrm{~A}$ GN=SMC1A SMC1A HUMAN $143.24100 .0 \%$ Structural maintenance of chromosomes protein $1 \mathrm{~A}$ GN=SMC1A SMC1A_HUMAN $143.24 \quad 100.0 \%$ Structural maintenance of chromosomes protein $2 \mathrm{GN}=\mathrm{SMC2}$ SMC2_HUMAN $135.66100 .0 \%$ Structural maintenance of chromosomes protein $2 \mathrm{GN}=\mathrm{SMC} 2 \mathrm{SMC} 2 \mathrm{HUMAN} 135.66100 .0 \%$ Structural maintenance of chromosomes protein $3 \mathrm{GN}=\mathrm{SMC} 3 \mathrm{SMC} 3$ _HUMAN $141.55 \quad 100.0 \%$ Structural maintenance of chromosomes protein $3 \mathrm{GN}=\mathrm{SMC} 3 \mathrm{SMC} 3$ HUMAN $141.55100 .0 \%$ Structural maintenance of chromosomes protein $3 \mathrm{GN}=\mathrm{SMC} 3 \mathrm{SMC} 3$ HUMAN $141.55100 .0 \%$ Structural maintenance of chromosomes protein $3 \mathrm{GN}=\mathrm{SMC} 3 \mathrm{SMC} 3$ HUMAN $141.55 \quad 100.0 \%$ Structural maintenance of chromosomes protein $3 \mathrm{GN}=\mathrm{SMC} 3 \mathrm{SMC} 3$ HUMAN $141.55100 .0 \%$ Structural maintenance of chromosomes protein $3 \mathrm{GN}=\mathrm{SMC} 3 \mathrm{SMC} 3$ _HUMAN $141.55 \quad 100.0 \%$ Structural maintenance of chromosomes protein 4 GN=SMC4 SMC4_HUMAN $147.19 \quad 100.0 \%$ Structural maintenance of chromosomes protein $4 \mathrm{GN}=\mathrm{SMC} 4 \mathrm{SMC} 4$ HUMAN $147.19100 .0 \%$ Succinyl-CoA ligase [ADP/GDP-forming] subunit alpha, mitochondrial GN=SUCLG1 SUCA_HUMAN $36.25 \quad 100.0 \%$ Succinyl-CoA ligase [ADP/GDP-forming] subunit apha, mitochondral GN=SUCLG1 SUCA HUMAN 36.25 $100.0^{\circ}$, Succinyl-COA ligase [ADP/GDP-forming] subunit alpha, mitcochondral GN=SUCLG1 SUCA_HUMAN 36.25 100.0\% Succinyl-CoA ligase [ADP/GDP-forming] subunit apha, mitochondrial GN=SUCLG1 SUCA_HUMAN $36.25 \quad 100.0^{\circ}$ (100.0\% Succinyl-CoA ligase [ADP/GDP-forming] subunit alpha, mitochondrial GN=SUCLG1 SUCA_HUMAN $36.25 \quad 100.0^{\circ}$ Succinyl-CoA ligase [ADP/GDP-forming] subunit apha, mitochondrial GN=SUCLG1 SUCA_HUMAN $36.25 \quad 100.0^{\circ}$, ind-CCA ligase [ADP/GDP-forming] subumit alpha, mitochondrial GN=SUCLG1 SUCA_HUMAN 36.25 100.0\% Succinyl-COA ligase [ADP-forming] subunit beta, mitochondrial GN=SUCLA2 SUCB1_HUMAN $50.32 \quad 100.0 \%$ Succinyl-COA ligase [ADP-forming] subunit beta, mitochondrial GN=SUCLA2 SUCB1_HUMAN $50.32100 .0 \%$ Succinyl-CoA ligase [ADP-forming] subunit beta, mitochondrial GN=SUCLA2 SUCB1_HUMAN $50.32 \quad 100.0 \%$ Succinyl-CoA ligase [ADP-forming] subunit beta, mitochondrial GN=SUCLA2 SUCB1_HUMAN $50.32 \quad 100.0 \%$ succinyl-COA ligase [ADP-forming] subumit beta mitochondrial GN=SUCLA2 SUCB1_HUMAN $50.32 \quad 100.0 \%$ Succinyl-CoA ligase [ADP-forming] subunit beta, mitochondrial GN=SUCLA2 SUCB1_HUMAN $50.32 \quad 100.0 \%$ Succinyl-COA ligase [ADP-forming] subunit beta, mitochondrial GN=SUCLA2 SUCB1_HUMAN $50.32 \quad 100.0^{\circ}$ Succinyl-COA ligase [ADP-forming] subunit beta, mitochondrial GN=SUCLA2 SUCB1 HUMAN $50.32 \quad 100.0 \%$ Succinyl-CoA ligase [ADP-forming] subunit beta, mitochondrial GN=SUCLA2 SUCB1_HUMAN $50.32 \quad 100.0 \%$ Succinyl-COA ligase [ADP-forming] subunit beta, mitochondrial GN=SUCLA2 SUCB1_HUMAN $50.32 \quad 100.0 \%$ Succinyl-COA ligase [ADP-forming] subunit beta, mitochondrial GN=SUCLA2 SUCB1_HUMAN $50.32 \quad 100.0 \%$ Succinyl-COA ligase [ADP-forming] subunit beta, mitochondrial GN=SUCLA2 SUCB1_HUMAN $50.32 \quad 100.0$ Succinyl-COA ligase [ADP-forming] subunit beta, mitochondrial GN=SUCLA2 SUCB1_HUMAN $50.32100 .0 \%$ Succinyl-COA ligase [ADP-forming] subunit beta, mitochondrial GN=SUCLA2 SUCB1_HUMAN $50.32 \quad 100.0 \%$ Succinyl-COA ligase [ADP-forming] subunit beta, mitochondrial GN=SUCLA2 SUCB1 HUMAN $50.32 \quad 100.0^{\circ}$ Succinyl-COA ligase [ADP-forming] subunit beta, mitochondrial GN=SUCLA2 SUCB1_HUMAN $50.32 \quad 100.0 \%$ Succinyl-CoA ligase [ADP-forming] subunit beta, mitochondrial GN=SUCLA2 SUCB1_HUMAN $50.32 \quad 100.0^{\circ}$, . Succinyl-COA ligase [GDP-forming] subunit beta, mitochondrial GN=SUCLG2 SUCB2_HUMAN $46.51 \quad 100.0 \%$
$0.09 \% \quad 20.9 \%$ VQQTVQDLFGRAPS

$\begin{array}{ll}0.09 \% & 20.9 \% \text { QAASSLQQASLK } \\ 0.01 \% & 2.4 \%\end{array}$

LDGLEVTAR

$0.01 \% \quad 2.4 \%$ ILLAAAPTSK

$0.02 \% \quad 4.4 \%$ QIIGPFQR

$0.02 \% \quad 4.4 \% \quad$ FTAIIGPNGSGK

$0.02 \% \quad 4.4 \%$ TALFEEISR

$0.02 \% \quad 4.4 \%$ TVALDGTLFQK

$0.02 \% \quad 4.4 \%$ SGVISGGASDLKAK

$0.01 \% \quad 1.8 \%$ SLEDALAEAQR

$0.01 \% \quad 1.8 \%$ FVDGVSTVAR

$0.03 \% \quad 5.8 \%$ LALLHEGTGPR

$0.03 \% \quad 5.8 \%$ SNPYYIVKQGK

$0.03 \% \quad 5.8 \%$ LAQATQERTDLYAK

$0.03 \% \quad 5.8 \%$ SMEVSTQLAR

$0.03 \% \quad 5.8 \%$ GALTGGYYDTR

$0.03 \% \quad 5.8 \%$ ALDQFVNFSEQKEK

$0.01 \% \quad 1.8 \%$ GKVLDAIIQEK

$0.01 \% \quad 1.8 \%$ SVAVNPKEIASK

$0.05 \% \quad 22.0 \%$ QHLYVDKNTK

$0.05 \% \quad 22.0 \%$ IICQGFTGK

$0.05 \% \quad 22.0 \%$ QGTFHSQQALEYGTK

$0.05 \% \quad 22.0 \%$ LVGGTTPGK

$0.05 \% \quad 22.0 \%$ LIGPNCPGVINPGECK

$0.05 \% \quad 22.0 \%$ RMGHAGAIIAGGK

$0.05 \% \quad 22.0 \%$ MGHAGAIIAGGK

$0.05 \% \quad 22.0 \%$ MGHAGAIIAGGKGGAK

$0.08 \% \quad 28.7 \%$ GYVAKSPDEAYAIAK

$0.08 \% \quad 28.7 \%$ SPDEAYAIAK

$0.08 \% \quad 28.7 \%$ SPDEAYAIAKK

$0.08 \% \quad 28.7 \%$ LGSKDVVIK

$0.08 \% \quad 28.7 \%$ GKGTFESGLK

$0.08 \% \quad 28.7 \%$ GTFESGLKGGVK

$0.08 \% \quad 28.7 \%$ IVFSPEEAK

$0.08 \% \quad 28.7 \%$ AVSSQMIGKK

$0.08 \% \quad 28.7 \%$ GRICNQVLVCER

$0.08 \% \quad 28.7 \%$ ICNQVLVCER

$0.08 \% \quad 28.7 \%$ REYYFAITMER

$0.08 \% \quad 28.7 \%$ EYYFAITMER

$0.08 \% 28.7 \%$ EQALQLAQK

$0.08 \% \quad 28.7 \%$ INFDSNSAYR

$0.08 \% \quad 28.7 \%$ INFDSNSAYRQK

$0.08 \% \quad 28.7 \%$ LQGTRVDDAK

$0.08 \% \quad 28.7 \%$ ILACDDLDEAAR

$0.08 \% \quad 28.7 \%$ LSEIVTLAK

$0.04 \% \quad 20.6 \%$ KLMSDNGVR $\begin{array}{llllll}99.7 \% & 58.7 & 25.0 & 57.6 & 4 & 0\end{array}$

$\begin{array}{llllll}99.7 \% & 72.4 & 25.0 & 66.8 & 2 & 2\end{array}$

$\begin{array}{llll}99.2 \% & 20.3 & 25.0 & 20.2\end{array}$

$\begin{array}{llll}99.7 \% & 37.7 & 25.0 & 27.2\end{array}$

$\begin{array}{llll}99.7 \% & 28.5 & 25.0 & 28.5\end{array}$

$\begin{array}{llll}99.0 \% & 29.3 & 25.0 & 18.1\end{array}$

$\begin{array}{llll}99.7 \% & 32.0 & 25.0 & 25.9\end{array}$

$\begin{array}{lllll}99.7 \% & 46.8 & 25.0 & 40.3 & 2\end{array}$

$99.7 \% \quad 45.8 \quad 25.0 \quad 36.6$

$99.7 \% \quad 71.1 \quad 25.0 \quad 43.1$

$\begin{array}{lllll}99.7 \% & 44.8 & 25.0 & 44.8 & 2\end{array}$

$\begin{array}{llll}97.5 \% & 19.5 & 25.0 & 15.6\end{array}$

$\begin{array}{llll}99.7 \% & 51.1 & 25.0 & 42.4\end{array}$

$\begin{array}{llll}99.7 \% & 30.5 & 25.0 & 30.5\end{array}$

$99.7 \% \quad 35.0 \quad 25.0 \quad 35.0$

$\begin{array}{llll}99.7 \% & 52.7 & 25.0 & 41.0\end{array}$

$99.7 \% \quad 34.0 \quad 25.0 \quad 23.9$

$\begin{array}{llll}99.7 \% & 36.8 & 25.0 & 36.8\end{array}$

$\begin{array}{llll}99.7 \% & 57.9 & 25.0 & 53.6\end{array}$

$\begin{array}{llll}98.2 \% & 22.3 & 25.0 & 15.1\end{array}$

$99.5 \% \quad 27.3 \quad 25.0 \quad 24.3$

$\begin{array}{llll}99.7 \% & 38.3 & 25.0 & 32.3\end{array}$

$\begin{array}{llll}99.7 \% & 30.3 & 25.0 & 29.5\end{array}$

$\begin{array}{llll}99.7 \% & 30.5 & 25.0 & 21.8\end{array}$

$99.7 \% \quad 60.6 \quad 25.0 \quad 57.3$

$\begin{array}{llll}99.7 \% & 29.9 & 25.0 & 29.9\end{array}$

$\begin{array}{llll}99.7 \% & 49.8 & 25.0 & 47.1\end{array}$

$\begin{array}{llll}99.7 \% & 37.4 & 25.0 & 37.4\end{array}$

$\begin{array}{llll}99.7 \% & 37.9 & 25.0 & 37.9\end{array}$

$\begin{array}{llll}99.7 \% & 57.5 & 25.0 & 50.7\end{array}$

$\begin{array}{llll}99.7 \% & 58.2 & 25.0 & 51.4\end{array}$

$\begin{array}{llll}99.7 \% & 48.9 & 25.0 & 29.3\end{array}$

$99.7 \% \quad 37.8 \quad 25.0 \quad 28.0$

$\begin{array}{lllll}99.7 \% & 45.9 & 25.0 & 45.2 & 2\end{array}$

$\begin{array}{llll}99.7 \% & 30.2 & 25.0 & 26.8\end{array}$

$\begin{array}{llll}99.7 \% & 35.9 & 25.0 & 33.9\end{array}$

$\begin{array}{llll}99.7 \% & 43.9 & 25.0 & 42.2\end{array}$

$99.7 \% \quad 67.7 \quad 25.0 \quad 67.7$

$\begin{array}{llll}99.7 \% & 30.0 & 25.0 & 26.8\end{array}$

$\begin{array}{llll}99.7 \% & 27.8 & 25.0 & 27.8\end{array}$

$99.7 \% \quad 51.9 \quad 25.0 \quad 47.3$

$99.7 \% \quad 65.1 \quad 25.0 \quad 65.1 \quad 2$

$\begin{array}{llll}99.7 \% & 49.1 & 25.0 & 49.1\end{array}$

$\begin{array}{llll}96.3 \% & 22.3 & 25.0 & 11.6\end{array}$

$\begin{array}{lllll}99.7 \% & 56.0 & 25.0 & 56.0\end{array}$

$\begin{array}{llll}99.7 \% & 56.8 & 25.0 & 40.7\end{array}$

$\begin{array}{llll}98.8 \% & 26.4 & 25.0 & 21.8\end{array}$
1673.90

1231.66

1086.62

984.61

958.55

1161.63

1065.56

1192.66

1289.71

1202.60

1050.56

1163.65

1296.69

1607.84

1121.56

1173.55

1682.84

1213.72

1242.7

1245.66

1023.53

1694.81

829.48

1724.85

1238.68

1082.58

1411.75

1582.81

1064.53

1192.62

958.59

1023.55

1179.64

1019.54

1048.58

1503.75

1290.63

1494.70

1338.60

1028.57

1186.55

1442.70

1102.59

1361.64

973.59

1019.53

\begin{tabular}{|c|c|}
\hline \multicolumn{2}{|l|}{405} \\
\hline 409 & \\
\hline 646 & \\
\hline 138 & \\
\hline 536 & \\
\hline 26 & \\
\hline 38 & \\
\hline 160 & \\
\hline 648 & \\
\hline 662 & \\
\hline 308 & \\
\hline 1170 & \\
\hline 72 & \\
\hline 143 & \\
\hline 378 & \\
\hline 644 & \\
\hline 672 & \\
\hline 999 & \\
\hline 607 & \\
\hline 1285 & \\
\hline 57 & \\
\hline 66 & \\
\hline 81 & \\
\hline 90 & \\
\hline 182 & \\
\hline 308 & \\
\hline 308 & \\
\hline 312 & \\
\hline 88 & \\
\hline 88 & \\
\hline 89 & \\
\hline 98 & \\
\hline 116 & \\
\hline 120 & \\
\hline 129 & \\
\hline 139 & \\
\hline 160 & \\
\hline 160 & \\
\hline 175 & \\
\hline 175 & \\
\hline 225 & \\
\hline 284 & \\
\hline 286 & \\
\hline 417 & \\
\hline 438 & \\
\hline 451 & \\
\hline 55 & \\
\hline
\end{tabular}




(1)

3
2
2

(2)

3
3
3

3
3
4

4

4
4

4

2
2
6

6
6
6

6

6
6
6

6
6
2
2

2
5
5

5

5

5

5
3
3

3

3

2

28

28
28
28

$28 \quad 35$

35

$19 \begin{array}{lll}0.04 \% & 20.6 \% & \text { LNAKEIVLK } \\ 19 & 0.04 \% & 20.6 \%\end{array}$

$19 \quad 0.0$

Q $\%$ QMIGYNLATK

$19 \quad 0.04 \% \quad 20.6 \%$ INFDDNAEFRQK

$19 \quad 0.04 \% \quad 20.6 \%$ EAQVYQAFK

$19 \quad 0.04 \% \quad 20.6 \%$ LEGTNVQEAQK

$11 \quad 0.02 \% \quad 5.0 \%$ DSSPHFQAEQR

$11 \quad 0.02 \% \quad 5.0 \%$ EAAASLSLTLQK

$11 \quad 0.02 \% \quad 5.0 \%$ IRPTAVTLEHVPK

$0.01 \% \quad 1.9 \%$ SFYQFQHYR

$0.01 \% \quad 1.9 \%$ VIQKVEAFEHR

$0.01 \% \quad 6.6 \%$ VMEPLTASR

$0.01 \% \quad 6.6 \% \quad$ VNLNTIKR

$0.01 \% \quad 6.6 \%$ VGGSDEEASGIPSR

$0.02 \% \quad 4.3 \%$ GGVGKLVTLR

$0.02 \% \quad 4.3 \% \quad$ APSSLSDAVPQR

$0.02 \% \quad 4.3 \%$ VIEGSLSPKER

$0.02 \% \quad 4.3 \%$ ATTGTQTLLSSGTR

$0.01 \% \quad 6.5 \%$ AYDKAVASFK

$0.01 \% \quad 6.5 \% \quad$ LGPGKPGLK

$0.03 \% \quad 5.3 \% \quad$ SVCLIGDKEQR

$0.03 \% \quad 5.3 \% \quad$ MVVLDKLLPK

$0.03 \% \quad 5.3 \%$ VLIFSQMTR

$0.03 \% \quad 5.3 \%$ TAEMNEKLSK

$0.03 \% \quad 5.3 \%$ TIGYKVPR

$0.03 \% \quad 5.3 \%$ ALDTKIGR

$0.01 \% \quad 3.4 \%$ ALYFITPTSK

$0.01 \% \quad 3.4 \%$ SAEETFQLSR

$0.02 \% \quad 12.6 \%$ YRNPVSQCMR

$0.02 \% \quad 12.6 \%$ KMDETDASSAVK

$0.02 \% \quad 12.6 \%$ FTEYETQVK

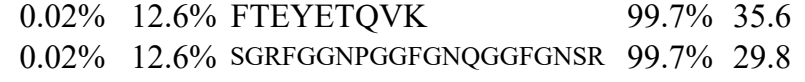

$\begin{array}{llllll}0.02 \% & 12.6 \% & \text { FGGNPGGFGNQGGFGNSR } & 99.7 \% & 78.6\end{array}$

$0.01 \% \quad 1.7 \%$ IAAGQAVEAIVK

$0.01 \% \quad 1.7 \%$ AVTLAVQPR

$0.01 \% \quad 1.7 \%$ NTIDINNFDGK

$0.01 \% \quad 5.6 \%$ GEATVSFDDPPSAK

$\begin{array}{ccc}0.01 \% & 5.6 \% & \text { SGGGYGGDRSSGGGYSGD } \\ 0.15 \% & 42.6 \% & \text { SQNVMAAASIANIVK }\end{array}$

$0.15 \% \quad 42.6 \%$ SSLGPVGLDK

$0.15 \% \quad 42.6 \%$ LLEVEHPAAK

$0.15 \% \quad 42.6 \%$ NADELVKQK

$\begin{array}{lll}0.15 \% & 42.6 \% & \text { QKIHPTSVISGYR }\end{array}$

$0.15 \% \quad 42.6 \%$ IHPTSVISGYR

$0.15 \% \quad 42.6 \%$ LACKEAVR
$99.7 \% \quad 64.4$

$99.7 \% \quad 44.8$

$99.3 \% \quad 22.2$

$99.7 \% \quad 71.3$

$\begin{array}{llll}99.7 \% & 37.1\end{array}$

$99.7 \% \quad 55.7$

$99.7 \% \quad 32.2$

$99.7 \% \quad 61.0$

40

$99.7 \% \quad 45.2$

$99.7 \% \quad 41.0$

$\begin{array}{lll}99.5 \% & 28.2\end{array}$

$99.0 \% \quad 35.5$

$95.5 \% \quad 16.4$

$99.7 \% \quad 38.6$

$99.7 \% 57.4$

$99.7 \% \quad 50.1$

$99.7 \% \quad 63.1$

$99.7 \% \quad 33.5$

$98.6 \% \quad 20.3$

$\begin{array}{ll}98.0 \% & 21.7 \\ 26.9\end{array}$

$99.7 \% \quad 38.6$

$99.7 \% \quad 75.6$

$99.5 \% \quad 25.8$$$
99.7
$$

$\begin{array}{llll}99.7 \% & 65.7 & 25.0 & 58.4\end{array}$

$\begin{array}{llll}99.7 \% & 40.5 & 25.0 & 28.2\end{array}$

$\begin{array}{llll}99.7 \% & 43.7 & 25.0 & 43.7\end{array}$

$\begin{array}{llll}98.6 \% & 18.3 & 25.0 & 18.3 \\ 99.0 \% & 30.6 & 25.0 & 9.9\end{array}$
1027.65

1027.65

1732.97

1154.59

1291.67

1240.56

1496.71

1083.55

1216.62

1301.59

1231.69

1460.86

1275.59

1355.74

1003.52

957.58

1360.63

999.63

1227.63

1214.67

1393.73

1099.58

866.55

1304.66

1171.71

1094.60

1150.58

933.55

873.52

1140.63

1167.56

1310.61

1281.60

1144.55

2026.92

1726.77

1169.69

954.57

1250.60

1420.66

1748.72

1516.82

972.54

1106.62

1044.57

1485.82

1229.66

946.51

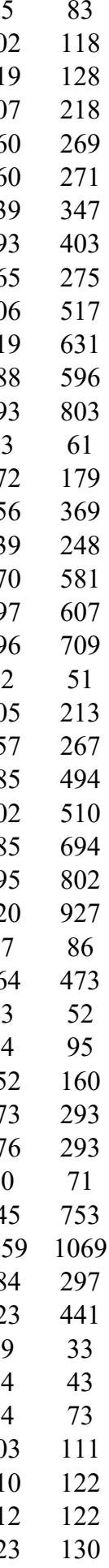

Page 78 of Table S-1-3 
T-complex protein 1 subunit alpha GN=TCP1 TCPA_HUMAN $60.35 \quad 100.0 \% \quad 28$ T-complex protein 1 subunit alpha GN=TCP1 TCPA_HUMAN $60.35 \quad 100.0 \% \quad 28$ T-complex protein 1 subunit alpha GN=TCP1 TCPA_HUMAN 60.35 T-complex protein 1 subunit alpha GN=TCP1 TCPA HUMAN 60.35 T-complex protein 1 subunit alpha GN=TCP1 TCPA_HUMAN 60.35 T-complex protein 1 subunit alpha GN=TCP1 TCPA_HUMAN 60.3 T-complex protein 1 subunit alpha GN=TCP1 TCPA_HUMAN 60.3 T-complex protein 1 subunit alpha GN=TCP1 TCPA_HUMAN 60.3 T-complex protein 1 subunit alpha GN=TCP1 TCPA_HUMAN 60.3 T-complex protein 1 subunit alpha GN=TCP1 TCPA_HUMAN 60.35 T-complex protein 1 subunit alpha GN=TCP1 TCPA_HUMAN 60.35 T-complex protein 1 subunit alpha GN=TCP1 TCPA_HUMAN 60.3 T-complex protein 1 subunit alpha GN=TCP1 TCPA_HUMAN 60.35 T-complex protein 1 subunit alpha GN=TCP1 TCPA_HUMAN 60.35 T-complex protein 1 subunit alpha GN=TCP1 TCPA_HUMAN 60.35 T-complex protein 1 subunit alpha GN=TCP1 TCPA_HUMAN 60.3 T-complex protein 1 subunit alpha GN=TCP1 TCPA HUMAN 60.35 T-complex protein 1 subunit alpha GN=TCP1 TCPA_HUMAN 60.35 T-complex protein 1 subunit alpha GN=TCP1 TCPA_HUMAN 60.3 T-complex protein 1 subunit alpha GN=TCP1 TCPA_HUMAN 60.3 T-complex protein 1 subunit alpha GN=TCP1 TCPA_HUMAN 60.35 T-complex protein 1 subunit delta GN=CCT4 TCPD HUMAN 57.93 T-complex protein 1 subunit delta GN=CCT4 TCPD_HUMAN 57.93 T-complex protein 1 subunit delta GN=CCT4 TCPD_HUMAN 57.93 T-complex protein 1 subunit delta GN=CCT4 TCPD HUMAN 57.93 T-complex protein 1 subunit delta GN=CCT4 TCPD_HUMAN 57.93 T-complex protein 1 subunit delta $\mathrm{GN}=\mathrm{CCT} 4$ TCPD_HUMAN 57.9 . T-complex protein 1 subunit epsilon GN=CCT5 TCPE_HUMAN $59.6^{\circ}$ T-complex protein 1 subunit epsilon GN=CCT5 TCPE_HUMAN 59.67 T-complex protein 1 subunit epsilon $\mathrm{GN}=\mathrm{CCT} 5$ TCPE HUMAN 59.67 T-complex protein 1 subunit epsilon GN=CCT5 TCPE_HUMAN 59.67 T-complex protein 1 subunit epsilon GN=CCT5 TCPE_HUMAN 59.6 T-complex protein 1 subunit epsilon GN=CCT5 TCPE_HUMAN $59.6^{\circ}$ T-complex protein 1 subunit epsilon GN=CCT5 TCPE_HUMAN 59.67 T-complex protein 1 subunit epsilon GN=CCT5 TCPE HUMAN 59.67 T-complex protein 1 subunit epsilon GN=CCT5 TCPE HUMAN 59.67 T-complex protein 1 subunit epsilon GN=CCT5 TCPE_HUMAN 59.67 T-complex protein 1 subunit epsilon GN=CCT5 TCPE HUMAN 59.67 T-complex protein 1 subunit epsilon GN=CCT5 TCPE_HUMAN 59.67 T-complex protein 1 subunit epsilon GN=CCT5 TCPE_HUMAN $59.6^{\circ}$ T-complex protein 1 subunit epsilon GN=CCT5 TCPE HUMAN $59.6^{\circ}$ T-complex protein 1 subunit eta GN=CCT7 TCPH_HUMAN 59.37 T-complex protein 1 subunit eta $\mathrm{GN}=\mathrm{CCT} 7 \mathrm{TCPH}$ HUMAN $59.3{ }^{\circ}$ T-complex protein 1 subunit eta GN=CCT7 TCPH_HUM T-complex protein 1 subunit gamma GN=CCT3 TCPG_HUMAN 60.54 T-complex protein 1 subunit gamma GN=CCT3 TCPG_HUMAN 60.54 T-complex protein 1 subunit gamma GN=CCT3 TCPG_HUMAN 60.54
$0.15 \% \quad 42.6 \%$ DCLINAAK

$0.15 \% \quad 42.6 \%$ YTDIRGQPR

$0.15 \% \quad 42.6 \%$ YPVNSVNILK

$0.15 \% \quad 42.6 \%$ IACLDFSLQK

$0.15 \% \quad 42.6 \%$ IACLDFSLQKTK

$0.15 \% \quad 42.6 \%$ YFVEAGAMAVR

$0.15 \% \quad 42.6 \%$ ICDDELILIK

$0.15 \% \quad 42.6 \%$ ICDDELILIKNTK

$0.15 \% \quad 42.6 \%$ TSASIILR

$0.15 \% \quad 42.6 \%$ GANDFMCDEMER

$0.15 \% \quad 42.6 \%$ SLHDALCVVK

$0.15 \% \quad 42.6 \%$ SLHDALCVVKR

$0.15 \% \quad 42.6 \%$ EQLAIAEFAR

$0.15 \% \quad 42.6 \%$ LRAFHNEAQVNPER

$0.15 \% \quad 42.6 \%$ AFHNEAQVNPER

$0.15 \% \quad 42.6 \%$ AFHNEAQVNPERK

$0.15 \% \quad 42.6 \%$ WIGLDLSNGKPR

$0.15 \% \quad 42.6 \%$ DNKQAGVFEPTIVK

$0.15 \% \quad 42.6 \%$ QAGVFEPTIVK

$0.15 \% \quad 42.6 \%$ FATEAAITILR

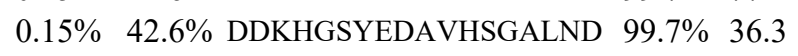

$0.05 \% \quad 13.9 \%$ PENVAPRSGATAGAAGGR $99.7 \% 38.5$

$0.05 \% \quad 13.9 \%$ GAYQDRDKPAQIR

$0.05 \% \quad 13.9 \%$ AVADAIRTSLGPK

$0.05 \% \quad 13.9 \%$ TGCNVLLIQK

$0.05 \% \quad 13.9 \%$ SIHDALCVIR

$0.05 \% \quad 13.9 \%$ TLSGMESYCVR

$0.07 \% \quad 25.1 \%$ SRLMGLEALK

$0.07 \% \quad 25.1 \%$ LMGLEALK

$0.07 \% \quad 25.1 \%$ TSLGPNGLDK

$0.07 \% \quad 25.1 \%$ IADGYEQAAR

$0.07 \% \quad 25.1 \%$ TTLGSKVVNSCHR

$0.07 \% \quad 25.1 \%$ DVDFELIKVEGK

$0.07 \% \quad 25.1 \%$ GVIVDKDFSHPQMPK

$0.07 \% \quad 25.1 \%$ MLVIEQCKNSR

$0.07 \% \quad 25.1 \%$ MIIEEAKR

$0.07 \% \quad 25.1 \%$ SLHDALCVIR

$0.07 \% \quad 25.1 \%$ EMNPALGIDCLHK

$0.07 \% \quad 25.1 \%$ KQQISLATQMVR

$0.07 \% \quad 25.1 \%$ QQISLATQMVR

$0.07 \% \quad 25.1 \%$ IDDIRKPGESEE

$0.01 \% \quad 6.8 \%$ ATISNDGATILK

$0.01 \% \quad 6.8 \% \quad$ LLDVVHPAAK

$0.01 \% \quad 6.8 \%$ TIPGKQQLLIGAYAK

$0.11 \% \quad 28.3 \%$ EIQVQHPAAK

$0.11 \% \quad 28.3 \%$ ALDDMISTLK

$0.11 \% \quad 28.3 \%$ ALDDMISTLKK $\begin{array}{llllllll}99.0 \% & 40.3 & 25.0 & 23.6 & 2 & 0 & 0 & 904.46\end{array}$

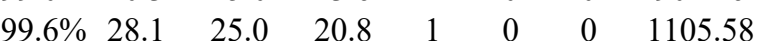

$\begin{array}{llllllll}99.7 \% & 45.6 & 25.0 & 30.2 & 6 & 0 & 0 & 1146.65\end{array}$

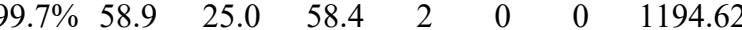

$\begin{array}{llllllll}99.7 \% & 49.4 & 25.0 & 47.6 & 2 & 2 & 0 & 1423.76\end{array}$

$\begin{array}{llllllll}99.7 \% & 60.5 & 25.0 & 55.1 & 4 & 0 & 0 & 1213.60\end{array}$

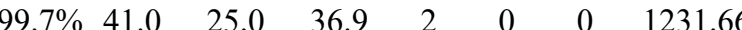

$\begin{array}{llllllll}99.7 \% & 62.0 & 25.0 & 53.8 & 2 & 0 & 0 & 1574.85\end{array}$

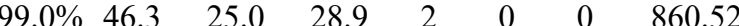

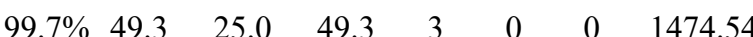

$\begin{array}{llllllll}99.7 \% & 47.7 & 25.0 & 36.5 & 2 & 0 & 0 & 1141.60\end{array}$

$\begin{array}{llllllll}99.7 \% & 50.8 & 25.0 & 49.7 & 2 & 0 & 0 & 1297.70\end{array}$

$\begin{array}{llllllll}99.7 \% & 65.6 & 25.0 & 56.6 & 4 & 0 & 0 & 1147.61\end{array}$

$\begin{array}{llllllll}99.7 \% & 46.3 & 25.0 & 44.0 & 0 & 1 & 0 & 1680.86\end{array}$

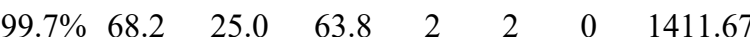

$\begin{array}{llllllll}99.7 \% & 48.9 & 25.0 & 41.4 & 2 & 3 & 0 & 1539.77\end{array}$

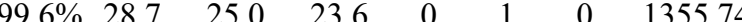

$60.5 \quad 25.0-58.9$

$99.7 \% \quad 45.2 \quad 25.0 \quad 37.2$

$9.7 \%-77.2=25.0-63.3$

$\begin{array}{llll}99.4 \% & 23.0 & 25.0 & 18.8\end{array}$

$99.7 \% \quad 55.5 \quad 25.0 \quad 50.8$

$99.7 \% \quad 42.2 \quad 25.0 \quad 42.2$

$99.2 \% \quad 61.5 \quad 25.0 \quad 0.0$

$\begin{array}{llll}99.7 \% & 35.7 & 25.0 & 35.6\end{array}$

$\begin{array}{lllll}98.8 \% & 28.1 & 25.0 & 13.0\end{array}$

$\begin{array}{llll}99.0 \% & 26.3 & 25.0 & 17.9\end{array}$

$99.7 \% \quad 36.3 \quad 25.0 \quad 31.6$

$99.7 \% \quad 60.6 \quad 25.0 \quad 50.9$

$\begin{array}{llll}99.7 \% & 31.5 & 25.0 & 28.0\end{array}$

$99.7 \% \quad 43.7 \quad 25.0 \quad 39.3$

$\begin{array}{llll}99.7 \% & 51.2 & 25.0 & 49.0\end{array}$

$99.7 \% \quad 47.1 \quad 25.0 \quad 46.2$

$99.0 \% \quad 54.5 \quad 25.0 \quad 40.7$

$\begin{array}{cccc}99.2 \% & 61.5 & 25.0 & 0.0\end{array}$

$99.7 \% \quad 41.6 \quad 25.0 \quad 40.0$

$\begin{array}{llll}99.7 \% & 36.9 & 25.0 & 26.7\end{array}$

$\begin{array}{llll}99.7 \% & 53.9 & 25.0 & 50.4\end{array}$

$\begin{array}{llll}96.2 \% & 16.2 & 25.0 & 16.2\end{array}$

$\begin{array}{llll}99.1 \% & 28.0 & 25.0 & 13.1\end{array}$

$\begin{array}{llll}99.7 \% & 37.2 & 25.0 & 33.9\end{array}$

$\begin{array}{llll}96.7 \% & 17.8 & 25.0 & 17.8\end{array}$

$\begin{array}{llll}99.7 \% & 49.2 & 25.0 & 39.2\end{array}$

$\begin{array}{llll}99.7 \% & 43.1 & 25.0 & 40.8\end{array}$

$\begin{array}{llll}99.7 \% & 43.4 & 25.0 & 43.4\end{array}$
$146 \quad 153$

$181 \quad 189$

$190 \quad 199$

$234 \quad 243$

$234 \quad 245$

299309

$356 \quad 368$

$379 \quad 390$

400

$434 \quad 443$

$469 \quad 480$

$469 \quad 481$

1545.83

1188.66

1205.69

1929.82

1638.83

1517.78

1298.74

1145.63

1183.63

1302.58

1117.64

874.51

001.53

1093.53

1458.75

1391.74

1713.86

1377.70

989.54

1183.63

1497.72

1402.78

1290.68

1387.67

1203.66

1062.63

1600.94

1120.61

1122.5

1234.67 
T-complex protein 1 subunit gamma GN=CCT3 TCPG_HUMAN $60.54 \quad 100.0 \%$ T-complex protein 1 subunit gamma GN=CCT3 TCPG_HUMAN $60.54 \quad 100.0 \% \quad 18$ T-complex protein 1 subunit gamma GN=CCT3 TCPG_HUMAN $60.54 \quad 100.0 \% \quad 18$ T-complex protein 1 subunit gamma $\mathrm{GN}=\mathrm{CCT} 3 \mathrm{TCPG}$ HUMAN $60.54 \quad 100.0 \%$ T-complex protein 1 subunit gamma GN=CCT3 TCPG_HUMAN $60.54 \quad 100.0 \% \quad 18$ T-complex protein 1 subunit gamma GN=CCT3 TCPG_HUMAN $60.54 \quad 100.0 \% \quad 18$ T-complex protein 1 subunit gamma GN=CCT3 TCPG_HUMAN $60.54 \quad 100.0 \% \quad 18$ T-complex protein 1 subunit gamma GN=CCT3 TCPG_HUMAN $^{6} 60.54 \quad 100.0 \% \quad 18$ T-complex protein 1 subunit gamma GN=CCT3 TCPG_HUMAN $60.54 \quad 100.0 \% \quad 18$ T-complex protein 1 subunit gamma GN=CCT3 TCPG_HUMAN $60.54 \quad 100.0 \% \quad 18$ T-complex protein 1 subunit gamma GN=CCT3 $\quad$ TCPG_HUMAN $60.54 \quad 100.0 \%$ T-complex protein 1 subunit gamma GN=CCT3 TCPG_HUMAN $60.54 \quad 100.0 \%$ T-complex protein 1 subunit gamma GN=CCT3 TCPG_HUMAN $_{6} 60.54 \quad 100.0 \% \quad 1$ T-complex protein 1 subunit gamma GN=CCT3 TCPG_HUMAN $60.54 \quad 100.0 \% \quad 18$ T-complex protein 1 subunit gamma GN=CCT3 TCPG_HUMAN $60.54 \quad 100.0 \% \quad 18$ T-complex protein 1 subunit theta GN=CCT8 TCPQ_HUMAN $59.62 \quad 100.0 \%$ T-complex protein 1 subunit theta $\mathrm{GN}=\mathrm{CCT} 8 \mathrm{TCPQ}$ HUMAN $59.62 \quad 100.0 \%$ T-complex protein 1 subunit theta GN=CCT8 TCPQ_HUMAN $59.62 \quad 100.0 \%$ T-complex protein 1 subunit theta $\mathrm{GN}=\mathrm{CCT} 8$ TCPQ_HUMAN $59.62 \quad 100.0 \%$ T-complex protein 1 subunit theta GN=CCT8 TCPQ HUMAN $59.62 \quad 100.0 \%$ T-complex protein 1 subunit theta GN=CCT8 TCPQ_HUMAN $59.62 \quad 100.0 \%$ T-complex protein 1 subunit theta $\mathrm{GN}=\mathrm{CCT} 8 \mathrm{TCPQ}$ HUMAN $59.62 \quad 100.0 \%$ T-complex protein 1 subunit zeta GN=CCT6A TCPZ_HUMAN $58.03 \quad 100.0 \%$ T-complex protein 1 subunit zeta GN=CCT6A TCPZ_HUMAN $58.03 \quad 100.0 \%$ T-complex protein 1 subunit zeta GN=CCT6A TCPZ HUMAN $58.03 \quad 100.0 \%$ T-complex protein 1 subunit zeta GN=CCT6A TCPZ_HUMAN $58.03 \quad 100.0 \%$ T-complex protein 1 subunit zeta GN=CCT6A TCPZ_HUMAN $58.03 \quad 100.0 \%$ T-complex protein 1 subunit zeta GN=CCT6A TCPZ_HUMAN $58.03 \quad 100.0 \%$ T-complex protein 1 subunit zeta GN=CCT6A TCPZ_HUMAN $58.03 \quad 100.0 \%$ T-complex protein 1 subunit zeta $\mathrm{GN}=\mathrm{CCT} 6 \mathrm{~A}$ TCPZ HUMAN $58.03 \quad 100.0 \%$ T-complex protein 1 subunit zeta GN=CCT6A TCPZ_HUMAN $58.03 \quad 100.0 \%$ T-complex protein 1 subunit zeta GN=CCT6A TCPZ_HUMAN $58.03 \quad 100.0 \%$ T-complex protein 1 subunit zeta $\mathrm{GN}=\mathrm{CCT} 6 \mathrm{~A}$ TCPZ HUMAN $58.03 \quad 100.0 \%$ T-complex protein 1 subunit zeta GN=CCT6A TCPZ_HUMAN $58.03 \quad 100.0 \%$ T-complex protein 1 subunit zeta GN=CCT6A TCPZ_HUMAN $58.03 \quad 100.0 \%$ T-complex protein 1 subunit zeta GN=CCT6A TCPZ_HUMAN $58.03 \quad 100.0 \%$ Telomere-associated protein RIF1 GN=RIF1 RIF1_HUMAN $274.47 \quad 100.0 \%$ Telomere-associated protein RIF1 GN=RIF1 RIF1 HUMAN $274.47 \quad 100.0 \%$ Telomere-associated protein RIF1 GN=RIF1 RIF1_HUMAN $274.47 \quad 100.0 \%$ Telomere-associated protein RIF1 GN=RIF1 RIF1_HUMAN $274.47 \quad 100.0 \%$ Telomere-associated protein RIF1 GN=RIF1 RIF1_HUMAN $274.47 \quad 100.0 \%$ Testis-expressed sequence 10 protein GN=TEX10 TEX10_HUMAN $105.68 \quad 100.0 \%$ Testis-expressed sequence 10 protein GN=TEX10 TEX10 HUMAN $105.68 \quad 100.0 \%$ Testis-expressed sequence 10 protein GN=TEX10 TEX10_HUMAN $105.68 \quad 100.0 \%$ Tetratricopeptide repeat protein 37 GN=TTC37 TTC37_HUMAN $175.49 \quad 100.0 \%$ Tetratricopeptide repeat protein $37 \mathrm{GN}=\mathrm{TTC} 37$ TTC37 HUMAN $175.49 \quad 100.0 \%$ Tetratricopeptide repeat protein 37 GN=TTC37 TTC37_HUMAN $175.49 \quad 100.0 \%$
$50 \quad 0.11 \% \quad 28.3 \%$ MVQFEENGRK $0.11 \% \quad 28.3 \%$ IPGGIIEDSCVLR

$50 \quad 0.11 \% \quad 28.3 \%$ GVMINKDVTHPR $50 \quad 0.11 \% \quad 28.3 \%$ IVLLDSSLEYK

$50 \quad 0.11 \% \quad 28.3 \%$ IVLLDSSLEYKK

$50 \quad 0.11 \% \quad 28.3 \%$ GISDLAQHYLMR

$0.11 \% \quad 28.3 \%$ ANITAIRR

$50 \quad 0.11 \% \quad 28.3 \%$ GASKEILSEVER

$50 \quad 0.11 \% \quad 28.3 \%$ EILSEVER

$50 \quad 0.11 \% \quad 28.3 \%$ NLQDAMQVCR

$50 \quad 0.11 \% \quad 28.3 \%$ AMTGVEQWPYR

$50 \quad 0.11 \% \quad 28.3 \%$ AVAQALEVIPR

$50 \quad 0.11 \% \quad 28.3 \%$ TLIQNCGASTIR

$50 \quad 0.11 \% \quad 28.3 \%$ IDDIVSGHK

$50 \quad 0.11 \% \quad 28.3 \%$ IDDIVSGHKK

$11 \quad 0.02 \% \quad 16.2 \%$ HFSGLEEAVYR

$11 \quad 0.02 \% \quad 16.2 \%$ NIQACKELAQTTR

$11 \quad 0.02 \% \quad 16.2 \%$ QYGNEVFLAK

$11 \quad 0.02 \% \quad 16.2 \%$ AIADTGANVVVTGGK

$11 \quad 0.02 \% \quad 16.2 \%$ LVPGGGATEIELAK

$11 \quad 0.02 \% \quad 16.2 \%$ FAEAFEAIPR

$11 \quad 0.02 \% \quad 16.2 \%$ ALAENSGVKANEVISK

$0.09 \% \quad 23.9 \%$ TLNPKAEVAR

$44 \quad 0.09 \% \quad 23.9 \%$ AQAALAVNISAAR

$0.09 \% \quad 23.9 \%$ MLVSGAGDIK

$4 \quad 0.09 \% \quad 23.9 \%$ MLVSGAGDIKLTK

$44 \quad 0.09 \% \quad 23.9 \%$ QADLYISEGLHPR

$\quad 0.09 \% \quad 23.9 \%$ IITEGFEAAK

$44 \quad 0.09 \% \quad 23.9 \%$ IITEGFEAAKEK

$44 \quad 0.09 \% \quad 23.9 \%$ EMDRETLIDVAR

$44 \quad 0.09 \% \quad 23.9 \%$ HKSETDTSLIR

$44 \quad 0.09 \% \quad 23.9 \%$ SETDTSLIR

$44 \quad 0.09 \% \quad 23.9 \%$ GLVLDHGAR

$44 \quad 0.09 \% \quad 23.9 \%$ VCGDSDKGFVVINQK

$0.09 \% \quad 23.9 \%$ EGIVALRR

$0.09 \% \quad 23.9 \%$ SVTLLIKGPNK

$0.03 \% \quad 2.4 \%$ GASSPYGAPGTPR

$0.03 \% \quad 2.4 \%$ DSFLAQTK

$0.03 \% \quad 2.4 \%$ DSFDNCSLGESSK

$0.03 \% \quad 2.4 \%$ IGISDISSLSEK

$0.03 \% \quad 2.4 \%$ SQEDEISSPVNKVR

$0.01 \% \quad 2.9 \% \quad$ LQNATPTNFK

$0.01 \% \quad 2.9 \% \quad$ AVYTLYQQR

$0.01 \% \quad 2.9 \%$ SLQATALR

$0.01 \% \quad 2.0 \%$ SGPGLIGLGIK

$0.01 \% \quad 2.0 \%$ VVYQPGYPK

$0.01 \% \quad 2.0 \%$ ALELNQRLSSQ
$99.0 \% \quad 24.7$

$99.7 \% 50.6$

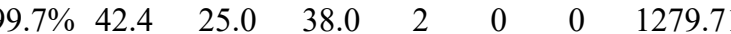

$99.7 \% \quad 39.0$

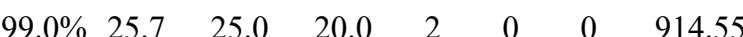

$99.7 \% \quad 72.5$

$99.7 \% \quad 64.8$

$99.7 \% \quad 39.0$

$99.7 \% \quad 73.8$

$99.7 \% \quad 70.3$

$99.7 \% \quad 45.0$

$99.3 \% \quad 27.3$

$99.2 \% \quad 24.8$

$99.1 \% \quad 28.9$

$99.7 \% \quad 33.9$

$99.7 \% \quad 87.1$

$99.6 \% \quad 27.5$

$99.7 \% \quad 64.9$

$97.5 \% \quad 19.7$

$99.7 \% \quad 39.2$

$99.7 \% \quad 66.3$

$98.5 \% \quad 22.7$

$99.7 \% \quad 83.4$

$99.7 \% \quad 69.4$

$99.3 \% 32.6$

$99.7 \% \quad 68.3$

$99.7 \% \quad 43.0$

$97.8 \% \quad 20.0$

$99.7 \% \quad 39.9$

$99.7 \% \quad 48.0$

$99.7 \% \quad 57.3$

$99.0 \% \quad 34.9$

$99.7 \% \quad 42.1$

$99.7 \% \quad 65.0$

$99.0 \% \quad 45.2$

$99.7 \% \quad 39.7$

$99.7 \% \quad 45.8$

$99.7 \% \quad 45.9$

$99.7 \% \quad 32.3$

$99.7 \% \quad 46.0$

$99.0 \% \quad 33.3$

$99.5 \% \quad 26.6$

$98.8 \% \quad 18.9$

$99.7 \% \quad 47.5$
1366.73

1407.81

1419.71

914.55
1317.70

974.52

$204 \quad 216$

248

$238 \quad 249$

$295 \quad 306$

$307 \quad 314$

$378 \quad 389$

$\begin{array}{lll}1234.57 & 390 & 399\end{array}$

1337.63

1166.69

1333.69

983.52

1111.61

1307.64

1532.79

1168.60

1372.74

1354.76

1150.59

1629.88

1098.63

1255.71

1006.52

1332.76

1498.77

1078.58

1335.72

1447.72

1286.67

1021.52

937.52

1665.83

913.56

1169.73

1217.59

909.47

1445.59

1248.67

1587.80

1133.60

1141.60

859.50

1011.62

1050.56

1258.68
$428 \quad 438$

44

$519 \quad 527$

$519 \quad 528$

$21 \quad 3$

$172 \quad 181$

$82 \quad 296$

$408 \quad 421$

$441 \quad 450$

$\begin{array}{cc}6 & 15 \\ 16 & 28\end{array}$

$46 \quad 55$

$46 \quad 58$

$105 \quad 117$

$\begin{array}{ll}118 & 127\end{array}$

$42 \quad 153$

$198 \quad 208$

$200 \quad 208$

$209 \quad 217$

$281 \quad 295$

$371 \quad 381$

$007 \quad 1014$

$1687 \quad 1699$

$1700 \quad 1711$

$2189 \quad 2202$

$25 \quad 34$

$505 \quad 513$

$591 \quad 598$

$\begin{array}{cc}71 & 281 \\ 508 & 1516\end{array}$

$1554 \quad 1564$ 
TGF-beta-activated kinase 1 and MAP3K7-binding protein $1 \mathrm{GN}=\mathrm{TAB} 1 \quad \mathrm{TAB} 1$ HUMAN $54.64 \quad 100.0 \%$ TGF-beta-activated kinase 1 and MAP3K7-binding protein $1 \mathrm{GN}=\mathrm{TAB} 1$ TAB1_HUMAN $54.64 \quad 100.0 \%$ TGF-beta-activated kinase 1 and MAP3K7-binding protein $1 \mathrm{GN}=\mathrm{TAB} 1$ TAB1_HUMAN $54.64 \quad 100.0 \%$ TGF-beta-activated kinase 1 and MAP3K7-binding protein $1 \mathrm{GN}=\mathrm{TAB} 1$ TAB1_HUMAN $54.64 \quad 100.0 \%$ TGF-beta-activated kinase 1 and MAP3K7-binding protein $1 \mathrm{GN}=\mathrm{TAB} 1$ TAB1_HUMAN $54.64 \quad 100.0 \%$ TGF-beta-activated kinase 1 and MAP3K7-binding protein 1 GN=TAB1 TAB1_HUMAN $54.64 \quad 100.0 \%$ TGF-beta-activated kinase 1 and MAP3K7-binding protein $1 \mathrm{GN}=\mathrm{TAB} 1$ TAB1_HUMAN $54.64 \quad 100.0 \%$ TGF-beta-activated kinase 1 and MAP3K7-binding protein 2 GN=TAB2 TAB2_HUMAN $76.49 \quad 100.0 \%$ TGF-beta-activated kinase 1 and MAP3K7-binding protein $2 \mathrm{GN}=\mathrm{TAB} 2$ TAB2 HUMAN $76.49 \quad 100.0 \%$ TGF-beta-activated kinase 1 and MAP3K7-binding protein 2 GN=TAB2 $\quad$ TAB2_HUMAN $76.49 \quad 100.0 \%$ THO complex subunit $2 \mathrm{GN}=\mathrm{THOC} 2$ THO complex subunit $2 \mathrm{GN}=\mathrm{THOC} 2$ THO complex subunit $2 \mathrm{GN}=\mathrm{THOC} 2$

THO complex subunit $2 \mathrm{GN}=\mathrm{THOC} 2$ THOMAN $182.78 \quad 100.0 \%$ THOC2 HUMAN $182.78 \quad 100.0 \%$ THOC2_HUMAN $182.78 \quad 100.0 \%$ THOC2_HUMAN $182.78 \quad 100.0 \%$ THUMP domain-containing protein $3 \mathrm{GN}=$ THUMPD3 THUM3_HUMAN $57.00 \quad 100.0 \%$ THUMP domain-containing protein 3 GN=THUMPD3 THUM3_HUMAN $57.00 \quad 100.0 \%$ THUMP domain-containing protein $3 \mathrm{GN}=$ THUMPD3 THUM3 HUMAN $57.00 \quad 100.0 \%$ THUMP domain-containing protein 3 GN=THUMPD3 THUM3_HUMAN $57.00 \quad 100.0 \%$ Thyroid hormone receptor-associated protein 3 GN=THRAP3 TR150_HUMAN $108.67 \quad 100.0 \%$ Thyroid hormone receptor-associated protein $3 \mathrm{GN}=$ THRAP3 TR150_HUMAN $108.67 \quad 100.0 \%$ Thyroid hormone receptor-associated protein $3 \mathrm{GN}=\mathrm{THRAP} 3$ TR150_HUMAN $108.67 \quad 100.0 \%$ Thyroid hormone receptor-associated protein 3 GN=THRAP3 TR150_HUMAN $108.67 \quad 100.0 \%$ Thyroid hormone receptor-associated protein $3 \mathrm{GN}=$ THRAP3 TR150_HUMAN $108.67 \quad 100.0 \%$ Thyroid hormone receptor-associated protein 3 GN=THRAP3 TR150_HUMAN $108.67 \quad 100.0 \%$ Thyroid hormone receptor-associated protein $3 \mathrm{GN}=$ THRAP3 TR150 HUMAN $108.67 \quad 100.0 \%$ Thyroid hormone receptor-associated protein 3 GN=THRAP3 TR150_HUMAN $108.67 \quad 100.0 \%$ Thyroid hormone receptor-associated protein 3 GN=THRAP3 TR150_HUMAN $108.67 \quad 100.0 \%$ Thyroid hormone receptor-associated protein 3 GN=THRAP3 TR150_HUMAN $108.67 \quad 100.0 \%$ Thyroid hormone receptor-associated protein 3 GN=THRAP3 TR150_HUMAN $108.67 \quad 100.0 \%$ Thyroid hormone receptor-associated protein $3 \mathrm{GN}=$ THRAP3 TR150 HUMAN $108.67 \quad 100.0 \%$ Thyroid hormone receptor-associated protein $3 \mathrm{GN}=$ THRAP3 TR150_HUMAN $108.67 \quad 100.0 \%$ Thyroid hormone receptor-associated protein $3 \mathrm{GN}=$ THRAP3 TR150_HUMAN $108.67 \quad 100.0 \%$ Thyroid hormone receptor-associated protein $3 \mathrm{GN}=$ THRAP3 $\mathrm{TR} 150$ HUMAN $108.67 \quad 100.0 \%$ Thyroid hormone receptor-associated protein $3 \mathrm{GN}=\mathrm{THRAP} 3$ TR150_HUMAN $108.67 \quad 100.0 \% \quad 25$ Thyroid hormone receptor-associated protein $3 \mathrm{GN}=\mathrm{THRAP} 3 \mathrm{TR} 150$ HUMAN $108.67 \quad 100.0 \% \quad 2$ Thyroid hormone receptor-associated protein $3 \mathrm{GN}=$ THRAP3 TR150_HUMAN $108.67 \quad 100.0 \% \quad 25$ Thyroid hormone receptor-associated protein 3 GN=THRAP3 TR150_HUMAN $108.67 \quad 100.0 \%$ Thyroid hormone receptor-associated protein 3 GN=THRAP3 TR150 HUMAN $108.67 \quad 100.0 \%$ Thyroid hormone receptor-associated protein 3 GN=THRAP3 TR150_HUMAN $108.67 \quad 100.0 \%$ Thyroid hormone receptor-associated protein 3 GN=THRAP3 TR150_HUMAN $108.67 \quad 100.0 \%$ Thyroid hormone receptor-associated protein $3 \mathrm{GN}=$ THRAP3 TR150_HUMAN $108.67 \quad 100.0 \%$ Thyroid hormone receptor-associated protein $3 \mathrm{GN}=$ THRAP3 TR150_HUMAN $108.67 \quad 100.0 \%$ Thyroid hormone receptor-associated protein $3 \mathrm{GN}=$ THRAP3 TR150 HUMAN $108.67 \quad 100.0 \%$ Thyroid transcription factor 1-associated protein $26 \mathrm{GN}=\mathrm{CCDC} 59$ TAP26_HUMAN $28.67 \quad 100.0 \%$ Thyroid transcription factor 1-associated protein $26 \mathrm{GN}=\mathrm{CCDC} 59$ TAP26_HUMAN $28.67 \quad 100.0 \%$ TP53-regulating kinase $\mathrm{GN}=\mathrm{TP} 53 \mathrm{RK}$ TP53-regulating kinase $\mathrm{GN}=\mathrm{TP} 53 \mathrm{RK}$
$0.05 \% \quad 16.5 \%$ VLLQAFDVVER

$0.05 \% \quad 16.5 \%$ LSQLGLDAGK

$0.05 \% \quad 16.5 \%$ QVGIICGQESTR

$0.05 \% \quad 16.5 \%$ YGYTDIDLLSAAK

$0.05 \% \quad 16.5 \%$ IHSDTFASGGER

$0.05 \% \quad 16.5 \%$ HEDMTLLVR

$0.05 \% \quad 16.5 \%$ VYPVSVPYSSAQSTSK

$0.01 \% \quad 5.3 \% \quad$ GTSSLSQQTPR

$0.01 \% \quad 5.3 \%$ TSSTSSSVNSQTLNR

$0.01 \% \quad 5.3 \%$ AIGNNSATSPR

$0.02 \% \quad 2.4 \%$ GSPVNALQNK

$0.02 \% \quad 2.4 \% \quad$ FVELVHQQK

$0.02 \% \quad 2.4 \% \quad$ VLNLGQALER

$0.02 \% \quad 2.4 \%$ TPATTPEAR

$0.01 \% \quad 8.1 \%$ STLAYGMLR

$0.01 \% \quad 8.1 \%$ AANNIASLLTK

$0.01 \% \quad 8.1 \%$ AVLLTQDTKCFTK

$0.01 \% \quad 8.1 \%$ AAVYVLIR

$119 \quad 0.25 \% \quad 22.6 \%$ EQTFSGGTSQDTK

$119 \quad 0.25 \% \quad 22.6 \%$ ASESSKPWPDATYGTGSASR

$119 \quad 0.25 \% \quad 22.6 \%$ ASAVSELSPR

$119 \quad 0.25 \% \quad 22.6 \%$ ASAVSELSPRER

$119 \quad 0.25 \% \quad 22.6 \%$ SPALKSPLQSVVVR

$119 \quad 0.25 \% \quad 22.6 \%$ SPLQSVVVR

$119 \quad 0.25 \% \quad 22.6 \%$ SPPSTGSTYGSSQKEESAASGGAAYTK

$119 \quad 0.25 \% \quad 22.6 \%$ EESAASGGAAYTK

$119 \quad 0.25 \% \quad 22.6 \%$ EESAASGGAAYTKR

$119 \quad 0.25 \% \quad 22.6 \%$ GSFSDTGLGDGK

$119 \quad 0.25 \% \quad 22.6 \%$ GSFSDTGLGDGKMK

$119 \quad 0.25 \% \quad 22.6 \%$ VIGANKNQEEEK

$119 \quad 0.25 \% \quad 22.6 \%$ KTEELEEESFPER

$119 \quad 0.25 \% \quad 22.6 \%$ TEELEEESFPER

$119 \quad 0.25 \% \quad 22.6 \%$ GFVPEKNFR

$119 \quad 0.25 \% \quad 22.6 \%$ NFRVTAYK

$119 \quad 0.25 \% \quad 22.6 \%$ VTAYKAVQEK

$119 \quad 0.25 \% \quad 22.6 \%$ LGAKGDFPTGK

$119 \quad 0.25 \% \quad 22.6 \%$ GDFPTGKSSFSITR

$119 \quad 0.25 \% \quad 22.6 \%$ SSFSITREAQVNVR

$119 \quad 0.25 \% \quad 22.6 \%$ SIFQHIQSAQSQR

$119 \quad 0.25 \% \quad 22.6 \%$ RIDISPSTFR

$119 \quad 0.25 \% \quad 22.6 \%$ IDISPSTFRK

$119 \quad 0.25 \% \quad 22.6 \%$ YKDDPVDLR

$119 \quad 0.25 \% \quad 22.6 \%$ NREEEWDPEYTPK

$0.01 \% \quad 7.9 \%$ GEGVSTVGYR

$0.01 \% \quad 7.9 \% \quad$ TVNSFTIPK

$0.00 \% \quad 7.1 \%$ TPQGLSNLAK

$0.00 \% \quad 7.1 \%$ TIGQVLAR $\begin{array}{llll}99.7 \% & 57.5 & 25.0 & 57.5\end{array}$

$\begin{array}{llll}99.7 \% & 46.5 & 25.0 & 35.2\end{array}$

$\begin{array}{lllll}99.4 \% & 24.0 & 25.0 & 22.1 & 2\end{array}$

$99.7 \% \quad 30.6 \quad 25.0 \quad 30.6$

$\begin{array}{llll}99.7 \% & 53.4 & 25.0 & 44.3\end{array}$

$\begin{array}{llll}99.7 \% & 47.8 & 25.0 & 43.1\end{array}$

$\begin{array}{llll}99.7 \% & 49.2 & 25.0 & 48.5\end{array}$

$\begin{array}{llll}97.8 \% & 23.0 & 25.0 & 14.1\end{array}$

$\begin{array}{llll}99.7 \% & 43.0 & 25.0 & 43.0\end{array}$

$\begin{array}{llll}99.7 \% & 35.9 & 25.0 & 35.9\end{array}$

$\begin{array}{lllll}99.6 \% & 34.3 & 25.0 & 21.7 & 2\end{array}$

$\begin{array}{llll}97.2 \% & 19.3 & 25.0 & 15.4\end{array}$

$\begin{array}{llll}99.7 \% & 62.6 & 25.0 & 52.6\end{array}$

$\begin{array}{llll}99.3 \% & 30.4 & 25.0 & 17.0\end{array}$

$\begin{array}{llll}95.3 \% & 14.9 & 25.0 & 14.9\end{array}$

$\begin{array}{llll}99.7 \% & 45.2 & 25.0 & 42.4\end{array}$

$\begin{array}{llll}97.1 \% & 17.0 & 25.0 & 17.0\end{array}$

$\begin{array}{llll}99.0 \% & 35.4 & 25.0 & 25.1\end{array}$

$\begin{array}{llll}99.7 \% & 50.9 & 25.0 & 50.9\end{array}$

$99.7 \% \quad 37.1$

$99.7 \% \quad 67.5$

$99.7 \% \quad 51.3$

$99.7 \% \quad 33.0$

$99.7 \% \quad 59.5$

$99.7 \% \quad 38.5$

$99.7 \% \quad 69.9$

$99.7 \% \quad 47.4$

$99.7 \% \quad 66.2$

$99.7 \% \quad 32.7$

$99.7 \% \quad 49.3$

$99.7 \% \quad 58.8$

$99.7 \% \quad 43.2$

$99.7 \% 37.1$

$97.7 \% \quad 22.9$

$99.7 \% \quad 52.6$

$99.7 \% \quad 31.7$

$99.7 \% \quad 44.8$

$99.3 \% 20.6$

$99.7 \% \quad 74.6$

$98.5 \% \quad 18.3$

$99.6 \% \quad 28.5$

$99.7 \% \quad 43.3$

$99.7 \% \quad 27.6$

$99.7 \% \quad 49.2$

$95.3 \% \quad 18.7$

$97.6 \% 26.3$

$95.3 \% \quad 23.1$
1001.56

1347.67

1429.72

1276.59

1113.57

1699.85

1161.59

1568.75

1087.55

1027.55

1127.62

1112.64

943.48

1011.53

1115.64

1524.81

904.56

1385.62

2054.94

1016.54

1301.68

1480.88

984.58

2606.19

1241.56

1397.67

1140.52

1415.65

1358.69

1622.75

1494.66

1093.58

998.54

1136.63

1090.59

1499.75

1593.83

1529.78

1191.65

1163.64

1120.56

1692.75

1024.51

1006.56

1028.57

857.52

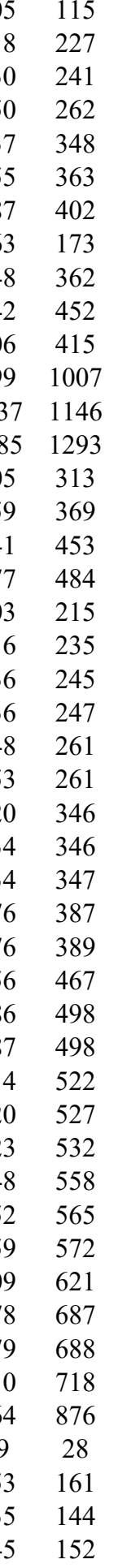

Page 81 of Table S-1-3 
Transcription activator BRG1 GN=SMARCA4 SMCA4 HUMAN $184.65100 .0 \%$ Transcription activator BRG1 GN=SMARCA4 SMCA4_HUMAN $184.65 \quad 100.0 \%$ Transcription activator BRG1 GN=SMARCA4 SMCA4_HUMAN $184.65 \quad 100.0 \%$ Transcription activator BRG1 GN=SMARCA4 SMCA4_HUMAN $184.65 \quad 100.0 \%$ Transcription activator BRG1 GN=SMARCA4 SMCA4_HUMAN $184.65 \quad 100.0 \%$ Transcription activator BRG1 GN=SMARCA4 SMCA4_HUMAN $184.65 \quad 100.0 \%$ Transcription activator BRG1 GN=SMARCA4 SMCA4_HUMAN $184.65 \quad 100.0 \%$ Transcription elongation factor, mitochondrial GN=TEFM TEFM_HUMAN $41.68 \quad 100.0 \%$ Transcription elongation factor, mitochondrial GN=TEFM TEFM HUMAN $41.68 \quad 100.0 \%$ Transcription initiation factor TFIID subunit 4 GN=TAF4 TAF4_HUMAN $110.11 \quad 100.0 \%$ Transcription initiation factor TFIID subunit $4 \mathrm{GN}=\mathrm{TAF} 4$ TAF4_HUMAN $110.11 \quad 100.0 \%$ Transcriptional activator protein Pur-alpha GN=PURA PURA HUMAN $34.91 \quad 100.0 \%$ Transcriptional activator protein Pur-alpha GN=PURA PURA_HUMAN $34.91 \quad 100.0 \%$ Transcriptional activator protein Pur-alpha GN=PURA PURA_HUMAN $34.91 \quad 100.0 \%$ Transcriptional activator protein Pur-beta GN=PURB PURB_HUMAN $33.24 \quad 100.0 \%$ Transcriptional activator protein Pur-beta GN=PURB PURB_HUMAN $33.24 \quad 100.0 \%$ Transcriptional activator protein Pur-beta GN=PURB PURB HUMAN $33.24 \quad 100.0 \%$ Transcriptional activator protein Pur-beta GN=PURB PURB_HUMAN $33.24 \quad 100.0 \%$ Transformer-2 protein homolog alpha GN=TRA2A TRA2A_HUMAN $32.69 \quad 100.0 \%$ Transformer-2 protein homolog alpha GN=TRA2A TRA2A_HUMAN $32.69 \quad 100.0 \%$ Transformer-2 protein homolog alpha GN=TRA2A TRA2A_HUMAN $32.69 \quad 100.0 \%$ Transformer-2 protein homolog alpha GN=TRA2A TRA2A_HUMAN $32.69 \quad 100.0 \%$ Transformer-2 protein homolog alpha GN=TRA2A TRA2A_HUMAN $32.69 \quad 100.0 \%$ Transformer-2 protein homolog alpha GN=TRA2A TRA2A_HUMAN $32.69 \quad 100.0 \%$ Transformer-2 protein homolog alpha GN=TRA2A TRA2A_HUMAN $32.69 \quad 100.0 \%$ Transformer-2 protein homolog alpha GN=TRA2A TRA2A_HUMAN $32.69 \quad 100.0 \%$ Transformer-2 protein homolog alpha GN=TRA2A TRA2A_HUMAN $32.69 \quad 100.0 \%$ Transformer-2 protein homolog beta GN=TRA2B TRA2B_HUMAN $33.67 \quad 100.0 \%$ Transformer-2 protein homolog beta GN=TRA2B TRA2B_HUMAN $33.67 \quad 100.0 \%$ Transformer-2 protein homolog beta GN=TRA2B TRA2B HUMAN $33.67 \quad 100.0 \%$ Transformer-2 protein homolog beta GN=TRA2B TRA2B_HUMAN $33.67 \quad 100.0 \%$ Transformer-2 protein homolog beta GN=TRA2B TRA2B_HUMAN $33.67 \quad 100.0 \%$ Transformer-2 protein homolog beta GN=TRA2B TRA2B HUMAN $33.67 \quad 100.0 \%$ Transformer-2 protein homolog beta GN=TRA2B TRA2B_HUMAN $33.67 \quad 100.0 \%$ Transformer-2 protein homolog beta GN=TRA2B TRA2B_HUMAN $33.67 \quad 100.0 \%$ Transformer-2 protein homolog beta GN=TRA2B TRA2B_HUMAN $33.67 \quad 100.0 \%$ Translation initiation factor eIF-2B subunit alpha GN=EIF2B1 EI2BA_HUMAN $33.71 \quad 100.0 \%$ Translation initiation factor eIF-2B subunit alpha GN=EIF2B1 EI2BA HUMAN $33.71 \quad 100.0 \%$ Translation initiation factor eIF-2B subunit beta GN=EIF2B2 EI2BB_HUMAN $38.99 \quad 100.0 \%$ Translation initiation factor eIF-2B subunit beta GN=EIF2B2 EI2BB_HUMAN $38.99 \quad 100.0 \%$ Translation initiation factor eIF-2B subunit beta GN=EIF2B2 EI2BB HUMAN $38.99 \quad 100.0 \%$ Translation initiation factor eIF-2B subunit beta GN=EIF2B2 EI2BB_HUMAN $38.99 \quad 100.0 \%$ Translation initiation factor eIF-2B subunit delta GN=EIF2B4 EI2BD HUMAN $57.56 \quad 100.0 \%$ Translation initiation factor eIF-2B subunit delta GN=EIF2B4 EI2BD_HUMAN $57.56 \quad 100.0 \%$ Translation initiation factor eIF-2B subunit epsilon GN=EIF2B5 EI2BE_HUMAN $80.38 \quad 100.0 \%$ Translation initiation factor eIF-2B subunit epsilon GN=EIF2B5 $\quad$ EI2BE HUMAN $80.38 \quad 100.0 \%$ Translational activator GCN1 GN=GCN1L1 GCN1L_HUMAN $292.76 \quad 100.0 \%$
$13 \quad 0.03 \% \quad 3.9 \% \quad$ RDTALETALNAK $0.03 \% \quad 3.9 \%$ DTALETALNAK $0.03 \% \quad 3.9 \% \quad$ ILTGTDAPK

$0.03 \% \quad 3.9 \% \quad$ LTQVLNTHYVAPR $0.03 \% \quad 3.9 \%$ CDMSALQR $0.03 \% \quad 3.9 \% \quad$ IGQQNEVR

$0.03 \% \quad 3.9 \%$ DSDAGSSTPTTSTR $0.01 \% \quad 5.8 \%$ STVQVCNSILCPK $0.01 \% \quad 5.8 \%$ ADFYVLEK

$0.01 \% \quad 2.4 \%$ GAAGAVTQSLSR $0.01 \% \quad 2.4 \%$ ALSAVSAQAAAAQK $0.03 \% \quad 8.7 \%$ FYLDVKQNAK $0.03 \% \quad 8.7 \%$ ALKSEFLVR $0.03 \% \quad 8.7 \%$ VSEVKPTYR $0.01 \% \quad 13.1 \%$ GGGEQETQELASK $0.01 \% \quad 13.1 \%$ FYLDVKQNAK $0.01 \% \quad 13.1 \%$ ALKSEFLVR $0.01 \% \quad 13.1 \%$ VSEVKPSYR $0.05 \% \quad 22.7 \%$ DLREVFSR

$0.05 \% \quad 22.7 \%$ YGPLSGVNVVYDQR $0.05 \% \quad 22.7 \%$ YGPLSGVNVVYDQRTGR $0.05 \% \quad 22.7 \%$ IDDSKEAMER

$0.05 \% \quad 22.7 \%$ ANGMELDGRR $0.05 \% \quad 22.7 \%$ IRVDYSITK $0.05 \% \quad 22.7 \%$ VDYSITKR $0.05 \% \quad 22.7 \%$ RSPSPYYSR $0.05 \% \quad 22.7 \%$ SPSPYYSR

$0.08 \% \quad 25.3 \%$ DLREVFSK $0.08 \% \quad 25.3 \%$ YGPIADVSIVYDQQSR $0.08 \% \quad 25.3 \%$ YGPIADVSIVYDQQSRR $0.08 \% \quad 25.3 \%$ ANGMELDGRR $0.08 \% \quad 25.3 \%$ IRVDFSITK $0.08 \% \quad 25.3 \%$ GYDDRDYYSR $0.08 \% \quad 25.3 \%$ AAQDRDQIYR $0.08 \% \quad 25.3 \%$ RSPSPYYSR $0.08 \% \quad 25.3 \%$ SPSPYYSR $0.01 \% \quad 6.2 \%$ DKGETIQGLR $0.01 \% \quad 6.2 \% \quad$ VLEAAVAAK $0.01 \% \quad 14.8 \%$ MTAAQPSETTVGNMVR $0.01 \% \quad 14.8 \%$ SDESDQQESLHK $0.01 \% \quad 14.8 \%$ TVEAFLKEAAR $0.01 \% \quad 14.8 \%$ AVTGTHTLALAAK $0.01 \% \quad 5.2 \%$ LGLQYSQGLVSGSNAR $0.01 \% \quad 5.2 \%$ VGTAQLALVAR $0.01 \% \quad 2.8 \% \quad$ IITSELYR $0.01 \% \quad 2.8 \%$ SLGDVLRDVDAK $0.07 \% \quad 5.7 \%$ NLLHSLQSSGIGSK $\begin{array}{lll}99.1 \% & 22.0\end{array}$ $99.7 \% \quad 59.4$ $\begin{array}{lll}99.7 \% & 28.9\end{array}$ $99.0 \% \quad 22.2$ $99.0 \% 25.0$ $99.0 \% \quad 40.1$

$99.7 \% \quad 60.2$ $99.7 \% \quad 38.3$ $97.8 \% \quad 20.8$ $99.7 \% \quad 54.5$

$99.0 \% 19.9$

$99.7 \% \quad 27.2$

$99.6 \% \quad 30.0$

$99.7 \% \quad 40.0$

$99.7 \% 56.1$

$99.7 \% \quad 27.2$

$99.6 \% \quad 30.0$

$99.7 \% \quad 44.0$

$99.0 \% \quad 26.3$

$99.7 \% \quad 67.3$

$99.3 \% \quad 29.3$

$\begin{array}{lll}99.7 \% & 53.7\end{array}$

$99.0 \% \quad 19.9$

$99.7 \% \quad 44.3$

$98.6 \% \quad 22.5$

$99.4 \% \quad 26.4$

$99.0 \% \quad 37.2$

$99.0 \% \quad 32.3$

$99.7 \% \quad 51.0$

$99.7 \% \quad 29.9$

$99.0 \% \quad 19.9$

$99.7 \% \quad 34.5$

$99.7 \% \quad 27.7$

$99.7 \% \quad 38.3$

$99.4 \% \quad 26.4$

$99.0 \% \quad 37.2$

$99.7 \% \quad 33.8$

$99.7 \% \quad 43.6$

$99.7 \% \quad 28.7$

$98.1 \% \quad 17.8$

$99.7 \% \quad 43.3$

$99.7 \% \quad 71.8$

$99.7 \% \quad 67.2$

$99.7 \% \quad 87.0$

$99.0 \% \quad 49.4$

$98.6 \% 24.6$

$99.7 \% \quad 45.9$
1146.60

915.51

1511.83

980.43

943.50

1382.60

1505.75

984.50

1117.60

1286.71

1225.66

1062.63

1078.59

1333.62

1225.66

1062.63

1064.57

1021.54

1566.79

1880.96

1193.55

1118.54

1094.62

981.54

1112.55

956.45

993.54

1810.90

1967.00

1118.54

1078.63

1309.54

1235.61

1112.55

956.45

1116.60

871.52

1692.80

1402.61

1234.68

1253.72

1649.86

1098.66

994.56

287.69

1440.78

$\begin{array}{cc}26 & 437 \\ 27 & 437 \\ 27 & 635 \\ 93 & 905 \\ 98 & 1005 \\ 93 & 1200 \\ 16 & 1429 \\ 25 & 137 \\ 26 & 233 \\ 03 & 414 \\ 04 & 817 \\ 3 & 82 \\ 42 & 150 \\ 46 & 254 \\ 5 & 37 \\ 6 & 55 \\ 18 & 126 \\ 47 & 255 \\ 34 & 141 \\ 42 & 155 \\ 42 & 158 \\ 70 & 179 \\ 80 & 189 \\ 90 & 198 \\ 92 & 199 \\ 59 & 267 \\ 60 & 267 \\ 33 & 140 \\ 41 & 156 \\ 41 & 157 \\ 79 & 188 \\ 89 & 197 \\ 29 & 238 \\ 52 & 261 \\ 63 & 271 \\ 64 & 271 \\ 7 & 46 \\ 37 & 145 \\ 8 & 83 \\ 00 & 111 \\ 73 & 183 \\ 47 & 259 \\ 10 & 225 \\ 18 & 428 \\ 22 & 129 \\ 30 & 141 \\ & \end{array}$

Page 82 of Table S-1-3 
Translational activator GCN1 GN=GCN1L1 GCN1L_HUMAN $292.76 \quad 100.0 \%$ Translational activator GCN1 GN=GCN1L1 GCN1L_HUMAN $292.76 \quad 100.0 \%$ Translational activator GCN1 GN=GCN1L1 GCN1L_HUMAN $292.76 \quad 100.0 \%$ Translational activator GCN1 GN=GCN1L1 GCN1L_HUMAN $292.76 \quad 100.0 \%$ Translational activator GCN1 GN=GCN1L1 GCN1L_HUMAN $292.76 \quad 100.0 \%$ Translational activator GCN1 GN=GCN1L1 GCN1L_HUMAN $292.76 \quad 100.0 \%$ Translational activator GCN1 GN=GCN1L1 GCN1L_HUMAN $292.76 \quad 100.0 \%$ Translational activator GCN1 GN=GCN1L1 GCN1L_HUMAN $292.76 \quad 100.0 \%$ Translational activator GCN1 GN=GCN1L1 GCN1L HUMAN $292.76 \quad 100.0 \%$ Translational activator GCN1 GN=GCN1L1 GCN1L_HUMAN $292.76 \quad 100.0 \%$ Translational activator GCN1 GN=GCN1L1 GCN1L_HUMAN $292.76 \quad 100.0 \%$ Translational activator GCN1 GN=GCN1L1 GCN1L_HUMAN $292.76 \quad 100.0 \%$ Translational activator GCN1 GN=GCN1L1 GCN1L_HUMAN $292.76 \quad 100.0 \%$ Transmembrane protein 199 GN=TMEM199 TM199_HUMAN $23.13 \quad 100.0 \%$ Transmembrane protein 199 GN=TMEM199 TM199_HUMAN $23.13 \quad 100.0 \%$ Transmembrane protein 201 GN=TMEM201 TM201_HUMAN $72.24 \quad 100.0 \%$ Transmembrane protein $201 \mathrm{GN}=\mathrm{TMEM} 201 \mathrm{TM} 201$ HUMAN $72.24 \quad 100.0 \%$ Transmembrane protein 201 GN=TMEM201 TM201_HUMAN $72.24 \quad 100.0 \%$ Transportin- $1 \mathrm{GN}=\mathrm{TNPO}$

Transportin-1 GN=TNPO

Transportin-1 GN=TNPO1 TNPO1_HUMAN $102.36 \quad 100.0 \%$ TNPO1_HUMAN $102.36 \quad 100.0 \%$ TNPO1_HUMAN $102.36 \quad 100.0 \%$ GN=SLC25A1 TXTP HUMAN $34.01 \quad 100.0 \%$ Tricarboxylate transport protein, mitochondrial GN=SLC25A1 TXTP_HUMAN $34.01 \quad 100.0 \%$ Tricarboxylate transport protein, mitochondrial GN=SLC25A1 TXTP_HUMAN $34.01 \quad 100.0 \%$ Tricarboxylate transport protein, mitochondrial GN=SLC25A1 TXTP HUMAN 34.01 $100.0^{\circ}$ Tricarboxylate transport protein, mitochondrial GN=SLC25A1 TXTP_HUMAN $34.01 \quad 100.0 \%$ Tricarboxylate transport protein, mitochondrial GN=SLC25A1 TXTP_HUMAN 34.01 100.0\% Tricarboxylate transport protein, mitochondrial GN=SLC25A1 TXTP HUMAN $34.01 \quad 100.0 \%$ Tricarboxylate transport protein, mitochondrial GN=SLC25A1 TXTP_HUMAN 34.01 100.0\% Tricarboxylate transport protein, mitochondrial GN=SLC25A1 TXTP_HUMAN 34.01 100.0\% Trifunctional enzyme subunit alpha, mitochondrial GN=HADHA ECHA_HUMAN $83.00 \quad 100.0 \%$ Trifunctional enzyme subunit alpha, mitochondrial GN=HADHA ECHA_HUMAN $83.00 \quad 100.0 \%$ Tifunctional enzyme subunit alpha, mitochondria GN=HADHA ECHA_HUMAN $83.00 \quad 100.0 \%$ Trifunctional enzyme subunit alpha, mitochondrial GN=HADHA ECHA_HUMAN $83.00 \quad 100.0 \%$ Trifunctional enzyme subunit alpha, mitochondrial GN=HADHA ECHA HUMAN $83.00 \quad 100.0 \%$ Trifunctional enzyme subunit beta, mitochondrial GN=HADHB ECHB HUMAN $51.30 \quad 100.0 \%$ Trifunctional enzyme subunit beta, mitochondrial GN=HADHB ECHB_HUMAN $51.30 \quad 100.0 \%$ Trifunctional enzyme subunit beta, mitochondrial GN=HADHB ECHB HUMAN $51.30 \quad 100.0 \%$ Trifunctional enzyme subunit beta, mitochondrial GN=HADHB ECHB_HUMAN $51.30 \quad 100.0 \%$ Trifunctional enzyme subunit beta, mitochondrial GN=HADHB ECHB_HUMAN $51.30 \quad 100.0^{\circ}$ Trifunctional enzyme subunit beta, mitochondrial GN=HADHB ECHB HUMAN $51.30100 .0 \%$ Trifunctional enzyme subunit beta, mitochondrial GN=HADHB ECHB_HUMAN $51.30 \quad 100.0 \%$ Trifunctional enzyme subunit beta, mitochondrial GN=HADHB ECHB HUMAN $51.30 \quad 100.0 \%$ Trifunctional enzyme subunit beta, mitochondrial GN=HADHB ECHB_HUMAN $51.30 \quad 100.0 \%$ Trifunctional enzyme subunit beta, mitochondrial GN=HADHB ECHB_HUMAN $51.30 \quad 100.0 \%$ Trifunctional enzyme subunit beta, mitochondrial GN=HADHB ECHB HUMAN $51.30 \quad 100.0 \%$ Trifunctional purine biosynthetic protein adenosine-3 GN=GART PUR2_HUMAN $107.77 \quad 100.0 \%$
$0.07 \% \quad 5.7 \% \quad$ LMDEAVLALR $0.07 \% \quad 5.7 \% \quad$ ALVAVLLSR $0.07 \% \quad 5.7 \%$ QAGAEALSQAVAR $0.07 \% \quad 5.7 \%$ GAAYGLAGLVK $0.07 \% \quad 5.7 \%$ AVMSNLSAHGVK $0.07 \% \quad 5.7 \% \quad$ LTEVLTDSHVK $0.07 \% \quad 5.7 \% \quad$ ASLLDPVPEVR $0.07 \% \quad 5.7 \% \quad$ LMPEIVATASK $0.07 \% \quad 5.7 \%$ VDIAPHVR $0.07 \% \quad 5.7 \%$ SDTQLVVR $0.07 \% \quad 5.7 \%$ ADYTSHLR $0.07 \% \quad 5.7 \% \quad$ EGVLTGSPEQKEEAAK $0.07 \% \quad 5.7 \%$ ALQDSNRGVR $0.01 \% \quad 9.1 \%$ ASSLLAGER $0.01 \% \quad 9.1 \%$ AELEAALGKK $0.01 \% \quad 5.1 \%$ IKQLAAFAPR $0.01 \% \quad 5.1 \%$ ALLLSHQFK $0.01 \% \quad 5.1 \%$ EADQTHAQNFSSAVK $0.01 \% \quad 3.7 \%$ SLSGLILKNNVK $0.01 \% \quad 3.7 \%$ SITCWTLSR $0.01 \% \quad 3.7 \%$ TLLENTAITIGR $0.06 \% \quad 27.3 \%$ TQLQLDER $0.06 \% \quad 27.3 \%$ GIGDCVRQTVR $0.06 \% \quad 27.3 \%$ SHGVLGLYR $0.06 \% \quad 27.3 \%$ GLSSLLYGSIPK $0.06 \% \quad 27.3 \%$ DAQGRLDSTR $0.06 \% \quad 27.3 \%$ VKFIHDQTSPNPK $0.06 \% \quad 27.3 \%$ FIHDQTSPNPK $0.06 \% \quad 27.3 \%$ GTYQGLTATVLK $0.06 \% \quad 27.3 \%$ MQGLEAHKYR $0.02 \% \quad 7.7 \%$ TLQEVTQLSQEAQR $0.02 \% \quad 7.7 \%$ DTSASAVAVGLKQGK $0.02 \% \quad 7.7 \% \quad$ CLAPMMSEVIR $0.02 \% \quad 7.7 \%$ ILQEGVDPK $0.02 \% \quad 7.7 \%$ GFYIYQEGVK $0.04 \% \quad 20.3 \%$ TLAKPNIR $0.04 \% \quad 20.3 \%$ NVVVVDGVR $0.04 \% \quad 20.3 \%$ AALTGLLHR $0.04 \% \quad 20.3 \%$ EAALGAGFSDK $19 \quad 0.04 \% \quad 20.3 \%$ KLMLDLNK $0.04 \% \quad 20.3 \%$ LSLISKFR $0.04 \% \quad 20.3 \%$ LAAAFAVSR $9 \quad 0.04 \% \quad 20.3 \%$ LEQDEYALR $19 \quad 0.04 \% \quad 20.3 \%$ ALAMGYKPK $19 \quad 0.04 \% \quad 20.3 \%$ VGLPPLEK $9 \quad 0.04 \% \quad 20.3 \%$ LVMAAANR $0.01 \% \quad 2.5 \%$ ASGLAAGKGVIVAK $\begin{array}{lllll}99.3 \% & 21.2 & 25.0 & 21.2 & 1\end{array}$ $\begin{array}{llll}99.7 \% & 57.6 & 25.0 & 47.0\end{array}$ $99.7 \% \quad 74.4$ $99.7 \% \quad 39.2$ $99.6 \% 26.6$ $99.5 \% \quad 31.2$ $99.7 \% \quad 31.0$ $95.5 \% 16.9$ $98.7 \% \quad 18.2$ $95.4 \% \quad 26.0$ $95.7 \% \quad 21.4$ $99.7 \% \quad 28.4$ $99.1 \% \quad 19.6$ $99.7 \% \quad 31.9$ $96.3 \% \quad 23.7$ $\begin{array}{lll}99.7 \% & 29.3\end{array}$ $99.7 \% \quad 33.0$ $99.4 \% \quad 24.6$ $99.7 \% \quad 42.4$ $98.3 \% \quad 27.4$ $99.7 \% \quad 64.7$ $99.0 \% \quad 42.1$ $99.4 \% \quad 23.0$ $99.7 \% \quad 35.8$ $99.7 \% \quad 44.1$ $96.7 \% \quad 21.0$ $\begin{array}{lll}99.7 \% & 29.8\end{array}$ $99.7 \% \quad 49.3$ $99.7 \% \quad 55.3$ $99.6 \% \quad 29.0$ $99.7 \% \quad 66.6$ $99.7 \% \quad 42.9$ $99.5 \% \quad 25.2$ $99.7 \% \quad 32.1$ $99.7 \% \quad 45.1$ $99.0 \% \quad 19.8$ $99.7 \% \quad 53.9$ $99.7 \% \quad 57.1$ $99.7 \% \quad 34.5$ $\begin{array}{lll}99.0 \% & 35.9\end{array}$ $99.0 \% \quad 40.7$ $99.7 \% \quad 56.9$ $99.7 \% \quad 58.7$ $99.4 \% \quad 24.9$ $95.2 \% \quad 14.8$ $99.0 \% \quad 52.5$ $99.7 \% \quad 43.7$
146.62 941.61

1271.67

1019.5

1213.64

1241.67

1195.67

1159.6

906.52

917.51

962.47

1672.84

1115.59

903.49

1029.59

1114.67

1056.62

1632.76

1285.78

1123.56

1301.74

1002.52

1260.65

1001.55

1234.70

1118.56

1510.80

1283.64

1251.69

1232.62

1630.84

1431.78

1338.62

998.55

1203.60

912.56

956.55

951.57

1065.52

974.57

963.60

905.52

1136.56

994.54

852.52

845.47 1241.76

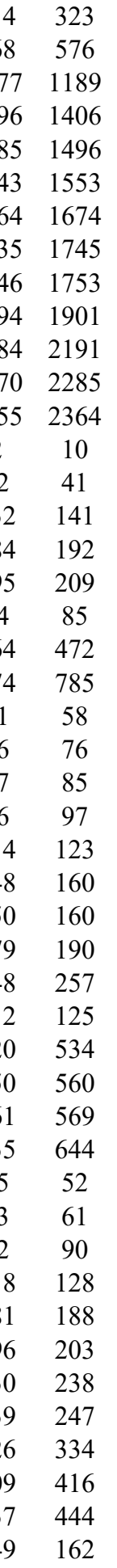

Page 83 of Table S-1-3 
Tuberin $\mathrm{GN}=\mathrm{TSC} 2$

Tuberin $\mathrm{GN}=\mathrm{TSC} 2$

Tubulin alpha-1B chain $\mathrm{GN}=\mathrm{TUBA} 1 \mathrm{~B}$

Tubulin alpha-1B chain GN=TUBA1B

Tubulin alpha-1B chain GN=TUBA1B

Tubulin alpha-1B chain $\mathrm{GN}=$ TUBA1B

Tubulin alpha-1B chain GN=TUBA1E

Tubulin alpha-1B chain GN=TUBA1B

Tubulin alpha-1B chain GN=TUBA1B

Tubulin alpha-1B chain GN=TUBA1B

Tubulin alpha-1B chain GN=TUBA1E

Tubulin alpha-1B chain GN=TUBA1B

Tubulin beta chain GN=TUBB

Tubulin beta chain $\mathrm{GN}=\mathrm{TUBB}$

Tubulin beta chain GN=TUBE

Tubulin beta chain GN=TUBE

Tubulin beta chain GN=TUBB

Tubulin beta chain $\mathrm{GN}=\mathrm{TUBB}$

Tubulin beta chain $\mathrm{GN}=\mathrm{TUB}$

Tubulin beta chain $\mathrm{GN}=\mathrm{TUBB}$

Tubulin beta chain $\mathrm{GN}=\mathrm{TUBB}$

Tubulin beta chain GN=TUBB

Tubulin beta chain GN=TUBE

Tubulin beta chain $\mathrm{GN}=\mathrm{TUB}$

Tubulin beta chain GN=TUBB

Tubulin beta chain GN=TUBB

Tubulin beta chain $\mathrm{GN}=\mathrm{TUBE}$

Tubulin beta chain $\mathrm{GN}=\mathrm{TUBB}$

Tubulin beta chain $\mathrm{GN}=\mathrm{TUBB}$

Tubulin beta chain $\mathrm{GN}=\mathrm{TUBB}$

Tubulin beta-4B chain $\mathrm{GN}=\mathrm{TUBB} 4 \mathrm{H}$

Tubulin beta-4B chain $\mathrm{GN}=$ TUBB4B

Tubulin beta- $4 \mathrm{~B}$ chain $\mathrm{GN}=\mathrm{TUBB} 4 \mathrm{~B}$

Tubulin beta-4B chain $\mathrm{GN}=\mathrm{TUBB} 4 \mathrm{E}$

Tubulin beta-4B chain GN=TUBB4B

Tubulin beta-4B chain $\mathrm{GN}=\mathrm{TUBB} 4 \mathrm{H}$

Tubulin beta-4B chain $\mathrm{GN}=\mathrm{TUBB} 4 \mathrm{~B}$

Tubulin beta-4B chain $\mathrm{GN}=\mathrm{TUBB} 4 \mathrm{~B}$

Tubulin beta- $4 \mathrm{~B}$ chain $\mathrm{GN}=\mathrm{TUBB} 4 \mathrm{~B}$

Tubulin beta-4B chain $\mathrm{GN}=$ TUBB4

Tubulin beta- $4 \mathrm{~B}$ chain $\mathrm{GN}=\mathrm{TUBB} 4 \mathrm{~B}$
TSC2 HUMAN 200.61 99.8\%

TSC2_HUMAN $200.61 \quad 99.8 \%$

TBA1B HUMAN $50.15 \quad 100.0 \%$

TBA1B HUMAN $50.15 \quad 100.0 \%$

TBA1B_HUMAN $50.15 \quad 100.0 \%$

BA1B HUMAN $50.15 \quad 100.0 \%$

TBA1B_HUMAN $50.15 \quad 100.0 \%$

TBA1B HUMAN $50.15 \quad 100.0 \%$

TBA1B HUMAN $50.15 \quad 100.0 \%$

TBA1B_HUMAN $50.15 \quad 100.0 \%$

TBA1B_HUMAN $50.15 \quad 100.0 \%$

TBA1B HUMAN $50.15 \quad 100.0 \%$

TBB5 HUMAN $49.67 \quad 100.0 \%$

TBB5 HUMAN $49.67 \quad 100.0 \%$

TBB5_HUMAN $49.67 \quad 100.0 \%$

TBB5 HUMAN $49.67 \quad 100.0 \%$

TBB5_HUMAN $49.67 \quad 100.0 \%$

TBB5_HUMAN $49.67 \quad 100.0 \%$

TBB5 HUMAN $49.67 \quad 100.0 \%$

TBB5_HUMAN $49.67 \quad 100.0 \% \quad 18$

TBB5 HUMAN $49.67 \quad 100.0 \% \quad 18$

TBB5 HUMAN $49.67 \quad 100.0 \% \quad 18$

TBB5_HUMAN $49.67 \quad 100.0 \% \quad 18$

TBB5 HUMAN $49.67 \quad 100.0 \% \quad 18$

TBB5 HUMAN $49.67 \quad 100.0 \% \quad 18$

TBB5_HUMAN $49.67 \quad 100.0 \% \quad 18$

TBB5 HUMAN $49.67 \quad 100.0 \% \quad 18$

TBB5_HUMAN $49.67 \quad 100.0 \% \quad 18$

TBB5 HUMAN $49.67 \quad 100.0 \%$

TBB5 HUMAN $49.67 \quad 100.0 \% \quad 18$

TBB4B_HUMAN $49.83 \quad 100.0 \% \quad 3$

TBB4B HUMAN $49.83 \quad 100.0 \%-3$

TBB4B_HUMAN $49.83 \quad 100.0 \%$

TBB4B_HUMAN $49.83 \quad 100.0 \%$

TBB4B HUMAN $49.83 \quad 100.0 \%$

TBB4B_HUMAN $49.83 \quad 100.0 \%$

TBB4B HUMAN $49.83 \quad 100.0 \%$

TBB4B HUMAN $49.83 \quad 100.0 \%$

TBB4B_HUMAN $49.83 \quad 100.0 \%$

TBB4B HUMAN $49.83 \quad 100.0 \%$

TBB4B_HUMAN $49.83 \quad 100.0 \%$
$0.01 \% \quad 2.5 \% \quad$ AAVAGLDKAER

$0.00 \% \quad 4.2 \% \quad$ HLEAAALLSER

$0.00 \% \quad 4.2 \%$ NADGLIVASR

$0.02 \% \quad 3.3 \% \quad$ ILDMCAAPGSK

$0.02 \% \quad 3.3 \%$ IATRGAEQLAEGGR

$0.02 \% \quad 3.3 \%$ GAEQLAEGGR

$0.00 \% \quad 1.3 \%$ EAPAKLESQAGQQVSR

$0.00 \% \quad 1.3 \%$ SPSGLRPR

$0.16 \% \quad 20.8 \%$ AVFVDLEPTVIDEVR

$0.16 \% \quad 20.8 \%$ EIIDLVLDR

$0.16 \% 20.8 \%$ LSVDYGKK

$0.16 \% \quad 20.8 \%$ NLDIERPTYTNLNR

$0.16 \% \quad 20.8 \%$ HGKYMACCLLYR

$0.16 \% \quad 20.8 \%$ YMACCLLYR

$0.16 \% 20.8 \%$ GDVVPKDVNAAIATIK

$0.16 \% \quad 20.8 \%$ DVNAAIATIK

$0.16 \% \quad 20.8 \%$ DVNAAIATIKTK

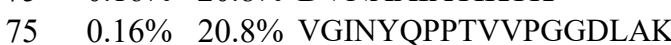

$167 \quad 0.35 \% \quad 32.0 \%$ MREIVHIQAGQCGNQIGAK

$167 \quad 0.35 \% \quad 32.0 \%$ ISVYYNEATGGK

$167 \quad 0.35 \% \quad 32.0 \%$ ISVYYNEATGGKYVPR

$167 \quad 0.35 \% \quad 32.0 \%$ AILVDLEPGTMDSVR

$167 \quad 0.35 \% \quad 32.0 \%$ IMNTFSVVPSPK

$167 \quad 0.35 \% \quad 32.0 \%$ FPGQLNADLR

$167 \quad 0.35 \% \quad 32.0 \%$ FPGQLNADLRK

$167 \quad 0.35 \% \quad 32.0 \%$ KLAVNMVPFPR

$167 \quad 0.35 \% \quad 32.0 \%$ LAVNMVPFPR

$167 \quad 0.35 \% \quad 32.0 \%$ NMMAACDPR

$167 \quad 0.35 \% \quad 32.0 \% \quad$ YLTVAAVFR

$167 \quad 0.35 \% \quad 32.0 \%$ YLTVAAVFRGR

$167 \quad 0.35 \% \quad 32.0 \%$ MSMKEVDEQMLNVQNK

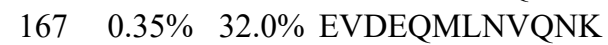

$167 \quad 0.35 \% \quad 32.0 \%$ TAVCDIPPR

$167 \quad 0.35 \% \quad 32.0 \%$ TAVCDIPPRGLK

$167 \quad 0.35 \% \quad 32.0 \%$ ISEQFTAMFR

$167 \quad 0.35 \% \quad 32.0 \%$ ISEQFTAMFRR

$0.06 \% \quad 31.9 \%$ MREIVHLQAGQCGNQIGAK

$29 \quad 0.06 \% \quad 31.9 \%$ INVYYNEATGGK

$0.06 \% 31.9 \%$ INVYYNEATGGKYVPR

$0.06 \% 31.9 \%$ AVLVDLEPGTMDSVR

$0.06 \% \quad 31.9 \%$ IMNTFSVVPSPK

$0.06 \% \quad 31.9 \%$ FPGQLNADLR

$0.06 \% \quad 31.9 \%$ FPGQLNADLRK

$0.06 \% 31.9 \%$ KLAVNMVPFPR

$0.06 \% \quad 31.9 \%$ LAVNMVPFPR

$0.06 \% \quad 31.9 \%$ NMMAACDPR

$0.06 \% \quad 31.9 \%$ YLTVAAVFR
$99.6 \% \quad 26.8 \quad 25.0=26.8$

$99.7 \% \quad 45.0 \quad 25.0 \quad 36.9$

$99.7 \% \quad 57.9 \quad 25.0 \quad 51.1$

$\begin{array}{llll}99.7 \% & 30.4 & 25.0 & 30.4\end{array}$

$99.7 \% \quad 61.4 \quad 25.0 \quad 53.7$

$\begin{array}{llll}95.0 \% & 15.0 & 25.0 & 15.0\end{array}$

$\begin{array}{llll}96.5 \% & 23.7 & 25.0 & 11.6\end{array}$

$99.7 \% \quad 57.4 \quad 25.0 \quad 51.5$

$\begin{array}{llll}99.7 \% & 28.9 & 25.0 & 28.9\end{array}$

$99.0 \% \quad 41.1 \quad 25.0 \quad 30.5 \quad 2$

$\begin{array}{llll}99.7 \% & 48.5 & 25.0 & 41.2\end{array}$

$\begin{array}{llll}99.7 \% & 42.6 & 25.0 & 42.6\end{array}$

$99.7 \% \quad 46.3 \quad 25.0 \quad 43.4$

$\begin{array}{llll}99.5 \% & 25.2 & 25.0 & 25.2\end{array}$

$\begin{array}{lllll}99.7 \% & 75.3 & 25.0 & 54.8 & 24\end{array}$

$\begin{array}{llll}99.7 \% & 64.2 & 25.0 & 59.9\end{array}$

$\begin{array}{lll}99.7 \% & 31.4\end{array}$

$\begin{array}{ll}99.2 \% & 56.4 \\ 99.7 \% & 68.1\end{array}$

$99.7 \% \quad 60.6$

$99.7 \% \quad 62.5$

$99.7 \% \quad 73.8$

$97.2 \% \quad 20.1$

$99.5 \% \quad 28.3$

$99.7 \% \quad 36.9$

$99.7 \% \quad 67.3$

$99.7 \% \quad 47.2$

$99.7 \% \quad 72.4$

$99.7 \% \quad 37.5$

$99.7 \% \quad 34.5$

$\begin{array}{lll}99.7 \% & 38.3\end{array}$

$99.7 \% \quad 43.8$

$99.7 \% \quad 37.0$

$99.7 \% \quad 70.2$

$96.9 \% \quad 18.5$

$99.2 \% \quad 56.4$

$\begin{array}{lll}99.7 \% & 44.4\end{array}$

$99.7 \% \quad 65.4$

$99.7 \% \quad 63.5$

$99.7 \% \quad 73.8$

$97.2 \% \quad 20.1$

$99.5 \% \quad 28.3$

$99.7 \% \quad 36.9$

$99.7 \% \quad 67.3$

$99.7 \% \quad 47.2$

$99.7 \% \quad 72.4$
1209.66

1015.55

1162.56

1428.76

987.49

1698.88

869.50

1701.91

1085.62

909.50

1718.88

1587.72

1249.55

1610.91

1015.58

1244.72

1824.99

2126.06

1301.64

1816.92

1615.84

1319.70

1130.60

1258.69

1271.73

1143.63

1065.43

1039.59

1252.72

1971.88

1446.69

1028.52

1326.72

1245.59

1401.69

2126.06

1328.65

1843.93

1617.82

1319.70

1130.60

1258.69

1271.73

1143.63

1065.43

1039.59 $\begin{array}{cc}45 & 855 \\ 57 & 367 \\ 68 & 377 \\ 80 & 190 \\ 02 & 315 \\ 66 & 315 \\ 07 & 1122 \\ 52 & 1459 \\ 5 & 79 \\ 13 & 121 \\ 57 & 164 \\ 16 & 229 \\ 09 & 320 \\ 12 & 320 \\ 21 & 336 \\ 27 & 336 \\ 27 & 338 \\ 53 & 370 \\ 1 & 19 \\ 7 & 58 \\ 7 & 62 \\ 3 & 77 \\ 63 & 174 \\ 42 & 251 \\ 42 & 252 \\ 52 & 262 \\ 53 & 262 \\ 98 & 306 \\ 10 & 318 \\ 10 & 320 \\ 21 & 336 \\ 25 & 336 \\ 51 & 359 \\ 51 & 362 \\ 81 & 390 \\ 81 & 391 \\ 1 & 19 \\ 7 & 58 \\ 7 & 62 \\ 3 & 77 \\ 63 & 174 \\ 42 & 251 \\ 42 & 252 \\ 52 & 262 \\ 53 & 262 \\ 98 & 306 \\ 10 & 318 \\ & \end{array}$

Page 84 of Table S-1-3 
Tubulin beta-4B chain $\mathrm{GN}=\mathrm{TUBB} 4 \mathrm{~B}$ Tubulin beta- $4 \mathrm{~B}$ chain $\mathrm{GN}=\mathrm{TUBB} 4 \mathrm{~B}$ Tubulin beta- $4 \mathrm{~B}$ chain $\mathrm{GN}=\mathrm{TUBB} 4 \mathrm{~B}$ Tubulin beta- $4 \mathrm{~B}$ chain $\mathrm{GN}=\mathrm{TUBB} 4 \mathrm{~B}$ Tubulin beta- $4 \mathrm{~B}$ chain $\mathrm{GN}=\mathrm{TUBB} 4 \mathrm{~B}$ Tubulin beta- $4 \mathrm{~B}$ chain $\mathrm{GN}=\mathrm{TUBB} 4 \mathrm{~B}$

Tubulin beta-4B chain $\mathrm{GN}=\mathrm{TUBB} 4 \mathrm{~B}$ Tubulin gamma- 1 chain GN=TUBG1 Tubulin gamma- 1 chain $\mathrm{GN}=\mathrm{TUBG}$ Tubulin gamma- 1 chain GN=TUBG1 Tubulin gamma- 1 chain $\mathrm{GN}=\mathrm{TUBG} 1$ Tubulin gamma- 1 chain $\mathrm{GN}=\mathrm{TUBG} 1$

Tubulin-specific chaperone D GN=T Tubulin-specific chaperone D GN=TBCD TBCD_HUMAN $132.60 \quad 100.0 \%$ Tuftelin-interacting protein $11 \mathrm{GN}=$ TFIP11 TFP11_HUMAN $96.82 \quad 100.0 \%$ Tuftelin-interacting protein $11 \mathrm{GN}=$ TFIP11 TFP11_HUMAN $96.82 \quad 100.0 \%$ Tyrosine--tRNA ligase, cytoplasmic GN=YARS SYYC HUMAN $59.15 \quad 100.0 \%$ Tyrosine--tRNA ligase, cytoplasmic GN=YARS SYYC_HUMAN $59.15 \quad 100.0 \%$ Tyrosine--tRNA ligase, cytoplasmic GN=YARS SYYC_HUMAN $59.15 \quad 100.0 \%$ Tyrosine--tRNA ligase, cytoplasmic GN=YARS SYYC_HUMAN $59.15 \quad 100.0 \%$ Tyrosine--tRNA ligase, cytoplasmic GN=YARS SYYC_HUMAN $59.15 \quad 100.0 \%$ Tyrosine--tRNA ligase, cytoplasmic GN=YARS SYYC_HUMAN $59.15 \quad 100.0 \%$ Tyrosine--tRNA ligase, cytoplasmic GN=YARS SYYC_HUMAN $59.15 \quad 100.0 \%$ Tyrosine--tRNA ligase, cytoplasmic GN=YARS SYYC_HUMAN $59.15 \quad 100.0 \%$ Tyrosine--tRNA ligase, cytoplasmic GN=YARS SYYC_HUMAN $59.15 \quad 100.0 \%$ Tyrosine--tRNA ligase, cytoplasmic GN=YARS SYYC_HUMAN $59.15 \quad 100.0 \%$ Tyrosine--tRNA ligase, cytoplasmic GN=YARS SYYC_HUMAN $59.15 \quad 100.0 \%$ U1 small nuclear ribonucleoprotein $70 \mathrm{kDa}$ GN=SNRNP70 RU17_HUMAN $51.56 \quad 100.0 \%$ U1 small nuclear ribonucleoprotein $70 \mathrm{kDa}$ GN=SNRNP70 RU17_HUMAN $51.56 \quad 100.0 \%$ U1 small nuclear ribonucleoprotein A GN=SNRPA SNRPA HUMAN $31.28 \quad 100.0 \%$

$\begin{array}{lll}\text { U1 small nuclear ribonucleoprotein A GN=SNRPA SNRPA_HUMAN } 31.28 \quad 100.0 \% & 0.00 \%\end{array}$

U1 small nuclear ribonucleoprotein A GN=SNRPA SNRPA_HUMAN $31.28 \quad 100.0 \%$

$\begin{array}{llll}\text { U1 small nuclear ribonucleoprotein A GN=SNRPA SNRPA_HUMAN } 31.28 \quad 100.0 \% & 0.0 \%\end{array}$

U4/U6 small nuclear ribonucleoprotein Prp31 GN=PRPF31 PRP31_HUMAN $55.46 \quad 100.0 \%$ U4/U6 small nuclear ribonucleoprotein Prp31 GN=PRPF31 PRP31_HUMAN $55.46 \quad 100.0 \%$ U4/U6 small nuclear ribonucleoprotein Prp31 GN=PRPF31 PRP31_HUMAN $55.46 \quad 100.0 \%$ U4/U6 small nuclear ribonucleoprotein Prp31 GN=PRPF31 PRP31_HUMAN 55.46 $100.0 \%$ U4/U6 small nuclear ribonucleoprotein Prp31 GN=PRPF31 PRP31_HUMAN $55.46 \quad 100.0 \%$ U4/U6 small nuclear ribonucleoprotein Prp31 GN=PRPF31 PRP31_HUMAN $55.46 \quad 100.0 \%$ U4/U6 small nuclear ribonucleoprotein Prp31 GN=PRPF31 PRP31_HUMAN 55.46 100.0\% U4/U6 small nuclear ribonucleoprotein Prp31 GN=PRPF31 PRP31_HUMAN $55.46100 .0 \%$ U4/U6 small nuclear ribonucleoprotein Prp31 GN=PRPF31 PRP31_HUMAN 55.46 $100.0 \%$ U4/U6 small nuclear ribonucleoprotein Prp31 GN=PRPF31 PRP31_HUMAN 55.46 100.0\% U4/U6 small nuclear ribonucleoprotein Prp31 GN=PRPF31 PRP31_HUMAN $55.46 \quad 100.0 \%$ U4/U6 small nuclear ribonucleoprotein Prp31 GN=PRPF31 PRP31_HUMAN 55.46 $100.0 \%$ U4/U6 small nuclear ribonucleoprotein Prp31 GN=PRPF31 PRP31 HUMAN 55.46 100.0\% U4/U6 small nuclear ribonucleoprotein Prp31 GN=PRPF31 PRP31_HUMAN $55.46 \quad 100.0 \%$
$29 \quad 0.06 \% \quad 31.9 \%$ YLTVAAVFRGR $99.7 \% \quad 37.5$ $0.06 \% \quad 31.9 \%$ MSMKEVDEQMLNVQNK $0.06 \% \quad 31.9 \%$ EVDEQMLNVQNK $9.7 \% \quad 34.5$ $99.7 \% \quad 38.3$ $99.7 \% \quad 43.8$ $0.06 \% \quad 31.9 \%$ TAVCDIPPR

$0.06 \% \quad 31.9 \%$ TAVCDIPPRGLK $0.06 \% 31.9 \%$ ISEQFTAMFR $0.06 \% \quad 31.9 \%$ ISEQFTAMFRR $0.02 \% \quad 8.7 \%$ AVLLDLEPR $0.02 \% \quad 8.7 \%$ VIHSILNSPYAK $0.02 \% \quad 8.7 \% \quad$ KTTVLDVMR $0.02 \% \quad 8.7 \%$ TTVLDVMR $0.02 \% \quad 8.7 \%$ SPYLPSAHR $0.01 \% \quad 1.5 \%$ LGLTFLKPK $0.01 \% \quad 1.5 \%$ LQQVLTGLR $0.01 \% \quad 2.6 \%$ NAQGIINPIEAK $0.01 \% \quad 2.6 \%$ GAVGAYGSER $0.04 \% \quad 17.0 \%$ EYTLDVYR $0.04 \% \quad 17.0 \%$ KIFTFAEK $0.04 \% \quad 17.0 \%$ YLPALGYSK $0.04 \% \quad 17.0 \%$ YLPALGYSKR $0.04 \% \quad 17.0 \%$ NSVEVALNK $0.04 \% \quad 17.0 \%$ FNTPALKK $0.04 \% \quad 17.0 \%$ LASAAYPDPSK $0.04 \% \quad 17.0 \%$ LASAAYPDPSK $0.04 \% \quad 17.0 \%$ IDVGEAEPR $0.04 \% \quad 17.0 \%$ GQPDEELKPK $0.01 \% \quad 3.9 \% \quad$ VNYDTTESK $0.01 \% \quad 3.9 \%$ GGADVNIR $0.02 \% \quad 16.3 \%$ EVSSATNALR $0.02 \% \quad 16.3 \%$ IQYAKTDSDIIAK $0.02 \% \quad 16.3 \%$ GTFVERDR $0.02 \% \quad 16.3 \%$ DALQGFKITQNNAMK $0.16 \% \quad 29.5 \%$ ASEVMGPVEAAPEYR $0.16 \% 29.5 \%$ TVKELGNSLDK $0.16 \% \quad 29.5 \%$ HRIYEYVESR $0.16 \% \quad 29.5 \%$ IYEYVESR $0.16 \% \quad 29.5 \%$ IMGVAGGLTNLSK $0.16 \% \quad 29.5 \%$ MPACNIMLLGAQR $0.16 \% \quad 29.5 \%$ MPACNIMLLGAQRK $0.16 \% \quad 29.5 \%$ CTLAARVDSFHESTEGK $0.16 \% \quad 29.5 \%$ VDSFHESTEGK $0.16 \% \quad 29.5 \%$ VGYELKDEIER $0.16 \% \quad 29.5 \%$ QVKPLPAPLDGQR $0.16 \% \quad 29.5 \%$ LGLTEIRK $0.16 \% \quad 29.5 \%$ VRQTQVNEATK $0.16 \% \quad 29.5 \%$ QTQVNEATKAR
$99.7 \% \quad 37.0$

$99.7 \% \quad 70.2$

$96.9 \% \quad 18.5$

$\begin{array}{lll}99.7 \% & 37.8\end{array}$

$99.7 \% \quad 46.8$

$99.7 \% \quad 40.2$

$98.9 \% \quad 25.7$

$99.7 \% \quad 37.2$

$99.7 \% \quad 32.7$

$99.7 \% \quad 37.6$

$99.7 \% \quad 40.6$

$99.3 \% \quad 23.4$

$99.0 \% 23.6$

$99.0 \% \quad 32.8$

$98.7 \% \quad 26.3$

$99.7 \% \quad 32.3$

$99.7 \% \quad 50.6$

$99.0 \% \quad 28.9$

$99.7 \% \quad 48.7$

$99.1 \% \quad 19.2$

$\begin{array}{lll}99.6 \% & 27.2\end{array}$

$99.7 \% 36.1$

$99.7 \% \quad 38.2$

$99.3 \% \quad 24.2$

$99.0 \% 38.5$

$99.7 \% \quad 50.0$

$99.7 \% \quad 54.6$

$96.0 \% \quad 19.2$

$99.7 \% \quad 28.4$

$99.7 \% \quad 60.4$

$99.7 \% \quad 44.5$

$99.7 \% \quad 29.0$

$99.0 \% \quad 47.3$

$99.7 \% \quad 66.9$

$99.7 \% \quad 61.2$

$99.7 \% \quad 35.6$

$99.7 \% \quad 32.8$

$99.7 \% \quad 56$.

$99.7 \% \quad 39.5$

$99.7 \% 33.8$

$99.0 \% \quad 66.6$

$99.7 \% \quad 47.0$

$99.7 \% \quad 47.4$ $\begin{array}{ll}0 & 33.2\end{array}$

$\begin{array}{ll}0 & 31.1\end{array}$

$\begin{array}{ll}0 & 42.0\end{array}$

$\begin{array}{ll}0 & 37.0\end{array}$

$\begin{array}{lll} & 66.5 & 20\end{array}$

$\begin{array}{lll}0 & 15.8\end{array}$

$\begin{array}{lll} & 23.7 \\ 0 & 39.3 & 2\end{array}$

$\begin{array}{ll}25.0 & 35.8\end{array}$

$\begin{array}{ll}25.0 & 18.5\end{array}$

$\begin{array}{ll}0.7 \\ 0 & 26.8\end{array}$

$\begin{array}{lll}25.0 & 36.4 & 2\end{array}$

\begin{tabular}{ll}
.0 & 23.4 \\
\hline & 23.6
\end{tabular}

23.6
25.7

$\begin{array}{ll}25.0 & 13.5\end{array}$

$\begin{array}{ll}25.0 & 27.9\end{array}$

$\begin{array}{ll} & 0.0\end{array}$

$\begin{array}{ll}25.0 & 21.9\end{array}$

\begin{tabular}{ll}
39.0 \\
\hline
\end{tabular}

$\begin{array}{ll}25.0 & 19.2\end{array}$

$\begin{array}{ll}.0 & 22.4\end{array}$

\begin{tabular}{ll}
25.1 \\
\hline
\end{tabular}

\begin{tabular}{ll}
3.0 & 34.8 \\
\hline
\end{tabular}

\begin{tabular}{ll}
17.6 \\
\hline
\end{tabular}

\begin{tabular}{ll}
5.0 & 26.5 \\
\hline
\end{tabular}

$\begin{array}{ll}5.0 & 31.9\end{array}$

\begin{tabular}{ll}
.0 & 42.2 \\
\hline & 13.2
\end{tabular}

0
28.4

$\begin{array}{ll}5.0 & 50.0\end{array}$

$\begin{array}{ll}25.0 & 23.4\end{array}$

$\begin{array}{ll}28.0 & 28.7\end{array}$

$\begin{array}{ll}5.0 & 32.6\end{array}$

$\begin{array}{ll}0 & 54.9\end{array}$

$\begin{array}{ll}0 & 48.7\end{array}$

29.9
25.0

$\begin{array}{lll}25.0 & 32.8\end{array}$

$\begin{array}{ll}5.0 & 51.8\end{array}$

$\begin{array}{ll}25.0 & 31.3\end{array}$

33.8

$\begin{array}{ll}25.0 & 52.7\end{array}$

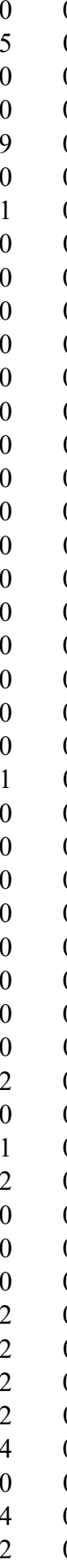

1252.72

1971.88

1446.69

1028.52

1326.72

1245.59

1401.69

1025.60

1341.75

1062.60

934.50

1027.53

1016.65

1027.63

1267.70

966.46

1058.52

983.56

1011.55

1167.65

973.53

918.54

1119.57

1818.94

1256.61

985.50

1140.59

1056.48

801.42

1047.54

1465.79

979.50

1678.86

1621.75

1203.66

1351.68

1058.52

1276.69

1490.73

1634.82

1907.89

1235.55

1350.69

1418.81

929.58

1273.69

1245.65

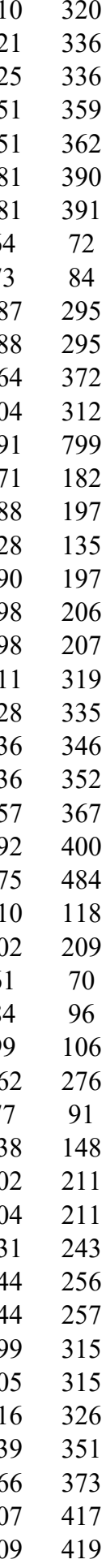

Page 85 of Table S-1-3 
U4/U6 small nuclear ribonucleoprotein Prp31 GN=PRPF31 PRP31_HUMAN $55.46 \quad 100.0 \%$ U4/U6 small nuclear ribonucleoprotein Prp31 GN=PRPF31 PRP31_HUMAN $55.46 \quad 100.0 \% \quad 16$ U4/U6 small nuclear ribonucleoprotein Prp4 GN=PRPF4 PRP4_HUMAN $58.45 \quad 100.0 \%$ U4/U6 small nuclear ribonucleoprotein Prp4 GN=PRPF4 PRP4 HUMAN 58.45 100.0\% U5 small nuclear ribonucleoprotein $200 \mathrm{kDa}$ helicase GN=SNRNP200 U520_HUMAN $244.51 \quad 100.0 \%$ U5 small nuclear ribonucleoprotein $200 \mathrm{kDa}$ helicase GN=SNRNP200 U520_HUMAN $244.51 \quad 100.0 \% 22$ U5 small nuclear ribonucleoprotein $200 \mathrm{kDa}$ helicase GN=SNRNP200 U520 HUMAN $244.51 \quad 100.0 \%$ U5 small nuclear ribonucleoprotein $200 \mathrm{kDa}$ helicase GN=SNRNP200 U520_HUMAN $244.51 \quad 100.0 \% \quad 22$ U5 small nuclear ribonucleoprotein $200 \mathrm{kDa}$ helicase GN=SNRNP200 U520 HUMAN $244.51 \quad 100.0 \%$ U5 small nuclear ribonucleoprotein $200 \mathrm{kDa}$ helicase GN=SNRNP200 $\quad$ U520_HUMAN $244.51 \quad 100.0 \% 22$ U5 small nuclear ribonucleoprotein $200 \mathrm{kDa}$ helicase GN=SNRNP200 U520_HUMAN $244.51 \quad 100.0 \% 22$ U5 small nuclear ribonucleoprotein $200 \mathrm{kDa}$ helicase GN=SNRNP200 U520 HUMAN $244.51 \quad 100.0 \% \quad 22$ U5 small nuclear ribonucleoprotein $200 \mathrm{kDa}$ helicase GN=SNRNP200 U520_HUMAN $244.51 \quad 100.0 \%$ U5 small nuclear ribonucleoprotein $200 \mathrm{kDa}$ helicase GN=SNRNP200 U520_HUMAN $244.51 \quad 100.0 \%$ U5 small nuclear ribonucleoprotein $200 \mathrm{kDa}$ helicase GN=SNRNP200 U520 HUMAN $244.51 \quad 100.0 \% \quad 22$ U5 small nuclear ribonucleoprotein $200 \mathrm{kDa}$ helicase GN=SNRNP200 U520_HUMAN $244.51 \quad 100.0 \% \quad 22$ U5 small nuclear ribonucleoprotein $200 \mathrm{kDa}$ helicase GN=SNRNP200 U520 HUMAN $244.51 \quad 100.0 \% \quad 22$ U5 small nuclear ribonucleoprotein $200 \mathrm{kDa}$ helicase GN=SNRNP200 U520_HUMAN $244.51 \quad 100.0 \%$ U5 small nuclear ribonucleoprotein $200 \mathrm{kDa}$ helicase GN=SNRNP200 U520_HUMAN $244.51 \quad 100.0 \% \quad 22$ U5 small nuclear ribonucleoprotein $200 \mathrm{kDa}$ helicase GN=SNRNP200 U520 HUMAN $244.51 \quad 100.0 \%$ U5 small nuclear ribonucleoprotein $200 \mathrm{kDa}$ helicase GN=SNRNP200 U520_HUMAN $244.51 \quad 100.0 \% \quad 22$ U5 small nuclear ribonucleoprotein $200 \mathrm{kDa}$ helicase GN=SNRNP200 U520 HUMAN $244.51 \quad 100.0 \% \quad 22$ U5 small nuclear ribonucleoprotein $200 \mathrm{kDa}$ helicase GN=SNRNP200 U520 HUMAN $244.51 \quad 100.0 \%$ U5 small nuclear ribonucleoprotein $200 \mathrm{kDa}$ helicase GN=SNRNP200 U520_HUMAN $244.51 \quad 100.0 \% \quad 22$ U5 small nuclear ribonucleoprotein $200 \mathrm{kDa}$ helicase GN=SNRNP200 U520 HUMAN $244.51 \quad 100.0 \%$ U5 small nuclear ribonucleoprotein $200 \mathrm{kDa}$ helicase GN=SNRNP200 U520_HUMAN $244.51 \quad 100.0 \%$ U7 snRNA-associated Sm-like protein LSm11 GN=LSM11 LSM11_HUMAN $39.50 \quad 100.0 \%$ 77 snRNA-a UAP56-interacting factor GN=FYTTD1 UIF_HUMAN $35.82 \quad 100.0 \%$ UAP56-interacting factor GN=FYTTD1 UIF HUMAN $35.82 \quad 100.0 \%$ UAP56-interacting factor GN=FYTTD1 UIF_HUMAN $35.82 \quad 100.0 \%$ UAP56-interacting factor GN=FYTTD1 UIF_HUMAN $35.82 \quad 100.0 \%$ UAP56-interacting factor GN=FYTTD1 UIF HUMAN $35.82 \quad 100.0 \%$ UAP56-interacting factor GN=FYTTD1 UIF_HUMAN $35.82 \quad 100.0 \%$ Ubiquitin-40S ribosomal protein S27a GN=RPS27A RS27A_HUMAN $17.97 \quad 100.0 \%$ Ubiquitin-40S ribosomal protein S27a GN=RPS27A RS27A HUMAN $17.97 \quad 100.0 \%$ Ubiquitin-40S ribosomal protein S27a GN=RPS27A RS27A_HUMAN $17.97 \quad 100.0 \%$ Ubiquitin-protein ligase E3A GN=UBE3A UBE3A HUMAN $100.69 \quad 100.0 \%$ Ubiquitin-protein ligase E3A GN=UBE3A UBE3A_HUMAN $100.69 \quad 100.0 \%$ Uncharacterized protein $\mathrm{C} 3$ orf $17 \mathrm{GN}=\mathrm{C} 3$ orf17 $\quad$ CC017_HUMAN $64.55 \quad 100.0 \%$ Uncharacterized protein $\mathrm{C} 3$ orf $17 \mathrm{GN}=\mathrm{C} 3$ orf17 $\mathrm{CC} 017$ HUMAN $64.55 \quad 100.0 \%$ Unconventional myosin-Id GN=MYO1D MYO1D_HUMAN $116.21 \quad 100.0 \%$ Unconventional myosin-Id GN=MYO1D MYO1D_HUMAN $116.21 \quad 100.0 \%$ Unconventional myosin-Va GN=MYO5A MYO5A_HUMAN $215.41 \quad 100.0 \%$ Unconventional myosin-Va GN=MYO5A MYO5A_HUMAN $215.41 \quad 100.0 \%$ Unconventional myosin-Va GN=MYO5A MYO5A HUMAN $215.41 \quad 100.0 \%$ Unconventional myosin-Va GN=MYO5A MYO5A_HUMAN $215.41 \quad 100.0 \%$

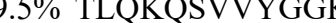

$0.16 \% \quad 29.5 \%$ YFSSMAEFLK

$0.01 \% \quad 4.2 \%$ TKAPDDLVAPVVK

$0.01 \% \quad 4.2 \% \quad$ FLGTTCYDR

$1 \quad 0.09 \% \quad 10.2 \%$ ANSNLVLQADR

$0.09 \% \quad 10.2 \%$ FYDDAIVSQK

$0.09 \% \quad 10.2 \%$ KADEVLEILK

$0.09 \% \quad 10.2 \%$ ADEVLEILK

$0.09 \% \quad 10.2 \%$ YAQAGFEGFK

$0.09 \% \quad 10.2 \%$ SLVQEMVGSFGK

$0.09 \% \quad 10.2 \%$ NIEMTQEDVR

$0.09 \% \quad 10.2 \%$ NQVLVFVHSR

$0.09 \% \quad 10.2 \%$ EGSASTEVLR

$0.09 \% \quad 10.2 \%$ GTQVYSPEK

$0.09 \% \quad 10.2 \%$ TGNFQVTELGR

$0.09 \% \quad 10.2 \%$ VPIPVKESIEEPSAK

$0.09 \% \quad 10.2 \%$ ESIEEPSAK

$0.09 \% \quad 10.2 \%$ MWQSMCPLR

$0.09 \% \quad 10.2 \%$ TICAEFAILR

$0.09 \% \quad 10.2 \%$ MLLQSSEGR

$0.09 \% \quad 10.2 \%$ VVLLTGETSTDLK

$0.09 \% \quad 10.2 \%$ IVALSSSLSNAK

$0.09 \% \quad 10.2 \%$ KPVIVFVPSR

$0.09 \% \quad 10.2 \%$ MTQNPNYYNLQGISHR

$0.09 \% \quad 10.2 \%$ TNLLLQAHLSR

$0.09 \% \quad 10.2 \%$ SNSLISIKR

$0.01 \% \quad 5.3 \%$ SAVEDSTLSR

$0.01 \% \quad 5.3 \%$ VDYQQVFTR

$10.02 \% \quad 21.4 \%$ LVGATATSSPPPKAR

$10 \quad 0.02 \% \quad 21.4 \%$ LLQQSGAQQFR

$10 \quad 0.02 \% \quad 21.4 \%$ KNNIPANFTR

$10 \quad 0.02 \% \quad 21.4 \%$ GVPLQFDINSVGK

$10 \quad 0.02 \% \quad 21.4 \%$ FGILKEQR

$10 \quad 0.02 \% \quad 21.4 \%$ ATLTYNKGGSR

$3 \quad 0.01 \% \quad 24.4 \%$ TITLEVEPSDTIENVK

$0.01 \% \quad 24.4 \%$ IQDKEGIPPDQQR

$0.01 \% \quad 24.4 \%$ TLSDYNIQK

$0.01 \% \quad 3.1 \%$ IGDSSQGDNNLQK

$0.01 \% \quad 3.1 \%$ NLVNDDDAIVAASK

$0.01 \% \quad 4.4 \% \quad$ ASEETLLGISK

$0.01 \% \quad 4.4 \%$ INVQNNVDLGQPVK

$0.01 \% \quad 2.1 \%$ SNCVLEAFGNAK

$0.01 \% \quad 2.1 \%$ VIVQQPGER

$0.01 \% \quad 3.7 \%$ NQSIIVSGESGAGK

$0.01 \% \quad 3.7 \%$ ACGVLETIR

$0.01 \% \quad 3.7 \%$ AGQVAYLEK

$0.01 \% \quad 3.7 \% \quad$ VLSLQEEIAK

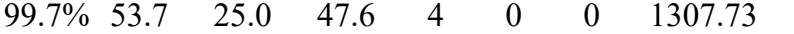

1238.58

1352.78

1132.51

$\begin{array}{llll}9.7 \% & 35.8 & 25.0 & 34.7\end{array}$

$\begin{array}{lll}25.0 & 32.0\end{array}$

$\begin{array}{llll}99.7 \% & 52.4 & 25.0 & 50.4\end{array}$

$\begin{array}{llll}99.7 \% & 54.9 & 25.0 & 54.9\end{array}$

$\begin{array}{llll}99.7 \% & 57.3 & 25.0 & 46.4\end{array}$

$\begin{array}{lllll}99.3 \% & 23.9 & 25.0 & 20.2 & 2\end{array}$

$99.7 \% \quad 57.7 \quad 25.0 \quad 52.6$

$\begin{array}{llll}99.7 \% & 34.3 & 25.0 & 34.3\end{array}$

$\begin{array}{lllll}99.7 \% & 40.3 & 25.0 & 25.6 & 2\end{array}$

$\begin{array}{lllll}99.7 \% & 32.4 & 25.0 & 32.4 & 2\end{array}$

$\begin{array}{lllll}99.7 \% & 55.4 & 25.0 & 49.1 & 2\end{array}$

$\begin{array}{llll}96.6 \% & 19.4 & 25.0 & 15.2\end{array}$

$99.7 \% \quad 61.0 \quad 25.0 \quad 56.2$

$\begin{array}{llll}99.3 \% & 21.2 & 25.0 & 21.2\end{array}$

$96.5 \% \quad 25.1 \quad 25.0 \quad 12.4$

$\begin{array}{llll}99.7 \% & 42.7 & 25.0 & 32.4\end{array}$

$99.7 \% \quad 40.4 \quad 25.0 \quad 38.5$

$99.7 \% \quad 39.8 \quad 25.0 \quad 24.6$

$\begin{array}{llll}99.7 \% & 70.6 & 25.0 & 70.2\end{array}$

$\begin{array}{llll}99.7 \% & 75.8 & 25.0 & 72.5\end{array}$

$\begin{array}{llll}99.7 \% & 69.8 & 25.0 & 67.3\end{array}$

$\begin{array}{llll}99.3 \% & 22.0 & 25.0 & 22.0\end{array}$

$\begin{array}{llll}99.7 \% & 60.5 & 25.0 & 60.5\end{array}$

$\begin{array}{lllll}99.7 \% & 43.5 & 25.0 & 21.7 & 2\end{array}$

$\begin{array}{llll}99.7 \% & 30.0 & 25.0 & 25.2\end{array}$

$\begin{array}{llll}99.7 \% & 40.4 & 25.0 & 40.0\end{array}$

$\begin{array}{llll}99.4 \% & 23.7 & 25.0 & 23.7\end{array}$

$\begin{array}{llll}99.7 \% & 52.3 & 25.0 & 36.1\end{array}$

$\begin{array}{llll}95.0 \% & 21.6 & 25.0 & 9.7\end{array}$

$\begin{array}{llll}99.6 \% & 28.3 & 25.0 & 27.4\end{array}$

$99.0 \% \quad 45.8 \quad 25.0 \quad 33.1$

$\begin{array}{lllll}99.7 \% & 47.7 & 25.0 & 30.8 & 2\end{array}$

$\begin{array}{llll}96.1 \% & 17.5 & 25.0 & 16.6\end{array}$

$99.7 \% \quad 31.4 \quad 25.0 \quad 28.0$

$\begin{array}{llll}96.5 \% & 20.0 & 25.0 & 13.6\end{array}$

$97.6 \% \quad 20.8 \quad 25.0 \quad 15.6$

$\begin{array}{llll}99.7 \% & 43.5 & 25.0 & 40.6\end{array}$

$\begin{array}{llll}99.7 \% & 50.7 & 25.0 & 46.3\end{array}$

$\begin{array}{llll}98.5 \% & 20.6 & 25.0 & 20.6\end{array}$

$\begin{array}{lllll}99.7 \% & 66.4 & 25.0 & 60.8 & 2\end{array}$

$99.2 \% \quad 21.6 \quad 25.0 \quad 21.2$

$\begin{array}{llll}99.7 \% & 33.5 & 25.0 & 33.5\end{array}$

$\begin{array}{lllll}99.7 \% & 32.9 & 25.0 & 18.1 & 2\end{array}$

$99.7 \% \quad 40.6 \quad 25.0 \quad 28.5$

$95.0 \% \quad 22.4 \quad 25.0 \quad 17.8$

1200.63
1185.58

1157.68

1029.58

1117.53

1297.65

1234.57

1198.67

1048.53

1008.50

1221.62

1622.90

989.48

1208.54

1193.63

1020.51

1375.77

1189.68

1141.71

1951.91

1265.73

1017.61

1064.52

1155.58

1452.82

1275.68

1174.63

1373.74

990.57

1167.61

1787.93

1523.78

1081.55

1375.65

1444.73

1147.62

1537.83

1309.62

1025.57

1346.69

1018.54

978.53

1129.65 
Unconventional myosin-Va GN=MYO5A MYO5A_HUMAN $215.41 \quad 100.0 \%$. Unconventional myosin-Va GN=MYO5A MYO5A_HUMAN $215.41 \quad 100.0 \%$ Unconventional myosin-Vb GN=MYO5B MYO5B_HUMAN $213.68 \quad 100.0 \%$ Unconventional myosin- $\mathrm{Vb}$ GN=MYO5B MYO5B_HUMAN $213.68 \quad 100.0 \%$ Unconventional myosin-Vb GN=MYO5B MYO5B_HUMAN $213.68 \quad 100.0 \%$ Unconventional myosin-Vb GN=MYO5B MYO5B_HUMAN $213.68 \quad 100.0 \%$ Unconventional myosin-Vb GN=MYO5B MYO5B_HUMAN $213.68 \quad 100.0 \%$ Unconventional myosin-Vb GN=MYO5B MYO5B_HUMAN $213.68 \quad 100.0 \%$ Unconventional myosin-Vb GN=MYO5B MYO5B HUMAN $213.68 \quad 100.0 \%$ Unconventional myosin- $\mathrm{Vb}$ GN=MYO5B MYO5B_HUMAN $213.68 \quad 100.0 \%$ Unconventional myosin-Vb GN=MYO5B MYO5B_HUMAN $213.68 \quad 100.0 \%$ Unconventional myosin-Vb GN=MYO5B MYO5B_HUMAN $213.68 \quad 100.0 \%$ Unconventional myosin-Vb GN=MYO5B MYO5B_HUMAN $213.68 \quad 100.0 \%$ Unconventional myosin-Vb GN=MYO5B MYO5B_HUMAN $213.68 \quad 100.0 \%$ Unconventional myosin- $\mathrm{Vb}$ GN=MYO5B MYO5B_HUMAN $213.68 \quad 100.0 \%$ Unconventional myosin-Vb GN=MYO5B MYO5B_HUMAN $213.68 \quad 100.0 \%$ Unconventional myosin-Vb GN=MYO5B MYO5B HUMAN $213.68 \quad 100.0 \%$ UPF0488 protein C80133 GN=C80rf3 CH033_HUMAN 24.99 CH033_HUMAN $24.99 \quad 100.0 \%$ UPF0488 protein C8orf33 GN=C8orf33 CH033 HUMAN $24.99 \quad 100.0 \%$ Uridine-cytidine kinase-like 1 GN=UCKL1 UCKL1_HUMAN $61.14 \quad 100.0 \%$ Uridine-cytidine kinase-like $1 \mathrm{GN}=\mathrm{UCKL} 1$ UCKL1_HUMAN $61.14 \quad 100.0 \%$ Uridine-cytidine kinase-like $1 \mathrm{GN}=\mathrm{UCKL} 1$ UCKL1_HUMAN $61.14 \quad 100.0 \%$ Vacuolar protein sorting-associated protein 35 GN=VPS35 VPS35_HUMAN $91.71 \quad 100.0 \%$ Vacuolar protein sorting-associated protein $35 \mathrm{GN}=\mathrm{VPS} 35 \mathrm{VPS} 35$ HUMAN $91.71 \quad 100.0 \%$ Vacuolar protein sorting-associated protein $35 \mathrm{GN}=\mathrm{VPS} 35$ VPS35_HUMAN $91.71 \quad 100.0 \%$ Vacuolar protein sorting-associated protein $35 \mathrm{GN}=\mathrm{VPS} 35$ VPS35_HUMAN $91.71 \quad 100.0 \%$ Verolar protein sorting-associated protein 51 homolog GN=VPS51 VPS51_HUMAN $86.04 \quad 100.0 \%$ Vacuolar protein sorting-associated protein 51 homolog GN=VPS51 VPS51_HUMAN $86.04 \quad 100.0 \%$ Vacuolar protein sorting-associated protein 52 homolog GN=VPS52 VPS52 HUMAN $82.22 \quad 100.0 \%$ Vocular protein sorting-associated protein 52 homolog GN=VPS52 VPS52_HUMAN $82.22 \quad 100.0 \%$ Very-long-chain (3R)-3-hydroxyacyl-CoA dehydratase 3 GN=HACD3 HACD3_HUMAN $43.16 \quad 100.0 \%$ Very-long Very-long-chain (3R)-3-hydroxyacyl-CoA dehydratase $3 \mathrm{GN}=\mathrm{HACD} 3 \quad \mathrm{HACD} 3$ HUMAN $43.16 \quad 100.0 \%$ Very-long-chain 3-oxoacyl-CoA reductase GN=HSD17B12 DHB12_HUMAN $34.33 \quad 100.0 \%$ GN=HSD17B 12 DHB12 HUMAN 34.33

Vesicle-fusing ATPase GN=NSF Vesicle-fusing ATPase $\mathrm{GN}=\mathrm{NSF}$ Vesicle-fusing ATPase GN=NSF Vesicle-fusing ATPase $\mathrm{GN}=\mathrm{NSH}$ Vesicle-fusing ATPase $\mathrm{GN}=\mathrm{NSF}$ Vesicle-fusing ATPase GN=NSF Vimentin GN=VIM

Vimentin GN=VIM

Vimentin $\mathrm{GN}=\mathrm{VIM}$

Vimentin GN=VIM

Vimentin GN=VIM

NSF HUMAN $82.60 \quad 100.0 \%$

NSF_HUMAN $82.60 \quad 100.0 \%$

NSF_HUMAN $82.60 \quad 100.0 \%$

NSF HUMAN $82.60 \quad 100.0 \%$

NSF_HUMAN $82.60 \quad 100.0 \%$

VIME HUMAN $53.65 \quad 100.0 \%$

VIME HUMAN $53.65 \quad 100.0 \%$

VIME_HUMAN $53.65 \quad 100.0 \%$

VIME HUMAN $53.65 \quad 100.0 \%$

VIME_HUMAN $53.65 \quad 100.0 \%$
$0.01 \% \quad 3.7 \%$ SAPEVTAPGAPAYR

$0.01 \% \quad 3.7 \%$ HADYLNDDQKVR

$0.06 \% \quad 8.6 \%$ DEKNQSIIVSGESGA

$99.3 \% \quad 25.2$

$99.3 \% \quad 22.4$

$0.06 \% \quad 8.6 \%$ NQSIIVSGESGAGK

\begin{tabular}{lllll}
$99.7 \%$ & 47.4 & 25.0 & 22.4 \\
\hline
\end{tabular}

$99.7 \% \quad 58.8$

$0.06 \% \quad 8.6 \%$ YIQIGFDKR

$0.06 \% \quad 8.6 \%$ YHIIGANMR

$0.06 \% \quad 8.6 \%$ KLVTTSETYVK

$0.06 \% \quad 8.6 \%$ TMSLQQVINAR

$0.06 \% \quad 8.6 \%$ ACGVLETIR

$0.06 \% \quad 8.6 \%$ AGQVAYLEK

$0.06 \% \quad 8.6 \%$ LNVGMENKVVQLQR

$0.06 \% \quad 8.6 \%$ AAMDMTVFLK

$0.06 \% \quad 8.6 \%$ VRELEQER

$0.06 \% \quad 8.6 \%$ TQIVSADQRR

$0.06 \% \quad 8.6 \%$ AQDLEAAQALAQSER

$0.06 \% \quad 8.6 \%$ TIQAQLQER

$0.01 \% \quad 13.1 \%$ AHPLGDEGGTASK

$0.01 \% \quad 13.1 \%$ AHPLGDEGGTASKK

$0.01 \% \quad 13.1 \%$ AAAYSAQVQPVDGATR

$0.01 \% \quad 5.8 \%$ EAFAIGLGGGSASGK

$0.01 \% \quad 5.8 \%$ LADIVVPR

$0.01 \% \quad 5.8 \%$ QITGVSILR

$0.01 \% \quad 5.5 \%$ ILVGTNLVR

$0.01 \% \quad 5.5 \% \quad$ LSQLEGVNVER

$0.01 \% \quad 5.5 \%$ SEDPDQQYLILNTAR

$0.01 \% \quad 5.5 \%$ LLKKPDQGR

$0.01 \% \quad 2.9 \% \quad$ ISATLQDRHER

$0.01 \% \quad 2.9 \% \quad$ AIQDDCQVITAR

$0.01 \% \quad 2.4 \%$ NTIFTLGTR

$0.01 \% \quad 2.4 \%$ VLSQPQLR

$0.01 \% \quad 6.4 \% \quad$ QVNITVQK

$0.01 \% \quad 6.4 \%$ LESEGSPETLTNLR

$0.01 \% \quad 6.4 \%$ LESEGSPETLTNLRK

$0.01 \% \quad 8.0 \% \quad$ KPTLDKPSPETFVK

$0.01 \% \quad 8.0 \%$ SAIKTVGLQSR

$0.04 \% \quad 7.5 \%$ GILLYGPPGCGK

$0.04 \% \quad 7.5 \%$ VLDDGELLVQQTK
$0.04 \% \quad 7.5 \%$ IAEESNFPFIK

$0.04 \% \quad 7.5 \%$ LLDYVPIGPR

$0.04 \% \quad 7.5 \%$ KLLIIGTTSR

$0.04 \% \quad 7.5 \%$ LLIIGTTSR

$101 \quad 0.21 \% \quad 32.2 \%$ RMFGGPGTASRPSSSR

$101 \quad 0.21 \% \quad 32.2 \%$ MFGGPGTASRPSSSR

$101 \quad 0.21 \% \quad 32.2 \%$ SYVTTSTR

$101 \quad 0.21 \% \quad 32.2 \%$ SYVTTSTRTYSLGSALRPSTSR

$101 \quad 0.21 \% \quad 32.2 \%$ TYSLGSALRPSTSR
$97.3 \% \quad 16.8$

$99.7 \% \quad 57.0$

$99.7 \% \quad 51.6$

$99.7 \% \quad 32.9$

$99.7 \% \quad 40.6$

$99.7 \% \quad 33.1$

$97.1 \% \quad 30.5$

$96.3 \% \quad 15.2$

$97.3 \% \quad 21.7$

$99.7 \% \quad 82.3$

$98.0 \% \quad 20.9$

$96.1 \% \quad 20.3$

$99.4 \% \quad 23.6$

$99.7 \% \quad 68.8$

$99.7 \% \quad 67.3$

$99.0 \% \quad 49.2$

$96.0 \% 20.1$

$99.7 \% \quad 48.7$

$99.7 \% \quad 55.2$

$99.7 \% \quad 30.5$

$\begin{array}{lll}97.0 \% & 20.7\end{array}$

$98.9 \% 23.8$

$99.7 \% \quad 61.6$

$99.4 \% 23.1$

$98.9 \% \quad 22.9$

$95.3 \% \quad 22.0$

$99.7 \% \quad 64.2$

$95.4 \% \quad 16.1$

$97.0 \% \quad 18.7$

$99.7 \% \quad 51.1$

$99.6 \% \quad 29.0$

$99.7 \% \quad 65.6$

$99.7 \% \quad 32.9$

$99.7 \% \quad 32.0$

$99.7 \% \quad 42.6$

$99.4 \% 24.4$

$98.8 \% 20.5$

$99.7 \% \quad 32.8$

$99.0 \% 33.6$

$99.7 \% \quad 26.8$
1718.86

1346.69

1802.84

1139.62

1090.55

1268.71

1260.67

1018.54

978.53

1643.89

1142.56

1058.56

1173.63

1600.79

1086.59

1239.60

1367.69

1604.80

1321.67

882.54

986.60

984.62

1243.66

1762.86

1054.64

1325.69

1389.68

1022.56

940.56

929.54

1545.78

1673.87

1586.88

1159.68

1231.65

1457.78

1294.67

1142.66

1101.70

973.60

1650.81

1510.71

914.46

2391.23 1495.79
$19 \quad 1530$

$\begin{array}{ll}153 & 169 \\ 156 & 169\end{array}$

$\begin{array}{ll}56 & 169 \\ 79 & 195\end{array}$

$223 \quad 231$

$232 \quad 240$

$380 \quad 390$

491

$680 \quad 688$

758

11391148

$1153 \quad 1160$

$266 \quad 1275$

$1434 \quad 1448$

$796 \quad 1804$

$57 \quad 69$

$57 \quad 70$

$183 \quad 198$

$97 \quad 111$

$274 \quad 281$

$393 \quad 401$

237

$500 \quad 514$

$660 \quad 668$

$153 \quad 163$

$221 \quad 232$

$691 \quad 698$

$133 \quad 146$

$133 \quad 147$

$258 \quad 268$

$255 \quad 266$

$517 \quad 529$

$556 \quad 566$

$608 \quad 617$

$639 \quad 648$

$640 \quad 648$

$13 \quad 28$

$14 \quad 28$

$29 \quad 36$

$37 \quad 50$ 
Vimentin GN=VIM

Vimentin $\mathrm{GN}=\mathrm{VIM}$

Vimentin GN=VIM

Vimentin GN=VIM

Vimentin GN=VIM

Vimentin GN=VIM

Vimentin GN=VIM

Vimentin $\mathrm{GN}=\mathrm{VIM}$

Vimentin GN=VIM

Vimentin GN=VIM
Vimentin GN=VIM

Vimentin GN=VIM

Vimentin GN=VIM

VIME HUMAN $53.65 \quad 100.0 \% \quad 18$ VIME_HUMAN $53.65 \quad 100.0 \% \quad 18$ VIME_HUMAN $53.65 \quad 100.0 \% \quad 18$ VIME HUMAN $53.65 \quad 100.0 \% \quad 18$ VIME_HUMAN $53.65 \quad 100.0 \% \quad 18$ VIME_HUMAN $53.65 \quad 100.0 \% \quad 18$ VIME HUMAN $53.65 \quad 100.0 \% \quad 18$ VIME_HUMAN $53.65 \quad 100.0 \% \quad 18$ VIME HUMAN $53.65 \quad 100.0 \% \quad 18$ VIME_HUMAN $53.65 \quad 100.0 \% \quad 18$ VIME_HUMAN $53.65 \quad 100.0 \% \quad 18$ VIME HUMAN $53.65 \quad 100.0 \% \quad 18$ VIME_HUMAN $53.65 \quad 100.0 \% \quad 18$ VDAC1_HUMAN $30.77 \quad 100.0 \%$ Voltage-dependent anion-selective channel protein $1 \mathrm{GN}=\mathrm{VDAC1}$ VDAC1_HUMAN $30.77 \quad 100.0 \%$ Voltage-dependent anion-selective channel protein $1 \mathrm{GN}=\mathrm{VDACl}$ VDAC1_HUMAN $30.77 \quad 100.0 \%$ Voltage-dependent anion-selective channel protein $1 \mathrm{GN}=\mathrm{VDAC1}$ VDAC1_HUMAN 30.77 Voltage-dependent anion-selective channel protein $1 \mathrm{GN}=\mathrm{VDAC1}$ VDAC1_HUMAN 30.77 Voltage-dependent anion-selective channel protein $2 \mathrm{GN}=\mathrm{VDAC2}$ VDAC2_HUMAN 31.57 Voltage-dependent anion-selective channel protein $2 \mathrm{GN}=\mathrm{VDAC2}$ VDAC2_HUMAN 31.57 Voltage-dependent anion-selective channel protein $2 \mathrm{GN}=\mathrm{VDAC2}$ VDAC2_HUMAN $31.5^{\circ}$ Voltage-dependent anion-selective channel protein $2 \mathrm{GN}=\mathrm{VDAC2}$ VDAC2 $\mathrm{HUMAN} 31.5^{\circ}$ Voltage-dependent anion-selective channel protein 2 GN=VDAC2 VDAC2_HUMAN 31.57 Voltage-dependent anion-selective channel protein $3 \mathrm{GN}=\mathrm{VDAC} 3$ VDAC3_HUMAN 30.66 Voltage-dependent anion-selective channel protein $3 \mathrm{GN}=\mathrm{VDAC} 3$ VDAC3_HUMAN 30.66 Voltage-dependent anion-selective channel protein $3 \mathrm{GN}=\mathrm{VDAC} 3$ VDAC3_HUMAN 30.66 Voltage-dependent anion-selective channel protein $3 \mathrm{GN}=\mathrm{VDAC} 3$ VDAC3_HUMAN 30.66 Voltage-dependent anion-selective channel protein 3 GN=VDAC3 VDAC3 HUMAN 30.66 Voltage-dependent anion-selective channel protein $3 \mathrm{GN}=\mathrm{VDAC} 3$ VDAC3_HUMAN 30.66 Voltage-dependent anion-selective channel protein $3 \mathrm{GN}=\mathrm{VDAC} 3$ VDAC3 HUMAN 30.66 Voltage-dependent anion-selective channel protein 3 GN=VDAC3 VDAC3_HUMAN 30.66 V-type proton ATPase subunit d 1 GN=ATP6V0D1 VA0D1_HUMAN 40.3? V-type proton ATPase subunit d 1 GN=ATP6V0D1 VA0D1 HUMAN 40.3 V-type proton ATPase subunit d 1 GN=ATP6V0D1 VA0D1_HUMAN 40.3? WD repeat-containing protein $1 \mathrm{GN}=$ WDR1 WDR1_HUMAN 66.19 WD repeat-containing protein $1 \mathrm{GN}=$ WDR1 WDR1_HUMAN 66.19 WD repeat-containing protein 1 GN=WDR1 WDR1_HUMAN 66.19 WD repeat-containing protein 5 GN=WDR5 WDR5 HUMAN 36.59 WD repeat-containing protein 5 GN=WDR5 WDR5_HUMAN 36.59 WD repeat-containing protein 5 GN=WDR5 WDR5_HUMAN 36.59 WD repeat-containing protein $5 \mathrm{GN}=$ WDR5 WDR5_HUMAN 36.59 WD repeat-containing protein $82 \mathrm{GN}=$ WDR82 WDR82_HUMAN 35.08 WD repeat-containing protein $82 \mathrm{GN}=$ WDR82 WDR82 HUMAN 35.08 WD repeat-containing protein $82 \mathrm{GN}=$ WDR82 WDR82_HUMAN $35.08 \quad 100.0 \%$ X-ray repair cross-complementing protein $5 \mathrm{GN}=\mathrm{XRCC} 5$ XRCC5_HUMAN $82.71 \quad 100.0 \%$ X-ray repair cross-complementing protein $5 \mathrm{GN}=\mathrm{XRCC} 5 \mathrm{XRCC} 5$ HUMAN $82.71 \quad 100.0 \%$ X-ray repair cross-complementing protein $5 \mathrm{GN}=\mathrm{XRCC} 5 \mathrm{XRCC} 5$ _HUMAN $82.71 \quad 100.0 \%$

$100.0 \%$

$100.0 \%$

$100.0 \%$

$100.0 \%$

$100.0 \%$

$100.0 \%$

$100.0 \%$

$100.0 \%$

$100.0 \%$

$100.0 \%$

$100.0 \%$

$00.0 \%$

$00.0 \%$

$100.0 \%$

$100.0 \%$

$100.0 \%$

$100.0 \%$

$100.0 \%$

$100.0 \%$
$25 \quad 101 \quad 0.21 \% \quad 32.2 \%$ SLYASSPGGVYATR

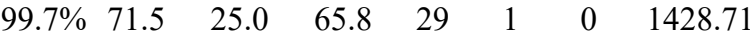
1928.98 970.58

1287.67

$101 \quad 0.21 \% \quad 32.2 \%$ QVDQLTNDKAR

$101 \quad 0.21 \% \quad 32.2 \%$ QDVDNASLAR

$\begin{array}{llll}101 & 0.21 \% & 32.2 \% & \text { DVRQQYESVAAK }\end{array}$

$101 \quad 0.21 \% \quad 32.2 \%$ QQYESVAAK

$\begin{array}{llll}101 & 0.21 \% & 32.2 \% & \text { FADLSEAANR }\end{array}$

$101 \quad 0.21 \% \quad 32.2 \%$ FADLSEAANRNNDALR

$101 \quad 0.21 \% \quad 32.2 \%$ KLLEGEESR

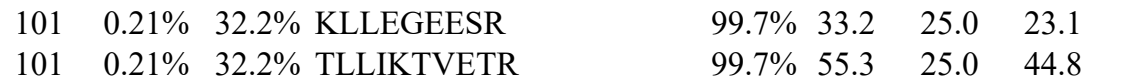

$\begin{array}{lllll}99.4 \% & 24.6 & 25.0 & 24.1 & 2 \\ 99.1 \% & 26.6 & 25.0 & 15.8 & 3\end{array}$

$99.5 \% \quad 30.6 \quad 25.0 \quad 17.9$

$99.3 \% \quad 24.4 \quad 25.0 \quad 20.8$

$99.3 \% \quad 24.1 \quad 25.0 \quad 19.0$

$99.7 \% \quad 37.5 \quad 25.0 \quad 28.4$

$99.7 \% \quad 57.3 \quad 25.0 \quad 43.2$

$101 \quad 0.21 \% \quad 32.2 \%$ TVETRDGQVINETSQHHDDLE $99.7 \% \quad 54.5 \quad 25.0 \quad 54.5$

$101 \quad 0.21 \% \quad 32.2 \%$ DGQVINETSQHHDDLE

$5 \quad 0.01 \% \quad 22.6 \%$ VTGSLETKYR

$0.01 \% \quad 22.6 \%$ LTFDSSFSPNTGKK

$99.7 \%$. 36.7

$99.7 \% \quad 47.0$

$\begin{array}{lllll}0.01 \% & 22.6 \% & \text { KLETAVNLAWTAGNSNTR } & 99.7 \% & 33.5\end{array}$

$0.01 \% \quad 22.6 \%$ YQIDPDACFSAK

$0.01 \% \quad 22.6 \%$ LTLSALLDGK

$6 \quad 0.03 \% \quad 15.0 \%$ LTFDTTFSPNTGK

$6 \quad 0.03 \% \quad 15.0 \%$ LTFDTTFSPNTGKK

$0.03 \% \quad 15.0 \%$ NNFAVGYR

$6 \quad 0.03 \% \quad 15.0 \%$ YQLDPTASISAK

$0.03 \% \quad 15.0 \%$ LTLSALVDGK

$25.0 \quad 33.5$

$25.0 \quad 52.6$

$\begin{array}{cccc}98.2 \% & 30.7 & 25.0 & 0.0 \\ 99.7 \% & 59.6 & 25.0 & 55.7\end{array}$

$99.7 \% \quad 45.4 \quad 25.0 \quad 43.3$

$\begin{array}{llll}99.0 \% & 49.2 & 25.0 & 45.1\end{array}$

$99.7 \% \quad 62.3 \quad 25.0 \quad 54.2$

$\begin{array}{llll}99.7 \% & 51.4 & 25.0 & 45.8\end{array}$ $0.05 \% \quad 33.6 \%$ SCSGVEFSTSGHAYTDTGK

$0.05 \% 33.6 \%$ ASGNLETKYK

$0.05 \% \quad 33.6 \%$ VCNYGLTFTQK

$0.05 \% 33.6 \%$ SKLSQNNFALGYK

$0.05 \% \quad 33.6 \%$ LSQNNFALGYK

$99.7 \% \quad 67.3$

$99.3 \% \quad 22.8$

$99.7 \% \quad 51.7$

$99.7 \% \quad 62.3$

$99.7 \% \quad 60.5$

$99.7 \% \quad 39.7$

$0.05 \% \quad 33.6 \%$ YMLDCRTSLSAK

$99.7 \% \quad 71.2$

$98.2 \% \quad 30.7$

$99.7 \% \quad 42.1$

$99.1 \% \quad 23.4$

$99.7 \% \quad 34.6$

$99.7 \% \quad 32.9$

$99.6 \% \quad 28.5$

$97.8 \% \quad 22.2$

$99.0 \% \quad 29.6$ $0.01 \% \quad 15.9 \%$ DGSLIVSSSYDGLCR $0.01 \% \quad 15.9 \%$ TLIDDDNPPVSFVK $0.01 \% \quad 9.9 \%$ MKLTDSVLR $0.01 \% \quad 9.9 \% \quad$ YLSLHDNKYIR $0.01 \% \quad 9.9 \%$ SFDKGPFATFK $0.06 \% \quad 13.5 \%$ KVITMFVQR $0.06 \% \quad 13.5 \%$ VITMFVQR $0.06 \% \quad 13.5 \%$ HIEIFTDLSSR \begin{tabular}{cc}
51 & 64 \\
51 & 69 \\
70 & 78 \\
160 & 170 \\
208 & 217 \\
271 & 282 \\
274 & 282 \\
295 & 304 \\
295 & 310 \\
402 & 410 \\
441 & 450 \\
446 & 466 \\
451 & 466 \\
54 & 63 \\
97 & 110 \\
201 & 218 \\
225 & 236 \\
257 & 266 \\
108 & 120 \\
108 & 121 \\
178 & 185 \\
236 & 247 \\
268 & 277 \\
35 & 53 \\
54 & 63 \\
64 & 74 \\
162 & 174 \\
164 & 174 \\
225 & 236 \\
237 & 256 \\
257 & 266 \\
247 & 257 \\
266 & 275 \\
276 & 288 \\
8 & 17 \\
96 & 104 \\
36 & 101 \\
117 & 126 \\
39 & 46 \\
166 & 181 \\
182 & 196 \\
208 & 221 \\
1 & 9 \\
& 141 \\
\hline 17 & \\
136
\end{tabular}

Page 88 of Table S-1-3 
$\begin{array}{llllllll}\text { X-ray repair cross-complementing protein } 5 \text { GN=XRCC5 XRCC5_HUMAN } & 82.71 & 100.0 \% & 12 & 14 & 27 & 0.06 \% & 13.5 \% \\ \text { GITEQQKEGLEIVK }\end{array}$ X-ray repair cross-complementing protein $5 \mathrm{GN}=\mathrm{XRCC} 5$ XRCC5_HUMAN $82.71 \quad 100.0 \% \quad 12$ $\begin{array}{llll}X \text {-ray repair cross-complementing protein } 5 \text { GN=XRCC5 XRCC5_HUMAN } 82.71 \quad 100.0 \% & 12\end{array}$ X-ray repair cross-complementing protein $5 \mathrm{GN}=\mathrm{XRCC} 5$ XRCC5_HUMAN $82.71 \quad 100.0 \% \quad 12$

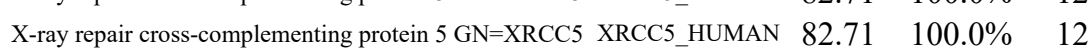

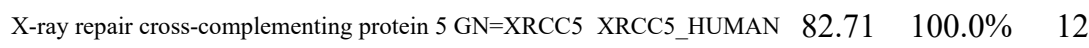
$\begin{array}{lllll}X \text { X-ray repair cross-complementing protein } 5 \mathrm{GN}=\mathrm{XRCC} 5 & \mathrm{XRCC} 5 \text { HUMAN } & 82.71 & 100.0 \% & 12\end{array}$ $\begin{array}{lllll}X \text { X-ray repair cross-complementing protein } 5 \mathrm{GN}=\mathrm{XRCC} 5 & \mathrm{XRCC} 5 \text { HUMAN } & 82.71 & 100.0 \% & 12\end{array}$ X-ray repair cross-complementing protein $5 \mathrm{GN}=\mathrm{XRCC} 5 \mathrm{XRCC} 5$ HUMAN $82.71 \quad 100.0 \%$ X-ray repair cross-complementing protein $6 \mathrm{GN}=\mathrm{XRCC6}$ XRCC6_HUMAN $69.85 \quad 100.0 \%$ X-ray repair cross-complementing protein $6 \mathrm{GN}=\mathrm{XRCC6}$ XRCC6_HUMAN $69.85 \quad 100.0 \%$ X-ray repair cross-complementing protein $6 \mathrm{GN}=\mathrm{XRCC} 6 \mathrm{XRCC} 6$ HUMAN $69.85 \quad 100.0 \%$ X-ray repair cross-complementing protein $6 \mathrm{GN}=\mathrm{XRCC} 6$ XRCC6_HUMAN $69.85 \quad 100.0 \%$ X-ray repair cross-complementing protein $6 \mathrm{GN}=\mathrm{XRCC} 6 \mathrm{XRCC6}$ _HUMAN $69.85 \quad 100.0 \%$ X-ray repair cross-complementing protein $6 \mathrm{GN}=\mathrm{XRCC} 6 \mathrm{XRCC6}$ _HUMAN $69.85 \quad 100.0 \%$ YTH domain-containing protein $1 \mathrm{GN}=$ YTHDC1 YTDC1_HUMAN $84.70 \quad 100.0 \%$ YTH domain-containing protein $1 \mathrm{GN}=$ YTHDC1 1 YTDC1 HUMAN $84.70 \quad 100.0 \%$ YTH domain-containing protein $1 \mathrm{GN}=$ YTHDC1 YTDC1_HUMAN $84.70 \quad 100.0 \%$ Zinc finger CCCH domain-containing protein $18 \mathrm{GN}=\mathrm{ZC} 3 \mathrm{H} 18$ ZCH18_HUMAN $106.38 \quad 100.0 \%$ Zinc finger CCCH domain-containing protein $18 \mathrm{GN}=\mathrm{ZC} 3 \mathrm{H} 18 \mathrm{ZCH} 18$ HUMAN $106.38 \quad 100.0 \%$ Zinc finger CCCH domain-containing protein $18 \mathrm{GN}=\mathrm{ZC} 3 \mathrm{H} 18 \mathrm{ZCH} 18$ _HUMAN $106.38 \quad 100.0 \%$ Zinc finger CCCH-type antiviral protein $1 \mathrm{GN}=\mathrm{ZC} 3 \mathrm{HAV} 1 \mathrm{ZCCHV} \_H U M A N \quad 101.43 \quad 100.0 \%$ Zinc finger CCCH-type antiviral protein $1 \mathrm{GN}=\mathrm{ZC} 3 \mathrm{HAV} 1 \mathrm{ZCCHV}$ HUMAN $101.43 \quad 100.0 \%$

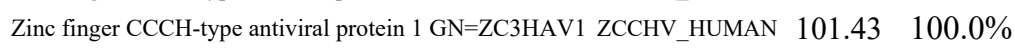
Zinc finger CCCH-type antiviral protein $1 \mathrm{GN}=\mathrm{ZC} 3 \mathrm{HAV} 1 \mathrm{ZCCHV}$ HUMAN $101.43 \quad 100.0 \%$ Zinc finger protein $346 \mathrm{GN}=\mathrm{ZNF} 346$ Zinc finger protein $346 \mathrm{GN}=\mathrm{ZNF} 346$ Zinc finger protein $512 \mathrm{GN}=\mathrm{ZNF} 512$ Zinc finger protein $512 \mathrm{GN}=\mathrm{ZNF} 512$ Zinc finger protein $512 \mathrm{GN}=\mathrm{ZNF} 512$ Zinc finger protein $768 \mathrm{GN}=\mathrm{ZNF} 768$ Zinc finger protein $768 \mathrm{GN}=\mathrm{ZNF} 768$ Zinc finger protein $768 \mathrm{GN}=\mathrm{ZNF} 768$ Zinc finger protein $768 \mathrm{GN}=\mathrm{ZNF} 768$ ZN346_HUMAN $32.93 \quad 100.0 \%$ ZN346_HUMAN $32.93 \quad 100.0 \%$ ZN512 HUMAN $64.68 \quad 100.0 \%$ ZN512_HUMAN $64.68 \quad 100.0 \%$ ZN512 HUMAN $64.68 \quad 100.0 \%$ ZN768_HUMAN $60.23 \quad 100.0 \%$ ZN768_HUMAN $60.23 \quad 100.0 \%$ ZN768_HUMAN $60.23 \quad 100.0 \%$ ZN768_HUMAN $60.23 \quad 100.0 \%$ Zinc finger RNA-binding protein GN=ZFR ZFR_HUMAN $117.01 \quad 100.0 \%$ Zinc finger RNA-binding protein GN=ZFR ZFR_HUMAN $117.01 \quad 100.0 \%$

\begin{tabular}{ccc}
1571.86 & 196 & 209 \\
1291.74 & 261 & 271 \\
1112.56 & 316 & 325 \\
1117.52 & 339 & 347 \\
1099.56 & 355 & 363 \\
1086.59 & 490 & 497 \\
1013.64 & 526 & 534 \\
1272.79 & 533 & 543 \\
1031.61 & 535 & 543 \\
1207.66 & 36 & 46 \\
1631.88 & 116 & 129 \\
1918.86 & 166 & 182 \\
1295.82 & 280 & 290 \\
1807.96 & 302 & 318 \\
1348.67 & 389 & 399 \\
1743.97 & 68 & 83 \\
1003.56 & 306 & 314 \\
1212.60 & 362 & 372 \\
1110.47 & 576 & 585 \\
1919.00 & 652 & 669 \\
1707.74 & 683 & 701 \\
1401.69 & 283 & 295 \\
1449.69 & 315 & 329 \\
1159.65 & 375 & 385 \\
1546.81 & 386 & 400 \\
1301.67 & 225 & 237 \\
1403.73 & 270 & 282 \\
1758.95 & 5 & 21 \\
1695.90 & 83 & 100 \\
1169.62 & 367 & 376 \\
1142.58 & 325 & 334 \\
1128.57 & 353 & 362 \\
1285.70 & 438 & 449 \\
1123.57 & 521 & 530 \\
1858.87 & 192 & 208 \\
1682.82 & 468 & 484 \\
\hline & &
\end{tabular}


Peptide index

[3-methyl-2-oxobutanoate dehydrogenase [lipoamide]] kinase, mitochondrial GN=BCKDK $\quad$ BCKD_HUMAN $46.36 \quad 100.0 \% \quad 4$ [3-methy-2-oxobutanoate dehydrogenase [lipoamide] kinase, mitochondrial GN=BCKDK BCKD_HUMAN $46.36 \quad 100.0 \% \quad 4$ [3-methyl-2-oxobutanoate dehydrogenase [lipoamide] k kinase, mitochondrial GN=BCKDK BCKD_HUMAN $46.36 \quad 100.0 \%$

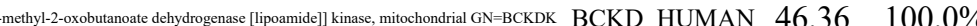
[Pyruvate dehydrogenase (acetyl-transferring]] kinase isozyme 1, mitochondrial GN=PDK1 $\quad$ PDK1_HUMAN $49.25 \quad 100.0 \%$ [Pyrnvate dehydrogenase (acetyl-transferring)] kinase isozyme 1, mitochondral GN=PDK1 $\quad$ PDK1_HUMAN $49.25 \quad 100.0 \%$ [Pyruvate dehydrogenase (acetyl-transferring)] kinase isozyme 1, mitochondral GN=PDK1 PDK1_HUMAN 49.25 $100.0 \%$ [Pyruvate dehydrogenase (acetyl-transferring]) kinase isozyme 3, mitochondrial GN=PDK3 PDK3_HUMAN $46.94 \quad 100.0 \%$ [Pyruvate dehydrogenase (acetyl-transferring)] kinase isozyme 3, mitcochondral GN=PDK3 PDK3_HUMAN $46.94 \quad 100.0 \%$ $116 \mathrm{kDa}$ U5 small nuclear ribonucleoprotein component GN=EFTUD2 U5S1_HUMAN $109.44 \quad 100.0 \%$ $116 \mathrm{kDa}$ U5 small nuclear ribonucleoprotein component GN=EFTUD2 U5S1_HUMAN $109.44 \quad 100.0 \%$ $116 \mathrm{kDa}$ U5 small nuclear ribonucleoprotein component GN=EFTUD2 U5S1_HUMAN $109.44 \quad 100.0 \%$ $116 \mathrm{kDa}$ U5 small nuclear ribonucleoprotein component GN=EFTUD2 U5S1_HUMAN $109.44 \quad 100.0 \%$ $116 \mathrm{kDa}$ U5 small nuclear ribonucleoprotein component GN=EFTUD2 U5S1_HUMAN $109.44 \quad 100.0 \%$ $116 \mathrm{kDa}$ U5 small nuclear ribonucleoprotein component GN=EFTUD2 U5S1_HUMAN $109.44100 .0 \%$ $116 \mathrm{kDa}$ U5 small nuclear ribonucleoprotein component GN=EFTUD2 U5S1_HUMAN $109.44 \quad 100.0 \%$ $116 \mathrm{kDa}$ U5 small nuclear ribonucleoprotein component GN=EFTUD2 U5S1_HUMAN $109.44 \quad 100.0 \%$ $116 \mathrm{kDa}$ U5 small nuclear ribonucleoprotein component GN=EFTUD2 U5S1_HUMAN $109.44 \quad 100.0 \%$ $116 \mathrm{kDa}$ U5 small nuclear ribonucleoprotein component GN=EFTUD2 U5S1_HUMAN $109.44 \quad 100.0 \%$ $116 \mathrm{kDa}$ U5 small nuclear ribonucleoprotein componen GN=EFTUD2 U5S1_HUMAN 109.44 100.0\% $116 \mathrm{kDa}$ U5 small nuclear ribonucleoprotein component GN=EFTUD2 U5S1_HUMAN $109.44 \quad 100.0 \%$ 14-3-3 protein beta/alpha $\mathrm{GN}=\mathrm{YWHAB}$ 14-3-3 protein beta/alpha $\mathrm{GN}=\mathrm{YWHAB}$ 14-3-3 protein beta/alpha $\mathrm{GN}=\mathrm{YWHAB}$ 14-3-3 protein beta/alpha $\mathrm{GN}=\mathrm{YWHAB}$ 14-3-3 protein beta/alpha $\mathrm{GN}=\mathrm{YWHAB}$ 14-3-3 protein beta/alpha $\mathrm{GN}=\mathrm{YWHAB}$ 14-3-3 protein beta/alpha $\mathrm{GN}=\mathrm{YWHAE}$ 14-3-3 protein beta/alpha $\mathrm{GN}=\mathrm{YWHAE}$ 14-3-3 protein beta/alpha $\mathrm{GN}=\mathrm{YWHAE}$ 14-3-3 protein beta/alpha $\mathrm{GN}=\mathrm{YWHAB}$ 14-3-3 protein epsilon $\mathrm{GN}=\mathrm{YWHAE}$ 14-3-3 protein epsilon $\mathrm{GN}=\mathrm{YWHAE}$ 14-3-3 protein epsilon $\mathrm{GN}=\mathrm{YWHAE}$ 14-3-3 protein epsilon $\mathrm{GN}=\mathrm{YWHAE}$ 14-3-3 protein epsilon $\mathrm{GN}=\mathrm{YWHAE}$ 14-3-3 protein epsilon $\mathrm{GN}=\mathrm{YWHAE}$ 14-3-3 protein epsilon $\mathrm{GN}=\mathrm{YWHAE}$ 14-3-3 protein epsilon $\mathrm{GN}=\mathrm{YWHAE}$ 14-3-3 protein epsilon $\mathrm{GN}=\mathrm{YWHAE}$ 14-3-3 protein epsilon $\mathrm{GN}=\mathrm{YWHAE}$
1433B_HUMAN $28.08 \quad 100.0 \%$ 1433B_HUMAN $28.08 \quad 100.0 \%$ 1433B_HUMAN $28.08 \quad 100.0 \%$ 1433B HUMAN $28.08 \quad 100.0 \%$ 1433B_HUMAN $28.08 \quad 100.0 \%$ 1433B_HUMAN $28.08 \quad 100.0 \%$ 1433B HUMAN $28.08 \quad 100.0 \%$ 1433B_HUMAN $28.08 \quad 100.0 \%$ 1433B_HUMAN $28.08 \quad 100.0 \%$ 1433B_HUMAN $28.08 \quad 100.0 \%$ 1433E_HUMAN $29.18 \quad 100.0 \%$ 1433E_HUMAN $29.18 \quad 100.0 \%$ 1433E_HUMAN $29.18 \quad 100.0 \%$ 1433E_HUMAN $29.18 \quad 100.0 \% \quad 12$ 1433E_HUMAN $29.18 \quad 100.0 \% \quad 12$ 1433E_HUMAN $29.18 \quad 100.0 \% \quad 12$ 1433E HUMAN $29.18 \quad 100.0 \% \quad 12$ 1433E_HUMAN $29.18 \quad 100.0 \% \quad 12$ 1433E_HUMAN $29.18 \quad 100.0 \% \quad 12$ 1433E HUMAN $29.18 \quad 100.0 \%$ $0.01 \% \quad 12.1 \%$ TVTSFYNQSAIDAAAEKPSVR $0.01 \% \quad 12.1 \%$ LTPTMMLYAGR $0.01 \% \quad 12.1 \%$ SQDGSHLLK $0.01 \% \quad 12.1 \%$ YLQQELPVR $0.00 \% \quad 8.5 \%$ EISLLPDNLLR $0.00 \% \quad 8.5 \%$ AIYDFTDTVIR $0.00 \% \quad 8.5 \%$ AVPLAGFGYGLPISR $0.00 \% \quad 7.4 \%$ AAPLAGFGYGLPISR $0.00 \% \quad 7.4 \%$ ALSSESFERLPVFNK $0.02 \% \quad 12.2 \%$ STPVTVVLPDTK $0.02 \% \quad 12.2 \%$ STPVTVVLPDTKGK $0.02 \% \quad 12.2 \%$ ILAQVVGDVDTSLPR $0.02 \% \quad 12.2 \%$ VLSGTIHAGQPVK $0.02 \% \quad 12.2 \%$ IAVEPVNPSELPK $0.02 \% \quad 12.2 \%$ LGEFFQTK $0.02 \% \quad 12.2 \%$ FKILDAVVAQEPLHR $0.02 \% \quad 12.2 \%$ ILDAVVAQEPLHR $0.02 \% \quad 12.2 \%$ GGGQIIPTAR $0.02 \% \quad 12.2 \%$ GGGQIIPTARR $0.02 \% \quad 12.2 \%$ RVVYSAFLMATPR

$99.7 \% \quad 46.7$

$99.7 \% \quad 29.3$ $99.7 \% \quad 63.1$ $\begin{array}{lll}99.7 \% & 30.5\end{array}$ $99.7 \% \quad 60.3$ $99.7 \% 53.6$ $99.7 \% \quad 67.3$ $99.3 \% \quad 19.5$ $99.7 \% \quad 45.4$ $99.7 \% \quad 62.2$ $99.7 \% \quad 59.6$ $99.7 \% \quad 41.0$ $99.7 \% \quad 64.4$ $99.0 \% \quad 27.0$ $99.7 \% \quad 29.7$ $99.7 \% \quad 50.1$ $99.7 \% \quad 47.7$ $96.3 \% \quad 25.1$ $\begin{array}{lll}99.0 \% & 25.7\end{array}$ $0.02 \% \quad 12.2 \%$ GHVTQDAPIPGSPLYTIK $\quad 99.7 \% \quad 39.0$ $0.01 \% \quad 40.2 \%$ LAEQAERYDDMAAAMK 97.9\% 29.7 $0.01 \% \quad 40.2 \%$ YDDMAAAMK $0.01 \% \quad 40.2 \%$ AVTEQGHELSNEER $0.01 \% \quad 40.2 \%$ NLLSVAYK $0.01 \% \quad 40.2 \%$ VISSIEQK $0.01 \% \quad 40.2 \%$ VISSIEQKTER $0.01 \% \quad 40.2 \%$ YLSEVASGDNK $0.01 \% \quad 40.2 \%$ QTTVSNSQQAYQEAFEISKK $0.01 \% \quad 40.2 \%$ EMQPTHPIR $0.01 \% \quad 40.2 \%$ DSTLIMQLLR $0.03 \% \quad 49.0 \%$ YDEMVESMKK $0.03 \% \quad 49.0 \%$ VAGMDVELTVEER $0.03 \% \quad 49.0 \%$ NLLSVAYK $0.03 \% \quad 49.0 \%$ IISSIEQK $0.03 \% \quad 49.0 \%$ IISSIEQKEENK $0.03 \% \quad 49.0 \%$ QMVETELK $0.03 \% \quad 49.0 \%$ LICCDILDVLDK $0.03 \% \quad 49.0 \%$ HLIPAANTGESK $0.03 \% \quad 49.0 \%$ YLAEFATGNDR $0.03 \% \quad 49.0 \%$ YLAEFATGNDRK
$99.7 \% \quad 55.3 \quad 25.0 \quad 20.1$

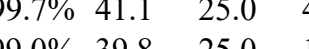

$99.0 \% \quad 50.0 \quad 25.0 \quad 0.0$

$99.7 \% \quad 40.0 \quad 25.0 \quad 27.0$

$99.7 \% \quad 32.5 \quad 25.0 \quad 27.9$

$\begin{array}{llll}99.6 \% & 26.2 & 25.0 & 26.2\end{array}$

$\begin{array}{llll}99.7 \% & 45.5 & 25.0 & 30.4\end{array}$

$\begin{array}{llll}99.7 \% & 49.0 & 25.0 & 25.1\end{array}$

$\begin{array}{llll}99.7 \% & 28.4 & 25.0 & 28.4\end{array}$

$99.7 \% \quad 73.4 \quad 25.0 \quad 73.4$

$\begin{array}{llll}99.0 \% & 39.8 & 25.0 & 15.8\end{array}$

$\begin{array}{llll}97.5 \% & 24.7 & 25.0 & 9.6\end{array}$

$99.7 \% \quad 57.1 \quad 25.0 \quad 51.0$

$\begin{array}{lllll}99.0 \% & 55.4 & 25.0 & 32.0 & 4\end{array}$

$99.7 \% \quad 63.3 \quad 25.0 \quad 55.8 \quad 2$

$\begin{array}{llll}99.7 \% & 55.3 & 25.0 & 48.0\end{array}$

$\begin{array}{lllll}99.7 \% & 57.6 & 25.0 & 54.6 & 3\end{array}$

$99.7 \% \quad 39.7 \quad 25.0 \quad 31.9$

225

(255.13

start stop

255.13

49

69

253.64

984.51

1145.63

1282.74

1313.67

1517.85

1489.82

1723.90

1256.71

1441.83

1582.88

1306.75

1392.77

969.50

1735.99

1460.82

969.55

1125.65

1510.82

1894.01

1844.82

1047.41

1598.74

907.52

903.51

1289.71

1182.56

2287.12

1124.55

1189.66

1259.56

1447.71

907.52

917.53

1417.75

977.50

1476.74

1237.65

1256.59

1384.69

$\begin{array}{cc}0 & 80 \\ 1 & 89 \\ 3 & 101 \\ 3 & 103 \\ 34 & 144 \\ 49 & 363 \\ 18 & 332 \\ 60 & 374 \\ 83 & 194 \\ 83 & 196 \\ 00 & 394 \\ 96 & 508 \\ 90 & 602 \\ 14 & 721 \\ 89 & 803 \\ 91 & 803 \\ 04 & 813 \\ 04 & 814 \\ 14 & 826 \\ 55 & 872 \\ 4 & 29 \\ 1 & 29 \\ 0 & 43 \\ 4 & 51 \\ 3 & 70 \\ 3 & 73 \\ 30 & 140 \\ 41 & 160 \\ 61 & 169 \\ 15 & 224 \\ 0 & 29 \\ 0 & 42 \\ 3 & 50 \\ 2 & 69 \\ 2 & 73 \\ 7 & 94 \\ 5 & 106 \\ 07 & 118 \\ 31 & 141 \\ 31 & 142 \\ & \end{array}$

Page 1 of Table S-1-4 
14-3-3 protein epsilon $\mathrm{GN}=\mathrm{YWHAE}$ 14-3-3 protein epsilon $\mathrm{GN}=\mathrm{YWHAF}$ 14-3-3 protein epsilon $\mathrm{GN}=\mathrm{YWHAE}$ 14-3-3 protein epsilon $\mathrm{GN}=\mathrm{YWHAE}$ 14-3-3 protein eta $\mathrm{GN}=\mathrm{YWHAH}$ 14-3-3 protein eta $\mathrm{GN}=\mathrm{YWHAH}$ 14-3-3 protein eta $\mathrm{GN}=\mathrm{YWHAH}$ 14-3-3 protein eta $\mathrm{GN}=\mathrm{YWHAH}$ 14-3-3 protein eta $\mathrm{GN}=\mathrm{YWHAH}$ 14-3-3 protein eta $\mathrm{GN}=\mathrm{YWHAH}$ 14-3-3 protein eta $\mathrm{GN}=\mathrm{YWHAH}$ 14-3-3 protein eta $\mathrm{GN}=\mathrm{YWHAH}$ 14-3-3 protein eta $\mathrm{GN}=\mathrm{YWHAH}$ 14-3-3 protein gamma $\mathrm{GN}=\mathrm{YWHAG}$ 14-3-3 protein gamma $\mathrm{GN}=\mathrm{YWHAG}$ 14-3-3 protein gamma $\mathrm{GN}=\mathrm{YWHAC}$ 14-3-3 protein gamma $\mathrm{GN}=\mathrm{YWHAG}$ 14-3-3 protein gamma GN=YWHAG 14-3-3 protein gamma $\mathrm{GN}=\mathrm{YWHAC}$ 14-3-3 protein gamma $\mathrm{GN}=\mathrm{YWHAG}$ 14-3-3 protein gamma $\mathrm{GN}=\mathrm{YWHAG}$ $14-3-3$ protein gamma $\mathrm{GN}=\mathrm{YWHAG}$ 14-3-3 protein gamma $\mathrm{GN}=\mathrm{YWHAG}$ 14-3-3 protein gamma $\mathrm{GN}=\mathrm{YWHAG}$ 14-3-3 protein theta $\mathrm{GN}=\mathrm{YWHAQ}$ 14-3-3 protein theta $\mathrm{GN}=\mathrm{YWHAQ}$ 14-3-3 protein theta $\mathrm{GN}=\mathrm{YWHAQ}$ 14-3-3 protein theta $\mathrm{GN}=\mathrm{YWHAQ}$ 14-3-3 protein theta $\mathrm{GN}=\mathrm{YWHAQ}$ 14-3-3 protein theta $\mathrm{GN}=\mathrm{YWHAQ}$ 14-3-3 protein theta $\mathrm{GN}=\mathrm{YWHAQ}$ 14-3-3 protein theta $\mathrm{GN}=\mathrm{YWHAQ}$ 14-3-3 protein zeta/delta $\mathrm{GN}=\mathrm{YWHAZ}$ 14-3-3 protein zeta/delta GN=YWHAZ 14-3-3 protein zeta/delta $\mathrm{GN}=\mathrm{YWHAZ}$ 14-3-3 protein zeta/delta $\mathrm{GN}=\mathrm{YWHAZ}$ 14-3-3 protein zeta/delta GN=YWHAZ 14-3-3 protein zeta/delta GN=YWHAZ 14-3-3 protein zeta/delta GN=YWHAZ 14-3-3 protein zeta/delta GN=YWHAZ 14-3-3 protein zeta/delta GN=YWHAZ 14-3-3 protein zeta/delta GN=YWHAZ 14-3-3 protein zeta/delta GN=YWHAZ 14-3-3 protein zeta/delta GN=YWHAZ 14-3-3 protein zeta/delta GN=YWHAZ
1433E HUMAN $29.18 \quad 100.0 \% \quad 12 \quad 17 \quad 34 \quad 0.03 \% \quad 49.0 \%$ KEAAENSLVAYK 1433E_HUMAN $29.18 \quad 100.0 \% \quad 12 \quad 17 \quad 34 \quad 0.03 \% \quad 49.0 \%$ EAAENSLVAYK 1433E_HUMAN $29.18 \quad 100.0 \% \quad 12$ 1433E HUMAN $29.18 \quad 100.0 \% \quad 12$ 1433F_HUMAN $28.22 \quad 100.0 \% \quad 6$ 1433F_HUMAN $28.22 \quad 100.0 \%$ 1433F HUMAN $28.22 \quad 100.0 \%$ 1433F_HUMAN $28.22 \quad 100.0 \%$ 1433F HUMAN $28.22 \quad 100.0 \%$ 1433F_HUMAN $28.22 \quad 100.0 \%$ 1433F_HUMAN $28.22 \quad 100.0 \%$ 1433F HUMAN $28.22 \quad 100.0 \%$ 1433F_HUMAN $28.22 \quad 100.0 \%$ 1433G_HUMAN $28.30 \quad 100.0 \%$ 1433G HUMAN $28.30 \quad 100.0 \%$ 1433G_HUMAN $28.30 \quad 100.0 \%$ 1433G_HUMAN $28.30 \quad 100.0 \%$ 1433G_HUMAN $28.30 \quad 100.0 \%$ 1433G_HUMAN $28.30 \quad 100.0 \%$ 1433G_HUMAN $28.30 \quad 100.0 \%$ 1433G_HUMAN $28.30 \quad 100.0 \%$ 1433G_HUMAN $28.30 \quad 100.0 \%$ 1433G_HUMAN $28.30 \quad 100.0 \%$ 1433G_HUMAN $28.30 \quad 100.0 \%$ 433T_HUMAN $27.77 \quad 100.0 \%$ 1433T_HUMAN $27.77 \quad 100.0 \%$ 1433T_HUMAN $27.77 \quad 100.0 \%$ 1433T HUMAN 27.77 1433T_HUMAN $27.77 \quad 100.0 \%$ 1433T HUMAN $27.77 \quad 100.0 \%$ 1433T HUMAN $27.77 \quad 100.0 \%$ 1433T_HUMAN $27.77 \quad 100.0 \%$ 14337 HUMAN $27.75 \quad 100.0 \%$ 1433Z_HUMAN $27.75 \quad 100.0 \%$ 1433Z_HUMAN $27.75 \quad 100.0 \%$ 1433Z_HUMAN $27.75 \quad 100.0 \% \quad 13$ 1433Z_HUMAN $27.75 \quad 100.0 \% \quad 13$ 1433Z_HUMAN $27.75 \quad 100.0 \% \quad 13$ 1433Z_HUMAN $27.75 \quad 100.0 \% \quad 13$ 1433Z_HUMAN $27.75 \quad 100.0 \% \quad 13$ 1433Z HUMAN $27.75 \quad 100.0 \% \quad 13$ 1433Z_HUMAN $27.75 \quad 100.0 \% \quad 13$ 1433Z HUMAN $27.75 \quad 100.0 \% \quad 13$ 1433Z_HUMAN $27.75 \quad 100.0 \% \quad 13$ 1433Z_HUMAN $27.75 \quad 100.0 \% \quad 13$$$
11
$$$$
11
$$

$0.01 \% \quad 36.2 \%$ NLLSVAYK

$0.01 \% \quad 36.2 \%$ VISSIEQK

$0.01 \% \quad 36.2 \%$ NCNDFQYESK

$0.01 \% \quad 36.2 \%$ YLAEVASGEK

$0.01 \% 36.2 \%$ YLAEVASGEKK

$0.01 \% \quad 36.2 \%$ DSTLIMQLLR

$0.01 \% \quad 38.9 \%$ YDDMAAAMK

$0.01 \% 38.9 \%$ NLLSVAYK

$0.01 \% \quad 38.9 \%$ VISSIEQK

$0.01 \% \quad 38.9 \%$ NCSETQYESK

$0.01 \% \quad 38.9 \%$ YLAEVATGEK

$0.01 \% \quad 38.9 \%$ RATVVESSEK

$0.01 \% \quad 38.9 \%$ ATVVESSEK

$0.01 \% 38.9 \%$ AYSEAHEISK

$0.01 \% 38.9 \%$ DSTLIMQLLR

$0.01 \% 35.9 \%$ NLLSVAYK

$0.01 \% \quad 35.9 \%$ VISSIEQK

$0.01 \% \quad 35.9 \%$ EKVESELR

$0.01 \% 35.9 \%$ YLAEVACGDDRK

$0.01 \% \quad 35.9 \%$ EMQPTHPIR

$0.01 \% \quad 35.9 \%$ DSTLIMQLLR

$\begin{array}{lll}0.03 \% & 54.7 \% & \text { SVTEQGAELSN } \\ 0.03 \% & 54.7 \% & \text { NLLSVAYK }\end{array}$

$0.03 \% \quad 54.7 \%$ EKIETELR

$0.03 \% \quad 54.7 \%$ DICNDVLSLLEK

$0.03 \% \quad 54.7 \%$ FLIPNASQAESK

$0.03 \% \quad 54.7 \%$ EMQPTHPIR

$0.03 \% \quad 54.7 \%$ DSTLIMQLLR
$0.01 \% \quad 36.2 \%$ LAEQAERYDDMASAMK $98.5 \% 29.6$

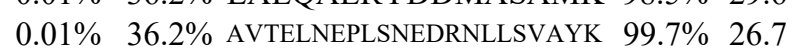

$99.0 \% \quad 39.8$

$99.0 \% \quad 50.0$

$99.7 \% \quad 46.8$

$99.7 \% 51.6$

$99.7 \% \quad 57.7$

$99.7 \% \quad 55.2$

$99.7 \% \quad 49.0$

$0.01 \% \quad 38.9 \%$ LAEQAERYDDMAAAMK $97.9 \% 29.7$

$0.01 \% 38.9 \%$ NVTELNEPLSNEER

$0.01 \% 35.9 \%$ AVTEQGAELSNEER

$99.7 \% \quad 55.3$

$99.7 \% \quad 73.5$

$99.0 \% 39.8$

$99.0 \% \quad 50.0$

$99.7 \% \quad 43.4$

$99.7 \% \quad 53.5$

$99.7 \% \quad 34.2$

$99.4 \% \quad 20.9$

$99.7 \% \quad 59.5$

$99.7 \% \quad 49.0$

$99.7 \% 78.7$

$99.0 \% \quad 39.8$

$99.0 \% \quad 50.0$

$99.0 \% \quad 42.0$

$99.7 \% \quad 55.8$

$\begin{array}{lllll} & 35.9 \% & \text { QTIDNSQGAYQEAFDISKK } & 99.7 \% & 50.2\end{array}$

$99.7 \% \quad 45.5$

$99.7 \% \quad 49.0$

$0.03 \% \quad 54.7 \%$ LAEQAERYDDMAACMK $99.7 \% \quad 30.8$

$0.03 \% \quad 54.7 \%$ SVTEQGAELSNEER

$99.7 \% \quad 67.4$

$0.03 \% \quad 54.7 \%$ VVSSIEQKTEGAEK

$99.7 \% 54.2$

$\begin{array}{ll}99.0 \% & 39.8 \\ 99.7 \% & 57.2\end{array}$

$99.0 \% \quad 29.4$

$99.7 \% \quad 69.7$

$99.7 \% \quad 27.9$

$99.7 \% \quad 58.7$

$0.03 \% \quad 54.7 \%$ GIVDQSQQAYQEAFEISK $\quad 99.7 \% \quad 68.2$

$0.03 \% \quad 54.7 \%$ GIVDQSQQAYQEAFEISKK $99.7 \% 34.7$

$0.00 \% \quad 5.8 \%$ LLSAFLPAR

$\begin{array}{llll}99.7 \% & 45.5 & 25.0 & 34.7\end{array}$

$\begin{array}{llll}99.7 \% & 49.0 & 25.0 & 25.1\end{array}$

$\begin{array}{llll}99.7 \% & 36.8 & 25.0 & 31.3\end{array}$

$0.00 \% \quad 5.8 \%$ VLSASQAFAAQR $\begin{array}{llll}99.7 \% & 55.4 & 25.0 & 49.8\end{array}$
1322.70

1194.60

1819.94

1189.66

1844.82

2475.27

907.52

903.51

1304.52

1066.54

1194.64

1267.62

1189.66

1844.82

1047.4

1643.79

907.52

903.51

1245.51

1080.56

1105.58

949.48

1134.54

1189.66

1532.72

907.52

903.51

989.53

1396.65

2143.03

1124.55

1189.66

1917.81

1548.71

2437.22

907.52

1504.79

1017.56

1418.72

1304.68

1279.65

2040.99

2169.08

1124.55

1189.66

987.60

1248.67 $\begin{array}{ll}100.0 \% & 2 \\ 100.0 \% & 2\end{array}$ 
2',3'-cyclic-nucleotide 3'-phosphodiesterase GN=CNP CN37_HUMAN $47.58 \quad 100.0 \% \quad 10 \quad 12 \quad 17 \quad 0.02 \% \quad 21.6 \%$ GAFSEEYKR 2',3'-cyclic-nucleotide 3 '-phosphodiesterase GN=CNP CN37_HUMAN $47.58 \quad 100.0 \%$ 2',3'-cyclic-nucleotide 3 '-phosphodiesterase GN=CNP CN37_HUMAN $47.58 \quad 100.0 \%$ 2',3'-cyclic-nucleotide 3 '-phosphodiesterase GN=CNP CN37_HUMAN $47.58 \quad 100.0 \%$ 2',3'-cyclic-nucleotide 3'-phosphodiesterase GN=CNP CN37_HUMAN $47.58 \quad 100.0 \%$ 2',3'-cyclic-nucleotide 3'-phosphodiesterase GN=CNP CN37_HUMAN $47.58 \quad 100.0 \%$ 2',3'-cyclic-nucleotide 3'-phosphodiesterase GN=CNP CN37_HUMAN $47.58 \quad 100.0 \%$ 2',3'-cyclic-nucleotide 3'-phosphodiesterase GN=CNP CN37_HUMAN $47.58 \quad 100.0 \%$ 2',3'-cyclic-nucleotide 3'-phosphodiesterase GN=CNP CN37_HUMAN 47.58 2',3'-cyclic-nucleotide 3'-phosphodiesterase GN=CNP CN37_HUMAN 47.58 26 protease regulatory subunit 10B GN=PSMC6 PRS10_HUMAN 44.17 $26 \mathrm{~S}$ protease regulatory subunit 10B GN=PSMC6 PRS10_HUMAN 44.17 26S protease regulatory subunit 10B GN=PSMC6 PRS10_HUMAN 44.17 $26 \mathrm{~S}$ protease regulatory subunit 10B GN=PSMC6 PRS10_HUMAN 44.17 $26 \mathrm{~S}$ protease regulatory subunit $10 \mathrm{~B} \mathrm{GN}=\mathrm{PSMC} 6$ PRS10 HUMAN 44.17 26S protease regulatory subunit 10B GN=PSMC6 PRS10_HUMAN 44.17 $26 \mathrm{~S}$ protease regulatory subunit 10B GN=PSMC6 $\mathrm{PRS} 10$ HUMAN 44.17 26S protease regulatory subunit 10B GN=PSMC6 PRS10_HUMAN 44.17 26 S protease regulatory subunit 10B GN=PSMC6 PRS10_HUMAN 44.17 $26 \mathrm{~S}$ protease regulatory subunit 10B GN=PSMC6 PRS10_HUMAN 44.17 26S protease regulatory subunit 10B GN=PSMC6 PRS10_HUMAN 44.17 $26 \mathrm{~S}$ protease regulatory subunit 10B GN=PSMC6 PRS10_HUMAN 44.17 $26 \mathrm{~S}$ protease regulatory subunit 10B GN=PSMC6 PRS10_HUMAN 44.17 $26 \mathrm{~S}$ protease regulatory subunit 10B GN=PSMC6 PRS10_HUMAN 44.1 $26 \mathrm{~S}$ protease regulatory subunit 10B GN=PSMC6 PRS10 HUMAN 44.17 26S protease regulatory subunit 10B GN=PSMC6 PRS10_HUMAN 44.17 $26 \mathrm{~S}$ protease regulatory subunit 10B GN=PSMC6 PRS10_HUMAN 44.17 $26 \mathrm{~S}$ protease regulatory subunit 10B GN=PSMC6 PRS10 HUMAN 44.17 $26 \mathrm{~S}$ protease regulatory subunit 10B GN=PSMC6 PRS10_HUMAN 44.17 $26 \mathrm{~S}$ protease regulatory subunit $4 \mathrm{GN}=\mathrm{PSMC1}$ PRS4 HUMAN 49.19 $26 \mathrm{~S}$ protease regulatory subunit $4 \mathrm{GN}=\mathrm{PSMC} 1 \mathrm{PRS} 4 \mathrm{HUMAN} 49.19$ $26 \mathrm{~S}$ protease regulatory subunit $4 \mathrm{GN}=\mathrm{PSMC} 1 \mathrm{PRS} 4$ HUMAN 49.19 $26 \mathrm{~S}$ protease regulatory subunit $4 \mathrm{GN}=\mathrm{PSMC} 1 \mathrm{PRS} 4$ HUMAN 49.19 26S protease regulatory subunit 4 GN=PSMC1 PRS4_HUMAN 49.19 $26 \mathrm{~S}$ protease regulatory subunit $4 \mathrm{GN}=\mathrm{PSMC} 1 \mathrm{PRS} 4$ HUMAN 49.19 $26 \mathrm{~S}$ protease regulatory subunit $4 \mathrm{GN}=\mathrm{PSMC} 1 \mathrm{PRS} 4$ HUMAN 49.1 26S protease regulatory subunit $4 \mathrm{GN}=\mathrm{PSMC1}$ PRS4_HUMAN $49.1 \mathrm{C}$ $26 \mathrm{~S}$ protease regulatory subunit $4 \mathrm{GN}=\mathrm{PSMC1} \mathrm{PRS}_{2} \mathrm{HUMAN} 49.1$ $26 \mathrm{~S}$ protease regulatory subunit $4 \mathrm{GN}=\mathrm{PSMC1}$ PRS4_HUMAN 49.19 $26 \mathrm{~S}$ protease regulatory subunit $6 \mathrm{~A}$ GN=PSMC3 $\mathrm{PRS6A}$ _HUMAN 49.2 $26 \mathrm{~S}$ protease regulatory subunit $6 \mathrm{~A} \mathrm{GN}=\mathrm{PSMC} 3$ PRS6A_HUMAN 49.2 $26 \mathrm{~S}$ protease regulatory subunit $6 \mathrm{~A}$ GN=PSMC3 PRS6A_HUMAN 49.2 $26 \mathrm{~S}$ protease regulatory subunit $6 \mathrm{~A}$ GN=PSMC3 $\mathrm{PRS} 6 \mathrm{~A} \_$HUMAN 49.21 $26 \mathrm{~S}$ protease regulatory subunit $6 \mathrm{~A}$ GN=PSMC3 PRS6A HUMAN 49.2 $26 \mathrm{~S}$ protease regulatory subunit $6 \mathrm{~A}$ GN=PSMC3 $3 R$ PRSA_HUMAN $^{2} 49.21$ $26 \mathrm{~S}$ protease regulatory subunit $6 \mathrm{~A} \mathrm{GN}=\mathrm{PSMC} 3$ PRS6A HUMAN 49.2 $26 \mathrm{~S}$ protease regulatory subunit $6 \mathrm{~A}$ GN=PSMC3 $\mathrm{PRS6A}$ _HUMAN 49.21
$0.02 \% \quad 21.6 \%$ RLDEDLAAYCR

$0.02 \% \quad 21.6 \%$ LDEDLAAYCR

$0.02 \% \quad 21.6 \%$ ILVLDDTNHER

$0.02 \% \quad 21.6 \%$ AGQVFLEELGNHK

$0.02 \% \quad 21.6 \%$ MDLVTYFGK

$0.02 \% \quad 21.6 \%$ RPPGVLHCTTK

$0.02 \% \quad 21.6 \%$ APGAEEYAQQDVLK

\begin{tabular}{llllll}
$100.0 \%$ & 10 & 12 & 17 & $0.02 \%$ & $21.6 \%$ \\
\hline
\end{tabular}

$\begin{array}{lllllll}100.0 \% & 10 & 12 & 17 & 0.02 \% & 21.6 \% & \text { GGSRGEEVGELSR }\end{array}$

$100.0 \%$

$100.0 \%$ $100.0 \%$

$100.0 \%$

$100.0 \%$ $100.0 \%$ $100.0 \%$ $100.0 \%$ $100.0 \% \quad 19$ $100.0 \%$ $100.0 \% \quad 19$ $100.0 \% \quad 19$ $100.0 \%$ $100.0 \%$ $100.0 \%$ $100.0 \% \quad 19$ $100.0 \% \quad 19$ $100.0 \% \quad 19$ $100.0 \% \quad 19$ $100.0 \%$ $100.0 \%$ $100.0 \%$ $100.0 \%$ $100.0 \%$ $100.0 \%$ $100.0 \%$ $100.0 \%$ $100.0 \%$ $100.0 \%$ $100.0 \%$ $100.0 \%$ $100.0 \%$ $100.0 \%$ $100.0 \%$ $100.0 \%$ $100.0 \%$ $100.0 \%$ $0.02 \% \quad 25.0 \%$ YDSNSGGEREIQR $0.02 \% \quad 25.0 \%$ IFQIHTSR

$0.02 \% \quad 25.0 \%$ SKENVLYK

$0.02 \% \quad 25.0 \%$ KQEGTPEGLYL

$0.02 \% \quad 33.7 \%$ MSTEEIIQR

$0.02 \% 33.7 \%$ QTYFLPVIGLVDAEK

$0.02 \% \quad 33.7 \%$ DSYLILETLPTEYDSR $0.02 \% \quad 33.7 \%$ APSIIFIDELDAIGTK
$0.02 \% \quad 25.0 \%$ VAEEHAPSIVFIDEIDAIGTK

$25.0 \quad 19.2$

$\begin{array}{llll}1 & 25.0 & 31.1 & 0\end{array}$

$99.7 \% \quad 26.0 \quad 25.0 \quad 26.0$

$\begin{array}{llll}99.0 \% & 39.3 & 25.0 & 30.1\end{array}$

$96.5 \% \quad 17.8 \quad 25.0 \quad 13.5$

$\begin{array}{llll}99.7 \% & 58.1 & 25.0 & 48.3\end{array}$

$99.7 \% \quad 35.0 \quad 25.0 \quad 21.6$

$\begin{array}{llll}99.7 \% & 61.9 & 25.0 & 59.1\end{array}$

$\begin{array}{llll}99.7 \% & 34.5 & 25.0 & 34.5\end{array}$

$\begin{array}{llll}99.7 \% & 35.1 & 25.0 & 27.8\end{array}$

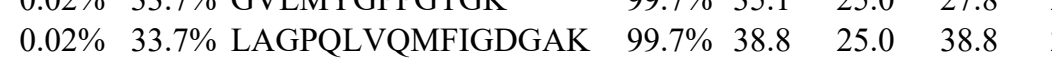
$\begin{array}{lllllll}0.02 \% & 33.7 \% & \text { EKAPSIIFIDELDAIGTK } & 99.3 \% & 19.5 & 25.0 & 19.5\end{array}$

$99.7 \% \quad 46.0$ $\begin{array}{lllll}0.02 \% & 33.7 \% & \text { TMLELLNQLDGFQPNTQVK } & 99.7 \% & 49.8\end{array}$
1381.65

1225.55

1324.69

1441.74

1089.53

1265.68

1518.74

1646.84

1332.65

1008.51

1209.66

1440.84

1380.72

3350.55

1797.97

1219.61

1365.68

1709.91

1125.53

969.43

1495.71

2065.97

1433.79

836.50

1273.64

1164.56

1368.64

1596.70

1086.59

1158.65

1278.68

972.57

1702.94

2254.16

1510.69

1001.55

980.54

1234.63

1106.55

1692.92

1914.93

1192.60

1644.88

1960.06

1702.93 2189.13

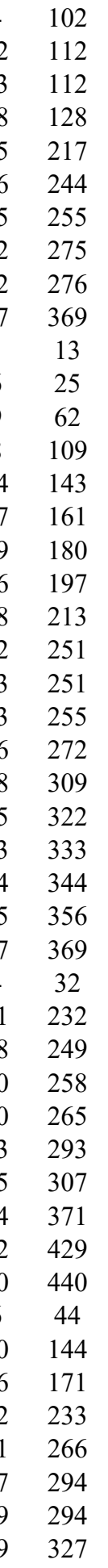


26S protease regulatory subunit 6A GN=PSMC3 PRS6A_HUMAN $49.21 \quad 100.0 \%$ $26 \mathrm{~S}$ protease regulatory subunit $6 \mathrm{~A}$ GN=PSMC3 $\mathrm{PRS6A}$ _HUMAN $49.21 \quad 100.0 \%$ 26S protease regulatory subunit 6A GN=PSMC3 PRS6A_HUMAN $49.21 \quad 100.0 \%$ $26 \mathrm{~S}$ protease regulatory subunit $6 \mathrm{~B}$ GN=PSMC4 PRS6B_HUMAN 47.37 $26 \mathrm{~S}$ protease regulatory subunit $6 \mathrm{~B}$ GN=PSMC4 PRS6B_HUMAN 47.37 $26 \mathrm{~S}$ protease regulatory subunit $6 \mathrm{~B} \mathrm{GN}=\mathrm{PSMC} 4$ PRS6B_HUMAN 47.37 $26 \mathrm{~S}$ protease regulatory subunit $6 \mathrm{~B} \mathrm{GN}=\mathrm{PSMC} 4 \mathrm{PRS} 6 \mathrm{~B}$ HUMAN $47.3^{7}$ $26 \mathrm{~S}$ protease regulatory subunit $6 \mathrm{~B} \mathrm{GN}=\mathrm{PSMC} 4$ PRS6B_HUMAN 47.37 $26 \mathrm{~S}$ protease regulatory subunit $6 \mathrm{~B} \mathrm{GN}=\mathrm{PSMC} 4 \mathrm{PRS} 6 \mathrm{~B}$ HUMAN 47.37 $26 \mathrm{~S}$ protease regulatory subunit $6 \mathrm{~B} \mathrm{GN}=\mathrm{PSMC} 4$ PRS6B_HUMAN 47.37 $26 \mathrm{~S}$ protease regulatory subunit $6 \mathrm{~B} \mathrm{GN}=\mathrm{PSMC} 4 \mathrm{PRS6B}+\mathrm{HUMAN} 47.37$ $26 \mathrm{~S}$ protease regulatory subunit $6 \mathrm{~B} \mathrm{GN}=\mathrm{PSMC} 4 \mathrm{PRS} 6 \mathrm{~B}$ HUMAN 47.37 $26 \mathrm{~S}$ protease regulatory subunit $6 \mathrm{~B}$ GN=PSMC4 PRS6B_HUMAN 47.37 $26 \mathrm{~S}$ protease regulatory subunit $6 \mathrm{~B} \mathrm{GN}=\mathrm{PSMC} 4 \mathrm{PRS6B}$ HUMAN 47.37 $26 \mathrm{~S}$ protease regulatory subunit $7 \mathrm{GN}=\mathrm{PSMC} 2 \mathrm{PRS} 7$ HUMAN 48.62 $26 \mathrm{~S}$ protease regulatory subunit $7 \mathrm{GN}=\mathrm{PSMC} 2 \mathrm{PRS} 7$ HUMAN 48.64 $26 \mathrm{~S}$ protease regulatory subunit $7 \mathrm{GN}=\mathrm{PSMC} 2 \mathrm{PRS} 7 \mathrm{HUMAN} 48.64$ $26 \mathrm{~S}$ protease regulatory subunit $7 \mathrm{GN}=\mathrm{PSMC} 2$ PRS7_HUMAN 48.64 $26 \mathrm{~S}$ protease regulatory subunit $7 \mathrm{GN}=\mathrm{PSMC} 2$ PRS7_HUMAN 48.64 $26 \mathrm{~S}$ protease regulatory subunit $7 \mathrm{GN}=\mathrm{PSMC} 2$ PRS7 HUMAN 48.64 $26 \mathrm{~S}$ protease regulatory subunit $7 \mathrm{GN}=\mathrm{PSMC} 2 \mathrm{PRS} 7$ _HUMAN 48.64 $26 \mathrm{~S}$ protease regulatory subunit $7 \mathrm{GN}=\mathrm{PSMC} 2 \mathrm{PRS} 7 \mathrm{HUMAN} 48.64$ $26 \mathrm{~S}$ protease regulatory subunit $7 \mathrm{GN}=\mathrm{PSMC} 2$ PRS7 HUMAN 48.64 $26 \mathrm{~S}$ protease regulatory subunit $7 \mathrm{GN}=\mathrm{PSMC} 2 \mathrm{PRS} 7$ _HUMAN 48.64 $26 \mathrm{~S}$ protease regulatory subunit $7 \mathrm{GN}=\mathrm{PSMC} 2 \mathrm{PRS} 7 \mathrm{HUMAN} 48.64$ $26 \mathrm{~S}$ protease regulatory subunit $7 \mathrm{GN}=\mathrm{PSMC} 2$ PRS7_HUMAN 48.64 $26 \mathrm{~S}$ protease regulatory subunit $7 \mathrm{GN}=\mathrm{PSMC} 2$ PRS7_HUMAN 48.64 $26 \mathrm{~S}$ protease regulatory subunit $7 \mathrm{GN}=\mathrm{PSMC} 2 \mathrm{PRS} 7 \mathrm{HUMAN} 48.64$ $26 \mathrm{~S}$ protease regulatory subunit $8 \mathrm{GN}=$ PSMC5 PRS8_HUMAN 45.63 $26 \mathrm{~S}$ protease regulatory subunit $8 \mathrm{GN}=\mathrm{PSMC} 5 \mathrm{PRS} 8 \mathrm{HUMAN} 45.63$ $26 \mathrm{~S}$ protease regulatory subunit $8 \mathrm{GN}=\mathrm{PSMC} 5$ PRS8_HUMAN 45.63 $26 \mathrm{~S}$ protease regulatory subunit $8 \mathrm{GN}=$ PSMC5 PRS8_HUMAN 45.63 $26 \mathrm{~S}$ protease regulatory subunit $8 \mathrm{GN}=\mathrm{PSMC} 5 \mathrm{PRS} 8$ HUMAN 45.63 26S protease regulatory subunit $8 \mathrm{GN}=$ PSMC5 PRS8_HUMAN 45.63 $26 \mathrm{~S}$ protease regulatory subunit $8 \mathrm{GN}=$ PSMC5 $\mathrm{PRS} 8$ HUMAN 45.63 $26 \mathrm{~S}$ protease regulatory subunit $8 \mathrm{GN}=\mathrm{PSMC} 5 \mathrm{PRS} 8$ HUMAN 45.6 $26 \mathrm{~S}$ protease regulatory subunit $8 \mathrm{GN}=\mathrm{PSMC} 5 \mathrm{PRS} 8$ _HUMAN 45.63 $26 \mathrm{~S}$ protease regulatory subunit $8 \mathrm{GN}=\mathrm{PSMC} 5 \mathrm{PRS} 8 \mathrm{HUMAN} 45.63$ 26S proteasome non-ATPase regulatory subunit 1 GN=PSMD1 PSMD1_HUMAN 105.84 26S proteasome non-ATPase regulatory subunit $1 \mathrm{GN}=$ PSMD1 PSMD1_HUMAN 105.84 26S proteasome non-ATPase regulatory subunit $1 \mathrm{GN}=$ PSMD1 PSMD1_HUMAN 105.84 26S proteasome non-ATPase regulatory subunit 11 GN=PSMD11 PSD11_HUMAN 47.47 $26 \mathrm{~S}$ proteasome non-ATPase regulatory subunit $11 \mathrm{GN}=$ PSMD11 PSD11_HUMAN $47.4^{7}$ 26S protensone noD-ATPasegdaty $26 \mathrm{~S}$ proteasome non-ATPase regulatory subunit $13 \mathrm{GN}=$ PSMD13 PSD13_HUMAN 42.9 . 26S proteasome non-ATPase regulatory subunit 13 GN=PSMD13 PSD13 HUMAN 42.95 26S proteasome non-ATPase regulatory subunit 13 GN=PSMD13 PSD13_HUMAN 42.95
$100.0 \%$ $100.0 \%$ $100.0 \%$

$100.0 \%$ $100.0 \%$ $100.0 \%$ $100.0 \%$ $100.0 \%$ $100.0 \%$ $100.0 \%$ $100.0 \%$ $100.0 \%$ $100.0 \%$ $100.0 \%$ $100.0 \%$ $100.0 \%$

$100.0 \%$ $100.0 \%$ $100.0 \%$ $100.0 \%$ $100.0 \%$

$100.0 \%$ $100.0 \%$ $100.0 \%$ $100.0 \%$ $100.0 \%$ $100.0 \%$ $100.0 \%$ $100.0 \%$ $100.0 \%$ $100.0 \%$ $100.0 \%$ $100.0 \%$ $100.0 \%$ $100.0 \%$ $100.0 \%$ $00.0 \%$ $100.0 \%$ $100.0 \%$ $100.0 \%$ $100.0 \%$ $100.0 \%$ $100.0 \%$ $100.0 \%$

12

1

(2

12

12

1

12

12

1

1

1

4

14
14

14
14

14

14

14

14
14

14

14

14
14

14
14

14
14

10

10

10
10

10

10

10

10
10

10

3
3

3

3
3

3

9

21
$0.02 \% \quad 33.7 \%$ CTDDFNGAQCK $0.02 \% \quad 27.0 \%$ EFLHAQEEVKR

$0.02 \% \quad 27.0 \%$ EAVELPLTHFELYK

$0.02 \% \quad 27.0 \%$ GVLMYGPPGCGK

$0.02 \% \quad 27.0 \%$ AVAHHTTAAFIR

$0.02 \% \quad 27.0 \%$ VVGSEFVQK

$0.02 \% \quad 27.0 \%$ FDAQTGADREVQR

$0.02 \% \quad 27.0 \%$ ILLELLNQMDGFDQNVNVK

$0.02 \% \quad 27.0 \%$ RLIFSTITSK

$0.02 \% \quad 27.0 \%$ LIFSTITSK

$0.02 \% \quad 27.0 \%$ ENRYIVLAK

$0.02 \% \quad 27.0 \%$ YIVLAKDFEK

$0.02 \% \quad 38.1 \%$ PDYLGADQRK

$0.02 \% \quad 38.1 \%$ ALDEGDIALLK

$0.02 \% \quad 38.1 \%$ TYGQSTYSR

$0.02 \% \quad 38.1 \%$ IINADSEDPKYIINVK

$0.02 \% \quad 38.1 \%$ FVNLGIEPPK

$0.02 \% \quad 38.1 \%$ FVNLGIEPPKGVLLFGPPGTGK

$\begin{array}{ll}0.02 \% & 38.1 \% \\ 0.02 \% & 38.1 \%\end{array}$

$0.02 \% \quad 38.1 \%$ ACLIFFDEIDAIGGAR

$0.02 \% \quad 38.1 \%$ FDDGAGGDNEVQR

$0.02 \% \quad 38.1 \%$ TMLELINQLDGFDPR

$0.02 \% \quad 38.1 \%$ KIEFSLPDLEGR

$0.02 \% \quad 38.1 \%$ DIRFELLAR

$0.02 \% \quad 38.1 \%$ LCPNSTGAEIR

$0.02 \% \quad 38.1 \%$ SVCTEAGMFAIR

$\begin{array}{lll}0.03 \% & 35.2 \% & \text { LLREELQLLQEQGSYVGEVVR } \\ 0.03 \% & 35.2 \% & \text { FVVDVDKNIDINDVTPNCR }\end{array}$

$\begin{array}{lll}0.03 \% & 35.2 \% & \text { VALRNDSYTLHK }\end{array}$

$0.03 \% \quad 35.2 \%$ GVLLYGPPGTGK

$0.03 \% \quad 35.2 \%$ AVAHHTDCTFIR

$0.03 \% \quad 35.2 \%$ VSGSELVQK

$0.03 \% 35.2 \%$ LEGGSGGDSEVQR

$0.03 \% \quad 35.2 \%$ TMLELLNQLDGFEATK

$0.03 \% \quad 35.2 \%$ IAELMPGASGAEVK

$0.03 \% \quad 35.2 \%$ RVHVTQEDFEMAVAK

$0.01 \% \quad 4.0 \%$ LLHVAVSDVNDDVRR

$0.01 \% \quad 4.0 \%$ AAVESLGFILFR

$0.01 \% \quad 4.0 \%$ VSTAVLSITAK

$0.01 \% \quad 8.3 \%$ TGQAAELGGLLK

$0.01 \% \quad 8.3 \% \quad$ LYDNLLEQNLIR

$0.01 \% \quad 8.3 \%$ VQIEHISSLIK

$0.02 \% \quad 25.0 \%$ LYENFISEFEHR

$0.02 \% \quad 25.0 \%$ QMTDPNVALTFLEK

$0.02 \% \quad 25.0 \%$ SSDEAVILCK
$99.7 \% \quad 45.8$

$99.7 \% \quad 43.2$

$99.7 \% \quad 47.2$

$99.7 \% \quad 40.6$

$99.7 \% \quad 35.5$

$99.7 \% \quad 27.6$

$99.7 \% \quad 46.4$

$99.7 \% \quad 44.8$

$99.6 \% 27.5$

$99.7 \% \quad 60.2$

$99.7 \% \quad 32.2$

$99.7 \% \quad 33.6$

$97.9 \% \quad 28.5$

$99.7 \% \quad 46.3$

$99.7 \% \quad 40.8$

$99.7 \% \quad 55.1$

$99.7 \% \quad 36.7$

$\begin{array}{lll}99.7 \% & 48.5\end{array}$

$98.8 \% \quad 22.3$

$99.7 \% 33.3$

$99.7 \% \quad 35.0$

$99.7 \% \quad 67.5$

$99.7 \% \quad 50.4$

$99.7 \% \quad 52.0$

$99.7 \% \quad 77.2$

$99.6 \% \quad 25.0$

$99.7 \% \quad 36.6$

$99.7 \% \quad 27.9$

$\begin{array}{lll}99.7 \% & 60.7\end{array}$

$\begin{array}{lll}99.7 \% & 37.0\end{array}$

$\begin{array}{lll}99.7 \% & 37.9\end{array}$

$99.3 \% \quad 47.0$

$99.7 \% \quad 41.2$

$99.7 \% \quad 56.8$

$99.7 \% \quad 74.3$

$99.7 \% \quad 60.3$

$99.7 \% \quad 43.7$

$\begin{array}{lll}99.7 \% & 49.6\end{array}$

$99.7 \% \quad 45.8$

$99.7 \% \quad 57.2$

$99.7 \% \quad 47.8$

$99.7 \% \quad 56.0$

$99.7 \% \quad 38.0$

$\begin{array}{lll}99.7 \% & 42.2\end{array}$

$99.4 \% \quad 20.2$

$99.7 \% \quad 29.0$

$99.7 \% \quad 58.6$
45.8

47.2

$34.0 \quad 34.3$
25.0

\begin{tabular}{ll}
27.6 \\
\hline
\end{tabular}

\begin{tabular}{l}
04.6 \\
\hline
\end{tabular}

55.0
25.0

$\begin{array}{ll}.0 & 24.3\end{array}$

\begin{tabular}{ll}
25.0 & 60.2 \\
\hline
\end{tabular}

$\begin{array}{ll}25.0 & 32.2\end{array}$

$\begin{array}{ll}.0 & 29.9\end{array}$

$\begin{array}{ll}25.0 & 10.1\end{array}$

\begin{tabular}{ll}
0 & 40.4 \\
\hline
\end{tabular}

31.8
.5 $\quad 42.4$

$\begin{array}{ll}25.0 & 29.5\end{array}$

$\begin{array}{ll}25.0 & 48.5\end{array}$

$\begin{array}{ll}5.0 & 15.4\end{array}$

$\begin{array}{ll}5.0 & 33.3\end{array}$

$\begin{array}{ll}52.0 & 22.9\end{array}$

$\begin{array}{ll}6.0 & 67.5\end{array}$

\begin{tabular}{ll}
50.4 \\
\hline
\end{tabular}

\begin{tabular}{ll}
25.0 & 47.9 \\
\hline & 77.2
\end{tabular}

\begin{tabular}{ll}
77.2 \\
\hline
\end{tabular}

$\begin{array}{ll}.0 & 20.7\end{array}$

$\begin{array}{ll}27.9 & 27.9 \\ 25.0 & 60.7\end{array}$

$\begin{array}{ll}5.0 & 60.7\end{array}$

$\begin{array}{ll}5.0 & 36.3\end{array}$

$\begin{array}{ll}2.0 & 31.2\end{array}$

$\begin{array}{ll}25.0 & 0.0\end{array}$

$\begin{array}{ll}5.0 & 27.5\end{array}$

27.0
25.0

$\begin{array}{ll}27.0 & 74.3\end{array}$

$\begin{array}{ll}74.0 & 60.3\end{array}$

$\begin{array}{ll}5.0 & 39.0\end{array}$

$\begin{array}{ll}25.0 & 49.4\end{array}$

$25.0 \quad 45.8$

$\begin{array}{ll}5.0 & 57.2\end{array}$

$\begin{array}{lll} & 47.8\end{array}$

$\begin{array}{lll}.0 & 42.3 & 2\end{array}$

34.8

11
11

2
2
0
0
0
0
3
0
0
0
0
0
0
0
0
0
0
1
0
1
0
0
0
0
0
0
0
0
0
0
0
0
1
2
2
0
0
0
0
0
0
0
0
0
0
0
0
0
0
0
0
0
0
0



$26 \mathrm{~S}$ proteasome non-ATPase regulatory subunit $13 \mathrm{GN}=\mathrm{PSMD} 13$ PSD13 HUMAN $42.95 \quad 100.0 \%$ $26 \mathrm{~S}$ proteasome non-ATPase regulatory subunit $13 \mathrm{GN}=\mathrm{PSMD} 13$ PSD13_HUMAN $42.95 \quad 100.0 \%$ $26 \mathrm{~S}$ proteasome non-ATPase regulatory subunit $13 \mathrm{GN}=\mathrm{PSMD} 13 \mathrm{PSD} 13$ HUMAN $42.95 \quad 100.0^{\circ}$ 26S proteasome non-ATPase regulatory subunit $13 \mathrm{GN}=\mathrm{PSMD} 13$ PSD13_HUMAN $42.95 \quad 100.0 \%$ $26 \mathrm{~S}$ proteasome non-ATPase regulatory subunit $13 \mathrm{GN}=\mathrm{PSMD} 13$ PSD13_HUMAN $42.95 \quad 100.0 \%$ $26 \mathrm{~S}$ proteasome non-ATPase regulatory subunit $2 \mathrm{GN}=\mathrm{PSMD} 2 \mathrm{PSMD} 2$ HUMAN $100.20100 .0 \%$ $26 \mathrm{~S}$ proteasome non-ATPase regulatory subunit $2 \mathrm{GN}=\mathrm{PSMD} 2 \mathrm{PSMD} 2$ HUMAN $100.20 \quad 100.0 \%$ $26 \mathrm{~S}$ proteasome non-ATPase regulatory subunit $2 \mathrm{GN}=\mathrm{PSMD} 2 \mathrm{PSMD} 2$ HUMAN $100.20100 .0 \%$ $26 \mathrm{~S}$ proteasome non-ATPase regulatory subunit $2 \mathrm{GN}=$ PSMD2 PSMD2_HUMAN $100.20 \quad 100.0 \%$ $26 \mathrm{~S}$ proteasome non-ATPase regulatory subunit $3 \mathrm{GN}=\mathrm{PSMD} 3$ PSMD3_HUMAN $60.98 \quad 100.0 \%$ $26 \mathrm{~S}$ proteasome non-ATPase regulatory subunit $3 \mathrm{GN}=$ PSMD3 PSMD3 HUMAN $60.98 \quad 100.0^{\circ}$ 26S proteasome non-ATPase regulatory subunit 3 GN=PSMD3 PSMD3_HUMAN $60.98 \quad 100.0 \%$ $26 \mathrm{~S}$ proteasome non-ATPase regulatory subunit $3 \mathrm{GN}=\mathrm{PSMD} 3$ PSMD3_HUMAN $60.98 \quad 100.0 \%$ $26 \mathrm{~S}$ proteasome non-ATPase regulatory subunit $3 \mathrm{GN}=\mathrm{PSMD} 3$ PSMD3_HUMAN $60.98 \quad 100.0 \%$ 26S proteasome non-ATPase regulatory subunit $3 \mathrm{GN}=$ PSMD3 $\quad$ PSMD3_HUMAN $60.98 \quad 100.0 \%$ 26S proteasome non-ATPase regulatory subunit $3 \mathrm{GN}=\mathrm{PSMD} 3$ PSMD3 HUMAN $60.98 \quad 100.0^{\circ}$ 26S proteasome non-ATPase regulatory subunit 3 GN=PSMD3 PSMD3_HUMAN $60.98 \quad 100.0 \%$ 26S proteasome non-ATPase regulatory subunit 3 GN=PSMD3 PSMD3_HUMAN 60.98 $26 \mathrm{~S}$ proteasome non-ATPase regulatory subunit $3 \mathrm{GN}=$ PSMD3 3 PSD3 HUMAN 60.98 26S proteasome non-ATPase regulatory subunit 3 GN=PSMD3 PSMD3_HUMAN 60.98 26S proteasome non-ATPase regulatory subunit 3 GN=PSMD3 PSMD3_HUMAN 60.9 26S proteasome non-ATPase regulatory subunit 3 GN=PSMD3 PSMD3_HUMAN 60.98 26S proteasome non-ATPase regulatory subunit $3 \mathrm{GN}=$ PSMD3 PSMD3_HUMAN 60.98 $26 \mathrm{~S}$ proteasome non-ATPase regulatory subunit $3 \mathrm{GN}=$ PSMD3 PSMD3_HUMAN 60.98 26S proteasome non-ATPase regulatory subunit 3 GN=PSMD3 PSMD3_HUMAN 60.98 26S proteasome non-ATPase regulatory subunit 3 GN=PSMD3 PSMD3_HUMAN 60.98 26S proteasome non-ATPase regulatory subunit $3 \mathrm{GN}=\mathrm{PSMD} 3 \quad \mathrm{PSMD} 3$ HUMAN 60.98 26S proteasome non-ATPase regulatory subunit 3 GN=PSMD3 PSMD3_HUMAN 60.98 $26 \mathrm{~S}$ proteasome non-ATPase regulatory subunit $3 \mathrm{GN}=\mathrm{PSMD} 3 \quad$ PSMD3 HUMAN 60.9 $26 \mathrm{~S}$ proteasome non-ATPase regulatory subunit $3 \mathrm{GN}=\mathrm{PSMD} 3$ PSMD3 HUMAN 60.9 26S proteasome non-ATPase regulatory subunit $3 \mathrm{GN}=$ PSMD3 PSMD3_HUMAN 60.98 $26 \mathrm{~S}$ proteasome non-ATPase regulatory subunit $4 \mathrm{GN}=\mathrm{PSMD} 4 \quad \mathrm{PSMD} 4$ HUMAN 40.74 26S proteasome non-ATPase regulatory subunit 4 GN=PSMD4 PSMD4_HUMAN 40.7 26S proteasome non-ATPase regulatory subunit $4 \mathrm{GN}=$ PSMD4 PSMD4_HUMAN 40.74 26S protensonent 作 26S proteasome non-ATPase regulatory subunit 4 GN=PSMD4 PSMD4_HUMAN $40.74 \quad 100.0 \%$ 26S proteasome non-ATPase regulatory subunit $4 \mathrm{GN}=$ PSMD4 PSMD4_HUMAN $40.74 \quad 100.0 \%$ $26 \mathrm{~S}$ proteasome non-ATPase regulatory subunit $6 \mathrm{GN}=$ PSMD6 PSMD6 HUMAN $45.53100 .0 \%$ 26S proteasome non-ATPase regulatory subunit 6 GN=PSMD6 PSMD6_HUMAN 45.53 100.0\% 26S proteasome non-ATPase regulatory subunit $6 \mathrm{GN}=$ PSMD6 PSMD6_HUMAN $45.53 \quad 100.0 \%$ 26S proteasome non-ATPase regulatory subunit 6 GN=PSMD6 PSMD6_HUMAN $45.53 \quad 100.0 \%$ 26S proteasome non-ATPase regulatory subunit 6 GN=PSMD6 PSMD6_HUMAN 45.53 100.0\% $26 \mathrm{~S}$ proteasome non-ATPase regulatory subunit $6 \mathrm{GN}=\mathrm{PSMD} 6$ PSMD6 HUMAN $45.53100 .0 \%$ 26S proteasome non-ATPase regulatory subunit 6 GN=PSMD6 PSMD6_HUMAN $45.53 \quad 100.0 \%$
$17 \quad 0.02 \% \quad 25.0 \%$ LNIGDLQVTK $0.02 \% \quad 25.0 \%$ DLPVSEQQER $0.02 \% \quad 25.0 \%$ QLTFEEIAK $0.02 \% \quad 25.0 \%$ ITVNEVELLVMK $0.02 \% \quad 25.0 \%$ GSIDEVDKR $0.02 \% \quad 25.0 \%$ VLDLQQIK

$\begin{array}{llll}10.01 \% & 6.2 \% & \text { SSTTSMTSVPKPLK }\end{array}$ $10 \quad 0.01 \% \quad 6.2 \% \quad$ FGGSGSQVDSAR

$\quad 0.01 \% \quad 6.2 \% \quad$ AVPLALALISVSNPR $10 \quad 0.01 \% \quad 6.2 \% \quad$ VGQAVDVVGQAGKPK $55 \quad 0.05 \% \quad 38.6 \%$ RLNHYVLYK

$\quad 0.05 \% \quad 38.6 \%$ LNHYVLYK

$0.05 \% \quad 38.6 \%$ AVQGFFTSNNATR $0.05 \% \quad 38.6 \%$ ISDDLMQK

$0.05 \% 38.6 \%$ RALDLVAAK $0.05 \% \quad 38.6 \%$ VYEFLDKLDVVR $0.05 \% \quad 38.6 \%$ NYLHYSLYDQAEK $0.05 \% \quad 38.6 \%$ NYLHYSLYDQAEKLVSK $0.05 \% \quad 38.6 \%$ SVFPEQANNNEWAR $0.05 \% \quad 38.6 \%$ IKAIQLEYSEAR $0.05 \% \quad 38.6 \%$ AIQLEYSEAR $0.05 \% \quad 38.6 \%$ APQHTAVGFK $0.05 \% \quad 38.6 \%$ SLMPYFLLTQAVR $0.05 \% 38.6 \%$ FNQVLDQFGEK $0.05 \% \quad 38.6 \%$ MISLSYSR $0.05 \% \quad 38.6 \%$ ISLADIAQK $0.05 \% 38.6 \%$ LQLDSPEDAEFIVAK $0.05 \% \quad 38.6 \%$ AIRDGVIEASINHEK $0.05 \% \quad 38.6 \%$ DGVIEASINHEK $0.05 \% \quad 38.6 \%$ DGVIEASINHEKGYVQSK $0.05 \% \quad 38.6 \%$ ISFCLDIHNMSVK $0.05 \% \quad 38.6 \%$ SYNKDLESAEER $0.03 \% \quad 22.5 \%$ NGDFLPTRLQAQQDAVNIVC $0.03 \% 22.5 \%$ LQAQQDAVNIVCHSK $0.03 \% 22.5 \%$ ILSKLHTVQPK $0.03 \% \quad 22.5 \%$ GKITFCTGIR $0.03 \% \quad 22.5 \%$ ITFCTGIR

ENEKDLVK $99.7 \% \quad 64.1$ $99.7 \% \quad 45.6 \quad 25.0$ $0.03 \% \quad 22.5 \%$ LTAFVNTLNGK $0.03 \% \quad 22.5 \%$ NAMGSLASQATK $0.03 \% \quad 40.9 \%$ PLENLEEEGLPK $\begin{array}{llll}99.7 \% & 58.6 & 25.0 & 58.6\end{array}$ $99.7 \% \quad 60.5 \quad 25.0 \quad 59.1$ $0.03 \% \quad 40.9 \%$ PLENLEEEGLPKNPDLR $0.03 \% \quad 40.9 \%$ FLLSLPEHR $0.03 \% \quad 40.9 \%$ GDAAVRDELMAAVR $0.03 \% \quad 40.9 \%$ DNNMAPYYEALCK $0.03 \% \quad 40.9 \%$ ANEDELKR $0.03 \% \quad 40.9 \%$ IGDKEGALTAFR $\begin{array}{llll}99.7 \% & 60.5 & 25.0 & 59.1 \\ 99.7 \% & 40.4 & 25.0 & 40.2\end{array}$ $99.7 \% \quad 55.4 \quad 25.0 \quad 46.5$ $\begin{array}{llll}99.1 \% & 23.3 & 25.0 & 21.5\end{array}$ $\begin{array}{lllll}99.7 \% & 35.9 & 25.0 & 35.9 & 2\end{array}$ $\begin{array}{llll}99.0 \% & 38.6 & 25.0 & 17.8\end{array}$ $\begin{array}{llll}99.7 \% & 40.3 & 25.0 & 33.5\end{array}$
200.59

1078.58

1018.52

956.58

1479.77

1167.54

1520.92

1452.82

1205.68

1049.58

1412.69

949.47

956.59

1495.82

1643.77

2071.05

1661.77

1420.78

1179.60

1055.56

1554.84

1324.65

956.49

958.56

1674.86

1651.88

1311.65

1973.99

1563.77

1440.66

2611.30

1710.86

1263.78

1152.62

967.50

1973.06

1177.66

1194.58

1367.71

1963.01

1111.63

1489.74

1604.67

974.49

1277.69

\begin{tabular}{cc}
23 & 132 \\
87 & 196 \\
90 & 298 \\
02 & 313 \\
22 & 330 \\
40 & 347 \\
4 & 97 \\
58 & 369 \\
89 & 703 \\
46 & 860 \\
07 & 115 \\
08 & 115 \\
16 & 128 \\
87 & 194 \\
01 & 209 \\
17 & 228 \\
57 & 269 \\
57 & 273 \\
74 & 287 \\
95 & 306 \\
97 & 306 \\
16 & 325 \\
56 & 368 \\
75 & 385 \\
09 & 416 \\
17 & 425 \\
26 & 440 \\
41 & 455 \\
44 & 455 \\
44 & 461 \\
80 & 492 \\
00 & 511 \\
8 & 40 \\
6 & 40 \\
1 & 81 \\
2 & 91 \\
4 & 91 \\
09 & 126 \\
53 & 163 \\
54 & 365 \\
2 & 125 \\
2 & 18 \\
& 32 \\
& 46 \\
\hline 4
\end{tabular}




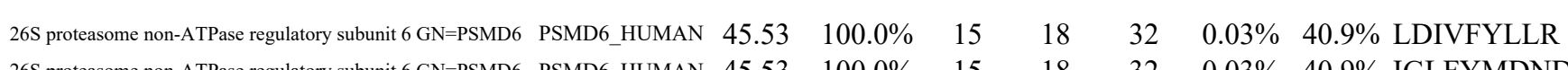
26S proteasome non-ATPase regulatory subunit 6 GN=PSMD6 PSMD6 HUMAN $45.53 \quad 100.0 \% \quad 1$ $26 \mathrm{~S}$ proteasome non-ATPase regulatory subunit 6 GN=PSMD6 PSMD6_HUMAN $45.53 \quad 100.0 \%$ 26S proteasome non-ATPase regulatory subunit 6 GN=PSMD6 PSMD6_HUMAN $45.53 \quad 100.0 \% \quad 1$ 26S proteasome non-ATPase regulatory subunit 6 GN=PSMD6 PSMD6_HUMAN $45.53 \quad 100.0 \% \quad 1$ 26S proteasome non-ATPase regulatory subunit 6 GN=PSMD6 PSMD6_HUMAN $45.53 \quad 100.0 \% \quad 15$ 26S proteasome non-ATPase regulatory subunit 6 GN=PSMD6 PSMD6_HUMAN $45.53 \quad 100.0 \% \quad 15$ 26S proteasome non-ATPase regulatory subunit $7 \mathrm{GN}=\mathrm{PSMD} 7 \mathrm{PSMD} 7$ HUMAN $37.03 \quad 100.0 \%$ 26S proteasome non-ATPase regulatory subunit 7 GN=PSMD7 PSMD7_HUMAN $37.03 \quad 100.0 \%$ 26S proteasome non-ATPase regulatory subunit 7 GN=PSMD7 PSMD7_HUMAN $37.03 \quad 100.0 \%$ 26S proteasome non-ATPase regulatory subunit 8 GN=PSMD8 PSMD8 HUMAN $39.61 \quad 100.0 \%$ 26S proteasome non-ATPase regulatory subunit 8 GN=PSMD8 PSMD8_HUMAN $39.61 \quad 100.0 \%$ 26S proteasome non-ATPase regulatory subunit 8 GN=PSMD8 PSMD8_HUMAN $39.61 \quad 100.0 \%$ $28 \mathrm{~S}$ ribosomal protein S18b, mitochondrial GN=MRPS18B RT18B_HUMAN $29.40 \quad 100.0 \%$ $28 \mathrm{~S}$ ribosomal protein S18b, mitochondrial GN=MRPS18B RT18B_HUMAN $29.40 \quad 100.0 \%$ $28 \mathrm{~S}$ ribosomal protein $\mathrm{S} 18 \mathrm{~b}$, mitochondrial GN=MRPS18B RT18B HUMAN $29.40 \quad 100.0^{\circ}$ $28 \mathrm{~S}$ ribosomal protein S18b, mitochondrial GN=MRPS18B RT18B_HUMAN $29.40 \quad 100.0 \%$ $28 \mathrm{~S}$ ribosomal protein S18b, mitochondrial GN=MRPS18B RT18B_HUMAN $29.40 \quad 100.0 \%$ 28 ribosomal protein S18b, mitochondrial GN=MRPS18B RT18B_HUMAN $29.40 \quad 100.0 \%$ $28 \mathrm{~S}$ ribosomal protein S2, mitochondrial GN=MRPS2 RT02_HUMAN $33.25 \quad 100.0 \%$ $28 \mathrm{~S}$ ribosomal protein S2, mitochondrial GN=MRPS2 RT02_HUMAN $33.25 \quad 100.0 \%$ $28 \mathrm{~S}$ ribosomal protein S2, mitochondrial GN=MRPS2 RT02_HUMAN $33.25 \quad 100.0 \%$ $28 \mathrm{~S}$ ribosomal protein S2, mitochondrial GN=MRPS2 RT02_HUMAN 33.25 28S ribosomal protein S2, mitochondrial GN=MRPS2 RT02 HUMAN 33.25 $28 \mathrm{~S}$ ribosomal protein S2, mitochondrial GN=MRPS2 RT02_HUMAN 33.25 $28 \mathrm{~S}$ ribosomal protein $\mathrm{S} 2$, mitochondrial GN=MRPS2 RT02_HUMAN 33.25 $28 \mathrm{~S}$ ribosomal protein $\mathrm{S} 2$, mitochondrial GN=MRPS2 RT02_HUMAN 33.2. $28 \mathrm{~S}$ ribosomal protein $\mathrm{S} 2$, mitochondrial GN=MRPS2 RT02_HUMAN 33.25 $28 \mathrm{~S}$ ribosomal protein $\mathrm{S} 2$, mitochondrial GN=MRPS2 RT02 HUMAN 33.25 $28 \mathrm{~S}$ ribosomal protein S2, mitochondrial GN=MRPS2 RT02_HUMAN 33.25 $28 \mathrm{~S}$ ribosomal protein S22, mitochondrial GN=MRPS22 RT22_HUMAN 41.28 $28 \mathrm{~S}$ ribosomal protein S22, mitochondrial GN=MRPS22 RT22 HUMAN 41.28 $28 \mathrm{~S}$ ribosomal protein S22, mitochondrial GN=MRPS22 RT22_HUMAN 41.28 $28 \mathrm{~S}$ ribosomal protein S22, mitochondrial GN=MRPS22 RT22_HUMAN 41.28 $28 \mathrm{~S}$ ribosomal protein S22, mitochondrial GN=MRPS22 RT22_HUMAN 41.28 $28 \mathrm{~S}$ ribosomal protein S22, mitochondrial GN=MRPS22 RT22_HUMAN 41.2 $28 \mathrm{~S}$ ribosomal protein S22, mitochondrial GN=MRPS22 RT22 HUMAN 41.28 $28 \mathrm{~S}$ ribosomal protein S22, mitochondrial GN=MRPS22 RT22_HUMAN 41.28 $28 \mathrm{~S}$ ribosomal protein S22, mitochondrial GN=MRPS22 RT22_HUMAN 41.28 $28 \mathrm{~S}$ ribosomal protein S22, mitochondrial GN=MRPS22 RT22 HUMAN 41.28 $28 \mathrm{~S}$ ribosomal protein S22, mitochondrial GN=MRPS22 RT22_HUMAN 41.28 $28 \mathrm{~S}$ ribosomal protein S22, mitochondrial GN=MRPS22 RT22 HUMAN 41.28 $28 \mathrm{~S}$ ribosomal protein S22, mitochondrial GN=MRPS22 RT22 HUMAN 41.2 $28 \mathrm{~S}$ ribosomal protein S22, mitochondrial GN=MRPS22 RT22_HUMAN 41.28 $28 \mathrm{~S}$ ribosomal protein S22, mitochondrial GN=MRPS22 RT22 HUMAN 41.28 $28 \mathrm{~S}$ ribosomal protein S22, mitochondrial GN=MRPS22 RT22_HUMAN 41.28 $\begin{array}{lllllll}100.0 \% & 11 & 12 & 20 & 0.02 \% & 35.5 \% & \text { QFSYLIENMAR } \\ 100.0 \% & 11 & 12 & 20 & 0.02 \% & 35.5 \% \text { DCGEYAHTR }\end{array}$

$\begin{array}{llllll}100.0 \% & 11 & 12 & 20 & 0.02 \% & 35.5 \% \\ 10 & \text { GGMLTNAR }\end{array}$

$100.0 \%$

$100.0 \%$

$100.0 \%$

$100.0 \%$

$100.0 \%$

$100.0 \%$

$100.0 \%$

$100.0 \%$

$100.0 \%$

$100.0 \%$

$100.0 \%$

$100.0 \%$

$100.0 \%$

$100.0 \%$

$100.0 \%$

$100.0 \%$

$100.0 \%$

$100.0 \%$

$100.0 \%$ $100.0 \%$

$0.02 \% \quad 35.5 \%$ RQQVEALYR

20
20
$0.03 \% \quad 40.9 \%$ IGLFYMDNDLITR

$0.03 \% \quad 40.9 \%$ VYQGLYCVAIR

$0.03 \% \quad 40.9 \%$ GAEILEVLHSLPAVR

$0.03 \% \quad 40.9 \%$ QYLFSLYECR

$0.03 \% \quad 40.9 \%$ IHAYSQLLESYR

$0.03 \% \quad 40.9 \%$ IDKVNEIVETNRPDSK

$0.03 \% \quad 40.9 \%$ VNEIVETNRPDSK

$0.00 \% \quad 10.5 \%$ DIKDTTVGTLSQR

$0.00 \% \quad 10.5 \%$ ITNQVHGLK

$0.00 \% \quad 10.5 \%$ SVVALHNLINNK

$0.01 \% \quad 9.1 \%$ LVLLELNFLPTTGTK

$0.01 \% \quad 9.1 \%$ DIQTNVYIK

$0.01 \% \quad 9.1 \%$ ILFTEATR

$0.01 \% \quad 33.3 \%$ APSEEDSLSSVPISPYKDEPWK

$0.01 \% \quad 33.3 \%$ YLESEEYQER

$0.01 \% \quad 33.3 \%$ VVGNPCPICR

$0.01 \% \quad 33.3 \%$ RLTQAIQK

$0.01 \% \quad 33.3 \%$ LYQGHLQEESGPPPESMPK

$0.01 \% \quad 33.3 \%$ TPAEASSTGQTGPQSAL

$0.02 \% \quad 35.5 \%$ ESEDSTDFNDK

$0.02 \% 35.5 \%$ ESEDSTDFNDKILNEPLK

$0.02 \% \quad 35.5 \%$ HSDFFNVK

$0.02 \% \quad 35.5 \%$ FMEPYIFGSR

$99.7 \% \quad 63.9$

$99.7 \% \quad 54.7$

$99.7 \% \quad 51.6$

$99.7 \% \quad 56.5$

$99.7 \% \quad 48.5$

$99.7 \% \quad 57.4$

$99.7 \% \quad 32.7$

$99.5 \% \quad 34.1$

$99.7 \% 48.6$

$99.7 \% \quad 30.2$

$99.7 \% \quad 54.6$

$99.7 \% \quad 42.0$

$99.7 \% \quad 33.2$

$99.0 \% \quad 30.1$

$99.7 \% \quad 54.7$

$99.7 \% \quad 56.4$

$99.7 \% \quad 47.9$

$99.0 \% \quad 23.3$

$\begin{array}{lll}99.7 \% & 39.1\end{array}$

34.0

$98.9 \% \quad 21.5$

$99.7 \% \quad 48.7$

$99.7 \% \quad 56.2$

$99.7 \% \quad 40.4$

$99.0 \% \quad 48.0$

$99.0 \% \quad 53.1$

$99.7 \% \quad 28.7$

$99.0 \% \quad 20.0$

$0.02 \% \quad 35.5 \%$ QQVEALYR

$0.02 \% \quad 35.5 \%$ LQGQKEPGDQGPAHPPGADMSHS

$0.06 \% \quad 45.0 \%$ KPTFMDEEVQSILTK

$0.06 \% \quad 45.0 \%$ MTGLNLQK

$0.06 \% \quad 45.0 \%$ TFKPAIQELKPPTYK

$0.06 \% \quad 45.0 \%$ LMTQAQLEEATR

$0.06 \% \quad 45.0 \%$ LKMPPVLEER

$0.06 \% \quad 45.0 \%$ MPPVLEER

$0.06 \% \quad 45.0 \%$ VPINDVLAEDK

$0.06 \% \quad 45.0 \%$ VPINDVLAEDKILEGTETTK

$0.06 \% \quad 45.0 \%$ YVFTDISYSIPHR

$0.06 \% \quad 45.0 \%$ MIQVYFPK

$0.06 \% \quad 45.0 \%$ ILTPIIFKEENLR

$0.06 \% \quad 45.0 \%$ TYEDIDKR

$0.06 \% \quad 45.0 \%$ KIDGLLIDQIQR

$0.06 \% \quad 45.0 \%$ IDGLLIDQIQR

$0.06 \% \quad 45.0 \%$ DQAAEGINLIK

$0.06 \% \quad 45.0 \%$ GAYIELTLQTYQEALSR
$99.6 \% \quad 26.0$

$98.9 \% \quad 18.7$

$99.0 \% \quad 29.4$

$99.4 \% \quad 23.1$

$99.7 \% \quad 60.4$

$95.5 \% \quad 16.3$

$99.0 \% \quad 30.4$

$99.7 \% 48$.

$99.7 \% \quad 54.2$

$99.7 \% \quad 53.0$

$99.0 \% \quad 35$.

$99.7 \% \quad 27.5$

$99.0 \% 27.8$

$99.7 \% \quad 64.2$

$99.7 \% \quad 60.6$

$99.7 \% \quad 60.3$

$99.7 \% \quad 55.4$

$.0 \quad 54.7-2$.

046

56.5

$\begin{array}{ll}0 & 53.4\end{array}$

$\begin{array}{ll}0 & 32.7\end{array}$

$\begin{array}{ll}.0 & 17.3\end{array}$

$\begin{array}{ll}0 & 40.9\end{array}$

$\begin{array}{ll}0 & 26.3\end{array}$

$\begin{array}{ll}0 & 45.4\end{array}$

$\begin{array}{ll}0 & 42.0\end{array}$

\begin{tabular}{ll}
5.0 & 28.8 \\
\hline
\end{tabular}

$\begin{array}{ll}22.0 & 22.8\end{array}$

$\begin{array}{ll}0.0 & 54.7\end{array}$

$\begin{array}{ll}0 & 56.4\end{array}$

$\begin{array}{ll}0 & 47.9\end{array}$

\begin{tabular}{ll}
23.1 \\
\hline
\end{tabular}

33.0

$\begin{array}{ll}0 & 34.0\end{array}$

$\begin{array}{ll}51.0 & 21.5\end{array}$

$\begin{array}{ll}0 & 20.4\end{array}$

34.9

\begin{tabular}{ll}
0 & 48.7 \\
\hline
\end{tabular}

$\begin{array}{ll}0 & 48.6\end{array}$

$\begin{array}{ll}34.2 \\ 0 & 26.0\end{array}$

$\begin{array}{lll} & 39.0 & 39.5\end{array}$

$\begin{array}{lll}5.0 & 19.1 \quad 2\end{array}$

17.1
-0

$\begin{array}{ll}26.0 & 26.0\end{array}$

$\begin{array}{ll}0.0 & 18.7\end{array}$

16.2

$\begin{array}{ll}.0 & 23.1\end{array}$

$\begin{array}{ll}53.0 & 53.7\end{array}$

$\begin{array}{ll}.0 & 19.2\end{array}$

$0 \quad 48.1$

$25.0 \quad 54.2$

53.0
5.0

$\begin{array}{ll}0 & 35.1\end{array}$

\begin{tabular}{ll}
27.5 \\
\hline
\end{tabular}

$\begin{array}{ll}.0 & 16.0\end{array}$

59.0
25.0

\begin{tabular}{ll}
0 & 40.2 \\
\hline
\end{tabular}

1586.79

1341.70

1603.92

1378.65

1479.76

1856.97

1500.77

1433.76

1009.58

1321.76

1658.97

1093.59

950.53

2461.18

1345.59

1171.57

957.58

2140.00

1602.76

1286.50

2093.99

993.48

1246.59

1387.67

1108.45

819.41

949.55

1162.63

1006.53

2470.14

1765.90

904.49

1760.99

1406.69

1227.68

986.50

1212.65

2185.16

1597.80

1025.55

1585.93

1039.51

1411.83

1283.73

1171.63

1956.01 
$28 \mathrm{~S}$ ribosomal protein S27, mitochondrial GN=MRPS27 RT27 HUMAN $47.61 \quad 100.0 \%$ $28 \mathrm{~S}$ ribosomal protein S27, mitochondrial GN=MRPS27 RT27 HUMAN $47.61 \quad 100.0 \%$ $28 \mathrm{~S}$ ribosomal protein S27, mitochondrial GN=MRPS27 RT27_HUMAN $47.61 \quad 100.0 \%$ 28 ribosomal protein S27, mitochondrial GN=MRPS27 RT27 HUMAN $47.61 \quad 100.0 \%$ $28 \mathrm{~S}$ ribosomal protein S27, mitochondrial GN=MRPS27 RT27_HUMAN $47.61 \quad 100.0 \% \quad 1$ $28 \mathrm{~S}$ ribosomal protein S27, mitochondrial GN=MRPS27 RT27_HUMAN $47.61 \quad 100.0 \% \quad 13$ $28 \mathrm{~S}$ ribosomal protein S27, mitochondrial GN=MRPS27 RT27_HUMAN $47.61 \quad 100.0 \% \quad 13$ $28 \mathrm{~S}$ ribosomal protein S27, mitochondrial GN=MRPS27 RT27_HUMAN $47.61 \quad 100.0 \% \quad 13$ $28 \mathrm{~S}$ ribosomal protein S27, mitochondrial GN=MRPS27 RT27 HUMAN $47.61 \quad 100.0 \% \quad 1$ $28 \mathrm{~S}$ ribosomal protein S27, mitochondrial GN=MRPS27 RT27_HUMAN $47.61 \quad 100.0 \% \quad 1$ $28 \mathrm{~S}$ ribosomal protein S27, mitochondrial GN=MRPS27 RT27_HUMAN $47.61 \quad 100.0 \% \quad 1$ $28 \mathrm{~S}$ ribosomal protein S27, mitochondrial GN=MRPS27 RT27 HUMAN 47.61 $100.0 \%$ $28 \mathrm{~S}$ ribosomal protein S27, mitochondrial GN=MRPS27 RT27_HUMAN $47.61 \quad 100.0 \% \quad 1$ $28 \mathrm{~S}$ ribosomal protein $\mathrm{S} 29$, mitochondrial GN=DAP3 RT29 HUMAN 45.57 $28 \mathrm{~S}$ ribosomal protein $\mathrm{S} 29$, mitochondrial GN=DAP3 RT29 HUMAN 45.57 $28 \mathrm{~S}$ ribosomal protein $\mathrm{S} 29$, mitochondrial GN=DAP3 RT29_HUMAN 45.57 $28 \mathrm{~S}$ ribosomal protein $\mathrm{S} 29$, mitochondrial GN=DAP3 RT29 HUMAN 45.57 $28 \mathrm{~S}$ ribosomal protein S29, mitochondrial GN=DAP3 RT29_HUMAN 45.57 28S ribosomal protein S29, mitochondrial GN=DAP3 RT29_HUMAN 45.57 $28 \mathrm{~S}$ ribosomal protein $\mathrm{S} 29$, mitochondrial GN=DAP3 RT29 HUMAN 45.57 $28 \mathrm{~S}$ ribosomal protein $\mathrm{S} 29$, mitochondrial GN=DAP3 RT29_HUMAN 45.57 $28 \mathrm{~S}$ ribosomal protein S29, mitochondrial GN=DAP3 RT29_HUMAN 45.57 28S ribosomal protein $\mathrm{S} 29$, mitochondrial GN=DAP3 RT29 HUMAN 45.57 $28 \mathrm{~S}$ ribosomal protein S29, mitochondrial GN=DAP3 RT29_HUMAN 45.57 $28 \mathrm{~S}$ ribosomal protein $\mathrm{S} 30$, mitochondrial GN=MRPS30 RT30 HUMAN 50.37 28S ribosomal protein S30, mitochondrial GN=MRPS30 RT30_HUMAN 50.37 $28 \mathrm{~S}$ ribosomal protein S31, mitochondrial GN=MRPS31 RT31_HUMAN 45.32 $28 \mathrm{~S}$ ribosomal protein $\mathrm{S} 31$, mitochondrial GN=MRPS31 RT31_HUMAN 45.32 $28 \mathrm{~S}$ ribosomal protein S31, mitochondrial GN=MRPS31 RT31_HUMAN 45.32 28S ribosomal protein S31, mitochondrial GN=MRPS31 RT31_HUMAN 45.32 $28 \mathrm{~S}$ ribosomal protein $\mathrm{S} 31$, mitochondrial GN=MRPS31 RT31_HUMAN 45.32 $28 \mathrm{~S}$ ribosomal protein $\mathrm{S} 35$, mitochondrial GN=MRPS35 RT35_HUMAN 36.8 $28 \mathrm{~S}$ ribosomal protein S35, mitochondrial GN=MRPS35 RT35 HUMAN 36.8 $28 \mathrm{~S}$ ribosomal protein $\mathrm{S} 35$, mitochondrial GN=MRPS35 RT35_HUMAN 36.8 _ $28 \mathrm{~S}$ ribosomal protein S35, mitochondrial GN=MRPS35 RT35 HUMAN 36.8 $28 \mathrm{~S}$ ribosomal protein $\mathrm{S} 35$, mitochondrial GN=MRPS35 RT35 HUMAN 36.8 $28 \mathrm{~S}$ ribosomal protein S35, mitochondrial GN=MRPS35 RT35_HUMAN 36.8 $28 \mathrm{~S}$ ribosomal protein S35, mitochondrial GN=MRPS35 RT35 HUMAN 36.8 $28 \mathrm{~S}$ ribosomal protein $\mathrm{S} 35$, mitochondrial GN=MRPS35 RT35_HUMAN 36.85 $28 \mathrm{~S}$ ribosomal protein $\mathrm{S} 5$, mitochondrial GN=MRPS5 RT05_HUMAN 48.0 $28 \mathrm{~S}$ ribosomal protein $\mathrm{S} 5$, mitochondrial GN=MRPS5 RT05 HUMAN 48.0 $28 \mathrm{~S}$ ribosomal protein $\mathrm{S} 5$, mitochondrial GN=MRPS5 RT05_HUMAN 48.0 $28 \mathrm{~S}$ ribosomal protein $\mathrm{S} 5$, mitochondrial GN=MRPS5 RT05 HUMAN 48.0 $28 \mathrm{~S}$ ribosomal protein $\mathrm{S} 5$, mitochondrial GN=MRPS5 RT05 HUMAN 48.01 28S ribosomal protein S5, mitochondrial GN=MRPS5 RT05_HUMAN 48.0 28S ribosomal protein $\mathrm{S} 5$, mitochondrial GN=MRPS5 RT05 HUMAN 48.0 $28 \mathrm{~S}$ ribosomal protein S5, mitochondrial GN=MRPS5 RT05_HUMAN 48.01
$0.03 \% \quad 33.3 \%$ KLPVSSLTISR

$0.03 \% \quad 33.3 \%$ LIDNISSR

$0.03 \% \quad 33.3 \%$ EEIDHAEYYLYK

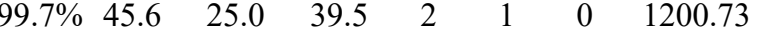
$\begin{array}{llllllll}99.0 \% & 46.1 & 25.0 & 12.1 & 2 & 0 & 0 & 917.51\end{array}$

$\begin{array}{llllllll}99.7 \% & 41.2 & 25.0 & 30.6 & 2 & 0 & 0 & 1572.72\end{array}$

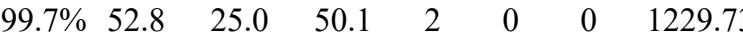

$0.03 \% \quad 33.3 \%$ NFGASLLLPGLK

$99.7 \% \quad 52.0$

$99.0 \% \quad 36.5$

$99.7 \% \quad 48.3$

$99.7 \% \quad 39.5$

$99.7 \% 57.6$

$\begin{array}{ll}99.7 \% & 72.8 \\ 99.7 \% & 67.7\end{array}$

$0.03 \% \quad 33.3 \%$ VAASPEDIKLCR

$0.03 \% 33.3 \%$ EALDVLGAVLK

$0.03 \% \quad 33.3 \%$ LVEQLDIEETEQSK

$99.7 \% \quad 61.7$

$0.03 \% \quad 33.3 \%$ IESEGLLSLTTQLVK

$0.03 \% \quad 33.3 \%$ EQAKQEYQAQK

$0.03 \% \quad 27.4 \%$ TFSEACLMVR

$0.03 \% \quad 27.4 \%$ KPALELLHYLK

$0.03 \% \quad 27.4 \%$ NTSFAYPAIR

$0.03 \% \quad 27.4 \%$ DLLQSSYNK

$0.03 \% \quad 27.4 \%$ GSPLGEVVEQGITR

$0.03 \% \quad 27.4 \%$ NATDAVGIVLK

\begin{tabular}{ll}
$0.03 \%$ & $27.4 \%$ \\
$0.03 \%$ & $27.4 \%$ EDKSPIAPEELALVHNLLR \\
\hline
\end{tabular}

$0.03 \% \quad 27.4 \%$ KAYLPQELLGK

$0.03 \% \quad 27.4 \%$ AYLPQELLGK

$0.03 \% \quad 27.4 \%$ ELLFLSNANPSLLER

$0.00 \% \quad 5.2 \%$ QYENHIFVGSK

$0.00 \% \quad 5.2 \%$ QNCADQIEVVFR

$0.01 \% \quad 15.2 \%$ SLEATLGR

$0.01 \% \quad 15.2 \%$ SELLSQLQQHEEESR

$0.01 \% \quad 15.2 \%$ ISFSNIISDMK

$0.01 \% \quad 15.2 \%$ IQFDEGYDNYPGQEK

$0.01 \% \quad 15.2 \%$ LNIFDMMAVTK

$0.02 \% \quad 28.2 \%$ TPGNERPPR

$0.02 \% \quad 28.2 \%$ EGNLELLK

$0.02 \% \quad 28.2 \%$ IPNFLHLTPVAIK

$99.7 \% \quad 49.6$

$99.7 \% \quad 47.8$

$99.7 \% \quad 38.3$

$99.7 \% \quad 45.9$

$99.7 \% \quad 28.0$

$99.7 \% \quad 70.3$

$99.7 \% \quad 73.0$

$99.7 \% \quad 57.7$

$99.7 \% \quad 46.2$

$98.7 \% \quad 25.4$

$99.7 \% \quad 44.8$

$99.3 \% \quad 21.4$

$99.7 \% \quad 50.5$

$99.0 \% \quad 29.4$

$99.7 \% \quad 70.3$

$99.7 \% \quad 56.1$

$99.7 \% \quad 83.3$

$99.7 \% \quad 42.5$

$97.2 \% 16.6$

$99.0 \% \quad 43.3$

$\begin{array}{ll}99.5 \% & 22.7\end{array}$

$0.02 \% \quad 28.2 \%$ HFPIEIDSTDYVSSGPSVR $99.7 \% \quad 59.1$

$0.02 \% \quad 28.2 \%$ NILETLLQMK

$99.7 \% \quad 41.1$

$99.7 \% \quad 44.2$

$0.02 \% \quad 28.2 \%$ SVVSLKNEEENENSISQYK $99.5 \% 22.9$

$0.02 \% \quad 28.2 \%$ NEEENENSISQYK

$0.03 \% \quad 23.3 \%$ NGAVQTIAQR

$0.03 \% \quad 23.3 \%$ VLVAVGNGK

$0.03 \% \quad 23.3 \%$ GAAGFSIGK

$0.03 \% \quad 23.3 \%$ AVHHLHYIER

$0.03 \% \quad 23.3 \%$ YEDHTIFHDISLR

$0.03 \% \quad 23.3 \%$ VSGSINMLSLTQGLFR

$99.6 \% 24.1$

$99.7 \% \quad 46.5$

$99.7 \% \quad 34.3$

$99.7 \% \quad 33.6$

$99.7 \% \quad 34.8$

$99.7 \% \quad 45.5$

$99.7 \% \quad 59.4$

$99.7 \% \quad 36.0$

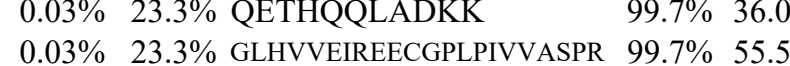

1803.93

942.54

929.49

1358.71

1127.67

1660.83

2560.31

1630.93

1350.66

1213.57

1324.80

1139.58

1067.54

1441.76

1100.63

2031.09

1658.92

1259.74

1131.64

1715.93

1321.65

1478.71

846.47

1812.87

1270.63

1802.79

1282.65

1023.53

915.51

1462.88

2106.01

1202.68

1534.78

2197.06

1583.68

1057.57

856.53

807.44

1274.68

1645.80

1738.92

1325.68 2427.32 \begin{tabular}{|c|}
\hline 74 \\
82 \\
94 \\
214 \\
233 \\
\hline 241 \\
274 \\
277 \\
288 \\
326 \\
333 \\
361 \\
408 \\
102 \\
113 \\
123 \\
175 \\
232 \\
245 \\
\hline 294 \\
294 \\
331 \\
\hline 331 \\
393 \\
287 \\
325 \\
\hline 135 \\
189 \\
209 \\
240 \\
266 \\
\hline 369 \\
\hline
\end{tabular} 
$28 \mathrm{~S}$ ribosomal protein S9, mitochondrial GN=MRPS9 RT09 HUMAN $45.84 \quad 100.0 \%$ $28 \mathrm{~S}$ ribosomal protein $\mathrm{S} 9$, mitochondrial GN=MRPS9 RT09_HUMAN $45.84 \quad 100.0 \%$ $28 \mathrm{~S}$ ribosomal protein $\mathrm{S} 9$, mitochondrial GN=MRPS9 RT09_HUMAN $45.84 \quad 100.0 \%$ $28 \mathrm{~S}$ ribosomal protein $\mathrm{S} 9$, mitochondrial GN=MRPS9 RT09 HUMAN $45.84 \quad 100.0 \%$ $28 \mathrm{~S}$ ribosomal protein S9, mitochondrial GN=MRPS9 RT09_HUMAN $45.84 \quad 100.0 \%$ $28 \mathrm{~S}$ ribosomal protein S9, mitochondrial GN=MRPS9 RT09_HUMAN $45.84 \quad 100.0 \%$ $28 \mathrm{~S}$ ribosomal protein S9, mitochondrial GN=MRPS9 RT09_HUMAN $45.84 \quad 100.0 \%$ 2-amino-3-ketobutyrate coenzyme A ligase, mitochondrial GN=GCAT KBL_HUMAN $45.29 \quad 100.0 \%$ 2-amino-3-ketobutyrate coenzyme A ligase, mitochondrial GN=GCAT KBL HUMAN $45.29 \quad 100.0 \%$ 2-amino-3-ketobutyrate coenzyme A ligase, mitochondrial GN=GCAT KBL_HUMAN $45.29 \quad 100.0 \%$ 2-amino-3-ketobutyrate coenzyme A ligase, mitochondrial GN=GCAT KBL_HUMAN $45.29 \quad 100.0 \%$ 2-amino-3-ketobutyrate coenzyme A ligase, mitochondrial GN=GCAT KBL HUMAN 45.29 2-amino-3-ketobutyrate coenzyme A ligase, mitochondrial GN=GCAT KBL_HUMAN 45.29 2-amino-3-ketobutyrate coenzyme A ligase, mitochondrial GN=GCAT KBL_HUMAN 45.29 2-amino-3-ketobutyrate coenzyme A ligase, mitochondrial GN=GCAT KBL HUMAN 45.29 2-amino-3-ketobutyrate coenzyme A ligase, mitochondrial GN=GCAT KBL_HUMAN 45.29 2-amino-3-ketobutyrate coenzyme A ligase, mitochondrial GN=GCAT KBL HUMAN 45.29 2-amino-3-ketobutyrate coenzyme A ligase, mitochondrial $\mathrm{GN}=\mathrm{GCAT} \quad \mathrm{KBL}$ HUMAN 45.29 2-methoxy-6-polyprenyl-1,4-benzoquinol methylase, mitochondrial GN=COQ5 COQ5_HUMAN 37.14 2-methoxy-6-polyprenyl-1,4-benzoquinol methylase, mitochondrial GN=COQ5 COQ5 HUMAN 37.14 2-methoxy-6-polyprenyl-1,4-benzoquinol methylase, mitochondrial GN=COQ5 COQ5_HUMAN 37.14 2-methoxy-6-polyprenyl-1,4-benzoquinol methylase, mitochondrial GN=COQ5 COQ5 HUMAN 37.14 2-oxoisovalerate dehydrogenase subunit alpha, mitochondrial GN=BCKDHA ODBA_HUMAN 50.47 2-oxoisovalerate dehydrogenase subunit alpha, mitochondrial GN=BCKDHA ODBA_HUMAN 50.47 2-oxoisovalerate dehydrogenase subunit beta, mitochondrial GN=BCKDHB ODBB_HUMAN 43.12 2-oxoisovalerate dehydrogenase subunit beta, mitochondrial GN=BCKDHB ODBB_HUMAN 43.12 2-oxoisovalerate dehydrogenase subunit beta, mitochondrial $\mathrm{GN}=\mathrm{BCKDHB} \quad \mathrm{ODBB} \_\mathrm{HUMAN} 43.12$ $3^{\prime}\left(2^{\prime}\right), 5^{\prime}$-bisphosphate nucleotidase $1 \mathrm{GN}=\mathrm{BPNT1}$ BPNT1_HUMAN $33.3 \mathrm{C}$ $3^{\prime}\left(2^{\prime}\right), 5^{\prime}$-bisphosphate nucleotidase $1 \mathrm{GN}=\mathrm{BPNT} 1$ BPNT1 HUMAN 33.3 3'(2'),5'-bisphosphate nucleotidase $1 \mathrm{GN}=\mathrm{BPNT1}$ BPNT1_HUMAN 33.39 39S ribosomal protein L10, mitochondrial GN=MRPL10 RM10_HUMAN 29.28 39S ribosomal protein L10, mitochondrial GN=MRPL10 RM10 HUMAN 29.28 39S ribosomal protein L10, mitochondrial GN=MRPL10 RM10_HUMAN 29.28 39S ribosomal protein L15, mitochondrial GN=MRPL15 RM15_HUMAN 33.42 39S ribosomat 39S ribosomal protein L15, mitochondrial GN=MRPL15 RM15_HUMAN $33.42 \quad 100.0 \%$ 39 ribosomal protein $\mathrm{L} 15$, mitochondrial GN=MRPL15 RM15 HUMAN $33.42 \quad 100.0 \%$ 39S ribosomal protein L15, mitochondrial GN=MRPL15 RM15_HUMAN $33.42 \quad 100.0 \%$ 39S ribosomal protein L15, mitochondrial GN=MRPL15 RM15_HUMAN $33.42 \quad 100.0 \%$ 39 ribosomal protein $\mathrm{L} 15$, mitochondrial GN=MRPL15 RM15 HUMAN $33.42 \quad 100.0 \%$ 39S ribosomal protein L19, mitochondrial GN=MRPL19 RM19_HUMAN $33.54 \quad 100.0 \%$ 39S ribosomal protein $\mathrm{L} 19$, mitochondrial GN=MRPL19 RM19 HUMAN $33.54100 .0 \%$ 39S ribosomal protein L19, mitochondrial GN=MRPL19 RM19_HUMAN $33.54 \quad 100.0 \%$ 39S ribosomal protein L19, mitochondrial GN=MRPL19 RM19_HUMAN $33.54 \quad 100.0 \%$ 39S ribosomal protein L19, mitochondrial GN=MRPL19 RM19 HUMAN $33.54 \quad 100.0 \%$ 39S ribosomal protein L19, mitochondrial GN=MRPL19 RM19_HUMAN $33.54 \quad 100.0 \%$
$0.02 \% \quad 19.9 \%$ ETYTEDFIKK

$0.02 \% \quad 19.9 \%$ QIEEFNIGK

$0.02 \% \quad 19.9 \%$ AIAYLFPSGLFEK

$0.02 \% \quad 19.9 \%$ HPEQIFPR

$0.02 \% \quad 19.9 \%$ LSDLDYMQFIR

$0.02 \% \quad 19.9 \%$ LLTSQCGAAEEEFVQR

$0.02 \% \quad 19.9 \%$ HDVTCTVSGGGR

$0.02 \% \quad 37.7 \%$ GILEGELEGIR

$0.02 \% \quad 37.7 \%$ FICGTQSIHK

$0.02 \% \quad 37.7 \%$ HLDMADLEAK

$0.02 \% \quad 37.7 \%$ YGALVFMDECHATGFLGPTGR $\quad 99.7 \% \quad 38.9$

$0.02 \% \quad 37.7 \%$ GTDELLGVMDQVTIINSTLGK $99.7 \% 39.2$

$\begin{array}{llll}0.02 \% & 37.7 \% & \text { ALGGASGGYTTGPGPLVSLLR } \quad 99.7 \% & 57.9\end{array}$

$0.02 \% \quad 37.7 \%$ ALDLLMGSNTIVQSMAAK $99.7 \% \quad 58.0$

$0.02 \% \quad 37.7 \%$ MADDMLKR

$0.02 \% \quad 37.7 \%$ GIFVIGFSYPVVPK

$0.02 \% \quad 37.7 \%$ VQISAVHSEEDIDR

$0.02 \% \quad 37.7 \%$ CVEAFVEVGR

$0.01 \% \quad 14.4 \%$ VYQVFESVAK

$0.01 \% \quad 14.4 \%$ FLNYVQSQHQR

$0.01 \% \quad 14.4 \%$ AQQNLSWEEIAK

$96.5 \% \quad 22.2$

$99.7 \% \quad 34.4$

$99.7 \% 31.9$

$99.7 \% \quad 57.1$

$99.7 \% 55.1$

$99.7 \% 37.2$

$99.7 \% \quad 50.4$

$99.7 \% \quad 36.1$

$\begin{array}{llll}0.00 \% & 8.1 \% & \text { NNGYAISTPTSEQYRGDGIA } \\ 0.00 \% & 8.1 \% & \text { IGHHSTSDDSSAYR }\end{array}$

$99.6 \% \quad 23.7$

$99.4 \% \quad 24.3$

$0.01 \% \quad 13.5 \%$ MNLFQSVTSALDNSLAK $99.6 \%$ \#\#\#\#

$0.01 \% \quad 13.5 \%$ SGDLFNCGSLTIR

$0.01 \% \quad 13.5 \%$ LGVSCEVIDLR

$0.01 \% \quad 13.5 \%$ TIIPWDVDTICK

$0.00 \% \quad 10.1 \%$ LVASAYSIAQK

$0.00 \% \quad 10.1 \%$ IIQLIEGK

$0.00 \% \quad 10.1 \%$ HMNSAGVLATLR

$0.00 \% \quad 14.2 \%$ EIAAVFQDNR

$99.7 \% \quad 64.0$

$99.7 \% \quad 71.1$

$98.3 \% \quad 21.4$

$99.7 \% \quad 67.1$

$96.4 \% 22.1$

$99.6 \% 24.1$

$99.7 \% \quad 61.0$

$0.00 \% \quad 14.2 \%$ TVPFLPLLGGCIDDTILSR $99.7 \% \quad 78.7$

$0.00 \% \quad 14.2 \%$ QGFINYSK

$0.01 \% \quad 27.7 \%$ VSLANLKPNPGSK

$0.01 \% \quad 27.7 \%$ LGFEGGQTPFYIR

$0.01 \% \quad 27.7 \%$ LQYLIDLGR

$0.01 \% \quad 27.7 \%$ GVTIQPLKR

$0.01 \% \quad 27.7 \%$ SLDIVCKPVPFFLR

$0.01 \% \quad 27.7 \%$ GYLADPAKFPEAR

$0.01 \% \quad 27.7 \%$ ILKPTDENLLK

$0.01 \% \quad 23.6 \%$ FLSPEFIPR

$0.01 \% \quad 23.6 \%$ VTTADPYASGK

$0.01 \% \quad 23.6 \%$ ISQFLGICIQR

$0.01 \% \quad 23.6 \%$ GLGATFILR

$0.01 \% \quad 23.6 \%$ VQEIQVVK

$0.01 \% \quad 23.6 \%$ RLDDSLLYLR
$99.0 \% \quad 30.5$

$99.7 \% \quad 40.4$

$99.7 \% \quad 52.6$

$99.7 \% \quad 38.8$

$99.6 \% \quad 24.9$

$99.7 \% \quad 32.5$

$99.7 \% \quad 54.0$

$\begin{array}{lll}98.9 \% & 25.7\end{array}$

$99.7 \% \quad 41.0$

$99.7 \% 49.6$

$99.7 \% \quad 57.5$

$99.7 \% \quad 57.4$

$99.0 \% \quad 28.0$

$99.7 \% \quad 31.0$
1077.56

1455.79

1023.54

1416.68

1837.88

1245.56

1185.65

1190.60

1142.55

2315.06

2220.14

1944.06

1894.96

979.47

1522.87

1597.78

1165.57

1169.62

1419.7

1416.71

1631.82

2341.12

1532.67

1854.93

1439.69

1260.66

1460.75

1150.65

913.57

1285.67

1162.59

2087.12

956.48

1324.76

1484.75

1090.63

1011.63

1690.94

1434.74

1283.76

1105.60

1109.55

1334.73

947.57

942.56

1263.71

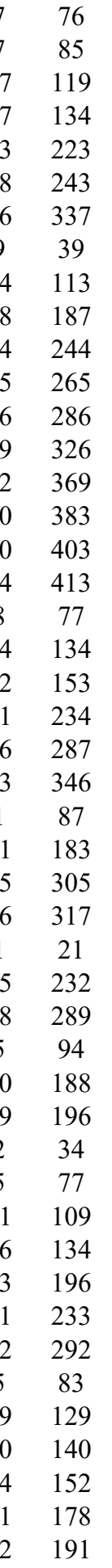

Page 8 of Table S-1-4 
39S ribosomal protein L19, mitochondrial GN=MRPL19 RM19 HUMAN $33.54 \quad 100.0 \%$ 39S ribosomal protein L19, mitochondrial GN=MRPL19 RM19_HUMAN $33.54 \quad 100.0 \%$ 39S ribosomal protein L2, mitochondrial GN=MRPL2 RM02_HUMAN $33.30 \quad 100.0 \%$ $39 \mathrm{~S}$ ribosomal protein $\mathrm{L} 2$, mitochondrial GN=MRPL2 RM02 HUMAN $33.30 \quad 100.0 \%$ 39S ribosomal protein L24, mitochondrial GN=MRPL24 RM24_HUMAN $24.92 \quad 100.0 \%$ 39S ribosomal protein L24, mitochondrial GN=MRPL24 RM24_HUMAN $24.92 \quad 100.0 \%$ 39 S ribosomal protein $\mathrm{L} 28$, mitochondrial GN=MRPL28 RM28 HUMAN $30.16 \quad 100.0 \%$ 39S ribosomal protein L28, mitochondrial GN=MRPL28 RM28_HUMAN $30.16 \quad 100.0 \%$ 39S ribosomal protein $\mathrm{L} 3$, mitochondrial GN=MRPL3 RM03 HUMAN $38.63 \quad 100.0 \%$ $39 \mathrm{~S}$ ribosomal protein $\mathrm{L} 3$, mitochondrial GN=MRPL3 RM03_HUMAN $38.63 \quad 100.0 \%$ 39S ribosomal protein $\mathrm{L} 3$, mitochondrial GN=MRPL3 RM03_HUMAN $38.63 \quad 100.0 \%$ S9 ribosomal protein L3, mitochondrial GN=MRPL3 RM03_HUMAN $38.63 \quad 100.0 \%$ 39S ribosomal protein L3, mitochondrial GN=MRPL3 RM03_HUMAN $38.63 \quad 100.0 \%$ 39S ribosomal protein $\mathrm{L} 37$, mitochondrial GN=MRPL37 RM37 HUMAN $48.12 \quad 100.0 \%$ 39S ribosomal protein $\mathrm{L} 37$, mitochondrial GN=MRPL37 RM37 HUMAN $48.12 \quad 100.0 \%$ 39S ribosomal protein L37, mitochondrial GN=MRPL37 RM37_HUMAN $48.12 \quad 100.0 \%$ $39 \mathrm{~S}$ ribosomal protein $\mathrm{L} 37$, mitochondrial GN=MRPL37 RM37 HUMAN $48.12 \quad 100.0 \%$ 39S ribosomal protein L37, mitochondrial GN=MRPL37 RM37_HUMAN $48.12 \quad 100.0 \%$ 39S ribosomal protein L37, mitochondrial GN=MRPL37 RM37_HUMAN $48.12 \quad 100.0 \%$ 39S ribosomal protein $\mathrm{L} 37$, mitochondrial GN=MRPL37 RM37_HUMAN $48.12 \quad 100.0 \%$ 39S ribosomal protein $\mathrm{L} 37$, mitochondrial GN=MRPL37 RM37_HUMAN $48.12 \quad 100.0 \%$ 39S ribosomal protein $\mathrm{L} 37$, mitochondrial GN=MRPL37 RM37 HUMAN $48.12 \quad 100.0 \%$ 39 S ribosomal protein L37, mitochondrial GN=MRPL37 RM37_HUMAN $48.12 \quad 100.0 \%$ 39S ribosomal protein L37, mitochondrial GN=MRPL37 RM37_HUMAN $48.12 \quad 100.0 \%$ 39S ribosomal protein L38, mitochondrial GN=MRPL38 RM38 HUMAN $44.60 \quad 100.0 \%$ 39S ribosomal protein $\mathrm{L} 38$, mitochondrial GN=MRPL38 RM38_HUMAN $44.60 \quad 100.0 \%$ 39S ribosomal protein L38, mitochondrial GN=MRPL38 RM38_HUMAN $44.60 \quad 100.0 \%$ 39S ribosomal protein $\mathrm{L} 38$, mitochondrial GN=MRPL38 RM38 HUMAN $44.60 \quad 100.0 \%$ 39S ribosomal protein L38, mitochondrial GN=MRPL38 RM38_HUMAN $44.60 \quad 100.0 \%$ $39 \mathrm{~S}$ ribosomal protein $\mathrm{L} 38$, mitochondrial GN=MRPL38 RM38 HUMAN $44.60100 .0 \%$ 39S ribosomal protein L38, mitochondrial GN=MRPL38 RM38_HUMAN $44.60 \quad 100.0 \%$ 39S ribosomal protein L38, mitochondrial GN=MRPL38 RM38_HUMAN $44.60 \quad 100.0 \%$ 39S ribosomal protein $\mathrm{L} 39$, mitochondrial GN=MRPL39 RM39 HUMAN $38.71 \quad 100.0 \%$ 39S ribosomal protein L39, mitochondrial GN=MRPL39 RM39_HUMAN $38.71 \quad 100.0 \%$ 39S ribosomal protein L39, mitochondrial GN=MRPL39 RM39_HUMAN $38.71 \quad 100.0 \%$ 39S ribosomal protein L39, mitochondrial GN=MRPL39 RM39_HUMAN $38.71 \quad 100.0 \%$ 39S ribosomal protein L39, mitochondrial GN=MRPL39 RM39_HUMAN $38.71 \quad 100.0 \%$ 39S ribosomal protein L39, mitochondrial GN=MRPL39 RM39 HUMAN $38.71 \quad 100.0 \%$ 39S ribosomal protein L39, mitochondrial GN=MRPL39 RM39_HUMAN $38.71 \quad 100.0 \%$ 39S ribosomal protein L39, mitochondrial GN=MRPL39 RM39_HUMAN $38.71 \quad 100.0 \%$ 39S ribosomal protein $\mathrm{L} 4$, mitochondrial GN=MRPL4 RM04 HUMAN $34.92 \quad 100.0 \%$ 39S ribosomal protein L4, mitochondrial GN=MRPL4 RM04_HUMAN $34.92 \quad 100.0 \%$ $39 \mathrm{~S}$ ribosomal protein $\mathrm{L} 4$, mitochondrial GN=MRPL4 RM04 HUMAN $34.92 \quad 100.0 \%$ 39S ribosomal protein L4, mitochondrial GN=MRPL4 RM04_HUMAN $34.92 \quad 100.0 \%$ 39S ribosomal protein L44, mitochondrial GN=MRPL44 RM44_HUMAN $37.54 \quad 100.0 \%$ 39S ribosomal protein L44, mitochondrial GN=MRPL44 RM44 HUMAN $37.54 \quad 100.0 \%$ 39S ribosomal protein L44, mitochondrial GN=MRPL44 RM44_HUMAN $37.54 \quad 100.0 \%$
$14 \quad 0.01 \% \quad 23.6 \%$ LDDSLLYLR $0.01 \% \quad 23.6 \%$ FDLCLTEQQMK

$0.00 \% \quad 11.1 \%$ TKYTITPVK

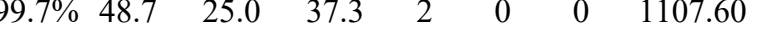
$99.7 \% \quad 37.6$ $99.5 \% \quad 23.5$

$0.00 \% \quad 11.1 \%$ EGDAPLGALPVGTLINVESEPGR $\quad 99.7 \% \quad 56.7$

$0.00 \% \quad 10.2 \%$ GTMIPSEAPLLHR

$0.00 \% \quad 10.2 \%$ IIPKPEFPR

$0.00 \% \quad 9.0 \% \quad$ EFYSEILDKK

$0.00 \% \quad 9.0 \%$ QDPQLHPEDPERR

$0.01 \% \quad 17.2 \%$ QLVSDEDKAQLASK

$0.01 \% \quad 17.2 \%$ HVVTLLQVQDCHVLK

$0.01 \% \quad 17.2 \%$ MATLSVGGK

$0.01 \% \quad 17.2 \%$ KATSILEFYR

$0.01 \% \quad 17.2 \%$ RPGAVATGDIGR

$0.02 \% \quad 35.0 \%$ VYEIPGLEPITFAGK

$0.02 \% \quad 35.0 \%$ SPPLHEHPLYK

$0.02 \% \quad 35.0 \%$ TKLIEGLPEK

$0.02 \% \quad 35.0 \%$ VLSLVDDPR

$99.7 \% \quad 29.3$

$\begin{array}{lll}96.4 \% & 15.4\end{array}$

$99.6 \% \quad 28.7$

$99.7 \% \quad 41.8$

$99.0 \% \quad 26.3$

$99.7 \% \quad 39.7$

$98.2 \% \quad 22.6$

$99.7 \% \quad 29.9$

$99.7 \% \quad 36.6$

$99.7 \% \quad 29.0$

$98.1 \% \quad 16.4$

$99.7 \% \quad 41.9$

$99.7 \% \quad 33.7$

$0.02 \% \quad 35.0 \%$ NHIENQDECVLNVISHAR

$0.02 \% \quad 35.0 \%$ ETYCPVIVDNLIQLCK

$99.7 \% \quad 31$

$0.02 \% \quad 35.0 \%$ ESLLLQVR

$0.02 \% \quad 35.0 \%$ LSTKDPLPTIASR

$0.02 \% \quad 35.0 \%$ MILFAFGSALAQAR

$99.0 \% \quad 46.9$

$97.2 \% \quad 16.0$

$99.7 \% \quad 57.8$

$0.02 \% \quad 35.0 \%$ VLEQPVVVQSVGTDGR

$0.02 \% \quad 35.0 \%$ VVVEPVGPVGFKPETFRK

$0.02 \% \quad 24.2 \%$ IDIGLPPPK

$0.02 \% \quad 24.2 \%$ KQAIQELR

$0.02 \% \quad 24.2 \%$ TASVPLDAVR

$0.02 \% \quad 24.2 \%$ LAEYYGLYR

$0.02 \% \quad 24.2 \%$ DLFHGATFVPR

$99.7 \% \quad 65.5$

$99.0 \% \quad 45.8$

$99.7 \% \quad 38.5$

$99.7 \% \quad 60.8$

$99.7 \% \quad 44.1$

$0.02 \% \quad 24.2 \%$ VAEGQVTCPYLPPFPAR

$0.02 \% \quad 24.2 \%$ HQETMTPAGLSFFQCR

$0.02 \% \quad 24.2 \%$ YRDSHEPTYGIY

$0.02 \% \quad 28.1 \%$ TDPGTVFVMNK

$0.02 \% \quad 28.1 \%$ FLTFKDCDPGEVNK

$0.02 \% \quad 28.1 \%$ AFKDEYMVNLVR

$0.02 \% \quad 28.1 \%$ DLPFETLEVEAK

$0.02 \% \quad 28.1 \%$ VALEIFQHSK

$0.02 \% \quad 28.1 \%$ YKVDFIEEK

$0.02 \% \quad 28.1 \%$ IGDFIDVSEGPLIPR

$0.02 \% \quad 28.1 \%$ RFQGVSLPVHLR

$0.01 \% \quad 18.3 \%$ ATENPEQVASEGLPEPVLR

$0.01 \% \quad 18.3 \%$ KVELPVPTHR

$0.01 \% \quad 18.3 \%$ VGLADLHPDVFATAPR

$0.01 \% \quad 18.3 \%$ GPTSYYYMLPMK

$0.02 \% \quad 34.6 \%$ LQENFSLDLLK

$0.02 \% \quad 34.6 \%$ TAFVNSCYIK

$0.02 \% \quad 34.6 \%$ EAVLLNLK
$99.6 \% 23$.

$99.6 \% \quad 26.5$

$99.4 \% \quad 21.1$

$99.7 \% \quad 30.4$

$\begin{array}{lll}99.4 \% & 20.7\end{array}$

$99.7 \% \quad 34.4$

$99.7 \% \quad 53.8$

$99.7 \% \quad 33.1$

$99.7 \% \quad 61.0$

$99.7 \% \quad 29.5$

$9.7 \% \quad 54.3$

$99.7 \% \quad 27.9$

$99.7 \% \quad 56.4$

$99.7 \% \quad 54.9$

$99.7 \% \quad 45.9$

$99.7 \% \quad 35.7$

$99.0 \% \quad 20.6$
37.3
37.6

$\begin{array}{ll}25.0 & 17.7\end{array}$

$\begin{array}{ll}0 & 56.7\end{array}$

$\begin{array}{ll}0 & 29.3 \\ 2 & -0\end{array}$

$\begin{array}{ll}0 & 15.0\end{array}$

15.5

$\begin{array}{ll}.0 & 41.8\end{array}$

$\begin{array}{ll}.0 & 26.3\end{array}$

$\begin{array}{ll}0 & 39.7\end{array}$

$\begin{array}{ll}25.0 & 13.1\end{array}$

$\begin{array}{ll} & \\ & 22.1\end{array}$

27.0
25.0

$\begin{array}{ll}0 & 25.2\end{array}$

$\begin{array}{ll}0 & 16.4\end{array}$

$\begin{array}{ll}58.0 & 38.2\end{array}$

$\begin{array}{ll}0 & 23.1\end{array}$

0

$\begin{array}{ll}57.2 \\ 25.0 & 35.2\end{array}$

57.2
0.0

\begin{tabular}{ll}
15.7 \\
\hline
\end{tabular}

$\begin{array}{ll}0 & 51.9\end{array}$

$\begin{array}{ll}5.0 & 65.5\end{array}$

$\begin{array}{ll}5.0 & 29.0\end{array}$

$\begin{array}{ll}.0 & 23.8\end{array}$

.027 .6

51.

5.036

\begin{tabular}{ll}
$25.0 \quad 46.0$ \\
\hline
\end{tabular}

\begin{tabular}{ll}
23.1 \\
\hline
\end{tabular}

\begin{tabular}{ll}
26.5 \\
\hline
\end{tabular}

21.1
25.0

\begin{tabular}{ll}
30.4 \\
\hline
\end{tabular}

$\begin{array}{ll}25.0 & 20.7\end{array}$

$\begin{array}{ll}20.7 & 32.0\end{array}$

$\begin{array}{ll}25.0 & 40.3\end{array}$

$\begin{array}{ll}0 & 28.3\end{array}$

$25.0 \quad 59.1$

$\begin{array}{ll}0 & 29.5\end{array}$

53.0

$25.0 \quad 27.9$

$\begin{array}{ll}27.9 & 56.4\end{array}$

$54.0 \quad 54.9$

31.0

1122

$\begin{array}{ll}11 & 22\end{array}$

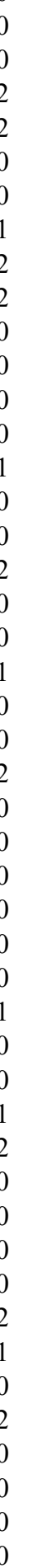

1428.65

1050.62

2542.29

1437.75

1096.65

1271.65

1616.78

1531.80

1788.98

863.47

1227.67

1169.64

1633.88

1317.70

1127.67

1013.56

2148.03

1964.98

957.57

1398.80

1511.80

1682.91

1985.12

949.57

985.58

1028.57

1147.58

1259.65

1901.96

1925.86

1500.68

1208.60

1669.79

1500.75

1390.71

1171.65

1170.60

1627.87

1408.82

2036.03

1175.69

1678.89

1482.66

1319.72

1202.59

899.56 
39S ribosomal protein L44, mitochondrial GN=MRPL44 RM44_HUMAN $37.54 \quad 100.0 \%$ 39S ribosomal protein L44, mitochondrial GN=MRPL44 RM44_HUMAN $37.54 \quad 100.0 \%$ 39S ribosomal protein L44, mitochondrial GN=MRPL44 RM44 HUMAN $37.54 \quad 100.0^{\circ}$ 39S ribosomal protein L44, mitochondrial GN=MRPL44 RM44_HUMAN $37.54 \quad 100.0 \%$ 39S ribosomal protein L44, mitochondrial GN=MRPL44 RM44_HUMAN $37.54 \quad 100.0 \%$ 39S ribosomal protein L44, mitochondrial GN=MRPL44 RM44_HUMAN $37.54 \quad 100.0 \%$ 39S ribosomal protein L46, mitochondrial GN=MRPL46 RM46_HUMAN $31.71 \quad 100.0 \%$ 39S ribosomal protein L46, mitochondrial GN=MRPL46 RM46 HUMAN $31.71 \quad 100.0 \%$ 39S ribosomal protein L46, mitochondrial GN=MRPL46 RM46_HUMAN $31.71 \quad 100.0 \%$ 39S ribosomal protein L46, mitochondrial GN=MRPL46 RM46_HUMAN $31.71 \quad 100.0 \%$ 3-hydroxyacyl-CoA dehydrogenase type-2 GN=HSD17B10 HCD2 HUMAN $26.92 \quad 100.0 \%$ 3-hydroxyacyl-CoA dehydrogenase type-2 GN=HSD17B10 HCD2_HUMAN $26.92 \quad 100.0 \%$ $40 \mathrm{~S}$ ribosomal protein $\mathrm{S} 2 \mathrm{GN}=\mathrm{RPS} 2$ $40 \mathrm{~S}$ ribosomal protein $\mathrm{S} 2 \mathrm{GN}=\mathrm{RPS} 2$ $40 \mathrm{~S}$ ribosomal protein $\mathrm{S} 2 \mathrm{GN}=\mathrm{RPS} 2$ $40 \mathrm{~S}$ ribosomal protein $\mathrm{S} 2 \mathrm{GN}=\mathrm{RPS} 2$ $40 \mathrm{~S}$ ribosomal protein $\mathrm{S} 2 \mathrm{GN}=\mathrm{RPS} 2$ $40 \mathrm{~S}$ ribosomal protein $\mathrm{S} 2 \mathrm{GN}=\mathrm{RPS} 2$ $40 \mathrm{~S}$ ribosomal protein $\mathrm{S} 2 \mathrm{GN}=\mathrm{RPS} 2$ $40 \mathrm{~S}$ ribosomal protein $\mathrm{S} 2 \mathrm{GN}=\mathrm{RPS} 2$ $40 \mathrm{~S}$ ribosomal protein $\mathrm{S} 2 \mathrm{GN}=\mathrm{RPS} 2$ $40 \mathrm{~S}$ ribosomal protein $\mathrm{S} 2 \mathrm{GN}=\mathrm{RPS} 2$ $40 \mathrm{~S}$ ribosomal protein $\mathrm{S} 2 \mathrm{GN}=\mathrm{RPS} 2$ $40 \mathrm{~S}$ ribosomal protein $\mathrm{S} 2 \mathrm{GN}=\mathrm{RPS} 2$ $40 \mathrm{~S}$ ribosomal protein $\mathrm{S} 3 \mathrm{GN}=\mathrm{RPS} 3$ $40 \mathrm{~S}$ ribosomal protein $\mathrm{S} 3 \mathrm{GN}=\mathrm{RPS} 3$ $40 \mathrm{~S}$ ribosomal protein $\mathrm{S} 3 \mathrm{GN}=\mathrm{RPS} 3$ $40 \mathrm{~S}$ ribosomal protein $\mathrm{S} 3 \mathrm{GN}=\mathrm{RPS} 3$ $40 \mathrm{~S}$ ribosomal protein $\mathrm{S} 3 \mathrm{GN}=\mathrm{RPS} 3$ $40 \mathrm{~S}$ ribosomal protein $\mathrm{S} 3 \mathrm{GN}=\mathrm{RPS} 3$ $40 \mathrm{~S}$ ribosomal protein $\mathrm{S} 3 \mathrm{GN}=\mathrm{RPS} 3$ $40 \mathrm{~S}$ ribosomal protein $\mathrm{S} 3 \mathrm{GN}=\mathrm{RPS} 3$ $40 \mathrm{~S}$ ribosomal protein $\mathrm{S} 3 \mathrm{GN}=\mathrm{RPS} 3$ $40 \mathrm{~S}$ ribosomal protein $\mathrm{S} 3 \mathrm{GN}=\mathrm{RPS} 3$ $40 \mathrm{~S}$ ribosomal protein $\mathrm{S} 3 \mathrm{GN}=\mathrm{RPS} 3$ $40 \mathrm{~S}$ ribosomal protein $\mathrm{S} 3 \mathrm{GN}=\mathrm{RPS} 3$ 40S ribosomal protein $\mathrm{S} 3 \mathrm{GN}=\mathrm{RPS} 3$ $40 \mathrm{~S}$ ribosomal protein $\mathrm{S} 3 \mathrm{GN}=\mathrm{RPS} 3$ $40 \mathrm{~S}$ ribosomal protein $\mathrm{S} 3 \mathrm{GN}=\mathrm{RPS} 3$ $40 \mathrm{~S}$ ribosomal protein $\mathrm{S} 3 \mathrm{GN}=\mathrm{RPS} 3$ $40 \mathrm{~S}$ ribosomal protein $\mathrm{S} 3 \mathrm{GN}=\mathrm{RPS} 3$ $40 \mathrm{~S}$ ribosomal protein $\mathrm{S} 3 \mathrm{GN}=\mathrm{RPS} 3$ $40 \mathrm{~S}$ ribosomal protein $\mathrm{S} 3 \mathrm{GN}=\mathrm{RPS} 3$ $40 \mathrm{~S}$ ribosomal protein $\mathrm{S} 3 \mathrm{GN}=\mathrm{RPS} 3$ $40 \mathrm{~S}$ ribosomal protein $\mathrm{S} 3 \mathrm{a} \mathrm{GN}=\mathrm{RPS} 3 \mathrm{~A}$ $40 \mathrm{~S}$ ribosomal protein $\mathrm{S} 3 \mathrm{a} \mathrm{GN}=\mathrm{RPS} 3 \mathrm{~A}$
RS2 HUMAN $31.33 \quad 100.0 \% \quad 12$ RS2_HUMAN $31.33 \quad 100.0 \% \quad 12$ RS2_HUMAN $31.33 \quad 100.0 \% \quad 12$ RS2 HUMAN $31.33 \quad 100.0 \% \quad 12$ RS2_HUMAN $31.33 \quad 100.0 \% \quad 12$ RS2_HUMAN $31.33 \quad 100.0 \% \quad 12$ RS2 HUMAN $31.33 \quad 100.0 \% \quad 12$ RS2_HUMAN $31.33 \quad 100.0 \% \quad 12$ RS2 HUMAN $31.33 \quad 100.0 \% \quad 12$ RS2 HUMAN $31.33 \quad 100.0 \% \quad 12$ RS2_HUMAN $31.33 \quad 100.0 \% \quad 12$ RS2 HUMAN $31.33 \quad 100.0 \% \quad 12$ RS3_HUMAN $26.69 \quad 100.0 \% \quad 20$ RS3_HUMAN $26.69 \quad 100.0 \% \quad 20$ RS3 HUMAN $26.69 \quad 100.0 \% \quad 20$ RS3_HUMAN $26.69 \quad 100.0 \% \quad 20$ RS3 HUMAN $26.69 \quad 100.0 \% \quad 20$ RS3_HUMAN $26.69 \quad 100.0 \% \quad 20$ RS3_HUMAN $26.69 \quad 100.0 \% \quad 20$ RS3 HUMAN $26.69 \quad 100.0 \% \quad 20$ RS3_HUMAN $26.69 \quad 100.0 \% \quad 20$ RS3_HUMAN $26.69 \quad 100.0 \% \quad 20$ RS3_HUMAN $26.69 \quad 100.0 \% \quad 20$ RS3_HUMAN $26.69 \quad 100.0 \% \quad 20$ RS3 HUMAN $26.69 \quad 100.0 \% \quad 20$ RS3_HUMAN $26.69 \quad 100.0 \% \quad 20$ RS3_HUMAN $26.69 \quad 100.0 \% \quad 20$ RS3 HUMAN $26.69 \quad 100.0 \% \quad 20$ RS3_HUMAN $26.69 \quad 100.0 \% \quad 20$ RS3 HUMAN $26.69 \quad 100.0 \% \quad 20$ RS3_HUMAN $26.69 \quad 100.0 \% \quad 20$ RS3_HUMAN $26.69 \quad 100.0 \% \quad 20$ RS3A_HUMAN $29.95 \quad 100.0 \% \quad 20$ RS3A_HUMAN $29.95 \quad 100.0 \% \quad 20$
$0.02 \% \quad 34.6 \%$ NLVDFLTGEEVVC $0.02 \% \quad 34.6 \%$ IINPMGLLVEELK

$0.02 \% \quad 34.6 \%$ NVSAPESR

$\begin{array}{lll}99.7 \% & 52.1 & 25.0\end{array}$

$99.0 \% 22$.

$0.02 \% \quad 34.6 \%$ LIAEGPGETVLVAEEEAAR $\quad 99.7 \% \quad 74.6$

$0.02 \% 34.6 \%$ KLYGFTENR

$0.02 \% \quad 34.6 \%$ LYGFTENR

$0.01 \% \quad 16.5 \%$ SLYSDHELR

$0.01 \% \quad 16.5 \%$ ITEADEKNDR

$0.01 \% \quad 16.5 \%$ TLATLSENNMEAK

$0.01 \% \quad 16.5 \%$ ALLLTGDFSQAGNK

$0.00 \% \quad 7.7 \%$ GGIVGMTLPIAR

$0.00 \% \quad 7.7 \%$ DLAPIGIR

$90 \quad 0.09 \% \quad 43.7 \%$ AEDKEWMPVTK

$90 \quad 0.09 \% \quad 43.7 \%$ SLEEIYLFSLPIK

$90 \quad 0.09 \% \quad 43.7 \%$ AFVAIGDYNGHVGLGVK

$90 \quad 0.09 \% \quad 43.7 \%$ LSIVPVRR

$90 \quad 0.09 \% \quad 43.7 \%$ IGKPHTVPCK

$90 \quad 0.09 \% \quad 43.7 \%$ GTGIVSAPVPK

$99.7 \% \quad 34$

$99.0 \% \quad 29.0$

$99.7 \% \quad 40.3$

$99.7 \% 55.8$

$99.7 \% \quad 47.1$

$99.7 \% \quad 47.8$

$99.7 \% 34.1$

$99.0 \% \quad 27.6$

$99.7 \% \quad 62.7$

$99.7 \% \quad 50.2$

$99.7 \% \quad 68.9$

$99.0 \% \quad 46.5$

$99.7 \% \quad 45.6$

$99.7 \% \quad 51.2$

$99.7 \% \quad 53.3$

$99.7 \% \quad 52.0$

$99.7 \% \quad 55.5$

$99.0 \% \quad 49.8$

$99.7 \% \quad 53.6$

$99.7 \% \quad 46.0$

$99.7 \% \quad 57.0$

$98.5 \% 18.1$

$99.7 \% \quad 56.5$

$99.7 \% \quad 66.9$

$99.7 \% \quad 54.2$

$99.0 \% \quad 41.4$

$99.7 \% \quad 51.5$

$99.0 \% \quad 49.6$

$99.7 \% \quad 44.7$

$99.7 \% \quad 54.5$

$99.7 \% \quad 62.1$

$99.7 \% \quad 58.9$

$99.7 \% \quad 29.8$

$99.0 \% \quad 44.6$

$99.7 \% \quad 50.2$

$99.7 \% \quad 53.8$

$\begin{array}{lll}99.7 \% & 37.1\end{array}$

$99.7 \% \quad 29.0$

$99.7 \% \quad 44.6$

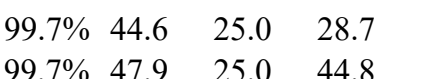

$\begin{array}{llll}99.7 \% & 32.0 & 25.0 & 44.8\end{array}$

$\begin{array}{llll}99.0 \% & 60.8 & 25.0 & 49.7\end{array}$
1954.01

1127.58

999.49

1119.54

1190.56

1437.69

1434.76

1184.68

854.51

1333.65

1551.87

1716.91

939.61

1136.62

1025.60

1844.87

1748.77

1139.55

852.45

1386.69

1463.72

1024.58

896.49

1092.57

1423.67

1029.63

888.48

1156.70

887.52

1043.62

1728.86

1572.76

1288.67

1089.68

882.44

934.47

2468.19

1173.60

1458.83

1470.77

1573.80

919.52

919.48 $\begin{array}{cc}34 & 246 \\ 49 & 256 \\ 60 & 279 \\ 80 & 298 \\ 03 & 311 \\ 04 & 311 \\ 32 & 90 \\ 37 & 146 \\ 91 & 203 \\ 36 & 249 \\ 73 & 184 \\ 85 & 192 \\ 55 & 65 \\ 77 & 89 \\ 26 & 142 \\ 60 & 167 \\ 74 & 183 \\ 01 & 211 \\ 12 & 227 \\ 13 & 227 \\ 28 & 238 \\ 39 & 246 \\ 47 & 257 \\ 64 & 275 \\ 10 & 18 \\ 11 & 18 \\ 19 & 27 \\ 28 & 40 \\ 46 & 54 \\ 55 & 62 \\ 56 & 75 \\ 68 & 75 \\ 68 & 76 \\ 76 & 90 \\ 77 & 90 \\ 95 & 106 \\ 07 & 116 \\ 25 & 132 \\ 33 & 141 \\ 52 & 173 \\ 88 & 197 \\ 02 & 214 \\ 15 & 227 \\ 28 & 243 \\ 21 & 28 \\ 35 & 42 \\ & \end{array}$

Page 10 of Table S-1-4 
$40 \mathrm{~S}$ ribosomal protein $\mathrm{S} 3 \mathrm{a} \mathrm{GN}=\mathrm{RPS} 3 \mathrm{~A}$ $40 \mathrm{~S}$ ribosomal protein $\mathrm{S} 3 \mathrm{a} \mathrm{GN}=\mathrm{RPS} 3 \mathrm{~A}$ 40 S ribosomal protein $\mathrm{S} 3 \mathrm{a}$ GN=RPS3A $40 \mathrm{~S}$ ribosomal protein $\mathrm{S} 3 \mathrm{a} \mathrm{GN}=\mathrm{RPS} 3 \mathrm{~A}$ $40 \mathrm{~S}$ ribosomal protein $\mathrm{S} 3 \mathrm{a} \mathrm{GN}=\mathrm{RPS} 3 \mathrm{~A}$ $40 \mathrm{~S}$ ribosomal protein $\mathrm{S} 3 \mathrm{a} \mathrm{GN}=\mathrm{RPS} 3 \mathrm{~A}$ $40 \mathrm{~S}$ ribosomal protein $\mathrm{S} 3 \mathrm{a} \mathrm{GN}=\mathrm{RPS3A}$ $40 \mathrm{~S}$ ribosomal protein $\mathrm{S} 3 \mathrm{a} \mathrm{GN}=\mathrm{RPS3A}$ 40 S ribosomal protein $\mathrm{S} 3 \mathrm{a} \mathrm{GN}=\mathrm{RPS} 3 \mathrm{~A}$ $40 \mathrm{~S}$ ribosomal protein $\mathrm{S} 3 \mathrm{a} \mathrm{GN}=\mathrm{RPS3} \mathrm{A}$ $40 \mathrm{~S}$ ribosomal protein $\mathrm{S} 3 \mathrm{a} \mathrm{GN}=\mathrm{RPS} 3 \mathrm{~A}$ $40 \mathrm{~S}$ ribosomal protein $\mathrm{S} 3 \mathrm{a} \mathrm{GN}=\mathrm{RPS} 3 \mathrm{~A}$ $40 \mathrm{~S}$ ribosomal protein $\mathrm{S} 3 \mathrm{a} \mathrm{GN}=\mathrm{RPS} 3 \mathrm{~A}$ $40 \mathrm{~S}$ ribosomal protein $\mathrm{S} 3 \mathrm{a} \mathrm{GN}=\mathrm{RPS} 3 \mathrm{~A}$ $40 \mathrm{~S}$ ribosomal protein $\mathrm{S} 3 \mathrm{a} \mathrm{GN}=\mathrm{RPS} 3 \mathrm{~A}$ $40 \mathrm{~S}$ ribosomal protein $\mathrm{S} 3 \mathrm{a}$ GN=RPS3A $40 \mathrm{~S}$ ribosomal protein $\mathrm{S} 3 \mathrm{a} \mathrm{GN}=\mathrm{RPS} 3 \mathrm{~A}$ $40 \mathrm{~S}$ ribosomal protein $\mathrm{S} 3 \mathrm{a} \mathrm{GN}=\mathrm{RPS} 3 \mathrm{~A}$ 40S ribosomal protein S4, X isoform GN=RPS4X RS4X_HUMAN 29.60 40S ribosomal protein S4, X isoform GN=RPS4X RS4X_HUMAN 29.60 40S ribosomal protein S4, X isoform GN=RPS4X RS4X_HUMAN 29.60 40 S ribosomal protein S4, X isoform GN=RPS4X RS4X HUMAN 29.60 $40 \mathrm{~S}$ ribosomal protein S4, X isoform GN=RPS4X RS4X_HUMAN 29.60 40S ribosomal protein S4, X isoform GN=RPS4X RS4X_HUMAN 29.60 40S ribosomal protein S4, X isoform GN=RPS4X RS4X_HUMAN 29.60 40 S ribosomal protein S4, X isoform GN=RPS4X RS4X_HUMAN 29.60 40S ribosomal protein S4, X isoform GN=RPS4X RS4X_HUMAN 29.60 40S ribosomal protein S4, X isoform GN=RPS4X RS4X HUMAN 29.60 40S ribosomal protein S4, X isoform GN=RPS4X RS4X_HUMAN 29.60 40S ribosomal protein S4, X isoform GN=RPS4X RS4X_HUMAN 29.60 40S ribosomal protein S4, X isoform GN=RPS4X RS4X_HUMAN 29.60 40S ribosomal protein S4, X isoform GN=RPS4X RS4X_HUMAN 29.60 40S ribosomal protein S4, X isoform GN=RPS4X RS4X_HUMAN 29.60 40S ribosomal protein S4, X isoform GN=RPS4X RS4X_HUMAN 29.60 40S ribosomal protein S4, X isoform GN=RPS4X RS4X_HUMAN 29.60 $40 \mathrm{~S}$ ribosomal protein $\mathrm{S} 4, \mathrm{X}$ isoform GN=RPS4X RS4X HUMAN 29.60 40S ribosomal protein S4, X isoform GN=RPS4X RS4X_HUMAN 29.60 40S ribosomal protein S4, X isoform GN=RPS4X RS4X HUMAN 29.60 40S ribosomal protein S4, X isoform GN=RPS4X RS4X_HUMAN 29.60 40S ribosomal protein S4, X isoform GN=RPS4X RS4X_HUMAN 29.60 $40 \mathrm{~S}$ ribosomal protein $\mathrm{S} 6 \mathrm{GN}=\mathrm{RPS} 6$ $40 \mathrm{~S}$ ribosomal protein $\mathrm{S} 6 \mathrm{GN}=\mathrm{RPS} 6$ $40 \mathrm{~S}$ ribosomal protein $\mathrm{S} 6 \mathrm{GN}=\mathrm{RPS} 6$ $40 \mathrm{~S}$ ribosomal protein $\mathrm{S} 6 \mathrm{GN}=\mathrm{RPS} 6$ $40 \mathrm{~S}$ ribosomal protein $\mathrm{S} 6 \mathrm{GN}=\mathrm{RPS} 6$ $40 \mathrm{~S}$ ribosomal protein $\mathrm{S} 6 \mathrm{GN}=\mathrm{RPS} 6$ $40 \mathrm{~S}$ ribosomal protein $\mathrm{S} 6 \mathrm{GN}=\mathrm{RPS} 6$ $\begin{array}{ll}100.0 \% & 22\end{array}$ $\begin{array}{llll}\text { RS6 HUMAN } & 28.68 & 100.0 \% & 15\end{array}$ RS6_HUMAN $28.68 \quad 100.0 \% \quad 15$ RS6 HUMAN $28.68 \quad 100.0 \% \quad 15$ RS6_HUMAN $28.68 \quad 100.0 \% \quad 15$ RS6_HUMAN $28.68 \quad 100.0 \% \quad 15$ RS6 HUMAN $28.68 \quad 100.0 \% \quad 15$ RS6_HUMAN $28.68 \quad 100.0 \% \quad 15$

33

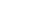

33

33

33

33

33
33
20

33

33
35

35

35

35

35

35
35

$\begin{array}{ll}35 \\ 22 & 35 \\ & 35\end{array}$

35

22
22

$\begin{array}{ll}22 & 35 \\ 22 & 35 \\ 22 & 35\end{array}$

22

22
22
22

$\begin{array}{ll}22 & 35 \\ 22 & 35 \\ 22 & 35\end{array}$

$\begin{array}{ll}32 & 35 \\ 22 & 35 \\ 2 & 35\end{array}$

$\begin{array}{ll}22 & 35 \\ 2 & 35 \\ 2 & 35\end{array}$

$\begin{array}{ll}35 \\ 22 & 35 \\ 2 & 35\end{array}$

35
35

35
25
25

25
25
25

25
25
25

25
25
25
25

\begin{tabular}{|c|c|c|c|c|c|}
\hline $0.09 \%$ & $\% \mathrm{~V}$ & $99.7 \%$ & 61.9 & 25.0 & 59.5 \\
\hline $0.09 \%$ & 67.4\% VFEVSLADLQNDEVAFRK & $99.7 \%$ & 54.3 & 25.0 & 52.7 \\
\hline $0.09 \%$ & $67.4 \%$ LITEDVQGK & $99.7 \%$ & 53.5 & 25.0 & 44.0 \\
\hline $0.09 \%$ & 67.4\% NCLTNFHGMDLTR & $99.7 \%$ & 51.1 & 25.0 & 51.1 \\
\hline $0.09 \%$ & 67.4\% KWQTMIEAHVDVK & $94.7 \%$ & 18.9 & 25.0 & 10.5 \\
\hline $0.09 \%$ & $67.4 \%$ TTDGYLLR & $99.0 \%$ & 47.6 & 25.0 & 29.5 \\
\hline $0.09 \%$ & $67.4 \%$ LFCVGFTK & $99.0 \%$ & 42.6 & 25.0 & 31.3 \\
\hline $0.09 \%$ & 67.4\% LFCVGFTKK & $99.5 \%$ & 23.9 & 25.0 & 18.9 \\
\hline $0.09 \%$ & 67.4\% KTSYAQHQQVR & $99.7 \%$ & 61.7 & 25.0 & 47.6 \\
\hline $0.09 \%$ & 67.4\% TSYAQHQQVR & $99.7 \%$ & 60.4 & 25.0 & 49.0 \\
\hline $0.09 \%$ & $67.4 \%$ EVQTNDLK & $99.0 \%$ & 32.2 & 25.0 & 18.1 \\
\hline $0.09 \%$ & 67.4\% EVQTNDLKEVVNK & $99.7 \%$ & 57.9 & 25.0 & 48.6 \\
\hline $0.09 \%$ & 67.4\% LIPDSIGKDIEK & $99.7 \%$ & 47.6 & 25.0 & 43.7 \\
\hline $0.09 \%$ & 67.4\% ACQSIYPLHDVFVR & $99.7 \%$ & 57.2 & 25.0 & 53.6 \\
\hline $0.09 \%$ & 67.4\% FELGKLMELHGEGSSSGK & $99.6 \%$ & 24.8 & 25.0 & 17.7 \\
\hline $0.09 \%$ & $67.4 \%$ LMELHGEGSSSGK & $99.7 \%$ & 55.0 & 25.0 & 54.3 \\
\hline $0.09 \%$ & 67.4\% ATGDETGAKVER & $99.7 \%$ & 61.8 & 25.0 & 49.6 \\
\hline $0.09 \%$ & 67.4\% ADGYEPPVQESV & $99.7 \%$ & 46.3 & 25.0 & 46.3 \\
\hline $0.10 \%$ & 71.9\% LTGVFAPRPSTGPHK & $99.7 \%$ & 41.1 & 25.0 & 34.7 \\
\hline $0.10 \%$ & 71.9\% LRECLPLIIFLR & $99.7 \%$ & 52.2 & 25.0 & 52.2 \\
\hline $0.10 \%$ & 71.9\% LKYALTGDEVK & $99.7 \%$ & 48.8 & 25.0 & 44.8 \\
\hline $0.10 \%$ & 71.9\% YALTGDEVK & $99.7 \%$ & 41.8 & 25.0 & 34.0 \\
\hline $0.10 \%$ & 71.9\% YALTGDEVKK & $99.7 \%$ & 53.5 & 25.0 & 44.5 \\
\hline $0.10 \%$ & 71.9\% VRTDITYPAGFMDVISIDK & $99.7 \%$ & 58.3 & 25.0 & 52.2 \\
\hline $0.10 \%$ & 71.9\% TDITYPAGFMDVISIDK & $99.7 \%$ & 37.4 & 25.0 & 37.4 \\
\hline $0.10 \%$ & 71.9\% TDITYPAGFMDVISIDKTGENFR & $99.7 \%$ & 33.4 & 25.0 & 32.1 \\
\hline $0.10 \%$ & 71.9\% LIYDTKGR & $99.0 \%$ & 30.5 & 25.0 & 30.5 \\
\hline $0.10 \%$ & 71.9\% ITPEEAKYK & $99.7 \%$ & 31.0 & 25.0 & 19.7 \\
\hline $0.10 \%$ & 71.9\% GIPHLVTHDAR & $99.7 \%$ & 55.4 & 25.0 & 49.6 \\
\hline $0.10 \%$ & 71.9\% TIRYPDPLIK & $99.7 \%$ & 40.9 & 25.0 & 29.0 \\
\hline $0.10 \%$ & 71.9\% VNDTIQIDLETGK & $99.7 \%$ & 52.0 & 25.0 & 51.4 \\
\hline $0.10 \%$ & 71.9\% VNDTIQIDLETGKITDFIK & $99.7 \%$ & 41.1 & 25.0 & 41.1 \\
\hline $0.10 \%$ & 71.9\% ITDFIKFDTGNLCMVTGGANLGR & $99.7 \%$ & 44.4 & 25.0 & 44.4 \\
\hline $0.10 \%$ & 71.9\% FDTGNLCMVTGGANLGR & $99.7 \%$ & 67.9 & 25.0 & 67.8 \\
\hline $0.10 \%$ & 71.9\% ERHPGSFDVVHVK & $99.7 \%$ & 42.5 & 25.0 & 40.9 \\
\hline $0.10 \%$ & 71.9\% HPGSFDVVHVK & $99.7 \%$ & 43.4 & 25.0 & 43.4 \\
\hline $0.10 \%$ & 71.9\% DANGNSFATR & $99.7 \%$ & 59.5 & 25.0 & 51.2 \\
\hline $0.10 \%$ & $71.9 \%$ LSNIFVIGK & $99.7 \%$ & 59.7 & 25.0 & 55.5 \\
\hline $0.10 \%$ & 71.9\% GNKPWISLPR & $99.7 \%$ & 36.3 & 25.0 & 36.3 \\
\hline $0.10 \%$ & 71.9\% LTIAEERDK & $99.7 \%$ & 33.3 & 25.0 & 22.4 \\
\hline $0.07 \%$ & $50.6 \%$ MKLNISFPATGCQK & $99.7 \%$ & 56.8 & 25.0 & 56.8 \\
\hline $0.07 \%$ & $50.6 \%$ LNISFPATGCQK & $99.7 \%$ & 39.9 & 25.0 & 37.5 \\
\hline $0.07 \%$ & $50.6 \%$ LIEVDDER & $99.0 \%$ & 53.0 & 25.0 & 45.6 \\
\hline $0.07 \%$ & $50.6 \%$ LIEVDDERK & $98.3 \%$ & 25.5 & 25.0 & 12.3 \\
\hline $0.07 \%$ & $50.6 \%$ RMATEVAADALGEEWK & $97.9 \%$ & 20.7 & 25.0 & 18.2 \\
\hline $0.07 \%$ & $50.6 \%$ MATEVAADALGEEWK & $99.7 \%$ & 70.4 & 25.0 & 69.4 \\
\hline $0.07 \%$ & $50.6 \%$ MATEVAADALGEEWKGYVVR & $99.7 \%$ & 72.9 & 25.0 & 72.9 \\
\hline
\end{tabular}

$\begin{array}{ccccc}0 & 0 & 1951.98 & 66 & 82 \\ 4 & 0 & 2080.07 & 66 & 83 \\ 0 & 0 & 1002.55 & 86 & 94 \\ 4 & 0 & 1594.71 & 95 & 107 \\ 1 & 0 & 1584.82 & 116 & 128 \\ 0 & 0 & 938.49 & 129 & 136 \\ 0 & 0 & 971.50 & 137 & 144 \\ 0 & 0 & 1099.60 & 137 & 145 \\ 3 & 0 & 1345.70 & 152 & 162 \\ 1 & 0 & 1217.60 & 153 & 162 \\ 0 & 0 & 946.48 & 175 & 182 \\ 1 & 0 & 1515.80 & 175 & 187 \\ 0 & 0 & 1327.75 & 188 & 199 \\ 4 & 0 & 1704.85 & 200 & 213 \\ 2 & 0 & 1921.93 & 223 & 240 \\ 4 & 0 & 1331.63 & 228 & 240 \\ 2 & 0 & 1233.61 & 241 & 252 \\ 0 & 0 & 1290.58 & 253 & 264 \\ 1 & 0 & 1564.86 & 23 & 37 \\ 2 & 0 & 1542.92 & 38 & 49 \\ 0 & 0 & 1236.68 & 52 & 62 \\ 0 & 0 & 995.50 & 54 & 62 \\ 0 & 0 & 1123.60 & 54 & 63 \\ 4 & 0 & 2157.09 & 76 & 94 \\ 0 & 0 & 1885.93 & 78 & 94 \\ 4 & 0 & 2606.24 & 78 & 100 \\ 0 & 0 & 965.54 & 101 & 108 \\ 0 & 0 & 1078.58 & 114 & 122 \\ 3 & 0 & 1215.66 & 135 & 145 \\ 3 & 0 & 1215.71 & 146 & 155 \\ 0 & 0 & 1445.75 & 156 & 168 \\ 2 & 0 & 2163.15 & 156 & 174 \\ 1 & 0 & 2516.23 & 169 & 191 \\ 3 & 0 & 1798.82 & 175 & 191 \\ 2 & 0 & 1506.78 & 199 & 211 \\ 4 & 0 & 1221.64 & 201 & 211 \\ 0 & 0 & 1052.48 & 212 & 221 \\ 0 & 0 & 990.60 & 222 & 230 \\ 0 & 0 & 1167.66 & 231 & 240 \\ 0 & 0 & 1074.58 & 246 & 254 \\ 4 & 0 & 1594.81 & 1 & 14 \\ 0 & 0 & 1335.67 & 3 & 14 \\ 0 & 0 & 988.49 & 15 & 22 \\ 0 & 0 & 1116.59 & 15 & 23 \\ 1 & 0 & 1792.85 & 31 & 46 \\ 0 & 0 & 1620.76 & 32 & 46 \\ 6 & 0 & 2195.08 & 32 & 51 \\ & & & \end{array}$

Page 11 of Table S-1-4 
$40 \mathrm{~S}$ ribosomal protein $\mathrm{S} 6 \mathrm{GN}=\mathrm{RPS} 6$ 40S ribosomal protein $\mathrm{S} 6 \mathrm{GN}=\mathrm{RPS} 6$ $40 \mathrm{~S}$ ribosomal protein $\mathrm{S} 6 \mathrm{GN}=\mathrm{RPS} 6$ $40 \mathrm{~S}$ ribosomal protein $\mathrm{S} 6 \mathrm{GN}=\mathrm{RPS} 6$ $40 \mathrm{~S}$ ribosomal protein $\mathrm{S} 6 \mathrm{GN}=\mathrm{RPS} 6$ 40S ribosomal protein $\mathrm{S} 6 \mathrm{GN}=\mathrm{RPS} 6$ $40 \mathrm{~S}$ ribosomal protein $\mathrm{S} 6 \mathrm{GN}=\mathrm{RPS} 6$ $40 \mathrm{~S}$ ribosomal protein $\mathrm{S} 6 \mathrm{GN}=\mathrm{RPS} 6$ $40 \mathrm{~S}$ ribosomal protein $\mathrm{S} 8 \mathrm{GN}=\mathrm{RPS} 8$ $40 \mathrm{~S}$ ribosomal protein $\mathrm{S} 8 \mathrm{GN}=\mathrm{RPS} 8$ $40 \mathrm{~S}$ ribosomal protein $\mathrm{S} 8 \mathrm{GN}=\mathrm{RPS} 8$ $40 \mathrm{~S}$ ribosomal protein $\mathrm{S} 8 \mathrm{GN}=\mathrm{RPS} 8$ $40 \mathrm{~S}$ ribosomal protein $\mathrm{S} 8 \mathrm{GN}=\mathrm{RPS} 8$ $40 \mathrm{~S}$ ribosomal protein $\mathrm{S} 8 \mathrm{GN}=\mathrm{RPS} 8$ $40 \mathrm{~S}$ ribosomal protein $\mathrm{S} 8 \mathrm{GN}=\mathrm{RPS} 8$ $40 \mathrm{~S}$ ribosomal protein $\mathrm{S} 8 \mathrm{GN}=\mathrm{RPS} 8$ $40 \mathrm{~S}$ ribosomal protein $\mathrm{S} 8 \mathrm{GN}=\mathrm{RPS} 8$ $40 \mathrm{~S}$ ribosomal protein $\mathrm{S} 8 \mathrm{GN}=\mathrm{RPS} 8$ $40 \mathrm{~S}$ ribosomal protein $\mathrm{S} 8 \mathrm{GN}=\mathrm{RPS} 8$ $40 \mathrm{~S}$ ribosomal protein $\mathrm{S} 9 \mathrm{GN}=\mathrm{RPS} 9$ $40 \mathrm{~S}$ ribosomal protein $\mathrm{S} 9 \mathrm{GN}=\mathrm{RPS} 9$ $40 \mathrm{~S}$ ribosomal protein $\mathrm{SA} \mathrm{GN}=\mathrm{RPSA}$ $40 \mathrm{~S}$ ribosomal protein $\mathrm{SA}$ GN=RPSA 40S ribosomal protein SA GN=RPSA $40 \mathrm{~S}$ ribosomal protein $\mathrm{SA} \mathrm{GN}=\mathrm{RPSA}$ 40 S ribosomal protein $S A$ GN=RPSA $40 \mathrm{~S}$ ribosomal protein $\mathrm{SA}$ GN=RPSA $5^{\prime}-3$ ' exoribonuclease $2 \mathrm{GN}=\mathrm{XRN} 2$ $5^{\prime}-3$ ' exoribonuclease $2 \mathrm{GN}=\mathrm{XRN} 2$ $5^{\prime}-3$ ' exoribonuclease $2 \mathrm{GN}=\mathrm{XRN} 2$ $40 \mathrm{~S}$ ribosomal protein $\mathrm{S} 8 \mathrm{GN}=\mathrm{RPS} 8$ $40 \mathrm{~S}$ ribosomal protein $\mathrm{SA}$ GN=RPSA

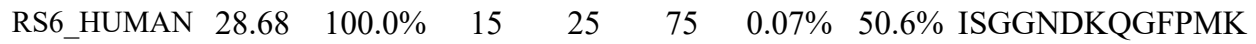
RS6_HUMAN $28.68 \quad 100.0 \% \quad 15$ RS6_HUMAN $28.68 \quad 100.0 \% \quad 15$ RS6 HUMAN $28.68 \quad 100.0 \% \quad 15$ RS6_HUMAN $28.68 \quad 100.0 \% \quad 15$ RS6_HUMAN $28.68 \quad 100.0 \% \quad 15$ RS6 HUMAN $28.68 \quad 100.0 \% \quad 15$ RS6_HUMAN $28.68 \quad 100.0 \% \quad 15$ RS8 HUMAN $24.21 \quad 100.0 \% \quad 12$ RS8_HUMAN $24.21 \quad 100.0 \% \quad 12$ RS8_HUMAN $24.21 \quad 100.0 \% \quad 12$ RS8 HUMAN $24.21 \quad 100.0 \% \quad 12$ RS8_HUMAN $24.21 \quad 100.0 \% \quad 12$ RS8_HUMAN $24.21 \quad 100.0 \% \quad 12$ RS8 HUMAN $24.21 \quad 100.0 \% \quad 12$ RS8_HUMAN $24.21 \quad 100.0 \% \quad 12$ RS8 HUMAN $24.21 \quad 100.0 \% \quad 12$ RS8_HUMAN $24.21 \quad 100.0 \% \quad 12$ RS8_HUMAN $24.21 \quad 100.0 \% \quad 12$ RS8 HUMAN $24.21 \quad 100.0 \% \quad 12$ RS9_HUMAN $22.59 \quad 100.0 \% \quad 2$ RS9_HUMAN $22.59 \quad 100.0 \% \quad 2$ RSSA HUMAN $32.85 \quad 100.0 \% \quad 7$ RSSA_HUMAN $32.85 \quad 100.0 \%$ RSSA HUMAN $32.85 \quad 100.0 \% \quad 7$ RSSA_HUMAN $32.85 \quad 100.0 \% \quad 7$ RSSA_HUMAN $32.85 \quad 100.0 \%$ RSSA HUMAN $32.85 \quad 100.0 \%$ RSSA_HUMAN $32.85 \quad 100.0 \%$ XRN2 HUMAN $108.59 \quad 100.0 \%$ XRN2_HUMAN $108.59 \quad 100.0 \%$ XRN2_HUMAN $108.59 \quad 100.0 \%$ S 5'-AMP-activated protein kinase subunit gamma-1 GN=PRKAG1 AAKG1_HUMAN $37.58 \quad 100.0 \%$ 5'-AMP-activated protein kinase subunit gamma-1 GN=PRKAG1 AAKG1 HUMAN $37.58 \quad 100.0 \%$ 5'-AMP-activated protein kinase subunit gamma-1 GN=PRKAG1 AAKG1_HUMAN $37.58 \quad 100.0 \%$ 5'-AMP-activated protein kinase subunit gamma-1 GN=PRKAG1 AAKG1_HUMAN $37.58 \quad 100.0 \%$ 5'-AMP-activated protein kinase subunit agmma-1 GN=PRKAG1 AAKG1_HUMAN $37.58 \quad 100.0 \%$ 5-methylcytosine rRNA methyltransferase NSUN4 GN=NSUN4 NSUN4_HUMAN $43.09 \quad 100.0 \%$ 5-methylcytosine rRNA methyltransferase NSUN4 GN=NSUN4 NSUN4_HUMAN $43.09 \quad 100.0 \%$ 5-methylcytosine rRNA methyltransferase NSUN4 GN=NSUN4 NSUN4_HUMAN $43.09 \quad 100.0 \%$ 5-methylcytosine rRNA methyltransferase NSUN4 GN=NSUN4 NSUN4_HUMAN $43.09 \quad 100.0 \%$ 5 '-nucleotidase domain-containing protein $2 \mathrm{GN}=\mathrm{NT} 5 \mathrm{DC} 2 \mathrm{NT} 5 \mathrm{D} 2$ HUMAN $60.72 \quad 100.0 \%$ 5 '-nucleotidase domain-containing protein 2 GN=NT5DC2 NT5D2_HUMAN $60.72 \quad 100.0 \%$ $60 \mathrm{kDa}$ heat shock protein, mitochondrial GN=HSPD1 CH60_HUMAN $61.06 \quad 100.0 \% \quad 2$ $60 \mathrm{kDa}$ heat shock protein, mitochondrial GN=HSPD1 CH60_HUMAN $61.06 \quad 100.0 \% \quad 22$ $60 \mathrm{kDa}$ heat shock protein, mitochondrial GN=HSPD1 CH60_HUMAN $61.06 \quad 100.0 \% \quad 22$ $0.00 \% \quad 9.8 \%$ LFEGNALLR $0.02 \% \quad 25.4 \%$ SDGIYIINLKR

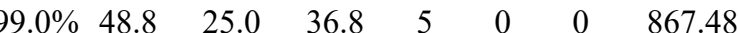
$\begin{array}{llllllll}99.0 \% & 29.4 & 25.0 & 22.4 & 2 & 0 & 0 & 1032.48\end{array}$ $0.07 \% \quad 50.6 \%$ GHSCYRPR $99.7 \% \quad 61.6-25.0-61.6-6$ $0.07 \% \quad 50.6 \%$ GCIVDANLSVLNLVIVK $0.07 \% \quad 50.6 \%$ GEKDIPGLTDTTVPR $0.07 \% \quad 50.6 \%$ DIPGLTDTTVPR $0.07 \% \quad 50.6 \%$ LFNLSKEDDVR $0.07 \% \quad 50.6 \%$ NKEEAAEYAK $0.06 \% 52.4 \%$ KYELGRPAANTK $0.06 \% \quad 52.4 \%$ YELGRPAANTK $99.7 \% \quad 50.5 \quad 25.0 \quad 39.7$ $\begin{array}{llll}99.7 \% & 58.2 & 25.0 & 49.5\end{array}$ $99.7 \% \quad 54.5 \quad 25.0 \quad 39.9$ $99.7 \% \quad 37.2 \quad 25.0 \quad 28.9$ $99.7 \% \quad 56.7 \quad 25.0 \quad 51.4$ $\begin{array}{llll}99.7 \% & 49.5 & 25.0 & 42.2\end{array}$ $\begin{array}{lllllll}0.06 \% & 52.4 \% & \text { TRIIDVVYNASNNELVR } & 99.7 \% & 31.6 & 25.0 & 31.6\end{array}$ $0.06 \% \quad 52.4 \%$ IIDVVYNASNNELVR $0.06 \% \quad 52.4 \%$ NCIVLIDSTPYR $0.06 \% 52.4 \%$ QWYESHYALPLGR $0.06 \% \quad 52.4 \%$ LTPEEEEILNK $0.06 \% 52.4 \%$ ISSLLEEQFQQGK $0.06 \% 52.4 \%$ LLACIASRPGQCGR $0.06 \% 52.4 \%$ ADGYVLEGK $0.06 \% \quad 52.4 \%$ ADGYVLEGKELEFYLR $0.06 \% \quad 52.4 \%$ ELEFYLRK $0.00 \% \quad 9.8 \%$ SPYGGGRPGR $0.02 \% \quad 25.4 \%$ SDGIYIINLK $0.02 \% \quad 25.4 \%$ AIVAIENPADVSVISSR $0.02 \% \quad 25.4 \%$ FAAATGATPIAGR $0.02 \% \quad 25.4 \%$ FTPGTFTNQIQAAFR $0.02 \% \quad 25.4 \%$ LLVVTDPR $0.02 \% \quad 25.4 \%$ YVDIAIPCNNK $99.7 \% \quad 55.8$ $99.7 \% \quad 57.6$ $96.3 \% \quad 14.5$ $99.7 \% \quad 58.0$ $99.7 \% \quad 54.6$ $99.7 \% \quad 38.8$ $99.7 \% \quad 50.6$ $99.7 \% \quad 58.8$ $96.1 \% 16.6$ $99.7 \% \quad 26.7$ $99.7 \% 29.1$ $99.7 \% \quad 44.9$ $99.6 \% \quad 23.8$ $99.7 \% \quad 59.4$ $99.7 \% \quad 51.0$ $99.7 \% \quad 58.9$ $99.0 \% \quad 54.8$ $99.7 \% \quad 51.7$ $0.01 \% \quad 5.1 \%$ DQPAFTPSGILTPHALGSR $0.01 \% \quad 5.1 \%$ NSPGSQVASNPR $.7 \% \quad 45.8$ $99.7 \% \quad 61.3$ $0.01 \% \quad 5.1 \%$ AALEEVYPDLTPEETRR $0.01 \% \quad 20.5 \%$ LVVFDTSLQVK $\begin{array}{llll}99.7 \% & 45.5 & 25.0 & 45.5\end{array}$ $0.01 \% \quad 20.5 \%$ LPVIDPESGNTLYILTHK $0.01 \% \quad 20.5 \%$ VSALPVVDEK $0.01 \% \quad 20.5 \%$ FDVINLAAEK $0.01 \% \quad 20.5 \%$ TYNNLDVSVTK $0.01 \% \quad 20.5 \%$ LVEAEVHR $0.01 \% \quad 12.2 \%$ VSLLSEQK $0.01 \% \quad 12.2 \%$ NLAANDLSPSR $99.5 \% \quad 23.5$ $99.7 \% \quad 39.4$ $99.7 \% \quad 55.8$ $99.7 \% \quad 59.4$ $99.0 \% \quad 43.7$ $99.0 \% \quad 43.6$ $99.7 \% \quad 43.2$

$0.01 \% \quad 12.2 \%$ ILHSYVPEEIRDGNQVR $0.01 \% \quad 12.2 \%$ VLVDVPCTTDR $0.00 \% \quad 4.2 \%$ QGNLFDFLR

$0.00 \% \quad 4.2 \%$ TGAIIPELEREIR $0.05 \% \quad 40.3 \%$ TVIIEQSWGSPK $7 \% 31.7$ $99.7 \% \quad 28.9$ $99.7 \% 38.6$ $99.3 \% 19.4$ $99.7 \% \quad 67.0$ $99.7 \% \quad 60.8$ $0.05 \% \quad 40.3 \%$ LVQDVANNTNEEAGDGTTTATVLAR $\quad 99.7 \% \quad 53.7$
1219.64

1976.06

1718.91

1450.74

1619.80

1314.68

1506.78

1558.79

951.48

1901.96

1097.60

1032.58

1003.5

1135.64

1291.74

1203.65

1698.86

912.55

1306.65

1965.02

1213.59

1988.99

1248.72

2010.09

1056.59

1119.60

1253.64

952.52

903.51

1157.59

2025.05

1274.64

1109.5

1496.8

2560.25

Page 12 of Table S-1-4 
$60 \mathrm{kDa}$ heat shock protein, mitochondrial GN=HSPD1 CH60_HUMAN $61.06 \quad 100.0 \% \quad 22$ $60 \mathrm{kDa}$ heat shock protein, mitochondrial GN=HSPD1 CH60_HUMAN $61.06 \quad 100.0 \% \quad 22$ $60 \mathrm{kDa}$ heat shock protein, mitochondrial GN=HSPD1 CH60_HUMAN $61.06 \quad 100.0 \% \quad 22$ $60 \mathrm{kDa}$ heat shock protein, mitochondrial GN=HSPD1 CH60 HUMAN $61.06 \quad 100.0 \%$ $60 \mathrm{kDa}$ heat shock protein, mitochondrial GN=HSPD1 CH60_HUMAN $61.06 \quad 100.0 \% \quad 22$ $60 \mathrm{kDa}$ heat shock protein, mitochondrial GN=HSPD1 CH60_HUMAN $61.06 \quad 100.0 \% \quad 22$ $60 \mathrm{kDa}$ heat shock protein, mitochondrial GN=HSPD1 CH60_HUMAN $61.06 \quad 100.0 \% \quad 22$ $60 \mathrm{kDa}$ heat shock protein, mitochondrial GN=HSPD1 CH60_HUMAN $61.06 \quad 100.0 \% \quad 22$ $60 \mathrm{kDa}$ heat shock protein, mitochondrial GN=HSPD1 CH60 HUMAN $61.06 \quad 100.0 \%$ $60 \mathrm{kDa}$ heat shock protein, mitochondrial GN=HSPD1 CH60_HUMAN $61.06 \quad 100.0 \% \quad 22$ $60 \mathrm{kDa}$ heat shock protein, mitochondrial GN=HSPD1 CH60_HUMAN $61.06 \quad 100.0 \% 22$ $60 \mathrm{kDa}$ heat shock protein, mitochondrial GN=HSPD1 CH60_HUMAN $61.06 \quad 100.0 \% 22$ $60 \mathrm{kDa}$ heat shock protein, mitochondrial GN=HSPD1 CH60_HUMAN $61.06 \quad 100.0 \% \quad 22$ $60 \mathrm{kDa}$ heat shock protein, mitochondrial GN=HSPD1 CH60_HUMAN $61.06 \quad 100.0 \% 22$ $60 \mathrm{kDa}$ heat shock protein, mitochondrial GN=HSPD1 CH60_HUMAN $61.06 \quad 100.0 \% \quad 22$ $60 \mathrm{kDa}$ heat shock protein, mitochondrial GN=HSPD1 CH60_HUMAN $61.06 \quad 100.0 \% \quad 22$ $60 \mathrm{kDa}$ heat shock protein, mitochondrial GN=HSPD1 CH60 HUMAN $61.06 \quad 100.0 \% 22$ $60 \mathrm{kDa}$ heat shock protein, mitochondrial GN=HSPD1 CH60_HUMAN $61.06 \quad 100.0 \% \quad 22$ $60 \mathrm{kDa}$ heat shock protein, mitochondrial GN=HSPD1 CH60_HUMAN $61.06 \quad 100.0 \% \quad 22$ $60 \mathrm{kDa}$ SS-A/Ro ribonucleoprotein GN=TROVE2 RO60 HUMAN $60.67 \quad 100.0 \%$ $60 \mathrm{kDa}$ SS-A/Ro ribonucleoprotein GN=TROVE2 RO60_HUMAN $60.67 \quad 100.0 \%$ $60 \mathrm{kDa}$ SS-A/Ro ribonucleoprotein GN=TROVE2 RO60_HUMAN $60.67 \quad 100.0 \%$ $60 \mathrm{kDa}$ SS-A/Ro ribonucleoprotein GN=TROVE2 RO60_HUMAN $60.67 \quad 100.0 \%$ $60 \mathrm{kDa}$ SS-A/Ro ribonucleoprotein GN=TROVE2 RO60_HUMAN 60.67 $60 \mathrm{~S}$ acidic ribosomal protein P0 GN=RPLP0 RLA0 HUMAN 34.27 $60 \mathrm{~S}$ acidic ribosomal protein P0 GN=RPLP0 RLA0_HUMAN 34.27 $60 \mathrm{~S}$ acidic ribosomal protein P0 GN=RPLP0 RLA0_HUMAN 34.27 $60 \mathrm{~S}$ acidic ribosomal protein $\mathrm{P} 0 \mathrm{GN}=\mathrm{RPLP0}$ RLA0 HUMAN 34.27 $60 \mathrm{~S}$ acidic ribosomal protein P0 GN=RPLP0 RLA0_HUMAN 34.27 $60 \mathrm{~S}$ acidic ribosomal protein P0 GN=RPLP0 RLA0 HUMAN 34.27 $60 \mathrm{~S}$ acidic ribosomal protein P0 GN=RPLP0 RLA0_HUMAN 34.27 $60 \mathrm{~S}$ acidic ribosomal protein P0 GN=RPLP0 RLA0_HUMAN 34.27 $60 \mathrm{~S}$ acidic ribosomal protein P0 GN=RPLP0 RLA0_HUMAN 34.27 $60 \mathrm{~S}$ acidic ribosomal protein P0 GN=RPLP0 RLA0_HUMAN 34.27 $60 \mathrm{~S}$ acidic ribosomal protein P0 GN=RPLP0 RLA0_HUMAN 34.27 $60 \mathrm{~S}$ acidic ribosomal protein P0 GN=RPLP0 RLA0 HUMAN 34.27 $60 \mathrm{~S}$ acidic ribosomal protein P0 GN=RPLP0 RLA0_HUMAN 34.27 $60 \mathrm{~S}$ acidic ribosomal protein P0 GN=RPLP0 RLA0 HUMAN 34.27 $60 \mathrm{~S}$ acidic ribosomal protein P0 GN=RPLP0 RLA0_HUMAN 34.27 $60 \mathrm{~S}$ acidic ribosomal protein P0 GN=RPLP0 RLA0 HUMAN 34.27 $60 \mathrm{~S}$ acidic ribosomal protein P0 GN=RPLP0 RLA0 HUMAN 34.27 $60 \mathrm{~S}$ ribosomal protein $\mathrm{L} 10 \mathrm{GN}=\mathrm{RPL} 10$ $60 \mathrm{~S}$ ribosomal protein $\mathrm{L} 10 \mathrm{GN}=\mathrm{RPL} 10$ $60 \mathrm{~S}$ ribosomal protein $\mathrm{L} 10 \mathrm{GN}=\mathrm{RPL} 10$ $60 \mathrm{~S}$ ribosomal protein $\mathrm{L} 10 \mathrm{GN}=\mathrm{RPL} 10$ $60 \mathrm{~S}$ ribosomal protein $\mathrm{L} 10 \mathrm{GN}=\mathrm{RPL} 10$ $60 \mathrm{~S}$ ribosomal protein $\mathrm{L} 10 \mathrm{GN}=\mathrm{RPL} 10$

6

$$
\begin{aligned}
& 6 \\
& 6
\end{aligned}
$$

6

6

6

22

22
22
22

22
22
22

22

2

22

2

77

17

17
17

17

17
17

17
17
13

13
$\begin{array}{llll}\text { RL10_HUMAN } & 24.60 & 100.0 \% & 13\end{array}$ RL10_HUMAN $24.60 \quad 100.0 \% \quad 13$ RL10_HUMAN $24.60 \quad 100.0 \% \quad 13$ RL10_HUMAN $24.60 \quad 100.0 \% \quad 13$ RL10_HUMAN $24.60 \quad 100.0 \% \quad 13$
$99.7 \% \quad 30.0$

$99.7 \% \quad 45.9$

$99.7 \% \quad 39.3$

$99.7 \% \quad 52.1$

$99.7 \% \quad 49.5$

$99.7 \% \quad 64.8$

$99.7 \% \quad 31.1$

$99.7 \% \quad 61.9$

$99.7 \% \quad 26.5$

$\begin{array}{lll}99.0 \% & 22.2\end{array}$

$99.7 \% \quad 51.7$

$99.7 \% \quad 66.4$

$99.4 \% \quad 25.6$

$99.7 \% \quad 70.5$

$0.05 \% \quad 40.3 \%$ LSDGVAVLK

$0.05 \% \quad 40.3 \%$ DRVTDALNATR

$0.05 \% \quad 40.3 \%$ VTDALNATR

$99.7 \% \quad 76.4$

$0.05 \% \quad 40.3 \%$ AAVEEGIVLGGGCALLR

$0.05 \% \quad 40.3 \%$ IGIEIIKR

$0.05 \% \quad 40.3 \%$ TLKIPAMTIAK

$0.05 \% \quad 40.3 \%$ NAGVEGSLIVEK

$0.05 \% \quad 40.3 \%$ GIIDPTKVVR

$0.01 \% \quad 11.0 \%$ LGLENAEALIR

$0.01 \% \quad 11.0 \%$ LSHLKPSSEGLAIVTK

$0.01 \% \quad 11.0 \%$ ALSVETEKLLK

$0.01 \% \quad 11.0 \%$ ALLQEMPLTALLR

$0.01 \% \quad 11.0 \%$ ALDAAFYK

$0.09 \% \quad 63.4 \%$ IIQLLDDYPK

$0.09 \% \quad 63.4 \%$ CFIVGADNVGSK

$0.09 \% \quad 63.4 \%$ GKAVVLMGK

$0.09 \% \quad 63.4 \%$ GHLENNPALEK

$0.09 \% \quad 63.4 \%$ GNVGFVFTK

$0.09 \% \quad 63.4 \%$ GNVGFVFTKEDLTEIR

$0.09 \% \quad 63.4 \%$ EDLTEIRDMLLANK

$0.09 \% \quad 63.4 \%$ DMLLANKVPAAAR

0.09\% $63.4 \%$ AGAIAPCEVTVPAQNTGLGPEK

$0.09 \% \quad 63.4 \%$ TSFFQALGITTK

$0.09 \% \quad 63.4 \%$ TSFFQALGITTKISR

$0.09 \% \quad 63.4 \%$ GTIEILSDVQLIK

$99.0 \% \quad 49.5$

$98.9 \% \quad 18.5$

$99.7 \% \quad 64.1$

$99.7 \% \quad 41.5$

$99.7 \% 72.8$

$99.7 \% \quad 34.1$

$99.7 \% \quad 36.9$

$99.7 \% \quad 59.5$

$98.2 \% \quad 17.4$

$99.7 \% \quad 60.8$

$99.7 \% \quad 49.4$

$99.7 \% \quad 30.2$

$99.7 \% \quad 60.6$

$99.7 \% \quad 50.8$

$99.7 \% \quad 54.2$

$99.7 \% \quad 33.3$

$99.7 \% \quad 56.7$

$99.7 \% \quad 54.2$

$99.7 \% \quad 56.8$

$99.7 \% \quad 52.0$

$99.7 \% \quad 57.2$

$\begin{array}{lllll}0.09 \% & 63.4 \% & \text { NVASVCLQIGYPTVASVPHSIINGYK } & 99.7 \% & 50.6 \\ 0.09 \% & 63.4 \% & \text { VLALSVETDYTFPLAEK } & 99.7 \% & 55.0\end{array}$

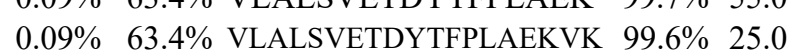

$0.09 \% \quad 63.4 \%$ AFLADPSAFVAAAPVAAATTAAPAAAAAPAK $99.7 \% \quad 48.9$

$0.09 \% \quad 63.4 \%$ afLaDPSAFVAaAPVAAATTAAPAAAAAPAKVEAK $\quad 99.7 \% \quad 40.2$

$0.05 \% \quad 53.3 \%$ GVPDAKIR

$0.05 \% \quad 53.3 \%$ IRIFDLGR

$0.05 \% \quad 53.3 \%$ ICANKYMVK

$0.05 \% \quad 53.3 \%$ SCGKDGFHIR $\begin{array}{lllll}99.0 \% & 30.3 & 25.0 & 30.3 & 2\end{array}$

$\begin{array}{ccccc}98.3 \% & 26.0 & 25.0 & 9.6 & 4\end{array}$

$\begin{array}{lllll}99.5 \% & 23.2 & 25.0 & 20.5 & 2\end{array}$

$99.7 \% \quad 48.9 \quad 25.0 \quad 44.3 \quad 4$

$\begin{array}{llll}99.7 \% & 38.8 & 25.0 & 35.9 \\ 99.7 \% & 44.3 & 25.0 & 36.6\end{array}$ $\begin{array}{llll}19 & 49 & 0.05 \% & 53.3 \% \text { VRLHPFHVIR } \\ 19 & 49 & 0.05 \% & 53.3 \% \text { INKMLSCAGADR }\end{array}$

$\begin{array}{llll}19 & 49 & 0.05 \% & 53.3 \% \text { INKMLSCAGADR }\end{array}$
1008.54

916.55

1389.70

1702.88

1601.75

1919.07

912.59

961.49

844.51

1630.91

901.54

1231.64

960.51

1684.91

941.61

1186.72

1215.66

1097.67

1198.68

1679.97

1230.73

1484.85

898.47

1217.68

1266.61

902.55

1221.62

968.52

1824.95

1660.86

1369.76

2180.10

1313.71

1669.93

1428.83

2787.45

1896.00

2123.16

2752.47

3179.71

855.50

989.59

1142.57

1176.56

1273.76

1351.65

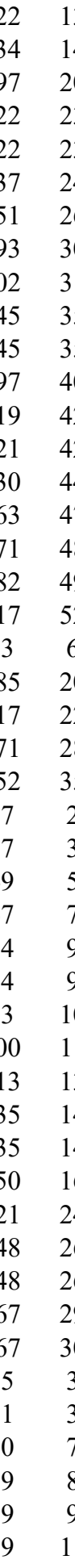

Page 13 of Table S-1-4 
$60 \mathrm{~S}$ ribosomal protein $\mathrm{L} 10 \mathrm{GN}=\mathrm{RPL} 10$ $60 \mathrm{~S}$ ribosomal protein $\mathrm{L} 10 \mathrm{GN}=\mathrm{RPL} 10$ $60 \mathrm{~S}$ ribosomal protein $\mathrm{L} 10 \mathrm{GN}=\mathrm{RPL} 10$ $60 \mathrm{~S}$ ribosomal protein $\mathrm{L} 10 \mathrm{GN}=\mathrm{RPL} 10$ $60 \mathrm{~S}$ ribosomal protein $\mathrm{L} 10 \mathrm{GN}=\mathrm{RPL} 10$ $60 \mathrm{~S}$ ribosomal protein $\mathrm{L} 10 \mathrm{GN}=\mathrm{RPL} 10$ $60 \mathrm{~S}$ ribosomal protein $\mathrm{L} 10 \mathrm{GN}=\mathrm{RPL} 10$ RL10_HUMAN 24.60 60S ribosomal protein L10a GN=RPL10A RL10A_HUMAN 24.83 60S ribosomal protein L10a GN=RPL10A RL10__HUMAN 24.83 60S ribosomal protein L10a GN=RPL10A RL10A_HUMAN 24.83 60 S ribosomal protein L10a GN=RPL10A RL10A_HUMAN 24.83 60S ribosomal protein L10a GN=RPL10A RL10A_HUMAN 24.83 $60 \mathrm{~S}$ ribosomal protein L10a GN=RPL10A RL10A_HUMAN 24.83 $60 \mathrm{~S}$ ribosomal protein L10a GN=RPL10A RL10A_HUMAN 24.83 60 S ribosomal protein L10a GN=RPL10A RL10A_HUMAN 24.83 $60 \mathrm{~S}$ ribosomal protein $\mathrm{L} 13 \mathrm{GN}=\mathrm{RPL} 13$ $60 \mathrm{~S}$ ribosomal protein $\mathrm{L} 13 \mathrm{GN}=\mathrm{RPL} 13$ $60 \mathrm{~S}$ ribosomal protein $\mathrm{L} 13 \mathrm{GN}=\mathrm{RPL} 13$ $60 \mathrm{~S}$ ribosomal protein $\mathrm{L} 13 \mathrm{GN}=\mathrm{RPL} 13$ $60 \mathrm{~S}$ ribosomal protein $\mathrm{L} 13 \mathrm{GN}=\mathrm{RPL} 13$ $60 \mathrm{~S}$ ribosomal protein $\mathrm{L} 13 \mathrm{GN}=\mathrm{RPL} 13$ $60 \mathrm{~S}$ ribosomal protein $\mathrm{L} 13 \mathrm{GN}=\mathrm{RPL} 13$ 60 S ribosomal protein $\mathrm{L} 13 \mathrm{GN}=\mathrm{RPL} 13$ $60 \mathrm{~S}$ ribosomal protein $\mathrm{L} 13 \mathrm{GN}=\mathrm{RPL} 13$ $60 \mathrm{~S}$ ribosomal protein $\mathrm{L} 13 \mathrm{GN}=\mathrm{RPL} 13$ $60 \mathrm{~S}$ ribosomal protein $\mathrm{L} 13 \mathrm{GN}=\mathrm{RPL} 13$ $60 \mathrm{~S}$ ribosomal protein $\mathrm{L} 13 \mathrm{GN}=\mathrm{RPL} 13$ $60 \mathrm{~S}$ ribosomal protein $\mathrm{L} 13 \mathrm{GN}=\mathrm{RPL} 13$ $60 \mathrm{~S}$ ribosomal protein $\mathrm{L} 13 \mathrm{GN}=\mathrm{RPL} 13$ $60 \mathrm{~S}$ ribosomal protein $\mathrm{L} 13 \mathrm{GN}=\mathrm{RPL} 13$ $60 \mathrm{~S}$ ribosomal protein $\mathrm{L} 13 \mathrm{GN}=\mathrm{RPL} 13$ $60 \mathrm{~S}$ ribosomal protein $\mathrm{L} 13 \mathrm{GN}=\mathrm{RPL} 13$ 60 S ribosom 24.26 60S ribosomal protein L13a GN=RPL13A RL13A_HUMAN 23.58 60 S ribosomal protein L13a GN=RPL13A RL13A_HUMAN 23.58 60S ribosomal protein L13a GN=RPL13A RL13A_HUMAN 23.58 60 S ribosomal protein L13a GN=RPL13A RL13A_HUMAN 23.58 60S ribosomal protein L13a GN=RPL13A RL13A_HUMAN 23.58 $60 \mathrm{~S}$ ribosomal protein $\mathrm{L} 13 \mathrm{a} \mathrm{GN}=\mathrm{RPL} 13 \mathrm{~A}$ $60 \mathrm{~S}$ ribosomal protein $\mathrm{L} 14 \mathrm{GN}=\mathrm{RPL} 14$ $60 \mathrm{~S}$ ribosomal protein $\mathrm{L} 14 \mathrm{GN}=\mathrm{RPL} 14$ 60 S ribosomal protein $\mathrm{L} 14 \mathrm{GN}=\mathrm{RPL} 14$ $60 \mathrm{~S}$ ribosomal protein $\mathrm{L} 14 \mathrm{GN}=\mathrm{RPL} 14$ $60 \mathrm{~S}$ ribosomal protein $\mathrm{L} 14 \mathrm{GN}=\mathrm{RPL} 14$ $60 \mathrm{~S}$ ribosomal protein $\mathrm{L} 15 \mathrm{GN}=\mathrm{RPL} 15$ $60 \mathrm{~S}$ ribosomal protein $\mathrm{L} 15 \mathrm{GN}=\mathrm{RPL} 15$ \begin{tabular}{lll} 
RLI3_HUMAN $24.26 \quad 100.0 \%$ \\
\hline
\end{tabular} RL13_HUMAN $24.26 \quad 100.0 \%$ RL13_HUMAN $24.26 \quad 100.0 \% \quad 17$ RL13 HUMAN $24.26 \quad 100.0 \% \quad 17$ RL13_HUMAN $24.26 \quad 100.0 \% \quad 17$ RL13_HUMAN $24.26 \quad 100.0 \% \quad 17$ RL13_HUMAN $24.26 \quad 100.0 \% \quad 17$ RL13_HUMAN $24.26 \quad 100.0 \% \quad 17$ RL13_HUMAN $24.26 \quad 100.0 \% \quad 17$ RL13_HUMAN $24.26 \quad 100.0 \% \quad 17$ RL13 HUMAN $24.26 \quad 100.0 \% \quad 17$ RL13_HUMAN $24.26 \quad 100.0 \% \quad 17$ RL13_HUMAN $24.26 \quad 100.0 \% \quad 17$ RL13_HUMAN $24.26 \quad 100.0 \% \quad 17$

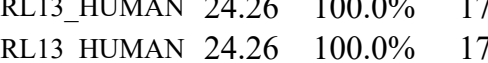
$100.0 \% \quad 17$ $00.0 \%$ $00.0 \%$ $00.0 \%$ $100.0 \%$ $00.0 \%$ $100.0 \%$ $100.0 \%$ RL14_HUMAN $23.43 \quad 100.0 \%$ RL14_HUMAN $23.43 \quad 100.0 \%$ RL14_HUMAN $23.43 \quad 100.0 \%$ RL14_HUMAN $23.43 \quad 100.0 \%$ RL14_HUMAN $23.43 \quad 100.0 \%$ RL15 HUMAN $24.15 \quad 100.0 \%$ RL15_HUMAN $24.15 \quad 100.0 \%$
$19 \quad 49 \quad 0.05 \% \quad 53.3 \%$ MLSCAGADR $19 \quad 49 \quad 0.05 \% \quad 53.3 \%$ GAFGKPQGTVAR

$\begin{array}{llll}19 & 49 & 0.05 \% & 53.3 \% \\ 19 & \text { VHIGQVIMSIR }\end{array}$

$19 \quad 49 \quad 0.05 \% \quad 53.3 \%$ LQNKEHVIEALR

$19 \quad 49 \quad 0.05 \% \quad 53.3 \%$ EHVIEALRR

$19 \quad 49 \quad 0.05 \% \quad 53.3 \%$ FNADEFEDMVAEKR

$\begin{array}{llll}19 & 49 & 0.05 \% & 53.3 \% \\ 19 & \text { LIPDGCGVK }\end{array}$

$0.02 \% \quad 42.4 \%$ DTLYEAVR

$0.02 \% \quad 42.4 \%$ DTLYEAVREVLHGNQR

$0.02 \% \quad 42.4 \%$ FSVCVLGDQQHCDEAK

$0.02 \% \quad 42.4 \%$ KYDAFLASESLIK

$0.02 \% \quad 42.4 \%$ ILGPGLNK

$0.02 \% \quad 42.4 \%$ AGKFPSLLTHNENMVAK

$0.02 \% \quad 42.4 \%$ VLCLAVAVGHVK

$0.02 \% \quad 42.4 \%$ STMGKPQR

$0.02 \% \quad 42.4 \%$ STMGKPQRLY

$0.08 \% \quad 56.9 \%$ RVATWFNQPAR

$0.08 \% 56.9 \%$ VATWFNQPAR

$0.08 \% \quad 56.9 \%$ VATWFNQPARK

$0.08 \% 56.9 \%$ IAPRPASGPIRPIVR

$0.08 \% 56.9 \%$ GFSLEELR

$0.08 \% 56.9 \%$ TIGISVDPR

$0.08 \% \quad 56.9 \%$ TIGISVDPRR

$0.08 \% \quad 56.9 \%$ NKSTESLQANVQR

$0.08 \% 56.9 \%$ STESLQANVQR

$0.08 \% \quad 56.9 \%$ SKLILFPR

$0.08 \% 56.9 \%$ KGDSSAEELK

$0.08 \% 56.9 \%$ LATQLTGPVMPVR

$0.08 \% 56.9 \%$ VITEEEKNFK

$0.08 \% 56.9 \%$ ANARLFGIR

$0.08 \% 56.9 \%$ AKEAAEQDVEK

$0.08 \% 56.9 \%$ EAAEQDVEK

$0.08 \% 56.9 \%$ EAAEQDVEKK

$0.01 \% 31.5 \%$ CEGINISGNFYR

$0.01 \% 31.5 \%$ TVRGMLPHK

$0.01 \% 31.5 \%$ GQAALDRLK

$0.01 \% 31.5 \%$ VFDGIPPPYDKK

$0.01 \% \quad 31.5 \%$ MVVPAALK

$0.01 \% \quad 31.5 \%$ MVVPAALKVVR

$0.01 \% \quad 31.5 \%$ YQAVTATLEEK

$0.02 \% \quad 25.1 \%$ VAYVSFGPHAGK

$0.02 \% \quad 25.1 \%$ LVAIVDVIDQNR

$0.02 \% \quad 25.1 \%$ ADINTKWAATR

$0.02 \% 25.1 \%$ AALLKASPK

$0.02 \% \quad 25.1 \%$ APAQKAPAPK

$0.02 \% 29.4 \%$ AKQGYVIYR

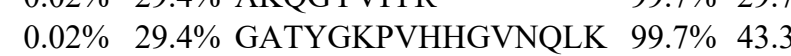

$98.9 \% \quad 21.2$

$99.7 \% 52.3$

$99.7 \% \quad 50.6$

$99.7 \% \quad 27.4$

$99.5 \% \quad 34.0$

$99.7 \% \quad 50.7$

$97.9 \% 17.6$

$99.0 \% \quad 37.3$

$99.7 \% \quad 42.9$

$99.5 \% \quad 22.3$

$\begin{array}{ll}96.2 \% & 19.4\end{array}$

$\begin{array}{lll}99.7 \% & 43.7\end{array}$

$98.4 \% \quad 21.1$

$\begin{array}{lll}99.7 \% & 26.3\end{array}$

$99.7 \% \quad 37.8$

$99.7 \% \quad 66.6$

$99.7 \% \quad 30.9$

$99.1 \% 19.4$

$99.0 \% \quad 46.6$

$99.7 \% \quad 57.0$

$99.7 \% \quad 37.2$

$99.7 \% \quad 72.3$

$99.7 \% \quad 62.0$

$99.0 \% \quad 43.1$

$99.7 \% \quad 37.7$

$99.7 \% \quad 56.6$

$99.7 \% \quad 52.0$

$96.3 \% 18.6$

$99.7 \% \quad 68.5$

$99.7 \% \quad 54.0$

$99.7 \% \quad 61.4$

$99.7 \% \quad 39.7$

$94.7 \% \quad 15.3$

$99.7 \% \quad 38.4$

$98.3 \% \quad 21.9$

$98.0 \% \quad 16.3$

$99.5 \% \quad 21.2$

$99.7 \% \quad 31.5$

$99.7 \% \quad 56.7$

$99.7 \% \quad 53.8$

$99.7 \% \quad 45.1$

$99.7 \% \quad 28.8$

$99.7 \% \quad 51.3$

$99.7 \% 29.7$

21
980.43

1188.65

1252.72

1449.82

1122.64

1700.76

958.50

966.49

1899.97

1892.83

1484.80

811.50

1872.96

1265.74

904.47

1180.61

1345.71

1189.61

1317.71

1599.98

950.49

957.54

1113.64

1474.76

1232.62

973.62

1063.53

1398.78

1236.65

1017.60

1217.60

1018.47

1146.56

1429.65

1054.58

971.56

1375.73

828.50

1198.73

1252.64

1232.64

1354.77

1246.65

898.57

978.57

1097.61

1705.91

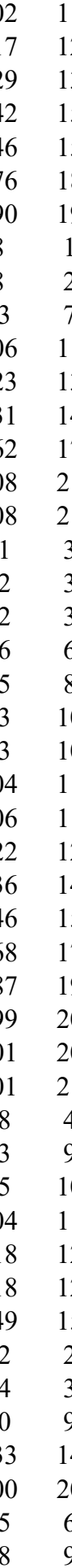


$60 \mathrm{~S}$ ribosomal protein $\mathrm{L} 15 \mathrm{GN}=\mathrm{RPL} 15$ $60 \mathrm{~S}$ ribosomal protein $\mathrm{L} 15 \mathrm{GN}=\mathrm{RPL} 15$ $60 \mathrm{~S}$ ribosomal protein $\mathrm{L} 15 \mathrm{GN}=\mathrm{RPL} 15$ $60 \mathrm{~S}$ ribosomal protein $\mathrm{L} 15 \mathrm{GN}=\mathrm{RPL} 15$ $60 \mathrm{~S}$ ribosomal protein $\mathrm{L} 18 \mathrm{GN}=\mathrm{RPL} 18$ $60 \mathrm{~S}$ ribosomal protein $\mathrm{L} 18 \mathrm{GN}=\mathrm{RPL} 18$ $60 \mathrm{~S}$ ribosomal protein $\mathrm{L} 18 \mathrm{GN}=\mathrm{RPL} 18$ $60 \mathrm{~S}$ ribosomal protein $\mathrm{L} 18 \mathrm{GN}=\mathrm{RPL} 18$ $60 \mathrm{~S}$ ribosomal protein $\mathrm{L} 18 \mathrm{GN}=\mathrm{RPL} 18$ $60 \mathrm{~S}$ ribosomal protein $\mathrm{L} 19 \mathrm{GN}=\mathrm{RPL} 19$ $60 \mathrm{~S}$ ribosomal protein $\mathrm{L} 19 \mathrm{GN}=\mathrm{RPL} 19$ $60 \mathrm{~S}$ ribosomal protein $\mathrm{L} 19 \mathrm{GN}=\mathrm{RPL} 19$ 60S ribosomal protein $\mathrm{L} 19 \mathrm{GN}=\mathrm{RPL} 19$ $60 \mathrm{~S}$ ribosomal protein $\mathrm{L} 19 \mathrm{GN}=\mathrm{RPL} 19$ $60 \mathrm{~S}$ ribosomal protein $\mathrm{L} 19 \mathrm{GN}=\mathrm{RPL} 19$ 60 S ribosomal protein $\mathrm{L} 19 \mathrm{GN}=\mathrm{RPL} 19$ $60 \mathrm{~S}$ ribosomal protein $\mathrm{L} 24 \mathrm{GN}=\mathrm{RPL} 24$ $60 \mathrm{~S}$ ribosomal protein $\mathrm{L} 24 \mathrm{GN}=\mathrm{RPL} 24$ $60 \mathrm{~S}$ ribosomal protein $\mathrm{L} 24 \mathrm{GN}=\mathrm{RPL} 24$ $60 \mathrm{~S}$ ribosomal protein $\mathrm{L} 29 \mathrm{GN}=\mathrm{RPL} 29$ $60 \mathrm{~S}$ ribosomal protein $\mathrm{L} 29 \mathrm{GN}=\mathrm{RPL} 29$ $60 \mathrm{~S}$ ribosomal protein $\mathrm{L} 29 \mathrm{GN}=\mathrm{RPL} 29$ $60 \mathrm{~S}$ ribosomal protein $\mathrm{L} 3 \mathrm{GN}=\mathrm{RPL} 3$ $60 \mathrm{~S}$ ribosomal protein $\mathrm{L} 3 \mathrm{GN}=\mathrm{RPL} 3$ $60 \mathrm{~S}$ ribosomal protein $\mathrm{L} 3 \mathrm{GN}=\mathrm{RPL} 3$ $60 \mathrm{~S}$ ribosomal protein $\mathrm{L} 3 \mathrm{GN}=\mathrm{RPL} 3$ $60 \mathrm{~S}$ ribosomal protein $\mathrm{L} 3 \mathrm{GN}=\mathrm{RPL} 3$ $60 \mathrm{~S}$ ribosomal protein $\mathrm{L} 3 \mathrm{GN}=\mathrm{RPL} 3$ $60 \mathrm{~S}$ ribosomal protein $\mathrm{L} 3 \mathrm{GN}=\mathrm{RPL} 3$ $60 \mathrm{~S}$ ribosomal protein $\mathrm{L} 3 \mathrm{GN}=\mathrm{RPL} 3$ $60 \mathrm{~S}$ ribosomal protein $\mathrm{L} 3 \mathrm{GN}=\mathrm{RPL} 3$ $60 \mathrm{~S}$ ribosomal protein $\mathrm{L} 3 \mathrm{GN}=\mathrm{RPL} 3$ $60 \mathrm{~S}$ ribosomal protein $\mathrm{L} 3 \mathrm{GN}=\mathrm{RPL} 3$ $60 \mathrm{~S}$ ribosomal protein $\mathrm{L} 3 \mathrm{GN}=\mathrm{RPL} 3$ $60 \mathrm{~S}$ ribosomal protein $\mathrm{L} 3 \mathrm{GN}=\mathrm{RPL} 3$ $60 \mathrm{~S}$ ribosomal protein $\mathrm{L} 3 \mathrm{GN}=\mathrm{RPL} 3$ $60 \mathrm{~S}$ ribosomal protein $\mathrm{L} 3 \mathrm{GN}=\mathrm{RPL} 3$ $60 \mathrm{~S}$ ribosomal protein $\mathrm{L} 3 \mathrm{GN}=\mathrm{RPL} 3$ $60 \mathrm{~S}$ ribosomal protein $\mathrm{L} 3 \mathrm{GN}=\mathrm{RPL} 3$ $60 \mathrm{~S}$ ribosomal protein $\mathrm{L} 3 \mathrm{GN}=\mathrm{RPL} 3$ $60 \mathrm{~S}$ ribosomal protein $\mathrm{L} 3 \mathrm{GN}=\mathrm{RPL} 3$ $60 \mathrm{~S}$ ribosomal protein $\mathrm{L} 3 \mathrm{GN}=\mathrm{RPL} 3$ $60 \mathrm{~S}$ ribosomal protein $\mathrm{L} 3 \mathrm{GN}=\mathrm{RPL} 3$ $60 \mathrm{~S}$ ribosomal protein $\mathrm{L} 3 \mathrm{GN}=\mathrm{RPL} 3$ $60 \mathrm{~S}$ ribosomal protein $\mathrm{L} 3 \mathrm{GN}=\mathrm{RPL} 3$ $60 \mathrm{~S}$ ribosomal protein $\mathrm{L} 34 \mathrm{GN}=\mathrm{RPL} 34$ $60 \mathrm{~S}$ ribosomal protein $\mathrm{L} 34 \mathrm{GN}=\mathrm{RPL} 34$ $\begin{array}{lllllll}\text { RL15_HUMAN } 24.15 & 100.0 \% & 6 & 7 & 21 & 0.02 \% & 29.4 \% \\ \text { SLQSVAEER }\end{array}$ $0.02 \% \quad 29.4 \%$ SLQSVAEERAGR $0.02 \% \quad 29.4 \%$ RNPDTQWITKPVHK $0.02 \% \quad 29.4 \%$ FHHTIGGSR

$0.01 \% \quad 33.0 \%$ TNSTFNQVVLKR $0.01 \% \quad 33.0 \%$ TNRPPLSLSR

$0.01 \% \quad 33.0 \%$ TAVVVGTITDDVR $0.01 \% \quad 33.0 \%$ ILTFDQLALDSPK $0.01 \% 33.0 \%$ APGTPHSHTKPYVR RL18_HUMAN $21.64 \quad 100.0 \%$ RL18 HUMAN $21.64 \quad 100.0 \%$ RL19 HUMAN $23.47 \quad 100.0 \%$ RL19_HUMAN $23.47 \quad 100.0 \%$ RL19_HUMAN $23.47 \quad 100.0 \%$ RL19_HUMAN $23.47 \quad 100.0 \%$ RL19_HUMAN $23.47 \quad 100.0 \%$ RL19 HUMAN $23.47 \quad 100.0 \%$ RL19_HUMAN $23.47 \quad 100.0 \%$ RL24_HUMAN $17.78 \quad 100.0 \%$ RL24_HUMAN $17.78 \quad 100.0 \%$ RL24_HUMAN $17.78 \quad 100.0 \%$ RL29 HUMAN $17.75 \quad 100.0 \%$ RL29_HUMAN $17.75 \quad 100.0 \%$ RL29 HUMAN $17.75 \quad 100.0 \%$ RL3 HUMAN $46.11 \quad 100.0 \%$ RL3_HUMAN $46.11 \quad 100.0 \% \quad 23$ RL3 HUMAN $46.11 \quad 100.0 \%$ RL3_HUMAN $46.11 \quad 100.0 \% \quad 23$ RL3_HUMAN $46.11 \quad 100.0 \% \quad 23$ RL3 HUMAN $46.11 \quad 100.0 \% \quad 23$ RL3_HUMAN $46.11 \quad 100.0 \% \quad 23$ RL3 HUMAN $46.11 \quad 100.0 \% \quad 23$ RL3 HUMAN $46.11 \quad 100.0 \% \quad 23$ RL3_HUMAN $46.11 \quad 100.0 \% \quad 23$ RL3 HUMAN $46.11 \quad 100.0 \% \quad 23$ RL3_HUMAN $46.11 \quad 100.0 \% \quad 23$ RL3_HUMAN $46.11 \quad 100.0 \% \quad 23$ RL3 HUMAN $46.11 \quad 100.0 \% \quad 23$ RL3_HUMAN $46.11 \quad 100.0 \% \quad 23$ RL3 HUMAN $46.11 \quad 100.0 \% \quad 23$ RL3_HUMAN $46.11 \quad 100.0 \% \quad 23$ RL3_HUMAN $46.11 \quad 100.0 \% \quad 23$ RL3 HUMAN $46.11 \quad 100.0 \% \quad 23$ RL3_HUMAN $46.11 \quad 100.0 \% \quad 23$ RL3 HUMAN $46.11 \quad 100.0 \% \quad 23$ RL3_HUMAN $46.11 \quad 100.0 \% \quad 23$ RL3_HUMAN $46.11 \quad 100.0 \% \quad 23$ RL34 HUMAN $13.29 \quad 100.0 \% \quad 2$ RL34_HUMAN $13.29 \quad 100.0 \%$

$0.01 \% \quad 15.1 \%$ LAYIAHI

$101 \quad 0.10 \% \quad 49.9 \%$ HGSLGFLPR

$101 \quad 0.10 \% \quad 49.9 \%$ TVFAEHISDECKR

$101 \quad 0.10 \% \quad 49.9 \%$ VIAHTQMR $\begin{array}{lllll}75.0 & 25.0 & 42.0 & 10 & 0\end{array}$

1302.68

1719.93

1011.51

$97.2 \% \quad 24.8 \quad 25.0 \quad 8.7$

$\begin{array}{llll}99.7 \% & 58.7 & 25.0 & 50.8\end{array}$

$\begin{array}{llll}99.1 \% & 19.5 & 25.0 & 19.5\end{array}$

$99.7 \% \quad 68.2 \quad 25.0 \quad 64.4$

$\begin{array}{llll}99.7 \% & 49.8 & 25.0 & 49.8\end{array}$

$\begin{array}{llll}97.1 \% & 16.3 & 25.0 & 16.3\end{array}$

$\begin{array}{llll}99.0 \% & 39.4 & 25.0 & 23.2\end{array}$

$\begin{array}{llll}99.7 \% & 28.7 & 25.0 & 28.2\end{array}$

$\begin{array}{llll}99.0 \% & 33.5 & 25.0 & 21.8\end{array}$

$97.0 \% \quad 19.6 \quad 25.0 \quad 13.3$

$\begin{array}{llll}99.7 \% & 59.3 & 25.0 & 48.9\end{array}$

$99.7 \% \quad 34.3 \quad 25.0 \quad 28.2$

$99.7 \% \quad 33.9 \quad 25.0 \quad 25.3$

$99.0 \% \quad 33.5 \quad 25.0 \quad 29.7$

$99.7 \% \quad 58.5 \quad 25.0 \quad 49.4$

$99.0 \% \quad 32.9 \quad 25.0 \quad 27.5$

$99.0 \% 32.6$

$99.7 \% \quad 47.6$

$99.7 \% \quad 33.1$

$99.7 \% \quad 55.6$

$25.0 \quad 19.1$

$0.01 \% \quad 15.1 \%$ AQAAAPASVPAQAPK

$13 \quad 0.01 \% \quad 15.1 \%$ AQAAAPASVPAQAPKR

$99.7 \% \quad 37.5$

$101 \quad 0.10 \% \quad 49.9 \%$ DDPSKPVHLTAFLGYK

$99.7 \% \quad 36.0$

$99.0 \% \quad 49.7$

$\begin{array}{lll}99.6 \% & 24.1\end{array}$

$99.7 \% \quad 63.1$

$99.7 \% \quad 59.9$

$99.0 \% \quad 21.5$

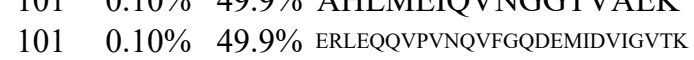

$99.7 \% \quad 38.3$

$101 \quad 0.10 \% \quad 49.9 \%$ LEQQVPVVNQVFGQDEMIDVIGVTK

$7 \% \quad 46.1$

$99.7 \% \quad 44.5$

$99.7 \% \quad 57.6$

$99.0 \% \quad 52.2$

$99.7 \% \quad 54.9$

$96.7 \% \quad 16.9$

$99.7 \% \quad 60.8$

$101 \quad 0.10 \% \quad 49.9 \%$ LIKNNASTDYDLSDK

$25.0 \quad 38.3$

$\begin{array}{llll}98.6 \% & 23.2 & 25.0 & 14.3\end{array}$

$\begin{array}{llll}99.0 \% & 40.7 & 25.0 & 40.7\end{array}$

$99.7 \% \quad 29.0 \quad 25.0 \quad 24.9$

$\begin{array}{llll}99.7 \% & 36.8 & 25.0 & 36.8\end{array}$

$99.0 \% \quad 32.6 \quad 25.0 \quad 22.2 \quad 2$

$99.2 \% \quad 21.2 \quad 25.0 \quad 17.5$

$96.7 \% \quad 15.6 \quad 25.0 \quad 15.6$

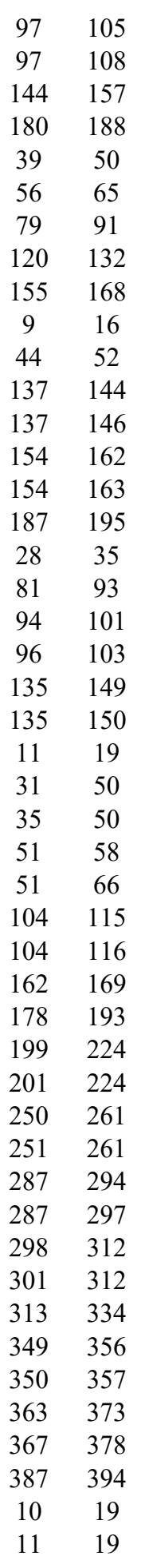

Page 15 of Table S-1-4 
$60 \mathrm{~S}$ ribosomal protein $\mathrm{L} 4 \mathrm{GN}=\mathrm{RPL} 4$ $60 \mathrm{~S}$ ribosomal protein $\mathrm{L} 4 \mathrm{GN}=\mathrm{RPL} 4$ $60 \mathrm{~S}$ ribosomal protein $\mathrm{L} 4 \mathrm{GN}=\mathrm{RPL} 4$ $60 \mathrm{~S}$ ribosomal protein $\mathrm{L} 4 \mathrm{GN}=\mathrm{RPL} 4$ $60 \mathrm{~S}$ ribosomal protein $\mathrm{L} 4 \mathrm{GN}=\mathrm{RPL} 4$ $60 \mathrm{~S}$ ribosomal protein $\mathrm{L} 4 \mathrm{GN}=\mathrm{RPL} 4$ $60 \mathrm{~S}$ ribosomal protein $\mathrm{L} 4 \mathrm{GN}=\mathrm{RPL} 4$ $60 \mathrm{~S}$ ribosomal protein $\mathrm{L} 4 \mathrm{GN}=\mathrm{RPL} 4$ $60 \mathrm{~S}$ ribosomal protein $\mathrm{L} 4 \mathrm{GN}=\mathrm{RPL} 4$ $60 \mathrm{~S}$ ribosomal protein $\mathrm{L} 4 \mathrm{GN}=\mathrm{RPL} 4$ $60 \mathrm{~S}$ ribosomal protein $\mathrm{L} 4 \mathrm{GN}=\mathrm{RPL} 4$ $60 \mathrm{~S}$ ribosomal protein $\mathrm{L} 4 \mathrm{GN}=\mathrm{RPL} 4$ $60 \mathrm{~S}$ ribosomal protein $\mathrm{L} 4 \mathrm{GN}=\mathrm{RPL} 4$ $60 \mathrm{~S}$ ribosomal protein $\mathrm{L} 4 \mathrm{GN}=\mathrm{RPL} 4$ $60 \mathrm{~S}$ ribosomal protein $\mathrm{L} 4 \mathrm{GN}=\mathrm{RPL} 4$ $60 \mathrm{~S}$ ribosomal protein $\mathrm{L} 4 \mathrm{GN}=\mathrm{RPL} 4$ $60 \mathrm{~S}$ ribosomal protein $\mathrm{L} 4 \mathrm{GN}=\mathrm{RPL} 4$ $60 \mathrm{~S}$ ribosomal protein $\mathrm{L} 4 \mathrm{GN}=\mathrm{RPL} 4$ $60 \mathrm{~S}$ ribosomal protein $\mathrm{L} 4 \mathrm{GN}=\mathrm{RPL} 4$ $60 \mathrm{~S}$ ribosomal protein $\mathrm{L} 4 \mathrm{GN}=\mathrm{RPL} 4$ $60 \mathrm{~S}$ ribosomal protein $\mathrm{L} 4 \mathrm{GN}=\mathrm{RPL} 4$ $60 \mathrm{~S}$ ribosomal protein $\mathrm{L} 4 \mathrm{GN}=\mathrm{RPL} 4$ $60 \mathrm{~S}$ ribosomal protein $\mathrm{L} 4 \mathrm{GN}=\mathrm{RPL} 4$ $60 \mathrm{~S}$ ribosomal protein $\mathrm{L} 4 \mathrm{GN}=\mathrm{RPL} 4$ $60 \mathrm{~S}$ ribosomal protein $\mathrm{L} 5 \mathrm{GN}=\mathrm{RPL} 5$ $60 \mathrm{~S}$ ribosomal protein $\mathrm{L} 5 \mathrm{GN}=\mathrm{RPL} 5$ $60 \mathrm{~S}$ ribosomal protein $\mathrm{L} 5 \mathrm{GN}=\mathrm{RPL} 5$ $60 \mathrm{~S}$ ribosomal protein $\mathrm{L} 5 \mathrm{GN}=\mathrm{RPL} 5$ $60 \mathrm{~S}$ ribosomal protein $\mathrm{L} 5 \mathrm{GN}=\mathrm{RPL} 5$ $60 \mathrm{~S}$ ribosomal protein $\mathrm{L} 5 \mathrm{GN}=\mathrm{RPL} 5$ $60 \mathrm{~S}$ ribosomal protein $\mathrm{L} 5 \mathrm{GN}=\mathrm{RPL} 5$ $60 \mathrm{~S}$ ribosomal protein $\mathrm{L} 5 \mathrm{GN}=\mathrm{RPL} 5$ $60 \mathrm{~S}$ ribosomal protein $\mathrm{L} 5 \mathrm{GN}=\mathrm{RPL} 5$ $60 \mathrm{~S}$ ribosomal protein $\mathrm{L} 5 \mathrm{GN}=\mathrm{RPL} 5$ $60 \mathrm{~S}$ ribosomal protein $\mathrm{L} 5 \mathrm{GN}=\mathrm{RPL} 5$ $60 \mathrm{~S}$ ribosomal protein $\mathrm{L} 5 \mathrm{GN}=\mathrm{RPL} 5$ $60 \mathrm{~S}$ ribosomal protein $\mathrm{L} 5 \mathrm{GN}=\mathrm{RPL} 5$ $60 \mathrm{~S}$ ribosomal protein $\mathrm{L} 5 \mathrm{GN}=\mathrm{RPL} 5$ $60 \mathrm{~S}$ ribosomal protein $\mathrm{L} 5 \mathrm{GN}=\mathrm{RPL} 5$ $60 \mathrm{~S}$ ribosomal protein $\mathrm{L} 5 \mathrm{GN}=\mathrm{RPL} 5$ $60 \mathrm{~S}$ ribosomal protein $\mathrm{L} 5 \mathrm{GN}=\mathrm{RPL} 5$ $60 \mathrm{~S}$ ribosomal protein $\mathrm{L} 6 \mathrm{GN}=\mathrm{RPL} 6$ $60 \mathrm{~S}$ ribosomal protein $\mathrm{L} 6 \mathrm{GN}=\mathrm{RPL} 6$ $60 \mathrm{~S}$ ribosomal protein $\mathrm{L} 6 \mathrm{GN}=\mathrm{RPL} 6$ $60 \mathrm{~S}$ ribosomal protein $\mathrm{L} 6 \mathrm{GN}=\mathrm{RPL} 6$ $60 \mathrm{~S}$ ribosomal protein $\mathrm{L} 6 \mathrm{GN}=\mathrm{RPL} 6$ $60 \mathrm{~S}$ ribosomal protein $\mathrm{L} 6 \mathrm{GN}=\mathrm{RPL} 6$
RL4_HUMAN $47.70 \quad 100.0 \% \quad 24 \quad 35 \quad 167 \quad 0.17 \% \quad 52.7 \%$ NVTLPAVFK 政 RL4_HUMAN $47.70 \quad 100.0 \% \quad 24$ RL4 HUMAN $47.70 \quad 100.0 \% \quad 24$ RL4_HUMAN $47.70 \quad 100.0 \% \quad 24$ RL4_HUMAN $47.70 \quad 100.0 \% \quad 24$ RL4 HUMAN $47.70 \quad 100.0 \% \quad 24$ RL4_HUMAN $47.70 \quad 100.0 \% \quad 24$ RL4 HUMAN $47.70 \quad 100.0 \% \quad 24$ RL4_HUMAN $47.70 \quad 100.0 \% \quad 24$ RL4_HUMAN $47.70 \quad 100.0 \% \quad 24$ RL4 HUMAN $47.70 \quad 100.0 \% \quad 24$ RL4_HUMAN $47.70 \quad 100.0 \% \quad 24$ RL4_HUMAN $47.70 \quad 100.0 \% \quad 24$ RL4 HUMAN $47.70 \quad 100.0 \% \quad 24$ RL4_HUMAN $47.70 \quad 100.0 \% \quad 24$ RL4 HUMAN $47.70 \quad 100.0 \% \quad 24$ RL4_HUMAN $47.70 \quad 100.0 \% \quad 24$ RL4_HUMAN $47.70 \quad 100.0 \% \quad 24$ RL4 HUMAN $47.70 \quad 100.0 \% \quad 24$ RL4_HUMAN $47.70 \quad 100.0 \% \quad 24$ RL4 HUMAN $47.70 \quad 100.0 \% \quad 24$ RL4 HUMAN $47.70 \quad 100.0 \% \quad 24$ RL4_HUMAN $47.70 \quad 100.0 \% \quad 24$ RL5 HUMAN $34.36 \quad 100.0 \% \quad 17$ RL5_HUMAN $34.36 \quad 100.0 \% \quad 17$ RL5_HUMAN $34.36 \quad 100.0 \% \quad 17$ RL5 HUMAN $34.36 \quad 100.0 \% \quad 17$ RL5_HUMAN $34.36 \quad 100.0 \% \quad 17$ RL5 HUMAN $34.36 \quad 100.0 \% \quad 17$ RL5_HUMAN $34.36 \quad 100.0 \% \quad 17$ RL5_HUMAN $34.36 \quad 100.0 \% \quad 17$ RL5 HUMAN $34.36 \quad 100.0 \% \quad 17$ RL5_HUMAN $34.36 \quad 100.0 \% \quad 17$ RL5_HUMAN $34.36 \quad 100.0 \% \quad 17$ RL5 HUMAN $34.36 \quad 100.0 \% \quad 17$ RL5_HUMAN $34.36 \quad 100.0 \% \quad 17$ RL5 HUMAN $34.36 \quad 100.0 \% \quad 17$ RL5_HUMAN $34.36 \quad 100.0 \% \quad 17$ RL5_HUMAN $34.36 \quad 100.0 \% \quad 17$ RL5 HUMAN $34.36 \quad 100.0 \% \quad 17$ RL6_HUMAN $32.73 \quad 100.0 \% \quad 19$ RL6 HUMAN $32.73 \quad 100.0 \% \quad 19$ RL6 HUMAN $32.73 \quad 100.0 \% \quad 19$ RL6_HUMAN $32.73 \quad 100.0 \% \quad 19$ RL6 HUMAN $32.73 \quad 100.0 \% \quad 19$ RL6_HUMAN $32.73 \quad 100.0 \% \quad 19$
$67 \quad 0.17 \% \quad 52.7 \%$ APIRPDIVNFVHTNLR

$167 \quad 0.17 \% \quad 52.7 \%$ APIRPDIVNFVHTNLRK

$167 \quad 0.17 \% \quad 52.7 \%$ NNRQPYAVSELAGHQTSAESWGTGR

167

$0.17 \% \quad 52.7 \%$ QPYAVSELAGHQTSAESWGTGR

$67 \quad 0.17 \% \quad 52.7 \%$ SGQGAFGNMCR

$167 \quad 0.17 \% \quad 52.7 \%$ IEEVPELPLVVEDKVEGYK $98.9 \% \quad 18.5$

$167 \quad 0.17 \% \quad 52.7 \%$ TKEAVLLLK

$167 \quad 0.17 \% \quad 52.7 \%$ EAVLLLKK

$167 \quad 0.17 \% \quad 52.7 \%$ RGPCIIYNEDNGIIK

$167 \quad 0.17 \% \quad 52.7 \%$ GPCIIYNEDNGIIK

$167 \quad 0.17 \% \quad 52.7 \%$ AFRNIPGITLLNVSK

$167 \quad 0.17 \% \quad 52.7 \%$ NIPGITLLNVSK

$167 \quad 0.17 \% \quad 52.7 \%$ NIPGITLLNVSKLNILK

$167 \quad 0.17 \% \quad 52.7 \%$ LAPGGHVGR

$167 \quad 0.17 \% \quad 52.7 \%$ FCIWTESAFR

$167 \quad 0.17 \% \quad 52.7 \%$ KLDELYGTWR

$167 \quad 0.17 \% \quad 52.7 \%$ SNYNLPMHK

$167 \quad 0.17 \% \quad 52.7 \%$ MINTDLSR

$167 \quad 0.17 \% \quad 52.7 \%$ ILKSPEIQR

$167 \quad 0.17 \% \quad 52.7 \%$ VDKAAAAAAALQAK

$167 \quad 0.17 \% \quad 52.7 \%$ AAAAAAALQAK

$167 \quad 0.17 \% \quad 52.7 \%$ KPTTEEKKPAA

$81 \quad 0.08 \% \quad 46.1 \%$ EGKTDYYAR

$81 \quad 0.08 \% \quad 46.1 \%$ LVIQDKNK

$81 \quad 0.08 \% \quad 46.1 \%$ VTNRDIICQIAYAR

$81 \quad 0.08 \% \quad 46.1 \%$ DIICQIAYAR

$\begin{array}{lllll}0.08 \% & 46.1 \% & \text { IEGDMIVCAAYAHELPK } \quad 99.7 \% \quad 50.3\end{array}$

$81 \quad 0.08 \% \quad 46.1 \%$ VGLTNYAAAYCTGLLLAR $\quad 99.7 \% \quad 52.5$

$81 \quad 0.08 \% \quad 46.1 \%$ GAVDGGLSIPHSTK

$81 \quad 0.08 \% \quad 46.1 \%$ GAVDGGLSIPHSTKR

$81 \quad 0.08 \% \quad 46.1 \%$ RFPGYDSESK

$81 \quad 0.08 \% \quad 46.1 \%$ FPGYDSESK

$81 \quad 0.08 \% \quad 46.1 \%$ FPGYDSESKEFNAEVHR

$81 \quad 0.08 \% \quad 46.1 \%$ EFNAEVHR

$81 \quad 0.08 \% \quad 46.1 \%$ EFNAEVHRK

$81 \quad 0.08 \% \quad 46.1 \%$ HIMGQNVADYMR

$81 \quad 0.08 \% \quad 46.1 \%$ YLMEEDEDAYKK

$81 \quad 0.08 \% \quad 46.1 \%$ NSVTPDMMEEMYK

$81 \quad 0.08 \% \quad 46.1 \%$ NSVTPDMMEEMYKK

$102 \quad 0.10 \% \quad 55.6 \%$ AGEKVEKPDTK

$102 \quad 0.10 \% \quad 55.6 \%$ EKVLATVTKPVGGDK

$102 \quad 0.10 \% \quad 55.6 \%$ VLATVTKPVGGDK

$102 \quad 0.10 \% \quad 55.6 \%$ VLATVTKPVGGDKNGGTR

$102 \quad 0.10 \% \quad 55.6 \%$ YYPTEDVPR

$102 \quad 0.10 \% \quad 55.6 \%$ YYPTEDVPRK
$99.0 \% \quad 18.1$

$99.7 \% \quad 38.5 \quad 25.0 \quad 38.5$

$99.7 \% \quad 53.1 \quad 25.0 \quad 53.1$

$\begin{array}{llll}97.9 \% & 23.9 & 25.0 & 23.9\end{array}$

$99.7 \% \quad 43.8 \quad 25.0 \quad 43.8$

$\begin{array}{llll}99.7 \% & 54.2 & 25.0 & 43.3\end{array}$

$99.7 \% \quad 73.7 \quad 25.0 \quad 69.1$

$\begin{array}{llll}99.7 \% & 59.7 & 25.0 & 58.5\end{array}$

$\begin{array}{lll}99.7 \% & 42.0\end{array}$

$99.7 \% \quad 50.7$

$99.7 \% \quad 39.3$
$99.0 \% \quad 42.6 \quad 25.0 \quad 31.7$ $\begin{array}{llllllll}99.7 \% & 37.9 & 25.0 & 18.7 & 6 & 0 & 0 & 988.58\end{array}$ $99.7 \% \quad 47.5 \quad 25.0-47.5$

$99.7 \% \quad 43.4$ $99.7 \% \quad 57.2$

$99.7 \% \quad 49.2$

$99.0 \% \quad 61.9$

$99.7 \% \quad 74.7$

$99.7 \% \quad 54.3$

$99.7 \% \quad 73.9$

$99.7 \% \quad 46.0$

$99.7 \% \quad 44.1$

$99.7 \% \quad 39.2$

$99.7 \% \quad 58.2$

$99.7 \% \quad 59.7$

$\begin{array}{lll}99.7 \% & 38.5\end{array}$

$99.0 \% \quad 55.2$

$99.7 \% \quad 32.7$

$99.7 \% \quad 41.8$

$99.7 \% \quad 61.5$

$99.7 \% \quad 45.5$

$99.4 \% 24.9$

$99.0 \% \quad 31.8$

$99.7 \% \quad 53.7$

$99.7 \% \quad 59.8$

$\begin{array}{llll}99.7 \% & 65.9 & 25.0 & 57.9\end{array}$

$\begin{array}{llll}99.7 \% & 50.1 & 25.0 & 49.7\end{array}$

$\begin{array}{llll}99.7 \% & 40.3 & 25.0 & 26.7\end{array}$

$\begin{array}{llll}99.7 \% & 37.1 & 25.0 & 30.2\end{array}$

$\begin{array}{llll}99.7 \% & 36.5 & 25.0 & 26.9\end{array}$

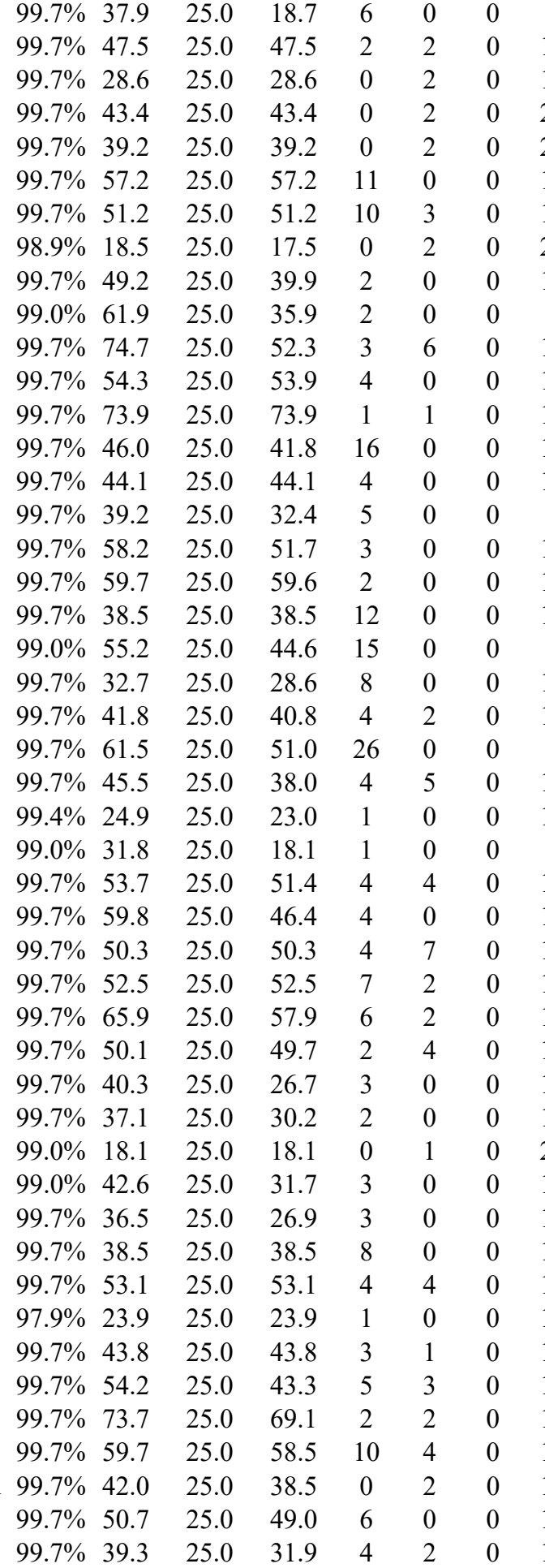

862.04

1990.13

716.28

2332.10

1184.49

1937.02

2185.16

1014.66

913.61

1761.90

1605.79

1642.96

1268.76

1850.15

863.48

1316.61

1280.66

1119.53

949.48

1083.65

1298.74

956.55

1199.66

1102.52

957.57

1692.89

1222.63

1932.92

1927.01

1338.70

1494.80

185.55

1029.45

2011.91

1001.48

1129.57

1466.65

1549.67

1574.65

1702.75

1201.64

1541.89

1284.75

1769.99

139.54

1267.63 
$60 \mathrm{~S}$ ribosomal protein $\mathrm{L} 6 \mathrm{GN}=\mathrm{RPL} 6$ $60 \mathrm{~S}$ ribosomal protein $\mathrm{L} 6 \mathrm{GN}=\mathrm{RPL} 6$ $60 \mathrm{~S}$ ribosomal protein $\mathrm{L} 6 \mathrm{GN}=\mathrm{RPL} 6$ $60 \mathrm{~S}$ ribosomal protein $\mathrm{L} 6 \mathrm{GN}=\mathrm{RPL} 6$ $60 \mathrm{~S}$ ribosomal protein $\mathrm{L} 6 \mathrm{GN}=\mathrm{RPL} 6$ $60 \mathrm{~S}$ ribosomal protein $\mathrm{L} 6 \mathrm{GN}=\mathrm{RPL} 6$ $60 \mathrm{~S}$ ribosomal protein $\mathrm{L} 6 \mathrm{GN}=\mathrm{RPL} 6$ $60 \mathrm{~S}$ ribosomal protein $\mathrm{L} 6 \mathrm{GN}=\mathrm{RPL} 6$ $60 \mathrm{~S}$ ribosomal protein $\mathrm{L} 6 \mathrm{GN}=\mathrm{RPL} 6$ $60 \mathrm{~S}$ ribosomal protein $\mathrm{L} 6 \mathrm{GN}=\mathrm{RPL} 6$ $60 \mathrm{~S}$ ribosomal protein $\mathrm{L} 6 \mathrm{GN}=\mathrm{RPL} 6$ $60 \mathrm{~S}$ ribosomal protein $\mathrm{L} 6 \mathrm{GN}=\mathrm{RPL} 6$ $60 \mathrm{~S}$ ribosomal protein $\mathrm{L} 6 \mathrm{GN}=\mathrm{RPL} 6$ $60 \mathrm{~S}$ ribosomal protein $\mathrm{L} 7 \mathrm{GN}=\mathrm{RPL} 7$ $60 \mathrm{~S}$ ribosomal protein $\mathrm{L} 7 \mathrm{GN}=\mathrm{RPL} 7$ 60 S ribosomal protein $\mathrm{L} 7 \mathrm{GN}=\mathrm{RPL} 7$ $60 \mathrm{~S}$ ribosomal protein $\mathrm{L} 7 \mathrm{GN}=\mathrm{RPL} 7$ $60 \mathrm{~S}$ ribosomal protein $\mathrm{L} 7 \mathrm{GN}=\mathrm{RPL} 7$ $60 \mathrm{~S}$ ribosomal protein $\mathrm{L} 7 \mathrm{GN}=\mathrm{RPL} 7$ $60 \mathrm{~S}$ ribosomal protein $\mathrm{L} 7 \mathrm{GN}=\mathrm{RPL} 7$ 60 S ribosomal protein $\mathrm{L} 7 \mathrm{GN}=\mathrm{RPL} 7$ $60 \mathrm{~S}$ ribosomal protein $\mathrm{L} 7 \mathrm{GN}=\mathrm{RPL} 7$ $60 \mathrm{~S}$ ribosomal protein $\mathrm{L} 7 \mathrm{GN}=\mathrm{RPL} 7$ $60 \mathrm{~S}$ ribosomal protein $\mathrm{L} 7 \mathrm{GN}=\mathrm{RPL} 7$ $60 \mathrm{~S}$ ribosomal protein $\mathrm{L} 7 \mathrm{GN}=\mathrm{RPL} 7$ 60 S ribosomal protein $\mathrm{L} 7 \mathrm{GN}=\mathrm{RPL} 7$ $60 \mathrm{~S}$ ribosomal protein $\mathrm{L} 7 \mathrm{GN}=\mathrm{RPL} 7$ $60 \mathrm{~S}$ ribosomal protein $\mathrm{L} 7 \mathrm{GN}=\mathrm{RPL} 7$ $60 \mathrm{~S}$ ribosomal protein $\mathrm{L} 7 \mathrm{GN}=\mathrm{RPL} 7$ $60 \mathrm{~S}$ ribosomal protein $\mathrm{L} 7 \mathrm{GN}=\mathrm{RPL} 7$ $60 \mathrm{~S}$ ribosomal protein $\mathrm{L} 7 \mathrm{a} \mathrm{GN}=\mathrm{RPL} 7 \mathrm{~A}$ $60 \mathrm{~S}$ ribosomal protein $\mathrm{L} 7 \mathrm{a} \mathrm{GN}=\mathrm{RPL} 7 \mathrm{~A}$ $60 \mathrm{~S}$ ribosomal protein $\mathrm{L} 7 \mathrm{a} \mathrm{GN}=\mathrm{RPL} 7 \mathrm{~A}$ 60S ribosomal protein $\mathrm{L} 7 \mathrm{a} \mathrm{GN}=\mathrm{RPL7A}$ $60 \mathrm{~S}$ ribosomal protein $\mathrm{L} 7 \mathrm{a} \mathrm{GN}=\mathrm{RPL} 7 \mathrm{~A}$ $60 \mathrm{~S}$ ribosomal protein $\mathrm{L} 7 \mathrm{a} \mathrm{GN}=\mathrm{RPL7A}$ $60 \mathrm{~S}$ ribosomal protein $\mathrm{L} 7 \mathrm{a} \mathrm{GN}=\mathrm{RPL7A}$ $60 \mathrm{~S}$ ribosomal protein $\mathrm{L} 7 \mathrm{a} \mathrm{GN}=\mathrm{RPL} 7 \mathrm{~A}$ $60 \mathrm{~S}$ ribosomal protein $\mathrm{L} 7 \mathrm{a} \mathrm{GN}=\mathrm{RPL} 7 \mathrm{~A}$ $60 \mathrm{~S}$ ribosomal protein $\mathrm{L} 7 \mathrm{a} \mathrm{GN}=\mathrm{RPL} 7 \mathrm{~A}$ $60 \mathrm{~S}$ ribosomal protein $\mathrm{L} 7 \mathrm{a} \mathrm{GN}=\mathrm{RPL7A}$ $60 \mathrm{~S}$ ribosomal protein $\mathrm{L} 7 \mathrm{a} \mathrm{GN}=\mathrm{RPL} 7 \mathrm{~A}$ $60 \mathrm{~S}$ ribosomal protein $\mathrm{L} 7 \mathrm{a} \mathrm{GN}=\mathrm{RPL} 7 \mathrm{~A}$ $60 \mathrm{~S}$ ribosomal protein $\mathrm{L} 7 \mathrm{a} \mathrm{GN}=\mathrm{RPL} 7 \mathrm{~A}$ $60 \mathrm{~S}$ ribosomal protein $\mathrm{L} 7 \mathrm{a} \mathrm{GN}=\mathrm{RPL} 7 \mathrm{~A}$ $60 \mathrm{~S}$ ribosomal protein $\mathrm{L} 7 \mathrm{a} \mathrm{GN}=\mathrm{RPL7A}$ $60 \mathrm{~S}$ ribosomal protein $\mathrm{L} 7 \mathrm{a} \mathrm{GN}=\mathrm{RPL} 7 \mathrm{~A}$
RL6_HUMAN $32.73 \quad 100.0 \% \quad 19 \quad 25 \quad 102 \quad 0.10 \% \quad 55.6 \%$ KPFSQHVR RL6_HUMAN $32.73 \quad 100.0 \% \quad 19 \quad 25 \quad 102 \quad 0.10 \% \quad 55.6 \%$ ASITPGTILIILTGR $99.7 \% \quad 53.5$ RL6 HUMAN $32.73 \quad 100.0 \% \quad 19 \quad 25 \quad 102 \quad 0.10 \% \quad 55.6 \%$ FVIATSTK

RL6_HUMAN $32.73 \quad 100.0 \% \quad 19 \quad 25 \quad 102 \quad 0.10 \% \quad 55.6 \%$ IDISNVKIPK

RL6_HUMAN $32.73 \quad 100.0 \% \quad 19 \quad 25 \quad 102 \quad 0.10 \% \quad 55.6 \%$ HLTDAYFK

RL6 HUMAN $32.73 \quad 100.0 \% \quad 19 \quad 25 \quad 102 \quad 0.10 \% \quad 55.6 \%$ HLTDAYFKK

RL6_HUMAN $32.73 \quad 100.0 \% \quad 19 \quad 25 \quad 102 \quad 0.10 \% \quad 55.6 \%$ HQEGEIFDTEK

RL6 HUMAN $32.73 \quad 100.0 \% \quad 19 \quad 25 \quad 102 \quad 0.10 \% \quad 55.6 \%$ HQEGEIFDTEKEK

RL6_HUMAN $32.73 \quad 100.0 \% \quad 19 \quad 25 \quad 102 \quad 0.10 \% \quad 55.6 \%$ EKYEITEQR

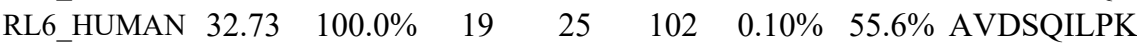

RL6 HUMAN $32.73 \quad 100.0 \% \quad 19 \quad 25 \quad 102 \quad 0.10 \% \quad 55.6 \%$ AIPQLQGYLR

RL6_HUMAN $32.73 \quad 100.0 \% \quad 19 \quad 25 \quad 102 \quad 0.10 \% \quad 55.6 \%$ SVFALTNGIYPHK

RL7_HUMAN $29.23 \quad 100.0 \% \quad 17 \quad 21 \quad 42 \quad 0.04 \% \quad 52.0 \%$ EVPAVPETLK

$\begin{array}{lllllll}\text { RL7_HUMAN } 29.23 & 100.0 \% & 17 & 21 & 42 & 0.04 \% & 52.0 \% \\ \text { EVPAVPETLKK }\end{array}$

RL7_HUMAN $29.23 \quad 100.0 \% \quad 17 \quad 21 \quad 42 \quad 0.04 \% \quad 52.0 \%$ KAGNFYVPAEPK

RL7 HUMAN $29.23 \quad 100.0 \% \quad 17 \quad 21 \quad 42 \quad 0.04 \% \quad 52.0 \%$ AGNFYVPAEPK

RL7_HUMAN $29.23 \quad 100.0 \% \quad 17 \quad 21 \quad 42 \quad 0.04 \% \quad 52.0 \%$ IRGINGVSPK

RL7_HUMAN $29.23 \quad 100.0 \% \quad 17 \quad 21 \quad 42 \quad 0.04 \% \quad 52.0 \%$ LRQIFNGTFVK

RL7 HUMAN $29.23 \quad 100.0 \% \quad 17 \quad 21 \quad 42 \quad 0.04 \% \quad 52.0 \%$ QIFNGTFVK

RL7_HUMAN $29.23 \quad 100.0 \% \quad 17 \quad 21 \quad 42 \quad 0.04 \% \quad 52.0 \%$ IVEPYIAWGYPNLK

RL7_HUMAN $29.23 \quad 100.0 \% \quad 17 \quad 21 \quad 42 \quad 0.04 \% \quad 52.0 \%$ SVNELIYK

RL7_HUMAN $29.23 \quad 100.0 \% \quad 17 \quad 21 \quad 42 \quad 0.04 \% \quad 52.0 \%$ SVNELIYKR

RL7_HUMAN $29.23 \quad 100.0 \% \quad 17 \quad 21 \quad 42 \quad 0.04 \% \quad 52.0 \%$ RIALTDNALIAR

\begin{tabular}{lllllll} 
RL7 HUMAN 29.23 & $100.0 \%$ & 17 & 21 & 42 & $0.04 \%$ & $52.0 \%$ \\
\hline
\end{tabular}

RL7_HUMAN $29.23 \quad 100.0 \% \quad 17$

RL7_HUMAN $29.23 \quad 100.0 \% \quad 17$

RL7 HUMAN $29.23 \quad 100.0 \% \quad 17$

RL7_HUMAN $29.23 \quad 100.0 \% \quad 17$

RL7 HUMAN $29.23 \quad 100.0 \% \quad 17$

RL7A_HUMAN $30.00 \quad 100.0 \% \quad 20$

RL7A_HUMAN $30.00 \quad 100.0 \% \quad 20$

RL7A_HUMAN $30.00 \quad 100.0 \% \quad 20$

RL7A_HUMAN $30.00 \quad 100.0 \% \quad 20$

RL7A_HUMAN $30.00 \quad 100.0 \% \quad 20$

RL7A_HUMAN $30.00 \quad 100.0 \% \quad 20$

RL7A_HUMAN $30.00 \quad 100.0 \% \quad 20$

RL7A HUMAN $30.00 \quad 100.0 \% \quad 20$

RL7A_HUMAN $30.00 \quad 100.0 \% \quad 20$

RL7A_HUMAN $30.00 \quad 100.0 \% \quad 20$

RL7A HUMAN $30.00 \quad 100.0 \% \quad 20$

RL7A_HUMAN $30.00 \quad 100.0 \% \quad 20$

RL7A HUMAN $30.00 \quad 100.0 \% \quad 20$

RL7A_HUMAN $30.00 \quad 100.0 \% \quad 20$

RL7A_HUMAN $30.00 \quad 100.0 \% \quad 20$

RL7A HUMAN $30.00 \quad 100.0 \% \quad 20$ RL7A HUMAN $30.00 \quad 100.0 \% \quad 20$
$102 \quad 0.10 \% \quad 55.6 \%$ QLASGLLLVTGPLVLNR

$\begin{array}{lll}0.04 \% & 52.0 \% & \text { YGIICMEDLIHEIYTV } \\ 0.04 \% & 52.0 \% & \text { FKEANNFLWPFK }\end{array}$

$0.04 \% \quad 52.0 \%$ EANNFLWPFK

$0.04 \% 52.0 \%$ TTHFVEGGDAGNR

$0.04 \% \quad 52.0 \%$ TTHFVEGGDAGNREDQINR

$0.07 \% \quad 49.6 \%$ KVAPAPAVVK

$0.07 \% \quad 49.6 \%$ VAPAPAVVK

$0.07 \% \quad 49.6 \%$ VAPAPAVVKK

$0.07 \% \quad 49.6 \%$ KVVNPLFEK

$0.07 \% \quad 49.6 \%$ VVNPLFEK

$0.07 \% \quad 49.6 \%$ NFGIGQDIQPK

$66 \quad 0.07 \% \quad 49.6 \%$ LKVPPAINQFTQALDR

$66 \quad 0.07 \% \quad 49.6 \%$ VPPAINQFTQALDR

$66 \quad 0.07 \% \quad 49.6 \%$ QTATQLLK

$66 \quad 0.07 \% \quad 49.6 \%$ AAGKGDVPTK

$0.07 \% \quad 49.6 \%$ AGVNTVTTLVENK

$66 \quad 0.07 \% \quad 49.6 \%$ AGVNTVTTLVENKK

$66 \quad 0.07 \% \quad 49.6 \%$ KMGVPYCIIK

$66 \quad 0.07 \% \quad 49.6 \%$ MGVPYCIIK

$66 \quad 0.07 \% \quad 49.6 \%$ KTCTTVAFTQVNSEDK

$99.7 \% 54.8$

$99.0 \% \quad 31.2$

$99.7 \% \quad 42.2$

$99.0 \% \quad 32.5$

$99.7 \% \quad 36.8$

$99.7 \% \quad 59.2$

$99.7 \% \quad 26.9$

$99.7 \% \quad 46.7$

$99.7 \% \quad 68.7$

$99.7 \% \quad 54.2$

$99.7 \% \quad 56.2$

$\begin{array}{lll}98.1 \% & 22.8\end{array}$

$99.5 \% \quad 23.0$

$99.7 \% \quad 60.3$

$99.7 \% \quad 45.1$

$99.7 \% \quad 27.0$

$99.7 \% 28.1$

$99.7 \% \quad 28.5$

$99.7 \% \quad 68.6$

$99.0 \% \quad 48.7$

$99.7 \% \quad 47.5$

$99.7 \% \quad 63.0$

$99.7 \% \quad 49.6$

99.7

$\begin{array}{llll}9.7 \% & 36.5 & 25.0 & 32.9\end{array}$

$99.7 \% \quad 45.1 \quad 25.0 \quad 33.7$

$\begin{array}{llll}99.7 \% & 50.1 & 25.0 & 49.6\end{array}$

$\begin{array}{llll}99.7 \% & 48.4 & 25.0 & 48.4\end{array}$

$\begin{array}{llll}98.8 \% & 17.4 & 25.0 & 17.4\end{array}$

$98.7 \% \quad 17.4 \quad 25.0 \quad 17.4$

$\begin{array}{lllll}99.7 \% & 38.5 & 25.0 & 23.2\end{array}$

$99.0 \% \quad 33.4 \quad 25.0 \quad 23.0$

$99.7 \% \quad 60.3 \quad 25.0 \quad 46.9$

$\begin{array}{llll}99.7 \% & 32.6 & 25.0 & 32.6\end{array}$

$99.7 \% \quad 76.7 \quad 25.0 \quad 74.0$

$\begin{array}{llll}99.0 \% & 48.0 & 25.0 & 28.3\end{array}$

$99.7 \% \quad 50.6 \quad 25.0 \quad 31.9$

$99.7 \% \quad 78.3 \quad 25.0 \quad 77.9$

$99.7 \% \quad 54.4 \quad 25.0 \quad 54.4$

$99.7 \% \quad 45.0 \quad 25.0 \quad 39.5$

$\begin{array}{llll}99.7 \% & 27.8 & 25.0 & 19.7\end{array}$

66
$0.07 \% \quad 49.6 \%$ TCTTVAFTQVNSEDK

$99.7 \% \quad 64.1$

25.0

5.0 \begin{tabular}{ll}
$0.04 \%$ & $52.0 \%$ \\
$0.04 \%$ & $52.0 \%$ \\
\hline
\end{tabular} 
60S ribosomal protein L7a GN=RPL7A $\quad$ RL7A_HUMAN $30.00 \quad 100.0 \% \quad 20 \quad 28 \quad 66 \quad 0.07 \% \quad 49.6 \%$ TNYNDRYDEIR

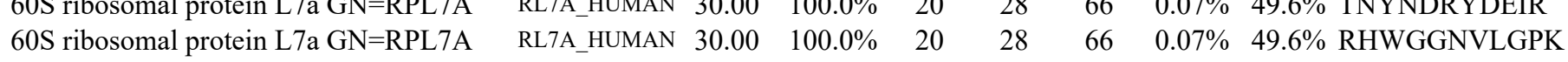
$60 \mathrm{~S}$ ribosomal protein $\mathrm{L} 7 \mathrm{a} \mathrm{GN}=\mathrm{RPL7A} \quad$ RL7A_HUMAN $30.00 \quad 100.0 \% \quad 20$ $60 \mathrm{~S}$ ribosomal protein L7-like $1 \mathrm{GN}=\mathrm{RPL7L1}$ RL7L HUMAN $28.66 \quad 100.0 \%$ $60 \mathrm{~S}$ ribosomal protein L7-like $1 \mathrm{GN}=\mathrm{RPL7L1}$ RL7L_HUMAN $28.66 \quad 100.0 \%$ $60 \mathrm{~S}$ ribosomal protein L7-like $1 \mathrm{GN}=\mathrm{RPL} 7 \mathrm{~L} 1 \quad \mathrm{RL} 7 \mathrm{~L}$ HUMAN $28.66 \quad 100.0 \%$ $60 \mathrm{~S}$ ribosomal protein L7-like $1 \mathrm{GN}=\mathrm{RPL} 7 \mathrm{~L} 1 \mathrm{RL7L}$ HUMAN $28.66 \quad 100.0 \%$ $60 \mathrm{~S}$ ribosomal protein $\mathrm{L} 8 \mathrm{GN}=\mathrm{RPL} 8$ $60 \mathrm{~S}$ ribosomal protein $\mathrm{L} 8 \mathrm{GN}=\mathrm{RPL} 8$ $60 \mathrm{~S}$ ribosomal protein $\mathrm{L} 8 \mathrm{GN}=\mathrm{RPL} 8$ $60 \mathrm{~S}$ ribosomal protein $\mathrm{L} 8 \mathrm{GN}=\mathrm{RPL} 8$ $60 \mathrm{~S}$ ribosomal protein $\mathrm{L} 8 \mathrm{GN}=\mathrm{RPL} 8$ $60 \mathrm{~S}$ ribosomal protein $\mathrm{L} 8 \mathrm{GN}=\mathrm{RPL} 8$ $60 \mathrm{~S}$ ribosomal protein $\mathrm{L} 8 \mathrm{GN}=\mathrm{RPL} 8$ $60 \mathrm{~S}$ ribosomal protein $\mathrm{L} 8 \mathrm{GN}=\mathrm{RPL} 8$ $60 \mathrm{~S}$ ribosomal protein $\mathrm{L} 8 \mathrm{GN}=\mathrm{RPL} 8$ $60 \mathrm{~S}$ ribosomal protein $\mathrm{L} 8 \mathrm{GN}=\mathrm{RPL} 8$ $60 \mathrm{~S}$ ribosomal protein $\mathrm{L} 8 \mathrm{GN}=\mathrm{RPL} 8$ $60 \mathrm{~S}$ ribosomal protein $\mathrm{L} 9 \mathrm{GN}=\mathrm{RPL} 9$ $60 \mathrm{~S}$ ribosomal protein $\mathrm{L} 9 \mathrm{GN}=\mathrm{RPL} 9$ $60 \mathrm{~S}$ ribosomal protein $\mathrm{L} 9 \mathrm{GN}=\mathrm{RPL} 9$ 60 S ribosomal protein $\mathrm{L} 9 \mathrm{GN}=\mathrm{RPL} 9$ RL8 HUMAN $28.02 \quad 100.0 \%$ RL8_HUMAN $28.02 \quad 100.0 \%$ RL8_HUMAN $28.02 \quad 100.0 \%$ RL8 HUMAN $28.02 \quad 100.0 \%$ RL8_HUMAN $28.02 \quad 100.0 \%$ RL8_HUMAN $28.02 \quad 100.0 \%$ RL8 HUMAN $28.02 \quad 100.0 \%$ RL8_HUMAN $28.02 \quad 100.0 \%$ RL8 HUMAN $28.02 \quad 100.0 \%$ RL8_HUMAN $28.02 \quad 100.0 \%$ RL9_HUMAN $21.86 \quad 100.0 \%$ RL9 HUMAN $21.86 \quad 100.0 \%$ RL9_HUMAN $21.86 \quad 100.0 \%$ RL9 HUMAN $21.86 \quad 100.0 \%$ $78 \mathrm{kDa}$ glucose-regulated protein GN=HSPA5 GRP78_HUMAN $72.33 \quad 100.0 \%$ $78 \mathrm{kDa}$ glucose-regulated protein GN=HSPA5 GRP78_HUMAN $72.33 \quad 100.0 \%$ $78 \mathrm{kDa}$ glucose-regulated protein GN=HSPA5 GRP78_HUMAN 72.33 $78 \mathrm{kDa}$ glucose-regulated protein GN=HSPA5 GRP78_HUMAN 72.33 $78 \mathrm{kDa}$ glucose-regulated protein GN=HSPA5 GRP78_HUMAN 72.33 $78 \mathrm{kDa}$ glucose-regulated protein GN=HSPA5 GRP78_HUMAN 72.33 $78 \mathrm{kDa}$ glucose-regulated protein GN=HSPA5 GRP78_HUMAN 72.33 $78 \mathrm{kDa}$ glucose-regulated protein GN=HSPA5 GRP78_HUMAN 72.33 $78 \mathrm{kDa}$ glucose-regulated protein GN=HSPA5 GRP78_HUMAN 72.33 $78 \mathrm{kDa}$ glucose-regulated protein GN=HSPA5 GRP78_HUMAN 72.33 $78 \mathrm{kDa}$ glucose-regulated protein GN=HSPA5 GRP78_HUMAN 72.33 $78 \mathrm{kDa}$ glucose-regulated protein GN=HSPA5 GRP78_HUMAN 72.33 $78 \mathrm{kDa}$ glucose-regulated protein GN=HSPA5 GRP78_HUMAN 72.33 7-dehydrocholesterol reductase GN=DHCR7 DHCR7_HUMAN 54.49 7-dehydrocholesterol reductase GN=DHCR7 DHCR7_HUMAN 54.49 7-dehydrocholesterol reductase GN=DHCR7 DHCR7_HUMAN 54.49 7-dehydrocholesterol reductase GN=DHCR7 DHCR7_HUMAN 54.49 7-dehydrocholesterol reductase GN=DHCR7 DHCR7_HUMAN 54.49 7-dehydrocholesterol reductase GN=DHCR7 DHCR7_HUMAN 54.49 Acetolactate synthase-like protein GN=ILVBL ILVBL_HUMAN 67.87 Acetolactate synthase-like protein GN=ILVBL ILVBL_HUMAN 67.87 Acetolactate synthase-like protein GN=ILVBL ILVBL_HUMAN 67.87 Acetolactate synthase-like protein GN=ILVBL ILVBL_HUMAN 67.87 Acetolactate synthase-like protein GN=ILVBL ILVBL_HUMAN 67.87 Acetolactate synthase-like protein GN=ILVBL ILVBL_HUMAN 67.87
$100.0 \%$ $100.0 \%$ $100.0 \%$ $100.0 \%$ $100.0 \%$ $100.0 \%$ $100.0 \%$ $100.0 \%$ $100.0 \%$ $100.0 \%$ $100.0 \%$ $100.0 \%$ $100.0 \%$ $100.0 \%$ $100.0 \%$ $100.0 \%$ $100.0 \%$ $100.0 \%$ $100.0 \%$ $100.0 \%$ $100.0 \%$ $100.0 \%$ $100.0 \%$ $0 \quad 1458.66$ $99.4 \%$ $99.7 \% \quad 37.4$ $\begin{array}{lllll}99.7 \% & 31.0 & 25.0 & 31.0\end{array}$ $0.01 \% \quad 20.7 \%$ KIPLVPENLLK

$99.7 \% \quad 79.4 \quad 25.0 \quad 58.8$ $\begin{array}{llll}96.7 \% & 20.7 & 25.0 & 11.7\end{array}$ $99.7 \% \quad 52.4 \quad 25.0 \quad 52.4$ $\begin{array}{lllll}99.0 \% & 51.3 & 25.0 & 33.3 & 3\end{array}$ $\begin{array}{llll}99.7 \% & 50.0 & 25.0 & 50.0\end{array}$ $\begin{array}{llll}99.0 \% & 37.3 & 25.0 & 26.5\end{array}$ $0.01 \% \quad 20.7 \%$ IVEPYVTWGFPNLK $0.01 \% \quad 20.7 \%$ TIPLTDNTVIEEHLGK $0.05 \% \quad 38.5 \%$ KGAGSVFR $0.05 \% \quad 38.5 \%$ GIVKDIIHDPGR

$0.05 \% \quad 38.5 \%$ DIIHDPGR $\begin{array}{lllll}0.05 \% & 38.5 \% & \text { TELFIAAEGIHTGQFVYCGK } & 99.7 \% & 58.8 \\ 0.05 \% & 38.5 \% & \text { ASGNYATVISHNPETK } & 99.7 \% & 54.6\end{array}$ $0.05 \% \quad 38.5 \%$ ASGNYATVISHNPETK

$0.05 \% \quad 38.5 \%$ ASGNYATVISHNPETKK $0.05 \% \quad 38.5 \%$ VKLPSGSK

$0.05 \% \quad 38.5 \%$ KVISSANR

$98.6 \% \quad 25.5 \quad 25.0 \quad 14.0$

$98.9 \% 28.1$

$99.7 \% \quad 59.3$

$0.05 \% \quad 38.5 \%$ AVVGVVAGGGR

$99.7 \% \quad 28.5$

$25.0 \quad 9.8$

$0.05 \% \quad 38.5 \%$ AVVGVVAGGGRIDKPILK $99.0 \% \quad 46.0$

$0.05 \% 38.5 \%$ KVGLIAAR

$99.7 \% \quad 41.8$

$0.01 \% \quad 24.0 \%$ DFNHINVELSLLGK

$0.01 \% \quad 24.0 \%$ DFNHINVELSLLGKK

$0.01 \% \quad 24.0 \%$ FLDGIYVSEK

$0.04 \% \quad 23.7 \%$ VEIIANDQGNR

$0.04 \% \quad 23.7 \%$ ITPSYVAFTPEGER

$99.7 \% 35$.

$99.7 \% \quad 45.6$

$99.7 \% \quad 30.6$

$99.3 \% 57.6$

$99.7 \% \quad 48.9$

$99.7 \% \quad 60.1$

$0.04 \% \quad 23.7 \%$ NQLTSNPENTVFDAK

$0.04 \% \quad 23.7 \%$ NQLTSNPENTVFDAKR

$0.04 \% \quad 23.7 \%$ TKPYIQVDIGGGQTK

$99.7 \% \quad 62.5$

$99.7 \% \quad 66.8$

$99.7 \% \quad 62.0$

$0.04 \% \quad 23.7 \%$ TFAPEEISAMVLTK

$99.7 \% \quad 54.3$

$99.7 \% \quad 49.9$

$0.04 \% \quad 23.7 \%$ DAGTIAGLNVMR

$99.7 \% \quad 67.4$

$99.7 \% \quad 88.3$

$99.7 \% \quad 56.8$

$0.04 \% \quad 23.7 \%$ IINEPTAAAIAYGLDKR

$0.04 \% \quad 23.7 \%$ AKFEELNMDLFR

$0.04 \% \quad 23.7 \%$ SQIFSTASDNQPTVTIK

$99.7 \% \quad 59.3$

$99.7 \% \quad 34.2$

$99.7 \% \quad 43.8$

$0.02 \% \quad 15.2 \%$ SLDGVTNDR

$99.7 \% \quad 57.0$

$99.6 \% \quad 23.9$

$99.7 \% \quad 50.4$

$99.7 \% \quad 43.4$

$99.0 \% \quad 20.8$

$99.6 \% \quad 25.8$

$0.02 \% \quad 15.2 \%$ YTAAVPYR

$0.01 \% \quad 18.0 \%$ HGGENVAAVLR

$99.7 \% \quad 59.9$

$0.01 \% \quad 18.0 \%$ GALQAVDQLSLFRPLCK $98.2 \% \quad 25.5$

$\begin{array}{lll}0.01 \% & 18.0 \% & \text { AAVETLGVPCFLGGMAR } \quad 99.7 \% \quad 39.0\end{array}$

$0.01 \% \quad 18.0 \%$ WLDPGAFGTLGVGAGFALGAK $\quad 99.7 \% \quad 59.0$

$99.7 \% \quad 28.5$
1220.66

1064.56

1263.80

1099.65

1662.89

1779.95

821.46

1319.74

922.47

2241.10

1688.82

1816.92

815.50

874.51

941.55

1749.07

827.55

2326.26

1598.85

1726.95

1170.60

1228.63

1566.78

1677.81

1833.91

1604.86

1536.80

1887.97

1233.63

1659.90

1816.00

1528.75

1836.93

1191.64

976.47

2173.17

1045.51

1485.66

1204.68

940.49

1122.60

2184.22

1916.04

1748.88

2005.05

1599.87

\begin{tabular}{cc}
24 & 234 \\
35 & 245 \\
36 & 245 \\
8 & 18 \\
6 & 105 \\
33 & 146 \\
64 & 179 \\
0 & 17 \\
3 & 54 \\
7 & 54 \\
3 & 92 \\
29 & 144 \\
29 & 145 \\
48 & 155 \\
56 & 163 \\
64 & 174 \\
64 & 181 \\
34 & 241 \\
3 & 23 \\
7 & 50 \\
7 & 51 \\
75 & 184 \\
0 & 60 \\
1 & 74 \\
2 & 96 \\
2 & 97 \\
24 & 138 \\
39 & 152 \\
65 & 181 \\
86 & 197 \\
98 & 213 \\
98 & 214 \\
25 & 336 \\
48 & 464 \\
65 & 474 \\
4 & 22 \\
21 & 142 \\
99 & 207 \\
77 & 389 \\
94 & 404 \\
62 & 469 \\
3 & 63 \\
11 & 134 \\
58 & 174 \\
06 & 322 \\
87 & 507 \\
86 & 599 \\
& \\
\hline
\end{tabular}

Page 18 of Table S-1-4 
Actin, cytoplasmic $1 \mathrm{GN}=\mathrm{ACTB}$ Actin, cytoplasmic $1 \mathrm{GN}=\mathrm{ACTB}$ Actin, cytoplasmic $1 \mathrm{GN}=\mathrm{ACTB}$ Actin, cytoplasmic $1 \mathrm{GN}=\mathrm{ACTB}$ Actin, cytoplasmic $1 \mathrm{GN}=\mathrm{ACTB}$ Actin, cytoplasmic $1 \mathrm{GN}=\mathrm{ACTB}$ Actin, cytoplasmic $1 \mathrm{GN}=\mathrm{ACTB}$ Actin, cytoplasmic $1 \mathrm{GN}=\mathrm{ACTE}$ Actin, cytoplasmic $1 \mathrm{GN}=\mathrm{ACTB}$ Actin, cytoplasmic $1 \mathrm{GN}=\mathrm{ACTB}$ Actin, cytoplasmic $1 \mathrm{GN}=\mathrm{ACTB}$ Actin, cytoplasmic $1 \mathrm{GN}=\mathrm{ACTB}$ Actin, cytoplasmic $1 \mathrm{GN}=\mathrm{ACTB}$ Actin, cytoplasmic $1 \mathrm{GN}=\mathrm{ACTB}$ Actin, cytoplasmic $1 \mathrm{GN}=\mathrm{ACTB}$ ACTB HUMAN $41.74 \quad 100.0 \% \quad 25$ ACTB_HUMAN $41.74 \quad 100.0 \% \quad 25$ ACTB_HUMAN $41.74 \quad 100.0 \% \quad 25$ ACTB HUMAN $41.74 \quad 100.0 \% \quad 25$ ACTB_HUMAN $41.74 \quad 100.0 \% \quad 25$ ACTB HUMAN $41.74 \quad 100.0 \% \quad 25$ ACTB_HUMAN $41.74 \quad 100.0 \% \quad 25$ ACTB_HUMAN $41.74 \quad 100.0 \% \quad 25$ ACTB HUMAN $41.74 \quad 100.0 \% \quad 25$ ACTB_HUMAN $41.74 \quad 100.0 \% \quad 25$ ACTB_HUMAN $41.74 \quad 100.0 \% \quad 25$ ACTB_HUMAN $41.74 \quad 100.0 \% \quad 25$ ACTB_HUMAN $41.74 \quad 100.0 \% \quad 25$ ACTB HUMAN $41.74 \quad 100.0 \% \quad 25$ ACTB_HUMAN $41.74 \quad 100.0 \% \quad 25$ ACTB_HUMAN $41.74 \quad 100.0 \% \quad 25$ ACTB HUMAN $41.74 \quad 100.0 \% \quad 25$ ACTB_HUMAN $41.74 \quad 100.0 \% \quad 25$ ACTB_HUMAN $41.74 \quad 100.0 \% \quad 25$ ACTB_HUMAN $41.74 \quad 100.0 \% \quad 25$ ACTB_HUMAN $41.74 \quad 100.0 \% \quad 25$ ACTB HUMAN $41.74 \quad 100.0 \% \quad 25$ ACTB_HUMAN $41.74 \quad 100.0 \% \quad 25$

$14 \quad 0.01 \% \quad 18.0 \%$ TDFRDGSIAV

$130.01 \%$

$99.7 \% \quad 37.0$ $\begin{array}{lll}99.7 \% & 59.7\end{array}$

$\begin{array}{lll}99.7 \% & 42.9\end{array}$ $99.7 \% \quad 44.5$

$\begin{array}{ll}99.7 \% & 57.3 \\ 99.7 \% & 75.3\end{array}$ $99.0 \% \quad 39.9$

$96.3 \% \quad 14.8$ $99.7 \% 33.3$ $99.7 \% \quad 37.2$ $98.4 \% \quad 16.7$ $99.7 \% \quad 34.0$ $99.7 \% \quad 32.1$

$\begin{array}{llllll}0.01 \% & 4.0 \% & \text { TIQVENSHLILTGAGALNK } & 99.7 \% & 27.2\end{array}$

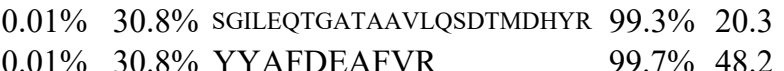

0.01\% 30.8\% GSLVDNIQQHFLLSDR $\quad 99.7 \% \quad 31.9$

$99.7 \% \quad 44.1$

$99.4 \% \quad 24.8$

$99.7 \% \quad 63.3$

$99.7 \% \quad 26.5$

$99.7 \% \quad 33.0$

$\begin{array}{ll}99.0 \% & 41.8 \\ 99.7 \% & 34.1\end{array}$ $99.7 \% \quad 63.2$

$99.7 \% \quad 54.7$ $99.7 \% \quad 60.0$

$9.7 \% \quad 34.7$ $\begin{array}{ll}99.7 \% & 56.5 \\ 99.7 \% & 62.1\end{array}$ $\begin{array}{lll}99.7 \% & 39.2\end{array}$ $99.7 \% \quad 37.5$ $99.0 \% \quad 35.9$ $99.7 \% \quad 36.0$ $99.7 \% \quad 59.5$ $\begin{array}{llllll}262 & 0.26 \% & 60.3 \% & \text { SYELPDGQVITIGNERFR } & 97.1 \% & 16.8\end{array}$ $262 \quad 0.26 \% \quad 60.3 \%$ KDLYANTVLSGGTTMYPGIADR $\quad 99.7 \% \quad 35.4$ $262 \quad 0.26 \% \quad 60.3 \%$ DLYANTVLSGGTTMYPGIADR $99.7 \% \quad 55.6$ $262 \quad 0.26 \% \quad 60.3 \%$ MQKEITALAPSTMK

$262 \quad 0.26 \% \quad 60.3 \%$ EITALAPSTMK

$262 \quad 0.26 \% \quad 60.3 \%$ EITALAPSTMKIK

$262 \quad 0.26 \% \quad 60.3 \%$ IKIIAPPER $262 \quad 0.26 \% \quad 60.3 \%$ IIAPPERK
$99.7 \% \quad 36.3$

$99.7 \% \quad 49.5$

$99.7 \% \quad 27.3$ $99.7 \% \quad 42.0$ $98.7 \% \quad 26.1$

$\begin{array}{ccc}1080.53 & 623 & 632 \\ 973.57 & 41 & 49 \\ 1701.98 & 50 & 66 \\ 1199.70 & 67 & 78 \\ 1941.05 & 106 & 124 \\ 1544.70 & 209 & 221 \\ 883.54 & 304 & 311 \\ 1088.66 & 394 & 403 \\ 1439.72 & 99 & 111 \\ 1657.87 & 336 & 350 \\ 2552.23 & 510 & 532 \\ 1591.85 & 1688 & 1701 \\ 1032.62 & 1824 & 1833 \\ 1979.09 & 1838 & 1856 \\ 2480.17 & 39 & 61 \\ 1280.59 & 96 & 105 \\ 1841.95 & 153 & 168 \\ 1400.70 & 172 & 183 \\ 1478.86 & 246 & 258 \\ 1387.66 & 269 & 280 \\ 1077.58 & 301 & 309 \\ 1987.97 & 326 & 342 \\ 988.54 & 68 & 75 \\ 1193.62 & 76 & 86 \\ 976.45 & 19 & 28 \\ 1198.71 & 29 & 39 \\ 1171.57 & 40 & 50 \\ 2383.07 & 40 & 61 \\ 1198.52 & 51 & 61 \\ 1354.62 & 51 & 62 \\ 1954.06 & 96 & 113 \\ 3199.61 & 148 & 177 \\ 1639.84 & 178 & 191 \\ 1014.48 & 184 & 191 \\ 1744.89 & 192 & 206 \\ 1132.53 & 197 & 206 \\ 1629.82 & 197 & 210 \\ 2566.17 & 216 & 238 \\ 1790.89 & 239 & 254 \\ 2094.06 & 239 & 256 \\ 2359.16 & 291 & 312 \\ 2215.07 & 292 & 312 \\ 1580.80 & 313 & 326 \\ 1177.61 & 316 & 326 \\ 1418.79 & 316 & 328 \\ 1036.65 & 327 & 335 \\ 923.57 & 329 & 336 \\ & & \end{array}$

Page 19 of Table S-1-4 
Actin, cytoplasmic $1 \mathrm{GN}=\mathrm{ACTB}$ Actin, cytoplasmic $1 \mathrm{GN}=\mathrm{ACTB}$ Actin-related protein $2 \mathrm{GN}=\mathrm{ACTR} 2$ Actin-related protein $2 \mathrm{GN}=\mathrm{ACTR} 2$ Actin-related protein $2 \mathrm{GN}=\mathrm{ACTR} 2$ Actin-related protein $2 \mathrm{GN}=\mathrm{ACTR} 2$ Actin-related protein $2 \mathrm{GN}=\mathrm{ACTR} 2$ Actin-related protein $2 \mathrm{GN}=\mathrm{ACTR} 2$ Activating signal cointegrator 1 complex subunit $3 \mathrm{GN}=\mathrm{ASCC} 3 \mathrm{ASCC} 3 \mathrm{HUMAN} 251.47 \quad 100.0 \%$ Activating signal cointegrator 1 complex subunit $3 \mathrm{GN}=\mathrm{ASCC} 3$ ASCC3_HUMAN $251.47 \quad 100.0 \%$ Activating signal cointegrator 1 complex subunit $3 \mathrm{GN}=\mathrm{ASCC} 3$ ASCC3_HUMAN $251.47 \quad 100.0 \%$ Activating signal cointegrator 1 complex subunit $3 \mathrm{GN}=\mathrm{ASCC} 3 \mathrm{ASCC} 3$ HUMAN $251.47 \quad 100.0 \%$ Activating signal cointegrator 1 complex subunit $3 \mathrm{GN}=\mathrm{ASCC} 3 \mathrm{ASCC} 3$ _HUMAN $251.47 \quad 100.0 \%$ Activating signal cointegrator 1 complex subunit $3 \mathrm{GN}=\mathrm{ASCC} 3$ ASCC3_HUMAN $251.47 \quad 100.0 \%$ Activating signal cointegrator 1 complex subunit $3 \mathrm{GN}=\mathrm{ASCC} 3 \mathrm{ASCC} 3$ HUMAN $251.47 \quad 100.0 \%$ Activating signal cointegrator 1 complex subunit $3 \mathrm{GN}=\mathrm{ASCC} 3 \mathrm{ASCC} 3$ HUMAN $251.47 \quad 100.0 \%$ Activating signal cointegrator 1 complex subunit $3 \mathrm{GN}=\mathrm{ASCC} 3$ ASCC3 HUMAN $251.47 \quad 100.0 \%$ Activating signal cointegrator 1 complex subunit $3 \mathrm{GN}=\mathrm{ASCC} 3 \mathrm{ASCC} 3$ HUMAN $251.47 \quad 100.0 \%$ Activator of $90 \mathrm{kDa}$ heat shock protein ATPase homolog $1 \mathrm{GN}=\mathrm{AHSA}$ AHSA1_HUMAN $38.27 \quad 100.0 \%$ Activator of $90 \mathrm{kDa}$ heat shock protein ATPase homolog $1 \mathrm{GN}=\mathrm{AHSA} 1$ AHSA1 HUMAN $38.27 \quad 100.0 \%$ Activator of $90 \mathrm{kDa}$ heat shock protein ATPase homolog $1 \mathrm{GN}=\mathrm{AHSA}$ AHSA1_HUMAN $38.27 \quad 100.0 \%$ Activator of $90 \mathrm{kDa}$ heat shock protein ATPase homolog $1 \mathrm{GN}=\mathrm{AHSA} 1$ AHSA1_HUMAN $38.27100 .0 \%$ Activator of $90 \mathrm{kDa}$ heat shock protein ATPase homolog $1 \mathrm{GN}=\mathrm{AHSA}$ AHSA1_HUMAN $38.27 \quad 100.0 \%$ Activator of basal transcription $1 \mathrm{GN}=\mathrm{ABT} 1 \mathrm{ABT1}$ _HUMAN $31.08 \quad 100.0 \%$ Activator of basal transcription $1 \mathrm{GN}=\mathrm{ABT} 1 \mathrm{ABT1}$ HUMAN $31.08 \quad 100.0 \%$ Activator of basal transcription $1 \mathrm{GN}=\mathrm{ABT} 1 \mathrm{ABT} 1$ _HUMAN $31.08 \quad 100.0 \%$ Activator of basal transcription $1 \mathrm{GN}=\mathrm{ABT} 1 \mathrm{ABT1}$ HUMAN $31.08 \quad 100.0 \%$ Activator of basal transcription $1 \mathrm{GN}=\mathrm{ABT} 1 \mathrm{ABT1}$ HUMAN $31.08 \quad 100.0 \%$ Acyl-CoA dehydrogenase family member 9, mitochondrial GN=ACAD9 ACAD9_HUMAN $68.76 \quad 100.0 \%$ Acyl-CoA dehydrogenase family member 9 , mitochondrial GN=ACAD9 ACAD9 HUMAN $68.76 \quad 100.0 \%$ Acyl-CoA dehydrogenase family member 9, mitochondrial GN=ACAD9 ACAD9_HUMAN $68.76 \quad 100.0 \%$ Acyl-CoA dehydrogenase family member 9, mitochondrial GN=ACAD9 ACAD9_HUMAN $68.76 \quad 100.0 \%$ Acyl-coenzyme A thioesterase $1 \mathrm{GN}=$ ACOT1 ACOT1_HUMAN $46.28 \quad 100.0 \%$ Acyl-coenzyme A thioesterase $1 \mathrm{GN}=\mathrm{ACOT} 1$ ACOT1_HUMAN $46.28 \quad 100.0 \%$ Acyl-coenzyme A thioesterase $8 \mathrm{GN}=\mathrm{ACOT} 8$ ACOT8_HUMAN $35.91 \quad 100.0 \%$ Acyl-coenzyme A thioesterase $8 \mathrm{GN}=$ ACOT8 ACOT8_HUMAN $35.91 \quad 100.0 \%$ Acyl-coenzyme A thioesterase $8 \mathrm{GN}=$ ACOT8 ACOT8_HUMAN $35.91 \quad 100.0 \%$ Adenylate kinase 4, mitochondrial GN=AK4 KAD4 HUMAN $25.27 \quad 100.0 \%$ Adenylate kinase 4, mitochondrial GN=AK4 KAD4_HUMAN $25.27 \quad 100.0 \%$ Adenylate kinase 4, mitochondrial GN=AK4 KAD4_HUMAN $25.27 \quad 100.0 \%$ Adenylate kinase 4, mitochondrial GN=AK4 KAD4_HUMAN $25.27 \quad 100.0 \%$ Adenylate kinase 4, mitochondrial GN=AK4 KAD4_HUMAN $25.27 \quad 100.0 \%$ Adenylosuccinate synthetase isozyme $2 \mathrm{GN}=\mathrm{ADSS}$ PURA2 HUMAN $50.10 \quad 100.0 \%$ Adenylosuccinate synthetase isozyme $2 \mathrm{GN}=$ ADSS PURA2_HUMAN $50.10 \quad 100.0 \%$ Adenylosuccinate synthetase isozyme 2 GN=ADSS PURA2_HUMAN $50.10 \quad 100.0 \%$ ADP/ATP translocase $1 \mathrm{GN}=\mathrm{SLC} 25 \mathrm{~A} 4 \quad$ ADT1 HUMAN $33.07 \quad 100.0 \%$ ADP/ATP translocase $1 \mathrm{GN}=\mathrm{SLC} 25 \mathrm{~A} 4 \quad$ ADT1_HUMAN $33.07 \quad 100.0 \%$
$42 \quad 262 \quad 0.26 \% \quad 60.3 \%$ QEYDESGPSIVHR $42-262-0.26 \% \quad 60.3 \%$ QEYDESGPS

$19 \quad 0.02 \% \quad 21.8 \%$ DLMVGDEASELR

$19 \quad 0.02 \% \quad 21.8 \%$ ILLTEPPMNPTK

$19 \quad 0.02 \% \quad 21.8 \%$ GYAFNHSADFETVR

$19 \quad 0.02 \% \quad 21.8 \%$ LCYVGYNIEQEQK

$0.02 \% 21.8 \%$ LALETTVLVESYTLPDG

$19.02 \% \quad 21.8 \%$ HIVLSGGSTMYPGLPSR

$0.03 \% \quad 4.8 \%$ IQREQALLNAR

$0.03 \% \quad 4.8 \%$ MILPEGIQR

$0.03 \% \quad 4.8 \%$ RLEPLGIIVK

$0.03 \% \quad 4.8 \%$ SVGDVALSQIVR

$0.03 \% \quad 4.8 \%$ QVESTQSMIR

$0.03 \% \quad 4.8 \%$ TGYFSSTDLGR

$0.03 \% \quad 4.8 \%$ TVAAELAIFR

$0.03 \% \quad 4.8 \%$ VFNKYPTSK

$0.03 \% \quad 4.8 \%$ VIELTGDVTPDMK

$0.03 \% \quad 4.8 \%$ VSDSLTDLALK

$0.01 \% \quad 14.5 \%$ LDGEASINNR

$0.01 \% \quad 14.5 \%$ EAMGIYISTLK

$0.01 \% \quad 14.5 \%$ TQARPVGVK

$0.01 \% \quad 14.5 \%$ GIPAPEEERTR

$0.01 \% \quad 14.5 \%$ QTFGYGAR

$0.01 \% \quad 19.1 \%$ NLLSAYGEVGR

$0.01 \% \quad 19.1 \%$ VFFQAEDR

$0.01 \% \quad 19.1 \%$ VAASLHNTPMGAR

$0.01 \% \quad 19.1 \%$ LRAEVAQAK

$0.01 \% \quad 19.1 \%$ ETDFYLQSVER

$0.01 \% \quad 6.6 \%$ LIEMTAEYACTR

$0.01 \% \quad 6.6 \%$ ILLIFEGTNEILR

$0.01 \% \quad 6.6 \% \quad$ TVETLLLR

$0.01 \% \quad 6.6 \%$ VSQQILEK

$0.00 \% \quad 5.2 \%$ AATLILEPAGR

$0.00 \% \quad 5.2 \%$ GLAPEQPVTLR

$0.01 \% \quad 11.0 \%$ LFGGQIVGQALVAAAK

$0.01 \% \quad 11.0 \%$ LPVLYQVER

$0.01 \% \quad 11.0 \%$ VKPQVSESKL

$\quad 0.01 \% \quad 23.3 \%$ AVILGPPGSGK

$10 \quad 0.01 \% \quad 23.3 \%$ ASTEVGEMAK

$10 \quad 0.01 \% \quad 23.3 \%$ SLLVPDHVITR

$10 \quad 0.01 \% \quad 23.3 \%$ LMMSELENR

$10 \quad 0.01 \% \quad 23.3 \%$ DVAKPVIELYK

$0.00 \% \quad 8.3 \%$ VVDLLAQDADIVCR

$0.00 \% \quad 8.3 \%$ GREFGVTTGR

$0.00 \% \quad 8.3 \%$ AFKELPVNAQNYVR

$0.01 \% \quad 62.1 \%$ DFLAGGVAAAVSK

$0.01 \% \quad 62.1 \%$ TAVAPIER $\begin{array}{llll}99.7 \% & 53.0 & 25.0 & 48.0\end{array}$

$\begin{array}{llll}99.4 \% & 22.6 & 25.0 & 22.6\end{array}$

$\begin{array}{llll}98.7 \% & 19.8 & 25.0 & 16.7\end{array}$

$\begin{array}{llll}99.7 \% & 42.1 & 25.0 & 41.7\end{array}$

$\begin{array}{llll}99.7 \% & 56.5 & 25.0 & 48.6\end{array}$

$99.7 \% \quad 45.3$

$\begin{array}{llll}95.6 \% & 16.4 & 25.0 & 16.1\end{array}$

$\begin{array}{llll}99.7 \% & 39.4 & 25.0 & 36.5\end{array}$

$99.7 \% \quad 60.9 \quad 25.0 \quad 51.4$

$99.7 \% \quad 40.7 \quad 25.0 \quad 27.4$

$\begin{array}{llll}99.7 \% & 33.3 & 25.0 & 25.9\end{array}$

$99.7 \% \quad 57.2 \quad 25.0 \quad 54.0$

$\begin{array}{llll}99.5 \% & 21.4 & 25.0 & 21.4\end{array}$

$99.7 \% \quad 48.7 \quad 25.0 \quad 48.5$

$\begin{array}{llll}99.7 \% & 37.2 & 25.0 & 33.0\end{array}$

$\begin{array}{llll}99.7 \% & 53.0 & 25.0 & 40.6\end{array}$

$\begin{array}{llll}99.7 \% & 44.8 & 25.0 & 41.6\end{array}$

$99.7 \% \quad 38.4 \quad 25.0 \quad 33.1 \quad 2$

$\begin{array}{llll}99.7 \% & 46.1 & 25.0 & 45.0\end{array}$

$\begin{array}{llll}99.0 \% & 47.2 & 25.0 & 34.7\end{array}$

$99.7 \% \quad 70.8 \quad 25.0 \quad 56.5$

$\begin{array}{llll}99.0 \% & 29.9 & 25.0 & 16.9\end{array}$

$\begin{array}{llll}99.7 \% & 27.3 & 25.0 & 23.8\end{array}$

$\begin{array}{llll}99.7 \% & 43.6 & 25.0 & 28.6\end{array}$

$99.7 \% \quad 61.4 \quad 25.0 \quad 61.4$

$99.4 \% \quad 21.5 \quad 25.0 \quad 21.5$

$\begin{array}{llll}99.7 \% & 56.8 & 25.0 & 56.8\end{array}$

$\begin{array}{llll}99.0 \% & 31.3 & 25.0 & 25.8\end{array}$

$\begin{array}{llll}99.0 \% & 22.9 & 25.0 & 17.4\end{array}$

$\begin{array}{llll}99.7 \% & 36.7 & 25.0 & 36.7\end{array}$

$96.3 \% \quad 23.3$

$\begin{array}{lll}99.7 \% & 59.7\end{array}$

$99.7 \% \quad 39.3$

$99.2 \% 22.1$

$99.7 \% 28$.

$99.7 \% 34$.

$99.7 \% \quad 40.6$

$99.7 \% \quad 37.9$

$99.7 \% \quad 28.2$

$99.7 \% \quad 56.2$

$99.5 \% \quad 25.6$

$99.7 \% \quad 38.1$

$99.7 \% 77.8$

$99.0 \% \quad 41.8$

0

0

1516.70

1644.80

1350.62

1369.74

1613.73

1643.77

1977.05

1787.91

1311.75

1056.59

1137.74

1243.70

1178.58

1203.56

1090.63

1083.58

1417.72

1161.64

1088.53

1225.65

955.57

1254.64

899.44

1178.62

1011.49

1324.68

985.58

1386.65

1457.68

1530.89

944.58

944.54

1111.65

1180.67

1542.90

1116.64

1114.65

995.59

1022.48

1249.73

1154.52

1274.74

1586.82

1079.56

1648.88

1205.65

856.49 
ADP/ATP translocase $1 \mathrm{GN}=\mathrm{SLC} 25 \mathrm{~A} 4$ $\mathrm{ADP} / \mathrm{ATP}$ translocase $1 \mathrm{GN}=\mathrm{SLC} 25 \mathrm{~A}$ ADP/ATP translocase $1 \mathrm{GN}=\mathrm{SLC} 25 \mathrm{~A} 4$ ADP/ATP translocase $1 \mathrm{GN}=\mathrm{SLC} 25 \mathrm{~A} 4$ $\mathrm{ADP} / \mathrm{ATP}$ translocase $1 \mathrm{GN}=\mathrm{SLC} 25 \mathrm{~A} 4$ $\mathrm{ADP} / \mathrm{ATP}$ translocase $1 \mathrm{GN}=\mathrm{SLC} 25 \mathrm{~A}$ ADP/ATP translocase $1 \mathrm{GN}=\mathrm{SLC} 25 \mathrm{~A} 4$ $\mathrm{ADP} / \mathrm{ATP}$ translocase $1 \mathrm{GN}=\mathrm{SLC} 25 \mathrm{~A} 4$ ADP/ATP translocase $1 \mathrm{GN}=\mathrm{SLC} 25 \mathrm{~A} 4$ $\mathrm{ADP} / \mathrm{ATP}$ translocase $1 \mathrm{GN}=\mathrm{SLC} 25 \mathrm{~A} 4$ ADP/ATP translocase $1 \mathrm{GN}=\mathrm{SLC} 25 \mathrm{~A} 4$ ADP/ATP translocase $1 \mathrm{GN}=\mathrm{SLC} 25 \mathrm{~A}$ $\mathrm{ADP} / \mathrm{ATP}$ translocase $1 \mathrm{GN}=\mathrm{SLC} 25 \mathrm{~A}^{2}$ $\mathrm{ADP} / \mathrm{ATP}$ translocase $1 \mathrm{GN}=\mathrm{SLC} 25 \mathrm{~A}$ ADP/ATP translocase $1 \mathrm{GN}=\mathrm{SLC} 25 \mathrm{~A} 4$ $\mathrm{ADP} / \mathrm{ATP}$ translocase $1 \mathrm{GN}=\mathrm{SLC} 25 \mathrm{~A} 4$ ADP/ATP translocase $1 \mathrm{GN}=\mathrm{SLC} 25 \mathrm{~A} 4$ ADP/ATP translocase $2 \mathrm{GN}=\mathrm{SLC} 25 \mathrm{~A} 5$ ADP/ATP translocase $2 \mathrm{GN}=\mathrm{SLC} 25 \mathrm{~A}$ $\mathrm{ADP} / \mathrm{ATP}$ translocase $2 \mathrm{GN}=\mathrm{SLC} 25 \mathrm{~A}$ $\mathrm{ADP} / \mathrm{ATP}$ translocase $2 \mathrm{GN}=\mathrm{SLC} 25 \mathrm{~A} 5$ ADP/ATP translocase $2 \mathrm{GN}=\mathrm{SLC} 25 \mathrm{~A}$ $\mathrm{ADP} / \mathrm{ATP}$ translocase $2 \mathrm{GN}=\mathrm{SLC} 25 \mathrm{~A} 5$ ADP/ATP translocase $2 \mathrm{GN}=\mathrm{SLC} 25 \mathrm{~A} 5$ $\mathrm{ADP} / \mathrm{ATP}$ translocase $2 \mathrm{GN}=\mathrm{SLC} 25 \mathrm{~A}$ $\mathrm{ADP} / \mathrm{ATP}$ translocase $2 \mathrm{GN}=\mathrm{SLC} 25 \mathrm{~A} 5$ ADP/ATP translocase $2 \mathrm{GN}=\mathrm{SLC} 25 \mathrm{~A}$ $\mathrm{ADP} / \mathrm{ATP}$ translocase $2 \mathrm{GN}=\mathrm{SLC} 25 \mathrm{~A} 5$ $\mathrm{ADP} / \mathrm{ATP}$ translocase $2 \mathrm{GN}=\mathrm{SLC} 25 \mathrm{~A} 5$ ADP/ATP translocase $2 \mathrm{GN}=\mathrm{SLC} 25 \mathrm{~A}$ ADP/ATP translocase $2 \mathrm{GN}=\mathrm{SLC} 25 \mathrm{~A} 5$ ADP/ATP translocase $2 \mathrm{GN}=\mathrm{SLC} 25 \mathrm{~A} 5$ ADP/ATP translocase $2 \mathrm{GN}=\mathrm{SLC} 25 \mathrm{~A}$ ADP/ATP translocase $2 \mathrm{GN}=\mathrm{SLC} 25 \mathrm{~A}$ : ADP/ATP translocase $2 \mathrm{GN}=\mathrm{SLC} 25 \mathrm{~A} 5$ $\mathrm{ADP} / \mathrm{ATP}$ translocase $2 \mathrm{GN}=\mathrm{SLC} 25 \mathrm{~A} 5$ ADP/ATP translocase $2 \mathrm{GN}=\mathrm{SLC} 25 \mathrm{~A} 5$ $\mathrm{ADP} / \mathrm{ATP}$ translocase $2 \mathrm{GN}=\mathrm{SLC} 25 \mathrm{~A}$ $\mathrm{ADP} / \mathrm{ATP}$ translocase $2 \mathrm{GN}=\mathrm{SLC} 25 \mathrm{~A} 5$ ADP/ATP translocase $2 \mathrm{GN}=\mathrm{SLC} 25 \mathrm{~A}$ : $\mathrm{ADP} / \mathrm{ATP}$ translocase $2 \mathrm{GN}=\mathrm{SLC} 25 \mathrm{~A} 5$ $\mathrm{ADP} / \mathrm{ATP}$ translocase $2 \mathrm{GN}=\mathrm{SLC} 25 \mathrm{~A} 5$ ADP/ATP translocase $2 \mathrm{GN}=\mathrm{SLC} 25 \mathrm{~A}$ ADP/ATP translocase $2 \mathrm{GN}=\mathrm{SLC} 25 \mathrm{~A} 5$ ADP/ATP translocase $2 \mathrm{GN}=\mathrm{SLC} 25 \mathrm{~A} 5$ ADP/ATP translocase $2 \mathrm{GN}=\mathrm{SLC} 25 \mathrm{~A} 5$ $\mathrm{ADP} / \mathrm{ATP}$ translocase $3 \mathrm{GN}=\mathrm{SLC} 25 \mathrm{~A} 6$ $\begin{array}{lllllll}\text { ADT1 HUMAN } 33.07 & 100.0 \% & 4 & 4 & 8 & 0.01 \% & 62.1 \% \\ \text { VKLLLQVQHASK }\end{array}$ $0.01 \% \quad 62.1 \%$ LLLQVQHASK $0.01 \% \quad 62.1 \%$ GIIDCVVR $0.01 \% \quad 62.1 \%$ EQGFLSFWR $0.01 \% \quad 62.1 \%$ GNLANVIR $0.01 \% \quad 62.1 \%$ YFPTQALNFAFK $0.01 \% \quad 62.1 \%$ YFPTQALNFAFKDK $0.01 \% \quad 62.1 \%$ QLFLGGVDR $0.01 \% \quad 62.1 \%$ YFAGNLASGGAAGATSLCFVYPLDFAR $0.01 \% \quad 62.1 \%$ TRLAADVGK $0.01 \% \quad 62.1 \%$ EFHGLGDCIIK $0.01 \% \quad 62.1 \%$ AAYFGVYDTAK $0.01 \% \quad 62.1 \%$ RMMMQSGR $0.01 \% \quad 62.1 \%$ GADIMYTGTVDCWR $0.01 \% \quad 62.1 \%$ GAWSNVLR $0.01 \% \quad 62.1 \%$ GMGGAFVLVLYDEIK $0.01 \% \quad 62.1 \%$ GMGGAFVLVLYDEIKK $0.10 \% \quad 66.1 \%$ DFLAGGVAAAISK $0.10 \% \quad 66.1 \%$ DFLAGGVAAAISKTAVAPIER $0.10 \% \quad 66.1 \%$ TAVAPIER $0.10 \% \quad 66.1 \%$ VKLLLQVQHASK $0.10 \% \quad 66.1 \%$ LLLQVQHASK $0.10 \% \quad 66.1 \%$ QITADKQYK $0.10 \% \quad 66.1 \%$ GIIDCVVR $0.10 \% \quad 66.1 \%$ IPKEQGVLSFWR $0.10 \% \quad 66.1 \%$ EQGVLSFWR $0.10 \% \quad 66.1 \%$ GNLANVIR $0.10 \% \quad 66.1 \%$ YFPTQALNFAFK $0.10 \% \quad 66.1 \%$ YFPTQALNFAFKDK $0.10 \% \quad 66.1 \%$ YKQIFLGGVDK $0.10 \% \quad 66.1 \%$ QIFLGGVDK $0.10 \% \quad 66.1 \%$ QIFLGGVDKR $0.10 \% \quad 66.1 \%$ TRLAADVGK $0.10 \% \quad 66.1 \%$ LAADVGKAGAER $0.10 \% \quad 66.1 \%$ GLGDCLVK

$0.10 \% \quad 66.1 \%$ IYKSDGIK

$0.10 \% \quad 66.1 \%$ AAYFGIYDTAK $0.10 \% \quad 66.1 \%$ RMMMQSGR $\begin{array}{llll} & \end{array}$ ADT2_HUMAN $32.85 \quad 100.0 \% \quad 29$ ADT2_HUMAN $32.85 \quad 100.0 \% \quad 29$ ADT2 HUMAN $32.85 \quad 100.0 \% \quad 29$ ADT2_HUMAN $32.85 \quad 100.0 \% \quad 29$ ADT2 HUMAN $32.85 \quad 100.0 \% \quad 29$ ADT2_HUMAN $32.85 \quad 100.0 \% \quad 29$ ADT2_HUMAN $32.85 \quad 100.0 \% \quad 29$ ADT2 HUMAN $32.85 \quad 100.0 \% \quad 29$ ADT3_HUMAN $32.87 \quad 100.0 \%$

$0.10 \% \quad 66.1 \%$ GTDIMYTGTLDCWR

$0.10 \% \quad 66.1 \%$ GTDIMYTGTLDCWRK

$0.10 \% \quad 66.1 \%$ IARDEGGK

$0.10 \% \quad 66.1 \%$ DEGGKAFFK

$0.10 \% \quad 66.1 \%$ GAWSNVLR

$0.10 \% \quad 66.1 \%$ GMGGAFVLVLYDEIKK $\begin{array}{llllllll}9.7 \% & 58.0 & 25.0 & 47.0 & 2 & 3 & 0 & 1363.84\end{array}$

1136.68

931.50

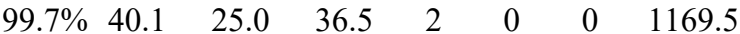

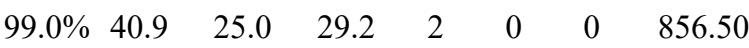

$\begin{array}{llllllll}99.7 \% & 55.7 & 25.0 & 42.0 & 12 & 0 & 0 & 1446.74\end{array}$

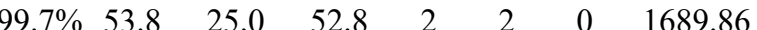

$\begin{array}{llllllll}99.7 \% & 62.7 & 25.0 & 43.3 & 2 & 0 & 0 & 1004.55\end{array}$

2796.35

$\begin{array}{llllllll}96.0 \% & 25.4 & 25.0 & 1.0 & 1 & 0 & 0 & 930.54\end{array}$

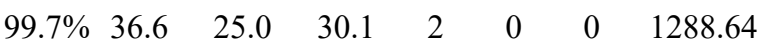

$\begin{array}{llllllll}99.7 \% & 55.7 & 25.0 & 55.7 & 2 & 0 & 0 & 1205.58\end{array}$

$\begin{array}{llllllll}99.0 \% & 27.4 & 25.0 & 25.6 & 2 & 0 & 0 & 996.45\end{array}$

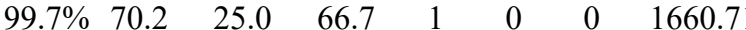

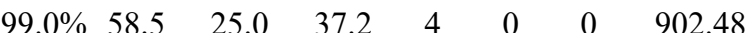

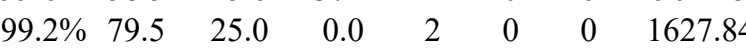

$\begin{array}{llllllll}99.0 \% & 41.7 & 25.0 & 0.0 & 1 & 0 & 0 & 1755.94\end{array}$

$\begin{array}{llllllll}99.7 \% & 75.2 & 25.0 & 71.5 & 3 & 0 & 0 & 1219.67\end{array}$

1219.67

856.49

1363.84

1136.68

1094.58

931.50

1459.81

1121.57

856.50

1446.74

1689.86

1267.70

976.55

1132.65

930.54

1157.63

861.45

923.52

1219.60

996.45

1832.83

1704.74

1816.84

845.45

998.49

902.48

1627.84

1755.94

$99.0 \% \quad 58.5 \quad 25.0 \quad 37.2$

$99.2 \% \quad 79.5 \quad 25.0 \quad 0.0 \quad 2$

$\begin{array}{lllll} & 99.0 \% & 41.7 & 25.0 & 0.0\end{array}$ 
ADP/ATP translocase $3 \mathrm{GN}=\mathrm{SLC} 25 \mathrm{~A} 6$ $\mathrm{ADP} / \mathrm{ATP}$ translocase $3 \mathrm{GN}=\mathrm{SLC} 25 \mathrm{~A} 6$ $\mathrm{ADP} / \mathrm{ATP}$ translocase $3 \mathrm{GN}=\mathrm{SLC} 25 \mathrm{~A} 6$ ADP/ATP translocase $3 \mathrm{GN}=\mathrm{SLC} 25 \mathrm{~A} 6$ ADP/ATP translocase $3 \mathrm{GN}=\mathrm{SLC} 25 \mathrm{~A} 6$ ADP/ATP translocase $3 \mathrm{GN}=\mathrm{SLC} 25 \mathrm{~A} 6$ ADP/ATP translocase $3 \mathrm{GN}=\mathrm{SLC} 25 \mathrm{~A} 6$ ADP/ATP translocase $3 \mathrm{GN}=\mathrm{SLC} 25 \mathrm{~A} 6$ $\mathrm{ADP} / \mathrm{ATP}$ translocase $3 \mathrm{GN}=\mathrm{SLC} 25 \mathrm{~A} 6$ ADP/ATP translocase $3 \mathrm{GN}=\mathrm{SLC} 25 \mathrm{~A} 6$ ADP/ATP translocase $3 \mathrm{GN}=\mathrm{SLC} 25 \mathrm{~A} 6$ ADP/ATP translocase $3 \mathrm{GN}=\mathrm{SLC} 25 \mathrm{~A} 6$ ADP/ATP translocase $3 \mathrm{GN}=\mathrm{SLC} 25 \mathrm{~A} 6$ ADP/ATP translocase $3 \mathrm{GN}=\mathrm{SLC} 25 \mathrm{~A} 6$ ADP/ATP translocase $3 \mathrm{GN}=\mathrm{SLC} 25 \mathrm{~A} 6$ ADP/ATP translocase $3 \mathrm{GN}=\mathrm{SLC} 25 \mathrm{~A} 6$ ADP/ATP translocase $3 \mathrm{GN}=\mathrm{SLC} 25 \mathrm{~A} 6$ ADP/ATP translocase $3 \mathrm{GN}=\mathrm{SLC} 25 \mathrm{~A} 6$ ADP/ATP translocase $3 \mathrm{GN}=\mathrm{SLC} 25 \mathrm{~A} 6$ ADP/ATP translocase $3 \mathrm{GN}=\mathrm{SLC} 25 \mathrm{~A} 6$ ADP/ATP translocase $3 \mathrm{GN}=\mathrm{SLC} 25 \mathrm{~A} 6$ ADP/ATP translocase $3 \mathrm{GN}=\mathrm{SLC} 25 \mathrm{~A} 6$ AFG3-like protein $2 \mathrm{GN}=\mathrm{AFG} 3 \mathrm{~L} 2$ AFG3-like protein $2 \mathrm{GN}=\mathrm{AFG} 3 \mathrm{~L} 2$ AFG32_HUMAN 88.59 Aflatoxin B1 aldehyde reductase member $2 \mathrm{GN}=\mathrm{AKR} 7 \mathrm{~A} 2$ ARK72_HUMAN $39.59 \quad 100.0 \%$ AH receptor-interacting protein GN=AIP AIP HUMAN $37.64 \quad 100.0 \%$ $\mathrm{AH}$ receptor-interacting protein $\mathrm{GN}=\mathrm{AIP}$ Aladin GN=AAAS

Aladin $\mathrm{GN}=\mathrm{AAAS}$

Aladin $\mathrm{GN}=\mathrm{AAAS}$

Aladin GN=AAAS

Aladin GN=AAAS

Aladin $\mathrm{GN}=\mathrm{AAAS}$

Aladin GN=AAAS Alanine--tRNA ligase, mitochondrial GN=AARS2 SYAM_HUMAN $107.34 \quad 100.0 \%$ Alanine--tRNA ligase, mitochondrial GN=AARS2 SYAM_HUMAN $107.34 \quad 100.0 \%$ Alanine--tRNA ligase, mitochondrial GN=AARS2 SYAM_HUMAN $107.34 \quad 100.0 \%$ Alcohol dehydrogenase class-3 GN=ADH5 ADHX_HUMAN $39.72 \quad 99.9 \%$ Alcohol dehydrogenase class-3 GN=ADH5 ADHX_HUMAN $39.72 \quad 99.9 \%$ Aldehyde dehydrogenase $X$, mitochondrial GN=ALDH1B1 AL1B1_HUMAN $57.21 \quad 100.0 \%$ Aldehyde dehydrogenase $\mathrm{X}$, mitochondrial GN=ALDH1B1 AL1B1_HUMAN $57.21 \quad 100.0 \%$ Aldehyde dehydrogenase $X$, mitochondrial GN=ALDH1B1 AL1B1_HUMAN $57.21 \quad 100.0 \%$ Aldehyde dehydrogenase $X$, mitochondrial GN=ALDH1B1 AL1B1_HUMAN $57.21 \quad 100.0 \%$ Aldehyde dehydrogenase $\mathrm{X}$, mitochondrial GN=ALDH1B1 AL1B1_HUMAN $57.21 \quad 100.0 \%$ Aldehyde dehydrogenase $X$, mitochondrial GN=ALDH1B1 AL1B1_HUMAN $57.21 \quad 100.0 \%$
$15 \quad 0.01 \% \quad 66.1 \%$ TAVAPIER $0.01 \% \quad 66.1 \%$ VKLLLQVQHASK $0.01 \% \quad 66.1 \%$ LLLQVQHASK $0.01 \% \quad 66.1 \%$ IPKEQGVLSFWR $0.01 \% \quad 66.1 \%$ EQGVLSFWR $0.01 \% \quad 66.1 \%$ GNLANVIR $0.01 \% \quad 66.1 \%$ YFPTQALNFAFK $0.01 \% \quad 66.1 \%$ YFPTQALNFAFKDK $0.01 \% \quad 66.1 \%$ YKQIFLGGVDK $0.01 \% \quad 66.1 \%$ QIFLGGVDK $0.01 \% \quad 66.1 \%$ QIFLGGVDKHTQFWR $0.01 \% \quad 66.1 \%$ YFAGNLASGGAAGATSLCFVYPLDFAR $0.01 \% \quad 66.1 \%$ TRLAADVGK $0.01 \% \quad 66.1 \%$ GLGDCLVK $0.01 \% \quad 66.1 \%$ AAYFGVYDTAK $0.01 \% \quad 66.1 \%$ RMMMQSGR $0.01 \% \quad 66.1 \%$ GADIMYTGTVDCWR $0.01 \% \quad 66.1 \%$ IFRDEGGK $0.01 \% \quad 66.1 \%$ DEGGKAFFK $0.01 \% \quad 66.1 \%$ GAWSNVLR $0.01 \% \quad 66.1 \%$ GMGGAFVLVLYDELK $0.01 \% \quad 66.1 \%$ GMGGAFVLVLYDELKK $0.00 \% \quad 3.4 \%$ GAILTGPPGTGKTLLAK $0.00 \% \quad 3.4 \%$ VGQISFDLPR

$0.00 \% \quad 9.5 \% \quad$ ALQAAYGASAPSVTSAALR $\quad 99.7 \% \quad 58.9$

$0.00 \% \quad 7.6 \%$ AVPLIHQEGNR

$0.00 \% \quad 7.6 \%$ VLELDPALAPVVSR

$0.01 \% \quad 15.8 \%$ FAVALLDDSVR

$0.01 \% \quad 15.8 \%$ VYNASSTIVPSLK

$0.01 \% \quad 15.8 \%$ LLSASPVDAAIR

$0.01 \% \quad 15.8 \%$ GGGVTNLLWSPDGSK

$0.01 \% \quad 15.8 \%$ ILATTPSAVFR

$0.01 \% \quad 15.8 \%$ VQDGKPVILLFR

$0.01 \% \quad 15.8 \%$ GALLSVGWSTGR

$0.01 \% \quad 4.7 \% \quad$ LVPSASVRPR

$0.01 \% \quad 4.7 \%$ AGQEDVLFPVAR

$0.01 \% \quad 4.7 \% \quad$ LLAVTGEQAQQAR

$0.01 \% \quad 4.7 \%$ ELGQSLAQEVK

$0.00 \% \quad 5.1 \% \quad$ IIGVDINKDK

$0.00 \% \quad 5.1 \%$ AFELMHSGK

$10 \quad 0.01 \% \quad 13.5 \%$ LAPALATGNTVVMK

$10 \quad 0.01 \% \quad 13.5 \%$ TFVEESIYNEFLER

$10 \quad 0.01 \% \quad 13.5 \%$ IAKEEIFGPVQPLFK

$10 \quad 0.01 \% \quad 13.5 \%$ KIEEVVER

$10 \quad 0.01 \% \quad 13.5 \%$ YGLAAAVFTR

$10 \quad 0.01 \% \quad 13.5 \%$ TVTIKVPQK $\begin{array}{llll}99.7 \% & 28.7 & 25.0 & 23.9\end{array}$

$99.7 \% \quad 42.6 \quad 25.0 \quad 42.6$

$\begin{array}{llll}99.7 \% & 40.7 & 25.0 & 32.9\end{array}$

$\begin{array}{llll}99.7 \% & 63.9 & 25.0 & 60.9\end{array}$

$\begin{array}{llll}99.7 \% & 36.2 & 25.0 & 36.2\end{array}$

$99.7 \% \quad 35.7 \quad 25.0 \quad 35.7$

$\begin{array}{llll}99.7 \% & 73.2 & 25.0 & 72.0\end{array}$

$\begin{array}{llll}99.7 \% & 51.2 & 25.0 & 51.2\end{array}$

$\begin{array}{llll}99.7 \% & 33.2 & 25.0 & 33.2\end{array}$

$\begin{array}{llll}99.7 \% & 25.2 & 25.0 & 20.6\end{array}$

$\begin{array}{llll}99.7 \% & 39.4 & 25.0 & 29.6\end{array}$

$\begin{array}{llll}99.7 \% & 57.8 & 25.0 & 53.0\end{array}$

$\begin{array}{llll}99.7 \% & 50.1 & 25.0 & 45.7\end{array}$

$\begin{array}{llll}97.0 \% & 28.5 & 25.0 & 0.0\end{array}$

$\begin{array}{llll}97.8 \% & 16.6 & 25.0 & 16.6\end{array}$

$99.7 \% \quad 60.1 \quad 25.0 \quad 60.1 \quad 2$

$\begin{array}{llll}99.7 \% & 59.2 & 25.0 & 55.7\end{array}$

$\begin{array}{llll}99.6 \% & 27.9 & 25.0 & 27.9\end{array}$

$99.0 \% \quad 45.0 \quad 25.0 \quad 15.4 \quad 2$

$\begin{array}{llll}99.7 \% & 81.7 & 25.0 & 74.7\end{array}$

$99.7 \% \quad 31.7 \quad 25.0 \quad 17.0$
1363.84

1136.68

1459.81

1121.57

856.50

1446.74

1689.86

1267.70

976.55

1831.96

2796.35

930.54

861.45

1205.58

996.45

1660.71

921.48

998.49

902.48

1627.84

1755.94

1594.95

1131.62

1584.84

1804.96

1233.67

1478.86

1205.65

1378.76

1212.69

1487.75

1175.68

1384.83

1203.65

1081.65

1301.68

1384.75

1201.64

1114.65

1019.50

1385.78

1775.85

1715.97

1001.56

1068.58

1013.64

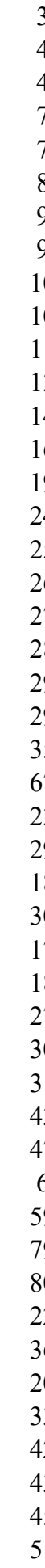

Page 22 of Table S-1-4 
Aldose reductase $\mathrm{GN}=\mathrm{AKR} 1 \mathrm{~B} 1$ Aldose reductase $\mathrm{GN}=\mathrm{AKR} 1 \mathrm{~B} 1$ Aldose reductase $\mathrm{GN}=\mathrm{AKR} 1 \mathrm{~B} 1$ Alpha-2-HS-glycoprotein GN=AHSG Alpha-2-HS-glycoprotein GN=AHSG

Alpha-aminoadipic semialdehyde synthase, mitocho
Alpha-centractin GN=ACTR1A Alpha-centractin GN $=$ ACTR1A Alpha-centractin GN=ACTR1A Alpha-centractin GN=ACTR1A Alpha-centractin GN $=$ ACTR1A Alpha-centractin GN=ACTR1A Alpha-centractin GN=ACTR1A

Alpha-centractin GN=ACTR1A Alpha-enolase $\mathrm{GN}=\mathrm{ENO} 1$ Alpha-enolase $\mathrm{GN}=\mathrm{ENO} 1$ Alpha-enolase $\mathrm{GN}=\mathrm{ENO} 1$ Alpha-enolase $\mathrm{GN}=\mathrm{ENO} 1$ Alpha-enolase $\mathrm{GN}=\mathrm{ENO} 1$ Alpha-enolase $\mathrm{GN}=\mathrm{ENO} 1$ Alpha-enolase $\mathrm{GN}=\mathrm{ENO} 1$ Alpha-enolase GN=ENO1 Alpha-enolase $\mathrm{GN}=\mathrm{ENO}$ Alpha-enolase GN=ENO1 Alpha-enolase GN=ENO1 Alpha-enolase $\mathrm{GN}=\mathrm{ENO} 1$ Alpha-enolase $\mathrm{GN}=\mathrm{ENO} 1$ Alpha-internexin GN=INA Alpha-internexin GN=INA Alpha-internexin GN=INA Alpha-internexin GN=INA Alpha-internexin GN=INA Alpha-internexin GN=INA Alpha-internexin GN=INA Alpha-internexin GN=INA Alpha-internexin GN=INA Alpha-internexin GN=INA Alpha-internexin GN=INA Alpha-internexin GN=INA Alpha-internexin GN=INA Alpha-internexin GN $=$ INA Alpha-internexin GN=INA Alpha-internexin GN=INA

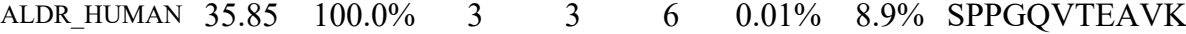
$\begin{array}{llllllll}\text { ALDR_HUMAN } & 35.85 & 100.0 \% & 3 & 3 & 6 & 0.01 \% & 8.9 \% \\ \text { REELFIVSK }\end{array}$

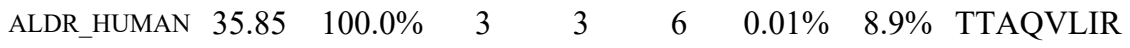

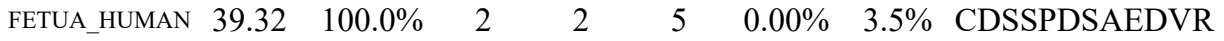

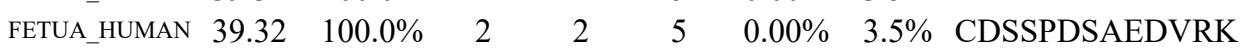
$0.00 \% \quad 2.8 \%$ VLIQPSNRR

$0.00 \% \quad 2.8 \%$ SIGPLTFVFTGTGNVSK AASS_HUMAN $102.14 \quad 100.0 \%$ ACTZ_HUMAN $42.62 \quad 100.0 \%$ ACTZ HUMAN $42.62 \quad 100.0 \%$ ACTZ_HUMAN $42.62 \quad 100.0 \%$ ACTZ_HUMAN $42.62 \quad 100.0 \%$ ACTZ_HUMAN $42.62 \quad 100.0 \%$ ACTZ_HUMAN $42.62 \quad 100.0 \%$ ACTZ_HUMAN $42.62 \quad 100.0 \%$ ACTZ_HUMAN $42.62 \quad 100.0 \%$ ENOA_HUMAN $47.17 \quad 100.0 \%$ ENOA HUMAN $47.17 \quad 100.0 \%$ ENOA_HUMAN $47.17 \quad 100.0 \%$ ENOA_HUMAN $47.17 \quad 100.0 \%$ ENOA_HUMAN $47.17 \quad 100.0 \% \quad 13$ ENOA_HUMAN $47.17 \quad 100.0 \% \quad 13$ ENOA_HUMAN $47.17 \quad 100.0 \% \quad 13$ ENOA_HUMAN $47.17 \quad 100.0 \% \quad 13$ ENOA_HUMAN $47.17 \quad 100.0 \% \quad 13$ ENOA_HUMAN $47.17 \quad 100.0 \% \quad 13$ ENOA_HUMAN $47.17 \quad 100.0 \% \quad 13$ ENOA_HUMAN $47.17 \quad 100.0 \% \quad 13$ ENOA_HUMAN $47.17 \quad 100.0 \% \quad 13$ AINX_HUMAN $55.39 \quad 100.0 \% \quad 14$ AINX HUMAN $55.39 \quad 100.0 \% \quad 14$ AINX_HUMAN $55.39 \quad 100.0 \% \quad 14$ AINX_HUMAN $55.39 \quad 100.0 \% \quad 14$ AINX_HUMAN $55.39 \quad 100.0 \% \quad 14$ AINX_HUMAN $55.39 \quad 100.0 \% \quad 14$ AINX_HUMAN $55.39 \quad 100.0 \% \quad 14$ AINX_HUMAN $55.39 \quad 100.0 \% \quad 14$ AINX_HUMAN $55.39 \quad 100.0 \% \quad 14$ AINX HUMAN $55.39 \quad 100.0 \% \quad 14$ AINX_HUMAN $55.39 \quad 100.0 \% \quad 14$ AINX_HUMAN $55.39 \quad 100.0 \% \quad 14$ AINX_HUMAN $55.39 \quad 100.0 \% \quad 14$ AINX_HUMAN $55.39 \quad 100.0 \% \quad 14$ AINX_HUMAN $55.39 \quad 100.0 \% \quad 14$ AINX_HUMAN $55.39 \quad 100.0 \% \quad 14$ AIMP1_HUMAN $34.35 \quad 100.0 \% \quad 8$ AIMP1_HUMAN $34.35 \quad 100.0 \%$

2
$0.02 \% \quad 25.0 \%$ AGFAGDQIPK $0.02 \% \quad 25.0 \%$ YCFPNYVGRPK $0.02 \% \quad 25.0 \%$ VMAGALEGDIFIGPK $0.02 \% \quad 25.0 \%$ IDIAGRDVSR

$0.02 \% \quad 25.0 \%$ EGYDFHSSSEFEIVK $0.02 \% \quad 25.0 \%$ AQYYLPDGSTIEIGPSR $0.02 \% \quad 25.0 \%$ TLFSNIVLSGGSTLFK $0.06 \% \quad 36.2 \%$ GNPTVEVDLFTSK $0.06 \% \quad 36.2 \%$ IGAEVYHNLK $0.06 \% \quad 36.2 \%$ SCNCLLLK

$0.06 \% \quad 36.2 \%$ VNQIGSVTESLQACK

$0.06 \% \quad 36.2 \%$ YNQLLRIEEELGSK

$0.06 \% \quad 36.2 \%$ IEEELGSK

$0.03 \% \quad 34.7 \%$ LSGAGGAGGFR

$0.03 \% \quad 34.7 \%$ VHQLETQNR

$0.03 \% \quad 34.7 \%$ ALEAELAALR

$0.03 \% \quad 34.7 \%$ ALEAELAALRQR

$0.03 \% \quad 34.7 \%$ AQLEEASSAR

$0.03 \% \quad 34.7 \%$ SQALLERDGLAEEVQR

$0.03 \% \quad 34.7 \%$ DVDGATLAR

$0.03 \% \quad 34.7 \%$ AQYESLAAK

$0.03 \% \quad 34.7 \%$ FANLNEQAAR

$0.03 \% \quad 34.7 \%$ TIEIEGLRGANESLER

$0.03 \% \quad 34.7 \%$ HLREYQDLLNVK

$0.03 \% \quad 34.7 \%$ EYQDLLNVK

$0.03 \% \quad 34.7 \%$ LLEGEETR

$0.03 \% \quad 34.7 \%$ SNIEETTISSQKI

$0.02 \% \quad 30.8 \%$ GAEADQIIEYLK $\begin{array}{llllllll}99.7 \% & 35.5 & 25.0 & 26.8 & 2 & 0 & 0 & 1112.59\end{array}$ $\begin{array}{llllllll}99.6 \% & 25.4 & 25.0 & 17.7 & 2 & 0 & 0 & 1120.64\end{array}$ $99.0 \% \quad 60.9 \quad 25.0 \quad 33.5 \quad 2$ $\begin{array}{llll}98.6 \% & 20.0 & 25.0 & 20.0\end{array}$ $\begin{array}{llll}99.7 \% & 33.3 & 25.0 & 33.3\end{array}$ $99.0 \% \quad 24.6 \quad 25.0 \quad 14.2$ $99.7 \% \quad 47.6 \quad 25.0 \quad 47.6$ $\begin{array}{llll}0.06 \% & 36.2 \% & \text { EIFDSRGNPTVEVDLFTSK } 99.7 \% \quad 30.6\end{array}$ $\begin{array}{llll}99.7 \% & 53.1 & 25.0 & 53.1\end{array}$ $99.3 \% \quad 67.0 \quad 25.0 \quad 0.0$ $\begin{array}{llll}99.7 \% & 40.7 & 25.0 & 27.5\end{array}$ $\begin{array}{lllll}99.7 \% & 30.8 & 25.0 & 29.4 & 2\end{array}$ $\begin{array}{llll}99.7 \% & 83.4 & 25.0 & 83.4\end{array}$ $99.7 \% \quad 76.5$ $\begin{array}{lll}0.06 \% & 36.2 \% & \text { LAMQEFMILPVGAANFR } 99.7 \% \quad 32.9\end{array}$

$0.06 \% \quad 36.2 \%$ FTASAGIQVVGDDLTVTNPK $\quad 99.7 \% \quad 54.2$

$\begin{array}{lllllllll}0.06 \% & 36.2 \% & \text { FTASAGIQVVGDDLTVTNPKR } & 99.7 \% & 38.0\end{array}$

$99.0 \% 33.7$

$99.2 \% \quad 44.8$

$99.7 \% \quad 55.4$

$97.0 \% \quad 25.1$

$99.7 \% \quad 60.8$

$99.7 \% \quad 96.5$

$\begin{array}{lllllll}0.03 \% & 34.7 \% & \text { RPPASDGLDLSQAAAR } \quad 99.7 \% & 52.0\end{array}$

$99.7 \% \quad 32.0$

$99.7 \% \quad 64.8$

$99.7 \% \quad 43.7$

$99.7 \% \quad 54.5$

$99.7 \% \quad 47.7$

$99.7 \% \quad 36.9$

$99.1 \% \quad 32.1$

$99.7 \% \quad 69.8$

$99.7 \% \quad 25.2$

$99.7 \% \quad 47.0$

$99.7 \% \quad 51.7$

$\begin{array}{lll}98.3 \% & 28.4\end{array}$

$99.7 \% \quad 56.2$

$99.7 \% \quad 68.4$

$99.7 \% \quad 42.4$

$\begin{array}{lllll}0.02 \% & 30.8 \% & \text { KQQSIAGSADSKPIDVSR } & 99.7 \% & 35.3\end{array}$

1724.92

1003.52

2385.18

1400.68

1533.80

1101.60

1773.80

1866.92

1683.93

2154.07

1406.72

1519.83

1939.98

1143.62

2743.38

1425.73

2033.06

2189.16

1007.50

1633.82

1691.90

904.46

949.49

2129.03

1624.84

1124.58

1056.60

1340.76

1061.52

1813.94

917.47

980.50

1133.57

1786.93

1527.83

1121.58

946.48

1449.74

1349.69

1271.73 1886.99 

Anaphase-promoting complex subunit $7 \mathrm{GN}=\mathrm{ANAPC7}$ APC7_HUMAN $66.86 \quad 100.0 \%$ Anaphase-promoting complex subunit $7 \mathrm{GN}=$ ANAPC7 APC7 HUMAN $66.86 \quad 100.0 \%$ Anaphase-promoting complex subunit $7 \mathrm{GN}=\mathrm{ANAPC7}$ APC7_HUMAN $66.86 \quad 100.0 \%$ Anaphase-promoting complex subunit $7 \mathrm{GN}=\mathrm{ANAPC} 7 \mathrm{APC} 7$ HUMAN $66.86 \quad 100.0 \%$ Anaphase-promoting complex subunit $7 \mathrm{GN}=\mathrm{ANAPC} 7 \mathrm{APC} 7$ HUMAN $66.86 \quad 100.0 \%$ Anaphase-promoting complex subunit $7 \mathrm{GN}=\mathrm{ANAPC} 7 \mathrm{APC7}$ _HUMAN $66.86 \quad 100.0 \%$ Ancient ubiquitous protein $1 \mathrm{GN}=$ AUP1 AUP1_HUMAN $53.03 \quad 100.0 \%$ Ancient ubiquitous protein $1 \mathrm{GN}=$ AUP1 AUP1_HUMAN $53.03 \quad 100.0 \%$ Ancient ubiquitous protein $1 \mathrm{GN}=\mathrm{AUP} 1$ Ancient ubiquitous protein $1 \mathrm{GN}=\mathrm{AUP} 1$ Ancient ubiquitous protein $1 \mathrm{GN}=\mathrm{AUP} 1$ Ancient ubiquitous protein $1 \mathrm{GN}=\mathrm{AUP} 1$ Ancient ubiquitous protein $1 \mathrm{GN}=\mathrm{AUP}$ Annexin A1 GN=ANXA1 Annexin A1 GN=ANXA1 Annexin A1 GN=ANXA1 Annexin A1 GN=ANXA Annexin $\mathrm{A} 2 \mathrm{GN}=\mathrm{ANXA}$ Annexin A2 GN=ANXA2 Annexin A2 GN=ANXA2 Annexin A2 GN=ANXA2 Antigen KI-67 GN=MKI67 Antigen KI-67 GN=MKI67 Antigen KI-67 GN=MKI67 Antigen KI-67 GN=MKI67 $\begin{array}{lll}\text { AUP1_HUMAN } & 53.03 & 100.0 \% \\ \text { AUP1_HUMAN } & 53.03 & 100.0 \%\end{array}$ AUP1_HUMAN $53.03 \quad 100.0 \%$ AUP1_HUMAN $53.03 \quad 100.0 \%$ AUP1_HUMAN $53.03 \quad 100.0 \%$ AUP1 HUMAN $53.03 \quad 100.0 \%$ ANXA1_HUMAN $38.72 \quad 100.0 \%$ ANXA1_HUMAN $38.72 \quad 100.0 \%$ ANXA1_HUMAN $38.72 \quad 100.0 \%$ ANXA1_HUMAN $38.72 \quad 100.0 \%$ ANXA2 HUMAN $38.61 \quad 100.0 \%$ ANXA2_HUMAN $38.61 \quad 100.0 \%$ ANXA2_HUMAN $38.61 \quad 100.0 \%$ ANXA2 HUMAN $38.61 \quad 100.0 \%$ KI67_HUMAN $358.70 \quad 100.0 \%$ KI67_HUMAN $358.70 \quad 100.0 \%$ KI67 HUMAN $358.70 \quad 100.0 \%$ KI67 HUMAN $358.70 \quad 100.0 \%$ AP-1 complex subunit beta-1 GN=AP1B1 AP1B1 HUMAN $104.64 \quad 100.0 \%$ AP-1 complex subunit beta-1 GN=AP1B1 AP1B1_HUMAN $104.64 \quad 100.0 \%$

$0.01 \% \quad 23.7 \%$ VLSTVHTHSSVK

$99.7 \% \quad 54.3$

$0.01 \% \quad 23.7 \%$ FSIQTMCPIEGEGNIAR $99.7 \% \quad 46.6$ $0.01 \% \quad 23.7 \%$ FLFSLFGQK

$0.01 \% \quad 23.7 \%$ SCENLAPFNTALK $99.7 \% \quad 42.2$ $99.7 \% \quad 58.6$ $94.5 \% \quad 17.8$

$0.01 \% \quad 5.3 \%$ FSEQGGTPQNVATSSSLTAHLR $\quad 99.7 \% \quad 28.6$ $99.7 \% \quad 32.7$

$0.01 \% \quad 15.5 \%$ EQKYEDGIALLR

$0.01 \% \quad 15.5 \%$ NALANQSDCVLHR

$0.02 \% \quad 20.0 \%$ TMCAVLGLVAR

$99.1 \% 26.7$

$\begin{array}{lllll}0.02 \% & 20.0 \% & \text { LPPTPLLLFPEEEATNGR } & 99.1 \% & 26.7 \\ 0.02 \% & 20.0 \% & \text { QLGEANEEFALR } & 99.7 \% & 39.5\end{array}$

$0.02 \% \quad 20.0 \%$ VKEVLPHVPLGVIQR

$99.7 \% \quad 27.6$

$99.7 \% 51.6$

$0.02 \% \quad 20.0 \%$ GTQSLPTASASK

$99.7 \% \quad 45.0$

$0.02 \% \quad 20.0 \%$ KQALYEYAR

$99.7 \% \quad 33.0$

$0.01 \% \quad 14.5 \%$ AAYLQETGKPLDETLKK

$0.01 \% \quad 14.5 \%$ TPAQFDADELR

$0.01 \% \quad 14.5 \%$ ALYEAGER

$0.01 \% \quad 14.5 \%$ GTDVNVFNTILTTR

$0.01 \% \quad 13.6 \%$ GVDEVTIVNILTNR

$0.01 \% \quad 13.6 \%$ QDIAFAYQR

$0.01 \% \quad 13.6 \%$ KELASALK

$0.01 \% \quad 13.6 \%$ TPAQYDASELKASMK

$0.01 \% \quad 1.6 \%$ SGASEANLIVAK

$0.01 \% \quad 1.6 \%$ SPQSDPADTPTNTK

$0.01 \% \quad 1.6 \%$ SPQPDPVDTPASTK

$0.01 \% \quad 1.6 \%$ QTPAPAASVTGSR

$0.00 \% \quad 2.2 \%$ CAIKVEQSAER

$0.00 \% \quad 2.2 \% \quad$ LLSTDPVAAK

$\begin{array}{lll}99.7 \% & 53.1\end{array}$

$95.9 \% \quad 28.5$

$99.7 \% \quad 44.7$

$99.7 \% \quad 51.8$

$99.7 \% \quad 45.0$

$96.0 \% \quad 28.0$

$95.0 \% \quad 16.0$

$99.0 \% 26.1$

$99.7 \% \quad 45.5$

$97.2 \% 15.6$

$\begin{array}{lll}99.7 \% & 30.8\end{array}$

$99.7 \% \quad 38.2$

$95.3 \% 23.6$

$159 \quad 166$

399.82

1917.96

2597.26

1294.71

1938.91

1086.60

1464.72

1273.70

2288.13

1058.52

1233.63

1620.83

1173.59

1326.72

1168.65

1241.61

982.50

1257.63

1546.73

1611.94

1112.62

1434.76

1497.72

1190.64

1994.06

1376.68

1684.03

1147.60

1845.97

1141.60

1905.03

1262.60

908.45

1550.82

1542.85

1111.55

859.52

1639.80

1159.63

1458.67

1439.70

1242.64

1290.65 1014.58 
AP-1 complex subunit gamma-1 GN=AP1G1 AP1G1_HUMAN $91.35 \quad 100.0 \%$ AP-1 complex subunit gamma-1 GN=AP1G1 AP1G1_HUMAN $91.35 \quad 100.0 \%$ AP-1 complex subunit gamma-1 GN=AP1G1 AP1G1_HUMAN $91.35 \quad 100.0 \%$ AP-1 complex subunit mu-1 GN=AP1M1 AP1M1_HUMAN $48.59 \quad 100.0 \%$ AP-1 complex subunit mu-1 GN=AP1M1 AP1M1_HUMAN $48.59 \quad 100.0 \%$ AP-1 complex subunit mu-1 GN=AP1M1 AP1M1_HUMAN $48.59 \quad 100.0 \%$ AP-1 complex subunit mu-1 GN=AP1M1 AP1M1_HUMAN $48.59 \quad 100.0 \%$ AP-1 complex subunit mu-1 GN=AP1M1 AP1M1_HUMAN $48.59 \quad 100.0 \%$ AP-1 complex subunit mu-1 GN=AP1M1 AP1M1_HUMAN $48.59 \quad 100.0 \%$ AP-1 complex subunit mu-1 GN=AP1M1 AP1M1_HUMAN $48.59 \quad 100.0 \%$ AP-1 complex subunit mu-1 GN=AP1M1 AP1M1_HUMAN $48.59 \quad 100.0 \%$ AP-1 complex subunit mu-1 GN=AP1M1 AP1M1_HUMAN $48.59 \quad 100.0 \%$ AP-2 complex subunit alpha-2 GN=AP2A2 AP2A2_HUMAN $103.96 \quad 100.0 \%$ AP-2 complex subunit alpha-2 GN=AP2A2 AP2A2_HUMAN $103.96 \quad 100.0 \%$ AP-2 complex subunit alpha-2 GN=AP2A2 AP2A2_HUMAN $103.96 \quad 100.0 \%$ AP-2 complex subunit mu GN=AP2M1 AP2M1_HUMAN $49.66 \quad 100.0 \%$ AP- 2 complex subunit mu GN=AP2M1 AP-2 complex subunit $\mathrm{mu} \mathrm{GN}=\mathrm{AP} 2 \mathrm{M} 1$ AP-2 complex subunit $\mathrm{mu}$ GN=AP2M1 AP-2 complex subunit mu GN=AP2M1 AP-2 complex subunit mu GN=AP2M1 AP- 2 complex subunit mu $\mathrm{GN}=\mathrm{AP} 2 \mathrm{M} 1$ AP-2 complex subunit mu GN=AP2M AP2M1 HUMAN $49.66 \quad 100.0 \%$ AP2M1_HUMAN $49.66 \quad 100.0 \%$ AP2M1_HUMAN $49.66 \quad 100.0 \%$ AP2M1_HUMAN $49.66 \quad 100.0 \%$ AP2M1_HUMAN $49.66 \quad 100.0 \%$ AP2M1_HUMAN $49.66 \quad 100.0 \%$ AP2M1_HUMAN $49.66 \quad 100.0 \%$ AP-3 complex subunit beta-1 GN=AP3B1 AP3B1_HUMAN $121.32 \quad 100.0 \%$ AP-3 complex subunit beta-1 GN=AP3B1 AP3B1_HUMAN $121.32 \quad 100.0 \%$ AP-3 complex subunit mu-1 GN=AP3M1 AP3M1_HUMAN $46.94 \quad 100.0 \%$ AP-3 complex subunit mu-1 GN=AP3M1 AP3M1_HUMAN $46.94 \quad 100.0 \%$ AP-3 complex subunit mu-1 GN=AP3M1 AP3M1_HUMAN $46.94 \quad 100.0 \%$ Apoptosis-inducing factor 1, mitochondrial GN=AIFM1 AIFM1_HUMAN $66.90 \quad 100.0 \%$ Apoptosis-inducing factor 1, mitochondrial GN=AIFM1 AIFM1_HUMAN $66.90 \quad 100.0 \%$ Apoptosis-inducing factor 1, mitochondrial GN=AIFM1 AIFM1_HUMAN $66.90 \quad 100.0 \%$ Apoptosis-inducing factor 1, mitochondrial GN=AIFM1 AIFM1_HUMAN $66.90 \quad 100.0 \%$ Apoptosis-inducing factor 1, mitochondrial GN=AIFM1 AIFM1_HUMAN $66.90 \quad 100.0 \%$ Apoptosis-inducing factor 1, mitochondrial GN=AIFM1 AIFM1_HUMAN $66.90 \quad 100.0 \%$ Apoptosis-inducing factor 1, mitochondrial GN=AIFM1 AIFM1_HUMAN $66.90 \quad 100.0 \%$ Apoptosis-inducing factor 1, mitochondrial GN=AIFM1 AIFM1_HUMAN $66.90 \quad 100.0 \%$ Apoptotic chromatin condensation inducer in the nucleus GN=ACIN1 ACINU_HUMAN $151.86 \quad 100.0 \%$ Apoptotic chromatin condensation inducer in the nucleus $\mathrm{GN}=\mathrm{ACIN} 1$ ACINU_HUMAN $151.86 \quad 100.0 \%$ Apoptotic chromatin condensation inducer in the nucleus GN=ACIN1 ACINU_HUMAN $151.86 \quad 100.0 \%$ Apoptotic chromatin condensation inducer in the nucleus $\mathrm{GN}=\mathrm{ACIN} 1 \quad \mathrm{ACINU} \_$HUMAN $151.86 \quad 100.0 \%$ Apoptotic chromatin condensation inducer in the nucleus GN=ACIN1 ACINU_HUMAN $151.86 \quad 100.0 \%$ Apoptotic chromatin condensation inducer in the nucleus GN=ACIN1 ACINU_HUMAN $151.86 \quad 100.0 \%$ Apoptotic chromatin condensation inducer in the nucleus $\mathrm{GN}=\mathrm{ACIN} 1 \mathrm{ACINU}$ HUMAN $151.86 \quad 100.0 \%$ Apoptotic chromatin condensation inducer in the nucleus GN=ACIN1 ACINU_HUMAN $151.86 \quad 100.0 \%$ Apoptotic chromatin condensation inducer in the nucleus $\mathrm{GN}=\mathrm{ACIN} 1$ ACINU_HUMAN $151.86 \quad 100.0 \%$ Apoptotic chromatin condensation inducer in the nucleus GN=ACIN1 ACINU HUMAN $151.86 \quad 100.0 \%$ Apoptotic chromatin condensation inducer in the nucleus GN=ACIN1 ACINU_HUMAN $151.86 \quad 100.0 \%$
$0.00 \% \quad 3.7 \% \quad$ AALCAVHVIR $0.00 \% \quad 3.7 \%$ VLAINILGR

$0.00 \% \quad 3.7 \% \quad$ TVQTDHNAVQR $0.02 \% \quad 25.3 \%$ ILQEYITQEGHK $0.02 \% \quad 25.3 \%$ VFLSGMPELR $0.02 \% \quad 25.3 \%$ LGLNDKVLFDNTGR

$0.02 \% \quad 25.3 \%$ SVELEDVKFHQCVR

$0.02 \% \quad 25.3 \%$ STANNVEIHIPVPNDADSPK $0.02 \% \quad 25.3 \%$ FEIPYFTTSGIQVR

$0.02 \% \quad 25.3 \%$ SGYQALPWVR

$0.02 \% \quad 25.3 \%$ YITQNGDYQLR

$0.02 \% \quad 25.3 \%$ YITQNGDYQLRTQ

$0.00 \% \quad 4.7 \%$ EMAEAFAGEIPK

$0.00 \% \quad 4.7 \%$ VGGYILGEFGNLIAGD

$\begin{array}{ccc}0.00 \% & 4.7 \% & \text { QLSNPQQE } \\ 0.01 \% & 18.2 \% & \text { VYRDDIGR }\end{array}$

$0.01 \% \quad 18.2 \%$ NAVDAFRVNVIHAR

$0.01 \% \quad 18.2 \%$ SPVTNIAR

$0.01 \% \quad 18.2 \%$ TFITQQGIK

$0.01 \% \quad 18.2 \%$ LSKFDSER

$0.01 \% \quad 18.2 \%$ DIILPFRVIPLVR

$0.01 \% \quad 18.2 \%$ SNFKPSLLAQK

$0.01 \% \quad 18.2 \%$ SGIYETRC

$0.00 \% \quad 1.9 \% \quad$ ALKDPNQLIR

$0.00 \% \quad 1.9 \% \quad$ LLDSITVPVAR

$0.00 \% \quad 12.9 \%$ SVVSQSVCDYFFEAQEK

$0.00 \% \quad 12.9 \%$ VSSQNLVAIPVYVK

$0.00 \% \quad 12.9 \%$ GLVNLQSGAPKPEENPSLNIQFK

$0.02 \% \quad 15.3 \%$ ISGLGLTPEQK

$0.02 \% \quad 15.3 \%$ LNDGSQITYEK

$0.02 \% \quad 15.3 \%$ CLIATGGTPR

$0.02 \% \quad 15.3 \%$ SLSAIDRAGAEVK

$99.7 \% \quad 55.9$

$99.7 \% \quad 36.7$

$99.7 \% \quad 33.5$

$99.7 \% \quad 61.8$

$99.7 \% \quad 35.5$

$99.7 \% \quad 62.4$

$99.7 \% \quad 33.5$

$99.7 \% \quad 54.1$

$99.7 \% \quad 41.5$

$99.7 \% 33.5$

$99.7 \% \quad 39.6$

$99.7 \% \quad 58.6$

$97.4 \% \quad 16.4$

$99.7 \% \quad 40.1$

$96.2 \% \quad 14.6$

$98.3 \% \quad 29.0$

$99.2 \% \quad 27.3$

$99.0 \% 39.8$

$\begin{array}{lll}99.7 \% & 35.6\end{array}$

$99.0 \% \quad 41.5$

$99.4 \% \quad 21.3$

$99.4 \% \quad 20.3$

$99.0 \% \quad 46.6$

$94.5 \% 19.6$

$99.7 \% 53.7$

$99.7 \% \quad 50.5$

$99.7 \% \quad 34.4$

$9.7 \% \quad 37.9$

$99.7 \% \quad 60.3$

$99.7 \% \quad 37.1$

$99.7 \% \quad 64.9$

$99.7 \% \quad 50.5$

$0.02 \% \quad 15.3 \%$ ALGTEVIQLFPEKGNMGK $99.6 \% 26.2$

$\begin{array}{lllll}0.02 \% & 15.3 \% & \text { EGVKVMPNAIVQSVGVSSGK } & 99.7 \% & 46.3\end{array}$

$0.02 \% \quad 15.3 \%$ VMPNAIVQSVGVSSGK

$0.02 \% \quad 15.3 \%$ SATEQSGTGIR

$0.03 \% \quad 10.6 \%$ VTDLKAALEQR

$0.03 \% \quad 10.6 \%$ GALMLENLQK

$99.7 \% \quad 70.5$

$99.7 \% \quad 71.2$

$99.7 \% \quad 49.8$

$99.6 \% \quad 27.0$

$0.03 \% \quad 10.6 \%$ LSEGSQPAEEEEDQETPSR

$0.03 \% \quad 10.6 \%$ SQEQEVLER

$0.03 \% \quad 10.6 \%$ RLSQPESAEK

$99.7 \% 43.0$

$99.7 \% \quad 47.6$

$99.3 \% 23.5$

$98.8 \% \quad 23.1$

$0.03 \% \quad 10.6 \%$ KISVVSATK

$0.03 \% \quad 10.6 \%$ GVPAGNSDTEGGQPGRK

$0.03 \% \quad 10.6 \%$ WGASTATTQK

$0.03 \% \quad 10.6 \%$ VTLGDTLTR

$0.03 \% \quad 10.6 \%$ VTLGDTLTRR
$99.7 \% \quad 40.6$

$99.7 \% \quad 40.7$

$99.4 \% 32.8$

$96.6 \% \quad 15.7$
1109.62

968.63

1268.63

1458.76

1164.61

1561.83

1745.86

2118.05

1657.86

1176.62

1370.67

1599.78

1308.61

1847.97

1672.87

993.51

1581.86

857.48

1035.58

981.50

1550.98

1232.70

985.44

1167.68

1183.70

2022.91

1516.87

2480.31

1142.64

1267.62

1045.55

1316.72

1948.02

2002.06

1572.84

1106.54

1243.70

1116.61

2117.91

1117.55

1144.60

932.58

1498.69

1626.78

1050.52

975.55

1131.65 $\begin{array}{cc}57 & 166 \\ 07 & 315 \\ 35 & 345 \\ 30 & 141 \\ 02 & 211 \\ 12 & 225 \\ 30 & 243 \\ 05 & 324 \\ 80 & 393 \\ 01 & 410 \\ 11 & 421 \\ 11 & 423 \\ 42 & 153 \\ 98 & 515 \\ 43 & 856 \\ 9 & 26 \\ 7 & 40 \\ 5 & 52 \\ 31 & 139 \\ 54 & 261 \\ 82 & 294 \\ 09 & 319 \\ 28 & 435 \\ 23 & 132 \\ 86 & 496 \\ 2 & 38 \\ 64 & 277 \\ 56 & 378 \\ 9 & 109 \\ 45 & 255 \\ 56 & 265 \\ 66 & 278 \\ 25 & 342 \\ 59 & 378 \\ 63 & 378 \\ 19 & 529 \\ 7 & 87 \\ 04 & 113 \\ 39 & 257 \\ 28 & 336 \\ 08 & 717 \\ 23 & 831 \\ 32 & 847 \\ 32 & 848 \\ 51 & 860 \\ 71 & 979 \\ & 980 \\ & \end{array}$

Page 25 of Table S-1-4 

Arginase-1 GN=ARG1 Arginase-1 GN=ARG1 Arginase- $1 \mathrm{GN}=\mathrm{ARG} 1$ HUMAN $34.74 \quad 100.0 \%$

Arginine and glutamate-rich protein 1 GN=ARGLU1 ARGL1_HUMAN $33.22 \quad 100.0 \%$ Arginine and glutamate-rich protein $1 \mathrm{GN}=$ ARGLU1 ARGL1_HUMAN $33.22 \quad 100.0 \%$ Arginine--tRNA ligase, cytoplasmic GN=RARS SYRC HUMAN $75.38 \quad 100.0 \%$ Arginine--tRNA ligase, cytoplasmic GN=RARS SYRC_HUMAN $75.38 \quad 100.0 \%$ Arginine--tRNA ligase, cytoplasmic GN=RARS SYRC_HUMAN $75.38 \quad 100.0 \%$ Arginine--tRNA ligase, cytoplasmic GN=RARS SYRC HUMAN $75.38 \quad 100.0^{\circ}$ Arginine--tRNA ligase, cytoplasmic GN=RARS SYRC_HUMAN $75.38 \quad 100.0 \%$ Arginine--tRNA ligase, cytoplasmic GN=RARS SYRC_HUMAN $75.38 \quad 100.0 \%$ Arginine--tRNA ligase, cytoplasmic GN=RARS SYRC_HUMAN $75.38 \quad 100.0 \%$ Arginine--tRNA ligase, cytoplasmic GN=RARS SYRC_HUMAN $75.38 \quad 100.0 \%$ Arginine--tRNA ligase, cytoplasmic GN=RARS SYRC HUMAN $75.38 \quad 100.0 \%$ Arginine--tRNA ligase, cytoplasmic GN=RARS SYRC_HUMAN $75.38 \quad 100.0 \%$ Arginine--tRNA ligase, cytoplasmic GN=RARS SYRC_HUMAN $75.38 \quad 100.0 \%$ Arginine--tRNA ligase, cytoplasmic GN=RARS SYRC HUMAN 75.38 $100.0 \%$ Arginine--tRNA ligase, cytoplasmic GN=RARS SYRC_HUMAN $75.38 \quad 100.0 \%$ Arginine--tRNA ligase, cytoplasmic GN=RARS SYRC HUMAN $75.38 \quad 100.0 \%$ Arginine--tRNA ligase, cytoplasmic GN=RARS SYRC_HUMAN $75.38 \quad 100.0 \%$ Argininosuccinate synthase GN=ASS1 ASSY_HUMAN $46.53 \quad 100.0 \%$ Argininosuccinate synthase GN=ASS1 ASSY HUMAN $46.53 \quad 100.0 \%$ Asparagine synthetase [glutamine-hydrolyzing] GN=ASNS ASNS_HUMAN $64.37 \quad 100.0 \%$ Asparagine synthetase [glutamine-hydrolyzing] GN=ASNS ASNS_HUMAN $64.37 \quad 100.0 \%$ Asparagine synthetase [glutamine-hydrolyzing] GN=ASNS ASNS HUMAN $64.37 \quad 100.0 \%$ Asparagine synthetase [glutamine-hydrolyzing] GN=ASNS ASNS_HUMAN $64.37 \quad 100.0 \%$ Asparagine synthetase [glutamine-hydrolyzing] GN=ASNS ASNS HUMAN $64.37100 .0 \%$ Aspartate aminotransferase, mitochondrial GN=GOT2 AATM_HUMAN $47.52 \quad 100.0 \%$ Aspartate aminotransferase, mitochondrial GN=GOT2 AATM_HUMAN $47.52 \quad 100.0 \%$ Aspartate aminotransferase, mitochondrial GN=GOT2 AATM HUMAN $47.52 \quad 100.0 \%$ Aspartate aminotransferase, mitochondrial GN=GOT2 AATM_HUMAN $47.52 \quad 100.0 \%$ Aspartate aminotransferase, mitochondrial GN=GOT2 AATM_HUMAN 47.52 100.0\% Aspartate--tRNA ligase, cytoplasmic GN=DARS SYDC_HUMAN $57.14 \quad 100.0 \%$ Aspartate--tRNA ligase, cytoplasmic GN=DARS SYDC_HUMAN $57.14 \quad 100.0 \%$ Aspartate--tRNA ligase, cytoplasmic GN=DARS SYDC HUMAN $57.14100 .0 \%$ Aspartate--tRNA ligase, cytoplasmic GN=DARS SYDC_HUMAN $57.14 \quad 100.0 \%$ Aspartate--tRNA ligase, cytoplasmic GN=DARS SYDC HUMAN $57.14 \quad 100.0 \%$ Ataxin-10 GN=ATXN10 Ataxin-10 GN=ATXN10 Ataxin-10 GN=ATXN10 Ataxin-10 GN=ATXN10 Ataxin $-10 \mathrm{GN}=\mathrm{ATXN} 10$ Ataxin-10 GN=ATXN10 Ataxin-10 GN=ATXN10 ARGI1_HUMAN $34.74 \quad 100.0 \%$ ARGI1_HUMAN $34.74 \quad 100.0 \%$

18
18

18

18

15

15
15

$\begin{array}{ll}5 & 18 \\ 15 & 18\end{array}$

5

$\begin{array}{ll}5 & 18 \\ 5 & 18\end{array}$

18
18
2
2

2
6

6
6
6

6
6
6

5
5
5

5

5
5
5

5
5
5

5

$\begin{array}{llll}\text { SYDC_HUMAN } & 57.14 & 100.0 \% & 5 \\ \text { ATX10_HUMAN } & 53.49 & 100.0 \% & 9 \\ \text { ATX10_HUMAN } & 53.49 & 100.0 \% & 9 \\ \text { ATX10_HUMAN } & 53.49 & 100.0 \% & 9 \\ \text { ATX10_HUMAN } & 53.49 & 100.0 \% & 9 \\ \text { ATX10_HUMAN } & 53.49 & 100.0 \% & 9 \\ \text { ATX10_HUMAN } & 53.49 & 100.0 \% & 9 \\ \text { ATX10_HUMAN } & 53.49 & 100.0 \% & 9\end{array}$

$0.03 \% \quad 10.6 \%$ LLDDLFRK

$0.01 \% \quad 9.3 \%$ GGVEEGPTVLR

\begin{tabular}{ll}
25.0 \\
\hline
\end{tabular}

$99.7 \% \quad 42.1$

$\begin{array}{ll}99.7 \% & 38.2 \\ 99.7 \% & 52.6\end{array}$

$0.01 \% \quad 9.3 \%$ GGVEEGPTVLRK

$\begin{array}{llllll}0.01 \% & 9.3 \% & \text { TGLLSGLDIMEVNPSLGK } & 99.7 \% & 52.6 \\ 0.00 \% & 5.9 \% & \text { LIEEETAR } & 96.1 \% & 16.8\end{array}$

$0.00 \% \quad 5.9 \%$ QLLEELER

$0.04 \% \quad 26.7 \%$ LLQQEEEIK

$99.0 \% \quad 30.8$

$96.4 \% \quad 21.1$

$\begin{array}{lll}99.0 \% & 30.7\end{array}$

$99.7 \% \quad 49.0$

$0.04 \% \quad 26.7 \%$ LQEVFGHAIK

$99.7 \% \quad 54.5$

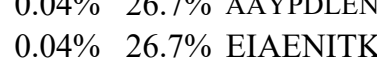

$0.04 \% \quad 26.7 \%$ VIVDFSSPNIAK

$0.04 \% \quad 26.7 \%$ STIIGESISR

$0.04 \% \quad 26.7 \%$ LFEFAGYDVLR

$0.04 \% \quad 26.7 \%$ AYQCVVLLQGK

$0.04 \% \quad 26.7 \%$ IVFVPGCSIPLTIVK

$99.0 \% \quad 34.5$

$99.7 \% \quad 49.4$

$99.7 \% \quad 56.2$

$99.7 \% \quad 54.0$

$99.7 \% \quad 47.9$

$99.7 \% \quad 50.8$

$0.04 \% \quad 26.7 \%$ SDGGYTYDTSDLAAIKQR $\quad 99.7 \% \quad 49.2$

$0.04 \% \quad 26.7 \%$ LMDLLGEGLKR

$0.04 \% \quad 26.7 \%$ LNDYIFSFDK

$0.04 \% \quad 26.7 \%$ LANIDEEMLQK

$0.04 \% \quad 26.7 \%$ GFDILGIKPVQR

$0.00 \% \quad 3.9 \% \quad$ KQVEIAQR

$0.00 \% \quad 3.9 \%$ GQVYILGR

$10 \quad 0.01 \% \quad 12.3 \%$ LAVVDPLFGMQPIR

$99.7 \% \quad 29.3$

$99.7 \% \quad 38.5$

$99.7 \% \quad 53.8$

$99.7 \% \quad 46.7$

$99.0 \% \quad 32.3$

$99.0 \% \quad 32.8$

$99.7 \% \quad 59.0$

$99.7 \% \quad 70.5$

$-0.01 \% \quad 12.3 \%$ AMTEDGFLAVCSEAK

$\begin{array}{llll}0.01 \% & 12.3 \% & \text { IGCLLSGGLDSSLVAATLLK } & 99.7 \% \quad 50.7\end{array}$

$10 \quad 0.01 \% \quad 12.3 \%$ ELYLFDVLR

$0 \quad 0.01 \% \quad 12.3 \%$ EAFSDGITSVK

$0.01 \% \quad 15.1 \%$ ASAELALGENSEVLK

$0.01 \% \quad 15.1 \%$ FVTVQTISGTGALR

$0.01 \% \quad 15.1 \%$ TCGFDFTGAVEDISK

$0.01 \% \quad 15.1 \%$ IAAAILNTPDLR

$0.01 \% \quad 15.1 \%$ TQLVSNLKK

$0.01 \% \quad 11.4 \%$ FAANINKESIVDVEGVVR

$0.01 \% \quad 11.4 \%$ ATVNQDTR

$0.01 \% \quad 11.4 \%$ VFSIGPVFR

$0.01 \% \quad 11.4 \%$ IHDPQLLTER

$0.01 \% \quad 11.4 \%$ VTMLFLGLHNVR

$0.01 \% \quad 24.4 \%$ ALTALFKEQR

$0.01 \% 24.4 \%$ NACIECSVNQNSIR

$0.01 \% \quad 24.4 \%$ CGLQFLGNIASR

$0.01 \% \quad 24.4 \%$ VTLLDLMIAK

$0.01 \% 24.4 \%$ ITSDEPLTKDDIPVFLR

$0.01 \% \quad 24.4 \%$ LASEEPPDDEEALATIR

$0.01 \% \quad 24.4 \%$ AEGDISNVANGFK
$99.7 \% \quad 48.2$

$99.7 \% \quad 55.6$

$99.7 \% \quad 75.6$

$99.7 \% \quad 97.2$

$99.7 \% \quad 45.2$

$99.7 \% \quad 62.0$

$99.6 \% \quad 26.5$

$\begin{array}{ll}99.0 \% & 38.3 \\ 99.6 \% & 26.8\end{array}$

$99.7 \% \quad 30.6$

$99.4 \% \quad 23.8$

$99.7 \% \quad 40.2$

$99.7 \% \quad 55.9$

$99.7 \% \quad 60.1$

$99.7 \% \quad 30.9$

$99.7 \% \quad 33.8$

$\begin{array}{lll}9.7 \% & 47.2 & 25.0\end{array}$

$\begin{array}{lll}99.7 \% & 58.8 \quad 25.0\end{array}$
$99.3 \% \quad 25.9$

1019.59

1113.59

1241.69

1859.98

960.50

1029.56

1129.61

976.52

1141.64

2152.13

917.49

1289.71

1062.58

1329.68

1278.69

1642.96

1960.92

1244.70

1261.61

1319.65

1342.78

971.56

905.52

1571.86

1628.73

1988.11

1167.64

1153.57

1530.80

1449.81

1646.74

1267.74

1030.63

1960.05

904.45

1021.58

1221.66

1399.79

1176.67

1664.75

1335.68

1116.67

1959.04

1855.89

1321.64

Page 26 of Table S-1-4 
$14 \quad 0.01 \% \quad 24.4 \%$ LIGNLCYK

$14 \quad 0.01 \% \quad 24.4 \%$ NLTEDNSQNQDLIAK

$198 \quad 0.20 \% \quad 50.6 \%$ TGTAEMSSILEER

$198 \quad 0.20 \% \quad 50.6 \%$ ILGADTSVDLEETGR

$198 \quad 0.20 \% \quad 50.6 \%$ VLSIGDGIAR

$198 \quad 0.20 \% \quad 50.6 \%$ NVQAEEMVEFSSGLK

$198 \quad 0.20 \% \quad 50.6 \%$ GMSLNLEPDNVGVVVFGNDK

$198 \quad 0.20 \% \quad 50.6 \%$ TGAIVDVPVGEELLGR

$198 \quad 0.20 \% \quad 50.6 \%$ VVDALGNAIDGK

$198 \quad 0.20 \% \quad 50.6 \%$ VVDALGNAIDGKGPIGSK

$198 \quad 0.20 \% \quad 50.6 \%$ VGLKAPGIIPR

$198 \quad 0.20 \% \quad 50.6 \%$ ISVREPMQTGIK

$198 \quad 0.20 \% \quad 50.6 \%$ AVDSLVPIGR

$198 \quad 0.20 \% \quad 50.6 \%$ AVDSLVPIGRGQR

$198 \quad 0.20 \% \quad 50.6 \%$ GQRELIIGDR

$198 \quad 0.20 \% \quad 50.6 \%$ ELIIGDRQTGK

$198 \quad 0.20 \% \quad 50.6 \%$ TSIAIDTIINQK

$198 \quad 0.20 \% \quad 50.6 \%$ TSIAIDTIINQKR

$198 \quad 0.20 \% \quad 50.6 \%$ LYCIYVAIGQK

$198 \quad 0.20 \% \quad 50.6 \%$ LYCIYVAIGQKR

$198 \quad 0.20 \% \quad 50.6 \%$ RSTVAQLVK

$198 \quad 0.20 \% \quad 50.6 \%$ STVAQLVK

$198 \quad 0.20 \% \quad 50.6 \%$ STVAQLVKR

$198 \quad 0.20 \% \quad 50.6 \%$ HALIIYDDLSK

$\begin{array}{ll}8.7 \% & 17.5\end{array}$

$99.7 \% \quad 62.5$

$99.7 \% \quad 62.5$

$99.7 \% \quad 49.3$

$99.7 \% \quad 56.4$

$99.7 \% \quad 50.7$

$99.7 \% \quad 55.2$

$99.7 \% \quad 56.1$

$99.7 \% 71.0$

$99.7 \% 56$.

$99.7 \% \quad 36.9$

$99.7 \% \quad 58.0$

$99.7 \% \quad 55.2$

$99.7 \% \quad 42.0$

$99.7 \% \quad 38.5$

$99.7 \% \quad 45.6$

$99.7 \% \quad 60.4$

$99.7 \% \quad 65.4$

$99.7 \% \quad 59.8$

$99.4 \% \quad 23.9$

$99.7 \% \quad 33.4$

$99.0 \% \quad 33.2$

$99.7 \% \quad 59.0$

$99.7 \% \quad 55.7$

$100.0 \% \quad 30$

$100.0 \% \quad 30$

$100.0 \% \quad 30$

$100.0 \% \quad 30$

$100.0 \% \quad 30$

$100.0 \% \quad 30$

$100.0 \% \quad 30$

$100.0 \% \quad 30$

$100.0 \% \quad 30$

$100.0 \% \quad 17$

$100.0 \% \quad 17$

$100.0 \% \quad 17$

$100.0 \% \quad 17$

$100.0 \% \quad 17$

$100.0 \% \quad 17$

$100.0 \% \quad 17$

$100.0 \% \quad 17$

$100.0 \% \quad 17$

$100.0 \% \quad 17$

$100.0 \% \quad 17$

$100.0 \% \quad 17$

$100.0 \% \quad 17$

$100.0 \% \quad 17$

$100.0 \% \quad 17$
$198 \quad 0.20 \% \quad 50.6 \%$ RPPGREAYPGDVFYLI

$198 \quad 0.20 \% \quad 50.6 \%$ EAYPGDVFYLHSR

$\begin{array}{llll}198 & 0.20 \% & 50.6 \% & \text { EAYPGDVFYLHSRL } \\ 198 & 0.20 \% & 50.6 \% & \text { GIRPAINVGLSVR }\end{array}$

$\begin{array}{lll}198 & 0.20 \% & 50.6 \% \\ 198 & 0.20 \% & 50.6 \% \text { GIRPAINVTELLLK }\end{array}$

$198 \quad 0.20 \% \quad 50.6 \%$ GYLDKLEPSK

$198 \quad 0.20 \% \quad 50.6 \%$ ADGKISEQSDAK

$198 \quad 0.20 \% \quad 50.6 \%$ LKEIVTNFLAGFEA

$9.2 \% \quad 18.9$ $\begin{array}{llll}9.7 \% & 38.3 & 25.0 & 52.1\end{array}$ $\begin{array}{llll}99.7 \% & 38.7 & 25.0 & 22.6\end{array}$ $99.7 \% \quad 35.0 \quad 25.0 \quad 24.2$ $99.5 \% \quad 21.4 \quad 25.0 \quad 21.4$ $99.7 \% \quad 55.5$

$24 \quad 110 \quad 0.11 \% \quad 43.7 \%$ ETRLVLEVAQHLGESTVR $\quad 99.7 \% \quad 30.7$

$110 \quad 0.11 \% \quad 43.7 \%$ LVLEVAQHLGESTVR

$110 \quad 0.11 \% \quad 43.7 \%$ TIAMDGTEGLVR

$110 \quad 0.11 \% \quad 43.7 \%$ TIAMDGTEGLVRGQK

$110 \quad 0.11 \% \quad 43.7 \%$ VLDSGAPIK $\begin{array}{llll}99.7 \% & 62.5 & 25.0 & 62.5\end{array}$ $99.7 \% \quad 57.5 \quad 25.0 \quad 46.4$ $99.7 \% \quad 40.3 \quad 25.0 \quad 38.8$ $99.7 \% \quad 31.3 \quad 25.0 \quad 27.2$

$\begin{array}{llllllll}110 & 0.11 \% & 43.7 \% & \text { VLDSGAPIKIPVGPETLGR } & 99.7 \% & 51.1 & 25.0 & 51.1\end{array}$

$110 \quad 0.11 \% \quad 43.7 \%$ VVDLLAPYAK

$110 \quad 0.11 \% \quad 43.7 \%$ IGLFGGAGVGK

$110 \quad 0.11 \% \quad 43.7 \%$ TVLIMELINNVAK

$110 \quad 0.11 \% \quad 43.7 \%$ AHGGYSVFAGVGER

$110 \quad 0.11 \% \quad 43.7 \%$ VALVYGQMNEPPGAR

$110 \quad 0.11 \% \quad 43.7 \%$ VALTGLTVAEYFR

$110 \quad 0.11 \% \quad 43.7 \%$ FTQAGSEVSALLGR

$99.7 \% \quad 50.7$

$99.7 \% \quad 53.7$

$99.7 \% \quad 58.8$

$99.7 \% \quad 44.7$

$99.7 \% \quad 34.5$

$99.7 \% 54.1$

$99.7 \% \quad 64.8$

DATTVLSR $\quad 99.7 \% \quad 50.7$

$110 \quad 0.11 \% \quad 43.7 \%$ AIAELGIYPAVDPLDSTSR $99.7 \% \quad 56.2$
$99.7 \% \quad 61.3$
980.52

1702.82

1439.67

1575.79

1000.58

1667.79

2120.03

1624.89

1171.63

1710.94

1120.72

1358.75

1026.59

1367.78

1156.64

1229.69

1316.74

1472.84

1327.71

1483.81

1001.61

845.51

1001.61

1287.69

2117.07

1553.74

2065.05

1438.85

1028.65

1149.62

1248.61

1551.84

2037.11

1650.92

1278.64

1591.81

899.52

1919.10

1088.64

975.56

1473.83

1406.68

1601.81

1439.79

1435.75

3714.89 1988.03

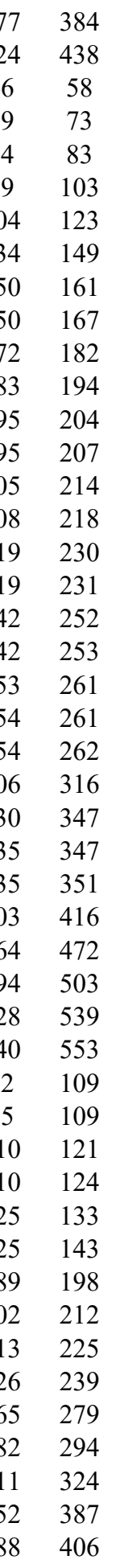

Page 27 of Table S-1-4 

ATP synthase subunit beta, mitochond ATP synthase subunit gamma, mitochondrial GN=ATP5C1 ATPG_HUMAN $33.00 \quad 100.0 \%$ ATP synthase subunit gamma, mitochondrial GN=ATP5C1 ATPG_HUMAN $33.00 \quad 100.0 \%$ ATP synthase subunit gamma, mitochondrial GN=ATP5C1 ATPG_HUMAN $33.00 \quad 100.0 \%$ ATP synthase subunit gamma, mitochondrial GN=ATP5C1 ATPG_HUMAN $33.00 \quad 100.0 \%$ ATP synthase subunit gamma, mitochondrial GN=ATP5C1 ATPG HUMAN $33.00 \quad 100.0 \%$ ATP synthase subunit gamma, mitochondrial GN=ATP5C1 ATPG_HUMAN $33.00 \quad 100.0 \%$ ATP synthase subunit gamma, mitochondrial GN=ATP5C1 ATPG HUMAN 33.00 100.0\% ATP synthase subunit gamma, mitochondrial GN=ATP5C1 ATPG_HUMAN $33.00 \quad 100.0 \%$ ATP synthase subunit gamma, mitochondrial GN=ATP5C1 ATPG_HUMAN $33.00 \quad 100.0 \%$ ATP synthase subunit gamma, mitochondrial GN=ATP5C1 ATPG_HUMAN 33.00 ATPase family AAA domain-containing protein $1 \mathrm{GN}=$ ATAD1 ATAD1_HUMAN 40.75 ATPase family AAA domain-containing protein $1 \mathrm{GN}=$ ATAD1 ATAD1_HUMAN 40.75 ATPase family AAA domain-containing protein $1 \mathrm{GN}=$ ATAD1 ATAD1_HUMAN 40.75 ATPase family AAA domain-containing protein 3A GN=ATAD3A ATD3A_HUMAN 71.3 ATPase family AAA domain-containing protein 3A GN=ATAD3A ATD3A_HUMAN 71.37 ATPase family AAA domain-containing protein 3A GN=ATAD3A ATD3A_HUMAN 71.37 ATPase family AAA domain-containing protein 3A GN=ATAD3A ATD3A_HUMAN 71.37 ATPase family AAA domain-containing protein 3A GN=ATAD3A ATD3A_HUMAN 71.3 ATPase family AAA domain-containing protein 3A GN=ATAD3A ATD3A_HUMAN 71.37 ATPase family AAA domain-containing protein 3A GN=ATAD3A ATD3A_HUMAN 71.37 ATPase family AAA domain-containing protein 3A GN=ATAD3A ATD3A_HUMAN 71.37 ATPase family AAA domain-containing protein $3 \mathrm{~A}$ GN=ATAD3A ATD3A_HUMAN 71.37 ATPase family AAA domain-containing protein $3 \mathrm{~A}$ GN=ATAD3A ATD3A_HUMAN 71.3 ATPase family AAA domain-containing protein 3A GN=ATAD3A ATD3A_HUMAN 71.37 ATPase family AAA domain-containing protein 3A GN=ATAD3A ATD3A_HUMAN 71.37 ATPase family AAA domain-containing protein $3 \mathrm{~A}$ GN=ATAD3A ATD3A HUMAN 71.37 ATPase family AAA domain-containing protein 3A GN=ATAD3A ATD3A_HUMAN 71.37 ATPase family AAA domain-containing protein $3 \mathrm{~A}$ GN=ATAD3A ATD3A HUMAN 71.37 ATPase family AAA domain-containing protein 3A GN=ATAD3A ATD3A_HUMAN 71.37 ATPase family AAA domain-containing protein 3A GN=ATAD3A ATD3A_HUMAN 71.3 ATPase family AAA domain-containing protein $3 \mathrm{~A}$ GN=ATAD3A ATD3A HUMAN 71.37 ATPase family AAA domain-containing protein $3 \mathrm{~A}$ GN=ATAD3A ATD3A_HUMAN 71.37 ATPase family AAA domain-containing protein 3A GN=ATAD3A ATD3A_HUMAN 71.37 ATPase family AAA domain-containing protein 3A GN=ATAD3A ATD3A_HUMAN 71.37 ATPase family AAA domain-containing protein 3A GN=ATAD3A ATD3A_HUMAN 71.3 ATPase family AAA domain-containing protein $3 \mathrm{~A}$ GN=ATAD3A ATD3A_HUMAN 71.37 ATPase family AAA domain-containing protein 3A GN=ATAD3A ATD3A_HUMAN 71.37 ATPase family AAA domain-containing protein 3A GN=ATAD3A ATD3A_HUMAN 71.37 ATPase family AAA domain-containing protein $3 \mathrm{~A}$ GN=ATAD3A ATD3A_HUMAN 71.37 ATPase family AAA domain-containing protein 3B GN=ATAD3B ATD3B_HUMAN 72.5 ATPase family AAA domain-containing protein 3B GN=ATAD3B ATD3B_HUMAN 72.57 ATPase family AAA domain-containing protein $3 \mathrm{~B}$ GN=ATAD3B ATD3B HUMAN 72.57 ATPase family AAA domain-containing protein 3B GN=ATAD3B ATD3B_HUMAN 72.5 ATPase family AAA domain-containing protein 3B GN=ATAD3B ATD3B_HUMAN 72.5? ATPase family AAA domain-containing protein $3 \mathrm{~B}$ GN=ATAD3B ATD3B_HUMAN 72.57
$100.0 \% \quad 10$

$100.0 \%$

$100.0 \%$

$100.0 \% \quad 3$

$100.0 \% \quad 26$

$100.0 \% \quad 26$

$100.0 \% \quad 26$

$100.0 \% \quad 26$

$100.0 \% \quad 26$ $100.0 \% \quad 26$

$100.0 \% \quad 26$ $100.0 \% \quad 26$ $100.0 \% \quad 26$ $100.0 \% \quad 26$ $100.0 \% \quad 26$ $100.0 \% \quad 26$ $100.0 \% \quad 26$ $100.0 \% \quad 26$ $100.0 \% \quad 26$ $100.0 \% \quad 26$ $100.0 \% \quad 26$ $100.0 \% \quad 26$ $100.0 \% \quad 26$ $100.0 \% \quad 26$ $100.0 \% \quad 26$ $100.0 \% \quad 26$ $100.0 \% \quad 26$ $100.0 \% \quad 26$ $100.0 \% \quad 26$ $100.0 \% \quad 26$ $100.0 \%$ $100.0 \%$ $100.0 \%$ $100.0 \%$ $100.0 \%$ $100.0 \%$
$0.11 \% \quad 43.7 \%$ IMDPNIVGSEHYDVAR

$0.03 \% \quad 35.2 \%$ IYGLGSLALYEK

$0.03 \% \quad 35.2 \%$ HLLIGVSSDR

$0.03 \% \quad 35.2 \%$ GLCGAIHSSIAK

$99.5 \% \quad 22.0$

$0.08 \% \quad 39.7 \%$ ITVLEALR

$0.08 \% \quad 39.7 \%$ ITVLEALRHPIQVSR

$0.08 \% \quad 39.7 \%$ LLSRPQDALEGVVLSPSLEA

$0.08 \% \quad 39.7 \%$ VRDIAIATR

$0.08 \% \quad 39.7 \%$ NILMYGPPGTGK

$0.08 \% \quad 39.7 \%$ LFDWANTSR

$0.08 \% \quad 39.7 \%$ GLLLFVDEADAFLR

$0.08 \% \quad 39.7 \%$ ATEKISEDLR

$0.08 \% \quad 39.7 \%$ MYFDKYVLKPATEGK

$0.08 \% \quad 39.7 \%$ LKLAQFDYGR

$0.08 \% \quad 39.7 \%$ LAQFDYGR

$0.08 \% \quad 39.7 \%$ LAQFDYGRK

$0.08 \% \quad 39.7 \%$ LTEGMSGR

$0.08 \% \quad 39.7 \%$ VQDAVQQHQQK

$0.08 \% \quad 39.7 \%$ AEGPGRGDEPSPS

$0.01 \% \quad 31.8 \%$ GLGDRPAPK

$0.01 \% 31.8 \%$ DKWSNFDPTGLER

$0.01 \% \quad 31.8 \%$ TLSEETRQHQAR

$0.01 \% \quad 31.8 \%$ AQYQDKLAR

$0.01 \% \quad 31.8 \%$ ATVEREMELR

$0.01 \% \quad 31.8 \%$ ENADIIREQIR
$99.6 \% \quad 25.3$

$99.7 \% \quad 33.3$

25.0

$99.7 \% \quad 53.0$

$99.7 \% \quad 40.1$

$99.7 \% \quad 66.9$

$\begin{array}{lll}99.7 \% & 54.3\end{array}$

$99.7 \% \quad 69.5$

$99.7 \% \quad 56.7$

$99.7 \% 31$.

$99.7 \% \quad 62.1$

$99.7 \% \quad 56.4$

$99.7 \% \quad 40.2$

$99.7 \% \quad 65.3$

$99.0 \% \quad 37.5$

$99.7 \% \quad 40.5$

$99.7 \% \quad 51.8$

$99.7 \% \quad 37.2$

$99.7 \% \quad 47.8$

$99.7 \% \quad 32.6$

$99.7 \% \quad 33.7$

$99.7 \% \quad 38.2$

$99.0 \% \quad 59.0$

$99.7 \% \quad 53.2$

$99.0 \% \quad 34.3$

$99.0 \% \quad 39.2$

$99.0 \% \quad 54.2$

$99.7 \% \quad 39.5$

$99.7 \% \quad 41.9 \quad 25.0-37.0$

$\begin{array}{llll}99.7 \% & 52.1 & 25.0 & 47.1\end{array}$

$\begin{array}{llll}99.7 \% & 38.0 & 25.0 & 31.1\end{array}$

$99.7 \% \quad 34.6 \quad 25.0 \quad 34.6$

$\begin{array}{llll}99.7 \% & 45.7 & 25.0 & 13.6\end{array}$

$\begin{array}{llll}98.3 \% & 16.5 & 25.0 & 16.5\end{array}$

$99.7 \% \quad 58.4 \quad 25.0 \quad 51.0$

$\begin{array}{llll}99.0 \% & 46.3 & 25.0 & 22.7\end{array}$

$99.7 \% \quad 33.5 \quad 25.0 \quad 33.5$

$\begin{array}{llll}99.0 \% & 45.8 & 25.0 & 45.8\end{array}$

$\begin{array}{llll}99.7 \% & 41.5 & 25.0 & 31.3\end{array}$

$99.7 \% \quad 47.4 \quad 25.0 \quad 47.1$

$99.7 \% \quad 40.5 \quad 25.0 \quad 36.5 \quad 2$

$99.7 \% \quad 51.8 \quad 25.0 \quad 51.5$

$\begin{array}{llll}99.7 \% & 37.2 & 25.0 & 33.4\end{array}$

$\begin{array}{llll}99.7 \% & 47.8 & 25.0 & 41.4\end{array}$

$\begin{array}{llll}99.7 \% & 32.6 & 25.0 & 15.3\end{array}$

$\begin{array}{llll}99.7 \% & 33.7 & 25.0 & 20.2\end{array}$
1831.86

2023.0

1326.73

972.50

1096.6

1213.64

1047.57

1076.57

1345.75

1292.66

1768.89

1314.72

1046.60

1103.68

917.49

910.51

564.74

1455.73

1092.58

1233.63

1356.72

1509.81

945.54

1155.58

801.46

869.56

914.57

1732.02

2250.25

1014.6

7422 $463 \quad 480$ $80 \quad 88$ $91 \quad 100$ $101 \quad 112$ $116 \quad 126$ $27 \quad 138$ $144 \quad 154$ $263 \quad 277$ $286 \quad 298$ $173 \quad 183$ $36 \quad 44$ $45 \quad 57$ 786
220 $250 \quad 260$ $268 \quad 275$ 76
14
14 $327 \quad 334$ 339346 $376 \quad 384$

$\begin{array}{lll}1578.85 & 453 & 466\end{array}$ $\begin{array}{lll}1161.61 \quad 469 & 478\end{array}$ $\begin{array}{lll}1789.92 & 535 & 549\end{array}$

$\begin{array}{lll}210.66 & 552 & 561\end{array}$ $969.48 \quad 554 \quad 561$ $\begin{array}{lll}097.57 & 554 & 562\end{array}$ 850.41 1308.67

1255.56 910.51 1564.74 1455.73 1092.58 1233.63 1356.72 
ATPase family AAA domain-containing protein 3B GN=ATAD3B ATD3B_HUMAN $72.57 \quad 100.0 \%$ ATPase family AAA domain-containing protein 3B GN=ATAD3B ATD3B_HUMAN $72.57 \quad 100.0 \%$ ATPase family AAA domain-containing protein 3B GN=ATAD3B ATD3B_HUMAN $72.57 \quad 100.0 \%$ ATPase family AAA domain-containing protein 3B GN=ATAD3B ATD3B_HUMAN $72.57 \quad 100.0 \%$ ATPase family AAA domain-containing protein 3B GN=ATAD3B ATD3B_HUMAN $72.57 \quad 100.0 \%$ ATPase family AAA domain-containing protein 3B GN=ATAD3B ATD3B_HUMAN $72.57 \quad 100.0 \%$ ATPase family AAA domain-containing protein 3B GN=ATAD3B ATD3B_HUMAN $72.57 \quad 100.0 \%$ ATPase family AAA domain-containing protein 3B GN=ATAD3B ATD3B_HUMAN $72.57 \quad 100.0 \%$ ATPase family AAA domain-containing protein 3B GN=ATAD3B ATD3B_HUMAN $72.57 \quad 100.0 \%$ ATPase family AAA domain-containing protein 3B GN=ATAD3B ATD3B_HUMAN $72.57 \quad 100.0 \%$ ATPase family AAA domain-containing protein 3B GN=ATAD3B ATD3B_HUMAN $72.57 \quad 100.0 \%$ ATPase family AAA domain-containing protein 3B GN=ATAD3B ATD3B_HUMAN $72.57 \quad 100.0 \%$ ATPase family AAA domain-containing protein 3B GN=ATAD3B ATD3B_HUMAN $72.57 \quad 100.0 \%$ ATPase family AAA domain-containing protein 3B GN=ATAD3B ATD3B_HUMAN $72.57 \quad 100.0 \%$ ATPase family AAA domain-containing protein 3B GN=ATAD3B ATD3B_HUMAN $72.57 \quad 100.0 \%$ ATPase family AAA domain-containing protein 3B GN=ATAD3B ATD3B_HUMAN $72.57 \quad 100.0 \%$ ATP-binding cassette sub-family B member 7, mitochondrial $\mathrm{GN}=\mathrm{ABCB} 7 \quad \mathrm{ABCB} 7$ HUMAN $82.64 \quad 100.0 \%$ ATP-binding cassette sub-family B member 7, mitochondrial $\mathrm{GN}=\mathrm{ABCB} 7 \mathrm{ABCB} 7$ HUMAN $82.64 \quad 100.0 \%$ ATP-binding cassette sub-family D member $3 \mathrm{GN}=\mathrm{ABCD} 3 \quad \mathrm{ABCD} 3$ _HUMAN $75.48 \quad 100.0 \%$ ATP-binding cassette sub-family D member $3 \mathrm{GN}=\mathrm{ABCD} 3 \mathrm{ABCD} 3$ _HUMAN $75.48 \quad 100.0 \%$ ATP-binding cassette sub-family D member $3 \mathrm{GN}=\mathrm{ABCD} 3 \mathrm{ABCD} 3$ _HUMAN $75.48 \quad 100.0 \%$ ATP-binding cassette sub-family D member $3 \mathrm{GN}=\mathrm{ABCD} 3 \quad \mathrm{ABCD} 3$ _HUMAN $75.48 \quad 100.0 \%$ ATP-binding cassette sub-family D member $3 \mathrm{GN}=\mathrm{ABCD} 3 \mathrm{ABCD} 3$ _HUMAN $75.48 \quad 100.0 \%$ ATP-binding cassette sub-family F member $2 \mathrm{GN}=\mathrm{ABCF} 2 \mathrm{ABCF} 2$ HUMAN $71.29 \quad 100.0 \%$ ATP-binding cassette sub-family F member $2 \mathrm{GN}=\mathrm{ABCF} 2 \quad \mathrm{ABCF} 2 \mathrm{HUMAN} 71.29 \quad 100.0 \%$ ATP-citrate synthase GN=ACLY ATP-citrate synthase $\mathrm{GN}=\mathrm{ACLY}$ ATP-citrate synthase GN=ACLY ATP-citrate synthase $\mathrm{GN}=\mathrm{ACLY}$ ATP-citrate synthase $\mathrm{GN}=\mathrm{ACLY}$ ATP-citrate synthase GN=ACLY ATP-citrate synthase $\mathrm{GN}=\mathrm{ACLY}$ ATP-citrate synthase GN=ACLY ATP-citrate synthase GN=ACLY ATP-citrate synthase $\mathrm{GN}=\mathrm{ACLY}$ ATP-citrate synthase GN=ACLY ATP-citrate synthase GN=ACLY ATP-citrate synthase $\mathrm{GN}=\mathrm{ACLY}$ ATP-citrate synthase GN=ACLY ATP-citrate synthase $\mathrm{GN}=\mathrm{ACLY}$ ATP-citrate synthase $\mathrm{GN}=\mathrm{ACLY}$ ATP-citrate synthase GN=ACLY ATP-citrate synthase GN=ACLY ATP-citrate synthase GN=ACLY ATP-citrate synthase $\mathrm{GN}=\mathrm{ACLY}$ ATP-citrate synthase GN=ACLY ATP-citrate synthase GN=ACLY ACLY_HUMAN $120.84 \quad 100.0 \%$ ACLY_HUMAN $120.84 \quad 100.0 \%$ ACLY_HUMAN $120.84 \quad 100.0 \%$ ACLY_HUMAN $120.84 \quad 100.0 \%$ ACLY_HUMAN $120.84 \quad 100.0 \%$ ACLY_HUMAN $120.84 \quad 100.0 \%$ ACLY_HUMAN $120.84 \quad 100.0 \%$ ACLY_HUMAN $120.84 \quad 100.0 \%$ ACLY_HUMAN $120.84 \quad 100.0 \% \quad 30$ ACLY_HUMAN $120.84 \quad 100.0 \% \quad 30$ ACLY_HUMAN $120.84 \quad 100.0 \% \quad 30$ ACLY_HUMAN $120.84 \quad 100.0 \% \quad 30$ ACLY_HUMAN $120.84 \quad 100.0 \% \quad 30$ ACLY_HUMAN $120.84 \quad 100.0 \% \quad 30$ ACLY_HUMAN $120.84 \quad 100.0 \% \quad 30$ ACLY_HUMAN $120.84 \quad 100.0 \% \quad 30$ ACLY_HUMAN $120.84 \quad 100.0 \% \quad 30$ ACLY_HUMAN $120.84 \quad 100.0 \% \quad 30$ ACLY_HUMAN $120.84 \quad 100.0 \% \quad 30$ ACLY_HUMAN $120.84 \quad 100.0 \% \quad 30$ ACLY HUMAN $120.84 \quad 100.0 \% \quad 30$ ACLY_HUMAN $120.84 \quad 100.0 \% \quad 30$
$0.01 \% \quad 31.8 \%$ ASEHRQTVLESIR $0.01 \% 31.8 \%$ QTVLESIR

$0.01 \% \quad 31.8 \%$ TAGTLFGEGFR

$0.01 \% 31.8 \%$ LGKPSLVR

$0.01 \% \quad 31.8 \%$ ITVLEALR

$0.01 \% \quad 31.8 \%$ ITVLEALRHPIQVSR

$0.01 \% 31.8 \%$ LLSRPQDVLEGVVLSPSLEAR

$0.01 \% \quad 31.8 \%$ VRDIAIATR

$0.01 \% 31.8 \%$ HILLYGPPGTGK

$0.01 \% \quad 31.8 \%$ LFDWANTSR

$0.01 \% \quad 31.8 \%$ ATEEISKDLR

$0.01 \% \quad 31.8 \%$ LHFDNCVLKPATEGK

$0.01 \% 31.8 \%$ LKLAQFDYGR

$0.01 \% \quad 31.8 \%$ LAQFDYGR

$0.01 \% \quad 31.8 \%$ LAQFDYGRK

$0.01 \% \quad 31.8 \%$ LTEGMSGR

$0.00 \% \quad 2.9 \%$ VAISLGFLGGAK

$0.00 \% \quad 2.9 \%$ AGAAFFNEVR

$10 \quad 0.01 \% \quad 10.0 \%$ AVVDKVFFSR

$10 \quad 0.01 \% \quad 10.0 \%$ LITNSEEIAFYNGNKR

$10 \quad 0.01 \% \quad 10.0 \%$ STHSELLEDYYQSGR

$10 \quad 0.01 \% \quad 10.0 \%$ IVLAGREMTR

$10 \quad 0.01 \% \quad 10.0 \%$ SGANVLICGPNGCGK

$0.00 \% \quad 3.2 \%$ SMLLSAIGKR

$0.00 \% \quad 3.2 \% \quad$ LVDEEPQLTK

$0.08 \% \quad 27.5 \%$ AISEQTGKELLYK

$0.08 \% \quad 27.5 \%$ FICTTSAIQNR

$0.08 \% \quad 27.5 \%$ FICTTSAIQNRFK

$0.08 \% \quad 27.5 \%$ VTPDTDWAR

$0.08 \% \quad 27.5 \%$ GKLGLVGVNLTLDGVK

$0.08 \% \quad 27.5 \%$ LGLVGVNLTLDGVK

$0.08 \% \quad 27.5 \%$ LGQEATVGK

$0.08 \% \quad 27.5 \%$ LGQEATVGKATGFLK

$0.08 \% \quad 27.5 \%$ VDATADYICK

$0.08 \% \quad 27.5 \%$ EAYPEEAYIADLDAK

$0.08 \% \quad 27.5 \%$ TILSLMTR

$0.08 \% \quad 27.5 \%$ RGGPNYQEGLR

$0.08 \% \quad 27.5 \%$ GGPNYQEGLR

$0.08 \% \quad 27.5 \%$ TASFSESRADEVAPAK

$0.08 \% \quad 27.5 \%$ AKPAMPQDSVPSPR

$0.08 \% \quad 27.5 \%$ SLQGKSTTLFSR

$0.08 \% \quad 27.5 \%$ SAYDSTMETMNYAQIR

$0.08 \% \quad 27.5 \%$ TIAIIAEGIPEALTR

$0.08 \% \quad 27.5 \%$ TIAIIAEGIPEALTRK

$99.7 \% \quad 27.5$

$99.0 \% \quad 59.0$

$99.7 \% 53.2$

$99.0 \% 39.2$

$99.0 \% \quad 54.2$

$99.7 \% \quad 39.5$

$9.7 \% \quad 27.2$

$99.7 \% \quad 41.9$

$99.7 \% \quad 50.1$

$99.7 \% \quad 38.0$

$99.7 \% \quad 55.9$

$97.3 \% \quad 17.6$

$99.7 \% \quad 58.4$

$99.0 \% \quad 46.3$

$99.7 \% 33.5$

$99.0 \% \quad 45.8$

$99.7 \% \quad 56.4$

$99.7 \% \quad 52.7$

$99.7 \% \quad 32.9$

$99.7 \% \quad 84.6$

$99.7 \% \quad 77.6$

$99.1 \% \quad 21.1$

$99.7 \% \quad 48.0$

$99.1 \% \quad 20.1$

$\begin{array}{lll}98.3 \% & 28.4\end{array}$

$99.7 \% \quad 51.9$

$99.7 \% \quad 60.0$

$99.7 \% \quad 60.5$

$97.4 \% \quad 16.2$

$99.7 \% \quad 65.0$

$99.7 \% \quad 62.7$

$99.7 \% \quad 51.7$

$99.7 \% \quad 43.3$

$99.7 \% \quad 37.6$

$99.7 \% \quad 53.5$

$99.0 \% \quad 31.0$

$99.7 \% \quad 30.4$

$97.6 \% \quad 21.8$

$99.7 \% \quad 39.2$

$99.7 \% \quad 30.4$

$99.6 \% \quad 29.1$

$\begin{array}{ll}99.7 \% & 59.0\end{array}$

$99.7 \% \quad 67.2$

$99.5 \% \quad 21.1$

$\begin{array}{lllll}0.08 \% & 27.5 \% & \text { ADQKGVTIIGPATVGGIKPGCFK } & 99.7 \% & 31.5\end{array}$

$0.08 \% \quad 27.5 \%$ GVTIIGPATVGGIKPGCFK $99.7 \% \quad 59.8$

$0.08 \% \quad 27.5 \%$ IGNTGGMLDNILASK

$99.7 \% \quad 59.2$

$41 \quad 82$

$99.7 \%$

945.54

1155.58

869.56

914.57

1732.02

2278.28

1014.61

1252.71

1109.54

1161.61

1728.87

1210.66

969.48

1097.57

850.41

1132.67

1081.54

1167.65

1868.95

1784.81

1145.65

1503.70

1091.62

1171.62

1479.81

1310.65

1585.82

1060.51

1582.95

1397.84

902.49

1519.85

1155.54

1697.79

934.54

1246.63

1090.53

1665.81

1496.75

1324.72

1912.81

1567.91

1696.00

2314.26

1872.04

1519.78 
ATP-citrate synthase $\mathrm{GN}=\mathrm{ACLY}$ ATP-citrate synthase GN=ACLY ATP-citrate synthase $\mathrm{GN}=\mathrm{ACLY}$ ATP-citrate synthase $\mathrm{GN}=\mathrm{ACLY}$ ATP-citrate synthase GN=ACLY ATP-citrate synthase $\mathrm{GN}=\mathrm{ACLY}$ ATP-citrate synthase GN=ACLY ATP-citrate synthase GN=ACLY $\begin{array}{llll}\text { ATP-dependent 6-phosphofructokinase, liver type GN=PFKL PFKAL_HUMAN } & 85.02 & 100.0 \% \\ \text { ATP-dependent 6-phosphofructokinase, liver type GN=PFKL PFKAL_HUMAN } & 85.02 & 100.0 \%\end{array}$ ATP-dependent 6-phosphofructokinase, liver type GN=PFKL PFKAL_HUMAN $85.02 \quad 100.0 \%$ ATP-dependent 6-phosphofructokinase, liver type GN=PFKL PFKAL_HUMAN $85.02 \quad 100.0 \%$ ATP-dependent 6-phosphofructokinase, platelet type GN=PFKP PFKAP_HUMAN $85.60 \quad 100.0 \%$ ATP-dependent 6-phosphofructokinase, platelet type GN=PFKP PFKAP_HUMAN $85.60 \quad 100.0 \%$ ATP-dependent 6-phosphofructokinase, platelet type GN=PFKP PFKAP_HUMAN $85.60 \quad 100.0 \%$ $\begin{array}{llll}\text { ATP-dependent 6-phosphofructokinase, platelet type GN=PFKP PFKAP_HUMAN } 85.60 & 100.0 \%\end{array}$ ATP-dependent 6-phosphofructokinase, platelet type GN=PFKP PFKAP HUMAN $85.60 \quad 100.0 \%$ ATP-dependent Clp protease ATP-binding subunit clpX-like, mitochondrial GN=CLPX CLPX_HUMAN $69.22 \quad 100.0 \%$ ATP-dependent Clp protease ATP-binding subunit clpX-like, mitochondrial GN=CLPX CLPX_HUMAN $69.22 \quad 100.0 \%$ ATP-dependent Clp protease ATP-binding subunit clpX-like, mitochondrial GN=CLPX CLPX_HUMAN $69.22 \quad 100.0 \%$ ATP-dependent Clp protease ATP-binding subunit clpX-like, mitochondrial GN=CLPX CLPX_HUMAN $69.22 \quad 100.0 \%$ ATP-dependent Clp protease ATP-binding subunit clpX-like, mitochondrial GN=CLPX CLPX_HUMAN 69.22 $100.0 \%$ ATP-dependent Clp protease ATP-binding subunit clpX-like, mitochondrial GN=CLPX CLPX_HUMAN $69.22 \quad 100.0 \%$ $\begin{array}{llll}\text { ATP-dependent Clp protease ATP-binding subunit clpX-like, mitochondrial GN=CLPX } & \text { CLPX_HUMAN } 69.22 & 100.0 \\ \text { ATP-dependent Clp protease ATP-binding subunit clpX-like, mitochondrial GN=CLPX } & \text { CLPX_HUMAN } & 69.22 & 100.0\end{array}$ ATP-dependent Clp protease ATP-binding subunit clpX-like, mitochondrial GN=CLPX CLPX_HUMAN 69.22 ATP-dependent Clp protease ATP-binding subunit clpX-like, mitochondral GN=CLPX CLPX_HUMAN $69.22 \quad 1$ ATP-dependent Clp protease ATP-binding subunit clpX-like, mitcochondrial GN=CLPX CLPX_HUMAN 69.22 ATP-dependent Clp protease ATP-binding subunit clpX-like, mitochondrial GN=CLPX CLPX_HUMAN 69.22 100.0 ATP-dependent Clp protease ATP-binding subunit clpX-like, mitochondrial GN=CLPX CLPX_HUMAN 69.22 100.0 $\begin{array}{llll}\text { ATP-dependent Clp protease proteolytic subunit, mitochondrial GN=CLPP } & \text { CLPP_HUMAN } & 30.18 & 100.0 \% \\ \text { ATP-dependent Clp protease proteolytic subunit, mitochondrial GN=CLPP } & \text { CLPP_HUMAN } & 30.18 & 100.0 \%\end{array}$ ATP-dependent Clp protease proteolytic subunit, mitochondrial GN=CLPP CLPP_HUMAN $30.18 \quad 100.0 \%$ ATP-dependent Clp protease proteolytic subunit, mitochondrial GN=CLPP CLPP_HUMAN $30.18 \quad 100.0 \%$ ATP-dependent RNA helicase A GN=DHX9 DHX9_HUMAN $140.96 \quad 100.0 \%$ ATP-dependent RNA helicase A GN=DHX9 DHX9_HUMAN $140.96 \quad 100.0 \% 42$ ATP-dependent RNA helicase A GN=DHX9 DHX9_HUMAN $140.96 \quad 100.0 \%$ ATP-dependent RNA helicase A GN=DHX9 DHX9_HUMAN $140.96 \quad 100.0 \%$ ATP-dependent RNA helicase A GN=DHX9 DHX9 HUMAN $140.96 \quad 100.0 \%$ ATP-dependent RNA helicase A GN=DHX9 DHX9_HUMAN $140.96 \quad 100.0 \% \quad 42$ ATP-dependent RNA helicase A GN=DHX9 DHX9_HUMAN $140.96 \quad 100.0 \% \quad 42$ ATP-dependent RNA helicase A GN=DHX9 DHX9_HUMAN $140.96 \quad 100.0 \%$ ATP-dependent RNA helicase A GN=DHX9 DHX9_HUMAN $140.96 \quad 100.0 \% \quad 42$ ATP-dependent RNA helicase A GN=DHX9 DHX9_HUMAN $140.96 \quad 100.0 \%$ ATP-dependent RNA helicase A GN=DHX9 DHX9_HUMAN $140.96 \quad 100.0 \%$ ATP-dependent RNA helicase A GN=DHX9 DHX9_HUMAN $140.96 \quad 100.0 \%$ ATP-dependent RNA helicase A GN=DHX9 DHX9_HUMAN $140.96 \quad 100.0 \% 42$ ATP-dependent RNA helicase A GN=DHX9 DHX9_HUMAN $140.96 \quad 100.0 \% \quad 42$ $0.08 \% 27.5 \%$ SGGMSNELNNIISR $\begin{array}{lll}0.08 \% & 27.5 \% & \text { YQDTPGVK }\end{array}$

$0.08 \% \quad 27.5 \%$ NQALKEAGVFVPR $0.08 \% \quad 27.5 \%$ AFDSGIIPMEFVNK $0.08 \% \quad 27.5 \%$ EGKLIMGIGHR

$0.08 \% \quad 27.5 \%$ LIMGIGHR

$0.08 \% \quad 27.5 \%$ VQILKDYVR

$0.01 \% \quad 7.7 \%$ GGTPSAFDRILSSK

$0.01 \% \quad 7.7 \% \quad$ VFANAPDSACVIGLK

$0.01 \% \quad 7.7 \%$ AVAFSPVTELKK

$99.7 \% \quad 42.1 \quad 25.0 \quad 32.3$

$\begin{array}{llll}99.7 \% & 37.0 & 25.0 & 31.5\end{array}$

$\begin{array}{llll}99.7 \% & 34.7 & 25.0 & 34.7\end{array}$

$0.01 \% \quad 7.9 \%$ AIGVLTSGGDAQGMNAAVR

$0.01 \% \quad 7.9 \%$ SFAGNLNTYKR

$0.01 \% \quad 7.9 \%$ LAIKLPDDQIPK

$0.01 \% \quad 7.9 \%$ VGIADGHR

$0.01 \% \quad 7.9 \%$ NVIFQPVAELKK

$0.02 \% \quad 19.6 \%$ SIIKEPESAAEAVK

$20 \quad 0.02 \% \quad 19.6 \%$ IYNNIPANLR

$0.02 \% \quad 19.6 \%$ GGEVLDSSHDDIKLEK

$0.02 \% \quad 19.6 \%$ SNILLLGPTGSGK

$0.02 \% \quad 19.6 \%$ TLLAQTLAK

$0.02 \% \quad 19.6 \%$ LLQDANYNVEK

$0.02 \% \quad 19.6 \%$ DVGGEGVQQGLLK

$0.02 \% \quad 19.6 \%$ LLEGTIVNVPEK

$0.02 \% \quad 19.6 \%$ LLEGTIVNVPEKNSR

$0.02 \% \quad 19.6 \%$ YLGFGTPSNLGK

$0.02 \% \quad 19.6 \%$ RAAAAADLANR

$0.02 \% \quad 19.6 \%$ AAAAADLANR

$0.01 \% \quad 26.0 \%$ IMIHQPSGGAR

$0.01 \% \quad 26.0 \%$ GQATDIAIQAEEIMK

$0.01 \% \quad 26.0 \%$ QSLQVIESAMER

$0.01 \% \quad 26.0 \%$ VLVHPPQDGEDPTLVQKEPVEAPPAPPVAST $99.7 \% \quad 50.3$

$288 \quad 0.29 \%$

$288 \quad 0.29 \% \quad 32.9 \%$ MTPSYEIR

$99.7 \% 73.8$

$99.7 \% \quad 48.1$

$99.7 \% \quad 29.8$

$99.0 \% \quad 28.2$

$99.7 \% \quad 33.8$

$99.7 \% \quad 54.9$

$99.7 \% \quad 29.4$

$96.7 \% \quad 19.0$

$99.7 \% \quad 70.5$

$99.7 \% \quad 45.6$

$99.7 \% \quad 66.2$

$98.9 \% \quad 21.8$

$99.7 \% \quad 36.2$

$99.7 \% \quad 46.3$

$99.7 \% \quad 43.1$

$96.2 \% \quad 21.7$

$99.7 \% \quad 43.9$

$99.5 \% \quad 22.7$

$99.7 \% \quad 81.9$

$99.7 \% \quad 55.8$

$99.7 \% \quad 41.4$

$99.0 \% \quad 32.1$

$288 \quad 0.29 \% \quad 32.9 \%$ DAQSNAARDFVNYLVR

$288 \quad 0.29 \% \quad 32.9 \%$ DFVNYLVR

$\begin{array}{ll}99.7 \% & 46.8 \\ 99.0 \% & 52.3\end{array}$

$0.29 \% \quad 32.9 \%$ AENNSEVGASGYGVPGPTWDR

$288 \quad 0.29 \% \quad 32.9 \%$ GANLKDYYSR

$288 \quad 0.29 \% \quad 32.9 \%$ LNQYFQKEK

$99.7 \% \quad 51.8$

$99.5 \% 33.2$

$99.7 \% \quad 36.3$

$99.7 \% \quad 43.3$

$99.7 \% \quad 58.5$

$99.7 \% \quad 57.3$

$99.7 \% \quad 61.7$

$99.7 \% \quad 55.6$

$99.7 \% \quad 56.7$
907.45

1428.80

1567.78

1226.67

912.51

1133.67

1803.90

1435.75

1561.80

1289.75

1803.90

1270.65

1350.80

824.44

1385.82

1471.80

1187.65

1741.86

1256.72

958.59

1306.66

1299.69

1311.75

1668.93

1253.65

1099.60

943.50

1182.61

1617.82

1390.70

3517.77

1124.58

996.48

1838.91

1025.54

2162.97

1186.59

1197.63

1904.93

1186.56

1331.69

1416.80

1288.70

1777.95 1075.55

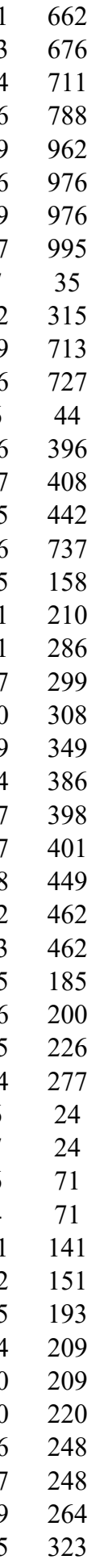

Page 30 of Table S-1-4 
ATP-dependent RNA helicase A GN=DHX9 DHX9_HUMAN $140.96 \quad 100.0 \% 42$ ATP-dependent RNA helicase A GN=DHX9 DHX9_HUMAN $140.96 \quad 100.0 \% \quad 42$ ATP-dependent RNA helicase A GN=DHX9 DHX9_HUMAN $140.96 \quad 100.0 \%$ ATP-dependent RNA helicase A GN=DHX9 DHX9_HUMAN $140.96 \quad 100.0 \% \quad 42$ ATP-dependent RNA helicase A GN=DHX9 DHX9_HUMAN $140.96 \quad 100.0 \%$ ATP-dependent RNA helicase A GN=DHX9 DHX9_HUMAN $140.96 \quad 100.0 \% \quad 42$ ATP-dependent RNA helicase A GN=DHX9 DHX9_HUMAN $140.96 \quad 100.0 \%$ ATP-dependent RNA helicase A GN=DHX9 DHX9_HUMAN $140.96 \quad 100.0 \%$ ATP-dependent RNA helicase A GN=DHX9 DHX9 HUMAN $140.96 \quad 100.0 \%$ ATP-dependent RNA helicase A GN=DHX9 DHX9_HUMAN $140.96 \quad 100.0 \% \quad 4$ ATP-dependent RNA helicase A GN=DHX9 DHX9_HUMAN $140.96 \quad 100.0 \% \quad 4$ ATP-dependent RNA helicase A GN=DHX9 DHX9_HUMAN $140.96 \quad 100.0 \%$ ATP-dependent RNA helicase A GN=DHX9 DHX9_HUMAN $140.96 \quad 100.0 \% \quad 4$ ATP-dependent RNA helicase A GN=DHX9 DHX9_HUMAN $140.96 \quad 100.0 \%$ ATP-dependent RNA helicase A GN=DHX9 DHX9_HUMAN $140.96 \quad 100.0 \%$ ATP-dependent RNA helicase A GN=DHX9 DHX9_HUMAN $140.96 \quad 100.0 \%$ ATP-dependent RNA helicase A GN=DHX9 DHX9 HUMAN $140.96 \quad 100.0 \%$ ATP-dependent RNA helicase A GN=DHX9 DHX9_HUMAN $140.96 \quad 100.0 \% \quad 4$ ATP-dependent RNA helicase A GN=DHX9 DHX9_HUMAN $140.96 \quad 100.0 \%$ ATP-dependent RNA helicase A GN=DHX9 DHX9_HUMAN $140.96 \quad 100.0 \% 42$ ATP-dependent RNA helicase A GN=DHX9 DHX9_HUMAN $140.96 \quad 100.0 \%$ ATP-dependent RNA helicase A GN=DHX9 DHX9_HUMAN $140.96 \quad 100.0 \%$ ATP-dependent RNA helicase A GN=DHX9 DHX9_HUMAN $140.96 \quad 100.0 \%$ ATP-dependent RNA helicase A GN=DHX9 DHX9_HUMAN $140.96 \quad 100.0 \%$ ATP-dependent RNA helicase A GN=DHX9 DHX9_HUMAN $140.96 \quad 100.0 \%$ ATP-dependent RNA helicase A GN=DHX9 DHX9_HUMAN $140.96 \quad 100.0 \%$ ATP-dependent RNA helicase A GN=DHX9 DHX9_HUMAN $140.96 \quad 100.0 \%$ ATP-dependent RNA helicase A GN=DHX9 DHX9 HUMAN $140.96 \quad 100.0 \%$ ATP-dependent RNA helicase DDX18 GN=DDX18 DDX18_HUMAN $75.41 \quad 100.0 \%$ ATP-dependent RNA helicase DDX18 GN=DDX18 DDX18 HUMAN 75.41 $100.0 \%$ ATP-dependent RNA helicase DDX18 GN=DDX18 DDX18_HUMAN $75.41 \quad 100.0 \%$ ATP-dependent RNA helicase DDX18 GN=DDX18 DDX18_HUMAN $75.41 \quad 100.0 \%$ ATP-dependent RNA helicase DDX19A GN=DDX19A DD19A_HUMAN $53.98 \quad 100.0 \%$ ATP-dependent RNA helicase DDX19A GN=DDX19A DD19A_HUMAN $53.98 \quad 100.0 \%$ ATP-dependent RNA helicase DDX19A GN=DDX19A DD19A_HUMAN $53.98100 .0 \%$ ATP-dependent RNA helicase DDX19A GN=DDX19A DD19A_HUMAN $53.98 \quad 100.0 \%$ ATP-dependent RNA helicase DDX24 GN=DDX24 DDX24_HUMAN $96.33 \quad 100.0 \%$ ATP-dependent RNA helicase DDX24 GN=DDX24 DDX24 HUMAN $96.33100 .0 \%$ ATP-dependent RNA helicase DDX24 GN=DDX24 DDX24_HUMAN $96.33 \quad 100.0 \%$ ATP-dependent RNA helicase DDX39A GN=DDX39A DX39A_HUMAN $49.13100 .0 \%$ ATP-dependent RNA helicase DDX39A GN=DDX39A DX39A_HUMAN $49.13 \quad 100.0 \%$ ATP-dependent RNA helicase DDX39A GN=DDX39A DX39A_HUMAN $49.13 \quad 100.0 \%$ ATP-dependent RNA helicase DDX39A GN=DDX39A DX39A HUMAN $49.13100 .0 \%$ ATP-dependent RNA helicase DDX39A GN=DDX39A DX39A HUMAN $49.13 \quad 100.0 \%$ ATP-dependent RNA helicase DDX39A GN=DDX39A DX39A_HUMAN $49.13 \quad 100.0 \%$ ATP-dependent RNA helicase DDX39A GN=DDX39A DX39A_HUMAN $49.13 \quad 100.0 \%$ ATP-dependent RNA helicase DDX39A GN=DDX39A DX39A_HUMAN $49.13 \quad 100.0 \%$ $4 \quad 288 \quad 0.29 \% \quad 32.9 \%$ AAECNIVVTQPR

$\begin{array}{llll}54 & 288 & 0.29 \% & 32.9 \% \\ 54 & \text { RISAVSVAER }\end{array}$

$54 \quad 288 \quad 0.29 \% \quad 32.9 \%$ ISAVSVAER

$54 \quad 288 \quad 0.29 \% \quad 32.9 \%$ GEEPGKSCGYSVR

$54 \quad 288 \quad 0.29 \% \quad 32.9 \%$ GISHVIVDEIHER

$54 \quad 288 \quad 0.29 \% \quad 32.9 \%$ DINTDFLLVVLR

$\begin{array}{llll}54 & 288 & 0.29 \% & 32.9 \% \\ 5 & \text { DVVQAYPEVR }\end{array}$

$54 \quad 288 \quad 0.29 \% \quad 32.9 \%$ LSMSQLNEK

$\begin{array}{lllll}54 & 288 & 0.29 \% & 32.9 \% & \text { YQILPLHSQIPR }\end{array}$

$54 \quad 288 \quad 0.29 \% \quad 32.9 \%$ YQILPLHSQIPREEQR

$54 \quad 288 \quad 0.29 \% \quad 32.9 \%$ KVFDPVPVGVTK

$\begin{array}{llll}54 & 288 & 0.29 \% & 32.9 \% \\ 54 & 288 & 0.29 \% & 32.9 \%\end{array}$

$54 \quad 288 \quad 0.29 \% \quad 32.9 \%$ VRPGFCFHLCSR

$54 \quad 288 \quad 0.29 \% \quad 32.9 \%$ TPLHEIALSIK

$54 \quad 288 \quad 0.29 \% \quad 32.9 \%$ LGGIGQFLAK

$54 \quad 288 \quad 0.29 \% \quad 32.9 \%$ ELDALDANDELTPLGR

$54 \quad 288 \quad 0.29 \% \quad 32.9 \%$ ILAKLPIEPR

$54 \quad 288 \quad 0.29 \% \quad 32.9 \%$ MGGEEAEIR

$54 \quad 288 \quad 0.29 \% \quad 32.9 \%$ KILTTEGR

\begin{tabular}{llll}
54 & 288 & $0.29 \%$ & $32.9 \%$ \\
\hline
\end{tabular}

$54 \quad 288 \quad 0.29 \% \quad 32.9 \%$ YPSPFFVFGEK

$54 \quad 288 \quad 0.29 \% \quad 32.9 \%$ LQISHEAAACITGLR

$\begin{array}{llll}54 & 288 & 0.29 \% & 32.9 \% \\ 54 & \text { AAMEALVVEVTK }\end{array}$

$54 \quad 288 \quad 0.29 \% \quad 32.9 \%$ QPAIISQLDPVNER

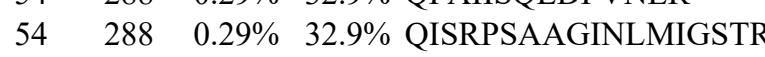

$54 \quad 288 \quad 0.29 \% \quad 32.9 \%$ YGDGPRPPK

$288 \quad 0.29 \% \quad 32.9 \%$ YGDGPRPPKMAR

$0.01 \% \quad 7.2 \%$ NGTGVLILSPTR

$0.01 \% \quad 7.2 \%$ LGNGINIIVATPGR

$0.01 \% \quad 7.2 \% \quad$ QTMLFSATQTR

$0.01 \% \quad 7.2 \%$ SAQEAYKSYIR

$0.01 \% \quad 11.3 \%$ SNLVDNTNQVEVLQRDPNSI

$0.01 \% \quad 11.3 \%$ TAAFVLAMLSR

$0.01 \% \quad 11.3 \%$ VLVTTNVCAR

$0.01 \% \quad 11.3 \%$ HSMNILNR

$0.00 \% \quad 4.3 \% \quad$ TSEIYVHR

$0.00 \% \quad 4.3 \%$ TKYPTQSGKPPLLVSAPSK

$0.00 \% \quad 4.3 \%$ SESALSCLSK

$0.01 \% \quad 16.2 \%$ ELAFQISK

$0.01 \% \quad 16.2 \%$ ELAFQISKEYER

$0.01 \% \quad 16.2 \%$ VSVFFGGLSIK

$0.01 \% \quad 16.2 \%$ NCPHVVVGTPGR

$0.01 \% \quad 16.2 \%$ YQQFKDFQR

$0.01 \% \quad 16.2 \%$ RILVATNLFGR

$0.01 \% \quad 16.2 \%$ ILVATNLFGR

$0.01 \% \quad 16.2 \%$ GLAITFVSDENDAK
$99.7 \% \quad 44.9$

$99.7 \% \quad 50.1$

$99.7 \% \quad 54.3$

$99.7 \% \quad 60.9$

$99.7 \% \quad 33.9$

$99.7 \% \quad 55.7$

$99.7 \% \quad 36.3$

$99.7 \% \quad 48.0$

$99.7 \% \quad 52.5$

$99.7 \% 35.5$

$99.3 \% \quad 21.6$

$99.7 \% \quad 55.5$

$99.7 \% 30.1$

$99.7 \% \quad 29.3$

$99.7 \% \quad 57.5$

$99.7 \% \quad 59.4$

$99.7 \% \quad 65.5$

$99.7 \% \quad 48.4$

$\begin{array}{lll}99.7 \% & 44.2\end{array}$

$99.0 \% \quad 30.0$

$99.6 \% \quad 23.4$

$99.7 \% \quad 34.6$

$99.7 \% \quad 68.9$

$99.7 \% \quad 61.1$

$99.7 \% \quad 55.8$

$\begin{array}{lll}99.7 \% & 48.4\end{array}$

$99.7 \% \quad 43.2$

$99.2 \% \quad 19.0$

$99.1 \% \quad 27.0$

$99.7 \% \quad 46.5$

$99.7 \% \quad 53.3$

$\begin{array}{lll}99.7 \% & 40.8\end{array}$

$99.7 \% \quad 47.3$

$99.7 \% \quad 47.5$

$99.0 \% 29.4$

$99.0 \% \quad 36.0$

$99.7 \% \quad 33.9$

$99.7 \% \quad 32.9$

$99.0 \% \quad 20.4$

$99.7 \% \quad 53.7$

$98.6 \% \quad 18.3$

$99.7 \% \quad 65$.

$99.7 \% \quad 43.5$

$99.0 \% \quad 17.9$

$99.7 \% \quad 59.1$

$99.7 \% \quad 40.2$
1417.8

1175.61

1065.52

1464.83

2007.08

1285.75

1157.66

1535.74

1221.72

1003.59

1741.86

1149.74

1007.45

917.54

1465.85

1317.65

1639.86

1260.69

1579.84

1888.01

986.51

1360.68

1227.71

1394.8

1283.64

1315.66

2829.44

1179.66

1132.61

1000.50

1004.52

1999.12

1081.52

935.52

1512.77

1153.66

1292.65

1259.62

1259.76

1103.66

1103.66
1479.73 $\begin{array}{cc}18 & 434 \\ 35 & 446 \\ 47 & 456 \\ 48 & 456 \\ 62 & 474 \\ 04 & 516 \\ 17 & 528 \\ 29 & 538 \\ 22 & 630 \\ 81 & 692 \\ 81 & 696 \\ 97 & 708 \\ 98 & 708 \\ 68 & 779 \\ 96 & 806 \\ 10 & 819 \\ 38 & 853 \\ 54 & 863 \\ 30 & 938 \\ 11 & 1018 \\ 12 & 1024 \\ 38 & 1048 \\ 90 & 1104 \\ 05 & 1116 \\ 17 & 1130 \\ 37 & 1154 \\ 55 & 1163 \\ 55 & 1166 \\ 50 & 261 \\ 98 & 311 \\ 59 & 369 \\ 78 & 588 \\ 7 & 91 \\ 44 & 154 \\ 85 & 394 \\ 46 & 453 \\ 67 & 674 \\ 07 & 825 \\ 26 & 835 \\ 23 & 130 \\ 23 & 134 \\ 44 & 154 \\ 63 & 174 \\ 29 & 337 \\ 38 & 348 \\ 39 & 348 \\ 84 & 397\end{array}$

Page 31 of Table S-1-4 
ATP-dependent RNA helicase DDX3X GN=DDX3X DDX3X_HUMAN $73.25 \quad 100.0 \% \quad 19 \quad 23 \quad 57 \quad 0.06 \% \quad 27.9 \%$ SSFFSDRGSGSR ATP-dependent RNA helicase DDX3X GN=DDX3X DDX3X_HUMAN $73.25 \quad 100.0 \% \quad 1$ ATP-dependent RNA helicase DDX3X GN=DDX3X DDX3X_HUMAN $73.25 \quad 100.0 \% \quad 19$ ATP-dependent RNA helicase DDX3X GN=DDX3X DDX3X HUMAN $73.25 \quad 100.0 \%$ ATP-dependent RNA helicase DDX3X GN=DDX3X DDX3X_HUMAN $73.25 \quad 100.0 \% \quad 19$ ATP-dependent RNA helicase DDX3X GN=DDX3X DDX3X_HUMAN $73.25 \quad 100.0 \% \quad 19$ ATP-dependent RNA helicase DDX3X GN=DDX3X DDX3X_HUMAN $73.25 \quad 100.0 \% \quad 19$ ATP-dependent RNA helicase DDX3X GN=DDX3X DDX3X_HUMAN $73.25 \quad 100.0 \% \quad 19$ ATP-dependent RNA helicase DDX3X GN=DDX3X DDX3X_HUMAN $73.25 \quad 100.0 \% \quad 19$ ATP-dependent RNA helicase DDX3X GN=DDX3X DDX3X_HUMAN $73.25 \quad 100.0 \% \quad 19$ ATP-dependent RNA helicase DDX3X GN=DDX3X DDX3X_HUMAN $73.25 \quad 100.0 \% \quad 19$ ATP-dependent RNA helicase DDX3X GN=DDX3X DDX3X_HUMAN 73.25 ATP-dependent RNA helicase DDX3X GN=DDX3X DDX3X_HUMAN 73.25 ATP-dependent RNA helicase DDX3X GN=DDX3X DDX3X_HUMAN 73.25 ATP-dependent RNA helicase DDX3X GN=DDX3X DDX3X HUMAN 73.25 ATP-dependent RNA helicase DDX3X GN=DDX3X DDX3X_HUMAN 73.25 ATP-dependent RNA helicase DDX3X GN=DDX3X DDX3X_HUMAN 73.25 ATP-dependent RNA helicase DDX3X GN=DDX3X DDX3X_HUMAN 73.25 ATP-dependent RNA helicase DDX3X GN=DDX3X DDX3X_HUMAN 73.25 ATP-dependent RNA helicase DDX54 GN=DDX54 DDX54 HUMAN 98.60 ATP-dependent RNA helicase DDX54 GN=DDX54 DDX54_HUMAN 98.60 ATP-dependent RNA helicase DDX54 GN=DDX54 DDX54 HUMAN 98.60 ATP-dependent RNA helicase DHX8 GN=DHX8 DHX8_HUMAN $139.32 \quad 100.0 \%$ ATP-dependent RNA helicase DHX8 GN=DHX8 DHX8_HUMAN $139.32 \quad 100.0 \%$ ATP-dependent RNA helicase DHX8 GN=DHX8 DHX8 HUMAN $139.32 \quad 100.0 \%$ ATP-dependent RNA helicase DHX8 GN=DHX8 DHX8_HUMAN $139.32 \quad 100.0 \%$ ATP-dependent RNA helicase DHX8 GN=DHX8 DHX8_HUMAN $139.32 \quad 100.0 \%$ ATP-dependent RNA helicase DHX8 GN=DHX8 DHX8 HUMAN $139.32 \quad 100.0 \%$ ATP-dependent RNA helicase DHX8 GN=DHX8 DHX8_HUMAN $139.32 \quad 100.0 \%$ ATP-dependent zinc metalloprotease YME1L1 GN=YME1L1 YMEL1_HUMAN $86.46 \quad 100.0 \%$ ATP-dependent zinc metalloprotease YME1L1 GN=YME1L1 YMEL1_HUMAN $86.46 \quad 100.0 \%$ ATP-dependent zinc metalloprotease YME1L1 GN=YME1L1 YMEL1_HUMAN $86.46 \quad 100.0 \%$ Atypical kinase ADCK3, mitochondrial GN=ADCK3 ADCK3_HUMAN $71.95 \quad 100.0 \%$ Atypical kinase ADCK3, mitochondrial GN=ADCK3 ADCK3_HUMAN $71.95 \quad 100.0 \%$ Basic leucine zipper and W2 domain-containing protein $2 \mathrm{GN}=\mathrm{BZW} 2 \mathrm{BZW} 2$ HUMAN $48.16 \quad 100.0 \%$ Basic leucine zipper and W2 domain-containing protein $2 \mathrm{GN}=\mathrm{BZW} 2 \mathrm{BZW} 2$ _HUMAN $48.16 \quad 100.0 \%$ Bcl-2-associated transcription factor $1 \mathrm{GN}=\mathrm{BCLAF1}$ BCLF1_HUMAN $106.13 \quad 100.0 \%$ Bcl-2-associated transcription factor $1 \mathrm{GN}=\mathrm{BCLAF} 1 \mathrm{BCLF} 1 \mathrm{HUMAN} 106.13 \quad 100.0 \%$ Bcl-2-associated transcription factor $1 \mathrm{GN}=\mathrm{BCLAF} 1 \mathrm{BCLF} 1$ HUMAN $106.13 \quad 100.0 \%$ Bcl-2-associated transcription factor $1 \mathrm{GN}=\mathrm{BCLAF} 1 \mathrm{BCLF} 1 \_$HUMAN $106.13 \quad 100.0 \%$ Bcl-2-associated transcription factor $1 \mathrm{GN}=\mathrm{BCLAF} 1 \mathrm{BCLF} 1$ HUMAN $106.13100 .0 \%$ Bcl-2-associated transcription factor $1 \mathrm{GN}=\mathrm{BCLAF} 1$ BCLF1_HUMAN $106.13 \quad 100.0 \%$ Bcl-2-associated transcription factor $1 \mathrm{GN}=\mathrm{BCLAF} 1 \mathrm{BCLF} 1$ HUMAN $106.13 \quad 100.0 \%$ Bcl-2-associated transcription factor $1 \mathrm{GN}=\mathrm{BCLAF} 1 \mathrm{BCLF} 1$ HUMAN $106.13 \quad 100.0 \%$ Bcl-2-associated transcription factor $1 \mathrm{GN}=\mathrm{BCLAF} 1$ BCLF1_HUMAN $106.13 \quad 100.0 \%$ Beta-galactosidase $\mathrm{GN}=\mathrm{GLB} 1$ Beta-galactosidase $\mathrm{GN}=\mathrm{GLB} 1$
23

23

23
23

23

23

23

9

7

7
7

7

7

7
7

3

3

2

2

2
2
9

2
9
9

9

9

9

9
9
9
9
1
1

$0.06 \% \quad 27.9 \%$ SGFGKFER

$0.06 \% \quad 27.9 \%$ YTRPTPVQK

$0.06 \% \quad 27.9 \%$ DLMACAQTGSGK

$0.06 \% \quad 27.9 \%$ KQYPISLVLAPTR

$0.06 \% \quad 27.9 \%$ QYPISLVLAPTR

$0.06 \% \quad 27.9 \%$ ELAVQIYEEAR

$0.06 \% \quad 27.9 \%$ ELAVQIYEEARK

$0.06 \% \quad 27.9 \%$ VRPCVVYGGADIGQQIR

$0.06 \% \quad 27.9 \%$ GCHLLVATPGR

$0.06 \% \quad 27.9 \%$ IVEQDTMPPKGVR

$0.06 \% \quad 27.9 \%$ HTMMFSATFPK

$0.06 \% \quad 27.9 \%$ VGSTSENITQK

$0.06 \% \quad 27.9 \%$ DREEALHQFR

$0.06 \% \quad 27.9 \%$ SGKSPILVATAVAAR

$0.06 \% \quad 27.9 \%$ SPILVATAVAAR

$0.06 \% \quad 27.9 \%$ VGNLGLATSFFNER

$0.06 \% \quad 27.9 \%$ DYRQSSGASSSSFSSSR

$0.06 \% \quad 27.9 \%$ QSSGASSSSFSSSR

$0.01 \% \quad 3.9 \%$ VADNAQQQYVR

$0.01 \% \quad 3.9 \% \quad$ SRPAPSPESIKR

$0.01 \% \quad 3.9 \%$ ATIFEINASSR

$0.01 \% \quad 6.8 \% \quad$ NGAEFTDSLISNLLR

$0.01 \% \quad 6.8 \%$ VANVADVVSK

$0.01 \% \quad 6.8 \% \quad$ LIVTSATLDAVK

$0.01 \% \quad 6.8 \%$ IFDPAPPGSR

$0.01 \% \quad 6.8 \%$ TGIDQLVVTPISQAQAK

$0.01 \% \quad 6.8 \%$ TNLASTVLSLK

$0.01 \% \quad 6.8 \%$ AICSGFFR

$0.00 \% \quad 5.1 \%$ LAETQNIAPSFVK

$0.00 \% \quad 5.1 \%$ GILLVGPPGTGK

$0.00 \% \quad 5.1 \%$ IKFDQSVDPEIIAR

$0.00 \% \quad 5.9 \%$ LANFGGLAVGLGFGALAEVAKK

$0.00 \% \quad 5.9 \%$ AVLGSSPFLSEANAER

$0.00 \% \quad 4.3 \%$ LLELFPVNR

$0.00 \% \quad 4.3 \% \quad$ ELQKELQER

$0.02 \% \quad 9.9 \%$ KAEGEPQEESPLK

$0.02 \% \quad 9.9 \%$ TIAPQNAPR

$0.02 \% \quad 9.9 \%$ TIAPQNAPRDESR

$0.02 \% \quad 9.9 \%$ SSFYPDGGDQETAK

$0.02 \% \quad 9.9 \%$ SSFYPDGGDQETAKTGK

$0.02 \% \quad 9.9 \%$ SVLADQGKSFATASHR

$0.02 \% \quad 9.9 \% \quad$ NTEEEGLKYK

$0.02 \% \quad 9.9 \%$ ETQSPEQVKSEK

$0.02 \% \quad 9.9 \%$ STFREESPLR

$0.03 \% \quad 21.3 \%$ DSFLKDGQPFR

$0.03 \% \quad 21.3 \%$ YISGSIHYSR $\begin{array}{llllllll}98.0 \% & 16.3 & 25.0 & 16.3 & 1 & 0 & 0 & 1289.59\end{array}$

$\begin{array}{llllllll}99.0 \% & 51.5 & 25.0 & 41.4 & 2 & 0 & 0 & 927.47\end{array}$

$\begin{array}{llllllll}99.7 \% & 31.6 & 25.0 & 22.4 & 3 & 0 & 0 & 1089.61\end{array}$

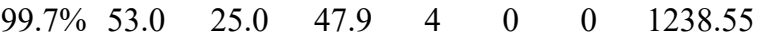

$\begin{array}{llllllll}99.7 \% & 64.4 & 25.0 & 51.0 & 2 & 0 & 0 & 1485.88\end{array}$

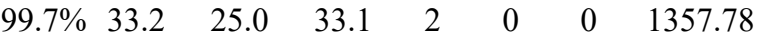

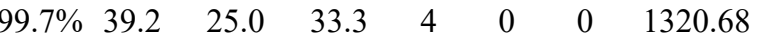

$\begin{array}{llllllll}99.7 \% & 74.8 & 25.0 & 66.4 & 3 & 0 & 0 & 1448.77\end{array}$

1887.99

1180.63

1485.77

1297.61

1163.59

1300.64

1440.85

1168.70

1524.78

1795.78

1361.59

1291.64

1324.73

1208.63

1649.85

1001.56

1230.73

1056.55

1768.98

1146.67

957.46

1417.77

1108.67

1630.88

2103.20

1647.83

1100.65

1172.63

1441.72

967.53

1454.73

1501.64

1787.81

1674.86

1210.60

1389.69

1221.62

1309.65

$\begin{array}{llll}99.0 \% & 18.7 & 25.0 & 17.8\end{array}$

$\begin{array}{llll}99.7 \% & 32.3 & 25.0 & 29.6\end{array}$

$\begin{array}{llll}99.7 \% & 51.9 & 25.0 & 50.6\end{array}$
Page 32 of Table S-1-4 
Beta-galactosidase $\mathrm{GN}=\mathrm{GLB} 1$ Beta-galactosidase $\mathrm{GN}=\mathrm{GLB} 1$ Beta-galactosidase $\mathrm{GN}=\mathrm{GLB} 1$ Beta-galactosidase $\mathrm{GN}=\mathrm{GLB} 1$ Beta-galactosidase $\mathrm{GN}=\mathrm{GLB} 1$ Beta-galactosidase $\mathrm{GN}=\mathrm{GLB} 1$

Beta-galactosidase $\mathrm{GN}=\mathrm{GLB} 1$ Beta-galactosidase $\mathrm{GN}=\mathrm{GLB} 1$ Beta-galactosidase $\mathrm{GN}=\mathrm{GLB} 1$

Beta-lactamase-like protein 2 GN=LACTB2 LACB2_HUMAN $32.81 \quad 100.0 \%$ Beta-lactamase-like protein 2 GN=LACTB2 LACB2_HUMAN $32.81 \quad 100.0 \%$

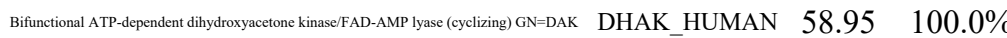

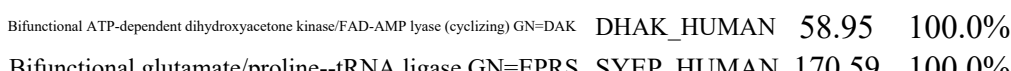
Bifunctional glutamate/proline--tRNA ligase GN=EPRS SYEP_HUMAN $170.59 \quad 100.0 \%$ Bifunctional glutamate/proline--tRNA ligase GN=EPRS SYEP_HUMAN $170.59 \quad 100.0 \%$ Bifunctional glutamate/proline--tRNA ligase GN=EPRS SYEP HUMAN $170.59 \quad 100.0 \%$ Bifunctional glutamate/proline--tRNA ligase GN=EPRS SYEP_HUMAN $170.59 \quad 100.0 \%$ Bifunctional glutamate/proline--tRNA ligase GN=EPRS SYEP_HUMAN $170.59 \quad 100.0 \%$ Bifunctional glutamate/proline--tRNA ligase GN=EPRS SYEP_HUMAN $170.59 \quad 100.0 \%$ Bifunctional glutamate/proline--tRNA ligase GN=EPRS SYEP_HUMAN $170.59 \quad 100.0 \%$ Bifunctional glutamate/proline--tRNA ligase GN=EPRS SYEP_HUMAN $170.59 \quad 100.0 \%$ Bifunctional glutamate/proline--tRNA ligase GN=EPRS SYEP_HUMAN $170.59 \quad 100.0 \%$ Bifunctional glutamate/proline--tRNA ligase GN=EPRS SYEP_HUMAN $170.59 \quad 100.0 \%$ Bifunctional glutamate/proline--tRNA ligase GN=EPRS SYEP HUMAN $170.59 \quad 100.0 \%$ Bifunctional glutamate/proline--tRNA ligase GN=EPRS SYEP_HUMAN $170.59 \quad 100.0 \%$ $\begin{array}{lll}\text { Bifunctional glutamate/proline--tRNA ligase GN=EPRS SYEP_HUMAN } & 170.59 & 100.0 \%\end{array}$ $\begin{array}{llll}\text { Bifunctional glutamate/proline--tRNA ligase GN=EPRS SYEP_HUMAN } & 170.59 & 100.0 \% & 2\end{array}$ Bifunctional glutamate/proline--tRNA ligase GN=EPRS SYEP_HUMAN $170.59 \quad 100.0 \% \quad 2$ Bifunctional glutamate/proline--tRNA ligase GN=EPRS SYEP HUMAN $170.59 \quad 100.0 \%$ Bifunctional glutamate/proline--tRNA ligase GN=EPRS SYEP_HUMAN $170.59 \quad 100.0 \% \quad 2$ Bifunctional glutamate/proline--tRNA ligase GN=EPRS SYEP_HUMAN $170.59 \quad 100.0 \%$ Bifunctional glutamate/proline--tRNA ligase GN=EPRS SYEP HUMAN $170.59 \quad 100.0 \%$ Bifunctional glutamate/proline--tRNA ligase GN=EPRS SYEP_HUMAN $170.59 \quad 100.0 \%$ MTDC HUMAN $37.90 \quad 100.0 \%$ MTDC HUMAN $37.90 \quad 100.0 \%$ MTDC_HUMAN $37.90 \quad 100.0 \%$ MTDC HUMAN $37.90 \quad 100.0 \%$ MTDC_HUMAN $37.90 \quad 100.0 \%$

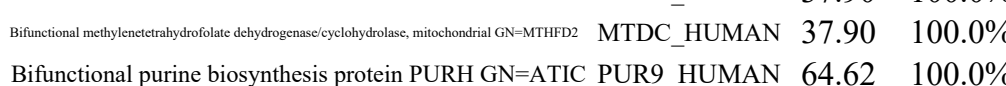

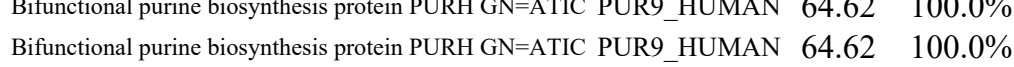
Bifunctional purine biosynthesis protein PURH GN=ATIC PUR9 HUMAN $64.62 \quad 100.0 \%$ Bifunctional purine biosynthesis protein PURH GN=ATIC PUR9_HUMAN $64.62 \quad 100.0 \%$ Bifunctional purine biosynthesis protein PURH GN=ATIC PUR9 HUMAN $64.62 \quad 100.0 \%$ Biliverdin reductase $\mathrm{A} G \mathrm{GN}=\mathrm{BLVRA}$ Biliverdin reductase $\mathrm{A}$ GN $=\mathrm{BLVRA}$

12

12

12
12

12
2

2

2

1

21

21

21

1

21

1

1

$21 \quad 22$

2

22

2

2

2

12

22

6
6
6
6
6
6
5
5
5
5
5
2
2

$26 \quad 0.03 \% \quad 21.3 \%$ TEAVASSLYDILAR $0.03 \% \quad 21.3 \%$ FAYGKVTLEK

$0.03 \% \quad 21.3 \%$ TVGAALDILCPSGPIK

$0.03 \% \quad 21.3 \%$ SLYPLTFIQVK

$0.03 \% \quad 21.3 \%$ QHYGFVLYR

$0.03 \% 21.3 \%$ TTLPQDCSNPAPLSSPLNGVHDR

$0.03 \% \quad 21.3 \%$ AYVAVDGIPQGVLER

$0.03 \% \quad 21.3 \%$ AGATLDLLVENMGR

$0.03 \% \quad 21.3 \%$ VNYGAYINDFK

$0.00 \% \quad 5.9 \% \quad$ IQQYISHR

$0.00 \% \quad 5.9 \%$ EQQILTLFR

$0.00 \% \quad 3.5 \% \quad$ LSVLLLEK

$0.00 \% \quad 3.5 \%$ SPGADLLQVLTK

$40 \quad 0.04 \% \quad 14.5 \%$ FVELPGAEMGK

$40 \quad 0.04 \% \quad 14.5 \%$ AALLNQHYQVNFKGK

$40 \quad 0.04 \% \quad 14.5 \%$ YAEKLIQEGK

$40 \quad 0.04 \% \quad 14.5 \%$ GSQFGQSCCLR

$40 \quad 0.04 \% \quad 14.5 \%$ LNLNNTVLSK

$40 \quad 0.04 \% \quad 14.5 \%$ LNLNNTVLSKR

$40 \quad 0.04 \% \quad 14.5 \%$ KVIDPVAPR

$40 \quad 0.04 \% \quad 14.5 \%$ VIDPVAPR

$40 \quad 0.04 \% \quad 14.5 \%$ VAVQGDVVR

$40 \quad 0.04 \% \quad 14.5 \%$ VAVQGDVVRELK

$40 \quad 0.04 \% \quad 14.5 \%$ SLYDEVAAQGEVVR

$40 \quad 0.04 \% \quad 14.5 \%$ SLYDEVAAQGEVVRK

$40 \quad 0.04 \% \quad 14.5 \%$ TGKEYIPGQPPLSQSSDSSPTR

$40 \quad 0.04 \% \quad 14.5 \%$ NSEPAGLETPEAK

\section{$0.04 \% \quad 14.5 \%$ VLFDKVASQGEVVR}

$\begin{array}{lll}0.04 \% & 14.5 \% & \text { DPSKNQGGGLSSSGAGEGQGPK } \\ 0.04 \% & 14.5 \% \text { NQGGGLSSSGAGEGQGPK }\end{array}$

$40 \quad 0.04 \% \quad 14.5 \%$ AIQGGTSHHLGQNFSK

$40 \quad 0.04 \% \quad 14.5 \%$ GVPIRLEVGPR

$40 \quad 0.04 \% \quad 14.5 \%$ SCQFVAVRR

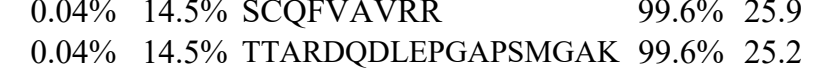

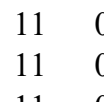

$11 \quad 0.01 \% \quad 20.3 \%$ VHDPVTAKPK

$11 \quad 0.01 \% \quad 20.3 \%$ LVGDVDFEGVR

$1 \quad 0.01 \% \quad 20.3 \%$ LEEREVLK

$11 \quad 0.01 \% \quad 20.3 \%$ SKELGVATN

$0.01 \% \quad 11.1 \%$ NLTALGLNLVASGGTAK

$0.01 \% \quad 11.1 \%$ VVACNLYPFVK

$0.01 \% \quad 11.1 \%$ YGMNPHQTPAQLYTLQPK

$0.01 \% \quad 11.1 \%$ TLTPISAAYAR

$0.01 \% \quad 11.1 \%$ SLFSNVVTK

$0.00 \% \quad 8.1 \%$ FGVVVVGVGR

$0.00 \% \quad 8.1 \%$ SGSLENVPNVGVNK $\begin{array}{llllllll}99.7 \% & 54.0 & 25.0 & 46.2 & 4 & 0 & 0 & 1508.80\end{array}$

$99.7 \% \quad 34.6 \quad 25.0 \quad 31.2 \quad 2$

$99.7 \% \quad 56.2 \quad 25.0 \quad 56.2$

$\begin{array}{llll}99.7 \% & 37.2 & 25.0 & 37.2\end{array}$

$\begin{array}{llll}99.7 \% & 38.2 & 25.0 & 35.9\end{array}$

$\begin{array}{llll}99.7 \% & 39.8 & 25.0 & 36.5\end{array}$

$\begin{array}{lllll}99.7 \% & 51.4 & 25.0 & 51.4 & 2\end{array}$

$\begin{array}{llll}9.7 \% & 55.5 & 25.0 & 55.5 \\ 99.7 \% & 37.8 & 25.0 & 33.3\end{array}$

$99.0 \% \quad 33.4 \quad 25.0 \quad 20.2$

$\begin{array}{llll}97.7 \% & 17.2 & 25.0 & 17.2\end{array}$

$97.0 \% \quad 15.4 \quad 25.0 \quad 15.4$

$99.7 \% \quad 45.5 \quad 25.0 \quad 45.5$

$\begin{array}{llll}99.5 \% & 29.2 & 25.0 & 16.2\end{array}$

$\begin{array}{llll}98.5 \% & 16.9 & 25.0 & 16.9\end{array}$

$99.7 \% \quad 41.2 \quad 25.0 \quad 25.9$

$99.7 \% \quad 44.9 \quad 25.0 \quad 44.9$

$\begin{array}{lllll}99.7 \% & 36.2 & 25.0 & 30.9\end{array}$

$\begin{array}{lllll}99.7 \% & 34.3 & 25.0 & 28.1 & 2\end{array}$

$\begin{array}{llll}99.7 \% & 29.0 & 25.0 & 29.0\end{array}$

$99.0 \% \quad 25.8 \quad 25.0 \quad 25.8$

$\begin{array}{llll}99.7 \% & 47.4 & 25.0 & 33.3\end{array}$

$\begin{array}{llll}99.7 \% & 38.4 & 25.0 & 22.8\end{array}$

$\begin{array}{llll}99.7 \% & 78.4 & 25.0 & 77.4\end{array}$

$\begin{array}{llll}99.7 \% & 65.3 & 25.0 & 65.3\end{array}$

$\begin{array}{llll}99.7 \% & 58.3 & 25.0 & 43.4\end{array}$

$\begin{array}{llll}99.4 \% & 21.7 & 25.0 & 21.7\end{array}$

$\begin{array}{llll}99.7 \% & 72.3 & 25.0 & 72.3\end{array}$

$\begin{array}{llll}99.7 \% & 40.8 & 25.0 & 39.3\end{array}$

$\begin{array}{llll}98.7 \% & 23.3 & 25.0 & 15.3\end{array}$

$\begin{array}{llll}99.6 \% & 25.9 & 25.0 & 19.3\end{array}$

$99.7 \% \quad 51.7$

$\begin{array}{llll}99.7 \% & 66.6 & 25.0 & 51.7\end{array}$

\begin{tabular}{llll}
$99.7 \%$ & 37.7 & 25.0 & 58.2 \\
\hline
\end{tabular}

\begin{tabular}{llll}
$99.7 \%$ & 58.2 & 25.0 & 37.7 \\
\hline
\end{tabular}

$\begin{array}{cccc}96.4 \% & 24.3 & 25.0 & 4.7\end{array}$

$\begin{array}{ccccc}99.7 \% & 43.0 & 25.0 & 26.4 & 2\end{array}$

$\begin{array}{lllll}99.7 \% & 89.2 & 25.0 & 89.2 & 2 \\ 99.7 \% & 31.8 & 25.0 & 29.7 & 2\end{array}$

$\begin{array}{lllll}99.7 \% & 31.8 & 25.0 & 29.7 & 2 \\ 99.5 \% & 24.0 & 25.0 & 24.0 & 0\end{array}$

$\begin{array}{llll}99.6 \% & 26.7 & 25.0 & 17.2\end{array}$

$\begin{array}{llll}99.5 \% & 25.3 & 25.0 & 20.2\end{array}$

$\begin{array}{lllll}99.7 \% & 49.7 & 25.0 & 48.5 & 2\end{array}$

$\begin{array}{llll}99.7 \% & 55.0 & 25.0 & 55.0\end{array}$

155.64

1182.61

2476.19

1586.85

1475.75

1303.63

1044.56

1147.65

914.59

1241.71

1193.59

1730.93

1178.64

1299.56

1115.64

1271.74

994.60

866.51

942.54

1312.76

1535.77

1663.87

2332.14

1342.65

1546.86

2014.94

1587.74

1681.84

1192.72

1122.58

1860.88

2312.15

1213.65

1091.62

1205.62

1015.58

918.49

1599.91

1309.70

2103.03

1163.64

994.56

988.59

1413.73 
Bleomycin hydrolase $\mathrm{GN}=\mathrm{BLMH}$ Bleomycin hydrolase $\mathrm{GN}=\mathrm{BLMH}$ Bloom syndrome protein $\mathrm{GN}=\mathrm{BLM}$ Bloom syndrome protein $\mathrm{GN}=\mathrm{BLM}$ BRCA2 and CDKN1A-interacting protein GN=BCCIP BCCIP_HUMAN $35.98 \quad 100.0 \%$ BRCA2 and CDKN1A-interacting protein GN=BCCIP BCCIP_HUMAN $35.98 \quad 100.0 \%$ Brefectin A-inhibited guanine nucleotide-exchange protein 2 GN=ARFGEF2 BIG2_HUMAN $202.04 \quad 100.0 \%$ Brefeldin A-inhibited guanine nucleotide-exchange protein 2 GN=ARFGEF2 BIG2_HUMAN $202.04 \quad 100.0 \%$ Brefeldin A-inhibited guanine nucleotide-exchange protein 2 GN=ARFGEF2 BIG2_HUMAN 202.04 100.0\% Brefeldin A-inhibited guanine nucleotide-exchange protein 2 GN=ARFGEF2 BIG2_HUMAN $202.04 \quad 100.0 \%$ BRISC and BRCA1-A complex member 1 GN=BABAM1 BABA1_HUMAN $36.56 \quad 100.0 \%$ BRISC and BRCA1-A complex member 1 GN=BABAM1 BABA1_HUMAN $36.56 \quad 100.0 \%$ Bromodomain adjacent to zinc finger domain protein $1 \mathrm{~A}$ GN=BAZ1A BAZ1A_HUMAN $178.71 \quad 100.0 \%$ Bromodomain adjacent to zinc finger domain protein $1 \mathrm{~A}$ GN=BAZ1A BAZ1A_HUMAN $178.71 \quad 100.0 \%$ Bromodomain adjacent to zinc finger domain protein 1A GN=BAZ1A BAZ1A_HUMAN $178.71 \quad 100.0 \%$ Bromodomain adjacent to zinc finger domain protein $1 \mathrm{~A}$ GN=BAZ1A BAZ1A_HUMAN $178.71 \quad 100.0 \%$ Bystin GN=BYSL

Bystin GN=BYSL

Bystin GN=BYSL

BYST_HUMAN $49.60 \quad 100.0 \%$ BYST_HUMAN $49.60 \quad 100.0 \%$ BYST_HUMAN $49.60 \quad 100.0 \%$

C-1-tetrahydrofolate synthase, cytoplasmic GN=MTHFD1 C1TC_HUMAN $101.56 \quad 100.0 \%$ C-1-tetrahydrofolate synthase, cytoplasmic GN=MTHFD1 C1TC_HUMAN $101.56 \quad 100.0 \%$ C-1-tetrahydrofolate synthase, cytoplasmic GN=MTHFD1 C1TC_HUMAN $101.56 \quad 100.0 \%$ C-1-tetrahydrofolate synthase, cytoplasmic GN=MTHFD1 C1TC_HUMAN $101.56 \quad 100.0 \%$ C-1-tetrahydrofolate synthase, cytoplasmic GN=MTHFD1 C1TC_HUMAN $101.56 \quad 100.0 \%$ C-1-tetrahydrofolate synthase, cytoplasmic GN=MTHFD1 C1TC_HUMAN $101.56 \quad 100.0 \%$ C-1-tetrahydrofolate synthase, cytoplasmic GN=MTHFD1 C1TC_HUMAN $101.56 \quad 100.0 \%$ C-1-tetrahydrofolate synthase, cytoplasmic GN=MTHFD1 C1TC_HUMAN $101.56 \quad 100.0 \%$ $\mathrm{CAD}$ protein $\mathrm{GN}=\mathrm{CAD}$ $\mathrm{CAD}$ protein $\mathrm{GN}=\mathrm{CAD}$ $\mathrm{CAD}$ protein $\mathrm{GN}=\mathrm{CAD}$ $\mathrm{CAD}$ protein $\mathrm{GN}=\mathrm{CAD}$ $\mathrm{CAD}$ protein $\mathrm{GN}=\mathrm{CAD}$ $\mathrm{CAD}$ protein $\mathrm{GN}=\mathrm{CAD}$ $\mathrm{CAD}$ protein $\mathrm{GN}=\mathrm{CAD}$ $\mathrm{CAD}$ protein $\mathrm{GN}=\mathrm{CAD}$ $\mathrm{CAD}$ protein $\mathrm{GN}=\mathrm{CAD}$ $\mathrm{CAD}$ protein $\mathrm{GN}=\mathrm{CAD}$ $\mathrm{CAD}$ protein $\mathrm{GN}=\mathrm{CAD}$ $\mathrm{CAD}$ protein $\mathrm{GN}=\mathrm{CAD}$ $\mathrm{CAD}$ protein $\mathrm{GN}=\mathrm{CAD}$ $\mathrm{CAD}$ protein $\mathrm{GN}=\mathrm{CAD}$ $\mathrm{CAD}$ protein $\mathrm{GN}=\mathrm{CAD}$ $\mathrm{CAD}$ protein $\mathrm{GN}=\mathrm{CAD}$ $\mathrm{CAD}$ protein $\mathrm{GN}=\mathrm{CAD}$ $\mathrm{CAD}$ protein $\mathrm{GN}=\mathrm{CAD}$ $\mathrm{CAD}$ protein $\mathrm{GN}=\mathrm{CAD}$ $\mathrm{CAD}$ protein $\mathrm{GN}=\mathrm{CAD}$ PYR1_HUMAN $242.98 \quad 100.0 \%$ PYR1_HUMAN $242.98 \quad 100.0 \%$ PYR1 HUMAN $242.98 \quad 100.0 \%$ PYR1_HUMAN $242.98 \quad 100.0 \%$ PYR1_HUMAN $242.98 \quad 100.0 \%$ PYR1_HUMAN $242.98 \quad 100.0 \%$ PYR1_HUMAN $242.98 \quad 100.0 \%$ PYR1_HUMAN $242.98 \quad 100.0 \%$ PYR1_HUMAN $242.98 \quad 100.0 \%$ PYR1_HUMAN $242.98 \quad 100.0 \%$ PYR1 HUMAN $242.98 \quad 100.0 \%$ PYR1_HUMAN $242.98 \quad 100.0 \%$ PYR1_HUMAN $242.98 \quad 100.0 \%$ PYR1 HUMAN $242.98 \quad 100.0 \%$ PYR1_HUMAN $242.98 \quad 100.0 \%$ PYR1_HUMAN $242.98 \quad 100.0 \%$ PYR1_HUMAN $242.98 \quad 100.0 \%$ PYR1_HUMAN $242.98 \quad 100.0 \%$ PYR1_HUMAN $242.98 \quad 100.0 \%$ PYR1_HUMAN $242.98 \quad 100.0 \%$
$0.00 \% \quad 5.3 \% \quad$ IGPITPLEFYR

$0.00 \% \quad 5.3 \%$ TLYNNQPIDFLKK

$0.00 \% \quad 2.4 \%$ SVEGYYQESGR

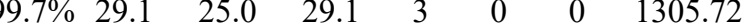
$99.1 \% \quad 19.2$

$99.7 \% \quad 45.4$

$0.00 \% \quad 2.4 \%$ SSSIIGSSSASHTSQATSGANSK $\quad 95.4 \% \quad 14.7$

$0.00 \% \quad 7.3 \%$ LLQQLFLK

$0.00 \% \quad 7.3 \%$ KGTQCVEQIQELVLR

$0.00 \% \quad 2.4 \%$ TCYNIYLASK

$0.00 \% \quad 2.4 \%$ ALMEAVSHAK

$0.00 \% \quad 2.4 \%$ CIAQMVNSQAANIR

$0.00 \% \quad 2.4 \% \quad$ AFNSNYEQR

$0.00 \% \quad 6.1 \%$ AVGAQASVGSR

$0.00 \% \quad 6.1 \%$ TNALNVSQK

$0.01 \% \quad 3.5 \% \quad$ LHILASGADVTSANAK

$0.01 \% \quad 3.5 \%$ ESALKETLLQEK

$0.01 \% \quad 3.5 \%$ APLDASDSGR

$0.01 \% \quad 3.5 \%$ SANNTPENSPNFPNFR

$0.00 \% \quad 8.0 \%$ HAPLADQILAGNAVR

$0.00 \% \quad 8.0 \% \quad$ FYNLVLLPR

$0.00 \% \quad 8.0 \%$ EAIIVGSIITK

$0.02 \% \quad 10.2 \%$ APAEILNGKEISAQIR

$0.02 \% \quad 10.2 \%$ GDLNDCFIPCTPK

$10 \quad 20 \quad 0.02 \% \quad 10.2 \%$ VVGDVAYDEAKER

$10 \quad 20 \quad 0.02 \% \quad 10.2 \%$ TPVPSDIDISR

$\begin{array}{llll}10 & 20 & 0.02 \% & 10.2 \%\end{array}$

$10 \quad 20 \quad 0.02 \% \quad 10.2 \%$ YVVVTGITPTPLGEGK

$10 \quad 20 \quad 0.02 \% \quad 10.2 \%$ FSDIQIRR

$\begin{array}{llll}10 & 20 & 0.02 \% & 10.2 \% \\ & \text { VLDTNDRFLR }\end{array}$

$47 \quad 122 \quad 0.12 \% \quad 19.7 \%$ VFNTGGAPR

$47 \quad 122 \quad 0.12 \% \quad 19.7 \%$ ILALDCGLK

$47 \quad 122 \quad 0.12 \% \quad 19.7 \%$ ILALDCGLKYNQIR

$47 \quad 122 \quad 0.12 \% \quad 19.7 \%$ GHNQPCLLVGSGR

$47 \quad 122 \quad 0.12 \% \quad 19.7 \%$ EATAGNPGGQTVR

$47 \quad 122 \quad 0.12 \% \quad 19.7 \%$ LCPPGIPTPGSGLPPPR

$47 \quad 122 \quad 0.12 \% \quad 19.7 \%$ LGYPVLVR

$47 \quad 122 \quad 0.12 \% \quad 19.7 \%$ AAFALGGLGSGFASNR

$47 \quad 122 \quad 0.12 \% \quad 19.7 \%$ ATGYPLAYVAAK

$47 \quad 122 \quad 0.12 \% \quad 19.7 \%$ LALGIPLPELR

47

47

47

47

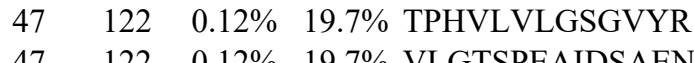

$47 \quad 122 \quad 0.12 \% \quad 19.7 \%$ VLGTSPEAIDSAENR

$47 \quad 122 \quad 0.12 \% \quad 19.7 \%$ VLGTSPEAIDSAENRFK

$\begin{array}{ll}25.0 & 14.7\end{array}$

$99.0 \% \quad 34.2 \quad 25.0 \quad 24.5$

$\begin{array}{llll}99.6 \% & 24.2 & 25.0 & 24.1\end{array}$

$99.7 \% \quad 36.0 \quad 25.0 \quad 36.0$

$\begin{array}{llll}99.7 \% & 27.1 & 25.0 & 22.7\end{array}$

$99.7 \% \quad 35.7 \quad 25.0 \quad 33.7$

$\begin{array}{llll}98.4 \% & 19.1 & 25.0 & 19.1\end{array}$

$\begin{array}{lllll}99.7 \% & 49.1 & 25.0 & 42.3 & 2\end{array}$

$99.7 \% \quad 35.9 \quad 25.0 \quad 24.8$

$\begin{array}{llll}99.7 \% & 40.9 & 25.0 & 40.9\end{array}$

$\begin{array}{llll}96.3 \% & 15.8 & 25.0 & 15.4\end{array}$

$\begin{array}{llll}99.7 \% & 29.5 & 25.0 & 27.8\end{array}$

$\begin{array}{lllll}98.9 \% & 18.8 & 25.0 & 18.8\end{array}$

$95.5 \% \quad 17.0 \quad 25.0 \quad 13.5$

$\begin{array}{llll}99.7 \% & 65.7 & 25.0 & 57.7\end{array}$

$98.8 \% \quad 24.4 \quad 25.0 \quad 24.4$

$99.7 \% \quad 43.4 \quad 25.0 \quad 43.4$

$\begin{array}{lllll}99.7 \% & 30.2 & 25.0 & 25.5 & 2\end{array}$

$99.7 \% \quad 63.6 \quad 25.0 \quad 57.0$

$99.7 \% \quad 42.5 \quad 25.0 \quad 39.3$

$\begin{array}{lllll}99.0 \% & 38.6 & 25.0 & 31.8 & 2\end{array}$

$99.7 \% \quad 43.6 \quad 25.0 \quad 43.6$

$\begin{array}{llll}99.0 \% & 26.4 & 25.0 & 19.4\end{array}$

$\begin{array}{llll}99.4 \% & 25.1 & 25.0 & 17.8\end{array}$

$99.7 \% \quad 47.1 \quad 25.0 \quad 38.8$

$\begin{array}{llll}99.7 \% & 28.8 & 25.0 & 19.0\end{array}$

$99.7 \% \quad 46.5 \quad 25.0 \quad 43.7$

$99.7 \% \quad 47.9 \quad 25.0 \quad 47.9$

$\begin{array}{lllll}99.7 \% & 46.3 & 25.0 & 46.3 & 4\end{array}$

$99.7 \% \quad 26.9 \quad 25.0 \quad 26.9$

$\begin{array}{llll}99.0 \% & 38.3 & 25.0 & 28.9\end{array}$

$99.7 \% \quad 78.9 \quad 25.0 \quad 78.9$

$99.7 \% \quad 42.5 \quad 25.0 \quad 41.9$

$\begin{array}{llll}99.7 \% & 50.5 & 25.0 & 50.5\end{array}$

$22 \quad 0.12 \% \quad 19.7 \%$ NSVTGGTAAFEPSVDYCVVK $\quad 99.7 \% \quad 54.8 \quad 25.0 \quad 54.8$

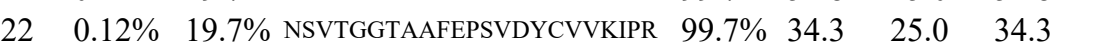

0.12\% $19.7 \%$ SVGEVMGIGR

$0.12 \% \quad 19.7 \%$ SFEEAFQK

$22 \quad 0.12 \% \quad 19.7 \%$ IIAHAQLLEQHR

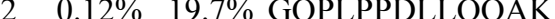

\section{$99.7 \% \quad 55.8$}

$99.0 \% \quad 37.0 \quad 25.0 \quad 28.5$

$99.7 \% \quad 45.1 \quad 25.0 \quad 40.4$

$96.8 \% \quad 16.4 \quad 25.0 \quad 16.4$

$\begin{array}{llll}99.7 \% & 25.2 & 25.0 & 23.7\end{array}$

$99.7 \% \quad 33.3 \quad 25.0 \quad 32.2 \quad 2$

$99.7 \% \quad 68.0 \quad 25.0 \quad 68.0$

$\begin{array}{llll}99.7 \% & 46.2 & 25.0 & 46.2\end{array}$
0
0
0
0
0
0
0
0
0
0
0
0
1
0
0
2
0
0
0
0
0
0
1
0
0
0
0
0
0
0
0
0
0
0
0
0
0
0
0
0
0
0

0

0

0


$\mathrm{CAD}$ protein $\mathrm{GN}=\mathrm{CAD}$ $\mathrm{CAD}$ protein $\mathrm{GN}=\mathrm{CAD}$ CAD protein $\mathrm{GN}=\mathrm{CAD}$ $\mathrm{CAD}$ protein $\mathrm{GN}=\mathrm{CAD}$ $\mathrm{CAD}$ protein $\mathrm{GN}=\mathrm{CAD}$ $\mathrm{CAD}$ protein $\mathrm{GN}=\mathrm{CAD}$ $\mathrm{CAD}$ protein $\mathrm{GN}=\mathrm{CAD}$ $\mathrm{CAD}$ protein $\mathrm{GN}=\mathrm{CAD}$ $\mathrm{CAD}$ protein $\mathrm{GN}=\mathrm{CAD}$ $\mathrm{CAD}$ protein $\mathrm{GN}=\mathrm{CAD}$ $\mathrm{CAD}$ protein $\mathrm{GN}=\mathrm{CAD}$ $\mathrm{CAD}$ protein $\mathrm{GN}=\mathrm{CAD}$ CAD protein $\mathrm{GN}=\mathrm{CAD}$ $\mathrm{CAD}$ protein $\mathrm{GN}=\mathrm{CAD}$ $\mathrm{CAD}$ protein $\mathrm{GN}=\mathrm{CAD}$ $\mathrm{CAD}$ protein $\mathrm{GN}=\mathrm{CAD}$ $\mathrm{CAD}$ protein $\mathrm{GN}=\mathrm{CAD}$ CAD protein $\mathrm{GN}=\mathrm{CAD}$ $\mathrm{CAD}$ protein $\mathrm{GN}=\mathrm{CAD}$ $\mathrm{CAD}$ protein $\mathrm{GN}=\mathrm{CAD}$ $\begin{array}{lrrr}\text { CAD protein GN=CAD } & \text { PYR1_HUMAN } 242.98 & 100.0 \% \\ \text { Calcium uniporter protein, mitochondrial GN=MCU MCU_HUMAN } 39.87 & 100.0 \%\end{array}$ Calcium uniporter protein, mitochondrial GN=MCU MCU_HUMAN $39.87 \quad 100.0 \%$ Calcium-binding mitochondrial carrier protein Aralar1 GN=SLC25A12 CMC1_HUMAN $74.76 \quad 100.0 \%$ Calcium-binding mitochondrial carrier protein Aralar1 GN=SLC25A12 CMC1_HUMAN $74.76 \quad 100.0 \%$ Calcium-binding mitochondrial carrier protein Aralar1 GN=SLC25A12 CMC1_HUMAN $74.76 \quad 100.0 \%$ Calcium-binding mitochondrial carrier protein Aralar1 GN=SLC25A12 CMC1_HUMAN $74.76 \quad 100.0 \%$ Calcium-binding mitochondrial carrier protein Aralar1 GN=SLC25A12 CMC1_HUMAN $74.76 \quad 100.0 \%$ Calcium-binding mitochondrial carrier protein Aralar1 GN=SLC25A12 CMC1_HUMAN $74.76 \quad 100.0 \%$ Calcium-binding mitochondrial carrier protein Aralar $1 \mathrm{GN}=\mathrm{SLC} 25 \mathrm{~A} 12 \mathrm{CMC} 1$ HUMAN $74.76 \quad 100.0 \%$ Calcium-binding mitochondrial carrier protein Aralar1 GN=SLC25A12 CMC1_HUMAN $74.76 \quad 100.0 \%$ Calcium-binding mitochondrial carrier protein Aralarl GN=SLC25A12 CMC1_HUMAN $74.76 \quad 100.0 \%$ Calcium-binding mitochondrial carrier protein Aralar2 GN=SLC25A13 CMC2_HUMAN $74.18 \quad 100.0 \%$ Calcium-binding mitochondrial carrier protein Aralar2 GN=SLC25A13 $\quad$ CMC2_HUMAN $74.18 \quad 100.0 \% \quad 21$ Calcium-binding mitochondrial carrier protein Aralar2 GN=SLC25A13 $\mathrm{CMC}_{2}$ HUMAN $74.18 \quad 100.0 \% \quad 21$ $\begin{array}{lllll}\text { Calcium-binding mitochondrial carrier protein Aralar2 GN=SLC25A13 } & \text { CMC2_HUMAN } 74.18 \quad 100.0 \% & 21\end{array}$ Calcium-binding mitochondrial carrier protein Aralar2 $\mathrm{GN}=\mathrm{SLC} 25 \mathrm{~A} 13 \mathrm{CMC2}$ _HUMAN $74.18 \quad 100.0 \%$ Calcium-binding mitochondrial carrier protein Aralar2 GN=SLC25A13 CMC2 HUMAN $74.18 \quad 100.0 \%$ Calcium-binding mitochondrial carrier protein Aralar2 GN=SLC25A13 $\quad$ CMC2_HUMAN $74.18 \quad 100.0 \% \quad 21$ Calcium-binding mitochondrial carrier protein Aralar2 GN=SLC25A13 CMC2_HUMAN $74.18 \quad 100.0 \% \quad 21$ Calcium-binding mitochondrial carrier protein Aralar2 GN=SLC25A13 $\quad$ CMC2_HUMAN $74.18 \quad 100.0 \%$ Calcium-binding mitochondrial carrier protein Aralar2 GN=SLC25A13 $\mathrm{CMC}_{2}$ HUMAN $74.18 \quad 100.0 \% \quad 21$ Calcium-binding mitochondrial carrier protein Aralar2 GN=SLC25A13 CMC2_HUMAN $74.18 \quad 100.0 \% \quad 21$ Calcium-binding mitochondrial carrier protein Aralar2 GN=SLC25A13 $\mathrm{CMC}_{2}$ HUMAN $74.18 \quad 100.0 \% \quad 21$ Calcium-binding mitochondrial carrier protein Aralar2 GN=SLC25A13 $\mathrm{CMC}_{2}$ HUMAN $74.18 \quad 100.0 \% \quad 21$ Calcium-binding mitochondrial carrier protein Aralar2 GN=SLC25A13 $\mathrm{CMC}_{2}$ HUMAN $74.18 \quad 100.0 \% \quad 21$

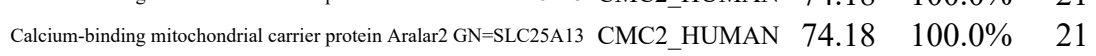

$47 \quad 122 \quad 0.12 \% \quad 19.7 \%$ LLDTIGISQPQWR

$47 \quad 122 \quad 0.12 \% \quad 19.7 \%$ ELSDLESAR

$47 \quad 122 \quad 0.12 \% \quad 19.7 \%$ FLSSAAAVSK

$99.7 \% \quad 38.3 \quad 25.0 \quad 38.3 \quad 4$ $99.7 \% \quad 53.7$ $99.7 \% \quad 30.0$ $0.12 \% \quad 19.7 \%$ FLSSAAAVSKEHPVVISK

$47 \quad 122 \quad 0.12 \% \quad 19.7 \%$ TLGVDLVALATR

$47 \quad 122 \quad 0.12 \% \quad 19.7 \%$ VPQFSFSR

$47 \quad 122 \quad 0.12 \% \quad 19.7 \%$ KNILLTIGSYK

$47 \quad 122 \quad 0.12 \% \quad 19.7 \%$ NKSELLPTVR

$47 \quad 122 \quad 0.12 \% \quad 19.7 \%$ SELLPTVR

$47 \quad 122 \quad 0.12 \% \quad 19.7 \%$ LFVEALGQIGPAPPLK

$47 \quad 122 \quad 0.12 \% \quad 19.7 \%$ VHVDCMTSQK

$47 \quad 122 \quad 0.12 \% \quad 19.7 \%$ KEEILLIK

$47 \quad 122 \quad 0.12 \% \quad 19.7 \%$ AHWTPFEGQK

$47 \quad 122 \quad 0.12 \% \quad 19.7 \%$ ASDPGLPAEEPKEK

$47 \quad 122 \quad 0.12 \% \quad 19.7 \%$ VMASMFYEVSTR

$47 \quad 122 \quad 0.12 \% \quad 19.7 \%$ TSSSFAAAMAR

$47 \quad 122 \quad 0.12 \% \quad 19.7 \%$ LGGAVLSFSEATSSVQK

$47 \quad 122 \quad 0.12 \% \quad 19.7 \%$ YVAPPSLR

$47 \quad 122 \quad 0.12 \% \quad 19.7 \%$ VNEISVEVDSDPR

$47 \quad 122 \quad 0.12 \% \quad 19.7 \%$ QAENGMYIR

$47 \quad 122 \quad 0.12 \% \quad 19.7 \%$ MALLATVLGRF

$3 \quad 0.00 \% \quad 8.0 \% \quad$ DLLSHENAATLNDVK

$0.00 \% \quad 8.0 \% \quad$ LEDLKEQLAPLEK

$0.00 \% \quad 13.1 \%$ IAPLAEGALPYNLAELQR

$0.00 \% \quad 13.1 \%$ GLIPQLIGVAPEK

$0.00 \% \quad 13.1 \%$ AIKLTVNDFVR

$0.00 \% \quad 13.1 \%$ LTVNDFVR

$0.00 \% \quad 13.1 \%$ LQVAGEITTGPR

$0.00 \% \quad 13.1 \%$ TRLQVAAR

$0.00 \% \quad 13.1 \%$ AGQTTYSGVIDCFR

$0.00 \% \quad 13.1 \%$ AGQTTYSGVIDCFRK

$0.00 \% \quad 13.1 \%$ FKSPSVAVVQPK

$0.04 \% \quad 35.6 \%$ YLNIFGESQPNPK

$0.04 \% \quad 35.6 \%$ TVELLSGVVDQTK

$43 \quad 0.04 \% \quad 35.6 \%$ DVEVTKEEFVLAAQK

$0.04 \% 35.6 \%$ MTLADIER

$\begin{array}{lllll}0.04 \% & 35.6 \% & \text { IAPLEEGTLPFNLAEAQR } & 99.7 \% & 69.9\end{array}$

$0.04 \% \quad 35.6 \%$ ASGDSARPVLLQVAESAYR $99.7 \% \quad 34.0$

$0.04 \% \quad 35.6 \%$ GLLPQLLGVAPEK

$0.04 \% \quad 35.6 \%$ AIKLTVNDFVR

$43 \quad 0.04 \% \quad 35.6 \%$ LTVNDFVR

$43 \quad 0.04 \% \quad 35.6 \%$ LQVAGEITTGPR

$43 \quad 0.04 \% \quad 35.6 \%$ VSALSVVR

$43 \quad 0.04 \% \quad 35.6 \%$ DLGFFGIYKGAK

$24 \quad 43 \quad 0.04 \% \quad 35.6 \%$ DIPFSAIYFPCYAHVK $\begin{array}{lll}42.2 & 25.0 & 42.2\end{array}$

$\begin{array}{llll}9.0 \% & 38.7 & 25.0 & 33.3\end{array}$

$99.7 \% \quad 30.3 \quad 25.0 \quad 30.3$

$\begin{array}{llll}99.7 \% & 36.9 & 25.0 & 29.0\end{array}$

$\begin{array}{llll}99.0 \% & 27.8 & 25.0 & 25.8\end{array}$

$\begin{array}{llll}99.7 \% & 41.8 & 25.0 & 41.8\end{array}$

$\begin{array}{llll}9.7 \% & 26.4 & 25.0 & 21.5\end{array}$

$\begin{array}{lllll}99.0 \% & 33.1 & 25.0 & 17.5 & 2\end{array}$

$\begin{array}{lll}59.2 & 25.0 & 51.5\end{array}$

$98.9 \% \quad 22.1 \quad 25.0 \quad 22.1$

$99.7 \% \quad 43.3 \quad 25.0 \quad 43.3$

$\begin{array}{llll}99.7 \% & 49.0 & 25.0 & 48.2\end{array}$

$99.7 \% \quad 53.8 \quad 25.0 \quad 40.2$

$\begin{array}{lllll}99.7 \% & 59.1 & 25.0 & 50.8\end{array}$

$99.7 \% \quad 30.9 \quad 25.0 \quad 30.9$

$\begin{array}{llll}99.7 \% & 49.9 & 25.0 & 46.5\end{array}$

\begin{tabular}{llll}
$9.7 \%$ & 41.5 & 25.0 & 41.5 \\
\hline $9.2 \%$ & 38.5 & 25.0 & 0.0
\end{tabular}

$\begin{array}{llll}99.7 \% & 49.9 & 25.0 & 49.9\end{array}$

$99.0 \% \quad 37.0 \quad 25.0 \quad 37.0$

$99.7 \% \quad 64.6 \quad 25.0 \quad 52.4$

$\begin{array}{lllll}99.0 \% & 31.8 & 25.0 & 17.7 & 2\end{array}$

$\begin{array}{llll}99.7 \% & 60.8 & 25.0 & 60.8\end{array}$

$\begin{array}{llll}99.7 \% & 55.5 & 25.0 & 55.5\end{array}$

$\begin{array}{llll}9.5 \% & 21.9 & 25.0 & 21.9\end{array}$

$\begin{array}{llll}99.7 \% & 49.9 & 25.0 & 49.9\end{array}$

$\begin{array}{llll}99.7 \% & 55.3 & 25.0 & 49.9\end{array}$

$99.7 \% \quad 53.8 \quad 25.0 \quad 53.8$

$\begin{array}{llll}99.0 \% & 28.5 & 25.0 & 27.5\end{array}$

$\begin{array}{lll}36.7 & 25.0 & 33.6\end{array}$

$\begin{array}{lllll}99.2 \% & 38.5 & 25.0 & 0.0\end{array}$

$\begin{array}{lllll}99.7 \% & 49.9 & 25.0 & 49.9 & 2\end{array}$

$\begin{array}{llll}99.0 \% & 37.0 & 25.0 & 37.0\end{array}$

$\begin{array}{llll}99.7 \% & 64.6 & 25.0 & 52.4\end{array}$

$\begin{array}{lllll}99.0 \% & 39.9 & 25.0 & 26.8 & 2\end{array}$

$\begin{array}{lllll}99.7 \% & 34.6 & 25.0 & 27.5 & 2\end{array}$

$\begin{array}{llll}99.5 \% & 43.6 & 25.0 & 10.1\end{array}$ $\begin{array}{llll}99.7 \% & 58.7 & 25.0 & 49.8\end{array}$

$\begin{array}{llll}99.7 \% & 59.0 & 25.0 & 47.7\end{array}$

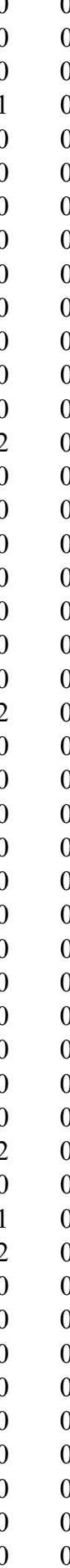

1019.50

980.54

1870.04

967.50

1249.75

1156.67

914.53

1649.96

1204.55

985.63

1200.58

1467.73

1420.66

1099.52

1680.88

902.51

1458.71

1081.5

1207.69

1639.83

1525.85

1939.06

1334.80

1275.74

963.53

1241.69

914.55

1574.73

1702.82

1286.75

1506.76

1388.76

1705.90

948.48

1969.04

1990.04

2105.16

1334.63

1334.80

1275.74

963.53

1241.69

830.51

1315.70

1927.94 
Calcium-binding mitochondrial carrier protein Aralar2 GN=SLC25A13 $\quad$ CMC2_HUMAN $74.18 \quad 100.0 \% \quad 21$ Calcium-binding mitochondrial carrier protein Aralar2 GN=SLC25A13 $\mathrm{CMC}_{2}$ HUMAN $74.18 \quad 100.0 \% \quad 21$ Calcium-binding mitochondrial carrier protein Aralar2 $\mathrm{GN}=\mathrm{SLC} 25 \mathrm{~A} 13 \mathrm{CMC} 2$ _HUMAN $74.18 \quad 100.0 \% \quad 2$ Calcium-binding mitochondrial carrier protein Aralar2 GN=SLC25A13 CMC2 HUMAN $74.18 \quad 100.0 \%$ Calcium-binding mitochondrial carrier protein Aralar2 GN=SLC25A13 CMC2_HUMAN $74.18 \quad 100.0 \% \quad 21$ Calcium-binding mitochondrial carrier protein Aralar2 GN=SLC25A13 $\quad$ CMC2_HUMAN $74.18 \quad 100.0 \%$ Calcium-binding mitochondrial carrier protein SCaMC-1 GN=SLC25A24 SCMC1_HUMAN $53.36 \quad 100.0 \%$ Calcium-binding mitochondrial carrier protein SCaMC-1 GN=SLC25A24 SCMC1_HUMAN $53.36 \quad 100.0 \%$ Calcium-binding mitochondrial carrier protein SCaMC-1 GN=SLC25A24 SCMC1_HUMAN $53.36 \quad 100.0 \%$ Calcium-binding mitochondrial carrier protein SCaMC-1 GN=SLC25A24 SCMC1_HUMAN $53.36 \quad 100.0 \%$ Calcium-binding mitochondrial carrier protein SCaMC-1 GN=SLC25A24 SCMC1_HUMAN $53.36 \quad 100.0 \%$ Calcium-binding mitochondrial carrier protein SCaMC-1 GN=SLC25A24 SCMC1_HUMAN $53.36100 .0 \%$ Calcium-binding mitochondrial carrier protein SCaMC-1 GN=SLC25A24 SCMC1_HUMAN $53.36 \quad 100.0 \%$ Calcium-binding mitochondrial carrier protein SCaMC-1 GN=SLC25A24 SCMC1_HUMAN 53.36 Calcium-binding mitochondrial carrier protein SCaMC-1 GN=SLC25A24 SCMC1_HUMAN 53.36 Calcium-binding mitochondrial carrier protein SCaMC-1 GN=SLC25A24 SCMC1_HUMAN 53.36 Calcium-binding mitochondrial carrier protein SCaMC-1 GN=SLC25A24 SCMC1_HUMAN 53.36 Calcyclin-binding protein GN=CACYBP CYBP_HUMAN 26.21 Calcyclin-binding protein GN=CACYBP CYBP_HUMAN 26.21 Calcyclin-binding protein GN=CACYBP CYBP_HUMAN 26.21 Calponin $-3 \mathrm{GN}=\mathrm{CNN} 3$ Calponin $-3 \mathrm{GN}=\mathrm{CNN} 3$ CNN3_HUMAN $36.41 \quad 100.0 \%$ CNN3 HUMAN $36.41 \quad 100.0 \%$ cAMP-dependent protein kinase catalytic subunit beta GN=PRKACB $\quad$ KAPCB_HUMAN $40.62 \quad 100.0 \%$ cAMP-dependent protein kinase catalytic subunit beta GN=PRKACB KAPCB_HUMAN $40.62 \quad 100.0 \%$ cAMP-dependent protein kinase catalytic subunit beta GN=PRKACB KAPCB_HUMAN $40.62 \quad 100.0 \%$ cAMP-dependent protein kinase catalytic subunit beta GN=PRKACB $\quad$ KAPCB_HUMAN $40.62 \quad 100.0 \%$ cAMP-dependent protein kinase catalytic subunit beta GN=PRKACB KAPCB_HUMAN $40.62 \quad 100.0 \%$ cAMP-dependent protein kinase catalytic subunit beta GN=PRKACB KAPCB_HUMAN $40.62 \quad 100.0 \%$ Carbonyl reductase [NADPH] $1 \mathrm{GN}=\mathrm{CBR} 1$ CBR1_HUMAN $30.37 \quad 100.0 \%$ Carbonyl reductase [NADPH] $1 \mathrm{GN}=\mathrm{CBR} 1$ CBR1_HUMAN $30.37 \quad 100.0 \%$ Carbonyl reductase [NADPH] $1 \mathrm{GN}=\mathrm{CBR} 1$ CBR1_HUMAN $30.37 \quad 100.0 \%$ Carbonyl reductase [NADPH] 1 GN=CBR1 CBR1_HUMAN $30.37 \quad 100.0 \%$ Carbonyl reductase [NADPH] $1 \mathrm{GN}=\mathrm{CBR} 1$ CBR1_HUMAN $30.37 \quad 100.0 \%$ Carbonyl reductase [NADPH] 1 GN=CBR1 CBR1_HUMAN $30.37 \quad 100.0 \%$ Carbonyl reductase [NADPH] $1 \mathrm{GN}=\mathrm{CBR} 1$ CBR1_HUMAN $30.37 \quad 100.0 \%$ Carbonyl reductase [NADPH] $1 \mathrm{GN}=\mathrm{CBR} 1$ CBR1_HUMAN $30.37 \quad 100.0 \%$ Casein kinase I isoform alpha GN=CSNK1A1 KC1A_HUMAN $38.92 \quad 100.0 \%$ Casein kinase I isoform alpha GN=CSNK1A1 KC1A_HUMAN $38.92 \quad 100.0 \%$ Casein kinase I isoform alpha GN=CSNK1A1 KC1A_HUMAN $38.92 \quad 100.0 \%$ Casein kinase I isoform alpha GN=CSNK1A1 KC1A_HUMAN $38.92 \quad 100.0 \%$ Casein kinase II subunit alpha GN=CSNK2A1 CSK21_HUMAN $45.14 \quad 100.0 \%$ Casein kinase II subunit alpha GN=CSNK2A1 CSK21_HUMAN $45.14 \quad 100.0 \%$ Casein kinase II subunit alpha GN=CSNK2A1 CSK21 HUMAN $45.14 \quad 100.0 \%$ Casein kinase II subunit alpha GN=CSNK2A1 CSK21_HUMAN $45.14 \quad 100.0 \%$ Casein kinase II subunit alpha' GN=CSNK2A2 CSK22_HUMAN $41.21 \quad 100.0 \%$ Casein kinase II subunit alpha' GN=CSNK2A2 CSK22_HUMAN $41.21 \quad 100.0 \%$ Casein kinase II subunit alpha' GN=CSNK2A2 CSK22_HUMAN $41.21 \quad 100.0 \%$
$0.04 \% \quad 35.6 \%$ TRLQVAAR $0.04 \% \quad 35.6 \%$ AGQTTYSGVIDCFR $0.04 \% \quad 35.6 \%$ AGQTTYSGVIDCFRK $0.04 \% \quad 35.6 \%$ ILREEGPK

$0.04 \% \quad 35.6 \%$ SRINLPAPNPDHVGGYK $0.04 \% \quad 35.6 \%$ INLPAPNPDHVGGYK

$0.02 \% \quad 22.9 \%$ QLLAGGIAGAVSR $0.02 \% \quad 22.9 \%$ TSTAPLDRLK $0.02 \% \quad 22.9 \%$ SDKMNIFGGFR $0.02 \% \quad 22.9 \%$ LLTEEGQKIGTFER $0.02 \% \quad 22.9 \%$ TGQYSGIYDCAK $0.02 \% \quad 22.9 \%$ TGQYSGIYDCAKK $0.02 \% \quad 22.9 \%$ ILKHEGLGAFYK $0.02 \% \quad 22.9 \%$ HEGLGAFYK

$0.02 \% \quad 22.9 \%$ IISKEGIPGLYR $0.02 \% \quad 22.9 \%$ VLPAVGISYVVYENMK $0.02 \% \quad 22.9 \%$ QTLGVTQK

$0.00 \% \quad 18.4 \%$ VRDALTAEK $0.00 \% \quad 18.4 \%$ KAELLDNEKPAAVVAPITTGYTVK $0.00 \% \quad 18.4 \%$ TDTVLILCR $0.00 \% \quad 9.1 \%$ GPSYGLSAEVK $0.00 \% \quad 9.1 \%$ LTLQPVDNSTISLQMGTNK $16 \quad 0.02 \% \quad 16.5 \%$ TLGTGSFGR

$16 \quad 0.02 \% \quad 16.5 \%$ ATEQYYAMK

$16 \quad 0.02 \% \quad 16.5 \%$ QIEHTLNEKR

$16 \quad 0.02 \% \quad 16.5 \%$ ILQAVNFPFLVR

$16 \quad 0.02 \% \quad 16.5 \%$ NLLQVDLTK

$16 \quad 0.02 \% \quad 16.5 \%$ KVEAPFIPK

$19 \quad 0.02 \% \quad 37.9 \%$ LFSGDVVLTAR $0.02 \% \quad 37.9 \%$ GQAAVQQLQAEGLSPR $0.02 \% \quad 37.9 \%$ FHQLDIDDLQSIR

$9 \quad 0.02 \% \quad 37.9 \%$ EYGGLDVLVNNAGIAFK $0.02 \% \quad 37.9 \%$ DVCTELLPLIKPQGR $0.02 \% \quad 37.9 \%$ SCSPELQQK

$19 \quad 0.02 \% \quad 37.9 \%$ EGWPSSAYGVTK $0.02 \% \quad 37.9 \%$ ILLNACCPGWVR $0.01 \% \quad 15.4 \%$ HPQLLYESK $0.01 \% \quad 15.4 \%$ ILQGGVGIPHIR $0.01 \% \quad 15.4 \%$ LFLIDFGLAK $0.01 \% \quad 15.4 \%$ AAQQAASSSGQGQQAQTPTGK $11 \quad 0.01 \% \quad 11.5 \%$ GGPNIITLADIVK $0.01 \% \quad 11.5 \%$ GGPNIITLADIVKDPVSR $0.01 \% \quad 11.5 \%$ TPALVFEHVNNTDFK $0.01 \% \quad 11.5 \%$ QLYQTLTDYDIR $0.01 \% \quad 13.4 \%$ VYAEVNSLR $0.01 \% \quad 13.4 \%$ YSEVFEAINITNNER $0.01 \% \quad 13.4 \%$ LIDTVKDPVSK $\begin{array}{llllllll}99.0 \% & 31.8 & 25.0 & 17.7 & 2 & 0 & 0 & 914.55\end{array}$ $\begin{array}{llllllll}99.7 \% & 60.8 & 25.0 & 60.8 & 2 & 0 & 0 & 1574.73\end{array}$ $\begin{array}{llllllll}99.7 \% & 55.5 & 25.0 & 55.5 & 2 & 0 & 0 & 1702.82\end{array}$

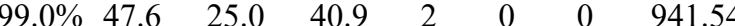
$99.5 \% \quad 21.5$ $99.7 \% \quad 60.4$ $99.7 \% \quad 57.0$ $99.7 \% 32.6$ $98.7 \% \quad 18.0$ $99.7 \% 78.2$ $99.7 \% \quad 67.8$ $99.7 \% \quad 48.8$ $99.5 \% \quad 22.9$ $99.5 \% 28.9$ $99.7 \% \quad 37.0$ $99.7 \% \quad 44.3$ $97.9 \% \quad 18.7$ $98.3 \% \quad 23.5$ $99.7 \% \quad 33.7$ $99.7 \% \quad 54.4$ $99.7 \% \quad 33.8$ $99.1 \% 29.6$ $99.7 \% \quad 34.2$ $99.7 \% \quad 30.3$ $99.5 \% \quad 22.6$ $99.7 \% \quad 57.0$ $99.7 \% \quad 35.4$ $99.7 \% \quad 49.5$ $99.7 \% \quad 69.7$ $\begin{array}{lll}99.7 \% & 76.8\end{array}$ $99.7 \% \quad 52.8$ $99.7 \% \quad 59.2$ $\begin{array}{lll}99.7 \% & 49.7\end{array}$ $96.3 \% \quad 14.9$ $\begin{array}{lll}99.7 \% & 26.8\end{array}$ $99.7 \% \quad 44.7$ $\begin{array}{lll}98.7 \% & 18.5\end{array}$ $\begin{array}{lll}99.3 \% & 23.8\end{array}$ $99.7 \% \quad 39.6$ $99.7 \% \quad 67.6$ $99.7 \% \quad 27.0$ $\begin{array}{lll}99.7 \% & 36.0\end{array}$ $\begin{array}{lll}99.7 \% & 44.7\end{array}$ $\begin{array}{lll}99.7 \% & 52.3\end{array}$ $99.7 \% \quad 61.1$ $\begin{array}{lll}98.7 \% & 23.9\end{array}$ $99.7 \% \quad 44.6$ $554 \quad 567$

1834.96

1591.82

1212.71

1101.63

1287.62

1620.86

1362.60

1490.69

1375.77

1021.51

1345.78

1781.95

874.50

1002.56

2528.40

1090.59

1107.57

2076.06

895.46

1120.50

1267.68

1416.84

1043.61

1028.6

1177.66

1652.87

1599.81

1779.93

1738.95

1076.50

1281.61

1458.73

1114.59

1259.76

1136.67

2001.96

1310.77

1865.05

1731.87

1528.76

1050.56

1798.86 1214.70
$625 \quad 641$

$627 \quad 641$

\begin{tabular}{ll}
197 & 209 \\
\hline
\end{tabular}

$229 \quad 239$

$278 \quad 291$

$321 \quad 332$

$321 \quad 333$

$334 \quad 345$

$337 \quad 345$

$470 \quad 477$

$25 \quad 33$

74
47

$7 \quad 17$

$49 \quad 57$

$85 \quad 94$

$95 \quad 106$

$310 \quad 318$

$43 \quad 58$

$59 \quad 7$

$80 \quad 96$

$120 \quad 134$

$149 \quad 157$

$221 \quad 232$

$54 \quad 62$

$\begin{array}{ll}66 & 77 \\ 153 & 162\end{array}$

$153 \quad 162$

$305 \quad 325$

$\begin{array}{ll}90 & 107 \\ 108 & 122\end{array}$

$\begin{array}{ll}108 & 122 \\ 123 & 134\end{array}$

$\begin{array}{cc}123 & 134 \\ 12 & 20\end{array}$

$51 \quad 65$ 
Casein kinase II subunit alpha' GN=CSNK2A2 CSK22_HUMAN $41.21 \quad 100.0 \%$ Caspase-14 GN=CASP14 Caspase- 14 GN=CASP14

Caspase-14 GN=CASP14

Caspase- 14 GN=CASP 14

Caspase- 14 GN $=$ CASP 14

Cat eye syndrome critical region protein $5 \mathrm{GN}=\mathrm{CECR} 5$ CECR5_HUMAN $46.32 \quad 100.0 \%$ Cat eye syndrome critical region protein $5 \mathrm{GN}=\mathrm{CECR} 5$ CECR5_HUMAN $46.32 \quad 100.0 \%$ Cat eye syndrome critical region protein $5 \mathrm{GN}=$ CECR5 CECR5_HUMAN $46.32 \quad 100.0 \%$ Cat eye syndrome critical region protein $5 \mathrm{GN}=\mathrm{CECR} 5$ CECR5_HUMAN $46.32 \quad 100.0 \%$ Cat eye syndrome critical region protein $5 \mathrm{GN}=\mathrm{CECR} 5$ CECR5_HUMAN $46.32 \quad 100.0 \%$ Cat eye syndrome critical region protein $5 \mathrm{GN}=$ CECR5 CECR5_HUMAN $46.32 \quad 100.0 \%$ Cat eye syndrome critical region protein $5 \mathrm{GN}=\mathrm{CECR} 5$ CECR5_HUMAN $46.32 \quad 100.0 \%$ Cat eye syndrome critical region protein $5 \mathrm{GN}=$ CECR5 CECR5_HUMAN $46.32 \quad 100.0 \%$ Cat eye syndrome critical region protein $5 \mathrm{GN}=$ CECR5 CECR5_HUMAN $46.32 \quad 100.0 \%$ Cat eye syndrome critical region protein $5 \mathrm{GN}=\mathrm{CECR} 5$ CECR5_HUMAN $46.32 \quad 100.0 \%$ Cat eye syndrome critical region protein $5 \mathrm{GN}=$ CECR5 CECR5 HUMAN $46.32 \quad 100.0 \%$ CCAAT/enhancer-binding protein zeta GN=CEBPZ CEBPZ_HUMAN $120.98 \quad 100.0 \%$ CCAAT/enhancer-binding protein zeta GN=CEBPZ CEBPZ_HUMAN $120.98 \quad 100.0 \%$ CCAAT/enhancer-binding protein zeta GN=CEBPZ CEBPZ_HUMAN $120.98 \quad 100.0 \%$ CCAAT/enhancer-binding protein zeta GN=CEBPZ CEBPZ_HUMAN $120.98 \quad 100.0 \%$ CCR4-NOT transcription complex subunit $1 \mathrm{GN}=\mathrm{CNOT1}$ CNOT1_HUMAN $266.94 \quad 100.0 \%$ CCR4-NOT transcription complex subunit $1 \mathrm{GN}=\mathrm{CNOT1}$ CNOT1_HUMAN $266.94 \quad 100.0 \%$ CCR4-NOT transcription complex subunit $1 \mathrm{GN}=\mathrm{CNOT1}$ CNOT1_HUMAN $266.94 \quad 100.0 \%$ CCR4-NOT transcription complex subunit $1 \mathrm{GN}=\mathrm{CNOT} 1$ CNOT1_HUMAN $266.94100 .0 \%$ CCR4-NOT transcription complex subunit $1 \mathrm{GN}=\mathrm{CNOT} 1$ CNOT1_HUMAN $266.94 \quad 100.0 \%$ CCR4-NOT transcription complex subunit $1 \mathrm{GN}=\mathrm{CNOT1}$ CNOT1_HUMAN $266.94 \quad 100.0 \%$ CCR4-NOT transcription complex subunit $1 \mathrm{GN}=\mathrm{CNOT1}$ CNOT1_HUMAN $266.94 \quad 100.0 \%$ CCR4-NOT transcription complex subunit $1 \mathrm{GN}=\mathrm{CNOT1}$ CNOT1_HUMAN $266.94 \quad 100.0 \%$ Cell cycle and apoptosis regulator protein $2 \mathrm{GN}=\mathrm{CCAR} 2$ CCAR2 HUMAN $102.90 \quad 100.0 \%$ Cell cycle and apoptosis regulator protein 2 GN=CCAR2 CCAR2_HUMAN $102.90 \quad 100.0 \%$ Cell cycle and apoptosis regulator protein $2 \mathrm{GN}=\mathrm{CCAR} 2$ CCAR2_HUMAN $102.90 \quad 100.0 \%$ Cell cycle and apoptosis regulator protein $2 \mathrm{GN}=$ CCAR2 CCAR2_HUMAN $102.90 \quad 100.0 \%$ Cell cycle and apoptosis regulator protein $2 \mathrm{GN}=$ CCAR2 CCAR2_HUMAN $102.90 \quad 100.0 \%$ Cell cycle and apoptosis regulator protein $2 \mathrm{GN}=$ CCAR2 CCAR2_HUMAN $102.90 \quad 100.0 \%$ Cell differentiation protein RCD1 homolog GN=RQCD1 RCD1_HUMAN $33.63 \quad 100.0 \%$ Cell differentiation protein RCD1 homolog GN=RQCD1 RCD1_HUMAN $33.63 \quad 100.0 \%$ Cell differentiation protein RCD1 homolog GN=RQCD1 RCD1 HUMAN $33.63 \quad 100.0 \%$ Cell differentiation protein RCD1 homolog GN=RQCD1 RCD1_HUMAN $33.63 \quad 100.0 \%$ Cell differentiation protein RCD1 homolog GN=RQCD1 RCD1_HUMAN $33.63 \quad 100.0 \%$ Cell division cycle 5-like protein GN=CDC5L CDC5L_HUMAN $92.25 \quad 100.0 \%$ Cell division cycle 5-like protein GN=CDC5L CDC5L_HUMAN $92.25 \quad 100.0 \%$ Cell division cycle 5-like protein $\mathrm{GN}=\mathrm{CDC} 5 \mathrm{~L} \quad \mathrm{CDC} 5 \mathrm{~L} \_$HUMAN $92.25 \quad 100.0 \%$ Cell division cycle 5-like protein GN=CDC5L CDC5L_HUMAN $92.25 \quad 100.0 \%$ Cell division cycle 5-like protein GN=CDC5L CDC5L_HUMAN $92.25 \quad 100.0 \%$ Cell division cycle 5-like protein $\mathrm{GN}=\mathrm{CDC} 5 \mathrm{~L}$ CDC5L_HUMAN $92.25 \quad 100.0 \%$ Cell division cycle 5-like protein GN=CDC5L CDC5L_HUMAN $92.25 \quad 100.0 \%$
$0.01 \% \quad 13.4 \%$ VLGTEELYGYLK $0.01 \% \quad 13.2 \%$ LALILCVTK

$1 \quad 0.01 \% \quad 13.2 \%$ RMAEAELVQEGK $0.01 \% \quad 13.2 \%$ MAEAELVQEGK $0.01 \% \quad 13.2 \%$ KTNPEIQSTLR $0.01 \% \quad 13.2 \%$ TNPEIQSTLR

$0.03 \% \quad 35.0 \%$ RLVNSQGQLR $0.03 \% \quad 35.0 \%$ LVNSQGQLR

$99.7 \% 47.8$ $99.7 \% \quad 40.5$ $99.7 \% \quad 54.9$ $99.7 \% 55.6$ $99.7 \% \quad 32.6$ $99.7 \% \quad 44.8$ $99.5 \% \quad 27.5$ $99.7 \% \quad 46.7$ $\begin{array}{lllll}0.03 \% & 35.0 \% & \text { VPVVFVTNAGNILQHSK } \quad 99.7 \% & 42.1\end{array}$ $0.03 \% \quad 35.0 \%$ AQELSALLGCEVDADQVILSHSPMK $99.5 \% 25.8$ $0.03 \% \quad 35.0 \%$ LFSEYHEK $99.0 \% \quad 32.5$

$0.03 \% \quad 35.0 \%$ MLVSGQGPVMENAQGLGFR $\quad 99.7 \% \quad 61.0$ $0.03 \% \quad 35.0 \%$ NVVTVDELR $0.03 \% \quad 35.0 \%$ MAFPLLDMVDLER

$0.03 \% \quad 35.0 \%$ IEGVLLLGEPVR

$0.03 \% \quad 35.0 \%$ ATHDGAPELGAGGTR $0.03 \% \quad 35.0 \%$ NPQSTEPVLGGGEPPFHGHR $0.01 \% \quad 4.7 \%$ NRPEPHSDENGSTTPK $0.01 \% \quad 4.7 \%$ ALLVQVVNK

$0.01 \% \quad 4.7 \%$ MLSALLTGVNR $0.01 \% \quad 4.7 \%$ GKENTDSVVMQPK $0.01 \% \quad 3.4 \%$ EVTAAQVAR

$0.01 \% \quad 3.4 \%$ SLDLIESLLR $0.01 \% \quad 3.4 \%$ LAEVGQYEQVK $0.01 \% \quad 3.4 \%$ NLDEQLSAPK $0.01 \% \quad 3.4 \%$ SLLEVVVLSR $0.01 \% \quad 3.4 \%$ DAIAALGLLQK $0.01 \% \quad 3.4 \% \quad$ NLILSAFPR $0.01 \% \quad 3.4 \% \quad$ SPVTFLSDLR $0.01 \% \quad 9.5 \%$ VQTLSNQPLLK $0.01 \% \quad 9.5 \%$ SPAPPLLHVAALGQK $0.01 \% \quad 9.5 \%$ IQVSSEKEAAPDAGAEPITADSDPAYSSK $0.01 \% \quad 9.5 \%$ FAEFQYLQPGPPR $0.01 \% \quad 9.5 \%$ VVTQNICQYR $0.01 \% \quad 9.5 \% \quad$ LTPLQLEIQR $0.01 \% \quad 18.7 \%$ IYQWINELSSPETR $0.01 \% \quad 18.7 \%$ LTSLGVIGALVK $0.01 \% \quad 18.7 \%$ IMESGSELSK $0.01 \% \quad 18.7 \%$ TVATFILQK $0.01 \% \quad 18.7 \%$ NLQEGQVTDPR $0.02 \% \quad 15.8 \%$ TIAPIIGR $0.02 \% \quad 15.8 \%$ AAGIEIQK $0.02 \% \quad 15.8 \%$ GVDYNAEIPFEK $99.7 \% \quad 38.6$ $99.7 \% \quad 52.0$ $99.7 \% \quad 70.9$ $99.7 \% \quad 53.7$ $99.7 \% \quad 46.9$ $96.4 \% 17.9$ $98.8 \% \quad 18.5$ $99.7 \% \quad 31.5$ $99.7 \% \quad 50.0$ $99.7 \% \quad 34.0$ $99.7 \% 33.3$ $99.7 \% \quad 43.6$ $99.7 \% \quad 41.9$ $99.7 \% \quad 33.0$ $\begin{array}{lll}99.7 \% & 38.9\end{array}$ $99.6 \% 26.6$ $99.4 \% \quad 22.9$ $\begin{array}{lll}99.7 \% & 32.8\end{array}$ $96.5 \% \quad 16.8$ $99.7 \% \quad 37.5$ $99.7 \% \quad 36.2$ $99.7 \% \quad 46.7$ $99.6 \% \quad 24.5$ $99.7 \% \quad 31.5$ $99.7 \% \quad 63.9$ $95.4 \% \quad 16.2$ $99.7 \% \quad 31.6$ $99.7 \% \quad 43.0$ $98.5 \% \quad 20.9$ $97.2 \% \quad 20.6$ $99.7 \% \quad 37.0$

$\begin{array}{lllll}0.02 \% & 15.8 \% & \text { ESDLPSAILQTSGVSEFTK } & 99.7 \% & 61.7\end{array}$ $\begin{array}{llllll}0.02 \% & 15.8 \% & \text { LVLPAPQISDAELQEVVK } & 99.7 \% & 40.4\end{array}$ $0.02 \% \quad 15.8 \%$ VGQASEIAR

$99.7 \% \quad 65.5$

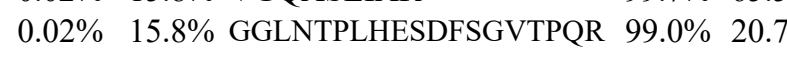

1030.63

1360.69

1204.59

1286.71

1158.61

1170.67

1014.57

1823.02

2727.33

1052.50

2006.98

1044.57

1581.77

1294.77

1409.68

2113.02

1765.81

983.62

1190.66

1448.71

944.52

1158.67

1263.66

1114.57

1114.68

1112.67

1030.60

1134.62

1240.73

1498.87

2934.39

1549.78

1280.64

1210.72

1735.87

1170.75

1080.52

1020.61

1256.62

840.53

829.48

1381.66

2009.01

1949.10

930.50

2011.98 
Cell division cycle 5-like protein GN=CDC5L CDC5L_HUMAN $92.25 \quad 100.0 \%$ Cell division cycle 5-like protein GN=CDC5L CDC5L_HUMAN $92.25 \quad 100.0 \%$ Cell division cycle 5-like protein GN=CDC5L CDC5L_HUMAN $92.25 \quad 100.0 \%$ Cell division cycle protein 23 homolog $\mathrm{GN}=\mathrm{CDC} 23 \mathrm{CDC} 23$ HUMAN $68.84 \quad 100.0 \%$ Cell division cycle protein 23 homolog GN=CDC23 CDC23_HUMAN $68.84 \quad 100.0 \%$ Cell division cycle protein 23 homolog GN=CDC23 CDC23_HUMAN $68.84 \quad 100.0 \%$ Cell division cycle protein 23 homolog $\mathrm{GN}=\mathrm{CDC} 23$ CDC23_HUMAN $68.84 \quad 100.0 \%$ Cell division cycle protein 23 homolog GN=CDC23 CDC23_HUMAN $68.84 \quad 100.0 \%$ Cell division cycle protein 23 homolog $\mathrm{GN}=\mathrm{CDC} 23 \mathrm{CDC} 23$ HUMAN $68.84 \quad 100.0 \%$ Cell growth-regulating nucleolar protein GN=LYAR LYAR_HUMAN $43.62 \quad 100.0 \%$ Cell growth-regulating nucleolar protein GN=LYAR LYAR_HUMAN $43.62 \quad 100.0 \%$ Cell growth-regulating nucleolar protein GN=LYAR LYAR_HUMAN $43.62 \quad 100.0^{\circ}$ Cell growth-regulating nucleolar protein GN=LYAR LYAR_HUMAN $43.62 \quad 100.0 \%$ Cell growth-regulating nucleolar protein GN=LYAR LYAR_HUMAN $43.62 \quad 100.0 \%$ Cell growth-regulating nucleolar protein GN=LYAR LYAR_HUMAN $43.62 \quad 100.0 \%$ Cell growth-regulating nucleolar protein GN=LYAR LYAR_HUMAN $43.62 \quad 100.0 \%$ Cellular tumor antigen p53 GN=TP53 Cellular tumor antigen $\mathrm{p} 53 \mathrm{GN}=\mathrm{TP} 53$ Cellular tumor antigen $\mathrm{p} 53 \mathrm{GN}=\mathrm{TP} 53$ Cellular tumor antigen $\mathrm{p} 53 \mathrm{GN}=\mathrm{TP} 53$ Cellular tumor antigen p53 GN=TP53 Cellular tumor antigen p53 GN=TP53 Centromere protein $\mathrm{V}$ GN $=\mathrm{CENPV}$ Centromere protein $\mathrm{V} \mathrm{GN}=\mathrm{CENPV}$ Centromere protein $\mathrm{V}$ GN $=\mathrm{CENPV}$ Centromere protein $\mathrm{V}$ GN $=\mathrm{CENPV}$ Centromere protein $\mathrm{V}$ GN $=\mathrm{CENPV}$ Centromere protein $\mathrm{V}$ GN $=\mathrm{CENPV}$ Centromere protein $\mathrm{V} \mathrm{GN}=\mathrm{CENPV}$ P53 HUMAN $43.65 \quad 100.0 \%$ P53_HUMAN $43.65 \quad 100.0 \%$ P53_HUMAN $43.65 \quad 100.0 \%$ P53 HUMAN $43.65 \quad 100.0 \%$ P53_HUMAN $43.65 \quad 100.0 \%$ P53 HUMAN $43.65 \quad 100.0 \%$ CENPV_HUMAN $29.95 \quad 100.0 \%$ CENPV_HUMAN $29.95 \quad 100.0 \%$ CENPV HUMAN $29.95 \quad 100.0 \%$ CENPV_HUMAN $29.95 \quad 100.0 \%$ CENPV_HUMAN $29.95 \quad 100.0 \%$ CENPV HUMAN $29.95 \quad 100.0 \%$ CENPV_HUMAN $29.95 \quad 100.0 \%$ Charged multivesicular body protein $4 \mathrm{~b}$ GN=CHMP4B CHM4B HUMAN $24.95 \quad 100.0 \%$ Charged multivesicular body protein 4b GN=CHMP4B CHM4B_HUMAN $24.95 \quad 100.0 \%$ Charged multivesicular body protein $4 \mathrm{~b}$ GN=CHMP4B $\quad$ CHM4B_HUMAN $24.95 \quad 100.0 \%$ Charged multivesicular body protein $4 \mathrm{~b}$ GN=CHMP4B CHM4B_HUMAN $24.95 \quad 100.0 \%$ Chitobiosyldiphosphodolichol beta-mannosyltransferase GN=ALG1 ALG1_HUMAN $52.52 \quad 100.0 \%$ Chitobiosyldiphosphodolichol beta-mannosyltransferase GN=ALG1 ALG1_HUMAN $52.52 \quad 100.0 \%$ Chitobiosyldiphosphodolichol beta-mannosyltransferase GN=ALG1 ALG1_HUMAN $52.52 \quad 100.0 \%$ Chloride intracellular channel protein $1 \mathrm{GN}=$ CLIC1 CLIC1_HUMAN $26.92 \quad 100.0 \%$ Chloride intracellular channel protein $1 \mathrm{GN}=$ CLIC1 CLIC1_HUMAN $26.92 \quad 100.0 \%$ Chromatin target of PRMT1 protein GN=CHTOP CHTOP_HUMAN $26.40 \quad 100.0 \%$ Chromatin target of PRMT1 protein GN=CHTOP CHTOP_HUMAN $26.40 \quad 100.0 \%$ Chromatin target of PRMT1 protein GN=CHTOP CHTOP_HUMAN $26.40 \quad 100.0 \%$ Chromatin target of PRMT1 protein GN=CHTOP CHTOP_HUMAN $26.40 \quad 100.0 \%$ Chromatin target of PRMT1 protein GN=CHTOP CHTOP_HUMAN $26.40 \quad 100.0 \%$ Chromatin target of PRMT1 protein GN=CHTOP CHTOP_HUMAN $26.40 \quad 100.0 \%$ Chromodomain-helicase-DNA-binding protein $1 \mathrm{GN}=\mathrm{CHD} 1$ CHD1_HUMAN $196.69100 .0 \%$ Chromodomain-helicase-DNA-binding protein $1 \mathrm{GN}=\mathrm{CHD} 1$ CHD1_HUMAN $196.69100 .0 \%$ Chromodomain-helicase-DNA-binding protein 1-like GN=CHD1L CHD1L_HUMAN $100.99 \quad 100.0 \%$

6
6
8
8

6
8
8
8
8

8
8
8

8

8
8
6
6
6

6
6
6

6

6
6
6

6

6
11
11
11

1

$7 \quad 11$

11
11

1

4

3

3

3

$\begin{array}{ll}3 & 3 \\ 2 & 2 \\ 2 & 2\end{array}$

$\begin{array}{ll}2 & 2 \\ 6 & 10 \\ 6 & 10\end{array}$

610

$\begin{array}{ll}6 & 10 \\ 6 & 10\end{array}$

\section{$6 \quad 10$}

$\begin{array}{ll}6 & 10 \\ 6 & 10 \\ 2 & 2\end{array}$

10
2
2

$22 \quad 0.02 \% \quad 15.8 \%$ QVVQTPNTVLSTPFR

$0.02 \% \quad 15.8 \%$ LGLLGLPAPK

$0.02 \% \quad 15.8 \%$ ILLGGYQSR

$0.01 \% \quad 10.4 \%$ QLLLIAGLTR

$0.01 \% \quad 10.4 \%$ AYFDVKEYDR

$0.01 \% \quad 10.4 \%$ GQVKNEALR

$0.01 \% \quad 10.4 \%$ AWYGLGQTYEILK

$0.01 \% \quad 10.4 \%$ AYAVGDVEK

$0.01 \% \quad 10.4 \%$ VSPLNLSSVTP

$3 \quad 0.01 \% \quad 18.7 \%$ VFFTCNACGESVKK

$0.01 \% \quad 18.7 \%$ CISEDQKYGGK

$0.01 \% \quad 18.7 \%$ VRELLEQISAFDNVPR

$0.01 \% \quad 18.7 \%$ ELLEQISAFDNVPR

$0.01 \% \quad 18.7 \%$ VKDAVEQQGEVK

$0.01 \% \quad 18.7 \%$ QAPDNEITIK

$0.01 \% \quad 18.7 \%$ ISKNPTFK

$0.02 \% \quad 19.6 \%$ TYQGSYGFR

$0.02 \% \quad 19.6 \%$ LGFLHSGTAK

$0.02 \% \quad 19.6 \%$ SVTCTYSPALNK

$0.02 \% \quad 19.6 \%$ RPILTIITLEDSSGNLLGR

$0.02 \% \quad 19.6 \%$ ALPNNTSSSPQPK

$0.02 \% \quad 19.6 \%$ KKPLDGEYFTLQIR

$0.02 \% \quad 37.5 \%$ SGASGASAAPAASAAAALAPSATR

$0.02 \% \quad 37.5 \%$ SQAVEKPPSEKPR

$0.02 \% 37.5 \%$ QKLTSEGAAK

$0.02 \% \quad 37.5 \%$ LLLDTFEYQGLVK

$0.02 \% \quad 37.5 \%$ GAEHITTYTFNTHK

$0.02 \% \quad 37.5 \%$ CGVQSFYTPR

$0.02 \% \quad 37.5 \%$ SNPGGFGIAPHCLDEGTVR

$0.01 \% \quad 22.8 \%$ GGPTPQEAIQR

$0.01 \% \quad 22.8 \%$ KIEQELTAAK

$0.01 \% \quad 22.8 \%$ QLAQIDGTLSTIEFQR

$0.01 \% \quad 22.8 \%$ EALENANTNTEVLK

$0.00 \% \quad 8.8 \%$ IQIVGLTELQSLAVGPR

$0.00 \% \quad 8.8 \%$ ETPLDLQHR

$0.00 \% \quad 8.8 \%$ SAFTERDAGSGLVTR

$0.00 \% \quad 8.3 \% \quad$ NSNPALNDNLEK

$0.00 \% \quad 8.3 \%$ YLSNAYAR

$0.03 \% \quad 32.3 \%$ MAAQSAPK

$0.03 \% \quad 32.3 \%$ NKQPTPVNIR

$0.03 \% \quad 32.3 \%$ ASMQQQQQLASAR

$\begin{array}{lll}0.03 \% & 32.3 \% & \text { LAQQMENRPSVQAALK } \\ 0.03 \% & 32.3 \% & \text { EQLDNQLDAYMSK }\end{array}$

$\begin{array}{lll}0.03 \% & 32.3 \% & \text { GHLDAELDAYMAQTDPETND }\end{array}$

$0.01 \% \quad 1.1 \%$ LKNDDSLLYK

$0.01 \% \quad 1.1 \% \quad$ VLIFSQMVR

$0.00 \% \quad 5.4 \%$ GGQAPGFLLR
$99.7 \% \quad 45.4$

$99.7 \% \quad 33.4$

$99.7 \% \quad 39.6$

$99.7 \% \quad 25.6$

$99.7 \% \quad 43.2$

$99.5 \% \quad 21.1$

$97.2 \% 21.7$

$99.7 \% \quad 56.4$

$99.7 \% \quad 41.3$

$99.7 \% \quad 46.5$

$99.7 \% \quad 51.7$

$99.7 \% \quad 51.1$

$99.7 \% \quad 33.7$

$98.8 \% 24.1$

$99.7 \% \quad 32.2$

$99.7 \% \quad 41.2$

$99.7 \% \quad 52.3$

$99.5 \% \quad 24.6$

$99.7 \% \quad 45.2$

$99.2 \% 20.3$

$99.7 \% 63.6$

$\begin{array}{lll}-1 & -1 \\ 9 & 31.6 \\ 99.7 \% & 34.5\end{array}$

$99.7 \% \quad 61.5$

$99.7 \% \quad 53.2$

$99.7 \% \quad 59.2$

$\begin{array}{ll}99.7 \% & 53.7 \\ 99.7 \% & 46.0\end{array}$

$99.7 \% \quad 41.2$

$99.7 \% \quad 74.1$

$99.7 \% \quad 55.2$

$99.7 \% \quad 55.3$

$\begin{array}{lll}98.5 \% & 27.2\end{array}$

$99.7 \% \quad 30.9$

$99.7 \% \quad 58.6$

$\begin{array}{lll}99.0 \% & 41.7\end{array}$

$99.0 \% \quad 27.9$

$99.7 \% \quad 27.1$

$99.7 \% \quad 59.3$

$\begin{array}{ll}99.7 \% & 60.4 \\ 99.7 \% & 61.2\end{array}$

$\begin{array}{ll}99.7 \% & 61.2 \\ 99.7 \% & 53.2\end{array}$

$\begin{array}{lll}97.6 \% & 21.6\end{array}$

$99.7 \% \quad 37.3$

$99.7 \% \quad 49.9$

$\begin{array}{ll}.0 & 39.6 \\ .0 & 19.9\end{array}$

$\begin{array}{ll}0 & 40.1\end{array}$

20.6

$\begin{array}{ll}0 & 18.6\end{array}$

56.4
25.0

$\begin{array}{ll}0 & 46.5\end{array}$

$\begin{array}{lll}51.0 & 5\end{array}$

$\begin{array}{ll}5.0 & 40.5\end{array}$

$\begin{array}{ll}0 & 13.9 \\ & 32.2\end{array}$

32.9
25.0

$\begin{array}{ll}5.0 & 52.3\end{array}$

$\begin{array}{ll}5.0 & 39.2\end{array}$

Page 38 of Table S-1-4 
Citron Rho-interacting kinase $\mathrm{GN}=\mathrm{CIT}$

Citron Rho-interacting kinase $\mathrm{GN}=\mathrm{CIT}$

Citron Rho-interacting kinase $\mathrm{GN}=\mathrm{CIT}$

Citron Rho-interacting kinase $\mathrm{GN}=\mathrm{CIT}$

Citron Rho-interacting kinase $\mathrm{GN}=\mathrm{CIT}$

Citron Rho-interacting kinase $\mathrm{GN}=\mathrm{CIT}$

athrin heavy chain $1 \mathrm{GN}=\mathrm{CLTC}$

Clathrin heavy chain $1 \mathrm{GN}=\mathrm{CLTC}$

Clathrin heavy chain $1 \mathrm{GN}=\mathrm{CLTC}$

Clathrin heavy chain $1 \mathrm{GN}=\mathrm{CLTC}$

Clathrin heavy chain $1 \mathrm{GN}=\mathrm{CLTC}$

Clathrin heavy chain $1 \mathrm{GN}=\mathrm{CLTC}$

Clathrin heavy chain $1 \mathrm{GN}=\mathrm{CLTC}$

Clathrin heavy chain $1 \mathrm{GN}=\mathrm{CLTC}$

Clathrin heavy chain $1 \mathrm{GN}=\mathrm{CLTC}$

Clathrin heavy chain $1 \mathrm{GN}=\mathrm{CLTC}$

Clathrin heavy chain $1 \mathrm{GN}=\mathrm{CLTC}$

Clathrin interactor $1 \mathrm{GN}=\mathrm{CLINT} 1$

Clathrin interactor $1 \mathrm{GN}=\mathrm{CLINT}$
Clathrin heavy chain $1 \mathrm{GN}=\mathrm{CLTC}$

CTRO_HUMAN $231.44 \quad 100.0 \%$

CTRO HUMAN $231.44 \quad 100.0 \%$

CTRO_HUMAN $231.44 \quad 100.0 \%$

CTRO HUMAN $231.44 \quad 100.0 \%$

CTRO HUMAN $231.44 \quad 100.0 \%$

CTRO_HUMAN $231.44 \quad 100.0 \%$

CLH1_HUMAN $191.62 \quad 100.0 \%$

CLH1_HUMAN $191.62 \quad 100.0 \%$

CLH1_HUMAN $191.62 \quad 100.0 \%$

CLH1_HUMAN $191.62 \quad 100.0 \%$

CLH1_HUMAN $191.62 \quad 100.0 \%$

CLH1 HUMAN $191.62 \quad 100.0 \%$

CLH1_HUMAN $191.62 \quad 100.0 \%$

CLH1_HUMAN $191.62 \quad 100.0 \%$

CLH1 HUMAN $191.62 \quad 100.0 \%$

CLH1_HUMAN $191.62 \quad 100.0 \%$

CLH1 HUMAN $191.62 \quad 100.0 \%$

CLH1_HUMAN $191.62 \quad 100.0 \%$

EPN4_HUMAN $68.26 \quad 100.0 \%$

EPN4 HUMAN $68.26 \quad 100.0 \%$

1 CPSF1 HUMAN $160.89 \quad 100.0 \%$

Cleavage and polyadenylation specificity factor subunit $1 \mathrm{GN}=\mathrm{CPSF} 1$ CPSF1_HUMAN $160.89 \quad 100.0 \%$ Cleavage and polyadenylation specificity factor subunit $1 \mathrm{GN}=\mathrm{CPSF} 1 \mathrm{CPSF} 1$ HUMAN $160.89100 .0 \%$

Cleavage and polyadenylation specificity factor subunit $1 \mathrm{GN}=\mathrm{CPSF} 1$ CPSF1_HUMAN $160.89 \quad 100.0 \%$ Cleavage and polyadenylation specificity factor subunit $1 \mathrm{GN}=\mathrm{CPSF} 1$ CPSF1_HUMAN $160.89100 .0 \%$ Cleavage and polyadenylation specificity factor subunit $1 \mathrm{GN}=\mathrm{CPSF} 1$ CPSF1_HUMAN $160.89100 .0 \%$ Cleavage and polyadenylation specificity factor subunit $1 \mathrm{GN}=\mathrm{CPSF} 1$ CPSF1_HUMAN $160.89 \quad 100.0 \%$ Cleavage and polyadenylation specificity factor subunit $1 \mathrm{GN}=\mathrm{CPSF} 1 \mathrm{CPSF} 1$ HUMAN $160.89 \quad 100.0 \%$ Cleavage and polyadenylation specificity factor subunit $1 \mathrm{GN}=\mathrm{CPSF} 1 \quad \mathrm{CPSF} 1 \_$HUMAN $160.89 \quad 100.0 \%$ Cleavage and polyadenylation specificity factor subunit $1 \mathrm{GN}=\mathrm{CPSF} 1 \mathrm{CPSF} 1$ HUMAN $160.89 \quad 100.0 \%$ Cleavage and polyadenylation specificity factor subunit $1 \mathrm{GN}=\mathrm{CPSF} 1 \mathrm{CPSF} 1$ HUMAN $160.89100 .0 \%$ Cleavage and polyadenylation specificity factor subunit $1 \mathrm{GN}=\mathrm{CPSF} 1$ CPSF1_HUMAN $160.89 \quad 100.0 \%$ Cleavage and polyadenylation specificity factor subunit $2 \mathrm{GN}=\mathrm{CPSF} 2 \mathrm{CPSF} 2 \mathrm{HUMAN} 88.49100 .0^{\circ}$ Cleavage and polyadenylation specificity factor subunit $2 \mathrm{GN}=\mathrm{CPSF} 2 \quad \mathrm{CPSF} 2$ HUMAN $88.49 \quad 100.0 \%$ Cleavage and polyadenylation specificity factor subunit $4 \mathrm{GN}=\mathrm{CPSF} 4 \quad \mathrm{CPSF} 4$ _HUMAN $30.25 \quad 100.0 \%$ Cleavage and polyadenylation specificity factor subunit $4 \mathrm{GN}=\mathrm{CPSF} 4 \mathrm{CPSF} 4$ HUMAN $30.25 \quad 100.0 \%$ Cleavage and polyadenylation specificity factor subunit 6 GN=CPSF6 CPSF6_HUMAN $59.21 \quad 100.0 \%$
$0.00 \% \quad 5.4 \% \quad$ LHTEGRAEAAR

$99.5 \% \quad 24.9$

$0.00 \% \quad 5.4 \%$ FAPGLSCVTYAGDKEER

$0.00 \% \quad 5.4 \%$ SFEQLVNLQK

.

$99.7 \% \quad 29.2$

$99.7 \% \quad 28.4$

$0.01 \% \quad 3.1 \%$ VGGNIEVLGFNAR

$0.01 \% \quad 3.1 \%$ GAADVEKVEEK

$0.01 \% \quad 3.1 \%$ WQDIQNDPR

$99.7 \% \quad 44.9$

$\begin{array}{lll}97.7 \% & 30.4\end{array}$

$97.5 \% 15.9$

$0.01 \% \quad 3.1 \%$ LANRAPEPTPQQVAQQQ

$0.00 \% \quad 2.5 \%$ TTLAHVIAR

$0.00 \% \quad 2.5 \%$ NLIQTLVSGIAPATR

$10 \quad 0.01 \% \quad 3.3 \%$ SPFAEGTSAR

$10 \quad 0.01 \% \quad 3.3 \%$ SESVVSGLDSPAK

$0.01 \% \quad 3.3 \%$ LAAEEFKR

$10 \quad 0.01 \% \quad 3.3 \% \quad$ ASTEATELLQNIR

$0.01 \% \quad 3.3 \%$ WVTALESVVAGGR

$0.01 \% \quad 3.3 \%$ AYLDIPNPR

$0.03 \% \quad 9.5 \% \quad$ NNLAGAEELFAR

$0.03 \% \quad 9.5 \%$ KFNALFAQGNYSEAAK

$0.03 \% \quad 9.5 \%$ SVDPTLALSVYLR

$0.03 \% \quad 9.5 \%$ ALEHFTDLYDIKR

$0.03 \% \quad 9.5 \%$ TGQIKEVER

$0.03 \% \quad 9.5 \%$ IHEGCEEPATHNALAK

$0.03 \% \quad 9.5 \% \quad$ IYIDSNNNPER

$0.03 \% \quad 9.5 \% \quad$ FLRENPYYDSR

$0.03 \% \quad 9.5 \%$ LLYNNVSNFGR

$\begin{array}{ll}99.7 \% & 44.7 \\ 98.3 \% & 20\end{array}$

$99.7 \% \quad 56.4$

$\begin{array}{lll}99.7 \% & 40.8\end{array}$

$99.7 \% \quad 65.1$

$99.0 \% \quad 27.4$

$99.7 \% \quad 52.7$

$99.7 \% \quad 59.1$

$99.7 \% \quad 31.6$

$99.7 \% \quad 68.4$

$\begin{array}{ll}99.7 \% & 55.7 \\ 99.7 \% & 40.9\end{array}$

$99.7 \% \quad 40.8$

$99.7 \% \quad 40.9$

$99.7 \% \quad 43.4$

$99.7 \% \quad 30.9$

$99.7 \% \quad 44.8$

$95.8 \% \quad 20.4$

$99.7 \% \quad 38.9$

$0.03 \% \quad 9.5 \%$ LASTLVHLGEYQAAVDGAR

$0.03 \% \quad 9.5 \%$ VANVELYYR

$0.00 \% \quad 4.0 \%$ VVTSAREHIYDLR

$0.00 \% \quad 4.0 \%$ QDAFANFANFSK

$0.03 \% \quad 10.0 \%$ NLVVAGTSQLYVYR

$0.03 \% \quad 10.0 \%$ CAAMLVYGTR

$0.03 \% \quad 10.0 \%$ LVVLPFRR

$0.03 \% \quad 10.0 \%$ ESLAEEHEGLVGEGQR

$0.03 \% \quad 10.0 \%$ SSFLPSYIIDVR

$0.03 \% \quad 10.0 \%$ LGNSLLLK

$0.03 \% \quad 10.0 \%$ YTEKLQEPPASAVR

$0.03 \% \quad 10.0 \%$ LGGARDELGGR

$0.03 \% \quad 10.0 \%$ VLVDSSFGQPTTQGEAR

$0.03 \% \quad 10.0 \%$ EVLLVALGSR

$0.03 \% \quad 10.0 \%$ VYAVATSTNTPCAR

$0.03 \% \quad 10.0 \%$ NVLDGELLNR

$0.00 \% \quad 4.5 \%$ LGLNCAIYATIPVYK

$0.00 \% \quad 4.5 \%$ QLIIVHGPPEASQDLAECCR

$0.00 \% \quad 7.4 \%$ SGAAVCEFFLK

$0.00 \% \quad 7.4 \%$ QSNNPPLQR

$0.01 \% \quad 9.1 \%$ GFALVGVGSEASSK
$99.7 \% \quad 53.1$

$99.3 \% \quad 19.8$

$99.7 \% \quad 48.2$

$99.7 \% \quad 31.4$

$\begin{array}{lll}99.7 \% & 29.2\end{array}$

$99.0 \% 31.0$

$99.0 \% \quad 18.6$

$99.7 \% \quad 52.9$

$97.6 \% \quad 25.1$

$99.6 \% \quad 25.0$

$96.3 \% 24$.

$99.7 \% \quad 60.6$

$99.7 \% \quad 58.9$

$99.7 \% \quad 60.0$

$99.7 \% \quad 39.6$

$99.7 \% \quad 38.9$

$99.7 \% \quad 36.0$

$\begin{array}{lll}99.7 \% & 36.7\end{array}$

$99.6 \% 26.3$

$99.7 \% \quad 37.8$
121

1899.89

1205.65

1082.59

1345.72

1174.60

1171.55

1875.97

981.58

1553.90

1022.49

1275.64

963.53

1445.76

1344.73

1058.56

1304.66

1758.88

1433.80

2131.10

1620.84

1059.58

1776.83

1334.63

1459.70

1296.67

1971.03

1126.59

1558.83

1359.63

1582.86

1141.55

999.65

1739.82

1396.75

857.55

1588.83

1100.58

1791.89

1056.64

1510.73

1142.62

1695.91

2293.11

1228.60

1053.54

1308.68
$0 \quad 30$

$17 \quad 133$

$069 \quad 1077$

$1407 \quad 1419$

$1637 \quad 1647$

$1749 \quad 1757$

$1896 \quad 1912$

381389

$735 \quad 749$

310

$594 \quad 601$

$651 \quad 663$

15541566

$1864 \quad 1872$

$355 \quad 366$

$367 \quad 382$

$\begin{array}{ll}469 & 481 \\ 482 & 500\end{array}$

$626 \quad 638$

$738 \quad 746$

$866 \quad 881$

892

$1216 \quad 1226$

$1227 \quad 1245$

$1398 \quad 1406$

$97 \quad 109$

$29 \quad 42$

$149 \quad 158$

$159 \quad 166$

$167 \quad 182$

$\begin{array}{ll}183 & 194 \\ 388 & 395\end{array}$

$388 \quad 395$

$714 \quad 724$

$817 \quad 833$

$848 \quad 857$

10331046

$1397 \quad 1406$

$560 \quad 579$

$36 \quad 46$

$191 \quad 199$ 
Coatomer subunit alpha $\mathrm{GN}=\mathrm{COPA}$

Coatomer subunit alpha $\mathrm{GN}=\mathrm{COPA}$

Coatomer subunit alpha $\mathrm{GN}=\mathrm{COPA}$

Coatomer subunit alpha $\mathrm{GN}=\mathrm{COPA}$

Coatomer subunit alpha $\mathrm{GN}=\mathrm{COPA}$

Coatomer subunit alpha $\mathrm{GN}=\mathrm{COPA}$

Coatomer subunit alpha $\mathrm{GN}=\mathrm{COPA}$

Coatomer subunit alpha $\mathrm{GN}=\mathrm{COPA}$

Coatomer subunit alpha $\mathrm{GN}=\mathrm{COPA}$

Coatomer subunit alpha $\mathrm{GN}=\mathrm{COPA}$

Coatomer subunit alpha $\mathrm{GN}=\mathrm{COPA}$

Coatomer subunit alpha $\mathrm{GN}=\mathrm{COPA}$

Coatomer subunit alpha $\mathrm{GN}=\mathrm{COPA}$

Coatomer subunit alpha $\mathrm{GN}=\mathrm{COPA}$

Coatomer subunit alpha $\mathrm{GN}=\mathrm{COPA}$

Coatomer subunit alpha $\mathrm{GN}=\mathrm{COPA}$

Coatomer subunit alpha $\mathrm{GN}=\mathrm{COPA}$

Coatomer subunit beta $\mathrm{GN}=\mathrm{COPB} 1$

Coatomer subunit beta $\mathrm{GN}=\mathrm{COPB} 1$

Coatomer subunit beta $\mathrm{GN}=\mathrm{COPB} 1$

Coatomer subunit beta $\mathrm{GN}=\mathrm{COPB} 1$

Coatomer subunit beta $\mathrm{GN}=\mathrm{COPB} 1$

Coatomer subunit beta $\mathrm{GN}=\mathrm{COPB} 1$

Coatomer subunit beta $\mathrm{GN}=\mathrm{COPB} 1$

Coatomer subunit beta $\mathrm{GN}=\mathrm{COPB} 1$

Coatomer subunit beta' $\mathrm{GN}=\mathrm{COPB} 2$

Coatomer subunit beta' $\mathrm{GN}=\mathrm{COPB} 2$

Coatomer subunit beta' $\mathrm{GN}=\mathrm{COPB} 2$

Coatomer subunit delta $\mathrm{GN}=\mathrm{ARCN} 1$

Coatomer subunit delta $\mathrm{GN}=\mathrm{ARCN} 1$

Coatomer subunit delta $\mathrm{GN}=\mathrm{ARCN}$

Coatomer subunit delta $\mathrm{GN}=\mathrm{ARCN} 1$

Coatomer subunit delta $\mathrm{GN}=\mathrm{ARCN} 1$

Coatomer subunit delta $\mathrm{GN}=\mathrm{ARCN} 1$

Coatomer subunit delta $\mathrm{GN}=\mathrm{ARCN} 1$

Coatomer subunit delta $\mathrm{GN}=\mathrm{ARCN} 1$

Coatomer subunit delta $\mathrm{GN}=\mathrm{ARCN} 1$

Coatomer subunit delta $\mathrm{GN}=\mathrm{ARCN} 1$

Coatomer subunit delta $\mathrm{GN}=\mathrm{ARCN} 1$

Coatomer subunit epsilon $\mathrm{GN}=\mathrm{COPE}$

Coatomer subunit epsilon $\mathrm{GN}=\mathrm{COPE}$
COPA_HUMAN $138.35 \quad 100.0 \%$

COPA_HUMAN $138.35 \quad 100.0 \%$

COPA HUMAN $138.35 \quad 100.0 \%$

COPA_HUMAN $138.35 \quad 100.0 \%$

COPA_HUMAN $138.35 \quad 100.0 \%$ COPA_HUMAN $138.35 \quad 100.0 \%$ COPA_HUMAN $138.35 \quad 100.0 \%$ COPA_HUMAN $138.35 \quad 100.0 \%$ COPA HUMAN $138.35 \quad 100.0 \%$ COPA_HUMAN $138.35 \quad 100.0 \%$ COPA HUMAN $138.35 \quad 100.0 \%$ COPA_HUMAN $138.35 \quad 100.0 \%$ COPA_HUMAN $138.35 \quad 100.0 \%$ COPA HUMAN $138.35 \quad 100.0 \%$ COPA_HUMAN $138.35 \quad 100.0 \%$ COPA_HUMAN $138.35 \quad 100.0 \%$ COPA_HUMAN $138.35 \quad 100.0 \%$ COPB_HUMAN $107.15 \quad 100.0 \%$ COPB HUMAN $107.15 \quad 100.0 \%$ COPB_HUMAN $107.15 \quad 100.0 \%$ COPB_HUMAN $107.15 \quad 100.0 \%$ COPB HUMAN $107.15 \quad 100.0 \%$ COPB_HUMAN $107.15 \quad 100.0 \%$ COPB HUMAN $107.15 \quad 100.0 \%$ COPB_HUMAN $107.15 \quad 100.0 \%$ COPB2_HUMAN $102.49 \quad 100.0 \%$ COPB2 HUMAN $102.49 \quad 100.0 \%$ COPB2_HUMAN $102.49 \quad 100.0 \%$ COPD HUMAN $57.21 \quad 100.0 \%$ COPD HUMAN $57.21 \quad 100.0 \%$ COPD_HUMAN $57.21 \quad 100.0 \%$ COPD HUMAN $57.21 \quad 100.0 \%$ COPD_HUMAN $57.21 \quad 100.0 \%$ COPD_HUMAN $57.21 \quad 100.0 \%$ COPD HUMAN $57.21 \quad 100.0 \%$ COPD_HUMAN $57.21 \quad 100.0 \%$ COPD HUMAN $57.21 \quad 100.0 \%$ COPD HUMAN $57.21 \quad 100.0 \%$ COPD_HUMAN $57.21 \quad 100.0 \%$ COPE HUMAN $34.48 \quad 100.0 \%$ COPE_HUMAN $34.48 \quad 100.0 \%$
$10 \quad 0.01 \% \quad 9.1 \%$ GFALVGVGSEASSKK

$10 \quad 0.01 \% \quad 9.1 \%$ RELHGQNPVVTPCNK

$10 \quad 0.01 \% \quad 9.1 \% \quad$ QFLSQFEMQSR

$10 \quad 0.01 \% \quad 9.1 \%$ AISSSAISR

$0.00 \% \quad 4.9 \%$ QNLSQFEAQAR

$0.00 \% \quad 4.9 \% \quad$ SYSVGASGSSSR

$0.03 \% \quad 17.2 \%$ NLSPGAVESDVR

$0.03 \% \quad 17.2 \%$ GITGVDLFGTTDAVVK

$0.03 \% \quad 17.2 \%$ ASNLENSTYDLYTIPK

$0.03 \% \quad 17.2 \%$ DADSQNPDAPEGKR

$0.03 \% \quad 17.2 \%$ HAIVICNR

$0.03 \% \quad 17.2 \%$ KLDALCNIHENIR

$0.03 \% \quad 17.2 \%$ YAVTTGDHGIIR

$0.03 \% \quad 17.2 \%$ TLDLPIYVTR

$0.03 \% \quad 17.2 \%$ VKGNNVYCLDR

$0.03 \% \quad 17.2 \%$ VLTIDPTEFKFK

$0.03 \% \quad 17.2 \%$ LVGQSIIAYLQK

$0.03 \% \quad 17.2 \%$ GFFEGTIASK

$30 \quad 0.03 \% \quad 17.2 \%$ GFFEGTIASKGK

$0.03 \% \quad 17.2 \%$ LLHDQVGVIQFGPYK

$0.03 \% \quad 17.2 \%$ LLELGPKPEVAQQTR

$0.03 \% \quad 17.2 \%$ CPLSGACYSPEFKGQICR

$0.03 \% \quad 17.2 \%$ VTTVTEIGKDVIGLR

$0.01 \% \quad 11.8 \%$ DLQHPNEFIR

$0.01 \% \quad 11.8 \%$ VLQDLVMDILR

$0.01 \% \quad 11.8 \%$ TLQLALDLVSSR

$0.01 \% \quad 11.8 \%$ TNNVSEHEDTDKYR

$0.01 \% \quad 11.8 \%$ SLGEIPIVESEIKK

$\begin{array}{lllll}0.01 \% & 11.8 \% & \text { LVTEMGTYATQSALSSSRPTK } & 98.6 \% & 17.3\end{array}$

$0.01 \% \quad 11.8 \%$ EAADPLASKLNK

$0.01 \% \quad 3.4 \%$ HSEVQQANLK

$0.01 \% \quad 3.4 \%$ TGRLPEAAFLAR

$0.01 \% \quad 3.4 \%$ TYLPSQVSR

$0.02 \% \quad 22.7 \%$ VLLAAAVCTK

$0.02 \% \quad 22.7 \%$ TRIEGLLAAFPK

$0.02 \% \quad 22.7 \%$ IEGLLAAFPK

$0.02 \% \quad 22.7 \%$ NSNILEDLETLR

$0.02 \% \quad 22.7 \%$ VAPAPARPSGPSK

$0.02 \% \quad 22.7 \%$ ISDDKYGR

$0.02 \% \quad 22.7 \%$ LFTAESLIGLKNPEK

$0.02 \% \quad 22.7 \%$ SFPVNSDVGVLK

$0.02 \% \quad 22.7 \%$ NTLEWCLPVIDAK

$0.02 \% \quad 22.7 \%$ KNYCNIQVTK

$0.02 \% \quad 22.7 \%$ VTQVDGNSPVR

$99.0 \% \quad 24.8$

$99.7 \% 35.4$

$98.4 \% 17.6$

$99.6 \% \quad 25.5$

$99.7 \% 52.4$

$99.7 \% \quad 26.2$

$99.2 \% \quad 22.6$

$99.7 \% \quad 54.0$

$99.6 \% \quad 24.2$

$99.0 \% 32$.

$99.7 \% \quad 43.6$

$99.7 \% \quad 30.6$

$99.7 \% \quad 54.9$

$99.7 \% \quad 40.9$

$99.7 \% \quad 53.4$

0.00\% $11.7 \%$ KFGVVLDEIKPSSAPELQAVR $99.7 \% 34.7$

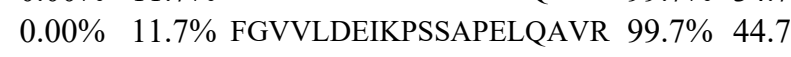

1416.66

891.49

1291.64

1144.52

1243.63

1592.85

1828.90

1499.67

982.53

1595.83

1302.68

1190.68

1337.66

1437.80

1332.79

1056.54

1241.65

1713.93

1678.95

2129.96

1600.93

1268.64

1314.75

1315.76

1707.76

1541.88

1953.02

2228.12

1256.68

1153.60

1301.73

1050.56

1045.61

1315.77

1058.62

1416.73

1234.69

953.47

1659.93

1261.68

1558.79

1267.65

1171.61

2283.27

2155.18

$\begin{array}{cc}25 & 139 \\ 47 & 161 \\ 62 & 172 \\ 23 & 431 \\ 63 & 173 \\ 07 & 418 \\ 71 & 182 \\ 83 & 198 \\ 83 & 398 \\ 99 & 412 \\ 09 & 516 \\ 17 & 529 \\ 51 & 562 \\ 63 & 572 \\ 73 & 583 \\ 89 & 600 \\ 20 & 631 \\ 16 & 825 \\ 16 & 827 \\ 42 & 956 \\ 28 & 1142 \\ 185 & 1202 \\ 203 & 1217 \\ 08 & 117 \\ 17 & 327 \\ 40 & 351 \\ 67 & 380 \\ 82 & 495 \\ 96 & 513 \\ 14 & 534 \\ 04 & 715 \\ 19 & 328 \\ 48 & 759 \\ 60 & 768 \\ 2 & 11 \\ 27 & 38 \\ 79 & 38 \\ 73 & 84 \\ 12 & 224 \\ 05 & 312 \\ 37 & 351 \\ 52 & 363 \\ 36 & 448 \\ 76 & 485 \\ 86 & 496 \\ 55 & 85 \\ 66 & 85 \\ & \end{array}$

Page 40 of Table S-1-4 
Coatomer subunit epsilon $\mathrm{GN}=\mathrm{COPE}$

COPE HUMAN $34.48 \quad 100.0 \%$ COPG1_HUMAN $97.72 \quad 100.0 \%$ COPG1_HUMAN 97.72 $100.0 \%$ $100.0 \%$ $100.0 \%$ $100.0 \%$ $\begin{array}{ll}62 & 100.0 \% \\ 62 & 100.0 \%\end{array}$ $62 \quad 100.0 \%$ $23 \quad 100.0 \%$ $23 \quad 100.0 \%$ $23 \quad 100.0 \%$ $100.0 \%$ $100.0 \%$ $100.0 \%$ $100.0 \%$ $100.0 \%$ $36 \quad 100.0 \%$ $100.0 \%$ CIQBP_HUMA C1QBP_HUMAN 31.36

$\begin{array}{lll}\text { Complement component } 1 \mathrm{Q} \text { subcomponent-binding protein, mitcohondrial GN=ClQBP } & \mathrm{C} 1 \mathrm{QBP} \_ \text {HUMAN } 31.36 & 100.0 \% \\ \text { Condensin }\end{array}$ Condensin complex subunit $1 \mathrm{GN}=\mathrm{NCAPD} 2 \mathrm{CND} 1$ _HUMAN $157.19 \quad 100.0 \%$ Condensin complex subunit $1 \mathrm{GN}=\mathrm{NCAPD} 2$ CND1_HUMAN $157.19 \quad 100.0 \%$ Condensin complex subunit $1 \mathrm{GN}=\mathrm{NCAPD} 2$ CND1_HUMAN $157.19 \quad 100.0 \%$ Condensin complex subunit $1 \mathrm{GN}=\mathrm{NCAPD} 2 \mathrm{CND} 1$ HUMAN $157.19 \quad 100.0 \%$ Condensin complex subunit $1 \mathrm{GN}=\mathrm{NCAPD} 2$ CND1_HUMAN $157.19 \quad 100.0 \%$ Condensin complex subunit 1 GN=NCAPD2 CND1_HUMAN $157.19 \quad 100.0 \%$ Condensin complex subunit $1 \mathrm{GN}=\mathrm{NCAPD} 2 \mathrm{CND} 1$ HUMAN $157.19 \quad 100.0 \%$ Condensin complex subunit $1 \mathrm{GN}=\mathrm{NCAPD} 2$ CND1 HUMAN $157.19100 .0 \%$ Condensin complex subunit $1 \mathrm{GN}=\mathrm{NCAPD} 2 \mathrm{CND} 1$ HUMAN $157.19 \quad 100.0 \%$ Condensin complex subunit 1 GN=NCAPD2 CND1_HUMAN $157.19 \quad 100.0 \%$ Condensin complex subunit $3 \mathrm{GN}=\mathrm{NCAPG}$ CND3_HUMAN $114.34 \quad 100.0 \%$ Condensin complex subunit $3 \mathrm{GN}=\mathrm{NCAPG}$ CND3_HUMAN $114.34 \quad 100.0 \%$ Condensin-2 complex subunit D3 GN=NCAPD3 CNDD3_HUMAN $168.89100 .0 \%$ Condensin-2 complex subunit D3 GN=NCAPD3 CNDD3_HUMAN $168.89 \quad 100.0 \%$ Condensin-2 complex subunit G2 GN=NCAPG2 CNDG2_HUMAN $130.96 \quad 100.0 \%$ Condensin-2 complex subunit $\mathrm{G} 2 \mathrm{GN}=\mathrm{NCAPG} 2$ CNDG2_HUMAN $130.96100 .0 \%$ Conserved oligomeric Golgi complex subunit $1 \mathrm{GN}=\mathrm{COG} 1$ COG1_HUMAN $108.98 \quad 100.0 \%$ Conserved oligomeric Golgi complex subunit $1 \mathrm{GN}=$ COG1 COG1_HUMAN $108.98 \quad 100.0 \%$ Constitutive coactivator of PPAR-gamma-like protein 1 GN=FAM120A F120A_HUMAN $121.89100 .0 \%$ Constitutive coactivator of PPAR-gamma-like protein 1 GN=FAM120A F120A_HUMAN $121.89 \quad 100.0 \%$ Constitutive coactivator of PPAR-gamma-like protein 1 GN=FAM120A F120A_HUMAN $121.89 \quad 100.0 \%$ Constitutive coactivator of PPAR-gamma-like protein 1 GN=FAM120A F120A_HUMAN $121.89 \quad 100.0 \%$ Cof losome complex subunit $3 \mathrm{GN}=\mathrm{COPS} 3$ CSN3_HUMAN $47.87 \quad 100.0 \%$ COP9 signalosome complex subunit $3 \mathrm{GN}=\mathrm{COPS} 3 \mathrm{CSN} 3$ _HUMAN $47.87 \quad 100.0 \%$
$0.00 \% \quad 11.7 \%$ ENDFDRLVLQYAPSA

$0.02 \% \quad 5.6 \%$ SAVLQEAR

$99.6 \% \quad 23.0$ $99.0 \% \quad 47.1$ $99.7 \% \quad 57.7$ $0.02 \% \quad 5.6 \%$ SSPEPVALTESETEYVIR $0.02 \% \quad 5.6 \%$ TLEEAVGNIVK $0.00 \% \quad 6.0 \% \quad$ SAVLQEAR

$0.00 \% \quad 6.0 \% \quad$ IFNETPINPR

$0.00 \% \quad 6.0 \% \quad$ ITDGTMLQAIER

$0.00 \% \quad 6.0 \%$ SQFAYCMLIR

$0.00 \% \quad 6.0 \%$ SIATLAITTLLK

$0.00 \% \quad 12.8 \%$ KGESDGAYIHR

9.7\% 62.5

$99.6 \% \quad 27.4$

$99.0 \% \quad 47.1$

$99.7 \% \quad 31.3$

$99.7 \% 41.0$

$95.5 \% \quad 14.4$

$99.7 \% \quad 57.7$

$99.7 \% \quad 42.5$

$0.00 \% \quad 12.8 \%$ MLLSPGGVSQPLTASLAR $99.7 \% \quad 44.7$

$0.00 \% \quad 12.8 \%$ IVEEERER

$0.00 \% \quad 9.7 \%$ VCCEGMLIQLR

$0.00 \% \quad 9.7 \%$ RQDLLNVLAR

$98.4 \% \quad 26.0$

$\begin{array}{lll}99.7 \% & 28.2\end{array}$

$99.7 \% \quad 44.3$

$0.00 \% \quad 9.7 \%$ TLLFTFNVPGSGNTYPK

$0.00 \% \quad 9.7 \%$ ARVEENFLK

$0.01 \% \quad 27.0 \%$ AFVDFLSDEIKEER

$99.6 \% 28.0$

$96.3 \% 21.6$

$99.7 \% \quad 41.6$

$\begin{array}{ll}99.7 \% & 34.2\end{array}$

\begin{tabular}{ll}
$0.01 \%$ & $27.0 \%$ \\
$0.01 \%$ & $27.0 \%$ \\
\hline
\end{tabular}

$0.02 \% \quad 9.1 \%$ LLENPTINHQK

$0.02 \% \quad 9.1 \%$ LADKSVLVCK

$0.02 \% \quad 9.1 \%$ LSDADLAGPLQK

$0.02 \% \quad 9.1 \%$ ESTGNMVTGQTVCK

$0.02 \% \quad 9.1 \%$ KITEAIGIISK

$0.02 \% \quad 9.1 \%$ EAVLNAYR

$0.02 \% \quad 9.1 \%$ VACCPLER

$0.02 \% \quad 9.1 \%$ LRDPAQQVR

$0.02 \% \quad 9.1 \%$ DLAYCVSQLPLTER

$0.02 \% \quad 9.1 \%$ AIIDEFEQKLR

$0.02 \% \quad 9.1 \% \quad$ YQPLASTASDNDFVTPEPR

$0.00 \% \quad 2.0 \%$ IQAVLALSR

$0.00 \% \quad 2.0 \%$ AVLSCIAPSAK

$0.00 \% \quad 1.9 \%$ NSSAFSYQR

$0.00 \% \quad 1.9 \%$ ASAGHVAVSSPTPETGPLQR

$0.00 \% \quad 1.7 \%$ LETDSRPVSR

$0.00 \% \quad 1.7 \%$ GFSEAAAPR

$0.00 \% \quad 2.9 \%$ QALTDFLLAR

$99.7 \% \quad 56.7$

$99.7 \% \quad 48.5$

$99.7 \% \quad 65.4$

$98.9 \% \quad 18.0$

$99.7 \% \quad 54.6$

$99.7 \% \quad 43.6$

$99.7 \% \quad 46.2$

$99.0 \% \quad 28.2$

$97.9 \% \quad 20.2$

$96.3 \% 19.9$

$99.7 \% \quad 46.6$

$99.7 \% \quad 34.7$

$99.7 \% \quad 59.7$

$99.7 \% \quad 65.5$

$99.7 \% \quad 32.6$

$99.7 \% \quad 39.9$

$99.7 \% \quad 45.5$

$\begin{array}{lll}99.5 \% & 28.9\end{array}$

$99.1 \% \quad 26.1$

$94.7 \% \quad 13.8$

$0.00 \% \quad 2.9 \%$ TSVLFGLVTGTENQLAPR

$0.01 \% \quad 6.0 \%$ QTAQQIVSHVQNK

$99.4 \% \quad 21.8$

$0.01 \% \quad 6.0 \%$ VAAASGHCGAFSGSDSSR

$0.01 \% \quad 6.0 \%$ SQGGVQPIPSQGGK

$0.01 \% \quad 6.0 \%$ GVISTPVIR

$0.01 \% \quad 6.0 \%$ EAALEAAVLNKEE

$0.00 \% \quad 6.6 \%$ TFLTLSLQDMASR

$0.00 \% \quad 6.6 \%$ AMDQEITVNPQFVQK $\begin{array}{lll}99.7 \% & 38.3\end{array}$

$99.7 \% \quad 33.9$

$99.7 \% 35.0$

$99.7 \% \quad 36.1$

$99.7 \% \quad 45.5$

$99.7 \% \quad 48.0$
873.48

1244.78

2006.99

1172.65

873.48

1200.64

1347.69

1288.62

1244.78

1232.60

1797.99

1059.54

1378.66

1197.71

1855.96

1105.60

1697.84

1621.75

2287.17

3136.41

1306.71

1132.64

1227.66

1527.68

1172.73

935.49

1004.47

1082.61

1664.83

1361.74

2107.99

970.60

1116.61

1059.49

1962.00

1159.61

905.45

1147.65

1903.03

1480.79

1723.75

1339.70

941.58

1386.71

1482.76

1763.86

$\begin{array}{cc}94 & 308 \\ 5 & 32 \\ 39 & 350 \\ 32 & 649 \\ 96 & 806 \\ 5 & 32 \\ 3 & 42 \\ 31 & 142 \\ 25 & 234 \\ 39 & 350 \\ 18 & 128 \\ 30 & 247 \\ 50 & 257 \\ 13 & 223 \\ 27 & 236 \\ 58 & 374 \\ 11 & 419 \\ 1 & 94 \\ 05 & 119 \\ 55 & 174 \\ 81 & 207 \\ 05 & 215 \\ 13 & 422 \\ 41 & 452 \\ 84 & 597 \\ 33 & 643 \\ 91 & 698 \\ 64 & 771 \\ 01 & 1109 \\ 25 & 1238 \\ 80 & 1290 \\ 25 & 1343 \\ 60 & 168 \\ 98 & 208 \\ 06 & 514 \\ 20 & 1339 \\ 07 & 516 \\ 12 & 820 \\ 25 & 234 \\ 72 & 889 \\ 17 & 129 \\ 12 & 929 \\ 33 & 946 \\ 87 & 995 \\ 06 & 1118 \\ 13 & 325 \\ 92 & 406 \\ & \end{array}$

Page 41 of Table S-1-4 
COP9 signalosome complex subunit $4 \mathrm{GN}=\mathrm{COPS} 4$ CSN4_HUMAN $46.27 \quad 100.0 \%$ COP9 signalosome complex subunit $4 \mathrm{GN}=\mathrm{COPS} 4 \mathrm{CSN} 4$ HUMAN $46.27 \quad 100.0 \%$ COP9 signalosome complex subunit $4 \mathrm{GN}=\mathrm{COPS} 4 \mathrm{CSN} 4$ _HUMAN $46.27 \quad 100.0 \%$ $\mathrm{COP} 9$ signalosome complex subunit $4 \mathrm{GN}=\mathrm{COPS} 4 \mathrm{CSN} 4$ HUMAN $46.27100 .0^{\circ}$ COP9 signalosome complex subunit 6 GN=COPS6 CSN6_HUMAN $36.16 \quad 100.0 \%$ COP9 signalosome complex subunit $6 \mathrm{GN}=$ COPS6 CSN6_HUMAN $36.16 \quad 100.0 \%$ Core histone macro-H2A $1 \mathrm{GN}=\mathrm{H} 2 \mathrm{AFY} \quad \mathrm{H} 2 \mathrm{AY}$ HUMAN $39.62 \quad 100.0 \%$ Core histone macro-H2A.1 GN=H2AFY Creatine kinase B-type $\mathrm{GN}=\mathrm{CKB}$

Creatine kinase B-type $\mathrm{GN}=\mathrm{CKB}$

Creatine kinase B-type $\mathrm{GN}=\mathrm{CKB}$

Creatine kinase $\mathrm{B}$-type $\mathrm{GN}=\mathrm{CKB}$

Creatine kinase $\mathrm{B}$-type $\mathrm{GN}=\mathrm{CKB}$

Creatine kinase $\mathrm{B}$-type $\mathrm{GN}=\mathrm{CKB}$

Creatine kinase $\mathrm{B}$-type $\mathrm{GN}=\mathrm{CKB}$

Creatine kinase $\mathrm{B}$-type $\mathrm{GN}=\mathrm{CKB}$

Crk-like protein $\mathrm{GN}=\mathrm{CRKL}$

Crk-like protein $\mathrm{GN}=\mathrm{CRKL}$

Crk-like protein $\mathrm{GN}=\mathrm{CRKL}$

Crk-like protein $\mathrm{GN}=\mathrm{CRKL}$

Crk-like protein $\mathrm{GN}=\mathrm{CRKL}$

$\begin{array}{lll}\text { H2AY_HUMAN } & 39.62 & 100.0 \%\end{array}$ KCRB HUMAN $42.65 \quad 100.0 \%$ KCRB_HUMAN $42.65 \quad 100.0 \%$ KCRB_HUMAN $42.65 \quad 100.0 \%$ KCRB HUMAN $42.65 \quad 100.0 \%$ KCRB_HUMAN $42.65 \quad 100.0 \%$ KCRB_HUMAN $42.65 \quad 100.0 \%$ KCRB_HUMAN $42.65 \quad 100.0 \%$ KCRB_HUMAN $42.65 \quad 100.0 \%$ CRKL HUMAN $33.78 \quad 100.0 \%$ CRKL_HUMAN $33.78 \quad 100.0 \%$ CRKL_HUMAN $33.78 \quad 100.0 \%$ CRKL HUMAN $33.78 \quad 100.0 \%$ CRKL_HUMAN $33.78 \quad 100.0 \%$ rooked neck-like protein $1 \mathrm{GN}=\mathrm{CRNKL} 1$ CRNL1_HUMAN $100.45100 .0 \%$ Crooked neck-like protein $1 \mathrm{GN}=\mathrm{CRNKL} 1$ CRNL1_HUMAN $100.45 \quad 100.0 \%$ C-terminal-binding protein $1 \mathrm{GN}=\mathrm{CTBP} 1 \quad$ CTBP1_HUMAN $47.54 \quad 100.0 \%$ C-terminal-binding protein $1 \mathrm{GN}=\mathrm{CTBP} 1 \quad$ CTBP1_HUMAN $47.54 \quad 100.0 \%$ C-terminal-binding protein $1 \mathrm{GN}=\mathrm{CTBP} 1 \quad$ CTBP1_HUMAN $47.54 \quad 100.0 \%$ C-terminal-binding protein $1 \mathrm{GN}=\mathrm{CTBP} 1 \quad$ CTBP1_HUMAN $47.54 \quad 100.0 \%$ CTP synthase $1 \mathrm{GN}=\mathrm{CTPS} 1$ CTP synthase $1 \mathrm{GN}=\mathrm{CTPS} 1$ CTP synthase $1 \mathrm{GN}=\mathrm{CTPS} 1$ CTP synthase $1 \mathrm{GN}=\mathrm{CTPS} 1$ CTP synthase $1 \mathrm{GN}=\mathrm{CTPS}$ CTP synthase $1 \mathrm{GN}=\mathrm{CTPS} 1$ CTP synthase $1 \mathrm{GN}=\mathrm{CTPS} 1$ CTP synthase $1 \mathrm{GN}=\mathrm{CTPS} 1$ CTP synthase $1 \mathrm{GN}=\mathrm{CTPS} 1$ CTP synthase $1 \mathrm{GN}=\mathrm{CTPS}$ CTP synthase $2 \mathrm{GN}=\mathrm{CTPS} 2$ CTP synthase $2 \mathrm{GN}=\mathrm{CTPS} 2$ CTP synthase $2 \mathrm{GN}=\mathrm{CTPS} 2$ CTP synthase $2 \mathrm{GN}=\mathrm{CTPS} 2$ PYRG1 HUMAN $66.69 \quad 100.0 \%$ PYRG1_HUMAN $66.69 \quad 100.0 \%$ PYRG1 HUMAN $66.69 \quad 100.0 \%$ PYRG1_HUMAN $66.69 \quad 100.0 \%$ PYRG1_HUMAN $66.69 \quad 100.0 \%$ PYRG1_HUMAN $66.69 \quad 100.0 \%$ PYRG1_HUMAN $66.69 \quad 100.0 \%$ PYRG1_HUMAN $66.69 \quad 100.0 \%$ PYRG1_HUMAN $66.69 \quad 100.0 \%$ PYRG1_HUMAN $66.69 \quad 100.0 \%$ PYRG2 HUMAN $65.68 \quad 100.0 \%$ PYRG2_HUMAN $65.68 \quad 100.0 \%$ PYRG2_HUMAN $65.68 \quad 100.0 \%$ PYRG2_HUMAN $65.68 \quad 100.0 \%$ Cullin-associated NEDD8-dissociated protein $1 \mathrm{GN}=\mathrm{CAND1}$ CAND1_HUMAN $136.38 \quad 100.0 \%$ Cullin-associated NEDD8-dissociated protein $1 \mathrm{GN}=$ CAND1 CAND1_HUMAN $136.38 \quad 100.0 \%$ Cullin-associated NEDD8-dissociated protein 1 GN=CAND1 CAND1_HUMAN $136.38 \quad 100.0 \%$ Cullin-associated NEDD8-dissociated protein $1 \mathrm{GN}=$ CAND1 CAND1_HUMAN $136.38 \quad 100.0 \%$ Cullin-associated NEDD8-dissociated protein $1 \mathrm{GN}=$ CAND1 CAND1_HUMAN $136.38 \quad 100.0 \%$ Cullin-associated NEDD8-dissociated protein $1 \mathrm{GN}=\mathrm{CAND1}$ CAND1_HUMAN $136.38 \quad 100.0 \%$
$0.01 \% \quad 11.8 \%$ AIQLSGAEQLEALK $0.01 \% \quad 11.8 \%$ VISFEEQVASIR $0.01 \% \quad 11.8 \%$ ATTADGSSILDR $0.01 \% \quad 11.8 \%$ IASQMITEGR $0.00 \% \quad 7.0 \%$ IGVDHVAR $0.00 \% \quad 7.0 \%$ ASEAGEVPFNHEILR $0.00 \% \quad 8.6 \%$ AASADSTTEGTPADGFTVLSTK $0.00 \% \quad 8.6 \%$ EFVEAVLELR $0.05 \% \quad 26.2 \%$ PFSNSHNALK $0.05 \% \quad 26.2 \%$ VLTPELYAELR $0.05 \% \quad 26.2 \%$ LAVEALSSLDGDLAGR $0.05 \% \quad 26.2 \%$ GGNMKEVFTR $0.05 \% \quad 26.2 \%$ FCTGLTQIETLFK $0.05 \% \quad 26.2 \%$ LGFSEVELVQMVVDGVK $0.05 \% \quad 26.2 \%$ LLIEMEQR $0.05 \% \quad 26.2 \%$ LEQGQAIDDLMPAQK $0.01 \% \quad 22.8 \%$ DSSTCPGDYVLSVSENSR $99.7 \% \quad 32.4$ $0.01 \% \quad 22.8 \%$ VSHYIINSLPNRR $0.01 \% 22.8 \%$ IHYLDTTTLIEPAPR $0.01 \% 22.8 \%$ VGMIPVPYVEK $0.01 \% \quad 22.8 \%$ TALALEVGDIVK $0.00 \% \quad 2.5 \%$ GIEDIIVSKR

$0.00 \% \quad 2.5 \%$ AIYELAISQPR $0.01 \% \quad 13.6 \%$ IGSGFDNIDIK $0.01 \% \quad 13.6 \%$ VQSVEQIREVASGAAR $0.01 \% \quad 13.6 \%$ IRGETLGIIGLGR $0.01 \% \quad 13.6 \%$ GAALDVHESEPFSFSQGPLK $0.03 \% \quad 18.4 \%$ MKYILVTGGVISGIGK $0.03 \% \quad 18.4 \%$ GIIASSVGTILK $0.03 \% \quad 18.4 \%$ FLDIRLTK

$0.03 \% \quad 18.4 \%$ LTKDNNLTTGK $0.03 \% \quad 18.4 \%$ IYQYVINKER $0.03 \% \quad 18.4 \%$ GLGLSPDLVVCR $0.03 \% \quad 18.4 \%$ CSNPLDTSVKEK $0.03 \% \quad 18.4 \%$ RLDLPIER

$0.03 \% \quad 18.4 \%$ FSDSYASVIK $0.03 \% \quad 18.4 \%$ GTEGKIQAIAWAR $0.00 \% \quad 8.7 \%$ MKYILVTGGVISGIGK $0.00 \% \quad 8.7 \%$ GIIASSIGTILK $0.00 \% \quad 8.7 \%$ GLGLSPDLIVCR $0.00 \% \quad 8.7 \%$ TVFKTENSILR $0.04 \% \quad 15.0 \%$ LLEDKNGEVQNLAVK $0.04 \% \quad 15.0 \%$ CLGPLVSK

$0.04 \% \quad 15.0 \%$ TVIGELPPASSGSALAANVCK $0.04 \% \quad 15.0 \%$ TYIQCIAAISR $0.04 \% \quad 15.0 \%$ TVSPALISR $0.04 \% \quad 15.0 \%$ AADIDQEVKER $\begin{array}{llllllll}99.7 \% & 57.4 & 25.0 & 49.0 & 1 & 0 & 0 & 1377.74\end{array}$ $\begin{array}{llllllll}99.7 \% & 55.7 & 25.0 & 51.1 & 1 & 0 & 0 & 1206.60\end{array}$ $97.6 \% \quad 19.9 \quad 25.0 \quad 14.5$ $\begin{array}{llll}99.7 \% & 30.5 & 25.0 & 30.5\end{array}$ $\begin{array}{llll}99.7 \% & 42.7 & 25.0 & 42.7\end{array}$ $\begin{array}{llll}99.7 \% & 40.7 & 25.0 & 32.7\end{array}$ $\begin{array}{llll}99.7 \% & 58.6 & 25.0 & 50.8\end{array}$ $99.7 \% \quad 55.4 \quad 25.0 \quad 48.7$ $\begin{array}{lllll}99.7 \% & 59.2 & 25.0 & 55.5 & 15\end{array}$ $\begin{array}{lllll}99.7 \% & 29.1 & 25.0 & 21.9 & 2\end{array}$ $99.7 \% \quad 58.4 \quad 25.0 \quad 55.2 \quad 12$ $\begin{array}{llll}99.7 \% & 40.9 & 25.0 & 40.9\end{array}$ $\begin{array}{llll}99.0 \% & 41.3 & 25.0 & 32.9\end{array}$ $\begin{array}{llll}9.7 \% & 60.2 & 25.0 & 60.2 \\ 9.7 \% & 32.4 & 25.0 & 27.5\end{array}$ $\begin{array}{llll}98.4 \% & 22.2 & 25.0 & 22.2\end{array}$ $99.7 \% \quad 59.1 \quad 25.0 \quad 38.2 \quad 2$ $\begin{array}{llll}99.0 \% & 22.0 & 25.0 & 17.3\end{array}$ $99.7 \% \quad 73.9 \quad 25.0 \quad 67.2$ $\begin{array}{llll}99.1 \% & 24.2 & 25.0 & 14.8\end{array}$ $\begin{array}{llll}99.6 \% & 26.8 & 25.0 & 16.5\end{array}$ $99.7 \% \quad 47.0 \quad 25.0 \quad 33.6$ $\begin{array}{llll}99.7 \% & 40.0 & 25.0 & 39.2\end{array}$ $\begin{array}{llll}99.6 \% & 24.7 & 25.0 & 24.7\end{array}$ $\begin{array}{llll}99.7 \% & 41.9 & 25.0 & 41.9\end{array}$ $\begin{array}{llll}99.7 \% & 65.5 & 25.0 & 65.5\end{array}$ $\begin{array}{lllll}99.7 \% & 52.3 & 25.0 & 49.3 & 2\end{array}$ $\begin{array}{llll}99.0 \% & 25.1 & 25.0 & 17.9\end{array}$ $\begin{array}{llll}99.7 \% & 47.5 & 25.0 & 42.7\end{array}$ $\begin{array}{llll}99.7 \% & 35.2 & 25.0 & 35.2\end{array}$ $\begin{array}{llll}99.7 \% & 43.0 & 25.0 & 37.3\end{array}$ $\begin{array}{llll}99.2 \% & 23.8 & 25.0 & 15.6\end{array}$ $\begin{array}{llll}99.0 \% & 36.4 & 25.0 & 20.8\end{array}$ $99.7 \% \quad 65.4 \quad 25.0 \quad 45.5$ $\begin{array}{llll}99.7 \% & 58.9 & 25.0 & 50.7\end{array}$ $\begin{array}{llll}99.7 \% & 65.5 & 25.0 & 65.5\end{array}$ $\begin{array}{llll}99.7 \% & 42.8 & 25.0 & 27.0\end{array}$ $\begin{array}{llll}99.7 \% & 46.2 & 25.0 & 39.2\end{array}$ $\begin{array}{llll}99.1 \% & 19.2 & 25.0 & 19.2\end{array}$ $99.7 \% \quad 46.6 \quad 25.0 \quad 38.9$ $\begin{array}{llll}97.7 \% & 26.2 & 25.2 & 12.4\end{array}$ $\begin{array}{llll}97.7 \% & 26.2 & 25.2 & 12.4 \\ 99.7 \% & 55.4 & 25.0 & 54.4\end{array}$ $\begin{array}{lllll}99.7 \% & 56.5 & 25.0 & 53.6 & 7\end{array}$ $\begin{array}{lllll}99.7 \% & 40.9 & 25.0 & 26.4 & 2\end{array}$ $\begin{array}{llll}99.7 \% & 40.9 & 25.0 & 30.3\end{array}$

\begin{tabular}{cc}
33 & 46 \\
6 & 107 \\
91 & 302 \\
38 & 347 \\
98 & 205 \\
44 & 258 \\
68 & 189 \\
40 & 249 \\
2 & 11 \\
33 & 43 \\
57 & 172 \\
43 & 252 \\
53 & 265 \\
42 & 358 \\
59 & 366 \\
67 & 381 \\
40 & 57 \\
58 & 70 \\
90 & 104 \\
70 & 180 \\
54 & 265 \\
67 & 476 \\
61 & 671 \\
98 & 108 \\
56 & 171 \\
72 & 184 \\
86 & 305 \\
1 & 16 \\
17 & 28 \\
77 & 84 \\
32 & 92 \\
73 & 102 \\
06 & 217 \\
18 & 229 \\
69 & 276 \\
10 & 319 \\
77 & 389 \\
1 & 16 \\
77 & 28 \\
06 & 217 \\
55 & 465 \\
56 & 70 \\
71 & 78 \\
& 132 \\
& 243 \\
\hline 38 \\
\hline 3
\end{tabular}

Page 42 of $\mathrm{Table}-1-4$ 

Cullin-associated NEDD8-dissociated protein 1 GN=CAND1 CAND1_HUMAN $136.38 \quad 100.0 \%$ Cullin-associated NEDD8-dissociated protein $1 \mathrm{GN}=\mathrm{CAND} 1$ CAND1_HUMAN $136.38 \quad 100.0^{\circ}$ Cullin-associated NEDD8-dissociated protein $1 \mathrm{GN}=$ CAND1 CAND1_HUMAN $136.38 \quad 100.0 \%$ Cullin-associated NEDD8-dissociated protein $1 \mathrm{GN}=$ CAND1 CAND1_HUMAN $136.38 \quad 100.0 \%$ Cullin-associated NEDD8-dissociated protein $1 \mathrm{GN}=$ CAND1 CAND1_HUMAN $136.38 \quad 100.0 \%$ Cullin-associated NEDD8-dissociated protein $1 \mathrm{GN}=$ CAND1 CAND1_HUMAN $136.38 \quad 100.0 \%$ Cullin-associated NEDD8-dissociated protein $1 \mathrm{GN}=\mathrm{CAND} 1$ CAND1 HUMAN $136.38100 .0 \%$ Cullin-associated NEDD8-dissociated protein $1 \mathrm{GN}=$ CAND1 CAND1_HUMAN $136.38 \quad 100.0 \%$ Cullin-associated NEDD8-dissociated protein 1 GN=CAND1 CAND1_HUMAN $136.38 \quad 100.0 \%$ Cullin-associated NEDD8-dissociated protein $2 \mathrm{GN}=\mathrm{CAND} 2$ CAND2 HUMAN $135.26 \quad 100.0 \%$ Cullin-associated NEDD8-dissociated protein 2 GN=CAND2 CAND2_HUMAN $135.26 \quad 100.0 \%$ Cullin-associated NEDD8-dissociated protein $2 \mathrm{GN}=\mathrm{CAND} 2 \mathrm{CAND} 2$ HUMAN $135.26100 .0 \%$ Cyclin-dependent kinase $1 \mathrm{GN}=\mathrm{CDK} 1$ Cyclin-dependent kinase $1 \mathrm{GN}=\mathrm{CDK} 1$ Cyclin-dependent kinase $1 \mathrm{GN}=\mathrm{CDK} 1$ Cyclin-dependent kinase $1 \mathrm{GN}=\mathrm{CDK} 1$ Cyclin-dependent kinase $1 \mathrm{GN}=\mathrm{CDK} 1$ Cyclin-dependent kinase $1 \mathrm{GN}=\mathrm{CDK} 1$ Cyclin-dependent kinase $1 \mathrm{GN}=\mathrm{CDK} 1$ Cyclin-dependent kinase $1 \mathrm{GN}=\mathrm{CDK} 1$ Cyclin-dependent kinase $1 \mathrm{GN}=\mathrm{CDK} 1$ Cyclin-dependent kinase $1 \mathrm{GN}=\mathrm{CDK} 1$ Cyclin-dependent kinase $1 \mathrm{GN}=\mathrm{CDK} 1$ Cyclin-dependent kinase $1 \mathrm{GN}=\mathrm{CDK} 1$ Cyclin-dependent kinase $1 \mathrm{GN}=\mathrm{CDK} 1$ Cyclin-dependent kinase $1 \mathrm{GN}=\mathrm{CDK} 1$ Cyclin-dependent kinase $1 \mathrm{GN}=\mathrm{CDK} 1$ Cyclin-dependent kinase $1 \mathrm{GN}=\mathrm{CDK} 1$ Cyclin-dependent kinase $1 \mathrm{GN}=\mathrm{CDK} 1$ Cyclin-dependent kinase $1 \mathrm{GN}=\mathrm{CDK} 1$ Cyclin-dependent kinase $1 \mathrm{GN}=\mathrm{CDK} 1$ Cyclin-dependent kinase $2 \mathrm{GN}=\mathrm{CDK} 2$ Cyclin-dependent kinase $2 \mathrm{GN}=\mathrm{CDK} 2$ Cyclin-dependent kinase $2 \mathrm{GN}=\mathrm{CDK} 2$ Cyclin-dependent kinase $2 \mathrm{GN}=\mathrm{CDK} 2$ Cyclin-dependent kinase $2 \mathrm{GN}=\mathrm{CDK} 2$ Cyclin-dependent kinase $2 \mathrm{GN}=\mathrm{CDK} 2$ Cyclin-dependent kinase $2 \mathrm{GN}=\mathrm{CDK} 2$

Cyclin-dependent kinase $2 \mathrm{GN}=\mathrm{CDK} 2$ Cyclin-dependent kinase $2 \mathrm{GN}=\mathrm{CDK} 2$ Cyclin-dependent kinase $9 \mathrm{GN}=\mathrm{CDK} 9$ Cyclin-dependent kinase $9 \mathrm{GN}=\mathrm{CDK} 9$ Cyclin-dependent kinase $9 \mathrm{GN}=\mathrm{CDK} 9$ Cyclin-dependent kinase $9 \mathrm{GN}=\mathrm{CDK} 9$ Cyclin-dependent-like kinase 5 GN=CDK5 CDK5_HUMAN $33.31 \quad 100.0 \%$

21

77

21

17 21

7

17

CDK1_HUMAN $34.10 \quad 100.0 \%$ CDK1_HUMAN $34.10 \quad 100.0 \%$ CDK1_HUMAN $34.10 \quad 100.0 \%$ CDK1_HUMAN $34.10 \quad 100.0 \%$ CDK1 HUMAN $34.10 \quad 100.0 \%$ CDK1 HUMAN $34.10 \quad 100.0 \%$ CDK1_HUMAN $34.10 \quad 100.0 \%$ CDK1_HUMAN $34.10 \quad 100.0 \% \quad 19$ CDK1 HUMAN $34.10 \quad 100.0 \% \quad 19$ CDK1_HUMAN $34.10 \quad 100.0 \% \quad 19$ CDK1_HUMAN $34.10 \quad 100.0 \% \quad 19$ CDK1_HUMAN $34.10 \quad 100.0 \% \quad 19$ CDK1_HUMAN $34.10 \quad 100.0 \% \quad 19$ CDK1 HUMAN $34.10 \quad 100.0 \% \quad 19$ CDK1_HUMAN $34.10 \quad 100.0 \% \quad 19$ CDK1_HUMAN $34.10 \quad 100.0 \% \quad 19$ CDK1_HUMAN $34.10 \quad 100.0 \% \quad 19$ CDK1_HUMAN $34.10 \quad 100.0 \% \quad 19$ CDK1_HUMAN $34.10 \quad 100.0 \% \quad 19$ CDK2_HUMAN $33.93 \quad 100.0 \% \quad 7$ CDK2 HUMAN $33.93 \quad 100.0 \%$ CDK2_HUMAN $33.93 \quad 100.0 \%$ CDK2_HUMAN $33.93 \quad 100.0 \%$ CDK2 HUMAN $33.93 \quad 100.0 \%$ CDK2_HUMAN $33.93 \quad 100.0 \%$ CDK2_HUMAN $33.93 \quad 100.0 \%$ CDK2 HUMAN $33.93 \quad 100.0 \%$ CDK2_HUMAN $33.93 \quad 100.0 \%$ CDK9 HUMAN $42.78 \quad 100.0 \%$ CDK9 HUMAN $42.78 \quad 100.0 \%$ CDK9_HUMAN $42.78 \quad 100.0 \%$ CDK9 HUMAN $42.78 \quad 100.0 \%$
$0.04 \% \quad 15.0 \%$ ALTLIAGSPLK $0.04 \% \quad 15.0 \%$ VYPSSLSK

$0.04 \% \quad 15.0 \%$ MLTGPVYSQSTALTHK $99.7 \% \quad 62.9$ $95.2 \% \quad 20.7$

$0.04 \% \quad 15.0 \%$ EGPAVVGQFIQDVK

$95.1 \% \quad 18.3$

$99.7 \% \quad 46.3$

$0.04 \% \quad 15.0 \%$ EGPAVVGQFIQDVKNSR

$0.04 \% \quad 15.0 \%$ NVVAECLGK

$0.04 \% \quad 15.0 \%$ LTLIDPETLLPR

$0.04 \% \quad 15.0 \%$ LKGYLISGSSYAR

$0.04 \% \quad 15.0 \%$ TLEDPDLNVR

$0.04 \% \quad 15.0 \%$ TLEDPDLNVRR

$0.04 \% \quad 15.0 \%$ LSTLCPSAVLQR

$0.00 \% \quad 2.8 \% \quad$ LLEDKNGEVQNLAVK

$0.00 \% \quad 2.8 \%$ VPTSPTAIR

$0.00 \% \quad 2.8 \%$ TLIQCLGSVGR

$0.07 \% \quad 67.3 \%$ IGEGTYGVVYK

$0.07 \% \quad 67.3 \%$ TTGQVVAMK

$0.07 \% \quad 67.3 \%$ TTGQVVAMKK

$0.07 \% \quad 67.3 \%$ IRLESEEEGVPSTAIR

$0.07 \% \quad 67.3 \%$ LESEEEGVPSTAIR

$\begin{array}{ll}99.7 \% & 52.3 \\ 99.3 \% & 20.4\end{array}$

$99.7 \% \quad 45.4$

$99.7 \% \quad 34.7$

$99.7 \% \quad 32.0$

$99.1 \% \quad 26.8$

$99.7 \% \quad 31.8$

$99.7 \% \quad 46.6$

$99.6 \% \quad 27.1$

$99.4 \% \quad 29.8$

$99.7 \% \quad 61.0$

$99.7 \% \quad 51.2$

$99.7 \% \quad 45.4$

$99.7 \% \quad 40.5$

$99.7 \% \quad 48.4$

$0.07 \% \quad 67.3 \%$ HPNIVSLQDVLMQDSR $\quad 99.7 \% \quad 39.6$

$0.07 \% \quad 67.3 \%$ YLDSIPPGQYMDSSLVK

$0.07 \% \quad 67.3 \%$ DLKPQNLLIDDKGTIK

$0.07 \% \quad 67.3 \%$ LADFGLAR

$0.07 \% \quad 67.3 \%$ VYTHEVVTLWYR

$0.07 \% \quad 67.3 \%$ SPEVLLGSAR

$0.07 \% \quad 67.3 \%$ KPLFHGDSEIDQLFR

$0.07 \% \quad 67.3 \%$ ALGTPNNEVWPEVESLQDYK

$0.07 \% \quad 67.3 \%$ WKPGSLASHVK

$0.07 \% \quad 67.3 \%$ NLDENGLDLLSK

$0.07 \% \quad 67.3 \%$ MLIYDPAK

$0.07 \% \quad 67.3 \%$ MLIYDPAKR

$99.7 \% \quad 33.8$

$99.7 \% 56.4$

$99.0 \% \quad 41.5$

$99.7 \% \quad 59.4$

$99.7 \% \quad 49.5$

$99.1 \% \quad 29.7$

$\begin{array}{lll}99.7 \% & 53.7\end{array}$

$99.7 \% \quad 36.5$

$99.7 \% \quad 62.1$

$99.0 \% \quad 39.3$

$99.7 \% \quad 42.6$

$\begin{array}{lll}0.07 \% & 67.3 \% & \text { MALNHPYFNDLDNQIK } \quad 99.7 \% \quad 46.0\end{array}$

\begin{tabular}{ll}
$0.07 \%$ & $67.3 \%$ \\
\hline
\end{tabular}

$0.02 \% \quad 33.6 \%$ IGEGTYGVVYK

$0.02 \% 33.6 \%$ LTGEVVALKK

$0.02 \% \quad 33.6 \%$ IRLDTETEGVPSTAIR

$0.02 \% \quad 33.6 \%$ LDTETEGVPSTAIR

$0.02 \% 33.6 \%$ FMDASALTGIPLPLIK

$0.02 \% \quad 33.6 \%$ DLKPQNLLINTEGAIK

$0.02 \% \quad 33.6 \%$ LADFGLAR

$0.02 \% 33.6 \%$ APEILLGCK

$0.02 \% \quad 33.6 \%$ ALFPGDSEIDQLFR

$0.00 \% \quad 11.3 \%$ LADFGLAR

$0.00 \% \quad 11.3 \%$ LLVLDPAQR

$0.00 \% \quad 11.3 \%$ GSQITQQSTNQSR

$0.00 \% \quad 11.3 \%$ NPATTNQTEFER

$0.00 \% \quad 13.0 \%$ IGEGTYGTVFK

1185.62

934.50

1078.59

1785.93

1516.75

1867.93

1912.94

1811.03

862.48

1565.81

1028.57

1801.92

2289.10

1209.67

1330.69

950.50

1106.60

1948.92

2077.02

1185.62

1057.66

1757.94

1488.75

1702.95

1767.00

862.48

1000.55

1607.81

862.48

1024.62

1434.69

1407.65

1171.60 
Cytoplasmic dynein 1 heavy chain $1 \mathrm{GN}=\mathrm{DYNC1H} 1$ DYHC1_HUMAN $532.41 \quad 100.0 \% \quad 78$ Cytoplasmic dynein 1 heavy chain $1 \mathrm{GN}=$ DYNC1H1 DYHC1_HUMAN $532.41 \quad 100.0 \% \quad 78$ Cytoplasmic dynein 1 heavy chain $1 \mathrm{GN}=$ DYNC1H1 DYHC1_HUMAN $532.41 \quad 100.0 \% \quad 78$ Cytoplasmic dynein 1 heavy chain $1 \mathrm{GN}=$ DYNC1H1 DYHC1_HUMAN $532.41 \quad 100.0 \% \quad 78$

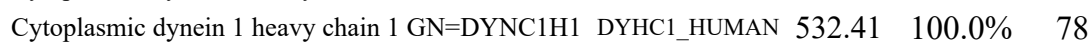
$\begin{array}{lllll}\text { Cytoplasmic dynein } 1 \text { heavy chain } 1 \mathrm{GN}=\mathrm{DYNC1H} 1 & \text { DYHC1_HUMAN } & 532.41 & 100.0 \% & 78\end{array}$ Cytoplasmic dynein 1 heavy chain 1 GN=DYNC1H1 DYHC1_HUMAN $532.41 \quad 100.0 \% \quad 78$

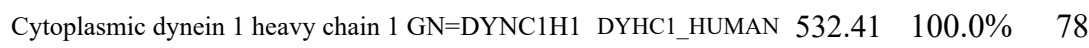
Cytoplasmic dynein 1 heavy chain $1 \mathrm{GN}=\mathrm{DYNC1H} 1$ DYHC1_HUMAN $532.41 \quad 100.0 \% \quad 78$ Cytoplasmic dynein 1 heavy chain $1 \mathrm{GN}=\mathrm{DYNC} 1 \mathrm{H} 1$ DYHC1_HUMAN $532.41 \quad 100.0 \% \quad 78$ Cytoplasmic dynein 1 heavy chain $1 \mathrm{GN}=\mathrm{DYNC1H} 1$ DYHC1_HUMAN $532.41 \quad 100.0 \% \quad 78$ Cytoplasmic dynein 1 heavy chain $1 \mathrm{GN}=$ DYNC1H1 DYHC1_HUMAN $532.41 \quad 100.0 \% \quad 78$ $\begin{array}{llll}\text { Cytoplasmic dynein } 1 \text { heavy chain } 1 \mathrm{GN}=\mathrm{DYNC} 1 \mathrm{H} 1 & \text { DYHC1_HUMAN } & 532.41 & 100.0 \%\end{array}$ Cytoplasmic dynein 1 heavy chain $1 \mathrm{GN}=\mathrm{DYNC1H} 1$ DYHC1_HUMAN $532.41 \quad 100.0 \% 78$ Cytoplasmic dynein 1 heavy chain $1 \mathrm{GN}=\mathrm{DYNC} 1 \mathrm{H} 1$ DYHC1_HUMAN $532.41 \quad 100.0 \% \quad 78$ Cytoplasmic dynein 1 heavy chain $1 \mathrm{GN}=$ DYNC1H1 DYHC1_HUMAN $532.41 \quad 100.0 \% \quad 78$ Cytoplasmic dynein 1 heavy chain $1 \mathrm{GN}=\mathrm{DYNC1H} 1$ DYHC1_HUMAN $532.41 \quad 100.0 \% \quad 78$ Cytoplasmic dynein 1 heavy chain $1 \mathrm{GN}=\mathrm{DYNC} 1 \mathrm{H} 1$ DYHC1_HUMAN $532.41 \quad 100.0 \% \quad 78$ Cytoplasmic dynein 1 heavy chain $1 \mathrm{GN}=\mathrm{DYNC1H} 1$ DYHC1_HUMAN $532.41 \quad 100.0 \% \quad 78$ Cytoplasmic dynein 1 heavy chain $1 \mathrm{GN}=$ DYNC1H1 DYHC1_HUMAN $532.41 \quad 100.0 \% \quad 78$ Cytoplasmic dynein 1 heavy chain $1 \mathrm{GN}=$ DYNC1H1 DYHC1_HUMAN $532.41 \quad 100.0 \% \quad 78$ Cytoplasmic dynein 1 heavy chain $1 \mathrm{GN}=\mathrm{DYNC1H} 1$ DYHC1_HUMAN $532.41 \quad 100.0 \% \quad 78$ $\begin{array}{llll}\text { Cytoplasmic dynein } 1 \text { heavy chain } 1 \mathrm{GN}=\mathrm{DYNC} 1 \mathrm{H} 1 \text { DYHC1_HUMAN } 532.41 & 100.0 \% & 78\end{array}$ Cytoplasmic dynein 1 heavy chain $1 \mathrm{GN}=$ DYNC1H1 DYHC1_HUMAN $532.41 \quad 100.0 \% \quad 78$ Cytoplasmic dynein 1 heavy chain $1 \mathrm{GN}=\mathrm{DYNC1H} 1$ DYHC1_HUMAN $532.41 \quad 100.0 \% \quad 78$ Cytoplasmic dynein 1 heavy chain $1 \mathrm{GN}=\mathrm{DYNC} 1 \mathrm{H} 1$ DYHC1_HUMAN $532.41 \quad 100.0 \% \quad 78$ Cytoplasmic dynein 1 heavy chain 1 GN=DYNC1H1 DYHC1_HUMAN $532.41 \quad 100.0 \% \quad 78$ Cytoplasmic dynein 1 heavy chain $1 \mathrm{GN}=\mathrm{DYNC1H} 1$ DYHC1_HUMAN $532.41 \quad 100.0 \% \quad 78$ Cytoplasmic dynein 1 heavy chain $1 \mathrm{GN}=\mathrm{DYNC1H} 1$ DYHC1_HUMAN $532.41 \quad 100.0 \% \quad 78$ Cytoplasmic dynein 1 heavy chain $1 \mathrm{GN}=\mathrm{DYNC1H} 1$ DYHC1 HUMAN $532.41 \quad 100.0 \% \quad 78$ Cytoplasmic dynein 1 heavy chain $1 \mathrm{GN}=\mathrm{DYNC} 1 \mathrm{H} 1$ DYHC1_HUMAN $532.41 \quad 100.0 \% \quad 78$ Cytoplasmic dynein 1 heavy chain $1 \mathrm{GN}=$ DYNC1H1 DYHC1_HUMAN $532.41 \quad 100.0 \% \quad 78$ Cytoplasmic dynein 1 heavy chain $1 \mathrm{GN}=$ DYNC1H1 DYHC1_HUMAN $532.41 \quad 100.0 \% \quad 78$ $\begin{array}{llll}\text { Cytoplasmic dynein } 1 \text { heavy chain } 1 \mathrm{GN}=\mathrm{DYNC1H} 1 & \text { DYHC1_HUMAN } & 532.41 & 100.0 \%\end{array}$ Cytoplasmic dynein 1 heavy chain $1 \mathrm{GN}=\mathrm{DYNC1H} 1$ DYHC1_HUMAN $532.41 \quad 100.0 \% \quad 78$ Cytoplasmic dynein 1 heavy chain $1 \mathrm{GN}=$ DYNC1H1 DYHC1_HUMAN $532.41 \quad 100.0 \% \quad 78$ Cytoplasmic dynein 1 heavy chain $1 \mathrm{GN}=$ DYNC1H1 DYHC1_HUMAN $532.41 \quad 100.0 \% \quad 78$ Cytoplasmic dynein 1 heavy chain $1 \mathrm{GN}=\mathrm{DYNC1H} 1$ DYHC1 HUMAN $532.41 \quad 100.0 \%$ $\begin{array}{llll}\text { Cytoplasmic dynein } 1 \text { heavy chain } 1 \mathrm{GN}=\mathrm{DYNC} 1 \mathrm{H} 1 & \text { DYHC1_HUMAN } & 532.41 & 100.0 \%\end{array}$ Cytoplasmic dynein 1 heavy chain $1 \mathrm{GN}=\mathrm{DYNC1H} 1$ DYHC1_HUMAN $532.41 \quad 100.0 \% \quad 78$ Cytoplasmic dynein 1 heavy chain $1 \mathrm{GN}=$ DYNC1H1 DYHC1_HUMAN $532.41 \quad 100.0 \% \quad 78$ Cytoplasmic dynein 1 heavy chain $1 \mathrm{GN}=\mathrm{DYNC} 1 \mathrm{H} 1$ DYHC1_HUMAN $532.41 \quad 100.0 \% \quad 78$ Cytoplasmic dynein 1 heavy chain $1 \mathrm{GN}=\mathrm{DYNC1H} 1$ DYHC1_HUMAN $532.41 \quad 100.0 \% \quad 78$ Cytoplasmic dynein 1 heavy chain $1 \mathrm{GN}=$ DYNC1H1 DYHC1_HUMAN $532.41 \quad 100.0 \% 78$ Cytoplasmic dynein 1 heavy chain $1 \mathrm{GN}=$ DYNC1H1 DYHC1_HUMAN $532.41 \quad 100.0 \% \quad 7$ Cytoplasmic dynein 1 heavy chain $1 \mathrm{GN}=\mathrm{DYNC} 1 \mathrm{H} 1$ DYHC1_HUMAN $532.41 \quad 100.0 \% \quad 78$ Cytoplasmic dynein 1 heavy chain $1 \mathrm{GN}=\mathrm{DYNC1H} 1$ DYHC1_HUMAN $532.41 \quad 100.0 \% \quad 78$
$87 \quad 301 \quad 0.30 \% \quad 17.1 \%$ QYASYEFVQR

$87 \quad 301 \quad 0.30 \% \quad 17.1 \%$ INMLVIELK

$87 \quad 301 \quad 0.30 \% \quad 17.1 \%$ HLLPVETQR

$87 \quad 301 \quad 0.30 \% \quad 17.1 \%$ SPLVMDVLNIQGVQR

$87 \quad 301 \quad 0.30 \% \quad 17.1 \%$ TPVSITEHPK

$87 \quad 301 \quad 0.30 \% \quad 17.1 \%$ LLAESVTEVEIFGK

$87 \quad 301 \quad 0.30 \% \quad 17.1 \%$ QTDVLQQLSIQMANAK

$87 \quad 301 \quad 0.30 \% \quad 17.1 \%$ CYLTMTQALEAR

$87 \quad 301 \quad 0.30 \% \quad 17.1 \%$ LGGSPFGPAGTGK

$87 \quad 301 \quad 0.30 \% \quad 17.1 \%$ LGGSPFGPAGTGKTESVK

$87 \quad 301 \quad 0.30 \% \quad 17.1 \%$ ALGHQLGR

$87 \quad 301 \quad 0.30 \% \quad 17.1 \%$ TSAPITCELLNK

$87 \quad 301 \quad 0.30 \% \quad 17.1 \%$ SNLPDNLKK

$87 \quad 301 \quad 0.30 \% \quad 17.1 \%$ SLAMTKPDR

$87 \quad 301 \quad 0.30 \% \quad 17.1 \%$ QLIAQVMLYSQGFR

$87 \quad 301 \quad 0.30 \% \quad 17.1 \%$ SVLVSAGNVK

$87 \quad 301 \quad 0.30 \% \quad 17.1 \%$ SVLVSAGNVKR

$87 \quad 301 \quad 0.30 \% \quad 17.1 \%$ IIDSVRGELQK

$87 \quad 301 \quad 0.30 \% \quad 17.1 \%$ SIPLDEGEDEAQR

$87 \quad 301 \quad 0.30 \% \quad 17.1 \%$ SIPLDEGEDEAQRR

$87 \quad 301 \quad 0.30 \% \quad 17.1 \%$ DAATIMQPYFTSNGLVTK

$87 \quad 301 \quad 0.30 \% \quad 17.1 \%$ AELGEYIR

$87 \quad 301 \quad 0.30 \% \quad 17.1 \%$ AELGEYIRR

$87 \quad 301 \quad 0.30 \% \quad 17.1 \%$ VPQIEVETHK

$87 \quad 301 \quad 0.30 \% \quad 17.1 \%$ TMTLFSALR

$87 \quad 301 \quad 0.30 \% \quad 17.1 \%$ TFDHYCEYR

$87 \quad 301 \quad 0.30 \% \quad 17.1 \%$ TSDQTWVKLER

$87 \quad 301 \quad 0.30 \% \quad 17.1 \%$ IQFVGACNPPTDPGR

$87 \quad 301 \quad 0.30 \% \quad 17.1 \%$ FTQDTQPHYIYSPR

$87 \quad 301 \quad 0.30 \% \quad 17.1 \%$ WTDENIDTVALK

$87 \quad 301 \quad 0.30 \% \quad 17.1 \%$ AATSPALFNR

$87 \quad 301 \quad 0.30 \% \quad 17.1 \%$ EAIVNSCVFVHQTLHQANAR

$87 \quad 301 \quad 0.30 \% \quad 17.1 \%$ SMANPPAAVK

$87 \quad 301 \quad 0.30 \% \quad 17.1 \%$ NYMSNPSYNYEIVNR

$87 \quad 301 \quad 0.30 \% \quad 17.1 \%$ ASLACGPMVK

$87 \quad 301 \quad 0.30 \% \quad 17.1 \%$ VEPLRNELQK

$87 \quad 301 \quad 0.30 \% \quad 17.1 \%$ TEYLSNADER

$87 \quad 301 \quad 0.30 \% \quad 17.1 \%$ TEYLSNADERLR

$87 \quad 301 \quad 0.30 \% \quad 17.1 \%$ TSFLDDAFRK

$87 \quad 301 \quad 0.30 \% \quad 17.1 \%$ VTFVNFTVTR

$87 \quad 301 \quad 0.30 \% \quad 17.1 \%$ SSLQSQCLNEVLK

$87 \quad 301 \quad 0.30 \% \quad 17.1 \%$ LQGEFQLR

$87 \quad 301 \quad 0.30 \% \quad 17.1 \%$ SLLQALNEVK

$87 \quad 301 \quad 0.30 \% \quad 17.1 \%$ SLLQALNEVKGR

$87 \quad 301 \quad 0.30 \% \quad 17.1 \%$ DLFQVAFNR

$87 \quad 301 \quad 0.30 \% \quad 17.1 \%$ IQGLTVEQAEAVVR

$87 \quad 301 \quad 0.30 \% \quad 17.1 \%$ LSCLPAFKDLIAK
$99.7 \% \quad 42.8 \quad 25.0 \quad 41.3 \quad 6$

$\begin{array}{llll}99.7 \% & 31.4 & 25.0 & 24.9\end{array}$

$99.7 \% \quad 36.7 \quad 25.0 \quad 36.7 \quad 3$

$\begin{array}{llll}99.7 \% & 54.7 & 25.0 & 54.7\end{array}$

$\begin{array}{llll}99.7 \% & 47.1 & 25.0 & 38.8\end{array}$

$\begin{array}{llll}99.7 \% & 59.5 & 25.0 & 59.5\end{array}$

$99.7 \% \quad 33.3$

$99.7 \% \quad 50.5$

$99.7 \% \quad 55.5$

$25.0 \quad 33.3$

$25.0 \quad 43.3$

$99.4 \% \quad 22.0$

$99.0 \% \quad 30.5$

$99.7 \% \quad 31.4$

$98.4 \% 21.1$

$99.5 \% \quad 28.5$

$99.7 \% \quad 39.9$

$99.7 \% \quad 33.5$

$99.7 \% \quad 57.2$

$99.3 \% \quad 31.9$

$\begin{array}{lll}99.7 \% & 42.1\end{array}$

$99.7 \% \quad 32.7$

$99.7 \% \quad 47.1$

$99.0 \% \quad 29.4$

$99.4 \% \quad 20.2$

$99.7 \% \quad 45.6$

$99.7 \% \quad 41.3$

$99.7 \% \quad 32.2$

$95.8 \% \quad 18.9$

$99.7 \% \quad 53.2$

$99.7 \% \quad 65.0$

$99.7 \% \quad 28.7$

$99.7 \% \quad 52.6$

$99.7 \% \quad 31.3$

$99.7 \% \quad 32.9$

$99.7 \% \quad 54.5$

$96.0 \% \quad 17.2$

$97.5 \% 23.6$

$99.5 \% \quad 26.8$

$98.5 \% \quad 19.5$

$99.7 \% \quad 55.2$

$99.7 \% \quad 69.8$

$99.7 \% \quad 54.5$

$99.0 \% \quad 38.3$

$99.7 \% \quad 40.0$

$99.7 \% \quad 51.8$

$99.7 \% \quad 56.5$

$99.7 \% \quad 55.9$

$99.5 \% \quad 21.1$
108

$\begin{array}{lll}1396 & 1404\end{array}$

$\begin{array}{lll}1668.91 & 1559 & 1567\end{array}$

$\begin{array}{lll}1534.84 & 1716 & 1729\end{array}$

$\begin{array}{lll}1787.93 & 1850 & 1865\end{array}$

$\begin{array}{lll}1456.69 & 1888 & 1899\end{array}$

$\begin{array}{lll}1145.60 & 1900 & 1912\end{array}$

$\begin{array}{lll}1689.88 & 1900 \quad 1917\end{array}$

$\begin{array}{lll}851.48 & 1918 \quad 1925\end{array}$

$\begin{array}{lll}1346.70 & 1993 \quad 2004\end{array}$

$1028.57 \quad 2026 \quad 2034$

$1018.54 \quad 2038 \quad 2046$

$\begin{array}{lll}1653.88 & 2047 \quad 2060\end{array}$

$\begin{array}{ccc}973.57 & 2095 & 2104\end{array}$

$1129.67 \quad 2095 \quad 2105$

$\begin{array}{lll}1257.72 & 2287 & 2297\end{array}$

$\begin{array}{lll}1458.67 & 2384 & 2396\end{array}$

$\begin{array}{lll}1614.77 & 2384 & 2397\end{array}$

$\begin{array}{lll}1972.97 & 2418 \quad 2435\end{array}$

$950.49 \quad 2512 \quad 2519$

$\begin{array}{lll}1106.60 & 2512 \quad 2520\end{array}$

$\begin{array}{lll}1179.64 & 2552 & 2561\end{array}$

$1055.56 \quad 2602 \quad 2610$

$\begin{array}{lll}1290.52 & 2634 & 2642\end{array}$

$\begin{array}{lll}1362.70 & 2695 & 2705\end{array}$

$\begin{array}{lll}1628.79 & 2706 \quad 2720\end{array}$

$\begin{array}{lll}1752.83 & 2784 & 2797\end{array}$

$\begin{array}{lll}1404.70 & 2845 \quad 2856\end{array}$

$\begin{array}{lll}1047.56 & 3079 & 3088\end{array}$

$\begin{array}{lll}2294.15 & 3141 & 3160\end{array}$

$1001.51 \quad 3309 \quad 3318$

$\begin{array}{lll}1879.83 & 3370 & 3384\end{array}$

$1049.51 \quad 3385 \quad 3394$

$1225.69 \quad 3409 \quad 3418$

$\begin{array}{lll}1197.54 & 3550 & 3559\end{array}$

$1466.72 \quad 3550 \quad 3561$

$\begin{array}{lll}1199.61 & 3612 & 3621\end{array}$

$\begin{array}{lll}1183.65 & 3696 & 3705\end{array}$

$1505.76 \quad 3706 \quad 3718$

$\begin{array}{lll}990.54 & 3734 & 3741\end{array}$

$1114.65 \quad 3748 \quad 3757$

$\begin{array}{lll}1327.77 & 3748 & 3759\end{array}$

$\begin{array}{lll}1109.57 & 3862 & 3870\end{array}$

$1512.84 \quad 3924 \quad 3937$

$1475.83 \quad 3938 \quad 3950$ 

Cytoplasmic dynein 1 heavy chain $1 \mathrm{GN}=$ DYNC1H1 DYHC1_HUMAN $532.41 \quad 100.0 \% \quad 78$ Cytoplasmic dynein 1 heavy chain $1 \mathrm{GN}=$ DYNC1H1 DYHC1_HUMAN $532.41 \quad 100.0 \% \quad 78$ Cytoplasmic dynein 1 heavy chain $1 \mathrm{GN}=$ DYNC1H1 DYHC1_HUMAN $532.41 \quad 100.0 \% \quad 78$ Cytoplasmic dynein 1 heavy chain $1 \mathrm{GN}=\mathrm{DYNC} 1 \mathrm{H} 1$ DYHC1_HUMAN $532.41 \quad 100.0 \%$ Cytoplasmic dynein 1 heavy chain $1 \mathrm{GN}=$ DYNC1H1 DYHC1_HUMAN $532.41 \quad 100.0 \% 7$ Cytoplasmic dynein 1 heavy chain $1 \mathrm{GN}=$ DYNC1H1 DYHC1_HUMAN $532.41 \quad 100.0 \% \quad 78$ $\begin{array}{llll}\text { Cytoplasmic dynein } 1 \text { heavy chain } 1 \mathrm{GN}=\text { DYNC1H1 DYHC1_HUMAN } 532.41 & 100.0 \% & 7\end{array}$ Cytoplasmic dynein 1 heavy chain $1 \mathrm{GN}=$ DYNC1H1 DYHC1_HUMAN $532.41 \quad 100.0 \% \quad 7$ Cytoplasmic dynein 1 light intermediate chain 1 GN=DYNC1LI1 DC1L1_HUMAN $56.58 \quad 100.0 \%$ Cytoplasmic dynein 1 light intermediate chain $1 \mathrm{GN}=$ DYNC1LI1 DC1L1_HUMAN $56.58 \quad 100.0 \%$ Cytoplasmic dynein 1 light intermediate chain 1 GN=DYNC1LI1 DC1L1_HUMAN $56.58 \quad 100.0 \%$ Cytoplasmic dynein 1 light intermediate chain 1 GN=DYNC1LI1 DC1L1_HUMAN $56.58 \quad 100.0 \%$ Cytoplasmic dynein 1 light intermediate chain 1 GN=DYNC1LI1 DC1L1_HUMAN $56.58 \quad 100.0 \%$ Cytoplasmic dynein 2 heavy chain $1 \mathrm{GN}=\mathrm{DYNC} 2 \mathrm{H} 1$ DYHC2_HUMAN $492.63 \quad 100.0 \%$ Cytoplasmic dynein 2 heavy chain $1 \mathrm{GN}=\mathrm{DYNC} 2 \mathrm{H} 1 \quad$ DYHC2_HUMAN $492.63 \quad 100.0 \%$ Cytoplasmic dynein 2 heavy chain $1 \mathrm{GN}=\mathrm{DYNC} 2 \mathrm{H} 1$ DYHC2 HUMAN $492.63 \quad 100.0 \%$ Cytoplasmic dynein 2 heavy chain $1 \mathrm{GN}=\mathrm{DYNC2H} 1$ DYHC2_HUMAN $492.63 \quad 100.0 \%$ Cytoplasmic dynein 2 heavy chain $1 \mathrm{GN}=\mathrm{DYNC} 2 \mathrm{H} 1$ DYHC2_HUMAN $492.63 \quad 100.0 \%$ Cytoplasmic dynein 2 heavy chain $1 \mathrm{GN}=\mathrm{DYNC} 2 \mathrm{H} 1$ DYHC2_HUMAN $492.63100 .0 \%$ Cytoplasmic FMR1-interacting protein 1 GN=CYFIP1 CYFP1_HUMAN $145.19 \quad 100.0 \%$ Cytoplasmic FMR1-interacting protein $1 \mathrm{GN}=$ CYFIP1 CYFP1_HUMAN $145.19100 .0 \%$ Cytoplasmic FMR1-interacting protein 1 GN=CYFIP1 CYFP1_HUMAN $145.19 \quad 100.0 \%$ Cytoplasmic FMR1-interacting protein 1 GN=CYFIP1 CYFP1_HUMAN $145.19 \quad 100.0 \%$ Cytoplasmic FMR1-interacting protein $1 \mathrm{GN}=$ CYFIP1 CYFP1_HUMAN $145.19 \quad 100.0 \%$ Cytoplasmic FMR1-interacting protein $1 \mathrm{GN}=\mathrm{CYFIP} 1$ CYFP1_HUMAN $145.19 \quad 100.0 \%$ Cytoplasmic FMR1-interacting protein 1 GN=CYFIP1 CYFP1_HUMAN $145.19100 .0 \%$ Cytoplasmic FMR1-interacting protein $1 \mathrm{GN}=$ CYFIP1 CYFP1_HUMAN $145.19100 .0 \%$ Cytoplasmic FMR1-interacting protein $1 \mathrm{GN}=$ CYFIP1 CYFP1_HUMAN $145.19 \quad 100.0 \%$ Cytoplasmic FMR1-interacting protein $1 \mathrm{GN}=$ CYFIP1 CYFP1_HUMAN $145.19100 .0 \%$ Cytoplasmic FMR1-interacting protein 2 GN=CYFIP2 CYFP2_HUMAN $148.40 \quad 100.0 \%$ Cytoplasmic FMR1-interacting protein 2 GN=CYFIP2 CYFP2_HUMAN $148.40 \quad 100.0 \%$ Cytoplasmic FMR1-interacting protein 2 GN=CYFIP2 CYFP2_HUMAN $148.40 \quad 100.0 \%$ Cytoplasmic FMR1-interacting protein 2 GN=CYFIP2 CYFP2_HUMAN $148.40 \quad 100.0 \%$ Cytoplasmic FMR1-interacting protein $2 \mathrm{GN}=$ CYFIP2 CYFP2_HUMAN $148.40 \quad 100.0 \%$ Cytoplasmic FMR1-interacting protein 2 GN=CYFIP2 CYFP2_HUMAN $148.40 \quad 100.0 \%$ Cytoskeleton-associated protein 5 GN=CKAP5 CKAP5_HUMAN $225.50 \quad 100.0 \%$ Cytoskeleton-associated protein $5 \mathrm{GN}=\mathrm{CKAP} 5$ CKAP5 HUMAN $225.50 \quad 100.0 \%$ Cytoskeleton-associated protein 5 GN=CKAP5 CKAP5_HUMAN $225.50 \quad 100.0 \%$ Cytoskeleton-associated protein $5 \mathrm{GN}=$ CKAP5 CKAP5_HUMAN $225.50 \quad 100.0 \%$ Cytoskeleton-associated protein $5 \mathrm{GN}=\mathrm{CKAP} 5$ CKAP5 HUMAN $225.50 \quad 100.0 \%$ Cytosolic acyl coenzyme A thioester hydrolase GN=ACOT7 BACH_HUMAN $41.80 \quad 100.0 \%$ Cytosolic acyl coenzyme A thioester hydrolase GN=ACOT7 BACH HUMAN $41.80 \quad 100.0 \%$ Cytosolic acyl coenzyme A thioester hydrolase GN=ACOT7 BACH_HUMAN $41.80 \quad 100.0 \%$ Cytosolic Fe-S cluster assembly factor NUBP2 GN=NUBP2 NUBP2_HUMAN $28.83 \quad 100.0 \%$ Cytosolic Fe-S cluster assembly factor NUBP2 GN=NUBP2 NUBP2_HUMAN $28.83 \quad 100.0 \%$ D-3-phosphoglycerate dehydrogenase GN=PHGDH SERA_HUMAN $56.65 \quad 100.0 \%$
$87 \quad 301 \quad 0.30 \% \quad 17.1 \%$ LFLTMEINPK

$87 \quad 301 \quad 0.30 \% \quad 17.1 \%$ IFVFEPPPGVK

$87 \quad 301 \quad 0.30 \% \quad 17.1 \%$ TFSSIPVSR

$87 \quad 301 \quad 0.30 \% \quad 17.1 \%$ KYEFGESDLR

$87 \quad 301 \quad 0.30 \% \quad 17.1 \%$ TLMAQSIYGGR

$87 \quad 301 \quad 0.30 \% \quad 17.1 \%$ VDNEFDQR

$87 \quad 301 \quad 0.30 \% \quad 17.1 \%$ LLNTFLER

$87 \quad 301 \quad 0.30 \% \quad 17.1 \%$ VLLTTQGVDMISK

$87 \quad 301 \quad 0.30 \% \quad 17.1 \%$ ASVVTLPVYLNFTR

$12 \quad 0.01 \% \quad 14.5 \%$ NVLLLGEDGAGKTSLIR

$12 \quad 0.01 \% \quad 14.5 \%$ IPAVVVEK

$0.01 \% \quad 14.5 \%$ QPPTAAGRPVDASPR

$0.01 \% \quad 14.5 \%$ SVSSNVASVSPIPAGSK

0.01\% $14.5 \%$ KPVTVSPTTPTSPTEGEAS

$0.01 \% \quad 2.0 \% \quad$ VTTLTTHAGIR

$\quad 0.01 \% \quad 2.0 \%$ SLEGEVVPFK

$0.01 \% \quad 2.0 \%$ SGTTQNANESHIVVQALR

$0.01 \% \quad 2.0 \%$ STQIATVHCSAQTTSR

$0.01 \% \quad 2.0 \%$ LAVGNIKPESLSEIR

$19 \quad 0.02 \% \quad 9.5 \% \quad$ YSNSEVVTGSGR

$9 \quad 0.02 \% \quad 9.5 \% \quad$ NVIQSVLQAIR

$9 \quad 0.02 \% \quad 9.5 \%$ SGFDIKVPR

$19 \quad 0.02 \% \quad 9.5 \%$ RAVGPSSTQLYMVR

$0.02 \% \quad 9.5 \%$ SIDLNRLITQR

$9 \quad 0.02 \% \quad 9.5 \% \quad$ TVLPFSQEFQR

$19 \quad 0.02 \% \quad 9.5 \% \quad$ DKQPNAQPQYLHGSK

$0.02 \% \quad 9.5 \% \quad$ YAPLHLVPLIER

$190.02 \% \quad 9.5 \% \quad$ LGTPQQIAIAR

$19 \quad 0.02 \% \quad 9.5 \%$ CFQPPIHQSLASS

$0.00 \% \quad 5.2 \%$ GGFDIKVPR

$0.00 \% \quad 5.2 \% \quad$ SIDLNRLITQR

$0.00 \% \quad 5.2 \%$ TAIPFTQEPQR

$0.00 \% \quad 5.2 \% \quad$ YAPLHLVPLIER

$0.00 \% \quad 5.2 \% \quad$ LGTPQQIAIAR

$0.00 \% \quad 5.2 \% \quad$ SVETDSSTVEHVR

$0.01 \% \quad 2.7 \%$ TTGEVVSGVVSK

$0.01 \% \quad 2.7 \% \quad$ LIAVEIYR

$0.01 \% \quad 2.7 \%$ QQTSLFIAR

$0.01 \% \quad 2.7 \%$ TALAATNPAVR

$0.01 \% \quad 2.7 \%$ TEISDKITSELVSK

$0.00 \% \quad 10.3 \%$ MIEEAGAIISTR

$0.00 \% \quad 10.3 \%$ VLEVPPVVYSR

$0.00 \% \quad 10.3 \%$ AASAFFTYVSLSQEGR

$0.01 \% \quad 10.0 \%$ STISTELALALR

$0.01 \% \quad 10.0 \%$ VGILDVDLCGPSIPR

$0.06 \% \quad 35.8 \%$ ILQDGGLQVVEK
$0.01 \% \quad 2.0 \%$ TVAGGGLETISNLK
$99.7 \% \quad 62.6$

$99.7 \% \quad 34.0$

$\begin{array}{lll}99.7 \% & 52.7\end{array}$

$99.7 \% \quad 34.3$

$99.7 \% \quad 40.9$

$99.0 \% \quad 34.3$

$99.0 \% \quad 32.8$

$99.7 \% \quad 55.7$

$97.0 \% \quad 15.4$

$99.7 \% \quad 29.0$

$99.0 \% \quad 20.3$

$96.8 \% \quad 15.0$

$99.7 \% \quad 54.3$

$99.7 \% \quad 44.6$

$99.7 \% 61.4$

$99.7 \% \quad 40.4$

$97.0 \% \quad 20.8$

$99.5 \% \quad 21.2$

$99.7 \% \quad 38.0$

$98.2 \% \quad 17.8$

$99.7 \% \quad 29.1$

$99.7 \% \quad 51.5$

$99.7 \% \quad 54.3$

$\begin{array}{lll}99.5 \% & 24.2\end{array}$

$99.7 \% \quad 26.8$

$99.7 \% \quad 33.6$

$94.9 \% \quad 14.5$

$99.7 \% \quad 36.6$

$99.7 \% \quad 60.1$

$99.1 \% \quad 19.2$

$99.7 \% \quad 30.3$

$99.7 \% \quad 26.8$

$99.7 \% \quad 31.0$

$99.7 \% \quad 36.6$

$99.7 \% \quad 60$.

$99.7 \% \quad 54.5$

$99.7 \% \quad 44.5$

$97.9 \% \quad 19.6$

$99.7 \% \quad 26.3$

$99.7 \% \quad 33.8$

$99.7 \% 32.6$

$99.7 \% \quad 47.6$

$99.6 \% 27.7$

$99.7 \% \quad 72.2$

$99.7 \% \quad 51.4$

$99.7 \% \quad 62.2$

$99.7 \% \quad 52.8$

-0
5.0

$\begin{array}{ll}0 & 45.8 \\ & \end{array}$

25.7

\begin{tabular}{ll}
.0 & 34.3 \\
\hline
\end{tabular}

$\begin{array}{ll}0 & 26.3\end{array}$

$\begin{array}{ll}23.9 & 23.9\end{array}$

54.0

$\begin{array}{ll}0 & 15.4\end{array}$

$\begin{array}{ll}25.0 & 29.0\end{array}$

$\begin{array}{ll}25.0 & 17.5\end{array}$

$\begin{array}{ll}0 & 15.0\end{array}$

$\begin{array}{ll}0 & 48.3\end{array}$

$\begin{array}{ll}0.0 & 44.4\end{array}$

$\begin{array}{ll}.0 & 54.7\end{array}$

$\begin{array}{lll} & 34.0 & 2\end{array}$

$\begin{array}{ll}0 & 20.8\end{array}$

$\begin{array}{ll}5.0 & 21.2\end{array}$

38.0
25.0

$\begin{array}{ll}25.0 & 17.8\end{array}$

29.

37.6
25.0

$25.0 \quad 51.7$

\begin{tabular}{ll}
23.5 \\
\hline
\end{tabular}

$.0 \quad 21.4$

\begin{tabular}{ll}
26.6 \\
\hline
\end{tabular}

$\begin{array}{ll}25.0 & 14.5\end{array}$

$.0 \quad 36.6$

$5.0 \quad 56.3$

18.1
-0

\begin{tabular}{ll}
20.6 \\
\hline
\end{tabular}

$\begin{array}{ll}25.0 & 21.4\end{array}$

$\begin{array}{ll}.0 & 21.4 \\ 0 & 30.2\end{array}$

$\begin{array}{ll}36.0 & 36.6\end{array}$

$\begin{array}{ll}5.0 & 56.3\end{array}$

$\begin{array}{ll}5.0 & 54.2\end{array}$

\begin{tabular}{l}
30.6 \\
\hline
\end{tabular}

$0 \quad 15.4$

$\begin{array}{ll}25.0 & 19.5\end{array}$

$\begin{array}{ll}5.0 & 29.3\end{array}$

32.6

$\begin{array}{ll}5.0 & 47.6\end{array}$

$\begin{array}{ll}27.0 & 27.7\end{array}$

$\begin{array}{ll}72.2 \\ 25.0 & 46.0\end{array}$

$\begin{array}{ll}75.0 & 46.0\end{array}$

$\begin{array}{lll} & 46.0 \\ 5 & 54.9 & 4\end{array}$

2

1018.57

1580.82

1328.76

1351.70

1710.86

1420.83

1167.68

1471.70

988.56

1328.76

1287.67

1420.83

1167.68

1445.69

1162.63

976.58

1063.59

1084.61

1549.83

1306.67

1257.72

1733.85

1274.73

1610.86

1298.73 
D-3-phosphoglycerate dehydrogenase GN=PHGDH SERA_HUMAN $56.65 \quad 100.0 \%$ D-3-phosphoglycerate dehydrogenase GN=PHGDH SERA HUMAN $56.65 \quad 100.0 \%$ D-3-phosphoglycerate dehydrogenase GN=PHGDH SERA_HUMAN $56.65 \quad 100.0 \%$ D-3-phosphoglycerate dehydrogenase GN=PHGDH SERA_HUMAN $56.65 \quad 100.0 \%$ $\begin{array}{llll}\text { D-3-phosphoglycerate dehydrogenase GN=PHGDH SERA_HUMAN } & 56.65 & 100.0 \% & 1\end{array}$ D-3-phosphoglycerate dehydrogenase GN=PHGDH SERA_HUMAN $56.65 \quad 100.0 \%$ D-3-phosphoglycerate dehydrogenase GN=PHGDH SERA HUMAN $56.65 \quad 100.0 \% \quad 1$ D-3-phosphoglycerate dehydrogenase GN=PHGDH SERA_HUMAN $56.65 \quad 100.0 \% \quad 1$ D-3-phosphoglycerate dehydrogenase GN=PHGDH SERA HUMAN $56.65 \quad 100.0 \%$ D-3-phosphoglycerate dehydrogenase GN=PHGDH SERA_HUMAN $56.65 \quad 100.0 \% \quad 19$ D-3-phosphoglycerate dehydrogenase GN=PHGDH SERA_HUMAN $56.65 \quad 100.0 \%$ D-3-phosphoglycerate dehydrogenase GN=PHGDH SERA_HUMAN 56.65 D-3-phosphoglycerate dehydrogenase GN=PHGDH SERA_HUMAN 56.65 D-3-phosphoglycerate dehydrogenase GN=PHGDH SERA HUMAN 56.65 D-3-phosphoglycerate dehydrogenase GN=PHGDH SERA HUMAN 56.65 D-3-phosphoglycerate dehydrogenase GN=PHGDH SERA_HUMAN 56.65 D-3-phosphoglycerate dehydrogenase GN=PHGDH SERA HUMAN 56.65 D-3-phosphoglycerate dehydrogenase GN=PHGDH SERA_HUMAN 56.65 DBIRD complex subunit ZNF326 GN=ZNF326 ZN326_HUMAN 65.65 DBIRD complex subunit ZNF326 GN=ZNF326 ZN326 HUMAN 65.65 DBIRD complex subunit ZNF326 GN=ZNF326 ZN326_HUMAN 65.65 DBIRD complex subunit ZNF326 GN=ZNF326 ZN326 HUMAN 65.65 DBIRD complex subunit ZNF326 GN=ZNF326 ZN326_HUMAN 65.65 DBIRD complex subunit ZNF326 GN=ZNF326 ZN326 HUMAN 65.65 DBIRD complex subunit ZNF326 GN=ZNF326 ZN326 HUMAN 65.65 DBIRD complex subunit ZNF326 GN=ZNF326 ZN326_HUMAN 65.65 DDB1- and CUL4-associated factor 7 GN=DCAF7 DCAF7_HUMAN 38.93 DDB1- and CUL4-associated factor $7 \mathrm{GN}=\mathrm{DCAF} 7$ DCAF7 HUMAN 38.93 DDB1- and CUL4-associated factor 7 GN=DCAF7 DCAF7_HUMAN 38.93 DDB1- and CUL4-associated factor $7 \mathrm{GN}=$ DCAF7 DCAF7 HUMAN 38.93 DDB1- and CUL4-associated factor 7 GN=DCAF7 DCAF7 HUMAN 38.93 DDB1- and CUL4-associated factor 7 GN=DCAF7 DCAF7_HUMAN 38.93 DDRGK domain-containing protein $1 \mathrm{GN}=$ DDRGK1 DDRGK HUMAN 35.61 DDRGK domain-containing protein $1 \mathrm{GN}=$ DDRGK1 DDRGK_HUMAN 35.61 DDRGK domain-containing protein 1 GN=DDRGK1 DDRGK HUMAN 35.61 DDRGK domain-containing protein $1 \mathrm{GN}=$ DDRGK1 DDRGK_HUMAN $35.61100 .0 \%$ Dedicator of cytokinesis protein $11 \mathrm{GN}=$ DOCK11 DOC11_HUMAN $237.68 \quad 100.0 \%$ Dedicator of cytokinesis protein $11 \mathrm{GN}=$ DOCK11 DOC11 HUMAN $237.68100 .0 \%$ Dedicator of cytokinesis protein 4 GN=DOCK4 DOCK4_HUMAN $225.21 \quad 100.0 \%$ Dedicator of cytokinesis protein 4 GN=DOCK4 DOCK4_HUMAN $225.21 \quad 100.0 \%$ Dedicator of cytokinesis protein 4 GN=DOCK4 DOCK4_HUMAN $225.21 \quad 100.0 \%$ Dedicator of cytokinesis protein 4 GN=DOCK4 DOCK4_HUMAN $225.21 \quad 100.0 \%$ Dedicator of cytokinesis protein 4 GN=DOCK4 DOCK4_HUMAN $225.21 \quad 100.0 \%$ Dehydrogenase/reductase SDR family member 7B GN=DHRS7B DRS7B HUMAN $35.12 \quad 100.0 \%$ Dehydrogenase/reductase SDR family member 7B GN=DHRS7B DRS7B_HUMAN $35.12 \quad 100.0 \%$ Dehydrogenase/reductase SDR family member 7B GN=DHRS7B DRS7B_HUMAN $35.12 \quad 100.0 \%$ Dehydrogenase/reductase SDR family member 7B GN=DHRS7B DRS7B_HUMAN $35.12 \quad 100.0 \%$

8

6
6
6

6

6
6
6
6
4
4
4
4
2
2
5
5
5
5
5
5
5
5
5

$0.06 \% \quad 35.8 \%$ VTADVINAAEK

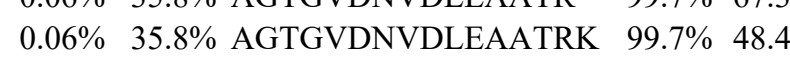

$0.06 \% 35.8 \%$ TLGILGLGR

$0.06 \% \quad 35.8 \%$ IGREVATR

$99.7 \% \quad 48.6$

$99.0 \% \quad 34.5$

$0.06 \% \quad 35.8 \%$ GGIVDEGALLR

$99.7 \% \quad 65.7$

$0.06 \% \quad 35.8 \%$ ALQSGQCAGAALDVFTEEPPRDR $\quad 99.7 \% \quad 34.9$

$0.06 \% \quad 35.8 \%$ ALVDHENVISCPHLGASTK $99.7 \% \quad 41.1$

$0.06 \% \quad 35.8 \%$ ALVDHENVISCPHLGASTKEAQSR $\quad 99.7 \% \quad 31.5$

$0.06 \% \quad 35.8 \%$ CGEEIAVQFVDMVKGK $\quad 99.7 \% \quad 50.1$

$0.06 \% \quad 35.8 \%$ GTIQVITQGTSLK

$99.7 \% 63.0$

$\begin{array}{llllll}0.06 \% & 35.8 \% & \text { GTIQVITQGTSLKNAGNCLSPAVIVGLLK } & 99.7 \% & 40.2\end{array}$

$0.06 \% \quad 35.8 \%$ NAGNCLSPAVIVGLLK $\quad 99.7 \% \quad 47.3$

$\begin{array}{lllll}0.06 \% & 35.8 \% & \text { NAGNCLSPAVIVGLLKEASK } & 98.9 \% & 18.2\end{array}$

$0.06 \% 35.8 \%$ EASKQADVNLVNAK

$99.7 \% \quad 63.7$

$0.06 \% \quad 35.8 \%$ DLPLLLFR

$0.02 \% \quad 16.2 \%$ FGPYESYDSR

$0.02 \% \quad 16.2 \%$ SSLGGRDLYR

$0.02 \% \quad 16.2 \%$ SGYGFNEPEQSR

$0.02 \% \quad 16.2 \%$ FGGSYGGRFESSYR

$0.02 \% \quad 16.2 \%$ NQGGSSWEAPYSR

$0.02 \% \quad 16.2 \%$ NSEKYGDGYR

$0.02 \% \quad 16.2 \%$ MAFTCSFCK

$0.02 \% \quad 16.2 \%$ ESVLTATSILNNPIVK

$0.01 \% \quad 25.1 \%$ VQLVGLDEESSEFICR

$0.01 \% \quad 25.1 \%$ GVYPDLLATSGDYLR

$0.01 \% \quad 25.1 \%$ VGETETRLECLLNNNK

$0.01 \% \quad 25.1 \%$ VNLVSGHVK

$\begin{array}{ll}99.0 \% & 44.1 \\ 99.7 \% & 38.2\end{array}$

$99.7 \% \quad 28.9$

$99.7 \% \quad 45.0$

$\begin{array}{lll}95.6 \% & 16.2\end{array}$

$99.7 \% \quad 42.2$

$99.4 \% 20.7$

$99.1 \% \quad 21.3$

$99.7 \% \quad 53.1$

$99.7 \% \quad 87.7$

$99.7 \% \quad 64.2$

$99.5 \% \quad 21.2$

$99.7 \% \quad 29.7$

$0.01 \% \quad 25.1 \%$ TQLIAHDKEVYDIAFSR

$0.01 \% \quad 25.1 \%$ DMFASVGADGSVR

$\begin{array}{ll}99.7 \% & 41.4 \\ 99.7 \% & 56.5\end{array}$

0.00\% 20.7\% AASAGQEPLHNEELAGAGR $95.4 \% 13.9$

$0.00 \% \quad 20.7 \%$ VAQPGPLEPEEPR

$99.7 \% 27.2$

$0.00 \% \quad 20.7 \%$ VVLLEDLASQVGLR

$99.7 \% \quad 48.8$

$\begin{array}{lllll}0.00 \% & 20.7 \% & \text { IQDLLAEGTITGVIDDRGK } & 97.7 \% & 23.3\end{array}$

$0.00 \% \quad 1.0 \%$ LTGLSEISLR

$0.00 \% \quad 1.0 \% \quad$ IIQDSDKVNAK

$0.01 \% \quad 3.0 \%$ ESGVSLIATVTR

$0.01 \% \quad 3.0 \%$ TSLYLVQSLPGISR

$0.01 \% \quad 3.0 \% \quad$ TLISQCQTR

$0.01 \% \quad 3.0 \%$ NSAPASVSPDGTR

$0.01 \% \quad 3.0 \%$ SDPNLSAPEK

$0.01 \% \quad 19.4 \%$ ELTASHATK

$0.01 \% \quad 19.4 \%$ GTIMDTTVDVDKR

$99.7 \% 62.7$

$99.7 \% \quad 70.3$

$99.7 \% \quad 43.8$

$97.8 \% \quad 16.5$

$99.7 \% \quad 37.0$

$99.4 \% \quad 20.7$

$\begin{array}{ll}99.7 \% & 85.8 \\ 96.9 \% & 20.6\end{array}$

$99.7 \% \quad 39.2$

$\begin{array}{ll}99.7 \% & 57.8\end{array}$

$\begin{array}{ccc}1517.82 & 55 & 69 \\ 1130.61 & 59 & 69 \\ 1783.01 & 59 & 75 \\ 1488.73 & 76 & 90 \\ 1616.82 & 76 & 91 \\ 899.57 & 147 & 155 \\ 901.52 & 156 & 163 \\ 1099.61 & 237 & 247 \\ 2488.19 & 248 & 270 \\ 2048.02 & 271 & 289 \\ 2619.29 & 271 & 294 \\ 1809.89 & 295 & 310 \\ 1345.77 & 352 & 364 \\ 2952.66 & 352 & 380 \\ 1625.90 & 365 & 380 \\ 2041.11 & 365 & 384 \\ 1486.79 & 381 & 394 \\ 986.60 & 462 & 469 \\ 1220.52 & 71 & 80 \\ 1123.59 & 81 & 90 \\ 1370.60 & 91 & 102 \\ 1569.71 & 103 & 116 \\ 1438.63 & 126 & 138 \\ 1188.53 & 300 & 309 \\ 1151.47 & 310 & 318 \\ 1698.96 & 444 & 459 \\ 1880.91 & 47 & 62 \\ 1639.83 & 82 & 96 \\ 1889.94 & 100 & 115 \\ 952.56 & 159 & 167 \\ 2006.03 & 168 & 184 \\ 1327.59 & 190 & 202 \\ 1877.91 & 28 & 46 \\ 1418.73 & 47 & 59 \\ 1511.88 & 228 & 241 \\ 2014.08 & 249 & 267 \\ 1088.63 & 1789 & 1798 \\ 1230.67 & 1814 & 1824 \\ 1232.68 & 1146 & 1157 \\ 1533.86 & 1441 & 1454 \\ 1106.56 & 1485 & 1493 \\ 1258.60 & 1613 & 1625 \\ 1057.52 & 1750 & 1759 \\ 1386.80 & 52 & 66 \\ 957.50 & 95 & 103 \\ 1450.72 & 149 & 161 \\ 1569.80 & 162 & 175 \\ & & \end{array}$

Page 47 of Table S-1-4 
Dehydrogenase/reductase SDR family member 7B GN=DHRS7B DRS7B_HUMAN $35.12 \quad 100.0 \%$ Delta-1-pyrroline-5-carboxylate synthase GN=ALDH18A1 P5CS HUMAN 87.30 100.0\% Delta-1-pyrroline-5-carboxylate synthase GN=ALDH18A1 P5CS_HUMAN $87.30 \quad 100.0 \%$ Delta-1-pyrroline-5-carboxylate synthase GN=ALDH18A1 P5CS HUMAN 87.30 100.0\% Deoxynucleoside triphosphate triphosphohydrolase SAMHDI GN=SAMHDI SAMH1_HUMAN $72.20 \quad 100.0 \%$ Deoxynucleoside triphosphate triphosphohydrolase SAMHDI GN=SAMHD1 SAMH1_HUMAN $72.20 \quad 100.0 \%$ Deoxynucleoside triphosphate triphosphohydrolase SAMHDI GN=SAMHDI SAMH1 HUMAN $72.20 \quad 100.0 \%$ Deoxynucleoside triphosphate triphosphohydrolase SAMHDI GN=SAMHD1 SAMH1_HUMAN 72.20 $100.0 \%$ Desmoglein-1 GN=DSG Desmoglein-1 GN=DSG Desmoglein-1 GN=DSG Desmoglein-1 GN=DSG Desmoglein-1 GN=DSG Desmoplakin GN=DSP Desmoplakin GN=DSF Desmoplakin GN=DSP Desmoplakin GN=DSP Desmoplakin GN=DSF Desmoplakin GN=DSP Desmoplakin GN=DSF Desmoplakin GN=DSF Desmoplakin GN=DSP Desmoplakin GN=DSF Desmoplakin GN=DSP Desmoplakin GN=DSF Desmoplakin GN=DSF Desmoplakin GN=DSP Desmoplakin GN=DSF Desmoplakin GN=DSF Desmoplakin GN=DSP Desmoplakin GN=DSF Desmoplakin GN=DSP Desmoplakin GN=DSF Desmoplakin GN=DSF Desmoplakin GN=DSP Desmoplakin GN=DSF Desmoplakin GN=DSF Desmoplakin GN=DSF Desmoplakin GN=DSF Desmoplakin GN=DSF Desmoplakin GN=DSF Desmoplakin $\mathrm{GN}=\mathrm{DSF}$ Desmoplakin GN=DSP Desmoplakin GN=DSF Desmoplakin GN=DSF Desmoplakin GN=DSP DSG1_HUMAN $113.75 \quad 100.0 \%$ DSG1_HUMAN $113.75 \quad 100.0 \%$ DSG1 HUMAN $113.75 \quad 100.0 \%$ DSG1_HUMAN $113.75 \quad 100.0 \%$ DSG1_HUMAN $113.75 \quad 100.0 \%$ DESP HUMAN $331.78 \quad 100.0 \%$ DESP_HUMAN $331.78 \quad 100.0 \%$
0.01\% $19.4 \%$ YGVMDTTTAQGR $99.7 \% \quad 51.4$ $99.7 \% \quad 63.9$ $99.7 \% \quad 37.9$ $99.7 \% \quad 59.4$ $0.01 \% \quad 5.9 \%$ FASYLTFSPSEVK DESP HUMAN $331.78 \quad 100.0 \% \quad 34$ DESP_HUMAN $331.78 \quad 100.0 \% \quad 34$ DESP_HUMAN $331.78 \quad 100.0 \% \quad 34$ DESP HUMAN $331.78 \quad 100.0 \% \quad 34$ DESP_HUMAN $331.78 \quad 100.0 \% \quad 34$ DESP HUMAN $331.78 \quad 100.0 \% \quad 34$ DESP_HUMAN $331.78 \quad 100.0 \% \quad 34$ DESP_HUMAN $331.78 \quad 100.0 \% \quad 34$ DESP HUMAN $331.78 \quad 100.0 \% \quad 34$ DESP_HUMAN $331.78 \quad 100.0 \% \quad 34$ DESP_HUMAN $331.78 \quad 100.0 \% \quad 34$ DESP HUMAN $331.78 \quad 100.0 \% \quad 34$ DESP_HUMAN $331.78 \quad 100.0 \% \quad 34$ DESP HUMAN $331.78 \quad 100.0 \% \quad 34$ DESP HUMAN $331.78 \quad 100.0 \% \quad 34$ DESP_HUMAN $331.78 \quad 100.0 \% \quad 34$ DESP HUMAN $331.78 \quad 100.0 \% \quad 34$ DESP_HUMAN $331.78 \quad 100.0 \% \quad 34$ DESP_HUMAN $331.78 \quad 100.0 \% \quad 34$ DESP HUMAN $331.78 \quad 100.0 \% \quad 34$ DESP_HUMAN $331.78 \quad 100.0 \% \quad 34$ DESP HUMAN $331.78 \quad 100.0 \% \quad 34$ DESP_HUMAN $331.78 \quad 100.0 \% \quad 34$ DESP_HUMAN $331.78 \quad 100.0 \% \quad 34$ DESP HUMAN $331.78 \quad 100.0 \% \quad 34$ DESP_HUMAN $331.78 \quad 100.0 \% \quad 34$ DESP HUMAN $331.78 \quad 100.0 \% \quad 34$ DESP HUMAN $331.78 \quad 100.0 \% \quad 34$ DESP_HUMAN $331.78 \quad 100.0 \% \quad 34$ DESP HUMAN $331.78 \quad 100.0 \% \quad 34$ DESP_HUMAN $331.78 \quad 100.0 \% \quad 34$ $0.01 \% \quad 8.8 \%$ GGFEEPVLLK $0.01 \% \quad 8.8 \%$ IIDTPQFQR $0.01 \% \quad 8.8 \% \quad$ SFLYEIVSNKR $0.01 \% \quad 8.8 \% \quad$ YVGETQPTGQIK $0.01 \% \quad 8.8 \%$ EWNDSTSVQNPTR $0.01 \% \quad 6.4 \%$ IHSDCAANQQVTYR

$99.7 \% \quad 40.8 \quad 25.0 \quad 24.9$

$\begin{array}{llll}99.7 \% & 37.3 & 25.0 & 27.0\end{array}$

$99.7 \% \quad 44.5 \quad 25.0 \quad 41.4$

$99.7 \% \quad 59.6 \quad 25.0 \quad 52.0$

$99.7 \% \quad 37.9 \quad 25.0 \quad 37.9$

$\begin{array}{llll}99.7 \% & 37.5 & 25.0 & 37.5\end{array}$

$0.01 \% \quad 6.4 \%$ ALNSMGQDLERPLELR

$0.01 \% \quad 6.4 \%$ MTGFELTEGVK

$0.01 \% \quad 6.4 \%$ ESSNVVVTER

$0.09 \% \quad 12.6 \%$ AESGPDLR

$0.09 \% \quad 12.6 \%$ YEVTSGGGGTSR

$0.09 \% \quad 12.6 \%$ AELIVQPELK

$0.09 \% \quad 12.6 \%$ YGDGIQLTR

$0.09 \% \quad 12.6 \%$ LLQLQEQMR

$0.09 \% \quad 12.6 \%$ QLQNIIQATSR

$0.09 \% \quad 12.6 \%$ SNKPIILR

$0.09 \% \quad 12.6 \%$ IQSQFTDAQK

$0.09 \% \quad 12.6 \%$ ALLQAILQTEDMLK

$0.09 \% \quad 12.6 \%$ FGDSNTVMR

$0.09 \% \quad 12.6 \%$ IEVLEEELR

$0.09 \% \quad 12.6 \%$ YQAECSQFK

$0.09 \% \quad 12.6 \%$ LASLEELKR

$0.09 \% \quad 12.6 \%$ EKEYEIER

$0.09 \% \quad 12.6 \%$ NKYETEINITK

$0.09 \% \quad 12.6 \%$ DLKDEIVR

$0.09 \% \quad 12.6 \%$ AQIDNLTR

$0.09 \% \quad 12.6 \%$ SLSEEIKR

$0.09 \% \quad 12.6 \%$ RVEEDIQQQK

$0.09 \% \quad 12.6 \%$ YKQSLDDAAK

$0.09 \% \quad 12.6 \%$ ITNLTQQLEQASIVK

$0.09 \% \quad 12.6 \%$ QLLQEQESVK

$0.09 \% \quad 12.6 \%$ SLNESKIEIER

$0.09 \% \quad 12.6 \%$ LQSLTENLTK

$0.09 \% \quad 12.6 \%$ SEADSDKNATILELR

$0.09 \% \quad 12.6 \%$ SQLQISNNR

$0.09 \% \quad 12.6 \%$ TLELQGLINDLQR

$0.09 \% \quad 12.6 \%$ NQCTQVVQER

$0.09 \% \quad 12.6 \%$ ETQSQLETER

$0.09 \% \quad 12.6 \%$ SVEEVASEIQPFLR

$0.09 \% \quad 12.6 \%$ AITGFDDPFSGK

$0.09 \% \quad 12.6 \%$ GLVGIEFKEK

$0.09 \% \quad 12.6 \%$ LLEAQIATGGIIDPK
$99.7 \% \quad 56.2$

$\begin{array}{lll}99.4 \% & 26.8\end{array}$

$\begin{array}{lll}99.4 \% & 21.7\end{array}$

$99.0 \% \quad 24.8$

$99.7 \% \quad 64.2$

$99.7 \% \quad 42.4$

$99.7 \% \quad 56.4$

$\begin{array}{lll}99.7 \% & 49.8\end{array}$

$99.7 \% \quad 58.2$

$95.4 \% \quad 13.9$

$99.7 \% \quad 36.2$

$99.7 \% \quad 53.8$

$99.7 \% \quad 51.5$

$99.7 \% \quad 57.3$

$99.7 \% \quad 30.9$

$\begin{array}{lll}99.7 \% & 36.1\end{array}$

$99.0 \% \quad 38.8$

$99.7 \% \quad 27.9$

$97.7 \% 23.6$

$97.2 \% \quad 21.4$

$99.0 \% \quad 43.6$

$99.7 \% 44$.

$99.7 \% \quad 41.8$

$99.7 \% \quad 63.3$

$99.2 \% \quad 23.1$

$99.7 \% \quad 35.6$

$99.7 \% \quad 36.8$

$96.1 \% \quad 14.4$

$\begin{array}{lll}99.7 \% & 36.5\end{array}$

$99.7 \% \quad 59.1$

$99.7 \% 59.1$

$99.7 \% 31.6$

$98.5 \% 31.4$

$99.7 \% \quad 31.6$

$99.5 \% \quad 25.6$

$99.7 \% \quad 62.3$
2481.2

1230.68

1475.74

1088.60

1117.60

1355.73

1320.68

1533.69

1662.77

1857.95

1750.84

1227.59

1119.56

844.42

1170.54

1139.67

1022.53

1174.63

1271.7

940.59

1165.58

1602.88

1026.47

1129.61

1160.50

1058.62

1095.53

1352.71

987.55

930.50

961.53

1272.65

1138.57

1685.94

1201.64

1317.70

1146.64

1661.83

1059.55

1512.84

1261.60

1220.58

1603.83

1254.60

1119.64

1538.88 


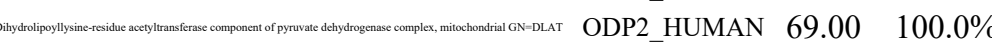

Dihydropyrimidinase-related protein $1 \mathrm{GN}=\mathrm{CRMP} 1$ DPYL1 HUMAN $62.18 \quad 100.0 \%$ Dihydropyrimidinase-related protein $1 \mathrm{GN}=\mathrm{CRMP} 1$ DPYL1_HUMAN $62.18 \quad 100.0 \%$ Dihydropyrimidinase-related protein $1 \mathrm{GN}=$ CRMP1 DPYL1_HUMAN $62.18 \quad 100.0 \%$ Dihydropyrimidinase-related protein $1 \mathrm{GN}=\mathrm{CRMP1}$ DPYL1_HUMAN $62.18 \quad 100.0 \%$ Dihydropyrimidinase-related protein 4 GN=DPYSL4 DPYL4_HUMAN $61.88 \quad 100.0 \%$ Dihydropyrimidinase-related protein 4 GN=DPYSL4 DPYL4_HUMAN $61.88 \quad 100.0 \%$ Dimethyladenosine transferase 1, mitochondrial GN=TFB1M TFB1M_HUMAN $39.54 \quad 100.0 \%$ Dimethyladenosine transferase 1, mitochondrial GN=TFB1M TFB1M_HUMAN $39.54 \quad 100.0 \%$ Dimethyladenosine transferase 1, mitochondrial GN=TFB1M TFB1M HUMAN $39.54 \quad 100.0 \%$ Dimethyladenosine transferase 1, mitochondrial GN=TFB1M TFB1M_HUMAN $39.54 \quad 100.0 \%$ Dimethyladenosine transferase 1, mitochondrial GN=TFB1M TFB1M_HUMAN $39.54100 .0 \%$ Dimethyladenosine transferase 1, mitochondrial GN=TFB1M TFB1M HUMAN $39.54 \quad 100.0 \%$ Dimethyladenosine transferase 1 , mitochondrial GN=TFB1M TFB1M_HUMAN $39.54 \quad 100.0 \%$ Dimethyladenosine transferase 1, mitochondrial GN=TFB1M TFB1M HUMAN $39.54100 .0 \%$ Dimethyladenosine transferase 1, mitochondrial GN=TFB1M TFB1M_HUMAN $39.54 \quad 100.0 \%$ Dimethyladenosine transferase 1, mitochondrial GN=TFB1M TFB1M_HUMAN $39.54100 .0 \%$ Dimethyladenosine transferase 1, mitochondrial GN=TFB1M TFB1M HUMAN $39.54 \quad 100.0 \%$ Dimethyladenosine transferase 1, mitochondrial GN=TFB1M TFB1M_HUMAN $39.54 \quad 100.0 \%$ Dimethyladenosine transferase 1, mitochondrial GN=TFB1M TFB1M_HUMAN $39.54 \quad 100.0 \%$ Dimethyladenosine transferase 1, mitochondrial GN=TFB1M TFB1M HUMAN $39.54 \quad 100.0 \%$ Dimethyladenosine transferase 2, mitochondrial GN=TFB2M TFB2M_HUMAN $45.35100 .0 \%$ Dimethyladenosine transferase 2, mitochondrial GN=TFB2M TFB2M HUMAN $45.35100 .0 \%$ Dimethyladenosine transferase 2, mitochondrial GN=TFB2M TFB2M_HUMAN $45.35 \quad 100.0 \%$ Dimethyladenosine transferase 2, mitochondrial GN=TFB2M TFB2M_HUMAN $45.35 \quad 100.0 \%$ Dimethyladenosine transferase 2, mitochondrial GN=TFB2M TFB2M HUMAN 45.35 Dimethyladenosine transferase 2, mitochondrial GN=TFB2M TFB2M_HUMAN $45.35 \quad 100.0 \%$ Dimethyladenosine transferase 2, mitochondrial GN=TFB2M TFB2M_HUMAN $45.35 \quad 100.0 \%$ Dimethyladenosine transferase 2, mitochondrial GN=TFB2M TFB2M HUMAN $45.35 \quad 100.0 \%$ Dimethyladenosine transferase 2, mitochondrial GN=TFB2M TFB2M_HUMAN $45.35 \quad 100.0 \%$ Dimethyladenosine transferase 2, mitochondrial GN=TFB2M TFB2M HUMAN $45.35 \quad 100.0 \%$ DNA dC->dU-editing enzyme APOBEC-3B GN=APOBEC3B ABC3B_HUMAN $45.93 \quad 100.0 \%$ DNA dC->dU-editing enzyme APOBEC-3B GN=APOBEC3B ABC3B_HUMAN $45.93 \quad 100.0 \%$ DNA dC->dU-editing enzyme APOBEC-3B GN=APOBEC3B ABC3B HUMAN $45.93 \quad 100.0 \%$ DNA mismatch repair protein Msh2 GN=MSH2 MSH2_HUMAN $104.75 \quad 100.0 \%$ DNA mismatch repair protein Msh2 GN=MSH2 MSH2 HUMAN $104.75 \quad 100.0 \%$ DNA mismatch repair protein Msh2 GN=MSH2 MSH2_HUMAN $104.75100 .0 \%$ DNA mismatch repair protein Msh6 GN=MSH6 MSH6_HUMAN $152.79 \quad 100.0 \%$ DNA mismatch repair protein Msh6 GN=MSH6 MSH6 HUMAN $152.79100 .0 \%$ DNA mismatch repair protein Msh6 GN=MSH6 MSH6_HUMAN $152.79 \quad 100.0 \%$

$\begin{array}{lllll}6 & 0.01 \% & 6.8 \% & \text { GVETIANDVV } & \text { YLEKPITMLL }\end{array}$

$6 \quad 0.01 \% \quad 5.2 \%$ INCPVYITK

$6 \quad 0.01 \% \quad 5.2 \%$ SAADIIALAR

$6 \quad 0.01 \% \quad 5.2 \%$ NKVFGLQGVSR

$\begin{array}{llll}6 & 0.01 \% & 5.2 \% & \text { VFGLQGVSR }\end{array}$

$4 \quad 0.00 \% \quad 3.7 \%$ GAADAIAQAK

$4 \quad 0.00 \% \quad 3.7 \%$ GAPAVVISQGR

$27 \quad 0.03 \% \quad 40.2 \%$ LPPLPTIR

$27 \quad 0.03 \% \quad 40.2 \%$ QLSQNFLLDLR

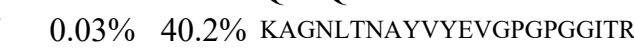

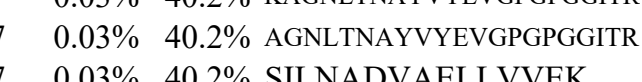

$\begin{array}{llll}27 & 0.03 \% & 40.2 \% & \text { SILNADVAELLVVEK } \\ 27 & 0.03 \% & 40.2 \% & \text { SILNADVAELLVVEKDTR }\end{array}$

$\begin{array}{llll}27 & 0.03 \% & 40.2 \% & 40.2 \% \\ \text { FIPGLQMLSDAAPGK }\end{array}$

$27 \quad 0.03 \% \quad 40.2 \%$ IVHGDVLTFK

$0.03 \% \quad 40.2 \%$ IVHGDVLTFKVEK

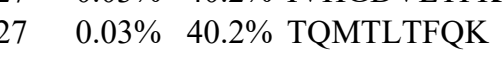

$0.03 \% \quad 40.2 \%$ LSVMAQYLCNVR

$0.03 \% \quad 40.2 \%$ VVQNVFQFR

$0.03 \% \quad 40.2 \%$ MLFPEAQR

$0.03 \% \quad 40.2 \%$ LLELADIDPTLRPR

$0.02 \% \quad 25.5 \%$ VIHCDFFK

$21 \quad 0.02 \% \quad 25.5 \%$ SGGVIKPPAMSSR

$0.02 \% \quad 25.5 \%$ NLGIEAVPWTADIPLK

$21 \quad 0.02 \% \quad 25.5 \%$ VVGMFPSR

$0.02 \% 25.5 \%$ LAYDLYSCTSIYK

$0.02 \% 25.5 \%$ KGPLENPK

$0.02 \% \quad 25.5 \%$ ELLDQLQQK

$0.02 \% \quad 25.5 \%$ LYLIQMIPR

$0.02 \% \quad 25.5 \%$ SATVIDHLR

$0.02 \% \quad 25.5 \%$ TLFETIER

$0.01 \% \quad 7.6 \%$ FDENYAFLHR

$0.01 \% \quad 7.6 \%$ NLLCGFYGR

$6 \quad 0.01 \% \quad 7.6 \%$ AFLQENTHVR

$5 \quad 0.00 \% \quad 3.5 \%$ QVGVGYVDSIQR

$5.00 \% \quad 3.5 \%$ LTSLNEEYTK

$5 \quad 0.00 \% \quad 3.5 \%$ NNSFVNEIISR

$19 \quad 0.02 \% \quad 7.5 \%$ SPALSDANKASAR

$19 \quad 0.02 \% \quad 7.5 \%$ QATSISSETKNTLR $19 \quad 0.02 \% \quad 7.5 \% \quad$ YSDSLVQK

Page 49 of Table S-1-4 
DNA mismatch repair protein Msh6 GN=MSH6 MSH6 HUMAN $152.79 \quad 100.0 \%$ DNA mismatch repair protein Msh6 GN=MSH6 MSH6_HUMAN $152.79 \quad 100.0 \%$ DNA mismatch repair protein Msh6 GN=MSH6 MSH6_HUMAN $152.79 \quad 100.0 \%$ DNA mismatch repair protein Msh6 GN=MSH6 MSH6 HUMAN $152.79 \quad 100.0 \%$ DNA mismatch repair protein Msh6 GN=MSH6 MSH6_HUMAN $152.79 \quad 100.0 \%$ DNA mismatch repair protein Msh6 GN=MSH6 MSH6_HUMAN $152.79 \quad 100.0 \%$ DNA mismatch repair protein Msh6 GN=MSH6 MSH6_HUMAN $152.79 \quad 100.0 \%$ DNA polymerase alpha catalytic subunit GN=POLA1 DPOLA_HUMAN $165.92 \quad 100.0 \%$ DNA polymerase alpha catalytic subunit GN=POLA1 DPOLA HUMAN $165.92 \quad 100.0 \%$ DNA polymerase delta catalytic subunit GN=POLD1 DPOD1_HUMAN $123.63 \quad 100.0 \%$ DNA polymerase delta catalytic subunit GN=POLD1 DPOD1_HUMAN $123.63 \quad 100.0 \%$ DNA polymerase delta catalytic subunit GN=POLD1 DPOD1_HUMAN $123.63100 .0 \%$ DNA polymerase delta catalytic subunit GN=POLD1 DPOD1_HUMAN $123.63100 .0 \%$ DNA polymerase epsilon catalytic subunit A GN=POLE DPOE1_HUMAN $261.52100 .0 \%$ DNA polymerase epsilon catalytic subunit A GN=POLE DPOE1_HUMAN $261.52 \quad 100.0 \%$ DNA polymerase epsilon catalytic subunit A GN=POLE DPOE1_HUMAN $261.52 \quad 100.0 \%$ DNA polymerase epsilon catalytic subunit A GN=POLE DPOE1 HUMAN $261.52 \quad 100.0 \%$ DNA polymerase epsilon catalytic subunit A GN=POLE DPOE1_HUMAN $261.52 \quad 100.0 \%$ DNA polymerase epsilon catalytic subunit A GN=POLE DPOE1_HUMAN $261.52 \quad 100.0 \%$ DNA polymerase epsilon catalytic subunit A GN=POLE DPOE1_HUMAN $261.52 \quad 100.0 \%$ DNA polymerase epsilon catalytic subunit A GN=POLE DPOE1_HUMAN $261.52 \quad 100.0 \%$ DNA primase small subunit GN=PRIM1 PRI1 HUMAN $49.90 \quad 100.0 \%$ DNA primase small subunit GN=PRIM1 PRI1_HUMAN $49.90 \quad 100.0 \%$ DNA repair protein RAD50 GN=RAD50 RAD50_HUMAN $153.90 \quad 100.0 \%$ DNA repair protein RAD50 GN=RAD50 RAD50_HUMAN $153.90 \quad 100.0 \%$ DNA repair protein RAD50 GN=RAD50 RAD50_HUMAN $153.90 \quad 100.0 \%$ DNA repair protein RAD50 GN=RAD50 RAD50_HUMAN $153.90 \quad 100.0 \%$ DNA repair protein RAD50 GN=RAD50 RAD50_HUMAN $153.90 \quad 100.0 \%$ DNA repair protein RAD50 GN=RAD50 RAD50_HUMAN $153.90 \quad 100.0 \%$ DNA repair protein RAD50 GN=RAD50 RAD50 HUMAN $153.90 \quad 100.0 \%$ DNA repair protein RAD50 GN=RAD50 RAD50_HUMAN $153.90 \quad 100.0 \%$ DNA repair protein RAD50 GN=RAD50 RAD50_HUMAN $153.90 \quad 100.0 \%$ DNA repair protein RAD50 GN=RAD50 RAD50_HUMAN $153.90 \quad 100.0 \%$ DNA repair protein RAD50 GN=RAD50 RAD50_HUMAN $153.90 \quad 100.0 \%$ DNA repair protein RAD50 GN=RAD50 RAD50_HUMAN $153.90 \quad 100.0 \%$ DNA repair protein RAD50 GN=RAD50 RAD50_HUMAN $153.90 \quad 100.0 \%$ DNA repair protein RAD50 GN=RAD50 RAD50_HUMAN $153.90 \quad 100.0 \%$ DNA repair protein RAD51 homolog 3 GN=RAD51C RA51C HUMAN $42.19 \quad 100.0 \%$ DNA repair protein RAD51 homolog 3 GN=RAD51C RA51C_HUMAN $42.19 \quad 100.0 \%$ DNA repair protein RAD51 homolog 3 GN=RAD51C RA51C_HUMAN $42.19 \quad 100.0 \%$ DNA repair protein RAD51 homolog $3 \mathrm{GN}=\mathrm{RAD} 51 \mathrm{C}$ RA51C_HUMAN $42.19 \quad 100.0 \%$ DNA replication licensing factor MCM2 GN=MCM2 MCM2_HUMAN $101.90 \quad 100.0 \%$ DNA replication licensing factor MCM2 GN=MCM2 MCM2 HUMAN $101.90 \quad 100.0 \%$ DNA replication licensing factor MCM2 GN=MCM2 MCM2_HUMAN $101.90 \quad 100.0 \%$ DNA replication licensing factor MCM3 GN=MCM3 MCM3_HUMAN $90.98 \quad 100.0 \%$ DNA replication licensing factor MCM3 GN=MCM3 MCM3 HUMAN $90.98 \quad 100.0 \%$ DNA replication licensing factor MCM3 GN=MCM3 MCM3_HUMAN $90.98 \quad 100.0 \%$
$19 \quad 0.02 \% \quad 7.5 \% \quad$ YSDSLVQKGYK $0.02 \% \quad 7.5 \%$ IHNVGSPLK $0.02 \% \quad 7.5 \% \quad$ ILKQVISLQTK $0.02 \% \quad 7.5 \% \quad$ NRYQLEIPENFTTR $0.02 \% \quad 7.5 \%$ NLPEEYELKSTK $0.02 \% \quad 7.5 \% \quad$ LANLINAEER $0.02 \% \quad 7.5 \%$ EVCLASER $0.00 \% \quad 1.5 \%$ AAYAGGLVLDPK $0.00 \% \quad 1.5 \%$ SGYSEVNLSK $0.01 \% \quad 3.5 \%$ ELNLAISR $0.01 \% \quad 3.5 \%$ VQTFPFLGR $0.01 \% \quad 3.5 \%$ VTGVPLSYLLSR $0.01 \% \quad 3.5 \% \quad$ LGLTEDQFIR $\begin{array}{llll}6 & 0.02 \% & 4.0 \% & \text { DSYLPVGSHNLK }\end{array}$ $0.02 \% \quad 4.0 \% \quad$ KLEDYGEQK $0.02 \% \quad 4.0 \%$ AIPLAIFQAEPTVR $0.02 \% \quad 4.0 \%$ SLAQFSYLEPGSIR $0.02 \% \quad 4.0 \%$ ALFGIFIPSQR $0.02 \% \quad 4.0 \%$ ASVFVLDTVR $0.02 \% \quad 4.0 \% \quad$ LGSSVIYANFNR $0.02 \% \quad 4.0 \% \quad$ SYVLPEVICR $0.00 \% \quad 4.5 \%$ SGIVEYLSLVK $0.00 \% \quad 4.5 \%$ SPFSVHPK $0.03 \% \quad 12.3 \%$ LQFRDVNGELIAVQR $0.03 \% \quad 12.3 \%$ ACEIRDQITSK $0.03 \% \quad 12.3 \%$ SYENELDPLKNR $0.03 \% \quad 12.3 \%$ LKEIEHNLSK $0.03 \% \quad 12.3 \%$ LLNQEKSELLVEQGR $0.03 \% \quad 12.3 \%$ IIELKSEILSK $0.03 \% \quad 12.3 \%$ LQGIDLDR $0.03 \% \quad 12.3 \%$ TVQQVNQEKQEK $0.03 \% \quad 12.3 \%$ KLIQDQQEQIQHLK $0.03 \% \quad 12.3 \%$ QDIDTQKIQER $0.03 \% \quad 12.3 \%$ TTELVNKDLDIYYK $0.03 \% \quad 12.3 \%$ VLASLIIR

$0.03 \% \quad 12.3 \%$ NIDQCSEIVK $0.03 \% \quad 12.3 \%$ CSVSSLGFNVH $0.00 \% \quad 15.2 \%$ DLVSFPLSPAVR $0.00 \% \quad 15.2 \%$ LVSAGFQTAEELLEVKPSELSK $0.00 \% \quad 15.2 \%$ AEALETLQIIR $0.00 \% \quad 15.2 \%$ TTEICGAPGVGK $0.00 \% \quad 3.4 \%$ IRIQESPGK $0.00 \% \quad 3.4 \%$ GLALALFGGEPK $0.00 \% \quad 3.4 \%$ AGIVTSLQAR $0.01 \% \quad 11.3 \%$ LIVNVNDLR $0.01 \% \quad 11.3 \%$ LLNNAFEELVAFQR $0.01 \% \quad 11.3 \%$ SVHYCPATK
1109.55

1525.87 
DNA replication licensing factor MCM3 GN=MCM3 MCM3_HUMAN $90.98 \quad 100.0 \%$ DNA replication licensing factor MCM3 GN=MCM3 MCM3_HUMAN $90.98 \quad 100.0 \%$ DNA replication licensing factor MCM3 GN=MCM3 MCM3_HUMAN $90.98 \quad 100.0 \%$ DNA replication licensing factor MCM3 GN=MCM3 MCM3 HUMAN $90.98 \quad 100.0 \%$ DNA replication licensing factor MCM4 GN=MCM4 MCM4_HUMAN $96.56 \quad 100.0 \%$ DNA replication licensing factor MCM4 GN=MCM4 MCM4_HUMAN $96.56 \quad 100.0 \%$ DNA replication licensing factor MCM5 GN=MCM5 MCM5_HUMAN $82.29 \quad 100.0 \%$ DNA replication licensing factor MCM5 GN=MCM5 MCM5_HUMAN $82.29 \quad 100.0 \%$ DNA replication licensing factor MCM5 GN=MCM5 MCM5_HUMAN $82.29 \quad 100.0 \%$ DNA replication licensing factor MCM5 GN=MCM5 MCM5_HUMAN $82.29 \quad 100.0 \%$ DNA replication licensing factor MCM5 GN=MCM5 MCM5_HUMAN $82.29 \quad 100.0 \%$ DNA replication licensing factor MCM6 GN=MCM6 MCM6_HUMAN 92.89 DNA replication licensing factor MCM6 GN=MCM6 MCM6_HUMAN 92.89 DNA replication licensing factor MCM6 GN=MCM6 MCM6_HUMAN 92.89 DNA replication licensing factor MCM6 GN=MCM6 MCM6_HUMAN 92.89 DNA replication licensing factor MCM6 GN=MCM6 MCM6_HUMAN 92.89 DNA replication licensing factor MCM6 GN=MCM6 MCM6_HUMAN 92.89 DNA replication licensing factor MCM6 GN=MCM6 MCM6_HUMAN 92.89 DNA replication licensing factor MCM6 GN=MCM6 MCM6_HUMAN 92.89 DNA replication licensing factor MCM6 GN=MCM6 MCM6 HUMAN 92.89 DNA replication licensing factor MCM6 GN=MCM6 MCM6_HUMAN 92.89 DNA replication licensing factor MCM7 GN=MCM7 MCM7_HUMAN 81.31 DNA replication licensing factor MCM7 GN=MCM7 MCM7_HUMAN 81.31 DNA replication licensing factor MCM7 GN=MCM7 MCM7_HUMAN 81.31 DNA replication licensing factor MCM7 GN=MCM7 MCM7_HUMAN 81.31 DNA replication licensing factor MCM7 GN=MCM7 MCM7_HUMAN 81.31 DNA replication licensing factor MCM7 GN=MCM7 MCM7_HUMAN 81.31 DNA replication licensing factor MCM7 GN=MCM7 MCM7_HUMAN 81.3 DNA replication licensing factor MCM7 GN=MCM7 MCM7_HUMAN 81.31 DNA replication licensing factor MCM7 GN=MCM7 MCM7_HUMAN 81.31 DNA replication licensing factor MCM7 GN=MCM7 MCM7_HUMAN 81.31 DNA replication licensing factor MCM7 GN=MCM7 MCM7_HUMAN 81.31 DNA replication licensing factor MCM7 GN=MCM7 MCM7_HUMAN 81.31 DNA replication licensing factor $\mathrm{MCM} 7 \mathrm{GN}=\mathrm{MCM} 7 \mathrm{MCM} 7$ HUMAN 81.31 DNA replication licensing factor MCM7 GN=MCM7 MCM7_HUMAN 81.31 DNA topoisomerase $1 \mathrm{GN}=\mathrm{TOP} 1$ DNA topoisomerase $1 \mathrm{GN}=\mathrm{TOP} 1$ DNA topoisomerase $1 \mathrm{GN}=\mathrm{TOP} 1$ DNA topoisomerase $1 \mathrm{GN}=\mathrm{TOP} 1$ DNA topoisomerase $1 \mathrm{GN}=\mathrm{TOP} 1$ TOP1 HUMAN TOP1_HUMAN $90.73 \quad 100.0 \%$ TOP1 HUMAN $90.73 \quad 100.0 \%$ TOP1_HUMAN $90.73 \quad 100.0 \%$ TOP1_HUMAN $90.73 \quad 100.0 \%$ DNA topoisomerase 2-alpha GN=TOP2A TOP2A_HUMAN $174.39 \quad 100.0 \%$ DNA topoisomerase 2-alpha GN=TOP2A TOP2A_HUMAN $174.39 \quad 100.0 \% \quad 2$ DNA topoisomerase 2-alpha GN=TOP2A TOP2A_HUMAN $174.39 \quad 100.0 \% \quad 2$ DNA topoisomerase 2-alpha GN=TOP2A $\quad$ TOP2A_HUMAN $174.39 \quad 100.0 \% \quad 2$ DNA topoisomerase 2-alpha GN=TOP2A TOP2A_HUMAN $174.39 \quad 100.0 \%$ DNA topoisomerase 2-alpha GN=TOP2A $\quad$ TOP2A_HUMAN $174.39 \quad 100.0 \% \quad 21$ DNA topoisomerase 2-alpha GN=TOP2A $\quad$ TOP2A_HUMAN $174.39 \quad 100.0 \%$

$13 \quad 0.01 \% \quad 11.3 \%$ GGYTSGTFR

$\begin{array}{llll}10 & 0.01 \% & 8.9 \% & \text { IPGIIIAASAVR } \\ 10 & 0.01 \% & 8.9 \% & \text { LAALPNVYEVISK } \\ 10 & 0.01 \% & 8.9 \% & \text { AIACLLFGGSRK }\end{array}$

$10 \quad 0.01 \% \quad 8.9 \% \quad$ AGITTTLNSR

$10 \quad 0.01 \% \quad 8.9 \%$ FAIGSQVSEHSIIKDFTK

$20 \quad 0.02 \% \quad 14.4 \%$ FLLDTNKSR

$20 \quad 0.02 \% \quad 14.4 \%$ IQETQAELPRGSIPR

$20 \quad 0.02 \% \quad 14.4 \%$ VSGVDGYETEGIRGLR

$20 \quad 0.02 \% \quad 14.4 \%$ LVFLACCVAPTNPR

$20 \quad 0.02 \% \quad 14.4 \%$ GVLLMLFGGVPK

$20 \quad 0.02 \% \quad 14.4 \%$ HVEEFSPR

$20 \quad 0.02 \% \quad 14.4 \%$ AGVKATLNAR

$20 \quad 0.02 \% \quad 14.4 \%$ TSILAAANPISGHYDR

$0.02 \% \quad 14.4 \%$ LGFSEYCR

$20 \quad 0.02 \% \quad 14.4 \%$ ISNLIVLHLR

$48 \quad 0.05 \% \quad 21.7 \%$ SPQNQYPAELMR

$48 \quad 0.05 \% \quad 21.7 \%$ RFELYFQGPSSNKPR

$48 \quad 0.05 \% \quad 21.7 \%$ ADSVGKLVTVR

$48 \quad 0.05 \% \quad 21.7 \%$ SGGRLYLQTR

$48 \quad 0.05 \% \quad 21.7 \%$ SITVLVEGENTR

$48 \quad 0.05 \% \quad 21.7 \%$ ALLLLLVGGVDQSPR

$\quad 0.05 \% \quad 21.7 \%$ SQLLSYIDR

$48 \quad 0.05 \% \quad 21.7 \%$ SQLLSYIDRLAPR

$48 \quad 0.05 \% \quad 21.7 \%$ SQYTTGRGSSGVGLTAAVLR

$8 \quad 0.05 \% \quad 21.7 \%$ GSSGVGLTAAVLR

$48 \quad 0.05 \% \quad 21.7 \%$ AGILTTLNAR

$48 \quad 0.05 \% \quad 21.7 \%$ CSILAAANPAYGR

$48 \quad 0.05 \% \quad 21.7 \%$ SLEQNIQLPAALLSR

$48 \quad 0.05 \% \quad 21.7 \%$ SVRFSEAEQR

$14 \quad 0.01 \% \quad 6.0 \% \quad$ LSPKAEEVATFFAK

$14 \quad 0.01 \% \quad 6.0 \% \quad$ AEEVATFFAK

$14 \quad 0.01 \% \quad 6.0 \%$ IANFKIEPPGLFR

$14 \quad 0.01 \% \quad 6.0 \% \quad$ VPSPPPGHK

$14 \quad 0.01 \% \quad 6.0 \% \quad$ AVAILCNHQR

$46 \quad 0.05 \% \quad 13.8 \%$ EVTFVPGLYK

$46 \quad 0.05 \% \quad 13.8 \%$ IFDEILVNAADNK

$46 \quad 0.05 \% \quad 13.8 \%$ IFDEILVNAADNKQR

$46 \quad 0.05 \% \quad 13.8 \%$ GIPVVEHKVEK

$46 \quad 0.05 \% \quad 13.8 \%$ LCNIFSTK

$46 \quad 0.05 \% \quad 13.8 \%$ FTVETASR

$46 \quad 0.05 \% \quad 13.8 \%$ RAYDIAGSTK
Q

$\begin{array}{lllllll}.5 \% & 22.4 & 25.0 & 18.2 & 1 & 0 & 0\end{array}$

$\begin{array}{cccccccc}99.5 \% & 22.4 & 25.0 & 18.2 & 1 & 0 & 0 & 945.44\end{array}$ $99.7 \% \quad 57.7 \quad 25.0 \quad 51.0 \quad 5$ $\begin{array}{lllll}99.7 \% & 50.7 & 25.0 & 50.7 & 0\end{array}$ $99.7 \% \quad 32.4 \quad 25.0 \quad 15.6$ $99.7 \% \quad 58.6 \quad 25.0 \quad 50.1$ $99.7 \% \quad 57.0 \quad 25.0 \quad 57.0 \quad 4$ $\begin{array}{llll}99.7 \% & 36.5 & 25.0 & 36.5\end{array}$ $\begin{array}{llll}99.7 \% & 61.0 & 25.0 & 49.1\end{array}$ $\begin{array}{llll}96.2 \% & 16.4 & 25.0 & 14.5\end{array}$ $\begin{array}{llll}98.9 \% & 31.7 & 25.0 & 20.4\end{array}$ $\begin{array}{llll}99.7 \% & 41.4 & 25.0 & 39.7\end{array}$ $\begin{array}{llll}99.7 \% & 51.1 & 25.0 & 49.8\end{array}$ $\begin{array}{llll}99.7 \% & 37.1 & 25.0 & 36.8\end{array}$ $\begin{array}{lllll}99.7 \% & 30.6 & 25.0 & 23.6 & 1\end{array}$ $\begin{array}{llll}99.0 \% & 32.9 & 25.0 & 32.9\end{array}$ $\begin{array}{llll}99.7 \% & 27.4 & 25.0 & 25.7\end{array}$ $\begin{array}{lllll}99.7 \% & 62.9 & 25.0 & 62.5 & 1\end{array}$ $\begin{array}{llll}97.1 \% & 15.5 & 25.0 & 15.5\end{array}$ $\begin{array}{lllll}99.7 \% & 55.5 & 25.0 & 45.9 & 2\end{array}$ $\begin{array}{lllll}99.7 \% & 34.4 & 25.0 & 31.1 & 2\end{array}$ $\begin{array}{llll}99.7 \% & 29.3 & 25.0 & 29.3\end{array}$ $\begin{array}{lllll}99.7 \% & 80.1 & 25.0 & 73.4 & 2\end{array}$ $\begin{array}{llll}99.7 \% & 34.1 & 25.0 & 28.2\end{array}$ $\begin{array}{llll}99.7 \% & 36.5 & 25.0 & 29.7\end{array}$ $\begin{array}{llll}99.7 \% & 53.5 & 25.0 & 53.5\end{array}$ $\begin{array}{llll}99.7 \% & 40.4 & 25.0 & 21.3\end{array}$ $\begin{array}{llll}99.7 \% & 39.9 & 25.0 & 39.9\end{array}$ $\begin{array}{llll}99.7 \% & 34.1 & 25.0 & 33.3\end{array}$ $\begin{array}{llll}99.7 \% & 58.9 & 25.0 & 54.8\end{array}$ $\begin{array}{llll}99.7 \% & 57.8 & 25.0 & 49.7\end{array}$ $\begin{array}{llll}99.7 \% & 56.7 & 25.0 & 50.0\end{array}$ $\begin{array}{llll}99.7 \% & 49.7 & 25.0 & 49.7\end{array}$ $\begin{array}{llll}99.2 \% & 18.6 & 25.0 & 18.6\end{array}$ $\begin{array}{llll}99.7 \% & 32.6 & 25.0 & 28.2\end{array}$ $99.7 \% \quad 48.2 \quad 25.0 \quad 33.9$ $\begin{array}{lllll}99.7 \% & 43.7 & 25.0 & 38.1\end{array}$ $\begin{array}{llll}95.5 \% & 20.6 & 25.0 & 9.6\end{array}$ $\begin{array}{llll}99.7 \% & 53.4 & 25.0 & 40.4\end{array}$ $\begin{array}{llll}99.4 \% & 20.3 & 25.0 & 20.3\end{array}$ $\begin{array}{lllll}99.7 \% & 73.4 & 25.0 & 68.5 & 2\end{array}$ $\begin{array}{lllll}99.7 \% & 52.2 & 25.0 & 48.7 & 1\end{array}$ $\begin{array}{llll}99.7 \% & 33.1 & 25.0 & 33.1\end{array}$ $\begin{array}{lllll}99.0 \% & 26.0 & 25.0 & 24.7 & 3\end{array}$ $\begin{array}{llll}99.0 \% & 35.3 & 25.0 & 33.0\end{array}$ $\begin{array}{llll}99.7 \% & 38.3 & 25.0 & 29.8\end{array}$

0
0
1
0
0
0
0
0
0
1
0
2
2
0
0
0
0
2
0
0
0
2
0
0
0
0
0
0
2
0
0
0
0
1
0
0
2
0
0
0
0
2
0
0
0


0
0
0
0
0
0
0
0
0
0

1378.65
1164.63

2632.32

1099.59

1115.60

1180.74

1416.81

1292.71

1033.56

2007.05

1093.60

1694.92

1707.87

1617.82

1230.73

1000.48

1000.59

1685.86

1031.46

1177.74

1449.68

1825.93

1144.67

1150.63

1317.70

1550.93

1094.58

1531.86

1981.05

1187.67

1029.61

1363.68

1652.93

1208.60

1537.83

1112.56

1501.85

915.50

1181.62

1152.63

1461.76

1745.92 
DNA topoisomerase 2-alpha GN=TOP2A TOP2A_HUMAN $174.39 \quad 100.0 \% \quad 21$ DNA topoisomerase 2-alpha GN=TOP2A $\quad$ TOP2A_HUMAN $174.39 \quad 100.0 \% \quad 21$ DNA topoisomerase 2-alpha GN=TOP2A TOP2A_HUMAN $174.39 \quad 100.0 \% \quad 21$ DNA topoisomerase 2-alpha GN=TOP2A TOP2A_HUMAN $174.39 \quad 100.0 \% \quad 21$ DNA topoisomerase 2-alpha GN=TOP2A TOP2A_HUMAN $174.39 \quad 100.0 \% \quad 21$ DNA topoisomerase 2-alpha GN=TOP2A $\quad$ TOP2A_HUMAN $174.39 \quad 100.0 \% \quad 21$ DNA topoisomerase 2-alpha GN=TOP2A $\quad$ TOP2A_HUMAN $174.39 \quad 100.0 \% \quad 21$ DNA topoisomerase 2-alpha GN=TOP2A $\quad$ TOP2A_HUMAN $174.39 \quad 100.0 \% \quad 21$ DNA topoisomerase 2-alpha GN=TOP2A TOP2A_HUMAN $174.39 \quad 100.0 \% \quad 21$ DNA topoisomerase 2-alpha GN=TOP2A $\quad$ TOP2A_HUMAN $174.39 \quad 100.0 \%$ DNA topoisomerase 2-alpha GN=TOP2A TOP2A_HUMAN $174.39 \quad 100.0 \% \quad 21$ DNA topoisomerase 2-alpha GN=TOP2A TOP2A_HUMAN $174.39 \quad 100.0 \% \quad 21$ DNA topoisomerase 2-alpha GN=TOP2A TOP2A_HUMAN $174.39 \quad 100.0 \% \quad 21$ DNA topoisomerase 2-alpha GN=TOP2A TOP2A_HUMAN $174.39 \quad 100.0 \% \quad 21$ DNA topoisomerase 2-beta GN=TOP2B TOP2B_HUMAN $183.27 \quad 100.0 \%$ DNA topoisomerase 2-beta GN=TOP2B TOP2B_HUMAN $183.27 \quad 100.0 \%$ DNA topoisomerase 2-beta GN=TOP2B TOP2B HUMAN $183.27 \quad 100.0 \%$ DNA topoisomerase 2-beta GN=TOP2B TOP2B_HUMAN $183.27 \quad 100.0 \%$ DNA topoisomerase 2-beta GN=TOP2B TOP2B_HUMAN $183.27 \quad 100.0 \%$ DNA topoisomerase 2-beta $\mathrm{GN}=\mathrm{TOP} 2 \mathrm{~B}$ DNA topoisomerase 2-beta $\mathrm{GN}=\mathrm{TOP} 2 \mathrm{~B}$ DNA topoisomerase 2-beta $\mathrm{GN}=\mathrm{TOP} 2 \mathrm{~B}$ DNA topoisomerase 2-beta $\mathrm{GN}=\mathrm{TOP} 2 \mathrm{~B}$ DNA topoisomerase 2-beta $\mathrm{GN}=\mathrm{TOP} 2 \mathrm{~B}$ DNA topoisomerase 2-beta $\mathrm{GN}=\mathrm{TOP} 2 \mathrm{~B}$ DNA topoisomerase 2-beta $\mathrm{GN}=\mathrm{TOP} 2 \mathrm{~B}$ DNA topoisomerase 2-beta $\mathrm{GN}=\mathrm{TOP} 2 \mathrm{~B}$

DNA topoisomerase 2-beta $\mathrm{GN}=\mathrm{TOP} 2 \mathrm{~B}$ DNA topoisomerase 2-beta $\mathrm{GN}=\mathrm{TOP} 2 \mathrm{~B}$ TOP2B HUMAN $183.27 \quad 100.0 \%$ TOP2B_HUMAN $183.27 \quad 100.0 \%$ TOP2B HUMAN $183.27 \quad 100.0 \%$ TOP2B_HUMAN $183.27 \quad 100.0 \%$ TOP2B_HUMAN $183.27 \quad 100.0 \%$ TOP2B HUMAN $183.27 \quad 100.0 \%$ TOP2B_HUMAN $183.27 \quad 100.0 \%$ TOP2B_HUMAN $183.27 \quad 100.0 \%$ TOP2B HUMAN $183.27 \quad 100.0 \%$ TOP2B_HUMAN $183.27 \quad 100.0 \%$ TOP2B HUMAN $183.27 \quad 100.0 \%$ DNA-dependent protein kinase catalytic subunit GN=PRKDC PRKDC_HUMAN $469.10 \quad 100.0 \% \quad 116$ DNA-dependent protein kinase catalytic subunit GN=PRKDC PRKDC_HUMAN $469.10 \quad 100.0 \% \quad 116$ DNA-dependent protein kinase catalytic subunit GN=PRKDC PRKDC HUMAN $469.10 \quad 100.0 \% \quad 116$ DNA-dependent protein kinase catalytic subunit GN=PRKDC PRKDC_HUMAN $469.10 \quad 100.0 \% \quad 116$ DNA-dependent protein kinase catalytic subunit GN=PRKDC PRKDC_HUMAN $469.10 \quad 100.0 \% \quad 116$ DNA-dependent protein kinase catalytic subunit GN=PRKDC PRKDC_HUMAN $469.10 \quad 100.0 \% \quad 116$ DNA-dependent protein kinase catalytic subunit GN=PRKDC PRKDC_HUMAN $469.10 \quad 100.0 \% \quad 116$ DNA-dependent protein kinase catalytic subunit GN=PRKDC PRKDC_HUMAN $469.10 \quad 100.0 \% \quad 116$ DNA-dependent protein kinase catalytic subunit GN=PRKDC PRKDC_HUMAN $469.10 \quad 100.0 \% \quad 116$ DNA-dependent protein kinase catalytic subunit GN=PRKDC PRKDC_HUMAN $469.10 \quad 100.0 \% \quad 116$ DNA-dependent protein kinase catalytic subunit GN=PRKDC PRKDC_HUMAN $469.10 \quad 100.0 \% \quad 116$ DNA-dependent protein kinase catalytic subunit GN=PRKDC PRKDC_HUMAN $469.10 \quad 100.0 \% \quad 116$ DNA-dependent protein kinase catalytic subunit GN=PRKDC PRKDC_HUMAN $469.10 \quad 100.0 \% \quad 116$ DNA-dependent protein kinase catalytic subunit GN=PRKDC PRKDC_HUMAN $469.10 \quad 100.0 \% \quad 116$ DNA-dependent protein kinase catalytic subunit GN=PRKDC PRKDC_HUMAN $469.10 \quad 100.0 \% \quad 116$ DNA-dependent protein kinase catalytic subunit GN=PRKDC PRKDC_HUMAN $469.10 \quad 100.0 \% \quad 116$ DNA-dependent protein kinase catalytic subunit GN=PRKDC PRKDC_HUMAN $469.10 \quad 100.0 \% \quad 116$

(1)

9

9
9
9
9

9

9

9

9
9
9

9

9
9
9
9

9

$0.05 \% \quad 13.8 \%$ AYDIAGSTKDVK $0.05 \% \quad 13.8 \%$ VFLNGNKLPVK $\quad 0.05 \% \quad 13.8 \%$ GFQQISFVNSIATSK $0.05 \% \quad 13.8 \%$ HVDYVADQIVTK $0.05 \% \quad 13.8 \%$ SFGSTCQLSEK $0.05 \% \quad 13.8 \%$ SFGSTCQLSEKFIK $0.05 \% \quad 13.8 \%$ NSTECTLILTEGDSAK $0.05 \% \quad 13.8 \%$ TLAVSGLGVVGR $0.05 \% \quad 13.8 \%$ QIMENAEINNIIK $0.05 \% \quad 13.8 \%$ IVGLQYKK $0.05 \% \quad 13.8 \%$ NYEDEDSLKTLR $0.05 \% \quad 13.8 \%$ FLEEFITPIVK $0.05 \% \quad 13.8 \%$ YIFTMLSSLAR $0.05 \% \quad 13.8 \%$ TQMAEVLPSPR $0.02 \% \quad 10.5 \%$ EVTFVPGLYK $0.02 \% \quad 10.5 \%$ IFDEILVNAADNK $19 \quad 0.02 \% \quad 10.5 \%$ IFDEILVNAADNKQR $19 \quad 0.02 \% \quad 10.5 \%$ GIPVVEHKVEK $19 \quad 0.02 \% \quad 10.5 \%$ LCNIFSTK $19 \quad 0.02 \% \quad 10.5 \%$ AYDLAGSCR $19 \quad 0.02 \% \quad 10.5 \%$ AGVSVKPFQVK $19 \quad 0.02 \% \quad 10.5 \%$ SLAVSGLGVIGR $19 \quad 0.02 \% \quad 10.5 \%$ DRYGVFPLR $19 \quad 0.02 \% \quad 10.5 \%$ QIMENAEINNIIK $19 \quad 0.02 \% \quad 10.5 \%$ IVGLQYKK

$19 \quad 0.02 \% \quad 10.5 \%$ SYDDAESLKTLR $19 \quad 0.02 \% \quad 10.5 \%$ YAGPEDDAAITLAFSK $19 \quad 0.02 \% \quad 10.5 \%$ SIPSLVDGFKPGQR $19 \quad 0.02 \% \quad 10.5 \%$ LLFPAVDDNLLK $19 \quad 0.02 \% \quad 10.5 \%$ NTVEITELPVR $667 \quad 0.66 \% \quad 29.6 \%$ LQETLSAADR $667 \quad 0.66 \% \quad 29.6 \%$ CGAALAGHQLIR $667 \quad 0.66 \% \quad 29.6 \%$ DFGLLVFVR $667 \quad 0.66 \% \quad 29.6 \%$ IAPYSVEIK $667 \quad 0.66 \% \quad 29.6 \%$ NTCTSVYTKDR $667 \quad 0.66 \% \quad 29.6 \%$ TQMTSAVREPK $667 \quad 0.66 \% \quad 29.6 \%$ LPVLAGCLK $667 \quad 0.66 \% \quad 29.6 \%$ GLSSLLCNFTK $667 \quad 0.66 \% \quad 29.6 \%$ SMEEDPQTSR $667 \quad 0.66 \% \quad 29.6 \%$ AIRPQIDLKR $667 \quad 0.66 \% \quad 29.6 \%$ YAVPSAGLR $667 \quad 0.66 \% \quad 29.6 \%$ AALSALESFLK $667 \quad 0.66 \% \quad 29.6 \%$ QVSNMVAK $667 \quad 0.66 \% \quad 29.6 \%$ NVDSNNKELSIAIR $667 \quad 0.66 \% \quad 29.6 \%$ DVDFMYVELIQR $667 \quad 0.66 \% \quad 29.6 \%$ VFLALAAK $667 \quad 0.66 \% \quad 29.6 \%$ NCISTVVHQGLIR

0
0
0
0
1
0
0
0
0
0
0
0
0
0
0
0
2
0
0
0
0
0
0
0
0
0
0
0
0
0
0
0
0
0
0
0
0
0
0
0
0
0
0
0
0
0
0
0
0
0
0
0
0
0
0
0
0
0
0
0
0
0
0
0

162

1626.85

1122.61

1529.80 


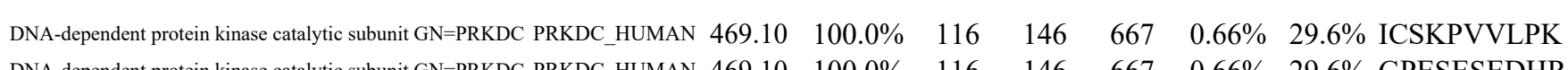
DNA-dependent protein kinase catalytic subunit GN=PRKDC PRKDC_HUMAN $469.10 \quad 100.0 \% \quad 116$ DNA-dependent protein kinase catalytic subunit GN=PRKDC PRKDC_HUMAN $469.10 \quad 100.0 \% \quad 116$ DNA-dependent protein kinase catalytic subunit GN=PRKDC PRKDC_HUMAN $469.10 \quad 100.0 \% \quad 116$ DNA-dependent protein kinase catalytic subunit GN=PRKDC PRKDC_HUMAN $469.10 \quad 100.0 \% \quad 116$ DNA-dependent protein kinase catalytic subunit GN=PRKDC PRKDC_HUMAN $469.10 \quad 100.0 \% \quad 116$ DNA-dependent protein kinase catalytic subunit GN=PRKDC PRKDC_HUMAN $469.10 \quad 100.0 \% \quad 116$ DNA-dependent protein kinase catalytic subunit GN=PRKDC PRKDC HUMAN $469.10 \quad 100.0 \% \quad 116$ DNA-dependent protein kinase catalytic subunit GN=PRKDC PRKDC_HUMAN $469.10 \quad 100.0 \% \quad 116$ DNA-dependent protein kinase catalytic subunit GN=PRKDC PRKDC_HUMAN $469.10 \quad 100.0 \% \quad 116$ DNA-dependent protein kinase catalytic subunit GN=PRKDC PRKDC_HUMAN $469.10 \quad 100.0 \% \quad 116$ DNA-dependent protein kinase catalytic subunit GN=PRKDC PRKDC_HUMAN $469.10 \quad 100.0 \% \quad 116$ DNA-dependent protein kinase catalytic subunit GN=PRKDC PRKDC_HUMAN $469.10 \quad 100.0 \% \quad 116$ DNA-dependent protein kinase catalytic subunit GN=PRKDC PRKDC_HUMAN $469.10 \quad 100.0 \% \quad 116$ DNA-dependent protein kinase catalytic subunit GN=PRKDC PRKDC_HUMAN $469.10 \quad 100.0 \% \quad 116$ DNA-dependent protein kinase catalytic subunit GN=PRKDC PRKDC HUMAN $469.10 \quad 100.0 \% \quad 116$ DNA-dependent protein kinase catalytic subunit GN=PRKDC PRKDC_HUMAN $469.10 \quad 100.0 \% \quad 116$ DNA-dependent protein kinase catalytic subunit GN=PRKDC PRKDC_HUMAN $469.10 \quad 100.0 \% 116$ DNA-dependent protein kinase catalytic subunit GN=PRKDC PRKDC_HUMAN $469.10 \quad 100.0 \% 116$ DNA-dependent protein kinase catalytic subunit GN=PRKDC PRKDC_HUMAN $469.10 \quad 100.0 \% \quad 116$ DNA-dependent protein kinase catalytic subunit GN=PRKDC PRKDC_HUMAN $469.10 \quad 100.0 \% \quad 116$ DNA-dependent protein kinase catalytic subunit GN=PRKDC PRKDC_HUMAN $469.10 \quad 100.0 \% \quad 116$ DNA-dependent protein kinase catalytic subunit GN=PRKDC PRKDC_HUMAN $469.10 \quad 100.0 \% \quad 116$ DNA-dependent protein kinase catalytic subunit GN=PRKDC PRKDC_HUMAN $469.10 \quad 100.0 \% \quad 116$ DNA-dependent protein kinase catalytic subunit GN=PRKDC PRKDC_HUMAN $469.10 \quad 100.0 \% \quad 116$ DNA-dependent protein kinase catalytic subunit GN=PRKDC PRKDC_HUMAN $469.10 \quad 100.0 \% 116$ DNA-dependent protein kinase catalytic subunit GN=PRKDC PRKDC_HUMAN $469.10 \quad 100.0 \% \quad 116$ DNA-dependent protein kinase catalytic subunit GN=PRKDC PRKDC_HUMAN $469.10 \quad 100.0 \% \quad 116$ DNA-dependent protein kinase catalytic subunit GN=PRKDC PRKDC HUMAN $469.10 \quad 100.0 \% \quad 116$ DNA-dependent protein kinase catalytic subunit GN=PRKDC PRKDC_HUMAN $469.10 \quad 100.0 \% \quad 116$ DNA-dependent protein kinase catalytic subunit GN=PRKDC PRKDC_HUMAN $469.10 \quad 100.0 \% \quad 116$ DNA-dependent protein kinase catalytic subunit GN=PRKDC PRKDC_HUMAN $469.10 \quad 100.0 \% \quad 116$ DNA-dependent protein kinase catalytic subunit GN=PRKDC PRKDC_HUMAN $469.10 \quad 100.0 \% \quad 116$ DNA-dependent protein kinase catalytic subunit GN=PRKDC PRKDC_HUMAN $469.10 \quad 100.0 \% \quad 116$ DNA-dependent protein kinase catalytic subunit GN=PRKDC PRKDC_HUMAN $469.10 \quad 100.0 \% \quad 116$ DNA-dependent protein kinase catalytic subunit GN=PRKDC PRKDC_HUMAN $469.10 \quad 100.0 \% \quad 116$ DNA-dependent protein kinase catalytic subunit GN=PRKDC PRKDC HUMAN $469.10 \quad 100.0 \% \quad 116$ DNA-dependent protein kinase catalytic subunit GN=PRKDC PRKDC_HUMAN $469.10 \quad 100.0 \% \quad 116$ DNA-dependent protein kinase catalytic subunit GN=PRKDC PRKDC_HUMAN $469.10 \quad 100.0 \% \quad 116$ DNA-dependent protein kinase catalytic subunit GN=PRKDC PRKDC HUMAN $469.10 \quad 100.0 \% \quad 116$ DNA-dependent protein kinase catalytic subunit GN=PRKDC PRKDC_HUMAN $469.10 \quad 100.0 \% \quad 116$ DNA-dependent protein kinase catalytic subunit GN=PRKDC PRKDC_HUMAN $469.10 \quad 100.0 \% \quad 116$ DNA-dependent protein kinase catalytic subunit GN=PRKDC PRKDC_HUMAN $469.10 \quad 100.0 \% \quad 116$ DNA-dependent protein kinase catalytic subunit GN=PRKDC PRKDC_HUMAN $469.10 \quad 100.0 \% \quad 116$ DNA-dependent protein kinase catalytic subunit GN=PRKDC PRKDC_HUMAN $469.10 \quad 100.0 \% \quad 116$ DNA-dependent protein kinase catalytic subunit GN=PRKDC PRKDC_HUMAN $469.10 \quad 100.0 \% \quad 116$

\section{7}

.

6

.

46

146
0.66\% 29.6\% GPESESEDHRASGEVR

$0.66 \% \quad 29.6 \%$ IKYFEGVSPK

$667 \quad 0.66 \% \quad 29.6 \%$ FGKEVAVK

$667 \quad 0.66 \% \quad 29.6 \%$ AYVPALQMAFK

$667 \quad 0.66 \% \quad 29.6 \%$ DILPCLDGYLK

$667 \quad 0.66 \% \quad 29.6 \%$ TSALSDETKNNWEVSALSR

$667 \quad 0.66 \% \quad 29.6 \%$ NNWEVSALSR

$667 \quad 0.66 \% \quad 29.6 \%$ GFNKVVLK

$667 \quad 0.66 \% \quad 29.6 \%$ NLSSNEAISLEEIR

$667 \quad 0.66 \% \quad 29.6 \%$ VVQMLGSLGGQINK

$667 \quad 0.66 \% \quad 29.6 \%$ NLLTVTSSDEMMK

$667 \quad 0.66 \% \quad 29.6 \%$ SYVAWDREK

$667 \quad 0.66 \% \quad 29.6 \%$ RLSFAVPFR

$667 \quad 0.66 \% \quad 29.6 \%$ VTELALTASDR

$667 \quad 0.66 \% \quad 29.6 \%$ VTELALTASDRQTK

$667 \quad 0.66 \% \quad 29.6 \%$ ATQMPEGGQGAPPMYQLYK $\quad 99.4 \% \quad 21.5$

$667 \quad 0.66 \% \quad 29.6 \%$ ATQMPEGGQGAPPMYQLYKR $99.5 \% \quad 21.5$

$667 \quad 0.66 \% \quad 29.6 \%$ RTFPVLLR

$667 \quad 0.66 \% \quad 29.6 \%$ LACDVDQVTR

$667 \quad 0.66 \% \quad 29.6 \%$ QITPQQQEK

$667 \quad 0.66 \% \quad 29.6 \%$ LYSLALHPNAFK

$667 \quad 0.66 \% \quad 29.6 \%$ LGASLAFNNIYR

$667 \quad 0.66 \% \quad 29.6 \%$ SLGTIQQCCDAIDHLCR

$667 \quad 0.66 \% \quad 29.6 \%$ FVPLLPGNR

$667 \quad 0.66 \% \quad 29.6 \%$ TVGALQVLGTEAQSSLLK

$667 \quad 0.66 \% \quad 29.6 \%$ CFGTGAAGNR

$667 \quad 0.66 \% \quad 29.6 \%$ TSPQEGERYNYSK

$667 \quad 0.66 \% \quad 29.6 \%$ DLCNTHLMR

$667 \quad 0.66 \% \quad 29.6 \%$ SRLAAVVSACK

$667 \quad 0.66 \% \quad 29.6 \%$ LAAVVSACK

$667 \quad 0.66 \% \quad 29.6 \%$ GIAPGDER

$667 \quad 0.66 \% \quad 29.6 \%$ QCLPSLDLSCK

$667 \quad 0.66 \% \quad 29.6 \%$ NLDLAVLELMQSSVDNTK

$667 \quad 0.66 \% \quad 29.6 \%$ LATTILQHWK

$667 \quad 0.66 \% \quad 29.6 \%$ EFPPGTPR

$667 \quad 0.66 \% \quad 29.6 \%$ FNNYVDCMK

$667 \quad 0.66 \% \quad 29.6 \%$ FNNYVDCMKK

$667 \quad 0.66 \% \quad 29.6 \%$ LNESTFDTQITK

$667 \quad 0.66 \% \quad 29.6 \%$ LNESTFDTQITKK

$667 \quad 0.66 \% \quad 29.6 \%$ ILDVMYSR

$667 \quad 0.66 \% \quad 29.6 \%$ LPKDDVHAK

$667 \quad 0.66 \% \quad 29.6 \%$ INQVFHGSCITEGNELTK

$667 \quad 0.66 \% \quad 29.6 \%$ RYNFPVEVEVPMER

$667 \quad 0.66 \% \quad 29.6 \%$ YNFPVEVEVPMER

$667 \quad 0.66 \% \quad 29.6 \%$ SLGPPQGEEDSVPR

$667 \quad 0.66 \% \quad 29.6 \%$ LGNPIVPLNIR $\begin{array}{llllllll}99.6 \% & 28.3 & 25.0 & 19.6 & 5 & 0 & 0 & 1140.68\end{array}$

$\begin{array}{llllllll}99.7 \% & 36.5 & 25.0 & 36.5 & 3 & 7 & 0 & 1741.77\end{array}$

$\begin{array}{llllllll}99.7 \% & 38.4 & 25.0 & 28.6 & 6 & 0 & 0 & 1167.64\end{array}$

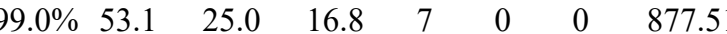

$\begin{array}{llll}99.7 \% & 43.5 & 25.0 & 36.7\end{array}$

$\begin{array}{llll}97.4 \% & 17.1 & 25.0 & 15.2\end{array}$

$\begin{array}{llll}99.7 \% & 43.5 & 25.0 & 43.5\end{array}$

$\begin{array}{llll}9.7 \% & 46.7 & 25.0 & 41.6 \\ 99.0 \% & 37.1 & 25.0 & 22.4\end{array}$

$99.7 \% \quad 60.8 \quad 25.0 \quad 52.9$

$99.7 \% \quad 59.4 \quad 25.0 \quad 54.0$

$99.7 \% \quad 55.9 \quad 25.0 \quad 55.9$

$99.7 \% \quad 31.9 \quad 25.0 \quad 29.7$

$99.7 \% \quad 36.1 \quad 25.0 \quad 33.2$

$99.7 \% \quad 70.2 \quad 25.0 \quad 63.2$

$\begin{array}{llll}97.4 \% & 27.0 & 25.0 & 4.2\end{array}$

$99.7 \% \quad 61.2 \quad 25.0 \quad 48.8$

$99.6 \% \quad 23.2 \quad 25.0 \quad 20.1$

$99.7 \% \quad 25.8 \quad 25.0 \quad 24.9$

$\begin{array}{llll}99.7 \% & 54.4 & 25.0 & 28.0\end{array}$

$99.7 \% \quad 45.2 \quad 25.0 \quad 45.2$

$\begin{array}{llll}99.7 \% & 30.2 & 25.0 & 28.8\end{array}$

$\begin{array}{llll}99.7 \% & 48.7 & 25.0 & 48.7\end{array}$

$\begin{array}{llll}99.7 \% & 64.7 & 25.0 & 56.5\end{array}$

$99.7 \% \quad 40.7 \quad 25.0 \quad 39.2$

$\begin{array}{llll}99.7 \% & 34.2 & 25.0 & 34.2\end{array}$

$99.7 \% \quad 32.0 \quad 25.0 \quad 27.9$

$99.7 \% \quad 57.7 \quad 25.0 \quad 44.8$

$\begin{array}{llll}99.0 \% & 32.2 & 25.0 & 24.6\end{array}$

$99.7 \% \quad 58.8 \quad 25.0 \quad 53.8$

$\begin{array}{llll}99.7 \% & 49.5 & 25.0 & 49.5\end{array}$

$99.1 \% \quad 18.1 \quad 25.0 \quad 18.1$

$96.0 \% \quad 18.7 \quad 25.0 \quad 13.9$

$\begin{array}{llll}99.4 \% & 24.1 & 25.0 & 23.5\end{array}$

$99.7 \% \quad 35.0 \quad 25.0 \quad 35.0$

$\begin{array}{llll}99.7 \% & 61.9 & 25.0 & 48.2\end{array}$

$\begin{array}{llll}99.7 \% & 56.3 & 25.0 & 51.6\end{array}$

$\begin{array}{llll}99.0 \% & 45.8 & 25.0 & 39.3\end{array}$

$\begin{array}{llll}99.7 \% & 51.5 & 25.0 & 39.8\end{array}$

$\begin{array}{llll}99.7 \% & 57.0 & 25.0 & 57.0\end{array}$

$\begin{array}{llll}99.7 \% & 26.2 & 25.0 & 19.5\end{array}$

$\begin{array}{llll}99.7 \% & 47.7 & 25.0 & 47.7\end{array}$

$\begin{array}{llll}99.7 \% & 59.8 & 25.0 & 58.4\end{array}$

$\begin{array}{llll}99.7 \% & 38.6 & 25.0 & 38.6\end{array}$

1238.66

1306.67

2108.03

1175.58

904.56

1574.80

1443.80

1500.69

1153.56

1092.63

1175.63

1532.83

2066.97

2255.06

1001.63

1176.57

1099.57

1373.76

1338.72

2046.92

1012.59

1815.02

1010.45

1558.71

1159.53

1161.64

918.51

814.41

1320.63

2006.01

1210.69

900.46

1190.50

1318.59

1396.70

1524.79

996.52

1022.56

2046.99

1764.87

1624.77

1467.71

1205.74 
DNA-dependent protein kinase catalytic subunit GN=PRKDC PRKDC_HUMAN $469.10 \quad 100.0 \% \quad 116 \quad 146 \quad 667 \quad 0.66 \% \quad 29.6 \%$ LVINTEEVFRPYAK

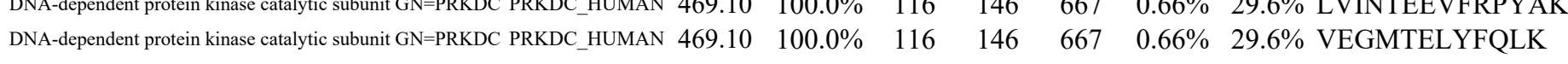
DNA-dependent protein kinase catalytic subunit GN=PRKDC PRKDC_HUMAN $469.10 \quad 100.0 \% \quad 116 \quad 146 \quad 667 \quad 0.66 \% \quad 29.6 \%$ SKDFVQVMR

DNA-dependent protein kinase catalytic subunit GN=PRKDC PRKDC_HUMAN $469.10 \quad 100.0 \% \quad 116 \quad 146 \quad 667 \quad 0.66 \% \quad 29.6 \%$ VCLDIIYK DNA-dependent protein kinase catalytic subunit GN=PRKDC PRKDC_HUMAN $469.10 \quad 100.0 \% \quad 116$ DNA-dependent protein kinase catalytic subunit GN=PRKDC PRKDC_HUMAN $469.10 \quad 100.0 \% \quad 116$ DNA-dependent protein kinase catalytic subunit GN=PRKDC PRKDC_HUMAN $469.10 \quad 100.0 \% \quad 116$ DNA-dependent protein kinase catalytic subunit GN=PRKDC PRKDC_HUMAN $469.10 \quad 100.0 \% \quad 116$ DNA-dependent protein kinase catalytic subunit GN=PRKDC PRKDC_HUMAN $469.10 \quad 100.0 \% \quad 116$ DNA-dependent protein kinase catalytic subunit GN=PRKDC PRKDC_HUMAN $469.10 \quad 100.0 \% \quad 116$ DNA-dependent protein kinase catalytic subunit GN=PRKDC PRKDC_HUMAN $469.10 \quad 100.0 \% \quad 116$ DNA-dependent protein kinase catalytic subunit GN=PRKDC PRKDC_HUMAN $469.10 \quad 100.0 \% \quad 116$ DNA-dependent protein kinase catalytic subunit GN=PRKDC PRKDC_HUMAN $469.10 \quad 100.0 \% \quad 116$ DNA-dependent protein kinase catalytic subunit GN=PRKDC PRKDC_HUMAN $469.10 \quad 100.0 \% \quad 116$ DNA-dependent protein kinase catalytic subunit GN=PRKDC PRKDC_HUMAN $469.10 \quad 100.0 \% 116$ DNA-dependent protein kinase catalytic subunit GN=PRKDC PRKDC_HUMAN $469.10 \quad 100.0 \% \quad 116$ DNA-dependent protein kinase catalytic subunit GN=PRKDC PRKDC_HUMAN $469.10 \quad 100.0 \% \quad 116$ DNA-dependent protein kinase catalytic subunit GN=PRKDC PRKDC_HUMAN $469.10 \quad 100.0 \% \quad 116$ DNA-dependent protein kinase catalytic subunit GN=PRKDC PRKDC_HUMAN $469.10 \quad 100.0 \% 116$ DNA-dependent protein kinase catalytic subunit GN=PRKDC PRKDC_HUMAN $469.10 \quad 100.0 \% \quad 116$ DNA-dependent protein kinase catalytic subunit GN=PRKDC PRKDC_HUMAN $469.10 \quad 100.0 \% \quad 116$ DNA-dependent protein kinase catalytic subunit GN=PRKDC PRKDC_HUMAN $469.10 \quad 100.0 \% 116$ DNA-dependent protein kinase catalytic subunit GN=PRKDC PRKDC_HUMAN $469.10 \quad 100.0 \% \quad 116$ DNA-dependent protein kinase catalytic subunit GN=PRKDC PRKDC_HUMAN $469.10 \quad 100.0 \% \quad 116$ DNA-dependent protein kinase catalytic subunit GN=PRKDC PRKDC_HUMAN $469.10 \quad 100.0 \% 116$ DNA-dependent protein kinase catalytic subunit GN=PRKDC PRKDC_HUMAN $469.10 \quad 100.0 \% \quad 116$ DNA-dependent protein kinase catalytic subunit GN=PRKDC PRKDC_HUMAN $469.10 \quad 100.0 \% \quad 116$ DNA-dependent protein kinase catalytic subunit GN=PRKDC PRKDC_HUMAN $469.10 \quad 100.0 \% 116$ DNA-dependent protein kinase catalytic subunit GN=PRKDC PRKDC_HUMAN $469.10 \quad 100.0 \% \quad 116$ DNA-dependent protein kinase catalytic subunit GN=PRKDC PRKDC_HUMAN $469.10 \quad 100.0 \% \quad 116$ DNA-dependent protein kinase catalytic subunit GN=PRKDC PRKDC_HUMAN $469.10 \quad 100.0 \% \quad 116$ DNA-dependent protein kinase catalytic subunit GN=PRKDC PRKDC_HUMAN $469.10 \quad 100.0 \% \quad 116$ DNA-dependent protein kinase catalytic subunit GN=PRKDC PRKDC_HUMAN $469.10 \quad 100.0 \% \quad 116$ DNA-dependent protein kinase catalytic subunit GN=PRKDC PRKDC_HUMAN $469.10 \quad 100.0 \% \quad 116$ DNA-dependent protein kinase catalytic subunit GN=PRKDC PRKDC_HUMAN $469.10 \quad 100.0 \% \quad 116$ DNA-dependent protein kinase catalytic subunit GN=PRKDC PRKDC_HUMAN $469.10 \quad 100.0 \% \quad 116$ DNA-dependent protein kinase catalytic subunit GN=PRKDC PRKDC_HUMAN $469.10 \quad 100.0 \% \quad 116$ DNA-dependent protein kinase catalytic subunit GN=PRKDC PRKDC_HUMAN $469.10 \quad 100.0 \% \quad 116$ DNA-dependent protein kinase catalytic subunit GN=PRKDC PRKDC_HUMAN $469.10 \quad 100.0 \% \quad 116$ DNA-dependent protein kinase catalytic subunit GN=PRKDC PRKDC_HUMAN $469.10 \quad 100.0 \% 116$ DNA-dependent protein kinase catalytic subunit GN=PRKDC PRKDC_HUMAN $469.10 \quad 100.0 \% 116$ DNA-dependent protein kinase catalytic subunit GN=PRKDC PRKDC_HUMAN $469.10 \quad 100.0 \% \quad 116$ DNA-dependent protein kinase catalytic subunit GN=PRKDC PRKDC_HUMAN $469.10 \quad 100.0 \% 116$ DNA-dependent protein kinase catalytic subunit GN=PRKDC PRKDC_HUMAN $469.10 \quad 100.0 \% \quad 116$ DNA-dependent protein kinase catalytic subunit GN=PRKDC PRKDC_HUMAN $469.10 \quad 100.0 \% \quad 116$ DNA-dependent protein kinase catalytic subunit GN=PRKDC PRKDC_HUMAN $469.10 \quad 100.0 \% \quad 116$ DNA-dependent protein kinase catalytic subunit GN=PRKDC PRKDC_HUMAN $469.10 \quad 100.0 \% \quad 116$

$667 \quad 0.66 \% \quad 29.6 \%$ QITQSALLAEAR
$667 \quad 0.66 \% \quad 29.6 \%$ ELLNPVVEFVSHPSTTCR

$667 \quad 0.66 \% \quad 29.6 \%$ LPSNTLDR

$667 \quad 0.66 \% \quad 29.6 \%$ STVLTPMFVETQASQGTLQTR

$667 \quad 0.66 \% \quad 29.6 \%$ ATQQQHDFTLTQTADGR

$667 \quad 0.66 \% \quad 29.6 \%$ SVGPDFGKK

$667 \quad 0.66 \% \quad 29.6 \%$ LGLPGDEVDNKVK

$667 \quad 0.66 \% \quad 29.6 \%$ MKQDAQVVLYR

$667 \quad 0.66 \% \quad 29.6 \%$ QDAQVVLYR

$667 \quad 0.66 \% \quad 29.6 \%$ SYRHGDLPDIQIK

$667 \quad 0.66 \% \quad 29.6 \%$ HGDLPDIQIK

$667 \quad 0.66 \% \quad 29.6 \%$ HSSLITPLQAVAQR

$667 \quad 0.66 \% \quad 29.6 \%$ HSSLITPLQAVAQRDPIIAK

$667 \quad 0.66 \% \quad 29.6 \%$ QLFSSLFSGILK

$667 \quad 0.66 \% \quad 29.6 \%$ TLSEKNNITQK

$667 \quad 0.66 \% \quad 29.6 \%$ LLEEALLR

$667 \quad 0.66 \% \quad 29.6 \%$ LLPAELPAK

$667 \quad 0.66 \% \quad 29.6 \%$ LLPAELPAKR

$667 \quad 0.66 \% \quad 29.6 \%$ SIGEYDVLR

$667 \quad 0.66 \% \quad 29.6 \%$ GIFTSEIGTK

$99.7 \% 50.0$

$\begin{array}{ll}99.1 \% & 20.2 \\ 99.7 \% & 51.2\end{array}$

$99.0 \% 39.8$

$95.9 \% \quad 14.9$

$99.0 \% \quad 44.9$

$99.7 \% \quad 55.1$

$99.7 \% \quad 52.1$

$99.2 \% \quad 27.1$

$99.7 \% \quad 53.3$

$99.7 \% \quad 58.9$

$99.7 \% \quad 36.4$

$99.6 \% \quad 31.8$

$99.7 \% \quad 60.8$

$99.7 \% \quad 47.2$

$\begin{array}{ll}99.5 \% & 22.4 \\ 99.7 \% & 59.9\end{array}$

$99.7 \% \quad 59$.

$99.7 \% \quad 42.2$

$99.0 \% \quad 58.6$

$95.5 \% \quad 15.4$

$99.7 \% \quad 35.9$

$99.7 \% \quad 48.0$

$99.7 \% \quad 57.5$

$99.7 \% \quad 67.2$

667 $29.6 \%$ SLEYCSTASIDSENPPDLNK $99.7 \% \quad 31.8$

$667 \quad 0.66 \% \quad 29.6 \%$ QGNLSSQVPLK

$667 \quad 0.66 \% \quad 29.6 \%$ QGNLSSQVPLKR

$667 \quad 0.66 \% \quad 29.6 \%$ KQNNFSLAMK

$667 \quad 0.66 \% \quad 29.6 \%$ SRSQGCSEQVLTVLK

$667 \quad 0.66 \% \quad 29.6 \%$ SQGCSEQVLTVLK

$667 \quad 0.66 \% \quad 29.6 \%$ TVSLLDENNVSSYLSK

$667 \quad 0.66 \% \quad 29.6 \%$ NILAFRDQNILLGTTYR

$667 \quad 0.66 \% \quad 29.6 \%$ DQNILLGTTYR

$\begin{array}{llllll}667 & 0.66 \% & 29.6 \% & \text { IIANALSSEPACLAEIEEDKAR } & 99.7 \% & 27.0\end{array}$

$667 \quad 0.66 \% \quad 29.6 \%$ ILELSGSSSEDSEKVIAGLYQR $99.7 \% \quad 28.2$

$667 \quad 0.66 \% \quad 29.6 \%$ ALKLNSNEAR

$667 \quad 0.66 \% \quad 29.6 \%$ NIEKMYER

$667 \quad 0.66 \% \quad 29.6 \%$ MYAALGDPK

$667 \quad 0.66 \% \quad 29.6 \%$ KFIQTFGK

$667 \quad 0.66 \% \quad 29.6 \%$ NELEIPGQYDGR

$667 \quad 0.66 \% \quad 29.6 \%$ TYSVVPMTSR

$667 \quad 0.66 \% \quad 29.6 \%$ GANRTETVTSFR

$\begin{array}{llll}0.66 \% & 29.6 \% & \text { TETVTSFR }\end{array}$

$667 \quad 0.66 \% \quad 29.6 \%$ MSTSPEAFLALR
$99.7 \% \quad 43.0$

$99.7 \% \quad 29.4$

$99.7 \% \quad 56.9$

$99.7 \% \quad 39.5$

$99.7 \% \quad 58.5$

$99.7 \% \quad 58.8$

$99.7 \% \quad 29.5$$$
\begin{array}{lll}
96.4 \% & 24.2
\end{array}
$$

$99.0 \% \quad 31.3$

$99.7 \% \quad 45.9$

$96.3 \% 22.0$

$99.6 \% \quad 26.6$

$99.0 \% \quad 49.2$

$99.7 \% \quad 36.5$

$99.7 \% \quad 43.1$

$99.0 \% \quad 35.3$

$99.0 \% \quad 53.6$

$99.7 \% \quad 58.9$
$99.6 \% \quad 24.3$

(16


DNA-dependent protein kinase catalytic subunit GN=PRKDC PRKDC_HUMAN $469.10 \quad 100.0 \% \quad 116$ DNA-dependent protein kinase catalytic subunit GN=PRKDC PRKDC_HUMAN $469.10 \quad 100.0 \% \quad 116$ DNA-dependent protein kinase catalytic subunit GN=PRKDC PRKDC_HUMAN $469.10 \quad 100.0 \% \quad 116$ DNA-dependent protein kinase catalytic subunit GN=PRKDC PRKDC_HUMAN $469.10 \quad 100.0 \% \quad 116$ DNA-dependent protein kinase catalytic subunit GN=PRKDC PRKDC_HUMAN $469.10 \quad 100.0 \% \quad 116$ DNA-directed RNA polymerase I subunit RPA34 GN=CD3EAP RPA34_HUMAN $54.99 \quad 100.0 \%$ DNA-directed RNA polymerase I subunit RPA34 GN=CD3EAP RPA34_HUMAN $54.99 \quad 100.0 \%$ DNA-directed RNA polymerase II subunit RPB1 GN=POLR2A RPB1_HUMAN $217.18 \quad 100.0 \%$ DNA-directed RNA polymerase II subunit RPB1 GN=POLR2A RPB1_HUMAN $217.18 \quad 100.0 \%$ DNA-directed RNA polymerase II subunit RPB1 GN=POLR2A RPB1_HUMAN $217.18 \quad 100.0 \%$ DNA-directed RNA polymerase II subunit RPB1 GN=POLR2A RPB1_HUMAN $217.18 \quad 100.0 \%$ DNA-directed RNA polymerase II subunit RPB1 GN=POLR2A RPB1_HUMAN $217.18 \quad 100.0 \%$ DNA-directed RNA polymerase II subunit RPB3 GN=POLR2C RPB3_HUMAN $31.44 \quad 100.0 \%$ DNA-directed RNA polymerase II subunit RPB3 GN=POLR2C RPB3_HUMAN $31.44 \quad 100.0 \%$ DNA-directed RNA polymerase II subunit RPB3 GN=POLR2C RPB3 HUMAN $31.44 \quad 100.0 \%$ DNA-directed RNA polymerase III subunit RPC1 GN=POLR3A RPC1_HUMAN $155.65100 .0 \%$ DNA-directed RNA polymerase III subunit RPC1 GN=POLR3A RPC1_HUMAN $155.65 \quad 100.0 \%$ DNA-directed RNA polymerase III subunit RPC1 GN=POLR3A RPC1_HUMAN $155.65 \quad 100.0 \%$ DNA-directed RNA polymerase III subunit RPC1 GN=POLR3A RPC1_HUMAN $155.65 \quad 100.0 \%$ DNA-directed RNA polymerases I and III subunit RPACI GN=POLRIC RPAC1_HUMAN $39.25 \quad 100.0 \%$ DNA-directed RNA polymerases I and III subunit RPAC1 GN=POLRIC RPAC1_HUMAN $39.25 \quad 100.0 \%$ DNA-directed RNA polymerases I and III subunit RPAC1 GN=POLRIC RPAC1_HUMAN $39.25 \quad 100.0 \%$ DNA-directed RNA polymerases I and III subunit RPAC1 GN=POLRIC RPAC1_HUMAN $39.25 \quad 100.0 \%$ DnaJ homolog subfamily A member $1 \mathrm{GN}=$ DNAJA1 DNJA1_HUMAN $44.87 \quad 100.0 \%$ DnaJ homolog subfamily A member $1 \mathrm{GN}=$ DNAJA1 DNJA1_HUMAN $44.87 \quad 100.0 \%$ DnaJ homolog subfamily A member 1 GN=DNAJA1 DNJA1_HUMAN $44.87 \quad 100.0 \%$ DnaJ homolog subfamily A member $1 \mathrm{GN}=$ DNAJA1 DNJA1_HUMAN $44.87 \quad 100.0 \%$ DnaJ homolog subfamily A member $1 \mathrm{GN}=$ DNAJA1 DNJA1_HUMAN $44.87 \quad 100.0 \%$ DnaJ homolog subfamily A member $1 \mathrm{GN}=$ DNAJA1 DNJA1_HUMAN $44.87 \quad 100.0 \%$ DnaJ homolog subfamily A member $2 \mathrm{GN}=$ DNAJA2 DNJA2 HUMAN $45.75100 .0 \%$ DnaJ homolog subfamily A member 2 GN=DNAJA2 DNJA2_HUMAN $45.75 \quad 100.0 \%$ DnaJ homolog subfamily A member 2 GN=DNAJA2 DNJA2_HUMAN $45.75 \quad 100.0 \%$ DnaJ homolog subfamily A member $2 \mathrm{GN}=$ DNAJA2 DNJA2_HUMAN $45.75 \quad 100.0 \%$ DnaJ homolog subfamily A member 2 GN=DNAJA2 DNJA2_HUMAN $45.75 \quad 100.0 \%$ DnaJ homolog subfamily A member 3, mitochondrial GN=DNAJA3 DNJA3_HUMAN $52.49 \quad 100.0 \%$ DnaJ homolog subfamily A member 3, mitochondrial GN=DNAJA3 DNJA3_HUMAN $52.49 \quad 100.0 \%$ DnaJ homolog subfamily A member 3, mitochondrial GN=DNAJA3 DNJA3_HUMAN $52.49 \quad 100.0 \%$ DnaJ homolog subfamily A member 3 , mitochondrial GN=DNAJA3 DNJA3 HUMAN $52.49100 .0 \%$ DnaJ homolog subfamily A member 3, mitochondrial GN=DNAJA3 DNJA3_HUMAN $52.49 \quad 100.0 \%$ DnaJ homolog subfamily A member 3, mitochondrial GN=DNAJA3 DNJA3_HUMAN $52.49 \quad 100.0 \%$ DnaJ homolog subfamily A member 3, mitochondrial GN=DNAJA3 DNJA3 HUMAN $52.49 \quad 100.0 \%$ DnaJ homolog subfamily A member 3, mitochondrial GN=DNAJA3 DNJA3_HUMAN $52.49 \quad 100.0 \%$ DnaJ homolog subfamily B member 11 GN=DNAJB11 DJB11_HUMAN $40.51 \quad 100.0 \%$ DnaJ homolog subfamily B member 11 GN=DNAJB11 DJB11_HUMAN $40.51 \quad 100.0 \%$ DnaJ homolog subfamily B member 11 GN=DNAJB11 DJB11_HUMAN $40.51 \quad 100.0 \%$ DnaJ homolog subfamily B member 11 GN=DNAJB11 DJB11 HUMAN $40.51 \quad 100.0 \%$ DnaJ homolog subfamily B member 11 GN=DNAJB11 DJB11_HUMAN $40.51 \quad 100.0 \%$

(2)

5

3

4

4

4

4
4
4

4
4
6

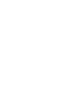

$\begin{array}{ll}5 & 6 \\ 5 & 6 \\ 8 & 11 \\ 8 & 11\end{array}$

1

$\begin{array}{ll}7 & 7 \\ 7 & 7 \\ 7 & 7\end{array}$

5
5
3
3

4

6
6
6

6
6
6
6

6

$\begin{array}{ll}5 & 6 \\ 5 & 6 \\ 5 & 6\end{array}$

1

1
1
1
1

$\begin{array}{ll}8 & 1 \\ 8 & 1 \\ 8 & 1 \\ 8 & 1\end{array}$

$\begin{array}{llll}667 & 0.66 \% & 29.6 \% & \text { SDPGLLTNTMDVFVK } \\ 667 & 0.66 \% & 29.6 \% & \text { LAGANPAVITCDELLLGHEK }\end{array}$

$667 \quad 0.66 \% \quad 29.6 \%$ APAFRDYVAVAR

$667 \quad 0.66 \% \quad 29.6 \%$ AQEPESGLSEETQVK

$667 \quad 0.66 \% \quad 29.6 \%$ CLMDQATDPNILGR

$4 \quad 0.00 \% \quad 5.1 \%$ FCAFGGNPPVTGPR

$0.00 \% \quad 5.1 \%$ SALAPNLLTSGK

$0.01 \% \quad 3.3 \%$ TVITPDPNLSIDQVGVPR

$0.01 \% \quad 3.3 \%$ QTFENQVNR

$0.01 \% \quad 3.3 \% \quad$ NSINQVVQLR

$0.01 \% \quad 3.3 \% \quad$ YSPTSPTYSPTTPK

$0.01 \% \quad 3.3 \% \quad$ YSPTSPTYSPTSPK

$0.00 \% \quad 12.4 \%$ PYANQPTVR

$0.00 \% \quad 12.4 \%$ ITELTDENVK

$0.00 \% \quad 12.4 \%$ FIIENTDLAVANSIR

$0.01 \% \quad 3.5 \%$ LAPVYLSNR

$0.01 \% 3.5 \%$ GFSIGIGDVTPGQGLLK

$0.01 \% \quad 3.5 \%$ AKYELLNAGYK

$0.01 \% \quad 3.5 \%$ VVVQGIPEVSR

$10 \quad 0.01 \% \quad 15.0 \%$ ILLAEVPTMAVEK

$10 \quad 0.01 \% \quad 15.0 \%$ NQGDEEGTEIDTLQFR

$10 \quad 0.01 \% \quad 15.0 \%$ DSSDPNELYVNHK

$10 \quad 0.01 \% \quad 15.0 \%$ FSPVATASYR

$11 \quad 0.01 \% \quad 17.1 \%$ YHPDKNPNEGEK

$11 \quad 0.01 \% \quad 17.1 \%$ QISQAYEVLSDAK

$11 \quad 0.01 \% \quad 17.1 \%$ ELYDKGGEQAIK

$11 \quad 0.01 \% \quad 17.1 \%$ NVICDKCEGR

$11 \quad 0.01 \% \quad 17.1 \%$ ILEVHIDK

$11 \quad 0.01 \% \quad 17.1 \%$ TIVITSHPGQIVK

$11 \quad 0.01 \% \quad 13.1 \%$ ELYDRYGEQGLR

$11 \quad 0.01 \% \quad 13.1 \%$ VSLEDLYNGK

$11 \quad 0.01 \% \quad 13.1 \%$ NVLCSACSGQGGK

$11 \quad 0.01 \% \quad 13.1 \%$ ILEVHVDKGMK

$11 \quad 0.01 \% \quad 13.1 \%$ VIEPGCVR

$30 \quad 0.03 \% \quad 21.5 \%$ KAYYQLAK

$30 \quad 0.03 \% \quad 21.5 \%$ FSQLAEAYEVLSDEVK

$30 \quad 0.03 \% \quad 21.5 \%$ GGPTVDPEELFR

$30 \quad 0.03 \% \quad 21.5 \%$ EFTVNIMDTCER

$30 \quad 0.03 \% \quad 21.5 \%$ GSIIISPCVVCR

$30 \quad 0.03 \% \quad 21.5 \%$ VMIPVPAGVEDGQTVR

$0.03 \% \quad 21.5 \%$ INSYGYGDHYIHIK

$0.03 \% \quad 21.5 \%$ REAGEDEEGFLSK

$99.7 \% 32.9$

$99.1 \% \quad 18.5$

$99.7 \% 60.4$

$99.7 \% \quad 56.2$

$99.7 \% \quad 60.5$

$98.9 \% \quad 21.5$

$\begin{array}{ll}99.7 \% & 30.3 \\ 99.6 \% & 28.8\end{array}$

$9.6 \% \quad 28.8$

$99.7 \% \quad 55.0$

$99.7 \% \quad 36.5$

$99.7 \% \quad 44.1$

$99.7 \% \quad 26.4$

$99.7 \% \quad 30.5$

$99.7 \% \quad 68.2$

$98.2 \% \quad 17.5$

$99.7 \% \quad 35.8$

$98.1 \% \quad 20.5$

$99.7 \% \quad 36.3$

$99.7 \% \quad 55.6$

$99.7 \% \quad 38.2$

$99.7 \% \quad 42.1$

$95.9 \% \quad 14.4$

$99.7 \% \quad 92.1$

$99.7 \% \quad 52.9$

$\begin{array}{lll}99.7 \% & 40.7\end{array}$

$98.4 \% \quad 24.6$

$99.7 \% \quad 55.1$

$\begin{array}{lll}99.7 \% & 31.8\end{array}$

$99.7 \% \quad 59.8$

$99.7 \% \quad 66.4$

$99.7 \% \quad 47.7$

$99.0 \% \quad 21.3$

$99.0 \% \quad 32.5$

$99.7 \% \quad 53.9$

$99.7 \% \quad 51.5$

$\begin{array}{lll}99.7 \% & 53.8\end{array}$

$99.7 \% \quad 49.9$

$99.7 \% \quad 57.0$

$\begin{array}{llll}99.7 \% & 46.0 \quad 25.0\end{array}$

$\begin{array}{llll}99.7 \% & 34.1 & 25.0\end{array}$

$\begin{array}{lll}0.01 \% & 24.3 \% & \text { LALQLHPDRNPDDPQAQEK } \\ 0.01 \% & 24.3 \% & \text { FQDLGAAYEVLSDSEK }\end{array}$

$\begin{array}{lll}0.01 \% & 24.3 \% & \text { TTQLGPGR }\end{array}$

$99.7 \% \quad 41.3$

$0.01 \% \quad 24.3 \%$ FQMTQEVVCDECPNVK

$0.01 \% \quad 24.3 \%$ TLEVEIEPGVR

\section{0
$\mathrm{~K} \quad 99.7$}

$99.7 \% \quad 62.7$

2121.10

1335.72

631.78

1603.76

1476.71

1171.67

1921.04

135.55

1170.66

1526.74

1512.72

1045.54

1161.60

1675.90

1032.58

1658.91

1269.68

1182.68

1413.80

1851.84

1517.69

1098.56

1427.66

1451.74

1350.69

1250.56

966.56

1392.82

1498.73

1137.58

1337.59
1284.70

929.49

984.55

1827.90

1316.65
1530.66

1360.71

1667.88

1679.82

1466.68

2185.10

1771.84

829.45

\begin{tabular}{l}
241.67 \\
\hline
\end{tabular}

Page 55 of Table S-1-4 
DnaJ homolog subfamily B member 11 GN=DNAJB11 DJB11 HUMAN $40.51 \quad 100.0 \%$ DnaJ homolog subfamily B member 11 GN=DNAJB11 DJB11_HUMAN $40.51 \quad 100.0 \%$ DnaJ homolog subfamily B member 12 GN=DNAJB12 DJB12_HUMAN $41.82 \quad 100.0 \%$ DnaJ homolog subfamily B member 12 GN=DNAJB12 DJB12_HUMAN $41.82 \quad 100.0 \%$ DnaJ homolog subfamily B member 12 GN=DNAJB12 DJB12_HUMAN $41.82 \quad 100.0 \%$ DnaJ homolog subfamily B member $6 \mathrm{GN}=$ DNAJB6 DNJB6_HUMAN $36.09 \quad 100.0 \%$ DnaJ homolog subfamily B member 6 GN=DNAJB6 DNJB6_HUMAN $36.09 \quad 100.0 \%$ DnaJ homolog subfamily B member 6 GN=DNAJB6 DNJB6_HUMAN $36.09 \quad 100.0 \%$ DnaJ homolog subfamily C member $10 \mathrm{GN}=$ DNAJC10 DJC10 HUMAN $91.08 \quad 100.0 \%$ DnaJ homolog subfamily C member $10 \mathrm{GN}=$ DNAJC10 DJC10_HUMAN $91.08 \quad 100.0 \%$ DnaJ homolog subfamily C member $10 \mathrm{GN}=$ DNAJC10 DJC10_HUMAN $91.08 \quad 100.0 \%$ DnaJ homolog subfamily C member $10 \mathrm{GN}=$ DNAJC10 DJC10_HUMAN $91.08 \quad 100.0 \%$ DnaJ homolog subfamily C member $10 \mathrm{GN}=$ DNAJC10 DJC10_HUMAN $91.08 \quad 100.0 \%$ DnaJ homolog subfamily C member $11 \mathrm{GN}=$ DNAJC11 DJC11_HUMAN $63.28 \quad 100.0 \%$ DnaJ homolog subfamily C member 11 GN=DNAJC11 DJC11_HUMAN $63.28 \quad 100.0 \%$ DnaJ homolog subfamily C member $11 \mathrm{GN}=$ DNAJC11 DJC11_HUMAN $63.28 \quad 100.0 \%$ DnaJ homolog subfamily C member 11 GN=DNAJC11 DJC11_HUMAN $63.28 \quad 100.0 \%$ DnaJ homolog subfamily C member 11 GN=DNAJC11 DJC11_HUMAN $63.28 \quad 100.0 \%$ DnaJ homolog subfamily C member 11 GN=DNAJC11 DJC11_HUMAN $63.28 \quad 100.0 \%$ DnaJ homolog subfamily C member 11 GN=DNAJC11 DJC11_HUMAN $63.28 \quad 100.0 \%$ DnaJ homolog subfamily C member 13 GN=DNAJC13 DJC13_HUMAN $254.42 \quad 100.0 \%$ DnaJ homolog subfamily C member 13 GN=DNAJC13 DJC13_HUMAN $254.42 \quad 100.0 \%$ DnaJ homolog subfamily C member 13 GN=DNAJC13 DJC13_HUMAN $254.42 \quad 100.0 \%$ DnaJ homolog subfamily C member 13 GN=DNAJC13 DJC13_HUMAN $254.42 \quad 100.0 \%$ DnaJ homolog subfamily C member $13 \mathrm{GN}=$ DNAJC13 DJC13 HUMAN $254.42 \quad 100.0 \%$ DnaJ homolog subfamily C member 13 GN=DNAJC13 DJC13_HUMAN $254.42 \quad 100.0 \%$ DnaJ homolog subfamily C member $13 \mathrm{GN}=$ DNAJC13 DJC13_HUMAN $254.42 \quad 100.0 \%$ DnaJ homolog subfamily C member 13 GN=DNAJC13 DJC13_HUMAN $254.42 \quad 100.0 \%$ DnaJ homolog subfamily C member 13 GN=DNAJC13 DJC13_HUMAN $254.42 \quad 100.0 \%$ DnaJ homolog subfamily C member $13 \mathrm{GN}=$ DNAJC13 DJC13 HUMAN $254.42100 .0 \%$ DnaJ homolog subfamily C member 13 GN=DNAJC13 DJC13_HUMAN $254.42 \quad 100.0 \%$ DnaJ homolog subfamily C member 13 GN=DNAJC13 DJC13_HUMAN $254.42 \quad 100.0 \%$ DnaJ homolog subfamily C member $13 \mathrm{GN}=$ DNAJC13 DJC13 HUMAN $254.42 \quad 100.0 \%$ DnaJ homolog subfamily C member 13 GN=DNAJC13 DJC13_HUMAN $254.42 \quad 100.0 \%$ DnaJ homolog subfamily C member $13 \mathrm{GN}=$ DNAJC13 DJC13_HUMAN $254.42 \quad 100.0 \%$ Dolichol-phosphate mannosyltransferase subunit 1 GN=DPM1 DPM1_HUMAN $29.64 \quad 100.0 \%$ Dolichol-phosphate mannosyltransferase subunit 1 GN=DPM1 DPM1_HUMAN $29.64 \quad 100.0 \%$ Dolichol-phosphate mannosyltransferase subunit 1 GN=DPM1 DPM1 HUMAN $29.64 \quad 100.0 \%$ Dolichol-phosphate mannosyltransferase subunit 1 GN=DPM1 DPM1_HUMAN $29.64 \quad 100.0 \%$ Dolichol-phosphate mannosyltransferase subunit 1 GN=DPM1 DPM1_HUMAN $29.64 \quad 100.0 \%$ Dolichol-phosphate mannosyltransferase subunit 1 GN=DPM1 DPM1_HUMAN $29.64 \quad 100.0 \%$ Dolichol-phosphate mannosyltransferase subunit 1 GN=DPM1 DPM1_HUMAN $29.64 \quad 100.0 \%$ Dolichol-phosphate mannosyltransferase subunit 1 GN=DPM1 DPM1 HUMAN $29.64100 .0 \%$ Dolichol-phosphate mannosyltransferase subunit 1 GN=DPM1 DPM1_HUMAN $29.64 \quad 100.0 \%$ Dolichol-phosphate mannosyltransferase subunit 1 GN=DPM1 DPM1_HUMAN $29.64100 .0 \%$ ollichy-diphosphooligosaccharide-protetin glycosyltransfererse 48 kDa subunit GN=DDOST $\quad$ OST 48_HUMAN $50.80 \quad 100.0 \%$
$01 \% \quad 24.3 \%$ DKITRPGAK

$0.01 \% \quad 9.1 \%$ AIQSNQPDR

$0.01 \% \quad 9.1 \%$ GYTAEQVAAVK

$0.01 \% \quad 9.1 \%$ AIGTAYAVLSNPEK

$0.01 \% \quad 12.6 \%$ VDYYEVLGVQR

$0.01 \% \quad 12.6 \%$ QVAEAYEVLSDAK

$0.01 \% \quad 12.6 \%$ SLTINGVADDDALAEER

$.01 \% \quad 7.2 \%$ IGAVNCGDDRMLCR

$0.01 \% \quad 7.2 \%$ ALLPELRR

$0.01 \% \quad 7.2 \%$ ASNLLYGQLK

$0.01 \% \quad 7.2 \%$ AGKVDCQAYAQTCQK

$0.01 \% \quad 7.2 \% \quad$ NFQEEQINTR

$0.01 \% \quad 16.6 \%$ EASSEELKAAYR

$0.01 \% \quad 16.6 \%$ AIYDIYGKR

$0.01 \% \quad 16.6 \%$ CFVTTNCALQFSSR

$0.01 \% \quad 16.6 \%$ GIRPGLTTVLAR

$0.01 \% \quad 16.6 \%$ AGFFGTVVEYGAER

$0.01 \% \quad 16.6 \%$ HSVLGAAVSVGVPQG

$\begin{array}{lll}0.02 \% & 7.6 \% & \text { GQGTEFNLTFR }\end{array}$

$0.02 \% \quad 7.6 \%$ AGFLAFTQLPK

$0.02 \% \quad 7.6 \%$ AIIEEGDKEIATK

$0.02 \% \quad 7.6 \%$ ENINQKPVVLR

$0.02 \% \quad 7.6 \%$ SNLIWNFK

$0.02 \% \quad 7.6 \%$ IAAHLADFTPR

$0.02 \% \quad 7.6 \%$ IVDGPDPENIILILK

$0.02 \% \quad 7.6 \%$ TQSILFNR

$0.02 \% \quad 7.6 \%$ SEETNQQEVANSLAK

$0.02 \% \quad 7.6 \%$ LAVASVTEILK

$0.02 \% \quad 7.6 \%$ ELIVGEIFVR

$0.02 \% \quad 7.6 \%$ VYNEVPTFQLEVPK

$0.02 \% \quad 7.6 \%$ VEMALEALR

$0.02 \% \quad 7.6 \%$ IFIAQPAWVLR

$0.02 \% \quad 7.6 \%$ VIHALSENELCVR

$0.02 \% \quad 42.7 \%$ YSVLLPTYNER

$0.02 \% \quad 42.7 \%$ DVAEQLEK

$0.02 \% \quad 42.7 \%$ KLGLGTAYIHGMK

$0.02 \% \quad 42.7 \%$ LGLGTAYIHGMK

$0.02 \% \quad 42.7 \%$ QKEGNFDIVSGTR

$0.02 \% \quad 42.7 \%$ GANFLTQILLRPGASDLTGSFR

$0.02 \% \quad 42.7 \%$ GYVFQMEMIVR

$0.02 \% \quad 42.7 \%$ QLNYTIGEVPISFVDR

$0.02 \% \quad 42.7 \%$ QLNYTIGEVPISFVDRVYGESK

$0.02 \% \quad 42.7 \%$ LGGNEIVSFLK

$0.01 \% \quad 10.5 \%$ TLVLLDNLNVR

$0.01 \% \quad 10.5 \%$ TADDPSLSLIK
$99.7 \% \quad 32.9$

$99.0 \% \quad 25.6$

$\begin{array}{lll}99.5 \% & 34.7\end{array}$

$99.7 \% \quad 36.7$

$99.7 \% \quad 51.8$

$99.7 \% \quad 61.2$

$99.7 \% \quad 55.3$

$99.7 \% \quad 49.5$

$96.5 \% \quad 15.0$

$99.0 \% \quad 25.1$

$99.7 \% \quad 44.3$

$99.7 \% 71.4$

$99.7 \% \quad 50.2$

$99.7 \% \quad 64.8$

$99.7 \% 51.3$

$99.7 \% \quad 68.6$

$99.7 \% \quad 32.5$

$99.7 \% \quad 61.3$

$99.7 \% \quad 34.4$

$99.7 \% \quad 35.4$

$99.7 \% \quad 35.1$

$99.7 \% \quad 45.3$

$99.7 \% \quad 34.4$

$99.6 \% \quad 27.3$

$\begin{array}{lll}98.9 \% & 28.1\end{array}$

$99.7 \% \quad 30.4$

$\begin{array}{lll}99.7 \% & 28.8\end{array}$

$99.0 \% \quad 25.4$

$99.7 \% \quad 80.4$

$99.7 \% \quad 26.6$

$98.2 \% \quad 20.6$

$98.7 \% \quad 25.1$

$\begin{array}{lll}99.7 \% & 48.7\end{array}$

$99.7 \% \quad 34.2$

$96.4 \% \quad 14.9$

$99.7 \% \quad 30.1$

$99.0 \% \quad 29.7$

$99.3 \% \quad 25.4$

$99.7 \% \quad 34.5$

$99.7 \% \quad 45.6$

$99.7 \% \quad 44.1$

$99.7 \% \quad 48.8$

$99.7 \% \quad 54.4$

$99.4 \% \quad 27$.

$99.7 \% \quad 64.7$

$99.6 \% \quad 28.7$

$99.7 \% \quad 36.6$

1098.59

1690.77

1253.77

1502.73

1805.03

1483.86

1269.62

1192.67

1416.76

1309.76

1021.55

1211.65

1648.95

978.54

1647.78

1143.70

1174.68

1662.87

1031.56

1313.77

1539.79

1354.70

931.47

1404.77

1276.67

1450.73

2334.26

1404.67

1850.96

2514.29

1176.66

1269.75

1159.62 

Dual specificity protein phosphatase $9 \mathrm{GN}=$ DUSP9 DUS9_HUMAN $41.87 \quad 100.0 \%$ Dual specificity protein phosphatase 9 GN=DUSP9 DUS9_HUMAN $41.87 \quad 100.0 \%$ Dynactin subunit $1 \mathrm{GN}=\mathrm{DCTN} 1$

$0.01 \% \quad 10.5 \%$ NTLLIAGLQAR $0.01 \% \quad 10.5 \%$ YSQTGNYELAVALSR

$10 \quad 0.01 \% \quad 14.2 \%$ ATSFLLALEPELEAR

$10 \quad 0.01 \% \quad 14.2 \%$ YDYQRQPDSGISSIR

$10 \quad 0.01 \% \quad 14.2 \%$ NIEIDSPYEISR

$0.01 \% \quad 14.2 \%$ SLETEHKALTSEIALLQSR

$10 \quad 0.01 \% \quad 14.2 \%$ SAVEAERLVAGK

$10 \quad 0.01 \% \quad 14.2 \%$ DTYIENEKLISGK

$0.00 \% \quad 7.7 \%$ ETLPSIWDSPTK

$0.00 \% \quad 7.7 \%$ QLSVVVPSYNEEK

$0.03 \% \quad 17.2 \%$ NLPVNFEVAR

$0.03 \% \quad 17.2 \%$ VSVGEFVGEGEGK

$0.03 \% \quad 17.2 \%$ NAAIAVLEELK

$0.03 \% \quad 17.2 \%$ NAAIAVLEELKK

$0.03 \% \quad 17.2 \%$ LPPLPAVER

$0.03 \% \quad 17.2 \%$ TKPIVKPQTSPEYGQGINPISR

$0.03 \% \quad 17.2 \%$ LAQIQQAK

$0.03 \% \quad 17.2 \%$ LAQIQQAKK

$0.03 \% \quad 17.2 \%$ EKEPEYTLLTER

$0.03 \% \quad 17.2 \%$ VPQAQPTKPALK

$0.00 \% \quad 8.8 \%$ VSVGEFSAEGEGNSKK

$0.00 \% \quad 8.8 \%$ LAQIQQAK

$0.00 \% \quad 8.8 \%$ LAQIQQAKK

$0.00 \% \quad 8.8 \%$ VGNEVATGTGPNKK

$0.00 \% \quad 8.8 \%$ ASTNLQDQLEK

$12 \quad 0.01 \% \quad 5.2 \% \quad$ NTNSVPETAPAAIPETKR

$12 \quad 0.01 \% \quad 5.2 \% \quad$ AMTILLEEAKAK

$0.01 \% \quad 5.2 \%$ YLNTNPVGGLLEYAR

$0.01 \% \quad 5.2 \%$ VLIGENEKAER

$0.01 \% \quad 5.2 \% \quad$ VSIYDSKR

$0.00 \% \quad 11.0 \%$ RLEAFLTQK

$0.00 \% \quad 11.0 \%$ ISELGAGNGGVVTK

$0.00 \% \quad 11.0 \%$ DVKPSNILVNSR

$0.00 \% \quad 11.0 \%$ LNQPGTPTR

$0.01 \% \quad 15.6 \%$ GAYGVVEK

$0.01 \% \quad 15.6 \%$ HAQSGTIMAVK

$0.01 \% \quad 15.6 \%$ ALEHLHSK

$0.01 \% \quad 15.6 \%$ DVKPSNVLINK

$0.01 \% \quad 15.6 \%$ MCDFGISGYLVDSVAK

$0.00 \% \quad 9.3 \%$ LNFANPPFK

$0.00 \% \quad 9.3 \% \quad$ FTLNPNPTGVQNPHIER

$0.00 \% \quad 9.3 \%$ DIKPSNILLDR

$0.01 \% \quad 10.9 \%$ ASFPVQILPNLYLGSAR

$0.01 \% \quad 10.9 \%$ DSANLESLAK

$0.01 \% \quad 10.9 \%$ YILNVTPNLPNFFEK

$16 \quad 0.02 \% \quad 9.8 \%$ GTVAYVGATLFATGK $0.02 \% \quad 9.8 \%$ DLEEKLETLR
$99.7 \% \quad 79.2$

$99.7 \% 86.3$

$99.7 \% \quad 52.0$

$99.6 \% \quad 24.0$

$99.7 \% \quad 40.9$

$99.7 \% \quad 34.1$

$99.7 \% \quad 61.1$

$99.5 \% \quad 21.2$

$99.1 \% 22.6$

$99.7 \% \quad 40.4$

$98.7 \% \quad 17.6$

$99.7 \% 71.1$

$99.6 \% \quad 28.8$

$99.7 \% \quad 62.0$

$99.6 \% \quad 23.4$

$99.7 \% \quad 42.5$

$99.0 \% \quad 50.5$

$99.7 \% \quad 34.5$

$99.7 \% \quad 35.7$

$99.7 \% \quad 42.4$

$99.7 \% \quad 43.5$

$99.0 \% \quad 50.5$

$99.7 \% \quad 34.5$

$99.7 \% \quad 37.4$

$99.7 \% \quad 34.0$

$99.3 \% \quad 28.3$

$99.7 \% \quad 55.6$

$98.7 \% \quad 23.6$

$\begin{array}{lll}97.8 \% & 22.2\end{array}$

$98.7 \% \quad 21.0$

$99.7 \% \quad 41.3$

$99.7 \% \quad 30.3$

$99.7 \% \quad 39.3$

$\begin{array}{ll}99.0 \% & 26.9\end{array}$

$99.3 \% \quad 27.8$

$95.4 \% \quad 21.9$

$99.5 \% 24.0$

$99.7 \% \quad 47.0$

$\begin{array}{lll}99.7 \% & 29.5\end{array}$

$99.7 \% \quad 42.7$

$96.7 \% \quad 18.9$

$99.7 \% \quad 37.9$

$99.7 \% \quad 67.8$

$99.7 \% \quad 34.9$

$99.7 \% 41.5$
1671.83

1659.90

1784.86

1435.71

2126.15

1229.68

1509.78

1373.69

1491.77

1158.63

1293.63

1170.67

1298.77

991.59

2410.31

899.53

1027.63

1507.76

1277.76

1624.78

899.53

1027.63

1371.72

1246.63

1895.98

1317.74

1679.88

1257.68

967.52

1105.64

1301.71

1341.75

983.53

822.44

1142.60

934.51

1226.7

1761.82

1047.56

1933.99

1283.73

1846.02

1047.53

1808.96

1455.78

1245.67

\begin{tabular}{cc}
0 & 250 \\
3 & 297 \\
6 & 80 \\
4 & 278 \\
0 & 391 \\
8 & 536 \\
5 & 576 \\
0 & 592 \\
4 & 65 \\
6 & 78 \\
7 & 206 \\
0 & 232 \\
0 & 250 \\
0 & 251 \\
2 & 260 \\
9 & 290 \\
1 & 298 \\
1 & 299 \\
0 & 311 \\
6 & 367 \\
3 & 258 \\
2 & 319 \\
2 & 320 \\
6 & 359 \\
7 & 387 \\
8 & 385 \\
5 & 576 \\
2 & 736 \\
1 & 801 \\
09 & 1116 \\
3 & 61 \\
5 & 88 \\
4 & 205 \\
9 & 397 \\
3 & 80 \\
3 & 93 \\
6 & 183 \\
0 & 200 \\
6 & 221 \\
6 & 54 \\
9 & 75 \\
9 & 239 \\
1 & 217 \\
\hline & 227 \\
\hline & 56 \\
0
\end{tabular}

Page 57 of Table S-1-4 
Dynactin subunit $1 \mathrm{GN}=\mathrm{DCTN} 1$ Dynactin subunit $1 \mathrm{GN}=\mathrm{DCTN} 1$ Dynactin subunit $1 \mathrm{GN}=\mathrm{DCTN} 1$ Dynactin subunit $1 \mathrm{GN}=\mathrm{DCTN} 1$ Dynactin subunit $1 \mathrm{GN}=\mathrm{DCTN} 1$ Dynactin subunit $1 \mathrm{GN}=\mathrm{DCTN} 1$ Dynactin subunit $1 \mathrm{GN}=\mathrm{DCTN} 1$ Dynactin subunit $1 \mathrm{GN}=\mathrm{DCTN} 1$ Dynamin-2 GN=DNM2

Dynamin-2 GN=DNM2

Dynamin-2 GN=DNM2 E3 SUMO-protein ligase RanBP2 GN=RANBP2 RBP2_HUMAN $358.20 \quad 100.0 \%$ E3 SUMO-protein ligase RanBP2 GN=RANBP2 RBP2_HUMAN $358.20 \quad 100.0 \%$ E3 SUMO-protein ligase RanBP2 GN=RANBP2 RBP2_HUMAN $358.20 \quad 100.0 \%$ E3 SUMO-protein ligase RanBP2 GN=RANBP2 RBP2 HUMAN $358.20 \quad 100.0 \%$ E3 ubiquitin-protein ligase HUWE1 GN=HUWE1 HUWE1_HUMAN $481.89 \quad 100.0 \%$ E3 ubiquitin-protein ligase HUWE1 GN=HUWE1 HUWE1_HUMAN $481.89 \quad 100.0 \%$ E3 ubiquitin-protein ligase HUWE1 GN=HUWE1 HUWE1_HUMAN $481.89 \quad 100.0 \%$ E3 ubiquitin-protein ligase HUWE1 GN=HUWE1 HUWE1_HUMAN $481.89 \quad 100.0 \%$ E3 ubiquitin-protein ligase HUWE1 GN=HUWE1 HUWE1_HUMAN $481.89 \quad 100.0 \% 23$ E3 ubiquitin-protein ligase HUWE1 GN=HUWE1 HUWE1_HUMAN $481.89 \quad 100.0 \% 23$ E3 ubiquitin-protein ligase HUWE1 GN=HUWE1 HUWE1_HUMAN $481.89 \quad 100.0 \% 23$ E3 ubiquitin-protein ligase HUWE1 GN=HUWE1 HUWE1_HUMAN $481.89 \quad 100.0 \% 23$ E3 ubiquitin-protein ligase HUWE1 GN=HUWE1 HUWE1_HUMAN $481.89 \quad 100.0 \% \quad 23$ E3 ubiquitin-protein ligase HUWE1 GN=HUWE1 HUWE1_HUMAN $481.89 \quad 100.0 \% 23$ E3 ubiquitin-protein ligase HUWE1 GN=HUWE1 HUWE1_HUMAN $481.89 \quad 100.0 \% 23$ E3 ubiquitin-protein ligase HUWE1 GN=HUWE1 HUWE1_HUMAN $481.89 \quad 100.0 \%$ E3 ubiquitin-protein ligase HUWE1 GN=HUWE1 HUWE1_HUMAN $481.89 \quad 100.0 \% 23$ E3 ubiquitin-protein ligase HUWE1 GN=HUWE1 HUWE1_HUMAN $481.89 \quad 100.0 \% 23$ E3 ubiquitin-protein ligase HUWE1 GN=HUWE1 HUWE1_HUMAN $481.89 \quad 100.0 \% \quad 23$ E3 ubiquitin-protein ligase HUWE1 GN=HUWE1 HUWE1_HUMAN $481.89 \quad 100.0 \% \quad 23$ E3 ubiquitin-protein ligase HUWE1 GN=HUWE1 HUWE1_HUMAN $481.89 \quad 100.0 \% \quad 23$ E3 ubiquitin-protein ligase HUWE1 GN=HUWE1 HUWE1_HUMAN $481.89 \quad 100.0 \% 23$ E3 ubiquitin-protein ligase HUWE1 GN=HUWE1 HUWE1_HUMAN $481.89 \quad 100.0 \% 23$ E3 ubiquitin-protein ligase HUWE1 GN=HUWE1 HUWE1_HUMAN $481.89 \quad 100.0 \%$ E3 ubiquitin-protein ligase HUWE1 GN=HUWE1 HUWE1_HUMAN $481.89 \quad 100.0 \%$ E3 ubiquitin-protein ligase HUWE1 GN=HUWE1 HUWE1_HUMAN $481.89 \quad 100.0 \% \quad 23$ E3 ubiquitin-protein ligase HUWE1 GN=HUWE1 HUWE1_HUMAN $481.89 \quad 100.0 \% 23$ E3 ubiquitin-protein ligase MYCBP2 GN=MYCBP2 MYCB2_HUMAN $510.08 \quad 100.0 \%$ E3 ubiquitin-protein ligase MYCBP2 GN=MYCBP2 MYCB2_HUMAN $510.08 \quad 100.0 \%$ E3 ubiquitin-protein ligase MYCBP2 GN=MYCBP2 MYCB2 HUMAN $510.08 \quad 100.0 \%$ E3 ubiquitin-protein ligase MYCBP2 GN=MYCBP2 MYCB2_HUMAN $510.08 \quad 100.0 \%$ E3 ubiquitin-protein ligase MYCBP2 GN=MYCBP2 MYCB2_HUMAN $510.08 \quad 100.0 \%$ E3 ubiquitin-protein ligase MYCBP2 GN=MYCBP2 MYCB2_HUMAN $510.08 \quad 100.0 \%$ E3 ubiquitin-protein ligase RING2 GN=RNF2 RING2_HUMAN $37.66 \quad 100.0 \%$
$16 \quad 0.02 \% \quad 9.8 \% \quad$ MQEQQADLQR

$0.02 \% \quad 9.8 \%$ IKGEELSEANVR

$98.9 \% 28.8$

$99.6 \% \quad 25.9$

$99.7 \% \quad 42.4$

$99.7 \% \quad 51.0$

$99.7 \% \quad 46.8$

$0.02 \% \quad 9.8 \%$ DSPLLLQQISAMR

$0.02 \% \quad 9.8 \%$ ASLASLPPLHVAK

$0.02 \% \quad 9.8 \%$ LSHEGPGSELPAGALYR

$99.7 \% \quad 46.2$

$99.7 \% \quad 43.8$

$99.7 \% \quad 55.5$

$99.7 \% \quad 25.9$

$99.0 \% \quad 30.3$

$99.0 \% \quad 30.9$

$\begin{array}{lll}99.1 \% & 20.2\end{array}$

$99.7 \% \quad 26.8$

$99.1 \% 33.3$

$98.5 \% 27.0$

$99.7 \% \quad 57.5$

$99.7 \% \quad 29.1$

$99.7 \% \quad 29.4$

$99.7 \% \quad 45.8$

$99.7 \% \quad 36.2$

$99.7 \% \quad 47.6$

$99.5 \% 23.5$

$99.0 \% 18.7$

$99.6 \% 30.6$

$98.5 \% \quad 17.0$

$97.4 \% 16.7$

$99.7 \% \quad 48.3$

$99.7 \% \quad 26.0$

$0.08 \% \quad 6.6 \%$ SHHAASTTTAPTPAAR

$0.08 \% \quad 6.6 \% \quad$ AALPLTTSDTK

$0.08 \% \quad 6.6 \%$ HIIEDPCTLR

$0.08 \% \quad 6.6 \%$ SAATSGAGSTTSGVVSGSLGSR

$0.08 \% \quad 6.6 \%$ IKGPNAVQLVK

$\begin{array}{lll}0.08 \% & 6.6 \% & \text { IVNQPSSLFGSK }\end{array}$

$99.7 \% 68.8$

$99.7 \% \quad 34.7$

$0.08 \% \quad 6.6 \%$ HADHSSLTLGSGSSTTR $\quad 99.7 \% \quad 46.1$

$0.08 \% \quad 6.6 \%$ AGSSTPGDAPPAVAEVQGR $99.7 \% \quad 50.6$

$0.08 \% \quad 6.6 \%$ DSAVAISGADSR

$0.08 \% \quad 6.6 \%$ NLCYHAQTR

$0.08 \% \quad 6.6 \%$ TNIFQIQR

$0.08 \% \quad 6.6 \%$ VFPSHFTQQR

$99.7 \% 58.8$

$99.5 \% \quad 23.5$

$99.0 \% \quad 34.5$

$99.6 \% \quad 28.5$

$0.08 \% \quad 6.6 \%$ LGSSGLGSASSIQAAVR

$0.08 \% \quad 6.6 \%$ QQQAATSESSQSEASVR

$0.08 \% \quad 6.6 \% \quad$ FLQFVTGTSK

$0.01 \% \quad 1.4 \%$ IGSGYSGTVR

$0.01 \% \quad 1.4 \%$ VYTCEIYPVSATGK

$0.01 \% \quad 1.4 \%$ ALSVVSTVVR

$0.01 \% \quad 1.4 \%$ LITSQVFGK

$0.01 \% \quad 1.4 \% \quad$ QVTSLLRR

$0.01 \% \quad 1.4 \%$ GTTITGTAGTTVGK

$0.00 \% \quad 9.2 \%$ TPQEAITDGLEIVVSPR
$99.7 \% \quad 50.5$

$99.6 \% 30.4$

$98.5 \% \quad 22.5$

$99.7 \% 40$.

$97.0 \% 22.6$

$95.6 \% \quad 19.2$

$99.7 \% 27.7$

$99.7 \% \quad 44.7$
1344.7

1487.79

1303.77

1753.89

1545.79

1300.61

1065.64

913.47

877.49

1352.75

1164.48

1404.72

1281.62

1201.68

1436.69

1117.49

1168.67

1289.65

1595.76

1264.67

1053.53

1124.63

1173.72

1576.78

1117.61

1253.63

1896.93

1166.73

1276.69

1713.82

1766.87

1148.55

1162.54

1019.56

1246.63

1560.83

1793.83

1127.61

996.51

1587.77

1030.63

992.58

972.59

1264.67

1264.67
1824.97
$961 \quad 972$

1101

$134 \quad 1150$

$180 \quad 1193$

$1248 \quad 1259$

$114 \quad 123$

$192 \quad 199$

$230 \quad 237$

$34 \quad 46$

$84 \quad 93$

$721 \quad 733$

$1447 \quad 1458$

$\begin{array}{ll}467 & 2477 \\ 582 & 2594\end{array}$

1120

$330 \quad 339$

$518 \quad 529$

$617 \quad 629$

$707 \quad 717$

$830 \quad 839$

$1062 \quad 1072$

10841099

$498 \quad 1508$

$1826 \quad 1835$

$\begin{array}{ll}844 & 1865 \\ 916 & 1926\end{array}$

$2256 \quad 2267$

$2522 \quad 2538$

$2930 \quad 2941$

32113219

32983305

$3750 \quad 3766$

$3788 \quad 3804$

$4296 \quad 4305$

$349 \quad 358$

$1434 \quad 1447$

$1871 \quad 1880$

$3866 \quad 3874$

40194026

$087 \quad 4100$ 
E3 ubiquitin-protein ligase RING2 GN=RNF2 RING2_HUMAN $37.66 \quad 100.0 \% \quad 2$ E3 ubiquitin-protein ligase TRIM21 GN=TRIM21 RO52_HUMAN $54.17 \quad 100.0 \%$ E3 ubiquitin-protein ligase TRIM21 GN=TRIM21 RO52_HUMAN $54.17 \quad 100.0 \%$ E3 ubiquitin-protein ligase TRIM21 GN=TRIM21 RO52_HUMAN $54.17 \quad 100.0 \%$ E3 ubiquitin-protein ligase TRIM21 GN=TRIM21 RO52_HUMAN $54.17 \quad 100.0 \%$ E3 ubiquitin-protein ligase TRIM21 GN=TRIM21 RO52_HUMAN $54.17 \quad 100.0 \% \quad 1$ $\begin{array}{lllll}\text { E3 ubiquitin-protein ligase TRIM21 GN=TRIM21 RO52_HUMAN } 54.17 & 100.0 \% & 1\end{array}$ E3 ubiquitin-protein ligase TRIM21 GN=TRIM21 RO52_HUMAN $54.17 \quad 100.0 \%$ E3 ubiquitin-protein ligase TRIM21 GN=TRIM21 RO52 HUMAN $54.17 \quad 100.0 \% \quad 1$ E3 ubiquitin-protein ligase TRIM21 GN=TRIM21 RO52_HUMAN $54.17 \quad 100.0 \% \quad 1$ E3 ubiquitin-protein ligase TRIM21 GN=TRIM21 RO52_HUMAN $54.17 \quad 100.0 \%$ E3 ubiquitin-protein ligase TRIM21 GN=TRIM21 RO52_HUMAN $54.17 \quad 100.0 \%$ E3 ubiquitin-protein ligase TRIM21 GN=TRIM21 RO52_HUMAN $54.17 \quad 100.0 \%$ E3 ubiquitin-protein ligase TRIP12 GN=TRIP12 TRIPC_HUMAN $220.44 \quad 100.0 \%$ E3 ubiquitin-protein ligase TRIP12 GN=TRIP12 TRIPC_HUMAN $220.44 \quad 100.0 \%$ E3 ubiquitin-protein ligase TRIP12 GN=TRIP12 TRIPC_HUMAN $220.44 \quad 100.0 \%$ E3 ubiquitin-protein ligase UBR4 GN=UBR4 UBR4 HUMAN $573.84 \quad 100.0 \%$ E3 ubiquitin-protein ligase UBR4 GN=UBR4 UBR4_HUMAN $573.84 \quad 100.0 \%$ E3 ubiquitin-protein ligase UBR4 GN=UBR4 UBR4_HUMAN $573.84 \quad 100.0 \%$ E3 ubiquitin-protein ligase UBR4 GN=UBR4 UBR4_HUMAN $573.84 \quad 100.0 \%$ E3 ubiquitin-protein ligase UBR4 GN=UBR4 UBR4_HUMAN $573.84 \quad 100.0 \%$ E3 ubiquitin-protein ligase UBR4 GN=UBR4 UBR4_HUMAN $573.84 \quad 100.0 \%$ E3 ubiquitin-protein ligase UBR4 GN=UBR4 UBR4_HUMAN $573.84 \quad 100.0 \%$ E3 ubiquitin-protein ligase UBR4 GN=UBR4 UBR4_HUMAN $573.84 \quad 100.0 \%$ E3 ubiquitin-protein ligase UBR4 GN=UBR4 UBR4_HUMAN $573.84 \quad 100.0 \%$ E3 ubiquitin-protein ligase UBR4 GN=UBR4 UBR4_HUMAN $573.84 \quad 100.0 \%$ E3 ubiquitin-protein ligase UBR4 GN=UBR4 UBR4_HUMAN $573.84 \quad 100.0 \%$ E3 UFM1-protein ligase $1 \mathrm{GN}=$ UFL1 UFL1_HUMAN $89.60 \quad 100.0 \%$ E3 UFM1-protein ligase 1 GN=UFL1 UFL1_HUMAN $89.60 \quad 100.0 \%$ EH domain-containing protein $1 \mathrm{GN}=$ EHD1 EHD1 HUMAN $60.63 \quad 100.0 \%$ EH domain-containing protein $1 \mathrm{GN}=$ EHD1 EHD1_HUMAN $60.63 \quad 100.0 \%$ EH domain-containing protein $1 \mathrm{GN}=$ EHD1 EHD1_HUMAN $60.63 \quad 100.0 \%$ EH domain-containing protein $1 \mathrm{GN}=\mathrm{EHD} 1 \mathrm{EHD1}$ HUMAN $60.63 \quad 100.0^{\circ}$ EH domain-containing protein $1 \mathrm{GN}=\mathrm{EHD} 1$ EHD1_HUMAN $60.63 \quad 100.0 \%$ ELAV-like protein $1 \mathrm{GN}=$ ELAVL1 ELAV-like protein $1 \mathrm{GN}=\mathrm{ELAVL}$ ELAV-like protein $1 \mathrm{GN}=\mathrm{ELAVL}$ ELAV-like protein $1 \mathrm{GN}=\mathrm{ELAVL} 1$ ELAV-like protein $1 \mathrm{GN}=\mathrm{ELAVL} 1$ ELAV-like protein $1 \mathrm{GN}=\mathrm{ELAVL}$ ELAV-like protein $1 \mathrm{GN}=\mathrm{ELAVL}$ ELAV-like protein $1 \mathrm{GN}=\mathrm{ELAVL}$. ELAV-like protein $1 \mathrm{GN}=\mathrm{ELAVL} 1$ ELAV-like protein $1 \mathrm{GN}=$ ELAVL ELAV-like protein $1 \mathrm{GN}=$ ELAVL 1 ELAV-like protein $1 \mathrm{GN}=\mathrm{ELAVL}$ ELAV-like protein $1 \mathrm{GN}=\mathrm{ELAVL} 1$ ELAV1_HUMAN $36.09 \quad 100.0 \%$ ELAV1_HUMAN $36.09 \quad 100.0 \%$ ELAV1_HUMAN $36.09 \quad 100.0 \%$ ELAV1_HUMAN $36.09 \quad 100.0 \%$ ELAV1_HUMAN $36.09 \quad 100.0 \%$ ELAV1_HUMAN $36.09 \quad 100.0 \%$ ELAV1_HUMAN $36.09 \quad 100.0 \%$ ELAV1_HUMAN $36.09 \quad 100.0 \%$ ELAV1_HUMAN $36.09 \quad 100.0 \%$ ELAV1 HUMAN $36.09 \quad 100.0 \%$ ELAV1_HUMAN $36.09 \quad 100.0 \%$ ELAV1_HUMAN $36.09 \quad 100.0 \% \quad 17$ ELAV1_HUMAN $36.09 \quad 100.0 \% \quad 17$
$0.00 \% \quad 9.2 \%$ IYPSRDEYEAHQER

$0.02 \% \quad 29.1 \%$ QLANMVNNLKEISQEAR $0.02 \% \quad 29.1 \%$ LHLFCEKDGK

$0.02 \% \quad 29.1 \%$ ALCWVCAQSR

$0.02 \% \quad 29.1 \%$ LQVALGELRR

$0.02 \% \quad 29.1 \%$ SRIHAEFVQQK

$0.02 \% \quad 29.1 \%$ IHAEFVQQK

$0.02 \% \quad 29.1 \%$ NFLVEEEQR

$0.02 \% \quad 29.1 \%$ LAQQSQALQELISELDRR

$0.02 \% \quad 29.1 \%$ SVCHVPGLK

$0.02 \% \quad 29.1 \%$ LGDTQQSIPGNEER

$0.02 \% \quad 29.1 \%$ NTAPLTLCPLNIGSQGSTDY

$0.01 \% \quad 1.7 \%$ SSFLASLNPK

$0.01 \% \quad 1.7 \%$ LSTQSNSNNIEPAR

$0.01 \% \quad 1.7 \%$ SVYHLEDIVR

$0.02 \% \quad 2.5 \%$ ILGPAESDEFLAR

$0.02 \% \quad 2.5 \%$ AQQALSELHTVEK

$0.02 \% \quad 2.5 \%$ IQDMVAIR

$0.02 \% \quad 2.5 \% \quad$ IQIGTQAIER

$0.02 \% \quad 2.5 \%$ APSYIEIFGR

$0.02 \% \quad 2.5 \%$ TMQLNLSR

$0.02 \% \quad 2.5 \% \quad$ SLLASLHTSR

$0.02 \% \quad 2.5 \%$ TINLYYNNR

$0.02 \% \quad 2.5 \%$ TVQAIVELK

$0.02 \% \quad 2.5 \% \quad$ VNEAAPEKPQDDSGTAGGISSTSASVNR

$0.02 \% \quad 2.5 \%$ TSVQPTFTASQYR

$0.00 \% \quad 2.4 \%$ AQFAEATQR

$0.00 \% \quad 2.4 \% \quad$ AVFVPDIYSR

$0 \quad 0.01 \% \quad 8.6 \% \quad$ KLNAFGNAFLNR

$10 \quad 0.01 \% \quad 8.6 \% \quad$ LNAFGNAFLNR

$10 \quad 0.01 \% \quad 8.6 \%$ IINTPEVVR

$10 \quad 0.01 \% \quad 8.6 \% \quad$ LLDTVDDMLANDIAR

$0.01 \% \quad 8.6 \%$ SKLPNTVLGK

$0.09 \% \quad 59.5 \%$ TNLIVNYLPQNMTQDELR

$0.09 \% \quad 59.5 \%$ SLFSSIGEVESAK

$0.09 \% \quad 59.5 \%$ DKVAGHSLGYGFVNYVTAK $99.7 \% \quad 55.0$

$0.09 \% \quad 59.5 \%$ VAGHSLGYGFVNYVTAK $99.7 \% \quad 58.3$

$0.09 \% \quad 59.5 \%$ AINTLNGLR

$0.09 \% \quad 59.5 \%$ VSYARPSSEVIK

$0.09 \% \quad 59.5 \%$ DANLYISGLPR

$0.09 \% \quad 59.5 \%$ TMTQKDVEDMFSR

$0.09 \% \quad 59.5 \%$ DVEDMFSR

$0.09 \% \quad 59.5 \%$ VLVDQTTGLSR

$0.09 \% \quad 59.5 \%$ GVAFIRFDK

$0.09 \% \quad 59.5 \%$ SEAEEAITSFNGHKPPGSSEPITVK

$0.09 \% \quad 59.5 \%$ FAANPNQNK
$99.6 \% 23.5$

$99.7 \% \quad 43.8$

$99.7 \% \quad 39.7$

$99.7 \% \quad 35.0$

$99.7 \% \quad 54.4$

$99.7 \% \quad 44.4$

$95.9 \% \quad 18.8$

$99.7 \% \quad 62.1$

$99.7 \% \quad 34.3$

$99.7 \% \quad 41.8$

$99.5 \% \quad 26.0$

$99.7 \% \quad 58.2$

$99.7 \% \quad 39.7$

$\begin{array}{lll}95.7 \% & 26.2\end{array}$

$99.7 \% \quad 47.9$

$99.7 \% \quad 45.5$

$99.7 \% \quad 43.6$

$98.2 \% \quad 16.4$

$99.1 \% 21.0$

$99.7 \% 32.8$

$\begin{array}{ll}99.7 \% & 37.0 \\ 99.7 \% & 47.8\end{array}$

$98.6 \% \quad 18.5$

$95.1 \% 14.1$

$99.7 \% \quad 59.7$

$\begin{array}{lll}99.7 \% & 32.8\end{array}$

$99.7 \% \quad 41.6$

$99.4 \% \quad 20.5$

$99.7 \% \quad 58.3$

$99.7 \% \quad 37.2$

$99.7 \% \quad 57.9$

$99.7 \% \quad 44.1$

$99.0 \% \quad 37.0$

$99.7 \% \quad 64.5$

$99.6 \% \quad 25.3$

$99.7 \% \quad 48.0$

$99.7 \% \quad 33.9$
179

1048.47

1958.01

1246.63

1250.58

1154.70

1342.72

1099.59

1163.57

2098.13

996.53

1543.73

2122.01

1063.58

1530.75

1230.65

1417.73

1453.76

945.52

1128.64

1152.60

962.51

1084.61

1170.59

1000.60

2745.29

1485.73

1021.51

1166.62

1364.74

1236.65

1040.61

1674.84

1056.64

2162.09

1353.69

2026.04

1782.92

971.56

1335.73

1218.65

1619.70

998.42

1188.66

1052.59

2612.28

1003.50 \begin{tabular}{cc}
3 & 126 \\
6 & 55 \\
8 & 84 \\
9 & 108 \\
9 & 118 \\
9 & 148 \\
6 & 186 \\
8 & 186 \\
7 & 195 \\
8 & 235 \\
1 & 279 \\
1 & 324 \\
6 & 475 \\
39 & 1048 \\
53 & 1066 \\
48 & 1757 \\
37 & 1349 \\
38 & 1850 \\
11 & 2218 \\
54 & 2363 \\
64 & 2373 \\
74 & 2381 \\
27 & 2536 \\
89 & 3597 \\
98 & 3606 \\
67 & 3794 \\
45 & 3857 \\
8 & 26 \\
2 & 251 \\
4 & 135 \\
5 & 135 \\
3 & 251 \\
8 & 392 \\
4 & 483 \\
0 & 192 \\
0 & 37 \\
8 & 50 \\
4 & 728 \\
6 & 72 \\
6 & 72 \\
7 & 85 \\
3 & 104 \\
5 & 115 \\
& 128 \\
\hline & 128 \\
\hline
\end{tabular}

Page 59 of Table S-1-4 
ELAV-like protein $1 \mathrm{GN}=\mathrm{ELAVL} 1$ ELAV-like protein $1 \mathrm{GN}=\mathrm{ELAVL} 1$ ELAV-like protein $1 \mathrm{GN}=\mathrm{ELAVL} 1$ ELAV-like protein $1 \mathrm{GN}=\mathrm{ELAVL} 1$ ELAV-like protein $2 \mathrm{GN}=\mathrm{ELAVL} 2$ ELAV-like protein $2 \mathrm{GN}=\mathrm{ELAVL} 2$ ELAV-like protein $2 \mathrm{GN}=\mathrm{ELAVL} 2$ ELAV-like protein $2 \mathrm{GN}=\mathrm{ELAVL} 2$ ELAV-like protein $2 \mathrm{GN}=\mathrm{ELAVL} 2$ ELAV-like protein $2 \mathrm{GN}=$ ELAVL2 ELAV-like protein $2 \mathrm{GN}=\mathrm{ELAVL} 2$ ELAV-like protein $2 \mathrm{GN}=\mathrm{ELAVL} 2$ ELAV-like protein $2 \mathrm{GN}=\mathrm{ELAVL} 2$ ELAV-like protein $2 \mathrm{GN}=\mathrm{ELAVL} 2$ ELAV-like protein $2 \mathrm{GN}=\mathrm{ELAVL} 2$ ELAV-like protein $2 \mathrm{GN}=\mathrm{ELAVL} 2$ ELAV-like protein $2 \mathrm{GN}=\mathrm{ELAVL} 2$ ELAV-like protein $2 \mathrm{GN}=\mathrm{ELAVL} 2$ ELAV-like protein $2 \mathrm{GN}=$ ELAVL2 ELAV-like protein $2 \mathrm{GN}=\mathrm{ELAVL} 2$ ELAV-like protein $2 \mathrm{GN}=\mathrm{ELAVL} 2$ ELAV-like protein $2 \mathrm{GN}=\mathrm{ELAVL} 2$

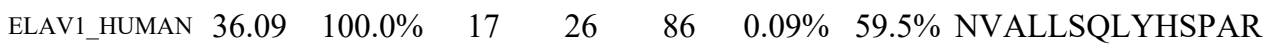
ELAV1_HUMAN $36.09 \quad 100.0 \% \quad 17 \quad 26 \quad 86 \quad 0.09 \% \quad 59.5 \%$ FGGPVHHQAQR ELAV1_HUMAN $36.09 \quad 100.0 \% \quad 17$ ELAV1_HUMAN $36.09 \quad 100.0 \% \quad 17$ ELAV2_HUMAN $39.51 \quad 100.0 \% \quad 16$ ELAV2_HUMAN $39.51 \quad 100.0 \% \quad 16$ ELAV2_HUMAN $39.51 \quad 100.0 \% \quad 16$ ELAV2_HUMAN $39.51 \quad 100.0 \% \quad 16$ ELAV2 HUMAN $39.51 \quad 100.0 \% \quad 16$ ELAV2_HUMAN $39.51 \quad 100.0 \% \quad 16$ ELAV2_HUMAN $39.51 \quad 100.0 \% \quad 16$ ELAV2_HUMAN $39.51 \quad 100.0 \% \quad 16$ ELAV2_HUMAN $39.51 \quad 100.0 \% \quad 16$ ELAV2_HUMAN $39.51 \quad 100.0 \% \quad 16$ ELAV2_HUMAN $39.51 \quad 100.0 \% \quad 16$ ELAV2_HUMAN $39.51 \quad 100.0 \% \quad 16$ ELAV2_HUMAN $39.51 \quad 100.0 \% \quad 16$ ELAV2_HUMAN $39.51 \quad 100.0 \% \quad 16$ ELAV2_HUMAN $39.51 \quad 100.0 \% \quad 16$ ELAV2_HUMAN $39.51 \quad 100.0 \% \quad 16$ ELAV2_HUMAN $39.51 \quad 100.0 \% \quad 16$ ELAV2_HUMAN $39.51 \quad 100.0 \% \quad 16$ FA ETFA_HUMAN $35.08 \quad 100.0 \% \quad 10$ $\begin{array}{ll}00.0 \% & 10 \\ 100.0 \% & 10\end{array}$ $100.0 \% \quad 10$ $100.0 \% \quad 10$ $100.0 \% \quad 10$ $100.0 \% \quad 10$ $100.0 \% \quad 10$ $100.0 \% \quad 10$ $100.0 \% \quad 10$ $100.0 \%$ $100.0 \%$ $100.0 \%$ $100.0 \%$ $100.0 \%$ $100.0 \%$ $100.0 \%$ $100.0 \%$ $100.0 \%$ $100.0 \%$ $100.0 \%$ $100.0 \%$ $100.0 \%$ $100.0 \%$ $100.0 \%$ $100.0 \%$

$0.09 \% \quad 59.5 \%$ VIRDFNTNK

$0.03 \% \quad 48.5 \%$ SLFGSIGEIESCK

$0.03 \% \quad 48.5 \%$ AINTLNGLR

$0.03 \% \quad 48.5 \%$ VSYARPSSASIR

$0.03 \% \quad 48.5 \%$ DANLYVSGLPK

$0.03 \% \quad 48.5 \%$ ELEQLFSQYGR

$0.03 \% \quad 48.5 \%$ ILVDQVTGISR

$0.03 \% \quad 48.5 \%$ RIEAEEAIK

$0.03 \% \quad 48.5 \%$ IEAEEAIK

$0.03 \% \quad 48.5 \%$ FANNPSQK

$0.03 \% \quad 48.5 \%$ RYPGPLAQQAQR

$0.03 \% \quad 48.5 \%$ YPGPLAQQAQR

$0.03 \% \quad 48.5 \%$ VIRDFNTNK

$0.03 \% \quad 43.2 \%$ LGGEVSCLVAGTK

$0.03 \% \quad 43.2 \%$ CDKVAQDLCK

$0.03 \% \quad 43.2 \%$ VLVAQHDVYK

$0.03 \% \quad 43.2 \%$ LEVAPISDIIAIK

$0.03 \% \quad 43.2 \%$ TIYAGNALCTVK

$0.01 \% \quad 39.2 \%$ TGVVTDGVK

$0.01 \% \quad 39.2 \%$ TALAMGADR

$0.01 \% 39.2 \%$ EIDGGLETLR

$0.01 \% 39.2 \%$ LKLPAVVTADLR

$0.01 \% 39.2 \%$ LSVISVEDPPQR $\begin{array}{clll}10 & 0.01 \% & 16.7 \% \text { MCLLQITGYK }\end{array}$

$10 \quad 0.01 \% \quad 16.7 \%$ LWNLLMPTK

$26 \quad 233 \quad 0.23 \% \quad 42.4 \%$ THINIVVIGHVDSGK

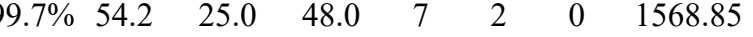

$\begin{array}{llllllll}99.7 \% & 55.5 & 25.0 & 44.4 & 2 & 2 & 0 & 1233.62\end{array}$

$\begin{array}{llllllll}99.7 \% & 34.7 & 25.0 & 26.4 & 3 & 0 & 0 & 1106.60\end{array}$

$\begin{array}{llllllll}99.7 \% & 31.4 & 25.0 & 29.2 & 1 & 0 & 0 & 1247.74\end{array}$

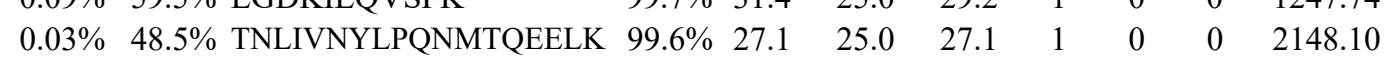

$\begin{array}{llll}99.7 \% & 52.6 & 25.0 & 52.6\end{array}$

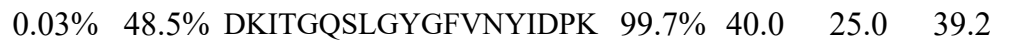

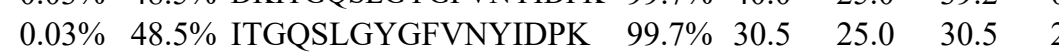

$0.03 \% \quad 48.5 \%$ GLNGQKPPGATEPITVK

$99.7 \% \quad 58.3 \quad 25.0 \quad 48.9$

$99.7 \% \quad 29.1 \quad 25.0 \quad 18.1$

$99.7 \% \quad 66.8 \quad 25.0 \quad 61.5 \quad 3$

$\begin{array}{llll}99.7 \% & 52.9 & 25.0 & 52.9\end{array}$

$99.7 \% \quad 58.4 \quad 25.0 \quad 52.2$

$\begin{array}{llll}99.6 \% & 33.4 & 25.0 & 12.6\end{array}$

$\begin{array}{llll}99.0 \% & 37.4 & 25.0 & 24.2\end{array}$

$0.03 \% \quad 48.5 \%$ TNQAILSQLYQSPNR

$0.03 \% \quad 48.5 \%$ TNQAILSQLYQSPNRR

$0.03 \% \quad 43.2 \%$ GLLPEELTPLILATQK

$99.7 \% 44.5$

$\begin{array}{lllll}99.7 \% & 73.0 & 25.0 & 18.7 & 2 \\ 99.0 & 71.2 & 2\end{array}$

$\begin{array}{llll}99.7 \% & 29.9 & 25.0 & 29.8\end{array}$

$\begin{array}{llll}99.7 \% & 36.5 & 25.0 & 30.4\end{array}$

$\begin{array}{llll}99.7 \% & 28.1 & 25.0 & 27.7\end{array}$

$\begin{array}{lllll}99.7 \% & 34.7 & 25.0 & 26.4 & 3\end{array}$

$\begin{array}{llll}99.7 \% & 51.7 & 25.0 & 51.7\end{array}$

$\begin{array}{llll}97.5 \% & 26.8 & 25.0 & 26.8\end{array}$

$99.7 \% \quad 47.7 \quad 25.0 \quad 42.0$

$\begin{array}{llll}99.7 \% & 48.8 & 25.0 & 48.8\end{array}$

$\begin{array}{llll}99.7 \% & 58.8 & 25.0 & 54.4\end{array}$

$\begin{array}{llll}99.7 \% & 53.1 & 25.0 & 46.8\end{array}$

$\begin{array}{lllllll}0.03 \% & 43.2 \% & \text { GTSFDAAATSGGSASSEK } & 99.7 \% & 82.4 & 25.0 & 82.4\end{array}$

$0.03 \% \quad 43.2 \%$ ASSTSPVEISEWLDQK

$99.7 \% \quad 38.0$

$\begin{array}{llllll}0.03 \% & 43.2 \% & \text { LLYDLADQLHAAVGASR } & 99.7 \% & 53.5\end{array}$

$\begin{array}{lllll}0.03 \% & 43.2 \% & \text { AAVDAGFVPNDMQVGQTGK } & 99.7 \% & 36.3\end{array}$

$0.01 \% \quad 39.2 \%$ EVIAVSCGPAQCQETIR

$0.01 \% \quad 39.2 \%$ IEVIKPGDLGVDLTSK

$0.01 \% 39.2 \%$ TAGVKVETTEDLVAK

$99.7 \% \quad 41.1$

$\begin{array}{lll}99.7 \% & 45.3\end{array}$

$\begin{array}{llll}99.7 \% & 58.4\end{array}$

$99.7 \% \quad 56.8$

$97.8 \% 16.7$

$99.7 \% \quad 45.5$

$99.7 \% 53.1$

$99.7 \% 27.4$

$99.7 \% \quad 33.5$

$\begin{array}{llll}99.7 \% & 45.7 & 25.0 & 44.7\end{array}$

\begin{tabular}{llll}
$99.7 \%$ & 38.0 & 25.0 & 24.2 \\
\hline
\end{tabular}

$\begin{array}{llll}99.6 \% & 24.2 & 25.0 & 24.2\end{array}$

$\begin{array}{llll}99.7 \% & 38.6 & 25.0 & 32.8\end{array}$

$\begin{array}{llll}99.7 \% & 53.7 & 25.0 & 53.7\end{array}$
217

$275 \quad 283$

$0 \quad 320$
56

1426.69

2115.08

1871.95

971.56

1293.69

1176.63

1369.67

1200.69

1058.58

902.48

1706.94

905.45

1732.90

1889.00

1384.74

1228.64

1106.60

1290.67

1236.57

1171.65

1736.02

1381.83

1310.68

1630.72

1776.87

1812.96

1904.92

875.48

1917.92

905.45

1102.57

1295.80

1683.95

1339.72

1560.85

1104.58

1169.60

1054.54

1262.64

1226.63

1115.63

1588.88

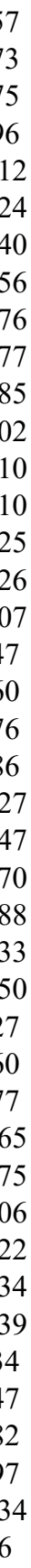


Elongation factor 1-alpha $1 \mathrm{GN}=\mathrm{EEF} 1 \mathrm{~A} 1 \quad$ EF1A1_HUMAN $50.14 \quad 100.0 \% \quad 1$ ' $\begin{array}{lllll}\text { Elongation factor 1-alpha 1 GN=EEF1A1 } & \text { EF1A1_HUMAN } & 50.14 & 100.0 \% & 17 \\ \text { Elongation factor 1-alpha } 1 \mathrm{GN}=\mathrm{EEF} 1 \mathrm{~A} 1 & \text { EF1A1_HUMAN } & 50.14 & 100.0 \% & 17\end{array}$ Elongation factor 1-alpha $1 \mathrm{GN}=\mathrm{EEF} 1 \mathrm{~A} 1 \quad$ EF1A1_HUMAN $50.14 \quad 100.0 \% \quad 17$ Elongation factor 1-alpha $1 \mathrm{GN}=\mathrm{EEF} 1 \mathrm{~A} 1 \quad$ EF1A1_HUMAN $50.14 \quad 100.0 \%$ $\begin{array}{lllll}\text { Elongation factor 1-alpha } 1 \mathrm{GN}=\mathrm{EEF} 1 \mathrm{~A} 1 & \text { EF1A1_HUMAN } & 50.14 & 100.0 \% & 17\end{array}$ Elongation factor 1-alpha 1 GN=EEF1A1 EF1A1_HUMAN $50.14 \quad 100.0 \% \quad 17$ $\begin{array}{lllll}\text { Elongation factor 1-alpha } 1 \mathrm{GN}=\mathrm{EEF} 1 \mathrm{~A} 1 & \text { EF1A1_HUMAN } & 50.14 & 100.0 \% & 17\end{array}$ Elongation factor 1-alpha $1 \mathrm{GN}=\mathrm{EEF} 1 \mathrm{~A} 1 \quad$ EF1A1_HUMAN $50.14 \quad 100.0 \% \quad 17$ Elongation factor 1-alpha $1 \mathrm{GN}=\mathrm{EEF} 1 \mathrm{~A} 1 \quad$ EF1A1_HUMAN $50.14 \quad 100.0 \% \quad 17$ Elongation factor 1-alpha $1 \mathrm{GN}=\mathrm{EEF} 1 \mathrm{~A} 1 \quad$ EF1A1_HUMAN $50.14 \quad 100.0 \% \quad 17$ $\begin{array}{lllll}\text { Elongation factor 1-alpha } 1 \mathrm{GN}=\mathrm{EEF} 1 \mathrm{~A} 1 & \text { EF1A1_HUMAN } & 50.14 & 100.0 \% & 17\end{array}$ Elongation factor 1-alpha $1 \mathrm{GN}=\mathrm{EEF} 1 \mathrm{~A} 1 \quad$ EF1A1_HUMAN $50.14 \quad 100.0 \% \quad 17$ $\begin{array}{lllll}\text { Elongation factor 1-alpha } 1 \mathrm{GN}=\mathrm{EEF} 1 \mathrm{~A} 1 & \text { EF1A1_HUMAN } & 50.14 & 100.0 \% & 17\end{array}$ Elongation factor 1-alpha $1 \mathrm{GN}=\mathrm{EEF} 1 \mathrm{~A} 1 \quad$ EF1A1_HUMAN $50.14 \quad 100.0 \% \quad 17$ Elongation factor 1-alpha $1 \mathrm{GN}=\mathrm{EEF} 1 \mathrm{~A} 1 \quad$ EF1A1_HUMAN $50.14 \quad 100.0 \% \quad 17$ Elongation factor 1-alpha $1 \mathrm{GN}=\mathrm{EEF} 1 \mathrm{~A} 1 \quad$ EF1A1_HUMAN $50.14 \quad 100.0 \% \quad 17$ Elongation factor 1-beta $\mathrm{GN}=\mathrm{EEF} 1 \mathrm{~B} 2$ Elongation factor 1-beta GN=EEF1B2 Elongation factor 1-delta GN=EEF1D

Elongation factor 1-delta $\mathrm{GN}=\mathrm{EEF} 1 \mathrm{D}$ Elongation factor 1-delta GN=EEF1D Elongation factor 1-delta GN=EEF1D Elongation factor 1-gamma GN=EEF1G Elongation factor 1-gamma $\mathrm{GN}=\mathrm{EEF} 1 \mathrm{G}$ Elongation factor 1-gamma GN=EEF1G Elongation factor 1-gamma GN=EEF1G Elongation factor 1-gamma GN=EEF1G Elongation factor 1-gamma GN=EEF1G Elongation factor 1-gamma GN=EEF1G Elongation factor 1-gamma GN=EEF1G Elongation factor 1-gamma GN=EEF1G Elongation factor 1-gamma GN=EEF1G Elongation factor 1-gamma GN=EEF1G Elongation factor 1-gamma GN=EEF1G Elongation factor 1-gamma $\mathrm{GN}=\mathrm{EEF} 1 \mathrm{G}$ Elongation factor 1-gamma GN=EEF1G Elongation factor 1-gamma GN=EEF1G Elongation factor $2 \mathrm{GN}=\mathrm{EEF} 2$ Elongation factor $2 \mathrm{GN}=\mathrm{EEF} 2$ Elongation factor $2 \mathrm{GN}=\mathrm{EEF} 2$ Elongation factor $2 \mathrm{GN}=\mathrm{EEF} 2$ Elongation factor $2 \mathrm{GN}=\mathrm{EEF} 2$ Elongation factor $2 \mathrm{GN}=\mathrm{EEF} 2$ Elongation factor $2 \mathrm{GN}=\mathrm{EEF} 2$ Elongation factor $2 \mathrm{GN}=\mathrm{EEF} 2$ Elongation factor $2 \mathrm{GN}=\mathrm{EEF} 2$ Elongation factor $2 \mathrm{GN}=\mathrm{EEF} 2$ EF1B HUMAN $24.76 \quad 100.0 \%$ EF1B_HUMAN $24.76 \quad 100.0 \%$ EF1D HUMAN $31.12 \quad 100.0 \% \quad 4$ EF1D_HUMAN $31.12 \quad 100.0 \% \quad 4$ EF1D HUMAN $31.12 \quad 100.0 \% \quad 4$ EF1G_HUMAN $50.12 \quad 100.0 \% \quad 15$ EF1G_HUMAN $50.12 \quad 100.0 \% \quad 15$ EF1G HUMAN $50.12 \quad 100.0 \% \quad 15$ EF1G_HUMAN $50.12 \quad 100.0 \% \quad 15$ EF1G_HUMAN $50.12 \quad 100.0 \% \quad 15$ EF1G HUMAN $50.12 \quad 100.0 \% \quad 15$ EF1G_HUMAN $50.12 \quad 100.0 \% \quad 15$ EF1G_HUMAN $50.12 \quad 100.0 \% \quad 15$ EF1G_HUMAN $50.12 \quad 100.0 \% \quad 15$ EF1G_HUMAN $50.12 \quad 100.0 \% \quad 15$ EF1G_HUMAN $50.12 \quad 100.0 \% \quad 15$ EF1G_HUMAN $50.12 \quad 100.0 \% \quad 15$ EF1G_HUMAN $50.12 \quad 100.0 \% \quad 15$ EF1G_HUMAN $50.12 \quad 100.0 \% \quad 15$ EF1G_HUMAN $50.12 \quad 100.0 \% \quad 15$ EF2 HUMAN $95.34 \quad 100.0 \% \quad 16$ EF2_HUMAN $95.34 \quad 100.0 \% \quad 16$ EF2_HUMAN $95.34 \quad 100.0 \% \quad 16$ EF2 HUMAN $95.34 \quad 100.0 \% \quad 16$ EF2_HUMAN $95.34 \quad 100.0 \% \quad 16$ EF2 HUMAN $95.34 \quad 100.0 \% \quad 16$ EF2_HUMAN $95.34 \quad 100.0 \% \quad 16$ EF2_HUMAN $95.34 \quad 100.0 \% \quad 16$ EF2 HUMAN $95.34 \quad 100.0 \% \quad 16$ EF2_HUMAN $95.34 \quad 100.0 \% \quad 16$ EF1D_HUMAN $31.12 \quad 100.0 \% \quad 4$ $\begin{array}{llll}26 & 233 & 0.23 \% & 42.4 \% \\ 26 & \text { STTTGHLIYK }\end{array}$ $26 \quad 233 \quad 0.23 \% \quad 42.4 \%$ FEKEAAEMGK

$\begin{array}{llll}26 & 233 & 0.23 \% & 42.4 \%\end{array}$ YYVTIIDAPGHR

$\begin{array}{ll}99.7 \% & 42.7\end{array}$

$233 \quad 0.23 \% \quad 42.4 \%$ NGQTREHALLAYTLGVK

$233 \quad 0.23 \% \quad 42.4 \%$ EHALLAYTLGVK

$99.7 \% \quad 58.7$

$99.0 \% \quad 45.4$

$99.7 \% \quad 55.4$

$99.0 \% \quad 48.0$

$99.0 \% \quad 60.1$

$99.7 \% \quad 59.4$

$233 \quad 0.23 \% \quad 42.4 \%$ EVSTYIKK

$233 \quad 0.23 \% \quad 42.4 \%$ LPLQDVYK

$233 \quad 0.23 \% \quad 42.4 \%$ IGGIGTVPVGR

$99.7 \% \quad 55.4$

$233 \quad 0.23 \% \quad 42.4 \%$ SVEMHHEALSEALPGDNVGFNVK $\quad 99.7 \% \quad 58.9$

$233 \quad 0.23 \% \quad 42.4 \%$ SGDAAIVDMVPGKPMCVESFSDYPPLGR

$233 \quad 0.23 \% \quad 42.4 \%$ DMRQTVAVGVIK

$233 \quad 0.23 \% \quad 42.4 \%$ QTVAVGVIK

$0.00 \% \quad 12.4 \%$ SPAGLQVLNDYLADK

$\begin{array}{ll}99.7 \% & 55.4 \\ 99.7 \% & 33.8\end{array}$

$99.7 \% 33.8$

$99.7 \% \quad 43.9$

$99.7 \% \quad 80.0$

$99.7 \% \quad 67.5$

$0.00 \% \quad 12.4 \%$ SIQADGLVWGSSK

$99.7 \% \quad 36.5$

$99.7 \% \quad 68.1$

$99.7 \% \quad 61.0$

$96.2 \% \quad 14.7$

$99.7 \% \quad 86.5$

$99.7 \% \quad 40.3$

$99.7 \% \quad 41.7$

$99.3 \% 21.1$

$99.7 \% \quad 56.8$

$99.0 \% \quad 27.9$

$97.0 \% \quad 21.0$

$99.7 \% \quad 44.4$

$99.7 \% \quad 53.9$

$97.4 \% \quad 21.2$

$99.2 \% \quad 23.2$

$99.7 \% \quad 57.6$

$99.7 \% \quad 38.0$

$99.7 \% \quad 44.2$

$99.0 \% \quad 17.9$

$99.7 \% \quad 55.2$

$99.7 \% \quad 55.6$

$99.7 \% \quad 44.5$

$99.7 \% 33.6$

$99.6 \% \quad 24.7$

$99.7 \% \quad 63.0$

$99.7 \% \quad 57.3$

$0.08 \% \quad 17.5 \%$ VFSGLVSTGLK

80

$0.08 \% \quad 17.5 \%$ VFSGLVSTGLKVR

$19 \quad 80 \quad 0.08 \% \quad 17.5 \%$ VAVEAKNPADLPK

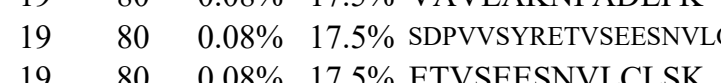

$\begin{array}{llll}80 & 0.08 \% & 17.5 \% & \text { ETVSEESN } \\ 80.08 \% & 17.5 \% & \text { EGALCEENMR }\end{array}$
$99.2 \% \quad 18.6$

$99.7 \% \quad 63.6$

$99.7 \% \quad 67.1$

\begin{tabular}{|c|c|}
\hline \multicolumn{2}{|l|}{45.0} \\
\hline 53.3 & \\
\hline 37.0 & \\
\hline 42.7 & \\
\hline 52.9 & \\
\hline 25.6 & \\
\hline 55.4 & \\
\hline 43.7 & \\
\hline 49.7 & \\
\hline 47.6 & \\
\hline 55.4 & \\
\hline 58.9 & \\
\hline 55.4 & \\
\hline 25.6 & \\
\hline 27.4 & \\
\hline 80.0 & \\
\hline 67.5 & \\
\hline 36.5 & \\
\hline 59.7 & \\
\hline 49.7 & \\
\hline 14.7 & \\
\hline 86.5 & \\
\hline 40.0 & \\
\hline 24.0 & \\
\hline 21.1 & \\
\hline 50.4 & \\
\hline 10.4 & \\
\hline 12.2 & \\
\hline 29.9 & \\
\hline 50.2 & \\
\hline 12.6 & \\
\hline 17.0 & \\
\hline 53.0 & \\
\hline 32.6 & \\
\hline 41.6 & \\
\hline 17.9 & \\
\hline 43.9 & \\
\hline 47.1 & \\
\hline 36.8 & \\
\hline 33.6 & \\
\hline 22.9 & \\
\hline 63.0 & \\
\hline 55.5 & \\
\hline 18.6 & \\
\hline 56.8 & \\
\hline 58.4 & \\
\hline
\end{tabular}

30
51
96
100
146
146
154
179
180
255
266
290
313
423
439
439
22
176
83
95
107
241
30
45
136
147
147
181
189
201
212
227
285
295
414
414
428
10
249
249
299
426
428
519
594
594
698

Page 61 of Table S-1-4 
Elongation factor $\mathrm{Tu}$, mitochondrial GN=TUFM EFTU HUMAN $49.54 \quad 100.0 \% \quad 20$ Elongation factor $\mathrm{Tu}$, mitochondrial GN=TUFM EFTU_HUMAN $49.54 \quad 100.0 \% \quad 20$ Elongation factor Tu, mitochondrial GN=TUFM EFTU HUMAN $49.54 \quad 100.0 \% \quad 20$ Elongation factor $\mathrm{Tu}$, mitochondrial GN=TUFM EFTU_HUMAN $49.54 \quad 100.0 \% \quad 20$ Elongation factor Tu, mitochondrial GN=TUFM EFTU_HUMAN $49.54 \quad 100.0 \% 20$ Elongation factor $\mathrm{Tu}$, mitochondrial GN=TUFM EFTU_HUMAN $49.54 \quad 100.0 \% 20$ Elongation factor Tu, mitochondrial GN=TUFM EFTU_HUMAN $49.54 \quad 100.0 \% \quad 20$ Elongation factor Tu, mitochondrial GN=TUFM EFTU_HUMAN $49.54 \quad 100.0 \% \quad 20$ Elongation factor Tu, mitochondrial GN=TUFM EFTU_HUMAN $49.54 \quad 100.0 \% 20$ Elongation factor Tu, mitochondrial GN=TUFM EFTU_HUMAN $49.54 \quad 100.0 \% \quad 20$ Elongation factor $\mathrm{Tu}$, mitochondrial GN=TUFM EFTU HUMAN $49.54 \quad 100.0 \%-20$ Elongation factor $\mathrm{Tu}$, mitochondrial GN=TUFM EFTU_HUMAN $49.54 \quad 100.0 \% \quad 20$ Elongation factor Tu, mitochondrial GN=TUFM EFTU_HUMAN $49.54 \quad 100.0 \% 20$ Elongation factor Tu, mitochondrial GN=TUFM EFTU_HUMAN $49.54 \quad 100.0 \% 20$ Elongation factor Tu, mitochondrial GN=TUFM EFTU_HUMAN $49.54 \quad 100.0 \% \quad 20$ Elongation factor Tu, mitochondrial GN=TUFM EFTU HUMAN $49.54 \quad 100.0 \% \quad 20$ Elongation factor Tu, mitochondrial GN=TUFM EFTU_HUMAN $49.54 \quad 100.0 \% 20$ Elongation factor Tu, mitochondrial GN=TUFM EFTU_HUMAN $49.54 \quad 100.0 \% 20$ Elongation factor Tu, mitochondrial GN=TUFM EFTU_HUMAN $49.54 \quad 100.0 \%$ Elongation factor Tu, mitochondrial GN=TUFM EFTU_HUMAN $49.54 \quad 100.0 \% \quad 20$ Elongator complex protein $1 \mathrm{GN}=$ IKBKAP ELP1_HUMAN $150.26 \quad 100.0 \%$ Elongator complex protein $1 \mathrm{GN}=\mathrm{IKBKAP}$ ELP1_HUMAN $150.26 \quad 100.0 \%$ Elongator complex protein $1 \mathrm{GN}=$ IKBKAP ELP1_HUMAN $150.26 \quad 100.0 \%$ Elongator complex protein $1 \mathrm{GN}=$ IKBKAP ELP1_HUMAN $150.26 \quad 100.0 \%$ Elongator complex protein $3 \mathrm{GN}=\mathrm{ELP} 3 \quad$ ELP3_HUMAN $62.26 \quad 100.0 \%$ Elongator complex protein $3 \mathrm{GN}=\mathrm{ELP} 3$ Emerin GN=EMD Emerin GN=EMD Emerin $\mathrm{GN}=\mathrm{EMD}$

Emerin GN=EMD

Emerin GN=EMD

Emerin $\mathrm{GN}=\mathrm{EMD}$

Emerin $\mathrm{GN}=\mathrm{EMD}$

Emerin GN=EMD

Emerin $\mathrm{GN}=\mathrm{EMD}$

Emerin GN=EMD

Endoplasmin $\mathrm{GN}=\mathrm{HSP} 90 \mathrm{~B}$

Endoplasmin GN=HSP90B

Endoplasmin $\mathrm{GN}=\mathrm{HSP} 90 \mathrm{~B}$

Endoplasmin GN=HSP90B

Endoplasmin GN=HSP90B

ELP3_HUMAN $62.26 \quad 100.0 \%$

EMD_HUMAN $28.99 \quad 100.0 \%$

EMD_HUMAN $28.99 \quad 100.0 \%$

EMD HUMAN $28.99 \quad 100.0 \%$

EMD HUMAN $28.99 \quad 100.0 \%$

EMD_HUMAN $28.99 \quad 100.0 \%$

EMD_HUMAN $28.99 \quad 100.0 \%$

EMD_HUMAN $28.99 \quad 100.0 \%$ EMD HUMAN $28.99 \quad 100.0 \%$ EMD HUMAN $28.99 \quad 100.0 \%$ EMD_HUMAN $28.99 \quad 100.0 \%$ ENPL HUMAN $92.47 \quad 100.0 \%$ ENPL_HUMAN $92.47 \quad 100.0 \%$ ENPL_HUMAN $92.47 \quad 100.0 \%$ ENPL HUMAN $92.47 \quad 100.0 \%$ ENPL_HUMAN $92.47 \quad 100.0 \%$

$80 \quad 0.08 \% \quad 17.5 \%$ GHVFEESQVAGTPMFVVK

$80 \quad 0.08 \% \quad 17.5 \%$ AYLPVNESFGFTADLR

$100 \quad 0.10 \% \quad 47.1 \%$ DKPHVNVGTIGHVDHGK

$100 \quad 0.10 \% \quad 47.1 \%$ TTLTAAITK

$100 \quad 0.10 \% \quad 47.1 \%$ YEEIDNAPEER

$100 \quad 0.10 \% \quad 47.1 \%$ YEEIDNAPEERAR

$100 \quad 0.10 \% \quad 47.1 \%$ ARGITINAAHVEYSTAAR

$100 \quad 0.10 \% \quad 47.1 \%$ GITINAAHVEYSTAAR

$100 \quad 0.10 \% \quad 47.1 \%$ HYAHTDCPGHADYVK

$100 \quad 0.10 \% \quad 47.1 \%$ QIGVEHVVVYVNK

$100 \quad 0.10 \% \quad 47.1 \%$ LLDAVDTYIPVPAR

$100 \quad 0.10 \% \quad 47.1 \%$ DLEKPFLLPVEAVYSVPGR

$100 \quad 0.10 \% \quad 47.1 \%$ GTVVTGTLER

$100 \quad 0.10 \% \quad 47.1 \%$ KGDECELLGHSK

$100 \quad 0.10 \% \quad 47.1 \%$ GDECELLGHSK

$100 \quad 0.10 \% \quad 47.1 \%$ TVVTGIEMFHK

$100 \quad 0.10 \% \quad 47.1 \%$ SLERAEAGDNLGALVR

$100 \quad 0.10 \% \quad 47.1 \%$ AEAGDNLGALVR

$100 \quad 0.10 \% \quad 47.1 \%$ GLVMVKPGSIKPHQK

$100 \quad 0.10 \% \quad 47.1 \%$ VEAQVYILSK

$100 \quad 0.10 \% \quad 47.1 \%$ VEAQVYILSKEEGGR

$100 \quad 0.10 \% \quad 47.1 \%$ TIGTGLVTNTLAMTEEEK $0.00 \% \quad 3.8 \%$ SNDLAVLDASNQISVYK

SVVLQLADGQIFK

$0.00 \% \quad 3.8 \%$ TTPELEIVLQK

$0.00 \% \quad 3.8 \%$ TLAGKLVEQR

$0.00 \% \quad 4.2 \%$ SYSPSDLVELVAR

$0.00 \% \quad 4.2 \%$ ILALVPPWTR

$0.02 \% \quad 46.5 \%$ RYNIPHGPVVGSTR

$0.02 \% \quad 46.5 \%$ YNIPHGPVVGSTR

$0.02 \% \quad 46.5 \%$ KIFEYETQR

$0.02 \% \quad 46.5 \%$ LSPPSSSAASSYSFSDLNSTR

$0.02 \% \quad 46.5 \%$ GDADMYDLPK

$0.02 \% \quad 46.5 \%$ KEDALLYQSK

$0.02 \% \quad 46.5 \%$ GYNDDYYEESYFTTR

$0.02 \% \quad 46.5 \%$ TYGEPESAGPSR

$0.02 \% \quad 46.5 \%$ DSAYQSITHYRPVSASR

$0.02 \% \quad 46.5 \%$ APGAGLGQDR

$0.00 \% \quad 7.1 \%$ ELISNASDALDK

$0.00 \% \quad 7.1 \%$ ELISNASDALDKIR

$0.00 \% \quad 7.1 \%$ LISLTDENALSGNEELTVK

$0.00 \% \quad 7.1 \%$ GVVDSDDLPLNVSR

$0.00 \% \quad 7.1 \%$ EAESSPFVER $\begin{array}{ll}99.7 \% & 40.2 \\ 99.7 \% & 63.4\end{array}$ $99.7 \% \quad 38.8$ $99.7 \% \quad 52.3$ $99.7 \% \quad 73.4$ $99.7 \% \quad 41.1$

$99.3 \% \quad 21.1$

$99.7 \% \quad 59.6$

$99.7 \% \quad 41.4$

$99.7 \% \quad 58.6$

$99.7 \% \quad 61.7$

$99.7 \% 55.5$

$99.7 \% \quad 55.2$

$\begin{array}{lll}99.7 \% & 33.8\end{array}$

$99.7 \% \quad 54.0$

$99.7 \% \quad 59.9$

$99.7 \% \quad 70.4$

$96.4 \% \quad 14.7$

$99.7 \% \quad 60.1$

$99.7 \% \quad 58.2$

62.2

$99.7 \% \quad 37.5$

$94.5 \% 14.4$

$99.7 \% \quad 28.0$

$99.7 \% \quad 43.5$

$99.7 \% \quad 31.2$

$99.7 \% \quad 31.6$

$99.7 \% \quad 42.8$

$99.7 \% \quad 55.0$

$99.7 \% \quad 68.9$

$99.7 \% \quad 37.4$

$99.7 \% \quad 46.7$

$99.7 \% \quad 62.4$ $99.7 \% \quad 67.1$

$99.7 \% \quad 56.0$

$99.7 \% \quad 48.4$

$99.7 \% \quad 42.0$

$99.7 \% \quad 53.8$

$99.7 \% \quad 49.1$

$99.7 \% \quad 54.6$

$99.1 \% \quad 18.3$
1534.82

1378.71

1977.97

1799.90

1809.94

919.55

1364.60

1591.73

1901.00

1673.86

1770.77

1483.83

1542.85

2129.16

1032.57

1372.65

1244.56

1277.66

1670.88

1185.62

1634.94

1149.65

1677.88

1907.96

1836.93

1417.8

1270.73

1114.66

1435.74

1165.71

1552.83

1396.73

1213.62

2161.00

1140.49

1194.64

1922.77

1250.56

1937.95

941.48

1275.64

1544.83

2046.06

1485.75

1150.54

$\begin{array}{cc}17 & 726 \\ 17 & 727 \\ 27 & 739 \\ 28 & 739 \\ 68 & 785 \\ 86 & 801 \\ 4 & 70 \\ 1 & 79 \\ 2 & 102 \\ 2 & 104 \\ 03 & 120 \\ 05 & 120 \\ 21 & 135 \\ 70 & 182 \\ 39 & 252 \\ 53 & 271 \\ 72 & 281 \\ 86 & 297 \\ 87 & 297 \\ 01 & 311 \\ 12 & 327 \\ 16 & 327 \\ 37 & 351 \\ 52 & 361 \\ 52 & 366 \\ 30 & 447 \\ 36 & 452 \\ 68 & 580 \\ 47 & 857 \\ 51 & 1060 \\ 39 & 351 \\ 52 & 361 \\ 8 & 31 \\ 9 & 31 \\ 7 & 45 \\ 8 & 68 \\ 9 & 78 \\ 9 & 88 \\ 9 & 103 \\ 04 & 115 \\ 58 & 174 \\ 12 & 221 \\ 03 & 114 \\ 03 & 116 \\ 17 & 135 \\ 35 & 448 \\ 48 & 557\end{array}$


ER membrane protein complex subunit 3 GN=EMC3 EMC3_HUMAN $29.95 \quad 100.0 \%$ ER membrane protein complex subunit $3 \mathrm{GN}=\mathrm{EMC} 3$ EMC3_HUMAN $29.95 \quad 100.0 \%$ ER membrane protein complex subunit $3 \mathrm{GN}=\mathrm{EMC} 3$ EMC3_HUMAN $29.95 \quad 100.0 \%$ Erlin-1 GN=ERLIN1 Erlin-1 GN=ERLIN1 Erlin-1 GN=ERLIN Erlin-1 GN=ERLIN Erlin-1 GN=ERLIN 1 Erlin-1 GN=ERLIN Erlin-1 GN=ERLIN1 Erlin-1 GN=ERLIN Erlin-1 GN=ERLIN Erlin-1 GN=ERLIN Erlin-1 GN=ERLIN Erlin-1 GN=ERLIN Erlin-2 GN=ERLIN2 Erlin-2 GN=ERLIN 2 Erlin-2 GN=ERLIN2 Erlin-2 GN=ERLIN2 Erlin-2 GN=ERLIN2 Erlin-2 GN=ERLIN2 Erlin-2 GN=ERLIN 2 Erlin-2 GN=ERLIN2 Erlin-2 GN=ERLIN2 Erlin-2 GN=ERLIN 2 Erlin-2 GN=ERLIN2 Erlin-2 GN=ERLIN2

Erlin-2 GN=ERLIN2 Erlin-2 GN=ERLIN2 Erlin-2 GN=ERLIN 2 Erlin-2 GN=ERLIN2 Erlin-2 GN=ERLIN2 Erlin-2 GN=ERLIN2 Erythrocyte band 7 integral membrane protein GN=STOM STOM_HUMAN $31.73 \quad 100.0 \%$ Erythrocyte band 7 integral membrane protein GN=STOM STOM_HUMAN $31.73 \quad 100.0 \%$ Erythrocyte band 7 integral membrane protein GN=STOM STOM_HUMAN $31.73 \quad 100.0 \%$ Erythrocyte band 7 integral membrane protein GN=STOM STOM_HUMAN $31.73 \quad 100.0 \%$ Estradiol 17-beta-dehydrogenase $11 \mathrm{GN}=$ HSD17B11 DHB11 HUMAN $32.94 \quad 100.0 \%$ Estradiol 17-beta-dehydrogenase $11 \mathrm{GN}=$ HSD17B11 DHB11_HUMAN $32.94 \quad 100.0 \%$ Estradiol 17-beta-dehydrogenase $11 \mathrm{GN}=$ HSD17B11 DHB11_HUMAN $32.94100 .0 \%$ Estradiol 17-beta-dehydrogenase $11 \mathrm{GN}=$ HSD17B11 DHB11_HUMAN $32.94100 .0 \%$ Ethylmalonyl-CoA decarboxylase GN=ECHDC1 ECHD1_HUMAN $33.70 \quad 100.0 \%$ Ethylmalonyl-CoA decarboxylase GN=ECHDC1 ECHD1_HUMAN $33.70 \quad 100.0 \%$ Ethylmalonyl-CoA decarboxylase GN=ECHDC1 ECHD1_HUMAN $33.70 \quad 100.0 \%$ Ethylmalonyl-CoA decarboxylase GN=ECHDC1 ECHD1_HUMAN $33.70 \quad 100.0 \%$ Ethylmalonyl-CoA decarboxylase GN=ECHDC1 ECHD1 HUMAN $33.70 \quad 100.0 \%$ Ethylmalonyl-CoA decarboxylase GN=ECHDC1 ECHD1_HUMAN $33.70 \quad 100.0 \%$
$0.00 \% \quad 13.0 \%$ AGPELLLDSNIR $0.00 \% \quad 13.0 \%$ LTQEQVSDSQVLIR $0.00 \% \quad 13.0 \%$ VPFPLTLR

$0.03 \% \quad 41.6 \%$ SVQTTLQTDEVK

$0.03 \% \quad 41.6 \%$ IEVVNMLAPYAVFDIVR

$0.03 \% \quad 41.6 \%$ DLNLMAPGLTIQAVR

$0.03 \% \quad 41.6 \%$ NFELMEAEK

$0.03 \% \quad 41.6 \%$ VVEKEAETER

$0.03 \% \quad 41.6 \%$ ISEIEDAAFLAR

$0.03 \% \quad 41.6 \%$ ADAEYYAAHK

$0.03 \% \quad 41.6 \%$ LTPEYLELKK

$0.03 \% \quad 41.6 \%$ YQAIASNSK

$\begin{array}{llllllll}99.7 \% & 55.4 & 25.0 & 47.2 & 2 & 0 & 0 & 1297.71\end{array}$

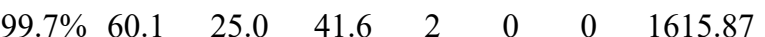

$95.5 \% \quad 18.1 \quad 25.0 \quad 12.0$

$99.7 \% \quad 63.0 \quad 25.0 \quad 54.5$

$\begin{array}{llll}99.7 \% & 79.6 & 25.0 & 71.7\end{array}$

$\begin{array}{lllll}99.7 \% & 60.3 & 25.0 & 48.2 & 8\end{array}$

$\begin{array}{llll}97.5 \% & 27.2 & 25.0 & 5.4\end{array}$

$99.7 \% \quad 46.5 \quad 25.0 \quad 45.2 \quad 4$

$99.7 \% \quad 92.7 \quad 25.0 \quad 85.8$

$\begin{array}{llll}99.7 \% & 52.7 & 25.0 & 49.8\end{array}$

$\begin{array}{llll}94.7 \% & 16.2 & 25.0 & 12.4\end{array}$

$99.7 \% \quad 43.5 \quad 25.0 \quad 40.5$

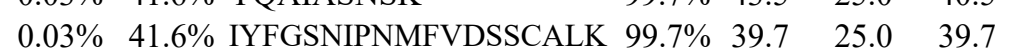

$0.03 \% \quad 41.6 \%$ ESSLPSKEALEPSGENVIQNK

$99.7 \% \quad 39.9$

$0.03 \% \quad 41.6 \%$ EALEPSGENVIQNK

$0.06 \% \quad 48.4 \%$ IEEGHIGVYYR

$99.7 \% \quad 71.7$

$99.7 \% \quad 50.8$

$99.7 \% \quad 63.0$

$0.06 \% \quad 48.4 \%$ SVQTTLQTDEVK

$0.06 \% \quad 48.4 \%$ LALQQDLTSMAPGLVIQAVR $\quad 99.7 \% \quad 53.2$

$0.06 \% \quad 48.4 \%$ VTKPNIPEAIR

$0.06 \% \quad 48.4 \%$ VTKPNIPEAIRR

$0.06 \% \quad 48.4 \%$ NYELMESEK

$0.06 \% \quad 48.4 \%$ NYELMESEKTK

$0.06 \% \quad 48.4 \%$ VVEKEAETER

$99.7 \% \quad 36.3$

$99.6 \% \quad 24.8$

$99.5 \% \quad 32.7$

$99.7 \% \quad 42.4$

$99.7 \% \quad 46.5$

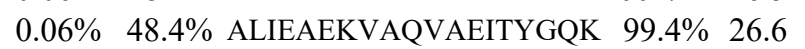

$0.06 \% \quad 48.4 \%$ VAQVAEITYGQK

$0.06 \% \quad 48.4 \%$ KISEIEDAAFLAR

$0.06 \% \quad 48.4 \%$ ISEIEDAAFLAR

$0.06 \% \quad 48.4 \%$ AKADAECYTAMK

$0.06 \% \quad 48.4 \%$ ADAECYTAMK

$0.06 \% \quad 48.4 \%$ LKLTPEYLQLMK

$0.06 \% \quad 48.4 \%$ LTPEYLQLMK

$99.7 \% \quad 59.3$

$99.7 \% \quad 41.4$

$99.7 \% \quad 92.7$

$99.7 \% \quad 53.8$

$99.7 \% \quad 59.6$

$94.9 \% \quad 15.4$

$99.7 \% \quad 51.6$

$99.7 \% \quad 55.2$

$0.06 \% \quad 48.4 \%$ LSFGLEDEPLETATKEN $\quad 99.7 \% \quad 47.2$

$0.00 \% \quad 17.0 \%$ VQNATLAVANITNADSATR

$0.00 \% \quad 17.0 \%$ LLAQTTLR

$0.00 \% \quad 17.0 \%$ AMAAEAEASR

$0.00 \% \quad 17.0 \%$ VIAAEGEMNASR

$0.00 \% \quad 16.7 \%$ HGLEETAAK

$0.00 \% \quad 16.7 \%$ FAAVGFHK

$0.00 \% \quad 16.7 \%$ TLTDELAALQITGVK

$99.6 \%$ \#\#\#\#

$99.6 \% 26.6$

$99.7 \% \quad 47.8$

$99.7 \% \quad 42.4$

$99.0 \% \quad 53.4$

$99.7 \% \quad 67.1$

$\begin{array}{llllll}0.00 \% & 16.7 \% & \text { NPSTSLGPTLEPEEVVNR } & 99.7 \% & 69.3\end{array}$

$0.02 \% \quad 36.2 \%$ EDNGIGILTLNNPSR

$0.02 \% \quad 36.2 \%$ VIELENWTEGK

$0.02 \% \quad 36.2 \%$ NTFSSGSDLNAVK

$99.7 \% \quad 41.5$

$99.7 \% \quad 56.8$

$99.7 \% \quad 49.6$

$96.6 \% \quad 15.1$

$0.02 \% \quad 36.2 \%$ NALNIGMVEEVLQSSDETK $\quad 99.7 \% \quad 61.6$

$99.7 \% \quad 57.9$

942.58

1348.70

1965.05

1627.88

1126.5

1189.61

1334.70

1138.52

1233.71

981.50

2163.03

2256.14

1527.77

1335.67

1348.70

2140.18

1237.73

1393.83

1142.50

1371.65

1189.61

2061.12

1306.70

1462.79

1334.70

1358.6

1175.47

1492.84

1251.67

1630.71

1892.91

1930.00

915.56

1022.46

1263.60

955.48

876.47

1572.88

1938.98

1612.83

1317.67

1339.65

1404.69

2077.01

$0.02 \% \quad 36.2 \%$ SLEEAQEWLK 
Ethylmalonyl-CoA decarboxylase GN=ECHDC1 ECHD1_HUMAN $33.70 \quad 100.0 \%$ Ethylmalonyl-CoA decarboxylase GN=ECHDC1 ECHD1_HUMAN $33.70 \quad 100.0 \%$ Etoposide-induced protein 2.4 homolog GN=EI24 EI24_HUMAN $38.97 \quad 100.0 \%$ Etoposide-induced protein 2.4 homolog GN=EI24 EI24_HUMAN $38.97 \quad 100.0 \%$ Eukaryotic initiation factor 4A-I GN=EIF4A1 IF4A1_HUMAN $46.16 \quad 100.0 \%$ Eukaryotic initiation factor 4A-I GN=EIF4A1 IF4A1_HUMAN $46.16 \quad 100.0 \%$ Eukaryotic initiation factor 4A-I GN=EIF4A1 IF4A1_HUMAN $46.16 \quad 100.0 \%$ Eukaryotic initiation factor 4A-I GN=EIF4A1 IF4A1_HUMAN $46.16 \quad 100.0 \%$ Eukaryotic initiation factor 4A-I GN=EIF4A1 IF4A1_HUMAN $46.16 \quad 100.0 \%$ Eukaryotic initiation factor 4A-I GN=EIF4A1 IF4A1_HUMAN $46.16 \quad 100.0 \%$ Eukaryotic initiation factor 4A-I GN=EIF4A1 IF4A1_HUMAN $46.16 \quad 100.0 \%$ Eukaryotic initiation factor 4A-I GN=EIF4A1 IF4A1_HUMAN $46.16 \quad 100.0 \%$ Eukaryotic initiation factor 4A-I GN=EIF4A1 IF4A1_HUMAN $46.16 \quad 100.0 \%$ Eukaryotic initiation factor 4A-I GN=EIF4A1 IF4A1_HUMAN $46.16 \quad 100.0 \%$ Eukaryotic initiation factor 4A-I GN=EIF4A1 IF4A1_HUMAN $46.16 \quad 100.0 \%$ Eukaryotic initiation factor 4A-I GN=EIF4A1 IF4A1_HUMAN $46.16 \quad 100.0 \%$ Eukaryotic initiation factor 4A-I GN=EIF4A1 IF4A1 HUMAN $46.16 \quad 100.0 \%$ Eukaryotic initiation factor 4A-III GN=EIF4A3 IF4A3_HUMAN $46.87 \quad 100.0 \%$ Eukaryotic initiation factor 4A-III GN=EIF4A3 IF4A3_HUMAN $46.87 \quad 100.0 \%$ Eukaryotic initiation factor 4A-III GN=EIF4A3 IF4A3_HUMAN $46.87 \quad 100.0 \%$ Eukaryotic initiation factor 4A-III GN=EIF4A3 IF4A3_HUMAN $46.87 \quad 100.0 \%$ Eukaryotic initiation factor 4A-III GN=EIF4A3 IF4A3_HUMAN $46.87 \quad 100.0 \%$ Eukaryotic initiation factor 4A-III GN=EIF4A3 IF4A3_HUMAN $46.87 \quad 100.0 \%$ Eukaryotic initiation factor 4A-III GN=EIF4A3 IF4A3_HUMAN $46.87 \quad 100.0 \%$ Eukaryotic initiation factor 4A-III GN=EIF4A3 IF4A3_HUMAN 46.87 Eukaryotic initiation factor 4A-III GN=EIF4A3 IF4A3_HUMAN 46.87 Eukaryotic initiation factor 4A-III GN=EIF4A3 IF4A3_HUMAN 46.87 Eukaryotic initiation factor 4A-III GN=EIF4A3 IF4A3_HUMAN 46.87 Eukaryotic translation initiation factor 2 subunit 1 GN=EIF2S1 IF2A_HUMAN 36.11 Eukaryotic translation initiation factor 2 subunit 1 GN=EIF2S1 IF2A_HUMAN 36.1 Eukaryotic translation initiation factor 2 subunit $1 \mathrm{GN}=\mathrm{EIF} 2 \mathrm{~S} 1 \mathrm{IF} 2 \mathrm{~A}$ _HUMAN 36.1 Eukaryotic translation initiation factor 3 subunit A GN=EIF3A EIF3A_HUMAN 166.57 Eukaryotic translation initiation factor 3 subunit A GN=EIF3A EIF3A_HUMAN 166.57 Eukaryotic translation initiation factor 3 subunit A GN=EIF3A EIF3A_HUMAN 166.57 Eukaryotic translation initiation factor 3 subunit A GN=EIF3A EIF3A_HUMAN 166.57 Eukaryotic translation initiation factor 3 subunit A GN=EIF3A EIF3A_HUMAN $166.57 \quad 100.0$ Eukaryotic translation initiation factor 3 subunit A GN=EIF3A EIF3A_HUMAN $166.57 \quad 100.0 \%$ Eukaryotic translation initiation factor 3 subunit A GN=EIF3A EIF3A_HUMAN $166.57 \quad 100.0 \%$ Eukaryotic translation initiation factor 3 subunit A GN=EIF3A EIF3A_HUMAN $166.57 \quad 100.0 \%$ Eukaryotic translation initiation factor 3 subunit A GN=EIF3A EIF3A_HUMAN $166.57 \quad 100.0 \%$ Eukaryotic translation initiation factor 3 subunit A GN=EIF3A EIF3A_HUMAN $166.57 \quad 100.0 \%$ Eukaryotic translation initiation factor 3 subunit A GN=EIF3A EIF3A_HUMAN $166.57 \quad 100.0 \%$ Eukaryotic translation initiation factor 3 subunit A GN=EIF3A EIF3A HUMAN $166.57 \quad 100.0 \%$ Eukaryotic translation initiation factor 3 subunit A GN=EIF3A EIF3A_HUMAN $166.57 \quad 100.0 \%$ Eukaryotic translation initiation factor 3 subunit A GN=EIF3A EIF3A_HUMAN $166.57 \quad 100.0 \%$ Eukaryotic translation initiation factor 3 subunit A GN=EIF3A EIF3A_HUMAN $166.57 \quad 100.0 \%$ Eukaryotic translation initiation factor 3 subunit A GN=EIF3A EIF3A_HUMAN $166.57 \quad 100.0 \%$
$0.02 \% \quad 36.2 \%$ ELYLEEALQNER $99.7 \% \quad 64.5$ $0.02 \% \quad 36.2 \%$ DLLGTVWGGPANLEAIAK $0.00 \% \quad 5.9 \%$ TFLQDLAR

$0.00 \% \quad 5.9 \%$ VFIPVLQSVTAR

$0.05 \% \quad 36.5 \%$ GIYAYGFEKPSAIQQR 0.05\% 36.5\% AILPCIKGYDVIAQAQSGTGK

$0.05 \% \quad 36.5 \%$ GYDVIAQAQSGTGK

$0.05 \% \quad 36.5 \%$ ATQALVLAPTR

$0.05 \% \quad 36.5 \%$ ELAQQIQK

$0.05 \% \quad 36.5 \%$ AEVQKLQMEAPHIIVGTPGR

$0.05 \% \quad 36.5 \%$ LQMEAPHIIVGTPGR

$0.05 \% \quad 36.5 \%$ MFVLDEADEMLSR

$0.05 \% \quad 36.5 \%$ GFKDQIYDIFQK

$0.05 \% \quad 36.5 \%$ KEELTLEGIR

$0.05 \% 36.5 \%$ KVDWLTEK

$0.05 \% \quad 36.5 \%$ VLITTDLLAR

$99.0 \% \quad 33.6$

$99.7 \% \quad 33.1$

$99.7 \% \quad 55.8$

$99.3 \% \quad 44.3$

$99.7 \% \quad 83.4$

$99.7 \% \quad 27.3$

$99.0 \% \quad 46.2$

$99.7 \% \quad 42.0$

$99.7 \% \quad 53.8$

$99.7 \% \quad 49.8$

$99.7 \% \quad 54.9$

$99.7 \% \quad 55.5$

$97.3 \% \quad 21.0$

$99.7 \% 56.1$

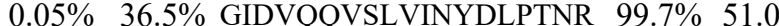

$0.02 \% \quad 29.4 \%$ GIYAYGFEKPSAIQQR

$0.02 \% \quad 29.4 \%$ GRDVIAQSQSGTGK

$99.7 \% \quad 55.8$

$99.7 \% \quad 43.7$

$99.7 \% \quad 42.6$

$99.0 \% 37.9$

$0.02 \% \quad 29.4 \%$ ELAVQIQK

$0.02 \% \quad 29.4 \%$ KLDYGQHVVAGTPGR

$0.02 \% \quad 29.4 \%$ LDYGQHVVAGTPGR

$0.02 \% \quad 29.4 \%$ GFKEQIYDVYR

$0.02 \% \quad 29.4 \%$ KVDWLTEK

$0.02 \% \quad 29.4 \%$ VLISTDVWAR

$99.7 \% \quad 35.0$

$99.7 \% \quad 68.3$

$99.7 \% \quad 38.3$

$97.3 \% 21.0$

$99.7 \% \quad 46.9$

$0.02 \% \quad 29.4 \%$ GLDVPQVSLIINY

$0.01 \% \quad 11.1 \%$ AGLNCSTENMPIK

$0.01 \% \quad 11.1 \%$ GVFNVQMEPK

$0.01 \% \quad 11.1 \%$ VVTDTDETELAR

$0.03 \% \quad 13.7 \%$ PAYFQRPENALKR

$0.03 \% \quad 13.7 \%$ ANEFLEVGKK

$0.03 \% \quad 13.7 \%$ YLELCVDLRK

$0.03 \% \quad 13.7 \%$ NICQQVNIK

$0.03 \% \quad 13.7 \%$ SGNALFHASTLHR

$0.03 \% \quad 13.7 \%$ NLTQDEMQR

$0.03 \% \quad 13.7 \%$ VLLATLSIPITPER

$0.03 \% \quad 13.7 \%$ VLLATLSIPITPERTDIAR

$0.03 \% \quad 13.7 \%$ LLDMDGIIVEK

$0.03 \% \quad 13.7 \%$ RLATLLGLQAPPTR

$0.03 \% \quad 13.7 \%$ IGLINDMVR

$0.03 \% \quad 13.7 \%$ LLQQVSQIYQSIEFSR

$0.03 \% \quad 13.7 \%$ LTSLVPFVDAFQLER

$0.03 \% \quad 13.7 \%$ TLSFGSDLNYATR

$0.03 \% \quad 13.7 \%$ NQLTAMSSVLAK

$0.03 \% \quad 13.7 \%$ LESLNIQR
$99.7 \% \quad 39.2$

$99.2 \% 19.8$

$99.4 \% 25.7$

$99.7 \% \quad 54.1$

$99.5 \% \quad 21.8$

$99.7 \% \quad 42.2$

$99.7 \% \quad 30.6$

$99.7 \% \quad 35.6$

$99.7 \% \quad 35.2$

$99.7 \% \quad 35.6$

$99.7 \% \quad 41.5$

$99.7 \% \quad 34.9$

$\begin{array}{ll}99.6 \% & 23.4 \\ 9\end{array}$

$99.7 \% \quad 31.8$

$99.7 \% \quad 69.0$

$\begin{array}{lll}99.7 \% & 62.1\end{array}$

$99.7 \% \quad 61.5$

$99.7 \% \quad 45.7$

$99.0 \% \quad 26.6$
506.74

1824.99

963.53

1329.79

1827.94

2190.16

1394.69

1140.67

957.54

2190.17

1634.87

1555.71

1501.77

1187.66

1018.56

1114.68

2144.13

1827.94

1403.72

1212.69

928.55

1597.84

1469.75

1417.71

1018.56

1159.65

2140.14

975.60

1450.67

1164.57

1348.66

1589.85

1134.62

1308.70

1116.58

1410.72

1150.52

1522.92

2079.22

1245.68

1506.91

1046.57

1939.03

1734.94

1444.71

1278.67

972.55 $\begin{array}{cc}284 & 301 \\ 7 & 14 \\ 92 & 103 \\ 46 & 6 \\ 62 & 82 \\ 69 & 82 \\ 00 & 1 \\ 11 & 1 \\ 42 & 161 \\ 47 & 161 \\ 78 & 190 \\ 91 & 202 \\ 238 & 247 \\ 284 & 291 \\ 325 & 334 \\ 335 & 353 \\ 52 & 67 \\ 75 & 88 \\ 06 & 1 \\ 17 & 124 \\ 52 & 166 \\ 53 & 166 \\ 96 & 206 \\ 289 & 296 \\ 330 & 339 \\ 340 & 358 \\ 374 & 382 \\ 214 & 226 \\ 267 & 276 \\ 277 & 288 \\ 2 & 14 \\ 15 & 24 \\ 54 & 63 \\ 76 & 84 \\ 286 & 298 \\ 309 & 3 \\ 322 & 335 \\ 322 & 340 \\ 341 & 351 \\ 354 & 367 \\ 368 & 376 \\ 439 & 454 \\ 455 & 469 \\ 490 & 502 \\ 521 & 532 \\ 582 & 589 \\ & \end{array}$ 
Eukaryotic translation initiation factor 3 subunit A GN=EIF3A EIF3A_HUMAN $166.57 \quad 100.0 \%$ Eukaryotic translation initiation factor 3 subunit B GN=EIF3B EIF3B_HUMAN $92.48 \quad 100.0 \%$ Eukaryotic translation initiation factor 3 subunit B GN=EIF3B EIF3B_HUMAN $92.48 \quad 100.0 \%$ Eukaryotic translation initiation factor 3 subunit B GN=EIF3B EIF3B_HUMAN $92.48 \quad 100.0 \%$ Eukaryotic translation initiation factor 3 subunit B GN=EIF3B EIF3B_HUMAN $92.48 \quad 100.0 \%$ Eukaryotic translation initiation factor 3 subunit B GN=EIF3B EIF3B_HUMAN $92.48 \quad 100.0 \%$ Eukaryotic translation initiation factor 3 subunit B GN=EIF3B EIF3B_HUMAN $92.48 \quad 100.0 \%$ Eukaryotic translation initiation factor 3 subunit B GN=EIF3B EIF3B_HUMAN $92.48 \quad 100.0 \%$ Eukaryotic translation initiation factor 3 subunit B GN=EIF3B EIF3B HUMAN $92.48 \quad 100.0 \%$ Eukaryotic translation initiation factor 3 subunit D GN=EIF3D EIF3D_HUMAN $63.97 \quad 100.0 \%$ Eukaryotic translation initiation factor 3 subunit D GN=EIF3D EIF3D_HUMAN $63.97 \quad 100.0 \%$ Eukaryotic translation initiation factor 3 subunit D GN=EIF3D EIF3D HUMAN $63.97 \quad 100.0^{\circ} \%$ Eukaryotic translation initiation factor 3 subunit D GN=EIF3D EIF3D_HUMAN $63.97 \quad 100.0 \%$ Eukaryotic translation initiation factor 3 subunit D GN=EIF3D EIF3D_HUMAN $63.97 \quad 100.0 \%$ Eukaryotic translation initiation factor 3 subunit D GN=EIF3D EIF3D_HUMAN $63.97 \quad 100.0 \%$ Eukaryotic translation initiation factor 3 subunit D GN=EIF3D EIF3D_HUMAN $63.97 \quad 100.0 \%$ Eukaryotic translation initiation factor 3 subunit D GN=EIF3D EIF3D HUMAN $63.97 \quad 100.0 \%$ Eukaryotic translation initiation factor 3 subunit E GN=EIF3E EIF3E_HUMAN $52.22 \quad 100.0 \%$ Eukaryotic translation initiation factor 3 subunit $\mathrm{E}$ GN=EIF3E EIF3E_HUMAN $52.22 \quad 100.0 \%$ Eukaryotic translation initiation factor 3 subunit E GN=EIF3E EIF3E_HUMAN 52.22 Eukaryotic translation initiation factor 3 subunit E GN=EIF3E EIF3E_HUMAN 52.22 Eukaryotic translation initiation factor 3 subunit E GN=EIF3E EIF3E_HUMAN 52.22 Eukaryotic translation initiation factor 3 subunit E GN=EIF3E EIF3E_HUMAN $52.22 \quad 100.0 \%$ Eukaryotic translation initiation factor 3 subunit E GN=EIF3E EIF3E_HUMAN 52.22 Eukaryotic translation initiation factor 3 subunit E GN=EIF3E EIF3E HUMAN 52.22 Eukaryotic translation initiation factor 3 subunit $\mathrm{E}$ GN=EIF3E EIF3E_HUMAN 52.22 Eukaryotic translation initiation factor 3 subunit $\mathrm{E}$ GN=EIF3E EIF3E_HUMAN 52.22 Eukaryotic translation initiation factor 3 subunit E GN=EIF3E EIF3E_HUMAN 52.22 Eukaryotic translation initiation factor 3 subunit $\mathrm{E}$ GN=EIF3E EIF3E_HUMAN 52.22 Eukaryotic translation initiation factor 3 subunit $\mathrm{E}$ GN=EIF3E EIF3E_HUMAN 52.22 Eukaryotic translation initiation factor 3 subunit E GN=EIF3E EIF3E_HUMAN 52.22 Eukaryotic translation initiation factor 3 subunit E GN=EIF3E EIF3E_HUMAN 52.22 Eukaryotic translation initiation factor 3 subunit F GN=EIF3F EIF3F_HUMAN 37.56 Eukaryotic translation initiation factor 3 subunit $\mathrm{F}$ GN=EIF3F EIF3F_HUMAN 37.56 Eukaryotic translation initiation factor 3 subunit $F$ GN=EIF3F EIF3F_HUMAN 37.56 Eukaryotic translation initiation factor 3 subunit F GN=EIF3F EIF3F_HUMAN 37.56 Eukaryotic translation initiation factor 3 subunit $\mathrm{F}$ GN=EIF3F EIF3F_HUMAN 37.56 Eukaryotic translation initiation factor 3 subunit G GN=EIF3G EIF3G_HUMAN 35.61 Eukaryotic translation initiation factor 3 subunit $\mathrm{G} \mathrm{GN}=\mathrm{EIF} 3 \mathrm{G}$ EIF3G_HUMAN $35.61 \quad 100.0 \%$ Eukaryotic translation initiation factor 3 subunit $\mathrm{G}$ GN=EIF3G EIF3G_HUMAN $35.61 \quad 100.0 \%$ Eukaryotic translation initiation factor 3 subunit G GN=EIF3G EIF3G_HUMAN $35.61 \quad 100.0 \%$ Eukaryotic translation initiation factor 3 subunit $\mathrm{H}$ GN=EIF3H EIF3H_HUMAN $39.93 \quad 100.0 \%$ Eukaryotic translation initiation factor 3 subunit $\mathrm{H}$ GN=EIF3H EIF3H_HUMAN $39.93 \quad 100.0 \%$ Eukaryotic translation initiation factor 3 subunit $\mathrm{H}$ GN=EIF3H EIF3H_HUMAN $39.93 \quad 100.0 \%$ Eukaryotic translation initiation factor 3 subunit I GN=EIF3I EIF3I_HUMAN $36.50 \quad 100.0 \%$ Eukaryotic translation initiation factor 3 subunit I GN=EIF3I EIF3I_HUMAN $36.50 \quad 100.0 \%$ Eukaryotic translation initiation factor 3 subunit I GN=EIF3I EIF3I_HUMAN $36.50 \quad 100.0 \%$
$0.03 \% \quad 13.7 \%$ ILQEHEQIK

$0.02 \% \quad 10.8 \%$ AQAVSEDAGGNEGR

$99.6 \% \quad 24.5$

$99.7 \% \quad 55.5$

$\begin{array}{lll}0.02 \% & 10.8 \% & \text { AQAVSEDAGGNE } \\ 0.02 \% & 10.8 \% & \text { GTYLATFHQR }\end{array}$

$0.02 \% \quad 10.8 \%$ FSHQGVQLIDFSPCER

$0.02 \% \quad 10.8 \%$ VTLMQLPTR

$0.02 \% \quad 10.8 \%$ GTQGVVTNFEIFR

$0.02 \% \quad 10.8 \%$ FAVLHGEAPR

$0.02 \% \quad 10.8 \%$ ISVSFYHVK

$0.03 \% \quad 17.9 \%$ VADWTGATYQDKR

$0.03 \% \quad 17.9 \%$ NMLQFNLQILPK

$0.03 \% \quad 17.9 \%$ IFHTVTTTDDPVIR

$0.03 \% \quad 17.9 \%$ IFHTVTTTDDPVIRK

$0.03 \% \quad 17.9 \%$ SVYSWDIVVQR

$0.03 \% \quad 17.9 \%$ NLAMEATYINHNFSQQCLR

$0.03 \% \quad 17.9 \%$ GAVIATELKNNSYK

$0.03 \% \quad 17.9 \%$ WTCCALLAGSEYLK

$0.04 \% \quad 29.0 \%$ NLYSDDIPHALR

$0.04 \% \quad 29.0 \%$ RTTVVAQLK

$0.04 \% \quad 29.0 \%$ TTVVAQLK

$0.04 \% \quad 29.0 \%$ TTVVAQLKQLQAETEPIVK

$0.04 \% \quad 29.0 \%$ QLQAETEPIVK

$0.04 \% \quad 29.0 \%$ MFEDPETTR

$0.04 \% \quad 29.0 \%$ VLVPATDR

PR

$96.7 \% \quad 15.1$

$99.7 \% \quad 27.0$

$99.7 \% \quad 49.6$

$99.7 \% \quad 36.6$

$99.7 \% \quad 29.6$

$99.7 \% \quad 59.9$

$99.7 \% \quad 55.3$

$99.7 \% \quad 65.8$

$99.7 \% \quad 53.8$

$99.7 \% \quad 56.5$

$99.7 \% \quad 50.3$

$99.7 \% 62.5$

$99.7 \% \quad 34.2$

$99.7 \% \quad 55.2$

$99.6 \% \quad 24.1$

$99.0 \% \quad 31.6$

$\begin{array}{lll}99.7 \% & 32.2 \\ 99.7 \% & 47.3\end{array}$

$99.7 \% \quad 40.4$

$99.0 \% \quad 25.1$

$0.04 \% \quad 29.0 \%$ LKETIDNNSVSSPLQSLQQR $\quad 99.7 \% \quad 41.5$

$0.04 \% \quad 29.0 \%$ ETIDNNSVSSPLQSLQQR

$0.04 \% \quad 29.0 \%$ YLTTAVITNK

$0.04 \% \quad 29.0 \%$ YLTTAVITNKDVR

$0.04 \% \quad 29.0 \%$ QVLKDLVK

$0.04 \% \quad 29.0 \%$ LFIFETFCR

$99.7 \% \quad 92.6$

$99.7 \% \quad 57.2$

$99.7 \% \quad 54.7$

$99.0 \% \quad 29.6$

$99.7 \% \quad 48.6$

$0.04 \% \quad 29.0 \%$ LGHVVMGNNAVSPYQQVIEK

$0.04 \% \quad 29.0 \%$ SQMLAMNIEK

$99.7 \% \quad 47.0$

$0.01 \% \quad 19.3 \%$ LHPVILASIVDSYER

$0.01 \% \quad 19.3 \%$ EAPNPIHLTVDTSLQNGR

$9.9 \% \quad 16.3$

$0.01 \% \quad 19.3 \%$ YAYYDTER

$0.01 \% \quad 19.3 \%$ VIGLSSDLQQVGGASAR

$0.01 \% \quad 19.3 \%$ FLMSLVNQVPK

$0.00 \% \quad 15.0 \%$ ELAEQLGLSTGEK

$0.00 \% \quad 15.0 \%$ LPGELEPVQATQNK

$0.00 \% \quad 15.0 \%$ YVPPSLRDGASR

$0.00 \% \quad 15.0 \%$ GFAFISFHR

$8.4 \%$

$99.7 \% \quad 93.9$

$99.7 \% \quad 32.0$

$99.7 \% \quad 59.8$

$99.7 \% \quad 40.3$

$95.1 \% \quad 20.4$

$99.7 \% \quad 30.7$

$\begin{array}{llllll}0.00 \% & 8.2 \% & \text { KEGTGSTATSSSSTAGAAGK } & 99.7 \% & 37.1\end{array}$

$0.00 \% \quad 8.2 \% \quad$ EGTGSTATSSSSTAGAAGK $\quad 99.7 \% \quad 57.2$

$0.00 \% \quad 8.2 \%$ EFTAQNLGK

$0.03 \% \quad 40.9 \%$ MKPILLQGHER

$0.03 \% \quad 40.9 \%$ EGDLLFTVAK

$0.03 \% \quad 40.9 \%$ HVLTGSADNSCR
$99.4 \% 31.0$

$99.7 \% 31.6$

$99.7 \% 55.5$

$99.7 \% \quad 53.0$
113

1137.63

1360.61

2084.96

1193.6

1919.91

1058.60

1467.76

1096.59

1079.59

1510.73

1458.81

1614.85

1742.94

1351.70

2310.08

1507.81

1671.79

1413.71

1015.63

859.52

2096.20

1255.69

1141.48

870.50

2257.18

2016.00

1123.64

1493.83

942.60

1232.6

2199.12

1196.57

1711.94

1962.00

1080.46

1657.89

1275.71

1374.71

1523.81

1317.69

1081.56

1755.84

1627.74

1007.52

1321.74

1092.59

1316.60 \begin{tabular}{c}
\hline 632 \\
134 \\
141 \\
355 \\
386 \\
501 \\
548 \\
586 \\
595 \\
54 \\
124 \\
236 \\
237 \\
271 \\
329 \\
431 \\
448 \\
71 \\
82 \\
82 \\
93 \\
93 \\
102 \\
163 \\
211 \\
211 \\
265 \\
268 \\
279 \\
346 \\
407 \\
424 \\
11 \\
108 \\
210 \\
246 \\
278 \\
317 \\
193 \\
209 \\
224 \\
289 \\
\hline
\end{tabular}

Page 65 of Table S-1-4 

Eukaryotic translation initiation factor 3 subunit I GN=EIF3I EIF3I_HUMAN $36.50 \quad 100.0 \%$ Eukaryotic translation initiation factor 3 subunit I GN=EIF3I EIF3I_HUMAN $36.50 \quad 100.0 \% \quad 1$ Eukaryotic translation initiation factor 3 subunit I GN=EIF3I EIF3I_HUMAN $36.50 \quad 100.0 \%$ Eukaryotic translation initiation factor 3 subunit I GN=EIF3I EIF3I_HUMAN $36.50 \quad 100.0 \%$ Eukaryotic translation initiation factor 3 subunit I GN=EIF3I EIF3I_HUMAN $36.50 \quad 100.0 \% \quad 1$ Eukaryotic translation initiation factor 3 subunit I GN=EIF3I EIF3I_HUMAN $36.50 \quad 100.0 \% \quad 1$ $\begin{array}{lllll}\text { Eukaryotic translation initiation factor } 3 \text { subunit I GN=EIF3I } & \text { EIF3I_HUMAN } & 36.50 & 100.0 \% & 1\end{array}$ Eukaryotic translation initiation factor 3 subunit I GN=EIF3I EIF3I HUMAN $36.50 \quad 100.0 \%$ Eukaryotic translation initiation factor 3 subunit $\mathrm{L}$ GN=EIF3L $\quad$ EIF3L_HUMAN $66.73 \quad 100.0 \%$ Eukaryotic translation initiation factor 3 subunit L GN=EIF3L EIF3L_HUMAN $66.73 \quad 100.0 \%$ Eukaryotic translation initiation factor 3 subunit L GN=EIF3L EIF3L HUMAN $66.73 \quad 100.0 \%$ Eukaryotic translation initiation factor 3 subunit $\mathrm{L}$ GN=EIF3L EIF3L_HUMAN $66.73 \quad 100.0 \%$ Eukaryotic translation initiation factor 3 subunit L GN=EIF3L EIF3L_HUMAN $66.73 \quad 100.0 \%$ Eukaryotic translation initiation factor 3 subunit L GN=EIF3L EIF3L_HUMAN $66.73 \quad 100.0 \%$ Eukaryotic translation initiation factor 3 subunit L GN=EIF3L EIF3L_HUMAN $66.73 \quad 100.0 \% \quad 1$ Eukaryotic translation initiation factor 3 subunit L GN=EIF3L EIF3L HUMAN $66.73 \quad 100.0 \%$ Eukaryotic translation initiation factor 3 subunit L GN=EIF3L EIF3L_HUMAN $66.73 \quad 100.0 \%$ Eukaryotic translation initiation factor 3 subunit L GN=EIF3L EIF3L_HUMAN $66.73 \quad 100.0 \% \quad 1$ ' Eukaryotic translation initiation factor 3 subunit L GN=EIF3L EIF3L HUMAN $66.73 \quad 100.0 \%$ Eukaryotic translation initiation factor 3 subunit $\mathrm{L}$ GN=EIF3L EIF3L_HUMAN $66.73 \quad 100.0 \%$ Eukaryotic translation initiation factor 3 subunit L GN=EIF3L EIF3L HUMAN $66.73 \quad 100.0 \%$ Eukaryotic translation initiation factor 3 subunit $\mathrm{L}$ GN=EIF3L EIF3L_HUMAN $66.73 \quad 100.0 \%$ Eukaryotic translation initiation factor 3 subunit L GN=EIF3L EIF3L_HUMAN $66.73 \quad 100.0 \%$ Eukaryotic translation initiation factor 3 subunit $\mathrm{L}$ GN=EIF3L EIF3L HUMAN 66.73 Eukaryotic translation initiation factor 3 subunit L GN=EIF3L EIF3L_HUMAN 66.73 Eukaryotic translation initiation factor 3 subunit $\mathrm{M}$ GN=EIF3M EIF3M_HUMAN 42.50 Eukaryotic translation initiation factor 3 subunit M GN=EIF3M EIF3M HUMAN 42.50 Eukaryotic translation initiation factor 3 subunit $\mathrm{M}$ GN=EIF3M EIF3M_HUMAN 42.50 Eukaryotic translation initiation factor 3 subunit $\mathrm{M}$ GN=EIF3M EIF3M HUMAN 42.50 Eukaryotic translation initiation factor 4 gamma 1 GN=EIF4G1 IF4G1_HUMAN 175.49 Eukaryotic translation initiation factor 4 gamma $1 \mathrm{GN}=\mathrm{EIF} 4 \mathrm{G} 1$ IF4G1_HUMAN $175.49 \quad 100.0 \%$ Eukaryotic translation initiation factor 4 gamma $1 \mathrm{GN}=\mathrm{EIF} 4 \mathrm{G} 1$ IF4G1 HUMAN $175.49 \quad 100.0 \%$ Eukaryotic translation initiation factor 4 gamma $1 \mathrm{GN}=\mathrm{EIF} 4 \mathrm{G} 1 \quad$ IF4G1_HUMAN $175.49 \quad 100.0 \%$ Eukaryotic translation initiation factor 4 gamma $1 \mathrm{GN}=$ EIF4G1 IF4G1_HUMAN $175.49 \quad 100.0 \%$ Eukaryotic translation initiation factor 4 gamma 2 GN=EIF4G2 IF4G2_HUMAN $102.37 \quad 100.0 \%$ Eukaryotic translation initiation factor 4 gamma 2 GN=EIF4G2 IF4G2_HUMAN $102.37 \quad 100.0 \%$ Eukaryotic translation initiation factor 4 gamma $2 \mathrm{GN}=\mathrm{EIF} 4 \mathrm{G} 2 \quad \mathrm{IF} 4 \mathrm{G} 2$ HUMAN $102.37 \quad 100.0 \%$ Eukaryotic translation initiation factor 4 gamma $2 \mathrm{GN}=\mathrm{EIF} 4 \mathrm{G} 2 \mathrm{IF} 4 \mathrm{G} 2$ _HUMAN $102.37 \quad 100.0 \%$ Eukaryotic translation initiation factor 4 gamma 2 GN=EIF4G2 IF4G2_HUMAN $102.37 \quad 100.0 \%$ Eukaryotic translation initiation factor 4 gamma 2 GN=EIF4G2 IF4G2 HUMAN $102.37 \quad 100.0 \%$ Eukaryotic translation initiation factor 4B GN=EIF4B IF4B_HUMAN $69.15 \quad 100.0 \%$ Eukaryotic translation initiation factor 4B GN=EIF4B IF4B HUMAN $69.15100 .0 \%$ Eukaryotic translation initiation factor 4B GN=EIF4B IF4B_HUMAN $69.15 \quad 100.0 \%$ Eukaryotic translation initiation factor 4B GN=EIF4B IF4B_HUMAN $69.15 \quad 100.0 \%$ Eukaryotic translation initiation factor 4B GN=EIF4B IF4B HUMAN $69.15 \quad 100.0 \%$ Eukaryotic translation initiation factor 4B GN=EIF4B IF4B_HUMAN $69.15 \quad 100.0 \%$

35$$
8
$$

$$
\begin{aligned}
& 11 \\
& 11
\end{aligned}
$$

$\begin{array}{ll}6 & 11 \\ 6 & 11 \\ 6 & 11\end{array}$

$$
\begin{aligned}
& 11 \\
& 11 \\
& 11
\end{aligned}
$$

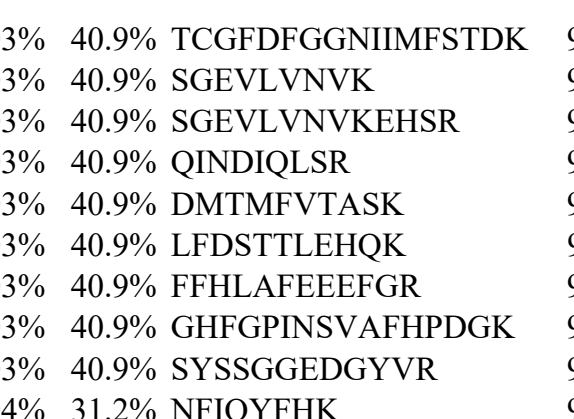

$0.04 \% \quad 31.2 \%$ NFIQYFHK

$0.04 \% \quad 31.2 \%$ TVSDLIDQKVYELQASR

$0.04 \% \quad 31.2 \%$ VYELQASR

$0.04 \% \quad 31.2 \%$ VSGGPSLEQR

$0.04 \% 31.2 \%$ KSEEEIDFLR

$0.04 \% \quad 31.2 \%$ SEEEIDFLR

$0.04 \% \quad 31.2 \%$ QLEVYTSGGDPESVAGEYGR

$0.04 \% 31.2 \%$ MLGYFSLVGLLR

$0.04 \% 31.2 \%$ LHSLLGDYYQAIK

$0.04 \% \quad 31.2 \%$ VLENIELNKK

$0.04 \% 31.2 \%$ TTYKYEMINK

$0.04 \% \quad 31.2 \%$ IDESIHLQLR

$0.04 \% 31.2 \%$ VFSDEVQQQAQLSTIR

$0.04 \% 31.2 \%$ LYTTMPVAK

$0.04 \% \quad 31.2 \%$ LAGFLDLTEQEFR

$0.04 \% \quad 31.2 \%$ RYGDFFIR

$\begin{array}{lll}0.04 \% & 31.2 \% & \text { QIHKFEELNR } \\ 0.01 \% & 8.3 \% & \text { YTVYCSLIK }\end{array}$

$0.01 \% \quad 8.3 \%$ LLTFMGMAVENK

$0.01 \% \quad 8.3 \%$ KVVVSHSTHR

$0.01 \% \quad 8.3 \%$ VVVSHSTHR

$\begin{array}{llllll}0.01 \% & 5.1 \% & \text { ITKPGSIDSNNQLFAPGGR } & 99.7 \% & 33.2\end{array}$

$\begin{array}{llll}0.01 \% & 5.1 \% & \text { GSSGGSGAKPSDAASEAARPATSTLNR } \\ 0.01 \% & 5.1 \% & \text { FSALQQAVPTESTDNRR }\end{array}$

$0.01 \% \quad 5.1 \%$ SFSKEVEER

$0.01 \% \quad 5.1 \%$ HGVESTLER

$0.01 \% \quad 7.1 \%$ GAPQHYPK

$0.01 \% \quad 7.1 \%$ TAGNSEFLGK

$0.01 \% \quad 7.1 \%$ LQDEFENRTR

$0.01 \% \quad 7.1 \%$ TQTPPLGQTPQLGLK

$0.01 \% \quad 7.1 \%$ TNPPLIQEKPAK

$0.01 \% \quad 7.1 \%$ SYLAQFAAR

$\begin{array}{ll}0.04 \% & 15.7 \% \text { SILPTAPR } \\ 0.04 \% & 15.7 \% \text { GLNISAVR }\end{array}$

$0.04 \% \quad 15.7 \%$ STPKEDDSSASTSQSTR

$0.04 \% \quad 15.7 \%$ AASIFGGAKPVDTAAR

$0.04 \% \quad 15.7 \%$ QLDEPKLER

$\begin{array}{lllll}0.04 \% & 15.7 \% & \text { SRTGSESSQTGTSTTSSR } & 99.7 \% & 53.0\end{array}$

$99.7 \% 54.0$

$99.7 \% \quad 32.6$

$99.7 \% \quad 51.8$

$99.7 \% \quad 52.6$

$99.7 \% \quad 63.1$

$99.5 \% \quad 24.3$

$99.7 \% 32.8$

$\begin{array}{lll}95.4 \% & 23.5\end{array}$

$99.7 \% 38.9$

$99.0 \% \quad 28.2$

$99.7 \% \quad 69.5$

$99.7 \% \quad 58.8$

$99.7 \% \quad 51.6$

$99.7 \% \quad 52.4$

$99.7 \% \quad 45.8$

$\begin{array}{llll}99.7 \% & 57.4\end{array}$

$99.0 \% \quad 23.0$

$\begin{array}{lll}99.5 \% & 25.5\end{array}$

$99.7 \% \quad 58.7$

$99.2 \% \quad 27.0$

$\begin{array}{lll}99.7 \% & 55.8\end{array}$

$99.0 \% \quad 26.5$

$\begin{array}{lll}99.7 \% & 31.9 \\ 99.7 \% & 29.8 & 2\end{array}$

$\begin{array}{llll}99.7 \% & 29.8\end{array}$

$99.7 \% \quad 42.9$

$99.7 \% \quad 44.5$

$99.7 \% \quad 49.2$

$99.7 \% \quad 46$

$\begin{array}{lll}99.4 \% & 20.3\end{array}$

$\begin{array}{llll}99.7 \% & 36.5\end{array}$

$99.0 \% \quad 36.1$

$\begin{array}{llll}97.7 \% & 17.8\end{array}$

$\begin{array}{lll}99.3 \% & 28.5\end{array}$

$\begin{array}{lll}99.7 \% & 58.1\end{array}$

$\begin{array}{lll}99.7 \% & 36.4\end{array}$

$\begin{array}{ll}99.7 \% & 41.7 \\ 98.5 \% & 22.1\end{array}$

$99.0 \% \quad 41.1$

$99.0 \% \quad 41.1$

$\begin{array}{lll}99.7 \% & 53.4\end{array}$

$\begin{array}{lll}97.5 \% & 22.1\end{array}$

.
1925.84

944.54

1453.78

1086.59

1130.52

1318.66

1528.72

1679.83

1276.54

1096.56

1965.03

965.51

1029.53

1265.64

1137.54

2113.97

1384.77

1520.81

1199.70

1290.64

1223.67

1848.95

1039.55

1538.79

1073.55

1313.70

1146.59

1353.69

1149.65

1021.55

1972.02

2503.21

1919.96

1110.54

1027.52

897.46

1023.51

1307.63

1578.89

1335.76

1026.54

854.51

829.49

1783.79

1531.82

1127.61 1816.83

$\begin{array}{cc}8 & 114 \\ 77 & 185 \\ 77 & 189 \\ 90 & 198 \\ 99 & 208 \\ 14 & 224 \\ 69 & 280 \\ 83 & 298 \\ 99 & 310 \\ 4 & 61 \\ 2 & 78 \\ 1 & 78 \\ 44 & 153 \\ 07 & 216 \\ 08 & 216 \\ 43 & 262 \\ 68 & 279 \\ 80 & 292 \\ 93 & 302 \\ 53 & 362 \\ 32 & 391 \\ 46 & 461 \\ 66 & 474 \\ 75 & 487 \\ 38 & 545 \\ 46 & 555 \\ 21 & 129 \\ 79 & 290 \\ 31 & 340 \\ 32 & 340 \\ 72 & 1090 \\ 96 & 1122 \\ 23 & 1139 \\ 85 & 1193 \\ 81 & 1289 \\ 4 & 31 \\ 2 & 41 \\ 71 & 180 \\ 06 & 520 \\ 21 & 532 \\ 41 & 649 \\ 1 & 78 \\ 18 & 125 \\ 40 & 356 \\ 57 & 372 \\ 90 & 398 \\ 18 & 435 \\ & \end{array}$


Eukaryotic translation initiation factor 4B GN=EIF4B IF4B_HUMAN $69.15 \quad 100.0 \%$ Eukaryotic translation initiation factor 4B GN=EIF4B IF4B HUMAN $69.15 \quad 100.0 \%$ Eukaryotic translation initiation factor 4B GN=EIF4B IF4B_HUMAN $69.15 \quad 100.0 \%$ Exocyst complex component 4 GN=EXOC4 EXOC4_HUMAN $110.50 \quad 100.0 \%$ Exocyst complex component 4 GN=EXOC4 EXOC4_HUMAN $110.50 \quad 100.0 \%$ Exosome complex component MTR3 GN=EXOSC6 EXOS6_HUMAN $28.24 \quad 100.0 \%$ Exosome complex component MTR3 GN=EXOSC6 EXOS6_HUMAN $28.24 \quad 100.0 \%$ Exosome complex component MTR3 GN=EXOSC6 EXOs6_HUMAN $28.24 \quad 100.0 \%$ Exosome complex component MTR3 GN=EXOSC6 EXOS6 HUMAN $28.24 \quad 100.0 \%$ Exosome complex component MTR3 GN=EXOSC6 EXOS6_HUMAN $28.24 \quad 100.0 \%$ Exosome complex component MTR3 GN=EXOSC6 EXOS6_HUMAN $28.24 \quad 100.0 \%$ Exosome complex component MTR3 GN=EXOSC6 EXOS6 HUMAN $28.24 \quad 100.0 \%$ Exosome complex component RRP43 GN=EXOSC8 EXOS8_HUMAN $30.04 \quad 100.0 \%$ Exosome complex component RRP43 GN=EXOSC8 EXOS8_HUMAN $30.04 \quad 100.0 \%$ Exosome complex component RRP43 GN=EXOSC8 EXOS8_HUMAN $30.04 \quad 100.0 \%$ Exosome complex component RRP43 GN=EXOSC8 EXOS8_HUMAN $30.04 \quad 100.0 \%$ Exosome complex component RRP43 GN=EXOSC8 EXOS8 HUMAN $30.04 \quad 100.0 \%$ Exosome complex exonuclease RRP44 GN=DIS3 RRP44_HUMAN $109.01 \quad 100.0 \%$ Exosome complex exonuclease RRP44 GN=DIS3 RRP44_HUMAN $109.01 \quad 100.0 \%$ Exosome complex exonuclease RRP44 GN=DIS3 RRP44_HUMAN $109.01 \quad 100.0 \%$ Exosome complex exonuclease RRP44 GN=DIS3 RRP44_HUMAN $109.01 \quad 100.0 \%$ Exosome complex exonuclease RRP44 GN=DIS3 RRP44_HUMAN 109.01 $100.0 \%$ Exosome complex exonuclease RRP44 GN=DIS3 RRP44_HUMAN $109.01 \quad 100.0 \%$ Exosome complex exonuclease RRP44 GN=DIS3 RRP44_HUMAN $109.01 \quad 100.0 \%$ Exportin-1 GN=XPO1 Exportin-1 GN=XPO1 Exportin-1 GN=XPO1 Exportin-1 GN=XPO1 Exportin-1 GN=XPO1 Exportin-1 GN=XPO1 Exportin-1 GN=XPO1 Exportin-1 GN=XPO1 Exportin-1 GN=XPO1 Exportin-1 GN=XPO1 Exportin-1 GN=XPO1 Exportin-1 GN=XPO1 Exportin-1 GN=XPO1 Exportin-1 GN=XPO1 Exportin-2 GN=CSE1L Exportin-2 GN=CSE1L

Exportin-2 GN=CSE1L Exportin-2 GN=CSE1L Exportin-2 GN=CSE1L Exportin-2 GN $=\mathrm{CSE} 1 \mathrm{~L}$ Exportin-2 GN=CSE1L Exportin-2 GN=CSE1L Exportin-2 GN=CSE1L XPO1_HUMAN $123.39 \quad 100.0 \%$ XPO1_HUMAN $123.39 \quad 100.0 \%$ XPO1_HUMAN $123.39 \quad 100.0 \%$ XPO1_HUMAN $123.39 \quad 100.0 \%$ XPO1_HUMAN $123.39 \quad 100.0 \%$ XPO1 HUMAN $123.39 \quad 100.0 \%$ XPO1_HUMAN $123.39 \quad 100.0 \%$ XPO1_HUMAN $123.39 \quad 100.0 \%$ XPO1_HUMAN $123.39 \quad 100.0 \%$ XPO1_HUMAN $123.39 \quad 100.0 \%$ XPO1_HUMAN $123.39 \quad 100.0 \%$ XPO1_HUMAN $123.39 \quad 100.0 \%$ XPO1_HUMAN $123.39 \quad 100.0 \%$ XPO1 HUMAN $123.39 \quad 100.0 \%$ XPO2_HUMAN $110.42 \quad 100.0 \%$ XPO2_HUMAN $110.42 \quad 100.0 \%$ XPO2 HUMAN $110.42 \quad 100.0 \%$ XPO2_HUMAN $110.42 \quad 100.0 \%$ XPO2 HUMAN $110.42 \quad 100.0 \%$ XPO2_HUMAN $110.42 \quad 100.0 \%$ XPO2_HUMAN $110.42 \quad 100.0 \%$ XPO2 HUMAN $110.42 \quad 100.0 \%$ XPO2_HUMAN $110.42 \quad 100.0 \%$
$99.7 \% \quad 72.1$

$0.04 \% \quad 15.7 \%$ TGSESSQTGTSTTSSR

$99.7 \% 76.8$

$99.7 \% 33.5$

$99.7 \% \quad 44.0$

$99.7 \% \quad 60.8$

$99.7 \% 57.6$

$0.01 \% \quad 29.4 \%$ GSAYLEAGGTK

$0.01 \% \quad 29.4 \%$ VLCAVSGPR

$99.7 \% \quad 61.4$

$\begin{array}{lll}96.9 \% & 20.3\end{array}$

$99.7 \% \quad 65.9$

$99.0 \% \quad 45.3$

$99.7 \% \quad 46.5$

$99.7 \% \quad 42.7$

$0.01 \% \quad 29.4 \%$ ELALALQEALEPAVR

$0.01 \% \quad 29.4 \%$ LGLEGCQR

$0.01 \% \quad 29.4 \%$ LYPVLQQSLVR

$0.01 \% \quad 21.7 \%$ TVEPLEYYR

$99.7 \% \quad 52.6$

$0.01 \% \quad 21.7 \%$ LGNTTVICGVK

$0.01 \% \quad 21.7 \%$ AEFAAPSTDAPDK

$0.01 \% \quad 21.7 \%$ KLMDEVIK

$0.01 \% \quad 8.3 \%$ AIEEGIPAFTCEEYVK

$0.01 \% \quad 8.3 \%$ SGTYLQGTFR

$0.01 \% \quad 8.3 \%$ AVHEDIVAVELLPK

$0.01 \% \quad 8.3 \%$ RGTTVYLCEK

$0.01 \% \quad 8.3 \%$ GALTLSSPEVR

$0.01 \% \quad 8.3 \%$ NLEIKTDTAK

$0.01 \% \quad 8.3 \%$ YADVIVHR

$0.03 \% \quad 15.7 \%$ PAIMTMLADHAAR

$0.03 \% \quad 15.7 \%$ YYGLQILENVIK

$0.03 \% \quad 15.7 \%$ TSSDPTCVEKEK

$0.03 \% \quad 15.7 \%$ LNMILVQILK

$99.7 \% \quad 44.8$

$99.7 \% \quad 27.6$

$94.8 \% \quad 24.9$

$98.9 \% \quad 22.2$

$\begin{array}{lll}99.7 \% & 33.0\end{array}$

$99.7 \% \quad 53.7$

$99.5 \% \quad 28.0$

$99.7 \% \quad 44.8$

$99.5 \% \quad 23.3$

$99.0 \% \quad 35.0$

$99.5 \% \quad 20.9$

$99.7 \% \quad 41.8$

$99.7 \% \quad 39.2$

$99.4 \% \quad 27.0$

$99.7 \% \quad 66.4$

$99.7 \% \quad 49.1$

$99.7 \% \quad 43.4$

$99.7 \% \quad 61.1$

$99.7 \% \quad 36.8$

$98.4 \% \quad 25.3$

$0.03 \% \quad 15.7 \%$ AVGHPFVIQLGR

$0.03 \% \quad 15.7 \%$ IYLDMLNVYK

$0.03 \% \quad 15.7 \%$ LISGWVSR

$99.4 \% \quad 24.5$

$0.03 \% \quad 15.7 \%$ EPEVLSTMAIIVNK

$0.03 \% \quad 15.7 \%$ SAFPHLQDAQVK

$0.03 \% \quad 15.7 \%$ EFAGEDTSDLFLEER

$0.03 \% \quad 13.2 \%$ TLDPDPAIR

$0.03 \% \quad 13.2 \%$ TLDPDPAIRRPAEK

$0.03 \% \quad 13.2 \%$ ANIVHLMLSSPEQIQK

$0.03 \% \quad 13.2 \%$ NLFEDQNTLTSICEK

$0.03 \% \quad 13.2 \%$ VIVPNMEFR

$0.03 \% \quad 13.2 \%$ DLEGSDIDTRR

$0.03 \% \quad 13.2 \%$ ALTLPGSSENEYIMK

$0.03 \% \quad 13.2 \%$ TGNIPALVR

$0.03 \% \quad 13.2 \%$ LLQAFLER

1622.91

932.46

1315.77

1169.58

1834.98

1161.63

1319.61

975.55

1855.88

1129.56

1532.87

1226.62

1129.62

1132.62

972.53

1429.69

1452.81

1380.63

1200.74

1652.80

2027.03

1370.75

1293.74

1271.67

917.52

2168.17

1543.84

1340.70

1757.79

997.53

1578.86

1807.97

1811.85

1104.59

1276.61

1668.82

940.56

989.58 
Exportin-2 GN=CSE1L Exportin-2 GN=CSE1L Exportin-2 GN=CSE1L Exportin-5 GN=XPO5 Exportin-5 GN=XPO5 Exportin-5 GN=XPO5

Exportin-7 GN=XPO7 Exportin-7 GN=XPO7 F-actin-capping protein subunit alpha-1 GN=CAPZA1 CAZ__H F-actin-capping protein subunit alpha-1 GN=CAPZA1 CAZA1_HUMAN $32.92 \quad 100.0 \%$ F-actin-capping protein subunit alpha-1 GN=CAPZA1 CAZA1_HUMAN $32.92 \quad 100.0 \%$ F-actin-capping protein subunit alpha-1 GN=CAPZA1 CAZA1_HUMAN $32.92 \quad 100.0 \%$ F-actin-capping protein subunit beta GN=CAPZB CAPZB_HUMAN $31.35 \quad 100.0 \%$ F-actin-capping protein subunit beta GN=CAPZB CAPZB_HUMAN $31.35 \quad 100.0 \%$ Fanconi anemia group D2 protein GN=FANCD2 FACD2_HUMAN $164.13 \quad 100.0 \%$ Fanconi anemia group D2 protein GN=FANCD2 FACD2_HUMAN $164.13 \quad 100.0 \%$ Fanconi anemia group D2 protein GN=FANCD2 FACD2_HUMAN $164.13 \quad 100.0 \%$ Fanconi anemia group D2 protein GN=FANCD2 FACD2_HUMAN $164.13 \quad 100.0 \%$ Fanconi anemia group D2 protein GN=FANCD2 FACD2_HUMAN $164.13 \quad 100.0 \%$ Fanconi anemia group D2 protein GN=FANCD2 FACD2_HUMAN $164.13 \quad 100.0 \%$ Fanconi anemia group I protein GN=FANCI FANCI_HUMAN $149.33 \quad 100.0 \%$ Fanconi anemia group I protein GN=FANCI FANCI_HUMAN $149.33 \quad 100.0 \%$ Fanconi anemia group I protein GN=FANCI FANCI_HUMAN $149.33 \quad 100.0 \%$ Fanconi anemia group I protein GN=FANCI FANCI_HUMAN $149.33 \quad 100.0 \%$ Fanconi anemia group I protein GN=FANCI FANCI_HUMAN $149.33 \quad 100.0 \%$ Fanconi anemia group I protein GN=FANCI FANCI_HUMAN $149.33 \quad 100.0 \%$ Fanconi anemia group I protein GN=FANCI FANCI_HUMAN $149.33 \quad 100.0 \%$ Fanconi anemia group I protein GN=FANCI FANCI_HUMAN $149.33 \quad 100.0 \%$ Fanconi anemia group I protein GN=FANCI FANCI_HUMAN $149.33 \quad 100.0 \%$ Far upstream element-binding protein 2 GN=KHSRP FUBP2_HUMAN $73.12 \quad 100.0 \%$ Far upstream element-binding protein 2 GN=KHSRP FUBP2_HUMAN $73.12 \quad 100.0 \%$ Far upstream element-binding protein 2 GN=KHSRP FUBP2_HUMAN $73.12 \quad 100.0 \%$ Far upstream element-binding protein $3 \mathrm{GN}=$ FUBP3 FUBP3_HUMAN $61.64 \quad 100.0 \%$ Far upstream element-binding protein 3 GN=FUBP3 FUBP3_HUMAN $61.64 \quad 100.0 \%$ Far upstream element-binding protein $3 \mathrm{GN}=$ FUBP3 FUBP3_HUMAN $61.64 \quad 100.0 \%$ Far upstream element-binding protein 3 GN=FUBP3 FUBP3_HUMAN $61.64 \quad 100.0 \%$ Far upstream element-binding protein $3 \mathrm{GN}=$ FUBP3 FUBP3_HUMAN $61.64 \quad 100.0 \%$ Far upstream element-binding protein $3 \mathrm{GN}=$ FUBP3 FUBP3_HUMAN $61.64 \quad 100.0 \%$ Far upstream element-binding protein 3 GN=FUBP3 FUBP3_HUMAN $61.64 \quad 100.0 \%$ Far upstream element-binding protein 3 GN=FUBP3 FUBP3_HUMAN $61.64 \quad 100.0 \%$ Far upstream element-binding protein $3 \mathrm{GN}=\mathrm{FUBP} 3$ FUBP3_HUMAN $61.64 \quad 100.0 \%$ Far upstream element-binding protein $3 \mathrm{GN}=\mathrm{FUBP} 3$ FUBP3_HUMAN $61.64 \quad 100.0 \%$ Far upstream element-binding protein $3 \mathrm{GN}=\mathrm{FUBP} 3$ FUBP3_HUMAN $61.64 \quad 100.0 \%$ Far upstream element-binding protein 3 GN=FUBP3 FUBP3_HUMAN $61.64 \quad 100.0 \%$ Farnesyl pyrophosphate synthase GN=FDPS FPPS_HUMAN $48.28 \quad 100.0 \%$ Farnesyl pyrophosphate synthase GN=FDPS FPPS_HUMAN $48.28 \quad 100.0 \%$ Farnesyl pyrophosphate synthase GN=FDPS FPPS_HUMAN $48.28 \quad 100.0 \%$
$0.03 \% \quad 13.2 \%$ KICAVGITK

$0.03 \% \quad 13.2 \%$ EHDPVGQMVNNPK

$0.03 \% \quad 13.2 \%$ IHLAQSLHK

$0.00 \% \quad 3.9 \%$ TDTSQESKAQANCR

$0.00 \% \quad 3.9 \% \quad$ LFSSVTFETVEESKAPR

$0.00 \% \quad 3.9 \% \quad$ LIAGCIGKPLGEQFRK

$0.00 \% \quad 1.8 \%$ TNNPLPLEQR

$0.00 \% \quad 1.8 \%$ SNYQLGELVK

$99.7 \% \quad 40.9$

$99.7 \% \quad 58.1$

$99.7 \% \quad 40.2$

$99.7 \% \quad 60.2$

$96.1 \% \quad 14.6$

$99.7 \% \quad 37.4$

$99.6 \% 24.1$

$95.2 \% \quad 21.0$

$0.01 \% \quad 17.8 \%$ FITHAPPGEFNEVFNDVR

$0.01 \% \quad 17.8 \%$ LLLNNDNLLR

$0.01 \% \quad 17.8 \%$ ESCDSALR

$0.01 \% \quad 17.8 \%$ FTITPPTAQVVGVLK

$0.00 \% \quad 8.7 \%$ SGSGTMNLGGSLTR

$0.00 \% \quad 8.7 \%$ STLNEIYFGK

$0.01 \% \quad 4.5 \% \quad$ SESPSLTQER

$0.01 \% \quad 4.5 \%$ DGGPVTSQESGQK

$0.01 \% \quad 4.5 \% \quad$ LVSPLCLAPYFR

$0.01 \% \quad 4.5 \%$ NIGFSHLQQR

$0.01 \% \quad 4.5 \%$ DASSSTFPTLTR

$0.01 \% \quad 4.5 \%$ TLELLVCR

$0.02 \% \quad 7.9 \%$ GSPCSEEAGTLR

$0.02 \% \quad 7.9 \%$ QLINTLCSGR

$0.02 \% \quad 7.9 \%$ TIETSPSLSR

$0.02 \% \quad 7.9 \% \quad$ YAVNVALQK

$0.02 \% \quad 7.9 \% \quad$ IFQNLCDITR

$0.02 \% \quad 7.9 \%$ YTSIPTSVEESGKK

$0.02 \% \quad 7.9 \%$ SISLLCLEGLQK

$0.02 \% \quad 7.9 \%$ IFSAVQQFYQPK

$0.02 \% \quad 7.9 \% \quad$ TAAPTVCLLVLSQAEK

$\begin{array}{llllll}0.00 \% & 6.3 \% & \text { IGGDAATTVNNSTPDFGFGGQKR } & 99.7 \% & 55.5\end{array}$

$0.00 \% \quad 6.3 \%$ GGETIKQLQER

$0.00 \% \quad 6.3 \% \quad$ IGGGIDVPVPR

$99.7 \% \quad 37.4$

$99.7 \% \quad 65.1$

$99.0 \% \quad 29.4$

$99.7 \% \quad 62.8$

$99.7 \% \quad 67.6$

$99.7 \% \quad 28.7$

$94.5 \% \quad 17.2$

$99.7 \% \quad 42.4$

$98.9 \% \quad 20.0$

$99.7 \% \quad 47.5$

$99.6 \% 24.9$

$98.4 \% \quad 31.2$

$99.7 \% \quad 34.2$

$98.4 \% 18.0$

$99.7 \% \quad 29.4$

$99.7 \% \quad 36.7$

$99.7 \% 37.6$

$99.7 \% \quad 28.8$

$99.7 \% \quad 37.4$

$99.7 \% \quad 57.2$

$0.02 \% \quad 27.3 \%$ IDSIPHLNNSTPLVDPSVYGYGVQK

$0.02 \% \quad 27.3 \%$ RPLDDGVGNQLGALVHQR

$0.02 \% \quad 27.3 \%$ LLGQIVDRCR

$0.02 \% \quad 27.3 \%$ GGETIKQLQER

$0.02 \% \quad 27.3 \%$ ITGDAFKVQQAR

$0.02 \% \quad 27.3 \%$ MGGGSIEVSVPR

$0.02 \% \quad 27.3 \%$ FAVGIVIGR

$0.02 \% \quad 27.3 \%$ IQFKPDDGISPER

$0.02 \% \quad 27.3 \%$ DGFGGLAAAR

$0.02 \% \quad 27.3 \%$ SINQQSGAHVELQR

$0.02 \% \quad 27.3 \%$ NPPPNSDPNLRR

$0.02 \% \quad 27.3 \%$ GVPQQIEVAR

$99.7 \% \quad 56.8$

$99.7 \% \quad 52.1$

$96.9 \% \quad 20.7$

$98.7 \% \quad 17.4$

$99.7 \% \quad 56.8$

$99.7 \% \quad 57.9$

$99.7 \% \quad 58.9$

$99.7 \% \quad 66.8$

$99.7 \% \quad 39.0$

$99.7 \% \quad 49.3$

$99.7 \% \quad 51.3$

$98.9 \% 17.7$

$99.7 \% \quad 41.0$

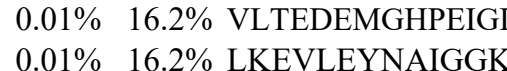

$0.01 \% \quad 16.2 \%$ GLTVVVAFR $\begin{array}{llll}99.7 \% & 41.8\end{array}$

$99.7 \% \quad 53.3$
989.58

1480.69

1046.61

1595.71

1926.98

1787.00

1181.63

1150.61

2089.01

1197.70

937.40

1570.92

1353.64

1171.60

1133.54

1289.60

1435.78

1199.63

1282.63

1003.56

1263.56

1161.60

1090.57

1005.57

1279.65

1525.77

1360.75

1455.76

1700.93

2310.11

1258.68

1079.62

2713.38

1945.04

1229.68

1258.68

1333.72

1204.60

931.57

1501.76

934.47

1566.80

1376.70

1096.61

1968.93

1433.80

961.58 $\begin{array}{cc}40 & 848 \\ 13 & 925 \\ 26 & 934 \\ 09 & 222 \\ 77 & 593 \\ 53 & 1168 \\ 4 & 83 \\ 39 & 348 \\ 0 & 37 \\ 8 & 47 \\ 22 & 129 \\ 79 & 193 \\ 82 & 195 \\ 26 & 235 \\ 90 & 599 \\ 11 & 723 \\ 24 & 735 \\ 98 & 1007 \\ 17 & 1228 \\ 63 & 1370 \\ 3 & 64 \\ 59 & 168 \\ 03 & 412 \\ 41 & 849 \\ 70 & 879 \\ 85 & 898 \\ 03 & 914 \\ 15 & 926 \\ 79 & 1094 \\ 8 & 110 \\ 52 & 262 \\ 21 & 331 \\ 3 & 57 \\ 8 & 75 \\ 40 & 149 \\ 81 & 191 \\ 14 & 225 \\ 51 & 262 \\ 63 & 271 \\ 87 & 299 \\ 28 & 337 \\ 79 & 392 \\ 93 & 404 \\ 99 & 418 \\ 3 & 110 \\ 11 & 123 \\ 27 & 135 \\ & \end{array}$ 
Farnesyl pyrophosphate synthase GN=FDPS FPPS_HUMAN $48.28 \quad 100.0 \%$ Farnesyl pyrophosphate synthase GN=FDPS FPPS_HUMAN $48.28 \quad 100.0 \%$ Farnesyl pyrophosphate synthase GN=FDPS FPPS_HUMAN $48.28 \quad 100.0 \%$ FAST kinase domain-containing protein $3 \mathrm{GN}=$ FASTKD3 FAKD3 HUMAN 75.69 FAST kinase domain-containing protein 3 GN=FASTKD3 FAKD3_HUMAN $75.69 \quad 100.0 \%$ FAST kinase domain-containing protein 3 GN=FASTKD3 FAKD3_HUMAN $75.69 \quad 100.0 \%$ FAST kinase domain-containing protein 5 GN=FASTKD5 FAKD5_HUMAN $86.58 \quad 100.0 \%$ FAST kinase domain-containing protein 5 GN=FASTKD5 FAKD5_HUMAN $86.58 \quad 100.0 \%$ Fatty acid synthase GN=FASN Fatty acid synthase GN=FASN Fatty acid synthase GN=FASN Fatty acid synthase GN=FASN Fatty acid synthase GN=FASI Fatty acid synthase GN=FASN Fatty acid synthase GN=FASN Fatty acid synthase GN=FASI Fatty acid synthase GN=FASN Fatty acid synthase GN=FASN Fatty acid synthase GN=FASN Fatty acid synthase GN=FASN Fatty acid synthase GN=FASN Fatty acid synthase GN=FASN Fatty acid synthase GN=FASN Fatty acid synthase GN=FASN Fatty acid synthase GN=FASN Fatty acid synthase GN=FASN Fatty acid synthase GN=FASN Fatty acid synthase GN=FASN Fatty acid synthase GN=FASN Fatty acid synthase GN=FASN Fatty acid synthase GN=FASN Fatty acid synthase GN=FASN Fatty acid synthase GN=FASN Fatty acid synthase GN=FASN F-box only protein $22 \mathrm{GN}=\mathrm{FBXO} 22$ F-box only protein $22 \mathrm{GN}=\mathrm{FBXO} 22$ F-box only protein $22 \mathrm{GN}=\mathrm{FBXO} 22$ F-box/SPRY domain-containing protein $1 \mathrm{GN}=\mathrm{FBXO45}$ FBSP1_HUMAN $30.63 \quad 100.0 \%$ F-box/SPRY domain-containing protein $1 \mathrm{GN}=$ FBXO45 FBSP1_HUMAN $30.63 \quad 100.0 \%$ Ferrochelatase, mitochondrial GN=FECH HEMH_HUMAN $47.86 \quad 100.0 \%$ Ferrochelatase, mitochondrial GN=FECH HEMH_HUMAN $47.86 \quad 100.0 \%$ Ferrochelatase, mitochondrial GN=FECH HEMH_HUMAN $47.86 \quad 100.0 \%$ Filaggrin $\mathrm{GN}=\mathrm{FLG}$

Filaggrin $\mathrm{GN}=\mathrm{FLC}$

Filaggrin $\mathrm{GN}=\mathrm{FLG}$

Filaggrin $\mathrm{GN}=\mathrm{FLC}$

Filaggrin $\mathrm{GN}=\mathrm{FLC}$

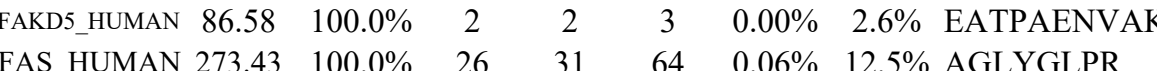

FAS HUMAN $273.43 \quad 100.0 \%$ FAS_HUMAN $273.43 \quad 100.0 \% \quad 26 \quad 31 \quad 64 \quad 0.06 \% \quad 12.5 \%$ LGMLSPEGTCK FAS HUMAN $273.43 \quad 100.0 \% \quad 26 \quad 31 \quad 64 \quad 0.06 \% \quad 12.5 \%$ AFDTAGNGYCR FAS_HUMAN $273.43 \quad 100.0 \% \quad 26 \quad 31 \quad 64 \quad 0.06 \% \quad 12.5 \%$ SEGVVAVLLTK FAS HUMAN $273.43 \quad 100.0 \% \quad 26 \quad 31 \quad 64 \quad 0.06 \% \quad 12.5 \%$ SEGVVAVLLTKK FAS HUMAN $273.43 \quad 100.0 \% \quad 26$ FAS_HUMAN $273.43 \quad 100.0 \% \quad 26$ FAS HUMAN $273.43 \quad 100.0 \% \quad 26$ FAS_HUMAN $273.43 \quad 100.0 \% \quad 26$ FAS_HUMAN $273.43 \quad 100.0 \% \quad 26$ FAS HUMAN $273.43 \quad 100.0 \% \quad 26$ FAS_HUMAN $273.43 \quad 100.0 \% \quad 26$ FAS HUMAN $273.43 \quad 100.0 \% \quad 26$ FAS_HUMAN $273.43 \quad 100.0 \% \quad 26$ FAS HUMAN $273.43 \quad 100.0 \% \quad 26$ FAS HUMAN $273.43 \quad 100.0 \% \quad 26$ FAS_HUMAN $273.43 \quad 100.0 \% \quad 26$ FAS_HUMAN $273.43 \quad 100.0 \% \quad 26$ FAS HUMAN $273.43 \quad 100.0 \% \quad 26$ FAS_HUMAN $273.43 \quad 100.0 \% \quad 26$ FAS HUMAN $273.43 \quad 100.0 \% \quad 26$ FAS HUMAN $273.43 \quad 100.0 \% \quad 26$ FAS_HUMAN $273.43 \quad 100.0 \% \quad 26$ FAS HUMAN $273.43 \quad 100.0 \% \quad 26$ FAS_HUMAN $273.43 \quad 100.0 \% \quad 26$ FBX22 HUMAN $44.51 \quad 100.0 \%$ FBX22 HUMAN $44.51 \quad 100.0 \%$ FBX22_HUMAN $44.51 \quad 100.0 \%$ FILA HUMAN $435.15 \quad 100.0 \%$ FILA HUMAN $435.15 \quad 100.0 \%$ FILA_HUMAN $435.15 \quad 100.0 \%$ FILA_HUMAN $435.15 \quad 100.0 \%$ FILA_HUMAN $435.15 \quad 100.0 \%$

$0.06 \% \quad 12.5 \%$ LQVVDQPLPVR

$0.06 \% \quad 12.5 \%$ VYQWDDPDPR

$0.06 \% \quad 12.5 \%$ HGLYLPTR

$0.06 \% \quad 12.5 \%$ RQQEQQVPILEK

$0.06 \% \quad 12.5 \%$ AALQEELQLCK

$0.06 \% \quad 12.5 \%$ GLVQALQTK

$0.06 \% 12.5 \%$ SFYGSTLFLCR

$0.06 \% \quad 12.5 \%$ FPQLDSTSFANSR

$0.06 \% \quad 12.5 \%$ LSIPTYGLQCTR

$0.06 \% \quad 12.5 \%$ VAAAVDLIIK

$0.01 \% \quad 8.2 \%$ VVAEELENVR

$0.01 \% \quad 8.2 \% \quad$ IVTGNFILR

$0.00 \% \quad 7.3 \%$ NPIAQSTDGAR

$0.00 \% \quad 7.3 \%$ GYEFLGVAFR

$0.00 \% \quad 9.2 \%$ AESLNGNPLFSK

$0.01 \% \quad 1.0 \%$ LAQAYYESTR

$0.01 \% \quad 1.0 \%$ LAQAYYESTRK

$0.01 \% \quad 1.0 \%$ ENLPISGHK

$0.01 \% \quad 1.0 \% \quad$ KRPSSLER

$0.01 \% \quad 1.0 \%$ HSASQEGQDTIR

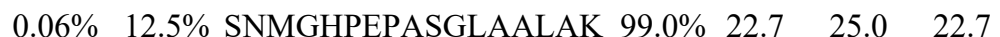

$99.7 \% \quad 40.0$

$99.7 \% 56.2$

25.0

$0.06 \% 12.5 \%$ AFEVSENGNLVVSGK

$99.7 \% \quad 27.3$

$\begin{array}{lll}99.0 \% & 26.1\end{array}$

$0.06 \% \quad 12.5 \%$ VTVAGGVHISGLHTESAPR $99.1 \% 21.7$

$0.06 \% \quad 12.5 \%$ ACLDTAVENMPSLK

$0.06 \% \quad 12.5 \%$ VLQGDLVMNVYR

$97.1 \% 21.2$

$99.7 \% \quad 45.5$

$99.7 \% \quad 39.6$

$99.7 \% \quad 56.0$

$99.7 \% \quad 48.3$

$99.7 \% \quad 43.9$

$99.7 \% \quad 56.8$

$0.06 \% 12.5 \%$ VVVQVLAEEPEAVLK

$99.7 \% \quad 58.6$

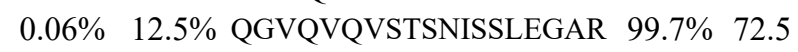

$0.06 \% \quad 12.5 \%$ GNAGQSNYGFANSAMER $99.7 \% \quad 58.8$

$0.06 \% \quad 12.5 \%$ EDGLAQQQTQLNLR

$0.06 \% \quad 12.5 \%$ SLLVNPEGPTLMR

$0.01 \% \quad 8.2 \%$ STFVLSNLAEVVER

$0.00 \% \quad 9.2 \% \quad$ LLDELSPNTAPHK

$0.00 \% \quad 9.2 \%$ GDPYPQEVSATVQK
$99.7 \% \quad 68.2$

$99.7 \% \quad 47.5$

$99.7 \% \quad 30.6$

$99.7 \% \quad 26.7$

$99.7 \% \quad 58.4$

$99.7 \% \quad 54.8$

$99.6 \% \quad 24.8$

$99.7 \% \quad 44.9$

$99.7 \% \quad 36.7$

$\begin{array}{lll}99.7 \% & 43.8\end{array}$

$\begin{array}{lll}99.7 \% & 40.5\end{array}$

$99.7 \% \quad 25.9$

$99.7 \% \quad 51.3$

$99.7 \% \quad 34.8$

$\begin{array}{lll}99.5 \% & 39.2\end{array}$

$97.9 \% 28.3$

$97.5 \% 16.4$
060.54

1003.51

1190.64

957.50

1027.63

1049.56

1029.57

1029.52

846.48

1251.62

1192.57

1231.52

1115.67

1243.76

1666.82

1263.74

1549.79

1290.58

956.53

1888.00

1495.82

1302.67

957.57

1548.74

1350.65

1406.75

1469.70

1622.94

1960.01

1789.76

1613.82

1442.77

1408.73

1012.64

1563.84

1157.62

1032.62

1129.56

1158.59

1434.76

1518.74

1276.65

1201.58

1329.68

994.53

972.56

1328.62

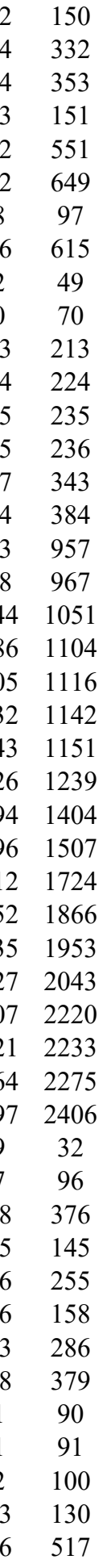

Page 69 of Table S-1-4 
Filaggrin-2 GN=FLG2 Filaggrin-2 GN=FLG2 Filaggrin-2 GN=FLG2 Filamin-A GN=FLNA Filamin-A GN=FLNA Filamin-A GN=FLNA

Filamin-A GN=FLNA Filamin-A GN=FLNA Filamin-A GN=FLNA Filamin-A GN=FLNA Filamin-A GN=FLNA Filamin-A GN=FLNA Filamin-A GN=FLNA Filamin-A GN=FLNA

Filamin-A GN=FLNA Filamin-A GN=FLNA Filamin-A GN=FLNA

Flap endonuclease $1 \mathrm{GN}=\mathrm{FEN} 1$ Flap endonuclease $1 \mathrm{GN}=\mathrm{FEN} 1$

Flap endonuclease $1 \mathrm{GN}=\mathrm{FEN} 1$ Flap endonuclease $1 \mathrm{GN}=\mathrm{FEN} 1$ Flotillin-2 GN=FLOT2

Flotillin-2 GN=FLOT2 Four and a half LIM domains protein $1 \mathrm{GN}=$ FHL1 FHL1_HUMAN $36.26 \quad 100.0 \%$ retardation protein $1 \mathrm{GN}=$ FMR1 FMR1_HUMAN $71.17 \quad 100.0 \%$ Fragile X mental retardation protein 1 GN=FMR1 FMR1_HUMAN $71.17 \quad 100.0 \%$ Fragile X mental retardation protein $1 \mathrm{GN}=\mathrm{FMR} 1$ FMR1_HUMAN $71.17 \quad 100.0 \%$ Fragile X mental retardation protein 1 GN=FMR1 FMR1_HUMAN $71.17 \quad 100.0 \%$

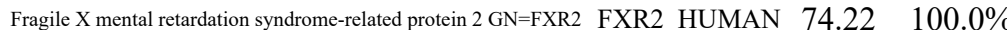
Fragile X mental retardation syndrome-related protein 2 GN=FXR2 $\quad$ FXR2_HUMAN $74.22 \quad 100.0 \%$ Fragile X mental retardation syndrome-related protein 2 GN=FXR2 FXR2_HUMAN $74.22 \quad 100.0 \%$ Fragile X mental retardation syndrome-related protein 2 GN=FXR2 FXR2_HUMAN $74.22 \quad 100.0 \%$ Fructose-bisphosphate aldolase A GN=ALDOA ALDOA_HUMAN $39.42 \quad 100.0 \%$ Fructose-bisphosphate aldolase A GN=ALDOA ALDOA_HUMAN $39.42 \quad 100.0 \%$ Fructose-bisphosphate aldolase A GN=ALDOA ALDOA_HUMAN $39.42 \quad 100.0 \%$ Fructose-bisphosphate aldolase A GN=ALDOA ALDOA_HUMAN $39.42 \quad 100.0 \%$ Fructose-bisphosphate aldolase A GN=ALDOA ALDOA HUMAN $39.42 \quad 100.0 \%$ Fructose-bisphosphate aldolase A GN=ALDOA ALDOA_HUMAN $39.42 \quad 100.0 \%$ Fructose-bisphosphate aldolase A GN=ALDOA ALDOA_HUMAN $39.42 \quad 100.0 \%$ Fructose-bisphosphate aldolase A GN=ALDOA ALDOA_HUMAN $39.42 \quad 100.0 \%$ Galactokinase $\mathrm{GN}=\mathrm{GALK} 1$ Galactokinase GN=GALK1 Galactokinase $\mathrm{GN}=\mathrm{GALK} 1$ Galactokinase $\mathrm{GN}=\mathrm{GALK} 1$ Galactokinase GN=GALK1 Galactokinase $\mathrm{GN}=\mathrm{GALK} 1$ GALK1_HUMAN $42.27 \quad 100.0 \%$ GALK1_HUMAN $42.27 \quad 100.0 \%$ GALK1_HUMAN $42.27 \quad 100.0 \%$ GALK1_HUMAN $42.27 \quad 100.0 \%$ GALK1_HUMAN $42.27 \quad 100.0 \%$ GALK1_HUMAN $42.27 \quad 100.0 \%$ $\begin{array}{llll}0.01 \% & 2.0 \% & \text { SVVTVIDVFYK }\end{array}$

$0.01 \% \quad 2.0 \%$ FSNSSSSNEFSK

$\begin{array}{llllllll}99.7 \% & 57.0 & 25.0 & 51.8 & 8 & 0 & 0 & 1269.71\end{array}$

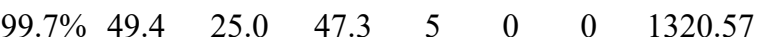

$\begin{array}{lllll}0.01 \% & 2.0 \% & \text { SGQSSYGQHSSGSSQSSGYGQHGSR } & 99.7 \% & 41.9\end{array}$

$\begin{array}{lllllllll} & & & \end{array}$

$0.03 \% \quad 7.5 \% \quad$ SPYTVTVGQACNPSACR $99.7 \% \quad 36.0$

$0.03 \% \quad 7.5 \%$ AWGPGLEGGVVGK

$97.5 \% \quad 18.5$

$\begin{array}{llll}0.03 \% & 7.5 \% & \text { TGVAVNKPAEFTVDAK } \quad 99.7 \% \quad 29.3\end{array}$

$0.03 \% \quad 7.5 \%$ SPFSVAVSPSLDLSK

$99.7 \% \quad 48.4$

$\begin{array}{lllll}0.03 \% & 7.5 \% & \text { IVGPSGAAVPCKVEPGLGADNSVVR } & 99.6 \% & 24.0\end{array}$

$0.03 \% \quad 7.5 \%$ AFGPGLQGGSAGSPAR

$0.03 \% \quad 7.5 \%$ CSGPGLER

$0.03 \% \quad 7.5 \%$ EATTEFSVDAR

$99.7 \% \quad 55.9$

$95.0 \% \quad 22.5$

$94.7 \% \quad 14.5$

$0.03 \% \quad 7.5 \%$ ALTQTGGPHVK

$99.5 \% \quad 24.1$

$0.03 \% \quad 7.5 \%$ GAGTGGLGLAVEGPSEAK $99.7 \% \quad 47.5$

$0.03 \% \quad 7.5 \%$ ANLPQSFQVDTSK

$0.03 \% \quad 7.5 \%$ AGVAPLQVK

$0.03 \% \quad 7.5 \%$ TPCEEILVK

$0.01 \% \quad 14.2 \%$ LIADVAPSAIRENDIK

$99.7 \% \quad 43.6$

$99.4 \% \quad 22.4$

$\begin{array}{lll}99.7 \% & 30.9\end{array}$

$99.2 \% \quad 21.8$

$0.01 \% \quad 14.2 \%$ QLQQAQAAGAEQEVEKFTK

$0.01 \% \quad 14.2 \%$ KLPIQEFHLSR

$0.01 \% \quad 14.2 \%$ RAVDLIQK

$0.00 \% \quad 5.4 \%$ EVAAPDVGR

$0.00 \% \quad 5.4 \%$ MALVLEALPQIAAK

$0.00 \% \quad 7.1 \%$ AIVAGDQNVEYK

$0.00 \% \quad 7.1 \%$ QVIGTGSFFPK

$0.01 \% \quad 7.0 \% \quad$ SVNPNKPATK

$0.01 \% \quad 7.0 \%$ SFLEFAEDVIQVPR

$0.01 \% \quad 7.0 \%$ VGPNAPEEK

$0.01 \% \quad 7.0 \%$ TLQNTSSEGSR

$0.01 \% \quad 7.9 \%$ LRPVNPNPLATK

$0.01 \% \quad 7.9 \%$ VIQEIVDKSGVVR

$0.01 \% \quad 7.9 \%$ AGYSTDESSSSSLHATR

$0.01 \% \quad 7.9 \%$ GPPPAPRPTSR

$0.02 \% \quad 30.2 \%$ ELSDIAHR

$0.02 \% \quad 30.2 \%$ GILAADESTGSIAK

$0.02 \% \quad 30.2 \%$ LQSIGTENTEENRR

$0.02 \% \quad 30.2 \%$ ADDGRPFPQVIK

$99.7 \% \quad 34.3$

$99.7 \% \quad 30.0$

$99.0 \% \quad 34.8$

$98.2 \% \quad 16.5$

$99.7 \% \quad 46.8$

$99.7 \% \quad 56.0$

$99.7 \% \quad 26.9$

$99.7 \% \quad 30.6$

$99.7 \% \quad 34.8$

$95.4 \% 20.6$

$99.7 \% \quad 32.6$

$99.7 \% \quad 42.9$

$99.7 \% \quad 42.7$

$99.7 \% \quad 57.7$

$99.6 \% \quad 24.3$

$99.0 \% \quad 33.1$

$99.7 \% \quad 68.2$

$99.6 \% \quad 24.7$

$99.2 \% \quad 23.8$

$\begin{array}{llllll}0.02 \% & 30.2 \% & \end{array}$

$0.02 \% \quad 30.2 \%$ AAQEEYVKR

$99.7 \% \quad 84.1$

$99.7 \% \quad 52.6$

$0.02 \% \quad 30.2 \%$ ALANSLACQGK

$\begin{array}{ll}99.7 \% & 70.0 \\ 99.7 \% & 33.8\end{array}$

$0.02 \% \quad 37.2 \%$ QPQVAELLAEAR

$99.7 \% 51.8$

$\begin{array}{lllll}0.02 \% & 37.2 \% & \text { AFREEFGAEPELAVSAPGR } & 99.7 \% & 51.8 \\ 0.02 \% & 37.2 \% & \text { KDGLVSLLTTSEGADEPQR } & 99.7 \% & 45.9\end{array}$

$\begin{array}{lll}0.02 \% & 37.2 \% & \text { KDGLVSLLTTSEG } \\ 0.02 \% & 37.2 \% & \text { LQFPLPTAQR }\end{array}$

$0.02 \% \quad 37.2 \%$ GHALLIDCR

$98.7 \% \quad 24.8$

$99.7 \% \quad 50.2$

$0.02 \% \quad 37.2 \%$ SLETSLVPLSDPK
$99.7 \% \quad 49.4$
404

613

$384 \quad 400$

1867.84

1226.65

1646.87

1533.82

2449.29

1429.72

875.40

1225.57

1108.61

1570.81

1434.72

882.54

1088.57

1724.95

2104.07

1367.78

942.57

913.47

1483.86

1306.66

1180.64

1055.58

1649.85

940.47

1179.56

1319.78

1441.84

1755.78

1132.62

940.48

1332.70

1646.81

1342.71

2107.10

1093.56

1132.58

2228.03

1324.72

2033.01

2016.02

1170.66

1054.55

1385.75
468484

$581 \quad 593$

$685 \quad 700$

$1008 \quad 1032$

$1072 \quad 1087$

11651172

$382 \quad 1399$

$1465 \quad 1477$

$1478 \quad 1486$

$2599 \quad 2607$

$9 \quad 24$

$10 \quad 128$

$201 \quad 211$

$136 \quad 144$

$357 \quad 370$

$107 \quad 118$

$134 \quad 144$

$114 \quad 123$

$277 \quad 290$

$345 \quad 353$

$594 \quad 604$

$122 \quad 133$

$313 \quad 325$

$407 \quad 423$

$491 \quad 501$

$15 \quad 22$

$29 \quad 42$

$88 \quad 99$

$154 \quad 173$

$323 \quad 331$

$332 \quad 342$

$6 \quad 17$

$19 \quad 37$

$69 \quad 87$

$96 \quad 204$

204
-205 
Galactokinase $\mathrm{GN}=\mathrm{GALK} 1$ Galactokinase GN=GALK1 Galactokinase GN=GALK1 Galactokinase $\mathrm{GN}=\mathrm{GALK} 1$ Galactokinase GN=GALK1 Gamma-glutamylcyclotransferase GN=GGCT GGCT_HUMAN $21.01 \quad 100.0 \%$ Gamma-glutamylcyclotransferase GN=GGCT GGCT_HUMAN $21.01 \quad 100.0 \%$ Gamma-glutamylcyclotransferase GN=GGCT GGCT_HUMAN $21.01 \quad 100.0 \%$ GDP-mannose 4,6 dehydratase GN=GMDS GMDS HUMAN $41.95 \quad 100.0 \%$ GDP-mannose 4,6 dehydratase GN=GMDS GMDS_HUMAN $41.95 \quad 100.0 \%$ GDP-mannose 4,6 dehydratase GN=GMDS GMDS_HUMAN $41.95 \quad 100.0 \%$ GDP-mannose 4,6 dehydratase GN=GMDS GMDS HUMAN $41.95 \quad 100.0 \%$ GDP-mannose 4,6 dehydratase GN=GMDS GMDS_HUMAN $41.95 \quad 100.0 \%$ GDP-mannose 4,6 dehydratase GN=GMDS GMDS_HUMAN $41.95 \quad 100.0 \%$ GDP-mannose 4,6 dehydratase GN=GMDS GMDS_HUMAN $41.95 \quad 100.0 \%$ GDP-mannose 4,6 dehydratase GN=GMDS GMDS_HUMAN $41.95 \quad 100.0 \%$ GDP-mannose 4,6 dehydratase GN=GMDS GMDS_HUMAN $41.95 \quad 100.0 \%$ GDP-mannose 4,6 dehydratase GN=GMDS GMDS_HUMAN $41.95 \quad 100.0 \%$ Gem-associated protein $4 \mathrm{GN}=$ GEMIN4 GEMI4_HUMAN $120.04 \quad 100.0 \%$ Gem-associated protein $4 \mathrm{GN}=$ GEMIN4 4 GEMI4_HUMAN $120.04 \quad 100.0 \%$ Gem-associated protein $4 \mathrm{GN}=$ GEMIN4 GEMI4_HUMAN $120.04 \quad 100.0 \%$ General transcription factor 3C polypeptide $1 \mathrm{GN}=\mathrm{GTF} 3 \mathrm{C} 1 \mathrm{TF} 3 \mathrm{C} 1$ HUMAN $238.88 \quad 100.0 \%$ General transcription factor 3C polypeptide 1 GN=GTF3C1 TF3C1_HUMAN $238.88 \quad 100.0 \%$ General transcription factor 3C polypeptide $1 \mathrm{GN}=\mathrm{GTF} 3 \mathrm{C} 1 \quad \mathrm{TF} 3 \mathrm{C} 1 \_$HUMAN $238.88 \quad 100.0 \%$ General transcription factor $3 \mathrm{C}$ polypeptide $1 \mathrm{GN}=\mathrm{GTF} 3 \mathrm{C} 1 \quad \mathrm{TF} 3 \mathrm{C} 1 \_$HUMAN $238.88 \quad 100.0 \%$ General transcription factor $3 \mathrm{C}$ polypeptide $1 \mathrm{GN}=\mathrm{GTF} 3 \mathrm{C} 1 \quad \mathrm{TF} 3 \mathrm{C} 1$ _HUMAN $238.88 \quad 100.0 \%$ General transcription factor $3 \mathrm{C}$ polypeptide $1 \mathrm{GN}=\mathrm{GTF} 3 \mathrm{C} 1 \quad \mathrm{TF} 3 \mathrm{C} 1$ _HUMAN $238.88 \quad 100.0 \%$ General transcription factor 3C polypeptide $1 \mathrm{GN}=\mathrm{GTF} 3 \mathrm{C} 1 \quad \mathrm{TF} 3 \mathrm{C} 1$ HUMAN $238.88 \quad 100.0 \%$ General transcription factor 3C polypeptide $1 \mathrm{GN}=\mathrm{GTF} 3 \mathrm{C} 1 \quad \mathrm{TF} 3 \mathrm{C} 1 \_$HUMAN $238.88 \quad 100.0 \%$ General transcription factor $3 \mathrm{C}$ polypeptide $1 \mathrm{GN}=\mathrm{GTF} 3 \mathrm{C} 1 \quad \mathrm{TF} 3 \mathrm{C} 1$ HUMAN $238.88 \quad 100.0 \%$ General transcription factor 3C polypeptide $1 \mathrm{GN}=\mathrm{GTF} 3 \mathrm{C} 1 \quad \mathrm{TF} 3 \mathrm{C} 1 \_$HUMAN $238.88 \quad 100.0 \% \quad 21$ General transcription factor 3C polypeptide $1 \mathrm{GN}=\mathrm{GTF} 3 \mathrm{C} 1 \quad$ TF3C1_HUMAN $238.88 \quad 100.0 \% \quad 2$ General transcription factor 3C polypeptide $1 \mathrm{GN}=\mathrm{GTF} 3 \mathrm{C} 1 \quad \mathrm{TF} 3 \mathrm{C} 1 \_$HUMAN $238.88 \quad 100.0 \% \quad 21$ General transcription factor 3C polypeptide 1 GN=GTF3C1 $\quad$ TF3C1_HUMAN $238.88 \quad 100.0 \% \quad 21$ General transcription factor 3C polypeptide 1 GN=GTF3C1 TF3C1_HUMAN $238.88 \quad 100.0 \%$ General transcription factor 3C polypeptide $1 \mathrm{GN}=\mathrm{GTF} 3 \mathrm{C} 1 \quad \mathrm{TF} 3 \mathrm{C} 1 \_$HUMAN $238.88 \quad 100.0 \% \quad 21$ General transcription factor $3 \mathrm{C}$ polypeptide $1 \mathrm{GN}=\mathrm{GTF} 3 \mathrm{C} 1 \quad \mathrm{TF} 3 \mathrm{C} 1$ _HUMAN $238.88 \quad 100.0 \%$ General transcription factor $3 \mathrm{C}$ polypeptide $1 \mathrm{GN}=\mathrm{GTF} 3 \mathrm{C} 1 \quad \mathrm{TF} 3 \mathrm{C} 1$ HUMAN $238.88 \quad 100.0 \%$ General transcription factor 3C polypeptide $1 \mathrm{GN}=\mathrm{GTF} 3 \mathrm{C} 1 \quad \mathrm{TF} 3 \mathrm{C} 1 \_$HUMAN $238.88 \quad 100.0 \% \quad 21$ General transcription factor $3 \mathrm{C}$ polypeptide $1 \mathrm{GN}=\mathrm{GTF} 3 \mathrm{C} 1 \quad \mathrm{TF} 3 \mathrm{C} 1$ _HUMAN $238.88 \quad 100.0 \% \quad 2$ General transcription factor 3C polypeptide $1 \mathrm{GN}=\mathrm{GTF} 3 \mathrm{C} 1 \quad \mathrm{TF} 3 \mathrm{C} 1 \_$HUMAN $238.88 \quad 100.0 \% \quad 2$ General transcription factor 3C polypeptide $1 \mathrm{GN}=\mathrm{GTF} 3 \mathrm{C} 1 \quad$ TF3C1_HUMAN $238.88 \quad 100.0 \%$ General transcription factor 3C polypeptide $5 \mathrm{GN}=\mathrm{GTF} 3 \mathrm{C} 5$ TF3C5_HUMAN $59.57 \quad 100.0 \%$ General transcription factor $3 \mathrm{C}$ polypeptide $5 \mathrm{GN}=\mathrm{GTF} 3 \mathrm{C} 5 \quad$ TF3C5_HUMAN $59.57 \quad 100.0 \%$ General transcription factor $3 \mathrm{C}$ polypeptide $5 \mathrm{GN}=\mathrm{GTF} 3 \mathrm{C} 5$ TF3C5_HUMAN $59.57 \quad 100.0 \%$ General transcription factor $3 \mathrm{C}$ polypeptide $5 \mathrm{GN}=\mathrm{GTF} 3 \mathrm{C} 5$ TF3 5 HUMAN $59.57 \quad 100.0 \%$ General transcription factor 3C polypeptide 5 GN=GTF3C5 TF3C5_HUMAN $59.57 \quad 100.0 \%$ $0.02 \% \quad 37.2 \%$ HSLASSE) $0.02 \% \quad 37.2 \%$ EVQLEELEAAR $99.7 \% \quad 51.4 \quad 25.0 \quad 51.4$ $99.7 \% \quad 49.3 \quad 25.0 \quad 42.4 \quad 2$ $99.7 \% \quad 66.2 \quad 25.0 \quad 59.9 \quad 2$ $\begin{array}{llll}99.7 \% & 47.7 & 25.0 & 36.0\end{array}$ $0.02 \% \quad 37.2 \%$ TAQAAAALR $\begin{array}{llll}99.7 \% & 63.7 & 25.0 & 63.7\end{array}$ $0.02 \% \quad 37.2 \%$ HIQEHYGGTATFYLSQAADGAK $0.00 \% \quad 20.7 \%$ LQDFKLDFGNSQGK $\begin{array}{llll}99.7 \% & 38.3\end{array}$ $99.7 \% \quad 32.2$ $99.7 \% \quad 51.9$ $99.7 \% \quad 43.0$ $99.7 \% 27.3$ $0.00 \% \quad 20.7 \%$ VATQEGKEITCR $0.02 \% \quad 36.0 \%$ GYEVHGIVR $0.02 \% \quad 36.0 \%$ NPQAHIEGNMK $\begin{array}{lll}98.9 \% & 25.3\end{array}$ $0.02 \% \quad 36.0 \%$ IINEVKPTEIYNLGAQSHVK $\quad 99.7 \% \quad 38.5$

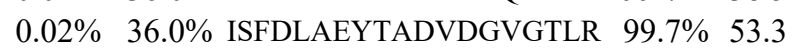
$0.02 \% \quad 36.0 \%$ FYQASTSELYGK $99.7 \% \quad 61.6$

$0.02 \% \quad 36.0 \%$ IYLGQLECFSLGNLDAK $\quad 99.7 \% \quad 65.7$ $\begin{array}{lll}0.02 \% & 36.0 \% \text { VHVTVDLK }\end{array}$ $0.02 \% \quad 36.0 \%$ YYRPTEVDFLQGDCTK $0.02 \% \quad 36.0 \%$ VAFDELVR $0.00 \% \quad 3.0 \%$ GLTQIQSR

$0.00 \% \quad 3.0 \% \quad$ LLETVIDVSTADR $0.00 \% \quad 3.0 \%$ SIAEGIGPEER $0.04 \% \quad 11.0 \%$ LIIVASQAMR

$40 \quad 0.04 \% \quad 11.0 \%$ SRWQGELQR $40 \quad 0.04 \% \quad 11.0 \%$ LREELGLCER $40 \quad 0.04 \% \quad 11.0 \%$ LYQYMLNAGLAK $40 \quad 0.04 \% \quad 11.0 \%$ LQEIHPECGPCK $40 \quad 0.04 \% \quad 11.0 \%$ GISQAEIR

$40 \quad 0.04 \% \quad 11.0 \%$ YISCVFAEESDLSR $40 \quad 0.04 \% \quad 11.0 \%$ QPPSFPGAAEER $40 \quad 0.04 \% \quad 11.0 \%$ NLIIEAVTNLR

$40 \quad 0.04 \% \quad 11.0 \%$ NLSEEGLLR

$40 \quad 0.04 \% \quad 11.0 \%$ TTVIQDGIK

$40 \quad 0.04 \% \quad 11.0 \%$ TTVIQDGIKK

$40 \quad 0.04 \% \quad 11.0 \%$ NYHPIVVPGLGR

$0.04 \% \quad 11.0 \%$ NAVIVDTTICDPHYNLAR

$40 \quad 0.04 \% \quad 11.0 \%$ ENTAAENGLTVR

$40 \quad 0.04 \% \quad 11.0 \%$ YHDEADQSALQR

$40 \quad 0.04 \% \quad 11.0 \%$ IASNVLNTK

$40 \quad 0.04 \% \quad 11.0 \%$ NPQAYLNYK

$40 \quad 0.04 \% \quad 11.0 \%$ NLNPNDSIVVNSCQMK

$40 \quad 0.04 \% \quad 11.0 \%$ GFTESFGAANISQAAR

$40 \quad 0.04 \% \quad 11.0 \%$ VVDGHLNLPVCK

$6 \quad 0.02 \% \quad 22.4 \%$ MLPTLGGEEGVSR

$0.02 \% \quad 22.4 \%$ FSTSSLLLR

$16 \quad 0.02 \% \quad 22.4 \%$ EGYNNPPISGENLIGLSR

$\begin{array}{llll}10 & 16 & 0.02 \% & 22.4 \% \\ 10 & \text { RVCTNPVDR }\end{array}$

$\begin{array}{llll}10 & 16 & 0.02 \% & 22.4 \% \\ & & \text { IYQVLDFRIR }\end{array}$ $\begin{array}{lll}25.0 & 61.7\end{array}$

$\begin{array}{llll}99.7 \% & 40.6 & 25.0 & 40.6\end{array}$

$\begin{array}{llll}99.0 \% & 39.7 & 25.0 & 32.6\end{array}$

$\begin{array}{llll}99.0 \% & 32.5 & 25.0 & 22.9\end{array}$

$99.7 \% \quad 57.6 \quad 25.0 \quad 57.6$

$\begin{array}{llll}97.9 \% & 24.4 & 25.0 & 11.2\end{array}$

$99.7 \% \quad 36.2 \quad 25.0 \quad 36.2$

$\begin{array}{llll}99.5 \% & 29.8 & 25.0 & 14.1\end{array}$

$\begin{array}{llll}99.7 \% & 28.2 & 25.0 & 28.2\end{array}$

$99.7 \% \quad 56.8 \quad 25.0 \quad 56.8$

$\begin{array}{llll}99.7 \% & 32.7 & 25.0 & 30.0\end{array}$

$99.0 \% \quad 35.0 \quad 25.0 \quad 24.1$

$99.7 \% \quad 76.4 \quad 25.0 \quad 69.3$

$99.3 \% \quad 23.1 \quad 25.0 \quad 22.6$

$\begin{array}{llll}99.7 \% & 38.8 & 25.0 & 38.8\end{array}$

$\begin{array}{llll}99.7 \% & 46.0 & 25.0 & 34.7\end{array}$

$96.0 \% \quad 15.3 \quad 25.0 \quad 14.2$

$99.4 \% \quad 25.8 \quad 25.0 \quad 15.3$

$99.5 \% \quad 21.6 \quad 25.0 \quad 21.6$

$\begin{array}{llll}99.7 \% & 36.5 & 25.0 & 36.2\end{array}$

$\begin{array}{lllll}99.7 \% & 31.8 & 25.0 & 31.8\end{array}$

$\begin{array}{llll}99.7 \% & 44.5 & 25.0 & 44.5\end{array}$

$99.7 \% \quad 36.2 \quad 25.0 \quad 35.1$

$99.7 \% \quad 25.4 \quad 25.0 \quad 25.4$

$\begin{array}{llll}99.7 \% & 47.4 & 25.0 & 47.4\end{array}$

$\begin{array}{llll}99.7 \% & 48.3 & 25.0 & 43.9\end{array}$

$\begin{array}{llll}99.5 \% & 22.5 & 25.0 & 22.5\end{array}$

$\begin{array}{llll}99.7 \% & 67.4 & 25.0 & 62.6\end{array}$

$\begin{array}{llll}99.7 \% & 45.2 & 25.0 & 38.7\end{array}$

$\begin{array}{llll}99.7 \% & 49.4 & 25.0 & 49.4\end{array}$

$\begin{array}{llll}97.3 \% & 19.6 & 25.0 & 13.6\end{array}$

$99.0 \% \quad 18.4 \quad 25.0 \quad 18.4$ $\begin{array}{llll}99.0 \% & 34.8 & 25.0 & 21.1\end{array}$

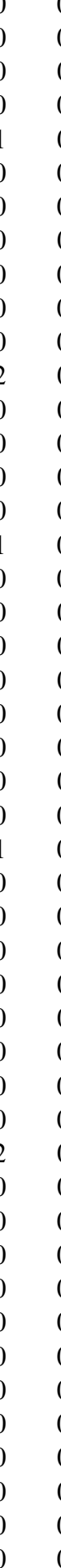

286.66

2365.12

1596.80

1432.69

1391.69

1029.55

1254.59

1621.79

2253.22

2042.01

1393.66

1940.98

910.54

1991.92

948.51

902.51

1431.77

1157.58

1101.64

1159.60

1274.65

1384.73

1467.67

873.48

1675.76

1285.62

1255.74

1030.55

974.55

1102.65

1321.74

2072.02

1274.63

1432.65

959.55

1110.56

1832.86

1626.79

1350.72

1345.68

1023.58

1929.97

1116.56

1116.56
1322.76

$\begin{array}{cc}18 & 228 \\ 29 & 239 \\ 57 & 267 \\ 88 & 296 \\ 67 & 388 \\ 6 & 59 \\ 9 & 101 \\ 12 & 123 \\ 7 & 55 \\ 1 & 81 \\ 2 & 95 \\ 6 & 115 \\ 16 & 134 \\ 50 & 161 \\ 30 & 246 \\ 15 & 322 \\ 23 & 338 \\ 49 & 356 \\ 22 & 229 \\ 57 & 469 \\ 37 & 1047 \\ 49 & 158 \\ 77 & 195 \\ 79 & 288 \\ 93 & 304 \\ 10 & 321 \\ 83 & 390 \\ 28 & 441 \\ 31 & 542 \\ 19 & 629 \\ 65 & 673 \\ 77 & 685 \\ 77 & 686 \\ 78 & 789 \\ 99 & 1016 \\ 44 & 1155 \\ 46 & 1257 \\ 78 & 1286 \\ 26 & 1334 \\ 61 & 1676 \\ 58 & 1973 \\ 89 & 2000 \\ 9 & 51 \\ 9 & 87 \\ 92 & 209 \\ 40 & 248 \\ 15 & 324 \\ & \end{array}$


General transcription factor 3C polypeptide $5 \mathrm{GN}=\mathrm{GTF} 3 \mathrm{C} 5 \quad$ TF3C5_HUMAN $59.57 \quad 100.0 \%$ General transcription factor 3C polypeptide $5 \mathrm{GN}=\mathrm{GTF} 3 \mathrm{C} 5$ TF3C5_HUMAN $59.57 \quad 100.0 \%$ General transcription factor $3 \mathrm{C}$ polypeptide $5 \mathrm{GN}=\mathrm{GTF} 3 \mathrm{C} 5$ TF3C5_HUMAN $59.57 \quad 100.0 \%$ General transcription factor $3 \mathrm{C}$ polypeptide $5 \mathrm{GN}=\mathrm{GTF} 3 \mathrm{C} 5 \mathrm{TF} 3 \mathrm{C} 5$ HUMAN $59.57 \quad 100.0 \%$ General transcription factor 3C polypeptide $5 \mathrm{GN}=\mathrm{GTF} 3 \mathrm{C} 5$ TF3C5_HUMAN $59.57 \quad 100.0 \%$ General vesicular transport factor p115 GN=USO1 USO1_HUMAN $107.90 \quad 100.0 \%$ General vesicular transport factor p115 GN=USO1 USO1_HUMAN $107.90 \quad 100.0 \%$ General vesicular transport factor p115 GN=USO1 USO1_HUMAN $107.90 \quad 100.0 \%$ General vesicular transport factor p115 GN=USO1 USO1_HUMAN $107.90100 .0 \%$ Geranylgeranyl pyrophosphate synthase GN=GGPS1 GGPPS_HUMAN $34.87 \quad 100.0 \%$ Geranylgeranyl pyrophosphate synthase GN=GGPS1 GGPPS_HUMAN $34.87 \quad 100.0 \%$ Glioma tumor suppressor candidate region gene 2 protein GN=GLTSCR2 GSCR2_HUMAN $54.39 \quad 100.0 \%$ Glioma tumor suppressor candidate region gene 2 protein GN=GLTSCR2 GSCR2_HUMAN $54.39 \quad 100.0 \%$ Glioma tumor suppressor candidate region gene 2 protein GN=GLTSCR2 GSCR2_HUMAN $54.39 \quad 100.0 \%$ Glomulin $\mathrm{GN}=\mathrm{GLMN}$

Glomulin $\mathrm{GN}=\mathrm{GLMN}$

GLMN_HUMAN $68.21 \quad 100.0 \%$ GLMN_HUMAN $68.21 \quad 100.0 \%$ 作 Glutamate--cysteine ligase regulatory subunit GN=GCLM GSH0_HUMAN $30.73 \quad 100.0 \%$ Glutamine--tRNA ligase GN=QARS

Glutamine--tRNA ligase $\mathrm{GN}=\mathrm{QARS}$ SYQ_HUMAN $87.80 \quad 100.0 \%$ SYQ HUMAN $87.80 \quad 100.0 \%$ SYQ_HUMAN $87.80 \quad 100.0 \%$ Glutamine--tRNA ligase $\mathrm{GN}=\mathrm{QARS}$ QPCT_HUMAN 40.88 Glutaminyl-peptide cyclotransferase GN=QPCT QPCT_HUMAN $40.88 \quad 100.0 \%$ Glutaminyl-peptide cyclotransferase-like protein GN=QPCTL QPCTL_HUMAN $42.93 \quad 100.0 \%$ Glutaminyl-peptide cyclotransferase-like protein GN=QPCTL QPCTL HUMAN $42.93 \quad 100.0 \%$ Glutaminyl-peptide cyclotransferase-like protein GN=QPCTL QPCTL_HUMAN $42.93 \quad 100.0 \%$ Glutaminyl-peptide cyclotransferase-like protein GN=QPCTL QPCTL_HUMAN $42.93 \quad 100.0 \%$ Glutaminyl-peptide cyclotransferase-like protein GN=QPCTL QPCTL_HUMAN $42.93 \quad 100.0 \%$ Glutaminyl-peptide cyclotransferase-like protein GN=QPCTL QPCTL_HUMAN $42.93 \quad 100.0 \%$ Glutaminyl-peptide cyclotransferase-like protein $\mathrm{GN}=\mathrm{QPCTL}$ QPCTL HUMAN $42.93 \quad 100.0 \%$ Glutaminyl-peptide cyclotransferase-like protein GN=QPCTL QPCTL_HUMAN $42.93 \quad 100.0 \%$ Glutaminyl-peptide cyclotransferase-like protein GN=QPCTL QPCTL_HUMAN $42.93 \quad 100.0 \%$ Glutaminyl-peptide cyclotransferase-like protein GN=QPCTL QPCTL_HUMAN $42.93 \quad 100.0 \%$ Glutaredoxin-3 GN=GLRX3 Glutaredoxin- $3 \mathrm{GN}=\mathrm{GLRX} 3$

Glutaredoxin- 3 GN $=$ GLRX 3 GLRX__HUMAN $37.43 \quad 100.0 \%$ GLRX3_HUMAN $37.43 \quad 100.0 \%$ GLRX3_HUMAN $37.43 \quad 100.0 \%$ Glyceraldehyde-3-phosphate dehydrogenase GN=GAPDH G3P_HUMAN $36.05 \quad 100.0 \%$ Glyceraldehyde-3-phosphate dehydrogenase GN=GAPDH G3P HUMAN $36.05 \quad 100.0 \%$ Glyceraldehyde-3-phosphate dehydrogenase GN=GAPDH G3P_HUMAN 36.05 $100.0 \%$ Glyceraldehyde-3-phosphate dehydrogenase GN=GAPDH G3P_HUMAN $36.05 \quad 100.0 \%$ Glyceraldehyde-3-phosphate dehydrogenase GN=GAPDH G3P HUMAN $36.05 \quad 100.0 \%$ Glyceraldehyde-3-phosphate dehydrogenase GN=GAPDH G3P_HUMAN $36.05 \quad 100.0 \%$ Glyceraldehyde-3-phosphate dehydrogenase GN=GAPDH G3P HUMAN $36.05 \quad 100.0 \%$ Glyceraldehyde-3-phosphate dehydrogenase GN=GAPDH G3P_HUMAN $36.05 \quad 100.0 \%$ Glyceraldehyde-3-phosphate dehydrogenase GN=GAPDH G3P_HUMAN $36.05 \quad 100.0 \%$ Glycerol-3-phosphate dehydrogenase 1-like protein GN=GPD1L GPD1L_HUMAN $38.42 \quad 100.0 \%$ Glycerol-3-phosphate dehydrogenase 1-like protein GN=GPDIL GPDIL_HUMAN $38.42 \quad 100.0 \%$
$10 \quad 16 \quad 0.02 \% \quad 22.4 \%$ HGYAPSDLPVK

$\begin{array}{llll}10 & 16 & 0.02 \% & 22.4 \% \\ 10 & 16 & 0.02 \% & 22.4 \%\end{array}$

$\begin{array}{llll}10 & 16 & 0.02 \% & 22.4 \% \\ 10 & 16 & 0.02 \% & 22.4 \% \text { LKLGPSGTSGAR }\end{array}$

$\begin{array}{lllll}10 & 16 & 0.02 \% & 22.4 \% & \text { LKDSVYIFR }\end{array}$

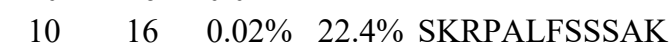

$0.01 \% \quad 6.4 \% \quad$ VLVSPTNPPGATSSCQK

$0.01 \% \quad 6.4 \% \quad$ LGFISKHELYSR

$0.01 \% \quad 6.4 \% \quad$ SSQTSGTNEQSSAIVSAR

$0.01 \% \quad 6.4 \%$ SVEVQGETETIIATK

$0.00 \% \quad 6.3 \% \quad$ YLLQLPGK

$0.00 \% \quad 6.3 \%$ GGNPELVALVK

$0.00 \% \quad 8.4 \%$ SDADSGFLGLRPTSVDPAI

$0.00 \% \quad 8.4 \%$ DVLAHQVPNAK

$0.00 \% \quad 8.4 \%$ LRVQQAALR

$0.00 \% \quad 4.4 \%$ GLELLENSLLR

$0.00 \% \quad 4.4 \%$ AHYEAEIKNSQEAQK

$0.00 \% \quad 8.4 \%$ INPDEREEMK

$0.00 \% \quad 8.4 \%$ LFIVESNSSSSTR

$0.01 \% \quad 3.9 \%$ AINFNFGYAK

$0.01 \% \quad 3.9 \%$ ANNGICFLR

$0.01 \% \quad 3.9 \%$ GKFSEGEATLR

$0.01 \% \quad 6.9 \%$ YPGSPGSYAAR

$0.01 \% \quad 6.9 \%$ SFSNIISTLNPTAK

$0.05 \% \quad 23.3 \%$ GLMEPLLPPK

$0.05 \% \quad 23.3 \%$ RTEELPLGR

$0.05 \% \quad 23.3 \%$ TEELPLGR

$0.05 \% \quad 23.3 \%$ ELRVPLIGSLPEAR

$0.05 \% \quad 23.3 \%$ VPLIGSLPEAR

$0.05 \% \quad 23.3 \%$ VVGQLDPQR

$0.05 \% \quad 23.3 \%$ TPGSPGNLQVR

$0.05 \% \quad 23.3 \%$ KFLEATLR

$0.05 \% \quad 23.3 \%$ HLTLACHYDSK

$0.05 \% \quad 23.3 \%$ HLAQLMESIPHSPGPTR

$0.01 \% \quad 10.1 \%$ ELPQVSFVK

$0.01 \% \quad 10.1 \%$ IDRLDGAHAPELTK

$0.01 \% \quad 10.1 \%$ GELVGGLDIVK

$0.04 \% \quad 31.0 \%$ VGVNGFGR

$0.04 \% \quad 31.0 \%$ LVINGNPITIFQER

$0.04 \% \quad 31.0 \%$ LVINGNPITIFQERDPSK

$0.04 \% \quad 31.0 \%$ IISNASCTTNCLAPLAK

$0.04 \% \quad 31.0 \%$ GALQNIIPASTGAAK

$0.04 \% \quad 31.0 \%$ VPTANVSVVDLTCR

$0.04 \% \quad 31.0 \%$ VPTANVSVVDLTCRLEKPA

$0.04 \% \quad 31.0 \%$ LISWYDNEFGYSNR

$0.04 \% \quad 31.0 \%$ VVDLMAHMASKE

$0.01 \% \quad 17.7 \%$ KLTDIINNDHENVK

$0.01 \% \quad 17.7 \%$ LTDIINNDHENVK
$99.7 \% \quad 41.7$

$99.6 \% \quad 27.8$

$99.7 \% \quad 39.4$

$99.7 \% \quad 30.5$

$99.7 \% \quad 49.0$

$98.7 \% \quad 23.6$

$99.7 \% 53.3$

$99.0 \% \quad 28.0$

$99.7 \% \quad 41.6$

$99.7 \% \quad 57.8$

$99.2 \% \quad 19.5$

$99.6 \% \quad 30.2$

$99.7 \% \quad 33.2$

$99.7 \% \quad 30.5$

$99.7 \% \quad 81.1$

$99.7 \% \quad 32.5$

$99.7 \% \quad 27.0$

$99.7 \% \quad 45.3$

$99.7 \% \quad 32.6$

$99.7 \% \quad 51.2$

$99.7 \% \quad 39.4$

$99.7 \% \quad 45.7$

$99.0 \% \quad 27.1$

$99.7 \% \quad 40.7$

$99.7 \% \quad 62.8$

$99.7 \% \quad 39.9$

$99.7 \% \quad 57.6$

$99.0 \% \quad 46.3$

$99.7 \% \quad 54.7$

$99.7 \% \quad 47.6$

$99.7 \% \quad 36.3$

$99.3 \% \quad 25.1$

$99.7 \% 51$.

$99.0 \% \quad 54.5$

$99.7 \% \quad 60.2$

$99.7 \% \quad 47.1$

$99.7 \% \quad 58.4$

$99.7 \% \quad 45.5$

$99.7 \% \quad 50.5$

99.6\% 24.0

$99.7 \% \quad 60.6$

$99.7 \% \quad 49.9$

$99.3 \% \quad 20.6$

$99.7 \% \quad 26.9$

118 
$11 \quad 0.01 \% \quad 17.7 \%$ ICDEITGR $0.01 \% \quad 17.7 \%$ KALGITLIK $0.01 \% \quad 17.7 \%$ ALGITLIK $0.01 \% \quad 17.7 \%$ GIDEGPEGLK $0.01 \% \quad 17.7 \%$ ELLQTPNFR $0.01 \% \quad 17.7 \%$ LQGPQTSAEVYR $0.01 \% \quad 7.3 \%$ GIVGVENVAELKK $0.01 \% \quad 7.3 \%$ VLYPNDNFFEGKELR $0.01 \% \quad 7.3 \%$ VIFLENYR $0.01 \% \quad 7.3 \% \quad$ LVIDQIDNGFFSPK $0.01 \% \quad 7.3 \%$ NIAASGKFSSDR $0.00 \% \quad 13.4 \%$ ILDAAGANLK $0.00 \% \quad 13.4 \%$ RLPEAIEEVK $0.00 \% \quad 13.4 \%$ IAAAGLDVTSPEPLPTNHPLLTLK $0.00 \% \quad 8.4 \%$ GCMLIELALR

$0.00 \% \quad 8.4 \%$ SDAPTGDVLLDEALK $0.01 \% \quad 5.2 \%$ SEDTTGPITGLALTSVNK $0.01 \% \quad 5.2 \%$ VLNSLTQQEK $0.01 \% \quad 5.2 \%$ VLNSLTQQEKK $0.01 \% \quad 5.2 \%$ FSCLLPDPR $0.01 \% \quad 5.2 \%$ LLITGTEQFNQKPK $0.01 \% \quad 5.2 \%$ KGIQFLQEK $0.01 \% \quad 5.2 \%$ GATPEGIFLR $0.01 \% \quad 5.2 \%$ MQALTYLQR $0.01 \% \quad 5.2 \% \quad$ AASSSSPGSPVASSPSR $0.01 \% \quad 6.9 \%$ ALGQLISK $0.01 \% \quad 6.9 \%$ TLTEPCPLASESR $0.01 \% \quad 6.9 \% \quad$ LYVHTLTITSK $0.01 \% \quad 6.9 \%$ TFHIEEPR $0.01 \% \quad 20.3 \%$ HVANTLSVYR $0.01 \% \quad 20.3 \%$ NPKPATVFSHK $0.01 \% \quad 20.3 \%$ SYEVTVENFLR $0.01 \% \quad 20.3 \%$ SLCVSTPGHR $0.01 \% 20.3 \%$ NVLITDFFGSVR $0.01 \% \quad 20.3 \%$ KVEITTETIK $0.01 \% \quad 20.3 \%$ YAEQLPVAQIIHQKPK $0.00 \% \quad 7.2 \% \quad$ SLANAESQQQR $0.00 \% \quad 7.2 \%$ DSLSPVLHPSDLILTR $0.00 \% \quad 4.2 \%$ SSPVVNDGVVR $0.00 \% \quad 4.2 \%$ KIASFPTAK $0.02 \% \quad 24.9 \%$ VVLLGAPNAGK $0.02 \% 24.9 \%$ STLSNQLLGR $0.02 \% \quad 24.9 \%$ ETQVILLDTPGIISPGK $0.02 \% \quad 24.9 \%$ YSQIPSVLVMNK $0.02 \% \quad 24.9 \%$ DPNTQSVGNPQR $0.02 \% \quad 24.9 \%$ EIFMLSALSQEDVK $0.02 \% \quad 24.9 \%$ LLEHLPQEVPYNVQQK 
GTPase Era, mitochondrial GN=ERAL1 ERAL1_HUMAN $48.35 \quad 100.0 \%$ GTPase-activating protein and VPS9 domain-contaning protein 1 GN=GAPVD1 GAPD1_HUMAN $164.98 \quad 100.0 \%$ GTPase-activating protein and VPS9 domain-containing protein 1 GN=GAPVD1 GAPD1_HUMAN $164.98 \quad 100.0 \%$ GTP-binding nuclear protein Ran GN=RAN RAN_HUMAN $24.42 \quad 100.0 \%$ GTP-binding nuclear protein Ran GN=RAN RAN_HUMAN $24.42 \quad 100.0 \%$ GTP-binding nuclear protein Ran GN=RAN RAN_HUMAN $24.42 \quad 100.0 \%$ GTP-binding protein $10 \mathrm{GN}=$ GTPBP10 GTPBA_HUMAN $42.93 \quad 100.0 \%$ GTP-binding protein $10 \mathrm{GN}=$ GTPBP10 GTPBA_HUMAN $42.93 \quad 100.0 \%$ GTP-binding protein $10 \mathrm{GN}=\mathrm{GTPBP} 10 \quad$ GTPBA_HUMAN $42.93 \quad 100.0 \%$ GTP-binding protein $10 \mathrm{GN}=$ GTPBP10 GTPBA_HUMAN $42.93 \quad 100.0 \%$ GTP-binding protein $10 \mathrm{GN}=\mathrm{GTPBP} 10 \quad$ GTPBA_HUMAN $42.93 \quad 100.0 \%$ GTP-binding protein $10 \mathrm{GN}=$ GTPBP10 GTPBA_HUMAN $42.93 \quad 100.0 \%$ GTP-binding protein $10 \mathrm{GN}=$ GTPBP10 GTPBA_HUMAN $42.93 \quad 100.0 \%$ GTP-binding protein $10 \mathrm{GN}=\mathrm{GTPBP} 10 \quad$ GTPBA_HUMAN $42.93 \quad 100.0 \%$ GTP-binding protein $10 \mathrm{GN}=\mathrm{GTPBP} 10 \quad$ GTPBA_HUMAN $42.93 \quad 100.0 \%$ Guanine nucleotide-binding protein $\mathrm{G}(\mathrm{I}) / \mathrm{G}(\mathrm{S}) / \mathrm{G}(\mathrm{T})$ subunit beta-1 $\mathrm{GN}=\mathrm{GNB} 1 \mathrm{GBB} 1$ _HUMAN $37.38 \quad 100.0 \%$

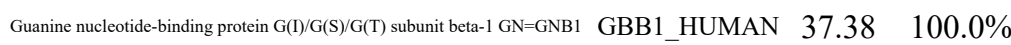
Guanine nucleotide-binding protein $\mathrm{G}(\mathrm{I}) / \mathrm{G}(\mathrm{S}) / \mathrm{G}(\mathrm{T})$ subunit beta-1 $\mathrm{GN}=\mathrm{GNB} 1 \mathrm{GBB} 1$ _HUMAN $37.38 \quad 100.0 \%$ Guanine nucleotide-binding protein $\mathrm{G}(\mathrm{I}) / \mathrm{G}(\mathrm{S}) / \mathrm{G}(\mathrm{T})$ subunit beta-1 $\mathrm{GN}=\mathrm{GNB} 1 \mathrm{GBB} 1$ _HUMAN $37.38 \quad 100.0 \%$ Guanine nucleotide-binding protein $\mathrm{G}(\mathrm{I}) / \mathrm{G}(\mathrm{S}) / \mathrm{G}(\mathrm{T})$ subunit beta-1 $\mathrm{GN}=\mathrm{GNB} 1 \quad \mathrm{GBB} 1 \_H U M A N \quad 37.38 \quad 100.0 \%$ Guanine nucleotide-binding protein $\mathrm{G}(\mathrm{I}) / \mathrm{G}(\mathrm{S}) / \mathrm{G}(\mathrm{T})$ subunit beta-2 $\mathrm{GN}=\mathrm{GNB} 2 \quad \mathrm{GBB} 2$ _HUMAN $37.33 \quad 100.0 \%$ Guanine nucleotide-binding protein $\mathrm{G}(\mathrm{I}) / \mathrm{G}(\mathrm{S}) / \mathrm{G}(\mathrm{T})$ subunit beta-2 $\mathrm{GN}=\mathrm{GNB} 2 \quad \mathrm{GBB} 2$ _HUMAN $37.33 \quad 100.0 \%$ Guanine nucleotide-binding protein $\mathrm{G}(\mathrm{I}) / \mathrm{G}(\mathrm{S}) / \mathrm{G}(\mathrm{T})$ subunit beta-2 $\mathrm{GN}=\mathrm{GNB} 2 \quad \mathrm{GBB} 2$ _HUMAN $37.33 \quad 100.0 \%$ Guanine nucleotide-binding protein $\mathrm{G}(\mathrm{I}) / \mathrm{G}(\mathrm{S}) / \mathrm{G}(\mathrm{T})$ subunit beta-2 $\mathrm{GN}=\mathrm{GNB} 2 \quad \mathrm{GBB} 2$ _HUMAN $37.33 \quad 100.0 \%$ Guanine nucleotide-binding protein $\mathrm{G}(\mathrm{I}) / \mathrm{G}(\mathrm{S}) / \mathrm{G}(\mathrm{T})$ subunit beta-2 $\mathrm{GN}=\mathrm{GNB} 2 \quad \mathrm{GBB} 2$ HUMAN $37.33 \quad 100.0 \%$ Guanine nucleotide-binding protein $\mathrm{G}(\mathrm{I}) / \mathrm{G}(\mathrm{S}) / \mathrm{G}(\mathrm{T})$ subunit beta-2 $\mathrm{GN}=\mathrm{GNB} 2 \quad \mathrm{GBB} 2$ _HUMAN $37.33 \quad 100.0 \%$ Guanine nucleotide-binding protein $\mathrm{G}(\mathrm{I}) / \mathrm{G}(\mathrm{S}) / \mathrm{G}(\mathrm{T})$ subunit beta-2 $\mathrm{GN}=\mathrm{GNB} 2 \quad \mathrm{GBB} 2$ _HUMAN $37.33 \quad 100.0 \%$ Guanine nucleotide-binding protein $\mathrm{G}(\mathrm{k})$ subunit alpha GN=GNAI3 GNAI3_HUMAN $40.53 \quad 100.0 \%$ Guanine nucleotide-binding protein $\mathrm{G}(\mathrm{k})$ subunit alpha $\mathrm{GN}=\mathrm{GNAI} 3$ GNAI3_HUMAN $40.53 \quad 100.0 \%$ Guanine nucleotide-binding protein $\mathrm{G}(\mathrm{k})$ subunit alpha $\mathrm{GN}=\mathrm{GNAI3}$ GNAI3_HUMAN $40.53 \quad 100.0 \%$ Guanine nucleotide-binding protein $\mathrm{G}(\mathrm{k})$ subunit alpha GN=GNAI3 GNAI3_HUMAN $40.53 \quad 100.0 \%$ Guanine nucleotide-binding protein $\mathrm{G}(\mathrm{k})$ subunit alpha $\mathrm{GN}=\mathrm{GNAI} 3$ GNAI3_HUMAN $40.53 \quad 100.0 \%$ Guanine nucleotide-binding protein $\mathrm{G}(\mathrm{k})$ subunit alpha GN=GNAI3 GNAI3_HUMAN $40.53 \quad 100.0 \%$ Guanine nucleotide-binding protein $\mathrm{G}(\mathrm{k})$ subunit alpha $\mathrm{GN}=\mathrm{GNAI} 3$ GNAI3_HUMAN $40.53 \quad 100.0 \%$ Guanine nucleotide-binding protein $\mathrm{G}(\mathrm{k})$ subunit alpha $\mathrm{GN}=\mathrm{GNAI} 3$ GNAI3_HUMAN $40.53 \quad 100.0 \%$ Guanine nucleotide-binding protein $\mathrm{G(s)}$ subunit alpha isoforms short GN=GNAS GNAS2_HUMAN $45.67 \quad 100.0 \%$ Guanine nucleotide-binding protein $\mathrm{G}(\mathrm{s})$ subunit alpha isoforms short GN=GNAS GNAS2_HUMAN $45.67 \quad 100.0 \%$ Guanine nucleotide-binding protein $\mathrm{G}(\mathrm{s})$ subunit alpha isoforms short $\mathrm{GN}=\mathrm{GNAS}$ GNAS2_HUMAN $45.67 \quad 100.0 \%$ Guanine nucleotide-binding protein subunit alpha-11 GN=GNA11 GNA11_HUMAN $42.13 \quad 100.0 \%$ Guanine nucleotide-binding protein subunit alpha-11 GN=GNA11 GNA11_HUMAN $42.13 \quad 100.0 \%$ Guanine nucleotide-binding protein subunit alpha-11 GN=GNA11 GNA11_HUMAN $42.13 \quad 100.0 \%$ Guanine nucleotide-binding protein subunit beta-2-like 1 GN=GNB2L1 GBLP_HUMAN $35.08 \quad 100.0 \%$ Guanine nucleotide-binding protein subunit beta-2-like 1 GN=GNB2L1 GBLP_HUMAN $35.08 \quad 100.0 \%$ Guanine nucleotide-binding protein subunit beta-2-like 1 GN=GNB2L1 GBLP_HUMAN $35.08 \quad 100.0 \%$ Guanine nucleotide-binding protein subunit beta-2-like $1 \mathrm{GN}=\mathrm{GNB} 2 \mathrm{~L} 1$ GBLP_HUMAN $35.08 \quad 100.0 \%$ Guanine nucleotide-binding protein subunit beta-2-like $1 \mathrm{GN}=\mathrm{GNB} 2 \mathrm{~L} 1$ GBLP_HUMAN $35.08 \quad 100.0 \%$ Guanine nucleotide-binding protein subunit beta-2-like 1 GN=GNB2L1 GBLP_HUMAN $35.08 \quad 100.0 \%$
4

$5-0.00 \%-14.8 \%$ HLTGEFE

$0.00 \% \quad 14.8 \%$ NLQYYDISAK

$0.00 \% \quad 14.8 \%$ SNYNFEKPFLWLAR

$19 \quad 0.02 \% \quad 26.1 \%$ GGSGGMGYPR

$19 \quad 0.02 \% \quad 26.1 \%$ FVAGVGANSK

$19 \quad 0.02 \% \quad 26.1 \%$ IIGELNKENDR

$19 \quad 0.02 \% \quad 26.1 \%$ ILVAQGGLGGK

$19 \quad 0.02 \% \quad 26.1 \%$ LLTNFLPLK

$19 \quad 0.02 \% \quad 26.1 \%$ LIADVGLVGFPNAGK

$0.02 \% \quad 26.1 \%$ TAFETIILLTK

$19 \quad 0.02 \% \quad 26.1 \%$ DFLHLFEK

$19 \quad 0.02 \% \quad 26.1 \%$ SLDEQANQENDALHKK

$0.00 \% \quad 16.5 \%$ LLVSASQDGK

$0.00 \% \quad 16.5 \%$ LIIWDSYTTNK

$0.00 \% \quad 16.5 \%$ ELAGHTGYLSCCR

$0.00 \% \quad 16.5 \%$ LFVSGACDASAK

$0.00 \% \quad 16.5 \%$ AGVLAGHDNR

$\begin{array}{llll}0.02 \% & 22.4 \% \text { KACGDSTLTQITAGLDPVGR } & 99.7 \% & 36.6\end{array}$

$0.02 \% \quad 22.4 \%$ ACGDSTLTQITAGLDPVGR

$0.02 \% \quad 22.4 \%$ LLVSASQDGK

$0.02 \% \quad 22.4 \%$ LIIWDSYTTNK

$0.02 \% \quad 22.4 \%$ ELPGHTGYLSCCR

$0.02 \% \quad 22.4 \%$ TFVSGACDASIK

$0.02 \% \quad 22.4 \%$ AGVLAGHDNR

$0.01 \% \quad 28.8 \%$ LLLLGAGESGK

$0.01 \% \quad 28.8 \%$ VVVYSNTIQSIIAIIR

$0.01 \% \quad 28.8 \%$ LKIDFGEAAR

$0.01 \% \quad 28.8 \%$ DGGVQACFSR

$0.01 \% \quad 28.8 \%$ ISQSNYIPTQQDVLR

$0.01 \% \quad 28.8 \%$ TTGIVETHFTFK

$0.01 \% \quad 28.8 \%$ EIYTHFTCATDTK

$0.01 \% \quad 28.8 \%$ NVQFVFDAVTDVIIK

$0.01 \% \quad 7.9 \%$ LLLLGAGESGK

$0.01 \% \quad 7.9 \%$ VLTSGIFETK

$0.01 \% \quad 7.9 \%$ TISVILFLNK

$0.00 \% \quad 7.5 \%$ LLLLGTGESGK

$0.00 \% \quad 7.5 \% \quad$ YYLTDVDR

$0.00 \% \quad 7.5 \%$ MVDVGGQR

$0.04 \% \quad 41.3 \%$ LWDLTTGTTTR

$0.04 \% \quad 41.3 \%$ DVLSVAFSSDNR

$0.04 \% \quad 41.3 \%$ LWNTLGVCK

$0.04 \% \quad 41.3 \%$ YTVQDESHSEWVSCVR

$0.04 \% \quad 41.3 \%$ FSPNSSNPIIVSCGWDK

$0.04 \% \quad 41.3 \%$ VWNLANCK
$99.7 \% \quad 43.5$

$99.0 \% \quad 19.9$

$99.5 \% \quad 21.8$

$95.9 \% \quad 14.8$

$99.0 \% \quad 20.4$

$\begin{array}{lll}99.7 \% & 28.5\end{array}$

$99.7 \% \quad 28.5$

$\begin{array}{lll}99.7 \% & 48.3\end{array}$

$99.2 \% 21.0$

$99.7 \% \quad 46.5$

$99.7 \% \quad 40.5$

$99.7 \% \quad 54.6$

$99.7 \% \quad 52.5$

$96.3 \% \quad 20.2$

$5.7 \% \quad 14.5$

$99.7 \% 55.1$

$99.7 \% \quad 33.6$

$99.7 \% \quad 59.6$

$99.7 \% \quad 58.6$

$9.7 \% \quad 48.7$

$99.7 \% \quad 59.0$

$99.7 \% \quad 55.1$

$99.4 \% \quad 29.8$

$99.7 \% \quad 59.2$

$99.7 \% \quad 58.6$

$99.3 \% \quad 60.8$

$99.7 \% \quad 30.8$

$99.7 \% \quad 32.8$

$99.7 \% \quad 51.5$

$99.7 \% \quad 66.4$

$99.7 \% \quad 63.2$

$99.7 \% \quad 42.5$

$\begin{array}{lll}99.7 \% & 39.0\end{array}$

$99.3 \% 60.8$

$99.7 \% \quad 52.4$

$99.7 \% \quad 46.2$

$99.7 \% \quad 57.6$

$\begin{array}{lll}98.7 \% & 30.7\end{array}$

$99.0 \% 22.1$

$99.7 \% \quad 54.1$

$99.7 \% \quad 60.7$

$99.7 \% \quad 53.3$

$99.7 \% \quad 59.6$

$99.7 \% \quad 63.3$

$99.0 \% \quad 27.1$
1840.94

940.57

1201.69

960.48

1214.61

1784.91

938.42

949.51

1300.69

1012.62

1058.66

1470.83

1249.74

1048.55

1839.88

1017.56

1353.71

1523.67

1225.59

1009.52

2060.04

1931.95

1017.56

1353.71

1549.69

1255.60

1009.52

1057.63

1789.06

1119.62

1096.48

1761.91

1380.72

1586.72

1707.93

1057.63

1094.61

1147.71

1087.64

1044.50

861.42

1264.65

1309.64

1090.57

1981.87

1907.90

1004.50

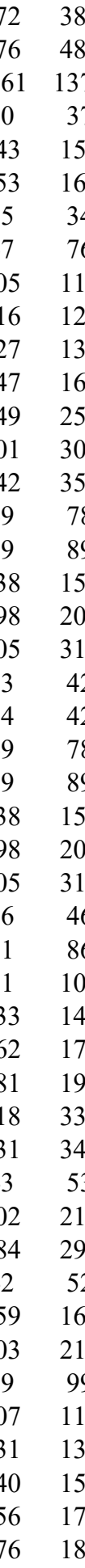

Page 74 of Table S-1-4 

$\mathrm{H} / \mathrm{ACA}$ ribonucleoprotein complex subunit $4 \mathrm{GN}=\mathrm{DKC1}$ DKC1_HUMAN $57.68 \quad 100.0 \%$ $\mathrm{H} / \mathrm{ACA}$ ribonucleoprotein complex subunit $4 \mathrm{GN}=\mathrm{DKCl} \mathrm{DKCl} H U M A N \quad 57.68 \quad 100.0 \%$ $\mathrm{H} / \mathrm{ACA}$ ribonucleoprotein complex subunit $4 \mathrm{GN}=\mathrm{DKC1} \mathrm{DKC1}$ _HUMAN $57.68 \quad 100.0 \%$ Haptoglobin GN=HP

Haptoglobin GN=HP

HPT HUMAN $45.20 \quad 100.0 \%$ HCLS1-associated protein X-1 GN=HAX1 HAX1_HUMAN $31.62 \quad 100.0 \%$ HCLS1-associated protein X-1 GN=HAX1 HAX1 HUMAN $31.62100 .0 \%$ HCLS1-associated protein X-1 GN=HAX1 HAX1_HUMAN $31.62 \quad 100.0 \%$ HCLS1-associated protein X-1 GN=HAX1 HAX1_HUMAN $31.62 \quad 100.0 \%$ HCLS1-associated protein X-1 GN=HAX1 HAX1 HUMAN $31.62 \quad 100.0 \%$ HCLS1-associated protein X-1 GN=HAX1 HAX1_HUMAN $31.62 \quad 100.0 \%$ HCLS1-associated protein X-1 GN=HAX1 HAX1_HUMAN $31.62 \quad 100.0 \%$ HCLS1-associated protein X-1 GN=HAX1 HAX1_HUMAN $31.62 \quad 100.0 \%$ HCLS1-associated protein X-1 GN=HAX1 HAX1_HUMAN $31.62 \quad 100.0 \%$ HEAT repeat-containing protein $1 \mathrm{GN}=$ HEATR1 HEAT1 HUMAN $242.38100 .0 \%$ HEAT repeat-containing protein 1 GN=HEATR1 HEAT1_HUMAN $242.38 \quad 100.0 \%$ HEAT repeat-containing protein $1 \mathrm{GN}=$ HEATR1 HEAT1_HUMAN $242.38 \quad 100.0 \%$ HEAT repeat-containing protein $1 \mathrm{GN}=$ HEATR1 HEAT1_HUMAN $242.38100 .0 \%$ HEAT repeat-containing protein 1 GN=HEATR1 HEAT1_HUMAN $242.38 \quad 100.0 \%$ HEAT repeat-containing protein $1 \mathrm{GN}=$ HEATR1 HEAT1 HUMAN $242.38100 .0 \%$ HEAT repeat-containing protein $1 \mathrm{GN}=$ HEATR1 HEAT1_HUMAN $242.38 \quad 100.0 \%$ HEAT repeat-containing protein 1 GN=HEATR1 HEAT1_HUMAN $242.38 \quad 100.0 \%$ HEAT repeat-containing protein $1 \mathrm{GN}=$ HEATR1 HEAT1 HUMAN $242.38100 .0 \%$ Heat shock $70 \mathrm{kDa}$ protein $1 \mathrm{~A} / 1 \mathrm{~B}$ GN=HSPA1A HSP71_HUMAN $70.05 \quad 100.0 \%$

9

9

10

$\begin{array}{llll}10 & 33 & 0.03 \% & 19.5 \% \\ 10 & 33 & 0.03 \% & 19.5 \%\end{array}$

$10 \quad 33 \quad 0.03 \% \quad 19.5 \%$ LLGGFQETCSK

$\begin{array}{lllll}10 & 33 & 0.03 \% & 19.5 \% & \text { VGVIGFPNVGK } \\ 10 & 33 & 0.03 \% & 19.5 \% \text { GGIPNVEGAAK }\end{array}$

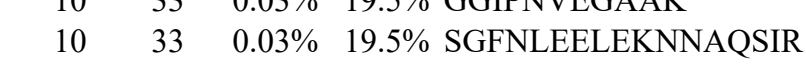

$4 \quad 6 \quad 0.01 \% \quad 9.1 \%$ TIESYCQDVLR

$\begin{array}{lllll}4 & 6 & 0.01 \% & 9.1 \% & \text { SSLINSLKR }\end{array}$

$\begin{array}{lll}0.01 \% & 9.1 \% & \text { LLDAPGIVPGPNSEVGTILR }\end{array}$

$0.01 \% \quad 9.1 \%$ IADAIENKTTVYK

$0.02 \% \quad 14.0 \%$ LDTSQWPLLLK

$0.02 \% \quad 14.0 \%$ SQQSAGKEYVGIVR

$0.02 \% \quad 14.0 \%$ LHNAIEGGTQLSR

$0.02 \% \quad 14.0 \%$ RVVYPLEK

\begin{tabular}{ll}
$0.02 \%$ & $14.0 \%$ \\
\hline & LVMKDSAVNAICYGAK
\end{tabular}

$0.02 \% \quad 14.0 \%$ DSAVNAICYGAK

$0.02 \% \quad 14.0 \%$ APQVVAEAAK

$0.00 \% \quad 4.7 \%$ VGYVSGWGR

$0.00 \% \quad 4.7 \%$ VTSIQDWVQK

$0.01 \% \quad 35.8 \%$ GFFGFPGPR

$0.01 \% \quad 35.8 \%$ FHDNFGFDDLVR

$0.01 \% \quad 35.8 \%$ LREGQTLR

$0.01 \% \quad 35.8 \%$ YPDSHQPR

$0.01 \% \quad 35.8 \%$ IFGGVLESDAR

$0.01 \% 35.8 \%$ TREDNDLDSQVSQEGLGPVLQPQPK

$0.01 \% \quad 35.8 \%$ ITKPDGIVEERR

$0.01 \% \quad 35.8 \%$ RTVVDSEGR

$0.01 \% \quad 35.8 \%$ TVVDSEGRTETTVTR

$0.01 \% \quad 4.5 \% \quad$ LLESKYPR

$0.01 \% \quad 4.5 \% \quad$ LIGVANQK

$0.01 \% \quad 4.5 \% \quad$ LDDTYSFQVINK

$0.01 \% \quad 4.5 \% \quad$ VVESGGPEILK

$0.01 \% \quad 4.5 \%$ GLVGNPLPSVR

$0.01 \% \quad 4.5 \% \quad$ LVPDLLAIVQR

$0.01 \% \quad 4.5 \% \quad$ NFGAENPDPFVPVLNTAVK

$0.01 \% \quad 4.5 \%$ TLATTLAPR

$0.01 \% \quad 4.5 \%$ VLLPAIKK

$\begin{array}{lllll}0.39 \% & 64.6 \% & \text { AAAIGIDLGTTYSCVGVFQHGK } & 99.7 \% & 40.0\end{array}$
$99.7 \% \quad 30.3$

$\begin{array}{ll}99.7 \% & 56.0\end{array}$

$99.7 \% \quad 55.5$

$99.7 \% \quad 38.0$

$99.5 \% \quad 25.4$

$96.3 \% \quad 17.9$

$99.6 \% \quad 23.5$

$99.7 \% \quad 41.5$

$99.0 \% \quad 21.5$

$99.0 \% \quad 38.2$

$99.7 \% \quad 41.1$

$99.7 \% \quad 40.7$

$\begin{array}{lll}99.7 \% & 26.3\end{array}$

$99.7 \% \quad 44.9$

$99.7 \% \quad 37.4$

$99.7 \% \quad 33.5$

$99.7 \% \quad 36.2$

$99.7 \% \quad 37.3$

$99.7 \% \quad 59.8$

$\begin{array}{lll}99.7 \% & 42.3\end{array}$

$99.0 \% \quad 29.7$

$\begin{array}{ll}99.7 \% & 35.4 \\ 99.7 \% & 53.7\end{array}$

$99.7 \% \quad 40.5$

$99.4 \% \quad 27.0$

$99.7 \% \quad 33.8$

$99.7 \% \quad 38.4$

$99.7 \% \quad 33.1$

$99.0 \% \quad 33.4$

$99.0 \% \quad 44.4$

$99.7 \% \quad 66.8$

$99.7 \% \quad 54.3$

$99.6 \% \quad 23.1$

$94.6 \% \quad 18.7$

$\begin{array}{lll}97.0 \% & 29.5\end{array}$

$99.0 \% \quad 28.4$

$99.7 \% \quad 76.2$

$99.7 \% \quad 43.2$

$99.7 \% \quad 39.1$

$99.7 \% \quad 39.4$

\section{$997 \%$}

$25.0 \quad 35.4$
Page 75 of Table S-1-4 
Heat shock $70 \mathrm{kDa}$ protein 1A/1B GN=HSPA1A HSP71_HUMAN $70.05 \quad 100.0 \%$ Heat shock $70 \mathrm{kDa}$ protein 1A/1B GN=HSPA1A HSP71_HUMAN $70.05 \quad 100.0 \%$ Heat shock $70 \mathrm{kDa}$ protein $1 \mathrm{~A} / 1 \mathrm{~B}$ GN=HSPA1A HSP71_HUMAN $70.05 \quad 100.0 \%$ Heat shock $70 \mathrm{kDa}$ protein 1A/1B GN=HSPA1A HSP71_HUMAN 70.05 Heat shock $70 \mathrm{kDa}$ protein 1A/1B GN=HSPA1A HSP71_HUMAN 70.05 Heat shock $70 \mathrm{kDa}$ protein $1 \mathrm{~A} / 1 \mathrm{~B}$ GN=HSPA1A HSP71_HUMAN 70.05 Heat shock $70 \mathrm{kDa}$ protein $1 \mathrm{~A} / 1 \mathrm{~B}$ GN=HSPA1A HSP71_HUMAN 70.0 Heat shock $70 \mathrm{kDa}$ protein $1 \mathrm{~A} / 1 \mathrm{~B}$ GN=HSPA1A HSP71_HUMAN 70.05 Heat shock $70 \mathrm{kDa}$ protein $1 \mathrm{~A} / 1 \mathrm{~B}$ GN=HSPA1A HSP71_HUMAN 70.0 Heat shock $70 \mathrm{kDa}$ protein $1 \mathrm{~A} / 1 \mathrm{~B}$ GN=HSPA1A HSP71_HUMAN 70.05 Heat shock $70 \mathrm{kDa}$ protein $1 \mathrm{~A} / 1 \mathrm{~B}$ GN=HSPA1A HSP71_HUMAN 70.05 Heat shock $70 \mathrm{kDa}$ protein $1 \mathrm{~A} / 1 \mathrm{~B}$ GN=HSPA1A HSP71_HUMAN 70.05 Heat shock $70 \mathrm{kDa}$ protein $1 \mathrm{~A} / 1 \mathrm{~B}$ GN=HSPA1A HSP71_HUMAN 70.05 Heat shock $70 \mathrm{kDa}$ protein $1 \mathrm{~A} / 1 \mathrm{~B}$ GN=HSPA1A HSP71_HUMAN 70.05 Heat shock $70 \mathrm{kDa}$ protein $1 \mathrm{~A} / 1 \mathrm{~B}$ GN=HSPA1A HSP71_HUMAN 70.0 Heat shock $70 \mathrm{kDa}$ protein $1 \mathrm{~A} / 1 \mathrm{~B}$ GN=HSPA1A HSP71_HUMAN 70.0 Heat shock $70 \mathrm{kDa}$ protein $1 \mathrm{~A} / 1 \mathrm{~B}$ GN=HSPA1A HSP71_HUMAN 70.0 Heat shock $70 \mathrm{kDa}$ protein $1 \mathrm{~A} / 1 \mathrm{~B}$ GN=HSPA1A HSP71_HUMAN 70.05 Heat shock $70 \mathrm{kDa}$ protein $1 \mathrm{~A} / 1 \mathrm{~B}$ GN=HSPA1A HSP71_HUMAN 70.05 Heat shock $70 \mathrm{kDa}$ protein $1 \mathrm{~A} / 1 \mathrm{~B}$ GN=HSPA1A HSP71_HUMAN 70.05 Heat shock $70 \mathrm{kDa}$ protein $1 \mathrm{~A} / 1 \mathrm{~B}$ GN=HSPA1A HSP71_HUMAN 70.05 Heat shock $70 \mathrm{kDa}$ protein 1A/1B GN=HSPA1A HSP71_HUMAN 70.05 Heat shock $70 \mathrm{kDa}$ protein $1 \mathrm{~A} / 1 \mathrm{~B}$ GN=HSPA1A HSP71_HUMAN 70.05 Heat shock $70 \mathrm{kDa}$ protein $1 \mathrm{~A} / 1 \mathrm{~B}$ GN=HSPA1A HSP71_HUMAN 70.0 Heat shock $70 \mathrm{kDa}$ protein $1 \mathrm{~A} / 1 \mathrm{~B}$ GN=HSPA1A HSP71_HUMAN 70.05 Heat shock $70 \mathrm{kDa}$ protein $1 \mathrm{~A} / 1 \mathrm{~B}$ GN=HSPA1A HSP71_HUMAN 70.05 Heat shock $70 \mathrm{kDa}$ protein $1 \mathrm{~A} / 1 \mathrm{~B}$ GN=HSPA1A HSP71_HUMAN 70.0 Heat shock $70 \mathrm{kDa}$ protein $1 \mathrm{~A} / 1 \mathrm{~B}$ GN=HSPA1A HSP71_HUMAN 70.05 Heat shock $70 \mathrm{kDa}$ protein $1 \mathrm{~A} / 1 \mathrm{~B}$ GN=HSPA1A HSP71_HUMAN 70.0 Heat shock $70 \mathrm{kDa}$ protein $1 \mathrm{~A} / 1 \mathrm{~B}$ GN=HSPA1A HSP71_HUMAN 70.05 Heat shock $70 \mathrm{kDa}$ protein 1A/1B GN=HSPA1A HSP71_HUMAN 70.05 Heat shock $70 \mathrm{kDa}$ protein $1 \mathrm{~A} / 1 \mathrm{~B}$ GN=HSPA1A HSP71_HUMAN 70.05 Heat shock $70 \mathrm{kDa}$ protein $1 \mathrm{~A} / 1 \mathrm{~B}$ GN=HSPA1A HSP71_HUMAN 70.05 Heat shock $70 \mathrm{kDa}$ protein $1 \mathrm{~A} / 1 \mathrm{~B}$ GN=HSPA1A HSP71_HUMAN 70.05 Heat shock $70 \mathrm{kDa}$ protein $1 \mathrm{~A} / 1 \mathrm{~B}$ GN=HSPA1A HSP71_HUMAN 70.05 Heat shock $70 \mathrm{kDa}$ protein $1 \mathrm{~A} / 1 \mathrm{~B}$ GN=HSPA1A HSP71_HUMAN 70.0 Heat shock $70 \mathrm{kDa}$ protein $1 \mathrm{~A} / 1 \mathrm{~B}$ GN=HSPA1A HSP71_HUMAN 70.0 Heat shock $70 \mathrm{kDa}$ protein $1 \mathrm{~A} / 1 \mathrm{~B}$ GN=HSPA1A HSP71_HUMAN 70.05 Heat shock $70 \mathrm{kDa}$ protein $1 \mathrm{~A} / 1 \mathrm{~B}$ GN=HSPA1A HSP71_HUMAN 70.05 Heat shock $70 \mathrm{kDa}$ protein $1 \mathrm{~A} / 1 \mathrm{~B}$ GN=HSPA1A HSP71_HUMAN 70.0 Heat shock $70 \mathrm{kDa}$ protein $4 \mathrm{GN}=$ HSPA4 HSP74_HUMAN 94.33 Heat shock $70 \mathrm{kDa}$ protein $4 \mathrm{GN}=$ HSPA4 HSP74_HUMAN 94.33 Heat shock $70 \mathrm{kDa}$ protein $4 \mathrm{GN}=\mathrm{HSPA} 4$ HSP74 HUMAN 94.33 Heat shock $70 \mathrm{kDa}$ protein $4 \mathrm{GN}=\mathrm{HSPA} 4$ HSP74_HUMAN 94.33 Heat shock $70 \mathrm{kDa}$ protein $4 \mathrm{GN}=\mathrm{HSPA} 4$ HSP74_HUMAN 94.33 Heat shock $70 \mathrm{kDa}$ protein $4 \mathrm{GN}=$ HSPA4 HSP74_HUMAN 94.33 Heat shock $70 \mathrm{kDa}$ protein $4 \mathrm{~L}$ GN=HSPA4L HS74L_HUMAN 94.51
$100.0 \% \quad 41$ $100.0 \% \quad 41$ $100.0 \% \quad 41$ $100.0 \% \quad 41$ $100.0 \% \quad 4$ $100.0 \% \quad 41$ $100.0 \% \quad 4$ $100.0 \% \quad 4$ $100.0 \% \quad 4$ $100.0 \% \quad 4$ $100.0 \% \quad 41$ $100.0 \% \quad 4$ $100.0 \% \quad 41$ $100.0 \% \quad 41$ $100.0 \% \quad 4$ $100.0 \% \quad 4$ $100.0 \% \quad 4$ $100.0 \% \quad 41$ $100.0 \% \quad 41$ $100.0 \% \quad 41$ $100.0 \% \quad 41$ $100.0 \% \quad 41$ $100.0 \% \quad 41$ $100.0 \% \quad 4$ $100.0 \% \quad 4$ $100.0 \% \quad 41$ $100.0 \% \quad 4$ $100.0 \% \quad 4$ $100.0 \% \quad 4$ $100.0 \% \quad 4$ $100.0 \% \quad 4$ $100.0 \% \quad 4$ $100.0 \%$ $100.0 \% \quad 41$ $100.0 \% \quad 4$ $100.0 \%$ $100.0 \%$ $100.0 \%$ $100.0 \%$ $100.0 \%$ $100.0 \%$ $100.0 \%$ $100.0 \%$ $100.0 \%$
$59 \quad 392 \quad 0.39 \% \quad 64.6 \%$ VEIIANDQGNR $99.3 \% 57.6 \quad 25.0-0.0=16$ $99.7 \% 53.6$ $392 \quad 0.39 \% \quad 64.6 \%$ TTPSYVAFTDTER $99.7 \% \quad 51.3$

$59 \quad 392 \quad 0.39 \% \quad 64.6 \%$ TTPSYVAFTDTERLIG $392 \quad 0.39 \% \quad 64.6 \%$ LIGDAAKNQVALNPQNTVFDAK $\quad 99.7 \% \quad 60.5$

$\begin{array}{lllllll}59 & 392 & 0.39 \% & 64.6 \% & \text { NQVALNPQNTVFDAK } & 99.7 \% & 58.9\end{array}$

$59 \quad 392 \quad 0.39 \% \quad 64.6 \%$ NQVALNPQNTVFDAKR

$59 \quad 392 \quad 0.39 \% \quad 64.6 \%$ FGDPVVQSDMK

$99.5 \% 22.8$

$\begin{array}{llll}392 & 0.39 \% & 64.6 \% & \text { FGDPVVQSDMK } \\ 392 & 0.39 \% & 64.6 \% & \text { FGDPVVQSDMKHWPFQV }\end{array}$ $99.5 \% 22.8$

$392 \quad 0.39 \% \quad 64.6 \%$ VQVSYKGETK

$99.5 \%$ \% 21.9

$99.7 \% \quad 44.3$

$392 \quad 0.39 \% \quad 64.6 \%$ AFYPEEISSMVLTK

$99.7 \% \quad 57.2$

$\begin{array}{lllllll}59 & 392 & 0.39 \% & 64.6 \% & \text { MKEIAEAYLGYPVTNAVITVPAYFNDSQR } & 99.7 \% & 36.2\end{array}$

$59 \quad 392 \quad 0.39 \% \quad 64.6 \%$ QATKDAGVIAGLNVLR $\quad 99.7 \% \quad 46.2$

$59 \quad 392 \quad 0.39 \% \quad 64.6 \%$ DAGVIAGLNVLR

$99.7 \% \quad 59.3$

$392 \quad 0.39 \% \quad 64.6 \%$ IINEPTAAAIAYGLDR

$99.7 \% \quad 55.3$

$\begin{array}{lllllll}59 & 392 & 0.39 \% & 64.6 \% & \text { IINEPTAAAIAYGLDRTGK } & 98.8 \% & 19.2\end{array}$

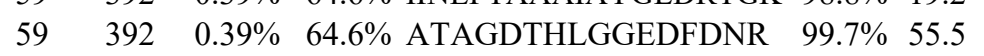

$59 \quad 392 \quad 0.39 \% \quad 64.6 \%$ LVNHFVEEFKR

$59 \quad 392 \quad 0.39 \% \quad 64.6 \%$ ARFEELCSDLFR

$59 \quad 392 \quad 0.39 \% \quad 64.6 \%$ FEELCSDLFR

$59 \quad 392 \quad 0.39 \% \quad 64.6 \%$ STLEPVEK

$59 \quad 392 \quad 0.39 \% \quad 64.6 \%$ STLEPVEKALR

$99.7 \% \quad 31.4$

$99.7 \% \quad 54.2$

$99.7 \% \quad 54.2$

$98.2 \% \quad 25.7$

$99.3 \% 21.1$

$59392 \quad 0.39 \% \quad 64.6 \%$ LDKAQIHDLVLVGGSTR

$59 \quad 392 \quad 0.39 \% \quad 64.6 \%$ AQIHDLVLVGGSTR

$59 \quad 392 \quad 0.39 \% \quad 64.6 \%$ AQIHDLVLVGGSTRIPK

$59392 \quad 0.39 \% \quad 64.6 \%$ VQKLLQDFFNGR

$59 \quad 392 \quad 0.39 \% \quad 64.6 \%$ LLQDFFNGR

$59 \quad 392 \quad 0.39 \% \quad 64.6 \%$ LLQDFFNGRDLNK

$99.7 \% \quad 70.7$

$\begin{array}{ll}99.7 \% & 70.7 \\ 99.7 \% & 37.6\end{array}$

$99.7 \% \quad 44.2$

$99.7 \% \quad 62.5$

$99.7 \% \quad 55.8$

$392 \quad 0.39 \% \quad 64.6 \%$ NSTIPTKOTQIFTTYSDNQPGVLIQVYEGER $\quad 99.7 \% \quad 55.8$

$\begin{array}{lllllll}59 & 392 & 0.39 \% & 64.6 \% & \text { QTQIFTTYSDNQPGVLIQVYEGER } & 99.7 \% & 63.5\end{array}$

$59 \quad 392 \quad 0.39 \% \quad 64.6 \%$ AMTKDNNLLGR

$\begin{array}{ll}99.7 \% & 63.5 \\ 99.7 \% & 53.9\end{array}$

$96.3 \% \quad 20.8$

$99.7 \% \quad 61.4$

$99.0 \% \quad 59.4$

$99.7 \% \quad 26.1$

$99.7 \% \quad 37.1$

$99.7 \% \quad 50.4$

$99.7 \% \quad 56.1$

$99.7 \% \quad 38.8$

$99.7 \% \quad 79.9$

$99.7 \% \quad 56.6$

$99.7 \% \quad 63.6$

$99.0 \% \quad 28.4$

$99.7 \% \quad 29.7$

$99.7 \% 90.1$

$99.7 \% \quad 57.2$

$99.5 \% 26.2$

$99.0 \% \quad 34.0$
2156.09

2327.24

1658.85

1814.95

1238.57

2900.40

1138.61

1614.81

3276.62

1625.93

1197.70

1687.90

1974.07

1675.73

1417.76

1542.74

1315.60

902.48

1242.71

1822.02

1465.81

1804.04

1464.80

1109.57

1579.82

3527.77

2786.36

1232.64

1117.62

1017.57

1003.54

1125.56

1137.55

1672.84

1287.60

947.47

3055.49

1204.53

1495.70

949.52

1239.59

1321.71

1535.77

1319.68

916.52

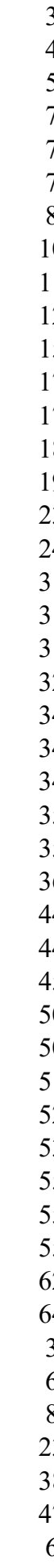


Heat shock $70 \mathrm{kDa}$ protein 4L GN=HSPA4L HS74L_HUMAN $94.51 \quad 100.0 \%$ Heat shock $70 \mathrm{kDa}$ protein 4L GN=HSPA4L HS74L_HUMAN $94.51 \quad 100.0 \%$ Heat shock $70 \mathrm{kDa}$ protein 4L GN=HSPA4L HS74L_HUMAN $94.51 \quad 100.0 \%$ Heat shock $70 \mathrm{kDa}$ protein 4L GN=HSPA4L HS74L_HUMAN $94.51 \quad 100.0 \%$ Heat shock $70 \mathrm{kDa}$ protein 4L GN=HSPA4L HS74L_HUMAN $94.51 \quad 100.0 \%$ Heat shock $70 \mathrm{kDa}$ protein 4L GN=HSPA4L HS74L_HUMAN $94.51 \quad 100.0 \%$ Heat shock cognate $71 \mathrm{kDa}$ protein GN=HSPA8 HSP7C_HUMAN $70.90 \quad 100.0 \%$ Heat shock cognate $71 \mathrm{kDa}$ protein GN=HSPA8 HSP7C_HUMAN $70.90 \quad 100.0 \%$ Heat shock cognate $71 \mathrm{kDa}$ protein GN=HSPA8 HSP7C_HUMAN $70.90 \quad 100.0 \%$ Heat shock cognate $71 \mathrm{kDa}$ protein GN=HSPA8 HSP7C_HUMAN $70.90 \quad 100.0 \%$ Heat shock cognate $71 \mathrm{kDa}$ protein GN=HSPA8 HSP7C_HUMAN $70.90 \quad 100.0 \%$ Heat shock cognate $71 \mathrm{kDa}$ protein GN=HSPA8 HSP7C_HUMAN $70.90 \quad 100.0 \%$ Heat shock cognate $71 \mathrm{kDa}$ protein GN=HSPA8 HSP7C_HUMAN $70.90 \quad 100.0 \%$ Heat shock cognate $71 \mathrm{kDa}$ protein GN=HSPA8 HSP7C_HUMAN $70.90 \quad 100.0 \%$ Heat shock cognate $71 \mathrm{kDa}$ protein GN=HSPA8 HSP7C_HUMAN $70.90 \quad 100.0 \%$ Heat shock cognate $71 \mathrm{kDa}$ protein GN=HSPA8 HSP7C_HUMAN $70.90 \quad 100.0 \%$ Heat shock cognate $71 \mathrm{kDa}$ protein GN=HSPA8 HSP7C HUMAN $70.90 \quad 100.0 \%$ Heat shock cognate $71 \mathrm{kDa}$ protein GN=HSPA8 HSP7C_HUMAN $70.90 \quad 100.0 \%$ Heat shock cognate $71 \mathrm{kDa}$ protein GN=HSPA8 HSP7C_HUMAN $70.90 \quad 100.0 \%$ Heat shock cognate $71 \mathrm{kDa}$ protein $\mathrm{GN}=$ HSPA 8 HSP7C HUMAN $70.90 \quad 100.0 \%$ Heat shock cognate $71 \mathrm{kDa}$ protein GN=HSPA8 HSP7C_HUMAN $70.90 \quad 100.0 \%$ Heat shock cognate $71 \mathrm{kDa}$ protein GN=HSPA8 HSP7C_HUMAN $70.90 \quad 100.0 \%$ Heat shock cognate $71 \mathrm{kDa}$ protein GN=HSPA8 HSP7C_HUMAN $70.90 \quad 100.0 \%$ Heat shock cognate $71 \mathrm{kDa}$ protein GN=HSPA8 HSP7C_HUMAN $70.90 \quad 100.0 \%$ Heat shock cognate $71 \mathrm{kDa}$ protein GN=HSPA8 HSP7C_HUMAN 70.90 Heat shock cognate $71 \mathrm{kDa}$ protein GN=HSPA8 HSP7C_HUMAN 70.90 Heat shock cognate $71 \mathrm{kDa}$ protein GN=HSPA8 HSP7C_HUMAN 70.90 Heat shock cognate $71 \mathrm{kDa}$ protein GN=HSPA8 HSP7C_HUMAN 70.90 Heat shock cognate $71 \mathrm{kDa}$ protein GN=HSPA8 HSP7C_HUMAN 70.90 Heat shock cognate $71 \mathrm{kDa}$ protein GN=HSPA8 HSP7C HUMAN 70.90 Heat shock cognate $71 \mathrm{kDa}$ protein GN=HSPA8 HSP7C_HUMAN 70.90 Heat shock cognate $71 \mathrm{kDa}$ protein GN=HSPA8 HSP7C_HUMAN 70.90 Heat shock cognate $71 \mathrm{kDa}$ protein GN=HSPA8 HSP7C_HUMAN 70.90 Heat shock cognate $71 \mathrm{kDa}$ protein GN=HSPA8 HSP7C_HUMAN 70.90 Heat shock cognate $71 \mathrm{kDa}$ protein GN=HSPA8 HSP7C_HUMAN 70.90 Heat shock cognate $71 \mathrm{kDa}$ protein GN=HSPA8 HSP7C_HUMAN 70.90 Heat shock cognate $71 \mathrm{kDa}$ protein GN=HSPA8 HSP7C_HUMAN 70.90 Heat shock cognate $71 \mathrm{kDa}$ protein GN=HSPA8 HSP7C_HUMAN 70.90 Heat shock cognate $71 \mathrm{kDa}$ protein GN=HSPA8 HSP7C_HUMAN 70.90 Heat shock cognate $71 \mathrm{kDa}$ protein GN=HSPA8 HSP7C_HUMAN 70.90 Heat shock cognate $71 \mathrm{kDa}$ protein GN=HSPA8 HSP7C_HUMAN 70.90 Heat shock protein $105 \mathrm{kDa}$ GN=HSPH1 HS105_HUMAN 96.87 Heat shock protein $105 \mathrm{kDa}$ GN=HSPH1 HS105_HUMAN 96.87 Heat shock protein $105 \mathrm{kDa}$ GN=HSPH1 HS105_HUMAN 96.87 Heat shock protein $105 \mathrm{kDa}$ GN=HSPH1 HS105_HUMAN 96.87 Heat shock protein $105 \mathrm{kDa}$ GN=HSPH1 HS105_HUMAN 96.87 Heat shock protein $105 \mathrm{kDa}$ GN=HSPH1 HS105_HUMAN 96.87

$100.0 \%$

$100.0 \%$

$100.0 \%$

$100.0 \%$
$0.01 \% \quad 10.1 \%$ SFDDPIVQTER $0.01 \% \quad 10.1 \%$ VLATTFDPYLGGR $0.01 \% \quad 10.1 \%$ AQFEQLCASLLAR $0.01 \% \quad 10.1 \%$ DISTTLNADEAVAR $0.01 \% \quad 10.1 \%$ GCALQCAILSPAFK $8 \quad 0.01 \% \quad 10.1 \%$ SIDLPIQSSLCR

$194 \quad 0.19 \% \quad 48.5 \%$ VEIIANDQGNR

$194 \quad 0.19 \% \quad 48.5 \%$ TTPSYVAFTDTER

47

47

47

47

47

47

47

47
47
47

47
47

$\begin{array}{rr}100.0 \% & 30 \\ 100.0 \% & 30\end{array}$

$100.0 \% \quad 30$

$100.0 \% \quad 30$

$100.0 \% \quad 30$

$100.0 \% \quad 30$

$100.0 \% \quad 30$

$100.0 \% \quad 30$

$100.0 \% \quad 30$

$100.0 \% \quad 30$

$100.0 \% \quad 30$

$100.0 \% \quad 30$

$100.0 \% \quad 30$

$100.0 \% \quad 30$

$100.0 \% \quad 30$

$100.0 \% \quad 30$

$100.0 \%$

$100.0 \%$

$194 \quad 0.19 \% \quad 48.5 \%$ TTPSYVAFTDTERLIGDAAK

$194 \quad 0.19 \% \quad 48.5 \%$ LIGDAAKNQVAMNPTNTVFDAK

$194 \quad 0.19 \% \quad 48.5 \%$ NQVAMNPTNTVFDAK

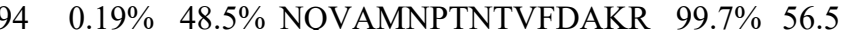

$194 \quad 0.19 \% \quad 48.5 \%$ VQVEYKGETK

$194 \quad 0.19 \% \quad 48.5 \%$ SFYPEEVSSMVLTK

$99.7 \% \quad 55.3$

$99.7 \% \quad 54.2$

$99.7 \% \quad 61.7$

$194 \quad 0.19 \% \quad 48.5 \%$ TVTNAVVTVPAYFNDSQR $\quad 99.7 \% \quad 57.2$

$194 \quad 0.19 \% \quad 48.5 \%$ TVTNAVVTVPAYFNDSQRQATK $99.7 \% \quad 34.3$

$194 \quad 0.19 \% \quad 48.5 \%$ QATKDAGTIAGLNVLR

$194 \quad 0.19 \% \quad 48.5 \%$ DAGTIAGLNVLR

$99.7 \% \quad 40.2$

$\begin{array}{ll}99.7 \% & 58.7\end{array}$

$194 \quad 0.19 \% \quad 48.5 \%$ IINEPTAAAIAYGLDK

$194 \quad 0.19 \% \quad 48.5 \%$ IINEPTAAAIAYGLDKK

$99.7 \% \quad 57.0$

$99.7 \% \quad 54.9$

$98.3 \% \quad 21.1$

$99.7 \% \quad 41.5$

$99.7 \% \quad 37.7$

$194 \quad 0.19 \% \quad 48.5 \%$ FEELNADLFR

$99.7 \% \quad 47.5$

$99.0 \% \quad 32.2$

$194 \quad 0.19 \% \quad 48.5 \%$ GTLDPVEK

$47 \quad 194 \quad 0.19 \% \quad 48.5 \%$ LDKSQIHDIVLVGGSTR

$194 \quad 0.19 \% \quad 48.5 \%$ SQIHDIVLVGGSTR

$194 \quad 0.19 \% \quad 48.5 \%$ SQIHDIVLVGGSTRIPK

$194 \quad 0.19 \% \quad 48.5 \%$ LLQDFFNGK

$194 \quad 0.19 \% \quad 48.5 \%$ LLQDFFNGKELNK

$99.7 \% \quad 34.0$

$99.7 \% \quad 37.1$

$99.7 \% \quad 46.3$

$194 \quad 0.19 \% \quad 48.5 \%$ SINPDEAVAYGAAVQAAILSGDK $\quad 99.7 \% \quad 44.4$

$194 \quad 0.19 \% \quad 48.5 \%$ RNTTIPTK

$98.7 \% \quad 24.4$

$194 \quad 0.19 \% \quad 48.5 \%$ NTTIPTKQTQTFTTYSDNQPGVLIQVYEGER $\quad 99.7 \% \quad 48.3$

$194 \quad 0.19 \% \quad 48.5 \%$ QTQTFTTYSDNQPGVLIQVYEGER

$194 \quad 0.19 \% \quad 48.5 \%$ ITITNDKGR

$194 \quad 0.19 \% \quad 48.5 \%$ LSKEDIER

$194 \quad 0.19 \% \quad 48.5 \%$ MVQEAEKYK

$194 \quad 0.19 \% \quad 48.5 \%$ NSLESYAFNMK

$194 \quad 0.19 \% \quad 48.5 \%$ VCNPIITK

$22 \quad 0.02 \% \quad 12.7 \%$ NQQITHANNTVSNFKR

$0.02 \% \quad 12.7 \%$ SVLDAAQIVGLNCLR

$0.02 \% \quad 12.7 \%$ VLGTAFDPFLGGK

$0.02 \% \quad 12.7 \%$ DISTTLNADEAVAR

$0.02 \% \quad 12.7 \%$ GCALQCAILSPAFK

$0.02 \% \quad 12.7 \%$ FVVQNVSAQK $\begin{array}{ll}99.7 \% & 54.1\end{array}$

$99.7 \% \quad 61.4$

$99.0 \% \quad 64.2$

$99.7 \% \quad 26.1$

$99.7 \% \quad 49.4$

$99.0 \% \quad 34.0$

$99.2 \% \quad 19.1 \quad 25.0$

$\begin{array}{llll}99.7 \% & 46.5 & 25.0\end{array}$

$99.7 \% \quad 45.4$

$99.7 \% \quad 51.6$

$99.7 \% \quad 57.2$

$99.7 \% \quad 36.3$
05

$0 \quad 59.1$

$\begin{array}{ll}0 & 51.5\end{array}$

$.0 \quad 40.6$

$\begin{array}{lll}0 & 30.9 & 2\end{array}$

$\begin{array}{lll}.0 & 52.5 & 20\end{array}$

$\begin{array}{lll}0 & 51.3 & 2\end{array}$

51.2

56.0

$\begin{array}{lll}.0 & 50.2 \quad 2\end{array}$

$\begin{array}{lll}0 & 54.2 & 10\end{array}$

$\begin{array}{ll}.0 & 41.0\end{array}$

0
56.0

$0 \quad 32.0$

$\begin{array}{ll}.0 & 40.2\end{array}$

$\begin{array}{lll}.0 & 49.2 \quad 12\end{array}$

$\begin{array}{lll}5.0 & 66.7 & 4 \\ 27.0 & 2\end{array}$

$\begin{array}{ll}25.0 & 54.9\end{array}$

$\begin{array}{ll}35.0 \\ 25.0 & 31.3\end{array}$

$\begin{array}{ll}31.3 \\ .0 & 45.2\end{array}$

$\begin{array}{ll}23.0 & 23.3\end{array}$

$\begin{array}{ll}5.0 & 49.6 \\ 25.0 & 34.0\end{array}$

$25.0 \quad 34.0$
25.0

22.1

$\begin{array}{ll}5.0 & 41.9\end{array}$

$\begin{array}{ll}5.0 & 44.4\end{array}$

$\begin{array}{ll}5.0 & 13.1\end{array}$

$\begin{array}{ll}25.0 & 48.3\end{array}$

$\begin{array}{ll}54.0 & 54.1 \\ 25.0 & 51.9\end{array}$

$\begin{array}{ll}25.0 & 51.9 \\ 25.0 & 17.5\end{array}$

.021 .4

$\begin{array}{ll}0 & 49.4\end{array}$

\begin{tabular}{ll}
0 & 12.2 \\
\hline & 18.3
\end{tabular}

\begin{tabular}{ll}
25.0 & 18.3 \\
\hline &
\end{tabular}

$\begin{array}{ll}25.0 & 46.1 \\ 25.0 & 29.4\end{array}$

$25.0 \quad 51.5$

0
0
0
0
0
0
0
0
1
0
4
0
0
2
3
2
6
0
0
3
5
1
3
0
0
0
4
8
2
0
0
3
0
0
0
3
0
0
0
0
0
0
0
0
0
0
0
0
0
0
0

1506.77

1475.73

1535.77

1388.72

1228.63

1487.70

2156.09

2334.18

1665.79

1821.89

1180.62

1616.79

1252.66

1982.00

2410.24

1627.91

1199.67

1659.90

1787.99

1691.73

1391.73

1480.75

1253.62

2093.06

858.46

1838.01

1481.81

1820.04

1081.57

1565.83

2260.15

930.54

3529.74

2774.33

1017.57

989.53

1125.56

1303.60

944.52

1871.95

1628.88

1321.72

1475.73

1535.77

1119.62

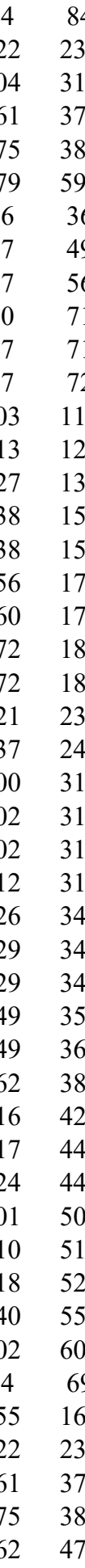

Page 77 of Table S-1-4 
Heat shock protein $105 \mathrm{kDa}$ GN=HSPH1 HS105_HUMAN $96.87 \quad 100.0 \%$ Heat shock protein $105 \mathrm{kDa}$ GN=HSPH1 HS105_HUMAN $96.87 \quad 100.0 \%$ Heat shock protein $75 \mathrm{kDa}$, mitochondrial GN=TRAP1 TRAP1_HUMAN $80.11 \quad 100.0 \%$ Heat shock protein $75 \mathrm{kDa}$, mitochondrial GN=TRAP1 TRAP1_HUMAN $80.11 \quad 100.0 \%$ Heat shock protein $75 \mathrm{kDa}$, mitochondrial GN=TRAP1 TRAP1_HUMAN $80.11 \quad 100.0 \%$ Heat shock protein $75 \mathrm{kDa}$, mitochondrial GN=TRAP1 TRAP1_HUMAN $80.11 \quad 100.0 \%$ Heat shock protein $75 \mathrm{kDa}$, mitochondrial GN=TRAP1 TRAP1_HUMAN $80.11 \quad 100.0 \%$ Heat shock protein $75 \mathrm{kDa}$, mitochondrial GN=TRAP1 TRAP1_HUMAN $80.11 \quad 100.0 \%$ Heat shock protein $75 \mathrm{kDa}$, mitochondrial GN=TRAP1 TRAP1 HUMAN $80.11 \quad 100.0 \%$ Heat shock protein $75 \mathrm{kDa}$, mitochondrial GN=TRAP1 TRAP1_HUMAN $80.11 \quad 100.0 \%$ Heat shock protein $75 \mathrm{kDa}$, mitochondrial GN=TRAP1 TRAP1_HUMAN $80.11 \quad 100.0 \%$ Heat shock protein beta-1 GN=HSPB1 HSPB1 HUMAN 22.78 Heat shock protein beta- $1 \mathrm{GN}=\mathrm{HSPB}$ Heat shock protein beta-1 GN=HSPB1 Heat shock protein beta-1 GN=HSPB Heat shock protein HSP 90-alpha GN=HSP90AA1 HS90A HUMAN $84.66 \quad 100.0 \%$ Heat shock protein HSP 90-alpha GN=HSP90AA1 HS90A HUMAN $84.66 \quad 100.0 \%$ Heat shock protein HSP 90-alpha GN=HSP90AA1 HS90A_HUMAN $84.66 \quad 100.0 \%$ Heat shock protein HSP 90-alpha GN=HSP90AA1 HS90A_HUMAN $84.66 \quad 100.0 \%$ Heat shock protein HSP 90-alpha GN=HSP90AA1 HS90A HUMAN $84.66 \quad 100.0 \%$ Heat shock protein HSP 90-alpha GN=HSP90AA1 HS90A_HUMAN $84.66 \quad 100.0 \%$ Heat shock protein HSP 90-alpha GN=HSP90AA1 HS90A HUMAN $84.66 \quad 100.0 \%$ Heat shock protein HSP 90-alpha GN=HSP90AA1 HS90A_HUMAN $84.66 \quad 100.0 \%$ Heat shock protein HSP 90-alpha GN=HSP90AA1 HS90A_HUMAN $84.66 \quad 100.0 \%$ Heat shock protein HSP 90-alpha GN=HSP90AA1 HS90A HUMAN $84.66 \quad 100.0 \%$ Heat shock protein HSP 90-alpha GN=HSP90AA1 HS90A_HUMAN $84.66 \quad 100.0 \%$ Heat shock protein HSP 90-alpha GN=HSP90AA1 HS90A_HUMAN $84.66 \quad 100.0 \%$ Heat shock protein HSP 90-alpha GN=HSP90AA1 HS90A_HUMAN $84.66 \quad 100.0 \%$ Heat shock protein HSP 90-alpha GN=HSP90AA1 HS90A_HUMAN $84.66 \quad 100.0 \%$ Heat shock protein HSP 90-alpha GN=HSP90AA1 HS90A HUMAN $84.66 \quad 100.0 \%$ Heat shock protein HSP 90-beta GN=HSP90AB1 HS90B_HUMAN $83.27 \quad 100.0 \%$ Heat shock protein HSP 90-beta GN=HSP90AB1 HS90B_HUMAN 83.27 Heat shock protein HSP 90-beta GN=HSP90AB1 HS90B_HUMAN 83.27 Heat shock protein HSP 90-beta GN=HSP90AB1 HS90B_HUMAN 83.27 Heat shock protein HSP 90-beta GN=HSP90AB1 HS90B_HUMAN 83.27 Heat shock protein HSP 90-beta GN=HSP90AB1 HS90B_HUMAN 83.27 Heat shock protein HSP 90-beta GN=HSP90AB1 HS90B_HUMAN 83.27 Heat shock protein HSP 90-beta GN=HSP90AB1 HS90B HUMAN 83.27 Heat shock protein HSP 90-beta GN=HSP90AB1 HS90B_HUMAN 83.27 Heat shock protein HSP 90-beta GN=HSP90AB1 HS90B_HUMAN 83.27 Heat shock protein HSP 90-beta GN=HSP90AB1 HS90B HUMAN 83.27 Heat shock protein HSP 90-beta GN=HSP90AB1 HS90B_HUMAN 83.27 Heat shock protein HSP 90-beta GN=HSP90AB1 HS90B HUMAN 83.2 Heat shock protein HSP 90-beta GN=HSP90AB1 HS90B_HUMAN 83.27 Heat shock protein HSP 90-beta GN=HSP90AB1 HS90B_HUMAN 83.27 Heat shock protein HSP 90-beta GN=HSP90AB1 HS90B HUMAN 83.2 Heat shock protein HSP 90-beta GN=HSP90AB1 HS90B_HUMAN 83.27
$0.02 \% \quad 12.7 \%$ FQEAEERPK

$99.7 \% \quad 42.3$

$0.02 \% \quad 12.7 \%$ IKELNNTCEPVVTQPKPK

$0.01 \% \quad 14.5 \%$ AFLDALQNQAEASSK

$0.01 \% \quad 14.5 \%$ YTLHYKTDAPLNIR

$0.01 \% \quad 14.5 \%$ TDAPLNIR

$0.01 \% \quad 14.5 \%$ GVVDSEDIPLNLSR

$0.01 \% \quad 14.5 \%$ ELLQESALIR

$0.01 \% \quad 14.5 \%$ ELLQESALIRK

$.5 \% 21$.

$99.7 \% \quad 79.8$

$99.7 \% \quad 27.2$

$99.0 \% \quad 30.6$

$99.3 \% \quad 65.7$

$99.7 \% \quad 59.9$

$97.6 \% \quad 23.1$

$0.01 \% \quad 14.5 \%$ YESSALPSGQLTSLSEYASR $\quad 99.7 \% \quad 67.8$

$0.01 \% \quad 14.5 \%$ NIYYLCAPNR

$98.8 \% \quad 24.5$

$0.01 \% \quad 14.5 \%$ TQEERAQLLQPTLEINPR

$0.00 \% \quad 25.9 \%$ LFDQAFGLPR

$0.00 \% \quad 25.9 \%$ LATQSNEITIPVTFESR

$0.00 \% \quad 25.9 \%$ AQLGGPEAAK

$0.01 \% \quad 22.0 \%$ ELISNSSDALDKIR

$0.01 \% \quad 22.0 \%$ YESLTDPSK

$0.01 \% \quad 22.0 \%$ YESLTDPSKLDSGK

$0.01 \% \quad 22.0 \%$ TLTIVDTGIGMTK

$0.01 \% \quad 22.0 \%$ ADLINNLGTIAK

$0.01 \% \quad 22.0 \%$ VILHLKEDQTEYLEER

$0.01 \% \quad 22.0 \%$ YIDQEELNK

$0.01 \% \quad 22.0 \%$ RAPFDLFENR

$0.01 \% \quad 22.0 \%$ NNIKLYVR

$0.01 \% \quad 22.0 \%$ GVVDSEDLPLNISR

$0.01 \% \quad 22.0 \%$ GVVDSEDLPLNISREMLQQSK

$0.01 \% \quad 22.0 \%$ LGIHEDSQNR

$0.01 \% \quad 22.0 \%$ DQVANSAFVER

$0.01 \% \quad 22.0 \%$ IMKAQALR

$1 \quad 0.01 \% \quad 22.0 \%$ HLEINPDHSIIETLR

$184 \quad 0.18 \% \quad 35.2 \%$ ELISNASDALDK

$184 \quad 0.18 \% \quad 35.2 \%$ ELISNASDALDKIR

$184 \quad 0.18 \% \quad 35.2 \%$ YESLTDPSK

$184 \quad 0.18 \% \quad 35.2 \%$ YESLTDPSKLDSGK

$184 \quad 0.18 \% \quad 35.2 \%$ ELKIDIIPNPQER

$184 \quad 0.18 \% \quad 35.2 \%$ IDIIPNPQER

$184 \quad 0.18 \% \quad 35.2 \%$ TLTLVDTGIGMTK

$184 \quad 0.18 \% \quad 35.2 \%$ ADLINNLGTIAK

$184 \quad 0.18 \% \quad 35.2 \%$ ADHGEPIGR

$184 \quad 0.18 \% \quad 35.2 \%$ VILHLKEDQTEYLEER

$184 \quad 0.18 \% \quad 35.2 \%$ YIDQEELNK

$184 \quad 0.18 \% \quad 35.2 \%$ NPDDITQEEYGEFYK

$184 \quad 0.18 \% \quad 35.2 \%$ RAPFDLFENK

$184 \quad 0.18 \% \quad 35.2 \%$ NNIKLYVR

$184 \quad 0.18 \% \quad 35.2 \%$ GVVDSEDLPLNISR

184

99.7

$99.7 \% \quad 59.2$

$99.7 \% \quad 31.2$

$99.7 \% \quad 30.6$

$97.4 \% \quad 15.8$

$99.7 \% \quad 63.5$

$\begin{array}{lll}97.5 \% & 26.8\end{array}$

$99.7 \% \quad 46.7$

$99.3 \% \quad 61.4$

$99.7 \% \quad 58.9$

$99.7 \% \quad 42.5$

$99.7 \% \quad 43.4$

$99.7 \% \quad 28.4$

$99.0 \% \quad 28.6$

$99.3 \% \quad 65.7$

$97.9 \% \quad 20.0$

$99.3 \% \quad 24.1$

$99.7 \% \quad 53.3$

$98.1 \% \quad 22.5$

$97.7 \% \quad 17.2$

$99.7 \% \quad 42.0$

$\begin{array}{lll}99.7 \% & 53.8\end{array}$

$\begin{array}{lll}97.5 \% & 26.8\end{array}$

$99.7 \% \quad 46.7$

$99.7 \% \quad 34.9$

$\begin{array}{lll}99.7 \% & 28.7\end{array}$

$99.3 \% \quad 61.4$

$99.7 \% \quad 58.9$

$99.7 \% \quad 53.3$

$99.7 \% \quad 39.0$

$99.7 \% \quad 42.5$

$99.7 \% \quad 43.4$

$99.7 \% \quad 46.7$

$99.7 \% \quad 37.7$

$99.0 \% \quad 28.6$

$99.3 \% \quad 65.7$
$0.00 \% \quad 25.9 \%$ VSLDVNHFAPDELTVK

$184 \quad 0.18 \% \quad 35.2 \%$ ADHGEPIGRGTK

$100.0 \% \quad 29$

$100.0 \% \quad 29$ $\begin{array}{ccc}1133.56 & 706 & 714 \\ 2095.12 & 789 & 806 \\ 1592.79 & 182 & 196 \\ 1704.91 & 327 & 340 \\ 899.49 & 333 & 340 \\ 1513.79 & 389 & 402 \\ 1171.67 & 403 & 412 \\ 1299.76 & 403 & 413 \\ 2146.03 & 470 & 489 \\ 1283.62 & 496 & 505 \\ 2136.14 & 630 & 647 \\ 1163.62 & 28 & 37 \\ 1783.92 & 97 & 112 \\ 1905.99 & 172 & 188 \\ 941.51 & 189 & 198 \\ 1560.82 & 47 & 60 \\ 1039.49 & 61 & 69 \\ 1539.75 & 61 & 74 \\ 1349.73 & 88 & 100 \\ 1242.71 & 101 & 112 \\ 2015.04 & 186 & 201 \\ 1151.56 & 284 & 292 \\ 1264.64 & 346 & 355 \\ 1019.60 & 359 & 366 \\ 1513.79 & 387 & 400 \\ 2374.19 & 387 & 407 \\ 1168.57 & 447 & 456 \\ 1235.60 & 500 & 510 \\ 946.55 & 613 & 620 \\ 1786.94 & 633 & 647 \\ 1275.64 & 42 & 53 \\ 1544.83 & 42 & 55 \\ 1039.49 & 56 & 64 \\ 1539.75 & 56 & 69 \\ 1564.87 & 70 & 82 \\ 1194.65 & 73 & 82 \\ 1349.73 & 83 & 95 \\ 1242.71 & 96 & 107 \\ 951.46 & 169 & 177 \\ 1237.63 & 169 & 180 \\ 2015.04 & 181 & 196 \\ 1151.56 & 276 & 284 \\ 1847.80 & 292 & 306 \\ 1236.64 & 338 & 347 \\ 1019.60 & 351 & 358 \\ 1513.79 & 379 & 392 \\ 2374.19 & 379 & 399 \\ & & \end{array}$

Page 78 of Table S-1-4 
Heat shock protein HSP 90-beta GN=HSP90AB1 HS90B_HUMAN $83.27 \quad 100.0 \%$ Heat shock protein HSP 90-beta GN=HSP90AB1 HS90B_HUMAN $83.27 \quad 100.0 \% \quad 29$ Heat shock protein HSP 90-beta GN=HSP90AB1 HS90B_HUMAN $83.27 \quad 100.0 \% \quad 29$ Heat shock protein HSP 90-beta GN=HSP90AB1 HS90B HUMAN $83.27 \quad 100.0 \%$ $\begin{array}{lllll}\text { Heat shock protein HSP 90-beta GN=HSP90AB1 HS90B_HUMAN } 83.27 & 100.0 \% & 29\end{array}$ Heat shock protein HSP 90-beta GN=HSP90AB1 HS90B_HUMAN $83.27 \quad 100.0 \% \quad 29$ $\begin{array}{llll}\text { Heat shock protein HSP 90-beta GN=HSP90AB1 HS90B_HUMAN } 83.27 & 100.0 \% & 29\end{array}$ $\begin{array}{lllll}\text { Heat shock protein HSP 90-beta GN=HSP90AB1 } & \text { HS90B_HUMAN } 83.27 & 100.0 \% & 29\end{array}$ Heat shock protein HSP 90-beta GN=HSP90AB1 HS90B HUMAN $83.27 \quad 100.0 \%$ Heat shock protein HSP 90-beta GN=HSP90AB1 HS90B_HUMAN $83.27 \quad 100.0 \% \quad 29$ Heat shock protein HSP 90-beta GN=HSP90AB1 HS90B_HUMAN $83.27 \quad 100.0 \% \quad 29$ Heat shock protein HSP 90-beta GN=HSP90AB1 HS90B_HUMAN $83.27 \quad 100.0 \%$ Helicase-like transcription factor GN=HLTF HLTF_HUMAN $113.93 \quad 100.0 \%$ Helicase-like transcription factor GN=HLTF HLTF_HUMAN $113.93 \quad 100.0 \%$ Helicase-like transcription factor GN=HLTF HLTF_HUMAN $113.93 \quad 100.0 \%$ Helicase-like transcription factor GN=HLTF HLTF_HUMAN $113.93 \quad 100.0 \%$ Helicase-like transcription factor GN=HLTF HLTF HUMAN $113.93 \quad 100.0 \%$ Hemoglobin subunit alpha GN=HBA1 Hemoglobin subunit alpha GN=HBA1 Hemoglobin subunit alpha GN=HBA1 Hemoglobin subunit beta $\mathrm{GN}=\mathrm{HBB}$ Hemoglobin subunit beta $\mathrm{GN}=\mathrm{HBB}$ Hemoglobin subunit beta $\mathrm{GN}=\mathrm{HBB}$ Heterochromatin protein 1-binding protein 3 GN=HP1BP3 3 HP1B__HUMAN 61.2 Heterochromatin protein 1-binding protein $3 \mathrm{GN}=\mathrm{HP} 1 \mathrm{BP} 3 \mathrm{HP} 1 \mathrm{~B} 3$ _HUMAN 61.21 Heterochromatin protein 1-binding protein $3 \mathrm{GN}=\mathrm{HP} 1 \mathrm{BP} 3 \mathrm{HP} 1 \mathrm{~B} 3$ _HUMAN 61.21 Heterochromatin protein 1-binding protein $3 \mathrm{GN}=\mathrm{HP} 1 \mathrm{BP} 3 \mathrm{HP} 1 \mathrm{~B} 3$ _HUMAN 61.21 Heterochromatin protein 1-binding protein $3 \mathrm{GN}=\mathrm{HP} 1 \mathrm{BP} 3 \mathrm{HP} 1 \mathrm{~B} 3$ _HUMAN 61.2 Heterochromatin protein 1-binding protein $3 \mathrm{GN}=\mathrm{HP} 1 \mathrm{BP} 3 \mathrm{HP} 1 \mathrm{~B} 3$ _HUMAN 61.21 Heterogeneous nuclear ribonucleoprotein A/B GN=HNRNPAB ROAA_HUMAN 36.23 Heterogeneous nuclear ribonucleoprotein A/B GN=HNRNPAB ROAA_HUMAN 36.2 ? Heterogeneous nuclear ribonucleoprotein A/B GN=HNRNPAB ROAA_HUMAN 36.23 Heterogeneous nuclear ribonucleoprotein A/B GN=HNRNPAB ROAA_HUMAN 36.23 Heterogeneous nuclear ribonucleoprotein A/B GN=HNRNPAB ROAA_HUMAN 36.23 Heterogeneous nuclear ribonucleoprotein A/B GN=HNRNPAB ROAA_HUMAN 36.23 Heterogeneous nuclear ribonucleoprotein A/B GN=HNRNPAB ROAA_HUMAN 36.23 Heterogeneous nuclear ribonucleoprotein $\mathrm{A} / \mathrm{B}$ GN=HNRNPAB ROAA_HUMAN 36.2 Heterogeneous nuclear ribonucleoprotein A/B GN=HNRNPAB ROAA_HUMAN 36.23 Heterogeneous nuclear ribonucleoprotein A/B GN=HNRNPAB ROAA_HUMAN 36.23 Heterogeneous nuclear ribonucleoprotein A/B GN=HNRNPAB ROAA_HUMAN 36.23 Heterogeneous nuclear ribonucleoprotein A/B GN=HNRNPAB ROAA_HUMAN 36.23 Heterogeneous nuclear ribonucleoprotein $\mathrm{A} / \mathrm{B}$ GN=HNRNPAB ROAA HUMAN 36.23 Heterogeneous nuclear ribonucleoprotein $\mathrm{A} / \mathrm{B}$ GN=HNRNPAB ROAA HUMAN 36.2 Heterogeneous nuclear ribonucleoprotein A0 GN=HNRNPA0 ROA0_HUMAN 30.84 Heterogeneous nuclear ribonucleoprotein $\mathrm{A} 0 \mathrm{GN}=\mathrm{HNRNPA} 0$ ROA0 HUMAN 30.84 Heterogeneous nuclear ribonucleoprotein A0 GN=HNRNPA0 ROA0_HUMAN 30.84

$100.0 \% \quad 13$

5

(1)

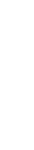

3

.

3

3
7
7

$100.0 \%-7$

$\begin{array}{ll}100.0 \% & 7 \\ 100.0 \% & 7\end{array}$

$100.0 \%$

$100.0 \%$

$100.0 \%$

$100.0 \%$

$100.0 \% \quad 13$

$100.0 \% \quad 13$

$100.0 \% \quad 13$

$100.0 \% \quad 13$

$100.0 \% \quad 13$

$100.0 \% \quad 13$

$100.0 \% \quad 13$

$100.0 \% \quad 13$

$100.0 \% \quad 13$

$100.0 \% \quad 13$

$100.0 \% \quad 13$

$100.0 \% \quad 13$

$100.0 \% \quad 13$

$100.0 \% \quad 10$

$100.0 \% \quad 10$

$100.0 \% \quad 10$
$184 \quad 0.18 \% \quad 35.2 \%$ NLKLGIHEDSTNR

$184 \quad 0.18 \% \quad 35.2 \%$ LGIHEDSTNRR

$184 \quad 0.18 \% \quad 35.2 \%$ YHTSQSGDEMTSI

$184 \quad 0.18 \% \quad 35.2 \%$ SIYYITGESK

$84 \quad 0.18 \% \quad 35.2 \%$ SIYYITGESKEQVANSAFVER

$184 \quad 0.18 \% \quad 35.2 \%$ EQVANSAFVER

$184 \quad 0.18 \% \quad 35.2 \%$ EFDGKSLVSVTK

$184 \quad 0.18 \% \quad 35.2 \%$ AKFENLCK

$184 \quad 0.18 \% \quad 35.2 \%$ IMKAQALR

$184 \quad 0.18 \% \quad 35.2 \%$ KHLEINPDHPIVETLR

$184 \quad 0.18 \% \quad 35.2 \%$ HLEINPDHPIVETLR

$9 \quad 0.01 \% \quad 6.0 \% \quad$ LSYPTFFPR

$9 \quad 0.01 \% \quad 6.0 \% \quad$ MSELSSSRPK

$0.01 \% \quad 6.0 \% \quad$ VILDEGHAIRNPNAQQTK

$9 \quad 0.01 \% \quad 6.0 \% \quad$ AGGVGLNLSAASR

$9 \quad 0.01 \% \quad 6.0 \% \quad$ INEIRTLIDL

$10 \quad 0.01 \% \quad 24.6 \%$ VLSPADKTNVK

$10 \quad 0.01 \% \quad 24.6 \%$ VGAHAGEYGAEALER

$10 \quad 0.01 \% \quad 24.6 \%$ MFLSFPTTK

$6 \quad 0.01 \% \quad 27.2 \%$ VHLTPEEK

$6 \quad 0.01 \% \quad 27.2 \%$ VNVDEVGGEALGR

$0.01 \% \quad 27.2 \%$ FFESFGDLSTPDAVMGNPK

$15 \quad 0.01 \% \quad 11.6 \%$ GKGASGSFVVVQK

$15 \quad 0.01 \% \quad 11.6 \%$ LEDVLPLAFTR

$15 \quad 0.01 \% \quad 11.6 \%$ KYVSQYYPK

$15 \quad 0.01 \% \quad 11.6 \%$ VDIRPQLLK

$15 \quad 0.01 \% \quad 11.6 \%$ AVERGQLEQITGK

$15 \quad 0.01 \% \quad 11.6 \%$ GQLEQITGK

$15 \quad 0.01 \% \quad 11.6 \%$ TRPSSTVIK

$73 \quad 0.07 \% \quad 33.7 \%$ MFVGGLSWDTSK

$0.07 \% \quad 33.7 \%$ MFVGGLSWDTSKK

$0.07 \% \quad 33.7 \%$ DLKDYFTK

$0.07 \% \quad 33.7 \%$ FGEVVDCTIK

$0.07 \% \quad 33.7 \%$ FGEVVDCTIKMDPNTGR

$0.07 \% \quad 33.7 \%$ GFGFILFK

$0.07 \% \quad 33.7 \%$ VLDQKEHR

$0.07 \% \quad 33.7 \%$ IREYFGEFGEIEAIELPMDPK $\quad 99.5 \% \quad 27.5$

$0.07 \% \quad 33.7 \%$ EYFGEFGEIEAIELPMDPK

$0.07 \% \quad 33.7 \%$ RGFVFITFK

$0.07 \% \quad 33.7 \%$ GFVFITFK

$0.07 \% \quad 33.7 \%$ GFVFITFKEEEPVK

$0.07 \% \quad 33.7 \%$ KFHTVSGSK

$0.07 \% \quad 33.7 \%$ EVYQQQQYGSGGR

$0.05 \% \quad 45.6 \%$ GHFEAFGTLTDCVVVVNPQTK $99.7 \% \quad 42.2$

$0.05 \% \quad 45.6 \%$ EDSARPGAHAK $\begin{array}{cccccc}99.7 \% & 39.6 & 25.0 & 33.5 & 13 & 0\end{array}$

$99.6 \% \quad 24.1 \quad 25.0 \quad 24.1$

$99.7 \% \quad 54.8$

$\begin{array}{lll}99.7 \% & 46.8\end{array}$

$99.7 \% 59.6$

$99.0 \% 31.9$

$94.7 \% \quad 13.9$

$98.1 \% \quad 22.5$

$99.5 \% \quad 22.6$

$99.7 \% \quad 39.5$

$99.7 \% \quad 29.7$

$99.7 \% \quad 28.5$

$99.7 \% 28.9$

$99.7 \% \quad 68.8$

$99.7 \% \quad 45.9$

$99.7 \% \quad 24.9$

$99.7 \% \quad 75.1$

$99.7 \% \quad 32.0$

$99.0 \% \quad 33.6$

$99.7 \% \quad 64.9$

$99.7 \% 77.1$

$99.7 \% \quad 58.5$

$98.1 \% \quad 25.9$

$99.7 \% \quad 40.6$

$96.3 \% \quad 14.5$

$99.7 \% \quad 35.9$

$99.7 \% \quad 45.1$

$96.3 \% \quad 25.0$

$99.7 \% \quad 37.0$

$99.7 \% \quad 58.9$

$99.0 \% \quad 36.4$

$99.3 \% \quad 62.0$

$99.7 \% \quad 45.2$

$99.0 \% \quad 37.3$

$99.0 \% \quad 53.0$

$99.7 \% \quad 55.0$

$99.7 \% \quad 31.3$

$99.0 \% \quad 19.2$

$99.7 \% \quad 60.5$

$\begin{array}{lll}99.4 \% & 29.3\end{array}$

$99.7 \% \quad 57.2$

$99.7 \% \quad 50.9$

1496.78

1141.56

1297.66

2192.94

1160.58

2391.18

1249.62

1309.70

1009.51

946.55

1911.04

1782.95

1127.59

1121.56

2004.06

1172.64

1199.70

1171.67

1529.73

1087.55

952.51

1314.66

2074.94

1263.71

1273.72

1175.61

1081.67

1428.78

973.53

988.58

1343.63

1455.73

1029.53

1167.57

1954.90

928.53

1024.55

2499.21

2230.03

1114.64

958.54

1669.88

990.54

1499.69

1690.91

2319.14

$\begin{array}{llll}99.7 \% & 29.6 & 25.0 & 21.7\end{array}$

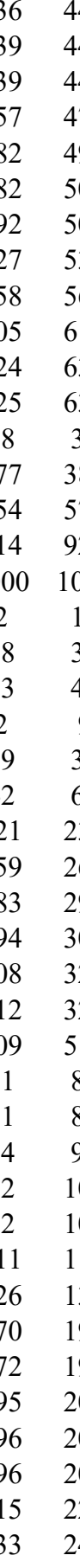

Page 79 of Table S-1-4 
Heterogeneous nuclear ribonucleoprotein A0 GN=HNRNPA0 ROA0_HUMAN $30.84 \quad 100.0 \%$ Herogencos Heterogeneous nuclear ribonucleoprotein A0 GN=HNRNPA0 ROA0_HUMAN $30.84 \quad 100.0 \%$ Heterogeneous nuclear ribonucleoprotein $\mathrm{A} 0 \mathrm{GN}=\mathrm{HNRNPA0}$ ROA0 HUMAN $30.84 \quad 100.0^{\circ}$ Heterogeneous nuclear ribonucleoprotein $\mathrm{A} 0 \mathrm{GN}=\mathrm{HNRNPA0}$ ROA0_HUMAN $30.84 \quad 100.0 \%$ Heterogeneous nuclear ribonucleoprotein A0 GN=HNRNPA0 ROA0_HUMAN $30.84 \quad 100.0 \%$ Heterogeneous nuclear ribonucleoprotein $\mathrm{A0} \mathrm{GN}=\mathrm{HNRNPA0}$ ROA0 HUMAN $30.84 \quad 100.0 \%$ Heterogeneous nuclear ribonucleoprotein A0 GN=HNRNPA0 ROA0_HUMAN $30.84 \quad 100.0 \%$ Heterogeneous nuclear ribonucleoprotein A1 GN=HNRNPA1 ROA1 HUMAN 38.75 Heterogeneous nuclear ribonucleoprotein A1 GN=HNRNPA1 ROA1_HUMAN 38.75 Heterogeneous nuclear ribonucleoprotein A1 GN=HNRNPA1 ROA1_HUMAN 38.75 Heterogeneous nuclear ribonucleoprotein A1 GN=HNRNPA1 ROA1_HUMAN 38.75 Heterogeneous nuclear ribonucleoprotein A1 GN=HNRNPA1 ROA1_HUMAN 38.75 Heterogeneous nuclear ribonucleoprotein A1 GN=HNRNPA1 ROA1_HUMAN 38.75 Heterogeneous nuclear ribonucleoprotein A1 GN=HNRNPA1 ROA1_HUMAN 38.75 Heterogeneous nuclear ribonucleoprotein A1 GN=HNRNPA1 ROA1_HUMAN 38.75 Heterogeneous nuclear ribonucleoprotein A1 GN=HNRNPA1 ROA1_HUMAN 38.75 Heterogeneous nuclear ribonucleoprotein A1 GN=HNRNPA1 ROA1_HUMAN 38.75 Heterogeneous nuclear ribonucleoprotein A1 GN=HNRNPA1 ROA1_HUMAN 38.75 Heterogeneous nuclear ribonucleoprotein A1 GN=HNRNPA1 ROA1_HUMAN 38.75 Heterogeneous nuclear ribonucleoprotein A1 GN=HNRNPA1 ROA1_HUMAN 38.75 Heterogeneous nuclear ribonucleoprotein A1 GN=HNRNPA1 ROA1_HUMAN 38.75 Heterogeneous nuclear ribonucleoprotein A1 GN=HNRNPA1 ROA1_HUMAN 38.75 Heterogeneous nuclear ribonucleoprotein A1 GN=HNRNPA1 ROA1_HUMAN 38.75 Heterogeneous nuclear ribonucleoprotein A1 GN=HNRNPA1 ROA1_HUMAN 38.75 Heterogeneous nuclear ribonucleoprotein A1 GN=HNRNPA1 ROA1_HUMAN 38.75 Heterogeneous nuclear ribonucleoprotein A1 GN=HNRNPA1 ROA1_HUMAN 38.75 Heterogeneous nuclear ribonucleoprotein A1 GN=HNRNPA1 ROA1_HUMAN 38.75 Heterogeneous nuclear ribonucleoprotein A1 GN=HNRNPA1 ROA1_HUMAN 38.75 Heterogeneous nuclear ribonucleoprotein $\mathrm{A} 1 \mathrm{GN}=\mathrm{HNRNPA} 1 \mathrm{ROA} 1$ HUMAN 38.75 Heterogeneous nuclear ribonucleoprotein A3 GN=HNRNPA3 ROA3_HUMAN 39.60 Heterogeneous nuclear ribonucleoprotein A3 GN=HNRNPA3 ROA3_HUMAN 39.60 Heterogeneous nuclear ribonucleoprotein A3 GN=HNRNPA3 ROA3_HUMAN 39.60 Heterogeneous nuclear ribonucleoprotein A3 GN=HNRNPA3 ROA3_HUMAN 39.60 Heterogeneous nuclear ribonucleoprotein A3 GN=HNRNPA3 ROA3_HUMAN 39.60 Heterogeneous nuclear ribonucleoprotein A3 GN=HNRNPA3 ROA3_HUMAN 39.60 Heterogeneous nuclear ribonucleoprotein A3 GN=HNRNPA3 ROA3_HUMAN 39.60 Heterogeneous nuclear ribonucleoprotein $\mathrm{A} 3 \mathrm{GN}=\mathrm{HNRNPA} 3 \mathrm{ROA} 3$ HUMAN 39.60 Heterogeneous nuclear ribonucleoprotein A3 GN=HNRNPA3 ROA3_HUMAN 39.60 Heterogeneous nuclear ribonucleoprotein A3 GN=HNRNPA3 ROA3_HUMAN 39.60 Heterogeneous nuclear ribonucleoprotein A3 GN=HNRNPA3 ROA3_HUMAN 39.60 Heterogeneous nuclear ribonucleoprotein A3 GN=HNRNPA3 ROA3_HUMAN 39.60 Heterogeneous nuclear ribonucleoprotein A3 GN=HNRNPA3 ROA3 HUMAN 39.60 Heterogeneous nuclear ribonucleoprotein A3 GN=HNRNPA3 ROA3_HUMAN 39.60 Heterogeneous nuclear ribonucleoprotein A3 GN=HNRNPA3 ROA3_HUMAN 39.60 Heterogeneous nuclear ribonucleoprotein A3 GN=HNRNPA3 ROA3_HUMAN 39.60 Heterogeneous nuclear ribonucleoprotein A3 GN=HNRNPA3 ROA3_HUMAN 39.60

13
13
13

13

$100.0 \% \quad 19$ $100.0 \% \quad 19$ $100.0 \% \quad 19$ $100.0 \% \quad 19$ $100.0 \% \quad 19$ $100.0 \% \quad 19$ $100.0 \% \quad 19$ $100.0 \% \quad 19$ $100.0 \% \quad 19$ $100.0 \% \quad 19$ $100.0 \% \quad 19$ $100.0 \% \quad 19$ $100.0 \% \quad 19$ $100.0 \% \quad 19$ $100.0 \% \quad 19$ $100.0 \% \quad 19$ $100.0 \% \quad 19$ $100.0 \% \quad 19$ $100.0 \% \quad 19$ $100.0 \% \quad 19$ $100.0 \% \quad 19$ $100.0 \% \quad 19$ $100.0 \% \quad 22$ $100.0 \% \quad 22$ $100.0 \% \quad 22$ $100.0 \% \quad 22$ $100.0 \% \quad 22$ $00.0 \% \quad 22$ $100.0 \% \quad 22$ $100.0 \% \quad 22$ $100.0 \% \quad 22$ $100.0 \% \quad 22$ $00.0 \% \quad 22$ $100.0 \% \quad 22$ $100.0 \% \quad 22$ $100.0 \% \quad 22$ $100.0 \% \quad 22$ $100.0 \% \quad 22$ $100.0 \% \quad 22$
$54 \quad 0.05 \% \quad 45.6 \%$ KLFVGGLK
$0.05 \% \quad 45.6 \%$ GFGFVYFQNHDAADK $\quad 99.7 \% \quad 49.4$

$0.05 \% \quad 45.6 \%$ AVPKEDIYSGGGGGGSR $99.7 \% \quad 42.7$

$0.05 \% \quad 45.6 \%$ EDIYSGGGGGGSR

$194 \quad 0.19 \% \quad 52.4 \%$ SESPKEPEQLR

$194 \quad 0.19 \% \quad 52.4 \%$ KLFIGGL SFETTDESLR

$194 \quad 0.19 \% \quad 52.4 \%$ LFIGGLSFETTDESLR

$194 \quad 0.19 \% \quad 52.4 \%$ SHFEQWGTLTDCVVMR

$194 \quad 0.19 \% \quad 52.4 \%$ GFGFVTYATVEEVDAAMNARPHK

$194 \quad 0.19 \% \quad 52.4 \%$ EDSQRPGAHLTVK

$194 \quad 0.19 \% \quad 52.4 \%$ EDSQRPGAHLTVKK

$194 \quad 0.19 \% \quad 52.4 \%$ KIFVGGIK

$194 \quad 0.19 \% \quad 52.4 \%$ IFVGGIKEDTEEHHLR

$194 \quad 0.19 \% \quad 52.4 \%$ EDTEEHHLR

$194 \quad 0.19 \% \quad 52.4 \%$ EDTEEHHLRDYFEQYGK

$194 \quad 0.19 \% \quad 52.4 \%$ DYFEQYGK

$194 \quad 0.19 \% \quad 52.4 \%$ DYFEQYGKIEVIEIMTDR

$194 \quad 0.19 \% \quad 52.4 \%$ IEVIEIMTDR

$99.7 \% 56.4$

$99.7 \% \quad 40.1$

$99.7 \% 41$.

$99.7 \% \quad 37.1$

$99.7 \% \quad 55.8$

$99.7 \% \quad 45.7$

$99.7 \% \quad 50.2$

$99.7 \% \quad 36.5$

$98.9 \% \quad 35.8$

$99.3 \% \quad 42.6$

$99.7 \% 56.6$

$99.0 \% 33.6$

$99.7 \% \quad 32.5$ $99.7 \% \quad 57.1$

$194 \quad 0.19 \% \quad 52.4 \%$ GFAFVTFDDHDSVDKIVIQK $99.2 \% \quad 27.9$

$194 \quad 0.19 \% \quad 52.4 \%$ YHTVNGHNCEVR

$194 \quad 0.19 \% \quad 52.4 \%$ YHTVNGHNCEVRK

$194 \quad 0.19 \% \quad 52.4 \%$ GGGFGGNDNFGR

$99.7 \% \quad 54.8$

$99.7 \% \quad 35.2$

$99.7 \% \quad 56.0$

$194 \quad 0.19 \% \quad 52.4 \%$ NQGGYGGSSSSSSYGSGR 99.7\% 84.7

$164 \quad 0.16 \% \quad 49.5 \%$ GEEGHDPKEPEQLR

$99.7 \% \quad 45.9$

$164 \quad 0.16 \% \quad 49.5 \%$ KLFIGGLSFETTDDSLR

$99.7 \% \quad 37.7$

$64 \quad 0.16 \% \quad 49.5 \%$ LFIGGLSFETTDDSLR

$99.7 \% 80.3$

$164 \quad 0.16 \% \quad 49.5 \%$ LFIGGLSFETTDDSLREHFEK $99.7 \% \quad 41.5$

$164 \quad 0.16 \% \quad 49.5 \%$ WGTLTDCVVMR

$99.7 \% \quad 51.6$

$64 \quad 0.16 \% \quad 49.5 \%$ WGTLTDCVVMRDPQTK $\quad 99.7 \% \quad 40.5$

$164 \quad 0.16 \% \quad 49.5 \%$ GFGFVTYSCVEEVDAAMCARPHK $\quad 99.3 \% \quad 19.8$

$164 \quad 0.16 \% \quad 49.5 \%$ AVSREDSVKPGAHLTVK $99.7 \% \quad 28.9$

$164 \quad 0.16 \% \quad 49.5 \%$ EDSVKPGAHLTVK

$164 \quad 0.16 \% \quad 49.5 \%$ EDSVKPGAHLTVKK

$164 \quad 0.16 \% \quad 49.5 \%$ KIFVGGIK

$164 \quad 0.16 \% \quad 49.5 \%$ IFVGGIKEDTEEYNLR

$164 \quad 0.16 \% \quad 49.5 \%$ EDTEEYNLR

$164 \quad 0.16 \% \quad 49.5 \%$ EDTEEYNLRDYFEK

$164 \quad 0.16 \% \quad 49.5 \%$ YGKIETIEVMEDR

$164 \quad 0.16 \% \quad 49.5 \%$ IETIEVMEDR

$164 \quad 0.16 \% \quad 49.5 \%$ IETIEVMEDRQSGK
$99.7 \% \quad 59.3$

$99.7 \% \quad 51.6$

$98.9 \% \quad 35.8$

$99.7 \% \quad 57.8$

$99.7 \% \quad 47.1$

$99.7 \% \quad 59.2$

$99.7 \% \quad 59.4$

$99.7 \% \quad 62.0$

$99.7 \% \quad 34.5$ $\begin{array}{lllll}0.19 \% & 52.4 \% & \text { GFAFVTFDDHDSVDK } \quad 99.7 \% & 55.3\end{array}$
178.04

1159.63

1715.78

2184.09

1606.78

1211.53

1192.51

1299.65

1913.00

1784.91

1965.89

2526.21

1437.74

1565.84

861.56

1879.97

1165.52

2195.96

1049.46

2265.07

1218.64

1855.86

1699.76

2281.15

1485.67

1613.76

1154.50

1628.78

1694.70

1620.76

1898.99

1770.89

2441.20

1337.63

1922.91

2647.17

1793.99

1380.75

1508.84

861.56

1882.95

1168.5

1850.81

1582.78

1234.60 1634.81

9 106 $7 \quad 126$ $\begin{array}{ll}27 & 137\end{array}$ $140 \quad 159$ $173 \quad 189$ $77 \quad 189$ 284
14 $15 \quad 3$ $16 \quad 31$ 47 $93 \quad 105$ $93 \quad 106$ $106 \quad 113$ $107 \quad 122$ $114 \quad 122$ $14 \quad 130$ $123 \quad 130$ $131 \quad 140$ $146 \quad 161$ $147 \quad 161$ 
Heterogeneous nuclear ribonucleoprotein A3 GN=HNRNPA3 ROA3_HUMAN $39.60 \quad 100.0 \% \quad 22$ Heterogeneous nuclear ribonucleoprotein A3 GN=HNRNPA3 ROA3_HUMAN $39.60 \quad 100.0 \% \quad 22$ Heterogeneous nuclear ribonucleoprotein A3 GN=HNRNPA3 ROA3_HUMAN $39.60 \quad 100.0 \% \quad 22$ Heterogeneous nuclear ribonucleoprotein A3 GN=HNRNPA3 ROA3_HUMAN $39.60 \quad 100.0 \% \quad 22$ Heterogeneous nuclear ribonucleoprotein A3 GN=HNRNPA3 ROA3_HUMAN $39.60 \quad 100.0 \% \quad 22$ Heterogeneous nuclear ribonucleoprotein A3 GN=HNRNPA3 ROA3_HUMAN $39.60 \quad 100.0 \% \quad 22$ Heterogeneous nuclear ribonucleoprotein D0 GN=HNRNPD HNRPD_HUMAN $38.43 \quad 100.0 \% \quad 14$ Heterogeneous nuclear ribonucleoprotein D0 GN=HNRNPD HNRPD_HUMAN $38.43 \quad 100.0 \% \quad 1$ Heterogeneous nuclear ribonucleoprotein D0 GN=HNRNPD HNRPD_HUMAN $38.43 \quad 100.0 \%$ Heterogeneous nuclear ribonucleoprotein D0 GN=HNRNPD HNRPD_HUMAN $38.43 \quad 100.0 \%$ Heterogeneous nuclear ribonucleoprotein D0 GN=HNRNPD HNRPD_HUMAN $38.43 \quad 100.0 \%$ Heterogeneous nuclear ribonucleoprotein D0 GN=HNRNPD HNRPD HUMAN $38.43 \quad 100.0^{\circ}$ Heterogeneous nuclear ribonucleoprotein D0 GN=HNRNPD HNRPD_HUMAN $38.43 \quad 100.0 \%$ Heterogeneous nuclear ribonucleoprotein D0 GN=HNRNPD HNRPD_HUMAN $38.43 \quad 100.0 \%$ Heterogeneous nuclear ribonucleoprotein D0 GN=HNRNPD HNRPD_HUMAN $38.43 \quad 100.0 \%$ Heterogeneous nuclear ribonucleoprotein D0 GN=HNRNPD HNRPD_HUMAN $38.43 \quad 100.0 \%$ Heterogeneous nuclear ribonucleoprotein D0 GN=HNRNPD HNRPD HUMAN $38.43 \quad 100.0 \%$ Heterogeneous nuclear ribonucleoprotein D0 GN=HNRNPD HNRPD_HUMAN $38.43 \quad 100.0 \%$ Heterogeneous nuclear ribonucleoprotein D0 GN=HNRNPD HNRPD_HUMAN $38.43 \quad 100.0 \%$ Heterogeneous nuclear ribonucleoprotein D0 GN=HNRNPD HNRPD_HUMAN $38.43 \quad 100.0 \%$ Heterogeneous nuclear ribonucleoprotein D0 GN=HNRNPD HNRPD_HUMAN $38.43 \quad 100.0 \%$ Heterogeneous nuclear ribonucleoprotein D0 GN=HNRNPD HNRPD HUMAN $38.43 \quad 100.0 \%$ Heterogeneous nuclear ribonucleoprotein D-like GN=HNRNPDL HNRDL_HUMAN $46.44 \quad 100.0 \%$ Heterogeneous nuclear ribonucleoprotein D-like GN=HNRNPDL HNRDL_HUMAN $46.44 \quad 100.0 \%$ Heterogeneous nuclear ribonucleoprotein D-like GN=HNRNPDL HNRDL_HUMAN $46.44 \quad 100.0 \%$ Heterogeneous nuclear ribonucleoprotein D-like GN=HNRNPDL HNRDL_HUMAN $46.44 \quad 100.0 \%$ Heterogeneous nuclear ribonucleoprotein D-like GN=HNRNPDL HNRDL_HUMAN $46.44 \quad 100.0 \%$ Heterogeneous nuclear ribonucleoprotein D-like GN=HNRNPDL HNRDL_HUMAN $46.44 \quad 100.0 \%$ Heterogeneous nuclear ribonucleoprotein D-like GN=HNRNPDL HNRDL_HUMAN $46.44 \quad 100.0 \%$ Heterogeneous nuclear ribonucleoprotein D-like GN=HNRNPDL HNRDL HUMAN $46.44 \quad 100.0 \%$ Heterogeneous nuclear ribonucleoprotein D-like GN=HNRNPDL HNRDL_HUMAN $46.44 \quad 100.0 \%$ Heterogeneous nuclear ribonucleoprotein D-like GN=HNRNPDL HNRDL_HUMAN $46.44 \quad 100.0 \%$ Heterogeneous nuclear ribonucleoprotein D-like GN=HNRNPDL HNRDL HUMAN $46.44 \quad 100.0^{\circ}$ Heterogeneous nuclear ribonucleoprotein D-like GN=HNRNPDL HNRDL_HUMAN $46.44 \quad 100.0 \%$ Heterogeneous nuclear ribonucleoprotein D-like GN=HNRNPDL HNRDL_HUMAN $46.44 \quad 100.0 \%$ Heterogeneous nuclear ribonucleoprotein D-like GN=HNRNPDL HNRDL_HUMAN $46.44 \quad 100.0 \%$ Heterogeneous nuclear ribonucleoprotein D-like GN=HNRNPDL HNRDL_HUMAN $46.44 \quad 100.0 \%$ Heterogeneous nuclear ribonucleoprotein D-like GN=HNRNPDL HNRDL HUMAN $46.44 \quad 100.0 \%$ Heterogeneous nuclear ribonucleoprotein F GN=HNRNPF HNRPF_HUMAN $45.67 \quad 100.0 \%$ Heterogeneous nuclear ribonucleoprotein F GN=HNRNPF HNRPF_HUMAN $45.67 \quad 100.0 \%$ Heterogeneous nuclear ribonucleoprotein F GN=HNRNPF HNRPF_HUMAN $45.67 \quad 100.0 \%$ Heterogeneous nuclear ribonucleoprotein F GN=HNRNPF HNRPF_HUMAN $45.67 \quad 100.0 \%$ Heterogeneous nuclear ribonucleoprotein F GN=HNRNPF HNRPF HUMAN $45.67 \quad 100.0 \%$ Heterogeneous nuclear ribonucleoprotein F GN=HNRNPF HNRPF_HUMAN $45.67 \quad 100.0 \%$ Heterogeneous nuclear ribonucleoprotein $\mathrm{F}$ GN=HNRNPF HNRPF_HUMAN $45.67 \quad 100.0 \%$ Heterogeneous nuclear ribonucleoprotein F GN=HNRNPF HNRPF HUMAN $45.67 \quad 100.0^{\circ}$; Heterogeneous nuclear ribonucleoprotein F GN=HNRNPF HNRPF_HUMAN $45.67 \quad 100.0 \%$

\begin{tabular}{ll}
19 & 19 \\
6 & 19 \\
\hline & 19
\end{tabular}

$64 \quad 0.16 \% \quad 49.5 \%$ RGFAFVTFDDHDTVDK

$164 \quad 0.16 \% \quad 49.5 \%$ GFAFVTFDDHDTVDKIVVQK

$0.16 \% \quad 49.5 \%$ YHTINGHNCEVK

$\begin{array}{llllll}0.16 \% & 49.5 \% & \text { SSGSPYGGGYGSGGGSGGYGSR } & 99.7 \% & 75.5 \\ 0.08 \% & 41.4 \% & \text { IDASKNEEDEGHSNSSPR } & 99.7 \% & 64.6\end{array}$

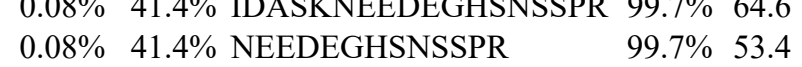

$0.08 \% \quad 41.4 \%$ HSEAATAQREEWK

$0.08 \% \quad 41.4 \%$ DLKDYFSK

$0.08 \% \quad 41.4 \%$ FGEVVDCTLK

$0.08 \% \quad 41.4 \%$ GFGFVLFK

$0.08 \% \quad 41.4 \%$ ESESVDKVMDQK

$0.08 \% \quad 41.4 \%$ IFVGGLSPDTPEEK

$0.08 \% \quad 41.4 \%$ IFVGGLSPDTPEEKIR

$\begin{array}{ll}0.08 \% & 41.4 \% \\ 0.08 \% & 41.4 \% \text { GFFGFITFKEEEPVK }\end{array}$

$0.08 \% \quad 41.4 \%$ KYHNVGLSK

$0.08 \% \quad 41.4 \%$ YHNVGLSK

$0.09 \% \quad 32.9 \%$ QLAPLLPSLAPSSAR

$0.09 \% \quad 32.9 \%$ HVTAQQPSR

$0.09 \% \quad 32.9 \%$ LAGGAAIKGGR

$0.09 \% \quad 32.9 \%$ MFIGGLSWDTSK

$0.09 \% \quad 32.9 \%$ MFIGGLSWDTSKK

$0.09 \% \quad 32.9 \%$ KDLTEYLSR

$0.09 \% \quad 32.9 \%$ DLTEYLSR

$0.09 \% \quad 32.9 \%$ FGEVVDCTIK

$0.09 \% \quad 32.9 \%$ FGEVVDCTIKTDPVTGR

$0.09 \% \quad 32.9 \%$ GFGFVLFK

$0.09 \% \quad 32.9 \%$ DAASVDKVLELK

$0.09 \% \quad 32.9 \%$ VLELKEHK

$0.09 \% \quad 32.9 \%$ VFVGGLSPDTSEEQIK

$0.09 \% \quad 32.9 \%$ GFCFITYTDEEPVK

$0.09 \% \quad 32.9 \%$ GFCFITYTDEEPVKK

$0.09 \% \quad 32.9 \%$ EVYRQQQQQQK

列

$\begin{array}{ll}0.04 \% & 33.0 \% \text { HSGPNSADSANDGFVR } \\ 0.04 \% & 33.0 \% \text { ITGEAFVQFASQELAEK }\end{array}$

$\begin{array}{lll}0.04 \% & 33.0 \% & \text { ITGEAFVQFASQELAI } \\ 0.04 \% & 33.0 \% & \text { YIEVFKSSQEEVR }\end{array}$

$0.04 \% \quad 33.0 \%$ SSQEEVRSYSDPPLK

$0.04 \% 33.0 \%$ SYSDPPLK

$\begin{array}{lllll}10 & 36 & 0.04 \% & 33.0 \% & \text { ATENDIYNFFSPLNPVR } \\ 10 & 36 & 0.04 \% & 33.0 \% \text { VHIEIGPDGR }\end{array}$
$99.7 \% \quad 38.7$ $99.7 \% \quad 42.9$

$99.7 \% \quad 60.5$

$99.7 \% \quad 52.8$

$99.7 \% \quad 40.9$

$99.7 \% 75.5$

$\begin{array}{lll}99.5 \% & 21.1\end{array}$

$99.7 \% \quad 33.7$

$99.7 \% \quad 31.1$

$99.0 \% \quad 27.9$

$99.3 \% \quad 62.0$

$99.0 \% \quad 38.4$

$99.7 \% \quad 59.5$

$99.7 \% \quad 57.1$

$99.7 \% \quad 63.3$

$\begin{array}{rr}99.7 \% & 49.4 \\ 99.7 \% & 53.8\end{array}$

$\begin{array}{ll}99.7 \% & 53.8 \\ 99.7 \% & 42.9\end{array}$

$99.0 \% \quad 41.3$

$99.7 \% \quad 25.6$

$99.7 \% \quad 47.0$

$99.7 \% \quad 63.9$

$99.7 \% \quad 45.8$

$99.7 \% \quad 52.6$

$99.7 \% \quad 49.4$

$99.0 \% \quad 60.2$

$99.3 \% \quad 62.0$

1869.88

1713.78

2281.15

1471.67

1599.77

1910.79

1971.86

1457.59

1542.73

1355.67

1499.76

1015.51

1167.57

1919.99

914.51

1394.65

1488.76

1757.94

2176.97

1730.85

1045.58

917.48

1520.88

1023.53

970.58

1341.65

1469.75

1124.59

996.50

1167.57

1893.94

914.51

1287.72

995.59

1705.86

1705.78

$\begin{array}{llll}99.7 \% & 53.9 & 25.0 & 44.8\end{array}$

$\begin{array}{llll}99.7 \% & 56.0 & 25.0 & 56.0\end{array}$

$\begin{array}{llll}9.7 \% & 55.8 & 25.0 & 55.8\end{array}$

$99.7 \% \quad 71.9 \quad 25.0 \quad 63.1$

$99.7 \% \quad 57.2 \quad 25.0 \quad 55.4$

$\begin{array}{lllll}99.7 \% & 58.1 & 25.0 & 54.9 & 11\end{array}$

$\begin{array}{lllll}99.7 \% & 54.7 & 25.0 & 52.0 & 2\end{array}$

$\begin{array}{llll}96.6 \% & 17.4 & 25.0 & 13.8 \\ 99.0 \% & 29.1 & 25.0 & 22.4\end{array}$

$\begin{array}{llll}99.7 \% & 36.1 & 25.0 & 36.1 \\ 99.7 \% & 56.1 & 25.0 & 56.1\end{array}$

$\begin{array}{llll}99.7 \% & 54.4 & 25.0 & 53.5\end{array}$ $\begin{array}{cc}67 & 182 \\ 68 & 182 \\ 68 & 187 \\ 88 & 199 \\ 88 & 200 \\ 55 & 376 \\ 58 & 85 \\ 73 & 85 \\ 36 & 98 \\ 99 & 110 \\ 99 & 111 \\ 12 & 119 \\ 20 & 129 \\ 20 & 136 \\ 39 & 146 \\ 47 & 158 \\ 84 & 197 \\ 84 & 199 \\ 00 & 218 \\ 24 & 237 \\ 43 & 251 \\ 44 & 251 \\ 37 & 51 \\ 50 & 68 \\ 59 & 79 \\ 50 & 161 \\ 50 & 162 \\ 62 & 170 \\ 63 & 170 \\ 71 & 180 \\ 71 & 187 \\ 90 & 197 \\ 98 & 209 \\ 05 & 212 \\ 35 & 250 \\ 75 & 288 \\ 75 & 289 \\ 12 & 322 \\ 53 & 68 \\ 79 & 114 \\ 51 & 167 \\ 80 & 192 \\ 86 & 200 \\ 93 & 200 \\ 76 & 294 \\ 00 & 316 \\ 17 & 326 \\ & \end{array}$

Page 81 of Table S-1-4 
$\begin{array}{cccc}36 & 0.04 \% & 33.0 \% & \text { VTGEADVEFATHEEAVAAMS } \\ 129 & 0.13 \% & 47.7 \% & \text { GLPWSCSADEVQR }\end{array}$

$99.7 \% \quad 35.4$ $99.7 \% 57.1$ $99.7 \% \quad 64.1$ $99.7 \% \quad 45.8$

$129 \quad 0.13 \% \quad 47.7 \%$ IQNGAQGIR

$129 \quad 0.13 \% \quad 47.7 \%$ EGRPSGEAFVELESEDEVK

$129 \quad 0.13 \% \quad 47.7 \%$ HTGPNSPDTANDGFVR

$129 \quad 0.13 \% \quad 47.7 \%$ GLPFGCSK

$129 \quad 0.13 \% \quad 47.7 \%$ STGEAFVQFASQEIAEK

$129 \quad 0.13 \% \quad 47.7 \%$ IGHRYIEIFK

$129 \quad 0.13 \% \quad 47.7 \%$ YIEIFKSSR

$129 \quad 0.13 \% \quad 47.7 \%$ THYDPPRK

$129 \quad 0.13 \% \quad 47.7 \%$ DLNYCFSGMSDHR

$99.7 \% \quad 57.7$

$\begin{array}{llll}99.7 \% & 57.7\end{array}$

$98.9 \% \quad 23.9$

$129 \quad 0.13 \% \quad 47.7 \%$ YGDGGSTFQSTTGHCVHM

$129 \quad 0.13 \% \quad 47.7 \%$ GLPYRATENDIYNFFSPLNPVR

$129 \quad 0.13 \% \quad 47.7 \%$ ATENDIYNFFSPLNPVR

$\begin{array}{llllll}129 & 0.13 \% & 47.7 \% & \text { VHIEIGPDGR } & 99.7 \% & 54.4 \\ 129 & 0.13 \% & 47.7 \% \text { VTGEADVEFATHEDAVAAMSK } & 99.7 \% & 48.6\end{array}$

$99.7 \% \quad 55.8$ $99.7 \% \quad 31.3$ $99.7 \% 36.4$ $96.8 \% \quad 15.5$ $99.7 \% \quad 52.4$
$0.13 \% \quad 47.7 \%$ YVELFLNSTAGASGGAYEHR $\quad 99.7 \% \quad 48.6$

$0.00 \% \quad 26.9 \%$ HTGPNSPDTANDGFVR

$0.00 \% \quad 26.9 \%$ GLPFGCSK

$99.7 \% 57.7$

$98.9 \% 23.9$

$0.00 \% \quad 26.9 \%$ STGEAFVQFASQEIAEK

$0.00 \% \quad 26.9 \%$ IGHRYIEIFK

$0.00 \% \quad 26.9 \%$ YIEIFKSSR

$0.00 \% \quad 26.9 \%$ THYDPPRK

$99.7 \% 55.8$

$99.7 \% \quad 31.3$

$99.7 \% 36.4$

$\begin{array}{lll}96.8 \% & 15.5\end{array}$

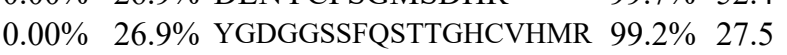

$0.00 \% \quad 26.9 \%$ ATENDIYNFFSPLNPMR $\quad 99.7 \% \quad 50.7$

$0.00 \% \quad 26.9 \%$ VHIEIGPDGR

$0.07 \% \quad 44.5 \%$ HNGPNDASDGTVR

$0.07 \% \quad 44.5 \%$ GLPFGCSK

$0.07 \% \quad 44.5 \%$ STGEAFVQFASK

$0.07 \% \quad 44.5 \%$ EIAENALGK

$0.07 \% \quad 44.5 \%$ GFYDPPRR

$0.07 \% \quad 44.5 \%$ LLGQRPGPYDRPIGGR

$0.07 \% \quad 44.5 \%$ ATENDIANFFSPLNPIR

$0.07 \% \quad 44.5 \%$ VHIDIGADGR

$99.7 \% 54.4$

$\begin{array}{lll}99.7 \% & 59.1\end{array}$

$98.9 \% \quad 23.9$

$99.7 \% \quad 59.9$

$99.7 \% \quad 49.5$

$99.0 \% \quad 22.5$

$94.9 \% \quad 13.9$

$\begin{array}{llll}99.7 \% & 59.0\end{array}$

$99.7 \% 58.8$

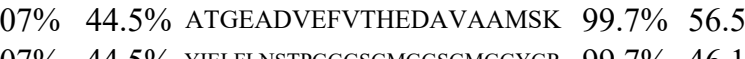

$0.07 \% \quad 44.5 \%$ DGMDNQGGYGSVGR

$0.10 \% \quad 40.2 \%$ RPAEDMEEEQAFKR

$0.10 \% \quad 40.2 \%$ SRNTDEMVELR

$0.10 \% \quad 40.2 \%$ NTDEMVELR

$0.10 \% \quad 40.2 \%$ NAGAVIGKGGK

$99.7 \% \quad 50.7$

$\begin{array}{llll}99.7 \% & 68.7\end{array}$

$99.7 \% \quad 49.9$

$99.7 \% \quad 61.4$

$99.7 \% 39.0$

$\begin{array}{lllll}0.10 \% & 40.2 \% & \text { ALRTDYNASVSVPDSGPER } & 99.7 \% & 48.7 \\ 0.10 \% & 40.2 \% & \text { TDYNASVSVPDSSGPER } & 99.7 \% & 47.6\end{array}$

$\begin{array}{llll}0.10 \% & 40.2 \% & \text { ILSISADIETIGEILKK } \quad 99.7 \% & 57.0\end{array}$ $0.10 \% \quad 40.2 \%$ LLIHQSLAGGIIGVK
$99.7 \% \quad 42.6$

$\begin{array}{ccc}2208.01 & 327 & 347 \\ 1504.69 & 17 & 29 \\ 1740.85 & 30 & 44 \\ 956.53 & 36 & 44 \\ 2106.98 & 50 & 68 \\ 1684.77 & 99 & 114 \\ 865.42 & 117 & 124 \\ 1841.89 & 151 & 167 \\ 1275.72 & 176 & 185 \\ 1142.62 & 180 & 188 \\ 1013.52 & 193 & 200 \\ 1601.65 & 263 & 275 \\ 2097.89 & 276 & 294 \\ 2583.30 & 295 & 316 \\ 1996.98 & 300 & 316 \\ 1092.58 & 317 & 326 \\ 2194.00 & 327 & 347 \\ 2142.03 & 356 & 375 \\ 1684.77 & 99 & 114 \\ 865.42 & 117 & 124 \\ 1841.89 & 151 & 167 \\ 1275.72 & 176 & 185 \\ 1142.62 & 180 & 188 \\ 1013.52 & 193 & 200 \\ 1601.65 & 263 & 275 \\ 2083.87 & 276 & 294 \\ 2044.94 & 300 & 316 \\ 1092.58 & 317 & 326 \\ 1339.60 & 7 & 19 \\ 865.42 & 22 & 29 \\ 1271.63 & 56 & 67 \\ 944.50 & 68 & 76 \\ 1007.51 & 98 & 105 \\ 1751.97 & 106 & 121 \\ 1918.97 & 206 & 222 \\ 1052.55 & 223 & 232 \\ 2178.00 & 233 & 253 \\ 2554.13 & 262 & 287 \\ 1428.58 & 288 & 301 \\ 1735.81 & 22 & 35 \\ 1349.65 & 36 & 46 \\ 1106.51 & 38 & 46 \\ 971.56 & 53 & 63 \\ 2121.02 & 67 & 86 \\ 1780.80 & 70 & 86 \\ 1843.08 & 87 & 103 \\ 1518.94 & 149 & 163\end{array}$

Page 82 of Table S-1-4 
Heterogeneous nuclear ribonucleoprotein K GN=HNRNPK HNRPK_HUMAN $50.98 \quad 100.0 \% \quad 21$ Heterogeneous nuclear ribonucleoprotein K GN=HNRNPK HNRPK_HUMAN $50.98 \quad 100.0 \% 21$ Heterogeneous nuclear ribonucleoprotein K GN=HNRNPK HNRPK_HUMAN $50.98 \quad 100.0 \% \quad 21$ Heterogeneous nuclear ribonucleoprotein K GN=HNRNPK HNRPK_HUMAN $50.98 \quad 100.0 \% \quad 21$ Heterogeneous nuclear ribonucleoprotein K GN=HNRNPK HNRPK_HUMAN $50.98 \quad 100.0 \% \quad 21$ Heterogeneous nuclear ribonucleoprotein K GN=HNRNPK HNRPK_HUMAN $50.98 \quad 100.0 \% \quad 21$ Heterogeneous nuclear ribonucleoprotein K GN=HNRNPK HNRPK_HUMAN $50.98 \quad 100.0 \% \quad 21$ Heterogeneous nuclear ribonucleoprotein K GN=HNRNPK HNRPK_HUMAN $50.98 \quad 100.0 \% \quad 21$ Heterogeneous nuclear ribonucleoprotein K GN=HNRNPK HNRPK_HUMAN $50.98 \quad 100.0 \%$ Heterogeneous nuclear ribonucleoprotein K GN=HNRNPK HNRPK_HUMAN $50.98 \quad 100.0 \%$ Heterogeneous nuclear ribonucleoprotein K GN=HNRNPK HNRPK_HUMAN $50.98 \quad 100.0 \%$ Heterogeneous nuclear ribonucleoprotein K GN=HNRNPK HNRPK HUMAN 50.98 Heterogeneous nuclear ribonucleoprotein K GN=HNRNPK HNRPK_HUMAN 50.98 Heterogeneous nuclear ribonucleoprotein L GN=HNRNPL HNRPL_HUMAN 64.13 Heterogeneous nuclear ribonucleoprotein L GN=HNRNPL HNRPL HUMAN 64.13 Heterogeneous nuclear ribonucleoprotein L GN=HNRNPL HNRPL_HUMAN 64.13 Heterogeneous nuclear ribonucleoprotein L GN=HNRNPL HNRPL HUMAN 64.13 Heterogeneous nuclear ribonucleoprotein L GN=HNRNPL HNRPL_HUMAN 64.13 Heterogeneous nuclear ribonucleoprotein L GN=HNRNPL HNRPL_HUMAN 64.13 Heterogeneous nuclear ribonucleoprotein L GN=HNRNPL HNRPL_HUMAN 64.13 Heterogeneous nuclear ribonucleoprotein L GN=HNRNPL HNRPL_HUMAN 64.13 Heterogeneous nuclear ribonucleoprotein L GN=HNRNPL HNRPL_HUMAN 64.13 Heterogeneous nuclear ribonucleoprotein L GN=HNRNPL HNRPL_HUMAN 64.13 Heterogeneous nuclear ribonucleoprotein L GN=HNRNPL HNRPL_HUMAN 64.13 Heterogeneous nuclear ribonucleoprotein L GN=HNRNPL HNRPL_HUMAN 64.13 Heterogeneous nuclear ribonucleoprotein L GN=HNRNPL HNRPL_HUMAN 64.13 Heterogeneous nuclear ribonucleoprotein L GN=HNRNPL HNRPL_HUMAN 64.13 Heterogeneous nuclear ribonucleoprotein L GN=HNRNPL HNRPL HUMAN 64.13 Heterogeneous nuclear ribonucleoprotein L GN=HNRNPL HNRPL_HUMAN 64.13 Heterogeneous nuclear ribonucleoprotein L GN=HNRNPL HNRPL_HUMAN 64.13 Heterogeneous nuclear ribonucleoprotein L GN=HNRNPL HNRPL_HUMAN 64.13 Heterogeneous nuclear ribonucleoprotein M GN=HNRNPM HNRPM_HUMAN 77.52 Heterogeneous nuclear ribonucleoprotein M GN=HNRNPM HNRPM_HUMAN 77.52 Heterogeneous nuclear ribonucleoprotein M GN=HNRNPM HNRPM_HUMAN 77.52 Heterogeneous nuclear ribonucleoprotein M GN=HNRNPM HNRPM_HUMAN 77.52 Heterogeneous nuclear ribonucleoprotein M GN=HNRNPM HNRPM_HUMAN 77.52 Heterogeneous nuclear ribonucleoprotein M GN=HNRNPM HNRPM_HUMAN 77.52 Heterogeneous nuclear ribonucleoprotein M GN=HNRNPM HNRPM_HUMAN 77.52 Heterogeneous nuclear ribonucleoprotein M GN=HNRNPM HNRPM_HUMAN 77.52 Heterogeneous nuclear ribonucleoprotein M GN=HNRNPM HNRPM_HUMAN 77.52 Heterogeneous nuclear ribonucleoprotein M GN=HNRNPM HNRPM_HUMAN 77.52 Heterogeneous nuclear ribonucleoprotein M GN=HNRNPM HNRPM_HUMAN 77.52 Heterogeneous nuclear ribonucleoprotein M GN=HNRNPM HNRPM_HUMAN 77.52 Heterogeneous nuclear ribonucleoprotein M GN=HNRNPM HNRPM_HUMAN 77.52 Heterogeneous nuclear ribonucleoprotein M GN=HNRNPM HNRPM_HUMAN 77.52 Heterogeneous nuclear ribonucleoprotein M GN=HNRNPM HNRPM_HUMAN 77.52 Heterogeneous nuclear ribonucleoprotein M GN=HNRNPM HNRPM_HUMAN 77.52
$100.0 \% \quad 21$ $100.0 \% \quad 21$ $100.0 \% \quad 18$ $100.0 \% \quad 18$ $100.0 \% \quad 18$ $00.0 \% \quad 18$ $100.0 \% \quad 18$ $100.0 \% \quad 18$ $100.0 \% \quad 18$ $100.0 \% \quad 18$ $100.0 \% \quad 18$ $100.0 \% \quad 18$ $100.0 \% \quad 18$ $100.0 \% \quad 18$ $100.0 \% \quad 18$ $100.0 \% \quad 18$ $00.0 \% \quad 18$ $100.0 \% \quad 18$ $100.0 \% \quad 18$ $100.0 \% \quad 18$ $100.0 \% \quad 62$ $100.0 \% \quad 62$ $100.0 \% \quad 62$ $100.0 \% \quad 62$ $00.0 \% \quad 62$ $100.0 \% \quad 62$ $100.0 \% \quad 62$ $100.0 \% \quad 62$ $100.0 \% \quad 62$ $100.0 \% \quad 62$ $100.0 \% \quad 62$ $100.0 \% \quad 62$ $100.0 \% \quad 62$ $100.0 \% \quad 62$ $100.0 \% \quad 62$ $100.0 \% \quad 62$
DLISESPIKGR

$99 \quad 0.10 \% \quad 40.2 \%$ RDYDDMSPR

$99 \quad 0.10 \% \quad 40.2 \%$ DYDDMSPR

$99 \quad 0.10 \% \quad 40.2 \%$ NLPLPPPPPPR

$99 \quad 0.10 \% \quad 40.2 \%$ GGDLMAYDR

$99 \quad 0.10 \% \quad 40.2 \%$ GGDLMAYDRR

$134 \quad 0.13 \% \quad 32.9 \%$ MAAAGGGGGGGRYYG

$134 \quad 0.13 \% \quad 32.9 \%$ YYGGGSEGGR

$134 \quad 0.13 \% \quad 32.9 \%$ YYGGGSEGGRAPK

$134 \quad 0.13 \% \quad 32.9 \%$ ISRPGDSDDSR

$\begin{array}{lllllll}134 & 0.13 \% & 32.9 \% & \text { NGVQAMVEFDSVQSAQR } & 99.7 \% & 69.1\end{array}$

$134 \quad 0.13 \% \quad 32.9 \%$ AKASLNGADIYSGCCTLK $99.7 \% \quad 29.3$

$134 \quad 0.13 \% \quad 32.9 \%$ ASLNGADIYSGCCTLK $\quad 99.7 \% \quad 61.0$

$134 \quad 0.13 \% \quad 32.9 \%$ IEYAKPTR

$134 \quad 0.13 \% \quad 32.9 \%$ MGPPVGGHR

$134 \quad 0.13 \% \quad 32.9 \%$ VFNVFCLYGNVEK

$99.0 \% \quad 51.8$

$99.7 \% \quad 49.2$

$99.7 \% \quad 57.5$

$134 \quad 0.13 \% \quad 32.9 \%$ VFNVFCLYGNVEKVK $\quad 99.7 \% \quad 47.0$

$134 \quad 0.13 \% \quad 32.9 \%$ SKPGAAMVEMADGYAVDR $99.7 \% \quad 60.3$

$134 \quad 0.13 \% \quad 32.9 \%$ AITHLNNNFMFGQK

$99.7 \% \quad 59.2$

$134 \quad 0.13 \% \quad 32.9 \%$ QPAIMPGQSYGLEDGSCSYKDFSESR

$134 \quad 0.13 \% \quad 32.9 \%$ NNRFSTPEQAAK

$134 \quad 0.13 \% \quad 32.9 \%$ FSTPEQAAK

$134 \quad 0.13 \% \quad 32.9 \%$ NPNGPYPYTLK

$134 \quad 0.13 \% \quad 32.9 \%$ LCFSTAQHAS

$109 \quad 529 \quad 0.52 \% \quad 70.1 \%$ GEGERPAQNEK

$109529 \quad 0.52 \% \quad 70.1 \%$ GGNRFEPYANPTK

$109 \quad 529 \quad 0.52 \% \quad 70.1 \%$ FEPYANPTKR

$109 \quad 529 \quad 0.52 \% \quad 70.1 \%$ YRAFITNIPFDVK

$109 \quad 529 \quad 0.52 \% \quad 70.1 \%$ AFITNIPFDVK

109

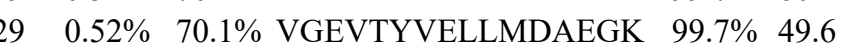

$50.52 \% \quad 70.1 \%$ VGEVTYVELLMDAEGKSR $99.7 \% \quad 54.8$

$529 \quad 0.52 \% \quad 70.1 \%$ GCAVVEFK

$529 \quad 0.52 \% \quad 70.1 \%$ AAEVLNKHSLSGRPLK

$529 \quad 0.52 \% \quad 70.1 \%$ HSLSGRPLK

$529 \quad 0.52 \% \quad 70.1 \%$ VKEDPDGEHAR

$529 \quad 0.52 \% \quad 70.1 \%$ LGSTVFVANLDYK

$529 \quad 0.52 \% \quad 70.1 \%$ LKEVFSMAGVVVR

$29 \quad 0.52 \% \quad 70.1 \%$ EVFSMAGVVVR

$29 \quad 0.52 \% \quad 70.1 \%$ ADILEDKDGK $\begin{array}{llll}99.7 \% & 30.7 & 25.0 & 30.7\end{array}$

$\begin{array}{llll}99.7 \% & 57.8 & 25.0 & 48.6\end{array}$

$99.2 \% \quad 26.1 \quad 25.0 \quad 14.2$

$\begin{array}{llll}99.7 \% & 33.3 & 25.0 & 28.3\end{array}$

$\begin{array}{llll}99.7 \% & 48.5 & 25.0 & 47.2\end{array}$

$\begin{array}{llll}99.7 \% & 44.3 & 25.0 & 31.2\end{array}$

$\begin{array}{llll}99.7 \% & 38.0 & 25.0 & 31.6\end{array}$

$96.3 \% \quad 17.1 \quad 25.0 \quad 13.7$

$99.7 \% \quad 30.3 \quad 25.0 \quad 24.4$

$\begin{array}{llll}99.7 \% & 60.2 & 25.0 & 47.6\end{array}$

$99.0 \% \quad 43.6 \quad 25.0 \quad 27.8$

$\begin{array}{llll}99.7 \% & 44.0 & 25.0 & 44.0\end{array}$

$\begin{array}{lllll}99.7 \% & 31.5 & 25.0 & 17.8\end{array}$

$\begin{array}{llll}99.7 \% & 58.4 & 25.0 & 52.2\end{array}$

$99.7 \% \quad 56.3 \quad 25.0 \quad 56.3$

$99.7 \% \quad 60.4 \quad 25.0 \quad 52.9$

$\begin{array}{llll}99.7 \% & 39.9 & 25.0 & 31.8\end{array}$

$\begin{array}{llll}99.7 \% & 51.1 & 25.0 & 44.5\end{array}$

$\begin{array}{llll}99.0 \% & 30.7 & 25.0 & 16.2\end{array}$
1053.64

1340.80

1553.93

1170.48

998.39

1194.70

1013.44

1153.54

1917.03

2771.52

873.50

1271.71

1917.83

1002.43

1298.61

1204.56

1865.88

1928.92

1729.79

977.54

907.46

1588.78

1815.95

1867.87

1634.81

2925.27

1362.68

978.49

1263.64

1121.50

1214.58

1450.71

1222.62

1583.86

1264.69

1768.87

2012.00

909.45

1719.99

994.58

1252.59

1426.76

1434.81

1193.63

1103.56

959.50 $\begin{array}{cc}80 & 191 \\ 92 & 201 \\ 08 & 219 \\ 08 & 221 \\ 78 & 286 \\ 79 & 286 \\ 06 & 316 \\ 17 & 325 \\ 17 & 326 \\ 78 & 396 \\ 78 & 405 \\ 97 & 405 \\ 97 & 409 \\ 5 & 56 \\ 7 & 56 \\ 7 & 59 \\ 79 & 189 \\ 30 & 246 \\ 47 & 264 \\ 49 & 264 \\ 65 & 272 \\ 45 & 353 \\ 99 & 411 \\ 99 & 413 \\ 17 & 434 \\ 35 & 448 \\ 56 & 481 \\ 82 & 493 \\ 85 & 493 \\ 69 & 579 \\ 80 & 589 \\ 8 & 48 \\ 7 & 69 \\ 1 & 70 \\ 1 & 83 \\ 3 & 83 \\ 5 & 110 \\ 5 & 112 \\ 13 & 120 \\ 28 & 143 \\ 35 & 143 \\ 44 & 154 \\ 02 & 214 \\ 20 & 232 \\ 22 & 232 \\ 33 & 242 \\ & 285\end{array}$ 
Heterogeneous nuclear ribonucleoprotein M GN=HNRNPM HNRPM_HUMAN $77.52 \quad 100.0 \% \quad 62$ Heterogeneous nuclear ribonucleoprotein M GN=HNRNPM HNRPM_HUMAN $77.52 \quad 100.0 \% \quad 62$ Heterogeneous nuclear ribonucleoprotein M GN=HNRNPM HNRPM_HUMAN $77.52 \quad 100.0 \% 62$ Heterogeneous nuclear ribonucleoprotein M GN=HNRNPM HNRPM_HUMAN $77.52 \quad 100.0 \% 62$ Heterogeneous nuclear ribonucleoprotein M GN=HNRNPM HNRPM_HUMAN $77.52 \quad 100.0 \% \quad 62$ Heterogeneous nuclear ribonucleoprotein M GN=HNRNPM HNRPM_HUMAN $77.52 \quad 100.0 \% \quad 62$ Heterogeneous nuclear ribonucleoprotein M GN=HNRNPM HNRPM_HUMAN $77.52 \quad 100.0 \% \quad 62$ Heterogeneous nuclear ribonucleoprotein M GN=HNRNPM HNRPM_HUMAN $77.52 \quad 100.0 \% \quad 62$ Heterogeneous nuclear ribonucleoprotein M GN=HNRNPM HNRPM_HUMAN $77.52 \quad 100.0 \% 62$ Heterogeneous nuclear ribonucleoprotein M GN=HNRNPM HNRPM_HUMAN $77.52 \quad 100.0 \% 62$ Heterogeneous nuclear ribonucleoprotein M GN=HNRNPM HNRPM_HUMAN $77.52 \quad 100.0 \% \quad 62$ Heterogeneous nuclear ribonucleoprotein M GN=HNRNPM HNRPM_HUMAN $77.52 \quad 100.0 \% 62$ Heterogeneous nuclear ribonucleoprotein M GN=HNRNPM HNRPM_HUMAN $77.52 \quad 100.0 \% \quad 62$ Heterogeneous nuclear ribonucleoprotein M GN=HNRNPM HNRPM_HUMAN $77.52 \quad 100.0 \% 62$ Heterogeneous nuclear ribonucleoprotein M GN=HNRNPM HNRPM_HUMAN $77.52 \quad 100.0 \% \quad 62$ Heterogeneous nuclear ribonucleoprotein M GN=HNRNPM HNRPM_HUMAN $77.52 \quad 100.0 \% 62$ Heterogeneous nuclear ribonucleoprotein M GN=HNRNPM HNRPM_HUMAN $77.52 \quad 100.0 \% 62$ Heterogeneous nuclear ribonucleoprotein M GN=HNRNPM HNRPM_HUMAN $77.52 \quad 100.0 \% \quad 62$ Heterogeneous nuclear ribonucleoprotein M GN=HNRNPM HNRPM_HUMAN $77.52 \quad 100.0 \% 62$ Heterogeneous nuclear ribonucleoprotein M GN=HNRNPM HNRPM_HUMAN $77.52 \quad 100.0 \% \quad 62$ Heterogeneous nuclear ribonucleoprotein M GN=HNRNPM HNRPM_HUMAN $77.52 \quad 100.0 \% \quad 62$ Heterogeneous nuclear ribonucleoprotein M GN=HNRNPM HNRPM_HUMAN $77.52 \quad 100.0 \% 62$ Heterogeneous nuclear ribonucleoprotein M GN=HNRNPM HNRPM_HUMAN $77.52 \quad 100.0 \% \quad 62$ Heterogeneous nuclear ribonucleoprotein M GN=HNRNPM HNRPM_HUMAN $77.52 \quad 100.0 \% 62$ Heterogeneous nuclear ribonucleoprotein M GN=HNRNPM HNRPM_HUMAN $77.52 \quad 100.0 \%$ Heterogeneous nuclear ribonucleoprotein M GN=HNRNPM HNRPM_HUMAN $77.52 \quad 100.0 \% \quad 62$ Heterogeneous nuclear ribonucleoprotein M GN=HNRNPM HNRPM_HUMAN $77.52 \quad 100.0 \% 62$ Heterogeneous nuclear ribonucleoprotein M GN=HNRNPM HNRPM_HUMAN $77.52 \quad 100.0 \% \quad 62$ Heterogeneous nuclear ribonucleoprotein M GN=HNRNPM HNRPM_HUMAN $77.52 \quad 100.0 \% \quad 62$ Heterogeneous nuclear ribonucleoprotein M GN=HNRNPM HNRPM HUMAN $77.52 \quad 100.0 \% \quad 62$ Heterogeneous nuclear ribonucleoprotein M GN=HNRNPM HNRPM_HUMAN $77.52 \quad 100.0 \% 62$ Heterogeneous nuclear ribonucleoprotein M GN=HNRNPM HNRPM_HUMAN $77.52 \quad 100.0 \% 62$ Heterogeneous nuclear ribonucleoprotein M GN=HNRNPM HNRPM_HUMAN $77.52 \quad 100.0 \% 62$ Heterogeneous nuclear ribonucleoprotein M GN=HNRNPM HNRPM_HUMAN $77.52 \quad 100.0 \% \quad 62$ Heterogeneous nuclear ribonucleoprotein M GN=HNRNPM HNRPM_HUMAN $77.52 \quad 100.0 \% 62$ Heterogeneous nuclear ribonucleoprotein M GN=HNRNPM HNRPM_HUMAN $77.52 \quad 100.0 \% 62$ Heterogeneous nuclear ribonucleoprotein M GN=HNRNPM HNRPM_HUMAN $77.52 \quad 100.0 \% 62$ Heterogeneous nuclear ribonucleoprotein M GN=HNRNPM HNRPM_HUMAN $77.52 \quad 100.0 \% 62$ Heterogeneous nuclear ribonucleoprotein M GN=HNRNPM HNRPM_HUMAN $77.52 \quad 100.0 \% \quad 62$ Heterogeneous nuclear ribonucleoprotein M GN=HNRNPM HNRPM_HUMAN $77.52 \quad 100.0 \% 62$ Heterogeneous nuclear ribonucleoprotein M GN=HNRNPM HNRPM_HUMAN $77.52 \quad 100.0 \% 62$ Heterogeneous nuclear ribonucleoprotein M GN=HNRNPM HNRPM_HUMAN $77.52 \quad 100.0 \% \quad 62$ Heterogeneous nuclear ribonucleoprotein M GN=HNRNPM HNRPM_HUMAN $77.52 \quad 100.0 \% 62$ Heterogeneous nuclear ribonucleoprotein M GN=HNRNPM HNRPM_HUMAN $77.52 \quad 100.0 \% \quad 62$ Heterogeneous nuclear ribonucleoprotein M GN=HNRNPM HNRPM_HUMAN $77.52 \quad 100.0 \% \quad 62$ Heterogeneous nuclear ribonucleoprotein M GN=HNRNPM HNRPM_HUMAN $77.52 \quad 100.0 \% \quad 62$ $\begin{array}{lllll}\text { Heterogeneous nuclear ribonucleoprotein Q GN=SYNCRIP } & \text { HNRPQ_HUMAN } & 69.60 & 100.0 \% & 15\end{array}$
109

109

109

109

109

109

109

109

109

109

109
109

109

109

109

109

109

109

109

109

109

109

109

109

109

109

109

109

109

109

109

109

109

109

109

109

109

109

109

109

109

109

109

109
17

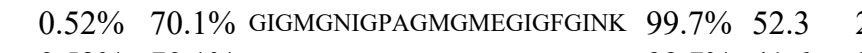

$0.52 \% \quad 70.1 \%$ MGGMEGPFGGGMENMGR $99.7 \% \quad 41.6$ $99.7 \% \quad 61.6$

$290.52 \% \quad 70.1 \%$ FGSGMNMGRINEILSNALK $99.5 \% \quad 28.8$

$529 \quad 0.52 \% \quad 70.1 \%$ INEILSNALK

$529 \quad 0.52 \% \quad 70.1 \%$ INEILSNALKR

$99.7 \% \quad 59.7$

$99.7 \% \quad 58.8$

$99.7 \% \quad 57.3$

$\begin{array}{llllll}29 & 0.52 \% & 70.1 \% & \text { QGGGGGGGSVPGIER } & 99.7 \% & 57.3 \\ 529 & 0.52 \% & 70.1 \% & \text { QGGGGGGGSVPGIERMGPGIDR } & 99.7 \% & 54.8\end{array}$

$529 \quad 0.52 \% \quad 70.1 \%$ MGPGIDRLGGAGMER

$99.7 \% \quad 49.5$

$99.7 \% \quad 56.8$

$\begin{array}{llll}529 & 0.52 \% & 70.1 \% & \text { MGAGLGHGMDRVGSEI }\end{array}$

$529 \quad 0.52 \% \quad 70.1 \%$ MGLVMDRMGSVER

$529 \quad 0.52 \% \quad 70.1 \%$ MGSVERMGSGIER

$99.7 \% \quad 34.5$

$99.7 \% \quad 30.8$

$99.7 \% \quad 37.1$

$529 \quad 0.52 \% \quad 70.1 \%$ MGSGIERMGPLGLDHMASSIER $\quad 99.6 \% 24.4$

$529 \quad 0.52 \% \quad 70.1 \%$ MGPLGLDHMASSIER $\quad 99.7 \% \quad 60.0$

$529 \quad 0.52 \% \quad 70.1 \%$ MGPLGLDHMASSIERMGOTMER $\quad 99.6 \% \quad 25.5$

$529 \quad 0.52 \% \quad 70.1 \%$ MGQTMERIGSGVER $\quad 99.7 \% \quad 28.1$

$529 \quad 0.52 \% \quad 70.1 \%$ IGSGVERMGAGMGFGLER $\quad 99.7 \% \quad 52.6$

$529 \quad 0.52 \% \quad 70.1 \%$ MGAGMGFGLER

$529 \quad 0.52 \% \quad 70.1 \%$ MAAPIDRVGQTIER

$529 \quad 0.52 \% \quad 70.1 \%$ VGQTIERMGSGVER

$529 \quad 0.52 \% \quad 70.1 \%$ MGSGVERMGPAIER

$529 \quad 0.52 \% \quad 70.1 \%$ MGPAIERMGLSMER

$99.7 \% \quad 64.9$

$99.7 \% \quad 47.3$

$99.7 \% \quad 34.6$

$99.7 \% \quad 40.0$

$99.7 \% \quad 26.9$

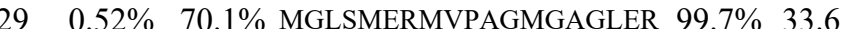

$529 \quad 0.52 \% \quad 70.1 \%$ MVPAGMGAGLER

$529 \quad 0.52 \% \quad 70.1 \%$ MGPVMDRMATGLER

$529 \quad 0.52 \% \quad 70.1 \%$ MATGLERMGANNLER

$529 \quad 0.52 \% \quad 70.1 \%$ MGANNLER

$529 \quad 0.52 \% \quad 70.1 \%$ MGANNLERMGLER

$529 \quad 0.52 \% \quad 70.1 \%$ MGLERMGANSLER

$529 \quad 0.52 \% \quad 70.1 \%$ MGANSLER

$529 \quad 0.52 \% \quad 70.1 \%$ MGANSLERMGLER

$529 \quad 0.52 \% \quad 70.1 \%$ MGANSLERMGPAMGPALGAGIE

$99.7 \% \quad 41.5$

$99.7 \% \quad 33.9$

$99.7 \% 28.1$

$99.0 \% \quad 71.1$

$99.7 \% \quad 35.1$

$99.7 \% 27$.

$99.0 \% \quad 70.6$

$99.6 \% \quad 25.3$

$529 \quad 0.52 \% \quad 70.1 \%$ MGPAMGPALGAGIER

$99.7 \% 54.3$

$99.7 \% \quad 55.2$

$529 \quad 0.52 \% \quad 70.1 \%$ MGLAMGGGGGASFDR $\quad 99.7 \% \quad 54.6$

$529 \quad 0.52 \% \quad 70.1 \%$ MGLAMGGGGGASFDRAIEMER $99.7 \% \quad 40.1$

$529 \quad 0.52 \% \quad 70.1 \%$ AIEMERGNFGGSFAGSFGGAGGHAPGVAR $\quad 99.7 \% \quad 56.6$

$529 \quad 0.52 \% \quad 70.1 \%$ GNFGGSFAGSFGGAGGHAPGVAR $\quad 99.7 \% \quad 53.3$

$529 \quad 0.52 \% \quad 70.1 \%$ GNFGGSFAGSFGGAGGHAPGVARK

$529 \quad 0.52 \% \quad 70.1 \%$ KACQIFVR

$529 \quad 0.52 \% \quad 70.1 \%$ NLPFDFTWK

$529 \quad 0.52 \% \quad 70.1 \%$ DKFNECGHVLYADIK

$529 \quad 0.52 \% \quad 70.1 \%$ GCGVVKFESPEVAER

$529 \quad 0.52 \% \quad 70.1 \%$ FESPEVAER

$\quad 0.52 \% \quad 70.1 \%$ EIDVRIDR

$99.7 \% \quad 56.4$

$99.0 \% 58.4$

$99.3 \% \quad 21.0$

$99.6 \% 29.4$

$99.7 \% \quad 60.0$

$99.7 \% \quad 48.7$

$97.5 \% 27.8$

$99.7 \% \quad 48.1$
217

1714.68

956.41

2084.03

1114.65

1270.75

1284.63

2026.97

1548.73

1101.49

1871.89

1623.78

1528.69

1440.66

2392.11

1629.77

2479.12

1550.74

1855.88

1141.51

1556.82

1534.76

1505.72

1609.75

2056.93

1220.58

1595.73

1678.80

904.43

1522.7

1495.70

877.42

1479.70

2334.10

1459.70

1415.60

2160.95

2764.30

2034.95

2163.05

1021.56

1167.58

1808.86

1663.81

1063.51

1015.55

1142.54

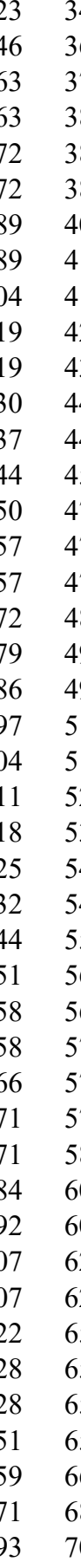

Page 84 
Heterogeneous nuclear ribonucleoprotein U GN=HNRNPU HNRPU_HUMAN $90.59 \quad 100.0 \% \quad 24$ Heterogeneous nuclear ribonucleoprotein U GN=HNRNPU HNRPU_HUMAN $90.59 \quad 100.0 \% \quad 24$ Heterogeneous nuclear ribonucleoprotein U GN=HNRNPU HNRPU_HUMAN $90.59 \quad 100.0 \% 24$ Heterogeneous nuclear ribonucleoprotein U GN=HNRNPU HNRPU_HUMAN $90.59 \quad 100.0 \% 24$ Heterogeneous nuclear ribonucleoprotein U GN=HNRNPU HNRPU_HUMAN $90.59 \quad 100.0 \% \quad 24$ Heterogeneous nuclear ribonucleoprotein U GN=HNRNPU HNRPU_HUMAN $90.59 \quad 100.0 \% 24$ Heterogeneous nuclear ribonucleoprotein U GN=HNRNPU HNRPU_HUMAN $90.59 \quad 100.0 \% 24$ Heterogeneous nuclear ribonucleoprotein U GN=HNRNPU HNRPU_HUMAN $90.59 \quad 100.0 \% \quad 24$ Heterogeneous nuclear ribonucleoprotein U GN=HNRNPU HNRPU HUMAN $90.59 \quad 100.0 \%$ Heterogeneous nuclear ribonucleoprotein U GN=HNRNPU HNRPU_HUMAN $90.59 \quad 100.0 \% \quad 24$ Heterogeneous nuclear ribonucleoprotein U GN=HNRNPU HNRPU_HUMAN $90.59 \quad 100.0 \% \quad 24$ Heterogeneous nuclear ribonucleoprotein U GN=HNRNPU HNRPU_HUMAN $90.59 \quad 100.0 \% 24$ Heterogeneous nuclear ribonucleoprotein U GN=HNRNPU HNRPU_HUMAN $90.59 \quad 100.0 \% \quad 24$ Heterogeneous nuclear ribonucleoprotein U GN=HNRNPU HNRPU_HUMAN $90.59 \quad 100.0 \% \quad 24$ Heterogeneous nuclear ribonucleoprotein U GN=HNRNPU HNRPU_HUMAN $90.59 \quad 100.0 \% 24$ Heterogeneous nuclear ribonucleoprotein U GN=HNRNPU HNRPU_HUMAN $90.59 \quad 100.0 \% \quad 24$ Heterogeneous nuclear ribonucleoprotein U GN=HNRNPU HNRPU HUMAN $90.59 \quad 100.0 \%$ Heterogeneous nuclear ribonucleoprotein U GN=HNRNPU HNRPU_HUMAN $90.59 \quad 100.0 \% \quad 24$ Heterogeneous nuclear ribonucleoprotein U GN=HNRNPU HNRPU_HUMAN $90.59 \quad 100.0 \% 24$ Heterogeneous nuclear ribonucleoprotein U GN=HNRNPU HNRPU HUMAN $90.59 \quad 100.0 \% \quad 24$ Heterogeneous nuclear ribonucleoprotein U GN=HNRNPU HNRPU_HUMAN $90.59 \quad 100.0 \% \quad 24$ Heterogeneous nuclear ribonucleoprotein U GN=HNRNPU HNRPU_HUMAN $90.59 \quad 100.0 \%$ Heterogeneous nuclear ribonucleoprotein U-like protein 1 GN=HNRNPUL1 HNRL1_HUMAN $95.74 \quad 100.0 \%$ Heterogeneous nuclear ribonucleoprotein U-like protein 1 GN=HNRNPUL1 HNRL1_HUMAN $95.74 \quad 100.0 \%$ Hetergeneous nuclear ribonucleoprotein U-like protein 1 GN=HNRNPUL1 HNRL1_HUMAN $95.74 \quad 100.0 \% \quad 11$ Heterogeneous nuclear ribonucleoprotein U-like protein 1 GN=HNRNPUL1 HNRL1_HUMAN $95.74 \quad 100.0 \% \quad 11$ Heterogeneous nuclear ribonucleoprotein U-like protein $1 \mathrm{GN}=$ HNRNPUL1 $\quad$ HNRL1_HUMAN $95.74 \quad 100.0 \% \quad 11$ Heterogeneous nuclear ribonucleoprotein U-like protein $1 \mathrm{GN}=$ HNRNPUL1 $\quad$ HNRL1_HUMAN $95.74 \quad 100.0 \% \quad 11$ Herogeneous nuclear ribonucleoprotein U-like protein $1 \mathrm{GN}=$ HNRNPUL1 $\quad$ HNRL1_HUMAN $95.74 \quad 100.0 \% \quad 11$ Heterogeneous nuclear ribonucleoprotein U-like protein $1 \mathrm{GN}=$ HNRNPUL1 HNRL1 HUMAN $95.74 \quad 100.0 \% \quad 11$ Heterogeneous nuclear ribonucleoprotein U-like protein 1 GN=HNRNPUL1 HNRL1_HUMAN $95.74 \quad 100.0 \%$ Heterogeneous nuclear ribonucleoprotein U-like protein 1 GN=HNRNPUL1 HNRL1_HUMAN $95.74 \quad 100.0 \% \quad 1$ Heterogeneous nuclear ribonucleoprotein U-like protein 2 GN=HNRNPUL2 HNRL2_HUMAN 85.11 $100.0 \%$ Heterogeneous nuclear ribonucleoprotein U-like protein 2 GN=HNRNPUL2 2 HNRL2_HUMAN $85.11 \quad 100.0 \%$ 作 Heterogeneous nuclear ribonucleoprotein U-like protein 2 GN=HNRNPUL2 HNRL2_HUMAN $85.11 \quad 100.0 \%$ Heterogeneous nuclear ribonucleoproteins A2/B1 GN=HNRNPA2B1 ROA2_HUMAN $37.43 \quad 100.0^{\circ}$ Heterogeneous nuclear ribonucleoproteins A2/B1 GN=HNRNPA2B1 ROA2 HUMAN $37.43 \quad 100.0 \%$ Heterogeneous nuclear ribonucleoproteins A2/B1 GN=HNRNPA2B1 $\quad$ ROA2_HUMAN $37.43 \quad 100.0 \% \quad 2$ Heterogeneous nuclear ribonucleoproteins A2/B1 GN=HNRNPA2B1 $\quad$ ROA2_HUMAN $37.43 \quad 100.0 \% \quad 28$ Heterogeneous nuclear ribonucleoproteins A2/B1 GN=HNRNPA2B1 ROA2_HUMAN $37.43 \quad 100.0 \% \quad 28$ $\begin{array}{lllll}\text { Heterogeneous nuclear ribonucleoproteins A2/B1 GN=HNRNPA2B1 } & \text { ROA2_HUMAN } 37.43 \quad 100.0 \% & 28\end{array}$ $\begin{array}{llll} & \end{array}$ Heterogeneous nuclear ribonucleoproteins A2/B1 GN=HNRNPA2B1 $\quad$ ROA2_HUMAN $37.43 \quad 100.0 \% \quad 28$

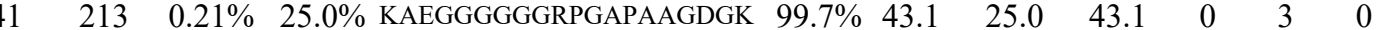

$41 \quad 213 \quad 0.21 \% \quad 25.0 \%$ GYFEYIEENKYSR

$41 \quad 213 \quad 0.21 \% \quad 25.0 \%$ GKVCFEMK

$\begin{array}{llll}41 & 213 & 0.21 \% & 25.0 \% \\ & 213 & \text { VTEKIPVR }\end{array}$

$41 \quad 213 \quad 0.21 \% \quad 25.0 \%$ DIDIHEVR

$41 \quad 213 \quad 0.21 \% \quad 25.0 \%$ NGQDLGVAFK

$41 \quad 213 \quad 0.21 \% \quad 25.0 \%$ NGQDLGVAFKISK $99.7 \% \quad 54.5$ $96.1 \% 16.4$ $99.0 \% \quad 45.9$ $99.0 \% \quad 46.8$ $99.7 \% \quad 43.3$ $99.7 \% \quad 58.3$

$41 \quad 213 \quad 0.21 \% \quad 25.0 \%$ HAAENPGKYNILGTNTI

$\begin{array}{llll}41 & 213 & 0.21 \% & 25.0 \% \\ 41 & 213 & 0.21 \% & 25.0 \%\end{array}$

$41 \quad 213 \quad 0.21 \% \quad 25.0 \%$ QMADTGKLNTLLQR

$41 \quad 213 \quad 0.21 \% \quad 25.0 \%$ APQCLGKFIEIAAR

$41 \quad 213 \quad 0.21 \% \quad 25.0 \%$ RNFILDQTNVSAAAQR

$41 \quad 213 \quad 0.21 \% \quad 25.0 \%$ NFILDQTNVSAAAQR

$41 \quad 213 \quad 0.21 \% \quad 25.0 \%$ NFILDQTNVSAAAQRR

$41 \quad 213 \quad 0.21 \% \quad 25.0 \%$ KMCLFAGFQR

$41 \quad 213 \quad 0.21 \% \quad 25.0 \%$ MCLFAGFQR

$41 \quad 213 \quad 0.21 \% \quad 25.0 \%$ MCLFAGFQRK

$41 \quad 213 \quad 0.21 \% \quad 25.0 \%$ AEVEGKDLPEHAVLK

$41 \quad 213 \quad 0.21 \% \quad 25.0 \%$ DLPEHAVLK

$41 \quad 213 \quad 0.21 \% \quad 25.0 \%$ LLEQYKEESK

$12 \quad 40 \quad 0.04 \% \quad 12.4 \%$ KRPYEENR

$12 \quad 40 \quad 0.04 \% \quad 12.4 \%$ HLPSTEPDPHVVR

$\begin{array}{llll}99.7 \% & 60.9 & 25.0 & 52.5\end{array}$

$99.0 \% \quad 30.8 \quad 25.0 \quad 24.2$

$99.7 \% \quad 50.9 \quad 25.0 \quad 48.7$

$99.7 \% \quad 51.4 \quad 25.0 \quad 51.4$

$99.7 \% \quad 59.1$

$99.7 \% \quad 48.0 \quad 25.0 \quad 40.8$

$99.5 \% \quad 25.5 \quad 25.0-20.2$

$99.7 \% \quad 58.6 \quad 25.0 \quad 47.7$

$99.7 \% \quad 35.4 \quad 25.0 \quad 31.9$

$99.7 \% \quad 73.8 \quad 25.0 \quad 72.9$

$\begin{array}{llll}99.7 \% & 31.3 & 25.0 & 25.3\end{array}$

$99.7 \% \quad 51.1 \quad 25.0 \quad 45.4$

$96.9 \% \quad 22.4 \quad 25.0 \quad 11.0$

$99.7 \% \quad 35.5 \quad 25.0 \quad 35.5$

$\begin{array}{llllllll}40 & 0.04 \% & 12.4 \% & \text { IQKEALGGQALYPHVLVK } & 99.7 \% & 39.1 & 25.0 & 32.8\end{array}$

$40 \quad 0.04 \% \quad 12.4 \%$ EALGGQALYPHVLVK

$\begin{array}{llll}99.7 \% & 39.3 & 25.0 & 33.5\end{array}$

$99.7 \% \quad 51.0 \quad 25.0 \quad 51.0$

$99.0 \% \quad 34.2 \quad 25.0 \quad 28.5$

$\begin{array}{llll}99.7 \% & 88.3 & 25.0 & 78.8\end{array}$

$\begin{array}{llll}97.6 \% & 18.7 & 25.0 & 16.4\end{array}$

$\begin{array}{llll}99.3 \% & 19.2 & 25.0 & 18.7\end{array}$

$99.0 \% \quad 42.4 \quad 25.0 \quad 25.7$

$99.4 \% \quad 20.3 \quad 25.0 \quad 18.7$

$\begin{array}{llll}99.7 \% & 33.8 & 25.0 & 14.5\end{array}$

$\quad 0.04 \% \quad 12.4 \%$ NPPGASTYNK

$0.01 \% \quad 10.7 \%$ GLKVDLAQR

$99.7 \% \quad 38.0$

$\begin{array}{llll}99.7 \% & 28.3 & 25.0 & 24.7\end{array}$

$99.7 \% \quad 71.0 \quad 25.0 \quad 71.0$

$\begin{array}{llll}99.7 \% & 29.1 & 25.0 & 29.1\end{array}$

$99.7 \% \quad 45.6 \quad 25.0 \quad 38.7$

$99.7 \% \quad 48.8 \quad 25.0$

$99.7 \% \quad 52.3 \quad 25.0 \quad 52.3$

$99.0 \% \quad 29.5 \quad 25.0 \quad 29.5$

$\begin{array}{llll}99.0 \% & 52.3 & 25.0 & 43.8\end{array}$

$99.7 \%$

$44 \quad 345 \quad 0.34 \% \quad 75.4 \%$ LTDCVVMR

$44 \quad 345 \quad 0.34 \% \quad 75.4 \%$ LTDCVVMRDPASK

$99.7 \% \quad 32.8$

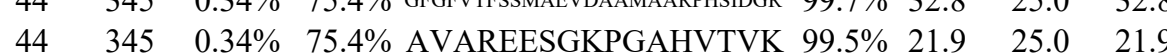

1666.83

2024.97

1697.78

941.58

996.51

1048.54

1376.75

2187.09

1382.70

911.48

1604.84

1573.85

1803.95

1647.84

1803.95

1273.62

1129.53

1257.62

1634.88

1021.57

1266.66

1091.56

1483.77

1964.13

1594.90

1341.60

827.51

1741.85

1897.95

1644.83

851.47

1048.5

999.59

2091.06

1607.82

1732.90

1827.84

1183.52

1057.59

1927.02

1798.92

1087.48

993.49

1491.73

2859.32

1735.95

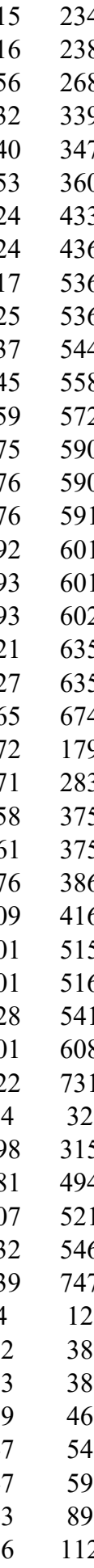

Page 86 of Table S-1-4 
$\begin{array}{lllll}\text { Heterogeneous nuclear ribonucleoproteins A2/B1 GN=HNRNPA2B1 } & \text { ROA2 HUMAN } 37.43 & 100.0 \% & 28\end{array}$ $\begin{array}{lllll}\text { Heterogeneous nuclear ribonucleoproteins A2/B1 GN=HNRNPA2B1 } & \text { ROA2_HUMAN } & 37.43 & 100.0 \% & 28\end{array}$ $\begin{array}{lllll}\text { Heterogeneous nuclear ribonucleoproteins A2/B1 GN=HNRNPA2B1 } & \text { ROA2_HUMAN } 37.43 & 100.0 \% & 28\end{array}$ $\begin{array}{lllll}\text { Heterogeneous nuclear ribonucleoproteins A2/B1 GN=HNRNPA2B1 } & \text { ROA2_HUMAN } 37.43 & 100.0 \% & 28\end{array}$ $\begin{array}{lllll}\text { Heterogeneous nuclear ribonucleoproteins A2/B1 GN=HNRNPA2B1 } & \text { ROA2_HUMAN } 37.43 & 100.0 \% & 28\end{array}$ Heterogeneous nuclear ribonucleoproteins A2/B1 GN=HNRNPA2B1 $\quad$ ROA2_HUMAN $37.43 \quad 100.0 \% \quad 28$ $\begin{array}{lllll}\text { Heterogeneous nuclear ribonucleoproteins A2/B1 GN=HNRNPA2B1 } & \text { ROA2 HUMAN } 37.43 \quad 100.0 \% & 28\end{array}$ $\begin{array}{lllll}\text { Heterogeneous nuclear ribonucleoproteins A2/B1 GN=HNRNPA2B1 } & \text { ROA2_HUMAN } & 37.43 & 100.0 \% & 28\end{array}$ $\begin{array}{lllll}\text { Heterogeneous nuclear ribonucleoproteins A2/B1 GN=HNRNPA2B1 } & \text { ROA2_HUMAN } 37.43 & 100.0 \% & 28\end{array}$ $\begin{array}{lllll}\text { Heterogeneous nuclear ribonucleoproteins A2/B1 GN=HNRNPA2B1 } & \text { ROA2_HUMAN } & 37.43 & 100.0 \% & 28\end{array}$ $\begin{array}{lllll}\text { Heterogeneous nuclear ribonucleoproteins A2/B1 GN=HNRNPA2B1 } & \text { ROA2_HUMAN } 37.43 \quad 100.0 \% & 28\end{array}$ $\begin{array}{lllll}\text { Heterogeneous nuclear ribonucleoproteins A2/B1 GN=HNRNPA2B1 } & \text { ROA2 HUMAN } 37.43 \quad 100.0 \% & 28\end{array}$ $\begin{array}{lllll}\text { Heterogeneous nuclear ribonucleoproteins A2/B1 GN=HNRNPA2B1 } & \text { ROA2_HUMAN } 37.43 & 100.0 \% & 28\end{array}$ $\begin{array}{lllll}\text { Heterogeneous nuclear ribonucleoproteins A2/B1 GN=HNRNPA2B1 } & \text { ROA2_HUMAN } & 37.43 & 100.0 \% & 28\end{array}$ Heterogeneous nuclear ribonucleoproteins A2/B1 GN=HNRNPA2B1 $\quad$ ROA2_HUMAN $37.43 \quad 100.0 \% \quad 28$ $\begin{array}{lllll}\text { Heterogeneous nuclear ribonucleoproteins A2/B1 GN=HNRNPA2B1 } & \text { ROA2_HUMAN } & 37.43 & 100.0 \% & 28\end{array}$ $\begin{array}{llll}\text { Heterogeneous nuclear ribonucleoproteins A2/B1 GN=HNRNPA2B1 } & \text { ROA2 HUMAN } 37.43 \quad 100.0 \% & 28\end{array}$ $\begin{array}{lllll}\text { Heterogeneous nuclear ribonucleoproteins A2/B1 GN=HNRNPA2B1 } & \text { ROA2_HUMAN } & 37.43 & 100.0 \% & 28\end{array}$ $\begin{array}{lllll}\text { Heterogeneous nuclear ribonucleoproteins A2/B1 GN=HNRNPA2B1 } & \text { ROA2_HUMAN } 37.43 & 100.0 \% & 28\end{array}$ $\begin{array}{llll}\text { Heterogeneous nuclear ribonucleoproteins A2/B1 GN=HNRNPA2B1 } & \text { ROA2 HUMAN } 37.43 \quad 100.0 \% & 28\end{array}$ Heterogeneous nuclear ribonucleoproteins $\mathrm{C} 1 / \mathrm{C} 2 \mathrm{GN}=\mathrm{HNRNPC}$ HNRPC_HUMAN $33.67 \quad 100.0 \% \quad 22$ Heterogeneous nuclear ribonucleoproteins $\mathrm{Cl} / \mathrm{C} 2 \mathrm{GN}=\mathrm{HNRNPC}$ HNRPC_HUMAN $33.67 \quad 100.0 \% 22$ Heterogeneous nuclear ribonucleoproteins $\mathrm{C} 1 / \mathrm{C} 2 \mathrm{GN}=\mathrm{HNRNPC}$ HNRPC_HUMAN $33.67 \quad 100.0 \% 22$ Heterogeneous nuclear ribonucleoproteins $\mathrm{C} 1 / \mathrm{C} 2 \mathrm{GN}=\mathrm{HNRNPC}$ HNRPC_HUMAN $33.67 \quad 100.0 \% \quad 22$ Heterogeneous nuclear ribonucleoproteins $\mathrm{C} 1 / \mathrm{C} 2 \mathrm{GN}=\mathrm{HNRNPC}$ HNRPC_HUMAN $33.67 \quad 100.0 \% 22$ Heterogeneous nuclear ribonucleoproteins $\mathrm{C} 1 / \mathrm{C} 2 \mathrm{GN}=\mathrm{HNRNPC}$ HNRPC_HUMAN $33.67 \quad 100.0 \% \quad 22$ Heterogeneous nuclear ribonucleoproteins $\mathrm{Cl} / \mathrm{C} 2 \mathrm{GN}=\mathrm{HNRNPC}$ HNRPC_HUMAN $33.67 \quad 100.0 \% 22$ Heterogeneous nuclear ribonucleoproteins $\mathrm{Cl} / \mathrm{C} 2 \mathrm{GN}=\mathrm{HNRNPC}$ HNRPC_HUMAN $33.67 \quad 100.0 \% 22$ Heterogeneous nuclear ribonucleoproteins $\mathrm{C} 1 / \mathrm{C} 2 \mathrm{GN}=\mathrm{HNRNPC}$ HNRPC_HUMAN $33.67 \quad 100.0 \% \quad 22$ Heterogeneous nuclear ribonucleoproteins $\mathrm{Cl} / \mathrm{C} 2 \mathrm{GN}=\mathrm{HNRNPC}$ HNRPC HUMAN $33.67 \quad 100.0 \% 22$ Heterogeneous nuclear ribonucleoproteins $\mathrm{Cl} / \mathrm{C} 2 \mathrm{GN}=\mathrm{HNRNPC}$ HNRPC_HUMAN $33.67 \quad 100.0 \% \quad 22$ Heterogeneous nuclear ribonucleoproteins $\mathrm{Cl} / \mathrm{C} 2 \mathrm{GN}=$ HNRNPC HNRPC_HUMAN $33.67 \quad 100.0 \% \quad 22$ Heterogeneous nuclear ribonucleoproteins $\mathrm{Cl} / \mathrm{C} 2 \mathrm{GN}=\mathrm{HNRNPC}$ HNRPC HUMAN $33.67 \quad 100.0 \% 22$ Heterogeneous nuclear ribonucleoproteins $\mathrm{C} 1 / \mathrm{C} 2 \mathrm{GN}=\mathrm{HNRNPC}$ HNRPC_HUMAN $33.67 \quad 100.0 \% \quad 22$ Heterogeneous nuclear ribonucleoproteins $\mathrm{Cl} / \mathrm{C} 2 \mathrm{GN}=\mathrm{HNRNPC}$ HNRPC_HUMAN $33.67 \quad 100.0 \% 22$ Heterogeneous nuclear ribonucleoproteins $\mathrm{Cl} / \mathrm{C} 2 \mathrm{GN}=\mathrm{HNRNPC}$ HNRPC_HUMAN $33.67 \quad 100.0 \% 22$ Heterogeneous nuclear ribonucleoproteins $\mathrm{Cl} / \mathrm{C} 2 \mathrm{GN}=\mathrm{HNRNPC}$ HNRPC_HUMAN $33.67 \quad 100.0 \% \quad 22$ Heterogeneous nuclear ribonucleoproteins $\mathrm{Cl} / \mathrm{C} 2 \mathrm{GN}=\mathrm{HNRNPC}$ HNRPC HUMAN $33.67 \quad 100.0 \% 22$ Heterogeneous nuclear ribonucleoproteins $\mathrm{C} 1 / \mathrm{C} 2 \mathrm{GN}=\mathrm{HNRNPC}$ HNRPC_HUMAN $33.67 \quad 100.0 \% \quad 22$ Heterogeneous nuclear ribonucleoproteins $\mathrm{Cl} / \mathrm{C} 2 \mathrm{GN}=\mathrm{HNRNPC}$ HNRPC_HUMAN $33.67 \quad 100.0 \% 22$ Heterogeneous nuclear ribonucleoproteins $\mathrm{Cl} / \mathrm{C} 2 \mathrm{GN}=\mathrm{HNRNPC}$ HNRPC_HUMAN $33.67 \quad 100.0 \% 22$ Heterogeneous nuclear ribonucleoproteins $\mathrm{C} 1 / \mathrm{C} 2 \mathrm{GN}=\mathrm{HNRNPC}$ HNRPC_HUMAN $33.67 \quad 100.0 \% \quad 22$ Histidine ammonia-lyase GN=HAL Histidine ammonia-lyase GN=HAI Histone deacetylase $1 \mathrm{GN}=\mathrm{HDAC}$ Histone deacetylase $1 \mathrm{GN}=\mathrm{HDAC} 1$ Histone deacetylase $1 \mathrm{GN}=\mathrm{HDAC}$ HUTH_HUMAN $72.70 \quad 100.0 \%$ HUTH_HUMAN $72.70 \quad 100.0 \%$ HDAC1_HUMAN $55.10 \quad 100.0 \% \quad 3$ HDAC1 HUMAN $55.10 \quad 100.0 \%$ HDAC1_HUMAN $55.10 \quad 100.0 \%$
$44 \quad 345 \quad 0.34 \% \quad 75.4 \%$ EESGKPGAHVTVK

$44345 \quad 0.34 \% \quad 75.4 \%$ EESGKPGAHVTVKK

$44 \quad 345 \quad 0.34 \% \quad 75.4 \%$ KLFVGGIK

$44 \quad 345 \quad 0.34 \% \quad 75.4 \%$ LFVGGIKEDTEEHHLR

$44 \quad 345 \quad 0.34 \% \quad 75.4 \%$ EDTEEHHLR

$44 \quad 345 \quad 0.34 \% \quad 75.4 \%$ DYFEEYGKIDTIEIITDR

$44 \quad 345 \quad 0.34 \% \quad 75.4 \%$ IDTIEIITDR

$44 \quad 345 \quad 0.34 \% \quad 75.4 \%$ IDTIEIITDRQSGK

$44 \quad 345 \quad 0.34 \% \quad 75.4 \%$ RGFGFVTFDDHDPVDK

$44 \quad 345 \quad 0.34 \% \quad 75.4 \%$ GFGFVTFDDHDPVDK

$44 \quad 345 \quad 0.34 \% \quad 75.4 \%$ GFGFVTFDDHDPVDKIVLQK

$44 \quad 345 \quad 0.34 \% \quad 75.4 \%$ YHTINGHNAEVR

$44 \quad 345 \quad 0.34 \% \quad 75.4 \%$ YHTINGHNAEVRK

$44 \quad 345 \quad 0.34 \% \quad 75.4 \%$ ALSRQEMQEVQSSR

$44 \quad 345 \quad 0.34 \% \quad 75.4 \%$ QEMQEVQSSR

$44 \quad 345 \quad 0.34 \% \quad 75.4 \%$ GGNFGFGDSR

$44 \quad 345 \quad 0.34 \% \quad 75.4 \%$ GGGGNFGPGPGSNFR

$44 \quad 345 \quad 0.34 \% \quad 75.4 \%$ GGSDGYGSGR

$44 \quad 345 \quad 0.34 \% \quad 75.4 \%$ GFGDGYNGYGGGPGGGNFGGSPGYGGGR

44
$99.7 \% \quad 50.5$

$99.7 \% \quad 56.1$

$\begin{array}{lll}98.9 \% & 35.8\end{array}$

$99.3 \% \quad 42.6$

$99.7 \% \quad 56.6$

$99.7 \% \quad 36.0$

$99.7 \% \quad 73.8$

$99.7 \% \quad 30.1$

$\begin{array}{lll}99.7 \% & 38.2\end{array}$

$99.7 \% \quad 56.2$

$99.7 \% \quad 41.6$

$99.7 \% \quad 63.1$

$99.7 \% \quad 51.3$

$99.7 \% \quad 59.8$

$99.7 \% 58.4$

$99.7 \% \quad 60.9$

$99.7 \% \quad 56.2$

$99.7 \% \quad 60.2$

$99.7 \% \quad 65.8$

$99.7 \% \quad 54.5$

$99.7 \% \quad 53.0$

$99.7 \% \quad 55.2$

$99.7 \% \quad 61.5$

$99.7 \% \quad 53.4$

$99.7 \% \quad 55.5$

$99.4 \% 24.9$

$99.0 \% \quad 46.7$

$99.7 \% \quad 55.9$

$99.7 \% \quad 60.0$

$99.7 \% \quad 56.0$

$\begin{array}{lll}99.7 \% & 43.2\end{array}$

$290 \quad 0.29 \% \quad 52.0 \%$ MIAGQVLDINLAAEPKVNR

$290 \quad 0.29 \% \quad 52.0 \%$ SAAEMYGSVTEHPSPSPLLSSSFDLDYDFQR

$290 \quad 0.29 \% \quad 52.0 \%$ VPPPPPIAR

$290 \quad 0.29 \% \quad 52.0 \%$ LKGDDLQAIK

$290 \quad 0.29 \% \quad 52.0 \%$ GDDLQAIK

$290 \quad 0.29 \% \quad 52.0 \%$ GDDLQAIKK

$290 \quad 0.29 \% \quad 52.0 \%$ QKVDSLLENLEK

$290 \quad 0.29 \% \quad 52.0 \%$ VDSLLENLEK

$290 \quad 0.29 \% \quad 52.0 \%$ NDKSEEEQSSSSVK

$290 \quad 0.29 \% \quad 52.0 \%$ SEEEQSSSSVK

$290 \quad 0.29 \% \quad 52.0 \%$ SEEEQSSSSVKK

$290 \quad 0.29 \% \quad 52.0 \%$ GDDQLELIK

$0.00 \% \quad 3.4 \%$ TVVYGITTGFGK

$0.00 \% \quad 3.4 \% \quad$ LQELQVNLVR

$6 \quad 0.01 \% \quad 6.9 \% \quad$ SIRPDNMSEYSK

$6 \quad 0.01 \% \quad 6.9 \% \quad$ YGEYFPGTGDLR

$6 \quad 0.01 \% \quad 6.9 \% \quad$ ISICSSDKR
$99.7 \% 35.0$

$99.7 \% \quad 50.6$

$99.0 \% \quad 34.6$

$99.7 \% 46.0$

$99.7 \% \quad 56.0$

$99.7 \% \quad 57$.

$99.7 \% \quad 52.4$

$99.7 \% \quad 47.8$

$99.7 \% \quad 46.0$

$99.7 \% \quad 38.5$

$99.7 \% 36.4$

$99.6 \% 25.3$

$99.7 \% \quad 38.0$

$99.7 \% \quad 42.1$

$98.3 \% \quad 22.0$
133

1338.70

1466.80

861.56

1879.97

1165.52

2220.07

1188.65

1588.85

1851.87

1695.77

2277.16

1410.69

1538.78

1648.81

1221.55

1013.44

1377.63

912.38

2495.04

2189.9

1316.79

1444.89

1123.60

995.50

1343.68

1247.66

899.48

1329.66

845.41

1698.9

2068.12

3433.55

943.57

1100.63

859.45

987.55

1415.77

1159.62

1553.69

1196.53

1324.62

1030.54

1242.67

1211.71

1426.66

1374.63 1065.54

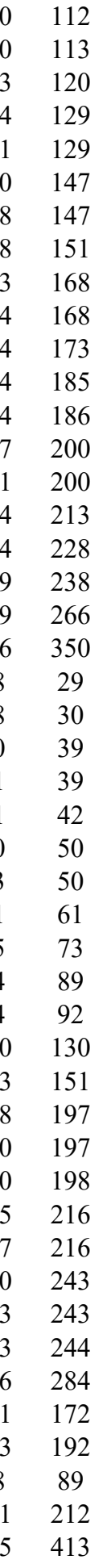

Page 87 of Table S-1-4 
Histone deacetylase $8 \mathrm{GN}=\mathrm{HDAC} 8$ Histone deacetylase $8 \mathrm{GN}=\mathrm{HDAC} 8$ Histone deacetylase $8 \mathrm{GN}=\mathrm{HDAC} 8$ Histone H1.2 GN=HIST1H1C Histone H1.2 GN=HIST1H1C Histone H1.2 GN=HIST1H1C Histone H1.2 GN=HIST1H1C Histone H1.2 GN=HIST1H1C Histone H1.2 GN=HIST1H1C Histone H1.2 GN=HIST1H1C Histone H1.2 GN=HIST1H1C Histone H1.2 GN=HIST1H1C Histone H1.2 GN=HIST1H1C Histone H1.2 GN=HIST1H1C Histone H1.2 GN=HIST1H1C Histone H1.2 GN=HIST1H1C Histone H1.2 GN=HIST1H1C Histone $\mathrm{H} 1.2 \mathrm{GN}=\mathrm{HIST} 1 \mathrm{H} 1 \mathrm{C}$ Histone H1.2 GN=HIST1H1C

Histone $\mathrm{H} 1 \mathrm{x} \mathrm{GN}=\mathrm{H} 1 \mathrm{FX}$ Histone $\mathrm{H} 1 \mathrm{x}$ GN=H1FX Histone $\mathrm{H} 1 \mathrm{x} \mathrm{GN}=\mathrm{H} 1 \mathrm{FX}$ Histone $\mathrm{H} 1 \mathrm{x} \mathrm{GN}=\mathrm{H} 1 \mathrm{FX}$ Histone $\mathrm{H} 1 \mathrm{x}$ GN=H1FX Histone $\mathrm{H} 1 \mathrm{x} \mathrm{GN}=\mathrm{H} 1 \mathrm{FX}$ Histone $\mathrm{H} 1 \mathrm{x} \mathrm{GN}=\mathrm{H} 1 \mathrm{FX}$ Histone $\mathrm{H} 1 \mathrm{x} \mathrm{GN}=\mathrm{H} 1 \mathrm{FX}$

Histone $\mathrm{H} 2 \mathrm{~B}$ type $1-\mathrm{C} / \mathrm{E} / \mathrm{F} / \mathrm{G}$ istone Histone lysine demethylase PHF8 GN=PHF8 PHF8_HUMAN $117.87 \quad 100.0 \%$ Histone-arginine methyltransferase CARM1 GN=CARM1 CARM1_HUMAN $65.85 \quad 100.0 \%$ Histone-arginine methyltransferase CARM1 GN=CARM1 CARM1 HUMAN $65.85 \quad 100.0 \%$ Homeobox protein Hox-B9 GN=HOXB9 HXB9_HUMAN $28.06 \quad 100.0 \%$ Homeobox protein Hox-B9 GN=HOXB9 Hornerin GN=HRNR Hornerin GN=HRNR Hornerin GN=HRNR Hornerin GN=HRNR Hornerin GN=HRNR

Hornerin GN=HRNR Hornerin GN=HRNR Hornerin GN=HRNR

Hsp70-binding protein $1 \mathrm{GN}=\mathrm{HSPBP} 1$ Hsp70-binding protein $1 \mathrm{GN}=\mathrm{HSPBP} 1$ Hsp70-binding protein $1 \mathrm{GN}=\mathrm{HSPBP} 1$ Hsp70-binding protein $1 \mathrm{GN}=\mathrm{HSPBP} 1$ \begin{tabular}{ll}
$0.76 \quad 100.0 \%$ \\
\hline
\end{tabular} HDAC8 HUMAN $41.76 \quad 100.0 \%$ DAC8_HUMAN $41.76 \quad 100.0 \%$ H12 HUMAN $21.37 \quad 100.0 \%$ H12_HUMAN $21.37 \quad 100.0 \%$ H12_HUMAN $21.37 \quad 100.0 \%$ H12 HUMAN $21.37 \quad 100.0 \%$ H12_HUMAN $21.37 \quad 100.0 \%$ H12 HUMAN $21.37 \quad 100.0 \%$ H12_HUMAN $21.37 \quad 100.0 \%$ 12_HUMAN $21.37 \quad 100.0 \%$ H12 HUMAN $21.37 \quad 100.0 \%$ H12_HUMAN $21.37 \quad 100.0 \%$ H12_HUMAN $21.37 \quad 100.0 \%$ H12_HUMAN $21.37 \quad 100.0 \%$ H12_HUMAN $21.37 \quad 100.0 \%$ H12_HUMAN $21.37 \quad 100.0 \%$ H12_HUMAN $21.37 \quad 100.0 \%$ H1X HUMAN $22.49 \quad 100.0 \%$ \begin{tabular}{ll} 
HIX_HUMAN 22.49 & $100.0 \%$ \\
\hline
\end{tabular} H1X_HUMAN $22.49 \quad 100.0 \%$ H1X_HUMAN $22.49 \quad 100.0 \%$ H1X_HUMAN $22.49 \quad 100.0 \%$ H1X_HUMAN $22.49 \quad 100.0 \%$ H1X HUMAN $22.49 \quad 100.0 \%$ H2B1C_HUMAN $13.90 \quad 99.9 \%$ XB9 HUMAN $28.06 \quad 100.0 \%$ HORN_HUMAN $282.37 \quad 100.0 \%$ HORN_HUMAN $282.37 \quad 100.0 \%$ HORN HUMAN $282.37 \quad 100.0 \%$ HORN_HUMAN $282.37 \quad 100.0 \%$ HORN_HUMAN $282.37 \quad 100.0 \%$ HORN HUMAN $282.37 \quad 100.0 \%$ HORN_HUMAN $282.37 \quad 100.0 \%$ HORN HUMAN $282.37 \quad 100.0 \%$ HPBP1_HUMAN $39.47 \quad 100.0 \%$ HPBP1_HUMAN $39.47 \quad 100.0 \%$ HPBP1_HUMAN $39.47 \quad 100.0 \%$ HPBP1_HUMAN $39.47 \quad 100.0 \%$
$0.00 \% \quad 9.8 \%$ FSPGFFPGTGDVSDVGLGK $0.00 \% \quad 9.8 \%$ EVYQAFNPK $0.00 \% \quad 9.8 \%$ IQQILNYIK $44 \quad 0.24 \% \quad 49.8 \%$ SETAPAAPAAAPPAEK $244 \quad 0.24 \% \quad 49.8 \%$ KASGPPVSELITK $244 \quad 0.24 \% \quad 49.8 \%$ ASGPPVSELITK

$244 \quad 0.24 \% \quad 49.8 \%$ AVAASKER

$244 \quad 0.24 \% \quad 49.8 \%$ SGVSLAALK

$244 \quad 0.24 \% \quad 49.8 \%$ SGVSLAALKK

$244 \quad 0.24 \% \quad 49.8 \%$ KALAAAGYDVEK

$244 \quad 0.24 \% \quad 49.8 \%$ ALAAAGYDVEK

$244 \quad 0.24 \% \quad 49.8 \%$ ALAAAGYDVEKNNSR

$244 \quad 0.24 \% \quad 49.8 \%$ SLVSKGTLVQTK

$244 \quad 0.24 \% \quad 49.8 \%$ GTLVQTKGTGASGSFK

$244 \quad 0.24 \% \quad 49.8 \%$ GTGASGSFK

$244 \quad 0.24 \% \quad 49.8 \%$ GTGASGSFKLNK

$244 \quad 0.24 \% \quad 49.8 \%$ KAAGGATPK

$244 \quad 0.24 \% \quad 49.8 \%$ AKKPAAATVTK

$244 \quad 0.24 \% \quad 49.8 \%$ KPAAATVTK

$0.03 \% \quad 37.1 \%$ SVELEEALPVTTAEGMAK

$0.03 \% \quad 37.1 \%$ AGGSAALSPSK

$0.03 \% \quad 37.1 \%$ YSQLVVETIR

$0.03 \% \quad 37.1 \%$ YSQLVVETIRR

$0.03 \% \quad 37.1 \%$ KVPWFDQQNGR

$0.03 \% \quad 37.1 \%$ ALVQNDTLLQVK

$0.03 \% \quad 37.1 \%$ RGAPAAATAPAPTAHK

$0.03 \% \quad 37.1 \%$ GAPAAATAPAPTAHK

$0.00 \% \quad 15.9 \%$ QVHPDTGISSK

$0.00 \% \quad 15.9 \%$ LLLPGELAK

$0.00 \% \quad 2.7 \%$ VASIETGLAAAAAK

$0.00 \% \quad 2.7 \%$ RPSVGSQSNQAGQGK

$0.00 \% \quad 4.3 \% \quad$ CLFQSPLFAK

$0.00 \% \quad 4.3 \%$ AGDTLSGTCLLIANKR

$0.00 \% \quad 10.4 \%$ GEAAPGQGQAAVK

$0.00 \% \quad 10.4 \%$ AEPLLGAPGELLK

$0.02 \% \quad 5.2 \%$ SSSGSSSSYGQHGSGSR

$0.02 \% \quad 5.2 \%$ GPYESGSGHSSGLGHQESR

$.7 \% 57.4$ $99.7 \% \quad 45.7$

$99.7 \% \quad 33.4$

$99.1 \% \quad 34.0$

$99.7 \% \quad 58.9$

$99.7 \% \quad 48.6$

$99.0 \% \quad 40.4$

$99.7 \% \quad 65.5$

$99.7 \% \quad 59.6$

$99.7 \% \quad 55.5$

$99.7 \% \quad 61.9$

$99.7 \% \quad 60.7$

$99.7 \% \quad 61.0$

$99.7 \% \quad 25.4$

$99.5 \% \quad 25.4$

$99.7 \% \quad 44.0$

$98.6 \% \quad 23.7$

$99.7 \% \quad 51.6$

$99.7 \% \quad 43.8$

$9.7 \% \quad 29.1$

$99.7 \% \quad 57.4$

$99.7 \% \quad 61.9$

$99.7 \% \quad 40.2$

$99.7 \% \quad 30.7$

$99.7 \% \quad 59.5$

$99.7 \% 35.8$

$99.7 \% \quad 53.2$

$97.9 \% \quad 17.1$

$95.1 \% \quad 23.3$

$99.7 \% \quad 55.7$

$99.7 \% \quad 31.2$

$99.3 \% \quad 20.6$

$98.7 \% \quad 20.4$

$99.7 \% \quad 35.5$

$98.7 \% \quad 28.1$

$99.7 \% \quad 44.0$

$0.02 \% \quad 5.2 \% \quad$ GSGSGQSPSYGR

$0.02 \% \quad 5.2 \% \quad$ SEQHGSSSGSSSSYGQHGSGSR $\quad 99.7 \% \quad 41.2$

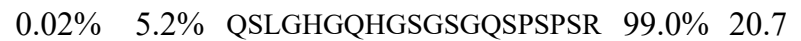

$0.02 \% \quad 5.2 \%$ GPYESGSGHSSGLGHR $\quad 99.7 \% 35.2$

$0.02 \% \quad 5.2 \%$ HGSSSGSSSSYGQHGSGSR $\quad 99.7 \% \quad 60.5$

$0.02 \% \quad 5.2 \%$ GEQHGSSSGSSSSYGQHGSGSR $\quad 99.7 \% \quad 40.0$

$0.03 \% \quad 16.9 \%$ GQREEVEQMK

$0.03 \% \quad 16.9 \%$ YLEAGAAGLR

$0.03 \% \quad 16.9 \%$ LLDRDACDTVR

$99.2 \% \quad 22.2$

$99.7 \% \quad 52.2$

$99.2 \% \quad 20.2$

$99.7 \% \quad 58.8$

$0 \quad 31.8$

0.0

$\begin{array}{lll}.0 & 51.8 \quad 35 \\ & & \end{array}$

43.82

$\begin{array}{ll}0 & 44.0 \\ & \end{array}$

$\begin{array}{lll}0 & 52.8 & 36 \\ -0 & -1\end{array}$

$\begin{array}{lll}25.0 & 55.2 & 4\end{array}$

51.7

60.7

53.6

\begin{tabular}{ll}
0 & 25.4 \\
\hline
\end{tabular}

$\begin{array}{lll}0 & 16.4 & 3\end{array}$

$\begin{array}{lll} & 31.4 & 17\end{array}$

\begin{tabular}{ll}
14.4 \\
\hline
\end{tabular}

$\begin{array}{lll}.0 & 41.3 \quad 2\end{array}$

30.0
25.0

29.

$\begin{array}{ll}40.2 & 40.2\end{array}$

$\begin{array}{ll}.0 & 46.4\end{array}$

$\begin{array}{ll}0 & 36.8\end{array}$

$\begin{array}{ll}.0 & 24.7\end{array}$

$.0 \quad 48.6$

$\begin{array}{ll}.0 & 35.8\end{array}$

48.4

$\begin{array}{ll}0.0 & 17.1\end{array}$

$\begin{array}{ll}5.0 & 4.0\end{array}$

.0 53.1

$\begin{array}{ll}26.0 & 26.2\end{array}$

20.6

$\begin{array}{ll}.0 & 20.4\end{array}$

23.0
25.0

$\begin{array}{ll}0 & 25.6\end{array}$

$\begin{array}{ll}5.0 & 40.0\end{array}$

\begin{tabular}{ll}
5.0 & 45.6 \\
\hline
\end{tabular}

$0 \quad 15.4$

$\begin{array}{ll}25.0 & 41.2\end{array}$

$\begin{array}{ll}25.0 & 19.7\end{array}$

$\begin{array}{ll} & 30.6\end{array}$

$\begin{array}{ll}0 & 60.5\end{array}$

$\begin{array}{ll}.0 & 40.0\end{array}$

$0.03 \% \quad 16.9 \%$ ALFAISCLVR
1883.92

1095.55

1132.67

1478.75

1326.76

1198.67

831.47

845.51

973.60

1235.66

1107.57

1578.79

1260.75

1538.82

811.39

1166.62

800.46

1085.67

886.54

1890.94

945.50

1207.67

1363.77

1374.69

1341.77

1487.81

1331.71

1168.60

953.60

1272.72

1500.75

1210.63

1689.90

1183.61

1307.76

1614.67

1928.85

1139.5

2152.89

1947.90

1584.72

1808.75

2122.88

1233.59

1020.55

1333.65

1149.64 
Hsp70-binding protein $1 \mathrm{GN}=\mathrm{HSPBP} 1$ Hsp70-binding protein $1 \mathrm{GN}=\mathrm{HSPBP} 1$ Huntingtin $\mathrm{GN}=\mathrm{HTT}$

Huntingtin GN=HTT

Huntingtin GN=HTT

Huntingtin GN=HTT

Huntingtin GN=HTT

Huntingtin GN=HTT

Hydroxysteroid dehydrogenase-like protein $2 \mathrm{GN}=\mathrm{HSDL} 2$ HSDL2 HUMAN $45.40 \quad 100.0 \%$

Hydroxysteroid dehydrogenase-like protein 2 GN=HSDL2 HSDL2_HUMAN $45.40 \quad 100.0 \%$ Hydroxysteroid dehydrogenase-like protein 2 GN=HSDL2 HSDL2_HUMAN $45.40 \quad 100.0 \%$ Hydroxysteroid dehydrogenase-like protein 2 GN=HSDL2 HSDL2_HUMAN $45.40 \quad 100.0 \%$ Hydroxysteroid dehydrogenase-like protein 2 GN=HSDL2 HSDL2_HUMAN $45.40 \quad 100.0 \%$ Hypoxia up-regulated protein $1 \mathrm{GN}=$ HYOU1 HYOU1_HUMAN $111.34 \quad 100.0 \%$ Hypoxia up-regulated protein $1 \mathrm{GN}=\mathrm{HYOU} 1$ HYOU1_HUMAN $111.34 \quad 100.0 \%$ Hypoxia up-regulated protein 1 GN=HYOU1 HYOU1_HUMAN $111.34 \quad 100.0 \%$ Hypoxia up-regulated protein $1 \mathrm{GN}=\mathrm{HYOU} 1 \mathrm{HYOU} 1 \mathrm{HUMAN} 111.34100 .0 \%$ Ig alpha- 1 chain $\mathrm{C}$ region $\mathrm{GN}=\mathrm{IGHA} 1$ Ig alpha- 1 chain $\mathrm{C}$ region $\mathrm{GN}=\mathrm{IGHA} 1$ Ig alpha- 1 chain $\mathrm{C}$ region $\mathrm{GN}=\mathrm{IGHA} 1$ Ig alpha- 1 chain $\mathrm{C}$ region $\mathrm{GN}=\mathrm{IGHA} 1$ Ig alpha- 1 chain $\mathrm{C}$ region $\mathrm{GN}=\mathrm{IGHA} 1$ Ig alpha- 1 chain $\mathrm{C}$ region $\mathrm{GN}=\mathrm{IGHA} 1$ Ig alpha- 1 chain $\mathrm{C}$ region $\mathrm{GN}=\mathrm{IGHA} 1$ $\begin{array}{llll} & \end{array}$ Ig kappa chain V-I region Lay OS=Homo sapiens KV113_HUMAN $11.83 \quad 100.0 \%$ Ig kappa chain V-II region RPMI 6410 OS=Homo sapiens KV206_HUMAN $14.71 \quad 100.0 \%$ Ig kappa chain V-II region RPMI 6410 OS=Homo sapiens KV206_HUMAN $14.71 \quad 100.0 \%$ Ig kappa chain V-II region RPMI 6410 OS=Homo sapiens KV206_HUMAN $14.71 \quad 100.0 \%$ Ig lambda-2 chain $\mathrm{C}$ regions GN=IGLC2 LAC2_HUMAN $11.29 \quad 100.0 \%$ Ig lambda-2 chain C regions GN=IGLC2 LAC2_HUMAN $11.29 \quad 100.0 \%$ Ig lambda-2 chain C regions GN=IGLC2 LAC2_HUMAN $11.29 \quad 100.0 \%$ Immunoglobulin lambda-like polypeptide 5 GN=IGLL5 IGLL5_HUMAN $23.06 \quad 100.0 \%$ Immunoglobulin lambda-like polypeptide 5 GN=IGLL5 IGLL5_HUMAN $23.06 \quad 100.0 \%$ Immunoglobulin-binding protein $1 \mathrm{GN}=\mathrm{IGBP} 1$ IGBP1_HUMAN $39.22 \quad 100.0 \%$ Immunoglobulin-binding protein 1 GN=IGBP1 IGBP1_HUMAN $39.22 \quad 100.0 \%$ Immunoglobulin-binding protein 1 GN=IGBP1 IGBP1_HUMAN $39.22 \quad 100.0 \%$ Importin subunit alpha-1 GN=KPNA2 Importin subunit alpha-1 GN=KPNA2 Importin subunit alpha-1 GN=KPNA2 Importin subunit alpha- $1 \mathrm{GN}=\mathrm{KPNA} 2$ Importin subunit alpha-5 GN=KPNA1 Importin subunit alpha-5 GN=KPNA1 Importin subunit alpha-5 GN=KPNA1 Importin subunit alpha-5 GN=KPNA1 Importin subunit alpha-5 GN=KPNA1 Importin subunit beta-1 GN=KPNB1
IMA1_HUMAN $57.86 \quad 100.0 \%$ IMA1_HUMAN $57.86 \quad 100.0 \%$ IMA1_HUMAN $57.86 \quad 100.0 \%$ IMA1_HUMAN $57.86 \quad 100.0 \%$ IMA5_HUMAN $60.22 \quad 100.0 \%$ IMA5 HUMAN $60.22 \quad 100.0 \%$ IMA5_HUMAN $60.22 \quad 100.0 \%$ IMA5_HUMAN $60.22 \quad 100.0 \%$ IMA5_HUMAN $60.22 \quad 100.0 \%$ IMB1_HUMAN $97.17 \quad 100.0 \%$
$99.7 \% \quad 54.4$

$99.7 \% \quad 43.8$

$99.7 \% \quad 38.6$

$99.2 \% \quad 21.0$

$99.6 \% \quad 25.1$

$99.7 \% 48$.

$99.7 \% \quad 46.2$

$96.8 \% \quad 32.1$

$99.7 \% \quad 60.5$

$99.7 \% 52.8$

$0.01 \% \quad 16.0 \%$ LAGCTVFITGASR

$0.01 \% \quad 16.0 \%$ DGANIVIAAK

$99.7 \% \quad 58.5$

$0.01 \% \quad 16.0 \%$ KVDIIADAAYSIFOKPK $\quad 99.7 \% \quad 30.9$

$0.01 \% \quad 16.0 \%$ SGAVEETFR

$0.01 \% \quad 4.3 \% \quad$ YFQHLLGK

$0.01 \% \quad 4.3 \%$ QADNPHVALYQAR

$0.01 \% \quad 4.3 \%$ LAGLFNEQR

$0.01 \% \quad 4.3 \%$ DAVVYPILVEFTR

$0.01 \% \quad 21.2 \%$ DASGVTFTWTPSSGK

$0.01 \% \quad 21.2 \%$ TFTCTAAYPESK

$0.01 \% \quad 21.2 \%$ TPLTATLSK

$0.01 \% \quad 21.2 \%$ GFSPKDVLVR

$0.01 \% \quad 21.2 \%$ WLQGSQELPR

$0.01 \% \quad 21.2 \%$ WLQGSQELPREK

$99.7 \% \quad 54.5$

$99.0 \% \quad 24.6$

$98.7 \% \quad 18.3$

$99.7 \% \quad 47.1$

$99.7 \% \quad 31.4$

$99.7 \% \quad 55.3$

$99.6 \% \quad 23.9$

$99.7 \% \quad 45.1$

$99.7 \% \quad 55.9$

$99.7 \% \quad 42.6$

$99.7 \% \quad 42.7$

$\begin{array}{llllll}0.01 \% & 21.2 \% & \text { QEPSQGTTTFAVTSILR } \quad 99.7 \% & 68.7\end{array}$

$0.01 \% \quad 25.0 \%$ DIQMTQSPSSLSVSVGDR $99.7 \% \quad 44.6$

$0.01 \% \quad 25.0 \%$ LLIYGASTR

$0.07 \% \quad 18.0 \%$ LIYKVSNR

$0.07 \% \quad 18.0 \%$ FSGSGSGTDFTLK

$99.7 \% \quad 53.7$

$\begin{array}{lll}99.0 \% & 29.3\end{array}$

$99.4 \% 57.7$

$0.07 \% \quad 18.0 \%$ FSGSGSGTDFTLKISR

$99.2 \% \quad 63.5$

$0.00 \% \quad 30.2 \%$ ADSSPVKAGVETTTPSK $\quad 96.6 \% \quad 15.3$

$0.00 \% \quad 30.2 \%$ AGVETTTPSK

$0.00 \% \quad 30.2 \%$ SYSCQVTHEGSTVEK

$99.7 \% \quad 42.7$

$99.7 \% \quad 37.9$

$99.0 \% \quad 47.8$

$0.00 \% \quad 10.7 \%$ SYSCQVTHEGSTVEK

$99.7 \% \quad 37.9$

$99.7 \% \quad 29.5$

0.00\% $10.6 \%$ LPELFETGR

$0.00 \% \quad 10.6 \%$ QLLDEVEVATEPAGSR

$99.6 \% 25.8$

$99.5 \% \quad 22.5$

$99.7 \% 28.3$

$0.02 \% \quad 10.4 \%$ EKQPPIDNIIR

$99.7 \% 33.0$

$99.7 \% \quad 30.4$

$0.02 \% \quad 10.4 \%$ TGVVPQLVK

$\begin{array}{lllll}0.02 \% & 10.4 \% & \text { LLGASELPIVTPALR } & 99.7 \% & 56.4 \\ 0.01 \% & 11.3 \% & \text { LLSKEPNPPIDEVISTPGVVAR } & 94.8 \% & 14.7\end{array}$

$0.01 \% \quad 11.3 \%$ EPNPPIDEVISTPGVVAR $\quad 98.3 \% 26.1$

$0.01 \% \quad 11.3 \%$ NAVWALSNLCR

$0.01 \% \quad 11.3 \%$ EACWTISNITAGNR

$0.01 \% \quad 11.3 \%$ IVQVALNGLENILR

$99.7 \% \quad 56.2$

$99.7 \% \quad 50.6$

$99.7 \% \quad 61.5$

$99.7 \% \quad 58.1$ $0.02 \% \quad 7.8 \%$ AAVENLPTFLVELSR
$0.00 \% \quad 10.7 \%$ VTVLGQPK

1206.7

937.56

1485.71

1597.89

1562.83

1058.62

1352.70

971.55

1834.98

1907.06

995.48

1005.55

1482.74

1047.56

1521.83

1540.73

1375.62

931.55

1117.64

1213.63

1470.77

1835.95

1922.91

993.57

992.59

1303.62

1659.83

1674.85

990.51

1711.76

841.51

1711.76

1061.56

1713.87

1132.60

1322.74

2185.23

940.58

1549.93

2331.29

1890.00

1303.66

1592.75

1551.92 
Importin subunit beta-1 $\mathrm{GN}=\mathrm{KPNB} 1$ Importin subunit beta- $1 \mathrm{GN}=\mathrm{KPNB} 1$ Importin subunit beta- $1 \mathrm{GN}=\mathrm{KPNB}$ Importin subunit beta- $1 \mathrm{GN}=\mathrm{KPNB} 1$ Importin subunit beta-1 GN=KPNB1 Importin-11 GN=IPO11

Importin-11 GN=IPO1 Importin-4 GN=IPO4 Importin- $4 \mathrm{GN}=\mathrm{IPO} 4$ Importin- $4 \mathrm{GN}=\mathrm{IPO} 4$ Importin- $4 \mathrm{GN}=\mathrm{IPO} 4$ Importin- $4 \mathrm{GN}=\mathrm{IPO} 4$ Importin- $4 \mathrm{GN}=\mathrm{IPO} 4$ Importin- $4 \mathrm{GN}=\mathrm{IPO} 4$ Importin- $4 \mathrm{GN}=\mathrm{IPO} 4$ Importin-4 GN=IPO Importin-5 GN=IPO5 Importin- $5 \mathrm{GN}=\mathrm{IPO} 5$ Importin-5 GN=IPO5 Importin-5 GN=IPO5 Importin-5 GN=IPO Importin-5 GN=IPO5 Importin-7 GN=IPO7 Importin-7 GN=IPO7
IMBI HUMAN $97.17 \quad 100.0 \%$ IMB1_HUMAN $97.17 \quad 100.0 \%$ IMB1_HUMAN $97.17 \quad 100.0 \%$ IMB1_HUMAN $97.17 \quad 100.0 \%$ IMB1_HUMAN $97.17 \quad 100.0 \%$ IPO11_HUMAN $112.54 \quad 100.0 \%$ IPO11 HUMAN $112.54 \quad 100.0 \%$ IPO4_HUMAN $118.72 \quad 100.0 \%$ IPO4 HUMAN $118.72 \quad 100.0 \%$ IPO4 HUMAN $118.72 \quad 100.0 \%$ IPO4_HUMAN $118.72 \quad 100.0 \%$ IPO4_HUMAN $118.72 \quad 100.0 \%$ IPO4_HUMAN $118.72 \quad 100.0 \%$ IPO4 HUMAN $118.72 \quad 100.0 \%$ IPO4_HUMAN $118.72 \quad 100.0 \%$ IPO4_HUMAN $118.72 \quad 100.0 \%$ IPO5 HUMAN $123.63 \quad 100.0 \%$ IPO5_HUMAN $123.63 \quad 100.0 \%$ IPO5_HUMAN $123.63 \quad 100.0 \%$ IPO5 HUMAN $123.63 \quad 100.0 \%$ IPO5_HUMAN $123.63 \quad 100.0 \%$ IPO5 HUMAN $123.63 \quad 100.0 \%$ IPO7 HUMAN $119.52 \quad 100.0 \%$ IPO7_HUMAN $119.52 \quad 100.0 \%$ 年 Inactive hydroxysteroid dehydrogenase-like protein $1 \mathrm{GN}=$ HSDL1 HSDL1_HUMAN $37.00 \quad 100.0 \%$ Inactive hydroxysteroid dehydrogenase-like protein $1 \mathrm{GN}=$ HSDL1 HSDL1_HUMAN $37.00 \quad 100.0 \%$ Inactive hydroxysteroid dehydrogenase-like protein 1 GN=HSDL1 HSDL1_HUMAN $37.00 \quad 100.0 \%$ Inactive hydroxysteroid dehydrogenase-like protein $1 \mathrm{GN}=\mathrm{HSDL} 1 \mathrm{HSDL} 1$ HUMAN $37.00 \quad 100.0 \%$ Inactive hydroxysteroid dehydrogenase-like protein $1 \mathrm{GN}=\mathrm{HSDL} 1 \mathrm{HSDL} 1$ HUMAN $37.00 \quad 100.0 \%$ Inactive hydroxysteroid dehydrogenase-like protein 1 GN=HSDL1 HSDL1_HUMAN $37.00 \quad 100.0 \%$ Inorganic pyrophosphatase GN=PPA1 IPYR_HUMAN $32.66 \quad 100.0 \%$ Inorganic pyrophosphatase GN=PPA1 IPYR_HUMAN $32.66 \quad 100.0 \%$ Inosine-5'-monophosphate dehydrogenase $2 \mathrm{GN}=\mathrm{IMPDH} 2$ IMDH2_HUMAN $55.81 \quad 100.0 \%$ Inosine-5'-monophosphate dehydrogenase 2 GN=IMPDH2 IMDH2 HUMAN $55.81 \quad 100.0 \%$ Inosine-5'-monophosphate dehydrogenase 2 GN=IMPDH2 IMDH2_HUMAN $55.81 \quad 100.0 \%$ Inosine-5'-monophosphate dehydrogenase 2 GN=IMPDH2 IMDH2_HUMAN $55.81 \quad 100.0 \%$ Inosine-5'-monophosphate dehydrogenase 2 GN=IMPDH2 IMDH2 HUMAN $55.81 \quad 100.0 \%$ Inosine-5'-monophosphate dehydrogenase 2 GN=IMPDH2 IMDH2_HUMAN $55.81 \quad 100.0 \%$ Inosine-5'-monophosphate dehydrogenase 2 GN=IMPDH2 IMDH2_HUMAN $55.81 \quad 100.0 \%$ Inosine-5'-monophosphate dehydrog 2 GN=IMPDH2 IMDH2 HUMAN $55.81 \quad 100.0 \%$ Insulin receptor substrate $4 \mathrm{GN}=\mathrm{IRS} 4$ Insulin receptor substrate $4 \mathrm{GN}=\mathrm{IRS} 4$ Insulin receptor substrate $4 \mathrm{GN}=\mathrm{IRS} 4$ Insulin receptor substrate $4 \mathrm{GN}=\mathrm{IRS}$ Insulin receptor substrate $4 \mathrm{GN}=\mathrm{IRS} 4$ Insulin receptor substrate $4 \mathrm{GN}=\mathrm{IRS} 4$ IRS4_HUMAN $133.77 \quad 100.0 \%$ IRS4 HUMAN $133.77 \quad 100.0 \%$ IRS4_HUMAN $133.77 \quad 100.0 \%$ IRS4_HUMAN $133.77 \quad 100.0 \%$ IRS4_HUMAN $133.77 \quad 100.0 \%$ IRS4_HUMAN $133.77 \quad 100.0 \% \quad 17$
$0.02 \% \quad 7.8 \%$ VLANPGNSQVAR $0.02 \% \quad 7.8 \%$ VAAGLQIK

$0.02 \% \quad 7.8 \%$ LAATNALLNSLEFTK

$0.02 \% \quad 7.8 \%$ ANFDKESER

$0.02 \% \quad 7.8 \%$ VAALQNLVK

$0.00 \% \quad 2.6 \%$ VAPHALSEEEKTTLR

$0.00 \% \quad 2.6 \%$ ALLTFYHVTK

$0.02 \% \quad 9.5 \% \quad$ ATEQLQIVLR

$0.02 \% \quad 9.5 \%$ QFAAVLTR

$0.02 \% \quad 9.5 \%$ TLTTMAPYLSTEDVPLAR

$0.02 \% \quad 9.5 \%$ EVMPLLLAYLK

$0.02 \% \quad 9.5 \%$ VVPSYMQAVNR

$0.02 \% \quad 9.5 \%$ LAELCGVLK

$0.02 \% \quad 9.5 \%$ LLPVLLSTAQEADPEVR

$0.02 \% \quad 9.5 \%$ VRDNICGALAR

$0.02 \% \quad 9.5 \%$ LLMASPTR

$0.02 \% \quad 7.4 \%$ VCDIAAELAR

$0.02 \% \quad 7.4 \%$ FLFDSVSSQNVGLR

$0.02 \% \quad 7.4 \%$ SLVEIADTVPK

$0.02 \% \quad 7.4 \%$ VQAHAAAALINFTEDCPK

$0.02 \% \quad 7.4 \%$ FVPYYDLFMPSLK

$0.02 \% \quad 7.4 \%$ VAAAESMPLLLECAR

$0.00 \% \quad 2.0 \%$ AFAVGVQQVLLK

$0.00 \% \quad 2.0 \%$ AIFQTIQNR

$0.01 \% \quad 23.0 \%$ SITVICDFYSLIR

$0.01 \% \quad 23.0 \%$ WAVVSGATDGIGK

$0.01 \% \quad 23.0 \%$ AYAEELASR

$0.01 \% \quad 23.0 \%$ GLNIILISR

$0.01 \% \quad 23.0 \%$ NEEKLQVVAK

$0.01 \% \quad 23.0 \%$ AYLDHFSR

$0.01 \% \quad 23.0 \%$ VYAHHAVSTLGISK

$0.00 \% \quad 10.7 \%$ AAPFSLEYR

$0.02 \% \quad 20.4 \%$ EANEILQR

ANYNDINDVKR

$0.02 \% \quad 20.4 \%$ GKLPIVNEDDELVAIIAR

$0.02 \% \quad 20.4 \%$ NRDYPLASK

$0.02 \% \quad 20.4 \%$ NLIDAGVDALR

$0.02 \% \quad 20.4 \%$ RFGVPVIADGGIQNVGHIAK

$0.02 \% \quad 20.4 \%$ YFSEADKIK

$0.02 \% \quad 20.4 \%$ VAQGVSGAVQDK

$0.02 \% \quad 20.4 \%$ TSSAQVEGGVHSLHSYEK $99.7 \% 29.8$

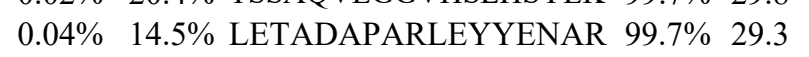

$0.04 \% \quad 14.5 \%$ LEYYENAR

$0.04 \% \quad 14.5 \%$ LCLTDEEVVFVR

$0.04 \% \quad 14.5 \%$ ALCADEYRAR

$0.04 \% \quad 14.5 \%$ AIGDGEDEMLFTR

$0.04 \% \quad 14.5 \%$ RFVTPSEPVAHSR

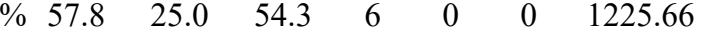

799.50

1605.88

1095.51

955.59

1680.89

1192.67

1170.68

905.52

1995.01

1305.75

1263.65

1002.57

1851.02

1244.65

904.49

1117.57

1568.81

1171.66

1955.96

1635.81

1630.83

1272.77

1090.60

1586.82

1260.66

1009.49

998.64

1157.65

1008.49

1482.81

1053.54

2444.2

972.51

1965.10

1063.55

1156.63

2048.14

1100.56

1158.61

1915.91

1981.96

1057.49

1479.75

1224.58

1469.66 $\begin{array}{llll}99.7 \% & 29.7 & 25.0 & 26.0\end{array}$ $\begin{array}{llll}99.7 \% & 38.4 & 25.0 & 38.4\end{array}$ $99.7 \% \quad 47.6 \quad 25.0 \quad 47.6$

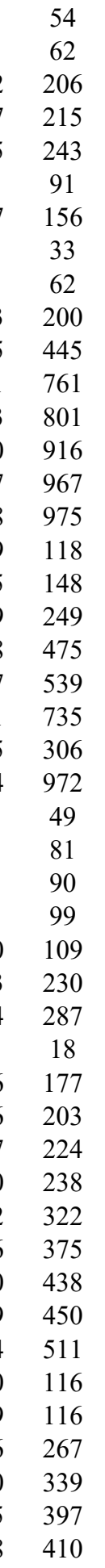

90 of Table S-1-4 
Insulin receptor substrate $4 \mathrm{GN}=\mathrm{IRS} 4$ Insulin receptor substrate $4 \mathrm{GN}=\mathrm{IRS} 4$ Insulin receptor substrate $4 \mathrm{GN}=\mathrm{IRS} 4$ Insulin receptor substrate $4 \mathrm{GN}=\mathrm{IRS} 4$ Insulin receptor substrate $4 \mathrm{GN}=\mathrm{IRS} 4$ Insulin receptor substrate $4 \mathrm{GN}=\mathrm{IRS} 4$ Insulin receptor substrate $4 \mathrm{GN}=\mathrm{IRS} 4$ Insulin receptor substrate $4 \mathrm{GN}=\mathrm{IRS} 4$ Insulin receptor substrate $4 \mathrm{GN}=\mathrm{IRS} 4$ Insulin receptor substrate $4 \mathrm{GN}=\mathrm{IRS} 4$ Insulin receptor substrate $4 \mathrm{GN}=\mathrm{IRS} 4$ Insulike grow for 2 mRNA-binding Insulin-like growth factor $2 \mathrm{mRNA}$-binding protein $1 \mathrm{GN}=1 \mathrm{GF} 2 \mathrm{BP} 1$
Insulin-like growth factor $2 \mathrm{mRNA}$-binding protein $1 \mathrm{GN}=\mathrm{IGF} 2 \mathrm{BP} 1$ Insulin-like growth factor $2 \mathrm{mRNA}$-binding protein $1 \mathrm{GN}=\mathrm{IGF} 2 \mathrm{BP} 1$ Insulin-like growth factor $2 \mathrm{mRNA}$-binding protein $1 \mathrm{GN}=\mathrm{IGF} 2 \mathrm{BP} 1$ Insulin-like growth factor 2 mRNA-binding protein $1 \mathrm{GN}=$ IGF2BP Insulin-like growth factor $2 \mathrm{mRNA}$-binding protein $1 \mathrm{GN}=$ IGF2BP
P Insulin-like growth factor 2 mRNA-binding protein 1 GN=IGF2BP
Insulin-like growth factor 2 mRNA-binding protein 1 GN=IGF2BP Insulin-like growth factor $2 \mathrm{mRNA}$-binding protein $1 \mathrm{GN}=\mathrm{IGF} 2 \mathrm{~B}$ Insulin-like growth factor 2 mRNA-binding protein $1 \mathrm{GN}=$ IGF2BP1 Insulin-like growth factor $2 \mathrm{mRNA}$-binding protein $1 \mathrm{GN}=$ IGF2BP1
Insulin-like growth factor $2 \mathrm{mRNA}$-binding protein $1 \mathrm{GN}=\mathrm{IGF} 2 \mathrm{BP} 1$ Insulin-like growth factor 2 mRNA-binding protein 1 GN=IGF2BP1 IF2B1_HUMAN 63.48 Insulin-like growth factor 2 mRNA-binding protein 1 GN=IGF2BP1 IF2B1_HUMAN 63.48 Insulin-like growth factor 2 mRNA-binding protein $1 \mathrm{GN}=$ IGF2BP1 IF2B1_HUMAN 63.48 Insulin-like growth factor 2 mRNA-binding protein 1 GN=IGF2BP1 IF2B1_HUMAN 63.48 Insulin-like growth factor 2 mRNA-binding protein 1 GN=IGF2BP1 IF2B1_HUMAN 63.48 Insulin-like growth factor 2 mRNA-binding protein $1 \mathrm{GN}=$ IGF2BP1 $\quad$ IF2B1_HUMAN 63.48 Insulin-like growth factor 2 mRNA-binding protein 1 GN=IGF2BP1 IF2B1_HUMAN 63.48 Insulin-like growth factor 2 mRNA-binding protein 1 GN=IGF2BP1 IF2B1_HUMAN 63.48 Insulin-like growth factor 2 mRNA-binding protein $1 \mathrm{GN}=I$ IGF2BP1 $\quad$ IF2B1_HUMAN 63.48 Insulin-like growth factor 2 mRNA-binding protein 1 GN=IGF2BP1 IF2B1_HUMAN 63.48 Insulin-like growth factor 2 mRNA-binding protein $1 \mathrm{GN}=$ IGF2BP1 IF2B1_HUMAN 63.48 Insulin-like growth factor 2 mRNA-binding protein 1 GN=IGF2BP1 IF2B1_HUMAN 63.48 Insulin-like growth factor 2 mRNA-binding protein 1 GN=IGF2BP1 IF2B1_HUMAN 63.48 Insulin-like growth factor 2 mRNA-binding protein $1 \mathrm{GN}=I G F 2 B P 1 \quad$ IF2B1_HUMAN $63.48 \quad 1$ Insulin-like growth factor 2 mRNA-binding protein $1 \mathrm{GN}=$ IGF2BP1 $\quad$ IF2B1_HUMAN 63.48 Insulin-like growth factor 2 mRNA-binding protein 1 GN=IGF2BP1 IF2B1_HUMAN 63.48 Insulin-like growth factor 2 mRNA-binding protein 1 GN=IGF2BP1 IF2B1_HUMAN 63.48 Insulin-like growth factor 2 mRNA-binding protein 1 GN=IGF2BP1 IF2B1_HUMAN 63.48 -binding protein 1 GN=IGF2BP1 IF2B1_HUMAN 63.48 Insulin-like growth factor 2 mRNA-binding protein 1 GN=IGF2BP1 IF2B1_HUMAN 63.48 Insulin-like growth factor 2 mRNA-binding protein 1 GN=IGF2BP1 IF2B1_HUMAN 63.48 $\begin{array}{llll}\text { Insulin-like growth factor } 2 \text { mRNA-binding protein } 1 \text { GN=IGF2BP1 } & \text { IF2B1_HUMAN } & 63.48 & 1\end{array}$ Insulin-like growth factor 2 mRNA-binding protein 1 GN=IGF2BP1 IF2B1_HUMAN 63.48 $\begin{array}{lll}\text { Insulin-like growth factor } 2 \text { mRNA-binding protein } 1 \mathrm{GN}=I G F 2 B P 1 & \text { IF2B1_HUMAN } & 63.48 \\ \text { Insulin-like growth factor } 2 \text { mRNA-binding protein } 1 \mathrm{GN}=I \text { IGF2BP1 } & \text { IF2B1_HUMAN } & 63.48\end{array}$

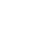

(7)

\section{$19 \quad 42 \quad 0.04 \% \quad 14.5 \%$ SQSFFAAAR}

$19 \quad 42 \quad 0.04 \% \quad 14.5 \%$ AAVSAFPTDSLER

19

19

(

(2)

57
57
57

57
57
57
57

(2)

57
57
57

37

37

$\begin{array}{ll}37 & 57 \\ 37 & 57 \\ 37 & 57\end{array}$

37
37
37
37

37

37
37
37

37
37
37

37
37
37

37
37
37

37
37
37

37
37
37
37

37
37
37

37

37
37
37

37
37
37

\begin{tabular}{lllllllll}
$0.16 \%$ & $61.0 \%$ & DQTPDENDQVIVK & $99.7 \%$ & 59.7 & 25.0 & 55.2 & 4 & 0 \\
\hline
\end{tabular}

\begin{tabular}{|c|c|c|c|c|c|c|}
\hline 42 & $0.04 \%$ & $14.5 \%$ AAVSAFPTDSLER & $99.7 \%$ & 43.5 & 25.0 & 34.6 \\
\hline 42 & $0.04 \%$ & $14.5 \%$ GAQDVAGGSNPGAHNPSANLAR & $99.7 \%$ & 59.5 & 25.0 & 59.5 \\
\hline 42 & $0.04 \%$ & 14.5\% GDNQAGGAAAAAAAPEPPPR & $99.7 \%$ & 55.1 & 25.0 & 54.9 \\
\hline 42 & $0.04 \%$ & $14.5 \%$ GDNQAGGAAAAAAAPEPPPRSR & $99.7 \%$ & 41.4 & 25.0 & 39.3 \\
\hline 162 & $0.16 \%$ & 61.0\% LYIGNLNESVTPADLEK & $99.7 \%$ & 77.7 & 25.0 & 68.5 \\
\hline 162 & $0.16 \%$ & 61.0\% VFAEHKISYSGQFLVK & $99.7 \%$ & 34.0 & 25.0 & 34.0 \\
\hline 162 & $0.16 \%$ & $61.0 \%$ ISYSGQFLVK & $99.7 \%$ & 59.8 & 25.0 & 49.7 \\
\hline 162 & $0.16 \%$ & 61.0\% SGYAFVDCPDEHWAMK & $99.7 \%$ & 57.5 & 25.0 & 57.5 \\
\hline 162 & $0.16 \%$ & 61.0\% AIETFSGKVELQGK & $99.7 \%$ & 66.5 & 25.0 & 61.1 \\
\hline 162 & $0.16 \%$ & 61.0\% RLEIEHSVPK & $99.7 \%$ & 36.3 & 25.0 & 36.3 \\
\hline 162 & $0.16 \%$ & 61.0\% LEIEHSVPK & $99.7 \%$ & 43.9 & 25.0 & 40.9 \\
\hline 162 & $0.16 \%$ & 61.0\% LNGHQLENHALK & $99.7 \%$ & 34.6 & 25.0 & 33.2 \\
\hline 162 & $0.16 \%$ & 61.0\% VSYIPDEQIAQGPENGR & $99.7 \%$ & 43.8 & 25.0 & 43.8 \\
\hline 162 & $0.16 \%$ & 61.0\% VSYIPDEQIAQGPENGRR & $99.5 \%$ & 21.9 & 25.0 & 21.9 \\
\hline 162 & $0.16 \%$ & $61.0 \%$ GGFGSRGQPR & $97.3 \%$ & 25.3 & 25.0 & 8.1 \\
\hline 162 & $0.16 \%$ & 61.0\% QGSPVAAGAPAK & $99.7 \%$ & 50.9 & 25.0 & 47.9 \\
\hline 162 & $0.16 \%$ & 61.0\% QGSPVAAGAPAKQQQVDIPLR & $99.7 \%$ & 56.0 & 25.0 & 56.0 \\
\hline 162 & $0.16 \%$ & 61.0\% QQQVDIPLR & $99.7 \%$ & 60.5 & 25.0 & 43.7 \\
\hline 162 & $0.16 \%$ & 61.0\% LLVPTQYVGAIIGK & $99.7 \%$ & 55.5 & 25.0 & 55.5 \\
\hline 162 & $0.16 \%$ & 61.0\% LLVPTQYVGAIIGKEGATIR & $99.7 \%$ & 58.4 & 25.0 & 58.4 \\
\hline 162 & $0.16 \%$ & $61.0 \%$ AISVHSTPEGCSSACK & $99.7 \%$ & 55.4 & 25.0 & 55.4 \\
\hline 162 & $0.16 \%$ & $61.0 \%$ TADEVPLK & $98.1 \%$ & 26.1 & 25.0 & 18.6 \\
\hline 162 & $0.16 \%$ & $61.0 \%$ TADEVPLKILAHNNFVGR & $99.7 \%$ & 55.7 & 25.0 & 50.8 \\
\hline 162 & $0.16 \%$ & $61.0 \%$ ILAHNNFVGR & $99.7 \%$ & 47.4 & 25.0 & 47.4 \\
\hline 162 & $0.16 \%$ & $61.0 \%$ VEQDTETKITISSLQDLTLYNPER & $98.8 \%$ & 24.0 & 25.0 & 24.0 \\
\hline 162 & $0.16 \%$ & 61.0\% ITISSLQDLTLYNPER & $99.7 \%$ & 36.5 & 25.0 & 34.3 \\
\hline 162 & $0.16 \%$ & 61.0\% GAIENCCRAEQEIMK & $99.7 \%$ & 44.1 & 25.0 & 38.1 \\
\hline 162 & $0.16 \%$ & 61.0\% GQHIKQLSR & $99.7 \%$ & 40.5 & 25.0 & 39.9 \\
\hline 162 & $0.16 \%$ & $61.0 \%$ FASASIKIAPPETPDSK & $99.7 \%$ & 50.8 & 25.0 & 44.8 \\
\hline 162 & $0.16 \%$ & 61.0\% IAPPETPDSKVR & $99.7 \%$ & 61.3 & 25.0 & 56.5 \\
\hline 162 & $0.16 \%$ & 61.0\% MVIITGPPEAQFK & $99.7 \%$ & 59.8 & 25.0 & 51.4 \\
\hline 162 & $0.16 \%$ & 61.0\% MVIITGPPEAQFKAQGR & $99.7 \%$ & 54.7 & 25.0 & 54.7 \\
\hline 162 & $0.16 \%$ & $61.0 \%$ LKEENFFGPK & $98.2 \%$ & 22.7 & 25.0 & 13.0 \\
\hline 162 & $0.16 \%$ & 61.0\% LETHIRVPASAAGR & $99.7 \%$ & 36.1 & 25.0 & 36.1 \\
\hline 162 & $0.16 \%$ & 61.0\% GGKTVNELQNLTAAEVVVPR & $98.2 \%$ & 16.6 & 25.0 & 16.6 \\
\hline 162 & $0.16 \%$ & 61.0\% TVNELQNLTAAEVVVPR & $99.7 \%$ & 61.9 & 25.0 & 51.0 \\
\hline 162 & $0.16 \%$ & $61.0 \%$ TVNELQNLTAAEVVVPRDQTPDENDQVIVK & $99.7 \%$ & 51.2 & 25.0 & 51.2 \\
\hline 162 & $0.16 \%$ & 61.0\% DQTPDENDQVIVK & $99.7 \%$ & 59.7 & 25.0 & 55.2 \\
\hline 162 & $0.16 \%$ & 61.0\% IIGHFYASQMAQR & $99.7 \%$ & 53.4 & 25.0 & 48.2 \\
\hline 162 & $0.16 \%$ & 61.0\% IIGHFYASQMAQRK & $99.3 \%$ & 25.8 & 25.0 & 24.9 \\
\hline
\end{tabular}

$\begin{array}{llllllllll}42 & 0.04 \% & 14.5 \% & \text { GAQDVAGGSNPGAHNPSANLAR } & 99.7 \% & 59.5 & 25.0 & 59.5 & 1 \\ 42 & 0.04 \% & 14.5 \% & \text { GDNQAGGAAAAAAAPEPPPR } & 99.7 \% & 55.1 & 25.0 & 54.9 & 2\end{array}$

$\begin{array}{llllllll}162 & 0.04 \% & 14.5 \% & \text { GDNQAGGAAAAAAAPEPPPRSR } & 99.7 \% & 41.4 & 25.0 & 39.3\end{array}$

$162 \quad 0.16 \% \quad 61.0 \%$ LEIEHSVPK

0.16\% 61.0\% VSYIPDEQIAQGPENGRR $99.5 \% \quad 21.9$

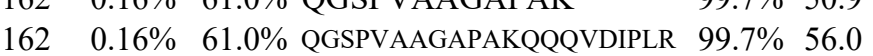

$162 \quad 0.16 \% \quad 61.0 \%$ QQQVDIPLR

$162 \quad 0.16 \% \quad 61.0 \%$ LLVPTQYVGAIIGKEGATIR

$0.16 \% \quad 61.0 \%$ AISVHSTPEGCSSACK

$162 \quad 0.16 \% \quad 61.0 \%$ TADEVPLKILAHNNFVGR

$62 \quad 0.16 \% \quad 61.0 \%$ VEQDTETKITISSLQDLTLYNPER

$162 \quad 0.16 \% \quad 61.0 \%$ IIGHFYASQMAQRK

$\begin{array}{lllll}99.3 \% & 25.8 & 25.0 & 24.9\end{array}$

Page 91 of Table S-1-4 

Insulin-like growth factor 2 mRNA-binding protein 2 GN=IGF2BP2 IF2B2_HUMAN $66.12 \quad 100.0 \%$ Insulin-like growth factor 2 mRNA-binding protein 2 GN=IGF2BP2 IF2B2_HUMAN $66.12 \quad 100.0 \%$ Insulin-like growth factor 2 mRNA-binding protein 2 GN=IGF2BP2 IF2B2_HUMAN $66.12 \quad 100.0 \%$ Insulin-like growth factor 2 mRNA-binding protein 2 GN=IGF2BP2 IF2B2_HUMAN $66.12 \quad 100.0 \%$ Insulin-like growth factor 2 mRNA-binding protein 2 GN=IGF2BP2 IF2B2_HUMAN $66.12 \quad 100.0 \%$ Insulin-like growth factor 2 mRNA-binding protein 2 GN=IGF2BP2 IF2B2_HUMAN $66.12 \quad 100.0 \%$ Insulin-like growth factor $2 \mathrm{mRNA}$-binding protein $2 \mathrm{GN}=\mathrm{IGF} 2 \mathrm{BP} 2$ IF2B2_HUMAN $66.12 \quad 100.0 \%$ Insulin-like growth factor 2 mRNA-binding protein 2 GN=IGF2BP2 IF2B2_HUMAN $66.12 \quad 100.0 \%$ Insulin-like growth factor 2 mRNA-binding protein 2 GN=IGF2BP2 $\quad$ IF2B2_HUMAN $66.12 \quad 100.0 \%$ Insulin-like growth factor 2 mRNA-binding protein 2 GN=IGF2BP2 IF2B2_HUMAN $66.12 \quad 100.0 \%$ Insulin-like growth factor 2 mRNA-binding protein 2 GN=IGF2BP2 IF2B2_HUMAN $66.12 \quad 100.0 \%$ Insulin-like growth factor 2 mRNA-binding protein 3 GN=IGF2BP3 IF2B3_HUMAN $63.71 \quad 100.0 \%$ Insulin-like growth factor 2 mRNA-binding protein $3 \mathrm{GN}=\mathrm{IGF} 2 \mathrm{BP} 3 \quad$ IF2B3_HUMAN $63.71 \quad 100.0 \%$ Insulin-like growth factor 2 mRNA-binding protein 3 GN=IGF2BP3 IF2B3_HUMAN $63.71 \quad 100.0 \%$ Insulin-like growth factor 2 mRNA-binding protein 3 GN=IGF2BP3 IF2B3_HUMAN $63.71 \quad 100.0 \%$ Insulin-like growth factor 2 mRNA-binding protein 3 GN=IGF2BP3 IF2B3_HUMAN $63.71 \quad 100.0 \%$ Insulin-like growth factor 2 mRNA-binding protein 3 GN=IGF2BP3 IF2B3_HUMAN $63.71 \quad 100.0 \%$ Insulin-like growth factor 2 mRNA-binding protein 3 GN=IGF2BP3 $\quad$ IF2B3_HUMAN $63.71 \quad 100.0 \%$ Insulin-like growth factor 2 mRNA-binding protein 3 GN=IGF2BP3 IF2B3_HUMAN $63.71 \quad 100.0 \%$ Insulin-like growth factor 2 mRNA-binding protein 3 GN=IGF2BP3 $\quad$ IF2B3_HUMAN $63.71 \quad 100.0 \%$ Insulin-like growth factor 2 mRNA-binding protein 3 GN=IGF2BP3 IF2B3_HUMAN $63.71 \quad 100.0 \%$ Insulin-like growth factor 2 mRNA-binding protein 3 GN=IGF2BP3 IF2B3_HUMAN $63.71 \quad 100.0 \%$ Insulin-like growth factor 2 mRNA-binding protein 3 GN=IGF2BP3 IF2B3_HUMAN $63.71 \quad 100.0 \%$ Insulin-like growth factor 2 mRNA-binding protein 3 GN=IGF2BP3 IF2B3_HUMAN $63.71 \quad 100.0 \%$ Insulin-like growth factor 2 mRNA-binding protein 3 GN=IGF2BP3 IF2B3_HUMAN $63.71 \quad 100.0 \%$ Integrator complex subunit $1 \mathrm{GN}=\mathrm{INTS} 1 \quad \mathrm{INT} 1$ HUMAN $244.30 \quad 100.0 \%$ Integrator complex subunit $1 \mathrm{GN}=\mathrm{INTS} 1 \quad$ INT1_HUMAN $244.30 \quad 100.0 \%$ Integrator complex subunit $1 \mathrm{GN}=\mathrm{INTS} 1 \quad$ INT1_HUMAN $244.30 \quad 100.0 \%$ Integrator complex subunit $1 \mathrm{GN}=\mathrm{INTS} 1 \quad$ INT1_HUMAN $244.30 \quad 100.0 \%$ Integrator complex subunit $1 \mathrm{GN}=\mathrm{INTS} 1 \quad$ INT1_HUMAN $244.30 \quad 100.0 \%$ Integrator complex subunit $1 \mathrm{GN}=\mathrm{INTS} 1 \quad$ INT1_HUMAN $244.30 \quad 100.0 \%$ Integrator complex subunit $1 \mathrm{GN}=\mathrm{INTS} 1 \quad$ INT1_HUMAN $244.30 \quad 100.0 \%$ Integrator complex subunit $1 \mathrm{GN}=\mathrm{INTS} 1 \quad$ INT1_HUMAN $244.30 \quad 100.0 \%$ Integrator complex subunit $1 \mathrm{GN}=\mathrm{INTS} 1 \quad$ INT1_HUMAN $244.30 \quad 100.0 \%$ Integrator complex subunit $1 \mathrm{GN}=\mathrm{INTS} 1 \quad$ INT1_HUMAN $244.30 \quad 100.0 \%$ Integrator complex subunit $1 \mathrm{GN}=\mathrm{INTS} 1 \quad$ INT1_HUMAN $244.30 \quad 100.0 \%$ Integrator complex subunit $1 \mathrm{GN}=\mathrm{INTS} 1$ INT1_HUMAN $244.30100 .0 \%$ Integrator complex subunit $1 \mathrm{GN}=\mathrm{INTS} 1 \quad$ INT1_HUMAN $244.30 \quad 100.0 \%$ Integrator complex subunit $1 \mathrm{GN}=\mathrm{INTS} 1 \quad$ INT1_HUMAN $244.30 \quad 100.0 \%$ Interferon-induced, double-stranded RNA-activated protein kinase GN=EIF2AK2 $\quad$ E2AK2_HUMAN $62.10 \quad 100.0 \%$ Interferon-induced, double-stranded RNA-activated protein kinase GN=EIF2AK2 E2AK2_HUMAN $62.10 \quad 100.0 \%$ Interferon-inducible double-stranded RNA-dependent protein kinase activator A GN=PRKRA PRKRA_HUMAN $34.41 \quad 100.0 \%$ Interferon-inducible double-stranded RNA-dependent protein kinase activator A GN=PRKRA PRKRA_HUMAN $34.41 \quad 100.0 \%$ Interferon-inducible double-stranded RNA-dependent protein kinase activator A GN=PRKRA PRKRA_HUMAN $34.41 \quad 100.0 \%$ terferen-inducible double-stranded RNA-dependent protein Kinase activator A GN=PRKRA PRKRA_HUMAN $34.41 \quad 100.0 \%$
$0.16 \% \quad 61.0 \%$ IRDILAQVK $0.02 \% \quad 24.9 \%$ KLPLAGQVLLK

$99.7 \% \quad 43.8$ $98.7 \% \quad 25.5$

24.9\% SGYAFVDYPDQNWAIR $\quad 99.7 \% \quad 43.9$

$0.02 \% \quad 24.9 \%$ GDHSSREQGHAPGGTSQAR $99.7 \% \quad 35.1$

$0.02 \% \quad 24.9 \%$ ILVPTQFVGAIIGK

$0.02 \% \quad 24.9 \%$ ITISSLQDLSIYNPER

$99.2 \% \quad 42.5$

$99.7 \% \quad 37.8$

$0.02 \% \quad 24.9 \%$ IAPAEGPDVSER

$99.7 \% \quad 42.9$

$0.02 \% \quad 24.9 \%$ MVIITGPPEAQFK

$99.7 \% \quad 59.8$

$0.02 \% \quad 24.9 \%$ MVIITGPPEAQFKAQGR

$0.02 \% \quad 24.9 \%$ TVNELQNLTSAEVIVPR

$0.02 \% \quad 24.9 \%$ IIGHFFASQTAQR

$0.02 \% \quad 24.9 \%$ QQEQKYPQGVASQR

$99.7 \% \quad 53.7$

$99.7 \% 38.1$

$0.04 \% \quad 26.4 \%$ IPVSGPFLVK

$99.6 \% \quad 24.4$

$0.04 \% \quad 26.4 \%$ VAYIPDEMAAQQNPLQQPR $99.7 \% 68.9$

$0.04 \% \quad 26.4 \%$ QKPCDLPLR

$99.3 \% \quad 26.5$

$99.2 \% \quad 42.5$

$0.04 \% \quad 26.4 \%$ LLVPTQFVGAIIGKEGATIR $99.6 \% \quad 25.2$

$0.04 \% \quad 26.4 \%$ SITILSTPEGTSAACK

$0.04 \% \quad 26.4 \%$ ILAHNNFVGR

$0.04 \% \quad 26.4 \%$ IAPAEAPDAK

$0.04 \% \quad 26.4 \%$ IAPAEAPDAKVR

$0.04 \% \quad 26.4 \%$ MVIITGPPEAQFK

$99.7 \% \quad 61.0$

$99.7 \% \quad 47.4$

$99.7 \% \quad 39.0$

$99.7 \% \quad 49.2$

$99.7 \% \quad 59.8$

$\begin{array}{llll}0.04 \% & 26.4 \% & \text { MVIITGPPEAQFKAQGR } \quad 99.7 \% & 54.7\end{array}$

$\begin{array}{lllll}0.04 \% & 26.4 \% & \text { TVNELQNLSSAEVVVPR } & 99.7 \% & 47.8\end{array}$

$0.04 \% \quad 26.4 \%$ DQTPDENDQVVVK

$99.7 \% \quad 33.5$

$0.04 \% \quad 26.4 \%$ ALQSGPPQSR

$99.7 \% \quad 44.1$

$0.03 \% \quad 7.1 \%$ DAAAALSSASALTGLTK $99.7 \% \quad 40.6$

$0.03 \% \quad 7.1 \%$ LSSTPPLSALGR

$0.03 \% \quad 7.1 \%$ LAEAAVAEKR

$0.03 \% \quad 7.1 \%$ SVLLQGEAGR

$0.03 \% \quad 7.1 \%$ RQPIDNVSR

$0.03 \% \quad 7.1 \% \quad$ LVIFNELSSAR

$0.03 \% \quad 7.1 \% \quad$ SFQNQIAAIQR

$0.03 \% \quad 7.1 \%$ ILVIGLSR

$0.03 \% \quad 7.1 \%$ AAAVQADDVEVLK

$0.03 \% \quad 7.1 \%$ LQDLLLGPK

$0.03 \% \quad 7.1 \%$ LGSSQVASR

$0.03 \% \quad 7.1 \% \quad$ STIMSHLFSK

$0.03 \% \quad 7.1 \%$ VVQGSPEVPGITVR

$0.03 \% \quad 7.1 \% \quad$ FITLLADTSDSR

$0.00 \% \quad 4.0 \%$ LAVEILNKEK

$0.00 \% \quad 4.0 \%$ VLALELFEQITK

$0.06 \% \quad 43.1 \%$ HRAEAPPLER

$0.06 \% \quad 43.1 \%$ EDSGTFSLGK

$0.06 \% \quad 43.1 \%$ MITAKPGK

$0.06 \% \quad 43.1 \%$ TPIQVLHEYGMK

$0.06 \% \quad 43.1 \%$ NIPVYECER
$99.4 \% \quad 27.0$

$99.7 \% \quad 63.4$

$99.7 \% \quad 44.4$

$98.4 \% \quad 20.6$

$99.7 \% \quad 38.8$

$99.6 \% 29.2$

$99.0 \% \quad 28.1$

$99.7 \% \quad 43.6$

$97.3 \% 22.0$

$99.7 \% \quad 38.0$

$97.8 \% \quad 16.2$

$99.7 \% \quad 36.8$

$99.7 \% \quad 57.3$

$99.7 \% \quad 33.7$

$99.7 \% \quad 74.0$

$99.7 \% \quad 25.8$

$99.7 \% \quad 50.3$

$95.8 \% \quad 20.6$

$99.7 \% \quad 47.0$

$98.6 \% \quad 20.1$
105

1055.66

1179.78

1901.88

1934.88

1455.89

1848.97

1240.62

1446.77

1842.99

1883.02

1475.78

1646.82

1056.65

2169.08

1126.60

1455.89

2083.23

1635.83

1140.63

982.52

1237.69

1446.77

1842.99

1854.99

1486.70

1040.55

1547.83

1198.68

1057.60

1029.57

1084.59

1248.69

1275.68

870.58

1328.71

996.61

904.48

1150.59

1437.81

1338.69

1156.69

1403.81

1175.63

1040.49

861.49

1415.74

1179.55

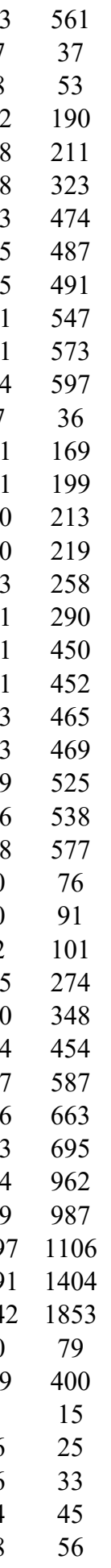

Page 92 of Table S-1-4 


\begin{tabular}{|c|c|c|c|c|c|c|c|c|c|c|c|c|c|c|c|c|c|c|}
\hline erferon-inducible double-stranded RNA-dependent I & PRKRA_HUMAN & 34.41 & $100.0 \%$ & 4 & 23 & 65 & $0.06 \%$ & 43.1\% SDVQIHVPTFTFR & $99.7 \%$ & 52.4 & 25.0 & 1.7 & 2 & 8 & 0 & 1546.80 & 57 & 69 \\
\hline erferon-inducible double-stranded RNA-dependent protetin kinase activator A GN=PRKRA & PRKRA_HUMAN & 34.41 & $100.0 \%$ & 4 & 3 & 65 & $.06 \%$ & 43.1\% VTVGDITCTGEGTSK & $99.7 \%$ & 72.6 & 25.0 & 72.6 & & & & 1524.72 & 70 & 84 \\
\hline Interferon-inducible double-stranded RNA-dependent protein kinase activator A GN=PRKRA & PRKRA_HUMAN & 34.41 & $100.0 \%$ & 4 & & 65 & $0.06 \%$ & 43.1\% VTVGDITCTGEGTSKK & $99.7 \%$ & 53.8 & 25.0 & 52.2 & 3 & & 0 & 1652.82 & 70 & 85 \\
\hline Interferon-inducible double-stranded RNA-dependent protein kinase activator A GN=PRKRA & PRKRA_HUMAN & 34.41 & $100.0 \%$ & 4 & & 65 & $06 \%$ & $43.1 \%$ AAEAAINILK & $99.7 \%$ & 59.4 & 25.0 & 42.7 & & & & 60 & 91 & 100 \\
\hline erferen-inducible double-stranded RNA-dependent protetein kinase activator A GN=PRKRA & PRKRA_HUMAN & 34.41 & $00.0 \%$ & 14 & & 65 & $.06 \%$ & 43.1\% ANASICFAVPDPLMPDPSK & $99.7 \%$ & 52.6 & 25.0 & 52.6 & & & & .97 & 101 & 119 \\
\hline terferon-inducible double-stranded RNA-dependent protein kinase activator A GN=PRKRA & PRKRA_HUMAN & 34.41 & $100.0 \%$ & 4 & 3 & 65 & $0.06 \%$ & 43.1\% ANASICFAVPDPLMPDPSKQPK & $96.0 \%$ & 19.5 & 25.0 & 19.5 & c & & 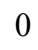 & 99.17 & 101 & 22 \\
\hline Interferon-inducible double-stranded RNA-dependent protein kinase activator A GN=PRKRA & PRKRA_HUMAN & 34.41 & $100.0 \%$ & 1 & & 65 & $.06 \%$ & 43.1\% LPEYTLSQEGGPAHK & $99.7 \%$ & 55.0 & 25.0 & 51.0 & & & & 5.81 & 142 & 156 \\
\hline erferen-inducible double-stranded RNA-dependent protetin kinase activator A GN=PRKRA & PRKRA_HUMAN & 34.41 & $100.0 \%$ & 14 & 3 & 65 & $.06 \%$ & 43.1\% LPEYTLSQEGGPAHKR & $99.7 \%$ & 42.4 & 25.0 & 41.6 & & & & 91 & 142 & 157 \\
\hline terferon-inducible double-stranded RNA-dependent protein kinase activator A GN=PRKRA & PRKRA_HUMAN & 34.41 & $100.0 \%$ & 14 & 3 & 65 & $06 \%$ & $43.1 \%$ LESFME $^{\prime}$ & $99.7 \%$ & 54.0 & 25.0 & 50.3 & 2 & & & 49 & 165 & 173 \\
\hline Interleukin enhancer-binding factor $2 \mathrm{GN}=\mathrm{ILF} 2$ & ILF2_HUMAN & 43.06 & $00.0 \%$ & 1 & 0 & 156 & $16 \%$ & $49.0 \%$ VKPAPDETS & $99.7 \%$ & 60.3 & 25.0 & 51.7 & 2 & & & .92 & 44 & 59 \\
\hline Interleukin enhancer-binding factor $2 \mathrm{GN}=\mathrm{ILF} 2$ & ILF2_HUMAN & 43.06 & $100.0 \%$ & 2 & & 156 & $.16 \%$ & 49.0\% VKPAPDETSFSEALLKR & $99.7 \%$ & 61.9 & 25.0 & 59.4 & & & & .02 & 44 & 60 \\
\hline Interleukin enhancer-binding factor $2 \mathrm{GN}=\mathrm{ILF} 2$ & ILF2_HUMAN & 06 & $0 \%$ & 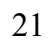 & & 156 & $6 \%$ & ASILSLVTK & $99.7 \%$ & 62.8 & 25.0 & 1.8 & 1 & & & 20 & 60 & 80 \\
\hline Interleukin enhancer-binding factor $2 \mathrm{GN}=\mathrm{ILF} 2$ & ILF2_H & 06 & $0 \%$ & 21 & 0 & 156 & $6 \%$ & ASILSLVTK & $99.7 \%$ & 56.5 & 25.0 & 56.5 & 15 & tan & U & .10 & 61 & 80 \\
\hline Interleukin enhancer-binding factor $2 \mathrm{GN}=\mathrm{ILF} 2$ & ILF2_HUMAN & 43.06 & $00.0 \%$ & 2 & & 156 & $.16 \%$ & DLVVILK & $99.7 \%$ & 44.5 & 25.0 & 44.5 & 0 & & & .05 & 110 & 127 \\
\hline Interleukin enhancer-bin & ILF2_H & 6 & $\%$ & & & 156 & & DLVVILK & $99.7 \%$ & 59.3 & 25.0 & 3 & 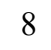 & & & & 111 & 127 \\
\hline Interleukin enhancer-binding factor $2 \mathrm{G}$ & ILF2_ & 6 & $\%$ & 2 & & 156 & $6 \%$ & iNK & $99.7 \%$ & 55.0 & 25.0 & 51.0 & 16 & 3 & 0 & & 128 & 141 \\
\hline Interleukin enhancer-binding factor $2 \mathrm{G}$ & ILF2_HUMAN & 43.06 & $\%$ & & & 156 & $16 \%$ & $49.0 \% \mathrm{AQ}$ & $99.7 \%$ & 33.9 & 25.0 & 9 & 0 & & & 36 & 148 & 174 \\
\hline Interleuki & ILF2 & 4 & & & & 156 & & 49 & $7 \%$ & 48.5 & 25.0 & & & & & & 5 & 185 \\
\hline Interleukin enhancer-binding factor $2 \mathrm{G}$ & ILF2 & 06 & $0 \%$ & 2 & & 156 & $6 \%$ & 49 & $5 \%$ & 26.2 & 25.0 & 26.2 & 1 & & 0 & & 175 & 186 \\
\hline enhancer-binc & ILF2_H & 06 & $\%$ & & & 156 & $6 \%$ & $\% \mathrm{~K}$ & $99.7 \%$ & 58.7 & 25.0 & 36.8 & 4 & & 0 & .75 & 186 & 196 \\
\hline Interl & ILF2 & 4 & 0 & & & 156 & & 49 & & 45.6 & .0 & & 4 & & & & & 196 \\
\hline Interleukin enhancer-binding factor $2 \mathrm{G}$ & ILF2_ & 06 & 10 & 21 & 3 & 156 & $\%$ & 49 & $99.7 \%$ & 61.4 & 25.0 & 49.7 & 14 & 0 & 0 & & 197 & 206 \\
\hline ctor $2 \mathrm{C}$ & ILF2_H & 6 & $\%$ & & & 156 & $6 \%$ & $49.0 \% \mathrm{~W}$ & $99.7 \%$ & 60.4 & 25.0 & 54.7 & 0 & & c & 66 & 210 & 221 \\
\hline tor $2 \mathrm{C}$ & ILF2_ & 3.06 & & & & 156 & $\%$ & 49 & & 62.5 & 25.0 & 52.7 & & & & & 260 & 269 \\
\hline Interleukin enhancer-bindi & ILF2 & 4 & & 1 & 30 & 156 & & 49 & $\%$ & 22.2 & 25.0 & .1 & 0 & 2 & 0 & & 260 & 270 \\
\hline r 2 G & ILF2_ & 6 & $\%$ & & & 156 & $\%$ & 49. & $99.7 \%$ & 53.0 & 25.0 & 53.0 & 0 & & 0 & & 298 & 319 \\
\hline Interleukin enhancer-bin & ILF2_HUMAN & 6 & $\%$ & & & 156 & $6 \%$ & 49 & $99.0 \%$ & 44.8 & 25.0 & 33 & 4 & & & & 320 & 327 \\
\hline ctor $2 \mathrm{GN}=\mathrm{ILF} 2$ & ILF2_H & 6 & $\%$ & 21 & 30 & 156 & & 49 & $4 \%$ & 23.7 & 25.0 & 10.5 & 3 & 0 & 0 & & 320 & 328 \\
\hline or $2 \mathrm{G}$ & ILF2_ & 6 & & & & 156 & & 49 & $\%$ & 46.6 & 25.0 & 42 & 2 & & $\mathrm{C}$ & & 357 & 364 \\
\hline nterleukin enhancer-bind & ILF2_HUMAN & 43.06 & $\%$ & & & 156 & $6 \%$ & 49. & $99.6 \%$ & 25.8 & 25.0 & 18 & 2 & & & & 357 & 365 \\
\hline ctor $3 \mathrm{GN}=\mathrm{ILF} 3$ & ILF3_ & 4 & $\%$ & & & 192 & $\%$ & $\mathrm{AK}$ & $\%$ & 45.4 & 25.0 & 43.2 & $\varepsilon$ & 6 & 0 & & 0 & 17 \\
\hline tor $3 \mathrm{GN}=\mathrm{ILF} 3$ & ILF3_1 & 4 & & & & 192 & & 39 & $99.7 \%$ & 41.7 & 25.0 & 41.7 & 7 & & ( & & 106 & 117 \\
\hline nterleukin enhancer-binding factor $3 \mathrm{GN}=\mathrm{ILF} 3$ & ILF3_HUMAN & 4 & & & & 192 & $\%$ & 39 & $99.4 \%$ & 25.3 & 25 & 15 & 1 & & & & 118 & 127 \\
\hline tor $3 \mathrm{GN}=\mathrm{ILF} 3$ & ILF3_HUMAN & 4 & $\%$ & 3 & & 192 & $\%$ & 39 & $\%$ & 28.7 & 25.0 & 28.7 & 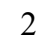 & 0 & 0 & & 162 & 177 \\
\hline $\mathrm{g}$ factor $3 \mathrm{GN}=\mathrm{ILF} 3$ & ILF3_H & 4 & & & & 192 & $\%$ & PDVLDR & $99.7 \%$ & 53.4 & 25.0 & 52.9 & 10 & 0 & 0 & & 183 & 200 \\
\hline nterleukin enhancer-binding factor $3 \mathrm{GN}=\mathrm{ILF} 3$ & ILF3_HUMAN & 4 & & & & 192 & $\%$ & DVLDRQK & $99.7 \%$ & 53.8 & 25.0 & 51.7 & 0 & & 0 & & 183 & 202 \\
\hline tor $3 \mathrm{GN}=\mathrm{ILF} 3$ & ILF3_HUMAN & 9 & $\%$ & & & 192 & $\%$ & 39 & $99.7 \%$ & 56.4 & 25.0 & 43.9 & 8 & 0 & 0 & & 203 & 211 \\
\hline Interleukin enhancer-binding factor $3 \mathrm{GN}=\mathrm{ILF} 3$ & ILF3_HUMAN & 95.34 & $100.0 \%$ & 31 & 4 & 192 & $0.19 \%$ & $39.3 \% \mathrm{G}$ & $96.8 \%$ & 25.8 & 25.0 & 0 & 3 & 0 & 0 & 63 & 248 & 257 \\
\hline nterleukin enhancer-binding factor $3 \mathrm{GN}=\mathrm{ILF} 3$ & ILF3_HUMAN & & & & & 192 & & 35 & $99.3 \%$ & 21.8 & 25.0 & 18 & 2 & & 0 & & 258 & 273 \\
\hline Interleukin enhancer-binding factor $3 \mathrm{GN}=\mathrm{ILF} 3$ & ILF3_HUMAN & 95.34 & & & & 192 & & AGEALRR & $99.7 \%$ & 36.0 & 25.0 & 36.0 & 0 & & ( & & 258 & 274 \\
\hline Interleukin enhancer-binding factor $3 \mathrm{GN}=\mathrm{ILF} 3$ & ILF3_HUMAN & 95.34 & $100.0 \%$ & 31 & 4 & 192 & $0.19 \%$ & $39.3 \% \mathrm{E}$ & $99.7 \%$ & 60.4 & 25.0 & 44.1 & 5 & 0 & 0 & .59 & 298 & 308 \\
\hline ctor $3 \mathrm{GN}=\mathrm{ILF} 3$ & ILF3_HUMAN & & & & & 192 & $9 \%$ & QHALR & $99.7 \%$ & 55.5 & 25.0 & 55.0 & 0 & 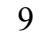 & 0 & & 309 & 323 \\
\hline Interleukin enhancer-binding factor $3 \mathrm{GN}=\mathrm{ILF} 3$ & ILF3_HUMAN & & & 31 & 44 & 192 & & & & 58.8 & 25.0 & 47.2 & ( & & 0 & & 312 & 323 \\
\hline Interleukin enhancer-binding factor $3 \mathrm{GN}=\mathrm{ILF} 3$ & ILF3_HUMAN & 95.34 & $100.0 \%$ & 31 & 4 & 192 & $0.19 \%$ & $39.3 \%$ LAA & $99.7 \%$ & 45.7 & 25.0 & 35.8 & 11 & 0 & 0 & & 324 & 332 \\
\hline ncer-binding factor $3 \mathrm{GN}=\mathrm{ILF} 3$ & ILF3_HUMAN & & & & & 192 & & 39 & $99.7 \%$ & 32.6 & 25.0 & 28.7 & 6 & 0 & 0 & .58 & 333 & 342 \\
\hline Interleukin enhancer-binding factor $3 \mathrm{GN}=\mathrm{ILF} 3$ & ILF3_HUMAN & 95.34 & $100.0 \%$ & 3 & 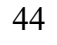 & 192 & & 39.3\% VLGMDPLPSKN & $99.6 \%$ & 25.0 & 25.0 & 21.6 & 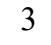 & 4 & & & 333 & 345 \\
\hline Interleukin enhancer-binding factor $3 \mathrm{GN}=\mathrm{ILF} 3$ & ILF3_HUMAN & 95.34 & $100.0 \%$ & 31 & 44 & 192 & $0.19 \%$ & 39.3\% RPMEEDGEEKSPSK & $99.6 \%$ & 28.8 & 25.0 & 25.5 & 0 & 4 & 0 & 1634.73 & 372 & 385 \\
\hline
\end{tabular}


Interleukin enhancer-binding factor 3 GN=ILF3 ILF3 HUMAN $95.34 \quad 100.0 \%$ Interleukin enhancer-binding factor $3 \mathrm{GN}=\mathrm{ILF} 3$ ILF3_HUMAN $95.34 \quad 100.0 \%$ Interleukin enhancer-binding factor $3 \mathrm{GN}=\mathrm{ILF} 3$ ILF3_HUMAN $95.34 \quad 100.0 \%$ Interleukin enhancer-binding factor $3 \mathrm{GN}=\mathrm{ILF} 3 \mathrm{ILF} 3$ HUMAN $95.34 \quad 100.0 \%$ Interleukin enhancer-binding factor $3 \mathrm{GN}=\mathrm{ILF} 3 \mathrm{ILF} 3$ _HUMAN $95.34 \quad 100.0 \%$ Interleukin enhancer-binding factor 3 GN=ILF3 ILF3_HUMAN $95.34 \quad 100.0 \% 3$ Interleukin enhancer-binding factor $3 \mathrm{GN}=\mathrm{ILF} 3 \mathrm{ILF} 3$ _HUMAN $95.34 \quad 100.0 \%$ Interleukin enhancer-binding factor $3 \mathrm{GN}=\mathrm{ILF} 3$ ILF3_HUMAN $95.34 \quad 100.0 \%$ Interleukin enhancer-binding factor $3 \mathrm{GN}=\mathrm{ILF} 3 \mathrm{ILF} 3$ HUMAN $95.34 \quad 100.0 \%$ Interleukin enhancer-binding factor $3 \mathrm{GN}=\mathrm{ILF} 3$ ILF3_HUMAN $95.34 \quad 100.0 \% 3$ Interleukin enhancer-binding factor 3 GN=ILF3 ILF3_HUMAN $95.34 \quad 100.0 \% 3$ Interleukin enhancer-binding factor $3 \mathrm{GN}=\mathrm{ILF} 3 \mathrm{ILF} 3$ HUMAN $95.34 \quad 100.0 \%$ Interleukin enhancer-binding factor 3 GN=ILF3 ILF3_HUMAN $95.34 \quad 100.0 \%$ Interleukin enhancer-binding factor $3 \mathrm{GN}=\mathrm{ILF} 3$ ILF3_HUMAN $95.34 \quad 100.0 \%$ Iron-sulfur protein NUBPL GN=NUBPL NUBPL_HUMAN $34.08 \quad 100.0 \%$ Iron-sulfur protein NUBPL GN=NUBPL NUBPL_HUMAN $34.08 \quad 100.0 \%$ Iron-sulfur protein NUBPL GN=NUBPL NUBPL_HUMAN $34.08 \quad 100.0^{\circ}$ Iron-sulfur protein NUBPL GN=NUBPL NUBPL_HUMAN $34.08 \quad 100.0 \%$ Isocitrate dehydrogenase [NAD] subunit alpha, mitochondrial GN=IDH3A IDH3A_HUMAN 39.59 Isocitrate dehydrogenase [NAD] subunit alpha, mitochondrial GN=IDH3A IDH3A HUMAN 39.59 Isocitrate dehydrogenase $[\mathrm{NAD}]$ subunit alpha, mitochondrial GN=IDH3A IDH3A_HUMAN 39.59 Isocitrate dehydrogenase [NAD] subunit alpha, mitochondrial GN=IDH3A IDH3A_HUMAN 39.59 Isocitrate dehydrogenase [NAD] subunit alpha, mitochondrial GN=IDH3A IDH3A_HUMAN 39.59 Isocitrate dehydrogenase [NAD] subunit alpha, mitochondrial GN=IDH3A IDH3A_HUMAN 39.59 Isocitrate dehydrogenase [NAD] subunit alpha, mitochondrial GN=IDH3A IDH3A_HUMAN 39.59 Isocitrate dehydrogenase [NAD] subunit alpha, mitochondrial GN=IDH3A IDH3A_HUMAN 39.59 Isocitrate dehydrogenase [NAD] subunit apha, mitochondrial GN=IDH3A IDH3A_HUMAN 39.59 Isocitrate dehydrogenase [NAD] subunit alpha, mitochondrial GN=IDH3A IDH3A HUMAN 39.59 Isocitrate dehydrogenase [NAD] subunit alpha, mitochondrial GN=IDH3A IDH3A_HUMAN 39.59 Isocitrate dehydrogenase [NAD] subunit alpha, mitochondrial GN=IDH3A IDH3A_HUMAN 39.5 Isocitrate dehydrogenase $[\mathrm{NAD}]$ subunit beta, mitochondrial GN=IDH3B IDH3B HUMAN 42.18 Isocitrate dehydrogenase [NAD] subunit beta, mitochondrial GN=IDH3B IDH3B HUMAN 42.18 Isocitrate dehydrogenase [NAD] subunit beta, mitochondrial GN=IDH3B IDH3B_HUMAN 42.1 Isocitrate dehydrogenase [NAD] subunit beta, mitochondrial GN=IDH3B IDH3B_HUMAN 42.18 Isocitrate dehydrogenase [NAD] subunit beta, mitochondrial GN=IDH3B IDH3B HUMAN 42.1 Isocitrate dehydrogenase [NAD] subunit beta, mitochondrial GN=IDH3B IDH3B_HUMAN 42.18 Isocitrate dehydrogenase [NAD] subunit beta, mitochondrial GN=IDH3B IDH3B HUMAN 42.1 Isocitrate dehydrogenase [NAD] subunit beta, mitochondrial GN=IDH3B IDH3B_HUMAN 42.1 Isocitrate dehydrogenase [NAD] subunit beta, mitochondrial GN=IDH3B IDH3B_HUMAN 42.18 Isocitrate dehydrogenase [NAD] subunit beta, mitochondrial GN=IDH3B IDH3B HUMAN 42.18 Isocitrate dehydrogenase [NAD] subunit beta, mitochondrial GN=IDH3B IDH3B_HUMAN 42.1 Isocitrate dehydrogenase [NAD] subunit beta, mitochondrial GN=IDH3B IDH3B_HUMAN 42.18 socitrate dehydrogenase [NAD] subunit beta, mitochondrial GN=IDH3B IDH3B HUMAN 42.1 Isocitrate dehydrogenase [NAD] subunit beta, mitochondrial GN=IDH3B IDH3B_HUMAN 42.18 Isocitrate dehydrogenase [NAD] subunit beta, mitochondrial GN=IDH3B IDH3B_HUMAN 42.18
$192 \quad 0.19 \% \quad 39.3 \%$ LNQLKPGLQYK

$192 \quad 0.19 \% \quad 39.3 \%$ VLQDMGLPTGAEGR

$192 \quad 0.19 \% \quad 39.3 \%$ HGKNPVMELNEK

$192 \quad 0.19 \% \quad 39.3 \%$ NPVMELNEK

$192 \quad 0.19 \% \quad 39.3 \%$ YELISETGGSHDKR

$192 \quad 0.19 \% \quad 39.3 \%$ FVMEVEVDGQK

$192 \quad 0.19 \% \quad 39.3 \%$ AYAALAALEK

$192 \quad 0.19 \% \quad 39.3 \%$ LFPDTPLALDANK

$192 \quad 0.19 \% \quad 39.3 \%$ LFPDTPLALDANKK

$192 \quad 0.19 \% \quad 39.3 \%$ FNYSGSGGR

$192 \quad 0.19 \% \quad 39.3 \%$

$192 \quad 0.19 \% \quad 39.3 \%$ QGGYSQSNYNSPGSGQNYSGPPSSYQSSQGGYGR

$192 \quad 0.19 \% \quad 39.3 \%$ NADHSMNYQYR

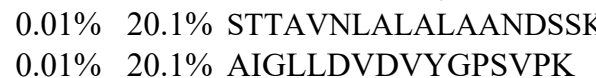

$\begin{array}{ll}0.01 \% & 20.1 \% \text { AIGLLDVDVYGPSVPK } \\ 0.01 \% & 20.1 \% \text { GLMVMSAIEK }\end{array}$

$0.01 \%$

$\begin{array}{lll}0.01 \% & 20.1 \% & \text { EASDTGQPIV } \\ 0.03 \% & 31.4 \% & \text { APIQWEER }\end{array}$

$0.03 \% \quad 31.4 \%$ NVTAIQGPGGK

$0.03 \% \quad 31.4 \%$ WMIPSEAK

$0.03 \% \quad 31.4 \%$ TPIAAGHPSMNLLLR

$0.03 \% \quad 31.4 \%$ TPYTDVNIVTIR

$0.03 \% \quad 31.4 \%$ LITEGASKR

$0.03 \% \quad 31.4 \%$ IAEFAFEYAR

$0.03 \% \quad 31.4 \%$ MSDGLFLQK

$0.03 \% \quad 31.4 \%$ EVAESCKDIK

$0.03 \% \quad 31.4 \%$ IEAACFATIK

$0.03 \% \quad 31.4 \%$ IEAACFATIKDGK

$0.03 \% \quad 31.4 \%$ CSDFTEEICR

$0.04 \% \quad 41.0 \%$ ENKVAIIGK

$0.04 \% \quad 41.0 \%$ GELASYDMR

$0.04 \% \quad 41.0 \%$ KLDLFANVVHVK

$0.04 \% \quad 41.0 \%$ LDLFANVVHVK

$39 \quad 0.04 \% \quad 41.0 \%$ SLPGYMTR

$39 \quad 0.04 \% \quad 41.0 \%$ HNNLDLVIIR

$39 \quad 0.04 \% \quad 41.0 \%$ EQTEGEYSSLEHESAR

$0.04 \% \quad 41.0 \%$ FAFDYATK

$20 \quad 39 \quad 0.04 \% \quad 41.0 \%$ FAFDYATKK

$39 \quad 0.04 \% \quad 41.0 \%$ LGDGLFLQCCEEVAELYPK

$20 \quad 39 \quad 0.04 \% \quad 41.0 \%$ HPFAQAVGR

$0.04 \% \quad 41.0 \%$ NIANPTAMLLSASNMLR

39

$20 \quad 39 \quad 0.04 \% \quad 41.0 \%$ TRDMGGYSTTTDFIK

$20 \quad 39 \quad 0.04 \% \quad 41.0 \%$ DMGGYSTTTDFIK

$0.04 \% \quad 41.0 \%$ SVIGHLQTK

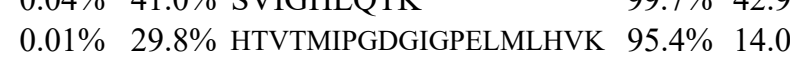

$99.7 \% \quad 47.3$

$99.7 \% \quad 48.2$

$99.7 \% \quad 62.2$

$99.7 \% \quad 43.2$

$99.7 \% \quad 26.1$

$\begin{array}{lll}99.7 \% & 28.7\end{array}$

$99.7 \% \quad 35.8$

$99.7 \% \quad 56.8$

$99.7 \% \quad 48.3$

$98.5 \% 27.1$

$99.7 \% 36.8$

$99.7 \% \quad 70.3$

$99.7 \% \quad 43.6$

$99.7 \% \quad 63.1$

$99.7 \% \quad 46.5$

$\begin{array}{lll}99.0 \% & 65.9\end{array}$

$99.7 \% \quad 54.3$

$98.9 \% \quad 18.9$

$99.7 \% \quad 45.8$

$\begin{array}{lll}99.7 \% & 56.7\end{array}$

$99.7 \% \quad 59.5$

$99.7 \% \quad 68.2$

$99.7 \% \quad 51.1$

$96.9 \% 22.6$

$99.7 \% \quad 62.0$

$99.7 \% \quad 58.0$

$99.7 \% \quad 53.5$

$94.6 \% 16.5$

$99.7 \% \quad 32.8$

$99.7 \% \quad 54.1$

$99.7 \% 36.1$

$96.4 \% \quad 16.7$

$99.7 \% \quad 62.0$

$99.7 \% \quad 61.5$

$99.0 \% \quad 31.9$

$99.7 \% \quad 41.7$

$99.7 \% \quad 45.8$

$99.7 \% \quad 59.9$

$99.3 \% \quad 19.9$

$98.2 \% \quad 17.0$

$99.7 \% \quad 49.9$

$99.7 \% \quad 42.9$

12
966.61

089.52

1591.77

1296.61

1020.57

1414.76

1542.85

944.42

3012.24

3503.48

1414.58

1746.92

1642.91

(078.56

2134.98

1028.52

04157

977.48

1606.87

1391.75

974.56

1216.60

1054.52

1178.57

1123.58

1423.73

1316.52

971.59

1041.47

382.82

254.72

940.46

1206.70

1851.80

962.46

1090.56

2241.06

982.52

1832.94

1843.90

1708.79

1435.64

982.57

2177.11 
Isocitrate dehydrogenase [NADP], mitochondrial GN=IDH2 IDHP_HUMAN $50.91 \quad 100.0 \%$ Isoleucine--tRNA ligase, cytoplasmic GN=IARS SYIC_HUMAN $144.50 \quad 100.0 \%$ Isoleucine--tRNA ligase, cytoplasmic GN=IARS SYIC HUMAN $144.50 \quad 100.0 \%$ Isoleucine--tRNA ligase, cytoplasmic GN=IARS SYIC_HUMAN $144.50 \quad 100.0 \%$ Isoleucine--tRNA ligase, cytoplasmic GN=IARS SYIC_HUMAN $144.50 \quad 100.0 \%$ Isoleucine--tRNA ligase, cytoplasmic GN=IARS SYIC_HUMAN $144.50 \quad 100.0 \%$ Isoleucine--tRNA ligase, cytoplasmic GN=IARS SYIC_HUMAN $144.50 \quad 100.0 \%$ Isoleucine--tRNA ligase, cytoplasmic GN=IARS SYIC HUMAN $144.50 \quad 100.0 \%$ Isoleucine--tRNA ligase, cytoplasmic GN=IARS SYIC_HUMAN $144.50 \quad 100.0 \%$ Isoleucine--tRNA ligase, cytoplasmic GN=IARS SYIC_HUMAN $144.50 \quad 100.0 \%$ Isoleucine--tRNA ligase, cytoplasmic GN=IARS SYIC_HUMAN $144.50 \quad 100.0 \%$ Isoleucine--tRNA ligase, cytoplasmic GN=IARS SYIC_HUMAN $144.50 \quad 100.0 \%$ Isoleucine--tRNA ligase, cytoplasmic GN=IARS SYIC_HUMAN $144.50 \quad 100.0 \%$ Isoleucine--tRNA ligase, cytoplasmic GN=IARS SYIC_HUMAN $144.50 \quad 100.0 \%$ Isoleucine--tRNA ligase, cytoplasmic GN=IARS SYIC_HUMAN $144.50 \quad 100.0 \%$ Isoleucine--tRNA ligase, cytoplasmic GN=IARS SYIC HUMAN $144.50 \quad 100.0 \%$ Isoleucine--tRNA ligase, cytoplasmic GN=IARS SYIC_HUMAN $144.50 \quad 100.0 \%$ Isoleucine--tRNA ligase, mitochondrial GN=IARS2 SYIM_HUMAN $113.79 \quad 100.0 \%$ Isoleucine-tRNA ligase, mitochondrial GN=IARS2 SYIM_HUMAN $113.79 \quad 100.0 \%$ Junction plakoglobin GN=JUP Junction plakoglobin $\mathrm{GN}=\mathrm{JUP}$ Junction plakoglobin GN=JUP Junction plakoglobin GN=JUP Junction plakoglobin GN=JUP Junction plakoglobin $\mathrm{GN}=\mathrm{JUP}$ PLAK_HUMAN $81.75 \quad 100.0 \%$ PLAK_HUMAN $81.75 \quad 100.0 \%$ PLAK_HUMAN $81.75 \quad 100.0 \%$ PLAK_HUMAN $81.75 \quad 100.0 \%$ PLAK HUMAN $81.75 \quad 100.0 \%$ PLAK_HUMAN $81.75 \quad 100.0 \%$

$\begin{array}{llll}99.7 \% & 59.5 & 25.0 & 56.7\end{array}$ $\begin{array}{llll}99.7 \% & 34.0 & 25.0 & 34.0\end{array}$ $\begin{array}{llll}99.7 \% & 54.2 & 25.0 & 54.2\end{array}$ $99.7 \% \quad 29.1 \quad 25.0 \quad 22.3$ $\begin{array}{llll}99.7 \% & 44.0 & 25.0 & 44.0\end{array}$ $99.7 \% \quad 55.4 \quad 25.0 \quad 55.4$ $99.7 \% \quad 45.4 \quad 25.0 \quad 29.6 \quad 2$ $\begin{array}{llll}99.7 \% & 38.9 & 25.0 & 30.9\end{array}$

$0.05 \% \quad 36.9 \%$ YFDLGLPNR

$99.7 \% \quad 41.1$ $99.7 \% \quad 67.3$ $\begin{array}{lll}99.7 \% & 49.7\end{array}$ $99.7 \% \quad 31.5$ $99.3 \% \quad 20.9$ $99.7 \% \quad 53.1$ $\begin{array}{lll}99.0 \% & 38.3\end{array}$ $99.7 \% \quad 54.6$ $99.7 \% \quad 75.5$ $99.7 \% \quad 51.2$ $99.7 \% \quad 46.5$ $99.7 \% \quad 77.7$ $99.7 \% \quad 54.6$ $99.7 \% \quad 37.7$ $99.7 \% \quad 29.7$ $99.7 \% \quad 44.6$ $99.7 \% \quad 31.4$ $99.7 \% \quad 29.9$ $99.6 \% 23.2$ $99.7 \% \quad 56.1$ $99.7 \% \quad 64.7$ $99.7 \% \quad 35.5$ $99.0 \% \quad 33.2$ $99.7 \% 55.6$ $98.1 \% \quad 24.6$ $99.7 \% \quad 37.5$ $99.0 \% 18.0$ $99.7 \% \quad 50.5$ $99.7 \% \quad 45.2$

$0.03 \% \quad 13.6 \%$ APLKPYPVSPSDK ELEITLTR $0.03 \% \quad 13.6 \%$ GSELEITLTR

$0.01 \% \quad 2.6 \%$ TALAEAELEY $\begin{array}{ll}95.5 \% & 23.6\end{array}$

$19 \quad 0.02 \% \quad 15.8 \%$ LAEPSQLLK $99.7 \% \quad 29.9$ $99.7 \% \quad 42.8$ $99.7 \% \quad 35.6$ $99.7 \% 35.6$ $99.7 \% \quad 37.5$

$\begin{array}{ccc}1533.77 & 137 & 149 \\ 1221.73 & 158 & 167 \\ 2493.16 & 168 & 190 \\ 1338.63 & 227 & 237 \\ 1047.56 & 341 & 349 \\ 3302.53 & 351 & 381 \\ 1708.79 & 46 & 60 \\ 1288.80 & 70 & 80 \\ 1094.56 & 81 & 89 \\ 2924.43 & 81 & 106 \\ 1848.88 & 90 & 106 \\ 1133.53 & 113 & 122 \\ 1765.84 & 113 & 127 \\ 976.56 & 141 & 149 \\ 1716.95 & 141 & 155 \\ 894.43 & 181 & 188 \\ 1244.69 & 289 & 299 \\ 1355.69 & 341 & 353 \\ 1228.66 & 383 & 393 \\ 1043.55 & 385 & 393 \\ 1410.66 & 401 & 413 \\ 1383.71 & 414 & 426 \\ 1920.97 & 427 & 442 \\ 1255.70 & 99 & 110 \\ 1401.59 & 111 & 121 \\ 1361.73 & 289 & 298 \\ 1232.63 & 419 & 428 \\ 1975.04 & 495 & 511 \\ 1253.65 & 501 & 511 \\ 1526.85 & 586 & 600 \\ 1173.70 & 625 & 634 \\ 1002.61 & 662 & 669 \\ 1465.72 & 918 & 929 \\ 999.59 & 989 & 996 \\ 1714.84 & 1001 & 1014 \\ 1398.76 & 1039 & 1051 \\ 1588.89 & 1058 & 1071 \\ 1118.61 & 1062 & 1071 \\ 2118.10 & 1227 & 1244 \\ 1928.93 & 251 & 267 \\ 1026.63 & 273 & 281 \\ 998.59 & 116 & 124 \\ 2029.04 & 125 & 142 \\ 1341.73 & 150 & 161 \\ 1090.59 & 162 & 171 \\ 1427.80 & 178 & 191 \\ 1368.61 & 192 & 203\end{array}$

Page 95 of Table S-1-4 
Katanin p60 ATPase-containing subunit A1 GN=KATNA1 KTNA1_HUMAN $55.97 \quad 100.0 \%$ Katanin p60 ATPase-containing subunit A1 GN=KATNA1 KTNA1_HUMAN $55.97 \quad 100.0 \%$ Kelch-like ECH-associated protein 1 GN=KEAP1 KEAP1_HUMAN $69.66 \quad 100.0 \%$ Kelch-like ECH-associated protein 1 GN=KEAP1 KEAP1_HUMAN $69.66 \quad 100.0 \%$ Keratinocyte proline-rich protein GN=KPRP KPRP_HUMAN $64.13 \quad 100.0 \%$ Keratinocyte proline-rich protein GN=KPRP KPRP_HUMAN $64.13 \quad 100.0 \%$ KH domain-contaning, RNA-binding, signal transduction-associated protein I GN=KHDRBSI KHDR1_HUMAN $48.23 \quad 100.0 \%$

Kinesin-1 heavy chain GN=KIF5B

Kinesin-1 heavy chain GN=KIF5B

Kinesin-like protein $\mathrm{KIF} 11 \mathrm{GN}=\mathrm{KIF} 11$

Kinesin-like protein KIF11 GN=KIF11

Kinesin-like protein KIF11 GN=KIF11

Kinesin-like protein KIF14 GN=KIF14

Kinesin-like protein KIF14 GN=KIF14

Kinesin-like protein KIF23 GN=KIF23

Kinesin-like protein KIF23 GN=KIF23

KHDR1_HUMAN 48.23

KINH HUMAN $109.69 \quad 99.9 \%$ KINH_HUMAN $109.69 \quad 99.9 \%$ KIF11_HUMAN $119.16 \quad 100.0 \%$ KIF11_HUMAN $119.16 \quad 100.0 \%$ KIF11_HUMAN $119.16 \quad 100.0 \%$ KIF14_HUMAN $186.50 \quad 100.0 \%$ KIF14_HUMAN $186.50 \quad 100.0 \%$ KIF23_HUMAN $110.06 \quad 100.0 \%$ KIF23_HUMAN $110.06 \quad 100.0 \%$ Kinetochore-associated protein $1 \mathrm{GN}=\mathrm{KNTC1}$ KNTC1_HUMAN $250.76 \quad 100.0 \%$ Kinetochore-associated protein $1 \mathrm{GN}=\mathrm{KNTC1} \mathrm{KNTC1}$ HUMAN $250.76 \quad 100.0 \%$ Kinetochore-associated protein $1 \mathrm{GN}=\mathrm{KNTC1} \mathrm{KNTC1}$ HUMAN $250.76 \quad 100.0 \%$ Kinetochore-associated protein $1 \mathrm{GN}=\mathrm{KNTC1} \mathrm{KNTC1}$ HUMAN $250.76 \quad 100.0 \%$ Kinetochore-associated protein $1 \mathrm{GN}=\mathrm{KNTC1} \mathrm{KNTC1}$ HUMAN $250.76 \quad 100.0 \%$ Kinetochore-associated protein $1 \mathrm{GN}=\mathrm{KNTC1} \mathrm{KNTC1}$ HUMAN $250.76 \quad 100.0 \%$ Kinetochore-associated protein $1 \mathrm{GN}=\mathrm{KNTC1} \mathrm{KNTC1}$ HUMAN $250.76 \quad 100.0 \%$ KRR1 small subunit processome component homolog GN=KRR1 KRR1_HUMAN $43.67 \quad 100.0 \%$ KRR1 small subunit processome component homolog GN=KRR1 KRR1_HUMAN $43.67 \quad 100.0 \%$ KRR1 small subunit processome component homolog GN=KRR1 KRR1 HUMAN $43.67 \quad 100.0 \%$ KRR1 small subunit processome component homolog GN=KRR1 KRR1_HUMAN $43.67 \quad 100.0 \%$ KRR1 small subunit processome component homolog GN=KRR1 KRR1_HUMAN $43.67 \quad 100.0 \%$ L-2-hydroxyglutarate dehydrogenase, mitochondrial GN=L2HGDH L2HDH_HUMAN $50.32 \quad 100.0 \%$ L-2-hydroxyglutarate dehydrogenase, mitochondrial GN=L2HGDH L2HDH_HUMAN $50.32 \quad 100.0 \%$ L-2-hydroxyglutarate dehydrogenase, mitochondrial GN=L2HGDH L2HDH_HUMAN $50.32 \quad 100.0 \%$ L-2-hydroxyglutarate dehydrogenase, mitochondrial GN=L2HGDH L2HDH_HUMAN $50.32 \quad 100.0 \%$ L-2-hydroxyglutarate dehydrogenase, mitochondrial GN=L2HGDH L2HDH_HUMAN $50.32 \quad 100.0 \%$ L-2-hydroxyglutarate dehydrogenase, mitochondrial GN=L2HGDH L2HDH_HUMAN $50.32 \quad 100.0 \%$ L-2-hydroxyglutarate dehydrogenase, mitochondrial GN=L2HGDH L2HDH_HUMAN $50.32 \quad 100.0 \%$ L-2-hydroxyglutarate dehydrogenase, mitochondrial GN=L2HGDH L2HDH HUMAN $50.32100 .0 \%$ L-2-hydroxyglutarate dehydrogenase, mitochondrial GN=L2HGDH L2HDH_HUMAN $50.32 \quad 100.0 \%$ L-2-hydroxyglutarate dehydrogenase, mitochondrial GN=L2HGDH L2HDH_HUMAN $50.32 \quad 100.0 \%$ Lactadherin GN=MFGE8 Lactadherin GN=MFGE8

M HUMAN $43.12 \quad 100.0 \%$

MFGM_HUMAN $43.12 \quad 100.0 \%$
$0.02 \% \quad 15.8 \%$ VSVELTNSLFK

$0.00 \% \quad 7.3 \%$ DIISQNPNVR KHDR1_HUMAN $48.23 \quad 100.0 \%$

GVLMGPPGTGK

7.3\% TTFFNVSSSTLTSK $0.00 \% \quad 3.0 \%$ LADLQVPR

$0.00 \% \quad 3.0 \%$ SALGITVHQGR

$0.00 \% \quad 3.6 \%$ RSEPIYNSR

$0.00 \% \quad 3.6 \%$ RLDQCPESPLQR

$0.01 \% \quad 8.4 \%$ SGSMDPSGAHPSVR

$0.01 \% \quad 8.4 \%$ QTPSRQPPLPHR

$0.01 \% \quad 8.4 \%$ ILGPQGNTIKR

$0.00 \% \quad 2.5 \% \quad$ LFVQDLATR

$0.00 \% \quad 2.5 \%$ GGGAFVQNSQPVAVR

$0.00 \% \quad 3.0 \%$ EAGNINQSLLTLGR

$0.00 \% \quad 3.0 \%$ VITALVER

$0.00 \% \quad 3.0 \%$ SYLYPSTLVR

$0.00 \% \quad 1.4 \%$ INLIDLAGSER

$0.00 \% \quad 1.4 \%$ VISALSEQANQR

$0.00 \% \quad 3.0 \% \quad$ ALLQEFDNAVLSK

$0.00 \% \quad 3.0 \%$ AGSQLGPGYQHHAQPK

$0.01 \% \quad 3.9 \%$ QTLLTNAFVQK

$0.01 \% \quad 3.9 \% \quad$ IQQAIENVDFSTAK

$0.01 \% \quad 3.9 \%$ LSEDSVSVLVLR

$0.01 \% \quad 3.9 \%$ LTTFYGAFGPEK

$0.01 \% \quad 3.9 \%$ LGISFQPVFR

$0.01 \% \quad 3.9 \%$ SSTLINKEITK

$99.5 \% \quad 21.8$

$99.7 \% \quad 30.0$

$94.8 \% \quad 16.4$

$99.7 \% 37.9$

$99.0 \% \quad 38.2$

$99.7 \% \quad 51.2$

$99.7 \% \quad 27.5$

$99.7 \% \quad 39.1$

$99.7 \% \quad 46.6$

$99.4 \% \quad 20.4$

$99.7 \% \quad 59.0$

$98.9 \% \quad 29.1$

$98.0 \% \quad 23.3$

$98.9 \% \quad 20.1$

$99.0 \% \quad 25.0$

$99.2 \% \quad 18.7$

$99.7 \% \quad 45.4$

$99.7 \% \quad 44.0$

$99.7 \% \quad 31.1$

$96.2 \% 14.4$

$99.7 \% \quad 28.0$

$99.7 \% \quad 67.1$

$99.7 \% \quad 55.0$

$99.7 \% \quad 60.4$

$99.7 \% \quad 55.7$

$97.2 \% \quad 21.4$

$0.02 \% \quad 25.5 \%$ LIVAVEQEEIPR
$0.01 \% \quad 3.9 \%$ IQNSSGTDYPDIHAAAK

$0.01 \% \quad 11.8 \%$ GLLEESSFATLFPK

$0.01 \% \quad 11.8 \%$ KTFDPYIIIR

$0.01 \% \quad 11.8 \%$ TFDPYIIIR

$0.01 \% \quad 11.8 \%$ SVSFEQAVR

$0.01 \% \quad 11.8 \%$ LGALTAEEIALK

$0.02 \% \quad 25.5 \%$ HPSLSIGVLEK

$0.02 \% \quad 25.5 \%$ GLQNGVPGLR

$0.02 \% \quad 25.5 \%$ SIDGMQYPIVIK

$0.02 \% \quad 25.5 \%$ CQYVVTCAGLYSDR

$0.02 \% \quad 25.5 \%$ ISELSGCTPDPR

$0.02 \% \quad 25.5 \%$ GDYLLLKPEK

$0.02 \% \quad 25.5 \%$ GNIYPVPDSR

$0.02 \% \quad 25.5 \%$ LASQNFSYGVTEMYK

$0.02 \% \quad 25.5 \%$ FIPEITISDILR

$0.01 \% \quad 15.8 \%$ NAVHVNLFETPVEAQYVR

$\begin{array}{ll}25.0 & 31.5\end{array}$

$\begin{array}{llll}99.7 \% & 47.6 & 25.0 & 44.9\end{array}$

$\begin{array}{llll}99.6 \% & 25.3 & 25.0 & 25.3\end{array}$

$99.7 \% \quad 35.7 \quad 25.0 \quad 28.7$

$99.4 \% \quad 27.5 \quad 25.0 \quad 14.9$

$99.7 \% \quad 34.1 \quad 25.0 \quad 16.5$

$\begin{array}{llll}99.7 \% & 30.8 & 25.0 & 26.3\end{array}$

$\begin{array}{llll}99.7 \% & 67.7 & 25.0 & 56.8\end{array}$

$97.7 \% \quad 19.9 \quad 25.0 \quad 15.4$

$\begin{array}{llll}99.7 \% & 63.3 & 25.0 & 56.8\end{array}$

$\begin{array}{llll}99.7 \% & 64.1 & 25.0 & 64.1\end{array}$

$99.7 \% \quad 46.7 \quad 25.0 \quad 37.9$

$\begin{array}{llll}99.7 \% & 30.1 & 25.0 & 30.1\end{array}$

$99.7 \% \quad 34.6 \quad 25.0 \quad 25.3$

$\begin{array}{llll}99.7 \% & 53.0 & 25.0 & 53.0\end{array}$

$\begin{array}{lllll}99.7 \% & 61.2 & 25.0 & 51.9 & 2\end{array}$

$0.01 \% \quad 15.8 \%$ EVTGIITQGAR $\begin{array}{ll}99.7 \% & 38.2\end{array}$

1519.76

911.53

1138.63

1121.57

1498.74

1400.62

1413.77

1196.71

1062.59

1486.78

1485.80

900.55

1198.65

1200.66

1315.70

1447.78

1675.83

1262.71

1563.80

1316.74

1330.67

1163.66

1233.71

1787.86

1538.81

1265.73

1137.63

1022.53

1228.71

1179.67

1395.78

1010.57

1379.72

1691.75

1331.63

1175.67

1117.56

1753.81

1416.81

2086.07

1144.63 
Lactadherin GN=MFGE8 Lactadherin GN=MFGE8 Lactadherin GN=MFGE\& Lactotransferrin $\mathrm{GN}=\mathrm{LTF}$ Lactotransferrin $\mathrm{GN}=\mathrm{LTF}$ Lamina-associated polypeptide 2, isoform alpha GN=TMPO LAP2A_HUMAN $75.49 \quad 100.0 \%$ Lamina-associated polypeptide 2, isoform alpha GN=TMPO LAP2A_HUMAN $75.49 \quad 100.0 \%$ Lamina-associated polypeptide 2, isoform alpha GN=TMPO LAP2A_HUMAN $75.49 \quad 100.0 \%$ Lamina-associated polypeptide 2, isoform alpha GN=TMPO LAP2A HUMAN $75.49 \quad 100.0 \%$ Lamin-B receptor $\mathrm{GN}=\mathrm{LBR}$ Lamin-B receptor $\mathrm{GN}=\mathrm{LBR}$ Lamin-B receptor $\mathrm{GN}=\mathrm{LBR}$ Lamin-B receptor $\mathrm{GN}=\mathrm{LBR}$ Lamin-B receptor $\mathrm{GN}=\mathrm{LBR}$ Lamin-B receptor $\mathrm{GN}=\mathrm{LBR}$ Lamin-B receptor $\mathrm{GN}=\mathrm{LBR}$ Lamin-B receptor $\mathrm{GN}=\mathrm{LBR}$ Lamin-B receptor $\mathrm{GN}=\mathrm{LBR}$ Lamin-B receptor $\mathrm{GN}=\mathrm{LBR}$

Lamin-B1 GN=LMNB Lamin-B1 GN=LMNB Lamin-B1 GN=LMNB1 Lamin-B1 GN=LMNB1 Lamin-B1 GN=LMNB Lamin-B1 GN=LMNB Lamin-B1 GN=LMNB1 Lamin-B1 GN=LMNB Lamin-B1 GN=LMNB1 Lamin-B1 GN=LMNB1 Lamin-B1 GN=LMNB Lamin-B1 GN=LMNB1 Lamin-B1 GN=LMNB1 Lamin-B1 GN=LMNB Lamin-B1 GN=LMNB Lamin-B1 GN=LMNB1 Lamin-B1 GN=LMNB1 Lamin-B1 GN=LMNB Lamin-B1 GN=LMNB Lamin-B1 GN=LMNB Lamin-B1 GN=LMNB Lamin-B1 GN=LMNB Lamin-B1 GN=LMNB1 Lamin-B1 GN=LMNB1 Lamin-B1 GN=LMNB1 Lamin-B1 GN=LMNB Lamin-B1 GN=LMNB1 Lamin-B1 GN=LMNB1 LBR HUMAN $70.71 \quad 100.0 \%$ LBR_HUMAN $70.71 \quad 100.0 \%$ LBR HUMAN $70.71 \quad 100.0 \%$
MFGM_HUMAN $43.12 \quad 100.0 \% \quad 5 \quad 5 \quad 13 \quad 0.01 \% \quad 15.8 \%$ NFGSVQFVASYK MFGM HUMAN $43.12 \quad 100.0 \% \quad 5 \quad 5 \quad 13 \quad 0.01 \% \quad 15.8 \%$ NLFETPILAR MFGM_HUMAN $43.12 \quad 100.0 \% \quad 5 \quad 5 \quad 13 \quad 0.01 \% \quad 15.8 \%$ IALRLELLGC TRFL HUMAN $78.18 \quad 99.9 \% \quad 2 \quad 20 \quad 3 \quad 0.00 \% \quad 2.8 \%$ THYYAVAVVK $0.00 \% \quad 2.8 \%$ DGAGDVAFIR $0.01 \% \quad 7.6 \%$ PEFLEDPSVLTK

$0.01 \% \quad 7.6 \%$ NRPPLPAGTNSK $0.01 \% \quad 7.6 \%$ YGVNPGPIVGTTR $0.01 \% \quad 7.6 \%$ SSTPLPTISSSAENTR LBR_HUMAN $70.71 \quad 100.0 \% \quad 10 \quad 11 \quad 44 \quad 0.04 \% \quad 15.9 \%$ KFADGEVVR LBR_HUMAN $70.71 \quad 100.0 \% \quad 10 \quad 11 \quad 44 \quad 0.04 \% \quad 15.9 \%$ FADGEVVR LBR HUMAN $70.71 \quad 100.0 \% \quad 10 \quad 11 \quad 44 \quad 0.04 \% \quad 15.9 \%$ SASASHQADIKEAR LBR_HUMAN $70.71 \quad 100.0 \% \quad 10 \quad 11 \quad 44 \quad 0.04 \% \quad 15.9 \%$ LTPLILKPFGNSISR LBR HUMAN $70.71 \quad 100.0 \% \quad 10 \quad 11 \quad 44 \quad 0.04 \% \quad 15.9 \%$ YNGEPEHIER LBR_HUMAN $70.71 \quad 100.0 \%$ LBR_HUMAN $70.71 \quad 100.0 \%$ LMNB1_HUMAN $66.41 \quad 100.0 \% \quad 32$ LMNB1_HUMAN $66.41 \quad 100.0 \% \quad 32$ LMNB1_HUMAN $66.41 \quad 100.0 \% \quad 32$ LMNB1_HUMAN $66.41 \quad 100.0 \% \quad 32$ LMNB1_HUMAN $\quad 66.41 \quad 100.0 \% \quad 32$ LMNB1_HUMAN $66.41 \quad 100.0 \% \quad 32$ LMNB1_HUMAN $66.41 \quad 100.0 \% \quad 32$ LMNB1_HUMAN $66.41 \quad 100.0 \% \quad 32$ LMNB1_HUMAN $66.41 \quad 100.0 \% \quad 32$ LMNB1_HUMAN $\quad 66.41 \quad 100.0 \% \quad 32$ LMNB1 HUMAN $66.41 \quad 100.0 \% \quad 32$ LMNB1_HUMAN $\quad 66.41 \quad 100.0 \% \quad 32$ LMNB1_HUMAN $66.41 \quad 100.0 \% \quad 32$ LMNB1 HUMAN $66.41 \quad 100.0 \% \quad 32$ LMNB1_HUMAN $66.41 \quad 100.0 \% \quad 32$ LMNB1_HUMAN $66.41 \quad 100.0 \% \quad 32$ LMNB1_HUMAN $66.41 \quad 100.0 \% \quad 32$ LMNB1_HUMAN $66.41 \quad 100.0 \% \quad 32$ LMNB1_HUMAN $66.41 \quad 100.0 \% \quad 32$ LMNB1_HUMAN $66.41 \quad 100.0 \% \quad 32$ LMNB1_HUMAN $66.41 \quad 100.0 \% \quad 32$ LMNB1 HUMAN $66.41 \quad 100.0 \% \quad 32$ LMNB1_HUMAN $66.41 \quad 100.0 \% \quad 32$ LMNB1_HUMAN $\quad 66.41 \quad 100.0 \% \quad 32$ LMNB1_HUMAN $66.41 \quad 100.0 \% \quad 32$ LMNB1_HUMAN $66.41 \quad 100.0 \% \quad 32$ LMNB1_HUMAN $66.41 \quad 100.0 \% \quad 32$ LMNB1_HUMAN $66.41 \quad 100.0 \% \quad 32$

$44 \quad 0.04 \% \quad 15.9 \%$ VVEGTPLIDGR $0.04 \% \quad 15.9 \%$ VVEGTPLIDGRR

$111 \quad 0.11 \% \quad 50.9 \%$ AGGPTTPLSPTR

$111 \quad 0.11 \% \quad 50.9 \%$ LQEKEELR

$1110.11 \% \quad 50.9 \%$ ALDDTARER

$111 \quad 0.11 \% \quad 50.9 \%$ EYEAALNSK

$111 \quad 0.11 \% \quad 50.9 \%$ DAALATALGDKK

$111 \quad 0.11 \% \quad 50.9 \%$ KQLADETLLK

$111 \quad 0.11 \% \quad 50.9 \%$ SMYEEEINETR

$111 \quad 0.11 \% \quad 50.9 \%$ SMYEEEINETRR

$111 \quad 0.11 \% \quad 50.9 \%$ LVEVDSGRQIEYEYK

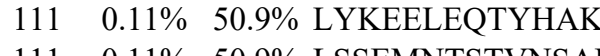

$\begin{array}{llll}111 & 0.11 \% & 50.9 \% & \text { MRIESLSSQLSNLQK }\end{array}$

$111 \quad 0.11 \% \quad 50.9 \%$ IESLSSQLSNLQK

$111 \quad 0.11 \% \quad 50.9 \%$ IQELEDLLAK

$43 \quad 111 \quad 0.11 \% \quad 50.9 \%$ KLLEGEEER

$43 \quad 111 \quad 0.11 \% \quad 50.9 \%$ LLEGEEERLK

$43 \quad 111 \quad 0.11 \% \quad 50.9 \%$ KIGDTSVSYK

$43 \quad 111 \quad 0.11 \% \quad 50.9 \%$ IGDTSVSYKYTSR
$111 \quad 0.11 \% \quad 50.9 \%$ IESLSSQLSNLQK $\begin{array}{llllllll}99.7 \% & 62.9 & 25.0 & 55.1 & 2 & 0 & 0 & 1346.67\end{array}$ $\begin{array}{llllllll}99.3 \% & 39.3 & 25.0 & 6.7 & 4 & 0 & 0 & 1173.66\end{array}$ $\begin{array}{llllllll}98.5 \% & 16.9 & 25.0 & 16.9 & 2 & 0 & 0 & 1157.67\end{array}$

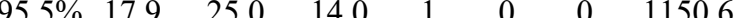
$\begin{array}{lllll}99.7 \% & 57.6 & 25.0 & 44.5 & 2\end{array}$ $\begin{array}{llll}99.7 \% & 39.4 & 25.0 & 34.0\end{array}$ $\begin{array}{llll}99.7 \% & 41.5 & 25.0 & 37.5\end{array}$ $\begin{array}{lllll}99.7 \% & 36.5 & 25.0 & 36.5 & 2\end{array}$ $\begin{array}{lllll}99.7 \% & 68.1 & 25.0 & 66.7 & 3\end{array}$ $\begin{array}{llll}99.7 \% & 45.2 & 25.0 & 39.7\end{array}$ $\begin{array}{llll}99.0 \% & 39.5 & 25.0 & 27.5\end{array}$ $99.7 \% \quad 42.1 \quad 25.0 \quad 42.1$ $96.6 \% \quad 14.9 \quad 25.0 \quad 14.9$ $99.7 \% \quad 41.3 \quad 25.0 \quad 27.3$ $99.0 \% \quad 37.3 \quad 25.0 \quad 35.8 \quad 11$ $99.7 \% \quad 47.4 \quad 25.0 \quad 45.1 \quad 4$ $\begin{array}{llll}98.4 \% & 16.8 & 25.0 & 16.8\end{array}$

$\begin{array}{lllll}99.7 \% & 54.9 & 25.0 & 54.9 & 8 \\ 99.2 \% & 21.0 & 25.0 & 18.2 & 0\end{array}$

$99.7 \% \quad 54.9 \quad 25.0 \quad 47.6 \quad 10$

$\begin{array}{lllll}99.0 \% & 35.6 & 25.0 & 6.1 & 3\end{array}$ $99.7 \% \quad 55.9$

$99.7 \% \quad 54.2$ $99.7 \% \quad 35.7$ $\begin{array}{lll}99.4 \% & 34.3\end{array}$ $99.7 \% \quad 55.8$ $99.7 \% \quad 34.7$ $99.6 \% \quad 27.9$ $99.7 \% \quad 58.6$ $98.9 \% \quad 17.9$ $99.7 \% \quad 53.8$ $99.7 \% \quad 38.8$ $98.1 \% 23.9$ $99.7 \% \quad 52.1$ $96.7 \% \quad 15.8$ $99.7 \% \quad 34.2$ $99.7 \% \quad 33.6$ $99.7 \% \quad 63.1$

$111 \quad 0.11 \% \quad 50.9 \%$ CKAEHDQLLLNYAK

$99.7 \% \quad 47.7$ $99.7 \% 67.1$ $99.7 \% \quad 72.0$ $99.3 \% \quad 32.4$ $99.7 \% \quad 66.0$ $\begin{array}{llll}99.7 \% & 44.1 & 25.0 & 35.3\end{array}$ $\begin{array}{llll}99.7 \% & 38.4 & 25.0 & 24.0\end{array}$ $\begin{array}{llll}99.7 \% & 59.5 & 25.0 & 45.6\end{array}$

1150.63
1020.51

1374.72

1251.68

1330.71

1647.82

1020.55

892.45

1470.73

1655.98

1243.57

962.53

1155.64

1311.74

2029.96

1219.68

1154.62

1044.57

2331.18

1251.62

1407.72

1046.52

999.62

1702.86

1202.64

1293.68

1024.49

1173.65

1158.67

1030.58

1400.60

1556.70

1827.91

1651.83

1512.70

2371.09

1733.92

1446.78

1818.96

1171.66

1102.57

1215.66

1097.58

1476.73 
Lamin-B1 GN=LMNB1 Lamin-B1 GN=LMNB Lamin-B1 GN=LMNB1 Lamin-B1 GN=LMNB Lamin-B2 GN=LMNB2 Lamin-B2 GN=LMNB2 Lamin-B2 GN=LMNB2 Lamin-B2 GN=LMNB2 Lamin-B2 GN=LMNB2 Lamin-B2 GN=LMNB2 Lamin-B2 GN=LMNB2 Lamin-B2 GN=LMNB2 Lamin-B2 GN=LMNB2 Lamin-B2 GN=LMNB2 Lamin-B2 GN=LMNB2 Lamin-B2 GN=LMNB2 Lamin-B2 GN=LMNB2 Lamin-B2 GN=LMNB2 Lamin-B2 GN=LMNB2 Lamin-B2 GN=LMNB2
LMNB1_HUMAN $66.41 \quad 100.0 \% \quad 32$ LMNB1_HUMAN $66.41 \quad 100.0 \% \quad 32$ LMNB1_HUMAN $66.41 \quad 100.0 \% \quad 32$ LMNB1 HUMAN $66.41 \quad 100.0 \% \quad 32$ LMNB2_HUMAN $67.69 \quad 100.0 \% \quad 13$ LMNB2_HUMAN $67.69 \quad 100.0 \% \quad 13$ LMNB2_HUMAN $67.69 \quad 100.0 \% \quad 13$ LMNB2_HUMAN $67.69 \quad 100.0 \% \quad 13$ LMNB2 HUMAN $67.69 \quad 100.0 \%$ LMNB2_HUMAN $67.69 \quad 100.0 \% \quad 13$ LMNB2_HUMAN $67.69 \quad 100.0 \% \quad 13$ LMNB2_HUMAN $67.69 \quad 100.0 \% \quad 13$ LMNB2_HUMAN $67.69 \quad 100.0 \% \quad 13$ LMNB2_HUMAN $67.69 \quad 100.0 \% \quad 13$ LMNB2 HUMAN $67.69 \quad 100.0 \% \quad 13$ LMNB2_HUMAN $67.69 \quad 100.0 \% \quad 13$ LMNB2 HUMAN $67.69 \quad 100.0 \% \quad 13$ LMNB2_HUMAN $67.69 \quad 100.0 \% \quad 13$ LMNB2_HUMAN $67.69 \quad 100.0 \% \quad 13$ LMNB2 HUMAN $67.69 \quad 100.0 \% \quad 13$ $\begin{array}{llll}\text { PT ADPPT_HUMAN } 35.78 & 100.0 \% & 3\end{array}$ T ADPPT_HUMAN $35.78 \quad 100.0 \%$

La-related protein $1 \mathrm{GN}=\mathrm{LARP}$ La-related protein $1 \mathrm{GN}=\mathrm{LARP}$ La-related protein $1 \mathrm{GN}=\mathrm{LARP} 1$ La-related protein $1 \mathrm{GN}=\mathrm{LARP} 1$ La-related protein $1 \mathrm{GN}=\mathrm{LARP} 1$ La-related protein $1 \mathrm{GN}=\mathrm{LARP} 1$ La-related protein $1 \mathrm{GN}=\mathrm{LARP}$ La-related protein $1 \mathrm{GN}=\mathrm{LARP} 1$ La-related protein $1 \mathrm{GN}=\mathrm{LARP}$ La-related protein $1 \mathrm{GN}=\mathrm{LARP} 1$ La-related protein $1 \mathrm{GN}=\mathrm{LARP} 1$ La-related protein $1 \mathrm{GN}=\mathrm{LARP} 1$ La-related protein $1 \mathrm{GN}=\mathrm{LARP} 1$ La-related protein $1 \mathrm{GN}=\mathrm{LARP}$ L $123.51 \quad 100.0 \%$ LARP1_HUMAN $123.51 \quad 100.0 \% \quad 14$ LARP1_HUMAN $123.51 \quad 100.0 \% \quad 14$ LARP1 HUMAN $123.51 \quad 100.0 \% \quad 14$ LARP1_HUMAN $123.51 \quad 100.0 \% \quad 14$ LARP1_HUMAN $123.51 \quad 100.0 \% \quad 14$ LARP1_HUMAN $123.51 \quad 100.0 \% \quad 14$ LARP1_HUMAN $123.51 \quad 100.0 \% \quad 14$
15

15

15
15

15
15

3
3

3
3

17

17

17
$\begin{array}{llll}\text { Large neutral amino acids transporter small subunit } 1 \mathrm{GN}=\mathrm{SLC7A5} & \text { LAT1_HUMAN } & 55.01 & 100.0 \%\end{array}$ Legumain $\mathrm{GN}=\mathrm{LGMN}$ Legumain $\mathrm{GN}=\mathrm{LGMN}$ LGMN_HUMAN $49.41 \quad 100.0 \% \quad 2$ LGMN_HUMAN $49.41 \quad 100.0 \% \quad 2$ Leucine-rich PPR motif-containing protein, mitochondrial GN=LRPPRC LPPRC_HUMAN $157.91 \quad 100.0 \%$ Leucine-rich PPR motif-containing protein, mitochondrial GN=LRPPRC LPPRC HUMAN $157.91 \quad 100.0 \%$ Leucine-rich PPR motif-containing protein, mitochondral GN=LRPPRC LPPRC HUMAN $157.91 \quad 100.0 \%$ Leucine-rich PPR motif-containing protein, mitochondrial GN=LRPPRC LPPRC_HUMAN $157.91 \quad 100.0 \%$ Leucine-rich PPR motif-containing protein, mitochondrial GN=LRPPRC LPPRC HUMAN $157.91 \quad 100.0 \%$ Leucine-rich PPR motif-containing protein, mitochondrial GN=LRPPRC LPPRC_HUMAN $157.91 \quad 100.0 \%$ $30 \quad 0.03 \% \quad 6.5 \% \quad$ KIIETPGIR
$43 \quad 111 \quad 0.11 \% \quad 50.9 \%$ NQNSWGTGEDVK

43 15 15

15

15

15

15

15

15

17

17

17

17

17

$111 \quad 0.11 \% \quad 50.9 \%$ NSQGEEVAQR $99.7 \% \quad 42.8$

0.11\% $50.9 \%$ TTIPEEEEEEEEAAGVVVE $0.03 \% \quad 27.7 \%$ AGGPATPLSPTR $0.03 \% 27.7 \%$ LQEKEELR $0.03 \% \quad 27.7 \%$ ALELENDRLLLK $\begin{array}{lll}0.03 \% & 27.7 \% & \text { ISEKEEVTTR }\end{array}$ $0.03 \% \quad 27.7 \%$ ALYESELADAR $0.03 \% \quad 27.7 \%$ ALYESELADARR $0.03 \% \quad 27.7 \%$ EGELTVAQGR $0.03 \% \quad 27.7 \%$ GLESDVAELR $0.03 \% \quad 27.7 \%$ RLVEVDSSR $0.03 \% \quad 27.7 \%$ LSSDQNDKAASAAR $0.03 \% \quad 27.7 \%$ MRLESLSYQLSGLQK $0.03 \% \quad 27.7 \%$ KLLEGEEER $0.03 \% \quad 27.7 \%$ LLEGEEERLK $0.03 \% \quad 27.7 \%$ ATSSSSGSLSATGR $0.03 \% \quad 27.7 \%$ QVLEGEEIAYKFTPK $0.03 \% \quad 27.7 \%$ TVLVNADGEEVAMR $0.00 \% \quad 11.3 \%$ IGQFVFAR $0.00 \% \quad 11.3 \%$ AIGVGLGFELQR $0.00 \% \quad 11.3 \%$ HQDVPSQDDSKPTQR $0.03 \% \quad 14.3 \%$ DFVEAPPPK

$0.03 \% \quad 14.3 \%$ SVQPQSHKPQPTR $0.03 \% \quad 14.3 \%$ THFDYQFGYR $0.03 \% \quad 14.3 \%$ KFDGVEGPR $0.03 \% \quad 14.3 \%$ VVEIVDEKVR $0.03 \% \quad 14.3 \%$ QHYQKETESAPGSPR $0.03 \% \quad 14.3 \%$ AVTPVPTKTEEVSNLK $0.03 \% \quad 14.3 \%$ FQQVPTDALANK

$17 \quad 33 \quad 0.03 \% \quad 14.3 \%$ FQQVPTDALANKLFGAPEPSTIAR $17 \quad 33 \quad 0.03 \% \quad 14.3 \%$ SLPTTVPESPNYR $17 \quad 33 \quad 0.03 \% \quad 14.3 \%$ SLPTTVPESPNYRNTR

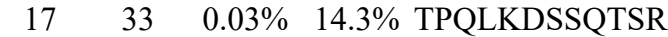
$17 \quad 33 \quad 0.03 \% \quad 14.3 \%$ FYPVVKEGR $17 \quad 33 \quad 0.03 \% \quad 14.3 \%$ LGIGQSQEMNTLFR $0.00 \% \quad 6.3 \%$ ALAAPAAEEKEEAR $\begin{array}{llllll}0.00 \% & 6.3 \% & \text { SADGSAPAGEGEGVTLQR } & 99.7 \% & 68.7\end{array}$

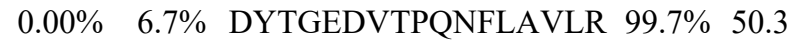
$0.00 \% \quad 6.7 \% \quad$ ESSYACYYDEKR $0.03 \% \quad 6.5 \% \quad$ EKDIQEESTFSSR $0.03 \% \quad 6.5 \%$ SGGLGGSHALLLLR $0.03 \% \quad 6.5 \% \quad$ NVQGIIEILK $30 \quad 0.03 \% \quad 6.5 \% \quad$ SNTLPISLQSIR $30 \quad 0.03 \% \quad 6.5 \% \quad$ SSLLLGFRR $\begin{array}{llll}99.7 \% & 55.7 & 25.0 & 52.6\end{array}$

$99.7 \% 33.2$ $99.0 \% \quad 35.6 \quad 25.0 \quad 6.1$

$\begin{array}{llll}99.7 \% & 52.2 & 25.0 & 48.5\end{array}$ $\begin{array}{lllll}99.7 \% & 47.8 & 25.0 & 33.6 & 2\end{array}$ $99.7 \% \quad 44.0 \quad 25.0 \quad 37.2$ $\begin{array}{llll}98.3 \% & 19.5 & 25.0 & 16.1\end{array}$ $99.7 \% \quad 61.0 \quad 25.0 \quad 39.6 \quad 4$ $99.7 \% \quad 64.9 \quad 25.0 \quad 46.0$ $\begin{array}{llll}99.7 \% & 30.4 & 25.0 & 20.4\end{array}$ $99.7 \% \quad 32.7 \quad 25.0 \quad 32.7$ $99.7 \% \quad 44.4 \quad 25.0 \quad 42.9$ $99.7 \% \quad 66.0 \quad 25.0 \quad 44.3 \quad 2$ $99.7 \% \quad 44.1 \quad 25.0 \quad 35.3$ $99.7 \% \quad 70.8 \quad 25.0 \quad 58.5$ $\begin{array}{lllll}99.7 \% & 53.9 & 25.0 & 52.3 & 2\end{array}$ $\begin{array}{lllll}99.7 \% & 54.6 & 25.0 & 54.6\end{array}$ $\begin{array}{llll}99.0 \% & 24.3 & 25.0 & 24.3\end{array}$ $\begin{array}{llll}98.5 \% & 17.0 & 25.0 & 17.0\end{array}$ $\begin{array}{llll}99.0 \% & 20.5 & 25.0 & 20.5\end{array}$ $\begin{array}{lllll}97.8 \% & 22.3 & 25.0 & 12.4 & 2\end{array}$ $\begin{array}{llll}99.7 \% & 33.9 & 25.0 & 33.9\end{array}$ $\begin{array}{llll}99.1 \% & 19.2 & 25.0 & 19.2\end{array}$ $\begin{array}{llll}99.7 \% & 32.4 & 25.0 & 24.4\end{array}$ $\begin{array}{llll}99.7 \% & 62.0 & 25.0 & 53.8\end{array}$ $\begin{array}{llll}99.5 \% & 22.0 & 25.0 & 22.0\end{array}$ $\begin{array}{llll}99.7 \% & 49.7 & 25.0 & 40.7\end{array}$ $\begin{array}{llll}99.7 \% & 32.1 & 25.0 & 23.4\end{array}$ $\begin{array}{llll}9.3 \% & 22.3 & 25.0 & 17.5 \\ 99.4 \% & 23.4 & 25.0 & 23.4\end{array}$ $\begin{array}{llll}98.6 \% & 18.7 & 25.0 & 18.0\end{array}$ $\begin{array}{llll}99.7 \% & 52.0 & 25.0 & 51.3\end{array}$ $99.7 \% \quad 32.8 \quad 25.0 \quad 31.1$ $\begin{array}{llll}99.7 \% & 32.8 & 25.0 & 31.1 \\ 99.7 \% & 45.5 & 25.0 & 45.5\end{array}$

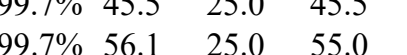
$\begin{array}{llll}99.7 \% & 27.7 & 25.0 & 27.7\end{array}$ $99.7 \% \quad 61.8 \quad 25.0 \quad 53.0 \quad 2$ $\begin{array}{llll}99.7 \% & 46.0 & 25.0 & 41.3\end{array}$ $\begin{array}{llll}99.7 \% & 33.8 & 25.0 & 28.1\end{array}$ $\begin{array}{lllll}99.7 \% & 72.7 & 25.0 & 56.2 & 4\end{array}$ $\begin{array}{llll}97.2 \% & 24.8 & 25.0 & 9.0\end{array}$ $\begin{array}{llll}99.5 \% & 22.6 & 25.0 & 22.6\end{array}$
1787.93

1117.52

3411.57

1124.61

1044.57

1426.83

1191.62

1237.61

1393.71

1059.54

1088.56

1060.57

1433.70

1768.93

1102.57

1215.66

1268.61

1751.92

1519.74

937.53

1259.71

1737.82

999.51

1489.79

1333.60

1004.52

1185.68

1714.81

1712.94

1331.70

2571.36

1460.74

1831.93

1347.69

1094.60

1609.80

1455.74

1701.80

1937.96

1570.65

1555.72

1350.79

1126.68

1328.75

1048.63 1026.63

$\begin{array}{cc}17 & 528 \\ 17 & 532 \\ 33 & 542 \\ 48 & 577 \\ 9 & 20 \\ 4 & 31 \\ 6 & 57 \\ 8 & 67 \\ 4 & 84 \\ 4 & 85 \\ 19 & 128 \\ 52 & 161 \\ 20 & 228 \\ 71 & 284 \\ 92 & 306 \\ 73 & 381 \\ 74 & 383 \\ 97 & 410 \\ 86 & 500 \\ 42 & 555 \\ 8 & 55 \\ 86 & 197 \\ 53 & 267 \\ 15 & 123 \\ 86 & 198 \\ 57 & 366 \\ 67 & 375 \\ 66 & 475 \\ 09 & 523 \\ 24 & 539 \\ 42 & 753 \\ 42 & 765 \\ 66 & 778 \\ 66 & 781 \\ 88 & 799 \\ 00 & 808 \\ 04 & 917 \\ 0 & 23 \\ 1 & 48 \\ 02 & 118 \\ 14 & 225 \\ 5 & 77 \\ 15 & 128 \\ 54 & 463 \\ 30 & 541 \\ 42 & 550 \\ 09 & 917\end{array}$


L-lactate dehydrogenase A chain GN=LDHA LDHA_HUMAN $36.69 \quad 100.0 \%$ L-lactate dehydrogenase A chain GN=LDHA LDHA_HUMAN $36.69 \quad 100.0 \%$ L-lactate dehydrogenase A chain GN=LDHA LDHA HUMAN $36.69 \quad 100.0 \%$ L-lactate dehydrogenase A chain GN=LDHA LDHA_HUMAN $36.69 \quad 100.0 \%$ L-lactate dehydrogenase A chain GN=LDHA LDHA_HUMAN $36.69 \quad 100.0 \%$ L-lactate dehydrogenase A chain GN=LDHA LDHA_HUMAN $36.69 \quad 100.0 \%$ L-lactate dehydrogenase A chain GN=LDHA LDHA_HUMAN $36.69 \quad 100.0 \%$ L-lactate dehydrogenase A chain GN=LDHA LDHA HUMAN $36.69 \quad 100.0 \%$ L-lactate dehydrogenase A chain GN=LDHA LDHA_HUMAN $36.69 \quad 100.0 \%$ L-lactate dehydrogenase A chain GN=LDHA LDHA_HUMAN $36.69 \quad 100.0 \%$ L-lactate dehydrogenase A chain GN=LDHA LDHA_HUMAN $36.69 \quad 100.0 \%$ L-lactate dehydrogenase A chain GN=LDHA LDHA_HUMAN $36.69 \quad 100.0 \%$ L-lactate dehydrogenase A chain GN=LDHA LDHA_HUMAN $36.69 \quad 100.0 \%$ L-lactate dehydrogenase A chain GN=LDHA LDHA_HUMAN $36.69 \quad 100.0 \%$ L-lactate dehydrogenase A chain GN=LDHA LDHA_HUMAN $36.69 \quad 100.0 \%$ L-lactate dehydrogenase A chain GN=LDHA LDHA HUMAN $36.69 \quad 100.0 \%$ L-lactate dehydrogenase A chain GN=LDHA LDHA_HUMAN $36.69 \quad 100.0 \%$ L-lactate dehydrogenase A chain GN=LDHA LDHA_HUMAN $36.69 \quad 100.0 \%$ L-lactate dehydrogenase B chain GN=LDHB LDHB_HUMAN $36.64 \quad 100.0 \%$ L-lactate dehydrogenase B chain GN=LDHB LDHB_HUMAN $36.64 \quad 100.0 \%$ L-lactate dehydrogenase B chain GN=LDHB LDHB HUMAN $36.64 \quad 100.0 \%$ L-lactate dehydrogenase B chain GN=LDHB LDHB_HUMAN $36.64 \quad 100.0 \%$ L-lactate dehydrogenase B chain GN=LDHB LDHB_HUMAN $36.64 \quad 100.0 \%$ L-lactate dehydrogenase B chain GN=LDHB LDHB HUMAN $36.64 \quad 100.0 \%$ L-lactate dehydrogenase B chain GN=LDHB LDHB_HUMAN $36.64 \quad 100.0 \%$

$30 \quad 0.03 \% \quad 6.5 \% \quad$ TVLDQQQTPSR

$9 \quad 0.01 \% \quad 9.3 \% \quad$ ILPEEITNLRNLK

$0.01 \% \quad 9.3 \% \quad$ FLALEGNPLR

$0.01 \% \quad 9.3 \%$ EIISKGTQEVLK

$0.01 \% \quad 9.3 \% \quad$ SNIVTSINFSK

$0.01 \% \quad 9.3 \%$ LQTINLSFNR

$0.00 \% \quad 5.5 \%$ NALGPGLSPELGPLPALR

$0.00 \% \quad 5.5 \%$ VLHVSENPVPLTVR

$0.00 \% \quad 7.2 \%$ LQQLPADFGR

$0.00 \% \quad 7.2 \% \quad$ LVTLPVSFAQLK

$0.01 \% \quad 13.0 \%$ QANVQIQEIQR

$0.01 \% \quad 13.0 \%$ LTADLSAETLQAR

$0.01 \% \quad 13.0 \%$ LSFISEGEIK

$0.01 \% \quad 13.0 \%$ DFVTTRPALK

$0.01 \% \quad 3.1 \%$ YGPDAFFNFPGK

$0.01 \% \quad 3.1 \%$ SAAAIALPPIAK

$0.01 \% \quad 3.1 \%$ ATDAQLCLESSPK

$1 \quad 0.01 \% \quad 3.1 \%$ LINDCHGSVSEAS

$0.01 \% \quad 3.1 \%$ VGVGTSFGLPQTR

$11 \quad 0.01 \% \quad 3.1 \%$ TSEEFVHINR

$104 \quad 0.10 \% \quad 48.5 \%$ DQLIYNLLK

$104 \quad 0.10 \% \quad 48.5 \%$ DQLIYNLLKEEQTPQNK

$104 \quad 0.10 \% \quad 48.5 \%$ EEQTPQNK

$104 \quad 0.10 \% \quad 48.5 \%$ DLADELALVDVIEDK

$104 \quad 0.10 \% \quad 48.5 \%$ LKGEMMDLQHGSLFLR

$104 \quad 0.10 \% \quad 48.5 \%$ GEMMDLQHGSLFLR

$104 \quad 0.10 \% \quad 48.5 \%$ IVSGKDYNVTANSK

$104 \quad 0.10 \% \quad 48.5 \%$ DYNVTANSK

$104 \quad 0.10 \% \quad 48.5 \%$ LVIITAGAR

$104 \quad 0.10 \% \quad 48.5 \%$ FIIPNVVK

$104 \quad 0.10 \% \quad 48.5 \%$ LLIVSNPVDILTYVAWK

$104 \quad 0.10 \% \quad 48.5 \%$ VIGSGCNLDSAR

$104 \quad 0.10 \% \quad 48.5 \%$ TLHPDLGTDK

$104 \quad 0.10 \% \quad 48.5 \%$ TLHPDLGTDKDK

$104 \quad 0.10 \% \quad 48.5 \%$ QVVESAYEVIK

$104 \quad 0.10 \% \quad 48.5 \%$ RVHPVSTMIK

$104 \quad 0.10 \% \quad 48.5 \%$ VTLTSEEEAR

$104 \quad 0.10 \% \quad 48.5 \%$ SADTLWGIQK

$117 \quad 0.12 \% \quad 51.8 \%$ EKLIAPVAEEEATVPNNK

$117 \quad 0.12 \% \quad 51.8 \%$ LIAPVAEEEATVPNNK

$117 \quad 0.12 \% \quad 51.8 \%$ ITVVGVGQVGMACAISILGK

$117 \quad 0.12 \% \quad 51.8 \%$ SLADELALVDVLEDK

$117 \quad 0.12 \% \quad 51.8 \%$ LKGEMMDLQHGSLFLQTPK $98.8 \% \quad 70.4$

$\begin{array}{llllll}117 & 0.12 \% & 51.8 \% & \text { IVADKDYSVTANSK } & 99.7 \% & 56.7\end{array}$
$99.7 \% \quad 56.2$

$99.7 \% \quad 34.3$

$99.7 \% \quad 33.5$

$99.7 \% \quad 41.2$

$99.7 \% \quad 57.4$

$99.7 \% 39.8$

$99.7 \% 51.5$

$99.7 \% 26.6$

$99.5 \% \quad 23.0$

$99.7 \% 37.8$

$99.7 \% \quad 63.6$

$99.7 \% \quad 50.5$

$99.7 \% \quad 40.0$

$99.7 \% \quad 34.8$

$99.7 \% \quad 51.7$

$\begin{array}{ll}9.5 \% & 22.6 \\ 99.7 \% & 52.5\end{array}$

$99.7 \% \quad 33.1$

$98.8 \% 24.1$

$99.7 \% \quad 51.9$

$99.0 \% \quad 29.1$

$99.7 \% \quad 91.1$

$\begin{array}{ll}99.7 \% & 26.5 \\ 99.7 \% & 46.0\end{array}$

$99.7 \% \quad 47.9$

$99.7 \% \quad 55.7$

$99.7 \% \quad 59.4$

$99.0 \% \quad 24.6$

$\begin{array}{ll}99.0 \% & 76.2 \\ 99.7 \% & 59.9\end{array}$

$99.7 \% \quad 31.2$

$99.5 \% \quad 23.2$

$\begin{array}{lll}99.7 \% & 59.4\end{array}$

$99.2 \% 24.9$

$99.7 \% 55.6$

$99.7 \% \quad 58.0$

$99.7 \% \quad 61.3$

$99.7 \% 53.9$
$99.7 \% 53.7$

$\begin{array}{ll}98.8 \% & 17.5 \\ 99.7 \% & 52.8\end{array}$
127

1313.66

1552.91

1129.64

1344.77

1209.65

1205.66

1772.01

1559.89

1144.61

1315.80

1326.7

1388.74

1122.60

1147.65

1359.64

1122.69

1419.68

1860.84

1248.66

1318.71

1231.61

1119.64

2074.08

973.46

1657.85

1906.95

1633.78

1495.78

1011.47

913.58

929.58

1944.12

1248.60

1096.56

1339.69

1264.68

1167.67

1134.56

1118.58

1952.03

1694.90

1989.09

1629.86

2205.10

1963.93

1510.77 
L-lactate dehydrogenase B chain GN=LDHB LDHB_HUMAN $36.64 \quad 100.0 \% \quad 1 \%$ L-lactate dehydrogenase B chain GN=LDHB LDHB_HUMAN $36.64 \quad 100.0 \% \quad 18$ L-lactate dehydrogenase B chain GN=LDHB LDHB_HUMAN $36.64 \quad 100.0 \% \quad 18$ L-lactate dehydrogenase B chain GN=LDHB LDHB HUMAN $36.64 \quad 100.0 \%$ L-lactate dehydrogenase B chain GN=LDHB LDHB_HUMAN $36.64 \quad 100.0 \% \quad 18$ L-lactate dehydrogenase B chain GN=LDHB LDHB_HUMAN $36.64 \quad 100.0 \% \quad 18$ L-lactate dehydrogenase B chain GN=LDHB LDHB_HUMAN $36.64 \quad 100.0 \% \quad 18$ $\begin{array}{llll}\text { L-lactate dehydrogenase B chain GN=LDHB LDHB_HUMAN } & 36.64 & 100.0 \% & 18\end{array}$ L-lactate dehydrogenase B chain GN=LDHB LDHB HUMAN $36.64 \quad 100.0 \% \quad 18$ L-lactate dehydrogenase B chain GN=LDHB LDHB_HUMAN $36.64 \quad 100.0 \% \quad 18$ L-lactate dehydrogenase B chain GN=LDHB LDHB_HUMAN $36.64 \quad 100.0 \% \quad 18$ L-lactate dehydrogenase B chain GN=LDHB LDHB_HUMAN $36.64 \quad 100.0 \% \quad 18$ Lon protease homolog, mitochondrial GN=LONP1 LONM_HUMAN $106.49 \quad 100.0 \%$ Lon protease homolog, mitochondrial GN=LONP1 LONM_HUMAN $106.49 \quad 100.0 \%$ Long-chain-fatty-acid--CoA ligase $3 \mathrm{GN}=$ ACSL3 ACSL3_HUMAN $80.42 \quad 100.0 \%$ Long-chain-fatty-acid--CoA ligase $3 \mathrm{GN}=$ ACSL3 ACSL3_HUMAN $80.42 \quad 100.0 \%$ Long-chain-fatty-acid--CoA ligase $3 \mathrm{GN}=\mathrm{ACSL} 3$ ACSL3 HUMAN $80.42 \quad 100.0 \%$ Long-chain-fatty-acid--CoA ligase $3 \mathrm{GN}=$ ACSL3 ACSL3_HUMAN $80.42 \quad 100.0 \%$ Lupus La protein $\mathrm{GN}=\mathrm{SSB}$

Lupus La protein $\mathrm{GN}=\mathrm{SSB}$ Lupus La protein $\mathrm{GN}=\mathrm{SSB}$ Lupus La protein $\mathrm{GN}=\mathrm{SSB}$ Lupus La protein $\mathrm{GN}=\mathrm{SSB}$ Lupus La protein $\mathrm{GN}=\mathrm{SSB}$ Lupus La protein $\mathrm{GN}=\mathrm{SSB}$ Lupus La protein $\mathrm{GN}=\mathrm{SSB}$ Lupus La protein $\mathrm{GN}=\mathrm{SSB}$ Lupus La protein $\mathrm{GN}=\mathrm{SSB}$ Lupus La protein $\mathrm{GN}=\mathrm{SSB}$ Lupus La protein $\mathrm{GN}=\mathrm{SSB}$ Lys-63-specific deubiquinas BRCC36 GN=BRC Lys-63-specific deubiquitinase BRCC36 GN=BRCC3 $\mathrm{BRCC} 3$ _HUMAN $36.07 \quad 100.0 \%$ 2ys-63-specific deubiquitinase $\mathrm{BRCC} 36 \mathrm{GN}=\mathrm{BRCC} 3 \mathrm{BRCC} 3$ HUMAN $36.07 \quad 100.0 \%$ Lysine--tRNA ligase GN=KARS Lysine--tRNA ligase GN=KARS Lysine--tRNA ligase GN=KARS LA HUMAN $46.84 \quad 100.0 \%$ LA HUMAN $46.84 \quad 100.0 \%$ LA_HUMAN $46.84 \quad 100.0 \% \quad 12$ LA HUMAN $46.84 \quad 100.0 \% \quad 12$ LA_HUMAN $46.84 \quad 100.0 \% \quad 12$ LA_HUMAN $46.84 \quad 100.0 \% \quad 12$ LA HUMAN $46.84 \quad 100.0 \% \quad 12$ LA_HUMAN $46.84 \quad 100.0 \% \quad 12$ LA_HUMAN $46.84 \quad 100.0 \% \quad 12$ LA HUMAN $46.84 \quad 100.0 \% \quad 12$ LA_HUMAN $46.84 \quad 100.0 \% \quad 12$ LA HUMAN $46.84 \quad 100.0 \%$ Lysophospholipid acyltransferase $7 \mathrm{GN}=$ MBOAT7 MBOA7_HUMAN $52.77 \quad 100.0 \%$ Lysophospholipid acyltransferase $7 \mathrm{GN}=$ MBOAT7 MBOA7 HUMAN $52.77 \quad 100.0 \%$ Lysophospholipid acyltransferase $7 \mathrm{GN}=$ MBOAT7 MBOA7_HUMAN $52.77 \quad 100.0 \%$ Lysozyme C GN=LYZ

Lysozyme $\mathrm{C}$ GN=LYZ Lysozyme C GN=LYZ LYSC_HUMAN $16.54 \quad 100.0 \%$ LYSC HUMAN $16.54 \quad 100.0 \%$ LYSC_HUMAN $16.54 \quad 100.0 \%$ Magnesium transporter protein $1 \mathrm{GN}=$ MAGT1 MAGT1 HUMAN $38.04 \quad 100.0 \%$ Magnesium transporter protein $1 \mathrm{GN}=$ MAGT1 MAGT1_HUMAN $38.04 \quad 100.0 \%$ Magnesium transporter protein $1 \mathrm{GN}=$ MAGT1 MAGT1_HUMAN $38.04 \quad 100.0 \%$ Malate dehydrogenase, mitochondrial GN=MDH2 MDHM HUMAN $35.50 \quad 100.0 \%$ Malate dehydrogenase, mitochondrial GN=MDH2 MDHM_HUMAN $35.50 \quad 100.0 \%$
$27 \quad 117 \quad 0.12 \% \quad 51.8 \%$ HRVIGSGCNLDSAR

$27 \quad 117 \quad 0.12 \% \quad 51.8 \%$ VIGSGCNLDSAR

$27 \quad 117 \quad 0.12 \% \quad 51.8 \%$ MVVESAYEVIK

$27 \quad 117 \quad 0.12 \% \quad 51.8 \%$ IHPVSTMVK

$27 \quad 117 \quad 0.12 \% \quad 51.8 \%$ GLTSVINQK

$27 \quad 117 \quad 0.12 \% \quad 51.8 \%$ LKDDEVAQLK

$27 \quad 117 \quad 0.12 \% \quad 51.8 \%$ KSADTLWDIQK

$117 \quad 0.12 \% \quad 51.8 \%$ SADTLWDIQK

$0.00 \% \quad 2.4 \%$ ILCFYGPPGVGK

$0.00 \% \quad 2.4 \%$ LSSDVLTLLIK

$0.01 \% \quad 7.4 \%$ AKPVNSKPDSAYR

$0.01 \% \quad 7.4 \%$ LKDIVSLVPR

$6.01 \% \quad 7.4 \% \quad$ IGYSSPQTLADQSSK

$0.01 \% \quad 7.4 \%$ LLLCGGAPLSATTQR

$0.04 \% \quad 28.2 \%$ ICHQIEYYFGDFNLPR

$0.04 \% \quad 28.2 \%$ LTTDFNVIVEALSK

$0.04 \% \quad 28.2 \%$ SPSKPLPEVTDEYKNDVK

$0.04 \% \quad 28.2 \%$ GSIFVVFDSIESAK

$0.04 \% \quad 28.2 \%$ GSIFVVFDSIESAKK

$0.04 \% \quad 28.2 \%$ KFVETPGQK

$0.04 \% \quad 28.2 \%$ QKLEEDAEMK

$0.04 \% \quad 28.2 \%$ EGIILFKEK

$0.04 \% \quad 28.2 \%$ AKDANNGNLQLR

$0.04 \% \quad 28.2 \%$ DANNGNLQLR

$0.04 \% \quad 28.2 \%$ IIEDQQESLNK

$0.04 \% \quad 28.2 \%$ IIEDQQESLNKWK

$0.00 \% \quad 10.8 \%$ FAYTGTEMR

$0.00 \% \quad 10.8 \%$ VLYTCFQSIQAQK

$0.00 \% \quad 10.8 \%$ IHSLTHLDSVTK

$0.00 \% \quad 5.4 \%$ RGDIIGVQGNPGK

$0.00 \% \quad 5.4 \% \quad$ YLDLILNDFVR

$0.00 \% \quad 5.4 \% \quad$ SKIITYIR

$0.01 \% \quad 8.7 \%$ AGGGPTLQCPPPSSPEK

$0.01 \% \quad 8.7 \%$ AASLEYDYETIR

$0.01 \% \quad 8.7 \%$ AASQPTSLAPEK

$0.01 \% \quad 19.6 \%$ WESGYNTR

$0.01 \% \quad 19.6 \%$ ATNYNAGDRSTDYGIFQINSR

$0.01 \% \quad 19.6 \%$ STDYGIFQINSR

$0.00 \% \quad 8.1 \% \quad$ YSSAFTNR

$0.00 \% \quad 8.1 \%$ RGDTYELQVR

$0.00 \% \quad 8.1 \%$ GFSAEQIAR

$\begin{array}{llllllll}99.7 \% & 57.0 & 25.0 & 46.9 & 13 & 0 & 0 & 913.58\end{array}$

$\begin{array}{llllllll}99.0 \% & 34.2 & 25.0 & 29.6 & 10 & 0 & 0 & 957.61\end{array}$

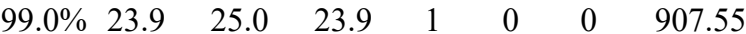

$99.7 \% \quad 52.8$

$99.7 \% \quad 59.9$

$99.7 \% \quad 55.2$

$96.8 \% \quad 22.8$

$99.7 \% \quad 47.0$

$99.7 \% \quad 58.0$

$99.7 \% \quad 32.5$

$99.7 \% \quad 61.1$

$99.7 \% \quad 65.6$

$99.4 \% 30.6$

$99.5 \% \quad 25.5$

$99.7 \% \quad 39.4$

$99.7 \% \quad 58.4$

$99.7 \% \quad 59.2$

$99.7 \% \quad 27.4$

$99.7 \% \quad 50.2$

$\begin{array}{ll}99.6 \% & 23.6 \\ 99.7 \% & 53.3\end{array}$

$99.7 \% \quad 53.5$

$99.7 \% \quad 37.3$

$99.3 \% \quad 20.3$

$99.7 \% \quad 33.6$

$99.7 \% \quad 75.2$

$99.7 \% \quad 46.7$

$99.7 \% \quad 56.8$

$99.7 \% \quad 47.4$

$97.9 \% \quad 18.2$

$99.7 \% \quad 50.4$

$94.8 \% \quad 15.9$

$99.7 \% \quad 48.2$

$99.7 \% \quad 41.5$

$\begin{array}{lll}99.0 \% & 21.8\end{array}$

$99.7 \% \quad 40.3$

$99.7 \% \quad 40.5$

$99.7 \% \quad 31.1$

$99.0 \% \quad 23.0$

$99.7 \% \quad 43.2$

$99.7 \% \quad 50.7$

$99.0 \% \quad 38.4$

$99.7 \% \quad 42.9$

$99.7 \% \quad 35.6$

$0.01 \% \quad 24.9 \%$ VAVLGASGGIGQPLSLLLK $99.7 \% \quad 80.4$

$99.7 \% \quad 53.7$
120

1541.76

1248.60

1283.66

1027.56

959.55

1158.64

1304.68

1176.59

1307.68

1201.74

1432.75

1139.71

1581.78

1557.84

2071.97

1549.85

2046.04

1498.78

1626.87

1033.57

1236.58

1076.64

1313.69

1114.56

1316.67

1630.84

1091.48

1585.80

1350.74

1310.72

1380.75

993.61

1679.81

1430.68

1199.63

1012.45

2363.10

1400.68

945.44

1236.63

978.50

1793.09

1793.09
1233.72
$151 \quad 158$

$157 \quad 170$

59

$271 \quad 279$

$300 \quad 308$

$309 \quad 318$

19
20

$518 \quad 529$

$57 \quad 69$

$349 \quad 363$

$447 \quad 461$

$17 \quad 32$

$61 \quad 74$

$92 \quad 109$

$152 \quad 165$

$152 \quad 166$

$15 \quad 224$

$270 \quad 278$

$286 \quad 297$

$288 \quad 297$

$318 \quad 330$

$52 \quad 60$

$168 \quad 180$

$250 \quad 261$

$178 \quad 190$

$248 \quad 255$

$272 \quad 288$

$289 \quad 300$

$457 \quad 468$

$60 \quad 80$

8980

$106 \quad 113$

$150 \quad 159$

$160 \quad 168$

$27 \quad 45$ 
Malate dehydrogenase, mitochondrial GN=MDH2 MDHM_HUMAN $35.50 \quad 100.0 \%$ Malate dehydrogenase, mitochondrial GN=MDH2 MDHM_HUMAN $35.50 \quad 100.0 \%$ Malate dehydrogenase, mitochondrial GN=MDH2 MDHM_HUMAN $35.50 \quad 100.0 \%$ Malate dehydrogenase, mitochondrial GN=MDH2 MDHM HUMAN $35.50 \quad 100.0 \%$ Malonyl-CoA-acyl carrier protein transacylase, mitochondrial GN=MCAT FABD_HUMAN $42.96 \quad 100.0 \%$ Malonyl-CoA-acyl carrier protein transacylase, mitochondrial GN=MCAT FABD_HUMAN $42.96 \quad 100.0 \%$ Malonyl-CoA-acyl carrier protein transacylase, mitochondrial GN=MCAT FABD HUMAN $42.96 \quad 100.0 \%$ Manganese-transporting ATPase 13A1 GN=ATP13A1 AT131_HUMAN $132.96 \quad 100.0 \%$ Manganese-transporting ATPase 13A1 GN=ATP13A1 AT131 HUMAN $132.96 \quad 100.0 \%$ Mannose-1-phosphate guanyltransferase alpha GN=GMPPA GMPPA_HUMAN $46.29 \quad 100.0 \%$ Mannose-1-phosphate guanyltransferase alpha GN=GMPPA GMPPA_HUMAN $46.29 \quad 100.0 \%$ Mannose-1-phosphate guanyltransferase alpha GN=GMPPA GMPPA_HUMAN $46.29 \quad 100.0^{\circ}$ Mannose-1-phosphate guanyltransferase alpha GN=GMPPA GMPPA_HUMAN $46.29 \quad 100.0 \%$ Mannose-1-phosphate guanyltransferase alpha GN=GMPPA GMPPA_HUMAN $46.29100 .0 \%$ Mannose-1-phosphate guanyltransferase alpha GN=GMPPA GMPPA_HUMAN $46.29 \quad 100.0 \%$ Mannose-1-phosphate guanyltransferase alpha GN=GMPPA GMPPA_HUMAN $46.29 \quad 100.0 \%$ MAP7 domain-containing protein 1 GN=MAP7D1 MA7D1_HUMAN $92.82 \quad 100.0 \%$ MAP7 domain-containing pr Matrin-3 GN=MATR3

Matrin-3 GN=MATR3

Matrin-3 GN=MATR3

Matrin-3 GN=MATR3

Matrin-3 GN=MATR3

Matrin-3 GN=MATR3

Matrin-3 GN=MATR3

Matrin-3 GN=MATR3

Matrin-3 GN=MATR3

Matrin-3 GN=MATR3

Matrin-3 GN=MATR3

Matrin-3 GN=MATR3

Matrin-3 GN=MATR3

Matrin-3 GN=MATR3

Matrin-3 GN=MATR3

Matrin-3 GN=MATR3

Matrin-3 GN=MATR3

Matrin-3 GN=MATR3

Matrin-3 GN=MATR3

Matrin-3 GN=MATR3

Matrin-3 GN=MATR3

Matrin-3 GN=MATR3

Matrin-3 GN=MATR3

MATR3_HUMAN $94.63 \quad 100.0 \%$ MATR3 HUMAN $94.63 \quad 100.0 \% \quad 23$ MATR3_HUMAN $94.63 \quad 100.0 \% \quad 23$ MATR__HUMAN $94.63 \quad 100.0 \% \quad 23$ MATR3_HUMAN $94.63 \quad 100.0 \% \quad 23$ MATR3_HUMAN $94.63 \quad 100.0 \% \quad 23$ MATR3 HUMAN $94.63 \quad 100.0 \% \quad 23$ MATR3_HUMAN $94.63 \quad 100.0 \% \quad 23$ MATR3_HUMAN $94.63 \quad 100.0 \% \quad 23$ MATR3_HUMAN $94.63 \quad 100.0 \% \quad 23$ MATR3_HUMAN $94.63 \quad 100.0 \% \quad 23$ MATR3 HUMAN $94.63 \quad 100.0 \% \quad 23$ MATR3_HUMAN $94.63 \quad 100.0 \% \quad 23$ MATR3_HUMAN $94.63 \quad 100.0 \% \quad 23$ MATR3 HUMAN $94.63 \quad 100.0 \% \quad 23$ MATR3_HUMAN $94.63 \quad 100.0 \% \quad 23$ MATR3_HUMAN $94.63 \quad 100.0 \% \quad 23$ MATR3 HUMAN $94.63 \quad 100.0 \% \quad 23$ MATR3_HUMAN $94.63 \quad 100.0 \% \quad 23$ MATR3 HUMAN $94.63 \quad 100.0 \% \quad 23$ MATR3_HUMAN $94.63 \quad 100.0 \% \quad 23$ MATR3_HUMAN $94.63 \quad 100.0 \% \quad 23$ MATR3 HUMAN $94.63 \quad 100.0 \% \quad 23$ Mediator of DNA damage checkpoint protein $1 \mathrm{GN}=\mathrm{MDC} 1 \quad$ MDC1_HUMAN $226.66 \quad 100.0 \%$ Mediator of DNA damage checkpoint protein $1 \mathrm{GN}=\mathrm{MDC1}$ MDC1_HUMAN $226.66 \quad 100.0 \%$ Mediator of DNA damage checkpoint protein $1 \mathrm{GN}=\mathrm{MDC} 1$ MDC1_HUMAN $226.66 \quad 100.0 \%$ Mediator of DNA damage checkpoint protein $1 \mathrm{GN}=\mathrm{MDC} 1$ MDC1_HUMAN $226.66 \quad 100.0 \%$ Mediator of DNA damage checkpoint protein $1 \mathrm{GN}=\mathrm{MDC} 1$ MDC1 HUMAN $226.66100 .0 \%$
$11 \quad 0.01 \% \quad 24.9 \%$ ANTFVAELK $0.01 \% \quad 24.9 \%$ VN

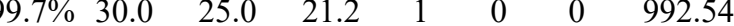

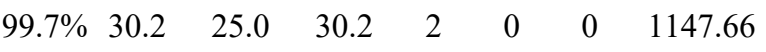

$1 \quad 0.01 \% \quad 24.9 \%$ AGAGSATLSMAYA

$0.01 \% \quad 24.9 \%$ SQETECTYFSTPLLLGK

$0.00 \% \quad 7.7 \%$ FNFACLEAR

$0.00 \% \quad 7.7 \%$ VISGHQEALR

$0.00 \% \quad 7.7 \%$ LLAQQLVSPVK

$0.00 \% \quad 2.1 \%$ SIDGSIVLPLAR

$0.00 \% \quad 2.1 \%$ LGDASIAAPFTSK

$0.01 \% \quad 18.8 \%$ AVILIGGPQK

$0.01 \% \quad 18.8 \%$ SAGSALYASR

$0.01 \% \quad 18.8 \%$ GNVYIHPTAK

$0.01 \% \quad 18.8 \%$ VAPSAVLGPNVSIGK

$0.01 \% \quad 18.8 \%$ GVTVGEGVR

$0.01 \% \quad 18.8 \%$ VEGTPSDPNPNDPR

$0.01 \% \quad 18.8 \%$ LLPAITILGCR

$0.00 \% \quad 2.5 \%$ RKPNAGGSPAPVR

$0.00 \% \quad 2.5 \% \quad$ QSLPASPR

$0.09 \% \quad 29.0 \%$ SFQQSSLSR

$0.09 \% \quad 29.0 \%$ GPLPLSSQHR

$0.09 \% \quad 29.0 \%$ GDADQASNILASFGLSAR

$0.09 \% \quad 29.0 \%$ RTEEGPTLSYGR

$0.09 \% \quad 29.0 \%$ TEEGPTLSYGR

$0.09 \% \quad 29.0 \%$ TEEGPTLSYGRDGR

$99.7 \% \quad 58.5$

58.5

$\begin{array}{llll}99.7 \% & 46.7 & 25.0 & 37.2\end{array}$

$\begin{array}{llll}99.1 \% & 22.7 & 25.0 & 16.4\end{array}$

\begin{tabular}{llll}
$99.7 \%$ & 29.7 & 25.0 & 29.7 \\
\hline
\end{tabular}

$99.7 \% \quad 27.8 \quad 25.0 \quad 27.8$

$99.7 \% \quad 32.2 \quad 25.0 \quad 31.1$

$\begin{array}{llll}99.7 \% & 38.7 & 25.0 & 38.7\end{array}$

$\begin{array}{lllll}99.7 \% & 46.0 & 25.0 & 38.1 & 2\end{array}$

$99.6 \% \quad 24.4 \quad 25.0 \quad 24.4$

$\begin{array}{lllll}99.7 \% & 39.9 & 25.0 & 39.9 & 2\end{array}$

$\begin{array}{llll}99.7 \% & 42.5 & 25.0 & 20.0\end{array}$

$99.6 \% \quad 31.4 \quad 25.0 \quad 15.2$

$99.7 \% \quad 41.5 \quad 25.0 \quad 41.1$

$99.7 \% \quad 27.1 \quad 25.0 \quad 27.1$

$\begin{array}{llll}95.4 \% & 21.0 & 25.0 & 9.0\end{array}$

$99.7 \% \quad 45.7 \quad 25.0 \quad 33.8$

$99.7 \% \quad 35.5 \quad 25.0 \quad 30.4$

$99.7 \% \quad 47.8$

$99.7 \% \quad 49.1$

$99.7 \% \quad 80.8$

$99.7 \% \quad 27.1$

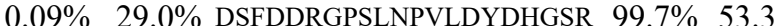

$0.09 \% \quad 29.0 \%$ MGRGPGPLQER

$0.09 \% \quad 29.0 \%$ GPGPLQER

$99.7 \% \quad 36.8$

$99.0 \% \quad 38.4$

$0.09 \% \quad 29.0 \%$ GAPPSSNIEDFHGLLPK

$0.09 \% \quad 29.0 \%$ GNLGAGNGNLQGPR

$0.09 \% \quad 29.0 \%$ VVHIMDFQR

$0.09 \% \quad 29.0 \%$ IKKPEGKPDQK

$0.09 \% \quad 29.0 \%$ FDQKQELGR

$7 \% \quad 47.7$

$99.7 \% \quad 58.9$

$99.7 \% \quad 30.1$

$99.7 \% \quad 29.7$

$99.7 \% \quad 44.1$

$0.09 \% \quad 29.0 \%$ VIHLSNLPHSGYSDSAVLK $99.7 \% \quad 51.1$

$0.09 \% \quad 29.0 \%$ LAEPYGKIK

$0.09 \% \quad 29.0 \%$ VDLSEKYK

$0.09 \% \quad 29.0 \%$ LVLRIPNR

$99.4 \% \quad 25.1$

$99.0 \% \quad 27.1$

$97.9 \% \quad 16.9$

$95.9 \% \quad 27.2$

$0.09 \% \quad 29.0 \%$ IPNRGIDLLK

$0.09 \% \quad 29.0 \%$ LCSLFYTNEEVAK

$0.09 \% \quad 29.0 \%$ NTHCSSLPHYQK

$0.09 \% \quad 29.0 \%$ FLNKLAEER

$0.01 \% \quad 3.5 \%$ EGAQVPTGR

$0.01 \% \quad 3.5 \%$ TPESIVPIAPELQPSTSR

$0.01 \% \quad 3.5 \%$ NQLVTPEPTSR

$0.01 \% \quad 3.5 \% \quad$ TPEPVVPTAPEPHPTTSTDQPVTPK

$0.01 \% \quad 3.5 \%$ SRFTPELQPK

$0.01 \% \quad 18.5 \%$ TGEYPVPLIR
$99.7 \% \quad 42.9$

$\begin{array}{llll}99.7 \% & 51.2 & 25.0 & 51.2\end{array}$

$99.7 \% \quad 28.1 \quad 25.0 \quad 28.1$

$96.0 \% \quad 20.0 \quad 25.0 \quad 14.5$

$\begin{array}{lllll}98.9 \% & 25.1 & 25.0 & 25.1 & 2\end{array}$

$\begin{array}{llll}99.7 \% & 38.1 & 25.0 & 29.1\end{array}$

$\begin{array}{llll}95.6 \% & 19.8 & 25.0 & 12.7\end{array}$

$98.2 \% \quad 22.0 \quad 25.0 \quad 14.0$
$99.7 \% \quad 44.1 \quad 25.0 \quad 27.5$

\begin{tabular}{llll}
$99.7 \%$ & 32.9 & 25.0 & 32.9 \\
\hline
\end{tabular}
1470.70

1973.95

1127.53

1109.61

1195.74

1240.73

1277.67

995.63

982.50

1099.59

1408.82

873.48

1494.68

1226.73

1306.73

855.47

1039.52

1091.60

1792.88

1365.68

1209.57

1537.72

2362.07

1213.61

853.45

1778.91

1324.67

1144.59

1267.74

1120.57

2037.08

1018.59

981.53

980.64

1138.69

1969.08

1573.76

1471.67

1119.62

914.47

1922.02

1241.65

2623.33

1202.65

1144.64
$7 \quad 185$

$92 \quad 203$

$280 \quad 296$

$204 \quad 212$

246
75

$786 \quad 797$

951963

$250 \quad 259$

$285 \quad 294$

$295 \quad 309$

$310 \quad 318$

$380 \quad 390$

441448

12

$103 \quad 120$

$149 \quad 160$

$150 \quad 160$

$150 \quad 163$

$187 \quad 207$

$253 \quad 263$

$256 \quad 263$

$271 \quad 287$

$399 \quad 407$

$477 \quad 487$

$488 \quad 496$

$497 \quad 515$

$516 \quad 524$

$566 \quad 573$

$575 \quad 582$

$781 \quad 798$

$805 \quad 817$

$818 \quad 829$

$833 \quad 841$

672

$67 \quad 1584$

$1585 \quad 1595$

1806

7079 
Methionine--tRNA ligase, cytoplasmic GN=MARS SYMC_HUMAN $101.12 \quad 100.0 \%$ Methionine--tRNA ligase, cytoplasmic GN=MARS SYMC_HUMAN $101.12 \quad 100.0 \%$ Methionine--tRNA ligase, cytoplasmic GN=MARS SYMC HUMAN $101.12 \quad 100.0 \%$ Methionine--tRNA ligase, cytoplasmic GN=MARS SYMC_HUMAN $101.12 \quad 100.0 \%$ Methionine--tRNA ligase, cytoplasmic GN=MARS SYMC_HUMAN $101.12 \quad 100.0 \%$ Methionine--tRNA ligase, mitochondrial GN=MARS2 SYMM HUMAN $66.59 \quad 100.0 \%$ Methionine--tRNA ligase, mitochondrial GN=MARS2 SYMM_HUMAN $66.59 \quad 100.0 \%$ Methionyl-tRNA formyltransferase, mitochondrial GN=MTFMT FMT HUMAN $43.83 \quad 100.0 \%$ Methionyl-tRNA formyltransferase, mitochondrial GN=MTFMT FMT_HUMAN $43.83 \quad 100.0 \%$ Methionyl-tRNA formyltransferase, mitochondrial GN=MTFMT FMT_HUMAN $43.83 \quad 100.0 \%$ Methylosome protein $50 \mathrm{GN}=$ WDR77 Methylosome protein $50 \mathrm{GN}=$ WDR77 Methylosome protein $50 \mathrm{GN}=$ WDR77 Methylosome protein $50 \mathrm{GN}=$ WDR77 Methylosome protein $50 \mathrm{GN}=\mathrm{WDR} 77$ Methylosome protein $50 \mathrm{GN}=$ WDR77 Methylosome protein $50 \mathrm{GN}=$ WDR77 Methylosome protein $50 \mathrm{GN}=$ WDR77 Methylosome protein $50 \mathrm{GN}=\mathrm{WDR} 77$ Methylosome protein $50 \mathrm{GN}=$ WDR77 Methylosome protein $50 \mathrm{GN}=$ WDR77 Methylosome protein $50 \mathrm{GN}=$ WDR77 Methylosome protein $50 \mathrm{GN}=\mathrm{WDR} 77$ MEP50 HUMAN $36.72 \quad 100.0 \%$ MEP50_HUMAN $36.72 \quad 100.0 \%$ MEP50_HUMAN $36.72 \quad 100.0 \%$ MEP50 HUMAN $36.72 \quad 100.0 \%$ MEP50_HUMAN $36.72 \quad 100.0 \%$ MEP50 HUMAN $36.72 \quad 100.0 \%$ MEP50_HUMAN $36.72 \quad 100.0 \%$ MEP50_HUMAN $36.72 \quad 100.0 \%$ MEP50 HUMAN $36.72 \quad 100.0 \%$ MEP50_HUMAN $36.72 \quad 100.0 \%$ MEP50 HUMAN $36.72 \quad 100.0 \%$ MEP50_HUMAN $36.72 \quad 100.0 \%$ MEP50_HUMAN $36.72 \quad 100.0 \%$ M the Methylosome subunit pICln GN=CLNS1A ICLN_HUMAN $26.22 \quad 100.0 \%$ Methylosome subunit pICln GN=CLNS1A ICLN_HUMAN $26.22 \quad 100.0 \%$ Methylosome subunit pICln GN=CLNS1A ICLN_HUMAN $26.22 \quad 100.0 \%$ Methylosome subunit pICln GN=CLNS1A ICLN_HUMAN $26.22 \quad 100.0 \%$ Methylthioribose-1-phosphate isomerase GN=MRI1 MTNA HUMAN $39.15100 .0 \%$ Methylthioribose-1-phosphate isomerase GN=MRI1 MTNA_HUMAN $39.15 \quad 100.0 \%$ Methylthioribose-1-phosphate isomerase GN=MRI1 MTNA_HUMAN $39.15 \quad 100.0 \%$ Methylthioribose-1-phosphate isomerase GN=MRI1 MTNA_HUMAN $39.15 \quad 100.0 \%$ Methylthioribose-1-phosphate isomerase GN=MRI1 MTNA_HUMAN $39.15 \quad 100.0 \%$

$13 \quad 0.01 \% \quad 18.5 \%$ KGDEYIINGQK $0.01 \% \quad 18.5 \%$ AFTGFIVEADTPGIQIGR $0.01 \% \quad 18.5 \%$ GIVFEDVKVPK $0.01 \% \quad 18.5 \%$ TRPVVAAGAVGLAQR $0.01 \% \quad 18.5 \%$ IYQIYEGTSQIQR $0.01 \% \quad 10.6 \%$ ALEVSEDVKVSK $0.01 \% \quad 10.6 \%$ ATEVSKTPEAR $0.01 \% \quad 10.6 \%$ VSHVADTKVNTK $0.01 \% \quad 10.6 \%$ GPIAFWAR

$0.01 \% \quad 10.6 \%$ LQSSQEPEAPPPRDVALLQGR $0.02 \% \quad 11.8 \%$ LFVSDGVPGCLPVLAAAGR $0.02 \% \quad 11.8 \%$ ALTHIDHSLSR $0.02 \% \quad 11.8 \%$ QPQPSPAEGR $0.02 \% \quad 11.8 \%$ ITQDIFQQLLK $0.02 \% \quad 11.8 \%$ ITQDIFQQLLKR $0.02 \% \quad 11.8 \%$ GFVLQDTVEQLR $0.02 \% \quad 11.8 \%$ TLPGSDWTPNAQFITR $0.02 \% \quad 11.8 \%$ ADKNEVAAEVAK

$0.02 \% \quad 11.8 \%$ QLAVAEGKPPEAPK $0.00 \% \quad 4.7 \%$ AQAEDYALVSAVATLPK $0.00 \% \quad 4.7 \%$ LGPETGLLFPR $0.00 \% \quad 9.3 \%$ LLNEALILK

$0.00 \% \quad 9.3 \%$ LGANMLISVLK $0.00 \% \quad 9.3 \%$ LLDLVEVNSSVLADPK $30.12 \% \quad 38.3 \%$ KETPPPLVPPAAR

$19 \quad 123 \quad 0.12 \% \quad 38.3 \%$ ETPPPLVPPAAR

$19 \quad 123 \quad 0.12 \% \quad 38.3 \%$ EWNLPPNAPACMER $\begin{array}{llll}99.7 \% & 52.5 & 25.0 & 52.5\end{array}$ $\begin{array}{llll}99.7 \% & 53.5 & 25.0 & 49.7\end{array}$ $\begin{array}{llll}99.7 \% & 70.8 & 25.0 & 60.8\end{array}$ $\begin{array}{llll}99.7 \% & 52.2 & 25.0 & 45.8\end{array}$ $\begin{array}{llll}99.6 \% & 24.3 & 25.0 & 24.3\end{array}$ $99.0 \% \quad 32.3 \quad 25.0 \quad 27.6$ $\begin{array}{llll}32.3 & 25.0 & 27.6\end{array}$ $\begin{array}{llll}99.7 \% & 33.4 & 25.0 & 33.4\end{array}$ $99.7 \% \quad 43.0 \quad 25.0 \quad 40.3$ $\begin{array}{llll}99.7 \% & 42.9 & 25.0 & 32.8\end{array}$ $99.7 \% \quad 37.9 \quad 25.0 \quad 33.8$ $99.7 \% \quad 55.9 \quad 25.0 \quad 50.8$ $99.7 \% \quad 77.2 \quad 25.0 \quad 75.0$ $\begin{array}{llll}98.3 \% & 17.7 & 25.0 & 16.2\end{array}$ $\begin{array}{llll}99.7 \% & 33.3 & 25.0 & 28.6\end{array}$ $97.5 \% \quad 19.4 \quad 25.0 \quad 14.2$ $99.7 \% \quad 45.9 \quad 25.0 \quad 45.9$ $99.7 \% \quad 46.3 \quad 25.0 \quad 46.3$ $99.7 \% \quad 46.7 \quad 25.0 \quad 44.6$ $99.7 \% \quad 34.1 \quad 25.0 \quad 21.5$ $\begin{array}{llll}99.7 \% & 46.7 & 25.0 & 46.7\end{array}$

$\begin{array}{llllll}19 & 123 & 0.12 \% & 38.3 \% & \text { YRSDGALLLGASSLSGR } \quad 99.7 \% & 53.2\end{array}$

$19 \quad 123 \quad 0.12 \% \quad 38.3 \%$ SDGALLLGASSLSGR

$19 \quad 123 \quad 0.12 \% \quad 38.3 \%$ CWAGSLWLFK

$99.7 \% \quad 56.2$ $99.7 \% \quad 34.2$

$19 \quad 123 \quad 0.12 \% \quad 38.3 \%$ FCKYEHDDIVSTVSVLSSGTQAVSGSK $\quad 99.7 \% \quad 65.2$

$19 \quad 123 \quad 0.12 \% \quad 38.3 \%$ YEHDDIVSTVSVLSSGTQAVSGSK $\quad 99.7 \% \quad 53.0$

$\begin{array}{lllllll}19 & 123 & 0.12 \% & 38.3 \% & \text { VWDLAQQVVLSSYR } & 99.7 \% & 57.8\end{array}$

$19 \quad 123 \quad 0.12 \% \quad 38.3 \%$ AHAAQVTCVAASPHK

$99.7 \% \quad 51.0$

$0.12 \% \quad 38.3 \%$ AHAAQVTCVAASPHKDSVFLSCSEDNR

$0.12 \% \quad 38.3 \%$ SQAHRDFVR

$0.03 \% \quad 31.2 \%$ SFPPPGPAEGLLR

$0.03 \% \quad 31.2 \%$ QQPDTEAVLNGK

$0.03 \% \quad 31.2 \%$ GLGTGTLYIAESR

$99.7 \% 64.0$

$99.7 \% \quad 54.9$

$99.5 \% \quad 29.8$

$99.7 \% \quad 38.8$

$99.7 \% \quad 48.0$

$99.7 \% \quad 59.1$

$0.03 \% \quad 31.2 \%$ DRSDCLGEHLYVMVNAK $99.7 \% \quad 36.4$

$0.03 \% \quad 31.2 \%$ LEGMLSQSVSSQYNMAGVR $\quad 99.7 \% \quad 68.6$

$0.02 \% \quad 32.0 \%$ GSLQILDQLLLPK

$99.7 \% \quad 56.2$

$97.6 \% \quad 23.1$

$99.0 \% \quad 32.9$

$99.7 \% \quad 39.8$

$99.7 \% \quad 46.1$

891.99

1465.86

1598.82

1303.71

1188.62

1298.71

917.50

2288.20

1899.02

1249.66

1066.53

1346.77

1502.87

1404.75

1803.90

1244.65

1434.80

1746.93

1199.68

1026.66

1158.69

1711.95

1372.79

1244.70

1684.76

1722.91

1403.75

1267.63

2901.39

2466.20

1663.88

1547.77

2957.36

1428.61

1115.57

1337.72

1299.65

1337.71

2022.94

2088.97

1437.87

$0.02 \% \quad 32.0 \%$ DLADVAAR

$0.02 \% \quad 32.0 \%$ EAEREGATEEAVR

$0.02 \% \quad 32.0 \%$ EGATEEAVR

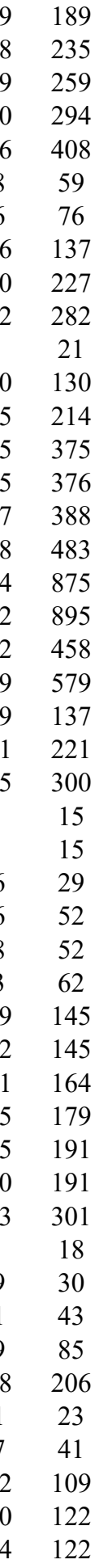



Methylthioribose-1-phosphate isomerase GN=MRI1 MTNA_HUMAN $39.15 \quad 100.0 \%$ $\begin{array}{llll}\text { Methylthioribose-1-phosphate isomerase GN=MRI1 MTNA_HUMAN } & 39.15 & 100.0 \% \\ \text { Methylthioribose-1-phosphate isomerase GN=MRI1 MTNA_HUMAN } & 39.15 & 100.0 \%\end{array}$

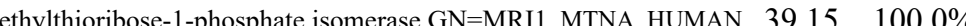
Methylthioribose-1-phosphate isomerase GN=MRI1 MTNA_HUMAN $39.15 \quad 100.0 \%$ MICOS complex subunit MIC27 GN=APOOL MIC27_HUMAN $29.16 \quad 100.0 \%$ MICOS complex subunit MIC27 GN=APOOL MIC27 HUMAN $29.16 \quad 100.0 \%$ MICOS complex subunit MIC27 GN=APOOL MIC27_HUMAN $29.16 \quad 100.0 \%$ MICOS complex subunit MIC27 GN=APOOL MIC27 HUMAN $29.16 \quad 100.0 \%$ MICOS complex subunit MIC27 GN=APOOL MIC27_HUMAN $29.16 \quad 100.0 \%$ MICOS complex subunit MIC27 GN=APOOL MIC27_HUMAN $29.16 \quad 100.0 \%$ MICOS complex subunit MIC27 GN=APOOL MIC27 HUMAN $29.16 \quad 100.0 \%$ MICOS complex subunit MIC27 GN=APOOL MIC27_HUMAN $29.16 \quad 100.0 \%$ MICOS complex subunit MIC60 GN=IMMT MIC60_HUMAN $83.68 \quad 100.0 \%$ MICOS complex subunit MIC60 GN=IMMT MIC60 HUMAN $83.68 \quad 100.0 \%$ MICOS complex subunit MIC60 GN=IMMT MIC60_HUMAN $83.68 \quad 100.0 \%$ MICOS complex subunit MIC60 GN=IMMT MIC60 HUMAN $83.68 \quad 100.0 \%$ MICOS complex subunit MIC60 GN=IMMT MIC60_HUMAN $83.68 \quad 100.0 \%$ Midasin GN=MDN1

Midasin GN=MDN1

Midasin GN=MDN1

Midasin GN=MDN1

Midasin GN=MDN1

Midasin GN=MDN1

Midasin GN=MDN1

Midasin GN=MDN1

Midasin GN=MDN1

Midasin GN=MDN1

Midasin GN=MDN1

Midasin GN=MDN1

Mitochondrial 2-oxoglutarate/malate carrier protein GN=SLC25A11 M2OM HUMAN $34.06 \quad 100.0 \%$

Mitochondrial 2-oxoglutarate/malate carrier protein GN=SLC25A11 M2OM_HUMAN $34.06 \quad 100.0 \%$ Mitochondrial 2-oxoglutarate/malate carrier protein GN=SLC25A11 M2OM_HUMAN $34.06 \quad 100.0 \%$ Mitochondrial 2-oxoglutarate/malate carrier protein GN=SLC25A11 M2OM_HUMAN $34.06 \quad 100.0 \%$ Mitochondrial 2-oxoglutarate/malate carrier protein GN=SLC25A11 M2OM_HUMAN $34.06 \quad 100.0 \%$ Mitochondrial 2-oxoglutarate/malate carrier protein GN=SLC25A11 M2OM HUMAN $34.06 \quad 100.0 \%$ Mitochondrial 2-oxoglutarate/malate carrier protein GN=SLC25A11 M2OM_HUMAN $34.06 \quad 100.0 \%$ Mitochondrial 2-oxoglutarate/malate carrier protein GN=SLC25A11 M2OM HUMAN $34.06 \quad 100.0 \%$ Mitochondrial 2-oxoglutarate/malate carrier protein GN=SLC25A11 M2OM_HUMAN $34.06 \quad 100.0 \%$ Mitochondrial 2-oxoglutarate/malate carrier protein GN=SLC25A11 M2OM_HUMAN $34.06 \quad 100.0^{\circ}$ Mitochondrial 2-oxoglutarate/malate carrier protein GN=SLC25A11 M2OM HUMAN $34.06 \quad 100.0 \%$ Mitochondrial 2-oxoglutarate/malate carrier protein GN=SLC25A11 M2OM_HUMAN $34.06 \quad 100.0 \%$ Mitochondrial 2-oxoglutarate/malate carrier protein GN=SLC25A11 M2OM_HUMAN $34.06 \quad 100.0 \%$ Mitochondrial 2-oxoglutarate/malate carrier protein GN=SLC25A11 M2OM HUMAN $34.06 \quad 100.0 \%$ Mitochondrial carnitine/acylcarnitine carrier protein GN=SLC25A20 MCAT_HUMAN $32.95 \quad 100.0 \%$ Mitochondrial carnitine/acylcarnitine carrier protein GN=SLC25A20 MCAT HUMAN 32.95 Mitochondrial carnitine/acylcarnitine carrier protein GN=SLC25A20 MCAT_HUMAN 32.95

9

9
9
9

8

8

5
5
5

5
5
5

2

$14 \quad 20$

1420

$\begin{array}{ll}14 & 20 \\ 14 & 20 \\ 14 & 20\end{array}$

$\begin{array}{ll}4 & 20 \\ 4 & 20 \\ 4 & 20\end{array}$

20

$\begin{array}{ll}14 & 20 \\ 14 & 20 \\ 14 & 20\end{array}$

420

1420

420

$21 \quad 0.02 \% \quad 32.0 \%$ GVSAVVVGADR

$0.02 \% \quad 32.0 \%$ VGTYQLAIVAK

$0.02 \% \quad 32.0 \%$ HHGIPFYVAAPSSSCDLR $\quad 98.9 \% \quad 24.3$

$0.02 \% \quad 32.0 \%$ EIIIEERPGQELTDVNGVR $\quad 99.7 \% \quad 43.4$

$0.02 \% \quad 32.0 \%$ TALTTTISSR

$99.7 \% \quad 59.7$

$0.01 \% \quad 38.4 \%$ QLVKPEQLPIYTAPPLQSK $99.4 \% \quad 21.8$

$0.01 \% \quad 38.4 \%$ YVEEQPGHLQMGFASIR $99.7 \% 33.4$

$0.01 \% \quad 38.4 \%$ TATGCYIGWCK

$\begin{array}{lll}99.7 \% & 52.2\end{array}$

$0.01 \% \quad 38.4 \%$ MGVITVSGLAGLVSAR

$0.01 \% \quad 38.4 \%$ KVYATSQQIFGAVK

$0.01 \% \quad 38.4 \%$ VYATSQQIFGAVK

$0.01 \% \quad 38.4 \%$ LGSSSEIEVPAK

$0.01 \% \quad 38.4 \%$ HSVPLPTELSSEAK

$0.01 \% \quad 7.0 \% \quad$ YSTSGSSGLTTGK

$0.01 \% \quad 7.0 \%$ ERPPEEVAAR

$0.01 \% \quad 7.0 \%$ TVEGALKER

$0.01 \% \quad 7.0 \%$ GVYSEETLRAR

$\begin{array}{lll}0.01 \% & 7.0 \% & \text { FVNQLKGESR }\end{array}$

$0.03 \% \quad 2.6 \%$ LFLESSDANPVR

$0.03 \% \quad 2.6 \%$ FAASNPCGNIQR

$99.7 \% 54.0$

$99.7 \% \quad 52.5$

$99.7 \% \quad 59.2$

$99.1 \% \quad 19.9$

$99.7 \% \quad 43.5$

$99.7 \% \quad 31.6$

$99.7 \% \quad 53.9$

$99.0 \% \quad 22.4$

$99.7 \% \quad 35.6$

$99.7 \% \quad 54.8$

$99.7 \% \quad 51.3$

$\begin{array}{lllll}0.03 \% & 2.6 \% & \text { VVSAGTYPVLIQGETSVGK } & 99.6 \% & 23.1\end{array}$

$0.03 \% \quad 2.6 \%$ GMIDGSTPTITPNPNFR $\quad 99.7 \% \quad 29.8$

$0.03 \% \quad 2.6 \%$ SQPFTLQDLEK

$0.03 \% \quad 2.6 \%$ VFTEANLVSVGSK

$0.03 \% \quad 2.6 \%$ GLSLGFLEK

$0.03 \% \quad 2.6 \%$ TDSQLQGQVLFR

$0.03 \% \quad 2.6 \%$ APAVQDLLTR

$0.03 \% \quad 2.6 \%$ SFPLSSPISK

$\begin{array}{lll}0.03 \% & 2.6 \% & \text { FLNGLEILLAK }\end{array}$

$0.03 \% \quad 2.6 \%$ LNAALATPAK

$0.05 \% \quad 47.8 \%$ MQLSGEGAK

$0.05 \% \quad 47.8 \%$ TSFHALTSILK

$0.05 \% \quad 47.8 \%$ GIYTGLSAGLLR

$0.05 \% \quad 47.8 \%$ QATYTTTR

$0.05 \% \quad 47.8 \%$ LGIYTVLFER

$0.05 \% \quad 47.8 \%$ LTGADGTPPGFLLK

$0.05 \% \quad 47.8 \%$ AVIGMTAGATGAFVGTPAEVALIR

$0.05 \% \quad 47.8 \%$ NVFNALIR

$0.05 \% \quad 47.8 \%$ ITREEGVLTLWR

$0.05 \% \quad 47.8 \%$ EEGVLTLWR

$0.05 \% \quad 47.8 \%$ AVVVNAAQLASYSQSK

$0.05 \% \quad 47.8 \%$ MIDGKPEYK

$0.05 \% \quad 47.8 \%$ YEGFFSLWK

$0.05 \% \quad 47.8 \%$ GFTPYYAR

$0.01 \% \quad 18.3 \%$ EGITGLYR

$0.01 \% \quad 18.3 \%$ YTGTLDCAK

$0.01 \% \quad 18.3 \%$ KLYQEFGIR

\section{$97.0 \% \quad 20.6$}

$99.7 \% \quad 36.1$

$96.8 \% \quad 16.4$

$99.7 \% \quad 54.6$

$99.7 \% \quad 43.8$

$99.1 \% \quad 22.4$

$98.3 \% \quad 16.7$

$99.7 \% \quad 48.6$

$99.3 \% \quad 41.0$

$99.7 \% \quad 61.8$

$99.7 \% \quad 56.2$

$99.0 \% \quad 24.5$

$99.7 \% \quad 51.0$

$99.7 \% \quad 53.2$

$99.7 \% \quad 41.3$

$99.0 \% \quad 32.7$

$99.7 \% \quad 33.1$

$99.7 \% \quad 36.8$

$99.7 \% \quad 54.6$

$\begin{array}{ll}99.7 \% & 26.8 \\ 99.7 \% & 40.8\end{array}$

$99.0 \% \quad 33.3$

$\begin{array}{llll}99.0 \% & 23.0 & 25.0 & 17.2 \\ 99.7 \% & 37.4 & 25.0 & 33.9\end{array}$

$\begin{array}{llll}99.7 \% & 37.4 & 25.0 & 33.9\end{array}$

$\begin{array}{llll}99.7 \% & 53.5 & 25.0 & 38.5\end{array}$

1162.68

2013.96

2167.14

1050.58

2150.22

1961.95

1316.58

1546.86

1539.85

1411.76

1216.64

1494.78

1245.60

1153.60

1002.56

1280.66

1177.63

1347.69

1334.63

1905.03

1817.89

1305.67

1350.73

963.55

1391.73

1083.62

1062.58
1230.75

969.57
936.45

936.45
1217.69

1220.70

941.47

1210.68

1386.76

2273.23

946.55

1472.82

1102.59

1635.87

1096.53

1176.57

974.47

908.48

1028.47

1153.64 

Mitochondrial folate transporter/carrier GN=SLC25A32 MFTC_HUMAN $35.41 \quad 100.0 \%$ Mitochondrial folate transporter/carrier GN=SLC25A32 MFTC HUMAN 35.41 $100.0 \%$ Mitochondrial glutamate carrier $1 \mathrm{GN}=\mathrm{SLC} 25 \mathrm{~A} 22 \mathrm{GHC1}$ _HUMAN $34.47 \quad 100.0 \%$ Mitochondrial glutamate carrier $1 \mathrm{GN}=\mathrm{SLC} 25 \mathrm{~A} 22 \mathrm{GHC1} 1 \mathrm{HUMAN} 34.47 \quad 100.0 \%$ Mitochondrial glutamate carrier $1 \mathrm{GN}=\mathrm{SLC} 25 \mathrm{~A} 22 \mathrm{GHCl}$ HUMAN $34.47 \quad 100.0 \%$ Mitochondrial glutamate carrier $1 \mathrm{GN}=\mathrm{SLC} 25 \mathrm{~A} 22 \mathrm{GHCl}$ _HUMAN $34.47 \quad 100.0 \%$ Mitochondrial glutamate carrier $1 \mathrm{GN}=\mathrm{SLC} 25 \mathrm{~A} 22 \mathrm{GHC} 1 \mathrm{HUMAN} 34.47 \quad 100.0 \%$ Mitochondrial glutamate carrier $1 \mathrm{GN}=\mathrm{SLC} 25 \mathrm{~A} 22 \mathrm{GHC1}$ _HUMAN $34.47 \quad 100.0 \%$ Mitochondrial glutamate carrier $1 \mathrm{GN}=\mathrm{SLC} 25 \mathrm{~A} 22 \mathrm{GHC} 1$ _HUMAN $34.47 \quad 100.0 \%$ Mitochondrial glutamate carrier $1 \mathrm{GN}=\mathrm{SLC} 25 \mathrm{~A} 22 \mathrm{GHC} 1$ HUMAN $34.47 \quad 100.0 \%$ Mitochondrial glutamate carrier $1 \mathrm{GN}=\mathrm{SLC} 25 \mathrm{~A} 22 \mathrm{GHC1}{ }_{-} \mathrm{HUMAN} 34.47 \quad 100.0 \%$ Mitochondrial import inner membrane translocase subunit TIM44 GN=TIMM44 TIM44_HUMAN 51.36

$0.01 \% \quad 18.3 \%$ VSELSAPR

$0.01 \% \quad 18.3 \%$ ELIRDEGVTSLYK

$0.01 \% \quad 18.3 \%$ GFNAVMIR

$0.03 \% \quad 49.1 \%$ VHLQTQQEVK

$0.03 \% \quad 49.1 \%$ TDGILALYSGLSASLCR

$0.03 \% \quad 49.1 \%$ QMTYSLTR

$0.03 \% \quad 49.1 \%$ FAIYETVR

$0.03 \% \quad 49.1 \%$ FAIYETVRDR

$0.03 \% \quad 49.1 \%$ GSQGPLPFHEK

$0.03 \% \quad 49.1 \%$ VLLGSVSGLAGGFVGTPADLVNVR

$0.03 \% \quad 49.1 \%$ NYAHALDGLYR

$0.03 \% \quad 49.1 \%$ LFSGATMASSR

$0.03 \% \quad 49.1 \%$ GALVTVGQLSCYDQAK

$0.03 \% \quad 49.1 \%$ GEYQGVFHCAVETAK

$0.03 \% \quad 49.1 \%$ LGPLAFYK

$0.00 \% \quad 6.4 \% \quad$ FAVSDGLELRPK

$0.00 \% \quad 6.4 \%$ GIAPNLIR

$0.02 \% \quad 35.3 \%$ VYTSMSDCLIK

$0.02 \% \quad 35.3 \%$ SEGYFGMYR

$0.02 \% 35.3 \%$ GAAVNLTLVTPEK

$0.02 \% \quad 35.3 \%$ LAANDFFR

$0.02 \% \quad 35.3 \%$ IQLQDAGR

$0.02 \% \quad 35.3 \%$ ILAAQgQLSAQGGAQPSVEAPAAPRPTATQLTR

$0.02 \% \quad 35.3 \%$ GLGATLLR

$0.02 \% \quad 35.3 \%$ GVNEDTYSGILDCAR

$0.02 \% \quad 35.3 \%$ HEGPSAFLK

$0.01 \% \quad 16.4 \%$ LGELTGTVK

$0.01 \% \quad 16.4 \%$ ALSQGVESVKK

$0.01 \% \quad 16.4 \%$ EIDDSVLGQTGPYR

$0.01 \% \quad 16.4 \%$ VFEPNEEALGVVLHK

$0.01 \% \quad 16.4 \%$ TEMSEVLTEILR

$0.01 \% \quad 16.4 \%$ LLDISASSTEQIL

$0.03 \% 38.0 \%$ RAPDQAAEIGSR

$0.03 \% \quad 38.0 \%$ AQGPQQQPGSEGPSYAKK $96.2 \% \quad 14.9$

$0.03 \% \quad 38.0 \%$ IPDEFDNDPILVQQLR

$0.03 \% \quad 38.0 \%$ IPDEFDNDPILVQQLRR

$0.03 \% 38.0 \%$ YMDGHHVK

$0.03 \% \quad 38.0 \%$ DISCLNRDPAR

$0.03 \% \quad 38.0 \%$ VVVVDCKK

$0.03 \% \quad 38.0 \%$ VLLDLSAFLK

$0.03 \% \quad 38.0 \%$ TIALNGVEDVR

$99.7 \% \quad 48.1$

$99.0 \% \quad 28.7$

$99.7 \% \quad 32.2$

$99.0 \% \quad 51.4$

$99.7 \% \quad 49.4$

$99.7 \% \quad 70.9$

$0.03 \% \quad 38.0 \%$ TVLEHYAL

$0.03 \% \quad 38.0 \%$ SNKQNLFLGSLTSR

$0.03 \% \quad 38.0 \%$ QNLFLGSLTSR

$0.02 \% \quad 17.2 \%$ ELFPIQMEGVK
$99.0 \% 53.6$

$99.7 \% \quad 58.8$

$99.7 \% \quad 40.2$
$99.7 \% \quad 67.4$
858.47

1522.81

907.48

1209.66

1796.92

999.49

998.53

1269.66

1196.61

2298.28

1292.64

1127.55

1709.85

1695.78

908.52

1331.73

853.53

1316.62

1109.47

1312.75

953.48

900.49

3256.74

800.50

1669.75

985.51

917.53

1145.65

1549.75

1680.90

1436.73

1389.75

1270.65

1729.81

1857.91

1911.98

2068.08

986.45

1316.64

946.54

1118.68

1186.64

1931.98

1059.51

1564.84

1235.67

1290.68

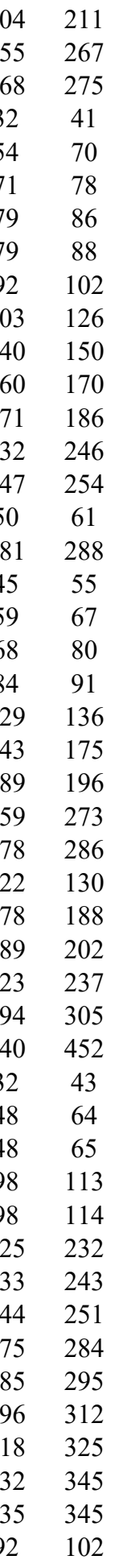

Page 104 of Table S-14 

Mitochondrial import receptor subunit TOM40 homolog GN=TOMM40 TOM40_HUMAN $37.89 \quad 100.0 \%$ Mitochondrial import receptor subunit TOM40 homolog GN=TOMM40 TOM40_HUMAN 37.89 Mitochondrial import receptor subunit TOM40 homolog GN=TOMM40 TOM40_HUMAN 37.89 Mitochondrial inner membrane protein OXA1L GN=OXA1L OXA1L_HUMAN 48.55 Mitochondrial inner membrane protein OXA1L GN=OXA1L OXA1L_HUMAN 48.55 Mitochondrial inner membrane protein OXA1L GN=OXA1L OXA1L_HUMAN 48.55 Mitochondrial ribonuclease P protein 1 GN=TRMT10C MRRP1_HUMAN 47.3 Mitochondrial ribonuclease P protein $1 \mathrm{GN}=$ TRMT10C MRRP1 HUMAN 47.3. Mitochondrial ribonuclease P protein $1 \mathrm{GN}=\mathrm{TRMT10C}$ MRRP1_HUMAN 47.35 Mitochondrial ribonuclease P protein $1 \mathrm{GN}=\mathrm{TRMT10C}$ MRRP1_HUMAN 47.3 Mitochondrial ribonuclease P protein $1 \mathrm{GN}=$ TRMT10C MRRP1 HUMAN 47.3 Mitochondrial ribonuclease P protein $1 \mathrm{GN}=\mathrm{TRMT10C}$ MRRP1_HUMAN 47.35 Mitochondrial ribonuclease P protein $1 \mathrm{GN}=$ TRMT10C MRRP1_HUMAN 47.3 Mitochondrial ribonuclease P protein $1 \mathrm{GN}=$ TRMT10C MRRP1_HUMAN 47.3 Mitochondrial ribonuclease P protein 1 GN=TRMT10C MRRP1_HUMAN 47.3 Mitochondrial ribonuclease P protein $1 \mathrm{GN}=$ TRMT10C MRRP1 HUMAN 47.3 Mitochondrial ribonuclease P protein $1 \mathrm{GN}=$ TRMT10C MRRP1_HUMAN 47.35 Mitochondrial ribonuclease P protein $1 \mathrm{GN}=$ TRMT10C MRRP1_HUMAN 47.3 Mitochondrial ribonuclease P protein $1 \mathrm{GN}=$ TRMT10C MRRP1 HUMAN 47.3 Mitochondrial ribonuclease P protein $1 \mathrm{GN}=\mathrm{TRMT10C}$ MRRP1_HUMAN 47.3 Mitochondrial ribonuclease P protein $1 \mathrm{GN}=$ TRMT10C MRRP1_HUMAN 47.3 Mitochondrial ribonuclease P protein $1 \mathrm{GN}=$ TRMT10C MRRP1_HUMAN 47.35 Mitochondrial ribonuclease P protein $1 \mathrm{GN}=$ TRMT10C MRRP1_HUMAN 47.3 Mitochondrial ribonuclease P protein $1 \mathrm{GN}=$ TRMT10C MRRP1_HUMAN 47.3 Mitochondrial ribonuclease P protein 1 GN=TRMT10C MRRP1_HUMAN 47.35 Mitochondrial ribonuclease $P$ protein $3 \mathrm{GN}=\mathrm{KIAA} 0391$ MRRP3_HUMAN 67.32 Mitochondrial ribonuclease $P$ protein $3 \mathrm{GN}=\mathrm{KIAA} 0391$ MRRP3 HUMAN 67.32 Mitochondrial ribosome-associated GTPase $1 \mathrm{GN}=\mathrm{MTG1}$ MTG1_HUMAN 37.2 Mitochondrial ribosome-associated GTPase $1 \mathrm{GN}=\mathrm{MTG} 1$ MTG1 HUMAN 37.2 Mitochondrial ribosome-associated GTPase 1 GN=MTG1 MTG1_HUMAN 37.24 Mitochondrial thiamine pyrophosphate carrier GN=SLC25A19 TPC_HUMAN 35.5 Mitochondrial thiamine pyrophosphate carrier GN=SLC25A19 TPC HUMAN 35.5 Mitochondrial-processing peptidase subunit beta GN=PMPCB MPPB_HUMAN 54.37 Mitochondrial-processing peptidase subunit beta GN=PMPCB MPPB_HUMAN 54.37 Mitochondrial-processing peptidase subunit beta GN=PMPCB MPPB HUMAN 54.37 Mitogen-activated protein kinase $1 \mathrm{GN}=$ MAPK1 MK01_HUMAN 41.3 Mitogen-activated protein kinase $1 \mathrm{GN}=\mathrm{MAPK} 1$ MK01 HUMAN 41.3 Mitotic checkpoint protein BUB3 GN=BUB3 BUB3_HUMAN 37.15 Mitotic checkpoint protein BUB3 GN=BUB3 BUB3_HUMAN 37.1 Mitotic checkpoint protein BUB3 GN=BUB3 BUB3 HUMAN 37.1 MKI67 FHA domain-interacting nucleolar phosphoprotein GN=NIFK MK67I_HUMAN 34.22 MKI67 FHA domain-interacting nucleolar phosphoprotein GN=NIFK MK67I HUMAN 34.2 MKI67 FHA domain-interacting nucleolar phosphoprotein GN=NIFK MK67I HUMAN 34.2 MKI67 FHA domain-interacting nucleolar phosphoprotein GN=NIFK MK67I_HUMAN 34.2 MKI67 FHA domain-interacting nucleolar phosphoprotein GN=NIFK MK67I HUMAN 34.2 MKI67 FHA domain-interacting nucleolar phosphoprotein GN=NIFK MK67I_HUMAN 34.22
$100.0 \%$

$100.0 \%$

$100.0 \%$

$100.0 \%$

$100.0 \%$

$100.0 \%$

$100.0 \%$

$100.0 \%$

$100.0 \%$

$100.0 \%$ $100.0 \%$ $100.0 \%$ $100.0 \%$ $100.0 \%$ $100.0 \% \quad 19$ $100.0 \%$ $100.0 \% \quad 19$ $100.0 \%$ $100.0 \% \quad 19$ $100.0 \% \quad 19$ $100.0 \%$ $100.0 \%$ $100.0 \% \quad 19$ $100.0 \% \quad 19$ $100.0 \%$ $100.0 \%$ $100.0 \%$ $100.0 \%$ $100.0 \%$ $99.9 \%$ $99.9 \%$ $100.0 \%$ $100.0 \%$ $100.0 \%$ $100.0 \%$ $100.0 \%$ $100.0 \%$ $100.0 \%$ $100.0 \%$ $100.0 \%$ $100.0 \%$ $100.0 \%$ $100.0 \%$ $100.0 \%$ $100.0 \%$
$6 \quad 0.02 \% \quad 17.2 \%$ MAIQTQQSK

$0.02 \% \quad 17.2 \%$ RPGEEC

$0.02 \% \quad 17.2 \%$ MQDTSVSFGYQLDLPK

$7 \% \quad 49.7$

$99.7 \% 55.5$

$99.7 \% \quad 54.5$

$99.7 \% 26.7$

$99.7 \% \quad 43.5$

$99.7 \% \quad 52.0$

$99.0 \% \quad 40.5$

$0.01 \% \quad 6.9 \% \quad$ ASSEMALYQK

$0.01 \% \quad 6.9 \%$ NQLELAAR

$99.7 \% 58.2$

$0.04 \% \quad 44.9 \%$ SSVQEECVSTISSSK

$99.7 \% \quad 60.0$

$0.04 \% \quad 44.9 \%$ EVPEHITEEELK

$0.04 \% \quad 44.9 \%$ TLMECVSNTAK

$0.04 \% \quad 44.9 \%$ LLETTEEDKQK

$0.04 \% \quad 44.9 \%$ NVDPFHIYFCNLK

$0.04 \% \quad 44.9 \%$ LLLTSTEK

$0.04 \% \quad 44.9 \%$ SHVDLFPK

$99.7 \% 56.5$

$99.7 \% \quad 30.6$

$98.9 \% \quad 24.9$

$98.9 \% \quad 20.2$

$0.04 \% \quad 44.9 \%$ DSIIYLTADSPNVMTTFR $99.7 \% \quad 54.7$

$0.04 \% \quad 44.9 \%$ DSIIYLTADSPNVMTTFRHDK $99.6 \% 24.2$

$0.04 \% \quad 44.9 \%$ HDKVYVIGSFVDK

$\begin{array}{lll}98.5 \% & 20.4\end{array}$

$\begin{array}{lll}99.7 \% & 44.3\end{array}$

$0.04 \% \quad 44.9 \%$ VYVIGSFVDKSMQPGTSLAK $99.7 \% \quad 46.8$

$0.04 \% \quad 44.9 \%$ SMQPGTSLAK

$0.04 \% \quad 44.9 \%$ RLNLATECLPLDK

$0.04 \% \quad 44.9 \%$ LNLATECLPLDK

$0.04 \% \quad 44.9 \%$ NLTLDQMIR

$0.04 \% \quad 44.9 \%$ NNGNWQEALQFVPK

$0.04 \% \quad 44.9 \%$ HTGFLEISQHSQEFINR

$0.00 \% \quad 4.0 \% \quad$ LLDILSYLR

$0.00 \% \quad 4.0 \%$ ESQLLLNVVSQLAK

$0.00 \% \quad 12.3 \%$ LVDCIIEVHDAR

$0.00 \% \quad 12.3 \%$ MDLADLTEQQK

$99.7 \% \quad 46.0$

$99.6 \% \quad 26.4$

$99.7 \% \quad 60.7$

$99.7 \% \quad 46.9$

$99.7 \% \quad 32.6$

$99.7 \% \quad 54.3$

$\begin{array}{lll}99.7 \% & 30.9\end{array}$

$99.7 \% \quad 34.1$

$98.4 \% \quad 18.1$

$99.7 \% \quad 45.2$

$0.00 \% \quad 12.3 \%$ FGYVQHYGLGSACDNVER

$0.00 \% \quad 6.3 \% \quad$ ALISPFDVIK

$0.00 \% \quad 6.3 \%$ LQVGGFEHAR

$0.00 \% \quad 8.0 \% \quad$ STQAATQVVLNVPETR

$0.00 \% \quad 8.0 \%$ LCTSVTESEVAR

$0.00 \% \quad 8.0 \%$ SPAIAAVGPIK

$0.00 \% \quad 5.0 \%$ YIHSANVLHR

$0.00 \% \quad 5.0 \%$ ICDFGLAR

$0.00 \% \quad 11.6 \%$ LNQPPEDGISSVK

$0.00 \% \quad 11.6 \%$ QGYVLSSIEGR

$0.00 \% \quad 11.6 \%$ VAVEYLDPSPEVQK

$0.01 \% \quad 23.9 \%$ GYAFVEFESEDVAK

$0.01 \% \quad 23.9 \%$ IVAETMNNYLFGER

$0.01 \% \quad 23.9 \%$ KGIDYDFPSLILQK

$0.01 \% \quad 23.9 \%$ GIDYDFPSLILQK

$0.01 \% \quad 23.9 \%$ VSGTLDTPEK

$0.01 \% \quad 23.9 \%$ TVDSQGPTPVCTPTFLER $99.7 \% \quad 60.8$
$94.7 \% \quad 15.2$

$96.0 \% \quad 22.9$

$99.7 \% \quad 51.5$

$99.7 \% \quad 65.5$

$99.7 \% \quad 29.7$

$96.3 \% 18.4$

$99.0 \% 32.6$

$99.7 \% \quad 33.7$

$99.7 \% \quad 43.2$

$99.7 \% \quad 42.0$

$\begin{array}{lll}99.7 \% & 59.4\end{array}$

$99.7 \% \quad 62.8$

$99.7 \% \quad 49.3$

$\begin{array}{lll}99.7 \% & 57.1\end{array}$

$99.7 \% \quad 57.1$

$99.7 \% 60.8$
1034.53

1447.72

1844.87

1341.66

1416.80

1127.54

914.51

1627.75

2596.20

1452.72

1269.58

1333.68

1666.80

904.54

942.50

2044.01

2440.18

1506.80

1126.61

2143.11

1019.52

1542.83

1386.73

1103.59

1644.81

2043.00

1105.66

1541.89

1439.73

1291.62

2071.93

1102.65

1113.58

1713.91

1351.65

1023.62

1209.65

951.47

1383.71

1208.63

1573.81

1590.73

1672.80

1636.89

1508.80

1046.54

2004.97 
MMS19 nucleotide excision repair protein homolog GN=MMS19 MMS19_HUMAN $113.29 \quad 100.0 \%$ HMS19_HUMAN $113.29 \quad 100.0 \%$ MOB kinase activator $2 \mathrm{GN}=\mathrm{MOB} 2$ MOB kinase activator $2 \mathrm{GN}=\mathrm{MOB} 2$ MOB kinase activator $2 \mathrm{GN}=\mathrm{MOB} 2$ MOB2_HUMAN $26.93 \quad 100.0 \%$ MOB2 HUMAN $26.93 \quad 100.0 \%$ MOB2_HUMAN $26.93 \quad 100.0 \%$ Monocarboxylate transporter $1 \mathrm{GN}=$ SLC16A1 MOT1_HUMAN $53.95 \quad 100.0 \%$ Monocarboxylate transporter 1 GN=SLC16A1 MOT1_HUMAN $53.95 \quad 100.0 \%$ Monocarboxylate transporter $1 \mathrm{GN}=\mathrm{SLC16A1}$ MOT1_HUMAN $53.95 \quad 100.0 \%$ Monocarboxylate transporter $1 \mathrm{GN}=$ SLC16A1 MOT1 HUMAN $53.95100 .0 \%$ Monofunctional C1-tetrahydrofolate synthase, mitochondrial GN=MTHFDIL C1TM_HUMAN $105.79 \quad 100.0 \%$ Monofunctional Cl-tetrahydrofolate synthase, mitochondrial GN=MTHFDIL C1TM_HUMAN $105.79 \quad 100.0 \%$ GTHFIL C1TM_HUMAN $105.79 \quad 100.0 \%$ Monofunctional C1-tetrahydrofolate synthase, mitochondrial GN=MTHFDIL C1TM_HUMAN $105.79 \quad 100.0 \%$ Monofunctional C1-tetrahydrofolate synthase, mitochondrial GN=MTHFDIL C1TM_HUMAN $105.79 \quad 100.0 \%$ Motile sperm domain-containing protein $2 \mathrm{GN}=$ MOSPD2 MSPD2_HUMAN $59.75 \quad 100.0 \%$ Motile sperm domain-containing protein 2 GN=MOSPD2 MSPD2_HUMAN $59.75 \quad 100.0 \%$ Motile sperm domain-containing protein $2 \mathrm{GN}=\mathrm{MOSPD} 2 \mathrm{MSPD} 2 \mathrm{HUMAN} 59.75100 .0 \%$ Motile sperm domain-containing protein 2 GN=MOSPD2 MSPD2_HUMAN $59.75 \quad 100.0 \%$ mRNA export factor $\mathrm{GN}=\mathrm{RAE} 1$ mRNA export factor $\mathrm{GN}=\mathrm{RAE} 1$ mRNA export factor $\mathrm{GN}=\mathrm{RAE} 1$ mRNA export factor $\mathrm{GN}=\mathrm{RAE} 1$ mRNA export factor $\mathrm{GN}=\mathrm{RAE} 1$ mRNA export factor $\mathrm{GN}=\mathrm{RAE} 1$ RAE1L_HUMAN $40.97 \quad 100.0 \%$ RAEIL HUMAN $40.97 \quad 100.0 \%$ RAEIL_HUMAN $40.97 \quad 100.0 \%$ RAEIL HUMAN $40.97 \quad 100.0 \%$ RAE1L_HUMAN $40.97 \quad 100.0 \%$ RAEIL_HUMAN $40.97 \quad 100.0 \%$

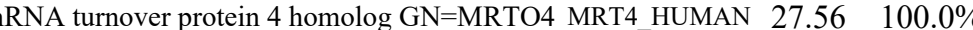
mRNA turnover protein 4 homolog GN=MRTO4 MRT4_HUMAN $27.56 \quad 100.0 \%$ mRNA turnover protein 4 homolog GN=MRTO4 MRT4_HUMAN $27.56 \quad 100.0 \%$ mRNA turnover protein 4 homolog GN=MRTO4 MRT4_HUMAN $27.56 \quad 100.0 \%$ mRNA turnover protein 4 homolog GN=MRTO4 MRT4_HUMAN $27.56 \quad 100.0 \%$ mRNA turnover protein 4 homolog GN=MRTO4 MRT4 HUMAN $27.56 \quad 100.0 \%$ mRNA turnover protein 4 homolog GN=MRTO4 MRT4_HUMAN $27.56 \quad 100.0 \%$ mRNA turnover protein 4 homolog GN=MRTO4 MRT4_HUMAN $27.56 \quad 100.0 \%$ mRNA turnover protein 4 homolog GN=MRTO4 MRT4 HUMAN $27.56 \quad 100.0 \%$ mRNA turnover protein 4 homolog GN=MRTO4 MRT4_HUMAN $27.56 \quad 100.0 \%$ mRNA turnover protein 4 homolog GN=MRTO4 MRT4_HUMAN $27.56 \quad 100.0 \%$ Multifunctional protein ADE2 GN=PAICS PUR6_HUMAN $47.08 \quad 100.0 \%$ Multifunctional protein ADE2 GN=PAICS PUR6_HUMAN 47.08 $100.0 \%$ Multifunctional protein ADE2 GN=PAICS PUR6 HUMAN 47.08 100.0\% Multifunctional protein ADE2 GN=PAICS PUR6_HUMAN $47.08 \quad 100.0 \%$ Multifunctional protein ADE2 GN=PAICS PUR6_HUMAN $47.08 \quad 100.0 \%$ Multifunctional protein ADE2 GN=PAICS PUR6_HUMAN $47.08 \quad 100.0 \%$ Multiple myeloma tumor-associated protein 2 GN=MMTAG2 MMTA2_HUMAN $29.41 \quad 100.0 \%$ Multiple myeloma tumor-associated protein 2 GN=MMTAG2 MMTA2_HUMAN $29.41 \quad 100.0 \%$ Myb-binding protein 1A GN=MYBBP1A MBB1A_HUMAN $148.86 \quad 100.0 \%$ Myb-binding protein 1A GN=MYBBP1A MBB1A_HUMAN $148.86 \quad 100.0 \%$ Myb-binding protein 1A GN=MYBBP1A MBB1A_HUMAN $148.86100 .0 \%$ Myb-binding protein 1A GN=MYBBP1A MBB1A_HUMAN $148.86 \quad 100.0 \%$
$0.00 \% \quad 1.8 \%$ AVLASTPR

$0.00 \% \quad 1.8 \%$ LLQAAAGASAR

$0.01 \% \quad 13.1 \%$ AYLEPEHTK

$0.01 \% \quad 13.1 \%$ LVTDEDVFPTK

$0.01 \% \quad 13.1 \%$ EFPSSFESLVR

$6 \quad 0.02 \% \quad 7.2 \% \quad$ KDLHDANTDLIGR

$0.02 \% \quad 7.2 \%$ DLHDANTDLIGR

$0.02 \% \quad 7.2 \%$ DLHDANTDLIGRHPK

$0.02 \% \quad 7.2 \%$ ESKEEETSIDVAGKPNEVTK

$0.01 \% \quad 6.3 \% \quad$ LQPLSPVPSDIEISR

$0.01 \% \quad 6.3 \% \quad$ VLDTNDRFLR

$0.01 \% \quad 6.3 \%$ ASGLVPNVVVLVATVR

$0.01 \% \quad 6.3 \%$ TIAQAVYGAK

$0.01 \% \quad 6.3 \%$ DIELSPEAQAK

$0.01 \% \quad 8.5 \%$ EISVNDLNESSIPR

$0.01 \% \quad 8.5 \%$ TWLGPEAVSLLK

$0.01 \% \quad 8.5 \%$ TLIVLTNVTK

$0.01 \% \quad 8.5 \%$ TTAPEKYR

$0.02 \% \quad 17.9 \%$ SSNPMMVLQLPER

$0.02 \% \quad 17.9 \%$ GLIVYQLENQPSEFR

$0.02 \% \quad 17.9 \%$ GLIVYQLENQPSEFRR

$0.02 \% \quad 17.9 \%$ QNKPTGFALGSIEGR

$0.02 \% \quad 17.9 \%$ VAIHYINPPNPAK

$0.02 \% \quad 17.9 \%$ NAAEELKPR

$0.02 \% \quad 45.6 \%$ QNLIEELRK

$0.02 \% \quad 45.6 \%$ YLFIFSVANMR

$0.02 \% \quad 45.6 \%$ VMMVALGR

$0.02 \% \quad 45.6 \%$ SPSDEYKDNLHQVSK

$0.02 \% \quad 45.6 \%$ LRGEVGLLFTNR

$0.02 \% \quad 45.6 \%$ GEVGLLFTNR

$0.02 \% \quad 45.6 \%$ TKEEVNEWFTK

$0.02 \% \quad 45.6 \%$ QLGLPTALKR

$0.02 \% \quad 45.6 \%$ GVVTLLSDYEVCK

$0.02 \% \quad 45.6 \%$ EGDVLTPEQAR

$0.02 \% \quad 45.6 \%$ YMWDSQSGR

$0.01 \% \quad 20.0 \%$ TKEVYELLDSPGK

$0.01 \% \quad 20.0 \%$ VLLQSKDQITAGNAAR

$0.01 \% \quad 20.0 \%$ ACGNFGIPCELR

$0.01 \% \quad 20.0 \%$ VTSAHKGPDETLR

$0.01 \% \quad 20.0 \%$ IKAEYEGDGIPTVFVAVAGR

$0.01 \% \quad 20.0 \%$ ASILNTWISLK

$0.01 \% \quad 10.3 \%$ LLGLGSASGSVGR

$0.01 \% \quad 10.3 \%$ VESGGPGTSAASAR

$0.08 \% \quad 29.7 \%$ LAATEKLLEYLR

$0.08 \% \quad 29.7 \%$ LITGLGVGR

$0.08 \% \quad 29.7 \%$ LVKDQEALMK

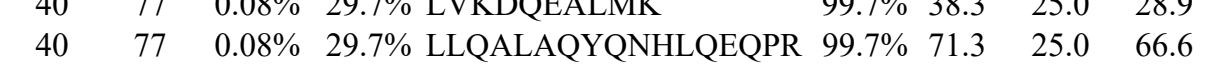

$\begin{array}{llll}99.0 \% & 27.5 & 25.0 & 22.8\end{array}$

$99.7 \% \quad 66.3 \quad 25.0 \quad 60.5$

$99.7 \% \quad 35.3 \quad 25.0 \quad 23.5$

$\begin{array}{llll}99.7 \% & 44.8 & 25.0 & 43.0\end{array}$

$99.7 \% \quad 37.1 \quad 25.0 \quad 20.1$

$\begin{array}{llll}99.7 \% & 36.5 & 25.0 & 36.5\end{array}$

$\begin{array}{llll}99.7 \% & 56.3 & 25.0 & 54.7\end{array}$

$99.3 \% \quad 20.0 \quad 25.0 \quad 20.0$

$\begin{array}{llll}9.7 \% & 46.2 & 25.0 & 46.2\end{array}$

$99.7 \% \quad 30.8 \quad 25.0 \quad 29.6$

$\begin{array}{llll}99.4 \% & 25.1 & 25.0 & 17.8\end{array}$

$\begin{array}{llll}99.7 \% & 57.2 & 25.0 & 57.2\end{array}$

$\begin{array}{llll}99.7 \% & 36.0 & 25.0 & 28.2\end{array}$

$\begin{array}{llll}99.7 \% & 32.9 & 25.0 & 27.6\end{array}$

$\begin{array}{llll}99.7 \% & 43.7 & 25.0 & 41.5\end{array}$

$\begin{array}{llll}96.7 \% & 22.7 & 25.0 & 10.6\end{array}$

$99.7 \% \quad 38.5 \quad 25.0 \quad 38.5$

$\begin{array}{llll}99.0 \% & 32.1 & 25.0 & 25.0\end{array}$

$\begin{array}{llll}99.7 \% & 69.7 & 25.0 & 53.7\end{array}$

$\begin{array}{llll}99.7 \% & 48.2 & 25.0 & 43.4\end{array}$

$\begin{array}{llll}99.7 \% & 50.4 & 25.0 & 50.4\end{array}$

$\begin{array}{llll}98.6 \% & 19.8 & 25.0 & 16.1\end{array}$

$\begin{array}{llll}99.7 \% & 37.8 & 25.0 & 37.8\end{array}$

$\begin{array}{llll}99.7 \% & 57.2 & 25.0 & 44.9\end{array}$

$\begin{array}{llll}99.6 \% & 43.0 & 25.0 & 12.9\end{array}$

$\begin{array}{llll}99.7 \% & 48.7 & 25.0 & 48.7\end{array}$

$\begin{array}{llll}99.0 \% & 37.6 & 25.0 & 29.4\end{array}$

$\begin{array}{llll}99.7 \% & 41.3 & 25.0 & 41.3\end{array}$

$\begin{array}{llll}99.2 \% & 19.5 & 25.0 & 19.5\end{array}$

$99.7 \% \quad 61.6 \quad 25.0 \quad 48.2$

$\begin{array}{llll}99.7 \% & 51.4 & 25.0 & 47.1\end{array}$

$\begin{array}{llll}99.5 \% & 27.3 & 25.0 & 16.2\end{array}$

$\begin{array}{llll}99.7 \% & 64.3 & 25.0 & 61.8\end{array}$

$\begin{array}{llll}99.7 \% & 36.1 & 25.0 & 36.1\end{array}$

$\begin{array}{llll}96.4 \% & 14.7 & 25.0 & 14.7\end{array}$

$\begin{array}{llll}99.7 \% & 40.7 & 25.0 & 40.7\end{array}$

$\begin{array}{llll}99.7 \% & 34.2 & 25.0 & 34.2\end{array}$

$99.7 \% \quad 27.2 \quad 25.0 \quad 27.2$

$\begin{array}{llll}99.7 \% & 27.3 & 25.0 & 27.3\end{array}$

$\begin{array}{llll}9.7 \% & 35.3 & 25.0 & 35.3\end{array}$

$\begin{array}{llll}98.9 \% & 22.4 & 25.0 & 15.6\end{array}$

$\begin{array}{llll}99.7 \% & 60.4 & 25.0 & 53.0\end{array}$

$99.7 \% \quad 54.9 \quad 25.0 \quad 52.2$

$99.7 \% \quad 50.9 \quad 25.0 \quad 39.9$

$\begin{array}{llll}99.7 \% & 52.8 & 25.0 & 46.2\end{array}$

$\begin{array}{llll}99.7 \% & 38.3 & 25.0 & 28.9\end{array}$

\subsection{8}

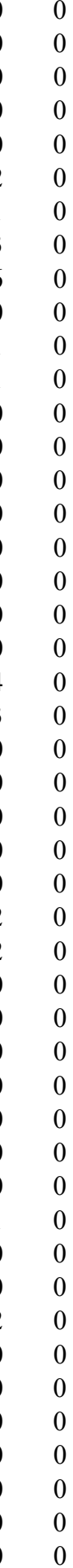

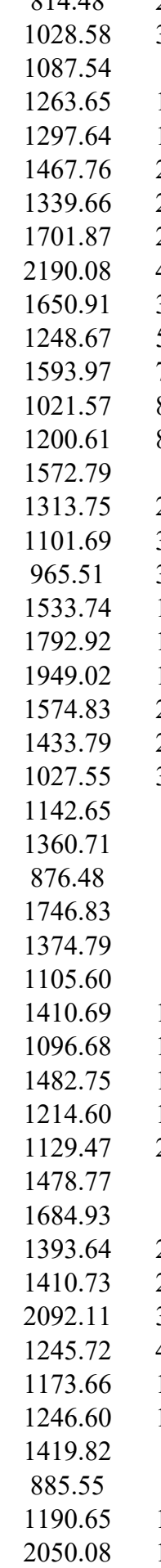


Myb-binding protein 1A GN=MYBBP1A $\quad$ MBB1A_HUMAN $148.86 \quad 100.0 \% \quad 39$ $\begin{array}{lllll}\text { Myb-binding protein 1A GN=MYBBP1A } & \text { MBB1A_HUMAN } & 148.86 & 100.0 \% & 39\end{array}$ Myb-binding protein 1A GN=MYBBP1A MBB1A_HUMAN $148.86 \quad 100.0 \% \quad 39$ Myb-binding protein 1A GN=MYBBP1A MBB1A_HUMAN $148.86 \quad 100.0 \%$ Myb-binding protein 1A GN=MYBBP1A MBB1A_HUMAN $148.86 \quad 100.0 \% \quad 39$ Myb-binding protein 1A GN=MYBBP1A MBB1A_HUMAN $148.86 \quad 100.0 \% \quad 39$ Myb-binding protein 1A GN=MYBBP1A MBB1A_HUMAN $148.86 \quad 100.0 \% \quad 39$ Myb-binding protein 1A GN=MYBBP1A MBB1A_HUMAN $148.86 \quad 100.0 \%$ Myb-binding protein 1A GN=MYBBP1A MBB1A_HUMAN $148.86 \quad 100.0 \% \quad 39$ $\begin{array}{lllll}\text { Myb-binding protein 1A GN=MYBBP1A } & \text { MBB1A_HUMAN } & 148.86 & 100.0 \% & 39\end{array}$ Myb-binding protein 1A GN=MYBBP1A MBB1A_HUMAN $148.86 \quad 100.0 \% \quad 39$ Myb-binding protein 1A GN=MYBBP1A MBB1A_HUMAN $148.86 \quad 100.0 \% \quad 39$ Myb-binding protein 1A GN=MYBBP1A MBB1A_HUMAN $148.86 \quad 100.0 \% \quad 39$ Myb-binding protein 1A GN=MYBBP1A MBB1A_HUMAN $148.86 \quad 100.0 \% \quad 39$ Myb-binding protein 1A GN=MYBBP1A MBB1A_HUMAN $148.86 \quad 100.0 \% \quad 39$ Myb-binding protein 1A GN=MYBBP1A MBB1A_HUMAN $148.86 \quad 100.0 \%$ Myb-binding protein 1A GN=MYBBP1A MBB1A_HUMAN $148.86 \quad 100.0 \%$ $\begin{array}{lllll}\text { Myb-binding protein 1A GN=MYBBP1A } & \text { MBB1A_HUMAN } & 148.86 & 100.0 \% & 39\end{array}$ Myb-binding protein 1A GN=MYBBP1A MBB1A_HUMAN $148.86 \quad 100.0 \% \quad 39$ Myb-binding protein 1A GN=MYBBP1A MBB1A_HUMAN $148.86 \quad 100.0 \% \quad 39$ Myb-binding protein 1A GN=MYBBP1A MBB1A_HUMAN $148.86 \quad 100.0 \% \quad 39$ Myb-binding protein 1A GN=MYBBP1A MBB1A_HUMAN $148.86 \quad 100.0 \% \quad 39$ Myb-binding protein 1A GN=MYBBP1A MBB1A_HUMAN $148.86 \quad 100.0 \% \quad 39$ Myb-binding protein 1A GN=MYBBP1A MBB1A_HUMAN $148.86 \quad 100.0 \%$ Myb-binding protein 1A GN=MYBBP1A MBB1A_HUMAN $148.86 \quad 100.0 \%$ Myb-binding protein 1A GN=MYBBP1A MBB1A_HUMAN $148.86 \quad 100.0 \% \quad 39$ Myb-binding protein 1A GN=MYBBP1A MBB1A_HUMAN $148.86 \quad 100.0 \% \quad 39$ $\begin{array}{lllll}\text { Myb-binding protein 1A GN=MYBBP1A } & \text { MBB1A_HUMAN } & 148.86 & 100.0 \% & 39\end{array}$ Myb-binding protein 1A GN=MYBBP1A MBB1A_HUMAN $148.86 \quad 100.0 \%$ Myb-binding protein 1A GN=MYBBP1A MBB1A_HUMAN $148.86 \quad 100.0 \%$ Myb-binding protein 1A GN=MYBBP1A MBB1A_HUMAN $148.86 \quad 100.0 \% \quad 39$ Myb-binding protein 1A GN=MYBBP1A MBB1A_HUMAN $148.86 \quad 100.0 \% \quad 39$ Myb-binding protein 1A GN=MYBBP1A MBB1A_HUMAN $148.86 \quad 100.0 \%$ Myb-binding protein 1A GN=MYBBP1A MBB1A_HUMAN $148.86 \quad 100.0 \% \quad 39$ Myb-binding protein 1A GN=MYBBP1A MBB1A_HUMAN $148.86 \quad 100.0 \% 39$ Myelin expression factor 2 GN=MYEF2 MYEF2_HUMAN $64.12 \quad 100.0 \%$ Myelin expression factor 2 GN=MYEF2 MYEF2_HUMAN $64.12 \quad 100.0 \%$ Myelin expression factor 2 GN=MYEF2 MYEF2 HUMAN $64.12 \quad 100.0 \%$ Myeloid leukemia factor $2 \mathrm{GN}=\mathrm{MLF} 2$ Myeloid leukemia factor $2 \mathrm{GN}=\mathrm{MLF} 2$

Myeloid leukemia factor $2 \mathrm{GN}=\mathrm{MLF} 2$ Myosin-10 GN=MYH10

Myosin-10 GN=MYH10

Myosin-10 GN=MYH10

Myosin-10 GN=MYH10

Myosin-10 GN=MYH10

Myosin-10 GN=MYH10

MLF2_HUMAN $28.15 \quad 100.0 \%$

MLF2 HUMAN $28.15 \quad 100.0 \%$

MYH10_HUMAN $229.01 \quad 100.0 \%$

MYH10_HUMAN $229.01 \quad 100.0 \%$

MYH10_HUMAN $229.01 \quad 100.0 \%$

MYH10_HUMAN $229.01 \quad 100.0 \%$

MYH10 HUMAN $229.01 \quad 100.0 \%$

MYH10_HUMAN $229.01 \quad 100.0 \%$
$0.08 \% \quad 29.7 \%$ KALVDILSEVSK $0.08 \% \quad 29.7 \%$ ALVDILSEVSK

$0.08 \% \quad 29.7 \%$ ATLQEILPEVLK

$0.08 \% \quad 29.7 \%$ KLVGSVNLFSDENVPR

$0.08 \% \quad 29.7 \%$ LVGSVNLFSDENVPR

$0.08 \% \quad 29.7 \%$ LPAIALDLLR

$0.08 \% \quad 29.7 \%$ EVVEQGLLK

$0.08 \% \quad 29.7 \%$ LLGAALPLLTK

$0.08 \% \quad 29.7 \%$ EQLHLVMQGDVIR

$0.08 \% \quad 29.7 \%$ HYGEHVCTAK

$0.08 \% \quad 29.7 \%$ AQDSSLHMPER

$0.08 \% \quad 29.7 \%$ KPTSQIPETK

$0.08 \% \quad 29.7 \%$ HPFSFPLENQAR

$0.08 \% 29.7 \%$ SPAESCDLLGDIQTCIR

$0.08 \% \quad 29.7 \%$ SPAESCDLLGDIQTCIRK

$0.08 \% \quad 29.7 \%$ VLDLVEVLVTK

$0.08 \% \quad 29.7 \%$ SSSSKQEQDLLHK

$0.08 \% \quad 29.7 \%$ IFTHHLCR

$0.08 \% \quad 29.7 \%$ RYCHDLGER

$0.08 \% \quad 29.7 \%$ AGALHAQVER

$0.08 \% \quad 29.7 \%$ VLKGNTAEGCVHETQEK

$0.08 \% \quad 29.7 \%$ GNTAEGCVHETQEK

$0.08 \% \quad 29.7 \%$ VYSTALSSFLTK

$0.08 \% \quad 29.7 \%$ VYSTALSSFLTKR

$0.08 \% \quad 29.7 \%$ HQACLLLQK

$0.08 \% \quad 29.7 \%$ TLGVQRPK

$0.08 \% \quad 29.7 \%$ DAKEIPSATQSPISK

$0.08 \% \quad 29.7 \%$ EIPSATQSPISK

$0.08 \% \quad 29.7 \%$ AKVPAQANGTPTTK

$0.08 \% \quad 29.7 \%$ SPAPGAPTR

$0.08 \% \quad 29.7 \%$ KNQKPSQVNGAPGSPTEPAGQK

$0.08 \% \quad 29.7 \%$ SPLSALAR

$0.08 \% \quad 29.7 \%$ SPSLLQSGAK

$0.08 \% \quad 29.7 \%$ SPSLLQSGAKK

$0.00 \% \quad 5.0 \%$ MGPGIGAILER

$0.00 \% \quad 5.0 \%$ IGSKGNQIFVR

$0.00 \% \quad 5.0 \%$ EIDVRLDR

$\begin{array}{lllllll}\text { MLF2_HUMAN } 28.15 & 100.0 \% & 3 & 4 & 10 & 0.01 \% & 14.9 \% \\ \text { VYYETSEMR }\end{array}$

$0.01 \% \quad 14.9 \%$ LAIQGPEDSPSR

$0.01 \% \quad 4.8 \%$ QLLQANPILESFGNAK

$0.01 \% \quad 4.8 \%$ EQADFAVEALAK

$0.01 \% \quad 4.8 \%$ CNGVLEGIR

$0.01 \% \quad 4.8 \%$ YEILTPNAIPK

$0.01 \% \quad 4.8 \%$ ALELDPNLYR

$0.01 \% \quad 4.8 \%$ ASRDEIFAQSK
$0.08 \% \quad 29.7 \%$ AGTDPSHMPTGPQAASCLDLNLVTR

$\begin{array}{llllllll}99.7 \% & 54.8 & 25.0 & 54.8 & 2 & 0 & 0 & 1301.77\end{array}$

1173.67

1353.80

1773.95

1645.85

1094.69

1014.58

1109.73

1553.81

1201.54

1286.58

1128.63

1442.72

1934.90

2062.99

1227.76

1486.75

1083.55

1205.55

1051.56

1899.92

1559.68

2625.24

1316.71

1472.81

1110.61

898.55

1571.83

1257.67

1383.76

853.45

2220.14

814.48

987.55

1115.64

1113.61

1218.70

1015.55

1142.51

1797.82

1269.64
$99.7 \% \quad 31.3 \quad 25.0 \quad 31.0$

$\begin{array}{llll}97.5 \% & 27.8 & 25.0 & 0.0\end{array}$

$\begin{array}{llll}99.7 \% & 55.7 & 25.0 & 40.7\end{array}$

$99.7 \% \quad 53.5 \quad 25.0 \quad 43.9$

$\begin{array}{llll}99.7 \% & 66.9 & 25.0 & 66.9\end{array}$

$\begin{array}{lllll}99.7 \% & 80.9 & 25.0 & 74.4\end{array}$

$\begin{array}{llll}99.7 \% & 43.8 & 25.0 & 37.9\end{array}$

$\begin{array}{llll}99.7 \% & 37.4 & 25.0 & 28.4\end{array}$

$\begin{array}{llll}99.7 \% & 44.1 & 25.0 & 43.5\end{array}$

$95.9 \% \quad 22.8 \quad 25.0 \quad 14.2$ $\begin{array}{llll}99.7 \% & 31.7 & 25.0 & 30.4\end{array}$

\begin{tabular}{cc} 
& 190 \\
& 190 \\
& 202 \\
& 246 \\
& 246 \\
& 273 \\
& 295 \\
8 & 318 \\
& 331 \\
2 & 341 \\
3 & 443 \\
9 & 498 \\
9 & 510 \\
9 & 625 \\
9 & 626 \\
8 & 838 \\
2 & 874 \\
8 & 885 \\
8 & 896 \\
7 & 906 \\
3 & 949 \\
6 & 949 \\
2 & 976 \\
7 & 988 \\
7 & 989 \\
8 & 1036 \\
1 & 1148 \\
3 & 1167 \\
6 & 1167 \\
8 & 1231 \\
2 & 1240 \\
4 & 1275 \\
0 & 1297 \\
08 & 1317 \\
8 & 1318 \\
7 & 497 \\
8 & 528 \\
1 & 598 \\
0 & 128 \\
3 & 158 \\
0 & 241 \\
7 & 232 \\
5 & 426 \\
1 & 709 \\
8 & 738 \\
36 & 1676 \\
\hline
\end{tabular}


Myosin-10 GN=MYH10

Myosin-10 GN=MYH10

Myosin-9 GN=MYH9

Myosin-9 GN=MYH9

Myosin-9 GN=MYH9

Myosin-9 GN=MYH9

Myosin-9 GN=MYH9

Myosin-9 GN=MYH9

Myosin-9 GN=MYH9

Myosin-9 GN=MYH9

$\mathrm{N}$-acetyltransferase $10 \mathrm{GN}=\mathrm{NAT} 10$

$\mathrm{N}$-acetyltransferase $10 \mathrm{GN}=\mathrm{NAT} 10$

$\mathrm{N}$-acetyltransferase $10 \mathrm{GN}=\mathrm{NAT} 10$

$\mathrm{N}$-acetyltransferase $10 \mathrm{GN}=\mathrm{NAT} 10$

$\mathrm{N}$-acetyltransferase $10 \mathrm{GN}=\mathrm{NAT} 10$

$\mathrm{N}$-acylneuraminate cytidylyltransferase GN=CMAS NEUA_HUMAN $48.38 \quad 100.0 \%$ $\mathrm{N}$-acylneuraminate cytidylyltransferase GN=CMAS NEUA HUMAN $48.38 \quad 100.0 \%$ NAD(P) transhydrogenase, mitochondrial GN=NNT NNTM_HUMAN $113.90 \quad 100.0 \%$ NAD(P) transhydrogenase, mitochondrial GN=NNT NNTM_HUMAN $113.90 \quad 100.0 \%$

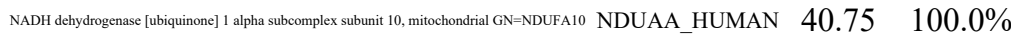
NADH dehydrogenase [ubiquinone] 1 alpha subcomplex subunit 10, mitochondralal GN=NDUFA10 NDUAA_HUMAN $40.75 \quad 100.0 \%$ NADH dehydrogenase [ubiquinone] 1 alpha subcomplex subunit 10, mitochondrial GN=NDUFAl0 NDUAA_HUMAN $40.75 \quad 100.0 \%$ NADH dehydrogenase [ubiguinone] 1 lapha subcomplex subunit 10, mitochondral GN=NDUFA10 NDUAA_HUMAN $40.75 \quad 100.0 \%$ NADH dechydrogenase [ubiquinone] 1 alpha subcomplex subunit 10, mitochondrial GN=NDUFA10 NDUAA_HUMAN $40.75 \quad 100.0 \%$ DH dehydrogenase [ubiquirone] 1 alph subbomplex subunit 10, mitochondral GN-NDUFA A10 NDUAA_HUMAN $40.75 \quad 100.0 \%$ NADH dehydrogenase [ubiquinone] 1 alpha subcomplex subunit 10, mitochondral GN=NDUFA10 NDUAA_HUMAN $40.75 \quad 100.0 \%$ NADH dehydrogenase [ubiquinone I I alpha subcomplex subunit 9 , mitochondrial GN=NDUFA9 NDUA9_HUMAN $42.51 \quad 100.0 \%$ NADH dehydrogenase [ubiquinone] 1 alpha subcomplex subunit 9 , mitochondrial GN=NDUFA9 NDUA9_HUMAN $42.51 \quad 100.0 \%$ ADH dehydrogenase [ubiquinone] 1 alpha subcomplex subunit 9 , mitochondral GN=NDUFA9 NDUA9_HUMAN $42.51 \quad 100.0 \%$ NADH dehydrogenase [ubiquinone] 1 alpha subcomplex subunit 9 , mitochondrial GN=NDUFA9 NDUA9_HUMAN $42.51 \quad 100.0 \%$
NADH dehydrogenase [ubiquinone] 1 alpha subcomplex subunit, 9 , mitochondral GN=NDUFA9 NDUA9_HUMAN $42.51 \quad 100.0 \%$ NADH dehydrogenase [ubiquinone] 1 alpha subcomplex subunit 9 , mitochondrial GN=NDUFA9 NDUA9_HUMAN $42.51 \quad 100.0 \%$ NADH dehydrogenase [ubiquinone] I alpha subcomplex subunit 9 , mitochondrial GN=NDUFA9 NDUA9_HUMAN $42.51 \quad 100.0 \%$ NADH dehydrogenase [ubiquinone] 1 alpha subcomplex subunit , mitochondral GN=NDUFA9 NDUA9_HUMAN $42.51 \quad 100.0 \%$ NADH dehydrogenase [ubiquinone] I alpha subcomplex subunit 9 , mitochondrial GN=NDUFA9 NDUA9_HUMAN $42.51 \quad 100.0 \%$ NADH dehydrogenase [ubiquinone] 1 alpha subcomplex subunit 9 , mitochondrial GN=NDUFA9 NDUA9_HUMAN $42.51 \quad 100.0 \%$ MDH dehydrogenase [ubiquinone] 1 alpha subcomplex subunit 9 , mitochondrial GN=NDUFA99 NDUA9_HUMAN $42.51 \quad 100.0 \%$ NADH dehydrogenase [ubiquinone] flavoprotein 1, mitochondrial GN=NDUFV1 NDUV1_HUMAN $50.82 \quad 100.0 \%$ NADH dehydrogenase [ubiquinone] flavoprotein 1, mitochondrial GN=NDUFV1 NDUV1_HUMAN $50.82 \quad 100.0 \%$ NADH dehydrogenase [ubiquinone] flavoprotein 1, mitochondrial GN=NDUFV1 NDUV1 HUMAN $50.82 \quad 100.0 \%$ NADH dehydrogenase [ubiquinone] iron-sulfur protein 2, mitochondrial GN=NDUFS2 NDUS2_HUMAN $52.55 \quad 100.0 \%$ NADH dehydrogenase [ubiquinone] iron-sulfur protein 2, mitochondrial GN=NDUFS2 NDUS2_HUMAN $52.55 \quad 100.0 \%$ NADH dehydrogenase [ubiquinone] iron-sulfur protein 2, mitochondrial GN=NDUFS2 NDUS2_HUMAN $52.55 \quad 100.0 \%$ NADH dehydrogenase [ubiquinone] iron-sulfur protein 3, mitochondrial GN=NDUFS3 NDUS3_HUMAN $30.24 \quad 100.0 \%$ ADH dehydrogenase [ubiquinone] iron-sulfur protein 3, mitochondrial GN=NDUFS3 NDUS3_HUMAN $30.24 \quad 100.0 \%$ NADH-ubiquinone oxidoreductase 75 kDa subunit, mitochondrial GN=NDUFS1 NDUS1_HUMAN $79.47 \quad 100.0 \%$

3

3

$\% \quad 4.8 \%$ TTLQVDTLNAELAAER $0.01 \% \quad 4.8 \%$ GGPISFSSSR $0.01 \% \quad 4.9 \%$ EQADFAIEALAK $0.01 \% \quad 4.9 \%$ TVGQLYKEQLAK $0.01 \% \quad 4.9 \%$ CNGVLEGIR

$0.01 \% \quad 4.9 \% \quad$ YEILTPNSIPK $0.01 \% \quad 4.9 \% \quad$ ALELDSNLYR $0.01 \% \quad 4.9 \%$ ANLQIDQINTDLNLER $0.01 \% \quad 4.9 \%$ ASITALEAK $0.01 \% \quad 6.6 \%$ ILIENGVAER $0.01 \% \quad 6.6 \%$ QQSAQSQVSTTAENKTTTTAR $0.01 \% \quad 6.6 \%$ QSILNSLSR $0.01 \% \quad 6.6 \%$ IAVHPDYQGMGYGSR $0.01 \% \quad 6.6 \%$ LDYLGVSYGLTPR $0.00 \% \quad 6.0 \% \quad$ GAATSVSNPR $0.00 \% \quad 6.0 \%$ VGLSGAPADACSTAQK $0.00 \% \quad 2.1 \%$ VALSPAGVQNLVK $0.00 \% \quad 2.1 \%$ AQYPIADLVK

$0.01 \% 22.3 \%$ VITVDGNICTGK

$0.01 \% \quad 22.3 \%$ LLQYSDALEHLLTTGQGVVLER $0.01 \% \quad 22.3 \%$ KQCVDHYNEVK

$0.01 \% \quad 22.3 \%$ ITSAYLQDIENAYK $0.01 \% \quad 22.3 \%$ ITSAYLQDIENAYKK $0.01 \% \quad 22.3 \%$ CEVLQYSAR $0.01 \% \quad 22.3 \%$ KVVEDIEYLK $0.02 \% \quad 36.6 \%$ YVVNHLGR $0.02 \% 36.6 \%$ MGSQVIIPYR $0.02 \% \quad 36.6 \%$ VVQHSNVVINLIGR $0.02 \% \quad 36.6 \%$ NFDFEDVFVK $0.02 \% \quad 36.6 \%$ FIHVSHLNANIK $0.02 \% \quad 36.6 \%$ DAFPEAIIVKPSDIFGR $0.02 \% \quad 36.6 \%$ QPVYVVDVSK $0.02 \% \quad 36.6 \%$ GIVNAVKDPDANGK $0.02 \% 36.6 \%$ SFAFVGPSR

$0.02 \% 36.6 \%$ YIFAVAHR $0.02 \% \quad 36.6 \%$ VFEISPFEPWITR $0.02 \% 36.6 \%$ WLSAEIEDVKPAK $0.00 \% \quad 7.3 \%$ GGAGFPTGLK $0.00 \% \quad 7.3 \%$ NACGSGYDFDVFVVR $0.00 \% \quad 7.3 \%$ HFRPELEER

$0.01 \% \quad 9.3 \%$ NITLNFGPQHPAAHGVLR $0.01 \% \quad 9.3 \% \quad$ IIAQCLNK

$0.01 \% \quad 9.3 \%$ GEFGVYLVSDGSSRPYR $0.00 \% \quad 11.7 \%$ ESAGADTRPTVRPR $0.00 \% \quad 11.7 \%$ TYTDELTPIESAVSVFK $0.01 \% \quad 11.6 \%$ AVEDKNIGPLVK
$99.7 \% \quad 68.7$ $99.6 \% \quad 30.6$ $99.7 \% \quad 48.1$ $99.2 \% \quad 34.8$ $99.7 \% \quad 51.2$ $\begin{array}{lll}99.7 \% & 43.8\end{array}$ $99.7 \% \quad 35.4$ $99.7 \% \quad 41.4$ $99.7 \% \quad 62.8$ $99.7 \% \quad 37.0$ $99.7 \% \quad 35.1$ $99.4 \% \quad 20.6$ $99.7 \% \quad 50.1$ $\begin{array}{lll}99.7 \% & 33.4\end{array}$ $99.7 \% \quad 43.8$ $99.7 \% \quad 46.1$ $99.7 \% \quad 45.3$ $98.2 \% \quad 16.6$ $\begin{array}{lll}99.7 \% & 27.8\end{array}$ $99.7 \% \quad 63.0$ $99.0 \% \quad 27.0$ $99.7 \% \quad 86.2$ $\begin{array}{lll}99.7 \% & 46.5\end{array}$ $99.7 \% \quad 43.2$ $99.7 \% \quad 51.5$ $\begin{array}{lll}99.0 \% & 28.2\end{array}$ $99.7 \% \quad 47.7$ $99.7 \% \quad 59.0$ $99.7 \% \quad 43.9$ $99.7 \% \quad 37.8$ $\begin{array}{lll}99.7 \% & 51.7\end{array}$ $99.7 \% \quad 32.2$ $99.7 \% \quad 35.4$ $99.7 \% \quad 40.2$ $98.2 \% \quad 22.4$ $99.7 \% \quad 57.2$ $99.7 \% \quad 62.0$ $99.5 \% \quad 21.7$ $99.7 \% \quad 68.3$ $99.5 \% \quad 23.9$ $99.0 \% \quad 35.3$ $99.7 \% \quad 35.3$ $99.7 \% \quad 33.7$ $98.5 \% \quad 16.9$ $99.7 \% \quad 53.1$
1726.95

1305.67

1377.77

1017.51

1274.70

1193.62

1869.97

903.51

1113.63

2238.10

1017.57

1666.76

1453.77

959.49

1532.74

1295.77

1117.63

1276.66

2455.32

1419.67

1628.82

1756.91

1125.54

1235.69

957.53

1179.62

1547.90

1259.59

1392.77

1875.00

1133.62

1397.74

967.50

976.54

1620.84

1485.79

904.49

1705.76

1212.6

1942.04

959.53

1888.92

1512.79

1899.96 1282.74

$\begin{array}{cc}31 & 1940 \\ 10 & 225 \\ 08 & 419 \\ 45 & 656 \\ 94 & 702 \\ 21 & 731 \\ 46 & 755 \\ 55 & 1770 \\ 07 & 1815 \\ 2 & 21 \\ 33 & 453 \\ 88 & 596 \\ 29 & 643 \\ 06 & 718 \\ 7 & 16 \\ 84 & 399 \\ 2 & 84 \\ 40 & 949 \\ 9 & 70 \\ 40 & 161 \\ 81 & 191 \\ 29 & 242 \\ 29 & 243 \\ 53 & 261 \\ 68 & 277 \\ 8 & 75 \\ 6 & 85 \\ 19 & 132 \\ 38 & 147 \\ 64 & 175 \\ 93 & 209 \\ 38 & 247 \\ 48 & 261 \\ 62 & 270 \\ 79 & 286 \\ 04 & 316 \\ 61 & 373 \\ 9 & 98 \\ 85 & 199 \\ 41 & 449 \\ 9 & 96 \\ 43 & 350 \\ 05 & 421 \\ 7 & 50 \\ 45 & 161 \\ 59 & 170 \\ & \end{array}$



Neuroblastoma-amplified sequence GN=NBAS NBAS_HUMAN $268.58 \quad 100.0 \%$ Neuroblastoma-amplified sequence GN=NBAS NBAS HUMAN $268.58 \quad 100.0 \%$ Neuroblastoma-amplified sequence GN=NBAS NBAS_HUMAN $268.58 \quad 100.0 \%$ Neuroblastoma-amplified sequence GN=NBAS NBAS_HUMAN $268.58 \quad 100.0 \%$ Neurofibromin GN=NF1

Neurofibromin GN=NF1

Neurofibromin GN=NF1 NF1 HUMAN $319.38 \quad 100.0 \%$ NF1_HUMAN $319.38 \quad 100.0 \%$ NF1 HUMAN $319.38 \quad 100.0 \%$

Neurofilament medium polypeptide GN=NEFM NFM_HUMAN $102.47 \quad 100.0 \%$ Neurofilament medium polypeptide GN=NEFM NFM_HUMAN $102.47 \quad 100.0 \%$ Neurofilament medium polypeptide GN=NEFM NFM_HUMAN $102.47 \quad 100.0 \%$ Neurofilament medium polypeptide GN=NEFM NFM_HUMAN $102.47 \quad 100.0 \%$ Neurofilament medium polypeptide GN=NEFM NFM_HUMAN $102.47 \quad 100.0 \%$ Neurofilament medium polypeptide GN=NEFM NFM_HUMAN $102.47 \quad 100.0 \%$ Neurofilament medium polypeptide GN=NEFM NFM_HUMAN $102.47 \quad 100.0 \%$ Neurofilament medium polypeptide GN=NEFM NFM HUMAN $102.47 \quad 100.0 \%$ Neuronal-specific septin-3 GN=SEPT3 SEPT3_HUMAN $40.70 \quad 100.0 \%$ Neuronal-specific septin-3 GN=SEPT3 SEPT3_HUMAN $40.70 \quad 100.0 \%$ Neuronal-specific septin-3 GN=SEPT3 SEPT3_HUMAN $40.70 \quad 100.0 \%$ Neutral alpha-glucosidase AB GN=GANAB GANAB_HUMAN $106.88 \quad 100.0 \%$ Neutral alpha-glucosidase AB GN=GANAB GANAB_HUMAN $106.88 \quad 100.0 \%$ NF-kappa-B-repressing factor GN=NKRF NKRF_HUMAN $77.67 \quad 100.0 \%$ NF-kappa-B-repressing factor GN=NKRF NKRF_HUMAN $77.67 \quad 100.0 \%$ NF-kappa-B-repressing factor GN=NKRF NKRF HUMAN $77.67 \quad 100.0 \%$ NF-kappa-B-repressing factor GN=NKRF NKRF_HUMAN $77.67 \quad 100.0 \%$

3

10 $\begin{array}{lll}0.01 \% & 2.0 \% & \text { NILFVITKPDVYK } \\ 0.01 \% & 2.0 \% & \text { SPASDTYIVFGEAK } \\ 0.01 \% & 2.0 \% & \text { IEDLSQQAQLAAAEK }\end{array}$

$0.00 \% \quad 2.3 \%$ IGQETDKTTTR

$0.00 \% \quad 2.3 \%$ NAYHAVYKQSVTSSA

$0.00 \% \quad 0.2 \%$ VQEAILAR

$0.00 \% \quad 0.2 \%$ VLFTSLADNK

$0.00 \% \quad 2.2 \%$ CSGALTVSSVK

$0.00 \% \quad 2.2 \%$ QVDCALSLIR

$0.00 \% \quad 2.2 \%$ LLGLAELLR

$0.00 \% \quad 2.2 \%$ SLTYLRPLQGQK

$0.00 \% \quad 2.2 \%$ FTADDQYKR

$0.01 \% \quad 1.3 \%$ VAQLAVINSLEK

$0.01 \% \quad 1.3 \%$ TLSIFYQAGTSK

$0.01 \% \quad 1.3 \%$ VGSTAVQVTSAER

$0.01 \% \quad 8.4 \%$ VSGSPSSGFR

$0.01 \% \quad 8.4 \%$ GSPSTVSSSYKR

$0.01 \% \quad 8.4 \%$ LRDDTEAAIR

$0.01 \% \quad 8.4 \%$ VQSLQDEVAFLR

$0.01 \% \quad 8.4 \%$ LTEAAEQNKEAIR

$0.01 \% \quad 8.4 \%$ HLREYQDLLNVK

$0.01 \% \quad 8.4 \%$ EYQDLLNVK

$0.01 \% \quad 8.4 \%$ LLEGEETR

$0.00 \% \quad 8.9 \%$ AIGHVIEEGGVK

$0.00 \% \quad 8.9 \%$ FLKEEVNIAR

$0.00 \% \quad 8.9 \%$ VVNIIPVIAK

$0.00 \% \quad 2.9 \%$ SIRPGLSPYR

$0.00 \% \quad 2.9 \%$ VVIIGAGKPAAVVLQTK

$0.01 \% \quad 9.3 \%$ HLSTCDGQNPPKK

$\begin{array}{lll}0.01 \% & 9.3 \% & \text { DASGQPIFNASAK } \\ 0.01 \% & 9.3 \% & \text { TVKYEAAGEAVK }\end{array}$

$0.01 \% \quad 9.3 \%$ GAVEDVISRNEIQGR
$99.7 \% \quad 46.4$ $\begin{array}{ll}99.4 \% & 22.8\end{array}$ $\begin{array}{lll}99.7 \% & 56.6\end{array}$ $99.7 \% \quad 51.2$ $\begin{array}{lll}99.7 \% & 48.2\end{array}$ $99.7 \% \quad 38.4$ $99.7 \% \quad 42.1$ $99.7 \% 31.4$ $\begin{array}{llll}99.7 \% & 45.5\end{array}$

K $99.7 \% 52.5$ $99.7 \% \quad 45.9$ $\begin{array}{llll}99.6 \% & 30.4\end{array}$ $\begin{array}{llll}99.7 \% & 35.7\end{array}$ $\begin{array}{llll}99.7 \% & 33.8\end{array}$ $\begin{array}{llll}99.7 \% & 35.8\end{array}$ $99.7 \% \quad 48.3$ $99.7 \% \quad 36.4$ $99.7 \% \quad 88.0$ $\begin{array}{llll}99.6 \% & 25.7\end{array}$ $\begin{array}{lll}98.5 \% & 17.9\end{array}$ $98.1 \% \quad 24.1$ $\begin{array}{lll}95.4 \% & 22.3\end{array}$

$\begin{array}{lll}96.4 \% & 20.3\end{array}$

$98.5 \% 19.9$ $\begin{array}{llll}99.7 \% & 37.5\end{array}$ $\begin{array}{llll}99.1 \% & 19.0\end{array}$ $99.2 \% \quad 18.2$ $\begin{array}{lll}99.7 \% & 33.6\end{array}$

$99.7 \% 28.3$ $\begin{array}{llll}99.7 \% & 59.0\end{array}$

$\begin{array}{llll}99.7 \% & 32.9\end{array}$

$\begin{array}{llll}99.7 \% & 49.7\end{array}$ $\begin{array}{lll}99.7 \% & 54.7\end{array}$ $\begin{array}{llll}99.7 \% & 67.9\end{array}$ $\begin{array}{llll}99.7 \% & 60.1\end{array}$ $99.7 \% \quad 47.0$ $\begin{array}{llll}99.7 \% & 51.7\end{array}$ $\begin{array}{lll}98.3 \% & 28.4\end{array}$ $99.7 \% \quad 41.8$ $97.2 \% \quad 18.1$ $99.7 \% \quad 32.0$ $\begin{array}{llll}99.7 \% & 26.9\end{array}$ $99.5 \% \quad 25.6$ $99.7 \% \quad 32.4$ $\begin{array}{llll}99.7 \% & 26.2\end{array}$ $\begin{array}{lll}97.5 \% & 19.4\end{array}$ $99.7 \% \quad 37.8$

2274.18

1522.86

1273.73

1168.61

1395.73

1502.73

1549.90

1484.73

1614.83

1249.64

1625.79

899.53

1107.60

1108.57

1174.63

997.64

1403.80

1143.54

1284.75

1315.69

1304.68
980.48

1255.63

1159.61

1404.75

1472.77

1527.83

1121.58

946.48

1208.66

1218.68

1065.70

1145.64 
NF-kappa-B-repressing factor GN=NKRF NKRF_HUMAN $77.67 \quad 100.0 \%$ NCLN_HUMAN $62.97 \quad 100.0 \%$ Nicalin GN=NCLN NCLN_HUMAN $62.97 \quad 100.0 \%$ Natinamide phosphoribosyltransferase GN=NAMPT NAMPT HUMAN $55.52 \quad 100.0 \%$ Nicotinamide phosphoribosyltransferase GN=NAMPT NAMPT_HUMAN $55.52 \quad 100.0 \%$ Nicotinamide phosphoribosyltransferase GN=NAMPT NAMPT_HUMAN $55.52 \quad 100.0 \%$ Nicotinamide phosphoribosyltransferase GN=NAMPT NAMPT_HUMAN $55.52 \quad 100.0 \%$ Nicotinamide/nicotinic acid mononucleotide adenylyltransferase 1 GN=NMNAT1 NMNA1_HUMAN $31.93 \quad 100.0 \%$ Nicotinamide/nicotinic acid mononucleotide adenylyltransferase 1 GN=NMNAT1 NMNA1_HUMAN $31.93 \quad 100.0 \%$ Nicotinamide/nicotinic acid mononucleotide adenylyltransferase 1 GN=NMNAT1 NMNA1_HUMAN $31.93 \quad 100.0 \%$ Nicotinamide/nicotinic acid mononucleotide adenylyltransferase 1 GN=NMNAT1 NMNA1_HUMAN $31.93 \quad 100.0 \%$ Nischarin GN=NISCH Nischarin GN=NISCH Nischarin GN=NISCH Nischarin GN=NISCH Nischarin GN=NISCH Non-POU domain-containing octamer-binding protein GN=NONO NONO_HUMAN $54.23 \quad 100.0 \%$ Non-POU domain-containing octamer-binding protein GN=NONO NONO HUMAN $54.23 \quad 100.0 \%$ Non-POU domain-containing octamer-binding protein GN=NONO NONO_HUMAN $54.23 \quad 100.0 \%$ Non-POU domain-containing octamer-binding protein GN=NONO NONO_HUMAN $54.23 \quad 100.0 \%$ Non-POU domain-containing octamer-binding protein GN=NONO NONO_HUMAN $54.23 \quad 100.0 \%$ Non-POU domain-containing octamer-binding protein GN=NONO NONO_HUMAN $54.23 \quad 100.0 \%$ Nuclear mitotic apparatus protein $1 \mathrm{GN}=\mathrm{NUMA} 1$ NUMA1_HUMAN $238.26 \quad 100.0 \%$ Nuclear mitotic apparatus protein 1 GN=NUMA1 NUMA1_HUMAN $238.26 \quad 100.0 \%$ Nuclear mitotic apparatus protein $1 \mathrm{GN}=\mathrm{NUMA} 1$ NUMA1_HUMAN $238.26 \quad 100.0 \%$ Nuclear mitotic apparatus protein 1 GN=NUMA1 NUMA1_HUMAN $238.26 \quad 100.0 \%$ Nuclear mitotic apparatus protein 1 GN=NUMA1 NUMA1_HUMAN $238.26 \quad 100.0 \%$ Nuclear mitotic apparatus protein 1 GN=NUMA1 NUMA1_HUMAN $238.26 \quad 100.0 \%$ Nuclear mitotic apparatus protein 1 GN=NUMA1 NUMA1_HUMAN $238.26 \quad 100.0 \%$ Nuclear mitotic apparatus protein 1 GN=NUMA1 NUMA1_HUMAN $238.26 \quad 100.0 \%$ Nuclear mitotic apparatus protein 1 GN=NUMA1 NUMA1_HUMAN $238.26 \quad 100.0 \%$ Nuclear mitotic apparatus protein 1 GN=NUMA1 NUMA1_HUMAN $238.26 \quad 100.0 \%$ Nuclear mitotic apparatus protein 1 GN=NUMA1 NUMA1_HUMAN $238.26 \quad 100.0 \%$ Nuclear mitotic apparatus protein 1 GN=NUMA1 NUMA1_HUMAN $238.26 \quad 100.0 \%$ Nuclear mitotic apparatus protein 1 GN=NUMA1 NUMA1_HUMAN $238.26 \quad 100.0 \%$ Nuclear mitotic apparatus protein 1 GN=NUMA1 NUMA1_HUMAN $238.26 \quad 100.0 \%$ Nuclear mitotic apparatus protein 1 GN=NUMA1 NUMA1_HUMAN $238.26 \quad 100.0 \%$ Nuclear mitotic apparatus protein 1 GN=NUMA1 NUMA1_HUMAN $238.26 \quad 100.0 \%$ Nuclear mitotic apparatus protein 1 GN=NUMA1 NUMA1_HUMAN $238.26 \quad 100.0 \%$ Nuclear mitotic apparatus protein 1 GN=NUMA1 NUMA1_HUMAN $238.26 \quad 100.0 \%$ Nuclear mitotic apparatus protein 1 GN=NUMA1 NUMA1_HUMAN $238.26 \quad 100.0 \%$ Nuclear mitotic apparatus protein 1 GN=NUMA1 NUMA1_HUMAN $238.26 \quad 100.0 \%$ Nuclear mitotic apparatus protein 1 GN=NUMA1 NUMA1_HUMAN $238.26 \quad 100.0 \%$ Nuclear mitotic apparatus protein 1 GN=NUMA1 NUMA1_HUMAN $238.26 \quad 100.0 \%$ Nuclear mitotic apparatus protein 1 GN=NUMA1 NUMA1_HUMAN $238.26 \quad 100.0 \%$
$10 \quad 0.01 \% \quad 9.3 \%$ SESHTDLTFSR

$0.00 \% \quad 4.3 \% \quad$ LLDFSYEQYQK

$0.00 \% \quad 4.3 \%$ AVSDWLIASVEGR

$99.7 \% \quad 35.2$

$99.7 \% \quad 52.4$

$99.7 \% \quad 41.0$

$99.7 \% 34.9$

$0.01 \% \quad 9.6 \%$ AVPEGFVIPR

$0.01 \% \quad 9.6 \%$ GVSSQETAGIGASAHLVNFK

$0.01 \% \quad 9.6 \%$ DLLNCSFK

$0.01 \% \quad 9.6 \%$ SYSFDEIRK

$0.01 \% \quad 23.7 \%$ GIISPVGDAYK

$0.01 \% \quad 23.7 \%$ VIMAELATK

$0.01 \% \quad 23.7 \%$ WVEVDTWESLQK

$0.01 \% \quad 23.7 \%$ FIYESDVLWK

$0.01 \% \quad 23.7 \%$ YLVPDLVQEYIEK

$0.01 \% \quad 23.7 \%$ NAGVILAPLQR

$10 \quad 0.01 \% \quad 3.6 \% \quad$ LLAAFPGVTPR

$10 \quad 0.01 \% \quad 3.6 \%$ SCCAPSEAVK

$10 \quad 0.01 \% \quad 3.6 \%$ VPLSTVLLDPTR

$99.6 \% \quad 24.3 \quad 25.0 \quad 24.3$

$\begin{array}{llll}99.0 \% & 23.1 & 25.0 & 23.1\end{array}$

$\begin{array}{llll}95.2 \% & 19.1 & 25.0 & 11.1\end{array}$

$99.4 \% \quad 25.0 \quad 25.0 \quad 21.8$

$\begin{array}{llll}99.7 \% & 31.8 & 25.0 & 29.1\end{array}$

$\begin{array}{llll}99.7 \% & 37.2 & 25.0 & 37.2\end{array}$

$99.7 \% \quad 33.4 \quad 25.0 \quad 30.3$

$\begin{array}{llll}96.3 \% & 20.7 & 25.0 & 14.6\end{array}$

$99.4 \% \quad 20.9 \quad 25.0 \quad 18.6$

$\begin{array}{llll}99.7 \% & 43.8 & 25.0 & 43.8\end{array}$

$\begin{array}{llll}99.5 \% & 27.5 & 25.0 & 17.2\end{array}$

$99.7 \% \quad 67.8$

$0.01 \% \quad 3.6 \%$ TPGTGGSPQGSFADGQPAER $\quad 99.7 \% \quad 58.9$

$\begin{array}{llllll}0.01 \% & 3.6 \% & \text { TPGTGGSPQGSFADGQPAERR } & 98.0 \% & 17.5\end{array}$

$34 \quad 0.03 \% \quad 12.3 \%$ AGEVFIHK

$0.03 \% \quad 12.3 \%$ FACHSASLTVR

$0.03 \% \quad 12.3 \%$ AVVIVDDRGRPSGK

$0.03 \% \quad 12.3 \%$ GIVEFSGKPAAR

$0.03 \% \quad 12.3 \%$ GIVEFSGKPAARK

$34 \quad 0.03 \% \quad 12.3 \%$ AAPGAEFAPNKR

$130 \quad 0.13 \% \quad 24.1 \%$ LDFVCSFLQK

$130 \quad 0.13 \% \quad 24.1 \%$ CLEEKNEILQGK

$130 \quad 0.13 \% \quad 24.1 \%$ VEMLETERGQQEAK $99.0 \% \quad 36.0$

$99.7 \% \quad 34.5$

$99.7 \% \quad 38.3$

$99.7 \% \quad 49.0$

$97.0 \% \quad 15.7$

$99.7 \% \quad 47.5$

$99.1 \% 20.5$

$99.7 \% \quad 37.9$

$\begin{array}{lll}99.7 \% & 42.9\end{array}$

$130 \quad 0.13 \% \quad 24.1 \%$ QAQLAQTLQQQEQASQGLR $\quad 99.7 \% \quad 80.2$

$130 \quad 0.13 \% \quad 24.1 \%$ HQVEQLSSSLK

$130 \quad 0.13 \% \quad 24.1 \%$ DSAQTSVTQAQR

$130 \quad 0.13 \% \quad 24.1 \%$ DSAQTSVTQAQREK

$130 \quad 0.13 \% \quad 24.1 \%$ RAADALEEQQR

$130 \quad 0.13 \% \quad 24.1 \%$ AADALEEQQR

$130 \quad 0.13 \% \quad 24.1 \%$ CISELKAETR

$99.7 \% \quad 42.1$

$99.7 \% \quad 61.4$

$99.7 \% \quad 30.3$

$99.7 \% \quad 28.6$

$99.7 \% \quad 65.9$

$99.7 \% \quad 48.2$

$130 \quad 0.13 \% \quad 24.1 \%$ LQQLGEAHQAETEVLRR $99.7 \% \quad 25.6$

$130 \quad 0.13 \% \quad 24.1 \%$ VAGIESHSELQISR

$130 \quad 0.13 \% \quad 24.1 \%$ QQNELAELHANLAR

$130 \quad 0.13 \% \quad 24.1 \%$ ALQQVQEKEVR

$130 \quad 0.13 \% \quad 24.1 \%$ LADDLSTLQEK

$130 \quad 0.13 \% \quad 24.1 \%$ ELVKEPAR

$130 \quad 0.13 \% \quad 24.1 \%$ AALMESQGQQQEERGQQER

$130 \quad 0.13 \% \quad 24.1 \%$ GRAQADLALEK

$130 \quad 0.13 \% \quad 24.1 \%$ AQADLALEK

$99.7 \% \quad 65.0$

$99.7 \% \quad 41.8$

$99.7 \% \quad 51.1$

$99.7 \% \quad 63.5$

$99.0 \% 31.8$

$95.8 \% 14.3$

$99.7 \%$

$99.7 \% \quad 27.6$

$49 \quad 130 \quad 0.13 \% \quad 24.1 \%$ EKEHASGSGAQSEAAGR

$49 \quad 130 \quad 0.13 \% \quad 24.1 \%$ AEVSKLEQQCQK

$49 \quad 130 \quad 0.13 \% \quad 24.1 \%$ QQEQADSLER

$49 \quad 130 \quad 0.13 \% \quad 24.1 \%$ LLQAETASNSAR
$99.7 \% \quad 33.8$

$99.7 \% \quad 36.6$

$99.7 \% \quad 69.7$
1

1279.59

1433.69

1402.73

1084.62

1973.01

996.48

1144.56

1119.60

975.55

1519.74

1299.66

1608.85

1151.69

1141.67

1108.48

1310.77

1916.87

2072.97

900.49

1248.62

1468.82

1231.68

1359.77

1228.64

1256.63

1460.74

1647.80

2126.10

1255.66

1291.62

1548.76

1286.64

1130.54

1206.61

1978.05

1525.80

1606.83

1327.73

1232.64

941.54

2203.02

1171.64

958.52

1671.77

1447.72

1203.56 1260.65

$\begin{array}{cc}16 & 626 \\ 9 & 99 \\ 95 & 207 \\ 18 & 127 \\ 97 & 216 \\ 93 & 400 \\ 70 & 478 \\ 6 & 56 \\ 7 & 75 \\ 9 & 90 \\ 96 & 205 \\ 38 & 250 \\ 62 & 272 \\ 9 & 109 \\ 93 & 902 \\ 46 & 957 \\ 16 & 1035 \\ 16 & 1036 \\ 00 & 107 \\ 43 & 153 \\ 77 & 190 \\ 91 & 202 \\ 91 & 203 \\ 57 & 468 \\ 1 & 70 \\ 75 & 386 \\ 36 & 449 \\ 32 & 550 \\ 51 & 561 \\ 32 & 643 \\ 32 & 645 \\ 24 & 734 \\ 25 & 734 \\ 35 & 744 \\ 71 & 787 \\ 56 & 869 \\ 70 & 883 \\ 94 & 894 \\ 98 & 908 \\ 36 & 943 \\ 96 & 1004 \\ 14 & 1024 \\ 16 & 1024 \\ 98 & 1114 \\ 27 & 1138 \\ 39 & 1148 \\ 71 & 1282 \\ & \end{array}$



Nuclear mitotic apparatus protein $1 \mathrm{GN}=\mathrm{NUMA1}$ NUMA1_HUMAN $238.26 \quad 100.0 \% \quad 4$ $\begin{array}{lllll}\text { Nuclear mitotic apparatus protein } 1 \text { GN=NUMA1 NUMA1_HUMAN } 238.26 & 100.0 \% & 4\end{array}$ Nuclear mitotic apparatus protein $1 \mathrm{GN}=\mathrm{NUMA1}$ NUMA1_HUMAN $238.26 \quad 100.0 \%$ Nuclear mitotic apparatus protein 1 GN=NUMA1 NUMA1_HUMAN $238.26 \quad 100.0 \%$ Nuclear mitotic apparatus protein 1 GN=NUMA1 NUMA1_HUMAN $238.26 \quad 100.0 \%$ Nuclear mitotic apparatus protein 1 GN=NUMA1 NUMA1_HUMAN $238.26 \quad 100.0 \%$ Nuclear mitotic apparatus protein 1 GN=NUMA1 NUMA1_HUMAN $238.26 \quad 100.0 \%$ Nuclear mitotic apparatus protein 1 GN=NUMA1 NUMA1_HUMAN $238.26100 .0 \%$ Nuclear mitotic apparatus protein $1 \mathrm{GN}=$ NUMA1 NUMA1_HUMAN $238.26 \quad 100.0 \%$ Nuclear mitotic apparatus protein $1 \mathrm{GN}=\mathrm{NUMA} 1$ NUMA1_HUMAN $238.26 \quad 100.0 \%$ Nuclear mitotic apparatus protein $1 \mathrm{GN}=\mathrm{NUMA1}$ NUMA1_HUMAN $238.26 \quad 100.0 \%$ Nuclear mitotic apparatus protein 1 GN=NUMA1 NUMA1_HUMAN $238.26 \quad 100.0 \%$ Nuclear mitotic apparatus protein $1 \mathrm{GN}=\mathrm{NUMA} 1$ NUMA1_HUMAN $238.26 \quad 100.0 \%$ Nuclear mitotic apparatus protein 1 GN=NUMA1 NUMA1_HUMAN $238.26 \quad 100.0 \%$ Nuclear mitotic apparatus protein $1 \mathrm{GN}=$ NUMA1 NUMA1_HUMAN $238.26 \quad 100.0 \%$ Nuclear mitotic apparatus protein $1 \mathrm{GN}=\mathrm{NUMA1}$ NUMA1 HUMAN $238.26 \quad 100.0 \%$ Nuclear mitotic apparatus protein 1 GN=NUMA1 NUMA1_HUMAN $238.26 \quad 100.0 \%$ Nuclear mitotic apparatus protein 1 GN=NUMA1 NUMA1_HUMAN $238.26 \quad 100.0 \%$ Nuclear mitotic apparatus protein $1 \mathrm{GN}=$ NUMA1 NUMA1_HUMAN $238.26 \quad 100.0 \%$ Nuclear mitotic apparatus protein 1 GN=NUMA1 NUMA1_HUMAN $238.26 \quad 100.0 \%$ Nuclear pore complex protein Nup107 GN=NUP107 NU107_HUMAN $106.38100 .0 \%$ Nuclear pore complex protein Nup107 GN=NUP107 NU107_HUMAN $106.38 \quad 100.0 \%$ Nuclear pore complex protein Nup107 GN=NUP107 NU107_HUMAN $106.38 \quad 100.0 \%$ Nuclear pore complex protein Nup107 GN=NUP107 NU107_HUMAN $106.38100 .0 \%$ Nuclear pore complex protein Nup160 GN=NUP160 NU160_HUMAN $162.13 \quad 100.0 \%$ Nuclear pore complex protein Nup160 GN=NUP160 NU160_HUMAN $162.13100 .0 \%$ Nuclear pore complex protein Nup160 GN=NUP160 NU160_HUMAN $162.13 \quad 100.0 \%$ Nuclear pore complex protein Nup160 GN=NUP160 NU160_HUMAN $162.13 \quad 100.0 \%$ Nuclear pore complex protein Nup160 GN=NUP160 NU160 HUMAN $162.13 \quad 100.0^{\circ}$ Nuclear pore complex protein Nup160 GN=NUP160 NU160_HUMAN $162.13 \quad 100.0 \%$ Nuclear pore complex protein Nup160 GN=NUP160 NU160_HUMAN $162.13100 .0 \%$ Nuclear pore complex protein Nup160 GN=NUP160 NU160_HUMAN $162.13 \quad 100.0 \%$ Nuclear pore complex protein Nup160 GN=NUP160 NU160_HUMAN $162.13 \quad 100.0 \%$ Nuclear pore complex protein Nup160 GN=NUP160 NU160 HUMAN $162.13 \quad 100.0 \%$ Nuclear pore complex protein Nup205 GN=NUP205 NU205 HUMAN $227.93 \quad 100.0 \%$ Nuclear pore complex protein Nup205 GN=NUP205 NU205_HUMAN $227.93 \quad 100.0 \%$ Nuclear pore complex protein Nup205 GN=NUP205 NU205 HUMAN $227.93 \quad 100.0^{\circ}$ Nuclear pore complex protein Nup205 GN=NUP205 NU205_HUMAN $227.93 \quad 100.0 \%$ Nuclear pore complex protein Nup205 GN=NUP205 NU205_HUMAN $227.93 \quad 100.0 \%$ Nuclear pore complex protein Nup205 GN=NUP205 NU205 HUMAN $227.93 \quad 100.0 \%$ Nuclear pore complex protein Nup205 GN=NUP205 NU205_HUMAN $227.93 \quad 100.0 \%$ Nuclear pore complex protein Nup205 GN=NUP205 NU205 HUMAN $227.93 \quad 100.0 \%$ Nuclear pore complex protein Nup205 GN=NUP205 NU205 HUMAN $227.93 \quad 100.0 \%$ Nuclear pore complex protein Nup205 GN=NUP205 NU205_HUMAN $227.93 \quad 100.0 \%$ Nuclear pore complex protein Nup205 GN=NUP205 NU205 HUMAN $227.93 \quad 100.0 \%$ Nuclear pore complex protein Nup205 GN=NUP205 NU205_HUMAN $227.93 \quad 100.0 \%$
$49 \quad 130 \quad 0.13 \% \quad 24.1 \%$ ELGELIPLRQK

$49 \quad 130 \quad 0.13 \% \quad 24.1 \%$ ASYAEQLSMLK

$49 \quad 130 \quad 0.13 \% \quad 24.1 \%$ QFLEVELDQAR

$49 \quad 130 \quad 0.13 \% \quad 24.1 \%$ QFLEVELDQAREK

$49 \quad 130 \quad 0.13 \% \quad 24.1 \%$ YVQELAAVR

$49 \quad 130 \quad 0.13 \% \quad 24.1 \%$ ELEVMTAKYEGAK

$49 \quad 130 \quad 0.13 \% \quad 24.1 \%$ LADSDQASKVQQQK

$49 \quad 130 \quad 0.13 \% \quad 24.1 \%$ AVQAQGGESQQEAQR

$49 \quad 130 \quad 0.13 \% \quad 24.1 \%$ KQQNQELQEQLR

$49 \quad 130 \quad 0.13 \% \quad 24.1 \%$ QQNQELQEQLR

$49 \quad 130 \quad 0.13 \% \quad 24.1 \%$ LGHELQQAGLK

$130 \quad 0.13 \% \quad 24.1 \%$ TQPDGTSVPGEPASPISQR

$130 \quad 0.13 \% \quad 24.1 \%$ TTQIINITMTK

$130 \quad 0.13 \% \quad 24.1 \%$ KLDVEEPDSANSSFYSTR

$130 \quad 0.13 \% \quad 24.1 \%$ SAPASQASLR

$130 \quad 0.13 \% \quad 24.1 \%$ ATSSTQSLAR

$130 \quad 0.13 \% \quad 24.1 \%$ SQAGVSSGAPPGR

$130 \quad 0.13 \% \quad 24.1 \%$ ASMQPIQIAEGTGITTR

$130 \quad 0.13 \% \quad 24.1 \%$ VSLEPHQGPGTPESK

$130 \quad 0.13 \% \quad 24.1 \%$ QSMAFSILNTPK

$130 \quad 0.13 \% \quad 24.1 \%$ IATTTASAATAAAIGATPR

$0.01 \% \quad 5.0 \%$ SGFGEISSPVIR

$0.01 \% \quad 5.0 \%$ SGFGEISSPVIREAEVTR

$0.01 \% \quad 5.0 \%$ VLLQASQDENFGNTTPR

$0.01 \% \quad 5.0 \%$ EADLDVATITK

$0.02 \% \quad 7.1 \%$ SFVELSGAER

$0.02 \% \quad 7.1 \%$ GFNPAQPLNIR

$0.02 \% \quad 7.1 \%$ TAPLLLSYYLIK

$0.02 \% \quad 7.1 \%$ CYLVTGEGQK

$0.02 \% \quad 7.1 \%$ SEDGEIVSTPR

$0.02 \% \quad 7.1 \%$ LQYYDKVLR

$0.02 \% \quad 7.1 \%$ QLVVVLCER

$0.02 \% \quad 7.1 \%$ QGNCYLAALNCLR

$0.02 \% \quad 7.1 \% \quad$ LLSTYLER

$0.02 \% \quad 7.1 \%$ KVDAAELLR

$0.05 \% \quad 10.9 \%$ RQPEAVHLLDK

$0.05 \% \quad 10.9 \%$ ASTEGVAIQGQQGTR

$0.05 \% \quad 10.9 \%$ FTDELMEQGLTYK

$0.05 \% \quad 10.9 \%$ VLTLVSQIDVNNEFEK

$0.05 \% \quad 10.9 \%$ EVSDLIKECR

$0.05 \% \quad 10.9 \%$ QYIATIHSR

$0.05 \% \quad 10.9 \%$ LPGLQATVR

$0.05 \% \quad 10.9 \%$ DLPSADSVQYR

$0.05 \% \quad 10.9 \%$ KADNVVNIAR

$0.05 \% \quad 10.9 \%$ ADNVVNIAR

$0.05 \% \quad 10.9 \%$ YLYHGNTNPELAFESAK

$0.05 \% \quad 10.9 \%$ ILCCISCNSNIQIK
$99.1 \% \quad 29.7$

$99.7 \% \quad 39.2$

$99.7 \% \quad 72.9$

$99.7 \% \quad 59.7$

$99.7 \% \quad 39.0$

$99.7 \% \quad 51.1$

$99.7 \% \quad 39.7$

$99.7 \% \quad 64.6$

$99.7 \% 33.2$

$99.7 \% \quad 35.2$

$99.7 \% \quad 38.1$

$99.7 \% \quad 60.3$

$99.7 \% \quad 56.2$

$99.7 \% \quad 40.0$

$99.7 \% \quad 48.4$

$99.7 \% \quad 37.9$

$99.7 \% \quad 50.5$

$99.7 \% \quad 65.5$

$99.7 \% \quad 50.3$

$99.7 \% \quad 50.0$

$99.7 \% \quad 49.7$

$99.5 \% \quad 24.5$

$99.1 \% \quad 28.5$

$\begin{array}{lll}9.7 \% & 83.4\end{array}$

$99.7 \% \quad 65.8$

$99.7 \% \quad 27.0$

$99.7 \% \quad 33.8$

$99.5 \% \quad 26.8$

$99.7 \% \quad 65.0$

$99.7 \% \quad 33.3$

$99.7 \% \quad 48.2$

$99.7 \% \quad 44.3$

$98.1 \% \quad 21.1$

$98.9 \% \quad 19.0$

$99.4 \% \quad 20.7$

$99.7 \% \quad 61.8$

$99.7 \% \quad 43$.

$99.7 \% \quad 68.6$

$99.7 \% \quad 33.8$

$99.7 \% \quad 64.7$

$99.7 \% \quad 44.0$

$99.7 \% \quad 46.0$

$99.7 \% \quad 56.6$

$99.7 \% \quad 35.7$

$99.7 \% \quad 45.1$

$99.7 \% \quad 52.9$
1240.62

1347.69

1604.83

1048.58

1468.74

1545.79

1586.75

1541.80

1413.7

1193.66

1923.94

1263.70

2044.95

987.52

1021.53

1170.59

1789.91

1562.78

1352.69

1715.93

1248.66

1934.00

1889.94

1175.62

1094.55

1226.66

1394.83

1154.55

1189.57

1197.66

1115.62

1552.74

994.56

1014.59

1305.73

1502.76

1590.74

1847.98

1248.63

1088.58

954.57

1250.60

1099.62

971.53

1953.93

1722.83 $\begin{array}{cc}05 & 1415 \\ 31 & 1441 \\ 63 & 1473 \\ 63 & 1475 \\ 76 & 1484 \\ 04 & 1516 \\ 58 & 1571 \\ 74 & 1588 \\ 25 & 1636 \\ 26 & 1636 \\ 55 & 1665 \\ 44 & 1762 \\ 11 & 1821 \\ 22 & 1839 \\ 40 & 1849 \\ 50 & 1859 \\ 87 & 1899 \\ 68 & 1984 \\ 90 & 2004 \\ 46 & 2057 \\ 90 & 2108 \\ 4 & 15 \\ 4 & 21 \\ 2 & 48 \\ 27 & 637 \\ 4 & 53 \\ 90 & 700 \\ 66 & 777 \\ 16 & 925 \\ 49 & 959 \\ 60 & 968 \\ 36 & 1044 \\ 21 & 1133 \\ 91 & 1298 \\ 31 & 1339 \\ 1 & 41 \\ 0 & 84 \\ 73 & 185 \\ 86 & 201 \\ 16 & 225 \\ 05 & 313 \\ 22 & 330 \\ 72 & 582 \\ 92 & 901 \\ 93 & 901 \\ 22 & 918 \\ 19 & 932 \\ & \end{array}$

Page 111 of Table S-1-4 
Nuclear pore complex protein Nup205 GN=NUP205 NU205_HUMAN $227.93 \quad 100.0 \% \quad 21$ Nuclear pore complex protein Nup205 GN=NUP205 NU205_HUMAN $227.93 \quad 100.0 \%$ Nuclear pore complex protein Nup205 GN=NUP205 NU205_HUMAN $227.93 \quad 100.0 \% \quad 21$ Nuclear pore complex protein Nup205 GN=NUP205 NU205_HUMAN $227.93 \quad 100.0 \%$ Nuclear pore complex protein Nup205 GN=NUP205 NU205_HUMAN $227.93 \quad 100.0 \%$ Nuclear pore complex protein Nup205 GN=NUP205 NU205_HUMAN $227.93 \quad 100.0 \% \quad 2$ Nuclear pore complex protein Nup205 GN=NUP205 NU205_HUMAN $227.93 \quad 100.0 \%$ Nuclear pore complex protein Nup205 GN=NUP205 NU205_HUMAN $227.93 \quad 100.0 \% \quad 2$ Nuclear pore complex protein Nup205 GN=NUP205 NU205_HUMAN $227.93 \quad 100.0 \% 2$ Nuclear pore complex protein Nup214 GN=NUP214 NU214_HUMAN $213.62 \quad 100.0 \%$ Nuclear pore complex protein Nup214 GN=NUP214 NU214_HUMAN $213.62 \quad 100.0 \%$ Nuclear pore complex protein Nup85 GN=NUP85 NUP85_HUMAN $75.02 \quad 100.0 \%$ Nuclear pore complex protein Nup85 GN=NUP85 NUP85_HUMAN $75.02 \quad 100.0 \%$ Nuclear pore complex protein Nup85 GN=NUP85 NUP85 HUMAN 75.02 $100.0 \%$ Nuclear pore complex protein Nup85 GN=NUP85 NUP85_HUMAN $75.02 \quad 100.0 \%$ Nuclear pore complex protein Nup93 GN=NUP93 NUP93_HUMAN $93.49 \quad 100.0 \%$ Nuclear pore complex protein Nup93 GN=NUP93 NUP93 HUMAN $93.49 \quad 100.0 \%$ Nuclear pore complex protein Nup93 GN=NUP93 NUP93_HUMAN $93.49 \quad 100.0 \%$ Nuclear pore complex protein Nup93 GN=NUP93 NUP93_HUMAN $93.49100 .0 \%$ Nuclear pore complex protein Nup93 GN=NUP93 NUP93_HUMAN $93.49 \quad 100.0 \%$ Nuclear pore complex protein Nup93 GN=NUP93 NUP93_HUMAN $93.49 \quad 100.0 \%$ Nuclear pore complex protein Nup93 GN=NUP93 NUP93 HUMAN $93.49 \quad 100.0 \%$ Nuclear pore complex protein Nup93 GN=NUP93 NUP93_HUMAN $93.49 \quad 100.0 \%$ Nuclear pore complex protein Nup93 GN=NUP93 NUP93_HUMAN $93.49100 .0 \%$ Nuclear pore complex protein Nup93 GN=NUP93 NUP93_HUMAN $93.49 \quad 100.0 \%$ Nuclear pore complex protein Nup93 GN=NUP93 NUP93_HUMAN $93.49 \quad 100.0 \%$ Nuclear pore membrane glycoprotein $210 \mathrm{GN}=\mathrm{NUP} 210$ PO210_HUMAN $205.11 \quad 100.0 \%$ Nuclear pore membrane glycoprotein $210 \mathrm{GN}=\mathrm{NUP} 210 \mathrm{PO} 210$ HUMAN $205.11 \quad 100.0 \%$ Nuclear pore membrane glycoprotein 210 GN=NUP210 PO210_HUMAN $205.11 \quad 100.0 \%$ Nuclear pore membrane glycoprotein $210 \mathrm{GN}=\mathrm{NUP} 210 \mathrm{PO} 210$ HUMAN $205.11 \quad 100.0 \%$ Nuclear receptor coactivator $5 \mathrm{GN}=\mathrm{NCOA} 5$ NCOA5_HUMAN $65.54 \quad 100.0 \%$ Nuclear receptor coactivator 5 GN=NCOA5 NCOA5_HUMAN $65.54 \quad 100.0 \%$ Nuclear receptor coactivator $5 \mathrm{GN}=\mathrm{NCOA} 5$ NCOA5_HUMAN $65.54 \quad 100.0 \%$ Nuclear receptor coactivator 5 GN=NCOA5 NCOA5_HUMAN $65.54 \quad 100.0 \%$ Nuclear receptor coactivator 5 GN=NCOA5 NCOA5_HUMAN $65.54 \quad 100.0 \%$ Nuclear RNA export factor $1 \mathrm{GN}=\mathrm{NXF1}$ NXF1_HUMAN $70.19 \quad 100.0 \%$ Nuclear RNA export factor 1 GN=NXF1 NXF1_HUMAN $70.19 \quad 100.0 \%$ Nuclear RNA export factor $1 \mathrm{GN}=\mathrm{NXF1}$ NXF1_HUMAN $70.19 \quad 100.0^{\circ}$ Nuclease-sensitive element-binding protein $1 \mathrm{GN}=\mathrm{YBX} 1$ YBOX1_HUMAN $35.92 \quad 100.0 \%$ Nuclease-sensitive element-binding protein $1 \mathrm{GN}=\mathrm{YBX} 1$ YBOX1_HUMAN $35.92100 .0 \%$ Nuclease-sensitive element-binding protein $1 \mathrm{GN}=\mathrm{YBX} 1$ YBOX1 HUMAN $35.92100 .0 \%$ Nuclease-sensitive element-binding protein $1 \mathrm{GN}=$ YBX1 YBOX1_HUMAN $35.92 \quad 100.0 \%$ Nuclease-sensitive element-binding protein $1 \mathrm{GN}=\mathrm{YBX} 1$ YBOX1_HUMAN $35.92100 .0 \%$ Nuclease-sensitive element-binding protein $1 \mathrm{GN}=\mathrm{YBX} 1$ YBOX1_HUMAN $35.92 \quad 100.0 \%$ Nuclease-sensitive element-binding protein $1 \mathrm{GN}=$ YBX1 YBOX1_HUMAN $35.92 \quad 100.0 \%$ Nuclease-sensitive element-binding protein $1 \mathrm{GN}=$ YBX1 YBOX1_HUMAN $35.92100 .0 \%$ Nuclease-sensitive element-binding protein $1 \mathrm{GN}=\mathrm{YBX} 1$ YBOX1_HUMAN $35.92 \quad 100.0 \%$

(1)

4

4
11
11

1112

$\begin{array}{ll}1 & 12 \\ 1 & 12 \\ 1 & 12\end{array}$

11
11
11

11

11

11

11

11
4

4

4

4

5
5

5
5
5

5
3
3

3
3
3

3
12
12

12
12
12

12

12

$0.05 \% \quad 10.9 \%$ LVGDFTHDQSISQK

0.05\% $10.9 \%$ LTAPEDVFSK

$0.05 \% \quad 10.9 \%$ DACDGHEIGR

$0.05 \% \quad 10.9 \%$ IQQGALELLR

$0.05 \% \quad 10.9 \%$ QCLGLLSR

$0.05 \% \quad 10.9 \%$ QDTQAPVVPYWR

$0.05 \% \quad 10.9 \%$ KLLDIEGLYSK

$0.05 \% \quad 10.9 \%$ LLDIEGLYSK

$0.05 \% \quad 10.9 \%$ YSFIQALVR

$0.00 \% \quad 1.3 \%$ SAQGSSSPVPSMVQK

$0.00 \% \quad 1.3 \% \quad$ ASSTSLTSTQPTK

$0.01 \% \quad 6.6 \%$ EADASPASAGICR

$0.01 \% \quad 6.6 \%$ VSLELHIER

$0.01 \% \quad 6.6 \%$ LGSALSWSIR

$0.01 \% \quad 6.6 \%$ AIIREGSLEGS

$0.02 \% \quad 16.4 \%$ NLQEIQQAGER

$0.02 \% \quad 16.4 \%$ TSQETADVKASVLLGSR

$0.02 \% \quad 16.4 \%$ CGDLLAASQVVNR

$0.02 \% \quad 16.4 \%$ LSPATENKLR

$0.02 \% \quad 16.4 \%$ AVYCIIGR

$0.02 \% \quad 16.4 \%$ EALQYFYFLR

$0.02 \% \quad 16.4 \%$ FTSDTKPIINK

$0.02 \% \quad 16.4 \%$ LLSPVVPQISAPQSNK

$0.02 \% \quad 16.4 \%$ LVPLNQESVEER

$0.02 \% \quad 16.4 \%$ LKGTSPSSSSRPQR

$0.02 \% \quad 16.4 \%$ TLITFAGMIPYR

$0.01 \% \quad 2.5 \%$ VGQALELPLR

$0.01 \% \quad 2.5 \%$ GVAIGQTSLTASVTNK

$0.01 \% \quad 2.5 \%$ AVDPTSGQLYGLAR

$0.01 \% \quad 2.5 \%$ VIVAVGDR

$0.01 \% \quad 10.0 \%$ GPPGPESQSR

$0.01 \% \quad 10.0 \%$ QYFEEIQR

$0.01 \% \quad 10.0 \%$ RFDAERPVDCSVIVVNK

$0.01 \% \quad 10.0 \%$ NMPQADAMVLVAR

$0.01 \% \quad 10.0 \%$ MADEAILQER

$0.00 \% \quad 5.8 \%$ AQFFVEDASTASALK

$0.00 \% \quad 5.8 \%$ SAQAFTHLK

$0.00 \% \quad 5.8 \%$ AKGEIPEVAFMK

$0.03 \% \quad 47.2 \%$ VLGTVKWFNVR

$0.03 \% \quad 47.2 \%$ NGYGFINR

$0.03 \% \quad 47.2 \%$ NDTKEDVFVHQTAIK

$0.03 \% \quad 47.2 \%$ SVGDGETVEFDVVEGEK

$0.03 \% \quad 47.2 \%$

$0.03 \% \quad 47.2 \%$ GAEAANVTGPGGVPVQGSK

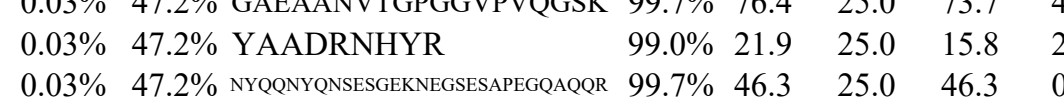

$0.03 \% \quad 47.2 \%$ NEGSESAPEGQAQQR
$99.7 \% \quad 54.5$

$99.5 \% 22.5$

$99.7 \% \quad 33.5$

$99.7 \% \quad 50.2$

$99.0 \% \quad 32.2$

$\begin{array}{lll}99.7 \% & 28.9\end{array}$

$99.7 \% \quad 41.2$

$99.7 \% \quad 52.5$

$99.7 \% \quad 58.4$

$99.7 \% \quad 38.0$

$99.7 \% \quad 37.0$

$99.7 \% \quad 55.5$

$99.7 \% \quad 33.3$

$99.7 \% \quad 81.2$

$99.7 \% \quad 58.6$

$99.7 \% \quad 42.0$

$9.7 \% \quad 38.2$

$99.7 \% \quad 54.8$

$\begin{array}{lll}99.7 \% & 34.8\end{array}$

$99.0 \% \quad 34.3$

$99.6 \% \quad 23.5$

$99.7 \% \quad 37.0$

$99.3 \% \quad 28.1$

$99.7 \% \quad 40.0$

$\begin{array}{lll}99.4 \% & 20.5\end{array}$

$99.7 \% \quad 43.0$

$99.7 \% \quad 47.9$

$99.7 \% \quad 49.7$

$99.7 \% \quad 56.0$

$98.3 \% \quad 23.2$

$99.3 \% \quad 19.1$

$99.0 \% \quad 34.9$

$99.7 \% \quad 29.3$

$99.7 \% \quad 37.6$

$99.7 \% \quad 52.8$

$99.7 \% \quad 52.7$

$99.7 \% \quad 26.6$

$99.7 \% \quad 49.3$

$\begin{array}{lll}99.7 \% & 32.8\end{array}$

$99.0 \% \quad 44.3$

$99.7 \% \quad 42.4$

$99.7 \% 34.5$
$99.7 \%$
55.6

$99.0 \% \quad 21.9$

$99.7 \% \quad 46.3$

$99.7 \% \quad 70.6$

\begin{tabular}{|c|c|c|c|c|c|c|c|c|}
\hline 52 & $0.05 \%$ & $10.9 \%$ LVGDFTHDQSISQK & $99.7 \%$ & 54.5 & 25.0 & 52.1 & 2 & 0 \\
\hline 52 & $0.05 \%$ & $10.9 \%$ LTAPEDVFSK & $99.5 \%$ & 22.5 & 25.0 & 22.5 & 1 & 0 \\
\hline 52 & $0.05 \%$ & 10.9\% DACDGHEIGR & $99.7 \%$ & 33.5 & 25.0 & 28.2 & 1 & 0 \\
\hline 52 & $0.05 \%$ & 10.9\% IQQGALELLR & $99.7 \%$ & 50.2 & 25.0 & 45.6 & 3 & 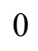 \\
\hline 52 & $0.05 \%$ & $10.9 \%$ QCLGLLSR & $99.0 \%$ & 32.2 & 25.0 & 23.7 & 2 & 0 \\
\hline 52 & $0.05 \%$ & 10.9\% QDTQAPVVPYWR & $99.7 \%$ & 28.9 & 25.0 & 28.9 & 2 & 0 \\
\hline 52 & $0.05 \%$ & $10.9 \%$ KLLDIEGLYSK & $99.7 \%$ & 41.2 & 25.0 & 37.2 & 2 & ( \\
\hline 52 & $0.05 \%$ & 10.9\% LLDIEGLYSK & $99.7 \%$ & 52.5 & 25.0 & 43.3 & 2 & 0 \\
\hline 52 & $0.05 \%$ & $10.9 \%$ YSFIQALVR & $99.7 \%$ & 58.4 & 25.0 & 53.2 & 2 & 0 \\
\hline 5 & $0.00 \%$ & $1.3 \%$ SAQGSSSPVPSMVQK & $99.7 \%$ & 38.0 & 25.0 & 36.6 & 2 & 0 \\
\hline 5 & $0.00 \%$ & $1.3 \%$ ASSTSLTSTQPTK & $99.7 \%$ & 37.0 & 25.0 & 23.7 & 3 & 0 \\
\hline 7 & $0.01 \%$ & $6.6 \%$ EADASPASAGICR & $99.7 \%$ & 55.5 & 25.0 & 55.5 & 2 & 0 \\
\hline 7 & $0.01 \%$ & $6.6 \%$ VSLELHIER & $99.7 \%$ & 33.3 & 25.0 & 33.3 & 1 & 0 \\
\hline 7 & $0.01 \%$ & $6.6 \%$ LGSALSWSIR & $99.7 \%$ & 81.2 & 25.0 & 62.9 & 2 & 0 \\
\hline 7 & $0.01 \%$ & $6.6 \%$ AIIREGSLEGS & $99.7 \%$ & 58.6 & 25.0 & 56.0 & 2 & 0 \\
\hline 19 & $0.02 \%$ & 16.4\% NLQEIQQAGER & $99.7 \%$ & 42.0 & 25.0 & 26.8 & 2 & 0 \\
\hline 19 & $0.02 \%$ & $16.4 \%$ TSQETADVKASVLLGSR & $99.7 \%$ & 38.2 & 25.0 & 38.2 & 0 & 2 \\
\hline 19 & $0.02 \%$ & 16.4\% CGDLLAASQVVNR & $99.7 \%$ & 54.8 & 25.0 & 45.6 & 2 & 0 \\
\hline 19 & $0.02 \%$ & $16.4 \%$ LSPATENKLR & $99.7 \%$ & 34.8 & 25.0 & 22.0 & 2 & 0 \\
\hline 19 & $0.02 \%$ & 16.4\% AVYCIIGR & $99.0 \%$ & 34.3 & 25.0 & 27.1 & 1 & 0 \\
\hline 19 & $0.02 \%$ & 16.4\% EALQYFYFLR & $99.6 \%$ & 23.5 & 25.0 & 23.5 & 1 & 0 \\
\hline 19 & $0.02 \%$ & 16.4\% FTSDTKPIINK & $99.7 \%$ & 37.0 & 25.0 & 36.9 & 1 & 0 \\
\hline 19 & $0.02 \%$ & 16.4\% LLSPVVPQISAPQSNK & $99.3 \%$ & 28.1 & 25.0 & 28.1 & 1 & 0 \\
\hline 19 & $0.02 \%$ & 16.4\% LVPLNQESVEER & $99.7 \%$ & 40.0 & 25.0 & 36.3 & 2 & 0 \\
\hline 19 & $0.02 \%$ & 16.4\% LKGTSPSSSSRPQR & $99.4 \%$ & 20.5 & 25.0 & 19.1 & 1 & 0 \\
\hline 19 & $0.02 \%$ & 16.4\% TLITFAGMIPYR & $99.7 \%$ & 43.0 & 25.0 & 43.0 & 4 & 0 \\
\hline 11 & $0.01 \%$ & $2.5 \%$ VGQALELPLR & $99.7 \%$ & 47.9 & 25.0 & 47.9 & 3 & 0 \\
\hline 11 & $0.01 \%$ & 2.5\% GVAIGQTSLTASVTNK & $99.7 \%$ & 49.7 & 25.0 & 49.7 & 3 & 0 \\
\hline 11 & $0.01 \%$ & 2.5\% AVDPTSGQLYGLAR & $99.7 \%$ & 56.0 & 25.0 & 46.2 & 4 & 0 \\
\hline 11 & $0.01 \%$ & $2.5 \%$ VIVAVGDR & $98.3 \%$ & 23.2 & 25.0 & 13.5 & 1 & 0 \\
\hline 11 & $0.01 \%$ & $10.0 \%$ GPPGPESQSR & $99.3 \%$ & 19.1 & 25.0 & 19.1 & 2 & 0 \\
\hline 11 & $0.01 \%$ & $10.0 \%$ QYFEEIQR & $99.0 \%$ & 34.9 & 25.0 & 21.4 & 3 & 0 \\
\hline 11 & $0.01 \%$ & $10.0 \%$ RFDAERPVDCSVIVVNK & $99.7 \%$ & 29.3 & 25.0 & 25.0 & 0 & 4 \\
\hline 11 & $0.01 \%$ & $10.0 \%$ NMPQADAMVLVAR & $99.7 \%$ & 37.6 & 25.0 & 29.6 & 1 & 0 \\
\hline 11 & $0.01 \%$ & $10.0 \%$ MADEAILQER & $99.7 \%$ & 52.8 & 25.0 & 44.3 & 1 & 0 \\
\hline 4 & $0.00 \%$ & $5.8 \%$ AQFFVEDASTASALK & $99.7 \%$ & 52.7 & 25.0 & 52.7 & 2 & 0 \\
\hline 4 & $0.00 \%$ & $5.8 \%$ SAQAFTHLK & $99.7 \%$ & 26.6 & 25.0 & 19.4 & 1 & 0 \\
\hline 4 & $0.00 \%$ & 5.8\% AKGEIPEVAFMK & $99.7 \%$ & 49.3 & 25.0 & 49.3 & 1 & 0 \\
\hline 29 & $0.03 \%$ & 47.2\% VLGTVKWFNVR & $99.7 \%$ & 32.8 & 25.0 & 32.8 & 1 & 0 \\
\hline 29 & $0.03 \%$ & $47.2 \%$ NGYGFINR & $99.0 \%$ & 44.3 & 25.0 & 34.4 & 2 & 0 \\
\hline 29 & $0.03 \%$ & 47.2\% NDTKEDVFVHQTAIK & $99.7 \%$ & 42.4 & 25.0 & 42.4 & 0 & 5 \\
\hline 29 & $0.03 \%$ & 47.2\% SVGDGETVEFDVVEGEK & $99.7 \%$ & 34.5 & 25.0 & 34.5 & 1 & 0 \\
\hline 29 & $0.03 \%$ & $47.2 \%$ SVGDGETVEFDVVEGEKGAEAANVTGPGGVPVQGSK & $99.7 \%$ & 55.6 & 25.0 & 55.6 & 0 & 2 \\
\hline 29 & $0.03 \%$ & 47.2\% GAEAANVTGPGGVPVQGSK & $99.7 \%$ & 76.4 & 25.0 & 73.7 & 4 & 0 \\
\hline 29 & $0.03 \%$ & 47.2\% YAADRNHYR & $99.0 \%$ & 21.9 & 25.0 & 15.8 & 2 & 0 \\
\hline 29 & $0.03 \%$ & $47.2 \%$ NYQQNYQNSESGEKNEGSESAPEGQAQQR & $99.7 \%$ & 46.3 & 25.0 & 46.3 & 0 & 2 \\
\hline 29 & $0.03 \%$ & 47.2\% NEGSESAPEGQAQQR & $99.7 \%$ & 70.6 & 25.0 & 69.9 & 1 & 0 \\
\hline
\end{tabular}

574.78

129.47

140.67

946.51

1459.73

1278.73

150.64

505.73

304.59

095.62

1089.61

131.60

1285.65

761.93

402.71

128.64

951.51

349.69
1263.69

1677.95

1412.74

487.79

1382.75

1095.65

546.84

1447.75

828.49

1011.49

1112.54

004.03

447.70
191.57

1191.57
1584.79

1002.54

1335.70

1318.76

940.46

1744.89

1795.82

3472.67

1695.87

1165.55

3257.40

1587.70

Page 112 of Table S-1-4 

Nuclease-sensitive element-binding protein $1 \mathrm{GN}=$ YBX1 YBOX1_HUMAN $35.92 \quad 100.0 \%$ Nuclease-sensitive element-binding protein $1 \mathrm{GN}=$ YBX1 YBOX1_HUMAN $35.92 \quad 100.0 \% \quad 12$ Nucleolar complex protein 2 homolog GN=NOC2L NOC2L HUMAN $84.92 \quad 100.0 \%$ Nucleolar complex protein 2 homolog GN=NOC2L NOC2L_HUMAN $84.92 \quad 100.0 \%$ Nucleolar complex protein 3 homolog GN=NOC3L NOC3L_HUMAN $92.55 \quad 100.0 \%$ Nucleolar complex protein 3 homolog GN=NOC3L NOC3L_HUMAN $92.55 \quad 100.0 \%$ Nucleolar complex protein 3 homolog GN=NOC3L NOC3L_HUMAN $92.55 \quad 100.0 \%$ Nucleolar complex protein 4 homolog GN=NOC4L NOC4L HUMAN $58.47 \quad 100.0 \%$ Nucleolar complex protein 4 homolog GN=NOC4L NOC4L_HUMAN $58.47 \quad 100.0 \%$ Nucleolar complex protein 4 homolog GN=NOC4L NOC4L_HUMAN $58.47 \quad 100.0 \%$ Nucleolar complex protein 4 homolog GN=NOC4L NOC4L_HUMAN $58.47 \quad 100.0 \%$ Nucleolar GTP-binding protein $1 \mathrm{GN}=$ GTPBP4 NOG1_HUMAN $73.97 \quad 100.0 \%$ Nucleolar GTP-binding protein $1 \mathrm{GN}=$ GTPBP4 NOG1_HUMAN $73.97 \quad 100.0 \%$ Nucleolar GTP-binding protein $1 \mathrm{GN}=$ GTPBP4 NOG1_HUMAN $73.97 \quad 100.0 \%$ Nucleolar GTP-binding protein 1 GN=GTPBP4 NOG1_HUMAN $73.97 \quad 100.0 \%$ Nucleolar GTP-binding protein $1 \mathrm{GN}=$ GTPBP4 NOG1_HUMAN $73.97 \quad 100.0 \%$ Nucleolar GTP-binding protein $1 \mathrm{GN}=$ GTPBP4 NOG1_HUMAN $73.97 \quad 100.0 \%$ Nucleolar GTP-binding protein $1 \mathrm{GN}=$ GTPBP4 NOG1_HUMAN $73.97 \quad 100.0 \%$ Nucleolar GTP-binding protein 2 GN=GNL2 NOG2_HUMAN $83.66 \quad 100.0 \%$ Nucleolar GTP-binding protein 2 GN=GNL2 NOG2_HUMAN $83.66 \quad 100.0 \%$ Nucleolar GTP-binding protein $2 \mathrm{GN}=\mathrm{GNL} 2$ NOG2 HUMAN $83.66100 .0 \%$ Nucleolar pre-ribosomal-associated protein 1 GN=URB1 NPA1P_HUMAN $254.39 \quad 100.0 \%$ Nucleolar pre-ribosomal-associated protein 1 GN=URB1 NPA1P_HUMAN $254.39 \quad 100.0 \%$ Nucleolar pre-ribosomal-associated protein $1 \mathrm{GN}=\mathrm{URB} 1 \mathrm{NPA1P}$ HUMAN $254.39100 .0 \%$ Nucleolar pre-ribosomal-associated protein 1 GN=URB1 NPA1P_HUMAN $254.39 \quad 100.0 \%$ Nucleolar protein $56 \mathrm{GN}=\mathrm{NOP} 56$ Nucleolar protein $56 \mathrm{GN}=\mathrm{NOP} 56$ Nucleolar protein $56 \mathrm{GN}=\mathrm{NOP} 56$ Nucleolar protein $56 \mathrm{GN}=\mathrm{NOP} 56$ Nucleolar protein $56 \mathrm{GN}=\mathrm{NOP} 56$ Nucleolar protein $56 \mathrm{GN}=\mathrm{NOP} 56$ Nucleolar protein $56 \mathrm{GN}=\mathrm{NOP} 56$ Nucleolar protein $56 \mathrm{GN}=\mathrm{NOP} 56$ Nucleolar protein $56 \mathrm{GN}=\mathrm{NOP} 56$ Nucleolar protein $58 \mathrm{GN}=\mathrm{NOP} 58$ Nucleolar protein $58 \mathrm{GN}=\mathrm{NOP} 58$ Nucleolar protein $58 \mathrm{GN}=\mathrm{NOP} 58$ Nucleolar protein $58 \mathrm{GN}=\mathrm{NOP} 58$ Nucleolar protein $58 \mathrm{GN}=\mathrm{NOP} 58$ Nucleolar protein $58 \mathrm{GN}=\mathrm{NOP} 58$ Nucleolar protein $58 \mathrm{GN}=\mathrm{NOP} 58$ Nucleolar protein $58 \mathrm{GN}=\mathrm{NOP} 58$ Nucleolar protein $58 \mathrm{GN}=\mathrm{NOP} 58$ Nucleolar protein $58 \mathrm{GN}=\mathrm{NOP} 58$ Nucleolar protein $58 \mathrm{GN}=\mathrm{NOP} 58$ Nucleolar protein $7 \mathrm{GN}=\mathrm{NOL} 7$
NOP56_HUMAN $66.05 \quad 100.0 \%$ NOP56 HUMAN $66.05 \quad 100.0 \%$ NOP56_HUMAN $66.05 \quad 100.0 \%$ NOP56 HUMAN $66.05 \quad 100.0 \%$ NOP56 HUMAN $66.05 \quad 100.0 \%$ NOP56_HUMAN $66.05 \quad 100.0 \%$ NOP56 HUMAN $66.05 \quad 100.0 \%$ NOP56_HUMAN $66.05 \quad 100.0 \%$ NOP56_HUMAN $66.05 \quad 100.0 \%$ NOP58 HUMAN $59.58 \quad 100.0 \%$ NOP58_HUMAN $59.58 \quad 100.0 \%$ NOP58 HUMAN $59.58 \quad 100.0 \%$ NOP58_HUMAN $59.58 \quad 100.0 \%$ NOP58_HUMAN $59.58 \quad 100.0 \%$ NOP58 HUMAN $59.58 \quad 100.0 \%$ NOP58_HUMAN $59.58 \quad 100.0 \%$ NOP58 HUMAN $59.58 \quad 100.0 \%$ NOP58_HUMAN $59.58 \quad 100.0 \%$ NOP58_HUMAN $59.58 \quad 100.0 \%$ NOP58 HUMAN $59.58 \quad 100.0 \%$ NOL7_HUMAN $29.43 \quad 100.0 \%$$$
6 \quad 0.01 \% \quad 4.1 \% \text { DLSSSEPVHAK }
$$$$
\begin{array}{llll}
6 & 0.01 \% & 4.1 \% & \text { SPLLPAVLEGLAK }
\end{array}
$$$$
5 \quad 0.00 \% \quad 8.1 \% \text { RLEAVLASR }
$$$$
0.00 \% \quad 8.1 \% \text { LGELLGHPSFQVK }
$$$$
0.00 \% \quad 8.1 \% \text { REPTVSSFYVK }
$$
$\begin{array}{lll}0.02 \% & 14.3 \% & \text { VVSLSEYR } \\ 0.02 \% & 14.3 \% & \text { VVSLSEYRQSL }\end{array}$

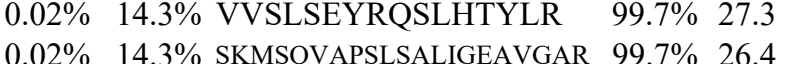

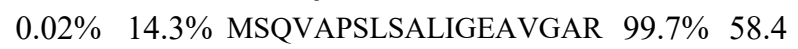
$0.02 \% \quad 14.3 \%$ LIAHAGSLTNLAK $99.0 \% 21.0$ 0.02\% 14.3\% LIAHAGSLTNLAKYPASTVQILGAEK $\quad 99.7 \% \quad 49.1$ $0.02 \% \quad 14.3 \%$ YPASTVQILGAEK $0.02 \% \quad 14.3 \%$ YGLIFHSTFIGR $0.03 \% \quad 26.3 \%$ EAHEPLAVADAK $0.03 \% \quad 26.3 \%$ LGGVIKEK $0.03 \% \quad 26.3 \%$ SQMDGLIPGVEPR $0.03 \% \quad 26.3 \%$ EMAAMCLGLAHSLSR $0.03 \% 26.3 \%$ IISDNLTYCK

$0.03 \% 26.3 \%$ LSELLPEEVEAEVK $0.03 \% \quad 26.3 \%$ TQLYEYLQNR $0.03 \% 26.3 \%$ LIAHAGSLLNLAK $0.03 \% \quad 26.3 \%$ HAASTVQILGAEK $0.03 \% \quad 26.3 \%$ YGLIYHASLVGQTSPK $0.03 \% \quad 26.3 \%$ TYDPSGDSTLPTCSK $99.7 \% 64.4$ $99.7 \% \quad 43.3$ $99.7 \% \quad 53.0$ $\begin{array}{lll}99.0 \% & 51.4\end{array}$ $\begin{array}{llll}99.7 \% & 50.3\end{array}$ $98.3 \% \quad 17.1$ $\begin{array}{llll}99.7 \% & 54.8\end{array}$ $\begin{array}{lll}99.7 \% & 29.8\end{array}$ $99.7 \% \quad 54.1$ $99.7 \% \quad 53.4$ $\begin{array}{lll}99.7 \% & 72.7\end{array}$ $99.7 \% \quad 62.3$ $99.7 \% \quad 55.6$ $99.7 \% \quad 30.2$
$5 \quad 0.00 \% \quad 8.2 \% \quad$ KLLPDTILEK

$\begin{array}{ccc}3239.53 & 205 & 234 \\ 1421.76 & 290 & 301 \\ 1623.85 & 291 & 304 \\ 1242.61 & 49 & 61 \\ 1245.67 & 169 & 178 \\ 1169.58 & 113 & 123 \\ 1056.60 & 275 & 283 \\ 1307.79 & 512 & 524 \\ 1014.61 & 17 & 25 \\ 1424.79 & 103 & 115 \\ 957.60 & 116 & 124 \\ 1312.69 & 222 & 232 \\ 1847.05 & 9 & 25 \\ 1405.74 & 104 & 115 \\ 1026.56 & 161 & 169 \\ 1334.71 & 170 & 181 \\ 1454.72 & 191 & 203 \\ 1824.96 & 369 & 384 \\ 988.54 & 576 & 584 \\ 1932.09 & 56 & 73 \\ 917.56 & 292 & 299 \\ 1478.80 & 310 & 323 \\ 1094.66 & 178 & 186 \\ 1205.62 & 400 & 409 \\ 1207.61 & 937 & 947 \\ 1128.64 & 2116 & 2126 \\ 1239.58 & 203 & 212 \\ 952.51 & 271 & 278 \\ 1951.04 & 271 & 286 \\ 2088.11 & 287 & 307 \\ 1872.98 & 289 & 307 \\ 1308.76 & 308 & 320 \\ 2666.49 & 308 & 333 \\ 1376.74 & 321 & 333 \\ 1410.75 & 348 & 359 \\ 1250.64 & 82 & 93 \\ 843.53 & 94 & 101 \\ 1414.70 & 121 & 133 \\ 1678.77 & 134 & 148 \\ 1226.61 & 197 & 206 \\ 1584.84 & 222 & 235 \\ 1327.66 & 269 & 278 \\ 1320.80 & 298 & 310 \\ 1324.72 & 311 & 323 \\ 1733.92 & 338 & 353 \\ 1628.71 & 427 & 441 \\ 1169.71 & 112 & 121 \\ & & \end{array}$


Nucleolar protein $7 \mathrm{GN}=\mathrm{NOL} 7$

Nucleolar protein $7 \mathrm{GN}=\mathrm{NOL} 7$

Nucleolar RNA helicase 2 GN=DDX2

Nucleolar RNA helicase $2 \mathrm{GN}=\mathrm{DDX} 2$ Nucleolar RNA helicase $2 \mathrm{GN}=\mathrm{DDX} 2$ : Nucleolar RNA helicase $2 \mathrm{GN}=\mathrm{DDX} 2$

Nucleolar RNA helicase 2 GN=DDX2 Nucleolar RNA helicase 2 GN=DDX21 Nucleolar RNA helicase $2 \mathrm{GN}=\mathrm{DDX} 2$ Nucleolar RNA helicase 2 GN=DDX21 Nucleolar RNA helicase $2 \mathrm{GN}=\mathrm{DDX} 2$ : Nucleolar RNA helicase 2 GN=DDX2 Nucleolar RNA helicase 2 GN=DDX2 Nucleolar RNA helicase 2 GN=DDX21

Nucleolar RNA helicase 2 GN=DDX21 Nucleolar transcription factor 1 GN=UBTF UBF1 HUMAN $89.41 \quad 100.0 \%$ Nucleolar transcription factor $1 \mathrm{GN}=$ UBTF UBF1_HUMAN $89.41 \quad 100.0 \%$ Nucleolar transcription factor 1 GN=UBTF UBF1_HUMAN $89.41 \quad 100.0 \%$ Nucleolin $\mathrm{GN}=\mathrm{NCL}$

Nucleolin $\mathrm{GN}=\mathrm{NCL}$

Nucleolin GN=NCL

Nucleolin $\mathrm{GN}=\mathrm{NCL}$

Nucleolin GN=NCL

Nucleolin $\mathrm{GN}=\mathrm{NCL}$

Nucleolin $\mathrm{GN}=\mathrm{NCL}$

Nucleolin GN=NCL

Nucleolin $\mathrm{GN}=\mathrm{NCL}$

Nucleolin $\mathrm{GN}=\mathrm{NCL}$

Nucleolin GN=NCL

Nucleolin $\mathrm{GN}=\mathrm{NCL}$

Nucleolin GN=NCL

Nucleolin $\mathrm{GN}=\mathrm{NCL}$

Nucleolin $\mathrm{GN}=\mathrm{NCL}$

Nucleolin $\mathrm{GN}=\mathrm{NCL}$

Nucleolin $\mathrm{GN}=\mathrm{NCL}$

Nucleolin $\mathrm{GN}=\mathrm{NCL}$

Nucleolin $\mathrm{GN}=\mathrm{NCL}$

Nucleolin $\mathrm{GN}=\mathrm{NCL}$

Nucleolin $\mathrm{GN}=\mathrm{NCL}$

Nucleolin $\mathrm{GN}=\mathrm{NCL}$

Nucleophosmin GN=NPM

Nucleophosmin GN=NPM

Nucleophosmin GN=NPM

Nucleophosmin GN=NPM1

Nucleophosmin GN=NPM

Nucleophosmin GN=NPM

Nucleophosmin GN=NPM1 DDX21_HUMAN $87.35 \quad 100.0 \% \quad 13$ DDX21 HUMAN $87.35 \quad 100.0 \%$ DDX21_HUMAN $87.35 \quad 100.0 \% \quad 13$ DDX21_HUMAN $87.35 \quad 100.0 \% \quad 13$ DDX21 HUMAN $87.35 \quad 100.0 \% \quad 13$ DDX21_HUMAN $87.35 \quad 100.0 \% \quad 13$ DDX21_HUMAN $87.35 \quad 100.0 \% \quad 13$ DDX21_HUMAN $87.35 \quad 100.0 \% \quad 13$ DDX21_HUMAN $87.35 \quad 100.0 \% \quad 13$ DDX21_HUMAN $87.35 \quad 100.0 \% \quad 13$ DDX21_HUMAN $87.35 \quad 100.0 \% \quad 13$ DDX21 HUMAN $87.35 \quad 100.0 \%-13$

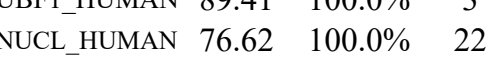
NUCL HUMAN $76.62 \quad 100.0 \% \quad 22$ NUCL_HUMAN $76.62 \quad 100.0 \% \quad 22$ NUCL_HUMAN $76.62 \quad 100.0 \% \quad 22$ NUCL_HUMAN $76.62 \quad 100.0 \% \quad 22$ NUCL_HUMAN $76.62 \quad 100.0 \% \quad 22$ NUCL HUMAN $76.62 \quad 100.0 \% \quad 22$ NUCL_HUMAN $76.62 \quad 100.0 \% \quad 22$ NUCL_HUMAN $76.62 \quad 100.0 \% \quad 22$ NUCL HUMAN $76.62 \quad 100.0 \% \quad 22$ NUCL_HUMAN $76.62 \quad 100.0 \% \quad 22$ NUCL HUMAN $76.62 \quad 100.0 \% \quad 22$ NUCL_HUMAN $76.62 \quad 100.0 \% \quad 22$ NUCL_HUMAN $76.62 \quad 100.0 \% \quad 22$ NUCL HUMAN $76.62 \quad 100.0 \% \quad 22$ NUCL_HUMAN $76.62 \quad 100.0 \% \quad 22$ NUCL_HUMAN $76.62 \quad 100.0 \% \quad 22$ NUCL_HUMAN $76.62 \quad 100.0 \% \quad 22$ NUCL_HUMAN $76.62 \quad 100.0 \% \quad 22$ NUCL HUMAN $76.62 \quad 100.0 \% \quad 22$ NUCL_HUMAN $76.62 \quad 100.0 \% \quad 22$ NUCL_HUMAN $76.62 \quad 100.0 \% \quad 22$ NPM HUMAN $32.58 \quad 100.0 \% \quad 12$ NPM_HUMAN $32.58 \quad 100.0 \% \quad 12$ NPM HUMAN $32.58 \quad 100.0 \% \quad 12$ NPM_HUMAN $32.58 \quad 100.0 \% \quad 12$ NPM_HUMAN $32.58 \quad 100.0 \% \quad 12$ NPM HUMAN $32.58 \quad 100.0 \% \quad 12$ NPM_HUMAN $32.58 \quad 100.0 \% \quad 12$
$0.02 \% \quad 19.2 \%$ KAEPSEVDMNSPK

$\begin{array}{llllllll}99.7 \% & 37.4 & 25.0 & 36.9 & 1 & 0 & 0 & 1076.59\end{array}$ $99.7 \% \quad 38.2$

$99.7 \% \quad 40.8$
$0.02 \% \quad 19.2 \%$ VTKNEEPSEEEIDAPK

$0.02 \% \quad 19.2 \%$ GRGVTFLFPIQAK

$0.02 \% \quad 19.2 \%$ GRAPQVLVLAPTR

$0.02 \% \quad 19.2 \%$ APQVLVLAPTR

$0.02 \% \quad 19.2 \%$ ELANQVSKDFSDITK

$0.02 \% \quad 19.2 \%$ NGIDILVGTPGR

$0.02 \% \quad 19.2 \%$ STYEQVDLIGKK

$0.02 \% \quad 19.2 \%$ AAVIGDVIR

$0.02 \% \quad 19.2 \%$ IGVPSATEIIK

$0.02 \% \quad 19.2 \%$ WQLSVATEQPELEGPR

$0.02 \% \quad 19.2 \%$ EGYGGFRGQR

$0.02 \% \quad 19.2 \%$ SFSKAFGQ

$0.00 \% \quad 4.8 \%$ FREDHPDLIQNAK

$0.00 \% \quad 4.8 \%$ STLTKAER

$0.00 \% \quad 4.8 \%$ QATSPASKKPAQEGGK

$126 \quad 0.13 \% \quad 33.7 \%$ VVVSPTKK

$126 \quad 0.13 \% \quad 33.7 \%$ VAVATPAKK

$126 \quad 0.13 \% \quad 33.7 \%$ ALVATPGKK

$99.5 \% \quad 26.8$

$99.7 \% \quad 54.6$

$99.7 \% \quad 48.0$

$99.7 \% \quad 47.7$

$99.7 \% \quad 58.8$

$99.7 \% \quad 46.2$

$99.6 \% \quad 28.6$

$99.7 \% \quad 36.5$

$99.7 \% \quad 41.0$

$99.6 \% 27.1$

$99.0 \% 22.5$

$99.7 \% \quad 31.7$

$99.0 \% \quad 32.4$

$99.4 \% 22.6$

$98.6 \% \quad 17.6$

$99.7 \% \quad 28.0$

$99.7 \% 29.1$

$126 \quad 0.13 \% \quad 33.7 \%$ QKVEGTEPTTAFNLFVGNLNFNK

$126 \quad 0.13 \% \quad 33.7 \%$ SAPELKTGISDVFAK

$126 \quad 0.13 \% \quad 33.7 \%$ TGISDVFAK

$\begin{array}{lll}99.7 \% & 61.1 \\ 99.7 \% & 57.4\end{array}$

$99.7 \% \quad 38.0$

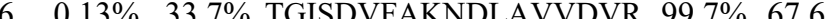

$126 \quad 0.13 \% \quad 33.7 \%$ NDLAVVDVR

$126 \quad 0.13 \% \quad 33.7 \%$ ALELTGLK

$126 \quad 0.13 \% \quad 33.7 \%$ VFGNEIKLEKPK

$99.7 \% \quad 50.8$

$96.2 \% \quad 14.3$

$99.7 \% \quad 41.4$

$126 \quad 0.13 \% \quad 33.7 \%$ VTQDELKEVFEDAAEIR

$99.5 \% 21.5$

$99.7 \% \quad 47.0$

$0.13 \% \quad 33.7 \%$ SISLYYTGEK

$94.8 \% \quad 15.3$

$126 \quad 0.13 \% \quad 33.7 \%$ ATFIKVPQNQNGK $\quad 99.7 \% \quad 39.1$

$126 \quad 0.13 \% \quad 33.7 \%$ EALNSCNKR

$126 \quad 0.13 \% \quad 33.7 \%$ AIRLELQGPR

$98.1 \% \quad 17.2$

$99.7 \% \quad 53.1$

$99.6 \% \quad 23.1$

$126 \quad 0.13 \% \quad 33.7 \%$ SQPSKTLFVK

$99.7 \% \quad 58.2$

$99.7 \% \quad 58.0$

$99.7 \% 57.9$

$126 \quad 0.13 \% \quad 33.7 \%$ IVTDRETGSSK

$26 \quad 0.13 \% \quad 33.7 \%$ GFGFVDFNSEEDAK

$99.7 \% \quad 45.6$

$99.0 \% \quad 43.3$

$99.7 \% \quad 55.6$

$96.6 \% \quad 30.4$

$0.06 \% \quad 43.2 \%$ VDNDENEHQLSLR

$0.06 \% \quad 43.2 \%$ TVSLGAGAK

$99.7 \% \quad 39.2$

$0.06 \% \quad 43.2 \%$ MSVQPTVSLGGFEITPPVVLR $\quad 99.7 \% \quad 57.1$

$99.0 \% \quad 51.0$

$95.0 \% \quad 15.4$

$0.06 \% \quad 43.2 \%$ SAPGGGSKVPQK $\begin{array}{llllll}126 & 0.13 \% & 33.7 \% & \text { TLVLSNLSYSATEETLQEVFEK } & 97.9 \% & 16.2\end{array}$

204.69

1447.67

2040.01

1433.83

1377.83

1164.7

1694.86

1211.67

1380.74

913.55

1127.67

1839.92

1126.54

871.43

1582.80

905.51

1584.83

857.55

884.56

884.56

2568.31

1562.84

937.50

1919.02

1000.54

844.51

1401.81

1991.99

1160.58

2021.96

2501.27

1444.79

1091.53

1152.68

1134.65

2200.03

1192.62

1561.68

1831.85

1023.49

1568.73

803.46

2145.02

2227.22

873.55 
Nucleophosmin GN=NPM1 Nucleophosmin GN=NPM1 Nucleophosmin GN=NPM1 Nucleophosmin GN=NPM1 Nucleophosmin GN=NPM1 Nucleoporin NDC1 GN=NDC1

Nucleoporin $\mathrm{NDC} 1 \mathrm{GN}=\mathrm{NDC} 1$ Nucleoporin NDC1 GN=NDC1 Nucleoporin NDC1 GN=NDC1

Nucleoporin NUP188 homolog GN Nucleoporin NUP188 homolog GN=NUP188 NU188 HUMAN $196.05100 .0 \%$ Nucleoporin NUP188 homolog GN=NUP188 NU188 HUMAN $196.05100 .0 \%$ Nucleoporin NUP188 homolog GN=NUP188 NU188_HUMAN $196.05 \quad 100.0 \%$ Nucleoporin NUP188 homolog GN=NUP188 NU188_HUMAN $196.05 \quad 100.0 \%$ Nucleoporin NUP188 homolog GN=NUP188 NU188_HUMAN $196.05 \quad 100.0 \%$ Nucleoporin SEH1 GN=SEH1L

Nucleoporin SEH1 GN=SEH1L

Nucleoporin-like protein 2 GN=NUPL2 Nucleoporin-like protein $2 \mathrm{GN}=\mathrm{NUPL} 2$

Nucleoporin-like protein 2 GN=NUPL2 SEH1_HUMAN $39.65 \quad 100.0 \%$ SEH1 HUMAN $39.65 \quad 100.0 \%$ NUPL2_HUMAN $44.87 \quad 100.0 \%$ NUPL2_HUMAN $44.87 \quad 100.0 \%$ NUPL2 HUMAN $44.87 \quad 100.0 \%$ Nucleoside diphosphate kinase 7 GN=NME7 NDK7_HUMAN $42.49 \quad 100.0 \%$ Nucleoside diphosphate kinase 7 GN=NME7 NDK7 HUMAN $42.49 \quad 100.0 \%$ Nucleoside diphosphate-linked moiety X motif 19, mitochondrial GN=NUDT19 NUD19 HUMAN $42.23 \quad 100.0 \%$ Nucleoside diphosphate-linked moiety X motif 19, mitochondrial GN=NUDT19 NUD19_HUMAN $42.23 \quad 100.0 \%$ Nucleosome assembly protein 1-like $1 \mathrm{GN}=\mathrm{NAP} 1 \mathrm{~L} 1 \mathrm{NP1L} 1$ HUMAN $45.38 \quad 100.0 \%$ Nucleosome assembly protein 1-like $1 \mathrm{GN}=\mathrm{NAP} 1 \mathrm{~L} 1$ NP1L1_HUMAN $45.38 \quad 100.0 \%$ Nucleosome assembly protein 1-like $1 \mathrm{GN}=\mathrm{NAP} 1 \mathrm{~L} 1$ NP1L1_HUMAN $45.38100 .0 \%$ Origin recognition complex subunit $5 \mathrm{GN}=\mathrm{ORC} 5$ ORC5_HUMAN $50.29 \quad 100.0 \%$ Origin recognition complex subunit $5 \mathrm{GN}=\mathrm{ORC} 5$ ORC5_HUMAN $50.29 \quad 100.0 \%$ Origin recognition complex subunit $5 \mathrm{GN}=\mathrm{ORC} 5$ ORC5 HUMAN $50.29 \quad 100.0 \%$ Origin recognition complex subunit $5 \mathrm{GN}=\mathrm{ORC5}$ ORC5_HUMAN $50.29 \quad 100.0 \%$ Origin recognition complex subunit 5 GN=ORC5 ORC5_HUMAN $50.29 \quad 100.0 \%$ Ornithine aminotransferase, mitochondrial GN=OAT OAT_HUMAN $48.54 \quad 100.0 \%$ Ornithine aminotransferase, mitochondrial GN=OAT OAT_HUMAN $48.54 \quad 100.0 \%$ Ornithine aminotransferase, mitochondrial GN=OAT OAT_HUMAN $48.54 \quad 100.0 \%$ Ornithine aminotransferase, mitochondrial $\mathrm{GN}=\mathrm{OAT}$ OAT HUMAN $48.54 \quad 100.0 \%$ Ornithine aminotransferase, mitochondrial GN=OAT OAT_HUMAN $48.54 \quad 100.0 \%$ Ornithine aminotransferase, mitochondrial GN=OAT OAT HUMAN $48.54 \quad 100.0^{\circ}$ Ornithine aminotransferase, mitochondrial GN=OAT OAT_HUMAN $48.54 \quad 100.0 \%$ Ornithine aminotransferase, mitochondrial GN=OAT OAT_HUMAN $48.54 \quad 100.0 \%$ Ornithine aminotransferase, mitochondrial GN=OAT OAT_HUMAN $48.54 \quad 100.0 \%$ Ornithine aminotransferase, mitochondrial GN=OAT OAT_HUMAN $48.54 \quad 100.0 \%$ Ornithine aminotransferase, mitochondrial $\mathrm{GN}=\mathrm{OAT}$ OAT HUMAN $48.54 \quad 100.0 \%$ Ornithine aminotransferase, mitochondrial GN=OAT OAT_HUMAN $48.54 \quad 100.0 \%$ Ornithine aminotransferase, mitochondrial GN=OAT OAT_HUMAN $48.54 \quad 100.0 \%$ Ornithine aminotransferase, mitochondrial GN=OAT OAT_HUMAN $48.54 \quad 100.0 \%$ Ornithine aminotransferase, mitochondrial GN=OAT OAT_HUMAN $48.54 \quad 100.0 \%$

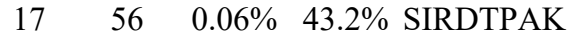

17

4

6

(1)

2

3

$\begin{array}{ll}3 & 3 \\ 3 & 3\end{array}$

2
2
2

2

3

3

3
3
5

5
5
5

5

5
5
17
17

17

17
17
17

17
17
17

$\begin{array}{ll}17 & 22 \\ 17 & 22 \\ 17 & 22\end{array}$

17
17

17
17
17

17
17
17

17

$0.06 \% \quad 43.2 \%$ GPSSVEDIK

$0.01 \% \quad 4.4 \%$ LAIQLLKR

$0.00 \% \quad 5.6 \%$ AGEIIEIINK

$0.01 \% \quad 13.6 \%$ CTVSLDFIR

$0.05 \% \quad 42.8 \%$ GLLNAIVIK
$6 \quad \begin{array}{llll}0.06 \% & 43.2 \% & 43.2 \% & \text { SNQNGKDSKPSSTPR }\end{array}$

$\quad 0.06 \% \quad 43.2 \%$ TPKGPSSVEDIK

$0.06 \% \quad 43.2 \%$ GPSSVEDIKAK

$0.01 \% \quad 7.1 \%$ LILYQEAAATNGR

$0.01 \% \quad 7.1 \%$ VSSSYPVEPK

$0.01 \% \quad 7.1 \% \quad$ KLNSPEETAFQTPK

$0.01 \% \quad 7.1 \%$ ISGSLVDTSYK

$0.01 \% \quad 4.4 \%$ LLYPLGGQTNLR

$0.01 \% \quad 4.4 \%$ LAFSVTNNVIR

$0.01 \% \quad 4.4 \% \quad$ ALLLVPASVNCLR

$0.01 \% \quad 4.4 \%$ VQRPPSAASAAPSSSK

$0.01 \% \quad 4.4 \%$ GAPSSPATGVLPSPQGK

$0.00 \% \quad 5.8 \%$ VQIFEYNENTR

$0.00 \% \quad 5.8 \%$ SFHILAIATK

$0.00 \% \quad 10.4 \%$ YSNVIQPSSFSK

$0.00 \% \quad 10.4 \%$ DQEKPYFSSFDSGASTNRK

$0.00 \% \quad 10.4 \%$ IPLKPPPLELLNV

$0.00 \% \quad 5.6 \%$ LLGPANSGVAR

$0.00 \% \quad 6.4 \% \quad$ FGLGPAPFSR

$0.00 \% \quad 6.4 \%$ EAFEEAGVLLLRPR

$0.01 \% \quad 11.5 \%$ LDGLVETPTGYIESLPR

$0.01 \% \quad 11.5 \%$ FYEEVHDLER

$0.01 \% \quad 11.5 \%$ NVDLLSDMVQEHDEPILK

$0.01 \% \quad 13.6 \%$ ESQVSILQSLFGER

$0.01 \% \quad 13.6 \%$ TYVTQTLLK

$0.01 \% \quad 13.6 \%$ LQKDDTDPGQLK

$0.01 \% \quad 13.6 \%$ FILIAAYLASYNPAR

$0.05 \% \quad 42.8 \%$ KTVQGPPTSDDIFER

$0.05 \% \quad 42.8 \%$ TVQGPPTSDDIFER

$0.05 \% \quad 42.8 \%$ YFDFLSSYSAVNQGHCHPK

$0.05 \% \quad 42.8 \%$ SQVDKLTLTSR

$\begin{array}{lll}0.05 \% & 42.8 \% & \text { AFYNNVLGEYEEYITK } \\ 0.05 \% & 42.8 \% & \text { VLPMNTGVEAGETACK }\end{array}$

$0.05 \% \quad 42.8 \%$ IVFAAGNFWGR

$0.05 \% \quad 42.8 \%$ HQVLFIADEIQTGLAR

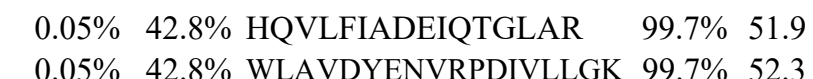

$\begin{array}{lllll}0.05 \% & 42.8 \% & \text { VAIAALEVLEEENLAENADK } & 99.7 \% & 43.8\end{array}$

$0.05 \% \quad 42.8 \%$ NELMKLPSDVVTAVR

$0.05 \% \quad 42.8 \%$ LPSDVVTAVR

$0.05 \% \quad 42.8 \%$ GKGLLNAIVIK

$0.05 \% \quad 42.8 \%$ GLLNAIVIKETK
$99.7 \% \quad 59.6 \quad 25.0 \quad 47.0$

$99.7 \% \quad 72.3 \quad 25.0 \quad 67.4$

$\begin{array}{llll}95.9 \% & 18.2 & 25.0 & 17.0\end{array}$

$\begin{array}{lllll}99.7 \% & 51.7 & 25.0 & 45.0 & 3\end{array}$

$\begin{array}{lllll}99.6 \% & 34.8 & 25.0 & 22.9 & 2\end{array}$

$\begin{array}{llll}99.3 \% & 23.2 & 25.0 & 17.3\end{array}$

$\begin{array}{llll}9.7 \% & 49.7 & 25.0 & 41.9\end{array}$

$\begin{array}{llll}9.7 .0 \% & 30.0 & 25.0 & 20.1\end{array}$

$\begin{array}{llll}98.7 \% & 24.8 & 25.0 & 18.3 \\ 99.7 \% & 39.5 & 25.0 & 32.6\end{array}$

$\begin{array}{llll}99.7 \% & 51.1 & 25.0 & 51.1\end{array}$

$\begin{array}{llll}99.2 \% & 19.3 & 25.0 & 19.3\end{array}$

$\begin{array}{llll}99.2 \% & 23.9 & 25.0 & 15.6\end{array}$

$\begin{array}{llll}99.7 \% & 48.8 & 25.0 & 48.8\end{array}$

$\begin{array}{lllll}9.5 \% & 22.1 & 25.0 & 22.1 & 0\end{array}$

$\begin{array}{llll}98.5 \% & 17.0 & 25.0 & 17.0\end{array}$

$\begin{array}{llll}9.7 \% & 40.5 & 25.0 & 19.4 \\ 99.7 \% & 28.8 & 25.0 & 20.4\end{array}$

$\begin{array}{llll}95.0 \% & 16.8 & 25.0 & 14.0\end{array}$

$\begin{array}{llll}99.7 \% & 29.8 & 25.0 & 29.1\end{array}$

$\begin{array}{llll}99.7 \% & 52.6 & 25.0 & 52.6\end{array}$

$\begin{array}{lllll}99.7 \% & 32.5 & 25.0 & 29.6 & 3\end{array}$

$\begin{array}{llll}99.6 \% & 29.8 & 25.0 & 29.8 \\ 99.7 \% & 59.2 & 25.0 & 58.3\end{array}$

$\begin{array}{lllll}99.7 \% & 44.8 & 25.0 & 42.2 & 2\end{array}$

$\begin{array}{llll}99.0 \% & 23.1 & 25.0 & 15.2\end{array}$

$\begin{array}{llll}99.3 \% & 24.0 & 25.0 & 16.1\end{array}$

$\begin{array}{llll}98.0 \% & 19.9 & 25.0 & 14.9\end{array}$

$\begin{array}{llll}99.6 \% & 24.8 & 25.0 & 24.8\end{array}$

$\begin{array}{llll}99.7 \% & 63.5 & 25.0 & 56.2\end{array}$

$\begin{array}{lllll}99.7 \% & 28.1 & 25.0 & 28.1 & 0\end{array}$

$\begin{array}{lllll}99.7 \% & 59.8 & 25.0 & 55.1 & 3\end{array}$

$\begin{array}{lllll}99.7 \% & 53.8 & 25.0 & 50.1 & 3 \\ 99.7 \% & 64.3 & 25.0 & 61.5 & 3\end{array}$

$\begin{array}{lllll}99.7 \% & 52.7 & 25.0 & 52.7 & 2\end{array}$

$\begin{array}{lllll}99.7 \% & 43.8 & 25.0 & 52.3 & 2 \\ 99.7 \% & 40.5 & 25.0 & 35.6 & 2\end{array}$

$\begin{array}{lllll}99.7 \% & 40.5 & 25.0 & 35.6 & 2\end{array}$

$\begin{array}{lllll}99.7 \% & 48.7 & 25.0 & 46.4 & 6\end{array}$

$\begin{array}{lllll}99.7 \% & 37.0 & 25.0 & 37.0 & 2\end{array}$

$\begin{array}{lllll}99.7 \% & 51.6 & 25.0 & 41.5 & 4\end{array}$

$\begin{array}{llll}99.7 \% & 55.1 & 25.0 & 55.1\end{array}$ \begin{tabular}{cc}
195 & 202 \\
207 & 221 \\
237 & 248 \\
240 & 248 \\
240 & 250 \\
380 & 392 \\
393 & 402 \\
403 & 416 \\
618 & 628 \\
501 & 512 \\
816 & 826 \\
870 & 877 \\
1142 & 1154 \\
1518 & 1533 \\
1705 & 1721 \\
197 & 207 \\
234 & 243 \\
54 & 65 \\
74 & 92 \\
411 & 423 \\
106 & 115 \\
175 & 185 \\
89 & 98 \\
131 & 144 \\
56 & 72 \\
95 & 104 \\
177 & 194 \\
12 & 25 \\
44 & 52 \\
281 & 292 \\
308 & 322 \\
409 & 417 \\
32 & 46 \\
33 & 46 \\
78 & 96 \\
103 & 113 \\
114 & 129 \\
136 & 151 \\
170 & 180 \\
256 & 271 \\
275 & 292 \\
332 & 351 \\
358 & 372 \\
363 & 372 \\
373 & 383 \\
375 & 383 \\
375 & 386 \\
& \\
\hline 5
\end{tabular}

Page 115 of Table S-1-4 

Paired amphipathic helix protein Sin3a GN=SIN3A SIN3A_HUMAN $145.18 \quad 100.0 \%$ Parafibromin $\mathrm{GN}=\mathrm{CDC} 73$ Parafibromin $\mathrm{GN}=\mathrm{CDC} 73$ CDC73_HUMAN $60.58 \quad 100.0 \%$ PCI domain-containing protein 2 GN=PCID2 PCID2_HUMAN $46.03 \quad 100.0 \%$ PCI domain-containing protein 2 GN=PCID2 PCID2_HUMAN 46.03 $100.0 \%$ PCI domain-containing protein $2 \mathrm{GN}=$ PCID2 PCID2_HUMAN $46.03 \quad 100.0 \%$ PCI domain-containing protein 2 GN=PCID2 PCID2_HUMAN $46.03 \quad 100.0 \%$ $\mathrm{PCI}$ domain-containing protein $2 \mathrm{GN}=\mathrm{PCID} 2 \mathrm{PCID} 2$ HUMAN $46.03 \quad 100.0 \%$ PCI domain-containing protein 2 GN=PCID2 PCID2_HUMAN $46.03 \quad 100.0 \%$ PCI domain-containing protein $2 \mathrm{GN}=$ PCID2 PCID2_HUMAN $46.03 \quad 100.0 \%$ PCI domain-containing protein $2 \mathrm{GN}=$ PCID2 PCID2 HUMAN $46.03 \quad 100.0 \%$ PCI domain-containing protein 2 GN=PCID2 PCID2_HUMAN $46.03 \quad 100.0 \%$ PCI domain-containing protein 2 GN=PCID2 PCID2_HUMAN 46.03 100.0\% Peptidyl-prolyl cis-trans isomerase E GN=PPIE PPIE_HUMAN $33.43 \quad 100.0 \%$ Peptidyl-prolyl cis-trans isomerase E GN=PPIE PPIE_HUMAN $33.43 \quad 100.0 \%$ Peroxiredoxin-1 GN=PRDX1 Peroxiredoxin- $1 \mathrm{GN}=\mathrm{PRDX} 1$ Peroxiredoxin- 1 GN=PRDX1 Peroxiredoxin-1 GN=PRDX1 PRDX1_HUMAN $22.11 \quad 100.0 \%$ PRDX1_HUMAN $22.11 \quad 100.0 \%$ PRDX1 HUMAN $22.11 \quad 100.0 \%$ PRDX1_HUMAN $22.11 \quad 100.0 \%$ (100.0\% Peroxisomal 2,4-dienoyl-CoA reductase GN=DECR2 DECR2_HUMAN $30.78 \quad 100.0 \%$ Peroxisomal 2,4-dienoyl-CoA reductase GN=DECR2 DECR2_HUMAN $30.78 \quad 100.0 \%$ Peroxisomal biogenesis factor $3 \mathrm{GN}=\mathrm{PEX} 3$ PEX3_HUMAN $42.14 \quad 100.0 \%$ Peroxisomal biogenesis factor 3 GN=PEX3 PEX3_HUMAN $42.14 \quad 100.0 \%$ Peroxisomal biogenesis factor $3 \mathrm{GN}=\mathrm{PEX} 3$ PEX3 HUMAN $42.14 \quad 100.0 \%$ Peroxisomal membrane protein PEX16 GN=PEX16 PEX16_HUMAN $38.63 \quad 100.0 \%$ Peroxisomal membrane protein PEX16 GN=PEX16 PEX16_HUMAN $38.63 \quad 100.0 \%$ Peroxisomal membrane protein PMP34 GN=SLC25A17 PM34 HUMAN 34.57 100.0\% Peroxisomal membrane protein PMP34 GN=SLC25A17 PM34_HUMAN $34.57 \quad 100.0 \%$

$0.05 \% \quad 42.8 \%$ LRDNGLLAKPTHGDIIR $0.05 \% \quad 42.8 \%$ DNGLLAKPTHGDIIR

$0.00 \% \quad 2.5 \%$ AVAEQVLHSQSR

$99.7 \% 31.0$

$99.7 \% \quad 38.4$

$0.00 \% \quad 2.5 \%$ TAADVVSPGANSVDSR $0.01 \% \quad 4.9 \%$ FGLFTPGSR

$0.01 \% \quad 4.9 \%$ IESILMSLPLTAR

$0.01 \% \quad 17.1 \%$ NVQSVSIIDTELKVK

$0.01 \% \quad 17.1 \%$ VVLLHGPPGTGK

$0.01 \% \quad 17.1 \%$ AGTEPSDAIR

$0.01 \% \quad 17.1 \%$ VVNAVLTQIDQIKR

$0.01 \% \quad 17.1 \%$ QYIGPPSAAAIFK

$0.01 \% \quad 17.1 \%$ LSLLLNDISR

$0.00 \% \quad 2.5 \%$ SQSIDTPGVISR

$0.00 \% \quad 2.5 \%$ DKSDSPAIQLR

$0.00 \% \quad 2.5 \% \quad$ SLLESTYQR

$0.00 \% \quad 3.8 \%$ SAPLEIGLQR

$0.00 \% \quad 3.8 \%$ NIFAILQSVK

$0.02 \% \quad 30.3 \%$ DGASCAELVSFK

$0.02 \% \quad 30.3 \%$ LQMASPEEK

$0.02 \% \quad 30.3 \%$ CTYAVGNHDFIEAYK

$0.02 \% \quad 30.3 \%$ CQTVIVQSFLR

$0.02 \% 30.3 \%$ VFANNADQQLVK

$0.02 \% \quad 30.3 \%$ AAELLMSCFR

$0.02 \% \quad 30.3 \%$ AIDSSNLKDDYSTAQR

$0.02 \% \quad 30.3 \%$ YHLMQFAEVTR

$0.02 \% \quad 30.3 \%$ AVSEGNLLLLHEALAK

$0.02 \% \quad 30.3 \%$ CGIFLILEK

$0.00 \% \quad 2.9 \% \quad$ LFDQPGDPLKR

$0.00 \% \quad 2.9 \%$ SAYESQPIR

$0.00 \% \quad 5.4 \%$ VAVACNLSGTK

$0.00 \% \quad 5.4 \%$ HVFSEEVLAK

$0.00 \% \quad 6.6 \%$ SNPQVYMDIK

$0.00 \% \quad 6.6 \% \quad$ KFDDENFILK

$0.01 \% \quad 20.1 \%$ IGHPAPNFK

$0.01 \% \quad 20.1 \%$ TIAQDYGVLK

$0.01 \% \quad 20.1 \%$ QITVNDLPVGR

$0.01 \% \quad 20.1 \%$ LVQAFQFTDK

$0.00 \% \quad 11.3 \%$ VAFITGGGSGIGFR

$0.00 \% \quad 11.3 \%$ VTASPLQR

$0.00 \% \quad 11.3 \%$ GLPDFASFSAK

$0.01 \% \quad 8.0 \%$ EAAEYIAQAR

$0.01 \% \quad 8.0 \%$ QYHFESNQR

$0.01 \% \quad 8.0 \%$ HSLSLLDLEQK

$0.00 \% \quad 6.6 \%$ HPAATAQLETAVR

$0.00 \% \quad 6.6 \%$ GFSYLLAGR

$0.01 \% \quad 17.3 \%$ FRNEDIVPTNYK

$0.01 \% \quad 17.3 \%$ LSSLDVFIIGAVAK
$99.7 \% 33.6$

$99.7 \% \quad 43.8$

$99.7 \% \quad 28.7$

$99.7 \% \quad 43.2$

$98.7 \% 23.7$

$99.7 \% \quad 36.4$

$99.7 \% \quad 34.5$

$99.7 \% 61.8$

$99.6 \% \quad 29.5$

$99.7 \% \quad 42.9$

$99.7 \% 33.5$

$99.7 \% \quad 37.0$

$99.7 \% \quad 42.8$

$99.7 \% \quad 53.0$

$99.7 \% \quad 41.0$

$99.7 \% \quad 72.9$

$99.7 \% \quad 43.5$

$99.7 \% \quad 49.8$

$99.7 \% \quad 44.2$

$99.7 \% \quad 67.8$

$99.7 \% \quad 48.4$

$99.5 \% 22.6$

$99.7 \% \quad 30.5$

$98.8 \% 20.9$

$99.5 \% \quad 24.5$

$99.7 \% 37.3$

$98.9 \% \quad 17.6$

$98.8 \% \quad 17.4$

$99.7 \% \quad 35.7$

$99.7 \% \quad 25.8$

$99.0 \% \quad 19.6$

$99.7 \% 53.2$

$98.2 \% \quad 17.1$

$99.7 \% \quad 42.7$

$99.0 \% \quad 28.5$

$\begin{array}{lll}96.0 \% & 16.8\end{array}$

$99.7 \% \quad 52.2$

$99.2 \% \quad 20.4$

$99.7 \% \quad 47.4$

$99.7 \% \quad 37.9$

$\begin{array}{lll}99.7 \% & 36.9\end{array}$

$96.3 \% \quad 24.8$

$99.7 \% \quad 89.9$
42.8

32.8

0
20.0

28.0

$\begin{array}{ll}0 & 43.8\end{array}$

$\begin{array}{ll}0 & 28.7\end{array}$

$\begin{array}{ll}5.0 & 39\end{array}$

$\begin{array}{ll}0 & 13.7\end{array}$

\begin{tabular}{ll}
\hline .0 & 34.3 \\
\hline
\end{tabular}

28.4

\begin{tabular}{ll}
5.0 & 44.4 \\
\hline
\end{tabular}

$\begin{array}{ll}5.0 & 15.4\end{array}$

$\begin{array}{ll}0 & 33.3\end{array}$

28.6

$\begin{array}{ll}5.0 & 36.0\end{array}$

$\begin{array}{ll}0 & 42.8\end{array}$

$\begin{array}{ll}48.0 & 48.9\end{array}$

\begin{tabular}{ll}
28.5 \\
\hline
\end{tabular}

$\begin{array}{ll}28.0 & 71.5\end{array}$

$5.0 \quad 34.5$

$\begin{array}{ll}5.0 & 43.4\end{array}$

$25.0 \quad 28.8$

$\begin{array}{ll}5.0 & 66.6\end{array}$

0
47.3

22.6

$\begin{array}{ll}53.0 & 23.3\end{array}$

$\begin{array}{ll}25.0 & 18.5\end{array}$

$5.0 \quad 17.0$

34.1

17.6
25.0

\begin{tabular}{ll}
17.4 \\
\hline
\end{tabular}

$\begin{array}{ll}25.0 & 17.4 \\ 25.0 & 30.0\end{array}$

$24.0 \quad 24.4$

$5.0 \quad 18.6$

$\begin{array}{ll}25.0 & 47.8\end{array}$

$\begin{array}{ll}5.0 & 17.1\end{array}$

$\begin{array}{ll}25.0 & 17.1 \\ 25.0 & 42.7\end{array}$

$\begin{array}{ll}5.0 & 12.9\end{array}$

$\begin{array}{ll}5.0 & 14.4\end{array}$

$\begin{array}{ll}25.0 & 43.8\end{array}$

$\begin{array}{ll}25.0 & 19.8\end{array}$

$\begin{array}{ll}38.0 & 38.2\end{array}$

$25.0 \quad 27.6$
1619.89

1324.70

1545.75

981.52

1459.82

1672.95

1174.69

1016.50

1596.94

1362.74

1143.67

1259.66

1229.65

1096.56

1083.62

1132.67

1283.59

1048.50

1787.8

1350.72

1346.71

1213.57

1783.85

1394.69

1677.95

1092.61

1285.69

1050.52

1119.58

1158.62

1210.58

1268.65

980.53

1107.60

1211.67

1196.63

1338.72

871.50

1139.57

1121.56

1208.54

1282.70

1364.73

983.53

1495.75

1432.84

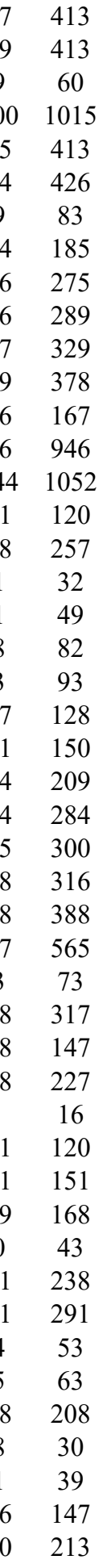


$9 \quad 0.02 \% \quad 27.7 \%$ EKPSQGIYMVYCR

$19 \quad 0.02 \% \quad 27.7 \%$ STSSHGTDEMESSSYR

$19 \quad 0.02 \% \quad 27.7 \%$ CGFCHVGEEENEAR

$190.02 \% \quad 27.7 \%$ TVLQEIKR

$19 \quad 0.02 \% \quad 27.7 \%$ CTLCSQPGATIGCEIK

$9 \quad 0.02 \% \quad 27.7 \%$ TYHYHCGVQDK

$0.08 \% \quad 34.5 \%$ GSSASLVLKR

$0.08 \% \quad 34.5 \%$ LPRPPPPEMPESLK

$0.08 \% \quad 34.5 \%$ LPRPPPPEMPESLKK

$100.0 \% \quad 17$

$100.0 \% \quad 17$

$100.0 \% \quad 17$

$100.0 \% \quad 17$
40

40

20
$0.01 \% \quad 17.3 \%$ AIATTVTYPL

$0.01 \% \quad 17.3 \%$ NILYLLHQR

$0.00 \% \quad 4.6 \%$ VVLVTGAGAGLGR

$0.00 \% \quad 4.6 \%$ AYALAFAER

$0.00 \% \quad 4.6 \%$ IDVVVNNAGILR

$0.01 \% \quad 8.5 \%$ GSATNYITR

$0.01 \% \quad 8.5 \%$ EVPREALAFIIR

$0.01 \% \quad 8.5 \%$ ITHQIVDRPGQQTSVIGR

$0.01 \% \quad 8.5 \%$ LAQEEESEAK

$0.01 \% \quad 8.5 \%$ LAQEEESEAKR

$0.02 \% \quad 27.7 \%$ DKECGQLLISENQK

$0.02 \% \quad 27.7 \%$ AEFGDFDIK

$0.00 \% \quad 7.5 \%$ SLQALGEVIEAELR

$0.00 \% \quad 7.5 \%$ VDKSAADGPR

$0.00 \% \quad 7.5 \%$ LDAEPRPPPTQEAA

$0.00 \% \quad 7.1 \%$ GLQVFKER

$0.00 \% \quad 7.1 \%$ LIITEETAK

$0.00 \% \quad 7.1 \% \quad$ NIFIECTGTDFTK

$0.00 \% \quad 7.1 \%$ VGIRETPENLAK

$0.08 \% \quad 34.5 \%$ MQVDPQKYK

$0.08 \% 34.5 \%$ GIFNGFSVTLK

$0.08 \% \quad 34.5 \%$ GIFNGFSVTLKEDGVR

$0.08 \% \quad 34.5 \%$ GWAPTFLGYSMQGLCK

$0.08 \% \quad 34.5 \%$ FGFYEVFK

$0.08 \% \quad 34.5 \%$ VLYSNMLGEENTYLWR

$0.08 \% \quad 34.5 \%$ IQTQPGYANTLR

$0.08 \% \quad 34.5 \%$ IQTQPGYANTLRDAAPK

$0.08 \% \quad 34.5 \%$ MYKEEGLK

$0.08 \% 34.5 \%$ GVAPLWMR

$0.08 \% \quad 34.5 \%$ EKGSSASLVLK

$0.08 \% \quad 34.5 \%$ GSSASLVLK

$0.00 \% \quad 6.0 \% \quad$ IISVNEDVTLR

$0.00 \% \quad 6.0 \% \quad$ ELYGSILQENPQVVYK

$0.04 \% \quad 27.1 \%$ ERPEDLELLPGDVLVVSR

$99.7 \% \quad 53.6$ $99.7 \% \quad 51.0$

$99.7 \% 71.1$

$99.7 \% \quad 31.8$

$99.7 \% \quad 49.3$

$99.7 \% \quad 53.9$

$99.1 \% 24.3$

$99.7 \% \quad 34.3$

$98.7 \% \quad 23.5$

$99.7 \% \quad 42.3$

$99.7 \% \quad 59.8$

$99.6 \% 23.8$

$99.6 \% \quad 23.2$

$99.7 \% \quad 36.7$

$99.7 \% 30.8$

$99.0 \% \quad 44.4$

$99.7 \% \quad 43.8$

$99.6 \% \quad 23.1$

$\begin{array}{ll}99.7 \% & 87.4\end{array}$

$95.9 \% \quad 17.5$

$99.6 \% \quad 26.9$

$99.0 \% \quad 36.9$

$98.7 \% \quad 23.1$

$99.7 \% \quad 32.8$

$99.7 \% \quad 30.8$

$99.7 \% \quad 43.0$

$99.7 \% \quad 55.3$

$99.7 \% \quad 61.0$

$99.7 \% \quad 53.4$

$99.0 \% \quad 32.3$

$99.7 \% \quad 52.0$

$99.7 \% \quad 55.6$

$99.7 \% \quad 38.4$

$99.0 \% \quad 42.1$

$99.0 \% \quad 45.8$

$99.7 \% \quad 39.3$

$99.7 \% \quad 44.5$

$99.7 \% \quad 53.2$

$99.7 \% \quad 47.0$

$99.7 \% \quad 27.4$

$99.7 \% \quad 34.9$

$99.7 \% \quad 55.8$

$\begin{array}{lll}99.7 \% & 43.1\end{array}$

$99.7 \% \quad 55.9$

0.04\% $27.1 \%$ AALQALGVAEGGER

$\begin{array}{ll}99.7 \% & 50.1\end{array}$

$0.04 \% \quad 27.1 \%$ ALREAAGPVGPALEPPTLPLHR $99.7 \% \quad 34.7$

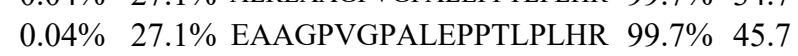

53.6

$\begin{array}{lll}6 & 67.1 & 2\end{array}$

$\begin{array}{ll}0 & 31.8\end{array}$

040.9

\begin{tabular}{lll}
0 & 46.2 \\
\hline & 15.6 & 2
\end{tabular}

0

34.3

$.0 \quad 23.5$

$\begin{array}{lll}.0 & 39.9 & 2\end{array}$

$\begin{array}{lll}54.0 & 54.1 & 2\end{array}$

$\begin{array}{ll}5.0 & 21.4\end{array}$

$\begin{array}{ll}.0 & 23.2\end{array}$

23.2
36.7

$\begin{array}{ll}.0 & 17.1\end{array}$

$\begin{array}{ll}25.0 & 17.6\end{array}$

$\begin{array}{ll}25.0 & 43.8\end{array}$

\begin{tabular}{ll}
23.0 & 23 \\
\hline
\end{tabular}

87.4

$\begin{array}{ll}25.0 & 12.4\end{array}$

26.9

0
27.6

$\begin{array}{ll}27.0 & 14.2\end{array}$

\begin{tabular}{ll}
32.8 \\
\hline
\end{tabular}

$\begin{array}{ll}5.0 & 17.2\end{array}$

$\begin{array}{ll}.0 & 48.2 \\ 25.0 & 54.5\end{array}$

$\begin{array}{lll}5.0 & 54.5 & 4\end{array}$

$\begin{array}{lll}5.0 & 53.4 & 4\end{array}$

$\begin{array}{lll}26.7 & 4 \\ 25.0 & 52.0 & 6\end{array}$

$\begin{array}{lll}5.0 & 47.4 & 15\end{array}$

$\begin{array}{ll}58.0 & 38.4\end{array}$

$\begin{array}{ll}26.0 & 26.9\end{array}$

$\begin{array}{ll}25.0 & 20.9\end{array}$

$\begin{array}{ll}5.0 & 26.7 \\ 25.0 & 29.2\end{array}$

$\begin{array}{ll}5.0 & 29.2 \\ 25.0 & 38.6\end{array}$

\begin{tabular}{l}
38.6 \\
\hline
\end{tabular}

$25.0 \quad 47.0$

$\begin{array}{ll}.0 & 20.1\end{array}$

$\begin{array}{ll}.0 & 29.7\end{array}$

$\begin{array}{lll}5.0 & 55.8 & 2\end{array}$

$\begin{array}{lll}25.0 & 43.1 & 2 \\ 25.0 & 51.9 & 4\end{array}$

$\begin{array}{lll}5.0 & 50.1 & 0\end{array}$

$\begin{array}{ll}.0 & 34.7 \\ .0 & 45.7\end{array}$

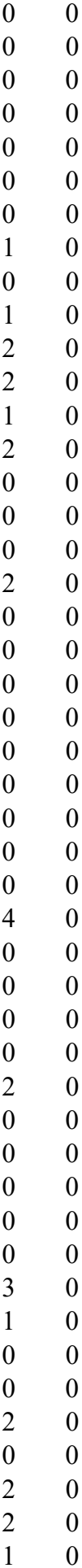

1169.68

1169.70

1011.53

1282.75

982.50

1413.82

2005.09

1133.53

1289.63

1661.82

1630.77

1760.70

1693.67

1041.49

986.60

1794.82

1407.61

1527.84

1015.52

1491.74

976.56

1017.58

1545.73

1326.74

1136.58

1182.65

1738.91

1815.86

1036.51

1987.96

1361.72

1843.97

1013.50

929.50

1118.64

861.50

1017.6

1587.86

1731.95

1258.70

1879.98

2036.10

1341.71

1924.95

2262.27

1922.05 $\begin{array}{cc}4 & 231 \\ 49 & 257 \\ 1 & 23 \\ 4 & 32 \\ 3 & 104 \\ 2 & 20 \\ 37 & 348 \\ 73 & 390 \\ 24 & 533 \\ 24 & 534 \\ 5 & 38 \\ 17 & 129 \\ 81 & 196 \\ 12 & 225 \\ 58 & 266 \\ 67 & 274 \\ 90 & 295 \\ 00 & 310 \\ 3 & 56 \\ 15 & 124 \\ 95 & 508 \\ 3 & 90 \\ 08 & 116 \\ 50 & 262 \\ 18 & 329 \\ 3 & 101 \\ 02 & 112 \\ 02 & 117 \\ 22 & 137 \\ 38 & 145 \\ 46 & 161 \\ 90 & 201 \\ 90 & 206 \\ 07 & 214 \\ 19 & 226 \\ 94 & 304 \\ 96 & 304 \\ 96 & 305 \\ 42 & 355 \\ 42 & 356 \\ 40 & 150 \\ 14 & 229 \\ 8 & 35 \\ 6 & 49 \\ 38 & 154 \\ 97 & 218 \\ 00 & 218 \\ & \end{array}$ 

$\begin{array}{lllll}\text { Phosphatidylinositol 3-kinase regulatory subunit beta GN=PIK3R2 } & \text { P85B_HUMAN } & 81.55 & 100.0 \% & 17\end{array}$ $\begin{array}{lllll}\text { Phosphatidylinositol 3-kinase regulatory subunit beta GN=PIK3R2 } & \text { P85B_HUMAN } & 81.55 & 100.0 \% & 17\end{array}$ Phosphatidylinositol 3-kinase regulatory subunit beta GN=PIK3R2 P85B_HUMAN 81.55 Phosphatidylinositol 3-kinase regulatory subunit beta GN=PIK3R2 P85B_HUMAN 81.55 Phosphatidylinositol 3-kinase regulatory subunit beta GN=PIK3R2 P85B_HUMAN 81.55 Phosphatidylinositol 3-kinase regulatory subunit beta GN=PIK3R2 P85B_HUMAN 81.55 Phosphatidylinositol 3-kinase regulatory subunit beta GN=PIK3R2 P85B_HUMAN 81.55 Phosphatidylinositol 3-kinase regulatory subunit beta GN=PIK3R2 P85B HUMAN 81.55 Phosphatidylinositol 3-kinase regulatory subunit beta GN=PIK3R2 P85B_HUMAN 81.55 Phosphatidylinositol 3-kinase regulatory subunit beta GN=PIK3R2 P85B_HUMAN 81.55 Phosphatidylinositol 3-kinase regulatory subunit beta GN=PIK3R2 P85B_HUMAN 81.55 Phosphatidylinositol 4-kinase alpha GN=PI4KA PI4KA_HUMAN 231.3 Phosphatidylinositol 4-kinase alpha GN=PI4KA PI4KA_HUMAN 231.33 Phosphatidylinositol 4-phosphate 5-kinase type-1 gamma GN=PIP5K1C PI51C_HUMAN 73.26 Phosphatidylinositol 4-phosphate 5-kinase type-1 gamma GN=PIP5K1C PI51C_HUMAN 73.26 Phosphatidylserine decarboxylase proenzyme GN=PISD PISD HUMAN 46.67 Phosphatidylserine decarboxylase proenzyme GN=PISD PISD_HUMAN 46.67 Phosphatidylserine decarboxylase proenzyme GN=PISD PISD_HUMAN 46.67 Phosphatidylserine decarboxylase proenzyme GN=PISD PISD HUMAN 46.67 Phosphoacetylglucosamine mutase GN=PGM3 AGM1_HUMAN 59.85 Phosphoacetylglucosamine mutase GN=PGM3 AGM1 HUMAN 59.8 Phosphoenolpyruvate carboxykinase [GTP], mitochondrial GN=PCK2 PCKGM_HUMAN 70.73 Phosphoenolpyruvate carboxykinase [GTP], mitochondrial GN=PCK2 PCKGM_HUMAN 70.7 . Phosphoenolpyruvate carboxykinase [GTP], mitochondrial GN=PCK2 PCKGM_HUMAN 70.73 Phosphoenolpyruvate carboxykinase [GTP], mitochondrial GN=PCK2 PCKGM_HUMAN 70.73 Phosphoenolpyruvate carboxykinase [GTP], mitochondrial GN=PCK2 PCKGM_HUMAN 70.73 Phosphoenolpyruvate carboxykinase [GTP], mitochondrial GN=PCK2 PCKGM_HUMAN 70.73 Phosphoenolpyruvate carboxykinase [GTP], mitochondrial GN=PCK2 PCKGM_HUMAN 70.73 作 Phosphoglycerate kinase $1 \mathrm{GN}=\mathrm{PGK} 1$ Phosphoglycerate kinase $1 \mathrm{GN}=\mathrm{PGK} 1$ Phosphoglycerate kinase $1 \mathrm{GN}=\mathrm{PGK} 1$ Phosphoglycerate kinase $1 \mathrm{GN}=\mathrm{PGK} 1$ Phosphoglycerate kinase $1 \mathrm{GN}=\mathrm{PGK} 1$

Phosphoglycerate mutase $1 \mathrm{GN}=$ PGAM1 Phosphoglycerate mutase $1 \mathrm{GN}=$ PGAM1 Phosphoglycerate mutase $1 \mathrm{GN}=$ PGAM1 Phosphoglycerate mutase 1 GN=PGAM1 Phosphoglycerate mutase $1 \mathrm{GN}=\mathrm{PGAM} 1$

Phosphoglycolate phosphatase GN=PGP Phosphoglycolate phosphatase GN=PGP Phosphoglycolate phosphatase GN=PGP Phosphoglycolate phosphatase GN=PGP Phosphoglycolate phosphatase GN=PGP PGK1_HUMAN $44.62 \quad 100.0 \%$ PGK1_HUMAN $44.62 \quad 100.0 \%$ PGK1_HUMAN $44.62 \quad 100.0 \%$ PGAM1_HUMAN $28.80 \quad 100.0 \%$ PGAM1_HUMAN $28.80 \quad 100.0 \%$ PGAM1 HUMAN $28.80 \quad 100.0 \%$ PGAM1_HUMAN $28.80 \quad 100.0 \%$ PGAM1_HUMAN $28.80 \quad 100.0 \%$ PGP HUMAN $34.01 \quad 100.0 \%$ PGP_HUMAN $34.01 \quad 100.0 \%$ PGP HUMAN $34.01 \quad 100.0 \%$ PGP_HUMAN $34.01 \quad 100.0 \%$ PGP_HUMAN $34.01 \quad 100.0 \%$ $\begin{array}{llll}\text { Phosphoribosyl pyrophosphate synthase-associated protein } 1 \text { GN=PRPSAP1 } & \text { KPRA_HUMAN } & 39.39 & 100.0 \% \\ \text { Phosphoribosyl pyrophosphate synthase-associated protein } 1 \text { GN=PRPSAP1 } & \text { KPRA_HUMAN } & 39.39 & 100.0 \%\end{array}$

$\begin{array}{llll}\text { Phosphoribosyl pyrophosphate synthase-associated protein } 1 \text { GN=PRPSAP1 } & \text { KPRA_HUMAN } & 39.39 & 100.0 \% \\ \text { Phosphoribosyl pyrophosphate synthase-associated protein } 1 \text { GN=PRPSAP1 } & \text { KPRA_HUMAN } & 39.39 & 100.0 \%\end{array}$

20

20

20

17
17
$40 \quad 0.04 \% \quad 27.1 \%$ FLLQHLGR $0.01 \% \quad 10.5 \%$ ILNFGQVK $0.01 \% \quad 10.5 \%$ ELFCHNER
$0.01 \% \quad 4.1 \%$ VISTTDAER $0.02 \% \quad 17.3 \%$ TVIVTPSQR $\begin{array}{llllllll}.0 \% & 40.8 & 25.0 & 40.8 & 2 & 0 & 0 & 983.58\end{array}$ $\begin{array}{llllllll}99.7 \% & 41.9 & 25.0 & 37.3 & 6 & 0 & 0 & 1228.74\end{array}$ $\begin{array}{llllllll}99.5 \% & 26.1 & 25.0 & 21.8 & 2 & 0 & 0 & 1321.75\end{array}$

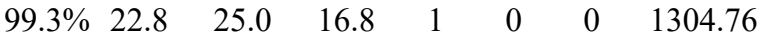
$0.04 \% \quad 27.1 \%$ LDTRLLYPVSK $\begin{array}{lllll}99.7 \% & 33.5 & 25.0 & 32.9 & 0\end{array}$ $\begin{array}{lllll}99.2 \% & 34.4 & 25.0 & 0.0 & 2\end{array}$ $99.5 \% \quad 24.0 \quad 25.0 \quad 17.9$ $\begin{array}{lllll}98.8 \% & 20.3 & 25.0 & 16.8 & 2\end{array}$ $99.7 \% \quad 39.9 \quad 25.0 \quad 27.7$ $99.0 \% \quad 50.2 \quad 25.0 \quad 23.5$ $\begin{array}{lllll}99.0 \% & 32.5 & 25.0 & 15.2 & 1\end{array}$ $99.7 \% \quad 36.4 \quad 25.0 \quad 30.7 \quad 2$ $\begin{array}{llll}99.0 \% & 18.7 & 25.0 & 18.7\end{array}$ $99.7 \% \quad 43.3 \quad 25.0 \quad 32.1$ $\begin{array}{llll}98.9 \% & 23.7 & 25.0 & 16.0\end{array}$

$0.00 \% \quad 1.0 \% \quad$ FKNTEAIGNEVTR

$0.00 \% \quad 4.5 \%$ GVDASGETTYKK

$0.00 \% \quad 4.5 \%$ QAQGAQSTSDEKRPVGQK

$0.01 \% \quad 10.5 \%$ GVTYSLESFLGPR

$0.01 \% \quad 10.5 \%$ GSYNDFSFVTHTNR

$0.01 \% \quad 4.1 \%$ AFVRPSGTEDVVR

$0.02 \% \quad 17.3 \%$ VLSGDLGQLPTGIRDFVEHSAR

$0.02 \% \quad 17.3 \%$ GQLGNWMSPADFQR

$0.02 \% \quad 17.3 \%$ TMYVLPFSMGPVGSPLSR $0.02 \% \quad 17.3 \%$ LGTPVLQALGDGDFVK $0.02 \% \quad 17.3 \%$ GVPLVYEAFNWR $0.02 \% \quad 17.3 \%$ HGVFVGSAMR

$0.02 \% \quad 17.3 \%$ EGALDLSGLR

$0.01 \% \quad 18.7 \%$ ACANPAAGSVILLENLR $0.01 \% \quad 18.7 \%$ LGDVYVNDAFGTAHR

$0.01 \% \quad 18.7 \%$ ALESPERPFLAILGGAK $0.01 \% \quad 18.7 \%$ ITLPVDFVTADKFDENAK $0.01 \% \quad 18.7 \%$ VLPGVDALSNI $0.01 \% \quad 18.1 \%$ HYGGLTGLNK $0.01 \% \quad 18.1 \%$ ALPFWNEEIVPQIK $0.01 \% \quad 18.1 \%$ VLIAAHGNSLR $0.01 \% \quad 18.1 \%$ KAMEAVAAQGK $0.01 \% \quad 18.1 \%$ AMEAVAAQGK $0.01 \% \quad 17.4 \%$ GETAVPGAPEALR $0.01 \% \quad 17.4 \%$ FIAGTGCLVR $0.01 \% \quad 17.4 \%$ AVEMAAQR $0.01 \% \quad 17.4 \%$ QADIIGKPSR $0.01 \% \quad 17.4 \%$ TILTLTGVSTLGDVK $0.02 \% \quad 25.3 \%$ VFSANSTAACTELAK $0.02 \% \quad 25.3 \%$ GQDIFIIQTIPR
$99.7 \% 26.5$ $96.5 \% \quad 24.1$

$99.7 \% 57.9$ $\begin{array}{llll}96.9 \% & 17.4\end{array}$ $99.7 \% \quad 58.5$ $99.7 \% \quad 41.4$ $99.7 \% 49.6$

$99.7 \% \quad 46.0$ $99.2 \% 24.0$ $99.7 \% 53.8$ $99.2 \% \quad 25.0$ $99.6 \% \quad 24.1$ $99.7 \% \quad 46.3$ $99.7 \% \quad 48.8$ $99.7 \% 48.5$ $99.7 \% 36.4$ $99.7 \% 36.6$ $\begin{array}{llll}99.7 \% & 36.7\end{array}$ $99.7 \% \quad 45.0$ $\begin{array}{lll}99.7 \% & 57.7\end{array}$ $99.7 \% \quad 41.0$ $\begin{array}{llll}99.7 \% & 55.4\end{array}$ $99.7 \% \quad 41.0$ $99.7 \% \quad 36.4$ $\begin{array}{llll}99.0 \% & 37.4\end{array}$ $99.1 \% \quad 26.3$ $\begin{array}{llll}99.7 \% & 78.3\end{array}$ $99.7 \% \quad 60.8$ $99.7 \% 68.5$

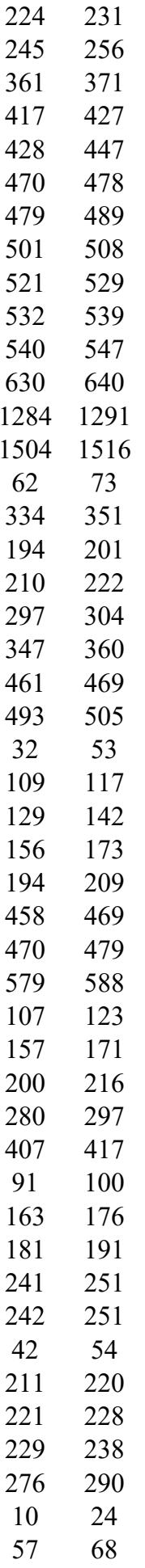

Page 118 of Table S-1-4 
Plectin GN=PLEC

Plectin GN=PLEC

Plectin GN=PLEC

Plectin GN=PLEC

Plectin GN=PLEC

Plectin GN=PLEC

Plectin GN=PLEC

Plectin GN=PLEC

Plectin GN=PLEC

Plectin $\mathrm{GN}=\mathrm{PLEC}$

Plectin GN=PLEC

Plectin GN=PLEC

Plectin GN=PLEC

Plectin GN=PLEC

Plectin GN=PLEC
$0.02 \% \quad 25.3 \%$ NIIGVIPYFPYSK
$0.02 \% \quad 25.3 \%$ EIQGFFSPVDNLR $0.02 \% \quad 25.3 \%$ EIQGFFSFPVDNLR

$0.02 \% \quad 25.3 \%$ EKPPITVVGDVGGR

$99.7 \% \quad 49.5$ $99.7 \% \quad 48.8$

$99.7 \% \quad 39.5$

$0.02 \% \quad 25.3 \%$ LIEESSVDEVVVTNTVPHEVQK $\quad 99.7 \% \quad 68.7$

$0.04 \% \quad 42.3 \%$ GGLVLFSANSNSSCMELSK

$0.04 \% \quad 42.3 \%$ VQVYQEPNR

$0.04 \% \quad 42.3 \%$ VQVYQEPNRETR

$0.04 \% \quad 42.3 \%$ VQIQESVR

$0.04 \% \quad 42.3 \%$ SIIGVIPYFPYSK

$0.04 \% \quad 42.3 \%$ EIQGFFNIPVDNLR

$0.04 \% \quad 42.3 \%$ RAQSFAER

$0.04 \% \quad 42.3 \%$ SVAAIHPSLEIPMLIPK

$0.04 \% \quad 42.3 \%$ EKPPITVVGDVGGR

$0.04 \% \quad 42.3 \%$ IFVMATHGLLSSDAPR

$99.7 \% \quad 46.3$

$99.7 \% \quad 41.0$

$96.3 \% 16.3$

$99.0 \% 57$.

$99.7 \% 43.8$

$99.7 \% \quad 57.2$

$99.0 \% \quad 33.2$

$99.1 \% \quad 19.3$

$99.7 \% \quad 39.5$

$99.7 \% \quad 60.9$

$0.04 \% \quad 42.3 \%$ RIEESAIDEVVVTNTIPHEVQK $99.7 \% \quad 39.1$

$0.04 \% \quad 42.3 \%$ TVDISMILSEAIR

$0.00 \% \quad 10.2 \%$ FCADLVEHLK

$0.00 \% \quad 10.2 \%$ NVLIVEDVVGTGR

$0.01 \% 21.9 \%$ QVVNFGPGPAK

$0.01 \% 21.9 \%$ LPHSVLLEIQK

$0.01 \% \quad 21.9 \%$ GVGISVLEMSHR

$0.01 \% \quad 21.9 \%$ IINNTENLVR

$0.01 \% \quad 21.9 \%$ FGVIFAGAQK

$0.01 \% \quad 21.9 \%$ NVGSAGVTVVIVR

$4 \quad 0.01 \% \quad 21.9 \%$ ASLYNAVTIEDVQK

$0.00 \% \quad 6.6 \%$ VQTVLGLVEPSK

$0.00 \% \quad 6.6 \%$ ILQEAGADISK

$0.00 \% \quad 14.9 \%$ GLGAQEQGATDHIK

$99.7 \% \quad 55.1$

$99.1 \% \quad 23.0$

$99.7 \% \quad 49.8$

$99.7 \% \quad 38.5$

$99.7 \% \quad 38.8$

$99.7 \% \quad 47.1$

$99.7 \% \quad 49.3$

$99.7 \% \quad 35.9$

$99.7 \% \quad 68.3$

$99.7 \% \quad 79.7$

$99.7 \% \quad 42.1$

$96.3 \% \quad 19.3$

$99.7 \% \quad 58.4$

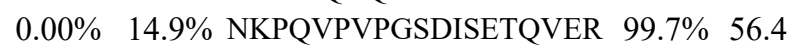

$0.00 \% \quad 14.9 \%$ ASAQDAGDHVQPPEGR $99.5 \% 23.5$

$0.00 \% \quad 7.4 \% \quad$ SAAQAAAQTNSNAAGK $\quad 99.7 \% \quad 53.7$

$0.00 \% \quad 7.4 \%$ VGRRPDQQLQGEGK

$0.08 \% \quad 8.3 \%$ VPDVQDGVR

$0.08 \% \quad 8.3 \% \quad$ ARSDEGQLSPATR

$0.08 \% \quad 8.3 \%$ SDEGQLSPATR

$0.08 \% \quad 8.3 \%$ IKELQNAGDR

$0.08 \% \quad 8.3 \% \quad$ AVVQLKPR

$0.08 \% \quad 8.3 \% \quad$ LQLEACETR

$0.08 \% \quad 8.3 \%$ GTQGAEEVLR

$0.08 \% \quad 8.3 \%$ AQLEPVASPAK

$0.08 \% \quad 8.3 \% \quad$ SIQEELQQLR

$0.08 \% \quad 8.3 \%$ LQLEATER

$0.08 \% \quad 8.3 \%$ GGAEGELQALR

$0.08 \% \quad 8.3 \%$ QVQVALETAQR

$0.08 \% \quad 8.3 \%$ SAEAELQSK

$0.08 \% \quad 8.3 \%$ SAEAELQSKR

PLEC_HUMAN $531.78 \quad 100.0 \%$

PLEC HUMAN $531.78 \quad 100.0 \%$

PLEC_HUMAN $531.78 \quad 100.0 \% \quad 40$
$98.5 \% \quad 18.3$

$99.7 \% \quad 52.8$

$99.7 \% \quad 36.9$

$99.7 \% \quad 34.8$

$99.2 \% \quad 22.0$

$99.0 \% \quad 29.2$

$99.7 \% \quad 32.2$

$99.7 \% \quad 51.2$

$99.7 \% \quad 35.0$

$99.7 \% \quad 68.0$

$\begin{array}{lll}97.8 \% & 23.7\end{array}$

$99.7 \% \quad 46.8$

$99.7 \% \quad 58.9$

$98.6 \% \quad 22.7$

$99.7 \% \quad 38.0$

$99.7 \% \quad 28.5$
151

1668.84

1423.79

2451.26

2000.94

1132.57

1518.77

958.53

1483.82

1661.86

964.50

1816.04

1423.79

1714.89

2506.31

1447.78

1231.61

1370.76

1113.61

1276.76

1284.67

1185.66

1037.58

1270.75

1550.81

1269.74

1144.62

1424.7

2080.07

1634.75

1460.71

1567.83

984.51

1387.69

1160.55

1143.61

910.58

1119.55

1059.54

1110.62

1243.66

959.52

1100.57

1242.68

962.48

1118.58 1412.79
103 $39 \quad 152$ $\begin{array}{ll}96 & 250 \\ & 317\end{array}$ $18 \quad 36$ 59 $61 \quad 68$ $103 \quad 115$ $151 \quad 164$ $195 \quad 202$ $233 \quad 249$ $250 \quad 263$ $293 \quad 308$ $309 \quad 330$ $338 \quad 350$ $136 \quad 148$ $\begin{array}{cc}6 & 16 \\ 17 & 27\end{array}$ $34 \quad 45$ $52 \quad 61$ 191200 356 $8 \quad 19$ $215 \quad 225$ $44 \quad 57$ $191 \quad 209$ $272 \quad 287$ $109 \quad 122$ $402 \quad 410$ $712 \quad 724$ $714 \quad 724$ $809 \quad 818$ $\begin{array}{ll}927 & 934 \\ 131 & 1139\end{array}$ $1234 \quad 1243$ $1428 \quad 1438$ $1554 \quad 1563$ $1596 \quad 1603$ $1606 \quad 1616$ $1699 \quad 1709$ $\begin{array}{ll}710 & 1718 \\ 710 & 1719\end{array}$ 17811792 
Plectin GN=PLEC Plectin GN=PLEC Plectin GN=PLEC Plectin GN=PLEC Plectin GN=PLEC Plectin GN=PLEC

Plectin GN=PLEC Plectin GN=PLEC Plectin GN=PLEC Plectin GN=PLEC Plectin GN=PLEC Plectin GN=PLEC Plectin GN=PLEC Plectin GN=PLEC

Plectin GN=PLEC Plectin GN=PLEC Plectin GN=PLEC Plectin GN=PLEC Plectin GN=PLEC

Plectin GN=PLEC Plectin GN=PLEC Plectin GN=PLEC Plectin GN=PLEC Plectin GN=PLEC Plectin GN=PLEC \begin{tabular}{lllll} 
Poly [ADP-ribose] polymerase 1 GN=PARP1 PARP1_HUMAN & 113.09 & $100.0 \%$ & 28 \\
\hline
\end{tabular} Poly [ADP-ribose] polymerase 1 GN=PARP1 PARP1_HUMAN $113.09 \quad 100.0 \% 28$ Poly [ADP-ribose] polymerase 1 GN=PARP1 PARP1_HUMAN $113.09 \quad 100.0 \%$ Poly [ADP-ribose] polymerase 1 GN=PARP1 PARP1 HUMAN $113.09 \quad 100.0 \% 28$ Poly [ADP-ribose] polymerase $1 \mathrm{GN}=$ PARP1 PARP1_HUMAN $113.09 \quad 100.0 \% 28$ Poly [ADP-ribose] polymerase 1 GN=PARP1 PARP1_HUMAN $113.09 \quad 100.0 \% 28$ Poly [ADP-ribose] polymerase 1 GN=PARP1 PARP1_HUMAN $113.09 \quad 100.0 \% 28$ Poly [ADP-ribose] polymerase 1 GN=PARP1 PARP1_HUMAN $113.09 \quad 100.0 \%$ Poly [ADP-ribose] polymerase 1 GN=PARP1 PARP1_HUMAN $113.09 \quad 100.0 \% 28$ Poly [ADP-ribose] polymerase 1 GN=PARP1 PARP1_HUMAN $113.09 \quad 100.0 \% \quad 28$ Poly [ADP-ribose] polymerase 1 GN=PARP1 PARP1_HUMAN $113.09 \quad 100.0 \% 28$ Poly [ADP-ribose] polymerase 1 GN=PARP1 PARP1_HUMAN $113.09 \quad 100.0 \% 28$ Poly [ADP-ribose] polymerase 1 GN=PARP1 PARP1_HUMAN $113.09 \quad 100.0 \%$ Poly [ADP-ribose] polymerase 1 GN=PARP1 PARP1_HUMAN $113.09 \quad 100.0 \% 28$ Poly [ADP-ribose] polymerase 1 GN=PARP1 PARP1_HUMAN $113.09 \quad 100.0 \% 28$ Poly [ADP-ribose] polymerase 1 GN=PARP1 PARP1_HUMAN $113.09 \quad 100.0 \% \quad 28$ Poly [ADP-ribose] polymerase 1 GN=PARP1 PARP1_HUMAN $113.09 \quad 100.0 \% 28$ Poly [ADP-ribose] polymerase 1 GN=PARP1 PARP1_HUMAN $113.09 \quad 100.0 \% 28$ Poly [ADP-ribose] polymerase $1 \mathrm{GN}=$ PARP1 PARP1_HUMAN $113.09 \quad 100.0 \% \quad 28$ Poly [ADP-ribose] polymerase 1 GN=PARP1 PARP1_HUMAN $113.09 \quad 100.0 \% 28$ Poly [ADP-ribose] polymerase 1 GN=PARP1 PARP1_HUMAN $113.09 \quad 100.0 \%$
$41 \quad 78 \quad 0.08 \% \quad 8.3 \%$ LQAEEVAQQK

41

41

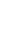

41

41

4

41

41

4

41
41

41
41
41

41
41

41
41

41
41

4
4

4
0

41

41
41
41

41
37

37
37
37

37
37

37
37

$\begin{array}{llll}37 & 103 & 0.10 \% & 31.5 \% \text { GQVKEEGINK } \\ 37 & 103 & 0.10 \% & 31.5 \% \text { GGAAVDPDSGLEHSAHVLEK }\end{array}$

$\begin{array}{lllll}37 & 103 & 0.10 \% & 31.5 \% & \text { GGAAVDPDSGLEHSAHVLEK } \\ 37 & 10.10 \% & 31.5 \% \text { GGKVFSATLGLVDIVK }\end{array}$

$37 \quad 103 \quad 0.10 \% \quad 31.5 \%$ VFSATLGLVDIVK

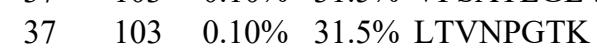

$37 \quad 103 \quad 0.10 \% \quad 31.5 \%$ SKLPKPVQDLIK

$\begin{array}{llll}37 & 103 & 0.10 \% & 31.5 \% \\ 37 & 103 & 0.10 \% & 31.5 \%\end{array}$

$37 \quad 103 \quad 0.10 \% \quad 31.5 \%$ AMVEYEIDLQK

$103 \quad 0.10 \% \quad 31.5 \%$ AEKTLGDFAAEYAK

$103 \quad 0.10 \% \quad 31.5 \%$ TLGDFAAEYAKSNR $\begin{array}{lllll}99.7 \% & 36.4 & 25.0 & 28.3 & 4\end{array}$

$99.7 \% \quad 43.6 \quad 25.0 \quad 25.4$

$99.5 \% \quad 22.5 \quad 25.0 \quad 18.2$

$99.7 \% \quad 33.2 \quad 25.0 \quad 30.9$

$99.7 \% \quad 43.3 \quad 25.0 \quad 31.6$

$\begin{array}{llll}99.7 \% & 46.7 & 25.0 & 32.2\end{array}$

$\begin{array}{llll}99.7 \% & 35.0 & 25.0 & 26.8\end{array}$

$\begin{array}{llll}99.7 \% & 41.3 & 25.0 & 29.6\end{array}$

$\begin{array}{llll}99.7 \% & 50.0 & 25.0 & 50.0\end{array}$

$99.7 \% \quad 75.1 \quad 25.0 \quad 49.6$

$\begin{array}{llll}99.7 \% & 60.7 & 25.0 & 54.2\end{array}$

$\begin{array}{llll}99.6 \% & 23.9 & 25.0 & 19.7\end{array}$

$\begin{array}{llll}97.2 \% & 16.1 & 25.0 & 16.1\end{array}$

$\begin{array}{llll}99.7 \% & 33.7 & 25.0 & 23.5\end{array}$

$\begin{array}{llll}99.7 \% & 41.4 & 25.0 & 36.5\end{array}$

$\begin{array}{llll}99.7 \% & 53.1 & 25.0 & 41.0\end{array}$

$95.4 \% \quad 13.9 \quad 25.0 \quad 13.9$

$\begin{array}{llll}98.9 \% & 21.8 & 25.0 & 20.2\end{array}$

$\begin{array}{llll}99.5 \% & 23.1 & 25.0 & 18.2\end{array}$

$\begin{array}{llll}99.7 \% & 34.3 & 25.0 & 34.3\end{array}$

$99.7 \% \quad 35.9 \quad 25.0 \quad 21.7$

$\begin{array}{llll}99.7 \% & 46.2 & 25.0 & 46.2\end{array}$

$\begin{array}{llll}99.7 \% & 41.9 & 25.0 & 41.9\end{array}$

$\begin{array}{llll}99.7 \% & 32.5 & 25.0 & 15.9\end{array}$

$\begin{array}{llll}98.2 \% & 17.8 & 25.0 & 17.8\end{array}$

$\begin{array}{llll}99.7 \% & 46.2 & 25.0 & 41.6\end{array}$

$\begin{array}{lllllllll}103 & 0.10 \% & 31.5 \% & \text { TAEAGGVTGKGQDGIGSK } & 99.7 \% & 41.5 & 25.0 & 41.5 & 3\end{array}$

$99.7 \% \quad 66.9 \quad 25.0 \quad 60.7$

$\begin{array}{llll}99.7 \% & 57.3 & 25.0 & 56.3\end{array}$

$\begin{array}{llll}99.7 \% & 71.7 & 25.0 & 58.8\end{array}$

$\begin{array}{lllll}98.7 \% & 21.6 & 25.0 & 14.9 & 0\end{array}$

$99.7 \% \quad 73.0 \quad 25.0 \quad 67.1 \quad 2$

$\begin{array}{llll}99.7 \% & 34.3 & 25.0 & 34.3\end{array}$

$\begin{array}{llll}99.7 \% & 28.5 & 25.0 & 27.2\end{array}$

$99.7 \% \quad 50.7 \quad 25.0 \quad 43.9$

$\begin{array}{llll}99.7 \% & 52.5 & 25.0 & 46.6\end{array}$

$\begin{array}{llll}99.7 \% & 27.9 & 25.0 & 18.6\end{array}$

$\begin{array}{llll}99.7 \% & 52.8 & 25.0 & 52.8\end{array}$

$\begin{array}{llll}99.7 \% & 67.0 & 25.0 & 55.9\end{array}$

$99.7 \% \quad 27.9 \quad 25.0 \quad 23.3$

$\begin{array}{llll}99.7 \% & 41.3 & 25.0 & 41.3\end{array}$

$\begin{array}{llll}99.7 \% & 47.5 & 25.0 & 47.5\end{array}$

$\begin{array}{llll}99.7 \% & 60.3 & 25.0 & 33.7\end{array}$

$\begin{array}{llll}99.0 \% & 26.9 & 25.0 & 17.5\end{array}$

$\begin{array}{llll}99.5 \% & 22.7 & 25.0 & 22.7\end{array}$

$\begin{array}{llll}98.7 \% & 17.5 & 25.0 & 17.2\end{array}$

$\begin{array}{llll}99.7 \% & 62.5 & 25.0 & 56.0\end{array}$

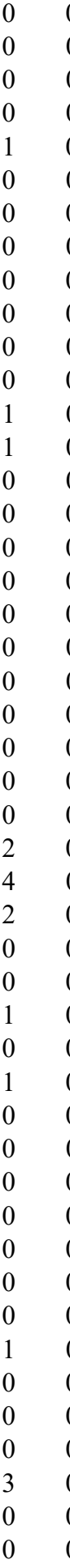

042.59

1444.71

1171.66

1231.63

1046.5

1330.67

1059.58

1322.66

1015.55

1569.83

1300.65

1309.69

1783.92

1556.83

1410.73
1020.58

918.50

877.48

1428.79

1284.72

1613.87

1566.89

915.53

1129.60

1291.63

1632.82

1513.75

1185.58

1542.75

2024.02

1360.66

1793.95

1399.72

1000.65

1059.62

1007.56

1624.81

1066.59

1101.59

1988.97

1603.94

1361.80

829.48

1365.85

1259.60

1338.66 
Polyadenylate-binding protein 4 GN=PABPC4 PABP4_HUMAN $70.78 \quad 100.0 \%$ Polyadenylate-binding protein $4 \mathrm{GN}=$ PABPC4 PABP4_HUMAN $70.78 \quad 100.0 \%$ Polyadenylate-binding protein $4 \mathrm{GN}=$ PABPC4 PABP4_HUMAN $70.78 \quad 100.0 \%$ Polymerase delta-interacting protein $2 \mathrm{GN}=$ POLDIP2 PDIP2 HUMAN $42.03 \quad 100.0 \%$ Polymerase delta-interacting protein 2 GN=POLDIP2 PDIP2_HUMAN $42.03 \quad 100.0 \%$ Polymerase delta-interacting protein 2 GN=POLDIP2 PDIP2_HUMAN $42.03 \quad 100.0 \%$ Polymerase delta-interacting protein 2 GN=POLDIP2 PDIP2_HUMAN $42.03 \quad 100.0 \%$ Polymerase delta-interacting protein 2 GN=POLDIP2 PDIP2_HUMAN $42.03 \quad 100.0 \%$ Polymerase delta-interacting protein 2 GN=POLDIP2 PDIP2 HUMAN $42.03 \quad 100.0 \%$ Polymerase delta-interacting protein 2 GN=POLDIP2 PDIP2_HUMAN $42.03 \quad 100.0 \%$ Polymerase delta-interacting protein 2 GN=POLDIP2 PDIP2_HUMAN $42.03 \quad 100.0 \%$ Polymerase delta-interacting protein $2 \mathrm{GN}=$ POLDIP2 PDIP2 HUMAN $42.03 \quad 100.0 \%$ Polymerase delta-interacting protein 2 GN=POLDIP2 PDIP2_HUMAN $42.03 \quad 100.0 \%$ Polymerase delta-interacting protein 3 GN=POLDIP3 PDIP3_HUMAN $46.09 \quad 100.0 \%$ Polymerase delta-interacting protein 3 GN=POLDIP3 PDIP3_HUMAN $46.09 \quad 100.0 \%$ Polymerase delta-interacting protein 3 GN=POLDIP3 PDIP3_HUMAN $46.09 \quad 100.0 \%$ Polypyrimidine tract-binding protein $1 \mathrm{GN}=\mathrm{PTBP} 1 \mathrm{PTBP} 1$ HUMAN $57.22 \quad 100.0^{\circ}$ Polypyrimidine tract-binding protein $1 \mathrm{GN}=$ PTBP1 PTBP1_HUMAN $57.22 \quad 100.0 \%$ Polypyrimidine tract-binding protein $1 \mathrm{GN}=$ PTBP1 PTBP1_HUMAN $57.22 \quad 100.0 \%$ Polypyrimidine tract-binding protein $1 \mathrm{GN}=\mathrm{PTBP} 1$ PTBP1_HUMAN 57.22 Polypyrimidine tract-binding protein 1 GN=PTBP1 PTBP1_HUMAN 57.22 Polypyrimidine tract-binding protein $1 \mathrm{GN}=$ =PTBP1 PTBP1 HUMAN 57.22 Polypyrimidine tract-binding protein 1 GN=PTBP1 PTBP1_HUMAN 57.22 Polypyrimidine tract-binding protein 1 GN=PTBP1 PTBP1_HUMAN 57.22 Polypyrimidine tract-binding protein $1 \mathrm{GN}=$ PTBP1 PTBP1_HUMAN 57.22 Polypyrimidine tract-binding protein $1 \mathrm{GN}=\mathrm{PTBP} 1 \mathrm{PTBP} 1$ _HUMAN 57.22 Polypyrimidine tract-binding protein $1 \mathrm{GN}=\mathrm{PTBP} 1$ PTBP1_HUMAN 57.22 Polypyrimidine tract-binding protein $1 \mathrm{GN}=\mathrm{PTBP} 1$ PTBP1_HUMAN 57.22 Pre-mRNA 3'-end-processing factor FIP1 GN=FIP1L1 FIP1_HUMAN 66.53 Pre-mRNA 3'-end-processing factor FIP1 GN=FIP1L1 FIP1 HUMAN 66.53 Pre-mRNA 3'-end-processing factor FIP1 GN=FIP1L1 FIP1_HUMAN 66.53 Pre-mRNA-processing factor 19 GN=PRPF19 PRP19_HUMAN 55.18 Pre-mRNA-processing factor 19 GN=PRPF19 PRP19_HUMAN 55.18 Pre-mRNA-processing factor 19 GN=PRPF19 PRP19_HUMAN 55.18 100.0\% Pre-mRNA-processing factor $19 \mathrm{GN}=$ PRPF19 PRP19 HUMAN $55.18100 .0 \%$ Pre-mRNA-processing factor $19 \mathrm{GN}=$ PRPF19 PRP19_HUMAN $55.18 \quad 100.0 \%$ Pre-mRNA-processing factor 19 GN=PRPF19 PRP19_HUMAN $55.18 \quad 100.0 \%$ Pre-mRNA-processing factor 19 GN=PRPF19 PRP19 HUMAN $55.18 \quad 100.0 \%$ Pre-mRNA-processing factor 19 GN=PRPF19 PRP19_HUMAN $55.18 \quad 100.0 \%$ Pre-mRNA-processing factor 6 GN=PRPF6 PRP6_HUMAN $106.93 \quad 100.0 \%$ Pre-mRNA-processing factor 6 GN=PRPF6 PRP6_HUMAN $106.93 \quad 100.0 \%$ Pre-mRNA-processing factor 6 GN=PRPF6 PRP6_HUMAN $106.93 \quad 100.0 \%$ Pre-mRNA-processing factor 6 GN=PRPF6 PRP6 HUMAN $106.93 \quad 100.0 \%$ Pre-mRNA-processing factor 6 GN=PRPF6 PRP6_HUMAN $106.93 \quad 100.0 \%$ Pre-mRNA-processing factor 6 GN=PRPF6 PRP6_HUMAN $106.93 \quad 100.0 \%$ Pre-mRNA-processing-splicing factor 8 GN=PRPF8 PRP8 HUMAN $273.61 \quad 100.0 \%$ Pre-mRNA-processing-splicing factor 8 GN=PRPF8 PRP8_HUMAN $273.61 \quad 100.0 \%$

(1)

12

12

12

(10

12

12

12

1

1

3

12

12
12
12

12
12
12

12

8
6

6
47

$\begin{array}{cc}6 & 7 \\ 47 & 54 \\ 47 & 54\end{array}$
$0.05 \% \quad 33.4 \%$ LFPLIQTMHSNLAGK $0.05 \% \quad 33.4 \%$ EAAQKVGAVAAATS $0.02 \% 32.1 \%$ VLETVGVFEVPK $0.02 \% \quad 32.1 \%$ GVVLFPWQAR $0.02 \% \quad 32.1 \%$ LYDRDVASAAPEK $0.02 \% 32.1 \%$ THTYYQVLIDAR $0.02 \% \quad 32.1 \%$ SQTEAVTFLANHDDSR $0.02 \% 32.1 \%$ FLLYDQTK

$0.02 \% \quad 32.1 \%$ LENLDSDVVQLR $0.02 \% \quad 32.1 \%$ IFSLSGTLETVR $0.02 \% \quad 32.1 \%$ GVVGREPVLSK $0.02 \% \quad 32.1 \%$ FERPDGSHFDVR $0.00 \% \quad 9.0 \% \quad$ KQQTTVPQKPR $0.00 \% \quad 9.0 \%$ INVVNNHQAK $0.00 \% \quad 9.0 \%$ VVQNDAYTAPALPSSIR $0.05 \% \quad 29.0 \%$ SAGVPSRVIHIR

$0.05 \% \quad 29.0 \%$ KLPIDVTEGEVISLGLPFGK

$0.05 \% \quad 29.0 \%$ VTNLLMLK

$0.05 \% \quad 29.0 \%$ ELKTDSSPNQAR

$0.05 \% \quad 29.0 \%$ NNQFQALLQYADPVSAQHAK

$0.05 \% \quad 29.0 \%$ LSLDGQNIYNACCTLR

$\begin{array}{ll}0.05 \% & 29.0 \% \text { IAIPGLAGAGNSVLLVSNLNPER } \\ 0.05 \% & 29.0 \% \text { ITL SKHQNVQLPR }\end{array}$

$0.05 \% \quad 29.0 \%$ ITLSKHQNVQLPR

$0.05 \% \quad 29.0 \%$ HQNVQLPR

$\begin{array}{ll}0.05 \% & 29.0 \% \\ 0.05 \% & 29.0 \% \text { EGQEDQGLTK }\end{array}$

$0.05 \% \quad 29.0 \%$ EGQEDQGLTKDYGNSPLHR

$0.05 \% \quad 29.0 \%$ VLFSSNGGVVK

$0.00 \% \quad 7.7 \%$ TGAPQYGSYGTAPVNLNIK

$0.00 \% \quad 7.7 \%$ TGNSEKETALPSTK

$0.00 \% \quad 7.7 \%$ ANENSNIQVLSER

$0.01 \% \quad 18.1 \%$ LTKEVTAAR

$0.01 \% \quad 18.1 \%$ LQDKATVLTTER

$0.01 \% \quad 18.1 \%$ TVPEELVKPEELSK

$0.01 \% \quad 18.1 \%$ TVPEELVKPEELSKYR

$0.01 \% \quad 18.1 \%$ SSEQILATLK

$0.01 \% \quad 18.1 \%$ KVTSVVFHPSQDLVFSASPDATIR

$0.01 \% \quad 18.1 \%$ TLQLDNNFEVK

$0.01 \% \quad 18.1 \%$ FIASTGMDR

$0.01 \% \quad 5.8 \%$ IQQQFSDLKR

$0.01 \% \quad 5.8 \%$ AVVAQAVR

$0.01 \% \quad 5.8 \%$ AAELETDIRAK

$0.01 \% \quad 5.8 \%$ AIYAYALQVFPSKK

$0.01 \% \quad 5.8 \%$ SKWLAGDVPAAR

$14 \quad 0.01 \% \quad 5.8 \%$ WLAGDVPAAR

$139 \quad 0.14 \% \quad 20.2 \%$ KWQQLQAK

$139 \quad 0.14 \% \quad 20.2 \% \quad$ YVNGSTYQR $\begin{array}{lllll}99.7 \% & 42.0 & 25.0 & 35.1 & 3 \\ 99.7 \% & 44.0 & 25.0 & 39.0 & 2\end{array}$

$\begin{array}{lllll}99.7 \% & 36.8 & 25.0 & 36.8 & 2\end{array}$

$99.7 \% \quad 83.1 \quad 25.0 \quad 82.0$

$\begin{array}{llll}99.5 \% & 23.4 & 25.0 & 20.5\end{array}$

$\begin{array}{llll}99.7 \% & 44.8 & 25.0 & 30.5\end{array}$

$99.7 \% \quad 40.0 \quad 25.0 \quad 39.4$

$\begin{array}{lllll}99.7 \% & 78.1 & 25.0 & 78.1 & 2\end{array}$

$\begin{array}{llll}99.0 \% & 24.6 & 25.0 & 15.6\end{array}$

$\begin{array}{llll}99.7 \% & 78.3 & 25.0 & 72.8\end{array}$

$\begin{array}{lllll}99.7 \% & 80.3 & 25.0 & 62.7 & 3\end{array}$

$\begin{array}{lllll}99.7 \% & 33.5 & 25.0 & 29.9 & 2\end{array}$

$98.5 \% \quad 18.7 \quad 25.0 \quad 16.2 \quad 0$

$\begin{array}{llll}99.3 \% & 20.0 & 25.0 & 20.0\end{array}$

$\begin{array}{llll}95.4 \% & 14.2 & 25.0 & 14.2\end{array}$

$\begin{array}{llll}98.9 \% & 25.7 & 25.0 & 25.7\end{array}$

$\begin{array}{llll}99.6 \% & 24.4 & 25.0 & 20.5\end{array}$

$\begin{array}{ccccc}99.7 \% & 61.8 & 25.0 & 61.8\end{array}$

$\begin{array}{lllll}99.0 \% & 50.1 & 25.0 & 0.0 & 4\end{array}$

$\begin{array}{llll}99.7 \% & 40.8 & 25.0 & 25.0\end{array}$

$\begin{array}{llll}99.7 \% & 43.2 & 25.0 & 43.2\end{array}$

$\begin{array}{lllll}99.7 \% & 64.8 & 25.0 & 64.8 & 6\end{array}$

$\begin{array}{lllll}99.7 \% & 56.4 & 25.0 & 56.4 & 5 \\ 97.5 \% & 17.1 & 25.0 & 17.1 & 0\end{array}$

$\begin{array}{llll}99.0 \% & 28.9 & 25.0 & 28.9\end{array}$

$\begin{array}{lllll}99.7 \% & 27.5 & 25.0 & 19.3 & 4\end{array}$

$\begin{array}{lllll}99.7 \% & 67.6 & 25.0 & 67.6 & 0\end{array}$

$\begin{array}{lllll}99.7 \% & 48.7 & 25.0 & 35.6 & 5\end{array}$

$\begin{array}{lllll}99.7 \% & 55.6 & 25.0 & 55.0 & 2 \\ 99.6 \% & 29.9 & 25.0 & 26.5 & 0\end{array}$

$\begin{array}{llll}99.7 \% & 53.0 & 25.0 & 52.5\end{array}$

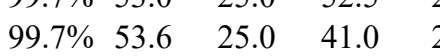

$99.7 \% \quad 41.0 \quad 25.0 \quad 31.2$

$\begin{array}{lllll}99.7 \% & 63.0 & 25.0 & 60.9 & 2\end{array}$

$\begin{array}{llll}99.7 \% & 26.2 & 25.0 & 23.4\end{array}$

$\begin{array}{llll}99.7 \% & 46.1 & 25.0 & 38.1\end{array}$

$\begin{array}{llll}99.7 \% & 43.2 & 25.0 & 43.2\end{array}$

$\begin{array}{llll}99.7 \% & 37.5 & 25.0 & 24.4\end{array}$

$\begin{array}{llll}99.7 \% & 26.4 & 25.0 & 19.9\end{array}$

$\begin{array}{llll}99.7 \% & 32.1 & 25.0 & 26.2\end{array}$

$\begin{array}{llll}99.0 \% & 44.2 & 25.0 & 42.3\end{array}$

$\begin{array}{lllll}99.7 \% & 45.5 & 25.0 & 34.1 & 2\end{array}$

$\begin{array}{lllll}99.7 \% & 42.3 & 25.0 & 38.0 & 2\end{array}$

$\begin{array}{lllll}99.7 \% & 35.7 & 25.0 & 31.5 & 1\end{array}$

$\begin{array}{lllll}96.6 \% & 15.5 & 25.0 & 15.5 & 1\end{array}$

$\begin{array}{llll}95.3 \% & 20.5 & 25.0 & 9.5\end{array}$

$\begin{array}{cccc}98.4 \% & 17.0 & 25.0 & 17.0\end{array}$

0
0
0
0
2
0
1
0
0
0
0
1
1
0
0
2
2
0
0
4
0
3
1
0
0
2
0
0
0
0
0
0
0
2
0
0
0
0
2
0
0
0
0
0
0
0
0
0
0
0
0

0

1685.90

1273.67

1316.75

1172.66

1434.72

1479.76

1790.83

1027.55

1400.74

1322.73

1140.67

1461.69

1310.75

1136.62

1801.94

1291.76

2112.20

931.56

1345.67

2243.12

1897.89

2275.28

1533.89

991.54

1104.52

2144.00

1106.62

1950.99

1462.74

1473.73

988.58

1374.76

1597.87

1917.03

1089.62

2601.37

1320.68

1013.47

1262.69

813.49

1216.65

1598.89

1270.69

1055.56

1029.58

1087.52

Page 123 of Table S-1-4 

Pre-mRNA-processing-splicing factor 8 GN=PRPF8 PRP8_HUMAN $273.61 \quad 100.0 \% \quad 47$ $\begin{array}{llll}\text { Pre-mRNA-processing-splicing factor } 8 \text { GN=PRPF8 } & \text { PRP8_HUMAN } 273.61 & 100.0 \% & 47\end{array}$ Pre-mRNA-processing-splicing factor 8 GN=PRPF8 PRP8_HUMAN $273.61 \quad 100.0 \% \quad 47$ Pre-mRNA-processing-splicing factor 8 GN=PRPF8 PRP8_HUMAN $273.61 \quad 100.0 \%$ Pre-mRNA-processing-splicing factor 8 GN=PRPF8 PRP8_HUMAN $273.61 \quad 100.0 \% \quad 4$ Pre-mRNA-processing-splicing factor 8 GN=PRPF8 PRP8_HUMAN $273.61 \quad 100.0 \%$ Pre-mRNA-processing-splicing factor 8 GN=PRPF8 PRP8_HUMAN 273.61 $100.0 \% \quad 4$ Pre-mRNA-processing-splicing factor 8 GN=PRPF8 PRP8 HUMAN $273.61 \quad 100.0 \% \quad 4$ Pre-mRNA-processing-splicing factor 8 GN=PRPF8 PRP8_HUMAN $273.61 \quad 100.0 \%$ Pre-mRNA-processing-splicing factor 8 GN=PRPF8 PRP8_HUMAN $273.61 \quad 100.0 \%$ Pre-mRNA-processing-splicing factor $8 \mathrm{GN}=$ PRPF8 PRP8_HUMAN $273.61 \quad 100.0 \% \quad 4$ Pre-mRNA-processing-splicing factor 8 GN=PRPF8 PRP8_HUMAN 273.61 $100.0 \% \quad 4$ Pre-mRNA-processing-splicing factor 8 GN=PRPF8 PRP8_HUMAN $273.61 \quad 100.0 \% \quad 4$ Pre-mRNA-processing-splicing factor 8 GN=PRPF8 PRP8_HUMAN $273.61 \quad 100.0 \% \quad 4$ Pre-mRNA-processing-splicing factor 8 GN=PRPF8 PRP8_HUMAN $273.61 \quad 100.0 \%$ Pre-mRNA-processing-splicing factor $8 \mathrm{GN}=$ =PRPF8 PRP8 HUMAN $273.61 \quad 100.0 \% \quad 4$ Pre-mRNA-processing-splicing factor 8 GN=PRPF8 PRP8_HUMAN $273.61 \quad 100.0 \%$ Pre-mRNA-processing-splicing factor 8 GN=PRPF8 PRP8_HUMAN $273.61 \quad 100.0 \%$ Pre-mRNA-processing-splicing factor $8 \mathrm{GN}=$ PRPF8 $\quad$ PRP8 HUMAN $273.61 \quad 100.0 \% \quad 4$ Pre-mRNA-processing-splicing factor 8 GN=PRPF8 PRP8_HUMAN $273.61 \quad 100.0 \% \quad 4$ Pre-mRNA-processing-splicing factor 8 GN=PRPF8 PRP8_HUMAN $273.61 \quad 100.0 \%$ Pre-mRNA-processing-splicing factor 8 GN=PRPF8 PRP8_HUMAN $273.61 \quad 100.0 \% \quad 4$ Pre-mRNA-processing-splicing factor 8 GN=PRPF8 PRP8_HUMAN $273.61 \quad 100.0 \%$ Pre-mRNA-processing-splicing factor 8 GN=PRPF8 PRP8 HUMAN $273.61 \quad 100.0 \% \quad 4$ Pre-mRNA-processing-splicing factor 8 GN=PRPF8 PRP8_HUMAN $273.61 \quad 100.0 \%$ Pre-mRNA-processing-splicing factor 8 GN=PRPF8 PRP8_HUMAN $273.61 \quad 100.0 \%$ Pre-mRNA-processing-splicing factor 8 GN=PRPF8 PRP8_HUMAN $273.61 \quad 100.0 \% \quad 47$ Pre-mRNA-processing-splicing factor $8 \mathrm{GN}=$ PRPF8 PRP8_HUMAN $273.61 \quad 100.0 \% \quad 4$ Pre-mRNA-processing-splicing factor $8 \mathrm{GN}=$ PRPF8 PRP8 HUMAN $273.61 \quad 100.0 \%$ Pre-mRNA-processing-splicing factor 8 GN=PRPF8 PRP8_HUMAN $273.61 \quad 100.0 \% \quad 4$ Pre-mRNA-processing-splicing factor 8 GN=PRPF8 PRP8_HUMAN $273.61 \quad 100.0 \%$ Pre-mRNA-processing-splicing factor 8 GN=PRPF8 PRP8_HUMAN $273.61 \quad 100.0 \% \quad 47$ Pre-mRNA-processing-splicing factor 8 GN=PRPF8 PRP8_HUMAN $273.61 \quad 100.0 \% \quad 47$ Pre-mRNA-processing-splicing factor 8 GN=PRPF8 PRP8_HUMAN $273.61 \quad 100.0 \%$ Pre-mRNA-processing-splicing factor 8 GN=PRPF8 PRP8_HUMAN $273.61 \quad 100.0 \% \quad 47$ Pre-mRNA-processing-splicing factor 8 GN=PRPF8 PRP8_HUMAN $273.61 \quad 100.0 \% \quad 4$ Pre-mRNA-processing-splicing factor 8 GN=PRPF8 PRP8_HUMAN $273.61 \quad 100.0 \%$ $\begin{array}{llll}\text { Pre-mRNA-processing-splicing factor } 8 \text { GN=PRPF8 } & \text { PRP8_HUMAN } 273.61 & 100.0 \% & 47\end{array}$ Pre-mRNA-processing-splicing factor 8 GN=PRPF8 PRP8_HUMAN $273.61 \quad 100.0 \%$ Pre-mRNA-processing-splicing factor 8 GN=PRPF8 PRP8_HUMAN $273.61 \quad 100.0 \% \quad 47$ Pre-mRNA-processing-splicing factor 8 GN=PRPF8 PRP8_HUMAN $273.61 \quad 100.0 \% \quad 4$ Pre-mRNA-processing-splicing factor 8 GN=PRPF8 PRP8 HUMAN $273.61 \quad 100.0 \% \quad 4$ Pre-mRNA-processing-splicing factor $8 \mathrm{GN}=$ PRPF8 PRP8_HUMAN $273.61 \quad 100.0 \%$ Pre-mRNA-processing-splicing factor 8 GN=PRPF8 PRP8_HUMAN $273.61 \quad 100.0 \%$ Pre-mRNA-splicing factor ATP-dependent RNA helicase DHX15 GN=DHX15 DHX15_HUMAN $90.94 \quad 100.0 \%$ $\begin{array}{lll}\text { Pre-mRNA-splicing factor ATP-dependent RNA helicase DHX15 GN=DHX15 } & \text { DHX15_HUMAN } 90.94 & 100.0 \%\end{array}$

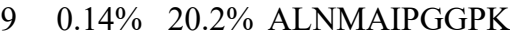

$39 \quad 0.14 \% \quad 20.2 \%$ RALDIPLVK

$139 \quad 0.14 \% \quad 20.2 \%$ ALDIPLVK

$139 \quad 0.14 \% \quad 20.2 \%$ EHCPAGQPVK

$139 \quad 0.14 \% \quad 20.2 \%$ EHCPAGQPVKVR

$139 \quad 0.14 \% \quad 20.2 \%$ YYVLNALK

$139 \quad 0.14 \% \quad 20.2 \%$ FGNAFHLCR

$139 \quad 0.14 \% \quad 20.2 \%$ LVVDSHVQYR

$139 \quad 0.14 \% \quad 20.2 \%$ FNTGPVGK

$139 \quad 0.14 \% \quad 20.2 \%$ GITPLLER

$139 \quad 0.14 \% \quad 20.2 \%$ WLGNLLAR

$139 \quad 0.14 \% \quad 20.2 \%$ VPGLPTPIENMILR

$139 \quad 0.14 \% \quad 20.2 \%$ LYLKAEQER

$139 \quad 0.14 \% \quad 20.2 \%$ LLILALER

$139 \quad 0.14 \% \quad 20.2 \%$ LKEAYSVK

$139 \quad 0.14 \% \quad 20.2 \%$ IDLTLLNR

$139 \quad 0.14 \% \quad 20.2 \%$ LIVDHNIADYMTAK

$139 \quad 0.14 \% \quad 20.2 \%$ NNVVINYKDMNHTNSYGIIR

$139 \quad 0.14 \% \quad 20.2 \%$ FTADEARDLIQR

$139 \quad 0.14 \% \quad 20.2 \%$ YLTEHPDPNNENIVGYNNK

$139 \quad 0.14 \% \quad 20.2 \%$ YLTEHPDPNNENIVGYNNKK

$139 \quad 0.14 \% \quad 20.2 \%$ TSYEEFTHK

$139 \quad 0.14 \% \quad 20.2 \%$ QILMASGSTTFTK

$139 \quad 0.14 \% \quad 20.2 \%$ IKIGLNSK

$139 \quad 0.14 \% \quad 20.2 \%$ QTDVGITHFR

$139 \quad 0.14 \% \quad 20.2 \%$ SGMSHEEDQLIPNLYR

$139 \quad 0.14 \% \quad 20.2 \%$ TDFKQYQVLK

$139 \quad 0.14 \% \quad 20.2 \%$ ASGFEESMK

$139 \quad 0.14 \% \quad 20.2 \%$ SGLNQIPNR

$139 \quad 0.14 \% \quad 20.2 \%$ ISLIQIFR

$139 \quad 0.14 \% \quad 20.2 \%$ ANPALYVLR

$139 \quad 0.14 \% \quad 20.2 \%$ IIHTSVWAGQK

$139 \quad 0.14 \% \quad 20.2 \%$ SLPVEEQPK

$139 \quad 0.14 \% \quad 20.2 \%$ SLPVEEQPKQIIVTR

$139 \quad 0.14 \% \quad 20.2 \%$ GSELQLPFQACLK

$139 \quad 0.14 \% \quad 20.2 \%$ TISSYTAFSR

$139 \quad 0.14 \% \quad 20.2 \%$ QQIAEIEKQTK

$139 \quad 0.14 \% \quad 20.2 \%$ QTKEQSQLTATQTR

$139 \quad 0.14 \% \quad 20.2 \%$ EQSQLTATQTR

$139 \quad 0.14 \% \quad 20.2 \%$ HGDEIITSTTSNYETQTFSSK

$139 \quad 0.14 \% \quad 20.2 \%$ AISAANLHLR

$139 \quad 0.14 \% \quad 20.2 \%$ FICISDLR

$139 \quad 0.14 \% \quad 20.2 \%$ AQIAGYLYGVSPPDNPQVK

$139 \quad 0.14 \% \quad 20.2 \%$ TIIITCSFTPGSCTLTAYK

$139 \quad 0.14 \% \quad 20.2 \%$ GYLPSHYER

$11 \quad 0.01 \% \quad 8.4 \% \quad$ RGVACTQPR

$11 \quad 0.01 \% \quad 8.4 \%$ YGVIILDEAHER
$99.7 \% \quad 38.3 \quad 25.0 \quad 27.2 \quad 3$ $99.7 \% \quad 36.9 \quad 25.0 \quad 29.2$

$\begin{array}{lllll}99.0 \% & 28.2 & 25.0 & 24.7 & 2\end{array}$

$99.5 \% 26.6 \quad 25.0 \quad 16.4$

$\begin{array}{llll}99.5 \% & 28.7 & 25.0 & 28.7\end{array}$

$99.0 \% \quad 25.9 \quad 25.0 \quad 16.5$

$99.7 \% \quad 31.1 \quad 25.0 \quad 23.1$

$99.7 \% \quad 56.0 \quad 25.0 \quad 49.0 \quad 2$

$99.0 \% \quad 33.2 \quad 25.0 \quad 21.9$

$\begin{array}{llll}99.0 \% & 23.6 & 25.0 & 18.6\end{array}$

$\begin{array}{llll}98.8 \% & 25.8 & 25.0 & 12.1\end{array}$

$99.6 \% \quad 22.8 \quad 25.0 \quad 22.8$

$\begin{array}{llll}99.7 \% & 32.6 & 25.0 & 27.5\end{array}$

$99.0 \% \quad 56.2 \quad 25.0 \quad 53.0$

$99.0 \% \quad 47.8 \quad 25.0 \quad 31.9$

$\begin{array}{llll}99.0 \% & 43.0 & 25.0 & 32.7\end{array}$

$99.7 \% \quad 55.2 \quad 25.0 \quad 55.2$

$\begin{array}{llll}99.4 \% & 26.6 & 25.0 & 26.6\end{array}$

$99.7 \% \quad 34.8 \quad 25.0 \quad 19.0$

$99.0 \% \quad 19.9$

$98.7 \% \quad 18.7$

$99.7 \% \quad 56.7$

$95.4 \% \quad 14.2$

$99.7 \% \quad 37.4$

$\begin{array}{lll}99.7 \% & 30.8\end{array}$

$99.7 \% \quad 29.7$

$\begin{array}{lll}99.0 \% & 18.7\end{array}$

$95.7 \% \quad 23.2$

$99.0 \% \quad 64.3$

$99.7 \% \quad 43.5$

$99.7 \% \quad 31.5$

$99.7 \% \quad 27.6$

$99.7 \% \quad 33.7$

$\begin{array}{lll}99.7 \% & 36.5\end{array}$

$99.7 \% \quad 35.4$

$99.7 \% \quad 33.8$

$99.7 \% \quad 45.5$

$99.7 \% \quad 58.4$

$\begin{array}{lll}99.7 \% & 32.2\end{array}$

$99.7 \% \quad 62.0$

$99.0 \% \quad 44.5$

$99.7 \% 47.3$

$99.7 \% \quad 36.6$

$99.7 \% \quad 44.3$

$98.2 \% \quad 16.7$
1024.65

868.55

1122.54

1377.71

983.56

1121.53

1215.65

819.44

898.54

942.55

1549.88

1149.63

940.62

937.54

957.57

1619.81

2381.17

1434.73

2231.04

2359.13

1141.52

1384.71

872.56

1173.60

1904.88

1269.68

985.43

998.54

989.61

1016.59

1239.68

1026.55

1736.99

1490.77

1132.56

1315.72

1619.83

1262.63

2346.07

1065.62

1023.53

2017.04

2134.06

1121.54

1044.54 1414.73 

Pre-mRNA-splicing factor ISY1 homolog GN=ISY1 ISY1 HUMAN $32.99 \quad 100.0 \%$ Pre-mRNA-splicing factor SPF27 GN=BCAS2 SPF27_HUMAN $26.13 \quad 100.0 \%$ Pre-mRNA-splicing factor SPF27 GN=BCAS2 SPF27 HUMAN $26.13 \quad 100.0 \%$ pre-rRNA processing protein FTSJ3 GN=FTSJ3 SPB1_HUMAN $96.56 \quad 100.0 \%$ pre-rRNA processing protein FTSJ3 GN=FTSJ3 SPB1_HUMAN $96.56 \quad 100.0 \%$ pre-rRNA processing protein FTSJ3 GN=FTSJ3 SPB1 HUMAN $96.56100 .0 \%$ Probable 28S rRNA (cytosine(4447)-C(5))-methyltransferase GN=NOP2 NOP2_HUMAN $89.30 \quad 100.0 \%$ Probable 28S rRNA (cytosine(4447)-C(5))-methyltransferase GN=NOP2 NOP2 HUMAN $89.30 \quad 100.0 \%$ Probable 28S rRNA (cytosine(4447)-C(5))-methyltransferase GN=NOP2 NOP2 HUMAN $89.30 \quad 100.0 \%$ Probable 28S rRNA (cytosine(4447)-C(5))-methyltransferase GN=NOP2 NOP2_HUMAN $89.30 \quad 100.0 \%$ Probable arginine--tRNA ligase, mitochondrial GN=RARS2 SYRM HUMAN $65.51 \quad 100.0 \%$ Probable arginine--tRNA ligase, mitochondrial GN=RARS2 SYRM_HUMAN $65.51 \quad 100.0 \%$ Probable arginine--tRNA ligase, mitochondrial GN=RARS2 SYRM_HUMAN $65.51 \quad 100.0 \%$ Probable arginine--tRNA ligase, mitochondrial GN=RARS2 SYRM HUMAN $65.51 \quad 100.0 \%$ Probable ATP-dependent RNA helicase DDX17 GN=DDX17 DDX17_HUMAN $80.27 \quad 100.0 \%$ Probable ATP-dependent RNA helicase DDX17 GN=DDX17 DDX17_HUMAN 80.27 Probable ATP-dependent RNA helicase DDX17 GN=DDX17 DDX17_HUMAN $80.27 \quad 100.0 \%$ Probable ATP-dependent RNA helicase DDX17 GN=DDX17 DDX17_HUMAN $80.27 \quad 100.0 \%$ Probable ATP-dependent RNA helicase DDX17 GN=DDX17 DDX17 HUMAN 80.27 Probable ATP-dependent RNA helicase DDX17 GN=DDX17 DDX17_HUMAN 80.27 Probable ATP-dependent RNA helicase DDX17 GN=DDX17 DDX17_HUMAN 80.27 Probable ATP-dependent RNA helicase DDX17 GN=DDX17 DDX17 HUMAN 80.27 Probable ATP-dependent RNA helicase DDX17 GN=DDX17 DDX17_HUMAN 80.27 Probable ATP-dependent RNA helicase DDX17 GN=DDX17 DDX17_HUMAN 80.27 Probable ATP-dependent RNA helicase DDX17 GN=DDX17 DDX17_HUMAN 80.27 Probable ATP-dependent RNA helicase DDX17 GN=DDX17 DDX17_HUMAN 80.27 Probable ATP-dependent RNA helicase DDX17 GN=DDX17 DDX17 HUMAN 80.27 Probable ATP-dependent RNA helicase DDX17 GN=DDX17 DDX17_HUMAN 80.27 Probable ATP-dependent RNA helicase DDX17 GN=DDX17 DDX17_HUMAN 80.27 Probable ATP-dependent RNA helicase DDX17 GN=DDX17 DDX17 HUMAN 80.27 Probable ATP-dependent RNA helicase DDX17 GN=DDX17 DDX17_HUMAN 80.27 Probable ATP-dependent RNA helicase DDX17 GN=DDX17 DDX17_HUMAN 80.27 Probable ATP-dependent RNA helicase DDX17 GN=DDX17 DDX17_HUMAN 80.27 Probable ATP-dependent RNA helicase DDX20 GN=DDX20 DDX20_HUMAN 92.24 Probable ATP-dependent RNA helicase DDX20 GN=DDX20 DDX20 HUMAN 92.24 Probable ATP-dependent RNA helicase DDX20 GN=DDX20 DDX20_HUMAN 92.24 Probable ATP-dependent RNA helicase DDX23 GN=DDX23 DDX23 HUMAN 95.59 Probable ATP-dependent RNA helicase DDX23 GN=DDX23 DDX23_HUMAN $95.59100 .0 \%$ Probable ATP-dependent RNA helicase DDX28 GN=DDX28 DDX28_HUMAN $59.58 \quad 100.0 \%$ Probable ATP-dependent RNA helicase DDX28 GN=DDX28 DDX28 HUMAN $59.58100 .0 \%$ Probable ATP-dependent RNA helicase DDX28 GN=DDX28 DDX28_HUMAN $59.58 \quad 100.0 \%$

$11 \quad 0.01 \% \quad 8.4 \% \quad$ TLATDILMGVLK $0.01 \% \quad 8.4 \%$ IRVESLLVTAISK

$11 \quad 0.01 \% \quad 8.4 \%$ SNLGSVVLQLKK

$0.01 \% \quad 8.4 \%$ LQSKEYSQY

$0.01 \% \quad 13.3 \%$ VAQIQNAGLGEFR

$0.01 \% \quad 13.3 \%$ IKELGGPDYGK

$0.01 \% \quad 13.3 \%$ YASETLQAQSEEAR

$0.00 \% \quad 11.6 \%$ EAAAALVEEETRR

$0.00 \% \quad 11.6 \%$ TIVQLENEIYQIK

$0.01 \% \quad 4.1 \%$ AANPVDFLSK

$0.01 \% \quad 4.1 \%$ ILDPEGLALGAVIASSK

$0.01 \% \quad 7.0 \%$ FLPAVSDENSKR

$0.01 \% \quad 7.0 \%$ LVPTGLDFGQEGFTR

$0.01 \% \quad 7.0 \%$ GADSELSTVPSVTK

$0.01 \% \quad 7.0 \%$ TQASSSFQDSSQPAGK

$0.01 \% \quad 8.1 \%$ TVLQQVIEDGSK

$0.01 \% \quad 8.1 \%$ IVVEFSSPNVAK

$0.01 \% \quad 8.1 \%$ SSQDFQPR

$0.01 \% \quad 8.1 \%$ TLQIKDSPPEVAGAR

$4 \quad 0.04 \% \quad 23.7 \%$ NFYVEHPEVAR

$44 \quad 0.04 \% \quad 23.7 \%$ LTPYEVDELRR

$0.04 \% \quad 23.7 \%$ DMVGIAQTGSGK

$100.0 \%$

$100.0 \%$

$100.0 \% \quad 12$

$100.0 \% \quad 12$

$100.0 \%$

$100.0 \% \quad 12$

$100.0 \%$

$100.0 \%$

$100.0 \%$

$100.0 \%$

$100.0 \%$

$100.0 \%$

$100.0 \%$

$100.0 \% \quad 12$

$100.0 \%$

$100.0 \%$

$100.0 \%$

$100.0 \%$

$100.0 \%$

$0.0 \% \quad 16$

$100.0 \% \quad 16$

$0.04 \% \quad 23.7 \%$ STCIYGGAPK

$0.04 \% \quad 23.7 \%$ GPQIRDLER

$0.04 \% \quad 23.7 \%$ GVEICIATPGR

$0.04 \% \quad 23.7 \%$ KIVDQIRPDR

$0.04 \% \quad 23.7 \%$ SGKAPILIATDVASR

$0.04 \% \quad 23.7 \%$ APILIATDVASR

$0.04 \% \quad 23.7 \%$ GTAYTFFTPGNLK

$0.04 \% \quad 23.7 \%$ ELIKVLEEANQAINPK

$0.04 \% \quad 23.7 \%$ VLEEANQAINPK

$0.04 \% \quad 23.7 \%$ SSQSSSQQFSGIGR

$0.01 \% \quad 3.9 \%$ TAQDLSSPR

$0.01 \% \quad 3.9 \%$ AAGFERPSPVQLK

$0.00 \% \quad 3.7 \% \quad$ HQVQLLGR

$0.03 \% \quad 30.9 \%$ SPDEPLPVVR

$0.03 \% \quad 30.9 \%$ RPELNQPAR
$0.01 \% \quad 4.1 \% \quad$ TSVTDFLR

$\begin{array}{llll}9.7 \% & 33.0 & 25.0 & 26.5\end{array}$

$\begin{array}{llll}99.5 \% & 22.7 & 25.0 & 22.5\end{array}$

$\begin{array}{llll}99.7 \% & 54.6 & 25.0 & 54.6\end{array}$

$\begin{array}{llll}99.7 \% & 41.9 & 25.0 & 37.1\end{array}$

$99.7 \% \quad 57.7 \quad 25.0 \quad 55.9$

$96.0 \% \quad 15.4 \quad 25.0 \quad 13.7$

$99.7 \% \quad 46.3 \quad 25.0 \quad 39.7$

$\begin{array}{llll}99.0 \% & 28.9 & 25.0 & 16.6\end{array}$

$\begin{array}{llll}99.6 \% & 23.8 & 25.0 & 23.8\end{array}$

$99.7 \% \quad 52.6 \quad 25.0 \quad 52.6$

$99.6 \% \quad 24.1 \quad 25.0 \quad 20.9$

$99.7 \% \quad 70.7 \quad 25.0 \quad 67.3$

$99.7 \% \quad 60.4 \quad 25.0 \quad 53.7$

$99.7 \% \quad 56.0 \quad 25.0 \quad 56.0 \quad 2$

$99.7 \% \quad 46.7 \quad 25.0 \quad 44.4$

$99.7 \% \quad 53.9 \quad 25.0 \quad 48.7$

$99.0 \% \quad 44.8 \quad 25.0 \quad 36.0$

$99.7 \% \quad 32.3 \quad 25.0 \quad 32.3$

$99.7 \% \quad 53.6 \quad 25.0 \quad 53.6$

$99.7 \% \quad 33.3 \quad 25.0 \quad 29.1$

$99.7 \% \quad 64.1 \quad 25.0 \quad 64.1$

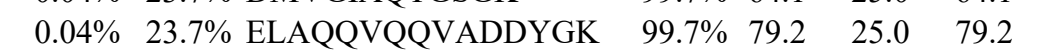

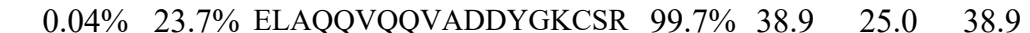

$\begin{array}{lllllll}0.04 \% & 23.7 \% & \text { LKSTCIYGGAPK } & 99.7 \% & 47.4 & 25.0 & 47.4\end{array}$

$99.7 \% \quad 62.5$

$99.7 \% \quad 34.0$

$\begin{array}{llll}99.7 \% & 61.9 & 25.0 & 43.6\end{array}$

$98.3 \% \quad 25.5 \quad 25.0 \quad 11.8$

$\begin{array}{llll}99.6 \% & 26.4 & 25.0 & 17.6\end{array}$

$99.7 \% \quad 62.1 \quad 25.0 \quad 62.1 \quad 2$

$99.7 \% \quad 56.3 \quad 25.0 \quad 56.3 \quad 21$

$0.04 \% \quad 23.7 \%$ STNKGTAYTFFTPGNLK

$\begin{array}{llll}99.7 \% & 52.3 & 25.0 & 52.3 \\ 99.7 \% & 42.0 & 25.0 & 42.0\end{array}$

$99.7 \% 88.0$

$\begin{array}{llll}99.7 \% & 58.6 & 25.0 & 50.8\end{array}$

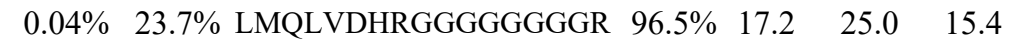

$99.7 \% \quad 79.7$

$99.7 \% \quad 60.4$

$99.7 \% \quad 30.4$

$95.7 \% \quad 15.9$

$99.0 \% \quad 39.5$

$0.00 \% \quad 3.7 \%$ QAIPIGLQNRDIIGVAETGSGK

$99.7 \%$

$99.7 \% \quad 46.6$

$99.7 \% \quad 36.4$
1290.73

1428.88

1285.78

1145.55

1402.74

1176.63

1582.73

1444.74

1590.87

938.49

1061.56

1653.94

1362.70

1636.83

1390.71

1625.74

1316.71

1289.71

964.45

1581.86

1360.66

1390.73

1163.57

1691.82

2094.99

1294.68

1053.50

1083.59

1172.61

1239.72

1111.62

1498.86

1226.7

1846.93

1416.72

1809.01

1325.71

1639.81

1455.68

974.49

1399.77

1104.63

950.55

2237.23

1108.60

1080.59

969.51 $\begin{array}{cc}66 & 277 \\ 51 & 463 \\ 05 & 516 \\ 87 & 795 \\ 57 & 69 \\ 11 & 101 \\ 67 & 280 \\ 30 & 42 \\ 98 & 210 \\ 52 & 259 \\ 60 & 269 \\ 62 & 678 \\ 31 & 42 \\ 39 & 553 \\ 56 & 669 \\ 70 & 685 \\ 00 & 111 \\ 27 & 138 \\ 12 & 519 \\ 38 & 552 \\ 33 & 143 \\ 44 & 154 \\ 10 & 221 \\ 55 & 269 \\ 55 & 272 \\ 73 & 284 \\ 75 & 284 \\ 85 & 293 \\ 94 & 304 \\ 41 & 350 \\ 42 & 350 \\ 66 & 480 \\ 69 & 480 \\ 12 & 528 \\ 16 & 528 \\ 32 & 547 \\ 36 & 547 \\ 48 & 564 \\ 71 & 684 \\ 42 & 50 \\ 79 & 91 \\ 62 & 371 \\ 94 & 301 \\ 20 & 441 \\ 28 & 37 \\ 73 & 81 \\ 12 & 120 \\ & \end{array}$

Page 125 of Table S-1-4 

$\begin{array}{lllllllll}\text { Probable ATP-dependent RNA helicase DDX28 GN=DDX28 DDX28_HUMAN } & 59.58 & 100.0 \% & 16 & 17 & 27 & 0.03 \% & 30.9 \% & \text { AQQEAPAVRK } \\ \text { Pronate } & 59.58 & 100.0 \% & 16 & 17 & 27 & 0.03 \% & 30.9 \% \text { LSSKGSFADL }\end{array}$ Probable ATP-dependent RNA helicase DDX28 GN=DDX28 DDX28_HUMAN $59.58 \quad 100.0 \%$ Probable ATP-dependent RNA helicase DDX28 GN=DDX28 DDX28 HUMAN $59.58100 .0 \%$ Probable ATP-dependent RNA helicase DDX28 GN=DDX28 DDX28_HUMAN $59.58 \quad 100.0 \%$ Probable ATP-dependent RNA helicase DDX28 GN=DDX28 DDX28_HUMAN $59.58 \quad 100.0 \%$ Probable ATP-dependent RNA helicase DDX28 GN=DDX28 DDX28_HUMAN $59.58 \quad 100.0 \%$ Probable ATP-dependent RNA helicase DDX28 GN=DDX28 DDX28_HUMAN $59.58 \quad 100.0 \%$ Probable ATP-dependent RNA helicase DDX28 GN=DDX28 DDX28 HUMAN 59.58 Probable ATP-dependent RNA helicase DDX28 GN=DDX28 DDX28_HUMAN $59.58 \quad 100.0 \%$ Probable ATP-dependent RNA helicase DDX28 GN=DDX28 DDX28_HUMAN 59.58 Probable ATP-dependent RNA helicase DDX28 GN=DDX28 DDX28_HUMAN 59.58 Probable ATP-dependent RNA helicase DDX28 GN=DDX28 DDX28_HUMAN 59.58 Probable ATP-dependent RNA helicase DDX46 GN=DDX46 DDX46_HUMAN 117.37 Probable ATP-dependent RNA helicase DDX46 GN=DDX46 DDX46_HUMAN 117.37 Probable ATP-dependent RNA helicase DDX47 GN=DDX47 DDX47_HUMAN 50.65 Probable ATP-dependent RNA helicase DDX47 GN=DDX47 DDX47 HUMAN 50.65 Probable ATP-dependent RNA helicase DDX47 GN=DDX47 DDX47_HUMAN 50.65 Probable ATP-dependent RNA helicase DDX47 GN=DDX47 DDX47_HUMAN 50.65 Probable ATP-dependent RNA helicase DDX47 GN=DDX47 DDX47_HUMAN 50.65 Probable ATP-dependent RNA helicase DDX47 GN=DDX47 DDX47_HUMAN 50.6 Probable ATP-dependent RNA helicase DDX47 GN=DDX47 DDX47_HUMAN 50.65 Probable ATP-dependent RNA helicase DDX5 GN=DDX5 DDX5 HUMAN 69.15 Probable ATP-dependent RNA helicase DDX5 GN=DDX5 DDX5_HUMAN 69.15 Probable ATP-dependent RNA helicase DDX5 GN=DDX5 DDX5 HUMAN 69.15 Probable ATP-dependent RNA helicase DDX5 GN=DDX5 DDX5_HUMAN 69.15 Probable ATP-dependent RNA helicase DDX5 GN=DDX5 DDX5_HUMAN 69.15 Probable ATP-dependent RNA helicase DDX5 GN=DDX5 DDX5_HUMAN 69.15 Probable ATP-dependent RNA helicase DDX5 GN=DDX5 DDX5_HUMAN 69.15 Probable ATP-dependent RNA helicase DDX5 GN=DDX5 DDX5 HUMAN 69.15 Probable ATP-dependent RNA helicase DDX5 GN=DDX5 DDX5_HUMAN 69.15 Probable ATP-dependent RNA helicase DDX5 GN=DDX5 DDX5_HUMAN 69.15 Probable ATP-dependent RNA helicase DDX5 GN=DDX5 DDX5 HUMAN 69.15 Probable ATP-dependent RNA helicase DDX5 GN=DDX5 DDX5_HUMAN 69.15 Probable ATP-dependent RNA helicase DDX5 GN=DDX5 DDX5_HUMAN 69.15 Probable ATP-dependent RNA helicase DDX5 GN=DDX5 DDX5 HUMAN 69.15 Probable ATP-dependent RNA helicase DDX5 GN=DDX5 DDX5_HUMAN 69.15 Probable ATP-dependent RNA helicase DDX5 GN=DDX5 DDX5 HUMAN 69.15 Probable ATP-dependent RNA helicase DDX5 GN=DDX5 DDX5_HUMAN 69.15 Probable ATP-dependent RNA helicase DDX5 GN=DDX5 DDX5_HUMAN 69.15 Probable ATP-dependent RNA helicase DDX5 GN=DDX5 DDX5_HUMAN 69.15 Probable ATP-dependent RNA helicase DDX5 GN=DDX5 DDX5_HUMAN 69.15 Probable ATP-dependent RNA helicase DDX5 GN=DDX5 DDX5_HUMAN 69.15 Probable ATP-dependent RNA helicase DDX5 GN=DDX5 DDX5 HUMAN 69.1 Probable ATP-dependent RNA helicase DDX5 GN=DDX5 DDX5_HUMAN 69.1 Probable ATP-dependent RNA helicase DDX5 GN=DDX5 DDX5_HUMAN 69.15 Probable ATP-dependent RNA helicase DDX5 GN=DDX5 DDX5_HUMAN 69.15
$0.03 \% \quad 30.9 \%$ LSSKGSFADLGLEPR

$0.03 \% \quad 30.9 \%$ GSFADLGLEPR

$17 \quad 27 \quad 0.03 \% \quad 30.9 \%$ GRHVVCAAETGSGK

$17 \quad 27 \quad 0.03 \% \quad 30.9 \% \quad$ LLGQPSLDSLPIPAPR

$\begin{array}{llll}17 & 27 & 0.03 \% & 30.9 \% \\ 17 & \text { GLVLVPSRELAQQVR }\end{array}$

$17 \quad 27 \quad 0.03 \% \quad 30.9 \%$ AVAQPLGR

$\begin{array}{ll}17 & 27\end{array}$

$17 \quad 27$

$17-27$

$\begin{array}{ll}17 & 27 \\ 17 & 27\end{array}$

$0.03 \% \quad 30.9 \%$ QPSADVLVATPGALWK

$0.03 \% \quad 30.9 \%$ VASPDAVTTITSSK

$0.03 \% \quad 30.9 \%$ VGIFQSFQK

$0.03 \% \quad 30.9 \%$ SSRDILLCTDIASR

$0.03 \% \quad 30.9 \%$ DILLCTDIASR

$0.03 \% \quad 30.9 \%$ SLPGLASSVKEPLPQAT

$0.00 \% \quad 2.2 \%$ GAEIIVCTPGR

$0.00 \% \quad 2.2 \%$ GGTILAPTVSAK

$0.01 \% \quad 15.4 \%$ IQIEAIPLALQGR

$0.01 \% \quad 15.4 \%$ LFALVLTPTR

$0.01 \% \quad 15.4 \%$ KPHIIIATPGR

$0.01 \% \quad 15.4 \%$ LIDHLENTK

$0.01 \% \quad 15.4 \%$ LIDHLENTKGFNLR

$0.01 \% \quad 15.4 \%$ LQQYYIFIPSK

$14 \quad 0.01 \% \quad 15.4 \%$ SILLATDVASR

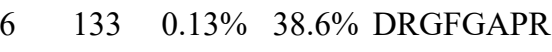

$36 \quad 133 \quad 0.13 \% \quad 38.6 \%$ FGNPGEKLVK

$36 \quad 133 \quad 0.13 \% \quad 38.6 \%$ NFYQEHPDLAR

$36 \quad 133 \quad 0.13 \% \quad 38.6 \%$ NFYQEHPDLARR

$\begin{array}{lllll}36 & 133 & 0.13 \% & 38.6 \% & \text { TAQEVETYR }\end{array}$

$36 \quad 133 \quad 0.13 \% \quad 38.6 \%$ TAQEVETYRR

$36 \quad 133 \quad 0.13 \% \quad 38.6 \%$ ELAQQVQQVAAEYCR

$36 \quad 133 \quad 0.13 \% \quad 38.6 \%$ LKSTCIYGGAPK

$36 \quad 133 \quad 0.13 \% \quad 38.6 \%$ STCIYGGAPK

$36 \quad 133 \quad 0.13 \% \quad 38.6 \%$ GPQIRDLER

$36 \quad 133 \quad 0.13 \% \quad 38.6 \%$ GVEICIATPGR

$36 \quad 133 \quad 0.13 \% \quad 38.6 \%$ LIDFLECGK

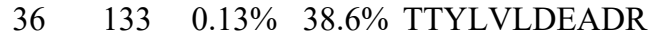

$36 \quad 133 \quad 0.13 \% \quad 38.6 \%$ TTYLVLDEADRMLDMGFEPQIR

$36 \quad 133 \quad 0.13 \% \quad 38.6 \%$ KIVDQIRPDR

$36 \quad 133 \quad 0.13 \% \quad 38.6 \%$ IVDQIRPDR

$\begin{array}{lllll}36 & 133 & 0.13 \% & 38.6 \% & \text { LMEEIMSEKENK }\end{array}$

$36 \quad 133 \quad 0.13 \% \quad 38.6 \%$ TIVFVETK

$36 \quad 133 \quad 0.13 \% \quad 38.6 \%$ TIVFVETKR

$36 \quad 133 \quad 0.13 \% \quad 38.6 \%$ HGKAPILIATDVASR

$36 \quad 133 \quad 0.13 \% \quad 38.6 \%$ APILIATDVASR

$36 \quad 133 \quad 0.13 \% \quad 38.6 \%$ GLDVEDVKFVINYDYPNSSEDYIH

$36 \quad 133 \quad 0.13 \% \quad 38.6 \%$ STKTGTAYTFFTPNNIK

$36 \quad 133 \quad 0.13 \% \quad 38.6 \%$ TGTAYTFFTPNNIK

$36 \quad 133 \quad 0.13 \% \quad 38.6 \%$ QVSDLISVLR
$99.0 \% \quad 25.2 \quad 25.0 \quad 14.6 \quad 1$

$96.4 \% \quad 14.8 \quad 25.0 \quad 14.8 \quad 0$

$\begin{array}{lllll}99.7 \% & 76.3 & 25.0 & 67.0 & 2\end{array}$

$99.5 \% \quad 32.0 \quad 25.0 \quad 32.0$

$\begin{array}{llll}99.7 \% & 58.1 & 25.0 & 58.1\end{array}$

$\begin{array}{llll}99.7 \% & 32.8 & 25.0 & 32.8\end{array}$

$99.0 \% \quad 25.7 \quad 25.0 \quad 21.3$

$\begin{array}{llll}99.7 \% & 36.4 & 25.0 & 36.4\end{array}$

$\begin{array}{llll}99.7 \% & 55.8 & 25.0 & 47.6\end{array}$

$\begin{array}{llll}99.7 \% & 34.3 & 25.0 & 34.3\end{array}$

$\begin{array}{llll}99.7 \% & 32.5 & 25.0 & 32.5\end{array}$

$\begin{array}{llll}99.7 \% & 39.0 & 25.0 & 36.6\end{array}$

$\begin{array}{lllll}99.7 \% & 50.4 & 25.0 & 50.4 & 2\end{array}$

$\begin{array}{llll}97.7 \% & 23.9 & 25.0 & 16.2\end{array}$

$\begin{array}{llll}98.7 \% & 23.4 & 25.0 & 13.9\end{array}$

$\begin{array}{lllll}99.7 \% & 61.9 & 25.0 & 61.9 & 2\end{array}$

$99.7 \% \quad 30.6 \quad 25.0 \quad 23.8$

$\begin{array}{llll}99.7 \% & 31.7 & 25.0 & 31.7\end{array}$

$\begin{array}{llll}99.7 \% & 35.8 & 25.0 & 26.8\end{array}$

$\begin{array}{llll}99.2 \% & 18.6 & 25.0 & 18.6\end{array}$

$\begin{array}{llll}99.6 \% & 30.4 & 25.0 & 17.3\end{array}$

$\begin{array}{llll}99.7 \% & 51.0 & 25.0 & 40.8\end{array}$

$\begin{array}{llll}96.5 \% & 23.4 & 25.0 & 9.1\end{array}$

$\begin{array}{lllll}99.7 \% & 54.6 & 25.0 & 42.4 & 5\end{array}$

$99.7 \% \quad 59.2 \quad 25.0 \quad 50.9$

$\begin{array}{llll}99.7 \% & 29.2 & 25.0 & 27.7\end{array}$

$\begin{array}{lllll}99.7 \% & 41.1 & 25.0 & 36.0 & 2\end{array}$

$\begin{array}{llll}99.7 \% & 28.4 & 25.0 & 26.3\end{array}$

$99.7 \% \quad 62.0 \quad 25.0 \quad 62.0$

$\begin{array}{llll}99.7 \% & 47.4 & 25.0 & 47.4\end{array}$

$\begin{array}{llll}99.7 \% & 62.5 & 25.0 & 54.1\end{array}$

$\begin{array}{llll}99.7 \% & 34.0 & 25.0 & 21.3\end{array}$

$99.7 \% \quad 61.9 \quad 25.0 \quad 43.6$

$\begin{array}{llll}99.7 \% & 58.2 & 25.0 & 58.2\end{array}$

$99.7 \% \quad 40.6 \quad 25.0 \quad 36.5$

$\begin{array}{llll}99.7 \% & 39.8 & 25.0 & 39.8\end{array}$

$\begin{array}{llll}98.3 \% & 25.5 & 25.0 & 11.8\end{array}$

$\begin{array}{llll}99.6 \% & 26.4 & 25.0 & 17.6\end{array}$

$\begin{array}{llll}99.7 \% & 47.1 & 25.0 & 36.9\end{array}$

$\begin{array}{llll}99.0 \% & 25.4 & 25.0 & 22.9\end{array}$

$\begin{array}{llll}99.7 \% & 32.8 & 25.0 & 32.8\end{array}$

$\begin{array}{lllll}99.7 \% & 30.1 & 25.0 & 30.1 & 0\end{array}$

$\begin{array}{lllll}99.7 \% & 56.3 & 25.0 & 56.3 & 2\end{array}$

$\begin{array}{lllll}99.7 \% & 54.0 & 25.0 & 54.0 & 0\end{array}$

$\begin{array}{lllll}99.7 \% & 42.2 & 25.0 & 37.1 & 1 \\ 99.7 \% & 54.8 & 25.0 & 51.3 & 5\end{array}$

$\begin{array}{llll}99.7 \% & 54.8 & 25.0 & 51.3 \\ 99.7 \% & 65.8 & 25.0 & 54.2\end{array}$

1576.83

1161.59

1428.70

1673.96

1664.98

811.48

1652.90

1376.73

1053.57

1606.82

1276.66

1694.93

1172.61

1114.65

1421.85

1130.69

1202.74

1082.58

1669.90

1399.76

1145.65

875.45

1088.61

1389.65

1545.76

1096.53

1252.63

1792.86

1294.68

1053.50

1083.59

1172.6

1094.56

1295.65

2645.26

1239.72

1111.62

1512.69

936.54

1092.64

1548.89

1226.71

2987.41

1890.96

1574.79

1129.66 
Probable ATP-dependent RNA helicase DDX5 GN=DDX5 DDX5_HUMAN $69.15 \quad 100.0 \% \quad 2$ Probable ATP-dependent RNA helicase DDX5 GN=DDX5 DDX5_HUMAN $69.15 \quad 100.0 \% \quad 29$ Probable ATP-dependent RNA helicase DDX5 GN=DDX5 DDX5_HUMAN $69.15 \quad 100.0 \% \quad 2$ Probable ATP-dependent RNA helicase DDX5 GN=DDX5 DDX5 HUMAN $69.15 \quad 100.0 \% 2$ Probable ATP-dependent RNA helicase DDX52 GN=DDX52 DDX52_HUMAN $67.50 \quad 100.0 \%$ Probable ATP-dependent RNA helicase DDX52 GN=DDX52 DDX52_HUMAN $67.50 \quad 100.0 \%$ Probable ATP-dependent RNA helicase DDX52 GN=DDX52 DDX52_HUMAN $67.50 \quad 100.0 \%$ Probable ATP-dependent RNA helicase DDX52 GN=DDX52 DDX52_HUMAN $67.50 \quad 100.0 \%$ Probable ATP-dependent RNA helicase DDX56 GN=DDX56 DDX56 HUMAN 61.59 Probable ATP-dependent RNA helicase DDX56 GN=DDX56 DDX56_HUMAN 61.59 Probable ATP-dependent RNA helicase DDX56 GN=DDX56 DDX56_HUMAN 61.5 Probable ATP-dependent RNA helicase DDX56 GN=DDX56 DDX56_HUMAN 61.59 Probable ATP-dependent RNA helicase DDX56 GN=DDX56 DDX56_HUMAN 61.59 Probable ATP-dependent RNA helicase DHX37 GN=DHX37 DHX37_HUMAN 129.55 Probable ATP-dependent RNA helicase DHX37 GN=DHX37 DHX37_HUMAN 129.5. Probable ATP-dependent RNA helicase DHX37 GN=DHX37 DHX37_HUMAN 129.55 Probable ATP-dependent RNA helicase DHX37 GN=DHX37 DHX37_HUMAN 129.55 Probable ATP-dependent RNA helicase YTHDC2 GN=YTHDC2 YTDC2_HUMAN 160.25 Probable ATP-dependent RNA helicase YTHDC2 GN=YTHDC2 YTDC2_HUMAN 160.25 Probable ATP-dependent RNA helicase YTHDC2 GN=YTHDC2 YTDC2 HUMAN 160.2 Probable ATP-dependent RNA helicase YTHDC2 GN=YTHDC2 YTDC2_HUMAN 160.25 Probable cytosolic iron-sulfur protein assembly protein CIAOI GN=CIAO1 CIAO1_HUMAN 37.84 $\begin{array}{lll}\text { Probable cytosolic iron-sulfur protein assembly protein CIAOI GN=CIAO1 } & \text { CIAO1_HUMAN } 37.84 \\ \text { Probable dimethyladenosine transferase GN=DIMT1 DIM1_HUMAN } & 35.24\end{array}$ Probable dimethyladenosine transferase GN=DIMT1 DIM1_HUMAN 35.24 Probable dimethyladenosine transferase GN=DIMT1 DIM1_HUMAN 35.24 Probable dimethyladenosine transferase GN=DIMT1 DIM1_HUMAN 35.24 Probable dimethyladenosine transferase GN=DIMT1 DIM1_HUMAN 35.24 Probable dimethyladenosine transferase GN=DIMT1 DIM1_HUMAN 35.24 Probable dimethyladenosine transferase GN=DIMT1 DIM1_HUMAN 35.24 Probable glutamate--tRNA ligase, mitochondrial GN=EARS2 SYEM_HUMAN 58.69 Probable glutamate--tRNA ligase, mitochondrial GN=EARS2 SYEM_HUMAN 58.69 Probable glutamate--tRNA ligase, mitochondrial GN=EARS2 SYEM_HUMAN 58.69 Probable glutamate--tRNA ligase, mitochondrial GN=EARS2 SYEM_HUMAN 58.69 Probable methyltransferase-like protein 15 GN=METTL15 MET15 HUMAN 46.12 Probable methyltransferase-like protein $15 \mathrm{GN}=$ METTL15 MET15 HUMAN 46.12 Probable methyltransferase-like protein 15 GN=METTL15 MET15_HUMAN 46.12 Probable proline--tRNA ligase, mitochondrial GN=PARS2 SYPM HUMAN 53.26 Probable proline--tRNA ligase, mitochondrial GN=PARS2 SYPM_HUMAN 53.26 Probable rRNA-processing protein EBP2 GN=EBNA1BP2 EBP2_HUMAN 34.85 Probable rRNA-processing protein EBP2 GN=EBNA1BP2 EBP2 HUMAN 34.8 Probable rRNA-processing protein EBP2 GN=EBNA1BP2 EBP2_HUMAN 34.8 Probable rRNA-processing protein EBP2 GN=EBNA1BP2 EBP2 HUMAN 34.8 Probable rRNA-processing protein EBP2 GN=EBNA1BP2 EBP2 HUMAN 34.8 Probable rRNA-processing protein EBP2 GN=EBNA1BP2 EBP2_HUMAN 34.8: Probable rRNA-processing protein EBP2 GN=EBNA1BP2 EBP2 HUMAN 34.85 Probable serine carboxypeptidase CPVL GN=CPVL CPVL_HUMAN 54.17
$133 \quad 0.13 \% \quad 38.6 \%$ QVSDLISVLRE

$0.13 \% \quad 38.6 \%$ LLQLVEDR

$0.13 \% 38.6 \%$ LLQLVEDRGSGR

$0.00 \% \quad 8.9 \%$ ELLASAPTGSGK

$0.00 \% \quad 8.9 \%$ ALIISPTRELASQIHR

$0.00 \% \quad 8.9 \% \quad$ KFDILVTTPNR

$0.00 \% \quad 8.9 \%$ AITFFTEDDKPLLR

$0.01 \% \quad 11.2 \%$ AIPLALEGKDLLAR

$0.01 \% \quad 11.2 \%$ ATGPVVEQAVR

$0.01 \% \quad 11.2 \%$ GLVLVPTKELAR

$0.01 \% \quad 11.2 \%$ VANVSAAEDSVSQR

$0.01 \% \quad 11.2 \%$ SLLFVNTLER

$0.00 \% \quad 3.6 \%$ VEDFTQNPR

$0.00 \% \quad 3.6 \%$ LSCPITALGR

$0.00 \% \quad 3.6 \%$ TMATFPVAPR

$0.00 \% \quad 3.6 \%$ QIVTAGLGDHLAR

$0.01 \% \quad 3.0 \%$ LSQSLGLVSK

$0.01 \% \quad 3.0 \%$ LAAIAVAER

$0.01 \% \quad 3.0 \%$ TLLTFCTNGVLLR

$0.01 \% \quad 3.0 \%$ APEPPPALIVR

$0.01 \% \quad 5.0 \%$ VPAHPDSR

$0.01 \% \quad 5.0 \%$ SVLSEGHQR

$0.01 \% \quad 21.4 \%$ NPLIINSIIDK

$0.01 \% \quad 21.4 \%$ VQGTPVASK

$0.01 \% \quad 21.4 \%$ LQVLVGDVLK

$0.01 \% \quad 21.4 \%$ LSINTQLLAR

$0.01 \% \quad 21.4 \%$ NNFRPPPK

$0.01 \% \quad 21.4 \%$ SSAVQQLLEK

$0.01 \% \quad 21.4 \%$ SMDIDDFIR

$0.01 \% \quad 7.5 \%$ TALYNYIFAK

$0.01 \% \quad 7.5 \%$ EALRNHQTPR

$0.01 \% \quad 7.5 \%$ NMSQEQVAQK

$0.01 \% \quad 7.5 \%$ LVSNESQRR

$0.00 \% \quad 9.3 \%$ IASAIVQAR

$0.00 \% \quad 9.3 \% \quad$ IFVNNELNELYTGLK

$0.00 \% \quad 9.3 \%$ VLSPQDQDVQDNPR

$0.00 \% \quad 5.1 \%$ VIDQEMQAIGGQK

$0.00 \% \quad 5.1 \%$ QLPFLLYQVTR

$0.02 \% \quad 29.1 \%$ ELQDAFSR

$0.02 \% \quad 29.1 \%$ GLLKPGLNVVLEGPK

$0.02 \% \quad 29.1 \%$ LDVTLGPVPEIGGSEAPAPQNKDQK

$0.02 \% \quad 29.1 \%$ AVDPEDDFQR

$0.02 \% \quad 29.1 \%$ QAQAAVLAVLPR

$0.02 \% \quad 29.1 \%$ RPTDYFAEMAK

$0.02 \% \quad 29.1 \%$ VQTEVLQK

$0.01 \% \quad 9.0 \%$ CTEPEDQLYYVK
$99.2 \% 19.0$

$99.0 \% \quad 54.8$

$99.7 \% \quad 52.7$

$99.7 \% 47.1$

$99.5 \% \quad 24.0$

$99.6 \% 27.8$

$99.7 \% \quad 52.3$

$99.7 \% \quad 39.3$

$99.7 \% \quad 30.5$

$\begin{array}{lll}99.6 \% & 24.9\end{array}$

$99.7 \% \quad 82.9$

$99.7 \% \quad 33.8$

$99.7 \% \quad 39.1$

$98.6 \% \quad 19.4$

$98.9 \% \quad 23.1$

$99.7 \% \quad 56.1$

$99.7 \% \quad 60.1$

$99.7 \% \quad 65.1$

$99.7 \% \quad 46.9$

$99.7 \% \quad 29.2$

$99.0 \% \quad 47.9$

$99.7 \% \quad 40.3$

$99.7 \% \quad 49.2$

$99.7 \% \quad 32.2$

$99.7 \% \quad 60.9$

$99.7 \% \quad 65.9$

$97.9 \% \quad 22.7$

$99.7 \% \quad 58.2$

$99.7 \% \quad 34.8$

$99.7 \% \quad 37.3$

$99.7 \% \quad 26.2$

$99.7 \% \quad 43.0$

$96.1 \% \quad 20.5$

$99.7 \% \quad 33.1$

$99.7 \% \quad 61.2$

$99.7 \% \quad 82.1$

$99.7 \% \quad 43.5$

$99.7 \% \quad 30.6$

$\begin{array}{lll}98.2 \% & 26.8\end{array}$

$98.4 \% \quad 17.7$

$\begin{array}{ll}96.8 \% & 20.4 \\ 99.7 \% & 45.1\end{array}$

$99.7 \% \quad 59.1$

$99.7 \% \quad 37.6$

$99.0 \% \quad 38.4$

$99.0 \% \quad 19.3$
1130.6

1805.04

1303.74

1665.88

1479.89

1126.62

1295.80

1432.70

1191.67

1105.53

1087.59

1106.57

1350.75

1031.61

913.55

1507.83

1159.68

878.45

1012.52

1239.73

886.50

1083.68

1128.67

969.53

1102.61

1127.50

1203.64

1221.64

1162.55

1088.58

928.56

1766.93

1610.78

1432.7

1377.79

965.47

1533.94

2560.33

1191.53

1236.74

1328.63

944.54 1544.69 $\begin{array}{cc}52 & 470 \\ 62 & 470 \\ 71 & 478 \\ 71 & 482 \\ 04 & 215 \\ 37 & 252 \\ 85 & 295 \\ 12 & 525 \\ 37 & 50 \\ 74 & 84 \\ 35 & 96 \\ 15 & 128 \\ 61 & 270 \\ 13 & 421 \\ 64 & 773 \\ 74 & 783 \\ 27 & 939 \\ 31 & 90 \\ 51 & 259 \\ 86 & 298 \\ 97 & 807 \\ 11 & 18 \\ 54 & 62 \\ 41 & 51 \\ 98 & 106 \\ 07 & 116 \\ 75 & 184 \\ 94 & 201 \\ 44 & 253 \\ 92 & 300 \\ 56 & 65 \\ 53 & 162 \\ 69 & 178 \\ 62 & 370 \\ 35 & 243 \\ 90 & 304 \\ 82 & 395 \\ 04 & 116 \\ 76 & 186 \\ 22 & 29 \\ 30 & 44 \\ 70 & 94 \\ 95 & 104 \\ 11 & 122 \\ 32 & 142 \\ 80 & 187 \\ 20 & 331 \\ & \end{array}$ 
Prohibitin GN=PHB

Prohibitin $\mathrm{GN}=\mathrm{PHB}$

Prohibitin $\mathrm{GN}=\mathrm{PHB}$

Prohibitin GN=PHB

Prohibitin $\mathrm{GN}=\mathrm{PHB}$

Prohibitin $\mathrm{GN}=\mathrm{PHB}$

Prohibitin GN=PHB

Prohibitin GN=PHB

Prohibitin GN=PHB

Prohibitin $\mathrm{GN}=\mathrm{PHB}$

Prohibitin $\mathrm{GN}=\mathrm{PHB}$

Prohibitin GN=PHB

Prohibitin $\mathrm{GN}=\mathrm{PHB}$

Prohibitin $\mathrm{GN}=\mathrm{PHB}$

Prohibitin $\mathrm{GN}=\mathrm{PHB}$

Prohibitin $\mathrm{GN}=\mathrm{PHB}$

Prohibitin $\mathrm{GN}=\mathrm{PHB}$

Prohibitin GN=PHB

Prohibitin GN=PHB
PHB_HUMAN $29.80 \quad 100.0 \% \quad 23$ PHB HUMAN $29.80 \quad 100.0 \% \quad 23$ PHB_HUMAN $29.80 \quad 100.0 \% \quad 23$ PHB_HUMAN $29.80 \quad 100.0 \% \quad 23$ PHB HUMAN $29.80 \quad 100.0 \% \quad 23$ PHB_HUMAN $29.80 \quad 100.0 \% \quad 23$ PHB_HUMAN $29.80 \quad 100.0 \% \quad 23$ PHB_HUMAN $29.80 \quad 100.0 \% \quad 23$ PHB_HUMAN $29.80 \quad 100.0 \% \quad 23$ PHB HUMAN $29.80 \quad 100.0 \% \quad 23$ PHB_HUMAN $29.80 \quad 100.0 \% \quad 23$ PHB_HUMAN $29.80 \quad 100.0 \% \quad 23$ PHB HUMAN $29.80 \quad 100.0 \% \quad 23$ PHB_HUMAN $29.80 \quad 100.0 \% \quad 23$ PHB HUMAN $29.80 \quad 100.0 \% \quad 23$ PHB_HUMAN $29.80 \quad 100.0 \% \quad 23$ PHB_HUMAN $29.80 \quad 100.0 \% \quad 23$ PHB HUMAN $29.80 \quad 100.0 \% \quad 23$ PHB_HUMAN $29.80 \quad 100.0 \% \quad 23$ $\begin{array}{llll}0.01 \% & 9.0 \% & \text { FLSLPEVR }\end{array}$ $0.01 \% \quad 9.0 \%$ SDSEVAGYIR

$0.01 \% \quad 9.0 \%$ GGGHILPYDQPLR

$0.01 \% \quad 29.0 \%$ PAVLGFEGSANK

$0.01 \% \quad 29.0 \%$ TYVTPPGTGFLPGDTAR $0.01 \% \quad 29.0 \%$ GPGMGAPLVSVAVVAR

$0.01 \% \quad 29.0 \%$ IFGETIDIAVGNCLDR

$0.01 \% \quad 29.0 \%$ ISNDPSPGYNIEQMAK

$0.01 \% \quad 29.0 \%$ LVELPYTVK

$0.01 \% \quad 29.0 \%$ TPLSDSGVTQR

$0.01 \% \quad 6.3 \% \quad$ GPTSAELLNR

$0.01 \% \quad 6.3 \%$ GVLVVGIGSGTK

$0.01 \% \quad 15.1 \%$ DTVELQLLK

$0.01 \% \quad 15.1 \%$ TTYDHVTR

$0.01 \% \quad 15.1 \%$ DGFFTLDSALLR

$0.01 \% \quad 15.1 \%$ AATPQVAAELEK

$0.01 \% \quad 15.1 \%$ SLSPGLDTK

$0.02 \% \quad 3.9 \%$ LLQISSFNGK

$0.02 \% \quad 3.9 \%$ VISSVSYYTHR

$0.02 \% \quad 3.9 \% \quad$ YSHVQEVQER

$0.02 \% \quad 3.9 \%$ VVIQSNDDIASR

$0.02 \% \quad 3.9 \%$ SGGLPLVLSMLTR

$0.02 \% \quad 3.9 \%$ NNFLPNADMETR

$0.02 \% \quad 3.9 \% \quad$ LLLTAIGYGHVR

$0.02 \% \quad 3.9 \% \quad$ ELLAFQTSEK

$0.02 \% \quad 3.9 \%$ VLGGSFADQK

$0.00 \% \quad 2.7 \%$ TSEVDLAKPLVK

$0.00 \% \quad 2.7 \%$ NIQVSHQEFSK

$0.09 \% \quad 80.1 \%$ FGLALAVAGGVVNSALYNVDAGHR

$0.09 \% \quad 80.1 \%$ AVIFDRFR

$0.09 \% \quad 80.1 \%$ NVPVITGSK

$0.09 \% \quad 80.1 \%$ NVPVITGSKDLQNVNITLR

$0.09 \% \quad 80.1 \%$ DLQNVNITLR

$0.09 \% \quad 80.1 \%$ ILFRPVASQLPR

$0.09 \% \quad 80.1 \%$ IFTSIGEDYDER

$0.09 \% \quad 80.1 \%$ IFTSIGEDYDERVLPSITTEILK

$0.09 \% \quad 80.1 \%$ VLPSITTEILK

$0.09 \% \quad 80.1 \%$ FDAGELITQR

$0.09 \% \quad 80.1 \%$ QVSDDLTER

$0.09 \% \quad 80.1 \%$ AATFGLILDDVSLTHLTFGK

$0.09 \% \quad 80.1 \%$ EFTEAVEAK

$0.09 \% \quad 80.1 \%$ QVAQQEAER

$0.09 \% \quad 80.1 \%$ FVVEKAEQQK

$0.09 \% \quad 80.1 \%$ KAAIISAEGDSK

$0.09 \% \quad 80.1 \%$ AAIISAEGDSK

$98.9 \% \quad 18.3$

$99.7 \% \quad 58.3$

$99.7 \% \quad 34.5$

$99.7 \% \quad 58.2$

$99.7 \% \quad 56.0$

$99.7 \% \quad 34.0$

$99.7 \% \quad 50.2$

$99.7 \% \quad 45.0$

$99.7 \% \quad 28.0$

$99.7 \% \quad 62.7$

$99.7 \% \quad 54.6$

$99.7 \% \quad 47.6$

$99.6 \% \quad 29.5$

$99.0 \% 33.1$

$99.7 \% \quad 56.4$

$\begin{array}{lll}97.0 \% & 19.7\end{array}$

$97.6 \% \quad 23.5$

$95.0 \% \quad 14.4$

$\begin{array}{lll}99.7 \% & 44.5\end{array}$

$99.5 \% \quad 25.4$

$99.7 \% \quad 57.2$

$99.7 \% \quad 31.1$

$98.6 \% \quad 18.2$

$99.7 \% \quad 40.1$

$99.7 \% \quad 48.9$

$99.7 \% \quad 33.3$

$99.7 \% \quad 31.2$

$99.5 \% \quad 21.5$

$\begin{array}{lll}99.7 \% & 58.5 \\ 99.0 \% & 29.8\end{array}$

$98.2 \% \quad 20.0$

$99.7 \% \quad 30.3$

$99.7 \% \quad 64.0$

$99.7 \% \quad 40.7$

$99.7 \% \quad 56.6$

$\begin{array}{lll}99.7 \% & 57.7\end{array}$

$99.7 \% \quad 64.2$

$99.7 \% \quad 49.3$

$99.7 \% \quad 38.2$

$99.7 \% \quad 49.3$

$99.7 \% \quad 59.9$

$99.7 \% \quad 45.6$

$99.7 \% \quad 57.1$

$99.7 \% \quad 59.2$

$0.09 \% \quad 80.1 \%$ AAELIANSLATAGDGLIELR $\quad 99.7 \% \quad 57.4$

$0.09 \% \quad 80.1 \%$ AAELIANSLATAGDGLIELRK $\quad 99.7 \% \quad 60.9$
960.55

1096.53

1422.75

1189.62

1749.88

1496.83

1792.89

1779.82

1061.62

1160.59

1057.56

1086.65

1058.6

992.48

1354.70

1227.66

917.49

1106.62

1311.67

1274.6

1316.68

1359.77

1437.64

1312.77

1165.61

1021.53

1299.75

1316.66

2371.25

1023.57

914.53

2081.17

1185.66

1396.84

1444.66

2639.38

1213.74

1149.59

1062.51

2119.14

1023.50

1058.52

1205.65

1189.64

1061.55

1998.09

2126.18

$\begin{array}{cc}32 & 339 \\ 24 & 433 \\ 45 & 457 \\ 2 & 13 \\ 1 & 47 \\ 9 & 94 \\ 48 & 163 \\ 70 & 185 \\ 90 & 198 \\ 13 & 323 \\ 9 & 88 \\ 26 & 137 \\ 8 & 36 \\ 51 & 158 \\ 60 & 271 \\ 85 & 296 \\ 97 & 305 \\ 42 & 351 \\ 61 & 371 \\ 48 & 657 \\ 77 & 788 \\ 20 & 1132 \\ 33 & 1144 \\ 57 & 1168 \\ 36 & 1445 \\ 13 & 1722 \\ 2 & 23 \\ 28 & 638 \\ 2 & 35 \\ 6 & 43 \\ 5 & 83 \\ 5 & 93 \\ 4 & 93 \\ 4 & 105 \\ 06 & 117 \\ 06 & 128 \\ 18 & 128 \\ 34 & 143 \\ 49 & 157 \\ 58 & 177 \\ 78 & 186 \\ 87 & 195 \\ 98 & 207 \\ 08 & 219 \\ 09 & 219 \\ 20 & 239 \\ 20 & 240 \\ & \end{array}$


Prohibitin GN=PHB Prohibitin GN=PHB Prohibitin GN=PHB Prohibitin GN=PHB Prohibitin-2 GN=PHB2 Prohibitin-2 GN=PHB2

Prohibitin-2 GN=PHB2 Prohibitin-2 GN=PHB2 Prohibitin-2 GN=PHB2 Prohibitin-2 GN=PHB2 Prohibitin-2 GN=PHB2 Prohibitin-2 GN=PHB2 Prohibitin-2 GN=PHB2 Prohibitin-2 GN=PHB2

Prohibitin-2 GN=PHB2 Prohibitin-2 GN=PHB2 Prohibitin-2 GN=PHB2 Prohibitin-2 GN=PHB2 Prohibitin-2 GN=PHB2

Prohibitin-2 GN=PHB2

Prohibitin-2 GN=PHB2

Prohibitin-2 GN=PHB2

Prohibitin-2 GN=PHB2

Prohibitin-2 GN=PHB2

Prolactin-inducible protein GN=PIP Prolactin-inducible protein GN=PIP Proliferating cell nuclear antigen GN=PCNA PCNA_HUMAN 28.77 Proliferating cell nuclear antigen GN=PCNA PCNA_HUMAN 28.77 Proliferating cell nuclear antigen GN=PCNA PCNA_HUMAN 28.77 Proliferating cell nuclear antigen GN=PCNA PCNA_HUMAN 28.77 Proliferating cell nuclear antigen GN=PCNA PCNA_HUMAN 28.77 Proliferating cell nuclear antigen GN=PCNA PCNA_HUMAN 28.77 Proliferating cell nuclear antigen GN=PCNA PCNA_HUMAN 28.77 Proliferating cell nuclear antigen GN=PCNA PCNA_HUMAN 28.77 Proliferating cell nuclear antigen GN=PCNA PCNA_HUMAN 28.77 Proliferating cell nuclear antigen GN=PCNA PCNA_HUMAN 28.77 Proliferating cell nuclear antigen GN=PCNA PCNA_HUMAN 28.77 Prolyl 4-hydroxylase subunit alpha-1 GN=P4HA1 P4HA1_HUMAN 61.05 Prolyl 4-hydroxylase subunit alpha-1 GN=P4HA1 P4HA1_HUMAN 61.05 Proteasomal ATPase-associated factor $1 \mathrm{GN}=$ PAAF1 PAAF1_HUMAN 42.19 Proteasomal ATPase-associated factor $1 \mathrm{GN}=$ PAAF1 PAAF1_HUMAN $42.1 \mathrm{c}$ Proteasomal ATPase-associated factor $1 \mathrm{GN}=\mathrm{PAAF} 1$ PAAF1_HUMAN 42.19 Proteasomal ATPase-associated factor $1 \mathrm{GN}=\mathrm{PAAF} 1$ PAAF1 HUMAN 42.19 Proteasomal ATPase-associated factor $1 \mathrm{GN}=$ PAAF1 PAAF1 HUMAN 42.19 Proteasomal ATPase-associated factor 1 GN=PAAF1 PAAF1_HUMAN 42.19 Proteasome activator complex subunit 3 GN=PSME3 PSME3_HUMAN 29.51 Proteasome activator complex subunit 3 GN=PSME3 PSME3_HUMAN 29.51

28

28

28

28

28

28

28
28

28

28

28
28
28

28
28

28

28
28

28
28

28
28
28

28
28
28

28
28
28

28

2

17
17

17
17
17

17
17
17

$\begin{array}{ll}17 \\ 1 & 17 \\ 1 & 17\end{array}$

$\begin{array}{ll}1 & 17 \\ 1 & 17 \\ 1 & 17 \\ 1 & 17\end{array}$

$0.09 \% \quad 80.1 \%$ KLEAAEDIAYQLSR $0.09 \% \quad 80.1 \%$ LEAAEDIAYQLSR

$0.09 \% \quad 80.1 \%$ NITYLPAGQSVLLQLPQ $\quad 99.7 \% \quad 42.4$

$0.09 \% \quad 66.9 \%$ LLLGAGAVAYGVR

$0.09 \% \quad 66.9 \%$ ESVFTVEGGHR

$0.09 \% \quad 66.9 \%$ IGGVQQDTILAEGLHFR

$0.09 \% \quad 66.9 \%$ IPWFQYPIIYDIR

$0.09 \% \quad 66.9 \%$ KISSPTGSK

$0.09 \% \quad 66.9 \%$ DLQMVNISLR

$0.09 \% \quad 66.9 \%$ VLSRPNAQELPSMYQR

$0.09 \% \quad 66.9 \%$ LGLDYEER

$0.09 \% \quad 66.9 \%$ VLPSIVNEVLK

$0.09 \% \quad 66.9 \%$ FNASQLITQR

$0.09 \% \quad 66.9 \%$ AQVSLLIR

$0.09 \% \quad 66.9 \%$ EYTAAVEAK

$0.09 \% \quad 66.9 \%$ EYTAAVEAKQVAQQEAQR

$\begin{array}{ll}0.09 \% & 66.9 \% \\ 0.09 \% & 66.9 \%\end{array}$

$0.09 \% \quad 66.9 \%$ QKIVQAEGEAEAAK

$0.09 \% \quad 66.9 \%$ IVQAEGEAEAAK

$0.09 \% \quad 66.9 \%$ MLGEALSK

$0.09 \% \quad 66.9 \%$ AAQNISKTIATSQNR

$0.09 \% \quad 66.9 \%$ TIATSQNR

$\begin{array}{lll}0.09 \% & 66.9 \% & \text { IYLTADNLVLNLQDESFTR }\end{array}$

$0.00 \% \quad 15.1 \%$ TVQIAAVVDVIR

$0.00 \% \quad 15.1 \%$ FYTIEILKVE

$0.03 \% \quad 52.5 \%$ LVQGSILK

$0.03 \% \quad 52.5 \%$ LVQGSILKK

$0.03 \% \quad 52.5 \%$ SEGFDTYR

\begin{tabular}{lll}
$0.03 \%$ & $52.5 \%$ & NLAMGVNLTSMSK \\
$0.03 \%$ & $52.5 \%$ & 99.7 \\
\hline
\end{tabular}

$33 \quad 0.03 \% \quad 52.5 \%$ LMDLDVEQLGIPEQEYSCVVK

$0.03 \% \quad 52.5 \%$ MPSGEFAR

$0.03 \% \quad 52.5 \%$ DLSHIGDAVVISCAK

$0.03 \% \quad 52.5 \%$ FSASGELGNGNIK

$0.03 \% 52.5 \%$ ATPLSSTVTLSMSADVPLVVEYK

$0.03 \% \quad 52.5 \%$ IADMGHLK

$0.00 \% \quad 4.7 \%$ SAWLSGYENPVVSR

$0.00 \% \quad 4.7 \%$ HAACPVLVGNK

$10 \quad 0.01 \% \quad 16.6 \%$ SIHISCPK

$10 \quad 0.01 \% \quad 16.6 \%$ FLAPYTTFSR

$10 \quad 0.01 \% \quad 16.6 \%$ SITCLDISSR

$10 \quad 0.01 \% \quad 16.6 \%$ GGLGVSSSTDGTMK

$10 \quad 0.01 \% \quad 16.6 \%$ GGILDTAIVDR

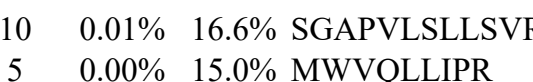

$5 \quad 0.00 \% \quad 15.0 \%$ TVESEAASYLDQISR
$9.7 \% \quad 55.0$

$\begin{array}{lllll}97.6 \% & 19.7 & 25.0 & 14.6 & 2\end{array}$

$\begin{array}{lllll}99.7 \% & 55.9 & 25.0 & 32.7 & 6\end{array}$

$\begin{array}{lllll}99.7 \% & 43.3 & 25.0 & 38.4 & 2\end{array}$

$99.0 \% \quad 53.0 \quad 25.0 \quad 41.2$

$\begin{array}{lllll}99.7 \% & 38.4 & 25.0 & 35.6 & 7\end{array}$

$\begin{array}{llll}99.7 \% & 63.1 & 25.0 & 56.0\end{array}$

$\begin{array}{llll}99.0 \% & 56.8 & 25.0 & 40.0\end{array}$

$\begin{array}{lllll}99.7 \% & 38.4 & 25.0 & 38.4 & 5\end{array}$

$\begin{array}{llll}9.7 \% & 73.8 & 25.0 & 73.8\end{array}$

$\begin{array}{lllll}99.7 \% & 60.4 & 25.0 & 52.2 & 8\end{array}$

$\begin{array}{lllll}99.7 \% & 50.2 & 25.0 & 42.4 & 2\end{array}$

$\begin{array}{lllll}99.7 \% & 65.3 & 25.0 & 60.2 & 5 \\ 99.0 \% & 48.2 & 25.0 & 23.3 & 2\end{array}$

$\begin{array}{llll}99.7 \% & 29.9 & 25.0 & 29.9\end{array}$

$\begin{array}{lllll}99.0 \% & 30.0 & 25.0 & 25.3 & 2\end{array}$

$\begin{array}{lll}99.7 \% & 61.2\end{array}$

$99.7 \% \quad 68.7$

$\begin{array}{lll}25.0 & 60.1 & 3\end{array}$

$\begin{array}{lllll}98.8 \% & 45.3 & 25.0 & 17.2 & 1\end{array}$

$\begin{array}{llll}99.3 \% & 34.2 & 25.0 & 17.2\end{array}$

$\begin{array}{ccccc}99.0 \% & 30.2 & 25.0 & 22.5 & 2\end{array}$

$\begin{array}{lllll}99.7 \% & 55.5 & 25.0 & 51.7 & 6\end{array}$

$\begin{array}{lllll}99.7 \% & 41.0 & 25.0 & 33.4 & 2 \\ 99.7 \% & 55.6 & 25.0 & 55.6 & 3\end{array}$

$\begin{array}{lllll}99.0 \% & 44.3 & 25.0 & 33.1 & 4\end{array}$

$\begin{array}{lllll}99.7 \% & 61.2 & 25.0 & 61.2 & 2\end{array}$

$\begin{array}{lllll}99.7 \% & 85.5 & 25.0 & 77.4 & 2\end{array}$

$\begin{array}{lllll}99.7 \% & 45.8 & 25.0 & 45.8 & 2 \\ 99.0 \% & 41.3 & 25.0 & 31.9 & 2\end{array}$

$\begin{array}{lllll}99.0 \% & 41.3 & 25.0 & 31.9 & 2 \\ 99.7 \% & 59.9 & 25.0 & 59.9 & 2\end{array}$

$\begin{array}{lllll}99.7 \% & 59.9 & 25.0 & 59.9 & 2 \\ 99.7 \% & 50.2 & 25.0 & 42.5 & 2\end{array}$

$\begin{array}{llll}98.7 \% & 20.4 & 25.0 & 18.8\end{array}$

$\begin{array}{llll}99.5 \% & 22.0 & 25.0 & 22.0\end{array}$

$\begin{array}{llll}99.7 \% & 47.6 & 25.0 & 36.0\end{array}$

$\begin{array}{llll}99.7 \% & 44.5 & 25.0 & 44.5\end{array}$

$\begin{array}{llll}99.7 \% & 51.8 & 25.0 & 33.9\end{array}$

$99.7 \% \quad 35.0 \quad 25.0 \quad 26.8$

$99.7 \% \quad 73.1 \quad 25.0 \quad 62.0$ 

Proteasome subunit alpha type-1 GN=PSMA1 PSA1_HUMAN $29.56 \quad 100.0 \%$ Proteasome subunit alpha type-3 GN=PSMA3 PSA3_HUMAN $28.43 \quad 100.0 \%$ Proteasome subunit alpha type-3 GN=PSMA3 PSA3_HUMAN $28.43 \quad 100.0 \%$ Proteasome subunit alpha type-3 GN=PSMA3 PSA3_HUMAN $28.43 \quad 100.0 \%$ Proteasome subunit alpha type-3 GN=PSMA3 PSA3_HUMAN $28.43 \quad 100.0 \%$ Proteasome subunit alpha type-4 GN=PSMA4 PSA4_HUMAN $29.48 \quad 100.0 \%$ Proteasome subunit alpha type-4 GN=PSMA4 PSA4_HUMAN $29.48 \quad 100.0 \%$ Proteasome subunit alpha type-4 GN=PSMA4 PSA4_HUMAN $29.48 \quad 100.0 \%$ Proteasome subunit alpha type-4 GN=PSMA4 PSA4_HUMAN $29.48 \quad 100.0 \%$ Proteasome subunit alpha type-4 GN=PSMA4 PSA4_HUMAN $29.48 \quad 100.0 \%$ Proteasome subunit alpha type-4 GN=PSMA4 PSA4_HUMAN $29.48 \quad 100.0 \%$ Proteasome subunit alpha type-4 GN=PSMA4 PSA4_HUMAN $29.48 \quad 100.0 \%$ Proteasome subunit alpha type-4 GN=PSMA4 PSA4 HUMAN $29.48 \quad 100.0 \%$ Proteasome subunit alpha type-4 GN=PSMA4 PSA4_HUMAN $29.48 \quad 100.0 \%$ Proteasome subunit alpha type-5 GN=PSMA5 PSA5_HUMAN $26.41 \quad 100.0 \%$ Proteasome subunit alpha type-5 GN=PSMA5 PSA5_HUMAN $26.41 \quad 100.0 \%$ Proteasome subunit alpha type-7 GN=PSMA7 PSA7_HUMAN $27.89 \quad 100.0 \%$ Proteasome subunit alpha type-7 GN=PSMA7 PSA7_HUMAN $27.89 \quad 100.0 \%$ Proteasome subunit alpha type-7 GN=PSMA7 PSA7_HUMAN $27.89 \quad 100.0 \%$ Proteasome-associated protein ECM29 homolog GN=ECM29 ECM29_HUMAN $204.30 \quad 100.0 \%$ Proteasome-associated protein ECM29 homolog GN=ECM29 ECM29_HUMAN $204.30 \quad 100.0 \%$ Proteasome-associated protein ECM29 homolog GN=ECM29 ECM29_HUMAN $204.30 \quad 100.0 \%$ Proteasome-associated protein ECM29 homolog GN=ECM29 ECM29_HUMAN $204.30 \quad 100.0 \%$ Proteasome-associated protein ECM29 homolog GN=ECM29 ECM29_HUMAN $204.30 \quad 100.0 \%$ Proteasome-associated protein ECM29 homolog GN=ECM29 ECM29_HUMAN 204.30 $100.0 \%$ Proteasome-associated protein ECM29 homolog GN=ECM29 ECM29 HUMAN 204.30 100.0\% Proteasome-associated protein ECM29 homolog GN=ECM29 ECM29_HUMAN 204.30 $100.0 \%$ Protein arginine N-methyltransferase 1 GN=PRMT1 ANM1_HUMAN $41.52 \quad 100.0 \%$ Protein arginine N-methyltransferase 1 GN=PRMT1 ANM1_HUMAN $41.52 \quad 100.0 \%$ Protein arginine N-methyltransferase 1 GN=PRMT1 ANM1_HUMAN $41.52 \quad 100.0 \%$ Protein arginine N-methyltransferase 1 GN=PRMT1 ANM1_HUMAN $41.52 \quad 100.0 \%$ Protein arginine N-methyltransferase 1 GN=PRMT1 ANM1_HUMAN $41.52 \quad 100.0 \%$ Protein arginine N-methyltransferase 1 GN=PRMT1 ANM1_HUMAN $41.52 \quad 100.0 \%$ Protein arginine N-methyltransferase 1 GN=PRMT1 ANM1 HUMAN $41.52 \quad 100.0 \%$ Protein arginine N-methyltransferase 1 GN=PRMT1 ANM1_HUMAN $41.52 \quad 100.0 \%$ Protein arginine N-methyltransferase $1 \mathrm{GN}=$ PRMT1 ANM1_HUMAN $41.52 \quad 100.0 \%$ Protein arginine N-methyltransferase 1 GN=PRMT1 ANM1_HUMAN $41.52 \quad 100.0 \%$ Protein arginine N-methyltransferase 1 GN=PRMT1 ANM1_HUMAN $41.52 \quad 100.0 \%$ Protein arginine N-methyltransferase $1 \mathrm{GN}=$ PRMT1 ANM1_HUMAN $41.52 \quad 100.0 \%$ Protein arginine N-methyltransferase 5 GN=PRMT5 ANM5_HUMAN $72.69 \quad 100.0 \%$ Protein arginine N-methyltransferase 5 GN=PRMT5 ANM5_HUMAN $72.69 \quad 100.0 \% \quad 29$ Protein arginine N-methyltransferase $5 \mathrm{GN}=$ PRMT5 ANM5 HUMAN $72.69 \quad 100.0 \% \quad 29$ Protein arginine N-methyltransferase 5 GN=PRMT5 ANM5_HUMAN $72.69 \quad 100.0 \% \quad 29$

$0.00 \% \quad 15.0 \%$ TVTEIDEKEYISLR $0.00 \% \quad 17.5 \%$ NQYDNDVTVWSPQGR $0.00 \% \quad 17.5 \%$ THAVLVALK $0.00 \% \quad 17.5 \%$ AQSELAAHQK $0.00 \% \quad 17.5 \%$ ETLPAEQDLTTK $0.01 \% \quad 15.3 \%$ VFQVEYAMK $0.01 \% \quad 15.3 \%$ CKDGVVFGVEK $0.01 \% \quad 15.3 \%$ LYEEGSNKR $0.01 \% \quad 15.3 \%$ SNFGYNIPLK

$0.02 \% \quad 39.1 \%$ TTIFSPEGR $20 \quad 0.02 \% \quad 39.1 \%$ LLDEVFFSEK $0.02 \% \quad 39.1 \%$ LNEDMACSVAGITSDANVLTNELR $0.02 \% \quad 39.1 \%$ QAYTQFGGK $0.02 \% \quad 39.1 \%$ ATCIGNNSAAAVSMLK $0.02 \% \quad 39.1 \%$ QDYKEGEMTLK $0.02 \% \quad 39.1 \%$ LSAEKVEIATLTR $0.02 \% 39.1 \%$ VEIATLTR

$0.02 \% \quad 39.1 \%$ HEEEEAKAER $0.00 \% \quad 12.0 \%$ GVNTFSPEGR $0.00 \% \quad 12.0 \%$ AIGSASEGAQSSLQEVYH $0.01 \% \quad 16.1 \%$ LTVEDPVTVEYITR $0.01 \% \quad 16.1 \%$ NYTDEAIETDDLTIK $0.01 \% \quad 16.1 \%$ ALLEVVQSGGK $0.02 \% \quad 5.6 \% \quad$ LSSTQEGVR $0.02 \% \quad 5.6 \%$ SASPFNLAEKPK $0.02 \% \quad 5.6 \%$ TLMSSGQMAPSSSNK $0.02 \% \quad 5.6 \%$ KGAAFGFNVIATR $0.02 \% \quad 5.6 \%$ AGEQLAPFLPQLVPR $0.02 \% \quad 5.6 \%$ AQGAIAMASIAK $0.02 \% \quad 5.6 \%$ AIACVVTACSAELEK $0.02 \% \quad 5.6 \%$ IVAISCAADILK $0.03 \% \quad 40.4 \%$ VVLDVGSGTGILCMFAAK $0.03 \% \quad 40.4 \%$ KVIGIECSSISDYAVK $0.03 \% \quad 40.4 \%$ VIGIECSSISDYAVK $0.03 \% \quad 40.4 \%$ ANKLDHVVTIIK $0.03 \% \quad 40.4 \%$ GKVEEVELPVEK $0.03 \% \quad 40.4 \%$ ATLYVTAIEDR $0.03 \% \quad 40.4 \%$ DVAIKEPLVDVVDPK $0.03 \% \quad 40.4 \%$ QLVTNACLIK $0.03 \% \quad 40.4 \%$ EVDIYTVK

$0.03 \% \quad 40.4 \%$ VEDLTFTSPFCLQVK $0.03 \% \quad 40.4 \%$ QTVFYMEDYLTVK $0.03 \% \quad 40.4 \%$ TGEEIFGTIGMRPNAK

$0.19 \% \quad 44.7 \%$ VSSGRDLNCVPEIADTLGAVAK

$41 \quad 189 \quad 0.19 \% \quad 44.7 \%$ QGFDFLCMPVFHPR $41 \quad 189 \quad 0.19 \% \quad 44.7 \%$ REFIQEPAK
$99.7 \% \quad 73.7 \quad 25.0 \quad 70.9$ $98.8 \% \quad 17.6 \quad 25.0 \quad 17.6$ $\begin{array}{llll}98.8 \% & 19.2 & 25.0 & 16.7\end{array}$ $99.7 \% \quad 44.5 \quad 25.0 \quad 28.6$ $99.7 \% \quad 29.2$ $99.7 \% \quad 54.2$ $99.7 \% \quad 30.6$ $99.7 \% \quad 35.0 \quad 25.0$ $99.7 \% \quad 28.1 \quad 25.0$ $99.6 \% \quad 27.3 \quad 25.0$ $99.7 \% \quad 60.2$ $99.7 \% 51.6$ $99.5 \% \quad 26.3$ $99.7 \% \quad 62.1$ $99.3 \% 24.0$ $99.7 \% \quad 39.2$ $99.0 \% \quad 45.1$ $99.4 \% \quad 20.0$ $99.7 \% \quad 31.2$ $96.8 \% 15.6$ $99.7 \% \quad 62.6$ $99.7 \% \quad 70.5$ $99.7 \% \quad 59.4$ $99.7 \% \quad 38.8$ $99.7 \% \quad 41.9$ $99.7 \% \quad 62.8$ $\begin{array}{lll}99.1 \% & 20.2\end{array}$ $99.7 \% \quad 33.2$ $99.7 \% \quad 49.9$ $99.7 \% \quad 58.8$ $99.7 \% \quad 33.3$ $99.7 \% \quad 49.9$ $99.7 \% \quad 58.0$ $99.7 \% \quad 70.3$ $99.7 \% \quad 41.0$ $\begin{array}{lll}99.7 \% & 52.2\end{array}$ $99.7 \% 70.7$ $99.7 \% \quad 46.0$ $99.7 \% \quad 33.4$ $99.0 \% \quad 18.3$ $99.7 \% \quad 55.8$ $99.7 \% \quad 70.4$ $99.7 \% \quad 49.6$ $99.7 \% 58.2$ $99.7 \% \quad 53.4$ $96.8 \% 21.9$ 1778.81

951.60

1082.56

1345.68

1114.56

1237.62

1095.54

1152.60

1007.52

1226.63

2593.22

999.49

1623.78

1357.63

1430.82

902.53

1227.56

1063.52

1961.96

1634.86

1740.82

1100.63

976.51

1288.69

1557.69

1351.75

1635.92

1147.61

1621.79

1273.72

1837.96

1768.92

1640.82

1350.81

1355.74

1251.66

1636.92

1159.65

966.51

1783.89

1652.79

1720.87

2272.16

1785.91

1750.82

1117.60

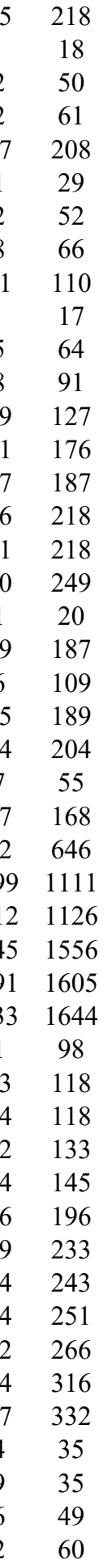


Protein arginine N-methyltransferase 5 GN=PRMT5 ANM5_HUMAN $72.69 \quad 100.0 \% \quad 29$ Protein arginine N-methyltransferase 5 GN=PRMT5 ANM5_HUMAN $72.69 \quad 100.0 \% \quad 29$ Protein arginine N-methyltransferase 5 GN=PRMT5 ANM5_HUMAN $72.69 \quad 100.0 \% \quad 29$ Protein arginine N-methyltransferase 5 GN=PRMT5 ANM5 HUMAN $72.69 \quad 100.0 \%$ Protein arginine N-methyltransferase 5 GN=PRMT5 ANM5_HUMAN $72.69 \quad 100.0 \% \quad 29$ Protein arginine N-methyltransferase 5 GN=PRMT5 ANM5_HUMAN $72.69 \quad 100.0 \% \quad 29$ Protein arginine N-methyltransferase 5 GN=PRMT5 ANM5_HUMAN $72.69 \quad 100.0 \% \quad 29$ Protein arginine N-methyltransferase 5 GN=PRMT5 ANM5_HUMAN $72.69 \quad 100.0 \% \quad 29$ Protein arginine N-methyltransferase $5 \mathrm{GN}=$ =PRMT5 ANM5 HUMAN $72.69 \quad 100.0 \%$ Protein arginine N-methyltransferase 5 GN=PRMT5 ANM5_HUMAN $72.69 \quad 100.0 \% \quad 29$ Protein arginine N-methyltransferase 5 GN=PRMT5 ANM5_HUMAN $72.69 \quad 100.0 \% \quad 29$ Protein arginine N-methyltransferase 5 GN=PRMT5 ANM5_HUMAN $72.69 \quad 100.0 \% \quad 29$ Protein arginine N-methyltransferase 5 GN=PRMT5 ANM5_HUMAN $72.69 \quad 100.0 \% \quad 29$ Protein arginine N-methyltransferase 5 GN=PRMT5 ANM5_HUMAN $72.69 \quad 100.0 \% \quad 29$ Protein arginine N-methyltransferase 5 GN=PRMT5 ANM5_HUMAN $72.69 \quad 100.0 \% \quad 29$ Protein arginine N-methyltransferase 5 GN=PRMT5 ANM5_HUMAN $72.69 \quad 100.0 \% \quad 2$ Protein arginine N-methyltransferase 5 GN=PRMT5 ANM5 HUMAN $72.69 \quad 100.0 \%$ Protein arginine N-methyltransferase 5 GN=PRMT5 ANM5_HUMAN $72.69 \quad 100.0 \% \quad 29$ Protein arginine N-methyltransferase 5 GN=PRMT5 ANM5_HUMAN $72.69 \quad 100.0 \% \quad 29$ Protein arginine N-methyltransferase 5 GN=PRMT5 ANM5 HUMAN $72.69 \quad 100.0 \% 29$ Protein arginine N-methyltransferase 5 GN=PRMT5 ANM5_HUMAN $72.69 \quad 100.0 \% \quad 29$ Protein arginine N-methyltransferase 5 GN=PRMT5 ANM5 HUMAN $72.69 \quad 100.0 \%$ Protein arginine N-methyltransferase 5 GN=PRMT5 ANM5_HUMAN $72.69 \quad 100.0 \% \quad 29$ Protein arginine N-methyltransferase 5 GN=PRMT5 ANM5_HUMAN $72.69 \quad 100.0 \%$ Protein arginine N-methyltransferase 5 GN=PRMT5 ANM5 HUMAN $72.69 \quad 100.0 \%$ Protein CMSS1 GN=CMSS 1 Protein CMSS1 GN $=$ CMSS Protein CMSS1 GN $=$ CMSS Protein $\mathrm{CMSS} 1 \mathrm{GN}=\mathrm{CMSS}$ Protein CMSS1 GN=CMSS1 Protein DEK GN=DEK Protein DEK GN=DEK Protein DEK GN=DEK Protein DEK GN=DEK Protein DEK GN=DEK

Protein DEK GN=DEK

Protein DENND6A GN=DENND6A Protein DENND6A GN=DENND6A Protein DENND6A GN=DENND6A iaphanous homolog $1 \mathrm{GN}=$ DIAPH1 DIAP1 HUMAN $141.35100 .0 \%$ Protein diaphanous homolog $1 \mathrm{GN}=$ DIAPH1 DIAP1_HUMAN $141.35 \quad 100.0 \%$ Protein FAM45B GN=FAM45B Protein FAM45B GN=FAM45B Protein flightless- 1 homolog GN=FLII Protein flightless -1 homolog GN=FLII Protein flightless- 1 homolog GN=FLII

CMS1_HUMAN $31.89 \quad 100.0 \%$ CMS1_HUMAN $31.89 \quad 100.0 \%$ CMS1_HUMAN $31.89 \quad 100.0 \%$ CMS1_HUMAN $31.89 \quad 100.0 \%$ CMS1_HUMAN $31.89 \quad 100.0 \%$ DEK_HUMAN $42.68 \quad 100.0 \%$ DEK_HUMAN $42.68 \quad 100.0 \%$ DEK_HUMAN $42.68 \quad 100.0 \%$ DEK HUMAN $42.68 \quad 100.0 \%$ DEK HUMAN $42.68 \quad 100.0 \%$ DEN6A_HUMAN $69.58 \quad 100.0 \%$ DEN6A HUMAN $69.58 \quad 100.0 \%$ DEN6A_HUMAN $69.58 \quad 100.0 \%$

FA45B HUMAN $40.52 \quad 100.0 \%$

FLII_HUMAN $144.76 \quad 100.0 \%$

FLII HUMAN $144.76 \quad 100.0 \%$

FLII_HUMAN $144.76 \quad 100.0 \%$
$41 \quad 189 \quad 0.19 \% \quad 44.7 \%$ EFIQEPAK

$41 \quad 189 \quad 0.19 \% \quad 44.7 \%$ EFIQEPAKNRPGPQTR

$41 \quad 189 \quad 0.19 \% \quad 44.7 \%$ SDLLLSGR

$89 \quad 0.19 \% \quad 44.7 \%$ SDLLLSGRDWNTLIVGK

$41 \quad 189 \quad 0.19 \% \quad 44.7 \%$ LSPWIRPDSK

$41 \quad 189 \quad 0.19 \% \quad 44.7 \%$ LSPWIRPDSKVEK

$41 \quad 189 \quad 0.19 \% \quad 44.7 \%$ VPLVAPEDLR

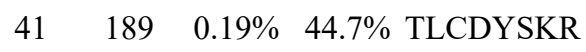

$\begin{array}{lllllll}89 & 0.19 \% & 44.7 \% & \text { RIAVALEIGADLPSNHVIDR } & 99.7 \% & 37.4\end{array}$

$189 \quad 0.19 \% \quad 44.7 \%$ IAVALEIGADLPSNHVID

$41 \quad 189 \quad 0.19 \% \quad 44.7 \%$ IAVALEIGADLPSNHVIDR

$41 \quad 189 \quad 0.19 \% \quad 44.7 \%$ AAILPTSIFLTNK

$41 \quad 189 \quad 0.19 \% \quad 44.7 \%$ AAILPTSIFLTNKK

$41 \quad 189 \quad 0.19 \% \quad 44.7 \%$ KGFPVLSK

$41 \quad 189 \quad 0.19 \% \quad 44.7 \%$ DPIKYSQYQQAIYK

$41 \quad 189 \quad 0.19 \% \quad 44.7 \%$ YSQYQQAIYK

$41 \quad 189 \quad 0.19 \% \quad 44.7 \%$ VPEEEKDTNVQVLMVLGAGR

$41 \quad 189 \quad 0.19 \% \quad 44.7 \%$ GPLVNASLR

$\begin{array}{llll}41 & 189 & 0.19 \% & 44.7 \% \\ 41 & 189 & 0.19 \% & 44.7 \%\end{array}$ DEK_HUMAN $42.68 \quad 100.0 \%$

$\begin{array}{ll}99.7 \% & 58.8 \\ 99.7 \% & 53.9\end{array}$

$99.7 \% \quad 44.2$

$99.0 \% \quad 44.8$

$99.7 \% \quad 38.8$

$99.7 \% \quad 51.8$

$99.7 \%$

$99.0 \% 29.0$

$0.19 \% \quad 44.7 \%$ DDGVSIPGEYTSFLAPISSSK $99.7 \% \quad 63.7$

$189 \quad 0.19 \% \quad 44.7 \%$ DRDPEAQFEMPYVVR $\quad 99.7 \% \quad 57.8$

$189 \quad 0.19 \% \quad 44.7 \%$ LHNFHQLSAPQPCFTFSHPNR

$189 \quad 0.19 \% \quad 44.7 \%$ QPITVREGQTICVR

$99.7 \% \quad 53.2$

$99.0 \% \quad 40.6$

$189 \quad 0.19 \% \quad 44.7 \%$ EGQTICVR

$99.7 \% \quad 63.2$

$189 \quad 0.19 \% \quad 44.7 \%$ VWYEWAVTAPVCSAIHNPTGR $\quad 95.7 \% \quad 24.8$

$0.01 \% \quad 17.2 \%$ SEPKPGLPEDLQK

$0.01 \% \quad 17.2 \%$ ANDLTHSLSSYLK

$0.01 \% \quad 17.2 \%$ RVVHLGVGTPGR

$0.01 \% \quad 17.2 \%$ VVHLGVGTPGR

$0.01 \% \quad 17.2 \%$ QGGLNLSPLK

$20 \quad 0.02 \% \quad 18.9 \%$ LLYNRPGTVSSLK

$20 \quad 0.02 \% \quad 18.9 \%$ NVGQFSGFPFEK

$0.02 \% \quad 18.9 \%$ SICEVLDLER

$0.02 \% \quad 18.9 \%$ SGVNSELVKR

$0.02 \% \quad 18.9 \%$ LLASANLEEVTMK

$0.02 \% \quad 18.9 \%$ VYENYPTYDLTER

$0.00 \% \quad 7.1 \%$ GPAGLGPGSR

$97.2 \% \quad 25.8$

$95.5 \% \quad 21.9$

$99.7 \% 35.1$

$99.7 \% \quad 40.5$

$99.7 \% \quad 32.0$

$99.7 \% \quad 28.9$

$99.7 \% \quad 47.5$

$99.7 \% \quad 58.1$

$99.7 \% \quad 47.6$

$99.7 \% \quad 55.5$

$99.7 \% \quad 54.2$

$98.0 \% \quad 24.3$

$0.00 \% \quad 7.1 \% \quad$ TQAPPSVILGVTNPFFAK $99.7 \% \quad 34.1$

$0.00 \% \quad 7.1 \%$ IGDLKPTGEIPKQVK

$0.01 \% \quad 3.2 \%$ SPDELPSAGGDGGK

$99.7 \% \quad 27.3$

$99.5 \% \quad 22.9$

$99.7 \% \quad 57.5$

$99.7 \% \quad 63.3$

$99.7 \% \quad 48.9$

$0.01 \% \quad 3.2 \%$ NAGAFGFNISFLCK

$0.00 \% \quad 7.8 \%$ IEAVQEFTR
$0.00 \% \quad 7.8 \%$ EIFTNLAPFSEVSADGEKR

$0.01 \% \quad 5.8 \%$ NQLTSLPSAICK

$0.01 \% \quad 5.8 \% \quad$ LLQSLLDTR

$0.01 \% \quad 5.8 \%$ SLEGTEAQVFK
99.70

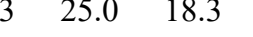

$25.0-31.3$
25.0

$\begin{array}{llll}99.7 \% & 48.4 & 25.0 & 43.7\end{array}$
1867.98

860.48

1887.03

1198.66

1554.86

1108.64

1042.50

2159.19

2003.09

1388.81

1516.91

875.54

1744.89

1291.63

2184.13

926.54

963.59

2170.06

1851.87

2535.21

1656.89

962.47

2542.27

2414.17

1437.76

1448.74

1247.73

1091.63

1026.59

1447.83

1356.66

1233.61

1088.61

1434.75

1662.76

868.46

1887.04

1622.95

1286.59

1453.78

1545.75

1092.57

2110.05

1331.70

1058.62

1208.62

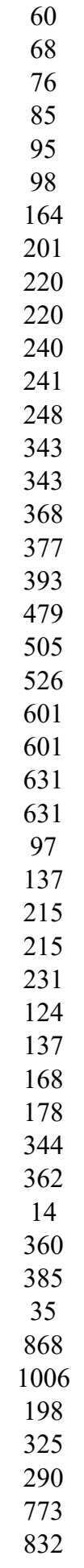

Page 131 of Table S-1-4 
Protein flightless-1 homolog GN=FLII Protein flightless-1 homolog GN=FLII Protein flightless-1 homolog GN=FLII Protein flightless-1 homolog GN=FLII Protein flightless-1 homolog GN=FLII Protein lin-28 homolog B GN=LIN28B Protein lin-28 homolog B GN=LIN28B Protein lin-28 homolog B GN=LIN28B Protein lin-28 homolog B GN=LIN28B Protein lin-28 homolog B GN=LIN28B Protein lin-28 homolog B GN=LIN28B Protein lin-28 homolog B GN=LIN28B Protein MON2 homolog GN=MON2 Protein MON2 homolog GN=MON2 Protein O-GlcNAcase GN=MGEA5 Protein O-GlcNAcase GN=MGEA5 Protein O-GlcNAcase GN=MGEA5 Protein O-GlcNAcase GN=MGEA5 Protein pelota homolog GN=PELO Protein pelota homolog GN=PELO Protein pelota homolog GN=PELO Protein pelota homolog GN=PELO Protein pelota homolog GN=PELO Protein pelota homolog GN=PELO Protein pelota homolog $\mathrm{GN}=\mathrm{PELO}$ Protein phosphatase 1B GN=PPM1B Protein phosphatase 1B GN=PPM1B Protein phosphatase 1B GN=PPM1B Protein phosphatase $1 \mathrm{~B}$ GN=PPM1B Protein phosphatase $1 \mathrm{~B} \mathrm{GN=PPM1B}$ Protein polybromo-1 GN=PBRM1 Protein polybromo-1 GN=PBRM1 Protein PRRC2A GN=PRRC2A Protein PRRC2A GN=PRRC2A Protein RFT1 homolog GN=RFT1 Protein RFT1 homolog GN=RFT1 Protein RRP5 homolog GN=PDCD1 Protein RRP5 homolog GN=PDCD1 Protein RRP5 homolog GN=PDCD11 Protein RRP5 homolog GN=PDCD1 Protein RRP5 homolog GN=PDCD1 Protein RRP5 homolog GN=PDCD11 Protein RRP5 homolog GN=PDCD1 Protein RRP5 homolog GN=PDCD1 Protein RRP5 homolog GN=PDCD1 Protein RRP5 homolog GN=PDCD11 Protein RRP5 homolog GN=PDCD11
FLII_HUMAN $144.76 \quad 100.0 \%$ FLII_HUMAN $144.76 \quad 100.0 \%$ FLII_HUMAN $144.76 \quad 100.0 \%$ FLII HUMAN $144.76 \quad 100.0 \%$ FLII HUMAN $144.76 \quad 100.0 \%$ LN28B_HUMAN $27.08 \quad 100.0 \%$ LN28B HUMAN $27.08 \quad 100.0 \%$ LN28B_HUMAN $27.08 \quad 100.0 \%$ LN28B HUMAN $27.08 \quad 100.0 \%$ LN28B HUMAN $27.08 \quad 100.0 \%$ LN28B_HUMAN $27.08 \quad 100.0 \%$ LN28B HUMAN $27.08 \quad 100.0 \%$ MON2_HUMAN $190.36 \quad 100.0 \%$ MON2_HUMAN $190.36 \quad 100.0 \%$ OGA HUMAN $102.92 \quad 100.0 \%$ OGA_HUMAN $102.92 \quad 100.0 \%$ OGA HUMAN $102.92 \quad 100.0 \%$ OGA HUMAN $102.92 \quad 100.0 \%$ PELO_HUMAN $43.36 \quad 100.0 \%$ PELO HUMAN $43.36 \quad 100.0 \%$ PELO_HUMAN $43.36 \quad 100.0 \%$ PELO HUMAN $43.36 \quad 100.0 \%$ PELO HUMAN $43.36 \quad 100.0 \%$ PELO_HUMAN $43.36 \quad 100.0 \%$ PELO HUMAN $43.36 \quad 100.0 \%$ PPM1B_HUMAN $52.64 \quad 100.0 \%$ PPM1B_HUMAN $52.64 \quad 100.0 \%$ PPM1B HUMAN $52.64 \quad 100.0 \%$ PPM1B_HUMAN $52.64 \quad 100.0 \%$ PPM1B HUMAN $52.64 \quad 100.0 \%$ PB1_HUMAN $192.95 \quad 100.0 \%$ PB1_HUMAN $192.95 \quad 100.0 \%$ PRC2A HUMAN $228.87 \quad 100.0 \%$ PRC2A_HUMAN $228.87 \quad 100.0 \%$ RFT1_HUMAN $60.34 \quad 100.0 \%$ RFT1_HUMAN $60.34 \quad 100.0 \%$ RRP5_HUMAN $208.70 \quad 100.0 \%$ RRP5 HUMAN $208.70 \quad 100.0 \%$ RRP5 HUMAN $208.70 \quad 100.0 \%$ RRP5_HUMAN $208.70 \quad 100.0 \%$ RRP5 HUMAN $208.70 \quad 100.0 \%$ RRP5_HUMAN $208.70 \quad 100.0 \%$ RRP5 HUMAN $208.70 \quad 100.0 \%$ RRP5 HUMAN $208.70 \quad 100.0 \%$ RRP5 HUMAN $208.70 \quad 100.0 \%$ RRP5 HUMAN $208.70 \quad 100.0 \%$ RRP5_HUMAN $208.70 \quad 100.0 \%$
$4 \quad 0.01 \% \quad 5.8 \% \quad$ SLEGTEAQVFKAK $0.01 \% \quad 5.8 \%$ NAEAVLQSPGLSGK $0.01 \% \quad 5.8 \% \quad$ ADLTALFLPR

$0.01 \% \quad 5.8 \% \quad$ KAVQGAQQPSLYQIR $0.01 \% \quad 5.8 \%$ AVQGAQQPSLYQIR $0.01 \% \quad 42.8 \%$ GGGEEPGKLPEPAEEESQVLR $0.01 \% \quad 42.8 \%$ MGFGFISMINR $0.01 \% \quad 42.8 \%$ EGSPLDIPVDVFVHQSK $0.01 \% \quad 42.8 \%$ VTGPGGSPCLGSER $0.01 \% \quad 42.8 \%$ NVAQPPASSQGR $0.01 \% \quad 42.8 \%$ QEAESQPCTSTLPR

$0.01 \% \quad 42.8 \%$ EVGGCHCCTSPPFPQEAR $\quad 99.4 \% \quad 20.2$

$0.00 \% \quad 1.2 \%$ ITQLCLAAIQR

$0.00 \% \quad 1.2 \%$ AVAVESIHR

$0.00 \% \quad 6.1 \%$ VVSKEIPVESIEEVSK

$0.00 \% \quad 6.1 \%$ LFLGPYKGR

$0.00 \% \quad 6.1 \%$ GGLAGEFQR

$99.7 \% \quad 45.5$

$95.1 \% \quad 26.6$

$95.8 \% \quad 18.6$

$97.4 \% \quad 24.5$

$99.7 \% \quad 30.4$

$0.00 \% \quad 6.1 \% \quad$ LLPIDGANDLFFQPPPLTPTSK $99.7 \% \quad 60.5$

$0.01 \% \quad 15.8 \%$ KVQTESSTGSVGSNR

$99.7 \% \quad 33.1$

$99.7 \% \quad 42.6$

$98.4 \% \quad 18.0$

$99.7 \% \quad 34.0$

$99.7 \% 46.6$

$99.7 \% \quad 36.8$

$99.7 \% \quad 58.2$

$99.7 \% \quad 63.4$

$99.7 \% \quad 34.7$

$99.7 \% \quad 55.3$

$99.7 \% \quad 28.9$

$99.7 \% \quad 30.1$

$99.7 \% \quad 34.5$

$99.7 \% \quad 47.4$

$99.7 \% \quad 29.5$

$0.00 \% \quad 1.1 \% \quad$ MPISLQQIR

$0.00 \% \quad 1.1 \% \quad$ VVDDEIYYFR

$0.00 \% \quad 1.5 \%$ SLEIQKPAVAPR

$99.7 \% \quad 29.6$

$0.01 \% \quad 3.9 \%$ GSQEVLGHAAR

$0.01 \% \quad 3.9 \% \quad$ ITDLLPNITR

$0.05 \% \quad 11.8 \%$ VGQYLNCIVEK

$0.05 \% \quad 11.8 \%$ ACILCVHPR

$0.05 \% \quad 11.8 \%$ LKDGVLAYAR

$40.05 \% \quad 11.8 \%$ YHDIEPGAVVK

$0.05 \% \quad 11.8 \%$ VLLCDPEAK

$0.05 \% \quad 11.8 \%$ VKDYGCIVK

$4 \quad 0.05 \% \quad 11.8 \%$ FYNNVQGLVPK

$0.05 \% \quad 11.8 \%$ VVVLNCEPSKER

$0.05 \% \quad 11.8 \%$ VLCLSQSEGR

$0.05 \% \quad 11.8 \%$ KPALVSTVEGGQDPK

$0.05 \% \quad 11.8 \%$ VTNVDEEKQR
$99.7 \% \quad 61.8$

$99.7 \% \quad 28.7$

$99.7 \% \quad 39.5$

$99.7 \% \quad 50.0$

$99.7 \% \quad 41.7$

$99.7 \% \quad 33.5$

$97.0 \% 19.4$

$99.7 \% 34.6$

$99.7 \% 53.4$

$99.7 \% \quad 47.6$

$99.7 \% \quad 42.8$

$99.7 \% \quad 29.4$
1116.64

1686.93

1558.83

2208.08

1272.62

1866.96

1373.65

1211.61

1603.74

1882.85

1286.73

981.55

1771.97

1050.61

934.47

2381.28

1536.76

1408.67

1521.79

1294.63

1025.61

1380.73

1387.75

1332.70

1249.65

1273.67

1710.82

1050.56

1085.61

1318.63

1308.76

1755.88

1124.58

1155.67

1322.68

1125.57

1105.64

1227.64

1044.54

1081.57

1278.68

1429.75

1148.57

1525.82

1217.61

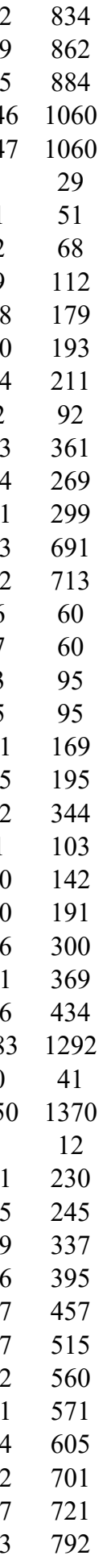

Page 132 of Table S-1-4 
Protein RRP5 homolog GN=PDCD11 Protein RRP5 homolog GN=PDCD11 Protein RRP5 homolog GN=PDCD11 Protein RRP5 homolog GN=PDCD1 Protein RRP5 homolog GN=PDCD11 Protein RRP5 homolog GN=PDCD1 Protein RRP5 homolog GN=PDCD11 Protein RRP5 homolog GN=PDCD1 1 Protein S100-A8 GN=S100A8 Protein S100-A8 GN=S100A8 Protein $\mathrm{S} 100-\mathrm{A} 8 \mathrm{GN}=\mathrm{S} 100 \mathrm{~A} 8$ Protein S100-A8 GN=S100A8 Protein S100-A9 GN=S100A9 Protein S100-A9 GN=S100A9 Protein $\mathrm{S} 100-\mathrm{A} 9 \mathrm{GN}=\mathrm{S} 100 \mathrm{~A} 9$ Protein SDA1 homolog GN=SDAD1 Protein SDA1 homolog GN=SDAD1 Protein SDA1 homolog GN=SDAD1 Protein SDA1 homolog GN=SDAD1 Protein SEC13 homolog GN=SEC13 Protein SEC13 homolog GN=SEC13 Protein $\mathrm{SEC} 13$ homolog $\mathrm{GN}=\mathrm{SEC} 13$ Protein SET GN=SET Protein SET GN=SET Protein SET GN=SET Protein SET GN=SET Protein $\mathrm{SON}$ GN $=\mathrm{SON}$ Protein $\mathrm{SON}$ GN $=\mathrm{SON}$ Protein $\mathrm{SON}$ GN $=\mathrm{SON}$ Protein $\mathrm{SON}$ GN=SON Protein TBRG4 GN=TBRG4 Protein TBRG4 GN=TBRG4 Protein TBRG4 GN=TBRG4

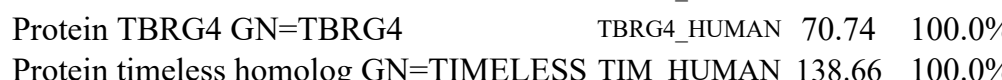
Protein timeless homolog GN=TIMELESS TIM_HUMAN $138.66 \quad 100.0 \%$ Protein transport protein Sec16A GN=SEC16A SC16A_HUMAN $233.52 \quad 100.0 \%$ Protein transport protein Sec16A GN=SEC16A SC16A_HUMAN $233.52 \quad 100.0 \%$ Protein transport protein Sec16A GN=SEC16A SC16A_HUMAN $233.52 \quad 100.0 \%$ Protein transport protein Sec61 subunit alpha isoform $1 \mathrm{GN}=\mathrm{SEC} 61 \mathrm{~A} 1$ S61A1_HUMAN $52.27 \quad 100.0 \%$ Protein transport protein Sec61 subunit alpha isoform $1 \mathrm{GN}=\mathrm{SEC} 61 \mathrm{~A} 1$ S61A1_HUMAN $52.27 \quad 100.0 \%$ Protein transport protein Sec61 subunit alpha isoform $1 \mathrm{GN}=\mathrm{SEC} 61 \mathrm{~A} 1$ S61A1_HUMAN $52.27 \quad 100.0 \%$ Protein transport protein Sec61 subunit alpha isoform $1 \mathrm{GN}=\mathrm{SEC} 61 \mathrm{~A} 1$ S61A1 HUMAN $52.27 \quad 100.0^{\circ}$ Protein transport protein Sec61 subunit alpha isoform $1 \mathrm{GN}=\mathrm{SEC} 61 \mathrm{~A} 1$ S61A1_HUMAN $52.27 \quad 100.0 \%$ Protein transport protein Sec61 subunit alpha isoform $1 \mathrm{GN}=\mathrm{SEC} 61 \mathrm{~A} 1$ S61A1_HUMAN $52.27 \quad 100.0 \%$ Protein unc-45 homolog A GN=UNC45A UN45A_HUMAN $103.08 \quad 100.0 \%$ Protein unc-45 homolog A GN=UNC45A UN45A_HUMAN $103.08 \quad 100.0 \%$ S10A8 HUMAN $10.84 \quad 100.0 \%$ RRP5 HUMAN $208.70 \quad 100.0 \% \quad 19$ RRP5_HUMAN $208.70 \quad 100.0 \% \quad 19$ RRP5_HUMAN $208.70 \quad 100.0 \% \quad 19$ S10A8_HUMAN $10.84 \quad 100.0 \%$ S10A8 HUMAN $10.84 \quad 100.0 \%$ S10A9 HUMAN $13.24 \quad 100.0 \%$ SDA1_HUMAN $79.88 \quad 100.0 \%$ SDA1_HUMAN $79.88 \quad 100.0 \%$ SDA1_HUMAN $79.88 \quad 100.0 \%$ SEC13 HUMAN $35.54 \quad 100.0 \%$ $\begin{array}{lll} & \end{array}$ SET HUMAN $33.49 \quad 100.0 \%$ SET_HUMAN $33.49 \quad 100.0 \%$ SET HUMAN $33.49 \quad 100.0 \%$ $\begin{array}{lll}\text { SET_HUMAN } 33.49 & 100.0 \%\end{array}$ SON HUMAN $263.83 \quad 100.0 \%$ SON_HUMAN $263.83 \quad 100.0 \%$ SON HUMAN $263.83 \quad 100.0 \%$ TBRG4_HUMAN $70.74 \quad 100.0 \%$ TBRG4_HUMAN $70.74 \quad 100.0 \%$ TBRG4 HUMAN $70.74 \quad 100.0 \%$ $.0 \%$ 2 3 3
6 6
6

5

$0.05 \% \quad 11.8 \%$ TTEPGVTGLLLAVEGPAAK 99 $0.05 \% \quad 11.8 \%$ IPLLLTSLSFK

$\begin{array}{lll}0.05 \% & 11.8 \% \text { VTPNEGLTVSFPFGK } \\ 0.05 \% & 11.8 \% \text { GYVGSIQPHGVFFR }\end{array}$

$0.05 \% \quad 11.8 \%$ LGPSVVGLAR

$54 \quad 0.05 \% \quad 11.8 \%$ FAQLEFQLGDAER

$54 \quad 0.05 \% \quad 11.8 \%$ AIFENTLSTYPK

$54 \quad 0.05 \% \quad 11.8 \%$ VIHLSLAPK

$11 \quad 0.01 \% \quad 33.3 \%$ ALNSIIDVYHK

$11 \quad 0.01 \% \quad 33.3 \%$ GNFHAVYR

$11 \quad 0.01 \% \quad 33.3 \%$ LLETECPQYIR

$0.01 \% \quad 33.3 \%$ LLETECPQYIRK

$0.01 \% \quad 31.6 \%$ NIETIINTFHQYSVK

$0.01 \% \quad 31.6 \%$ LGHPDTLNQGEFK

$0.01 \% \quad 31.6 \%$ LTWASHEK

$0.01 \% \quad 6.6 \%$ DLLVQYATGKK

$0.01 \% \quad 6.6 \%$ GKPTEASIEAR

$0.01 \% \quad 6.6 \%$ VLTQEDFQKIR

$0.01 \% \quad 6.6 \% \quad$ TNPFSSSTNKEK

$0.01 \% \quad 12.1 \%$ NGGQILIADLR

$0.01 \% \quad 12.1 \%$ FASGGCDNLIK

\begin{tabular}{lll}
$99.7 \%$ & 50.8 \\
\hline
\end{tabular} $\begin{array}{lll}99.7 \% & 33.3\end{array}$

$99.7 \% \quad 45.2$

$99.7 \% \quad 42.5$

$99.7 \% \quad 58.9$

$99.7 \% \quad 72.1$

$99.7 \% \quad 58.2$

$99.7 \% \quad 32.7$

$99.7 \% \quad 57.1$

$99.0 \% \quad 32.2$

$99.7 \% \quad 48.5$

$\begin{array}{lll}99.7 \% & 34.3\end{array}$

$99.7 \% \quad 50.6$

$99.7 \% \quad 36.5$

$99.0 \% \quad 25.2$

$99.7 \% \quad 32.1$

$97.2 \% \quad 21.3$

$99.7 \% \quad 28.0$

$99.5 \% \quad 26.3$

$99.7 \% \quad 60.4$

$99.7 \% \quad 45.5$

$0.01 \% \quad 12.1 \%$ GQGSVSASVTEGQQNEQ

$0.01 \% \quad 15.5 \%$ LRQPFFQK

$0.01 \% \quad 15.5 \%$ VEVTEFEDIK

$0.01 \% \quad 15.5 \%$ IDFYFDENPYFENK

$0.01 \% \quad 15.5 \%$ EFHLNESGDPSSK

$99.7 \% \quad 62.5$

$99.7 \% \quad 60.2$

$99.7 \% \quad 55.3$

$99.7 \% \quad 60.5$

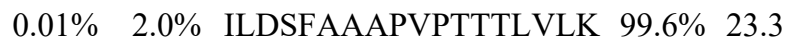

$0.01 \% \quad 2.0 \% \quad$ SVESTSPEPSK

$0.01 \% \quad 2.0 \%$ SMMSAYER

$0.01 \% \quad 2.0 \%$ SMMSSYSAADR

$0.01 \% \quad 7.1 \%$ LLGSLYALGIPK

$0.01 \% \quad 7.1 \%$ VLVMLAAQSR

$0.01 \% \quad 7.1 \%$ DVLLDVAYAYGK

$0.01 \% \quad 7.1 \%$ LSFHQTQVSQR

$0.00 \% \quad 1.8 \%$ FGGSYIVQGLK

$0.00 \% \quad 1.8 \% \quad$ NYSSDLGKQPK

$0.00 \% \quad 1.8 \%$ NPSSAAPVQSR

$0.00 \% \quad 1.8 \%$ FGPGGQLIK

$0.00 \% \quad 1.8 \%$ LLPSAPQTLPDGPLASPAR

$0.04 \% \quad 10.7 \%$ IIEVGDTPK

$0.04 \% \quad 10.7 \%$ IIEVGDTPKDR

$0.04 \% \quad 10.7 \%$ AFSPTTVNTGR

$0.04 \% \quad 10.7 \%$ GQYNTYPIK

$0.04 \% \quad 10.7 \%$ QLKEQQMVMR

$0.04 \% \quad 10.7 \%$ ETSMVHELNR

$0.00 \% \quad 5.1 \%$ SNGVQLLQR

$0.00 \% \quad 5.1 \%$ TLVGICSEHQSR

\section{$99.4 \% 22.8$}

$99.0 \% \quad 23.6$

$99.7 \% \quad 53.6$

$99.7 \% \quad 39.6$

$99.7 \% \quad 54.3$

$99.7 \% \quad 68.0$

$99.7 \% \quad 27.8$

$99.7 \% \quad 50.9$

$98.9 \% \quad 26.0$

$99.7 \% \quad 27.7$

$98.1 \% \quad 23.1$

$99.7 \% \quad 57.4$

$\begin{array}{ll}99.7 \% & 41.3 \\ 99.7 \% & 62.2\end{array}$

$99.7 \% \quad 48.5$

$99.7 \% \quad 32.5$

$95.9 \% \quad 22.5$

$99.7 \% \quad 40.9$

$97.5 \% \quad 16.1$

$98.4 \% \quad 16.7$
1824.01

1231.77

1592.83

563.8

968.59

1523.75

1383.72

977.61

272.69

963.48

1421.71

1549.80

1806.94

1455.72

971.49

1235.70

1158.6

1376.75

1339.65

1169.66

1181.56

1705.76

1063.60

1208.60

1840.81

1446.65

1857.07

1147.55

974.41

1205.49

1244.76

1103.62

1326.69

1330.69

1168.64

1236.62

1113.56

916.53

1901.05

971.54

1242.67

1150.59

1083.55

1290.67

1231.57

1014.57 1386.68

$240 \quad 1254$

$1329 \quad 1342$

$1343 \quad 1352$

\begin{tabular}{ll}
$767 \quad 1779$ \\
\hline 82
\end{tabular}

1793

$\begin{array}{cc}821 & 1829 \\ 8 & 18\end{array}$

$24 \quad 31$

$37 \quad 47$

$37 \quad 48$

$11 \quad 25$

$26 \quad 38$

$245 \quad 255$

$550 \quad 560$

$634 \quad 645$

$44 \quad 54$

$182 \quad 192$

$306 \quad 322$

$123 \quad 132$

$137 \quad 150$

$155 \quad 167$

$241 \quad 258$ 
Protein unc-45 homolog A GN=UNC45A UN45A_HUMAN $103.08 \quad 100.0 \%$ Protein unc-45 homolog A GN=UNC45A UN45A_HUMAN $103.08 \quad 100.0 \%$ Protein virilizer homolog GN=KIAA1429 VIR_HUMAN $202.03 \quad 100.0 \%$ Protein virilizer homolog GN=KIAA1429 VIR HUMAN $202.03 \quad 100.0 \%$ Protein virilizer homolog GN=KIAA1429 VIR_HUMAN $202.03 \quad 100.0 \%$ Protein virilizer homolog GN=KIAA1429 VIR_HUMAN $202.03 \quad 100.0 \%$ Protein virilizer homolog GN=KIAA1429 VIR_HUMAN $202.03 \quad 100.0 \%$ Protein VPRBP GN=VPRBP Protein VPRBP GN=VPRBP VPRBP_HUMAN $169.01 \quad 100.0 \%$ VPRBP HUMAN $169.01 \quad 100.0 \%$ Protein-glutamine gamma-glutamyltransferase E GN=TGM3 TGM3_HUMAN $76.63 \quad 100.0 \%$ Protein-glutamine gamma-glutamyltransferase E GN=TGM3 TGM3_HUMAN $76.63 \quad 100.0 \%$ Protein-glutamine gamma-glutamyltransferase E GN=TGM3 TGM3_HUMAN $76.63 \quad 100.0 \%$ Protein-glutamine gamma-glutamyltransferase E GN=TGM3 TGM3_HUMAN $76.63 \quad 100.0 \%$ Pumilio homolog 1 GN=PUM1 Pumilio homolog $1 \mathrm{GN}=\mathrm{PUM} 1$ PUM1 HUMAN $126.47 \quad 100.0 \%$ PUM1_HUMAN $126.47 \quad 100.0 \%$ Puromycin-sensitive aminopeptidase GN=NPEPPS PSA_HUMAN $103.28 \quad 100.0 \%$ Puromycin-sensitive aminopeptidase GN=NPEPPS PSA HUMAN $103.28100 .0 \%$ Puromycin-sensitive aminopeptidase GN=NPEPPS PSA_HUMAN $103.28 \quad 100.0 \%$ Puromycin-sensitive aminopeptidase GN=NPEPPS PSA_HUMAN $103.28 \quad 100.0 \%$ Puromycin-sensitive aminopeptidase GN=NPEPPS PSA_HUMAN $103.28100 .0 \%$ Puromycin-sensitive aminopeptidase GN=NPEPPS PSA_HUMAN $103.28 \quad 100.0 \%$ Puromycin-sensitive aminopeptidase GN=NPEPPS PSA HUMAN $103.28 \quad 100.0 \%$ Puromycin-sensitive aminopeptidase GN=NPEPPS PSA_HUMAN $103.28 \quad 100.0 \%$ Puromycin-sensitive aminopeptidase GN=NPEPPS PSA_HUMAN $103.28 \quad 100.0 \%$ Puromycin-sensitive aminopeptidase GN=NPEPPS PSA HUMAN $103.28 \quad 100.0 \%$ Puromycin-sensitive aminopeptidase GN=NPEPPS PSA_HUMAN $103.28 \quad 100.0 \%$ Puromycin-sensitive aminopeptidase GN=NPEPPS PSA_HUMAN $103.28100 .0 \%$ Putative ATP-dependent RNA helicase DHX30 GN=DHX30 DHX30 HUMAN $133.94 \quad 100.0 \%$ Putative ATP-dependent RNA helicase DHX30 GN=DHX30 DHX30_HUMAN $133.94 \quad 100.0 \%$ Putative ATP-dependent RNA helicase DHX30 GN=DHX30 DHX30 HUMAN $133.94 \quad 100.0^{\circ}$ Putative ATP-dependent RNA helicase DHX30 GN=DHX30 DHX30_HUMAN $133.94 \quad 100.0 \%$ Putative ATP-dependent RNA helicase DHX30 GN=DHX30 DHX30_HUMAN $133.94 \quad 100.0 \%$ Putative ATP-dependent RNA helicase DHX30 GN=DHX30 DHX30_HUMAN $133.94100 .0 \%$ Putative ATP-dependent RNA helicase DHX30 GN=DHX30 DHX30_HUMAN $133.94 \quad 100.0 \%$ Putative ATP-dependent RNA helicase DHX30 GN=DHX30 DHX30_HUMAN $133.94100 .0 \%$ Putative ATP-dependent RNA helicase DHX30 GN=DHX30 DHX30_HUMAN $133.94100 .0 \%$ Putative ATP-dependent RNA helicase DHX30 GN=DHX30 DHX30_HUMAN $133.94 \quad 100.0 \%$ Putative ATP-dependent RNA helicase DHX30 GN=DHX30 DHX30 HUMAN $133.94 \quad 100.0^{\circ}$ Putative ATP-dependent RNA helicase DHX30 GN=DHX30 DHX30_HUMAN $133.94 \quad 100.0 \%$ Putative ATP-dependent RNA helicase DHX30 GN=DHX30 DHX30_HUMAN $133.94100 .0 \%$ Putative ATP-dependent RNA helicase DHX30 GN=DHX30 DHX30_HUMAN $133.94 \quad 100.0 \%$ Putative ATP-dependent RNA helicase DHX30 GN=DHX30 DHX30_HUMAN $133.94 \quad 100.0 \%$ Putative ATP-dependent RNA helicase DHX30 GN=DHX30 DHX30 HUMAN $133.94 \quad 100.0 \%$ Putative ATP-dependent RNA helicase DHX30 GN=DHX30 DHX30 HUMAN $133.94100 .0 \%$ Putative ATP-dependent RNA helicase DHX30 GN=DHX30 DHX30_HUMAN $133.94 \quad 100.0 \%$ Putative ATP-dependent RNA helicase DHX30 GN=DHX30 DHX30_HUMAN $133.94 \quad 100.0 \%$ Putative ATP-dependent RNA helicase DHX30 GN=DHX30 DHX30_HUMAN $133.94 \quad 100.0 \%$
$0.00 \% \quad 5.1 \% \quad$ TVATLSILGTR $0.00 \% \quad 5.1 \%$ ALIPLALEGTDVGQTK $0.01 \% \quad 2.9 \% \quad$ VNTDGLVLR $0.01 \% \quad 2.9 \% \quad$ LLELILLDQTVR $0.01 \% \quad 2.9 \%$ VVTAGSAILQK $0.01 \% \quad 2.9 \%$ SAVGHVFSLEK $0.01 \% \quad 2.9 \%$ SEYIEPAKR $0.00 \% \quad 1.5 \%$ LQKADVVAQSR $0.00 \% \quad 1.5 \%$ GLGETATVLTK $0.01 \% \quad 6.8 \%$ DAATDVASRNDPK $0.01 \% \quad 6.8 \%$ SQGVFQCGPASVIGVR $0.01 \% \quad 6.8 \% \quad$ NSVNSHTIGR $0.01 \% \quad 6.8 \%$ ISYAQYEK $0.00 \% \quad 2.7 \%$ DSLTGSSDLYKR $0.00 \% \quad 2.7 \%$ SASSASSLFSPSSTLFSSSR $0.03 \% \quad 13.7 \%$ SKYTTPSGEVR $0.03 \% \quad 13.7 \%$ YAAVTQFEATDAR $0.03 \% \quad 13.7 \%$ YAAVTQFEATDARR $0.03 \% \quad 13.7 \%$ ATFDISLVVPKDR $0.03 \% \quad 13.7 \%$ FALEVAAK $0.03 \% \quad 13.7 \%$ LNLGTVGFYR $0.03 \% \quad 13.7 \%$ LGLQNDLFSLAR $0.03 \% \quad 13.7 \%$ AGIISTVEVLK $0.03 \% \quad 13.7 \%$ SPVYLTVLK $0.03 \% \quad 13.7 \%$ VLGATLLPDLIQK $0.03 \% \quad 13.7 \%$ AFFESHPAPSAER $0.03 \% \quad 13.7 \%$ DAESIHQYLLQR $0.08 \% \quad 23.5 \%$ NLLNSVIGR $0.08 \% \quad 23.5 \%$ SVEVEGYGSK $0.08 \% \quad 23.5 \%$ SVEVEGYGSKK $0.08 \% \quad 23.5 \%$ NELFDAAKYR $0.08 \% \quad 23.5 \%$ QLNPESIRPGGPGGLSR $0.08 \% 23.5 \%$ ALTQFPLPK $0.08 \% \quad 23.5 \%$ VIQIATSSSTAK $0.08 \% \quad 23.5 \%$ NLMQFHTVGTK $\quad 0.08 \% \quad 23.5 \%$ RPCTIQVPEPILR $80 \quad 0.08 \% \quad 23.5 \%$ LQSDDILPLGK $80 \quad 0.08 \% \quad 23.5 \%$ TTRIPQLLLER $80 \quad 0.08 \% \quad 23.5 \%$ IPQLLLER $80 \quad 0.08 \% \quad 23.5 \%$ CNVIITQPR $80 \quad 0.08 \% \quad 23.5 \%$ CNVIITQPRR $80 \quad 0.08 \% \quad 23.5 \%$ RISAVSVAQR $80 \quad 0.08 \% \quad 23.5 \%$ ISAVSVAQR $80 \quad 0.08 \% \quad 23.5 \%$ VSHELGPSLRR $80 \quad 0.08 \% \quad 23.5 \%$ LVLMSATGDNER $80 \quad 0.08 \% \quad 23.5 \%$ LVLMSATGDNERFSR $80 \quad 0.08 \% \quad 23.5 \%$ YFGGCPVIK $\begin{array}{llllllll}99.7 \% & 26.6 & 25.0 & 26.6 & 1 & 0 & 0 & 1131.67\end{array}$

$99.7 \% \quad 50.8$

$98.6 \% \quad 22.5$

$99.7 \% \quad 41.9$

$99.7 \% \quad 44.6$

$99.7 \% \quad 29.2$

$98.9 \% 21.5$

$99.6 \% \quad 24.2$

$99.7 \% \quad 45.4$

$99.4 \% \quad 27.3$

$99.7 \% \quad 51.9$

$99.7 \% \quad 49.0$

$95.8 \% 21.1$

$99.7 \% \quad 40.9$

$99.7 \% \quad 61.0$

$99.7 \% \quad 37.2$

$99.7 \% \quad 38.2$

$99.7 \% \quad 44.6$

$\begin{array}{lll}99.7 \% & 42.6\end{array}$

$97.6 \% \quad 21.1$

$99.7 \% \quad 43.5$

$\begin{array}{lll}99.7 \% & 58.7\end{array}$

$99.7 \% \quad 42.1$

$99.3 \% \quad 20.4$

$99.7 \% \quad 53.5$

$99.7 \% \quad 37.7$

$99.7 \% \quad 62.4$

$99.7 \% \quad 55.0$

$99.7 \% \quad 42.8$

$99.7 \% \quad 43.1$

$99.7 \% \quad 38.5$

$99.7 \% \quad 26.6$

$99.7 \% \quad 40.8$

$99.7 \% \quad 55.6$

$\begin{array}{lll}99.7 \% & 40.5\end{array}$

$\begin{array}{lll}99.7 \% & 29.2\end{array}$

$98.3 \% \quad 26.4$

$99.7 \% \quad 40.8$

$99.0 \% \quad 59.7$

$99.7 \% \quad 48.2$

$98.1 \% \quad 21.1$

$99.7 \% \quad 64.6$

$99.7 \% \quad 71.4$

$99.7 \% \quad 27.2$

$99.7 \% \quad 57.4$

$99.4 \% 23.9$

$99.5 \% \quad 23.3$
625.91

986.56

1425.87

1086.65

1173.63

1092.57

1214.69

1089.62

1359.65

1661.84

1084.55

1001.49

1341.66

1992.95

1224.62

1442.69

1598.79

1460.81

848.49

1139.62

1346.74

1129.68

1019.61

1380.85

1445.68

1472.75

985.58

1054.51

1182.60

1226.62

1734.92

1014.60

1205.67

1291.65

1578.88

1198.67

1339.81

981.61

1100.59

1256.69

1086.64

930.54

1250.70

1321.64

1711.84 1040.52 $\begin{array}{cc}30 & 240 \\ 92 & 707 \\ 06 & 114 \\ 34 & 545 \\ 46 & 556 \\ 10 & 820 \\ 06 & 1614 \\ 32 & 842 \\ 62 & 872 \\ 02 & 214 \\ 61 & 376 \\ 12 & 421 \\ 55 & 562 \\ 08 & 719 \\ 97 & 816 \\ 62 & 172 \\ 73 & 185 \\ 73 & 186 \\ 98 & 210 \\ 80 & 287 \\ 81 & 590 \\ 16 & 627 \\ 28 & 638 \\ 45 & 753 \\ 82 & 794 \\ 70 & 882 \\ 01 & 912 \\ 5 & 63 \\ 6 & 105 \\ 6 & 106 \\ 31 & 140 \\ 67 & 183 \\ 38 & 246 \\ 52 & 263 \\ 64 & 274 \\ 44 & 356 \\ 78 & 388 \\ 64 & 474 \\ 67 & 474 \\ 84 & 492 \\ 84 & 493 \\ 93 & 502 \\ 94 & 502 \\ 03 & 513 \\ 87 & 598 \\ 87 & 601 \\ 02 & 610 \\ & \end{array}$

Page 134 of Table S-1-4 
Putative ATP-dependent RNA helicase DHX30 GN=DHX30 DHX30_HUMAN $133.94 \quad 100.0 \% \quad 31$ Putative ATP-dependent RNA helicase DHX30 GN=DHX30 DHX30_HUMAN $133.94 \quad 100.0 \% \quad 31$ Putative ATP-dependent RNA helicase DHX30 GN=DHX30 DHX30_HUMAN $133.94 \quad 100.0 \%$ Putative ATP-dependent RNA helicase DHX30 GN=DHX30 DHX30_HUMAN $133.94 \quad 100.0 \% 3$ Putative ATP-dependent RNA helicase DHX30 GN=DHX30 DHX30_HUMAN $133.94 \quad 100.0 \%$ Putative ATP-dependent RNA helicase DHX30 GN=DHX30 DHX30_HUMAN $133.94 \quad 100.0 \%$ Putative ATP-dependent RNA helicase DHX30 GN=DHX30 DHX30_HUMAN $133.94 \quad 100.0 \%$ Putative ATP-dependent RNA helicase DHX30 GN=DHX30 DHX30_HUMAN $133.94 \quad 100.0 \%$ Putative ATP-dependent RNA helicase DHX30 GN=DHX30 DHX30_HUMAN $133.94 \quad 100.0 \%$ Putative ATP-dependent RNA helicase DHX30 GN=DHX30 DHX30_HUMAN $133.94 \quad 100.0 \%$ Putative ATP-dependent RNA helicase DHX30 GN=DHX30 DHX30_HUMAN $133.94 \quad 100.0 \%$ Putative ATP-dependent RNA helicase DHX33 GN=DHX33 DHX33_HUMAN $78.88 \quad 100.0 \%$ Putative ATP-dependent RNA helicase DHX33 GN=DHX33 DHX33_HUMAN 78.88 $100.0 \%$ Putative ATP-dependent RNA helicase DHX33 GN=DHX33 DHX33_HUMAN 78.88 $100.0 \%$ Putative ATP-dependent RNA helicase DHX33 GN=DHX33 DHX33_HUMAN $78.88 \quad 100.0 \%$ Putative ATP-dependent RNA helicase DHX33 GN=DHX33 DHX33_HUMAN 78.88 $100.0 \%$ Putative ATP-dependent RNA helicase DHX57 GN=DHX57 DHX57 HUMAN $155.61 \quad 100.0 \%$ Putative ATP-dependent RNA helicase DHX57 GN=DHX57 DHX57_HUMAN $155.61 \quad 100.0 \%$ Putative ATP-dependent RNA helicase DHX57 GN=DHX57 DHX57_HUMAN $155.61 \quad 100.0 \%$ Putative helicase MOV-10 GN=MOV10 MOV10_HUMAN $113.68 \quad 100.0 \%$ Putative helicase MOV-10 GN=MOV10 MOV10_HUMAN $113.68 \quad 100.0 \%$ Putative helicase MOV-10 GN=MOV10 MOV10_HUMAN $113.68 \quad 100.0 \%$ Putative helicase MOV-10 GN=MOV10 MOV10_HUMAN $113.68 \quad 100.0 \%$ Putative helicase MOV-10 GN=MOV10 MOV10_HUMAN $113.68 \quad 100.0 \%$ Putative helicase MOV-10 GN=MOV10 MOV10_HUMAN $113.68 \quad 100.0 \%$ Putative helicase MOV-10 GN=MOV10 MOV10_HUMAN $113.68 \quad 100.0 \%$ Putative helicase MOV-10 GN=MOV10 MOV10_HUMAN $113.68 \quad 100.0 \%$ Putative helicase MOV-10 GN=MOV10 MOV10_HUMAN $113.68 \quad 100.0 \%$ $\begin{array}{lll}\text { Putative helicase MOV-10 GN=MOV10 MOV10_HUMAN } 113.68 & 100.0 \%\end{array}$ Putative helicase MOV-10 GN=MOV10 MOV10 HUMAN $113.68 \quad 100.0 \%$ Putative helicase MOV-10 GN=MOV10 MOV10_HUMAN $113.68 \quad 100.0 \%$ Putative helicase MOV-10 GN=MOV10 MOV10_HUMAN $113.68 \quad 100.0 \%$ Putative helicase MOV-10 GN=MOV10 MOV10_HUMAN $113.68 \quad 100.0 \%$ Putative helicase MOV-10 GN=MOV10 MOV10_HUMAN $113.68 \quad 100.0 \%$ Putative oxidoreductase GLYR1 GN=GLYR1 GLYR1_HUMAN $60.56 \quad 100.0 \%$ Putative oxidoreductase GLYR1 GN=GLYR1 GLYR1_HUMAN $60.56 \quad 100.0 \%$ Putative oxidoreductase GLYR1 GN=GLYR1 GLYR1_HUMAN $60.56 \quad 100.0 \%$ Putative oxidoreductase GLYR1 GN=GLYR1 GLYR1 HUMAN $60.56 \quad 100.0 \%$ Putative oxidoreductase GLYR1 GN=GLYR1 GLYR1_HUMAN $60.56 \quad 100.0 \%$ Putative RNA-binding protein 15 GN=RBM15 RBM15_HUMAN $107.19 \quad 100.0 \%$ Putative RNA-binding protein 15 GN=RBM15 RBM15_HUMAN $107.19 \quad 100.0 \%$ Putative RNA-binding protein 15 GN=RBM15 RBM15_HUMAN $107.19 \quad 100.0 \%$ Putative RNA-binding protein 15 GN=RBM15 RBM15 HUMAN $107.19 \quad 100.0 \%$ Putative RNA-binding protein Luc7-like 1 GN=LUC7L LUC7L_HUMAN $43.73 \quad 100.0 \%$ Putative RNA-binding protein Luc7-like 1 GN=LUC7L LUC7L_HUMAN $43.73 \quad 100.0 \%$ Putative RNA-binding protein Luc7-like 1 GN=LUC7L LUC7L_HUMAN $43.73 \quad 100.0 \%$ Putative RNA-binding protein Luc7-like 1 GN=LUC7L LUC7L_HUMAN $43.73 \quad 100.0 \%$

(n)

2

5
5
5
3

5
3
3

3
15

15

15
15
15

15
15
15

15
15
15

15

15
15
15

15

15
15
15

15
15
15

15

5
5
5

5
5
5
5

5
5
4
4

4

4
4
2

2

2

$0.08 \% \quad 23.5 \%$ AVDSPNIK

$0.08 \% \quad 23.5 \%$ AIVLAAIFR

$80 \quad 0.08 \% \quad 23.5 \%$ DPFSSSLQNR

$0.08 \% \quad 23.5 \%$ ALLSHDSGSDHLAFVR

$0.08 \% \quad 23.5 \%$ FKPNSVTYR

$0.08 \% 23.5 \%$ SGNILLHK

$0.08 \% \quad 23.5 \%$ ATISLSDSDLLR

$0.08 \% \quad 23.5 \%$ ATISLSDSDLLRLEGDSR

$0.01 \% \quad 8.1 \%$ RSLPIFQAR

$0.01 \% \quad 8.1 \%$ GQLLAQLR

$0.01 \% \quad 8.1 \% \quad$ NLDNAVLIGETGSGK

$0.01 \% \quad 8.1 \%$ TTQIPQYLYEGGISR

$0.01 \% \quad 8.1 \%$ RVAAISLATR

$0.00 \% \quad 2.5 \%$ VANIICTQPR

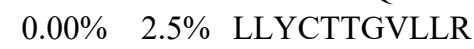

$0.00 \% \quad 2.5 \%$ QFTELLSDIGFAR

$0.03 \% \quad 18.4 \%$ EAGQCFESFLVVR

$0.03 \% \quad 18.4 \%$ IANLAYVTK

$0.03 \% \quad 18.4 \%$ HGVDVEVQGPHEAR

$\begin{array}{llll}99.7 \% & 42.1 & 25.0 & 42.1\end{array}$

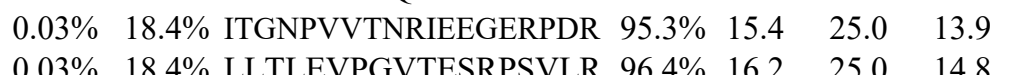

$0.03 \% \quad 18.4 \%$ LLTLEVPGVTESRPSVLR $96.4 \% \quad 16.2$

$0.03 \% \quad 18.4 \%$ DVPLLPSDVKLK

$0.03 \% \quad 18.4 \%$ SLESNPEQLQAMR

$99.6 \% \quad 25.2$

$99.7 \% \quad 57.0$

$\begin{array}{lllll}0.03 \% & 18.4 \% & \text { AHILACAPSNSGADLLCQR } & 99.7 \% & 61.4\end{array}$

$0.03 \% \quad 18.4 \%$ VLITTLITAGR

$0.03 \% \quad 18.4 \%$ HGLGYSLLER

$0.03 \% \quad 18.4 \%$ KGPDGYDPQFITK

$0.03 \% \quad 18.4 \%$ SVGVISPYR

$0.03 \% \quad 18.4 \%$ SVGVISPYRK

$0.03 \% \quad 18.4 \%$ SVILISTVR

$0.03 \% \quad 18.4 \%$ LDLQQGQNLLQGLSK

$0.01 \% \quad 11.9 \%$ IVNPPKDLK

$0.01 \% \quad 11.9 \%$ FQQAVDAVEEFLR

$0.01 \% \quad 11.9 \%$ TAEKCDLFIQEGAR

$\begin{array}{lllll}0.01 \% & 11.9 \% & \text { TAEKCDLFIQEGAR } & 99.7 \% & 44.5 \\ 0.01 \% & 11.9 \% & \text { DLVLGPSGVLQGIRPGK } & 99.7 \% & 44.8\end{array}$

$0.01 \% \quad 11.9 \%$ TSFFLGEVGNAAK

$0.01 \% \quad 6.0 \%$ SSGAASSAPGGGDGAEYKTLK

$0.01 \% \quad 6.0 \%$ VRPAYSLEPR

$\begin{array}{lll}0.01 \% & 6.0 \% & \text { SSSSSAASDTATSTQRPLR }\end{array}$

$0.01 \% \quad 6.0 \% \quad$ NLVSYLKQK

$0.00 \% \quad 17.3 \%$ ALLDQLMGTAR

$0.00 \% \quad 17.3 \%$ ADYEIASK

$0.00 \% \quad 17.3 \%$ VHELNEEIGK

$0.00 \% \quad 17.3 \%$ AEQLGAEGNVDESQK
$99.7 \% \quad 53.5$

$99.7 \% \quad 42.7$

$99.7 \% \quad 35.2$

$99.7 \% \quad 32.9$

$99.7 \% \quad 36.4$

$99.7 \% \quad 36.3$

$99.7 \% \quad 57.4$

$96.3 \% \quad 21.8$

$99.7 \% \quad 68.1$

$99.7 \% \quad 79.1$

$\begin{array}{ll}99.7 \% & 27.8 \\ 98.5 \% & 22.3\end{array}$

$99.7 \% \quad 60.0$

$99.4 \% \quad 20.0$

$\begin{array}{lll}99.7 \% & 42.5\end{array}$

$99.0 \% \quad 43.3$

$99.7 \% \quad 53.0$

$99.7 \% \quad 57.1$

1482.69

1344.73

1225.72

843.46

973.62

1150.55

1724.87

1111.59

881.52

1290.69

1948.00

1087.64

898.55

1487.77

1725.88

1057.65

1171.63

1308.73

1496.77

1541.74

992.58

1529.75

2152.11

1966.13

1323.79

1502.73

2053.99

1157.73

1144.61

1465.73

977.54

1105.64

987.62

1654.91

1023.62

1551.78

1637.80

1706.00

1340.68

1910.91

1187.65

1909.92

1092.64

1204.64

896.44

1167.60

1574.73

Page 135 of Table S-1-4 

Putative RNA-binding protein Luc7-like 1 GN=LUC7L LUC7L_HUMAN $43.73 \quad 100.0 \%$ Putative RNA-binding protein Luc7-like 2 GN=LUC7L2 LC7L2_HUMAN $46.51 \quad 100.0 \%$ atative RNA-binding protein Luc7-like 2 GN=LUC7L2 LC7L2_HUMAN 46.51 100.0 Putative RNA-binding protein Luc7-like 2 GN=LUC7L2 LC7L2_HUMAN $46.51 \quad 100.0 \%$ Putative RNA-binding protein Luc7-like 2 GN=LUC7L2 LC7L2_HUMAN $46.51 \quad 100.0 \%$ Putative RNA-binding protein Luc7-like 2 GN=LUC7L2 LC7L2 HUMAN $46.51 \quad 100.0 \%$ Putative RNA-binding protein Luc7-like 2 GN=LUC7L2 LC7L2_HUMAN $46.51 \quad 100.0 \%$ Putative RNA-binding protein Luc7-like $2 \mathrm{GN}=$ LUC7L2 LC7L2 HUMAN $46.51 \quad 100.0^{\circ}$ Putative RNA-binding protein Luc7-like 2 GN=LUC7L2 LC7L2_HUMAN $46.51 \quad 100.0 \%$ Putative RNA-binding protein Luc7-like 2 GN=LUC7L2 LC7L2_HUMAN $46.51 \quad 100.0 \%$ GN=FTSI1 TRM7 HUMAN $36.08 \quad 100.0 \%$ Putative tRNA (cytidine(32)/guanosine(34)-2'-0)-methyltransferase GN=FTSJI TRM7_HUMAN $36.08 \quad 100.0 \%$ Pyrroline-5-carboxylate reductase 1, mitochondrial GN=PYCR1 P5CR1 HUMAN $33.36100 .0 \%$ Pyrroline-5-carboxylate reductase 1, mitochondrial GN=PYCR1 P5CR1_HUMAN $33.36 \quad 100.0 \%$ Pyrroline-5-carboxylate reductase 1, mitochondrial GN=PYCR1 P5CR1_HUMAN $33.36 \quad 100.0 \%$ Pyrroline-5-carboxylate reductase 1, mitochondrial GN=PYCR1 P5CR1 HUMAN $33.36 \quad 100.0 \%$ Pyrroline-5-carboxylate reductase 1, mitochondrial GN=PYCR1 P5CR1_HUMAN $33.36 \quad 100.0 \%$ Pyrroline-5-carboxylate reductase 1, mitochondrial GN=PYCR1 P5CR1_HUMAN $33.36100 .0 \%$ Pyrroline-5-carboxylate reductase 1, mitochondrial GN=PYCR1 P5CR1_HUMAN $33.36100 .0 \%$ Pyrroline-5-carboxylate reductase 2 GN=PYCR2 P5CR2_HUMAN $33.64 \quad 100.0 \%$ Pyrroline-5-carboxylate reductase 2 GN=PYCR2 P5CR2 HUMAN $33.64100 .0 \%$ Pyrroline-5-carboxylate reductase 2 GN=PYCR2 P5CR2_HUMAN $33.64 \quad 100.0 \%$ Pyrroline-5-carboxylate reductase 2 GN=PYCR2 P5CR2_HUMAN $33.64100 .0 \%$ Pyrroline-5-carboxylate reductase 2 GN=PYCR2 P5CR2 HUMAN $33.64 \quad 100.0 \%$ Pyrroline-5-carboxylate reductase 2 GN=PYCR2 P5CR2_HUMAN $33.64 \quad 100.0 \%$ Pyrroline-5-carboxylate reductase 2 GN=PYCR2 P5CR2_HUMAN $33.64100 .0 \%$ Pyrroline-5-carboxylate reductase 2 GN=PYCR2 P5CR2_HUMAN $33.64100 .0 \%$ Pyrroline-5-carboxylate reductase 2 GN=PYCR2 P5CR2_HUMAN $33.64 \quad 100.0 \%$ Pyrroline-5-carboxylate reductase $2 \mathrm{GN}=\mathrm{PYCR} 2 \mathrm{P} 5 \mathrm{CR} 2$ HUMAN $33.64100 .0^{\circ}$ Pyrroline-5-carboxylate reductase 2 GN=PYCR2 P5CR2_HUMAN $33.64 \quad 100.0 \%$ Pyrroline-5-carboxylate reductase 2 GN=PYCR2 P5CR2_HUMAN $33.64100 .0 \%$ Pyrroline-5-carboxylate reductase $2 \mathrm{GN}=\mathrm{PYCR} 2$ P5CR2_HUMAN $33.64100 .0 \%$ Pyrroline-5-carboxylate reductase 2 GN=PYCR2 P5CR2_HUMAN $33.64 \quad 100.0 \%$ Pyrroline-5-carboxylate reductase 3 GN=PYCRL P5CR3_HUMAN $28.66 \quad 100.0 \%$ Pyrroline-5-carboxylate reductase 3 GN=PYCRL P5CR3_HUMAN $28.66 \quad 100.0 \%$ Pyrroline-5-carboxylate reductase 3 GN=PYCRL P5CR3_HUMAN $28.66 \quad 100.0 \%$ Pyrroline-5-carboxylate reductase $3 \mathrm{GN}=$ PYCRL P5CR3 HUMAN $28.66 \quad 100.0^{\circ}$ Pyrroline-5-carboxylate reductase 3 GN=PYCRL P5CR3_HUMAN $28.66 \quad 100.0 \%$ Pyrroline-5-carboxylate reductase 3 GN=PYCRL P5CR3_HUMAN $28.66100 .0 \%$
$0.00 \% \quad 17.3 \%$ NSMPASSFQQQK $0.00 \% \quad 17.3 \%$ LADHFGGK

$0.03 \% \quad 24.7 \%$ AMLDQLMGTSR $0.03 \% \quad 24.7 \%$ FSDDRVCK

$0.03 \% \quad 24.7 \%$ SHLLNCCPHDVLSGTR $0.03 \% 24.7 \%$ ADYEIASK

$0.03 \% \quad 24.7 \%$ LAETQEEISAEVAAK $0.03 \% \quad 24.7 \%$ VHELNEEIGK

$0.03 \% \quad 24.7 \%$ NSMPASSFQQQK

$0.03 \% \quad 24.7 \%$ LADHFGGK

$0.03 \% \quad 24.7 \%$ LHLGFIEIR

$\begin{array}{llll}99.7 \% & 32.4 & 25.0 & 32.4\end{array}$

$99.0 \% \quad 33.1 \quad 25.0 \quad 28.2 \quad 4$

$\begin{array}{lllll}99.7 \% & 48.3 & 25.0 & 47.0 & 2\end{array}$

$\begin{array}{llll}98.5 \% & 24.7 & 25.0 & 17.5\end{array}$

$99.7 \% \quad 34.2 \quad 25.0 \quad 34.2$

$99.0 \% \quad 43.3 \quad 25.0 \quad 43.3$

$\begin{array}{llll}99.7 \% & 74.2 & 25.0 & 68.3\end{array}$

$99.7 \% \quad 53.0 \quad 25.0 \quad 52.5$

$99.7 \% \quad 32.4 \quad 25.0 \quad 32.4$

$\begin{array}{llll}99.0 \% & 33.1 & 25.0 & 28.2\end{array}$

$\begin{array}{llll}99.7 \% & 29.5 & 25.0 & 29.3\end{array}$

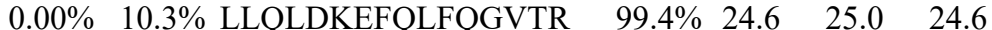

$0.00 \% \quad 10.3 \%$ IIVPFVTCGDLSSYDSDR

$0.01 \% \quad 25.7 \%$ GFTAAGVLAAHK

$0.01 \% \quad 25.7 \%$ CMTNTPVVVR

$99.7 \% \quad 54.4$

$99.7 \% \quad 35.0$

$0.01 \% \quad 25.7 \%$ EGATVYATGTHAQVEDGR

$0.01 \% \quad 25.7 \%$ LGAQALLGAAK

$0.01 \% \quad 25.7 \%$ SLLINAVEASCIR

$99.4 \% \quad 26.6$

$99.7 \% 75.9$

$99.7 \% \quad 59.9$

$0.01 \% \quad 25.7 \%$ VKLDSPAGTALSPSGHTK

$0.01 \% \quad 25.7 \%$ LDSPAGTALSPSGHTK

$0.06 \% \quad 42.2 \%$ GFTAAGILSAHK

$99.7 \%$

$99.7 \% \quad 60.8$

$99.7 \% \quad 77.0$

$\begin{array}{lllll}0.06 \% & 42.2 \% & \text { IIASSPEMNLPTVSALRK } & 99.2 \% & 19.1\end{array}$

$0.06 \% \quad 42.2 \%$ HIVVSCAAGVTISSVEK

$\begin{array}{ll}99.2 \% & 19.1 \\ 99.7 \% & 57.2\end{array}$

$0.06 \% \quad 42.2 \%$ KLMAFQPAPK

$0.06 \% \quad 42.2 \%$ LMAFQPAPK

$99.7 \% \quad 37.7$

$99.7 \% \quad 39.6$

$99.7 \% \quad 54.5$

$99.7 \% \quad 67.5$

$0.06 \% \quad 42.2 \%$ LAI

$0.06 \% \quad 42.2 \%$ MLLDSEQHPCQLK

$0.06 \% \quad 42.2 \%$ SLLINAVEASCIR

$99.3 \% \quad 19.8$

$99.7 \% \quad 59.9$

$99.7 \% \quad 54.9$

$99.0 \% \quad 31.9$

$0.06 \% \quad 42.2 \%$ ISPAALKK

$99.7 \% \quad 53.6$

$0.06 \% \quad 42.2 \%$ VKLESPTVSTLTPSSP

$0.06 \% \quad 42.2 \%$ LESPTVSTLTPSSPGK

$0.01 \% \quad 22.3 \%$ RVGFVGAGR

$0.01 \% \quad 22.3 \%$ MAGAIAQGLIR

$99.7 \% \quad 67.5$

$99.7 \% \quad 39.1$

$99.7 \% \quad 60.3$

$0.01 \% \quad 22.3 \%$ AGKVEAQHILASAPTDR $99.1 \% \quad 21.5$

$0.01 \% 22.3 \%$ VEAQHILASAPTDR

$0.01 \% \quad 22.3 \%$ IAAQTLLGTAK

$0.01 \% \quad 22.3 \%$ AATMSAVEAATCR

$99.7 \% \quad 43.6$

$99.7 \% \quad 62.2$

$99.7 \% \quad 41.2$

$99.7 \% \quad 68.0$

$99.0 \% \quad 29.6$

$99.7 \% \quad 45.2$

$0.03 \% 33.8 \%$ AHGFTFTR

$0.03 \% \quad 33.8 \%$ EILAELTGR

$0.03 \% \quad 33.8 \%$ NFYGGNGIVGAQVPLGAGIALACK

$0.03 \% \quad 33.8 \%$ LPCIFICENNR

$0.03 \% \quad 33.8 \%$ YGMGTSVER

$0.03 \% \quad 33.8 \%$ AAASTDYYK $\begin{array}{llll}99.7 \% & 64.1 & 25.0 & 58.5\end{array}$

$99.7 \% \quad 56.7 \quad 25.0 \quad 51.4$

$99.7 \% \quad 36.5 \quad 25.0 \quad 36.5$

0
0
0
0
2
0
0
0
0
0
0
0
0
1
0
0
0
0
2
0
0
0
2
2
1
0
0
0
0
0
0
0
0
0
0
3
0
0
0
0
0
0
0
0
0
0
0
0
0
0
0
0
0
0

844.43

1254.58

1026.47

1865.87

896.44

1588.81

1167.60

1368.62

844.43

1097.65

1935.07

2043.97

1142.63

1176.59

1861.87

1012.62

1445.78

1765.94

1538.78

1172.64

1798.97

1943.06

1756.93

1130.64

1002.54

1593.98

1437.88

1614.76

1445.78

1194.53

827.54

1828.01

1600.84

918.53

1100.62

1763.94

1507.79

1086.65

1338.61

1411.78

936.47

1001.56

2347.22

1435.68

1015.45

989.46

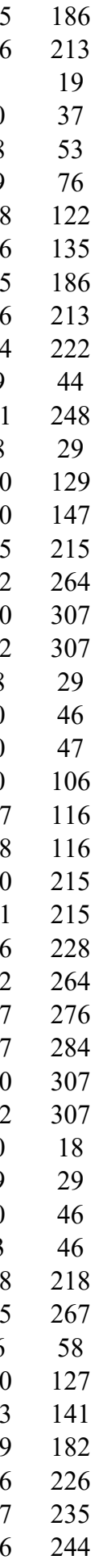


Rab-like protein $2 \mathrm{~B}$ GN=RABL2B Rab-like protein $2 \mathrm{~B}$ GN=RABL2B Rab-like protein $2 \mathrm{~B}$ GN=RABL2B 作 Rac GTPase-activating protein 1 GN=RACGAP1 RGAP1_HUMAN $71.03 \quad 100.0 \%$ Rac GTPase-activating protein $1 \mathrm{GN}=$ RACGAP1 RGAP1_HUMAN $71.03 \quad 100.0 \%$ Rac GTPase-activating protein $1 \mathrm{GN}=\mathrm{RACGAP1}$ RGAP1_HUMAN $71.03 \quad 100.0 \%$ Rac GTPase-activating protein 1 GN=RACGAP1 RGAP1_HUMAN $71.03 \quad 100.0 \%$ Radical S-adenosyl methionine domain-contaning protein 1, mitochondrial GN=RSAD1 RSAD1_HUMAN $48.71 \quad 100.0 \%$ GN=RSADI RSAD1_HUMAN $48.71 \quad 100.0 \%$ Ran GTPase-activating protein 1 GN=RANGAP1 RAGP1_HUMAN $63.54 \quad 100.0 \%$ Ran GTPase-activating protein $1 \mathrm{GN}=$ RANGAP1 RAGP1_HUMAN $63.54 \quad 100.0 \%$ Ran GTPase-activating protein 1 GN=RANGAP1 RAGP1_HUMAN $63.54 \quad 100.0 \%$ Ran GTPase-activating protein 1 GN=RANGAP1 RAGP1_HUMAN $63.54 \quad 100.0 \%$ Ran-specific GTPase-activating protein GN=RANBP1 RANG_HUMAN $23.31 \quad 100.0 \%$ Ran-specific GTPase-activating protein GN=RANBP1 RANG_HUMAN $23.31 \quad 100.0 \%$ Ran-specific GTPase-activating protein GN=RANBP1 RANG HUMAN $23.31 \quad 100.0 \%$ Ras GTPase-activating protein-binding protein $2 \mathrm{GN}=\mathrm{G} 3 \mathrm{BP} 2 \mathrm{G} 3 \mathrm{BP} 2$ _HUMAN $54.12 \quad 100.0 \%$ Ras GTPase-activating protein-binding protein $2 \mathrm{GN}=\mathrm{G} 3 \mathrm{BP} 2$ G3BP2_HUMAN $54.12 \quad 100.0 \%$ Ras GTPase-activating-like protein IQGAP1 GN=IQGAP1 IQGA1_HUMAN $189.26 \quad 100.0 \%$ Ras GTPase-activating-like protein IQGAP1 GN=IQGAP1 IQGA1_HUMAN $189.26 \quad 100.0 \%$ Ras GTPase-activating-like protein IQGAP1 GN=IQGAP1 IQGA1_HUMAN $189.26 \quad 100.0 \%$ Ras GTPase-activating-like protein IQGAP1 GN=IQGAP1 IQGA1_HUMAN $189.26 \quad 100.0 \%$ Ras GTPase-activating-like protein IQGAP1 GN=IQGAP1 IQGA1_HUMAN $189.26 \quad 100.0 \%$ Ras GTPase-activating-like protein IQGAP1 GN=IQGAP1 IQGA1_HUMAN $189.26 \quad 100.0 \%$ Ras GTPase-activating-like protein IQGAP1 GN=IQGAP1 IQGA1_HUMAN $189.26 \quad 100.0 \%$ Ras GTPase-activating-like protein IQGAP1 GN=IQGAP1 IQGA1_HUMAN $189.26 \quad 100.0 \%$ Ras GTPase-activating-like protein IQGAP1 GN=IQGAP1 IQGA1_HUMAN $189.26100 .0 \%$ Ras suppressor protein $1 \mathrm{GN}=\mathrm{RSU} 1$ Ras suppressor protein $1 \mathrm{GN}=\mathrm{RSU} 1$ RSU1_HUMAN $31.54 \quad 100.0 \%$ RSU1_HUMAN $31.54 \quad 100.0 \%$ APR1A_HUMAN $35.72 \quad 100.0 \%$ RPR1A_HUMAN $35.72 \quad 100.0 \%$ RPR1A HUMAN $35.72 \quad 100.0 \%$ $\begin{array}{llll}\text { Regulation of nuclear pre-mRNA domain-containing protein } 1 \mathrm{~A} G \mathrm{GN}=\mathrm{RPRD} 1 \mathrm{~A} & \text { RPR1A_HUMAN } & 35.72 & 100.0 \% \\ \text { Regulation of nuclear pre-mRNA domain-containing protein } 1 \mathrm{~A} \text { GN=RPRDIA } & \text { RPR1A_HUMAN } & 35.72 & 100.0 \%\end{array}$ $\begin{array}{llll}\text { Regulation of nuclear pre-mRNA domain-containing protein } 1 \mathrm{~A} \text { GN=RPRD1A } & \text { RPR1A_HUMAN } & 35.72 & 100.0 \% \\ \text { Regulation of nuclear pre-mRNA domain-containing protein } 1 \mathrm{~A} \text { GN=RPRDIA } & \text { RPR1A_HUMAN } & 35.72 & 100.0 \%\end{array}$ Regulation of nuclear pre-mRNA domain-containing protein $1 \mathrm{~A}$ GN=RPRD1A $\quad$ RPR1A_HUMAN $35.72 \quad 100.0 \%$ Regulator of nonsense transcripts 1 GN=UPF1 RENT1_HUMAN $124.35 \quad 100.0 \%$ Regulator of nonsense transcripts 1 GN=UPF1 RENT1_HUMAN $124.35 \quad 100.0 \%$ Regulator of nonsense transcripts 1 GN=UPF1 RENT1_HUMAN $124.35 \quad 100.0 \%$ Regulator of nonsense transcripts 1 GN=UPF1 RENT1_HUMAN $124.35 \quad 100.0 \%$ Regulator of nonsense transcripts 1 GN=UPF1 RENT1_HUMAN $124.35 \quad 100.0 \%$ Regulator of nonsense transcripts 1 GN=UPF1 RENT1_HUMAN $124.35 \quad 100.0 \%$ Regulator of nonsense transcripts 1 GN=UPF1 RENT1_HUMAN $124.35100 .0 \%$ Regulator of nonsense transcripts 1 GN=UPF1 RENT1_HUMAN $124.35 \quad 100.0 \%$ Regulator of nonsense transcripts 1 GN=UPF1 RENT1_HUMAN $124.35 \quad 100.0 \%$ Regulator of nonsense transcripts 1 GN=UPF1 RENT1_HUMAN $124.35100 .0 \%$ Regulator of nonsense transcripts 1 GN=UPF1 RENT1_HUMAN $124.35 \quad 100.0 \%$ $0.00 \% \quad 15.4 \%$ TILVDFWDTAGQER $0.00 \% \quad 15.4 \%$ NLSTWYTELR $0.01 \% \quad 10.1 \%$ QFVDGPPGPVKK $0.01 \% \quad 10.1 \%$ SIGSAVDQGNESIVAK $0.01 \% \quad 10.1 \%$ TGTLQPWNSDSTLNSR $0.01 \% \quad 10.1 \%$ NLKEPLLTFR $0.01 \% \quad 10.1 \%$ TPSSSSLSQR $0.00 \% \quad 4.8 \%$ LAEFGAAGVNR $0.00 \% \quad 4.8 \%$ GTALFAQVQR $0.01 \% \quad 8.9 \%$ GAVAIADAIRGGLPK $0.01 \% \quad 8.9 \%$ VSSVFKDEATVR $0.01 \% \quad 8.9 \%$ AFNSSSFNSNTFLTR $0.01 \% \quad 8.9 \%$ HSLLQTLYKV

$0.00 \% \quad 16.4 \%$ TLEEDEEELFK $0.00 \% \quad 16.4 \%$ FASENDLPEWKER $0.00 \% \quad 16.4 \%$ FLNAENAQK $0.00 \% \quad 5.2 \%$ VLSLNFSECHTK $0.00 \% \quad 5.2 \%$ VEAKPEVQSQPPR $0.02 \% \quad 6.2 \% \quad$ LGNFFSPK $0.02 \% \quad 6.2 \% \quad$ ALQSPALGLR $0.02 \% \quad 6.2 \%$ LAAVALINAAIQK $0.02 \% \quad 6.2 \% \quad$ ALESGDVNTVWK $0.02 \% \quad 6.2 \% \quad$ TLQALQIPAAK $0.02 \% \quad 6.2 \% \quad$ LIFQMPQNK $0.02 \% \quad 6.2 \%$ VDQIQEIVTGNPTVIK $0.02 \% \quad 6.2 \%$ LQQTYAALNSK $0.02 \% \quad 6.2 \%$ ATFYGEQVDYYK $\begin{array}{lll}0.00 \% & 12.6 \% & \text { ALYLSDNDFEILPPDIGK } \\ 0.00 \% & 12.6 \% & \text { LTVLPPELGNLDLTGQK }\end{array}$ $0.01 \% \quad 26.0 \%$ LTFLYLANDVIQNSK $0.01 \% \quad 26.0 \%$ DFAPVIVEAFK

$0.01 \% \quad 26.0 \%$ SVYENDVLEQLK $0.01 \% \quad 26.0 \%$ ALQDLENAASGDAAVHQR $0.01 \% \quad 26.0 \%$ IASLPVEVQEVSLLDK $0.01 \% \quad 26.0 \%$ IQSLPDLSR $0.03 \% \quad 12.5 \%$ IPSEQEQLR $0.03 \% \quad 12.5 \%$ IAYFTLPK $0.03 \% \quad 12.5 \%$ TVLQRPLSLIQGPPGTGK $0.03 \% \quad 12.5 \%$ TVTSATIVYHLAR $0.03 \% \quad 12.5 \%$ AGLSQSLFER $0.03 \% \quad 12.5 \%$ LVVLGIRPIR $0.03 \% \quad 12.5 \%$ AGAKPDQIGIITPYEGQR $0.03 \% \quad 12.5 \%$ ARYGVIIVGNPK $0.03 \% \quad 12.5 \%$ YGVIIVGNPK $0.03 \% \quad 12.5 \%$ KLVNTINPGAR $\begin{array}{llllllll}99.7 \% & 33.7 & 25.0 & 33.7 & 1 & 0 & 0 & 1132.60\end{array}$

1650.81

1282.64

1268.70

1574.80

1776.85

1230.72

1049.52

1104.58

$\begin{array}{llll}99.7 \% & 45.2 & 25.0 & 45.2\end{array}$

$\begin{array}{llll}99.6 \% & 39.3 & 25.0 & 12.6\end{array}$

$\begin{array}{llll}99.3 \% & 19.3 & 25.0 & 19.3\end{array}$

$99.7 \% \quad 58.0 \quad 25.0 \quad 54.6$

$\begin{array}{llll}99.7 \% & 79.0 & 25.0 & 73.6\end{array}$

$\begin{array}{llll}99.4 \% & 26.6 & 25.0 & 20.8\end{array}$

$\begin{array}{llll}99.7 \% & 46.5 & 25.0 & 46.5\end{array}$

$\begin{array}{llll}99.4 \% & 29.0 & 25.0 & 25.8\end{array}$

$\begin{array}{llll}99.7 \% & 38.3 & 25.0 & 18.0\end{array}$

$\begin{array}{llll}99.7 \% & 38.9 & 25.0 & 38.9\end{array}$

$\begin{array}{llll}99.7 \% & 54.4 & 25.0 & 49.5\end{array}$

$99.0 \% \quad 35.5 \quad 25.0 \quad 35.5$

$\begin{array}{lllll}99.7 \% & 36.6 & 25.0 & 30.1\end{array}$

$\begin{array}{llll}99.7 \% & 58.8 & 25.0 & 50.7\end{array}$

$\begin{array}{llll}99.7 \% & 40.5 & 25.0 & 33.6\end{array}$

$\begin{array}{llll}99.7 \% & 36.2 & 25.0 & 36.2\end{array}$

$\begin{array}{llll}99.7 \% & 26.9 & 25.0 & 22.6\end{array}$

$\begin{array}{llll}99.7 \% & 54.3 & 25.0 & 54.3\end{array}$

$\begin{array}{llll}99.7 \% & 49.0 & 25.0 & 43.4\end{array}$

$\begin{array}{llll}99.7 \% & 42.2 & 25.0 & 42.2\end{array}$

$\begin{array}{lllll}97.6 \% & 23.4 & 25.0 & 23.4 & 2\end{array}$

$\begin{array}{llll}99.7 \% & 32.5 & 25.0 & 26.4\end{array}$

$\begin{array}{llll}99.7 \% & 41.7 & 25.0 & 34.5\end{array}$

$\begin{array}{llll}9.7 \% & 33.5 & 25.0 & 25.7 \\ 99.7 \% & 63.6 & 25.0 & 54.9\end{array}$

$\begin{array}{llll}99.7 \% & 54.2 & 25.0 & 54.2\end{array}$

$\begin{array}{llll}99.7 \% & 43.0 & 25.0 & 43.0\end{array}$

$\begin{array}{llll}99.7 \% & 32.5 & 25.0 & 21.9\end{array}$

$\begin{array}{llll}98.1 \% & 22.4 & 25.0 & 15.9\end{array}$

$99.0 \% \quad 34.9 \quad 25.0 \quad 34.9$

$\begin{array}{llll}99.7 \% & 49.0 & 25.0 & 49.0\end{array}$

$\begin{array}{llll}99.7 \% & 75.5 & 25.0 & 68.8\end{array}$

$\begin{array}{lllll}99.7 \% & 56.6 & 25.0 & 33.6 & 2\end{array}$

$\begin{array}{lllll}98.1 \% & 16.5 & 25.0 & 16.5 & 1\end{array}$

$\begin{array}{llll}99.7 \% & 36.0 & 25.0 & 35.8\end{array}$

$\begin{array}{lllll}99.7 \% & 41.2 & 25.0 & 36.5 & 2\end{array}$

$\begin{array}{llll}99.7 \% & 38.3 & 25.0 & 38.3\end{array}$

$\begin{array}{llll}99.7 \% & 53.2 & 25.0 & 53.2\end{array}$

1090.60

1408.83

1337.71

1692.80

1201.69

1381.64

1620.77

1034.53

1434.70

1464.78

909.48

1025.61

1295.80

1318.66

1153.69

1118.60

1753.97

1236.66

1483.67

2020.03

1808.02

1738.94

1235.67

1436.73

1865.91

1739.98

1028.57

1099.57

952.55

2144.12

1862.09

1431.80

1107.58

1135.77

1914.01

1286.76

1059.62

1182.70 
Regulator of nonsense transcripts $1 \mathrm{GN}=\mathrm{UPF} 1$ RENT1_HUMAN $124.35 \quad 100.0 \%$ Regulatory-associated protein of mTOR GN=RPTOR RPTOR_HUMAN $149.04 \quad 100.0 \%$ Regulatory-associated protein of mTOR GN=RPTOR RPTOR_HUMAN $149.04 \quad 100.0 \%$ Regulatory-associated protein of mTOR GN=RPTOR RPTOR HUMAN $149.04 \quad 100.0 \%$ Renin receptor $\mathrm{GN}=\mathrm{ATP} 6 \mathrm{AP} 2$ Renin receptor GN=ATP6AP2 RENR_HUMAN $39.01 \quad 100.0 \%$ RENR HUMAN $39.01 \quad 100.0 \%$ Replication factor C subunit $1 \mathrm{GN}=\mathrm{RFC} 1 \quad$ RFC1_HUMAN $128.26 \quad 100.0 \%$ Replication factor C subunit $1 \mathrm{GN}=\mathrm{RFC1}$ RFC1_HUMAN $128.26 \quad 100.0 \%$ Replication factor $\mathrm{C}$ subunit $1 \mathrm{GN}=\mathrm{RFC} 1 \mathrm{RFC1} \mathrm{HUMAN} 128.26 \quad 100.0 \%$ Replication factor $\mathrm{C}$ subunit $1 \mathrm{GN}=\mathrm{RFC1}$ RFC1_HUMAN $128.26 \quad 100.0 \%$ Replication factor C subunit 2 GN=RFC2 RFC2_HUMAN $39.16 \quad 100.0 \%$ Replication factor $\mathrm{C}$ subunit $2 \mathrm{GN}=\mathrm{RFC} 2$ RFC2_HUMAN $39.16 \quad 100.0 \%$ Replication factor C subunit $2 \mathrm{GN}=\mathrm{RFC} 2 \mathrm{RFC2}$ _HUMAN $39.16 \quad 100.0 \%$ Replication factor $\mathrm{C}$ subunit $2 \mathrm{GN}=\mathrm{RFC} 2 \quad \mathrm{RFC} 2$ HUMAN $39.16 \quad 100.0 \%$ Replication factor C subunit $2 \mathrm{GN}=\mathrm{RFC} 2 \quad \mathrm{RFC} 2$ HUMAN $39.16 \quad 100.0 \%$ Replication factor C subunit $2 \mathrm{GN}=\mathrm{RFC} 2$ RFC2_HUMAN $39.16 \quad 100.0 \%$ Replication factor $\mathrm{C}$ subunit $2 \mathrm{GN}=\mathrm{RFC} 2 \mathrm{RFC} 2 \mathrm{HUMAN} 39.16 \quad 100.0 \%$ Replication factor C subunit 2 GN=RFC2 RFC2_HUMAN $39.16 \quad 100.0 \%$ Replication factor C subunit $2 \mathrm{GN}=\mathrm{RFC} 2$ RFC2_HUMAN $39.16 \quad 100.0 \%$ Replication factor $\mathrm{C}$ subunit $2 \mathrm{GN}=\mathrm{RFC} 2 \mathrm{RFC} 2$ HUMAN $39.16 \quad 100.0 \%$ Replication factor C subunit 2 GN=RFC2 RFC2_HUMAN $39.16 \quad 100.0 \%$ Replication factor C subunit $2 \mathrm{GN}=\mathrm{RFC} 2 \mathrm{RFC} 2$ HUMAN $39.16 \quad 100.0 \%$ Replication factor C subunit 2 GN=RFC2 RFC2_HUMAN $39.16 \quad 100.0 \%$ Replication factor C subunit $3 \mathrm{GN}=\mathrm{RFC} 3 \quad \mathrm{RFC} 3$ _HUMAN $40.56 \quad 100.0 \%$ Replication factor $\mathrm{C}$ subunit $3 \mathrm{GN}=\mathrm{RFC} 3 \mathrm{RFC} 3 \mathrm{HUMAN} \quad 40.56 \quad 100.0 \%$ $\begin{array}{llll}\text { Replication factor C subunit } 3 \mathrm{GN}=\mathrm{RFC} 3 & \mathrm{RFC} 3 \text { _HUMAN } & 40.56 & 100.0 \%\end{array}$ Replication factor $\mathrm{C}$ subunit $3 \mathrm{GN}=\mathrm{RFC} 3 \quad \mathrm{RFC} 3$ _HUMAN $40.56 \quad 100.0 \%$ Replication factor $\mathrm{C}$ subunit $3 \mathrm{GN}=\mathrm{RFC} 3 \quad \mathrm{RFC} 3$ HUMAN $40.56 \quad 100.0 \%$ Replication factor C subunit $3 \mathrm{GN}=\mathrm{RFC} 3$ RFC3_HUMAN $40.56 \quad 100.0 \%$ Replication factor $\mathrm{C}$ subunit $3 \mathrm{GN}=\mathrm{RFC} 3 \mathrm{RFC} 3$ HUMAN $40.56 \quad 100.0 \%$ Replication factor C subunit $3 \mathrm{GN}=\mathrm{RFC} 3 \quad \mathrm{RFC} 3$ _HUMAN $40.56 \quad 100.0 \%$ Replication factor C subunit $3 \mathrm{GN}=\mathrm{RFC} 3 \quad \mathrm{RFC} 3$ _HUMAN $40.56 \quad 100.0 \%$ Replication factor $\mathrm{C}$ subunit $3 \mathrm{GN}=\mathrm{RFC} 3 \mathrm{RFC} 3$ HUMAN $40.56 \quad 100.0 \%$ Replication factor C subunit $3 \mathrm{GN}=\mathrm{RFC} 3$ RFC3_HUMAN $40.56 \quad 100.0 \%$ Replication factor $\mathrm{C}$ subunit $3 \mathrm{GN}=\mathrm{RFC} 3$ RFC3_HUMAN $40.56 \quad 100.0 \%$ Replication factor C subunit $3 \mathrm{GN}=\mathrm{RFC} 3 \quad \mathrm{RFC} 3$ _HUMAN $40.56 \quad 100.0 \%$ Replication factor C subunit 4 GN=RFC4 RFC4_HUMAN $39.68 \quad 100.0 \%$ Replication factor $\mathrm{C}$ subunit $4 \mathrm{GN}=\mathrm{RFC} 4 \mathrm{RFC} 4$ HUMAN $39.68 \quad 100.0 \%$ Replication factor C subunit 4 GN=RFC4 RFC4_HUMAN $39.68 \quad 100.0 \%$ Replication factor C subunit 4 GN=RFC4 RFC4_HUMAN $39.68 \quad 100.0 \%$ Replication factor C subunit $4 \mathrm{GN}=\mathrm{RFC} 4$ RFC4_HUMAN $39.68 \quad 100.0 \%$ Replication factor C subunit 4 GN=RFC4 $\quad$ RFC4_HUMAN $39.68 \quad 100.0 \% \quad 1$ Replication factor C subunit 4 GN=RFC4 RFC4_HUMAN $39.68 \quad 100.0 \%$ Replication factor C subunit 4 GN=RFC4 $\quad$ RFC4_HUMAN $39.68 \quad 100.0 \% \quad 1$ Replication factor C subunit 4 GN=RFC4 $\quad$ RFC4_HUMAN $39.68 \quad 100.0 \% \quad 1$ Replication factor C subunit 4 GN=RFC4 RFC4_HUMAN $39.68 \quad 100.0 \%$

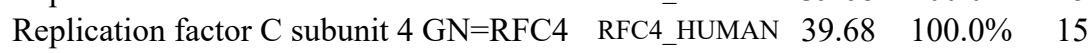

$0.03 \% \quad 12.5 \%$ AYQHGGVTGLSQY

$0.00 \% \quad 2.6 \%$ ALETIGANLQK

$0.00 \% \quad 2.6 \%$ SYNCTPVSSPR

$0.00 \% \quad 2.6 \%$ SLIVAGLGDGSIR

$0.00 \% \quad 7.4 \%$ SPGSVVFR

$0.00 \% \quad 7.4 \%$ LFQENSVLSSLPLNSLSR

$0.01 \% \quad 4.2 \%$ SSADKIGEVSSPK

$0.01 \% \quad 4.2 \% \quad$ IIDEDGLLNLIR

$0.01 \% \quad 4.2 \% \quad$ FSGKDDGSSFK

$0.01 \% \quad 4.2 \%$ AALLSGPPGVGK

$0.03 \% \quad 38.1 \%$ LNEIVGNEDTVSR

$0.03 \% \quad 38.1 \%$ EGNVPNIIIAGPPGTGK

$0.03 \% \quad 38.1 \%$ TTSILCLAR

$0.03 \% \quad 38.1 \%$ DAMLELNASNDR

$0.03 \% 38.1 \%$ IIILDEADSMTDGAQQALR

$0.03 \% \quad 38.1 \%$ IIILDEADSMTDGAQQALRR $98.8 \% \quad 17.9$

$0.03 \% 38.1 \%$ FALACNASDK

$0.03 \% \quad 38.1 \%$ FALACNASDKIIEPIQSR

$0.03 \% \quad 38.1 \%$ IIEPIQSR

$0.03 \% \quad 38.1 \%$ LTDAQILTR

$0.03 \% \quad 38.1 \%$ VCDEPHPLLVK

$0.03 \% \quad 38.1 \%$ TFQMAEYLK

$99.7 \% \quad 62.9$

$99.0 \% \quad 42.7$

$99.7 \% \quad 74.7$

$99.7 \% \quad 55.2$

$99.5 \% \quad 22.1$

$0.03 \% \quad 38.1 \%$ IAEGVNSLLQMAGLLAR $\quad 99.7 \% \quad 71.0$

$0.03 \% \quad 38.2 \%$ LDYHKEQAAQLR

$99.7 \% \quad 56.5$

PSGAGK $99.4 \% \quad 22.6$

$0.03 \% \quad 38.2 \%$ ELYGVGVEK

$0.03 \% \quad 38.2 \%$ LRIEHQTITTPSK

$0.03 \% 38.2 \%$ IEHQTITTPSK

$0.03 \% \quad 38.2 \%$ VVIQEMLK

$0.03 \% \quad 38.2 \%$ TVAQSQQLETNSQR

$0.03 \% \quad 38.2 \%$ VVLLTEVDK

$0.03 \% \quad 38.2 \%$ VVLLTEVDKLTK

$0.03 \% \quad 38.2 \%$ LILCCNSTSK

$0.03 \% \quad 38.2 \%$ EGLNLPSQLAHR

$0.03 \% \quad 38.2 \%$ ETANAIVSQQTPQR

$0.03 \% \quad 38.2 \%$ AIYHLEAFVAK

$0.03 \% \quad 45.7 \%$ GTSISTKPPLTK

$99.7 \% \quad 32.8$

$\begin{array}{lll}99.3 \% & 22.9\end{array}$

$99.7 \% \quad 43.0$

$99.0 \% \quad 40.5$

$99.7 \% \quad 64.0$

$99.7 \% \quad 39.2$

$99.7 \% \quad 54.1$

$99.7 \% \quad 31.1$

$99.7 \% \quad 42.9$

$99.7 \% \quad 48.5$

$99.7 \% \quad 56.9$

$99.7 \% \quad 34.9$

$99.7 \% \quad 58.8$

$0.03 \% \quad 45.7 \%$ GVAASAGSSGENKK

$99.7 \% 48.5$

$99.7 \% \quad 55.2$

$99.7 \% \quad 39.1$

$99.7 \% \quad 63.1$

$99.7 \% \quad 52.0$

$0.03 \% \quad 45.7 \%$

$0.03 \% \quad 45.7 \%$ VLELNASDER

$0.03 \% \quad 45.7 \%$ VKNFAQLTVSGSR

$99.7 \% \quad 66.0$

$0.03 \% \quad 45.7 \%$ IVILDEADSMTSAAQAALR

$0.03 \% \quad 45.7 \%$ FCLICNYVSR

$0.03 \% \quad 45.7 \%$ IIEPLTSR

$0.03 \% \quad 45.7 \%$ ISDEGIAYLVK
$99.7 \% 46$.

$99.0 \% 37.7$

$99.7 \% \quad 61.0$
138

1380.65

1267.57

1257.72

848.46

2004.08

1304.67

1383.78

1174.54

1066.63

1445.72

1633.89

1034.57

1364.61

2076.03

2232.13

1096.51

2033.05

955.56

1030.59

1306.68

1130.56

1771.97

1471.77

2229.11

993.53

1523.85

1254.67

975.55

1589.79

1015.60

1357.83

1195.58

1334.72

1542.79

1261.69

1229.71

1262.63

2046.05

903.53

1107.58

1145.58

1406.78

1975.02

1331.62

928.55

1207.66

$\begin{array}{lc}17 & 1129 \\ 8 & 108 \\ 59 & 369 \\ 79 & 1191 \\ 4 & 31 \\ 58 & 175 \\ 02 & 314 \\ 69 & 480 \\ 35 & 645 \\ 46 & 657 \\ 7 & 59 \\ 6 & 82 \\ 3 & 91 \\ 00 & 111 \\ 37 & 155 \\ 37 & 156 \\ 67 & 176 \\ 67 & 184 \\ 77 & 184 \\ 93 & 201 \\ 54 & 264 \\ 05 & 313 \\ 27 & 343 \\ 6 & 27 \\ 8 & 48 \\ 8 & 66 \\ 7 & 79 \\ 9 & 79 \\ 06 & 113 \\ 14 & 127 \\ 31 & 139 \\ 31 & 142 \\ 61 & 170 \\ 03 & 214 \\ 57 & 270 \\ 28 & 338 \\ 7 & 18 \\ 1 & 34 \\ 5 & 84 \\ 5 & 93 \\ 4 & 102 \\ 05 & 114 \\ 23 & 135 \\ 46 & 164 \\ 76 & 185 \\ 86 & 193 \\ 22 & 232 \\ & \end{array}$

Page 139 of Table S-1-4 


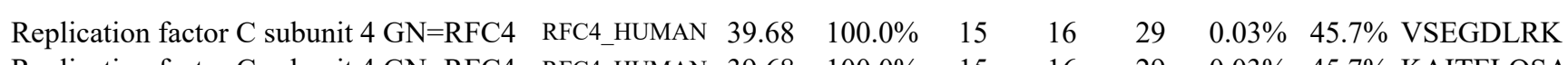
Replication factor C subunit $4 \mathrm{GN}=\mathrm{RFC4} \quad \mathrm{RFC} 4$ _HUMAN $39.68 \quad 100.0 \% \quad 1$ Replication factor C subunit $4 \mathrm{GN}=\mathrm{RFC} 4 \quad \mathrm{RFC} 4$ _HUMAN $39.68 \quad 100.0 \% \quad 1$

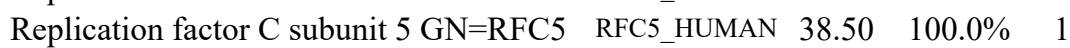
Replication factor C subunit $5 \mathrm{GN}=\mathrm{RFC} 5 \quad \mathrm{RFC} 5$ HUMAN $38.50 \quad 100.0 \% \quad 1$ Replication factor C subunit 5 GN=RFC5 $\quad$ RFC5_HUMAN $38.50 \quad 100.0 \% \quad 1$

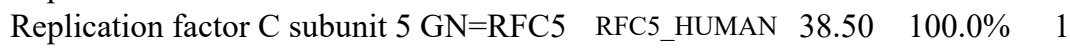
Replication factor C subunit 5 GN=RFC5 RFC5 HUMAN $38.50 \quad 100.0 \% \quad 1$ $\begin{array}{lllll}\text { Replication factor C subunit } 5 \text { GN=RFC5 } & \text { RFC5_HUMAN } & 38.50 & 100.0 \% & 1\end{array}$ $\begin{array}{lllll}\text { Replication factor } \mathrm{C} \text { subunit } 5 \mathrm{GN}=\mathrm{RFC} 5 & \mathrm{RFC5} \text { _HUMAN } & 38.50 & 100.0 \% & 1\end{array}$ Replication factor C subunit 5 GN=RFC5 RFC5 HUMAN $38.50 \quad 100.0 \%$ $\begin{array}{llll}\text { Replication factor C subunit } 5 \text { GN=RFC5 RFC5_HUMAN } & 38.50 & 100.0 \% & 1\end{array}$ Replication factor C subunit 5 GN=RFC5 $\quad$ RFC5_HUMAN $38.50 \quad 100.0 \% \quad 1$ Replication factor C subunit 5 GN=RFC5 RFC5_HUMAN $38.50 \quad 100.0 \%$ $\begin{array}{llll}\text { Replication factor C subunit } 5 \mathrm{GN}=\mathrm{RFC} 5 & \mathrm{RFC5} \text { _HUMAN } & 38.50 & 100.0 \%\end{array}$ Replication initiator $1 \mathrm{GN}=$ REPIN1 REPI1 HUMAN 63.57 Replication initiator $1 \mathrm{GN}=\mathrm{REPIN} 1$ REPI_HUMAN $63.57 \quad 100.0 \%$ RFA1_HUMAN $68.14 \quad 100.0 \%$ Replication protein A $70 \mathrm{kDa}$ DNA-binding subunit GN=RPA1 RFA1_HUMAN $68.14 \quad 100.0 \%$ Required for meiotic nuclear division protein 1 homolog GN=RMND1 RMND1_HUMAN $51.61 \quad 100.0 \%$ Required for meiotic nuclear division protein 1 homolog GN=RMND1 RMND1_HUMAN $51.61 \quad 100.0 \%$ Required for meiotic nuclear division protein 1 homolog GN=RMND1 RMND1_HUMAN $51.61 \quad 100.0 \%$ Retinitis pigmentosa 1-like 1 protein GN=RP1L1 RP1L1_HUMAN $261.20 \quad 99.9 \%$ Retinitis pigmentosa 1-like 1 protein GN=RP1L1 RP1L1 HUMAN $261.20 \quad 99.9 \%$ Rhomboid domain-containing protein 2 GN=RHBDD2 RHBD2_HUMAN $39.20 \quad 100.0 \%$ Rhomboid domain-containing protein 2 GN=RHBDD2 RHBD2_HUMAN $39.20 \quad 100.0 \%$ Ribonuclease P protein subunit p30 GN=RPP30 RPP30_HUMAN $29.32 \quad 100.0 \%$ Ribonuclease P protein subunit p30 GN=RPP30 RPP30_HUMAN $29.32 \quad 100.0 \%$ Ribonuclease P protein subunit $\mathrm{p} 30 \mathrm{GN}=\mathrm{RPP} 30$ RPP30 HUMAN $29.32 \quad 100.0 \%$ Ribonuclease P protein subunit p30 GN=RPP30 RPP30_HUMAN $29.32 \quad 100.0 \%$ Ribonuclease P protein subunit $\mathrm{p} 30 \mathrm{GN}=\mathrm{RPP} 30$ RPP30_HUMAN $29.32 \quad 100.0 \%$ Ribonuclease P protein subunit $\mathrm{p} 30 \mathrm{GN}=\mathrm{RPP} 30$ RPP30 HUMAN $29.32 \quad 100.0^{\circ}$ Ribonuclease P protein subunit p30 GN=RPP30 RPP30_HUMAN $29.32 \quad 100.0 \%$ Ribonuclease P protein subunit $\mathrm{p} 30 \mathrm{GN}=\mathrm{RPP} 30$ RPP30 HUMAN $29.32 \quad 100.0 \%$ Ribonuclease P protein subunit $\mathrm{p} 30 \mathrm{GN}=\mathrm{RPP} 30$ RPP30_HUMAN $29.32 \quad 100.0 \%$ Ribonuclease P protein subunit $\mathrm{p} 30 \mathrm{GN}=\mathrm{RPP} 30$ RPP30_HUMAN $29.32 \quad 100.0 \%$ Ribonuclease P protein subunit p38 GN=RPP38 RPP38 HUMAN $31.84 \quad 100.0 \%$ Ribonuclease P protein subunit p38 GN=RPP38 RPP38_HUMAN $31.84 \quad 100.0 \%$ Ribonuclease P protein subunit p38 GN=RPP38 RPP38_HUMAN $31.84 \quad 100.0 \%$ Ribonuclease P protein subunit $\mathrm{p} 38 \mathrm{GN}=\mathrm{RPP} 38$ RPP38_HUMAN $31.84 \quad 100.0 \%$ Ribonuclease P protein subunit p38 GN=RPP38 RPP38_HUMAN $31.84 \quad 100.0 \%$ Ribonuclease P protein subunit $\mathrm{p} 38 \mathrm{GN}=\mathrm{RPP} 38$ RPP38 HUMAN $31.84 \quad 100.0 \%$ Ribonucleases P/MRP protein subunit POP1 GN=POP1 POP1_HUMAN $114.71 \quad 100.0 \%$ Ribonucleases P/MRP protein subunit POP1 GN=POP1 POP1_HUMAN $114.71 \quad 100.0 \%$ Ribonucleases P/MRP protein subunit POP1 GN=POP1 POP1_HUMAN $114.71 \quad 100.0 \%$ Ribonucleases P/MRP protein subunit POP1 GN=POP1 POP1_HUMAN $114.71 \quad 100.0 \%$ $\begin{array}{llll}16 & 29 & 0.03 \% & 45.7 \% \\ 16 & \text { AITFLQSATR }\end{array}$

$16 \quad 29 \quad 0.03 \% \quad 45.7 \%$ VITDIAGVIPAEK

$17 \quad 35 \quad 0.03 \% \quad 43.2 \%$ GPILSFASTR

$0.03 \% \quad 43.2 \%$ LVILDEADAMTQDAQNALR

$0.03 \% \quad 43.2 \%$ FCLICNYLSK

$0.03 \% \quad 43.2 \%$ IIPALQSR

$0.03 \% \quad 43.2 \%$ FGPLTPELMVPR

$0.03 \% \quad 43.2 \%$ LEHVVEEEKVDISEDGMK

$0.03 \% \quad 43.2 \%$ ALVTLSSGDMR

$0.03 \% \quad 43.2 \%$ ALNILQSTNMAFGK

$0.03 \% \quad 43.2 \%$ VTEETVYTCTGHPLK

$0.03 \% \quad 43.2 \%$ VDFPSSVR

$0.03 \% \quad 43.2 \%$ LSVGTNEK

$0.03 \% \quad 43.2 \%$ IQLSSLIAAFQVTR

$99.0 \% \quad 40.3$

$96.4 \% \quad 16.2$

$99.7 \% \quad 59.0$

$99.7 \% \quad 62.5$

$99.7 \% \quad 53.3$

$99.7 \% \quad 73.1$

$99.7 \% \quad 37.8$

$99.0 \% \quad 18.5$

$99.7 \% 27.7$

$96.2 \% \quad 16.1$

$99.7 \% \quad 56.4$

$99.7 \% \quad 60.4$

$99.7 \% \quad 64.8$

$99.0 \% \quad 23.7$

$99.0 \% \quad 32.8$

99.7\% \#\#\#\#

$0.00 \% \quad 3.4 \%$ GLRQQGTSVAQSGAQAPGR $99.7 \% \quad 46.0$

$0.00 \% \quad 3.4 \%$ QQGTSVAQSGAQAPGR

$0.00 \% \quad 4.4 \%$ AAGPSLSHTSGGTQSK

$0.00 \% \quad 4.4 \%$ SYEDATKITVR

$0.00 \% \quad 6.2 \%$ EGDPGTIFFFR

$0.00 \% \quad 6.2 \% \quad$ IGELFALR

$0.00 \% \quad 6.2 \%$ TCQFLSIGR

$0.01 \% \quad 0.7 \% \quad$ NKNGSWGPK

$0.01 \% \quad 0.7 \% \quad$ KVSPMSPK

$0.00 \% \quad 8.8 \%$ LFLLQQPLAPSGLTLK

$0.00 \% \quad 8.8 \%$ GFTPVAFAMLGVTTVR

$0.02 \% \quad 43.7 \%$ LTIIVSDPSHCNVLR

$0.02 \% \quad 43.7 \%$ LYDVVAVFPK

$0.02 \% \quad 43.7 \%$ RPPINVAIDR

$0.02 \% \quad 43.7 \%$ GLAFELVYSPAIK

$0.02 \% \quad 43.7 \%$ YTISSALNLMQICK

$0.02 \% \quad 43.7 \%$ GKNVIISSAAERPLEIR

$0.02 \% \quad 43.7 \%$ NVIISSAAERPLEIR

$99.7 \% 58.3$

$99.7 \% \quad 41.8$

$99.7 \% \quad 29.5$

$99.0 \% \quad 69.5$

$99.7 \% \quad 28.9$

$95.7 \% 22.6$

$98.1 \% \quad 26.3$

$99.7 \% \quad 50.5$

$\begin{array}{lll}97.8 \% & 23.9\end{array}$

$99.7 \% \quad 41.8$

$99.7 \% \quad 36.5$

$99.7 \% \quad 35.9$

$99.7 \% \quad 57.3$

$99.7 \% \quad 52.0$

$99.0 \% \quad 19.5$

$99.7 \% \quad 37.5$

$0.02 \% \quad 43.7 \%$ GPYDVANLGLLFGLSESDAK $99.7 \% \quad 71.8$

$0.02 \% \quad 43.7 \%$ AAVSTNCR

$0.02 \% \quad 43.7 \%$ AALLHGETRK

$0.01 \% \quad 20.8 \%$ TSLNNPYIIR

$0.01 \% \quad 20.8 \%$ QLAIGVNEVTR

$0.01 \% \quad 20.8 \%$ ELLLVLVCK

$0.01 \% \quad 20.8 \%$ SVPACQVPR

$0.01 \% \quad 20.8 \%$ NTTDFVDEVR

$0.01 \% \quad 20.8 \%$ QASVTLQPLK

$0.00 \% \quad 5.3 \%$ VNPHSLPDPEVNEQSSSK

$0.00 \% \quad 5.3 \%$ AGPEGTSQEIPK

$0.00 \% \quad 5.3 \%$ SSNSLVFQTLPR

$0.00 \% \quad 5.3 \%$ EACLSILGHFPR
$99.0 \% \quad 26.0$

$97.0 \% \quad 25.8$

$99.7 \% \quad 58.5$

$99.7 \% \quad 62.2$

$99.7 \% \quad 42.2$

$97.4 \% \quad 21.8$

$99.7 \% \quad 52.3$

$96.5 \% 15.8$

$99.6 \% 23.6$

$99.7 \% \quad 33.0$

$99.7 \% \quad 52.2$

$99.7 \% \quad 32.1$
903.49

235.71

1107.62

1325.77

1048.58

2087.04

1317.63

897.55

1356.73

2102.00

1149.59

1507.79

1734.84

906.47

847.45

1546.90

1868.97

1542.76

1485.73

1282.66

1285.62

918.54

1081.55

987.50

873.49

1739.05

1666.90

1723.92

1150.65

1150.67

1407.79

1641.83

1853.06

1667.94

2066.04

878.41

1095.63

1190.65

1199.67

1086.66

1013.52

1195.56

1084.64

1963.94

1213.61

1348.72

1399.72

$\begin{array}{cc}233 & 240 \\ 240 & 250 \\ 241 & 250 \\ 261 & 273 \\ 103 & 112 \\ 121 & 139 \\ 151 & 160 \\ 161 & 168 \\ 174 & 185 \\ 186 & 203 \\ 204 & 214 \\ 216 & 229 \\ 230 & 244 \\ 291 & 298 \\ 312 & 319 \\ 320 & 333 \\ 37 & 55 \\ 40 & 55 \\ 168 & 183 \\ 325 & 335 \\ 220 & 230 \\ 353 & 360 \\ 389 & 397 \\ 248 & 256 \\ 1746 & 1753 \\ 36 & 51 \\ 134 & 149 \\ 77 & 91 \\ 99 & 108 \\ 139 & 148 \\ 149 & 161 \\ 168 & 181 \\ 182 & 198 \\ 184 & 198 \\ 199 & 218 \\ 219 & 226 \\ 227 & 236 \\ 23 & 32 \\ 112 & 122 \\ 128 & 136 \\ 155 & 163 \\ 185 & 194 \\ 251 & 260 \\ 61 & 78 \\ & 100 \\ 89 & \end{array}$

Page 140 of Table $S-1-4$ 

B B BN=RT2B_HUMAN $40.74 \quad 100.0 \%$ Ribose-phosphate pyrophosphokinase $1 \mathrm{GN}=$ PRPS1 PRPS1_HUMAN $34.83 \quad 100.0 \%$ Ribose-phosphate pyrophosphokinase $1 \mathrm{GN}=$ PRPS1 PRPS1_HUMAN $34.83 \quad 100.0 \%$ Ribose-phosphate pyrophosphokinase 1 GN=PRPS1 PRPS1_HUMAN $34.83 \quad 100.0 \%$ Ribose-phosphate pyrophosphokinase 1 GN=PRPS1 PRPS1_HUMAN $34.83 \quad 100.0 \%$ Ribose-phosphate pyrophosphokinase $1 \mathrm{GN}=$ PRPS1 PRPS1_HUMAN $34.83 \quad 100.0 \%$ Ribose-phosphate pyrophosphokinase 1 GN=PRPS1 PRPS1_HUMAN $34.83 \quad 100.0 \%$ Ribose-phosphate pyrophosphokinase $1 \mathrm{GN}=$ PRPS1 PRPS1_HUMAN $34.83 \quad 100.0 \%$ Ribose-phosphate pyrophosphokinase 2 GN=PRPS2 PRPS2_HUMAN $34.77 \quad 100.0 \%$ Ribose-phosphate pyrophosphokinase 2 GN=PRPS2 PRPS2_HUMAN $34.77 \quad 100.0 \%$ Ribose-phosphate pyrophosphokinase 2 GN=PRPS2 PRPS2 HUMAN $34.77 \quad 100.0^{\circ}$ Ribose-phosphate pyrophosphokinase 2 GN=PRPS2 PRPS2_HUMAN $34.77 \quad 100.0 \%$ Ribose-phosphate pyrophosphokinase 2 GN=PRPS2 PRPS2_HUMAN $34.77 \quad 100.0 \%$ Ribose-phosphate pyrophosphokinase 2 GN=PRPS2 PRPS2_HUMAN $34.77 \quad 100.0 \%$ Ribose-phosphate pyrophosphokinase 2 GN=PRPS2 PRPS2_HUMAN $34.77 \quad 100.0 \%$ Ribosomal L1 domain-containing protein $1 \mathrm{GN}=\mathrm{RSL} 1 \mathrm{D} 1 \mathrm{RL} 1 \mathrm{D} 1$ HUMAN $54.97 \quad 100.0 \%$ Ribosomal L1 domain-containing protein $1 \mathrm{GN}=$ RSL1D1 RL1D1_HUMAN $54.97 \quad 100.0 \%$ Ribosomal L1 domain-containing protein 1 GN=RSL1D1 RL1D1_HUMAN 54.97 Ribosomal L1 domain-containing protein 1 GN=RSL1D1 RL1D1_HUMAN 54.97 Ribosomal L1 domain-containing protein 1 GN=RSL1D1 RL1D1_HUMAN 54.97 Ribosomal L1 domain-containing protein 1 GN=RSL1D1 RL1D1_HUMAN 54.97 Ribosomal L1 domain-containing protein 1 GN=RSL1D1 RL1D1_HUMAN 54.97 Ribosomal L1 domain-containing protein 1 GN=RSL1D1 RL1D1_HUMAN 54.97 Ribosomal L1 domain-containing protein 1 GN=RSL1D1 RL1D1_HUMAN 54.97 Ribosomal L1 domain-containing protein 1 GN=RSL1D1 RL1D1_HUMAN 54.97 Ribosomal L1 domain-containing protein 1 GN=RSL1D1 RL1D1_HUMAN 54.97 Ribosomal L1 domain-containing protein 1 GN=RSL1D1 RL1D1 HUMAN 54.97 Ribosomal L1 domain-containing protein 1 GN=RSL1D1 RL1D1_HUMAN 54.97 Ribosomal RNA processing protein 1 homolog A GN=RRP1 RRP1 HUMAN 52.84 Ribosomal RNA processing protein 1 homolog A GN=RRP1 RRP1_HUMAN 52.84 Ribosomal RNA processing protein 1 homolog A GN=RRP1 RRP1_HUMAN 52.84 Ribosomal RNA processing protein 1 homolog A GN=RRP1 RRP1 HUMAN 52.84 Ribosomal RNA processing protein 1 homolog B GN=RRP1B RRP1B_HUMAN 84.43 Ribosomal RNA processing protein 1 homolog B GN=RRP1B RRP1B_HUMAN 84.43 Ribosomal RNA processing protein 1 homolog B GN=RRP1B RRP1B_HUMAN 84.43 Ribosomal RNA processing protein 1 homolog B GN=RRP1B RRP1B_HUMAN 84.43 Ribosomal RNA processing protein 1 homolog B GN=RRP1B RRP1B_HUMAN 84.43 Ribosomal RNA processing protein 1 homolog B GN=RRP1B RRP1B_HUMAN $84.43 \quad 100.0^{\circ}$ Ribosomal RNA processing protein 1 homolog B GN=RRP1B RRP1B_HUMAN $84.43 \quad 100.0 \%$ Ribosomal RNA processing protein 1 homolog B GN=RRP1B RRP1B HUMAN $84.43100 .0 \%$ Ribosomal RNA processing protein 1 homolog B GN=RRP1B RRP1B_HUMAN $84.43 \quad 100.0 \%$ Ribosomal RNA processing protein 1 homolog B GN=RRP1B RRP1B_HUMAN $84.43 \quad 100.0 \%$ Ribosomal RNA-processing protein 7 homolog A GN=RRP7A RRP7A_HUMAN $32.33 \quad 100.0 \%$ Ribosomal RNA-processing protein 7 homolog A GN=RRP7A RRP7A_HUMAN $32.33 \quad 100.0 \%$ Ribosomal RNA-processing protein 7 homolog A GN=RRP7A RRP7A_HUMAN $32.33 \quad 100.0 \%$ Ribosome biogenesis protein BMS1 homolog GN=BMS1 BMS1_HUMAN $145.81 \quad 100.0 \%$
$0.00 \% \quad 5.7 \% \quad$ FSQEVQVPEAR $0.01 \% \quad 26.1 \%$ VTAVIPCFPYAR $0.01 \% \quad 26.1 \%$ NCTIVSPDAGGAK $0.01 \% \quad 26.1 \%$ LNVDFALIHK $0.01 \% \quad 26.1 \%$ MVLVGDVK

$0.01 \% \quad 26.1 \%$ MVLVGDVKDR $0.01 \% \quad 26.1 \%$ VAILVDDMADTCGTICHAADK $0.01 \% \quad 26.1 \%$ VYAILTHGIFSGPAISR $0.00 \% \quad 28.9 \%$ PNIVLFSGSSHQDLSQR $0.00 \% \quad 28.9 \%$ FSNQETSVEIGESVR $0.00 \% \quad 28.9 \%$ VTAVIPCFPYAR $0.00 \% \quad 28.9 \%$ MVLVGDVK $0.00 \% \quad 28.9 \%$ MVLVGDVKDR

$0.00 \% \quad 28.9 \%$ VAILVDDMADTCGTICHAADK $0.00 \% \quad 28.9 \%$ VYAILTHGIFSGPAISR $0.02 \% \quad 25.7 \%$ KAVDALLTHCK $0.02 \% \quad 25.7 \%$ AVDALLTHCK $0.02 \% \quad 25.7 \%$ LTLPHSIR $0.02 \% \quad 25.7 \%$ TVSQIISLQTLKK $0.02 \% \quad 25.7 \%$ LLSSFDFFLTDAR $0.02 \% \quad 25.7 \%$ RLLPSLIGR $0.02 \% \quad 25.7 \%$ LLPSLIGR $0.02 \% \quad 25.7 \%$ KVPVSVNLLSK $0.02 \% \quad 25.7 \%$ EINDCIGGTVLNISK $0.02 \% \quad 25.7 \%$ LLFVKTEK $0.02 \% \quad 25.7 \%$ ATNESEDEIPQLVPIGK $0.02 \% \quad 25.7 \%$ TPANEKVEIQK $0.02 \% \quad 25.7 \%$ KALPASETPK $0.01 \% \quad 10.8 \%$ LAGNEQVTR $0.01 \% \quad 10.8 \%$ TKDSLVLNNITR $0.01 \% \quad 10.8 \%$ GVGADPEARAEAGEQPGTAER $0.01 \% \quad 10.8 \%$ ALLRDQPR $0.02 \% \quad 15.4 \%$ APAMQPAEIQFAQR $0.02 \% \quad 15.4 \%$ TKDHTLVQTIAR $0.02 \% \quad 15.4 \%$ VGDGDLSAEEIPENEVSLRR $0.02 \% \quad 15.4 \%$ GSPTGGAQLLK $0.02 \% \quad 15.4 \%$ GSPTGGAQLLKR $0.02 \% \quad 15.4 \%$ AGPGSLELCGLPSQK $0.02 \% \quad 15.4 \%$ SSTATHPPGPAVQLNK $0.02 \% \quad 15.4 \%$ SSTATHPPGPAVOLNKTPSSSK $0.02 \% \quad 15.4 \%$ KVTFGLNR $0.02 \% \quad 15.4 \%$ TPTSSPASSPLVAK $0.00 \% \quad 12.9 \%$ IPSPLGYAAIPIK $0.00 \% \quad 12.9 \%$ QQASHYLYVR $0.00 \% \quad 12.9 \%$ GPLLVSTESHPVK $0.00 \% \quad 2.5 \%$ AFAVQSAVR $\begin{array}{lll}98.9 \% & 22.2\end{array}$

$99.7 \% \quad 54.8$

$99.6 \% \quad 23.4$

$99.7 \% \quad 68.7$

$99.7 \% \quad 31.2$

$99.0 \% \quad 20.4$

$99.7 \% \quad 55.2$

$98.9 \% \quad 22.2$

$99.7 \% \quad 54.8$

$99.5 \% \quad 24.2$

$99.7 \% \quad 48.6$

$99.0 \% \quad 21.6$

$99.7 \% \quad 26.9$

$99.7 \% 72.5$

$99.6 \% \quad 26.6$

$98.3 \% \quad 26.3$

$99.7 \% \quad 33.8$

$99.7 \% \quad 33.7$

$97.5 \% 20.1$

$96.4 \% \quad 23.7$

$99.7 \% \quad 39.9$

$99.7 \% \quad 32.6$

$99.7 \% \quad 54.6$

$99.7 \% \quad 55.3$

$99.7 \% \quad 42.3$

$98.5 \% 22$.

$99.7 \% \quad 48.6$

$99.7 \% \quad 46.5$

$99.7 \% \quad 64.6$

$99.7 \% \quad 38.2$

$99.7 \% \quad 59.2$

$99.7 \% \quad 46.0$

$99.7 \% \quad 46.4$

$9.3 \% 20.6$

$99.0 \% \quad 37.2$

$99.7 \% \quad 50.9$

$99.7 \% 36.8$

$99.6 \% 27$.

$99.7 \% \quad 50.9$

$99.7 \% \quad 51.3$
128

1289.65 1005.60

1393.73

1289.62

1169.67

876.49

1131.62

2292.03

1802.00

1884.96

1681.80

1393.73

876.49

1131.62

2292.03

1802.00

1255.68

1127.59

936.56

1458.89

1531.78

1024.66

868.56

1183.74

1632.83

977.60

1839.93

1256.68

1041.59

987.52

1373.77

2067.97

968.56

1573.78

1382.78

2185.07

1028.57

1184.67

1513.77

1604.84

2192.13

934.55

1342.72

1339.80

1264.64

1363.76

948.53

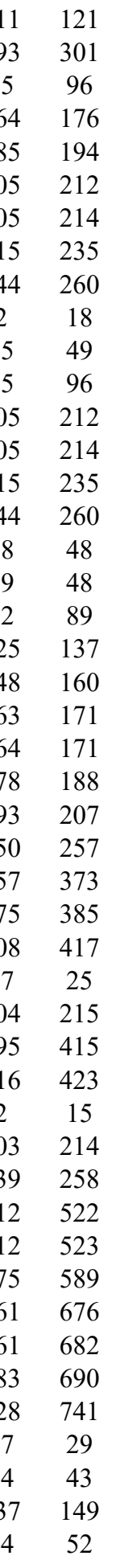

(4) 
Ribosome biogenesis protein BMS1 homolog GN=BMS1 BMS1 HUMAN $145.81 \quad 100.0 \%$ Ribosome biogenesis protein BMS1 homolog GN=BMS1 BMS1_HUMAN $145.81 \quad 100.0 \%$ Ribosome biogenesis protein BRX1 homolog GN=BRIX1 BRX1_HUMAN $41.40 \quad 100.0 \%$ Ribosome biogenesis protein BRX1 homolog GN=BRIX1 BRX1_HUMAN $41.40 \quad 100.0 \%$ Ribosome biogenesis protein BRX1 homolog GN=BRIX1 BRX1_HUMAN $41.40 \quad 100.0 \%$ Ribosome biogenesis protein BRX1 homolog GN=BRIX1 BRX1_HUMAN $41.40 \quad 100.0 \%$ Ribosome biogenesis protein BRX1 homolog GN=BRIX1 BRX1_HUMAN $41.40 \quad 100.0 \%$ Ribosome biogenesis protein NSA2 homolog GN=NSA2 NSA2_HUMAN $30.07 \quad 100.0 \%$ Ribosome biogenesis protein NSA2 homolog GN=NSA2 NSA2 HUMAN $30.07 \quad 100.0 \%$ Ribosome biogenesis protein NSA2 homolog GN=NSA2 NSA2_HUMAN $30.07 \quad 100.0 \%$ Ribosome biogenesis protein NSA2 homolog GN=NSA2 NSA2_HUMAN $30.07 \quad 100.0 \%$ Ribosome biogenesis protein NSA2 homolog GN=NSA2 NSA2 HUMAN $30.07 \quad 100.0 \%$ Ribosome biogenesis protein NSA2 homolog GN=NSA2 NSA2_HUMAN $30.07 \quad 100.0 \%$ Ribosome production factor 2 homolog GN=RPF2 RPF2 HUMAN $35.59100 .0 \%$ Ribosome production factor 2 homolog GN=RPF2 RPF2_HUMAN $35.59 \quad 100.0 \%$ Ribosome production factor 2 homolog GN=RPF2 RPF2_HUMAN $35.59 \quad 100.0 \%$ Ribosome production factor 2 homolog GN=RPF2 RPF2 HUMAN $35.59 \quad 100.0 \%$ Ribosome production factor 2 homolog GN=RPF2 RPF2_HUMAN $35.59 \quad 100.0 \%$ Ribosome production factor 2 homolog GN=RPF2 RPF2_HUMAN $35.59 \quad 100.0 \%$ Ribosome-binding protein $1 \mathrm{GN}=\mathrm{RRBP} 1$ RRBP1_HUMAN $152.47 \quad 100.0 \%$ Ribosome-binding protein $1 \mathrm{GN}=\mathrm{RRBP} 1$ RRBP1_HUMAN $152.47 \quad 100.0 \%$ Ribosome-binding protein 1 GN=RRBP1 RRBP1_HUMAN $152.47 \quad 100.0 \%$ Ribosome-binding protein $1 \mathrm{GN}=\mathrm{RRBP} 1 \quad$ RRBP1_HUMAN $152.47 \quad 100.0 \%$ Ribosome-binding protein $1 \mathrm{GN}=\mathrm{RRBP} 1$ RRBP1_HUMAN $152.47 \quad 100.0 \%$ RISC-loading complex subunit TARBP2 GN=TARBP2 TRBP2 HUMAN $39.04 \quad 100.0 \%$ RISC-loading complex subunit TARBP2 GN=TARBP2 TRBP2_HUMAN $39.04 \quad 100.0 \%$ RNA 3'-terminal phosphate cyclase GN=RTCA RTCA_HUMAN $39.34 \quad 100.0 \%$ RNA 3'-terminal phosphate cyclase GN=RTCA RTCA_HUMAN $39.34 \quad 100.0 \%$ RNA 3'-terminal phosphate cyclase GN=RTCA RTCA_HUMAN $39.34 \quad 100.0 \%$ RNA 3'-terminal phosphate cyclase GN=RTCA RTCA HUMAN $39.34 \quad 100.0 \%$ RNA 3'-terminal phosphate cyclase GN=RTCA RTCA_HUMAN $39.34 \quad 100.0 \%$ RNA 3'-terminal phosphate cyclase GN=RTCA RTCA_HUMAN $39.34 \quad 100.0 \%$ RNA 3'-terminal phosphate cyclase GN=RTCA RTCA HUMAN $39.34 \quad 100.0 \%$ RNA 3'-terminal phosphate cyclase GN=RTCA RTCA_HUMAN $39.34 \quad 100.0 \%$ RNA 3'-terminal phosphate cyclase-like protein GN=RCL1 RCL1_HUMAN $40.84 \quad 100.0 \%$ RNA 3'-terminal phosphate cyclase-like protein GN=RCL1 RCL1 HUMAN $40.84 \quad 100.0 \%$ RNA 3'-terminal phosphate cyclase-like protein GN=RCL1 RCL1_HUMAN $40.84 \quad 100.0 \%$ RNA binding motif protein, X-linked-like-1 GN=RBMXL1 RMXL1 HUMAN $42.14 \quad 100.0 \%$ RNA binding motif protein, X-linked-like-1 GN=RBMXL1 RMXL1_HUMAN $42.14 \quad 100.0 \%$ RNA binding motif protein, X-linked-like-1 GN=RBMXL1 RMXL1_HUMAN $42.14 \quad 100.0 \%$ RNA binding motif protein, X-linked-like-1 GN=RBMXL1 RMXL1_HUMAN $42.14 \quad 100.0 \%$ RNA binding motif protein, X-linked-like-1 GN=RBMXL1 RMXL1_HUMAN $42.14 \quad 100.0 \%$ RNA binding motif protein, X-linked-like-1 GN=RBMXL1 RMXL1_HUMAN $42.14 \quad 100.0 \%$ RNA binding motif protein, X-linked-like-1 GN=RBMXL1 RMXL1_HUMAN $42.14 \quad 100.0 \%$ RNA binding motif protein, X-linked-like-1 GN=RBMXL1 RMXL1_HUMAN $42.14 \quad 100.0 \%$ RNA binding motif protein, X-linked-like-1 GN=RBMXL1 RMXL1_HUMAN $42.14 \quad 100.0 \%$ RNA binding motif protein, X-linked-like-1 GN=RBMXL1 RMXL1_HUMAN $42.14 \quad 100.0 \%$
$0.00 \% \quad 2.5 \% \quad$ IAATGVVLDLDK $0.00 \% \quad 2.5 \%$ SSLKGAEGQLQ

$0.01 \% \quad 17.0 \%$ DKLFVINEVCEMK $0.01 \% \quad 17.0 \%$ LFVINEVCEMK

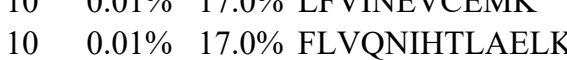

$10 \quad 0.01 \% \quad 17.0 \%$ SQPFVDHVFTFTILDNR

$10 \quad 0.01 \% \quad 17.0 \%$ NFQIIEEDAALVEIGPR

$10 \quad 0.01 \% \quad 29.2 \%$ PQNEYIELHR

$10 \quad 0.01 \% \quad 29.2 \%$ TPOGAVPAYLLDR

$10 \quad 0.01 \% \quad 29.2 \%$ AQGETEVLK

$10 \quad 0.01 \% \quad 29.2 \%$ VCFVGDGFTR

$10 \quad 0.01 \% \quad 29.2 \%$ NPSSPLYTTLGVITK

$10 \quad 0.01 \% \quad 29.2 \%$ GTVIEVNVSELGLVTQGGK

$11 \quad 0.01 \% \quad 23.2 \%$ NITRPFEDQTSLEFFSK

$0.01 \% \quad 23.2 \%$ SLLIDFFR

$0.01 \% \quad 23.2 \%$ GPTVSNIR

$11 \quad 0.01 \% \quad 23.2 \%$ IELEEMGPSLDLVLR

$0.01 \% \quad 23.2 \%$ THLASDDLYK

$0.01 \% \quad 23.2 \%$ NISHDTFGTTYGR

$0.01 \% \quad 4.6 \% \quad$ AAILETAPK

$0.01 \% \quad 4.6 \%$ NTDVAQSPEAPKQEAPAK

$0.01 \% \quad 4.6 \%$ EQEITAVQAR

$0.01 \% \quad 4.6 \%$ TLQEQLENGPNTQLAR

$0.01 \% \quad 4.6 \%$ SIEALLEAGQAR

$0.00 \% \quad 7.7 \%$ TPISLLQEYGTR

$0.00 \% \quad 7.7 \% \quad$ VTVGDTSCTGQGPSKK

$0.02 \% \quad 23.0 \%$ VEVDGSIMEGGGQILR

$0.02 \% \quad 23.0 \%$ VSTALSCLLGLPLR

$0.02 \% \quad 23.0 \%$ FGFIFNCDIK

$0.02 \% \quad 23.0 \%$ QLNPINLTER

$0.02 \% \quad 23.0 \%$ AFVAGVLPFK

$0.02 \% \quad 23.0 \%$ DMAAAAVR

$0.02 \% \quad 23.0 \%$ EIRDLYVNIQPVQEPK

$0.02 \% \quad 23.0 \%$ DLYVNIQPVQEPK

$0.00 \% \quad 9.4 \%$ LVLSTLSGRPVK

$0.00 \% \quad 9.4 \%$ GVTNDQVDPSVDVLK

$0.00 \% \quad 9.4 \%$ LLLEEIYR

$0.01 \% \quad 53.8 \%$ LFIGGLNTETNEK

$0.01 \% \quad 53.8 \%$ ALETVFGK

$0.01 \% \quad 53.8 \%$ GFAFVTFESPADAK

$0.01 \% \quad 53.8 \%$ GFAFVTFESPADAKDAAR

$0.01 \% \quad 53.8 \%$ VEQATKPSFER

$0.01 \% 53.8 \%$ HGPPPPPR

$0.01 \% \quad 53.8 \%$ GGHMDDGGYSMNFNMSSSR

$11 \quad 0.01 \% \quad 53.8 \%$ RSAPSGLVR

$11 \quad 0.01 \% \quad 53.8 \%$ GRDSYGGPPR

$11 \quad 0.01 \% \quad 53.8 \%$ DSYGGPPR
$99.2 \% \quad 27.8$

$99.7 \% \quad 42.5$

$99.7 \% \quad 45.8$

$99.7 \% \quad 37.0$

$99.7 \% \quad 64.4$

$\begin{array}{lll}96.6 \% & 20.2\end{array}$

$99.7 \% \quad 56.2$

$99.6 \% \quad 24.6$

$99.7 \% \quad 42.2$

$99.7 \% \quad 38.4$

$99.7 \% \quad 52.1$

$96.7 \% \quad 24.4$

$\begin{array}{lll}99.7 \% & 49.7\end{array}$

$99.5 \% \quad 21.3$

$99.0 \% \quad 22.2$

$99.0 \% \quad 26.9$

$99.7 \% \quad 57.7$

$99.7 \% \quad 48.7$

$99.7 \% \quad 54.5$

$99.7 \% \quad 42.3$

$\begin{array}{ll}99.7 \% & 33.9\end{array}$

$99.7 \% \quad 44.3$

$99.7 \% \quad 33.0$

$99.7 \% \quad 61.5$

$99.7 \% \quad 75.7$

$99.7 \% \quad 34.5$

$99.7 \% \quad 60.0$

$99.7 \% \quad 41.7$

$99.7 \% \quad 53.2$

$99.7 \% \quad 62.7$

$99.7 \% \quad 50.3$

$99.0 \% \quad 34.5$

$99.6 \% \quad 24.2$

$99.7 \% \quad 62.1$

$99.7 \% \quad 42.2$

$99.7 \% 43.8$

$99.0 \% \quad 42.9$

$99.7 \% 57.1$

$99.0 \% \quad 31.6$

$99.7 \% \quad 64.9$

$99.7 \% \quad 46.1$

$\begin{array}{ll}99.7 \% & 42.4\end{array}$

$99.7 \% \quad 51.0$

$99.0 \% \quad 32.7$
22.3

$\begin{array}{ll}0 & 45.4 \\ & \end{array}$

0

$\begin{array}{ll}5.0 & 58 \\ & \end{array}$

$\begin{array}{ll}0 & 20.2\end{array}$

$\begin{array}{ll}0 & 55.0\end{array}$

24.6

$\begin{array}{ll}0 & 42.2\end{array}$

$\begin{array}{lll}25.0 & 39.1 & 2\end{array}$

$\begin{array}{ll}.0 & 24.4\end{array}$

$\begin{array}{ll} & 49.7\end{array}$

$\begin{array}{ll}0 & 21.3\end{array}$

$\begin{array}{ll}25.0 & 18.0\end{array}$

$\begin{array}{ll}5.0 & 18.7\end{array}$

03.6
53.7

$\begin{array}{ll}25.0 & 47.7\end{array}$

\begin{tabular}{ll}
54.5 \\
\hline
\end{tabular}

$\begin{array}{ll}25.0 & 31.9\end{array}$

\begin{tabular}{ll}
33.9 \\
\hline
\end{tabular}

$\begin{array}{ll}0 & 39.6\end{array}$

$\begin{array}{ll}5.0 & 32.9\end{array}$

$\begin{array}{ll}52.0 & 42.0\end{array}$

$\begin{array}{ll}.0 & 63.8\end{array}$

27.0
25.0

\begin{tabular}{ll}
5.0 & 60.0 \\
\hline
\end{tabular}

$\begin{array}{lll}25.0 & 41.7\end{array}$

$\begin{array}{lll}5.0 & 53.2 & 2\end{array}$

.0 38.6

18.

.0
0

$\begin{array}{ll}5.0 & 62.1\end{array}$

$\begin{array}{ll}25.0 & 40.4\end{array}$

$\begin{array}{ll}25.0 & 39.2\end{array}$

$\begin{array}{ll}5.0 & 32.4\end{array}$

$\begin{array}{ll}0 & 49.0\end{array}$

$\begin{array}{ll}20.0 & 20.6\end{array}$

$\begin{array}{lll}25.0 & 52.2 & 15\end{array}$

$\begin{array}{lll}45.0 & 46.1\end{array}$

$\begin{array}{lll}5.0 & 35.6 & 2\end{array}$

$\begin{array}{ll}25.0 & 20.7\end{array}$

$5.0 \quad 55.2$

$\begin{array}{lll}5.0 & 17.3 & 2\end{array}$

$\begin{array}{ll}22.0 & 22.0\end{array}$

$\begin{array}{ccc}1214.70 & 1008 & 1019 \\ 1117.58 & 1272 & 1282 \\ 1640.80 & 98 & 110 \\ 1381.69 & 100 & 110 \\ 1525.87 & 141 & 153 \\ 2036.02 & 198 & 214 \\ 1914.00 & 219 & 235 \\ 1298.65 & 2 & 11 \\ 1400.75 & 81 & 93 \\ 974.52 & 126 & 134 \\ 1157.54 & 153 & 162 \\ 1590.87 & 202 & 216 \\ 1900.04 & 217 & 235 \\ 2059.01 & 67 & 83 \\ 1010.57 & 161 & 168 \\ 843.47 & 169 & 176 \\ 1729.90 & 212 & 226 \\ 1162.57 & 228 & 237 \\ 1468.68 & 253 & 265 \\ 913.54 & 167 & 175 \\ 1880.94 & 609 & 626 \\ 1144.60 & 752 & 761 \\ 1811.92 & 782 & 797 \\ 1257.68 & 959 & 970 \\ 1377.74 & 30 & 41 \\ 1621.79 & 66 & 81 \\ 1659.84 & 6 & 21 \\ 1499.86 & 22 & 35 \\ 1260.61 & 147 & 156 \\ 1197.66 & 177 & 186 \\ 1048.62 & 196 & 205 \\ 804.40 & 209 & 216 \\ 1941.04 & 221 & 236 \\ 1542.82 & 224 & 236 \\ 1269.79 & 20 & 31 \\ 1585.81 & 119 & 133 \\ 1048.60 & 282 & 289 \\ 1435.74 & 10 & 22 \\ 864.48 & 23 & 30 \\ 1486.72 & 50 & 63 \\ 1899.92 & 50 & 67 \\ 1291.66 & 81 & 91 \\ 854.46 & 94 & 101 \\ 2097.77 & 126 & 144 \\ 942.55 & 164 & 172 \\ 1061.51 & 186 & 195 \\ 848.39 & 188 & 195 \\ 159\end{array}$

Page 142 of Table S-1-4 
RNA binding motif protein, X-linked-like-1 GN=RBMXL1 RMXL1_HUMAN $42.14 \quad 100.0 \%$ RNA binding motif protein, X-linked-like-1 GN=RBMXL1 RMXL1_HUMAN $42.14 \quad 100.0 \%$ RNA binding motif protein, X-linked-like-1 GN=RBMXL1 RMXL1_HUMAN $42.14 \quad 100.0 \%$ RNA binding motif protein, X-linked-like-1 GN=RBMXL1 RMXL1_HUMAN $42.14 \quad 100.0 \%$ RNA binding motif protein, X-linked-like-1 GN=RBMXL1 RMXL1_HUMAN $42.14 \quad 100.0 \%$ RNA binding motif protein, X-linked-like-1 GN=RBMXL1 RMXL1_HUMAN $42.14 \quad 100.0 \%$ RNA binding motif protein, X-linked-like-1 GN=RBMXL1 RMXL1_HUMAN $42.14 \quad 100.0 \%$ RNA binding motif protein, X-linked-like-1 GN=RBMXL1 RMXL1_HUMAN $42.14 \quad 100.0 \%$ RNA binding motif protein, X-linked-like-1 GN=RBMXL1 RMXL1_HUMAN $42.14 \quad 100.0 \%$ RNA binding motif protein, X-linked-like-1 GN=RBMXL1 RMXL1_HUMAN $42.14 \quad 100.0 \%$ RNA binding motif protein, X-linked-like-1 GN=RBMXL1 RMXL1_HUMAN $42.14 \quad 100.0 \%$ RNA binding motif protein, X-linked-like-1 GN=RBMXL1 RMXL1_HUMAN $42.14 \quad 100.0 \%$ RNA binding motif protein, X-linked-like-1 GN=RBMXL1 RMXL1_HUMAN $42.14 \quad 100.0 \%$ RNA binding motif protein, X-linked-like-1 GN=RBMXL1 RMXL1_HUMAN $42.14 \quad 100.0 \%$ RNA binding motif protein, X-linked-like-1 GN=RBMXL1 RMXL1_HUMAN $42.14 \quad 100.0 \%$ RNA binding protein fox-1 homolog 2 GN=RBFOX2 RFOX2_HUMAN $41.37 \quad 100.0 \%$ RNA binding protein fox-1 homolog 2 GN=RBFOX2 RFOX2 HUMAN $41.37 \quad 100.0^{\circ}$ RNA binding protein fox-1 homolog 2 GN=RBFOX2 RFOX2_HUMAN $41.37 \quad 100.0 \%$ RNA binding protein fox-1 homolog $2 \mathrm{GN}=$ RBFOX2 RFOX2_HUMAN $41.37 \quad 100.0 \%$ RNA binding protein fox-1 homolog $2 \mathrm{GN}=\mathrm{RBFOX} 2 \mathrm{RFOX} 2 \mathrm{HUMAN} 41.37 \quad 100.0 \%$ RNA binding protein fox-1 homolog 2 GN=RBFOX2 RFOX2_HUMAN $41.37 \quad 100.0 \%$ RNA polymerase II-associated protein $1 \mathrm{GN}=$ RPAP1 RPAP1_HUMAN $152.76 \quad 100.0 \%$ RNA polymerase II-associated protein $1 \mathrm{GN}=$ RPAP1 RPAP1_HUMAN $152.76 \quad 100.0 \%$ RNA polymerase-associated protein CTR9 homolog GN=CTR9 CTR9_HUMAN $133.51 \quad 100.0 \%$ RNA polymerase-associated protein CTR9 homolog GN=CTR9 CTR9 HUMAN $133.51 \quad 100.0 \%$ RNA polymerase-associated protein CTR9 homolog GN=CTR9 CTR9_HUMAN $133.51 \quad 100.0 \%$ RNA pseudouridylate synthase domain-containing protein 3 GN=RPUSD3 RUSD3_HUMAN $38.46 \quad 100.0 \%$ RNA pseudouridylate synthase domain-containing protein 3 GN=RPUSD3 RUSD3 HUMAN $38.46 \quad 100.0 \%$ RNA pseudouridylate synthase domain-containing protein $3 \mathrm{GN}=\mathrm{RPUSD} 3$ RUSD3_HUMAN $38.46 \quad 100.0 \%$ RNA/RNP complex-1-interacting phosphatase GN=DUSP11 DUS11 HUMAN $38.94100 .0 \%$ RNA/RNP complex-1-interacting phosphatase GN=DUSP11 DUS11_HUMAN $38.94 \quad 100.0 \%$ RNA-binding motif protein, $X$ chromosome GN=RBMX RBMX_HUMAN $42.33 \quad 100.0 \%$ RNA-binding motif protein, $X$ chromosome GN=RBMX RBMX HUMAN $42.33 \quad 100.0^{\circ}$ RNA-binding motif protein, $X$ chromosome GN=RBMX RBMX_HUMAN $42.33 \quad 100.0 \%$ RNA-binding motif protein, $X$ chromosome GN=RBMX RBMX HUMAN $42.33 \quad 100.0 \%$ RNA-binding motif protein, $X$ chromosome GN=RBMX RBMX_HUMAN $42.33 \quad 100.0 \%$ RNA-binding motif protein, $X$ chromosome GN=RBMX RBMX_HUMAN $42.33 \quad 100.0 \%$ RNA-binding motif protein, $X$ chromosome GN=RBMX RBMX HUMAN $42.33 \quad 100.0 \%$ RNA-binding motif protein, $X$ chromosome GN=RBMX RBMX_HUMAN $42.33 \quad 100.0 \%$ RNA-binding motif protein, $X$ chromosome GN=RBMX RBMX_HUMAN $42.33 \quad 100.0 \%$ RNA-binding motif protein, $X$ chromosome GN=RBMX RBMX_HUMAN $42.33 \quad 100.0 \%$ RNA-binding motif protein, $X$ chromosome GN=RBMX RBMX_HUMAN $42.33 \quad 100.0 \%$ RNA-binding motif protein, $X$ chromosome GN=RBMX RBMX HUMAN $42.33 \quad 100.0 \%$ RNA-binding motif protein, $X$ chromosome GN=RBMX RBMX_HUMAN $42.33 \quad 100.0 \%$ RNA-binding motif protein, $X$ chromosome GN=RBMX RBMX_HUMAN $42.33 \quad 100.0 \%$ RNA-binding motif protein, $X$ chromosome GN=RBMX RBMX HUMAN $42.33100 .0 \%$ RNA-binding motif protein, $X$ chromosome GN=RBMX RBMX_HUMAN $42.33 \quad 100.0 \%$
$11 \quad 0.01 \% \quad 53.8 \%$ DSYGGPPRR

$11 \quad 0.01 \% \quad 53.8 \%$ RDVYLSPR

$11 \quad 0.01 \% \quad 53.8 \%$ DVYLSPRDDGYSTK

$11 \quad 0.01 \% \quad 53.8 \%$ DDGYSTKDSYSSR

$11 \quad 0.01 \% \quad 53.8 \%$ DSYSSRDYPSSR

$11 \quad 0.01 \% \quad 53.8 \%$ DTRDYAPPPR

$11 \quad 0.01 \% \quad 53.8 \%$ DYAPPPRDYTYR

$11 \quad 0.01 \% \quad 53.8 \%$ DYGHSSSRDDYPSR

$11 \quad 0.01 \% \quad 53.8 \%$ DRDYSDHPSGGSYR

$11 \quad 0.01 \% \quad 53.8 \%$ DSYESYGNSR

$11 \quad 0.01 \% \quad 53.8 \%$ GPPPSYGGSSR

$0.01 \% \quad 53.8 \%$ GPPPSYGGSSRYDDYSSSR 99

$0.01 \% \quad 53.8 \%$ YDDYSSSR

$11 \quad 0.01 \% \quad 53.8 \%$ YDDYSSSRDGYGGSR

$11 \quad 0.01 \% \quad 53.8 \%$ DGYGGSRDSYSSSR

$0.01 \% \quad 12.3 \%$ RLHVSNIPFR

$0.01 \% \quad 12.3 \%$ GFGFVTFENSADADR

$0.01 \% \quad 12.3 \%$ GFGFVTFENSADADRAR

$0.01 \% \quad 12.3 \%$ EKLHGTVVEGR

$0.01 \% \quad 12.3 \%$ LHGTVVEGR

$0.01 \% \quad 12.3 \%$ KIEVNNATAR

$0.00 \% \quad 1.5 \%$ SIFAQEIAAR

$0.00 \% \quad 1.5 \%$ ASLLASQALHR

$0.00 \% \quad 2.6 \%$ TNPGCPAEVR

$0.00 \% \quad 2.6 \%$ LATSVLKDEK

$0.00 \% \quad 2.6 \%$ FDLALAATEAR

$0.01 \% \quad 11.1 \%$ SGPLGDQPFAGLLPK

$0.01 \% \quad 11.1 \%$ VGTVLGQR

$0.01 \% \quad 11.1 \%$ DTPVELLAPLPPYFSR

$0.00 \% \quad 9.4 \% \quad$ YYKPEDLPETVPYLK

$0.00 \% \quad 9.4 \%$ IFTVGHQVPDDETIFK

$212 \quad 0.21 \% \quad 68.0 \%$ LFIGGLNTETNEK

$212 \quad 0.21 \% \quad 68.0 \%$ LFIGGLNTETNEKALEAVFGK

$212 \quad 0.21 \% \quad 68.0 \%$ ALEAVFGK

$212 \quad 0.21 \% \quad 68.0 \%$ ALEAVFGKYGR

$212 \quad 0.21 \% \quad 68.0 \%$ IVEVLLMK

$212 \quad 0.21 \% \quad 68.0 \%$ IVEVLLMKDR

$212 \quad 0.21 \% \quad 68.0 \%$ GFAFVTFESPADAK

$212 \quad 0.21 \% \quad 68.0 \%$ GFAFVTFESPADAKDAAR

$212 \quad 0.21 \% \quad 68.0 \%$ AIKVEQATKPSFESGR

$212 \quad 0.21 \% \quad 68.0 \%$ VEQATKPSFESGR

$212 \quad 0.21 \% \quad 68.0 \%$ VEQATKPSFESGRR

$212 \quad 0.21 \% \quad 68.0 \%$ RGPPPPPR

50

50

$98.5 \%$

$99.7 \% \quad 63.6$

$99.7 \% \quad 44.5$

$99.7 \% \quad 31.4$

$\begin{array}{lll}99.5 \% & 24.9\end{array}$

$99.1 \% \quad 21.7$

$99.7 \% \quad 36.9$

$99.7 \% \quad 57.2$

$99.7 \% \quad 53.8$

$99.7 \% \quad 54.7$

$99.0 \% \quad 45.8$

$99.7 \% \quad 27.6$

$99.7 \% \quad 39.6$

$99.7 \% \quad 35.7$

$99.7 \% \quad 37.7$

$97.7 \% \quad 17.7$

$\begin{array}{lll}99.6 \% & 26.6\end{array}$

$99.0 \% \quad 24.4$

$99.7 \% \quad 42.5$

$99.4 \% \quad 20.9$

$99.4 \% \quad 31.4$

$95.3 \% \quad 14.5$

$97.1 \% \quad 21.5$

$98.1 \% \quad 30.3$

$99.7 \% \quad 63.9$

$99.0 \% \quad 47.0$

$95.8 \% 22.5$

$99.7 \% \quad 45.6$

$99.6 \% \quad 24.8$

$99.7 \% \quad 57.1$

$99.7 \% \quad 57$.

$99.0 \% \quad 51.7$

$99.7 \% \quad 57.0$

$99.0 \% \quad 46.7$

$99.7 \% \quad 64.6$

$99.7 \% \quad 64.9$

$99.7 \% 46$.

$99.7 \% \quad 55.5$

$\begin{array}{lll}99.7 \% & 59.8\end{array}$

$99.7 \% \quad 26.7$

$99.0 \% \quad 56.5$

$212 \quad 0.21 \% \quad 68.0 \%$ GGHMDDGGYSMNFNMSSSR

$\begin{array}{lll}0.21 \% & 68.0 \% \text { SSSGMGGRAPVSR }\end{array}$

$0.21 \% \quad 68.0 \%$ GRDSYGGPPR

$\begin{array}{ll}99.7 \% & 55.2 \\ 98.2 \% & 22.2\end{array}$

$99.7 \% \quad 51.0$

$99.0 \% \quad 32.7$
1480.62

1419.61

1187.58

1513.7

1641.69

1611.68

1177.48

1061.50

2034.88

992.40

1684.68

1493.63

1238.71

1632.73

1859.87

1224.67

967.53

1115.62

1105.60

1166.66

1100.52

1103.63

1177.62

1496.81

829.49

1814.97

1854.95

1845.94

1435.74

2251.20

834.47

1210.66

960.58

1231.71

1486.72

1899.92

1747.93

1435.72

1591.82

873.51

2097.77

1264.61

1061.5

848.39 
RNA-binding motif protein, X chromosome GN=RBMX RBMX_HUMAN $42.33 \quad 100.0 \% \quad 37$ $\begin{array}{llll}\text { RNA-binding motif protein, X chromosome GN=RBMX RBMX_HUMAN } & 42.33 & 100.0 \% & 37 \\ \text { RNA-binding motif protein, X chromosome GN=RBMX RBMX_HUMAN } & 42.33 & 100.0 \% & 37\end{array}$ RNA-binding motif protein, $X$ chromosome GN=RBMX RBMX_HUMAN $42.33 \quad 100.0 \% 37$ RNA-binding motif protein, $X$ chromosome GN=RBMX RBMX HUMAN $42.33 \quad 100.0 \%$ RNA-binding motif protein, $X$ chromosome GN=RBMX RBMX_HUMAN $42.33 \quad 100.0 \% \quad 37$ RNA-binding motif protein, $\mathrm{X}$ chromosome GN=RBMX RBMX_HUMAN $\quad 42.33 \quad 100.0 \% \quad 37$ RNA-binding motif protein, $X$ chromosome GN=RBMX RBMX_HUMAN $42.33 \quad 100.0 \% \quad 37$ RNA-binding motif protein, $X$ chromosome GN=RBMX RBMX_HUMAN $42.33 \quad 100.0 \% \quad 37$ RNA-binding motif protein, $X$ chromosome GN=RBMX RBMX HUMAN $42.33 \quad 100.0 \% 37$ RNA-binding motif protein, $X$ chromosome GN=RBMX RBMX_HUMAN $42.33 \quad 100.0 \% \quad 37$ RNA-binding motif protein, $X$ chromosome GN=RBMX RBMX_HUMAN $42.33 \quad 100.0 \% \quad 37$ RNA-binding motif protein, $X$ chromosome GN=RBMX RBMX_HUMAN $42.33 \quad 100.0 \% \quad 37$ RNA-binding motif protein, X chromosome GN=RBMX RBMX_HUMAN $42.33 \quad 100.0 \% \quad 37$ RNA-binding motif protein, $X$ chromosome GN=RBMX RBMX_HUMAN $42.33 \quad 100.0 \% \quad 37$ RNA-binding motif protein, $X$ chromosome GN=RBMX RBMX_HUMAN $42.33 \quad 100.0 \% \quad 37$ RNA-binding motif protein, $\mathrm{X}$ chromosome GN=RBMX RBMX_HUMAN $42.33 \quad 100.0 \% \quad 37$ RNA-binding motif protein, $X$ chromosome GN=RBMX RBMX_HUMAN $42.33 \quad 100.0 \% \quad 37$ RNA-binding motif protein, $X$ chromosome GN=RBMX RBMX_HUMAN $42.33 \quad 100.0 \% \quad 37$ RNA-binding motif protein, $X$ chromosome GN=RBMX RBMX_HUMAN $42.33 \quad 100.0 \% \quad 37$ RNA-binding motif protein, $X$ chromosome GN=RBMX RBMX HUMAN $42.33 \quad 100.0 \% \quad 37$ RNA-binding motif protein, $X$ chromosome GN=RBMX RBMX_HUMAN $42.33 \quad 100.0 \% \quad 37$ RNA-binding motif, single-stranded-interacting protein $1 \mathrm{GN}=\mathrm{RBMS1}$ RBMS1_HUMAN $44.51 \quad 100.0 \% 2$ DBS1_HUMAN $44.51 \quad 100.0 \%$ RNA-binding protein $10 \mathrm{GN}=\mathrm{RBM} 10$ RNA-binding protein $10 \mathrm{GN}=\mathrm{RBM} 10$ RNA-binding protein $10 \mathrm{GN}=\mathrm{RBM} 10$ RNA-binding protein $10 \mathrm{GN}=\mathrm{RBM} 10$ RNA-binding protein $10 \mathrm{GN}=\mathrm{RBM} 10$ RNA-binding protein $10 \mathrm{GN}=\mathrm{RBM} 10$ RNA-binding protein $10 \mathrm{GN}=\mathrm{RBM} 10$ RNA-binding protein $10 \mathrm{GN}=\mathrm{RBM} 10$ RNA-binding protein $10 \mathrm{GN}=\mathrm{RBM} 10$ RNA-binding protein $10 \mathrm{GN}=\mathrm{RBM} 10$ RNA-binding protein $10 \mathrm{GN}=\mathrm{RBM} 10$ RNA-binding protein $10 \mathrm{GN}=\mathrm{RBM} 10$ RNA-binding protein $10 \mathrm{GN}=\mathrm{RBM} 10$ RNA-binding protein $10 \mathrm{GN}=\mathrm{RBM} 10$ RNA-binding protein $10 \mathrm{GN}=\mathrm{RBM} 10$ RNA-binding protein $10 \mathrm{GN}=\mathrm{RBM} 10$ RNA-binding protein $14 \mathrm{GN}=\mathrm{RBM} 14$ RNA-binding protein $14 \mathrm{GN}=\mathrm{RBM} 14$ RNA-binding protein $14 \mathrm{GN}=\mathrm{RBM} 14$ RNA-binding protein $14 \mathrm{GN}=\mathrm{RBM} 14$ RNA-binding protein $14 \mathrm{GN}=\mathrm{RBM} 14$ RNA-binding protein $14 \mathrm{GN}=\mathrm{RBM} 14$ RNA-binding protein $14 \mathrm{GN}=\mathrm{RBM} 14$ RNA-binding protein $14 \mathrm{GN}=\mathrm{RBM} 14$ RBM10_HUMAN $103.53 \quad 100.0 \% \quad 16$ RBM10_HUMAN $103.53 \quad 100.0 \% \quad 16$ RBM10_HUMAN $103.53 \quad 100.0 \% \quad 16$ RBM10 HUMAN $103.53 \quad 100.0 \% \quad 16$ RBM10_HUMAN $103.53 \quad 100.0 \% \quad 16$ RBM10 HUMAN $103.53 \quad 100.0 \% \quad 16$ RBM10_HUMAN $103.53 \quad 100.0 \% \quad 16$ RBM10_HUMAN $103.53 \quad 100.0 \% \quad 16$ RBM10 HUMAN $103.53 \quad 100.0 \% \quad 16$ RBM10_HUMAN $103.53 \quad 100.0 \% \quad 16$ RBM10 HUMAN $103.53 \quad 100.0 \% \quad 16$ RBM10_HUMAN $103.53 \quad 100.0 \% \quad 16$ RBM10_HUMAN $103.53 \quad 100.0 \% \quad 16$ RBM10 HUMAN $103.53 \quad 100.0 \% \quad 16$ RBM10_HUMAN $103.53 \quad 100.0 \% \quad 16$ RBM14_HUMAN $69.49 \quad 100.0 \% \quad 14$ RBM14 HUMAN $69.49 \quad 100.0 \% \quad 14$ RBM14_HUMAN $69.49 \quad 100.0 \% \quad 14$ RBM14 HUMAN $69.49 \quad 100.0 \% \quad 14$ RBM14 HUMAN $69.49 \quad 100.0 \% \quad 14$ RBM14_HUMAN $69.49 \quad 100.0 \% \quad 14$ RBM14_HUMAN $\quad 69.49 \quad 100.0 \% \quad 14$ RBM14_HUMAN $69.49 \quad 100.0 \% \quad 14$

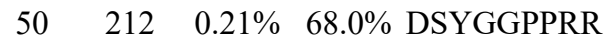

$50 \quad 212 \quad 0.21 \% \quad 68.0 \%$ RDVYLSPR

$50 \quad 212 \quad 0.21 \% \quad 68.0 \%$ DVYLSPRDDGYSTK

$50 \quad 212 \quad 0.21 \% \quad 68.0 \%$ DDGYSTKDSYSSR

$\begin{array}{llll}50 & 212 & 0.21 \% & 68.0 \% \\ 50 & \text { DSYSSRDYPSSR }\end{array}$

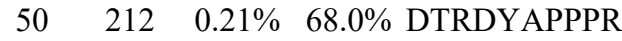

$50 \quad 212 \quad 0.21 \% \quad 68.0 \%$ DYAPPPRDYTYR

$50 \quad 212 \quad 0.21 \% \quad 68.0 \%$ DYGHSSSRDDYPSR

$50 \quad 212 \quad 0.21 \% \quad 68.0 \%$ GYSDRDGYGR

$\begin{array}{llll}50 & 212 & 0.21 \% & 68.0 \% \\ 50 & \text { DRDYSDHPSGGSYR }\end{array}$

$50 \quad 212 \quad 0.21 \% \quad 68.0 \%$ DSYESYGNSR

$50 \quad 212 \quad 0.21 \% \quad 68.0 \%$ SAPPTRGPPPSYGGSSR

$50 \quad 212 \quad 0.21 \% \quad 68.0 \%$ GPPPSYGGSSR

$50 \quad 212 \quad 0.21 \% \quad 68.0 \%$ GPPPSYGGSSRYDDYSSSR

$\begin{array}{llll}50 & 212 & 0.21 \% & 68.0 \% \\ 50 & \text { YDDYSSSR }\end{array}$

$50 \quad 212 \quad 0.21 \% \quad 68.0 \%$ YDDYSSSRDGYGGSR

$50 \quad 212 \quad 0.21 \% \quad 68.0 \%$ DGYGGSRDSYSSSR

$50 \quad 212 \quad 0.21 \% \quad 68.0 \%$ DSYSSSRSDLYSSGR

$\begin{array}{llll}50 & 212 & 0.21 \% & 68.0 \%\end{array}$

$50 \quad 212 \quad 0.21 \% \quad 68.0 \%$ SDLYSSGRDR

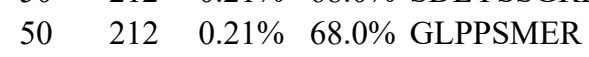

2

2

$0.04 \% \quad 22.5 \%$ MLPQAATEDDIRGQLQSHGVQA $\begin{array}{lll}25.0 & 18.0\end{array}$

$\begin{array}{llll}98.5 \% & 24.3 & 25.0 & 12.4\end{array}$

$99.7 \% \quad 63.6 \quad 25.0 \quad 57.8 \quad 2$

$99.7 \% \quad 44.5 \quad 25.0 \quad 44.5 \quad-2$

$\begin{array}{llll}99.7 \% & 31.4 & 25.0 & 30.7\end{array}$

$99.5 \% \quad 24.9 \quad 25.0 \quad 16.7$

$99.1 \% \quad 21.7 \quad 25.0 \quad 21.7$

$\begin{array}{llll}99.7 \% & 36.9 & 25.0 & 36.9\end{array}$

$96.1 \% \quad 16.5 \quad 25.0 \quad 15.8$

$\begin{array}{llll}99.7 \% & 57.2 & 25.0 & 57.2\end{array}$

$\begin{array}{llll}99.7 \% & 53.8 & 25.0 & 53.7\end{array}$

$\begin{array}{llll}99.7 \% & 28.0 & 25.0 & 23.7\end{array}$

$\begin{array}{llll}99.7 \% & 54.7 & 25.0 & 54.7\end{array}$

$\begin{array}{llll}9.7 \% & 43.9 & 25.0 & 41.2 \\ 99.0 \% & 45.8 & 25.0 & 45.8\end{array}$

$\begin{array}{llll}99.7 \% & 27.6 & 25.0 & 22.4\end{array}$

$99.7 \% \quad 39.6 \quad 25.0 \quad 39.6$

$\begin{array}{llll}99.7 \% & 27.7 & 25.0 & 27.0\end{array}$

$\begin{array}{llll}99.0 \% & 36.5 & 25.0 & 30.0\end{array}$

$\begin{array}{llll}99.2 \% & 22.0 & 25.0 & 17.1\end{array}$

$\begin{array}{llll}95.1 \% & 20.0 & 25.0 & 10.7\end{array}$

$\begin{array}{llll}99.7 \% & 40.6 & 25.0 & 38.4\end{array}$

$\begin{array}{llll}98.7 \% & 18.8 & 25.0 & 18.8\end{array}$

$0.00 \% \quad 7.4 \%$ GYGFVDFDSPAAAQK

$99.7 \% \quad 30.9$

$99.7 \% \quad 39.0 \quad 25.0$

$99.6 \% \quad 28.8 \quad 25.0$

$0.04 \% \quad 22.5 \%$ INEDWLCNK

$0.04 \% \quad 22.5 \%$ SEAEQKLPLGTR

$0.04 \% \quad 22.5 \%$ LDQQTLPLGGR

$\begin{array}{ll}0.04 \% & 22.5 \% \text { GPGITGTKGDPTGAGPEASLEPG } \\ 0.04 \% & 22.5 \% \text { TAQQIAKDMER }\end{array}$

$99.7 \%-61.0-25.0-53.9$

$\begin{array}{llll}99.7 \% & 61.0 & 25.0 & 53.9 \\ 99.7 \% & 40.1 & 25.0 & 40.1\end{array}$

$99.6 \% \quad 25.0 \quad 25.0 \quad 24.6$

$\begin{array}{llll}98.9 \% & 19.1 & 25.0 & 18.1\end{array}$

$0.04 \% \quad 22.5 \%$ GALAERQHTSMDLPK

$0.04 \% \quad 22.5 \%$ EKYGIPEPPEPK

$0.04 \% \quad 22.5 \%$ YGIPEPPEPK

$\begin{array}{llll}98.8 \% & 25.2 & 25.0 & 20.9\end{array}$

$\begin{array}{llll}99.7 \% & 31.6 & 25.0 & 21.7\end{array}$

$0.04 \% \quad 22.5 \%$ YGGISTASVDFEQPTR

$99.7 \% \quad 52.3$

$0.04 \% \quad 22.5 \%$ YGGISTASVDFEQPTRDGLGSDNIGSR

$0.04 \% 22.5 \%$ DGLGSDNIGSR

$\begin{array}{llll}99.7 \% & 47.5 & 25.0 & 44.3\end{array}$

$\begin{array}{llll}99.7 \% & 42.3 & 25.0 & 37.0\end{array}$

$\begin{array}{llll}99.7 \% & 53.6 & 25.0 & 36.9\end{array}$

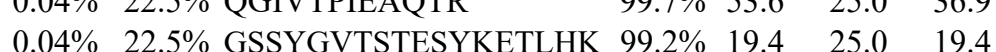

$\begin{array}{lllllll}0.04 \% & 22.5 \% & \text { TMVTRFNEAQ } & 99.7 \% & 38.9 & 25.0 & 28.7\end{array}$

$0.04 \% \quad 27.2 \%$ AIEALHGHELRPGR

$0.04 \% \quad 27.2 \%$ IFVGNVSAACTSQELR

$0.04 \% \quad 27.2 \%$ AAIAQLNGKEVK

$0.04 \% \quad 27.2 \%$ INVELSTKGQK

$0.04 \% \quad 27.2 \%$ KGPGLAVQSGDK

$0.04 \% \quad 27.2 \%$ ASYVAPLTAQPATYR

$0.04 \% \quad 27.2 \%$ AQPSVSLGAAYR

$0.04 \% \quad 27.2 \%$ AQPSASLGVGYR
$99.7 \% \quad 28.9 \quad 25.0 \quad 25.6$

$99.7 \% \quad 75.0 \quad 25.0 \quad 75.0$

$\begin{array}{llll}99.7 \% & 41.2 & 25.0 & 37.0\end{array}$

$99.7 \% \quad 46.4 \quad 25.0 \quad 41.4$

$\begin{array}{llll}99.7 \% & 50.3 & 25.0 & 47.6\end{array}$

$\begin{array}{llll}99.7 \% & 71.8 & 25.0 & 62.2\end{array}$

$\begin{array}{llll}99.7 \% & 53.9 & 25.0 & 48.7\end{array}$

$99.7 \% \quad 48.4 \quad 25.0 \quad 44.0$

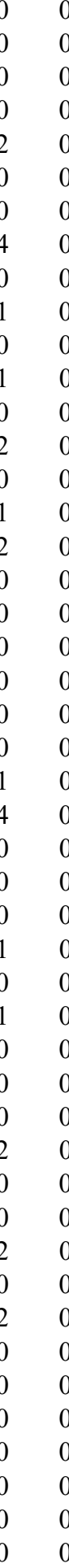
1005.55

1615.76

1480.62

1419.61

1187.58

1513.71

1641.69

1145.50

1611.68

1177.48

1670.82

1061.50

2034.88

992.40

1684.68

1493.63

1666.73

884.41

1155.54

902.44

1572.73

1566.82

2521.26

1724.84

1191.55

1328.72

1197.66

3261.53

1290.65

1669.83

1383.72

1126.58

1727.82

2799.32

1090.51

1312.72

1973.95

1196.57

1555.85

1751.87

1241.72

1216.69

1156.63

1608.84

1219.64

1219.64
1205.63 \begin{tabular}{cc}
88 & 196 \\
03 & 210 \\
04 & 217 \\
11 & 223 \\
18 & 229 \\
30 & 239 \\
33 & 244 \\
45 & 258 \\
59 & 268 \\
69 & 282 \\
83 & 292 \\
93 & 309 \\
99 & 309 \\
99 & 317 \\
10 & 317 \\
10 & 324 \\
18 & 331 \\
25 & 339 \\
32 & 339 \\
32 & 341 \\
48 & 355 \\
04 & 118 \\
08 & 222 \\
35 & 157 \\
72 & 186 \\
13 & 221 \\
41 & 252 \\
53 & 263 \\
65 & 498 \\
47 & 657 \\
01 & 715 \\
23 & 834 \\
25 & 834 \\
38 & 853 \\
38 & 864 \\
57 & 138 \\
54 & 864 \\
53 & 152 \\
24 & 238 \\
39 & 250 \\
53 & 923 \\
21 & 930 \\
& 262 \\
\hline 1 &
\end{tabular} 
RNA-binding protein $14 \mathrm{GN}=\mathrm{RBM} 14$ RNA-binding protein $14 \mathrm{GN}=\mathrm{RBM} 14$ RNA-binding protein $14 \mathrm{GN}=\mathrm{RBM} 14$ RNA-binding protein $14 \mathrm{GN}=\mathrm{RBM} 14$ RNA-binding protein $14 \mathrm{GN}=\mathrm{RBM} 14$ RNA-binding protein $14 \mathrm{GN}=\mathrm{RBM} 14$ RNA-binding protein $25 \mathrm{GN}=\mathrm{RBM} 25$ RNA-binding protein $25 \mathrm{GN}=\mathrm{RBM} 25$ RNA-binding protein $39 \mathrm{GN}=\mathrm{RBM} 39$ RNA-binding protein $39 \mathrm{GN}=\mathrm{RBM} 39$ RNA-binding protein $39 \mathrm{GN}=\mathrm{RBM} 39$ RNA-binding protein $39 \mathrm{GN}=\mathrm{RBM} 39$ RNA-binding protein $39 \mathrm{GN}=\mathrm{RBM} 39$ RNA-binding protein $39 \mathrm{GN}=\mathrm{RBM} 39$ RNA-binding protein $39 \mathrm{GN}=\mathrm{RBM} 39$ RNA-binding protein $4 \mathrm{GN}=\mathrm{RBM} 4$ RNA-binding protein $4 \mathrm{GN}=\mathrm{RBM} 4$ RNA-binding protein $4 \mathrm{GN}=\mathrm{RBM} 4$ RNA-binding protein $4 \mathrm{GN}=\mathrm{RBM} 4$ RNA-binding protein $4 \mathrm{GN}=\mathrm{RBM} 4$ RNA-binding protein $4 \mathrm{GN}=\mathrm{RBM} 4$ RNA-binding protein $4 \mathrm{GN}=\mathrm{RBM} 4$ RNA-binding protein $4 \mathrm{GN}=\mathrm{RBM} 4$ RNA-binding protein $4 \mathrm{GN}=\mathrm{RBM} 4$ RNA-binding protein $4 \mathrm{GN}=\mathrm{RBM} 4$ RNA-binding protein $4 \mathrm{GN}=\mathrm{RBM} 4$ RNA-binding protein $4 \mathrm{GN}=\mathrm{RBM} 4$ RNA-binding protein $4 \mathrm{GN}=\mathrm{RBM} 4$ RNA-binding protein $4 \mathrm{GN}=\mathrm{RBM} 4$ RNA-binding protein $4 \mathrm{GN}=\mathrm{RBM} 4$ RNA-binding protein $4 \mathrm{GN}=\mathrm{RBM} 4$ RNA-binding protein FUS GN=FUS RNA-binding protein FUS GN=FUS $\begin{array}{llll}\text { RNA-binding protein FUS GN=FUS } & \text { FUS_HUMAN } & 53.43 & 100.0 \% \\ \text { RNA-binding protein Musashi homolog 1 GN=MSII } & \text { MSIIH_HUMAN } & 39.12 & 100.0 \%\end{array}$ RNA-binding protein Musashi homolog 1 GN=MSI1 MSII__HUMAN $39.12 \quad 100.0 \%$ RNA-binding protein Musashi homolog $1 \mathrm{GN}=\mathrm{MSI} I$ MSIIH_HUMAN $39.12 \quad 100.0 \%$ RNA-binding protein Musashi homolog 1 GN=MSI1 MSIIH HUMAN $39.12 \quad 100.0 \%$ RNA-binding protein Musashi homolog 1 GN=MSII MSIIH_HUMAN $39.12 \quad 100.0 \%$ RNA-binding protein Musashi homolog 2 GN=MSI2 MSI2H_HUMAN $35.20 \quad 100.0 \%$ RNA-binding protein Musashi homolog $2 \mathrm{GN}=\mathrm{MSI} 2 \mathrm{MS} 2 \mathrm{H}$ HUMAN $35.20 \quad 100.0 \%$ RNA-binding protein $\mathrm{PNO} 1 \mathrm{GN}=\mathrm{PNO} 1$ RNA-binding protein $\mathrm{PNO} 1 \mathrm{GN}=\mathrm{PNO} 1$ RNA-binding protein $\mathrm{PNO} 1 \mathrm{GN}=\mathrm{PNO} 1$ RNA-binding protein $\mathrm{PNO} 1 \mathrm{GN}=\mathrm{PNO}$ RNA-binding protein $\mathrm{PNO} 1 \mathrm{GN}=\mathrm{PNO} 1$ RNA-binding protein $\mathrm{PNO} 1 \mathrm{GN}=\mathrm{PNO} 1$ \begin{tabular}{lll} 
RBM25_HUMAN & 100.19 & $100.0 \%$ \\
\hline
\end{tabular} RBM39_HUMAN $59.38 \quad 100.0 \%$ RBM39_HUMAN $59.38 \quad 100.0 \%$ RBM39_HUMAN $59.38 \quad 100.0 \%$ RBM39_HUMAN $59.38 \quad 100.0 \%$ RBM39_HUMAN $59.38 \quad 100.0 \%$ RBM39 HUMAN $59.38 \quad 100.0 \%$ RBM4_HUMAN $40.31 \quad 100.0 \%$ RBM4 HUMAN $40.31 \quad 100.0 \%$ RBM4_HUMAN $40.31 \quad 100.0 \%$ RBM4_HUMAN $40.31 \quad 100.0 \%$ RBM4 HUMAN $40.31 \quad 100.0 \%$ RBM4_HUMAN $40.31 \quad 100.0 \%$ RBM4_HUMAN $40.31 \quad 100.0 \%$ RBM4_HUMAN $40.31 \quad 100.0 \%$ RBM4_HUMAN $40.31 \quad 100.0 \%$ RBM4_HUMAN $40.31 \quad 100.0 \%$ RBM4_HUMAN $40.31 \quad 100.0 \%$ RBM4_HUMAN $40.31 \quad 100.0 \%$ RBM4 HUMAN $40.31 \quad 100.0 \%$ RBM4_HUMAN $40.31 \quad 100.0 \%$ RBM4 HUMAN $40.31 \quad 100.0 \%$ RBM4_HUMAN $40.31 \quad 100.0 \%$ FUS HUMAN $53.43 \quad 100.0 \%$ FUS HUMAN $53.43 \quad 100.0 \%$ PNO1_HUMAN $27.93 \quad 100.0 \%$ PNO1_HUMAN $27.93 \quad 100.0 \%$ PNO1_HUMAN $27.93 \quad 100.0 \%$ PNO1_HUMAN $27.93 \quad 100.0 \%$ PNO1_HUMAN $27.93 \quad 100.0 \%$ PNO1_HUMAN $27.93 \quad 100.0 \%$

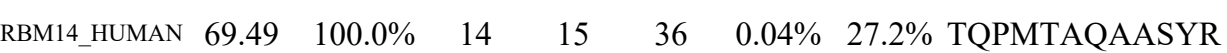
RBM14_HUMAN $69.49 \quad 100.0 \% \quad 14 \quad 15 \quad 36 \quad 0.04 \% \quad 27.2 \%$ AQPSVSLGAPYR RBM14_HUMAN $69.49 \quad 100.0 \% \quad 14$ RBM14 HUMAN $69.49 \quad 100.0 \% \quad 14$ RBM14_HUMAN $69.49 \quad 100.0 \% \quad 14$ RBM14_HUMAN $69.49 \quad 100.0 \% \quad 14$ RBM25_HUMAN $100.19 \quad 100.0 \%$

1536

$15 \quad 36$

7

7

7

$\begin{array}{ll}6 & 18 \\ 6 & 18 \\ 16 & 18\end{array}$

18
18

18
18

18
18

$\begin{array}{llll}18 & 33 & 0.03 \% & 44.2 \% \text { NYGFVHIEDK } \\ 18 & 33 & 0.03 \% & 44.2 \% \text { NYGFVHIEDKTAAEDAIR }\end{array}$

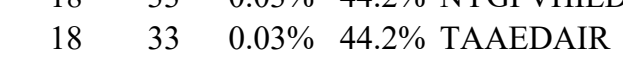

$\begin{array}{llll}18 & 33 & 0.03 \% & 44.2 \% \\ 6 & \text { LHGVNINVEASK }\end{array}$

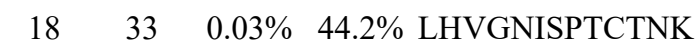

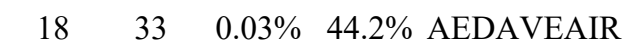

$18 \quad 33 \quad 0.03 \% \quad 44.2 \%$ GLDNTEFQGK

$18 \quad 33 \quad 0.03 \% \quad 44.2 \%$ GLDNTEFQGKR

$\begin{array}{llll}18 & 33 & 0.03 \% & 44.2 \% \\ 18 & 33 H V Q L S T S R\end{array}$

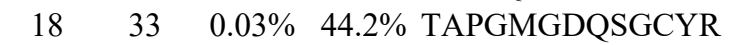

$\begin{array}{llll}18 & 33 & 0.03 \% & 44.2 \% \\ 18 & 33 & 0.03 \% & 44.2 \%\end{array}$

(1)

$\begin{array}{lllll}2 & 2 & 0.00 \% & 7.6 \% & \text { APKPDGPGGGPGGSHMGGNYGDDR } \\ 5 & 8 & 0.01 \% & 20.0 & \end{array}$

$8 \quad 0.01 \% \quad 20.2 \%$ EYFGQFGEVK

$0.01 \% \quad 20.2 \%$ GFGFVTFMDQAGVDK

$0.01 \% \quad 20.2 \%$ IFVGGLSVNTTVEDVK

$0.01 \% \quad 20.2 \%$ GFGFVTFESEDIVEK

$0.01 \% \quad 20.2 \%$ SYTGLAPGYTYQFPEFR

$0.01 \% \quad 9.5 \%$ GFGFVTFADPASVDK

$0.01 \% \quad 9.5 \%$ IFVGGLSANTVVEDVK

$\begin{array}{lll}0.01 \% & 36.1 \% & \text { AEEGFTQVTR }\end{array}$

$0.01 \% 36.1 \%$ QAEQLSAAGEGGDAGR

$\begin{array}{llll}10 & 15 & 0.01 \% & 36.1 \% \\ 10 & 15 & 0.01 \% & 36.1 \% \text { MDTEEARPAK }\end{array}$

$\begin{array}{llll}10 & 15 & 0.01 \% & 36.1 \% \text { KIPVPANR }\end{array}$

$\begin{array}{llll}10 & 15 & 0.01 \% & 36.1 \% \\ 10 & \text { IFTPIVEHLGLQIR }\end{array}$

$\begin{array}{lllll}10 & 15 & 0.01 \% & 36.1 \% & \text { FTIENVTR }\end{array}$ $\begin{array}{llllllll}9.7 \% & 54.8 & 25.0 & 50.6 & 5 & 0 & 0 & 1340.63\end{array}$

$\begin{array}{llllllll}99.7 \% & 46.0 & 25.0 & 40.4 & 4 & 0 & 0 & 1245.66\end{array}$

2465.18

1122.59

1300.64

1237.55

1355.69

1511.79

1054.53

1196.59

1271.62

1551.91

1822.05

1031.53

1691.90

929.56

975.47

989.53

1221.59

2049.00

846.43

1280.70

1440.73

973.49

1108.53

1264.63

1058.54

1399.57

1855.88

2776.32

969.45

1661.84

1420.66

2268.97

1203.57

1618.76

1677.91

1703.82

1996.94

1557.76

1647.90

1137.55

1516.70

1163.54

894.55

1635.96

979.52 $\begin{array}{llll}99.0 \% & 30.0 & 25.0 & 22.2 \\ 99.7 \% & 34.9 & 25.0 & 34.9 \\ 99.0 \% & 25.8 & 25.0 & 18.9\end{array}$

$\begin{array}{llll}99.0 \% & 25.8 & 25.0 & 18.9\end{array}$ 
RNA-binding protein $\mathrm{PNO} 1 \mathrm{GN}=\mathrm{PNO} 1$ RNA-binding protein $\mathrm{PNO} 1 \mathrm{GN}=\mathrm{PNO}$ RNA-binding protein Raly GN=RALY RNA-binding protein Raly GN=RALY RNA-binding protein Raly GN=RALY RNA-binding protein Raly GN=RALY RNA-binding protein Raly GN=RALY RNA-binding protein Raly GN=RALY RNA-binding protein Raly GN=RALY RNA-binding protein Raly GN=RALY RNA-binding protein Raly GN=RALY RNA-binding protein Raly GN=RALY RNA-binding protein Raly GN=RALY RNA-binding protein Raly GN=RALY RNA-binding protein Raly GN=RALY RNA-binding protein Raly GN=RALY RNA-binding protein Raly GN=RALY RNA-binding protein Raly GN=RALY RNA-binding protein Raly GN=RALY RNA-binding protein Raly GN=RALY $\begin{array}{llll}\text { RNA-binding protein with serine-rich domain } 1 \text { GN=RNPS1 } & \text { RNPS1_HUMAN } & 34.21 & 100.0 \%\end{array}$ RNA-binding protein with serine-rich domain 1 GN=RNPS1 RNPS1_HUMAN $34.21 \quad 100.0 \%$ $\begin{array}{lll}\text { rRNA 2'-O-methyltransferase fibrillarin GN=FBL FBRL_HUMAN } 33.78 \quad 100.0 \% & 1\end{array}$ rRNA 2'-O-methyltransferase fibrillarin GN=FBL FBRL_HUMAN $33.78 \quad 100.0 \%$ rRNA 2'-O-methyltransferase fibrillarin GN=FBL FBRL_HUMAN $33.78 \quad 100.0 \%$ rRNA 2'-O-methyltransferase fibrillarin GN=FBL FBRL_HUMAN $33.78 \quad 100.0 \%$ rRNA $2^{2}$-O-methyltransferase fibrillarin GN=FBL FBRL_HUMAN $33.78 \quad 100.0 \%$ rRNA 2'-O-methyltransferase fibrillarin GN=FBL FBRL HUMAN $33.78 \quad 100.0 \%$ rRNA 2'-O-methyltransferase fibrillarin GN=FBL FBRL_HUMAN $33.78 \quad 100.0 \%$ rRNA 2'-O-methyltransferase fibrillarin GN=FBL FBRL HUMAN $33.78 \quad 100.0 \%$ rRNA 2'-O-methyltransferase fibrillarin GN=FBL FBRL_HUMAN $33.78 \quad 100.0 \%$ rRNA 2'-O-methyltransferase fibrillarin GN=FBL FBRL_HUMAN $33.78 \quad 100.0 \%$ rRNA $2^{2}$-O-methyltransferase fibrillarin GN=FBL FBRL_HUMAN $33.78 \quad 100.0 \%$ rRNA 2'-O-methyltransferase fibrillarin GN=FBL FBRL_HUMAN $33.78 \quad 100.0 \%$ rRNA 2'-O-methyltransferase fibrillarin GN=FBL FBRL_HUMAN $33.78 \quad 100.0 \%$ rRNA 2'-O-methyltransferase fibrillarin GN=FBL FBRL HUMAN $33.78 \quad 100.0 \%$ rRNA 2'-O-methyltransferase fibrillarin GN=FBL FBRL_HUMAN $33.78 \quad 100.0 \%$ rRNA 2'-O-methyltransferase fibrillarin GN=FBL FBRL HUMAN $33.78 \quad 100.0 \%$ rRNA methyltransferase 3, mitochondrial GN=RNMTL1 MRM3_HUMAN $47.02 \quad 100.0 \%$ rRNA methyltransferase 3, mitochondrial GN=RNMTL1 MRM3_HUMAN $47.02 \quad 100.0 \%$ rRNA methyltransferase 3, mitochondrial GN=RNMTL1 MRM3 HUMAN $47.02 \quad 100.0 \%$ rRNA methyltransferase 3, mitochondrial GN=RNMTL1 MRM3_HUMAN $47.02 \quad 100.0 \%$ rRNA methyltransferase 3, mitochondrial GN=RNMTL1 MRM3 HUMAN $47.02 \quad 100.0 \%$ rRNA methyltransferase 3, mitochondrial GN=RNMTL1 MRM3_HUMAN $47.02 \quad 100.0 \%$ rRNA methyltransferase 3, mitochondrial GN=RNMTL1 MRM3_HUMAN $47.02 \quad 100.0 \%$ RRP12-like protein $\mathrm{GN}=\mathrm{RRP} 12$ RRP12-like protein GN=RRP12
RRP12 HUMAN $143.71 \quad 100.0 \%$ RRP12_HUMAN $143.71 \quad 100.0 \%$ $\begin{array}{llll}10 & 15 & 0.01 \% & 36.1 \% \\ 10 & 15 & 0.01 \% & 36.1 \%\end{array}$ $15.0 .01 \% \quad 36.1 \%$ TAICNLILCNPPSK $0.07 \% \quad 47.4 \%$ LQASNVTNK $0.07 \% \quad 47.4 \%$ LQASNVTNKNDPK $0.07 \% \quad 47.4 \%$ VFIGNLNTALVK $0.07 \% \quad 47.4 \%$ VFIGNLNTALVKK $0.07 \% \quad 47.4 \%$ KSDVETIFSK $0.07 \% \quad 47.4 \%$ SDVETIFSK $0.07 \% \quad 47.4 \%$ VAGCSVHK $0.07 \% \quad 47.4 \%$ GYAFVQYSNER $0.07 \% \quad 47.4 \%$ AAVLGENGR $0.07 \% \quad 47.4 \%$ VLAGQTLDINMAGEPKPDRPK $0.07 \% \quad 47.4 \%$ LSPVPVPR $0.07 \% \quad 47.4 \%$ VKTNVPVK $0.07 \% \quad 47.4 \%$ STAVTTSSAK $0.07 \% \quad 47.4 \%$ LKSSELQAIK $0.07 \% \quad 47.4 \%$ SSELQAIK

$0.07 \% \quad 47.4 \%$ SSELQAIKTELTQIK

$0.07 \% \quad 47.4 \%$ SNIDALLSR

$0.07 \% \quad 47.4 \%$ LEQIAAEQK

$0.00 \% \quad 10.2 \%$ NVTKDHIMEIFSTYGK $0.00 \% \quad 10.2 \%$ GYAYVEFENPDEAEK $0.04 \% \quad 57.6 \%$ NVMVEPHR $0.04 \% \quad 57.6 \%$ HEGVFICR $0.04 \% \quad 57.6 \%$ GKEDALVTK $0.04 \% \quad 57.6 \%$ NLVPGESVYGEK $0.04 \% 57.6 \%$ NLVPGESVYGEKR $0.04 \% 57.6 \%$ VSISEGDDKIEYR $0.04 \% 57.6 \%$ LAAAILGGVDQIHIKPGAK $0.04 \% 57.6 \%$ SGRDLINLAK $0.04 \% 57.6 \%$ TNIIPVIEDAR $0.04 \% \quad 57.6 \%$ MLIAMVDVIFADVAQPDQTR $0.04 \% \quad 57.6 \%$ IVALNAHTFLR $0.04 \% \quad 57.6 \%$ NGGHFVISIK $0.04 \% \quad 57.6 \%$ ANCIDSTASAEAVFASEVK $\quad 99.7 \% \quad 77.3$ $0.04 \% \quad 57.6 \%$ ANCIDSTASAEAVFASEVKK $\quad 99.7 \% \quad 61.9$

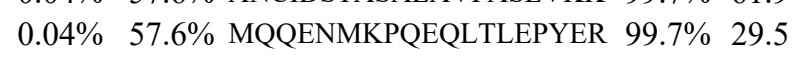
$0.04 \% 57.6 \%$ DHAVVVGVYRPPPK

$0.01 \% \quad 17.9 \%$ VVFPSGEVVEQK $0.01 \% \quad 17.9 \%$ KAPSEASAQEQR $0.01 \% \quad 17.9 \%$ APSEASAQEQR $0.01 \% \quad 17.9 \%$ EKQPLEESASR $0.01 \% \quad 17.9 \%$ LSSVMTIVK

$0.01 \% \quad 17.9 \%$ LISDALKAGAVPK $99.7 \% 56.5$ $99.7 \% 44.1$ $99.7 \% 64.0$ $96.3 \% 16.6$ $99.7 \% 36.0$ $98.9 \% 26.7$ $99.7 \% \quad 31.4$

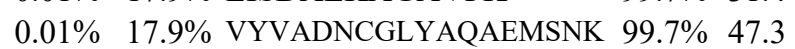
$0.02 \% \quad 7.8 \%$ SSGTFLSGLSDCTNVTFSK $99.7 \% \quad 67.5$ $0.02 \% \quad 7.8 \%$ AAQHGVCSVLK
$99.7 \% \quad 30.2$ $\begin{array}{ccc}1255.72 & 209 & 219 \\ 1497.81 & 223 & 236 \\ 974.53 & 5 & 13 \\ 1428.74 & 5 & 17 \\ 1288.76 & 23 & 34 \\ 1416.86 & 23 & 35 \\ 1153.61 & 35 & 44 \\ 1025.52 & 36 & 44 \\ 857.43 & 48 & 55 \\ 1333.62 & 56 & 66 \\ 886.47 & 70 & 78 \\ 2266.19 & 79 & 99 \\ 864.53 & 134 & 141 \\ 884.56 & 158 & 165 \\ 952.49 & 170 & 179 \\ 1116.66 & 182 & 191 \\ 875.48 & 184 & 191 \\ 1688.94 & 184 & 198 \\ 988.54 & 199 & 207 \\ 1029.56 & 208 & 216 \\ 1898.93 & 171 & 186 \\ 1760.77 & 204 & 218 \\ 997.49 & 85 & 92 \\ 1017.49 & 93 & 100 \\ 960.54 & 101 & 109 \\ 1291.65 & 110 & 121 \\ 1447.75 & 110 & 122 \\ 1510.74 & 123 & 135 \\ 1872.11 & 144 & 162 \\ 1086.63 & 196 & 205 \\ 1240.69 & 208 & 218 \\ 2265.13 & 225 & 244 \\ 1254.73 & 245 & 255 \\ 1071.59 & 256 & 265 \\ 1969.92 & 266 & 284 \\ 2098.01 & 266 & 285 \\ 2424.12 & 286 & 304 \\ 1533.85 & 305 & 318 \\ 1317.70 & 40 & 51 \\ 1301.64 & 60 & 71 \\ 1173.55 & 61 & 71 \\ 1273.64 & 72 & 82 \\ 993.57 & 104 & 112 \\ 1282.77 & 130 & 142 \\ 2048.91 & 284 & 301 \\ 2007.93 & 91 & 109 \\ 1169.61 & 255 & 265 \\ & & \end{array}$

Page 146 of Table S-1-4 
RRP12-like protein GN=RRP12 RRP12-like protein GN=RRP12 RRP12-like protein GN=RRP12 RRP12-like protein $\mathrm{GN}=\mathrm{RRP} 12$ RRP12-like protein GN=RRP12 RRP12-like protein $\mathrm{GN}=\mathrm{RRP} 12$ RRP12-like protein $\mathrm{GN}=\mathrm{RRP} 12$ RRP15-like protein GN=RRP15 RRP15-like protein GN=RRP15 RRP15-like protein GN=RRP15 RRP15-like protein GN=RRP15 RuvB-like 2 GN=RUVBL2 RuvB-like 2 GN=RUVBL2 RuvB-like 2 GN=RUVBL2

S1 RNA-binding domain-containing protein $1 \mathrm{GN}=$ SRBD1 SRBD1_HUMAN $111.78 \quad 100.0 \%$ S1 RNA-binding domain-containing protein $1 \mathrm{GN}=$ SRBD1 SRBD1_HUMAN $111.78 \quad 100.0 \%$ S1 RNA-binding domain-containing protein $1 \mathrm{GN}=$ SRBD1 SRBD1_HUMAN $111.78 \quad 100.0 \%$ S-adenosylmethionine synthase isoform type-2 GN=MAT2A METK2_HUMAN $43.66 \quad 100.0 \%$ S-adenosylmethionine synthase isoform type-2 GN=MAT2A METK2_HUMAN $43.66 \quad 100.0 \%$ S-adenosylmethionine synthase isoform type-2 GN=MAT2A METK2_HUMAN $43.66 \quad 100.0 \%$ S-adenosylmethionine synthase isoform type-2 GN=MAT2A METK2_HUMAN $43.66 \quad 100.0 \%$ S-adenosylmethionine synthase isoform type-2 GN=MAT2A METK2_HUMAN $43.66 \quad 100.0 \%$ Sarcoplasmic/endoplasmic reticulum calcium ATPase $2 \mathrm{GN}=\mathrm{ATP} 2 \mathrm{~A} 2$ AT2A2_HUMAN $114.76 \quad 100.0 \%$ Sarcoplasmic/endoplasmic reticulum calcium ATPase $2 \mathrm{GN}=\mathrm{ATP} 2 \mathrm{~A} 2$ AT2A2_HUMAN $114.76 \quad 100.0 \%$ Sarcoplasmic/endoplasmic reticulum calcium ATPase $2 \mathrm{GN}=\mathrm{ATP} 2 \mathrm{~A} 2$ AT2A2_HUMAN $114.76 \quad 100.0 \%$ Sarcoplasmic/endoplasmic reticulum calcium ATPase 2 GN=ATP2A2 AT2A2_HUMAN $114.76 \quad 100.0 \%$ Sarcoplasmic/endoplasmic reticulum calcium ATPase 2 GN=ATP2A2 AT2A2_HUMAN $114.76 \quad 100.0 \%$ Sarcoplasmic/endoplasmic reticulum calcium ATPase 2 GN=ATP2A2 AT2A2_HUMAN $114.76 \quad 100.0 \%$ Sarcoplasmic/endoplasmic reticulum calcium ATPase 2 GN=ATP2A2 AT2A2_HUMAN $114.76 \quad 100.0 \%$ Sarcoplasmic/endoplasmic reticulum calcium ATPase 2 GN=ATP2A2 AT2A2_HUMAN $114.76 \quad 100.0 \%$ Sarcoplasmic/endoplasmic reticulum calcium ATPase 2 GN=ATP2A2 AT2A2_HUMAN $114.76 \quad 100.0 \%$ Sarcoplasmic/endoplasmic reticulum calcium ATPase 2 GN=ATP2A2 AT2A2_HUMAN $114.76 \quad 100.0 \%$ Sarcoplasmic/endoplasmic reticulum calcium ATPase 2 GN=ATP2A2 AT2A2_HUMAN $114.76 \quad 100.0 \%$ $\begin{array}{llll}\text { Sarcoplasmic/endoplasmic reticulum calcium ATPase } 2 \text { GN=ATP2A2 } & \text { AT2A2_HUMAN } 114.76 & 100.0 \% \\ \text { Scaffold attachment factor B1 GN=SAFB } & \text { SAFB1_HUMAN } 102.64 & 100.0 \%\end{array}$ Scaffold attachment factor B1 GN=SAFB SAFB1_HUMAN $102.64 \quad 100.0 \%$ Scaffold attachment factor B1 GN=SAFB SAFB1_HUMAN $102.64 \quad 100.0 \%$ Scaffold attachment factor B1 GN=SAFB SAFB1_HUMAN $102.64 \quad 100.0 \%$ Scaffold attachment factor B1 GN=SAFB SAFB1_HUMAN $102.64 \quad 100.0 \%$ Scaffold attachment factor B1 GN=SAFB SAFB1_HUMAN $102.64 \quad 100.0 \%$ Scaffold attachment factor B1 GN=SAFB SAFB1_HUMAN $102.64 \quad 100.0 \%$ Scaffold attachment factor B1 GN=SAFB SAFB1_HUMAN $102.64 \quad 100.0 \%$ Scaffold attachment factor B1 GN=SAFB SAFB1_HUMAN $102.64 \quad 100.0 \%$ Scaffold attachment factor B1 GN=SAFB SAFB1_HUMAN $102.64 \quad 100.0 \%$ Scaffold attachment factor B1 GN=SAFB SAFB1_HUMAN $102.64 \quad 100.0 \%$ Scaffold attachment factor B1 GN=SAFB SAFB1_HUMAN $102.64 \quad 100.0 \%$ Scaffold attachment factor B1 GN=SAFB SAFB1_HUMAN $102.64 \quad 100.0 \%$
$16 \quad 0.02 \% \quad 7.8 \% \quad$ APAHHPAAISTAK $0.02 \% \quad 7.8 \%$ FCIQEIEK

$16 \quad 0.02 \% \quad 7.8 \% \quad$ VTVCQALR

$16 \quad 0.02 \% \quad 7.8 \%$ GCQAEADRAEVSR

$0.02 \% \quad 7.8 \%$ RAVLETIR

$6 \quad 0.02 \% \quad 7.8 \%$ VLDPASSDFTR

$0.02 \% \quad 7.8 \%$ VLATQPGPGR

$0.01 \% \quad 17.0 \%$ TPESKPTILVK

$0.01 \% \quad 17.0 \%$ VKPDVVQDKETER

$0.01 \% \quad 17.0 \%$ GVVQLFNAVQK

$0.01 \% \quad 17.0 \%$ GMDGSTNETASSR

$0.00 \% \quad 7.1 \%$ AVLIAGQPGTGK

$0.00 \% \quad 7.1 \%$ FVQCPDGELQK

$0.00 \% \quad 7.1 \%$ VYSLFLDESR

$0.00 \% \quad 3.3 \%$ LFNDDNTIPFIIR

$0.00 \% \quad 3.3 \%$ QLLLTSPVPGR

$0.00 \% \quad 3.3 \% \quad$ ITLDLIRVL

$0.01 \% \quad 16.5 \%$ TGMILLAGEITSR

$0.01 \% \quad 16.5 \%$ YLDEDTIYHLQPSGR

$0.01 \% \quad 16.5 \%$ FVIGGPQGDAGLTGR

$0.01 \% \quad 16.5 \%$ NFDLRPGVIVR

$0.01 \% \quad 16.5 \%$ DLDLKKPIYQR

$0.03 \% \quad 13.7 \%$ VDQSILTGESVSVIK

$0.03 \% \quad 13.7 \%$ NMLFSGTNIAAGK

$0.03 \% \quad 13.7 \%$ AMGVVVATGVNTEIGK

$0.03 \% \quad 13.7 \%$ VGEATETALTCLVEK

$0.03 \% \quad 13.7 \%$ ANACNSVIK

$0.03 \% \quad 13.7 \%$ EFTLEFSR

$0.03 \% \quad 13.7 \%$ SMSVYCTPNKPSR

$0.03 \% \quad 13.7 \%$ GAPEGVIDR

$0.03 \% \quad 13.7 \%$ RIGIFGQDEDVTSK

$0.03 \% \quad 13.7 \%$ IGIFGQDEDVTSK

$0.03 \% \quad 13.7 \%$ KAEIGIAMGSGTAVAK

$0.03 \% \quad 13.7 \%$ NYLEPGKECVQPATK

$0.04 \% \quad 20.9 \%$ VIDLRAELR

$0.04 \% \quad 20.9 \%$ NVDSSGNKSVLMER

$0.04 \% \quad 20.9 \%$ AIEDEGGNPDEIEITSEGNKK

$0.04 \% \quad 20.9 \%$ ILDILGETCK

$0.04 \% \quad 20.9 \%$ ADSLLAVVK

$43 \quad 0.04 \% \quad 20.9 \%$ NFWVSGLSSTTR

$0.04 \% \quad 20.9 \%$ ATDLKNLFSK

$0.04 \% \quad 20.9 \%$ YGKVVGAK

$43 \quad 0.04 \% \quad 20.9 \%$ VVGAKVVTNAR

$3 \quad 0.04 \% \quad 20.9 \%$ VVTNARSPGAR

$43 \quad 0.04 \% \quad 20.9 \%$ CYGFVTMSTAEEATK

$43 \quad 0.04 \% \quad 20.9 \%$ SKDQDDQKPGPSER

$0.04 \% \quad 20.9 \%$ SKGVPVISVK $\begin{array}{llllllll}99.7 \% & 28.8 & 25.0 & 23.0 & 0 & 2 & 0 & 1271.69\end{array}$

$\begin{array}{lllllll}98.9 \% & 21.4 & 25.0 & 16.0 & 1 & 0 & 0\end{array}$

$\begin{array}{lllllll}99.0 \% & 36.2 & 25.0 & 22.4 & 2 & 0 & 0\end{array}$

$\begin{array}{lllll}99.7 \% & 28.8 & 25.0 & 25.0 & 2\end{array}$

$\begin{array}{llll}99.0 \% & 44.0 & 25.0 & 30.8\end{array}$

$\begin{array}{llll}99.7 \% & 37.0 & 25.0 & 37.0\end{array}$

$\begin{array}{llll}99.7 \% & 43.9 & 25.0 & 39.1\end{array}$

$\begin{array}{llll}99.7 \% & 27.0 & 25.0 & 21.2\end{array}$

$98.7 \% \quad 23.9 \quad 25.0 \quad 22.5$

$\begin{array}{llll}99.7 \% & 54.1 & 25.0 & 43.1\end{array}$

$\begin{array}{lllll}99.7 \% & 61.0 & 25.0 & 61.0 & 2\end{array}$

$99.7 \% \quad 46.3 \quad 25.0 \quad 46.3$

$\begin{array}{llll}99.4 \% & 23.1 & 25.0 & 18.4\end{array}$

$\begin{array}{llll}98.1 \% & 23.2 & 25.0 & 12.1\end{array}$

$99.7 \% \quad 28.2 \quad 25.0 \quad 20.3$

$\begin{array}{llll}99.7 \% & 28.6 & 25.0 & 28.6\end{array}$

$99.7 \% \quad 52.9 \quad 25.0 \quad 45.6$

$\begin{array}{llll}99.7 \% & 65.1 & 25.0 & 62.4\end{array}$

$\begin{array}{llll}99.7 \% & 58.7 & 25.0 & 56.1\end{array}$

$\begin{array}{llll}99.7 \% & 65.9 & 25.0 & 64.1\end{array}$

$\begin{array}{llll}99.5 \% & 23.6 & 25.0 & 18.1\end{array}$

$\begin{array}{llll}95.0 \% & 16.7 & 25.0 & 12.7\end{array}$

$99.7 \% \quad 41.8 \quad 25.0 \quad 39.2$

$\begin{array}{llll}99.7 \% & 37.8 & 25.0 & 37.7\end{array}$

$\begin{array}{llll}99.7 \% & 60.5 & 25.0 & 52.7\end{array}$

$\begin{array}{llll}99.7 \% & 61.2 & 25.0 & 55.0\end{array}$

$99.1 \% \quad 23.2 \quad 25.0 \quad 17.1$

$99.0 \% \quad 23.1 \quad 25.0 \quad 22.3$

$99.7 \% \quad 34.0 \quad 25.0 \quad 34.0$

$95.2 \% \quad 22.4 \quad 25.0 \quad 17.9$

$\begin{array}{llll}99.7 \% & 37.5 & 25.0 & 37.5\end{array}$

$\begin{array}{llll}99.7 \% & 53.2 & 25.0 & 53.2\end{array}$

$99.7 \% \quad 35.6 \quad 25.0 \quad 35.6$

$\begin{array}{llll}99.7 \% & 27.9 & 25.0 & 25.3\end{array}$

$\begin{array}{llll}99.6 \% & 25.4 & 25.0 & 18.9\end{array}$

$\begin{array}{lllll}99.7 \% & 64.1 & 25.0 & 55.8\end{array}$

$\begin{array}{llll}99.7 \% & 32.4 & 25.0 & 32.2\end{array}$

$\begin{array}{llll}99.7 \% & 33.4 & 25.0 & 26.2\end{array}$

$\begin{array}{llll}99.7 \% & 57.3 & 25.0 & 46.2\end{array}$

$\begin{array}{llll}99.7 \% & 59.0 & 25.0 & 54.2\end{array}$

$99.7 \% \quad 51.3 \quad 25.0 \quad 34.3$

$99.0 \% \quad 25.9 \quad 25.0 \quad 17.3$

$\begin{array}{llll}98.0 \% & 18.0 & 25.0 & 18.0\end{array}$

$\begin{array}{llll}97.6 \% & 21.8 & 25.0 & 13.0\end{array}$

$\begin{array}{llll}99.7 \% & 53.9 & 25.0 & 53.9\end{array}$

$\begin{array}{llll}99.7 \% & 40.7 & 25.0 & 36.5\end{array}$

$\begin{array}{llll}99.7 \% & 27.9 & 25.0 & 27.9\end{array}$
066.52

946.51

1448.65

957.58

1207.60

995.56

1212.72

1542.81

1202.69

1312.54

1111.65

1320.63

1228.62

1577.83

1180.71

1055.68

1377.74

1806.87

1444.75

1285.74

1388.79

1574.86

1323.67

1561.83

1620.82

976.49

1028.50

1526.71

913.47

1564.80

1408.70

1519.82

1733.85

1084.65

1551.74

2245.05

1161.62

915.55

1354.67

1136.63

821.49

1113.67

1127.63

1710.74

1586.74

1013.64

$\begin{array}{cc}74 & 286 \\ 87 & 294 \\ 59 & 666 \\ 72 & 684 \\ 11 & 718 \\ 40 & 750 \\ 29 & 1138 \\ 04 & 114 \\ 48 & 160 \\ 69 & 179 \\ 16 & 228 \\ 2 & 83 \\ 24 & 234 \\ 29 & 438 \\ 35 & 247 \\ 27 & 537 \\ 87 & 995 \\ 2 & 74 \\ 35 & 249 \\ 50 & 264 \\ 52 & 362 \\ 63 & 373 \\ 75 & 189 \\ 06 & 218 \\ 19 & 234 \\ 37 & 451 \\ 68 & 476 \\ 82 & 489 \\ 93 & 505 \\ 15 & 523 \\ 37 & 650 \\ 38 & 650 \\ 12 & 727 \\ 89 & 1003 \\ 6 & 44 \\ 7 & 60 \\ 4 & 84 \\ 17 & 226 \\ 86 & 294 \\ 07 & 418 \\ 19 & 428 \\ 29 & 436 \\ 32 & 442 \\ 37 & 447 \\ 48 & 462 \\ 36 & 549 \\ 69 & 578 \\ & \end{array}$

Page 147 of Table S-1-4 
Scaffold attachment factor B1 GN=SAFB SAFB1_HUMAN $102.64 \quad 100.0 \%$ $\begin{array}{llll}\text { Scaffold attachment factor B1 GN=SAFB SAFB1_HUMAN } 102.64 & 100.0 \%\end{array}$ Scaffold attachment factor B1 GN=SAFB SAFB1_HUMAN $102.64 \quad 100.0 \%$ Scaffold attachment factor B1 GN=SAFB SAFB1_HUMAN $102.64 \quad 100.0 \%$ Scaffold attachment factor B2 GN=SAFB2 SAFB2_HUMAN $107.47 \quad 100.0 \%$ Scaffold attachment factor B2 GN=SAFB2 SAFB2_HUMAN $107.47 \quad 100.0 \%$ Scaffold attachment factor B2 GN=SAFB2 SAFB2_HUMAN $107.47 \quad 100.0 \%$ Scaffold attachment factor B2 GN=SAFB2 SAFB2_HUMAN $107.47 \quad 100.0 \%$ Scaffold attachment factor B2 GN=SAFB2 SAFB2_HUMAN $107.47 \quad 100.0 \%$ Scaffold attachment factor B2 GN=SAFB2 SAFB2_HUMAN $107.47 \quad 100.0 \%$ Scaffold attachment factor B2 GN=SAFB2 SAFB2_HUMAN $107.47 \quad 100.0 \%$ Scaffold attachment factor B2 GN=SAFB2 SAFB2_HUMAN $107.47 \quad 100.0 \%$ Scaffold attachment factor B2 GN=SAFB2 SAFB2_HUMAN $107.47 \quad 100.0 \%$ Scaffold attachment factor B2 GN=SAFB2 SAFB2_HUMAN $107.47 \quad 100.0 \%$ Scaffold attachment factor B2 GN=SAFB2 SAFB2_HUMAN $107.47 \quad 100.0 \%$ Scaffold attachment factor B2 GN=SAFB2 SAFB2_HUMAN $107.47 \quad 100.0 \%$ Scaffold attachment factor B2 GN=SAFB2 SAFB2 HUMAN $107.47 \quad 100.0 \%$ Septin-2 GN=SEPT2

Septin-2 GN=SEPT2

Septin-2 GN=SEPT2

Septin-2 GN=SEPT2

Septin-2 GN=SEPT2

Septin-2 GN=SEPT2

Septin-2 GN=SEPT2

Septin-9 GN=SEPT9

Septin-9 GN=SEPT9 $\begin{array}{lll}\text { SEPT2_HUMAN } & 41.49 & 100.0 \% \\ \text { SEPT2_HUMAN } & 41.49 & 100.0 \%\end{array}$ SEPT2 HUMAN $41.49 \quad 100.0 \%$ SEPT2_HUMAN $41.49 \quad 100.0 \%$ SEPT2_HUMAN $41.49 \quad 100.0 \%$ SEPT2_HUMAN $41.49 \quad 100.0 \%$ SEPT2_HUMAN $41.49 \quad 100.0 \%$ SEPT9 HUMAN $65.40 \quad 100.0 \%$ SEPT9_HUMAN $65.40 \quad 100.0 \%$ Serine hydroxymethyltransferase, mitochondrial GN=SHMT2 GLYM_HUMAN $55.99 \quad 100.0 \%$ Serine hydroxymethyltransferase, mitochondrial GN=SHMT2 GLYM_HUMAN $55.99 \quad 100.0 \%$ Serine hydroxymethyltransferase, mitochondrial GN=SHMT2 GLYM_HUMAN $55.99 \quad 100.0 \%$ Serine palmitoyltransferase $1 \mathrm{GN}=$ SPTLC1 SPTC1_HUMAN $52.75 \quad 100.0 \%$ Serine palmitoyltransferase $1 \mathrm{GN}=$ SPTLC1 SPTC1_HUMAN $52.75 \quad 100.0 \%$ Serine palmitoyltransferase $1 \mathrm{GN}=$ SPTLC1 SPTC1_HUMAN $52.75 \quad 100.0 \%$ Serine racemase $\mathrm{GN}=\mathrm{SRR}$

Serine racemase $\mathrm{GN}=\mathrm{SRR}$ SRR HUMAN $36.57 \quad 100.0 \%$ SRR_HUMAN $36.57 \quad 100.0 \%$

Serine/arginine repetitive matrix protein 2 GN=SRRM2 SRRM2_HUMAN $299.62 \quad 100.0 \%$ Serine/arginine repetitive matrix protein 2 GN=SRRM2 SRRM2_HUMAN $299.62 \quad 100.0 \%$ Serine/arginine repetitive matrix protein $2 \mathrm{GN}=\mathrm{SRRM} 2 \mathrm{SRRM} 2 \mathrm{HUMAN} 299.62 \quad 100.0 \%$ Serine/arginine repetitive matrix protein $2 \mathrm{GN}=$ SRRM2 SRRM2_HUMAN $299.62 \quad 100.0 \%$ Serine/arginine repetitive matrix protein 2 GN=SRRM2 SRRM2_HUMAN $299.62 \quad 100.0 \%$ Serine/arginine repetitive matrix protein 2 GN=SRRM2 SRRM2_HUMAN $299.62 \quad 100.0 \%$ Serine/arginine repetitive matrix protein 2 GN=SRRM2 SRRM2_HUMAN $299.62 \quad 100.0 \%$ Serine/arginine repetitive matrix protein $2 \mathrm{GN}=\mathrm{SRRM} 2 \mathrm{SRRM} 2$ HUMAN $299.62 \quad 100.0 \%$ Serine/arginine repetitive matrix protein $2 \mathrm{GN}=$ SRRM2 SRRM2_HUMAN $299.62 \quad 100.0 \%$ Serine/arginine repetitive matrix protein 2 GN=SRRM2 SRRM2_HUMAN $299.62 \quad 100.0 \%$ Serine/arginine repetitive matrix protein $2 \mathrm{GN}=\mathrm{SRRM} 2 \mathrm{SRRM} 2$ HUMAN $299.62 \quad 100.0 \%$ Serine/arginine repetitive matrix protein $2 \mathrm{GN}=$ SRRM2 SRRM2_HUMAN $299.62 \quad 100.0 \%$ Serine/arginine repetitive matrix protein 2 GN=SRRM2 SRRM2_HUMAN $299.62 \quad 100.0 \%$

(1)

8

6
6

7

7
7
7

7

7
7
7

7

2

2
3
3

3

$\begin{array}{ll}3 & 3 \\ 3 & 3 \\ 3 & 3\end{array}$

3

$\begin{array}{cc}2 & 2 \\ 16 & 16 \\ 16 & 16\end{array}$

16

$\begin{array}{ll}6 & 16 \\ 6 & 16 \\ 6 & 16\end{array}$

$\begin{array}{ll}16 & 16 \\ 6 & 16 \\ 6 & 16 \\ 6 & 16\end{array}$

$\begin{array}{ll}16 & 16 \\ 16 & 16\end{array}$

$16 \quad 16$

16
16
16
16

16
16

16
16
$0.04 \% \quad 20.9 \%$ AALDERYHSDFNR 0.04\% $20.9 \%$ SMMGEREGQHYPER $0.04 \% \quad 20.9 \%$ DGWGGYGSDKR $0.01 \% \quad 13.5 \%$ NLDTGGNKSVLMER $0.01 \% \quad 13.5 \%$ ILDILGETCK

$0.01 \% \quad 13.5 \%$ ADSLLAVVK $0.01 \% \quad 13.5 \%$ NLWVSGLSSTTR $0.01 \% \quad 13.5 \%$ ATDLKNLFSK $0.01 \% \quad 13.5 \%$ YGKVVGAK $0.01 \% \quad 13.5 \%$ VVGAKVVTNAR $0.01 \% \quad 13.5 \%$ VVTNARSPGAR $0.01 \% \quad 13.5 \%$ SKGEPVISVK $0.01 \% \quad 13.5 \%$ ERLQLECQR $0.01 \% \quad 13.5 \%$ QQEQLRYEQER $0.01 \% \quad 13.5 \%$ DGWGGYGSDKR $0.01 \% \quad 13.5 \%$ GLSGPSGPGHMASR $0.01 \% \quad 26.3 \%$ STLINSLFLTDLYPER $\begin{array}{lll}0.01 \% & 26.3 \% & \text { TVQIEASTVEIEER }\end{array}$ $0.01 \% \quad 26.3 \%$ LTVVDTPGYGDAINCR $0.01 \% \quad 26.3 \%$ TIISYIDEQFER

$0.01 \% \quad 26.3 \%$ VNIVPVIAK

$0.01 \% \quad 26.3 \%$ ILDEIEEHNIK

$0.01 \% \quad 26.3 \%$ ASIPFSVVGSNQLIEAK

$0.00 \% \quad 3.6 \%$ DAGLKQAPASR

$0.00 \% \quad 3.6 \%$ VVNIVPVIAK

$0.01 \% \quad 7.5 \% \quad$ YYGGAEVVDEIELLCQRR

$0.01 \% \quad 7.5 \%$ LIIAGTSAYAR

$0.01 \% \quad 7.5 \%$ SAITPGGLR

$0.00 \% \quad 5.1 \%$ AACFAIQK

$0.00 \% \quad 5.1 \%$ SFVIDHQR

$0.00 \% \quad 5.1 \%$ SIALTQAR

$0.00 \% \quad 9.4 \%$ AVVTHSSGNHGQALTYAAK

$0.00 \% \quad 9.4 \%$ QAERPASYQSVSV

$0.05 \% \quad 7.6 \%$ SSTGPEPPAPTPLLAER

$0.05 \% \quad 7.6 \%$ SLSGSSPCPK

$0.05 \% \quad 7.6 \%$ SSSPVTELASR

$0.05 \% \quad 7.6 \%$ SGSESSVDQKTVAR

$0.05 \% \quad 7.6 \%$ SGSSQELDVKPSASPQER

$0.05 \% \quad 7.6 \%$ SPSVSSPEPAEK

$0.05 \% \quad 7.6 \%$ TAPAANLASR

$0.05 \% \quad 7.6 \%$ IPAASAAAMNLASAR

$0.05 \% \quad 7.6 \%$ TPAIPTAVNLADSR

$0.05 \% \quad 7.6 \%$ TAVAPSAVNLADPR

$46 \quad 0.05 \% \quad 7.6 \%$ TPTAPAVNLAGAR

$0.05 \% \quad 7.6 \%$ SAHATAPVNIAGSR

$0.05 \% \quad 7.6 \%$ TAAALAPASLTSAR $\begin{array}{llllllll}99.5 \% & 23.2 & 25.0 & 18.9 & 1 & 0 & 0 & 1378.67\end{array}$ $\begin{array}{llllllll}99.5 \% & 23.0 & 25.0 & 23.0 & 0 & 1 & 0 & 1593.74\end{array}$

$\begin{array}{llllllll}99.3 \% & 21.7 & 25.0 & 20.1 & 0 & 1 & 0 & 1738.73\end{array}$

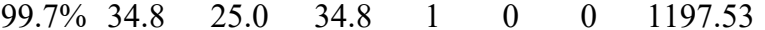

$\begin{array}{llllllll}99.7 \% & 37.1 & 25.0 & 36.5 & 2 & 1 & 0 & 1549.76\end{array}$

$\begin{array}{llllllll}99.7 \% & 33.4 & 25.0 & 26.2 & 1 & 0 & 0 & 1161.62\end{array}$

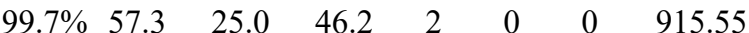

$\begin{array}{lllllllr}99.7 \% & 43.9 & 25.0 & 43.9 & 4 & 0 & 0 & 1320.69\end{array}$

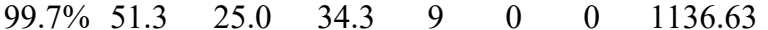

$\begin{array}{llllllll}99.0 \% & 25.9 & 25.0 & 17.3 & 2 & 0 & 0 & 821.49\end{array}$

$\begin{array}{llllllll}98.0 \% & 18.0 & 25.0 & 18.0 & 1 & 0 & 0 & 1113.67\end{array}$

$\begin{array}{llllllll}97.6 \% & 21.8 & 25.0 & 13.0 & 1 & 0 & 0 & 1127.63\end{array}$

$\begin{array}{llllllll}99.7 \% & 33.1 & 25.0 & 27.9 & 2 & 0 & 0 & 1043.61\end{array}$

$\begin{array}{llllllll}99.6 \% & 29.5 & 25.0 & 20.0 & 1 & 0 & 0 & 1231.62\end{array}$

$\begin{array}{llllllll}98.5 \% & 23.0 & 25.0 & 20.5 & 0 & 2 & 0 & 1506.73\end{array}$

$\begin{array}{llllllll}99.7 \% & 34.8 & 25.0 & 34.8 & 1 & 0 & 0 & 1197.53\end{array}$

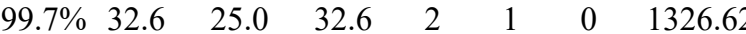

$\begin{array}{llllllll}99.7 \% & 28.0 & 25.0 & 28.0 & 1 & 0 & 0 & 1882.00\end{array}$

$\begin{array}{llllllll}99.7 \% & 66.9 & 25.0 & 61.9 & 1 & 0 & 0 & 1603.82\end{array}$

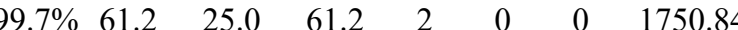

$\begin{array}{llllllll}99.7 \% & 59.0 & 25.0 & 46.4 & 2 & 0 & 0 & 1513.75\end{array}$

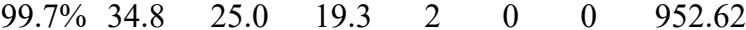

$\begin{array}{llllllll}99.7 \% & 34.4 & 25.0 & 31.0 & 1 & 0 & 0 & 1352.71\end{array}$

$\begin{array}{llllllll}99.7 \% & 54.6 & 25.0 & 48.2 & 2 & 0 & 0 & 1759.96\end{array}$

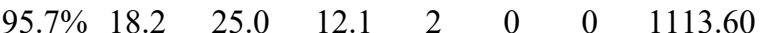

$99.2 \% \quad 19.1 \quad 25.0 \quad 19.1$

$\begin{array}{lllll}99.4 \% & 21.0 & 25.0 & 19.9 & 0\end{array}$

$99.7 \% \quad 52.5 \quad 25.0 \quad 52.5$

$\begin{array}{lllll}98.0 \% & 20.4 & 25.0 & 14.1 & 2\end{array}$

$99.0 \% \quad 27.4 \quad 25.0 \quad 18.5$

$\begin{array}{lllll}99.0 \% & 27.0 & 25.0 & 24.5 & 2\end{array}$

$\begin{array}{lllll}98.1 \% & 28.6 & 25.0 & 4.4 & 2\end{array}$

$95.9 \% \quad 14.4 \quad 25.0 \quad 14.4$

$\begin{array}{llll}99.7 \% & 29.9 & 25.0 & 29.9\end{array}$

$99.7 \% \quad 38.7 \quad 25.0 \quad 32.3$

$99.1 \% \quad 21.0 \quad 25.0 \quad 16.7$

$99.1 \% \quad 23.5 \quad 25.0 \quad 15.1$

$\begin{array}{llll}99.7 \% & 55.2 & 25.0 & 55.2\end{array}$

$\begin{array}{llll}99.7 \% & 56.4 & 25.0 & 56.4\end{array}$

$\begin{array}{lllll}99.7 \% & 28.3 & 25.0 & 20.9 & 4\end{array}$

$\begin{array}{llll}99.7 \% & 32.5 & 25.0 & 30.7 \\ 99.7 \% & 35.7 & 25.0 & 35.7\end{array}$

$\begin{array}{llll}96.9 \% & 17.6 & 25.0 & 16.7\end{array}$

$\begin{array}{llll}99.7 \% & 31.6 & 25.0 & 31.6\end{array}$

$\begin{array}{llll}99.7 \% & 38.2 & 25.0 & 38.2\end{array}$

$\begin{array}{llll}99.7 \% & 29.5 & 25.0 & 29.5\end{array}$

$\begin{array}{llll}99.7 \% & 56.0 & 25.0 & 43.2\end{array}$

1113.60
1051.69

2170.06

1135.65

871.50

908.47

1001.52

859.50

1911.97

1421.70

1719.89

1019.48

1133.58

1450.71

1901.92

1214.59

971.53

1430.74

1425.77

1381.74

1238.69

$\begin{array}{lll}1351.71 & 2343 & 2356\end{array}$

$\begin{array}{lll}2357 & 2370\end{array}$ 
Serine/arginine repetitive matrix protein 2 GN=SRRM2 SRRM2_HUMAN $299.62 \quad 100.0 \%$ Serine/arginine repetitive matrix protein $2 \mathrm{GN}=\mathrm{SRRM} 2 \mathrm{SRRM} 2$ HUMAN $299.62 \quad 100.0 \%$ Serine/arginine-rich splicing factor $1 \mathrm{GN}=$ SRSF1 SRSF1_HUMAN $27.75100 .0 \%$ Serine/arginine-rich splicing factor $1 \mathrm{GN}=\mathrm{SRSF} 1$ SRSF1_HUMAN $27.75 \quad 100.0 \%$ Serine/arginine-rich splicing factor $1 \mathrm{GN}=\mathrm{SRSF} 1$ SRSF1_HUMAN 27.75 Serine/arginine-rich splicing factor $1 \mathrm{GN}=\mathrm{SRSF} 1$ SRSF1_HUMAN 27.75 Serine/arginine-rich splicing factor $1 \mathrm{GN}=\mathrm{SRSF} 1$ SRSF1_HUMAN 27.7 Serine/arginine-rich splicing factor $1 \mathrm{GN}=\mathrm{SRSF} 1$ SRSF1 HUMAN 27.75 Serine/arginine-rich splicing factor $1 \mathrm{GN}=\mathrm{SRSF} 1$ SRSF1_HUMAN 27.75 Serine/arginine-rich splicing factor $1 \mathrm{GN}=$ SRSF1 SRSF1_HUMAN 27.75 Serine/arginine-rich splicing factor $1 \mathrm{GN}=$ SRSF1 SRSF1_HUMAN 27.75 Serine/arginine-rich splicing factor $1 \mathrm{GN}=\mathrm{SRSF} 1$ SRSF1_HUMAN 27.75 Serine/arginine-rich splicing factor $1 \mathrm{GN}=\mathrm{SRSF} 1$ SRSF1 HUMAN 27.7 Serine/arginine-rich splicing factor 1 GN=SRSF1 SRSF1_HUMAN 27.75 Serine/arginine-rich splicing factor $1 \mathrm{GN}=$ SRSF1 SRSF1_HUMAN 27.75 Serine/arginine-rich splicing factor $1 \mathrm{GN}=\mathrm{SRSF} 1$ SRSF1 HUMAN 27.75 Serine/arginine-rich splicing factor $10 \mathrm{GN}=$ SRSF10 SRS10_HUMAN 31.30 Serine/arginine-rich splicing factor $10 \mathrm{GN}=$ SRSF10 SRS10_HUMAN 31.31 Serine/arginine-rich splicing factor $10 \mathrm{GN}=\mathrm{SRSF} 10$ SRS10 HUMAN 31.30 Serine/arginine-rich splicing factor $10 \mathrm{GN}=$ SRSF10 SRS10_HUMAN 31.3 Serine/arginine-rich splicing factor $10 \mathrm{GN}=\mathrm{SRSF} 10$ SRS10 HUMAN 31.3 Serine/arginine-rich splicing factor $2 \mathrm{GN}=\mathrm{SRSF} 2$ SRSF2 HUMAN 25.48 Serine/arginine-rich splicing factor $2 \mathrm{GN}=$ SRSF2 SRSF2_HUMAN 25.48 Serine/arginine-rich splicing factor $2 \mathrm{GN}=\mathrm{SRSF} 2$ SRSF2 HUMAN 25.48 Serine/arginine-rich splicing factor $2 \mathrm{GN}=\mathrm{SRSF} 2$ SRSF2_HUMAN 25.48 Serine/arginine-rich splicing factor $2 \mathrm{GN}=\mathrm{SRSF} 2$ SRSF2_HUMAN 25.4 Serine/arginine-rich splicing factor $5 \mathrm{GN}=$ SRSF5 SRSF5_HUMAN 31.2 Serine/arginine-rich splicing factor 5 GN=SRSF5 SRSF5_HUMAN 31.2 Serine/arginine-rich splicing factor $5 \mathrm{GN}=\mathrm{SRSF} 5$ SRSF5 HUMAN 31.26 Serine/arginine-rich splicing factor $5 \mathrm{GN}=$ SRSF5 SRSF5_HUMAN 31.26 Serine/arginine-rich splicing factor $5 \mathrm{GN}=$ SRSF5 SRSF5_HUMAN 31.26 Serine/arginine-rich splicing factor $6 \mathrm{GN}=\mathrm{SRSF} 6$ SRSF6 HUMAN 39.59 Serine/arginine-rich splicing factor $6 \mathrm{GN}=$ SRSF6 SRSF6_HUMAN 39.59 Serine/arginine-rich splicing factor $6 \mathrm{GN}=$ SRSF6 SRSF6 HUMAN 39.59 Serine/arginine-rich splicing factor $6 \mathrm{GN}=$ SRSF6 SRSF6_HUMAN 39.59 Serine/arginine-rich splicing factor $6 \mathrm{GN}=$ SRSF6 SRSF6_HUMAN 39.59 Serine/arginine-rich splicing factor $6 \mathrm{GN}=\mathrm{SRSF} 6$ SRSF6 HUMAN 39.59 Serine/arginine-rich splicing factor 6 GN=SRSF6 SRSF6_HUMAN 39.59 Serine/arginine-rich splicing factor $6 \mathrm{GN}=$ SRSF6 SRSF6_HUMAN 39.59 Serine/arginine-rich splicing factor $7 \mathrm{GN}=$ SRSF7 SRSF7_HUMAN 27.37 Serine/arginine-rich splicing factor $7 \mathrm{GN}=\mathrm{SRSF} 7$ SRSF7_HUMAN 27.37 Serine/arginine-rich splicing factor $7 \mathrm{GN}=$ SRSF7 SRSF7_HUMAN 27.37 Serine/arginine-rich splicing factor $7 \mathrm{GN}=$ SRSF7 SRSF7_HUMAN 27.37 Serine/arginine-rich splicing factor $7 \mathrm{GN}=$ SRSF7 SRSF7_HUMAN 27.37 Serine/arginine-rich splicing factor $7 \mathrm{GN}=\mathrm{SRSF} 7$ SRSF7_HUMAN 27.37 Serine/arginine-rich splicing factor $7 \mathrm{GN}=$ SRSF7 SRSF7_HUMAN 27.37
$100.0 \%$

$100.0 \%$ $100.0 \%$ $100.0 \%$ $100.0 \%$ $100.0 \%$ $100.0 \%$ $100.0 \%$ $100.0 \%$ $100.0 \%$ $100.0 \%$ $100.0 \%$ $100.0 \%$ $100.0 \%$ $100.0 \%$ $100.0 \%$ $100.0 \%$ $100.0 \%$ $100.0 \%$ $100.0 \%$ $100.0 \%$ $100.0 \%$ $100.0 \%$ $100.0 \%$ $100.0 \%$ $100.0 \%$ $100.0 \%$ $100.0 \%$ $100.0 \%$ $100.0 \%$ $100.0 \%$ $100.0 \%$ $100.0 \%$ $100.0 \%$ $100.0 \%$ $100.0 \%$ $100.0 \%$ $100.0 \%$ $100.0 \%$ $100.0 \%$ $100.0 \%$ $100.0 \%$
$16 \quad 46 \quad 0.05 \% \quad 7.6 \%$ MAPALSGANLTSPR $99.5 \% \quad 25.6$ $99.0 \% \quad 25.4$ $99.5 \% \quad 24.7$ $99.7 \% \quad 55.5$ $99.7 \% 58$. $99.6 \% \quad 28.2$

$\begin{array}{ll}99.7 \% & 27.3 \\ 99.7 \% & 35.4\end{array}$

$0.06 \% \quad 50.0 \%$ TKDIEDVFYK $0.06 \% \quad 50.0 \%$ YGAIRDIDLK

$0.06 \% \quad 50.0 \%$ GGPPFAFVEFEDPR $99.7 \% \quad 49.4$ $99.7 \% \quad 43.3$ $0.06 \% \quad 50.0 \%$ DAEDAVYGR

$0.06 \% \quad 50.0 \%$ DGYDYDGYR

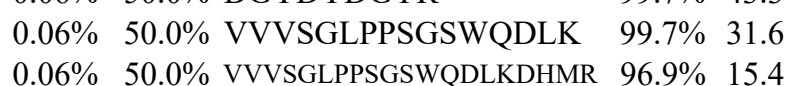

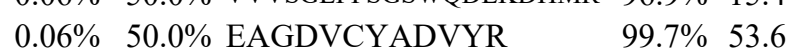
$0.06 \% \quad 50.0 \%$ EAGDVCYADVYRDGTGVVEFVR $99.7 \% \quad 60.1$ $99.7 \% 058$ $99.7 \% \quad 60.6$ $99.7 \% \quad 51.6$ $99.7 \% \quad 30.5$ $99.7 \% 53.3$ $99.7 \% \quad 45.4$ $99.7 \% \quad 62.0$ $99.7 \% 59.6$

$99.0 \% \quad 26.9$ $99.0 \% \quad 67.7$ $0.06 \% \quad 50.0 \%$ KEDMTYAVR 50.0\% SHEGETAYIR $0.02 \% \quad 19.5 \%$ YGPIVDVYVPLD $0.02 \% \quad 19.5 \%$ GFAYVQFEDVR $0.02 \% \quad 19.5 \%$ QIEIQFAQGDR $0.02 \% \quad 19.5 \%$ QIEIQFAQGDRK $0.02 \% \quad 24.0 \%$ TSPDTLRR $0.02 \% \quad 24.0 \%$ VGDVYIPR $99.7 \%$ $\begin{array}{lllll}0.02 \% & 24.0 \% & \text { DAEDAMDAMDGAVLDGR } & 99.7 \% & 44.7 \\ 0.02 \% & 24.0 \% & \text { YGRPPDSHHSR } & 99.7 \% & 39.5\end{array}$ $0.02 \% \quad 24.0 \%$ RYGGGGYGR $0.01 \% \quad 21.3 \%$ GFGFVEFEDPR $0.01 \% \quad 21.3 \%$ LIVENLSSR $0.01 \% \quad 21.3 \%$ QAGEVTFADAHRPK $0.01 \% \quad 21.3 \%$ LNEGVVEFASYGDLK $0.01 \% \quad 21.3 \%$ SKSPASVDR $0.05 \% \quad 20.3 \%$ DRDGYSYGSR $0.05 \% \quad 20.3 \%$ TEYRLIVENLSSR $0.05 \% \quad 20.3 \%$ LIVENLSSR

$0.05 \% \quad 20.3 \%$ QAGEVTYADAHK $0.05 \% \quad 20.3 \%$ QAGEVTYADAHKER $99.7 \% \quad 37.2$ $99.6 \% \quad 29.4$ $99.7 \% \quad 60.2$ $99.7 \% \quad 43.4$ $99.7 \% \quad 61.3$ $95.3 \% \quad 23.0$ $99.7 \% 28.1$ $99.7 \% \quad 35.9$ $99.7 \% \quad 60.2$ $99.7 \% \quad 41.2$ $99.7 \% \quad 51.8$ $99.7 \% \quad 62.8$ $99.7 \% \quad 56.9$ $99.7 \% \quad 34.8$ $99.7 \% \quad 65.9$

$0.05 \% \quad 20.3 \%$ ALDKLDGTEINGR $0.05 \% \quad 20.3 \%$ SNSPLPVPPSK

$0.05 \% \quad 34.5 \%$ VYVGNLGTGAGK $99.7 \% \quad 58.3$ $99.7 \% \quad 49.1$ $\begin{array}{ll}99.7 \% & 47.3 \\ 99.6 \% & 29.4\end{array}$ $0.05 \% \quad 34.5 \%$ AFSYYGPLR

$0.05 \% \quad 34.5 \%$ NPPGFAFVEFEDPR

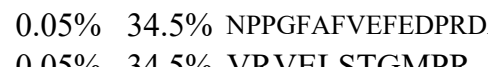
$99.7 \% \quad 41.2$ $99.7 \% \quad 44.7$ $0.05 \% \quad 34.5 \%$ VELSTGMPR
934.50

1277.6

24492460

163.64

1564.74

2541.17

995.44

1123.43

1668.90

2224.12

1417.6

2477.14

1078.55

1112.54

1162.55

1462.82

1916.98

1330.64

1304.66

1432.75

945.51

918.50

1751.72

1308.62

942.45

1299.60

1030.59

1526.77

1640.82

946.50

1175.5

1579.84

1030.59

1289.61

1574.76

1064.54

1401.73

1122.62

1135.6

1719.90

1073.54

1621.76

2378.10

244.68 

Serine/arginine-rich splicing factor 9 GN=SRSF9 SRSF9_HUMAN $25.54 \quad 100.0 \%$ Serine/arginine-rich splicing factor $9 \mathrm{GN}=\mathrm{SRSF} 9$ SRSF9 HUMAN $25.54 \quad 100.0 \%$ Serine/arginine-rich splicing factor 9 GN=SRSF9 SRSF9_HUMAN $25.54 \quad 100.0 \%$ Serine/arginine-rich splicing factor 9 GN=SRSF9 SRSF9_HUMAN $25.54 \quad 100.0 \%$ Serine/threonine-protein kinase $38 \mathrm{GN}=$ STK38 STK38_HUMAN $54.19 \quad 100.0 \%$ Serine/threonine-protein kinase 38 GN=STK38 STK38_HUMAN $54.19 \quad 100.0 \%$ Serine/threonine-protein kinase 38 GN=STK38 STK38_HUMAN $54.19 \quad 100.0 \%$ Serine/threonine-protein kinase 38 GN=STK38 STK38_HUMAN $54.19 \quad 100.0 \%$ Serine/threonine-protein kinase 38 GN=STK38 STK38_HUMAN $54.19 \quad 100.0 \%$ Serine/threonine-protein kinase 38-like GN=STK38L ST38L_HUMAN $54.01 \quad 100.0 \%$ Serine/threonine-protein kinase 38-like GN=STK38L ST38L_HUMAN $54.01 \quad 100.0 \%$ Serine/threonine-protein kinase 38-like GN=STK38L ST38L_HUMAN $54.01 \quad 100.0 \%$ Serine/threonine-protein kinase 38-like GN=STK38L ST38L_HUMAN $54.01 \quad 100.0 \%$ Serine/threonine-protein kinase 38-like GN=STK38L ST38L_HUMAN $54.01 \quad 100.0 \%$ Serine/threonine-protein kinase 38-like GN=STK38L ST38L_HUMAN $54.01 \quad 100.0 \%$ Serine/threonine-protein kinase 38-like GN=STK38L ST38L_HUMAN $54.01 \quad 100.0 \%$ Serine/threonine-protein kinase 38-like GN=STK38L ST38L_HUMAN $54.01 \quad 100.0 \%$ Serine/threonine-protein kinase 38-like GN=STK38L ST38L HUMAN $54.01 \quad 100.0 \%$ Serine/threonine-protein kinase 38-like GN=STK38L ST38L_HUMAN $54.01 \quad 100.0 \%$ Serine/threonine-protein kinase 38-like GN=STK38L ST38L_HUMAN $54.01 \quad 100.0 \%$ Serine/threonine-protein kinase 38-like GN=STK38L ST38L_HUMAN $54.01 \quad 100.0 \%$ Serine/threonine-protein kinase 38-like GN=STK38L ST38L_HUMAN $54.01 \quad 100.0 \%$ Serine/threonine-protein kinase 38-like GN=STK38L ST38L HUMAN $54.01 \quad 100.0 \%$ Serine/threonine-protein kinase 4 GN=STK4 STK4_HUMAN $55.63 \quad 100.0 \%$ Serine/threonine-protein kinase $4 \mathrm{GN}=\mathrm{STK} 4$ STK4_HUMAN $55.63 \quad 100.0 \%$ Serine/threonine-protein kinase ATR GN=ATR ATR HUMAN $301.37 \quad 100.0 \%$ Serine/threonine-protein kinase ATR GN=ATR ATR_HUMAN $301.37 \quad 100.0 \%$ Serine/threonine-protein kinase ATR GN=ATR ATR HUMAN $301.37 \quad 100.0 \%$ Serine/threonine-protein kinase ATR GN=ATR ATR_HUMAN $301.37 \quad 100.0 \%$ Serine/threonine-protein kinase ATR GN=ATR ATR_HUMAN $301.37 \quad 100.0 \%$ Serine/threonine-protein kinase ATR GN=ATR ATR_HUMAN $301.37 \quad 100.0 \%$ Serine/threonine-protein kinase haspin GN=GSG2 HASP_HUMAN $88.50 \quad 100.0 \%$ Serine/threonine-protein kinase haspin GN=GSG2 HASP_HUMAN $88.50 \quad 100.0 \%$ Serine/threonine-protein kinase MRCK alpha GN=CDC42BPA MRCKA_HUMAN $197.31 \quad 100.0 \%$ Serine/threonine-protein kinase MRCK alpha GN=CDC42BPA MRCKA_HUMAN $197.31 \quad 100.0 \%$ Serine/threonine-protein kinase mTOR GN=MTOR MTOR HUMAN $288.90 \quad 100.0 \%$ Serine/threonine-protein kinase mTOR GN=MTOR MTOR_HUMAN $288.90 \quad 100.0 \%$ Serine/threonine-protein kinase mTOR GN=MTOR MTOR_HUMAN $288.90 \quad 100.0 \%$ Serine/threonine-protein kinase mTOR GN=MTOR MTOR_HUMAN $288.90 \quad 100.0 \%$ Serine/threonine-protein kinase mTOR GN=MTOR MTOR_HUMAN $288.90 \quad 100.0 \%$

$\begin{array}{llll}13 & 47 & 0.05 \% & 34.5 \% \\ 13 & 47 & 0.05 \% & \text { RPFDPNDR }\end{array}$

(1)

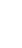

9

9
9
9
9
3

(1)

3

3
3

3

14

$\begin{array}{ll}16 \\ 4 & 16 \\ 14 & 16\end{array}$

$\begin{array}{llll}16 & 29 & 0.03 \% & 23.1 \% \\ 16 & 29 & 0.03 \% & 23.1 \% \text { LGLDDFESLK } \\ 16 & 29 & 0.03 \% & 23.1 \%\end{array}$

$\begin{array}{llll}16 & 29 & 0.03 \% & 23.1 \% \\ 16 & 29 & 0.03 \% & 23.1 \% \\ \end{array}$

$\begin{array}{llll}16 & 29 & 0.03 \% & 23.1 \% \\ 16 & 29 & 0.03 \% & 23.1 \%\end{array}$

\begin{tabular}{llll}
16 & 29 & $0.03 \%$ & $23.1 \%$ \\
16 & 29 & $0.03 \%$ & $23.1 \%$ \\
\hline
\end{tabular}

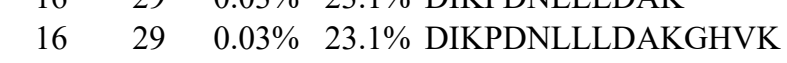

$\begin{array}{llll}16 & 29 & 0.03 \% & 23.1 \% \\ 16 & \text { LSDFGLCTGLK }\end{array}$

$\begin{array}{lllll}16 & 29 & 0.03 \% & 23.1 \% & \text { LSDFGLCTGLKK }\end{array}$

$\begin{array}{llll}16 & 29 & 0.03 \% & 23.1 \% \\ 16 & 29 & 0.03 \% & 23.1 \% \text { NLTHNPPSDFSFQNMNSK } \\ 16 & 29 & 0.03 \% & 23.1 \%\end{array}$

$\begin{array}{lllll}16 & 29 & 0.03 \% & 23.1 \% & \text { NLTHNPPSDFSF } \\ 16 & 29 & 0.03 \% & 23.1 \% \text { FCIDSENR }\end{array}$

$\begin{array}{llll}16 & 29 & 0.03 \% & 23.1 \% \\ 16 & \text { ERPAAIPIEIK }\end{array}$

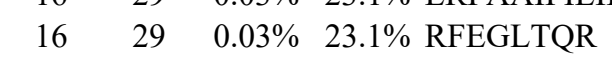

$\begin{array}{llll}16 & 29 & 0.03 \% & 23.1 \% \text { GSIPTYMK }\end{array}$

$3 \quad 0.00 \% \quad 5.3 \%$ AGNILLNTEGHAK

$0.00 \% \quad 5.3 \%$ ATATQLLQHPFVR

$0.01 \% \quad 2.3 \%$ ISDSYSPQAQSR

$\begin{array}{llll}0.01 \% & 2.3 \% & \text { TLQVLLPDLAAK }\end{array}$

$11 \quad 0.01 \% \quad 2.3 \% \quad$ ASPAASALIR

$1 \quad 0.01 \% \quad 2.3 \% \quad$ AYLAYADNSR

$11 \quad 0.01 \% \quad 2.3 \%$ LGQLLLSAK

$11 \quad 0.01 \% \quad 2.3 \%$ LAELYVER

$0.00 \% \quad 2.5 \%$ DRPSLTVTPK

$\begin{array}{lll}0.00 \% & 2.5 \% & \text { ARPSLTVTPR }\end{array}$

$0.00 \% \quad 1.6 \%$ VTAGPTSLDLDVNVQR

$0.00 \% \quad 1.6 \%$ GIGTAYEGHVR

$0.02 \% \quad 3.3 \% \quad$ VNIGMIDQSR

$0.02 \% \quad 3.3 \%$ DASAVSLSESK

$0.02 \% \quad 3.3 \%$ TLDQSPELR

$0.02 \% \quad 3.3 \% \quad$ LHVSTINLQK

$0.02 \% \quad 3.3 \%$ TLVLLLGVDPSR $\begin{array}{llllllll}99.0 \% & 25.9 & 25.0 & 17.6 & 2 & 0 & 0 & 1016.49\end{array}$

$\begin{array}{llllllll}98.5 \% & 19.7 & 25.0 & 19.5 & 0 & 1 & 0 & 1942.82\end{array}$

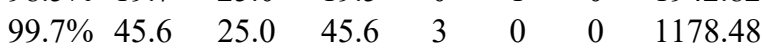

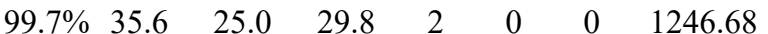

$\begin{array}{llllllll}99.7 \% & 32.9 & 25.0 & 32.9 & 4 & 0 & 0 & 1142.65\end{array}$

$\begin{array}{llllllll}99.5 \% & 21.4 & 25.0 & 18.4 & 0 & 1 & 0 & 1653.75\end{array}$

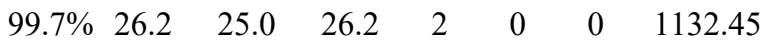

$\begin{array}{llllllll}99.7 \% & 38.2 & 25.0 & 38.2 & 1 & 0 & 0 & 1354.59\end{array}$

$\begin{array}{llllllll}99.7 \% & 35.9 & 25.0 & 35.9 & 2 & 0 & 0 & 1178.54\end{array}$

$\begin{array}{llllllll}99.3 \% & 18.7 & 25.0 & 18.7 & 0 & 1 & 0 & 1822.87\end{array}$

$\begin{array}{llllllll}99.7 \% & 42.1 & 25.0 & 41.4 & 4 & 2 & 0 & 1454.69\end{array}$

$\begin{array}{llllllll}99.4 \% & 21.1 & 25.0 & 20.5 & 0 & 2 & 0 & 1575.87\end{array}$

1792.00

$\begin{array}{llllllll}99.7 \% & 62.9 & 25.0 & 56.1 & 3 & 0 & 0 & 1210.61 \\ 99.7 \% & 52.7 & 25.0 & 47.6 & 2 & 0 & 0 & 1338.71\end{array}$

$\begin{array}{cccccccc}99.7 \% & 52.7 & 25.0 & 47.6 & 2 & 0 & 0 & 1338.71 \\ 99.0 \% & 40.3 & 25.0 & 33.3 & 2 & 0 & 0 & 949.52\end{array}$

$\begin{array}{llllllll}99.7 \% & 53.2 & 25.0 & 48.0 & 1 & 0 & 0 & 1393.73\end{array}$

$\begin{array}{llllllll}99.7 \% & 46.9 & 25.0 & 46.9 & 2 & 0 & 0 & 1136.58\end{array}$

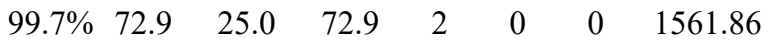

$\begin{array}{llllllll}99.7 \% & 31.5 & 25.0 & 24.1 & 3 & 0 & 0 & 1035.49\end{array}$

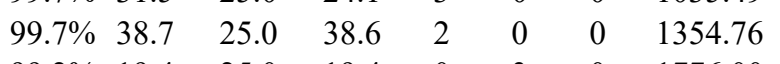

$\begin{array}{llllllll}99.2 \% & 19.4 & 25.0 & 19.4 & 0 & 3 & 0 & 1776.00\end{array}$

$\begin{array}{llllllll}99.7 \% & 62.9 & 25.0 & 56.1 & 3 & 0 & 0 & 1210.61\end{array}$

$\begin{array}{llllllll}99.7 \% & 52.7 & 25.0 & 47.6 & 2 & 0 & 0 & 1338.71\end{array}$

2077.94

2250.04

1040.45

1236.73

1006.54

896.45

1337.72

1481.82

1338.63

1281.78

956.55

1143.54

942.60

992.54

1113.63

1097.64

1684.89

1159.59

1132.58

1093.54

1058.55

1152.67

$\begin{array}{llll}99.7 \% & 31.2 & 25.0 & 28.0\end{array}$

$\begin{array}{llll}99.7 \% & 59.4 & 25.0 & 52.7\end{array}$
Page 150 of Table S-1-4 


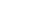

16

16

16

$\begin{array}{ll}2 & 16 \\ 2 & 16 \\ 2 & 16\end{array}$

2

12
12
3

2

3
3
3

3

6
6

6
6
6

2

5
5
5
11

5
11
11
11

11

11
11
11

11
11
11

11
9

9
9
9

$9 \quad 11$

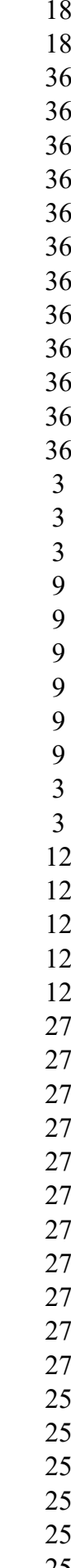
$0.02 \% \quad 3.3 \%$ IQSIAPSLQVITSK

$0.04 \% \quad 23.9 \%$ MSTPADKVLR

$0.04 \% \quad 23.9 \%$ ATVEQVLDPR

$0.04 \% \quad 23.9 \%$ GIITEINGCISTGK

$0.04 \% \quad 23.9 \%$ EANVYHASTANGESR

$0.04 \% \quad 23.9 \%$ LNTAEIPCPEPIMLR

$0.04 \% \quad 23.9 \%$ NVQLSESKAR

$0.04 \% \quad 23.9 \%$ ELYLQVIQYMR

$0.04 \% \quad 23.9 \%$ DCANVNDFFMR

$0.04 \% 23.9 \%$ HSVAVMTVR

$0.04 \% \quad 23.9 \%$ AMEIASQR

$0.04 \% \quad 23.9 \%$ SSQDHVDEEVFKR

$0.04 \% \quad 23.9 \%$ TLNEVKNYER

$0.00 \% \quad 0.9 \%$ VGLLAGQPAVTVR

$0.00 \% \quad 0.9 \%$ SIEVQLLR

$0.00 \% \quad 0.9 \% \quad$ KVVDNASQGEGVR

$0.01 \% \quad 12.6 \%$ LSTIALALGVER

$0.01 \% \quad 12.6 \%$ LAGGDWFTSR

$0.01 \% \quad 12.6 \%$ VSSAVKAELR

$0.01 \% \quad 12.6 \%$ YMVADKFTELQK

$0.01 \% \quad 12.6 \%$ MAGDPVANVR

$0.01 \% \quad 12.6 \%$ IGPILDNSTLQSEVKPILEK

$0.00 \% \quad 6.2 \%$ ESNVQEVR

$0.00 \% \quad 6.2 \% \quad$ YSFLQFDPAPR

$0.01 \% \quad 22.6 \%$ APLDLDKYVEIAR

$0.01 \% \quad 22.6 \%$ TGGQVPDTNYIFMGDFVDR

$\begin{array}{ll}0.01 \% & 22.6 \% \\ 0.01 \% & 22.6 \% \text { VTNQVFVHFINNLK }\end{array}$

$0.01 \% 22.6 \%$ AHQLVHEGYK

$0.03 \% \quad 45.0 \%$ QALQLAaCGLaGGSAaVlFsaVAVGKrR

$0.03 \% \quad 45.0 \%$ NVESGEEELASK

$\begin{array}{lllll}0.03 \% & 45.0 \% & \text { NVESGEEELASKLDHYK } & 99.7 \% & 52.4\end{array}$

$0.03 \% \quad 45.0 \%$ HSQYHVDGSLEKDR

$0.03 \% \quad 45.0 \%$ EQAELTGLR

$0.03 \% \quad 45.0 \%$ IVHSSMTR

$0.03 \% \quad 45.0 \%$ AIETTDIISR

$0.03 \% \quad 45.0 \%$ ADARQEEDSYEIFICHANVIR

$0.03 \% \quad 45.0 \%$ QEEDSYEIFICHANVIR

$0.03 \% \quad 45.0 \%$ ALQFPPEGWLR

$0.03 \% \quad 45.0 \%$ TLGDTGFMPPDK

$0.02 \% \quad 32.7 \%$ ICGDIHGQYYDLLR

$0.02 \% \quad 32.7 \%$ QSLETICLLLAYK

$0.02 \% \quad 32.7 \%$ IKYPENFFLLR

$0.02 \% 32.7 \%$ GNHECASINR

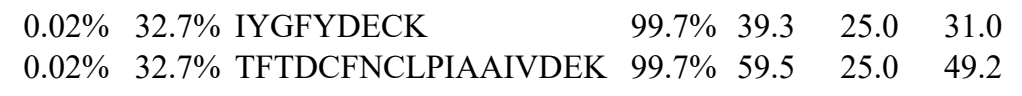

$\begin{array}{llll}96.3 \% & 23.4 & 25.0 & 23.4 \\ 99.7 \% & 51.5 & 25.0 & 38.3\end{array}$

$99.7 \% \quad 39.9 \quad 25.0 \quad 32.0$

$\begin{array}{llll}99.7 \% & 43.2 & 25.0 & 40.7\end{array}$

$99.7 \% \quad 45.3 \quad 25.0 \quad 45.3$

$99.7 \% \quad 51.0 \quad 25.0 \quad 51.0$

$\begin{array}{llll}99.7 \% & 43.3 & 25.0 & 31.7\end{array}$

$99.7 \% \quad 36.8 \quad 25.0 \quad 29.3$

$\begin{array}{llll}99.7 \% & 50.5 & 25.0 & 50.5\end{array}$

$\begin{array}{llll}99.7 \% & 52.5 & 25.0 & 52.5\end{array}$

$\begin{array}{llll}95.7 \% & 16.2 & 25.0 & 15.1\end{array}$

$\begin{array}{llll}99.0 \% & 45.7 & 25.0 & 19.1\end{array}$

$\begin{array}{llll}99.7 \% & 57.7 & 25.0 & 53.1\end{array}$

$\begin{array}{llll}99.7 \% & 38.9 & 25.0 & 38.9\end{array}$

$\begin{array}{llll}99.2 \% & 18.3 & 25.0 & 18.3\end{array}$

$\begin{array}{llll}99.0 \% & 28.6 & 25.0 & 11.7\end{array}$

$\begin{array}{lllll}99.7 \% & 31.0 & 25.0 & 27.5\end{array}$

$\begin{array}{llll}99.7 \% & 58.0 & 25.0 & 52.4\end{array}$

$\begin{array}{llll}99.7 \% & 54.7 & 25.0 & 53.5\end{array}$

$\begin{array}{llll}99.6 \% & 36.4 & 25.0 & 14.2\end{array}$

$\begin{array}{llll}99.7 \% & 44.2 & 25.0 & 44.2\end{array}$

$\begin{array}{llll}99.7 \% & 43.0 & 25.0 & 35.0\end{array}$

$99.0 \% \quad 22.2$

$99.0 \% \quad 32.3$

$99.7 \% 51.5$

$\begin{array}{lll}99.7 \% & 74.6\end{array}$

$99.7 \% \quad 45.5$

$\begin{array}{llllll}99.7 \% & 64.9\end{array}$

$99.7 \% \quad 44.6$

$\begin{array}{ll}99.7 \% & 64.0 \\ 99.7 \% & 52.4\end{array}$

$\begin{array}{lll}99.7 \% & 27.3 \\ 96.3 \% & 19.2\end{array}$

$\begin{array}{llll}99.7 \% & 52.0 & 2 \\ & & \end{array}$

$99.0 \% \quad 27.0$

\begin{tabular}{llll}
$99.7 \%$ & 54.8 \\
\hline
\end{tabular}

$\begin{array}{lll}99.7 \% & 36.2 \\ 99.7 \% & 37.9\end{array}$

$\begin{array}{lll}99.5 \% & 22.5 \\ 99.7 \% & 37.8 & 2\end{array}$

\begin{tabular}{lllll}
$99.7 \%$ & 37.8 & 25.0 & 19.8 \\
\hline $9.7 \%$ & 2.0 & 31.3
\end{tabular}

$\begin{array}{llll}99.2 \% & 19.6 & 25.0 & 19.2\end{array}$

$\begin{array}{llll}99.7 \% & 49.2 & 25.0 & 47.6\end{array}$

$\begin{array}{llll}98.9 \% & 17.8 & 25.0 & 17.8\end{array}$

$\begin{array}{llll}99.6 \% & 29.0 & 25.0 & 24.0\end{array}$

$\begin{array}{llll}99.7 \% & 39.3 & 25.0 & 31.0\end{array}$ $\begin{array}{ccc}2011.05 & 2135 & 2152 \\ 1484.87 & 2153 & 2166 \\ 1133.60 & 105 & 114 \\ 1127.61 & 156 & 165 \\ 1462.76 & 177 & 190 \\ 1605.73 & 191 & 205 \\ 1753.90 & 257 & 271 \\ 1131.61 & 292 & 301 \\ 1455.77 & 302 & 312 \\ 1388.57 & 360 & 370 \\ 1015.54 & 371 & 379 \\ 905.45 & 402 & 409 \\ 1575.74 & 415 & 427 \\ 1265.65 & 433 & 442 \\ 1280.77 & 1037 & 1049 \\ 957.57 & 1288 & 1295 \\ 1358.70 & 1632 & 1644 \\ 1242.74 & 35 & 46 \\ 1109.54 & 135 & 144 \\ 1059.62 & 158 & 167 \\ 1472.75 & 261 & 272 \\ 1045.51 & 528 & 537 \\ 2194.23 & 547 & 566 \\ 960.47 & 42 & 49 \\ 1340.66 & 284 & 294 \\ 1502.82 & 2 & 14 \\ 2131.98 & 67 & 85 \\ 1879.85 & 118 & 132 \\ 1427.76 & 220 & 231 \\ 1181.61 & 236 & 245 \\ 2683.47 & 5 & 32 \\ 1291.60 & 77 & 88 \\ 1947.93 & 77 & 93 \\ 1670.79 & 105 & 118 \\ 1016.54 & 126 & 134 \\ 930.48 & 145 & 152 \\ 1118.61 & 153 & 162 \\ 2536.19 & 215 & 235 \\ 2122.99 & 219 & 235 \\ 1313.70 & 241 & 251 \\ 1278.60 & 274 & 285 \\ 1722.83 & 61 & 74 \\ 1551.85 & 99 & 111 \\ 1439.80 & 112 & 122 \\ 1157.51 & 123 & 132 \\ 1194.51 & 133 & 141 \\ 2113.99 & 151 & 168 \\ & & \end{array}$

Page 151 of Table S-1-4 
Serum albumin $\mathrm{GN}=\mathrm{ALB}$

Serum albumin $\mathrm{GN}=\mathrm{ALB}$

Serum albumin $\mathrm{GN}=\mathrm{ALB}$

Serum albumin $\mathrm{GN}=\mathrm{ALB}$

Serum albumin $\mathrm{GN}=\mathrm{ALB}$

Serum albumin $\mathrm{GN}=\mathrm{ALB}$

$0.01 \% \quad 39.4 \%$ IKYPENFFLLR

$0.01 \% \quad 39.4 \%$ GNHECASINR

$99.7 \% \quad 49.2$

$0.01 \% \quad 39.4 \%$ TFTDCFNCLPIAAIVDEK

$0.01 \% \quad 39.4 \%$ GVSFTFGADVVSK

$99.7 \% \quad 59.5$

$0.01 \% 39.4 \%$ AHQVVEDGYEFFAK

$99.7 \% 52.9$

$0.01 \% 39.4 \%$ AHQVVEDGYEFFAKR

$99.7 \% \quad 37.3$

$96.3 \% \quad 15.2$

$0.00 \% \quad 0.7 \% \quad$ LVVNLLQLSK

$0.00 \% \quad 0.7 \% \quad$ ILPTPETVPFR

$0.02 \% \quad 36.9 \%$ AATAAADFTAK

$\begin{array}{llll}99.1 \% & 18.1 & 25.0 & 18.1\end{array}$

$0.02 \% \quad 36.9 \%$ TVDFTQDSNYLLTGGQDK

$99.7 \% 46.8$

$0.02 \% \quad 36.9 \%$ IYDLNKPEAEPK

$0.02 \% \quad 36.9 \%$ SIAFHSAVSLDPIK

$0.02 \% 36.9 \%$ CVLPEEDSGELAKPK

$0.00 \% \quad 4.7 \%$ TDYTLSIANR

$0.00 \% \quad 4.7 \%$ TQTILFYGR

$0.00 \% \quad 5.1 \%$ ETRVDLHLPR

$0.00 \% \quad 5.1 \%$ GLVLSGVLHK

$0.03 \% \quad 24.2 \%$ KPAAAAAPGTAEK

$0.03 \% 24.2 \%$ SAGLAFSLYQAMAK

$0.03 \% \quad 24.2 \%$ LYGPSSVSFADDFVR

$0.03 \% 24.2 \%$ LLTKEQLK

$0.03 \% \quad 24.2 \%$ GVVEVTHDLQK

$0.03 \% 24.2 \%$ HLAGLGLTEAIDKNK

$0.03 \% \quad 24.2 \%$ LFYADHPFIFLVR

$27 \quad 0.03 \% \quad 24.2 \%$ DTQSGSLLFIGR

$10 \quad 120 \quad 0.12 \% \quad 13.6 \%$ LVNEVTEFAK

$\begin{array}{llll}10 & 120 & 0.12 \% & 13.6 \% \\ & 10 & \text { CASLQKFGER }\end{array}$

$\begin{array}{llll}10 & 120 & 0.12 \% & 13.6 \% \\ 10 & 120 & 0.12 \% & \text { AEFAEVSK }\end{array}$

$\begin{array}{llll}10 & 120 & 0.12 \% & 13.6 \%\end{array}$ YICENQDSISSK

$\begin{array}{llll}10 & 120 & 0.12 \% & 13.6 \% \text { FQNALLVR }\end{array}$

$\begin{array}{llll}10 & 120 & 0.12 \% & 13.6 \% \text { KVPQVSTPTLVEVSR }\end{array}$

$\begin{array}{llll}10 & 120 & 0.12 \% & 13.6 \% \\ 10 & \text { VPQVSTPTLVEVSR }\end{array}$

$\begin{array}{llll}10 & 120 & 0.12 \% & 13.6 \% \\ 10 & \text { CCTESLVNR }\end{array}$

$\begin{array}{llll}10 & 120 & 0.12 \% & 13.6 \% \\ & 4 & 0.00 \% & 4.8 \%\end{array}$

$0.00 \% \quad 4.8 \%$ GPSAFIPVEEVLR

$\begin{array}{ccc}1639.78 & 247 & 260 \\ 1795.88 & 247 & 261 \\ 1914.00 & 306 & 323 \\ 1175.61 & 26 & 35 \\ 1660.81 & 60 & 73 \\ 1551.85 & 98 & 110 \\ 1439.80 & 111 & 121 \\ 1157.51 & 122 & 131 \\ 1194.51 & 132 & 140 \\ 2113.99 & 150 & 167 \\ 1313.67 & 221 & 233 \\ 1639.78 & 246 & 259 \\ 1795.88 & 246 & 260 \\ 1761.90 & 304 & 319 \\ 1126.72 & 1647 & 1656 \\ 1269.72 & 2899 & 2909 \\ 1037.53 & 74 & 84 \\ 2001.94 & 105 & 122 \\ 1416.74 & 126 & 137 \\ 1484.81 & 205 & 218 \\ 1798.90 & 219 & 235 \\ 1211.59 & 236 & 246 \\ 1596.67 & 250 & 262 \\ 1900.86 & 273 & 290 \\ 1671.83 & 305 & 319 \\ 1153.58 & 108 & 117 \\ 1098.59 & 393 & 401 \\ 1235.69 & 277 & 286 \\ 1022.64 & 322 & 331 \\ 1182.65 & 23 & 35 \\ 1457.75 & 47 & 60 \\ 1659.80 & 134 & 148 \\ 972.61 & 284 & 291 \\ 1224.66 & 309 & 319 \\ 1579.88 & 320 & 334 \\ 1637.88 & 381 & 393 \\ 1293.68 & 394 & 405 \\ 1149.62 & 66 & 75 \\ 1195.59 & 224 & 233 \\ 880.44 & 250 & 257 \\ 1443.64 & 287 & 298 \\ 960.56 & 427 & 434 \\ 1639.94 & 438 & 452 \\ 1511.84 & 439 & 452 \\ 1138.50 & 500 & 508 \\ 1013.60 & 599 & 609 \\ 1413.77 & 43 & 55 \\ & & \end{array}$ 
$\begin{array}{llllll}100.0 \% & 12 & 14 & 26 & 0.03 \% & 33.6 \% \text { VGSFCLSEAGAGSD } \\ 100.0 \% & 12 & 14 & 26 & 0.03 \% & 33.6 \% \text { GITSFLVDR } \\ 100.0 \% & 12 & 14 & 26 & 0.03 \% & 33.6 \% \text { ASSTCPLTFENVK }\end{array}$

$\begin{array}{lllll}\text { Short branched chain specific ayl-COA dehydrogenase, mitochondrial GN=ACADSB } & \text { ACDSB_HUMAN } & 47.49 & 100.0 \% & 12 \\ \text { Shorttbranched chain specific acyl-CoA dehydrogenase, mitochondrial GN=ACADSB } & \text { ACDSB_HUMAN } & 47.49 & 100.0 \% & 12\end{array}$

Sideroflexin- $1 \mathrm{GN}=\mathrm{SFXN1}$

Sideroflexin-1 GN=SFXN1

Sideroflexin-1 GN=SFXN1

Sideroflexin $-1 \mathrm{GN}=\mathrm{SFXN1}$

Sideroflexin-1 GN=SFXN1

Sideroflexin-1 GN=SFXN1

Sideroflexin-1 GN=SFXN1

Sideroflexin-1 GN=SFXN1

Sideroflexin-1 GN=SFXN1

Sideroflexin-1 GN=SFXN1

Sideroflexin-1 GN=SFXN1

Sideroflexin-2 GN=SFXN2

Sideroflexin-2 GN=SFXN2

Sideroflexin-4 GN=SFXN4

Sideroflexin- 4 GN=SFXN4

Sideroflexin-4 GN=SFXN4

Sideroflexin- 4 GN=SFXN4

Sideroflexin-4 GN=SFXN4

Sideroflexin-4 GN=SFXN4

Signal recognition particle receptor sub

Signal recognition particle receptor subunit beta GN=SRPRB SRPRB_HUMAN $29.70 \quad 100.0 \%$ Signal recognition particle receptor subunit beta GN=SRPRB SRPRB HUMAN $29.70 \quad 100.0 \%$ Signal recognition particle receptor subunit beta GN=SRPRB SRPRB_HUMAN $29.70 \quad 100.0 \%$ Signal recognition particle receptor subunit beta GN=SRPRB SRPRB_HUMAN $29.70 \quad 100.0 \%$ Signal recognition particle receptor subunit beta GN=SRPRB SRPRB_HUMAN $29.70 \quad 100.0 \%$ Signal recognition particle receptor subunit beta GN=SRPRB SRPRB_HUMAN $29.70 \quad 100.0 \%$ Signal recognition particle receptor subunit beta GN=SRPRB SRPRB_HUMAN $29.70 \quad 100.0 \%$ Signal recognition particle receptor subunit beta GN=SRPRB SRPRB_HUMAN $29.70 \quad 100.0 \%$ Signal recognition particle subunit SRP68 GN=SRP68 SRP68_HUMAN $70.73 \quad 100.0 \%$ Signal recognition particle subunit SRP68 GN=SRP68 SRP68 HUMAN $70.73 \quad 100.0 \%$ Signal recognition particle subunit SRP68 GN=SRP68 SRP68_HUMAN $70.73 \quad 100.0 \%$ Signal recognition particle subunit SRP68 GN=SRP68 SRP68_HUMAN $70.73 \quad 100.0 \%$ Signal recognition particle subunit SRP68 GN=SRP68 SRP68_HUMAN $70.73 \quad 100.0 \%$ Signal recognition particle subunit SRP68 GN=SRP68 SRP68_HUMAN $70.73 \quad 100.0 \%$
$0.03 \% \quad 33.6 \%$ VGSFCLSEAGAGSDSFALK

$0.03 \% \quad 33.6 \%$ VPEANILGQIGHGYK

$0.03 \% \quad 33.6 \%$ YAIGSLNEGR

$0.03 \% \quad 33.6 \%$ LLTYNAAR

$0.03 \% \quad 33.6 \%$ LLEAGKPFIK

$0.03 \% \quad 33.6 \%$ YYASEIAGQTTSK

$0.03 \% \quad 33.6 \%$ IGTIYEGASNIQLNTIAK

$0.02 \% \quad 42.2 \%$ WDQSTFIGR

$0.02 \% \quad 42.2 \%$ ANHFFTVTDPR

$0.02 \% \quad 42.2 \%$ NILLTNEQLESAR

$0.02 \% \quad 42.2 \%$ QGIVPPGLTENELWR

$0.02 \% \quad 42.2 \%$ YIYDSAFHPDTGEK

$0.02 \% \quad 42.2 \%$ HVSPLIGR

$99.7 \% \quad 53.0$

$99.7 \% \quad 43.1$

$99.7 \% \quad 41.2$

$99.7 \% \quad 38.5$

$99.7 \% \quad 59.6$

$99.0 \% 55.6$

$99.7 \% \quad 47.9$

$99.7 \% \quad 82.8$

$\begin{array}{lll}99.7 \% & 80.3 \\ 99.3 \% & 59.5\end{array}$

$\begin{array}{llll}99.4 \% & 23.2\end{array}$

$99.7 \% \quad 90.9$

$99.7 \% 50.9$

$99.7 \% \quad 61.1$

$99.0 \% \quad 31.0$

$0.02 \% \quad 42.2 \%$ FVPFAAVAAANCINIPLMR $\quad 98.5 \% \quad 26.6$

$0.02 \% \quad 42.2 \%$ VGIPVTDENGNR

$0.02 \% \quad 42.2 \%$ QAITQVVVSR

$0.02 \% \quad 42.2 \%$ SSMSVTSLEAELQAK

$0.02 \% \quad 42.2 \%$ IQESHPELRR

$0.00 \% \quad 7.8 \%$ AAAIGITQVVISR

$0.00 \% \quad 7.8 \%$ YGELEPYVYFNK

$0.01 \% \quad 22.8 \%$ DAVPAFIEPNVR

\section{$99.7 \% \quad 34.0$}

$99.7 \% \quad 68.3$

$99.7 \% \quad 54.8$

$99.7 \% \quad 27.7$

$97.9 \% \quad 25.6$

$99.7 \% \quad 40.3$

$99.7 \% \quad 40.2$

$0.01 \% \quad 22.8 \%$ QLLCTNEDVSSPASADQR $99.7 \% \quad 64.9$

$0.01 \% \quad 22.8 \%$ SLATVHPDSSNLIPK

$0.01 \% \quad 22.8 \%$ SYTCKPLER

$0.01 \% \quad 22.8 \%$ EGNVLGHSR

$99.7 \% \quad 40.0$

$99.7 \% \quad 29.7$

$99.7 \% \quad 39.9$

$0.01 \% \quad 22.8 \%$ IQSPTEETEIFYHR

$99.0 \% \quad 20.7$

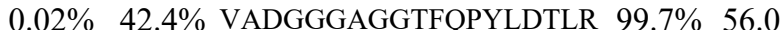

$0.02 \% \quad 42.4 \%$ AVLLVGLCDSGK

$99.7 \% \quad 60.2$

$99.7 \% \quad 71.5$

$99.7 \% \quad 33.9$

$99.7 \% \quad 66.1$

$99.0 \% \quad 38.2$

$0.02 \% \quad 42.4 \%$ GNSLTLIDLPGHESLR

$0.02 \% \quad 42.4 \%$ AIVFVVDSAAFQR

$0.02 \% \quad 42.4 \%$ LIQQQLEK

$\begin{array}{ll}99.0 \% & 38.2 \\ 99.7 \% & 61.3\end{array}$

$\begin{array}{lll}0.02 \% & 42.4 \% & \text { SAAPSTLDSSSTAPAQLGKK }\end{array}$

$0.02 \% \quad 42.4 \%$ GDVGSADIQDLEK

$99.7 \% \quad 73.7$

$\begin{array}{lllll}0.01 \% & 12.8 \% & \text { AAEKQVPGGGGGGGSGGGGGSGGGGSGGGR } & 99.7 \% & 75.1\end{array}$

$0.01 \% \quad 12.8 \%$ OVPGGGGGGGSGGGGGSGGGGSGGGR $\quad 99.7 \% \quad 93.6$

$0.01 \% \quad 12.8 \%$ SGGTEGLLAEKLEALITQTR

$0.01 \% \quad 12.8 \%$ ALLQQQPEDDSKR

$0.01 \% \quad 12.8 \%$ SPRPQDLIR

$0.01 \% \quad 12.8 \%$ SGLTGYIK
$99.7 \% \quad 38.8$

$97.9 \%$

$99.0 \% \quad 27.1$

1264.68
1902.89

1007.55

1453.70

1595.85

1079.55

921.52

1115.68

1418.68

1906.03

1109.54

1304.64

1500.80

1708.90

1642.74

878.52

2075.09

1270.64

1100.64

1596.78

1264.68

1298.78

1521.73

1327.70

1990.91

1578.85

1153.57

968.49

1749.84

1894.93

1231.67

1616.72

1721.92

1422.77

999.58

1788.90

1916.99

1346.64

2243.02

1843.80

2087.13

1527.78

1081.6

838.47 
Sister chromatid cohesion protein PDS5 homolog A GN=PDS5A PDS5A_HUMAN $150.84 \quad 100.0 \%$ Sister chromatid cohesion protein PDS5 homolog A GN=PDS5A PDS5A_HUMAN $150.84 \quad 100.0 \%$ Sister chromatid cohesion protein PDS5 homolog A GN=PDS5A PDS5A_HUMAN $150.84 \quad 100.0 \%$ Sister chromatid cohesion protein PDS5 homolog A GN=PDS5A PDS5A_HUMAN $150.84 \quad 100.0 \%$ Sister chromatid cohesion protein PDS5 homolog A GN=PDS5A PDS5A_HUMAN $150.84 \quad 100.0 \%$ Sister chromatid cohesion protein PDS5 homolog A GN=PDS5A PDS5A_HUMAN $150.84 \quad 100.0 \%$ Sister chromatid cohesion protein PDS5 homolog A GN=PDS5A PDS5A_HUMAN $150.84 \quad 100.0 \%$ Sister chromatid cohesion protein PDS5 homolog B GN=PDS5B PDS5B_HUMAN $164.67 \quad 100.0 \%$ Sister chromatid cohesion protein PDS5 homolog B GN=PDS5B PDS5B HUMAN $164.67 \quad 100.0 \%$ Sister chromatid cohesion protein PDS5 homolog B GN=PDS5B PDS5B_HUMAN $164.67 \quad 100.0 \%$ Sister chromatid cohesion protein PDS5 homolog B GN=PDS5B PDS5B_HUMAN $164.67 \quad 100.0 \%$ Sister chromatid cohesion protein PDS5 homolog B GN=PDS5B PDS5B_HUMAN $164.67100 .0 \%$ Small subunit processome component 20 homolog GN=UTP20 UTP20_HUMAN $318.40 \quad 100.0 \%$ Small subunit processome component 20 homolog GN=UTP20 UTP20 HUMAN $318.40 \quad 100.0 \%$ Small subunit processome component 20 homolog GN=UTP20 UTP20_HUMAN $318.40 \quad 100.0 \%$ SNW domain-containing protein $1 \mathrm{GN}=\mathrm{SNW} 1$ SNW1_HUMAN $61.50 \quad 100.0 \%$ SNW domain-containing protein $1 \mathrm{GN}=\mathrm{SNW} 1 \mathrm{SNW} 1$ HUMAN $61.50 \quad 100.0 \%$ SNW domain-containing protein $1 \mathrm{GN}=\mathrm{SNW} 1 \mathrm{SNW} 1$ _HUMAN $61.50 \quad 100.0 \%$ SNW domain-containing protein $1 \mathrm{GN}=\mathrm{SNW} 1 \mathrm{SNW} 1$ HUMAN $61.50 \quad 100.0 \%$ SNW domain-containing protein $1 \mathrm{GN}=$ SNW1 SNW1_HUMAN $61.50 \quad 100.0 \%$ SNW domain-containing protein $1 \mathrm{GN}=\mathrm{SNW} 1 \mathrm{SNW} 1$ _HUMAN $61.50 \quad 100.0 \%$ SNW domain-containing protein $1 \mathrm{GN}=\mathrm{SNW} 1 \mathrm{SNW} 1$ HUMAN $61.50 \quad 100.0 \%$ Sodium/potassium-transporting ATPase subunit alpha-1 GN=ATP1A1 AT1A1_HUMAN $112.90 \quad 100.0 \%$ Sodium/potassium-transporting ATPase subunit alpha-1 GN=ATP1A1 AT1A1_HUMAN $112.90 \quad 100.0 \%$ Sodium/potassium-transporting ATPase subunit alpha-1 GN=ATP1A1 AT1A1_HUMAN $112.90 \quad 100.0 \%$ Sodium/potassium-transporting ATPase subunit alpha-1 GN=ATP1A1 AT1A1_HUMAN $112.90 \quad 100.0 \%$ Sodium/potassium-transporting ATPase subunit alpha-1 GN=ATP1A1 AT1A1_HUMAN $112.90 \quad 100.0 \%$ Sodium/potassium-transporting ATPase subunit alpha-1 GN=ATPIA1 AT1A1_HUMAN $112.90 \quad 100.0 \%$ Sodium/potassium-transporting ATPase subunit alpha-1 GN=ATP1A1 AT1A1_HUMAN $112.90 \quad 100.0 \%$ Sodium/potassium-transporting ATPase subunit alpha-1 GN=ATP1A1 AT1A1_HUMAN $112.90 \quad 100.0 \%$ Sodium/potassium-transporting ATPase subunit alpha-1 GN=ATP1A1 AT1A1_HUMAN $112.90 \quad 100.0 \%$ Sodium/potassium-transporting ATPase subunit alpha-1 GN=ATP1A1 AT1A1_HUMAN $112.90 \quad 100.0 \%$ Sodium/potassium-transporting ATPase subunit alpha-1 GN=ATPIA1 AT1A1_HUMAN $112.90 \quad 100.0 \%$ Sodium/potassium-transporting ATPase subunit alpha-1 GN=ATP1A1 AT1A1_HUMAN $112.90 \quad 100.0 \%$ Solute carrier family 25 member $40 \mathrm{GN}=\mathrm{SLC} 25 \mathrm{~A} 40$ S2540_HUMAN $38.13 \quad 100.0 \%$ Solute carrier family 25 member $40 \mathrm{GN}=$ SLC25A40 S2540_HUMAN $38.13 \quad 100.0 \%$ Spectrin alpha chain, non-erythrocytic 1 GN=SPTAN1 SPTN1_HUMAN $284.54 \quad 100.0 \%$ Spectrin alpha chain, non-erythrocytic $1 \mathrm{GN}=$ SPTAN1 SPTN1_HUMAN $284.54100 .0 \%$ Spectrin beta chain, non-erythrocytic $1 \mathrm{GN}=$ SPTBN1 SPTB2_HUMAN $274.61 \quad 100.0 \%$ Spectrin beta chain, non-erythrocytic $1 \mathrm{GN}=$ SPTBN1 SPTB2_HUMAN $274.61 \quad 100.0 \%$ Spectrin beta chain, non-erythrocytic $1 \mathrm{GN}=$ SPTBN1 SPTB2_HUMAN $274.61 \quad 100.0 \%$ Spectrin beta chain, non-erythrocytic $1 \mathrm{GN}=$ SPTBN1 SPTB2_HUMAN $274.61 \quad 100.0 \%$ Spectrin beta chain, non-erythrocytic $1 \mathrm{GN}=$ SPTBN1 SPTB2 HUMAN $274.61 \quad 100.0 \%$ Spectrin beta chain, non-erythrocytic $1 \mathrm{GN}=$ SPTBN1 SPTB2_HUMAN $274.61 \quad 100.0 \%$ Spectrin beta chain, non-erythrocytic $1 \mathrm{GN}=$ SPTBN1 SPTB2_HUMAN $274.61 \quad 100.0 \%$ Spectrin beta chain, non-erythrocytic $1 \mathrm{GN}=$ SPTBN1 SPTB2 HUMAN $274.61 \quad 100.0 \%$ Spermatid perinuclear RNA-binding protein GN=STRBP STRBP_HUMAN $73.65 \quad 100.0 \%$

10

$$
10
$$

30
30

11
11
11
11

11
11
11

11
11
11
11

11
11
11

$\begin{array}{llll}11 & 0.01 \% & 3.6 \% & \text { YKEVAELTR } \\ 11 & 0.01 \% & 3.6 \% & \text { QALQDTLALYK }\end{array}$

$\begin{array}{llll}11 & 0.01 \% & 3.6 \% & \text { QALQDTLALYK } \\ 11 & 0.01 \% & 3.6 \% & \text { VAVVNQIAR }\end{array}$

$\begin{array}{lll}0.01 \% & 3.6 \% & \text { SQNIVTDSSSLSAEAIR }\end{array}$

$0.01 \% \quad 3.6 \%$ LVDTGDKFR

$0.01 \% \quad 3.6 \%$ LILEVHQFSR $0.00 \% \quad 11.2 \%$ GWPLELICEK
$10 \quad 0.01 \% \quad 7.1 \% \quad$ LLVACCLADIFR 7.1\% LAAGSAIMK $\begin{array}{llllllll}99.7 \% & 52.7 & 25.0 & 52.7 & 2 & 0 & 0 & 1450.75\end{array}$ $\begin{array}{llllllll}99.7 \% & 50.9 & 25.0 & 50.9 & 1 & 0 & 0 & 1572.87\end{array}$ $\begin{array}{llllllll}98.9 \% & 21.3 & 25.0 & 21.3 & 0 & 1 & 0 & 1621.87\end{array}$

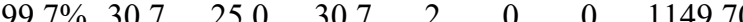
$\begin{array}{llll}99.7 \% & 30.0 & 25.0 & 27.9\end{array}$ $\begin{array}{llll}97.5 \% & 22.1 & 25.0 & 12.2\end{array}$ $0.01 \% \quad 7.1 \%$ LAAGSAIMK $\quad 97.5 \% 5$ . $\begin{array}{llll}99.7 \% & 52.7 & 25.0 & 52.7\end{array}$ $\begin{array}{llll}96.3 \% & 24.6 & 25.0 & 3.2 \\ 9.7 \% & 1\end{array}$ $\begin{array}{lllll}99.7 \% & 39.9 & 25.0 & 31.2 & 2\end{array}$ $0.01 \% \quad 4.8 \%$ YALQSAAGKDAAK $99.7 \% \quad 34.3$ 5.0

\begin{tabular}{cc}
88 & 99 \\
391 & 404 \\
704 & 717 \\
718 & 727 \\
751 & 763 \\
890 & 898 \\
1159 & 1181 \\
78 & 89 \\
209 & 219 \\
419 & 431 \\
1080 & 1096 \\
1127 & 1143 \\
1191 & 1204 \\
1778 & 1790 \\
2251 & 2261 \\
159 & 166 \\
167 & 178 \\
179 & 193 \\
259 & 267 \\
274 & 286 \\
383 & 400 \\
401 & 416 \\
213 & 227 \\
228 & 240 \\
241 & 255 \\
431 & 444 \\
446 & 458 \\
477 & 487 \\
597 & 607 \\
630 & 647 \\
648 & 658 \\
699 & 707 \\
708 & 726 \\
708 & 727 \\
43 & 52 \\
153 & 166 \\
1226 & 1237 \\
1608 & 1619 \\
478 & 486 \\
487 & 498 \\
831 & 839 \\
843 & 853 \\
905 & 913 \\
1548 & 1564 \\
1907 & 1915 \\
2015 & 2024 \\
240 & 249 \\
& \\
\hline 12
\end{tabular}


Spermatid perinuclear RNA-binding protein GN=STRBP STRBP_HUMAN $73.65 \quad 100.0 \%$ Spermatid perinuclear RNA-binding protein GN=STRBP STRBP_HUMAN $73.65 \quad 100.0 \%$ Spermatid perinuclear RNA-binding protein GN=STRBP STRBP HUMAN $73.65 \quad 100.0 \%$ Spermatid perinuclear RNA-binding protein GN=STRBP STRBP_HUMAN $73.65 \quad 100.0 \%$ Spermatid perinuclear RNA-binding protein GN=STRBP STRBP_HUMAN $73.65 \quad 100.0 \%$ Spermidine synthase GN=SRM Spermidine synthase GN=SRM Spermidine synthase $\mathrm{GN}=\mathrm{SRM}$ Spermidine synthase GN=SRM Spermidine synthase GN=SRM Spindlin-1 GN=SPIN1 Spindlin-1 GN=SPIN1 Spindlin-1 GN=SPIN1

Spindlin-1 GN=SPIN1 Spindlin-1 GN=SPIN1 Spindlin-1 GN=SPIN1 Spindlin-1 GN=SPIN1 Spindlin-1 GN=SPIN1

Spindlin-1 GN=SPIN1 SPEE HUMAN $33.82 \quad 100.0 \%$ SPEE_HUMAN $33.82 \quad 100.0 \%$ SPEE HUMAN $33.82 \quad 100.0 \%$ SPEE_HUMAN $33.82 \quad 100.0 \%$ SPEE_HUMAN $33.82 \quad 100.0 \%$ SPIN1_HUMAN $29.60 \quad 100.0 \%$ SPIN1_HUMAN $29.60 \quad 100.0 \%$ SPIN1_HUMAN $29.60 \quad 100.0 \%$ SPIN1_HUMAN $29.60 \quad 100.0 \%$ SPIN1_HUMAN $29.60 \quad 100.0 \%$ SPIN1_HUMAN $29.60 \quad 100.0 \%$ SPIN1_HUMAN $29.60 \quad 100.0 \%$ SPIN1_HUMAN $29.60 \quad 100.0 \%$ SPIN1_HUMAN $29.60 \quad 100.0 \%$ Spliceosome RNA helicase DDX39B GN=DDX39B DX39B_HUMAN $48.99 \quad 100.0 \%$ Spliceosome RNA helicase DDX39B GN=DDX39B DX39B HUMAN $48.99 \quad 100.0 \%$ Spliceosome RNA helicase DDX39B GN=DDX39B DX39B_HUMAN $48.99 \quad 100.0 \%$ Spliceosome RNA helicase DDX39B GN=DDX39B DX39B_HUMAN $48.99 \quad 100.0 \%$ Spliceosome RNA helicase DDX39B GN=DDX39B DX39B HUMAN $48.99100 .0 \%$ Spliceosome RNA helicase DDX39B GN=DDX39B DX39B_HUMAN $48.99 \quad 100.0 \%$ Spliceosome RNA helicase DDX39B GN=DDX39B DX39B_HUMAN $48.99100 .0 \%$ Spliceosome RNA helicase DDX39B GN=DDX39B DX39B_HUMAN $48.99 \quad 100.0 \%$ Splicing factor 3B subunit $1 \mathrm{GN}=\mathrm{SF} 3 \mathrm{~B} 1 \quad \mathrm{SF} 3 \mathrm{~B} 1 \_$HUMAN $145.84 \quad 100.0 \%$ Splicing factor $3 \mathrm{~B}$ subunit $1 \mathrm{GN}=\mathrm{SF} 3 \mathrm{~B} 1$ Splicing factor $3 \mathrm{~B}$ subunit $1 \mathrm{GN}=\mathrm{SF} 3 \mathrm{~B} 1$ Splicing factor $3 \mathrm{~B}$ subunit $1 \mathrm{GN}=\mathrm{SF} 3 \mathrm{~B} 1$

Splicing factor $3 \mathrm{~B}$ subunit $1 \mathrm{GN}=\mathrm{SF} 3 \mathrm{~B} 1$ Splicing factor $3 \mathrm{~B}$ subunit $1 \mathrm{GN}=\mathrm{SF} 3 \mathrm{~B} 1$ Splicing factor $3 \mathrm{~B}$ subunit $1 \mathrm{GN}=\mathrm{SF} 3 \mathrm{~B} 1$ Splicing factor $3 \mathrm{~B}$ subunit $1 \mathrm{GN}=\mathrm{SF} 3 \mathrm{~B} 1$ Splicing factor $3 \mathrm{~B}$ subunit $1 \mathrm{GN}=\mathrm{SF} 3 \mathrm{~B} 1$ Splicing factor $3 \mathrm{~B}$ subunit $1 \mathrm{GN}=\mathrm{SF} 3 \mathrm{~B} 1$ Splicing factor $3 \mathrm{~B}$ subunit $1 \mathrm{GN}=\mathrm{SF} 3 \mathrm{~B} 1$ Splicing factor $3 \mathrm{~B}$ subunit $1 \mathrm{GN}=\mathrm{SF} 3 \mathrm{~B} 1$

Splicing factor $3 \mathrm{~B}$ subunit $1 \mathrm{GN}=\mathrm{SF} 3 \mathrm{~B} 1$ Splicing factor $3 \mathrm{~B}$ subunit $1 \mathrm{GN}=\mathrm{SF} 3 \mathrm{~B} 1$ Splicing factor $3 \mathrm{~B}$ subunit $1 \mathrm{GN}=\mathrm{SF} 3 \mathrm{~B} 1$ Splicing factor $3 \mathrm{~B}$ subunit $1 \mathrm{GN}=\mathrm{SF} 3 \mathrm{~B} 1$ Splicing factor $3 \mathrm{~B}$ subunit $1 \mathrm{GN}=\mathrm{SF} 3 \mathrm{~B} 1$

Splicing factor $3 \mathrm{~B}$ subunit $1 \mathrm{GN}=\mathrm{SF} 3 \mathrm{~B}$ Splicing factor $3 \mathrm{~B}$ subunit $1 \mathrm{GN}=\mathrm{SF} 3 \mathrm{~B}$ SF3B1_HUMAN $145.84 \quad 100.0 \% \quad 20$ SF3B1_HUMAN $145.84 \quad 100.0 \% \quad 20$ SF3B1 HUMAN $145.84 \quad 100.0 \% \quad 20$ SF3B1_HUMAN $145.84 \quad 100.0 \% \quad 20$
$0.00 \% \quad 11.2 \%$ LNQIRPGLQYK $0.00 \% \quad 11.2 \%$ TAKLHVAVK $0.00 \% \quad 11.2 \%$ NPVMELNEK $0.00 \% \quad 11.2 \%$ YELISETGGSHDKR $0.00 \% \quad 11.2 \%$ FVMEVEVDGQK $0.00 \% \quad 11.2 \%$ LFSGPNAANNK $0.01 \% \quad 13.2 \%$ YQDILVFR $0.01 \% \quad 13.2 \%$ KVLIIGGGDGGVLR $0.01 \% \quad 13.2 \%$ VLIIGGGDGGVLR $0.01 \% \quad 13.2 \%$ YYNSDVHR $0.01 \% \quad 13.2 \%$ AAFVLPEFAR $99.7 \% \quad 38.3 \quad 25.0 \quad 36.4$ $99.7 \% \quad 48.2 \quad 25.0 \quad 43.4$ $\begin{array}{lllll}99.7 \% & 26.1 & 25.0 & 19.3 & 2\end{array}$ $99.7 \% \quad 28.7 \quad 25.0-27.7$ $\begin{array}{llll}99.7 \% & 35.8 & 25.0 & 31.8\end{array}$ $97.0 \% \quad 20.6 \quad 25.0 \quad 14.5$ $99.0 \% \quad 40.8 \quad 25.0 \quad 40.8$ $\begin{array}{llll}98.9 \% & 19.0 & 25.0 & 19.0\end{array}$ $99.7 \% \quad 29.6 \quad 25.0 \quad 29.6$ $99.0 \% \quad 39.1 \quad 25.0 \quad 39.1$ $\begin{array}{lllll}99.7 \% & 31.8 & 25.0 & 31.8 & 2\end{array}$ $\begin{array}{llllllll}30 & 0.03 \% & 46.2 \% & \text { SRADAGHAGVSANMMK } & 99.4 \% & 21.0 & 25.0 & 20.9\end{array}$ $0.03 \% \quad 46.2 \%$ ADAGHAGVSANMMK $0.03 \% \quad 46.2 \%$ SSVGPSKPVSQPR $0.03 \% \quad 46.2 \%$ EGNGPVTQWK $99.7 \% \quad 31.8$ $99.7 \% \quad 56.0$ $99.5 \% \quad 22.8$ $0.03 \% \quad 46.2 \%$ GTVLDQVPVNPSLYLIK $\quad 99.7 \% \quad 61.8$ $0.03 \% \quad 46.2 \%$ YDGFDCVYGLELNKDER $99.7 \% \quad 31.7$ $0.03 \% \quad 46.2 \%$ VSALEVLPDR $0.03 \% \quad 46.2 \%$ ISDAHLADTMIGK $\begin{array}{lll}99.7 \% & 58.2\end{array}$ $0.03 \% \quad 46.2 \%$ $0.02 \% \quad 18.2 \%$ ELAFQISK

$0.02 \% \quad 18.2 \%$ ELAFQISKEYER

$0.02 \% \quad 18.2 \%$ NCPHIVVGTPGR $9.0 \% 22.4$ $99.0 \% \quad 20.4$ $99.7 \% \quad 53.7$ $99.7 \% \quad 33.4$ SF3B1_HUMAN $145.84 \quad 100.0 \% \quad 20$ SF3B1_HUMAN $145.84 \quad 100.0 \% \quad 20$ SF3B1_HUMAN $145.84 \quad 100.0 \% \quad 20$ SF3B1_HUMAN $145.84 \quad 100.0 \% \quad 20$ SF3B1_HUMAN $145.84 \quad 100.0 \% \quad 20$ SF3B1_HUMAN $145.84 \quad 100.0 \% \quad 20$ SF3B1_HUMAN $145.84 \quad 100.0 \% \quad 20$ SF3B1_HUMAN $145.84 \quad 100.0 \% \quad 20$ SF3B1 HUMAN $145.84 \quad 100.0 \% \quad 20$ SF3B1_HUMAN $145.84 \quad 100.0 \% \quad 20$ SF3B1_HUMAN $145.84 \quad 100.0 \% \quad 20$ SF3B1_HUMAN $145.84 \quad 100.0 \% \quad 20$ SF3B1 HUMAN $145.84 \quad 100.0 \% \quad 20$ SF3B1_HUMAN $145.84 \quad 100.0 \% \quad 20$ $0.02 \% \quad 18.2 \%$ CIALAQLLVEQ $0.02 \% \quad 18.2 \%$ RILVATNLFGR $0.02 \% \quad 18.2 \%$ ILVATNLFGR $0.02 \% \quad 18.2 \%$ GLAITFVSDENDAK $0.04 \% \quad 14.3 \%$ LDPFADGGKTPDPK $0.04 \% \quad 14.3 \%$ VVNGAAASQPPSK

$0.04 \% \quad 14.3 \%$ VVNGAAASQPPSKR $99.7 \% \quad 43.5$ $99.0 \% \quad 17.9$ $99.7 \% \quad 59.1$ $99.7 \% \quad 40.2$ $97.4 \% \quad 15.8$ $99.7 \% \quad 43.2$ $99.7 \% \quad 51.0$ $0.04 \% \quad 14.3 \%$ GDTPGHATPGHGGATSSAR $\quad 99.7 \% \quad 39.5$ $0.04 \% \quad 14.3 \%$ TDRGGDSIGETPTPGASK $99.7 \% \quad 40.1$ $0.04 \% \quad 14.3 \%$ GGDSIGETPTPGASK $0.04 \% \quad 14.3 \%$ GGDSIGETPTPGASKR $0.04 \% \quad 14.3 \%$ QCCGTDGVEANYIK $99.7 \% \quad 48.0$ $99.6 \% \quad 28.3$ $99.7 \% \quad 30.5$ $99.7 \% \quad 58.9$ $0.04 \% \quad 14.3 \%$ QLVDTTVELANK

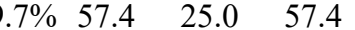
$0.04 \% \quad 14.3 \%$ VGAAEIISR $0.04 \% \quad 14.3 \%$ VRQQAADLISR $0.04 \% \quad 14.3 \%$ QQAADLISR $0.04 \% \quad 14.3 \%$ AIVNVIGMHK $0.04 \% \quad 14.3 \%$ MTPPIKDLLPR $0.04 \% \quad 14.3 \%$ VQENCIDLVGR $0.04 \% \quad 14.3 \%$ RATVNTFGYIAK $0.04 \% \quad 14.3 \%$ ATVNTFGYIAK $0.04 \% \quad 14.3 \%$ VPELNVQNGVLK $98.8 \% \quad 17.9$ $\begin{array}{llll}99.7 \% & 64.2 & 25.0 & 27.7\end{array}$ $\begin{array}{llll}99.7 \% & 47.6 & 25.0 & 43.0\end{array}$ $99.7 \% \quad 57.5 \quad 25.0 \quad 48.4$ $\begin{array}{llll}99.7 \% & 27.4 & 25.0 & 27.4\end{array}$ $99.2 \% \quad 21.1 \quad 25.0 \quad 17.8$ $99.7 \% \quad 58.4 \quad 25.0 \quad 54.4$ $\begin{array}{lllll}99.7 \% & 37.3 & 25.0 & 24.5 & 2\end{array}$ $\begin{array}{llll}99.7 \% & 55.4 & 25.0 & 53.5\end{array}$ $99.7 \% \quad 57.4 \quad 25.0 \quad 52.0$

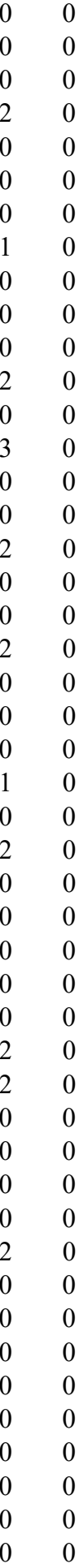

0

0

1296.6

1053.57

1353.82

1225.73

1053.47

1120.61

1634.74

1391.60

1325.72

1115.55

1856.05

2092.93

1098.62

1371.69

2654.26

935.52

1512.77

1306.67

2277.25

1259.62

1259.76

1103.66

1479.73

1457.73

1225.65

1381.75

1733.80

1745.83

1373.65

1529.76

1614.69

1330.72

2227.23

915.53

1256.71

1001.54

1097.61

1296.73

1302.65

1340.73

1184.63 1309.75 $\begin{array}{cc}95 & 405 \\ 38 & 446 \\ 13 & 521 \\ 27 & 540 \\ 41 & 551 \\ 74 & 584 \\ 8 & 55 \\ 6 & 109 \\ 7 & 109 \\ 78 & 285 \\ 86 & 295 \\ 3 & 28 \\ 5 & 28 \\ 8 & 50 \\ 4 & 73 \\ 4 & 90 \\ 1 & 107 \\ 08 & 117 \\ 23 & 135 \\ 92 & 216 \\ 24 & 131 \\ 24 & 135 \\ 64 & 175 \\ 00 & 319 \\ 30 & 338 \\ 39 & 349 \\ 40 & 349 \\ 85 & 398 \\ 33 & 146 \\ 83 & 195 \\ 83 & 196 \\ 71 & 289 \\ 16 & 333 \\ 19 & 333 \\ 19 & 334 \\ 94 & 807 \\ 32 & 843 \\ 32 & 852 \\ 44 & 852 \\ 47 & 957 \\ 49 & 957 \\ 99 & 1008 \\ 09 & 1019 \\ 31 & 1041 \\ 75 & 1086 \\ 76 & 1086 \\ 38 & 1149 \\ & \end{array}$

Page 155 of Table S-1-4 
Splicing factor 3B subunit $1 \mathrm{GN}=\mathrm{SF} 3 \mathrm{~B} 1 \quad$ SF3B1_HUMAN $145.84 \quad 100.0 \% \quad 2$ Splicing factor $3 \mathrm{~B}$ subunit $2 \mathrm{GN}=\mathrm{SF} 3 \mathrm{~B} 2 \quad \mathrm{SF} 3 \mathrm{~B} 2$ HUMAN $100.23 \quad 100.0 \%$ Splicing factor 3B subunit 2 GN=SF3B2 SF3B2_HUMAN $100.23 \quad 100.0 \%$ Splicing factor $3 \mathrm{~B}$ subunit $2 \mathrm{GN}=\mathrm{SF} 3 \mathrm{~B} 2 \quad \mathrm{SF} 3 \mathrm{~B} 2$ HUMAN $100.23 \quad 100.0^{\circ}$ Splicing factor 3B subunit $3 \mathrm{GN}=\mathrm{SF} 3 \mathrm{~B} 3 \quad$ SF3B3_HUMAN $135.58 \quad 100.0 \%$ Splicing factor 3B subunit $3 \mathrm{GN}=\mathrm{SF} 3 \mathrm{~B} 3 \quad$ SF3B3_HUMAN $135.58 \quad 100.0 \%$ Splicing factor 3B subunit $3 \mathrm{GN}=\mathrm{SF} 3 \mathrm{~B} 3 \quad$ SF3B3_HUMAN $135.58 \quad 100.0 \%$ Splicing factor 3B subunit $3 \mathrm{GN}=\mathrm{SF} 3 \mathrm{~B} 3 \quad$ SF3B3_HUMAN $135.58 \quad 100.0 \%$ Splicing factor $3 \mathrm{~B}$ subunit $3 \mathrm{GN}=\mathrm{SF} 3 \mathrm{~B} 3 \mathrm{SF} 3 \mathrm{~B} 3 \mathrm{HUMAN} 135.58 \quad 100.0 \%$ Splicing factor 3B subunit $3 \mathrm{GN}=\mathrm{SF} 3 \mathrm{~B} 3 \quad$ SF3B3_HUMAN $135.58 \quad 100.0 \%$ Splicing factor 3B subunit 3 GN=SF3B3 SF3B3_HUMAN $135.58 \quad 100.0 \%$ Splicing factor 3B subunit $3 \mathrm{GN}=\mathrm{SF} 3 \mathrm{~B} 3 \quad \mathrm{SF} 3 \mathrm{~B} 3$ HUMAN $135.58 \quad 100.0^{\circ}$ Splicing factor 3B subunit $3 \mathrm{GN}=\mathrm{SF} 3 \mathrm{~B} 3 \quad$ SF3B3_HUMAN $135.58 \quad 100.0 \%$ Splicing factor 3B subunit $3 \mathrm{GN}=\mathrm{SF} 3 \mathrm{~B} 3 \quad$ SF3B3_HUMAN $135.58 \quad 100.0 \%$ Splicing factor 3B subunit $3 \mathrm{GN}=\mathrm{SF} 3 \mathrm{~B} 3 \quad$ SF3B3_HUMAN $135.58 \quad 100.0 \%$ Splicing factor U2AF $35 \mathrm{kDa}$ subunit GN=U2AF1 U2AF1_HUMAN $27.87 \quad 100.0 \%$ Splicing factor U2AF $35 \mathrm{kDa}$ subunit GN=U2AF1 U2AF1 HUMAN $27.87 \quad 100.0 \%$ Splicing factor U2AF $35 \mathrm{kDa}$ subunit GN=U2AF1 U2AF1_HUMAN $27.87 \quad 100.0 \%$ Splicing factor U2AF $35 \mathrm{kDa}$ subunit GN=U2AF1 U2AF1_HUMAN $27.87 \quad 100.0 \%$ Splicing factor U2AF $35 \mathrm{kDa}$ subunit GN=U2AF1 U2AF1_HUMAN $27.87 \quad 100.0 \%$ Splicing factor U2AF $35 \mathrm{kDa}$ subunit GN=U2AF1 U2AF1_HUMAN $27.87 \quad 100.0 \%$ Splicing factor U2AF $35 \mathrm{kDa}$ subunit GN=U2AF1 U2AF1 HUMAN $27.87 \quad 100.0 \%$ Splicing factor U2AF $35 \mathrm{kDa}$ subunit GN=U2AF1 U2AF1_HUMAN $27.87 \quad 100.0 \%$ Splicing factor U2AF $35 \mathrm{kDa}$ subunit GN=U2AF1 U2AF1_HUMAN $27.87 \quad 100.0 \%$ Splicing factor U2AF $65 \mathrm{kD}$ a subunit GN=U2AF2 U2AF2 HUMAN $53.50 \quad 100.0^{\circ}$ Splicing factor U2AF $65 \mathrm{kDa}$ subunit GN=U2AF2 U2AF2_HUMAN $53.50 \quad 100.0 \%$ Splicing factor U2AF $65 \mathrm{kDa}$ subunit GN=U2AF2 U2AF2_HUMAN $53.50 \quad 100.0 \%$ Splicing factor U2AF $65 \mathrm{kDa}$ subunit GN=U2AF2 U2AF2 HUMAN $53.50 \quad 100.0 \%$ Splicing factor U2AF $65 \mathrm{kDa}$ subunit GN=U2AF2 U2AF2_HUMAN $53.50 \quad 100.0 \%$ Splicing factor U2AF $65 \mathrm{kDa}$ subunit GN=U2AF2 U2AF2 HUMAN $53.50 \quad 100.0 \%$ Splicing factor U2AF $65 \mathrm{kDa}$ subunit GN=U2AF2 U2AF2_HUMAN $53.50 \quad 100.0 \%$ Splicing factor U2AF $65 \mathrm{kDa}$ subunit GN=U2AF2 U2AF2_HUMAN $53.50 \quad 100.0 \%$ splicing factor U2AF $65 \mathrm{kDa}$ subunit GN=U2AF2 U2AF2 HUMAN $53.50 \quad 100.0 \%$ Splicing factor, arginine/serine-rich 15 GN=SCAF4 SFR15_HUMAN $125.87 \quad 100.0 \%$ Splicing factor, arginine/serine-rich $15 \mathrm{GN}=\mathrm{SCAF} 4 \mathrm{SFR} 15$ HUMAN $125.87 \quad 100.0 \%$ Splicing factor, proline- and glutamine-rich GN=SFPQ SFPQ HUMAN $76.15 \quad 100.0 \%$ Splicing factor, proline- and glutamine-rich GN=SFPQ SFPQ_HUMAN 76.15 $100.0 \%$ Splicing factor, proline- and glutamine-rich GN=SFPQ SFPQ HUMAN 76.15 $100.0^{\circ}$ Splicing factor, proline- and glutamine-rich GN=SFPQ SFPQ_HUMAN $76.15 \quad 100.0 \%$ Splicing factor, proline- and glutamine-rich GN=SFPQ SFPQ_HUMAN $76.15 \quad 100.0 \%$ Splicing factor, proline- and glutamine-rich GN=SFPQ SFPQ_HUMAN $76.15 \quad 100.0 \%$ Squamous cell carcinoma antigen recognized by T-cells $3 \mathrm{GN}=\mathrm{SART3}$ SART3_HUMAN $109.94 \quad 100.0 \%$ SRSF protein kinase $1 \mathrm{GN}=\mathrm{SRPK}$ SRSF protein kinase $1 \mathrm{GN}=\mathrm{SRPK}$ SRSF protein kinase $1 \mathrm{GN}=\mathrm{SRPK}$ SRPK1_HUMAN $74.33 \quad 100.0 \%$ SRPK1 HUMAN $74.33 \quad 100.0 \%$

2

3

3

$\begin{array}{ll}3 & 3 \\ 3 & 3\end{array}$
$0.00 \% \quad 4.8 \%$ LAEIGAPIQGNREELVER $99.4 \% 26.1$

$0.00 \% \quad 4.8 \%$ AAVLLEQERQQEIAK $.4 \% \quad 26.1$ $99.7 \% \quad 52.3$ $99.5 \% \quad 26.1$ $99.0 \% \quad 32.6$ $98.4 \% \quad 20.0$ $99.7 \% \quad 38.0$ $\begin{array}{lll}99.7 \% & 55.7\end{array}$ $99.7 \% \quad 54.2$ $99.7 \% \quad 35.5$ $\begin{array}{lll}99.7 \% & 48.1\end{array}$ $99.7 \% \quad 61.2$ $99.7 \% \quad 55.1$ $99.0 \% \quad 26.1$ $99.7 \% \quad 39.2$ $99.7 \% \quad 36.2$ $99.0 \% \quad 51.2$ $99.7 \% \quad 59.5$ $99.7 \% \quad 36.9$ $99.7 \% \quad 47.5$ $99.0 \% \quad 31.1$ $\begin{array}{lll}99.7 \% & 38.0\end{array}$ $99.7 \% \quad 61.7$ $0.03 \% \quad 42.5 \%$ QYEMGECTR $0.03 \% \quad 42.5 \%$ GGFCNFMHLKPISR $99.7 \% \quad 29.2$ $0.03 \% \quad 22.3 \%$ GAKEEHGGLIR $99.7 \% \quad 50.8$ $0.03 \% \quad 22.3 \%$ SVDETTQAMAFDGIIFQGQSLK $\quad 99.7 \% \quad 49.4$ $0.03 \% \quad 22.3 \%$ AFNLVKDSATGLSK $99.7 \% \quad 45.8$

$0.03 \% \quad 22.3 \%$ SIEIPRPVDGVEVPGCGK $99.7 \% \quad 49.2$ $0.03 \% \quad 22.3 \%$ IFVEFTSVFDCQK $0.03 \% 22.3 \%$ AMQGLTGRK $0.03 \% \quad 22.3 \%$ FANRVVVTK $0.03 \% \quad 22.3 \%$ YCDPDSYHR $0.03 \% \quad 22.3 \%$ YCDPDSYHRR $0.00 \% \quad 2.3 \%$ TTPTQPSEQK $0.00 \% \quad 2.3 \%$ DLSIGNPIPTVVSGAR $0.01 \% \quad 8.9 \% \quad$ YGEPGEVFINK $0.01 \% \quad 8.9 \%$ FATHAAALSVR $0.01 \% \quad 8.9 \%$ AVVIVDDRGR $0.01 \% \quad 8.9 \%$ STGKGIVEFASKPAAR $0.01 \% \quad 8.9 \%$ GIVEFASKPAAR $0.01 \% \quad 8.9 \%$ FGQGGAGPVGGQGPR $0.00 \% \quad 3.4 \%$ RVENSIPAAGETQNVEVAAGPAGK $0.00 \% \quad 3.4 \%$ VAISNPPQR $0.00 \% \quad 4.7 \% \quad$ KVLALQAR $0.00 \% \quad 4.7 \%$ STAGNFLVNPLEPK $0.00 \% \quad 4.7 \%$ HFTEDIQTR $0.00 \% \quad 5.9 \%$ FFLGDLCSR
2194.13 1994.07 1725.95

1129.59

958.53

1283.74

1061.50

1303.74

1488.75

1745.90

1407.67

1191.60

1681.89

1676.90

1699.85

1307.61

1064.49

1373.64

2769.25

1615.79

914.51

2114.05

1173.47

1679.81

1166.63

2402.15

1450.79

1908.99

1619.78

961.52

1033.62

1212.47

1368.58

1116.55

1595.88

1252.62

1143.63

1099.62

1618.89

1245.70

1341.67

2365.21

981.55

898.58

1486.79

1146.55

$\begin{array}{llll}99.7 \% & 42.6 & 25.0 & 39.6\end{array}$

$\begin{array}{llll}99.7 \% & 31.3 & 25.0 & 31.3\end{array}$

$\begin{array}{llll}99.4 \% & 20.6 & 25.0 & 20.6\end{array}$

$\begin{array}{cc}68 & 1286 \\ 6 & 53 \\ 84 & 198 \\ 05 & 614 \\ 7 & 34 \\ 15 & 126 \\ 60 & 268 \\ 04 & 615 \\ 77 & 690 \\ 77 & 692 \\ 06 & 718 \\ 19 & 929 \\ 43 & 958 \\ 00 & 1013 \\ 92 & 1206 \\ 4 & 23 \\ 6 & 23 \\ 4 & 66 \\ 3 & 116 \\ 20 & 133 \\ 26 & 133 \\ 34 & 151 \\ 57 & 165 \\ 66 & 179 \\ 8 & 78 \\ 04 & 225 \\ 87 & 300 \\ 14 & 431 \\ 32 & 444 \\ 45 & 453 \\ 54 & 462 \\ 63 & 471 \\ 63 & 472 \\ 36 & 245 \\ 78 & 793 \\ 20 & 330 \\ 66 & 376 \\ 00 & 409 \\ 10 & 425 \\ 14 & 425 \\ 67 & 681 \\ 46 & 669 \\ 73 & 881 \\ 4 & 11 \\ 73 & 486 \\ 07 & 515 \\ 0 & 88 \\ & \end{array}$

Page 156 of Table S-1-4 
Stomatin-like prote 3-dehydrogenase, decarboxylating GN=NSDHL NSDHL_HUMAN $41.90 \quad 100.0 \%$ atin-like protein 2, mitochondrial GN=STOML2 STML2_HUMAN $38.53 \quad 100.0 \%$ Stomatin-like protein 2, mitochondrial GN=STOML2 STML2_HUMAN $38.53 \quad 100.0 \%$ Stomatin-like protein 2, mitochondrial GN=STOML2 STML2 HUMAN $38.53 \quad 100.0^{\circ}$ Stomatin-like protein 2, mitochondrial GN=STOML2 STML2_HUMAN $38.53 \quad 100.0 \%$ Stomatin-like protein 2, mitochondrial GN=STOML2 STML2_HUMAN $38.53 \quad 100.0 \%$ Stomatin-like protein 2, mitochondrial GN=STOML2 STML2_HUMAN $38.53 \quad 100.0 \%$ Stomatin-like protein 2, mitochondrial GN=STOML2 STML2_HUMAN $38.53 \quad 100.0 \%$ Stress-70 protein, mitochondrial GN=HSPA9 GRP75 HUMAN $73.68100 .0 \%$ Stress-70 protein, mitochondrial GN=HSPA9 GRP75_HUMAN $73.68 \quad 100.0 \%$ Stress-70 protein, mitochondrial GN=HSPA9 GRP75_HUMAN $73.68 \quad 100.0 \%$ Stress-70 protein, mitochondrial GN=HSPA9 GRP75 HUMAN $73.68 \quad 100.0^{\circ}$ Stress-70 protein, mitochondrial GN=HSPA9 GRP75_HUMAN $73.68 \quad 100.0 \%$ Stress-70 protein, mitochondrial GN=HSPA9 GRP75_HUMAN $73.68 \quad 100.0 \%$ Stress-70 protein, mitochondrial GN=HSPA9 GRP75_HUMAN $73.68 \quad 100.0 \%$ Stress-70 protein, mitochondrial GN=HSPA9 GRP75_HUMAN $73.68 \quad 100.0 \%$ Stress-70 protein, mitochondrial GN=HSPA9 GRP75 HUMAN $73.68100 .0 \%$ Stress-70 protein, mitochondrial GN=HSPA9 GRP75_HUMAN $73.68 \quad 100.0 \%$ Stress-70 protein, mitochondrial GN=HSPA9 GRP75_HUMAN $73.68 \quad 100.0 \%$ Stress-70 protein, mitochondrial GN=HSPA9 GRP75_HUMAN $73.68100 .0 \%$ Stress-70 protein, mitochondrial GN=HSPA9 GRP75_HUMAN $73.68 \quad 100.0 \%$ Stress-70 protein, mitochondrial GN=HSPA9 GRP75_HUMAN $73.68 \quad 100.0 \%$ Stress-70 protein, mitochondrial GN=HSPA9 GRP75_HUMAN $73.68 \quad 100.0 \%$ Stress-70 protein, mitochondrial GN=HSPA9 GRP75_HUMAN $73.68 \quad 100.0 \%$ Stress-70 protein, mitochondrial GN=HSPA9 GRP75 HUMAN $73.68 \quad 100.0 \%$ Stress-70 protein, mitochondrial GN=HSPA9 GRP75_HUMAN $73.68 \quad 100.0 \%$ Stress-70 protein, mitochondrial GN=HSPA9 GRP75_HUMAN $73.68 \quad 100.0 \%$ Structural maintenance of chromosomes protein $1 \mathrm{~A}$ GN=SMC1A SMC1A_HUMAN $143.24 \quad 100.0 \%$ Structural maintenance of chromosomes protein $1 \mathrm{~A}$ GN=SMC1A SMC1A_HUMAN $143.24 \quad 100.0 \%$ Structural maintenance of chromosomes protein $1 \mathrm{~A}$ GN=SMC1A SMC1A HUMAN $143.24 \quad 100.0 \%$ Structural maintenance of chromosomes protein $1 \mathrm{~A}$ GN=SMC1A SMC1A_HUMAN $143.24 \quad 100.0 \%$ Structural maintenance of chromosomes protein 1A GN=SMC1A SMC1A_HUMAN $143.24 \quad 100.0 \%$

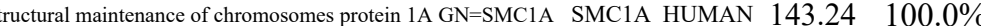
Structural maintenance of chromosomes protein $1 \mathrm{~A}$ GN=SMC1A SMC1A_HUMAN $143.24 \quad 100.0 \%$ Structural maintenance of chromosomes protein $1 \mathrm{~A}$ GN=SMC1A SMC1A HUMAN $143.24 \quad 100.0 \%$ Structural maintenance of chromosomes protein $1 \mathrm{~A}$ GN=SMC1A SMC1A HUMAN $143.24 \quad 100.0 \%$ Structural maintenance of chromosomes protein $1 \mathrm{~A}$ GN=SMC1A SMC1A_HUMAN $143.24 \quad 100.0 \%$ Structural maintenance of chromosomes protein $1 \mathrm{~A}$ GN=SMC1A SMC1A HUMAN $143.24 \quad 100.0^{\circ}$ Structural maintenance of chromosomes protein $2 \mathrm{GN}=\mathrm{SMC} 2 \mathrm{SMC2}$ HUMAN $135.66 \quad 100.0 \%$ Structural maintenance of chromosomes protein $2 \mathrm{GN}=\mathrm{SMC2}$ SMC2_HUMAN $135.66 \quad 100.0 \%$ Structural maintenance of chromosomes protein $2 \mathrm{GN}=\mathrm{SMC2} \mathrm{SMC2}$ HUMAN $135.66100 .0^{\circ} \%$ Structural maintenance of chromosomes protein $2 \mathrm{GN}=\mathrm{SMC} 2 \mathrm{SMC2}$ HUMAN $135.66 \quad 100.0 \%$ Structural maintenance of chromosomes protein $2 \mathrm{GN}=\mathrm{SMC2} \mathrm{SMC2}$ HUMAN $135.66100 .0^{\circ}$ Structural maintenance of chromosomes protein $2 \mathrm{GN}=\mathrm{SMC2} \mathrm{SMC2}$ HUMAN $135.66 \quad 100.0 \%$ Structural maintenance of chromosomes protein $3 \mathrm{GN}=\mathrm{SMC} 3 \mathrm{SMC} 3$ _HUMAN $141.55 \quad 100.0 \%$ Structural maintenance of chromosomes protein $3 \mathrm{GN}=\mathrm{SMC} 3 \mathrm{SMC} 3$ HUMAN $141.55100 .0 \%$ Structural maintenance of chromosomes protein $3 \mathrm{GN}=\mathrm{SMC} 3 \mathrm{SMC} 3$ _HUMAN $141.55 \quad 100.0 \%$
$0.00 \% \quad 5.9 \%$ DPQLVPILIEAAR $0.01 \% \quad 25.3 \%$ ILEPGLNILIPVLDR

$99.4 \% 20.4$ $99.7 \% 75.3$ $0.01 \% \quad 25.3 \%$ ASYGVEDPEYAVTQLAQTTMR $0.01 \% \quad 25.3 \%$ ATVLESEGTR $0.01 \% \quad 25.3 \%$ ESAINVAEGK $0.01 \% \quad 25.3 \%$ ESAINVAEGKK $99.7 \% \quad 53.2-25.0-53.2$ $99.7 \% \quad 45.4-25.0 \quad 33.9$ $99.7 \% \quad 57.1$

$0.01 \% \quad 25.3 \%$ AEQINQAAGEASAVLAK $99.7 \% \quad 80.6$ $0.01 \% \quad 25.3 \%$ APVPGTPDSLSSGSSR $0.07 \% \quad 28.0 \%$ VLENAEGAR

$0.07 \% \quad 28.0 \%$ TTPSVVAFTADGER $0.07 \% \quad 28.0 \%$ QAVTNPNNTFYATK $0.07 \% \quad 28.0 \%$ QAVTNPNNTFYATKR $0.07 \% \quad 28.0 \%$ RYDDPEVQK $0.07 \% \quad 28.0 \%$ NVPFKIVR

$0.07 \% \quad 28.0 \%$ MKETAENYLGHTAK $99.3 \% \quad 29.6$ $99.7 \% \quad 62.3$ $99.7 \% 77.2$ $99.7 \% \quad 78.1$ $99.7 \% \quad 49.5$ $99.7 \% \quad 40.4$ $99.0 \% \quad 23.2$ $99.7 \% \quad 39.3$ $99.7 \% \quad 55.5$ $0.07 \% \quad 28.0 \%$ NAVITVPAYFNDSQRQATK $99.7 \% \quad 32.4$ $0.07 \% \quad 28.0 \%$ QATKDAGQISGLNVLR $0.07 \% \quad 28.0 \%$ DAGQISGLNVLR

$99.7 \% \quad 57.3$ $99.7 \% \quad 60.0$

$0.07 \% \quad 28.0 \%$ VINEPTAAALAYGLDK $\quad 99.7 \% \quad 56.0$ $\begin{array}{lllll}0.07 \% & 28.0 \% & \text { STNGDTFLGGEDFDQALLR } & 99.7 \% & 80.1\end{array}$ $0.07 \% \quad 28.0 \%$ ETGVDLTKDNMALQR $0.07 \% \quad 28.0 \%$ AQFEGIVTDLIR $0.07 \% \quad 28.0 \%$ AQFEGIVTDLIRR $0.07 \% \quad 28.0 \%$ VQQTVQDLFGR $0.07 \% \quad 28.0 \%$ VQQTVQDLFGRAPSK $0.07 \% \quad 28.0 \%$ QAASSLQQASLK $0.02 \% \quad 10.8 \%$ FTAIIGPNGSGK $0.02 \% \quad 10.8 \%$ SGELAQEYDKR $0.02 \% \quad 10.8 \%$ LIDLCQPTQK $99.7 \% \quad 57.8$ $99.7 \% \quad 56.3$ $99.7 \% \quad 32.8$ $99.7 \% \quad 67.0$ $99.7 \% \quad 44.6$ $99.7 \% \quad 51.0$ $99.7 \% \quad 38.6$ $99.7 \% \quad 41.1$ $99.7 \% \quad 31.9$

$0.02 \% \quad 10.8 \%$ ALQYACGNALVCDNVEDARR $\quad 99.7 \% \quad 43.1$ $0.02 \% \quad 10.8 \%$ SGVISGGASDLK $0.02 \% \quad 10.8 \%$ SGVISGGASDLKAK $0.02 \% \quad 10.8 \%$ LKYSQSDLEQTK $0.02 \% \quad 10.8 \%$ SKLESELANFGPR $0.02 \% \quad 10.8 \%$ EVTAIETKLEQK $0.02 \% \quad 10.8 \%$ LNEQQSVLQR $99.7 \% \quad 39.5$ $99.7 \% \quad 56.3$ $99.6 \% \quad 27.4$ $99.7 \% 72.9$ $99.7 \% 38.0$ $99.7 \% 56.6$ $\begin{array}{lllll}0.02 \% & 10.8 \% & \text { VLTFDLTKYPDANPNPNEQ } & 99.7 \% & 45.5\end{array}$ $0.01 \% \quad 7.4 \%$ ASNLQDLVYKNGQAGITK $0.01 \% \quad 7.4 \%$ NKYLINGVNANNTR

$0.01 \% \quad 7.4 \%$ TILEEEITPTIQK

$0.01 \% \quad 7.4 \%$ SLEDALAEAQR

$99.7 \% 38.7$

$\begin{array}{lll}99.7 \% & 39.9\end{array}$ $99.7 \% \quad 35.8$

$0.01 \% \quad 7.4 \%$ TVTLGGDVFDPHGTLSGGAR $\quad 99.7 \% \quad 54.5$ $99.7 \% \quad 48.4$

$0.01 \% \quad 7.4 \%$ TKFVDGVSTVAR $0.02 \% \quad 12.4 \%$ QVIIQGFR $0.02 \% \quad 12.4 \%$ SYRDQTIVDPFSSK $0.02 \% \quad 12.4 \%$ LALLHEGTGPR $\begin{array}{llll}9.7 \% & 21.1 & 25.0 & 18.8\end{array}$

$25.0 \quad 40.2$
1450.72

1568.77

1724.87

1149.55

972.60

1592.77

1694.85

2123.09

1670.92

1242.68

1645.88

2055.96

1690.84

1361.74

1517.84

1290.68

1673.90

1231.66

1161.63

1295.62

1215.64

2295.06

1090.57

1289.71

1439.74

1447.75

1388.76

1214.65

2176.06

1920.02

1590.83

1514.83

1202.60

1956.98

1279.70

960.56

1642.81

1163.65

$\begin{array}{cc}08 & 220 \\ 8 & 72 \\ 15 & 135 \\ 02 & 211 \\ 12 & 221 \\ 12 & 222 \\ 34 & 250 \\ 22 & 337 \\ 77 & 85 \\ 6 & 99 \\ 08 & 121 \\ 08 & 122 \\ 27 & 135 \\ 39 & 146 \\ 74 & 187 \\ 88 & 202 \\ 88 & 206 \\ 03 & 218 \\ 07 & 218 \\ 19 & 234 \\ 66 & 284 \\ 93 & 307 \\ 49 & 360 \\ 49 & 361 \\ 95 & 405 \\ 95 & 409 \\ 35 & 646 \\ 27 & 38 \\ 61 & 171 \\ 19 & 528 \\ 08 & 627 \\ 49 & 660 \\ 49 & 662 \\ 12 & 723 \\ 35 & 747 \\ 11 & 922 \\ 10 & 1019 \\ 115 & 1233 \\ 99 & 76 \\ 13 & 126 \\ 97 & 209 \\ 98 & 308 \\ 49 & 668 \\ 59 & 1170 \\ 5 & 12 \\ 3 & 26 \\ 62 & 72 \\ & \end{array}$

Page 157 of Table S-1-4 
Structural maintenance of chromosomes protein $3 \mathrm{GN}=\mathrm{SMC} 3 \mathrm{SMC} 3$ HUMAN $141.55 \quad 100.0 \% \quad 12$ Structural maintenance of chromosomes protein $3 \mathrm{GN}=\mathrm{SMC} 3$ SMC3_HUMAN $141.55 \quad 100.0 \%$ Structural maintenance of chromosomes protein 3 GN=SMC3 SMC3_HUMAN $141.55 \quad 100.0 \% \quad 12$ Structural maintenance of chromosomes protein $3 \mathrm{GN}=$ SMC3 SMC3_HUMAN $141.55 \quad 100.0 \% \quad 12$ Structural maintenance of chromosomes protein 3 GN=SMC3 SMC3_HUMAN $141.55 \quad 100.0 \% \quad 12$ Structural maintenance of chromosomes protein $3 \mathrm{GN}=\mathrm{SMC} 3 \mathrm{SMC} 3$ _HUMAN $141.55 \quad 100.0 \%$ Structural maintenance of chromosomes protein $3 \mathrm{GN}=$ SMC3 SMC3_HUMAN $141.55 \quad 100.0 \%$ Structural maintenance of chromosomes protein $3 \mathrm{GN}=\mathrm{SMC} 3$ SMC3_HUMAN $141.55 \quad 100.0 \% \quad 12$ Structural maintenance of chromosomes protein $3 \mathrm{GN}=\mathrm{SMC} 3 \mathrm{SMC} 3$ HUMAN $141.55 \quad 100.0 \%$ Structural maintenance of chromosomes protein $4 \mathrm{GN}=$ SMC4 SMC4_HUMAN $147.19 \quad 100.0 \% \quad 13$ $\begin{array}{llll}\text { Structural maintenance of chromosomes protein } 4 \mathrm{GN}=\mathrm{SMC} 4 & \mathrm{SMC} 4 \text { HUMAN } & 147.19 & 100.0 \%\end{array}$ Structural maintenance of chromosomes protein $4 \mathrm{GN}=\mathrm{SMC} 4$ SMC4_HUMAN $147.19 \quad 100.0 \%$ Structural maintenance of chromosomes protein $4 \mathrm{GN}=\mathrm{SMC} 4 \mathrm{SMC4}$ _HUMAN $147.19 \quad 100.0 \% \quad 1$ Structural maintenance of chromosomes protein $4 \mathrm{GN}=$ SMC4 SMC4_HUMAN $147.19 \quad 100.0 \% \quad 13$ Structural maintenance of chromosomes protein $4 \mathrm{GN}=$ SMC4 SMC4_HUMAN $147.19 \quad 100.0 \%$ Structural maintenance of chromosomes protein $4 \mathrm{GN}=\mathrm{SMC} 4$ SMC4_HUMAN $147.19 \quad 100.0 \% \quad 1$ Structural maintenance of chromosomes protein 4 GN=SMC4 SMC4 HUMAN $147.19 \quad 100.0 \%$ Structural maintenance of chromosomes protein 4 GN=SMC4 SMC4_HUMAN $147.19 \quad 100.0 \% \quad 13$ Structural maintenance of chromosomes protein $4 \mathrm{GN}=\mathrm{SMC} 4$ SMC4_HUMAN $147.19 \quad 100.0 \% \quad 1$ Structural maintenance of chromosomes protein $4 \mathrm{GN}=\mathrm{SMC} 4$ SMC4 HUMAN $147.19 \quad 100.0 \%$ Structural maintenance of chromosomes protein 4 GN=SMC4 SMC4_HUMAN $147.19 \quad 100.0 \% \quad 13$ Structural maintenance of chromosomes protein $4 \mathrm{GN}=\mathrm{SMC} 4$ SMC4_HUMAN $147.19 \quad 100.0 \%$ Succinyl-CoA ligase [ADP/GDP-forming] subunit apha, mitochondral GN=SUCLG1 SUCA HUMAN $36.25100 .0 \%$ Succinyl-CoA ligase [ADP/GDP-forming] subunit alpha, mitochondrial GN=SUCLG1 SUCA_HUMAN 36.25 $100.0 \%$ SUCLI SUCA_HUMAN $36.25-100.0 \%$ Succinyl-CoA ligase [ADP/GDP-forming] subunit alpha, mitochondrial GN=SUCLG1 SUCA_HUMAN $36.25 \quad 100.0 \%$ Succinyl-CoA ligase [ADP/GDP-forming] subunit alpha, mitcochondrial GN=SUCLG1 SUCA_HUMAN $36.25100 .0^{\circ}$ succinyl-COA ligase [ADP/GDP-forming] subunit apha, mitochondrial GN=SUCLGI SUCA_HUMAN $36.25 \quad 100.0 \%$ Succinyl-CoA ligase [ADP-forming] subunit beta, mitochondrial GN=SUCLA2 SUCB1_HUMAN $50.32 \quad 100.0^{\circ}$ Succinyl-CoA ligase [ADP-forming] subunit beta, mitochondrial GN=SUCLA2 SUCB1_HUMAN $50.32 \quad 100.0 \%$ Succinyl-CoA ligase [ADP-forming] subunit beta, mitochondrial GN=SUCLA2 SUCB1_HUMAN 50.32 Succinyl-CoA ligase [ADP-forming] subunit beta, mitochondrial GN=SUCLA2 SUCB1_HUMAN 50.32 Succinyl-CoA ligase [ADP-forming] subunit beta, mitochondrial GN=SUCLA2 SUCB1_HUMAN $50.32 \quad 100.0$ Succinyl-COA ligase [ADP-forming] subunit beta, mitcohondrial GN=SUCLA2 SUCB1_HUMAN $50.32 \quad 100.0^{\circ}$ Succinyl-COA ligase [ADP-forming] subunit beta, mitochondrial GN=SUCLA2 SUCB1 HUMAN $50.32 \quad 100.0 \%$ Succinyl-COA ligase [ADP-forming] subunit beta, mitochondrial GN=SUCLA2 SUCB1_HUMAN $50.32 \quad 100.0 \%$ Succinyl-CoA ligase [ADP-forming] subunit beta, mitchondrial GN=SUCLA2 SUCB1_HUMAN $50.32 \quad 100.0 \%$ Succinyl-COA ligase [ADP-forming] subunit beta, mitochondrial GN=SUCLA2 SUCB1_HUMAN $50.32 \quad 100.0 \%$ Succinyl-COA ligase [ADP-forming] subunit beta, mitochondrial GN=SUCLA2 SUCB1_HUMAN $50.32 \quad 100.0 \%$ Succinyl-CoA ligase [ADP-forming] subunit beta, mitcochondrial GN=SUCLA2 SUCB1_HUMAN $50.32 \quad 100.0^{\circ}$ Succinyl-CoA ligase [ADP-forming] subunit beta, mitochondrial GN=SUCLA2 SUCB1_HUMAN $50.32 \quad 100.0 \%$ sccinyl-CoA ligase [GDP-forming] subunit beta, mitochondrial GN=SUCLG2 SUCB2_HUMAN 46.51 100.0\% Succinyl-COA ligase [GDP-forming] subunit beta, mitochondrial GN=SUCLG2 SUCB2 HUMAN $46.51 \quad 100.0 \%$ Succinyl-CoA ligase [GDP-forming] subunit beta, mitochondrial GN=SUCLG2 SUCB2_HUMAN 46.51 $100.0^{\circ}$

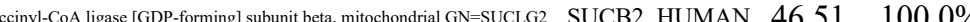
Succinyl-COA ligase [GDP-forming] subunit beta, mitochondrial GN=SUCLG2 SUCB2_HUMAN $46.51 \quad 100.0 \%$

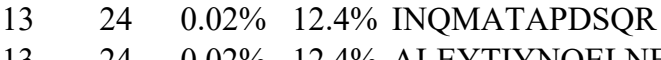

$13 \quad 24 \quad 0.02 \% \quad 12.4 \%$ LAQATQERTDLYAK

$13 \quad 24 \quad 0.02 \% \quad 12.4 \%$ GSQFTSKEER

$13 \quad 24 \quad 0.02 \% \quad 12.4 \%$ SMEVSTQLAR

$13 \quad 24 \quad 0.02 \% \quad 12.4 \%$ GALTGGYYDTRK

$13 \quad 24 \quad 0.02 \% \quad 12.4 \%$ VETYLNENLRK

$13 \quad 24$

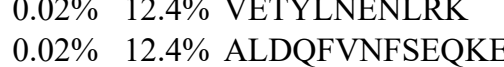

$0.02 \% \quad 12.4 \%$ GSGSQSSVPSVDQFTGVGIR

$13 \quad 20 \quad 0.02 \% \quad 10.8 \%$ FSCIIGPNGSGK

$13 \quad 20 \quad 0.02 \% \quad 10.8 \%$ TACRDNTSVYHISGK

$\begin{array}{llll}13 & 20 & 0.02 \% & 10.8 \% \\ 13 & \text { TFKDVGNLLR }\end{array}$

$\begin{array}{llll}13 & 20 & 0.02 \% & 10.8 \% \text { SNNIINETTTR }\end{array}$

$13 \quad 20 \quad 0.02 \% \quad 10.8 \%$ HNTAVSQLTK

$13 \quad 20 \quad 0.02 \% \quad 10.8 \%$ EALIAASETLKER

$13 \quad 20 \quad 0.02 \% \quad 10.8 \%$ VLDAIIQEKK

$13 \quad 20 \quad 0.02 \% \quad 10.8 \%$ MTEIQTPENTPR

$13 \quad 20 \quad 0.02 \% \quad 10.8 \%$ NTLEKFTASIQR

$13 \quad 20 \quad 0.02 \% \quad 10.8 \%$ VIQENEHALQK

$\begin{array}{llll}13 & 20 & 0.02 \% & 10.8 \% \\ 13 & \text { VAELDKITYER }\end{array}$

$13 \quad 20 \quad 0.02 \% \quad 10.8 \%$ SVAVNPKEIASK

$30 \quad 0.03 \% \quad 24.9 \%$ QHLYVDKNTK

$30 \quad 0.03 \% \quad 24.9 \%$ IICQGFTGK

$30 \quad 0.03 \% \quad 24.9 \%$ QGTFHSQQALEYGTK

$30 \quad 0.03 \% \quad 24.9 \%$ LVGGTTPGK

$30 \quad 0.03 \% \quad 24.9 \%$ GGQTHLGLPVFNTVK

$30 \quad 0.03 \% \quad 24.9 \%$ LIGPNCPGVINPGECK

$30 \quad 0.03 \% \quad 24.9 \%$ MGHAGAIIAGGK

$0.04 \% \quad 27.9 \%$ SPDEAYAIAK

$0.04 \% \quad 27.9 \%$ GKGTFESGLK

$0.04 \% \quad 27.9 \%$ GTFESGLKGGVK

$0.04 \% \quad 27.9 \%$ IVFSPEEAK

$0.04 \% \quad 27.9 \%$ ICNQVLVCER

$0.04 \% \quad 27.9 \%$ EQALQLAQK

$0.04 \% \quad 27.9 \%$ INFDSNSAYR

$0.04 \% \quad 27.9 \%$ CDVIAQGIVMAVK

$0.04 \% \quad 27.9 \%$ DLEIKIPVVVR

$0.04 \% \quad 27.9 \%$ LQGTRVDDAK

$0.04 \% \quad 27.9 \%$ ILACDDLDEAAR

$0.04 \% 27.9 \%$ LSEIVTLAK

$0.04 \% \quad 27.9 \%$ QAHVDVKFQLPI

$0.04 \% \quad 41.9 \%$ FFVADTANEALEAAK

$0.04 \% \quad 41.9 \%$ FFVADTANEALEAAKR

$0.04 \% \quad 41.9 \%$ DPNVVGQLAK

$0.04 \% \quad 41.9 \%$ QMIGYNLATK

$0.04 \% \quad 41.9 \%$ VMVAEALDISR $\begin{array}{lllllll}99.7 \% & 43.7 & 25.0 & 37.3 & 2 & 0 & 0\end{array}$ $\begin{array}{llllll}99.7 \% & 69.9 & 25.0 & 68.3 & 2 & 0\end{array}$ $99.7 \% \quad 43.4 \quad 25.0 \quad 37.9$ $\begin{array}{llll}98.4 \% & 22.5 & 25.0 & 16.8\end{array}$ $\begin{array}{llll}99.7 \% & 39.1 & 25.0 & 29.2\end{array}$ $\begin{array}{llll}99.7 \% & 50.7 & 25.0 & 44.0\end{array}$

$\begin{array}{llll}98.7 \% & 23.3 & 25.0 & 14.0\end{array}$

$\begin{array}{lllll}99.7 \% & 48.5 & 25.0 & 48.5 & 2\end{array}$

$\begin{array}{llll}99.7 \% & 36.9 & 25.0 & 32.3\end{array}$

$\begin{array}{llll}99.7 \% & 28.2 & 25.0 & 28.2\end{array}$

$\begin{array}{llll}99.7 \% & 27.1 & 25.0 & 22.1\end{array}$

$\begin{array}{llll}99.7 \% & 52.0 & 25.0 & 43.8\end{array}$

$\begin{array}{llll}99.7 \% & 30.5 & 25.0 & 29.9\end{array}$

$99.7 \% \quad 42.6 \quad 25.0 \quad 28.2$

$\begin{array}{llll}99.7 \% & 27.3 & 25.0 & 27.3\end{array}$

$99.7 \% \quad 36.8 \quad 25.0-28.4$

$\begin{array}{llll}99.7 \% & 36.9 & 25.0 & 36.9\end{array}$

$\begin{array}{llll}99.7 \% & 33.2 & 25.0 & 28.5\end{array}$

$99.7 \% \quad 31.5 \quad 25.0 \quad 31.5$

$99.7 \% \quad 52.5 \quad 25.0 \quad 52.5$

$\begin{array}{llll}99.7 \% & 38.9 & 25.0 & 29.8\end{array}$

$\begin{array}{llll}99.7 \% & 46.4 & 25.0 & 43.8\end{array}$

$\begin{array}{llll}99.7 \% & 41.7 & 25.0 & 32.7\end{array}$

$\begin{array}{lllll}99.7 \% & 52.3 & 25.0 & 50.6\end{array}$

$\begin{array}{llll}99.4 \% & 25.4 & 25.0 & 17.4\end{array}$

$\begin{array}{llll}99.7 \% & 42.7 & 25.0 & 42.7\end{array}$

$\begin{array}{llll}99.7 \% & 52.0 & 25.0 & 49.4\end{array}$

$\begin{array}{llll}99.7 \% & 59.1 & 25.0 & 54.5\end{array}$

$\begin{array}{llll}99.7 \% & 57.3 & 25.0 & 55.2\end{array}$

$\begin{array}{llll}99.7 \% & 29.1 & 25.0 & 29.0\end{array}$

$\begin{array}{llll}99.7 \% & 30.5 & 25.0 & 30.5\end{array}$

$\begin{array}{llll}99.4 \% & 22.0 & 25.0 & 17.9\end{array}$

$\begin{array}{llll}99.7 \% & 54.2 & 25.0 & 49.6\end{array}$

$\begin{array}{llll}99.7 \% & 46.9 & 25.0 & 41.5\end{array}$

$\begin{array}{llll}99.7 \% & 54.3 & 25.0 & 54.3\end{array}$

$\begin{array}{llll}99.7 \% & 58.7 & 25.0 & 47.5\end{array}$

$\begin{array}{llll}99.7 \% & 26.2 & 25.0 & 26.2\end{array}$

$\begin{array}{llll}97.5 \% & 19.6 & 25.0 & 14.3\end{array}$

$\begin{array}{llll}99.7 \% & 54.9 & 25.0 & 54.6\end{array}$

$99.7 \% \quad 40.0 \quad 25.0 \quad 29.6$

$\begin{array}{lllll}99.7 \% & 27.8 & 25.0 & 20.5 & 2\end{array}$

$99.7 \% \quad 81.0 \quad 25.0 \quad 73.1$

$\begin{array}{llll}99.7 \% & 30.4 & 25.0 & 25.1\end{array}$

$\begin{array}{lllll}99.7 \% & 42.1 & 25.0 & 38.8 & 2\end{array}$

$\begin{array}{llll}99.7 \% & 33.9 & 25.0 & 25.7\end{array}$

$99.7 \% \quad 62.0 \quad 25.0 \quad 54.7$
1856.90

1607.84

1168.56

1137.56

1301.65

1378.73

1682.84

1964.97

1236.60

1708.81

1162.66

1262.63

1098.59

1430.79

1028.60

1156.69

1432.67

1407.76

1308.69

1336.71

1242.71

1245.66

1023.53

1694.81

829.48

1567.86

1724.85

1098.57

1064.53

1023.55

1179.64

1019.54

1290.63

1028.57

1186.55

1403.74

1280.79

1102.59

1361.64

973.59

1394.78

1596.79

1752.89

1040.57

1154.59

1203.64 $\begin{array}{cc}44 & 155 \\ 22 & 236 \\ 65 & 378 \\ 82 & 391 \\ 35 & 644 \\ 62 & 673 \\ 28 & 838 \\ 86 & 999 \\ 80 & 1099 \\ 08 & 119 \\ 88 & 202 \\ 05 & 214 \\ 35 & 445 \\ 13 & 522 \\ 25 & 537 \\ 99 & 607 \\ 99 & 608 \\ 81 & 692 \\ 16 & 827 \\ 99 & 1009 \\ 07 & 1117 \\ 74 & 1285 \\ 8 & 57 \\ 8 & 66 \\ 7 & 81 \\ 2 & 90 \\ 1 & 105 \\ 67 & 182 \\ 97 & 308 \\ 9 & 88 \\ 07 & 116 \\ 09 & 120 \\ 21 & 129 \\ 51 & 160 \\ 17 & 225 \\ 75 & 284 \\ 84 & 396 \\ 97 & 407 \\ 08 & 417 \\ 27 & 438 \\ 43 & 451 \\ 52 & 463 \\ 9 & 73 \\ 9 & 74 \\ 09 & 118 \\ 19 & 128 \\ 40 & 150\end{array}$

Page 158 of Table S-14 
SUN domain-containing protein $2 \mathrm{GN}=\mathrm{SUN} 2$ SUN2_HUMAN $80.31 \quad 100.0 \%$ SUN domain-containing protein 2 GN=SUN2 SUN2_HUMAN $80.31 \quad 100.0 \%$ Superkiller viralicidic activity 2-like $2 \mathrm{GN}=$ SKIV2L2 SK2L2 HUMAN $117.81 \quad 100.0 \%$ Superkiller viralicidic activity 2-like 2 GN=SKIV2L2 SK2L2_HUMAN $117.81 \quad 100.0 \%$ Superkiller viralicidic activity 2-like 2 GN=SKIV2L2 SK2L2_HUMAN $117.81 \quad 100.0 \%$ Superkiller viralicidic activity 2-like $2 \mathrm{GN}=$ SKIV2L2 SK2L2 HUMAN $117.81 \quad 100.0 \%$ Superkiller viralicidic activity 2-like 2 GN=SKIV2L2 SK2L2_HUMAN $117.81 \quad 100.0 \%$ Superkiller viralicidic activity 2-like $2 \mathrm{GN}=$ SKIV2L2 SK2L2 HUMAN $117.81 \quad 100.0 \%$ Superkiller viralicidic activity 2-like 2 GN=SKIV2L2 SK2L2_HUMAN $117.81 \quad 100.0 \%$ Superkiller viralicidic activity 2-like 2 GN=SKIV2L2 SK2L2_HUMAN $117.81 \quad 100.0 \%$ Suppressor of SWI4 1 homolog GN=PPAN SSF1_HUMAN $53.19 \quad 100.0 \%$ Suppressor of SWI4 1 homolog GN=PPAN SSF1_HUMAN $53.19 \quad 100.0 \%$ Suppressor of SWI4 1 homolog GN=PPAN SSF1_HUMAN $53.19 \quad 100.0 \%$ Suppressor of SWI4 1 homolog GN=PPAN SSF1_HUMAN $53.19100 .0 \%$ Suppressor of SWI4 1 homolog GN=PPAN SSF1_HUMAN $53.19 \quad 100.0 \%$ SURP and G-patch domain-containing protein $2 \mathrm{GN}=$ SUGP2 SUGP2_HUMAN $120.21 \quad 100.0 \%$ SURP and G-patch domain-containing protein 2 GN=SUGP2 SUGP2_HUMAN $120.21 \quad 100.0 \%$ SURP and G-patch domain-containing protein 2 GN=SUGP2 SUGP2_HUMAN $120.21 \quad 100.0 \%$ SURP and G-patch domain-containing protein $2 \mathrm{GN}=\mathrm{SUGP} 2$ SUGP2 HUMAN $120.21 \quad 100.0 \%$ Survival motor neuron protein GN=SMN1 SMN_HUMAN $31.85 \quad 100.0 \%$ Survival motor neuron protein GN=SMN1 SMN HUMAN $31.85 \quad 100.0 \%$ Survival motor neuron protein GN=SMN1 SMN_HUMAN $31.85 \quad 100.0 \%$

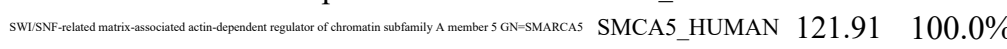

Synembryn-A GN=RIC8A

Synembryn-A GN=RIC8A Syntaxin-18 GN=STX18 SMCA5 HUMAN $121.91 \quad 100.0 \%$ SMCA5_HUMAN $121.91 \quad 100.0 \%$ SMCA5_HUMAN $121.91 \quad 100.0 \%$ SMCA5 HUMAN $121.91 \quad 100.0 \%$ SMCA5_HUMAN $121.91 \quad 100.0 \%$ SMCA5_HUMAN $121.91 \quad 100.0 \%$

(1)

(1)

8

8

(1)

8

8

8

$9 \quad 0.01 \% \quad 12.5 \%$ NLEAYAANPHSFVFTR

$9 \quad 0.01 \% \quad 12.5 \%$ VMEPLTASR

$9 \quad 0.01 \% \quad 12.5 \%$ LPGGPTLTFQVK

$9 \quad 0.01 \% \quad 12.5 \%$ VNLNTIKR

$9 \quad 0.01 \% \quad 12.5 \%$ VGGSDEEASGIPSR

$12 \quad 0.01 \% \quad 4.7 \% \quad$ APSSLSDAVPQR

$12 \quad 0.01 \% \quad 4.7 \% \quad$ VIEGSLSPKER

$12 \quad 0.01 \% \quad 4.7 \%$ GADQKPTSADCAVR

$12 \quad 0.01 \% \quad 4.7 \% \quad$ ATTGTQTLLSSGTR

$6 \quad 0.01 \% \quad 11.6 \%$ NGDICETSGKPK

$6 \quad 0.01 \% \quad 11.6 \%$ ETCVVVYTGYGNR

$6 \quad 0.01 \% \quad 11.6 \%$ LGPGKPGLK

$20 \quad 0.02 \% \quad 7.3 \% \quad$ NIPGPHMVLVPK

$20 \quad 0.02 \% \quad 7.3 \% \quad$ SVCLIGDKEQR

$20 \quad 0.02 \% \quad 7.3 \% \quad$ YLVIDEAHR

$20 \quad 0.02 \% \quad 7.3 \% \quad$ MVVLDKLLPK

$20 \quad 0.02 \% \quad 7.3 \% \quad$ VLIFSQMTR

$20 \quad 0.02 \% \quad 7.3 \%$ TAEMNEKLSK

$20 \quad 0.02 \% \quad 7.3 \% \quad$ TIGYKVPR

$20 \quad 0.02 \% \quad 7.3 \%$ ALDTKIGR

$4 \quad 0.00 \% \quad 4.1 \%$ ALLIFLEK

$4 \quad 0.00 \% \quad 4.1 \% \quad$ YTGYGNAAGLLAAR $\begin{array}{lll} & \\ \text { RIC8A_HUMAN } & 59.71 & 100.0 \%\end{array}$ STX18_HUMAN $38.67 \quad 100.0 \%$ $\begin{array}{llll}99.7 \% & 39.1 & 25.0 & 33.2\end{array}$

$99.7 \% \quad 63.4 \quad 25.0 \quad 54.3$

$99.7 \% \quad 44.9 \quad 25.0 \quad 37.7$

$\begin{array}{llll}99.7 \% & 32.1 & 25.0 & 32.1\end{array}$

$\begin{array}{llll}99.7 \% & 62.0 & 25.0 & 55.5\end{array}$

$\begin{array}{llll}99.7 \% & 51.3 & 25.0 & 44.2\end{array}$

$\begin{array}{lllll}99.7 \% & 40.3 & 25.0 & 39.4 & 2\end{array}$

$\begin{array}{llll}99.7 \% & 60.6 & 25.0 & 50.6\end{array}$

AK 99.7

$\begin{array}{lll}99.6 \% & 25.7\end{array}$

$95.5 \% \quad 22.9$

$99.7 \% \quad 40.5$

$99.7 \% \quad 41.8$

$99.3 \% \quad 19.1$

$99.3 \% \quad 22.6$

$99.2 \% 24.1$

$99.7 \% \quad 36.1$

$99.7 \% \quad 32.5$

$99.7 \% \quad 27.7$

$99.7 \% \quad 47.0$

$96.4 \% \quad 23.6$

$99.7 \% \quad 64.0$

$99.7 \% \quad 35.0$

$99.7 \% \quad 51.6$

$96.0 \% \quad 21.2$

$\begin{array}{lll}99.7 \% & 34.5\end{array}$

$99.0 \% \quad 38.8$

$99.7 \% \quad 45.7$

$99.7 \% \quad 60.3$

$\begin{array}{lll}99.7 \% & 32.1\end{array}$

$99.7 \% \quad 36.5$

$99.7 \% \quad 66.6$

$99.7 \% \quad 46.1$

$99.7 \% \quad 59.3$

$99.5 \% \quad 25.9$

$99.6 \% \quad 23.8$

$\begin{array}{lll}99.7 \% & 58.7\end{array}$

$99.7 \% \quad 39.9$

$99.7 \% \quad 34.7$

$\begin{array}{lll}99.7 \% & 27.8\end{array}$

$99.7 \% \quad 42.6$

$\begin{array}{lll}99.0 \% & 44.8\end{array}$

$99.0 \% \quad 35.3$

$99.0 \% \quad 20.2$

$99.7 \% \quad 59.9$

$0.00 \% \quad 6.3 \%$ TEAHKEIHSQQVK
1240.62

1876.94

1291.67

961.50

2750.30

1240.56

1083.55

1294.81

1216.62

2055.10

2183.19

827.54

1231.58

1387.68

1301.59

1460.86

1949.96

1398.71

1275.59

1250.64

1355.74

999.62

1097.63

1834.95

1836.90

1003.52

1257.72

957.58

1360.63

1227.63

1214.67

1475.69

1393.73

1305.61

1517.71

866.55

1317.74

1304.66

1115.58

1155.72

1094.60

1150.58

933.55

873.52

946.60

1397.72 1534.80 $\begin{array}{cc}51 & 160 \\ 91 & 206 \\ 07 & 218 \\ 19 & 227 \\ 35 & 259 \\ 60 & 269 \\ 39 & 347 \\ 82 & 392 \\ 93 & 403 \\ 04 & 423 \\ 04 & 424 \\ 4 & 61 \\ 84 & 195 \\ 84 & 196 \\ 65 & 275 \\ 19 & 631 \\ 5 & 81 \\ 35 & 145 \\ 88 & 596 \\ 49 & 658 \\ 93 & 803 \\ 25 & 833 \\ 24 & 933 \\ 13 & 1029 \\ 1 & 36 \\ 3 & 61 \\ 02 & 113 \\ 72 & 179 \\ 56 & 369 \\ 70 & 581 \\ 97 & 607 \\ 46 & 659 \\ 96 & 709 \\ 6 & 67 \\ 21 & 133 \\ 05 & 213 \\ 27 & 238 \\ 57 & 267 \\ 04 & 312 \\ 85 & 494 \\ 02 & 510 \\ 85 & 694 \\ 95 & 802 \\ 20 & 927 \\ 12 & 319 \\ 10 & 423 \\ 16 & 128\end{array}$

Page 159 of Table S-1-4 
TAR DNA-binding protein 43 GN=TARDBP TADBP_HUMAN $44.74 \quad 100.0 \%$ TAR DNA-binding protein 43 GN=TARDBP TADBP_HUMAN $44.74 \quad 100.0 \%$ TAR DNA-binding protein 43 GN=TARDBP TADBP HUMAN $44.74 \quad 100.0 \%$ TAR DNA-binding protein $43 \mathrm{GN}=$ TARDBP TADBP_HUMAN $44.74 \quad 100.0 \%$ Target of rapamycin complex subunit LST8 GN=MLST8 LST8_HUMAN $35.88 \quad 100.0 \%$ Target of rapamycin complex subunit LST8 GN=MLST8 LST8_HUMAN 35.88 Target of rapamycin complex subunit LST8 GN=MLST8 LST8_HUMAN 35.88 TATA box-binding protein-like protein $2 \mathrm{GN}=$ TBPL2 TBPL2 HUMAN 41.5 TATA-binding protein-associated factor $172 \mathrm{GN}=\mathrm{BTAF} 1$ BTAF1_HUMAN $206.89 \quad 100.0 \%$ TATA-binding protein-associated factor $172 \mathrm{GN}=\mathrm{BTAF} 1$ BTAF1_HUMAN $206.89 \quad 100.0 \%$ TATA-binding protein-associated factor $172 \mathrm{GN}=\mathrm{BTAF} 1$ BTAF1_HUMAN $206.89 \quad 100.0 \%$ TATA-binding protein-associated factor $172 \mathrm{GN}=\mathrm{BTAF} 1$ BTAF1_HUMAN $206.89 \quad 100.0 \%$ TATA-binding protein-associated factor $172 \mathrm{GN}=\mathrm{BTAF} 1$ BTAF1 HUMAN $206.89 \quad 100.0 \%$ TATA-binding protein-associated factor 2N GN=TAF15 RBP56_HUMAN $61.83 \quad 100.0 \%$ TATA-binding protein-associated factor 2N GN=TAF15 RBP56_HUMAN $61.83 \quad 100.0 \%$ TATA-binding protein-associated factor 2N GN=TAF15 RBP56_HUMAN $61.83 \quad 100.0 \%$ TATA-binding protein-associated factor 2N GN=TAF15 RBP56_HUMAN $61.83 \quad 100.0 \%$ TATA-binding protein-associated factor 2N GN=TAF15 RBP56 HUMAN $61.83 \quad 100.0^{\circ}$ TATA-binding protein-associated factor 2N GN=TAF15 RBP56_HUMAN $61.83 \quad 100.0 \%$ TATA-binding protein-associated factor 2N GN=TAF15 RBP56_HUMAN $61.83 \quad 100.0 \%$ T-complex protein 1 subunit alpha GN=TCP1 TCPA_HUMAN $60.35 \quad 100.0 \%$ T-complex protein 1 subunit alpha GN=TCP1 TCPA_HUMAN $60.35 \quad 100.0 \%$ T-complex protein 1 subunit alpha GN=TCP1 TCPA HUMAN $60.35 \quad 100.0 \%$ T-complex protein 1 subunit alpha GN=TCP1 TCPA_HUMAN $60.35 \quad 100.0 \%$ T-complex protein 1 subunit alpha GN=TCP1 TCPA_HUMAN 60.35 T-complex protein 1 subunit alpha GN=TCP1 TCPA_HUMAN 60.35 T-complex protein 1 subunit alpha GN=TCP1 TCPA_HUMAN 60.35 T-complex protein 1 subunit alpha GN=TCP1 TCPA_HUMAN 60.35 T-complex protein 1 subunit alpha GN=TCP1 TCPA_HUMAN 60.35 T-complex protein 1 subunit alpha GN=TCP1 TCPA_HUMAN 60.35 T-complex protein 1 subunit alpha GN=TCP1 TCPA_HUMAN 60.3 T-complex protein 1 subunit alpha GN=TCP1 TCPA_HUMAN 60.35 T-complex protein 1 subunit alpha GN=TCP1 TCPA_HUMAN 60.35 T-complex protein 1 subunit alpha GN=TCP1 TCPA_HUMAN 60.3 T-complex protein 1 subunit alpha GN=TCP1 TCPA_HUMAN 60.35 T-complex protein 1 subunit alpha GN=TCP1 TCPA HUMAN 60.3 T-complex protein 1 subunit alpha GN=TCP1 TCPA_HUMAN 60.35 T-complex protein 1 subunit alpha GN=TCP1 TCPA_HUMAN 60.35 T-complex protein 1 subunit alpha GN=TCP1 TCPA HUMAN 60.35 T-complex protein 1 subunit alpha GN=TCP1 TCPA_HUMAN 60.35 $100.0 \% \quad 32$ $100.0 \% \quad 32$ $100.0 \% \quad 32$ $100.0 \% \quad 32$ $100.0 \% \quad 32$ $100.0 \% \quad 32$ $100.0 \% \quad 32$ $100.0 \% \quad 32$ $100.0 \% \quad 32$ $100.0 \% \quad 32$ $100.0 \% \quad 32$ $100.0 \% \quad 32$ $100.0 \% \quad 32$ $100.0 \% \quad 32$ $100.0 \% \quad 32$ $100.0 \% \quad 32$

$0.01 \% \quad 12.3 \%$ FTEYETQVK

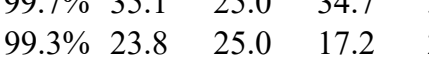

$13 \quad 0.01 \% \quad 12.3 \%$ GISVHISNAEPK

$\begin{array}{llll}99.7 \% & 41.2 & 25.0 & 32.8\end{array}$

$\begin{array}{lllllll}0.01 \% & 12.3 \% & \text { FGGNPGGFGNQGGFGNSR } & 99.7 \% & 58.1 & 25.0 & 58.1\end{array}$

$\begin{array}{lllllll}0.00 \% & 15.0 \% & \text { TVQHQDSQVNALEVTPDR } & 99.7 \% & 50.1 & 25.0 & 48.6\end{array}$

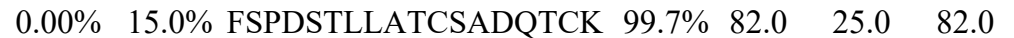

$0.00 \% \quad 15.0 \%$ TSNFSLMTELSIK

$0.00 \% \quad 5.3 \%$ TTALIFSSGK

$0.00 \% \quad 5.3 \% \quad$ IVLLIFVSGK

$0.01 \% \quad 3.1 \%$ LFILLDTGTTPVTR

$99.7 \% \quad 26.9$

$99.7 \% \quad 32.2$

$96.7 \% \quad 15.2$

$99.7 \% \quad 53.7$

$99.7 \% \quad 65.6$

$0.01 \% \quad 3.1 \%$ AVTLAVQPR

$0.01 \% \quad 3.1 \%$ GAEFALTTIVK

$99.7 \% \quad 37.7$

$99.7 \% \quad 34.8$

$0.01 \% \quad 3.1 \% \quad$ NTIDINNFDGK

$0.01 \% \quad 17.7 \%$ NFGGHRDYGPR

$99.7 \% \quad 37.9$

$0.01 \% \quad 17.7 \%$ GEATVSFDDPPSAK

$99.7 \% \quad 39.7$

$99.7 \% \quad 61.7$

$\begin{array}{lllll}0.01 \% & 17.7 \% & \text { AAIDWFDGKEFHGNIIK } \quad 99.7 \% \quad 28.3\end{array}$

$0.01 \% \quad 17.7 \%$ SGGGYGGDRSSGGGYSGDR $99.7 \% \quad 41.2$

$\begin{array}{lllll}0.01 \% & 17.7 \% & \text { SSGGGYSGDRSGGGYGGDR } \quad 99.7 \% \quad 44.7\end{array}$

$0.01 \% \quad 17.7 \%$ SGGGYGGDRGGGYGGDR $99.7 \% \quad 37.6$

$44 \quad 110 \quad 0.11 \% \quad 57.4 \%$ STGETIRSQNVMAAASIANIVK $\quad 99.7 \% \quad 43.4$

$44 \quad 110 \quad 0.11 \% \quad 57.4 \%$ SQNVMAAASIANIVK

$110 \quad 0.11 \% \quad 57.4 \%$ SSLGPVGLDK

$99.7 \% \quad 80.3$

$99.7 \% \quad 40.3$

$110 \quad 0.11 \% \quad 57.4 \%$ MLVDDIGDVTITNDGATILK

$110 \quad 0.11 \% \quad 57.4 \%$ LLEVEHPAAK

$110 \quad 0.11 \% \quad 57.4 \%$ NADELVKQK

$44 \quad 110 \quad 0.11 \% \quad 57.4 \%$ QKIHPTSVISGYR

$44 \quad 110 \quad 0.11 \% \quad 57.4 \%$ IHPTSVISGYR

$110 \quad 0.11 \% \quad 57.4 \%$ LACKEAVR

$\begin{array}{ll}99.7 \% & 71.0 \\ 99.7 \% & 53.2\end{array}$

$99.7 \% \quad 41.8$

$98.8 \% \quad 19.4$

$99.7 \% \quad 30.4$

$99.0 \% \quad 38.5$

$44 \quad 110 \quad 0.11 \% \quad 57.4 \%$ YINENLIVNTDELGRDCLINAAK

$110 \quad 0.11 \% \quad 57.4 \%$ YTDIRGQPR

$44 \quad 110 \quad 0.11 \% \quad 57.4 \%$ YPVNSVNILK

$44 \quad 110 \quad 0.11 \% \quad 57.4 \%$ IACLDFSLQK

$44 \quad 110 \quad 0.11 \% \quad 57.4 \%$ IACLDFSLQKTK

$44 \quad 110 \quad 0.11 \% \quad 57.4 \%$ LGVQVVITDPEKLDQIR

$44 \quad 110 \quad 0.11 \% \quad 57.4 \%$ YFVEAGAMAVR

$44 \quad 110 \quad 0.11 \% \quad 57.4 \%$ ICDDELILIK

$44 \quad 110 \quad 0.11 \% \quad 57.4 \%$ ICDDELILIKNTK

$44 \quad 110 \quad 0.11 \% \quad 57.4 \%$ TSASIILR

$44 \quad 110 \quad 0.11 \% \quad 57.4 \%$ GANDFMCDEMER

$99.7 \% \quad 58.7$

$99.7 \% \quad 69.9$

$99.7 \% \quad 35.0$

\section{$\begin{array}{lll}99.7 \% & 55.8\end{array}$}

$99.3 \% \quad 23.7$

$99.7 \% \quad 55.9$

$99.7 \% \quad 58.9$

$99.0 \% \quad 55.7$

$99.7 \% \quad 54.5$

1007.54

1140.63

1167.56

1084.67

1011.63

1031.61

1297.59

1144.55

1251.67

1726.77

2037.00

2001.89

1470.75

1024.57

1088.71

1546.88

1169.69

954.57

1149.65

1250.60

1275.60

1420.66

1960.99

2084.84

1748.72

1748.72

1544.65

2277.19

1516.82

972.54

2120.08

1106.62

1044.57

1485.82

1229.66

946.51

2648.34

1105.58

1146.65

1194.62

1423.76

1923.09

1229.60

1231.66

1574.85

860.52

860.52
1506.53 

T-complex protein 1 subunit alpha GN=TCP1 TCPA_HUMAN $60.35 \quad 100.0 \% \quad 32$ $\begin{array}{llll}\text { T-complex protein } 1 \text { subunit alpha GN=TCP1 TCPA_HUMAN } & 60.35 & 100.0 \% & 32\end{array}$ T-complex protein 1 subunit alpha GN=TCP1 TCPA HUMAN $60.35 \quad 100.0 \%$ T-complex protein 1 subunit alpha GN=TCP1 TCPA_HUMAN $60.35 \quad 100.0 \% \quad 32$ T-complex protein 1 subunit alpha GN=TCP1 TCPA_HUMAN 60.35 T-complex protein 1 subunit alpha GN=TCP1 TCPA_HUMAN 60.3 T-complex protein 1 subunit alpha GN=TCP1 TCPA_HUMAN 60.3 T-complex protein 1 subunit alpha GN=TCP1 TCPA_HUMAN 60.3 T-complex protein 1 subunit alpha GN=TCP1 TCPA_HUMAN 60.35 T-complex protein 1 subunit alpha GN=TCP1 TCPA_HUMAN 60.35 T-complex protein 1 subunit alpha GN=TCP1 TCPA_HUMAN 60.35 T-complex protein 1 subunit beta GN=CCT2 TCPB_HUMAN 57.49 T-complex protein 1 subunit beta GN=CCT2 TCPB_HUMAN 57.49 T-complex protein 1 subunit beta $\mathrm{GN}=\mathrm{CCT} 2$ TCPB_HUMAN 57.49 T-complex protein 1 subunit beta GN=CCT2 TCPB_HUMAN 57.49 T-complex protein 1 subunit delta GN=CCT4 TCPD HUMAN 57.93 T-complex protein 1 subunit delta GN=CCT4 TCPD_HUMAN 57.93 T-complex protein 1 subunit delta GN=CCT4 TCPD_HUMAN 57.93 T-complex protein 1 subunit delta GN=CCT4 TCPD_HUMAN 57.93 T-complex protein 1 subunit delta GN=CCT4 TCPD_HUMAN 57.93 T-complex protein 1 subunit delta GN=CCT4 TCPD HUMAN 57.93 T-complex protein 1 subunit delta GN=CCT4 TCPD_HUMAN 57.93 T-complex protein 1 subunit delta GN=CCT4 TCPD_HUMAN 57.93 T-complex protein 1 subunit delta GN=CCT4 TCPD HUMAN 57.93 T-complex protein 1 subunit delta GN=CCT4 TCPD_HUMAN 57.93 T-complex protein 1 subunit delta GN=CCT4 TCPD_HUMAN 57.93 T-complex protein 1 subunit delta GN=CCT4 TCPD_HUMAN 57.93 T-complex protein 1 subunit delta GN=CCT4 TCPD_HUMAN 57.93 T-complex protein 1 subunit delta $\mathrm{GN}=\mathrm{CCT} 4$ TCPD HUMAN 57.93 T-complex protein 1 subunit epsilon GN=CCT5 TCPE_HUMAN 59.67 T-complex protein 1 subunit epsilon GN=CCT5 TCPE_HUMAN 59.6 T-complex protein 1 subunit epsilon GN=CCT5 TCPE_HUMAN $59.6^{\circ}$ T-complex protein 1 subunit epsilon GN=CCT5 TCPE_HUMAN 59.67 T-complex protein 1 subunit epsilon GN=CCT5 TCPE HUMAN 59.67 T-complex protein 1 subunit epsilon GN=CCT5 TCPE HUMAN 59.67 T-complex protein 1 subunit epsilon GN=CCT5 TCPE_HUMAN 59.67 T-complex protein 1 subunit epsilon GN=CCT5 TCPE HUMAN 59.67 T-complex protein 1 subunit epsilon GN=CCT5 TCPE_HUMAN 59.67 T-complex protein 1 subunit epsilon GN=CCT5 TCPE_HUMAN $59.6^{\circ}$ T-complex protein 1 subunit epsilon $\mathrm{GN}=\mathrm{CCT} 5$ TCPE HUMAN 59.6 T-complex protein 1 subunit epsilon GN=CCT5 TCPE_HUMAN $59.6^{\circ}$ T-complex protein 1 subunit epsilon GN=CCT5 TCPE HUMAN 59.67 T-complex protein 1 subunit epsilon GN=CCT5 TCPE_HUMAN 59.67 T-complex protein 1 subunit epsilon GN=CCT5 TCPE_HUMAN 59.6 T-complex protein 1 subunit eta GN=CCT7 TCPH_HUMAN 59.37 T-complex protein 1 subunit eta $\mathrm{GN}=\mathrm{CCT} 7 \mathrm{TCPH} \_$HUMAN 59.37 $100.0 \%$
$44 \quad 110 \quad 0.11 \% \quad 57.4 \%$ SLHDALCVVK

$44 \quad 110 \quad 0.11 \% \quad 57.4 \%$ SLHDALCVVKR

$44 \quad 110 \quad 0.11 \% \quad 57.4 \%$ EQLAIAEFAR

$\begin{array}{llllllll}99.7 \% & 47.6 & 25.0 & 43.9 & 2 & 0 & 0 & 1141.60\end{array}$ $99.7 \% \quad 57.2$ $99.7 \% \quad 58.0$

$110 \quad 0.11 \% \quad 57.4 \%$ SLLVIPNTLAVNAAQ

$\begin{array}{ll}99.7 \% & 53.4 \\ 99.3 \% & 19.9\end{array}$

$110 \quad 0.11 \% \quad 57.4 \%$ SLLVIPNTLAVNAAQDSTDLVAKLR

$44 \quad 110 \quad 0.11 \% \quad 57.4 \%$ AFHNEAQVNPER

$99.7 \% \quad 60.1$

$99.7 \% \quad 51.7$

$99.7 \% \quad 40.3$

$99.7 \% \quad 48.9$

$99.7 \% \quad 38.2$

$99.7 \% \quad 62.3$

$110 \quad 0.11 \% \quad 57.4 \%$ DNKQAGVFEPTIVK

$44 \quad 110 \quad 0.11 \% \quad 57.4 \%$ QAGVFEPTIVK

$44 \quad 110 \quad 0.11 \% \quad 57.4 \%$ FATEAAITILR

$99.7 \% \quad 38.4$

$\begin{array}{lll}0.11 \% & 57.4 \% & \text { DDKHGSYEDAVHSGALI } \\ 0.00 \% & 10.3 \% & \text { LTSFIGAIAIGDLVK }\end{array}$

$99.7 \% \quad 68.6$

$0.00 \% \quad 10.3 \%$ LGGSLADSYLDEGFLLDKK

$0.00 \% \quad 10.3 \%$ HGINCFINR

$0.00 \% \quad 10.3 \%$ GATQQILDEAER

$63 \quad 0.06 \% \quad 27.8 \%$ GAYQDRDKPAQIR

$0.06 \% \quad 27.8 \%$ FSNISAAK

$63 \quad 0.06 \% \quad 27.8 \%$ VIDPATATSVDLR

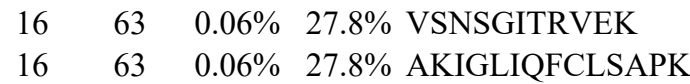

$\begin{array}{llll}16 & 63 & 0.06 \% & 27.8 \% \\ 16 & 63 & 0.06 \% & 27.8 \%\end{array}$

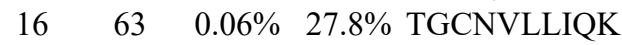

$\begin{array}{llll}16 & 63 & 0.06 \% & 27.8 \% \\ 16 & \text { DALSDLALHFLNK }\end{array}$

$\begin{array}{llll}16 & 63 & 0.06 \% & 27.8 \% \\ 16 & \text { GSNKLVIEEAER }\end{array}$

$\begin{array}{llll}16 & 63 & 0.06 \% & 27.8 \% \\ 16 & 63 \text { SIHDALCVIR }\end{array}$

$\begin{array}{llll}16 & 63 & 0.06 \% & 27.8 \% \\ 16 & 63 & \text { ALIAGGGAPEIELALR }\end{array}$

$16 \quad 63 \quad 0.06 \% \quad 27.8 \%$ ALIAGGGAPEIELALRLTEYSR

$\begin{array}{llll}16 & 63 & 0.06 \% & 27.8 \% \\ 16 & 63 & 0.06 \% & 27.8 \%\end{array}$

$16 \quad 63 \quad 0.06 \% \quad 27.8 \%$ HAQGEKTAGINVR

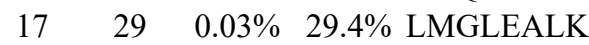

$17 \quad 29 \quad 0.03 \% \quad 29.4 \%$ TSLGPNGLDK

$17 \quad 29 \quad 0.03 \% \quad 29.4 \%$ IADGYEQAAR

$17 \quad 29 \quad 0.03 \% \quad 29.4 \%$ DVDFELIKVEGK

$17 \quad 29 \quad 0.03 \% \quad 29.4 \%$ GVIVDKDFSHPQMPK

$1729 \quad 0.03 \% \quad 29.4 \%$ IAILTCPFEPPKPK

$\begin{array}{llll}17 & 29 & 0.03 \% & 29.4 \% \\ 17 & 29 & 0.03 \% & \text { WVGGPEIELIAIATGGR }\end{array}$

$9.7 \% \quad 37.9$

$99.7 \% \quad 32.4$

$99.7 \% \quad 55.4$

$99.7 \% \quad 36.3$

$99.0 \% \quad 41.5$

$99.7 \% \quad 30.0$

$99.7 \% \quad 54.9$

$99.7 \% \quad 32.3$

$99.7 \% \quad 52.3$

$99.7 \% \quad 57.2$

$99.7 \% \quad 49.5$

$99.7 \% \quad 53.8$

$99.3 \% \quad 53.9$

$99.7 \% \quad 54.4$

$99.7 \% \quad 30.2$

$99.7 \% \quad 32.5$

$99.7 \% \quad 41.0$

$\begin{array}{lll}98.7 \% & 22.7\end{array}$

$99.7 \% \quad 30.7$

$99.7 \% \quad 59.0$

$99.7 \% \quad 62.3$

$99.7 \% \quad 36.5$

$99.7 \% \quad 43.2$

$0.03 \% \quad 29.4 \%$ LGFAGLVQEISFGTTK

$99.7 \% 74.5$

$\begin{array}{llll}17 & 29 & 0.03 \% & 29.4 \% \\ 17 & 29 & 0.03 \% & 29.4 \%\end{array}$

$\begin{array}{llll}17 & 29 & 0.03 \% & 29.4 \% \\ 17 & \text { MIIEEAKR }\end{array}$

$17 \quad 29 \quad 0.03 \% \quad 29.4 \%$ SLHDALCVIR

$\begin{array}{llll}17 & 29 & 0.03 \% & 29.4 \% \\ 17 & 29 & 0.03 \% & 29.4 \%\end{array}$

$17 \quad 29 \quad 0.03 \% \quad 29.4 \%$ KQQISLATQMVR

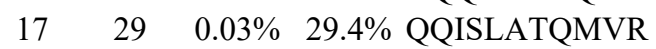

$29 \quad 0.03 \% \quad 29.4 \%$ IDDIRKPGESEE

$\begin{array}{llll}98.6 \% & 20.5 & 25.0 & 15.7\end{array}$

$\begin{array}{llll}99.0 \% & 38.6 & 25.0 & 23.2\end{array}$

$99.3 \% \quad 53.9 \quad 25.0 \quad 0.0$

$\begin{array}{llll}99.7 \% & 32.5 & 25.0 & 28.2\end{array}$

$\begin{array}{llll}99.4 \% & 24.9 & 25.0 & 19.5\end{array}$

$\begin{array}{llll}99.7 \% & 52.1 & 25.0 & 46.3\end{array}$

$\begin{array}{llll}99.7 \% & 32.3 & 25.0 & 27.7\end{array}$

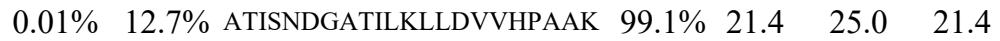
$0.01 \% \quad 12.7 \%$ LLDVVHPAAK

$98.7 \% \quad 20.7$
391400 391401 466 $444 \quad 468$ 480 469481 $497 \quad 510$ $500 \quad 510$ $516 \quad 526$ 539556 $26 \quad 40$ $\begin{array}{ll}205 & 223 \\ 285 & 293\end{array}$ $285 \quad 293$ $377 \quad 388$ $35-42$ $194 \quad 206$ $233 \quad 243$ $244 \quad 257$ $246 \quad 257$ $293 \quad 302$ $307 \quad 319$ 92403 $404 \quad 413$ $420 \quad 435$ $120 \quad 441$ $442 \quad 452$ $484 \quad 496$ $28 \quad 35$ $\begin{array}{cc}59 \\ 33 & 142\end{array}$ $203 \quad 214$ $227 \quad 241$ $248 \quad 261$ $324 \quad 340$ $353 \quad 368$ $353 \quad 370$ 393400 $401 \quad 410$ $484 \quad 496$ $14 \quad 525$ $515 \quad 525$ $530 \quad 541$ 677 
T-complex protein 1 subunit eta GN=CCT7 TCPH_HUMAN $59.37 \quad 100.0 \%$ T-complex protein 1 subunit eta $\mathrm{GN}=\mathrm{CCT} 7 \mathrm{TCPH}$ HUMAN $59.37 \quad 100.0 \%$ T-complex protein 1 subunit gamma GN=CCT3 TCPG_HUMAN $60.54 \quad 100.0 \%$ T-complex protein 1 subunit gamma GN=CCT3 TCPG_HUMAN $60.54 \quad 100.0^{\circ}$ T-complex protein 1 subunit gamma GN=CCT3 TCPG_HUMAN $60.54 \quad 100.0 \% \quad 2$ T-complex protein 1 subunit gamma GN=CCT3 TCPG_HUMAN $60.54 \quad 100.0 \% \quad 25$ T-complex protein 1 subunit gamma GN=CCT3 TCPG_HUMAN $60.54 \quad 100.0 \% 25$ T-complex protein 1 subunit gamma GN=CCT3 TCPG_HUMAN $60.54 \quad 100.0 \% \quad 25$ T-complex protein 1 subunit gamma GN=CCT3 TCPG_HUMAN $60.54 \quad 100.0 \%$ T-complex protein 1 subunit gamma GN=CCT3 TCPG_HUMAN $60.54 \quad 100.0 \% \quad 25$ T-complex protein 1 subunit gamma GN=CCT3 TCPG_HUMAN $60.54 \quad 100.0 \% \quad 25$ T-complex protein 1 subunit gamma GN=CCT3 TCPG_HUMAN $60.54 \quad 100.0 \% \quad 25$ T-complex protein 1 subunit gamma GN=CCT3 TCPG_HUMAN $60.54 \quad 100.0 \% \quad 25$ T-complex protein 1 subunit gamma GN=CCT3 TCPG_HUMAN $60.54 \quad 100.0 \% \quad 25$ T-complex protein 1 subunit gamma GN=CCT3 TCPG_HUMAN $60.54 \quad 100.0 \%$ T-complex protein 1 subunit gamma GN=CCT3 TCPG_HUMAN $60.54 \quad 100.0 \% \quad 25$ T-complex protein 1 subunit gamma GN=CCT3 TCPG_HUMAN $60.54 \quad 100.0 \% \quad 25$ T-complex protein 1 subunit gamma GN=CCT3 TCPG_HUMAN $60.54 \quad 100.0 \% \quad 25$ T-complex protein 1 subunit gamma GN=CCT3 TCPG_HUMAN $60.54 \quad 100.0 \%$ T-complex protein 1 subunit gamma GN=CCT3 TCPG_HUMAN $60.54 \quad 100.0 \% \quad 25$ T-complex protein 1 subunit gamma GN=CCT3 TCPG_HUMAN $60.54 \quad 100.0 \% \quad 25$ T-complex protein 1 subunit gamma GN=CCT3 TCPG_HUMAN $60.54 \quad 100.0 \% \quad 25$ T-complex protein 1 subunit gamma GN=CCT3 TCPG_HUMAN $60.54 \quad 100.0 \% \quad 25$ T-complex protein 1 subunit gamma GN=CCT3 TCPG_HUMAN $60.54 \quad 100.0 \% \quad 25$ T-complex protein 1 subunit gamma GN=CCT3 TCPG_HUMAN $60.54 \quad 100.0 \%$ T-complex protein 1 subunit gamma GN=CCT3 TCPG_HUMAN $60.54 \quad 100.0 \% \quad 25$ T-complex protein 1 subunit gamma GN=CCT3 TCPG_HUMAN $60.54 \quad 100.0 \% \quad 25$ T-complex protein 1 subunit theta GN=CCT8 TCPQ_HUMAN $59.62 \quad 100.0 \% \quad 10$ T-complex protein 1 subunit theta GN=CCT8 TCPQ_HUMAN $59.62 \quad 100.0 \% \quad 10$ T-complex protein 1 subunit theta GN=CCT8 TCPQ HUMAN $59.62 \quad 100.0 \% \quad 10$ T-complex protein 1 subunit theta GN=CCT8 TCPQ_HUMAN $59.62 \quad 100.0 \% \quad 10$ T-complex protein 1 subunit theta GN=CCT8 TCPQ_HUMAN $59.62 \quad 100.0 \% \quad 10$ T-complex protein 1 subunit theta GN=CCT8 TCPQ_HUMAN $59.62 \quad 100.0 \% \quad 10$ T-complex protein 1 subunit theta GN=CCT8 TCPQ_HUMAN $59.62 \quad 100.0 \% \quad 10$ T-complex protein 1 subunit theta $\mathrm{GN}=\mathrm{CCT} 8 \quad \mathrm{TCPQ} H \mathrm{HUMAN} 59.62 \quad 100.0 \%$ T-complex protein 1 subunit theta GN=CCT8 TCPQ_HUMAN $59.62 \quad 100.0 \%$ T-complex protein 1 subunit theta $\mathrm{GN}=\mathrm{CCT} 8$ TCPQ_HUMAN $59.62 \quad 100.0 \%$ T-complex protein 1 subunit zeta GN=CCT6A TCPZ HUMAN $58.03 \quad 100.0 \% \quad 22$ $\begin{array}{lllll}\text { T-complex protein } 1 \text { subunit zeta GN=CCT6A TCPZ_HUMAN } & 58.03 & 100.0 \% & 22\end{array}$ T-complex protein 1 subunit zeta GN=CCT6A TCPZ_HUMAN $58.03 \quad 100.0 \% \quad 22$ T-complex protein 1 subunit zeta GN=CCT6A TCPZ_HUMAN $58.03 \quad 100.0 \% 22$ T-complex protein 1 subunit zeta GN=CCT6A TCPZ_HUMAN $58.03 \quad 100.0 \% \quad 22$ T-complex protein 1 subunit zeta GN=CCT6A TCPZ HUMAN $58.03 \quad 100.0 \% \quad 22$ T-complex protein 1 subunit zeta GN=CCT6A TCPZ_HUMAN $58.03 \quad 100.0 \% 22$ T-complex protein 1 subunit zeta GN=CCT6A TCPZ_HUMAN $58.03 \quad 100.0 \% \quad 22$ T-complex protein 1 subunit zeta GN=CCT6A TCPZ HUMAN $58.03 \quad 100.0 \% \quad 22$ T-complex protein 1 subunit zeta GN=CCT6A TCPZ_HUMAN $58.03 \quad 100.0 \% \quad 22$
$0.01 \% \quad 12.7 \%$ SQDAEVGDGTTSVTLLAAEFLK $99.7 \% \quad 90.9$

$0.08 \% \quad 41.7 \%$ KVQSGNINAAK

$0.08 \% \quad 41.7 \%$ VQSGNINAAK

$0.08 \% \quad 41.7 \%$ EIQVQHPAAK

$0.08 \% \quad 41.7 \%$ ALDDMISTLK

$0.08 \% \quad 41.7 \%$ ALDDMISTLKK

$0.08 \% \quad 41.7 \%$ WSSLACNIALDAVK

$0.08 \% \quad 41.7 \%$ VEKIPGGIIEDSCVLR

$0.08 \% \quad 41.7 \%$ IPGGIIEDSCVLR

$0.08 \% \quad 41.7 \%$ GVMINKDVTHPR

$0.08 \% \quad 41.7 \%$ IVLLDSSLEYK

$0.08 \% \quad 41.7 \%$ IVLLDSSLEYKK

$0.08 \% \quad 41.7 \%$ GISDLAQHYLMR

$0.08 \% \quad 41.7 \%$ ANITAIRR

$0.08 \% \quad 41.7 \%$ IGDEYFTFITDCKDPK

$0.08 \% \quad 41.7 \%$ GASKEILSEVER

$0.08 \% \quad 41.7 \%$ EILSEVER

$0.08 \% \quad 41.7 \%$ NLQDAMQVCR

$0.08 \% \quad 41.7 \%$ NVLLDPQLVPGGA

$0.08 \% \quad 41.7 \%$ SKAMTGVEQWPYR

$0.08 \% \quad 41.7 \%$ AMTGVEQWPYR

$0.08 \% \quad 41.7 \%$ AVAQALEVIPR

$0.08 \% \quad 41.7 \%$ TLIQNCGASTIR

$0.08 \% \quad 41.7 \%$ TAVETAVLLLR

$0.08 \% \quad 41.7 \%$ IDDIVSGHK

$0.08 \% \quad 41.7 \%$ IDDIVSGHKK

$0.02 \% \quad 23.5 \%$ HFSGLEEAVYR

$0.02 \% \quad 23.5 \%$ NIQACKELAQTTR

$0.02 \% \quad 23.5 \%$ NLRDIDEVSSLLR

$0.02 \% \quad 23.5 \%$ QYGNEVFLAK

$0.02 \% \quad 23.5 \%$ ETEGDVTSVKDAK

$0.02 \% \quad 23.5 \%$ AIADTGANVVVTGGK

$0.02 \% \quad 23.5 \%$ LVPGGGATEIELAK

$0.02 \% \quad 23.5 \%$ QITSYGETCPGLEQYAIKK

$0.02 \% \quad 23.5 \%$ FAEAFEAIPR

$0.02 \% \quad 23.5 \%$ LATNAAVTVLR

$0.07 \% \quad 44.6 \%$ TLNPKAEVAR

$0.07 \% \quad 44.6 \%$ AQAALAVNISAAR

$0.07 \% \quad 44.6 \%$ MLVSGAGDIK

$0.07 \% \quad 44.6 \%$ MLVSGAGDIKLTK

$99.7 \% \quad 31.4$

$99.7 \% \quad 60.3$

$99.7 \% \quad 44.9$

$99.7 \% \quad 66.2$

$\begin{array}{lll}99.7 \% & 49.2\end{array}$

$99.7 \% \quad 42.3$

$99.7 \% \quad 63.9$

$99.7 \% \quad 61.0$

$99.7 \% \quad 60.3$

$99.7 \% \quad 50.9$

$99.7 \% \quad 59.8$

$99.7 \% \quad 45.1$

$99.7 \% \quad 58.5$

$99.0 \% \quad 28.3$

$94.7 \% \quad 14.9$

$99.7 \% \quad 51.4$

$99.0 \% 38.8$

$99.7 \% \quad 59.6$

$99.7 \% \quad 44.0$

$99.7 \% \quad 49.1$

$99.7 \% \quad 66.8$

$99.7 \% \quad 64.2$

$99.7 \% \quad 74.6$

$99.7 \% \quad 48.4$

$99.7 \% \quad 36.1$

$99.7 \% \quad 40.2$

$99.7 \% \quad 45.9$

$99.7 \% \quad 26.5$

$99.7 \% \quad 30.2$

$99.7 \% \quad 42.0$

$99.7 \% \quad 77.4$

$97.1 \% \quad 18.4$

$99.7 \% \quad 31.0$

$99.7 \% \quad 60.6$

$99.7 \% \quad 48.1$

$99.7 \% \quad 36.9$

$99.7 \% \quad 51.4$

$99.2 \% \quad 25$.

$99.7 \% \quad 62.9$

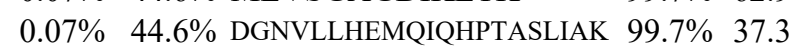

$0.07 \% \quad 44.6 \%$ VATAQDDITGDGTTSNVLIIGELLK $\quad 99.7 \% 56.7$

$0.07 \% \quad 44.6 \%$ QADLYISEGLHPR

$0.07 \% \quad 44.6 \%$ IITEGFEAAK

$0.07 \% \quad 44.6 \%$ IITEGFEAAKEK

$99.7 \% \quad 58.8$

$99.7 \% \quad 46.7$

$99.7 \% 55.6$

$99.7 \% \quad 31.8$
225

0

(5).40

1129.63

1001.54

1120.61

1106.58

1234.67

1547.79

1784.96

1428.75

1366.73

1279.71

1407.81

1419.71

914.55

1948.90

1317.70

974.52

1234.57

2633.36

1568.75

1337.63

1166.69

1333.69

1185.72

983.52

1111.61

1307.64

1532.79

1529.83

1168.60

1378.67

1372.74

1354.76

2186.08

1150.59

1128.67

1098.63

1255.71

1006.52

1348.75

2315.22

254434

1498.77

1078.58

1335.72

1076.60
106 524 213 31 $129 \quad 138$ $129 \quad 139$ $168 \quad 181$ $201 \quad 216$ $204 \quad 216$ 248 $238 \quad 249$ $295 \quad 306$ $307 \quad 314$ $355 \quad 370$ $378 \quad 389$ $382 \quad 389$ $390 \quad 399$ $400 \quad 425$ $426 \quad 438$ 
T-complex protein 1 subunit zeta GN=CCT6A TCPZ_HUMAN $58.03 \quad 100.0 \% \quad 22$ T-complex protein 1 subunit zeta GN=CCT6A TCPZ_HUMAN $58.03 \quad 100.0 \% \quad 22$ T-complex protein 1 subunit zeta GN=CCT6A TCPZ_HUMAN $58.03 \quad 100.0 \% \quad 22$ T-complex protein 1 subunit zeta GN=CCT6A TCPZ_HUMAN $58.03 \quad 100.0 \% \quad 22$ T-complex protein 1 subunit zeta GN=CCT6A TCPZ_HUMAN $58.03 \quad 100.0 \% \quad 22$ T-complex protein 1 subunit zeta GN=CCT6A TCPZ_HUMAN $58.03 \quad 100.0 \% \quad 22$ T-complex protein 1 subunit zeta GN=CCT6A TCPZ_HUMAN $58.03 \quad 100.0 \% \quad 22$ T-complex protein 1 subunit zeta GN=CCT6A TCPZ_HUMAN $58.03 \quad 100.0 \% \quad 22$ T-complex protein 1 subunit zeta GN=CCT6A TCPZ_HUMAN $58.03 \quad 100.0 \%$ T-complex protein 1 subunit zeta GN=CCT6A TCPZ_HUMAN $58.03 \quad 100.0 \% \quad 22$ T-complex protein 1 subunit zeta GN=CCT6A TCPZ_HUMAN $58.03 \quad 100.0 \% \quad 22$ T-complex protein 1 subunit zeta GN=CCT6A TCPZ_HUMAN $58.03 \quad 100.0 \%$ Terminal uridylyltransferase $7 \mathrm{GN}=$ ZCCHC6 TUT7_HUMAN $171.23 \quad 100.0 \%$ Terminal uridylyltransferase 7 GN=ZCCHC6 TUT7_HUMAN $171.23 \quad 100.0 \%$ Testis-expressed sequence 10 protein GN=TEX10 TEX10_HUMAN $105.68 \quad 100.0 \%$ Testis-expressed sequence 10 protein GN=TEX10 TEX10_HUMAN $105.68 \quad 100.0 \%$ Testis-expressed sequence 10 protein GN=TEX10 TEX10 HUMAN $105.68 \quad 100.0 \%$ Testis-expressed sequence 264 protein GN=TEX264 TX264_HUMAN $34.19 \quad 100.0 \%$ Testis-expressed sequence 264 protein GN=TEX264 TX264_HUMAN $34.19 \quad 100.0 \%$ Tetratricopeptide repeat protein $37 \mathrm{GN}=$ TTC37 TTC37_HUMAN $175.49 \quad 100.0 \%$ Tetratricopeptide repeat protein 37 GN=TTC37 TTC37_HUMAN $175.49 \quad 100.0 \%$ Tetratricopeptide repeat protein $37 \mathrm{GN}=$ TTC37 TTC37 HUMAN $175.49100 .0 \%$ Tetratricopeptide repeat protein 37 GN=TTC37 TTC37_HUMAN $175.49 \quad 100.0 \%$ Tetratricopeptide repeat protein 37 GN=TTC37 TTC37_HUMAN $175.49 \quad 100.0 \%$ Tetratricopeptide repeat protein 37 GN=TTC37 TTC37_HUMAN $175.49 \quad 100.0 \%$ TGF-beta-activated kinase 1 and MAP3K7-binding protein 1 GN=TAB1 TAB1_HUMAN $54.64 \quad 100.0 \%$ TGF-beta-activated kinase 1 and MAP3K7-binding protein $1 \mathrm{GN}=\mathrm{TAB} 1$ TAB1_HUMAN $54.64 \quad 100.0 \%$ TGF-beta-activated kinase 1 and MAP3K7-binding protein $1 \mathrm{GN}=\mathrm{TAB} 1 \mathrm{TAB} 1$ HUMAN $54.64 \quad 100.0 \%$ TGF-beta-activated kinase 1 and MAP3K7-binding protein $1 \mathrm{GN}=\mathrm{TAB} 1$ TAB1_HUMAN $54.64 \quad 100.0 \%$ TGF-beta-activated kinase 1 and MAP3K7-binding protein $1 \mathrm{GN}=\mathrm{TAB} 1$ TAB1_HUMAN $54.64100 .0 \%$ TGF-beta-activated kinase 1 and MAP3K7-binding protein 1 GN=TAB1 $\quad$ TAB1_HUMAN $54.64 \quad 100.0 \%$ Thioredoxin domain-containing protein 5 GN=TXNDC5 TXND5_HUMAN $47.63 \quad 100.0 \%$ Thioredoxin domain THO complex subunit $2 \mathrm{GN}=\mathrm{THOC} 2$ THO complex subunit $2 \mathrm{GN}=\mathrm{THOC} 2$ THO complex subunit $2 \mathrm{GN}=\mathrm{THOC} 2$ THO complex subunit $2 \mathrm{GN}=\mathrm{THOC}^{2}$ THO complex subunit $2 \mathrm{GN}=\mathrm{THOC} 2$ THO complex subunit $2 \mathrm{GN}=\mathrm{THOC} 2$ THO complex subunit $3 \mathrm{GN}=\mathrm{THOC}$ THO complex subunit $3 \mathrm{GN}=\mathrm{THOC}$ THO complex subunit $3 \mathrm{GN}=\mathrm{THOC}$ ? THO complex subunit $3 \mathrm{GN}=\mathrm{THOC} 3$ THO complex subunit $4 \mathrm{GN}=\mathrm{ALYREF}$ THO complex subunit $4 \mathrm{GN}=\mathrm{ALYREF}$ THO complex subunit $4 \mathrm{GN}=\mathrm{ALYREF}$ THO complex subunit $4 \mathrm{GN}=\mathrm{ALYREF}$ THOC2_HUMAN $182.78 \quad 100.0 \%$ THOC2_HUMAN $182.78 \quad 100.0 \%$ THOC2_HUMAN $182.78 \quad 100.0 \%$ THOC2_HUMAN $182.78 \quad 100.0 \%$ THOC2 HUMAN $182.78 \quad 100.0 \%$ THOC2_HUMAN $182.78 \quad 100.0 \%$ THOC3_HUMAN $38.77 \quad 100.0 \%$ THOC3 HUMAN $38.77 \quad 100.0 \%$ THOC3_HUMAN $38.77 \quad 100.0 \%$ THOC3 HUMAN $38.77 \quad 100.0 \%$ THOC4 HUMAN $26.89 \quad 100.0 \%$ THOC4_HUMAN $26.89 \quad 100.0 \%$ THOC4 HUMAN $26.89 \quad 100.0 \%$ THOC4_HUMAN $26.89 \quad 100.0 \%$
$67 \quad 0.07 \% \quad 44.6 \%$ ALQFLEEVKVSR $0.07 \% \quad 44.6 \%$ EMDRETLIDVAR $0.07 \% \quad 44.6 \%$ HKSETDTSLIR $0.07 \% \quad 44.6 \%$ SETDTSLIR $0.07 \% \quad 44.6 \%$ GLVLDHGAR $0.07 \% \quad 44.6 \%$ VCGDSDKGFVVINQK $0.07 \% \quad 44.6 \%$ GIDPFSLDALSK $0.07 \% \quad 44.6 \%$ EGIVALRR $0.07 \% \quad 44.6 \%$ SVTLLIKGPNK $0.07 \% \quad 44.6 \%$ GPNKHTLTQIK $0.07 \% \quad 44.6 \%$ AQLGVQAFADALLIIPK $0.07 \% \quad 44.6 \%$ VLAQNSGFDLQETLVK $0.00 \% \quad 1.5 \%$ ELLGLQQAEER $0.00 \% \quad 1.5 \%$ IQLEPLPPLTPK $0.00 \% \quad 2.2 \% \quad$ LQNATPTNFK $0.00 \% \quad 2.2 \% \quad$ LQNATPTNFKTK $0.00 \% \quad 2.2 \% \quad$ SLQATALR $0.00 \% \quad 8.0 \%$ LFTESCSISPK $0.00 \% \quad 8.0 \%$ ETSAATLSPGASSR $0.01 \% \quad 4.6 \%$ SGPGLIGLGIK $0.01 \% \quad 4.6 \%$ TLDQISDADNIPGLLVLK

$10 \quad 0.01 \% \quad 4.6 \% \quad$ CLLTSAIYALQGR $0.01 \% \quad 4.6 \%$ VVAQYAQR

$10 \quad 0.01 \% \quad 4.6 \% \quad$ SNPDQPAVILLLR $10 \quad 0.01 \% \quad 4.6 \% \quad$ VVYQPGYPK

$16 \quad 0.02 \% \quad 15.7 \%$ VLLQAFDVVER

$16 \quad 0.02 \% \quad 15.7 \%$ SFLESIDDALAEK

$16 \quad 0.02 \% \quad 15.7 \%$ YGYTDIDLLSAAK

$16 \quad 0.02 \% \quad 15.7 \%$ QTSLDAVAQAVVDR

$16 \quad 0.02 \% \quad 15.7 \%$ IHSDTFASGGER

$16 \quad 0.02 \% \quad 15.7 \%$ VYPVSVPYSSAQSTSK $0.00 \% \quad 4.6 \% \quad$ IAEVDCTAER

$0.00 \% \quad 4.6 \%$ FVLSQAKDEL

$0.02 \% \quad 3.8 \%$ LGLLEALLK

$0.02 \% \quad 3.8 \%$ GSPVNALQNK

$0.02 \% \quad 3.8 \%$ CIFSAIDAVYCAR

$0.02 \% \quad 3.8 \%$ FVELVHQQK

$0.02 \% \quad 3.8 \%$ VLNLGQALER

$0.02 \% \quad 3.8 \%$ TPATTPEAR

$0.01 \% \quad 8.6 \% \quad$ YVLGMQELFR

$0.01 \% \quad 8.6 \%$ TASVFLLEK

$0.01 \% \quad 8.6 \%$ TASVFLLEKDR

$0.01 \% \quad 8.6 \%$ TLSFSHDGK

$0.02 \% \quad 28.0 \%$ MDMSLDDIIK

$0.02 \% \quad 28.0 \%$ KAAVHYDR

$0.02 \% \quad 28.0 \%$ SLGTADVHFER

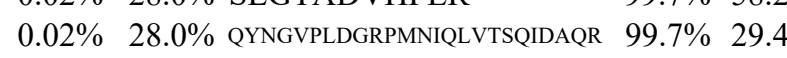

$99.7 \% \quad 65.9$

$99.7 \% \quad 43.9$

$99.3 \% \quad 20.1$

$99.7 \% \quad 42.0$

$99.7 \% \quad 52.4$

$99.7 \% \quad 41.9$

$99.7 \% 59.6$

$95.9 \% \quad 19.5$

$99.7 \% \quad 31.9$

$99.7 \% \quad 32.9$

$99.5 \% \quad 24.1$

$99.7 \% \quad 66.2$

$95.1 \% 15$.

$99.2 \% \quad 30.3$

$99.7 \% \quad 36.8$

$99.7 \% \quad 31.4$

$99.0 \% \quad 37.8$

$99.7 \% \quad 27.2$

$99.7 \% \quad 56.3$

$99.7 \% \quad 26.2$

$\begin{array}{ll}99.7 \% & 35.8\end{array}$

$99.7 \% \quad 89.1$

$99.0 \% \quad 37.8$

$99.7 \% \quad 31.0$

$99.7 \% \quad 33.3$

$99.7 \% \quad 57.0$

$99.7 \% \quad 57.4$

$99.7 \% \quad 69.3$

$99.7 \% \quad 76.6$

$99.7 \% \quad 41.8$

$99.7 \% \quad 47.9$

$99.7 \% \quad 48.3$

$99.1 \% \quad 23.4$

$99.7 \% \quad 32.3$

$99.1 \% \quad 23.3$

$99.7 \% \quad 54.7$

$\begin{array}{lll}99.7 \% & 36.7\end{array}$

$99.7 \% \quad 52.0$

$99.7 \% \quad 46.8$

$99.7 \% \quad 45.2$

$96.9 \% \quad 18.3$

$99.7 \% \quad 55.7$

$99.7 \% \quad 31.6$

$99.7 \% \quad 51.6$

$99.0 \% \quad 41.5$

$99.7 \% \quad 58.2$

19

\begin{tabular}{|c|c|c|c|c|c|c|c|c|c|}
\hline 31 & 67 & $0.07 \%$ & 44.6\% ALQFLEEVKVSR & $99.7 \%$ & 65.9 & 25.0 & 61.0 & & \\
\hline 31 & 67 & $0.07 \%$ & $44.6 \%$ EMDRETLIDVAR & $99.7 \%$ & 43.9 & 25.0 & 37.5 & & \\
\hline 31 & 67 & $0.07 \%$ & $446 \%$ HKSETDTSLIR & $993 \%$ & 201 & 250 & 186 & & \\
\hline 31 & 67 & $0.07 \%$ & $44.6 \%$ SETDTSLIR & $99.7 \%$ & 42.0 & 25.0 & 30.4 & & \\
\hline 31 & 67 & $0.07 \%$ & $44.6 \%$ GLVLDHGAR & $997 \%$ & 524 & 250 & 393 & & \\
\hline 31 & 67 & $0.07 \%$ & $44.6 \%$ VCGDSDKGFVVINOK & $997 \%$ & 419 & 25.0 & 393 & & \\
\hline 31 & 67 & $0.07 \%$ & $44.6 \%$ GIDPFSLDALSK & $99.7 \%$ & 59.6 & 25.0 & 27.1 & & \\
\hline 31 & 67 & $0.07 \%$ & $44.6 \%$ EGIVALRR & $95.9 \%$ & 195 & 250 & 112 & & \\
\hline 31 & 67 & $0.07 \%$ & $44.6 \%$ SVTLLJKGPNK & $997 \%$ & 31.9 & 25.0 & 293 & & \\
\hline 31 & 67 & $0.07 \%$ & $44.6 \%$ GPNKHTLTQIK & $99.7 \%$ & 32.9 & 25.0 & 32.5 & & \\
\hline 31 & 67 & $0.07 \%$ & $44.6 \%$ AOLGVOAFADALLIIPK & $99.5 \%$ & 24.1 & 25.0 & 24.1 & & \\
\hline 31 & 67 & $0.07 \%$ & $44.6 \%$ VLAONSGFDLOETLVK & $997 \%$ & 66.2 & 250 & 662 & & \\
\hline 2 & 2 & $0.00 \%$ & $15 \%$ ELLGLOOAEER & $95.1 \%$ & 15.1 & 25.0 & 14.9 & & \\
\hline 2 & 2 & $0.00 \%$ & $1.5 \%$ IOLEPLPPLTPK & $99.2 \%$ & 30.3 & 25.0 & 10.2 & & \\
\hline 3 & 4 & $0.00 \%$ & $2.2 \%$ LONATPTNFK & $997 \%$ & 36.8 & 250 & 36.8 & & \\
\hline 3 & 4 & $0.00 \%$ & $2.2 \%$ LQNATPTNFKTK & $99.7 \%$ & 31.4 & 25.0 & 28.4 & & \\
\hline 3 & 4 & $0.00 \%$ & $2.2 \%$ SLOATALR & $99.0 \%$ & 37.8 & 25.0 & 27.5 & & \\
\hline 2 & 2 & $0.00 \%$ & $8.0 \%$ LFTESCSISPK & $99.7 \%$ & 27.2 & 25.0 & 27.2 & & \\
\hline 2 & 2 & $0.00 \%$ & $8.0 \%$ ETSAATLSPGASSR & $99.7 \%$ & 56.3 & 25.0 & 51.5 & & \\
\hline 6 & 10 & $0.01 \%$ & $4.6 \%$ SGPGLIGLGIK & $99.7 \%$ & 26.2 & 25.0 & 18.6 & & \\
\hline 6 & 10 & $0.01 \%$ & $4.6 \%$ TLDOISDADNIPGLLVLK & $99.7 \%$ & 35.8 & 25.0 & 35.8 & & \\
\hline 6 & 10 & $0.01 \%$ & $4.6 \%$ CLLTSAIYALOGR & $99.7 \%$ & 89.1 & 25.0 & 81.0 & & \\
\hline 6 & 10 & $0.01 \%$ & $4.6 \%$ VVAOYAOR & $99.0 \%$ & 37.8 & 25.0 & 35.8 & & \\
\hline 6 & 10 & $0.01 \%$ & $4.6 \%$ SNPDOPAVILLLR & $99.7 \%$ & 31.0 & 25.0 & 31.0 & & \\
\hline 6 & 10 & $0.01 \%$ & $4.6 \%$ VVYOPGYPK & $99.7 \%$ & 33.3 & 25.0 & 24.0 & & \\
\hline 7 & 16 & $0.02 \%$ & $15.7 \%$ VLLOAFDVVER & $99.7 \%$ & 57.0 & 25.0 & 57.0 & & \\
\hline 7 & 16 & $0.02 \%$ & $15.7 \%$ SFLESIDDALAEK & $99.7 \%$ & 57.4 & 25.0 & 50.7 & & \\
\hline 7 & 16 & $0.02 \%$ & $15.7 \%$ YGYTDIDLLSAAK & $99.7 \%$ & 69.3 & 25.0 & 69.3 & & \\
\hline 7 & 16 & $0.02 \%$ & $15.7 \%$ OTSLDAVAOAVVDR & $99.7 \%$ & 76.6 & 25.0 & 67.3 & & \\
\hline 7 & 16 & $0.02 \%$ & $15.7 \%$ IHSDTFASGGER & $99.7 \%$ & 41.8 & 25.0 & 38.5 & 2 & \\
\hline 7 & 16 & $0.02 \%$ & $15.7 \%$ VYPVSVPYSSAOSTSK & $99.7 \%$ & 47.9 & 25.0 & 44.5 & & \\
\hline 2 & 3 & $0.00 \%$ & $4.6 \%$ IAEVDCTAER & $99.7 \%$ & 48.3 & 25.0 & 42.8 & & \\
\hline 2 & 3 & $0.00 \%$ & $4.6 \%$ FVLSOAKDEL & $99.1 \%$ & 23.4 & 25.0 & 17.0 & 2 & U \\
\hline 6 & 16 & $0.02 \%$ & $3.8 \%$ LGLLEALLK & $99.7 \%$ & 32.3 & 25.0 & 22.2 & & \\
\hline 6 & 16 & $0.02 \%$ & $3.8 \%$ GSPVNALONK & $99.1 \%$ & 23.3 & 25.0 & 22.9 & 1 & . \\
\hline 6 & 16 & $0.02 \%$ & $3.8 \%$ CIFSAIDAVYCAR & $99.7 \%$ & 54.7 & 25.0 & 54.7 & 2 & U \\
\hline 6 & 16 & $0.02 \%$ & $3.8 \%$ FVELVHOOK & $99.7 \%$ & 36.7 & 25.0 & 36.7 & 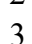 & \\
\hline 6 & 16 & $0.02 \%$ & $3.8 \%$ VLNLGQALER & $99.7 \%$ & 52.0 & 25.0 & 43.4 & 4 & 0 \\
\hline 6 & 16 & $0.02 \%$ & $3.8 \%$ TPATTPEAR & $99.7 \%$ & 46.8 & 25.0 & 41.6 & 3 & J \\
\hline 4 & 7 & $0.01 \%$ & $8.6 \%$ YVLGMOELFR & $99.7 \%$ & 45.2 & 25.0 & 39.6 & 2 & 0 \\
\hline 4 & 7 & $0.01 \%$ & $8.6 \%$ TASVFLLEK & $96.9 \%$ & 18.3 & 25.0 & 17.8 & 1 & \\
\hline 4 & 7 & $0.01 \%$ & $8.6 \%$ TASVFLLEKDR & $99.7 \%$ & $\begin{array}{l}10.5 \\
55.7\end{array}$ & 25.0 & 53.1 & 2 & J \\
\hline 4 & 7 & $0.01 \%$ & $8.6 \%$ TLSFSHDGK & $99.7 \%$ & 31.6 & 25.0 & 18.0 & 2 & 0 \\
\hline 7 & 19 & $0.02 \%$ & $28.0 \%$ MDMSLDDIIK & $99.7 \%$ & 51.6 & 25.0 & 45.3 & 2 & \\
\hline 7 & 19 & $0.02 \%$ & $28.0 \%$ KAAVHYDR & $99.0 \%$ & 41.5 & 25.0 & 28.3 & 2 & 0 \\
\hline 7 & 19 & $0.02 \%$ & $28.0 \%$ SLGTADVHFER & $99.7 \%$ & 58.2 & 25.0 & 47.2 & 4 & 3 \\
\hline
\end{tabular}

418.80

1447.72

1286.67

1021.52

937.52

1665.83

1262.66

913.56

1169.73

1236.71

1768.04

1761.94

1285.67

1345.81

1133.60

1362.74

859.50

1268.62

1334.65

1011.62

1925.06

1465.78

934.51

1435.83

1050.56

1288.73

1437.71

1429.72

1472.77

1276.59

1699.85

1163.54

1149.62

969.63

1027.55

1545.72

1127.62

1112.64

943.48

1255.65

1007.58

1278.71

991.48

1180.56

959.51

1231.61 2829.43

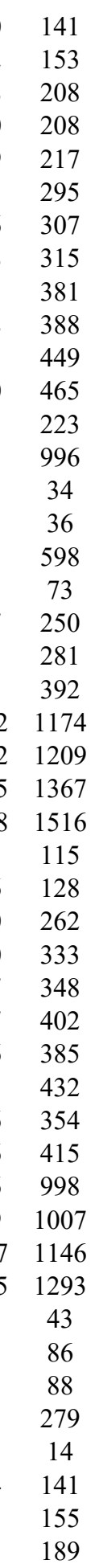

Page 163 of Table S-1-4 
THO complex subunit 4 GN=ALYREF $\quad$ THOC4_HUMAN $26.89 \quad 100.0 \%$ THUMP domain-containing protein 3 GN=THUMPD3 THUM3_HUMAN $57.00 \quad 100.0 \%$ THUMP domain-containing protein 3 GN=THUMPD3 THUM3_HUMAN $57.00 \quad 100.0 \%$ Thyroid hormone receptor-associated protein 3 GN=THRAP3 TR150_HUMAN $108.67 \quad 100.0 \%$ Thyroid hormone receptor-associated protein 3 GN=THRAP3 TR150_HUMAN $108.67 \quad 100.0 \%$ Thyroid hormone receptor-associated protein 3 GN=THRAP3 TR150_HUMAN $108.67 \quad 100.0 \%$ Thyroid hormone receptor-associated protein 3 GN=THRAP3 TR150_HUMAN $108.67 \quad 100.0 \%$ Thyroid hormone receptor-associated protein 3 GN=THRAP3 TR150_HUMAN $108.67 \quad 100.0 \%$ Thyroid hormone receptor-associated protein 3 GN=THRAP3 TR150_HUMAN $108.67 \quad 100.0 \%$ Thyroid hormone receptor-associated protein $3 \mathrm{GN}=$ THRAP3 TR150_HUMAN $108.67 \quad 100.0 \%$ Thyroid hormone receptor-associated protein 3 GN=THRAP3 TR150_HUMAN $108.67 \quad 100.0 \%$ Thyroid hormone receptor-associated protein $3 \mathrm{GN}=$ THRAP3 TR150 HUMAN $108.67 \quad 100.0 \%$ Thyroid hormone receptor-associated protein $3 \mathrm{GN}=\mathrm{THRAP3}$ TR150_HUMAN $108.67 \quad 100.0 \%$ Thyroid hormone receptor-associated protein 3 GN=THRAP3 TR150_HUMAN $108.67 \quad 100.0 \%$ Thyroid hormone receptor-associated protein 3 GN=THRAP3 TR150_HUMAN $108.67 \quad 100.0 \%$ Thyroid transcription factor 1-associated protein $26 \mathrm{GN}=\mathrm{CCDC} 59$ TAP26_HUMAN $28.67 \quad 100.0 \%$ Thyroid transcription factor 1-associated protein $26 \mathrm{GN}=\mathrm{CCDC} 59 \mathrm{TAP} 26$ HUMAN $28.67 \quad 100.0^{\circ}$ Thyroid transcription factor 1-associated protein $26 \mathrm{GN}=\mathrm{CCDC} 59$ TAP26_HUMAN $28.67 \quad 100.0 \%$ Tight junction protein ZO-1 GN=TJP1 ZO1 HUMAN $195.46 \quad 100.0 \%$ Tight junction protein $\mathrm{ZO}-1 \mathrm{GN}=\mathrm{TJP} 1$ Tight junction protein $\mathrm{ZO}-1 \mathrm{GN}=\mathrm{TJP} 1$ TP53-regulating kinase $\mathrm{GN}=\mathrm{TP} 53 \mathrm{RK}$ TP53-regulating kinase $\mathrm{GN}=\mathrm{TP} 53 \mathrm{RK}$ TP53-regulating kinase $\mathrm{GN}=\mathrm{TP} 53 \mathrm{RK}$ TP53-regulating kinase $\mathrm{GN}=\mathrm{TP} 53 \mathrm{RK}$ ZO1_HUMAN $195.46 \quad 100.0 \%$ ZO1_HUMAN $195.46 \quad 100.0 \%$ PRPK HUMAN $28.16 \quad 100.0 \%$ PRPK_HUMAN $28.16 \quad 100.0 \%$ PRPK_HUMAN $28.16 \quad 100.0 \%$ PRPK HUMAN $28.16 \quad 100.0 \%$ TraB domain-containing protein GN=TRABD TRABD_HUMAN $42.32 \quad 100.0 \%$ TraB domain-containing protein GN=TRABD TRABD_HUMAN $42.32 \quad 100.0 \%$ TraB domain-containing protein GN=TRABD TRABD_HUMAN $42.32 \quad 100.0 \%$ TraB domain-containing protein GN=TRABD TRABD_HUMAN $42.32 \quad 100.0 \%$ Transcription activator BRG1 GN=SMARCA4 SMCA4 HUMAN $184.65 \quad 100.0 \%$ Transcription activator BRG1 GN=SMARCA4 SMCA4_HUMAN $184.65 \quad 100.0 \%$ Transcription activator BRG1 GN=SMARCA4 SMCA4_HUMAN $184.65 \quad 100.0 \%$ Transcription activator BRG1 GN=SMARCA4 SMCA4_HUMAN $184.65 \quad 100.0 \%$ Transcription activator BRG1 GN=SMARCA4 SMCA4_HUMAN $184.65 \quad 100.0 \%$ Transcription activator BRG1 GN=SMARCA4 SMCA4_HUMAN $184.65 \quad 100.0 \%$ Transcription activator BRG1 GN=SMARCA4 SMCA4_HUMAN $184.65 \quad 100.0 \%$ Transcription activator BRG1 GN=SMARCA4 SMCA4_HUMAN $184.65 \quad 100.0 \%$ Transcription activator BRG1 GN=SMARCA4 SMCA4_HUMAN $184.65100 .0 \%$ Transcription activator BRG1 GN=SMARCA4 SMCA4_HUMAN $184.65 \quad 100.0 \%$ Transcription elongation factor, mitochondrial GN=TEFM TEFM_HUMAN $41.68 \quad 100.0 \%$ Transcription elongation factor, mitochondrial GN=TEFM TEFM HUMAN $41.68 \quad 100.0 \%$ Transcription factor A, mitochondrial GN=TFAM TFAM_HUMAN $29.10 \quad 100.0 \%$ Transcription factor A, mitochondrial GN=TFAM TFAM HUMAN $29.10 \quad 100.0 \%$ Transcription termination factor 1, mitochondrial GN=MTERF1 MTEF1_HUMAN $45.78 \quad 100.0 \%$ Transcription termination factor 1 , mitochondrial GN=MTERF1 MTEF1_HUMAN $45.78 \quad 100.0 \%$ Transcriptional activator protein Pur-alpha GN=PURA PURA HUMAN $34.91 \quad 100.0 \%$ Transcriptional activator protein Pur-alpha GN=PURA PURA_HUMAN $34.91 \quad 100.0 \%$
3
58

58

3

3
3
3

3

5

4

4

4
4
4

4

4

2

2

2
2
2
6

6


Transcriptional activator protein Pur-alpha GN=PURA PURA HUMAN $34.91 \quad 100.0 \%$ Transcriptional activator protein Pur-alpha GN=PURA PURA_HUMAN $34.91 \quad 100.0 \%$ Transcriptional activator protein Pur-alpha GN=PURA PURA_HUMAN $34.91 \quad 100.0 \%$ Transcriptional activator protein Pur-alpha GN=PURA PURA_HUMAN $34.91 \quad 100.0 \%$ Transcriptional activator protein Pur-beta GN=PURB PURB_HUMAN $33.24 \quad 100.0 \%$ Transcriptional activator protein Pur-beta GN=PURB PURB_HUMAN $33.24 \quad 100.0 \%$ Transcriptional activator protein Pur-beta GN=PURB PURB HUMAN $33.24 \quad 100.0 \%$ Transcriptional adapter $1 \mathrm{GN}=$ TADA1 TADA1_HUMAN $37.38 \quad 100.0 \%$ Transcriptional adapter $1 \mathrm{GN}=$ TADA1 TADA1 HUMAN $37.38 \quad 100.0 \%$ Transcriptional adapter 1 GN=TADA1 TADA1_HUMAN $37.38 \quad 100.0 \%$ Transducin beta-like protein 3 GN=TBL3 TBL3_HUMAN $89.03 \quad 100.0 \%$ Transducin beta-like protein 3 GN=TBL3 TBL3_HUMAN $89.03 \quad 100.0 \%$ Transformation/transcription domain-associated protein GN=TRRAP TRRAP_HUMAN $437.60 \quad 100.0 \%$ Transformation/transcription domain-associated protein GN=TRRAP TRRAP_HUMAN $437.60 \quad 100.0 \%$ Transformation/transcription domain-associated protein GN=TRRAP TRRAP_HUMAN $437.60 \quad 100.0 \%$ Transformation/transcription domain-associated protein GN=TRRAP TRRAP_HUMAN $437.60 \quad 100.0 \%$ Transformation/transcription domain-associated protein GN=TRRAP TRRAP HUMAN $437.60 \quad 100.0 \%$ Transformation/transcription domain-associated protein GN=TRRAP TRRAP_HUMAN $437.60 \quad 100.0 \%$ Transformation/transcription domain-associated protein GN=TRRAP TRRAP_HUMAN $437.60 \quad 100.0 \%$ Transformation/transcription domain-associated protein GN=TRRAP TRRAP_HUMAN $437.60 \quad 100.0 \%$ Transformation/transcription domain-associated protein GN=TRRAP TRRAP_HUMAN $437.60 \quad 100.0 \%$ Transformation/transcription domain-associated protein GN=TRRAP TRRAP HUMAN $437.60 \quad 100.0 \%$ Transformation/transcription domain-associated protein GN=TRRAP TRRAP_HUMAN $437.60 \quad 100.0 \%$ Transformation/transcription domain-associated protein GN=TRRAP TRRAP_HUMAN $437.60 \quad 100.0 \%$ Transformation/transcription domain-associated protein GN=TRRAP TRRAP_HUMAN $437.60 \quad 100.0 \%$ Transformation/transcription domain-associated protein GN=TRRAP TRRAP_HUMAN $437.60 \quad 100.0 \%$ Transformation/transcription domain-associated protein GN=TRRAP TRRAP_HUMAN $437.60 \quad 100.0 \%$ Transformer-2 protein homolog alpha GN=TRA2A TRA2A_HUMAN $32.69 \quad 100.0 \%$ Transformer-2 protein homolog alpha GN=TRA2A TRA2A_HUMAN $32.69 \quad 100.0 \%$ Transformer-2 protein homolog alpha GN=TRA2A TRA2A HUMAN $32.69 \quad 100.0 \%$ Transformer-2 protein homolog alpha GN=TRA2A TRA2A_HUMAN $32.69 \quad 100.0 \%$ Transformer-2 protein homolog alpha GN=TRA2A TRA2A_HUMAN $32.69 \quad 100.0 \%$ Transformer-2 protein homolog alpha $\mathrm{GN}=\mathrm{TRA} 2 \mathrm{~A}$ TRA2A HUMAN $32.69 \quad 100.0 \%$ Transformer-2 protein homolog alpha GN=TRA2A TRA2A_HUMAN $32.69 \quad 100.0 \%$ Transformer- 2 protein homolog alpha GN=TRA2A TRA2A_HUMAN $32.69 \quad 100.0 \%$ Transformer-2 protein homolog alpha GN=TRA2A TRA2A_HUMAN $32.69 \quad 100.0 \%$ Transformer-2 protein homolog alpha GN=TRA2A TRA2A_HUMAN $32.69 \quad 100.0 \%$ Transformer-2 protein homolog beta GN=TRA2B TRA2B HUMAN $33.67 \quad 100.0 \%$ Transformer-2 protein homolog beta GN=TRA2B TRA2B_HUMAN $33.67 \quad 100.0 \%$ Transformer-2 protein homolog beta GN=TRA2B TRA2B_HUMAN $33.67 \quad 100.0 \%$ Transformer- 2 protein homolog beta GN=TRA2B TRA2B HUMAN $33.67 \quad 100.0 \%$ Transformer-2 protein homolog beta GN=TRA2B TRA2B_HUMAN $33.67 \quad 100.0 \%$ Transformer-2 protein homolog beta GN=TRA2B TRA2B HUMAN $33.67 \quad 100.0 \%$ Transformer-2 protein homolog beta GN=TRA2B TRA2B_HUMAN $33.67 \quad 100.0 \%$ Transformer-2 protein homolog beta GN=TRA2B TRA2B_HUMAN $33.67 \quad 100.0 \%$ Transformer-2 protein homolog beta GN=TRA2B TRA2B HUMAN $33.67 \quad 100.0 \%$ Transformer-2 protein homolog beta GN=TRA2B TRA2B_HUMAN $33.67 \quad 100.0 \%$

15

$\begin{array}{ll}15 & 15 \\ 15 & 15 \\ 15 & 15\end{array}$

15

15
15
15

15
15
15

15
15
15

15

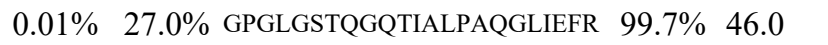
$0.01 \% \quad 27.0 \%$ LIDDYGVEEEPAELPEGTSLTVDNKR

$0.01 \% \quad 27.0 \%$ FFFDVGSNK

$0.01 \% \quad 11.5 \%$ GGGGGPCGFQPASR

$0.01 \% \quad 11.5 \%$ GGGEQETQELASK

$0.01 \% \quad 11.5 \%$ VSEVKPSYR

$0.00 \% \quad 11.9 \%$ NLSEALGDNVK

0.00\% $11.9 \%$ YAFGSNVTPQPYLK

$0.00 \% \quad 11.9 \%$ EVIPTHTVYALNIER

$0.00 \% \quad 3.3 \% \quad$ FKTNYAVER

$0.00 \% \quad 3.3 \% \quad$ NTAPDNGPILLQAQTTQR

$0.03 \% \quad 4.2 \% \quad$ APGEAQFIPNK

$0.03 \% \quad 4.2 \%$ TLRNPADSISHVAYR

$0.03 \% \quad 4.2 \%$ AIETALDCLK

$0.03 \% \quad 4.2 \%$ TIPNVIISHR

$0.03 \% \quad 4.2 \% \quad$ EVTSPNSTVR

$0.03 \% \quad 4.2 \%$ SLTLNVVNR

$0.03 \% \quad 4.2 \%$ DVLAANPNR

$0.03 \% \quad 4.2 \% \quad$ LGFTPSVTIEQR

$0.03 \% \quad 4.2 \%$ GLSVDSAQEVKR

$0.03 \% \quad 4.2 \%$ TATGAISAVFGR

$0.03 \% \quad 4.2 \%$ VIYEGLTNYEK

$0.03 \% \quad 4.2 \%$ GLSLQIKPK

$0.03 \% \quad 4.2 \%$ VYPQAVYFPIR

$0.03 \% \quad 4.2 \%$ RAQATAQDPVFQK

$0.03 \% \quad 4.2 \% \quad$ VVAVSPQMR

$0.05 \% \quad 30.1 \%$ ANPDPNTCLGVFGLSLYTTER

$0.05 \% \quad 30.1 \%$ YGPLSGVNVVYDQR

$0.05 \% \quad 30.1 \%$ SRGFAFVYFER

$0.05 \% \quad 30.1 \%$ GFAFVYFER

$0.05 \% \quad 30.1 \%$ IDDSKEAMER

$0.05 \% \quad 30.1 \%$ ANGMELDGRR

$0.05 \% \quad 30.1 \%$ IRVDYSITK

$0.05 \% \quad 30.1 \%$ VDYSITKR

$0.05 \% \quad 30.1 \%$ RSPSPYYSR

$0.05 \% \quad 30.1 \%$ SPSPYYSR

$99.7 \% \quad 52.2$

$\begin{array}{lll}99.7 \% & 48.0\end{array}$

$99.7 \% \quad 30.9$

$99.7 \% \quad 39.5$

$99.7 \% \quad 60.2$

$99.7 \% \quad 37.4$

$\begin{array}{lll}99.7 \% & 40.9\end{array}$

$99.7 \% \quad 36.3$

$99.5 \% \quad 22.9$

$\begin{array}{lll}99.5 \% & 32.1\end{array}$

$98.0 \% \quad 16.3$

$\begin{array}{lll}99.7 \% & 26.8\end{array}$

$99.7 \% \quad 37.4$

$\begin{array}{ll}99.7 \% & 36.6\end{array}$

$99.7 \% \quad 36.7$

$99.7 \% \quad 40.8$

$\begin{array}{lll}97.6 \% & 19.2\end{array}$

$99.7 \% \quad 30.0$

$99.7 \% \quad 64.4$

$99.7 \% \quad 54.6$

$99.7 \% \quad 38.2$

$99.5 \% \quad 22.1$

$\begin{array}{lll}99.3 \% & 20.2\end{array}$

$94.8 \% \quad 25.9$

$97.9 \% \quad 23.8$

$\begin{array}{ll}99.7 \% & 49.1\end{array}$

$99.7 \% \quad 56.3$

$99.2 \% \quad 27.8$

$99.7 \% \quad 61.3$

$99.7 \% \quad 56.0$

$99.3 \% \quad 22.0$

$99.7 \% \quad 45.7$

$97.9 \% \quad 25.6$

$99.7 \% \quad 32.5$

$99.0 \% \quad 29.7$

$0.08 \% \quad 38.5 \%$ ANPDPNCCLGVFGLSLYTTER

$0.08 \% \quad 38.5 \%$ DLREVFSK

$\begin{array}{ll}99.7 \% & 60.0 \\ 99.0 \% & 27.9\end{array}$

$99.7 \% \quad 52.9$

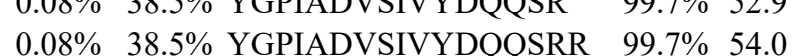

$99.7 \% \quad 55.8$

K 99.7

$\begin{array}{lll}0.08 \% & 38.5 \% & \text { ANGMELDGRR }\end{array}$

$0.08 \% \quad 38.5 \%$ IRVDFSITK

$0.08 \% \quad 38.5 \%$ GYDDRDYYSR

$0.08 \% \quad 38.5 \%$ AAQDRDQIYR $\begin{array}{lll}54.7 & 25.0 & 51.0\end{array}$

$\begin{array}{llll}99.3 \% & 22.0 & 25.0 & 17.1\end{array}$

$\begin{array}{llll}9.7 \% & 38.9 & 25.0 & 31.3 \\ 99.7 \% & 32.5 & 25.0 & 32.5\end{array}$

$\begin{array}{llll}99.7 \% & 39.8 & 25.0 & 39.2\end{array}$
1060.51

1078.59

1304.58

1333.62

1064.57

1159.60

1584.81

1754.94

1127.58

1938.00

1171.61

1699.89

1133.59

1149.67

1089.55

1015.59

969.51

1347.73

1288.69

1150.62

1328.67

983.63

1352.74

1459.77

986.55

2325.12

1566.79

1378.69

1135.56

1193.55

1118.54

1094.62

981.54

1112.55

956.45

2384.10

993.54

1810.90

1967.00

1621.75

1949.93

1118.54

1078.63

1309.54

1235.61

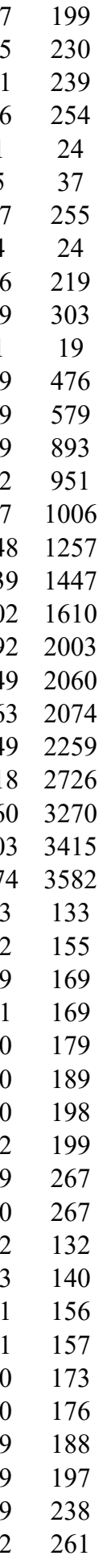

Page 165 of Table S-1-4 
Translational activator GCN1 GN=GCN1L1 GCN1L_HUMAN $292.76 \quad 100.0 \%$ Translational activator GCN1 GN=GCN1L1 GCN1L_HUMAN $292.76 \quad 100.0 \%$ Translational activator GCN1 GN=GCN1L1 GCN1L_HUMAN $292.76 \quad 100.0 \%$ Translational activator GCN1 GN=GCN1L1 GCN1L_HUMAN $292.76 \quad 100.0 \%$ Translational activator GCN1 GN=GCN1L1 GCN1L_HUMAN $292.76 \quad 100.0 \%$ Translational activator GCN1 GN=GCN1L1 GCN1L_HUMAN $292.76 \quad 100.0 \%$ Translational activator GCN1 GN=GCN1L1 GCN1L_HUMAN $292.76 \quad 100.0 \%$ Translational activator GCN1 GN=GCN1L1 GCN1L HUMAN $292.76 \quad 100.0 \%$ Translational activator GCN1 GN=GCN1L1 GCN1L_HUMAN $292.76 \quad 100.0 \%$ Translational activator GCN1 GN=GCN1L1 GCN1L_HUMAN $292.76 \quad 100.0 \%$ Translational activator GCN1 GN=GCN1L1 GCN1L_HUMAN $292.76 \quad 100.0 \%$ Translational activator GCN1 GN=GCN1L1 GCN1L_HUMAN $292.76 \quad 100.0 \%$ Translational activator GCN1 GN=GCN1L1 GCN1L_HUMAN $292.76 \quad 100.0 \%$ Translational activator GCN1 GN=GCN1L1 GCN1L_HUMAN $292.76 \quad 100.0 \%$ Translational activator GCN1 GN=GCN1L1 GCN1L_HUMAN $292.76 \quad 100.0 \%$ Translational activator GCN1 GN=GCN1L1 GCN1L HUMAN $292.76 \quad 100.0 \%$ Translational activator GCN1 GN=GCN1L1 GCN1L_HUMAN $292.76 \quad 100.0 \%$ Translational activator GCN1 GN=GCN1L1 GCN1L_HUMAN $292.76 \quad 100.0 \%$ Translational activator GCN1 GN=GCN1L1 GCN1L_HUMAN $292.76 \quad 100.0 \%$ Translational activator GCN1 GN=GCN1L1 GCN1L_HUMAN $292.76 \quad 100.0 \%$ Translational activator GCN1 GN=GCN1L1 GCN1L_HUMAN $292.76 \quad 100.0 \%$ Translational activator GCN1 GN=GCN1L1 GCN1L_HUMAN $292.76 \quad 100.0 \%$ Translational activator GCN1 GN=GCN1L1 GCN1L_HUMAN $292.76 \quad 100.0 \%$ Translational activator GCN1 GN=GCN1L1 GCN1L_HUMAN $292.76 \quad 100.0 \%$ Translational activator GCN1 GN=GCN1L1 GCN1L_HUMAN $292.76 \quad 100.0 \%$

$80 \quad 0.08 \% \quad 38.5 \%$ RSPSPYYSR

\section{0}

12

$0.01 \% \quad 30.8 \%$ DKGETIQGLR

$0.01 \% \quad 30.8 \%$ FISLASLEYSDYSK

$0.01 \% \quad 30.8 \%$ DGATILTHAYSR

$0.01 \% \quad 30.8 \%$ VLEAAVAAK

$0.01 \% \quad 30.8 \%$ FSVYVTESQPDLSGKK

$0.01 \% \quad 30.8 \%$ IGTNQMAVCAK

$0.01 \% \quad 30.8 \%$ AQNKPFYVVAESFK

$0.01 \% \quad 16.2 \%$ SDESDQQESLHK

$0.01 \% \quad 16.2 \%$ AVTGTHTLALAAK

$0.01 \% \quad 16.2 \%$ LSPQFPNEEDSFHK

$0.01 \% \quad 16.2 \%$ FVAPEEVLPFTEGDILEK

$0.01 \% \quad 12.8 \%$ ELPESGIQLGTPR

$0.01 \% \quad 12.8 \%$ ASPSTAGETPSGVK

$0.01 \% \quad 12.8 \%$ ASPSTAGETPSGVKR

$0.01 \% \quad 12.8 \%$ VSLFSHLPQYSR

$0.01 \% \quad 12.8 \%$ LGLQYSQGLVSGSNAR

$0.01 \% \quad 12.8 \%$ VGTAQLALVAR

$65 \quad 148 \quad 0.15 \% \quad 22.8 \%$ ALQAAIQQLAEAQPEATAK

$65 \quad 148 \quad 0.15 \% \quad 22.8 \%$ NLLHSLQSSGIGSK

$65 \quad 148 \quad 0.15 \% \quad 22.8 \%$ SALLDFYMK

$65 \quad 148 \quad 0.15 \% \quad 22.8 \%$ YLLDSCAPLLR

$65 \quad 148 \quad 0.15 \% \quad 22.8 \%$ LMDEAVLALR

$65 \quad 148 \quad 0.15 \% \quad 22.8 \%$ QCSDSSAMESLTK

$65 \quad 148 \quad 0.15 \% \quad 22.8 \%$ LSVADSQAEAK

$65 \quad 148 \quad 0.15 \% \quad 22.8 \%$ ALVAVLLSR

$65 \quad 148 \quad 0.15 \% \quad 22.8 \%$ VLPLEALVTDAGEVTEAGK

$65 \quad 148 \quad 0.15 \% \quad 22.8 \%$ MKIDPEAFITR

$65 \quad 148 \quad 0.15 \% \quad 22.8 \%$ HLDQIIPR

$65 \quad 148 \quad 0.15 \% \quad 22.8 \%$ GIKEEVQLTSK

$65 \quad 148 \quad 0.15 \% \quad 22.8 \%$ ASPNTPPGRVDENGPELLPR

$65 \quad 148 \quad 0.15 \% \quad 22.8 \%$ VDENGPELLPR

$65 \quad 148 \quad 0.15 \% \quad 22.8 \%$ QAGAEALSQAVAR

$65 \quad 148 \quad 0.15 \% \quad 22.8 \%$ LMEIYQEK

$65 \quad 148 \quad 0.15 \% \quad 22.8 \%$ LYRPPPVLDALGR

$65 \quad 148 \quad 0.15 \% \quad 22.8 \%$ VISESPPDQWEAR

$65 \quad 148 \quad 0.15 \% \quad 22.8 \%$ CGLALALNK

$65 \quad 148 \quad 0.15 \% \quad 22.8 \%$ NAPNDASYDAVR

$65 \quad 148 \quad 0.15 \% \quad 22.8 \%$ QSVVVLMGSLAK

$\begin{array}{lllll}65 & 148 & 0.15 \% & 22.8 \% & \text { EDAGGMIQR }\end{array}$

$65 \quad 148 \quad 0.15 \% \quad 22.8 \%$ LMQQLLESDKYAER

$65 \quad 148 \quad 0.15 \% \quad 22.8 \%$ KGAAYGLAGLVK

$65 \quad 148 \quad 0.15 \% \quad 22.8 \%$ GAAYGLAGLVK

$65 \quad 148 \quad 0.15 \% \quad 22.8 \%$ AVMSNLSAHGVK

$65 \quad 148 \quad 0.15 \% \quad 22.8 \%$ AGSVELLGAMAYCAPK
$99.7 \% \quad 32.5$

$99.0 \% \quad 29.7$

$99.0 \% \quad 33.1$

$98.6 \% 23.8$

$97.9 \% \quad 95.6$

$\begin{array}{llll}99.7 \% & 58.3\end{array}$

$99.7 \% \quad 48.5$

$99.7 \% \quad 56.4$

$99.7 \% \quad 25.7$

$99.7 \% \quad 32.0$

$99.7 \% \quad 58.4$

$99.7 \% \quad 53.2$

$98.1 \% \quad 21.0$

$99.7 \% \quad 39.8$

$99.7 \% \quad 37.4$

$99.7 \% \quad 30.3$

$98.1 \% \quad 18.7$

$99.7 \% \quad 39.5$

$99.7 \% \quad 50.6$

$99.7 \% \quad 65.7$

$99.7 \% \quad 57.4$

$99.6 \% \quad 24.6$

$99.7 \% \quad 45.4$

$99.7 \% \quad 47.2$

$99.7 \% \quad 54.2$

$99.7 \% \quad 55.0$

$99.7 \% \quad 60.4$

$\begin{array}{ll}99.2 \% & 18.7 \\ 99.6 \% & 25.5\end{array}$

$99.6 \% \quad 25.5$

$99.0 \% \quad 29.6$

$99.7 \% \quad 46.6$

$99.6 \% 24.9$

$99.7 \% \quad 44.7$

$99.7 \% \quad 57.2$

$99.0 \% \quad 37.0$

$99.7 \% \quad 32.2$

$99.7 \% \quad 33.2$

$98.4 \% \quad 28.4$

$99.7 \% \quad 60.3$

$99.7 \% \quad 34.4$

$99.7 \% \quad 38.7$

$96.8 \% \quad 15.2$

$99.5 \% \quad 22.5$

$99.7 \% \quad 39.2$

$99.7 \% \quad 53.8$

$99.7 \% \quad 43.9$
111

956.45

1019.62

1116.60

1622.79

1304.66

871.52

1784.91

1192.58

1627.85

1402.61

1253.72

1674.78

2033.05

1396.74

1288.64

1444.74

1433.75

1649.86

1098.66

1952.04

1440.78

1087.55

1320.70

1146.62

1443.61

1118.57

941.61

1912.03

1320.70

991.57

1231.69

2116.08

1238.64

1271.67

1053.53

1466.85

1513.73

959.53

1292.59

1231.71

976.45

1739.86

1147.68

1019.59

1213.64 1637.80

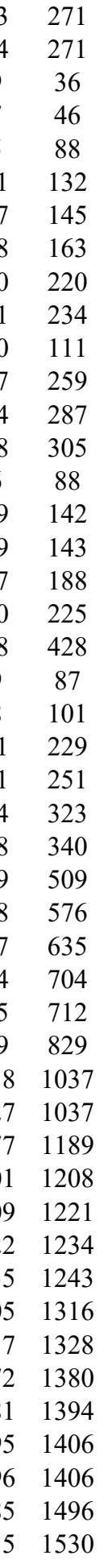


Translational activator GCN1 GN=GCN1L1 GCN1L_HUMAN $292.76 \quad 100.0 \%$ Translational activator GCN1 GN=GCN1L1 GCN1L_HUMAN $292.76 \quad 100.0 \% \quad 54$ Translational activator GCN1 GN=GCN1L1 GCN1L_HUMAN $292.76 \quad 100.0 \% \quad 54$ Translational activator GCN1 GN=GCN1L1 GCN1L_HUMAN $292.76 \quad 100.0 \%$ Translational activator GCN1 GN=GCN1L1 GCN1L_HUMAN $292.76 \quad 100.0 \% \quad 54$ Translational activator GCN1 GN=GCN1L1 GCN1L_HUMAN $292.76 \quad 100.0 \% \quad 54$ Translational activator GCN1 GN=GCN1L1 GCN1L_HUMAN $292.76 \quad 100.0 \% \quad 54$ Translational activator GCN1 GN=GCN1L1 GCN1L_HUMAN $292.76 \quad 100.0 \% \quad 54$ Translational activator GCN1 GN=GCN1L1 GCN1L HUMAN $292.76 \quad 100.0 \%$ Translational activator GCN1 GN=GCN1L1 GCN1L_HUMAN $292.76 \quad 100.0 \% \quad 54$ Translational activator GCN1 GN=GCN1L1 GCN1L_HUMAN $292.76 \quad 100.0 \%$ Translational activator GCN1 GN=GCN1L1 GCN1L_HUMAN $292.76 \quad 100.0 \%$ Translational activator GCN1 GN=GCN1L1 GCN1L_HUMAN $292.76 \quad 100.0 \%$ Translational activator GCN1 GN=GCN1L1 GCN1L_HUMAN $292.76 \quad 100.0 \%$ Translational activator GCN1 GN=GCN1L1 GCN1L_HUMAN $292.76 \quad 100.0 \%$ Translational activator GCN1 GN=GCN1L1 GCN1L_HUMAN $292.76 \quad 100.0 \%$ Translational activator GCN1 GN=GCN1L1 GCN1L HUMAN $292.76 \quad 100.0 \%$ Translational activator GCN1 GN=GCN1L1 GCN1L_HUMAN $292.76 \quad 100.0 \%$ Translational activator GCN1 GN=GCN1L1 GCN1L_HUMAN $292.76 \quad 100.0 \%$ Translational activator GCN1 GN=GCN1L1 GCN1L HUMAN $292.76 \quad 100.0 \%$ Translational activator GCN1 GN=GCN1L1 GCN1L_HUMAN $292.76 \quad 100.0 \%$ Translational activator GCN1 GN=GCN1L1 GCN1L HUMAN $292.76 \quad 100.0 \%$ Translational activator GCN1 GN=GCN1L1 GCN1L_HUMAN $292.76 \quad 100.0 \%$ Translational activator GCN1 GN=GCN1L1 GCN1L_HUMAN $292.76 \quad 100.0 \%$ Translational activator GCN1 GN=GCN1L1 GCN1L HUMAN $292.76 \quad 100.0 \%$ Translational activator GCN1 GN=GCN1L1 GCN1L_HUMAN $292.76 \quad 100.0 \%$ Translational activator GCN1 GN=GCN1L1 GCN1L_HUMAN $292.76100 .0 \%$ Transmembrane protein $201 \mathrm{GN}=$ TMEM201 TM201 HUMAN $72.24 \quad 100.0 \%$ Transmembrane protein 201 GN=TMEM201 TM201_HUMAN $72.24 \quad 100.0 \%$ Transportin-1 GN=TNPO

Transportin- $1 \mathrm{GN}=\mathrm{TNPO}$

Transportin-1 GN=TNPO

Transportin-1 GN=TNPO

Transportin- $1 \mathrm{GN}=\mathrm{TNPO}$

Transportin-3 GN=TNPO3

Transportin-3 GN=TNPO3

TNPO1_HUMAN $102.36 \quad 100.0 \%$

TNPO1_HUMAN $102.36 \quad 100.0 \%$

TNPO1_HUMAN $102.36 \quad 100.0 \%$

TNPO1 HUMAN $102.36 \quad 100.0 \%$

TNPO1_HUMAN $102.36 \quad 100.0 \%$

TNPO3 HUMAN $104.20 \quad 99.9 \%$

TNPO3 HUMAN $104.20 \quad 99.9 \%$

Tricarboxylate transport protein, mitochondrial GN=SLC25A1 TXTP_HUMAN $34.01 \quad 100.0 \%$

Tricarboxylate transport protein, mitochondrial GN=SLC25A1 TXTP_HUMAN $34.01 \quad 100.0 \%$

Tricarboxylate transport protein, mitochondrial GN=SLC25A1 TXTP_HUMAN $34.01 \quad 100.0 \%$

Tricarboxylate transport protein, mitochondrial GN=SLC25A1 TXTP HUMAN 34.01 $100.0 \%$

Tricarboxylate transport protein, mitochondrial GN=SLC25A1 TXTP HUMAN $34.01 \quad 100.0 \%$

Tricarboxylate transport protein, mitochondrial GN=SLC25A1 TXTP_HUMAN $34.01 \quad 100.0 \%$

Tricarboxylate transport protein, mitochondrial GN=SLC25A1 TXTP HUMAN $34.01 \quad 100.0 \%$

Tricarboxylate transport protein, mitochondrial GN=SLC25A1 TXTP_HUMAN 34.01 $100.0 \%$

Tricarboxylate transport protein, mitochondrial GN=SLC25A1 TXTP HUMAN $34.01 \quad 100.0 \%$

Tricarboxylate transort protein, mitochondrial GN=SLC25A1 TXTP HUMAN $34.01 \quad 100.0^{\circ}$

Tricarboxylate transport protein, mitochondrial GN=SLC25A1 TXTP_HUMAN $34.01 \quad 100.0 \%$
$65 \quad 148 \quad 0.15 \% \quad 22.8 \%$ QLSSCLPNIVPK

$65 \quad 148 \quad 0.15 \% \quad 22.8 \%$ LTEVLTDSHVK

$65 \quad 148 \quad 0.15 \% \quad 22.8 \%$ LTEVLTDSHVKVQK

$65 \quad 148 \quad 0.15 \% \quad 22.8 \%$ ASLLDPVPEVR

$65 \quad 148 \quad 0.15 \% \quad 22.8 \%$ LMPEIVATASK

$65 \quad 148 \quad 0.15 \% \quad 22.8 \%$ VDIAPHVR

$65 \quad 148 \quad 0.15 \% \quad 22.8 \%$ ALADENEFVR

$65 \quad 148 \quad 0.15 \% \quad 22.8 \%$ ALADENEFVRDTALR

$65 \quad 148 \quad 0.15 \% \quad 22.8 \%$ MTTETASEDDNFGTAQSNK

$65 \quad 148 \quad 0.15 \% \quad 22.8 \%$ AIITALGVER

$65 \quad 148 \quad 0.15 \% \quad 22.8 \%$ VLAGLYMGR

$65 \quad 148 \quad 0.15 \% \quad 22.8 \%$ SDTQLVVR

$\begin{array}{llll}65 & 148 & 0.15 \% & 22.8 \% \\ 6 & 148 & 0.15 \% & 22.8 \% \text { DGVIGLSEIMK }\end{array}$

$65 \quad 148 \quad 0.15 \% \quad 22.8 \%$ DAVLYFSESLVPTAR

$65 \quad 148 \quad 0.15 \% \quad 22.8 \%$ LTTPPVNTR

$65 \quad 148 \quad 0.15 \% \quad 22.8 \%$ VLAFLSSVAGDALTR

$65 \quad 148 \quad 0.15 \% \quad 22.8 \%$ QAAAIILNIYCSR

$65 \quad 148 \quad 0.15 \% \quad 22.8 \%$ SKADYTSHLR

$65 \quad 148 \quad 0.15 \% \quad 22.8 \%$ ADYTSHLR

$65 \quad 148 \quad 0.15 \% \quad 22.8 \%$ EGVLTGSPEQKEEAAK

$65 \quad 148 \quad 0.15 \% \quad 22.8 \%$ LTSADALRPSVVSITGPLIR

$65 \quad 148 \quad 0.15 \% \quad 22.8 \%$ ALQDSNRGVR

$65 \quad 148 \quad 0.15 \% \quad 22.8 \%$ HHIETGGGQLPAK

$65 \quad 148 \quad 0.15 \% \quad 22.8 \%$ CLQNPSSDIR

$65 \quad 148 \quad 0.15 \% \quad 22.8 \%$ AYSDQAIVNLLK

$65 \quad 148 \quad 0.15 \% \quad 22.8 \%$ QGEEVFQSLSK

$65 \quad 148 \quad 0.15 \% \quad 22.8 \%$ LASQADSTEQVDDTILT

$5 \quad 0.00 \% \quad 3.6 \%$ EADQTHAQNFSSAVK

$0.00 \% \quad 3.6 \%$ SPVQVILLR

$12 \quad 0.01 \% \quad 6.7 \% \quad$ ESQSPDTTIQR

$0.01 \% \quad 6.7 \% \quad$ SLSGLILKNNVK

$0.01 \% \quad 6.7 \% \quad$ ATVGILITTIASK

$0.01 \% \quad 6.7 \%$ QSSFALLGDLTK

$0.01 \% \quad 6.7 \% \quad$ TLLENTAITIGR

$0.00 \% \quad 2.3 \%$ GLCEKPLASAAAK

$0.00 \% \quad 2.3 \% \quad$ ADNRIVER

$0.04 \% \quad 34.1 \%$ AKLTHPGK

$0.04 \% \quad 34.1 \%$ TQLQLDER

$0.04 \% \quad 34.1 \%$ SHGVLGLYR

$0.04 \% \quad 34.1 \%$ GLSSLLYGSIPK

$0.04 \% \quad 34.1 \%$ FGMFEFLSNHMR

$0.04 \% 34.1 \%$ FIHDQTSPNPK

$0.04 \% 34.1 \%$ EQGLKGTYQGLTAT

$0.04 \% \quad 34.1 \%$ FFVMTSLR

$0.04 \% \quad 34.1 \%$ MQGLEAHKYR

$0.04 \% \quad 34.1 \%$ NTWDCGLQILK
$99.7 \% \quad 36.4$ $99.7 \% \quad 56.3$

$99.7 \% \quad 37.0$

$99.7 \% \quad 49.8$

$99.7 \% \quad 31.5$

$99.0 \% \quad 37.2$

$99.7 \% \quad 43.9$

$99.7 \% \quad 26.5$

$99.7 \% \quad 67.9$

$99.7 \% \quad 51.7$

$\begin{array}{lll}99.7 \% & 36.7\end{array}$

$99.0 \% \quad 39.5$

$94.7 \% \quad 16.0$

$99.7 \% \quad 38.6$

$99.5 \% \quad 26.8$

$99.7 \% \quad 55.8$

$99.7 \% \quad 52.8$

$99.7 \% \quad 26.5$

$98.7 \% \quad 18.9$

$99.7 \% \quad 48.1$

$\begin{array}{ll}99.7 \% & 29.6 \\ 99.4 \% & 23.8\end{array}$

$95.7 \% \quad 18.1$

$99.7 \% \quad 47.3$

$99.7 \% \quad 74.4$

$99.7 \% \quad 46.3$

$97.2 \% \quad 21.9$

$99.7 \% \quad 42.4$

$99.7 \% \quad 51.2$

$99.5 \% \quad 24.7$

$99.7 \% \quad 38.8$

$99.7 \% \quad 55.4$

$99.7 \% \quad 32.5$

$99.7 \% \quad 66.0$

$\begin{array}{lll}99.7 \% & 34.7\end{array}$

$94.5 \% \quad 21.8$

$99.0 \% \quad 26.3$

$99.0 \% \quad 30.0$

$99.7 \% \quad 38.4$

$99.7 \% \quad 59.3$

$99.7 \% \quad 45$.

$99.7 \% \quad 44.2$

$\begin{array}{lll}98.7 \% & 18.7\end{array}$

$99.7 \% \quad 59.0$

$99.0 \% \quad 44.3$

$99.5 \% 23.0$

$99.7 \% \quad 43.8$
1241.6

1596.90

1195.67

1159.64

906.52

1163.57

1719.87

2046.86

1042.63

979.54

917.51

1350.68

1667.86

998.56

1519.85

1492.79

1177.60

962.47

1672.84

2066.20

1115.59

1344.70

1189.56

1334.73

1251.62

1806.86

1632.76

1024.65

1261.60

1285.78

1287.79

1279.69

1301.74

1315.70

972.52

851.51

1002.52

1001.55

1234.70

1531.68

1283.64

1807.00

1251.69

1016.52

1232.62

1232.62
1347.67 

tRNA (cytosine(34)-C(5))-methyltransferase GN=NSUN2 NSUN2_HUMAN $86.47 \quad 100.0 \%$ RNA (cytosine(34)-C(5))-methyltransferase GN=NSUN2 NSUN2 HUMAN $86.47 \quad 100.0 \%$ tRNA (cytosine(34)-C(5))-methyltransferase GN=NSUN2 NSUN2_HUMAN $86.47 \quad 100.0 \%$ tRNA (cytosine(34)-C(5))-methyltransferase GN=NSUN2 NSUN2_HUMAN $86.47 \quad 100.0 \%$ RNA (cytosine(34)-C(5))-methyltransferase GN=NSUN2 NSUN2 HUMAN $86.47 \quad 100.0 \%$ tRNA (cytosine(34)-C(5))-methyltransferase GN=NSUN2 NSUN2_HUMAN $86.47 \quad 100.0 \%$ tRNA pseudouridine synthase A, mitochondrial GN=PUS1 TRUA HUMAN $47.47 \quad 100.0 \%$ tRNA pseudouridine synthase A, mitochondrial GN=PUS1 TRUA_HUMAN $47.47 \quad 100.0 \%$ tRNA-splicing ligase RtcB homolog GN=RTCB RTCB_HUMAN $55.21 \quad 100.0 \%$ tRNA-splicing ligase RtcB homolog GN=RTCB RTCB HUMAN $55.21 \quad 100.0 \%$ tRNA-splicing ligase RtcB homolog GN=RTCB RTCB_HUMAN $55.21 \quad 100.0 \%$

15.6\% INSPNSKVNTLSK

$\begin{array}{llllllll}99.7 \% & 52.3 & 25.0 & 46.0 & 1 & 0 & 0 & 1401.77\end{array}$

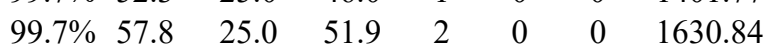

$99.7 \% 47.4$

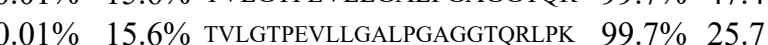

$0.01 \% \quad 15.6 \%$ FGAPQKDVK

$99.0 \% \quad 29.7$

$\begin{array}{ll}0.01 \% & 15.6 \% \text { DATLTALDRGQQQVFK } \\ 0.01 \% & 15.6 \% \text { DTSASAVAVGLKQGK }\end{array}$

$0.01 \% \quad 15.6 \%$ VIIVVKDGPGFYTTR

$0.01 \% 15.6 \%$ SGKGFYIYQEGVK

$0.02 \% \quad 27.8 \%$ TLAKPNIR

$0.02 \% \quad 27.8 \%$ NVVVVDGVR

$\begin{array}{llll}99.7 \% & 34.2\end{array}$

$99.7 \% \quad 43.9$

$\begin{array}{lll}99.7 \% & 49.2 \\ 99.7 \% & 56.7 & 2\end{array}$

$99.7 \% 56.7$

\begin{tabular}{lll}
$99.0 \%$ & 22.0 \\
$99.7 \%$ & 49.8 \\
\hline
\end{tabular}

$0.02 \% \quad 27.8 \%$ TPFLLSGTSYKDLMPHDLAR $99.7 \% \quad 61.6$

$0.02 \% \quad 27.8 \%$ AALTGLLHR

$0.02 \% \quad 27.8 \%$ EVVDYIIFGTVIQEVK

$0.02 \% \quad 27.8 \%$ EAALGAGFSDK

$0.02 \% 27.8 \%$ LAAAFAVSR

$99.7 \% \quad 60.8$

$\begin{array}{llll}99.7 \% & 80.1\end{array}$

$99.7 \% \quad 50.7$

$99.7 \% \quad 63.8$

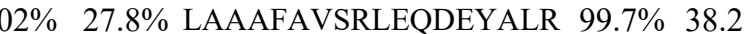

$0.02 \% \quad 27.8 \%$ DNGIRPSSLEQMAK

$0.02 \% \quad 27.8 \%$ ALAMGYKPK

$0.02 \% \quad 27.8 \%$ TKVGLPPLEK

$0.02 \% \quad 27.8 \%$ VGLPPLEK

$0.02 \% \quad 27.8 \%$ LVMAAANR

$99.2 \% \quad 22.7$

\begin{tabular}{lll}
$99.5 \%$ & 22.4 \\
\hline
\end{tabular}

$99.1 \% 18.3$

$99.0 \% \quad 28.0$

$99.0 \% \quad 33.9$

$0.01 \% \quad 11.2 \%$ SAGVQCFGPTAEAAQLESSKR $\quad 99.7 \% 26.3$

$\begin{array}{lllll}0.01 \% & 11.2 \% & \text { AFTKPEEACSFILSADFPALVVK } & 99.2 \% & 18.9\end{array}$

$0.01 \% \quad 11.2 \%$ ASGLAAGKGVIVAK $\quad 99.7 \% \quad 51.2$

$0.01 \% \quad 11.2 \%$ IKDTVLQR

$0.01 \% \quad 11.2 \%$ AIAFLQQPR

$0.01 \% \quad 11.2 \%$ IYSHSLLPVLR

$0.01 \% \quad 11.2 \%$ AFAHITGGGLLENIPR

$0.01 \% \quad 11.2 \%$ AAVAGLDKAER

$0.00 \% \quad 6.9 \%$ TLLVDGFYAAEQVLQK

$0.00 \% \quad 6.9 \%$ AVINTVPYDVVHR

$99.0 \% \quad 48.3$

$99.0 \% 31.1$

$99.7 \% \quad 42.8$

$\begin{array}{lll}99.3 \% & 28.6 \\ 99.7 \% & 49.5 & 2\end{array}$

$99.7 \% \quad 49.5$

$0.00 \% \quad 7.7 \%$ ILSIMYYAR

$99.7 \% 35.0$

$99.7 \% \quad 31.2$

$0.00 \% \quad 7.7 \%$ MGGFGSIIQLYPGGGPVR

$0.00 \% \quad 7.7 \%$ HLEAAALLSER

$0.02 \% \quad 8.6 \%$ ILDMCAAPGSK

$0.02 \% \quad 8.6 \%$ IATRGAEQLAEGGR

$0.02 \% \quad 8.6 \%$ GAEQLAEGGR

$0.02 \% \quad 8.6 \%$ NVLLNNSEK

$0.02 \% \quad 8.6 \%$ IITVSMEDVK

$0.02 \% \quad 8.6 \% \quad$ ILLTQENPFFR

$0.02 \% \quad 8.6 \%$ KLSSETYSQAK

$0.00 \% \quad 4.9 \% \quad$ LSAETLQQVNR

$0.00 \% \quad 4.9 \%$ APGLGLVLER

$0.00 \% \quad 6.9 \%$ QIGNVAALPGIVHR

$0.00 \% \quad 6.9 \%$ MLQADPNKVSAR

$0.00 \% \quad 6.9 \%$ LRPIAVIKG
$99.7 \% \quad 31.9$

$99.4 \% \quad 25.9$

$99.7 \% \quad 69.1$

$98.4 \% \quad 21.9$

$99.7 \% \quad 36.1$

$99.7 \% \quad 60.9$

$99.4 \% \quad 21.2$

$99.7 \% \quad 40.6$

$98.7 \% \quad 18.8$

$\begin{array}{lll}99.7 \% & 27.7\end{array}$

$\begin{array}{lll}99.7 \% & 51.8\end{array}$

$98.8 \% \quad 17.6$
$99.7 \% \quad 29.5$
2007.12

2345.36

989.54

1790.94

1431.78

1664.94

1475.75

912.56

956.55

2278.15

951.57

1852.01

1065.52

905.52

2023.06

1561.76

994.54

1081.66

852.52

845.47

2194.06

2540.31

1241.76

972.58

1043.60

1297.76

1665.91

1100.61

1794.96

1482.81

1129.61

1805.94

1209.66

1178.55

1428.76

987.49

1030.55

1134.61

1377.75

1241.64

1258.68

1024.62

1444.84

1329.69 966.65

\begin{tabular}{cc}
54 & 66 \\
12 & 125 \\
167 & 187 \\
167 & 190 \\
34 & 362 \\
91 & 406 \\
20 & 534 \\
535 & 549 \\
632 & 644 \\
5 & 52 \\
3 & 6 \\
62 & 8 \\
82 & 90 \\
6 & 11 \\
18 & 128 \\
230 & 238 \\
230 & 247 \\
778 & 291 \\
326 & 334 \\
407 & 416 \\
409 & 416 \\
47 & 444 \\
88 & 108 \\
126 & 148 \\
149 & 162 \\
250 & 257 \\
425 & 433 \\
661 & 671 \\
677 & 692 \\
845 & 855 \\
269 & 284 \\
339 & 351 \\
167 & 175 \\
221 & 238 \\
357 & 367 \\
180 & 190 \\
302 & 315 \\
306 & 315 \\
569 & 577 \\
619 & 628 \\
629 & 639 \\
640 & 650 \\
24 & 234 \\
328 & 337 \\
68 & 8 \\
199 & 210 \\
47 & 505 \\
& \\
\hline
\end{tabular}


Tubulin alpha-1A chain GN=TUBA1A Tubulin alpha-1A chain GN=TUBA1A Tubulin alpha-1A chain $\mathrm{GN}=\mathrm{TUBA} 1 \mathrm{~A}$ Tubulin alpha-1A chain $\mathrm{GN}=\mathrm{TUBA} 1 \mathrm{~A}$ Tubulin alpha-1A chain GN=TUBA1A Tubulin alpha-1A chain GN=TUBA1A

Tubulin alpha-1A chain $\mathrm{GN}=\mathrm{TUBA} 1 \mathrm{~A}$ Tubulin alpha- $1 \mathrm{~A}$ chain $\mathrm{GN}=\mathrm{TUBA} 1 \mathrm{~A}$ Tubulin alpha-1A chain $\mathrm{GN}=\mathrm{TUBA} 1 \mathrm{~A}$ Tubulin alpha-1A chain GN=TUBA1A Tubulin alpha-1A chain GN=TUBA1A Tubulin alpha-1A chain GN=TUBA1A Tubulin alpha-1A chain GN=TUBA1A Tubulin alpha-1A chain $\mathrm{GN}=$ TUBA1A Tubulin alpha-1A chain GN=TUBA1A Tubulin alpha-1A chain GN=TUBA1A Tubulin alpha-1A chain GN=TUBA1A Tubulin alpha- $1 \mathrm{~A}$ chain $\mathrm{GN}=\mathrm{TUBA} 1 \mathrm{~A}$ Tubulin alpha-1A chain $\mathrm{GN}=\mathrm{TUBA} 1 \mathrm{~A}$ Tubulin alpha-1A chain GN=TUBA1A Tubulin alpha-1A chain GN=TUBA1A Tubulin alpha-1A chain GN=TUBA1A Tubulin alpha-1A chain GN=TUBA1A Tubulin alpha-1A chain GN=TUBA1A Tubulin alpha-1A chain $\mathrm{GN}=$ TUBA1A Tubulin alpha-1A chain GN=TUBA1A Tubulin alpha-1A chain $\mathrm{GN}=$ TUBA1A Tubulin alpha-1A chain GN=TUBA1A Tubulin alpha-1A chain GN=TUBA1A Tubulin alpha-1A chain GN=TUBA1A Tubulin alpha-1B chain GN=TUBA1B Tubulin alpha-1B chain GN=TUBA1B Tubulin alpha-1B chain GN=TUBA1B Tubulin alpha-1B chain GN=TUBA1B Tubulin alpha-1B chain $\mathrm{GN}=$ TUBA1B Tubulin alpha-1B chain GN=TUBA1B Tubulin alpha-1B chain $\mathrm{GN}=$ TUBA1B Tubulin alpha-1B chain GN=TUBA1B Tubulin alpha-1B chain GN=TUBA1B Tubulin alpha-1B chain $\mathrm{GN}=\mathrm{TUBA} 1 \mathrm{~B}$ Tubulin alpha-1B chain GN=TUBA1B Tubulin alpha-1B chain GN=TUBA1B Tubulin alpha-1B chain GN=TUBA1B Tubulin alpha-1B chain GN=TUBA1B Tubulin alpha-1B chain GN=TUBA1B Tubulin alpha-1B chain GN=TUBA1B Tubulin alpha-1B chain GN=TUBA1B
DAIA_HUMAN $50.14 \quad 100.0 \%$ BA1A HUMAN $50.14 \quad 100.0 \%$ TBA1A_HUMAN $50.14 \quad 100.0 \%$ TBA1A HUMAN $50.14 \quad 100.0 \%$ TBA1A_HUMAN $50.14 \quad 100.0 \%$ TBA1A_HUMAN $50.14 \quad 100.0 \%$ TBA1A_HUMAN $50.14 \quad 100.0 \%$ TBA1A_HUMAN $50.14 \quad 100.0 \%$ TBA1A HUMAN $50.14 \quad 100.0 \%$ TBA1A_HUMAN $50.14 \quad 100.0 \%$ TBA1A_HUMAN $50.14 \quad 100.0 \%$ TBA1A HUMAN $50.14 \quad 100.0 \%$ TBA1A_HUMAN $50.14 \quad 100.0 \%$ TBA1A HUMAN $50.14 \quad 100.0 \%$ TBA1A HUMAN $50.14 \quad 100.0 \%$ TBA1A_HUMAN $50.14 \quad 100.0 \%$ TBA1A HUMAN $50.14 \quad 100.0 \%$ TBA1A HUMAN $50.14 \quad 100.0 \%$ TBA1A_HUMAN $50.14 \quad 100.0 \%$ TBA1A_HUMAN $50.14 \quad 100.0 \%$ TBA1A_HUMAN $50.14 \quad 100.0 \%$ TBA1A_HUMAN $50.14 \quad 100.0 \%$ TBA1A_HUMAN $50.14 \quad 100.0 \%$ TBA1A_HUMAN $50.14 \quad 100.0 \%$ TBA1A HUMAN $50.14 \quad 100.0 \%$ TBA1A_HUMAN $50.14 \quad 100.0 \%$ TBA1A_HUMAN $50.14 \quad 100.0 \%$ TBA1A HUMAN $50.14 \quad 100.0 \%$ TBA1A_HUMAN $50.14 \quad 100.0 \%$ TBA1A HUMAN $50.14 \quad 100.0 \%$ TBA1B HUMAN $50.15 \quad 100.0 \%$ TBA1B_HUMAN $50.15 \quad 100.0 \% \quad 30$ TBA1B HUMAN $50.15 \quad 100.0 \% \quad 30$ TBA1B_HUMAN $50.15 \quad 100.0 \% \quad 30$ TBA1B_HUMAN $50.15 \quad 100.0 \% \quad 30$ TBA1B HUMAN $50.15 \quad 100.0 \% \quad 30$ TBA1B_HUMAN $50.15 \quad 100.0 \% \quad 30$ TBA1B HUMAN $50.15 \quad 100.0 \% \quad 30$ TBA1B_HUMAN $50.15 \quad 100.0 \% \quad 30$ TBA1B_HUMAN $50.15 \quad 100.0 \% \quad 30$ TBA1B HUMAN $50.15 \quad 100.0 \% \quad 30$ TBA1B_HUMAN $50.15 \quad 100.0 \% \quad 30$ TBA1B HUMAN $50.15 \quad 100.0 \% \quad 30$ TBA1B HUMAN $50.15 \quad 100.0 \% \quad 30$ TBA1B_HUMAN $50.15 \quad 100.0 \% \quad 30$ TBA1B HUMAN $50.15 \quad 100.0 \% \quad 30$ TBA1B_HUMAN $50.15 \quad 100.0 \% \quad 30$ $0.01 \% \quad 67.8 \%$ TIGGGDDSFNTFFSETGAGKHVPR $99.7 \% 39.7$

$0.01 \% \quad 67.8 \%$ AVFVDLEPTVIDEVR $\quad 99.7 \% \quad 55.5$ $0.01 \% \quad 67.8 \%$ AVFVDLEPTVIDEVRTGTYR $99.7 \% \quad 46.8$ $\begin{array}{lll}0.01 \% & 67.8 \% & \text { QLFHPEQLITGKEDAANNYAR } 99.7 \% \quad 55.4\end{array}$ $0.01 \% \quad 67.8 \%$ EDAANNYAR $99.7 \% \quad 35.9$

$0.01 \% \quad 67.8 \%$ GHYTIGKEIIDLVLDR $99.7 \% \quad 60.3$

$0.01 \% \quad 67.8 \%$ EIIDLVLDR

$0.01 \% \quad 67.8 \%$ EIIDLVLDRIR

$99.7 \% \quad 60.2$

$99.7 \% \quad 32.6$

$0.01 \% \quad 67.8 \%$ KLADQCTGLQGFLVFHSFGGGTGSGFTSLLMER $\quad 99.7 \% \quad 61.8$

$0.01 \% \quad 67.8 \%$ LADQCTGLQGFLVFHSFGGGTGSGFTSLLMER $\quad 99.7 \% \quad 67.6$

$0.01 \% \quad 67.8 \%$ LSVDYGKK

$0.01 \% \quad 67.8 \%$ RNLDIERPTYTNLNR

$0.01 \% \quad 67.8 \%$ NLDIERPTYTNLNR

$99.0 \% \quad 46.9$

$99.3 \% \quad 19.4$

$99.7 \% \quad 54.5$

$\begin{array}{lllll}0.01 \% & 67.8 \% & \text { LIGQIVSSITASLR } & 99.7 \% & 78.1 \\ 0.01 \% & 67.8 \% & \text { FDGALNVDLTEFQTNLVPYPR } & 99.7 \% & 65.8\end{array}$

$0.01 \% \quad 67.8 \%$ IHFPLATYAPVISAEK $\quad 99.7 \% \quad 54.1$

$0.01 \% \quad 67.8 \%$ AYHEQLSVAEITNACFEPANQMVK $\quad 99.7 \% \quad 49.1$

$0.01 \% \quad 67.8 \%$ HGKYMACCLLYR

$99.7 \% \quad 45.4$

$99.7 \% \quad 44.1$

$0.01 \% \quad 67.8 \%$ YMACCLLYR

$0.01 \% \quad 67.8 \%$ YMACCLLYRGDVVPK

$0.01 \% \quad 67.8 \%$ GDVVPKDVNAAIATIK

$0.01 \% \quad 67.8 \%$ DVNAAIATIK

$0.01 \% \quad 67.8 \%$ DVNAAIATIKTK

$95.9 \% \quad 15.2$

$99.7 \% \quad 52.0$

$99.7 \% 59.0$

$99.7 \% \quad 52.5$

$99.7 \% 58.1$

$0.01 \% \quad 67.8 \%$ TIQFVDWCPTGFK

$\begin{array}{lllll}0.01 \% & 67.8 \% & \text { TIQFVDWCPTGFKVGINYQPPTVVPGGDLAK } & 99.7 \% & 44.0 \\ 0.01 \% & 67.8 \% & \text { VGINYQPPTVVPGGDLAK } & 99.7 \% & 57.9\end{array}$

$0.01 \% \quad 67.8 \%$ VGINYQPPTVVPGGDLAKVQR $\quad 99.7 \% \quad 36.1$

$0.01 \% \quad 67.8 \%$ AVCMLSNTTAIAEAWAR $99.7 \% \quad 56.3$

$0.01 \% \quad 67.8 \%$ LDHKFDLMYAK

$99.7 \% \quad 25.7$

$344 \quad 0.34 \% \quad 67.8 \%$ TIGGGDDSFNTFFSETGAGK $\quad 99.7 \% \quad 55.2$

$344 \quad 0.34 \% \quad 67.8 \%$ TIGGGDDSFNTFFSETGAGKHVPR $\quad 99.7 \% \quad 39.7$

$344 \quad 0.34 \% \quad 67.8 \%$ AVFVDLEPTVIDEVR $\quad 99.7 \% \quad 55.5$

$344 \quad 0.34 \% \quad 67.8 \%$ AVFVDLEPTVIDEVRTGTYR $99.7 \% \quad 46.8$

$344 \quad 0.34 \% \quad 67.8 \%$ QLFHPEQLITGKEDAANNYAR $99.7 \% \quad 55.4$

$344 \quad 0.34 \% \quad 67.8 \%$ EDAANNYAR

$344 \quad 0.34 \% \quad 67.8 \%$ GHYTIGKEIIDLVLDR

$99.7 \% 35.9$

$99.7 \% \quad 60.3$

$99.7 \% \quad 60.2$

$0.34 \% \quad 67.8 \%$ EIIDLVLDR

$344 \quad 0.34 \% \quad 67.8 \%$ EIIDLVLDRIR

$99.7 \% \quad 32.6$

$\begin{array}{lllllll}46 & 344 & 0.34 \% & 67.8 \% & \text { KLADQCTGLQGFLVFHSFGGGTGSGFTSLLMER } & 99.7 \% & 61.8\end{array}$

$46 \quad 344 \quad 0.34 \% \quad 67.8 \%$ LADOCTGLOGFLVFHSFGGGTGSGFTSLLMER $99.7 \% \quad 67.6$

$46 \quad 344 \quad 0.34 \% \quad 67.8 \%$ LSVDYGKK

$46 \quad 344 \quad 0.34 \% \quad 67.8 \%$ RNLDIERPTYTNLNR

$46 \quad 344 \quad 0.34 \% \quad 67.8 \%$ NLDIERPTYTNLNR

$99.0 \% \quad 46.9$

$99.3 \% \quad 19.4$

$99.7 \% \quad 54.5$

$99.7 \% \quad 63.3$

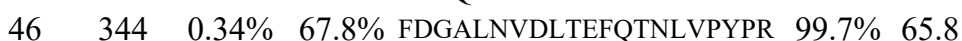

$\begin{array}{lllllll}46 & 344 & 0.34 \% & 67.8 \% & \text { IHFPLATYAPVISAEK } & 99.7 \% & 54.1\end{array}$

1457.87

2409.21

1756.96

2766.29

1015.58

1244.72

1023.45

1842.01

1085.62

1354.81

3534.71

3406.62

909.50

1874.98

1718.88

1487.88

2409.2

1756.96 
Tubulin alpha-1B chain GN=TUBA1B Tubulin alpha-1B chain $\mathrm{GN}=\mathrm{TUBA} 1 \mathrm{~B}$ Tubulin alpha- $1 \mathrm{~B}$ chain GN=TUBA1B Tubulin alpha-1B chain $\mathrm{GN}=\mathrm{TUBA} 1 \mathrm{~B}$ Tubulin alpha-1B chain GN=TUBA1B Tubulin alpha-1B chain GN=TUBA1B

Tubulin alpha- $1 \mathrm{~B}$ chain $\mathrm{GN}=\mathrm{TUB} A 1 \mathrm{~B}$ Tubulin alpha-1B chain GN=TUBA1B Tubulin alpha-1B chain $\mathrm{GN}=\mathrm{TUBA} 1 \mathrm{~B}$ Tubulin alpha- $1 \mathrm{~B}$ chain $\mathrm{GN}=\mathrm{TUBA} 1 \mathrm{~B}$ Tubulin alpha-1B chain $\mathrm{GN}=\mathrm{TUBA} 1 \mathrm{~B}$ Tubulin alpha-1B chain $\mathrm{GN}=\mathrm{TUBA} 1 \mathrm{~B}$ Tubulin alpha-1B chain GN=TUBA1B Tubulin alpha- $1 \mathrm{C}$ chain $\mathrm{GN}=\mathrm{TUBA} 1 \mathrm{C}$ Tubulin alpha- $1 \mathrm{C}$ chain $\mathrm{GN}=\mathrm{TUBA} 1 \mathrm{C}$ Tubulin alpha- $1 \mathrm{C}$ chain $\mathrm{GN}=\mathrm{TUBA} 1 \mathrm{C}$ Tubulin alpha- $1 \mathrm{C}$ chain $\mathrm{GN}=\mathrm{TUBA} 1 \mathrm{C}$ Tubulin alpha- $1 \mathrm{C}$ chain $\mathrm{GN}=\mathrm{TUBA} 1 \mathrm{C}$ Tubulin alpha- $1 \mathrm{C}$ chain $\mathrm{GN}=\mathrm{TUBA} 1 \mathrm{C}$ Tubulin alpha- $1 \mathrm{C}$ chain $\mathrm{GN}=\mathrm{TUBA} 1 \mathrm{C}$ Tubulin alpha- $1 \mathrm{C}$ chain $\mathrm{GN}=\mathrm{TUBA} 1 \mathrm{C}$ Tubulin alpha- $1 \mathrm{C}$ chain $\mathrm{GN}=\mathrm{TUBA} 1 \mathrm{C}$ Tubulin alpha- $1 \mathrm{C}$ chain $\mathrm{GN}=\mathrm{TUBA} 1 \mathrm{C}$ Tubulin alpha- $1 \mathrm{C}$ chain $\mathrm{GN}=\mathrm{TUBA} 1 \mathrm{C}$ Tubulin alpha- $1 \mathrm{C}$ chain $\mathrm{GN}=\mathrm{TUBA} 1 \mathrm{C}$ Tubulin alpha- $1 \mathrm{C}$ chain $\mathrm{GN}=\mathrm{TUBA} 1 \mathrm{C}$ Tubulin alpha- $1 \mathrm{C}$ chain $\mathrm{GN}=\mathrm{TUBA} 1 \mathrm{C}$ Tubulin alpha- $1 \mathrm{C}$ chain $\mathrm{GN}=\mathrm{TUBA} 1 \mathrm{C}$ Tubulin alpha- $1 \mathrm{C}$ chain $\mathrm{GN}=\mathrm{TUBA} 1 \mathrm{C}$ Tubulin alpha- $1 \mathrm{C}$ chain $\mathrm{GN}=\mathrm{TUBA} 1 \mathrm{C}$ Tubulin alpha- $1 \mathrm{C}$ chain $\mathrm{GN}=\mathrm{TUBA} 1 \mathrm{C}$ Tubulin alpha- $1 \mathrm{C}$ chain $\mathrm{GN}=\mathrm{TUBA} 1 \mathrm{C}$ Tubulin alpha- $1 \mathrm{C}$ chain $\mathrm{GN}=\mathrm{TUBA} 1 \mathrm{C}$ Tubulin alpha- $1 \mathrm{C}$ chain $\mathrm{GN}=\mathrm{TUBA} 1 \mathrm{C}$ Tubulin alpha- $1 \mathrm{C}$ chain $\mathrm{GN}=\mathrm{TUBA} 1 \mathrm{C}$ Tubulin alpha- $1 \mathrm{C}$ chain $\mathrm{GN}=\mathrm{TUBA} 1 \mathrm{C}$ Tubulin alpha- $1 \mathrm{C}$ chain $\mathrm{GN}=\mathrm{TUBA} 1 \mathrm{C}$ Tubulin alpha- $1 \mathrm{C}$ chain $\mathrm{GN}=\mathrm{TUBA} 1 \mathrm{C}$ Tubulin alpha- $1 \mathrm{C}$ chain GN=TUBA1C Tubulin alpha- $1 \mathrm{C}$ chain $\mathrm{GN}=$ TUBA1C Tubulin alpha- $1 \mathrm{C}$ chain $\mathrm{GN}=\mathrm{TUBA} 1 \mathrm{C}$ Tubulin alpha- $1 \mathrm{C}$ chain GN=TUBA1C Tubulin alpha- $1 \mathrm{C}$ chain $\mathrm{GN}=\mathrm{TUBA} 1 \mathrm{C}$ Tubulin beta chain GN=TUBB

Tubulin beta chain GN=TUBB

Tubulin beta chain GN=TUBE

Tubulin beta chain GN=TUBB
TBA1B_HUMAN $50.15 \quad 100.0 \% \quad 30$ TBA1B_HUMAN $50.15 \quad 100.0 \% \quad 30$ TBA1B_HUMAN $50.15 \quad 100.0 \% \quad 30$ TBA1B_HUMAN $50.15 \quad 100.0 \% \quad 30$ TBA1B_HUMAN $50.15 \quad 100.0 \% \quad 30$ TBA1B_HUMAN $50.15 \quad 100.0 \% \quad 30$ TBA1B HUMAN $50.15 \quad 100.0 \% \quad 30$ TBA1B_HUMAN $50.15 \quad 100.0 \% \quad 30$ TBA1B HUMAN $50.15 \quad 100.0 \% \quad 30$ TBA1B_HUMAN $50.15 \quad 100.0 \% \quad 30$ TBA1B_HUMAN $50.15 \quad 100.0 \% \quad 30$ TBA1B HUMAN $50.15 \quad 100.0 \% \quad 30$ TBA1B_HUMAN $50.15 \quad 100.0 \% \quad 30$ TBA1C HUMAN $49.90 \quad 100.0 \%$ TBAIC HUMAN $49.90 \quad 100.0 \%$ TBA1C_HUMAN $49.90 \quad 100.0 \% \quad 2$ TBAIC HUMAN $49.90 \quad 100.0 \%$ TBA1C HUMAN $49.90 \quad 100.0 \%$ TBA1C_HUMAN $49.90 \quad 100.0 \%$ TBA1C HUMAN $49.90 \quad 100.0 \%$ TBA1C_HUMAN $49.90 \quad 100.0 \% \quad 2$ TBA1C_HUMAN $49.90 \quad 100.0 \%$ TBAIC_HUMAN $49.90 \quad 100.0 \%$ TBA1C_HUMAN $49.90 \quad 100.0 \% \quad 2$ TBA1C HUMAN $49.90 \quad 100.0 \%$ TBA1C_HUMAN $49.90 \quad 100.0 \% \quad 2$ TBA1C_HUMAN $49.90 \quad 100.0 \%$ TBA1C HUMAN $49.90 \quad 100.0 \%$ TBA1C_HUMAN $49.90 \quad 100.0 \% \quad 2$ TBA1C HUMAN $49.90 \quad 100.0 \%$ TBAIC HUMAN $49.90 \quad 100.0 \%$ TBA1C_HUMAN $49.90 \quad 100.0 \% \quad 2$ TBA1C HUMAN $49.90 \quad 100.0 \%$ TBA1C_HUMAN $49.90 \quad 100.0 \% \quad 2$ TBA1C_HUMAN $49.90 \quad 100.0 \%$ TBAIC HUMAN $49.90 \quad 100.0 \%$ TBA1C_HUMAN $49.90 \quad 100.0 \% \quad 2$ TBA1C HUMAN $49.90 \quad 100.0 \%$ TBA1C_HUMAN $49.90 \quad 100.0 \% \quad 2$ TBA1C_HUMAN $49.90 \quad 100.0 \% \quad 2$ TBA1C HUMAN $49.90 \quad 100.0 \%$ TBA1C_HUMAN $49.90 \quad 100.0 \% \quad 2$ TBA1C_HUMAN $49.90 \quad 100.0 \% \quad 2$ TBB5 HUMAN $49.67 \quad 100.0 \% \quad 32$ TBB5_HUMAN $49.67 \quad 100.0 \% \quad 32$ TBB5 HUMAN $49.67 \quad 100.0 \% \quad 32$ TBB5_HUMAN $49.67 \quad 100.0 \% \quad 32$ $\begin{array}{llll}344 & 0.34 \% & 67.8 \% & \text { AYHEQLSVAEITNACFEPANQN } \\ 344 & 0.34 \% & 67.8 \% & \text { HGKYMACCLLYR }\end{array}$

$344 \quad 0.34 \% \quad 67.8 \%$ YMACCLLYR

$344 \quad 0.34 \% \quad 67.8 \%$ YMACCLLYRGDVVPK

$344 \quad 0.34 \% \quad 67.8 \%$ GDVVPKDVNAAIATIK

$344 \quad 0.34 \% \quad 67.8 \%$ DVNAAIATIK

$344 \quad 0.34 \% \quad 67.8 \%$ DVNAAIATIKTK

$344 \quad 0.34 \% \quad 67.8 \%$ SIQFVDWCPTGFK

$344 \quad 0.34 \% \quad 67.8 \%$ SIQFVDWCPTGFKVGINYQPPTVVPGGDLAK

$344 \quad 0.34 \% \quad 67.8 \%$ VGINYQPPTVVPGGDLAK $99.7 \% \quad 57.9$

$344 \quad 0.34 \% \quad 67.8 \%$ VGINYQPPTVVPGGDLAKVQR $\quad 99.7 \% \quad 36.1$

$344 \quad 0.34 \% \quad 67.8 \%$ AVCMLSNTTAIAEAWAR $99.7 \% \quad 56.3$

$344 \quad 0.34 \% \quad 67.8 \%$ LDHKFDLMYAK

$99.7 \% \quad 25.7$

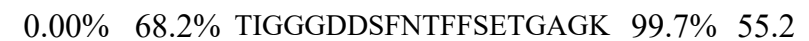

$0.00 \% \quad 68.2 \%$ TIGGGDDSFNTFFSETGAGKHVPR $\quad 99.7 \% \quad 39.7$

$0.00 \% \quad 68.2 \%$ AVFVDLEPTVIDEVR $\quad 99.7 \% \quad 55.5$

$0.00 \% \quad 68.2 \%$ AVFVDLEPTVIDEVRTGTYR $\quad 99.7 \% \quad 46.8$

$0.00 \% \quad 68.2 \%$ QLFHPEQLITGKEDAANNYAR $\quad 99.7 \% \quad 55.4$

$0.00 \% \quad 68.2 \%$ EDAANNYAR

$99.7 \% \quad 35.9$

$0.00 \% \quad 68.2 \%$ GHYTIGKEIIDLVLDR

$99.7 \% \quad 60.3$

$0.00 \% \quad 68.2 \%$ EIIDLVLDR

$0.00 \% \quad 68.2 \%$ EIIDLVLDRIR

$99.7 \% \quad 60.2$

$99.7 \% \quad 32.6$

$0.00 \% \quad 68.2 \%$ KLADQCTGLQGFLVFHSFGGGTGSGFTSLLMER $\quad 99.7 \% \quad 61.8$

$0.00 \% \quad 68.2 \%$ LAdQCTGLQGFLVFHSFGGGTGSGFTSLLMER $\quad 99.7 \% \quad 67.6$

$0.00 \% \quad 68.2 \%$ LSVDYGKK

$0.00 \% \quad 68.2 \%$ RNLDIERPTYTNLNR

$0.00 \% \quad 68.2 \%$ NLDIERPTYTNLNR

$0.00 \% \quad 68.2 \%$ LISQIVSSITASLR

$99.0 \% \quad 46.9$

$99.3 \% \quad 19.4$

$99.7 \% \quad 54.5$

$99.7 \% \quad 63.3$

$\begin{array}{lllll}0.00 \% & 68.2 \% & \text { FDGALNVDLTEFQTNLVPYPR } & 99.7 \% & 65.8\end{array}$

$0.00 \% \quad 68.2 \%$ IHFPLATYAPVISAEK $\quad 99.7 \% \quad 54.1$

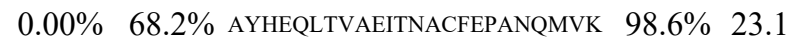

$0.00 \% \quad 68.2 \%$ HGKYMACCLLYR

$99.7 \% \quad 45.4$

$99.7 \% \quad 44.1$

$0.00 \% \quad 68.2 \%$ YMACCLLYR

$0.00 \% \quad 68.2 \%$ YMACCLLYRGDVVPK

$0.00 \% \quad 68.2 \%$ GDVVPKDVNAAIATIK

$0.00 \% \quad 68.2 \%$ DVNAAIATIK

$0.00 \% \quad 68.2 \%$ DVNAAIATIKTK

$0.00 \% \quad 68.2 \%$ TIQFVDWCPTGFK

$95.9 \% \quad 15.2$

$99.7 \% \quad 52.0$

$99.7 \% 59.0$

$99.7 \% \quad 52.5$

$99.7 \% \quad 58.1$

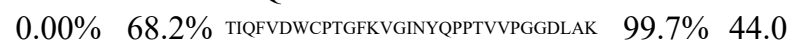

$0.00 \% \quad 68.2 \%$ VGINYQPPTVVPGGDLAK $99.7 \% \quad 57.9$

$0.00 \% \quad 68.2 \%$ VGINYQPPTVVPGGDLAKVQR $\quad 99.7 \% \quad 36.1$

$\begin{array}{lll}0.00 \% & 68.2 \% & \text { AVCMLSNTTAVAEAWAR } 99.7 \% \quad 47.5\end{array}$

$0.00 \% \quad 68.2 \%$ LDHKFDLMYAK

$99.7 \% \quad 25.7$

$491 \quad 0.49 \% \quad 71.2 \%$ MREIVHIQAGQCGNQIGAK $\quad 99.3 \% \quad 53.8$

$491 \quad 0.49 \% \quad 71.2 \%$ EIVHIQAGQCGNQIGAK $99.1 \% \quad 52.2$

$491 \quad 0.49 \% \quad 71.2 \%$ ISVYYNEATGGK

$99.7 \% \quad 52.5$

$491 \quad 0.49 \% \quad 71.2 \%$ ISVYYNEATGGKYVPR

$99.7 \% \quad 63.4$
Page 170 of Table S-1-4 
Tubulin beta chain GN=TUBB Tubulin beta chain $\mathrm{GN}=\mathrm{TUBB}$ Tubulin beta chain $\mathrm{GN}=\mathrm{TUBB}$ Tubulin beta chain $\mathrm{GN}=\mathrm{TUBB}$ Tubulin beta chain GN=TUBB Tubulin beta chain GN=TUBB

Tubulin beta chain $\mathrm{GN}=\mathrm{TUBB}$ Tubulin beta chain GN=TUBB Tubulin beta chain $\mathrm{GN}=\mathrm{TUBB}$

Tubulin beta chain GN=TUBB

Tubulin beta chain $\mathrm{GN}=\mathrm{TUBB}$

Tubulin beta chain $\mathrm{GN}=\mathrm{TUB}$

Tubulin beta chain GN=TUBB

Tubulin beta chain $\mathrm{GN}=\mathrm{TUBB}$

Tubulin beta chain GN=TUBB

Tubulin beta chain GN=TUBB

Tubulin beta chain $\mathrm{GN}=\mathrm{TUBB}$

Tubulin beta chain $\mathrm{GN}=\mathrm{TUBB}$

Tubulin beta chain GN=TUBB

Tubulin beta chain $\mathrm{GN}=\mathrm{TUBB}$

Tubulin beta chain GN=TUBB

Tubulin beta chain GN=TUBB

Tubulin beta chain $\mathrm{GN}=\mathrm{TUBB}$

Tubulin beta chain $\mathrm{GN}=\mathrm{TUBB}$

Tubulin beta chain $\mathrm{GN}=\mathrm{TUBB}$

Tubulin beta chain GN=TUBB

Tubulin beta chain $\mathrm{GN}=\mathrm{TUBB}$

Tubulin beta chain GN=TUBE

Tubulin beta-2A chain GN=TUBB2A

Tubulin beta- $2 A$ chain $\mathrm{GN}=\mathrm{TUBB} 2$

Tubulin beta- $2 A$ chain $\mathrm{GN}=\mathrm{TUBB} 2 \mathrm{~A}$

Tubulin beta-2A chain GN=TUBB2A

Tubulin beta-2A chain $\mathrm{GN}=\mathrm{TUBB} 2$

Tubulin beta-2A chain $\mathrm{GN}=\mathrm{TUBB} 2 \mathrm{~A}$

Tubulin beta-2A chain GN=TUBB2

Tubulin beta-2A chain $\mathrm{GN}=\mathrm{TUBB} 2 \mathrm{~A}$

Tubulin beta-2A chain $\mathrm{GN}=\mathrm{TUBB} 2 \mathrm{~A}$

Tubulin beta- $2 A$ chain $\mathrm{GN}=\mathrm{TUBB} 2 \mathrm{~A}$

Tubulin beta-2A chain $\mathrm{GN}=\mathrm{TUBB} 2 \mathrm{~A}$

Tubulin beta-2A chain GN=TUBB2A

Tubulin beta-2A chain $\mathrm{GN}=\mathrm{TUBB} 2$

Tubulin beta- $2 A$ chain $\mathrm{GN}=\mathrm{TUBB} 2 \mathrm{~A}$

Tubulin beta- $2 A$ chain $\mathrm{GN}=\mathrm{TUBB} 2 \mathrm{~A}$

Tubulin beta-2A chain GN=TUBB2A

Tubulin beta-2A chain GN=TUBB2A

Tubulin beta- $2 A$ chain $\mathrm{GN}=$ TUBB2A

Tubulin beta- $2 \mathrm{~A}$ chain GN=TUBB2A
TBB5 HUMAN $49.67 \quad 100.0 \% \quad 32$ TBB5 HUMAN $49.67 \quad 100.0 \% \quad 32$ TBB5_HUMAN $49.67 \quad 100.0 \% \quad 32$ TBB5 HUMAN $49.67 \quad 100.0 \% \quad 32$ TBB5_HUMAN $49.67 \quad 100.0 \% \quad 32$ TBB5_HUMAN $49.67 \quad 100.0 \% \quad 32$ TBB5 HUMAN $49.67 \quad 100.0 \% \quad 32$ TBB5_HUMAN $49.67 \quad 100.0 \% \quad 32$ TBB5 HUMAN $49.67 \quad 100.0 \% \quad 32$ TBB5_HUMAN $49.67 \quad 100.0 \% \quad 32$ TBB5_HUMAN $49.67 \quad 100.0 \% \quad 32$ TBB5 HUMAN $49.67 \quad 100.0 \% \quad 32$ TBB5_HUMAN $49.67 \quad 100.0 \% \quad 32$ TBB5 HUMAN $49.67 \quad 100.0 \% \quad 32$ TBB5 HUMAN $49.67 \quad 100.0 \% \quad 32$ TBB5_HUMAN $49.67 \quad 100.0 \% \quad 32$ TBB5 HUMAN $49.67 \quad 100.0 \% \quad 32$ TBB5_HUMAN $49.67 \quad 100.0 \% \quad 32$ TBB5_HUMAN $49.67 \quad 100.0 \% \quad 32$ TBB5 HUMAN $49.67 \quad 100.0 \% \quad 32$ TBB5_HUMAN $49.67 \quad 100.0 \% \quad 32$ TBB5 HUMAN $49.67 \quad 100.0 \% \quad 32$ TBB5_HUMAN $49.67 \quad 100.0 \% \quad 32$ TBB5 HUMAN $49.67 \quad 100.0 \% \quad 32$ TBB5 HUMAN $49.67 \quad 100.0 \% \quad 32$ TBB5_HUMAN $49.67 \quad 100.0 \% \quad 32$ TBB5_HUMAN $49.67 \quad 100.0 \% \quad 32$ TBB5 HUMAN $49.67 \quad 100.0 \% \quad 32$ TBB2A_HUMAN $49.91 \quad 100.0 \% \quad 6$ TBB2A HUMAN $49.91 \quad 100.0 \% \quad 6$ TBB2A HUMAN $49.91 \quad 100.0 \%$ TBB2A_HUMAN $49.91 \quad 100.0 \% \quad 6$ TBB2A HUMAN $49.91 \quad 100.0 \% \quad 6$ TBB2A_HUMAN $49.91 \quad 100.0 \% \quad 6$ TBB2A_HUMAN $49.91 \quad 100.0 \% \quad 6$ TBB2A HUMAN $49.91 \quad 100.0 \%$ TBB2A_HUMAN $49.91 \quad 100.0 \% \quad 6$ TBB2A HUMAN $49.91 \quad 100.0 \%-6$ TBB2A_HUMAN $49.91 \quad 100.0 \%$ TBB2A_HUMAN $49.91 \quad 100.0 \%$ TBB2A HUMAN $49.91 \quad 100.0 \%$ TBB2A_HUMAN $49.91 \quad 100.0 \%$ TBB2A_HUMAN $49.91 \quad 100.0 \%$ TBB2A HUMAN $49.91 \quad 100.0 \%$ TBB2A_HUMAN $49.91 \quad 100.0 \%$ TBB2A HUMAN $49.91 \quad 100.0 \%$ TBB2A_HUMAN $49.91 \quad 100.0 \%$
$491 \quad 0.49 \% \quad 71.2 \%$ AILVDLEPGTMDSVR

$99.7 \% \quad 61.2$ $491 \quad 0.49 \% \quad 71.2 \%$ SGPFGQIFRPDNFVFGQSGAGNNWAK $99.7 \% \quad 43.7$

$491 \quad 0.49 \% \quad 71.2 \%$ GHYTEGAELVDSVLDVVR $99.7 \% \quad 33.7$ $491 \quad 0.49 \% \quad 71.2 \%$ GHYTEGAELVDSVLDVVRK $99.7 \% \quad 60.1$

$491 \quad 0.49 \% \quad 71.2 \%$ IREEYPDR

$99.3 \% 57.8$

$99.7 \% \quad 61.5$

$491 \quad 0.49 \% \quad 71.2 \%$ IMNTFSVVPSPK

$99.7 \% \quad 56.1$

$99.7 \% \quad 50.0$

$99.7 \% \quad 37.9$

$99.7 \% \quad 56.6$

$99.7 \% \quad 62.1$

$99.7 \% \quad 50.7$

$99.7 \% \quad 56.4$

$491 \quad 0.49 \% \quad 71.2 \%$ LHFFMPGFAPLTSR

$99.6 \% \quad 26.5$

$491-0.49 \% \quad 71.2 \%$ ALTVRETQ

$491 \quad 0.49 \% \quad 71.2 \%$ NMMAACDPR

$491 \quad 0.49 \% \quad 71.2 \%$ HGRYLTVAAVFR

$99.7 \% \quad 39.4$

$99.7 \% \quad 54.2$

$99.7 \% \quad 60.2$

$99.7 \% \quad 40.0$

$491 \quad 0.49 \% \quad 71.2 \%$ YLTVAAVFRGR

$99.7 \% \quad 45.4$

$491 \quad 0.49 \% \quad 71.2 \%$ MSMKEVDEQMLNVQNK

$491 \quad 0.49 \% \quad 71.2 \%$ EVDEQMLNVQNK

$491 \quad 0.49 \% \quad 71.2 \%$ NSSYFVEWIPNNVK

$491 \quad 0.49 \% \quad 71.2 \%$ TAVCDIPPR

$491 \quad 0.49 \% \quad 71.2 \%$ TAVCDIPPRGLK

$99.7 \% 50.0$

$99.7 \% \quad 50.8$

$99.7 \% \quad 29.5$

$99.7 \% \quad 42.7$

$491 \quad 0.49 \% \quad 71.2 \%$ MAVTFIGNSTAIQELFKR

$491 \quad 0.49 \% \quad 71.2 \%$ ISEQFTAMFR

$491 \quad 0.49 \% \quad 71.2 \%$ ISEQFTAMFRR

$99.7 \% 64.8$

$99.7 \% \quad 62.0$

$99.7 \% \quad 34.2$

25

25

$\begin{array}{lllll}0.02 \% & 63.8 \% & \text { MREIVHIQAGQCGNQIGAK } & 99.3 \% & 53.8\end{array}$

$0.02 \% \quad 63.8 \%$ EIVHIQAGQCGNQIGAK $\quad 99.1 \% 52.2$

$\begin{array}{lllll}0.02 \% & 63.8 \% & \text { INVYYNEAAGNKYVPR } & 99.7 \% & 63.0\end{array}$

$0.02 \% \quad 63.8 \%$ AILVDLEPGTMDSVR $\quad 99.7 \% \quad 61.2$

$0.02 \% \quad 63.8 \%$ SGPFGQIFRPDNFVFGQSGAGNNWAK $\quad 99.7 \% \quad 43.7$

$0.02 \% \quad 63.8 \%$ GHYTEGAELVDSVLDVVR $99.7 \% \quad 33.7$

$0.02 \% \quad 63.8 \%$ GHYTEGAELVDSVLDVVRK $\quad 99.7 \% \quad 60.1$

$0.02 \% \quad 63.8 \%$ IREEYPDR

$99.0 \% 38.1$

$0.02 \% \quad 63.8 \%$ IMNTFSVMPSPK

$99.7 \% \quad 32.9$

.02\% $63.8 \%$ LTTPTYGDLNHLVSATMSGVTTCLR $99.7 \% \quad 56.1$

$99.7 \% 50.0$

$99.7 \% \quad 37.9$

$99.7 \% \quad 56.6$

$99.7 \% \quad 62.1$

$99.7 \% \quad 50.7$

$99.7 \% 39.0$

$99.7 \% \quad 39.4$

$99.7 \% \quad 51.5$

$99.7 \% \quad 56.8$ $\begin{array}{lll}0.02 \% & 63.8 \% & \text { NMMAACDPR }\end{array}$

$0.02 \% \quad 63.8 \%$ YLTVAAIFR
2798.34

1958.98

2087.08

3327.53

1077.53

1319.70

2724.33

1130.60

1258.69

1271.73

1143.63

1636.83

1659.90

2738.29

1065.43

1389.77

1039.59

1252.72

1971.88

1462.68

1696.83

1028.52

1326.72

1869.98

2042.07

1229.60

1401.69

2110.06

1822.92

1870.94

1631.83

2798.34

1958.98

2087.08

1077.53

1383.66

2724.33

1130.60

1258.69

1271.73

1143.63

1636.83

1723.86

1065.43

1403.79

1053.61

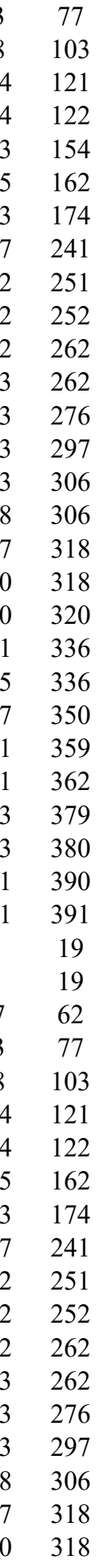

Page 171 of Table S-1-4 
Tubulin beta-2A chain GN=TUBB2A Tubulin beta-2A chain $\mathrm{GN}=\mathrm{TUBB} 2 \mathrm{~A}$ Tubulin beta-2A chain $\mathrm{GN}=\mathrm{TUBB} 2 \mathrm{~A}$ Tubulin beta- $2 \mathrm{~A}$ chain $\mathrm{GN}=\mathrm{TUBB} 2$ Tubulin beta-2A chain GN=TUBB2A Tubulin beta-2A chain GN=TUBB2A

Tubulin beta-2A chain $\mathrm{GN}=\mathrm{TUBB} 2$ Tubulin beta- $2 A$ chain $\mathrm{GN}=\mathrm{TUBB} 2 \mathrm{~A}$ Tubulin beta- $2 A$ chain $\mathrm{GN}=\mathrm{TUBB} 2$ Tubulin beta- $2 A$ chain $\mathrm{GN}=\mathrm{TUBB} 2 \mathrm{~A}$ Tubulin beta-2B chain GN=TUBB2B Tubulin beta-2B chain $\mathrm{GN}=\mathrm{TUBB} 2 \mathrm{E}$ Tubulin beta- $2 \mathrm{~B}$ chain $\mathrm{GN}=\mathrm{TUBB} 2 \mathrm{~B}$ Tubulin beta- $2 B$ chain $\mathrm{GN}=\mathrm{TUBB} 2 \mathrm{~B}$

Tubulin beta-2B chain GN=TUBB2

Tubulin beta-2B chain GN=TUBB2B Tubulin beta- $2 \mathrm{~B}$ chain $\mathrm{GN}=\mathrm{TUBB} 2 \mathrm{~B}$ Tubulin beta- $2 \mathrm{~B}$ chain $\mathrm{GN}=\mathrm{TUBB} 2 \mathrm{~B}$ Tubulin beta-2B chain GN=TUBB2B

Tubulin beta-2B chain $\mathrm{GN}=\mathrm{TUBB} 2 \mathrm{~B}$ Tubulin beta-2B chain GN=TUBB2E Tubulin beta- $2 \mathrm{~B}$ chain $\mathrm{GN}=\mathrm{TUBB} 2 \mathrm{~B}$ Tubulin beta- $2 B$ chain $\mathrm{GN}=\mathrm{TUBB} 2 \mathrm{~B}$ Tubulin beta- $2 \mathrm{~B}$ chain $\mathrm{GN}=\mathrm{TUBB} 2 \mathrm{~B}$ Tubulin beta-2B chain GN=TUBB2 Tubulin beta- $2 B$ chain $G N=T U B B 2 B$ Tubulin beta-2B chain GN=TUBB2B Tubulin beta-2B chain $\mathrm{GN}=\mathrm{TUBB} 2 \mathrm{~F}$ Tubulin beta-2B chain GN=TUBB2B Tubulin beta-2B chain $\mathrm{GN}=\mathrm{TUBB} 2 \mathrm{~B}$ Tubulin beta-2B chain $\mathrm{GN}=\mathrm{TUBB} 2 \mathrm{~B}$ Tubulin beta-2B chain GN=TUBB2B Tubulin beta- $2 \mathrm{~B}$ chain $\mathrm{GN}=\mathrm{TUBB} 2 \mathrm{P}$ Tubulin beta- $2 \mathrm{~B}$ chain $\mathrm{GN}=\mathrm{TUBB} 2 \mathrm{~B}$ Tubulin beta-2B chain $\mathrm{GN}=\mathrm{TUBB} 2 \mathrm{~B}$ Tubulin beta-2B chain GN=TUBB2B Tubulin beta-2B chain GN=TUBB2E Tubulin beta-2B chain $\mathrm{GN}=\mathrm{TUBB} 2 \mathrm{~B}$ Tubulin beta- $2 \mathrm{~B}$ chain $\mathrm{GN}=\mathrm{TUBB} 2 \mathrm{~B}$ Tubulin beta- $2 \mathrm{~B}$ chain $\mathrm{GN}=\mathrm{TUBB} 2 \mathrm{~B}$

Tubulin beta- 3 chain $\mathrm{GN}=\mathrm{TUBB} 3$

Tubulin beta- 3 chain GN=TUBB3

Tubulin beta- 3 chain GN=TUBB3

Tubulin beta- 3 chain $\mathrm{GN}=\mathrm{TUBB} 3$

Tubulin beta- 3 chain GN=TUBB3

Tubulin beta- 3 chain GN=TUBB3

Tubulin beta- 3 chain $\mathrm{GN}=\mathrm{TUBB} 3$
TBB2A_HUMAN $49.91 \quad 100.0 \% \quad 6 \quad 60 \quad 25 \quad 0.02 \% \quad 63.8 \%$ YLTVAAIFRGR TBB2A_HUMAN $49.91-100.0 \%$ BBB2A_HUMAN $49.91 \quad 100.0 \%$ TBB2A HUMAN $49.91 \quad 100.0 \%$ TBB2A_HUMAN $49.91 \quad 100.0 \%$ TBB2A_HUMAN $49.91 \quad 100.0 \%$ TBB2A_HUMAN $49.91 \quad 100.0 \%$ TBB2A_HUMAN $49.91 \quad 100.0 \%$ TBB2A HUMAN $49.91 \quad 100.0 \%$ TBB2A HUMAN $49.91 \quad 100.0 \%$ TBB2B_HUMAN $49.95 \quad 100.0 \%$ TBB2B HUMAN $49.95 \quad 100.0 \%$ TBB2B_HUMAN $49.95 \quad 100.0 \%$ TBB2B HUMAN $49.95 \quad 100.0 \%$ TBB2B HUMAN $49.95 \quad 100.0 \%$ TBB2B_HUMAN $49.95 \quad 100.0 \%$ TBB2B HUMAN $49.95 \quad 100.0 \%$ TBB2B_HUMAN $49.95 \quad 100.0 \%$ TBB2B_HUMAN $49.95 \quad 100.0 \%$ BBB2B HUMAN $49.95 \quad 100.0 \%$ TBB2B_HUMAN $49.95 \quad 100.0 \%$ TBB2B HUMAN $49.95 \quad 100.0 \%$ TBB2B HUMAN $49.95 \quad 100.0 \%$ TBB2B_HUMAN $49.95 \quad 100.0 \%$ TBB2B HUMAN $49.95 \quad 100.0 \%$ TBB2B HUMAN $49.95 \quad 100.0 \%$ TBB2B_HUMAN $49.95 \quad 100.0 \%$ TBB2B_HUMAN $49.95 \quad 100.0 \%$ TBB2B_HUMAN $49.95 \quad 100.0 \%$ TBB2B HUMAN $49.95 \quad 100.0 \%$ TBB2B_HUMAN $49.95 \quad 100.0 \%$ TBB2B_HUMAN $49.95 \quad 100.0 \%$ TBB2B_HUMAN $49.95 \quad 100.0 \%$ TBB2B_HUMAN $49.95 \quad 100.0 \%$ TBB2B_HUMAN $49.95 \quad 100.0 \%$ TBB2B HUMAN $49.95 \quad 100.0 \%$ TBB2B_HUMAN $49.95 \quad 100.0 \%$ TBB2B_HUMAN $49.95 \quad 100.0 \%$ TBB2B_HUMAN $49.95 \quad 100.0 \%$ TBB2B_HUMAN $49.95 \quad 100.0 \%$ TBB3_HUMAN $50.43 \quad 100.0 \%$ TBB3_HUMAN $50.43 \quad 100.0 \%$ TBB3 HUMAN $50.43 \quad 100.0 \%$ TBB3 HUMAN $50.43 \quad 100.0 \%$ TBB3_HUMAN $50.43 \quad 100.0 \%$ TBB3 HUMAN $50.43 \quad 100.0 \%$ TBB3_HUMAN $50.43 \quad 100.0 \%$

$0.00 \% \quad 63.8 \%$ KLAVNMVPFPR
$0.02 \% \quad 63.8 \%$ MSMKEVDEQMLNVQNK

$0.02 \% \quad 63.8 \%$ EVDEQMLNVQNK

$0.02 \% \quad 63.8 \%$ NSSYFVEWIPNNVK

$0.02 \% \quad 63.8 \%$ TAVCDIPPR

$0.02 \% \quad 63.8 \%$ TAVCDIPPRGLK

$99.7 \% \quad 56.1$

$99.7 \% \quad 50.0$

$99.7 \% \quad 50.8$

$\begin{array}{lll}99.7 \% & 29.5\end{array}$

$0.02 \% \quad 63.8 \%$ MSATFIGNSTAIQELFK

$99.3 \% \quad 60.3$

$0.02 \% \quad 63.8 \%$ MSATFIGNSTAIQELFKR

$0.02 \% \quad 63.8 \%$ ISEQFTAMFR

$0.02 \% \quad 63.8 \%$ ISEQFTAMFRR

$99.7 \% 62.0$

$0.00 \% \quad 63.8 \%$ MREIVHIQAGQCGNQIGAK $99.3 \% 53.8$

$0.00 \% \quad 63.8 \%$ EIVHIQAGQCGNQIGAK $\quad 99.1 \% \quad 52.2$

$0.00 \% \quad 63.8 \%$ INVYYNEATGNK

$99.7 \% \quad 48.7$

$0.00 \% \quad 63.8 \%$ INVYYNEATGNKYVPR

$99.7 \% \quad 68.6$

$0.00 \% \quad 63.8 \%$ AILVDLEPGTMDSVR $\quad 99.7 \% \quad 61.2$

$\begin{array}{lllll}0.00 \% & 63.8 \% & \text { SGPFGQIFRPDNFVFGQSGAGNNWAK } & 99.7 \% & 43.7\end{array}$

$0.00 \% \quad 63.8 \%$ GHYTEGAELVDSVLDVVR $\quad 99.7 \% \quad 33.7$

$0.00 \% \quad 63.8 \%$ GHYTEGAELVDSVLDVVRK $99.7 \% \quad 60.1$

$0.00 \% \quad 63.8 \%$ IREEYPDR

$\begin{array}{llll}9.7 \% & 60.1 & 25.0 & 58.9\end{array}$

$0.00 \% \quad 63.8 \%$ IMNTFSVMPSPK

$0.00 \% \quad 63.8 \%$ LTTPTYGDLNHLVSATMSGVTTCLR

$0.00 \% \quad 63.8 \%$ FPGQLNADLR

$0.00 \% \quad 63.8 \%$ FPGQLNADLRK

$0.00 \% \quad 63.8 \%$ LAVNMVPFPR

$0.00 \% \quad 63.8 \%$ LHFFMPGFAPLTSR

$0.00 \% \quad 63.8 \%$ ALTVPELTQQMFDSK

$0.00 \% \quad 63.8 \%$ NMMAACDPR

$0.00 \% \quad 63.8 \%$ HGRYLTVAAIFR

$0.00 \% \quad 63.8 \%$ YLTVAAIFR

$0.00 \% \quad 63.8 \%$ YLTVAAIFRGR

$99.7 \% \quad 56.1$

$99.7 \% \quad 50.0$

$99.7 \% \quad 37.9$

$99.7 \% \quad 56.6$

$99.7 \% \quad 62.1$

$99.7 \% \quad 50.7$

$99.7 \% \quad 39.0$

$99.7 \% \quad 39.4$

$99.7 \% \quad 51.5$

$99.7 \% \quad 56.8$

$99.5 \% \quad 25.2$

$0.00 \% \quad 63.8 \%$ MSMKEVDEQMLNVQNK $99.7 \% \quad 45.4$

$0.00 \% \quad 63.8 \%$ EVDEQMLNVQNK

$0.00 \% \quad 63.8 \%$ NSSYFVEWIPNNVK

$0.00 \% \quad 63.8 \%$ TAVCDIPPR

$0.00 \% \quad 63.8 \%$ TAVCDIPPRGLK

$99.7 \% 56$.

$99.7 \% \quad 50.0$

$99.7 \% \quad 50.8$

$99.7 \% \quad 29.5$

$0.00 \% \quad 63.8 \%$ MSATFIGNSTAIQELFK $\quad 99.3 \% \quad 60.3$

$0.00 \% \quad 63.8 \%$ MSATFIGNSTAIQELFKR $\quad 99.4 \% \quad 41.7$

$0.00 \% \quad 63.8 \%$ ISEQFTAMFR

$99.7 \% \quad 62.0$

$99.7 \% \quad 34.2$

$0.00 \% \quad 34.0 \%$ MREIVHIQAGQCGNQIGAK $99.3 \% \quad 53.8$

$\begin{array}{lllll}0.00 \% & 34.0 \% & \text { EIVHIQAGQCGNQIGAK } & 99.1 \% & 52.2\end{array}$

$0.00 \% \quad 34.0 \%$ AILVDLEPGTMDSVR

$99.7 \% \quad 61.2$

$0.00 \% \quad 34.0 \%$ GHYTEGAELVDSVLDVVR $\quad 99.7 \% \quad 33.7$

$0.00 \% \quad 34.0 \%$ GHYTEGAELVDSVLDVVRK $\quad 99.7 \% \quad 60.1$

$0.00 \% \quad 34.0 \%$ IMNTFSVVPSPK

$99.7 \% \quad 61.5$

$0.00 \% \quad 34.0 \%$ FPGQLNADLR

$99.7 \% \quad 50.0$

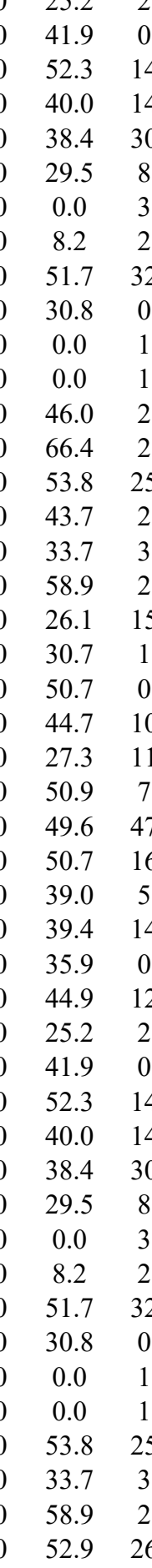

1401.69

2110.06

1822.92

1385.67

1900.96

1631.83

2798.34

1958.98

2087.08

1077.53

1383.66

2724.33

1130.60

1258.69

1271.73

1143.63

1636.83

1723.86

1065.43

1403.79

1053.61

1266.73

1971.88

1462.68

1696.83

1028.52

1326.72

1857.94

2014.04

1229.60

1401.69

2110.06

1822.92

1631.83

1958.98

2087.08

1319.70

1130.60 
Tubulin beta- 3 chain GN=TUBB3 Tubulin beta- 3 chain $\mathrm{GN}=\mathrm{TUBB} 3$ Tubulin beta- 3 chain GN=TUBB3 Tubulin beta- 3 chain GN=TUBB3 Tubulin beta- 3 chain GN=TUBB3 Tubulin beta- 3 chain GN=TUBB3

Tubulin beta- 3 chain $\mathrm{GN}=\mathrm{TUBB} 3$ Tubulin beta- 3 chain GN=TUBB3 Tubulin beta- 3 chain GN=TUBB3 Tubulin beta- 3 chain GN=TUBB3

Tubulin beta- $4 \mathrm{~A}$ chain $\mathrm{GN}=\mathrm{TUBB} 4 \mathrm{~A}$

Tubulin beta-4A chain GN=TUBB4A

Tubulin beta- $4 \mathrm{~A}$ chain $\mathrm{GN}=\mathrm{TUBB} 4 \mathrm{~A}$

Tubulin beta- $4 \mathrm{~A}$ chain $\mathrm{GN}=\mathrm{TUBB} 4 \mathrm{~A}$

Tubulin beta-4A chain $\mathrm{GN}=\mathrm{TUBB} 4 \mathrm{~A}$

Tubulin beta-4A chain $\mathrm{GN}=\mathrm{TUBB} 4 \mathrm{~A}$

Tubulin beta-4A chain $\mathrm{GN}=\mathrm{TUBB} 4 \mathrm{~A}$

Tubulin beta- $4 A$ chain $\mathrm{GN}=$ TUBB4A

Tubulin beta-4A chain GN=TUBB4A

Tubulin beta-4A chain $\mathrm{GN}=\mathrm{TUBB} 4 \mathrm{~A}$

Tubulin beta- $4 \mathrm{~A}$ chain $\mathrm{GN}=\mathrm{TUBB} 4 \mathrm{~A}$

Tubulin beta-4A chain $\mathrm{GN}=\mathrm{TUBB} 4 \mathrm{~A}$

Tubulin beta- $4 \mathrm{~A}$ chain $\mathrm{GN}=\mathrm{TUBB} 4 \mathrm{~A}$

Tubulin beta- $4 \mathrm{~A}$ chain $\mathrm{GN}=\mathrm{TUBB} 4 \mathrm{~A}$

Tubulin beta-4A chain $\mathrm{GN}=\mathrm{TUBB} 4$

Tubulin beta-4A chain GN=TUBB4A

Tubulin beta-4A chain $\mathrm{GN}=\mathrm{TUBB} 4 \mathrm{~A}$

Tubulin beta-4A chain $\mathrm{GN}=\mathrm{TUBB} 4$

Tubulin beta-4A chain GN=TUBB4A

Tubulin beta- 4 A chain $\mathrm{GN}=\mathrm{TUBB} 4$

Tubulin beta-4A chain GN=TUBB4A

Tubulin beta-4A chain GN=TUBB4A

Tubulin beta-4A chain $\mathrm{GN}=\mathrm{TUBB} 4 \mathrm{~A}$

Tubulin beta-4A chain $\mathrm{GN}=\mathrm{TUBB} 4 \mathrm{~A}$

Tubulin beta-4A chain $\mathrm{GN}=\mathrm{TUBB} 4 \mathrm{~A}$

Tubulin beta-4B chain $\mathrm{GN}=\mathrm{TUBB} 4 \mathrm{~B}$

Tubulin beta-4B chain GN=TUBB4H

Tubulin beta-4B chain $\mathrm{GN}=$ TUBB4B

Tubulin beta- $4 \mathrm{~B}$ chain $\mathrm{GN}=\mathrm{TUBB} 4 \mathrm{~B}$

Tubulin beta-4B chain GN=TUBB4B

Tubulin beta- $4 \mathrm{~B}$ chain $\mathrm{GN}=\mathrm{TUBB} 4 \mathrm{~B}$

Tubulin beta- $4 \mathrm{~B}$ chain $\mathrm{GN}=\mathrm{TUBB} 4 \mathrm{~B}$

Tubulin beta- $4 \mathrm{~B}$ chain $\mathrm{GN}=\mathrm{TUBB} 4 \mathrm{~B}$

Tubulin beta-4B chain GN=TUBB4B

Tubulin beta- $4 \mathrm{~B}$ chain $\mathrm{GN}=\mathrm{TUBB} 4 \mathrm{~B}$

Tubulin beta-4B chain $\mathrm{GN}=\mathrm{TUBB} 4 \mathrm{~B}$

Tubulin beta- $4 \mathrm{~B}$ chain $\mathrm{GN}=\mathrm{TUBB} 4 \mathrm{~B}$ $\begin{array}{llll} & \end{array}$ \begin{tabular}{lllllll} 
BBB3 HUMAN 50.43 & $100.0 \%$ & 2 & 2 & 4 & $0.00 \%$ & $34.0 \%$ \\
\hline
\end{tabular}

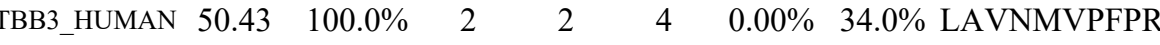
TBB3 HUMAN $50.43 \quad 100.0 \%$ TBB3_HUMAN $50.43 \quad 100.0 \%$ TBB3_HUMAN $50.43 \quad 100.0 \%$ TBB3 HUMAN $50.43 \quad 100.0 \%$ TBB3_HUMAN $50.43 \quad 100.0 \%$ TBB3 HUMAN $50.43 \quad 100.0 \%$ TBB3 HUMAN $50.43 \quad 100.0 \%$ TBB4A_HUMAN $49.59 \quad 100.0 \%$ TBB4A HUMAN $49.59 \quad 100.0 \%$ TBB4A_HUMAN $49.59 \quad 100.0 \%$ TBB4A_HUMAN $49.59 \quad 100.0 \%$ TBB4A HUMAN $49.59 \quad 100.0 \%$ TBB4A_HUMAN $49.59 \quad 100.0 \%$ TBB4A HUMAN $49.59 \quad 100.0 \%$ TBB4A HUMAN $49.59 \quad 100.0 \%$ TBB4A_HUMAN $49.59 \quad 100.0 \%$ TBB4A HUMAN $49.59 \quad 100.0 \%$ TBB4A_HUMAN $49.59 \quad 100.0 \%$ TBB4A_HUMAN $49.59 \quad 100.0 \%$ TBB4A HUMAN $49.59 \quad 100.0 \%$ TBB4A_HUMAN $49.59 \quad 100.0 \%$ TBB4A HUMAN $49.59 \quad 100.0 \%$ TBB4A_HUMAN $49.59 \quad 100.0 \%$ TBB4A_HUMAN $49.59 \quad 100.0 \%$ TBB4A HUMAN $49.59 \quad 100.0 \%$ TBB4A_HUMAN $49.59 \quad 100.0 \%$ TBB4A_HUMAN $49.59 \quad 100.0 \%$ TBB4A HUMAN $49.59 \quad 100.0 \%$ TBB4A_HUMAN $49.59 \quad 100.0 \%$ TBB4A HUMAN $49.59 \quad 100.0 \%$ TBB4A_HUMAN $49.59 \quad 100.0 \%$ TBB4A_HUMAN $49.59 \quad 100.0 \%$ TBB4B HUMAN $49.83 \quad 100.0 \%$ TBB4B_HUMAN $49.83 \quad 100.0 \%$ TBB4B HUMAN $49.83 \quad 100.0 \%$ TBB4B_HUMAN $49.83 \quad 100.0 \%$ TBB4B_HUMAN $49.83 \quad 100.0 \%$ TBB4B HUMAN $49.83 \quad 100.0 \%$ TBB4B_HUMAN $49.83 \quad 100.0 \%$ TBB4B HUMAN $49.83 \quad 100.0 \%$ TBB4B HUMAN $49.83 \quad 100.0 \%$ TBB4B_HUMAN $49.83 \quad 100.0 \%$ TBB4B HUMAN $49.83 \quad 100.0 \%$ TBB4B_HUMAN $49.83 \quad 100.0 \%$
$99.7 \% \quad 37.9$ $\begin{array}{lllll}99.7 \% & 56.6 & 25.0 & 50.9 & 7\end{array}$ $\begin{array}{lllll}99.7 \% & 62.1 & 25.0 & 49.6 & 47\end{array}$ $\begin{array}{lllll}99.7 \% & 38.1 & 25.0 & 37.3 & 19\end{array}$ $0.00 \% \quad 34.0 \%$ ALTVPELTQQMFDAK $0.00 \% \quad 34.0 \%$ NMMAACDPR $0.00 \% \quad 34.0 \%$ NSSYFVEWIPNNVK $99.7 \% \quad 39.4$ $99.7 \% \quad 50.0$ $99.5 \% 54.8$

$0.00 \% \quad 34.0 \%$ MSSTFIGNSTAIQELFK $\begin{array}{lll}98.8 \% & 32.9\end{array}$ $99.7 \% \quad 62.0$ $\begin{array}{ll}99.7 \% & 34.2 \\ 99.3 \% & 53.8\end{array}$ $0.00 \% \quad 34.0 \%$ ISEQFTAMFR $0.00 \% \quad 34.0 \%$ ISEQFTAMFRR $\begin{array}{llllll}0.01 \% & 61.9 \% & \text { MREIVHLQAGQCGNQIGAK } & 99.3 \% & 53.8 \\ 0.01 \% & 61.9 \% & \text { EIVHLQAGQCGNQIGAK } & 99.1 \% & 52.2\end{array}$ $\begin{array}{lllll}0.01 \% & 61.9 \% & \text { AVLVDLEPGTMDSVR } \quad 99.7 \% & 57.2\end{array}$ $0.01 \% \quad 61.9 \%$ SGPFGQIFRPDNFVFGQSGAGNNWAK $\quad 99.7 \% \quad 43.7$ $0.01 \% \quad 61.9 \%$ GHYTEGAELVDAVLDVVR $99.4 \% 23.6$ $0.01 \% \quad 61.9 \%$ EAESCDCLQGFQLTHSLGGGTGSGMGTLLISK $99.3 \% \quad 57.8$ $0.01 \% \quad 61.9 \%$ IMNTFSVVPSPK $99.7 \% \quad 61.5$

$0.01 \% \quad 61.9 \%$ LTTPTYGDLNHLVSATMSGVTTCLR $0.01 \% \quad 61.9 \%$ FPGQLNADLR

$0.01 \% \quad 61.9 \%$ FPGQLNADLRK

$0.01 \% \quad 61.9 \%$ KLAVNMVPFPR

$0.01 \% \quad 61.9 \%$ LAVNMVPFPR

$0.01 \% \quad 61.9 \%$ LHFFMPGFAPLTSR

$0.01 \% \quad 61.9 \%$ ALTVPELTQQMFDAK

$0.01 \% \quad 61.9 \%$ NMMAACDPR

$0.01 \% \quad 61.9 \%$ HGRYLTVAAVFR

$0.01 \% \quad 61.9 \%$ YLTVAAVFR

$0.01 \% \quad 61.9 \%$ YLTVAAVFRGR

$0.01 \% \quad 61.9 \%$ NSSYFVEWIPNNVK

$0.01 \% \quad 61.9 \%$ TAVCDIPPR

$0.01 \% \quad 61.9 \%$ TAVCDIPPRGLK

$99.7 \% \quad 56.1$

$99.7 \% \quad 50.0$

$99.7 \% \quad 37.9$

$99.7 \% \quad 56.6$

$99.7 \% \quad 62.1$

$99.7 \% \quad 50.7$

$99.7 \% \quad 38.1$

$99.7 \% \quad 39.4$

$99.7 \% \quad 54.2$

$99.7 \% \quad 60.2$

$99.7 \% \quad 40.0$

$99.7 \% \quad 50.0$

$99.7 \% \quad 50.8$

$99.7 \% \quad 29.5$

$0.01 \% \quad 61.9 \%$ MAATFIGNSTAIQELFK $\quad 99.7 \% \quad 87.3$

$0.01 \% \quad 61.9 \%$ MAATFIGNSTAIQELFKR $99.7 \% \quad 53.1$

$0.01 \% \quad 61.9 \%$ ISEQFTAMFR

$99.7 \% \quad 62.0$

$99.7 \% \quad 34.2$

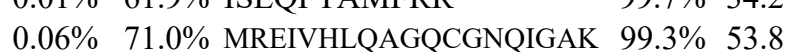

$\begin{array}{lllll}0.06 \% & 71.0 \% & \text { MREIVHLQAGQCGNQIGAK } & 99.3 \% & 53.8 \\ 0.06 \% & 71.0 \% & \text { EIVHLQAGQCGNQIGAK } & 99.1 \% & 52.2\end{array}$

$0.06 \% \quad 71.0 \%$ INVYYNEATGGK

$99.7 \% \quad 60.1$

$0.06 \% \quad 71.0 \%$ INVYYNEATGGKYVPR

$99.7 \% \quad 44.1$

$\begin{array}{llll}0.06 \% & 71.0 \% & \text { AVLVDLEPGTMDSVR } \quad 99.7 \% \quad 57.2\end{array}$

$0.06 \% \quad 71.0 \%$ SGPFGQIFRPDNFVFGQSGAGNNWAK $\quad 99.7 \% \quad 43.7$

$0.06 \% \quad 71.0 \%$ GHYTEGAELVDSVLDVVR $\quad 99.7 \% \quad 33.7$

$0.06 \% \quad 71.0 \%$ GHYTEGAELVDSVLDVVRK $99.7 \% \quad 60.1$

$0.06 \% \quad 71.0 \%$ EAESCDCLQGFQLTHSLGGGTGSGMGTLLISK $99.3 \% 57.8$

$0.06 \% \quad 71.0 \%$ IREEYPDR

$99.0 \% 38$.

$99.7 \% \quad 61.5$

$0.06 \% \quad 71.0 \%$ IMNTFSVVPSPK

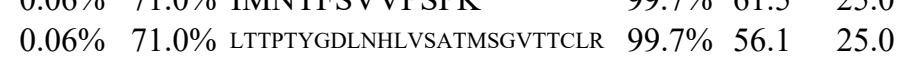

39.0

040.0

.0

.0

$\begin{array}{lll}0 & 51.7 & 32\end{array}$

$\begin{array}{lll}25.0 & 30.8 & 0\end{array}$

$5.0 \quad 0.0$

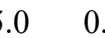

$\begin{array}{lll}0 & 54.4 & 12\end{array}$

$\begin{array}{lll}.0 & 43.7 & 2\end{array}$

$\begin{array}{lll}0 & 23.6 & 0\end{array}$

0.0

52.9

$\begin{array}{lll}.0 & 50.7 & 0\end{array}$

$\begin{array}{lll}.0 & 44.7 & 10\end{array}$

$\begin{array}{ll}25.0 & 50.9\end{array}$

$5.0 \quad 49.6$

$\begin{array}{lll}25.0 & 50.7 \quad 16\end{array}$

\begin{tabular}{ll}
37.0 & 37.3 \\
\hline
\end{tabular}

39.4
35.0

$\begin{array}{lll}0 & 48.4 & \\ & 51.5 & 15\end{array}$

$\begin{array}{lll}0 & 51.5 & 15\end{array}$

$\begin{array}{lll}5.0 & 40.0 & 14\end{array}$

$\begin{array}{rrr}25.0 & 38.4 \quad 30 \\ 25.0 & -1\end{array}$

$5.0 \quad 29.5$

$\begin{array}{ll}5.0 & 15.1\end{array}$

$\begin{array}{lll}5.0 & 53.1\end{array}$

$\begin{array}{lll}5.0 & 51.7 & 32\end{array}$

5.030 .8

$25.0 \quad 0.0$

$5.0 \quad 0.0$

$\begin{array}{ll}0.0 & 53.3\end{array}$

$25.0 \quad 40.7$

$25.0 \quad 54.4 \quad 12$

$25.0 \quad 43.7$

$\begin{array}{lll}25.0 & 33.7 & 3\end{array}$

$25.0 \quad 58.9 \quad 2$
$5.0 \quad 26.1$

\begin{tabular}{ll}
0 & 52.9 \\
\hline & 50.7
\end{tabular}
0

1143.63

1691.87

1065.43

1696.83

1873.94

2030.04

1229.60

1401.69

2110.06

1822.92

1617.82

2798.34

1942.99

3327.53

1319.70

2724.33

1130.60

1258.69

1271.73

1143.63

1636.83

1691.87

1065.43

1389.77

1039.59

1252.72

1696.83

1028.52

1326.72

1857.94

1998.05

1229.60

1401.69

2110.06

1822.92

1328.65

1843.93

1617.82

2798.34

1958.98

2087.08

3327.53

1077.53

1319.70

2724.33

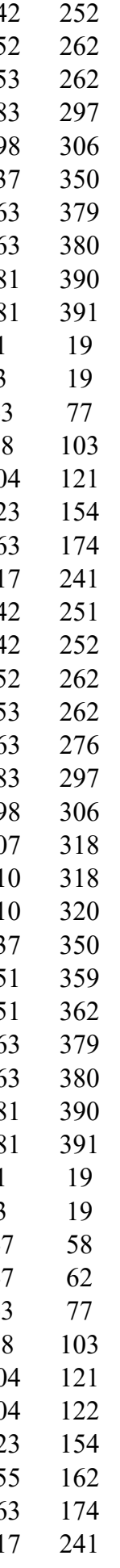

Page 173 of Table S-1-4 
Tubulin beta- $4 \mathrm{~B}$ chain $\mathrm{GN}=\mathrm{TUBB} 4 \mathrm{~B}$ Tubulin beta- $4 \mathrm{~B}$ chain $\mathrm{GN}=\mathrm{TUBB} 4 \mathrm{~B}$ Tubulin beta- $4 \mathrm{~B}$ chain $\mathrm{GN}=\mathrm{TUBB} 4 \mathrm{~B}$ Tubulin beta- $4 \mathrm{~B}$ chain $\mathrm{GN}=\mathrm{TUBB} 4 \mathrm{~B}$ Tubulin beta- $4 \mathrm{~B}$ chain $\mathrm{GN}=\mathrm{TUBB} 4 \mathrm{~B}$ Tubulin beta- $4 \mathrm{~B}$ chain $\mathrm{GN}=\mathrm{TUBB} 4 \mathrm{~B}$

Tubulin beta- $4 \mathrm{~B}$ chain $\mathrm{GN}=\mathrm{TUBB} 4 \mathrm{~B}$ Tubulin beta-4B chain GN=TUBB4B Tubulin beta- $4 \mathrm{~B}$ chain $\mathrm{GN}=\mathrm{TUBB} 4 \mathrm{~B}$ Tubulin beta- $4 \mathrm{~B}$ chain $\mathrm{GN}=\mathrm{TUBB} 4 \mathrm{~B}$ Tubulin beta $-4 \mathrm{~B}$ chain $\mathrm{GN}=\mathrm{TUBB} 4 \mathrm{~B}$ Tubulin beta- $4 \mathrm{~B}$ chain $\mathrm{GN}=\mathrm{TUBB} 4 \mathrm{~B}$ Tubulin beta-4B chain GN=TUBB4B Tubulin beta- $4 \mathrm{~B}$ chain $\mathrm{GN}=\mathrm{TUBB} 4 \mathrm{~B}$

Tubulin beta- $4 \mathrm{~B}$ chain $\mathrm{GN}=\mathrm{TUBB} 4 \mathrm{~B}$

Tubulin beta $-4 \mathrm{~B}$ chain $\mathrm{GN}=\mathrm{TUBB} 4 \mathrm{~B}$

Tubulin beta- $4 \mathrm{~B}$ chain $\mathrm{GN}=\mathrm{TUBB} 4 \mathrm{~B}$

Tubulin beta- $4 \mathrm{~B}$ chain $\mathrm{GN}=\mathrm{TUBB} 4 \mathrm{~B}$

Tubulin beta- $4 \mathrm{~B}$ chain $\mathrm{GN}=\mathrm{TUBB} 4 \mathrm{~B}$

Tubulin beta- 6 chain GN=TUBB 6

Tubulin beta- 6 chain GN=TUBB6

Tubulin beta- 6 chain GN $=$ TUBB 6

Tubulin beta- 6 chain GN=TUBB6

Tubulin beta -6 chain GN=TUBB 6

Tubulin beta- 6 chain GN=TUBB 6

Tubulin beta- 6 chain GN=TUBB6

Tubulin beta- 6 chain GN=TUBB 6

Tubulin beta- 6 chain $\mathrm{GN}=$ TUBB 6

Tubulin beta- 6 chain GN=TUBB6

Tubulin beta- 6 chain $\mathrm{GN}=\mathrm{TUBB} 6$

Tubulin beta -6 chain GN=TUBB 6

Tubulin beta- 6 chain GN=TUBB 6

Tubulin beta- 6 chain $\mathrm{GN}=$ TUBB 6

Tubulin beta- 6 chain GN=TUBB 6

Tubulin beta- 6 chain GN=TUBB 6

Tubulin gamma- 1 chain $\mathrm{GN}=\mathrm{TUBG}$

Tubulin gamma- 1 chain $\mathrm{GN}=\mathrm{TUBG}$

Tubulin gamma- 1 chain $\mathrm{GN}=\mathrm{TUBG}$

Tubulin gamma- 1 chain GN=TUBG1

Tubulin gamma-1 chain $\mathrm{GN}=\mathrm{TUBG}$

Tubulin gamma-1 chain $\mathrm{GN}=\mathrm{TUBG}$

Tubulin gamma- 1 chain GN=TUBG1

Tubulin-specific chaperone D GN=TBCD TBCD_HUMAN $132.60 \quad 100.0^{\circ}$

Tubulin-specific chaperone D GN=TBCD TBCD_HUMAN $132.60 \quad 100.0 \%$ Tuftelin-interacting protein $11 \mathrm{GN}=$ TFIP11 TFP11_HUMAN $96.82 \quad 100.0 \%$ Tuftelin-interacting protein $11 \mathrm{GN}=$ TFIP11 TFP11 HUMAN $96.82 \quad 100.0 \%$ Tyrosine--tRNA ligase, cytoplasmic GN=YARS SYYC_HUMAN $59.15 \quad 100.0 \%$ BBB4B HUMAN $49.83 \quad 100.0 \%$ TBB4B_HUMAN $49.83 \quad 100.0 \%$ TBB4B HUMAN $49.83 \quad 100.0 \%$ TBB4B_HUMAN $49.83 \quad 100.0 \%$ BB4B_HUMAN $49.83 \quad 100.0 \%$ TBB4B HUMAN $49.83 \quad 100.0 \%$ TBB4B_HUMAN $49.83 \quad 100.0 \%$ TBB4B HUMAN $49.83 \quad 100.0 \%$ TBB4B HUMAN $49.83 \quad 100.0 \%$ TBB4B_HUMAN $49.83 \quad 100.0 \%$ TBB4B HUMAN $49.83 \quad 100.0 \%$ TBB4B_HUMAN $49.83 \quad 100.0 \%$ BB4B_HUMAN $49.83 \quad 100.0 \%$ TBB4B HUMAN $49.83 \quad 100.0 \%$ PBB_BUMAN $49.83 \quad 100.0 \%$ TBB4B HUMAN $49.83 \quad 100.0 \%$ TBB4B_HUMAN $49.83 \quad 100.0 \%$ TBB6_HUMAN $49.86 \quad 100.0 \%$ TBB6_HUMAN $49.86 \quad 100.0 \%$ TBB6 HUMAN $49.86 \quad 100.0 \%$ TBB6 HUMAN $49.86 \quad 100.0 \%$ TBB6_HUMAN $49.86 \quad 100.0 \%$ TBB6_HUMAN $49.86 \quad 100.0 \%$ TBB6_HUMAN $49.86 \quad 100.0 \%$ TBB6 HUMAN $49.86 \quad 100.0 \%$ TBB6 HUMAN $49.86 \quad 100.0 \%$ TBB6_HUMAN $49.86 \quad 100.0 \%$ TBB6 HUMAN $49.86 \quad 100.0 \%$ TBB6 HUMAN $49.86 \quad 100.0 \%$ TBB6_HUMAN $49.86 \quad 100.0 \%$ TBB6 HUMAN $49.86 \quad 100.0 \%$ TBB6_HUMAN $49.86 \quad 100.0 \%$ TBB6 HUMAN $49.86 \quad 100.0 \%$ TBG1 HUMAN $51.17 \quad 100.0 \%$ TBG1_HUMAN $51.17 \quad 100.0 \%$ TBG1_HUMAN $51.17 \quad 100.0 \%$ TBG1_HUMAN $51.17 \quad 100.0 \%$ TBG1_HUMAN $51.17 \quad 100.0 \%$ TBG1_HUMAN $51.17 \quad 100.0 \%$ TBG1_HUMAN $51.17 \quad 100.0 \%$ $\begin{array}{lllllll}\text { TBB4B_HUMAN } 49.83 & 100.0 \% & 6 & 12 & 59 & 0.06 \% & 71.0 \% \\ \text { FPGQLNADLR }\end{array}$ $0 \%$

12

59

$\begin{array}{lll}59 & 0.06 \% & 71.0 \% \text { KLAVNMVPFPR }\end{array}$

$\begin{array}{llll}12 & 59 & 0.06 \% & 71.0 \% \\ 12 & 59 & 0.06 \% & 71.0 \%\end{array}$

$12 \quad 59 \quad 0.06 \% \quad 71.0 \%$ NMMAACDPR

$12 \quad 59 \quad 0.06 \% \quad 71.0 \%$ HGRYLTVAAVFR

$12 \quad 59 \quad 0.06 \% \quad 71.0 \%$ YLTVAAVFR

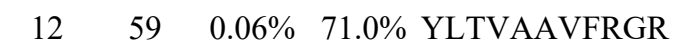

$1259 \quad 0.06 \% \quad 71.0 \%$ MSMKEVDEQMLNVQNK

$12 \quad 59 \quad 0.06 \% \quad 71.0 \%$ EVDEQMLNVQNK

$12 \quad 59 \quad 0.06 \% \quad 71.0 \%$ NSSYFVEWIPNNVK

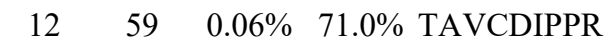

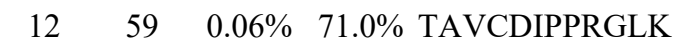

$12 \quad 59 \quad 0.06 \% \quad 71.0 \%$ MSATFIGNSTAIQELFK

$12 \quad 59 \quad 0.06 \% \quad 71.0 \%$ MSATFIGNSTAIQELFKR

$\begin{array}{llll}12 & 59 & 0.06 \% & 71.0 \% \\ 12 & 59 E Q F T A M F R\end{array}$

$12 \quad 59 \quad 0.06 \% \quad 71.0 \%$ ISEQFTAMFRR

$0.01 \% \quad 42.2 \%$ INVYYNESSSQKYVPR

$0.01 \% \quad 42.2 \%$ AALVDLEPGTMDSVR

$\begin{array}{lll}0.01 \% & 42.2 \% & \text { SGPFGQLFRPDNFIFGQTGAGNNWAK } \\ 0.01 \% & 42.2 \% & \text { GHYTEGAELVDAVLDVVR }\end{array}$

$\begin{array}{lll}0.01 \% & 42.2 \% & \text { GHYTEGAELVDAVLD } \\ 0.01 \% & 42.2 \% & \text { IMNTFSVMPSPK }\end{array}$

$0.01 \% \quad 42.2 \%$ FPGQLNADLR

$0.01 \% \quad 42.2 \%$ FPGQLNADLRK

$0.01 \% \quad 42.2 \%$ KLAVNMVPFPR

$0.01 \% \quad 42.2 \%$ LAVNMVPFPR

$0.01 \% \quad 42.2 \%$ LHFFMPGFAPLTSR

$0.01 \% \quad 42.2 \%$ ALTVPELTQQMFDAR

$0.01 \% \quad 42.2 \%$ NMMAACDPR

$0.01 \% \quad 42.2 \%$ NSSYFVEWIPNNVK

$0.01 \% \quad 42.2 \%$ MASTFIGNSTAIQELFK

$0.01 \% \quad 42.2 \%$ MASTFIGNSTAIQELFKR

$0.01 \% \quad 42.2 \%$ ISEQFSAMFR

$0.01 \% \quad 15.7 \%$ AVLLDLEPR

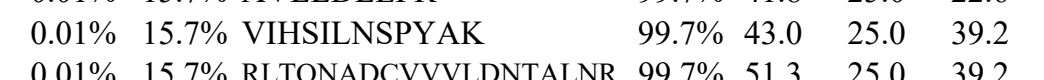

$\begin{array}{lllllll}0.01 \% & 15.7 \% & \text { LTQNADCVVVLDNTALNR } & 99.7 \% & 78.1 & 25.0 & 78.1\end{array}$

$\begin{array}{llllllll}0.01 \% & 15.7 \% & \text { LHFLMTGYTPLTTDQSVASVR } & 99.7 \% & 56.9 & 25.0 & 56.9 & 0\end{array}$

$0.01 \% \quad 15.7 \%$ KSPYLPSAHR

$0.01 \% \quad 15.7 \%$ SPYLPSAHR

$0.00 \% \quad 1.5 \%$ DAAAVLVSR

$0.00 \% \quad 1.5 \% \quad$ LQQVLTGLR

$0.00 \% \quad 2.9 \%$ NAQGIINPIEAK

$0.00 \% \quad 2.9 \%$ GKGAVGAYGSER

$\begin{array}{lllll}99.1 \% & 27.4 & 25.0 & 21.0 \\ 99.7 \% & 28.1 & 25.0 & 23.8 & 2\end{array}$

$99.7 \% \quad 56.3 \quad 25.0 \quad 43.8$

$\begin{array}{llll}99.7 \% & 42.7 & 25.0 & 32.7\end{array}$

$99.7 \% \quad 26.8 \quad 25.0 \quad 25.3$

$99.7 \% \quad 38.9 \quad 25.0 \quad 29.1$

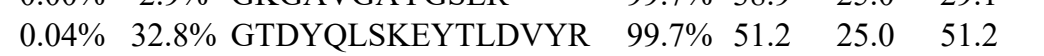

1130.60

1258.69

1271.73

1143.63

1636.83

1691.87

1065.43

1389.77

1039.59

1252.72

1971.88

1462.68

1696.83

1028.52

1326.72

1857.94

2014.04

1229.60

1401.69

1946.96

1589.78

2826.37

1942.99

1383.66

1130.60

1258.69

1271.73

1143.63

1636.83

1719.87

1065.43

1696.83

1857.94

2014.04

1231.58

1025.60

1341.75

2172.12

2016.02

2353.19

1155.63

1027.53

901.51

1027.63

1267.70

1151.58 1950.94 \begin{tabular}{cc}
42 & 251 \\
42 & 252 \\
52 & 262 \\
53 & 262 \\
63 & 276 \\
83 & 297 \\
98 & 306 \\
07 & 318 \\
10 & 318 \\
10 & 320 \\
21 & 336 \\
25 & 336 \\
37 & 350 \\
51 & 359 \\
51 & 362 \\
63 & 379 \\
63 & 380 \\
81 & 390 \\
81 & 391 \\
7 & 62 \\
3 & 77 \\
8 & 103 \\
04 & 121 \\
63 & 174 \\
42 & 251 \\
42 & 252 \\
52 & 262 \\
53 & 262 \\
63 & 276 \\
83 & 297 \\
98 & 306 \\
37 & 350 \\
63 & 379 \\
63 & 380 \\
81 & 390 \\
4 & 72 \\
3 & 84 \\
94 & 212 \\
95 & 212 \\
66 & 286 \\
63 & 372 \\
64 & 372 \\
05 & 213 \\
91 & 799 \\
71 & 182 \\
& 197 \\
& 135 \\
\hline
\end{tabular}

Page 174 of Table S-1-4 
Tyrosine--tRNA ligase, cytoplasmic GN=YARS SYYC_HUMAN $59.15 \quad 100.0 \% \quad 1$ Tyrosine--tRNA ligase, cytoplasmic GN=YARS SYYC_HUMAN $59.15 \quad 100.0 \% \quad 18$ Tyrosine--tRNA ligase, cytoplasmic GN=YARS SYYC_HUMAN $59.15 \quad 100.0 \% \quad 18$ Tyrosine--tRNA ligase, cytoplasmic GN=YARS SYYC HUMAN $59.15 \quad 100.0 \%$ Tyrosine--tRNA ligase, cytoplasmic GN=YARS SYYC_HUMAN $59.15 \quad 100.0 \% \quad 18$ Tyrosine--tRNA ligase, cytoplasmic GN=YARS SYYC_HUMAN $59.15 \quad 100.0 \% \quad 18$ Tyrosine--tRNA ligase, cytoplasmic GN=YARS SYYC_HUMAN $59.15 \quad 100.0 \% \quad 18$ Tyrosine--tRNA ligase, cytoplasmic GN=YARS SYYC_HUMAN $59.15 \quad 100.0 \% \quad 18$ Tyrosine--tRNA ligase, cytoplasmic GN=YARS SYYC HUMAN $59.15 \quad 100.0 \% \quad 18$ Tyrosine--tRNA ligase, cytoplasmic GN=YARS SYYC_HUMAN $59.15 \quad 100.0 \% \quad 18$ Tyrosine--tRNA ligase, cytoplasmic GN=YARS SYYC_HUMAN $59.15 \quad 100.0 \% \quad 18$ Tyrosine--tRNA ligase, cytoplasmic GN=YARS SYYC HUMAN $59.15 \quad 100.0 \%$ Tyrosine--tRNA ligase, cytoplasmic GN=YARS SYYC_HUMAN $59.15 \quad 100.0 \% \quad 18$ Tyrosine--tRNA ligase, cytoplasmic GN=YARS SYYC_HUMAN $59.15 \quad 100.0 \%$ Tyrosine--tRNA ligase, cytoplasmic GN=YARS SYYC_HUMAN $59.15 \quad 100.0 \% \quad 18$ Tyrosine--tRNA ligase, cytoplasmic GN=YARS SYYC_HUMAN $59.15 \quad 100.0 \% \quad 18$ Tyrosine--tRNA ligase, cytoplasmic GN=YARS SYYC HUMAN $59.15 \quad 100.0 \%$ U1 small nuclear ribonucleoprotein $70 \mathrm{kDa}$ GN=SNRNP70 RU17_HUMAN $51.56 \quad 100.0 \%$ U1 small nuclear ribonucleoprotein $70 \mathrm{kDa}$ GN=SNRNP70 RU17_HUMAN $51.56 \quad 100.0 \%$ U1 small nuclear ribonucleoprotein $70 \mathrm{kDa}$ GN=SNRNP70 RU17_HUMAN $51.56 \quad 100.0 \%$ U1 small nuclear ribonucleoprotein $70 \mathrm{kDa} \mathrm{GN=SNRNP70}$ RU17_HUMAN $51.56 \quad 100.0 \%$ U1 small nuclear ribonucleoprotein $70 \mathrm{kDa}$ GN=SNRNP70 RU17 HUMAN $51.56 \quad 100.0 \%$ U1 small nuclear ribonucleoprotein $70 \mathrm{kDa}$ GN=SNRNP70 RU17_HUMAN $51.56 \quad 100.0 \%$ U2 small nuclear ribonucleoprotein A' GN=SNRPA1 RU2A_HUMAN $28.42 \quad 100.0 \%$ 2 small nuclear ribonucleoprotein $\mathrm{A}^{\prime} \mathrm{GN}=\mathrm{SNRPA} 1$ RU2A HUMAN $28.42 \quad 100.0^{\circ}$ U2 small nuclear ribonucleoprotein $\mathrm{A}^{\prime}$ GN=SNRPA1 RU2A_HUMAN $28.42 \quad 100.0 \%$ U2 small nuclear ribonucleoprotein A' GN=SNRPA1 RU2A_HUMAN $28.42 \quad 100.0 \%$ 2 small nuclear ribonucleoprotein $\mathrm{A}^{\prime} \mathrm{GN}=\mathrm{SNRPA}$ RU2A HUMAN $28.42 \quad 100.0 \%$ U2 small nuclear ribonucleoprotein $\mathrm{A}^{\prime}$ GN=SNRPA1 RU2A_HUMAN $28.42 \quad 100.0 \%$ U2 small nuclear ribonucleoprotein $\mathrm{A}^{\prime} \mathrm{GN}=\mathrm{SNRPA} 1$ RU2A HUMAN $28.42 \quad 100.0 \%$ U3 small nucleolar ribonucleoprotein protein IMP4 GN=IMP4 IMP4_HUMAN $33.76 \quad 100.0 \%$ U3 small nucleolar ribonucleoprotein protein IMP4 GN=IMP4 IMP4_HUMAN $33.76 \quad 100.0 \%$ U3 small nucleolar ribonucleoprotein protein IMP4 GN=IMP4 IMP4_HUMAN $33.76 \quad 100.0 \%$ U3 small nucleolar RNA-associated protein 18 homolog GN=UTP18 UTP18_HUMAN $62.00 \quad 100.0 \%$ U3 small nucleolar RNA-associated protein 18 homolog GN=UTP18 UTP18_HUMAN $62.00 \quad 100.0 \%$ U4/U6 small nuclear ribonucleoprotein Prp31 GN=PRPF31 PRP31_HUMAN 55.46 100.0\% U4/U6 small nuclear ribonucleoprotein Prp31 GN=PRPF31 PRP31_HUMAN $55.46 \quad 100.0 \%$ U4/U6 small nuclear ribonucleoprotein Prp31 GN=PRPF31 PRP31 HUMAN 55.46 100.0\% U4/U6 small nuclear ribonucleoprotein Prp31 GN=PRPF31 PRP31_HUMAN $55.46 \quad 100.0 \%$ U4/U6 small nuclear ribonucleoprotein Prp31 GN=PRPF31 PRP31_HUMAN $55.46 \quad 100.0 \%$ U4/U6 small nuclear ribonucleoprotein Prp31 GN=PRPF31 PRP31_HUMAN 55.46 100.0\% U4/U6 small nuclear ribonucleoprotein Prp31 GN=PRPF31 PRP31_HUMAN 55.46 $100.0 \%$ U4/U6 small nuclear ribonucleoprotein Prp31 GN=PRPF31 PRP31_HUMAN 55.46 100.0\% U4/U6 small nuclear ribonucleoprotein Prp31 GN=PRPF31 PRP31_HUMAN 55.46 100.0\% U4/U6 small nuclear ribonucleoprotein Prp31 GN=PRPF31 PRP31_HUMAN 55.46 100.0\% U4/U6 small nuclear ribonucleoprotein Prp31 GN=PRPF31 PRP31_HUMAN 55.46 $100.0 \%$ U4/U6 small nuclear ribonucleoprotein Prp31 GN=PRPF31 PRP31_HUMAN 55.46 $100.0 \%$

16

16

\begin{tabular}{ll}
$0.04 \%$ & $32.8 \%$ \\
$0.04 \%$ & $32.8 \%$ KIFTFAEK \\
\hline $0.04 \%$ & $32.8 \%$ YLPALGYSK
\end{tabular}

$\begin{array}{lll}0.04 \% & 32.8 \% & \text { YLPALGYSKR }\end{array}$

$0.04 \% \quad 32.8 \%$ AFCEPGNVENNGVLSFIK

$0.04 \% \quad 32.8 \%$ NSVEVALNK

$0.04 \% \quad 32.8 \%$ FNTPALKK

$0.04 \% 32.8 \%$ KLASAAYPDPSK

$0.04 \% \quad 32.8 \%$ LASAAYPDPSK

$0.04 \% \quad 32.8 \%$ LASAAYPDPSKQKPMAK

$0.04 \% \quad 32.8 \%$ NSEPEEVIPSR

$0.04 \% \quad 32.8 \%$ NSEPEEVIPSRLDIR

$0.04 \% \quad 32.8 \%$ TVVSGLVQFVPK

$\begin{array}{lllll}0.04 \% & 32.8 \% & \text { GVESQGMLLCASIEGINR } \quad 99.7 \% & 52.2\end{array}$

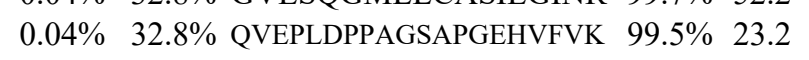

$0.04 \% \quad 32.8 \%$ GQPDEELKPK

$0.01 \% \quad 11.4 \%$ RQQEVETELK

$0.01 \% \quad 11.4 \%$ VNYDTTESK

$0.01 \% \quad 11.4 \%$ VNYDTTESKLR

$0.01 \% \quad 11.4 \%$ EFEVYGPIKR

$0.01 \% \quad 11.4 \%$ RLGGGLGGTR

$0.01 \% \quad 11.4 \%$ RGGADVNIR

$0.01 \% \quad 31.8 \%$ LTAELIEQAAQYTNAVR

$0.01 \% \quad 31.8 \%$ KLDGFPLLR

$0.01 \% 31.8 \%$ TLLVNNNR

$0.01 \% \quad 31.8 \%$ SLTYLSILR

$0.01 \% \quad 31.8 \%$ TFNPGAGLPTDK

$0.01 \% \quad 31.8 \%$ GGPSPGDVEAIK

$0.01 \% \quad 31.8 \%$ NAIANASTLAEVER

$0.00 \% \quad 8.9 \%$ LIPTELRR

$0.00 \% \quad 8.9 \%$ HEVGALVR

$0.00 \% \quad 8.9 \%$ NVELTEVGPR

$0.00 \% \quad 4.5 \%$ TGNFISTSTSLPR

$0.00 \% \quad 4.5 \%$ SGYFALGNEKGK

$0.04 \% 33.9 \%$ ASEVMGPVEAAPEYR

$0.04 \% \quad 33.9 \%$ TVKELGNSLDK

$0.04 \% 33.9 \%$ ELGNSLDKCK

$0.04 \% \quad 33.9 \%$ IYEYVESR

$0.04 \% \quad 33.9 \%$ MSFIAPNLSIIIGASTAAK

$0.04 \% \quad 33.9 \%$ IMGVAGGLTNLSK

$0.04 \% \quad 33.9 \%$ VDSFHESTEGK

$0.04 \% \quad 33.9 \%$ QVKPLPAPLDGQR

$0.04 \% \quad 33.9 \%$ LGLTEIRK

$0.04 \% \quad 33.9 \%$ VRQTQVNEATK

0.04\% $33.9 \%$ QTQVNEATKAR

0.04\% $33.9 \%$ TLQKQSVVYGGK $\begin{array}{llllllll}99.0 \% & 28.9 & 25.0 & 28.8 & 2 & 0 & 0 & 1058.52\end{array}$ $\begin{array}{llllllll}99.7 \% & 56.0 & 25.0 & 49.1 & 2 & 2 & 0 & 1328.72\end{array}$ $\begin{array}{llllllll}95.4 \% & 20.8 & 25.0 & 10.7 & 1 & 0 & 0 & 983.56\end{array}$ $\begin{array}{llllllll}98.3 \% & 24.5 & 25.0 & 11.4 & 1 & 0 & 0 & 1011.55\end{array}$ $99.7 \% \quad 45.2 \quad 25.0 \quad 40.5$ \begin{tabular}{llll}
$\%$ & 61.3 & 25.0 & 60.8 \\
\hline$\%$ & 46.0 & 25.0 & 36.5
\end{tabular} $\begin{array}{llll}99.0 \% & 28.5 & 25.0 & 20.4\end{array}$ $99.5 \% \quad 21.7 \quad 25.0 \quad 21.7$ $\begin{array}{llll}99.7 \% & 60.6 & 25.0 & 54.7\end{array}$ $\begin{array}{llll}98.6 \% & 17.0 & 25.0 & 17.0\end{array}$ $99.7 \% \quad 46.6 \quad 25.0 \quad 42.5$ $\begin{array}{llll}98.9 \% & 20.9 & 25.0 & 16.9\end{array}$ $\begin{array}{llll}99.5 \% & 23.2 & 25.0 & 23.2 \\ 99.0 & 29.7 & 25.0 & 28.3\end{array}$ $\begin{array}{llll}98.3 \% & 22.7 & 25.0 & 14.1\end{array}$ $\begin{array}{lllll}99.7 \% & 40.3 & 25.0 & 31.3 & 4\end{array}$ $99.1 \% \quad 20.3 \quad 25.0 \quad 20.3$ $\begin{array}{lllll}99.7 \% & 29.3 & 25.0 & 19.2 & 3\end{array}$ $\begin{array}{llll}99.7 \% & 34.0 & 25.0 & 16.5\end{array}$ $\begin{array}{llll}99.7 \% & 35.2 & 25.0 & 24.7\end{array}$ $\begin{array}{lllll}99.7 \% & 58.9 & 25.0 & 58.9 & 2\end{array}$ $\begin{array}{llll}99.6 \% & 24.7 & 25.0 & 19.0 \\ 27.2 & 25.0 & 12.8\end{array}$ $\begin{array}{llll}99.7 \% & 62.5 & 25.0 & 45.1\end{array}$ $\begin{array}{lllll}99.7 \% & 44.1 & 25.0 & 40.4 & 2\end{array}$ $\begin{array}{lllll}99.7 \% & 29.8 & 25.0 & 29.8 & 2\end{array}$ $\begin{array}{lllll}99.7 \% & 83.2 & 25.0 & 80.3 & 3\end{array}$ $\begin{array}{llll}99.0 \% & 36.7 & 25.0 & 19.5\end{array}$ $\begin{array}{lllll}99.0 \% & 26.1 & 25.0 & 16.8 & 1\end{array}$ $\begin{array}{llll}99.7 \% & 51.9 & 25.0 & 39.2\end{array}$ $\begin{array}{lllll}99.7 \% & 57.8 & 25.0 & 42.7 & 2\end{array}$ $\begin{array}{llll}99.6 \% & 29.3 & 25.0 & 25.0\end{array}$ $\begin{array}{llll}99.7 \% & 41.8 & 25.0 & 41.8\end{array}$ $\begin{array}{lllll}99.7 \% & 39.1 & 25.0 & 17.7 & 2\end{array}$ $99.5 \% \quad 26.4 \quad 25.0 \quad 16.0$ $\begin{array}{lllll}99.0 \% & 47.7 & 25.0 & 32.4 & 3\end{array}$ $\begin{array}{lllll}99.7 \% & 77.1 & 25.0 & 77.1 & 3\end{array}$ $99.7 \% \quad 63.5 \quad 25.0 \quad 51.3$ $\begin{array}{lllll}99.7 \% & 47.9 & 25.0 & 45.0 & 2\end{array}$ $\begin{array}{lllll}99.7 \% & 29.8 & 25.0 & 27.7 & 2\end{array}$ $\begin{array}{lllll}99.0 \% & 50.1 & 25.0 & 35.1 & 3\end{array}$ $\begin{array}{lllll}99.7 \% & 45.8 & 25.0 & 45.1 & 4\end{array}$ $\begin{array}{lllll}99.7 \% & 33.8 & 25.0 & 26.8 & 0\end{array}$ $\begin{array}{llll}99.7 \% & 50.1 & 25.0 & 45.7\end{array}$

\begin{tabular}{cc}
128 & 135 \\
136 & 147 \\
190 & 197 \\
198 & 206 \\
198 & 207 \\
248 & 265 \\
311 & 319 \\
328 & 335 \\
335 & 346 \\
336 & 346 \\
336 & 352 \\
357 & 367 \\
357 & 371 \\
401 & 412 \\
433 & 450 \\
451 & 470 \\
475 & 484 \\
78 & 87 \\
110 & 118 \\
110 & 120 \\
122 & 131 \\
191 & 200 \\
201 & 209 \\
4 & 20 \\
56 & 64 \\
68 & 75 \\
114 & 122 \\
180 & 191 \\
194 & 205 \\
206 & 219 \\
41 & 48 \\
119 & 126 \\
241 & 250 \\
221 & 233 \\
533 & 544 \\
77 & 91 \\
138 & 148 \\
141 & 150 \\
204 & 211 \\
212 & 230 \\
231 & 243 \\
305 & 315 \\
339 & 351 \\
366 & 373 \\
407 & 417 \\
409 & 419 \\
427 & 438 \\
& \\
\hline
\end{tabular}

Page 175 of Table S-1-4 
4/U6 small nuclear ribonucleoprotein Prp31 GN=PRPF31 PRP31_HUMAN $55.46 \quad 100.0 \%$ U4/U6 small nuclear ribonucleoprotein Prp31 GN=PRPF31 PRP31_HUMAN $55.46 \quad 100.0 \%$ U4/U6 small nuclear ribonucleoprotein Prp31 GN=PRPF31 PRP31_HUMAN $55.46 \quad 100.0 \%$ UU6 small nuclear ribonucleoprotein Prp31 GN=PRPF31 PRP31 HUMAN 55.46 $100.0 \%$ U4/U6 small nuclear ribonucleoprotein Prp4 GN=PRPF4 PRP4_HUMAN $58.45 \quad 100.0 \%$ U4/U6 small nuclear ribonucleoprotein Prp4 GN=PRPF4 PRP4_HUMAN $58.45 \quad 100.0 \%$ U4/U6 small nuclear ribonucleoprotein Prp4 GN=PRPF4 PRP4 HUMAN 58.45 100.0\% U4/U6 small nuclear ribonucleoprotein Prp4 GN=PRPF4 PRP4_HUMAN $58.45 \quad 100.0 \%$ U4/U6 small nuclear ribonucleoprotein Prp4 GN=PRPF4 PRP4 HUMAN 58.45 100.0\% U4/U6 small nuclear ribonucleoprotein Prp4 GN=PRPF4 PRP4_HUMAN $58.45 \quad 100.0 \%$ U5 small nuclear ribonucleoprotein $200 \mathrm{kDa}$ helicase GN=SNRNP200 U520_HUMAN $244.51 \quad 100.0 \%$ small nuclear ribonucleoprotein $200 \mathrm{kDa}$ helicase GN=SNRNP200 U520 HUMAN $244.51 \quad 100.0 \%$ U5 small nuclear ribonucleoprotein $200 \mathrm{kDa}$ helicase GN=SNRNP200 U520_HUMAN $244.51 \quad 100.0 \%$ U5 small nuclear ribonucleoprotein $200 \mathrm{kDa}$ helicase GN=SNRNP200 U520_HUMAN $244.51 \quad 100.0 \%$ U5 small nuclear ribonucleoprotein $200 \mathrm{kDa}$ helicase GN=SNRNP200 U520 HUMAN $244.51 \quad 100.0 \%$ U5 small nuclear ribonucleoprotein $200 \mathrm{kDa}$ helicase GN=SNRNP200 U520_HUMAN $244.51 \quad 100.0 \%$ U5 small nuclear ribonucleoprotein $200 \mathrm{kDa}$ helicase GN=SNRNP200 U520 HUMAN $244.51 \quad 100.0 \%$ U5 small nuclear ribonucleoprotein $200 \mathrm{kDa}$ helicase GN=SNRNP200 U520_HUMAN $244.51 \quad 100.0 \%$ U5 small nuclear ribonucleoprotein $200 \mathrm{kDa}$ helicase GN=SNRNP200 U520_HUMAN $244.51 \quad 100.0 \%$ 45 small nuclear ribonucleoprotein $200 \mathrm{kDa}$ helicase GN=SNRNP200 U520 HUMAN $244.51 \quad 100.0 \%$ U5 small nuclear ribonucleoprotein $200 \mathrm{kDa}$ helicase GN=SNRNP200 U520_HUMAN $244.51 \quad 100.0 \%$ U5 small nuclear ribonucleoprotein $200 \mathrm{kDa}$ helicase GN=SNRNP200 U520 HUMAN $244.51 \quad 100.0 \%$ Us small nuclear ribonucleoprotein $200 \mathrm{kDa}$ helicase GN=SNRNP200 U520 HUMAN $244.51 \quad 100.0 \%$ U5 small nuclear ribonucleoprotein $200 \mathrm{kDa}$ helicase GN=SNRNP200 U520_HUMAN $244.51 \quad 100.0 \%$ U5 small nuclear ribonucopon $244.51 \quad 100.0 \%$ U5 small nuclear ribonucleoprotein $200 \mathrm{kDa}$ helicase GN=SNRNP200 U520_HUMAN $244.51 \quad 100.0 \%$ U5 small nuclear ribonucleoprotein $200 \mathrm{kDa}$ helicase GN=SNRNP200 U520 HUMAN $244.51 \quad 100.0 \%$ 5 small nuclear ribonucleoprotein $200 \mathrm{kDa}$ helicase GN=SNRNP200 U520 HUMAN $244.51 \quad 100.0 \%$ U5 small nuclear ribonucleoprotein $200 \mathrm{kDa}$ helicase GN=SNRNP200 U520_HUMAN $244.51 \quad 100.0 \%$ U5 small nuclear ribonucleoprotein $200 \mathrm{kDa}$ helicase GN=SNRNP200 U520 HUMAN $244.51 \quad 100.0 \%$ U5 small nuclear ribonucleoprotein $200 \mathrm{kDa}$ helicase GN=SNRNP200 U520_HUMAN $244.51 \quad 100.0 \%$ U5 small nuclear ribonucleoprotein $200 \mathrm{kDa}$ helicase GN=SNRNP200 U520_HUMAN $244.51 \quad 100.0 \%$ U5 small nuclear ribonucleoprotein $200 \mathrm{kDa}$ helicase GN=SNRNP200 U520 HUMAN $244.51 \quad 100.0 \%$ U5 small nuclear ribonucleoprotein $200 \mathrm{kDa}$ helicase GN=SNRNP200 U520_HUMAN $244.51 \quad 100.0 \%$ U5 small nuclear ribonucleoprotein $200 \mathrm{kDa}$ helicase GN=SNRNP200 U520 HUMAN $244.51 \quad 100.0 \%$ U5 small nuclear ribonucleoprotein $200 \mathrm{kDa}$ helicase GN=SNRNP200 U520 HUMAN $244.51 \quad 100.0 \%$ U5 small nuclear ribonucleoprotein $200 \mathrm{kDa}$ helicase GN=SNRNP200 U520_HUMAN $244.51 \quad 100.0 \%$ 45 small nuclear ribonucleopein $200 \mathrm{kDa}$ helicase GN=SNRNP200 U520 HUMAN $244.51 \quad 100.0 \%$ U5 small nuclear ribonucleoprotein $200 \mathrm{kDa}$ helicase GN=SNRNP200 U520_HUMAN $244.51 \quad 100.0 \%$ U5 small nuclear ribonucleoprotein $200 \mathrm{kDa}$ helicase GN=SNRNP200 U520_HUMAN $244.51 \quad 100.0 \%$ 45 small nuclear ribonucleoprotein $200 \mathrm{kDa}$ helicase GN=SNRNP200 U520 HUMAN $244.51 \quad 100.0 \%$ U5 small nuclear ribonucleoprotein $40 \mathrm{kDa}$ protein GN=SNRNP40 SNR40_HUMAN $39.31 \quad 100.0 \%$ U5 small nuclear ribonucleoprotein $40 \mathrm{kDa}$ protein $\mathrm{GN}=\mathrm{SNRNP} 40 \mathrm{SNR} 40$ HUMAN $39.31 \quad 100.0 \%$ U5 small nuclear ribonucleoprotein $40 \mathrm{kDa}$ protein GN=SNRNP40 SNR40 HUMAN $39.31 \quad 100.0 \%$ U5 small nuclear ribonucleoprotein $40 \mathrm{kDa}$ protein GN=SNRNP40 SNR40_HUMAN $39.31 \quad 100.0 \%$ U5 small nuclear ribonucleoprotein $40 \mathrm{kDa}$ protein GN=SNRNP40 SNR40_HUMAN $39.31 \quad 100.0 \%$ U5 small nuclear ribonucleoprotein $40 \mathrm{kDa}$ protein GN=SNRNP40 SNR40_HUMAN $39.31 \quad 100.0 \%$ 22 22

(6)

6
6
6
40

$31 \quad 40$

31
31
31

31
31
31

31

31
31

31
31
31

$\begin{array}{ll}31 & 4 \\ 31 & 40 \\ 31 & 40\end{array}$

31
31
31

31

31
31
31

$\begin{array}{ll}31 & 40 \\ 31 & 40 \\ 31 & 40\end{array}$

31

$\begin{array}{ll}31 & 40 \\ 31 & 40 \\ 31 & 40\end{array}$

$\begin{array}{ll}31 & 4 \\ 31 & 40\end{array}$

31

$\begin{array}{ll}31 & 40 \\ 31 & 40 \\ 31 & 40\end{array}$

31
31
31

$\begin{array}{ll}31 & 40 \\ 31 & 40 \\ 8 & \end{array}$

8
8
8

$8 \quad 0.01 \% \quad 11.1 \%$ ARAPDDLVAPV

$8-0.01 \% \quad 11.1 \%$ ALGDLAPVVK

$8 \quad 0.01 \% \quad 11.1 \%$ LWIANYSLPR

$8 \quad 0.01 \% \quad 11.1 \%$ LHKEIPETTR

$0.01 \% \quad 11.1 \%$ FLGTTCYDR

$122 \quad 0.12 \% \quad 14.7 \%$ ANSNLVLQADR

$2.12 \% \quad 14.7 \%$ CTLSANLVASGELMSSK

$122 \quad 0.12 \% \quad 14.7 \%$ DIDAFWLQR

$22 \quad 0.12 \% \quad 14.7 \%$ FYDDAIVSQK

$122 \quad 0.12 \% \quad 14.7 \%$ FYDDAIVSQKK

$122 \quad 0.12 \% \quad 14.7 \%$ KADEVLEILK

$122 \quad 0.12 \% \quad 14.7 \%$ ADEVLEILK

$122 \quad 0.12 \% \quad 14.7 \%$ YAQAGFEGFK

$122 \quad 0.12 \% \quad 14.7 \%$ YAQAGFEGFKTLNR

$\quad 0.12 \% \quad 14.7 \%$ AALETDENLLLCAPTGAGK

$122 \quad 0.12 \% \quad 14.7 \%$ SLVQEMVGSFGK

$122 \quad 0.12 \% \quad 14.7 \%$ SLVQEMVGSFGKR

$122 \quad 0.12 \% \quad 14.7 \%$ NIEMTQEDVR

$122 \quad 0.12 \% \quad 14.7 \%$ FQIMNEIVYEK

$122 \quad 0.12 \% \quad 14.7 \%$ NQVLVFVHSR

$122 \quad 0.12 \% \quad 14.7 \%$ EGSASTEVLR

$122 \quad 0.12 \% \quad 14.7 \%$ GTQVYSPEK

$122 \quad 0.12 \% \quad 14.7 \%$ TGNFQVTELGR

$122 \quad 0.12 \% \quad 14.7 \%$ VPIPVKESIEEPSAK

$122 \quad 0.12 \% \quad 14.7 \%$ LYDLNHNEIGELIR

$122 \quad 0.12 \% \quad 14.7 \%$ LELSVHLQPITR

$122 \quad 0.12 \% \quad 14.7 \%$ TICAEFAILR

$122 \quad 0.12 \% \quad 14.7 \%$ MLLQSSEGR

$122 \quad 0.12 \% \quad 14.7 \%$ VVLLTGETSTDLK

$122 \quad 0.12 \% \quad 14.7 \%$ VVLLTGETSTDLKLLGK

$122 \quad 0.12 \% \quad 14.7 \%$ IVALSSSLSNAK

$122 \quad 0.12 \% \quad 14.7 \%$ KPVIVFVPSR

$122 \quad 0.12 \% \quad 14.7 \%$ LTAIDILTTCAADIQR

$122 \quad 0.12 \% \quad 14.7 \%$ MTQNPNYYNLQGISHR

$122 \quad 0.12 \% \quad 14.7 \%$ TNLLLQAHLSR

$122 \quad 0.12 \% \quad 14.7 \%$ SNSLISIKR

$16 \quad 0.02 \% \quad 24.4 \%$ FHPNGSTLASAGFDR

$16 \quad 0.02 \% \quad 24.4 \%$ TVAVWDSETGER

$16 \quad 0.02 \% \quad 24.4 \%$ GHTSFVNSCYPAR

$\begin{array}{llll}16 & 0.02 \% & 24.4 \% & \text { RGPQLVCTGSDDGTVK } \\ 16 & 0.02 \% & 24.4 \% & \text { GPQLVCTGSDDGTVK }\end{array}$

$16 \quad 0.02 \% \quad 24.4 \%$ VWDVRPFAPK

$95.4 \% 13.9$

$\begin{array}{lllll}99.6 \% & 26.5 & 25.0 & 26.5 & 0 \\ 99.7 \% & 54.0 & 25.0 & 54.0 & 8 \\ 99.7 \% & 36.3 & 25.0 & 24.2 & 4 \\ 99.7 \% & 31.3 & 25.0 & 31.3 & 2 \\ 99.7 \% & 37.8 & 25.0 & 37.8 & 2 \\ 94.8 \% & 15.6 & 25.0 & 15.2 & 0 \\ 99.7 \% & 44.4 & 25.0 & 44.1 & 3 \\ 99.7 \% & 49.6 & 25.0 & 49.6 & 2 \\ 95.4 \% & 13.9 & 25.0 & 13.9 & 1\end{array}$

$\begin{array}{ccc}2602.34 & 445 & 470 \\ 2730.43 & 445 & 471 \\ 1962.96 & 472 & 488 \\ 1238.58 & 479 & 488 \\ 1352.78 & 14 & 26 \\ 1123.64 & 16 & 26 \\ 1656.86 & 114 & 129 \\ 1232.68 & 179 & 188 \\ 1223.67 & 198 & 207 \\ 1132.51 & 337 & 345 \\ 1200.63 & 15 & 25 \\ 1767.86 & 238 & 254 \\ 1163.58 & 262 & 270 \\ 1185.58 & 275 & 284 \\ 1313.67 & 275 & 285 \\ 1157.68 & 285 & 294 \\ 1029.58 & 286 & 294 \\ 1117.53 & 470 & 479 \\ 1601.81 & 470 & 483 \\ 1943.97 & 491 & 509 \\ 1281.65 & 546 & 557 \\ 1437.75 & 546 & 558 \\ 1234.57 & 638 & 647 \\ 1429.70 & 701 & 711 \\ 1198.67 & 719 & 728 \\ 1048.53 & 754 & 763 \\ 1008.50 & 830 & 838 \\ 1221.62 & 976 & 986 \\ 1622.90 & 1044 & 1058 \\ 1698.88 & 1153 & 1166 \\ 1405.82 & 1184 & 1195 \\ 1193.63 & 1357 & 1366 \\ 1020.51 & 1367 & 1375 \\ 1375.77 & 1405 & 1417 \\ 1787.05 & 1405 & 1421 \\ 1189.68 & 1487 & 1498 \\ 1141.71 & 1557 & 1566 \\ 1774.94 & 1571 & 1586 \\ 1935.91 & 1764 & 1779 \\ 1265.73 & 1891 & 1901 \\ 1017.61 & 2073 & 2081 \\ 1576.75 & 74 & 88 \\ 1349.63 & 132 & 143 \\ 1495.67 & 149 & 161 \\ 1689.82 & 162 & 177 \\ 1533.72 & 163 & 177 \\ 1214.67 & 261 & 270\end{array}$

Page 176 of Table S-1-4 
$\begin{array}{lll} & \end{array}$ mall nuclear ribonucleoprotein $40 \mathrm{kDa}$ protein GN=SNRNP40 SNR40_HUMAN $39.31 \quad 100.0 \%$ UAP56-interacting factor GN=FYTTD1 UIF_HUMAN $35.82 \quad 100.0 \%$ UAP56-interacting factor GN=FYTTD1 UIF HUMAN 35.82 100.0\% UAP56-interacting factor GN=FYTTD1 UIF_HUMAN $35.82 \quad 100.0 \%$ UAP56-interacting factor GN=FYTTD1 UIF_HUMAN $35.82 \quad 100.0 \%$ UAP56-interacting factor GN=FYTTD1 UIF_HUMAN $35.82 \quad 100.0 \%$ UAP56-interacting factor GN=FYTTD1 UIF_HUMAN $35.82 \quad 100.0 \%$ UAP56-interacting factor GN=FYTTD1 UIF HUMAN $35.82 \quad 100.0 \%$ UAP56-interacting factor GN=FYTTD1 UIF_HUMAN $35.82 \quad 100.0 \%$ UAP56-interacting factor GN=FYTTD1 UIF_HUMAN $35.82 \quad 100.0 \%$ Ubiquitin carboxyl-terminal hydrolase 24 GN=USP24 UBP24_HUMAN $294.37 \quad 100.0 \%$ Ubiquitin carboxyl-terminal hydrolase 24 GN=USP24 UBP24_HUMAN $294.37 \quad 100.0 \%$ Ubiquitin carboxyl-terminal hydrolase 24 GN=USP24 UBP24_HUMAN $294.37 \quad 100.0 \%$ Ubiquitin carboxyl-terminal hydrolase 24 GN=USP24 UBP24_HUMAN $294.37 \quad 100.0 \%$ Ubiquitin carboxyl-terminal hydrolase 24 GN=USP24 UBP24_HUMAN $294.37 \quad 100.0 \%$ Ubiquitin carboxyl-terminal hydrolase 24 GN=USP24 UBP24 HUMAN $294.37 \quad 100.0 \%$ Ubiquitin thioesterase OTUB1 GN=OTUB1 OTUB1_HUMAN $31.28 \quad 100.0 \%$ Ubiquitin thioesterase OTUB1 GN=OTUB1 OTUB1_HUMAN $31.28 \quad 100.0 \%$ Ubiquitin thioesterase OTUB1 GN=OTUB1 OTUB1_HUMAN $31.28 \quad 100.0 \%$ Ubiquitin-40S ribosomal protein S27a GN=RPS27A RS27A_HUMAN $17.97 \quad 100.0 \%$ Ubiquitin-40S ribosomal protein S27a GN=RPS27A RS27A HUMAN $17.97 \quad 100.0 \%$ Ubiquitin-40S ribosomal protein S27a GN=RPS27A RS27A_HUMAN $17.97 \quad 100.0 \%$ Ubiquitin-40S ribosomal protein S27a GN=RPS27A RS27A_HUMAN $17.97 \quad 100.0 \%$ Ubiquitin-40S ribosomal protein S27a GN=RPS27A RS27A_HUMAN $17.97 \quad 100.0 \%$ Ubiquitin-40S ribosomal protein S27a GN=RPS27A RS27A_HUMAN $17.97 \quad 100.0 \%$ Ubiquitin-40S ribosomal protein S27a GN=RPS27A RS27A_HUMAN $17.97 \quad 100.0 \%$ Ubiquitin-associated domain-containing protein $2 \mathrm{GN}=\mathrm{UBAC} 2$ UBAC2 HUMAN $38.97 \quad 100.0 \%$ Ubiquitin-associated domain-containing protein $2 \mathrm{GN}=\mathrm{UBAC} 2$ UBAC2_HUMAN $38.97 \quad 100.0 \%$ Ubiquitin-like modifier-activating enzyme $1 \mathrm{GN}=$ UBA1 UBA1 HUMAN $117.85 \quad 100.0 \%$ Ubiquitin-like modifier-activating enzyme $1 \mathrm{GN}=$ UBA1 UBA1_HUMAN $117.85 \quad 100.0 \%$ Ubiquitin-like modifier-activating enzyme $1 \mathrm{GN}=$ UBA1 UBA1_HUMAN $117.85 \quad 100.0 \%$ Ubiquitin-like modifier-activating enzyme $1 \mathrm{GN}=$ UBA1 UBA1 HUMAN $117.85 \quad 100.0 \%$ Ubiquitin-like modifier-activating enzyme $1 \mathrm{GN}=$ UBA1 UBA1_HUMAN $117.85 \quad 100.0 \%$ Uncharacterized protein C19orf52 GN=C19orf52 CS052_HUMAN $29.23 \quad 100.0 \%$ Uncharacterized protein $\mathrm{C} 19$ orf52 GN=C19orf52 CS052_HUMAN $29.23 \quad 100.0 \%$ Uncharacterized protein C19orf52 GN=C19orf52 CS052_HUMAN $29.23 \quad 100.0 \%$ Uncharacterized protein $\mathrm{C} 3$ orf17 $\mathrm{GN}=\mathrm{C} 3$ orf17 $\mathrm{CC} 017$ HUMAN $64.55 \quad 100.0 \%$ Uncharacterized protein $\mathrm{C} 3$ orf $17 \mathrm{GN}=\mathrm{C} 3$ orf17 $\quad$ CC017_HUMAN $64.55 \quad 100.0 \%$ Unconventional myosin-Ib GN=MYO1B MYO1B_HUMAN $131.99 \quad 100.0 \%$ Unconventional myosin-Ib GN=MYO1B MYO1B_HUMAN $131.99 \quad 100.0 \%$ Unconventional myosin-Ib GN=MYO1B MYO1B_HUMAN $131.99 \quad 100.0 \%$ Unconventional myosin-Ic GN=MYO1C MYO1C_HUMAN $121.68 \quad 100.0 \%$ Unconventional myosin-Ic GN=MYO1C MYO1C_HUMAN $121.68 \quad 100.0 \%$ Unconventional myosin-Ic GN=MYO1C MYO1C_HUMAN $121.68 \quad 100.0 \%$ Unconventional myosin-Ic GN=MYO1C MYO1C HUMAN $121.68 \quad 100.0 \%$ Unconventional myosin-Id GN=MYO1D MYO1D_HUMAN $116.21 \quad 100.0 \%$
$16 \quad 0.02 \% \quad 24.4 \%$ IFQGNVHNFEK

$0.02 \% \quad 26.4 \%$ LVGATATSSPPPK

$0.02 \% \quad 26.4 \%$ RLLQQSGAQQFR

$0.02 \% \quad 26.4 \%$ LLQQSGAQQFR

$0.02 \% \quad 26.4 \%$ KNNIPANFTR

$0.02 \% \quad 26.4 \%$ VQAQLNTEQLLDDV

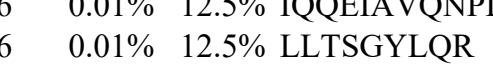

\begin{tabular}{lll}
6 & $0.01 \%$ & $12.5 \%$ \\
\hline & FFEHFIEGGR
\end{tabular}

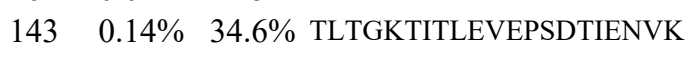

$143 \quad 0.14 \% \quad 34.6 \%$ TITLEVEPSDTIENVK

$143 \quad 0.14 \% \quad 34.6 \%$ TITLEVEPSDTIENVKAK

$143 \quad 0.14 \% \quad 34.6 \%$ IQDKEGIPPDQQR

$143 \quad 0.14 \% \quad 34.6 \%$ TLSDYNIQK

$\begin{array}{llll}143 & 0.14 \% & 34.6 \% & \text { TLSDYNIQKESTLHLVLR }\end{array}$

$143 \quad 0.14 \% \quad 34.6 \%$ ESTLHLVLR

$3 \quad 0.00 \% \quad 8.4 \%$ IGMGATLDIQR

$\begin{array}{lll}0.00 \% & 8.4 \% & \text { IGMGATLDIQR } \\ 0.00 \% & 8.4 \% & \text { QSEPAAPPLEVSEEQVAR }\end{array}$

$16 \quad 0.02 \% \quad 6.9 \% \quad$ GGIVSQVKVPK

$16 \quad 0.02 \% \quad 6.9 \% \quad$ SLVASLAEPDFVVTDFAK

$16 \quad 0.02 \% \quad 6.9 \% \quad$ LKSDTAAAAVR

$0.02 \% \quad 6.9 \%$ LAGTQPLEVLEAVQR

$16 \quad 0.02 \% \quad 6.9 \%$ AAVATFLQSVQVPEFTPK

$4 \quad 0.00 \% \quad 12.7 \%$ ESEAFVQR

$4 \quad 0.00 \% \quad 12.7 \%$ VLDVGFVGR

$4 \quad 0.00 \% \quad 12.7 \%$ LALSQAHSLVQAEAPR

$3 \quad 0.00 \% \quad 3.9 \% \quad$ ASEETLLGISK

$3 \quad 0.00 \% \quad 3.9 \%$ EIQQFSQGTRK

$4 \quad 0.00 \% \quad 3.4 \% \quad$ VSTTLNVAQAYYAR

$0.00 \% \quad 3.4 \%$ SLFPEGNPAK

$0.00 \% \quad 3.4 \% \quad$ IFLLTNNNLLLADQK

$6 \quad 0.01 \% \quad 6.2 \% \quad$ LLQFYAETCPAPER

$6 \quad 0.01 \% \quad 6.2 \% \quad$ LLQSNPVLEAFGNAK

$\begin{array}{llll}6 & 0.01 \% & 6.2 \% & \text { VLQALGSEPIQYAVPVVKYDR }\end{array}$

$6 \quad 0.01 \% \quad 6.2 \% \quad$ DGTIDFTPGSELLITK

$4 \quad 0.00 \% \quad 3.3 \%$ SRVIVQQPGER
$99.7 \% \quad 60.8$

$\begin{array}{lllll}98.3 \% & 23.1 & 25.0 & 12.7 & 2 \\ 99.7 \% & 76.9 & 25.0 & 76.9 & 2\end{array}$

$\begin{array}{llll}43.1 & 25.0 & 36.7\end{array}$

$\begin{array}{lllll}99.7 \% & 36.0 & 25.0 & 29.6 & 2\end{array}$

$\begin{array}{lllll}99.7 \% & 51.5 & 25.0 & 44.8 & 2\end{array}$

$\begin{array}{llll}99.7 \% & 43.4 & 25.0 & 41.5\end{array}$

$\begin{array}{llll}99.7 \% & 51.1 & 25.0 & 47.7\end{array}$

$\begin{array}{llll}99.7 \% & 36.0 & 25.0 & 32.0\end{array}$

$\begin{array}{llll}99.7 \% & 60.4 & 25.0 & 60.4\end{array}$

$99.2 \% \quad 24.3 \quad 25.0 \quad 16.1$

$99.7 \% \quad 32.2 \quad 25.0 \quad 27.5$

\section{TR $99.3 \%$}

$\begin{array}{llll}99.6 \% & 24.0 & 25.0 & 24.0\end{array}$

$\begin{array}{llll}99.6 \% & 27.9 & 25.0 & 20.0\end{array}$

$\begin{array}{lllll}99.7 \% & 34.3 & 25.0 & 20.0 & 3\end{array}$

$\begin{array}{llll}99.7 \% & 25.8 & 25.0 & 18.6\end{array}$

$\begin{array}{lllll}99.7 \% & 54.3 & 25.0 & 44.8\end{array}$

$\begin{array}{llll}99.7 \% & 41.8 & 25.0 & 39.7\end{array}$

$\begin{array}{llll}99.7 \% & 37.0 & 25.0 & 37.0\end{array}$

$\begin{array}{lllll}99.7 \% & 57.1 & 25.0 & 48.6 & 31\end{array}$

$\begin{array}{lllll}99.7 \% & 52.9 & 25.0 & 52.9\end{array}$

$\begin{array}{lllll}9.7 \% & 55.1 & 25.0 & 55.1 & 45\end{array}$

$\begin{array}{lllll}99.7 \% & 51.9 & 25.0 & 37.6 & 21\end{array}$

$\begin{array}{llll}99.7 \% & 60.0 & 25.0 & 47.3\end{array}$

$\begin{array}{llll}99.7 \% & 32.8 & 25.0 & 27.1\end{array}$

\begin{tabular}{lll}
77.8 & 25.0 & 57.8 \\
\hline & 25.0 & 2
\end{tabular}

$\begin{array}{llll}98.2 \% & 16.4 & 25.0 & 16.4\end{array}$

$\begin{array}{llll}99.7 \% & 52.7 & 25.0 & 52.7\end{array}$

$\begin{array}{lllll}99.7 \% & 54.0 & 25.0 & 41.8 & 3\end{array}$

$99.7 \% \quad 64.6 \quad 25.0 \quad 64.6$

$\begin{array}{llll}99.0 \% & 24.9 & 25.0 & 14.8\end{array}$

$99.7 \% \quad 54.0 \quad 25.0 \quad 54.0$

$\begin{array}{llll}99.7 \% & 37.8 & 25.0 & 37.8\end{array}$

$99.7 \% \quad 55.7 \quad 25.0 \quad 50.1$

$\begin{array}{llll}99.7 \% & 37.2 & 25.0 & 30.6\end{array}$

$\begin{array}{llll}95.0 \% & 21.2 & 25.0 & 10.7\end{array}$

$\begin{array}{llll}99.5 \% & 23.8 & 25.0 & 20.4\end{array}$

$\begin{array}{lllll}99.7 \% & 63.0 & 25.0 & 63.0 & 2\end{array}$

$\begin{array}{llll}99.7 \% & 56.0 & 25.0 & 56.0\end{array}$

$\begin{array}{lllll}99.7 \% & 39.8 & 25.0 & 39.8 & 2\end{array}$

$\begin{array}{lllll}99.7 \% & 25.5 & 25.0 & 24.0 & 0\end{array}$

$\begin{array}{llll}99.7 \% & 33.1 & 25.0 & 33.1\end{array}$

$99.6 \% \quad 26.8 \quad 25.0 \quad 16.8$ $\begin{array}{ccc}1332.67 & 276 & 286 \\ 1273.62 & 308 & 317 \\ 1225.68 & 8 & 20 \\ 1431.78 & 56 & 67 \\ 1275.68 & 57 & 67 \\ 1174.63 & 166 & 175 \\ 1884.01 & 199 & 215 \\ 2040.11 & 199 & 216 \\ 963.55 & 253 & 261 \\ 1373.74 & 273 & 285 \\ 1049.50 & 286 & 294 \\ 1167.62 & 153 & 162 \\ 1851.99 & 877 & 895 \\ 1264.71 & 1174 & 1184 \\ 1440.82 & 1304 & 1316 \\ 909.48 & 1684 & 1692 \\ 943.58 & 2236 & 2244 \\ 1723.93 & 37 & 51 \\ 1050.59 & 177 & 185 \\ 1238.60 & 189 & 198 \\ 2288.22 & 7 & 27 \\ 1787.93 & 12 & 27 \\ 1987.06 & 12 & 29 \\ 1523.78 & 30 & 42 \\ 1081.55 & 55 & 63 \\ 2130.16 & 55 & 72 \\ 1067.62 & 64 & 72 \\ 1174.63 & 233 & 243 \\ 1936.96 & 295 & 312 \\ 1111.68 & 289 & 299 \\ 1909.00 & 305 & 322 \\ 1102.62 & 527 & 537 \\ 1623.91 & 679 & 693 \\ 1933.04 & 785 & 802 \\ 965.47 & 105 & 112 \\ 961.55 & 163 & 171 \\ 1690.92 & 245 & 260 \\ 1147.62 & 268 & 278 \\ 1321.69 & 468 & 478 \\ 1556.81 & 336 & 349 \\ 1059.55 & 552 & 561 \\ 1729.98 & 1007 & 1021 \\ 1694.82 & 153 & 166 \\ 1600.87 & 174 & 188 \\ 2345.29 & 910 & 930 \\ 1706.89 & 1032 & 1047 \\ 1268.71 & 189 & 199\end{array}$

Page 177 of Table S-1-4 
Unconventional myosin-Id GN=MYO1D MYO1D_HUMAN $116.21 \quad 100.0 \%$ Unconventional myosin-Id GN=MYO1D MYO1D_HUMAN $116.21 \quad 100.0 \%$ Unconventional myosin-Va GN=MYO5A MYO5A_HUMAN $215.41 \quad 100.0 \%$ Unconventional myosin-Va GN=MYO5A MYO5A_HUMAN $215.41 \quad 100.0 \%$ Unconventional myosin-Va GN=MYO5A MYO5A_HUMAN $215.41 \quad 100.0 \%$ Unhealthy ribosome biogenesis protein 2 homolog GN=URB2 URB2_HUMAN $170.55 \quad 100.0 \%$ Unhealthy ribosome biogenesis protein 2 homolog GN=URB2 URB2 HUMAN $170.55100 .0 \%$ UPF0488 protein C8orf33 GN=C8orf33 CH033_HUMAN $24.99 \quad 100.0 \%$ $\mathrm{UPF} 0488$ protein $\mathrm{C} 8$ orf33 $\mathrm{GN}=\mathrm{C} 8$ orf3 3 UPF0488 protein $\mathrm{C} 8$ orf33 $\mathrm{GN}=\mathrm{C} 8$ orf33 UPF0488 protein $\mathrm{C} 8$ orf33 $\mathrm{GN}=\mathrm{C} 8$ orf33 $\mathrm{UPF} 0488$ protein $\mathrm{C} 8$ orf33 $\mathrm{GN}=\mathrm{C} 8$ orf33 Uridine-cytidine kinase $2 \mathrm{GN}=\mathrm{UCK} 2$ Uridine-cytidine kinase $2 \mathrm{GN}=\mathrm{UCK} 2$ Uridine-cytidine kinase $2 \mathrm{GN}=\mathrm{UCK} 2$ CH033 HUMAN $24.99 \quad 100.0 \%$ CH033_HUMAN $24.99 \quad 100.0 \%$ CH033_HUMAN $24.99 \quad 100.0 \%$ CH033 HUMAN $24.99 \quad 100.0 \%$ UCK2_HUMAN $29.30 \quad 100.0 \%$ UCK2 HUMAN $29.30 \quad 100.0 \%$ UCK2 HUMAN $29.30 \quad 100.0 \%$ Uridine-cytidine kinase-like 1 GN=UCKL1 UCKL1_HUMAN $61.14 \quad 99.9 \%$ Uridine-cytidine kinase-like $1 \mathrm{GN}=\mathrm{UCKL} 1 \mathrm{UCKL} 1$ HUMAN $61.1499 .9 \%$ Vacuolar protein sorting-associated protein 26A GN=VPS26A VP26A_HUMAN $38.17 \quad 100.0 \%$ Vacuolar protein sorting-associated protein 26A GN=VPS26A VP26A_HUMAN $38.17 \quad 100.0 \%$ Vacuolar protein sorting-associated protein 26A GN=VPS26A VP26A_HUMAN $38.17 \quad 100.0 \%$ Vacuolar protein sorting-associated protein 26B GN=VPS26B VP26B_HUMAN $39.16 \quad 100.0 \%$ Vacuolar protein sorting-associated protein 26B GN=VPS26B VP26B HUMAN $39.16 \quad 100.0 \%$ Vacuolar protein sorting-associated protein 33B GN=VPS33B VP33B_HUMAN $70.59 \quad 100.0 \%$ Vacuolar protein sorting-associated protein 33B GN=VPS33B VP33B_HUMAN $70.59 \quad 100.0 \%$ Vacuolar protein sorting-associated protein 33B GN=VPS33B VP33B HUMAN $70.59 \quad 100.0 \%$ Vacuolar protein sorting-associated protein 33B GN=VPS33B VP33B_HUMAN $70.59 \quad 100.0 \%$ Vacuolar protein sorting-associated protein $35 \mathrm{GN}=$ VPS35 VPS35_HUMAN $91.71 \quad 100.0 \%$ Vacuolar protein sorting-associated protein $35 \mathrm{GN}=\mathrm{VPS} 35$ VPS35 HUMAN $91.71 \quad 100.0 \%$ Vacuolar protein sorting-associated protein $35 \mathrm{GN}=\mathrm{VPS} 35$ VPS35_HUMAN $91.71 \quad 100.0 \%$ Very-long-chain (3R)-3-hydroxyacyl-CoA dehydratase $3 \mathrm{GN}=\mathrm{HACD} 3 \mathrm{HACD} 3$ HUMAN $43.16100 .0 \%$ Very-long-chain (3R)-3-hydroxyacyl-CoA dehydratase 3 GN=HACD3 HACD3_HUMAN $43.16 \quad 100.0 \%$ Very-long-chain (3R)-3-hydroxyacyl-CoA dehydratase 3 GN=HACD3 HACD3_HUMAN $43.16 \quad 100.0 \%$ Vry-long-chain (3R)-3-hydroxyacyl-CoA dehydratase $3 \mathrm{GN}=\mathrm{HACD} 3 \mathrm{HACD} 3 \mathrm{HUMAN} 43.16 \quad 100.0 \%$ Very-long-chain (3R)-3-hydroxyacyl-CoA dehydratase 3 GN=HACD3 HACD3_HUMAN $43.16 \quad 100.0 \%$ Very-long-chain 3-oxoacyl-CoA reductase GN=HSD17B12 DHB12_HUMAN $34.33 \quad 100.0 \%$ Very-long-chain 3-oxoacyl-CoA reductase GN=HSD17B12 DHB12_HUMAN $34.33 \quad 100.0 \%$ Very-long-chain 3-oxoacyl-CoA reductase GN=HSD17B12 DHB12_HUMAN $34.33 \quad 100.0 \%$ Very-long-chain 3-oxoacyl-CoA reductase GN=HSD17B12 DHB12 HUMAN $34.33100 .0 \%$ Very-long-chain 3-oxoacyl-CoA reductase GN=HSD17B12 DHB12_HUMAN $34.33 \quad 100.0 \%$ Very-long-chain 3-oxoacyl-CoA reductase GN=HSD17B12 DHB12_HUMAN $34.33 \quad 100.0 \%$ Very-long-chain 3-oxoacyl-CoA reductase GN=HSD17B12 DHB12_HUMAN $34.33 \quad 100.0 \%$ Very-long-chain 3-oxoacyl-CoA reductase GN=HSD17B12 DHB12_HUMAN $34.33 \quad 100.0 \%$ Very-long-chain 3-oxoacyl-CoA reductase GN=HSD17B12 DHB12 HUMAN $34.33 \quad 100.0 \%$ Very-long-chain enoyl-CoA reductase GN=TECR TECR_HUMAN $36.04 \quad 100.0 \%$ Very-long-chain enoyl-CoA reductase GN=TECR TECR_HUMAN $36.04 \quad 100.0 \%$ Very-long-chain enoyl-CoA reductase GN=TECR TECR HUMAN $36.04 \quad 100.0 \%$ Vesicle-fusing ATPase GN=NSF
$0.00 \% \quad 3.3 \% \quad$ LMYNSSNPVLK

$0.00 \% \quad 3.3 \%$ SIPASDLPQVR

$0.00 \% \quad 1.6 \%$ LGNADNFNYTK

$0.00 \% \quad 1.6 \%$ ACGVLETIR

$0.00 \% \quad 1.6 \%$ VLSLQEEIAK

$0.00 \% \quad 1.6 \%$ SLDSSTPLPIVR

$0.00 \% \quad 1.6 \%$ GEIAQNLLSLVK

$0.01 \% \quad 21.4 \%$ LPGPVSSAR

$0.01 \% \quad 21.4 \%$ AHPLGDEGGTASK

$0.01 \% 21.4 \%$ QKEQAIGAIR

$\begin{array}{lll}0.01 \% & 21.4 \% & \text { AAAYSAQVQPVDGATR } \\ 0.01 \% & 21.4 \% & \text { AAAYSAQVQPVDGATRK }\end{array}$

$0.01 \% \quad 13.0 \%$ QVVILSQDSFYR

$0.01 \% \quad 13.0 \%$ TVQIPVYDFVSHSR

$0.01 \% \quad 13.0 \%$ YADVIIPR

$0.00 \% \quad 3.1 \%$ LADIVVPR

$0.00 \% \quad 3.1 \%$ QITGVSILR

$0.01 \% \quad 13.1 \%$ ELALPGELTQSR

$0.01 \% \quad 13.1 \%$ EITGIGPSTTTETETIAK

$0.01 \% \quad 13.1 \%$ LFLAGYDPTPTMR

$0.00 \% \quad 7.1 \%$ LFLAGYELTPTMR

$0.00 \% \quad 7.1 \%$ FEGTTSLGEVR

$0.01 \% \quad 8.4 \%$ YIASLVNADKLAGR

$0.01 \% \quad 8.4 \%$ AGLLTEQAPGDTLTAVESK

$0.01 \% \quad 8.4 \%$ VDGEYDLKVPR

$0.01 \% \quad 8.4 \%$ IIEQVLER

$0.00 \% \quad 4.3 \% \quad$ ILVGTNLVR

$0.00 \% \quad 4.3 \% \quad$ LSQLEGVNVER

$0.00 \% \quad 4.3 \% \quad$ IPVDTYNNILTVLK

$0.03 \% \quad 9.7 \%$ QVNITVQK

$0.03 \% \quad 9.7 \% \quad$ LRLESEGSPETLTNLR

$0.03 \% \quad 9.7 \%$ LESEGSPETLTNLR

$0.03 \% \quad 9.7 \%$ LESEGSPETLTNLRK

$0.03 \% \quad 9.7 \% \quad$ FSFTLPYPVK

$0.03 \% \quad 35.9 \%$ ISYSLFTALR

$0.03 \% \quad 35.9 \%$ SYAEELAK

$0.03 \% \quad 35.9 \%$ DKLDQVSSEIK

$0.03 \% \quad 35.9 \%$ TIAVDFASEDIYDKIK

$0.03 \% \quad 35.9 \%$ MININILSVCK

$0.03 \% \quad 35.9 \%$ MTQLVLPGMVER

$0.03 \% 35.9 \%$ TFVDFFSQCLHEEYR

$0.03 \% \quad 35.9 \%$ GVFVQSVLPYFVATK

$0.03 \% \quad 35.9 \%$ KPTLDKPSPETFVK

$0.01 \% \quad 10.1 \%$ SLKDEDVLQK

$0.01 \% \quad 10.1 \%$ LPVGTTATLYFR

$0.01 \% \quad 10.1 \%$ LLETLFVHR

$0.01 \% \quad 14.5 \%$ GILLYGPPGCGK $\begin{array}{llllllll}97.0 \% & 16.8 & 25.0 & 14.8 & 1 & 0 & 0 & 1281.65\end{array}$

$\begin{array}{llllllll}99.7 \% & 30.6 & 25.0 & 19.6 & 2 & 0 & 0 & 1182.65\end{array}$

$\begin{array}{llllllll}99.7 \% & 30.1 & 25.0 & 30.1 & 2 & 0 & 0 & 1256.59\end{array}$

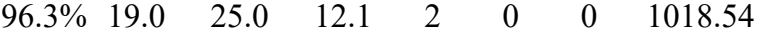

$\begin{array}{llllllll}94.5 \% & 15.3 & 25.0 & 13.4 & 1 & 0 & 0 & 1129.65\end{array}$

$\begin{array}{llllllll}99.7 \% & 34.3 & 25.0 & 30.0 & 2 & 0 & 0 & 1284.72\end{array}$

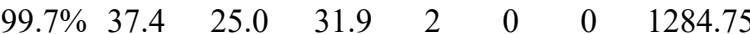

$\begin{array}{llllllll}99.7 \% & 40.8 & 25.0 & 17.8 & 2 & 0 & 0 & 883.50\end{array}$

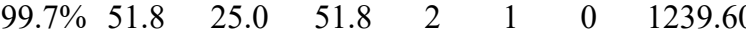

$\begin{array}{llllllll}95.5 \% & 19.4 & 25.0 & 10.6 & 1 & 0 & 0 & 1113.64\end{array}$

1113.64
1604.80

1732.90

1454.76

1647.85

946.54

882.54

986.60

1313.71

1848.94

1497.74

1527.79

1195.60

1490.83

1900.99

1290.67

999.58

984.62

1243.66

1602.91

929.54

1814.96

1545.78

1673.87

1198.65

1170.65

910.45

$\begin{array}{llll}99.7 \% & 71.0 & 25.0 & 63.2\end{array}$

$\begin{array}{lllll}99.0 \% & 22.3 & 25.0 & 15.6\end{array}$

$\begin{array}{llll}98.6 \% & 17.7 & 25.0 & 17.7\end{array}$

$\begin{array}{llll}99.7 \% & 85.7 & 25.0 & 82.2\end{array}$

$\begin{array}{llll}99.7 \% & 61.3 & 25.0 & 59.7\end{array}$

$\begin{array}{llll}99.7 \% & 64.5 & 25.0 & 51.8\end{array}$

$\begin{array}{llll}99.7 \% & 43.5 & 25.0 & 43.5\end{array}$

$99.7 \% \quad 41.3 \quad 25.0 \quad 41.3$

$\begin{array}{llll}99.6 \% & 23.9 & 25.0 & 23.9\end{array}$

$\begin{array}{llll}99.7 \% & 48.4 & 25.0 & 32.1\end{array}$

$\begin{array}{llll}99.7 \% & 67.9 & 25.0 & 67.9\end{array}$

$99.7 \% \quad 51.0 \quad 25.0 \quad 34.3$

$\begin{array}{llll}99.7 \% & 33.5 & 25.0 & 24.7\end{array}$ \begin{tabular}{cc}
34 & 544 \\
91 & 801 \\
79 & 289 \\
83 & 691 \\
85 & 994 \\
55 & 566 \\
68 & 879 \\
8 & 36 \\
7 & 69 \\
34 & 143 \\
83 & 198 \\
83 & 199 \\
5 & 66 \\
06 & 119 \\
03 & 210 \\
74 & 281 \\
93 & 401 \\
4 & 105 \\
15 & 232 \\
50 & 262 \\
48 & 260 \\
14 & 324 \\
4 & 107 \\
40 & 458 \\
97 & 507 \\
24 & 531 \\
18 & 226 \\
27 & 237 \\
04 & 417 \\
7 & 84 \\
31 & 146 \\
33 & 146 \\
32 & 150 \\
33 & 147 \\
10 & 319 \\
6 & 35 \\
5 & 72 \\
5 & 95 \\
04 & 119 \\
57 & 167 \\
68 & 179 \\
07 & 221 \\
24 & 238 \\
44 & 257 \\
& 67 \\
\hline
\end{tabular}

Page 178 of Table S-1-4 
Vesicle-fusing ATPase GN=NSF Vesicle-fusing ATPase $\mathrm{GN}=\mathrm{NSF}$ Vesicle-fusing ATPase $\mathrm{GN}=\mathrm{NSF}$ Vesicle-fusing ATPase $\mathrm{GN}=\mathrm{NSF}$ Vesicle-fusing ATPase $\mathrm{GN}=\mathrm{NSF}$ Vesicle-fusing ATPase GN=NSF

Vesicle-fusing ATPase GN=NSF

Vimentin GN=VIM

Vimentin GN=VIM

Vimentin GN=VIM

Vimentin $\mathrm{GN}=\mathrm{VIM}$

Vimentin GN=VIM

Vimentin $\mathrm{GN}=\mathrm{VIM}$

Vimentin GN=VIM

Vimentin GN=VIM

Vimentin GN=VIM

Vimentin $\mathrm{GN}=\mathrm{VIM}$

Vimentin GN=VIM

Vimentin GN=VIM

Vimentin GN=VIM

Vimentin GN=VIN

Vimentin GN=VIM

Vimentin GN=VIM

Vimentin GN=VIM

Vimentin GN=VIM

Vimentin GN=VIM

Vimentin GN=VIM

Vimentin GN=VIM

Vimentin $\mathrm{GN}=\mathrm{VIM}$

Vimentin GN=VIM

Vimentin GN=VIM

Vimentin GN=VIM

Vimentin GN=VIM

Vimentin $\mathrm{GN}=\mathrm{VIM}$

Vimentin GN=VIM

Vimentin GN=VIM

Vimentin GN=VIM

Vimentin GN=VIM

Vimentin GN=VIM

Vimentin GN=VIM

Vimentin GN=VIM

Vimentin $\mathrm{GN}=\mathrm{VIM}$

Vimentin GN=VIM

Vimentin GN=VIM

Vimentin GN=VIM
NSF_HUMAN $82.60 \quad 100.0 \% \quad 8$ NSF HUMAN $82.60 \quad 100.0 \%$ NSF_HUMAN $82.60 \quad 100.0 \%$ NSF HUMAN $82.60 \quad 100.0 \%$ NSF HUMAN $82.60 \quad 100.0 \%$ NSF_HUMAN $82.60 \quad 100.0 \%$ NSF HUMAN $82.60 \quad 100.0 \%$ VIME_HUMAN $53.65 \quad 100.0 \% \quad 38$ VIME HUMAN $53.65 \quad 100.0 \% \quad 38$ VIME HUMAN $53.65 \quad 100.0 \% \quad 38$ VIME_HUMAN $53.65 \quad 100.0 \% \quad 38$ VIME HUMAN $53.65 \quad 100.0 \% \quad 38$ VIME_HUMAN $53.65 \quad 100.0 \% \quad 38$ VIME_HUMAN $53.65 \quad 100.0 \% \quad 38$ VIME HUMAN $53.65 \quad 100.0 \% \quad 38$ VIME_HUMAN $53.65 \quad 100.0 \% \quad 38$ VIME HUMAN $53.65 \quad 100.0 \% \quad 38$ VIME_HUMAN $53.65 \quad 100.0 \% \quad 38$ VIME_HUMAN $53.65 \quad 100.0 \% \quad 38$ VIME HUMAN $53.65 \quad 100.0 \% \quad 38$ VIME_HUMAN $53.65 \quad 100.0 \% \quad 38$ VIME HUMAN $53.65 \quad 100.0 \% \quad 38$ VIME HUMAN $53.65 \quad 100.0 \% \quad 38$ VIME_HUMAN $53.65 \quad 100.0 \% \quad 38$ VIME HUMAN $53.65 \quad 100.0 \% \quad 38$ VIME_HUMAN $53.65 \quad 100.0 \% \quad 38$ VIME_HUMAN $53.65 \quad 100.0 \% \quad 38$ VIME HUMAN $53.65 \quad 100.0 \% \quad 38$ VIME_HUMAN $53.65 \quad 100.0 \% \quad 38$ VIME HUMAN $53.65 \quad 100.0 \% \quad 38$ VIME HUMAN $53.65 \quad 100.0 \% \quad 38$ VIME_HUMAN $53.65 \quad 100.0 \% \quad 38$ VIME HUMAN $53.65 \quad 100.0 \% \quad 38$ VIME_HUMAN $53.65 \quad 100.0 \% \quad 38$ VIME_HUMAN $53.65 \quad 100.0 \% \quad 38$ VIME HUMAN $53.65 \quad 100.0 \% \quad 38$ VIME_HUMAN $53.65 \quad 100.0 \% \quad 38$ VIME HUMAN $53.65 \quad 100.0 \% \quad 38$ VIME_HUMAN $53.65 \quad 100.0 \% \quad 38$ VIME_HUMAN $53.65 \quad 100.0 \% \quad 38$ VIME HUMAN $53.65 \quad 100.0 \% \quad 38$ VIME_HUMAN $53.65 \quad 100.0 \% \quad 38$ VIME HUMAN $53.65 \quad 100.0 \% \quad 38$ VIME HUMAN $53.65 \quad 100.0 \% \quad 38$ VIME_HUMAN $53.65 \quad 100.0 \% \quad 38$ $00.0 \% \quad 4$ $100.0 \%$$$
\begin{aligned}
& 15 \\
& 15
\end{aligned}
$$

$\begin{array}{llll}15 & 0.01 \% & 14.5 \% & \text { VLDDGELLVQQTK }\end{array}$

$15 \quad 0.01 \% \quad 14.5 \%$ NSDRTPLVSVLLEGPPH

$\begin{array}{lllll}99.7 \% & 68.8 & 25.0 & 68.8 & 2\end{array}$

$15 \quad 0.01 \% \quad 14.5 \%$ IAEESNFPFIK

$15 \quad 0.01 \% \quad 14.5 \%$ LLDYVPIGPR

$15 \quad 0.01 \% \quad 14.5 \%$ KLLIIGTTSR

$\begin{array}{llll}251 & 0.25 \% & 71.5 \% & \text { SVSSSSYR }\end{array}$

$251 \quad 0.25 \% \quad 71.5 \%$ SVSSSSYRR

$251 \quad 0.25 \% \quad 71.5 \%$ MFGGPGTASRPSSSR

$251 \quad 0.25 \% \quad 71.5 \%$ SYVTTSTR

$\begin{array}{llll}99.0 \% & 39.8 & 25.0 & 34.1\end{array}$

$251 \quad 0.25 \% \quad 71.5 \%$ TYSLGSALRPSTSR

$251 \quad 0.25 \% \quad 71.5 \%$ SLYASSPGGVYATR

$251 \quad 0.25 \% \quad 71.5 \%$ LRSSVPGVR

$96.0 \% \quad 14.3$

$99.7 \% \quad 41.8$

$99.7 \% \quad 56.3$

$99.5 \% \quad 27.7$

$251 \quad 0.25 \% \quad 71.5 \%$ LLQDSVDFSLADAINTEFK $99.7 \% \quad 75.4$

$251 \quad 0.25 \% \quad 71.5 \%$ LLQDSVDFSLADAINTEFKNTR $\quad 99.7 \% \quad 53.0$

$251 \quad 0.25 \% \quad 71.5 \%$ TNEKVELQELNDR

$251 \quad 0.25 \% \quad 71.5 \%$ FANYIDKVR

$251 \quad 0.25 \% \quad 71.5 \%$ ILLAELEQLK

$251 \quad 0.25 \% \quad 71.5 \%$ ILLAELEQLKGQGK

$251 \quad 0.25 \% \quad 71.5 \%$ QVDQLTNDKAR

$251 \quad 0.25 \% \quad 71.5 \%$ VEVERDNLAEDIMR

$251 \quad 0.25 \% \quad 71.5 \%$ QDVDNASLAR

$251 \quad 0.25 \% \quad 71.5 \%$ KVESLQEEIAFLK

$251 \quad 0.25 \% \quad 71.5 \%$ DVRQQYESVAAK

$251 \quad 0.25 \% \quad 71.5 \%$ QQYESVAAK

$251 \quad 0.25 \% \quad 71.5 \%$ NLQEAEEWYK

$251 \quad 0.25 \% \quad 71.5 \%$ NLQEAEEWYKSK

$251 \quad 0.25 \% \quad 71.5 \%$ FADLSEAANR

$97.1 \% \quad 15.6$

$99.7 \% \quad 45.3$

$99.7 \% \quad 58.6$

$99.7 \% \quad 55.6$

$99.7 \% \quad 56.4$

$99.7 \% \quad 38.8$

$99.7 \% \quad 67.4$

$99.7 \% \quad 55.9$

$99.7 \% \quad 54.9$

$99.7 \% \quad 52.1$

$99.7 \% \quad 32.4$

$99.7 \% \quad 49.0$

$99.7 \% \quad 63.5$

$251 \quad 0.25 \% \quad 71.5 \%$ FADLSEAANRNNDALR

$99.7 \% 56.1$

$\begin{array}{llllll}251 & 0.25 \% & 71.5 \% & \text { QVQSLTCEVDALKGTNESLER } & 99.7 \% & 54.8\end{array}$

$251 \quad 0.25 \% \quad 71.5 \%$ GTNESLER

$251 \quad 0.25 \% \quad 71.5 \%$ LQDEIQNMKEEMAR

$251 \quad 0.25 \% \quad 71.5 \%$ HLREYQDLLNVK

$251 \quad 0.25 \% \quad 71.5 \%$ EYQDLLNVK

$251 \quad 0.25 \% \quad 71.5 \%$ MALDIEIATYR

$251 \quad 0.25 \% \quad 71.5 \%$ KLLEGEESR

$99.0 \% 31.6$

$98.6 \% 18.7$

$99.7 \% \quad 47.0$

$99.7 \% \quad 51.7$

$99.7 \% \quad 61.7$

$99.7 \% \quad 51.5$

$99.0 \% \quad 37.7$

$99.7 \% \quad 51.6$

$251 \quad 0.25 \% \quad 71.5 \%$ ISLPLPNFSSLNLR

$99.7 \% \quad 65.8$

$\begin{array}{lllllll}251 & 0.25 \% & 71.5 \% & \text { ISLPLPNFSSLNLRETNLDSLPLVDTHSK } & 99.4 \% & 25.3\end{array}$

$251 \quad 0.25 \% \quad 71.5 \%$ ETNLDSLPLVDTHSKR $\quad 99.7 \% \quad 39.3$

$251 \quad 0.25 \% \quad 71.5 \%$ TVETRDGQVINETSQHHDDLE $99.7 \% \quad 52.5$

$\begin{array}{llllll}251 & 0.25 \% & 71.5 \% & \text { DGQVINETSQHHDDLE } & 99.7 \% & 55.3\end{array}$

$99.7 \% \quad 47.3$

$5 \quad 0.00 \% \quad 25.1 \%$ WTEYGLTFTEK

$\begin{array}{ll}99.7 \% & 47.3 \\ 99.7 \% & 80.9\end{array}$

$\begin{array}{ccc}2201.16 & 284 & 303 \\ 1291.66 & 435 & 446 \\ 1457.78 & 517 & 529 \\ 2103.12 & 530 & 549 \\ 1294.67 & 556 & 566 \\ 1142.66 & 608 & 617 \\ 1101.70 & 639 & 648 \\ 872.41 & 5 & 12 \\ 1028.51 & 5 & 13 \\ 1510.71 & 14 & 28 \\ 914.46 & 29 & 36 \\ 2391.23 & 29 & 50 \\ 1495.79 & 37 & 50 \\ 1428.71 & 51 & 64 \\ 970.58 & 70 & 78 \\ 2126.07 & 79 & 97 \\ 2497.26 & 79 & 100 \\ 1587.80 & 101 & 113 \\ 1125.61 & 114 & 122 \\ 1169.71 & 130 & 139 \\ 1539.91 & 130 & 143 \\ 1287.67 & 160 & 170 \\ 1688.83 & 171 & 184 \\ 1088.53 & 208 & 217 \\ 1533.85 & 223 & 235 \\ 1393.71 & 271 & 282 \\ 1023.51 & 274 & 282 \\ 1309.61 & 283 & 292 \\ 1524.73 & 283 & 294 \\ 1093.53 & 295 & 304 \\ 1776.86 & 295 & 310 \\ 2377.17 & 322 & 342 \\ 905.43 & 335 & 342 \\ 1766.81 & 365 & 378 \\ 1527.83 & 379 & 390 \\ 1121.58 & 382 & 390 \\ 1295.67 & 391 & 401 \\ 1060.56 & 402 & 410 \\ 932.47 & 403 & 410 \\ 2484.35 & 403 & 424 \\ 1570.90 & 411 & 424 \\ 3220.72 & 411 & 439 \\ 1824.95 & 425 & 440 \\ 2423.11 & 446 & 466 \\ 1836.80 & 451 & 466 \\ 1374.66 & 64 & 74 \\ 2176.05 & 75 & 93 \\ & & \end{array}$

Page 179 of Table S-1-4 

V-type proton ATPase subunit d 1 GN=ATP6V0D1 VA0D1_HUMAN $40.33 \quad 100.0 \%$ WD repeat-containing protein $1 \mathrm{GN}=$ WDR1 WDR1 HUMAN $66.19 \quad 100.0 \%$ WD repeat-containing protein 1 GN=WDR1 WDR1_HUMAN $66.19 \quad 100.0 \%$ WD repeat-containing protein $1 \mathrm{GN}=$ WDR1 WDR1_HUMAN $66.19 \quad 100.0 \%$ WD repeat-containing protein $5 \mathrm{GN}=$ WDR5 WDR5 HUMAN $36.59 \quad 100.0 \%$ WD repeat-containing protein 5 GN=WDR5 WDR5_HUMAN $36.59 \quad 100.0 \%$ WD repeat-containing protein $5 \mathrm{GN}=$ WDR5 WDR5 HUMAN $36.59100 .0 \%$ WD repeat-containing protein 5 GN=WDR5 WDR5_HUMAN $36.59 \quad 100.0 \%$ WD repeat-containing protein 5 GN=WDR5 WDR5_HUMAN $36.59 \quad 100.0 \%$ WD repeat-containing protein 5 GN=WDR5 WDR5 HUMAN $36.59 \quad 100.0 \%$ WD repeat-containing protein 6 GN=WDR6 WDR6_HUMAN $121.72 \quad 100.0 \%$

$0.00 \% \quad 25.1 \%$ VTQSNFAVGYK $99.7 \% \quad 36.2$ $0.00 \% \quad 25.1 \%$ VNNSSLIGLGYTQTLKPGIK $0.00 \% \quad 25.1 \%$ LTLSALLDGK

$0.03 \% \quad 46.3 \%$ GFGFGLVK

$0.03 \% \quad 46.3 \%$ VTGTLETK

$0.03 \% \quad 46.3 \%$ WCEYGLTFTEK $\begin{array}{lll}99.3 \% & 65.2\end{array}$ $97.7 \% 16.8$ $97.9 \% \quad 18.9$ $99.7 \% \quad 41.6$

$0.03 \% \quad 46.3 \%$ WNTDNTLGTEIAIEDQICQGLK $99.7 \% \quad 67.3$

$0.03 \% \quad 46.3 \%$ LTFDTTFSPNTGK

$0.03 \% \quad 46.3 \%$ LTFDTTFSPNTGKK

$99.7 \% \quad 61.8$ $99.7 \% \quad 61.7$ $99.0 \% \quad 58.8$

$0.03 \% \quad 46.3 \%$ NNFAVGYR

$0.03 \% \quad 46.3 \%$ TGDFQLHTNVNDGT

$\begin{array}{lll}99.7 \% & 52.8\end{array}$

$99.7 \% \quad 48.7$

$0.03 \% \quad 46.3 \%$ VNNSSLIGVGYTQTLRPGVK

$0.03 \% \quad 46.3 \%$ LTLSALVDGK

$0.05 \% \quad 54.1 \%$ GYGFGMVK

$99.7 \% \quad 60.1$

$99.0 \% \quad 34.5$

$0.05 \% \quad 54.1 \%$ SCSGVEFSTSGHAYTDTGK

$0.05 \% \quad 54.1 \%$ YKVCNYGLTFTQK

$99.7 \% 72.8$

$99.7 \% \quad 65.0$

$\begin{array}{llll}99.7 \% & 51.0 & 25.0 & 41.7 \\ 99.7 \% & 60.0 & 25.0 & 60.0\end{array}$

$\begin{array}{llll}99.7 \% & 60.0 & 25.0 & 60.0\end{array}$

$\begin{array}{lllll}99.7 \% & 29.9 & 25.0 & 29.9 & 4\end{array}$

$99.7 \% \quad 54.0 \quad 25.0 \quad 47.0$

$\begin{array}{llll}99.7 \% & 54.7 & 25.0 & 45.5\end{array}$

$0.05 \%$

$\begin{array}{lll}0.05 \% & 54.1 \% & \text { LTLDTIFVPNTGKK } \\ 0.05 \% & 54.1 \% & \text { SKLSQNNFALGYK }\end{array}$

3

3
3
2

2
2
5

5
5
5

5
5

5
3
3

3
3
3

3
6
6

6
6

6

6
6


WD repeat-containing protein $6 \mathrm{GN}=$ WDR6 WDR6_HUMAN $121.72 \quad 100.0 \%$ WD repeat-containing protein $81 \mathrm{GN}=$ WDR81 WDR81_HUMAN $211.70 \quad 100.0 \%$ WD repeat-containing protein $81 \mathrm{GN}=$ WDR81 WDR81_HUMAN $211.70 \quad 100.0 \%$ WD repeat-containing protein $81 \mathrm{GN}=$ WDR81 WDR81_HUMAN $211.70 \quad 100.0 \%$ WD repeat-containing protein $82 \mathrm{GN}=$ WDR82 WDR82_HUMAN $35.08 \quad 100.0 \%$ WD repeat-containing protein $82 \mathrm{GN}=$ WDR82 WDR82_HUMAN $35.08 \quad 100.0 \%$ WD repeat-containing protein $82 \mathrm{GN}=$ WDR82 WDR82_HUMAN $35.08 \quad 100.0 \%$ WD repeat-containing protein 82 GN=WDR82 WDR82_HUMAN $35.08 \quad 100.0 \%$ WD repeat-containing protein $82 \mathrm{GN}=$ WDR82 WDR82_HUMAN $35.08 \quad 100.0 \%$ WD repeat-containing protein 82 GN=WDR82 WDR82_HUMAN $35.08 \quad 100.0 \%$ X-ray repair cross-complementing protein $5 \mathrm{GN}=\mathrm{XRCC} 5 \mathrm{XRCC} 5$ HUMAN $82.71 \quad 100.0 \%$ X-ray repair cross-complementing protein $5 \mathrm{GN}=$ XRCC5 XRCC5_HUMAN $82.71 \quad 100.0 \%$ X-ray repair cross-complementing protein $5 \mathrm{GN}=\mathrm{XRCC} 5 \mathrm{XRCC5}$ _HUMAN $82.71 \quad 100.0 \%$ X-ray repair cross-complementing protein $5 \mathrm{GN}=\mathrm{XRCC} 5$ XRCC5_HUMAN $82.71 \quad 100.0 \%$ X-ray repair cross-complementing protein $5 \mathrm{GN}=\mathrm{XRCC} 5 \mathrm{XRCC5}$ _HUMAN $82.71 \quad 100.0 \%$ X-ray repair cross-complementing protein $5 \mathrm{GN}=\mathrm{XRCC} 5$ XRCC5_HUMAN $82.71 \quad 100.0 \%$ X-ray repair cross-complementing protein $5 \mathrm{GN}=\mathrm{XRCC} 5 \mathrm{XRCC} 5$ HUMAN $82.71 \quad 100.0 \%$ X-ray repair cross-complementing protein $6 \mathrm{GN}=\mathrm{XRCC6}$ XRCC6_HUMAN $69.85 \quad 100.0 \%$ X-ray repair cross-complementing protein $6 \mathrm{GN}=$ XRCC6 XRCC6_HUMAN $69.85 \quad 100.0 \%$ X-ray repair cross-complementing protein $6 \mathrm{GN}=\mathrm{XRCC} 6$ XRCC6_HUMAN $69.85 \quad 100.0 \%$ X-ray repair cross-complementing protein $6 \mathrm{GN}=\mathrm{XRCC} 6 \mathrm{XRCC6}$ _HUMAN $69.85 \quad 100.0 \%$ X-ray repair cross-complementing protein $6 \mathrm{GN}=$ XRCC6 XRCC6_HUMAN $69.85 \quad 100.0 \%$ X-ray repair cross-complementing protein $6 \mathrm{GN}=\mathrm{XRCC} 6$ XRCC6_HUMAN $69.85 \quad 100.0 \%$ X-ray repair cross-complementing protein $6 \mathrm{GN}=\mathrm{XRCC} 6$ XRCC6_HUMAN $69.85 \quad 100.0 \%$ X-ray repair cross-complementing protein $6 \mathrm{GN}=\mathrm{XRCC} 6$ XRCC6_HUMAN 69.85 X-ray repair cross-complementing protein $6 \mathrm{GN}=\mathrm{XRCC6}$ XRCC6_HUMAN 69.85 X-ray repair cross-complementing protein $6 \mathrm{GN}=\mathrm{XRCC} 6$ XRCC6_HUMAN 69.85 X-ray repair cross-complementing protein $6 \mathrm{GN}=\mathrm{XRCC} 6$ XRCC6_HUMAN 69.85 YTH domain-containing family protein $2 \mathrm{GN}=\mathrm{YTHDF} 2$ YTHD2_HUMAN $62.3 ?$ YTH domain-containing family protein $2 \mathrm{GN}=$ YTHDF2 YTHD2 HUMAN 62.33 YTH domain-containing family protein $2 \mathrm{GN}=$ YTHDF2 YTHD2_HUMAN 62.33 YTH domain-containing family protein $2 \mathrm{GN}=$ YTHDF2 YTHD2_HUMAN 62.33 YTH domain-containing protein $1 \mathrm{GN}=$ YTHDC1 YTDC1_HUMAN 84.70 YTH domain-containing protein $1 \mathrm{GN}=$ YTHDC1 YTDC1_HUMAN 84.70 YTH domain-containing protein $1 \mathrm{GN}=$ YTHDC1 YTDC1_HUMAN 84.70 YTH domain-containing protein $1 \mathrm{GN}=$ YTHDC1 YTDC1_HUMAN 84.70 YTH domain-containing protein $1 \mathrm{GN}=$ YTHDC1 YTDC1_HUMAN 84.70 Zinc finger $\mathrm{CCCH}$ domain-containing protein $11 \mathrm{~A} \mathrm{GN}=\mathrm{ZC} 3 \mathrm{H} 11 \mathrm{~A}$ ZCC11A_HUMAN 89.1 . Zinc finger CCCH domain-containing protein $11 \mathrm{~A}$ GN=ZC3H11A ZC11A_HUMAN $89.13 \quad 100.0 \%$ Zinc finger $\mathrm{CCCH}$ domain-containing protein $11 \mathrm{~A} \mathrm{GN}=\mathrm{ZC} 3 \mathrm{H} 11 \mathrm{~A}$ ZC11A_HUMAN $89.13 \quad 100.0 \%$ Zinc finger CCCH domain-containing protein $13 \mathrm{GN}=\mathrm{ZC} 3 \mathrm{H} 13$ ZC3HD_HUMAN $196.64100 .0 \%$ Zinc finger CCCH domain-containing protein $13 \mathrm{GN}=\mathrm{ZC} 3 \mathrm{H} 13 \mathrm{ZC} 3 \mathrm{HD} \_$HUMAN $196.64 \quad 100.0 \%$ Zinc finger CCCH domain-containing protein $13 \mathrm{GN}=\mathrm{ZC} 3 \mathrm{H} 13$ ZC3HD HUMAN $196.64100 .0 \%$ Zinc finger $\mathrm{CCCH}$ domain-containing protein $18 \mathrm{GN}=\mathrm{ZC} 3 \mathrm{H} 18 \mathrm{ZCH} 18$ _HUMAN $106.38 \quad 100.0 \%$ Zinc finger $\mathrm{CCCH}$ domain-containing protein $18 \mathrm{GN}=\mathrm{ZC} 3 \mathrm{H} 18 \mathrm{ZCH} 18 \_H U M A N \quad 106.38 \quad 100.0 \%$ Zinc finger $\mathrm{CCCH}$ domain-containing protein $8 \mathrm{GN}=\mathrm{ZC} 3 \mathrm{H} 8 \quad \mathrm{ZC} 3 \mathrm{H} 8$ _HUMAN $33.58 \quad 100.0 \%$ Zinc finger $\mathrm{CCCH}$ domain-containing protein $8 \mathrm{GN}=\mathrm{ZC} 3 \mathrm{H} 8 \mathrm{ZC} 3 \mathrm{H} 8$ _ $\mathrm{HUMAN} 33.58 \quad 100.0 \%$
$0.00 \% \quad 1.8 \%$ GLGVSALCFK $99.7 \% \quad 40.8$ $0.00 \% \quad 2.3 \%$ QLAPAPGGTHVVALVPAR $0.00 \% \quad 2.3 \% \quad$ LAGAPALAPEPPLIPK $0.00 \% \quad 2.3 \%$ LGGGLNPGLVR $0.01 \% \quad 24.9 \%$ YTHAANTVVYSSNK $0.01 \% \quad 24.9 \%$ YLSLHDNK $99.5 \% \quad 22.5$ $99.7 \% \quad 26.1$ $99.7 \% \quad 60.0$ $99.0 \% \quad 33.8$

$0.01 \% \quad 24.9 \%$ VVALSMSPVDDTFISGSLDK $99.7 \% 56.5$ $0.01 \% \quad 24.9 \%$ SFDKGPFATFK $0.01 \% \quad 24.9 \%$ LILISTNGSFIR $0.01 \% \quad 24.9 \%$ HTGPITCLQFNPK $0.01 \% \quad 7.9 \%$ VITMFVQR $0.01 \% \quad 7.9 \%$ CFSVLGFCK $0.01 \% \quad 7.9 \%$ LFQCLLHR $0.01 \% \quad 7.9 \%$ SQIPLSKIK $0.01 \% \quad 7.9 \%$ IKTLFPLIEAK $0.01 \% \quad 7.9 \%$ TLFPLIEAK $0.01 \% \quad 7.9 \%$ EEASGSSVTAEEAKK $0.04 \% \quad 20.9 \%$ DSLIFLVDASK $0.04 \% \quad 20.9 \%$ NIYVLQELDNPGAK $0.04 \% \quad 20.9 \%$ NIYVLQELDNPGAKR $0.04 \% \quad 20.9 \%$ ILELDQFKGQQGQK

$0.04 \% \quad 20.9 \%$ IMLFTNEDNPHGNDSAK $0.04 \% \quad 20.9 \%$ TFNTSTGGLLLPSDTKR $0.04 \% \quad 20.9 \%$ CLEKEVAALCR $0.04 \% \quad 20.9 \%$ IMATPEQVGK $0.04 \% \quad 20.9 \%$ FTYRSDSFENPVLQQHFR $0.04 \% \quad 20.9 \%$ SDSFENPVLQQHFR $0.04 \% \quad 20.9 \%$ VEYSEEELKTHISK $0.01 \% \quad 7.4 \%$ LGSTEVASNVPK $0.01 \% \quad 7.4 \%$ SYSEDDIHR $0.01 \% \quad 7.4 \% \quad$ LENNENKPVTNSR $0.01 \% \quad 7.4 \%$ DTQEVPLEK $0.01 \% \quad 7.4 \%$ QLVSKPLSSSVSNNKR $\begin{array}{llll}0.01 \% & 7.4 \% & \text { GISPIVFDR }\end{array}$ $0.01 \% \quad 7.4 \% \quad$ LKYVLQDAR $0.01 \% \quad 7.4 \%$ SNNHENVSLAK $0.01 \% \quad 7.4 \%$ TQAVVSGRR $0.00 \% \quad 4.0 \% \quad$ LSVQSNPSPQLR $0.00 \% \quad 4.0 \%$ TVVLPPIVASR $0.00 \% \quad 4.0 \% \quad$ VNVKPSVVK $0.01 \% \quad 2.3 \%$ LGPSTGSTAETQCR $0.01 \% \quad 2.3 \%$ TGNCLYGNTCR $0.01 \% \quad 2.3 \%$ TSAVSSPLLDQQR $0.00 \% \quad 3.0 \% \quad$ SSSYSSYSSR $0.00 \% \quad 3.0 \%$ TLSGSGSGSGSSYSGSSSR $0.00 \% \quad 10.0 \%$ ELQQYIQAR $0.00 \% \quad 10.0 \%$ EGVKDTPQAAK $\begin{array}{lllll}99.7 \% & 40.9 & 25.0 & 36.7\end{array}$ $\begin{array}{llll}99.7 \% & 54.9 & 25.0 & 52.7\end{array}$ $\begin{array}{llll}99.7 \% & 44.5 & 25.0 & 42.3\end{array}$ $\begin{array}{llll}99.0 \% & 28.4 & 25.0 & 19.9\end{array}$ $\begin{array}{llll}99.4 \% & 26.9 & 25.0 & 25.6\end{array}$ $\begin{array}{llll}99.0 \% & 33.5 & 25.0 & 22.6\end{array}$ $\begin{array}{llll}97.3 \% & 15.6 & 25.0 & 15.6\end{array}$ $\begin{array}{llll}99.7 \% & 34.3 & 25.0 & 34.3\end{array}$ $\begin{array}{llll}99.2 \% & 23.4 & 25.0 & 16.3\end{array}$ $\begin{array}{llll}97.4 \% & 16.1 & 25.0 & 15.9\end{array}$ $\begin{array}{llll}99.7 \% & 58.8 & 25.0 & 53.8\end{array}$ $\begin{array}{llll}99.7 \% & 80.0 & 25.0 & 78.2\end{array}$ $\begin{array}{llll}99.7 \% & 60.2 & 25.0 & 56.5\end{array}$ $\begin{array}{llll}99.7 \% & 60.9 & 25.0 & 54.1\end{array}$

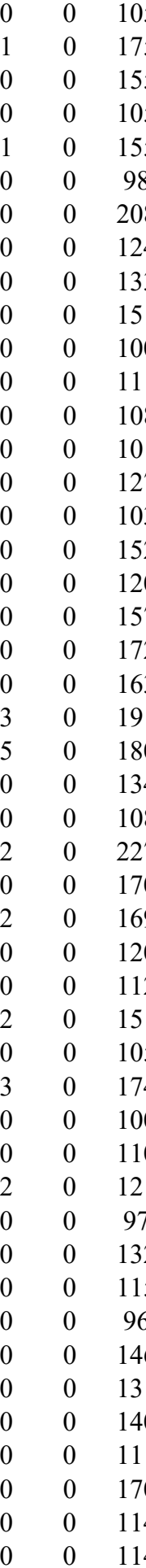

1051.56

1754.01

1554.93

1052.62

1554.75

989.51

2081.05

1244.63

1333.78

1512.76

1009.55

1117.52

1086.59

1013.64

1272.79

1031.61

1522.72

1207.66

1573.82

1729.92

1631.88

1918.86

1807.96

1348.67

1089.56

2271.09

1703.81

1691.85

1201.64

1121.49

1514.76

1058.54

1743.97

1003.56

1105.64

1212.60

973.55

1325.72

1151.71

969.61

1464.67

1315.55

1401.73

1110.47

1707.74

1148.61

1143.60 $\begin{array}{cc}34 & 343 \\ 4 & 61 \\ 92 & 607 \\ 80 & 1790 \\ 1 & 84 \\ 1 & 98 \\ 10 & 129 \\ 78 & 188 \\ 08 & 219 \\ 81 & 293 \\ 7 & 44 \\ 39 & 347 \\ 90 & 497 \\ 26 & 534 \\ 33 & 543 \\ 35 & 543 \\ 89 & 703 \\ 6 & 46 \\ 01 & 114 \\ 01 & 115 \\ 16 & 129 \\ 66 & 182 \\ 02 & 318 \\ 89 & 399 \\ 52 & 461 \\ 71 & 488 \\ 75 & 488 \\ 57 & 570 \\ 94 & 205 \\ 17 & 425 \\ 15 & 527 \\ 28 & 536 \\ 8 & 83 \\ 06 & 314 \\ 48 & 356 \\ 62 & 372 \\ 67 & 675 \\ 25 & 136 \\ 43 & 453 \\ 51 & 659 \\ 0 & 43 \\ 8 & 58 \\ 37 & 249 \\ 76 & 585 \\ 83 & 701 \\ 3 & 101 \\ 16 & 126 \\ & \end{array}$ 
Zinc finger $\mathrm{CCCH}$ domain-containing protein $8 \mathrm{GN}=\mathrm{ZC} 3 \mathrm{H} 8 \quad \mathrm{ZC} 3 \mathrm{H} 8$ _HUMAN $33.58 \quad 100.0 \%$ Zinc finger CCCH-type antiviral protein $1 \mathrm{GN}=\mathrm{ZC} 3 \mathrm{HAV} 1 \mathrm{ZCCHV} \_H U M A N \quad 101.43 \quad 100.0 \%$ Zinc finger CCCH-type antiviral protein $1 \mathrm{GN}=$ ZC3HAV1 ZCCHV_HUMAN $101.43 \quad 100.0 \%$ Zinc finger CCCH-type antiviral protein $1 \mathrm{GN}=\mathrm{ZC} 3 \mathrm{HAV} 1 \mathrm{ZCCHV}$ HUMAN $101.43 \quad 100.0 \%$ Zinc finger CCCH-type antiviral protein $1 \mathrm{GN}=\mathrm{ZC} 3 \mathrm{HAV} 1 \mathrm{ZCCHV} \_H U M A N \quad 101.43 \quad 100.0 \%$ Zinc finger CCCH-type antiviral protein $1 \mathrm{GN}=$ ZC3HAV1 ZCCHV_HUMAN $101.43 \quad 100.0 \%$ Zinc finger CCCH-type antiviral protein $1 \mathrm{GN}=\mathrm{ZC} 3 \mathrm{HAV} 1 \mathrm{ZCCHV} \_$HUMAN $101.43 \quad 100.0 \%$ Zinc finger $\mathrm{CCHC}$ domain-containing protein $3 \mathrm{GN}=\mathrm{ZCCHC} 3 \mathrm{ZCHC} 3$ HUMAN $43.62 \quad 100.0 \%$ Zinc finger CCHC domain-containing protein $3 \mathrm{GN}=\mathrm{ZCCHC} 3 \mathrm{ZCHC} 3$ HUMAN $43.62 \quad 100.0 \%$ Zinc finger $\mathrm{CCHC}$ domain-containing protein $3 \mathrm{GN}=\mathrm{ZCCHC} 3 \mathrm{ZCHC} 3$ _HUMAN $43.62 \quad 100.0 \%$ Zinc finger CCHC domain-containing protein $8 \mathrm{GN}=\mathrm{ZCCHC} 8 \mathrm{ZCHC} 8$ HUMAN $78.58 \quad 100.0 \%$ Zinc finger $\mathrm{CCHC}$ domain-containing protein $8 \mathrm{GN}=\mathrm{ZCCHC} 8 \mathrm{ZCHC} 8$ HUMAN $78.58 \quad 100.0 \%$ Zinc finger CCHC-type and RNA-binding motif-containing protein $1 \mathrm{GN}=Z \mathrm{ZCRB} 1$ ZCRB1_HUMAN $24.59 \quad 100.0 \%$ Zinc finger CCHC-type and RNA-binding motif-containing protein 1 GN=ZCRB1 ZCRB1_HUMAN $24.59 \quad 100.0 \%$ ZCRB1 ZCRB1_HUMAN $24.59-100.0 \%$ Zinc finger protein $346 \mathrm{GN}=\mathrm{ZNF} 346$ Zinc finger protein $346 \mathrm{GN}=\mathrm{ZNF} 346$ Zinc finger protein $346 \mathrm{GN}=\mathrm{ZNF} 346$ Zinc finger protein $346 \mathrm{GN}=\mathrm{ZNF} 346$ Zinc finger protein $346 \mathrm{GN}=\mathrm{ZNF} 346$ Zinc finger protein $346 \mathrm{GN}=\mathrm{ZNF} 346$ Zinc finger protein $346 \mathrm{GN}=\mathrm{ZNF} 346$ Zinc finger protein $512 \mathrm{GN}=\mathrm{ZNF} 512$ Zinc finger protein $512 \mathrm{GN}=\mathrm{ZNF} 512$ Zinc finger protein $512 \mathrm{GN}=\mathrm{ZNF} 512$ Zinc finger protein $638 \mathrm{GN}=\mathrm{ZNF} 638$ Zinc finger protein $638 \mathrm{GN}=\mathrm{ZNF} 638$ Zinc finger protein $768 \mathrm{GN}=\mathrm{ZNF} 768$ Zinc finger protein $768 \mathrm{GN}=\mathrm{ZNF} 768$ Zinc finger protein $768 \mathrm{GN}=\mathrm{ZNF} 768$ Zinc finger protein $768 \mathrm{GN}=\mathrm{ZNF} 768$ Zinc finger protein $771 \mathrm{GN}=\mathrm{ZNF} 771$ Zinc finger protein $771 \mathrm{GN}=\mathrm{ZNF} 771$ ZN346_HUMAN $32.93 \quad 100.0 \%$ ZN346 HUMAN $32.93 \quad 100.0 \%$ ZN346_HUMAN $32.93 \quad 100.0 \%$ ZN346_HUMAN $32.93 \quad 100.0 \%$ ZN346 HUMAN $32.93 \quad 100.0 \%$ ZN346_HUMAN $32.93 \quad 100.0 \%$ ZN346 HUMAN $32.93 \quad 100.0 \%$ ZN512_HUMAN $64.68 \quad 100.0 \%$ ZN512_HUMAN $64.68 \quad 100.0 \%$ ZN512_HUMAN $64.68 \quad 100.0 \%$ ZN638_HUMAN $220.63 \quad 100.0 \%$ ZN638_HUMAN $220.63 \quad 100.0 \%$ ZN768 HUMAN $60.23 \quad 100.0 \%$ ZN768_HUMAN $60.23 \quad 100.0 \%$ ZN768 HUMAN $60.23 \quad 100.0 \%$ ZN768_HUMAN $60.23 \quad 100.0 \%$ ZN771_HUMAN $35.70 \quad 100.0 \%$ ZN771_HUMAN $35.70 \quad 100.0 \%$ Zinc finger RNA-binding protein 2 GN=ZFR2 ZFR2_HUMAN $101.33 \quad 99.9 \%$ Zinc finger RNA-binding protein $2 \mathrm{GN}=\mathrm{ZFR} 2$ ZFR2 HUMAN $101.33 \quad 99.9 \%$ Zinc finger RNA-binding protein GN=ZFR ZFR_HUMAN $117.01 \quad 100.0 \%$ Zinc finger RNA-binding protein GN=ZFR ZFR_HUMAN $117.01 \quad 100.0 \%$ Zinc finger RNA-binding protein GN=ZFR ZFR HUMAN $117.01 \quad 100.0 \%$ Zinc finger RNA-binding protein GN=ZFR ZFR_HUMAN $117.01 \quad 100.0 \%$ Zinc finger RNA-binding protein GN=ZFR ZFR_HUMAN $117.01 \quad 100.0 \%$ Zinc finger RNA-binding protein GN=ZFR ZFR_HUMAN $117.01 \quad 100.0 \%$ Zinc transporter $7 \mathrm{GN}=\mathrm{SLC} 30 \mathrm{~A} 7$ Zinc transporter $7 \mathrm{GN}=\mathrm{SLC} 30 \mathrm{~A} 7$ Zinc transporter $7 \mathrm{GN}=\mathrm{SLC} 30 \mathrm{~A} 7$

ZNT7_HUMAN $41.63 \quad 100.0 \%$ ZNT7 HUMAN $41.63 \quad 100.0 \%$
$0.00 \% \quad 10.0 \%$ FYVQGYCTR

$0.01 \% \quad 9.3 \%$ FVVLETGGEAGITR

$0.01 \% \quad 9.3 \%$ ASLEDAPVDDLTR

$0.01 \% \quad 9.3 \%$ ATDLGGTSQAGTSQR

$0.01 \% \quad 9.3 \%$ TVFSPTLPAAR

$0.01 \% \quad 9.3 \% \quad$ SSLGSLQTPEAVTTR

$0.01 \% \quad 9.3 \%$ IQDAGPASRDVQATGR

$0.01 \% \quad 9.7 \%$ ICFQGDEGACPTR

$0.01 \% \quad 9.7 \%$ DFVVGALILR

$0.01 \% \quad 9.7 \%$ AVHNSVAAQLTGVAGH

$0.00 \% \quad 3.8 \%$ GTPPPVFTPPLPK

$0.00 \% \quad 3.8 \%$ GTPPLTPSDSPQTR

$0.00 \% \quad 19.8 \%$ STVYVSNLPFSLTNNDLYR

$0.00 \% \quad 19.8 \%$ ASIAIDNGR

$0.00 \% \quad 19.8 \%$ WKPSSGVPSTSDDSR

$0.02 \% \quad 30.3 \%$ NQCLFTNTQCK

$0.02 \% \quad 30.3 \%$ VCCALLISESQK

$0.02 \% \quad 30.3 \%$ YLAIHGMETLKGETK

$0.02 \% \quad 30.3 \%$ VEALHQNR

$0.02 \% \quad 30.3 \%$ LADPAVTDFPAGK

$0.02 \% \quad 30.3 \%$ IVLNSIEQYQAHVSGFK

$0.02 \% \quad 30.3 \%$ TVASSLGQIPMQR

$0.00 \% \quad 7.1 \%$ LGAVPATSGPTTFKQQR

$0.00 \% \quad 7.1 \%$ AGLAYHLR

$0.00 \% \quad 7.1 \%$ QQPGIELPETELSLR

$0.00 \% \quad 1.4 \%$ TSSGTKPSVKPTSATK

$0.00 \% \quad 1.4 \%$ AVEIVTSTSAAK

$0.00 \% \quad 7.4 \%$ AFADSSYLLR

$0.00 \% \quad 7.4 \%$ AFGDSSYLLR

$0.00 \% \quad 7.4 \%$ SALIPHAR

$0.00 \% \quad 7.4 \%$ FGQSSVLAIHAR

$0.00 \% \quad 6.3 \% \quad$ FSAASNLR

$0.00 \% \quad 6.3 \% \quad$ FAQSSNYAQHLR

$0.00 \% \quad 2.1 \% \quad$ SSVAPQTR

$0.00 \% \quad 2.1 \%$ ASGLQPCVIVIR

$0.01 \% \quad 7.0 \%$ AGYSQGATQYTQAQQTR

$0.01 \% \quad 7.0 \%$ GLTTTGNSSLNSTSNTK

$0.01 \% \quad 7.0 \%$ VSAVPTNMAAKK

$0.01 \% \quad 7.0 \% \quad$ KVNPDLQVEVKPSIR

$0.01 \% \quad 7.0 \% \quad$ VNPDLQVEVKPSIR

$0.01 \% \quad 7.0 \%$ NVNLVLLCSEKPSK

$0.00 \% \quad 10.9 \%$ TPPLLENSLPQCYQR

$0.00 \% \quad 10.9 \%$ LIVAPDADAR

$5 \quad 0.00 \% \quad 10.9 \%$ WILSQTHNIFTQAGVR
$99.3 \% \quad 20.6$

$99.7 \% \quad 86.6$

$99.7 \% \quad 37.9$

$99.7 \% \quad 61.7$

$99.1 \% \quad 25.2$

$99.7 \% \quad 49.7$

$99.7 \% \quad 30.8$

$99.7 \% \quad 59.5$

$99.7 \% \quad 40.6$

$99.7 \% \quad 32.5$

$99.6 \% 24.1$

$99.5 \% \quad 21.8$

$99.7 \% \quad 35.1$

$\begin{array}{lll}99.7 \% & 28.2\end{array}$

$99.5 \% \quad 21.6$

$99.7 \% \quad 58.0$

$99.7 \% \quad 54.8$

$99.2 \% \quad 18.8$

$99.0 \% \quad 61.5$

$99.7 \% \quad 64.0$

$\begin{array}{lll}99.7 \% & 41.4\end{array}$

$99.7 \% \quad 62.1$

$96.8 \% \quad 15.3$

$99.0 \% \quad 38.6$

$99.7 \% \quad 37.9$

$97.6 \% \quad 19.3$

$99.2 \% 27.1$

$99.7 \% \quad 46.8$

$99.3 \% \quad 21.2$

$99.0 \% \quad 18.8$

$99.7 \% \quad 53.1$

$98.5 \% \quad 25.6$

$99.6 \% \quad 26.0$

$97.1 \% \quad 25.5$

$99.6 \% \quad 24.5$

$99.7 \% \quad 85.1$

$99.7 \% \quad 79.5$

$99.6 \% 26.0$

$99.7 \% \quad 37.0$

$99.7 \% \quad 58.2$

$99.7 \% \quad 55.6$

$99.7 \% \quad 52.6$

$97.8 \% \quad 16.2$ 
Peptide index

[3-methyl-2-oxobutanoate dehydrogenase [lipoamide]] kinase, mitochondrial GN=BCKDK $\quad$ BCKD_HUMAN $46.36 \quad 100.0 \% \quad 3$ [3-methy-2-oxobutanoate dehydrogenase [lipoamide] kinase, mitochondrial GN=BCKDK BCKD_HUMAN $46.36 \quad 100.0 \% \quad 3$ [3-methyl-2-oxobutanoate dehydrogenase [lipoamide]] kinase, mitochondrial GN=BCKDK BCKD_HUMAN $46.36 \quad 100.0 \%$

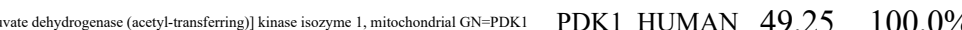
[Pyruvate dehydrogenase (acetyl-transferring]] kinase isozyme 1, mitochondral GN=PDK1 $\quad$ PDK1_HUMAN $49.25 \quad 100.0 \%$ [Pynn vate dehydrogenase (acetyl-transferringy)] kinase isozyme 1, mitochondral GN=PDK1 $\quad$ PDK1_HUMAN $49.25 \quad 100.0 \%$ [Pyruvate dehydrogenase (acetyl-transferringy)] kinase isozyme 3, mitochondrial GN=PDK3 $\quad$ PDK3 HUMAN $46.94 \quad 100.0 \%$ [Pyruvat dehydrogenase (acetyl-transferring]) kinase isozyme 3, mitcochondrial GN=PDK3 $\quad$ PDK3_HUMAN $46.94 \quad 100.0 \%$ $116 \mathrm{kDa}$ U5 small nuclear ribonucleoprotein component GN=EFTUD2 U5S1_HUMAN $109.44 \quad 100.0 \%$ 116 kDa U5 small nuclear ribonucleoprotein component GN=EFTUD2 U5S1_HUMAN $109.44 \quad 100.0 \%$ $116 \mathrm{kDa}$ U5 small nuclear ribonucleoprotein component GN=EFTUD2 U5S1_HUMAN $109.44 \quad 100.0 \%$ $116 \mathrm{kDa}$ U5 small nuclear ribonucleoprotein component GN=EFTUD2 U5S1_HUMAN $109.44100 .0 \%$ $116 \mathrm{kDa}$ U5 small nuclear ribonucleoprotein component GN=EFTUD2 U5S1_HUMAN $109.44 \quad 100.0 \%$ $116 \mathrm{kDa}$ U5 small nuclear ribonucleoprotein component GN=EFTUD2 U5S1_HUMAN $109.44100 .0 \%$ $116 \mathrm{kDa}$ U5 small nuclear ribonucleoprotein component GN=EFTUD2 U5S1_HUMAN $109.44100 .0 \%$ $116 \mathrm{kDa}$ U5 small nuclear ribonucleoprotein component GN=EFTUD2 U5S1_HUMAN $109.44 \quad 100.0 \%$ $116 \mathrm{kDa}$ U5 small nuclear ribonucleoprotein component GN=EFTUD2 U5S1_HUMAN $109.44100 .0 \%$ $116 \mathrm{kDa}$ U5 small nuclear ribonucleoprotein component GN=EFTUD2 U5S1_HUMAN $109.44 \quad 100.0 \%$ 14-3-3 protein beta/alpha $\mathrm{GN}=\mathrm{YWHAB}$ 14-3-3 protein beta/alpha $\mathrm{GN}=\mathrm{YWHAB}$ 14-3-3 protein beta/alpha $\mathrm{GN}=\mathrm{YWHAE}$ 14-3-3 protein beta/alpha $\mathrm{GN}=\mathrm{YWHAE}$ 14-3-3 protein beta/alpha $\mathrm{GN}=\mathrm{YWHAB}$ 14-3-3 protein beta/alpha $\mathrm{GN}=\mathrm{YWHAE}$ 14-3-3 protein beta/alpha $\mathrm{GN}=\mathrm{YWHAB}$ 14-3-3 protein beta/alpha $\mathrm{GN}=\mathrm{YWHAB}$ 14-3-3 protein beta/alpha $\mathrm{GN}=\mathrm{YWHAB}$ 14-3-3 protein epsilon $\mathrm{GN}=\mathrm{YWHAE}$ 14-3-3 protein epsilon $\mathrm{GN}=\mathrm{YWHAE}$ 14-3-3 protein epsilon $\mathrm{GN}=\mathrm{YWHAE}$ 14-3-3 protein epsilon $\mathrm{GN}=\mathrm{YWHAE}$ 14-3-3 protein epsilon $\mathrm{GN}=\mathrm{YWHAE}$ 14-3-3 protein epsilon $\mathrm{GN}=\mathrm{YWHAE}$ 14-3-3 protein epsilon $\mathrm{GN}=\mathrm{YWHAE}$ 14-3-3 protein epsilon $\mathrm{GN}=\mathrm{YWHAE}$ 14-3-3 protein epsilon $\mathrm{GN}=\mathrm{YWHAE}$ 14-3-3 protein epsilon $\mathrm{GN}=\mathrm{YWHAE}$ 14-3-3 protein epsilon $\mathrm{GN}=\mathrm{YWHAE}$ 14-3-3 protein epsilon $\mathrm{GN}=\mathrm{YWHAE}$ 14-3-3 protein eta $\mathrm{GN}=\mathrm{YWHAH}$ 14-3-3 protein eta $\mathrm{GN}=\mathrm{YWHAH}$
1433B_HUMAN $28.08 \quad 100.0 \%$ 1433B_HUMAN $28.08 \quad 100.0 \%$ 1433B_HUMAN $28.08 \quad 100.0 \%$ 1433B HUMAN $28.08 \quad 100.0 \%$ 1433B HUMAN $28.08 \quad 100.0 \%$ 1433B_HUMAN $28.08 \quad 100.0 \%$ 1433B HUMAN $28.08 \quad 100.0 \%$ 1433B_HUMAN $28.08 \quad 100.0 \%$ 1433B_HUMAN $28.08 \quad 100.0 \%$ 1433E HUMAN $29.18 \quad 100.0 \%$ 1433E_HUMAN $29.18 \quad 100.0 \%$ 1433E HUMAN $29.18 \quad 100.0 \%$ 1433E_HUMAN $29.18 \quad 100.0 \%$ 1433E_HUMAN $29.18 \quad 100.0 \%$ 1433E HUMAN $29.18 \quad 100.0 \%$ 1433E_HUMAN $29.18 \quad 100.0 \%$ 1433E_HUMAN $29.18 \quad 100.0 \%$ 1433E HUMAN $29.18 \quad 100.0 \%$ 1433E_HUMAN $29.18 \quad 100.0 \%$ 1433E HUMAN $29.18 \quad 100.0 \%$ 1433E_HUMAN $29.18 \quad 100.0 \%$ 1433F_HUMAN $28.22 \quad 100.0 \%$ 1433F HUMAN $28.22 \quad 100.0 \%$
$0.01 \% \quad 10.0 \%$ TVTSFYNQSAIDAAAEKPSVR

$0.01 \% \quad 10.0 \%$ LTPTMMLYAGR

$0.01 \% \quad 10.0 \%$ YLQQELPVR

$0.00 \% \quad 8.5 \% \quad$ EISLLPDNLLR

$0.00 \% \quad 8.5 \%$ AIYDFTDTVIR

$0.00 \% \quad 8.5 \%$ AVPLAGFGYGLPISR

$0.00 \% \quad 6.9 \% \quad$ TLVTLGKEDLSIK

$0.00 \% \quad 6.9 \%$ AAPLAGFGYGLPISR

$0.02 \% \quad 10.6 \%$ STPVTVVLPDTK

$0.02 \% \quad 10.6 \%$ STPVTVVLPDTKGK

$0.02 \% \quad 10.6 \%$ VLSGTIHAGQPVK

$0.02 \% \quad 10.6 \%$ IAVEPVNPSELPK

$0.02 \% \quad 10.6 \%$ CFAETPNKK

$0.02 \% \quad 10.6 \%$ LGEFFQTK

$0.02 \% \quad 10.6 \%$ EGPLCDELIR

$0.02 \% \quad 10.6 \%$ ILDAVVAQEPLHR

$0.02 \% \quad 10.6 \%$ GGGQIIPTAR

$0.02 \% \quad 10.6 \%$ RVVYSAFLMATPR

$0.01 \% \quad 33.3 \%$ LAEQAERYDDMAAAM

$0.01 \% \quad 33.3 \%$ NLLSVAYK

$0.01 \% 33.3 \%$ VISSIEQK

$0.01 \% 33.3 \%$ VISSIEQKTER

$0.01 \% \quad 33.3 \%$ YLIPNATQPESK

$0.01 \% 33.3 \%$ YLSEVASGDNK

$0.01 \% \quad 33.3 \%$ KEMQPTHPIR

$0.01 \% \quad 33.3 \%$ EMQPTHPIR

$0.03 \% \quad 41.2 \%$ VAGMDVELTVEER

$0.03 \% \quad 41.2 \%$ NLLSVAYK

$0.03 \% \quad 41.2 \%$ IISSIEQK

$0.03 \% \quad 41.2 \%$ IISSIEQKEENK

$0.03 \% \quad 41.2 \%$ QMVETELK

$0.03 \% \quad 41.2 \%$ LICCDILDVLDK

$0.03 \% \quad 41.2 \%$ HLIPAANTGESK

$0.03 \% \quad 41.2 \%$ YLAEFATGNDR

$0.03 \% \quad 41.2 \%$ YLAEFATGNDRK

$0.03 \% \quad 41.2 \%$ KEAAENSLVAYK

$0.03 \% \quad 41.2 \%$ EAAENSLVAYK

$0.03 \% \quad 41.2 \%$ AASDIAMTELPPTHPIR

$0.01 \% \quad 25.6 \%$ AVTELNEPLSNEDR

$0.01 \% \quad 25.6 \%$ AVTELNEPLSNEDRNLLSVAY
$99.7 \%$

$99.7 \% \quad 47.2$

$99.7 \% \quad 28.9$

$99.2 \% \quad 23.3$

$99.7 \% \quad 59.9$

$99.7 \% \quad 38.0$

$99.7 \% \quad 52.7$

$99.7 \% \quad 62.1$

$99.7 \% \quad 61.5$

$99.7 \% \quad 43.0$

$99.7 \% \quad 51.0$

$97.8 \% \quad 18.2$

$99.0 \% \quad 36.9$

$99.6 \% 25.8$

$99.7 \% \quad 43.0$

$99.7 \% \quad 35.9$

$94.6 \% \quad 17.9$

$99.7 \% \quad 43.3$

$99.7 \% \quad 57.3$

$99.0 \% \quad 43.5$

$99.0 \% \quad 43.3$

$99.7 \% \quad 46.8$

$99.7 \% \quad 30.6$

$99.7 \% \quad 40.6$

$99.6 \% \quad 22.0$

$99.7 \% \quad 50.3$

$99.7 \% \quad 63.7$

$99.0 \% \quad 43.5$

$94.6 \% 21.0$

$99.7 \% 53.1$

$99.0 \% \quad 45.4$

$99.7 \% \quad 55.9$

$99.7 \% \quad 61.6$

$99.7 \% \quad 40.7$

$99.7 \% \quad 51.8$

$99.7 \% \quad 32.4$

$99.7 \% \quad 55.9$

$99.7 \% \quad 53.1$

$99.7 \% \quad 64.8$

$99.7 \% \quad 33.0$

$\begin{array}{ccc}25.0 & 57.5 & 0 \\ 25.0 & 29.0 & 1 \\ 25.0 & 33.3 & 2 \\ 25.0 & 28.9 & 1 \\ 25.0 & 23.3 & 1 \\ 25.0 & 52.9 & 1 \\ 25.0 & 38.0 & 1 \\ 25.0 & 47.7 & 2 \\ 25.0 & 60.8 & 3 \\ 25.0 & 61.5 & 3 \\ 25.0 & 38.7 & 2 \\ 25.0 & 50.9 & 2 \\ 25.0 & 17.1 & 1 \\ 25.0 & 27.4 & 1 \\ 25.0 & 21.3 & 1 \\ 25.0 & 43.0 & 2 \\ 25.0 & 33.7 & 17 \\ 25.0 & 13.5 & 0 \\ 25.0 & 43.3 & 0 \\ 25.0 & 57.3 & 2 \\ 25.0 & 21.8 & 3 \\ 25.0 & 0.0 & 2 \\ 25.0 & 30.5 & 1 \\ 25.0 & 29.4 & 1 \\ 25.0 & 40.6 & 2 \\ 25.0 & 19.0 & 1 \\ 25.0 & 39.6 & 2 \\ 25.0 & 50.6 & 4 \\ 25.0 & 21.8 & 3 \\ 25.0 & 8.0 & 1 \\ 25.0 & 47.4 & 2 \\ 25.0 & 17.7 & 3 \\ 25.0 & 53.8 & 2 \\ 25.0 & 52.5 & 2 \\ 25.0 & 35.8 & 2 \\ 25.0 & 44.3 & 3 \\ 25.0 & 25.0 & 1 \\ 25.0 & 50.3 & 5 \\ 25.0 & 48.7 & 3 \\ 25.0 & 64.8 & 1 \\ 25.0 & 33.0 & 0\end{array}$

$\begin{array}{cccc}0 & 2255.13 & 49 & 69 \\ 0 & 1285.63 & 70 & 80 \\ 0 & 1145.63 & 93 & 101 \\ 0 & 1282.74 & 93 & 103 \\ 0 & 1313.67 & 134 & 144 \\ 0 & 1517.85 & 349 & 363 \\ 0 & 1416.83 & 272 & 284 \\ 0 & 1489.82 & 318 & 332 \\ 0 & 1256.71 & 183 & 194 \\ 0 & 1441.83 & 183 & 196 \\ 0 & 1306.75 & 496 & 508 \\ 0 & 1392.77 & 590 & 602 \\ 0 & 1094.53 & 674 & 682 \\ 0 & 969.50 & 714 & 721 \\ 0 & 1201.59 & 776 & 785 \\ 0 & 1460.82 & 791 & 803 \\ 0 & 969.55 & 804 & 813 \\ 0 & 1526.81 & 814 & 826 \\ 0 & 1812.83 & 14 & 29 \\ 0 & 1598.74 & 30 & 43 \\ 0 & 907.52 & 44 & 51 \\ 0 & 903.51 & 63 & 70 \\ 0 & 1289.71 & 63 & 73 \\ 0 & 1360.71 & 106 & 117 \\ 0 & 1182.56 & 130 & 140 \\ 0 & 1252.65 & 160 & 169 \\ 0 & 1108.56 & 161 & 169 \\ 0 & 1463.70 & 30 & 42 \\ 0 & 907.52 & 43 & 50 \\ 0 & 917.53 & 62 & 69 \\ 0 & 1417.75 & 62 & 73 \\ 0 & 993.49 & 87 & 94 \\ 0 & 1476.74 & 95 & 106 \\ 0 & 1237.65 & 107 & 118 \\ 0 & 1256.59 & 131 & 141 \\ 0 & 1384.69 & 131 & 142 \\ 0 & 1322.70 & 142 & 153 \\ 0 & 1194.60 & 143 & 153 \\ 0 & 1819.94 & 154 & 170 \\ 0 & 1586.77 & 29 & 42 \\ 0 & 2475.27 & 29 & 50\end{array}$

Page 1 of Table S-1-5 
14-3-3 protein eta $\mathrm{GN}=\mathrm{YWHAH}$ 14-3-3 protein eta $\mathrm{GN}=\mathrm{YWHAH}$ 14-3-3 protein eta $\mathrm{GN}=\mathrm{YWHAH}$ 14-3-3 protein eta $\mathrm{GN}=\mathrm{YWHAH}$ 14-3-3 protein eta $\mathrm{GN}=\mathrm{YWHAH}$ 14-3-3 protein eta $\mathrm{GN}=\mathrm{YWHAH}$ 14-3-3 protein gamma $\mathrm{GN}=\mathrm{YWHAG}$ 14-3-3 protein gamma $\mathrm{GN}=\mathrm{YWHAG}$ 14-3-3 protein gamma $\mathrm{GN}=\mathrm{YWHAG}$ 14-3-3 protein gamma $\mathrm{GN}=\mathrm{YWHAG}$ 14-3-3 protein gamma $\mathrm{GN}=\mathrm{YWHAG}$ 14-3-3 protein gamma GN=YWHAG 14-3-3 protein theta $\mathrm{GN}=\mathrm{YWHAQ}$ 14-3-3 protein theta $\mathrm{GN}=\mathrm{YWHAQ}$ $14-3-3$ protein theta $\mathrm{GN}=\mathrm{YWHAQ}$ 14-3-3 protein theta $\mathrm{GN}=\mathrm{YWHAQ}$ 14-3-3 protein theta $\mathrm{GN}=\mathrm{YWHAQ}$ 14-3-3 protein theta $\mathrm{GN}=\mathrm{YWHAQ}$ 14-3-3 protein theta $\mathrm{GN}=\mathrm{YWHAQ}$ 14-3-3 protein zeta/delta GN=YWHAZ 14-3-3 protein zeta/delta $\mathrm{GN}=\mathrm{YWHAZ}$ 14-3-3 protein zeta/delta GN=YWHAZ 14-3-3 protein zeta/delta $\mathrm{GN}=\mathrm{YWHAZ}$ 14-3-3 protein zeta/delta GN=YWHAZ 14-3-3 protein zeta/delta GN $=Y W H A Z$ 14-3-3 protein zeta/delta $\mathrm{GN}=\mathrm{YWHAZ}$ 14-3-3 protein zeta/delta GN=YWHAZ 14-3-3 protein zeta/delta $\mathrm{GN}=\mathrm{YWHAZ}$ 14-3-3 protein zeta/delta $\mathrm{GN}=\mathrm{YWHAZ}$ 14-3-3 protein zeta/delta $\mathrm{GN}=\mathrm{YWHAZ}$ 14-3-3 protein zeta/delta $\mathrm{GN}=\mathrm{YWHAZ}$ 14-3-3 protein zeta/delta GN $=$ YWHAZ 14-3-3 protein zeta/delta GN=YWHAZ 14-3-3 protein gamma GN=YWHAG 14-3-3 protein theta GN=YWHAQ

1433F HUMAN $28.22 \quad 100.0 \%$ 433F HUMAN $28.22 \quad 100.0 \%$ 1433F_HUMAN $28.22 \quad 100.0 \%$ 1433F HUMAN $28.22 \quad 100.0 \%$ 1433F_HUMAN $28.22 \quad 100.0 \%$ 1433F_HUMAN $28.22 \quad 100.0 \%$ 1433G_HUMAN $28.30 \quad 100.0 \%$ 1433G_HUMAN $28.30 \quad 100.0 \%$ 1433G HUMAN $28.30 \quad 100.0 \%$ 1433G_HUMAN $28.30 \quad 100.0 \%$ 1433G_HUMAN $28.30 \quad 100.0 \%$ 1433G HUMAN $28.30 \quad 100.0 \%$ 1433G_HUMAN $28.30 \quad 100.0 \%$ 1433T_HUMAN $27.77 \quad 100.0 \%$ 1433T HUMAN $27.77 \quad 100.0 \%$ 1433T_HUMAN $27.77 \quad 100.0 \%$ 1433T HUMAN $27.77 \quad 100.0 \%$ 1433T_HUMAN $27.77 \quad 100.0 \%$ 1433T_HUMAN $27.77 \quad 100.0 \%$ 1433T_HUMAN $27.77 \quad 100.0 \%$ 1433T_HUMAN $27.77 \quad 100.0 \%$ 1433Z HUMAN $27.75 \quad 100.0 \%$ 1433Z_HUMAN $27.75 \quad 100.0 \%$ 1433Z_HUMAN $27.75 \quad 100.0 \%$ 433Z_HUMAN $27.75 \quad 100.0 \%$ 1433Z_HUMAN $27.75 \quad 100.0 \%$ 1433Z_HUMAN $27.75 \quad 100.0 \%$ 1433Z_HUMAN 27.75 1433Z_HUMAN 27.75 1433Z HUMAN 27.75 1433Z HUMAN 27.75 1433Z_HUMAN 27.75 1433Z HUMAN 27.75 1433Z_HUMAN 27.75 1433Z HUMAN 27.75 PLCE_HUMAN 42.07 1-acyl-sn-glycerol-3-phosphate acyltransferase epsilon GN=AGPAT5 PLCE_HUMAN 42.07 2',3'-cyclic-nucleotide 3'-phosphodiesterase GN=CNP CN37 HUMAN 47.58 2',3'-cyclic-nucleotide 3'-phosphodiesterase GN=CNP CN37_HUMAN 47.58 2',3'-cyclic-nucleotide 3'-phosphodiesterase GN=CNP CN37_HUMAN 47.58 2',3'-cyclic-nucleotide 3'-phosphodiesterase GN=CNP CN37_HUMAN 47.58 2',3'-cyclic-nucleotide 3'-phosphodiesterase GN=CNP CN37_HUMAN 47.58 2',3'-cyclic-nucleotide 3'-phosphodiesterase GN=CNP CN37_HUMAN 47.58 2',3'-cyclic-nucleotide 3'-phosphodiesterase GN=CNP CN37_HUMAN $47.58 \quad 100.0 \%$ 2',3'-cyclic-nucleotide 3 '-phosphodiesterase GN=CNP CN37_HUMAN $47.58 \quad 100.0 \%$ $26 \mathrm{~S}$ protease regulatory subunit 10B GN=PSMC6 PRS10_HUMAN $44.17 \quad 100.0 \%$ $26 \mathrm{~S}$ protease regulatory subunit 10B GN=PSMC6 PRS10_HUMAN $44.17 \quad 100.0 \%$
$1 \quad 0.01 \% \quad 25.6 \%$ NLLSVAYK $0.01 \% \quad 25.6 \%$

$11 \quad 0.01 \% \quad 25.6 \%$ NCNDFQYESK

$0.01 \% \quad 25.6 \%$ YLAEVASGEK

$0.01 \% \quad 25.6 \%$ YLAEVASGEKK

$1 \quad 0.01 \% \quad 25.6 \%$ NSVVEASEAAYK

$0.02 \% \quad 27.1 \%$ LAEQAERYDDMAAAMK

$0.02 \% \quad 27.1 \%$ NVTELNEPLSNEER

$0.02 \% \quad 27.1 \%$ NLLSVAYK

$0.02 \% \quad 27.1 \%$ VISSIEQK

$0.02 \% \quad 27.1 \%$ YLAEVATGEK

$0.02 \% \quad 27.1 \%$ YLAEVATGEKR

$0.02 \% \quad 27.1 \%$ AYSEAHEISK

$0.01 \% \quad 31.8 \%$ AVTEQGAELSNEER

$0.01 \% \quad 31.8 \%$ NLLSVAYK

$0.01 \% \quad 31.8 \%$ VISSIEQK

$0.01 \% \quad 31.8 \%$ EKVESELR

$0.01 \% 31.8 \%$ YLAEVACGDDRK

$0.01 \% \quad 31.8 \%$ QTIDNSQGAYQEAFDISKK

$0.01 \% \quad 31.8 \%$ KEMQPTHPIR

$0.01 \% \quad 31.8 \%$ EMQPTHPIR

$0.03 \% \quad 50.6 \%$ LAEQAERYDDMAACMK

$0.03 \% \quad 50.6 \%$ SVTEQGAELSNEER

$0.03 \% \quad 50.6 \%$ SVTEQGAELSNEERNLLSVAYK

$0.03 \% \quad 50.6 \%$ NLLSVAYK

$0.03 \% \quad 50.6 \%$ VVSSIEQKTEGAEK

$0.03 \% \quad 50.6 \%$ EKIETELR

$0.03 \% \quad 50.6 \%$ DICNDVLSLLEK

$0.03 \% \quad 50.6 \%$ FLIPNASQAESK

$0.03 \% \quad 50.6 \%$ YLAEVAAGDDK

$0.03 \% \quad 50.6 \%$ YLAEVAAGDDKK

$\begin{array}{llllllll}99.0 \% & 43.5 & 25.0 & 21.8 & 3 & 0 & 0 & 907.52\end{array}$

$\begin{array}{llllllll}99.0 \% & 43.3 & 25.0 & 0.0 & 2 & 0 & 0 & 903.51\end{array}$

$\begin{array}{llllllll}99.7 \% & 38.0 & 25.0 & 38.0 & 2 & 0 & 0 & 1304.52\end{array}$

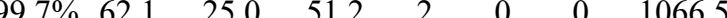

$\begin{array}{llllllll}99.7 \% & 48.0 & 25.0 & 26.0 & 2 & 0 & 0 & 1194.64\end{array}$

$\begin{array}{llllllll}99.7 \% & 63.4 & 25.0 & 43.7 & 2 & 0 & 0 & 1267.62\end{array}$

1812.83

1643.79

907.52

903.51

1080.56

1236.66

1134.54

1532.72

907.52

903.51

989.53

1396.65

2143.03

1252.65

1108.56

1901.82

1548.71

2437.22

907.52

1504.79

1017.56

1418.72

1304.68

1151.56

1279.65

2040.99

2169.08

$0.03 \% \quad 50.6 \%$ GIVDQSQQAYQEAFEISKK $99.7 \% \quad 28.0$

$0.03 \% \quad 50.6 \%$ KEMQPTHPIR

$0.03 \% \quad 50.6 \%$ EMQPTHPIR

$0.00 \% \quad 5.8 \% \quad$ LLSAFLPAR

$0.00 \% \quad 5.8 \%$ VLSASQAFAAQR

$0.02 \% \quad 18.8 \%$ RLDEDLAAYCR

$0.02 \% \quad 18.8 \%$ ILVLDDTNHER

$16 \quad 0.02 \% \quad 18.8 \%$ AGQVFLEELGNHK

$0.02 \% \quad 18.8 \%$ RPPGVLHCTTK

$0.02 \% \quad 18.8 \%$ APGAEEYAQQDVLK

$0.02 \% \quad 18.8 \%$ APGAEEYAQQDVLKK

$0.02 \% \quad 18.8 \%$ LSPTDNLPR

$16 \quad 0.02 \% \quad 18.8 \%$ AIFTGYYGK

$49 \quad 0.05 \% \quad 45.0 \%$ LLEHKEIDGR

$0.05 \% \quad 45.0 \%$ ALQSVGQIVGEVLK $\begin{array}{llll}99.7 \% & 50.3 & 25.0 & 39.6\end{array}$

$\begin{array}{llll}99.6 \% & 23.8 & 25.0 & 23.8\end{array}$

$99.7 \% \quad 56.4 \quad 25.0 \quad 56.4$

$99.7 \% \quad 49.1 \quad 25.0 \quad 49.1$

$\begin{array}{llll}99.7 \% & 46.5 & 25.0 & 36.7\end{array}$

$\begin{array}{llll}99.7 \% & 76.3 & 25.0 & 69.0\end{array}$

$\begin{array}{llll}99.6 \% & 23.2 & 25.0 & 20.6\end{array}$

$99.7 \% \quad 40.6 \quad 25.0 \quad 40.6 \quad 2$

$\begin{array}{llll}99.7 \% & 38.0 & 25.0 & 37.7\end{array}$

$99.7 \% \quad 32.6 \quad 25.0 \quad 18.4$

$\begin{array}{lllll}99.7 \% & 37.1 & 25.0 & 26.8 & 2\end{array}$

$99.7 \% \quad 26.4 \quad 25.0 \quad 26.4$

$99.7 \% \quad 75.2 \quad 25.0 \quad 75.2$ $\begin{array}{cc}3 & 50 \\ 2 & 69 \\ 11 & 120 \\ 33 & 142 \\ 33 & 143 \\ 44 & 155 \\ 3 & 28 \\ 9 & 42 \\ 3 & 50 \\ 2 & 69 \\ 33 & 142 \\ 33 & 143 \\ 53 & 162 \\ 8 & 41 \\ 2 & 49 \\ 1 & 68 \\ 4 & 91 \\ 28 & 139 \\ 40 & 158 \\ 58 & 167 \\ 59 & 167 \\ 2 & 27 \\ 8 & 41 \\ 8 & 49 \\ 2 & 49 \\ 1 & 74 \\ 4 & 91 \\ 2 & 103 \\ 04 & 115 \\ 28 & 138 \\ 28 & 139 \\ 40 & 157 \\ 40 & 158 \\ 58 & 167 \\ 59 & 167 \\ 7 & 45 \\ 84 & 195 \\ 02 & 112 \\ 18 & 128 \\ 05 & 217 \\ 45 & 255 \\ 62 & 275 \\ 62 & 276 \\ 17 & 325 \\ 92 & 400 \\ & 25 \\ & \\ 3\end{array}$

Page 2 of Table S-1-5 
26S protease regulatory subunit 10B GN=PSMC6 PRS10_HUMAN $44.17 \quad 100.0 \%$ $26 \mathrm{~S}$ protease regulatory subunit 10B GN=PSMC6 PRS10_HUMAN $44.17 \quad 100.0 \%$ 26S protease regulatory subunit 10B GN=PSMC6 PRS10_HUMAN $44.17 \quad 100.0 \%$ 26S protease regulatory subunit 10B GN=PSMC6 PRS10 HUMAN $44.17 \quad 100.0^{\circ}$ 26S protease regulatory subunit 10B GN=PSMC6 PRS10_HUMAN $44.17 \quad 100.0 \%$ $26 \mathrm{~S}$ protease regulatory subunit 10B GN=PSMC6 PRS10_HUMAN $44.17 \quad 100.0 \%$ $26 \mathrm{~S}$ protease regulatory subunit 10B GN=PSMC6 PRS10 HUMAN $44.17 \quad 100.0 \%$ 26S protease regulatory subunit 10B GN=PSMC6 PRS10_HUMAN $44.17 \quad 100.0 \%$ $26 \mathrm{~S}$ protease regulatory subunit 10B GN=PSMC6 PRS10 HUMAN $44.17 \quad 100.0 \%$ $26 \mathrm{~S}$ protease regulatory subunit 10B GN=PSMC6 PRS10_HUMAN $44.17 \quad 100.0 \%$ $26 \mathrm{~S}$ protease regulatory subunit 10B GN=PSMC6 PRS10_HUMAN $44.17 \quad 100.0 \%$ $26 \mathrm{~S}$ protease regulatory subunit $10 \mathrm{~B}$ GN=PSMC6 PRS10 HUMAN 44.17 $26 \mathrm{~S}$ protease regulatory subunit $10 \mathrm{~B}$ GN=PSMC6 PRS10_HUMAN 44.17 $26 \mathrm{~S}$ protease regulatory subunit 10B GN=PSMC6 PRS10 HUMAN 44.17 $26 \mathrm{~S}$ protease regulatory subunit $4 \mathrm{GN}=\mathrm{PSMC} 1 \mathrm{PRS} 4$ HUMAN 49.19 26S protease regulatory subunit $4 \mathrm{GN}=\mathrm{PSMC1}$ PRS4_HUMAN 49.1 $26 \mathrm{~S}$ protease regulatory subunit $4 \mathrm{GN}=\mathrm{PSMC1}$ PRS4 HUMAN $49.1 \mathrm{C}$ 26S protease regulatory subunit $4 \mathrm{GN}=\mathrm{PSMC} 1 \mathrm{PRS} 4$ HUMAN 49.19 $26 \mathrm{~S}$ protease regulatory subunit $4 \mathrm{GN}=\mathrm{PSMC} 1$ PRS4_HUMAN 49.1 $26 \mathrm{~S}$ protease regulatory subunit $4 \mathrm{GN}=\mathrm{PSMC1} \mathrm{PRS} 4 \mathrm{HUMAN} 49.1 \mathrm{C}$ 26S protease regulatory subunit $4 \mathrm{GN}=\mathrm{PSMC} 1 \mathrm{PRS} 4$ _HUMAN 49.19 $26 \mathrm{~S}$ protease regulatory subunit $4 \mathrm{GN}=\mathrm{PSMC1}$ PRS4 HUMAN $49.1 \mathrm{C}$ $26 \mathrm{~S}$ protease regulatory subunit $6 \mathrm{~A} \mathrm{GN}=\mathrm{PSMC} 3$ PRS6A_HUMAN 49.21 $26 \mathrm{~S}$ protease regulatory subunit $6 \mathrm{~A}$ GN=PSMC3 $\mathrm{PRS6A}$ _HUMAN 49.2 $26 \mathrm{~S}$ protease regulatory subunit $6 \mathrm{~A}$ GN=PSMC3 $\mathrm{PRS} 6 \mathrm{~A}$ HUMAN 49.2 $26 \mathrm{~S}$ protease regulatory subunit $6 \mathrm{~A}$ GN=PSMC3 $\mathrm{PRS} 6 \mathrm{~A} \_$HUMAN 49.21 $26 \mathrm{~S}$ protease regulatory subunit $6 \mathrm{~A}$ GN=PSMC3 $\mathrm{PRS6A}$ _HUMAN 49.21 $26 \mathrm{~S}$ protease regulatory subunit $6 \mathrm{~B} \mathrm{GN}=\mathrm{PSMC} 4 \mathrm{PRS} 6 \mathrm{~B}$ HUMAN 47.37 $26 \mathrm{~S}$ protease regulatory subunit $6 \mathrm{~B}$ GN=PSMC4 PRS6B_HUMAN 47.37 $26 \mathrm{~S}$ protease regulatory subunit $6 \mathrm{~B} \mathrm{GN}=\mathrm{PSMC} 4 \mathrm{PRS} 6 \mathrm{~B}$ HUMAN 47.37 $26 \mathrm{~S}$ protease regulatory subunit $6 \mathrm{~B} \mathrm{GN}=\mathrm{PSMC} 4$ PRS6B_HUMAN 47.37 $26 \mathrm{~S}$ protease regulatory subunit $6 \mathrm{~B} \mathrm{GN}=\mathrm{PSMC} 4 \mathrm{PRS} 6 \mathrm{~B} \_$HUMAN 47.37 $26 \mathrm{~S}$ protease regulatory subunit $6 \mathrm{~B} \mathrm{GN}=\mathrm{PSMC} 4 \mathrm{PRS} 6 \mathrm{~B} \_$HUMAN 47.37 $26 \mathrm{~S}$ protease regulatory subunit $6 \mathrm{~B} \mathrm{GN}=\mathrm{PSMC4}$ PRS6B_HUMAN 47.37 $26 \mathrm{~S}$ protease regulatory subunit $7 \mathrm{GN}=\mathrm{PSMC} 2$ PRS7 HUMAN 48.64 26S protease regulatory subuit 7 GN=PSMC2 PRS7_HUMAN 48.6 $26 \mathrm{~S}$ protease regulatory subunit $7 \mathrm{GN}=\mathrm{PSMC} 2 \mathrm{PRS7}$ _HUMAN $48.64 \quad 100.0 \%$ $26 \mathrm{~S}$ protease regulatory subunit $7 \mathrm{GN}=\mathrm{PSMC} 2 \mathrm{PRS} 7$ HUMAN $48.64 \quad 100.0^{\circ}$ $26 \mathrm{~S}$ protease regulatory subunit $7 \mathrm{GN}=\mathrm{PSMC} 2$ PRS7_HUMAN $48.64 \quad 100.0 \%$ $26 \mathrm{~S}$ protease regulatory subunit $7 \mathrm{GN}=\mathrm{PSMC} 2$ PRS7_HUMAN $48.64 \quad 100.0 \%$ $26 \mathrm{~S}$ protease regulatory subunit $7 \mathrm{GN}=\mathrm{PSMC} 2 \mathrm{PRS} 7$ HUMAN $48.64 \quad 100.0 \%$ $26 \mathrm{~S}$ protease regulatory subunit $7 \mathrm{GN}=\mathrm{PSMC} 2 \mathrm{PRS} 7$ _HUMAN $48.64 \quad 100.0 \%$ $26 \mathrm{~S}$ protease regulatory subunit $7 \mathrm{GN}=\mathrm{PSMC} 2 \mathrm{PRS} 7 \mathrm{HUMAN} 48.64100 .0 \%$ $26 \mathrm{~S}$ protease regulatory subunit $7 \mathrm{GN}=\mathrm{PSMC} 2$ PRS7_HUMAN $48.64 \quad 100.0 \%$ $26 \mathrm{~S}$ protease regulatory subunit $8 \mathrm{GN}=$ PSMC5 PRS8_HUMAN $45.63 \quad 100.0 \%$ $26 \mathrm{~S}$ protease regulatory subunit $8 \mathrm{GN}=\mathrm{PSMC} 5 \mathrm{PRS} 8 \mathrm{HUMAN} 45.63 \quad 100.0 \%$ $26 \mathrm{~S}$ protease regulatory subunit $8 \mathrm{GN}=$ PSMC5 PRS8_HUMAN $45.63 \quad 100.0 \%$

7

7

7

(1)

7
7

8
8
8
8

8
8
8
8

$\begin{array}{cc}7 & 8 \\ 10 & 10 \\ 0 & 10\end{array}$

10
10
10

10
10

10
10

10
10

10
10

10
10

10
10

6

$49 \quad 0.05 \% \quad 45.0 \%$ QLTEEKFIVK

$49 \quad 0.05 \% \quad 45.0 \%$ VALDMTTLTIMR

$49 \quad 0.05 \% \quad 45.0 \%$ EVIELPLTNPELFQR

$49 \quad 0.05 \% \quad 45.0 \%$ AVASQLDCNFLK

$49 \quad 0.05 \% \quad 45.0 \%$ VVSSSIVDK

$49 \quad 0.05 \% \quad 45.0 \%$ VVSSSIVDKYIGESAR

$0.05 \% \quad 45.0 \%$ FSEGTSADR

$49 \quad 0.05 \% \quad 45.0 \%$ FSEGTSADREIQR

$0.05 \% \quad 45.0 \%$ TLMELLNQMDGFDTLHR

$49 \quad 0.05 \% \quad 45.0 \%$ KIHIDLPNEQAR

$49 \quad 0.05 \% \quad 45.0 \%$ IHAGPITK

$49 \quad 0.05 \% \quad 45.0 \%$ HGEIDYEAIVK

$49 \quad 0.05 \% \quad 45.0 \%$ NVCTEAGMFAIR

$49 \quad 0.05 \% \quad 45.0 \%$ ADHDFVVQEDFMK

$14 \quad 0.02 \% \quad 20.0 \%$ KYEPPVPTR

$14 \quad 0.02 \% \quad 20.0 \%$ GVILYGPPGTGK

$14 \quad 0.02 \% \quad 20.0 \%$ AVANQTSATFLR

$14 \quad 0.02 \% \quad 20.0 \%$ VVGSELIQK

$14 \quad 0.02 \% \quad 20.0 \%$ VAEEHAPSIVFIDEIDAIGTK

$0.02 \% 20.0 \%$ VAEEHAPSIVFIDEIDAIGTKR

$0.02 \% \quad 20.0 \%$ YDSNSGGEREIQR

$0.02 \% \quad 20.0 \%$ KQEGTPEGLYL

$0.01 \% \quad 11.2 \%$ MSTEEIIQR

$\begin{array}{ll}0.01 \% & 11.2 \% \text { GVLMYGPPGTGK }\end{array}$

$0.01 \% \quad 11.2 \%$ VIAATNRVDILDPALLR

$0.01 \% \quad 11.2 \%$ VDILDPALLR

$10 \quad 0.01 \% \quad 11.2 \%$ CTDDFNGAQCK

$16 \quad 0.02 \% \quad 15.6 \%$ EFLHAQEEVKR

$16 \quad 0.02 \% \quad 15.6 \%$ AVAHHTTAAFIR

$16 \quad 0.02 \% \quad 15.6 \%$ VVGSEFVQK

$16 \quad 0.02 \% \quad 15.6 \%$ FDAQTGADREVQR

$16 \quad 0.02 \% \quad 15.6 \%$ RLIFSTITSK

$16 \quad 0.02 \% \quad 15.6 \%$ LIFSTITSK

$16 \quad 0.02 \% \quad 15.6 \%$ YIVLAKDFEK

$10 \quad 20 \quad 0.02 \% \quad 26.3 \%$ ALDEGDIALLK

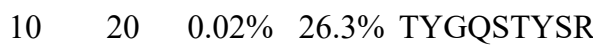

\begin{tabular}{llll}
10 & 20 & $0.02 \%$ & $26.3 \%$ \\
\hline & 20 & $0.02 \%$ & $26.3 \%$
\end{tabular}

$10 \quad 20 \quad 0.02 \% \quad 26.3 \%$ IINADSEDPKYIINVK

$\begin{array}{llll}10 & 20 & 0.02 \% & 26.3 \% \\ 10 & \text { FVNLGIEPPK }\end{array}$

$10 \quad 20 \quad 0.02 \% \quad 26.3 \%$ GVLLFGPPGTGK

$10 \quad 20 \quad 0.02 \% \quad 26.3 \%$ VIGSELVQK

$10 \quad 20 \quad 0.02 \% \quad 26.3 \%$ FDDGAGGDNEVQR

$\begin{array}{llll}10 & 20 & 0.02 \% & 26.3 \% \\ 10 & \text { LCPNSTGAEIR }\end{array}$

$\begin{array}{llll}10 & 20 & 0.02 \% & 26.3 \% \\ 8 & \text { SVCTEAGMFAIR }\end{array}$

$\begin{array}{lll}21 & 0.02 \% & 17.7 \% \\ 21 & 0.02 \% & 17.7 \%\end{array}$

$21 \quad 0.02 \% \quad 17.7 \%$ GVLLYGPPGTGK

$21 \quad 0.02 \% \quad 17.7 \%$ AVAHHTDCTFIR $\begin{array}{llllllll}99.5 \% & 26.0 & 25.0 & 16.2 & 1 & 0 & 0 & 1234.70\end{array}$

$\begin{array}{llllllll}99.7 \% & 59.2 & 25.0 & 54.1 & 8 & 0 & 0 & 1380.72\end{array}$

$\begin{array}{llllllll}99.7 \% & 40.2 & 25.0 & 39.2 & 2 & 0 & 0 & 1797.97\end{array}$

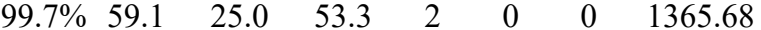

$\begin{array}{llllllll}99.7 \% & 35.6 & 25.0 & 35.6 & 2 & 0 & 0 & 933.53\end{array}$

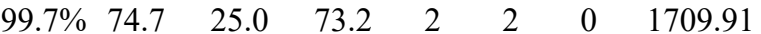

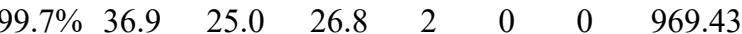

$\begin{array}{llllllll}99.7 \% & 37.6 & 25.0 & 36.3 & 2 & 2 & 0 & 1495.71 \\ 99.7 \% & 32.8 & 25.0 & 31.7 & 0 & 2 & 0 & 2065.97\end{array}$

1433.79

836.50

1273.64

1368.64

1596.70

1086.59

1158.65

1278.68

972.57

2254.16

2410.26

1510.69

1234.63

1106.55

1192.60

1850.09

1124.67

1315.50

1385.72

1294.70

992.54

1492.71

1165.69

1009.59

1225.68

1157.64

1062.49

1328.71

1831.98

1113.63

1142.66

972.57

$\begin{array}{llll}99.7 \% & 37.2 & 25.0 & 37.2\end{array}$

$\begin{array}{llll}99.7 \% & 31.7 & 25.0 & 20.4\end{array}$

$\begin{array}{lllll}99.7 \% & 62.6 & 25.0 & 62.6 & 2\end{array}$

$\begin{array}{llll}99.7 \% & 41.0 & 25.0 & 24.7\end{array}$

$\begin{array}{lllll}99.7 \% & 46.5 & 25.0 & 38.4\end{array}$

$\begin{array}{lllll}99.7 \% & 32.8 & 25.0 & 26.4 & 2\end{array}$

$\begin{array}{llll}99.4 \% & 57.4 & 25.0 & 0.0\end{array}$

$\begin{array}{llll}99.7 \% & 32.0 & 25.0 & 27.1\end{array}$ \begin{tabular}{cc} 
& \\
63 & 72 \\
8 & 109 \\
147 & 161 \\
186 & 197 \\
98 & 206 \\
198 & 213 \\
243 & 251 \\
243 & 255 \\
56 & 272 \\
298 & 309 \\
15 & 322 \\
323 & 333 \\
345 & 356 \\
357 & 369 \\
24 & 32 \\
221 & 232 \\
238 & 249 \\
250 & 258 \\
273 & 293 \\
273 & 294 \\
295 & 307 \\
430 & 440 \\
36 & 44 \\
222 & 233 \\
328 & 344 \\
335 & 344 \\
387 & 397 \\
1 & 81 \\
218 & 229 \\
230 & 238 \\
275 & 287 \\
42 & 351 \\
343 & 351 \\
392 & 401 \\
24 & 34 \\
35 & 43 \\
47 & 57 \\
101 & 116 \\
201 & 210 \\
211 & 222 \\
240 & 248 \\
285 & 297 \\
376 & 386 \\
387 & 398 \\
14 & 125 \\
102 & 196 \\
213 \\
\hline 2
\end{tabular}

Page 3 of Table S-1-5 
26S protease regulatory subunit $8 \mathrm{GN}=$ =PSMC5 PRS 8 HUMAN $45.63 \quad 100.0 \%$ $26 \mathrm{~S}$ protease regulatory subunit $8 \mathrm{GN}=\mathrm{PSMC} 5 \mathrm{PRS} 8$ HUMAN $45.63 \quad 100.0 \%$ $26 \mathrm{~S}$ protease regulatory subunit $8 \mathrm{GN}=$ PSMC5 PRS8_HUMAN $45.63 \quad 100.0 \%$ $26 \mathrm{~S}$ proteasome non-ATPase regulatory subunit $1 \mathrm{GN}=\mathrm{PSMD} 1$ PSMD1 HUMAN $105.84100 .0 \%$ 26S proteasome non-ATPase regulatory subunit 1 GN=PSMD1 PSMD1_HUMAN $105.84 \quad 100.0 \%$ $26 \mathrm{~S}$ proteasome non-ATPase regulatory subunit $11 \mathrm{GN}=$ =PSMD11 PSD11_HUMAN $47.47 \quad 100.0 \%$ $26 \mathrm{~S}$ proteasome non-ATPase regulatory subunit $11 \mathrm{GN}=\mathrm{PSMD} 11$ PSD11 HUMAN $47.47 \quad 100.0 \%$ $26 \mathrm{~S}$ proteasome non-ATPase regulatory subunit $11 \mathrm{GN}=\mathrm{PSMD} 11$ PSD11_HUMAN $47.47 \quad 100.0 \%$ $26 \mathrm{~S}$ proteasome non-ATPase regulatory subunit $13 \mathrm{GN}=\mathrm{PSMD} 13 \mathrm{PSD} 13$ HUMAN $42.95 \quad 100.0 \%$ $26 \mathrm{~S}$ proteasome non-ATPase regulatory subunit $13 \mathrm{GN}=\mathrm{PSMD} 13$ PSD13_HUMAN $42.95 \quad 100.0 \%$ 26S proteasome non-ATPase regulatory subunit $13 \mathrm{GN}=$ PSMD13 PSD13_HUMAN $42.95 \quad 100.0 \%$ 26S proteasome non-ATPase regulatory subunit $13 \mathrm{GN}=$ PSMD13 PSD13 HUMAN $42.95100 .0^{\circ}$ 26S proteasome non-ATPase regulatory subunit $13 \mathrm{GN}=$ PSMD13 PSD13_HUMAN $42.95 \quad 100.0 \%$ $26 \mathrm{~S}$ proteasome non-ATPase regulatory subunit $13 \mathrm{GN}=\mathrm{PSMD} 13 \mathrm{PSD} 13$ HUMAN $42.95 \quad 100.0 \%$ $26 \mathrm{~S}$ proteasome non-ATPase regulatory subunit $14 \mathrm{GN}=\mathrm{PSMD} 14$ PSDE_HUMAN $34.58 \quad 100.0 \%$ $26 \mathrm{~S}$ proteasome non-ATPase regulatory subunit $14 \mathrm{GN}=\mathrm{PSMD} 14$ PSDE_HUMAN $34.58 \quad 100.0 \%$ $26 \mathrm{~S}$ proteasome non-ATPase regulatory subunit $2 \mathrm{GN}=\mathrm{PSMD} 2 \mathrm{PSMD} 2 \mathrm{HUMAN} 100.20100 .0 \%$ 26S proteasome non-ATPase regulatory subunit 2 GN=PSMD2 PSMD2_HUMAN $100.20 \quad 100.0 \%$ $26 \mathrm{~S}$ proteasome non-ATPase regulatory subunit 2 GN=PSMD2 PSMD2_HUMAN $100.20 \quad 100.0 \%$ $26 \mathrm{~S}$ proteasome non-ATPase regulatory subunit $2 \mathrm{GN}=\mathrm{PSMD} 2 \mathrm{PSMD} 2$ HUMAN $100.20100 .0 \%$ 26S proteasome non-ATPase regulatory subunit 2 GN=PSMD2 PSMD2_HUMAN $100.20 \quad 100.0 \%$ $26 \mathrm{~S}$ proteasome non-ATPase regulatory subunit $3 \mathrm{GN}=\mathrm{PSMD} 3$ PSMD3_HUMAN $60.98100 .0 \%$ $26 \mathrm{~S}$ proteasome non-ATPase regulatory subunit $3 \mathrm{GN}=\mathrm{PSMD} 3$ PSMD3_HUMAN $60.98 \quad 100.0 \%$ 26S proteasome non-ATPase regulatory subunit $3 \mathrm{GN}=$ PSMD3 PSMD3_HUMAN $60.98 \quad 100.0 \%$ $26 \mathrm{~S}$ proteasome non-ATPase regulatory subunit $3 \mathrm{GN}=\mathrm{PSMD} 3$ PSMD3 HUMAN $60.98 \quad 100.0^{\circ}$ 26S proteasome non-ATPase regulatory subunit 3 GN=PSMD3 PSMD3_HUMAN $60.98 \quad 100.0 \%$ 26S proteasome non-ATPase regulatory subunit $3 \mathrm{GN}=$ PSMD3 PSMD3_HUMAN $60.98100 .0 \%$ $26 \mathrm{~S}$ proteasome non-ATPase regulatory subunit $3 \mathrm{GN}=\mathrm{PSMD} 3 \mathrm{PSMD} 3$ HUMAN $60.98 \quad 100.0 \%$ $26 \mathrm{~S}$ proteasome non-ATPase regulatory subunit $3 \mathrm{GN}=\mathrm{PSMD} 3 \mathrm{PSMD} 3$ _HUMAN $60.98 \quad 100.0 \%$ $26 \mathrm{~S}$ proteasome non-ATPase regulatory subunit $3 \mathrm{GN}=\mathrm{PSMD} 3 \mathrm{PSMD} 3$ HUMAN $60.98100 .0 \%$ 265 proteasome non-ATPase regulatory subunit 3 GN=PSMD3 PSMD3_HUMAN $60.98 \quad 100.0 \%$ 26S proteasome non-ATPase regulatory subunit 3 GN=PSMD3 PSMD3_HUMAN $60.98 \quad 100.0 \%$ $26 \mathrm{~S}$ proteasome non-ATPase regulatory subunit $3 \mathrm{GN}=\mathrm{PSMD} 3 \mathrm{PSMD} 3$ HUMAN $60.98100 .0 \%$ 26S proteasome non-ATPase regulatory subunit $3 \mathrm{GN}=$ PSMD3 PSMD3_HUMAN $60.98 \quad 100.0 \%$ 26S proteasome non-ATPase regulatory subunit $3 \mathrm{GN}=$ PSMD3 PSMD3_HUMAN $60.98100 .0 \%$ $26 \mathrm{~S}$ proteasome non-ATPase regulatory subunit $3 \mathrm{GN}=\mathrm{PSMD} 3$ PSMD3_HUMAN $60.98 \quad 100.0 \%$ 26S proteasome non-ATPase regulatory subunit 3 GN=PSMD3 PSMD3_HUMAN $60.98 \quad 100.0 \%$ $26 \mathrm{~S}$ proteasome non-ATPase regulatory subunit $3 \mathrm{GN}=$ PSMD3 PSMD3 HUMAN $60.98100 .0 \%$ 26S proteasome non-ATPase regulatory subunit 4 GN=PSMD4 PSMD4_HUMAN $40.74 \quad 100.0 \%$ 26S proteasome non-ATPase regulatory subunit 4 GN=PSMD4 PSMD4_HUMAN $40.74 \quad 100.0 \%$ $26 \mathrm{~S}$ proteasome non-ATPase regulatory subunit 4 GN=PSMD4 PSMD4 HUMAN $40.74100 .0^{\circ} \%$ 26S proteasome non-ATPase regulatory subunit 4 GN=PSMD4 PSMD4_HUMAN $40.74 \quad 100.0 \%$ $26 \mathrm{~S}$ proteasome non-ATPase regulatory subunit $4 \mathrm{GN}=\mathrm{PSMD} 4$ PSMD4_HUMAN $40.74 \quad 100.0 \%$ 26S proteasome non-ATPase regulatory subunit 4 GN=PSMD4 PSMD4_HUMAN $40.74 \quad 100.0 \%$ 26S proteasome non-ATPase regulatory subunit 4 GN=PSMD4 PSMD4_HUMAN $40.74 \quad 100.0 \%$ 26S proteasome non-ATPase regulatory subunit $4 \mathrm{GN}=$ PSMD4 PSMD4 HUMAN $40.74 \quad 100.0^{\circ}$ 26S proteasome non-ATPase regulatory subunit 6 GN=PSMD6 PSMD6_HUMAN $45.53 \quad 100.0 \%$
$0.02 \% \quad 17.7 \%$ VSGSELVQK

$0.02 \% \quad 17.7 \%$ LEGGSGGDSEVQR

$0.02 \% \quad 17.7 \%$ IAELMPGASGAEVK

$0.00 \% \quad 2.7 \%$ LLHVAVSDVNDDVRR

$0.00 \% \quad 2.7 \% \quad$ VSTAVLSITAK

$0.00 \% \quad 8.3 \%$ TGQAAELGGLLK

$0.00 \% \quad 8.3 \%$ LYDNLLEQNLIR

$0.00 \% \quad 8.3 \%$ VQIEHISSLIK

$0.01 \% \quad 16.8 \%$ QMTDPNVALTFLEK

$0.01 \% \quad 16.8 \%$ SSDEAVILCK

$0.01 \% \quad 16.8 \%$ DLPVSEQQER

$0.01 \% \quad 16.8 \%$ QLTFEEIAK

$0.01 \% \quad 16.8 \%$ ITVNEVELLVMK

$0.01 \% \quad 16.8 \%$ VLDLQQIK

$0.01 \% \quad 9.4 \%$ AVAVVVDPIQSVK

$0.01 \% \quad 9.4 \%$ AVEEEDKMTPEQLAIK

$0.01 \% \quad 6.4 \%$ SSTTSMTSVPKPLK

$0.01 \% \quad 6.4 \%$ CALGVFRK

$0.01 \% \quad 6.4 \% \quad$ FGGSGSQVDSAR

$0.01 \% \quad 6.4 \%$ LNILDTLSK

$0.01 \% \quad 6.4 \%$ VGQAVDVVGQAGKPK

$0.04 \% \quad 28.3 \%$ RLNHYVLYK

$0.04 \% \quad 28.3 \%$ LNHYVLYK

$0.04 \% \quad 28.3 \%$ AVQGFFTSNNATR

$0.04 \% \quad 28.3 \%$ ISDDLMQK

$0.04 \% \quad 28.3 \%$ RALDLVAAK

$0.04 \% \quad 28.3 \%$ ALDLVAAK

$0.04 \% \quad 28.3 \%$ NYLHYSLYDQAEK

$0.04 \% \quad 28.3 \%$ SVFPEQANNNEWAR

$0.04 \% \quad 28.3 \%$ IKAIQLEYSEAR

$0.04 \% \quad 28.3 \%$ AIQLEYSEAR

$0.04 \% \quad 28.3 \%$ TMTNALRK

$0.04 \% \quad 28.3 \%$ APQHTAVGFK

$0.04 \% \quad 28.3 \%$ FNQVLDQFGEK

$0.04 \% 28.3 \%$ MISLSYSR

$0.04 \% \quad 28.3 \%$ ISLADIAQK

$0.04 \% \quad 28.3 \%$ AIRDGVIEASINHEK

$0.04 \% \quad 28.3 \%$ SYNKDLESAEER

$0.03 \% \quad 27.1 \%$ NGDFLPTRLQAQQDAVNIVCHSK

$0.03 \% \quad 27.1 \%$ LQAQQDAVNIVCHSK

$0.03 \% 27.1 \%$ SNPENNVGLITLANDCEVLTTLTPDTGRILSK

$0.03 \% \quad 27.1 \%$ ILSKLHTVQPK

$0.03 \% \quad 27.1 \%$ GKITFCTGIR

$0.03 \% \quad 27.1 \%$ ITFCTGIR

$0.03 \% \quad 27.1 \%$ IIAFVGSPVEDNEKDLVK

$0.03 \% \quad 27.1 \%$ NAMGSLASQATK

$0.04 \% \quad 42.9 \%$ PLENLEEEGLPK $\begin{array}{llllllll}99.7 \% & 57.4 & 25.0 & 30.1 & 4 & 0 & 0 & 946.52\end{array}$

$\begin{array}{cccccccc}99.7 \% & 69.2 & 25.0 & 69.2 & 5 & 0 & 0 & 1290.59\end{array}$

$99.7 \% \quad 50.5$

$99.7 \% \quad 62.3$

$99.7 \% \quad 57.4$

$99.7 \% \quad 37.3$

$99.7 \% \quad 30.3$

$99.7 \% \quad 73.7$

$99.7 \% \quad 36.8$

$99.7 \% \quad 29.5$

$99.7 \% \quad 37.0$

$98.0 \% \quad 21.8$

$99.7 \% \quad 55.0$

$98.4 \% \quad 20.0$

$99.6 \% \quad 28.2$

$97.1 \% \quad 16.2$

$99.7 \% \quad 75.4$

$97.5 \% \quad 26.2$

$99.7 \% \quad 67.1$

$99.7 \% \quad 36.2$

$99.0 \% 32.1$

$99.7 \% \quad 68.8$

$99.0 \% \quad 35.8$

$99.6 \% \quad 25.0$

$99.0 \% 37.7$

$99.7 \% \quad 31.8$

$99.7 \% \quad 50.7$

$99.7 \% \quad 32.2$

$99.7 \% \quad 65.7$

$98.9 \% \quad 23.0$

$99.2 \% \quad 20.0$

$99.7 \% \quad 65.7$

$99.0 \% \quad 39.6$

$99.7 \% \quad 54.7$

$99.7 \% \quad 40.2$

$99.7 \% \quad 33.0$

$99.7 \% \quad 32.3$

$99.7 \% \quad 36.9$

$9.7 \% \quad 50.9$

$99.7 \% \quad 42.2$

$99.7 \% \quad 39.5$

$99.0 \% \quad 43.2$

$99.7 \% \quad 34.8$

$99.7 \% \quad 50.7$

$99.7 \% \quad 52.6$

1290.59
1388.71

1707.91

1089.65

1157.65

1503.82

1266.74

1622.81

1121.55

1200.59

1078.58

1387.79

956.58

1324.78

1846.91

1479.77

950.52

1167.54

1016.60

1452.82

1205.68

1049.58

1412.69

965.46

956.59

800.49

1643.77

1661.77

1420.78

1179.60

934.51

1055.56

1324.65

972.48

958.56

1651.88

1440.66

2611.30

1710.86

3455.77

1263.78

1152.62

967.50

1973.06

1194.58

1367.71 
26S proteasome non-ATPase regulatory subunit 6 GN=PSMD6 PSMD6_HUMAN $45.53 \quad 100.0 \%$ 26S proteasome non-ATPase regulatory subunit 6 GN=PSMD6 PSMD6_HUMAN $45.53 \quad 100.0 \%$ 26S proteasome non-ATPase regulatory subunit 6 GN=PSMD6 PSMD6_HUMAN $45.53 \quad 100.0 \%$ $26 \mathrm{~S}$ proteasome non-ATPase regulatory subunit 6 GN=PSMD6 PSMD6_HUMAN $45.53 \quad 100.0^{\circ}$ 26S proteasome non-ATPase regulatory subunit 6 GN=PSMD6 PSMD6_HUMAN $45.53 \quad 100.0 \%$ 26S proteasome non-ATPase regulatory subunit 6 GN=PSMD6 PSMD6_HUMAN $45.53 \quad 100.0 \%$ 26 S proteasome non-ATPase regulatory subunit $6 \mathrm{GN}=$ PSMD6 PSMD6_HUMAN $45.53 \quad 100.0 \%$ 26S proteasome non-ATPase regulatory subunit 6 GN=PSMD6 PSMD6_HUMAN $45.53 \quad 100.0 \%$ $26 \mathrm{~S}$ proteasome non-ATPase regulatory subunit $6 \mathrm{GN}=$ PSMD6 PSMD6 HUMAN $45.53100 .0 \%$ 26S proteasome non-ATPase regulatory subunit 6 GN=PSMD6 PSMD6_HUMAN $45.53 \quad 100.0 \%$ 26S proteasome non-ATPase regulatory subunit 6 GN=PSMD6 PSMD6_HUMAN $45.53 \quad 100.0 \%$ $26 \mathrm{~S}$ proteasome non-ATPase regulatory subunit 6 GN=PSMD6 PSMD6_HUMAN $45.53 \quad 100.0^{\circ}$ 26S proteasome non-ATPase regulatory subunit 6 GN=PSMD6 PSMD6_HUMAN $45.53 \quad 100.0 \%$ 26S proteasome non-ATPase regulatory subunit 6 GN=PSMD6 PSMD6_HUMAN $45.53 \quad 100.0 \%$ 26S proteasome non-ATPase regulatory subunit 6 GN=PSMD6 PSMD6_HUMAN $45.53 \quad 100.0 \%$ 26S proteasome non-ATPase regulatory subunit 8 GN=PSMD8 PSMD8_HUMAN $39.61 \quad 100.0 \%$ $26 \mathrm{~S}$ proteasome non-ATPase regulatory subunit $8 \mathrm{GN}=$ PSMD8 PSMD8 HUMAN $39.61100 .0 \%$ $28 \mathrm{~S}$ ribosomal protein S18b, mitochondrial GN=MRPS18B RT18B_HUMAN $29.40 \quad 100.0 \%$ $28 \mathrm{~S}$ ribosomal protein S18b, mitochondrial GN=MRPS18B RT18B_HUMAN $29.40 \quad 100.0 \%$ $28 \mathrm{~S}$ ribosomal protein $\mathrm{S} 18 \mathrm{~b}$, mitochondrial GN=MRPS18B RT18B HUMAN $29.40 \quad 100.0 \%$ $28 \mathrm{~S}$ ribosomal protein S18b, mitochondrial GN=MRPS18B RT18B_HUMAN $29.40 \quad 100.0 \%$ $28 \mathrm{~S}$ ribosomal protein $\mathrm{S} 18 \mathrm{~b}$, mitochondrial GN=MRPS18B RT18B HUMAN $29.40 \quad 100.0 \%$ $28 \mathrm{~S}$ ribosomal protein S18b, mitochondrial GN=MRPS18B RT18B_HUMAN $29.40 \quad 100.0 \%$ $28 \mathrm{~S}$ ribosomal protein S2, mitochondrial GN=MRPS2 RT02_HUMAN $33.25 \quad 100.0 \%$ 28S ribosomal protein S2, mitochondrial GN=MRPS2 RT02 HUMAN 33.25 $28 \mathrm{~S}$ ribosomal protein S2, mitochondrial GN=MRPS2 RT02_HUMAN 33.25 28S ribosomal protein S2, mitochondrial GN=MRPS2 RT02_HUMAN 33.25 28S ribosomal protein S2, mitochondrial GN=MRPS2 RT02 HUMAN 33.2 $28 \mathrm{~S}$ ribosomal protein $\mathrm{S} 2$, mitochondrial GN=MRPS2 RT02_HUMAN 33.25 $28 \mathrm{~S}$ ribosomal protein $\mathrm{S} 2$, mitochondrial GN=MRPS2 RT02 HUMAN 33.25 $28 \mathrm{~S}$ ribosomal protein $\mathrm{S} 2$, mitochondrial GN=MRPS2 RT02_HUMAN 33.25 $28 \mathrm{~S}$ ribosomal protein $\mathrm{S} 2$, mitochondrial GN=MRPS2 RT02_HUMAN 33.25 $28 \mathrm{~S}$ ribosomal protein S22, mitochondrial GN=MRPS22 RT22 HUMAN 41.28 $28 \mathrm{~S}$ ribosomal protein S22, mitochondrial GN=MRPS22 RT22_HUMAN 41.28 $28 \mathrm{~S}$ ribosomal protein S22, mitochondrial GN=MRPS22 RT22_HUMAN 41.28 $28 \mathrm{~S}$ ribosomal protein S22, mitochondrial GN=MRPS22 RT22_HUMAN 41.28 $28 \mathrm{~S}$ ribosomal protein S22, mitochondrial GN=MRPS22 RT22_HUMAN 41.2 $28 \mathrm{~S}$ ribosomal protein S22, mitochondrial GN=MRPS22 RT22 HUMAN 41.28 $28 \mathrm{~S}$ ribosomal protein S22, mitochondrial GN=MRPS22 RT22_HUMAN 41.28 $28 \mathrm{~S}$ ribosomal protein S22, mitochondrial GN=MRPS22 RT22_HUMAN 41.28 $28 \mathrm{~S}$ ribosomal protein S22, mitochondrial GN=MRPS22 RT22 HUMAN 41.28 $28 \mathrm{~S}$ ribosomal protein S22, mitochondrial GN=MRPS22 RT22_HUMAN 41.28 $28 \mathrm{~S}$ ribosomal protein S22, mitochondrial GN=MRPS22 RT22 HUMAN 41,2 $28 \mathrm{~S}$ ribosomal protein S22, mitochondrial GN=MRPS22 RT22_HUMAN 41.28 $28 \mathrm{~S}$ ribosomal protein S22, mitochondrial GN=MRPS22 RT22_HUMAN 41.28 $28 \mathrm{~S}$ ribosomal protein S23, mitochondrial GN=MRPS23 RT23 HUMAN 21.77 $28 \mathrm{~S}$ ribosomal protein S23, mitochondrial GN=MRPS23 RT23_HUMAN 21.77

20

20

20

20

20

$\begin{array}{ll}16 & 20 \\ 16 & 20 \\ 16 & 20\end{array}$

20

20

$\begin{array}{ll}16 & 20 \\ 16 & 20\end{array}$

$\begin{array}{ll}16 & 20 \\ 16 & 20\end{array}$

6

20

2

$\begin{array}{ll}2 & 2 \\ 6 & 6 \\ 6 & 6\end{array}$

6
6

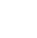


$28 \mathrm{~S}$ ribosomal protein S23, mitochondrial GN=MRPS23 RT23 HUMAN $21.77 \quad 100.0 \%$ $28 \mathrm{~S}$ ribosomal protein S23, mitochondrial GN=MRPS23 RT23_HUMAN $21.77 \quad 100.0 \%$ $28 \mathrm{~S}$ ribosomal protein S23, mitochondrial GN=MRPS23 RT23_HUMAN $21.77 \quad 100.0 \%$ $28 \mathrm{~S}$ ribosomal protein $\mathrm{S} 23$, mitochondrial GN=MRPS23 RT23 HUMAN $21.77 \quad 100.0 \%$ $28 \mathrm{~S}$ ribosomal protein S23, mitochondrial GN=MRPS23 RT23_HUMAN $21.77 \quad 100.0 \%$ $28 \mathrm{~S}$ ribosomal protein S25, mitochondrial GN=MRPS25 RT25_HUMAN $20.12 \quad 100.0 \%$ $28 \mathrm{~S}$ ribosomal protein S25, mitochondrial GN=MRPS25 RT25_HUMAN $20.12 \quad 100.0 \%$ $28 \mathrm{~S}$ ribosomal protein S25, mitochondrial GN=MRPS25 RT25_HUMAN $20.12 \quad 100.0 \%$ $28 \mathrm{~S}$ ribosomal protein $\mathrm{S} 25$, mitochondrial GN=MRPS25 RT25 HUMAN $20.12 \quad 100.0 \%$ $28 \mathrm{~S}$ ribosomal protein $\mathrm{S} 25$, mitochondrial GN=MRPS25 RT25_HUMAN $20.12 \quad 100.0 \%$ $28 \mathrm{~S}$ ribosomal protein S27, mitochondrial GN=MRPS27 RT27_HUMAN $47.61 \quad 100.0 \%$ $28 \mathrm{~S}$ ribosomal protein S27, mitochondrial GN=MRPS27 RT27_HUMAN $47.61 \quad 100.0 \%$ $28 \mathrm{~S}$ ribosomal protein S27, mitochondrial GN=MRPS27 RT27_HUMAN $47.61 \quad 100.0 \%$ $28 \mathrm{~S}$ ribosomal protein S27, mitochondrial GN=MRPS27 RT27_HUMAN $47.61 \quad 100.0 \%$ $28 \mathrm{~S}$ ribosomal protein S27, mitochondrial GN=MRPS27 RT27_HUMAN $47.61 \quad 100.0 \%$ $28 \mathrm{~S}$ ribosomal protein S27, mitochondrial GN=MRPS27 RT27_HUMAN $47.61 \quad 100.0 \%$ $28 \mathrm{~S}$ ribosomal protein $\mathrm{S} 27$, mitochondrial GN=MRPS27 RT27 HUMAN $47.61 \quad 100.0 \%$ $28 \mathrm{~S}$ ribosomal protein S27, mitochondrial GN=MRPS27 RT27_HUMAN $47.61 \quad 100.0 \%$ $28 \mathrm{~S}$ ribosomal protein S27, mitochondrial GN=MRPS27 RT27_HUMAN $47.61 \quad 100.0 \%$ $28 \mathrm{~S}$ ribosomal protein S27, mitochondrial GN=MRPS27 RT27_HUMAN $47.61 \quad 100.0 \%$ $28 \mathrm{~S}$ ribosomal protein S29, mitochondrial GN=DAP3 RT29_HUMAN $45.57 \quad 100.0 \%$ $28 \mathrm{~S}$ ribosomal protein $\mathrm{S} 29$, mitochondrial GN=DAP3 RT29 HUMAN $45.57 \quad 100.0 \%$ $28 \mathrm{~S}$ ribosomal protein $\mathrm{S} 29$, mitochondrial GN=DAP3 RT29_HUMAN $45.57 \quad 100.0 \%$ $28 \mathrm{~S}$ ribosomal protein S29, mitochondrial GN=DAP3 RT29_HUMAN $45.57 \quad 100.0 \%$ $28 \mathrm{~S}$ ribosomal protein $\mathrm{S} 29$, mitochondrial GN=DAP3 RT29 HUMAN 45.57 28S ribosomal protein S29, mitochondrial GN=DAP3 RT29_HUMAN 45.57 $28 \mathrm{~S}$ ribosomal protein S29, mitochondrial GN=DAP3 RT29_HUMAN 45.57 28S ribosomal protein $\mathrm{S} 29$, mitochondrial GN=DAP3 RT29 HUMAN $45.5^{7}$ $28 \mathrm{~S}$ ribosomal protein S29, mitochondrial GN=DAP3 RT29_HUMAN 45.57 28S ribosomal protein S31, mitochondrial GN=MRPS31 RT31_HUMAN 45.32 28S ribosomal protein S31, mitochondrial GN=MRPS31 RT31_HUMAN 45.32 $28 \mathrm{~S}$ ribosomal protein S31, mitochondrial GN=MRPS31 RT31_HUMAN 45.32 28 ribosomal protein S31, mitochondrial GN=MRPS31 RT31_HUMAN 45.3 $28 \mathrm{~S}$ ribosomal protein $\mathrm{S} 35$, mitochondrial GN=MRPS35 RT35_HUMAN 36.8 . $28 \mathrm{~S}$ ribosomal protein S35, mitochondrial GN=MRPS35 RT35 HUMAN 36.8 $28 \mathrm{~S}$ ribosomal protein $\mathrm{S} 35$, mitochondrial GN=MRPS35 RT35_HUMAN 36.8 $28 \mathrm{~S}$ ribosomal protein S35, mitochondrial GN=MRPS35 RT35_HUMAN 36.8 $28 \mathrm{~S}$ ribosomal protein $\mathrm{S} 35$, mitochondrial GN=MRPS35 RT35 HUMAN 36.85 $28 \mathrm{~S}$ ribosomal protein $\mathrm{S} 35$, mitochondrial GN=MRPS35 RT35_HUMAN 36.85 $28 \mathrm{~S}$ ribosomal protein S35, mitochondrial GN=MRPS35 RT35_HUMAN 36.8 $28 \mathrm{~S}$ ribosomal protein $\mathrm{S} 35$, mitochondrial GN=MRPS35 RT35 HUMAN 36.8 $28 \mathrm{~S}$ ribosomal protein $\mathrm{S} 5$, mitochondrial GN=MRPS5 RT05_HUMAN 48.0 28S ribosomal protein $\mathrm{S} 5$, mitochondrial GN=MRPS5 RT05 HUMAN 48.0 $28 \mathrm{~S}$ ribosomal protein $\mathrm{S} 5$, mitochondrial GN=MRPS5 RT05 HUMAN 48.0 28S ribosomal protein S5, mitochondrial GN=MRPS5 RT05_HUMAN 48.0 28S ribosomal protein $\mathrm{S} 5$, mitochondrial GN=MRPS5 RT05 HUMAN 48.0 $28 \mathrm{~S}$ ribosomal protein S5, mitochondrial GN=MRPS5 RT05_HUMAN 48.01
0.01\% 35.8\% AFDLFNPNFK $0.01 \% 35.8 \%$ FVEKYTELQK

$0.01 \% 35.8 \%$ LGETDEEKLFVETGK

$\begin{array}{llllllll}99.7 \% & 37.0 & 25.0 & 37.0 & 2 & 0 & 0 & 1212.60\end{array}$

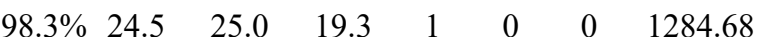
$0.01 \% \quad 35.8 \%$ ALLAEGVILR

$99.7 \% \quad 49.4$ $99.7 \% \quad 45.2$ $97.7 \% \quad 17.2$ $0.01 \% 35.8 \%$ ALLAEGVILRR $\begin{array}{lll}99.7 \% & 66.3\end{array}$ $0.01 \% \quad 38.2 \%$ VMTVNYNTHGELGEGAR $99.7 \% \quad 27.2$ $0.01 \% \quad 38.2 \%$ KFVFFNIPQIQYK $95.1 \% \quad 15.6$ $97.2 \% \quad 20.2$ 0.01\% 38.2\% NMTPSPFLR $0.01 \% \quad 38.2 \%$ SNKEIMEHIR $0.02 \% \quad 27.1 \%$ KLPVSSLTISR $0.02 \% \quad 27.1 \%$ LIDNISSR $0.02 \% \quad 27.1 \%$ EEIDHAEYYLYK $0.02 \% \quad 27.1 \%$ NFGASLLLPGLK $99.6 \% \quad 22.9$ $99.7 \% \quad 57.1$ $99.0 \% \quad 40.8$ $99.7 \% \quad 51.5$ $99.7 \% \quad 41.1$

$02 \% \quad 27.1 \%$ NSVGFSSQLYGYALLGK $99.7 \% \quad 65$ $0.02 \% \quad 27.1 \%$ VAASPEDIK $0.02 \% \quad 27.1 \%$ VAASPEDIKLCR $0.02 \% \quad 27.1 \%$ EALDVLGAVLK $0.02 \% \quad 27.1 \%$ LVEQLDIEETEQSK .02\% 27.1\% IESEGLLSLTTQLVK $0.02 \% \quad 24.6 \%$ TFSEACLMVR $0.02 \% \quad 24.6 \%$ NTSFAYPAIR $0.02 \% \quad 24.6 \%$ DLLQSSYNK $0.02 \% \quad 24.6 \%$ GSPLGEVVEQGITR $0.02 \% \quad 24.6 \%$ NATDAVGIVLK

\section{$99.7 \% \quad 51.9$} $99.7 \% \quad 46.5$ $99.7 \% \quad 67.9$ $99.7 \% \quad 66.2$ $99.7 \% \quad 57.4$ $\begin{array}{lllll}99.7 \% & 50.3\end{array}$ $99.7 \% \quad 49.5$ $99.7 \% \quad 32.5$ $99.7 \% \quad 65.8$ $99.7 \% \quad 59.5$

$0.02 \% \quad 24.6 \%$ EDKSPIAPEELALVHNLR $\quad 99.3 \% \quad 20.0$ $0.02 \% \quad 24.6 \%$ KAYLPQELLGK

$0.02 \% \quad 24.6 \%$ AYLPQELLGK

$0.02 \% \quad 24.6 \%$ ELLFLSNANPSLLER

$0.01 \% \quad 13.2 \%$ SELLSQLQQHEEESR

$0.01 \% \quad 13.2 \%$ ISFSNIISDMK

$0.01 \% \quad 13.2 \%$ IQFDEGYDNYPGQEK

$0.01 \% \quad 13.2 \%$ LNIFDMMAVTK

$0.02 \% \quad 28.8 \%$ EGNLELLK

$0.02 \% 28.8 \%$ IPNFLHLTPVAIK

$\begin{array}{lll}99.7 \% & 51.7\end{array}$

$99.7 \% \quad 37.8$

$99.7 \% \quad 69.1$

$99.7 \% 31.1$

$99.7 \% \quad 57.0$

$99.7 \% \quad 55.2$

$99.7 \% \quad 40.5$

$97.3 \% \quad 28.5$

$99.2 \% \quad 20.6$

$0.02 \% \quad 28.8 \%$ HFPIEIDSTDYVSSGPSVR $99.7 \% 56.5$

$0.02 \% \quad 28.8 \%$ LSSLNLDDHAK

$0.02 \% \quad 28.8 \%$ NILETLLQMK

$99.7 \% \quad 55.9$

$99.7 \% \quad 45.3$

$99.7 \% \quad 45.2$

$0.02 \% \quad 28.8 \%$ NMEINKEELLGTK

$0.02 \% \quad 28.8 \%$ NEEENENSISQYK

$0.02 \% \quad 18.8 \%$ NGAVQTIAQR

$0.02 \% \quad 18.8 \%$ VLVAVGNGK

$0.02 \% \quad 18.8 \%$ GAAGFSIGK

$0.02 \% \quad 18.8 \%$ AVHHLHYIER

$0.02 \% \quad 18.8 \%$ YEDHTIFHDISLR

$0.02 \% \quad 18.8 \%$ VSGSINMLSLTQGLFR
$99.7 \% 67.7$

$99.7 \% \quad 47.2$

$98.4 \% \quad 17.0$

$99.7 \% \quad 44.8$

$99.7 \% \quad 32.5$

$99.7 \% \quad 48.5$

$99.7 \% \quad 56.4$
1694.85

1054.66

1210.76

1926.03

1847.87

1671.93

1078.54

1272.64

1200.73

917.51

1572.72

1229.73

1803.93

929.49

1358.7

1127.67

1660.83

1630.93

1213.57

1139.58

1067.54

1441.76

1100.63

2031.09

1259.74

1131.64

1715.93

1812.87

1254.64

1802.79

1282.65

915.51

1462.88

2106.01

1212.62

1202.68

1518.78

2197.06

1583.68

1057.57

856.53

807.44

1274.68

1645.80

1738.92

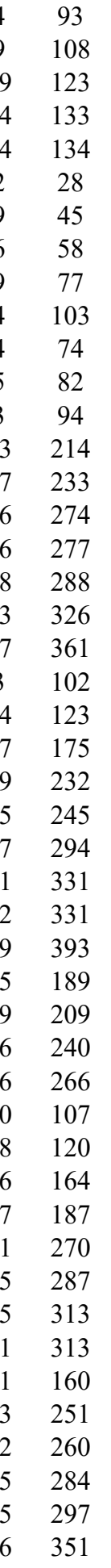


$28 \mathrm{~S}$ ribosomal protein $\mathrm{S} 5$, mitochondrial GN=MRPS5 RT05 HUMAN $48.01 \quad 100.0 \%$ $28 \mathrm{~S}$ ribosomal protein $\mathrm{S} 9$, mitochondrial GN=MRPS9 RT09_HUMAN $45.84 \quad 100.0 \%$ $28 \mathrm{~S}$ ribosomal protein S9, mitochondrial GN=MRPS9 RT09_HUMAN $45.84 \quad 100.0 \%$ $28 \mathrm{~S}$ ribosomal protein $\mathrm{S} 9$, mitochondrial GN=MRPS9 RT09 HUMAN $45.84 \quad 100.0 \%$ $28 \mathrm{~S}$ ribosomal protein S9, mitochondrial GN=MRPS9 RT09_HUMAN $45.84 \quad 100.0 \%$ $28 \mathrm{~S}$ ribosomal protein $\mathrm{S} 9$, mitochondrial GN=MRPS9 RT09_HUMAN $45.84 \quad 100.0 \%$ $28 \mathrm{~S}$ ribosomal protein S9, mitochondrial GN=MRPS9 RT09_HUMAN $45.84 \quad 100.0 \%$ $28 \mathrm{~S}$ ribosomal protein S9, mitochondrial GN=MRPS9 RT09_HUMAN $45.84 \quad 100.0 \%$ $28 \mathrm{~S}$ ribosomal protein S9, mitochondrial GN=MRPS9 RT09_HUMAN $45.84 \quad 100.0 \%$ $28 \mathrm{~S}$ ribosomal protein $\mathrm{S} 9$, mitochondrial GN=MRPS9 RT09_HUMAN $45.84 \quad 100.0 \%$ $28 \mathrm{~S}$ ribosomal protein S9, mitochondrial GN=MRPS9 RT09_HUMAN $45.84 \quad 100.0 \%$ 2-amino-3-ketobutyrate coenzyme A ligase, mitochondrial GN=GCAT KBL_HUMAN $45.29 \quad 100.0 \%$ 2-amino-3-ketobutyrate coenzyme A ligase, mitochondrial GN=GCAT KBL_HUMAN $45.29 \quad 100.0 \%$ 2-amino-3-ketobutyrate coenzyme A ligase, mitochondrial GN=GCAT KBL HUMAN $45.29 \quad 100.0 \%$ 2-amino-3-ketobutyrate coenzyme A ligase, mitochondrial GN=GCAT KBL HUMAN $45.29 \quad 100.0 \%$ 2-amino-3-ketobutyrate coenzyme A ligase, mitochondrial $\mathrm{GN}=\mathrm{GCAT} \quad \mathrm{KBL}$ HUMAN $45.29 \quad 100.0 \%$ 2-amino-3-ketobutyrate coenzyme A ligase, mitochondrial GN=GCAT KBL HUMAN 45.29 2-amino-3-ketobutyrate coenzyme A ligase, mitochondrial GN=GCAT KBL_HUMAN 45.29 2-amino-3-ketobutyrate coenzyme A ligase, mitochondrial GN=GCAT KBL_HUMAN 45.29 2-amino-3-ketobutyrate coenzyme A ligase, mitochondrial GN=GCAT KBL HUMAN 45.29 2-amino-3-ketobutyrate coenzyme A ligase, mitochondrial GN=GCAT KBL_HUMAN 45.29 2-methoxy-6--polyprenyl-1,4-benzoquinol methylase, mitochondrial GN=COQ5 COQ5_HUMAN 37.14 2-methoxy-6-polyprenyl-1,4-benzoquinol methylase, mitochondrial GN=COQ5 COQ5_HUMAN 37.14 100.0\% 2-methoxy-6-polyprenyl-1,4-benzoquinol methylase, mitochondrial GN=COQ5 COQ5_HUMAN $37.14 \quad 100.0 \%$ (2) $\mathrm{C}=\mathrm{CO} 5 \mathrm{COQ} 5$ HUMAN $37.14 \quad 100.0 \%$ 2-oxoisovalerate dehydrogenase subunit beta, mitochondrial GN=BCKDHB ODBB_HUMAN $43.12 \quad 100.0 \%$ 2-oxoisovalerate dehydrogenase subunit beta, mitochondrial GN=BCKDHB ODBB_HUMAN $43.12 \quad 100.0 \%$ 2oxoisovalerate dehydrogenase subunit beta, mitochondrial GN=BCKDHB ODBB_HUMAN $43.12 \quad 100.0 \%$ 2-oxoisovalerate dehydrogenase subunit beta, mitochondrial GN=BCKDHB ODBB_HUMAN $43.12 \quad 100.0 \%$ 3'(2'),5'-bisphosphate nucleotidase 1 GN=BPNT1 BPNT1_HUMAN $33.39100 .0 \%$ 3'(2'),5'-bisphosphate nucleotidase 1 GN=BPNT1 BPNT1_HUMAN $33.39 \quad 100.0 \%$ 39S ribosomal protein L11, mitochondrial GN=MRPL11 RM11_HUMAN $20.68 \quad 100.0 \%$ 39S ribosomal protein L11, mitochondrial GN=MRPL11 RM11 HUMAN $20.68 \quad 100.0 \%$ 39S ribosomal protein L11, mitochondrial GN=MRPL11 RM11_HUMAN $20.68 \quad 100.0 \%$ 39S ribosomal protein L11, mitochondrial GN=MRPL11 RM11_HUMAN $20.68100 .0 \%$ 39S ribosomal protein L11, mitochondrial GN=MRPL11 RM11_HUMAN $20.68 \quad 100.0 \%$ 39S ribosomal protein L12, mitochondrial GN=MRPL12 RM12_HUMAN $21.35 \quad 100.0 \%$ 39S ribosomal protein $\mathrm{L} 12$, mitochondrial GN=MRPL12 RM12 HUMAN $21.35100 .0 \%$ 39S ribosomal protein L15, mitochondrial GN=MRPL15 RM15_HUMAN $33.42 \quad 100.0 \%$ 39S ribosomal protein L15, mitochondrial GN=MRPL15 RM15_HUMAN $33.42 \quad 100.0 \%$ 39S ribosomal protein $\mathrm{L} 15$, mitochondrial GN=MRPL15 RM15 HUMAN $33.42 \quad 100.0 \%$ 39S ribosomal protein L15, mitochondrial GN=MRPL15 RM15_HUMAN $33.42 \quad 100.0 \%$ 39S ribosomal protein L15, mitochondrial GN=MRPL15 RM15 HUMAN $33.42 \quad 100.0 \%$ $39 \mathrm{~S}$ ribosomal protein L15, mitochondrial GN=MRPL15 RM15_HUMAN $33.42 \quad 100.0 \%$ 39S ribosomal protein L15, mitochondrial GN=MRPL15 RM15_HUMAN $33.42 \quad 100.0 \%$ 39S ribosomal protein $\mathrm{L} 15$, mitochondrial GN=MRPL15 RM15 HUMAN $33.42 \quad 100.0 \%$ 39S ribosomal protein L19, mitochondrial GN=MRPL19 RM19_HUMAN $33.54 \quad 100.0 \%$ $\begin{array}{cccc}9 & 19 & 0.02 \% & 18.8 \% \\ 13 & 33 & 0.04 \% & \text { EECGPLPIVVASPR }\end{array}$

$0.04 \% \quad 30.1 \%$ QIEEFNIGK

$99.7 \% \quad 66.2$

$99.7 \% \quad 32.2$

$99.7 \% \quad 41.1$

$0.04 \% \quad 30.1 \%$ HLANMMGEDPETFTQEDIDR $99.7 \% \quad 69.3$

$0.04 \% \quad 30.1 \%$ AIAYLFPSGLFEK

$0.04 \% \quad 30.1 \%$ HPEQIFPR

$0.04 \% \quad 30.1 \%$ LSDLDYMQFIR

$99.7 \% \quad 57.0$

$99.0 \% 25.4$

$99.7 \% \quad 60.6$

$\begin{array}{lllll}0.04 \% & 30.1 \% & \text { LLTSQCGAAEEEFVQR } \quad 99.7 \% & 57.1\end{array}$

$0.04 \% \quad 30.1 \%$ QLIEPVQYDEQGMAFSK

$0.04 \% \quad 30.1 \%$ LGKHDVTCTVSGGGR

$0.04 \% 30.1 \%$ HDVTCTVSGGGR

$0.03 \% \quad 35.8 \%$ GILEGELEGIR

$0.03 \% \quad 35.8 \%$ FICGTQSIHK

$0.03 \% \quad 35.8 \%$ HLDMADLEAK

$99.7 \% \quad 52.2$

$99.7 \% 33.0$

$99.7 \% \quad 46.6$

$99.7 \% 65.1$

$99.7 \% \quad 33.8$

$99.7 \% 57.9$

$0.03 \% \quad 35.8 \%$ YGALVFMDECHATGFLGPTGR $99.6 \% 29.7$

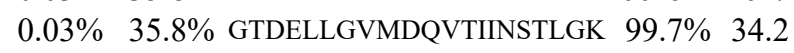

$0.03 \% \quad 35.8 \%$ ALGGASGGYTTGPGPLVSLLR $99.7 \% \quad 63.2$

$0.03 \% \quad 35.8 \%$ ALDLLMGSNTIVQSMAAK $99.7 \% 56.7$

$0.03 \% \quad 35.8 \%$ GIFVIGFSYPVVPK

$0.03 \% \quad 35.8 \%$ VQISAVHSEEDIDR

$99.7 \% \quad 28.6$

$99.7 \% \quad 39.4$

$0.03 \% \quad 35.8 \%$ CVEAFVEVGR

$0.01 \% \quad 15.0 \%$ VYQVFESVAK

$0.01 \% \quad 15.0 \%$ AQQNLSWEEIAK

$0.01 \% \quad 15.0 \%$ EYQNEEDSLGGSR

$99.7 \% \quad 59.8$

$99.7 \% \quad 38.2$

$99.7 \% \quad 52.0$

$99.7 \% \quad 37.6$

$0.01 \% \quad 15.0 \%$ NVTHIDQALQEAHR

$99.7 \% 33.8$

$0.01 \% \quad 13.5 \%$ MNLFQSVTSALDNSLAK

$0.01 \% \quad 13.5 \%$ SGDLFNCGSLTIR

$0.01 \% \quad 13.5 \%$ LGVSCEVIDLR

$0.01 \% \quad 13.5 \%$ TIIPWDVDTICK

$0.00 \% \quad 7.8 \%$ LVASAYSIAQK

$0.00 \% \quad 7.8 \%$ LTDIHGNVLQYHK

$0.01 \% \quad 38.0 \%$ GLRKPEVGGVIR

$99.7 \% \quad 42.2$

$99.7 \% \quad 56.3$

$99.7 \% \quad 56.3$

$99.4 \% \quad 23.6$

$99.7 \% \quad 57.8$

$99.0 \% \quad 22.6$

$99.7 \% \quad 47.7$

$0.01 \% 38.0 \%$ AGLAMPGPPLGPVLGQR $99.7 \% 36.1$

$0.01 \% \quad 38.0 \%$ IGQPTVSYFLK

$99.7 \% \quad 55.6$

$0.01 \% \quad 38.0 \%$ IKAQDEAFALQDVPLSSVVR $\quad 99.7 \% \quad 41.4$

$0.01 \% \quad 38.0 \%$ EADLAAQEEAAKK

$0.00 \% \quad 11.1 \%$ LTEAKPVDKVK

$0.00 \% \quad 11.1 \%$ KLVESLPQEIK

$0.02 \% \quad 31.4 \%$ VSLANLKPNPGSK

$0.02 \% \quad 31.4 \%$ LGFEGGQTPFYIR

$0.02 \% 31.4 \%$ YGFNEGHSFRR

$0.02 \% \quad 31.4 \%$ LQYLIDLGR

$0.02 \% \quad 31.4 \%$ GVTIQPLKR

$0.02 \% \quad 31.4 \%$ SLDIVCKPVPFFLR

$0.02 \% \quad 31.4 \%$ GYLADPAKFPEAR

$0.02 \% \quad 31.4 \%$ ILKPTDENLLK

$0.01 \% \quad 20.9 \%$ FLSPEFIPR
$96.4 \% \quad 22.3$

$99.7 \% \quad 33.0$

$99.7 \% \quad 42.6$

$99.7 \% \quad 38.0$

$99.7 \% \quad 55.4$

$98.3 \% 17.3$

$99.7 \% \quad 62.5$

$99.7 \% \quad 30.2$

$99.7 \% \quad 38.0$

$99.7 \% \quad 57.0$

$98.9 \% \quad 25.7$

$99.7 \% \quad 35.5$
27.3

$\begin{array}{ll}0 & 32.5\end{array}$

$\begin{array}{ll}0 & 69.1\end{array}$

$\begin{array}{ll}0 & 49.4\end{array}$

17.0
53.0

0
53.4

$\begin{array}{ll}0 & 52.2\end{array}$

.0 24.6

$\begin{array}{ll} & 46.6\end{array}$

$\begin{array}{ll}0 & 48.2\end{array}$

\begin{tabular}{ll}
25.0 & 25.8 \\
\hline
\end{tabular}

$\begin{array}{ll} & 47.4\end{array}$

$\begin{array}{ll}25.0 & 29.7\end{array}$

\begin{tabular}{ll}
34.0 \\
\hline
\end{tabular}

$\begin{array}{ll}0 & 63.2\end{array}$

$\begin{array}{ll}.0 & 55.8\end{array}$

$\begin{array}{ll}5.0 & 28.6\end{array}$

$\begin{array}{ll}.0 & 36.3\end{array}$

\begin{tabular}{ll}
5.0 & 45.5 \\
\hline
\end{tabular}

$\begin{array}{ll}25.0 & 34.2\end{array}$

$\begin{array}{ll}25.0 & 37.6\end{array}$

27.1
25.0

$\begin{array}{ll}27.0 & 42.2\end{array}$

50.4

$\begin{array}{ll}0.0 & 40.2\end{array}$

$\begin{array}{ll}5.0 & 16.7\end{array}$

$\begin{array}{ll}0 & 44.3\end{array}$

$\begin{array}{ll}25.0 & 47.7\end{array}$

36.1

50.6

$\begin{array}{ll}.0 & 41.1\end{array}$

$\begin{array}{ll}.0 & 10.9\end{array}$

$\begin{array}{ll}24.0 & 24.9\end{array}$

$\begin{array}{ll}0 & 37.8\end{array}$

$\begin{array}{ll}25.0 & 38.0\end{array}$

\begin{tabular}{ll}
46.5 \\
\hline
\end{tabular}

$\begin{array}{ll}25.0 & 17.3\end{array}$

$5.0 \quad 55.9$

$\begin{array}{ll}0 & 19.9\end{array}$

$\begin{array}{ll}5.0 & 38.0\end{array}$

$\begin{array}{lll}25.0 & 45.1 & 2\end{array}$

$\begin{array}{ll}25.0 & 14.7\end{array}$

\begin{tabular}{ll}
07.8 \\
\hline
\end{tabular}

1273.63

1077.56

2381.00

1455.79

1023.54

1416.68

1837.88

1998.95

1543.76

1245.56

1185.65

1190.60

1142.55

2315.06

2220.14

1944.06

1862.97

1522.87

1597.78

1165.57

1169.62

1416.71

1483.63

1631.82

1854.93

1439.69

1260.66

1460.75

1150.65

1537.81

1280.78

1646.91

1252.69

2186.18

1373.69

1227.73

1283.76

1324.76

1484.75

1369.64

1090.63

1011.63

1690.94

1434.74

1283.76

1105.60

$\begin{array}{cc} & 388 \\ 7 & 76 \\ 7 & 85 \\ 7 & 106 \\ 07 & 119 \\ 27 & 134 \\ 13 & 223 \\ 28 & 243 \\ 55 & 271 \\ 23 & 337 \\ 26 & 337 \\ 9 & 39 \\ 94 & 113 \\ 78 & 187 \\ 24 & 244 \\ 45 & 265 \\ 66 & 286 \\ 09 & 326 \\ 70 & 383 \\ 90 & 403 \\ 04 & 413 \\ 8 & 77 \\ 42 & 153 \\ 54 & 166 \\ 21 & 234 \\ 1 & 87 \\ 71 & 183 \\ 95 & 305 \\ 06 & 317 \\ 1 & 21 \\ 62 & 274 \\ 0 & 21 \\ 6 & 42 \\ 2 & 92 \\ 23 & 142 \\ 80 & 192 \\ 34 & 144 \\ 63 & 173 \\ 2 & 34 \\ 5 & 77 \\ 1 & 91 \\ 01 & 109 \\ 26 & 134 \\ 83 & 196 \\ 21 & 233 \\ & 292 \\ & \end{array}$

Page 7 of Table S-1-5 
39S ribosomal protein L19, mitochondrial GN=MRPL19 RM19 HUMAN $33.54 \quad 100.0 \%$ 39S ribosomal protein L19, mitochondrial GN=MRPL19 RM19_HUMAN $33.54 \quad 100.0 \%$ 39S ribosomal protein L19, mitochondrial GN=MRPL19 RM19_HUMAN $33.54 \quad 100.0 \%$ 39S ribosomal protein L19, mitochondrial GN=MRPL19 RM19 HUMAN $33.54 \quad 100.0 \%$ 39S ribosomal protein L19, mitochondrial GN=MRPL19 RM19_HUMAN $33.54 \quad 100.0 \%$ 39S ribosomal protein L19, mitochondrial GN=MRPL19 RM19_HUMAN $33.54 \quad 100.0 \%$ $39 \mathrm{~S}$ ribosomal protein L2, mitochondrial GN=MRPL2 RM02_HUMAN $33.30 \quad 100.0 \%$ 39S ribosomal protein L2, mitochondrial GN=MRPL2 RM02_HUMAN $33.30 \quad 100.0 \%$ 39S ribosomal protein $\mathrm{L} 28$, mitochondrial GN=MRPL28 RM28 HUMAN $30.16 \quad 100.0 \%$ $39 \mathrm{~S}$ ribosomal protein $\mathrm{L} 28$, mitochondrial GN=MRPL28 RM28_HUMAN $30.16 \quad 100.0 \%$ 39S ribosomal protein L28, mitochondrial GN=MRPL28 RM28_HUMAN $30.16 \quad 100.0 \%$ 39S ribosomal protein L28, mitochondrial GN=MRPL28 RM28_HUMAN $30.16 \quad 100.0 \%$ 39S ribosomal protein L3, mitochondrial GN=MRPL3 RM03_HUMAN $38.63 \quad 100.0 \%$ $39 \mathrm{~S}$ ribosomal protein $\mathrm{L} 3$, mitochondrial GN=MRPL3 RM03_HUMAN $38.63 \quad 100.0 \%$ 39S ribosomal protein $\mathrm{L} 3$, mitochondrial GN=MRPL3 RM03_HUMAN $38.63 \quad 100.0 \%$ 39S ribosomal protein L3, mitochondrial GN=MRPL3 RM03_HUMAN $38.63 \quad 100.0 \%$ 39S ribosomal protein $\mathrm{L} 3$, mitochondrial GN=MRPL3 RM03 HUMAN $38.63 \quad 100.0 \%$ 39S ribosomal protein $\mathrm{L} 37$, mitochondrial GN=MRPL37 RM37_HUMAN $48.12 \quad 100.0 \%$ 39S ribosomal protein $\mathrm{L} 37$, mitochondrial GN=MRPL37 RM37_HUMAN $48.12 \quad 100.0 \%$ 39S ribosomal protein L37, mitochondrial GN=MRPL37 RM37_HUMAN $48.12 \quad 100.0 \%$ 39S ribosomal protein L37, mitochondrial GN=MRPL37 RM37_HUMAN $48.12 \quad 100.0 \%$ 39S ribosomal protein $\mathrm{L} 37$, mitochondrial GN=MRPL37 RM37_HUMAN $48.12 \quad 100.0 \%$ $39 \mathrm{~S}$ ribosomal protein $\mathrm{L} 37$, mitochondrial GN=MRPL37 RM37_HUMAN $48.12 \quad 100.0 \%$ 39S ribosomal protein $\mathrm{L} 37$, mitochondrial GN=MRPL37 RM37_HUMAN $48.12 \quad 100.0 \%$ 39S ribosomal protein $\mathrm{L} 37$, mitochondrial GN=MRPL37 RM37_HUMAN $48.12 \quad 100.0 \%$ 39S ribosomal protein L37, mitochondrial GN=MRPL37 RM37_HUMAN $48.12 \quad 100.0 \%$ 39S ribosomal protein $\mathrm{L} 37$, mitochondrial GN=MRPL37 RM37_HUMAN $48.12 \quad 100.0 \%$ 39S ribosomal protein $\mathrm{L} 37$, mitochondrial GN=MRPL37 RM37_HUMAN $48.12 \quad 100.0 \%$ 39S ribosomal protein L38, mitochondrial GN=MRPL38 RM38_HUMAN $44.60 \quad 100.0 \%$ 39S ribosomal protein $\mathrm{L} 38$, mitochondrial GN=MRPL38 RM38 HUMAN $44.60 \quad 100.0 \%$ 39S ribosomal protein L38, mitochondrial GN=MRPL38 RM38_HUMAN $44.60 \quad 100.0 \%$ 39S ribosomal protein L38, mitochondrial GN=MRPL38 RM38_HUMAN $44.60 \quad 100.0 \%$ 39S ribosomal protein $\mathrm{L} 38$, mitochondrial GN=MRPL38 RM38 HUMAN $44.60 \quad 100.0 \%$ 39S ribosomal protein L38, mitochondrial GN=MRPL38 RM38_HUMAN $44.60 \quad 100.0 \%$ 39S ribosomal protein L39, mitochondrial GN=MRPL39 RM39 HUMAN $38.71 \quad 100.0 \%$ 39S ribosomal protein L39, mitochondrial GN=MRPL39 RM39_HUMAN $38.71 \quad 100.0 \%$ 39S ribosomal protein L39, mitochondrial GN=MRPL39 RM39_HUMAN $38.71 \quad 100.0 \%$ 39S ribosomal protein L39, mitochondrial GN=MRPL39 RM39 HUMAN $38.71 \quad 100.0 \%$ 39S ribosomal protein L39, mitochondrial GN=MRPL39 RM39_HUMAN $38.71 \quad 100.0 \%$ 39S ribosomal protein L39, mitochondrial GN=MRPL39 RM39_HUMAN $38.71 \quad 100.0 \%$ 39S ribosomal protein $\mathrm{L} 4$, mitochondrial GN=MRPL4 RM04 HUMAN $34.92 \quad 100.0 \%$ 39S ribosomal protein L4, mitochondrial GN=MRPL4 RM04_HUMAN $34.92 \quad 100.0 \%$ 39S ribosomal protein $\mathrm{L} 4$, mitochondrial GN=MRPL4 RM04 HUMAN $34.92 \quad 100.0 \%$ 39S ribosomal protein L4, mitochondrial GN=MRPL4 RM04_HUMAN $34.92 \quad 100.0 \%$ 39S ribosomal protein L44, mitochondrial GN=MRPL44 RM44_HUMAN $37.54 \quad 100.0 \%$ 39S ribosomal protein L44, mitochondrial GN=MRPL44 RM44_HUMAN $37.54 \quad 100.0 \%$ 39S ribosomal protein L44, mitochondrial GN=MRPL44 RM44_HUMAN $37.54 \quad 100.0 \%$
$13 \quad 0.01 \% \quad 20.9 \%$ VTTADPYASGK

7
13

$0.01 \% \quad 20.9 \%$ ISQFLGICIQR

$0.01 \% \quad 20.9 \%$ GLGATFILR

$0.01 \% \quad 20.9 \%$ RLDDSLLYLR

$0.01 \% \quad 20.9 \%$ LDDSLLYLR

$0.01 \% \quad 20.9 \%$ FDLCLTEQQMK

$0.00 \% \quad 12.1 \%$ SADIALVAGGSR

$0.00 \% \quad 16.8 \%$ EFYSEILDKK

$0.00 \% \quad 16.8 \%$ QDPQLHPEDPERR

$0.00 \% \quad 16.8 \%$ AAIYDKYK

$0.00 \% \quad 16.8 \%$ LLEEKDPVPLFK

$0.01 \% \quad 18.4 \%$ QLVSDEDKAQLASK

$0.01 \% \quad 18.4 \%$ HVVTLLQVQDCHVLK

$0.01 \% \quad 18.4 \%$ MATLSVGGK

$0.01 \% \quad 18.4 \%$ RPGAVATGDIGR

$0.01 \% \quad 18.4 \%$ HNIIYVNGSVPGHK

$0.02 \% \quad 30.7 \%$ VYEIPGLEPITFAGK

$0.02 \% \quad 30.7 \%$ SPPLHEHPLYK

$0.02 \% \quad 30.7 \%$ TKLIEGLPEK

$0.02 \% \quad 30.7 \%$ LIEGLPEK

$0.02 \% \quad 30.7 \%$ VLSLVDDPR

$0.02 \% \quad 30.7 \%$ ETYCPVIVDNLIQLCK

$0.02 \% \quad 30.7 \%$ ESLLLQVR

$0.02 \% \quad 30.7 \%$ LSTKDPLPTIASR

$0.02 \% \quad 30.7 \%$ MILFAFGSALAQAR

$0.02 \% \quad 30.7 \%$ VLEQPVVVQSVGTDGR

$0.02 \% \quad 30.7 \%$ VVVEPVGPVGFKPETFRK

$0.01 \% \quad 18.7 \%$ KQAIQELR

$0.01 \% \quad 18.7 \%$ TASVPLDAVR

$0.01 \% \quad 18.7 \%$ LAEYYGLYR

$11 \quad 0.01 \% \quad 18.7 \%$ DLFHGATFVPR

$0.01 \% \quad 18.7 \%$ VAEGQVTCPYLPPFPAR

$11 \quad 0.01 \% \quad 18.7 \%$ HQETMTPAGLSFFQCR

$10 \quad 0.01 \% \quad 21.3 \%$ TDPGTVFVMNK

$10 \quad 0.01 \% \quad 21.3 \%$ AFKDEYMVNLVR

$10 \quad 0.01 \% \quad 21.3 \%$ DLPFETLEVEAK

$10 \quad 0.01 \% \quad 21.3 \%$ VALEIFQHSK

$10 \quad 0.01 \% \quad 21.3 \%$ IGDFIDVSEGPLIPR

$10 \quad 0.01 \% \quad 21.3 \%$ RFQGVSLPVHLR

$\quad 0.01 \% \quad 18.3 \%$ ATENPEQVASEGLPEPVLR

$9 \quad 0.01 \% \quad 18.3 \%$ KVELPVPTHR

$9 \quad 0.01 \% \quad 18.3 \%$ VGLADLHPDVFATAPR

$0.01 \% \quad 18.3 \%$ GPTSYYYMLPMK

$0.02 \% \quad 34.9 \%$ LQENFSLDLLK

$0.02 \% \quad 34.9 \%$ TAFVNSCYIK

$0.02 \% \quad 34.9 \%$ EAVLLNLK $\begin{array}{llllllll}99.7 \% & 35.0 & 25.0 & 35.0 & 2 & 0 & 0 & 1109.55\end{array}$

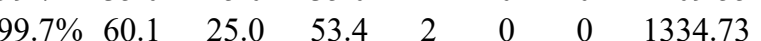

$\begin{array}{llllllll}99.7 \% & 58.5 & 25.0 & 53.8 & 2 & 0 & 0 & 947.57\end{array}$

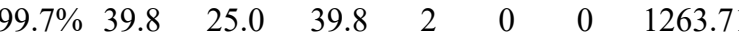

$\begin{array}{llllllll}99.7 \% & 61.0 & 25.0 & 46.9 & 2 & 0 & 0 & 1107.60\end{array}$

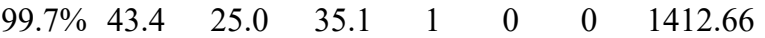

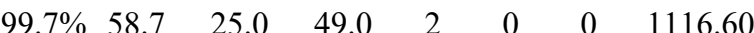

2542.29

1271.65

1616.78

971.52

1427.8

1531.80

1788.98

879.46

1169.64

1534.81

1633.88

1317.70

1127.67

$99.2 \% \quad 21.5 \quad 25.0 \quad 21.3$

$99.7 \% \quad 41.7 \quad 25.0 \quad 41.7$

$\begin{array}{llll}98.2 \% & 25.9 & 25.0 & 12.2\end{array}$

$99.7 \% \quad 42.2 \quad 25.0 \quad 21.7$

$99.7 \% \quad 61.8 \quad 25.0 \quad 59.6$

$99.0 \% \quad 61.5 \quad 25.0 \quad 46.4$

$\begin{array}{llll}99.4 \% & 19.1 & 25.0 & 19.1\end{array}$

$\begin{array}{llll}99.7 \% & 59.2 & 25.0 & 50.8\end{array}$

$\begin{array}{llll}99.7 \% & 94.8 & 25.0 & 94.8\end{array}$

$\begin{array}{llll}98.9 \% & 19.0 & 25.0 & 19.0\end{array}$

$\begin{array}{llll}98.3 \% & 25.2 & 25.0 & 14.9\end{array}$

$\begin{array}{llll}99.7 \% & 32.5 & 25.0 & 23.5\end{array}$

$\begin{array}{llll}99.7 \% & 57.2 & 25.0 & 48.2\end{array}$

$\begin{array}{llll}99.7 \% & 43.6 & 25.0 & 30.8\end{array}$

$\begin{array}{llll}99.7 \% & 39.5 & 25.0 & 38.5\end{array}$

$\begin{array}{llll}99.5 \% & 26.8 & 25.0 & 26.8\end{array}$

$\begin{array}{llll}99.6 \% & 23.0 & 25.0 & 22.2\end{array}$

$98.6 \% \quad 24.6 \quad 25.0 \quad 24.6$

$\begin{array}{llll}99.7 \% & 40.4 & 25.0 & 30.6\end{array}$

$99.7 \% \quad 61.2 \quad 25.0 \quad 52.4$

$\begin{array}{llll}99.7 \% & 63.4 & 25.0 & 60.0\end{array}$

$\begin{array}{llll}99.4 \% & 22.7 & 25.0 & 22.7\end{array}$

$\begin{array}{llll}99.7 \% & 81.6 & 25.0 & 79.3\end{array}$

$\begin{array}{llll}99.7 \% & 28.3 & 25.0 & 28.3\end{array}$

$\begin{array}{llll}99.7 \% & 48.8 & 25.0 & 48.8\end{array}$

$\begin{array}{lllll}99.7 \% & 60.1 & 25.0 & 56.1 & 2 \\ 99.7 \% & 49.0 & 25.0 & 34.0 & 3\end{array}$

$\begin{array}{lllll}99.7 \% & 32.4 & 25.0 & 32.4\end{array}$

$\begin{array}{llll}99.0 \% & 27.9 & 25.0 & 17.8\end{array}$ $\begin{array}{cc}19 & 129 \\ 30 & 140 \\ 44 & 152 \\ 82 & 191 \\ 83 & 191 \\ 45 & 255 \\ 36 & 147 \\ 78 & 202 \\ 13 & 122 \\ 72 & 184 \\ 85 & 192 \\ 17 & 228 \\ 53 & 76 \\ 17 & 131 \\ 42 & 150 \\ 39 & 250 \\ 80 & 293 \\ 49 & 63 \\ 90 & 100 \\ 26 & 135 \\ 28 & 135 \\ 36 & 144 \\ 74 & 189 \\ 16 & 223 \\ 30 & 242 \\ 13 & 326 \\ 35 & 350 \\ 96 & 413 \\ 07 & 114 \\ 27 & 136 \\ 51 & 159 \\ 60 & 170 \\ 45 & 261 \\ 07 & 322 \\ 73 & 83 \\ 57 & 168 \\ 13 & 224 \\ 25 & 234 \\ 57 & 271 \\ 96 & 307 \\ 31 & 49 \\ 50 & 59 \\ 77 & 92 \\ 57 & 168 \\ 79 & 89 \\ 90 & 99 \\ 13 & 120 \\ & \end{array}$

Page 8 of Table S-1-5 
39S ribosomal protein L44, mitochondrial GN=MRPL44 RM44_HUMAN $37.54 \quad 100.0 \%$ 39S ribosomal protein L44, mitochondrial GN=MRPL44 RM44_HUMAN $37.54 \quad 100.0 \%$ 39S ribosomal protein L44, mitochondrial GN=MRPL44 RM44_HUMAN $37.54 \quad 100.0 \%$ 39S ribosomal protein L44, mitochondrial GN=MRPL44 RM44 HUMAN $37.54 \quad 100.0^{\circ}$ 39S ribosomal protein L44, mitochondrial GN=MRPL44 RM44_HUMAN $37.54 \quad 100.0 \%$ 39S ribosomal protein L44, mitochondrial GN=MRPL44 RM44_HUMAN $37.54 \quad 100.0 \%$ 39S ribosomal protein L44, mitochondrial GN=MRPL44 RM44_HUMAN $37.54 \quad 100.0 \%$ 39S ribosomal protein L46, mitochondrial GN=MRPL46 RM46_HUMAN $31.71 \quad 100.0 \%$ 39 S ribosomal protein $\mathrm{L} 46$, mitochondrial GN=MRPL46 RM46 HUMAN $31.71 \quad 100.0 \%$ 39S ribosomal protein L46, mitochondrial GN=MRPL46 RM46_HUMAN $31.71 \quad 100.0 \%$ 39S ribosomal protein L47, mitochondrial GN=MRPL47 RM47_HUMAN $29.45 \quad 100.0 \%$ 39S ribosomal protein L47, mitochondrial GN=MRPL47 RM47 HUMAN $29.45100 .0 \%$ 3-hydroxyisobutyryl-CoA hydrolase, mitochondrial GN=HIBCH $\mathrm{HIBCH}_{-}$HUMAN $43.48 \quad 100.0 \%$ 3-hydroxyisobutyryl-CoA hydrolase, mitochondrial GN=HIBCH $\mathrm{HIBCH}_{\text {_HUMAN }} 43.48 \quad 100.0 \%$ 3-ketoacyl-CoA thiolase, mitochondrial GN=ACAA2 THIM_HUMAN $41.92 \quad 100.0 \%$ 3-ketoacyl-CoA thiolase, mitochondrial GN=ACAA2 THIM_HUMAN $41.92 \quad 100.0 \%$ 40S ribosomal protein $\mathrm{S} 11 \mathrm{GN}=\mathrm{RPS} 11$ $40 \mathrm{~S}$ ribosomal protein $\mathrm{S} 11 \mathrm{GN}=\mathrm{RPS} 11$ $40 \mathrm{~S}$ ribosomal protein $\mathrm{S} 11 \mathrm{GN}=\mathrm{RPS} 11$ $40 \mathrm{~S}$ ribosomal protein $\mathrm{S} 2 \mathrm{GN}=\mathrm{RPS} 2$ $40 \mathrm{~S}$ ribosomal protein $\mathrm{S} 2 \mathrm{GN}=\mathrm{RPS} 2$ $40 \mathrm{~S}$ ribosomal protein $\mathrm{S} 2 \mathrm{GN}=\mathrm{RPS} 2$ $40 \mathrm{~S}$ ribosomal protein $\mathrm{S} 2 \mathrm{GN}=\mathrm{RPS} 2$ $40 \mathrm{~S}$ ribosomal protein $\mathrm{S} 2 \mathrm{GN}=\mathrm{RPS} 2$ $40 \mathrm{~S}$ ribosomal protein $\mathrm{S} 2 \mathrm{GN}=\mathrm{RPS} 2$ $40 \mathrm{~S}$ ribosomal protein $\mathrm{S} 2 \mathrm{GN}=\mathrm{RPS} 2$ $40 \mathrm{~S}$ ribosomal protein $\mathrm{S} 2 \mathrm{GN}=\mathrm{RPS} 2$ $40 \mathrm{~S}$ ribosomal protein $\mathrm{S} 2 \mathrm{GN}=\mathrm{RPS} 2$ $40 \mathrm{~S}$ ribosomal protein $\mathrm{S} 2 \mathrm{GN}=\mathrm{RPS} 2$ $40 \mathrm{~S}$ ribosomal protein $\mathrm{S} 2 \mathrm{GN}=\mathrm{RPS} 2$ $40 \mathrm{~S}$ ribosomal protein $\mathrm{S} 2 \mathrm{GN}=\mathrm{RPS} 2$ $40 \mathrm{~S}$ ribosomal protein $\mathrm{S} 2 \mathrm{GN}=\mathrm{RPS} 2$ $40 \mathrm{~S}$ ribosomal protein $\mathrm{S} 2 \mathrm{GN}=\mathrm{RPS} 2$ $40 \mathrm{~S}$ ribosomal protein $\mathrm{S} 23 \mathrm{GN}=\mathrm{RPS} 23$ 40 S ribosomal protein $\mathrm{S} 23 \mathrm{GN}=\mathrm{RPS} 23$ $40 \mathrm{~S}$ ribosomal protein $\mathrm{S} 23 \mathrm{GN}=\mathrm{RPS} 23$ $40 \mathrm{~S}$ ribosomal protein $\mathrm{S} 3 \mathrm{GN}=\mathrm{RPS} 3$ 40S ribosomal protein $\mathrm{S} 3 \mathrm{GN}=\mathrm{RPS} 3$ $40 \mathrm{~S}$ ribosomal protein $\mathrm{S} 3 \mathrm{GN}=\mathrm{RPS} 3$ $40 \mathrm{~S}$ ribosomal protein $\mathrm{S} 3 \mathrm{GN}=\mathrm{RPS} 3$ $40 \mathrm{~S}$ ribosomal protein $\mathrm{S} 3 \mathrm{GN}=\mathrm{RPS} 3$ $40 \mathrm{~S}$ ribosomal protein $\mathrm{S} 3 \mathrm{GN}=\mathrm{RPS} 3$ $40 \mathrm{~S}$ ribosomal protein $\mathrm{S} 3 \mathrm{GN}=\mathrm{RPS} 3$ $40 \mathrm{~S}$ ribosomal protein $\mathrm{S} 3 \mathrm{GN}=\mathrm{RPS} 3$ $40 \mathrm{~S}$ ribosomal protein $\mathrm{S} 3 \mathrm{GN}=\mathrm{RPS} 3$ $40 \mathrm{~S}$ ribosomal protein $\mathrm{S} 3 \mathrm{GN}=\mathrm{RPS} 3$ $40 \mathrm{~S}$ ribosomal protein $\mathrm{S} 3 \mathrm{GN}=\mathrm{RPS} 3$ RS11_HUMAN $18.43 \quad 100.0 \%$ RS11_HUMAN $18.43 \quad 100.0 \%$ RS2 HUMAN $31.33 \quad 100.0 \%$ RS2_HUMAN $31.33 \quad 100.0 \%$ RS2 HUMAN $31.33 \quad 100.0 \%$ RS2_HUMAN $31.33 \quad 100.0 \%$ RS2_HUMAN $31.33 \quad 100.0 \%$ RS2 HUMAN $31.33 \quad 100.0 \% \quad 14$ RS2_HUMAN $31.33 \quad 100.0 \% \quad 14$ RS2_HUMAN $31.33 \quad 100.0 \% \quad 14$ RS2 HUMAN $31.33 \quad 100.0 \% \quad 14$ RS2_HUMAN $31.33 \quad 100.0 \% \quad 14$ RS2 HUMAN $31.33 \quad 100.0 \% \quad 14$ RS2_HUMAN $31.33 \quad 100.0 \% \quad 14$ RS2_HUMAN $31.33 \quad 100.0 \% \quad 14$ RS2 HUMAN $31.33 \quad 100.0 \% \quad 14$ RS23_HUMAN $15.81 \quad 100.0 \% \quad 3$ RS23_HUMAN $15.81 \quad 100.0 \% \quad 3$ RS23_HUMAN $15.81 \quad 100.0 \% \quad 3$ RS3_HUMAN $26.69 \quad 100.0 \% \quad 21$ RS3 HUMAN $26.69 \quad 100.0 \% \quad 21$ RS3_HUMAN $26.69 \quad 100.0 \% \quad 21$ RS3_HUMAN $26.69 \quad 100.0 \% \quad 21$ RS3 HUMAN $26.69 \quad 100.0 \% \quad 21$ RS3_HUMAN $26.69 \quad 100.0 \% \quad 21$ RS3 HUMAN $26.69 \quad 100.0 \% \quad 21$ RS3_HUMAN $26.69 \quad 100.0 \% \quad 21$ RS3_HUMAN $26.69 \quad 100.0 \% \quad 21$ RS3 HUMAN $26.69 \quad 100.0 \% \quad 21$ RS3_HUMAN $26.69 \quad 100.0 \% \quad 21$
RS11 HUMAN $18.43 \quad 100.0 \%$
$0.02 \% \quad 34.9 \%$ NLVDFLTGEE

$\begin{array}{lll}99.7 \% & 56.7\end{array}$

$98.9 \% 23.7$

$99.6 \% \quad 24.1$

$0.02 \% \quad 34.9 \%$ IINPMGLLVEELK

$99.7 \% \quad 31$.

$\begin{array}{lllll}0.02 \% & 34.9 \% & \text { QSGGTTALPLYFVGLYCDK } & 99.7 \% & 31.1 \\ 0.02 \% & 34.9 \% & \text { LIAEGPGETVLVAEEEAAR } & 99.7 \% & 30.9\end{array}$

$\begin{array}{lll}0.02 \% & 34.9 \% & \text { LIAEGPGETVLVA } \\ 0.02 \% & 34.9 \% & \text { KLYGFTENR }\end{array}$

$0.02 \% \quad 34.9 \%$ LYGFTENR

$0.01 \% \quad 12.9 \%$ SLYSDHELR

$0.01 \% \quad 12.9 \%$ TLATLSENNMEAK

$0.01 \% \quad 12.9 \%$ ALLLTGDFSQAGNK

$0.00 \% \quad 8.0 \% \quad$ NMLLTLEQEAKR

$0.00 \% \quad 8.0 \% \quad$ LLQTGQER

$0.00 \% \quad 5.7 \%$ LGYFLALTGFR

$0.00 \% \quad 5.7 \%$ AVLIDKDQSPK

$0.00 \% \quad 5.5 \%$ DFTATDLSEFAAK

$0.00 \% \quad 5.5 \%$ ETPALTINR

$0.01 \% \quad 18.4 \%$ EAIEGTYIDKK

$0.01 \% \quad 18.4 \%$ CPFTGNVSIR

$0.01 \% \quad 18.4 \%$ ILSGVVTK

$0.11 \% \quad 46.8 \%$ AEDKEWMPVTK

$0.11 \% \quad 46.8 \%$ SLEEIYLFSLPIK

$99.7 \% \quad 49.0$

$99.0 \% \quad 30.3$

$99.6 \% 30.1$

$99.7 \% 62.1$

$99.7 \% 70.1$

$99.7 \% \quad 35.5$

$98.2 \% 19.1$

$99.7 \% \quad 35.1$

$99.7 \% \quad 57.1$

$99.6 \% \quad 36.3$

$99.7 \% \quad 27.7$

$99.7 \% \quad 36.4$

$99.7 \% \quad 37.6$

$97.3 \% \quad 27.7$

$99.7 \% \quad 54.8$

$99.7 \% \quad 55.0$

$0.11 \% \quad 46.8 \%$ AFVAIGDYNGHVGLGVK $99.7 \% \quad 67.9$

$0.11 \% \quad 46.8 \%$ LSIVPVRR

$0.11 \% \quad 46.8 \%$ IGKPHTVPCK

$0.11 \% \quad 46.8 \%$ GTGIVSAPVPK

$0.11 \% \quad 46.8 \%$ GTGIVSAPVPKK

$99.0 \% \quad 45.0$

$99.7 \% \quad 44.5$

$99.7 \% \quad 37.3$

$99.6 \% \quad 23.2$

$0.11 \% \quad 46.8 \%$ KLLMMAGIDDCYTSAR

$0.11 \% \quad 46.8 \%$ LLMMAGIDDCYTSAR

$0.11 \% \quad 46.8 \%$ GCTATLGNFAK

$0.11 \% \quad 46.8 \%$ ATFDAISK

$0.11 \% \quad 46.8 \%$ TYSYLTPDLWK

$0.11 \% \quad 46.8 \%$ SPYQEFTDHLVK

$0.11 \% \quad 46.8 \%$ TQAPAVATT

$0.00 \% \quad 23.8 \%$ ANPFGGASHAK

$0.00 \% \quad 23.8 \%$ KGHAVGDIPGVR

$0.00 \% \quad 23.8 \%$ VANVSLLALYK

$0.11 \% \quad 78.6 \%$ KFVADGIFK

$0.11 \% \quad 78.6 \%$ FVADGIFK

$0.11 \% \quad 78.6 \%$ AELNEFLTR

$0.11 \% \quad 78.6 \%$ ELAEDGYSGVEVR

$0.11 \% 78.6 \%$ VTPTRTEIIILATR

$0.11 \% \quad 78.6 \%$ TEIIILATR

$0.11 \% \quad 78.6 \%$ IRELTAVVQK

$0.11 \% \quad 78.6 \%$ ELTAVVQK

$0.11 \% \quad 78.6 \%$ ELTAVVQKR

$0.11 \% \quad 78.6 \%$ RFGFPEGSVELYAEK

$0.11 \% \quad 78.6 \%$ FGFPEGSVELYAEK

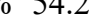

$99.7 \% \quad 53.0$

$99.7 \% \quad 57.9$

$99.0 \% \quad 50.2$

$99.7 \% \quad 57.1$

$99.7 \% \quad 53.8$

$95.4 \% 20.5$

$99.5 \% \quad 22.5$

$99.7 \% \quad 26.2$

$99.7 \% \quad 60.0$

$99.7 \% \quad 53.5$

$99.0 \% \quad 40.5$

$99.7 \% \quad 51.9$

$99.7 \% \quad 55.5$

$99.7 \% \quad 36.0$

$99.7 \% \quad 53.8$

$99.7 \% 34.8$

$99.0 \% \quad 56.0$

$99.7 \% \quad 56.6$

$99.7 \% \quad 51.2$

$99.7 \% \quad 57.2$
1957.98

1169.59

1484.84

2090.03

1954.01

1127.58

999.49

1119.54

1437.69

1434.76

1445.78

944.52

1257.70

1213.68

1415.67

1014.56

1266.66

1150.57

816.52

1349.64

1551.87

1716.91

939.61

1136.62

1025.60

1153.69

1844.87

1748.77

1139.55

852.45

1386.69

1463.72

859.45

1056.52

1205.68

1190.71

1024.58

896.49

1092.57

1423.67

1583.95

1029.63

1156.70

887.52

1043.62

1728.86

1572.76

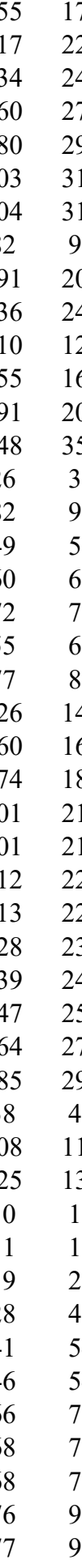


$40 \mathrm{~S}$ ribosomal protein $\mathrm{S} 3 \mathrm{GN}=\mathrm{RPS} 3$ $40 \mathrm{~S}$ ribosomal protein $\mathrm{S} 3 \mathrm{GN}=\mathrm{RPS} 3$ $40 \mathrm{~S}$ ribosomal protein $\mathrm{S} 3 \mathrm{GN}=\mathrm{RPS} 3$ $40 \mathrm{~S}$ ribosomal protein $\mathrm{S} 3 \mathrm{GN}=\mathrm{RPS} 3$ $40 \mathrm{~S}$ ribosomal protein $\mathrm{S} 3 \mathrm{GN}=\mathrm{RPS} 3$ $40 \mathrm{~S}$ ribosomal protein $\mathrm{S} 3 \mathrm{GN}=\mathrm{RPS} 3$ $40 \mathrm{~S}$ ribosomal protein $\mathrm{S} 3 \mathrm{GN}=\mathrm{RPS} 3$ $40 \mathrm{~S}$ ribosomal protein $\mathrm{S} 3 \mathrm{GN}=\mathrm{RPS} 3$ $40 \mathrm{~S}$ ribosomal protein $\mathrm{S} 3 \mathrm{GN}=\mathrm{RPS} 3$ $40 \mathrm{~S}$ ribosomal protein $\mathrm{S} 3 \mathrm{GN}=\mathrm{RPS} 3$ $40 \mathrm{~S}$ ribosomal protein $\mathrm{S} 3 \mathrm{a} \mathrm{GN}=\mathrm{RPS} 3 \mathrm{~A}$ $40 \mathrm{~S}$ ribosomal protein $\mathrm{S} 3 \mathrm{a} \mathrm{GN}=\mathrm{RPS} 3 \mathrm{~A}$ $40 \mathrm{~S}$ ribosomal protein $\mathrm{S} 3 \mathrm{a} \mathrm{GN}=\mathrm{RPS} 3 \mathrm{~A}$ $40 \mathrm{~S}$ ribosomal protein $\mathrm{S} 3 \mathrm{a} \mathrm{GN}=\mathrm{RPS} 3 \mathrm{~A}$ $40 \mathrm{~S}$ ribosomal protein $\mathrm{S} 3 \mathrm{a} \mathrm{GN}=\mathrm{RPS} 3 \mathrm{~A}$ $40 \mathrm{~S}$ ribosomal protein $\mathrm{S} 3 \mathrm{a} \mathrm{GN}=\mathrm{RPS} 3 \mathrm{~A}$ $40 \mathrm{~S}$ ribosomal protein $\mathrm{S} 3 \mathrm{a} \mathrm{GN}=\mathrm{RPS} 3 \mathrm{~A}$ $40 \mathrm{~S}$ ribosomal protein $\mathrm{S} 3 \mathrm{a} \mathrm{GN}=\mathrm{RPS} 3 \mathrm{~A}$ $40 \mathrm{~S}$ ribosomal protein $\mathrm{S} 3 \mathrm{a} \mathrm{GN}=\mathrm{RPS} 3 \mathrm{~A}$ $40 \mathrm{~S}$ ribosomal protein $\mathrm{S} 3 \mathrm{a} \mathrm{GN}=\mathrm{RPS} 3 \mathrm{~A}$ $40 \mathrm{~S}$ ribosomal protein $\mathrm{S} 3 \mathrm{a} \mathrm{GN}=\mathrm{RPS} 3 \mathrm{~A}$ $40 \mathrm{~S}$ ribosomal protein $\mathrm{S} 3 \mathrm{a} \mathrm{GN}=\mathrm{RPS} 3 \mathrm{~A}$ $40 \mathrm{~S}$ ribosomal protein $\mathrm{S} 3 \mathrm{a} \mathrm{GN}=\mathrm{RPS} 3 \mathrm{~A}$ $40 \mathrm{~S}$ ribosomal protein $\mathrm{S} 3 \mathrm{a} \mathrm{GN}=\mathrm{RPS} 3 \mathrm{~A}$ $40 \mathrm{~S}$ ribosomal protein $\mathrm{S} 3 \mathrm{a} \mathrm{GN}=\mathrm{RPS} 3 \mathrm{~A}$ $40 \mathrm{~S}$ ribosomal protein $\mathrm{S} 3 \mathrm{a} \mathrm{GN}=\mathrm{RPS} 3 \mathrm{~A}$ $40 \mathrm{~S}$ ribosomal protein $\mathrm{S} 3 \mathrm{a} \mathrm{GN}=\mathrm{RPS} 3 \mathrm{~A}$ $40 \mathrm{~S}$ ribosomal protein $\mathrm{S} 3 \mathrm{a} \mathrm{GN}=\mathrm{RPS} 3 \mathrm{~A}$ 40 ribosomal protein $\mathrm{S} 4, \mathrm{X}$ isoform GN=RPS4X RS4X_HUMAN 29.60 40S ribosomal protein S4, X isoform GN=RPS4X RS4X_HUMAN 29.60 40S ribosomal protein S4, X isoform GN=RPS4X RS4X_HUMAN 29.60 40S ribosomal protein S4, X isoform GN=RPS4X RS4X_HUMAN 29.60 40S ribosomal protein S4, X isoform GN=RPS4X RS4X_HUMAN 29.60 40S ribosomal protein S4, X isoform GN=RPS4X RS4X_HUMAN 29.60 $40 \mathrm{~S}$ ribosomal protein $\mathrm{S} 4, \mathrm{X}$ isoform GN=RPS4X RS4X HUMAN 29.60 40S ribosomal protein S4, X isoform GN=RPS4X RS4X_HUMAN 29.60 $40 \mathrm{~S}$ ribosomal protein $\mathrm{S} 4, \mathrm{X}$ isoform GN=RPS4X RS4X HUMAN 29.60 40S ribosomal protein S4, X isoform GN=RPS4X RS4X_HUMAN 29.60 $40 \mathrm{~S}$ ribosomal protein S4, X isoform GN=RPS4X RS4X_HUMAN 29.60 $40 \mathrm{~S}$ ribosomal protein $\mathrm{S} 4, \mathrm{X}$ isoform GN=RPS4X RS4X_HUMAN 29.60 $40 \mathrm{~S}$ ribosomal protein S4, X isoform GN=RPS4X RS4X_HUMAN 29.60 $40 \mathrm{~S}$ ribosomal protein $\mathrm{S} 4, \mathrm{X}$ isoform GN=RPS4X RS4X_HUMAN 29.60 $40 \mathrm{~S}$ ribosomal protein S4, X isoform GN=RPS4X RS4X_HUMAN 29.60 $40 \mathrm{~S}$ ribosomal protein S4, X isoform GN=RPS4X RS4X_HUMAN 29.60 $40 \mathrm{~S}$ ribosomal protein $\mathrm{S} 4, \mathrm{X}$ isoform GN=RPS4X RS4X_HUMAN 29.60 $40 \mathrm{~S}$ ribosomal protein S4, X isoform GN=RPS4X RS4X_HUMAN 29.60 29 29

(29)

29

29

(29)

$\begin{array}{ll}18 & 29 \\ 18 & 29\end{array}$

29

29

(29)

29

29

29

29

29

29

$\begin{array}{ll}18 & 29 \\ 18 & 29 \\ 18 & 29\end{array}$

29

8

18

18
22

22

22
22
22

22
22

22
22
22

22
22

22
22
22

22

22
22
22

22
22
22

22
22
22

22
22
22

22

22
22

$\begin{array}{ll}0.11 \% & 78.6 \% \text { GLCAIAQAESLR } \\ 0.11 \% & 78.6 \% \text { YKLLGGLAVR }\end{array}$

$\begin{array}{lll}0.11 \% & 78.6 \% & \text { YKLLGGLAVR }\end{array}$

$0.11 \% \quad 78.6 \%$ RACYGVLR

$0.11 \% \quad 78.6 \%$ FIMESGAK

$0.11 \% \quad 78.6 \%$ GCEVVVSGK

$0.11 \% \quad 78.6 \%$ FVDGLMIHSGDPVNYYVDTAVR

$0.11 \% \quad 78.6 \%$ IMLPWDPTGK

$0.11 \% \quad 78.6 \%$ KPLPDHVSIVEPK

$0.11 \% \quad 78.6 \%$ DEILPTTPISEQK

$0.11 \% \quad 78.6 \%$ GGKPEPPAMPQPVPTA

$0.09 \% \quad 63.6 \%$ VVDPFSKK

$0.09 \% \quad 63.6 \%$ APAMFNIR

$0.09 \% \quad 63.6 \%$ VFEVSLADLQNDEVAFR

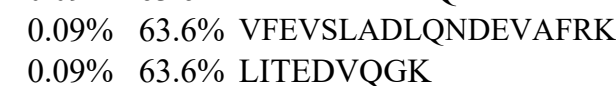

$0.09 \% \quad 63.6 \%$ LITEDVQGK

$\begin{array}{lll}0.09 \% & 63.6 \% & \text { NCLTNFHGMDLTR } \\ 0.09 \% & 63.6 \% & \text { KWQTMIEAHVDVK }\end{array}$

$0.09 \% \quad 63.6 \%$ TTDGYLLR

$0.09 \% \quad 63.6 \%$ LFCVGFTK

$0.09 \% \quad 63.6 \%$ TSYAQHQQVR

$0.09 \% \quad 63.6 \%$ EVQTNDLKEVVNK

$0.09 \% \quad 63.6 \%$ LIPDSIGKDIEK

$86 \quad 0.09 \% \quad 63.6 \%$ ACQSIYPLHDVFVR

$86 \quad 0.09 \% \quad 63.6 \%$ ACQSIYPLHDVFVRK

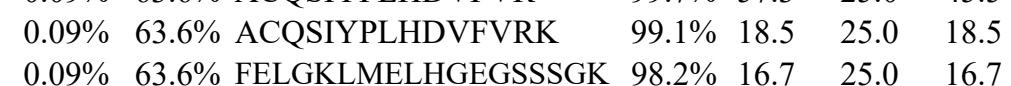

$86 \quad 0.09 \% \quad 63.6 \%$ LMELHGEGSSSGK

$86 \quad 0.09 \% \quad 63.6 \%$ VERADGYEPPVQESV

$0.09 \% \quad 63.6 \%$ ADGYEPPVQESV

$110 \quad 0.12 \% \quad 68.1 \%$ LTGVFAPRPSTGPHK

$110 \quad 0.12 \% \quad 68.1 \%$ LRECLPLIIFLR

$110 \quad 0.12 \% \quad 68.1 \%$ ECLPLIIFLR

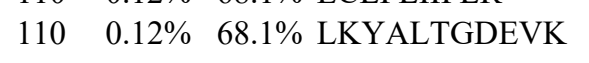

$110 \quad 0.12 \% \quad 68.1 \%$ YALTGDEVK

$110 \quad 0.12 \% \quad 68.1 \%$ YALTGDEVKK

$110 \quad 0.12 \% \quad 68.1 \%$ VRTDITYPAGFMDVISIDK

$110 \quad 0.12 \% \quad 68.1 \%$ TDITYPAGFMDVISIDK

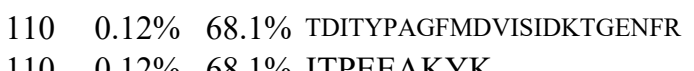

$\begin{array}{lll}110-0.12 \% & 68.1 \% & \text { ITPEEAKYK }\end{array}$

$110-0.12 \% \quad 68.1 \%$ GIPHLVTHDAR

$110 \quad 0.12 \% \quad 68.1 \%$ TIRYPDPLIK

$110 \quad 0.12 \% \quad 68.1 \%$ VNDTIQIDLETGK

$\begin{array}{llll}99.7 \% & 55.0 & 25.0 & 49.0\end{array}$

$\begin{array}{llll}99.7 \% & 43.9 & 25.0 & 42.5\end{array}$

$\begin{array}{llll}99.7 \% & 44.2 & 25.0 & 44.2\end{array}$

$\begin{array}{llll}99.7 \% & 39.6 & 25.0 & 32.5\end{array}$

$\begin{array}{llll}99.7 \% & 45.1 & 25.0 & 32.0\end{array}$

$\begin{array}{llll}99.7 \% & 36.1 & 25.0 & 31.5\end{array}$

$\begin{array}{llll}99.7 \% & 58.5 & 25.0 & 52.4 \\ 99.7 \% & 46.2 & 25.0 & 38.3\end{array}$

$\begin{array}{llll}99.7 \% & 46.2 & 25.0 & 38.3 \\ 99.7 \% & 60.2 & 25.0 & 45.1\end{array}$

$\begin{array}{lllll}99.7 \% & 59.0 & 25.0 & 52.8 & 2\end{array}$

$\begin{array}{llll}99.7 \% & 54.6 & 25.0 & 54.6\end{array}$

$\begin{array}{llll}99.7 \% & 31.3 & 25.0 & 28.4 \\ 99.7 \% & 26.3 & 25.0 & 18.0\end{array}$

$\begin{array}{llll}99.7 \% & 26.3 & 25.0 & 18.0 \\ 99.7 \% & 57.4 & 25.0 & 51.0\end{array}$

$\begin{array}{llll}99.7 \% & 57.4 & 25.0 & 51.0 \\ 99.7 \% & 35.3 & 25.0 & 26.3\end{array}$

$\begin{array}{llll}99.7 \% & 54.7 & 25.0 & 49.8\end{array}$

$\begin{array}{llllllllll}36 & 110 & 0.12 \% & 68.1 \% & \text { VNDTIQIDLETGKITDFIK } & 99.7 \% & 53.4 & 25.0 & 50.7 & 2\end{array}$

$\begin{array}{llllllllll}36 & 110 & 0.12 \% & 68.1 \% & \text { ITDFIKFDTGNLCMVTGGANLGR } & 99.7 \% & 49.8 & 25.0 & 49.8 & 0\end{array}$

$\begin{array}{llllllllll}36 & 110 & 0.12 \% & 68.1 \% & \text { FDTGNLCMVTGGANLGR } & 99.7 \% & 38.9 & 25.0 & 38.5 & 8\end{array}$

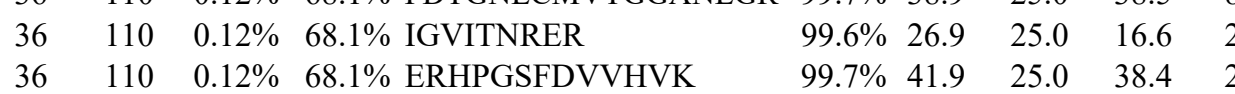

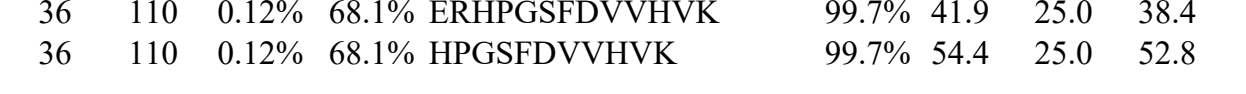


40S ribosomal protein S4, X isoform GN=RPS4X RS4X_HUMAN $29.60 \quad 100.0 \% \quad 22$ 40S ribosomal protein S4, X isoform GN=RPS4X RS4X_HUMAN $29.60 \quad 100.0 \% \quad 22$ 40S ribosomal protein S4, X isoform GN=RPS4X RS4X_HUMAN $29.60 \quad 100.0 \% \quad 22$ $40 \mathrm{~S}$ ribosomal protein $\mathrm{S} 5 \mathrm{GN}=\mathrm{RPS} 5$ $40 \mathrm{~S}$ ribosomal protein $\mathrm{S} 5 \mathrm{GN}=\mathrm{RPS} 5$ $40 \mathrm{~S}$ ribosomal protein $\mathrm{S} 5 \mathrm{GN}=\mathrm{RPS} 5$ $40 \mathrm{~S}$ ribosomal protein $\mathrm{S} 5 \mathrm{GN}=\mathrm{RPS} 5$ $40 \mathrm{~S}$ ribosomal protein $\mathrm{S} 5 \mathrm{GN}=\mathrm{RPS} 5$ $40 \mathrm{~S}$ ribosomal protein $\mathrm{S} 5 \mathrm{GN}=\mathrm{RPS} 5$ $40 \mathrm{~S}$ ribosomal protein $\mathrm{S} 5 \mathrm{GN}=\mathrm{RPS} 5$ $40 \mathrm{~S}$ ribosomal protein $\mathrm{S} 5 \mathrm{GN}=\mathrm{RPS} 5$ $40 \mathrm{~S}$ ribosomal protein $\mathrm{S} 6 \mathrm{GN}=\mathrm{RPS} 6$ $40 \mathrm{~S}$ ribosomal protein $\mathrm{S} 6 \mathrm{GN}=\mathrm{RPS} 6$ $40 \mathrm{~S}$ ribosomal protein $\mathrm{S} 6 \mathrm{GN}=\mathrm{RPS} 6$ $40 \mathrm{~S}$ ribosomal protein $\mathrm{S} 6 \mathrm{GN}=\mathrm{RPS} 6$ $40 \mathrm{~S}$ ribosomal protein $\mathrm{S} 6 \mathrm{GN}=\mathrm{RPS} 6$ 40S ribosomal protein $\mathrm{S} 6 \mathrm{GN}=\mathrm{RPS} 6$ $40 \mathrm{~S}$ ribosomal protein $\mathrm{S} 6 \mathrm{GN}=\mathrm{RPS} 6$ $40 \mathrm{~S}$ ribosomal protein $\mathrm{S} 6 \mathrm{GN}=\mathrm{RPS} 6$ $40 \mathrm{~S}$ ribosomal protein $\mathrm{S} 6 \mathrm{GN}=\mathrm{RPS} 6$ $40 \mathrm{~S}$ ribosomal protein $\mathrm{S} 6 \mathrm{GN}=\mathrm{RPS} 6$ $40 \mathrm{~S}$ ribosomal protein $\mathrm{S} 6 \mathrm{GN}=\mathrm{RPS} 6$ $40 \mathrm{~S}$ ribosomal protein $\mathrm{S} 6 \mathrm{GN}=\mathrm{RPS} 6$ $40 \mathrm{~S}$ ribosomal protein $\mathrm{S} 6 \mathrm{GN}=\mathrm{RPS} 6$ $40 \mathrm{~S}$ ribosomal protein $\mathrm{S} 7 \mathrm{GN}=\mathrm{RPS} 7$ $40 \mathrm{~S}$ ribosomal protein $\mathrm{S} 7 \mathrm{GN}=\mathrm{RPS} 7$ $40 \mathrm{~S}$ ribosomal protein $\mathrm{S} 7 \mathrm{GN}=\mathrm{RPS} 7$ $40 \mathrm{~S}$ ribosomal protein $\mathrm{S} 7 \mathrm{GN}=\mathrm{RPS} 7$ $40 \mathrm{~S}$ ribosomal protein $\mathrm{S} 7 \mathrm{GN}=\mathrm{RPS} 7$ $40 \mathrm{~S}$ ribosomal protein $\mathrm{S} 7 \mathrm{GN}=\mathrm{RPS} 7$ $40 \mathrm{~S}$ ribosomal protein $\mathrm{S} 7 \mathrm{GN}=\mathrm{RPS} 7$ $40 \mathrm{~S}$ ribosomal protein $\mathrm{S} 7 \mathrm{GN}=\mathrm{RPS} 7$ $40 \mathrm{~S}$ ribosomal protein $\mathrm{S} 7 \mathrm{GN}=\mathrm{RPS} 7$ $40 \mathrm{~S}$ ribosomal protein $\mathrm{S} 7 \mathrm{GN}=\mathrm{RPS} 7$ $40 \mathrm{~S}$ ribosomal protein $\mathrm{S} 7 \mathrm{GN}=\mathrm{RPS} 7$ $40 \mathrm{~S}$ ribosomal protein $\mathrm{S} 7 \mathrm{GN}=\mathrm{RPS} 7$ $40 \mathrm{~S}$ ribosomal protein $\mathrm{S} 7 \mathrm{GN}=\mathrm{RPS} 7$ 40S ribosomal protein $\mathrm{S} 7 \mathrm{GN}=\mathrm{RPS} 7$ $40 \mathrm{~S}$ ribosomal protein $\mathrm{S} 8 \mathrm{GN}=\mathrm{RPS} 8$ $40 \mathrm{~S}$ ribosomal protein $\mathrm{S} 8 \mathrm{GN}=\mathrm{RPS} 8$ $40 \mathrm{~S}$ ribosomal protein $\mathrm{S} 8 \mathrm{GN}=\mathrm{RPS} 8$ $40 \mathrm{~S}$ ribosomal protein $\mathrm{S} 8 \mathrm{GN}=\mathrm{RPS} 8$ $40 \mathrm{~S}$ ribosomal protein $\mathrm{S} 8 \mathrm{GN}=\mathrm{RPS} 8$ $40 \mathrm{~S}$ ribosomal protein $\mathrm{S} 8 \mathrm{GN}=\mathrm{RPS} 8$ $40 \mathrm{~S}$ ribosomal protein $\mathrm{S} 8 \mathrm{GN}=\mathrm{RPS} 8$ $40 \mathrm{~S}$ ribosomal protein $\mathrm{S} 8 \mathrm{GN}=\mathrm{RPS} 8$ $40 \mathrm{~S}$ ribosomal protein $\mathrm{S} 8 \mathrm{GN}=\mathrm{RPS} 8$
RS5 HUMAN $22.88 \quad 100.0 \% \quad 8$ RS5_HUMAN $22.88 \quad 100.0 \% \quad 8$ RS5_HUMAN $22.88 \quad 100.0 \% \quad 8$ RS5 HUMAN $22.88 \quad 100.0 \% \quad 8$ RS5_HUMAN $22.88 \quad 100.0 \%$ RS5 HUMAN $22.88 \quad 100.0 \%$ RS5_HUMAN $22.88 \quad 100.0 \% \quad 8$ RS5_HUMAN $22.88 \quad 100.0 \%$ RS6 HUMAN $28.68 \quad 100.0 \% \quad 13$ RS6_HUMAN $28.68 \quad 100.0 \% \quad 13$ RS6 HUMAN $28.68 \quad 100.0 \% \quad 13$ RS6_HUMAN $28.68 \quad 100.0 \% \quad 13$ RS6_HUMAN $28.68 \quad 100.0 \% \quad 13$ RS6 HUMAN $28.68 \quad 100.0 \% \quad 13$ RS6_HUMAN $28.68 \quad 100.0 \% \quad 13$ RS6_HUMAN $28.68 \quad 100.0 \% \quad 13$ RS6 HUMAN $28.68 \quad 100.0 \% \quad 13$ RS6_HUMAN $28.68 \quad 100.0 \% \quad 13$ RS6 HUMAN $28.68 \quad 100.0 \% \quad 13$ RS6_HUMAN $28.68 \quad 100.0 \% \quad 13$ RS6_HUMAN $28.68 \quad 100.0 \% \quad 13$ RS7 HUMAN $22.13 \quad 100.0 \% \quad 14$ RS7_HUMAN $22.13 \quad 100.0 \% \quad 14$ RS7_HUMAN $22.13 \quad 100.0 \% \quad 14$ RS7_HUMAN $22.13 \quad 100.0 \% \quad 14$ RS7_HUMAN $22.13 \quad 100.0 \% \quad 14$ RS7 HUMAN $22.13 \quad 100.0 \% \quad 14$ RS7_HUMAN $22.13 \quad 100.0 \% \quad 14$ RS7_HUMAN $22.13 \quad 100.0 \% \quad 14$ RS7_HUMAN $22.13 \quad 100.0 \% \quad 14$ RS7_HUMAN $22.13 \quad 100.0 \% \quad 14$ RS7_HUMAN $22.13 \quad 100.0 \% \quad 14$ RS7 HUMAN $22.13 \quad 100.0 \% \quad 14$ RS7_HUMAN $22.13 \quad 100.0 \% \quad 14$ RS7_HUMAN $22.13 \quad 100.0 \% \quad 14$ RS8_HUMAN $24.21 \quad 100.0 \% \quad 11$ RS8_HUMAN $24.21 \quad 100.0 \% \quad 11$ RS8 HUMAN $24.21 \quad 100.0 \% \quad 11$ RS8_HUMAN $24.21 \quad 100.0 \% \quad 11$ RS8 HUMAN $24.21 \quad 100.0 \% \quad 11$ RS8_HUMAN $24.21 \quad 100.0 \% \quad 11$ RS8_HUMAN $24.21 \quad 100.0 \% \quad 11$ RS8 HUMAN $24.21 \quad 100.0 \% \quad 11$ RS8_HUMAN $24.21 \quad 100.0 \% \quad 11$
$36 \quad 110 \quad 0.12 \% \quad 68.1 \%$ DANGNSFATR

$36 \quad 110 \quad 0.12 \% \quad 68.1 \%$ LSNIFVIGK

$36 \quad 110 \quad 0.12 \% \quad 68.1 \%$ GNKPWISLPR

$\begin{array}{llll}10 & 16 & 0.02 \% & 27.0 \% \\ 10 & \text { YLPHSAGR }\end{array}$

$10 \quad 16 \quad 0.02 \% \quad 27.0 \%$ KAQCPIVER

$\begin{array}{llll}10 & 16 & 0.02 \% & 27.0 \% \\ 10 & 16 & 0.02 \% & 27.0 \%\end{array}$

$\begin{array}{llll}10 & 16 & 0.02 \% & 27.0 \% \\ 10 & \text { QAVDVSPLR }\end{array}$

$10 \quad 16 \quad 0.02 \% \quad 27.0 \%$ QAVDVSPLRR

$10 \quad 16 \quad 0.02 \% \quad 27.0 \%$ RVNQAIWLLCTGAR

$\begin{array}{llll}10 & 16 & 0.02 \% & 27.0 \% \\ 10 & \text { VNQAIWLLCTGAR }\end{array}$

$10 \quad 16 \quad 0.02 \% \quad 27.0 \%$ TIAECLADELINAAK

$23 \quad 63 \quad 0.07 \% \quad 44.2 \%$ MKLNISFPATGCQK

$23 \quad 63 \quad 0.07 \% \quad 44.2 \%$ LNISFPATGCQK

$23 \quad 63 \quad 0.07 \% \quad 44.2 \%$ LIEVDDER

$23 \quad 63 \quad 0.07 \% \quad 44.2 \%$ LIEVDDERK

23

23

23

23

23

23

23
23

23
23

18

18

18

18

18
18

18
18

18
18

18

18
18

18

18
18

18

15

15

15

154

$0.05 \% \quad 52.9 \%$ TRIIDVVYNASNNELVR

$0.05 \% \quad 52.9 \%$ IIDVVYNASNNELVR

$0.05 \% 52.9 \%$ NCIVLIDSTPYR

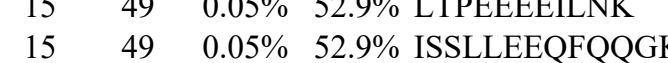

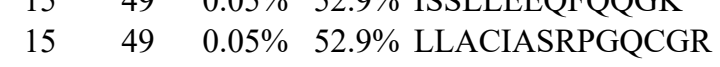
\%ATEVADALGEEWK $0.07 \% \quad 44.2 \%$ ISGGNDKQGFPMK 44.2\% GEKDIPGLTDTTVPR GLTDTTVPR $0.07 \% \quad 44.2 \%$ NKEEAAEYAK $0.03 \% \quad 62.4 \%$ AQLRELNITAAK $0.03 \% \quad 62.4 \%$ ELNITAAK $0.03 \% \quad 62.4 \%$ ELNITAAKEIEVGGGR $0.03 \% \quad 62.4 \%$ KAIIIFVPVPQLK $0.03 \% \quad 62.4 \%$ SFQKIQVR $0.03 \% \quad 62.4 \%$ HVVFIAQR $\begin{array}{ll}0.03 \% & 62.4 \% \text { HVVFIAQR } \\ 0.03 \% & 62.4 \%\end{array}$ $0.03 \% \quad 62.4 \%$ LIKVHLDK $0.03 \% \quad 62.4 \%$ LTGKDVNFEFPEFQL $\begin{array}{llllllll}99.7 \% & 59.4 & 25.0 & 47.1 & 2 & 0 & 0 & 1052.48\end{array}$ $\begin{array}{lllllll}99.7 \% & 59.2 & 25.0 & 53.8 & 10 & 0 & 0\end{array}$ $\begin{array}{llllll}99.7 \% & 36.1 & 25.0 & 35.8 & 4 & 0\end{array}$

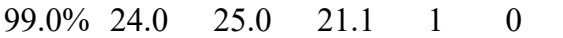
$\begin{array}{lllll}99.7 \% & 36.3 & 25.0 & 30.2 & 2\end{array}$ $\begin{array}{llll}99.0 \% & 31.4 & 25.0 & 26.2\end{array}$ $99.7 \% \quad 31.6 \quad 25.0 \quad 25.8$ $\begin{array}{llll}97.3 \% & 20.9 & 25.0 & 12.5\end{array}$ $\begin{array}{llll}99.7 \% & 46.0 & 25.0 & 46.0\end{array}$ $\begin{array}{llll}99.7 \% & 65.7 & 25.0 & 65.7\end{array}$ $\begin{array}{lllll}99.7 \% & 51.2 & 25.0 & 45.7 & 2\end{array}$ $\begin{array}{lllll}99.7 \% & 60.5 & 25.0 & 60.1\end{array}$ $\begin{array}{llll}99.7 \% & 53.3 & 25.0 & 53.3\end{array}$ $\begin{array}{llll}99.0 \% & 52.9 & 25.0 & 51.0\end{array}$ $\begin{array}{llll}99.7 \% & 43.6 & 25.0 & 28.7\end{array}$ $99.1 \% \quad 23.4$ $99.7 \% \quad 56.4$ $25.0 \quad 15.5$ $\begin{array}{llll}99.7 \% & 60.4 & 25.0 & 51.3\end{array}$ $\begin{array}{lllll} & 25.0 & 51.3\end{array}$ $\begin{array}{lllll}99.7 \% & 54.3 & 25.0 & 48.0 & 2\end{array}$ $\begin{array}{llll}99.7 \% & 56.6 & 25.0 & 54.0\end{array}$ $99.7 \% \quad 63.5 \quad 25.0 \quad 40.5$ $\begin{array}{llll}99.7 \% & 28.3 & 25.0 & 28.3\end{array}$ $99.6 \% \quad 22.9 \quad 25.0 \quad 22.9$ $\begin{array}{llll}99.0 \% & 48.1 & 25.0 & 36.3\end{array}$ $\begin{array}{llll}99.7 \% & 48.3 & 25.0 & 48.3\end{array}$ $\begin{array}{llll}99.7 \% & 56.5 & 25.0 & 56.5\end{array}$ $\begin{array}{lllll}99.7 \% & 57.3 & 25.0 & 57.3 & 2\end{array}$ $99.0 \% \quad 28.0 \quad 25.0 \quad 28.0$ $99.0 \% \quad 28.9 \quad 25.0 \quad 28.9$ $\begin{array}{llll}99.5 \% & 24.1 & 25.0 & 17.4\end{array}$ $99.0 \% \quad 26.0 \quad 25.0 \quad 24.5$ $\begin{array}{lllllll}0.03 \% & 62.4 \% & \text { TLTAVHDAILEDLVFPSEIVGK } & 99.7 \% & 55.9 & 25.0 & 55.9\end{array}$ $\begin{array}{lllllll}0.03 \% & 62.4 \% & \text { TLTAVHDAILEDLVFPSEIVGKR } & 99.7 \% & 55.0 & 25.0 & 55.0\end{array}$ $99.0 \% \quad 46.9 \quad 25.0 \quad 31.5$ $99.7 \% \quad 38.7$ $99.7 \% \quad 52.2 \quad 25.0 \quad 51.7$ $99.7 \% \quad 54.3 \quad 25.0 \quad 48.7$ $99.7 \% \quad 47.1 \quad 25.0 \quad 38.5$ $99.7 \% \quad 69.1 \quad 25.0 \quad 69.1$ $\begin{array}{llll}99.7 \% & 27.2 & 25.0 & 27.2 \\ 99.7 \% & 58.4 & 25.0 & 58.4\end{array}$ $\begin{array}{llll}99.7 \% & 58.4 & 25.0 & 58.4\end{array}$ $99.7 \% \quad 60.1 \quad 25.0 \quad 52.9$ $\begin{array}{lllll}99.7 \% & 53.0 & 25.0 & 47.8 & 5\end{array}$ $\begin{array}{llll}99.7 \% & 55.1 & 25.0 & 50.4\end{array}$ $99.7 \% \quad 45.1 \quad 25.0 \quad 42.9$ $\begin{array}{ccc}1052.48 & 212 & 221 \\ 990.60 & 222 & 230 \\ 1167.66 & 231 & 240 \\ 900.47 & 48 & 55 \\ 1100.59 & 63 & 71 \\ 972.49 & 64 & 71 \\ 984.55 & 137 & 145 \\ 1140.65 & 137 & 146 \\ 1657.90 & 146 & 159 \\ 1501.79 & 147 & 159 \\ 1631.83 & 168 & 182 \\ 1594.81 & 1 & 14 \\ 1335.67 & 3 & 14 \\ 988.49 & 15 & 22 \\ 1116.59 & 15 & 23 \\ 1792.85 & 31 & 46 \\ 1620.76 & 32 & 46 \\ 2195.08 & 32 & 51 \\ 1378.68 & 52 & 64 \\ 1827.04 & 99 & 115 \\ 1598.84 & 117 & 131 \\ 1284.68 & 120 & 131 \\ 1335.69 & 144 & 154 \\ 1152.55 & 202 & 211 \\ 1327.77 & 38 & 49 \\ 859.49 & 42 & 49 \\ 1656.89 & 42 & 57 \\ 1465.95 & 58 & 70 \\ 1337.86 & 59 & 70 \\ 1005.58 & 71 & 78 \\ 969.56 & 91 & 98 \\ 1125.66 & 91 & 99 \\ 980.64 & 99 & 106 \\ 2367.28 & 121 & 142 \\ 2523.38 & 121 & 143 \\ 965.61 & 153 & 160 \\ 2078.03 & 161 & 178 \\ 1783.89 & 180 & 194 \\ 1347.74 & 26 & 37 \\ 1219.64 & 27 & 37 \\ 1787.75 & 60 & 74 \\ 1976.06 & 76 & 92 \\ 1718.91 & 78 & 92 \\ 1450.74 & 99 & 110 \\ 1314.68 & 129 & 139 \\ 1506.78 & 158 & 170 \\ 1558.79 & 171 & 184\end{array}$

Page 11 of Table S-1-5 
$40 \mathrm{~S}$ ribosomal protein $\mathrm{S} 8 \mathrm{GN}=\mathrm{RPS} 8$ 40S ribosomal protein $\mathrm{S} 8 \mathrm{GN}=\mathrm{RPS} 8$ $40 \mathrm{~S}$ ribosomal protein $\mathrm{S} 9 \mathrm{GN}=\mathrm{RPS} 9$ $40 \mathrm{~S}$ ribosomal protein $\mathrm{S} 9 \mathrm{GN}=\mathrm{RPS} 9$ $40 \mathrm{~S}$ ribosomal protein $\mathrm{S} 9 \mathrm{GN}=\mathrm{RPS} 9$ 40S ribosomal protein $\mathrm{S} 9 \mathrm{GN}=\mathrm{RPS} 9$ $40 \mathrm{~S}$ ribosomal protein $\mathrm{S} 9 \mathrm{GN}=\mathrm{RPS} 9$ $40 \mathrm{~S}$ ribosomal protein $\mathrm{S} 9 \mathrm{GN}=\mathrm{RPS} 9$ $40 \mathrm{~S}$ ribosomal protein $\mathrm{S} 9 \mathrm{GN}=\mathrm{RPS} 9$ $40 \mathrm{~S}$ ribosomal protein $\mathrm{S} 9 \mathrm{GN}=\mathrm{RPS} 9$ $40 \mathrm{~S}$ ribosomal protein $\mathrm{S} 9 \mathrm{GN}=\mathrm{RPS} 9$ $40 \mathrm{~S}$ ribosomal protein $\mathrm{S} 9 \mathrm{GN}=\mathrm{RPS} 9$ $40 \mathrm{~S}$ ribosomal protein $\mathrm{S} 9 \mathrm{GN}=\mathrm{RPS} 9$ $40 \mathrm{~S}$ ribosomal protein $\mathrm{S} 9 \mathrm{GN}=\mathrm{RPS} 9$ $40 \mathrm{~S}$ ribosomal protein $\mathrm{S} 9 \mathrm{GN}=\mathrm{RPS} 9$ $40 \mathrm{~S}$ ribosomal protein $\mathrm{S} 9 \mathrm{GN}=\mathrm{RPS} 9$ $40 \mathrm{~S}$ ribosomal protein $\mathrm{S} 9 \mathrm{GN}=\mathrm{RPS} 9$ $40 \mathrm{~S}$ ribosomal protein $\mathrm{SA}$ GN=RPSA $40 \mathrm{~S}$ ribosomal protein $\mathrm{SA}$ GN=RPSA $40 \mathrm{~S}$ ribosomal protein $\mathrm{SA}$ GN=RPSA $40 \mathrm{~S}$ ribosomal protein $\mathrm{SA}$ GN=RPSA $40 \mathrm{~S}$ ribosomal protein $\mathrm{SA} \mathrm{GN}=\mathrm{RPSA}$ $40 \mathrm{~S}$ ribosomal protein $\mathrm{SA}$ GN=RPSA $40 \mathrm{~S}$ ribosomal protein $\mathrm{SA}$ GN=RPSA 5'-3' exoribonuclease $1 \mathrm{GN}=\mathrm{XRN} 1$ $5 '-3$ ' exoribonuclease $1 \mathrm{GN}=\mathrm{XRN} 1$ $5 '-3$ ' exoribonuclease $2 \mathrm{GN}=\mathrm{XRN} 2$ $5^{\prime}-3$ ' exoribonuclease $2 \mathrm{GN}=\mathrm{XRN} 2$ $5^{\prime}-3$ ' exoribonuclease $2 \mathrm{GN}=\mathrm{XRN} 2$ (1) exoribonuclease 2 GN=XRN2

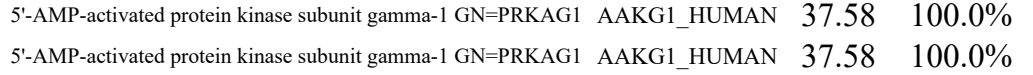
5'-AMP-activated protein kinase subunit gamma-1 GN=PRKAG1 AAKG1_HUMAN $37.58 \quad 100.0 \%$ 5'-AMP-activated protein kinase subunit gamma-1 GN=PRKAG1 AAKG1_HUMAN $37.58 \quad 100.0 \%$ 5'-AMP-activated protein kinase subunit gamma-1 GN=PRKAG1 AAKG1_HUMAN $37.58 \quad 100.0 \%$ 5'-AMP-activated protein kinase subunit gamma-1 GN=PRKAG1 AAKG1_HUMAN $37.58 \quad 100.0 \%$ 5'-AMP-activated protein kinase subunit gamma-1 GN=PRKAG1 AAKG1_HUMAN $37.58 \quad 100.0 \%$ 5-methylcytosine rRNA methyltransferase NSUN4 GN=NSUN4 NSUN4_HUMAN $43.09 \quad 100.0 \%$ 5-methylcytosine rRNA methyltransferase NSUN4 GN=NSUN4 NSUN4_HUMAN $43.09 \quad 100.0 \%$ 5-methylcytosine rRNA methyltransferase NSUN4 GN=NSUN4 NSUN4_HUMAN $43.09 \quad 100.0 \%$ 5-methylcytosine rRNA methyltransferase NSUN4 GN=NSUN4 NSUN4_HUMAN $43.09 \quad 100.0 \%$ 5-methylcytosine rRNA methyltransferase NSUN4 GN=NSUN4 NSUN4_HUMAN $43.09 \quad 100.0 \%$ $60 \mathrm{kDa}$ heat shock protein, mitochondrial GN=HSPD1 CH60_HUMAN $61.06 \quad 100.0 \%$ $60 \mathrm{kDa}$ heat shock protein, mitochondrial GN=HSPD1 CH60_HUMAN $61.06 \quad 100.0 \%$ $60 \mathrm{kDa}$ heat shock protein, mitochondrial GN=HSPD1 CH60_HUMAN $61.06 \quad 100.0 \%$ $60 \mathrm{kDa}$ heat shock protein, mitochondrial GN=HSPD1 CH60_HUMAN $61.06 \quad 100.0 \%$ $\begin{array}{llll}60 \mathrm{kDa} \text { heat shock protein, mitochondrial GN=HSPD1 CH60_HUMAN } & 61.06 & 100.0 \% \\ 60 \mathrm{kDa} \text { heat shock protein, mitochondrial GN=HSPD1 } & \text { CH60_HUMAN } & 61.06 & 100.0 \%\end{array}$
$0.04 \% \quad 46.4 \%$ SRLDQELK

$0.04 \% \quad 46.4 \%$ LDQELKLIGEYGLR

$0.04 \% \quad 46.4 \%$ LIGEYGLR

$0.04 \% \quad 46.4 \%$ ELLTLDEKDPR

$0.04 \% \quad 46.4 \%$ RLFEGNALLR

$0.04 \% \quad 46.4 \%$ LFEGNALLR

$0.04 \% \quad 46.4 \%$ LFEGNALLRR

$0.04 \% \quad 46.4 \%$ IGVLDEGK

$0.04 \% \quad 46.4 \%$ IGVLDEGKMK

$0.04 \% \quad 46.4 \%$ RLQTQVFK

$0.04 \% \quad 46.4 \%$ KQVVNIPSFIVR

$0.04 \% \quad 46.4 \%$ QVVNIPSFIVR

$0.04 \% \quad 46.4 \%$ QVVNIPSFIVRLDSQK

$0.04 \% \quad 46.4 \%$ LDSQKHIDFSLR

$0.04 \% \quad 46.4 \%$ SPYGGGRPGR

$0.02 \% \quad 25.4 \%$ SDGIYIINLK

$0.02 \% \quad 25.4 \%$ SDGIYIINLKR

$0.02 \% \quad 25.4 \%$ AIVAIENPADVSVISSR

$0.02 \% \quad 25.4 \%$ FAAATGATPIAGR

$0.02 \% \quad 25.4 \%$ FTPGTFTNQIQAAFR

$0.02 \% \quad 25.4 \%$ LLVVTDPR

$0.02 \% \quad 25.4 \%$ YVDIAIPCNNK

$0.00 \% \quad 1.1 \%$ LGVSGYLVSR

$0.00 \% \quad 1.1 \%$ FTGSIFIGR

$0.01 \% \quad 3.3 \%$ VREEILAK

$0.01 \% \quad 3.3 \% \quad$ NSPGSQVASNPR

$0.01 \% \quad 3.3 \%$ RPVHLDQAAFR

$0.01 \% \quad 19.3 \%$ LVVFDTSLQVK

$0.01 \% \quad 19.3 \%$ AFFALVTNGVR

$0.01 \% \quad 19.3 \%$ VSALPVVDEK

$0.01 \% \quad 19.3 \%$ VSALPVVDEKGR

$0.01 \% \quad 19.3 \%$ FDVINLAAEK

$0.01 \% \quad 19.3 \%$ TYNNLDVSVTK

$0.01 \% \quad 19.3 \%$ SHYFEGVLK

$0.01 \% \quad 15.1 \%$ VSLLSEQK

$0.01 \% \quad 15.1 \%$ TLALLQTGCCR

$0.01 \% \quad 15.1 \%$ NLAANDLSPSR

$0.01 \% \quad 15.1 \%$ ILHSYVPEEIRDGNQVR

$0.01 \% \quad 15.1 \%$ VLVDVPCTTDR

$0.03 \% \quad 26.5 \%$ TVIIEQSWGSPK

$0.03 \% \quad 26.5 \%$ VTKDGVTVAK

$0.03 \% \quad 26.5 \%$ LVQDVANNTNEEAGDGTTTATVLAR

$0.03 \% \quad 26.5 \%$ SIAKEGFEK

$0.03 \% \quad 26.5 \%$ GANPVEIRR

$0.03 \% \quad 26.5 \%$ GVITVKDGK $\begin{array}{llllll}99.7 \% & 47.3 & 25.0 & 32.0 & 2 & 0\end{array}$

$\begin{array}{lllll}99.7 \% & 39.8 & 25.0 & 39.8\end{array}$

$\begin{array}{lllll}99.0 \% & 31.9 & 25.0 & 9.5 & 2\end{array}$

$\begin{array}{lllll}99.7 \% & 52.9 & 25.0 & 51.0 & 2\end{array}$

$99.0 \% \quad 54.3 \quad 25.0 \quad 42.6$

$95.6 \% \quad 16.9 \quad 25.0 \quad 12.8$

$99.7 \% \quad 48.9 \quad 25.0 \quad 33.7$

$\begin{array}{llll}99.7 \% & 59.0 & 25.0 & 40.7\end{array}$

$99.4 \% \quad 24.4 \quad 25.0 \quad 16.8$

$\begin{array}{llll}99.0 \% & 54.8 & 25.0 & 26.1\end{array}$

$\begin{array}{lllll}99.7 \% & 42.4 & 25.0 & 39.9 & 2\end{array}$

$99.0 \% \quad 27.6 \quad 25.0 \quad 18.3$

$99.7 \% \quad 56.9 \quad 25.0 \quad 56.9$

$\begin{array}{llll}99.7 \% & 54.9 & 25.0 & 40.8\end{array}$

$95.4 \% \quad 14.6 \quad 25.0 \quad 14.6$

$99.7 \% \quad 52.1 \quad 25.0 \quad 52.1 \quad 2$

$\begin{array}{llll}99.7 \% & 42.0 & 25.0 & 32.7\end{array}$

$99.7 \% \quad 47.9 \quad 25.0 \quad 34.5$

$\begin{array}{llll}99.7 \% & 29.7 & 25.0 & 29.7\end{array}$

$99.7 \% \quad 59.6 \quad 25.0 \quad 59.6$

$99.7 \% \quad 53.4 \quad 25.0 \quad 51.9$

$\begin{array}{llll}99.7 \% & 65.2 & 25.0 & 59.9\end{array}$

$\begin{array}{llll}99.0 \% & 51.8 & 25.0 & 42.8\end{array}$

$\begin{array}{llll}99.7 \% & 48.8 & 25.0 & 48.7\end{array}$

$99.7 \% \quad 57.2 \quad 25.0 \quad 57.2$

$\begin{array}{llll}99.7 \% & 29.3 & 25.0 & 22.8\end{array}$

$99.0 \% \quad 33.4 \quad 25.0 \quad 14.7$

$99.7 \% \quad 55.7 \quad 25.0 \quad 55.7$

$\begin{array}{llll}98.0 \% & 18.7 & 25.0 & 15.8\end{array}$

$\begin{array}{llll}99.7 \% & 59.0 & 25.0 & 59.0\end{array}$

$\begin{array}{llll}99.7 \% & 52.5 & 25.0 & 49.2\end{array}$

$\begin{array}{llll}99.7 \% & 40.6 & 25.0 & 32.7\end{array}$

$95.6 \% \quad 19.8 \quad 25.0 \quad 12.3$

$\begin{array}{lllll}99.7 \% & 46.0 & 25.0 & 35.1 & 2\end{array}$

$99.7 \% \quad 65.3 \quad 25.0 \quad 62.9$

$\begin{array}{llll}99.6 \% & 24.3 & 25.0 & 18.1\end{array}$

$99.0 \% \quad 40.1 \quad 25.0 \quad 20.0$

$99.7 \% \quad 55.3 \quad 25.0 \quad 42.0$

$\begin{array}{llll}99.7 \% & 48.2 & 25.0 & 40.9\end{array}$

$\begin{array}{llll}99.3 \% & 24.5 & 25.0 & 24.5\end{array}$

$\begin{array}{llll}99.7 \% & 35.6 & 25.0 & 35.6\end{array}$

$\begin{array}{llll}99.7 \% & 55.7 & 25.0 & 47.5\end{array}$

$\begin{array}{llll}99.7 \% & 49.4 & 25.0 & 31.5\end{array}$

$99.7 \% \quad 39.8 \quad 25.0=39.8$

$\begin{array}{llll}99.7 \% & 27.2 & 25.0 & 18.9\end{array}$

$\begin{array}{llll}99.7 \% & 36.9 & 25.0 & 26.4\end{array}$

$\begin{array}{llll}99.4 \% & 19.8 & 25.0 & 19.8\end{array}$
988.54

1646.9

920.52

1328.71

1188.68

1032.58

1188.68

830.46

1089.60

1019.60

1399.84

1271.75

1843.04

1458.77

1003.5

1135.64

1291.74

1740.95

1203.65

1698.86

912.55

1306.65

1050.5

997.55

957.57

1213.59

1309.71

1248.72

1194.66

1056.59

1269.72

1119.60

1253.64

1079.55

903.51

1292.65

1157.59

2025.05

1274.64

1344.72

1017.59

2560.25

1008.54

1011.57

916.55 
$60 \mathrm{kDa}$ heat shock protein, mitochondrial GN=HSPD1 CH60 HUMAN $61.06 \quad 100.0 \% \quad 15 \quad 15 \quad 29 \quad 0.03 \% \quad 26.5 \%$ GYISPYFINTSK $60 \mathrm{kDa}$ heat shock protein, mitochondrial GN=HSPD1 CH60_HUMAN $61.06 \quad 100.0 \% \quad 15 \quad 15 \quad 29 \quad 0.03 \% \quad 26.5 \%$ LKVGLQVVAVK $60 \mathrm{kDa}$ heat shock protein, mitochondrial GN=HSPD1 CH60_HUMAN $61.06 \quad 100.0 \% \quad 15$ $60 \mathrm{kDa}$ heat shock protein, mitochondrial GN=HSPD1 CH60_HUMAN $61.06 \quad 100.0 \% \quad 15$ $60 \mathrm{kDa}$ heat shock protein, mitochondrial GN=HSPD1 CH60_HUMAN $61.06 \quad 100.0 \% \quad 15$ $60 \mathrm{kDa}$ heat shock protein, mitochondrial GN=HSPD1 CH60_HUMAN $61.06 \quad 100.0 \% \quad 15$ $60 \mathrm{kDa}$ heat shock protein, mitochondrial GN=HSPD1 CH60_HUMAN $61.06 \quad 100.0 \% \quad 15$ $60 \mathrm{kDa}$ heat shock protein, mitochondrial GN=HSPD1 CH60_HUMAN $61.06 \quad 100.0 \% \quad 15$ $60 \mathrm{kDa}$ heat shock protein, mitochondrial GN=HSPD1 CH60 HUMAN 61.06 60S acidic ribosomal protein P0 GN=RPLP0 RLA0_HUMAN 34.27 60S acidic ribosomal protein P0 GN=RPLP0 RLA0_HUMAN 34.27 60S acidic ribosomal protein P0 GN=RPLP0 RLA0_HUMAN 34.27 60S acidic ribosomal protein P0 GN=RPLP0 RLA0_HUMAN 34.27 60S acidic ribosomal protein P0 GN=RPLP0 RLA0_HUMAN 34.27 $60 \mathrm{~S}$ acidic ribosomal protein P0 GN=RPLP0 RLA0_HUMAN 34.27 $60 \mathrm{~S}$ acidic ribosomal protein P0 GN=RPLP0 RLA0_HUMAN 34.27 $60 \mathrm{~S}$ acidic ribosomal protein P0 GN=RPLP0 RLA0 HUMAN 34.27 $60 \mathrm{~S}$ acidic ribosomal protein P0 GN=RPLP0 RLA0_HUMAN 34.27 $60 \mathrm{~S}$ acidic ribosomal protein P0 GN=RPLP0 RLA0_HUMAN 34.27 $60 \mathrm{~S}$ acidic ribosomal protein $\mathrm{P} 0 \mathrm{GN}=\mathrm{RPLP0}$ RLA0 HUMAN 34.27 $60 \mathrm{~S}$ acidic ribosomal protein P0 GN=RPLP0 RLA0_HUMAN 34.27 $60 \mathrm{~S}$ acidic ribosomal protein P0 GN=RPLP0 RLA0 HUMAN 34.27 60S acidic ribosomal protein P0 GN=RPLP0 RLA0 HUMAN 34.27 $60 \mathrm{~S}$ acidic ribosomal protein P0 GN=RPLP0 RLA0_HUMAN 34.27 60 S ribosomal protein $\mathrm{L} 10 \mathrm{GN}=\mathrm{RPL} 10 \quad$ RL10 HUMAN 24.60 $60 \mathrm{~S}$ ribosomal protein $\mathrm{L} 10 \mathrm{GN}=\mathrm{RPL} 10$ $60 \mathrm{~S}$ ribosomal protein $\mathrm{L} 10 \mathrm{GN}=\mathrm{RPL} 10$ $60 \mathrm{~S}$ ribosomal protein $\mathrm{L} 10 \mathrm{GN}=\mathrm{RPL} 10$ $60 \mathrm{~S}$ ribosomal protein $\mathrm{L} 10 \mathrm{GN}=\mathrm{RPL} 10$ $60 \mathrm{~S}$ ribosomal protein $\mathrm{L} 10 \mathrm{GN}=\mathrm{RPL} 10$ $60 \mathrm{~S}$ ribosomal protein $\mathrm{L} 10 \mathrm{GN}=\mathrm{RPL} 10$ $60 \mathrm{~S}$ ribosomal protein $\mathrm{L} 10 \mathrm{GN}=\mathrm{RPL} 10$ $60 \mathrm{~S}$ ribosomal protein $\mathrm{L} 10 \mathrm{GN}=\mathrm{RPL} 10$ $60 \mathrm{~S}$ ribosomal protein $\mathrm{L} 10 \mathrm{GN}=\mathrm{RPL} 10$ $60 \mathrm{~S}$ ribosomal protein $\mathrm{L} 10 \mathrm{GN}=\mathrm{RPL} 10$ $60 \mathrm{~S}$ ribosomal protein $\mathrm{L} 10 \mathrm{GN}=\mathrm{RPL} 10$ 60S ribosomal protein L10a GN=RPL10A RL10A_HUMAN 24.83 60 ribosomal protein L10a GN=RPL10A RL10A HUMAN 24.83 60 S ribosomal protein L10a GN=RPL10A RL10A_HUMAN 24.83 60S ribosomal protein L10a GN=RPL10A RL10A_HUMAN 24.83 60S ribosomal protein L10a GN=RPL10A RL10A_HUMAN 24.83 60S ribosomal protein L10a GN=RPL10A RL10A_HUMAN 24.83 $60 \mathrm{~S}$ ribosomal protein L10a GN=RPL10A RL10A HUMAN 24.83 $60 \mathrm{~S}$ ribosomal protein L10a GN=RPL10A RL10A_HUMAN 24.8 $60 \mathrm{~S}$ ribosomal protein L10a GN=RPL10A RL10A_HUMAN 24.83 $60 \mathrm{~S}$ ribosomal protein $\mathrm{L} 11 \mathrm{GN}=\mathrm{RPL} 11$ $60 \mathrm{~S}$ ribosomal protein $\mathrm{L} 11 \mathrm{GN}=\mathrm{RPL} 11$
RL10_HUMAN 24.60

RL10 HUMAN 24.60 RL10_HUMAN 24.60 RL10_HUMAN 24.60 RL10 HUMAN 24.60 RL10_HUMAN 24.60 RL10 HUMAN 24.60 RL10_HUMAN 24.60 RL10 HUMAN 24.60 $100.0 \% \quad 15$ $100.0 \% \quad 15$ $100.0 \% \quad 15$ $100.0 \% \quad 15$ $100.0 \% \quad 15$ $100.0 \% \quad 15$ $100.0 \% \quad 15$ $100.0 \% \quad 15$ $100.0 \% \quad 15$ $100.0 \% \quad 15$ $100.0 \% \quad 15$ $100.0 \% \quad 15$ $100.0 \% \quad 15$ $100.0 \% \quad 15$ $100.0 \% \quad 15$ $100.0 \% \quad 15$ $100.0 \% \quad 12$ $100.0 \% \quad 12$ $100.0 \% \quad 12$ $100.0 \% \quad 12$ $100.0 \% \quad 12$ $100.0 \% \quad 12$ $100.0 \% \quad 12$ $100.0 \% \quad 12$ $100.0 \% \quad 12$ $100.0 \% \quad 12$ $100.0 \% \quad 12$ $100.0 \% \quad 12$ $100.0 \% \quad 9$ $100.0 \% \quad 9$ $100.0 \%$ $100.0 \%$ $100.0 \% \quad 9$ $100.0 \%$ $100.0 \%$ $100.0 \%$ $100.0 \%$ $100.0 \%$ RL11 HUMAN 20.25 RL11_HUMAN $20.25 \quad 100.0 \%$
$19 \quad 91 \quad 0.10 \% \quad 59.6 \%$ GTIEILSDVQLIK

$0.02 \% \quad 43.8 \%$ DTLYEAVR
$0.03 \% 26.5 \%$ VGLQVVAVK

$\begin{array}{llll}15 & 29 & 0.03 \% & 26.5 \% \\ 15 & 29 & 0.03 \% & 26.5 \% \text { VGEVIVTK } \\ 15 & 29 & 0.03 \% & 26.5 \% \text { LSEVIVTKDDAMLLK }\end{array}$

$0.03 \% \quad 26.5 \%$ LSDGVAVLK

$\begin{array}{llll}15 & 29 & 0.03 \% & 26.5 \% \\ 15 & 29 & 0.03 \% & 26.5 \%\end{array}$

$\begin{array}{llll}15 & 29 & 0.03 \% & 26.5 \% \\ 15 & \text { NAGVEGSLIVEK }\end{array}$

$\begin{array}{lllll}15 & 29 & 0.03 \% & 26.5 \% & \text { GIIDPTKVVR }\end{array}$

$19 \quad 91 \quad 0.10 \% \quad 59.6 \%$ IIQLLDDYPK

$19 \quad 91 \quad 0.10 \% \quad 59.6 \%$ CFIVGADNVGSK

$19 \quad 91 \quad 0.10 \% \quad 59.6 \%$ GHLENNPALEK

$19 \quad 91 \quad 0.10 \% \quad 59.6 \%$ GNVGFVFTK

$19 \quad 91 \quad 0.10 \% \quad 59.6 \%$ GNVGFVFTKEDLTEIR

$19 \quad 91 \quad 0.10 \% \quad 59.6 \%$ EDLTEIRDMLLANK

$19 \quad 91 \quad 0.10 \% \quad 59.6 \%$ DMLLANKVPAAAR

$19 \quad 91 \quad 0.10 \% \quad 59.6 \%$ AGAIAPCEVTVPAQNTGLGPEK

$19 \quad 91 \quad 0.10 \% \quad 59.6 \%$ TSFFQALGITTK

$99.7 \% \quad 60.6$

$\begin{array}{lll}9 & 9.7 \% & 60.6\end{array}$

$19 \quad 91 \quad 0.10 \% \quad 59.6 \%$ VLALSVETDYTFPLAEK $\quad 99.7 \% \quad 57.4$

19

19

19

20

20

20

20
20

20
20

20

20

20

20
20

20

20
11

11
11

11

11
11

1

11
11

11
11

9
$91 \quad 0.10 \% \quad 59.6 \%$ VLALSVETDYTFPLAEKVK

$0.10 \% \quad 59.6 \%$ AFLADPSAFVAAAPVAAATTAAPAAAAAPAK

$91 \quad 0.10 \% \quad 59.6 \%$ AFLADPSAFVAAAPVAAATTAAPAAAAAPAKVEAK

$0 \quad 0.05 \% \quad 50.0 \%$ GVPDAKIR

$0.05 \% \quad 50.0 \%$ IRIFDLGR

$\quad 0.05 \% \quad 50.0 \%$ ICANKYMVK

$50 \quad 0.05 \% \quad 50.0 \%$ SCGKDGFHIR

$50 \quad 0.05 \% \quad 50.0 \%$ VRLHPFHVIR

$50 \quad 0.05 \% \quad 50.0 \%$ INKMLSCAGADR

$50 \quad 0.05 \% \quad 50.0 \%$ MLSCAGADR

$50 \quad 0.05 \% \quad 50.0 \%$ MLSCAGADRLQTGMR

$0.05 \% \quad 50.0 \%$ GAFGKPQGTVAR

$\begin{array}{lll}0.05 \% & 50.0 \% \text { VHIGQVIMSIR }\end{array}$

$50 \quad 0.05 \% \quad 50.0 \%$ FNADEFEDMVAEKR

$0.05 \% \quad 50.0 \%$ RLIPDGCGVK

$0.02 \% \quad 43.8 \%$ VSRDTLYEAVR

$0.02 \% \quad 43.8 \%$ DTLYEAVREVLHGNQR

$0.02 \% \quad 43.8 \%$ FSVCVLGDQQHCDEAK

$0.02 \% \quad 43.8 \%$ KYDAFLASESLIK

$0.02 \% \quad 43.8 \%$ ILGPGLNK

$\begin{array}{ll}99.7 \% & 25.7 \\ 99.7 \% & 54.7\end{array}$

$\begin{array}{ll}99.7 \% & 54.7 \\ 99.7 \% & 47.5\end{array}$

$99.0 \% \quad 31.0$

$99.0 \% \quad 38.7$

$99.7 \% \quad 27.1$

$\begin{array}{lll}99.7 \% & 42.8\end{array}$

$99.7 \% \quad 26.9$

$99.6 \% \quad 23.7$

$99.7 \% \quad 29.1$

$99.6 \% \quad 24.4$

$99.7 \% \quad 55.3$

$99.7 \% \quad 46.4$

$99.7 \% \quad 51.7$

$99.7 \% \quad 42.9$

$99.5 \% \quad 28.6$

$99.0 \% \quad 41.0$

$\begin{array}{lll}99.7 \% & 32.7\end{array}$

$99.3 \% \quad 18.9$

$99.7 \% \quad 54.9$

$99.0 \% \quad 32.7$

$0.02 \% \quad 43.8 \%$ AGKFPSLLTHNENMVAK $99.7 \% \quad 25.9$

$0.02 \% \quad 43.8 \%$ VLCLAVAVGHVK

$0.02 \% \quad 43.8 \%$ STMGKPQRLY

$0.02 \% 38.2 \%$ LCLNICVGESGDRLTR

$99.7 \% \quad 77.3$

$99.3 \% \quad 25.3$

$99.7 \% \quad 36.2$

$0.02 \% \quad 38.2 \%$ VLEQLTGQTPVFSK

$99.7 \% \quad 69.2$

1389.70

1153.77

912.59

844.51

1646.90

901.54

960.51

1215.66

1097.67

1217.68

1266.61

1221.62

968.52

1824.95

1660.86

1369.76

2180.10

1313.71

1428.83

2787.45

1896.00

2123.16

2752.47

3179.71

855.50

989.59

1126.57

1176.56

1273.76

1351.65

980.43

1682.78

1188.65

1252.72

1700.76

1114.60

1308.69

966.49

1899.97

1892.83

1484.80

811.50

1872.96

1265.74

1180.61

1862.92

1546.85 
$60 \mathrm{~S}$ ribosomal protein $\mathrm{L} 11 \mathrm{GN}=\mathrm{RPL} 11$ $60 \mathrm{~S}$ ribosomal protein $\mathrm{L} 11 \mathrm{GN}=\mathrm{RPL} 11$ $60 \mathrm{~S}$ ribosomal protein $\mathrm{L} 11 \mathrm{GN}=\mathrm{RPL} 11$ $60 \mathrm{~S}$ ribosomal protein $\mathrm{L} 11 \mathrm{GN}=\mathrm{RPL} 11$ $60 \mathrm{~S}$ ribosomal protein $\mathrm{L} 11 \mathrm{GN}=\mathrm{RPL} 11$ $60 \mathrm{~S}$ ribosomal protein $\mathrm{L} 11 \mathrm{GN}=\mathrm{RPL} 11$ $60 \mathrm{~S}$ ribosomal protein $\mathrm{L} 13 \mathrm{GN}=\mathrm{RPL} 13$ $60 \mathrm{~S}$ ribosomal protein $\mathrm{L} 13 \mathrm{GN}=\mathrm{RPL} 13$ $60 \mathrm{~S}$ ribosomal protein $\mathrm{L} 13 \mathrm{GN}=\mathrm{RPL} 13$ $60 \mathrm{~S}$ ribosomal protein $\mathrm{L} 13 \mathrm{GN}=\mathrm{RPL} 13$ $60 \mathrm{~S}$ ribosomal protein $\mathrm{L} 13 \mathrm{GN}=\mathrm{RPL} 13$ $60 \mathrm{~S}$ ribosomal protein $\mathrm{L} 13 \mathrm{GN}=\mathrm{RPL} 13$ $60 \mathrm{~S}$ ribosomal protein $\mathrm{L} 13 \mathrm{GN}=\mathrm{RPL} 13$ $60 \mathrm{~S}$ ribosomal protein $\mathrm{L} 13 \mathrm{GN}=\mathrm{RPL} 13$ $60 \mathrm{~S}$ ribosomal protein $\mathrm{L} 13 \mathrm{GN}=\mathrm{RPL} 13$ $60 \mathrm{~S}$ ribosomal protein $\mathrm{L} 13 \mathrm{GN}=\mathrm{RPL} 13$ $60 \mathrm{~S}$ ribosomal protein $\mathrm{L} 13 \mathrm{GN}=\mathrm{RPL} 13$ 60 S ribosomal protein L13a GN=RPL13A RL13_HUMAN 24.26 60S ribosomal protein L13a GN=RPL13A RL13A_HUMAN 23.58 $60 \mathrm{~S}$ ribosomal protein L13a GN=RPL13A RL13A_HUMAN 23.58 60S ribosomal protein L13a GN=RPL13A RL13A_HUMAN 23.58 60 S ribosomal protein L13a GN=RPL13A RL13A_HUMAN 23.58 60 S ribosomal protein L13a GN=RPL13A RL13A_HUMAN 23.58 60S ribosomal protein L13a GN=RPL13A RL13A_HUMAN 23.58 60 S ribosomal protein L13a GN=RPL13A RL13A_HUMAN 23.58 60S ribosomal protein L13a GN=RPL13A RL13A_HUMAN 23.58 60 S ribosomal protein L13a GN=RPL13A RL13A_HUMAN 23.58 $60 \mathrm{~S}$ ribosomal protein L13a GN=RPL13A RL13A_HUMAN 23.58 $60 \mathrm{~S}$ ribosomal protein $\mathrm{L} 13 \mathrm{a} \mathrm{GN}=\mathrm{RPL} 13 \mathrm{~A}$ RL13A_HUMAN 23.58 $60 \mathrm{~S}$ ribosomal protein L13a GN=RPL13A RL13A_HUMAN 23.58 $60 \mathrm{~S}$ ribosomal protein $\mathrm{L} 14 \mathrm{GN}=\mathrm{RPL} 14$ $60 \mathrm{~S}$ ribosomal protein $\mathrm{L} 14 \mathrm{GN}=\mathrm{RPL} 14$ $60 \mathrm{~S}$ ribosomal protein $\mathrm{L} 14 \mathrm{GN}=\mathrm{RPL} 14$ 60 S ribosomal protein $\mathrm{L} 14 \mathrm{GN}=\mathrm{RPL} 14$ $60 \mathrm{~S}$ ribosomal protein $\mathrm{L} 15 \mathrm{GN}=\mathrm{RPL} 15$ $60 \mathrm{~S}$ ribosomal protein $\mathrm{L} 15 \mathrm{GN}=\mathrm{RPL} 15$ $60 \mathrm{~S}$ ribosomal protein $\mathrm{L} 15 \mathrm{GN}=\mathrm{RPL} 15$ $60 \mathrm{~S}$ ribosomal protein $\mathrm{L} 15 \mathrm{GN}=\mathrm{RPL} 15$ $60 \mathrm{~S}$ ribosomal protein $\mathrm{L} 15 \mathrm{GN}=\mathrm{RPL} 15$ $60 \mathrm{~S}$ ribosomal protein $\mathrm{L} 15 \mathrm{GN}=\mathrm{RPL} 15$ $60 \mathrm{~S}$ ribosomal protein $\mathrm{L} 17 \mathrm{GN}=\mathrm{RPL} 17$ $60 \mathrm{~S}$ ribosomal protein $\mathrm{L} 17 \mathrm{GN}=\mathrm{RPL} 17$ $60 \mathrm{~S}$ ribosomal protein $\mathrm{L} 17 \mathrm{GN}=\mathrm{RPL} 17$ $60 \mathrm{~S}$ ribosomal protein $\mathrm{L} 17 \mathrm{GN}=\mathrm{RPL} 17$ $60 \mathrm{~S}$ ribosomal protein $\mathrm{L} 17 \mathrm{GN}=\mathrm{RPL} 17$ $60 \mathrm{~S}$ ribosomal protein $\mathrm{L} 17 \mathrm{GN}=\mathrm{RPL} 17$ $60 \mathrm{~S}$ ribosomal protein $\mathrm{L} 17 \mathrm{GN}=\mathrm{RPL} 17$
RL14_HUMAN $23.43 \quad 100.0 \%$ RL14_HUMAN $23.43 \quad 100.0 \%$ RL14 HUMAN $23.43 \quad 100.0 \%$ RL14_HUMAN $23.43 \quad 100.0 \%$ RL15 HUMAN $24.15 \quad 100.0 \%$ RL15_HUMAN $24.15 \quad 100.0 \% \quad 6$ RL15_HUMAN $24.15 \quad 100.0 \%$ RL15_HUMAN $24.15 \quad 100.0 \%$ RL15_HUMAN $24.15 \quad 100.0 \%$ RL15_HUMAN $24.15 \quad 100.0 \%$ RL17 HUMAN $21.40 \quad 100.0 \% \quad 12$ RL17_HUMAN $21.40 \quad 100.0 \% \quad 12$ RL17 HUMAN $21.40 \quad 100.0 \% \quad 12$ RL17_HUMAN $21.40 \quad 100.0 \% \quad 12$ RL17_HUMAN $21.40 \quad 100.0 \% \quad 12$ RL17 HUMAN $21.40 \quad 100.0 \% \quad 12$ RL17_HUMAN $21.40 \quad 100.0 \% \quad 12$
$16 \quad 0.02 \% \quad 38.2 \%$ NEKIAVHCTVR

16

$16 \quad 0.02 \% \quad 38.2 \%$ GAKAEEILEK

$0.02 \% \quad 38.2 \%$ AEEILEKGLK

$0.02 \% \quad 38.2 \%$ WFQQKYDGIILPGK

$16 \quad 0.02 \% \quad 38.2 \%$ YDGIILPGK

$0.07 \% \quad 35.1 \%$ RVATWFNQPAR

$0.07 \% \quad 35.1 \%$ VATWFNQPAR

$0.07 \% \quad 35.1 \%$ VATWFNQPARK

$0.07 \% \quad 35.1 \%$ GFSLEELR

$0.07 \% \quad 35.1 \%$ TIGISVDPR

$0.07 \% \quad 35.1 \%$ TIGISVDPRR

$0.07 \% \quad 35.1 \%$ NKSTESLQANVQR

$0.07 \% \quad 35.1 \%$ STESLQANVQR

$0.07 \% \quad 35.1 \%$ SKLILFPR

$0.07 \% \quad 35.1 \%$ LATQLTGPVMPVR

$0.07 \% \quad 35.1 \%$ VITEEEKNFK

$0.04 \% \quad 45.8 \%$ CEGINISGNFYR

$0.04 \% \quad 45.8 \%$ LKYLAFLR

$0.04 \% \quad 45.8 \%$ MNTNPSRGPYHFR

$0.04 \% \quad 45.8 \%$ GQAALDRLK

$0.04 \% \quad 45.8 \%$ LKVFDGIPPPYDK

$0.04 \% \quad 45.8 \%$ VFDGIPPPYDK

$0.04 \% \quad 45.8 \%$ VFDGIPPPYDKK

$0.04 \% \quad 45.8 \%$ MVVPAALK

$0.04 \% \quad 45.8 \%$ MVVPAALKVVR

$0.04 \% \quad 45.8 \%$ LAHEVGWK

$0.04 \% \quad 45.8 \%$ LAHEVGWKYQAVTATLEEK

$0.04 \% \quad 45.8 \%$ YQAVTATLEEK

$0.04 \% \quad 45.8 \%$ IDKYTEVLK

$0.03 \% \quad 20.9 \%$ VAYVSFGPHAGK

$0.03 \% \quad 20.9 \%$ LVAIVDVIDQNR

$0.03 \% \quad 20.9 \%$ CMQLTDFILK

$0.03 \% \quad 20.9 \%$ ADINTKWAATR

$0.02 \% \quad 25.0 \%$ AKQGYVIYR

$0.02 \% \quad 25.0 \%$ GATYGKPVHHGVNQLK

$0.02 \% \quad 25.0 \%$ SLQSVAEER

$0.02 \% \quad 25.0 \%$ SLQSVAEERAGR

$0.02 \% \quad 25.0 \%$ RNPDTQWITKPVHK

$0.02 \% \quad 25.0 \%$ NPDTQWITKPVHK

$0.03 \% \quad 51.6 \%$ VRYSLDPENPTK

$0.03 \% \quad 51.6 \%$ YSLDPENPTK

$0.03 \% \quad 51.6 \%$ ETAQAIKGMHIR

$0.03 \% \quad 51.6 \%$ YLKDVTLQK

$0.03 \% \quad 51.6 \%$ QWGWTQGR

$0.03 \% \quad 51.6 \%$ KSAEFLLHMLK

$0.03 \% \quad 51.6 \%$ SAEFLLHMLK

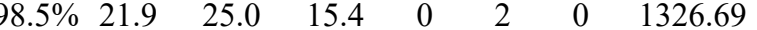

955.51

1087.60

1129.65

1692.91

975.55

1345.71

$99.7 \% \quad 48.0 \quad 25.0 \quad 44.4$

$\begin{array}{llll}99.7 \% & 30.5 & 25.0 & 30.0\end{array}$

$\begin{array}{lllll}99.7 \% & 51.4 & 25.0 & 33.7 & 4\end{array}$

$99.7 \% \quad 45.6 \quad 25.0 \quad 40.3$

$\begin{array}{llll}99.0 \% & 49.2 & 25.0 & 36.0\end{array}$

$\begin{array}{lllll}99.7 \% & 52.0 & 25.0 & 41.0 & 14\end{array}$

$99.6 \% \quad 28.6 \quad 25.0 \quad 15.8$

$\begin{array}{lllll}99.7 \% & 58.9 & 25.0 & 51.5\end{array}$

$\begin{array}{lllll}99.7 \% & 53.5 & 25.0 & 45.5 & 11\end{array}$

$\begin{array}{llll}99.0 \% & 46.0 & 25.0 & 46.0\end{array}$

$\begin{array}{lllll}99.7 \% & 55.4 & 25.0 & 55.4 & 4\end{array}$

$99.7 \% \quad 59.5 \quad 25.0 \quad 46.4 \quad 4$

$\begin{array}{llll}99.7 \% & 64.0 & 25.0 & 58.5\end{array}$

$99.0 \% \quad 44.1 \quad 25.0 \quad 38.4$

$99.7 \% \quad 25.6 \quad 25.0 \quad 25.0$

$\begin{array}{llll}99.7 \% & 42.5 & 25.0 & 32.6\end{array}$

$\begin{array}{llll}99.7 \% & 37.8 & 25.0 & 22.3\end{array}$

$\begin{array}{llll}98.7 \% & 19.9 & 25.0 & 16.6\end{array}$

$\begin{array}{llll}99.7 \% & 29.5 & 25.0 & 27.9\end{array}$

$99.0 \% \quad 25.1 \quad 25.3 \quad 21.8$

$\begin{array}{llll}99.7 \% & 27.8 & 25.0 & 27.8\end{array}$

$\begin{array}{llll}99.0 \% & 49.6 & 25.0 & 33.5\end{array}$

$\begin{array}{llll}99.7 \% & 46.0 & 25.0 & 46.0\end{array}$

$\begin{array}{lllll}99.7 \% & 56.0 & 25.0 & 49.6 & 2\end{array}$

$99.7 \% \quad 44.0 \quad 25.0 \quad 38.4$

$\begin{array}{llll}99.7 \% & 45.7 & 25.0 & 45.7\end{array}$

$\begin{array}{lllll}99.7 \% & 55.5 & 25.0 & 52.0 & 17\end{array}$

$99.0 \% \quad 19.3 \quad 25.0 \quad 18.8$

$\begin{array}{lllll}99.7 \% & 44.0 & 25.0 & 34.5 & 2\end{array}$

$99.7 \% \quad 32.9 \quad 25.0 \quad 23.5$

$\begin{array}{llll}99.7 \% & 34.3 & 25.0 & 28.6\end{array}$

$\begin{array}{llll}99.7 \% & 51.2 & 25.0 & 40.5\end{array}$

$\begin{array}{llll}99.7 \% & 35.7 & 25.0 & 30.2\end{array}$

$\begin{array}{llll}99.7 \% & 25.7 & 25.0 & 25.7\end{array}$

$\begin{array}{llll}98.2 \% & 16.8 & 25.0 & 16.8\end{array}$

$\begin{array}{llll}99.7 \% & 40.5 & 25.0 & 40.5\end{array}$

$\begin{array}{llll}99.7 \% & 56.7 & 25.0 & 55.6\end{array}$

$\begin{array}{llll}99.7 \% & 49.4 & 25.0 & 45.3\end{array}$

$\begin{array}{llll}99.7 \% & 48.8 & 25.0 & 38.5\end{array}$

$\begin{array}{llll}94.8 \% & 16.2 & 25.0 & 13.3\end{array}$

$\begin{array}{llll}99.7 \% & 47.8 & 25.0 & 46.2\end{array}$

$99.7 \% \quad 44.2 \quad 25.0 \quad 30.6$

1316.74
1188.64

65
68
6
9
65
170
1
2
22
75
3
3
104
106
122
46
168
38
52
95

Page 14 of Table S-1-5 
$60 \mathrm{~S}$ ribosomal protein $\mathrm{L} 17 \mathrm{GN}=\mathrm{RPL} 17$ $60 \mathrm{~S}$ ribosomal protein $\mathrm{L} 17 \mathrm{GN}=\mathrm{RPL} 17$ 60 S ribosomal protein $\mathrm{L} 17 \mathrm{GN}=\mathrm{RPL} 17$ $60 \mathrm{~S}$ ribosomal protein $\mathrm{L} 17 \mathrm{GN}=\mathrm{RPL} 17$ $60 \mathrm{~S}$ ribosomal protein $\mathrm{L} 17 \mathrm{GN}=\mathrm{RPL} 17$ $60 \mathrm{~S}$ ribosomal protein $\mathrm{L} 18 \mathrm{GN}=\mathrm{RPL} 18$ 60 S ribosomal protein $\mathrm{L} 18 \mathrm{GN}=\mathrm{RPL} 18$ $60 \mathrm{~S}$ ribosomal protein $\mathrm{L} 18 \mathrm{GN}=\mathrm{RPL} 18$ $60 \mathrm{~S}$ ribosomal protein $\mathrm{L} 18 \mathrm{GN}=\mathrm{RPL} 18$ $60 \mathrm{~S}$ ribosomal protein $\mathrm{L} 18 \mathrm{GN}=\mathrm{RPL} 18$ 60 S ribosomal protein $\mathrm{L} 18 \mathrm{GN}=\mathrm{RPL} 18$ $60 \mathrm{~S}$ ribosomal protein $\mathrm{L} 18 \mathrm{GN}=\mathrm{RPL} 18$ $60 \mathrm{~S}$ ribosomal protein $\mathrm{L} 18 \mathrm{GN}=\mathrm{RPL} 18$ $60 \mathrm{~S}$ ribosomal protein $\mathrm{L} 18 \mathrm{GN}=\mathrm{RPL} 18$ $60 \mathrm{~S}$ ribosomal protein $\mathrm{L} 18 \mathrm{GN}=\mathrm{RPL} 18$ $60 \mathrm{~S}$ ribosomal protein $\mathrm{L} 18 \mathrm{GN}=\mathrm{RPL} 18$ $60 \mathrm{~S}$ ribosomal protein $\mathrm{L} 18 \mathrm{GN}=\mathrm{RPL} 18$ $60 \mathrm{~S}$ ribosomal protein $\mathrm{L} 18 \mathrm{GN}=\mathrm{RPL} 18$ 60 S ribosomal protein 21.64 60S ribosomal protein L18a GN=RPL18A RL18A_HUMAN 20.76 60S ribosomal protein L18a GN=RPL18A RL18A_HUMAN 20.76
60S ribosomal protein L18a GN=RPL18A RL18A_HUMAN 20.76 60S ribosomal protein L18a GN=RPL18A RL18__HUMAN 20.76 60S ribosomal protein L18a GN=RPL18A RL18A_HUMAN 20.76 60S ribosomal protein L18a GN=RPL18A RL18A_HUMAN 20.76 60S ribosomal protein L18a GN=RPL18A RL18A_HUMAN 20.76 60S ribosomal protein L18a GN=RPL18A RL18A_HUMAN 20.76 60S ribosomal protein L18a GN=RPL18A RL18A_HUMAN 20.76 60S ribosomal protein L18a GN=RPL18A RL18A_HUMAN 20.76 60S ribosomal protein L18a GN=RPL18A RL18A_HUMAN 20.76 60S ribosomal protein L18a GN=RPL18A RL18A_HUMAN 20.76 60S ribosomal protein L18a GN=RPL18A RL18A_HUMAN 20.76 60S ribosomal protein L18a GN=RPL18A RL18A_HUMAN 20.76 60S ribosomal protein L18a GN=RPL18A RL18A_HUMAN 20.76 60S ribosomal protein L18a GN=RPL18A RL18A_HUMAN 20.76 $60 \mathrm{~S}$ ribosomal protein $\mathrm{L} 19 \mathrm{GN}=\mathrm{RPL} 19$ 60 S ribosomal protein $\mathrm{L} 19 \mathrm{GN}=\mathrm{RPL} 19$ $60 \mathrm{~S}$ ribosomal protein $\mathrm{L} 19 \mathrm{GN}=\mathrm{RPL} 19$ $60 \mathrm{~S}$ ribosomal protein $\mathrm{L} 19 \mathrm{GN}=\mathrm{RPL} 19$ 60S ribosomal protein $\mathrm{L} 19 \mathrm{GN}=\mathrm{RPL} 19$ 60 S ribosomal protein $\mathrm{L} 19 \mathrm{GN}=\mathrm{RPL} 19$ 60 S ribosomal protein $\mathrm{L} 19 \mathrm{GN}=\mathrm{RPL} 19$ $60 \mathrm{~S}$ ribosomal protein $\mathrm{L} 21 \mathrm{GN}=\mathrm{RPL} 21$ $60 \mathrm{~S}$ ribosomal protein $\mathrm{L} 21 \mathrm{GN}=\mathrm{RPL} 21$ $60 \mathrm{~S}$ ribosomal protein $\mathrm{L} 21 \mathrm{GN}=\mathrm{RPL} 21$ $60 \mathrm{~S}$ ribosomal protein $\mathrm{L} 21 \mathrm{GN}=\mathrm{RPL} 21$ $60 \mathrm{~S}$ ribosomal protein $\mathrm{L} 21 \mathrm{GN}=\mathrm{RPL} 21$ $\begin{array}{lll}100.0 \% & 17\end{array}$ RL19 HUMAN $23.47 \quad 100.0 \%$ RL19_HUMAN $23.47 \quad 100.0 \%$ RL19 HUMAN $23.47 \quad 100.0 \%$ RL19_HUMAN $23.47 \quad 100.0 \%$ RL19_HUMAN $23.47 \quad 100.0 \%$ RL19 HUMAN $23.47 \quad 100.0 \%$ RL19_HUMAN $23.47 \quad 100.0 \%$ RL21_HUMAN $18.57 \quad 100.0 \%$ RL21_HUMAN $18.57 \quad 100.0 \%$ RL21_HUMAN $18.57 \quad 100.0 \%$ RL21 HUMAN $18.57 \quad 100.0 \%$ RL21_HUMAN $18.57 \quad 100.0 \%$

26

16

16

17
17
17

17

17
17

17

17
17
17

17
17
17

17
17
17

17
17
17

17
17
17

17
17
17

17
17

$\begin{array}{ll}13 & 17 \\ 13 & 17 \\ 17 & 25 \\ 17 & 25\end{array}$

17
25
25

$\begin{array}{ll}17 & 25 \\ 17 & 25 \\ 17 & 25\end{array}$

17

17

17

17

17
17
17

$\begin{array}{ll}17 & 25 \\ 17 & 25 \\ 17 & 25\end{array}$

25

\begin{tabular}{|c|c|c|c|c|c|}
\hline$\%$ & $6 \% \mathrm{~N}$ & $.7 \%$ & 53.5 & 25.0 & 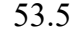 \\
\hline $0.03 \%$ & $51.6 \%$ GLDVDSLVIEHIQVNK & $99.7 \%$ & 70.7 & 25.0 & 68.2 \\
\hline $0.03 \%$ & $51.6 \%$ GLDVDSLVIEHIQVNKAPK & $99.7 \%$ & 43.8 & 25.0 & 43.8 \\
\hline $0.03 \%$ & 51.6\% EQIVPKPEEEVAQK & $99.7 \%$ & 55.6 & 25.0 & 44.8 \\
\hline $0.03 \%$ & 51.6\% EQIVPKPEEEVAQKK & $99.7 \%$ & 36.0 & 25.0 & 36.0 \\
\hline $0.05 \%$ & 51.1\% SQDIYLRLLVK & $99.7 \%$ & 26.0 & 5.0 & 26.0 \\
\hline $0.05 \%$ & 51.1\% RTNSTFNQVVLK & $99.2 \%$ & 38.1 & 5.0 & 3.1 \\
\hline $0.05 \%$ & $51.1 \%$ TNSTFNQVVLK & $99.7 \%$ & 55.5 & 5.0 & 54.5 \\
\hline $0.05 \%$ & $51.1 \%$ TNSTFNQVVLKR & $99.7 \%$ & 46.3 & 5.0 & 41.3 \\
\hline $0.05 \%$ & $51.1 \%$ TNRPPLSLSR & $99.7 \%$ & 31.9 & 5.0 & 31.9 \\
\hline $0.05 \%$ & $51.1 \%$ TAVVVGTITDDVR & $99.7 \%$ & 59.1 & 5.0 & 53.4 \\
\hline $0.05 \%$ & 51.1\% TAVVVGTITDDVRVQEVPK & $99.7 \%$ & 67.4 & 25.0 & 64.2 \\
\hline $0.05 \%$ & 51.1\% AGGKILTFDQLALDSPK & $99.7 \%$ & 48.2 & 5.0 & 46.6 \\
\hline $0.05 \%$ & $51.1 \%$ ILTFDQLALDSPK & $99.7 \%$ & 52.4 & 5.0 & 52.4 \\
\hline $0.05 \%$ & $51.1 \%$ ILTFDQLALDSPKGCGTVLLSGPR & $99.7 \%$ & 40.1 & 25.0 & 40.1 \\
\hline $0.05 \%$ & 51.1\% GCGTVLLSGPR & $99.7 \%$ & 62.8 & 25.0 & 51.7 \\
\hline $0.05 \%$ & 51.1\% GCGTVLLSGPRK & $99.7 \%$ & 51.8 & 25.0 & 34.5 \\
\hline $0.05 \%$ & 51.1\% APGTPHSHTKPYVR & $99.7 \%$ & 39.1 & 25.0 & 37.7 \\
\hline $0.05 \%$ & $67.0 \%$ ASGTLREYK & $94.7 \%$ & 20.3 & 25.0 & 9.5 \\
\hline $0.05 \%$ & $67.0 \%$ MRIFAPNHVVAK & $99.7 \%$ & 39.0 & 25.0 & 38.9 \\
\hline $0.05 \%$ & $67.0 \%$ IFA & $99.7 \%$ & 51.1 & 25.0 & 41.9 \\
\hline $0.05 \%$ & 67.0\% SRFWYFVSQLK & $99.7 \%$ & 36.4 & 25.0 & 27.6 \\
\hline $0.05 \%$ & $67.0 \%$ FWYFVSQLKK & $99.7 \%$ & 38.8 & 25.0 & 38.8 \\
\hline $0.05 \%$ & $67.0 \% \mathrm{KSSC}$ & $99.7 \%$ & 30.4 & 25.0 & 28.3 \\
\hline $0.05 \%$ & 67.0\% SSGEIVYCGQVFEK & $99.7 \%$ & 62.6 & 25.0 & 55.3 \\
\hline $0.05 \%$ & 67.0\% SSGEIVYCGQVFEKSPLR & $99.7 \%$ & 49.0 & 25.0 & 44.1 \\
\hline $0.05 \%$ & $67.0 \%$ VKNFGIWLR & $99.7 \%$ & 41.6 & 25.0 & 34.6 \\
\hline $0.05 \%$ & TTAGAVTQCYR & $99.7 \%$ & 70.7 & 25.0 & 60.5 \\
\hline $0.05 \%$ & 67.0\% DLTTAGAVTQCYR & $99.7 \%$ & 49.2 & 25.0 & 49.2 \\
\hline $0.05 \%$ & GAVTQCYRDMGAR & $99.7 \%$ & 54.5 & 25.0 & 54.5 \\
\hline $0.05 \%$ & $67.0 \%$ AHs & $96.2 \%$ & 18.6 & 25.0 & 12.8 \\
\hline $0.05 \%$ & $67.0 \%$ AHS & $99.7 \%$ & 54.7 & 25.0 & 54.7 \\
\hline $0.05 \%$ & $67.0 \%$ VEEIAASKCR & $99.7 \%$ & 65.6 & 25.0 & 50.8 \\
\hline $0.05 \%$ & $67.0 \%$ IKFPLPHR & $99.0 \%$ & 25.1 & 25.0 & 21.5 \\
\hline $0.05 \%$ & $67.0 \%$ FTTK & $99.7 \%$ & 32.4 & 25.0 & 30.6 \\
\hline $0.01 \%$ & $29.6 \%$ RLASSVLR & $99.0 \%$ & 33.1 & 25.0 & 18.1 \\
\hline $0.01 \%$ & 29.6\% KVWLDPNETNEIANANSR & $99.7 \%$ & 36.6 & 25.0 & 36.6 \\
\hline $0.01 \%$ & 29.6\% VWLDPNETNEIANANSR & $99.7 \%$ & 59.8 & 25.0 & 59.8 \\
\hline $0.01 \%$ & 29.6\% DGLIIRKPVTVHSR & $99.6 \%$ & 22.4 & 25.0 & 19.5 \\
\hline $0.01 \%$ & 29.6\% ILMEHIHK & $99.0 \%$ & 44.0 & 25.0 & 33.5 \\
\hline $0.01 \%$ & 29.6\% LLADQAEAR & $99.7 \%$ & 53.7 & 25.0 & 44.8 \\
\hline $0.01 \%$ & 29.6\% LLADQAEARR & $99.5 \%$ & 24.4 & 25.0 & 19.0 \\
\hline $0.03 \%$ & 56.2\% HGVVPLATYMR & $99.7 \%$ & 44.0 & 25.0 & 44.0 \\
\hline $0.03 \%$ & $56.2 \%$ GDIVDIKGMGTVQK & $99.7 \%$ & 37.0 & 25.0 & 29.1 \\
\hline $0.03 \%$ & $56.2 \%$ VYNVTQHAVGIVVNK & $99.7 \%$ & 57.7 & 25.0 & 54.0 \\
\hline $0.03 \%$ & $56.2 \%$ VYNVTQHAVGIVVNKQVK & $99.7 \%$ & 56.2 & 25.0 & 55.6 \\
\hline $0.03 \%$ & $56.2 \%$ INVRIEHIK & $99.6 \%$ & 2.7 & 25.0 & 20.7 \\
\hline
\end{tabular}

$\begin{array}{cccc}0 & 2735.42 & 97 & 121 \\ 0 & 1778.96 & 106 & 121 \\ 0 & 2075.15 & 106 & 124 \\ 0 & 1623.86 & 154 & 167 \\ 0 & 1751.95 & 154 & 168 \\ 0 & 1347.80 & 20 & 30 \\ 0 & 1406.78 & 38 & 49 \\ 0 & 1250.67 & 39 & 49 \\ 0 & 1406.78 & 39 & 50 \\ 0 & 1140.65 & 56 & 65 \\ 0 & 1345.73 & 79 & 91 \\ 0 & 2026.12 & 79 & 97 \\ 0 & 1773.97 & 116 & 132 \\ 0 & 1460.80 & 120 & 132 \\ 0 & 2558.37 & 120 & 143 \\ 0 & 1116.58 & 133 & 143 \\ 0 & 1244.68 & 133 & 144 \\ 0 & 1547.81 & 155 & 168 \\ 0 & 1024.54 & 3 & 11 \\ 0 & 1398.77 & 30 & 41 \\ 0 & 1095.63 & 32 & 41 \\ 0 & 1460.77 & 42 & 52 \\ 0 & 1345.73 & 44 & 53 \\ 0 & 1730.84 & 56 & 70 \\ 0 & 1602.75 & 57 & 70 \\ 0 & 2056.02 & 57 & 74 \\ 0 & 1132.66 & 75 & 83 \\ 0 & 1903.90 & 96 & 111 \\ 0 & 1455.69 & 99 & 111 \\ 0 & 2001.91 & 99 & 116 \\ 0 & 943.50 & 121 & 128 \\ 0 & 1770.94 & 121 & 136 \\ 0 & 1162.59 & 129 & 138 \\ 0 & 1007.62 & 150 & 157 \\ 0 & 1258.66 & 167 & 176 \\ 0 & 901.56 & 9 & 16 \\ 0 & 2071.02 & 21 & 38 \\ 0 & 1942.93 & 22 & 38 \\ 0 & 1590.94 & 47 & 60 \\ 0 & 1020.57 & 137 & 144 \\ 0 & 986.53 & 154 & 162 \\ 0 & 1142.63 & 154 & 163 \\ 0 & 1243.66 & 22 & 32 \\ 0 & 1476.77 & 37 & 50 \\ 0 & 1640.91 & 64 & 78 \\ 0 & 1996.13 & 64 & 81 \\ 0 & 1121.68 & 89 & 97\end{array}$

Page 15 of Table S-1-5 
$60 \mathrm{~S}$ ribosomal protein $\mathrm{L} 21 \mathrm{GN}=\mathrm{RPL} 21$ $60 \mathrm{~S}$ ribosomal protein $\mathrm{L} 21 \mathrm{GN}=\mathrm{RPL} 21$ $60 \mathrm{~S}$ ribosomal protein $\mathrm{L} 21 \mathrm{GN}=\mathrm{RPL} 21$ _LEUMAN 18.57 60S ribosomal protein L23a GN=RPL23A RL23A_HUMAN $17.70 \quad 100.0 \%$ 60S ribosomal protein L23a GN=RPL23A RL23A_HUMAN $17.70 \quad 100.0 \%$ $60 \mathrm{~S}$ ribosomal protein L23a GN=RPL23A RL23A_HUMAN $17.70 \quad 100.0 \%$ $60 \mathrm{~S}$ ribosomal protein L23a GN=RPL23A RL23A_HUMAN $17.70 \quad 100.0 \%$ $60 \mathrm{~S}$ ribosomal protein L23a GN=RPL23A RL23A HUMAN $17.70 \quad 100.0 \%$ $60 \mathrm{~S}$ ribosomal protein $\mathrm{L} 24 \mathrm{GN}=\mathrm{RPL} 24$ $60 \mathrm{~S}$ ribosomal protein $\mathrm{L} 24 \mathrm{GN}=\mathrm{RPL} 24$ $60 \mathrm{~S}$ ribosomal protein $\mathrm{L} 24 \mathrm{GN}=\mathrm{RPL} 24$ $60 \mathrm{~S}$ ribosomal protein $\mathrm{L} 24 \mathrm{GN}=\mathrm{RPL} 24$ $60 \mathrm{~S}$ ribosomal protein $\mathrm{L} 24 \mathrm{GN}=\mathrm{RPL} 24$ 60 S ribosomal protein $\mathrm{L} 24 \mathrm{GN}=\mathrm{RPL} 24$ $60 \mathrm{~S}$ ribosomal protein $\mathrm{L} 24 \mathrm{GN}=\mathrm{RPL} 24$ 60 S ribosomal protein $\mathrm{L} 24 \mathrm{GN}=\mathrm{RPL} 24$ $60 \mathrm{~S}$ ribosomal protein $\mathrm{L} 27 \mathrm{a} \mathrm{GN}=\mathrm{RPL} 27 \mathrm{~A}$ $60 \mathrm{~S}$ ribosomal protein $\mathrm{L} 27 \mathrm{a} \mathrm{GN}=\mathrm{RPL} 27$
$60 \mathrm{~S}$ ribosomal protein $\mathrm{L} 28 \mathrm{GN}=\mathrm{RPL} 28$ 60S ribosomal protein $\mathrm{L} 28 \mathrm{GN}=\mathrm{RPL} 28$ $60 \mathrm{~S}$ ribosomal protein $\mathrm{L} 28 \mathrm{GN}=\mathrm{RPL} 28$
$60 \mathrm{~S}$ ribosomal protein $\mathrm{L} 29 \mathrm{GN}=\mathrm{RPL} 29$ $60 \mathrm{~S}$ ribosomal protein $\mathrm{L} 29 \mathrm{GN}=\mathrm{RPL} 29$
$60 \mathrm{~S}$ ribosomal protein $\mathrm{L} 29 \mathrm{GN}=\mathrm{RPL} 29$ $60 \mathrm{~S}$ ribosomal protein $\mathrm{L} 29 \mathrm{GN}=\mathrm{RPL} 29$ $60 \mathrm{~S}$ ribosomal protein $\mathrm{L} 29 \mathrm{GN}=\mathrm{RPL} 29$ $60 \mathrm{~S}$ ribosomal protein $\mathrm{L} 3 \mathrm{GN}=\mathrm{RPL} 3$ $60 \mathrm{~S}$ ribosomal protein $\mathrm{L} 3 \mathrm{GN}=\mathrm{RPL} 3$ $60 \mathrm{~S}$ ribosomal protein $\mathrm{L} 3 \mathrm{GN}=\mathrm{RPL} 3$ $60 \mathrm{~S}$ ribosomal protein $\mathrm{L} 3 \mathrm{GN}=\mathrm{RPL} 3$ $60 \mathrm{~S}$ ribosomal protein $\mathrm{L} 3 \mathrm{GN}=\mathrm{RPL} 3$ $60 \mathrm{~S}$ ribosomal protein $\mathrm{L} 3 \mathrm{GN}=\mathrm{RPL} 3$ $60 \mathrm{~S}$ ribosomal protein $\mathrm{L} 3 \mathrm{GN}=\mathrm{RPL} 3$ $60 \mathrm{~S}$ ribosomal protein $\mathrm{L} 3 \mathrm{GN}=\mathrm{RPL} 3$ $60 \mathrm{~S}$ ribosomal protein $\mathrm{L} 3 \mathrm{GN}=\mathrm{RPL} 3$ $60 \mathrm{~S}$ ribosomal protein $\mathrm{L} 3 \mathrm{GN}=\mathrm{RPL} 3$ $60 \mathrm{~S}$ ribosomal protein $\mathrm{L} 3 \mathrm{GN}=\mathrm{RPL} 3$ $60 \mathrm{~S}$ ribosomal protein $\mathrm{L} 3 \mathrm{GN}=\mathrm{RPL} 3$ $60 \mathrm{~S}$ ribosomal protein $\mathrm{L} 3 \mathrm{GN}=\mathrm{RPL} 3$ $60 \mathrm{~S}$ ribosomal protein $\mathrm{L} 3 \mathrm{GN}=\mathrm{RPL} 3$ $60 \mathrm{~S}$ ribosomal protein $\mathrm{L} 3 \mathrm{GN}=\mathrm{RPL} 3$ $60 \mathrm{~S}$ ribosomal protein $\mathrm{L} 3 \mathrm{GN}=\mathrm{RPL} 3$ $60 \mathrm{~S}$ ribosomal protein $\mathrm{L} 3 \mathrm{GN}=\mathrm{RPL} 3$ $60 \mathrm{~S}$ ribosomal protein $\mathrm{L} 34 \mathrm{GN}=\mathrm{RPL} 34$ $60 \mathrm{~S}$ ribosomal protein $\mathrm{L} 34 \mathrm{GN}=\mathrm{RPL} 34$ $60 \mathrm{~S}$ ribosomal protein $\mathrm{L} 4 \mathrm{GN}=\mathrm{RPL} 4$ $60 \mathrm{~S}$ ribosomal protein $\mathrm{L} 4 \mathrm{GN}=\mathrm{RPL} 4$ $\begin{array}{lll}\text { RL24_HUMAN } & 17.78 & 100.0 \%\end{array}$ RL24_HUMAN $17.78 \quad 100.0 \%$ RL24_HUMAN $17.78 \quad 100.0 \%$ RL24_HUMAN $17.78 \quad 100.0 \%$ RL24 HUMAN $17.78 \quad 100.0 \%$ RL24_HUMAN $17.78 \quad 100.0 \%$ RL24_HUMAN $17.78 \quad 100.0 \%$ RL24_HUMAN $17.78 \quad 100.0 \%$ RL27A_HUMAN $16.56 \quad 100.0 \%$ RL27A_HUMAN $16.56 \quad 100.0 \%$ RL28_HUMAN $15.75 \quad 100.0 \%$ RL28_HUMAN $15.75 \quad 100.0 \%$ RL29_HUMAN $17.75 \quad 100.0 \%$ RL29_HUMAN $17.75 \quad 100.0 \%$ RL29 HUMAN $17.75 \quad 100.0 \%$ RL29_HUMAN $17.75 \quad 100.0 \%$ RL3_HUMAN $46.11 \quad 100.0 \%$ RL3 HUMAN $46.11 \quad 100.0 \%$ RL3_HUMAN $46.11 \quad 100.0 \%$ RL3 HUMAN $46.11 \quad 100.0 \% \quad 17$ RL3_HUMAN $46.11 \quad 100.0 \% \quad 17$ RL3_HUMAN $46.11 \quad 100.0 \% \quad 17$ RL3_HUMAN $46.11 \quad 100.0 \% \quad 17$ RL3_HUMAN $46.11 \quad 100.0 \% \quad 17$ RL3_HUMAN $46.11 \quad 100.0 \% \quad 17$ RL3_HUMAN $46.11 \quad 100.0 \% \quad 17$ RL3_HUMAN $46.11 \quad 100.0 \% \quad 17$ RL3 HUMAN $46.11 \quad 100.0 \% \quad 17$ RL3_HUMAN $46.11 \quad 100.0 \% \quad 17$ RL3_HUMAN $46.11 \quad 100.0 \% \quad 17$ RL3 HUMAN $46.11 \quad 100.0 \% \quad 17$ RL3_HUMAN $46.11 \quad 100.0 \% \quad 17$ RL3 HUMAN $46.11 \quad 100.0 \% \quad 17$ RL34_HUMAN $13.29 \quad 99.9 \% \quad 2$ RL34_HUMAN $13.29 \quad 99.9 \%$ RL4_HUMAN $\quad 47.70 \quad 100.0 \% \quad 20$ RL4_HUMAN $47.70 \quad 100.0 \% \quad 20$
$0.03 \% \quad 56.2 \%$ GTWVQLKR

$0.03 \% \quad 56.2 \%$ QPAPPREAHFVR

$\begin{array}{llllllll}99.0 \% & 48.9 & 25.0 & 32.6 & 2 & 0 & 0 & 987.57\end{array}$

$99.7 \% 32.1$

$\begin{array}{lll}0.03 \% & 56.2 \% & \text { TNGKEPELLEPIPY } \\ 0.01 \% & 40.4 \% & \text { EAPAPPKAEAK }\end{array}$

$0.01 \% \quad 40.4 \%$ KIEDNNTLVFIVDVK

$0.01 \% \quad 40.4 \%$ LYDIDVAK

$0.01 \% \quad 40.4 \%$ VNTLIRPDGEK

$0.01 \% \quad 40.4 \%$ VNTLIRPDGEKK

$0.01 \% \quad 40.4 \%$ LAPDYDALDVANK

$0.01 \% \quad 40.4 \%$ LAPDYDALDVANKIGII

$0.06 \% \quad 35.7 \%$ MKVELCSFSGYK

$0.06 \% 35.7 \%$ TDGKVFQFLNAK

$0.06 \% \quad 35.7 \%$ VFQFLNAK

$0.06 \% 35.7 \%$ CESAFLSK

$0.06 \% \quad 35.7 \%$ CESAFLSKR

$0.06 \% \quad 35.7 \%$ QINWTVLYR

$0.06 \% \quad 35.7 \%$ AITGASLADIMAK

$0.06 \% \quad 35.7 \%$ AITGASLADIMAKR

$0.02 \% \quad 13.5 \%$ TGAAPIIDVVR

$0.02 \% \quad 13.5 \%$ SGYYKVLGK

$0.00 \% \quad 16.1 \%$ NCSSFLIKR

$0.00 \% \quad 16.1 \%$ NKQTYSTEPNNLK

$0.04 \% \quad 17.6 \%$ LAYIAHPK

25.0

$\begin{array}{llllll}9.7 \% & 50.6 & 25.0 & 50.1 & 4 & 1\end{array}$

$\begin{array}{llll}99.7 \% & 53.8 & 25.0 & 50.0\end{array}$

$\begin{array}{llll}99.7 \% & 34.4 & 25.0 & 34.4\end{array}$

$\begin{array}{llll}97.2 \% & 23.9 & 25.0 & 11.2\end{array}$

$\begin{array}{llll}99.7 \% & 45.0 & 25.0 & 38.0\end{array}$

$\begin{array}{llll}99.3 \% & 18.9 & 25.0 & 18.9\end{array}$

$95.2 \% \quad 19.0 \quad 25.0 \quad 15.6$

$\begin{array}{llll}99.7 \% & 31.6 & 25.0 & 31.6\end{array}$

$\begin{array}{llll}99.7 \% & 60.2 & 25.0 & 47.2\end{array}$

$\begin{array}{llll}99.7 \% & 43.7 & 25.0 & 43.7\end{array}$

$\begin{array}{llll}99.0 \% & 41.2 & 25.0 & 23.7\end{array}$

$99.0 \% \quad 48.8 \quad 25.0 \quad 35.5$

$99.7 \% \quad 32.2 \quad 25.0 \quad 21.5$

$\begin{array}{llll}99.7 \% & 44.2 & 25.0 & 32.7\end{array}$

$\begin{array}{llll}99.7 \% & 56.7 & 25.0 & 55.5\end{array}$

$99.7 \% \quad 50.0 \quad 25.0 \quad 40.0$

$99.7 \% \quad 62.1 \quad 25.0 \quad 62.1$

$\begin{array}{llll}98.4 \% & 18.1 & 25.0 & 16.4\end{array}$

$98.3 \% \quad 17.1 \quad 25.0 \quad 16.8$

$\begin{array}{llll}99.7 \% & 56.1 & 25.0 & 51.2\end{array}$

$99.0 \% \quad 29.9 \quad 25.0 \quad 23.5$

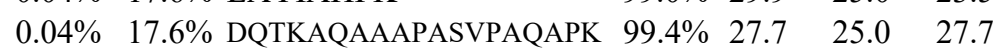

$0.04 \% \quad 17.6 \%$ AQAAAPASVPAQAPK

$0.04 \% \quad 17.6 \%$ AQAAAPASVPAQAPKR

$0.10 \% \quad 31.3 \%$ HGSLGFLPR

$0.10 \% \quad 31.3 \%$ AGMTHIVR

$0.10 \% \quad 31.3 \%$ TVFAEHISDECK

$0.10 \% \quad 31.3 \%$ TVFAEHISDECKR

$0.10 \% \quad 31.3 \%$ VIAHTQMR

$0.10 \% \quad 31.3 \%$ AHLMEIQVNGGTVAEK

$0.10 \% \quad 31.3 \%$ KVACIGAWHPAR

$0.10 \% \quad 31.3 \%$ VACIGAWHPAR

$0.10 \% \quad 31.3 \%$ IGQGYLIK

$0.10 \% \quad 31.3 \%$ IGQGYLIKDGK

$92 \quad 0.10 \% \quad 31.3 \%$ NNASTDYDLSDK

$0.10 \% \quad 31.3 \%$ KSLLVQTK

$0.10 \% \quad 31.3 \%$ SLLVQTKR

$0.10 \% \quad 31.3 \%$ ALEKIDLK

$0.10 \% \quad 31.3 \%$ IDLKFIDTTSK

$0.10 \% \quad 31.3 \%$ FIDTTSKFGHGR

$0.10 \% \quad 31.3 \%$ AFMGPLKK

$0.00 \% \quad 8.6 \%$ RLSYNTASNK

$0.00 \% \quad 8.6 \%$ LSYNTASNK

$132 \quad 0.14 \% \quad 44.7 \%$ NVTLPAVFK

$0.14 \% \quad 44.7 \%$ APIRPDIVNFVHTNLR

1097.54

1192.65

1261.68

1417.78

1111.65

1014.56

1124.59

1536.77

912.53

1849.98

1377.75

1533.85

983.54

$\begin{array}{llll}99.7 \% & 55.7 & 25.0 & 47.8\end{array}$

$\begin{array}{llll}99.0 \% & 59.4 & 25.0 & 48.2\end{array}$

$\begin{array}{llll}99.7 \% & 68.7 & 25.0 & 68.2\end{array}$

$\begin{array}{llll}99.7 \% & 55.5 & 25.0 & 55.5\end{array}$

$\begin{array}{llll}99.0 \% & 25.6 & 25.0 & 20.3\end{array}$

884.48

1435.65

1591.75

955.51

1696.87

1365.72

$\begin{array}{llll}99.7 \% & 44.4 & 25.0 & 44.4\end{array}$

$\begin{array}{llll}99.7 \% & 67.3 & 25.0 & 62.2\end{array}$

$99.0 \% \quad 48.0 \quad 25.0 \quad 35.7$

$\begin{array}{llll}99.7 \% & 54.7 & 25.0 & 48.1\end{array}$

$\begin{array}{llll}99.7 \% & 55.5 & 25.0 & 55.5\end{array}$

$99.0 \% \quad 28.2 \quad 25.0 \quad 17.4$

$\begin{array}{llll}99.0 \% & 40.1 & 25.0 & 39.9\end{array}$

$\begin{array}{llll}99.0 \% & 39.0 & 25.0 & 20.4\end{array}$

$99.7 \% \quad 37.5 \quad 25.0 \quad 36.6$

$\begin{array}{llll}99.7 \% & 34.9 & 25.0 & 31.1\end{array}$

$\begin{array}{llll}98.0 \% & 22.8 & 25.0 & 12.6\end{array}$

$\begin{array}{llll}97.4 \% & 17.2 & 25.0 & 16.8\end{array}$

$\begin{array}{llll}99.0 \% & 22.5 & 25.0 & 15.8\end{array}$

$\begin{array}{llll}99.3 \% & 26.4 & 25.0 & 14.2\end{array}$

$\begin{array}{llll}99.7 \% & 38.6 & 25.0 & 38.6\end{array}$
130
142
160
18
103
123
134
135
152
156
12
35
35
43
44
56
93
94
105
114
20
33
103
149
149
150
19
58
115
116
169
193
261
261
294
297
312
356
357
366
373
378
394
19
19
29
45

Page 16 of Table S-1-5 
$60 \mathrm{~S}$ ribosomal protein $\mathrm{L} 4 \mathrm{GN}=\mathrm{RPL} 4$ $60 \mathrm{~S}$ ribosomal protein $\mathrm{L} 4 \mathrm{GN}=\mathrm{RPL} 4$ $60 \mathrm{~S}$ ribosomal protein $\mathrm{L} 4 \mathrm{GN}=\mathrm{RPL} 4$ $60 \mathrm{~S}$ ribosomal protein $\mathrm{L} 4 \mathrm{GN}=\mathrm{RPL} 4$ $60 \mathrm{~S}$ ribosomal protein $\mathrm{L} 4 \mathrm{GN}=\mathrm{RPL} 4$ $60 \mathrm{~S}$ ribosomal protein $\mathrm{L} 4 \mathrm{GN}=\mathrm{RPL} 4$ $60 \mathrm{~S}$ ribosomal protein $\mathrm{L} 4 \mathrm{GN}=\mathrm{RPL} 4$ $60 \mathrm{~S}$ ribosomal protein $\mathrm{L} 4 \mathrm{GN}=\mathrm{RPL} 4$ $60 \mathrm{~S}$ ribosomal protein $\mathrm{L} 4 \mathrm{GN}=\mathrm{RPL} 4$ $60 \mathrm{~S}$ ribosomal protein $\mathrm{L} 4 \mathrm{GN}=\mathrm{RPL} 4$ $60 \mathrm{~S}$ ribosomal protein $\mathrm{L} 4 \mathrm{GN}=\mathrm{RPL} 4$ $60 \mathrm{~S}$ ribosomal protein $\mathrm{L} 4 \mathrm{GN}=\mathrm{RPL} 4$ $60 \mathrm{~S}$ ribosomal protein $\mathrm{L} 4 \mathrm{GN}=\mathrm{RPL} 4$ $60 \mathrm{~S}$ ribosomal protein $\mathrm{L} 4 \mathrm{GN}=\mathrm{RPL} 4$ $60 \mathrm{~S}$ ribosomal protein $\mathrm{L} 4 \mathrm{GN}=\mathrm{RPL} 4$ $60 \mathrm{~S}$ ribosomal protein $\mathrm{L} 4 \mathrm{GN}=\mathrm{RPL} 4$ $60 \mathrm{~S}$ ribosomal protein $\mathrm{L} 4 \mathrm{GN}=\mathrm{RPL} 4$ $60 \mathrm{~S}$ ribosomal protein $\mathrm{L} 4 \mathrm{GN}=\mathrm{RPL} 4$ $60 \mathrm{~S}$ ribosomal protein $\mathrm{L} 5 \mathrm{GN}=\mathrm{RPL} 5$ $60 \mathrm{~S}$ ribosomal protein $\mathrm{L} 5 \mathrm{GN}=\mathrm{RPL} 5$ $60 \mathrm{~S}$ ribosomal protein $\mathrm{L} 5 \mathrm{GN}=\mathrm{RPL} 5$ $60 \mathrm{~S}$ ribosomal protein $\mathrm{L} 5 \mathrm{GN}=\mathrm{RPL} 5$ $60 \mathrm{~S}$ ribosomal protein $\mathrm{L} 5 \mathrm{GN}=\mathrm{RPL} 5$ $60 \mathrm{~S}$ ribosomal protein $\mathrm{L} 5 \mathrm{GN}=\mathrm{RPL} 5$ $60 \mathrm{~S}$ ribosomal protein $\mathrm{L} 5 \mathrm{GN}=\mathrm{RPL} 5$ $60 \mathrm{~S}$ ribosomal protein $\mathrm{L} 5 \mathrm{GN}=\mathrm{RPL} 5$ $60 \mathrm{~S}$ ribosomal protein $\mathrm{L} 5 \mathrm{GN}=\mathrm{RPL} 5$ $60 \mathrm{~S}$ ribosomal protein $\mathrm{L} 5 \mathrm{GN}=\mathrm{RPL} 5$ $60 \mathrm{~S}$ ribosomal protein $\mathrm{L} 5 \mathrm{GN}=\mathrm{RPL} 5$ $60 \mathrm{~S}$ ribosomal protein $\mathrm{L} 5 \mathrm{GN}=\mathrm{RPL} 5$ $60 \mathrm{~S}$ ribosomal protein $\mathrm{L} 5 \mathrm{GN}=\mathrm{RPL} 5$ $60 \mathrm{~S}$ ribosomal protein $\mathrm{L} 5 \mathrm{GN}=\mathrm{RPL} 5$ $60 \mathrm{~S}$ ribosomal protein $\mathrm{L} 6 \mathrm{GN}=\mathrm{RPL} 6$ $60 \mathrm{~S}$ ribosomal protein $\mathrm{L} 6 \mathrm{GN}=\mathrm{RPL} 6$ $60 \mathrm{~S}$ ribosomal protein $\mathrm{L} 6 \mathrm{GN}=\mathrm{RPL} 6$ $60 \mathrm{~S}$ ribosomal protein $\mathrm{L} 6 \mathrm{GN}=\mathrm{RPL} 6$ $60 \mathrm{~S}$ ribosomal protein $\mathrm{L} 6 \mathrm{GN}=\mathrm{RPL} 6$ 60S ribosomal protein $\mathrm{L} 6 \mathrm{GN}=\mathrm{RPL} 6$ $60 \mathrm{~S}$ ribosomal protein $\mathrm{L} 6 \mathrm{GN}=\mathrm{RPL} 6$ $60 \mathrm{~S}$ ribosomal protein $\mathrm{L} 6 \mathrm{GN}=\mathrm{RPL} 6$ $60 \mathrm{~S}$ ribosomal protein $\mathrm{L} 6 \mathrm{GN}=\mathrm{RPL} 6$ $60 \mathrm{~S}$ ribosomal protein $\mathrm{L} 6 \mathrm{GN}=\mathrm{RPL} 6$ $60 \mathrm{~S}$ ribosomal protein $\mathrm{L} 6 \mathrm{GN}=\mathrm{RPL} 6$ $60 \mathrm{~S}$ ribosomal protein $\mathrm{L} 6 \mathrm{GN}=\mathrm{RPL} 6$ $60 \mathrm{~S}$ ribosomal protein $\mathrm{L} 6 \mathrm{GN}=\mathrm{RPL} 6$ $60 \mathrm{~S}$ ribosomal protein $\mathrm{L} 6 \mathrm{GN}=\mathrm{RPL} 6$ $60 \mathrm{~S}$ ribosomal protein $\mathrm{L} 6 \mathrm{GN}=\mathrm{RPL} 6$
RL4_HUMAN $47.70 \quad 100.0 \% \quad 20$ RL4_HUMAN $47.70 \quad 100.0 \% \quad 20$ RL4_HUMAN $47.70 \quad 100.0 \% \quad 20$ RL4 HUMAN $47.70 \quad 100.0 \% \quad 20$ RL4_HUMAN $47.70 \quad 100.0 \% \quad 20$ RL4 HUMAN $47.70 \quad 100.0 \% \quad 20$ RL4 HUMAN $47.70 \quad 100.0 \% \quad 20$ RL4_HUMAN $47.70 \quad 100.0 \% \quad 20$ RL4 HUMAN $47.70 \quad 100.0 \% \quad 20$ RL4_HUMAN $47.70 \quad 100.0 \% \quad 20$ RL4_HUMAN $47.70 \quad 100.0 \% \quad 20$ RL4 HUMAN $47.70 \quad 100.0 \% \quad 20$ RL4_HUMAN $47.70 \quad 100.0 \% \quad 20$ RL4 HUMAN $47.70 \quad 100.0 \% \quad 20$ RL4 HUMAN $47.70 \quad 100.0 \% \quad 20$ RL4_HUMAN $47.70 \quad 100.0 \% \quad 20$ RL4 HUMAN $47.70 \quad 100.0 \% \quad 20$ RL4_HUMAN $47.70 \quad 100.0 \% \quad 20$ RL5_HUMAN $34.36 \quad 100.0 \% \quad 14$ RL5 HUMAN $34.36 \quad 100.0 \% \quad 14$ RL5_HUMAN $34.36 \quad 100.0 \% \quad 14$ RL5 HUMAN $34.36 \quad 100.0 \% \quad 14$ RL5 HUMAN $34.36 \quad 100.0 \% \quad 14$ RL5_HUMAN $34.36 \quad 100.0 \% \quad 14$ RL5 HUMAN $34.36 \quad 100.0 \% \quad 14$ RL5_HUMAN $34.36 \quad 100.0 \% \quad 14$ RL5_HUMAN $34.36 \quad 100.0 \% \quad 14$ RL5 HUMAN $34.36 \quad 100.0 \% \quad 14$ RL5_HUMAN $34.36 \quad 100.0 \% \quad 14$ RL5 HUMAN $34.36 \quad 100.0 \% \quad 14$ RL5_HUMAN $34.36 \quad 100.0 \% \quad 14$ RL5_HUMAN $34.36 \quad 100.0 \% \quad 14$ RL6 HUMAN $32.73 \quad 100.0 \% \quad 17$ RL6_HUMAN $32.73 \quad 100.0 \% \quad 17$ RL6_HUMAN $32.73 \quad 100.0 \% \quad 17$ RL6 HUMAN $32.73 \quad 100.0 \% \quad 17$ RL6_HUMAN $32.73 \quad 100.0 \% \quad 17$ RL6 HUMAN $32.73 \quad 100.0 \% \quad 17$ RL6_HUMAN $32.73 \quad 100.0 \% \quad 17$ RL6_HUMAN $32.73 \quad 100.0 \% \quad 17$ RL6 HUMAN $32.73 \quad 100.0 \% \quad 17$ RL6_HUMAN $32.73 \quad 100.0 \% \quad 17$ RL6 HUMAN $32.73 \quad 100.0 \% \quad 17$ RL6_HUMAN $32.73 \quad 100.0 \% \quad 17$ RL6_HUMAN $32.73 \quad 100.0 \% \quad 17$ RL6 HUMAN $32.73 \quad 100.0 \% \quad 17$ RL6_HUMAN $32.73 \quad 100.0 \% \quad 17$

28
28
28
28
28
28
28
28
28
28
28
28
28
28
28
28
28
28
27
27
27
27
27
27
27
27
27
27
27
27
27
27
23
23
23
23
23
23
23
23
23
23
23
23
23

23

$99.7 \% \quad 31.8$

25.0

31.8

$32 \quad 0.14 \% \quad 44.7 \%$ TKEAVLLLK

$132 \quad 0.14 \% \quad 44.7 \%$ EAVLLLKK

$132 \quad 0.14 \% \quad 44.7 \%$ RGPCIIYNEDNGIIK

$132 \quad 0.14 \% \quad 44.7 \%$ GPCIIYNEDNGIIK

$132 \quad 0.14 \% \quad 44.7 \%$ AFRNIPGITLLNVSK

$132 \quad 0.14 \% \quad 44.7 \%$ NIPGITLLNVSK

$132 \quad 0.14 \% \quad 44.7 \%$ NIPGITLLNVSKLNILK

$132 \quad 0.14 \% \quad 44.7 \%$ LAPGGHVGR

$132 \quad 0.14 \% \quad 44.7 \%$ FCIWTESAFR

$132 \quad 0.14 \% \quad 44.7 \%$ KLDELYGTWR

$132 \quad 0.14 \% \quad 44.7 \%$ SNYNLPMHK

$132 \quad 0.14 \% \quad 44.7 \%$ MINTDLSR

$132 \quad 0.14 \% \quad 44.7 \%$ ILKSPEIQR

$132 \quad 0.14 \% \quad 44.7 \%$ VDKAAAAAAALQAK

$132 \quad 0.14 \% \quad 44.7 \%$ AAAAAAALQAK

$72 \quad 0.08 \% \quad 40.4 \%$ VTNRDIICQIAYAR

$0.08 \% \quad 40.4 \%$ DIICQIAYAR

$\begin{array}{lllll}0.08 \% & 40.4 \% & \text { IEGDMIVCAAYAHELPK } & 99.7 \% & 54.7 \\ 0.08 \% & 40.4 \% & \text { VGLTNYAAAYCTGLLLAR } & 99.7 \% & 40.4\end{array}$

$0.08 \% \quad 40.4 \%$ GAVDGGLSIPHSTK

$72 \quad 0.08 \% \quad 40.4 \%$ GAVDGGLSIPHSTKR

$\begin{array}{ll}0.08 \% & 40.4 \% \text { FPGYDSESK }\end{array}$

$\begin{array}{ll}0.08 \% & 40.4 \% \text { EFNAEVHR }\end{array}$

$0.08 \% \quad 40.4 \%$ EFNAEVHRK

$0.08 \% \quad 40.4 \%$ HIMGQNVADYMR

$72 \quad 0.08 \% \quad 40.4 \%$ YLMEEDEDAYKK

$72 \quad 0.08 \% \quad 40.4 \%$ NSVTPDMMEEMYKK

$101 \quad 0.11 \% \quad 48.3 \%$ EKVLATVTKPVGGDK

$101 \quad 0.11 \% \quad 48.3 \%$ VLATVTKPVGGDK

$101 \quad 0.11 \% \quad 48.3 \%$ VLATVTKPVGGDKNGGTR

$101 \quad 0.11 \% \quad 48.3 \% \quad$ YYPTEDVPR

$101 \quad 0.11 \% \quad 48.3 \%$ YYPTEDVPRK

$101 \quad 0.11 \% \quad 48.3 \%$ KPFSQHVR

$101 \quad 0.11 \% \quad 48.3 \%$ ASITPGTILIILTGR

$101 \quad 0.11 \% \quad 48.3 \%$ QLASGLLLVTGPLVLNR

$101 \quad 0.11 \% \quad 48.3 \%$ FVIATSTK

$101 \quad 0.11 \% \quad 48.3 \%$ HLTDAYFK

$101 \quad 0.11 \% \quad 48.3 \%$ HLTDAYFKK

$101 \quad 0.11 \% \quad 48.3 \%$ HQEGEIFDTEK

$101 \quad 0.11 \% \quad 48.3 \%$ HQEGEIFDTEKEK

$101 \quad 0.11 \% \quad 48.3 \%$ EKYEITEQR

$101 \quad 0.11 \% \quad 48.3 \%$ AVDSQILPK
$99.7 \% \quad 55.1$

$99.7 \% 56.6$

$99.7 \% \quad 46.7$

$99.0 \% \quad 55.6$

25.0

54.0

$\begin{array}{llll}99.7 \% & 47.0 & 25.0 & 44.2\end{array}$

$99.7 \% \quad 53.7 \quad 25.0 \quad 53.7$

$\begin{array}{llll}99.7 \% & 31.9 & 25.0 & 31.9\end{array}$

$99.7 \% \quad 44.0 \quad 25.0 \quad 39.6$

$99.7 \% \quad 47.5$

$99.7 \% \quad 44.5$

$99.7 \% \quad 38.3$

$99.7 \% \quad 42.6$

$99.7 \% \quad 40.2$

$99.0 \% \quad 53.5$

$\begin{array}{lll}99.7 \% & 38.4\end{array}$

$99.7 \% \quad 43.1$

$99.7 \% \quad 60.6$

$99.7 \% \quad 46.0$

$99.7 \% \quad 58.5$

$99.7 \% \quad 66.1$

$99.7 \% \quad 35.8$

$99.7 \% \quad 37.7$

$99.7 \% \quad 48.2$

$99.7 \% \quad 35.8$

$99.7 \% \quad 48.4$

$99.7 \% \quad 53.5$

$99.7 \% \quad 37.1$

$99.7 \% \quad 74.7$

$99.7 \% \quad 54.5$

$99.7 \% \quad 37.1$

$99.7 \% 53.1$

$99.7 \% \quad 40.1$

$99.0 \% \quad 29.0$

$99.7 \% \quad 31.8$

1184.49

1953.02

1014.66

913.61

1761.90

1605.79

1642.96

1268.76

1850.15

863.48

1316.61

1280.66

1119.53

949.48

1083.65

1298.74

956.55

1692.89

1222.63

1916.92

1927.01

1338.70

1494.80

1185.55

1029.45

2011.91

1001.48

1129.57

1434.66

1549.67

1702.75

1541.89

1284.75

1769.99

1139.54

1267.63

998.55

1525.93

1764.07

$25.0 \quad 47.7$

$\begin{array}{llll}9.0 \% & 32.5 & 25.0 & 29.8\end{array}$

$\begin{array}{llll}99.0 \% & 31.5 & 25.0 & 27.3\end{array}$

$\begin{array}{llll}99.7 \% & 40.8 & 25.0 & 33.6\end{array}$

$\begin{array}{llll}99.7 \% & 48.7 & 25.0 & 48.6\end{array}$

$\begin{array}{llll}99.7 \% & 41.0 & 25.0 & 41.0\end{array}$

$\begin{array}{llll}99.7 \% & 42.7 & 25.0 & 35.0\end{array}$

$\begin{array}{llll}99.7 \% & 62.1 & 25.0 & 39.7\end{array}$

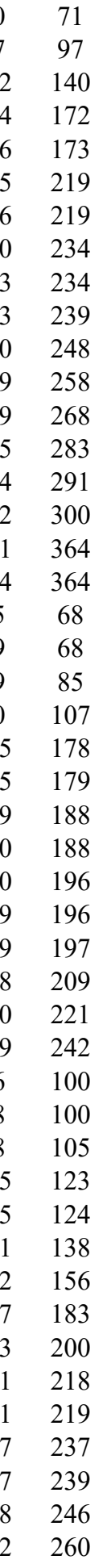

Page 17 of Table S-1-5 
$60 \mathrm{~S}$ ribosomal protein $\mathrm{L} 6 \mathrm{GN}=\mathrm{RPL} 6$ $60 \mathrm{~S}$ ribosomal protein $\mathrm{L} 6 \mathrm{GN}=\mathrm{RPL} 6$ $60 \mathrm{~S}$ ribosomal protein $\mathrm{L} 7 \mathrm{GN}=\mathrm{RPL} 7$ $60 \mathrm{~S}$ ribosomal protein $\mathrm{L} 7 \mathrm{GN}=\mathrm{RPL} 7$ $60 \mathrm{~S}$ ribosomal protein $\mathrm{L} 7 \mathrm{GN}=\mathrm{RPL} 7$ $60 \mathrm{~S}$ ribosomal protein $\mathrm{L} 7 \mathrm{GN}=\mathrm{RPL} 7$ $60 \mathrm{~S}$ ribosomal protein $\mathrm{L} 7 \mathrm{GN}=\mathrm{RPL} 7$ $60 \mathrm{~S}$ ribosomal protein $\mathrm{L} 7 \mathrm{GN}=\mathrm{RPL} 7$ $60 \mathrm{~S}$ ribosomal protein $\mathrm{L} 7 \mathrm{GN}=\mathrm{RPL} 7$ $60 \mathrm{~S}$ ribosomal protein $\mathrm{L} 7 \mathrm{GN}=\mathrm{RPL} 7$ $60 \mathrm{~S}$ ribosomal protein $\mathrm{L} 7 \mathrm{GN}=\mathrm{RPL} 7$ $60 \mathrm{~S}$ ribosomal protein $\mathrm{L} 7 \mathrm{GN}=\mathrm{RPL} 7$ $60 \mathrm{~S}$ ribosomal protein $\mathrm{L} 7 \mathrm{GN}=\mathrm{RPL} 7$ $60 \mathrm{~S}$ ribosomal protein $\mathrm{L} 7 \mathrm{GN}=\mathrm{RPL} 7$ $60 \mathrm{~S}$ ribosomal protein $\mathrm{L} 7 \mathrm{GN}=\mathrm{RPL} 7$ $60 \mathrm{~S}$ ribosomal protein $\mathrm{L} 7 \mathrm{GN}=\mathrm{RPL} 7$ $60 \mathrm{~S}$ ribosomal protein $\mathrm{L} 7 \mathrm{GN}=\mathrm{RPL} 7$ $60 \mathrm{~S}$ ribosomal protein $\mathrm{L} 7 \mathrm{GN}=\mathrm{RPL} 7$ $60 \mathrm{~S}$ ribosomal protein $\mathrm{L} 7 \mathrm{GN}=\mathrm{RPL} 7$ $60 \mathrm{~S}$ ribosomal protein $\mathrm{L} 7 \mathrm{a} \mathrm{GN}=\mathrm{RPL} 7 \mathrm{~A}$ $60 \mathrm{~S}$ ribosomal protein $\mathrm{L} 7 \mathrm{a} \mathrm{GN}=\mathrm{RPL} 7 \mathrm{~A}$ $60 \mathrm{~S}$ ribosomal protein $\mathrm{L} 7 \mathrm{a} \mathrm{GN}=\mathrm{RPL} 7 \mathrm{~A}$ $60 \mathrm{~S}$ ribosomal protein $\mathrm{L} 7 \mathrm{a} \mathrm{GN}=\mathrm{RPL} 7 \mathrm{~A}$ $60 \mathrm{~S}$ ribosomal protein $\mathrm{L} 7 \mathrm{a} \mathrm{GN}=\mathrm{RPL} 7 \mathrm{~A}$ $60 \mathrm{~S}$ ribosomal protein $\mathrm{L} 7 \mathrm{a} \mathrm{GN}=\mathrm{RPL} 7 \mathrm{~A}$ $60 \mathrm{~S}$ ribosomal protein $\mathrm{L} 7 \mathrm{a} \mathrm{GN}=\mathrm{RPL} 7 \mathrm{~A}$ $60 \mathrm{~S}$ ribosomal protein $\mathrm{L} 7 \mathrm{a} \mathrm{GN}=\mathrm{RPL} 7 \mathrm{~A}$ $60 \mathrm{~S}$ ribosomal protein $\mathrm{L} 7 \mathrm{a} \mathrm{GN}=\mathrm{RPL} 7 \mathrm{~A}$ $60 \mathrm{~S}$ ribosomal protein $\mathrm{L} 7 \mathrm{a} \mathrm{GN}=\mathrm{RPL} 7 \mathrm{~A}$ $60 \mathrm{~S}$ ribosomal protein $\mathrm{L} 7 \mathrm{a} \mathrm{GN}=\mathrm{RPL} 7 \mathrm{~A}$ $60 \mathrm{~S}$ ribosomal protein $\mathrm{L} 7 \mathrm{a} \mathrm{GN}=\mathrm{RPL} 7 \mathrm{~A}$ $60 \mathrm{~S}$ ribosomal protein $\mathrm{L} 7 \mathrm{a} \mathrm{GN}=\mathrm{RPL} 7 \mathrm{~A}$ $60 \mathrm{~S}$ ribosomal protein $\mathrm{L} 7 \mathrm{a} \mathrm{GN}=\mathrm{RPL} 7 \mathrm{~A}$ $60 \mathrm{~S}$ ribosomal protein $\mathrm{L} 7 \mathrm{a} \mathrm{GN}=\mathrm{RPL} 7 \mathrm{~A}$ $60 \mathrm{~S}$ ribosomal protein $\mathrm{L} 7 \mathrm{a} \mathrm{GN}=\mathrm{RPL} 7 \mathrm{~A}$ $60 \mathrm{~S}$ ribosomal protein $\mathrm{L} 7 \mathrm{a} \mathrm{GN}=\mathrm{RPL7A}$ $60 \mathrm{~S}$ ribosomal protein $\mathrm{L} 7 \mathrm{a} \mathrm{GN}=\mathrm{RPL} 7 \mathrm{~A}$

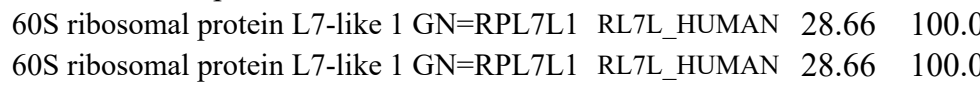
60S ribosomal protein L7-like $1 \mathrm{GN}=$ RPL7L1 RL7L_HUMAN $28.66 \quad 100.0 \%$ 60S ribosomal protein L7-like $1 \mathrm{GN}=$ RPL7L1 RL7L_HUMAN $28.66 \quad 100.0 \%$ 60S ribosomal protein L7-like 1 GN=RPL7L1 RL7L_HUMAN $28.66 \quad 100.0 \%$ 60 S ribosomal protein L7-like $1 \mathrm{GN}=$ RPL7L1 RL7L HUMAN $28.66 \quad 100.0 \%$ $60 \mathrm{~S}$ ribosomal protein $\mathrm{L} 8 \mathrm{GN}=\mathrm{RPL} 8$ $60 \mathrm{~S}$ ribosomal protein $\mathrm{L} 8 \mathrm{GN}=\mathrm{RPL} 8$ $60 \mathrm{~S}$ ribosomal protein $\mathrm{L} 8 \mathrm{GN}=\mathrm{RPL} 8$ $60 \mathrm{~S}$ ribosomal protein $\mathrm{L} 8 \mathrm{GN}=\mathrm{RPL} 8$ $\begin{array}{lllllll}\text { RL6 HUMAN } 32.73 & 100.0 \% & 17 & 23 & 101 & 0.11 \% & 48.3 \% \\ \text { AIPQLQGYLR }\end{array}$ RL6_HUMAN $32.73 \quad 100.0 \% \quad 17 \quad 23 \quad 101 \quad 0.11 \% \quad 48.3 \%$ SVFALTNGIYPHK

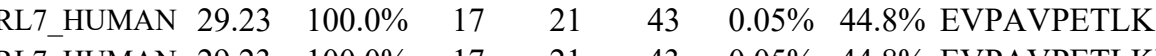
\begin{tabular}{lllllll} 
RL7_HUMAN 29.23 & $100.0 \%$ & 17 & 21 & 43 & $0.05 \%$ & $44.8 \%$ \\
\hline
\end{tabular} RL7_HUMAN $29.23 \quad 100.0 \% \quad 17 \quad 21 \quad 43 \quad 0.05 \% \quad 44.8 \%$ KAGNFYVPAEPK RL7_HUMAN $29.23 \quad 100.0 \% \quad 17 \quad 21 \quad 43 \quad 0.05 \% \quad 44.8 \%$ AGNFYVPAEPK $\begin{array}{lllllll}\text { RL7_HUMAN } 29.23 & 100.0 \% & 17 & 21 & 43 & 0.05 \% & 44.8 \% \\ \text { IRGINGVSPK }\end{array}$ RL7_HUMAN $29.23 \quad 100.0 \% \quad 17 \quad 21 \quad 43 \quad 0.05 \% \quad 44.8 \%$ LRQIFNGTFVK RL7 HUMAN $29.23 \quad 100.0 \% \quad 17 \quad 21 \quad 43 \quad 0.05 \% \quad 44.8 \%$ QIFNGTFVK RL7_HUMAN $29.23 \quad 100.0 \% \quad 17 \quad 21 \quad 43 \quad 0.05 \% \quad 44.8 \%$ IVEPYIAWGYPNLK RL7_HUMAN $29.23 \quad 100.0 \% \quad 17 \quad 21 \quad 43 \quad 0.05 \% \quad 44.8 \%$ SVNELIYK RL7 HUMAN $29.23 \quad 100.0 \% \quad 17 \quad 21 \quad 43 \quad 0.05 \% \quad 44.8 \%$ SVNELIYKR RL7_HUMAN $29.23 \quad 100.0 \% \quad 17 \quad 21 \quad 43 \quad 0.05 \% \quad 44.8 \%$ RIALTDNALIAR RL7_HUMAN $29.23 \quad 100.0 \% \quad 17 \quad 21 \quad 43 \quad 0.05 \% \quad 44.8 \%$ IALTDNALIAR RL7_HUMAN $29.23 \quad 100.0 \% \quad 17 \quad 21 \quad 43 \quad 0.05 \% \quad 44.8 \%$ FKEANNFLWPFK RL7 HUMAN $29.23 \quad 100.0 \% \quad 17 \quad 21 \quad 43 \quad 0.05 \% \quad 44.8 \%$ KTTHFVEGGDAGNR RL7_HUMAN $29.23 \quad 100.0 \% \quad 17 \quad 21 \quad 43 \quad 0.05 \% \quad 44.8 \%$ TTHFVEGGDAGNR RL7_HUMAN $29.23 \quad 100.0 \% \quad 17$ RL7A HUMAN $30.00 \quad 100.0 \% \quad 18$ RL7A_HUMAN $30.00 \quad 100.0 \% \quad 18$ RL7A_HUMAN $30.00 \quad 100.0 \% \quad 18$ RL7A_HUMAN $30.00 \quad 100.0 \% \quad 18$ RL7A_HUMAN $30.00 \quad 100.0 \% \quad 18$ RL7A HUMAN $30.00 \quad 100.0 \% \quad 18$ RL7A_HUMAN $30.00 \quad 100.0 \% \quad 18$ RL7A_HUMAN $30.00 \quad 100.0 \% \quad 18$ RL7A HUMAN $30.00 \quad 100.0 \% \quad 18$ RL7A_HUMAN $30.00 \quad 100.0 \% \quad 18$ RL7A HUMAN $30.00 \quad 100.0 \% \quad 18$ RL7A_HUMAN $30.00 \quad 100.0 \% \quad 18$ RL7A_HUMAN $30.00 \quad 100.0 \% \quad 18$ RL7A HUMAN $30.00 \quad 100.0 \% \quad 18$ RL7A_HUMAN $30.00 \quad 100.0 \% \quad 18$ RL7A_HUMAN $30.00 \quad 100.0 \% \quad 18$ RL7A_HUMAN $30.00 \quad 100.0 \% \quad 18$ $\begin{array}{llll}\text { RL7A_HUMAN } & 30.00 & 100.0 \% & 18\end{array}$ 6 $\begin{array}{ll}0 \\ 0 & 6\end{array}$ 0
0 RL8 HUMAN $28.02 \quad 100.0 \%$ RL8_HUMAN $28.02 \quad 100.0 \%$ RL8 HUMAN $28.02 \quad 100.0 \%$ RL8_HUMAN $28.02 \quad 100.0 \%$

$0.08 \% \quad 45.9 \%$ VAPAPAVVKK $\begin{array}{lllllll}99.7 \% & 53.2 & 25.0 & 41.1 & 7 & 0 & 0\end{array}$ $99.7 \% 58.2$

$94.6 \% \quad 19.1$

$99.6 \% \quad 24.4$

$99.7 \% \quad 44.2$

$99.7 \% \quad 52.0$

$98.1 \% \quad 20.7$

$99.7 \% \quad 41.8$

$99.7 \% \quad 26.4$

$99.7 \% \quad 67.2$

$99.0 \% \quad 45.4$

$99.7 \% \quad 41.6$

$99.7 \% \quad 55.9$

$99.7 \% \quad 59.0$

$99.7 \% \quad 49.9$

$99.7 \% \quad 31.0$

$99.1 \% \quad 24.0$

$99.7 \% \quad 44.8$

$\begin{array}{llll}0.05 \% & 44.8 \% & \text { TTHFVEGGDAGNREDQINR } \quad 99.7 \% \quad 52.2\end{array}$

$0.08 \% \quad 45.9 \%$ KVAPAPAVVK

$0.08 \% \quad 45.9 \%$ KVVNPLFEK

$0.08 \% \quad 45.9 \%$ VVNPLFEK

$0.08 \% \quad 45.9 \%$ NFGIGQDIQPK

$0.08 \% \quad 45.9 \%$ LKVPPAINQFTQALDR

$0.08 \% \quad 45.9 \%$ VPPAINQFTQALDR

$0.08 \% \quad 45.9 \%$ QTATQLLK

$0.08 \% \quad 45.9 \%$ AGVNTVTTLVENK

$0.08 \% \quad 45.9 \%$ AGVNTVTTLVENKK

$0.08 \% \quad 45.9 \%$ KMGVPYCIIK

$0.08 \% \quad 45.9 \%$ MGVPYCIIK

$0.08 \% \quad 45.9 \%$ KTCTTVAFTQVNSEDK

$99.7 \% \quad 42.3$

$99.7 \% \quad 46.8$

$99.7 \% \quad 42.9$

$99.0 \% \quad 24.9$

$99.7 \% \quad 58.4$

$99.7 \% \quad 52.7$

$99.7 \% 76.4$

$99.0 \% \quad 56.2$

$99.7 \% \quad 73.3$

$99.7 \% \quad 62.9$

$99.7 \% \quad 41.1$

$99.7 \% \quad 42.6$

$99.7 \% \quad 48.2$

$99.7 \% \quad 84.3$

$0.08 \% \quad 45.9 \%$ TCTTVAFTQVNSEDK

$\begin{array}{lll}0.08 \% & 45.9 \% & \text { TCTTVAFTQVNSED } \\ 0.08 \% & 45.9 \% & \text { TNYNDRYDEIR }\end{array}$

$0.08 \% \quad 45.9 \%$ RHWGGNVLGPK

$0.08 \% \quad 45.9 \%$ HWGGNVLGPK

$0.01 \% \quad 28.5 \%$ KIPLVPENLLK

$0.01 \% \quad 28.5 \%$ IDGVSLLVQR

$0.01 \% \quad 28.5 \%$ IFSGVFVK

$0.01 \% \quad 28.5 \%$ IVEPYVTWGFPNLK

$0.01 \% \quad 28.5 \%$ TIPLTDNTVIEEHLGK

$99.7 \% \quad 35.4$

$99.7 \% \quad 31.0$

$99.7 \% \quad 43.8$

$99.7 \% \quad 33.5$

$99.7 \% \quad 27.6$

$99.7 \% \quad 64.5$

$98.7 \% \quad 20.4$

$99.6 \% \quad 30.8$

$99.7 \% \quad 48.9$

$99.2 \% \quad 22.3$

$99.7 \% \quad 54.2$

\begin{tabular}{ll}
$99.0 \%$ & 32.5 \\
\hline
\end{tabular}

$0.05 \% \quad 32.3 \%$ GIVKDIIHDPGR

$\begin{array}{lllll}0.05 \% & 32.3 \% & \text { TELFIAAEGIHTGQFVYCGK } & 99.7 \% & 62.3 \\ 0.05 \% & 32.3 \% & \text { ASGNYATVISHNPETK } & 99.7 \% & 63.7\end{array}$

$\begin{array}{ccc}1158.66 & 263 & 272 \\ 1446.77 & 273 & 285 \\ 1082.61 & 10 & 19 \\ 1210.70 & 10 & 20 \\ 1320.69 & 77 & 88 \\ 1192.60 & 78 & 88 \\ 1040.62 & 95 & 104 \\ 1322.76 & 114 & 124 \\ 1053.57 & 116 & 124 \\ 1662.89 & 135 & 148 \\ 965.53 & 149 & 156 \\ 1121.63 & 149 & 157 \\ 1326.79 & 166 & 177 \\ 1170.68 & 167 & 177 \\ 1540.79 & 201 & 212 \\ 1265.63 & 203 & 212 \\ 1488.72 & 223 & 236 \\ 1360.62 & 224 & 236 \\ 2115.98 & 224 & 242 \\ 979.63 & 11 & 20 \\ 979.63 & 12 & 21 \\ 1073.64 & 26 & 34 \\ 945.54 & 27 & 34 \\ 1216.63 & 38 & 48 \\ 1811.02 & 74 & 89 \\ 1569.84 & 76 & 89 \\ 902.53 & 90 & 97 \\ 1345.73 & 138 & 150 \\ 1473.83 & 138 & 151 \\ 1224.65 & 176 & 185 \\ 1080.56 & 177 & 185 \\ 1828.87 & 197 & 212 \\ 1700.78 & 198 & 212 \\ 2141.05 & 198 & 217 \\ 1458.66 & 224 & 234 \\ 1220.66 & 235 & 245 \\ 1064.56 & 236 & 245 \\ 1263.80 & 8 & 18 \\ 1099.65 & 96 & 105 \\ 896.52 & 115 & 122 \\ 1662.89 & 133 & 146 \\ 1779.95 & 164 & 179 \\ 1268.57 & 227 & 237 \\ 1319.74 & 43 & 54 \\ 922.47 & 47 & 54 \\ 2241.10 & 73 & 92 \\ 1688.82 & 129 & 144\end{array}$ 
$60 \mathrm{~S}$ ribosomal protein $\mathrm{L} 8 \mathrm{GN}=\mathrm{RPL} 8$ $60 \mathrm{~S}$ ribosomal protein $\mathrm{L} 8 \mathrm{GN}=\mathrm{RPL} 8$ $60 \mathrm{~S}$ ribosomal protein $\mathrm{L} 8 \mathrm{GN}=\mathrm{RPL} 8$ $60 \mathrm{~S}$ ribosomal protein $\mathrm{L} 8 \mathrm{GN}=\mathrm{RPL} 8$ $60 \mathrm{~S}$ ribosomal protein $\mathrm{L} 8 \mathrm{GN}=\mathrm{RPL} 8$ $60 \mathrm{~S}$ ribosomal protein $\mathrm{L} 9 \mathrm{GN}=\mathrm{RPL} 9$ $60 \mathrm{~S}$ ribosomal protein $\mathrm{L} 9 \mathrm{GN}=\mathrm{RPL} 9$ $60 \mathrm{~S}$ ribosomal protein $\mathrm{L} 9 \mathrm{GN}=\mathrm{RPL} 9$ $60 \mathrm{~S}$ ribosomal protein $\mathrm{L} 9 \mathrm{GN}=\mathrm{RPL} 9$ $60 \mathrm{~S}$ ribosomal protein $\mathrm{L} 9 \mathrm{GN}=\mathrm{RPL} 9$ 60 S ribosomal protein $\mathrm{L} 9 \mathrm{GN}=\mathrm{RPL} 9$ $60 \mathrm{~S}$ ribosomal protein $\mathrm{L} 9 \mathrm{GN}=\mathrm{RPL} 9$ $60 \mathrm{~S}$ ribosomal protein $\mathrm{L} 9 \mathrm{GN}=\mathrm{RPL} 9$ $60 \mathrm{~S}$ ribosomal protein $\mathrm{L} 9 \mathrm{GN}=\mathrm{RPL} 9$ $60 \mathrm{~S}$ ribosomal protein $\mathrm{L} 9 \mathrm{GN}=\mathrm{RPL} 9$ 60 S ribosomal protein $\mathrm{L} 9 \mathrm{GN}=\mathrm{RPL} 9$ $60 \mathrm{~S}$ ribosomal protein $\mathrm{L} 9 \mathrm{GN}=\mathrm{RPL} 9$
RL8_HUMAN $28.02 \quad 100.0 \%$ RL8 HUMAN $28.02 \quad 100.0 \%$ RL8_HUMAN $28.02 \quad 100.0 \%$ RL8 HUMAN $28.02 \quad 100.0 \%$ RL8_HUMAN $28.02 \quad 100.0 \%$ RL9_HUMAN $21.86 \quad 100.0 \%$ RL9 HUMAN $21.86 \quad 100.0 \%$ RL9_HUMAN $21.86 \quad 100.0 \%$ RL9 HUMAN $21.86 \quad 100.0 \% \quad 12$ RL9_HUMAN $21.86 \quad 100.0 \% \quad 12$ RL9_HUMAN $21.86 \quad 100.0 \% \quad 12$ RL9 HUMAN $21.86 \quad 100.0 \% \quad 12$ RL9_HUMAN $21.86 \quad 100.0 \% \quad 12$ RL9_HUMAN $21.86 \quad 100.0 \% \quad 12$ RL9-HUMAN $21.86 \quad 100.0 \% \quad 12$ RL9_HUMAN $21.86 \quad 100.0 \% \quad 12$ RL9 HUMAN $21.86 \quad 100.0 \% \quad 12$ $100.0 \% \quad 2$ $100.0 \%$ $100.0 \% \quad 13$ $100.0 \% \quad 13$ $100.0 \% \quad 13$ $100.0 \% \quad 13$ $100.0 \% \quad 13$ $100.0 \% \quad 13$ $100.0 \% \quad 13$ $100.0 \% \quad 13$ $100.0 \% \quad 13$ $100.0 \% \quad 13$ $100.0 \% \quad 13$ $100.0 \% \quad 13$ $100.0 \% \quad 13$ $100.0 \% \quad 13$ $100.0 \% \quad 1$ $100.0 \%$ $100.0 \%$ $100.0 \%$ $100.0 \%$ $100.0 \%$ $100.0 \%$ $100.0 \%$ $100.0 \%$ $100.0 \%$ $100.0 \%$ $100.0 \%$ $100.0 \%$ $100.0 \%$
0.05\% 32.3\% ASGNYATVISHNPETKK $0.05 \% \quad 32.3 \%$ VKLPSGSK

$0.05 \% \quad 32.3 \%$ AVVGVVAGGGR

$0.05 \% 32.3 \%$ AVVGVVAGGGRIDKPILK $99.6 \% 23.4$

$0.05 \% \quad 32.3 \%$ KVGLIAAR

$99.0 \% \quad 45.2$

$0.04 \% \quad 55.7 \%$ MKTILSNQTVDIPENVDITLK $\quad 99.7 \% \quad 38.2$

$0.04 \% \quad 55.7 \%$ TILSNQTVDIPENVDITLK $99.7 \% \quad 47.7$

$\begin{array}{llll}0.04 \% & 55.7 \% & \text { TILSNQTVDIPENVDITLKGR } \quad 99.7 \% \quad 60.2\end{array}$

$0.04 \% \quad 55.7 \%$ TVIVKGPR

$0.04 \% \quad 55.7 \%$ DFNHINVELSLLGK

$0.04 \% \quad 55.7 \%$ DFNHINVELSLLGKK

$99.0 \% \quad 23.8$

$99.7 \% \quad 49.8$

$0.04 \% \quad 55.7 \%$ TICSHVQNMIK

$0.04 \% \quad 55.7 \%$ SVYAHFPINVVIQENGSLVEIR $\quad 99.7 \% \quad 47.6$

$0.04 \% \quad 55.7 \%$ NFLGEKYIR

$0.04 \% \quad 55.7 \%$ KFLDGIYVSEK

$96.7 \% \quad 24.3$

$99.7 \% \quad 52.4$

$99.7 \% \quad 50.1$

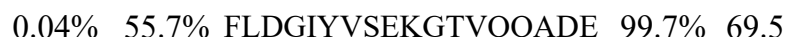

$0.00 \% \quad 18.3 \%$ LAANISGDKLVSLGTCFGK $99.7 \% 38.5$

$0.00 \% \quad 18.3 \%$ LHVTALDYLAPYAK

$0.03 \% \quad 24.5 \%$ VEIIANDQGNR

$0.03 \% \quad 24.5 \%$ ITPSYVAFTPEGER

$0.03 \% \quad 24.5 \%$ NQLTSNPENTVFDAK

$99.4 \% \quad 50.9$

$99.7 \% \quad 35.5$

$99.7 \% \quad 42.5$

$\begin{array}{lllll}0.03 \% & 24.5 \% & \text { TKPYIQVDIGGGQTK } & 99.7 \% & 38.5\end{array}$

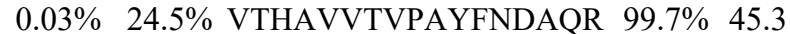

$\begin{array}{llll}0.03 \% & 24.5 \% & \text { QATKDAGTIAGLNVMR } \quad 99.7 \% \quad 29.2\end{array}$

$0.03 \% \quad 24.5 \%$ DAGTIAGLNVMR

$0.03 \% \quad 24.5 \%$ IINEPTAAAIAYGLDK

$0.03 \% \quad 24.5 \%$ IINEPTAAAIAYGLDKR

$99.7 \% \quad 54.9$

$99.7 \% \quad 60.7$

$99.7 \% \quad 26.4$

$99.7 \% \quad 35.1$

$\begin{array}{llllll}0.03 \% & 24.5 \% & \text { KSQIFSTASDNQPTVTIK } & 98.8 \% & 18.5\end{array}$

$0.03 \% \quad 24.5 \%$ SQIFSTASDNQPTVTIK

$99.7 \% \quad 71.3$

$0.03 \% \quad 24.5 \%$ VYEGERPLTK

$0.03 \% \quad 24.5 \%$ ELEEIVQPIISK

$0.02 \% \quad 15.2 \%$ SLDGVTNDR

$99.7 \% \quad 45.8$

$99.7 \% \quad 48.5$

$99.7 \% \quad 56.0$

$0.02 \% \quad 15.2 \%$ FLPGYVGGIQEGAVTPAGVVNK

$0.02 \% \quad 15.2 \%$ GYFFPTSAR

$0.02 \% \quad 15.2 \%$ VIECSYTSADGQR

$0.02 \% \quad 15.2 \%$ LLVSGFWGVAR

$0.02 \% \quad 15.2 \%$ YTAAVPYR

$0.01 \% \quad 11.9 \%$ EVVIVSATR

$0.01 \% \quad 11.9 \%$ TPIGSFLGSLSLLPATK

$0.01 \% \quad 11.9 \%$ LGSIAIQGAIEK

$0.01 \% \quad 11.9 \%$ NEQDAYAINSYTR

$99.7 \% \quad 65.9$

$99.7 \% \quad 37.1$

$99.7 \% \quad 54.7$

$99.7 \% \quad 36.8$

$99.0 \% \quad 27.2$

$99.7 \% \quad 53.8$

$99.7 \% \quad 93.6$

$99.7 \% \quad 39.1$

$99.7 \% 80.0$

$0.02 \% \quad 30.8 \%$ YYAFDEAFVR

$0.02 \% \quad 30.8 \%$ GSLVDNIQQHFLLSDR
$99.7 \% 52$.
$99.7 \% \quad 28.2$
1816.92

815.50

941.55

1749.07

827.55

2388.27

2113.14

2326.26

869.56

1598.85

1726.95

1346.66

2484.32

1139.62

1298.70

1170.60

1998.97

1951.03

1574.86

1228.63

1566.78

1677.81

1833.91

1604.86

1887.97

1645.87

1233.63

1659.90

1816.00

1460.76

1965.03

1836.93

1191.64

1397.79

976.47

2173.17

1045.51

1485.66

1204.68

940.49

973.57

1701.98

1199.70

1544.70

2480.17

1280.59 1841.95

$\begin{array}{cc}149 & 145 \\ 148 & 155 \\ 164 & 174 \\ 64 & 181 \\ 234 & 241 \\ 1 & 21 \\ 3 & 21 \\ 3 & 23 \\ 4 & 31 \\ 37 & 50 \\ 37 & 51 \\ 2 & 82 \\ 4 & 115 \\ 116 & 124 \\ 174 & 184 \\ 175 & 184 \\ 175 & 192 \\ 4 & 72 \\ 81 & 94 \\ 0 & 60 \\ 61 & 74 \\ 82 & 96 \\ 82 & 97 \\ 124 & 138 \\ 165 & 181 \\ 182 & 197 \\ 186 & 197 \\ 198 & 213 \\ 198 & 214 \\ 354 & 367 \\ 447 & 464 \\ 448 & 464 \\ 465 & 474 \\ 622 & 633 \\ 4 & 22 \\ 121 & 142 \\ 199 & 207 \\ 377 & 389 \\ 394 & 404 \\ 462 & 469 \\ 1 & 49 \\ 50 & 66 \\ 67 & 78 \\ 209 & 221 \\ 39 & 61 \\ 6 & 105 \\ 153 & 168 \\ & \end{array}$


Actin, alpha skeletal muscle GN=ACTA1 ACTS_HUMAN $42.05 \quad 100.0 \%$

Actin, alpha skeletal muscle GN=ACTA1 ACTS_HUMAN $42.05 \quad 100.0 \%$

Actin, alpha skeletal muscle GN=ACTA1 ACTS_HUMAN $42.05 \quad 100.0 \%$

Actin, alpha skeletal muscle GN=ACTA1 ACTS_HUMAN $42.05 \quad 100.0 \%$

Actin, alpha skeletal muscle GN=ACTA1 ACTS_HUMAN $42.05 \quad 100.0 \%$

Actin, alpha skeletal muscle GN=ACTA1 ACTS HUMAN $42.05 \quad 100.0 \%$

Actin, alpha skeletal muscle GN=ACTA1 ACTS_HUMAN $42.05 \quad 100.0 \%$

Actin, alpha skeletal muscle GN=ACTA1 ACTS_HUMAN $42.05 \quad 100.0 \%$

Actin, alpha skeletal muscle GN=ACTA1 ACTS HUMAN $42.05 \quad 100.0 \%$

Actin, alpha skeletal muscle GN=ACTA1 ACTS_HUMAN $42.05 \quad 100.0 \%$

Actin, alpha skeletal muscle GN=ACTA1 ACTS_HUMAN $42.05 \quad 100.0 \%$

Actin, cytoplasmic $1 \mathrm{GN}=\mathrm{ACTB}$

Actin, cytoplasmic $1 \mathrm{GN}=\mathrm{ACTB}$

Actin, cytoplasmic $1 \mathrm{GN}=\mathrm{ACTB}$

Actin, cytoplasmic $1 \mathrm{GN}=\mathrm{ACTB}$

Actin, cytoplasmic $1 \mathrm{GN}=\mathrm{ACTB}$

Actin, cytoplasmic $1 \mathrm{GN}=\mathrm{ACTB}$

Actin, cytoplasmic $1 \mathrm{GN}=\mathrm{ACTB}$

Actin, cytoplasmic $1 \mathrm{GN}=\mathrm{ACTB}$

Actin, cytoplasmic $1 \mathrm{GN}=\mathrm{ACTB}$

Actin, cytoplasmic $1 \mathrm{GN}=\mathrm{ACTB}$

Actin, cytoplasmic $1 \mathrm{GN}=\mathrm{ACTB}$

Actin, cytoplasmic $1 \mathrm{GN}=\mathrm{ACTB}$

Actin, cytoplasmic $1 \mathrm{GN}=\mathrm{ACTB}$

Actin, cytoplasmic $1 \mathrm{GN}=\mathrm{ACTB}$

Actin, cytoplasmic $1 \mathrm{GN}=\mathrm{ACTB}$

Actin, cytoplasmic $1 \mathrm{GN}=\mathrm{ACTB}$

Actin, cytoplasmic $1 \mathrm{GN}=\mathrm{ACTB}$

Actin, cytoplasmic $1 \mathrm{GN}=\mathrm{ACTE}$

Actin, cytoplasmic $1 \mathrm{GN}=\mathrm{ACTB}$

Actin, cytoplasmic $1 \mathrm{GN}=\mathrm{ACTB}$

Actin, cytoplasmic $1 \mathrm{GN}=\mathrm{ACTB}$

Actin-related protein $2 \mathrm{GN}=\mathrm{ACTR} 2$

Actin-related protein $2 \mathrm{GN}=\mathrm{ACTR} 2$

Actin-related protein $2 \mathrm{GN}=\mathrm{ACTR} 2$

Actin-related protein $2 \mathrm{GN}=\mathrm{ACTR} 2$ ACTB_HUMAN $41.74 \quad 100.0 \% \quad 2$ ACTB_HUMAN $41.74 \quad 100.0 \% \quad 2$ ACTB HUMAN $41.74 \quad 100.0 \% \quad 2$ ACTB_HUMAN $41.74 \quad 100.0 \% \quad 21$ ACTB_HUMAN $41.74 \quad 100.0 \% \quad 2$ ACTB_HUMAN $41.74 \quad 100.0 \% \quad 2$ ACTB_HUMAN $41.74 \quad 100.0 \% \quad 21$ ACTB HUMAN $41.74 \quad 100.0 \% \quad 21$ ACTB_HUMAN $41.74 \quad 100.0 \% \quad 21$ ACTB_HUMAN $41.74 \quad 100.0 \% \quad 2$ ACTB HUMAN $41.74 \quad 100.0 \% \quad 21$ ACTB_HUMAN $41.74 \quad 100.0 \% \quad 21$ ACTB_HUMAN $41.74 \quad 100.0 \% \quad 21$ ACTB_HUMAN $41.74 \quad 100.0 \% \quad 2$ ACTB_HUMAN $41.74 \quad 100.0 \% \quad 21$ ACTB HUMAN $41.74 \quad 100.0 \% \quad 21$ ACTB_HUMAN $41.74 \quad 100.0 \% \quad 21$ ACTB_HUMAN $41.74 \quad 100.0 \% \quad 2$ ACTB HUMAN $41.74 \quad 100.0 \% \quad 2$ ACTB_HUMAN $41.74 \quad 100.0 \% \quad 21$ ACTB_HUMAN $41.74 \quad 100.0 \% \quad 21$ ARP2_HUMAN $44.76 \quad 100.0 \%$ ARP2_HUMAN $44.76 \quad 100.0 \% \quad 8$ ARP2 HUMAN $44.76 \quad 100.0 \%$ ARP2_HUMAN $44.76 \quad 100.0 \%$

$14 \quad 0.02 \% \quad 30.8 \%$ DYAAIVFFANNR $0.02 \% 30.8 \%$ VLVADKDLLDLHK $0.02 \% \quad 30.8 \%$ LGVFSEMEANFK $\begin{array}{llllllll}99.7 \% & 53.0 & 25.0 & 53.0 & 2 & 0 & 0 & 1400.70\end{array}$ $99.7 \% \quad 59.7$ $99.7 \% 30.1$

$0.02 \% \quad 30.8 \%$ DLFVDLVEK

$0.02 \% \quad 30.8 \%$ FFLNQYSASVHSLDGFR

$0.00 \% \quad 7.6 \% \quad$ KLELSDNR

$0.00 \% \quad 7.6 \%$ VSGGLEVLAEK

$0.00 \% \quad 33.2 \%$ AGFAGDDAPR

$0.00 \% \quad 33.2 \%$ AVFPSIVGRPR

$0.00 \% \quad 33.2 \%$ HQGVMVGMGQK

$0.00 \% 33.2 \%$ HQGVMVGMGQKDSYVGDEAQSK

$0.00 \% \quad 33.2 \%$ DSYVGDEAQSK

$0.00 \% \quad 33.2 \%$ DSYVGDEAQSKR

$98.7 \% \quad 18.6$

$96.5 \% \quad 25.4$

$96.8 \% 21.6$

$99.7 \% \quad 57.0$

$99.7 \% \quad 47.7$

$99.7 \% \quad 43.7$

$99.7 \% 31.8$

$99.7 \% \quad 62.2$

$99.7 \% \quad 61.7$

$0.00 \% \quad 33.2 \%$ VAPEEHPTLLTEAPLNPK $98.7 \% \quad 17.5$

$0.00 \% \quad 33.2 \%$ LDLAGRDLTDYLMK

$0.00 \% \quad 33.2 \%$ DLTDYLMK

$0.00 \% \quad 33.2 \%$ GYSFVTTAER

$0.00 \% \quad 33.2 \%$ SYELPDGQVITIGNER

$0.00 \% \quad 33.2 \%$ MQKEITALAPSTMK

$0.00 \% \quad 33.2 \%$ EITALAPSTMK

$0.00 \% \quad 33.2 \%$ EITALAPSTMKIK

$0.00 \% \quad 33.2 \%$ IKIIAPPER

$243 \quad 0.27 \% \quad 51.2 \%$ AGFAGDDAPR

$243 \quad 0.27 \% \quad 51.2 \%$ AVFPSIVGRPR

$243 \quad 0.27 \% \quad 51.2 \%$ HQGVMVGMGQK

$243 \quad 0.27 \% \quad 51.2 \%$ HQGVMVGMGQKDSYVGDEAQSK

$243 \quad 0.27 \% \quad 51.2 \%$ DSYVGDEAQSK

$243 \quad 0.27 \% \quad 51.2 \%$ DSYVGDEAQSKR

$99.7 \% \quad 36.3$

$99.0 \% 42$.

$99.7 \% \quad 40.2$

$99.7 \% \quad 59.2$

$99.7 \% \quad 50.5$

$99.7 \% \quad 60.6$

$99.3 \% 19.1$

$99.7 \% \quad 36.6$

$99.7 \% \quad 57.0$

$99.7 \% \quad 47.7$

$99.7 \% \quad 43.7$

$99.7 \% 31.8$

$99.7 \% \quad 62.2$

$99.7 \% \quad 61.7$

$243 \quad 0.27 \% \quad 51.2 \%$ VAPEEHPVLLTEAPLNPK

$243 \quad 0.27 \% \quad 51.2 \%$ LDLAGRDLTDYLMK

$243 \quad 0.27 \% \quad 51.2 \%$ DLTDYLMK

$243 \quad 0.27 \% \quad 51.2 \%$ ILTERGYSFTTTAER

$243 \quad 0.27 \% \quad 51.2 \%$ GYSFTTTAER

$243 \quad 0.27 \% \quad 51.2 \%$ GYSFTTTAEREIVR

$243 \quad 0.27 \% \quad 51.2 \%$ LCYVALDFEQEMATAASSSSLEK

$243 \quad 0.27 \% \quad 51.2 \%$ SYELPDGQVITIGNER

$243 \quad 0.27 \% \quad 51.2 \%$ DLYANTVLSGGTTMYPGIADR

$243 \quad 0.27 \% \quad 51.2 \%$ MQKEITALAPSTMK

$243 \quad 0.27 \% \quad 51.2 \%$ EITALAPSTMK

$243 \quad 0.27 \% \quad 51.2 \%$ EITALAPSTMKIK

$243 \quad 0.27 \% \quad 51.2 \%$ IKIIAPPER

$243 \quad 0.27 \% \quad 51.2 \%$ QEYDESGPSIVHR

$243 \quad 0.27 \% \quad 51.2 \%$ QEYDESGPSIVHRK

$99.7 \% \quad 64.0$

$99.7 \% \quad 36.3$

$99.0 \% \quad 42.1$

$99.7 \% \quad 34.4$

$99.7 \% \quad 59.3$

$99.7 \% \quad 34.0$

$99.7 \% \quad 48.6$

$99.7 \% \quad 59.2$

$99.7 \% \quad 60.9$

$99.7 \% \quad 50.5$

$99.7 \% \quad 60.6$

$99.3 \% 19.1$

$99.7 \% \quad 36.6$

$99.7 \% \quad 55.1$

$99.5 \% \quad 24.0$

10

10

10

\section{9}

$0.02 \% \quad 27.4 \%$ VGNIEIKDLMVGDEASEL

$0.02 \% \quad 27.4 \%$ DLMVGDEASELR

.02\% 27.4\% SMLEVNYPMENGIVR

$0.02 \% \quad 27.4 \%$ ILLTEPPMNPTK
00

51.0

$.0 \quad 24.4$

18.6
-0

0.0

21.6

.0 48.9

$\begin{array}{ll}0 & 46.6\end{array}$

.0 40.5

31.8

\begin{tabular}{ll}
$0 \quad 59.2$ \\
\hline
\end{tabular}

$\begin{array}{ll}.0 & 60.8\end{array}$

$\begin{array}{ll}2.0 & 17.5\end{array}$

31.6

$\begin{array}{ll}5.0 & 33.3\end{array}$

34.3

$5.0 \quad 53.0$

31.2

$\begin{array}{lll} & 48.9 & 31\end{array}$

$\begin{array}{lll}5.0 & 19.1 \quad 2\end{array}$

36.0

$\begin{array}{lll}.0 & 48.9 & 17\end{array}$

$\begin{array}{ll}46.0 & 46.6\end{array}$

$\begin{array}{ll}25.0 & 40.5\end{array}$

31.8

\begin{tabular}{ll}
$25.0 \quad 59.2$ \\
\hline
\end{tabular}

$\begin{array}{ll}25.0 & 60.8\end{array}$

$\begin{array}{ll}5.0 & 45.9\end{array}$

.0 31.6

\begin{tabular}{ll}
33.0 \\
\hline
\end{tabular}

$\begin{array}{ll}2.0 & 32.5\end{array}$

$\begin{array}{lll}5.0 & 52.8 \quad 2\end{array}$

$\begin{array}{ll}53.0 & 33.1\end{array}$

$\begin{array}{lll}25.0 & 48.3 \quad 2\end{array}$

$\begin{array}{lll} & 53.0 & 23\end{array}$

$\begin{array}{ll}5.0 & 60.9\end{array}$

$\begin{array}{lll}25.0 & 31.2 & 3\end{array}$

. 19.1

25.0

52.0

$\begin{array}{ll}5.0 & 52.1 \\ 25.0 & 35.5\end{array}$

$\begin{array}{ll}24.0 & 35.5 \\ 25.0 & 32.7\end{array}$

$\begin{array}{ll}5.0 & 32.7\end{array}$

$25.0 \quad 53.1$
$99.7 \% \quad 39.3$

$7 \% \quad 53.1$

$99.7 \% \quad 56.8$
Page 20 of Table S-1-5 
Actin-related protein $2 \mathrm{GN}=\mathrm{ACTR} 2$ Actin-related protein $2 \mathrm{GN}=\mathrm{ACTR} 2$ Actin-related protein $2 \mathrm{GN}=\mathrm{ACTR} 2$ Actin-related protein $2 \mathrm{GN}=\mathrm{ACTR} 2$
ARP2_HUMAN $44.76 \quad 100.0 \%$ ARP2_HUMAN $44.76 \quad 100.0 \%$ ARP2_HUMAN $44.76 \quad 100.0 \%$ ARP2 HUMAN $44.76 \quad 100.0 \%$ Activating signal cointegrator 1 complex subunit $3 \mathrm{GN}=\mathrm{ASCC} 3 \mathrm{ASCC} 3$ HUMAN $251.47 \quad 100.0 \%$ Activating signal cointegrator 1 complex subunit $3 \mathrm{GN}=\mathrm{ASCC} 3$ ASCC3_HUMAN $251.47 \quad 100.0 \%$ Activating signal cointegrator 1 complex subunit $3 \mathrm{GN}=\mathrm{ASCC} 3$ ASCC3_HUMAN $251.47 \quad 100.0 \%$ Activating signal cointegrator 1 complex subunit $3 \mathrm{GN}=\mathrm{ASCC} 3 \mathrm{ASCC} 3$ HUMAN $251.47 \quad 100.0 \%$ Activating signal cointegrator 1 complex subunit $3 \mathrm{GN}=\mathrm{ASCC} 3 \mathrm{ASCC} 3$ HUMAN $251.47 \quad 100.0 \%$ Activating signal cointegrator 1 complex subunit $3 \mathrm{GN}=\mathrm{ASCC} 3$ ASCC3_HUMAN $251.47 \quad 100.0 \%$ Activating signal cointegrator 1 complex subunit $3 \mathrm{GN}=\mathrm{ASCC} 3$ ASCC3_HUMAN $251.47 \quad 100.0 \%$ Activating signal cointegrator 1 complex subunit $3 \mathrm{GN}=\mathrm{ASCC} 3 \mathrm{ASCC} 3$ HUMAN $251.47 \quad 100.0 \%$ Activating signal cointegrator 1 complex subunit $3 \mathrm{GN}=\mathrm{ASCC} 3$ ASCC3_HUMAN $251.47 \quad 100.0 \%$ Activator of $90 \mathrm{kDa}$ heat shock protein ATPase homolog $1 \mathrm{GN}=\mathrm{AHSA} 1$ AHSA1 HUMAN $38.27 \quad 100.0^{\circ} \%$ Activator of $90 \mathrm{kDa}$ heat shock protein ATPase homolog $1 \mathrm{GN}=\mathrm{AHSA} 1$ AHSA1 HUMAN $38.27 \quad 100.0 \%$ Activator of $90 \mathrm{kDa}$ heat shock protein ATPase homolog $1 \mathrm{GN}=\mathrm{AHSA} 1$ AHSA1_HUMAN $38.27 \quad 100.0 \%$ Activator of $90 \mathrm{kDa}$ heat shock protein ATPase homolog $1 \mathrm{GN}=\mathrm{AHSA} 1$ AHSA1 HUMAN $38.27 \quad 100.0 \%$ Activator of basal transcription $1 \mathrm{GN}=\mathrm{ABT} 1 \mathrm{ABT1}$ HUMAN $31.08 \quad 100.0 \%$ Activator of basal transcription $1 \mathrm{GN}=\mathrm{ABT} 1 \mathrm{ABT1}$ HUMAN $31.08 \quad 100.0 \%$ Activator of basal transcription $1 \mathrm{GN}=\mathrm{ABT} 1 \mathrm{ABT} 1$ HUMAN $31.08 \quad 100.0 \%$ Activator of basal transcription $1 \mathrm{GN}=\mathrm{ABT} 1 \mathrm{ABT1}$ HUMAN $31.08 \quad 100.0 \%$ Acyl-CoA dehydrogenase family member 9, mitochondrial GN=ACAD9 ACAD9_HUMAN $68.76 \quad 100.0 \%$ Acyl-CoA dehydrogenase family member 9, mitochondrial GN=ACAD9 ACAD9_HUMAN $68.76 \quad 100.0 \%$ Acyl-CoA dehydrogenase family member 9, mitochondrial GN=ACAD9 ACAD9_HUMAN $68.76 \quad 100.0 \%$ Acyl-CoA dehydrogenase family member 9, mitochondrial GN=ACAD9 ACAD9_HUMAN $68.76 \quad 100.0 \%$ Acyl-CoA dehydrogenase family member 9, mitochondrial GN=ACAD9 ACAD9_HUMAN $68.76 \quad 100.0 \%$ Acyl-CoA dehydrogenase family member 9, mitochondrial GN=ACAD9 ACAD9 HUMAN $68.76 \quad 100.0 \%$ Acyl-CoA dehydrogenase family member 9 , mitochondrial GN=ACAD9 ACAD9_HUMAN $68.76 \quad 100.0 \%$ Acyl-coenzyme A thioesterase $1 \mathrm{GN}=$ ACOT1 ACOT1_HUMAN $46.28 \quad 100.0 \%$ Acyl-coenzyme A thioesterase $1 \mathrm{GN}=\mathrm{ACOT} 1$ ACOT1_HUMAN $46.28 \quad 100.0^{\circ}$ Acyl-coenzyme A thioesterase $8 \mathrm{GN}=$ ACOT8 ACOT8_HUMAN $35.91 \quad 100.0 \%$ Acyl-coenzyme A thioesterase $8 \mathrm{GN}=$ ACOT8 ACOT8_HUMAN $35.91 \quad 100.0 \%$ Acyl-coenzyme A thioesterase $8 \mathrm{GN}=\mathrm{ACOT} 8$ ACOT8_HUMAN $35.91 \quad 100.0 \%$ Acyl-coenzyme A thioesterase $8 \mathrm{GN}=$ ACOT8 ACOT8_HUMAN $35.91 \quad 100.0 \%$ Acyl-coenzyme A thioesterase 9, mitochondrial GN=ACOT9 ACOT9_HUMAN $49.90 \quad 100.0 \%$ Acyl-coenzyme A thioesterase 9, mitochondrial GN=ACOT9 ACOT9_HUMAN $49.90 \quad 100.0 \%$ Acyl-coenzyme A thioesterase 9, mitochondrial GN=ACOT9 ACOT9_HUMAN $49.90 \quad 100.0 \%$ Acyl-coenzyme A thioesterase 9, mitochondrial GN=ACOT9 ACOT9 HUMAN $49.90 \quad 100.0^{\circ} \%$ Acyl-coenzyme A thioesterase 9, mitochondrial GN=ACOT9 ACOT9_HUMAN $49.90 \quad 100.0 \%$ Adenine phosphoribosyltransferase GN=APRT APT HUMAN $19.61 \quad 100.0 \%$ Adenine phosphoribosyltransferase GN=APRT APT HUMAN $19.61 \quad 100.0 \%$ Adenine phosphoribosyltransferase GN=APRT APT_HUMAN $19.61 \quad 100.0 \%$ Adenine phosphoribosyltransferase GN=APRT APT HUMAN $19.61 \quad 100.0 \%$ Adenosylhomocysteinase GN=AHCY SAHH_HUMAN $47.72 \quad 100.0 \%$ Adenosylhomocysteinase GN=AHCY SAHH_HUMAN $47.72 \quad 100.0 \%$ Adenylate kinase 2, mitochondrial GN=AK2 KAD2 HUMAN $26.48 \quad 100.0 \%$ Adenylate kinase 2, mitochondrial GN=AK2 KAD2_HUMAN $26.48 \quad 100.0 \%$
$19 \quad 0.02 \% \quad 27.4 \%$ GYAFNHSADFETVR

$99.7 \% \quad 60.7$ $0.02 \% \quad 27.4 \%$ LCYVGYNIEQEQK

$99.7 \% \quad 42.8$

$0.02 \% \quad 27.4 \%$ LALETTVLVESYTLPDGR $99.7 \% 56.5$

$0.02 \% \quad 27.4 \%$ HIVLSGGSTMYPGLPSR $\quad 99.7 \% 28.6$

$0.03 \% \quad 4.2 \% \quad$ IQREQALLNAR

$0.03 \% \quad 4.2 \%$ RLEPLGIIVK

$0.03 \% \quad 4.2 \%$ ANPLAYGISHK

$0.03 \% \quad 4.2 \%$ AYQIDPTLRK

$0.03 \% \quad 4.2 \%$ TGYFSSTDLGR

$0.03 \% \quad 4.2 \%$ VFNKYPTSK

$0.03 \% \quad 4.2 \%$ AVYIAPLK

$0.03 \% \quad 4.2 \%$ AGRPQFDDQGK

$0.03 \% \quad 4.2 \%$ VSDSLTDLALK

$0.01 \% \quad 11.8 \%$ LDGEASINNR

$0.01 \% \quad 11.8 \%$ EAMGIYISTLK

$0.01 \% \quad 11.8 \%$ GIPAPEEERTR

$0.01 \% \quad 11.8 \%$ QTFGYGAR

$0.01 \% \quad 16.2 \%$ NLLSAYGEVGR

$0.01 \% \quad 16.2 \%$ VAASLHNTPMGAR

$0.01 \% \quad 16.2 \%$ LRAEVAQAK

$0.01 \% \quad 16.2 \%$ ETDFYLQSVER

$0.01 \% \quad 11.4 \%$ AFAKELFLGK

$0.01 \% \quad 11.4 \%$ GIILAGTEEQKAK

$0.01 \% \quad 11.4 \%$ VAMNILNSGR

$0.01 \% \quad 11.4 \%$ LIEMTAEYACTR

$0.01 \% \quad 11.4 \%$ LSEFGLIQEK

$0.01 \% \quad 11.4 \%$ TVETLLLR

$0.01 \% \quad 11.4 \%$ VSQQILEK

$0.00 \% \quad 5.2 \%$ AATLILEPAGR

$0.00 \% \quad 5.2 \%$ GLAPEQPVTLR

$0.01 \% \quad 15.4 \%$ LFGGQIVGQALVAAAK

$0.01 \% \quad 15.4 \%$ LPVLYQVER

$0.01 \% \quad 15.4 \%$ RYPLALNR

$0.01 \% \quad 15.4 \%$ QDGVLAVTCAQEGVIR

$0.01 \% \quad 12.1 \%$ YLTVQNTVR

$0.01 \% \quad 12.1 \%$ IAFSSTSLLK

$0.01 \% \quad 12.1 \%$ SLEICHPQER

$0.01 \% \quad 12.1 \%$ VHSEVASLQEK

$0.01 \% \quad 12.1 \%$ TYGESMLYLDGQR

$0.01 \% \quad 23.3 \%$ SFPDFPTPGVVFR

$0.01 \% \quad 23.3 \%$ DISPVLKDPASFR

$0.01 \% \quad 23.3 \%$ ATHGGRIDYIAGLDSR

$0.01 \% \quad 23.3 \%$ IDYIAGLDSR

$0.00 \% \quad 5.3 \%$ GISEETTTGVHNLYK

$0.00 \% \quad 5.3 \% \quad$ IILLAEGR

$0.00 \% \quad 10.0 \%$ AVLLGPPGAGK

$0.00 \% \quad 10.0 \%$ LVSDEMVVELIEK $\begin{array}{llll}99.7 \% & 35.5 & 25.0 & 34.7\end{array}$

$\begin{array}{llll}99.7 \% & 37.6 & 25.0 & 30.1\end{array}$

$99.6 \% \quad 22.6 \quad 25.0 \quad 22.6$

$99.7 \% \quad 60.4 \quad 25.0 \quad 50.8$

$\begin{array}{llll}99.7 \% & 34.4 & 25.0 & 34.4\end{array}$

$97.9 \% \quad 21.5 \quad 25.0 \quad 14.4$

$99.7 \% \quad 40.0 \quad 25.0-40.0$

$\begin{array}{llll}99.7 \% & 36.3 & 25.0 & 28.5\end{array}$

$99.7 \% \quad 51.1 \quad 25.0 \quad 41.5$

$99.7 \% \quad 50.8 \quad 25.0 \quad 42.1$

$\begin{array}{lllll}99.7 \% & 38.0 & 25.0 & 34.0 & 2\end{array}$

$99.0 \% \quad 53.0 \quad 25.0 \quad 42.2$

$\begin{array}{llll}99.7 \% & 61.9 & 25.0 & 47.7\end{array}$

$\begin{array}{llll}99.7 \% & 43.4 & 25.0 & 43.4\end{array}$

$\begin{array}{llll}99.7 \% & 30.1 & 25.0 & 23.7\end{array}$

$99.7 \% \quad 46.4 \quad 25.0 \quad 46.4$

$\begin{array}{llll}99.7 \% & 34.5 & 25.0 & 34.5\end{array}$

$99.7 \% \quad 39.7 \quad 25.0 \quad 39.7$

$\begin{array}{llll}99.6 \% & 34.8 & 25.0 & 26.9\end{array}$

$99.7 \% \quad 43.6 \quad 25.0 \quad 43.6$

$\begin{array}{llll}99.0 \% & 21.3 & 25.0 & 16.5\end{array}$

$\begin{array}{llll}99.0 \% & 45.2 & 25.0 & 26.1\end{array}$

$\begin{array}{llll}98.8 \% & 24.2 & 25.0 & 14.2\end{array}$

$99.7 \% \quad 45.5 \quad 25.0 \quad 45.3 \quad 2$

$\begin{array}{llll}99.7 \% & 37.8 & 25.0 & 21.7\end{array}$

$99.7 \% \quad 55.0 \quad 25.0 \quad 51.9$

$\begin{array}{llll}99.7 \% & 54.1 & 25.0 & 50.2\end{array}$

$\begin{array}{llll}99.0 \% & 19.2 & 25.0 & 19.2\end{array}$

$99.7 \% \quad 44.1 \quad 25.0 \quad 44.1$

$\begin{array}{llll}99.7 \% & 33.8 & 25.0 & 28.4\end{array}$

$\begin{array}{llll}99.7 \% & 44.8 & 25.0 & 44.8\end{array}$

$\begin{array}{llll}99.7 \% & 44.3 & 25.0 & 44.3\end{array}$

$\begin{array}{lllll}97.7 \% & 21.0 & 25.0 & 13.3\end{array}$

$\begin{array}{llll}99.7 \% & 55.9 & 25.0 & 55.9\end{array}$

$\begin{array}{llll}99.7 \% & 33.8 & 25.0 & 33.8\end{array}$

$\begin{array}{llll}99.7 \% & 26.1 & 25.0 & 22.8\end{array}$

$\begin{array}{llll}99.7 \% & 26.1 & 25.0 & 25.4\end{array}$

$99.7 \% \quad 63.2 \quad 25.0 \quad 55.6$

$99.7 \% \quad 51.8 \quad 25.0 \quad 47.8$

$\begin{array}{llll}99.0 \% & 25.1 & 25.0 & 20.8\end{array}$

$\begin{array}{llll}99.6 \% & 23.1 & 25.0 & 23.1\end{array}$

$99.7 \% \quad 34.1 \quad 25.0 \quad 34.1$
1643.77

1977.05

1787.91

1311.75

1137.74

1170.63

1204.67

1203.56

1083.58

874.54

1218.59

1161.64

1088.53

1225.65

1254.64

899.44

1178.62

1340.67

985.58

1386.65

1123.65

1357.77

1090.57

1457.68

1163.63

944.58

944.54

1111.65

1180.67

1542.90

1116.64

1002.58

1715.87

1093.60

1066.61

1268.61

1226.64

1548.70

1465.75

1444.78

1701.87

1122.58

1648.82

884.56

979.59

1503.80

$\begin{array}{cc}01 & 214 \\ 20 & 232 \\ 33 & 250 \\ 00 & 316 \\ 74 & 384 \\ 53 & 562 \\ 28 & 938 \\ 39 & 948 \\ 73 & 983 \\ 66 & 1374 \\ 75 & 1382 \\ 90 & 1700 \\ 92 & 2202 \\ 4 & 73 \\ 46 & 156 \\ 06 & 316 \\ 29 & 336 \\ 4 & 74 \\ 21 & 133 \\ 71 & 179 \\ 81 & 191 \\ 8 & 47 \\ 52 & 164 \\ 95 & 304 \\ 18 & 329 \\ 36 & 345 \\ 11 & 518 \\ 01 & 608 \\ 2 & 12 \\ 5 & 35 \\ 4 & 69 \\ 2 & 100 \\ 70 & 177 \\ 94 & 309 \\ 04 & 112 \\ 41 & 250 \\ 95 & 304 \\ 73 & 383 \\ 08 & 420 \\ 5 & 27 \\ 8 & 40 \\ 2 & 67 \\ 8 & 67 \\ 52 & 166 \\ 36 & 343 \\ 8 & 28 \\ & 85 \\ & \end{array}$

8 
Adenylosuccinate lyase GN=ADSL

Adenylosuccinate lyase $\mathrm{GN}=\mathrm{ADSL}$

ADP/ATP translocase $1 \mathrm{GN}=\mathrm{SLC} 25 \mathrm{~A} 4$

$\mathrm{ADP} / \mathrm{ATP}$ translocase $1 \mathrm{GN}=\mathrm{SLC} 25 \mathrm{~A} 4$

ADP/ATP translocase $1 \mathrm{GN}=\mathrm{SLC} 25 \mathrm{~A} 4$

$\mathrm{ADP} / \mathrm{ATP}$ translocase $1 \mathrm{GN}=\mathrm{SLC} 25 \mathrm{~A}^{4}$

ADP/ATP translocase $1 \mathrm{GN}=\mathrm{SLC} 25 \mathrm{~A} 4$

ADP/ATP translocase $1 \mathrm{GN}=\mathrm{SLC} 25 \mathrm{~A} 4$

$\mathrm{ADP} / \mathrm{ATP}$ translocase $1 \mathrm{GN}=\mathrm{SLC} 25 \mathrm{~A} 4$

$\mathrm{ADP} / \mathrm{ATP}$ translocase $1 \mathrm{GN}=\mathrm{SLC} 25 \mathrm{~A} 4$

ADP/ATP translocase $1 \mathrm{GN}=\mathrm{SLC} 25 \mathrm{~A}$

ADP/ATP translocase $1 \mathrm{GN}=\mathrm{SLC} 25 \mathrm{~A} 4$

$\mathrm{ADP} / \mathrm{ATP}$ translocase $1 \mathrm{GN}=\mathrm{SLC} 25 \mathrm{~A} 4$

$\mathrm{ADP} / \mathrm{ATP}$ translocase $1 \mathrm{GN}=\mathrm{SLC} 25 \mathrm{~A} 4$

ADP/ATP translocase $1 \mathrm{GN}=\mathrm{SLC} 25 \mathrm{~A} 4$

$\mathrm{ADP} / \mathrm{ATP}$ translocase $1 \mathrm{GN}=\mathrm{SLC} 25 \mathrm{~A}$

ADP/ATP translocase $1 \mathrm{GN}=\mathrm{SLC} 25 \mathrm{~A} 4$

$\mathrm{ADP} / \mathrm{ATP}$ translocase $1 \mathrm{GN}=\mathrm{SLC} 25 \mathrm{~A} 4$

$\mathrm{ADP} / \mathrm{ATP}$ translocase $1 \mathrm{GN}=\mathrm{SLC} 25 \mathrm{~A}$

ADP/ATP translocase $1 \mathrm{GN}=\mathrm{SLC} 25 \mathrm{~A} 4$

$\mathrm{ADP} / \mathrm{ATP}$ translocase $2 \mathrm{GN}=\mathrm{SLC} 25 \mathrm{~A} 5$

$\mathrm{ADP} / \mathrm{ATP}$ translocase $2 \mathrm{GN}=\mathrm{SLC} 25 \mathrm{~A} 5$

ADP/ATP translocase $2 \mathrm{GN}=\mathrm{SLC} 25 \mathrm{~A} 5$

ADP/ATP translocase $2 \mathrm{GN}=\mathrm{SLC} 25 \mathrm{~A} 5$

ADP/ATP translocase $2 \mathrm{GN}=\mathrm{SLC} 25 \mathrm{~A} 5$

$\mathrm{ADP} / \mathrm{ATP}$ translocase $2 \mathrm{GN}=\mathrm{SLC} 25 \mathrm{~A} 5$

ADP/ATP translocase $2 \mathrm{GN}=\mathrm{SLC} 25 \mathrm{~A}$

ADP/ATP translocase $2 \mathrm{GN}=\mathrm{SLC} 25 \mathrm{~A} 5$

ADP/ATP translocase $2 \mathrm{GN}=\mathrm{SLC} 25 \mathrm{~A} 5$

ADP/ATP translocase $2 \mathrm{GN}=\mathrm{SLC} 25 \mathrm{~A} 5$

$\mathrm{ADP} / \mathrm{ATP}$ translocase $2 \mathrm{GN}=\mathrm{SLC} 25 \mathrm{~A} 5$

ADP/ATP translocase $2 \mathrm{GN}=\mathrm{SLC} 25 \mathrm{~A}$

ADP/ATP translocase $2 \mathrm{GN}=\mathrm{SLC} 25 \mathrm{~A} 5$

$\mathrm{ADP} / \mathrm{ATP}$ translocase $2 \mathrm{GN}=\mathrm{SLC} 25 \mathrm{~A} 5$

$\mathrm{ADP} / \mathrm{ATP}$ translocase $2 \mathrm{GN}=\mathrm{SLC} 25 \mathrm{~A} 5$

ADP/ATP translocase $2 \mathrm{GN}=\mathrm{SLC} 25 \mathrm{~A}$ s

ADP/ATP translocase $2 \mathrm{GN}=\mathrm{SLC} 25 \mathrm{~A}$

ADP/ATP translocase $2 \mathrm{GN}=\mathrm{SLC} 25 \mathrm{~A} 5$

$\mathrm{ADP} / \mathrm{ATP}$ translocase $2 \mathrm{GN}=\mathrm{SLC} 25 \mathrm{~A} 5$

ADP/ATP translocase $2 \mathrm{GN}=\mathrm{SLC} 25 \mathrm{~A}$

ADP/ATP translocase $2 \mathrm{GN}=\mathrm{SLC} 25 \mathrm{~A} 5$
RUR8_HUMAN $54.89 \quad 100.0 \%$ PUR8_HUMAN $54.89 \quad 100.0 \%$ ADT1_HUMAN $33.07 \quad 100.0 \%$ ADT1_HUMAN $33.07 \quad 100.0 \%$ ADT1_HUMAN $33.07 \quad 100.0 \%$ ADT1 HUMAN $33.07 \quad 100.0 \%$ ADT1_HUMAN $33.07 \quad 100.0 \%$ ADT1 HUMAN $33.07 \quad 100.0 \%$ ADT1 HUMAN $33.07 \quad 100.0 \%$ ADT1_HUMAN $33.07 \quad 100.0 \%$ ADT1 HUMAN $33.07 \quad 100.0 \%$ ADT1_HUMAN $33.07 \quad 100.0 \%$ ADT1_HUMAN $33.07 \quad 100.0 \%$ ADT1_HUMAN $33.07 \quad 100.0 \%$ ADT1_HUMAN $33.07 \quad 100.0 \%$ ADT1 HUMAN $33.07 \quad 100.0 \%$ ADT1 HUMAN $33.07 \quad 100.0 \%$ ADT1_HUMAN $33.07 \quad 100.0 \%$ ADT1_HUMAN $33.07 \quad 100.0 \%$ ADT1_HUMAN $33.07 \quad 100.0 \%$ ADT2_HUMAN $32.85 \quad 100.0 \%$ ADT2 HUMAN $32.85 \quad 100.0 \%$ ADT2_HUMAN $32.85 \quad 100.0 \% \quad 26$ ADT2 HUMAN $32.85 \quad 100.0 \% \quad 26$ ADT2_HUMAN $32.85 \quad 100.0 \% \quad 26$ ADT2_HUMAN $32.85 \quad 100.0 \% \quad 26$ ADT2 HUMAN $32.85 \quad 100.0 \% \quad 26$ ADT2_HUMAN $32.85 \quad 100.0 \% \quad 26$ ADT2_HUMAN $32.85 \quad 100.0 \% \quad 26$ ADT2 HUMAN $32.85 \quad 100.0 \% \quad 26$ ADT2_HUMAN $32.85 \quad 100.0 \% \quad 26$ ADT2 HUMAN $32.85 \quad 100.0 \% \quad 26$ ADT2_HUMAN $32.85 \quad 100.0 \% \quad 26$ ADT2_HUMAN $32.85 \quad 100.0 \% \quad 26$ ADT2 HUMAN $32.85 \quad 100.0 \% \quad 26$ ADT2_HUMAN $32.85 \quad 100.0 \% \quad 26$ ADT2 HUMAN $32.85 \quad 100.0 \% \quad 26$ ADT2_HUMAN $32.85 \quad 100.0 \% \quad 26$ ADT2_HUMAN $32.85 \quad 100.0 \% \quad 26$ ADT2 HUMAN $32.85 \quad 100.0 \% \quad 26$ ADT2_HUMAN $32.85 \quad 100.0 \% \quad 26$
0.01\% 29.1\% AVILGPPGSGK $0.01 \% 29.1 \%$ ASTEVGEMAK $0.01 \% \quad 29.1 \%$ SLLVPDHVITR $0.01 \% \quad 29.1 \%$ LMMSELENR $0.01 \% \quad 29.1 \%$ DVAKPVIELYK $0.01 \% \quad 29.1 \%$ GVLHQFSGTETNK

$0.00 \% \quad 3.5 \%$ NALDLLLPK $0.00 \% \quad 3.5 \%$ LADFAKER $0.01 \% 59.4 \%$ DFLAGGVAAAVSK $0.01 \% \quad 59.4 \%$ TAVAPIER $0.01 \% \quad 59.4 \%$ VKLLLQVQHASK $0.01 \% 59.4 \%$ LLLQVQHASK $0.01 \% \quad 59.4 \%$ GIIDCVVR $0.01 \% \quad 59.4 \%$ EQGFLSFWR $0.01 \% \quad 59.4 \%$ GNLANVIR $0.01 \% \quad 59.4 \%$ YFPTQALNFAFK $0.01 \% \quad 59.4 \%$ YFPTQALNFAFKDK $0.01 \% \quad 59.4 \%$ QLFLGGVDR $0.01 \% \quad 59.4 \%$ YFAGNLASGGAAGATSLCFVYPLDFAR $0.01 \% \quad 59.4 \%$ TRLAADVGK $0.01 \% \quad 59.4 \%$ EFHGLGDCIIK $0.01 \% 59.4 \%$ AAYFGVYDTAK $0.01 \% \quad 59.4 \%$ GADIMYTGTVDCWR $0.01 \% \quad 59.4 \%$ GAWSNVLR

$0.01 \% \quad 59.4 \%$ GMGGAFVLVLYDEIK $0.01 \% \quad 59.4 \%$ GMGGAFVLVLYDEIKK

$109 \quad 0.12 \% \quad 60.1 \%$ DFLAGGVAAAISK

$109 \quad 0.12 \% \quad 60.1 \%$ TAVAPIER

$109 \quad 0.12 \% \quad 60.1 \%$ VKLLLQVQHASK

$109 \quad 0.12 \% \quad 60.1 \%$ LLLQVQHASK

$109 \quad 0.12 \% \quad 60.1 \%$ GIIDCVVR

$109 \quad 0.12 \% \quad 60.1 \%$ IPKEQGVLSFWR

$109 \quad 0.12 \% \quad 60.1 \%$ EQGVLSFWR

$109 \quad 0.12 \% \quad 60.1 \%$ GNLANVIR

$109 \quad 0.12 \% \quad 60.1 \%$ YFPTQALNFAFK

$109 \quad 0.12 \% \quad 60.1 \%$ YFPTQALNFAFKDK

$109 \quad 0.12 \% \quad 60.1 \%$ YKQIFLGGVDK

$109 \quad 0.12 \% \quad 60.1 \%$ QIFLGGVDK

$109 \quad 0.12 \% \quad 60.1 \%$ QIFLGGVDKR

$109 \quad 0.12 \% \quad 60.1 \%$ TRLAADVGK

$109 \quad 0.12 \% \quad 60.1 \%$ LAADVGKAGAER

$109 \quad 0.12 \% \quad 60.1 \%$ EFRGLGDCLVK

$109 \quad 0.12 \% \quad 60.1 \%$ GLGDCLVK

$109 \quad 0.12 \% \quad 60.1 \%$ AAYFGIYDTAK

$109 \quad 0.12 \% \quad 60.1 \%$ AAYFGIYDTAKGMLPDP

$109 \quad 0.12 \% \quad 60.1 \%$ KGTDIMYTGTLDCWR $109 \quad 0.12 \% \quad 60.1 \%$ GTDIMYTGTLDCWR 
ADP/ATP translocase $2 \mathrm{GN}=\mathrm{SLC} 25 \mathrm{~A} 5$ $\mathrm{ADP} / \mathrm{ATP}$ translocase $2 \mathrm{GN}=\mathrm{SLC} 25 \mathrm{~A} 5$ $\mathrm{ADP} / \mathrm{ATP}$ translocase $2 \mathrm{GN}=\mathrm{SLC} 25 \mathrm{~A}$ ADP/ATP translocase $2 \mathrm{GN}=\mathrm{SLC} 25 \mathrm{~A} 5$ ADP/ATP translocase $2 \mathrm{GN}=\mathrm{SLC} 25 \mathrm{~A} 5$ $\mathrm{ADP} / \mathrm{ATP}$ translocase $3 \mathrm{GN}=\mathrm{SLC} 25 \mathrm{~A} 6$ $\mathrm{ADP} / \mathrm{ATP}$ translocase $3 \mathrm{GN}=\mathrm{SLC} 25 \mathrm{~A} 6$ $\mathrm{ADP} / \mathrm{ATP}$ translocase $3 \mathrm{GN}=\mathrm{SLC} 25 \mathrm{~A} 6$ $\mathrm{ADP} / \mathrm{ATP}$ translocase $3 \mathrm{GN}=\mathrm{SLC} 25 \mathrm{~A} 6$ $\mathrm{ADP} / \mathrm{ATP}$ translocase $3 \mathrm{GN}=\mathrm{SLC} 25 \mathrm{~A} 6$ ADP/ATP translocase $3 \mathrm{GN}=\mathrm{SLC} 25 \mathrm{~A} 6$ ADP/ATP translocase $3 \mathrm{GN}=\mathrm{SLC} 25 \mathrm{~A} 6$ ADP/ATP translocase $3 \mathrm{GN}=\mathrm{SLC} 25 \mathrm{~A} 6$ ADP/ATP translocase $3 \mathrm{GN}=\mathrm{SLC} 25 \mathrm{~A} 6$ $\mathrm{ADP} / \mathrm{ATP}$ translocase $3 \mathrm{GN}=\mathrm{SLC} 25 \mathrm{~A} 6$ $\mathrm{ADP} / \mathrm{ATP}$ translocase $3 \mathrm{GN}=\mathrm{SLC} 25 \mathrm{~A} 6$ $\mathrm{ADP} / \mathrm{ATP}$ translocase $3 \mathrm{GN}=\mathrm{SLC} 25 \mathrm{~A} 6$ ADP/ATP translocase $3 \mathrm{GN}=\mathrm{SLC} 25 \mathrm{~A} 6$ $\mathrm{ADP} / \mathrm{ATP}$ translocase $3 \mathrm{GN}=\mathrm{SLC} 25 \mathrm{~A} 6$ ADP/ATP translocase $3 \mathrm{GN}=\mathrm{SLC} 25 \mathrm{~A} 6$ $\mathrm{ADP} / \mathrm{ATP}$ translocase $3 \mathrm{GN}=\mathrm{SLC} 25 \mathrm{~A} 6$ ADP/ATP translocase $3 \mathrm{GN}=\mathrm{SLC} 25 \mathrm{~A} 6$ ADP/ATP translocase $3 \mathrm{GN}=\mathrm{SLC} 25 \mathrm{~A} 6$ ADP/ATP translocase $3 \mathrm{GN}=\mathrm{SLC} 25 \mathrm{~A} 6$ ADP/ATP translocase $3 \mathrm{GN}=\mathrm{SLC} 25 \mathrm{~A} 6$ $\mathrm{ADP} / \mathrm{ATP}$ translocase $3 \mathrm{GN}=\mathrm{SLC} 25 \mathrm{~A} 6$ ADP/ATP translocase $3 \mathrm{GN}=\mathrm{SLC} 25 \mathrm{~A} 6$

$\mathrm{AH}$ receptor-interacting protein $\mathrm{GN}=\mathrm{AIP}$

$\mathrm{AH}$ receptor-interacting protein $\mathrm{GN}=\mathrm{AIP}$

A-kinase anchor protein 8-like GN=AKAP8L AKP8L_HUM
A-kinase anchor protein 8-like GN=AKAP8L AKP8L_HUM

Aladin GN=AAAS

Aladin GN=AAAS

AAAS_HUMAN 59.57

AAAS HUMAN 59.57

Alanine--tRNA ligase, mitochondrial GN=AARS2 SYAM_HUMAN $107.34 \quad 100.0 \%$ Alanine--tRNA ligase, mitochondrial GN=AARS2 SYAM_HUMAN $107.34 \quad 100.0 \%$ Alanine--tRNA ligase, mitochondrial GN=AARS2 SYAM_HUMAN $107.34 \quad 100.0 \%$ Alanine--tRNA ligase, mitochondrial GN=AARS2 SYAM_HUMAN $107.34 \quad 100.0 \%$ Alanine--tRNA ligase, mitochondrial GN=AARS2 SYAM_HUMAN $107.34 \quad 100.0 \%$ Alanine--tRNA ligase, mitochondrial GN=AARS2 SYAM_HUMAN $107.34 \quad 100.0 \%$ Aldehyde dehydrogenase family 16 member Al GN=ALDH16A1 A16A1_HUMAN $85.13 \quad 100.0 \%$ Aldehyde dehydrogenase family 16 member $\mathrm{Al}$ GN=ALDH16A1 Al6A1 HUMAN $85.13 \quad 100.0 \%$ Aldehyde dehydrogenase X, mitochondrial GN=ALDH1B1 AL1B1_HUMAN $57.21 \quad 100.0 \%$ Aldehyde dehydrogenase $\mathrm{X}$, mitochondrial GN=ALDH1B1 AL1B1 HUMAN $57.21 \quad 100.0 \%$ Aldehyde dehydrogenase $\mathrm{X}$, mitochondrial GN=ALDHIB1 AL1B1_HUMAN $57.21 \quad 100.0 \%$ Aldehyde dehydrogenase X, mitochondrial GN=ALDH1B1 AL1B1_HUMAN $57.21 \quad 100.0 \%$ Aldehyde dehydrogenase $\mathrm{X}$, mitochondrial GN=ALDHIB1 AL1B1_HUMAN $57.21 \quad 100.0 \%$ Aldehyde dehydrogenase X, mitochondrial GN=ALDH1B1 AL1B1_HUMAN $57.21 \quad 100.0 \%$

6

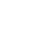

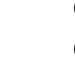

6

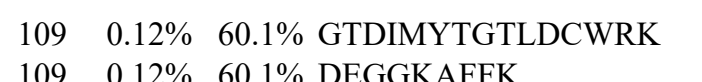

$109 \quad 0.12 \% \quad 60.1 \%$ GMGGAFVLVLYDEIK

$109 \quad 0.12 \% \quad 60.1 \%$ GMGGAFVLVLYDEIKK

$16 \quad 0.02 \% \quad 63.1 \%$ DFLAGGIAAAISK

$16 \quad 0.02 \% \quad 63.1 \%$ TAVAPIER

$16 \quad 0.02 \% \quad 63.1 \%$ VKLLLQVQHASK

$16 \quad 0.02 \% \quad 63.1 \%$ LLLQVQHASK

$16 \quad 0.02 \% \quad 63.1 \%$ IPKEQGVLSFWR

$16 \quad 0.02 \% \quad 63.1 \%$ EQGVLSFWR

$16 \quad 0.02 \% \quad 63.1 \%$ GNLANVIR

$16 \quad 0.02 \% \quad 63.1 \%$ YFPTQALNFAFK

$16 \quad 0.02 \% \quad 63.1 \%$ YFPTQALNFAFKDK

$16 \quad 0.02 \% \quad 63.1 \%$ YKQIFLGGVDK

$16 \quad 0.02 \% \quad 63.1 \%$ QIFLGGVDK

$16 \quad 0.02 \% \quad 63.1 \%$ YFAGNLASGGAAGATSLCFVYPLDFAR

$16 \quad 0.02 \% \quad 63.1 \%$ TRLAADVGK

$16 \quad 0.02 \% \quad 63.1 \%$ LAADVGKSGTER

$16 \quad 0.02 \% \quad 63.1 \%$ EFRGLGDCLVK

$16 \quad 0.02 \% \quad 63.1 \%$ GLGDCLVK

$16 \quad 0.02 \% \quad 63.1 \%$ AAYFGVYDTAK

$16 \quad 0.02 \% \quad 63.1 \%$ GADIMYTGTVDCWR

$16 \quad 0.02 \% \quad 63.1 \%$ DEGGKAFFK

$16 \quad 0.02 \% \quad 63.1 \%$ GAWSNVLR

$16 \quad 0.02 \% \quad 63.1 \%$ GMGGAFVLVLYDELK

$16 \quad 0.02 \% \quad 63.1 \%$ GMGGAFVLVLYDELKK $0.00 \% \quad 7.6 \%$ AVPLIHQEGNR

$0.00 \% \quad 7.6 \%$ VLELDPALAPVVSR

$0.00 \% \quad 2.9 \%$ IQFVCSLCK

$0.00 \% \quad 2.9 \% \quad$ SILNNKLISK

$0.00 \% \quad 4.4 \%$ VYNASSTIVPSLK

$0.00 \% \quad 4.4 \%$ ILATTPSAVFR

$0.01 \% \quad 6.9 \% \quad$ LVPSASVRPR

$11 \quad 0.01 \% \quad 6.9 \% \quad$ LAQEEAQHRAR

$11 \quad 0.01 \% \quad 6.9 \% \quad$ AGQEDVLFPVAR

$11 \quad 0.01 \% \quad 6.9 \% \quad$ SLDEVYPDPVR

$11 \quad 0.01 \% \quad 6.9 \% \quad$ LLAVTGEQAQQAR

$\begin{array}{llll}11 & 0.01 \% & 6.9 \% & \text { ELGQSLAQEVK }\end{array}$

$4 \quad 0.00 \% \quad 2.7 \%$ VAFCGAPEEGR

$4 \quad 0.00 \% \quad 2.7 \%$ EALLVANGTPR

$10 \quad 0.01 \% \quad 13.5 \%$ LAPALATGNTVVMK

$10 \quad 0.01 \% \quad 13.5 \%$ VLGYIQLGQK

$10 \quad 0.01 \% \quad 13.5 \%$ IAKEEIFGPVQPLFK

$10 \quad 0.01 \% \quad 13.5 \%$ KIEEVVER

$10 \quad 0.01 \% \quad 13.5 \%$ ELGEDGLKAYTEVK

$10 \quad 0.01 \% \quad 13.5 \%$ TVTIKVPQK $\begin{array}{lllll}99.3 \% & 24.3 & 25.0 & 24.3 & 1\end{array}$ $\begin{array}{llll}99.7 \% & 52.0 & 25.0 & 38.3\end{array}$ $\begin{array}{llll}99.0 \% & 58.5 & 25.0 & 41.2\end{array}$

$\begin{array}{llll}97.9 \% & 87.6 & 25.0 & 0.0\end{array}$

$\begin{array}{llll}99.3 \% & 45.3 & 25.0 & 0.0\end{array}$

$\begin{array}{llll}99.7 \% & 67.1 & 25.0 & 61.1\end{array}$

$99.0 \% \quad 41.9 \quad 25.0 \quad 29.6$

$\begin{array}{lllll}99.7 \% & 53.8 & 25.0 & 44.7 & 2\end{array}$

$\begin{array}{lllll}99.7 \% & 46.6 & 25.0 & 34.5 & 14\end{array}$

$\begin{array}{llll}99.6 \% & 24.0 & 25.0 & 24.0\end{array}$

$\begin{array}{lllll}99.7 \% & 56.6 & 25.0 & 47.6 & 8\end{array}$

$\begin{array}{llll}99.0 \% & 35.3 & 25.0 & 23.2\end{array}$

$\begin{array}{lllll}99.7 \% & 52.8 & 25.0 & 45.5 & 11\end{array}$

$99.7 \% \quad 72.2 \quad 25.0 \quad 70.4$

$99.7 \% \quad 41.0 \quad 25.0 \quad 41.0$

$\begin{array}{lllll}99.7 \% & 44.0 & 25.0 & 30.1 & 3\end{array}$

$\begin{array}{llll}99.7 \% & 52.1 & 25.0 & 49.6\end{array}$

$99.7 \% \quad 25.1 \quad 25.0 \quad 23.5$

$\begin{array}{llll}96.3 \% & 18.4 & 25.0 & 14.1\end{array}$

$\begin{array}{llll}99.0 \% & 32.8 & 25.0 & 20.2\end{array}$

$\begin{array}{llll}99.7 \% & 51.8 & 25.0 & 51.8\end{array}$

$\begin{array}{llll}99.7 \% & 31.8 & 25.0 & 31.8\end{array}$

$\begin{array}{llll}99.7 \% & 52.0 & 25.0 & 38.3\end{array}$

$\begin{array}{llll}99.0 \% & 58.5 & 25.0 & 41.2\end{array}$

$\begin{array}{lllll}97.9 \% & 87.6 & 25.0 & 0.0\end{array}$

$\begin{array}{llll}99.3 \% & 45.3 & 25.0 & 0.0\end{array}$

$\begin{array}{llll}99.5 \% & 22.1 & 25.0 & 19.1\end{array}$

$\begin{array}{lllll}99.7 \% & 49.6 & 25.0 & 49.6 & 2\end{array}$

$99.3 \% \quad 21.6 \quad 25.0 \quad 17.9$

$\begin{array}{llll}99.6 \% & 29.6 & 25.0 & 14.5\end{array}$

$\begin{array}{lllll}99.7 \% & 49.2 & 25.0 & 46.9 & 2\end{array}$

$\begin{array}{llll}98.7 \% & 18.6 & 25.0 & 18.6\end{array}$

$\begin{array}{llll}99.7 \% & 33.4 & 25.0 & 28.5\end{array}$

$\begin{array}{llll}99.5 \% & 21.5 & 25.0 & 21.5\end{array}$

$\begin{array}{llll}99.7 \% & 61.2 & 25.0 & 52.3\end{array}$

$\begin{array}{lllll}98.7 \% & 17.5 & 25.0 & 17.5 & 1\end{array}$

$\begin{array}{llll}99.7 \% & 66.8 & 25.0 & 56.6\end{array}$

$\begin{array}{llll}99.7 \% & 29.7 & 25.0 & 20.2\end{array}$

$\begin{array}{llll}99.7 \% & 42.3 & 25.0 & 37.6\end{array}$

$\begin{array}{llll}99.7 \% & 44.3 & 25.0 & 40.4\end{array}$

$\begin{array}{lllll}99.7 \% & 46.9 & 25.0 & 46.1 & 2\end{array}$

$\begin{array}{llll}99.7 \% & 32.2 & 25.0 & 29.7\end{array}$

$\begin{array}{llll}99.7 \% & 36.5 & 25.0 & 36.5\end{array}$

$\begin{array}{lllll}99.0 \% & 42.0 & 25.0 & 15.1 & 2\end{array}$

$\begin{array}{llll}99.7 \% & 30.6 & 25.0 & 29.1\end{array}$

$\begin{array}{llll}99.7 \% & 41.7 & 25.0 & 20.5\end{array}$

0

0

0

0

$\begin{array}{ll}0 & 0 \\ 6 & 0 \\ 0 & 0\end{array}$

0
0


Aldehyde dehydrogenase, mitochondrial GN=ALDH2 ALDH2_HUMAN $56.38 \quad 100.0 \%$ Aldehyde dehy Aldose reductase $\mathrm{GN}=\mathrm{AKR} 1 \mathrm{~B} 1$

Aldose reductase $\mathrm{GN}=\mathrm{AKR} 1 \mathrm{~B} 1$ Alpha-centractin $\mathrm{GN}=\mathrm{ACTR} 1 \mathrm{~A}$ Alpha-centractin GN=ACTR1A Alpha-centractin GN=ACTR1A Alpha-centractin GN=ACTR1A Alpha-centractin GN=ACTR1A Alpha-enolase $\mathrm{GN}=\mathrm{ENO} 1$

Alpha-enolase $\mathrm{GN}=\mathrm{ENO}$ Alpha-enolase $\mathrm{GN}=\mathrm{ENO}$ Alpha-enolase $\mathrm{GN}=\mathrm{ENO} 1$

Alpha-enolase $\mathrm{GN}=\mathrm{ENO} 1$ Alpha-enolase $\mathrm{GN}=\mathrm{ENO}$ Alpha-enolase $\mathrm{GN}=\mathrm{ENO} 1$ Alpha-enolase $\mathrm{GN}=\mathrm{ENO} 1$ Alpha-internexin GN=INA Alpha-internexin GN=INA Alpha-internexin GN=INA Alpha-internexin GN=INA Alpha-internexin GN=INA Alpha-internexin GN=INA Alpha-internexin GN=INA Alpha-internexin GN=INA Alpha-internexin GN=INA Alpha-internexin GN=INA Alpha-internexin GN=INA ALDR_HUMAN $35.85 \quad 100.0 \%$ ALDR HUMAN $35.85 \quad 100.0 \%$ ALDR_HUMAN $35.85 \quad 100.0 \%$ ACTZ_HUMAN $42.62 \quad 100.0 \%$ ACTZ HUMAN $42.62 \quad 100.0 \%$ ACTZ_HUMAN $42.62 \quad 100.0 \%$ ACTZ HUMAN $42.62 \quad 100.0 \%$ ACTZ_HUMAN $42.62 \quad 100.0 \%$ ENOA_HUMAN $47.17 \quad 100.0 \%$ ENOA_HUMAN $47.17 \quad 100.0 \%$ ENOA_HUMAN $47.17 \quad 100.0 \%$ ENOA_HUMAN $47.17 \quad 100.0 \%$ ENOA_HUMAN $47.17 \quad 100.0 \%$ AINX_HUMAN $55.39 \quad 100.0 \%$ AINX HUMAN $55.39 \quad 100.0 \%$ AINX_HUMAN $55.39 \quad 100.0 \%$ AINX_HUMAN $55.39 \quad 100.0 \%$ AINX HUMAN $55.39 \quad 100.0 \%$ AINX_HUMAN $55.39 \quad 100.0 \%$ AINX_HUMAN $55.39 \quad 100.0 \%$ AINX_HUMAN $55.39 \quad 100.0 \%$ AINX_HUMAN $55.39 \quad 100.0 \%$ AINX HUMAN $55.39 \quad 100.0 \%$ AINX_HUMAN $55.39 \quad 100.0 \%$ Aldose reductase $\mathrm{GN}=\mathrm{AKR} 1 \mathrm{~B} 1$ ENOA_HUMAN $47.17 \quad 100.0 \%$ ENOA HUMAN $47.17 \quad 100.0 \%$ ENOA_HUMAN $47.17 \quad 100.0 \%$ AIMP1 HUMAN $34.35 \quad 100.0 \%$

$100.0 \%$ $100.0 \%$

$100.0 \%$ $100.0 \%$ $100.0 \%$ $100.0 \%$ $100.0 \%$ $100.0 \%$ $100.0 \%$ $100.0 \%$ $100.0 \%$ $\begin{array}{lllll}\text { Aminoacyl tRNA synthase complex-interacting multifinctional protein } 2 \text { GN=AIMP2 } & \text { AIMP2_HUMAN } & 35.35 & 100.0 \% \\ \text { Aminoacy I tRNA synthase complex-interacting multifiunctional protein } 2 \text { GN=AIMP2 } & \text { AIMP2 HUMAN } & 35.35 & 100.0 \%\end{array}$ $\begin{array}{llll}\text { Aminoacyl tRNA synthase complex-interacting multifunctional protein } 2 \text { GN=AIMP2 } & \text { AIMP2_HUMAN } 35.35 & 100.0 \%\end{array}$ Anaphase-promoting complex subunit $1 \mathrm{GN}=\mathrm{ANAPC} 1$ APC1_HUMAN $216.50 \quad 100.0 \%$ Anaphase-promoting complex subunit $1 \mathrm{GN}=$ ANAPC1 APC1_HUMAN $216.50 \quad 100.0 \%$ Anaphase-promoting complex subunit $1 \mathrm{GN}=\mathrm{ANAPC} 1$ APC1_HUMAN $216.50 \quad 100.0 \%$ Anaphase-promoting complex subunit $1 \mathrm{GN}=\mathrm{ANAPC} 1 \mathrm{APC1}$ _HUMAN $216.50 \quad 100.0 \%$
$0.00 \% \quad 5.8 \% \quad$ VAEQTPLTALYVANLIK $0.00 \% \quad 5.8 \%$ VIQVAAGSSNLKR $0.01 \% \quad 8.9 \% \quad$ SPPGQVTEAVK

$0.01 \% \quad 8.9 \%$ REELFIVSK

$0.01 \% \quad 8.9 \%$ TTAQVLIR

$0.01 \% \quad 16.2 \%$ AGFAGDQIPK

$0.01 \% \quad 16.2 \%$ YCFPNYVGRPK

$0.01 \% \quad 16.2 \%$ VMAGALEGDIFIGPK

$0.01 \% \quad 16.2 \%$ IDIAGRDVSR

$0.01 \% \quad 16.2 \%$ EGYDFHSSSEFEIVK

$0.05 \% \quad 26.5 \%$ GNPTVEVDLFTSK

$0.05 \% \quad 26.5 \%$ IGAEVYHNLK

$0.05 \% \quad 26.5 \%$ DATNVGDEGGFAPNILENKEGLELLK

$0.05 \% \quad 26.5 \%$ VVIGMDVAASEFFR

$0.05 \% \quad 26.5 \%$ YISPDQLADLYK

$0.05 \% \quad 26.5 \%$ SCNCLLLK

$0.05 \% \quad 26.5 \%$ VNQIGSVTESLQACK

$0.02 \% \quad 23.2 \%$ LSGAGGAGGFR

$0.02 \% \quad 23.2 \%$ RPPASDGLDLSQAAAR

$0.02 \% \quad 23.2 \%$ ALEAELAALR

$0.02 \% \quad 23.2 \%$ AQLEEASSAR

$0.02 \% \quad 23.2 \%$ SQALLERDGLAEEVQR

$0.02 \% \quad 23.2 \%$ DVDGATLAR

$0.02 \% \quad 23.2 \%$ AQYESLAAK

$0.02 \% \quad 23.2 \%$ FANLNEQAAR

$0.02 \% \quad 23.2 \%$ HLREYQDLLNVK

$0.02 \% \quad 23.2 \%$ EYQDLLNVK

$0.02 \% \quad 23.2 \%$ SNIEETTISSQKI

$0.02 \% \quad 35.6 \%$ GAEADQIIEYLK

$0.02 \% \quad 35.6 \%$ AILQATLREEK

$0.02 \% \quad 35.6 \%$ KQQSIAGSADSKPIDVSR

$0.02 \% \quad 35.6 \%$ QQSIAGSADSKPIDVSR

$0.02 \% \quad 35.6 \%$ IGCIITAR

$0.02 \% \quad 35.6 \%$ MVILLCNLKPAK

$0.02 \% \quad 35.6 \%$ IEILAPPNGSVPGDR

$0.02 \% \quad 35.6 \%$ ITFDAFPGEPDKELNPK

$0.02 \% \quad 23.7 \%$ SYGPAPGAGHVQEESNLSLQALESR

$0.02 \% \quad 23.7 \%$ VLSTVHTHSSVK

$0.02 \% \quad 23.7 \%$ FSIQTMCPIEGEGNIAR

$0.02 \% \quad 23.7 \%$ FLFSLFGQK

$0.02 \% \quad 23.7 \%$ SCENLAPFNTALK

$0.01 \% \quad 2.3 \%$ SPSISNMAALSR

$0.01 \% \quad 2.3 \%$ VFITSDLCGQK

$0.01 \% \quad 2.3 \%$ HSTSVSSLAER

$0.01 \% \quad 2.3 \%$ HLYVLAAEPR $99.7 \% \quad 37.2$ $99.6 \% \quad 22.5$ $99.7 \% \quad 39.1$ $99.0 \% \quad 48.9$ $99.7 \% \quad 66.8$ $99.7 \% \quad 47.1$ $99.3 \% \quad 69.5$ $99.7 \% \quad 29.6$ $99.7 \% 34.1$ $99.7 \% \quad 64.5$ $99.7 \% \quad 60.4$ $\begin{array}{lll}99.7 \% & 48.8\end{array}$ $99.7 \% \quad 37.7$ $99.7 \% \quad 56.7$ $99.0 \% \quad 26.0$ $99.2 \% \quad 51.9$ $99.7 \% \quad 63.8$ $99.7 \% \quad 43.5$ $99.7 \% \quad 61.2$ $99.7 \% \quad 43.8$

$99.7 \% \quad 31.5$ $99.7 \% \quad 30.3$ $98.0 \% \quad 30.0$ $99.7 \% \quad 63.1$ $99.7 \% \quad 51.8$ $99.7 \% \quad 48.9$ $99.7 \% \quad 52.4$ $99.7 \% \quad 59.0$ $99.7 \% 44$. $99.7 \% \quad 46.0$ $99.0 \% 57.5$ $\begin{array}{lll}99.7 \% & 42.8\end{array}$ $99.7 \% \quad 43.1$ $99.3 \% \quad 24.1$ $\begin{array}{lll}99.7 \% & 42.0\end{array}$ $99.7 \% \quad 45.5$ $99.7 \% \quad 58.9$ $99.7 \% \quad 37.5$ $99.7 \% \quad 45.2$ $99.7 \% \quad 54.8$ $99.7 \% \quad 41.4$ $98.0 \% 17$. $99.7 \% \quad 46.1$
1844.05

1342.78

1112.59

1120.64

901.55

1003.52

1400.68

1533.80

1101.60

1773.80

1406.72

1939.98

1143.62

2743.38

1556.78

1425.73

1007.50

1633.82

949.49

1624.84

1056.60

1061.52

1813.94

917.47

980.50

1133.57

1527.83

1121.58

1449.74

1349.69

1271.73

1886.99

1758.90

903.51

2037.05

1399.82

1534.82

1917.96

2597.26

1294.71

1922.91

1086.60

1464.72

1233.63

1267.64

1173.59

1168.65

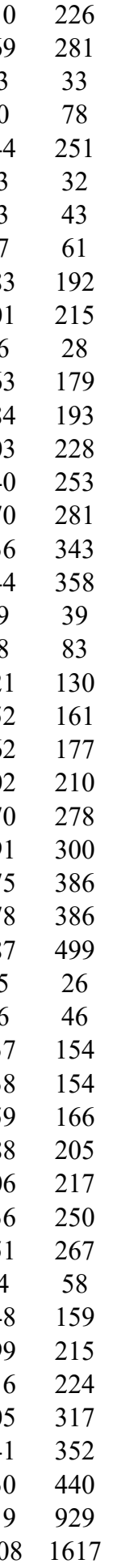

Page 24 of Table S-1-5 

Anaphase-promoting complex subunit $7 \mathrm{GN}=$ ANAPC7 APC7_HUMAN $66.86 \quad 100.0 \%$ Anaphase-promoting complex subunit $7 \mathrm{GN}=\mathrm{ANAPC} 7 \mathrm{APC} 7 \mathrm{HUMAN} 66.86 \quad 100.0 \%$ Anaphase-promoting complex subunit 7 GN=ANAPC7 APC7_HUMAN $66.86 \quad 100.0 \%$ Anaphase-promoting complex subunit $7 \mathrm{GN}=$ ANAPC7 APC7_HUMAN $66.86 \quad 100.0 \%$ Ancient ubiquitous protein $1 \mathrm{GN}=\mathrm{AUP} 1$ AUP1 HUMAN $53.03 \quad 100.0 \%$ Ancient ubiquitous protein $1 \mathrm{GN}=$ AUP1 AUP1_HUMAN $53.03 \quad 100.0 \%$ Ancient ubiquitous protein $1 \mathrm{GN}=\mathrm{AUP} 1$ Ancient ubiquitous protein $1 \mathrm{GN}=\mathrm{AUP} 1$ Ancient ubiquitous protein $1 \mathrm{GN}=\mathrm{AUP} 1$ Ancient ubiquitous protein $1 \mathrm{GN}=\mathrm{AUP} 1$ Ancient ubiquitous protein $1 \mathrm{GN}=\mathrm{AUP} 1$ Annexin A1 GN=ANXA1

Annexin A1 GN=ANXA1 Annexin A1 GN=ANXA Annexin A2 GN=ANXA2 Annexin A2 GN=ANXA2 Annexin A2 GN=ANXA2 Annexin A6 GN=ANXA6 Annexin A6 GN=ANXA6 Antigen KI-67 GN=MKI67 Antigen KI-67 GN=MKI67 AUP1_HUMAN $53.03 \quad 100.0 \%$ AUP1_HUMAN $53.03 \quad 100.0 \%$ AUP1_HUMAN $53.03 \quad 100.0 \%$ AUP1 HUMAN $53.03 \quad 100.0 \%$ AUP1_HUMAN $53.03 \quad 100.0 \%$ ANXA1_HUMAN $38.72 \quad 100.0 \%$ ANXA1_HUMAN $38.72 \quad 100.0 \%$ ANXA1_HUMAN $38.72 \quad 100.0 \%$ ANXA2 HUMAN $38.61 \quad 100.0 \%$ ANXA2_HUMAN $38.61 \quad 100.0 \%$ ANXA2_HUMAN $38.61 \quad 100.0 \%$ ANXA6 HUMAN $75.88 \quad 100.0 \%$ ANXA6_HUMAN $75.88 \quad 100.0 \%$ KI67 HUMAN $358.70 \quad 100.0 \%$ KI67 HUMAN $358.70 \quad 100.0 \%$ AP-1 complex subunit beta-1 GN=AP1B1 AP1B1_HUMAN $104.64 \quad 100.0 \%$ AP-1 complex subunit beta-1 GN=AP1B1 AP1B1_HUMAN $104.64100 .0 \%$ AP-1 complex subunit beta-1 GN=AP1B1 AP1B1_HUMAN $104.64 \quad 100.0 \%$ AP-1 complex subunit beta-1 GN=AP1B1 AP1B1_HUMAN $104.64 \quad 100.0 \%$ AP-1 complex subunit gamma-1 GN=AP1G1 AP1G1_HUMAN $91.35100 .0 \%$ AP-1 complex subunit gamma-1 GN=AP1G1 AP1G1_HUMAN $91.35100 .0 \%$ AP-1 complex subunit gamma-1 GN=AP1G1 AP1G1_HUMAN $91.35100 .0 \%$ AP-1 complex subunit gamma-1 GN=AP1G1 AP1G1_HUMAN $91.35 \quad 100.0 \%$ AP-1 complex subunit mu-1 GN=AP1M1 AP1M1_HUMAN $48.59 \quad 100.0 \%$ AP-1 complex subunit mu-1 GN=AP1M1 AP1M1_HUMAN $48.59 \quad 100.0 \%$ AP-1 complex subunit mu-1 GN=AP1M1 AP1M1_HUMAN $48.59 \quad 100.0 \%$ AP-1 complex subunit mu-1 GN=AP1M1 AP1M1 HUMAN $48.59 \quad 100.0 \%$ AP-1 complex subunit mu-1 GN=AP1M1 AP1M1_HUMAN $48.59 \quad 100.0 \%$ AP-1 complex subunit mu-1 GN=AP1M1 AP1M1_HUMAN $48.59 \quad 100.0 \%$ AP-1 complex subunit mu-1 GN=AP1M1 AP1M1 HUMAN $48.59 \quad 100.0 \%$ AP-1 complex subunit mu-1 GN=AP1M1 AP1M1_HUMAN $48.59 \quad 100.0 \%$ AP-1 complex subunit mu-1 GN=AP1M1 AP1M1_HUMAN $48.59 \quad 100.0 \%$ AP-1 complex subunit mu-1 GN=AP1M1 AP1M1_HUMAN $48.59 \quad 100.0 \%$ AP-2 complex subunit alpha-1 GN=AP2A1 AP2A1_HUMAN $107.55 \quad 100.0 \%$ AP-2 complex subunit alpha-1 GN=AP2A1 AP2A1 HUMAN $107.55100 .0 \%$ AP-2 complex subunit $\mathrm{mu}$ GN=AP2M1 AP-2 complex subunit mu GN=AP2M AP-2 complex subunit mu GN=AP2M AP-2 complex subunit mu GN=AP2M1 AP2M1_HUMAN $49.66 \quad 100.0 \%$ AP2M1_HUMAN $49.66 \quad 100.0 \%$ AP2M1 HUMAN $49.66 \quad 100.0 \%$ AP2M1_HUMAN $49.66 \quad 100.0 \%$

$110.01 \% \quad 11.5 \%$ DMAAAGLHSNVR $0.01 \% \quad 11.5 \%$ AISTICSLEK

$11 \quad 0.01 \% \quad 11.5 \%$ EGRLEDVENLGCR $0.01 \% \quad 11.5 \%$ VQEAIIHFR $0.01 \% \quad 11.5 \%$ EQKYEDGIALLR $0.01 \% \quad 11.5 \%$ NALANQSDCVLHR $0.02 \% \quad 20.0 \%$ TMCAVLGLVAR $0.02 \% \quad 20.0 \%$ LPPTPLLLFPEEEATNGR $0.02 \% \quad 20.0 \%$ QLGEANEEFALR $0.02 \% \quad 20.0 \%$ VKEVLPHVPLGVIQR $0.02 \% \quad 20.0 \%$ GTQSLPTASASK

$99.7 \% \quad 35.1$

$99.6 \% 29.3$ $99.7 \% 53.5$ $99.7 \% \quad 29.2$ $99.7 \% \quad 67.6$ $99.7 \% \quad 60.4$ $99.7 \% \quad 40.2$ $99.7 \% \quad 61.9$ $95.6 \% \quad 14.3$ $99.7 \% \quad 53.7$ $0.02 \% \quad 20.0 \%$ FPSSGPVTPQPTALTFAK $\quad 99.7 \% \quad 46.5$ $0.02 \% \quad 20.0 \%$ KQALYEYAR $99.7 \% \quad 36.2$ $0.01 \% \quad 12.1 \%$ AAYLQETGKPLDETLKK $99.2 \% 22.5$ $0.01 \% \quad 12.1 \%$ TPAQFDADELR $0.01 \% \quad 12.1 \%$ GTDVNVFNTILTTR $0.01 \% \quad 9.7 \%$ GVDEVTIVNILTNR $0.01 \% \quad 9.7 \%$ QDIAFAYQR $0.01 \% \quad 9.7 \%$ TNQELQEINR $0.00 \% \quad 3.3 \%$ DAFVAIVQSVK $0.00 \% \quad 3.3 \%$ GAGTDEKTLTR $0.00 \% \quad 0.8 \%$ SGASEANLIVAK $0.00 \% \quad 0.8 \% \quad$ SPQSDPADTPTNTK $0.01 \% \quad 4.4 \%$ CAIKVEQSAER $0.01 \% \quad 4.4 \%$ LLSTDPVAAK $0.01 \% \quad 4.4 \%$ GLEISGTFTR $0.01 \% \quad 4.4 \% \quad$ LQSSNIFTVAK $0.01 \% \quad 3.7 \%$ KAALCAVHVIR $0.01 \% \quad 3.7 \%$ AALCAVHVIR $0.01 \% \quad 3.7 \%$ VLAINILGR $0.01 \% \quad 3.7 \%$ VLNPQKQQLR $0.02 \% \quad 26.5 \%$ HNNLYLVATSK $0.02 \% \quad 26.5 \%$ ILQEYITQEGHK $0.02 \% \quad 26.5 \%$ SEIVGSIK $0.02 \% \quad 26.5 \%$ VFLSGMPELR $0.02 \% \quad 26.5 \%$ LGLNDKVLFDNTGR $0.02 \% \quad 26.5 \%$ SVELEDVKFHQCVR $0.02 \% \quad 26.5 \%$ STANNVEIHIPVPNDADSPK $0.02 \% \quad 26.5 \%$ SGYQALPWVR $0.02 \% \quad 26.5 \%$ YITQNGDYQLR $0.02 \% \quad 26.5 \%$ YITQNGDYQLRTQ $0.00 \% \quad 2.1 \% \quad$ LVECLETVLNK $0.00 \% \quad 2.1 \% \quad$ ALQVGCLLR $0.01 \% \quad 13.3 \%$ NAVDAFRVNVIHAR $0.01 \% \quad 13.3 \%$ SPVTNIAR $0.01 \% \quad 13.3 \%$ TFITQQGIK $0.01 \% \quad 13.3 \%$ LSKFDSER

\section{$99.7 \% \quad 51.9$}

$99.7 \% \quad 33.3$

$99.7 \% \quad 68.6$

$99.7 \% \quad 60.9$

$99.7 \% \quad 36.5$

$99.7 \% \quad 47$.

$99.7 \% \quad 54.9$

$99.4 \% \quad 34.5$

$99.7 \% \quad 45.8$

$99.7 \% \quad 33.1$

$99.7 \% \quad 28.1$

$99.6 \% 25.4$

$96.9 \% \quad 15.6$

$99.3 \% \quad 19.2$

$99.7 \% \quad 58.2$

$99.7 \% 32.6$

$99.6 \% \quad 27.7$

$99.7 \% \quad 50.2$

$99.7 \% \quad 69.6$

$97.1 \% \quad 17.2$

$99.6 \% 24.7$

$99.7 \% \quad 41.8$

$\begin{array}{lll}99.6 \% & 26.2\end{array}$

$99.7 \% \quad 37.8$

$99.7 \% \quad 39.0$

$99.7 \% \quad 47.5$

$99.7 \% \quad 59.7$

$99.6 \% \quad 36.1$

$97.3 \% \quad 24.2$

$99.7 \% 37.1$

$99.0 \% \quad 29.6$

$99.7 \% 35.1$

$99.0 \% \quad 41.2$
1241.61

1121.59

1546.73

1112.62

1434.76

1497.72

1190.64

1994.06

1376.68

1684.03

1147.60

1845.97

1141.60

1905.03

1262.60

1550.82

1542.85

1111.55

1244.62

1176.66

1148.59

1159.63

1458.67

1290.65

1014.58

1080.57

1207.67

1237.72

1109.62

968.63

1223.72

1259.67

1458.76

832.48

1164.61

1561.83

1745.86

2118.05

1176.62

1370.67

1599.78

1317.71

1029.59

1581.86

857.48

1035.58

981.50 $\begin{array}{cc}3 & 54 \\ 54 & 263 \\ 18 & 330 \\ 89 & 397 \\ 89 & 500 \\ 01 & 513 \\ 8 & 78 \\ 17 & 234 \\ 98 & 309 \\ 70 & 384 \\ 14 & 425 \\ 26 & 443 \\ 56 & 464 \\ 2 & 98 \\ 14 & 124 \\ 15 & 228 \\ 0 & 63 \\ 9 & 77 \\ 36 & 145 \\ 88 & 598 \\ 14 & 624 \\ 48 & 659 \\ 861 & 1874 \\ 80 & 390 \\ 29 & 538 \\ 31 & 740 \\ 77 & 887 \\ 56 & 166 \\ 57 & 166 \\ 07 & 315 \\ 84 & 793 \\ 62 & 72 \\ 30 & 141 \\ 92 & 199 \\ 02 & 211 \\ 12 & 225 \\ 30 & 243 \\ 05 & 324 \\ 01 & 410 \\ 11 & 421 \\ 11 & 423 \\ 80 & 290 \\ 36 & 944 \\ 77 & 40 \\ & 52 \\ & \\ 31 & \end{array}$ 
AP-2 complex subunit mu GN=AP2M1 AP2M1_HUMAN $49.66 \quad 100.0 \%$ AP-2 complex subunit mu GN=AP2M1 AP2M1_HUMAN $49.66 \quad 100.0 \%$ AP-3 complex subunit delta-1 GN=AP3D1 AP3D1_HUMAN $130.16 \quad 100.0 \%$ AP-3 complex subunit delta-1 GN=AP3D1 AP3D1_HUMAN $130.16100 .0 \%$ AP-3 complex subunit delta-1 GN=AP3D1 AP3D1_HUMAN $130.16 \quad 100.0 \%$ AP-3 complex subunit delta-1 GN=AP3D1 AP3D1_HUMAN $130.16 \quad 100.0 \%$ AP-3 complex subunit sigma-1 GN=AP3S1 AP3S1_HUMAN $21.73 \quad 100.0 \%$ AP-3 complex subunit sigma-1 GN=AP3S1 AP3S1_HUMAN $21.73 \quad 100.0 \%$ Apoptosis-inducing factor 1, mitochondrial GN=AIFM1 AIFM1_HUMAN $66.90 \quad 100.0 \%$ Apoptosis-inducing factor 1, mitochondrial GN=AIFM1 AIFM1_HUMAN $66.90 \quad 100.0 \%$ Apoptosis-inducing factor 1, mitochondrial GN=AIFM1 AIFM1_HUMAN $66.90 \quad 100.0 \%$ Apoptosis-inducing factor 1, mitochondrial GN=AIFM1 AIFM1_HUMAN $66.90 \quad 100.0 \%$ Apoptosis-inducing factor 1, mitochondrial GN=AIFM1 AIFM1_HUMAN $66.90 \quad 100.0 \%$ Apoptosis-inducing factor 1, mitochondrial GN=AIFM1 AIFM1_HUMAN $66.90 \quad 100.0 \%$ Apoptosis-inducing factor 1, mitochondrial GN=AIFM1 AIFM1_HUMAN $66.90 \quad 100.0 \%$ Apoptosis-inducing factor 1, mitochondrial GN=AIFM1 AIFM1_HUMAN $66.90 \quad 100.0 \%$ Apoptotic chromatin condensation inducer in the nucleus GN=ACIN1 ACINU_HUMAN $151.86 \quad 100.0 \%$ Apoptotic chromatin condensation inducer in the nucleus GN=ACIN1 ACINU_HUMAN $151.86 \quad 100.0 \%$ Apoptotic chromatin condensation inducer in the nucleus GN=ACIN1 ACINU_HUMAN $151.86 \quad 100.0 \%$ Apoptotic chromatin condensation inducer in the nucleus GN=ACIN1 ACINU_HUMAN $151.86 \quad 100.0 \%$ Apoptotic chromatin condensation inducer in the nucleus GN=ACIN1 ACINU_HUMAN $151.86 \quad 100.0 \%$ Apoptotic chromatin condensation inducer in the nucleus GN=ACIN 1 ACINU HUMAN $151.86 \quad 100.0 \%$ Apoptotic chromatin condensation inducer in the nucleus GN=ACIN1 ACINU_HUMAN $151.86 \quad 100.0 \%$ Apoptotic chromatin condensation inducer in the nucleus GN=ACIN1 ACINU_HUMAN $151.86 \quad 100.0 \%$ Apoptotic chromatin condensation inducer in the nucleus GN=ACIN1 ACINU_HUMAN $151.86 \quad 100.0 \%$ Apoptotic chromatin condensation inducer in the nucleus GN=ACIN1 ACINU_HUMAN $151.86 \quad 100.0 \%$ Apoptotic chromatin condensation inducer in the nucleus GN=ACIN1 ACINU_HUMAN $151.86 \quad 100.0 \%$ Arginase-1 GN=ARG1 Arginase-1 GN=ARG1 ARGII HUMAN $34.74 \quad 100.0 \%$ ARGI_HUMAN $34.74 \quad 100.0 \%$ Arginine and glutamate-rich protein $1 \mathrm{GN}=\mathrm{ARGLU} 1$ ARGL1 HUMAN $33.22 \quad 100.0 \%$ Arginine and glutamate-rich protein $1 \mathrm{GN}=$ ARGLU1 ARGL1_HUMAN $33.22 \quad 100.0 \%$ Arginine--tRNA ligase, cytoplasmic GN=RARS SYRC_HUMAN $75.38 \quad 100.0 \%$ Arginine--tRNA ligase, cytoplasmic GN=RARS SYRC_HUMAN $75.38 \quad 100.0 \%$ Arginine--tRNA ligase, cytoplasmic GN=RARS SYRC_HUMAN $75.38 \quad 100.0 \%$ Arginine--tRNA ligase, cytoplasmic GN=RARS SYRC_HUMAN $75.38 \quad 100.0 \%$ Arginine--tRNA ligase, cytoplasmic GN=RARS SYRC_HUMAN $75.38 \quad 100.0 \%$ Arginine--tRNA ligase, cytoplasmic GN=RARS SYRC_HUMAN $75.38 \quad 100.0 \%$ Arginine--tRNA ligase, cytoplasmic GN=RARS SYRC HUMAN $75.38 \quad 100.0 \%$ Arginine--tRNA ligase, cytoplasmic GN=RARS SYRC_HUMAN $75.38 \quad 100.0 \%$ Arginine--tRNA ligase, cytoplasmic GN=RARS SYRC_HUMAN $75.38 \quad 100.0 \%$ Arginine--tRNA ligase, cytoplasmic GN=RARS SYRC_HUMAN $75.38 \quad 100.0 \%$ Arginine--tRNA ligase, cytoplasmic GN=RARS SYRC_HUMAN $75.38 \quad 100.0 \%$ Armadillo repeat-containing protein $8 \mathrm{GN}=$ ARMC8 ARMC8_HUMAN $75.51 \quad 100.0 \%$ Armadillo repeat-containing protein $8 \mathrm{GN}=$ ARMC8 ARMC8_HUMAN $75.51 \quad 100.0 \%$ Asparagine synthetase [glutamine-hydrolyzing] GN=ASNS ASNS_HUMAN $64.37 \quad 100.0 \%$ Asparagine synthetase [glutamine-hydrolyzing] GN=ASNS ASNS_HUMAN $64.37 \quad 100.0 \%$ Asparagine synthetase [glutamine-hydrolyzing] GN=ASNS ASNS_HUMAN $64.37 \quad 100.0 \%$
$0.01 \% \quad 13.3 \%$ SNFKPSLLAQK $0.01 \% \quad 13.3 \%$ SGIYETRC $0.01 \% \quad 3.7 \%$ ASCILQLVK $0.01 \% \quad 3.7 \%$ AVFHEEEQRRPK $0.01 \% \quad 3.7 \%$ HRPSEADEEELAR $0.01 \% \quad 3.7 \%$ MSFQNLLAK $0.00 \% \quad 10.4 \%$ SEAGLAGAPAR $0.00 \% \quad 10.4 \%$ NMNLPEIPR $0.02 \% \quad 14.7 \%$ ISGLGLTPEQK $0.02 \% \quad 14.7 \%$ ELWFSDDPNVTK $0.02 \% \quad 14.7 \%$ LNDGSQITYEK $0.02 \% \quad 14.7 \%$ CLIATGGTPR $0.02 \% \quad 14.7 \%$ SLSAIDRAGAEVK $0.02 \% \quad 14.7 \%$ EGVKVMPNAIVQSVGVSSGK $0.02 \% \quad 14.7 \%$ VMPNAIVQSVGVSSGK $0.02 \% \quad 14.7 \%$ RVEHHDHAVVSGR $0.03 \% \quad 8.6 \%$ VTDLKAALEQR $0.03 \% \quad 8.6 \%$ GALMLENLQK $0.03 \% \quad 8.6 \%$ SSSISEEKGDSDDEKPR $0.03 \% \quad 8.6 \%$ SQEQEVLER $0.03 \% \quad 8.6 \%$ STLADYSAQK $0.03 \% \quad 8.6 \%$ RLSQPESAEK $0.03 \% \quad 8.6 \%$ GVPAGNSDTEGGQPGR $0.03 \% \quad 8.6 \%$ WGASTATTQK $0.03 \% \quad 8.6 \%$ VTLGDTLTR $0.03 \% \quad 8.6 \%$ VTLGDTLTRR $0.03 \% \quad 8.6 \%$ SGVSITIDDPVR $0.00 \% \quad 9.0 \%$ GGVEEGPTVLR $0.00 \% \quad 9.0 \%$ TGLLSGLDIMEVNPSLGK $0.00 \% \quad 8.4 \%$ QQEIEEKLIEEETAR $0.00 \% \quad 8.4 \%$ QLLEELER $0.04 \% \quad 17.7 \%$ NMINIISR

$0.04 \% \quad 17.7 \%$ EIAENITK $0.04 \% \quad 17.7 \%$ VIVDFSSPNIAK $0.04 \% \quad 17.7 \%$ STIIGESISR $0.04 \% \quad 17.7 \%$ AYQCVVLLQGK $\begin{array}{lllllll}0.04 \% & 17.7 \% & \text { AYQCVVLLQGKNPDITK } & 99.7 \% & 34.3 & 25.0 & 34.3\end{array}$

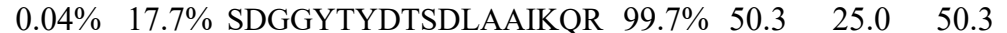
$0.04 \% \quad 17.7 \%$ LMDLLGEGLKR $0.04 \% \quad 17.7 \%$ LNDYIFSFDK $0.04 \% \quad 17.7 \%$ LANIDEEMLQK $0.04 \% \quad 17.7 \%$ GFDILGIKPVQR $0.00 \% \quad 3.0 \% \quad$ VLQGVIDMK $0.00 \% \quad 3.0 \%$ ANLIVLGAVPR $0.01 \% \quad 9.6 \%$ DTYGVRPLFK $0.01 \% \quad 9.6 \%$ AMTEDGFLAVCSEAK $0.01 \% \quad 9.6 \%$ EAFSDGITSVK
$99.6 \% \quad 26.2$ $99.0 \% \quad 32.0$ $99.2 \% \quad 30.8$ $98.9 \% \quad 20.3$ $99.7 \% \quad 47.0$ $99.6 \% \quad 26.5$ $99.7 \% \quad 61.8$ $96.3 \% \quad 17.8$ $99.7 \% \quad 50.0$ $99.7 \% \quad 35.8$ $99.7 \% \quad 53.2$ $99.7 \% \quad 52.3$ $99.7 \% \quad 54.0$ $99.7 \% \quad 48.1$ $.7 \% \quad 53.8$ $99.7 \% \quad 48.0$ $97.6 \% \quad 16.3$ $99.7 \% \quad 33.6$ $99.7 \% \quad 47.5$ $\begin{array}{lll}99.4 \% & 19.2\end{array}$ $99.7 \% \quad 31.3$

$99.7 \% \quad 52.4$ $99.7 \% \quad 45.9$ $99.7 \% \quad 42.1$ $97.3 \% \quad 16.6$ $99.7 \% \quad 58.2$ $98.6 \% 21.6$ $99.6 \% 22.1$ $97.0 \% \quad 24.2$ $99.0 \% \quad 27.5$ $99.0 \% 39.8$ $99.7 \% \quad 41.4$ $99.7 \% \quad 60.8$ $99.7 \% \quad 67.0$ $\begin{array}{llll}99.7 \% & 61.4 & 25.0 & 53.1\end{array}$ $\begin{array}{llll}99.1 \% & 23.3 & 25.0 & 23.3\end{array}$ $99.7 \% \quad 44.3 \quad 25.0 \quad 41.6$ $\begin{array}{llll}99.7 \% & 60.2 & 25.0 & 46.0\end{array}$ $\begin{array}{llll}97.2 \% & 19.4 & 25.0 & 13.8\end{array}$ $\begin{array}{llll}99.7 \% & 51.0 & 25.0 & 42.9\end{array}$ $\begin{array}{llll}99.7 \% & 39.6 & 25.0 & 35.9\end{array}$ $\begin{array}{llll}99.7 \% & 52.0 & 25.0 & 52.0\end{array}$ $\begin{array}{llll}99.7 \% & 53.2 \quad 25.0 \quad 53.2\end{array}$ $\begin{array}{ccc}1232.70 & 309 & 319 \\ 985.44 & 428 & 435 \\ 1031.59 & 572 & 580 \\ 1525.79 & 643 & 654 \\ 1538.72 & 655 & 667 \\ 1051.56 & 1079 & 1087 \\ 999.52 & 150 & 160 \\ 1099.56 & 167 & 175 \\ 1142.64 & 99 & 109 \\ 1450.69 & 178 & 189 \\ 1267.62 & 245 & 255 \\ 1045.55 & 256 & 265 \\ 1316.72 & 266 & 278 \\ 2002.06 & 359 & 378 \\ 1572.84 & 363 & 378 \\ 1498.76 & 451 & 463 \\ 1243.70 & 77 & 87 \\ 1116.61 & 104 & 113 \\ 1865.84 & 206 & 222 \\ 1117.55 & 328 & 336 \\ 1083.53 & 507 & 516 \\ 1144.60 & 708 & 717 \\ 1498.69 & 832 & 847 \\ 1050.52 & 851 & 860 \\ 975.55 & 971 & 979 \\ 1131.65 & 971 & 980 \\ 1258.66 & 987 & 998 \\ 1113.59 & 22 & 32 \\ 1859.98 & 267 & 284 \\ 1844.92 & 118 & 132 \\ 1029.56 & 171 & 178 \\ 960.53 & 72 & 79 \\ 917.49 & 136 & 143 \\ 1289.71 & 194 & 205 \\ 1062.58 & 214 & 223 \\ 1278.69 & 290 & 300 \\ 1947.04 & 290 & 306 \\ 1960.92 & 378 & 395 \\ 1244.70 & 462 & 472 \\ 1261.61 & 513 & 522 \\ 1303.66 & 547 & 557 \\ 1342.78 & 648 & 659 \\ 1018.56 & 36 & 44 \\ 1122.70 & 55 & 65 \\ 1195.65 & 138 & 147 \\ 1628.73 & 148 & 162 \\ 1153.57 & 468 & 478 \\ & & \end{array}$

Page 26 of Table S-1-5 

ATP synthase subunit alpha, mitochondrial GN=ATP5A1 ATPA_HUMAN $59.75 \quad 100.0 \% 28$ ATP synthase subunit alpha, mitochondrial GN=ATP5A1 ATPA_HUMAN $59.75 \quad 100.0 \% \quad 28$ ATP synthase subunit alpha, mitochondrial GN=ATP5A1 ATPA_HUMAN $59.75 \quad 100.0 \% 28$ $\begin{array}{llll}\text { ATP synthase subunit alpha, mitochondrial GN=ATP5A1 ATPA_HUMAN } 59.75 & 100.0 \% & 28\end{array}$ ATP synthase subunit alpha, mitochondrial GN=ATP5A1 ATPA_HUMAN $59.75 \quad 100.0 \% 28$ ATP synthase subunit alpha, mitochondrial GN=ATP5A1 ATPA HUMAN $59.75 \quad 100.0 \% 28$ ATP synthase subunit alpha, mitochondrial GN=ATP5A1 ATPA_HUMAN $59.75 \quad 100.0 \% \quad 28$ ATP synthase subunit alpha, mitochondrial GN=ATP5A1 ATPA_HUMAN $59.75 \quad 100.0 \% 28$ ATP synthase subunit alpha, mitochondrial GN=ATP5A1 ATPA_HUMAN $59.75 \quad 100.0 \% \quad 28$ ATP synthase subunit alpha, mitochondrial GN=ATP5A1 ATPA_HUMAN $59.75 \quad 100.0 \% \quad 28$ ATP synthase subunit alpha, mitochondrial GN=ATP5A1 ATPA_HUMAN $59.75 \quad 100.0 \% 28$ ATP synthase subunit alpha, mitochondrial GN=ATP5A1 ATPA_HUMAN $59.75 \quad 100.0 \% \quad 28$ $\begin{array}{llll}\text { ATP synthase subunit alpha, mitochondrial GN=ATP5A1 ATPA_HUMAN } 59.75 & 100.0 \% & 28\end{array}$ ATP synthase subunit alpha, mitochondrial GN=ATP5A1 ATPA_HUMAN $59.75 \quad 100.0 \% 28$ ATP synthase subunit alpha, mitochondrial GN=ATP5A1 ATPA_HUMAN $59.75 \quad 100.0 \% \quad 28$ $\begin{array}{llll}\text { ATP synthase subunit alpha, mitochondrial GN=ATP5A1 ATPA_HUMAN } 59.75 & 100.0 \% & 28\end{array}$ ATP synthase subunit alpha, mitochondrial GN=ATP5A1 ATPA_HUMAN $59.75 \quad 100.0 \% \quad 28$ ATP synthase subunit alpha, mitochondrial GN=ATP5A1 ATPA_HUMAN $59.75 \quad 100.0 \% \quad 28$ ATP synthase subunit alpha, mitochondrial GN=ATP5A1 ATPA_HUMAN $59.75 \quad 100.0 \% 28$ ATP synthase subunit alpha, mitochondrial GN=ATP5A1 ATPA_HUMAN $59.75 \quad 100.0 \% \quad 28$ ATP synthase subunit alpha, mitochondrial GN=ATP5A1 ATPA_HUMAN $59.75 \quad 100.0 \% \quad 28$ ATP synthase subunit alpha, mitochondrial GN=ATP5A1 ATPA HUMAN $59.75 \quad 100.0 \% 28$ ATP synthase subunit alpha, mitochondrial GN=ATP5A1 ATPA_HUMAN $59.75 \quad 100.0 \% \quad 28$ ATP synthase subunit alpha, mitochondrial GN=ATP5A1 ATPA_HUMAN $59.75 \quad 100.0 \% \quad 28$ $\begin{array}{llll}\text { ATP synthase subunit alpha, mitochondrial GN=ATP5A1 ATPA_HUMAN } 59.75 & 100.0 \% & 28\end{array}$ $\begin{array}{llll}\text { ATP synthase subunit alpha, mitochondrial GN=ATP5A1 ATPA_HUMAN } 59.75 & 100.0 \% & 28\end{array}$ ATP synthase subunit beta, mitochondrial GN=ATP5B ATPB HUMAN $56.56 \quad 100.0 \% \quad 17$ ATP synthase subunit beta, mitochondrial GN=ATP5B ATPB_HUMAN $56.56 \quad 100.0 \% \quad 17$

$11 \quad 0.01 \% \quad 9.6 \% \quad$ TKEGYYYR $0.01 \% \quad 9.6 \%$ WINATDPSAR $0.01 \% \quad 11.9 \%$ ASAELALGENSEVLK $0.01 \% \quad 11.9 \%$ FVTVQTISGTGALR $0.01 \% \quad 11.9 \%$ IAAAILNTPDLR $0.01 \% \quad 11.9 \%$ IAAAILNTPDLRK

$0.01 \% \quad 11.9 \%$ TQLVSNLKK

$10 \quad 0.01 \% \quad 12.4 \%$ FAANINKESIVDVEGVVR

$10 \quad 0.01 \% \quad 12.4 \%$ IGSCTQQDVELHVQK

$10 \quad 0.01 \% \quad 12.4 \%$ IYVISLAEPR

$10 \quad 0.01 \% \quad 12.4 \%$ VFSIGPVFR

$10 \quad 0.01 \% \quad 12.4 \%$ IHDPQLLTER

$10 \quad 0.01 \% \quad 13.1 \%$ ALTALFKEQR

$10 \quad 0.01 \% \quad 13.1 \%$ NACIECSVNQNSIR

$10 \quad 0.01 \% \quad 13.1 \%$ LASEEPPDDEEALATIR

$10 \quad 0.01 \% \quad 13.1 \%$ AEGDISNVANGFK

$10 \quad 0.01 \% \quad 13.1 \%$ LIGNLCYK

$37 \quad 196 \quad 0.21 \% \quad 44.8 \%$ TGTAEMSSILEER

$37 \quad 196 \quad 0.21 \% \quad 44.8 \%$ ILGADTSVDLEETGR

$196 \quad 0.21 \% \quad 44.8 \%$ ILGADTSVDLEETGRVLSIGDGIAR

$196 \quad 0.21 \% \quad 44.8 \%$ VLSIGDGIAR

$37 \quad 196 \quad 0.21 \% \quad 44.8 \%$ GMSLNLEPDNVGVVVFGNDK

$37 \quad 196 \quad 0.21 \% \quad 44.8 \%$ TGAIVDVPVGEELLGR

$37 \quad 196 \quad 0.21 \% \quad 44.8 \%$ VVDALGNAIDGK

$196 \quad 0.21 \% \quad 44.8 \%$ VVDALGNAIDGKGPIGSK

$196 \quad 0.21 \% \quad 44.8 \%$ VGLKAPGIIPR

$196 \quad 0.21 \% \quad 44.8 \%$ ISVREPMQTGIK

$196 \quad 0.21 \% \quad 44.8 \%$ AVDSLVPIGR

$196 \quad 0.21 \% \quad 44.8 \%$ AVDSLVPIGRGQR

$196 \quad 0.21 \% \quad 44.8 \%$ GQRELIIGDR

$196 \quad 0.21 \% \quad 44.8 \%$ ELIIGDRQTGK

$196 \quad 0.21 \% \quad 44.8 \%$ TSIAIDTIINQK

$196 \quad 0.21 \% \quad 44.8 \%$ TSIAIDTIINQKR

$196 \quad 0.21 \% \quad 44.8 \%$ LYCIYVAIGQK

$196 \quad 0.21 \% \quad 44.8 \%$ LYCIYVAIGQKR

$196 \quad 0.21 \% \quad 44.8 \%$ STVAQLVK

$196 \quad 0.21 \% \quad 44.8 \%$ STVAQLVKR

$196 \quad 0.21 \% \quad 44.8 \%$ DNGKHALIIYDDLSK

$196 \quad 0.21 \% \quad 44.8 \%$ HALIIYDDLSK

$196 \quad 0.21 \% \quad 44.8 \%$ RPPGREAYPGDVFYLHSR

$196 \quad 0.21 \% \quad 44.8 \%$ EAYPGDVFYLHSR

$196 \quad 0.21 \% \quad 44.8 \%$ EAYPGDVFYLHSRLLER

$196 \quad 0.21 \% \quad 44.8 \%$ GIRPAINVGLSVSR

$196 \quad 0.21 \% \quad 44.8 \%$ GYLDKLEPSK

$196 \quad 0.21 \% \quad 44.8 \%$ LKEIVTNFLAGFEA

$99.7 \% \quad 34.6$

$\begin{array}{llllll}110 & 0.12 \% & 43.3 \% & \text { ETRLVLEVAQHLGESTVR } & 99.7 \% & 28.9 \\ 110 & 0.12 \% & 43.3 \% & \text { LVLEVAQHLGESTVR } & 99.7 \% & 51.4\end{array}$
$99.0 \% \quad 28.5$

$99.7 \% 75.3$

$99.7 \% \quad 71.0$

$99.7 \% \quad 53.2$

$99.7 \% 48$.

$99.5 \% \quad 22.1$

$99.7 \% \quad 30.2$

$99.7 \% 36.8$

$97.7 \% \quad 22.6$

$99.4 \% 26.8$

$99.7 \% \quad 42.1$

$99.7 \% 73.1$

$99.7 \% \quad 57.3$

$99.0 \% \quad 26.8$

$99.7 \% \quad 64.9$

$99.7 \% \quad 60.8$

$\begin{array}{ll}99.7 \% & 58.3\end{array}$

$99.7 \% 50.4$

$99.7 \% \quad 54.8$

$99.7 \% 73.4$

$99.7 \% \quad 53.2$

$99.7 \% 52.6$

$99.7 \% \quad 45.9$

$99.7 \% \quad 28.9$

$99.7 \% \quad 55.3$

$99.7 \% \quad 59.7$

$99.7 \% \quad 65.1$

$99.7 \% \quad 59.7$

$97.2 \% \quad 18.6$

$99.0 \% \quad 57.3$

$\begin{array}{lll}99.7 \% & 59.0\end{array}$

$96.6 \% \quad 17.2$

$99.7 \% 59.7$

$99.7 \% \quad 53.8$

$99.7 \% \quad 32.5$

$99.7 \% \quad 54.2$
$99.7 \% \quad 32.7$
1530.80

1449.8

1267.74

1395.83

1030.63

1960.05

1741.85

1160.67

1021.58

1221.66

1176.67

1664.75

1855.89

1321.64

980.52

1439.67

1575.79

2557.35

1000.58

2120.03

1624.89

1171.63

1710.94

1120.72

1358.75

1026.59

1367.78

1156.64

1229.69

1316.74

1472.84

1327.7

1483.81

845.51

1001.61

1701.88

1287.69

2117.07

1553.74

2065.05

1438.85

1149.62

1551.84

2037.11 1650.92

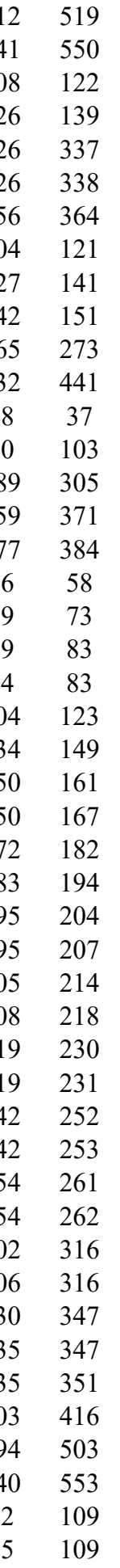

Page 27 of Table S-1-5 
ATP synthase subunit beta, mitochondrial GN=ATP5B ATPB HUMAN $56.56 \quad 100.0 \%$ ATP synthase subunit beta, mitochondrial GN=ATP5B ATPB_HUMAN $56.56 \quad 100.0 \% \quad 17$ $\begin{array}{lllll}\text { ATP synthase subunit beta, mitochondrial GN=ATP5B ATPB_HUMAN } 56.56 & 100.0 \% & 17\end{array}$ ATP synthase subunit beta, mitochondrial GN=ATP5B ATPB HUMAN $56.56 \quad 100.0 \%$ $\begin{array}{llll}\text { ATP synthase subunit beta, mitochondrial GN=ATP5B ATPB_HUMAN } & 56.56 & 100.0 \% & 17\end{array}$ $\begin{array}{llll}\text { ATP synthase subunit beta, mitochondrial GN=ATP5B ATPB_HUMAN } & 56.56 & 100.0 \% & 17\end{array}$ ATP synthase subunit beta, mitochondrial GN=ATP5B ATPB_HUMAN $56.56 \quad 100.0 \% \quad 17$ $\begin{array}{llll}\text { ATP synthase subunit beta, mitochondrial GN=ATP5B ATPB_HUMAN } & 56.56 & 100.0 \% & 17\end{array}$ ATP synthase subunit beta, mitochondrial GN=ATP5B ATPB HUMAN $56.56 \quad 100.0 \% \quad 17$ $\begin{array}{llll}\text { ATP synthase subunit beta, mitochondrial GN=ATP5B ATPB_HUMAN } 56.56 & 100.0 \% & 17\end{array}$ $\begin{array}{lllll}\text { ATP synthase subunit beta, mitochondrial GN=ATP5B ATPB_HUMAN } 56.56 & 100.0 \% & 17\end{array}$ ATP synthase subunit beta, mitochondrial GN=ATP5B ATPB HUMAN $56.56 \quad 100.0 \%$ $\begin{array}{lllll}\text { ATP synthase subunit beta, mitochondrial GN=ATP5B ATPB_HUMAN } & 56.56 & 100.0 \% & 17\end{array}$ ATP synthase subunit beta, mitochondrial GN=ATP5B ATPB_HUMAN $56.56 \quad 100.0 \% \quad 17$ ATP synthase subunit beta, mitochondrial GN=ATP5B ATPB_HUMAN $56.56 \quad 100.0 \% \quad 17$ ATP synthase subunit gamma, mitochondrial GN=ATP5C1 ATPG_HUMAN $33.00 \quad 100.0 \%$ ATP synthase subunit gamma, mitochondrial GN=ATP5C1 ATPG_HUMAN $33.00 \quad 100.0 \%$ ATP synthase subunit gamma, mitochondrial GN=ATP5C1 ATPG_HUMAN $33.00 \quad 100.0 \%$ ATP synthase subunit gamma, mitochondrial GN=ATP5C1 ATPG_HUMAN $33.00 \quad 100.0 \%$ ATP synthase subunit gamma, mitochondrial GN=ATP5Cl ATPG_HUMAN $33.00 \quad 100.0 \%$ ATP synthase subunit gamma, mitochondrial GN=ATP5C1 ATPG_HUMAN $33.00 \quad 100.0 \%$ ATP synthase subunit gamma, mitochondrial GN=ATP5C1 ATPG HUMAN $33.00 \quad 100.0^{\circ} \%$ ATP synthase subunit gamma, mitochondrial GN=ATP5C1 ATPG_HUMAN $33.00 \quad 100.0 \%$ ATP synthase subunit gamma, mitochondrial GN=ATP5C1 ATPG_HUMAN $33.00 \quad 100.0 \%$ ATP synthase subunit $\mathrm{O}$, mitochondrial GN=ATP5O ATPO HUMAN $23.28 \quad 100.0^{\circ}$ ATP synthase subunit O, mitochondrial GN=ATP5O ATPO_HUMAN $23.28 \quad 100.0 \%$ ATP synthase subunit $\mathrm{O}$, mitochondrial GN=ATP5O ATPO_HUMAN $23.28 \quad 100.0 \%$ ATP synthase subunit $\mathrm{O}$, mitochondrial GN=ATP5O ATPO HUMAN $23.28 \quad 100.0 \%$ ATP synthase subunit $\mathrm{O}$, mitochondrial GN=ATP5O ATPO_HUMAN $23.28 \quad 100.0 \%$ ATP synthase subunit $\mathrm{O}$, mitochondrial GN=ATP5O ATPO HUMAN $23.28 \quad 100.0 \%$ ATP synthase subunit $\mathrm{O}$, mitochondrial GN=ATP5O ATPO_HUMAN $23.28 \quad 100.0 \%$ ATP synthase subunit $\mathrm{O}$, mitochondrial GN=ATP5O ATPO_HUMAN $23.28 \quad 100.0 \%$ ATP synthase subunit $\mathrm{O}$, mitochondrial GN=ATP5O ATPO_HUMAN $23.28 \quad 100.0^{\circ}$ ATP synthase subunit s-like protein GN=ATP5SL AT5SL_HUMAN $29.27 \quad 100.0 \%$ ATP synthase subunit s-like protein GN=ATP5SL AT5SL_HUMAN $29.27 \quad 100.0 \%$ ATPase family AAA domain-containing protein $1 \mathrm{GN}=$ ATAD1 ATAD1_HUMAN $40.75 \quad 100.0 \%$ ATPase family AAA domain-containing protein 1 GN=ATAD1 ATAD1_HUMAN $40.75 \quad 100.0 \%$ ATPase family AAA domain-containing protein 3A GN=ATAD3A ATD3A HUMAN $71.37 \quad 100.0 \%$ ATPase family AAA domain-containing protein 3A GN=ATAD3A ATD3A_HUMAN $71.37 \quad 100.0 \%$ ATPase family AAA domain-containing protein 3A GN=ATAD3A ATD3A_HUMAN 71.37 ATPase family AAA domain-containing protein 3A GN=ATAD3A ATD3A_HUMAN 71.37 ATPase family AAA domain-containing protein 3A GN=ATAD3A ATD3A_HUMAN 71.37 ATPase family AAA domain-containing protein 3A GN=ATAD3A ATD3A_HUMAN 71.37 ATPase family AAA domain-containing protein $3 \mathrm{~A}$ GN=ATAD3A ATD3A_HUMAN 71.37 ATPase family AAA domain-containing protein 3A GN=ATAD3A ATD3A_HUMAN 71.3 ATPase family AAA domain-containing protein 3A GN=ATAD3A ATD3A_HUMAN 71.37 ATPase family AAA domain-containing protein 3A GN=ATAD3A ATD3A_HUMAN 71.37

2
23
23

23
23
23

9

(9)

19
19

19

19

19
19
$110 \quad 0.12 \% \quad 43.3 \%$ VLDSGAPIK

$110 \quad 0.12 \% \quad 43.3 \%$ VLDSGAPIKIPVGPETLGR

$110 \quad 0.12 \% \quad 43.3 \%$ VVDLLAPYAK

$110 \quad 0.12 \% \quad 43.3 \%$ IGLFGGAGVGK

$110 \quad 0.12 \% \quad 43.3 \%$ TVLIMELINNVAK

$110 \quad 0.12 \% \quad 43.3 \%$ AHGGYSVFAGVGER

$110 \quad 0.12 \% \quad 43.3 \%$ VALVYGQMNEPPGAR

$110 \quad 0.12 \% \quad 43.3 \%$ VALTGLTVAEYFR

$110 \quad 0.12 \% \quad 43.3 \%$ FTQAGSEVSALLGR

$110 \quad 0.12 \% \quad 43.3 \%$ KGSITSVQAIYVPADDLTDPAPATTFAHLDATTVLSR

$110 \quad 0.12 \% \quad 43.3 \%$

$110 \quad 0.12 \% \quad 43.3 \%$ AIAELGIYPAVDPLDSTSR

$110 \quad 0.12 \% \quad 43.3 \%$ IMDPNIVGSEHYDVAR

$110 \quad 0.12 \% \quad 43.3 \%$ FLSQPFQVAEVFTGHMGK

$34 \quad 0.04 \% \quad 32.2 \%$ IYGLGSLALYEK

$4 \quad 0.04 \% \quad 32.2 \%$ HLLIGVSSDR

$0.04 \% \quad 32.2 \%$ GLCGAIHSSIAK

$0.04 \% \quad 32.2 \%$ SEVATLTAAGK

$0.04 \% \quad 32.2 \%$ EVMLVGIGDK

$0.04 \% \quad 32.2 \%$ EVMLVGIGDKIR

$0.04 \% \quad 32.2 \%$ THSDQFLVAFK

$0.04 \% \quad 32.2 \%$ NASEMIDKLTLTFNR

$0.04 \% \quad 32.2 \%$ ELIEIISGAAALD

$0.02 \% \quad 47.4 \%$ LVRPPVQVYGIEGR

$0.02 \% \quad 47.4 \%$ YATALYSAASK

$0.02 \% \quad 47.4 \%$ VAQILKEPK

$0.02 \% \quad 47.4 \%$ VAASVLNPYVK

$0.02 \% \quad 47.4 \%$ VAASVLNPYVKR

$0.02 \% \quad 47.4 \%$ SLNDITAKER

$0.02 \% \quad 47.4 \%$ LSNTQGVVSAFSTMMSVHR

$0.02 \% \quad 47.4 \%$ SFLSQGQVLKLEAK

$0.02 \% \quad 47.4 \%$ TDPSILGGMIVR

$0.00 \% \quad 9.0 \%$ LGAAVAPEGNQK

$0.00 \% \quad 9.0 \% \quad$ LKELQSLSLQR

$0.00 \% \quad 5.5 \%$ NEVVGLIFR

$0.00 \% \quad 5.5 \%$ LAAAVFSLAIK

$0.08 \% \quad 25.7 \%$ GLGDRPAPK

$0.08 \% \quad 25.7 \%$ TLSEETRQHQAR

$0.08 \% \quad 25.7 \%$ AQYQDKLAR

$0.08 \% \quad 25.7 \%$ ATVEREMELR

$0.08 \% \quad 25.7 \%$ ENADIIREQIR

$0.08 \% \quad 25.7 \%$ AAEHRQTVLESIR

$0.08 \% \quad 25.7 \%$ QTVLESIR

$0.08 \% \quad 25.7 \%$ TAGTLFGEGFR

$0.08 \% \quad 25.7 \%$ LGKPSLVR

$0.08 \% \quad 25.7 \%$ ITVLEALR

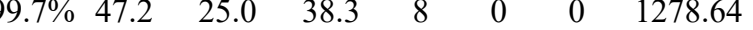

899.52

1919.10

1088.64

975.56

1473.83

1406.68

1617.81

1439.79

1435.75

3842.98

3714.89

1988.03

1831.86

2023.01

1326.73

1096.61

1213.64

1047.57

1076.57

1329.76

1292.66

1768.89

1314.72

1582.91

1145.58

1025.64

1160.67

1316.77

1146.61

2083.99

1547.88

1274.68

1154.62

1314.77

1046.60

1103.68

910.51

1455.73

1092.58

1233.63

1356.72

1509.81

945.54

1155.58

869.56

$\begin{array}{llll}99.7 \% & 55.3 & 25.0 & 50.2\end{array}$

$\begin{array}{llll}99.0 \% & 42.3 & 25.0 & 26.5\end{array}$

\begin{tabular}{c}
121 \\
133 \\
143 \\
198 \\
212 \\
225 \\
239 \\
279 \\
294 \\
324 \\
387 \\
387 \\
406 \\
422 \\
480 \\
79 \\
100 \\
112 \\
126 \\
136 \\
138 \\
154 \\
277 \\
298 \\
40 \\
346 \\
51 \\
73 \\
84 \\
84 \\
85 \\
100 \\
136 \\
176 \\
188 \\
36 \\
157 \\
22 \\
183 \\
44 \\
177 \\
186 \\
229 \\
260 \\
275 \\
\hline
\end{tabular}



ATPase family AAA domain-containing protein 3A GN=ATAD3A ATD3A_HUMAN $71.37 \quad 100.0 \% \quad 19$ ATPase family AAA domain-containing protein 3A GN=ATAD3A ATD3A_HUMAN $71.37 \quad 100.0 \%$ ATPase family AAA domain-containing protein 3A GN=ATAD3A ATD3A HUMAN $71.37 \quad 100.0 \%$ ATPase family AAA domain-containing protein 3A GN=ATAD3A ATD3A_HUMAN $71.37 \quad 100.0 \% \quad 19$ ATPase family AAA domain-containing protein 3A GN=ATAD3A ATD3A_HUMAN $71.37 \quad 100.0 \% \quad 19$ $\begin{array}{llll}\text { ATPase family AAA domain-containing protein 3A GN=ATAD3A ATD3A_HUMAN } 71.37 & 100.0 \% & 19\end{array}$ $\begin{array}{lllll}\text { ATPase family AAA domain-containing protein 3A GN=ATAD3A ATD3A_HUMAN } & 71.37 & 100.0 \% & 19\end{array}$ ATPase family AAA domain-containing protein 3A GN=ATAD3A ATD3A HUMAN $71.37 \quad 100.0 \% \quad 19$ ATPase family AAA domain-containing protein 3B GN=ATAD3B $\quad$ ATD3B_HUMAN $72.57 \quad 100.0 \%$ ATPase family AAA domain-containing protein 3B GN=ATAD3B ATD3B_HUMAN $72.57 \quad 100.0 \%$ ATPase family AAA domain-containing protein $3 \mathrm{~B}$ GN=ATAD3B ATD3B HUMAN $72.57 \quad 100.0 \%$ ATPase family AAA domain-containing protein 3B GN=ATAD3B ATD3B_HUMAN $72.57 \quad 100.0 \%$ ATPase family AAA domain-containing protein 3B GN=ATAD3B ATD3B_HUMAN $72.57 \quad 100.0 \%$ ATPase family AAA domain-containing protein 3B GN=ATAD3B ATD3B HUMAN $72.57 \quad 100.0 \%$ ATPase family AAA domain-containing protein 3B GN=ATAD3B ATD3B_HUMAN $72.57 \quad 100.0 \%$ ATPase family AAA domain-containing protein $3 \mathrm{~B}$ GN=ATAD3B ATD3B HUMAN $72.57100 .0 \%$ ATPase family AAA domain-containing protein 3B GN=ATAD3B ATD3B_HUMAN $72.57 \quad 100.0 \%$ ATPase family AAA domain-containing protein 3B GN=ATAD3B ATD3B_HUMAN $72.57 \quad 100.0 \%$ ATPase family AAA domain-containing protein 3B GN=ATAD3B ATD3B_HUMAN $72.57 \quad 100.0 \%$ ATPase family AAA domain-containing protein 3B GN=ATAD3B ATD3B_HUMAN $72.57 \quad 100.0 \%$ ATPase family AAA domain-containing protein 3B GN=ATAD3B ATD3B_HUMAN $72.57 \quad 100.0 \%$ ATPase family AAA domain-containing protein 3B GN=ATAD3B ATD3B_HUMAN $72.57 \quad 100.0 \%$ ATPase family AAA domain-containing protein 3B GN=ATAD3B ATD3B_HUMAN $72.57 \quad 100.0 \%$ ATPase family AAA domain-containing protein $3 B$ GN=ATAD3B ATD3B HUMAN $72.57 \quad 100.0^{\circ}$ ATPase family AAA domain-containing protein 3B GN=ATAD3B ATD3B_HUMAN $72.57 \quad 100.0 \%$ ATPase family AAA domain-containing protein 3B GN=ATAD3B ATD3B_HUMAN $72.57 \quad 100.0 \%$ ATPase WRNIP1 GN=WRNIP1 ATPase WRNIP1 GN=WRNIP1

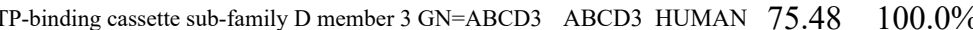
ATP-binding cassette sub-family D member $3 \mathrm{GN}=\mathrm{ABCD} 3 \mathrm{ABCD} 3$ _HUMAN $75.48 \quad 100.0 \%$ ATP-binding cassette sub-family D member $3 \mathrm{GN}=\mathrm{ABCD} 3 \quad \mathrm{ABCD} 3$ _HUMAN $75.48 \quad 100.0 \%$ ATP-binding cassette sub-family D member $3 \mathrm{GN}=\mathrm{ABCD} 3 \quad \mathrm{ABCD} 3$ _HUMAN $75.48 \quad 100.0 \%$ ATP-binding cassette sub-family E member $1 \mathrm{GN}=\mathrm{ABCE} 1 \mathrm{ABCE} 1$ HUMAN $67.32 \quad 100.0 \%$ ATP-binding cassette sub-family E member $1 \mathrm{GN}=\mathrm{ABCE} 1 \mathrm{ABCE} 1 \mathrm{HUMAN} 67.32 \quad 100.0 \%$ ATP-binding cassette sub-family F member $2 \mathrm{GN}=\mathrm{ABCF} 2 \mathrm{ABCF} 2$ HUMAN $71.29 \quad 100.0 \%$ ATP-binding cassette sub-family F member $2 \mathrm{GN}=\mathrm{ABCF} 2 \mathrm{ABCF} 2$ HUMAN $71.29 \quad 100.0 \%$ ATP-binding cassette sub-family $F$ member $2 \mathrm{GN}=\mathrm{ABCF} 2 \quad \mathrm{ABCF} 2$ HUMAN $71.29 \quad 100.0^{\circ}$ ATP-binding cassette sub-family F member $2 \mathrm{GN}=\mathrm{ABCF} 2 \mathrm{ABCF} 2$ _HUMAN $71.29 \quad 100.0 \%$ ATP-citrate synthase GN=ACLY ATP-citrate synthase $\mathrm{GN}=\mathrm{ACLY}$ ATP-citrate synthase $\mathrm{GN}=\mathrm{ACLY}$ ATP-citrate synthase $\mathrm{GN}=\mathrm{ACLY}$ ATP-citrate synthase $\mathrm{GN}=\mathrm{ACLY}$ ATP-citrate synthase $\mathrm{GN}=\mathrm{ACLY}$ ATP-citrate synthase $\mathrm{GN}=\mathrm{ACLY}$ ATP-citrate synthase GN=ACLY WRIP1_HUMAN $72.13 \quad 100.0 \%$ WRIP1_HUMAN $72.13 \quad 100.0 \%$

4

3
3
3

3
3
3

3

3
3
3

3

3
3
3

3
3
3
2

2

2

4
4
4

4

2

2
4
4

$\begin{array}{ll}4 & 4 \\ 4 & 4 \\ 4 & 4\end{array}$

4

4
23
23

$\begin{array}{ll}23 & 3 \\ 23 & 3 \\ 23 & 3\end{array}$
$\begin{array}{llll}\text { ACLY_HUMAN } & 120.84 & 100.0 \% & 23 \\ \text { ACLY_HUMAN } & 120.84 & 100.0 \% & 23\end{array}$ ACLY_HUMAN $120.84 \quad 100.0 \% \quad 23$ ACLY_HUMAN $120.84 \quad 100.0 \% \quad 23$ ACLY_HUMAN $120.84 \quad 100.0 \% \quad 23$

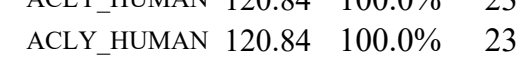

30
30
$0.08 \% \quad 25.7 \%$ VRDIAIATR

$0.08 \% 25.7 \%$ NILMYGPPGTGK

$0.08 \% \quad 25.7 \%$ LFDWANTSR

$0.08 \% \quad 25.7 \%$ ATEKISEDLR

$0.08 \% \quad 25.7 \%$ LKLAQFDYGR

$0.08 \% \quad 25.7 \%$ LAQFDYGR

$0.08 \% \quad 25.7 \%$ LAQFDYGRK

$0.08 \% \quad 25.7 \%$ LTEGMSGR

$0.08 \% \quad 25.7 \%$ AEGPGRGDEPSPS

$0.01 \% \quad 24.7 \%$ GLGDRPAPK

$0.01 \% \quad 24.7 \%$ TLSEETRQHQAR

$0.01 \% \quad 24.7 \%$ AQYQDKLAR

$0.01 \% \quad 24.7 \%$ ATVEREMELR

$0.01 \% \quad 24.7 \%$ ENADIIREQIR

$0.01 \% \quad 24.7 \%$ QTVLESIR

$0.01 \% \quad 24.7 \%$ TAGTLFGEGFR

$0.01 \% \quad 24.7 \%$ LGKPSLVR

$0.01 \% \quad 24.7 \%$ ITVLEALR

$0.01 \% \quad 24.7 \%$ VRDIAIATR

$0.01 \% \quad 24.7 \%$ HILLYGPPGTGK

$0.01 \% \quad 24.7 \%$ LFDWANTSR

$0.01 \% \quad 24.7 \%$ ATEEISKDLR

$0.01 \% \quad 24.7 \%$ LHFDNCVLKPATEGK

$0.01 \% \quad 24.7 \%$ LKLAQFDYGR

$0.01 \% \quad 24.7 \%$ LAQFDYGR

$0.01 \% \quad 24.7 \%$ LAQFDYGRK

$0.01 \% \quad 24.7 \%$ LTEGMSGR

$0.00 \% \quad 3.2 \%$ AVGQDTLLR

$0.00 \% \quad 3.2 \% \quad$ SIEVYSAYNNVK

$0.01 \% \quad 8.2 \%$ AVVDKVFFSR

$0.01 \% \quad 8.2 \%$ IANPDQLLTQDVEK

$0.01 \% \quad 8.2 \%$ STHSELLEDYYQSGR

$0.01 \% \quad 8.2 \%$ SGANVLICGPNGCGK

$0.00 \% \quad 3.7 \%$ FACAVVCIQK

$0.00 \% \quad 3.7 \%$ VAETANEEEVKK

$0.01 \% \quad 6.7 \%$ YGLIGLNGIGK

$0.01 \% \quad 6.7 \%$ SMLLSAIGKR

$0.01 \% \quad 6.7 \% \quad$ YYTGNYDQYVK

$0.01 \% \quad 6.7 \% \quad$ LVDEEPQLTK

$69 \quad 0.08 \% \quad 21.9 \%$ AISEQTGKELLYK

$69 \quad 0.08 \% \quad 21.9 \%$ FICTTSAIQNR

$69 \quad 0.08 \% \quad 21.9 \%$ FICTTSAIQNRFK

$69 \quad 0.08 \% \quad 21.9 \%$ LGQEATVGK

$69 \quad 0.08 \% \quad 21.9 \%$ LGQEATVGKATGFLK

$69 \quad 0.08 \% \quad 21.9 \%$ DGVYVLDLAAK

$69 \quad 0.08 \% \quad 21.9 \%$ VDATADYICK

$69 \quad 0.08 \% \quad 21.9 \%$ SGASLKLTLLNPK
$99.7 \% \quad 40.3 \quad 25.0 \quad 36.2$

$99.7 \% \quad 59.5 \quad 25.0 \quad 45.2$

$\begin{array}{llll}99.7 \% & 37.2 & 25.0 & 16.9\end{array}$

$99.7 \% \quad 34.0 \quad 25.0 \quad 16.9$

$\begin{array}{llll}99.7 \% & 50.3 & 25.0 & 50.3\end{array}$

$\begin{array}{llll}99.0 \% & 53.9 & 25.0 & 52.5\end{array}$

$\begin{array}{llll}99.7 \% & 33.1 & 25.0 & 33.1\end{array}$

$99.0 \% \quad 53.7 \quad 25.0 \quad 48.3 \quad 2$

$99.7 \% \quad 33.5 \quad 25.0 \quad 33.5$

$\begin{array}{llll}99.7 \% & 51.7 & 25.0 & 41.7\end{array}$

$\begin{array}{llll}99.7 \% & 33.2 & 25.0 & 33.0\end{array}$

$99.7 \% \quad 59.4 \quad 25.0 \quad 51.6$

$\begin{array}{llll}99.7 \% & 32.7 & 25.0 & 15.1\end{array}$

$\begin{array}{llll}99.7 \% & 38.3 & 25.0 & 28.2\end{array}$

$99.0 \% \quad 50.0 \quad 25.0 \quad 32.4$

$\begin{array}{llll}99.7 \% & 55.3 & 25.0 & 50.2\end{array}$

$99.0 \% \quad 42.3 \quad 25.0 \quad 26.5$

$\begin{array}{llll}99.0 \% & 42.8 & 25.0 & 31.3\end{array}$

$\begin{array}{llll}99.7 \% & 40.3 & 25.0 & 36.2\end{array}$

$\begin{array}{llll}99.7 \% & 46.2 & 25.0 & 41.5\end{array}$

$\begin{array}{llll}99.7 \% & 37.2 & 25.0 & 16.9\end{array}$

$\begin{array}{llll}99.7 \% & 48.6 & 25.0 & 22.3\end{array}$

$\begin{array}{llll}99.4 \% & 19.7 & 25.0 & 18.6\end{array}$

$\begin{array}{llll}99.7 \% & 50.3 & 25.0 & 50.3\end{array}$

$\begin{array}{llll}99.0 \% & 53.9 & 25.0 & 52.5\end{array}$

$\begin{array}{llll}99.7 \% & 33.1 & 25.0 & 33.1\end{array}$

$\begin{array}{llll}99.0 \% & 53.7 & 25.0 & 48.3\end{array}$

$\begin{array}{llll}99.5 \% & 25.4 & 25.0 & 17.7\end{array}$

$\begin{array}{llll}99.7 \% & 36.2 & 25.0 & 33.2\end{array}$

$\begin{array}{llll}99.7 \% & 44.4 & 25.0 & 44.4\end{array}$

$\begin{array}{llll}99.7 \% & 40.6 & 25.0 & 40.6\end{array}$

$\begin{array}{llll}99.7 \% & 44.7 & 25.0 & 44.7\end{array}$

$\begin{array}{llll}99.7 \% & 43.8 & 25.0 & 43.8\end{array}$

$\begin{array}{llll}99.7 \% & 44.0 & 25.0 & 40.0\end{array}$

$\begin{array}{llll}99.7 \% & 39.6 & 25.0 & 36.2\end{array}$

$\begin{array}{llll}99.6 \% & 22.0 & 25.0 & 20.6\end{array}$

$\begin{array}{llll}99.5 \% & 21.8 & 25.0 & 19.2\end{array}$

$\begin{array}{llll}99.7 \% & 35.3 & 25.0 & 33.8\end{array}$

$\begin{array}{llll}99.1 \% & 27.4 & 25.0 & 14.5\end{array}$

$\begin{array}{llll}99.7 \% & 53.9 & 25.0 & 53.8\end{array}$

$\begin{array}{llll}99.7 \% & 60.0 & 25.0 & 60.0\end{array}$

$\begin{array}{llll}99.6 \% & 22.4 & 25.0 & 20.7\end{array}$

$\begin{array}{llll}99.7 \% & 74.7 & 25.0 & 60.8\end{array}$

$\begin{array}{llll}99.7 \% & 43.4 & 25.0 & 39.7\end{array}$

$\begin{array}{lllll}99.7 \% & 34.8 & 25.0 & 24.7 & 2\end{array}$

$\begin{array}{llll}99.7 \% & 37.2 & 25.0 & 37.2\end{array}$

$\begin{array}{llll}99.7 \% & 57.7 & 25.0 & 44.7\end{array}$
1263.64

1109.54

1161.61

1210.66

969.48

1097.57

850.41

1255.56

910.51

1455.73

1092.58

1233.63

1356.72

945.54

1155.58

869.56

914.57

1014.61

1252.71

1109.54

1161.61

1728.87

1210.66

969.48

1097.57

850.41

972.55

1386.69

1167.65

1583.83

1784.81

1503.70

1195.60

1346.68

1104.64

1091.62

1413.63

1171.62

1479.81

1310.65

1585.82

902.49

1519.85

1163.63

1155.54

1341.81 
ATP-citrate synthase $\mathrm{GN}=\mathrm{ACLY}$ ATP-citrate synthase $\mathrm{GN}=\mathrm{ACLY}$ ATP-citrate synthase GN=ACLY ATP-citrate synthase $\mathrm{GN}=\mathrm{ACLY}$ ATP-citrate synthase GN=ACLY ATP-citrate synthase $\mathrm{GN}=\mathrm{ACLY}$ ATP-citrate synthase GN=ACLY ATP-citrate synthase GN=ACLY ATP-citrate synthase GN=ACLY ATP-citrate synthase GN=ACLY ATP-citrate synthase GN=ACLY ATP-citrate synthase GN=ACLY ATP-citrate synthase GN=ACLY ATP-citrate synthase GN=ACLY

ATP-citrate synthase GN=ACLY

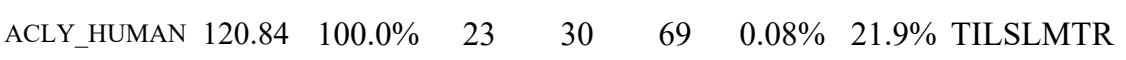
ACLY_HUMAN $120.84 \quad 100.0 \% \quad 23$ ACLY_HUMAN $120.84 \quad 100.0 \% \quad 23$ ACLY_HUMAN $120.84 \quad 100.0 \% \quad 23$ ACLY_HUMAN $120.84 \quad 100.0 \% \quad 23$ ACLY_HUMAN $120.84 \quad 100.0 \% \quad 23$ ACLY_HUMAN $120.84 \quad 100.0 \% \quad 23$ ACLY_HUMAN $120.84 \quad 100.0 \% \quad 23$ ACLY_HUMAN $120.84 \quad 100.0 \% \quad 23$ ACLY_HUMAN $120.84 \quad 100.0 \% \quad 23$ ACLY_HUMAN $120.84 \quad 100.0 \% \quad 23$ ACLY_HUMAN $120.84 \quad 100.0 \% \quad 23$ ACLY_HUMAN $120.84 \quad 100.0 \% \quad 23$ ACLY_HUMAN $120.84 \quad 100.0 \% \quad 23$ ACLY_HUMAN $120.84 \quad 100.0 \% \quad 23$ $\begin{array}{rrrr}\text { ACLY_HUMAN } & 120.84 & 100.0 \% & 23 \\ \text { KL PFKAL_HUMAN } & 85.02 & 100.0 \% & 4\end{array}$ ATP-dependent 6-phosphofructokinase, liver type GN=PFKL PFKAL HUMAN $85.02 \quad 100.0 \%$ ATP-dependent 6-phosphofructokinase, liver type GN=PFKL PFKAL_HUMAN $85.02 \quad 100.0 \%$ ATP-dependent 6-phosphofructokinase, liver type GN=PFKL PFKAL_HUMAN $85.02 \quad 100.0 \%$ ATP-dependent 6-phosphofructokinase, muscle type GN=PFKM PFKAM_HUMAN $85.18 \quad 100.0 \%$ ATP-dependent 6-phosphofructokinase, muscle type GN=PFKM PFKAM_HUMAN $85.18 \quad 100.0 \%$ ATP-dependent 6-phosphofructokinase, muscle type GN=PFKM PFKAM HUMAN $85.18 \quad 100.0 \%$ ATP-dependent 6-phosphofructokinase, muscle type GN=PFKM PFKAM_HUMAN $85.18 \quad 100.0 \%$ ATP-dependent 6-phosphofructokinase, platelet type GN=PFKP PFKAP_HUMAN $85.60 \quad 100.0 \%$ ATP-dependent 6-phosphofructokinase, platelet type GN=PFKP PFKAP_HUMAN $85.60 \quad 100.0 \%$ ATP-dependent 6-phosphofructokinase, platelet type GN=PFKP PFKAP_HUMAN $85.60 \quad 100.0 \%$ $\begin{array}{llll}\text { ATP-dependent 6-phosphofructokinase, platelet type GN=PFKP } & \text { PFKAP_HUMAN } 85.60 \quad 100.0 \%\end{array}$ ATP-dependent 6-phosphofructokinase, platelet type GN=PFKP PFKAP_HUMAN $85.60 \quad 100.0 \%$ ATP-dependent 6-phosphofructokinase, platelet type GN=PFKP PFKAP_HUMAN $85.60 \quad 100.0 \%$ ATP-dependent Clp protease ATP-binding subunit clpX-like, mitochondrial GN=CLPX CLPX HUMAN $69.22100 .0 \%$ ATP-dependent Clp protease ATP-binding subunit tlpX-like, mitochondrial GN=CLPX CLPX_HUMAN 69.22 100.0\% ATP-dependent Clp protease ATP-binding subunit clpX-like, mitochondrial GN=CLPX CLPX_HUMAN $69.22 \quad 100.0 \%$ ATP-dependent Clp protease ATP-binding subunit clpX-like, mitochondrial GN=CLPX CLPX_HUMAN $69.22 \quad 100.0 \%$ ATP-dependent Clp protease ATP-binding subunit te IP-like, mitchondrial GN=CLPX CLPX_HUMAN $69.22 \quad 100.0 \%$ ATP-dependent Clp protease ATP-binding subunit tlpX-like, mitochondrial GN=CLPX CLPX_HUMAN $69.22 \quad 100.0 \%$ ATP-dependent Clp protease ATP-binding subunit clpX-like, mitochondrial GN=CLPX CLPX_HUMAN $69.22 \quad 100.0 \%$ ATP-dependent Clp protease ATP-binding subunit clpX-like, mitcochondrial GN=CLPX CLPX_HUMAN $69.22 \quad 100.0 \%$ ATP-dependent Clp protease proteolytic subunit, mitochondrial GN=CLPP CLPP HUMAN $30.18 \quad 100.0 \%$ ATP-dependent Clp protease proteolytic subunit, mitochondrial GN=CLPP CLPP_HUMAN $30.18 \quad 100.0 \%$ ATP-dependent Clp protease proteolytic subunit, mitochondrial GN=CLPP CLPP_HUMAN $30.18 \quad 100.0 \%$ ATP-dependent Clp protease proteolytic subunit, mitochondrial GN=CLPP CLPP_HUMAN $30.18 \quad 100.0 \%$ ATP-dependent RNA helicase A GN=DHX9 DHX9_HUMAN $140.96 \quad 100.0 \%$ ATP-dependent RNA helicase A GN=DHX9 DHX9_HUMAN $140.96 \quad 100.0 \%$ ATP-dependent RNA helicase A GN=DHX9 DHX9_HUMAN $140.96 \quad 100.0 \% 38$ ATP-dependent RNA helicase A GN=DHX9 DHX9_HUMAN $140.96 \quad 100.0 \% 38$ ATP-dependent RNA helicase A GN=DHX9 DHX9_HUMAN $140.96 \quad 100.0 \% 38$ ATP-dependent RNA helicase A GN=DHX9 DHX9_HUMAN $140.96 \quad 100.0 \% \quad 38$
$30 \quad 69 \quad 0.08 \% \quad 21.9 \%$ RGGPNYQEGLR

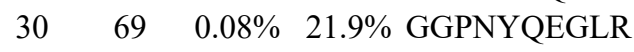

$30 \quad 69 \quad 0.08 \% \quad 21.9 \%$ TASFSESRADEVAPAK

$30 \quad 69 \quad 0.08 \% \quad 21.9 \%$ AKPAMPQDSVPSPR

$\begin{array}{llll}30 & 69 & 0.08 \% & 21.9 \% \\ 30 & \text { AIVWGMQTR }\end{array}$

$30 \quad 69 \quad 0.08 \% \quad 21.9 \%$ SAYDSTMETMNYAQIR

$30 \quad 69 \quad 0.08 \% \quad 21.9 \%$ IGNTGGMLDNILASK

$30 \quad 69 \quad 0.08 \% \quad 21.9 \%$ LYRPGSVAYVSR

$30 \quad 69 \quad 0.08 \% \quad 21.9 \%$ SGGMSNELNNIISR

$\begin{array}{llll}30 & 69 & 0.08 \% & 21.9 \% \\ 30 & 69 & 0.08 \% & 21.9 \% \\ & \end{array}$

$\begin{array}{llll}30 & 69 & 0.08 \% & 21.9 \% \\ 30 & 69 & 0.08 \% & 21.9 \%\end{array}$

$\begin{array}{llll}30 & 69 & 0.08 \% & 21.9 \% \\ 30 & 69 & 0.08 \% & 21.9 \%\end{array}$

$\begin{array}{llll}30 & 69 & 0.08 \% & 21.9 \% \\ 30 & 69 I L K D Y V R\end{array}$

$\begin{array}{llll}30 & 69 & 0.08 \% & 21.9 \% \\ 6 & 10 & 0.01 \% & 7.2 \%\end{array}$

$10 \quad 0.01 \% \quad 7.2 \% \quad$ AIGVLTSGGDAQGMNAAVR

$10 \quad 0.01 \% \quad 7.2 \%$ GGTPSAFDRILSSK

$10 \quad 0.01 \% \quad 7.2 \%$ GQLESIVENIR

$10 \quad 0.01 \% \quad 7.2 \% \quad$ AVAFSPVTELKK

$0.01 \% \quad 6.4 \%$ AIAVLTSGGDAQGMNAAVR

$0.01 \% \quad 6.4 \%$ VGIFTGAR

$0.01 \% \quad 6.4 \% \quad$ AAYNLVKR

$0.01 \% \quad 6.4 \%$ LGYDTRVTVLGHVQR

$0.01 \% \quad 9.2 \%$ FLEHLSGAGK

$0.01 \% \quad 9.2 \%$ AIGVLTSGGDAQGMNAAVR

$0.01 \% \quad 9.2 \%$ AACNLLQR

$0.01 \% \quad 9.2 \%$ SFAGNLNTYKR

$0.01 \% \quad 9.2 \%$ SAVRVGIADGHR

$0.01 \% \quad 9.2 \%$ NVIFQPVAELKK

$16 \quad 0.02 \% \quad 13.7 \%$ SIIKEPESAAEAVK

$0.02 \% \quad 13.7 \%$ SNILLLGPTGSGK

$0.02 \% \quad 13.7 \%$ TLLAQTLAK

$0.02 \% \quad 13.7 \%$ LLQDANYNVEK

$0.02 \% \quad 13.7 \%$ DVGGEGVQQGLLK

$0.02 \% \quad 13.7 \%$ LLEGTIVNVPEK

$0.02 \% \quad 13.7 \%$ LLEGTIVNVPEKNSR

$0.02 \% \quad 13.7 \%$ YLGFGTPSNLGK

$0.01 \% \quad 26.0 \%$ IMIHQPSGGAR

$0.01 \% \quad 26.0 \%$ GQATDIAIQAEEIMK

$0.01 \% \quad 26.0 \%$ QSLQVIESAMER

$0.01 \% \quad 26.0 \%$ VLVHPPQDGEDEPTLVQKEPV

$265 \quad 0.29 \% \quad 26.6 \%$ KMTPSYEIR

$265 \quad 0.29 \% \quad 26.6 \%$ MTPSYEIR

$265 \quad 0.29 \% \quad 26.6 \%$ DFVNYLVR

$45 \quad 265 \quad 0.29 \% \quad 26.6 \%$ GANLKDYYSR

$45 \quad 265 \quad 0.29 \% \quad 26.6 \%$ ARLNQYFQK

$45 \quad 265 \quad 0.29 \% \quad 26.6 \%$ LNQYFQKEK
$99.0 \% \quad 41.0 \quad 25.0 \quad 39.4$

$\begin{array}{llll}99.7 \% & 39.4 & 25.0 & 29.4\end{array}$

$99.1 \% \quad 21.5 \quad 25.0 \quad 16.9$

$99.7 \% \quad 42.6 \quad 25.0 \quad 42.6$

$\begin{array}{llll}99.7 \% & 33.0 & 25.0 & 33.0\end{array}$

$\begin{array}{llll}99.5 \% & 21.3 & 25.0 & 20.8\end{array}$

$99.7 \% \quad 63.2 \quad 25.0 \quad 63.2$

$\begin{array}{llll}99.7 \% & 61.6 & 25.0 & 61.6\end{array}$

$\begin{array}{llll}99.7 \% & 36.7 & 25.0 & 32.3\end{array}$

$\begin{array}{llll}99.7 \% & 64.3 & 25.0 & 54.4\end{array}$

$99.0 \% \quad 32.5 \quad 25.0 \quad 23.2 \quad 2$

$99.7 \% \quad 44.9 \quad 25.0 \quad 44.9$

$\begin{array}{llll}99.0 \% & 25.9 & 25.0 & 13.8\end{array}$

$99.7 \% \quad 42.0 \quad 25.0 \quad 34.6$

$99.3 \% \quad 18.9 \quad 25.0 \quad 18.9$

$\begin{array}{llll}99.7 \% & 66.9 & 25.0 & 66.9\end{array}$

$\begin{array}{llll}99.7 \% & 29.0 & 25.0 & 21.5\end{array}$

$\begin{array}{llll}99.6 \% & 23.7 & 25.0 & 23.7\end{array}$

$\begin{array}{lllll}99.7 \% & 35.1 & 25.0 & 35.1 & 2\end{array}$

$\begin{array}{llll}99.4 \% & 24.7 & 25.0 & 24.7\end{array}$

$\begin{array}{llll}99.0 \% & 42.5 & 25.0 & 28.2\end{array}$

$\begin{array}{llll}99.0 \% & 28.2 & 25.0 & 28.2\end{array}$

$\begin{array}{llll}99.7 \% & 40.2 & 25.0 & 40.2\end{array}$

$\begin{array}{llll}99.7 \% & 31.3 & 25.4 & 16.1\end{array}$

$\begin{array}{llll}9.7 \% & 66.9 & 25.0 & 66.9\end{array}$

$\begin{array}{llll}99.0 \% & 44.5 & 25.0 & 22.8\end{array}$

$\begin{array}{llll}99.7 \% & 55.5 & 25.0 & 55.2\end{array}$

$99.5 \% \quad 24.4 \quad 25.0 \quad 17.0$

$\begin{array}{lllll}99.7 \% & 42.4 & 25.0 & 42.4 & 2\end{array}$

$\begin{array}{lllll}99.3 \% & 28.7 & 25.0 & 14.4\end{array}$

$\begin{array}{llll}99.7 \% & 57.6 & 25.0 & 56.5\end{array}$

$99.7 \% \quad 46.6 \quad 25.0 \quad 41.1$

$99.7 \% \quad 38.4 \quad 25.0 \quad 31.1$

$\begin{array}{llll}99.7 \% & 50.2 & 25.0 & 38.4\end{array}$

$\begin{array}{llll}99.7 \% & 27.5 & 25.0 & 27.5\end{array}$

$\begin{array}{llll}98.5 \% & 23.5 & 25.0 & 22.8\end{array}$

$99.7 \% \quad 34.6 \quad 25.0 \quad 28.8$

$\begin{array}{lllll}99.4 \% & 21.0 & 25.0 & 21.0\end{array}$

$\begin{array}{llll}99.7 \% & 70.8 & 25.0 & 67.0\end{array}$

$\begin{array}{llll}99.7 \% & 49.7 & 25.0 & 40.2\end{array}$

$\begin{array}{llll}99.7 \% & 57.2 & 25.0 & 55.4\end{array}$

$\begin{array}{llll}99.7 \% & 39.1 & 25.0 & 30.0\end{array}$

$\begin{array}{llll}99.0 \% & 47.9 & 25.0 & 46.9\end{array}$

$\begin{array}{lllll}99.0 \% & 52.6 & 25.0 & 40.0\end{array}$

$\begin{array}{llll}99.7 \% & 63.4 & 25.0 & 53.2\end{array}$

$\begin{array}{llll}98.7 \% & 23.1 & 25.0 & 14.6\end{array}$

$\begin{array}{llll}99.7 \% & 39.1 & 25.0 & 18.9\end{array}$
1090.53

1665.8

1496.75

1061.56

1912.81

1519.78

1367.74

1507.72

907.45

1428.80

912.51

1133.67

1567.77

1787.91

1435.75

1257.68

1289.75

1817.92

820.47

934.55

1713.94

1058.56

1787.91

945.49

1270.65

1237.68

1385.82

1471.80

1256.72

958.59

1306.66

1299.69

1311.75

1668.93

1253.65

1166.61

1617.82

1406.69

3517.77

1124.58

996.48

1025.54

1186.59

1167.63

1197.63 
ATP-dependent RNA helicase A GN=DHX9 DHX9_HUMAN $140.96 \quad 100.0 \% 38$ ATP-dependent RNA helicase A GN=DHX9 DHX9_HUMAN $140.96 \quad 100.0 \% 38$ ATP-dependent RNA helicase A GN=DHX9 DHX9_HUMAN $140.96 \quad 100.0 \% 38$ ATP-dependent RNA helicase A GN=DHX9 DHX9 HUMAN $140.96 \quad 100.0 \% 38$ ATP-dependent RNA helicase A GN=DHX9 DHX9_HUMAN $140.96 \quad 100.0 \% 38$ ATP-dependent RNA helicase A GN=DHX9 DHX9_HUMAN $140.96 \quad 100.0 \% 38$ ATP-dependent RNA helicase A GN=DHX9 DHX9_HUMAN $140.96 \quad 100.0 \% 38$ ATP-dependent RNA helicase A GN=DHX9 DHX9_HUMAN $140.96 \quad 100.0 \% 38$ ATP-dependent RNA helicase A GN=DHX9 DHX9_HUMAN $140.96 \quad 100.0 \% 38$ ATP-dependent RNA helicase A GN=DHX9 DHX9_HUMAN $140.96 \quad 100.0 \% 38$ ATP-dependent RNA helicase A GN=DHX9 DHX9_HUMAN $140.96 \quad 100.0 \% 38$ ATP-dependent RNA helicase A GN=DHX9 DHX9_HUMAN $140.96 \quad 100.0 \% 38$ ATP-dependent RNA helicase A GN=DHX9 DHX9_HUMAN $140.96 \quad 100.0 \% 38$ ATP-dependent RNA helicase A GN=DHX9 DHX9_HUMAN $140.96 \quad 100.0 \% 38$ ATP-dependent RNA helicase A GN=DHX9 DHX9_HUMAN $140.96 \quad 100.0 \% 38$ ATP-dependent RNA helicase A GN=DHX9 DHX9_HUMAN $140.96 \quad 100.0 \% 38$ ATP-dependent RNA helicase A GN=DHX9 DHX9 HUMAN $140.96 \quad 100.0 \% 38$ ATP-dependent RNA helicase A GN=DHX9 DHX9_HUMAN $140.96 \quad 100.0 \% 38$ ATP-dependent RNA helicase A GN=DHX9 DHX9_HUMAN $140.96 \quad 100.0 \% 38$ ATP-dependent RNA helicase A GN=DHX9 DHX9_HUMAN $140.96 \quad 100.0 \% 38$ ATP-dependent RNA helicase A GN=DHX9 DHX9_HUMAN $140.96 \quad 100.0 \% 38$ ATP-dependent RNA helicase A GN=DHX9 DHX9_HUMAN $140.96 \quad 100.0 \% 38$ ATP-dependent RNA helicase A GN=DHX9 DHX9_HUMAN $140.96 \quad 100.0 \% 38$ ATP-dependent RNA helicase A GN=DHX9 DHX9_HUMAN $140.96 \quad 100.0 \%$ ATP-dependent RNA helicase A GN=DHX9 DHX9_HUMAN $140.96 \quad 100.0 \% 38$ ATP-dependent RNA helicase A GN=DHX9 DHX9_HUMAN $140.96 \quad 100.0 \% \quad 38$ ATP-dependent RNA helicase A GN=DHX9 DHX9_HUMAN $140.96 \quad 100.0 \% \quad 38$ ATP-dependent RNA helicase A GN=DHX9 DHX9_HUMAN $140.96 \quad 100.0 \% 38$ ATP-dependent RNA helicase A GN=DHX9 DHX9_HUMAN $140.96 \quad 100.0 \% 38$ ATP-dependent RNA helicase A GN=DHX9 DHX9_HUMAN $140.96 \quad 100.0 \% 38$ ATP-dependent RNA helicase A GN=DHX9 DHX9_HUMAN $140.96 \quad 100.0 \% 38$ ATP-dependent RNA helicase A GN=DHX9 DHX9_HUMAN $140.96 \quad 100.0 \% 38$ ATP-dependent RNA helicase DDX18 GN=DDX18 DDX18_HUMAN $75.41 \quad 100.0 \% 3$ ATP-dependent RNA helicase DDX18 GN=DDX18 DDX18_HUMAN $75.41 \quad 100.0 \%$ ATP-dependent RNA helicase DDX18 GN=DDX18 DDX18_HUMAN $75.41 \quad 100.0 \%$ ATP-dependent RNA helicase DDX19A GN=DDX19A DD19A HUMAN $53.98 \quad 100.0 \%$ ATP-dependent RNA helicase DDX19A GN=DDX19A DD19A_HUMAN $53.98 \quad 100.0 \%$ ATP-dependent RNA helicase DDX39A GN=DDX39A DX39A HUMAN $49.13 \quad 100.0 \%$ ATP-dependent RNA helicase DDX39A GN=DDX39A DX39A_HUMAN $49.13 \quad 100.0 \%$ ATP-dependent RNA helicase DDX39A GN=DDX39A DX39A_HUMAN $49.13 \quad 100.0 \%$ ATP-dependent RNA helicase DDX39A GN=DDX39A DX39A HUMAN $49.13 \quad 100.0 \%$ ATP-dependent RNA helicase DDX39A GN=DDX39A DX39A_HUMAN $49.13 \quad 100.0 \%$ ATP-dependent RNA helicase DDX39A GN=DDX39A DX39A HUMAN $49.13 \quad 100.0 \%$ ATP-dependent RNA helicase DDX39A GN=DDX39A DX39A_HUMAN $49.13 \quad 100.0 \%$ ATP-dependent RNA helicase DDX39A GN=DDX39A DX39A_HUMAN $49.13 \quad 100.0 \%$ ATP-dependent RNA helicase DDX3X GN=DDX3X DDX3X_HUMAN $73.25 \quad 100.0 \%$ ATP-dependent RNA helicase DDX3X GN=DDX3X DDX3X_HUMAN $73.25 \quad 100.0 \%$
$45 \quad 265 \quad 0.29 \% \quad 26.6 \%$ AAECNIVVTQPR

$45 \quad 265 \quad 0.29 \% \quad 26.6 \%$ AAECNIVVTQPRR

$45 \quad 265 \quad 0.29 \% \quad 26.6 \%$ RISAVSVAER

$45 \quad 265 \quad 0.29 \% \quad 26.6 \%$ ISAVSVAER

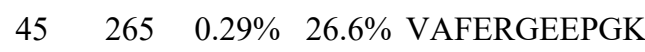

$45 \quad 265 \quad 0.29 \% \quad 26.6 \%$ GEEPGKSCGYSVR

$45 \quad 265 \quad 0.29 \% \quad 26.6 \%$ GISHVIVDEIHER

$45 \quad 265 \quad 0.29 \% \quad 26.6 \%$ DVVQAYPEVR

$45 \quad 265 \quad 0.29 \% \quad 26.6 \%$ LSMSQLNEK

$45 \quad 265 \quad 0.29 \% \quad 26.6 \%$ HLEMNPHFGSHR

$\begin{array}{llll}45 & 265 & 0.29 \% & 26.6 \% \\ & & \text { YQILPLHSQIPR }\end{array}$

$45 \quad 265 \quad 0.29 \% \quad 26.6 \%$ KVFDPVPVGVTK

$45 \quad 265 \quad 0.29 \% \quad 26.6 \%$ VFDPVPVGVTK

$45 \quad 265 \quad 0.29 \% \quad 26.6 \%$ VRPGFCFHLCSR

$45 \quad 265 \quad 0.29 \% \quad 26.6 \%$ LETHMTPEMFR

$45 \quad 265 \quad 0.29 \% \quad 26.6 \%$ TPLHEIALSIK

$45 \quad 265 \quad 0.29 \% \quad 26.6 \%$ LGGIGQFLAK

$45 \quad 265 \quad 0.29 \% \quad 26.6 \%$ ILAKLPIEPR

$45 \quad 265 \quad 0.29 \% \quad 26.6 \%$ MGGEEAEIR

$45 \quad 265 \quad 0.29 \% \quad 26.6 \%$ KILTTEGR

$45 \quad 265 \quad 0.29 \% \quad 26.6 \%$ ILTTEGRNALIHK

$45 \quad 265 \quad 0.29 \% \quad 26.6 \%$ YPSPFFVFGEK

$45 \quad 265 \quad 0.29 \% \quad 26.6 \%$ LQISHEAAACITGLR

$45 \quad 265 \quad 0.29 \% \quad 26.6 \%$ AAMEALVVEVTK

$45 \quad 265 \quad 0.29 \% \quad 26.6 \%$ QPAIISQLDPVNER

$45 \quad 265 \quad 0.29 \% \quad 26.6 \%$ YGDGPRPPK

$7 \quad 0.01 \% \quad 5.1 \% \quad$ NGTGVLILSPTR

\section{$0.01 \% \quad 5.1 \% \quad$ QTMLFSATQTR}

$0.01 \% \quad 5.1 \%$ SAQEAYKSYIR

$99.7 \% \quad 53.6$

$99.7 \% \quad 57.5$

$99.4 \% \quad 26.4$

$99.7 \% \quad 60.1$

$99.7 \% \quad 61.3$

$96.4 \% \quad 18.7$

$\begin{array}{lll}99.7 \% & 42.8\end{array}$

$99.7 \% \quad 42.9$

$\begin{array}{lll}99.7 \% & 46.1\end{array}$

$\begin{array}{lll}99.7 \% & 32.7\end{array}$

$99.7 \% \quad 36.8$

$94.7 \% \quad 13.6$

$\begin{array}{lll}99.7 \% & 55.8\end{array}$

$99.7 \% \quad 37.5$

$99.7 \% \quad 36.1$

$98.3 \% \quad 17.6$

$99.7 \% \quad 39.3$

$\begin{array}{lll}99.7 \% & 55.8\end{array}$

$99.7 \% \quad 36.2$

$99.7 \% \quad 50.0$

$99.0 \% \quad 31.2$

$99.7 \% \quad 27.4$

$99.7 \% \quad 30.9$

$99.7 \% \quad 31.3$

$99.7 \% \quad 58.1$

$99.7 \% \quad 46.0$

$99.7 \% \quad 52.2$

$99.7 \% \quad 48.5$

$99.7 \% \quad 48.2$

$99.7 \% \quad 37.0$

$0.01 \% \quad 7.3 \%$ SNLVDNTNQVEVLORDPNSPLYSVK $99.7 \% \quad 53.4$

$0.01 \% \quad 7.3 \%$ VLVTTNVCAR

$0.01 \% \quad 18.3 \%$ ELAFQISK

$0.01 \% \quad 18.3 \%$ VSVFFGGLSIK

$0.01 \% \quad 18.3 \%$ NCPHVVVGTPGR

$0.01 \% \quad 18.3 \%$ GMAQEERLSR

$0.01 \% \quad 18.3 \%$ YQQFKDFQR

$0.01 \% \quad 18.3 \%$ ILVATNLFGR

$\begin{array}{ll}99.7 \% & 53.4 \\ 99.7 \% & 42.4\end{array}$

$99.0 \% \quad 35.0$

$99.7 \% \quad 34.3$

$99.7 \% \quad 57.1$

$99.7 \% \quad 28.9$

$99.7 \% \quad 40.2$

$99.7 \% \quad 61.9$

$0.01 \% \quad 18.3 \%$ FGTKGLAITFVSDENDAK $98.7 \% 25.4$

$99.7 \% \quad 56.3$

$99.7 \% \quad 31.2$

$0.06 \% \quad 26.4 \%$ SSFFSDRGSGSR

$99.7 \% \quad 36.9$
1186.56

1416.80

1288.70

1777.95

1075.55

1357.69

1513.79

1087.62

931.52

1218.61

1425.6

1503.79

1175.61

1049.53

1461.68

1464.83

1285.75

1157.66

1535.74

1391.64

1221.72

1003.59

1149.74

991.45

917.54

1465.85

1317.65

1639.86

1260.69

1579.84

986.51

1227.7

1283.64

1315.66

2829.44

1132.61

935.52

1153.66

1292.65

1176.58

1259.62

1103.66

1912.97

1479.73

1289.59 1089.61 $\begin{array}{cc}94 & 209 \\ 00 & 209 \\ 36 & 248 \\ 37 & 248 \\ 49 & 264 \\ 15 & 323 \\ 35 & 446 \\ 35 & 447 \\ 47 & 456 \\ 48 & 456 \\ 57 & 467 \\ 62 & 474 \\ 04 & 516 \\ 29 & 538 \\ 22 & 630 \\ 69 & 680 \\ 81 & 692 \\ 97 & 708 \\ 98 & 708 \\ 68 & 779 \\ 85 & 795 \\ 96 & 806 \\ 10 & 819 \\ 54 & 863 \\ 30 & 938 \\ 11 & 1018 \\ 12 & 1024 \\ 38 & 1048 \\ 90 & 1104 \\ 05 & 1116 \\ 17 & 1130 \\ 55 & 1163 \\ 50 & 261 \\ 59 & 369 \\ 78 & 588 \\ 7 & 91 \\ 95 & 208 \\ 23 & 394 \\ 44 & 130 \\ 63 & 154 \\ 19 & 328 \\ 29 & 337 \\ 39 & 348 \\ 90 & 397 \\ 84 & 397 \\ & \end{array}$ 
ATP-dependent RNA helicase DDX3X GN=DDX3X DDX3X_HUMAN $73.25 \quad 100.0 \% \quad 18 \quad 21 \quad 53 \quad 0.06 \% \quad 26.4 \%$ DLMACAQTGSGK ATP-dependent RNA helicase DDX3X GN=DDX3X DDX3X_HUMAN $73.25 \quad 100.0 \% \quad 18 \quad 21 \quad 53 \quad 0.06 \% \quad 26.4 \%$ KQYPISLVLAPTR ATP-dependent RNA helicase DDX3X GN=DDX3X DDX3X_HUMAN $73.25 \quad 100.0 \% \quad 18$ ATP-dependent RNA helicase DDX3X GN=DDX3X DDX3X HUMAN $73.25 \quad 100.0 \%-18$ ATP-dependent RNA helicase DDX3X GN=DDX3X DDX3X_HUMAN $73.25 \quad 100.0 \% \quad 18$ ATP-dependent RNA helicase DDX3X GN=DDX3X DDX3X_HUMAN $73.25 \quad 100.0 \% \quad 18$ ATP-dependent RNA helicase DDX3X GN=DDX3X DDX3X_HUMAN $73.25 \quad 100.0 \% \quad 18$ ATP-dependent RNA helicase DDX3X GN=DDX3X DDX3X_HUMAN $73.25 \quad 100.0 \% \quad 18$ ATP-dependent RNA helicase DDX3X GN=DDX3X DDX3X HUMAN $73.25 \quad 100.0 \% \quad 18$ ATP-dependent RNA helicase DDX3X GN=DDX3X DDX3X_HUMAN $73.25 \quad 100.0 \% \quad 18$ ATP-dependent RNA helicase DDX3X GN=DDX3X DDX3X_HUMAN $73.25 \quad 100.0 \% \quad 18$ ATP-dependent RNA helicase DDX3X GN=DDX3X DDX3X_HUMAN 73.25 ATP-dependent RNA helicase DDX3X GN=DDX3X DDX3X_HUMAN 73.25 ATP-dependent RNA helicase DDX3X GN=DDX3X DDX3X_HUMAN 73.25 ATP-dependent RNA helicase DDX3X GN=DDX3X DDX3X HUMAN 73.2 ATP-dependent RNA helicase DDX3X GN=DDX3X DDX3X_HUMAN 73.25 ATP-dependent RNA helicase DDX50 GN=DDX50 DDX50 HUMAN 82.57 ATP-dependent RNA helicase DDX50 GN=DDX50 DDX50_HUMAN 82.57 ATP-dependent RNA helicase DDX50 GN=DDX50 DDX50_HUMAN 82.57 ATP-dependent RNA helicase DDX50 GN=DDX50 DDX50 HUMAN 82.57 ATP-dependent RNA helicase DDX50 GN=DDX50 DDX50_HUMAN 82.57 ATP-dependent RNA helicase DDX50 GN=DDX50 DDX50 HUMAN 82.57 ATP-dependent RNA helicase DDX51 GN=DDX51 DDX51_HUMAN 72.46 ATP-dependent RNA helicase DDX51 GN=DDX51 DDX51_HUMAN 72.46 ATP-dependent RNA helicase DDX54 GN=DDX54 DDX54_HUMAN 98.60 ATP-dependent RNA helicase DDX54 GN=DDX54 DDX54_HUMAN 98.60 ATP-dependent RNA helicase DDX54 GN=DDX54 DDX54_HUMAN 98.60 ATP-dependent RNA helicase DDX54 GN=DDX54 DDX54_HUMAN 98.60 ATP-dependent RNA helicase DHX36 GN=DHX36 DHX36_HUMAN $114.76 \quad 100.0 \%$ ATP-dependent RNA helicase DHX36 GN=DHX36 DHX36 HUMAN $114.76100 .0 \%$ ATP-dependent RNA helicase DHX36 GN=DHX36 DHX36_HUMAN $114.76 \quad 100.0 \%$ ATP-dependent RNA helicase DHX36 GN=DHX36 DHX36_HUMAN $114.76 \quad 100.0 \%$ ATP-dependent RNA helicase DHX8 GN=DHX8 DHX8 HUMAN $139.32100 .0 \%$ ATP-dependent RNA helicase DHX8 GN=DHX8 DHX8_HUMAN $139.32 \quad 100.0 \%$ ATP-dependent RNA helicase DHX8 GN=DHX8 DHX8 HUMAN $139.32 \quad 100.0 \%$ ATP-dependent RNA helicase DHX8 GN=DHX8 DHX8_HUMAN $139.32 \quad 100.0 \%$ ATP-dependent RNA helicase DHX8 GN=DHX8 DHX8_HUMAN $139.32 \quad 100.0 \%$ ATP-dependent RNA helicase DHX8 GN=DHX8 DHX8 HUMAN $139.32 \quad 100.0 \%$ ATP-dependent RNA helicase DHX8 GN=DHX8 DHX8_HUMAN $139.32 \quad 100.0 \%$ ATP-dependent RNA helicase DHX8 GN=DHX8 DHX8_HUMAN $139.32 \quad 100.0 \%$ ATP-dependent zinc metalloprotease YME1L1 GN=YME1L1 YMEL1 HUMAN $86.46 \quad 100.0 \%$ ATP-dependent zinc metalloprotease YME1L1 GN=YME1L1 YMEL1_HUMAN $86.46 \quad 100.0 \%$ Atypical kinase ADCK3, mitochondrial GN=ADCK3 ADCK3 HUMAN $71.95100 .0^{\circ}$, Atypical kinase ADCK3, mitochondrial GN=ADCK3 ADCK3_HUMAN $71.95 \quad 100.0 \%$ Basic leucine zipper and W2 domain-containing protein $1 \mathrm{GN}=\mathrm{BZW} 1 \quad$ BZW1_HUMAN $48.04 \quad 100.0 \%$ Basic leucine zipper and $\mathrm{W} 2$ domain-containing protein $1 \mathrm{GN}=\mathrm{BZW} 1$ BZW1 HUMAN $48.04 \quad 100.0 \%$ Bcl-2-associated transcription factor $1 \mathrm{GN}=\mathrm{BCLAF} 1 \mathrm{BCLF} 1$ HUMAN $106.13 \quad 100.0 \%$
$0.06 \% \quad 26.4 \%$ QYPISLVLAPTR

$0.06 \% \quad 26.4 \%$ ELAVQIYEEAR

$0.06 \% \quad 26.4 \%$ ELAVQIYEEARK

$0.06 \% \quad 26.4 \%$ VRPCVVYGGADIGQQIR

$0.06 \% \quad 26.4 \%$ IVEQDTMPPKGVR

$0.06 \% \quad 26.4 \%$ VGSTSENITQK

$0.06 \% \quad 26.4 \%$ VVWVEESDKR

$0.06 \% \quad 26.4 \%$ DREEALHQFR

$0.06 \% \quad 26.4 \%$ SGKSPILVATAVAAR

$0.06 \% \quad 26.4 \%$ SPILVATAVAAR

$0.06 \% \quad 26.4 \%$ VGNLGLATSFFNER

$0.06 \% \quad 26.4 \%$ DLLDLLVEAK

$0.06 \% \quad 26.4 \%$ DYRQSSGASSSSFSSSR

$0.06 \% 26.4 \%$ QSSGASSSSFSSSR

$0.01 \% \quad 7.6 \%$ NGIDILVGTPGR

$0.01 \% \quad 7.6 \%$ SRYEQVDLVGK

$0.01 \% \quad 7.6 \%$ VLVATNVAAR

$0.01 \% \quad 7.6 \%$ VGVPSTMDLVK

$0.01 \% \quad 7.6 \%$ KLSSNAVSQITR

$0.01 \% \quad 7.6 \%$ LSSNAVSQITR

$0.00 \% \quad 2.9 \%$ LFSTGLAHR

$0.00 \% \quad 2.9 \%$ TGQAFTLLLK

$0.01 \% \quad 5.2 \%$ CSTLIVTDLAAR

$0.01 \% \quad 5.2 \%$ VADNAQQQYVR

$0.01 \% \quad 5.2 \%$ SRPAPSPESIKR

$0.01 \% \quad 5.2 \% \quad$ ATIFEINASSR

$0.00 \% \quad 3.4 \%$ RISAISVAER

$0.00 \% \quad 3.4 \%$ ISAISVAER

$0.00 \% \quad 3.4 \%$ AVICAGLYPK

$0.00 \% \quad 3.4 \%$ VYTKTDGLVAVHPK

$0.02 \% \quad 6.6 \%$ VANVADVVSK

$0.02 \% \quad 6.6 \%$ VANVADVVSKGQR

$0.02 \% \quad 6.6 \% \quad$ NPDGSLSQAAMMQSALAK

$0.02 \% \quad 6.6 \% \quad$ LIVTSATLDAVK

$0.02 \% \quad 6.6 \%$ IFDPAPPGSR

$0.02 \% \quad 6.6 \%$ TNLASTVLSLK

$0.02 \% \quad 6.6 \%$ AICSGFFR

$0.00 \% \quad 2.7 \%$ TGFAEGFLK

$0.00 \% \quad 2.7 \%$ GILLVGPPGTGK

$0.01 \% \quad 5.9 \%$ LANFGGLAVGLGFGALAEVAKK

$0.01 \% \quad 5.9 \% \quad$ AVLGSSPFLSEANAER

$0.00 \% \quad 5.0 \%$ EGVSAAFAVK

$0.00 \% \quad 5.0 \%$ AEVLSEEPILK

$0.02 \% \quad 10.5 \%$ KAEGEPQEESPLK
$0.02 \% \quad 6.6 \%$ TQMSILEQR
$99.7 \% \quad 54.9$

$99.7 \% \quad 65.5$

$99.7 \% \quad 34.8$

$99.7 \% \quad 55.3$

$99.7 \% \quad 55.8$

$99.7 \% \quad 31.1$

$99.7 \% \quad 43.7$

$99.7 \% \quad 58.1$

$94.9 \% \quad 15.9$

$99.6 \% \quad 25.2$

$99.7 \% \quad 34.6$

$99.7 \% \quad 63.1$

$99.7 \% \quad 42.8$

$99.7 \% \quad 40.1$

$99.7 \% \quad 58.9$

$99.7 \% \quad 72.0$

$99.7 \% \quad 52.3$

$99.7 \% 36.8$

$99.7 \% \quad 32.6$

$95.7 \% \quad 19.4$

$99.7 \% \quad 57.6$

$99.7 \% 27.0$

$99.0 \% \quad 18.4$

$99.7 \% \quad 33.3$

$99.7 \% \quad 56.4$

$99.7 \% \quad 59.1$

$99.7 \% \quad 50.2$

$99.7 \% \quad 39.8$

$98.3 \% \quad 22.9$

$99.7 \% \quad 51.2$

$99.7 \% 39.1$

$\begin{array}{lll}98.5 \% & 19.2\end{array}$

$99.7 \% \quad 52.7$

$99.7 \% \quad 43.5$

$99.7 \% \quad 44.7$

$99.7 \% \quad 31.6$

$99.7 \% \quad 33.0$

$99.7 \% \quad 38.8$

$99.7 \% \quad 36.8$

$99.0 \% \quad 26.8$

$98.4 \% 22.4$

$95.4 \% \quad 14.3$

$99.7 \% \quad 53.8$

$99.7 \% \quad 50.0$

$99.7 \% \quad 31.0$

$99.7 \% \quad 43.5$

$99.7 \% \quad 32.3$
123

1238.55

1357.78

1320.68

1448.77

1887.99

1485.77

1163.59

1246.64

1300.64

1440.85

1168.70

1524.78

1128.65

1795.78

1361.59

1211.67

1293.68

1013.61

1145.62

1303.73

1175.64

1001.55

1091.65

1319.70

1291.64

1324.73

1208.63

1101.64

945.54

1091.59

1527.85

1001.56

1342.74

1851.86

1105.57

1230.73

1056.55

1146.67

957.46

969.50

1108.67

2103.20

1647.83

978.53

1227.68

1441.72 $\begin{array}{ll}19 & 230 \\ 64 & 276 \\ 65 & 276 \\ 77 & 287 \\ 77 & 288 \\ 95 & 311 \\ 64 & 376 \\ 08 & 418 \\ 19 & 428 \\ 79 & 488 \\ 89 & 503 \\ 92 & 503 \\ 35 & 548 \\ 55 & 564 \\ 01 & 617 \\ 04 & 617 \\ 58 & 269 \\ 43 & 353 \\ 41 & 450 \\ 14 & 524 \\ 11 & 622 \\ 12 & 622 \\ 51 & 459 \\ 02 & 611 \\ 89 & 400 \\ 11 & 521 \\ 22 & 533 \\ 73 & 583 \\ 66 & 275 \\ 67 & 275 \\ 33 & 842 \\ 59 & 872 \\ 06 & 315 \\ 06 & 318 \\ 67 & 484 \\ 54 & 562 \\ 13 & 724 \\ 24 & 833 \\ 23 & 933 \\ 106 & 1113 \\ 70 & 278 \\ 74 & 385 \\ 14 & 235 \\ 47 & 262 \\ 79 & 188 \\ 69 & 379 \\ 68 & 180\end{array}$

Page 32 of Table S-1-5 
Bcl-2-associated transcription factor 1 GN=BCLAF1 BCLF1_HUMAN $106.13 \quad 100.0 \%$ Bcl-2-associated transcription factor $1 \mathrm{GN}=\mathrm{BCLAF} 1 \mathrm{BCLF}$ _HUMAN $106.13 \quad 100.0 \%$ Bcl-2-associated transcription factor $1 \mathrm{GN}=\mathrm{BCLAF} 1$ BCLF1_HUMAN $106.13 \quad 100.0 \%$ Bcl-2-associated transcription factor $1 \mathrm{GN}=$ BCLAF1 BCLF1 HUMAN $106.13 \quad 100.0 \%$ Bcl-2-associated transcription factor $1 \mathrm{GN}=\mathrm{BCLAF} 1 \mathrm{BCLF} 1$ HUMAN $106.13 \quad 100.0 \%$ Bcl-2-associated transcription factor $1 \mathrm{GN}=\mathrm{BCLAF} 1 \mathrm{BCLF} 1$ HUMAN $106.13 \quad 100.0 \%$ Bcl-2-associated transcription factor $1 \mathrm{GN}=\mathrm{BCLAF} 1$ BCLF1_HUMAN $106.13 \quad 100.0 \%$ Beta-1,3-galactosyltransferase 6 GN=B3GALT6 B3GT6_HUMAN $37.14 \quad 100.0 \%$ Beta-1,3-galactosyltransferase 6 GN=B3GALT6 B3GT6 HUMAN $37.14 \quad 100.0 \%$ Beta-galactosidase $\mathrm{GN}=\mathrm{GLB} 1$ Beta-galactosidase $\mathrm{GN}=\mathrm{GLB} 1$

Beta-galactosidase $\mathrm{GN}=\mathrm{GLB} 1$ Beta-galactosidase $\mathrm{GN}=\mathrm{GLB}$ BGAL_HUMAN $76.08 \quad 100.0 \%$ BGAL_HUMAN $76.08 \quad 100.0 \%$ BGAL HUMAN $76.08 \quad 100.0 \%$ BGAL_HUMAN $76.08 \quad 100.0 \%$ Bifunctional glutamate/proline--tRNA ligase GN=EPRS SYEP_HUMAN $170.59 \quad 100.0 \%$ Bifunctional glutamate/proline--tRNA ligase GN=EPRS SYEP_HUMAN $170.59 \quad 100.0 \%$ Bifunctional glutamate/proline--tRNA ligase GN=EPRS SYEP_HUMAN $170.59 \quad 100.0 \%$ Bifunctional glutamate/proline--tRNA ligase GN=EPRS SYEP HUMAN $170.59100 .0 \%$ Bifunctional glutamate/proline--tRNA ligase GN=EPRS SYEP_HUMAN $170.59 \quad 100.0 \%$ Bifunctional glutamate/proline--tRNA ligase GN=EPRS SYEP_HUMAN $170.59100 .0 \%$ Bifunctional glutamate/proline--tRNA ligase GN=EPRS SYEP HUMAN $170.59100 .0 \%$ Bifunctional glutamate/proline--tRNA ligase GN=EPRS SYEP_HUMAN $170.59 \quad 100.0 \%$ Bifunctional glutamate/proline--tRNA ligase GN=EPRS SYEP HUMAN $170.59100 .0 \%$ Bifunctional glutamate/proline--tRNA ligase GN=EPRS SYEP_HUMAN $170.59 \quad 100.0 \%$ Bifunctional glutamate/proline--tRNA ligase GN=EPRS SYEP_HUMAN $170.59 \quad 100.0 \%$ Bifunctional glutamate/proline--tRNA ligase GN=EPRS SYEP_HUMAN $170.59100 .0 \%$ Bifunctional glutamate/proline--tRNA ligase GN=EPRS SYEP_HUMAN $170.59 \quad 100.0 \%$ Bifunctional glutamate/proline--tRNA ligase GN=EPRS SYEP_HUMAN $170.59100 .0 \%$ Bifunctional glutamate/proline--tRNA ligase GN=EPRS SYEP_HUMAN $170.59100 .0 \%$ Bifunctional glutamate/proline--tRNA ligase GN=EPRS SYEP_HUMAN $170.59 \quad 100.0 \%$ Bifunctional glutamate/proline--tRNA ligase GN=EPRS SYEP HUMAN $170.59100 .0 \%$ Bifunctional glutamate/proline--tRNA ligase GN=EPRS SYEP_HUMAN $170.59 \quad 100.0 \%$ Bifunctional glutamate/proline--tRNA ligase GN=EPRS SYEP_HUMAN $170.59100 .0 \%$ Bifunctional glutamate/proline--tRNA ligase GN=EPRS SYEP HUMAN $170.59100 .0 \%$ Bifunctional glutamate/proline--tRNA ligase GN=EPRS SYEP_HUMAN $170.59 \quad 100.0 \%$ Bifunctional glutamate/proline--tRNA ligase GN=EPRS SYEP_HUMAN $170.59 \quad 100.0 \%$ Bifunctional glutamate/proline--tRNA ligase GN=EPRS SYEP_HUMAN $170.59100 .0 \%$ Bifunctional glutamate/proline--tRNA ligase GN=EPRS SYEP_HUMAN $170.59100 .0 \%$ MTDC HUMAN $37.90 \quad 100.0 \%$ MTDC_HUMAN $37.90 \quad 100.0 \%$ MTDC_HUMAN $37.90 \quad 100.0 \%$ MTDC HUMAN $37.90 \quad 100.0 \%$ MTDC HUMAN $37.90 \quad 100.0 \%$

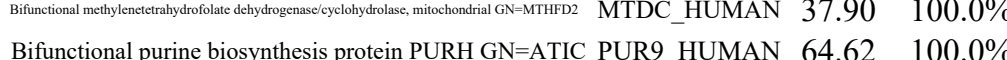
Bifunctional purine biosynthesis protein PURH GN=ATIC PUR9_HUMAN $64.62 \quad 100.0 \%$ Bifunctional purine biosynthesis protein PURH GN=ATIC PUR9_HUMAN $64.62 \quad 100.0 \%$ Bifunctional purine biosynthesis protein PURH GN=ATIC PUR9 HUMAN $64.62 \quad 100.0 \%$ Biliverdin reductase $\mathrm{A} \mathrm{GN}=\mathrm{BLVRA}$ BIEA_HUMAN $33.43 \quad 100.0 \%$
$0.02 \% \quad 10.5 \%$ SSFYPDGGDQETAK

\begin{tabular}{lll}
25.0 & 20.7 \\
\hline & 25.0 & 24.8
\end{tabular}

$0.02 \% \quad 10.5 \%$ SVLADQGKSFATASHR $0.02 \% \quad 10.5 \%$ NTEEEGLKYK

$20 \quad 0.02 \% \quad 10.5 \%$ STFREESPLR

$0.02 \% \quad 10.5 \%$ SAAMTLNER

$0.01 \% \quad 8.2 \%$ AAAFLAVLVASAPR

$0.01 \% \quad 8.2 \%$ FAVGTAGLGAEER

$0.01 \% \quad 6.4 \%$ MFEIDYSR

$0.01 \% \quad 6.4 \%$ DSFLKDGQPFR

$0.01 \% \quad 6.4 \%$ YISGSIHYSR

$0.01 \% \quad 6.4 \%$ AGATLDLLVENMGR

$0.06 \% \quad 14.4 \%$ FVELPGAEMGK

$0.06 \% 14.4 \%$ AALLNQHYQVNFKGK

$0.06 \% \quad 14.4 \%$ YAEKLIQEGK

$0.06 \% \quad 14.4 \%$ GSQFGQSCCLR

$0.06 \% \quad 14.4 \%$ KPYIWEYSR

$0.06 \% \quad 14.4 \%$ LNLNNTVLSK

$0.06 \% \quad 14.4 \%$ LNLNNTVLSKR

$0.06 \% \quad 14.4 \%$ KVIDPVAPR

$0.06 \% \quad 14.4 \%$ VIDPVAPR

$0.06 \% \quad 14.4 \%$ NADGKIISLDAK

$0.06 \% \quad 14.4 \%$ GDIIQLQR

$0.06 \% \quad 14.4 \%$ VAVQGDVVR

$0.06 \% \quad 14.4 \%$ VAVQGDVVRELK

$0.06 \% \quad 14.4 \%$ SLYDEVAAQGEVVR

$0.06 \% \quad 14.4 \%$ NSEPAGLETPEAK

$0.06 \% \quad 14.4 \%$ VLFDKVASQGEVVR

$0.06 \% \quad 14.4 \%$ VASQGEVVR

$0.06 \% \quad 14.4 \%$ NQGGGLSSSGAGEGQGPK

$0.06 \% \quad 14.4 \%$ AIQGGTSHHLGQNFSK

$0.06 \% \quad 14.4 \%$ RLLSVNIR

$0.06 \% \quad 14.4 \%$ SCQFVAVR

$0.06 \% \quad 14.4 \%$ SCQFVAVRR

$\begin{array}{llll}7 \% & 46.0 & 25.0 & 29.1 \\ 9 & & \end{array}$

$\begin{array}{llll}99.7 \% & 39.7 & 25.0 & 29.7\end{array}$

$\begin{array}{llll}99.7 \% & 28.9 & 25.0 & 20.5\end{array}$

$99.7 \% \quad 38.8 \quad 25.0 \quad 28.0$

$\begin{array}{llll}99.7 \% & 34.0 & 25.0 & 34.0\end{array}$

$96.0 \% \quad 23.6 \quad 25.0 \quad 23.6$

$\begin{array}{llll}98.8 \% & 22.0 & 25.0 & 22.0\end{array}$

$99.7 \% \quad 35.6 \quad 25.0 \quad 35.6$

$99.7 \% \quad 65.6 \quad 25.0 \quad 62.3$

$\begin{array}{llll}99.7 \% & 53.8 & 25.0 & 40.8\end{array}$

$99.7 \% \quad 29.0 \quad 25.0 \quad 21.2$

$\begin{array}{llll}97.9 \% & 16.2 & 25.0 & 16.2\end{array}$

$99.7 \% \quad 42.0 \quad 25.0 \quad 21.6$

$99.7 \% \quad 40.6 \quad 25.0 \quad 40.6$

$99.7 \% \quad 27.9 \quad 25.0 \quad 20.4$

$\begin{array}{llll}99.7 \% & 60.1 & 25.0 & 50.0\end{array}$

$99.7 \% \quad 47.7 \quad 25.0 \quad 42.1$

$99.7 \% \quad 28.1 \quad 25.0 \quad 28.1$

$\begin{array}{llll}99.0 \% & 37.3 & 25.0 & 37.3\end{array}$

$\begin{array}{llll}99.4 \% & 21.3 & 25.0 & 19.5\end{array}$

$\begin{array}{llll}99.0 \% & 38.1 & 25.0 & 5.5\end{array}$

$99.7 \% \quad 41.9 \quad 25.0 \quad 27.6$

$\begin{array}{llll}99.7 \% & 50.3 & 25.0 & 45.4\end{array}$

$\begin{array}{llll}99.7 \% & 55.5 & 25.0 & 51.7\end{array}$

$99.7 \% \quad 45.3 \quad 25.0 \quad 40.4$

$\begin{array}{lllll}99.7 \% & 61.8 & 25.0 & 58.2 & 3\end{array}$

$99.2 \% \quad 25.5 \quad 25.0 \quad 18.9$

$\begin{array}{llll}99.7 \% & 79.9 & 25.0 & 77.4\end{array}$

$\begin{array}{llll}99.7 \% & 52.8 & 25.0 & 52.8\end{array}$

$99.0 \% 31.8$

$99.0 \% \quad 37.8$

$98.3 \% \quad 20.6$

$0.06 \% \quad 14.4 \%$ TTARDQDLEPGAPSMGAK $99.6 \% 31.8$

$0.06 \% \quad 14.4 \%$ DQDLEPGAPSMGAK

$\begin{array}{lll}99.6 \% & 24.2\end{array}$

$0.01 \% \quad 17.7 \%$ ICNAVSPDKDVDGFHVINVGR $\quad 99.7 \% \quad 38.0$

$99.7 \% \quad 61.8$

$99.6 \% \quad 24.3$

$99.7 \% \quad 55.9$

$99.0 \% \quad 29.9$

$99.5 \% 26.2$

$98.1 \% 22.7$

$99.7 \% \quad 25.6$

$99.7 \% \quad 28.8$

$99.7 \% \quad 51.4$

$0.01 \% \quad 7.1 \%$ SLFSNVVTK

$0.01 \% \quad 7.1 \%$ YTQSNSVCYAK

$0.00 \% \quad 12.8 \%$ FGVVVVGVGR 967.53

1501.64

1674.86

1210.60

1221.62

992.48

1356.80

1277.65

1060.48

1309.65

1182.59

1475.75

1177.59

1730.93

1178.64

1299.56

1241.63

1115.64

1271.74

994.60

866.51

1244.68

942.54

942.54

1312.76

1535.77

1342.65

1546.86

944.52

1587.74

1681.84

970.62

966.48

1122.58

1860.88

1415.65

2312.15

1213.65

1091.62

1205.62

1015.58

1309.70

$\begin{array}{cc}56 & 271 \\ 04 & 312 \\ 19 & 332 \\ 14 & 429 \\ 30 & 439 \\ 25 & 534 \\ 23 & 631 \\ 55 & 68 \\ 4 & 106 \\ 31 & 38 \\ 99 & 49 \\ 0 & 59 \\ 69 & 482 \\ 87 & 197 \\ 17 & 231 \\ 79 & 288 \\ 29 & 339 \\ 17 & 425 \\ 26 & 435 \\ 26 & 436 \\ 98 & 506 \\ 99 & 506 \\ 82 & 593 \\ 67 & 674 \\ 57 & 765 \\ 57 & 768 \\ 25 & 838 \\ 90 & 902 \\ 03 & 916 \\ 08 & 916 \\ 92 & 1009 \\ 235 & 1250 \\ 333 & 1340 \\ 376 & 1383 \\ 376 & 1384 \\ 460 & 1477 \\ 464 & 1477 \\ 44 & 164 \\ 67 & 278 \\ 79 & 288 \\ 89 & 299 \\ 34 & 341 \\ 9 & 108 \\ 95 & 305 \\ 98 & 406 \\ 27 & 437 \\ 9 & 18 \\ & \end{array}$

994.56

1320.59 988.59 
. $49.60 \quad 100.0 \%$

Bystin $\mathrm{GN}=\mathrm{BYSL}$

PYR1_HUMAN $242.98 \quad 100.0 \% \quad 26$ PYR1_HUMAN $242.98 \quad 100.0 \% \quad 26$ PYR1_HUMAN $242.98 \quad 100.0 \% \quad 26$ PYR1 HUMAN $242.98 \quad 100.0 \% \quad 26$ PYR1_HUMAN $242.98 \quad 100.0 \% \quad 26$ PYR1_HUMAN $242.98 \quad 100.0 \% \quad 26$ PYR1_HUMAN $242.98 \quad 100.0 \% \quad 26$ PYR1_HUMAN $242.98 \quad 100.0 \% \quad 26$ PYR1 HUMAN $242.98 \quad 100.0 \% \quad 26$ PYR1_HUMAN $242.98 \quad 100.0 \% \quad 26$ PYR1_HUMAN $242.98 \quad 100.0 \% \quad 26$ PYR1 HUMAN $242.98 \quad 100.0 \% \quad 26$ PYR1_HUMAN $242.98 \quad 100.0 \% \quad 26$ PYR1 HUMAN $242.98 \quad 100.0 \% \quad 26$ PYR1_HUMAN $242.98 \quad 100.0 \% \quad 26$ PYR1_HUMAN $242.98 \quad 100.0 \% \quad 26$ PYR1 HUMAN $242.98 \quad 100.0 \% \quad 26$ PYR1_HUMAN $242.98 \quad 100.0 \% \quad 26$

$0.01 \% \quad 2.2 \%$ TCYNIYLASK

$0.01 \% \quad 2.2 \%$ DAYVQALAR

$0.01 \% \quad 2.2 \%$ AFNSNYEQR

$99.5 \% \quad 27.5$

$\begin{array}{llll}99.7 \% & 34.8\end{array}$

$99.7 \% \quad 55.0$

$0.00 \% \quad 13.1 \%$ AVGAQASVGSR

$\begin{array}{ll}99.7 \% & 55.0 \\ 99.7 \% & 61.1\end{array}$

$0.00 \% \quad 13.1 \%$ TNALNVSQK

$\begin{array}{lll}99.7 \% & 32.8\end{array}$

$\begin{array}{rr}98.2 \% & 22.4 \\ 99.7 \% & 28.3\end{array}$

$0.01 \% \quad 3.7 \% \quad$ LLTLVSTR

$0.01 \% \quad 3.7 \%$ TGEPLMSESTSN

$0.01 \% \quad 3.7 \%$ APLDASDSGR

$0.01 \% \quad 3.7 \%$ GKLSSSFSSR

$0.01 \% \quad 8.7 \% \quad$ FYNLVLLPR

$0.01 \% \quad 8.7 \%$ EAIIVGSIITK

$95.1 \% \quad 15.0$

$99.7 \% \quad 38.5$

$\begin{array}{lll}99.6 \% & 24.2\end{array}$

$99.7 \% \quad 42.7$

$0.01 \% \quad 8.7 \%$ ELQSAVPRDVEDVPITVE

$99.0 \% \quad 19.9$

$0.03 \% \quad 13.7 \%$ APAEILNGKEISAQIR

$0.03 \% \quad 13.7 \%$ GDLNDCFIPCTPK

$0.03 \% \quad 13.7 \%$ VVGDVAYDEAKER

$0.03 \% \quad 13.7 \%$ TPVPSDIDISR

$0.03 \% \quad 13.7 \%$ VLLSALER

$0.03 \% \quad 13.7 \%$ VLLSALERLK

$0.03 \% \quad 13.7 \%$ FSDIQIRR

$0.03 \% \quad 13.7 \%$ VLDTNDRFLR

$0.03 \% \quad 13.7 \%$ AYIQENLELVEK

$0.03 \% \quad 13.7 \%$ GALALAQAVQR

$0.03 \% \quad 13.7 \%$ QGFGNLPICMAK

$0.03 \% \quad 13.7 \%$ THLSLSHNPEQK

$0.10 \% \quad 11.4 \%$ VFNTGGAPR
$99.7 \% \quad 37.4$

$99.7 \% \quad 49.6$

$99.7 \% \quad 60.3$

$99.0 \% \quad 43.3$

$99.7 \% \quad 27.9$

$95.0 \% \quad 21.0$

$99.7 \% \quad 28.4$

$99.7 \% \quad 34.4$

$99.7 \% \quad 60.5$

$99.7 \% \quad 31.7$

$98.5 \% \quad 25.4$

$\begin{array}{lll}99.7 \% & 44.7\end{array}$

$99.5 \% \quad 29.9$

$99.7 \% \quad 37.6$

$99.7 \% \quad 54.2$

$99.0 \% \quad 40.3$

$99.7 \% \quad 41.0$

$99.7 \% \quad 35.8$

$99.0 \% \quad 39.4$

$99.7 \% \quad 39.7$

$99.1 \% \quad 19.7$

$99.7 \% \quad 34.3$

$99.7 \% \quad 57.7$

$99.7 \% \quad 49.3$

$99.7 \% \quad 33.3$

$99.0 \% \quad 28.2$

$99.1 \% \quad 25.5$

$99.3 \% \quad 30.4$

$99.7 \% \quad 44.0$
$99.7 \% \quad 49.7$

1413.73

1249.65

1232.60

1006.53

1128.51

1002.53

2106.91

974.53

902.57

1934.88

1388.76

988.47

1055.55

1134.67

1143.70

1996.02

1709.95

1536.68

1450.72

1199.63

900.55

1141.73

1034.57

1248.67

1448.76

1097.64

1351.65

1390.71

918.48

1002.57

1394.70

1257.62

916.56

1224.66

1020.51

985.46

1428.81

1114.59

1397.79

1558.77

1019.50

980.54

967.50

1249.75

1121.66 $0.10 \% \quad 11.4 \%$ NILLTIGSYK $0.10 \% \quad 11.4 \%$ NKSELLPTVR 
$\mathrm{CAD}$ protein $\mathrm{GN}=\mathrm{CAD}$ $\mathrm{CAD}$ protein $\mathrm{GN}=\mathrm{CAD}$ $\mathrm{CAD}$ protein $\mathrm{GN}=\mathrm{CAD}$ $\mathrm{CAD}$ protein $\mathrm{GN}=\mathrm{CAD}$ $\mathrm{CAD}$ protein $\mathrm{GN}=\mathrm{CAD}$ CAD protein $\mathrm{GN}=\mathrm{CAD}$ CAD protein $\mathrm{GN}=\mathrm{CAD}$ $\begin{array}{lrll}\text { PYR1_HUMAN } 242.98 & 100.0 \% & 2 \\ \text { CAD protein GN=CAD } & \text { Calcium uniporter protein, mitochondrial GN=MCU MCU_HUMAN } 39.87 & 100.0 \%\end{array}$ Calcium uniporter protein, mitochondrial GN=MCU MCU_HUMAN $39.87 \quad 100.0 \%$ Calcium-binding mitochondrial carrier protein Aralar2 GN=SLC25A13 CMC2_HUMAN $74.18 \quad 100.0 \%$ Calcium-binding mitochondrial carrier protein Aralar2 GN=SLC25A13 $\quad$ CMC2_HUMAN $74.18 \quad 100.0 \%$ Calcium-binding mitochondrial carrier protein Aralar2 GN=SLC25A13 $\mathrm{CMC}_{2}$ HUMAN $74.18 \quad 100.0 \%$ $\begin{array}{llll}\text { Calcium-binding mitochondrial carrier protein Aralar2 GN=SLC25A13 } & \text { CMC2_HUMAN } & 74.18 & 100.0 \%\end{array}$ Calcium-binding mitochondrial carrier protein Aralar2 GN=SLC25A13 $\quad$ CMC2_HUMAN $74.18 \quad 100.0 \% \quad 18$ Calcium-binding mitochondrial carrier protein Aralar2 GN=SLC25A13 $\mathrm{CMC}_{2}$ HUMAN $74.18 \quad 100.0 \%$ Calcium-binding mitochondrial carrier protein Aralar2 GN=SLC25A13 CMC2_HUMAN $74.18 \quad 100.0 \%$ Calcium-binding mitochondrial carrier protein Aralar2 GN=SLC25A13 $\mathrm{CMC}_{2}$ HUMAN $74.18 \quad 100.0 \% \quad 18$ Calcium-binding mitochondrial carrier protein Aralar2 $\mathrm{GN}=\mathrm{SLC} 25 \mathrm{~A} 13 \quad \mathrm{CMC} 2$ _HUMAN $74.18 \quad 100.0 \%$ $\begin{array}{lllll}\text { Calcium-binding mitochondrial carrier protein Aralar2 GN=SLC25A13 } & \text { CMC2_HUMAN } 74.18 & 100.0 \% & 18\end{array}$ Calcium-binding mitochondrial carrier protein Aralar2 $\mathrm{GN}=\mathrm{SLC} 25 \mathrm{~A} 13 \quad \mathrm{CMC} 2$ HUMAN $74.18 \quad 100.0 \%$ $\begin{array}{lllll}\text { Calcium-binding mitochondrial carrier protein Aralar2 GN=SLC25A13 } & \text { CMC2_HUMAN } 74.18 & 100.0 \% & 18\end{array}$ Calcium-binding mitochondrial carrier protein Aralar2 GN=SLC25A13 $\quad$ CMC2_HUMAN $74.18 \quad 100.0 \% \quad 18$ $\begin{array}{llll}\text { Calcium-binding mitochondrial carrier protein Aralar2 } \mathrm{GN}=\mathrm{SLC} 25 \mathrm{~A} 13 & \mathrm{CMC} 2 \text { HUMAN } & 74.18 & 100.0 \%\end{array}$ Calcium-binding mitochondrial carrier protein Aralar2 GN=SLC25A13 $\quad$ CMC2_HUMAN $74.18 \quad 100.0 \% \quad 1$ Calcium-binding mitochondrial carrier protein Aralar2 $\mathrm{GN}=\mathrm{SLC} 25 \mathrm{~A} 13 \quad \mathrm{CMC} 2$ HUMAN $74.18 \quad 100.0 \%$ $\begin{array}{llll}\text { Calcium-binding mitochondrial carrier protein Aralar2 } \mathrm{GN}=\mathrm{SLC} 25 \mathrm{~A} 13 & \mathrm{CMC} 2 \text { HUMAN } & 74.18 & 100.0 \%\end{array}$ $\begin{array}{lllll}\text { Calcium-binding mitochondrial carrier protein Aralar2 GN=SLC25A13 } & \text { CMC2_HUMAN } 74.18 & 100.0 \% & 18\end{array}$ Calcium-binding mitochondrial carrier protein SCaMC-1 GN=SLC25A24 SCMC1_HUMAN $53.36 \quad 100.0 \%$ Calcium-binding mitochondrial carrier protein SCaMC-1 GN=SLC25A24 SCMC1_HUMAN $53.36 \quad 100.0 \%$ Calcium-binding mitochondrial carrier protein SCaMC-1 GN=SLC25A24 SCMC1_HUMAN $53.36 \quad 100.0 \%$ Calcium-binding mitochondrial carrier protein SCaMC-1 GN=SLC25A24 SCMC1_HUMAN $53.36 \quad 100.0 \%$ Calcium-binding mitochondrial carrier protein SCaMC-1 GN=SLC25A24 SCMC1_HUMAN $53.36 \quad 100.0 \%$ Calcium-binding mitochondrial carrier protein SCaMC-1 GN=SLC25A24 SCMC1_HUMAN $53.36 \quad 100.0 \%$ Calcium-binding mitochondrial carrier protein SCaMC-1 GN=SLC25A24 SCMC1_HUMAN $53.36 \quad 100.0 \%$ Calmodulin-regulated spectrin-associated protein 3 GN=CAMSAP3 CAMP3_HUMAN $134.75 \quad 100.0 \%$ Calmodulin-regulated spectrin-associated protein 3 GN=CAMSAP3 CAMP3_HUMAN $134.75 \quad 100.0 \%$ Calponin-3 GN=CNN3 Calponin $-3 \mathrm{GN}=\mathrm{CNN} 3$ Calponin-3 GN=CNN3

cAMP-dependent protein kinase catalytic subunit beta GN=PRKACB KAPCB HUMAN $40.62 \quad 100.0^{\circ}$ cAMP-dependent protein kinase catalytic subunit beta GN=PRKACB KAPCB_HUMAN $40.62 \quad 100.0 \%$ cAMP-dependent protein kinase catalytic subunit beta GN=PRKACB KAPCB HUMAN $40.62 \quad 100.0 \%$ cAMP-dependent protein kinase catalytic subunit beta GN=PRKACB $\quad$ KAPCB_HUMAN $40.62 \quad 100.0 \%$ cAMP-dependent protein kinase catalytic subunit beta GN=PRKACB KAPCB_HUMAN $40.62 \quad 100.0 \%$ cAMP-dependent protein kinase catalytic subunit beta GN=PRKACB KAPCB_HUMAN $40.62 \quad 100.0 \%$ Cancer-related nucleoside-triphosphatase GN=NTPCR NTPCR_HUMAN $20.71 \quad 100.0 \%$ $\begin{array}{llll}30 & 92 & 0.10 \% & 11.4 \%\end{array}$

$30 \quad 92 \quad 0.10 \% \quad 11.4 \%$ VHVDCMTSQK

$\begin{array}{llll}30 & 92 & 0.10 \% & 11.4 \% \\ 30 & \text { KEEILLIK }\end{array}$

$30 \quad 92 \quad 0.10 \% \quad 11.4 \%$ ASDPGLPAEEPKEK

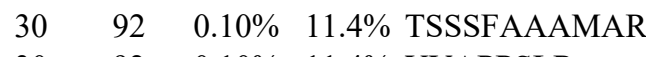

$\begin{array}{llll}30 & 92 & 0.10 \% & 11.4 \%\end{array}$

$30 \quad 92 \quad 0.10 \% \quad 11.4 \%$ VNEISVEVDSDPR

$30 \quad 92 \quad 0.10 \% \quad 11.4 \%$ QAENGMYIR

$2 \quad 0.00 \% \quad 5.4 \% \quad$ VAIYSPDGVR

$2 \quad 0.00 \% \quad 5.4 \%$ QEYVYPEAR

$40 \quad 0.04 \% \quad 25.9 \%$ YLNIFGESQPNPK

$40 \quad 0.04 \% \quad 25.9 \%$ TVELLSGVVDQTK

$40 \quad 0.04 \% \quad 25.9 \%$ DVEVTKEEFVLAAQK

$40 \quad 0.04 \% \quad 25.9 \%$ MTLADIER

$$
40
$$

$$
40
$$

3

3
3
6

6
6

6
6
6

$99.0 \% \quad 27.5 \quad 25.0 \quad 27.5 \quad 4$ $\begin{array}{lllll}99.5 \% & 21.9 & 25.0 & 21.9 & 2\end{array}$ $\begin{array}{lllll}99.0 \% & 32.9 & 25.0 & 17.6 & 4\end{array}$ $\begin{array}{lllll}99.7 \% & 29.4 & 25.0 & 29.4 & 2\end{array}$ $\begin{array}{lllll}99.7 \% & 59.4 & 25.0 & 52.8\end{array}$ $\begin{array}{llll}96.0 \% & 18.2 & 25.0 & 13.7\end{array}$ $\begin{array}{lllll}99.7 \% & 57.6 & 25.0 & 53.1 & 4\end{array}$ $\begin{array}{lllll}98.7 \% & 26.8 & 25.0 & 11.2 & 1\end{array}$ $\begin{array}{llll}99.6 \% & 23.1 & 25.0 & 21.7\end{array}$ $\begin{array}{llll}99.4 \% & 22.4 & 25.0 & 20.7\end{array}$ $\begin{array}{llll}99.7 \% & 62.7 & 25.0 & 62.7\end{array}$ $\begin{array}{lllll}99.7 \% & 81.5 & 25.0 & 73.9 & 2\end{array}$ $\begin{array}{lllll}99.7 \% & 32.1 & 25.0 & 32.1 & 2\end{array}$ $\begin{array}{llll}99.0 \% & 47.2 & 25.0 & 39.1\end{array}$ $\begin{array}{llll}99.7 \% & 49.1 & 25.0 & 49.1\end{array}$ $\begin{array}{lllll}99.7 \% & 39.5 & 25.0 & 39.5 & 3\end{array}$ $\begin{array}{lllll}99.7 \% & 42.9 & 25.0 & 42.9 & 2\end{array}$ $\begin{array}{llll}99.7 \% & 43.8 & 25.0 & 43.8\end{array}$ $\begin{array}{lllll}99.0 \% & 38.4 & 25.0 & 29.8 & 3\end{array}$ $\begin{array}{lllll}99.7 \% & 64.6 & 25.0 & 54.7 & 2\end{array}$ $\begin{array}{lllll}99.0 \% & 51.7 & 25.0 & 44.8 & 2\end{array}$ $\begin{array}{llll}99.7 \% & 28.8 & 25.0 & 25.2\end{array}$ $\begin{array}{llll}99.7 \% & 45.5 & 25.0 & 37.2\end{array}$ $\begin{array}{llll}99.0 \% & 28.1 & 25.0 & 12.6\end{array}$ $\begin{array}{lllll}99.7 \% & 63.0 & 25.0 & 63.0 & 2\end{array}$ $\begin{array}{lllll}99.7 \% & 57.8 & 25.0 & 53.5 & 2\end{array}$ $99.0 \% \quad 31.6 \quad 25.0 \quad 28.9$ $99.7 \% \quad 74.4 \quad 25.0 \quad 67.2$ $\begin{array}{lllll}99.7 \% & 90.6 & 25.0 & 85.8 & 2\end{array}$ $\begin{array}{llll}99.7 \% & 28.8 & 25.0 & 27.9\end{array}$ $99.7 \% \quad 55.0 \quad 25.0 \quad 53.6$ $\begin{array}{llll}99.7 \% & 65.2 & 25.0 & 65.2\end{array}$ $\begin{array}{llll}99.7 \% & 48.3 & 25.0 & 48.3\end{array}$ $\begin{array}{llll}99.7 \% & 41.2 & 25.0 & 41.2\end{array}$ $99.7 \% \quad 52.2 \quad 25.0 \quad 52.2$ $\begin{array}{llll}99.4 \% & 30.9 & 25.0 & 30.9\end{array}$ $\begin{array}{lllll}99.7 \% & 48.5 & 25.0 & 48.5 & 1\end{array}$ $\begin{array}{llll}99.7 \% & 33.7 & 25.0 & 27.6\end{array}$ $\begin{array}{llll}99.7 \% & 32.8 & 25.0 & 30.6\end{array}$ $\begin{array}{llll}95.4 \% & 23.2 & 25.0 & 19.1\end{array}$ $\begin{array}{llll}99.6 \% & 24.2 & 25.0 & 18.6\end{array}$ $\begin{array}{llll}99.6 \% & 23.3 & 25.0 & 20.4\end{array}$ $\begin{array}{llll}99.7 \% & 57.1 & 25.0 & 57.1\end{array}$ $\begin{array}{llll}99.7 \% & 31.8 & 25.0 & 18.7\end{array}$ $\begin{array}{lllll}99.7 \% & 33.0 & 25.0 & 26.1 & 2\end{array}$ $\begin{array}{llll}99.7 \% & 42.8 & 25.0 & 37.9\end{array}$ $\begin{array}{llll}99.7 \% & 52.1 & 25.0 & 52.1\end{array}$

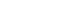

0

0
0

1154.55

1506.76

1388.76

1705.90

948.48

1990.04

1318.63

1151.55

1275.74

963.53

1241.69

830.51

1059.55

1315.70

914.55

1574.73

1702.82

941.54

1233.68

1212.71

101.63

1620.86

1362.60

1490.69

1021.51

1345.78

1647.85

1054.52

107.57

1403.73

1232.61

895.46

1267.68

1416.84

1043.61

1199.71

1028.61 1208.68 

Cancer-related nucleoside-triphosphatase GN=NTPCR NTPCR_HUMAN $20.71 \quad 100.0 \%$ Carbonyl reductase [NADPH] $1 \mathrm{GN}=\mathrm{CBR} 1$ CBR1 HUMAN $30.37 \quad 100.0 \%$ Carbonyl reductase [NADPH] 1 GN=CBR1 CBR1_HUMAN $30.37 \quad 100.0 \%$ Carbonyl reductase [NADPH] $1 \mathrm{GN}=\mathrm{CBR} 1$ CBR1_HUMAN $30.37 \quad 100.0 \%$ Carbonyl reductase [NADPH] $1 \mathrm{GN}=\mathrm{CBR} 1$ CBR1_HUMAN $30.37 \quad 100.0 \%$ Carbonyl reductase [NADPH] $1 \mathrm{GN}=\mathrm{CBR} 1$ CBR1_HUMAN $30.37 \quad 100.0 \%$ Carbonyl reductase [NADPH] $1 \mathrm{GN}=\mathrm{CBR} 1$ CBR1_HUMAN $30.37 \quad 100.0 \%$ Carbonyl reductase [NADPH] 1 GN=CBR1 CBR1_HUMAN $30.37 \quad 100.0 \%$ Carbonyl reductase [NADPH] $1 \mathrm{GN}=\mathrm{CBR} 1$ CBR1_HUMAN $30.37 \quad 100.0 \%$ Carbonyl reductase [NADPH] $1 \mathrm{GN}=\mathrm{CBR} 1$ CBR1_HUMAN $30.37 \quad 100.0 \%$ Casein kinase I isoform alpha $\mathrm{GN}=\mathrm{CSNK} 1 \mathrm{~A} 1 \quad \mathrm{KC1A}$ HUMAN $38.92 \quad 100.0 \%$ Casein kinase I isoform alpha $\mathrm{GN}=\mathrm{CSNK} 1 \mathrm{~A} 1 \mathrm{KC1A}$ HUMAN $38.92 \quad 100.0 \%$ Casein kinase II subunit alpha GN=CSNK2A1 CSK21_HUMAN $45.14 \quad 100.0 \%$ Casein kinase II subunit alpha GN=CSNK2A1 CSK21_HUMAN $45.14 \quad 100.0 \%$ Casein kinase II subunit alpha GN=CSNK2A1 CSK21_HUMAN $45.14 \quad 100.0 \%$ Casein kinase II subunit alpha GN=CSNK2A1 CSK21_HUMAN $45.14 \quad 100.0 \%$ Casein kinase II subunit alpha GN=CSNK2A1 CSK21_HUMAN $45.14 \quad 100.0 \%$ Casein kinase II subunit alpha' GN=CSNK2A2 CSK22_HUMAN $41.21 \quad 100.0 \%$ Casein kinase II subunit alpha' GN=CSNK2A2 CSK22_HUMAN $41.21 \quad 100.0 \%$ Casein kinase II subunit alpha' GN=CSNK2A2 CSK22_HUMAN $41.21 \quad 100.0 \%$ Casein kinase II subunit alpha' GN=CSNK2A2 CSK22_HUMAN $41.21 \quad 100.0 \%$ Cat eye syndrome critical region protein $5 \mathrm{GN}=\mathrm{CECR} 5$ CECR5_HUMAN $46.32 \quad 100.0 \%$ Cat eye syndrome critical region protein $5 \mathrm{GN}=$ CECR 5 CECR5 HUMAN $46.32 \quad 100.0 \%$ Cat eye syndrome critical region protein $5 \mathrm{GN}=$ CECR5 CECR5_HUMAN $46.32 \quad 100.0 \%$ Cat eye syndrome critical region protein $5 \mathrm{GN}=\mathrm{CECR} 5$ CECR5_HUMAN $46.32 \quad 100.0 \%$ Cat eye syndrome critical region protein $5 \mathrm{GN}=$ CECR5 CECR5 HUMAN $46.32 \quad 100.0 \%$ Cat eye syndrome critical region protein $5 \mathrm{GN}=\mathrm{CECR} 5$ CECR5_HUMAN $46.32 \quad 100.0 \%$ Cat eye syndrome critical region protein $5 \mathrm{GN}=\mathrm{CECR} 5$ CECR5 HUMAN $46.32 \quad 100.0 \%$ Cat eye syndrome critical region protein $5 \mathrm{GN}=$ CECR5 CECR5_HUMAN $46.32 \quad 100.0 \%$ Cat eye syndrome critical region protein $5 \mathrm{GN}=\mathrm{CECR} 5$ CECR5_HUMAN $46.32 \quad 100.0 \%$ Catenin delta-1 GN=CTNND1 CTND1_HUMAN $108.17 \quad 100.0 \%$ Catenin delta-1 GN=CTNND1 CTND1_HUMAN $108.17 \quad 100.0 \%$ CCAAT/enhancer-binding protein zeta GN=CEBPZ CEBPZ_HUMAN $120.98 \quad 100.0 \%$ CCAAT/enhancer-binding protein zeta GN=CEBPZ CEBPZ_HUMAN $120.98100 .0 \%$ CCAAT/enhancer-binding protein zeta GN=CEBPZ CEBPZ_HUMAN $120.98 \quad 100.0 \%$ CCAAT/enhancer-binding protein zeta GN=CEBPZ CEBPZ HUMAN $120.98 \quad 100.0 \%$ CCR4-NOT transcription complex subunit $1 \mathrm{GN}=\mathrm{CNOT1}$ CNOT1_HUMAN $266.94 \quad 100.0 \%$ CCR4-NOT transcription complex subunit $1 \mathrm{GN}=\mathrm{CNOT1}$ CNOT1_HUMAN $266.94 \quad 100.0 \%$ CCR4-NOT transcription complex subunit $1 \mathrm{GN}=\mathrm{CNOT} 1$ CNOT1_HUMAN $266.94100 .0 \%$ CCR4-NOT transcription complex subunit $1 \mathrm{GN}=\mathrm{CNOT} 1$ CNOT1_HUMAN $266.94 \quad 100.0 \%$

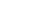

4

4

9

$\begin{array}{ll}5 & 5 \\ 5 & 5 \\ 5 & 5\end{array}$

$16 \quad 0.02 \% \quad 45.8 \%$ SSGVPVDGFYTEEVR

$99.7 \% \quad 67.6$

$0.02 \% \quad 45.8 \%$ SSGVPVDGFYTEEVRQGGR

$0.02 \% \quad 45.8 \%$ RIGFDVVTLSGTR

$0.02 \% \quad 45.8 \%$ IGFDVVTLSGTR

$99.7 \% \quad 39.6$

$0.02 \% \quad 45.8 \%$ IGFDVVTLSGTRGPLSR

$0.02 \% \quad 45.8 \%$ QTLSTPGTIILGTIPVPK

$99.7 \% \quad 43.8$

$\begin{array}{ll}0.02 \% & 45.8 \% \text { GKPLALVEEIR } \\ 0.02 \% & 45.8 \% \text { VFNVTKENR }\end{array}$

$0.02 \% \quad 44.0 \%$ LFSGDVVLTAR

$0.02 \% \quad 44.0 \%$ GQAAVQQLQAEGLSPR

$0.02 \% \quad 44.0 \%$ FHQLDIDDLQSIR

$0.02 \% \quad 44.0 \%$ EYGGLDVLVNNAGIAFK $99.7 \% 72.6$

$0.02 \% \quad 44.0 \%$ DVCTELLPLIKPQGR

$0.02 \% \quad 44.0 \%$ VVNVSSIMSVR

$0.02 \% \quad 44.0 \%$ SETITEEELVGLMNK

$0.02 \% \quad 44.0 \%$ EGWPSSAYGVTK

$0.02 \% \quad 44.0 \%$ ILLNACCPGWVR

$0.01 \% \quad 5.6 \%$ HPQLLYESK

$0.01 \% \quad 5.6 \%$ LFLIDFGLAK

$0.01 \% \quad 14.8 \%$ GGPNIITLADIVK

$99.7 \% \quad 47.3$

$0.01 \% \quad 14.8 \%$ GGPNIITLADIVKDPVSR

$0.01 \% \quad 14.8 \%$ TPALVFEHVNNTDFK

$0.01 \% \quad 14.8 \%$ QLYQTLTDYDIR

$0.01 \% \quad 14.8 \%$ EAMEHPYFYTVVK

$0.01 \% \quad 12.9 \%$ VYAEVNSLR

$0.01 \% \quad 12.9 \%$ LIDTVKDPVSK

$0.01 \% \quad 12.9 \%$ VLGTEELYGYLK

$0.01 \% \quad 12.9 \%$ HLVSPEALDLLDK

$0.02 \% \quad 26.2 \%$ RLVNSQGQLR

$0.02 \% \quad 26.2 \%$ LVNSQGQLR

$0.02 \% \quad 26.2 \%$ VPVVFVTNAGNILQHSK

$0.02 \% \quad 26.2 \%$ LFSEYHEK

$\begin{array}{lllll}0.02 \% & 26.2 \% & \text { MLVSGQGPVMENAQGLGFR } & 99.0 \% & 30.4\end{array}$

$0.02 \% \quad 26.2 \%$ NVVTVDELR

$0.02 \% \quad 26.2 \%$ MAFPLLDMVDLER

$\begin{array}{ll}98.7 \% & 17.6 \\ 99.7 \% & 38.5\end{array}$

$0.02 \% \quad 26.2 \%$ ATHDGAPELGAGGTR

$0.02 \% \quad 26.2 \%$ NPQSTEPVLGGGEPPFHGHR

$0.00 \% \quad 2.4 \%$ GSLASLDSLRK

$0.00 \% \quad 2.4 \%$ SDFQVNLNNASR

$0.01 \% \quad 4.7 \%$ NRPEPHSDENGSTTPK

$0.01 \% \quad 4.7 \% \quad$ ALLVQVVNK

$0.01 \% \quad 4.7 \%$ MLSALLTGVNR

$0.01 \% \quad 4.7 \%$ GKENTDSVVMQPK

$0.01 \% \quad 2.1 \%$ EVTAAQVAR

$1 \quad 0.01 \% \quad 2.1 \%$ GLHNVVYGIQR

$11 \quad 0.01 \% \quad 2.1 \%$ LAEVGQYEQVK

$0.01 \% \quad 2.1 \%$ NLDEQLSAPK
$98.6 \% 21.0$

$99.7 \% \quad 27.7$

$99.7 \% \quad 61.6$

$99.7 \% \quad 43.9$

$\begin{array}{ll}97.4 \% & 23.0 \\ 99.7 \% & 66.9\end{array}$

$\begin{array}{ll}99.7 \% & 66.9 \\ 99.7 \% & 92.9\end{array}$

$99.7 \% \quad 60.7$

$99.7 \% \quad 66.3$

$99.7 \% \quad 50.8$

$99.7 \% \quad 33.5$

$99.7 \% \quad 46.7$

$99.3 \% \quad 21.0$

$99.7 \% \quad 41.0$

$99.7 \% \quad 32.5$

$99.7 \% \quad 59.2$

$97.5 \% \quad 22.2$

$99.7 \% \quad 62.1$

$99.7 \% \quad 32.2$

$99.7 \% \quad 53.8$

$99.5 \% \quad 21.4$

$99.7 \% \quad 28.1$

$99.7 \% \quad 50.0$

1641.78

2039.98

1420.79

1264.69

1774.98

1836.08

1224.73

1106.60

1177.66

1652.87

1599.81

1779.93

1738.95

1190.66

1692.84

1281.61

1458.73

1114.59

1136.67

1310.77

1865.05

1731.87

1528.76

1629.76

1050.56

1214.70

1384.74

1449.80

1170.67

1014.57

1823.02

1052.50

2022.97

1044.57

1581.77

$99.7 \% \quad 39.9$

$99.7 \% \quad 43.8$

1409.68

2113.02

1146.65

1364.66

$\begin{array}{llll}99.7 \% & 73.4 & 25.0 & 60.1\end{array}$

$\begin{array}{llll}97.8 \% & 19.7 & 25.0 & 14.5\end{array}$

$\begin{array}{llll}99.7 \% & 30.0 & 25.0 & 20.3\end{array}$

$\begin{array}{llll}99.7 \% & 50.7 & 25.0 & 49.5\end{array}$

$\begin{array}{llll}99.7 \% & 57.3 & 25.0 & 57.3\end{array}$

$\begin{array}{llll}99.7 \% & 41.0 & 25.0 & 28.9\end{array}$

$\begin{array}{llll}98.6 \% & 17.5 & 25.0 & 17.5\end{array}$

$\begin{array}{llll}99.7 \% & 46.8 & 25.0 & 46.8\end{array}$

$\begin{array}{llll}99.7 \% & 37.9 & 25.0 & 29.4\end{array}$

\begin{tabular}{c}
42 \\
46 \\
59 \\
59 \\
64 \\
148 \\
159 \\
174 \\
38 \\
58 \\
71 \\
96 \\
134 \\
145 \\
174 \\
198 \\
232 \\
62 \\
162 \\
102 \\
107 \\
122 \\
134 \\
329 \\
20 \\
108 \\
260 \\
304 \\
82 \\
82 \\
99 \\
132 \\
152 \\
161 \\
174 \\
346 \\
389 \\
355 \\
858 \\
158 \\
390 \\
492 \\
781 \\
\\
392 \\
\hline
\end{tabular}


CCR4-NOT transcription complex subunit $1 \mathrm{GN}=\mathrm{CNOT1}$ CNOT1_HUMAN $266.94 \quad 100.0 \%$ Cell cycle and apoptosis regulator protein 2 GN=CCAR2 CCAR2_HUMAN $102.90 \quad 100.0 \%$ Cell cycle and apoptosis regulator protein $2 \mathrm{GN}=$ CCAR2 CCAR2_HUMAN $102.90 \quad 100.0 \%$ Cell cycle and apoptosis regulator protein $2 \mathrm{GN}=$ CCAR2 CCAR2_HUMAN $102.90 \quad 100.0 \%$ Cell differentiation protein RCD1 homolog GN=RQCD1 RCD1_HUMAN $33.63 \quad 100.0 \%$ Cell differentiation protein RCD1 homolog GN=RQCD1 RCD1_HUMAN $33.63 \quad 100.0 \%$ Cell differentiation protein RCD1 homolog GN=RQCD1 RCD1_HUMAN $33.63 \quad 100.0 \%$ Cell division cycle 5-like protein GN=CDC5L CDC5L_HUMAN $92.25 \quad 100.0 \%$ Cell division cycle 5-like protein $\mathrm{GN}=\mathrm{CDC} 5 \mathrm{~L}$ CDC5L_HUMAN $92.25 \quad 100.0 \%$ Cell division cycle 5-like protein $\mathrm{GN}=\mathrm{CDC} 5 \mathrm{~L} \quad \mathrm{CDC} 5 \mathrm{~L} \_$HUMAN $92.25 \quad 100.0 \%$ Cell division cycle 5-like protein GN=CDC5L CDC5L_HUMAN $92.25 \quad 100.0 \%$ Cell division cycle 5-like protein GN=CDC5L CDC5L_HUMAN $92.25 \quad 100.0 \%$ Cell division cycle 5-like protein GN=CDC5L CDC5L_HUMAN $92.25 \quad 100.0 \%$ Cell division cycle 5-like protein GN=CDC5L CDC5L_HUMAN $92.25 \quad 100.0 \%$ Cell division cycle 5-like protein GN=CDC5L CDC5L_HUMAN $92.25 \quad 100.0 \%$ Cell division cycle protein 23 homolog GN=CDC23 CDC23_HUMAN $68.84 \quad 100.0 \%$ Cell division cycle protein 23 homolog $\mathrm{GN}=\mathrm{CDC} 23 \mathrm{CDC} 23$ _HUMAN $68.84 \quad 100.0 \%$ Cell growth-regulating nucleolar protein GN=LYAR LYAR_HUMAN $43.62 \quad 100.0 \%$ Cell growth-regulating nucleolar protein GN=LYAR LYAR_HUMAN $43.62 \quad 100.0 \%$ Cell growth-regulating nucleolar protein GN=LYAR LYAR_HUMAN $43.62 \quad 100.0 \%$ Cell growth-regulating nucleolar protein GN=LYAR LYAR_HUMAN $43.62 \quad 100.0 \%$ Cell growth-regulating nucleolar protein GN=LYAR LYAR HUMAN $43.62 \quad 100.0 \%$ Cellular tumor antigen p53 GN=TP53 P53_HUMAN $43.65 \quad 100.0 \%$ Cellular tumor antigen p53 GN=TP53 Cellular tumor antigen $\mathrm{p} 53 \mathrm{GN}=\mathrm{TP} 53$ Cellular tumor antigen p53 GN=TP53 Cellular tumor antigen $\mathrm{p} 53 \mathrm{GN}=\mathrm{TP} 53$ Cellular tumor antigen p53 GN=TP53 Centromere protein $\mathrm{V} \mathrm{GN}=\mathrm{CENPV}$ Centromere protein $\mathrm{V} \mathrm{GN}=\mathrm{CENPV}$ Centromere protein $\mathrm{V}$ GN $=\mathrm{CENPV}$ Centromere protein $\mathrm{V} \mathrm{GN}=\mathrm{CENPV}$ Centromere protein $\mathrm{V} \mathrm{GN}=\mathrm{CENPV}$ Centromere protein $\mathrm{V}$ GN $=\mathrm{CENPV}$ P53_HUMAN $43.65 \quad 100.0 \%$ P53 HUMAN $43.65 \quad 100.0 \%$ P53_HUMAN $43.65 \quad 100.0 \%$ P53 HUMAN $43.65 \quad 100.0 \%$ P53 HUMAN $43.65 \quad 100.0 \%$ CENPV_HUMAN $29.95 \quad 100.0 \%$ CENPV HUMAN $29.95 \quad 100.0 \%$ CENPV_HUMAN $29.95 \quad 100.0 \%$ CENPV_HUMAN $29.95 \quad 100.0 \%$ CENPV_HUMAN $29.95 \quad 100.0 \%$ CENPV_HUMAN $29.95 \quad 100.0 \%$ Charged multivesicular body protein $4 \mathrm{~b}$ GN=CHMP4B CHM4B_HUMAN $24.95 \quad 100.0 \%$ Charged multivesicular body protein 4b GN=CHMP4B CHM4B_HUMAN $24.95 \quad 100.0 \%$ Charged multivesicular body protein 4b GN=CHMP4B CHM4B_HUMAN $24.95 \quad 100.0 \%$ Charged multivesicular body protein $4 \mathrm{~b}$ GN=CHMP4B CHM4B_HUMAN $24.95 \quad 100.0 \%$ Chloride intracellular channel protein $1 \mathrm{GN}=\mathrm{CLIC1}$ CLIC1_HUMAN $26.92 \quad 100.0 \%$ Chloride intracellular channel protein $1 \mathrm{GN}=\mathrm{CLIC1}$ CLIC1_HUMAN $26.92 \quad 100.0 \%$ Chloride intracellular channel protein $1 \mathrm{GN}=$ CLIC1 CLIC1_HUMAN $26.92 \quad 100.0 \%$ Chloride intracellular channel protein $4 \mathrm{GN}=\mathrm{CLIC} 4$ CLIC4_HUMAN $28.77 \quad 100.0 \%$ Chloride intracellular channel protein $4 \mathrm{GN}=\mathrm{CLIC} 4$ CLIC4_HUMAN $28.77 \quad 100.0 \%$ Chromatin target of PRMT1 protein GN=CHTOP CHTOP_HUMAN $26.40 \quad 100.0 \%$ Chromatin target of PRMT1 protein GN=CHTOP CHTOP_HUMAN $26.40 \quad 100.0 \%$ Chromatin target of PRMT1 protein GN=CHTOP CHTOP_HUMAN $26.40 \quad 100.0 \%$ Chromatin target of PRMT1 protein GN=CHTOP CHTOP_HUMAN $26.40 \quad 100.0 \%$
$0.01 \% \quad 2.1 \% \quad$ SNYEAMIDR

$0.00 \% \quad 3.4 \%$ VQTLSNQPLLK

$0.00 \% \quad 3.4 \%$ VVTQNICQYR

$0.00 \% \quad 3.4 \%$ LTPLQLEIQR

$0.01 \% \quad 10.7 \%$ LTSLGVIGALVK

$0.01 \% \quad 10.7 \%$ TVATFILQK

$0.01 \% \quad 10.7 \%$ NLQEGQVTDPR

$0.02 \% \quad 12.2 \%$ TIAPIIGR

$0.02 \% \quad 12.2 \%$ AAGIEIQK

$0.02 \% \quad 12.2 \%$ GVDYNAEIPFEK

$\begin{array}{lll}0.02 \% & 12.2 \% & \text { ESDLPSAILQTSGVSEFTK } \\ 0.02 \% & 12.2 \% & \text { LVLPAPQISDAELQEVVK }\end{array}$

$0.02 \% \quad 12.2 \%$ VGQASEIAR

$0.02 \% \quad 12.2 \%$ SGTTPKPVINSTPGR

$0.02 \% \quad 12.2 \%$ ILLGGYQSR

$0.00 \% \quad 3.0 \%$ AYFDVKEYDR

$0.00 \% \quad 3.0 \% \quad$ YLAQYYFK

$0.01 \% \quad 16.1 \%$ VFFTCNACGESVKK

$0.01 \% \quad 16.1 \%$ CISEDQKYGGK

$0.01 \% \quad 16.1 \%$ ELLEQISAFDNVPR

$0.01 \% \quad 16.1 \%$ VKDAVEQQGEVK

$0.01 \% \quad 16.1 \%$ QAPDNEITIK

$0.02 \% \quad 19.6 \%$ TYQGSYGFR

$0.02 \% \quad 19.6 \%$ LGFLHSGTAK

$0.02 \% \quad 19.6 \%$ SVTCTYSPALNK

$0.02 \% \quad 19.6 \%$ RPILTIITLEDSSGNLLGR

$0.02 \% \quad 19.6 \%$ ALPNNTSSSPQPK

$0.02 \% \quad 19.6 \%$ KKPLDGEYFTLQIR

$0.03 \% \quad 33.8 \%$ SGASGASAAPAASAAAALAPSATR

$0.03 \% \quad 33.8 \%$ SQAVEKPPSEKPR

$0.03 \% \quad 33.8 \%$ LLLDTFEYQGLVK

$0.03 \% \quad 33.8 \%$ GAEHITTYTFNTHK

$0.03 \% \quad 33.8 \%$ CGVQSFYTPR

$0.03 \% \quad 33.8 \%$ SNPGGFGIAPHCLDEGTVR

$0.01 \% 21.9 \%$ GGPTPQEAIQR

$0.01 \% \quad 21.9 \%$ AALQALKR

$0.01 \% \quad 21.9 \%$ QLAQIDGTLSTIEFQR

$0.01 \% \quad 21.9 \%$ EALENANTNTEVLK

$0.01 \% \quad 12.0 \%$ IGNCPFSQR

$0.01 \% \quad 12.0 \%$ NSNPALNDNLEK

$0.01 \% \quad 12.0 \%$ YLSNAYAR

$0.00 \% \quad 7.9 \% \quad$ NSRPEANEALER

$0.00 \% \quad 7.9 \% \quad$ YLTNAYSR

$0.03 \% \quad 29.8 \%$ NKQPTPVNIR

$0.03 \% \quad 29.8 \%$ ASMQQQQQLASAR

$98.2 \% \quad 16.6$

$99.7 \% \quad 34.6$

$99.7 \% \quad 58.6$

$99.3 \% \quad 19.7$

$99.7 \% \quad 67.2$

$99.5 \% 31$.

$99.7 \% \quad 48.9$

$99.0 \% \quad 34.0$

$99.0 \% \quad 25.6$

$99.7 \% 34.6$

$99.7 \% \quad 51.7$

$\begin{array}{lll}99.7 \% & 44.1\end{array}$

$99.7 \% \quad 46.9$

$99.7 \% \quad 30.9$

$99.7 \% \quad 32.7$

$99.1 \% \quad 25.9$

$97.2 \% \quad 16.5$

$99.7 \% \quad 54.4$

$\begin{array}{lll}99.7 \% & 39.5\end{array}$

$99.7 \% \quad 62.1$

$99.7 \% \quad 60.8$

$99.6 \% \quad 24.5$

$99.7 \% \quad 28.8$

$99.7 \% \quad 45.6$

$99.7 \% \quad 51.5$

$99.7 \% \quad 26.0$

$99.7 \% \quad 31.0$

$98.3 \% \quad 28.1$

\section{$99.7 \% \quad 68.6$}

$99.7 \% \quad 52.7$

$99.7 \% \quad 67.7$

$99.7 \% \quad 61.4$

$99.7 \% \quad 56.1$

$99.7 \% \quad 38.5$

$99.7 \% \quad 47.3$

$99.0 \% \quad 29.9$

$99.7 \% \quad 79.9$

$99.7 \% \quad 61.7$

$99.7 \% \quad 27.6$

$99.7 \% \quad 60.9$

$99.0 \% \quad 36.1$

$99.7 \% 31.6$

$99.0 \% \quad 28.2$

$99.7 \% \quad 28.1$

$99.7 \% \quad 59.5$

$0.03 \% \quad 29.8 \%$ LAQQMENRPSVQAALK $\quad 99.7 \% \quad 38.4$

$0.03 \% \quad 29.8 \%$ EQLDNQLDAYMSK

$99.7 \% \quad 60.0$
1114.48

1240.73

1280.64

1210.72

1170.75

1020.61

1256.62

840.53

829.48

1381.66

2009.01

1949.10

930.50

1511.82

1006.57

1305.61

1095.55

1646.77

1284.59

1630.84

1329.70

1128.59

1078.50

1030.57

1340.65

2068.18

1340.68

1707.94

1985.00

1452.78

1538.85

1619.78

1214.56

1983.93

1153.60

870.55

1819.96

1545.78

1078.51

1328.64

957.48

1385.68

987.49

1166.66

1446.71

1799.94

1570.71 \begin{tabular}{cc}
15 & 1823 \\
13 & 123 \\
48 & 757 \\
96 & 905 \\
37 & 148 \\
90 & 188 \\
82 & 292 \\
4 & 91 \\
93 & 200 \\
97 & 218 \\
72 & 290 \\
95 & 312 \\
13 & 321 \\
27 & 441 \\
19 & 727 \\
2 & 101 \\
15 & 522 \\
2 & 15 \\
1 & 61 \\
6 & 109 \\
74 & 185 \\
21 & 330 \\
92 & 110 \\
11 & 120 \\
21 & 132 \\
49 & 267 \\
97 & 319 \\
20 & 333 \\
8 & 41 \\
3 & 65 \\
35 & 147 \\
97 & 210 \\
19 & 228 \\
29 & 247 \\
8 & 28 \\
4 & 71 \\
8 & 93 \\
4 & 226 \\
1 & 107 \\
20 & 131 \\
99 & 216 \\
31 & 142 \\
20 & 227 \\
\hline & 38 \\
\hline
\end{tabular}

Page 37 of Table S-1-5 
Chromatin target of PRMT1 protein GN=CHTOP CHTOP_HUMAN $26.40 \quad 100.0 \%$ Chromodomain-helicase-DNA-binding protein 1-like GN=CHD1L CHD1L_HUMAN $100.99 \quad 100.0 \%$ Chromodomain-helicase-DNA-binding protein 1-like GN=CHD1L CHD1L_HUMAN $100.99 \quad 100.0 \%$ Chromodomain-helicase-DNA-binding protein 1-like GN=CHD1L CHD1L_HUMAN $100.99 \quad 100.0 \%$ Chromodomain-helicase-DNA-binding protein 4 GN=CHD4 CHD4_HUMAN 218.01 $100.0 \%$ Chromodomain-helicase-DNA-binding protein $4 \mathrm{GN}=\mathrm{CHD} 4$ CHD4_HUMAN $218.01 \quad 100.0 \%$ Chromodomain-helicase-DNA-binding protein 4 GN=CHD4 CHD4_HUMAN $218.01 \quad 100.0 \%$ Chromodomain-helicase-DNA-binding protein 4 GN=CHD4 CHD4_HUMAN $218.01 \quad 100.0 \%$ Citron Rho-interacting kinase $\mathrm{GN}=\mathrm{CIT}$ Citron Rho-interacting kinase $\mathrm{GN}=\mathrm{CIT}$ Citron Rho-interacting kinase $\mathrm{GN}=\mathrm{CIT}$ Citron Rho-interacting kinase $\mathrm{GN}=\mathrm{CIT}$ Citron Rho-interacting kinase $\mathrm{GN}=\mathrm{CIT}$

Citron Rho-interacting kinase $\mathrm{GN}=\mathrm{CIT}$ Citron Rho-interacting kinase $\mathrm{GN}=\mathrm{CIT}$ Clathrin heavy chain $1 \mathrm{GN}=\mathrm{CLTC}$ Clathrin heavy chain $1 \mathrm{GN}=\mathrm{CLTC}$ Clathrin heavy chain $1 \mathrm{GN}=\mathrm{CLTC}$

Clathrin heavy chain $1 \mathrm{GN}=\mathrm{CLTC}$ Clathrin heavy chain $1 \mathrm{GN}=\mathrm{CLTC}$ Clathrin heavy chain $1 \mathrm{GN}=\mathrm{CLTC}$ Clathrin heavy chain $1 \mathrm{GN}=\mathrm{CLTC}$ Clathrin heavy chain $1 \mathrm{GN}=\mathrm{CLTC}$ Clathrin heavy chain $1 \mathrm{GN}=\mathrm{CLTC}$ Clathrin heavy chain $1 \mathrm{GN}=\mathrm{CLTC}$ Clathrin heavy chain $1 \mathrm{GN}=\mathrm{CLTC}$

CTRO HUMAN $231.44 \quad 100.0 \%$ CTRO_HUMAN $231.44 \quad 100.0 \%$ CTRO_HUMAN $231.44 \quad 100.0 \%$ CTRO HUMAN $231.44 \quad 100.0 \%$ CTRO_HUMAN $231.44 \quad 100.0 \%$ CTRO_HUMAN $231.44 \quad 100.0 \%$ CTRO_HUMAN $231.44 \quad 100.0 \%$ CTRO_HUMAN $231.44 \quad 100.0 \%$ CLH1_HUMAN $191.62 \quad 100.0 \%$ CLH1_HUMAN $191.62 \quad 100.0 \%$ CLH1_HUMAN $191.62 \quad 100.0 \%$ CLH1 HUMAN $191.62 \quad 100.0 \%$ CLH1_HUMAN $191.62 \quad 100.0 \%$ CLH1 HUMAN $191.62 \quad 100.0 \%$ CLH1_HUMAN $191.62 \quad 100.0 \%$ CLH1_HUMAN $191.62 \quad 100.0 \%$ CLH1_HUMAN $191.62 \quad 100.0 \%$ CLH1_HUMAN $191.62 \quad 100.0 \%$ CLH1_HUMAN $191.62 \quad 100.0 \%$ Citron Rho-interacting kinase $\mathrm{GN}=\mathrm{CIT}$ 1 CPSF1_HUMAN $160.89 \quad 100.0 \%$ Cleavage and polyadenylation specificity factor subunit $1 \mathrm{GN}=\mathrm{CPSF} 1$ CPSF1_HUMAN $160.89 \quad 100.0 \%$ Cleavage and polyadenylation specificity factor subunit $1 \mathrm{GN}=\mathrm{CPSF} 1$ CPSF1_HUMAN $160.89100 .0 \%$ Cleavage and polyadenylation specificity factor subunit $1 \mathrm{GN}=\mathrm{CPSF} 1$ CPSF1_HUMAN $160.89 \quad 100.0 \%$ Cleavage and polyadenylation specificity factor subunit $1 \mathrm{GN}=\mathrm{CPSF} 1$ CPSF1_HUMAN $160.89 \quad 100.0 \%$ Cleavage and polyadenylation specificity factor subunit $1 \mathrm{GN}=\mathrm{CPSF} 1$ CPSF1_HUMAN $160.89100 .0 \%$ Cleavage and polyadenylation specificity factor subunit $1 \mathrm{GN}=\mathrm{CPSF} 1$ CPSF1_HUMAN $160.89 \quad 100.0 \%$ Cleavage and polyadenylation specificity factor subunit $1 \mathrm{GN}=\mathrm{CPSF} 1 \quad \mathrm{CPSF} 1$ HUUMAN $160.89 \quad 100.0 \%$ Cleavage and polyadenylation specificity factor subunit $1 \mathrm{GN}=\mathrm{CPSF} 1 \quad \mathrm{CPSF} 1$ HUMAN $160.89 \quad 100.0 \%$ Cleavage and polyadenylation specificity factor subunit $1 \mathrm{GN}=\mathrm{CPSF} 1$ CPSF1_HUMAN $160.89 \quad 100.0 \%$ Cleavage and polyadenylation specificity factor subunit $1 \mathrm{GN}=\mathrm{CPSF} 1 \quad \mathrm{CPSF} 1$ HUMAN $160.89100 .0 \%$ Cleavage and polyadenylation specificity factor subunit $1 \mathrm{GN}=\mathrm{CPSF} 1$ CPSF1_HUMAN $160.89 \quad 100.0 \%$ Cleavage and polyadenylation specificity factor subunit $1 \mathrm{GN}=\mathrm{CPSF} 1 \quad$ CPSF1_HUMAN $160.89 \quad 100.0 \%$ Cleavage and polyadenylation specificity factor subunit $6 \mathrm{GN}=\mathrm{CPSF} 6 \quad \mathrm{CPSF} 6$ HUMAN $59.21 \quad 100.0 \%$ Cleavage and polyadenylation specificity factor subunit $6 \mathrm{GN}=\mathrm{CPSF} 6$ CPSF6_HUMAN $59.21 \quad 100.0 \%$ Cleavage and polyadenylation specificity factor subunit $6 \mathrm{GN}=\mathrm{CPSF} 6 \quad \mathrm{CPSF} 6$ HUMAN $59.21 \quad 100.0 \%$ Cleavage and polyadenylation specificity factor subunit $6 \mathrm{GN}=\mathrm{CPSF} 6$ CPSF6_HUMAN $59.21 \quad 100.0 \%$ Cleavage and polyadenylation specificity factor subunit $6 \mathrm{GN}=\mathrm{CPSF} 6$ CPSF6_HUMAN $59.21 \quad 100.0 \%$ Cevage and polyadenylation specificity factor subunit 6 GN=CPSF6 $\quad$ CPSF6 HUMAN $59.21 \quad 100.0 \%$ Coatomer subunit alpha $\mathrm{GN}=\mathrm{COPA}$ COPA_HUMAN $138.35 \quad 100.0 \%$ $\begin{array}{lll}0.03 \% & 29.8 \% & \text { TKGHLDAELDAYM } \\ 0.01 \% & 3.3 \% & \text { GGQAPGFLLR }\end{array}$ $0.01 \% \quad 3.3 \%$ SFEQLVNLQK $0.01 \% \quad 3.3 \%$ GGLFTALEKR $0.01 \% \quad 2.1 \%$ VLIFSQMTK $0.01 \% \quad 2.1 \%$ VGGNIEVLGFNAR $0.01 \% \quad 2.1 \%$ AYVSLFMR $0.01 \% \quad 2.1 \%$ GAADVEKVEEK $0.02 \% \quad 4.0 \%$ NPLDAGAAEPIASR $0.02 \% \quad 4.0 \%$ SPFAEGTSAR $0.02 \% \quad 4.0 \%$ SESVVSGLDSPAK $0.02 \% \quad 4.0 \%$ LAAEEFKR $0.02 \% \quad 4.0 \%$ QQIAMSAIVR $0.02 \% \quad 4.0 \% \quad$ FNVGLNMR

$0.02 \% \quad 4.0 \%$ ADVPYILK $0.02 \% \quad 4.0 \% \quad$ AYLDIPNPR $0.03 \% \quad 7.6 \% \quad$ VVGAMQLYSVDR $0.03 \% \quad 7.6 \%$ NNLAGAEELFAR $0.03 \% \quad 7.6 \%$ KFNALFAQGNYSEAAK $0.03 \% \quad 7.6 \%$ VIQCFAETGQVQK $0.03 \% \quad 7.6 \%$ TGQIKEVER $0.03 \% \quad 7.6 \%$ YIEIYVQK

$0.03 \% \quad 7.6 \%$ IHEGCEEPATHNALAK $0.03 \% \quad 7.6 \%$ IYIDSNNNPER $0.03 \% \quad 7.6 \%$ FLRENPYYDSR $0.03 \% \quad 7.6 \%$ LLYNNVSNFGR $0.03 \% \quad 7.6 \%$ VANVELYYR $0.05 \% \quad 10.5 \%$ LSVVEYDPGTHDLK $0.05 \% \quad 10.5 \%$ CAAMLVYGTR $0.05 \% \quad 10.5 \%$ LVVLPFRR

$0.05 \% \quad 10.5 \%$ ESLAEEHEGLVGEGQR $0.05 \% \quad 10.5 \%$ LGNSLLLK $0.05 \% \quad 10.5 \%$ YTEKLQEPPASAVR $0.05 \% \quad 10.5 \%$ HGFLILSR $0.05 \% \quad 10.5 \%$ DLSGMFTTESR $0.05 \% \quad 10.5 \%$ LGGARDELGGR $0.05 \% \quad 10.5 \%$ VLVDSSFGQPTTQGEAR $0.05 \% \quad 10.5 \%$ EVLLVALGSR $0.05 \% \quad 10.5 \%$ VYAVATSTNTPCAR $0.05 \% \quad 10.5 \%$ NVLDGELLNR $0.01 \% \quad 10.3 \%$ GFALVGVGSEASSK $0.01 \% \quad 10.3 \%$ GFALVGVGSEASSKK $0.01 \% \quad 10.3 \%$ KLMDLLPK

$0.01 \% \quad 10.3 \%$ RELHGQNPVVTPCNK $0.01 \% \quad 10.3 \%$ QFLSQFEMQSR $0.01 \% \quad 10.3 \%$ AISSSAISR $0.03 \% \quad 11.6 \%$ NLSPGAVESDVR
$99.7 \% \quad 67.1$ $99.7 \% \quad 31.8$ $99.7 \% \quad 38.0$ $99.7 \% \quad 56.5$ $99.7 \% \quad 25.0$ $99.7 \% \quad 33.2$ $99.0 \% \quad 26.9$ $99.6 \% \quad 29.9$ $99.7 \% \quad 41.3$ $99.7 \% \quad 64.5$ $99.7 \% \quad 58.5$ $95.4 \% \quad 20.5$ $99.7 \% \quad 26.2$ $99.0 \% \quad 35.6$ $99.0 \% 25.3$ $99.7 \% \quad 25.6$ $99.7 \% \quad 61.9$ $99.7 \% \quad 69.1$

$99.7 \% \quad 44.6$ $99.7 \% \quad 53.9$ $99.7 \% \quad 34.0$ $99.0 \% \quad 27.9$ $99.7 \% \quad 34.0$ $99.7 \% \quad 55.0$ $99.5 \% \quad 25.2$ $99.7 \% \quad 52.9$ $99.7 \% \quad 56.0$ $\begin{array}{lll}98.0 \% & 17.7\end{array}$ $99.7 \% \quad 40.2$ $99.0 \% \quad 21.7$

$\begin{array}{lll}98.5 \% & 25.7\end{array}$ $96.1 \% \quad 19.2$ $99.7 \% \quad 28.3$ $99.0 \% \quad 19.9$ $99.7 \% \quad 47.5$ $99.6 \% \quad 28.1$ $\begin{array}{ll}99.7 \% & 54.1 \\ 99.7 \% & 55.6\end{array}$ $99.7 \% \quad 60.1$ $99.7 \% \quad 51.2$ $99.7 \% \quad 81.6$ $99.7 \% \quad 35.1$ $95.4 \% \quad 22.2$ $99.7 \% \quad 33.3$ $99.7 \% \quad 33.1$ $99.7 \% \quad 45.9$ $99.7 \% \quad 62$.

$\begin{array}{ccc}2451.06 & 227 & 248 \\ 1015.57 & 10 & 19 \\ 1205.65 & 591 & 600 \\ 1091.62 & 749 & 758 \\ 1082.59 & 1069 & 1077 \\ 1345.72 & 1407 & 1419 \\ 986.51 & 1458 & 1465 \\ 1174.60 & 1637 & 1647 \\ 1381.71 & 10 & 23 \\ 1022.49 & 301 & 310 \\ 1275.64 & 431 & 443 \\ 963.53 & 594 & 601 \\ 1116.62 & 1312 & 1321 \\ 950.49 & 1365 & 1372 \\ 918.53 & 1519 & 1526 \\ 1058.56 & 1864 & 1872 \\ 1337.69 & 177 & 188 \\ 1304.66 & 355 & 366 \\ 1758.88 & 367 & 382 \\ 1507.76 & 488 & 500 \\ 1059.58 & 738 & 746 \\ 1055.58 & 799 & 806 \\ 1776.83 & 866 & 881 \\ 1334.63 & 882 & 892 \\ 1459.70 & 893 & 903 \\ 1296.67 & 1216 & 1226 \\ 1126.59 & 1398 & 1406 \\ 1572.79 & 103 & 116 \\ 1141.55 & 149 & 158 \\ 999.65 & 159 & 166 \\ 1739.82 & 167 & 182 \\ 857.55 & 388 & 395 \\ 1588.83 & 396 & 409 \\ 942.55 & 572 & 579 \\ 1243.56 & 703 & 713 \\ 1100.58 & 714 & 724 \\ 1791.89 & 817 & 833 \\ 1056.64 & 848 & 857 \\ 1510.73 & 1033 & 1046 \\ 1142.62 & 1397 & 1406 \\ 1308.68 & 125 & 138 \\ 1436.77 & 125 & 139 \\ 957.58 & 139 & 146 \\ 1748.89 & 147 & 161 \\ 1400.66 & 162 & 172 \\ 891.49 & 423 & 431 \\ 1243.63 & 171 & 182 \\ & & \end{array}$

Page 38 of Table S-1-5 
Coatomer subunit alpha $\mathrm{GN}=\mathrm{COPA}$ Coatomer subunit alpha $\mathrm{GN}=\mathrm{COPA}$ Coatomer subunit alpha $\mathrm{GN}=\mathrm{COPA}$ Coatomer subunit alpha $\mathrm{GN}=\mathrm{COPA}$ Coatomer subunit alpha $\mathrm{GN}=\mathrm{COPA}$ Coatomer subunit alpha $\mathrm{GN}=\mathrm{COPA}$ Coatomer subunit alpha $\mathrm{GN}=\mathrm{COPA}$ Coatomer subunit alpha $\mathrm{GN}=\mathrm{COPA}$ Coatomer subunit alpha $\mathrm{GN}=\mathrm{COPA}$ Coatomer subunit alpha $\mathrm{GN}=\mathrm{COPA}$ Coatomer subunit alpha $\mathrm{GN}=\mathrm{COPA}$ Coatomer subunit beta $\mathrm{GN}=\mathrm{COPB} 1$ Coatomer subunit beta $\mathrm{GN}=\mathrm{COPB} 1$ Coatomer subunit beta $\mathrm{GN}=\mathrm{COPB} 1$ Coatomer subunit beta' $\mathrm{GN}=\mathrm{COPB} 2$ Coatomer subunit beta' $\mathrm{GN}=\mathrm{COPB} 2$ Coatomer subunit beta' $\mathrm{GN}=\mathrm{COPB} 2$ Coatomer subunit delta $\mathrm{GN}=\mathrm{ARCN} 1$ Coatomer subunit delta $\mathrm{GN}=\mathrm{ARCN}$ Coatomer subunit delta $\mathrm{GN}=\mathrm{ARCN} 1$ Coatomer subunit delta $\mathrm{GN}=\mathrm{ARCN} 1$ Coatomer subunit delta $\mathrm{GN}=\mathrm{ARCN} 1$ Coatomer subunit delta $\mathrm{GN}=\mathrm{ARCN} 1$ Coatomer subunit delta $\mathrm{GN}=\mathrm{ARCN} 1$ Coatomer subunit epsilon $\mathrm{GN}=\mathrm{COPE}$ Coatomer subunit epsilon $\mathrm{GN}=\mathrm{COPE}$ Coatomer subunit gamma-1 GN=COPG1

Coatomer subunit gamma-1 GN=COPG1 Coatomer subunit gamma-1 GN=COPG1 Coatomer subunit gamma-1 $\mathrm{GN}=\mathrm{COPG}$

Coatomer subunit gamma-1 GN=COPG1

Coatomer subunit gamma-1 GN=COPG1

Coatomer subunit gamma-2 $\mathrm{GN}=\mathrm{COPG} 2$

Coatomer subunit gamma-2 $\mathrm{GN}=\mathrm{COPG} 2$

Coatomer subunit gamma-2 $\mathrm{GN}=\mathrm{COPG} 2$

Coatomer subunit gamma-2 $\mathrm{GN}=\mathrm{COPG} 2$

Coiled-coil domain-containing protein $137 \mathrm{GN}=\mathrm{CCDC137} \quad \mathrm{CC} 137$ _HUMAN $33.23 \quad 100.0 \%$

Coiled-coil domain-containing protein $137 \mathrm{GN}=\mathrm{CCDC} 137 \quad \mathrm{CC} 137$ HUMAN $33.23 \quad 100.0 \%$ Coiled-coil domain-containing protein $47 \mathrm{GN}=\mathrm{CCDC} 47$ CCD47_HUMAN $55.87 \quad 100.0 \%$ Coiled-coil domain-containing protein $47 \mathrm{GN}=\mathrm{CCDC} 47$ CCD47_HUMAN $55.87 \quad 100.0 \%$ Collagen alpha-2(IV) chain GN=COL4A2 CO4A2_HUMAN $167.56 \quad 100.0 \%$ Collagen alpha-2(IV) chain GN=COL4A2 CO4A2_HUMAN $167.56 \quad 100.0 \%$

$\begin{array}{lllll} & & \end{array}$ $\begin{array}{ll}\text { Con } 31.36 & 100.0 \%\end{array}$ Condensin complex subunit $1 \mathrm{GN}=\mathrm{NCAPD} 2 \mathrm{CND} 1$ _HUMAN $157.19 \quad 100.0 \%$

$0.03 \% \quad 11.6 \%$ GHYNNVSCAVFHPR $0.03 \% \quad 11.6 \%$ DADSQNPDAPEGKR $0.03 \% \quad 11.6 \%$ SSGLTAVWVAR $0.03 \% \quad 11.6 \%$ DADSITLFDVQQKR $0.03 \% \quad 11.6 \%$ KLDALCNIHENIR $0.03 \% \quad 11.6 \%$ YAVTTGDHGIIR $0.03 \% \quad 11.6 \%$ KYDEVLHMVR $0.03 \% \quad 11.6 \%$ GFFEGTIASK $0.03 \% \quad 11.6 \%$ QLFLQTYAR

$0.03 \% \quad 11.6 \%$ TALNLFFK

$0.03 \% \quad 11.6 \%$ LLELGPKPEVAQQTR $0.01 \% \quad 3.5 \%$ DLQHPNEFIR

$0.01 \% \quad 3.5 \%$ NVEELVIVLKK $0.01 \% \quad 3.5 \%$ EAADPLASKLNK $0.01 \% \quad 3.4 \%$ HSEVQQANLK $0.01 \% \quad 3.4 \%$ TGRLPEAAFLAR $0.01 \% \quad 3.4 \%$ TYLPSQVSR

$10 \quad 0.01 \% \quad 13.7 \%$ VLLAAAVCTK

$10 \quad 0.01 \% \quad 13.7 \%$ TFTEMDSHEEKVFR

$10 \quad 0.01 \% \quad 13.7 \%$ VAPAPARPSGPSK

$10 \quad 0.01 \% \quad 13.7 \%$ SFPVNSDVGVLK

$10 \quad 0.01 \% \quad 13.7 \%$ KNYCNIQVTK

$10 \quad 0.01 \% \quad 13.7 \%$ NYCNIQVTK

$10 \quad 0.01 \% \quad 13.7 \%$ VTQVDGNSPVR $0.00 \% \quad 11.7 \%$ KFGVVLDEIKPSSAPELQAVR $0.00 \% \quad 11.7 \%$ ENDFDRLVLQYAPSA

$10 \quad 0.01 \% \quad 7.3 \%$ SAVLQEAR

$10 \quad 0.01 \% \quad 7.3 \% \quad$ SIATLAITTLLK

$10 \quad 0.01 \% \quad 7.3 \%$ ILHLLGQEGPK

$10 \quad 0.01 \% \quad 7.3 \% \quad$ TTNPSKYIR

$10 \quad 0.01 \% \quad 7.3 \% \quad$ SVPLATAPMAEQR

$10 \quad 0.01 \% \quad 7.3 \%$ TLEEAVGNIVK

$0.00 \% \quad 4.5 \%$ SAVLQEAR

$0.00 \% \quad 4.5 \% \quad$ IFNETPINPR

$0.00 \% \quad 4.5 \%$ SIATLAITTLLK

$0.00 \% \quad 4.5 \%$ AAAVSALAK

$0.01 \% \quad 13.1 \%$ NQDEQEIPFR

$0.01 \% \quad 13.1 \%$ KGESDGAYIHR

$0.01 \% \quad 13.1 \%$ FGEVVLQPPELTARPQR

$0.00 \% \quad 3.9 \%$ RQDLLNVLAR

$0.00 \% \quad 3.9 \% \quad$ ARVEENFLK

$0.00 \% \quad 1.8 \%$ GVPGNIGAPGPKGAK

$0.00 \% \quad 1.8 \%$ GIPGFAGADGGPGPR

$0.01 \% \quad 21.6 \%$ AFVDFLSDEIKEER

$0.01 \% \quad 21.6 \%$ VEEQEPELTSTPNFVVEVIK

$0.01 \% \quad 21.6 \%$ ALVLDCHYPEDEVGQEDEAESDIFSIR

$0.01 \% \quad 6.1 \%$ LLENPTINHQK $\begin{array}{llllllll}98.7 \% & 17.7 & 25.0 & 17.7 & 0 & 1 & 0 & 1657.77\end{array}$

$\begin{array}{llllllll}99.7 \% & 30.5 & 25.0 & 24.9 & 1 & 0 & 0 & 1499.67\end{array}$

$\begin{array}{llllllll}99.7 \% & 54.1 & 25.0 & 27.4 & 3 & 0 & 0 & 1146.63\end{array}$

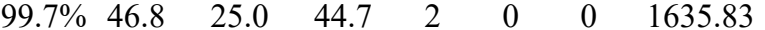

$\begin{array}{llllllll}99.7 \% & 30.3 & 25.0 & 29.6 & 0 & 2 & 0 & 1595.83\end{array}$

$\begin{array}{llllllll}99.7 \% & 39.8 & 25.0 & 37.5 & 2 & 0 & 0 & 1302.68\end{array}$

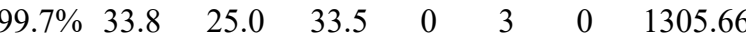

$\begin{array}{llllllll}99.7 \% & 49.6 & 25.0 & 43.3 & 3 & 0 & 0 & 1056.54\end{array}$

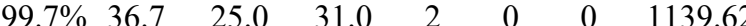

$\begin{array}{llllllll}99.0 \% & 35.4 & 25.0 & 30.4 & 2 & 0 & 0 & 953.55\end{array}$

$\begin{array}{llll}99.7 \% & 39.9 & 25.0 & 38.5\end{array}$

$99.7 \% \quad 34.6 \quad 25.0 \quad 26.4$

$98.9 \% \quad 18.0 \quad 25.0 \quad 18.0$

$\begin{array}{llll}99.6 \% & 26.5 & 25.0 & 16.7\end{array}$

$99.7 \% \quad 43.5 \quad 25.0 \quad 37.1$

$99.2 \% \quad 21.4 \quad 25.0 \quad 21.4$

$99.7 \% \quad 28.9 \quad 25.0 \quad 25.7$

$99.7 \% \quad 51.7 \quad 25.0 \quad 43.2$

$\begin{array}{llll}95.7 \% & 15.5 & 25.0 & 14.0\end{array}$

$99.7 \% \quad 32.7$

$95.2 \% \quad 18.0$

$99.7 \% \quad 27.2$

$99.7 \% \quad 32.9$

$99.7 \% \quad 50.3$

$25.0 \quad 29.1$

$25.0 \quad 11.9$

\begin{tabular}{ll}
27.2 \\
\hline
\end{tabular}

$7 \% \quad 43.0$

$99.5 \% \quad 27.6$

$99.0 \% \quad 46.5$

$99.1 \% \quad 19.3$

$99.7 \% 34.6$

$99.7 \% \quad 34.4$

$99.7 \% \quad 40.1$

$\begin{array}{lll}99.7 \% & 33.5\end{array}$

$99.0 \% \quad 46.5$

$98.2 \% \quad 19.3$

$99.1 \% \quad 19.3$

$99.7 \% \quad 27.9$

$99.6 \% \quad 24.5$

$99.7 \% 26.7$

$98.7 \% 24$.

$99.7 \% \quad 49.8$

$99.7 \% \quad 27.8$

$96.5 \% \quad 17.5$

$95.3 \% \quad 19.9$

$99.7 \% \quad 61.9$

$99.7 \% \quad 54.9$

$99.7 \% \quad 31.9$
$413 \quad 423$

$468 \quad 481$

$517 \quad 529$

$607-616$

$816 \quad 825$

$957 \quad 965$

$\begin{array}{lll}953.55 & 1107 & 1114\end{array}$

$\begin{array}{ll}1128 & 1142 \\ 108 & 117\end{array}$

$\begin{array}{lll}1268.64 & 108 & 117 \\ 1283.79 & 352 & 362\end{array}$

$1256.68 \quad 704 \quad 715$

$\begin{array}{lll}1153.60 & 319 & 328\end{array}$

$\begin{array}{lll}1301.73 & 748 & 759\end{array}$

$\begin{array}{lll}1050.56 & 760 \quad 768\end{array}$

1045.61

1755.80

1234.69

1261.68

1267.65

1139.55

1171.61

2283.27

1737.84

873.48

1244.78

1204.71

1079.58

1386.70

1172.65

873.48

1200.64

1244.78

801.48

1275.60

1232.60

1937.06

1197.71

1105.60

1319.74

1325.66

1697.84

2287.17

3136.4 1306.71
2
132
212
352
476
47
486
65
294
25
339
455
466
578
796
25
33
339
489
57
118
198
227
411
533
705
8
155
181
205

Page 39 o 
Condensin complex subunit $1 \mathrm{GN}=\mathrm{NCAPD} 2$ CND1_HUMAN $157.19100 .0 \%$ Condensin complex subunit 1 GN=NCAPD2 CND1_HUMAN $157.19100 .0 \%$ Condensin complex subunit 1 GN=NCAPD2 CND1_HUMAN $157.19 \quad 100.0 \%$ Condensin complex subunit 1 GN=NCAPD2 CND1 HUMAN 157.19 100.0\% Condensin complex subunit $1 \mathrm{GN}=\mathrm{NCAPD} 2 \mathrm{CND} 1$ HUMMAN $157.19 \quad 100.0 \%$ Condensin complex subunit 1 GN=NCAPD2 CND1_HUMAN $157.19 \quad 100.0 \%$ Condensin complex subunit $1 \mathrm{GN}=\mathrm{NCAPD} 2$ CND1_HUMAN $157.19 \quad 100.0 \%$ Condensin complex subunit $2 \mathrm{GN}=\mathrm{NCAPH}$ CND2_HUMAN $82.57 \quad 100.0 \%$ Condensin complex subunit $2 \mathrm{GN}=\mathrm{NCAPH}$ CND2 HUMAN $82.57 \quad 100.0 \%$ Condensin complex subunit $3 \mathrm{GN}=\mathrm{NCAPG}$ CND3_HUMAN $114.34 \quad 100.0 \%$ Condensin complex subunit 3 GN=NCAPG CND3_HUMAN $114.34 \quad 100.0 \%$ Condensin-2 complex subunit D3 GN=NCAPD3 CNDD3_HUMAN $168.89 \quad 100.0 \%$ Condensin-2 complex subunit D3 GN=NCAPD3 CNDD3_HUMAN $168.89 \quad 100.0 \%$ Condensin-2 complex subunit D3 GN=NCAPD3 CNDD3_HUMAN $168.89100 .0 \%$ Constitutive coactivator of PPAR-gamma-like protein $1 \mathrm{GN}=$ FAM120A F120A_HUMAN $121.89100 .0 \%$ Constitutive coactivator of PPAR-gamma-like protein 1 GN=FAM120A F120A_HUMAN $121.89 \quad 100.0 \%$ C P PAR-gamma-like protein 1 GN=FAM120A F120A_HUMAN $121.89 \quad 100.0 \%$ Con $121.89 \quad 100.0 \%$ COP9 signalosome complex subunit $4 \mathrm{GN}=\mathrm{COPS} 4 \mathrm{CSN} 4$ _HUMAN $46.27 \quad 100.0 \%$ COP9 signalosome complex subunit $4 \mathrm{GN}=\mathrm{COPS} 4 \mathrm{CSN} 4$ HUMAN $46.27 \quad 100.0 \%$ COP9 signalosome complex subunit 4 GN=COPS4 CSN4_HUMAN $46.27 \quad 100.0 \%$ COP9 signalosome complex subunit $6 \mathrm{GN}=\mathrm{COPS} 6 \mathrm{CSN} 6$ HUMAN $36.16 \quad 100.0 \%$ COP9 signalosome complex subunit $6 \mathrm{GN}=\mathrm{COPS} 6 \mathrm{CSN} 6$ HUMAN $36.16 \quad 100.0 \%$ Core histone macro-H2A.1 GN=H2AFY H2AY_HUMAN $39.62 \quad 100.0 \%$ Core histone macro-H2A.1 GN=H2AFY Cornifin-B GN=SPRR1B

Cornifin-B GN=SPRR1B

Creatine kinase $\mathrm{B}$-type $\mathrm{GN}=\mathrm{CKB}$

Creatine kinase $\mathrm{B}$-type $\mathrm{GN}=\mathrm{CKB}$

Creatine kinase B-type $\mathrm{GN}=\mathrm{CKB}$

Creatine kinase B-type $\mathrm{GN}=\mathrm{CKB}$

Creatine kinase B-type $\mathrm{GN}=\mathrm{CKB}$

Creatine kinase $\mathrm{B}$-type $\mathrm{GN}=\mathrm{CKB}$

Creatine kinase $\mathrm{B}$-type $\mathrm{GN}=\mathrm{CKB}$

Creatine kinase $\mathrm{B}$-type $\mathrm{GN}=\mathrm{CKB}$

Crk-like protein $\mathrm{GN}=\mathrm{CRKL}$

Crk-like protein $\mathrm{GN}=\mathrm{CRKI}$

Crk-like protein $\mathrm{GN}=\mathrm{CRKL}$

Crk-like protein $\mathrm{GN}=\mathrm{CRKL}$

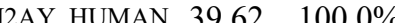

SPR1B_HUMAN $9.89 \quad 100.0 \%$ SPR1B HUMAN $9.89 \quad 100.0 \%$ KCRB HUMAN $42.65 \quad 100.0 \%$ KCRB_HUMAN $42.65 \quad 100.0 \%$ KCRB HUMAN $42.65 \quad 100.0 \%$ KCRB_HUMAN $42.65 \quad 100.0 \%$ KCRB_HUMAN $42.65 \quad 100.0 \%$ KCRB HUMAN $42.65 \quad 100.0 \%$ KCRB_HUMAN $42.65 \quad 100.0 \%$ KCRB HUMAN $42.65 \quad 100.0 \%$ CRKL_HUMAN $33.78 \quad 100.0 \%$ CRKL_HUMAN $33.78 \quad 100.0 \%$ CRKL HUMAN $33.78 \quad 100.0 \%$ CRKL_HUMAN $33.78 \quad 100.0 \%$ Crooked neck-like protein $1 \mathrm{GN}=\mathrm{CRNKL} 1$ CRNL1_HUMAN $100.45100 .0 \%$ Crooked neck-like protein $1 \mathrm{GN}=$ CRNKL1 CRNL1_HUMAN $100.45 \quad 100.0 \%$ C-terminal-binding protein $1 \mathrm{GN}=\mathrm{CTBP} 1 \quad$ CTBP1_HUMAN $47.54 \quad 100.0 \%$ C-terminal-binding protein $1 \mathrm{GN}=\mathrm{CTBP} 1 \quad$ CTBP1 HUMAN $47.54 \quad 100.0 \%$ C-terminal-binding protein $1 \mathrm{GN}=\mathrm{CTBP} 1 \quad$ CTBP1_HUMAN $47.54 \quad 100.0 \%$ C-terminal-binding protein $1 \mathrm{GN}=\mathrm{CTBP} 1 \quad$ CTBP1_HUMAN $47.54 \quad 100.0 \%$ C-terminal-binding protein $1 \mathrm{GN}=\mathrm{CTBP} 1 \quad$ CTBP1_HUMAN $47.54 \quad 100.0 \%$ C-terminal-binding protein $1 \mathrm{GN}=\mathrm{CTBP} 1 \quad$ CTBP1_HUMAN $47.54 \quad 100.0 \%$
$13 \quad 0.01 \% \quad 6.1 \% \quad$ SRVLQLFTR

$0.01 \% \quad 6.1 \% \quad$ FQAVVALAVGR

$0.01 \% \quad 6.1 \%$ LADKSVLVCK

$0.01 \% \quad 6.1 \%$ LSDADLAGPLQK

$0.01 \% \quad 6.1 \%$ ESTGNMVTGQTVCK

$0.01 \% \quad 6.1 \%$ KITEAIGIISK

$0.01 \% \quad 6.1 \%$ EAVLNAYR

$0.00 \% \quad 2.7 \%$ SIDISATIPK

$0.00 \% \quad 2.7 \%$ VDAVHADVYR

$0.01 \% \quad 2.0 \%$ IQAVLALSR

$0.01 \% \quad 2.0 \%$ AVLSCIAPSAK

$0.01 \% \quad 2.8 \%$ APLAVTSQVINCR

$0.01 \% \quad 2.8 \% \quad$ NSSAFSYQR

A

$0.01 \% \quad 5.4 \%$ GVISTPVIR

$\begin{array}{llll}5 \% & 22.0 & 25.0 & 18.6\end{array}$

$99.7 \% \quad 59.1$

$99.7 \% \quad 35.0$

$99.7 \% \quad 40.8$

$99.7 \% \quad 50.6$

$99.7 \% \quad 46.7$

$99.0 \% 31.7$

$96.9 \% 20.1$

$99.7 \% 25.6$

$99.7 \% \quad 60.8$

$99.7 \% \quad 38.7$

$99.7 \% \quad 44.7$

$99.7 \% 44.7$

$99.7 \% \quad 38.6$

$99.7 \% \quad 43.1$

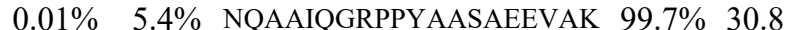

$0.01 \% \quad 5.4 \%$ EAALEAAVLNKEE

$0.00 \% \quad 9.4 \%$ AIQLSGAEQLEALK

$0.00 \% \quad 9.4 \%$ VISFEEQVASIR

$0.00 \% \quad 9.4 \%$ AVIEHNLLSASK

$0.00 \% \quad 8.6 \%$ QVCEIIESPLFLK

$0.00 \% \quad 8.6 \%$ ASEAGEVPFNHEILR

$99.7 \% \quad 56.5$

$99.7 \% \quad 49.7$

$99.7 \% \quad 53.8$

$99.7 \% \quad 39.1$

$99.7 \% \quad 46.5$

$99.7 \% \quad 43.8$

$\begin{array}{lll}0.00 \% & 8.6 \% & \text { AASADSTTEGTPAD } \\ 0.00 \% & 8.6 \% & \text { EFVEAVLELR }\end{array}$

$0.01 \% \quad 18.0 \%$ VPEPCHPK

$0.01 \% \quad 18.0 \%$ VPEPCQPK

$0.04 \% \quad 26.2 \%$ PFSNSHNALK

$0.04 \% \quad 26.2 \%$ VLTPELYAELR

$0.04 \% \quad 26.2 \%$ LAVEALSSLDGDLAGR

$0.04 \% \quad 26.2 \%$ GGNMKEVFTR

$0.04 \% \quad 26.2 \%$ FCTGLTQIETLFK

$99.7 \% 55.4$

$99.7 \% \quad 51.4$

$99.0 \% \quad 34.7$

$99.0 \% \quad 25.8$

$99.7 \% \quad 55.2$

$99.7 \% \quad 56.9$

$99.7 \% \quad 75.2$

$96.5 \% 16.1$

$99.7 \% \quad 57.1$

$0.04 \% \quad 26.2 \%$ LGFSEVELVQMVVDGVK $99.7 \% \quad 39.1$

$0.04 \% \quad 26.2 \%$ LLIEMEQR

$99.0 \% \quad 54.7$

$99.7 \% \quad 45.5$

$0.04 \% \quad 26.2 \%$ LEQGQAIDDLMPAQK

$0.01 \% \quad 18.5 \%$ DSSTCPGDYVLSVSENSR
$0.01 \% \quad 18.5 \%$ IHYLDTTTLIEPAPR

$0.01 \% \quad 18.5 \%$ VGMIPVPYVEK

$0.01 \% \quad 18.5 \%$ TALALEVGDIVK

$0.00 \% \quad 2.4 \%$ GIEDIIVSK

$0.00 \% \quad 2.4 \%$ AIYELAISQPR

$0.01 \% \quad 15.5 \%$ IGSGFDNIDIK

$0.01 \% \quad 15.5 \%$ VQSVEQIR

$0.01 \% \quad 15.5 \%$ VQSVEQIREVASGAAR

$0.01 \% \quad 15.5 \%$ IRGETLGIIGLGR

$0.01 \% \quad 15.5 \%$ VGQAVALR

$\begin{array}{llll}0.01 \% & 15.5 \% \text { GAALDVHESEPFSFSQGPLK } & 99.4 \% & 21.3\end{array}$

$99.7 \% \quad 62.5$

$\begin{array}{lll}97.6 \% & 20.8\end{array}$

$99.7 \% \quad 71.7$

$99.7 \% \quad 43.9$

$99.7 \% \quad 28.3$

$99.7 \% \quad 42.7$

$99.0 \% 32.8$

$99.7 \% \quad 38.4$

$99.7 \% \quad 27.0$

$99.0 \% \quad 64.9$

1 $\begin{array}{ccc}1119.66 & 382 & 390 \\ 1130.67 & 402 & 412 \\ 1132.64 & 413 & 422 \\ 1227.66 & 441 & 452 \\ 1511.68 & 584 & 597 \\ 1172.73 & 633 & 643 \\ 935.49 & 691 & 698 \\ 1044.59 & 92 & 101 \\ 1144.57 & 169 & 178 \\ 970.60 & 160 & 168 \\ 1116.61 & 198 & 208 \\ 1428.76 & 319 & 331 \\ 1059.49 & 506 & 514 \\ 1962.00 & 1320 & 1339 \\ 1723.75 & 912 & 929 \\ 941.58 & 987 & 995 \\ 2071.06 & 1010 & 1029 \\ 1386.71 & 1106 & 1118 \\ 1470.82 & 33 & 46 \\ 1377.74 & 96 & 107 \\ 1281.72 & 303 & 314 \\ 1575.85 & 141 & 153 \\ 1668.83 & 244 & 258 \\ 2127.01 & 168 & 189 \\ 1204.66 & 240 & 249 \\ 963.47 & 45 & 52 \\ 954.47 & 53 & 60 \\ 1114.56 & 2 & 11 \\ 1303.73 & 33 & 43 \\ 1586.84 & 157 & 172 \\ 1154.56 & 243 & 252 \\ 1557.80 & 253 & 265 \\ 1864.97 & 342 & 358 \\ 1047.55 & 359 & 366 \\ 1656.83 & 367 & 381 \\ 1972.86 & 40 & 57 \\ 1739.93 & 90 & 104 \\ 1247.67 & 170 & 180 \\ 1228.71 & 254 & 265 \\ 973.56 & 467 & 475 \\ 1260.69 & 661 & 671 \\ 1178.61 & 98 & 108 \\ 958.53 & 156 & 163 \\ 1699.91 & 156 & 171 \\ 1354.82 & 172 & 184 \\ 813.49 & 185 & 192 \\ 2116.03 & 286 & 305 \\ & & \end{array}$

Page 40 of Table S-1-5 
CTP synthase $1 \mathrm{GN}=\mathrm{CTPS} 1$ CTP synthase $1 \mathrm{GN}=\mathrm{CTPS} 1$ CTP synthase $1 \mathrm{GN}=\mathrm{CTPS} 1$ CTP synthase $1 \mathrm{GN}=\mathrm{CTPS} 1$ CTP synthase $1 \mathrm{GN}=\mathrm{CTPS} 1$ CTP synthase $1 \mathrm{GN}=\mathrm{CTPS} 1$ CTP synthase $1 \mathrm{GN}=\mathrm{CTPS} 1$ CTP synthase $1 \mathrm{GN}=\mathrm{CTPS} 1$ CTP synthase $1 \mathrm{GN}=\mathrm{CTPS} 1$

CTP synthase $1 \mathrm{GN}=\mathrm{CTPS} 1$
PYRG1_HUMAN $66.69 \quad 100.0 \% \quad 10 \quad 12 \quad 23 \quad 0.03 \% \quad 15.7 \%$ GIIASSVGTILK PYRG1_HUMAN $66.69 \quad 100.0 \% \quad 10 \quad 12 \quad 23 \quad 0.03 \% \quad 15.7 \%$ FLDIRLTK PYRG1_HUMAN $66.69 \quad 100.0 \% \quad 10 \quad 12 \quad 23 \quad 0.03 \% \quad 15.7 \%$ LTKDNNLTTGK PYRG1_HUMAN $66.69 \quad 100.0 \% \quad 10 \quad 12 \quad 23 \quad 0.03 \% \quad 15.7 \%$ IYQYVINKER

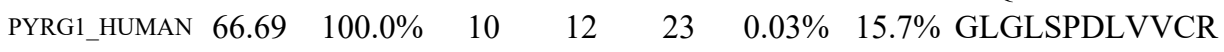

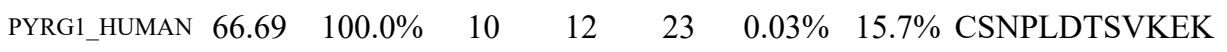
PYRG1_HUMAN $66.69 \quad 100.0 \% \quad 10 \quad 12 \quad 23 \quad 0.03 \% \quad 15.7 \%$ RLDLPIER

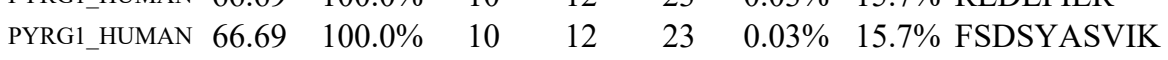
PYRG1_HUMAN $66.69 \quad 100.0 \% \quad 10 \quad 12 \quad 23 \quad 0.03 \% \quad 15.7 \%$ GTEGKIQAIAWAR

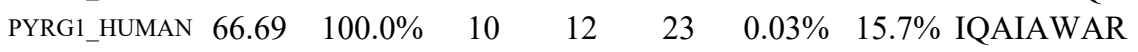

$13 \quad 30 \quad 0.03 \% \quad 8.9 \%$ LLEDKNGEVQNLAVK $13 \quad 30 \quad 0.03 \% \quad 8.9 \% \quad$ TYIQCIAAISR $13 \quad 30 \quad 0.03 \% \quad 8.9 \% \quad$ TVSPALISR $13 \quad 30 \quad 0.03 \% \quad 8.9 \%$ AADIDQEVKER $13 \quad 30 \quad 0.03 \% \quad 8.9 \%$ ALTLIAGSPLK $13 \quad 30 \quad 0.03 \% \quad 8.9 \%$ NVVAECLGK $13 \quad 30 \quad 0.03 \% \quad 8.9 \% \quad$ LKGYLISGSSYAR $13 \quad 30 \quad 0.03 \% \quad 8.9 \%$ NCIGDFLK

$13 \quad 30 \quad 0.03 \% \quad 8.9 \% \quad$ TLEDPDLNVR

$13 \quad 30 \quad 0.03 \% \quad 8.9 \% \quad$ TLEDPDLNVRR $\begin{array}{lllll}13 & 30 & 0.03 \% & 8.9 \% & \text { LSTLCPSAVLQR }\end{array}$

2

2
32

32

(1)

1
CDK1_HUMAN $34.10 \quad 100.0 \% \quad 21$ $\begin{array}{llll}\text { CDK1_HUMAN } & 34.10 & 100.0 \% & 21\end{array}$ CDK1 HUMAN $34.10 \quad 100.0 \% \quad 21$ CDK1_HUMAN $34.10 \quad 100.0 \% \quad 21$ CDK1_HUMAN $34.10 \quad 100.0 \% \quad 21$ CDK1 HUMAN $34.10 \quad 100.0 \% \quad 21$ CDK1_HUMAN $34.10 \quad 100.0 \% \quad 21$ CDK1_HUMAN $34.10 \quad 100.0 \% \quad 21$ CDK1_HUMAN $34.10 \quad 100.0 \% \quad 21$ CDK1_HUMAN $34.10 \quad 100.0 \% \quad 21$ CDK1 HUMAN $34.10 \quad 100.0 \% \quad 21$ $\begin{array}{llll}\text { CDK1_HUMAN } & 34.10 & 100.0 \% & 21\end{array}$ CDK1_HUMAN $34.10 \quad 100.0 \% \quad 21$ CDK1_HUMAN $34.10 \quad 100.0 \% \quad 21$ CDK1_HUMAN $34.10 \quad 100.0 \% \quad 21$ CDK1 HUMAN $34.10 \quad 100.0 \% \quad 21$ CDK1_HUMAN $34.10 \quad 100.0 \% \quad 21$ CDK1_HUMAN $34.10 \quad 100.0 \% \quad 21$ CDK2 HUMAN $33.93 \quad 100.0 \% \quad 6$ CDK2_HUMAN $33.93 \quad 100.0 \%$

$0.09 \% \quad 68.0 \%$ VYTHEVVTLWYR

$0.09 \% \quad 68.0 \%$ SPEVLLGSAR

$0.09 \% \quad 68.0 \%$ KPLFHGDSEIDQLFR

$0.09 \% \quad 68.0 \%$ NLDENGLDLLSK

$0.09 \% \quad 68.0 \%$ MLIYDPAK

$0.09 \% \quad 68.0 \%$ MLIYDPAKR

$\begin{array}{ll}0.02 \% & 33.6 \% \\ 0.02 \% & 33.6 \%\end{array}$

$21 \quad 0.02 \% \quad 33.6 \%$ LTGEVVALKK

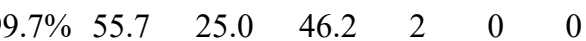

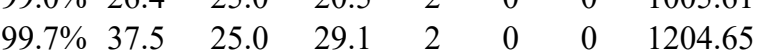
$\begin{array}{llllllll}99.7 \% & 25.7 & 25.0 & 25.7 & 0 & 1 & 0 & 1325.72\end{array}$ $99.7 \% \quad 51.1 \quad 25.0 \quad 46.0$ $99.7 \% \quad 38.0 \quad 25.0 \quad 26.8$ $99.0 \% \quad 45.9 \quad 25.0 \quad 29.9$ $\begin{array}{lllll}99.7 \% & 62.3 & 25.0 & 35.2 & 3\end{array}$ $99.7 \% \quad 60.0 \quad 25.0 \quad 51.3$ $\begin{array}{llll}99.0 \% & 30.3 & 25.0 & 21.6\end{array}$ $\begin{array}{llll}99.7 \% & 34.5 & 25.0 & 24.8\end{array}$ $\begin{array}{llll}99.7 \% & 55.2 & 25.0 & 53.0\end{array}$ $99.7 \% \quad 43.4 \quad 25.0 \quad 29.3$ $99.7 \% \quad 49.5 \quad 25.0 \quad 46.7$ $\begin{array}{llll}99.7 \% & 56.9 & 25.0 & 47.4\end{array}$ $96.3 \% \quad 15.1 \quad 25.0 \quad 14.7$ $\begin{array}{llll}99.7 \% & 43.0 & 25.0 & 39.3\end{array}$

$\begin{array}{llll}97.3 \% & 21.3 & 25.0 & 12.2\end{array}$

$99.6 \% \quad 24.4 \quad 25.0 \quad 21.7$

$\begin{array}{llll}97.6 \% & 20.1 & 25.0 & 14.1\end{array}$

$\begin{array}{llll}99.6 \% & 27.6 & 25.0 & 26.8\end{array}$

$\begin{array}{llll}99.7 \% & 34.5 & 25.0 & 24.8\end{array}$

$\begin{array}{llll}99.7 \% & 38.5 & 25.0 & 28.8\end{array}$

$\begin{array}{llll}99.7 \% & 60.3 & 25.0 & 47.2\end{array}$

$\begin{array}{llll}99.7 \% & 83.8 & 25.0 & 35.7\end{array}$

$\begin{array}{lllll}99.7 \% & 27.3 & 25.0 & 23.4\end{array}$

$\begin{array}{llll}99.7 \% & 46.6 & 25.0 & 36.6\end{array}$

$\begin{array}{llll}99.7 \% & 30.9 & 25.0 & 25.1\end{array}$

$\begin{array}{llll}99.7 \% & 65.9 & 25.0 & 65.9\end{array}$

$\begin{array}{llll}99.7 \% & 56.7 & 25.0 & 53.7\end{array}$

$\begin{array}{llll}99.7 \% & 56.0 & 25.0 & 56.0\end{array}$

$\begin{array}{llll}99.7 \% & 33.5 & 25.0 & 31.7\end{array}$

$\begin{array}{llll}98.0 \% & 21.0 & 25.0 & 21.0\end{array}$

$\begin{array}{llll}99.7 \% & 49.3 & 25.0 & 49.3\end{array}$

$99.0 \% \quad 55.6 \quad 25.0 \quad 0.0$

$\begin{array}{llll}99.7 \% & 27.2 & 25.0 & 25.6\end{array}$

$\begin{array}{llll}99.7 \% & 65.9 & 25.0 & 55.7\end{array}$

$\begin{array}{llll}99.7 \% & 63.2 & 25.0 & 61.1\end{array}$

$99.7 \% \quad 38.1$

$\begin{array}{llll}99.7 \% & 40.3 & 25.0 & 32.3 \\ 98.0 & 25.0 & 35.7\end{array}$

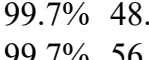

$0.09 \% \quad 68.0 \%$ MALNHPYFNDLDNQIK

$99.7 \% \quad 56.4$

$99.7 \% \quad 83.8$

$99.7 \% \quad 40.7$

$25.0 \quad 54.5$

$\begin{array}{lll}25.0 & 36.7 & 0 \\ 25.0 & 35.7 & \end{array}$

0

1285.69

1377.67

1011.59

1116.56

1400.76

928.54

1669.91

1295.68

943.56

1273.64

1083.68

989.51

1414.77

966.47

1171.60

1327.70

1344.73

1669.91

941.54

1203.65

1185.62

1199.66

934.50

1062.60

1785.93

1516.75

1867.93

1928.93

1411.78

1811.03

862.48

1565.81

1028.57

1801.92

2289.10

1209.67

1330.69

950.50

1122.60

1932.93

2077.02

1185.62

1057.66

Cyclin-dependent kinase 2 (N)

Cyclin-dependent kinase $2 \mathrm{GN}=\mathrm{CDK} 2$ 
Cyclin-dependent kinase $2 \mathrm{GN}=\mathrm{CDK} 2$ Cyclin-dependent kinase $2 \mathrm{GN}=\mathrm{CDK} 2$ Cyclin-dependent kinase $2 \mathrm{GN}=\mathrm{CDK} 2$ Cyclin-dependent kinase $2 \mathrm{GN}=\mathrm{CDK} 2$ Cyclin-dependent kinase $2 \mathrm{GN}=\mathrm{CDK} 2$ Cyclin-dependent kinase $2 \mathrm{GN}=\mathrm{CDK} 2$ Cyclin-dependent kinase $4 \mathrm{GN}=\mathrm{CDK} 4$ Cyclin-dependent kinase $4 \mathrm{GN}=\mathrm{CDK} 4$ Cyclin-dependent kinase $4 \mathrm{GN}=\mathrm{CDK} 4$ Cyclin-dependent kinase $9 \mathrm{GN}=\mathrm{CDK} 9$ Cyclin-dependent kinase $9 \mathrm{GN}=\mathrm{CDK} 9$ Cyclin-dependent kinase $9 \mathrm{GN}=\mathrm{CDK} 9$ Cyclin-dependent-like kinase 5 GN=CDK5 CDK5 HUMAN $33.31 \quad 100.0 \%$ Cyclin-dependent-like kinase $5 \mathrm{GN}=\mathrm{CDK} 5$ CDK5_HUMAN $33.31 \quad 100.0 \%$ Cyclin-dependent-like kinase 5 GN=CDK5 CDK5_HUMAN $33.31 \quad 100.0 \%$ Cyclin-dependent-like kinase 5 GN=CDK5 CDK5_HUMAN $33.31 \quad 100.0 \%$ Cyclin-dependent-like kinase 5 GN=CDK5 CDK5 HUMAN $33.31 \quad 100.0 \%$ Cystathionine beta-synthase GN=CBS $\quad$ CBS_HUMAN $60.59 \quad 100.0 \%$ Cystathionine beta-synthase $\mathrm{GN}=\mathrm{CBS}$

Cystathionine beta-synthase $\mathrm{GN}=\mathrm{CBS}$

CBS_HUMAN $60.59 \quad 100.0 \%$ CBS HUMAN $60.59 \quad 100.0 \%$ $\begin{array}{lll} & \\ \text { CRC1 QCR1_HUMAN } & 52.65 & 100.0 \%\end{array}$ Cytochrome b-cl complex subunit 1, mitochondrial GN=UQCRC1 QCR1_HUMAN $52.65 \quad 100.0 \%$ Cytochrome b-c1 complex subunit 1, mitochondrial GN=UQCRC1 QCR1_HUMAN 52.65 $100.0 \%$ Cytochrome b-c1 complex subunit 1, mitochondrial GN=UQCRC1 QCR1_HUMAN $52.65 \quad 100.0 \%$ Cytochrome b-c1 complex subunit 2, mitochondrial GN=UQCRC2 QCR2_HUMAN $48.44 \quad 100.0 \%$ Cytochrome b-c1 complex subunit 2, mitochondrial GN=UQCRC2 QCR2_HUMAN $48.44 \quad 100.0 \%$ Cytochrome b-c1 complex subunit 2, mitochondrial GN=UQCRC2 QCR2_HUMAN $48.44 \quad 100.0 \%$ Cytochrome b-c1 complex subunit 2, mitochondrial GN=UQCRC2 QCR2_HUMAN $48.44 \quad 100.0 \%$ Cytochrome b-c1 complex subunit 2, mitochondrial GN=UQCRC2 QCR2_HUMAN $48.44 \quad 100.0 \%$ Cytochrome b-c1 complex subunit 2, mitochondrial GN=UQCRC2 QCR2_HUMAN $48.44 \quad 100.0 \%$ Cytochrome b-c1 complex subunit 2, mitochondrial GN=UQCRC2 QCR2_HUMAN $48.44 \quad 100.0 \%$ Cytochrome b-c1 complex subunit 2, mitochondrial GN=UQCRC2 QCR2_HUMAN $48.44 \quad 100.0 \%$ Cytochrome b-c1 complex subunit 2, mitochondrial GN=UQCRC2 QCR2_HUMAN $48.44 \quad 100.0 \%$ Cytochrome c oxidase subunit $2 \mathrm{GN}=\mathrm{MT}-\mathrm{CO} 2$ COX2_HUMAN $25.57 \quad 100.0 \%$ Cytochrome c oxidase subunit 2 GN=MT-CO2 COX2_HUMAN $25.57 \quad 100.0 \%$ Cytochrome c oxidase subunit $2 \mathrm{GN}=\mathrm{MT}-\mathrm{CO} 2$ COX2_HUMAN $25.57 \quad 100.0 \%$ Cytochrome $\mathrm{c} 1$, heme protein, mitochondrial $\mathrm{GN}=\mathrm{CYCl}$ CY1_HUMAN $35.42 \quad 100.0 \%$ Cytochrome $\mathrm{c} 1$, heme protein, mitochondrial $\mathrm{GN}=\mathrm{CYC} 1 \mathrm{CY} 1$ HUMAN $35.42 \quad 100.0 \%$ Cytoplasmic dynein 1 heavy chain $1 \mathrm{GN}=\mathrm{DYNC} 1 \mathrm{H} 1$ DYHC1_HUMAN $532.41 \quad 100.0 \%$ Cytoplasmic dynein 1 heavy chain $1 \mathrm{GN}=\mathrm{DYNC1H} 1$ DYHC1_HUMAN $532.41 \quad 100.0 \%$ Cytoplasmic dynein 1 heavy chain $1 \mathrm{GN}=$ DYNC1H1 DYHC1_HUMAN $532.41 \quad 100.0 \%$ Cytoplasmic dynein 1 heavy chain $1 \mathrm{GN}=\mathrm{DYNC} 1 \mathrm{H} 1$ DYHC1_HUMAN $532.41 \quad 100.0 \%$ Cytoplasmic dynein 1 heavy chain $1 \mathrm{GN}=\mathrm{DYNC1H} 1$ DYHC1_HUMAN $532.41 \quad 100.0 \%$ Cytoplasmic dynein 1 heavy chain $1 \mathrm{GN}=\mathrm{DYNC1H} 1$ DYHC1_HUMAN $532.41 \quad 100.0 \%$ Cytoplasmic dynein 1 heavy chain $1 \mathrm{GN}=\mathrm{DYNC1H} 1$ DYHC1_HUMAN $532.41 \quad 100.0 \%$ Cytoplasmic dynein 1 heavy chain $1 \mathrm{GN}=\mathrm{DYNC1H} 1$ DYHC1_HUMAN $532.41 \quad 100.0 \%$ Cytoplasmic dynein 1 heavy chain $1 \mathrm{GN}=\mathrm{DYNC1H} 1$ DYHC1_HUMAN $532.41 \quad 100.0 \%$ $0.02 \% 33.6 \%$ FMDASALTGIPLPLIK $0.02 \% 33.6 \%$ DLKPQNLLINTEGAIK $0.02 \% \quad 33.6 \%$ LADFGLAR $0.02 \% 33.6 \%$ APEILLGCK $0.02 \% \quad 33.6 \%$ ALFPGDSEIDQLFR $0.00 \% \quad 10.9 \%$ RLEAFEHPNVVR $0.00 \% \quad 10.9 \%$ VTLVFEHVDQDLR $0.00 \% \quad 10.9 \%$ LADFGLAR

$0.00 \% \quad 8.9 \% \quad$ LADFGLAR $0.00 \% \quad 8.9 \%$ GSQITQQSTNQSR $0.00 \% \quad 8.9 \%$ NPATTNQTEFER $0.01 \% \quad 15.8 \%$ IGEGTYGTVFK $0.01 \% \quad 15.8 \%$ SFLFQLLK $0.01 \% \quad 15.8 \%$ DLKPQNLLINR $0.01 \% \quad 15.8 \%$ LADFGLAR $0.01 \% \quad 15.8 \%$ DLLQNLLK $0.01 \% \quad 6.9 \%$ PSETPQAEVGPTGCPHR $0.01 \% \quad 6.9 \% \quad$ SNDEEAFTFAR

$0.01 \% \quad 6.9 \% \quad$ AAQELQEGQR $0.01 \% \quad 9.4 \%$ EHTAYYIK $0.01 \% \quad 9.4 \%$ ADLTEYLSTHYKAPR $0.01 \% \quad 9.4 \%$ LCTSATESEVAR $0.01 \% \quad 9.4 \%$ IAEVDASVVR

$\begin{array}{lllllll}0.03 \% & 24.3 \% & \text { AGSRYEDFSNLGTTHLLR } & 99.7 \% & 36.0 & 25.0 & 36.0\end{array}$

$0.03 \% \quad 24.3 \%$ YEDFSNLGTTHLLR

$0.03 \% \quad 24.3 \%$ LTSSLTTK

$0.03 \% 24.3 \%$ NALANPLYCPDYR

$0.03 \% \quad 24.3 \%$ MALIGLGVSHPVLK

$0.03 \% \quad 24.3 \%$ QVAEQFLNMR

$\begin{array}{llll}99.7 \% & 84.1 & 25.0 & 84.1\end{array}$

$99.0 \% \quad 19.1 \quad 25.0 \quad 19.1$

$99.7 \% \quad 51.7 \quad 25.0 \quad 43.4$

$\begin{array}{llll}99.7 \% & 68.2 & 25.0 & 64.2\end{array}$

$99.7 \% \quad 59.1 \quad 25.0 \quad 57.2$

$99.7 \% \quad 65.9 \quad 25.0 \quad 61.3$

$0.03 \% \quad 24.3 \%$ GSNTTSHLHQAVAK

$99.7 \% \quad 54.2$

$0.03 \% \quad 24.3 \%$ SMAASGNLGHTPFVDEL $99.7 \% \quad 55.7$

$0.01 \% \quad 14.5 \%$ ILYMTDEVNDPSLTIK

$0.01 \% \quad 14.5 \%$ LLDVDNRVVLPIEAPIR

$0.01 \% \quad 14.5 \%$ VVLPIEAPIR

$0.00 \% \quad 8.6 \%$ GLLSSLDHTSIR

$0.00 \% \quad 8.6 \%$ LFDYFPKPYPNSEAAR

$256 \quad 0.28 \% \quad 11.9 \%$ SNSLAFIK

$256 \quad 0.28 \% \quad 11.9 \%$ TPVIDADKPVSSQLR

$\begin{array}{llll}66 & 256 & 0.28 \% & 11.9 \% \\ 66 & \text { DLSSQLLK }\end{array}$

$66 \quad 256 \quad 0.28 \% \quad 11.9 \%$ LRDQLGTAK

$66 \quad 256 \quad 0.28 \% \quad 11.9 \%$ GAIREYQTQLIQR

$66 \quad 256 \quad 0.28 \% \quad 11.9 \%$ EYQTQLIQR

$\begin{array}{llll}66 & 256 & 0.28 \% & 11.9 \% \\ 66 & 256 & 0.28 \% & 11.9 \%\end{array}$

$66 \quad 256 \quad 0.28 \% \quad 11.9 \%$ LKQDGDSFR

$99.7 \% \quad 42.8$

$\begin{array}{lll}99.7 \% & 39.8\end{array}$

$99.6 \% 24.9$

$99.2 \% \quad 25.5$

$99.7 \% \quad 34.4$

$99.0 \% 37.0$

$99.7 \% \quad 44.6$

$98.3 \% \quad 22.5$

$99.7 \% \quad 40.8$

$99.7 \% \quad 36.7$

$99.7 \% \quad 63.8$

$99.7 \% \quad 29.9$

$99.7 \% \quad 49.4$

$96.6 \% \quad 26.6$
1702.95

1767.00

862.48

1000.55

1607.81

1466.79

1570.82

862.48

862.48

1434.69

1407.65

1171.60

995.59

1323.77

862.48

956.58

1819.84

1286.56

1129.56

1024.51

1764.89

1323.62

1058.58

2037.01

1665.82

850.49

1566.74

1434.85

1251.62

1450.74

1630.84

1761.81

1851.94

1932.13

1106.69

1298.71

1914.94

879.49

1625.89

903.51

1001.57

1575.86

1178.62

1208.57

1065.53

966.53

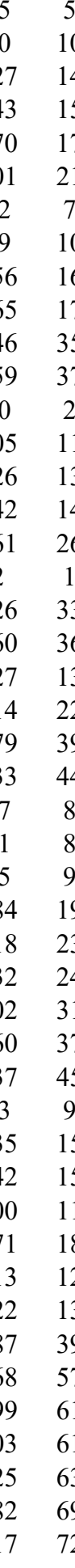


Cytoplasmic dynein 1 heavy chain $1 \mathrm{GN}=$ DYNC1H1 DYHC1 HUMAN $532.41 \quad 100.0 \%$ Cytoplasmic dynein 1 heavy chain $1 \mathrm{GN}=\mathrm{DYNC} 1 \mathrm{H} 1$ DYHC1_HUMAN $532.41 \quad 100.0 \%$ Cytoplasmic dynein 1 heavy chain $1 \mathrm{GN}=\mathrm{DYNC1H} 1$ DYHC1_HUMAN $532.41 \quad 100.0 \%$ Cytoplasmic dynein 1 light intermediate chain $1 \mathrm{GN}=$ DYNCILI1 DC1L1_HUMAN $56.58 \quad 100.0 \%$ Cytoplasmic dynein 1 light intermediate chain 1 GN=DYNC1LI1 DC1L1_HUMAN $56.58 \quad 100.0 \%$ Cytoplasmic dynein 1 light intermediate chain 1 GN=DYNC1LI1 DC1L1_HUMAN $56.58 \quad 100.0 \%$ Cytoplasmic dynein 2 heavy chain $1 \mathrm{GN}=\mathrm{DYNC} 2 \mathrm{H} 1$ DYHC2_HUMAN $492.63 \quad 100.0 \%$ Cytoplasmic dynein 2 heavy chain $1 \mathrm{GN}=\mathrm{DYNC} 2 \mathrm{H} 1 \quad$ DYHC2_HUMAN $492.63 \quad 100.0 \%$ Cytoplasmic dynein 2 heavy chain $1 \mathrm{GN}=\mathrm{DYNC} 2 \mathrm{H} 1$ DYHC2 HUMAN $492.63100 .0 \%$ Cytoplasmic dynein 2 heavy chain 1 GN=DYNC2H1 DYHC2_HUMAN $492.63 \quad 100.0 \%$ Cytoplasmic dynein 2 heavy chain 1 GN=DYNC2H1 DYHC2_HUMAN $492.63 \quad 100.0 \%$ Cytoplasmic FMR1-interacting protein $1 \mathrm{GN}=$ CYFIP1 CYFP1_HUMAN $145.19 \quad 100.0 \%$ Cytoplasmic FMR1-interacting protein $1 \mathrm{GN}=$ CYFIP1 CYFP1_HUMAN $145.19100 .0 \%$ Cytoplasmic FMR1-interacting protein $1 \mathrm{GN}=$ CYFIP1 CYFP1_HUMAN $145.19 \quad 100.0 \%$ Cytoplasmic FMR1-interacting protein $1 \mathrm{GN}=$ CYFIP1 CYFP1_HUMAN $145.19100 .0 \%$ Cytoplasmic FMR1-interacting protein $1 \mathrm{GN}=$ CYFIP1 CYFP1_HUMAN $145.19 \quad 100.0 \%$ Cytoplasmic FMR1-interacting protein $1 \mathrm{GN}=$ CYFIP1 CYFP1 HUMAN $145.19100 .0 \%$ Cytoplasmic FMR1-interacting protein $1 \mathrm{GN}=$ CYFIP1 CYFP1_HUMAN $145.19 \quad 100.0 \%$ Cytoplasmic FMR1-interacting protein 2 GN=CYFIP2 CYFP2_HUMAN $148.40 \quad 100.0 \%$ Cytoplasmic FMR1-interacting protein 2 GN=CYFIP2 CYFP2_HUMAN $148.40 \quad 100.0 \%$ Cytoplasmic FMR1-interacting protein 2 GN=CYFIP2 CYFP2_HUMAN $148.40 \quad 100.0 \%$ Cytoplasmic FMR1-interacting protein $2 \mathrm{GN}=$ CYFIP2 CYFP2_HUMAN $148.40 \quad 100.0 \%$ Cytoplasmic FMR1-interacting protein 2 GN=CYFIP2 CYFP2_HUMAN $148.40 \quad 100.0 \%$ Cytoskeleton-associated protein 5 GN=CKAP5 CKAP5_HUMAN $225.50 \quad 100.0 \%$ Cytoskeleton-associated protein $5 \mathrm{GN}=\mathrm{CKAP} 5$ CKAP5 HUMAN $225.50 \quad 100.0 \%$ Cytoskeleton-associated protein 5 GN=CKAP5 CKAP5_HUMAN $225.50 \quad 100.0 \%$ Cytoskeleton-associated protein $5 \mathrm{GN}=\mathrm{CKAP} 5$ CKAP5_HUMAN $225.50 \quad 100.0 \%$ Cytoskeleton-associated protein $5 \mathrm{GN}=\mathrm{CKAP} 5$ CKAP5_HUMAN $225.50 \quad 100.0 \%$ Cytoskeleton-associated protein 5 GN=CKAP5 CKAP5_HUMAN $225.50 \quad 100.0 \%$ Cytoskeleton-associated protein $5 \mathrm{GN}=\mathrm{CKAP} 5$ CKAP5 HUMAN $225.50 \quad 100.0 \%$ Cytoskeleton-associated protein $5 \mathrm{GN}=\mathrm{CKAP} 5$ CKAP5_HUMAN $225.50 \quad 100.0 \%$ Cytosolic Fe-S cluster assembly factor NUBP2 GN=NUBP2 NUBP2_HUMAN $28.83 \quad 100.0 \%$ Cytosolic Fe-S cluster assembly factor NUBP2 GN=NUBP2 NUBP2 HUMAN $28.83 \quad 100.0 \%$ Cytosolic Fe-S cluster assembly factor NUBP2 GN=NUBP2 NUBP2_HUMAN $28.83 \quad 100.0 \%$ D-3-phosphoglycerate dehydrogenase GN=PHGDH SERA HUMAN $56.65 \quad 100.0 \%$ D-3-phosphoglycerate dehydrogenase GN=PHGDH SERA_HUMAN $56.65100 .0 \%$ D-3-phosphoglycerate dehydrogenase GN=PHGDH SERA_HUMAN $56.65 \quad 100.0 \%$ D-3-phosphoglycerate dehydrogenase GN=PHGDH SERA HUMAN $56.65100 .0 \%$ D-3-phosphoglycerate dehydrogenase GN=PHGDH SERA_HUMAN $56.65 \quad 100.0 \%$ D-3-phosphoglycerate dehydrogenase GN=PHGDH SERA_HUMAN $56.65100 .0 \%$ D-3-phosphoglycerate dehydrogenase GN=PHGDH SERA HUMAN $56.65 \quad 100.0 \%$ D-3-phosphoglycerate dehydrogenase GN=PHGDH SERA_HUMAN $56.65 \quad 100.0 \%$ D-3-phosphoglycerate dehydrogenase GN=PHGDH SERA HUMAN $56.65100 .0 \%$ D-3-phosphoglycerate dehydrogenase GN=PHGDH SERA_HUMAN $56.65 \quad 100.0 \%$ D-3-phosphoglycerate dehydrogenase GN=PHGDH SERA_HUMAN $56.65100 .0 \%$ D-3-phosphoglycerate dehydrogenase GN=PHGDH SERA HUMAN $56.65100 .0 \%$ D-3-phosphoglycerate dehydrogenase GN=PHGDH SERA_HUMAN $56.65 \quad 100.0 \%$

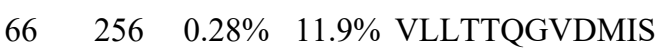

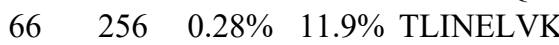

$256 \quad 0.28 \% \quad 11.9 \%$ QLQNISLAAASGGAK $95.6 \% 22.6$ $99.7 \% \quad 57.7$ $0.01 \% \quad 9.4 \%$ NVLLLGEDGAGKTSLIR $0.01 \% \quad 9.4 \%$ QPPTAAGRPVDASPR $0.01 \% \quad 9.4 \%$ SVSSNVASVSPIPAGSK $0.01 \% \quad 1.4 \%$ TVAGGGLETISNLK $0.01 \% \quad 1.4 \%$ VADTIVAK $0.01 \% \quad 1.4 \% \quad$ VTTLTTHAGIR $0.01 \% \quad 1.4 \%$ SLEGEVVPFK $0.01 \% \quad 1.4 \%$ STQIATVHCSAQTTSR $0.01 \% \quad 6.8 \% \quad$ YSNSEVVTGSGR $0.01 \% \quad 6.8 \%$ SGFDIKVPR $0.01 \% \quad 6.8 \%$ AVGPSSTQLYMVR $0.01 \% \quad 6.8 \%$ EANHNVSAPYGR $0.01 \% \quad 6.8 \%$ DKQPNAQPQYLHGSK $0.01 \% \quad 6.8 \% \quad$ LGTPQQIAIAR $0.01 \% \quad 6.8 \% \quad$ CFQPPIHQSLASS $0.00 \% \quad 4.4 \%$ GGFDIKVPR $0.00 \% \quad 4.4 \%$ EANHNVSAPYGR $0.00 \% \quad 4.4 \%$ TAIPFTQEPQR $0.00 \% \quad 4.4 \%$ LGTPQQIAIAR $0.00 \% \quad 4.4 \% \quad$ SVETDSSTVEHVR $0.02 \% \quad 4.4 \% \quad$ FVTDSNAVVQLK $0.02 \% \quad 4.4 \%$ TTGEVVSGVVSK $0.02 \% \quad 4.4 \%$ LIAVEIYR $0.02 \% \quad 4.4 \%$ LEAGDYADLVK $0.02 \% \quad 4.4 \%$ TALAATNPAVR $0.02 \% \quad 4.4 \%$ MQGQSPPAPTR $0.02 \% \quad 4.4 \% \quad$ AQNISSNANMLR $0.02 \% \quad 4.4 \% \quad$ NSSQFFQSYVER $0.01 \% \quad 13.3 \%$ HIILVLSGK $0.01 \% \quad 13.3 \%$ STISTELALALR $0.01 \% \quad 13.3 \%$ VGILDVDLCGPSIPR $0.06 \% 34.7 \%$ ILQDGGLQVVEK $0.06 \% \quad 34.7 \%$ SATKVTADVINAAEK $0.06 \% \quad 34.7 \%$ VTADVINAAEK

$\begin{array}{lll}23.8 & 25.0 & 23.8\end{array}$

$96.8 \% 15.4$ $99.7 \% \quad 59.7$ $99.7 \% \quad 43.1$ $99.0 \% \quad 21.8$ $97.9 \% \quad 17.5$ $99.7 \% \quad 31.1$ $99.7 \% \quad 34.3$ $99.7 \% 63.1$ $99.7 \% \quad 53.8$ $99.7 \% \quad 36.0$ $95.1 \% \quad 14.4$ $99.6 \% \quad 24.2$ $99.7 \% \quad 57.8$ $99.3 \% \quad 25.6$ $\begin{array}{lll}99.7 \% & 34.0\end{array}$ $95.1 \% \quad 14.4$ $99.7 \% \quad 37.0$ $99.7 \% \quad 57.8$ $99.7 \% 57.1$ $99.7 \% \quad 49.9$ $99.7 \% \quad 59.5$ $99.0 \% 30.1$ $\begin{array}{lll}99.7 \% & 38.0\end{array}$ $99.7 \% \quad 60.7$ $99.7 \% \quad 38.6$ $99.7 \% \quad 57.7$ $99.7 \% \quad 36.6$ $99.7 \% \quad 28.1$ $99.7 \% \quad 62.6$ $99.7 \% \quad 54.5$ $99.7 \% \quad 60.2$ $99.7 \% \quad 49.5$ $99.7 \% \quad 59.1$ $0.06 \% \quad 34.7 \%$ VTADVINAAEKLQVVGR $99.7 \% \quad 55.7$ $0.06 \% \quad 34.7 \%$ AGTGVDNVDLEAATR

$99.7 \% \quad 55.4$ $0.06 \% \quad 34.7 \%$ AGTGVDNVDLEAATRK $0.06 \% 34.7 \%$ QIPQATASMK $0.06 \% \quad 34.7 \%$ TLGILGLGR $0.06 \% 34.7 \%$ GGIVDEGALLR $99.7 \% \quad 25.9$ $99.7 \% \quad 50.7$ $99.7 \% \quad 59.9$ $0.06 \% \quad 34.7 \%$ ALQSGQCAGAALDVFTEEPPRDR $\quad 99.7 \% 33.2$ $0.06 \% \quad 34.7 \%$ ALVDHENVISCPHLGASTK $99.7 \% \quad 59.6$ $0.06 \% \quad 34.7 \%$ ALVDHENVISCPHLGASTKEAQSR $\quad 99.7 \% \quad 46.5$ $0.06 \% \quad 34.7 \%$ CGEEIAVQFVDMVKGK $\quad 99.7 \% \quad 50.8$
1314.62

1710.86

1471.70

988.56

1314.62

1287.67

1167.68

1445.69

1320.72

1162.63

976.58

1193.61

1084.61

1169.57

1318.65

1491.69

979.63

1274.73

1610.86

1298.73

1517.82

1130.61

1783.01

1488.73

1616.82

1090.56

899.57

1099.61

2488.19

2048.02

2619.29 1809.89 
D-3-phosphoglycerate dehydrogenase GN=PHGDH SERA_HUMAN $56.65 \quad 100.0 \%$ D-3-phosphoglycerate dehydrogenase GN=PHGDH SERA_HUMAN $56.65 \quad 100.0 \%$ D-3-phosphoglycerate dehydrogenase GN=PHGDH SERA_HUMAN $56.65 \quad 100.0 \% \quad 18$ D-3-phosphoglycerate dehydrogenase GN=PHGDH SERA_HUMAN 56.65 100.0\% D-3-phosphoglycerate dehydrogenase GN=PHGDH SERA_HUMAN $56.65 \quad 100.0 \%$ DBIRD complex subunit ZNF326 GN=ZNF326 ZN326_HUMAN $65.65 \quad 100.0 \%$ DBIRD complex subunit ZNF326 GN=ZNF326 ZN326 HUMAN $65.65 \quad 100.0 \%$ DBIRD complex subunit ZNF326 GN=ZNF326 ZN326_HUMAN $65.65 \quad 100.0 \%$ DBIRD complex subunit ZNF326 GN=ZNF326 ZN326 HUMAN $65.65 \quad 100.0 \%$ DBIRD complex subunit ZNF326 GN=ZNF326 ZN326_HUMAN $65.65 \quad 100.0 \%$ DBIRD complex subunit ZNF326 GN=ZNF326 ZN326_HUMAN $65.65 \quad 100.0 \%$ DBIRD complex subunit ZNF326 GN=ZNF326 ZN326 HUMAN $65.65100 .0 \%$ DBIRD complex subunit ZNF326 GN=ZNF326 ZN326_HUMAN $65.65 \quad 100.0 \%$ DDB1- and CUL4-associated factor $7 \mathrm{GN}=\mathrm{DCAF} 7$ DCAF7_HUMAN $38.93 \quad 100.0 \%$ DDB1- and CUL4-associated factor 7 GN=DCAF7 DCAF7 HUMAN $38.93 \quad 100.0 \%$ DDB1- and CUL4-associated factor 7 GN=DCAF7 DCAF7_HUMAN $38.93 \quad 100.0 \%$ DDB1- and CUL4-associated factor $7 \mathrm{GN}=\mathrm{DCAF} 7$ DCAF7 HUMAN $38.93 \quad 100.0 \%$ DDB1- and CUL4-associated factor 7 GN=DCAF7 DCAF7_HUMAN $38.93 \quad 100.0 \%$ DDRGK domain-containing protein 1 GN=DDRGK1 DDRGK_HUMAN $35.61 \quad 100.0 \%$ DDRGK domain-containing protein $1 \mathrm{GN}=$ DDRGK1 DDRGK HUMAN $35.61 \quad 100.0 \%$ Dedicator of cytokinesis protein $1 \mathrm{GN}=$ DOCK1 DOCK1_HUMAN $215.35 \quad 100.0 \%$ Dedicator of cytokinesis protein $1 \mathrm{GN}=$ DOCK1 DOCK1_HUMAN $215.35 \quad 100.0 \%$ Dedicator of cytokinesis protein 4 GN=DOCK4 DOCK4_HUMAN $225.21 \quad 100.0 \%$ Dedicator of cytokinesis protein 4 GN=DOCK4 DOCK4_HUMAN $225.21 \quad 100.0 \%$ Dedicator of cytokinesis protein $4 \mathrm{GN}=$ DOCK4 DOCK4_HUMAN $225.21 \quad 100.0 \%$ Dedicator of cytokinesis protein 4 GN=DOCK4 DOCK4_HUMAN $225.21 \quad 100.0 \%$ Dedicator of cytokinesis protein 4 GN=DOCK4 DOCK4_HUMAN $225.21 \quad 100.0 \%$ Dedicator of cytokinesis protein 4 GN=DOCK4 DOCK4_HUMAN $225.21 \quad 100.0 \%$ Dedicator of cytokinesis protein 4 GN=DOCK4 DOCK4_HUMAN $225.21 \quad 100.0 \%$ Dehydrogenase/reductase SDR family member 7B GN=DHRS7B DRS7B_HUMAN $35.12 \quad 100.0 \%$ Dehydrogenase/reductase SDR family member 7B GN=DHRS7B DRS7B_HUMAN $35.12 \quad 100.0 \%$ Dehydrogenase/reductase SDR family member 7B GN=DHRS7B DRS7B_HUMAN $35.12 \quad 100.0 \%$ Dehydrogenase/reductase SDR family member 7B GN=DHRS7B DRS7B_HUMAN $35.12 \quad 100.0^{\circ}$ Dehydrogenase/reductase SDR family member 7B GN=DHRS7B DRS7B_HUMAN $35.12 \quad 100.0 \%$ Delta-1-pyrroline-5-carboxylate synthase GN=ALDH18A1 P5CS HUMAN 87.30 100.0\% Delta-1-pyrroline-5-carboxylate synthase GN=ALDH18A1 P5CS HUMAN 87.30 $100.0 \%$ Delta-1-pyrroline-5-carboxylate synthase GN=ALDH18A1 P5CS_HUMAN 87.30 100.0\% Delta-1-pyrroline-5-carboxylate synthase GN=ALDH18A1 P5CS_HUMAN 87.30 100.0\% Delta-1-pyrroline-5-carboxylate synthase GN=ALDH18A1 P5CS_HUMAN 87.30 $100.0 \%$ Delta-1-pyrroline-5-carboxylate synthase GN=ALDH18A1 P5CS_HUMAN 87.30 100.0\% Deoxynucleoside triphosphate triphosphohydrolase SAMHDI GN=SAMHDI SAMH1 HUMAN $72.20100 .0 \%$ Deoxynucleoside triphosphate triphosphohydrolase SAMHDI GN=SAMHDI SAMH1_HUMAN $72.20 \quad 100.0 \%$ Derlin-1 GN=DERL Derlin-1 GN=DERL Desmoglein-1 GN=DSG Desmoglein-1 GN=DSG1

DSG1_HUMAN $113.75 \quad 100.0 \%$
$99.7 \% \quad 55.4 \quad 25.0 \quad 51.8 \quad 9$

$0.06 \% \quad 34.7 \%$ GTIQVITQGTSLK

$99.7 \% \quad 53.2$

$0.06 \% \quad 34.7 \%$ NAGNCLSPAVIVGLLKEASK

$0.06 \% \quad 34.7 \%$ EASKQADVNLVNAK

$0.01 \% \quad 12.7 \%$ FGPYESYDSR

$0.01 \% \quad 12.7 \%$ SSLGGRDLYR

$0.01 \% \quad 12.7 \%$ SGYGFNEPEQSR

$99.7 \% \quad 38.7$

$99.5 \% 26.4$

$99.7 \% \quad 47.5$

$99.7 \% \quad 55.2$

$99.7 \% \quad 29.0$

$99.7 \% \quad 60.7$

$0.01 \% \quad 12.7 \%$ SGYGFNEPEQSRFGGSYGGR $99.6 \% 23.4$

$0.01 \% \quad 12.7 \%$ FGGSYGGRFESSYR

$0.01 \% \quad 12.7 \%$ NSLDSFGGR

$0.01 \% \quad 12.7 \%$ STNVTVAAAR

$0.01 \% \quad 12.7 \%$ MAFTCSFCK

$0.01 \% \quad 18.7 \%$ VQLVGLDEESSEFICR

$0.01 \% \quad 18.7 \%$ GVYPDLLATSGDYLR

$0.01 \% \quad 18.7 \%$ VGETETRLECLLNNNK

$0.01 \% \quad 18.7 \%$ VNLVSGHVK

$0.01 \% \quad 18.7 \%$ VPCTPVAR

$99.6 \% 24.6$

$99.7 \% \quad 53.1$

$99.7 \% \quad 61.1$

$99.7 \% \quad 33.7$

$99.7 \% \quad 66.5$

$99.7 \% 53.1$

$99.7 \% \quad 28.7$

$99.7 \% \quad 32.7$

$99.0 \% \quad 39.9$

$0.00 \% \quad 10.5 \%$ AASAGQEPLHNEELAGAGR

$0.00 \% \quad 10.5 \%$ VVLLEDLASQVGLR

$0.00 \% \quad 1.2 \%$ AHEIASKQVEER

$0.00 \% \quad 1.2 \%$ SNTSLLQQNLR

$0.01 \% \quad 4.0 \%$ GIFLGNNNQAMK

$0.01 \% \quad 4.0 \%$ TVESQLYTNPDSR

$0.01 \% \quad 4.0 \%$ ESGVSLIATVTR

$\begin{array}{lll}0.01 \% & 4.0 \% & \text { EGVPDNIK }\end{array}$

$0.01 \% \quad 4.0 \%$ TLISQCQTR

$0.01 \% \quad 4.0 \%$ NSAPASVSPDGTR

$0.01 \% \quad 4.0 \%$ HTTSVSPSPAGR

$0.01 \% \quad 19.1 \%$ NAVVVITGATSGLGK

$0.01 \% \quad 19.1 \%$ GTIMDTTVDVDKR

$0.01 \% \quad 19.1 \%$ VMETNYFGPVALTK

$0.01 \% \quad 19.1 \%$ ALLPSMIK

$0.01 \% \quad 19.1 \%$ YGVMDTTTAQGR

$0.01 \% \quad 7.7 \% \quad$ LRHEILLSQSVR

$0.01 \% \quad 7.7 \% \quad$ NLNGTLHELLR

$0.01 \% \quad 7.7 \% \quad$ MLATLEPEQR

$0.01 \% \quad 7.7 \%$ LNSLAIGLR

$0.01 \% \quad 7.7 \%$ MIDLIIPR

$0.01 \% \quad 7.7 \%$ GSSQLVRDIQK

$0.01 \% \quad 5.3 \%$ GGFEEPVLLK

$0.01 \% \quad 5.3 \% \quad$ SFLYEIVSNKR

$0.01 \% \quad 5.3 \% \quad$ YVGETQPTGQIK

$0.00 \% \quad 10.0 \%$ YWFAATVAVPLVGK

$0.00 \% \quad 10.0 \%$ NFLSTPQFLYR

$98.6 \% \quad 17.5$

$99.7 \% \quad 40.1$

$\begin{array}{lll}94.7 \% & 18.9\end{array}$

$99.7 \% \quad 39.0$

$99.7 \% \quad 34.3$

$99.7 \% \quad 60.0$

$99.7 \% \quad 53.4$

$94.6 \% \quad 17.7$

$99.6 \% \quad 23.6$

$99.7 \% \quad 36.3$

$95.3 \% \quad 15.3$

$99.7 \% \quad 63.5$

$\begin{array}{lll}99.7 \% & 39.8\end{array}$

$99.7 \% \quad 65.1$

$95.2 \% \quad 20.3$

$99.7 \% \quad 54.0$

$99.6 \% \quad 22.2$

$99.7 \% \quad 37.8$

$99.7 \% \quad 33.4$

$99.6 \% \quad 31.0$

$98.3 \% \quad 22.3$

$99.7 \% \quad 36.5$

$99.7 \% \quad 42.0$

$99.7 \% \quad 64.8$

$99.7 \% \quad 36.4$

$99.7 \% \quad 27.2$

$99.7 \% \quad 35.5$

$99.7 \% \quad 47.8$

0.01\% 3.8\% IHSDCAANQQVTYR

$0.01 \% \quad 3.8 \% \quad$ YVMGNNPADLLAVDSR $\quad 99.7 \% \quad 53.6$ 
Desmoglein-1 GN=DSG1 Desmoplakin GN=DSP Desmoplakin $\mathrm{GN}=\mathrm{DSF}$ Desmoplakin GN=DSP Desmoplakin GN=DSP Desmoplakin GN=DSP Desmoplakin GN=DSP Desmoplakin $\mathrm{GN}=\mathrm{DSP}$ Desmoplakin GN=DSP Desmoplakin GN=DSP Desmoplakin GN=DSF Desmoplakin GN=DSP Desmoplakin GN=DSP Desmoplakin GN=DSP Desmoplakin GN=DSP Desmoplakin $\mathrm{GN}=\mathrm{DSP}$ Desmoplakin GN=DSP Desmoplakin GN=DSP Desmoplakin GN=DSP Desmoplakin GN=DSP Desmoplakin $\mathrm{GN}=\mathrm{DSP}$ Desmoplakin GN=DSP Desmoplakin GN=DSP Desmoplakin GN=DSF Desmoplakin GN=DSP Desmoplakin GN=DSP Desmoplakin GN=DSP Desmoplakin GN=DSP Desmoplakin GN=DSP Desmoplakin GN=DSP Desmoplakin GN=DSP Desmoplakin GN=DSF Desmoplakin GN=DSP Desmoplakin GN=DSP Desmoplakin GN=DSP

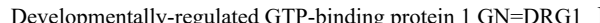
Developmentally-regulated GTP-binding protein 1 GN=DRG1 DRG1_HUMAN $40.54 \quad 100.0 \%$ Developmentally-regulated GTP-binding protein $1 \mathrm{GN}=\mathrm{DRG} 1$ DRG1_HUMAN $40.54 \quad 100.0 \%$ Developmentally-regulated GTP-binding protein 1 GN=DRG1 DRG1_HUMAN $40.54 \quad 100.0 \%$ ODP2_HUMAN $69.00 \quad 100.0 \%$ ODP2_HUMAN $69.00 \quad 100.0 \%$ ODP2_HUMAN $69.00 \quad 100.0 \%$ ODP2 HUMAN $69.00 \quad 100.0 \%$

Dihydropyrimidinase-related protein $1 \mathrm{GN}=\mathrm{CRMP} 1$ DPYL1_HUMAN $62.18 \quad 100.0 \%$ Dihydropyrimidinase-related protein 1 GN=CRMP1 DPYL1_HUMAN $62.18 \quad 100.0 \%$ Dimethyladenosine transferase 1, mitochondrial GN=TFB1M TFB1M HUMAN $39.54 \quad 100.0 \%$ Dimethyladenosine transferase 1, mitochondrial GN=TFB1M TFB1M_HUMAN $39.54 \quad 100.0 \%$
$0.01 \% \quad 3.8 \% \quad$ ESSNVVVTER $0.11 \% \quad 12.6 \%$ YEVTSGGGGTSR $0.11 \% \quad 12.6 \%$ AELIVQPELK $0.11 \% \quad 12.6 \%$ YGDGIQLTR $0.11 \% \quad 12.6 \%$ LLQLQEQMR $0.11 \% \quad 12.6 \%$ QLQNIIQATSR

$0.11 \% \quad 12.6 \%$ QVQNLVNK $0.11 \% \quad 12.6 \%$ IQSQFTDAQK $0.11 \% \quad 12.6 \%$ ALLQAILQTEDMLK $0.11 \% \quad 12.6 \%$ IEVLEEELR $0.11 \% \quad 12.6 \%$ YQAECSQFK $0.11 \% \quad 12.6 \%$ LASLEELKR $0.11 \% \quad 12.6 \%$ LTYEIEDEKR $0.11 \% \quad 12.6 \%$ NKYETEINITK $0.11 \% \quad 12.6 \%$ DLKDEIVR $0.11 \% \quad 12.6 \%$ SLSEEIKR $0.11 \% \quad 12.6 \%$ LKNTLTQTTENLR $0.11 \% \quad 12.6 \%$ RVEEDIQQQK $0.11 \% \quad 12.6 \%$ YKQSLDDAAK $0.11 \% \quad 12.6 \%$ ANSSATETINKLK $0.11 \% \quad 12.6 \%$ VQEQELTR $0.11 \% \quad 12.6 \%$ QLLQEQESVK $0.11 \% \quad 12.6 \%$ SLNESKIEIER $0.11 \% \quad 12.6 \%$ LQSLTENLTK $0.11 \% \quad 12.6 \%$ SEADSDKNATILELR $0.11 \% \quad 12.6 \%$ SQLQISNNR $0.11 \% \quad 12.6 \%$ TLELQGLINDLQR $0.11 \% \quad 12.6 \%$ NQCTQVVQER $0.11 \% \quad 12.6 \%$ AITGFDDPFSGK $0.11 \% \quad 12.6 \%$ GLVGIEFKEK $0.11 \% \quad 12.6 \%$ LLEAQIATGGIIDPK $0.11 \% \quad 12.6 \%$ GFFDPNTEENLTYLQLK $0.11 \% \quad 12.6 \%$ ISITEGIER

$0.11 \% \quad 12.6 \%$ AFIGFEGVK

$0.11 \% \quad 12.6 \%$ LLEAASVSSK

$0.01 \% \quad 13.6 \%$ IAEIEAEMAR $0.01 \% \quad 13.6 \%$ GGGGGGPGEGFDVAK $0.01 \% \quad 13.6 \%$ IGFVGFPSVGK $0.01 \% \quad 13.6 \%$ IQLLDLPGIIEGAK $0.01 \% \quad 4.5 \% \quad$ ILVPEGTR

$0.01 \% \quad 4.5 \%$ SKISVNDFIIK $0.01 \% \quad 4.5 \% \quad$ ISVNDFIIK $0.01 \% \quad 4.5 \% \quad$ YLEKPITMLL

$0.00 \% \quad 3.3 \% \quad$ INCPVYITK

$0.00 \% \quad 3.3 \%$ SAADIIALAR

$0.02 \% \quad 26.9 \%$ QLSQNFLLDLR $0.02 \% \quad 26.9 \%$ SILNADVAELLVVEK $\begin{array}{lllll}99.7 \% & 48.8 & 25.0 & 47.4 & 2\end{array}$

$\begin{array}{llll}99.7 \% & 50.0 & 25.0 & 44.6\end{array}$

$99.7 \% \quad 42.6 \quad 25.0 \quad 33.0$

$\begin{array}{llll}99.7 \% & 48.2 & 25.0 & 36.1\end{array}$

$99.7 \% \quad 35.0 \quad 25.0 \quad 23.5$

$\begin{array}{llll}99.7 \% & 56.3 & 25.0 & 54.2\end{array}$

$\begin{array}{llll}98.8 \% & 22.1 & 25.0 & 15.9\end{array}$

$\begin{array}{llll}99.7 \% & 36.7 & 25.0 & 25.9\end{array}$

$\begin{array}{llll}99.7 \% & 63.0 & 25.0 & 63.0\end{array}$

$\begin{array}{llll}99.7 \% & 56.9 & 25.0 & 41.2\end{array}$

$\begin{array}{lllll}99.7 \% & 32.7 & 25.0 & 32.4 & 3\end{array}$

$99.5 \% \quad 27.8 \quad 25.0 \quad 22.3$

$\begin{array}{llll}99.7 \% & 33.7 & 25.0 & 28.4\end{array}$

$\begin{array}{llll}99.7 \% & 37.5 & 25.0 & 31.3\end{array}$

$\begin{array}{llll}99.0 \% & 32.9 & 25.0 & 16.8\end{array}$

$\begin{array}{llll}99.0 \% & 43.7 & 25.0 & 15.9\end{array}$

$\begin{array}{llll}95.2 \% & 17.6 & 25.0 & 17.6\end{array}$

$\begin{array}{llll}99.7 \% & 62.0 & 25.0 & 42.4\end{array}$

$\begin{array}{llll}99.7 \% & 35.7 & 25.0 & 35.7\end{array}$

$99.7 \% \quad 27.0 \quad 25.0 \quad 23.7$

$99.0 \% \quad 28.5 \quad 25.0 \quad 15.3 \quad 2$

$\begin{array}{llll}99.7 \% & 44.1 & 25.0 & 35.1\end{array}$

$\begin{array}{llll}99.6 \% & 27.4 & 25.0 & 17.9\end{array}$

$99.7 \% \quad 44.3 \quad 25.0 \quad 22.5 \quad 2$

$\begin{array}{llll}99.3 \% & 20.0 & 25.0 & 20.0\end{array}$

$\begin{array}{llll}99.7 \% & 52.7 & 25.0 & 40.9\end{array}$

$\begin{array}{llll}99.7 \% & 47.0 & 25.0 & 45.6\end{array}$

$\begin{array}{llll}99.7 \% & 42.6 & 25.0 & 30.1\end{array}$

$\begin{array}{llll}99.6 \% & 24.5 & 25.0 & 24.5\end{array}$

$\begin{array}{llll}99.3 \% & 23.8 & 25.0 & 22.1\end{array}$

$\begin{array}{llll}99.7 \% & 61.6 & 25.0 & 59.9\end{array}$

$\begin{array}{llll}99.7 \% & 53.4 & 25.0 & 53.4\end{array}$

$\begin{array}{llll}99.7 \% & 37.4 & 25.0 & 30.0\end{array}$

$96.2 \% \quad 20.5 \quad 25.0 \quad 14.4$

$\begin{array}{llll}97.7 \% & 17.1 & 25.0 & 17.1\end{array}$

$99.7 \% \quad 44.3 \quad 25.0 \quad 38.3$

$\begin{array}{lllll}99.7 \% & 37.1 & 25.0 & 37.1\end{array}$

$\begin{array}{llll}99.6 \% & 22.1 & 25.0 & 22.1\end{array}$

$\begin{array}{llll}99.7 \% & 56.1 & 25.0 & 55.0\end{array}$

$\begin{array}{llll}99.0 \% & 24.8 & 25.0 & 18.6\end{array}$

$\begin{array}{llll}99.7 \% & 40.1 & 25.0 & 30.5\end{array}$

$\begin{array}{llll}99.3 \% & 20.3 & 25.0 & 20.3\end{array}$

$\begin{array}{llll}99.7 \% & 35.8 & 25.0 & 31.8\end{array}$

$\begin{array}{llll}99.7 \% & 33.3 & 25.0 & 27.9\end{array}$

$\begin{array}{lllll}99.7 \% & 53.1 & 25.0 & 37.2 & 2\end{array}$

$\begin{array}{llll}99.7 \% & 60.2 & 25.0 & 47.7\end{array}$

$\begin{array}{llll}99.7 \% & 70.7 & 25.0 & 66.8\end{array}$

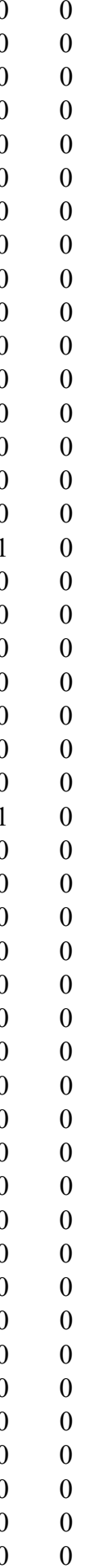

1119.56

1170.54

1139.67

1022.53

1174.63

1271.71

942.54

1165.58

1602.88

1129.61

1160.50

1058.62

1295.65

1352.71

987.55

961.53

1531.84

1272.65

1138.57

1376.74

1002.52

1201.64

1317.70

1146.64

1661.83

1059.55

1512.84

1261.60

1254.60

1119.64

1538.88

2028.99

1017.56

967.52

1004.56

1148.56

1261.58

1107.62

1479.88

884.52

1263.73

1048.60

1236.69

1107.59

1000.58

1346.74

1612.92

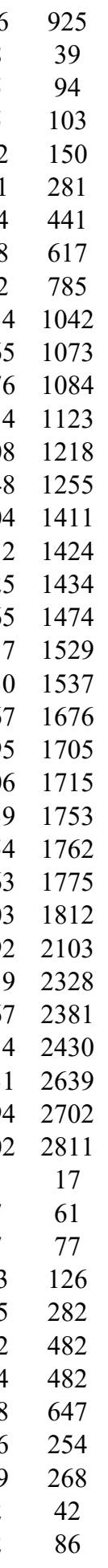

Page 46 of Table S-1-5 
Dimethyladenosine transferase 1, mitochondrial GN=TFB1M TFB1M_HUMAN $39.54 \quad 100.0 \%$ Dimethyladenosine transferase 1, mitochondrial GN=TFB1M TFB1M_HUMAN $39.54 \quad 100.0 \%$ Dimethyladenosine transferase 1, mitochondrial GN=TFB1M TFB1M_HUMAN $39.54 \quad 100.0 \%$ Dimethyladenosine transferase 1, mitochondrial GN=TFB1M TFB1M_HUMAN $39.54 \quad 100.0 \%$ Dimethyladenosine transferase 1, mitochondrial GN=TFB1M TFB1M_HUMAN $39.54 \quad 100.0 \%$ Dimethyladenosine transferase 1, mitochondrial GN=TFB1M TFB1M_HUMAN $39.54 \quad 100.0 \%$ Dimethyladenosine transferase 2, mitochondrial GN=TFB2M TFB2M_HUMAN $45.35 \quad 100.0 \%$ Dimethyladenosine transferase 2, mitochondrial GN=TFB2M TFB2M_HUMAN $45.35 \quad 100.0 \%$ Dimethyladenosine transferase 2, mitochondrial GN=TFB2M TFB2M_HUMAN $45.35 \quad 100.0 \%$ Dimethyladenosine transferase 2, mitochondrial GN=TFB2M TFB2M_HUMAN $45.35 \quad 100.0 \%$ Dimethyladenosine transferase 2, mitochondrial GN=TFB2M TFB2M_HUMAN $45.35 \quad 100.0 \%$ Dimethyladenosine transferase 2, mitochondrial GN=TFB2M TFB2M_HUMAN $45.35 \quad 100.0 \%$ Dimethyladenosine transferase 2, mitochondrial GN=TFB2M TFB2M_HUMAN $45.35 \quad 100.0 \%$ Dimethyladenosine transferase 2, mitochondrial GN=TFB2M TFB2M_HUMAN $45.35 \quad 100.0 \%$ Dimethyladenosine transferase 2, mitochondrial GN=TFB2M TFB2M_HUMAN $45.35 \quad 100.0 \%$ Dimethyladenosine transferase 2, mitochondrial GN=TFB2M TFB2M_HUMAN $45.35 \quad 100.0 \%$ DNA dC->dU-editing enzyme APOBEC-3B GN=APOBEC3B ABC3B_HUMAN $45.93 \quad 100.0 \%$ DNA dC->dU-editing enzyme APOBEC-3B GN=APOBEC3B ABC3B_HUMAN $45.93 \quad 100.0 \%$ DNA dC->dU-editing enzyme APOBEC-3B GN=APOBEC3B ABC3B_HUMAN $45.93 \quad 100.0 \%$ DNA dC->dU-editing enzyme APOBEC-3B GN=APOBEC3B ABC3B_HUMAN $45.93 \quad 100.0 \%$ DNA dC->dU-editing enzyme APOBEC-3C GN=APOBEC3C ABC3C_HUMAN $22.83 \quad 100.0 \%$ DNA dC->dU-editing enzyme APOBEC-3C GN=APOBEC3C ABC3C_HUMAN $22.83 \quad 100.0 \%$ DNA mismatch repair protein Msh2 GN=MSH2 MSH2_HUMAN $104.75 \quad 100.0 \%$ DNA mismatch repair protein Msh2 GN=MSH2 MSH2_HUMAN $104.75 \quad 100.0 \%$ DNA mismatch repair protein Msh2 GN=MSH2 MSH2_HUMAN $104.75100 .0 \%$ DNA mismatch repair protein Msh2 GN=MSH2 MSH2_HUMAN $104.75 \quad 100.0 \%$ DNA mismatch repair protein Msh2 GN=MSH2 MSH2_HUMAN $104.75 \quad 100.0 \%$ DNA mismatch repair protein Msh6 GN=MSH6 MSH6_HUMAN $152.79 \quad 100.0 \%$ DNA mismatch repair protein Msh6 GN=MSH6 MSH6_HUMAN $152.79 \quad 100.0 \%$ DNA mismatch repair protein Msh6 GN=MSH6 MSH6_HUMAN $152.79 \quad 100.0 \%$ DNA mismatch repair protein Msh6 GN=MSH6 MSH6_HUMAN $152.79 \quad 100.0 \%$ DNA mismatch repair protein Msh6 GN=MSH6 MSH6_HUMAN $152.79 \quad 100.0 \%$ DNA mismatch repair protein Msh6 GN=MSH6 MSH6_HUMAN $152.79 \quad 100.0 \%$ DNA mismatch repair protein Msh6 GN=MSH6 MSH6_HUMAN $152.79 \quad 100.0 \%$ DNA mismatch repair protein Msh6 GN=MSH6 MSH6_HUMAN $152.79 \quad 100.0 \%$ DNA mismatch repair protein Msh6 GN=MSH6 MSH6_HUMAN $152.79 \quad 100.0 \%$ DNA mismatch repair protein Msh6 GN=MSH6 MSH6_HUMAN $152.79 \quad 100.0 \%$ DNA mismatch repair protein Msh6 GN=MSH6 MSH6 HUMAN $152.79 \quad 100.0 \%$ DNA polymerase alpha catalytic subunit GN=POLA1 DPOLA_HUMAN $165.92 \quad 100.0 \%$ DNA polymerase alpha catalytic subunit GN=POLA1 DPOLA_HUMAN $165.92 \quad 100.0 \%$ DNA polymerase delta catalytic subunit GN=POLD1 DPOD1_HUMAN $123.63 \quad 100.0 \%$ DNA polymerase delta catalytic subunit GN=POLD1 DPOD1_HUMAN $123.63 \quad 100.0 \%$ DNA polymerase delta catalytic subunit GN=POLD1 DPOD1_HUMAN $123.63 \quad 100.0 \%$ DNA polymerase delta catalytic subunit GN=POLD1 DPOD1_HUMAN $123.63 \quad 100.0 \%$ DNA polymerase delta catalytic subunit GN=POLD1 DPOD1_HUMAN $123.63 \quad 100.0 \%$ DNA polymerase delta catalytic subunit GN=POLD1 DPOD1_HUMAN $123.63 \quad 100.0 \%$ DNA polymerase delta catalytic subunit GN=POLD1 DPOD1_HUMAN $123.63 \quad 100.0 \%$

8

12

8

8
10

10
10

10
10

10
10

10
10

10
10

10

10
10

10
4

4

4

2

2

5

5

5

5
11
11

11
11

22

$0.02 \% \quad 26.9 \%$ TQMTLTFQK

$0.02 \% \quad 26.9 \%$ LSVMAQYLCNVR

$0.02 \% \quad 26.9 \%$ VVQNVFQFR

$0.02 \% \quad 26.9 \%$ MLFPEAQR

$0.02 \% \quad 26.9 \%$ LLELADIDPTLRPR

$0.02 \% \quad 26.0 \%$ MWIPVVGLPR

$0.02 \% \quad 26.0 \%$ VIHCDFFK

$0.02 \% \quad 26.0 \%$ SGGVIKPPAMSSR

$0.02 \% \quad 26.0 \%$ NLGIEAVPWTADIPLK

$0.02 \% \quad 26.0 \%$ VVGMFPSR

$0.02 \% \quad 26.0 \%$ LAYDLYSCTSIYK

$0.02 \% \quad 26.0 \%$ ELLDQLQQK

$0.02 \% \quad 26.0 \%$ LYLIQMIPR

$0.02 \% \quad 26.0 \%$ SATVIDHLR

$0.02 \% \quad 26.0 \%$ TLFETIER

$0.01 \% \quad 10.5 \%$ SNLLWDTGVFR

$0.01 \% \quad 10.5 \%$ FDENYAFLHR

$0.01 \% \quad 10.5 \%$ NLLCGFYGR

$0.01 \% \quad 10.5 \%$ AFLQENTHVR

$0.01 \% \quad 13.7 \%$ HSNVNLTIFTAR

$0.01 \% \quad 13.7 \%$ LYYFQYPCYQEGLR

$0.01 \% \quad 5.4 \% \quad$ NLQSVVLSK

$0.01 \% \quad 5.4 \%$ QVGVGYVDSIQR

$0.01 \% \quad 5.4 \%$ GGILITER

$0.01 \% \quad 5.4 \%$ LTSLNEEYTK

$0.01 \% \quad 5.4 \%$ NNSFVNEIISR

$0.02 \% \quad 8.2 \% \quad$ SPALSDANKASAR

$0.02 \% \quad 8.2 \% \quad$ VHVQFFDDSPTR

$0.02 \% \quad 8.2 \% \quad$ QATSISSETKNTLR

$0.02 \% \quad 8.2 \%$ YSDSLVQK

$0.02 \% \quad 8.2 \% \quad$ YSDSLVQKGYK

$0.02 \% \quad 8.2 \%$ VEQTETPEMMEAR

$0.02 \% \quad 8.2 \%$ IHNVGSPLK

$0.02 \% \quad 8.2 \%$ AIMYEETTYSK

$0.02 \% \quad 8.2 \% \quad$ LANLINAEER

$0.02 \% \quad 8.2 \% \quad$ LANLPEEVIQK

$0.02 \% \quad 8.2 \%$ EVCLASER

$0.00 \% \quad 1.5 \%$ AAYAGGLVLDPK

$0.00 \% \quad 1.5 \%$ SGYSEVNLSK

$0.01 \% \quad 7.7 \%$ ELNLAISR

$0.01 \% \quad 7.7 \%$ VLSFDIECAGR

$0.01 \% \quad 7.7 \%$ VQTFPFLGR

$0.01 \% \quad 7.7 \%$ GQQVKVVSQLLR

$0.01 \% \quad 7.7 \%$ LGLTEDQFIR

$0.01 \% \quad 7.7 \%$ IFEPILGEGR

$0.01 \% \quad 7.7 \%$ VGGLLAFAK $\begin{array}{lll}0 & 0 & 1544.81\end{array}$

$\begin{array}{llllllll}99.7 \% & 33.6 & 25.0 & 27.1 & 4 & 0 & 0 & 1113.56\end{array}$

$\begin{array}{llllllll}99.7 \% & 44.1 & 25.0 & 42.5 & 3 & 0 & 0 & 1469.72\end{array}$

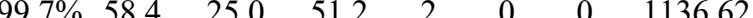

$\begin{array}{llllllll}95.4 \% & 23.9 & 25.0 & 6.6 & 1 & 0 & 0 & 991.50\end{array}$

$99.7 \% \quad 40.4$

991.50
1621.93

1167.67

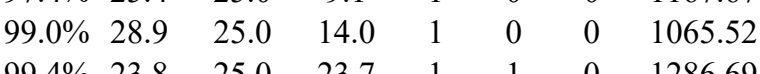

$99.4 \% \quad 23.8 \quad 25.0 \quad 23.7$

$99.7 \% \quad 55.4 \quad 25.0 \quad 55.4$

$\begin{array}{lllll}98.5 \% & 25.1 & 25.0 & 12.4 & 2\end{array}$

$99.7 \% \quad 55.0 \quad 25.0 \quad 49.1$

$99.7 \% \quad 48.0 \quad 25.0 \quad 20.0 \quad 2$

$\begin{array}{llll}99.7 \% & 42.0 & 25.0 & 28.8\end{array}$

$\begin{array}{lllll}99.7 \% & 47.5 & 25.0 & 28.5 & 2\end{array}$

$\begin{array}{lllll}99.0 \% & 31.5 & 25.0 & 25.7 & 2\end{array}$

$99.3 \% \quad 24.3 \quad 25.0 \quad 24.3$

$99.0 \% \quad 24.4 \quad 25.0 \quad 20.8$

$99.6 \% 23.0 \quad 25.0 \quad 23.0$

$99.7 \% \quad 48.0 \quad 25.0 \quad 44.2 \quad 2$

$\begin{array}{lllll}99.7 \% & 50.3 & 25.0 & 41.2 & 2\end{array}$

$\begin{array}{llll}99.5 \% & 29.8 & 25.0 & 29.8\end{array}$

$\begin{array}{llll}99.7 \% & 29.1 & 25.0 & 19.7\end{array}$

$\begin{array}{lllll}99.7 \% & 61.0 & 25.0 & 51.1 & 2\end{array}$

$\begin{array}{llll}99.0 \% & 38.7 & 25.0 & 19.3\end{array}$

$\begin{array}{llll}98.7 \% & 17.6 & 25.0 & 17.6\end{array}$

$99.7 \% \quad 57.0 \quad 25.0 \quad 48.5$

$\begin{array}{llll}99.7 \% & 47.2 & 25.0 & 40.3\end{array}$

$99.7 \% \quad 36.4 \quad 25.0 \quad 36.4$

$99.7 \% \quad 41.6 \quad 25.0 \quad 38.8$

$99.0 \% \quad 38.9 \quad 25.0 \quad 31.0$

$\begin{array}{llll}98.6 \% & 18.8 & 25.0 & 18.8\end{array}$

$99.7 \% \quad 44.7 \quad 25.0 \quad 44.7$

$\begin{array}{llll}99.4 \% & 21.7 & 25.0 & 21.7\end{array}$

$\begin{array}{llll}99.7 \% & 44.1 & 25.0 & 44.1\end{array}$

$\begin{array}{llll}99.7 \% & 29.3 & 25.0 & 26.0\end{array}$

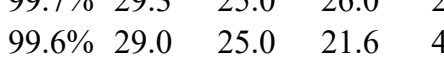

$\begin{array}{llll}99.0 \% & 27.5 & 25.0 & 19.0\end{array}$

$\begin{array}{lllll}99.7 \% & 30.9 & 25.0 & 30.0 & 2\end{array}$

$\begin{array}{llll}99.7 \% & 35.5 & 25.0 & 29.9\end{array}$

$\begin{array}{llll}99.0 \% & 42.3 & 25.0 & 15.4\end{array}$

$\begin{array}{lllll}99.7 \% & 53.5 & 25.0 & 49.9 & 2\end{array}$

$\begin{array}{llll}99.5 \% & 28.8 & 25.0 & 21.0\end{array}$

$\begin{array}{llll}99.7 \% & 31.9 & 25.0 & 28.6\end{array}$

$\begin{array}{lllll}99.7 \% & 55.6 & 25.0 & 47.0 & 2\end{array}$

$\begin{array}{lllll}99.7 \% & 46.6 & 25.0 & 36.4 & 2\end{array}$

$\begin{array}{llll}99.5 \% & 26.1 & 25.0 & 26.1\end{array}$

1736.96

908.47

1596.76

1114.61

1146.67

1011.56

1008.54

1307.67

1311.61

1099.54

1214.63

1372.73

1899.87

987.58

1320.69

858.50

1197.60

1292.66

1287.67

1447.70

1535.80

939.48

1287.66

1550.68

964.56

1351.61

1142.62

1253.71

963.46

1174.65

1083.53

915.53

1266.61

1064.59

1354.82

1191.64

1130.62

875.54 
DNA polymerase delta catalytic subunit GN=POLD1 DPOD1_HUMAN $123.63 \quad 100.0 \%$ DNA polymerase epsilon catalytic subunit A GN=POLE DPOE1_HUMAN $261.52 \quad 100.0 \%$ DNA polymerase epsilon catalytic subunit A GN=POLE DPOE1_HUMAN $261.52 \quad 100.0 \%$ DNA polymerase epsilon catalytic subunit A GN=POLE DPOE1_HUMAN $261.52 \quad 100.0 \%$ DNA polymerase epsilon catalytic subunit A GN=POLE DPOE1_HUMAN $261.52 \quad 100.0 \%$ DNA polymerase epsilon catalytic subunit A GN=POLE DPOE1_HUMAN $261.52 \quad 100.0 \%$ DNA polymerase epsilon catalytic subunit A GN=POLE DPOE1_HUMAN $261.52 \quad 100.0 \%$ DNA polymerase epsilon catalytic subunit A GN=POLE DPOE1_HUMAN $261.52 \quad 100.0 \%$ DNA polymerase epsilon catalytic subunit A GN=POLE DPOE1_HUMAN $261.52 \quad 100.0 \%$ DNA polymerase epsilon catalytic subunit A GN=POLE DPOE1_HUMAN $261.52 \quad 100.0 \%$ DNA polymerase epsilon catalytic subunit A GN=POLE DPOE1_HUMAN $261.52 \quad 100.0 \%$ DNA repair protein RAD50 GN=RAD50 RAD50_HUMAN $153.90 \quad 100.0 \%$ DNA repair protein RAD50 GN=RAD50 RAD50_HUMAN $153.90 \quad 100.0 \%$ DNA repair protein RAD50 GN=RAD50 RAD50_HUMAN $153.90 \quad 100.0 \%$ DNA repair protein RAD50 GN=RAD50 RAD50_HUMAN $153.90 \quad 100.0 \%$ DNA repair protein RAD50 GN=RAD50 RAD50_HUMAN $153.90 \quad 100.0 \%$ DNA repair protein RAD50 GN=RAD50 RAD50 HUMAN $153.90 \quad 100.0 \%$ DNA repair protein RAD50 GN=RAD50 RAD50_HUMAN $153.90 \quad 100.0 \%$ DNA repair protein RAD50 GN=RAD50 RAD50_HUMAN $153.90 \quad 100.0 \%$ DNA repair protein RAD50 GN=RAD50 RAD50_HUMAN $153.90 \quad 100.0 \%$ DNA repair protein RAD50 GN=RAD50 RAD50_HUMAN $153.90 \quad 100.0 \%$ DNA repair protein RAD50 GN=RAD50 RAD50_HUMAN $153.90 \quad 100.0 \%$ DNA repair protein RAD50 GN=RAD50 RAD50_HUMAN $153.90 \quad 100.0 \%$ DNA repair protein RAD50 GN=RAD50 RAD50_HUMAN $153.90 \quad 100.0 \%$ DNA repair protein RAD50 GN=RAD50 RAD50_HUMAN $153.90 \quad 100.0 \%$ DNA repair protein RAD50 GN=RAD50 RAD50_HUMAN $153.90 \quad 100.0 \%$ DNA repair protein RAD51 homolog 2 GN=RAD51B RA51B_HUMAN $42.20 \quad 100.0 \%$ DNA repair protein RAD51 homolog 2 GN=RAD51B RA51B HUMAN $42.20 \quad 100.0 \%$ DNA repair protein RAD51 homolog 2 GN=RAD51B RA51B_HUMAN $42.20 \quad 100.0 \%$ DNA repair protein XRCC3 GN=XRCC3 XRCC3 HUMAN $37.85 \quad 100.0 \%$ DNA repair protein XRCC3 GN=XRCC3 XRCC3_HUMAN $37.85 \quad 100.0 \%$ DNA replication licensing factor MCM3 GN=MCM3 MCM3_HUMAN $90.98 \quad 100.0 \%$ DNA replication licensing factor MCM3 GN=MCM3 MCM3 HUMAN $90.98 \quad 100.0 \%$ DNA replication licensing factor MCM3 GN=MCM3 MCM3_HUMAN $90.98 \quad 100.0 \%$ DNA replication licensing factor MCM3 GN=MCM3 MCM3_HUMAN $90.98 \quad 100.0 \%$ DNA replication licensing factor MCM3 GN=MCM3 MCM3_HUMAN $90.98 \quad 100.0 \%$ DNA replication licensing factor MCM3 GN=MCM3 MCM3_HUMAN $90.98 \quad 100.0 \%$ DNA replication licensing factor MCM3 GN=MCM3 MCM3 HUMAN $90.98 \quad 100.0 \%$ DNA replication licensing factor MCM3 GN=MCM3 MCM3_HUMAN $90.98 \quad 100.0 \%$ DNA replication licensing factor MCM4 GN=MCM4 MCM4_HUMAN $96.56 \quad 100.0 \%$ DNA replication licensing factor MCM4 GN=MCM4 MCM4 HUMAN $96.56 \quad 100.0 \%$ DNA replication licensing factor MCM5 GN=MCM5 MCM5_HUMAN $82.29 \quad 100.0 \%$ DNA replication licensing factor MCM5 GN=MCM5 MCM5 HUMAN $82.29 \quad 100.0 \%$ DNA replication licensing factor MCM5 GN=MCM5 MCM5_HUMAN $82.29 \quad 100.0 \%$ DNA replication licensing factor MCM5 GN=MCM5 MCM5_HUMAN $82.29 \quad 100.0 \%$ DNA replication licensing factor MCM5 GN=MCM5 MCM5_HUMAN $82.29 \quad 100.0 \%$ DNA replication licensing factor MCM6 GN=MCM6 MCM6_HUMAN $92.89 \quad 100.0 \%$

10

10

10
10

10
15
15

15
15

$0.02 \% \quad 4.6 \%$ GGVITDEEETSKK

4.6\% GNAFPVEITR

$9 \quad 0.02 \% \quad 4.6 \%$ ENSFYVDTVR

$19 \quad 0.02 \% \quad 4.6 \% \quad$ KLEDYGEQK

$9 \quad 0.02 \% \quad 4.6 \% \quad$ KPEGSPVTER

$19 \quad 0.02 \% \quad 4.6 \% \quad$ SSSLQDFDIR

$\begin{array}{llll}0.02 \% & 4.6 \% & \text { ASVFVLDTVR }\end{array}$

$9 \quad 0.02 \% \quad 4.6 \%$ FLLAYKEER

$10 \quad 19 \quad 0.02 \% \quad 4.6 \% \quad$ LGSSVIYANFNR

$\begin{array}{llll}16 & 23 & 0.03 \% & 12.4 \% \\ 16 & \text { VAQETDVRAQIR }\end{array}$

$\begin{array}{llll}16 & 23 & 0.03 \% & 12.4 \% \\ 16 & 23 & 0.03 \% & 12.4 \%\end{array}$

$16 \quad 23 \quad 0.03 \% \quad 12.4 \%$ QKFDEIFSATR

$\begin{array}{llll}16 & 23 & 0.03 \% & 12.4 \%\end{array}$

$16 \quad 23 \quad 0.03 \% \quad 12.4 \%$ SYENELDPLKNR

$16 \quad 23 \quad 0.03 \% \quad 12.4 \%$ LKEIEHNLSK

$16 \quad 23 \quad 0.03 \% \quad 12.4 \%$ LLNQEKSELLVEQGR

$16 \quad 23 \quad 0.03 \% \quad 12.4 \%$ IIELKSEILSK

$16 \quad 23 \quad 0.03 \% \quad 12.4 \%$ FQMELKDVER

$16 \quad 23 \quad 0.03 \% \quad 12.4 \%$ LQGIDLDR

$16 \quad 23 \quad 0.03 \% \quad 12.4 \%$ KLIQDQQEQIQHLK

$\begin{array}{llll}16 & 23 & 0.03 \% & 12.4 \%\end{array}$ WLQDNLTLR

$16 \quad 23 \quad 0.03 \% \quad 12.4 \%$ VLASLIIR

$16 \quad 23 \quad 0.03 \% \quad 12.4 \%$ NIDQCSEIVK

$0.03 \% \quad 12.4 \%$ CSVSSLGFNVH

$0.00 \% \quad 8.6 \%$ VGLSQELCDR

$0.00 \% \quad 8.6 \% \quad$ IESLEEEIISK

$0.00 \% \quad 8.6 \%$ LVILDSVASVVR

$0.00 \% \quad 6.7 \% \quad$ LVVIDSVAAPFR

$0.00 \% \quad 6.7 \%$ CEFDSQASAPR

$0.01 \% \quad 9.3 \%$ ELISDNQYR

$0.01 \% \quad 9.3 \% \quad$ LIVNVNDLR

$0.01 \% \quad 9.3 \%$ LIVNVNDLRR

$0.01 \% \quad 9.3 \%$ SVHYCPATK

$0.01 \% \quad 9.3 \%$ GGYTSGTFR

$0.01 \% \quad 9.3 \%$ SKDIFDQLAK

$0.01 \% \quad 9.3 \% \quad$ YVLCTAPR

$0.01 \% \quad 9.3 \%$ GSSGVGLTAAVTTDQETGER

$0.01 \% \quad 2.1 \%$ AGIICQLNAR

$0.01 \% \quad 2.1 \%$ GMVSAYPR

$0.01 \% \quad 6.3 \% \quad$ VLGIQVDTDGSGR

$0.01 \% \quad 6.3 \%$ AIACLLFGGSR

$0.01 \% \quad 6.3 \%$ AIACLLFGGSRK

$\begin{array}{lll}0.01 \% & 6.3 \% & \text { CSPIGVYTSGK }\end{array}$

$0.01 \% \quad 6.3 \% \quad$ LSAEAAEKLK

$0.02 \% \quad 7.2 \% \quad$ FLLDTNKSR $\begin{array}{llll}99.7 \% & 33.4 & 25.0 & 28.7\end{array}$

$\begin{array}{llll}99.7 \% & 39.7 & 25.0 & 39.7\end{array}$

$\begin{array}{llll}98.3 \% & 20.1 & 25.0 & 16.0\end{array}$

$\begin{array}{llll}99.7 \% & 37.7 & 25.0 & 30.6\end{array}$

$\begin{array}{llll}99.7 \% & 27.1 & 25.0 & 27.1\end{array}$

$\begin{array}{lllll}99.5 \% & 25.1 & 25.0 & 16.8 & 2\end{array}$

$\begin{array}{llll}99.7 \% & 36.1 & 25.0 & 16.4\end{array}$

$\begin{array}{llll}99.7 \% & 32.8 & 25.0 & 17.4\end{array}$

$99.7 \% \quad 51.6 \quad 25.0 \quad 41.3$

$\begin{array}{llll}99.7 \% & 30.9 & 25.0 & 25.4\end{array}$

$\begin{array}{llll}99.6 \% & 24.7 & 25.0 & 24.7\end{array}$

$\begin{array}{llll}99.6 \% & 26.6 & 25.0 & 24.4\end{array}$

$\begin{array}{llll}96.8 \% & 20.4 & 25.0 & 12.5\end{array}$

$\begin{array}{llll}99.6 \% & 28.5 & 25.0 & 25.8\end{array}$

$\begin{array}{llll}99.6 \% & 24.6 & 25.0 & 17.6\end{array}$

$\begin{array}{llll}99.6 \% & 27.9 & 25.0 & 27.8\end{array}$

$\begin{array}{lllll}99.6 \% & 26.0 & 25.0 & 17.1\end{array}$

$99.7 \% \quad 32.0 \quad 25.0 \quad 32.0$

$\begin{array}{llll}99.7 \% & 47.0 & 25.0 & 41.2\end{array}$

$\begin{array}{llll}99.3 \% & 22.3 & 25.0 & 20.8\end{array}$

$99.0 \% \quad 23.5 \quad 25.0 \quad 17.3$

$99.7 \% \quad 31.4$

$99.7 \% \quad 38$

$99.0 \% 57.1$

$99.7 \% \quad 43.0$

$99.7 \% \quad 49.5$

$99.7 \% \quad 32.4$

$99.6 \% \quad 24.4$

$99.7 \% \quad 61.3$

$99.7 \% \quad 42.0$

$\begin{array}{lll}99.7 \% & 44.5\end{array}$

$99.7 \% \quad 40.1$

$99.5 \% \quad 27.2$

$99.3 \% \quad 20.2$

$\begin{array}{lll}99.3 \% & 26.8\end{array}$

$99.4 \% \quad 26.4$

$99.7 \% \quad 54.3$

$99.0 \% 39.6$

$99.7 \% \quad 81.3$

$99.7 \% \quad 61.0$

$96.0 \% \quad 18.3$

$99.3 \% \quad 19.7$

$99.7 \% \quad 53.6$

$99.5 \% \quad 22.1$

$99.6 \% \quad 24.2$

$99.7 \% \quad 42.5$

$99.6 \% \quad 27.4$
1888.88

1392.69

1103.58

1329.68

1229.58

1109.55

1099.57

1167.56

1106.62

1168.64

1340.70

1385.75

1213.65

1341.68

1320.66

1477.73

1210.68

1755.96

1272.78

1294.65

929.51

1748.97

1158.63

884.59

1205.58

1206.56

1176.57

1289.68

1270.77

1286.75

1267.54

1137.55

1055.62

1211.72

1062.50

945.44

1164.63

979.50

1935.93

1115.60

896.43

1316.68

1164.62

1292.71

1168.57

1059.60

1093.60
$98 \quad 210$

$250 \quad 259$

$414 \quad 425$

$1042 \quad 1050$

$1083 \quad 1092$

$1116 \quad 1125$

$1510 \quad 1519$

$1571 \quad 1579$

18591870

$72 \quad 83$

$174 \quad 184$

$220 \quad 230$

$243 \quad 254$

$255 \quad 264$

$338 \quad 352$

$42 \quad 452$

$816 \quad 823$

$851 \quad 864$

$1017 \quad 1025$

$1207 \quad 1214$

$1292 \quad 1301$

$1302 \quad 1312$

$\begin{array}{ll}9 & 18\end{array}$

$192 \quad 202$

$206 \quad 217$

$221 \quad 231$

$38 \quad 46$

$47 \quad 55$

$47 \quad 56$

$144 \quad 152$

$249 \quad 257$

$292 \quad 301$

$357 \quad 364$

$601 \quad 610$

$725 \quad 732$

$296 \quad 308$

$352 \quad 363$

$397 \quad 407$

$574 \quad 583$ 
DNA replication licensing factor MCM6 GN=MCM6 MCM6_HUMAN $92.89 \quad 100.0 \%$ DNA replication licensing factor MCM6 GN=MCM6 MCM6_HUMAN $92.89 \quad 100.0 \%$ DNA replication licensing factor MCM6 GN=MCM6 MCM6_HUMAN $92.89 \quad 100.0 \%$ DNA replication licensing factor MCM6 GN=MCM6 MCM6_HUMAN 92.89 DNA replication licensing factor MCM6 GN=MCM6 MCM6_HUMAN $92.89 \quad 100.0 \%$ DNA replication licensing factor MCM7 GN=MCM7 MCM7_HUMAN $81.31 \quad 100.0 \%$ DNA replication licensing factor MCM7 GN=MCM7 MCM7_HUMAN $81.31 \quad 100.0 \%$ DNA replication licensing factor MCM7 GN=MCM7 MCM7_HUMAN $81.31 \quad 100.0 \%$ DNA replication licensing factor MCM7 GN=MCM7 MCM7 HUMAN $81.31 \quad 100.0 \%$ DNA replication licensing factor MCM7 GN=MCM7 MCM7_HUMAN $81.31 \quad 100.0 \%$ DNA replication licensing factor MCM7 GN=MCM7 MCM7_HUMAN $81.31 \quad 100.0 \%$ DNA replication licensing factor MCM7 GN=MCM7 MCM7_HUMAN $81.31 \quad 100.0 \%$ DNA replication licensing factor MCM7 GN=MCM7 MCM7_HUMAN $81.31 \quad 100.0 \%$ DNA replication licensing factor MCM7 GN=MCM7 MCM7_HUMAN $81.31 \quad 100.0 \%$ DNA replication licensing factor MCM7 GN=MCM7 MCM7_HUMAN $81.31 \quad 100.0 \%$ DNA replication licensing factor MCM7 GN=MCM7 MCM7_HUMAN $81.31 \quad 100.0 \%$ DNA topoisomerase $1 \mathrm{GN}=\mathrm{TOP} 1$ DNA topoisomerase $1 \mathrm{GN}=\mathrm{TOP} 1$ DNA topoisomerase $1 \mathrm{GN}=\mathrm{TOP} 1$ DNA topoisomerase $1 \mathrm{GN}=\mathrm{TOP} 1$ DNA topoisomerase $1 \mathrm{GN}=\mathrm{TOP} 1$ TOP1_HUMAN $90.73 \quad 100.0 \%$ DA topoisomerase 2-alpha GN=TOP2A TOP2A_HUMAN $174.39 \quad 100.0 \%$ DNA topoisomerase 2-alpha GN=TOP2A TOP2A_HUMAN $174.39 \quad 100.0 \%$ DNA topoisomerase 2-alpha GN=TOP2A TOP2A_HUMAN $174.39 \quad 100.0 \%$ DNA topoisomerase 2-alpha GN=TOP2A TOP2A_HUMAN $174.39 \quad 100.0 \%$ DNA topoisomerase 2-alpha GN=TOP2A TOP2A_HUMAN $174.39 \quad 100.0 \%$ DNA topoisomerase 2-alpha GN=TOP2A TOP2A_HUMAN $174.39 \quad 100.0 \%$ DNA topoisomerase 2-alpha GN=TOP2A TOP2A_HUMAN $174.39 \quad 100.0 \%$ DNA topoisomerase 2-alpha GN=TOP2A TOP2A_HUMAN $174.39 \quad 100.0 \%$ DNA topoisomerase 2-alpha GN=TOP2A TOP2A HUMAN $174.39 \quad 100.0 \%$ DNA topoisomerase 2-alpha GN=TOP2A TOP2A_HUMAN $174.39 \quad 100.0 \%$ DNA topoisomerase 2-alpha GN=TOP2A TOP2A_HUMAN $174.39 \quad 100.0 \%$ DNA topoisomerase 2-alpha GN=TOP2A TOP2A_HUMAN $174.39 \quad 100.0 \%$ DNA topoisomerase 2-alpha GN=TOP2A TOP2A_HUMAN $174.39 \quad 100.0 \%$ DNA topoisomerase 2-alpha GN=TOP2A TOP2A HUMAN $174.39 \quad 100.0 \%$ DNA topoisomerase 2-alpha GN=TOP2A TOP2A_HUMAN $174.39 \quad 100.0 \%$ DNA topoisomerase 2-alpha GN=TOP2A TOP2A_HUMAN $174.39 \quad 100.0 \%$ DNA topoisomerase 2-alpha GN=TOP2A TOP2A_HUMAN $174.39 \quad 100.0 \%$ DNA topoisomerase 2-beta GN=TOP2B TOP2B_HUMAN $183.27 \quad 100.0 \%$ DNA topoisomerase 2-beta $\mathrm{GN}=\mathrm{TOP} 2 \mathrm{~B}$ DNA topoisomerase 2-beta $\mathrm{GN}=\mathrm{TOP} 2 \mathrm{~B}$ DNA topoisomerase 2-beta $\mathrm{GN}=\mathrm{TOP} 2 \mathrm{~B}$ DNA topoisomerase 2-beta $\mathrm{GN}=\mathrm{TOP} 2 \mathrm{~B}$ DNA topoisomerase 2-beta $\mathrm{GN}=\mathrm{TOP} 2 \mathrm{~B}$ DNA topoisomerase 2-beta $\mathrm{GN}=\mathrm{TOP} 2 \mathrm{~B}$ DNA topoisomerase 2-beta $\mathrm{GN}=\mathrm{TOP} 2 \mathrm{~B}$ DNA topoisomerase 2-beta $\mathrm{GN}=\mathrm{TOP} 2 \mathrm{~B}$ TOP1_HUMAN $90.73 \quad 100.0 \%$ TOP1_HUMAN $90.73 \quad 100.0 \%$ TOP1_HUMAN $90.73 \quad 100.0 \%$ TOP1_HUMAN $90.73 \quad 100.0 \%$

5

5
5
17
TOP2B_HUMAN $183.27 \quad 100.0 \%$ TOP2B_HUMAN $183.27 \quad 100.0 \%$ TOP2B_HUMAN $183.27 \quad 100.0 \%$ TOP2B HUMAN $183.27 \quad 100.0 \%$ TOP2B HUMAN $183.27 \quad 100.0 \%$ TOP2B_HUMAN $183.27 \quad 100.0 \%$ TOP2B_HUMAN $183.27 \quad 100.0 \%$ TOP2B_HUMAN $183.27 \quad 100.0 \%$
$0.02 \% \quad 7.2 \%$ VSGVDGYETEGIRGLR $0.02 \% \quad 7.2 \%$ HVEEFSPR

$99.7 \% \quad 45.7$ $99.7 \% \quad 53.8$ $0.02 \% \quad 7.2 \%$ TSILAAANPISGHYDRSK $99.7 \% \quad 29.1$

$0.02 \% \quad 7.2 \%$ LGFSEYCR

$0.04 \% \quad 17.4 \%$ SPQNQYPAELMR

$0.04 \% \quad 17.4 \%$ ADSVGKLVTVR

$0.04 \% \quad 17.4 \%$ SITVLVEGENTR

$0.04 \% \quad 17.4 \%$ GNINICLMGDPGVAK

$99.0 \% \quad 43.9$

$99.7 \% \quad 37.5$

$99.7 \% \quad 59.4$

$99.7 \% 58.6$

$99.7 \% \quad 34.2$

$97.6 \% \quad 30.2$

$0.04 \% \quad 17.4 \%$ SQLLSYIDR

$0.04 \% \quad 17.4 \%$ SQYTTGRGSSGVGLTAAVLR $99.6 \% 26.6$

$0.04 \% \quad 17.4 \%$ GSSGVGLTAAVLR

$0.04 \% \quad 17.4 \%$ AGILTTLNAR

$0.04 \% \quad 17.4 \%$ CSILAAANPAYGR

$0.04 \% \quad 17.4 \%$ TQRPADVIFATVR

$0.04 \% \quad 17.4 \%$ SVRFSEAEQR

$0.01 \% \quad 6.9 \% \quad$ AEEVATFFAK

$0.01 \% \quad 6.9 \%$ CDFTQMSQYFK

$0.01 \% \quad 6.9 \% \quad$ YIMLNPSSR

$0.01 \% \quad 6.9 \% \quad$ TYNASITLQQQLK

$0.01 \% \quad 6.9 \%$ AVAILCNHQR

$0.05 \% \quad 11.1 \%$ GIPVVEHKVEK

$0.05 \% \quad 11.1 \%$ LCNIFSTK

$0.05 \% \quad 11.1 \%$ FTVETASR

$0.05 \% \quad 11.1 \%$ RAYDIAGSTK

$0.05 \% \quad 11.1 \%$ AYDIAGSTKDVK

$0.05 \% \quad 11.1 \%$ HVDYVADQIVTK

$0.05 \% \quad 11.1 \%$ SFGSTCQLSEK

$0.05 \% \quad 11.1 \%$ NSTECTLILTEGDSAK

$0.05 \% \quad 11.1 \%$ TLAVSGLGVVGR

$0.05 \% \quad 11.1 \%$ DKYGVFPLR

$0.05 \% \quad 11.1 \%$ IVGLQYKK

$0.05 \% \quad 11.1 \%$ NYEDEDSLKTLR

$0.05 \% \quad 11.1 \%$ MTEEKLAEAER

$0.05 \% \quad 11.1 \%$ IDGKIIIENKPK

$0.05 \% \quad 11.1 \%$ IIIENKPK

$0.05 \% \quad 11.1 \%$ TQMAEVLPSPR

$0.05 \% \quad 11.1 \%$ DPALNSGVSQKPDPAK

$0.02 \% \quad 5.8 \%$ GIPVVEHKVEK

$0.02 \% \quad 5.8 \%$ LCNIFSTK

$0.02 \% \quad 5.8 \%$ RAYDLAGSCR

$0.02 \% \quad 5.8 \%$ AYDLAGSCR

$0.02 \% \quad 5.8 \%$ HVDYVVDQVVGK

$0.02 \% \quad 5.8 \%$ AGVSVKPFQVK

$0.02 \% \quad 5.8 \%$ SLAVSGLGVIGR

$0.02 \% \quad 5.8 \% \quad$ IVGLQYKK

$0.02 \% \quad 5.8 \%$ SYDDAESLKTLR
$25.0 \quad 24.5$

$\begin{array}{llll}99.7 \% & 66.2 & 25.0 & 56.5\end{array}$

$\begin{array}{llll}99.7 \% & 47.8 & 25.0 & 32.3\end{array}$

$99.7 \% \quad 65.5 \quad 25.0 \quad 64.2$

$99.7 \% \quad 34.5 \quad 25.0 \quad 34.5$

$\begin{array}{llll}99.7 \% & 35.3 & 25.0 & 22.1\end{array}$

$99.7 \% \quad 50.8 \quad 25.0 \quad 37.8$

$\begin{array}{llll}99.7 \% & 36.0 & 25.0 & 36.0\end{array}$

$\begin{array}{llll}99.5 \% & 21.4 & 25.0 & 20.9\end{array}$

$99.7 \% \quad 47.4 \quad 25.0-44.7$

$\begin{array}{llll}99.7 \% & 34.9 & 25.0 & 31.2\end{array}$

$\begin{array}{llll}99.7 \% & 29.7 & 25.0 & 28.9\end{array}$

$99.0 \% \quad 41.3 \quad 25.0 \quad 35$.

$\begin{array}{llll}99.0 \% & 54.1 & 25.0 & 46.2\end{array}$

$99.7 \% \quad 39.5 \quad 25.0-36.5$

$\begin{array}{llll}99.7 \% & 37.2 & 25.0 & 36.4\end{array}$

$\begin{array}{llll}99.7 \% & 61.5 & 25.0 & 61.5\end{array}$

$99.7 \% \quad 44.4 \quad 25.0 \quad 44.2$

$\begin{array}{llll}99.7 \% & 74.0 & 25.0 & 59.2\end{array}$

$99.7 \% \quad 52.8 \quad 25.0 \quad 52.8$

$\begin{array}{llll}99.7 \% & 34.2 & 25.0 & 28.4\end{array}$

$\begin{array}{llll}99.0 \% & 42.9 & 25.0 & 42.9\end{array}$

$\begin{array}{llll}99.7 \% & 60.2 & 25.0 & 57.1\end{array}$

$\begin{array}{llll}99.4 \% & 21.2 & 25.0 & 21.2\end{array}$

$99.1 \% \quad 21.6 \quad 25.0 \quad 16.5$

$\begin{array}{llll}99.0 \% & 24.7 & 25.0 & 19.7\end{array}$

$99.7 \% \quad 65.0 \quad 25.0 \quad 57.5$

$99.7 \% \quad 31.2 \quad 25.0 \quad 31.2$

$\begin{array}{llll}99.7 \% & 29.7 & 25.0 & 28.9\end{array}$

$\begin{array}{llll}99.0 \% & 41.3 & 25.0 & 35.1\end{array}$

$99.7 \% \quad 35.3 \quad 25.0 \quad 34.3$

$\begin{array}{llll}99.3 \% & 22.3 & 25.0 & 22.3\end{array}$

$\begin{array}{llll}99.7 \% & 50.0 & 25.0 & 45.7\end{array}$

$\begin{array}{llll}99.7 \% & 31.9 & 25.0 & 23.2\end{array}$

$\begin{array}{llll}99.7 \% & 78.1 & 25.0 & 55.8\end{array}$

$99.0 \% \quad 42.9 \quad 25.0 \quad 42.9$

$\begin{array}{llll}99.7 \% & 57.2 & 25.0 & 51.5\end{array}$
000.48

1685.86

1900.99

1031.46

1449.68

1144.67

1317.70

1574.77

1094.58

1981.05

1187.67

1029.61

1363.68

1473.82

1208.60

1112.56

1470.60

1096.55

1507.81

1181.62

1234.72

982.50

910.46

1081.56

1267.65

1387.72

1243.56

1738.82

1128.67

1094.60

948.59

1482.71

1322.63

1367.83

954.60

1228.64

1623.83

1234.72

982.50

1168.55

1012.45

1357.71

1159.68

1128.67

948.59

1397.69

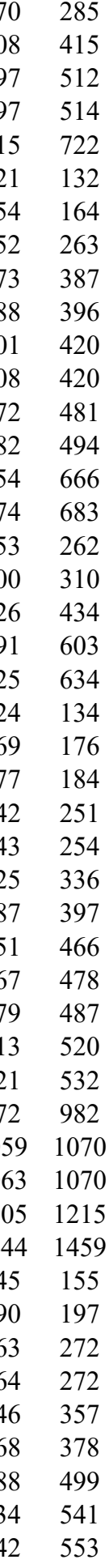

Page 49 of Table S-1-5 
DNA topoisomerase 2-beta GN=TOP2B TOP2B_HUMAN $183.27 \quad 100.0 \%$ DNA-dependent protein kinase catalytic subunit GN=PRKDC PRKDC_HUMAN $469.10 \quad 100.0 \%$ DNA-dependent protein kinase catalytic subunit GN=PRKDC PRKDC_HUMAN $469.10 \quad 100.0 \%$ DNA-dependent protein kinase catalytic subunit GN=PRKDC PRKDC_HUMAN $469.10 \quad 100.0 \%$ DNA-dependent protein kinase catalytic subunit GN=PRKDC PRKDC_HUMAN $469.10 \quad 100.0 \%$ DNA-dependent protein kinase catalytic subunit GN=PRKDC PRKDC_HUMAN $469.10 \quad 100.0 \%$ DNA-dependent protein kinase catalytic subunit GN=PRKDC PRKDC_HUMAN $469.10 \quad 100.0 \%$ DNA-dependent protein kinase catalytic subunit GN=PRKDC PRKDC_HUMAN $469.10 \quad 100.0 \%$ DNA-dependent protein kinase catalytic subunit GN=PRKDC PRKDC_HUMAN $469.10 \quad 100.0 \%$ DNA-dependent protein kinase catalytic subunit GN=PRKDC PRKDC_HUMAN $469.10 \quad 100.0 \%$ DNA-dependent protein kinase catalytic subunit GN=PRKDC PRKDC_HUMAN $469.10 \quad 100.0 \%$ DNA-dependent protein kinase catalytic subunit GN=PRKDC PRKDC_HUMAN $469.10 \quad 100.0 \%$ DNA-dependent protein kinase catalytic subunit GN=PRKDC PRKDC_HUMAN $469.10 \quad 100.0 \%$ DNA-dependent protein kinase catalytic subunit GN=PRKDC PRKDC_HUMAN $469.10 \quad 100.0 \%$ DNA-dependent protein kinase catalytic subunit GN=PRKDC PRKDC_HUMAN $469.10 \quad 100.0 \%$ DNA-dependent protein kinase catalytic subunit GN=PRKDC PRKDC_HUMAN 469.10 $100.0 \%$ DNA-dependent protein kinase catalytic subunit GN=PRKDC PRKDC HUMAN 469.10 100.0\% DNA-dependent protein kinase catalytic subunit GN=PRKDC PRKDC_HUMAN $469.10 \quad 100.0 \%$ DNA-dependent protein kinase catalytic subunit GN=PRKDC PRKDC_HUMAN $469.10 \quad 100.0 \%$ DNA-dependent protein kinase catalytic subunit GN=PRKDC PRKDC_HUMAN $469.10 \quad 100.0 \%$ DNA-dependent protein kinase catalytic subunit GN=PRKDC PRKDC_HUMAN $469.10 \quad 100.0 \%$ DNA-dependent protein kinase catalytic subunit GN=PRKDC PRKDC_HUMAN $469.10 \quad 100.0 \%$ DNA-dependent protein kinase catalytic subunit GN=PRKDC PRKDC_HUMAN $469.10 \quad 100.0 \%$ DNA-dependent protein kinase catalytic subunit GN=PRKDC PRKDC_HUMAN $469.10 \quad 100.0 \%$ DNA-dependent protein kinase catalytic subunit GN=PRKDC PRKDC_HUMAN $469.10 \quad 100.0 \%$ DNA-dependent protein kinase catalytic subunit GN=PRKDC PRKDC_HUMAN $469.10 \quad 100.0 \%$ DNA-dependent protein kinase catalytic subunit GN=PRKDC PRKDC_HUMAN $469.10 \quad 100.0 \%$ DNA-dependent protein kinase catalytic subunit GN=PRKDC PRKDC_HUMAN $469.10 \quad 100.0 \%$ DNA-dependent protein kinase catalytic subunit GN=PRKDC PRKDC_HUMAN $469.10 \quad 100.0 \%$ DNA-dependent protein kinase catalytic subunit GN=PRKDC PRKDC_HUMAN $469.10 \quad 100.0 \%$ DNA-dependent protein kinase catalytic subunit GN=PRKDC PRKDC_HUMAN $469.10 \quad 100.0 \%$ DNA-dependent protein kinase catalytic subunit GN=PRKDC PRKDC_HUMAN $469.10 \quad 100.0 \%$ DNA-dependent protein kinase catalytic subunit GN=PRKDC PRKDC_HUMAN $469.10 \quad 100.0 \%$ DNA-dependent protein kinase catalytic subunit GN=PRKDC PRKDC_HUMAN $469.10 \quad 100.0 \%$ DNA-dependent protein kinase catalytic subunit GN=PRKDC PRKDC_HUMAN $469.10 \quad 100.0 \%$ DNA-dependent protein kinase catalytic subunit GN=PRKDC PRKDC_HUMAN $469.10 \quad 100.0 \%$ DNA-dependent protein kinase catalytic subunit GN=PRKDC PRKDC_HUMAN $469.10 \quad 100.0 \%$ DNA-dependent protein kinase catalytic subunit GN=PRKDC PRKDC HUMAN $469.10 \quad 100.0 \%$ DNA-dependent protein kinase catalytic subunit GN=PRKDC PRKDC_HUMAN $469.10 \quad 100.0 \%$ DNA-dependent protein kinase catalytic subunit GN=PRKDC PRKDC_HUMAN $469.10 \quad 100.0 \%$ DNA-dependent protein kinase catalytic subunit GN=PRKDC PRKDC_HUMAN 469.10 $100.0 \%$ DNA-dependent protein kinase catalytic subunit GN=PRKDC PRKDC_HUMAN $469.10 \quad 100.0 \%$ DNA-dependent protein kinase catalytic subunit GN=PRKDC PRKDC_HUMAN $469.10 \quad 100.0 \%$ DNA-dependent protein kinase catalytic subunit GN=PRKDC PRKDC_HUMAN $469.10 \quad 100.0 \%$ DNA-dependent protein kinase catalytic subunit GN=PRKDC PRKDC_HUMAN $469.10 \quad 100.0 \%$ DNA-dependent protein kinase catalytic subunit GN=PRKDC PRKDC_HUMAN $469.10 \quad 100.0 \%$ DNA-dependent protein kinase catalytic subunit GN=PRKDC PRKDC_HUMAN $469.10 \quad 100.0 \%$ $\begin{array}{lllll}7 & 16 & 0.02 \% & 5.8 \% & \text { RIIPEITAMK }\end{array}$ $104 \quad 482 \quad 0.53 \% \quad 20.0 \%$ LQETLSAADR

$104 \quad 482 \quad 0.53 \% \quad 20.0 \%$ CGAALAGHQLIR

$104 \quad 482 \quad 0.53 \% \quad 20.0 \%$ IAPYSVEIK

$104 \quad 482 \quad 0.53 \% \quad 20.0 \%$ NTCTSVYTKDR

$104 \quad 482 \quad 0.53 \% \quad 20.0 \%$ TQMTSAVREPK

$104 \quad 482 \quad 0.53 \% \quad 20.0 \%$ LPVLAGCLK

$104 \quad 482 \quad 0.53 \% \quad 20.0 \%$ GLSSLLCNFTK

$104 \quad 482 \quad 0.53 \% \quad 20.0 \%$ SMEEDPQTSR

$104 \quad 482 \quad 0.53 \% \quad 20.0 \%$ EIFNFVLK

$104 \quad 482 \quad 0.53 \% \quad 20.0 \%$ AIRPQIDLKR

$104 \quad 482 \quad 0.53 \% \quad 20.0 \%$ YAVPSAGLR

$104 \quad 482 \quad 0.53 \% \quad 20.0 \%$ AALSALESFLK

$104 \quad 482 \quad 0.53 \% \quad 20.0 \%$ NVDSNNKELSIAIR

$104 \quad 482 \quad 0.53 \% \quad 20.0 \%$ GYGLFAGPCK

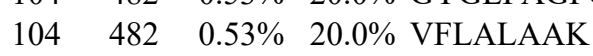

$104 \quad 482 \quad 0.53 \% \quad 20.0 \%$ NCISTVVHQGLIR

$104 \quad 482 \quad 0.53 \% \quad 20.0 \%$ ICSKPVVLPK

104

104

104

104

104

104

104

104

104

104

104

104

104

104

104

104

104

104

104

104

104

104

104

104
$482 \quad 0.53 \% \quad 20.0 \%$ GPESESEDHRASGEVR

$482 \quad 0.53 \% \quad 20.0 \%$ IKYFEGVSPK

$482 \quad 0.53 \% \quad 20.0 \%$ FGKEVAVK

$\begin{array}{lll}0.53 \% & 20.0 \% \text { NNWEVSALSR }\end{array}$

$482 \quad 0.53 \% \quad 20.0 \%$ GFNKVVLK

$482 \quad 0.53 \% \quad 20.0 \%$ VVQMLGSLGGQINK

$482 \quad 0.53 \% \quad 20.0 \%$ NLLTVTSSDEMMK

$482 \quad 0.53 \% \quad 20.0 \%$ VTELALTASDR

$482 \quad 0.53 \% \quad 20.0 \%$ VTELALTASDRQTK

$482 \quad 0.53 \% \quad 20.0 \%$ RTFPVLLR

$482 \quad 0.53 \% \quad 20.0 \%$ LACDVDQVTR

$482 \quad 0.53 \% \quad 20.0 \%$ LGASLAFNNIYR

$482 \quad 0.53 \% \quad 20.0 \%$ FVPLLPGNR

$482 \quad 0.53 \% \quad 20.0 \%$ CFGTGAAGNR

$482 \quad 0.53 \% \quad 20.0 \%$ TSPQEGERYNYSK

$482 \quad 0.53 \% \quad 20.0 \%$ DLCNTHLMR

$482 \quad 0.53 \% \quad 20.0 \%$ LAAVVSACK

$482 \quad 0.53 \% \quad 20.0 \%$ QCLPSLDLSCK

$482 \quad 0.53 \% \quad 20.0 \%$ LATTILQHWK

$482 \quad 0.53 \% \quad 20.0 \%$ EFPPGTPR

$482 \quad 0.53 \% \quad 20.0 \%$ FNNYVDCMKK

$482 \quad 0.53 \% \quad 20.0 \%$ LNESTFDTQITK

$482 \quad 0.53 \% \quad 20.0 \%$ LNESTFDTQITKK

$482 \quad 0.53 \% \quad 20.0 \%$ ILDVMYSR

$482 \quad 0.53 \% \quad 20.0 \%$ LPKDDVHAK

$482 \quad 0.53 \% \quad 20.0 \%$ INQVFHGSCITEGNELTK

$482 \quad 0.53 \% \quad 20.0 \%$ SLGPPQGEEDSVPR

$\quad 0.53 \% \quad 20.0 \%$ LGNPIVPLNIR

$482 \quad 0.53 \% \quad 20.0 \%$ SKDFVQVMR $\begin{array}{lllll}99.6 \% & 22.7 & 25.0 & 22.7 & 1\end{array}$

$\begin{array}{llll}99.7 \% & 59.0 & 25.0 & 45.4\end{array}$

$\begin{array}{llll}99.7 \% & 56.1 & 25.0 & 49.7\end{array}$

$99.7 \% \quad 31.9 \quad 25.0 \quad 15.8$

$99.7 \% \quad 37.1 \quad 25.0 \quad 36.0$

$\begin{array}{llll}99.6 \% & 26.2 & 25.0 & 26.2\end{array}$

$\begin{array}{llll}99.7 \% & 39.4 & 25.0 & 38.9\end{array}$

$96.3 \% \quad 22.3 \quad 25.0 \quad 14.9$

$99.5 \% \quad 23.6 \quad 25.0 \quad 17.3$

$\begin{array}{llll}99.0 \% & 21.7 & 25.0 & 17.7\end{array}$

$99.7 \% \quad 38.4 \quad 25.0 \quad 32.1$

$99.7 \% \quad 45.0 \quad 25.0 \quad 39.9$

$\begin{array}{llll}99.7 \% & 35.3 & 25.0 & 35.3\end{array}$

$99.7 \% \quad 59.9 \quad 25.0 \quad 59.9$

$99.7 \% \quad 35.8 \quad 25.0 \quad 32.1$

$99.0 \% \quad 33.8 \quad 25.0 \quad 21.7$

$99.7 \% \quad 57.9 \quad 25.0 \quad 55.2$

$99.7 \% \quad 32.9 \quad 25.0 \quad 22.3$

$99.7 \% \quad 43.1 \quad 25.0 \quad 43$.

$\begin{array}{llll}99.7 \% & 32.6 & 25.0 & 23.8\end{array}$

$99.0 \% \quad 63.6 \quad 25.0 \quad 32.2$

$99.7 \% \quad 36.3 \quad 25.0 \quad 31.8$

$\begin{array}{llll}99.0 \% & 33.4 & 25.0 & 14.0\end{array}$

$\begin{array}{llll}99.7 \% & 59.4 & 25.0 & 53.1\end{array}$

$\begin{array}{llll}99.7 \% & 52.3 & 25.0 & 52.3\end{array}$

$99.7 \% \quad 56.1 \quad 25.0 \quad 56.1 \quad 10$

$\begin{array}{llll}99.7 \% & 50.7 & 25.0 & 39.8\end{array}$

$\begin{array}{llll}96.9 \% & 27.3 & 25.0 & 10.7\end{array}$

$\begin{array}{llll}99.7 \% & 61.6 & 25.0 & 44.8\end{array}$

$\begin{array}{llll}99.7 \% & 51.4 & 25.0 & 23.4\end{array}$

$\begin{array}{llll}99.7 \% & 33.9 & 25.0 & 31.8\end{array}$

$\begin{array}{llll}99.7 \% & 58.7 & 25.0 & 52.7\end{array}$

$99.7 \% \quad 35.8 \quad 25.0 \quad 34.9$

$\begin{array}{llll}99.7 \% & 35.6 & 25.0 & 32.9\end{array}$

$99.7 \% \quad 52.4 \quad 25.0 \quad 40.9$

$\begin{array}{llll}99.7 \% & 41.4 & 25.0 & 31.9\end{array}$

$\begin{array}{llll}99.7 \% & 28.8 & 25.0 & 28.8\end{array}$

$\begin{array}{llll}95.7 \% & 20.7 & 25.0 & 11.4\end{array}$

$\begin{array}{llll}99.7 \% & 27.7 & 25.0 & 27.7\end{array}$

$\begin{array}{llll}99.7 \% & 60.9 & 25.0 & 56.5\end{array}$

$99.7 \% \quad 58.8 \quad 25.0 \quad 50.0$

$99.0 \% \quad 52.4 \quad 25.0 \quad 50.6$

$\begin{array}{llll}99.7 \% & 34.0 & 25.0 & 27.2\end{array}$

$\begin{array}{llll}99.7 \% & 44.0 & 25.0 & 44.0\end{array}$

$\begin{array}{llll}99.7 \% & 51.2 & 25.0 & 51.2\end{array}$

$\begin{array}{llll}98.8 \% & 21.3 & 25.0 & 21.3\end{array}$

$\begin{array}{llll}99.6 \% & 22.7 & 25.0 & 20.9\end{array}$

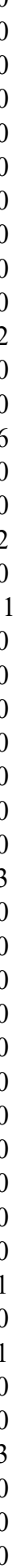

1103.57

1266.67

1019.58

1344.62

1247.64

970.58

1239.64

1179.49

1009.57

1209.74

933.52

1149.65

1572.83

1069.51

832.53

1496.80

1140.68

1741.77

167.64

877.51

1175.58

904.56

1459.79

1468.70

1175.63

1532.83

1001.63

1176.57

1338.72

1012.59

1010.45

558.71

1175.53

918.51

1320.63

1210.69

900.46

1318.59

1396.70

1524.79

1012.51

1022.56

2046.99

1467.71

1205.74

1125.57 
DNA-dependent protein kinase catalytic subunit GN=PRKDC PRKDC_HUMAN $469.10 \quad 100.0 \% \quad 84$ DNA-dependent protein kinase catalytic subunit GN=PRKDC PRKDC_HUMAN $469.10 \quad 100.0 \% \quad 84$ DNA-dependent protein kinase catalytic subunit GN=PRKDC PRKDC_HUMAN $469.10 \quad 100.0 \% \quad 84$ DNA-dependent protein kinase catalytic subunit GN=PRKDC PRKDC_HUMAN $469.10 \quad 100.0 \% 8$ DNA-dependent protein kinase catalytic subunit GN=PRKDC PRKDC_HUMAN $469.10 \quad 100.0 \% \quad 8$ DNA-dependent protein kinase catalytic subunit GN=PRKDC PRKDC_HUMAN $469.10 \quad 100.0 \% \quad 84$ DNA-dependent protein kinase catalytic subunit GN=PRKDC PRKDC_HUMAN $469.10 \quad 100.0 \% \quad 84$ DNA-dependent protein kinase catalytic subunit GN=PRKDC PRKDC_HUMAN $469.10 \quad 100.0 \% \quad 8$ DNA-dependent protein kinase catalytic subunit GN=PRKDC PRKDC HUMAN $469.10 \quad 100.0 \% 8$ DNA-dependent protein kinase catalytic subunit GN=PRKDC PRKDC_HUMAN $469.10 \quad 100.0 \%$ DNA-dependent protein kinase catalytic subunit GN=PRKDC PRKDC_HUMAN $469.10 \quad 100.0 \%$ DNA-dependent protein kinase catalytic subunit GN=PRKDC PRKDC_HUMAN $469.10 \quad 100.0 \%$ DNA-dependent protein kinase catalytic subunit GN=PRKDC PRKDC_HUMAN $469.10 \quad 100.0 \%$ DNA-dependent protein kinase catalytic subunit GN=PRKDC PRKDC_HUMAN $469.10 \quad 100.0 \%$ DNA-dependent protein kinase catalytic subunit GN=PRKDC PRKDC_HUMAN $469.10 \quad 100.0 \%$ DNA-dependent protein kinase catalytic subunit GN=PRKDC PRKDC_HUMAN $469.10 \quad 100.0 \%$ DNA-dependent protein kinase catalytic subunit GN=PRKDC PRKDC HUMAN $469.10 \quad 100.0 \%$ DNA-dependent protein kinase catalytic subunit GN=PRKDC PRKDC_HUMAN 469.10 $100.0 \%$ DNA-dependent protein kinase catalytic subunit GN=PRKDC PRKDC_HUMAN 469.10 $100.0 \%$ DNA-dependent protein kinase catalytic subunit GN=PRKDC PRKDC_HUMAN $469.10 \quad 100.0 \%$ DNA-dependent protein kinase catalytic subunit GN=PRKDC PRKDC_HUMAN $469.10 \quad 100.0 \%$ DNA-dependent protein kinase catalytic subunit GN=PRKDC PRKDC_HUMAN $469.10 \quad 100.0 \%$ DNA-dependent protein kinase catalytic subunit GN=PRKDC PRKDC_HUMAN $469.10 \quad 100.0 \%$ DNA-dependent protein kinase catalytic subunit GN=PRKDC PRKDC_HUMAN $469.10 \quad 100.0 \%$ DNA-dependent protein kinase catalytic subunit GN=PRKDC PRKDC_HUMAN $469.10 \quad 100.0^{\circ}$ DNA-dependent protein kinase catalytic subunit GN=PRKDC PRKDC_HUMAN $469.10 \quad 100.0 \%$ DNA-dependent protein kinase catalytic subunit GN=PRKDC PRKDC_HUMAN $469.10 \quad 100.0 \%$ DNA-dependent protein kinase catalytic subunit GN=PRKDC PRKDC_HUMAN $469.10 \quad 100.0 \%$ DNA-dependent protein kinase catalytic subunit GN=PRKDC PRKDC_HUMAN $469.10 \quad 100.0 \%$ DNA-dependent protein kinase catalytic subunit GN=PRKDC PRKDC HUMAN $469.10 \quad 100.0^{\circ}$ DNA-dependent protein kinase catalytic subunit GN=PRKDC PRKDC_HUMAN $469.10 \quad 100.0 \%$ DNA-dependent protein kinase catalytic subunit GN=PRKDC PRKDC_HUMAN 469.10 $100.0 \%$ DNA-dependent protein kinase catalytic subunit GN=PRKDC PRKDC_HUMAN $469.10 \quad 100.0 \%$ DNA-dependent protein kinase catalytic subunit GN=PRKDC PRKDC_HUMAN $469.10 \quad 100.0 \%$ DNA-dependent protein kinase catalytic subunit GN=PRKDC PRKDC_HUMAN $469.10 \quad 100.0 \%$ DNA-dependent protein kinase catalytic subunit GN=PRKDC PRKDC_HUMAN 469.10 $100.0 \%$ DNA-dependent protein kinase catalytic subunit GN=PRKDC PRKDC_HUMAN 469.10 $100.0 \%$ DNA-dependent protein kinase catalytic subunit GN=PRKDC PRKDC_HUMAN $469.10 \quad 100.0 \%$ DNA-directed RNA polymerase I subunit RPA1 GN=POLR1A RPA1_HUMAN $194.81 \quad 100.0 \%$ DNA-directed RNA polymerase I subunit RPA1 GN=POLR1A RPA1_HUMAN $194.81 \quad 100.0 \%$ DNA-directed RNA polymerase I subunit RPA34 GN=CD3EAP RPA34 HUMAN $54.99 \quad 100.0 \%$ DNA-directed RNA polymerase I subunit RPA34 GN=CD3EAP RPA34_HUMAN $54.99 \quad 100.0 \%$ DNA-directed RNA polymerase II subunit RPB1 GN=POLR2A RPB1 HUMAN $217.18100 .0 \%$ DNA-directed RNA polymerase II subunit RPB1 GN=POLR2A RPB1_HUMAN $217.18 \quad 100.0 \%$ DNA-directed RNA polymerase II subunit RPB1 GN=POLR2A RPB1_HUMAN $217.18 \quad 100.0 \%$ DNA-directed RNA polymerase II subunit RPB1 GN=POLR2A RPB1_HUMAN $217.18 \quad 100.0 \%$ DNA-directed RNA polymerase II subunit RPB3 GN=POLR2C RPB3_HUMAN $31.44 \quad 100.0 \%$

4

$99.0 \% \quad 28.2$

$96.8 \%$

$\begin{array}{lll}.0 \% & 52.7 & 25.0\end{array}$

$99.7 \% \quad 54.5$

$99.7 \% \quad 42.8$

$99.7 \% \quad 51.2$

$99.7 \% \quad 57.8$

$99.4 \% \quad 27.7$

$99.7 \% \quad 57.0$

$99.7 \% \quad 44.4$

$99.0 \% \quad 51.4$

$99.7 \% \quad 46.8$

$97.7 \% \quad 19.6$

$99.7 \% \quad 44.6$

$99.7 \% \quad 57.6$

$99.7 \% \quad 51.5$

$99.7 \% \quad 37.8$

$99.6 \% \quad 26.3$

$99.7 \% \quad 57.0$

$99.7 \% \quad 32.9$

$99.7 \% \quad 57.8$

$99.7 \% \quad 52.7$

$99.7 \% \quad 47$.

$99.0 \% \quad 32.1$

$99.7 \% \quad 42.0$

$99.4 \% \quad 25.9$

$99.7 \% \quad 34$.

$99.0 \% \quad 45.7$

$95.5 \% 14.6$

$99.7 \% \quad 32.9$

$99.7 \% \quad 42.8$

$99.0 \% \quad 33.6$

$99.0 \% \quad 44.4$

$99.7 \% \quad 47.5$

$99.7 \% \quad 62.2$

$99.7 \% \quad 63.4$

$99.5 \% \quad 25.8$

$97.4 \% \quad 23.7$

$99.7 \% \quad 55.4$

$99.7 \% \quad 28.9$

$99.7 \% \quad 36.0$

$99.7 \% \quad 58.1$

$99.5 \% \quad 26.8$

$99.7 \% \quad 45.2$

$99.7 \% \quad 49.3$
1448.74

1293.68

1115.62

1171.67

1135.55

1170.66

1526.74

1512.72 1161.60 
DNA-directed RNA polymerase II subunit RPB3 GN=POLR2C RPB3_HUMAN $31.44 \quad 100.0 \%$ DNA-directed RNA polymerase II subunit RPB3 GN=POLR2C RPB3_HUMAN $31.44 \quad 100.0 \%$ DNA-directed RNA polymerases I and III subunit RPACI GN=POLRIC RPAC1_HUMAN $39.25 \quad 100.0 \%$ DNA-directed RNA polymerases I and III subunit RPAC1 GN=POLRIC RPAC1_HUMAN $39.25 \quad 100.0 \%$ DNA-directed RNA polymerases I and III subunit RPACI GN=POLRIC RPAC1_HUMAN $39.25 \quad 100.0 \%$ DNA-directed RNA polymerases I and III subunit RPACI GN=POLRIC RPAC1_HUMAN $39.25 \quad 100.0 \%$ DnaJ homolog subfamily A member 1 GN=DNAJA1 DNJA1_HUMAN $44.87 \quad 100.0 \%$ DnaJ homolog subfamily A member 1 GN=DNAJA1 DNJA1_HUMAN $44.87 \quad 100.0 \%$ DnaJ homolog subfamily A member $1 \mathrm{GN}=$ DNAJA1 DNJA1_HUMAN $44.87 \quad 100.0 \%$ DnaJ homolog subfamily A member 1 GN=DNAJA1 DNJA1_HUMAN $44.87 \quad 100.0 \%$ DnaJ homolog subfamily A member 1 GN=DNAJA1 DNJA1_HUMAN $44.87 \quad 100.0 \%$ DnaJ homolog subfamily A member 2 GN=DNAJA2 DNJA2_HUMAN $45.75 \quad 100.0 \%$ DnaJ homolog subfamily A member 2 GN=DNAJA2 DNJA2_HUMAN $45.75 \quad 100.0 \%$ DnaJ homolog subfamily A member $2 \mathrm{GN}=$ DNAJA2 DNJA2_HUMAN $45.75 \quad 100.0 \%$ DnaJ homolog subfamily A member 2 GN=DNAJA2 DNJA2_HUMAN $45.75 \quad 100.0 \%$ DnaJ homolog subfamily A member 3, mitochondrial GN=DNAJA3 DNJA3_HUMAN $52.49 \quad 100.0 \%$ DnaJ homolog subfamily A member 3, mitochondrial GN=DNAJA3 DNJA3 HUMAN $52.49 \quad 100.0 \%$ DnaJ homolog subfamily A member 3, mitochondrial GN=DNAJA3 DNJA3_HUMAN $52.49 \quad 100.0 \%$ DnaJ homolog subfamily A member 3 , mitochondrial GN=DNAJA3 DNJA3_HUMAN $52.49 \quad 100.0 \%$ DnaJ homolog subfamily A member 3, mitochondrial GN=DNAJA3 DNJA3_HUMAN $52.49 \quad 100.0 \%$ DnaJ homolog subfamily A member 3, mitochondrial GN=DNAJA3 DNJA3_HUMAN $52.49 \quad 100.0 \%$ DnaJ homolog subfamily A member 3, mitochondrial GN=DNAJA3 DNJA3_HUMAN $52.49 \quad 100.0 \%$ DnaJ homolog subfamily B member 11 GN=DNAJB11 DJB11_HUMAN $40.51 \quad 100.0 \%$ DnaJ homolog subfamily B member 11 GN=DNAJB11 DJB11_HUMAN $40.51 \quad 100.0 \%$ DnaJ homolog subfamily B member 11 GN=DNAJB11 DJB11_HUMAN $40.51 \quad 100.0 \%$ DnaJ homolog subfamily B member 12 GN=DNAJB12 DJB12_HUMAN $41.82 \quad 100.0 \%$ DnaJ homolog subfamily B member 12 GN=DNAJB12 DJB12_HUMAN $41.82 \quad 100.0 \%$ DnaJ homolog subfamily B member 12 GN=DNAJB12 DJB12_HUMAN $41.82 \quad 100.0 \%$ DnaJ homolog subfamily B member 12 GN=DNAJB12 DJB12_HUMAN $41.82 \quad 100.0 \%$ DnaJ homolog subfamily B member 6 GN=DNAJB6 DNJB6 HUMAN $36.09 \quad 100.0 \%$ DnaJ homolog subfamily B member 6 GN=DNAJB6 DNJB6_HUMAN $36.09 \quad 100.0 \%$ DnaJ homolog subfamily B member 6 GN=DNAJB6 DNJB6_HUMAN $36.09 \quad 100.0 \%$ DnaJ homolog subfamily B member 6 GN=DNAJB6 DNJB6_HUMAN $36.09 \quad 100.0 \%$ DnaJ homolog subfamily C member $10 \mathrm{GN}=$ DNAJC10 DJC10_HUMAN $91.08 \quad 100.0 \%$ DnaJ homolog subfamily C member $10 \mathrm{GN}=$ DNAJC10 DJC10 HUMAN $91.08 \quad 100.0 \%$ DnaJ homolog subfamily C member $10 \mathrm{GN}=$ DNAJC10 DJC10_HUMAN $91.08 \quad 100.0 \%$ DnaJ homolog subfamily C member $10 \mathrm{GN}=$ DNAJC10 DJC10_HUMAN $91.08 \quad 100.0 \%$ DnaJ homolog subfamily C member $10 \mathrm{GN}=$ DNAJC10 DJC10 HUMAN $91.08 \quad 100.0 \%$ DnaJ homolog subfamily C member 11 GN=DNAJC11 DJC11_HUMAN $63.28 \quad 100.0 \%$ DnaJ homolog subfamily C member $11 \mathrm{GN}=$ DNAJC11 DJC11_HUMAN $63.28 \quad 100.0 \%$ DnaJ homolog subfamily C member 11 GN=DNAJC11 DJC11_HUMAN $63.28 \quad 100.0 \%$ DnaJ homolog subfamily C member 11 GN=DNAJC11 DJC11_HUMAN $63.28 \quad 100.0 \%$ DnaJ homolog subfamily C member 13 GN=DNAJC13 DJC13_HUMAN $254.42100 .0 \%$ DnaJ homolog subfamily C member 13 GN=DNAJC13 DJC13_HUMAN $254.42 \quad 100.0 \%$ DnaJ homolog subfamily C member 13 GN=DNAJC13 DJC13_HUMAN $254.42 \quad 100.0 \%$ DnaJ homolog subfamily C member 13 GN=DNAJC13 DJC13_HUMAN $254.42 \quad 100.0 \%$ DnaJ homolog subfamily C member 13 GN=DNAJC13 DJC13_HUMAN $254.42 \quad 100.0 \%$
$0.01 \% \quad 12.0 \%$ FIIENTDLAVANSIR $0.01 \% \quad 12.0 \%$ DLISNSPR

$10 \quad 0.01 \% \quad 15.0 \%$ ILLAEVPTMAVEK

$10 \quad 0.01 \% \quad 15.0 \%$ NQGDEEGTEIDTLQFR

$10 \quad 0.01 \% \quad 15.0 \%$ DSSDPNELYVNHK

$10 \quad 0.01 \% \quad 15.0 \%$ FSPVATASYR

$0.01 \% \quad 14.1 \%$ QISQAYEVLSDAK

$0.01 \% \quad 14.1 \%$ ELYDKGGEQAIK

$9 \quad 0.01 \% \quad 14.1 \%$ NVICDKCEGR

$0.01 \% \quad 14.1 \%$ ILEVHIDK

$0.01 \% \quad 14.1 \%$ TIVITSHPGQIVK

$0.01 \% \quad 10.4 \%$ ELYDRYGEQGLR

$0.01 \% \quad 10.4 \%$ VSLEDLYNGK

$0.01 \% \quad 10.4 \%$ NVLCSACSGQGGK

$0.01 \% \quad 10.4 \%$ VIEPGCVR

$0.03 \% \quad 16.5 \%$ GGPTVDPEELFR

$0.03 \% \quad 16.5 \%$ EFTVNIMDTCER

$0.03 \% \quad 16.5 \%$ GSIIISPCVVCR

$0.03 \% \quad 16.5 \%$ VMIPVPAGVEDGQTVR

$0.03 \% \quad 16.5 \%$ INSYGYGDHYIHIK

$0.03 \% \quad 16.5 \%$ REAGEDEEGFLSK

$0.03 \% \quad 16.5 \%$ EAGEDEEGFLSK

$0.01 \% \quad 12.8 \%$ LALQLHPDRNPDDPQAQEK

$0.01 \% \quad 12.8 \%$ FQDLGAAYEVLSDSEK

$0.01 \% \quad 12.8 \%$ TLEVEIEPGVR

$0.01 \% \quad 9.9 \%$ GYTAEQVAAVK

$0.01 \% \quad 9.9 \%$ GYTAEQVAAVKR

$0.01 \% \quad 9.9 \%$ AIGTAYAVLSNPEK

$0.01 \% \quad 9.9 \% \quad$ NVEDDYIANLR

$0.01 \% \quad 17.2 \%$ VDYYEVLGVQR

$0.01 \% \quad 17.2 \%$ QVAEAYEVLSDAK

$0.01 \% \quad 17.2 \%$ SLTINGVADDDALAEER

$0.01 \% \quad 17.2 \%$ APGPWDPLASAAGLK

$0.01 \% \quad 7.2 \%$ IGAVNCGDDRMLCR

$0.01 \% \quad 7.2 \%$ ALLPELRR

$0.01 \% \quad 7.2 \%$ ASNLLYGQLK

$0.01 \% \quad 7.2 \%$ AGKVDCQAYAQTCQK

$0.01 \% \quad 7.2 \%$ NFQEEQINTR

$0.01 \% \quad 7.9 \%$ EASSEELKAAYR

$0.01 \% \quad 7.9 \%$ AIYDIYGKR

$0.01 \% \quad 7.9 \%$ GIRPGLTTVLAR

$0.01 \% \quad 7.9 \% \quad$ DSKLILTEASK

$0.02 \% \quad 5.0 \%$ GQGTEFNLTFR

$0.02 \% \quad 5.0 \% \quad$ FRTDFSEGK

$0.02 \% \quad 5.0 \%$ ENINQKPVVLR

$0.02 \% \quad 5.0 \% \quad$ LLLEEDENEESGSIKR

$0.02 \% \quad 5.0 \%$ IAAHLADFTPR $\begin{array}{llllllll}99.7 \% & 52.5 & 25.0 & 51.5 & 2 & 0 & 0 & 1675.90\end{array}$

$\begin{array}{llllllll}99.0 \% & 33.3 & 25.0 & 23.0 & 2 & 0 & 0 & 901.47\end{array}$

$\begin{array}{llllllll}99.7 \% & 49.2 & 25.0 & 49.2 & 4 & 0 & 0 & 1413.80\end{array}$

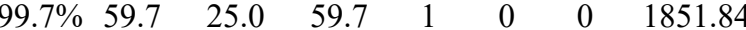

$\begin{array}{llllllll}99.7 \% & 33.9 & 25.0 & 33.9 & 2 & 0 & 0 & 1517.69\end{array}$

$\begin{array}{llllllll}99.7 \% & 43.3 & 25.0 & 39.5 & 3 & 0 & 0 & 1098.56\end{array}$

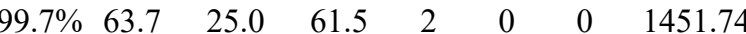

$\begin{array}{llllllll}99.7 \% & 51.3 & 25.0 & 26.6 & 2 & 0 & 0 & 1350.69\end{array}$

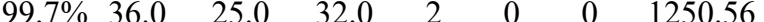

$\begin{array}{llllllll}94.7 \% & 22.0 & 25.0 & 11.2 & 1 & 0 & 0 & 966.56\end{array}$

$\begin{array}{llllllll}99.7 \% & 56.0 & 25.0 & 56.0 & 2 & 0 & 0 & 1392.82\end{array}$

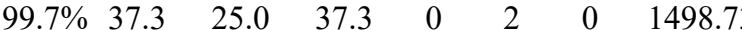

$99.7 \% \quad 56.1 \quad 25.0 \quad 50.0$

$99.7 \% \quad 79.6 \quad 25.0 \quad 76.5$

$\begin{array}{llll}99.0 \% & 35.7 & 25.0 & 29.4\end{array}$

$99.7 \% \quad 46.0 \quad 25.0 \quad 43.5$

$99.7 \% \quad 37.5 \quad 25.0 \quad 37.5$

$99.7 \% \quad 44.0 \quad 25.0 \quad 33.9$

$\begin{array}{llll}99.7 \% & 53.3 & 25.0 & 53.3\end{array}$

$\begin{array}{llll}99.7 \% & 38.3 & 25.0 & 38.1\end{array}$

$99.7 \% \quad 45.0 \quad 25.0 \quad 42.2$

$99.7 \% \quad 30.4 \quad 25.0 \quad 30.4$

$\begin{array}{llll}99.7 \% & 27.5 & 25.0 & 27.5\end{array}$

$\begin{array}{llll}99.7 \% & 99.4 & 25.0 & 99.4\end{array}$

$99.7 \% \quad 57.3 \quad 25.0 \quad 44.5$

$\begin{array}{llll}99.7 \% & 57.7 & 25.0 & 45.1\end{array}$

$99.7 \% \quad 45.9 \quad 25.0 \quad 41.5$

$\begin{array}{llll}99.7 \% & 55.7 & 25.0 & 51.3\end{array}$

$\begin{array}{lllll}99.7 \% & 60.8 & 25.0 & 55.6 & 2\end{array}$

$99.7 \% \quad 67.8 \quad 25.0 \quad 41.6$

$\begin{array}{llll}99.7 \% & 64.7 & 25.0 & 63.2\end{array}$

$\begin{array}{llll}99.7 \% & 77.9 & 25.0 & 77.9\end{array}$

$\begin{array}{llll}99.7 \% & 34.3 & 25.0 & 33.3\end{array}$

$\begin{array}{llll}99.7 \% & 40.6 & 25.0 & 40.6\end{array}$

$99.0 \% \quad 22.4 \quad 25.0 \quad 22.4$

$\begin{array}{llll}99.7 \% & 36.8 & 25.0 & 30.6\end{array}$

$\begin{array}{llll}99.7 \% & 35.7 & 25.0 & 35.7\end{array}$

$\begin{array}{llll}99.7 \% & 33.3 & 25.0 & 21.2\end{array}$

$\begin{array}{llll}99.7 \% & 34.9 & 25.0 & 32.6\end{array}$

$\begin{array}{llll}99.7 \% & 47.7 & 25.0 & 37.7\end{array}$

$\begin{array}{llll}99.7 \% & 32.7 & 25.0 & 32.7\end{array}$

$\begin{array}{llll}99.5 \% & 21.7 & 25.0 & 20.3\end{array}$

$99.7 \% \quad 38.7 \quad 25.0 \quad 33.6$

$\begin{array}{llll}98.9 \% & 19.5 & 25.0 & 17.1\end{array}$

$\begin{array}{llll}99.4 \% & 25.3 & 25.0 & 19.2\end{array}$

$\begin{array}{llll}99.4 \% & 19.6 & 25.0 & 19.6\end{array}$

$\begin{array}{llll}99.2 \% & 23.9 & 25.0 & 23.6\end{array}$

\begin{tabular}{cc}
21 & 35 \\
19 & 126 \\
79 & 91 \\
26 & 141 \\
55 & 167 \\
25 & 234 \\
47 & 59 \\
52 & 73 \\
31 & 140 \\
07 & 214 \\
84 & 296 \\
54 & 75 \\
22 & 131 \\
40 & 152 \\
03 & 310 \\
76 & 187 \\
27 & 238 \\
82 & 293 \\
04 & 319 \\
96 & 409 \\
61 & 473 \\
62 & 473 \\
48 & 66 \\
67 & 82 \\
07 & 217 \\
93 & 103 \\
93 & 104 \\
53 & 166 \\
16 & 326 \\
2 & 12 \\
48 & 60 \\
26 & 242 \\
88 & 302 \\
81 & 194 \\
85 & 492 \\
93 & 502 \\
23 & 737 \\
57 & 766 \\
24 & 35 \\
76 & 84 \\
49 & 260 \\
98 & 508 \\
63 & 73 \\
00 & 108 \\
36 & 746 \\
34 & 849 \\
215 & 1225 \\
& \\
\hline 3
\end{tabular}



DnaJ homolog subfamily C member $13 \mathrm{GN}=$ DNAJC13 DJC13_HUMAN $254.42 \quad 100.0 \%$ DnaJ homolog subfamily C member 13 GN=DNAJC13 DJC13_HUMAN $254.42 \quad 100.0 \%$ DnaJ homolog subfamily C member $13 \mathrm{GN}=$ DNAJC13 DJC13 HUMAN $254.42 \quad 100.0 \%$ DnaJ homolog subfamily C member 13 GN=DNAJC13 DJC13_HUMAN $254.42 \quad 100.0 \%$ DnaJ homolog subfamily C member 13 GN=DNAJC13 DJC13_HUMAN $254.42 \quad 100.0 \%$ DnaJ homolog subfamily C member 7 GN=DNAJC7 DNJC7_HUMAN $56.44 \quad 100.0 \%$ DnaJ homolog subfamily C member 7 GN=DNAJC7 DNJC7_HUMAN $56.44 \quad 100.0 \%$ Dolichol-phosphate mannosyltransferase subunit $1 \mathrm{GN}=\mathrm{DPM} 1$ DPM1 HUMAN $29.64 \quad 100.0 \%$ Dolichol-phosphate mannosyltransferase subunit 1 GN=DPM1 DPM1_HUMAN $29.64 \quad 100.0 \%$ Dolichol-phosphate mannosyltransferase subunit 1 GN=DPM1 DPM1_HUMAN $29.64 \quad 100.0 \%$ Dolichol-phosphate mannosyltransferase subunit $1 \mathrm{GN}=$ DPM1 DPM1_HUMAN $29.64100 .0 \%$ Dolichol-phosphate mannosyltransferase subunit 1 GN=DPM1 DPM1_HUMAN $29.64 \quad 100.0 \%$ Dolichol-phosphate mannosyltransferase subunit $1 \mathrm{GN}=$ DPM1 DPM1_HUMAN $29.64100 .0 \%$ Dolichol-phosphate mannosyltransferase subunit 1 GN=DPM1 DPM1 HUMAN $29.64 \quad 100.0 \%$ Dolichol-phosphate mannosyltransferase subunit 1 GN=DPM1 DPM1_HUMAN $29.64 \quad 100.0 \%$ Dolichol-phosphate mannosyltransferase subunit 1 GN=DPM1 DPM1 HUMAN $29.64100 .0 \%$ Dolichyl-diphosphooligosaccharide-protein glycosyltransferase 48 kDa subunit GN=DDOST OST48_HUMAN $50.80 \quad 100.0 \%$ Dolichyl-diphospholigosaccharide-protein glycosyltransferase 48 kDa subunit GN=DDOST OST48_HUMAN $50.80 \quad 100.0 \%$

$0.02 \% \quad 5.0 \% \quad$ TQSILFNR

$0.02 \% \quad 5.0 \%$ YAGYPMLIR

$0.02 \% \quad 5.0 \% \quad$ SEETNQQEVANSLAK

$0.02 \% \quad 5.0 \%$ VEMALEALR

$0.02 \% \quad 5.0 \%$ RADTVGLACEAINR

$0.02 \% \quad 5.0 \%$ ADTVGLACEAINR

$0.00 \% \quad 4.5 \%$ AATLMMLGR

$0.00 \% \quad 4.5 \%$ FREALGDAQQSVR

$0.02 \% \quad 40.0 \%$ YSVLLPTYNER

$0.02 \% \quad 40.0 \%$ DVAEQLEK

$0.02 \% \quad 40.0 \%$ LGLGTAYIHGMK

$0.02 \% \quad 40.0 \%$ QKEGNFDIVSGTR

$0.02 \% \quad 40.0 \%$ EGNFDIVSGTR

$0.02 \% \quad 40.0 \%$ GANFLTQILLRPGASD

$0.02 \% \quad 40.0 \%$ LGGNEIVSFLK

$0.01 \% \quad 10.5 \%$ TLVLLDNLNVR

$0.01 \% \quad 10.5 \%$ TADDPSLSLIK

$0.01 \% \quad 10.5 \%$ NTLLIAGLQAR

$0.01 \% \quad 10.5 \%$ YSQTGNYELAVALSR

$0.01 \% \quad 12.9 \%$ VTAEVVLAHLGG

$0.01 \% \quad 12.9 \%$ LPVALDPGAK

$11 \quad 0.01 \% \quad 12.9 \%$ YDYQRQPDSGISSIR

$0.01 \% \quad 12.9 \%$ NIEIDSPYEISR

$0.01 \% \quad 12.9 \%$ ALTSEIALLQSR

$0.01 \% \quad 12.9 \%$ SAVEAERLVAGK

$0.00 \% \quad 7.7 \%$ ETLPSIWDSPTK

$0.00 \% \quad 7.7 \%$ QLSVVVPSYNEEK

$9 \quad 0.02 \% \quad 17.5 \%$ VSVGEFVGEGEGK

$0.02 \% \quad 17.5 \%$ NAAIAVLEELK

$\begin{array}{llll}10 & 19 & 0.02 \% & 17.5 \% \\ 10 & 19 & 0.02 \% & 17.5 \% \text { NAAIAVLEELKK }\end{array}$

$10 \quad 19 \quad 0.02 \% \quad 17.5 \%$ LPPLPAVER

$10 \quad 19 \quad 0.02 \% \quad 17.5 \%$ TKPIVKPQTSPEYGQGINPISR

$\begin{array}{llll}10 & 19 & 0.02 \% & 17.5 \% \\ 10 & \text { LAQIQQAK }\end{array}$

$10 \quad 19 \quad 0.02 \% \quad 17.5 \%$ LAQIQQAKK

$\begin{array}{llll}10 & 19 & 0.02 \% & 17.5 \% \\ 10 & \text { EKEPEYTLLTER }\end{array}$

$10 \quad 19 \quad 0.02 \% \quad 17.5 \%$ VPQAQPTKPALK

$10 \quad 19 \quad 0.02 \% \quad 17.5 \%$ TGNGPMSVCGRC

(1)

$0.02 \% \quad 40.0 \%$ QLNYTIGEVPISFVDR

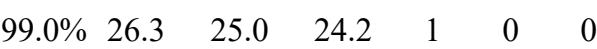

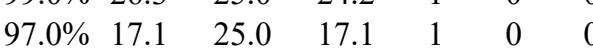
$\begin{array}{llllll}99.7 \% & 70.1 & 25.0 & 65.2 & 2 & 0\end{array}$ $99.7 \% \quad 52.9 \quad 25.0 \quad 28.4$ $\begin{array}{llll}99.5 \% & 23.8 & 25.0 & 18.2\end{array}$ $\begin{array}{llll}99.6 \% & 25.8 & 25.0 & 21.5\end{array}$ $99.7 \% \quad 47.6 \quad 25.0 \quad 40.2$ $\begin{array}{llll}97.9 \% & 29.1 & 25.0 & 26.1\end{array}$ $99.7 \% \quad 27.9 \quad 25.0 \quad 27.9$ $95.1 \% 23.3 \quad 25.0 \quad 7.9$ $99.7 \% \quad 40.6 \quad 25.0 \quad 40.6$ $\begin{array}{llll}99.7 \% & 30.2 & 25.0 & 25.8\end{array}$ $99.7 \% \quad 53.9 \quad 25.0 \quad 51.6$ $\begin{array}{llll}99.7 \% & 55.0 & 25.0 & 52.8\end{array}$ $\begin{array}{llll}99.7 \% & 36.5 & 25.0 & 36.5\end{array}$ $99.7 \% \quad 61.0 \quad 25.0 \quad 58.5$ $99.7 \% \quad 65.1 \quad 25.0 \quad 62.1$ $\begin{array}{llll}99.7 \% & 38.3 & 25.0 & 33.8\end{array}$ $\begin{array}{llll}99.7 \% & 30.7 & 25.0 & 18.7\end{array}$ $\begin{array}{llll}99.7 \% & 65.1 & 25.0 & 49.8\end{array}$ $\begin{array}{llll}99.7 \% & 77.7 & 25.0 & 77.7\end{array}$ $99.7 \% \quad 65.2$ $\begin{array}{lll}99.7 \% & 29.2\end{array}$ $99.7 \% \quad 42.9$ $99.7 \% \quad 57.2$ $99.7 \% \quad 41.9$ $\begin{array}{lll}99.7 \% & 59.7\end{array}$ $99.6 \% \quad 26.2$ $99.7 \% \quad 32.1$ $99.7 \% \quad 48.2$ $99.7 \% \quad 44.7$ $99.7 \% \quad 54.0$ $98.8 \% \quad 17.8$ $99.7 \% 32.3$ $99.0 \% \quad 45.5$ $99.6 \% 29.8$ $95.5 \% \quad 18.6$ $99.7 \% \quad 28.1$ $99.7 \% \quad 28.5$ $\begin{array}{lll}99.7 \% & 44.0\end{array}$ $99.0 \% \quad 45.5$ $99.6 \% \quad 29.8$ $99.6 \% \quad 25.4$ $96.6 \% \quad 24.2$ $0.01 \% \quad 8.4 \%$ VGNEVATGTGPNKK $0.01 \% \quad 8.4 \% \quad$ ASTNLQDQLEK $\begin{array}{lllll}0.01 \% & 3.1 \% & \text { NTNSVPETAPAAIPETKR } & 99.6 \% & 22.5\end{array}$ $0.01 \% \quad 3.1 \%$ AMTILLEEAK $0.01 \% \quad 3.1 \%$ AMTILLEEAKAK
$98.2 \% \quad 23.5$

$99.7 \% \quad 29.8$ 1083.57 1647.78

1031.56

1545.78

1389.68

963.51

1476.76

1354.70

931.47

1276.67

1450.73

1194.58

2334.26

1404.67

1850.96

1176.66

1269.75

1159.62

1169.70

1671.83

1653.89

980.58

1784.86

1435.71

1301.74

1229.68

1373.69

1491.77

1293.63

1170.67

1298.77

991.59

2410.3

899.53

1027.63

1507.76

1277.76

1311.52

1476.69

899.53

1027.63

1371.72

1246.63

1895.98

1118.61 1317.74

\begin{tabular}{cc}
75 & 1382 \\
92 & 1400 \\
66 & 1580 \\
49 & 1757 \\
02 & 2115 \\
03 & 2115 \\
9 & 77 \\
8 & 90 \\
7 & 37 \\
3 & 80 \\
6 & 107 \\
35 & 147 \\
37 & 147 \\
67 & 188 \\
06 & 216 \\
19 & 234 \\
41 & 251 \\
7 & 57 \\
8 & 88 \\
40 & 250 \\
83 & 297 \\
9 & 65 \\
17 & 126 \\
64 & 278 \\
80 & 391 \\
25 & 536 \\
65 & 576 \\
4 & 65 \\
6 & 78 \\
20 & 232 \\
40 & 250 \\
40 & 251 \\
52 & 260 \\
69 & 290 \\
91 & 298 \\
91 & 299 \\
00 & 311 \\
56 & 367 \\
66 & 577 \\
98 & 311 \\
12 & 319 \\
12 & 320 \\
46 & 359 \\
77 & 387 \\
68 & 385 \\
65 & 574 \\
65 & 576 \\
& \\
\hline
\end{tabular}

Page 53 of Table S-1-5 
Dynactin subunit $1 \mathrm{GN}=\mathrm{DCTN}$

Dynactin subunit $1 \mathrm{GN}=\mathrm{DCTN}$

Dynactin subunit $1 \mathrm{GN}=\mathrm{DCTN} 1$

Dynactin subunit $1 \mathrm{GN}=\mathrm{DCTN}$

Dynactin subunit $1 \mathrm{GN}=\mathrm{DCTN}$

DCTN1 HUMAN $141.70 \quad 100.0 \%$ DCTN1_HUMAN $141.70 \quad 100.0 \%$ DCTN1_HUMAN $141.70 \quad 100.0 \%$ DCTN1_HUMAN $141.70 \quad 100.0 \%$ DCTN1_HUMAN $141.70 \quad 100.0 \%$ DCTN1_HUMAN $141.70 \quad 100.0 \%$ DYN2_HUMAN $98.07 \quad 100.0 \%$ DYN2_HUMAN $98.07 \quad 100.0 \%$ DYN2 HUMAN $98.07 \quad 100.0 \%$ DYN2_HUMAN $98.07 \quad 100.0 \%$ Dynamin-2 GN=DNM

Dynamin-2 GN=DNM 2

Dynamin-2 GN=DNM2

Dynamin -2 GN=DNM 2

DAAF5

$\begin{array}{lll}\text { Dynein assembly factor 5, axonemal GN=DNAAF5 DAAF_HUMAN } & 93.52 & 100.0 \% \\ \text { Dynein assembly factor 5, axonemal GN=DNAAF5 DAAF5_HUMAN } 93.52 & 100.0 \%\end{array}$ Dynein assembly factor 5 , axonemal GN=DNAAF5 DAAF5 HUMAN $93.52 \quad 100.0 \%$ E3 SUMO-protein ligase RanBP2 GN=RANBP2 RBP2 HUMAN 358.20 100.0\% E3 SUMO-protein ligase RanBP2 GN=RANBP2 RBP2_HUMAN $358.20 \quad 100.0 \%$ E3 SUMO-protein ligase RanBP2 GN=RANBP2 RBP2 HUMAN $358.20 \quad 100.0 \%$ E3 SUMO-protein ligase RanBP2 GN=RANBP2 RBP2_HUMAN $358.20 \quad 100.0 \%$ E3 SUMO-protein ligase RanBP2 GN=RANBP2 RBP2_HUMAN $358.20 \quad 100.0 \%$ E3 SUMO-protein ligase RanBP2 GN=RANBP2 RBP2 HUMAN $358.20 \quad 100.0 \%$ E3 SUMO-protein ligase RanBP2 GN=RANBP2 RBP2_HUMAN $358.20 \quad 100.0 \%$ E3 ubiquitin-protein ligase HERC2 GN=HERC2 HERC2_HUMAN $527.22 \quad 100.0 \%$ E3 ubiquitin-protein ligase HERC2 GN=HERC2 HERC2_HUMAN $527.22 \quad 100.0 \%$ E3 ubiquitin-protein ligase HUWE1 GN=HUWE1 HUWE1_HUMAN $481.89 \quad 100.0 \%$ E3 ubiquitin-protein ligase HUWE1 GN=HUWE1 HUWE1 HUMAN $481.89 \quad 100.0 \%$ E3 ubiquitin-protein ligase HUWE1 GN=HUWE1 HUWE1_HUMAN $481.89 \quad 100.0 \%$ E3 ubiquitin-protein ligase HUWE1 GN=HUWE1 HUWE1_HUMAN $481.89100 .0 \%$ E3 ubiquitin-protein ligase HUWE1 GN=HUWE1 HUWE1_HUMAN $481.89100 .0 \%$ E3 ubiquitin-protein ligase HUWE1 GN=HUWE1 HUWE1_HUMAN $481.89 \quad 100.0 \%$ E3 ubiquitin-protein ligase HUWE1 GN=HUWE1 HUWE1_HUMAN $481.89100 .0 \%$ E3 ubiquitin-protein ligase HUWE1 GN=HUWE1 HUWE1_HUMAN $481.89 \quad 100.0 \%$ E3 ubiquitin-protein ligase HUWE1 GN=HUWE1 HUWE1_HUMAN $481.89 \quad 100.0 \%$ E3 ubiquitin-protein ligase HUWE1 GN=HUWE1 HUWE1_HUMAN $481.89 \quad 100.0 \%$ E3 ubiquitin-protein ligase HUWE1 GN=HUWE1 HUWE1_HUMAN $481.89 \quad 100.0 \% \quad 22$

$0.01 \% \quad 3.1 \% \quad$ VSIYDSKR $0.01 \% \quad 13.2 \%$ RLEAFLTQK $0.01 \% \quad 13.2 \%$ ISELGAGNGGVVTK $0.01 \% \quad 13.2 \%$ RIPEEILGK $0.01 \% \quad 13.2 \%$ DVKPSNILVNSR $0.01 \% \quad 13.2 \%$ LNQPGTPTR

$0.01 \% \quad 17.3 \%$ GAYGVVEK $0.01 \% \quad 17.3 \%$ HAQSGTIMAVK $0.01 \% \quad 17.3 \%$ DVKPSNVLINK $0.01 \% \quad 17.3 \%$ MCDFGISGYLVDSVAK $0.01 \% \quad 17.3 \%$ QVVEEPSPQLPADR $0.00 \% \quad 9.4 \%$ SRELYESAR

$0.00 \% \quad 9.4 \%$ ASFPVQILPNLYLGSAR $0.00 \% \quad 9.4 \%$ DSANLESLAK

$10 \quad 0.01 \% \quad 5.6 \% \quad$ KYFTCDEGHGIFVR

$10 \quad 0.01 \% \quad 5.6 \% \quad$ MQEQQADLQR

$10 \quad 0.01 \% \quad 5.6 \% \quad$ ELTNQQEASVER

$10 \quad 0.01 \% \quad 5.6 \% \quad$ QSCNILISTMNK

$10 \quad 0.01 \% \quad 5.6 \%$ IKGEELSEANVR

$10 \quad 0.01 \% \quad 5.6 \% \quad$ VTFSCAAGFGQR

$10 \quad 0.01 \% \quad 4.1 \%$ SSVLENFVGR

$10 \quad 0.01 \% \quad 4.1 \%$ GISPVPINLR

$10 \quad 0.01 \% \quad 4.1 \% \quad$ EVDPQGLR

$10 \quad 0.01 \% \quad 4.1 \%$ GYIGVVNR

$4 \quad 0.00 \% \quad 3.7 \% \quad$ LLPGLEADSKPGR

$0.00 \% \quad 3.7 \%$ CLSDPAEGCR

$0.00 \% \quad 3.7 \% \quad$ LFDDVPQVR

$0.02 \% \quad 2.9 \% \quad$ YIASVQGSTPSPR

$0.02 \% \quad 2.9 \% \quad$ IIDDSDSNLSVVK

$0.02 \% \quad 2.9 \%$ SGSSFVHQASFK

$0.02 \% \quad 2.9 \%$ FGISEPGNQEK

$0.02 \% \quad 2.9 \%$ IAVAVLEETTR

$0.02 \% \quad 2.9 \% \quad$ SNNSETSSVAQSGSESKVEPK

$0.02 \% \quad 2.9 \%$ NSDIEQSSDSKVK

$0.00 \% \quad 0.5 \%$ SLNVSSSVNQASR

$0.00 \% \quad 0.5 \%$ AAGLESAATIR

$0.10 \% \quad 6.3 \%$ TPTEAPADCR

$0.10 \% \quad 6.3 \%$ TLTSIVHLER

$0.10 \% \quad 6.3 \%$ AIQDPAFSDGIR

$0.10 \% \quad 6.3 \% \quad$ YICQKPSIQK

$0.10 \% \quad 6.3 \% \quad$ ADGTATAPPPR

$0.10 \% \quad 6.3 \%$ SILTLSHEPK

$0.10 \% \quad 6.3 \% \quad$ SHHAASTTTAPTPAAR

$0.10 \% \quad 6.3 \% \quad$ AALPLTTSDTK

$\begin{array}{lll}0.10 \% & 6.3 \% & \text { YLQSNSNNWR }\end{array}$

$0.10 \% \quad 6.3 \%$ HIIEDPCTLR

$\begin{array}{lllll}0.10 \% & 6.3 \% & \text { SAATSGAGSTTSGVVSGSLGSR } & 99.7 \% & 75.0\end{array}$

$97.9 \% \quad 24.2$

$99.3 \% \quad 19.5$

$99.7 \% \quad 47.5$

$99.6 \% \quad 25.9$

$98.7 \% \quad 18.2$

$99.7 \% \quad 28.6$

$99.0 \% 34.6$

$99.7 \% \quad 33.7$

$99.7 \% \quad 26.7$

$99.7 \% \quad 59.5$

$96.7 \% \quad 26.5$

$99.7 \% \quad 35.8$

$99.7 \% \quad 56.8$

$99.7 \% \quad 42.6$

$97.3 \% 22.1$

$99.6 \% \quad 25.5$

$99.7 \% \quad 36.0$

$99.7 \% \quad 44.7$

$99.7 \% \quad 42.3$

$99.7 \% \quad 46.6$

$99.7 \% \quad 35.0$

$99.7 \% \quad 28.6$

$99.0 \% \quad 56.0$

$99.0 \% \quad 31.1$

$99.7 \% \quad 27.2$

$99.7 \% \quad 27.9$

$\begin{array}{lll}99.3 \% & 20.3\end{array}$

$96.6 \% 15.8$

$99.2 \% \quad 37.8$

$99.6 \% \quad 35.7$

$99.7 \% 25$.

$99.7 \% \quad 46.1$

$99.6 \% 22.7$

$99.7 \% \quad 42.4$

$99.7 \% \quad 43.5$

$99.6 \% 28.6$

$99.7 \% \quad 32.8$

$\begin{array}{lll}99.7 \% & 29.9\end{array}$

$99.7 \% \quad 33.8$

$99.3 \% 22.1$

$\begin{array}{lll}99.7 \% & 29.5\end{array}$

$\begin{array}{lll}99.7 \% & 29.9\end{array}$

$99.5 \% \quad 22.3$

$99.7 \% \quad 42.8$

$99.7 \% \quad 31.4$

$99.7 \% \quad 31.4$

23
23

1105.64

1301.71

1054.63

1341.75

983.53

822.44

1142.60

1226.7

1777.81

1564.80

1110.55

1846.02

1047.53

1728.82

1262.58

1403.68

1408.69

1344.71

1300.61

1107.58

1065.64

913.47

877.49

1352.75

1164.48

1088.57

1362.70

1404.72

1281.62

1205.58

1201.68

2152.00

1436.69

1348.68

1059.58

1117.49

1168.67

1289.65

1264.67

1053.53

1124.63

1576.78

1117.61

1281.60

1253.63 1896.93 
E3 ubiquitin-protein ligase HUWE1 GN=HUWE1 HUWE1_HUMAN $481.89 \quad 100.0 \% 22$ E3 ubiquitin-protein ligase HUWE1 GN=HUWE1 HUWE1_HUMAN $481.89 \quad 100.0 \% 22$ E3 ubiquitin-protein ligase HUWE1 GN=HUWE1 HUWE1_HUMAN $481.89 \quad 100.0 \% 22$ E3 ubiquitin-protein ligase HUWE1 GN=HUWE1 HUWE1_HUMAN $481.89 \quad 100.0 \% 22$ E3 ubiquitin-protein ligase HUWE1 GN=HUWE1 HUWE1_HUMAN $481.89 \quad 100.0 \% \quad 22$ E3 ubiquitin-protein ligase HUWE1 GN=HUWE1 HUWE1_HUMAN $481.89 \quad 100.0 \% 22$ E3 ubiquitin-protein ligase HUWE1 GN=HUWE1 HUWE1_HUMAN $481.89 \quad 100.0 \% 22$ E3 ubiquitin-protein ligase HUWE1 GN=HUWE1 HUWE1_HUMAN $481.89 \quad 100.0 \% \quad 22$ E3 ubiquitin-protein ligase HUWE1 GN=HUWE1 HUWE1_HUMAN $481.89 \quad 100.0 \% 22$ E3 ubiquitin-protein ligase HUWE1 GN=HUWE1 HUWE1_HUMAN $481.89 \quad 100.0 \%$ E3 ubiquitin-protein ligase HUWE1 GN=HUWE1 HUWE1_HUMAN $481.89 \quad 100.0 \%$ E3 ubiquitin-protein ligase MYCBP2 GN=MYCBP2 MYCB2 HUMAN $510.08 \quad 100.0 \%$ E3 ubiquitin-protein ligase MYCBP2 GN=MYCBP2 MYCB2_HUMAN $510.08 \quad 100.0 \%$ E3 ubiquitin-protein ligase MYCBP2 GN=MYCBP2 MYCB2_HUMAN $510.08 \quad 100.0 \%$ E3 ubiquitin-protein ligase MYCBP2 GN=MYCBP2 MYCB2_HUMAN $510.08 \quad 100.0 \%$ E3 ubiquitin-protein ligase MYCBP2 GN=MYCBP2 MYCB2_HUMAN $510.08 \quad 100.0 \%$ E3 ubiquitin-protein ligase MYCBP2 GN=MYCBP2 MYCB2 HUMAN $510.08 \quad 100.0 \%$ E3 ubiquitin-protein ligase MYCBP2 GN=MYCBP2 MYCB2_HUMAN $510.08 \quad 100.0 \%$ E3 ubiquitin-protein ligase MYCBP2 GN=MYCBP2 MYCB2_HUMAN $510.08 \quad 100.0 \%$ E3 ubiquitin-protein ligase RING2 GN=RNF2 RING2 HUMAN $37.66 \quad 100.0 \%$ E3 ubiquitin-protein ligase RING2 GN=RNF2 RING2_HUMAN $37.66 \quad 100.0 \%$ E3 ubiquitin-protein ligase RING2 GN=RNF2 RING2_HUMAN $37.66 \quad 100.0 \%$ E3 ubiquitin-protein ligase RNF213 GN=RNF213 RN213_HUMAN $591.41 \quad 100.0 \%$ E3 ubiquitin-protein ligase RNF213 GN=RNF213 RN213_HUMAN $591.41 \quad 100.0 \%$ E3 ubiquitin-protein ligase RNF213 GN=RNF213 RN213_HUMAN $591.41 \quad 100.0 \%$ E3 ubiquitin-protein ligase TRIM21 GN=TRIM21 RO52_HUMAN $54.17 \quad 100.0 \%$ E3 ubiquitin-protein ligase TRIM21 GN=TRIM21 RO52_HUMAN $54.17 \quad 100.0 \%$ E3 ubiquitin-protein ligase TRIM21 GN=TRIM21 RO52 HUMAN $54.17 \quad 100.0 \%$ E3 ubiquitin-protein ligase TRIM21 GN=TRIM21 RO52_HUMAN $54.17 \quad 100.0 \%$ E3 ubiquitin-protein ligase TRIM21 GN=TRIM21 RO52 HUMAN $54.17 \quad 100.0 \%$ E3 ubiquitin-protein ligase TRIM21 GN=TRIM21 RO52_HUMAN $54.17 \quad 100.0 \%$ E3 ubiquitin-protein ligase TRIM21 GN=TRIM21 RO52_HUMAN $54.17 \quad 100.0 \%$ E3 ubiquitin-protein ligase TRIM21 GN=TRIM21 RO52 HUMAN $54.17 \quad 100.0 \%$ E3 ubiquitin-protein ligase TRIM21 GN=TRIM21 RO52_HUMAN $54.17 \quad 100.0 \%$ E3 ubiquitin-protein ligase TRIM21 GN=TRIM21 RO52_HUMAN $54.17 \quad 100.0 \%$ E3 ubiquitin-protein ligase TRIM21 GN=TRIM21 RO52 HUMAN $54.17 \quad 100.0 \%$ E3 ubiquitin-protein ligase TRIM21 GN=TRIM21 RO52_HUMAN $54.17 \quad 100.0 \%$ E3 ubiquitin-protein ligase TRIM21 GN=TRIM21 RO52_HUMAN $54.17 \quad 100.0 \%$ E3 ubiquitin-protein ligase TRIP12 GN=TRIP12 TRIPC_HUMAN $220.44 \quad 100.0 \%$ E3 ubiquitin-protein ligase TRIP12 GN=TRIP12 TRIPC_HUMAN $220.44 \quad 100.0 \%$ E3 ubiquitin-protein ligase TRIP12 GN=TRIP12 TRIPC_HUMAN $220.44 \quad 100.0 \%$ E3 ubiquitin-protein ligase TRIP12 GN=TRIP12 TRIPC_HUMAN $220.44 \quad 100.0 \%$ E3 ubiquitin-protein ligase UBR4 GN=UBR4 UBR4 HUMAN 573.84 $100.0^{\circ}$ E3 ubiquitin-protein ligase UBR4 GN=UBR4 UBR4_HUMAN $573.84 \quad 100.0 \%$ E3 ubiquitin-protein ligase UBR4 GN=UBR4 UBR4_HUMAN $573.84 \quad 100.0 \%$ E3 ubiquitin-protein ligase UBR4 GN=UBR4 UBR4 HUMAN $573.84 \quad 100.0 \%$ E3 ubiquitin-protein ligase UBR4 GN=UBR4 UBR4_HUMAN $573.84 \quad 100.0 \%$

8

8
8

8

8
8
3

8
3
3

3

3
3
3

$\begin{array}{cc}3 & 3 \\ 3 & 3 \\ 3 & 3 \\ 13 & 13\end{array}$

3

13
13
13

13

13

13

13
13
13

4

4

4
4
7

6.3\% VLGPAACR

$0.10 \% \quad 6.3 \% \quad$ IVNQPSSLFGSK

$99.7 \% 34.6$

$\begin{array}{lllll}0.10 \% & 6.3 \% & \text { HADHSSLTLGSGSSTTR } & 99.7 \% & 31.1\end{array}$

$\begin{array}{lll}0.10 \% & 6.3 \% & \text { DSAVAISGADSR }\end{array}$

$0.10 \% \quad 6.3 \% \quad$ NLCYHAQTR

$0.10 \% \quad 6.3 \%$ SSESELCIETPK

$99.7 \% \quad 60.9$

$99.7 \% \quad 27.2$

$99.7 \% \quad 33.4$

$99.0 \% \quad 37.2$

$\begin{array}{lll}0.10 \% & 6.3 \% & \text { TNIFQIQR }\end{array}$

$99.7 \% \quad 59.3$

$0.10 \% \quad 6.3 \%$ LGSSGLGSASSIQAAVR

$0.10 \% \quad 6.3 \% \quad$ FLQFVTGTSK

$0.02 \% \quad 1.9 \%$ IGSGYSGTVR

$0.02 \% \quad 1.9 \%$ VYTCEIYPVSATGK

$0.02 \% \quad 1.9 \% \quad$ ALSVVSTVVR

$0.02 \% \quad 1.9 \%$ TVQNSGYGPK

$0.02 \% \quad 1.9 \%$ IAGQISASVAQQR

$0.02 \% \quad 1.9 \%$ LITSQVFGK

$0.02 \% \quad 1.9 \%$ GTTITGTAGTTVGK

$0.02 \% \quad 1.9 \%$ YAYYVCYK

$0.00 \% \quad 11.6 \%$ FCADCIITALR

$0.00 \% \quad 11.6 \%$ SLRPDPNFDALISK

$0.00 \% \quad 11.6 \%$ IYPSRDEYEAHQER

$0.00 \% \quad 0.6 \%$ SSLTLATAINQR

$0.00 \% \quad 0.6 \%$ GIYVIQAPK

$0.00 \% \quad 0.6 \%$ LIDPQVDESR

$0.03 \% \quad 23.2 \%$ GGGSVCPVCR

$0.03 \% \quad 23.2 \%$ QLANMVNNLK

$\begin{array}{ll}99.7 \% & 27.8 \\ 99.7 \% & 57.4\end{array}$

$99.7 \% \quad 38.0$

$99.7 \% \quad 52.9$

$99.7 \% \quad 40.0$

$97.7 \% \quad 20.0$

$99.7 \% \quad 46.7$

$99.3 \% \quad 26.8$

$\begin{array}{lll}99.7 \% & 40.7\end{array}$

$98.5 \% \quad 25.5$

$99.7 \% \quad 43.0$

$99.6 \% \quad 28.2$

$95.2 \% \quad 18.7$

$96.6 \% \quad 20.2$

$99.7 \% \quad 26.8$

$\begin{array}{lll}96.5 \% & 22.2\end{array}$

$99.7 \% \quad 28.8$

$99.7 \% \quad 35.1$

$0.03 \% \quad 23.2 \%$ QLANMVNNLKEISQEAR $99.5 \% 26.8$

$0.03 \% \quad 23.2 \%$ LQVALGELR

$0.03 \% \quad 23.2 \%$ LQVALGELRR

$0.03 \% \quad 23.2 \%$ SRIHAEFVQQK

$0.03 \% \quad 23.2 \%$ IHAEFVQQK

$0.03 \% \quad 23.2 \%$ NFLVEEEQR

$0.03 \% \quad 23.2 \%$ SVCHVPGLK

$0.03 \% \quad 23.2 \%$ SVCHVPGLKK

$0.03 \% \quad 23.2 \%$ LGDTQQSIPGNEER

$0.03 \% \quad 23.2 \%$ KGHFLLSSK

$0.03 \% \quad 23.2 \%$ NTAPLTLCPLNIGSQGSTDY

$10 \quad 0.01 \% \quad 2.4 \%$ SSFLASLNPK

$10 \quad 0.01 \% \quad 2.4 \% \quad$ LSTQSNSNNIEPAR

$0.01 \% \quad 2.4 \%$ QAESVMQDLGSSR

$0.01 \% \quad 2.4 \%$ SVYHLEDIVR

$0.02 \% \quad 1.4 \%$ MNYSGDQGQTIR

$0.02 \% \quad 1.4 \%$ IQIGTQAIER

$0.02 \% \quad 1.4 \%$ SLLASLHTSR

$0.02 \% \quad 1.4 \% \quad$ TINLYYNNR

$0.02 \% \quad 1.4 \%$ TVQAIVELK $\begin{array}{llll}9.7 \% & 40.8 & 25.0 & 22.6\end{array}$

$\begin{array}{llll}99.7 \% & 31.8 & 25.0 & 31.8\end{array}$

$\begin{array}{llll}99.7 \% & 34.9 & 25.0 & 34.1\end{array}$

$\begin{array}{llll}99.7 \% & 44.8 & 25.0 & 30.8\end{array}$

$\begin{array}{llll}99.7 \% & 45.5 & 25.0 & 31.7\end{array}$

$\begin{array}{llll}98.5 \% & 24.0 & 25.0 & 19.0\end{array}$

$\begin{array}{llll}95.2 \% & 15.2 & 25.0 & 15.2\end{array}$

$\begin{array}{llll}99.7 \% & 49.3 & 25.0 & 47.5\end{array}$

$\begin{array}{llll}98.3 \% & 24.2 & 25.0 & 21.2\end{array}$

$\begin{array}{llll}99.7 \% & 41.5 & 25.0 & 41.5\end{array}$

$\begin{array}{llll}99.7 \% & 53.0 & 25.0 & 29.3\end{array}$

$\begin{array}{llll}99.7 \% & 35.6 & 25.0 & 35.4\end{array}$

$\begin{array}{llll}99.7 \% & 37.3 & 25.0 & 37.3\end{array}$

$\begin{array}{llll}99.7 \% & 33.2 & 25.0 & 29.0\end{array}$

$\begin{array}{llll}99.7 \% & 27.4 & 25.0 & 27.4\end{array}$

$\begin{array}{llll}99.7 \% & 43.6 & 25.0 & 34.0\end{array}$

$\begin{array}{llll}99.7 \% & 60.4 & 25.0 & 53.7\end{array}$

$\begin{array}{llll}99.1 \% & 28.8 & 25.0 & 28.8\end{array}$

$\begin{array}{llll}99.6 \% & 27.4 & 25.0 & 17.3\end{array}$

1276.69

1713.82

1766.87

1148.55

1162.54

1379.64

1019.56

1560.83

1949.93

1127.6

996.51

1587.77

1030.63

1050.52

1328.73

992.58

1264.67

1129.50

1339.65

1572.84

1792.82

1274.71

988.58

1171.60

1048.47

1160.61

1974.01

998.60

1154.70

1342.72

1099.59

1163.57

996.53

1124.62

1543.73

1016.59

2122.01

1063.58

1530.75

1407.65

1230.65

1385.61

1128.64

1084.61

1170.59

1000.60

Page 55 of Table S-1-5 
E3 ubiquitin-protein ligase UBR4 GN=UBR4 UBR4_HUMAN $573.84 \quad 100.0 \%$ E3 ubiquitin-protein ligase UBR4 GN=UBR4 UBR4_HUMAN $573.84 \quad 100.0 \%$ EH domain-containing protein $1 \mathrm{GN}=\mathrm{EHD} 1$ EHD1_HUMAN $60.63 \quad 100.0 \%$ EH domain-containing protein $1 \mathrm{GN}=\mathrm{EHD} 1 \mathrm{EHD} 1$ HUMAN $60.63100 .0 \%$ EH domain-containing protein $1 \mathrm{GN}=$ EHD1 EHD1_HUMAN $60.63 \quad 100.0 \%$ ELAV-like protein $1 \mathrm{GN}=\mathrm{ELAVL} 1$

ELAV-like protein $1 \mathrm{GN}=\mathrm{ELAVL}$ ELAV-like protein $1 \mathrm{GN}=\mathrm{ELAVL}$ ELAV-like protein $1 \mathrm{GN}=$ ELAVL ELAV-like protein $1 \mathrm{GN}=\mathrm{ELAVL} 1$ ELAV-like protein $1 \mathrm{GN}=\mathrm{ELAVL}$ ELAV-like protein $1 \mathrm{GN}=\mathrm{ELAVL}$ ELAV-like protein $1 \mathrm{GN}=\mathrm{ELAVL}$ : ELAV-like protein $1 \mathrm{GN}=\mathrm{ELAVL}$ ELAV-like protein $1 \mathrm{GN}=\mathrm{ELAVL}$ ELAV-like protein $1 \mathrm{GN}=\mathrm{ELAVL}$ ELAV-like protein $1 \mathrm{GN}=\mathrm{ELAVL}$ ELAV-like protein $1 \mathrm{GN}=\mathrm{ELAVL} 1$ ELAV-like protein $1 \mathrm{GN}=\mathrm{ELAVL}$ ELAV-like protein $1 \mathrm{GN}=\mathrm{ELAVL}$ ELAV-like protein $1 \mathrm{GN}=\mathrm{ELAVL}$ ELAV-like protein $1 \mathrm{GN}=\mathrm{ELAVL} 1$ ELAV-like protein $2 \mathrm{GN}=\mathrm{ELAVL} 2$ ELAV-like protein $2 \mathrm{GN}=\mathrm{ELAVL}$ : ELAV-like protein $2 \mathrm{GN}=$ ELAVL2 ELAV-like protein $2 \mathrm{GN}=\mathrm{ELAVL} 2$ ELAV-like protein $2 \mathrm{GN}=$ ELAVL2 ELAV-like protein $2 \mathrm{GN}=$ ELAVL2 ELAV-like protein $2 \mathrm{GN}=\mathrm{ELAVL} 2$ ELAV-like protein $2 \mathrm{GN}=$ ELAVL2 ELAV-like protein $2 \mathrm{GN}=\mathrm{ELAVL} 2$ ELAV-like protein $2 \mathrm{GN}=\mathrm{ELAVL} 2$ ELAV-like protein $2 \mathrm{GN}=\mathrm{ELAVL} 2$ ELAV-like protein $2 \mathrm{GN}=\mathrm{ELAVL} 2$ ELAV-like protein $2 \mathrm{GN}=\mathrm{ELAVL} 2$ ELAV-like protein $2 \mathrm{GN}=$ ELAVL2 ELAV1_HUMAN $36.09 \quad 100.0 \%$ ELAV1 HUMAN $36.09 \quad 100.0 \%$ ELAV1 HUMAN $36.09 \quad 100.0 \%$ ELAV1_HUMAN $36.09 \quad 100.0 \%$ ELAV1_HUMAN $36.09 \quad 100.0 \%$ ELAV1_HUMAN $36.09 \quad 100.0 \%$ ELAV1_HUMAN $36.09 \quad 100.0 \%$ ELAV1_HUMAN $36.09 \quad 100.0 \% \quad 17$ ELAV1_HUMAN $36.09 \quad 100.0 \% \quad 17$ ELAV1_HUMAN $36.09 \quad 100.0 \% \quad 17$ ELAV1_HUMAN $36.09 \quad 100.0 \% \quad 17$ ELAV1 HUMAN $36.09 \quad 100.0 \% \quad 17$ ELAV1_HUMAN $36.09 \quad 100.0 \% \quad 17$ ELAV1_HUMAN $36.09 \quad 100.0 \% \quad 17$ ELAV1 HUMAN $36.09 \quad 100.0 \% \quad 17$ ELAV1_HUMAN $36.09 \quad 100.0 \% \quad 17$ ELAV1_HUMAN $36.09 \quad 100.0 \% \quad 17$ ELAV2_HUMAN $39.51 \quad 100.0 \% \quad 12$ ELAV2_HUMAN $39.51 \quad 100.0 \% \quad 12$ ELAV2 HUMAN $39.51 \quad 100.0 \% \quad 12$ ELAV2_HUMAN $39.51 \quad 100.0 \% \quad 12$ ELAV2 HUMAN $39.51 \quad 100.0 \% \quad 12$ ELAV2 HUMAN $39.51 \quad 100.0 \% \quad 12$ ELAV2_HUMAN $39.51 \quad 100.0 \% \quad 12$ ELAV2 HUMAN $39.51 \quad 100.0 \% \quad 12$ ELAV2_HUMAN $39.51 \quad 100.0 \% \quad 12$ ELAV2_HUMAN $39.51 \quad 100.0 \% \quad 12$ ELAV2 HUMAN $39.51 \quad 100.0 \% \quad 12$ ELAV2_HUMAN $39.51 \quad 100.0 \% \quad 12$ ELAV2_HUMAN $39.51 \quad 100.0 \% \quad 12$ ELAV2_HUMAN $39.51 \quad 100.0 \% \quad 12$ TFA ETFA_HUMAN $35.08 \quad 100.0 \%$ Flectron transfer flavoprosing $35.08 \quad 100.0 \%$ Electron transfer flavoprotein subunit alpha, mitochondrial GN=ETFA ETFA_HUMAN $35.08 \quad 100.0 \%$ Electron transfer flavoprotein subunit alpha, mitochondrial GN=ETFA ETFA_HUMAN $35.08 \quad 100.0 \%$ Electron transfer flavoprotein subunit alpha, mitochondrial GN=ETFA ETFA HUMAN $35.08 \quad 100.0 \%$ Electron transfer flavoprotein subunit alpha, mitochondrial GN=ETFA ETFA_HUMAN 35.08 100.0\% Electron transfer flavoprotein subunit alpha, mitochondrial GN=ETFA ETFA HUMAN $35.08 \quad 100.0 \%$ Electron transfer flavoprotein subunit alpha, mitochondrial GN=ETFA ETFA_HUMAN $35.08 \quad 100.0 \%$ Electron transfer flavoprotein subunit beta GN=ETFB ETFB_HUMAN $27.84 \quad 100.0 \%$ Electron transfer flavoprotein subunit beta GN=ETFB ETFB_HUMAN $27.84 \quad 100.0 \%$ Electron transfer flavoprotein subunit beta GN=ETFB ETFB_HUMAN $27.84 \quad 100.0 \%$
$0.02 \% \quad 1.4 \%$ ELLEYDLQQR $0.02 \% \quad 1.4 \%$ TSVQPTFTASQYR $0.01 \% \quad 6.0 \%$ HLIEQDFPGMR $0.01 \% \quad 6.0 \% \quad$ LNAFGNAFLNR $0.01 \% \quad 6.0 \% \quad$ SKLPNTVLGK $0.11 \% \quad 57.1 \%$ TNLIVNYLPQNMTQI $0.11 \% \quad 57.1 \%$ SLFSSIGEVESAK

$\begin{array}{lllll}0.11 \% & 57.1 \% & \text { DKVAGHSLGYGFVNYVTAK } & 99.7 \% & 52.2 \\ 0.11 \% & 57.1 \% & \text { VAGHSLGYGFVNYVTAK } & 99.7 \% & 53.8\end{array}$ $0.11 \% 57.1 \%$ VAGHSLGYGFVNYVTAK $0.11 \% \quad 57.1 \%$ AINTLNGLR $0.11 \% \quad 57.1 \%$ VSYARPSSEVIK $0.11 \% 57.1 \%$ DANLYISGLPR $0.11 \% \quad 57.1 \%$ TMTQKDVEDMFSR $0.11 \% \quad 57.1 \%$ DVEDMFSR

$0.11 \% 57.1 \%$ VLVDQTTGLSR

$0.11 \% \quad 57.1 \%$ SEAEEAITSFNGHKPPGSSEPITVK $0.11 \% \quad 57.1 \%$ FAANPNQNK

$0.11 \% \quad 57.1 \%$ NVALLSQLYHSPAR

$0.11 \% \quad 57.1 \%$ RFGGPVHHQAQR

$0.11 \% \quad 57.1 \%$ FGGPVHHQAQR

$0.11 \% \quad 57.1 \%$ VIRDFNTNK

$0.11 \% \quad 57.1 \%$ LGDKILQVSFK

$0.03 \% \quad 37.9 \%$ SLFGSIGEIESCK

$0.03 \% \quad 37.9 \%$ DKITGQSLGYGFVNYIDPK

$0.03 \% 37.9 \%$ AINTLNGLR

$0.03 \% \quad 37.9 \%$ DANLYVSGLPK

$0.03 \% \quad 37.9 \%$ ELEQLFSQYGR

$0.03 \% \quad 37.9 \%$ ILVDQVTGISR

$0.03 \% \quad 37.9 \%$ RIEAEEAIK

$0.03 \% \quad 37.9 \%$ IEAEEAIK

$0.03 \% \quad 37.9 \%$ GLNGQKPPGATEPITVK

$0.03 \% \quad 37.9 \%$ TNQAILSQLYQSPNR

$0.03 \% \quad 37.9 \%$ TNQAILSQLYQSPNRR

$0.03 \% \quad 37.9 \%$ RYPGPLAQQAQR

$0.03 \% \quad 37.9 \%$ YPGPLAQQAQR

$0.03 \% \quad 37.9 \%$ VIRDFNTNK

$0.03 \% \quad 34.2 \%$ LGGEVSCLVAGTK

$0.03 \% \quad 34.2 \%$ VLVAQHDVYK

$0.03 \% \quad 34.2 \%$ GLLPEELTPLILATQK

$0.03 \% \quad 34.2 \%$ QFNYTHICAGASAFGK

$0.03 \% \quad 34.2 \%$ LEVAPISDIIAIK

$0.03 \% \quad 34.2 \%$ SDRPELTGAK

$99.7 \% \quad 29.7$

$99.7 \% \quad 46.4$

$96.2 \% 18$.

$99.7 \% \quad 44.8$

$99.6 \% \quad 25.2$

$99.7 \% \quad 55.9$

$99.7 \% \quad 55.3$

$99.7 \% \quad 33.4$

$99.7 \% 55$.

$99.7 \% \quad 53.8$

$99.0 \% \quad 41.0$

$99.7 \% \quad 64.7$

$99.7 \% 54.2$

$99.7 \% \quad 33.0$

$99.7 \% \quad 54.5$

$96.1 \% \quad 18.7$

$99.7 \% 55.6$

$99.3 \% \quad 23.0$

$99.7 \% \quad 31.9$

$99.7 \% \quad 62.1$

$94.9 \% \quad 23.1$

$99.7 \% \quad 55.3$

$99.7 \% \quad 57.3$

$99.7 \% \quad 53.0$

$99.7 \% \quad 46.0$

$99.4 \% \quad 36.2$

$98.4 \% \quad 25.7$

$\begin{array}{lll}99.7 \% & 53.7\end{array}$

$99.7 \% \quad 56.7$

$99.7 \% \quad 38.0$

$99.7 \% \quad 42.3$

$99.7 \% \quad 32.9$

$99.3 \% \quad 23.0$

$99.7 \% \quad 76.3$

$99.7 \% \quad 57.0$

$99.7 \% \quad 40.8$

$99.4 \% 24.0$

$99.7 \% \quad 46.3$

$99.7 \% \quad 33.4$

$\begin{array}{llll}0.03 \% & 34.2 \% & \end{array}$

$0.03 \% \quad 34.2 \%$ AAVDAGFVPNDMQVGQTGK

$99.7 \% \quad 63.3$

$99.4 \% \quad 26.9$

$0.02 \% \quad 47.1 \%$ EVIAVSCGPAQCQETIR

$0.02 \% \quad 47.1 \%$ TALAMGADR

$.7 \% 63.1$

$99.7 \% \quad 41.8 \quad 25.0$

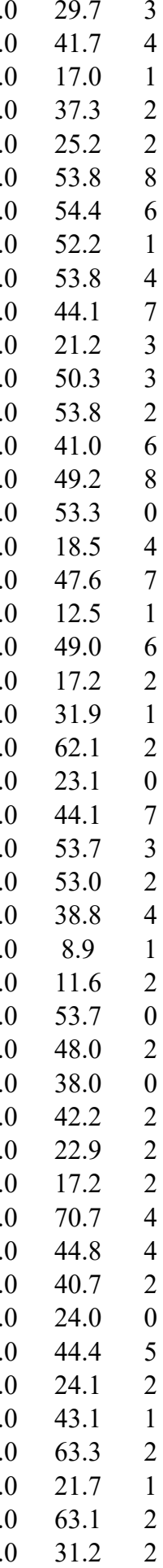

0
0
0
0
0
0
0
0
0
0
0
0
0
0
0
0
0
0
0
0
0
0
0
0
0
0
0
0
0
0
0
0
0
0
0
0
0
0
0
0
0
0
0
0

0
0
0
0
0
0
0
0
0
0
0
0
0
0
0
0
0
0
0
0
0
0
0
0
0
0
0
0
0
0
0
0
0
0
0
0
0
0
0
0
0
0
0
0
0
0
0
0
0
0
0
0
0
0
0
0
0
0
0
0
0
0
0

$\begin{array}{lll}306.66 & 3827 & 3836 \\ 1485.73 & 3845 & 3857\end{array}$

$485.73-3845 \quad 3857$

$\begin{array}{lll}1342.66 & 77 & 87\end{array}$

$\begin{array}{lll}1236.65 & 125 & 135\end{array}$

$1056.64 \quad 474 \quad 483$

$2162.09 \quad 20 \quad 37$

$1353.69 \quad 38 \quad 50$

$2026.04 \quad 54 \quad 72$

1782.92

971.56

1335.73

218.65

1619.70

1014.42

1188.66

2612.28

1003.50

1568.85

1389.72

233.62

1106.60

1247.74

1426.69

2115.08

971.56

1176.63

1369.67

1200.69

1058.58

902.48

1706.94

1732.90

1889.00

1384.74

1228.64

1106.60

1290.67

171.65

1736.02

1771.82

381.83

1073.56

1812.96

1920.91

875.48

917.92

905.45 

Electron transfer flavoprotein subunit beta GN=ETFB ETFB_HUMAN $27.84 \quad 100.0 \%$ Electron transfer flavoprotein subunit beta GN=ETFB ETFB_HUMAN $27.84 \quad 100.0 \%$ ELMO domain-containing protein 2 GN=ELMOD2 ELMD2 HUMAN $34.96 \quad 100.0 \%$ ELMO domain-containing protein 2 GN=ELMOD2 ELMD2_HUMAN $34.96 \quad 100.0 \%$ ELMO domain-containing protein 2 GN=ELMOD2 ELMD2_HUMAN $34.96 \quad 100.0 \%$ ELMO domain-containing protein 2 GN=ELMOD2 ELMD2_HUMAN $34.96 \quad 100.0 \%$ ELMO domain-containing protein 2 GN=ELMOD2 ELMD2_HUMAN $34.96 \quad 100.0 \%$ ELMO domain-containing protein 2 GN=ELMOD2 ELMD2_HUMAN $34.96 \quad 100.0 \%$ ELMO domain-containing protein 2 GN=ELMOD2 ELMD2_HUMAN $34.96 \quad 100.0 \%$ Elongation factor 1-alpha $1 \mathrm{GN}=\mathrm{EEF} 1 \mathrm{~A} 1 \quad$ EF1A1_HUMAN $50.14 \quad 100.0 \%$ Elongation factor 1-alpha $1 \mathrm{GN}=\mathrm{EEF} 1 \mathrm{~A} 1$ EF1A1 HUMAN $50.14 \quad 100.0 \%$ Elongation factor 1-alpha $1 \mathrm{GN}=\mathrm{EEF} 1 \mathrm{~A} 1 \quad$ EF1A1_HUMAN $50.14 \quad 100.0 \%$ Elongation factor 1-alpha $1 \mathrm{GN}=\mathrm{EEF} 1 \mathrm{~A} 1 \quad$ EF1A1_HUMAN $50.14 \quad 100.0 \%$ Elongation factor 1-alpha $1 \mathrm{GN}=\mathrm{EEF} 1 \mathrm{~A} 1 \quad$ EF1A1_HUMAN $50.14 \quad 100.0 \%$ Elongation factor 1-alpha $1 \mathrm{GN}=\mathrm{EEF} 1 \mathrm{~A} 1 \quad$ EF1A1_HUMAN $50.14 \quad 100.0 \%$ Elongation factor 1-alpha $1 \mathrm{GN}=\mathrm{EEF} 1 \mathrm{~A} 1 \quad$ EF1A1_HUMAN $50.14 \quad 100.0 \%$ Elongation factor 1-alpha $1 \mathrm{GN}=\mathrm{EEF} 1 \mathrm{~A} 1 \quad$ EF1A1_HUMAN $50.14 \quad 100.0 \%$ Elongation factor 1-alpha $1 \mathrm{GN}=\mathrm{EEF} 1 \mathrm{~A} 1 \quad$ EF1A1_HUMAN $50.14 \quad 100.0 \%$ Elongation factor 1-alpha $1 \mathrm{GN}=\mathrm{EEF} 1 \mathrm{~A} 1 \quad$ EF1A1_HUMAN $50.14 \quad 100.0 \%$ Elongation factor 1-alpha $1 \mathrm{GN}=\mathrm{EEF} 1 \mathrm{~A} 1 \quad$ EF1A1_HUMAN $50.14 \quad 100.0 \%$ Elongation factor 1-alpha $1 \mathrm{GN}=\mathrm{EEF} 1 \mathrm{~A} 1$ EF1A1_HUMAN $50.14 \quad 100.0 \%$ Elongation factor 1-alpha $1 \mathrm{GN}=\mathrm{EEF} 1 \mathrm{~A} 1 \quad$ EF1A1_HUMAN $50.14 \quad 100.0 \%$ Elongation factor 1-alpha $1 \mathrm{GN}=\mathrm{EEF} 1 \mathrm{~A} 1 \quad$ EF1A1_HUMAN $50.14 \quad 100.0 \%$ Elongation factor 1 -alpha $1 \mathrm{GN}=\mathrm{EEF} 1 \mathrm{~A} 1 \mathrm{EF} 1 \mathrm{~A} 1$ HUMAN $50.14 \quad 100.0 \%$ Elongation factor 1-beta $\mathrm{GN}=\mathrm{EEF} 1 \mathrm{~B} 2$ Elongation factor 1-beta GN=EEF1B2 Elongation factor 1-beta GN=EEF1B2 Elongation factor 1-delta GN=EEF1D Elongation factor 1-delta GN=EEF1D Elongation factor 1-delta GN=EEF1D Elongation factor 1-delta GN=EEF1D Elongation factor 1-gamma GN=EEF1G Elongation factor 1-gamma GN=EEF1G Elongation factor 1-gamma $\mathrm{GN}=\mathrm{EEF} 1 \mathrm{G}$ Elongation factor 1-gamma GN=EEF1G Elongation factor 1-gamma $\mathrm{GN}=\mathrm{EEF} 1 \mathrm{G}$ Elongation factor 1-gamma GN=EEF1G Elongation factor 1-gamma GN=EEF1G Elongation factor 1-gamma $\mathrm{GN}=\mathrm{EEF} 1 \mathrm{G}$ Elongation factor $2 \mathrm{GN}=\mathrm{EEF} 2$ Elongation factor $2 \mathrm{GN}=\mathrm{EEF} 2$ EF1B_HUMAN $24.76 \quad 100.0 \%$ EF1B_HUMAN $24.76 \quad 100.0 \%$ EF1B HUMAN $24.76 \quad 100.0 \%$ EF1D_HUMAN $31.12 \quad 100.0 \%$ EF1D HUMAN $31.12 \quad 100.0 \%$ EF1D HUMAN $31.12 \quad 100.0 \%$ EF1D_HUMAN $31.12 \quad 100.0 \%$ EF1G_HUMAN $50.12 \quad 100.0 \%$ EF1G_HUMAN $50.12 \quad 100.0 \%$ EF1G_HUMAN $50.12 \quad 100.0 \%$ EF1G_HUMAN $50.12 \quad 100.0 \%$ EF1G_HUMAN $50.12 \quad 100.0 \%$ EF1G_HUMAN $50.12 \quad 100.0 \%$ EF1G HUMAN $50.12 \quad 100.0 \%$ EF1G_HUMAN $50.12 \quad 100.0 \%$ EF2 HUMAN $95.34 \quad 100.0 \%$ EF2_HUMAN $95.34 \quad 100.0 \% \quad 17$

$0.02 \% \quad 47.1 \%$ GIHVEVPPAEAER $0.02 \% \quad 47.1 \%$ LGPLQVAR $0.02 \% \quad 47.1 \%$ EKVDLVLLGK $0.02 \% \quad 47.1 \%$ EIDGGLETLR $0.02 \% \quad 47.1 \%$ KIEVIKPGDLGVDLTSK $0.02 \% \quad 47.1 \%$ LSVISVEDPPQR $0.02 \% \quad 47.1 \%$ TAGVKVETTEDLVAK $0.02 \% \quad 47.1 \%$ VETTEDLVAK $0.02 \% \quad 24.6 \%$ IFDTYVGAQR $0.02 \% \quad 24.6 \%$ IENSLTYSK $0.02 \% \quad 24.6 \%$ NINPEKDASFK $0.02 \% \quad 24.6 \%$ MCLLQITGYK $0.02 \% \quad 24.6 \%$ QLYLDVESVR $0.02 \% \quad 24.6 \%$ LWNLLMPTK $0.02 \% \quad 24.6 \%$ QWAEIGFQGDDPK $235 \quad 0.26 \% \quad 34.2 \%$ THINIVVIGHVDSGK $235 \quad 0.26 \% \quad 34.2 \%$ STTTGHLIYK

$235 \quad 0.26 \% \quad 34.2 \%$ YYVTIIDAPGHR

$235 \quad 0.26 \% \quad 34.2 \%$ YYVTIIDAPGHRDFIK

$235 \quad 0.26 \% \quad 34.2 \%$ NGQTREHALLAYTLGVK

$235 \quad 0.26 \% \quad 34.2 \%$ EHALLAYTLGVK

$235 \quad 0.26 \% \quad 34.2 \%$ QLIVGVNK

$235 \quad 0.26 \% \quad 34.2 \%$ YEEIVKEVSTYIK

$235 \quad 0.26 \% \quad 34.2 \%$ EVSTYIKK

$235 \quad 0.26 \% \quad 34.2 \%$ LPLQDVYK

$235 \quad 0.26 \% \quad 34.2 \%$ IGGIGTVPVGR

$235 \quad 0.26 \% \quad 34.2 \%$ VETGVLKPGMVVTFAPVNVTTEVK

235

$20 \quad 235 \quad 0.26 \% \quad 34.2 \%$ DMRQTVAVGVIK

$20 \quad 235 \quad 0.26 \% \quad 34.2 \%$ QTVAVGVIK

$0.01 \% \quad 16.0 \%$ SPAGLQVLNDYLADK

$0.01 \% \quad 16.0 \%$ ASLPGVKK

$0.01 \% \quad 16.0 \%$ SIQADGLVWGSSK

$0.01 \% \quad 20.3 \%$ SLAGSSGPGASSGTSGDHGELVVR

$0.01 \% \quad 20.3 \%$ IASLEVENQSLR

$0.01 \% \quad 20.3 \%$ GVVQELQQAISK

$0.01 \% \quad 20.3 \%$ LVPVGYGIR

$0.02 \% \quad 16.9 \%$ ALIAAQYSGAQVR

$0.02 \% \quad 16.9 \%$ ILGLLDAYLK

$0.02 \% \quad 16.9 \%$ QVLEPSFR

$0.02 \% \quad 16.9 \%$ QAFPNTNR

$0.02 \% \quad 16.9 \%$ AVLGEVKLCEK

$0.02 \% \quad 16.9 \%$ STFVLDEFKR

$0.02 \% \quad 16.9 \%$ KLDPGSEETQTLVR

$0.02 \% \quad 16.9 \%$ LDPGSEETQTLVR

$0.09 \% \quad 19.7 \%$ VNFTVDQIR

$0.09 \% \quad 19.7 \%$ STLTDSLVCK $\begin{array}{llll}94.7 \% & 15.1 & 25.0 & 12.9\end{array}$

$99.0 \% \quad 64.7 \quad 25.0 \quad 53.6$

$\begin{array}{llll}96.9 \% & 16.5 & 25.0 & 15.0\end{array}$

$\begin{array}{llll}99.7 \% & 42.2 & 25.0 & 38.5\end{array}$

$\begin{array}{llll}96.1 \% & 14.9 & 25.0 & 14.9\end{array}$

$\begin{array}{llll}99.7 \% & 55.2 & 25.0 & 54.8\end{array}$

$\begin{array}{llll}99.7 \% & 33.0 & 25.0 & 33.0\end{array}$

$\begin{array}{lllll}99.7 \% & 46.7 & 25.0 & 37.7 & 2\end{array}$

$\begin{array}{llll}99.7 \% & 58.5 & 25.0 & 49.9\end{array}$

$99.7 \% \quad 50.6 \quad 25.0 \quad 48.9$

$99.7 \% \quad 34.2 \quad 25.0 \quad 24.9$

$99.7 \% \quad 38.1 \quad 25.0 \quad 32.4$

$\begin{array}{llll}99.7 \% & 46.5 & 25.0 & 43.8\end{array}$

$99.7 \% \quad 48.1 \quad 25.0 \quad 42.4$

$\begin{array}{llll}99.7 \% & 37.9 & 25.0 & 37.9\end{array}$

$99.7 \% \quad 54.3 \quad 25.0 \quad 54.3$

$99.7 \% \quad 49.0 \quad 25.0 \quad 42.4$

$\begin{array}{llll}99.7 \% & 53.8 & 25.0 & 51.5\end{array}$

$\begin{array}{llll}99.7 \% & 40.7 & 25.0 & 40.7\end{array}$

$\begin{array}{llll}99.7 \% & 31.3 & 25.0 & 31.3\end{array}$

$\begin{array}{llll}99.7 \% & 58.9 & 25.0 & 49.8\end{array}$

$\begin{array}{llll}99.0 \% & 42.2 & 25.0 & 31.3\end{array}$

$\begin{array}{llll}99.7 \% & 57.8 & 25.0 & 57.8\end{array}$

$\begin{array}{llll}99.0 \% & 46.1 & 25.0 & 38.5\end{array}$

$99.0 \% \quad 59.9 \quad 25.0 \quad 52.2$

$\begin{array}{llll}99.7 \% & 60.7 & 25.0 & 51.5\end{array}$

$\begin{array}{llll}99.7 \% & 52.1 & 25.0 & 52.1\end{array}$

$\begin{array}{llll}99.7 \% & 60.4 & 25.0 & 59.9\end{array}$

$\begin{array}{llll}99.7 \% & 47.5 & 25.0 & 19.5\end{array}$

$99.7 \% \quad 47.4 \quad 25.0 \quad 36.9$

$\begin{array}{llll}99.7 \% & 70.4 & 25.0 & 70.4\end{array}$

$\begin{array}{llll}99.0 \% & 21.2 & 25.0 & 21.2\end{array}$

$\begin{array}{llll}99.7 \% & 82.2 & 25.0 & 82.0\end{array}$

$\begin{array}{llll}99.7 \% & 30.1 & 25.0 & 29.9\end{array}$

$\begin{array}{llll}99.7 \% & 48.8 & 25.0 & 42.0\end{array}$

$\begin{array}{llll}99.7 \% & 59.1 & 25.0 & 46.2\end{array}$

$\begin{array}{llll}95.7 \% & 14.6 & 25.0 & 14.6\end{array}$

$99.7 \% \quad 56.6 \quad 25.0 \quad 51.2$

$\begin{array}{llll}99.7 \% & 33.6 & 25.0 & 32.4\end{array}$

$\begin{array}{llll}99.0 \% & 34.8 & 25.0 & 22.0\end{array}$

$\begin{array}{llll}98.8 \% & 19.7 & 25.0 & 16.8\end{array}$

$99.7 \% \quad 58.1 \quad 25.0 \quad 51.5$

$\begin{array}{llll}99.7 \% & 55.8 & 25.0 & 48.5\end{array}$

$\begin{array}{llll}99.7 \% & 46.5 & 25.0 & 32.3\end{array}$

$\begin{array}{llll}99.7 \% & 59.5 & 25.0 & 55.8\end{array}$

$\begin{array}{llll}99.7 \% & 61.4 & 25.0 & 50.2\end{array}$

$99.7 \% \quad 51.4 \quad 25.0 \quad 45.0$

0
0
0
0
0
0
0
0
0
0
0
0
8
0
3
4
3
5
0
0
0
0
0
0
0
0
0
1
0
0
0
0
0
0
0
0
0
0
0
0
0
0
853.53

1113.69

1102.57

1812.05

1339.72

1560.85

1104.58

1169.60

1054.54

1262.64

1242.62

1221.65

1115.63

1490.69

1588.88

1120.60

1404.73

1908.00

1871.01

1314.74

870.54

1600.85

967.55

975.55

1025.61

2531.38

2496.18

1316.74

914.57

1603.83

799.50

1347.69

2185.05

1358.73

1299.73

973.58

1347.74

1118.68

975.53

947.47

1245.69

1241.65

1572.82

1444.73

1091.58

1123.57

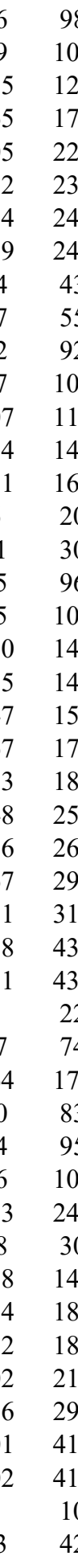

(1) 
$\begin{array}{lllllll}\text { EF2 HUMAN } 95.34 & 100.0 \% & 17 & 20 & 81 & 0.09 \% & 19.7 \% \\ \end{array}$ EF2_HUMAN $95.34 \quad 100.0 \% \quad 17 \quad 20 \quad 81 \quad 0.09 \% \quad 19.7 \%$ GEGQLGPAER EF2_HUMAN $95.34 \quad 100.0 \% \quad 17$ EF2 HUMAN $95.34 \quad 100.0 \% \quad 17$ EF2_HUMAN $95.34 \quad 100.0 \% \quad 17$ EF2_HUMAN $95.34 \quad 100.0 \% \quad 17$ EF2 HUMAN $95.34 \quad 100.0 \% \quad 17$ EF2_HUMAN $95.34 \quad 100.0 \% \quad 17$ EF2 HUMAN $95.34 \quad 100.0 \% \quad 17$ EF2_HUMAN $95.34 \quad 100.0 \% \quad 17$ EF2_HUMAN $95.34 \quad 100.0 \% \quad 17$ EF2 HUMAN $95.34 \quad 100.0 \% \quad 17$ EF2_HUMAN $95.34 \quad 100.0 \% \quad 17$ EF2_HUMAN $95.34 \quad 100.0 \% \quad 17$ EF2 HUMAN $95.34 \quad 100.0 \% \quad 17$ $\begin{array}{rrrr}\text { EF2_HUMAN } & 95.34 & 100.0 \% & 17 \\ & \end{array}$

$\begin{array}{llll}20 & 81 & 0.09 \% & 19.7 \% \\ 20 & \text { TFCQLILDPIFK }\end{array}$

$\begin{array}{llll}20 & 81 & 0.09 \% & 19.7 \% \\ & 8 F D A I M N F K\end{array}$

$\begin{array}{llll}20 & 81 & 0.09 \% & 19.7 \% \\ 20 & \text { VFSGLVSTGLK }\end{array}$

$20 \quad 81 \quad 0.09 \% \quad 19.7 \%$ FSVSPVVR

$\begin{array}{llll}20 & 81 & 0.09 \% & 19.7 \% \\ 20 & 81 & 0.09 \% & 19.7 \% \text { EAVAKNPADLPK }\end{array}$

$20 \quad 81 \quad 0.09 \% \quad 19.7 \%$ ETVSEESNVLCLSK

$\begin{array}{llll}20 & 81 & 0.09 \% & 19.7 \% \\ 20 & 81 & 0.09 \% & 19.7 \%\end{array}$

$20 \quad 81 \quad 0.09 \% \quad 19.7 \%$ GGGQIIPTAR

$20 \quad 81 \quad 0.09 \% \quad 19.7 \%$ RCLYASVLTAQPR

$\begin{array}{llll}20 & 81 & 0.09 \% & 19.7 \% \\ 20 & \text { CLYASVLTAQPR }\end{array}$
$20 \quad 81 \quad 0.09 \% \quad 19.7 \%$ VFSGLVSTGLKVR

$\begin{array}{llll}20 & 81 & 0.09 \% & 19.7 \% \\ 20 & \text { GHVFEESQVAGTPMFVVK }\end{array}$

$20 \quad 81 \quad 0.09 \% \quad 19.7 \%$ AYLPVNESFGFTADLR

$\begin{array}{llll}25 & 91 & 0.10 \% & 43.8 \% \\ 25 & 91 & \text { DKPHVNVGTIGHVDHGK }\end{array}$

\begin{tabular}{llll}
25 & 91 & $0.10 \%$ & $43.8 \%$ \\
\hline
\end{tabular}

$25 \quad 91 \quad 0.10 \% \quad 43.8 \%$ YEEIDNAPEER

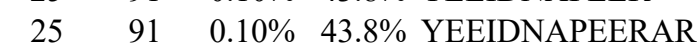

$25 \quad 91 \quad 0.10 \% \quad 43.8 \%$ GITINAAHVEYSTAAR

$25 \quad 91 \quad 0.10 \% \quad 43.8 \%$ HYAHTDCPGHADYVK

$25 \quad 91 \quad 0.10 \% \quad 43.8 \%$ QIGVEHVVVYVNK

$\begin{array}{llll}25 & 91 & 0.10 \% & 43.8 \% \\ 25 & \text { LLDAVDTYIPVPAR }\end{array}$

25

25

18

$0.10 \% \quad 43.8 \%$ DLEKPFLLPVEAVYSVPGR

$0.10 \% \quad 43.8 \%$ GDECELLGHSK

$0.10 \% \quad 43.8 \%$ TVVTGIEMFHK

$\begin{array}{lll}0.10 \% & 43.8 \% & \text { AEAGDNLGALVR }\end{array}$

$0.10 \% \quad 43.8 \%$ VEAQVYILSK

$0.10 \% \quad 43.8 \%$ VEAQVYILSKEEGGR

$\begin{array}{llll}\text { Elongation factor Tu, mitochondrial GN=TUFM EFTU_HUMAN } & 49.54 & 100.0 \% & 18 \\ \text { Elongation factor Tu, mitochondrial GN=TUFM EFTU_HUMAN } & 49.54 & 100.0 \% & 18\end{array}$

Elongator complex protein $1 \mathrm{GN}=$ IKBKAP ELP1_HUMAN $150.26 \quad 100.0 \% \quad 2$

Elongator complex protein $1 \mathrm{GN}=\mathrm{IKBKAP}$ ELP1_HUMAN $150.26 \quad 100.0 \%$

Emerin GN=EMD

Emerin $\mathrm{GN}=\mathrm{EMD}$

Emerin GN=EMD

Emerin $\mathrm{GN}=\mathrm{EMD}$

Emerin GN=EMD

Emerin GN=EMD

Emerin $\mathrm{GN}=\mathrm{EMD}$

Emerin GN=EMD

Emerin GN=EMD

Endoplasmin GN=HSP90B1

Endoplasmin GN=HSP90B1

Endoplasmin GN=HSP90B1

EMD HUMAN

EMD_HUMAN $28.99 \quad 100.0 \%$

EMD_HUMAN $28.99 \quad 100.0 \% \quad-9$

EMD_HUMAN $28.99 \quad 100.0 \% \quad 9$

EMD_HUMAN $28.99 \quad 100.0 \%$

EMD HUMAN $28.99 \quad 100.0 \% \quad 9$

EMD_HUMAN $28.99 \quad 100.0 \%$

EMD HUMAN $28.99 \quad 100.0 \%$

EMD_HUMAN $28.99 \quad 100.0 \%$

ENPL_HUMAN $92.47 \quad 100.0 \%$

ENPL HUMAN $92.47 \quad 100.0 \%$

ENPL_HUMAN $92.47 \quad 100.0 \%$

$99.3 \% \quad 18.5$

$\begin{array}{lll}99.7 \% & 58.6\end{array}$

$0.10 \% \quad 43.8 \%$ TIGTGLVTNTLAMTEEEK $99.7 \% \quad 44.9$

$0.00 \% \quad 1.2 \%$ ALVLAQIR

$0.00 \% \quad 1.2 \% \quad$ FTIDKYLK

$0.03 \% \quad 46.1 \%$ YNIPHGPVVGSTR

$0.03 \% \quad 46.1 \%$ KIFEYETQR

$\begin{array}{llll}99.0 \% & 24.5 & 25.0 & 20.8\end{array}$

$0.03 \% \quad 46.1 \%$ LSPPSSSAASSYSFSDLNSTR $99.7 \% \quad 97.0$

$0.03 \% \quad 46.1 \%$ GDADMYDLPK

$0.03 \% \quad 46.1 \%$ KEDALLYQSK

$0.03 \% \quad 46.1 \%$ GYNDDYYEESYFTTR

$0.03 \% \quad 46.1 \%$ TYGEPESAGPSR

$99.7 \% \quad 70.9$

$99.7 \% \quad 73.5$

$0.03 \% \quad 46.1 \%$ DSAYQSITHYRPVSASR

$0.03 \% \quad 46.1 \%$ APGAGLGQDR

$0.00 \% \quad 4.7 \%$ ELISNASDALDK

$0.00 \% \quad 4.7 \% \quad$ ELISNASDALDKIR

$0.00 \% \quad 4.7 \%$ GVVDSDDLPLNVSR $\begin{array}{llllll}99.7 \% & 37.2 & 25.0 & 41.2 & 2 & 2 \\ & 25.0 & 28.8 & 10 & 0\end{array}$

$\begin{array}{llllll}99.7 \% & 43.0 & 25.0 & 43.0 & 2 & 0\end{array}$

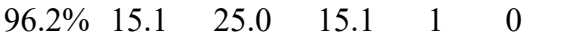

$\begin{array}{llllll}99.7 \% & 49.7 & 25.0 & 37.2 & 2 & 0\end{array}$

$\begin{array}{llllll}99.7 \% & 46.9 & 25.0 & 46.9 & 2 & 0\end{array}$

$\begin{array}{lllllll}98.4 \% & 18.4 & 25.0 & 16.7 & 2 & 0\end{array}$

$\begin{array}{llllll}99.7 \% & 49.4 & 25.0 & 48.0 & 2 & 4\end{array}$

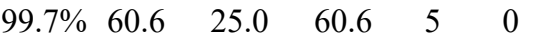

$99.7 \% \quad 53.9 \quad 25.0 \quad 47.4 \quad 3$

$\begin{array}{lllll}99.7 \% & 35.9 & 25.0 & 33.7 & 17\end{array}$

$99.7 \% \quad 47.1 \quad 25.0 \quad 46.9 \quad 2$

$\begin{array}{lllll}99.7 \% & 55.5 & 25.0 & 51.7 & 7\end{array}$

$\begin{array}{llll}99.7 \% & 50.6 & 25.0 & 49.6\end{array}$

$\begin{array}{lllll}99.7 \% & 46.5 & 25.0 & 46.5 & 0\end{array}$

$\begin{array}{llll}99.7 \% & 53.3 & 25.0 & 48.5\end{array}$

$\begin{array}{lllll}99.7 \% & 58.5 & 25.0 & 58.5 & 2\end{array}$

$\begin{array}{llll}99.7 \% & 41.9 & 25.0 & 36.7\end{array}$

$\begin{array}{llll}99.7 \% & 58.7 & 25.0 & 51.0\end{array}$

$99.7 \% \quad 38.4 \quad 25.0 \quad 38.4$

$\begin{array}{lllll}99.7 \% & 60.8 & 25.0 & 51.9 & 5\end{array}$

$\begin{array}{llll}99.7 \% & 55.3 & 25.0 & 55.3\end{array}$

$99.7 \% \quad 57.3$

$99.7 \% \quad 67.5$

$\begin{array}{lll}99.7 \% & 39.8\end{array}$

$99.7 \% \quad 57.0$

$\begin{array}{lll}99.7 \% & 56.9\end{array}$

$99.0 \% \quad 28.8$

$99.7 \% \quad 47.0$

$99.7 \% \quad 48.4$

$99.7 \% \quad 28.8$

$99.7 \% \quad 61.7$

1430.74

1013.50

1494.80

1084.55

1107.64

1362.81

890.51

1351.76

1594.76

1208.50

969.55

1534.82

1378.71

1977.97

1799.90

1809.94

919.55

1364.60

1591.73

1673.86

1770.77

1483.83

1542.85

2129.16

1032.57

1372.65

1244.56

1277.66

1670.88

1185.62

1149.65

1677.88

1907.96

883.57

1027.58

1396.73

1213.62

2161.00

1140.49

1194.64

1922.77

1250.56

1937.95

941.48

$\begin{array}{lllll}99.7 \% & 43.5 & 25.0 & 34.5\end{array}$

$\begin{array}{llll}99.7 \% & 57.2 & 25.0 & 52.6\end{array}$

$99.7 \% \quad 522 \quad 25.0 \quad 46.6$ $\begin{array}{llll}99.7 \% & 52.7 & 25.0 & 50.5\end{array}$

1275.64

1544.83 1485.75 
Endoplasmin GN=HSP90B1 Epiplakin GN=EPPK1 Epiplakin GN=EPPK1

Epiplakin GN=EPPK1

Epiplakin $\mathrm{GN}=\mathrm{EPPK} 1 \mathrm{n}$ ER membrane protein complex subunit 2 GN=EMC2 EMC2_HUMAN $34.83 \quad 100.0 \%$ ER membrane protein complex subunit $3 \mathrm{GN}=\mathrm{EMC} 3$ EMC3_HUMAN $29.95 \quad 100.0 \%$ ER membrane protein complex subunit $3 \mathrm{GN}=\mathrm{EMC} 3$ EMC3_HUMAN $29.95 \quad 100.0 \%$ Erlin-1 GN=ERLIN1

Erlin-1 GN=ERLIN1

Erlin-1 GN=ERLIN1

Erlin-1 GN=ERLIN1

Erlin-1 GN=ERLIN1

Erlin-1 GN=ERLIN1

Erlin-1 GN=ERLIN1

Erlin-1 GN=ERLIN1

Erlin-1 GN=ERLIN1

Erlin-1 GN=ERLIN1

Erlin-1 GN=ERLIN1

Erlin-2 GN=ERLIN2

Erlin-2 GN=ERLIN2

Erlin-2 GN=ERLIN2

Erlin-2 GN=ERLIN2

Erlin-2 GN=ERLIN2

Erlin-2 GN=ERLIN2

Erlin-2 GN=ERLIN2

Erlin-2 GN=ERLIN2

Erlin-2 GN=ERLIN2

Erlin-2 GN=ERLIN2

Erlin-2 GN=ERLIN2

Erlin-2 GN=ERLIN2

Erlin-2 GN=ERLIN2

Erlin-2 GN=ERLIN2

Erlin-2 GN=ERLIN2

Erlin-2 GN=ERLIN2

Erlin-2 GN=ERLIN2

Erlin-2 GN=ERLIN2

Erythrocyte band 7 integral membrane protein GN=STOM STOM_HUMAN $31.73 \quad 100.0 \%$ $\begin{array}{lll}\text { Erythrocyte band } 7 \text { integral membrane protein GN=STOM STOM_HUMAN } 31.73 \quad 100.0 \% & 0.00\end{array}$ Erythrocyte band 7 integral membrane protein GN=STOM STOM_HUMAN $31.73 \quad 100.0 \%$ Erythrocyte band 7 integral membrane protein GN=STOM STOM_HUMAN $31.73 \quad 100.0 \%$ Erythrocyte band 7 integral membrane protein GN=STOM STOM_HUMAN $31.73 \quad 100.0 \%$ Estradiol 17-beta-dehydrogenase $11 \mathrm{GN}=$ HSD17B11 DHB11_HUMAN $32.94 \quad 100.0 \%$ Estradiol 17-beta-dehydrogenase $11 \mathrm{GN}=$ HSD17B11 DHB11_HUMAN $32.94 \quad 100.0 \%$ Estradiol 17-beta-dehydrogenase $11 \mathrm{GN}=$ HSD17B11 DHB11_HUMAN $32.94 \quad 100.0 \%$ Ethylmalonyl-CoA decarboxylase GN=ECHDC1 ECHD1_HUMAN $33.70 \quad 100.0 \%$ Ethylmalonyl-CoA decarboxylase GN=ECHDC1 ECHD1_HUMAN $33.70 \quad 100.0 \%$

$\begin{array}{lll}2 & \end{array}$

ERLN1_HUMAN $38.93 \quad 100.0 \%$

ERLN1_HUMAN $38.93 \quad 100.0 \%$

ERLN2 HUMAN $37.84 \quad 100.0 \%$

ERLN2 HUMAN $37.84 \quad 100.0 \%$

ERLN2_HUMAN $37.84 \quad 100.0 \%$

ERLN2 HUMAN $37.84 \quad 100.0 \%$

ERLN2 HUMAN $37.84 \quad 100.0 \%$

ERLN2 HUMAN $37.84 \quad 100.0 \%$

ERLN2_HUMAN $37.84 \quad 100.0 \%$

$\begin{array}{llll}\text { ERLN2_HUMAN } & 37.84 & 100.0 \% & 18 \\ \text { ERLN2 HUMAN } & 37.84 & 100.0 \% & 18\end{array}$
$0.00 \% \quad 4.7 \% \quad$ EAESSPFVER

$0.00 \% \quad 0.6 \%$ VPVDVAYR

$99.7 \% \quad 31.4$

$99.0 \% 36.8$

ERLN2_HUMAN $37.84 \quad 100.0 \%$

ERLN2 HUMAN $37.84 \quad 100.0 \% \quad 18$

ERLN2 HUMAN $37.84 \quad 100.0 \% \quad 18$

ERLN2_HUMAN $37.84 \quad 100.0 \% \quad 18$

ERLN2_HUMAN $37.84 \quad 100.0 \% \quad 18$

ERLN2 HUMAN $37.84 \quad 100.0 \% \quad 18$

10

$0.03 \% \quad 37.3 \%$ EALEPSGENVIQNK

$0.07 \% \quad 52.8 \%$ KISEIEDAAFLAR

$0.07 \% \quad 52.8 \%$ AKADAECYTAMK

$0.01 \% \quad 22.6 \%$ AMAAEAEASR
$0.00 \% \quad 0.6 \%$ GSAVHQLSEELR

$0.00 \% \quad 0.6 \%$ AEAEAGSPRPDPR

$0.00 \% \quad 8.4 \% \quad$ ILQEDPTNTAAR

$0.00 \% \quad 8.4 \% \quad$ YTQGGLENLELSR

$0.00 \% \quad 10.0 \%$ AGPELLLDSNIR

$0.00 \% \quad 10.0 \%$ LTQEQVSDSQVLIR

$0.03 \% \quad 37.3 \%$ IEEGHLAVYYR

$0.03 \% \quad 37.3 \%$ SVQTTLQTDEVK

$0.03 \% \quad 37.3 \%$ DLNLMAPGLTIQAVR

$0.03 \% \quad 37.3 \%$ NFELMEAEK

$0.03 \% \quad 37.3 \%$ VVEKEAETER

$0.03 \% \quad 37.3 \%$ ISEIEDAAFLAR

$0.03 \% \quad 37.3 \%$ ADAEYYAAHK

$0.03 \% \quad 37.3 \%$ LTPEYLELKK

$99.2 \% \quad 24.8$

$99.7 \% \quad 30.2$

$99.7 \% \quad 59.9$

$99.7 \% 78.6$

$99.7 \% \quad 63.8$

$99.7 \% \quad 53.2$

$99.7 \% \quad 45$.

$99.7 \% \quad 53.9$

$99.7 \% \quad 59.8$

$99.7 \% 32.1$

$99.7 \% \quad 48.2$

$99.7 \% \quad 89.4$

$99.7 \% \quad 52.5$

$99.7 \% 33.1$

$0.03 \% \quad 37.3 \%$ IYFGSNIPNMFVDSSCALK

$0.03 \% \quad 37.3 \%$ ESSLPSKEALEPSGENVIQNK

$0.07 \% \quad 52.8 \%$ IEEGHIGVYYR

$0.07 \% \quad 52.8 \%$ SVQTTLQTDEVK

$\begin{array}{lll}99.7 \% & 45.3\end{array}$

$99.7 \% \quad 58.7$

$99.7 \% \quad 44.0$

$99.7 \% \quad 53.9$

$0.07 \% \quad 52.8 \%$ NVPCGTSGGVMIYFDR $\quad 97.8 \% \quad 17.5$

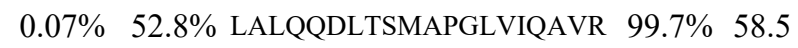

$0.07 \% \quad 52.8 \%$ VTKPNIPEAIR

$0.07 \% \quad 52.8 \%$ VTKPNIPEAIRR

$0.07 \% \quad 52.8 \%$ NYELMESEK

$0.07 \% \quad 52.8 \%$ NYELMESEKTK

$0.07 \% \quad 52.8 \%$ VVEKEAETER

$0.07 \% \quad 52.8 \%$ VAQVAEITYGQK

$0.07 \% \quad 52.8 \%$ ISEIEDAAFLAR

$0.07 \% \quad 52.8 \%$ ADAECYTAMK

$0.07 \% \quad 52.8 \%$ LTPEYLQLMK

$0.07 \% \quad 52.8 \%$ DIPNMFMDSAGSVSK

$99.7 \% \quad 42.0$

$98.8 \% 18.9$

$99.7 \% 33.8$

$99.7 \% \quad 52.4$

$99.7 \% \quad 48.2$

$99.7 \% \quad 62.6$

$99.7 \% \quad 35.7$

$99.7 \% \quad 89.4$

$99.7 \% \quad 58.7$

$99.7 \% \quad 51.8$

$99.7 \% \quad 49.8$

$99.7 \% \quad 59.5$

$99.0 \% \quad 26.4$

$0.07 \% \quad 52.8 \%$ QFEGLADK

$\begin{array}{llll}0.07 \% & 52.8 \% & \text { LSFGLEDEPLETATKEN } \quad 99.7 \% \quad 61.8\end{array}$

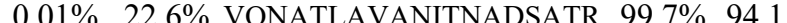

$0.01 \% \quad 22.6 \%$ LLAQTTLR

$0.01 \% \quad 22.6 \%$ VIAAEGEMNASR

$99.0 \% \quad 52.2$

$97.1 \% \quad 16.8$

$99.7 \% 53.5$

$0.01 \% \quad 22.6 \%$ EASMVITESPAALQLR

$99.7 \% \quad 27.4$

$99.7 \% \quad 57.5$

$0.00 \% \quad 13.7 \%$ TLTDELAALQITGVK

$\begin{array}{rr}99.7 \% & 68.6\end{array}$

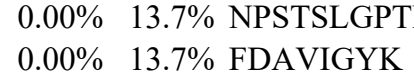

$99.0 \% \quad 35.1$

$99.7 \% \quad 58.0$

$99.7 \% \quad 63.0$

1325.68

1352.66

1328.68

1479.74

1297.71

1615.87

1349.68

1348.70

1611.89

1126.51

1189.61

1334.70

1138.52

1233.71

2179.02

2256.14

1527.77

1335.67

1348.70

1788.80

2140.18

1237.73

1393.83

1158.50

1387.64

1189.61

1306.70

1462.79

1334.70

1358.61

1175.47

1251.67

1630.71

907.45

1892.91

1930.00

915.56

1006.46

1263.60

1715.90

1572.88

1938.98

912.48

1612.83

$0.02 \% \quad 39.7 \%$ EDNGIGILTLNNPSR

$0.02 \% \quad 39.7 \%$ VIELENWTEGK

1317.67 
Ethylmalonyl-CoA decarboxylase GN=ECHDC1 ECHD1_HUMAN $33.70 \quad 100.0 \%$ Ethylmalonyl-CoA decarboxylase GN=ECHDC1 ECHD1_HUMAN $33.70 \quad 100.0 \%$ Ethylmalonyl-CoA decarboxylase GN=ECHDC1 ECHD1_HUMAN $33.70 \quad 100.0 \%$ Ethylmalonyl-CoA decarboxylase GN=ECHDC1 ECHD1 HUMAN $33.70 \quad 100.0 \%$ Ethylmalonyl-CoA decarboxylase GN=ECHDC1 ECHD1_HUMAN $33.70 \quad 100.0 \%$ Ethylmalonyl-CoA decarboxylase GN=ECHDC1 ECHD1_HUMAN $33.70 \quad 100.0 \%$ Ethylmalonyl-CoA decarboxylase GN=ECHDC1 ECHD1_HUMAN $33.70 \quad 100.0 \%$ Etoposide-induced protein 2.4 homolog GN=EI24 EI24_HUMAN $38.97 \quad 100.0 \%$ Etoposide-induced protein 2.4 homolog GN=EI24 EI24_HUMAN $38.97 \quad 100.0 \%$ Eukaryotic initiation factor 4A-I GN=EIF4A1 IF4A1_HUMAN $46.16 \quad 100.0 \%$ Eukaryotic initiation factor 4A-I GN=EIF4A1 IF4A1_HUMAN $46.16 \quad 100.0 \%$ Eukaryotic initiation factor 4A-I GN=EIF4A1 IF4A1_HUMAN $46.16 \quad 100.0 \%$ Eukaryotic initiation factor 4A-I GN=EIF4A1 IF4A1_HUMAN $46.16 \quad 100.0 \%$ Eukaryotic initiation factor 4A-I GN=EIF4A1 IF4A1_HUMAN $46.16 \quad 100.0 \%$ Eukaryotic initiation factor 4A-I GN=EIF4A1 IF4A1_HUMAN $46.16 \quad 100.0 \%$ Eukaryotic initiation factor 4A-I GN=EIF4A1 IF4A1_HUMAN $46.16 \quad 100.0 \%$ Eukaryotic initiation factor 4A-I GN=EIF4A1 IF4A1 HUMAN $46.16 \quad 100.0 \%$ Eukaryotic initiation factor 4A-I GN=EIF4A1 IF4A1_HUMAN $46.16 \quad 100.0 \%$ Eukaryotic initiation factor 4A-I GN=EIF4A1 IF4A1_HUMAN $46.16 \quad 100.0 \%$ Eukaryotic initiation factor 4A-I GN=EIF4A1 IF4A1_HUMAN $46.16 \quad 100.0 \%$ Eukaryotic initiation factor 4A-I GN=EIF4A1 IF4A1_HUMAN $46.16 \quad 100.0 \%$ Eukaryotic initiation factor 4A-III GN=EIF4A3 IF4A3_HUMAN 46.87 Eukaryotic initation factor 4 A-III GN=EIF4A3 IF4A3_HUMAN Eukaryotic initiation factor 4A-III GN=EIF4A3 IF4A3_HUMAN 46.87 Eukaryotic initiation factor 4A-III GN=EIF4A3 IF4A3 HUMAN 46.87 Eukaryotic initiation factor 4A-III GN=EIF4A3 IF4A3_HUMAN 46.87 Eukaryotic initiation factor 4A-III GN=EIF4A3 IF4A3_HUMAN 46.87 Eukaryotic initiation factor 4A-III GN=EIF4A3 IF4A3_HUMAN 46.87 Eukaryotic initiation factor 4A-III GN=EIF4A3 IF4A3_HUMAN $46.8^{\circ}$ Eukaryotic initiation factor 4A-III GN=EIF4A3 IF4A3 HUMAN 46.8 Eukaryotic initiation factor 4A-III GN=EIF4A3 IF4A3_HUMAN 46.87 Eukaryotic initiation factor 4A-III GN=EIF4A3 IF4A3_HUMAN 46.87 Eukaryotic initiation factor 4A-III GN=EIF4A3 IF4A3_HUMAN 46.87 Eukaryotic translation initiation factor 2 subunit $1 \mathrm{GN}=\mathrm{EIF} 2 \mathrm{~S} 1 \mathrm{IF} 2 \mathrm{~A}$ _HUMAN 36.11 Eukaryotic translation initiation factor 2 subunit 1 GN=EIF2S1 IF2A_HUMAN 36.11 Eukaryotic translation initiation factor 3 subunit A GN=EIF3A EIF3A_HUMAN 166.57 Eukaryotic translation initiation factor 3 subunit A GN=EIF3A EIF3A_HUMAN 166.57 Eukaryotic translation initiation factor 3 subunit A GN=EIF3A EIF3A_HUMAN 166.57 Eukaryotic translation initiation factor 3 subunit A GN=EIF3A EIF3A_HUMAN 166.57 Eukaryotic translation initiation factor 3 subunit A GN=EIF3A EIF3A_HUMAN 166.57 Eukaryotic translation initiation factor 3 subunit A GN=EIF3A EIF3A HUMAN 166.57 Eukaryotic translation initiation factor 3 subunit A GN=EIF3A EIF3A_HUMAN $166.57 \quad 100.0^{\circ}$ Eukaryotic translation initiation factor 3 subunit A GN=EIF3A EIF3A_HUMAN $166.57 \quad 100.0 \%$ Eukaryotic translation initiation factor 3 subunit A GN=EIF3A EIF3A_HUMAN $166.57 \quad 100.0 \%$ Eukaryotic translation initiation factor 3 subunit A GN=EIF3A EIF3A_HUMAN $166.57 \quad 100.0 \%$ Eukaryotic translation initiation factor 3 subunit A GN=EIF3A EIF3A_HUMAN $166.57 \quad 100.0 \%$ Eukaryotic translation initiation factor 3 subunit A GN=EIF3A EIF3A_HUMAN $166.57 \quad 100.0 \%$

\section{$0.02 \% 39.7 \%$ NALNIGMVEELQSSDE} $99.7 \% \quad 57.0$ $99.6 \% 23.5$ $0.02 \% \quad 39.7 \%$ EMGIIPSWGGTT $99.7 \% \quad 66.8$ $99.7 \% \quad 58.1$ $99.7 \% \quad 36.3$ $99.7 \% \quad 45.8$ $0.02 \% \quad 39.7 \%$ SLEEAQEWLK $0.02 \% \quad 39.7 \%$ QFIQGPPEVIR

$10 \quad 20 \quad 0.02 \% \quad 39.7 \%$ ELYLEEALQNER $\begin{array}{rr}99.7 \% & 57.6\end{array}$

$0.02 \% \quad 39.7 \%$ DLLGTVWGGPANLEAIAK $0.01 \% \quad 5.9 \%$ TFLQDLAR

$0.01 \% \quad 5.9 \%$ VFIPVLQSVTAR

$0.05 \% \quad 35.7 \%$ GIYAYGFEKPSAIQQR $99.0 \% \quad 46.8$ $99.7 \% \quad 39.9$

$99.7 \% \quad 60.1$

$99.7 \% \quad 70.3$

$99.7 \% \quad 27.8$

$0.05 \% \quad 35.7 \%$ ATQALVLAPTR

$\begin{array}{lllll}0.05 \% & 35.7 \% & \text { VVMALGDYMGASCHACIGGTNVR } & 99.7 \% & 43.5\end{array}$

$\begin{array}{llll}0.05 \% & 35.7 \% & \text { AEVQKLQMEAPHIIVGTPGR } \quad 99.7 \% \quad 39.8\end{array}$

$0.05 \% \quad 35.7 \%$ LQMEAPHIIVGTPGR

$0.05 \% \quad 35.7 \%$ MFVLDEADEMLSR

$0.05 \% \quad 35.7 \%$ GFKDQIYDIFQK

$25.0 \quad 39.8$

$\begin{array}{llll}99.7 \% & 58.0 & 25.0 & 44.9\end{array}$

$99.7 \% \quad 51.9 \quad 25.0 \quad 46.4$

$\begin{array}{llll}99.7 \% & 42.7 & 25.0 & 30.1\end{array}$

$0.05 \% \quad 35.7 \%$ KEELTLEGIR

$0.05 \% \quad 35.7 \%$ EELTLEGIR

$99.6 \% \quad 23.0$

$0.05 \% \quad 35.7 \%$ DFTVSAMHGDMDQKER $99.4 \% 21.2$

$0.05 \% \quad 35.7 \%$ VLITTDLLAR

$0.03 \% \quad 26.5 \%$ GIYAYGFEKPSAIQQR

$0.03 \% \quad 26.5 \%$ GRDVIAQSQSGTGK

$0.03 \% \quad 26.5 \%$ ETQALILAPTR

$0.03 \% \quad 26.5 \%$ ELAVQIQK

$0.03 \% \quad 26.5 \%$ KLDYGQHVVAGTPGR

$0.03 \% \quad 26.5 \%$ LDYGQHVVAGTPGR

$0.03 \% \quad 26.5 \%$ GFKEQIYDVYR

$0.03 \% \quad 26.5 \%$ EQIYDVYR

$0.03 \% \quad 26.5 \%$ RDELTLEGIK

$0.03 \% \quad 26.5 \%$ VLISTDVWAR

$0.03 \% \quad 26.5 \%$ KGVAINFVK

$0.03 \% \quad 26.5 \%$ GVAINFVKNDDIR

$0.01 \% \quad 8.6 \%$ TEGLSVLSQAMAVIK

$0.01 \% \quad 8.6 \%$ VVTDTDETELAR

$0.05 \% \quad 14.0 \%$ PAYFQRPENALKR

$0.05 \% \quad 14.0 \%$ ANEFLEVGK

$0.05 \% \quad 14.0 \%$ IHEPIMLK

$\begin{array}{lll}0.05 \% & 14.0 \% \text { YLELCVDLRK }\end{array}$

$0.05 \% \quad 14.0 \%$ NICQQVNIK

$0.05 \% \quad 14.0 \%$ MHLSQIQR

$\quad 0.05 \% \quad 14.0 \%$ KPPKPQLMANYYNK

$0.05 \% \quad 14.0 \%$ SGNALFHASTLHR

$0.05 \% \quad 14.0 \%$ KNLTQDEMQR

$0.05 \% \quad 14.0 \%$ NLTQDEMQR

$0.05 \% \quad 14.0 \%$ LLDMDGIIVEK

$0.05 \% \quad 14.0 \%$ IGLINDMVR $\begin{array}{llll}99.7 \% & 60.1 & 25.0 & 59.4\end{array}$

$99.7 \% \quad 43.0 \quad 25.0 \quad 43.0$

$\begin{array}{llll}99.7 \% & 27.1 & 25.0 & 19.3\end{array}$

$99.0 \% \quad 38.9 \quad 25.0 \quad 30.9$

$\begin{array}{llll}99.7 \% & 42.9 & 25.0 & 39.3\end{array}$

$99.7 \% \quad 62.4 \quad 25.0 \quad 57.4$

$99.7 \% \quad 38.2 \quad 25.0 \quad 38.2$

$99.0 \% \quad 19.6 \quad 25.0 \quad 19.6$

$99.5 \% \quad 30.4 \quad 25.0 \quad 15.7$

$99.7 \% \quad 48.8 \quad 25.0 \quad 43.7$

$\begin{array}{llll}99.7 \% & 27.1 & 25.0 & 20.2\end{array}$

$\begin{array}{llll}96.6 \% & 18.8 & 25.0 & 17.2\end{array}$

$99.2 \% \quad 29.2 \quad 25.0 \quad 29.2$

$99.7 \% \quad 35.5 \quad 25.0 \quad 35.5$

$\begin{array}{llll}99.5 \% & 21.6 & 25.0 & 20.9\end{array}$

$\begin{array}{llll}99.7 \% & 40.7 & 25.0 & 35.1\end{array}$

$\begin{array}{llll}98.4 \% & 17.4 & 25.0 & 16.8\end{array}$

$\begin{array}{llll}99.7 \% & 31.0 & 25.0 & 29.2\end{array}$

$\begin{array}{llll}99.7 \% & 35.5 & 25.0 & 26.1\end{array}$

$\begin{array}{llll}99.0 \% & 35.2 & 25.0 & 24.6\end{array}$

$\begin{array}{llll}96.1 \% & 20.4 & 25.0 & 20.4\end{array}$

$\begin{array}{llll}99.7 \% & 37.2 & 25.0 & 33.5\end{array}$

$\begin{array}{llll}99.7 \% & 29.2 & 25.0 & 22.9\end{array}$

$99.7 \% \quad 53.0 \quad 25.0 \quad 50.0$

$\begin{array}{llll}99.7 \% & 38.7 & 25.0 & 35.2\end{array}$

$\begin{array}{llll}99.7 \% & 49.8 & 25.0 & 42.4\end{array}$
133

1404.69

2093.01

1232.62

1283.71

1506.74

1824.99

963.53

1329.79

1827.94

1394.69

1140.67

2471.09

2190.17

1634.87

1587.70

1501.77

1187.66

1059.57

1898.80

1114.68

1827.94

1403.72

1212.69

928.55

1597.84

1469.75

1417.71

1085.53

1173.65

1159.65

975.60

1460.79

1562.85

1348.66

1589.85

1006.52

980.56

1308.70

1116.58

1012.54

1707.89

1410.72

1262.62

1134.52

1261.67

1046.57

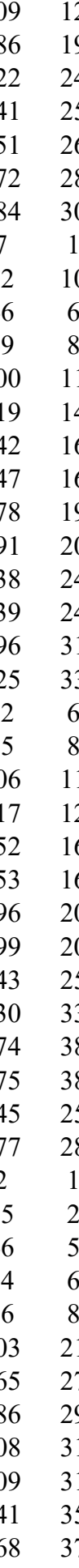


Eukaryotic translation initiation factor 3 subunit A GN=EIF3A EIF3A_HUMAN $166.57 \quad 100.0 \% \quad 22$ Eukaryotic translation initiation factor 3 subunit A GN=EIF3A EIF3A_HUMAN $166.57 \quad 100.0 \% 22$ Eukaryotic translation initiation factor 3 subunit A GN=EIF3A EIF3A_HUMAN $166.57 \quad 100.0 \% \quad 22$ Eukaryotic translation initiation factor 3 subunit A GN=EIF3A EIF3A_HUMAN $166.57 \quad 100.0 \%$ Eukaryotic translation initiation factor 3 subunit A GN=EIF3A EIF3A_HUMAN $166.57 \quad 100.0 \% \quad 22$ Eukaryotic translation initiation factor 3 subunit A GN=EIF3A EIF3A_HUMAN $166.57 \quad 100.0 \% 22$ Eukaryotic translation initiation factor 3 subunit A GN=EIF3A EIF3A_HUMAN $166.57 \quad 100.0 \% \quad 22$ Eukaryotic translation initiation factor 3 subunit A GN=EIF3A EIF3A_HUMAN $166.57 \quad 100.0 \% \quad 22$ Eukaryotic translation initiation factor 3 subunit A GN=EIF3A EIF3A_HUMAN $166.57 \quad 100.0 \% 22$ Eukaryotic translation initiation factor 3 subunit A GN=EIF3A EIF3A_HUMAN $166.57 \quad 100.0 \% 22$ Eukaryotic translation initiation factor 3 subunit B GN=EIF3B EIF3B_HUMAN $92.48 \quad 100.0 \%$ Eukaryotic translation initiation factor 3 subunit B GN=EIF3B EIF3B_HUMAN $92.48 \quad 100.0 \%$ Eukaryotic translation initiation factor 3 subunit B GN=EIF3B EIF3B_HUMAN $92.48 \quad 100.0 \%$ Eukaryotic translation initiation factor 3 subunit B GN=EIF3B EIF3B_HUMAN $92.48 \quad 100.0 \%$ Eukaryotic translation initiation factor 3 subunit B GN=EIF3B EIF3B_HUMAN $92.48 \quad 100.0 \%$ Eukaryotic translation initiation factor 3 subunit B GN=EIF3B EIF3B_HUMAN $92.48 \quad 100.0 \%$ Eukaryotic translation initiation factor 3 subunit $\mathrm{C}$ GN=EIF3C EIF3C HUMAN $105.35 \quad 100.0 \%$ Eukaryotic translation initiation factor 3 subunit $\mathrm{C}$ GN=EIF3C EIF3C_HUMAN $105.35 \quad 100.0 \%$ Eukaryotic translation initiation factor 3 subunit D GN=EIF3D EIF3D_HUMAN $63.97 \quad 100.0 \%$ Eukaryotic translation initiation factor 3 subunit D GN=EIF3D EIF3D HUMAN $63.97 \quad 100.0 \%$ Eukaryotic translation initiation factor 3 subunit D GN=EIF3D EIF3D_HUMAN $63.97 \quad 100.0 \%$ Eukaryotic translation initiation factor 3 subunit D GN=EIF3D EIF3D HUMAN $63.97 \quad 100.0 \%$ Eukaryotic translation initiation factor 3 subunit D GN=EIF3D EIF3D_HUMAN $63.97 \quad 100.0 \%$ Eukaryotic translation initiation factor 3 subunit D GN=EIF3D EIF3D_HUMAN $63.97 \quad 100.0 \%$ Eukaryotic translation initiation factor 3 subunit $\mathrm{E}$ GN=EIF3E EIF3E HUMAN $52.22 \quad 100.0^{\circ}$ Eukaryotic translation initiation factor 3 subunit $\mathrm{E}$ GN=EIF3E EIF3E_HUMAN $52.22 \quad 100.0 \%$ Eukaryotic translation initiation factor 3 subunit $\mathrm{E}$ GN=EIF3E EIF3E_HUMAN $52.22 \quad 100.0 \%$ Eukaryotic translation initiation factor 3 subunit E GN=EIF3E EIF3E_HUMAN $52.22 \quad 100.0 \%$ Eukaryotic translation initiation factor 3 subunit $\mathrm{E}$ GN=EIF3E EIF3E_HUMAN $52.22 \quad 100.0 \%$ Eukaryotic translation initiation factor 3 subunit $\mathrm{E}$ GN=EIF3E EIF3E HUMAN $52.22100 .0 \%$ Eukaryotic translation initiation factor 3 subunit E GN=EIF3E EIF3E_HUMAN $52.22 \quad 100.0 \%$ Eukaryotic translation initiation factor 3 subunit $\mathrm{E}$ GN=EIF3E EIF3E_HUMAN $52.22 \quad 100.0 \%$ Eukaryotic translation initiation factor 3 subunit $\mathrm{E}$ GN=EIF3E EIF3E HUMAN 52.22 Eukaryotic translation initiation factor 3 subunit $\mathrm{E}$ GN=EIF3E EIF3E_HUMAN 52.22 Eukaryotic translation initiation factor 3 subunit E GN=EIF3E EIF3E_HUMAN 52.22 Eukaryotic translation initiation factor 3 subunit $\mathrm{E}$ GN=EIF3E EIF3E HUMAN 52.22 Eukaryotic translation initiation factor 3 subunit E GN=EIF3E EIF3E HUMAN $52.22 \quad 100.0$ Eukaryotic translation initiation factor 3 subunit $\mathrm{E}$ GN=EIF3E EIF3E HUMAN $52.22 \quad 100.0^{\circ}$ Eukaryotic translation initiation factor 3 subunit E GN=EIF3E EIF3E_HUMAN $52.22 \quad 100.0 \%$ Eukaryotic translation initiation factor 3 subunit $\mathrm{F}$ GN=EIF3F EIF3F_HUMAN $37.56 \quad 100.0 \%$ Eukaryotic translation initiation factor 3 subunit $\mathrm{F}$ GN=EIF3F EIF3F HUMAN $37.56 \quad 100.0 \%$ Eukaryotic translation initiation factor 3 subunit F GN=EIF3F EIF3F_HUMAN $37.56 \quad 100.0 \%$ Eukaryotic translation initiation factor 3 subunit F GN=EIF3F EIF3F HUMAN $37.56 \quad 100.0 \%$ Eukaryotic translation initiation factor 3 subunit G GN=EIF3G EIF3G_HUMAN $35.61 \quad 100.0 \%$ Eukaryotic translation initiation factor 3 subunit G GN=EIF3G EIF3G_HUMAN $35.61 \quad 100.0 \%$ Eukaryotic translation initiation factor 3 subunit $\mathrm{H}$ GN=EIF3H EIF3H_HUMAN $39.93 \quad 100.0 \%$ Eukaryotic translation initiation factor 3 subunit $\mathrm{H}$ GN=EIF3H EIF3H_HUMAN $39.93 \quad 100.0 \%$

6

6
6
6

6
6
15

15
15

6

6

8

6
6

6
6

15

2

$46 \quad 0.05 \% \quad 14.0 \%$ TLSFGSDLNYATR $46 \quad 0.05 \% \quad 14.0 \%$ NQLTAMSSVLAK $46 \quad 0.05 \% \quad 14.0 \%$ LESLNIQR

$0.05 \% \quad 14.0 \%$ ILQEHEQIK

$0.05 \% \quad 14.0 \%$ ILQEHEQIKK

$\begin{array}{lll}4.05 \% & 14.0 \% \text { RLGDSSLSR }\end{array}$

$0.05 \% \quad 14.0 \%$ LGDSSLSR

$0.05 \% \quad 14.0 \%$ GLDDDRGPR

$0.05 \% \quad 14.0 \%$ NMDDDRLSR

$0.05 \% \quad 14.0 \%$ RVPPPALSR

$0.02 \% \quad 7.7 \%$ AQAVSEDAGGNEGR

$0.02 \% \quad 7.7 \% \quad$ AQAVSEDAGGNEGRAAEAEPR

$0.02 \% \quad 7.7 \%$ GTYLATFHQR

$14 \quad 0.02 \% \quad 7.7 \%$ GTQGVVTNFEIFR

$0.02 \% \quad 7.7 \%$ FAVLHGEAPR

$0.02 \% \quad 7.7 \%$ ISVSFYHVK

$0.00 \% \quad 2.4 \%$ SIVDKEGVPR

$0.00 \% \quad 2.4 \%$ AKELLGQGLLLR

$0.02 \% \quad 11.5 \%$ VADWTGATYQDKR

$0.02 \% \quad 11.5 \%$ IFHTVTTTDDPVIR

$0.02 \% \quad 11.5 \%$ IFHTVTTTDDPVIRK

$0.02 \% \quad 11.5 \%$ SVYSWDIVVQR

$0.02 \% \quad 11.5 \%$ LGDDIDLIVR

$0.02 \% \quad 11.5 \%$ GAVIATELKNNSYK

$0.04 \% \quad 32.1 \%$ NLYSDDIPHALR

$0.04 \% \quad 32.1 \%$ RTTVVAQLK

$0.04 \% \quad 32.1 \%$ TTVVAQLK

$0.04 \% 32.1 \%$ QLQAETEPIVK

$0.04 \% \quad 32.1 \%$ MFEDPETTR

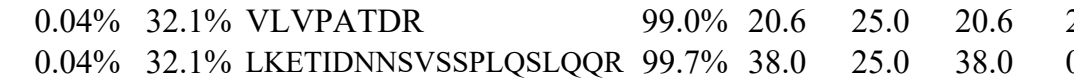

$41 \quad 0.04 \% \quad 32.1 \%$ ETIDNNSVSSPLQSLQQR

$0.04 \% \quad 32.1 \%$ YLTTAVITNK

$0.04 \% \quad 32.1 \%$ YLTTAVITNKDVR

$0.04 \% \quad 32.1 \%$ QVLKDLVK

$0.04 \% \quad 32.1 \%$ LFIFETFCR

$\begin{array}{lll}0.04 \% & 32.1 \% & \text { LGHVVMGNNAVSPYQQVIEK }\end{array}$

$0.04 \% 32.1 \%$ SQMLAMNIEK

$0.04 \% \quad 32.1 \%$ SEAPNWATQDSGFY

$0.01 \% \quad 15.1 \%$ EAPNPIHLTVDTSLQNGR

$0.01 \% \quad 15.1 \%$ YAYYDTER

$0.01 \% \quad 15.1 \%$ VIGLSSDLQQVGGASAR

$0.01 \% \quad 15.1 \%$ FLMSLVNQVPK

$0.00 \% \quad 7.2 \%$ LPGELEPVQATQNK

$0.00 \% \quad 7.2 \%$ GFAFISFHR

$\begin{array}{lllllll}0.01 \% & 8.2 \% & \text { KEGTGSTATSSSSTAGAAGK } & 99.7 \% & 30.3 & 25.0 & 23.8 \\ 0.01 \% & 8.2 \% & \text { EGTGSTATSSSSTAGAAGK } & 99.7 \% & 58.4 & 25.0 & 52.2\end{array}$ $\begin{array}{llll}2 & 0 & 0 & 1444.71\end{array}$

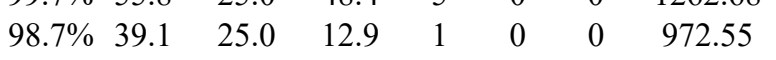

$\begin{array}{llllllll}99.5 \% & 25.7 & 25.0 & 16.1 & 1 & 0 & 0 & 1137.63\end{array}$

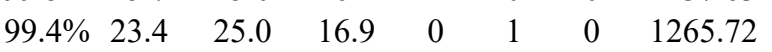

$\begin{array}{llllllll}96.0 \% & 26.1 & 25.0 & 18.2 & 1 & 0 & 0 & 990.53\end{array}$

$\begin{array}{llllllll}99.0 \% & 56.0 & 25.0 & 40.9 & 2 & 0 & 0 & 834.43\end{array}$

$\begin{array}{lllll}98.9 \% & 20.7 & 25.0 & 16.6 & 2\end{array}$

$99.7 \% \quad 36.6 \quad 25.0 \quad 36.6$

$\begin{array}{lllll}99.3 \% & 19.2 & 25.0 & 19.2\end{array}$

$99.7 \% \quad 66.8 \quad 25.0 \quad 66.8 \quad 2$

$\begin{array}{llll}99.7 \% & 43.6 & 25.0 & 42.7 \\ 99.7 \% & 56.9 & 25.0 & 51.7\end{array}$

$\begin{array}{lllll}99.7 \% & 53.4 & 25.0 & 53.4 & 3\end{array}$

$\begin{array}{llll}99.7 \% & 50.6 & 25.0 & 47.5\end{array}$

$99.7 \% \quad 31.9 \quad 25.0 \quad 22.2 \quad 2$

$\begin{array}{lllll}99.7 \% & 31.1 & 25.0 & 20.3 & 2 \\ 99.7 \% & 53.8 & 25.0 & 53.1 & \end{array}$

$\begin{array}{lllll}99.7 \% & 45.5 & 25.0 & 45.5 & 2\end{array}$

$\begin{array}{llll}99.7 \% & 36.9 & 25.0 & 36.9\end{array}$

$\begin{array}{llll}97.5 \% & 24.0 & 25.0 & 24.0\end{array}$

$\begin{array}{llll}99.7 \% & 55.7 & 25.0 & 47.9\end{array}$

$\begin{array}{lllll}99.7 \% & 52.5 & 25.0 & 44.4\end{array}$

$\begin{array}{lllll}99.7 \% & 72.5 & 25.0 & 49.6 & 4\end{array}$

$\begin{array}{lllll}99.7 \% & 59.2 & 25.0 & 52.6 & 3\end{array}$

$\begin{array}{lllll}99.7 \% & 29.4 & 25.0 & 21.9 & 2\end{array}$

$99.0 \% \quad 33.4 \quad 25.0 \quad 17.1 \quad 2$

$\begin{array}{lllll}99.7 \% & 49.0 & 25.0 & 33.1 & 3\end{array}$

$\begin{array}{lllll}99.7 \% & 40.0 & 25.0 & 28.4 & 2\end{array}$

$99.7 \% \quad 38.0$

$99.7 \% \quad 56.5$

$99.7 \% \quad 60.5$

$99.0 \% \quad 27.8$

$99.7 \% \quad 49.2$

$99.7 \% \quad 33.7$

$99.7 \% \quad 42.4$

$99.6 \% \quad 21.8$

$99.7 \% \quad 33.2$

$99.7 \% \quad 89.2$

$99.7 \% \quad 44.8$

$99.7 \% \quad 47.0$

$\begin{array}{ll}99.7 \% & 47.0 \\ 99.7 \% & 33.1\end{array}$

834.43
1000.48

1121.50

992.60

1360.61

2084.96

1193.61

1467.76

1096.59

1079.59

1099.61

1310.82

1510.73

1614.85

1742.94

1351.70

1128.63

1507.81

1413.71

1015.63

859.52

1255.69

1141.48

870.50

2257.18

2016.00

1123.64

1493.83

942.60

1232.61

2199.12

1196.57

1572.66

1962.00

1080.46

1657.89

1275.71

1523.81

1081.56

1755.84

1627.74 


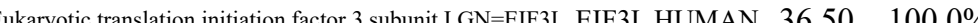
(a) translation initiation factor 3 subunit I GN=EIF3I EIF3I_HUMAN 36.50 Eukaryotic translation initiation factor 3 subunit I GN=EIF3I EIF3I_HUMAN 36.50 Eukaryotic translation initiation factor 3 subunit I GN=EIF3I EIF3I_HUMAN 36.50 Eukaryotic translation initiation factor 3 subunit I GN=EIF3I EIF3I_HUMAN 36.50 Eukaryotic translation initiation factor 3 subunit I GN=EIF3I EIF3I_HUMAN 36.50 Eukaryotic translation initiation factor 3 subunit I GN=EIF3I EIF3I_HUMAN 36.50 Eukaryotic translation initiation factor 3 subunit I GN=EIF3I EIF3I_HUMAN 36.50

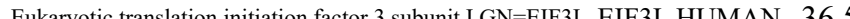
Eukaryotic translation initiation factor 3 subunit I GN=EIF3I EIF3I_HUMAN 36.50 Eukaryotic translation initiation factor 3 subunit I GN=EIF3I EIF3I_HUMAN 36.50 Eukaryotic translation initiation factor 3 subunit I GN=EIF3I EIF3I_HUMAN 36.50 Eukaryotic translation initiation factor 3 subunit $\mathrm{K}$ GN=EIF3K EIF3K_HUMAN 25.06 Eukaryotic translation initiation factor 3 subunit $\mathrm{K}$ GN=EIF3K EIF3K_HUMAN 25.06 Eukaryotic translation initiation factor 3 subunit K GN=EIF3K EIF3K_HUMAN 25.06 Eukaryotic translation initiation factor 3 subunit $\mathrm{K}$ GN=EIF3K EIF3K_HUMAN 25.0 Eukaryotic translation initiation factor 3 subunit $\mathrm{L}$ GN=EIF3L EIF3L_HUMAN 66.7 . Eukaryotic translation initiation factor 3 subunit $\mathrm{L}$ GN=EIF3L EIF3L_HUMAN 66.73 Eukaryotic translation initiation factor 3 subunit L GN=EIF3L EIF3L HUMAN 66.73 Eukaryotic translation initiation factor 3 subunit L GN=EIF3L EIF3L_HUMAN 66.7 Eukaryotic translation initiation factor 3 subunit $\mathrm{L}$ GN=EIF3L EIF3L_HUMAN 66.73 Eukaryotic translation initiation factor 3 subunit L GN=EIF3L EIF3L_HUMAN 66.73 Eukaryotic translation initiation factor 3 subunit $\mathrm{L}$ GN=EIF3L EIF3L_HUMAN 66.73 Eukaryotic translation initiation factor 3 subunit L GN=EIF3L EIF3L_HUMAN 66.73 Eukaryotic translation initiation factor 3 subunit L GN=EIF3L EIF3L_HUMAN 66.73 Eukaryotic translation initiation factor 3 subunit L GN=EIF3L EIF3L_HUMAN 66.73 Eukaryotic translation initiation factor 3 subunit L GN=EIF3L EIF3L HUMAN 66.73 Eukaryotic translation initiation factor 3 subunit L GN=EIF3L EIF3L_HUMAN 66.73 Eukaryotic translation initiation factor 3 subunit L GN=EIF3L EIF3L_HUMAN 66.73 Eukaryotic translation initiation factor 3 subunit M GN=EIF3M EIF3M_HUMAN 42.50 Eukaryotic translation initiation factor 3 subunit M GN=EIF3M EIF3M_HUMAN 42.50 Eukaryotic translation initiation factor 4 gamma $1 \mathrm{GN}=\mathrm{EIF} 4 \mathrm{G} 1 \quad$ IF4G1 HUMAN 175.49 Eukaryotic translation initiation factor 4 gamma 1 GN=EIF4G1 IF4G1_HUMAN $175.49 \quad 100.0 \%$ Eukaryotic translation initiation factor 4 gamma $1 \mathrm{GN}=\mathrm{EIF} 4 \mathrm{G} 1 \mathrm{IF} 4 \mathrm{G} 1$ HUMAN $175.49 \quad 100.0 \%$ Eukaryotic translation initiation factor 4 gamma $1 \mathrm{GN}=\mathrm{EIF} 4 \mathrm{G} 1 \quad$ IF4G1_HUMAN $175.49 \quad 100.0 \%$ Eukaryotic translation initiation factor 4 gamma 1 GN=EIF4G1 IF4G1_HUMAN $175.49 \quad 100.0 \%$ Eukaryotic translation initiation factor 4 gamma $2 \mathrm{GN}=\mathrm{EIF} 4 \mathrm{G} 2$ IF4G2 HUMAN $102.37 \quad 100.0^{\circ}$ Eukaryotic translation initiation factor 4 gamma $2 \mathrm{GN}=\mathrm{EIF} 4 \mathrm{G} 2 \mathrm{IF} 4 \mathrm{G} 2$ _HUMAN $102.37 \quad 100.0 \%$ Eukaryotic translation initiation factor 4 gamma 2 GN=EIF4G2 IF4G2_HUMAN $102.37 \quad 100.0 \%$ Eukaryotic translation initiation factor 4 gamma $2 \mathrm{GN}=\mathrm{EIF} 4 \mathrm{G} 2 \mathrm{IF} 4 \mathrm{G} 2$ HUMAN $102.37 \quad 100.0 \%$ Eukaryotic translation initiation factor 4B GN=EIF4B IF4B_HUMAN $69.15 \quad 100.0 \%$ Eukaryotic translation initiation factor 4B GN=EIF4B IF4B HUMAN $69.15 \quad 100.0 \%$ Eukaryotic translation initiation factor 4B GN=EIF4B IF4B_HUMAN $69.15 \quad 100.0 \%$ Eukaryotic translation initiation factor 4B GN=EIF4B IF4B_HUMAN $69.15 \quad 100.0 \%$ Eukaryotic translation initiation factor 4B GN=EIF4B IF4B HUMAN $69.15 \quad 100.0 \%$ Eukaryotic translation initiation factor 4B GN=EIF4B IF4B_HUMAN $69.15 \quad 100.0 \%$
$0.01 \% \quad 8.2 \% \quad$ EFTAQNLGK

$0.03 \% \quad 40.9 \%$ MKPILLQGHER

$0.03 \% \quad 40.9 \%$ EGDLLFTVAK

$0.03 \% \quad 40.9 \%$ HVLTGSADNSCR

$0.03 \% \quad 40.9 \%$ TCGFDFGGNIIMFSTDK

$0.03 \% \quad 40.9 \%$ SGEVLVNVK

$0.03 \% \quad 40.9 \%$ SGEVLVNVKEHSR

$0.03 \% \quad 40.9 \%$ QINDIQLSR

$0.03 \% \quad 40.9 \%$ DMTMFVTASK

$0.03 \% \quad 40.9 \%$ LFDSTTLEHQK

$0.03 \% \quad 40.9 \%$ FFHLAFEEEFGR

$0.03 \% \quad 40.9 \%$ GHFGPINSVAFHPDGK

$0.03 \% \quad 40.9 \%$ SYSSGGEDGYVR

$0.01 \% \quad 22.9 \%$ GIDRYNPENLATLER

$0.01 \% \quad 22.9 \%$ YNPENLATLER

$0.01 \% \quad 22.9 \%$ YVETQAKENAYDLEANLAVLK

$0.01 \% 22.9 \%$ ALTNLPHTDFTLCK

$0.03 \% \quad 20.4 \%$ NFIQYFHK

$0.03 \% \quad 20.4 \%$ VYELQASR

$0.03 \% \quad 20.4 \%$ VSSDVIDQK

$0.03 \% \quad 20.4 \%$ VSGGPSLEQR

$0.03 \% \quad 20.4 \%$ KSEEEIDFLR

$0.03 \% \quad 20.4 \%$ SEEEIDFLR

$0.03 \% \quad 20.4 \%$ SEEEIDFLRSNPK

$0.03 \% \quad 20.4 \%$ VLENIELNKK

$0.03 \% \quad 20.4 \%$ IDESIHLQLR

$0.03 \% \quad 20.4 \%$ VFSDEVQQQAQLSTIR

$0.03 \% \quad 20.4 \%$ LYTTMPVAK

$0.03 \% \quad 20.4 \%$ LAGFLDLTEQEFR

$0.03 \% \quad 20.4 \%$ RYGDFFIR

$0.00 \% \quad 7.2 \% \quad$ YTVYCSLIK

$0.00 \% \quad 7.2 \%$ VMVELLGSYTEDNASQAR

$0.01 \% \quad 4.6 \%$ GGPPGPPISR

$0.01 \% \quad 4.6 \%$ GSSGGSGAKPSDAASEAARPATSTLNR

$0.01 \% \quad 4.6 \%$ FSALQQAVPTESTDNRR

$0.01 \% \quad 4.6 \%$ AALSEEELEKK

$0.01 \% \quad 4.6 \%$ HGVESTLER

$0.01 \% \quad 4.5 \%$ TAGNSEFLGK

$0.01 \% \quad 4.5 \% \quad$ LQDEFENRTR

$0.01 \% \quad 4.5 \%$ TNPPLIQEKPAK

$0.01 \% \quad 4.5 \%$ SYLAQFAAR

$0.04 \% \quad 19.0 \%$ SILPTAPR

$0.04 \% \quad 19.0 \%$ GLNISAVR

$0.04 \% \quad 19.0 \%$ STPKEDDSSASTSQSTR

$0.04 \% \quad 19.0 \%$ AASIFGGAKPVDTAAR

$0.04 \% \quad 19.0 \%$ QLDEPKLER

$0.04 \% \quad 19.0 \%$ SRTGSESSQTGTSTTSSR
$99.6 \% 26.0$

$99.7 \% \quad 44.5$

$99.7 \% \quad 54.8$

$99.7 \% \quad 71.8$

$99.7 \% \quad 64.4$

$99.7 \% \quad 47.1$

$99.7 \% \quad 50.7$

$99.7 \% \quad 42.7$

$99.7 \% \quad 51.5$

$99.7 \% \quad 58.4$

$99.5 \% \quad 22.5$

$98.7 \% \quad 25.7$

$99.7 \% \quad 28.5$

$99.7 \% \quad 58.4$

$97.6 \% 16.3$

$99.7 \% \quad 39.3$

$98.3 \% \quad 24.4$

$\begin{array}{lll}99.0 \% & 42.8\end{array}$

$99.7 \% \quad 36.5$

$99.7 \% \quad 63.0$

$99.7 \% \quad 55.0$

$99.7 \% \quad 57.2$

$99.7 \% \quad 29.6$

$99.7 \% \quad 38.4$

$99.7 \% \quad 34.8$

$99.7 \% \quad 53.7$

$99.7 \% \quad 39.8$

$99.7 \% \quad 58.5$

$99.0 \% \quad 30.3$

$99.3 \% \quad 20.5$

$99.7 \% \quad 51.2$

$98.4 \% \quad 23.4$

$99.7 \% \quad 41.9$

$99.7 \% \quad 46.7$

$\begin{array}{ll}99.7 \% & 29.1\end{array}$

$99.7 \% \quad 33.0$

$99.7 \% \quad 45.7$

$99.5 \% 24.1$

$99.7 \% \quad 35.4$

$99.7 \% \quad 47.2$

$99.0 \% \quad 31.2$

$99.0 \% 34.8$

$99.7 \% \quad 48.0$

$99.7 \% \quad 42.9$

$98.4 \% 27.0$

$99.7 \% \quad 57.0$ $\begin{array}{ll}0 & 34.0\end{array}$

\begin{tabular}{ll}
53.4 \\
\hline
\end{tabular}

71.8

$\begin{array}{ll}0 & 64.4\end{array}$

$\begin{array}{lll}64.4 & 1\end{array}$

48.6

$\begin{array}{lll}0 & 12.7 & 2\end{array}$

$\begin{array}{ll} & 43.6 \\ 25.0 & 45.8\end{array}$

$\begin{array}{ll}22.0 & 22.5\end{array}$

$\begin{array}{ll}.0 & 25.7\end{array}$

$\begin{array}{ll}.0 & 28.5\end{array}$

51.0

$\begin{array}{ll}0.0 & 16.3\end{array}$

\begin{tabular}{ll}
0 & 39.3 \\
\hline
\end{tabular}

$\begin{array}{ll}0 & 27.2\end{array}$

12.6
37.6

37.6

$\begin{array}{ll}25.0 & 50.9\end{array}$

$\begin{array}{ll}.0 & 48.5\end{array}$

$\begin{array}{ll}45.0 & 44.9\end{array}$

29.6
25.0

$\begin{array}{ll}0 & 23.6\end{array}$

$\begin{array}{ll}24.0 & 24.6\end{array}$

\begin{tabular}{ll}
53.7 \\
\hline
\end{tabular}

\begin{tabular}{ll}
.0 & 29.0 \\
\hline
\end{tabular}

$\begin{array}{lll}0 & 58.5 & 2\end{array}$

\begin{tabular}{ll}
$25.0 \quad 17.6$ \\
\hline
\end{tabular}

$\begin{array}{ll}5.0 & 51.2\end{array}$

\begin{tabular}{ll}
16.4 \\
\hline
\end{tabular}

\begin{tabular}{l}
$25.0 \quad 41.9$ \\
\hline
\end{tabular}

$\begin{array}{ll}.0 & 45.2\end{array}$

$\begin{array}{ll}0 & 29.1\end{array}$

$\begin{array}{ll}5.0 & 26.4\end{array}$

36.4

20.0

$\begin{array}{lll}25.0 & 35.4 & 2\end{array}$

$\begin{array}{lll} & 34.1 & 2\end{array}$

$\begin{array}{lll}5.0 & 17.3 & 2\end{array}$

$\begin{array}{lll}25 & 19.4 & 2\end{array}$

13

$\begin{array}{cccc}0 & 1007.52 & 332 & 340 \\ 0 & 1321.74 & 1 & 11 \\ 0 & 1092.59 & 21 & 30 \\ 0 & 1316.60 & 66 & 77 \\ 0 & 1925.84 & 98 & 114 \\ 0 & 944.54 & 177 & 185 \\ 0 & 1453.78 & 177 & 189 \\ 0 & 1086.59 & 190 & 198 \\ 0 & 1130.52 & 199 & 208 \\ 0 & 1318.66 & 214 & 224 \\ 0 & 1528.72 & 269 & 280 \\ 0 & 1679.83 & 283 & 298 \\ 0 & 1276.54 & 299 & 310 \\ 0 & 1760.89 & 17 & 31 \\ 0 & 1319.66 & 21 & 31 \\ 0 & 2382.22 & 32 & 52 \\ 0 & 1630.83 & 73 & 86 \\ 0 & 1096.56 & 54 & 61 \\ 0 & 965.51 & 71 & 78 \\ 0 & 990.51 & 79 & 87 \\ 0 & 1029.53 & 144 & 153 \\ 0 & 1265.64 & 207 & 216 \\ 0 & 1137.54 & 208 & 216 \\ 0 & 1563.77 & 208 & 220 \\ 0 & 1199.70 & 293 & 302 \\ 0 & 1223.67 & 382 & 391 \\ 0 & 1848.95 & 446 & 461 \\ 0 & 1039.55 & 466 & 474 \\ 0 & 1538.79 & 475 & 487 \\ 0 & 1073.55 & 538 & 545 \\ 0 & 1146.59 & 121 & 129 \\ 0 & 1982.95 & 184 & 201 \\ 0 & 934.51 & 1033 & 1042 \\ 0 & 2503.21 & 1096 & 1122 \\ 0 & 1919.96 & 1123 & 1139 \\ 0 & 1246.65 & 1235 & 1245 \\ 0 & 1027.52 & 1281 & 1289 \\ 0 & 1023.51 & 32 & 41 \\ 0 & 1307.63 & 171 & 180 \\ 0 & 1335.76 & 521 & 532 \\ 0 & 1026.54 & 641 & 649 \\ 0 & 854.51 & 71 & 78 \\ 0 & 829.49 & 118 & 125 \\ 0 & 1783.79 & 340 & 356 \\ 0 & 1531.82 & 357 & 372 \\ 0 & 1127.61 & 390 & 398 \\ 0 & 1816.83 & 418 & 435 \\ & & & \end{array}$

Page 62 of Table S-1-5 
Eukaryotic translation initiation factor 4B GN=EIF4B IF4B_HUMAN $69.15 \quad 100.0 \%$ Eukaryotic translation initiation factor 4B GN=EIF4B IF4B HUMAN $69.15 \quad 100.0 \%$ Eukaryotic translation initiation factor 4B GN=EIF4B IF4B_HUMAN $69.15 \quad 100.0 \%$ Eukaryotic translation initiation factor 4B GN=EIF4B IF4B HUMAN $69.15 \quad 100.0 \%$ Exosome complex component MTR3 GN=EXOSC6 EXOS6_HUMAN $28.24 \quad 100.0 \%$ Exosome complex component MTR3 GN=EXOSC6 EXOS6_HUMAN $28.24 \quad 100.0 \%$ Exosome complex component MTR3 GN=EXOSC6 EXOS6_HUMAN $28.24 \quad 100.0 \%$ Exosome complex component MTR3 GN=EXOSC6 EXOs6_HUMAN $28.24 \quad 100.0 \%$ Exosome complex component MTR3 GN=EXOSC6 EXOS6 HUMAN $28.24 \quad 100.0 \%$ Exosome complex component MTR3 GN=EXOSC6 EXOS6_HUMAN $28.24 \quad 100.0 \%$ Exosome complex component RRP43 GN=EXOSC8 EXOS8_HUMAN $30.04 \quad 100.0 \%$ Exosome complex component RRP43 GN=EXOSC8 EXOS8 HUMAN $30.04 \quad 100.0 \%$ Exosome complex component RRP43 GN=EXOSC8 EXOS8_HUMAN $30.04 \quad 100.0 \%$ Exosome complex component RRP43 GN=EXOSC8 EXOS8_HUMAN $30.04 \quad 100.0 \%$ Exosome complex component RRP45 GN=EXOSC9 EXOS9 HUMAN $48.95 \quad 100.0 \%$ Exosome complex component RRP45 GN=EXOSC9 EXOS9_HUMAN $48.95 \quad 100.0 \%$ Exosome complex exonuclease RRP44 GN=DIS3 RRP44 HUMAN 109.01 $100.0 \%$ Exosome complex exonuclease RRP44 GN=DIS3 RRP44_HUMAN $109.01 \quad 100.0 \%$ Exosome complex exonuclease RRP44 GN=DIS3 RRP44_HUMAN $109.01 \quad 100.0 \%$ Exosome complex exonuclease RRP44 GN=DIS3 RRP44_HUMAN $109.01 \quad 100.0 \%$ Exosome complex exonuclease RRP44 GN=DIS3 RRP44_HUMAN $109.01 \quad 100.0 \%$ Exosome complex exonuclease RRP44 GN=DIS3 RRP44_HUMAN $109.01 \quad 100.0 \%$ Exportin-1 GN=XPO1 Exportin-1 GN=XPO1 Exportin-1 GN=XPO1 Exportin-1 GN=XPO1 Exportin-1 GN=XPO1 Exportin-1 GN=XPO1 Exportin-1 GN=XPO1 Exportin-1 GN=XPO1 Exportin-2 GN=CSE1L Exportin-2 GN=CSE1L Exportin-2 GN=CSE1L Exportin-2 GN=CSE1I Exportin-2 GN=CSE1L Exportin-2 GN=CSE1L Exportin-2 GN=CSE1L Exportin-2 GN=CSE1L Exportin-2 GN $=\mathrm{CSE} 1 \mathrm{~L}$ Exportin-2 GN=CSE1I

Exportin-2 GN=CSE1I Exportin-2 GN=CSE1L Exportin-7 GN=XPO7 Exportin-7 GN=XPO7 Exportin-7 GN=XPO7 Exportin-7 GN=XPO7 Exportin-7 GN=XPO7
XPO1_HUMAN $123.39 \quad 100.0 \%$ XPO1_HUMAN $123.39 \quad 100.0 \%$ XPO1 HUMAN $123.39 \quad 100.0 \%$ XPO1_HUMAN $123.39 \quad 100.0 \%$ XPO1_HUMAN $123.39 \quad 100.0 \%$ XPO1_HUMAN $123.39 \quad 100.0 \%$ XPO1_HUMAN $123.39 \quad 100.0 \%$ XPO1_HUMAN $123.39 \quad 100.0 \%$ XPO2_HUMAN $110.42 \quad 100.0 \%$ XPO2_HUMAN $110.42 \quad 100.0 \%$ XPO2 HUMAN $110.42 \quad 100.0 \%$ XPO2_HUMAN $110.42 \quad 100.0 \%$ XPO2_HUMAN $110.42 \quad 100.0 \%$ XPO2_HUMAN $110.42 \quad 100.0 \%$ XPO2_HUMAN $110.42 \quad 100.0 \%$ XPO2 HUMAN $110.42 \quad 100.0 \%$ XPO2_HUMAN $110.42 \quad 100.0 \%$ XPO2_HUMAN $110.42 \quad 100.0 \%$ XPO2_HUMAN $110.42 \quad 100.0 \%$ XPO2_HUMAN $110.42 \quad 100.0 \%$ XPO7_HUMAN $123.91 \quad 100.0 \%$ XPO7_HUMAN $123.91 \quad 100.0 \%$ XPO7_HUMAN $123.91 \quad 100.0 \%$ XPO7_HUMAN $123.91 \quad 100.0 \%$ XPO7_HUMAN $123.91 \quad 100.0 \%$
13

13

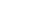

6

6

6
4
4

4

$\begin{array}{ll}4 & 4 \\ 2 & 2 \\ 2 & 2\end{array}$

2
2
6

6
6
6

6
6
6

6
6

6
8
8

8
8
8
8

8
8
8

8
8
8

$\begin{array}{ll}8 & 10 \\ 8 & 10\end{array}$

8
12
12

12

12
12
12

2

12
12
12

$\begin{array}{ll}12 & 13 \\ 12 & 13 \\ 12 & 13\end{array}$

$\begin{array}{ll}12 & 13 \\ 12 & 13 \\ 2 & 13\end{array}$

$\begin{array}{cc}2 & 13 \\ 2 & 13 \\ 5 & 6\end{array}$

13
6

6
6
6
6
6

$36 \quad 0.04$

$\begin{array}{lllll}0.04 \% & 19.0 \% & \text { TGSESSQTGTSTTSSRNAR } & 99.7 \% & 36.3 \\ 0.04 \% & 19.0 \% & \text { SSNPPARSQSSDTEQQSPTSGGGK } & 99.7 \% & 36.3 \\ 0.04 \% & 19.0 \% & \text { SQSSDTEQQSPTSGGGK } & 99.7 \% & 65.3\end{array}$

\begin{abstract}
$0.04 \% \quad 19.0 \%$ VAPAQPSEEGPGR
$0.01 \% \quad 25.7 \%$ GSAYLEAGGTK
\end{abstract}

$0.01 \% \quad 25.7 \%$ VLCAVSGPR

$0.01 \% \quad 25.7 \%$ GGGPAGAGGEAPAALR $\quad 99.7 \% \quad 56.6$

$0.01 \% \quad 25.7 \%$ LGLEGCQR

$0.01 \% \quad 25.7 \%$ LYPVLQQSLVR

$0.01 \% \quad 18.8 \%$ TVEPLEYYR

$\begin{array}{rrrrr}99.7 \% & 36.1 & 25.0 & 16.4 & 2 \\ 99.7 \% & 62.3 & 25.0 & 62.3 & 2 \\ 99.7 \% & 44.4 & 25.0 & 37.9 & 2 \\ 99.7 \% & 42.5 & 25.0 & 42.2 & 2\end{array}$

$0.01 \% \quad 18.8 \%$ LGNTTVICGVK

$0.01 \% \quad 18.8 \%$ AEFAAPSTDAPDK

$0.00 \% \quad 5.2 \% \quad$ VLGQVSCELVSPK

$0.00 \% \quad 5.2 \%$ VAEITELILK

$0 \quad 0.01 \% \quad 6.1 \%$ SGTYLQGTFR

$10 \quad 0.01 \% \quad 6.1 \% \quad$ RGTTVYLCEK

$10 \quad 0.01 \% \quad 6.1 \% \quad$ GALTLSSPEVR

$10 \quad 0.01 \% \quad 6.1 \% \quad$ NLEIKTDTAK

$0.01 \% \quad 6.1 \%$ YADVIVHR

$0.01 \% \quad 6.1 \%$ NAIVVLIPK

$0.02 \% \quad 8.4 \%$ TSSDPTCVEKEK

$0.02 \% \quad 8.4 \% \quad$ LNMILVQILK

$0.02 \% \quad 8.4 \%$ TSESLCQNNMVILK

$\begin{array}{lll}0.02 \% & 8.4 \% & \text { TSESLCQNNMVILK } \\ 0.02 \% & 8.4 \% & \text { NVDILKDPETVK }\end{array}$

$\begin{array}{llll}0.02 \% & 8.4 \% & \text { AVGHPFVIQLGR }\end{array}$

$0.02 \% \quad 8.4 \%$ IYLDMLNVYK

$0.02 \% \quad 8.4 \%$ LISGWVSR

$0.02 \% \quad 8.4 \%$ SAFPHLQDAQVK

$0.04 \% \quad 10.1 \%$ TLDPDPAIR

$0.04 \% \quad 10.1 \%$ TLDPDPAIRRPAEK

$0.04 \% \quad 10.1 \%$ TAHSLFKR

$0.04 \% \quad 10.1 \%$ VIVPNMEFR

$0.04 \% \quad 10.1 \%$ SANVNEFPVLK

$0.04 \% \quad 10.1 \%$ TGNIPALVR

$0.04 \% \quad 10.1 \%$ LLQAFLER

$0.04 \% \quad 10.1 \%$ IIIPEIQK

$0.04 \% \quad 10.1 \%$ KICAVGITK

$\begin{array}{ll}0.04 \% & 10.1 \% \text { ICAVGITK }\end{array}$

$0.04 \% \quad 10.1 \%$ EHDPVGQMVNNPK

$0.04 \% \quad 10.1 \%$ IHLAQSLHK

$0.01 \% \quad 4.9 \% \quad$ ALVEFTNSPDCLSK $\begin{array}{lllll}99.7 \% & 42.5 & 25.0 & 42.2 & 2\end{array}$

$99.3 \% \quad 19.2 \quad 25.0 \quad 19.2$

$\begin{array}{lllll}99.7 \% & 36.8 & 25.0 & 30.0 & 2\end{array}$

$\begin{array}{lllll}99.7 \% & 43.1 & 25.0 & 37.3 & 2\end{array}$

$\begin{array}{lllll}99.6 \% & 25.6 & 25.0 & 21.0 & 2\end{array}$

$\begin{array}{lllll}99.7 \% & 43.0 & 25.0 & 31.4 & 2\end{array}$

$\begin{array}{llll}99.7 \% & 26.8 & 25.0 & 24.2\end{array}$

$\begin{array}{lllll}99.0 \% & 49.3 & 25.0 & 47.3 & 1\end{array}$

$\begin{array}{lllll}99.3 \% & 18.7 & 25.0 & 18.7 & 1\end{array}$

$\begin{array}{lllll}99.7 \% & 36.7 & 25.0 & 29.1 & 2 \\ 97.5 \% & 19.0 & 25.0 & 19.0 & 2\end{array}$

$\begin{array}{lllll}99.7 \% & 47.7 & 25.0 & 34.7 & 4\end{array}$

$\begin{array}{lllll}99.7 \% & 43.4 & 25.0 & 31.3 & 2\end{array}$

$\begin{array}{lllll}99.7 \% & 32.5 & 25.0 & 29.0 & 2\end{array}$

$\begin{array}{llll}99.7 \% & 42.4 & 25.0 & 42.4\end{array}$

$\begin{array}{lllll}99.0 \% & 60.9 & 25.0 & 38.9 & 2\end{array}$

$\begin{array}{lllll}99.7 \% & 39.2 & 25.0 & 27.5 & 2\end{array}$

$\begin{array}{lllll}99.5 \% & 21.2 & 25.0 & 20.3 & 2\end{array}$

$\begin{array}{lllll}95.3 \% & 14.4 & 25.0 & 14.4 & 0 \\ 94.6 \% & 16.4 & 25.0 & 11.9 & 1\end{array}$

$\begin{array}{lllll}99.7 \% & 35.5 & 25.0 & 35.4 & 1\end{array}$

$\begin{array}{lllll}99.7 \% & 41.6 & 25.0 & 32.4 & 1\end{array}$

$\begin{array}{lllll}99.7 \% & 43.8 & 25.0 & 29.7 & 6\end{array}$

$\begin{array}{ccccc}99.0 \% & 57.3 & 25.0 & 44.0 & 10 \\ 98.5 \% & 30.0 & 25.0 & 0.0 & 1\end{array}$

$\begin{array}{lllll}99.7 \% & 41.8 & 25.0 & 36.2 & 4\end{array}$

$\begin{array}{lllll}98.3 \% & 17.4 & 25.0 & 16.3 & 2\end{array}$

$\begin{array}{lllll}99.7 \% & 51.2 & 25.0 & 48.2 & 2\end{array}$

$\begin{array}{lllll}99.7 \% & 37.8 & 25.0 & 34.7 & 3\end{array}$

$\begin{array}{lllll}99.7 \% & 39.2 & 25.0 & 39.2\end{array}$
$0.01 \% \quad 4.9 \%$ TNNPLPLEQR

$0.01 \% \quad 4.9 \%$ LAASVPYVK

$0.01 \% \quad 4.9 \% \quad$ VLQLMNLTDSR

$0.01 \% \quad 4.9 \%$ TTFYTALGR

$\begin{array}{lllllllllll}9 & 99.7 \% & 36.2 & 25.0 & 31.2 & 1 \\ 6 & 9 & 0.01 \% & 4.9 \% & \text { TTFYTALGR } & 99.6 \% & 24.0 & 25.0 & 24.0 & 2 \\ 6 & 99.7 \% & 36.2 & 25.0 & 36.2 & 2 \\ & & 99.7 \% & 38.7 & 25.0 & 28.1 & 2\end{array}$

$\begin{array}{lllll}99.7 \% & 38.7 & 25.0 & 28.1 & 2\end{array}$ 

F-actin-capping protein subunit alpha-1 GN=CAPZA1 CAZA1_HUMAN $32.92 \quad 100.0 \%$ F-actin-capping protein subunit alpha-1 GN=CAPZA1 CAZA1_HUMAN $32.92 \quad 100.0 \%$ F-actin-capping protein subunit alpha-1 GN=CAPZA1 CAZA1_HUMAN $32.92 \quad 100.0 \%$ F-actin-capping protein subunit beta GN=CAPZB CAPZB_HUMAN $31.35 \quad 100.0 \%$ F-actin-capping protein subunit beta GN=CAPZB CAPZB_HUMAN $31.35 \quad 100.0 \%$ F-actin-capping protein subunit beta GN=CAPZB CAPZB_HUMAN $31.35 \quad 100.0 \%$ Fanconi anemia group D2 protein GN=FANCD2 FACD2_HUMAN $164.13100 .0 \%$ Fanconi anemia group D2 protein GN=FANCD2 FACD2_HUMAN $164.13 \quad 100.0 \%$ Fanconi anemia group D2 protein GN=FANCD2 FACD2_HUMAN $164.13 \quad 100.0 \%$ Fanconi anemia group D2 protein GN=FANCD2 FACD2 HUMAN $164.13 \quad 100.0 \%$ Fanconi anemia group I protein GN=FANCI FANCI_HUMAN $149.33 \quad 100.0 \%$ Fanconi anemia group I protein GN=FANCI FANCI HUMAN $149.33 \quad 100.0 \%$ Fanconi anemia group I protein GN=FANCI FANCI_HUMAN $149.33 \quad 100.0 \%$ Fanconi anemia group I protein GN=FANCI FANCI_HUMAN $149.33 \quad 100.0 \%$ Far upstream element-binding protein 2 GN=KHSRP FUBP2_HUMAN $73.12 \quad 100.0 \%$ Far upstream element-binding protein 2 GN=KHSRP FUBP2_HUMAN $73.12 \quad 100.0 \%$ Far upstream element-binding protein 2 GN=KHSRP FUBP2_HUMAN $73.12 \quad 100.0 \%$ Far upstream element-binding protein 2 GN=KHSRP FUBP2_HUMAN $73.12 \quad 100.0 \%$ Far upstream element-binding protein 3 GN=FUBP3 FUBP3_HUMAN $61.64 \quad 100.0 \%$ Far upstream element-binding protein $3 \mathrm{GN}=\mathrm{FUBP} 3$ FUBP3_HUMAN $61.64100 .0 \%$ Far upstream element-binding protein 3 GN=FUBP3 FUBP3_HUMAN $61.64 \quad 100.0 \%$ Far upstream element-binding protein $3 \mathrm{GN}=$ FUBP3 3 FUBP3_HUMAN $61.64 \quad 100.0 \%$ Far upstream element-binding protein $3 \mathrm{GN}=\mathrm{FUBP} 3$ FUBP3_HUMAN $61.64 \quad 100.0 \%$ Far upstream element-binding protein 3 GN=FUBP3 FUBP3_HUMAN $61.64 \quad 100.0 \%$ Far upstream element-binding protein $3 \mathrm{GN}=\mathrm{FUBP} 3$ FUBP3_HUMAN $61.64100 .0 \%$ Farnesyl pyrophosphate synthase GN=FDPS FPPS_HUMAN $48.28 \quad 100.0 \%$ Farnesyl pyrophosphate synthase GN=FDPS FPPS_HUMAN $48.28 \quad 100.0 \%$ Farnesyl pyrophosphate synthase GN=FDPS FPPS HUMAN $48.28 \quad 100.0 \%$ Farnesyl pyrophosphate synthase GN=FDPS FPPS_HUMAN $48.28 \quad 100.0 \%$ Farnesyl pyrophosphate synthase GN=FDPS FPPS_HUMAN $48.28 \quad 100.0 \%$ Farnesyl pyrophosphate synthase GN=FDPS FPPS_HUMAN $48.28 \quad 100.0 \%$ FAS-associated factor $2 \mathrm{GN}=\mathrm{FAF} 2$ FAS-associated factor $2 \mathrm{GN}=\mathrm{FAF} 2$ FAF2_HUMAN $52.62 \quad 100.0 \%$ FAF2 HUMAN $52.62 \quad 100.0 \%$ $\begin{array}{llll}\text { FAS-associated factor 2 GN=FAF2 } & \text { FAF2_HUMAN } & 52.62 & 100.0 \% \\ \text { FAST kinase domain-containing protein 2 GN=FASTKD2 } & \text { FAKD2_HUMAN } & 81.47 & 100.0 \%\end{array}$ FAST kinase domain-containing protein 2 GN=FASTKD2 FAKD2 HUMAN $81.47 \quad 100.0 \%$ FAST kinase domain-containing protein 2 GN=FASTKD2 FAKD2_HUMAN $81.47 \quad 100.0 \%$ FAST kinase domain-containing protein 3 GN=FASTKD3 FAKD3_HUMAN $75.69 \quad 100.0 \%$ FAST kinase domain-containing protein 3 GN=FASTKD3 FAKD3_HUMAN $75.69100 .0 \%$ FAST kinase domain-containing protein 3 GN=FASTKD3 FAKD3_HUMAN $75.69 \quad 100.0 \%$ FAST kinase domain-containing protein 5 GN=FASTKD5 FAKD5_HUMAN $86.58 \quad 100.0 \%$ FAST kinase domain-containing protein 5 GN=FASTKD5 FAKD5_HUMAN $86.58 \quad 100.0 \%$ Fatty acid synthase GN=FASN Fatty acid synthase GN=FASN Fatty acid synthase GN=FASN FAS_HUMAN $273.43 \quad 100.0 \%$ FAS HUMAN $273.43 \quad 100.0 \%$ FAS_HUMAN $273.43 \quad 100.0 \%$

\begin{tabular}{|c|c|c|c|c|c|c|c|c|}
\hline 5 & 9 & $0.01 \%$ & 27.3\% FITHAPPGEFNEVFNDVR & $99.7 \% \quad 52.5$ & 25.0 & 52.5 & 0 & 2 \\
\hline 5 & 9 & $0.01 \%$ & $27.3 \%$ LLLNNDNLLR & $99.7 \% \quad 60.3$ & 25.0 & 44.8 & 2 & 0 \\
\hline 5 & 9 & $0.01 \%$ & 27.3\% EASDPQPEEADGGLK & $99.7 \% \quad 37.7$ & 25.0 & 37.7 & 2 & 0 \\
\hline 5 & 9 & $0.01 \%$ & 27.3\% TIDGQQTIIACIESHQFQPK & $97.1 \% \quad 15.3$ & 25.0 & 15.3 & 0 & 1 \\
\hline 5 & 9 & $0.01 \%$ & 27.3\% FTITPPTAQVVGVLK & $99.7 \% \quad 36.7$ & 25.0 & 36.7 & 2 & 0 \\
\hline 3 & 5 & $0.01 \%$ & $11.9 \%$ SGSGTMNLGGSLTR & $99.7 \% \quad 79.5$ & 25.0 & 70.7 & 2 & 0 \\
\hline 3 & 5 & $0.01 \%$ & $11.9 \%$ STLNEIYFGK & $99.7 \% \quad 32.5$ & 25.0 & 26.8 & 2 & 0 \\
\hline 3 & 5 & $0.01 \%$ & $11.9 \%$ TKDIVNGLR & $99.6 \% \quad 29.0$ & 25.0 & 25.8 & 1 & 0 \\
\hline 4 & 8 & $0.01 \%$ & 2.8\% SESPSLTQER & $99.7 \% \quad 36.7$ & 25.0 & 24.9 & 2 & 0 \\
\hline 4 & 8 & $0.01 \%$ & 2.8\% DGGPVTSQESGQK & $99.7 \% \quad 39.3$ & 25.0 & 39.3 & 2 & 0 \\
\hline 4 & 8 & $0.01 \%$ & $2.8 \%$ NIGFSHLQQR & $99.7 \% \quad 59.5$ & 25.0 & 53.8 & 2 & 0 \\
\hline 4 & 8 & $0.01 \%$ & $2.8 \%$ TLELLVCR & $99.0 \% \quad 35.9$ & 25.0 & 20.9 & 2 & 0 \\
\hline 4 & 6 & $0.01 \%$ & 2.9\% TIETSPSLSR & $99.7 \% \quad 33.2$ & 25.0 & 25.2 & 2 & 0 \\
\hline 4 & 6 & $0.01 \%$ & $2.9 \%$ YAVNVALQK & $99.7 \% \quad 41.4$ & 25.0 & 41.4 & 2 & 0 \\
\hline 4 & 6 & $0.01 \%$ & $2.9 \%$ IFQNLCDITR & $99.7 \% \quad 55.5$ & 25.0 & 45.5 & 1 & 0 \\
\hline 4 & 6 & $0.01 \%$ & 2.9\% SKVNLMQHMK & $96.8 \% \quad 15.4$ & 25.0 & 15.4 & 0 & 1 \\
\hline 3 & 6 & $0.01 \%$ & $6.3 \%$ DAFADAVQR & $99.7 \% \quad 40.0$ & 25.0 & 33.7 & 2 & 0 \\
\hline 3 & 6 & $0.01 \%$ & $6.3 \%$ GGETIKQLQER & $99.7 \% \quad 48.8$ & 25.0 & 23.7 & 1 & 0 \\
\hline 3 & 6 & $0.01 \%$ & $6.3 \%$ IGGGIDVPVPR & $99.7 \% \quad 72.3$ & 25.0 & 59.5 & 2 & 0 \\
\hline 3 & 6 & $0.01 \%$ & $6.3 \%$ AINQQTGAFVEISR & $99.7 \% \quad 59.1$ & 25.0 & 55.3 & 2 & 0 \\
\hline 7 & 11 & $0.01 \%$ & 14.0\% GGETIKQLQER & $99.7 \% \quad 48.8$ & 25.0 & 23.7 & 1 & 0 \\
\hline 7 & 11 & $0.01 \%$ & $14.0 \%$ MGGGSIEVSVPR & $99.7 \% \quad 66.3$ & 25.0 & 65.7 & 2 & 0 \\
\hline 7 & 11 & $0.01 \%$ & $14.0 \%$ FAVGIVIGR & $99.7 \% \quad 51.7$ & 25.0 & 42.3 & 2 & 0 \\
\hline 7 & 11 & $0.01 \%$ & 14.0\% IQFKPDDGISPER & $99.7 \% \quad 33.4$ & 25.0 & 33.0 & 0 & 2 \\
\hline 7 & 11 & $0.01 \%$ & 14.0\% SINQQSGAHVELQR & $99.7 \% \quad 48.0$ & 25.0 & 45.1 & 1 & 0 \\
\hline 7 & 11 & $0.01 \%$ & 14.0\% GVPQQIEVAR & $99.7 \% \quad 56.4$ & 25.0 & 49.3 & 2 & 0 \\
\hline 7 & 11 & $0.01 \%$ & $14.0 \%$ SSGCFPNMAAK & $98.9 \% \quad 20.8$ & 25.0 & 16.9 & 1 & 0 \\
\hline 8 & 15 & $0.02 \%$ & 16.9\% QDFVQHFSQIVR & $99.6 \% \quad 23.1$ & 25.0 & 23.1 & 0 & 2 \\
\hline 8 & 15 & $0.02 \%$ & 16.9\% VLTEDEMGHPEIGDAIAR & $99.7 \% \quad 26.5$ & 25.0 & 26.5 & 0 & 4 \\
\hline 8 & 15 & $0.02 \%$ & 16.9\% LKEVLEYNAIGGK & $99.7 \% \quad 62.3$ & 25.0 & 62.3 & 2 & 1 \\
\hline 8 & 15 & $0.02 \%$ & $16.9 \%$ GLTVVVAFR & $99.7 \% \quad 32.2$ & 25.0 & 30.5 & 2 & 0 \\
\hline 8 & 15 & $0.02 \%$ & 16.9\% IGTDIQDNK & $99.7 \% \quad 38.0$ & 25.0 & 30.2 & 2 & 0 \\
\hline 8 & 15 & $0.02 \%$ & 16.9\% ATPEQYQILK & $99.4 \% \quad 25.1$ & 25.0 & 15.8 & 2 & 0 \\
\hline 3 & 3 & $0.00 \%$ & 8.1\% IYSYVVSRPQPR & $98.8 \% \quad 17.8$ & 25.0 & 17.8 & 1 & 0 \\
\hline 3 & 3 & $0.00 \%$ & $8.1 \%$ NTLCAPEVISLINTR & $99.7 \% \quad 46.9$ & 25.0 & 46.9 & 1 & 0 \\
\hline 3 & 3 & $0.00 \%$ & 8.1\% FQIEANFPR & $98.5 \% \quad 27.8$ & 25.0 & 16.4 & 1 & 0 \\
\hline 3 & 6 & $0.01 \%$ & 4.1\% SLILLDECSK & $99.7 \% \quad 44.8$ & 25.0 & 37.2 & 2 & 0 \\
\hline 3 & 6 & $0.01 \%$ & 4.1\% VAVLCVSR & $99.0 \% \quad 41.1$ & 25.0 & 33.7 & 2 & 0 \\
\hline 3 & 6 & $0.01 \%$ & 4.1\% SAYCLGSSHPR & $99.5 \% \quad 26.6$ & 25.0 & 26.6 & 2 & 0 \\
\hline 3 & 5 & $0.01 \%$ & 4.1\% KDGDQGLPK & $96.1 \% \quad 28.5$ & 25.0 & 13.6 & 1 & 0 \\
\hline 3 & 5 & $0.01 \%$ & $4.1 \%$ IGLTNLLGAR & $99.7 \% \quad 47.3$ & 25.0 & 27.7 & 2 & 0 \\
\hline 3 & 5 & $0.01 \%$ & $4.1 \%$ ELVEYLQR & $99.0 \% \quad 33.7$ & 25.0 & 25.9 & 2 & 0 \\
\hline 2 & 4 & $0.00 \%$ & 2.6\% ASTLQLGSPR & $99.7 \% \quad 44.3$ & 25.0 & 36.0 & 2 & 0 \\
\hline 2 & 4 & $0.00 \%$ & $2.6 \%$ EATPAENVAK & $99.7 \% \quad 50.2$ & 25.0 & 45.2 & 2 & 0 \\
\hline 20 & 43 & $0.05 \%$ & 8.3\% AGLYGLPR & $99.0 \% \quad 30.4$ & 25.0 & 23.5 & 4 & 0 \\
\hline 20 & 43 & $0.05 \%$ & 8.3\% LGMLSPEGTCK & $99.7 \% \quad 26.5$ & 25.0 & 19.1 & 1 & 0 \\
\hline 20 & 43 & $0.05 \%$ & $8.3 \%$ SEGVVAVLLTK & $99.7 \% \quad 53.1$ & 25.0 & 53.1 & 2 & 0 \\
\hline
\end{tabular}

1279.65

1215.63 
Fatty acid synthase GN=FASN Fatty acid synthase GN=FASN Fatty acid synthase GN=FASN Fatty acid synthase GN=FASN Fatty acid synthase GN=FASN Fatty acid synthase GN=FASN Fatty acid synthase GN=FASN Fatty acid synthase GN=FASN Fatty acid synthase GN=FASN Fatty acid synthase GN=FASN Fatty acid synthase GN=FASN Fatty acid synthase GN=FASN Fatty acid synthase GN=FASN Fatty acid synthase GN=FASN Fatty acid synthase GN=FASN Fatty acid synthase GN=FASN F-box only protein $22 \mathrm{GN}=\mathrm{FBXO} 22$ F-box only protein $22 \mathrm{GN}=\mathrm{FBXO} 22$ F-box only protein $22 \mathrm{GN}=\mathrm{FBXO} 22$ F-box only protein $22 \mathrm{GN}=\mathrm{FBXO} 22$ $\begin{array}{llll}\text { F-box/LRR-repeat protein } 12 \text { GN=FBXL12 FXL12_HUMAN } & 37.03 & 100.0 \% \\ & \text { FXL12_HUMAN } & 37.03 & 100.0 \%\end{array}$ F-box/LRR-repeat protein $12 \mathrm{GN}=$ FBXL12 FXL12_HUMAN $37.03 \quad 100.0 \%$ F-box/LRR-repeat protein 12 GN=FBXL12 FXL12_HUMAN $37.03 \quad 100.0 \%$ $\begin{array}{lllll}\text { Ferrochelatase, mitochondrial GN=FECH HEMH_HUMAN } & 47.86 & 100.0 \% & 3\end{array}$ Ferrochelatase, mitochondrial GN=FECH HEMH_HUMAN $47.86 \quad 100.0 \%$ Ferrochelatase, mitochondrial GN=FECH HEMH_HUMAN $47.86 \quad 100.0 \%$ Filaggrin $\mathrm{GN}=\mathrm{FLG}$ Filaggrin $\mathrm{GN}=\mathrm{FLG}$ Filaggrin $\mathrm{GN}=\mathrm{FLG}$

Filaggrin-2 GN=FLG2 Filaggrin-2 GN=FLG2 Filamin-A GN=FLNA Filamin-A GN=FLNA Filamin-A GN=FLNA Filamin-A GN=FLNA Filamin-A GN=FLNA Filamin-A GN=FLNA Filamin-A GN=FLNA Filamin-A GN=FLNA Filamin-A GN=FLNA Filamin-A GN=FLNA Filamin-A GN=FLNA Filamin-A GN=FLNA Filamin-A GN=FLNA Filamin-A GN=FLNA Filamin-A GN=FLNA FAS_HUMAN $273.43 \quad 100.0 \% \quad 19$ FAS_HUMAN $273.43 \quad 100.0 \% \quad 19$ FAS HUMAN $273.43 \quad 100.0 \% \quad 19$ FAS_HUMAN $273.43 \quad 100.0 \% \quad 19$ FAS_HUMAN $273.43 \quad 100.0 \% \quad 19$ FAS_HUMAN $273.43 \quad 100.0 \% \quad 19$ FAS_HUMAN $273.43 \quad 100.0 \% \quad 19$ FAS_HUMAN $273.43 \quad 100.0 \% \quad 19$ FAS_HUMAN $273.43 \quad 100.0 \% \quad 19$ FAS HUMAN $273.43 \quad 100.0 \% \quad 19$ FAS_HUMAN $273.43 \quad 100.0 \% \quad 19$ FAS_HUMAN $273.43 \quad 100.0 \% \quad 19$ FAS_HUMAN $273.43 \quad 100.0 \% \quad 19$ FBX22 HUMAN $44.51 \quad 100.0 \% \quad 4$ FBX22_HUMAN $44.51 \quad 100.0 \% \quad 4$ $\begin{array}{llll}\text { FBX22_HUMAN } & 44.51 & 100.0 \% & 4 \\ \text { FBX22_HUMAN } & 44.51 & 100.0 \% & 4\end{array}$ FBX22 HUMAN $44.51 \quad 100.0 \% \quad 4$ FILA HUMAN $435.15 \quad 100.0 \%$ FILA_HUMAN $435.15 \quad 100.0 \%$ FILA HUMAN $435.15 \quad 100.0 \% \quad 3$ FILA2_HUMAN $248.05 \quad 100.0 \%$ FILA2_HUMAN $248.05 \quad 100.0 \%$ FLNA_HUMAN $280.73 \quad 100.0 \% \quad 15$ FLNA_HUMAN $280.73 \quad 100.0 \% \quad 15$ FLNA_HUMAN $280.73 \quad 100.0 \% \quad 15$ FLNA_HUMAN $280.73 \quad 100.0 \% \quad 15$ FLNA_HUMAN $280.73 \quad 100.0 \% \quad 15$ FLNA_HUMAN $280.73 \quad 100.0 \% \quad 15$ FLNA_HUMAN $280.73 \quad 100.0 \% \quad 15$ FLNA HUMAN $280.73 \quad 100.0 \% \quad 15$ FLNA_HUMAN $280.73 \quad 100.0 \% \quad 15$ FLNA_HUMAN $280.73 \quad 100.0 \% \quad 15$ FLNA_HUMAN $280.73 \quad 100.0 \% \quad 15$ FLNA_HUMAN $280.73 \quad 100.0 \% \quad 15$ FLNA_HUMAN $280.73 \quad 100.0 \% \quad 15$
FAS HUMAN $273.43 \quad 100.0 \% \quad 19 \quad 20 \quad 43 \quad 0.05 \% \quad 8.3 \%$ SEGVVAVLLTKK FAS HUMAN $273.43 \quad 100.0 \% \quad 19$ FAS_HUMAN $273.43 \quad 100.0 \% \quad 19$ FLNA_HUMAN $280.73 \quad 100.0 \% \quad 15$ FLNA_HUMAN $280.73 \quad 100.0 \% \quad 15$

$0.05 \% \quad 8.3 \% \quad$ QEPLLIGSTK

$0.05 \% \quad 8.3 \%$ LQVVDQPLPVR

$0.05 \% \quad 8.3 \%$ HGLYLPTR

$0.05 \% \quad 8.3 \%$ RQQEQQVPILEK

$0.05 \% \quad 8.3 \%$ GLVQALQTK

$0.01 \% \quad 10.9 \%$ VVAEELENVR

$0.01 \% \quad 10.9 \%$ VVLVFGYNCCK

$\begin{array}{lll}0.01 \% & 10.9 \% & \text { IVTGNFILR } \\ 0.01 \% & 19.0 \% \text { MGGYLFSGSQA }\end{array}$

$0.01 \% \quad 19.0 \%$ SLVLGGTYR

$0.01 \% \quad 0.7 \% \quad$ ENLPISGHK

$0.01 \% \quad 1.0 \%$ SVVTVIDVFYK

$0.01 \% \quad 1.0 \%$ FSNSSSSNEFSK

$0.05 \% \quad 7.2 \%$ AHVVPCFDASK

$0.05 \% \quad 7.2 \%$ CSGPGLER

$\begin{array}{lll}0.05 \% & 7.2 \% & \text { ALTQTGGPHVK }\end{array}$

$0.05 \% \quad 7.2 \%$ ANLPQSFQVDTSK

$0.05 \% \quad 7.2 \%$ KGEITGEVR

$0.05 \% \quad 7.2 \%$ TPCEEILVK
$0.05 \% \quad 8.3 \% \quad$ ALCATRQEPLLIGSTK

$99.0 \% \quad 19.7$

$\begin{array}{llll}99.7 \% & 27.8 & 25.0 & 27.8\end{array}$

$\begin{array}{llll}99.7 \% & 44.4 & 25.0 & 44.4\end{array}$

$99.7 \% \quad 45.2$

$99.7 \% \quad 50.0$

$0.05 \% \quad 8.3 \%$ AFEVSENGNLVVSGK

$\begin{array}{lllll}99.6 \% & 26.5 & 25.0 & 26.5\end{array}$

$\begin{array}{llll}99.7 \% & 42.0 & 25.0 & 29.3\end{array}$

$\begin{array}{lllll}99.7 \% & 47.1 & 25.0 & 26.3 & 6\end{array}$

$\begin{array}{llll}98.8 \% & 27.5 & 25.0 & 24.9\end{array}$

$0.05 \% \quad 8.3 \%$ ACLDTAVENMPSLK

$99.4 \% \quad 27.9$

$0.05 \% \quad 8.3 \%$ VVEVLAGHGHLYSR

$99.7 \% \quad 48.8$

$\begin{array}{lll}25.0 & 25.4 & 0\end{array}$

$\begin{array}{lll}0.05 \% & 8.3 \% & \text { GNAGQSNYGFANSAM } \\ 0.05 \% & 8.3 \% & \text { EDGLAQQQTQLNLR }\end{array}$

$99.7 \% \quad 72.9$

$99.7 \% \quad 45.2$

$99.7 \% \quad 55.4$

$0.01 \% \quad 10.9 \%$ STFVLSNLAEVVER

$\begin{array}{lll}99.7 \% & 42.7\end{array}$

$99.7 \% \quad 43.0$

$99.7 \% \quad 34.9$

$99.7 \% \quad 41.9$

$0.01 \% \quad 19.0 \%$ VPAFRDEHLQGLTR

$99.7 \% \quad 27.9$

$\begin{array}{ll}99.7 \% & 31.3 \\ 99.7 \% & 53.1\end{array}$

$0.00 \% \quad 8.0 \%$ GDPYPQEVSATVQK $\quad 99.6 \% 28.5$

$96.1 \% \quad 14.9$

$97.8 \% \quad 17.4$

$99.0 \% \quad 24.0$

$99.7 \% \quad 43.9$

$99.2 \% \quad 29.1$

$99.7 \% \quad 45.6$

$99.7 \% \quad 38.2$

$99.7 \% \quad 31.3$

$\begin{array}{lllll}0.05 \% & 7.2 \% & \text { VTVLFAGQHIAK } & 99.7 \% & 31.3 \\ 0.05 \% & 7.2 \% & \text { VTAQGPGLEPSGNIANK } & 99.6 \% & 26.8 \\ 0.05 \% & 7.2 \% & \text { SPYTVTVGQACNPSACR } & 99.7 \% & 56.1\end{array}$

$\begin{array}{lllll}0.05 \% & 7.2 \% & \text { SPYTVTVGQACNPSACR } & 99.7 \% & 56.1 \\ 0.05 \% & 7.2 \% & \text { AWGPGLEGGVVGK } & 95.6 \% & 15.9\end{array}$

$\begin{array}{ll}95.6 \% & 15.9 \\ 99.7 \% & 24.9\end{array}$

$0.05 \% \quad 7.2 \%$ AFGPGLQGGSAGSPAR

$99.7 \% \quad 54.8$

$99.5 \% \quad 23.2$

$99.0 \% \quad 32.3$

$99.7 \% \quad 48.3$

$99.7 \% \quad 32.9$

$99.7 \% \quad 41.8$

$99.7 \% \quad 28.5$

$98.6 \% \quad 25.3$

$99.7 \% \quad 29.6$ $\begin{array}{ccc}1243.76 & 225 & 236 \\ 1757.96 & 311 & 326 \\ 1085.62 & 317 & 326 \\ 1666.82 & 327 & 343 \\ 1263.74 & 374 & 384 \\ 961.53 & 928 & 936 \\ 1549.79 & 943 & 957 \\ 956.53 & 1044 & 1051 \\ 1495.82 & 1105 & 1116 \\ 1302.67 & 1132 & 1142 \\ 957.57 & 1143 & 1151 \\ 1564.73 & 1226 & 1239 \\ 1536.83 & 1242 & 1255 \\ 1773.76 & 2027 & 2043 \\ 1613.82 & 2207 & 2220 \\ 1012.64 & 2397 & 2406 \\ 1563.84 & 19 & 32 \\ 1157.62 & 87 & 96 \\ 1358.66 & 219 & 229 \\ 1032.62 & 368 & 376 \\ 2109.08 & 76 & 95 \\ 1638.87 & 161 & 174 \\ 965.54 & 180 & 188 \\ 2019.08 & 207 & 225 \\ 1518.74 & 273 & 286 \\ 1114.50 & 291 & 298 \\ 1276.65 & 368 & 379 \\ 1063.58 & 35 & 42 \\ 1201.58 & 81 & 90 \\ 994.53 & 92 & 100 \\ 1269.71 & 7 & 17 \\ 1320.57 & 404 & 415 \\ 1283.75 & 356 & 367 \\ 1652.86 & 384 & 400 \\ 1867.84 & 468 & 484 \\ 1226.65 & 581 & 593 \\ 1646.87 & 685 & 700 \\ 1429.72 & 1072 & 1087 \\ 1230.59 & 1152 & 1162 \\ 875.40 & 1165 & 1172 \\ 1225.57 & 1273 & 1283 \\ 1108.61 & 1284 & 1294 \\ 1570.81 & 1382 & 1399 \\ 1434.72 & 1465 & 1477 \\ 882.54 & 1478 & 1486 \\ 988.54 & 1801 & 1809 \\ 1088.57 & 2599 & 2607\end{array}$

Page 65 of Table S-1-5 
Filamin- $\mathrm{C} \mathrm{GN}=\mathrm{FLNC}$ Filamin-C GN=FLNC

Flap endonuclease $1 \mathrm{GN}=\mathrm{FEN} 1$

Flap endonuclease $1 \mathrm{GN}=\mathrm{FEN} 1$

Flap endonuclease $1 \mathrm{GN}=\mathrm{FEN} 1$

Flotillin-1 GN=FLOT1

Flotillin-1 GN=FLOT1

Fragile X mental retardation protein 1 GN=FMR1 FMR1_HUMAN $71.17 \quad 100.0 \%$ Fragile X mental retardation protein $1 \mathrm{GN}=\mathrm{FMR} 1$ FMR1 HUMAN $71.17 \quad 100.0 \%$ Fragile X mental retardation protein 1 GN=FMR1 FMR1_HUMAN $71.17 \quad 100.0 \%$ Fragile X mental retardation syndrome-related protein 2 GN=FXR2 $\quad$ FXR2_HUMAN $74.22 \quad 100.0 \%$ Fragile X mental retardation syndrome-related protein 2 GN=FXR2 $\quad$ FXR2_HUMAN $74.22 \quad 100.0 \%$ Fragile X mental retardation syndrome-related protein 2 GN=FXR2 FXR2_HUMAN 74.22 $100.0 \%$ Fragile $X$ mental retardation syndrome-related protein 2 GN=FXR2 FXR2_HUMAN $74.22 \quad 100.0 \%$ Fragile $\mathrm{X}$ mental retardation syndrome-related protein $2 \mathrm{GN}=\mathrm{FXR} 2 \mathrm{FXR} 2$ HUMAN $74.22 \quad 100.0 \%$ Fragile X mental retardation syndrome-related protein 2 GN=FXR2 FXR2_HUMAN $74.22 \quad 100.0 \%$ Fructose-bisphosphate aldolase A GN=ALDOA ALDOA_HUMAN $39.42 \quad 100.0 \%$ Fructose-bisphosphate aldolase A GN=ALDOA ALDOA_HUMAN $39.42 \quad 100.0 \%$ Fructose-bisphosphate aldolase A GN=ALDOA ALDOA_HUMAN $39.42 \quad 100.0 \%$ Fructose-bisphosphate aldolase A GN=ALDOA ALDOA_HUMAN $39.42 \quad 100.0 \%$ Fructose-bisphosphate aldolase A GN=ALDOA ALDOA_HUMAN $39.42 \quad 100.0 \%$ Fructose-bisphosphate aldolase A GN=ALDOA ALDOA HUMAN $39.42 \quad 100.0 \%$ Galactokinase $\mathrm{GN}=\mathrm{GALK} 1$ Galactokinase $\mathrm{GN}=\mathrm{GALK} 1$

Galactokinase GN=GALK1 Galactokinase $\mathrm{GN}=\mathrm{GALK} 1$ Galactokinase GN=GALK1 Galactokinase GN=GALK1 Galactokinase $\mathrm{GN}=\mathrm{GALK} 1$ Galactokinase GN=GALK1 Galactokinase $\mathrm{GN}=\mathrm{GALK} 1$ Galactokinase $\mathrm{GN}=\mathrm{GALK} 1$

(100.0\% Gamma-tubulin complex component 6 GN=TUBGCP6 GCP6_HUMAN $200.50 \quad 100.0 \%$ GDP-mannose 4,6 dehydratase GN=GMDS GMDS HUMAN $41.95 \quad 100.0 \%$ GDP-mannose 4,6 dehydratase GN=GMDS GMDS_HUMAN $41.95 \quad 100.0 \%$ GDP-mannose 4,6 dehydratase GN=GMDS GMDS_HUMAN $41.95 \quad 100.0 \%$ GDP-mannose 4,6 dehydratase GN=GMDS GMDS_HUMAN $41.95 \quad 100.0 \%$ GDP-mannose 4,6 dehydratase GN=GMDS GMDS_HUMAN $41.95 \quad 100.0 \%$ GDP-mannose 4,6 dehydratase GN=GMDS GMDS_HUMAN $41.95 \quad 100.0 \%$ GDP-mannose 4,6 dehydratase GN=GMDS GMDS_HUMAN $41.95 \quad 100.0 \%$ GDP-mannose 4,6 dehydratase GN=GMDS GMDS_HUMAN $41.95 \quad 100.0 \%$ GDP-mannose 4,6 dehydratase GN=GMDS GMDS_HUMAN $41.95 \quad 100.0 \%$ GDP-mannose 4,6 dehydratase GN=GMDS GMDS_HUMAN $41.95 \quad 100.0 \%$ Gem-associated protein 4 GN=GEMIN4 GEMI4_HUMAN $120.04 \quad 100.0 \%$ Gem-associated protein 4 GN=GEMIN4 GEMI4_HUMAN $120.04 \quad 100.0 \%$ Gem-associated protein 4 GN=GEMIN4 GEMI4_HUMAN $120.04 \quad 100.0 \%$
$0.00 \% \quad 1.0 \%$ VAVGQEQAFSVNTR $0.00 \% \quad 1.0 \% \quad$ LEPGGGAEAQAVR

$0.01 \% \quad 9.2 \% \quad$ LIADVAPSAIRENDIK

$0.01 \% \quad 9.2 \%$ KLPIQEFHLSR

$0.01 \% \quad 9.2 \%$ RAVDLIQK

$0.00 \% \quad 5.4 \%$ AAYDIEVNTR

$0.00 \% \quad 5.4 \%$ AQQVAVQEQEIAR

$0.00 \% \quad 5.7 \% \quad$ SVNPNKPATKDTFHK

$0.00 \% \quad 5.7 \%$ LIQEIVDKSGVVR

$0.00 \% \quad 5.7 \% \quad$ LQIDEQLR

$0.01 \% \quad 10.5 \%$ LRPVNPNPLATK

$0.01 \% \quad 10.5 \%$ ASLLGDMHFR

$0.01 \% \quad 10.5 \%$ VIQEIVDKSGVVR

$0.01 \% \quad 10.5 \%$ LQIDEQLR

$0.01 \% \quad 10.5 \%$ AGYSTDESSSSSLHATR

$0.01 \% \quad 10.5 \%$ GPPPAPRPTSR

$0.01 \% \quad 20.9 \%$ ELSDIAHR

$0.01 \% \quad 20.9 \%$ GILAADESTGSIAK

$0.01 \% \quad 20.9 \%$ ADDGRPFPQVIK

$0.01 \% \quad 20.9 \%$ AAQEEYVKR

$0.01 \% \quad 20.9 \%$ ALANSLACQGK

$0.01 \% \quad 20.9 \%$ YTPSGQAGAAASESLFVSNHAY

$0.02 \% \quad 29.1 \%$ QPQVAELLAEAR

$0.02 \% \quad 29.1 \%$ KDGLVSLLTTSEGADEPQR $99.7 \% 53.2$

$0.02 \% \quad 29.1 \%$ SLEPGTPR

$0.02 \% \quad 29.1 \%$ GHALLIDCR

$0.02 \% \quad 29.1 \%$ SLETSLVPLSDPK

$0.02 \% \quad 29.1 \%$ LAVLITNSNVR

$0.02 \% \quad 29.1 \%$ HSLASSEYPVR

$0.02 \% \quad 29.1 \%$ HSLASSEYPVRR

$0.02 \% \quad 29.1 \%$ EVQLEELEAAR

$0.00 \% \quad 1.5 \%$ VGENVSDVAPTQPR

$0.00 \% \quad 1.5 \%$ VGENVSDVAPTRPR

$0.02 \% \quad 33.6 \%$ NPQAHIEGNMK

$0.02 \% 33.6 \%$ LHYGDLTDSTCLVK

$95.9 \% \quad 17.7$

$99.7 \% \quad 54.6$

$99.7 \% \quad 56.2$

$99.7 \% \quad 61.5$

$99.7 \% \quad 44.5$

$97.8 \% \quad 17.2$

$99.7 \% \quad 64.1$

$96.8 \% 17.0$

$99.7 \% \quad 38.3$

$99.2 \% \quad 23.7$

$99.5 \% \quad 29.5$

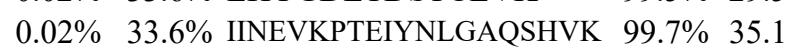

$0.02 \% \quad 33.6 \%$ ISFDLAEYTADVDGVGTLR $\quad 99.7 \% \quad 79.6$

$0.02 \% \quad 33.6 \%$ TCGLINSVK

$0.02 \% \quad 33.6 \%$ FYQASTSELYGK

$0.02 \% \quad 33.6 \%$ ETTPFYPR

$0.02 \% \quad 33.6 \%$ VHVTVDLK

$0.02 \% 33.6 \%$ YYRPTEVDFLQGDCTK

$0.02 \% 33.6 \%$ VAFDELVR

$0.01 \% \quad 3.0 \%$ GLTQIQSR

$0.01 \% \quad 3.0 \%$ LLETVIDVSTADR

$0.01 \% \quad 3.0 \%$ SIAEGIGPEER
$98.1 \% 21.2$

$99.0 \% \quad 38.5 \quad 25.0 \quad 27.6$

$\begin{array}{llll}99.7 \% & 33.2 & 25.0 & 32.9\end{array}$

$\begin{array}{llll}99.0 \% & 47.4 & 25.0 & 33.2\end{array}$

$\begin{array}{lllll}99.0 \% & 43.1 & 25.0 & 31.5 & 2\end{array}$

$99.7 \% \quad 69.6 \quad 25.0 \quad 69.1$

$99.7 \% \quad 36.9 \quad 25.0 \quad 34.2$
1254.64

1724.95

1367.78

942.57

1151.57

1469.77

1683.88

1455.85

1014.56

1319.78

1162.57

1441.84

1014.56

1755.78

1132.62

940.48

1332.70

1342.71

1093.56

1132.58

2228.03

1324.72

2033.01

2016.02

856.45

1054.55

1385.75

1199.71

1245.62

1401.72

1286.66

1468.74

1496.78

1254.59

1621.79

2253.22

2042.01

991.52

1393.66

1010.49

910.54

1991.92

948.51

902.51

1431.77

1157.58 $\begin{array}{cc}78 & 991 \\ 15 & 1027 \\ 9 & 24 \\ 1 & 211 \\ 45 & 252 \\ 21 & 230 \\ 62 & 274 \\ 14 & 128 \\ 03 & 315 \\ 35 & 442 \\ 22 & 133 \\ 91 & 200 \\ 13 & 325 \\ 79 & 386 \\ 07 & 423 \\ 91 & 501 \\ 5 & 22 \\ 9 & 42 \\ 8 & 99 \\ 23 & 331 \\ 32 & 342 \\ 43 & 364 \\ 6 & 17 \\ 9 & 37 \\ 9 & 87 \\ 8 & 105 \\ 96 & 204 \\ 05 & 217 \\ 18 & 228 \\ 29 & 239 \\ 29 & 240 \\ 57 & 267 \\ 63 & 1076 \\ 17 & 1130 \\ 1 & 81 \\ 2 & 95 \\ 6 & 115 \\ 16 & 134 \\ 41 & 149 \\ 50 & 161 \\ 69 & 176 \\ 15 & 322 \\ 23 & 338 \\ 49 & 356 \\ 22 & 229 \\ 57 & 469 \\ & 1047\end{array}$

Page 66 of Table S-1-5 
General transcription factor 3C polypeptide $1 \mathrm{GN}=\mathrm{GTF} 3 \mathrm{C} 1 \quad \mathrm{TF} 3 \mathrm{C} 1 \_$HUMAN $238.88 \quad 100.0 \% \quad 1$ Gener. General transcription factor 3C polypeptide $1 \mathrm{GN}=\mathrm{GTF} 3 \mathrm{C} 1 \quad$ TF3C1_HUMAN $238.88 \quad 100.0 \%$ General transcription factor $3 \mathrm{C}$ polypeptide $1 \mathrm{GN}=\mathrm{GTF} 3 \mathrm{C} 1 \quad \mathrm{TF} 3 \mathrm{C} 1 \_$HUMAN $238.88 \quad 100.0 \%$ General transcription factor 3C polypeptide $1 \mathrm{GN}=\mathrm{GTF} 3 \mathrm{C} 1 \quad$ TF3C1_HUMAN $238.88 \quad 100.0 \%$ General transcription factor 3C polypeptide $1 \mathrm{GN}=\mathrm{GTF} 3 \mathrm{C} 1 \quad$ TF3C1_HUMAN $238.88 \quad 100.0 \%$ General transcription factor $3 \mathrm{C}$ polypeptide $1 \mathrm{GN}=\mathrm{GTF} 3 \mathrm{C} 1 \quad$ TF3C1_HUMAN $238.88 \quad 100.0 \% \quad 1$ General transcription factor 3C polypeptide $1 \mathrm{GN}=\mathrm{GTF} 3 \mathrm{C} 1 \quad \mathrm{TF} 3 \mathrm{C} 1 \_$HUMAN $238.88 \quad 100.0 \%$ General transcription factor 3C polypeptide $1 \mathrm{GN}=\mathrm{GTF} 3 \mathrm{C} 1 \quad \mathrm{TF} 3 \mathrm{C} 1$ HUMAN $238.88 \quad 100.0 \%$ General transcription factor $3 \mathrm{C}$ polypeptide $1 \mathrm{GN}=\mathrm{GTF} 3 \mathrm{C} 1 \quad \mathrm{TF} 3 \mathrm{C} 1$ _HUMAN $238.88 \quad 100.0 \%$ General transcription factor 3C polypeptide $1 \mathrm{GN}=\mathrm{GTF} 3 \mathrm{C} 1 \quad \mathrm{TF} 3 \mathrm{C} 1 \_$HUMAN $238.88 \quad 100.0 \%$ General transcription factor $3 \mathrm{C}$ polypeptide $1 \mathrm{GN}=\mathrm{GTF} 3 \mathrm{Cl}$ TF3C1_HUMAN $238.88 \quad 100.0 \%$ General transcription factor $3 \mathrm{C}$ polypeptide $1 \mathrm{GN}=\mathrm{GTF} 3 \mathrm{C} 1 \quad \mathrm{TF} 3 \mathrm{C} 1 \_$HUMAN $238.88 \quad 100.0 \%$ General transcription factor 3C polypeptide $1 \mathrm{GN}=\mathrm{GTF} 3 \mathrm{C} 1 \quad$ TF3C1_HUMAN $238.88 \quad 100.0 \%$ General transcription factor $3 \mathrm{C}$ polypeptide $1 \mathrm{GN}=\mathrm{GTF} 3 \mathrm{C} 1 \quad \mathrm{TF} 3 \mathrm{C} 1$ HUMAN $238.88 \quad 100.0 \%$ General transcription factor $3 \mathrm{C}$ polypeptide $1 \mathrm{GN}=\mathrm{GTF} 3 \mathrm{C} 1 \quad \mathrm{TF} 3 \mathrm{C} 1 \_$HUMAN $238.88 \quad 100.0 \%$ General transcription factor $3 \mathrm{C}$ polypeptide $1 \mathrm{GN}=\mathrm{GTF} 3 \mathrm{C} 1$ TF3C1 HUMAN $238.88 \quad 100.0 \%$ General transcription factor $3 \mathrm{C}$ polypeptide $5 \mathrm{GN}=\mathrm{GTF} 3 \mathrm{C} 5$ TF3C5_HUMAN $59.57 \quad 100.0 \%$ General transcription factor $3 \mathrm{C}$ polypeptide $5 \mathrm{GN}=\mathrm{GTF} 3 \mathrm{C} 5$ TF3C5_HUMAN $59.57 \quad 100.0 \%$ General transcription factor $3 \mathrm{C}$ polypeptide $5 \mathrm{GN}=\mathrm{GTF} 3 \mathrm{C} 5 \mathrm{TF} 3 \mathrm{C} 5$ HUMAN $59.57 \quad 100.0 \%$ General vesicular transport factor p115 GN=USO1 USO1_HUMAN $107.90 \quad 100.0 \%$ General vesicular transport factor $\mathrm{p} 115 \mathrm{GN}=$ USO1 USO1 HUMAN $107.90 \quad 100.0 \%$ General vesicular transport factor $\mathrm{p} 115 \mathrm{GN}=$ USO1 USO1_HUMAN $107.90 \quad 100.0 \%$ General vesicular transport factor p115 GN=USO1 USO1_HUMAN $107.90 \quad 100.0 \%$ Geranylgeranyl pyrophosphate synthase GN=GGPS1 GGPPS HUMAN $34.87 \quad 100.0 \%$ Geranylgeranyl pyrophosphate synthase GN=GGPS1 GGPPS_HUMAN $34.87 \quad 100.0 \%$ Geranylgeranyl transferase type-2 subunit beta GN=RABGGTB PGTB2_HUMAN $36.93 \quad 100.0 \%$ Geranylgeranyl transferase type-2 subunit beta GN=RABGGTB PGTB2 HUMAN $36.93 \quad 100.0 \%$ Glioma tumor suppressor candidate region gene 2 protein GN=GLTSCR2 GSCR2_HUMAN $54.39 \quad 100.0 \%$ Glioma tumor suppressor candidate region gene 2 protein GN=GLTSCR2 GSCR2 HUMAN $54.39100 .0 \%$ Giom tumor suppressor candidate region gene 2 protein GN=GLTSCR2 GSCR2 HUMAN $54.39 \quad 100.0 \%$ Glomulin $\mathrm{GN}=\mathrm{GLMN}$ Glomulin $\mathrm{GN}=\mathrm{GLMN}$ GLMN_HUMAN $68.21 \quad 100.0 \%$ GLMN_HUMAN $68.21 \quad 100.0 \%$ Glutamate--cysteine ligase regulatory subunit GN=GCLM GSH0_HUMAN $30.73 \quad 100.0 \%$ Glutamate--cysteine ligase regulatory subunit GN=GCLM GSH0 HUMAN $30.73 \quad 100.0 \%$ Glutamine--tRNA ligase GN=QARS Glutamine--tRNA ligase $\mathrm{GN}=\mathrm{QAR}$ Glutamine--tRNA ligase GN=QARS Glutamine--tRNA ligase GN=QARS Glutamine--tRNA ligase GN=QARS SYQ HUMAN $87.80 \quad 100.0 \%$ SYQ_HUMAN $87.80 \quad 100.0 \%$ SYQ HUMAN $87.80 \quad 100.0 \%$ SYQ_HUMAN $87.80 \quad 100.0 \%$ SYQ HUMAN $87.80 \quad 100.0 \%$ Glutaminyl-peptide cyclotransferase GN=QPCT QPCT_HUMAN $40.88 \quad 100.0 \%$ Glutaminyl-peptide cyclotransferase GN=QPCT QPCT_HUMAN $40.88 \quad 100.0 \%$ Glutaminyl-peptide cyclotransferase-like protein GN=QPCTL QPCTL HUMAN $42.93 \quad 100.0 \%$ Glutaminyl-peptide cyclotransferase-like protein GN=QPCTL QPCTL_HUMAN $42.93 \quad 100.0 \%$ Glutaminyl-peptide cyclotransferase-like protein GN=QPCTL QPCTL_HUMAN $42.93 \quad 100.0 \%$ Glutaminyl-peptide cyclotransferase-like protein GN=QPCTL QPCTL_HUMAN $42.93 \quad 100.0^{\circ}$ Glutaminyl-peptide cyclotransferase-like protein GN=QPCTL QPCTL_HUMAN $42.93 \quad 100.0 \%$

18

18
18

18

7

17

5
$0.04 \% \quad 7.8 \% \quad$ LREELGLCER $0.04 \% \quad 7.8 \%$ LYQYMLNAGLAK $0.04 \% \quad 7.8 \%$ LQEIHPECGPCK $0.04 \% \quad 7.8 \%$ GISQAEIR $0.04 \% \quad 7.8 \%$ NLSEEGLLR

$0.04 \% \quad 7.8 \%$ TTVIQDGIKK $0.04 \% \quad 7.8 \%$ NYHPIVVPGLGR $0.04 \% \quad 7.8 \%$ KENTAAENGLTVR $0.04 \% \quad 7.8 \%$ ENTAAENGLTVR $0.04 \% \quad 7.8 \%$ IASNVLNTK $0.04 \% \quad 7.8 \%$ VCLAEVYQDK $0.04 \% \quad 7.8 \%$ ALVGDFMNR $0.04 \% \quad 7.8 \%$ VLAIGDEKDQTR

$0.04 \% \quad 7.8 \%$ SYQSFQTFR $0.04 \% \quad 7.8 \%$ VNHTLGPK $0.04 \% \quad 7.8 \%$ GYYSPGIVSTR $0.01 \% \quad 5.8 \%$ MLPTLGGEEGVSR $0.01 \% \quad 5.8 \% \quad$ FSTSSLLLR

$0.01 \% \quad 5.8 \%$ IYQVLDFR

$0.01 \% \quad 5.2 \% \quad$ IVAFENAFER $0.01 \% \quad 5.2 \% \quad$ VLVSPTNPPGATSSCQK $0.01 \% \quad 5.2 \%$ LGFISKHELYSR $0.01 \% \quad 5.2 \% \quad$ LVKELEGVITK $0.00 \% \quad 6.3 \% \quad$ YLLQLPGK $0.00 \% \quad 6.3 \%$ GGNPELVALVK $0.00 \% \quad 6.7 \% \quad$ SDAPDTLLLEK $0.00 \% \quad 6.7 \%$ HADYIASYGSK $0.00 \% \quad 5.9 \% \quad$ DVLAHQVPNAK $0.00 \% \quad 5.9 \%$ LLNPSATR $0.00 \% \quad 5.9 \%$ LRVQQAALR $0.00 \% \quad 4.2 \%$ AHYEAEIKNSQEAQK $0.00 \% \quad 4.2 \%$ STSEENIGIK $0.00 \% \quad 8.4 \% \quad$ INPDEREEMK $0.00 \% \quad 8.4 \%$ LFIVESNSSSSTR

$10 \quad 0.01 \% \quad 5.0 \% \quad$ NSALSAQLR

$10 \quad 0.01 \% \quad 5.0 \%$ AINFNFGYAK

$10 \quad 0.01 \% \quad 5.0 \% \quad$ ANNGICFLR

$10 \quad 0.01 \% \quad 5.0 \% \quad$ GKFSEGEATLR

$10 \quad 0.01 \% \quad 5.0 \%$ FSEGEATLR

$0.01 \% \quad 6.9 \%$ YPGSPGSYAAR

$6 \quad 0.01 \% \quad 6.9 \%$ SFSNIISTLNPTAK

$42 \quad 0.05 \% \quad 23.3 \%$ GLMEPLLPPK

$0.05 \% \quad 23.3 \%$ RTEELPLGR

$42 \quad 0.05 \% \quad 23.3 \%$ TEELPLGR

$14 \quad 42 \quad 0.05 \% \quad 23.3 \%$ ELRVPLIGSLPEAR $0.05 \% \quad 23.3 \%$ VPLIGSLPEAR
1163.55

865.49

199.6

1345.68

1023.58

1053.57

1195.61

1742.87

1449.78

1228.75

931.56

1096.64

1201.63

1211.57

1191.65

871.50

1054.65

1745.85

1077.54

1260.59

1426.72

959.53

1144.58

1064.53

1194.61

1009.49

1125.53

1492.80

1094.63

1070.60

914.49

1549.91 1151.68 
Glutaminyl-peptide cyclotransferase-like protein GN=QPCTL QPCTL_HUMAN $42.93 \quad 100.0 \%$ Glutaminyl-pep Glutaminyl-peptide cyclotransferase-like protein GN=QPCTL QPCTL_HUMAN $42.93 \quad 100.0 \%$ Gerting $42.93 \quad 100.0 \%$ Glutaredoxin- $3 \mathrm{GN}=\mathrm{GLRX} 3$

Glutaredoxin $-3 \mathrm{GN}=\mathrm{GLRX} 3$

Glutaredoxin $-3 \mathrm{GN}=\mathrm{GLRX} 3$

Glutaredoxin-3 GN=GLRX 3

GLRX3_HUMAN $37.43 \quad 100.0 \%$

GLRX3_HUMAN $37.43 \quad 100.0 \%$

GLRX3_HUMAN $37.43 \quad 100.0 \%$

GLRX3 HUMAN $37.43 \quad 100.0 \%$

Glutathione S-transferase omega-1 GN=GSTO1 GSTO1_HUMAN $27.57 \quad 100.0 \%$ Glutathione S-transferase omega-1 GN=GSTO1 GSTO1_HUMAN $27.57 \quad 100.0 \%$ Glutathione S-transferase omega-1 GN=GSTO1 GSTO1_HUMAN $27.57 \quad 100.0 \%$ Glyceraldehyde-3-phosphate dehydrogenase GN=GAPDH G3P_HUMAN $36.05 \quad 100.0 \%$ Glyceraldehyde-3-phosphate dehydrogenase GN=GAPDH G3P_HUMAN 36.05 $100.0 \%$ Glyceraldehyde-3-phosphate dehydrogenase GN=GAPDH G3P_HUMAN $36.05 \quad 100.0 \%$ Glyceraldehyde-3-phosphate dehydrogenase GN=GAPDH G3P_HUMAN $36.05 \quad 100.0 \%$ Glyceraldehyde-3-phosphate dehydrogenase GN=GAPDH G3P HUMAN $36.05 \quad 100.0 \%$ Glyceraldehyde-3-phosphate dehydrogenase GN=GAPDH G3P_HUMAN $36.05 \quad 100.0 \%$ Glyceraldehyde-3-phosphate dehydrogenase GN=GAPDH G3P_HUMAN $36.05 \quad 100.0 \%$ Glyceraldehyde-3-phosphate dehydrogenase GN=GAPDH G3P HUMAN $36.05 \quad 100.0 \%$ Glyceraldehyde-3-phosphate dehydrogenase GN=GAPDH G3P_HUMAN $36.05 \quad 100.0 \%$ Glycerol-3-phosphate dehydrogenase 1-like protein GN=GPDIL GPD1L_HUMAN $38.42 \quad 100.0 \%$ Glycerol-3-phosphate dehydrogenase 1-like protein GN=GPDIL GPD1L_HUMAN 38.42 $100.0 \%$ Glycerol-3-phosphate dehydrogenase 1-like protein GN=GPDIL GPD1L_HUMAN $38.42 \quad 100.0 \%$ Glycerol-3-phosphate dehydrogenase 1-like protein GN=GPD1L GPD1L_HUMAN $38.42 \quad 100.0 \%$ Glycerol-3-phosphate dehydrogenase 1-like protein GN=GPDIL GPDIL_HUMAN $38.42 \quad 100.0 \%$ Glycerol-3-phosphate dehydrogenase 1-like protein GN=GPD1L GPD1L_HUMAN $38.42 \quad 100.0 \%$ Glycerol-3-phosphate dehydrogenase 1-like protein GN=GPD1L GPD1L_HUMAN $38.42 \quad 100.0 \%$ Glycerol-3-phosphate dehydrogenase 1-like protein GN=GPDIL GPD1L_HUMAN $38.42 \quad 100.0 \%$ Glycogen phosphorylase, liver form GN=PYGL PYGL HUMAN $97.15 \quad 100.0 \%$ Glycogen phosphorylase, liver form GN=PYGL PYGL_HUMAN $97.15 \quad 100.0 \%$ Glycogen phosphorylase, liver form GN=PYGL PYGL_HUMAN $97.15 \quad 100.0 \%$ Glycogen phosphorylase, liver form GN=PYGL PYGL_HUMAN $97.15 \quad 100.0 \%$ Glycogen phosphorylase, liver form GN=PYGL PYGL_HUMAN $97.15 \quad 100.0 \%$ Glycogen phosphorylase, liver form GN=PYGL PYGL_HUMAN $97.15 \quad 100.0 \%$ Glyoxylate reductase/hydroxypyruvate reductase GN=GRHPR GRHPR_HUMAN $35.67 \quad 100.0 \%$ Glyoxylate reductase/hydroxypyruvate reductase GN=GRHPR GRHPR_HUMAN $35.67 \quad 100.0 \%$ Golgi phosphoprotein 3 GN=GOLPH3 GOLP3_HUMAN $33.81 \quad 100.0 \%$ Golgi phosphoprotein $3 \mathrm{GN}=\mathrm{GOLPH} 3 \quad$ GOLP3_HUMAN $33.81 \quad 100.0 \%$ Golg-specific brefeldin A-resistance guanine nucleotide exchange factor $1 \mathrm{GN}=\mathrm{GBF} 1 \mathrm{GBF} 1$ _HUMAN $206.45 \quad 100.0 \%$

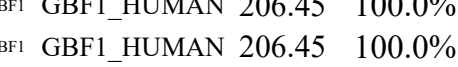
BF1 GBF1_HUMAN $206.45 \quad 100.0 \%$ 1 GBF1_HUMAN $206.45 \quad 100.0 \%$ BF1 GBF1_HUMAN $206.45 \quad 100.0 \%$ GBF1 GBF1_HUMAN $206.45 \quad 100.0 \%$ 1 GBF1_HUMAN $206.45 \quad 100.0 \%$ GBF1_HUMAN $206.45 \quad 100.0 \%$
$42 \quad 0.05 \% \quad 23.3 \%$ VVGQLDPQR

$0.05 \% \quad 23.3 \%$ TPGSPGNLQVR

$0.05 \% \quad 23.3 \%$ KFLEATLR

$\begin{array}{llllllll}99.7 \% & 48.2 & 25.0 & 36.5 & 7 & 0 & 0 & 1011.56\end{array}$

$0.05 \% \quad 23.3 \%$ HLTLACHYDSK

$0.05 \% \quad 23.3 \%$ HLAQLMESIPHSPGPTR

$0.01 \% \quad 10.1 \%$ ELPQVSFVK

$0.01 \% \quad 10.1 \%$ IDRLDGAHAPELTK

$0.01 \% \quad 10.1 \%$ LDGAHAPELTK

$0.01 \% \quad 10.1 \%$ GELVGGLDIVK

$0.00 \% \quad 13.7 \%$ GSAPPGPVPEGSIR

$0.00 \% \quad 13.7 \%$ HEVININLK

$0.00 \% \quad 13.7 \%$ LNECVDHTPK

$0.03 \% \quad 35.8 \%$ LVINGNPITIFQER

$0.03 \% \quad 35.8 \%$ LVINGNPITIFQERDPSK

$0.03 \% \quad 35.8 \%$ IISNASCTTNCLAPLAK

$0.03 \% \quad 35.8 \%$ VIHDNFGIVEGLMTTVHAITATQK

$0.03 \% \quad 35.8 \%$ GALQNIIPASTGAAK

$0.03 \% \quad 35.8 \%$ VPTANVSVVDLTCR

$\begin{array}{ll}0.03 \% & 35.8 \% \\ 0.03 \% & 35.8 \%\end{array}$

$0.03 \% \quad 35.8 \%$ VVDLMAHMASKE

$0.01 \% \quad 24.8 \%$ LTDIINNDHENVK

$0.01 \% \quad 24.8 \%$ ICDEITGR

$0.01 \% \quad 24.8 \%$ KALGITLIK

$0.01 \% \quad 24.8 \%$ GIDEGPEGLK

$0.01 \% \quad 24.8 \%$ VMENGLLFK

$0.01 \% \quad 24.8 \%$ ELLQTPNFR

$99.7 \% \quad 57.3$

$99.0 \% \quad 49.2$

$99.7 \% \quad 55.1$

$99.7 \% \quad 40.6$

$99.5 \% 23.0$

$98.0 \% \quad 16.4$

$99.7 \% \quad 41.3$

$99.7 \% \quad 61.3$

$99.5 \% \quad 22.3$

$99.7 \% \quad 31.6$

$99.6 \% 22.8$

$99.7 \% \quad 63.0$

$99.7 \% \quad 51.1$

$99.7 \% \quad 67.4$

$99.7 \% \quad 36.5$

$99.7 \% \quad 54.2$

$99.7 \% \quad 53.2$

$99.7 \% \quad 35.6$

$99.7 \% \quad 64.3$

$99.7 \% \quad 49.6$

$96.2 \% 18.0$

$99.0 \% \quad 48.5$

$99.7 \% \quad 31.8$

$99.7 \% \quad 26.4$

$\begin{array}{lll}99.3 \% & 22.8\end{array}$

$97.7 \% \quad 25.9$

$0.01 \% \quad 24.8 \%$ ITVVDDADTVELCGALK $\quad 99.7 \% \quad 54.5$

$0.01 \% \quad 24.8 \%$ LQGPQTSAEVYR

$0.02 \% \quad 8.2 \%$ GIVGVENVAELKK

$0.02 \% \quad 8.2 \%$ FSQFLETEYKVK

$0.02 \% \quad 8.2 \% \quad$ VIFLENYR

$0.02 \% \quad 8.2 \% \quad$ LVIDQIDNGFFSPK

$0.02 \% \quad 8.2 \%$ VFADYEAYVK

$0.02 \% \quad 8.2 \%$ NIAASGKFSSDR

$0.00 \% \quad 10.4 \%$ ILDAAGANLK

$0.00 \% \quad 10.4 \%$ IAAAGLDVTSPEPLPTNHPLLTLK

$0.00 \% \quad 8.4 \%$ GCMLIELALR

$0.00 \% \quad 8.4 \%$ SDAPTGDVLLDEALK

$0.03 \% \quad 6.1 \% \quad$ VLNSLTQQEK

$0.03 \% \quad 6.1 \%$ VLNSLTQQEKK

$0.03 \% \quad 6.1 \%$ ETARPSCEIVDGTR

$0.03 \% \quad 6.1 \% \quad$ FSCLLPDPR

$0.03 \% \quad 6.1 \%$ LLITGTEQFNQKPK

$0.03 \% \quad 6.1 \%$ KGIQFLQEK

$0.03 \% \quad 6.1 \%$ GIQFLQEK

$0.03 \% \quad 6.1 \%$ LLEAFTER

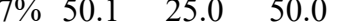

$\begin{array}{llll}99.7 \% & 35.3 & 25.0 & 32.7\end{array}$

$99.0 \% \quad 44.4 \quad 25.0 \quad 39.2$

$99.7 \% \quad 44.2 \quad 25.0 \quad 44.2$

$99.7 \% \quad 34.9 \quad 25.0 \quad 33.5$

$99.7 \% \quad 54.2 \quad 25.0 \quad 52.4$

$99.7 \% \quad 55.5 \quad 25.0 \quad 43.9$

$\begin{array}{llll}99.7 \% & 65.9 & 25.0 & 65.9\end{array}$

$99.7 \% \quad 32.3 \quad 25.0 \quad 19.8$

$99.7 \% \quad 74.3 \quad 25.0 \quad 74.3$

$\begin{array}{llll}99.7 \% & 28.2 & 25.0 & 23.9\end{array}$

$99.7 \% \quad 47.5 \quad 25.0 \quad 47.5$

$99.5 \% \quad 23.1 \quad 25.0 \quad 23.1$

$\begin{array}{llll}98.5 \% & 17.3 & 25.0 & 17.3\end{array}$

$\begin{array}{llll}99.7 \% & 39.2 & 25.0 & 39.2\end{array}$

$99.0 \% \quad 26.0 \quad 25.0 \quad 21.0$

$94.8 \% \quad 16.4 \quad 25.0 \quad 12.3$
$99.6 \% \quad 24.6 \quad 25.0 \quad 24.2$
125.60

977.58

1344.64

1870.96

1046.59

1535.82

1151.61

1099.64

1320.69

1079.62

1212.57

1613.90

2041.11

1833.92

2611.36

1411.79

1530.79

2197.20

1763.80

1362.64

1524.77

963.46

956.65

1014.51

1066.56

1117.60

1818.92

1348.69

1355.79

1518.78

1053.57

1592.83

1204.59

1252.63

985.57

2468.38

1175.63

1543.79

1159.63

1287.73

1590.75

1104.55

1616.90

1090.63

962.53

978.53

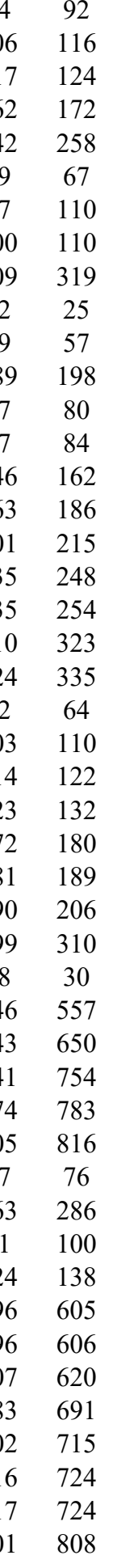

Page 68 of Table S-1-5 

are $\begin{array}{lll} & 100.0 \%\end{array}$ GPI transamidase component PIG-T GN=PIGT PIGT_HUMAN $65.70 \quad 100.0 \%$ GPI transamidase component PIG-T GN=PIGT PIGT_HUMAN $65.70 \quad 100.0 \%$ GPI-anchor transamidase GN=PIGK GPI-anchor transamidase GN=PIGK GPI-anchor transamidase GN=PIGK G-rich sequence factor $1 \mathrm{GN}=\mathrm{GRSF} 1$ G-rich sequence factor $1 \mathrm{GN}=\mathrm{GRSF} 1$ GTPase Era, mitochondrial GN=ERAL 1 GTPase Era, mitochondrial GN=ERAL GTPase Era, mitochondrial GN=ERAL1 GTPase Era, mitochondrial GN=ERAL1 GTPase Era, mitochondrial GN=ERAL1 GTPase Era, mitochondrial GN=ERAL1 GTPase Era, mitochondrial GN=ERAL1 GTPase-activating protein and VPS9 domain-containing protein $1 \mathrm{GN}=\mathrm{GAPVD} 1$ GTPase-activating protein and VPS9 domain-containing protein $1 \mathrm{GN}=\mathrm{GAPVD}$ GTPase-activating protein and VPS9 domain-containing protein 1 GN=GAPVD1 GAPD1_HUMAN 164.98 TP-binding nuclear protein Ran GN=RAN RAN_HUMAN $24.42 \quad 100.0 \%$

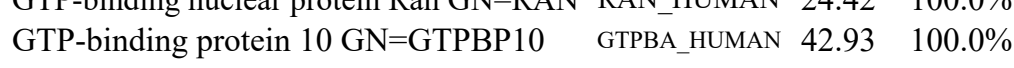
GTP-binding protein $10 \mathrm{GN}=\mathrm{GTPBP} 10$ GTP-binding protein $10 \mathrm{GN}=\mathrm{GTPBP} 10$ GTP-binding protein $10 \mathrm{GN}=\mathrm{GTPBP} 10$ GTP-binding protein $10 \mathrm{GN}=\mathrm{GTPBP} 10$ GTP-binding protein $10 \mathrm{GN}=\mathrm{GTPBP} 10$ GTP-binding protein $10 \mathrm{GN}=\mathrm{GTPBP} 1 \mathrm{C}$ ERAL1_HUMAN $48.35 \quad 100.0 \%$
GPI8 HUMAN $45.25 \quad 100.0 \% \quad 3$ GPI8_HUMAN $45.25 \quad 100.0 \%$ GPI8 HUMAN $45.25 \quad 100.0 \%$ GRSF1_HUMAN $53.13 \quad 100.0 \%$ GRSF1_HUMAN $53.13 \quad 100.0 \%$ ERAL1 HUMAN $48.35 \quad 100.0 \%$ ERAL1_HUMAN $48.35 \quad 100.0 \%$ ERAL1_HUMAN $48.35 \quad 100.0 \%$ ERAL1 HUMAN $48.35 \quad 100.0 \%$ ERAL1_HUMAN $48.35 \quad 100.0 \%$ ERAL1_HUMAN $48.35 \quad 100.0 \%$ GAPD1_HUMAN $164.98 \quad 100.0 \%$ $00.0 \%$ GTPBA_HUMAN $42.93 \quad 100.0 \%$ GTPBA_HUMAN $42.93 \quad 100.0 \%$ GTPBA_HUMAN $42.93 \quad 100.0 \%$ GTPBA HUMAN $42.93 \quad 100.0 \%$ GTPBA_HUMAN $42.93 \quad 100.0 \%$ GTPBA HUMAN $42.93 \quad 100.0 \%$ $100.0 \%$ $100.0 \%$ $100.0 \%$ $100.0 \%$ $100.0 \%$ $100.0 \%$ $100.0 \%$ $100.0 \%$ $100.0 \%$ $100.0 \%$ $100.0 \%$ $100.0 \%$ $100.0 \%$ $100.0 \%$ $100.0 \%$ $100.0 \%$ $100.0 \%$
$0.03 \% \quad 6.1 \%$ AASSSSPGSPVASSPSR

$0.00 \% \quad 3.6 \%$ ALGQLISK

$0.00 \% \quad 3.6 \%$ TLTEPCPLASESR

$0.01 \% \quad 7.9 \%$ NPKPATVFSHK

$0.01 \% \quad 7.9 \%$ SLCVSTPGHR

$0.01 \% \quad 7.9 \%$ KVEITTETIK

$0.00 \% \quad 1.9 \%$ KIASFPTAK

$0.00 \% \quad 1.9 \%$ IASFPTAK

$0.02 \% \quad 22.4 \%$ STLSNQLLGR

$0.02 \% \quad 22.4 \%$ ETQVILLDTPGIISPGK

$0.02 \% \quad 22.4 \%$ YSQIPSVLVMNK

$0.02 \% \quad 22.4 \%$ DPNTQSVGNPQR

$0.02 \% \quad 22.4 \%$ EIFMLSALSQEDVK

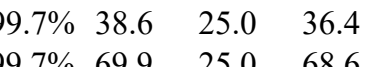

$99.0 \% \quad 25.9 \quad 25.0$

$99.7 \% \quad 48.4 \quad 25.0 \quad 45.0$

$97.2 \% \quad 16.3 \quad 25.0 \quad 16.3$

$\begin{array}{llll}99.7 \% & 39.3 & 25.0 & 38.9\end{array}$

$99.7 \% \quad 35.8 \quad 25.0 \quad 35.8$

$\begin{array}{llll}99.7 \% & 31.3 & 25.0 & 24.0\end{array}$

$\begin{array}{llll}95.1 \% & 22.0 & 25.0 & 9.1\end{array}$

$99.7 \% \quad 61.3 \quad 25.0 \quad 22.6$

$99.7 \% \quad 81.3 \quad 25.0 \quad 81.1$

$\begin{array}{llll}99.7 \% & 40.5 & 25.0 & 38.2\end{array}$

$99.7 \% \quad 54.1 \quad 25.0 \quad 53.4$

$\begin{array}{llll}99.7 \% & 54.9 & 25.0 & 49.9\end{array}$

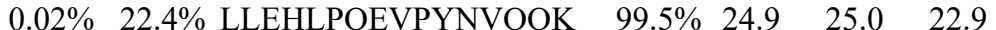

$0.02 \% \quad 22.4 \%$ TAVWEEGPGGELVIQQK

$0.00 \% \quad 2.0 \% \quad$ LIASSLVAGEK

$0.00 \% \quad 2.0 \%$ FNLMQVGR

$0.00 \% \quad 2.0 \%$ ALQIPEVYLR

$0.01 \% \quad 11.1 \%$ NLQYYDISAK

$0.01 \% \quad 11.1 \%$ SNYNFEKPFLWLAR

$0.02 \% \quad 21.4 \%$ FVAGVGANSK

$0.02 \% \quad 21.4 \%$ IIGELNKENDR

$0.02 \% \quad 21.4 \%$ ILVAQGGLGGK

$0.02 \% \quad 21.4 \%$ LLTNFLPLK

$0.02 \% \quad 21.4 \%$ LIADVGLVGFPNAGK

$0.02 \% \quad 21.4 \%$ TAFETIILLTK

$\begin{array}{llll}99.7 \% & 47.4 & 25.0 & 46.1\end{array}$

$95.1 \% \quad 19.5 \quad 25.0 \quad 14.0$

$98.3 \% \quad 19.9 \quad 25.0 \quad 15.0$

$\begin{array}{llll}97.2 \% & 17.3 & 25.0 & 17.3\end{array}$

$\begin{array}{llll}99.7 \% & 34.5 & 25.0 & 34.5\end{array}$

$99.7 \% \quad 28.9 \quad 25.0 \quad 28.9$

$99.7 \% \quad 44.8 \quad 25.0 \quad 38.0$

$\begin{array}{lllll}99.5 \% & 31.8 & 25.0 & 24.8\end{array}$

$99.7 \% \quad 38.0 \quad 25.0 \quad 27.9$

$\begin{array}{llll}99.3 \% & 20.6 & 25.0 & 20.3\end{array}$

$99.7 \% \quad 56.8 \quad 25.0 \quad 56.8$

$\begin{array}{llll}99.7 \% & 55.4 & 25.0 & 49.3\end{array}$

$0.02 \% \quad 21.4 \%$ SLDEQANQENDALHKK

$0.00 \% \quad 20.0 \%$ LLLLGAGESGK

$0.00 \% \quad 20.0 \%$ IAQSDYIPTQQDVLR

$0.00 \% \quad 20.0 \%$ TTGIVETHFTFK

$0.00 \% \quad 20.0 \%$ LFDSICNNK

$0.00 \% \quad 20.0 \%$ YDEAASYIQSK

$0.00 \% \quad 20.0 \%$ EIYTHFTCATDTK

$9.7 \% \quad 25.0$

$99.4 \% 57.8$

$99.7 \% \quad 39.4$

$99.7 \% \quad 52.1$

$99.7 \% \quad 55.8$

$99.7 \% \quad 32.0$

$99.7 \% \quad 31.4$

$0.01 \% \quad 19.1 \%$ ACGDSTLTQITAGLDPVGR $99.7 \% \quad 66.6$

$\quad 0.01 \% \quad 19.1 \%$ LLVSASQDGK

$0.01 \% \quad 19.1 \%$ LIIWDSYTTNK

$10 \quad 0.01 \% \quad 19.1 \%$ ELPGHTGYLSCCR

$10 \quad 0.01 \% \quad 19.1 \%$ TFVSGACDASIK

$10 \quad 0.01 \% \quad 22.6 \%$ LLLLGAGESGK

$10 \quad 0.01 \% \quad 22.6 \%$ LKIDFGEAAR

$10 \quad 0.01 \% \quad 22.6 \%$ DGGVQACFSR

$10 \quad 0.01 \% \quad 22.6 \%$ ISQSNYIPTQQDVLR

$10 \quad 0.01 \% \quad 22.6 \%$ TTGIVETHFTFK

$0.01 \% \quad 22.6 \%$ LFDSICNNK
$25.0 \quad 66.6$

$\begin{array}{llll}99.2 \% & 30.1 & 25.0 & 28.7\end{array}$

$99.7 \% \quad 56.7 \quad 25.0 \quad 51.9$

$\begin{array}{lllll}99.4 \% & 57.8 & 25.0 & 0.0 & 11\end{array}$

$\begin{array}{llll}97.6 \% & 19.7 & 25.0 & 14.6\end{array}$

$\begin{array}{llll}99.7 \% & 60.7 & 25.0 & 55.6\end{array}$

$\begin{array}{lllll}99.7 \% & 56.3 & 25.0 & 44.5 & 2\end{array}$

$\begin{array}{llll}99.7 \% & 52.1 & 25.0 & 35.8\end{array}$

$99.7 \% \quad 55.8 \quad 25.0 \quad 54.6$
829.51

1460.71

1225.67

1113.55

1161.67

962.57

834.47

1088.61

1781.01

1394.73

1312.62

1609.81

1935.03

1840.94

1087.64

980.50

1201.69

1214.61

1784.91

949.51

1300.69

1012.62

1058.66

1470.83

1249.74

1839.88

1057.63

1746.90

1380.72

1110.52

1274.59

1586.72

1931.95

1017.56

1353.71

1549.69

1255.60

1057.63

1119.62

1096.48

1761.91

1380.72

1110.52 

CI 1 -associated protein X-1 GN=HAX1 HAX1_HUMAN 31.6 HCLS1-associated protein X-1 GN=HAX1 HAX1_HUMAN $31.62 \quad 100.0 \%$ HCLS1-associated protein X-1 GN=HAX1 HAX1 HUMAN $31.62 \quad 100.0 \%$ HCLS1-associated protein X-1 GN=HAX1 HAX1_HUMAN $31.62 \quad 100.0 \%$ HCLS1-associated protein X-1 GN=HAX1 HAX1_HUMAN $31.62 \quad 100.0 \%$ HCLS1-associated protein X-1 GN=HAX1 HAX1 HUMAN $31.62 \quad 100.0 \%$ HCLS1-associated protein X-1 GN=HAX1 HAX1_HUMAN $31.62 \quad 100.0 \%$ HEAT repeat-containing protein $1 \mathrm{GN}=$ HEATR1 HEAT1_HUMAN $242.38100 .0 \%$ HEAT repeat-containing protein $1 \mathrm{GN}=$ HEATR1 HEAT1_HUMAN $242.38 \quad 100.0 \%$ HEAT repeat-containing protein $1 \mathrm{GN}=$ HEATR1 HEAT1_HUMAN $242.38 \quad 100.0 \%$ HEAT repeat-containing protein $1 \mathrm{GN}=$ HEATR1 HEAT1_HUMAN $242.38 \quad 100.0 \%$ HEAT repeat-containing protein 1 GN=HEATR1 HEAT1_HUMAN $242.38 \quad 100.0 \%$

$10 \quad 0.01 \% \quad 22.6 \%$ EIYTHFTCATDTK

(1)

(5)

$0.02 \% \quad 25.1 \%$ LLLLGAGESGK $0.02 \% \quad 25.1 \%$ VLTSGIFETK $0.02 \% \quad 25.1 \%$ TISVILFLNK

$0.02 \% \quad 25.1 \%$ IEDYFPEFAR $0.02 \% \quad 25.1 \%$ YFIRDEFLR $0.04 \% \quad 62.1 \%$ LWDLTTGTTTR

$0.04 \% \quad 62.1 \%$ DVLSVAFSSDNR

$0.04 \% \quad 62.1 \%$ LWNTLGVCK

$0.04 \% \quad 62.1 \%$ VWNLANCK

$0.04 \% \quad 62.1 \%$ VWQVTIGTR

$0.03 \% \quad 8.9 \% \quad$ KLVLILNK

$0.03 \% \quad 8.9 \%$ ELPTVVFR

$0.03 \% \quad 8.9 \%$ LLGGFQETCSK

$0.03 \% \quad 8.9 \%$ VGVIGFPNVGK

$0.03 \% \quad 8.9 \%$ GGIPNVEGAAK

$10 \quad 0.01 \% \quad 9.8 \%$ TIESYCQDVLR

$10 \quad 0.01 \% \quad 9.8 \% \quad$ SSLINSLKR

$10 \quad 0.01 \% \quad 9.8 \% \quad$ AVLADWVSGK

$10 \quad 0.01 \% \quad 9.8 \%$ IADAIENKTTVYK

$9 \quad 0.01 \% \quad 8.8 \% \quad$ LHNAIEGGTQLSR

$0.01 \% \quad 8.8 \%$ RVVYPLEK

$0.01 \% \quad 8.8 \%$ APQVVAEAAK

$0.01 \% \quad 32.6 \%$ GFFGFPGPR

$0.01 \% \quad 32.6 \%$ FHDNFGFDDLVR

$0.01 \% 32.6 \%$ YPDSHQPR

$0.01 \% \quad 32.6 \%$ IFGGVLESDAR

$11 \quad 0.01 \% \quad 32.6 \%$ ITKPDGIVEER

$10 \quad 17 \quad 0.02 \% \quad 4.9 \% \quad$ VFAEYPGSSAQLR

$10 \quad 17 \quad 0.02 \% \quad 4.9 \% \quad$ LLESKYPR

$10 \quad 17 \quad 0.02 \% \quad 4.9 \%$ LIGVANQK

$\begin{array}{lllll}10 & 17 & 0.02 \% & 4.9 \% & \text { LDDTYSFQVINK }\end{array}$

$10 \quad 17 \quad 0.02 \% \quad 4.9 \%$ VVESGGPEILK
$99.7 \% \quad 31.4$ $0.02 \% \quad 25.1 \%$ ILHVNGFNGEGGEEDPQAAR $0.02 \% \quad 25.1 \%$ QADYVPSDQDLLR $0.02 \% \quad 25.1 \%$ YTTPEDATPEPGEDPR

$0.04 \% \quad 62.1 \%$ GHNGWVTQIATTPQFPDMILSASR

$0.04 \% \quad 62.1 \%$ YTVQDESHSEWVSCVR $0.04 \% \quad 62.1 \%$ FSPNSSNPIIVSCGWDK

$99.1 \% \quad 18.9$

$97.9 \% \quad 25.8$

$99.7 \% \quad 37.9$

$99.7 \% \quad 35.5$

$99.7 \% 36.4$

$99.7 \% \quad 27.5$

$97.1 \% \quad 17.4$

$\begin{array}{ll}99.7 \% & 55.4 \\ 99.7 \% & 58.8\end{array}$

$99.7 \% \quad 51.8$

$99.7 \% \quad 49.5$

$99.7 \% \quad 41.4$

$99.7 \% \quad 53.0$

$99.0 \% \quad 22.4$

$0.04 \% \quad 62.1 \%$ TNHIGHTGYLNTVTVSPDGSLCASGGK $99.7 \% \quad 56.7$

$0.04 \% \quad 62.1 \%$ HLYTLDGGDIINALCFSPNR $99.7 \% \quad 42.3$

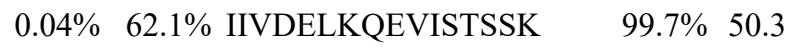

$0.04 \% \quad 62.1 \%$ AEPPQCTSLAWSADGQTLFAGYTDNLVR $\quad 95.0 \% 25.8$

$10 \quad 0.01 \% \quad 9.8 \% \quad$ CSVPVDQASESLLK

$9 \quad 0.01 \% \quad 8.8 \%$ SQQSAGKEYVGIVR

$11 \quad 0.01 \% \quad 32.6 \%$ TREDNDLDSQVSQEGLGPVLQPQPK

$11 \quad 0.01 \% \quad 32.6 \%$ TVVDSEGRTETTVTR
$99.7 \% \quad 54.8$

$99.0 \% \quad 31.4$

$99.0 \% \quad 41.5$

$99.7 \% \quad 39.0$

$99.7 \% \quad 45.5$

$94.7 \% \quad 16.8$

$99.7 \% \quad 34.4$

$99.7 \% \quad 43.5$

$98.6 \% \quad 25.9$

$\begin{array}{lll}99.4 \% & 20.8\end{array}$

$99.7 \% \quad 54.6$

$99.7 \% \quad 47.0$

$99.7 \% \quad 76.9$

$99.0 \% \quad 30.0$

$99.7 \% \quad 44.2$

$99.7 \% \quad 42.0$

$99.7 \% \quad 55.0$

$99.0 \% \quad 33.1$

$99.7 \% \quad 69.9$

$99.7 \% \quad 52.6$

$99.7 \% \quad 31.6$

$99.7 \% \quad 29.3$

$\begin{array}{lll}99.7 \% & 36.9\end{array}$

$98.4 \% \quad 22.5$

$95.2 \% \quad 20.6$

$99.7 \% \quad 61.2$

$99.7 \% \quad 45.0$
158

1057.63

2110.00

1519.74

1094.61

1147.71

1286.6

1774.78

1258.66

2627.30

1264.65

1309.64

1090.57

1981.87

1907.90

1004.50

2743.31

2276.11

1789.00

3068.44

1059.59

940.66

960.55

1239.60

1086.63

1012.54

1383.66

1532.76

1017.61

1045.57

1465.79

1521.80

1395.73

1003.59

983.55

981.49

1481.68

999.46

1163.61

2750.36

1256.68

1650.83

1424.72

1005.57

842.51

1442.72 1127.63 
HEAT repeat-containing protein 1 GN=HEATR1 HEAT1_HUMAN $242.38 \quad 100.0 \%$ HEAT repeat-containing protein 1 GN=HEATR1 HEAT1_HUMAN $242.38 \quad 100.0 \%$ HEAT repeat-containing protein $1 \mathrm{GN}=$ HEATR1 HEAT1_HUMAN $242.38 \quad 100.0 \%$ HEAT repeat-containing protein 1 GN=HEATR1 HEAT1_HUMAN $242.38 \quad 100.0 \%$ HEAT repeat-containing protein $1 \mathrm{GN}=$ HEATR1 HEAT1_HUMAN $242.38 \quad 100.0 \%$ Heat shock $70 \mathrm{kDa}$ protein 1A/1B GN=HSPA1A HSP71_HUMAN $70.05 \quad 100.0 \%$ Heat shock $70 \mathrm{kDa}$ protein $1 \mathrm{~A} / 1 \mathrm{~B}$ GN=HSPA1A HSP71 HUMAN $70.05 \quad 100.0 \%$ Heat shock $70 \mathrm{kDa}$ protein 1A/1B GN=HSPA1A HSP71_HUMAN $70.05 \quad 100.0 \%$ Heat shock $70 \mathrm{kDa}$ protein 1A/1B GN=HSPA1A HSP71 HUMAN $70.05 \quad 100.0 \%$ Heat shock $70 \mathrm{kDa}$ protein $1 \mathrm{~A} / 1 \mathrm{~B}$ GN=HSPA1A HSP71_HUMAN $70.05 \quad 100.0 \%$ Heat shock $70 \mathrm{kDa}$ protein $1 \mathrm{~A} / 1 \mathrm{~B}$ GN=HSPA1A HSP71_HUMAN $70.05 \quad 100.0 \% 30$ Heat shock $70 \mathrm{kDa}$ protein $1 \mathrm{~A} / 1 \mathrm{~B}$ GN=HSPA1A HSP71_HUMAN $70.05 \quad 100.0 \%$ Heat shock $70 \mathrm{kDa}$ protein $1 \mathrm{~A} / 1 \mathrm{~B}$ GN=HSPA1A HSP71_HUMAN $70.05 \quad 100.0 \%$ Heat shock $70 \mathrm{kDa}$ protein $1 \mathrm{~A} / 1 \mathrm{~B}$ GN=HSPA1A HSP71_HUMAN $70.05 \quad 100.0 \% 30$ Heat shock $70 \mathrm{kDa}$ protein 1A/1B GN=HSPA1A HSP71_HUMAN $70.05 \quad 100.0 \% 30$ Heat shock $70 \mathrm{kDa}$ protein $1 \mathrm{~A} / 1 \mathrm{~B}$ GN=HSPA1A HSP71_HUMAN $70.05 \quad 100.0 \% 30$ Heat shock $70 \mathrm{kDa}$ protein $1 \mathrm{~A} / 1 \mathrm{~B}$ GN=HSPA1A HSP71 HUMAN $70.05 \quad 100.0 \%$ Heat shock $70 \mathrm{kDa}$ protein $1 \mathrm{~A} / 1 \mathrm{~B}$ GN=HSPA1A HSP71_HUMAN $70.05 \quad 100.0 \%$ Heat shock $70 \mathrm{kDa}$ protein 1A/1B GN=HSPA1A HSP71_HUMAN $70.05 \quad 100.0 \% 30$ Heat shock $70 \mathrm{kDa}$ protein 1A/1B GN=HSPA1A HSP71_HUMAN $70.05 \quad 100.0 \% 30$ Heat shock $70 \mathrm{kDa}$ protein 1A/1B GN=HSPA1A HSP71_HUMAN $70.05 \quad 100.0 \% 30$ Heat shock $70 \mathrm{kDa}$ protein 1A/1B GN=HSPA1A HSP71_HUMAN $70.05 \quad 100.0 \% 30$ Heat shock $70 \mathrm{kDa}$ protein $1 \mathrm{~A} / 1 \mathrm{~B}$ GN=HSPA1A HSP71_HUMAN $70.05 \quad 100.0 \% 30$ Heat shock $70 \mathrm{kDa}$ protein $1 \mathrm{~A} / 1 \mathrm{~B}$ GN=HSPA1A HSP71_HUMAN $70.05 \quad 100.0 \% 30$ Heat shock $70 \mathrm{kDa}$ protein $1 \mathrm{~A} / 1 \mathrm{~B}$ GN=HSPA1A HSP71_HUMAN $70.05 \quad 100.0 \%$ Heat shock $70 \mathrm{kDa}$ protein $1 \mathrm{~A} / 1 \mathrm{~B}$ GN=HSPA1A HSP71_HUMAN $70.05 \quad 100.0 \% \quad 30$ Heat shock $70 \mathrm{kDa}$ protein $1 \mathrm{~A} / 1 \mathrm{~B}$ GN=HSPA1A HSP71_HUMAN $70.05 \quad 100.0 \% \quad 30$ Heat shock $70 \mathrm{kDa}$ protein $1 \mathrm{~A} / 1 \mathrm{~B}$ GN=HSPA1A HSP71_HUMAN $70.05 \quad 100.0 \% 30$ Heat shock $70 \mathrm{kDa}$ protein $1 \mathrm{~A} / 1 \mathrm{~B}$ GN=HSPA1A HSP71_HUMAN $70.05 \quad 100.0 \% \quad 30$ Heat shock $70 \mathrm{kDa}$ protein $1 \mathrm{~A} / 1 \mathrm{~B}$ GN=HSPA1A HSP71 HUMAN $70.05 \quad 100.0 \%$ Heat shock $70 \mathrm{kDa}$ protein $1 \mathrm{~A} / 1 \mathrm{~B}$ GN=HSPA1A HSP71_HUMAN $70.05 \quad 100.0 \% \quad 30$ Heat shock $70 \mathrm{kDa}$ protein 1A/1B GN=HSPA1A HSP71_HUMAN $70.05 \quad 100.0 \% 30$ Heat shock $70 \mathrm{kDa}$ protein $1 \mathrm{~A} / 1 \mathrm{~B}$ GN=HSPA1A HSP71_HUMAN $70.05 \quad 100.0 \%$ Heat shock $70 \mathrm{kDa}$ protein $1 \mathrm{~A} / 1 \mathrm{~B}$ GN=HSPA1A HSP71_HUMAN $70.05 \quad 100.0 \% 30$ Heat shock $70 \mathrm{kDa}$ protein 1A/1B GN=HSPA1A HSP71_HUMAN $70.05 \quad 100.0 \% 30$ Heat shock $70 \mathrm{kDa}$ protein $4 \mathrm{GN}=$ HSPA4 HSP74_HUMAN $94.33 \quad 100.0 \%$ Heat shock $70 \mathrm{kDa}$ protein $4 \mathrm{GN}=\mathrm{HSPA} 4$ HSP74_HUMAN $94.33 \quad 100.0 \%$ Heat shock $70 \mathrm{kDa}$ protein $4 \mathrm{GN}=\mathrm{HSPA} 4$ HSP74_HUMAN $94.33 \quad 100.0 \%$ Heat shock $70 \mathrm{kDa}$ protein $4 \mathrm{GN}=\mathrm{HSPA} 4 \quad$ HSP74_HUMAN $94.33 \quad 100.0 \%$ Heat shock $70 \mathrm{kDa}$ protein $4 \mathrm{GN}=$ HSPA4 HSP74_HUMAN $94.33 \quad 100.0 \%$ Heat shock $70 \mathrm{kDa}$ protein $4 \mathrm{~L}$ GN=HSPA4L HS74L_HUMAN $94.51 \quad 100.0 \%$ Heat shock $70 \mathrm{kDa}$ protein $4 \mathrm{~L}$ GN=HSPA4L HS74L_HUMAN $94.51 \quad 100.0 \%$ Heat shock $70 \mathrm{kDa}$ protein 4L GN=HSPA4L HS74L HUMAN $94.51 \quad 100.0 \%$ Heat shock cognate $71 \mathrm{kDa}$ protein GN=HSPA8 HSP7C_HUMAN $70.90 \quad 100.0 \%$ Heat shock cognate $71 \mathrm{kDa}$ protein GN=HSPA8 HSP7C_HUMAN $70.90 \quad 100.0 \% \quad 24$ Heat shock cognate $71 \mathrm{kDa}$ protein GN=HSPA8 HSP7C_HUMAN $70.90 \quad 100.0 \% \quad 24$ Heat shock cognate $71 \mathrm{kDa}$ protein GN=HSPA8 HSP7C_HUMAN $70.90 \quad 100.0 \% \quad 24$
$10 \quad 17 \quad 0.02 \% \quad 4.9 \% \quad$ GLVGNPLPSVR

$10 \quad 17 \quad 0.02 \% \quad 4.9 \%$ EGEEEQAINR

$10 \quad 17 \quad 0.02 \% \quad 4.9 \%$ ITSEMGSASQANIR

$\begin{array}{lllll}10 & 17 & 0.02 \% & 4.9 \% & \text { TLATTLAPR }\end{array}$

$\begin{array}{lllll}10 & 17 & 0.02 \% & 4.9 \% & \text { LGGEEKFQER }\end{array}$

$44 \quad 337 \quad 0.37 \% \quad 47.1 \%$ VEIIANDQGNR

$44 \quad 337 \quad 0.37 \% \quad 47.1 \%$ TTPSYVAFTDTER

$44 \quad 337 \quad 0.37 \% \quad 47.1 \%$ NQVALNPQNTVFDAK

$44 \quad 337 \quad 0.37 \% \quad 47.1 \%$ NQVALNPQNTVFDAKR

$44 \quad 337 \quad 0.37 \% \quad 47.1 \%$ HWPFQVINDGDKPK

$44 \quad 337 \quad 0.37 \% \quad 47.1 \%$ VQVSYKGETK

$44 \quad 337 \quad 0.37 \% \quad 47.1 \%$ AFYPEEISSMVLTK

$44 \quad 337 \quad 0.37 \% \quad 47.1 \%$ QATKDAGVIAGLNVLR

$44 \quad 337 \quad 0.37 \% \quad 47.1 \%$ DAGVIAGLNVLR

$44 \quad 337 \quad 0.37 \% \quad 47.1 \%$ IINEPTAAAIAYGLDR

$44 \quad 337 \quad 0.37 \% \quad 47.1 \%$ ATAGDTHLGGEDFDNR

$44 \quad 337 \quad 0.37 \% \quad 47.1 \%$ LVNHFVEEFKR

$44 \quad 337 \quad 0.37 \% \quad 47.1 \%$ ARFEELCSDLFR

$44 \quad 337 \quad 0.37 \% \quad 47.1 \%$ FEELCSDLFR

$44 \quad 337 \quad 0.37 \% \quad 47.1 \%$ STLEPVEK

$44 \quad 337 \quad 0.37 \% \quad 47.1 \%$ LDKAQIHDLVLVGGSTR

$44 \quad 337 \quad 0.37 \% \quad 47.1 \%$ AQIHDLVLVGGSTR

$44 \quad 337 \quad 0.37 \% \quad 47.1 \%$ AQIHDLVLVGGSTRIPK

$44 \quad 337 \quad 0.37 \% \quad 47.1 \%$ LLQDFFNGR

$44 \quad 337 \quad 0.37 \% \quad 47.1 \%$ LLQDFFNGRDLNK

$44 \quad 337 \quad 0.37 \% \quad 47.1 \%$ NSTIPTKQTQIFTTYSDNQPGVLIQVYEGER

$44 \quad 337 \quad 0.37 \% \quad 47.1 \%$ AMTKDNNLLGR

$44 \quad 337 \quad 0.37 \% \quad 47.1 \%$ ITITNDKGR

$44 \quad 337 \quad 0.37 \% \quad 47.1 \%$ LSKEEIER

$44 \quad 337 \quad 0.37 \% \quad 47.1 \%$ MVQEAEKYK

$44 \quad 337 \quad 0.37 \% \quad 47.1 \%$ YKAEDEVQR

$44 \quad 337 \quad 0.37 \% \quad 47.1 \%$ VSAKNALESYAFNMK

$44 \quad 337 \quad 0.37 \% \quad 47.1 \%$ NALESYAFNMK

$44 \quad 337 \quad 0.37 \% \quad 47.1 \%$ SAVEDEGLK

$44 \quad 337 \quad 0.37 \% \quad 47.1 \%$ GGSGSGPTIEEVD

$12 \quad 0.01 \% \quad 7.1 \% \quad$ AGGIETIANEYSDR

$\begin{array}{llll}12 & 0.01 \% & 7.1 \% & \text { NTVQGFKR }\end{array}$

$12 \quad 0.01 \% \quad 7.1 \% \quad$ AFSDPFVEAEK

$12 \quad 0.01 \% \quad 7.1 \%$ VLATAFDTTLGGR

$12 \quad 0.01 \% \quad 7.1 \%$ ELSTTLNADEAVTR

$4 \quad 0.00 \% \quad 3.9 \% \quad$ SQIVTNVR

$4 \quad 0.00 \% \quad 3.9 \% \quad$ SFDDPIVQTER

$4 \quad 0.00 \% \quad 3.9 \%$ DISTTLNADEAVAR

$43 \quad 188 \quad 0.21 \% \quad 41.6 \%$ GPAVGIDLGTTYSCVGVFQHGK

$43 \quad 188 \quad 0.21 \% \quad 41.6 \%$ VEIIANDQGNR

$43 \quad 188 \quad 0.21 \% \quad 41.6 \%$ TTPSYVAFTDTER

$43 \quad 188 \quad 0.21 \% \quad 41.6 \%$ NQVAMNPTNTVFDAK
$99.7 \% \quad 27.8$

$99.7 \% \quad 37.1$

$99.7 \% \quad 39.9$

$99.7 \% \quad 63.8$

$99.7 \% \quad 48.6$

$99.4 \% \quad 50.9$

$99.7 \% \quad 55.2$

$99.7 \% \quad 56.4$

$99.7 \% \quad 90.8$

$99.7 \% \quad 34.1$

$99.7 \% \quad 51.3$

$99.7 \% \quad 53.4$

$99.7 \% \quad 56.9$

$99.7 \% \quad 60.8$

$99.7 \% \quad 57.7$

$99.7 \% \quad 54.2$

$\begin{array}{lll}99.7 \% & 39.7\end{array}$

$99.7 \% \quad 54.7$

$99.7 \% \quad 51.8$

$99.0 \% \quad 29.6$

$\begin{array}{ll}99.7 \% & 50.4 \\ 99.7 \% & 57.7\end{array}$

$99.7 \% \quad 57.7$

$99.7 \% \quad 27.2$

$99.7 \% \quad 53.5$

$99.7 \% \quad 62.1$

$99.7 \% \quad 39.4$

$99.7 \% \quad 42.4$

$99.7 \% \quad 58.0$

$99.0 \% \quad 61.7$

$99.7 \% \quad 31.0$

$\begin{array}{lll}99.7 \% & 34.8\end{array}$

$99.7 \% \quad 34.5$

$99.7 \% \quad 55.6$

$99.7 \% \quad 51.5$

$99.7 \% \quad 55.9$

$99.7 \% \quad 50.9$

$99.0 \% \quad 35.4$

$99.7 \% 35.4$

$99.7 \% \quad 53.6$

$99.7 \% \quad 49.3$

$99.0 \% 34.1$

$99.7 \% \quad 51.8$

$99.7 \% \quad 53.7$

$99.7 \% \quad 40.7$

$99.4 \% \quad 50.9$

$99.7 \% \quad 55.2$

$99.7 \% \quad 50.1$
1108.65

1174.53

1464.71

943.56

1192.60

1228.63

1487.70

1658.85

1814.95

1680.85

1138.61

1614.81

1625.93

1197.70

1687.90

1675.73

1417.76

1542.74

1315.60

902.48

1822.02

1465.81

1804.04

1109.57

1579.82

3527.77

1248.64

1017.57

1003.54

1125.56

1137.55

1688.83

1287.60

947.47

1204.53

1495.70

949.52

1239.59

1321.71

1519.76

916.52

1306.63

1475.73

2263.12

1228.63

1487.70

1665.79 \begin{tabular}{cc}
1606 & 1616 \\
168 & 1667 \\
92 & 1805 \\
12 & 1820 \\
31 & 2040 \\
6 & 36 \\
7 & 49 \\
7 & 71 \\
57 & 72 \\
89 & 102 \\
103 & 11 \\
113 & 126 \\
156 & 17 \\
160 & 17 \\
172 & 187 \\
221 & 236 \\
237 & 247 \\
300 & 31 \\
302 & 311 \\
312 & 319 \\
326 & 342 \\
329 & 342 \\
329 & 345 \\
349 & 357 \\
349 & 361 \\
417 & 447 \\
448 & 458 \\
501 & 509 \\
510 & 517 \\
518 & 526 \\
525 & 533 \\
536 & 550 \\
40 & 550 \\
551 & 559 \\
629 & 641 \\
20 & 33 \\
62 & 69 \\
74 & 84 \\
22 & 234 \\
361 & 374 \\
54 & 6 \\
74 & 84 \\
361 & 374 \\
46 & 25 \\
37 & 49 \\
57 & 7 \\
& \\
\hline 3
\end{tabular} 
Heat shock cognate $71 \mathrm{kDa}$ protein GN=HSPA8 HSP7C_HUMAN $70.90 \quad 100.0 \% \quad 24$ $\begin{array}{lllll}\text { Heat shock cognate } 71 \mathrm{kDa} \text { protein GN=HSPA8 } & \text { HSP7C_HUMAN } & 70.90 & 100.0 \% & 24\end{array}$ Heat shock cognate $71 \mathrm{kDa}$ protein GN=HSPA8 HSP7C_HUMAN $70.90 \quad 100.0 \% \quad 24$ Heat shock cognate $71 \mathrm{kDa}$ protein GN=HSPA8 HSP7C_HUMAN $70.90 \quad 100.0 \% \quad 24$ Heat shock cognate $71 \mathrm{kDa}$ protein GN=HSPA8 HSP7C_HUMAN $70.90 \quad 100.0 \% \quad 24$ Heat shock cognate $71 \mathrm{kDa}$ protein GN=HSPA8 HSP7C_HUMAN $70.90 \quad 100.0 \% \quad 24$ Heat shock cognate $71 \mathrm{kDa}$ protein GN=HSPA8 HSP7C_HUMAN $70.90 \quad 100.0 \% \quad 24$ Heat shock cognate $71 \mathrm{kDa}$ protein GN=HSPA8 HSP7C_HUMAN $70.90 \quad 100.0 \% \quad 24$ Heat shock cognate $71 \mathrm{kDa}$ protein GN=HSPA8 HSP7C_HUMAN $70.90 \quad 100.0 \% 24$ Heat shock cognate $71 \mathrm{kDa}$ protein GN=HSPA8 HSP7C_HUMAN $70.90 \quad 100.0 \% \quad 24$ Heat shock cognate $71 \mathrm{kDa}$ protein GN=HSPA8 HSP7C_HUMAN $70.90 \quad 100.0 \% \quad 24$ Heat shock cognate $71 \mathrm{kDa}$ protein GN=HSPA8 HSP7C_HUMAN $70.90 \quad 100.0 \%$ Heat shock cognate $71 \mathrm{kDa}$ protein GN=HSPA8 HSP7C_HUMAN $70.90 \quad 100.0 \% \quad 24$ Heat shock cognate $71 \mathrm{kDa}$ protein GN=HSPA8 HSP7C_HUMAN $70.90 \quad 100.0 \%$ Heat shock cognate $71 \mathrm{kDa}$ protein GN=HSPA8 HSP7C_HUMAN $70.90 \quad 100.0 \% \quad 24$ Heat shock cognate $71 \mathrm{kDa}$ protein GN=HSPA8 HSP7C_HUMAN $70.90 \quad 100.0 \%$ Heat shock cognate $71 \mathrm{kDa}$ protein GN=HSPA8 HSP7C HUMAN $70.90 \quad 100.0 \%$ Heat shock cognate $71 \mathrm{kDa}$ protein GN=HSPA8 HSP7C_HUMAN $70.90 \quad 100.0 \%$ Heat shock cognate $71 \mathrm{kDa}$ protein GN=HSPA8 HSP7C_HUMAN $70.90 \quad 100.0 \%$ Heat shock cognate $71 \mathrm{kDa}$ protein GN=HSPA8 HSP7C_HUMAN $70.90 \quad 100.0 \%$ Heat shock cognate $71 \mathrm{kDa}$ protein GN=HSPA8 HSP7C_HUMAN $70.90 \quad 100.0 \% \quad 24$ Heat shock cognate $71 \mathrm{kDa}$ protein GN=HSPA8 HSP7C_HUMAN $70.90 \quad 100.0 \%$ Heat shock cognate $71 \mathrm{kDa}$ protein GN=HSPA8 HSP7C_HUMAN $70.90 \quad 100.0 \%$ Heat shock cognate $71 \mathrm{kDa}$ protein GN=HSPA8 HSP7C_HUMAN $70.90 \quad 100.0 \% \quad 24$ Heat shock protein $105 \mathrm{kDa}$ GN=HSPH1 HS105 HUMAN $96.87 \quad 100.0 \%$ Heat shock protein $105 \mathrm{kDa}$ GN=HSPH1 HS105_HUMAN $96.87 \quad 100.0 \%$ Heat shock protein $105 \mathrm{kDa}$ GN=HSPH1 HS105_HUMAN $96.87 \quad 100.0 \%$ Heat shock protein $105 \mathrm{kDa}$ GN=HSPH1 HS105_HUMAN $96.87 \quad 100.0 \%$, Heat shock protein $105 \mathrm{kDa}$ GN=HSPH1 HS105_HUMAN $96.87 \quad 100.0 \%$ Heat shock protein $105 \mathrm{kDa}$ GN=HSPH1 HS105 HUMAN $96.87 \quad 100.0 \%$ Heat shock protein $105 \mathrm{kDa}$ GN=HSPH1 HS105_HUMAN $96.87 \quad 100.0 \%$ Heat shock protein $75 \mathrm{kDa}$, mitochondrial GN=TRAP1 TRAP1_HUMAN $80.11 \quad 100.0 \%$ Heat shock protein $75 \mathrm{kDa}$, mitochondrial GN=TRAP1 TRAP1 HUMAN $80.11 \quad 100.0 \%$ Heat shock protein $75 \mathrm{kDa}$, mitochondrial GN=TRAP1 TRAP1_HUMAN $80.11 \quad 100.0 \%$ Heat shock protein $75 \mathrm{kDa}$, mitochondrial GN=TRAP1 TRAP1_HUMAN $80.11 \quad 100.0 \%$ Heat shock protein $75 \mathrm{kDa}$, mitochondrial GN=TRAP1 TRAP1_HUMAN $80.11 \quad 100.0 \%$ Heat shock protein $75 \mathrm{kDa}$, mitochondrial GN=TRAP1 TRAP1_HUMAN $80.11 \quad 100.0 \%$ Heat shock protein $75 \mathrm{kDa}$, mitochondrial GN=TRAP1 TRAP1 HUMAN $80.11 \quad 100.0^{\circ}$ Heat shock protein HSP 90-alpha GN=HSP90AA1 HS90A_HUMAN $84.66 \quad 100.0 \%$ Heat shock protein HSP 90-alpha GN=HSP90AA1 HS90A_HUMAN $84.66100 .0 \%$ Heat shock protein HSP 90-alpha GN=HSP90AA1 HS90A_HUMAN $84.66 \quad 100.0 \%$ Heat shock protein HSP 90-alpha GN=HSP90AA1 HS90A_HUMAN $84.66 \quad 100.0 \%$ Heat shock protein HSP 90-alpha GN=HSP90AA1 HS90A HUMAN $84.66 \quad 100.0 \%$ Heat shock protein HSP 90-alpha GN=HSP90AA1 HS90A_HUMAN $84.66 \quad 100.0 \%$ Heat shock protein HSP 90-alpha GN=HSP90AA1 HS90A_HUMAN $84.66 \quad 100.0 \%$ Heat shock protein HSP 90-alpha GN=HSP90AA1 HS90A_HUMAN $84.66100 .0 \%$ Heat shock protein HSP 90-alpha GN=HSP90AA1 HS90A_HUMAN $84.66 \quad 100.0 \%$
$188 \quad 0.21 \% \quad 41.6 \%$ NQVAMNPTNTVFDAKR

$99.7 \% 73.3$ $99.7 \% \quad 56.1$ $99.7 \% \quad 53.3$ $99.7 \% \quad 67.7$ $99.7 \% \quad 39.7$ $188 \quad 0.21 \% \quad 41.6 \%$ MKEIAEAYLGK

$188 \quad 0.21 \% \quad 41.6 \%$ EIAEAYLGK $99.7 \% \quad 46.9$

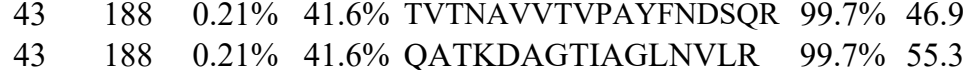

$0.21 \% \quad 41.6 \%$ DAGTIAGLNVLR $99.7 \% \quad 60.5$ $99.7 \% \quad 60.7$

$43 \quad 188 \quad 0.21 \% \quad 41.6 \%$ IINEPTAAAIAYGLDK $99.7 \% \quad 63.8$

$99.7 \% \quad 52.8$

$99.7 \% \quad 45.8$

$99.7 \% \quad 41.2$

$99.7 \% \quad 59.2$

$99.0 \% \quad 29.6$

$99.7 \% \quad 49.8$

$99.7 \% \quad 66.8$

$99.7 \% \quad 44.9$

$\begin{array}{lll}99.7 \% & 51.7\end{array}$

$99.7 \% \quad 58.0$

$99.0 \% \quad 56.4$

$99.7 \% \quad 31.0$

$99.7 \% \quad 59.0$

$99.0 \% \quad 30.6$

$99.7 \% \quad 29.0$

$\begin{array}{ll}99.7 \% & 32.2\end{array}$

$99.7 \% \quad 53.7$

$99.7 \% \quad 32.6$

$99.7 \% 37.8$

$99.7 \% \quad 29.3$

$99.6 \% \quad 27.9$

$99.7 \% \quad 60.3$

$99.7 \% \quad 54.7$

$99.4 \% \quad 52.7$

$99.7 \% \quad 47.5$

$99.7 \% \quad 35.9$

$99.7 \% \quad 31.5$

$99.7 \% \quad 58.4$

$99.7 \% \quad 58.7$

$\begin{array}{lll}99.7 \% & 39.5\end{array}$

$99.4 \% \quad 45.4$

$99.7 \% \quad 59.2$

$99.7 \% \quad 48.0$

$99.7 \% \quad 29.2$

$99.7 \% \quad 51.9$

$99.7 \% \quad 26.9$

$99.7 \% \quad 37.2$

$0.01 \% \quad 18.3 \%$ EKYIDQEELNK

$\begin{array}{lll}0.01 \% & 18.3 \% & \text { YIDQEELNK } \\ 0.01 \% & 18.3 \% & \text { HFSVEGQLEFR }\end{array}$

$0.01 \% \quad 18.3 \%$ RAPFDLFENR
180.62

1616.79

1268.66

993.53

1982.00

1627.91

1199.67

1659.90

1787.99

1691.73

1235.62

1480.75

1253.62

858.46

1838.01

1481.81

1081.57

1565.83

1017.57

989.53

1125.56

1319.59

944.52

1871.95

1321.72

1475.73

1119.62

1133.56

1156.63

1028.54

1592.79

1704.91

1513.79

1171.67

1299.76

1283.62

1492.85

1560.82

1539.75

1349.73

1242.7

2015.04

1408.70 $\begin{array}{cc}7 & 72 \\ 03 & 112 \\ 13 & 126 \\ 27 & 137 \\ 29 & 137 \\ 38 & 155 \\ 56 & 171 \\ 60 & 171 \\ 72 & 187 \\ 72 & 188 \\ 21 & 236 \\ 37 & 246 \\ 00 & 311 \\ 02 & 311 \\ 12 & 319 \\ 26 & 342 \\ 29 & 342 \\ 49 & 357 \\ 49 & 361 \\ 01 & 509 \\ 10 & 517 \\ 18 & 526 \\ 40 & 550 \\ 02 & 609 \\ 4 & 69 \\ 22 & 234 \\ 61 & 374 \\ 62 & 471 \\ 06 & 714 \\ 72 & 781 \\ 73 & 781 \\ 82 & 196 \\ 27 & 340 \\ 89 & 402 \\ 03 & 412 \\ 03 & 413 \\ 96 & 505 \\ 35 & 647 \\ 7 & 60 \\ 1 & 74 \\ 8 & 100 \\ 01 & 112 \\ 86 & 201 \\ 82 & 292 \\ 84 & 292 \\ & 338 \\ \end{array}$ 
Heat shock protein HSP 90-alpha GN=HSP90AA1 HS90A_HUMAN $84.66 \quad 100.0 \%$ Heat shock protein HSP 90-alpha GN=HSP90AA1 HS90A_HUMAN $84.66 \quad 100.0 \%$ Heat shock protein HSP 90-alpha GN=HSP90AA1 HS90A_HUMAN $84.66 \quad 100.0 \%$ at shock protein HSP 90-beta GN=HSP90AB1 HS90B HUMAN 83.2. Heat shock protein HSP 90-beta GN=HSP90AB1 HS90B_HUMAN 83.27 Heat shock protein HSP 90-beta GN=HSP90AB1 HS90B_HUMAN 83.27 Heat shock protein HSP 90-beta GN=HSP90AB1 HS90B HUMAN 83.2 Heat shock protein HSP 90-beta GN=HSP90AB1 HS90B_HUMAN 83.2 Heat shock protein HSP 90-beta GN=HSP90AB1 HS90B HUMAN 83.27 Heat shock protein HSP 90-beta GN=HSP90AB1 HS90B HUMAN 83.27 Heat shock protein HSP 90-beta GN=HSP90AB1 HS90B_HUMAN 83.2 Heat shock protein HSP 90-beta GN=HSP90AB1 HS90B HUMAN 83.27 Heat shock protein HSP 90-beta GN=HSP90AB1 HS90B_HUMAN 83.27 Heat shock protein HSP 90-beta GN=HSP90AB1 HS90B HUMAN 83.27 Heat shock protein HSP 90-beta GN=HSP90AB1 HS90B HUMAN 83.27 Heat shock protein HSP 90-beta GN=HSP90AB1 HS90B_HUMAN 83.2 Heat shock protein HSP 90-beta GN=HSP90AB1 HS90B HUMAN 83.2' Heat shock protein HSP 90-beta GN=HSP90AB1 HS90B_HUMAN 83.27 Heat shock protein HSP 90-beta GN=HSP90AB1 HS90B_HUMAN 83.2 Heat shock protein HSP 90-beta GN=HSP90AB1 HS90B HUMAN 83.2 Heat shock protein HSP 90-beta GN=HSP90AB1 HS90B_HUMAN 83.2 Heat shock protein HSP 90-beta GN=HSP90AB1 HS90B_HUMAN 83.2 Heat shock protein HSP 90-beta GN=HSP90AB1 HS90B HUMAN 83.27 Heat shock protein HSP 90-beta GN=HSP90AB1 HS90B_HUMAN 83.2 Heat shock protein HSP 90-beta GN=HSP90AB1 HS90B HUMAN 83.27 Heat shock protein HSP 90-beta GN=HSP90AB1 HS90B_HUMAN 83.27 Heat shock protein HSP 90-beta GN=HSP90AB1 HS90B_HUMAN 83.27 Heat shock protein HSP 90-beta GN=HSP90AB1 HS90B HUMAN 83.2" Heat shock protein HSP 90-beta GN=HSP90AB1 HS90B_HUMAN 83.2 Helicase-like transcription factor GN=HLTF HLTF HUMAN 113.9 Helicase-like transcription factor GN=HLTF HLTF_HUMAN 113.93 Helicase-like transcription factor GN=HLTF HLTF_HUMAN 113.93 Hermansky-Pudlak syndrome 6 protein GN=HPS6 HPS6 HUMAN 82.98 Hermansky-Pudlak syndrome 6 protein GN=HPS6 HPS6_HUMAN 82.98 Hermansky-Pudlak syndrome 6 protein GN=HPS6 HPS6 HUMAN 82.9 Heterochromatin protein 1-binding protein $3 \mathrm{GN}=\mathrm{HP} 1 \mathrm{BP} 3 \mathrm{HP} 1 \mathrm{~B} 3$ HUMAN 61.21 Heterochromatin protein 1-binding protein $3 \mathrm{GN}=\mathrm{HP} 1 \mathrm{BP} 3$ HP1B3 HUMAN 61.2 Heterochromatin protein 1-binding protein $3 \mathrm{GN}=\mathrm{HP} 1 \mathrm{BP} 3 \mathrm{HP} 1 \mathrm{~B} 3 \mathrm{HUMAN} 61.2$ Heterochromatin protein 1-binding protein $3 \mathrm{GN}=\mathrm{HP} 1 \mathrm{BP} 3$ HP1B3_HUMAN 61.2 Heterochromatin protein 1-binding protein $3 \mathrm{GN}=\mathrm{HP} 1 \mathrm{BP} 3 \mathrm{HP} 1 \mathrm{~B} 3$ _HUMAN 61.2 Heterochromatin protein 1-binding protein $3 \mathrm{GN}=\mathrm{HP} 1 \mathrm{BP} 3 \mathrm{HP} 1 \mathrm{~B} 3$ HUMAN 61.2 Heterochromatin protein 1-binding protein $3 \mathrm{GN}=\mathrm{HP} 1 \mathrm{BP} 3 \mathrm{HP} 1 \mathrm{~B} 3$ _HUMAN 61.2 Heterochromatin protein 1-binding protein $3 \mathrm{GN}=\mathrm{HP} 1 \mathrm{BP} 3 \mathrm{HP} 1 \mathrm{~B} 3$ HUMAN 61.2 I Heterogeneous nuclear ribonucleoprotein $\mathrm{A} / \mathrm{B}$ GN=HNRNPAB ROAA_HUMAN 36.2 列 Heterogeneous nuclear ribonucleoprotein A/B GN=HNRNPAB ROAA_HUMAN 36.23
$100.0 \% \quad 26$ $100.0 \% \quad 26$ $100.0 \% \quad 26$ $100.0 \% \quad 26$ $100.0 \% \quad 26$ $100.0 \% \quad 26$ $100.0 \% \quad 26$ $100.0 \% \quad 26$ $100.0 \% \quad 26$ $100.0 \% \quad 26$ $100.0 \% \quad 26$ $100.0 \% \quad 26$ $100.0 \% \quad 26$ $100.0 \% \quad 26$ $100.0 \% \quad 26$ $100.0 \% \quad 26$ $100.0 \% \quad 26$ $100.0 \% \quad 26$ $100.0 \% \quad 26$ $100.0 \% \quad 26$ $100.0 \% \quad 26$ $100.0 \% \quad 26$ $100.0 \% \quad 26$ $100.0 \% \quad 26$ $100.0 \% \quad 26$ $100.0 \% \quad 26$ $100.0 \%$ $100.0 \% \quad 3$ $100.0 \% \quad 3$ $100.0 \% \quad 3$ $100.0 \%$ $100.0 \%$ $100.0 \%$ $100.0 \%$ $100.0 \%$ $100.0 \%$ $100.0 \%$ $100.0 \%$ $100.0 \%$ $100.0 \%$ $100.0 \%$ $100.0 \%$ $100.0 \% \quad 13$ $100.0 \%$
$9 \quad 0.01 \% \quad 18.3 \%$ NNIKLYVR $9 \quad 0.01 \% \quad 18.3 \%$ GVVDSEDLPLNISR

$9 \quad 0.01 \% \quad 18.3 \%$ DQVANSAFVER

$166 \quad 0.18 \% \quad 35.1 \%$ ELISNASDALDK

$166 \quad 0.18 \% \quad 35.1 \%$ ELISNASDALDKIR

$166 \quad 0.18 \% \quad 35.1 \%$ YESLTDPSKLDSGK

$166 \quad 0.18 \% \quad 35.1 \%$ IDIIPNPQER

$166 \quad 0.18 \% \quad 35.1 \%$ TLTLVDTGIGMTK

$166 \quad 0.18 \% \quad 35.1 \%$ ADLINNLGTIAK

$166 \quad 0.18 \% \quad 35.1 \%$ VILHLKEDQTEYLEER

$166 \quad 0.18 \% \quad 35.1 \%$ EKYIDQEELNK

$166 \quad 0.18 \% \quad 35.1 \%$ YIDQEELNK

$166 \quad 0.18 \% \quad 35.1 \%$ NPDDITQEEYGEFYK

$166 \quad 0.18 \% \quad 35.1 \%$ HFSVEGQLEFR

$166 \quad 0.18 \% \quad 35.1 \%$ RAPFDLFENK

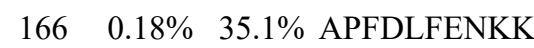

$166 \quad 0.18 \% \quad 35.1 \%$ NNIKLYVR

$166 \quad 0.18 \% \quad 35.1 \%$ GVVDSEDLPLNISR

$166 \quad 0.18 \% \quad 35.1 \%$ FYEAFSKNLK

$166 \quad 0.18 \% \quad 35.1 \%$ NLKLGIHEDSTNR

$166 \quad 0.18 \% \quad 35.1 \%$ LGIHEDSTNR

$166 \quad 0.18 \% \quad 35.1 \%$ LGIHEDSTNRR

$166 \quad 0.18 \% \quad 35.1 \%$ YHTSQSGDEMTSLSEYVSR

$166 \quad 0.18 \% \quad 35.1 \%$ SIYYITGESK

$166 \quad 0.18 \% \quad 35.1 \%$ EQVANSAFVER

$166 \quad 0.18 \% \quad 35.1 \%$ EFDGKSLVSVTK

$166 \quad 0.18 \% \quad 35.1 \%$ AQALRDNSTMGYMMAK

$166 \quad 0.18 \% \quad 35.1 \%$ KHLEINPDHPIVETLR

$166 \quad 0.18 \% \quad 35.1 \%$ HLEINPDHPIVETLR

$6 \quad 0.01 \% \quad 4.1 \% \quad$ MSELSSSRPK

$0.01 \% \quad 4.1 \%$ VILDEGHAIRNPNAQQTK

$0.01 \% \quad 4.1 \%$ AGGVGLNLSAASR

$0.00 \% \quad 4.8 \%$ LLSDLSAFGGAAR

$0.00 \% \quad 4.8 \%$ TLEPSGEASTSLGR

$0.00 \% \quad 4.8 \%$ KVLGGITAGK

$0.03 \% 11.6 \%$ SGASVVAIRK

$0.03 \% \quad 11.6 \%$ GKGASGSFVVVQK

$0.03 \% \quad 11.6 \%$ LEDVLPLAFTR

$0.03 \% \quad 11.6 \%$ EASYSLIR

$0.03 \% \quad 11.6 \%$ KYVSQYYPK

$0.03 \% \quad 11.6 \%$ YVSQYYPK

$0.03 \% \quad 11.6 \%$ AVERGQLEQITGK

$0.03 \% \quad 11.6 \%$ GQLEQITGK

$0.07 \% \quad 33.1 \%$ MFVGGLSWDTSK

$65 \quad 0.07 \% \quad 33.1 \%$ MFVGGLSWDTSKK

$65 \quad 0.07 \% \quad 33.1 \%$ DLKDYFTK

$65 \quad 0.07 \% \quad 33.1 \%$ FGEVVDCTIK
$99.0 \% \quad 29.2$

$99.4 \% \quad 52.7$

$99.7 \% \quad 66.5$

$99.7 \% \quad 57.2$

$99.7 \% \quad 52.2$

$\begin{array}{lll}99.7 \% & 39.5\end{array}$

$99.7 \% \quad 30.4$

$99.4 \% \quad 45.4$

$99.7 \% \quad 59.2$

$99.7 \% \quad 48.0$

$99.7 \% \quad 29.2$

$99.7 \% \quad 51.9$

$99.7 \% \quad 52.6$

$\begin{array}{lll}99.7 \% & 26.9\end{array}$

$99.7 \% \quad 41.2$

$97.7 \% \quad 17.2$

$99.0 \% \quad 29.2$

$99.4 \% \quad 52.7$

$98.9 \% \quad 27.4$

$\begin{array}{lll}99.7 \% & 28.7\end{array}$

$99.7 \% \quad 39.4$

$99.4 \% \quad 20.4$

$99.7 \% \quad 49.7$

$99.7 \% \quad 54.1$

$99.7 \% \quad 57.4$

$98.9 \% \quad 23.2$

$99.4 \% \quad 20.7$

$99.7 \% \quad 32.5$

$99.7 \% \quad 54.9$

$99.7 \% \quad 31.4$

$99.7 \% \quad 39.7$

$99.7 \% \quad 68.1$

$95.9 \% \quad 27.0$

$99.7 \% \quad 37.2$

$99.5 \% \quad 20.9$

$99.7 \% \quad 42.5$

$99.7 \% \quad 50.9$

$99.4 \% 27.8$

$96.4 \% \quad 20.4$

$\begin{array}{lll}99.7 \% & 38.8\end{array}$

$99.0 \% \quad 22.7$

$99.7 \% \quad 47.6$

$99.7 \% \quad 50.0$

$99.7 \% \quad 48.7$

$99.7 \% \quad 58.3$

$99.0 \% \quad 44.2$

$\begin{array}{lll}99.4 \% & 53.7\end{array}$
1019.60

1513.79

1235.60

1275.64

1544.83

1539.75

1194.65

1349.73

1242.71

2015.04

1408.70

1151.56

1847.80

1348.66

1236.64

1208.63

1019.60

1513.79

1246.65

1496.78

1141.56

1297.66

2192.94

1160.58

1249.62

1309.70

1835.81

1911.04

1782.95

1121.56

2004.06

1172.64

1277.68

1404.70

943.59

987.59

1263.71

1273.72

938.49

1175.61

1047.51

1428.78

973.53

1343.63

1455.73

1029.53

1167.57 \begin{tabular}{cc}
359 & 366 \\
87 & 400 \\
500 & 510 \\
\hline 2 & 5 \\
42 & 5 \\
6 & 69 \\
73 & 8 \\
83 & 95 \\
6 & 107 \\
181 & 196 \\
74 & 284 \\
276 & 284 \\
292 & 306 \\
20 & 330 \\
338 & 347 \\
339 & 348 \\
351 & 358 \\
379 & 392 \\
29 & 438 \\
436 & 448 \\
439 & 448 \\
439 & 449 \\
457 & 475 \\
482 & 491 \\
492 & 502 \\
527 & 538 \\
608 & 623 \\
624 & 639 \\
625 & 639 \\
\hline 77 & 386 \\
554 & 571 \\
914 & 926 \\
67 & 180 \\
546 & 555 \\
176 & 185 \\
221 & 233 \\
59 & 269 \\
775 & 282 \\
283 & 291 \\
284 & 291 \\
308 & 320 \\
312 & 320
\end{tabular}

Page 73 of Table S-1-5 
$\begin{array}{lll}0.07 \% & 33.1 \% & \text { FGEVVDCTI } \\ 0.07 \% & 33.1 \% \text { GFGFILFK }\end{array}$ $99.0 \% \quad 42.2$

$\begin{array}{lllll}0.07 \% & 33.1 \% & \text { IREYFGEFGEIEAIELPMDPK } \quad 98.9 \% & 21.2\end{array}$

$0.07 \% \quad 33.1 \%$ EYFGEFGEIEAIELPMDPK $99.7 \% \quad 48.4$

$0.07 \% \quad 33.1 \%$ RGFVFITFK

$0.07 \% 33.1 \%$ GFVFITFK

$99.4 \% 27$.

$99.0 \% \quad 26.0$

$0.07 \% 33.1 \%$ GFVFITFKEEEPVK $\quad 99.7 \% \quad 52.8$

$\begin{array}{lllll}0.07 \% & 33.1 \% & \text { VAQPKEVYQQQQYGSGGR } & 99.7 \% & 28.8\end{array}$

$0.07 \% \quad 33.1 \%$ EVYQQQQYGSGGR $99.7 \% \quad 62.7$

$0.07 \% 33.1 \%$ GGHQNNYKPY

$99.5 \% \quad 26.4$

$\begin{array}{llll}0.05 \% & 37.7 \% & \text { LFIGGLNVQTSESGLR } \quad 99.7 \% & 47.4\end{array}$

$$
.05 \% \quad 37.7 \% \text { KLFVGGLK }
$$

$0.05 \% \quad 37.7 \%$ GDVAEGDLIEHFSQFGTVEK $99.7 \% 54.1$

$0.05 \% \quad 37.7 \%$ AEIIADKQSGK $99.7 \% 56.4$

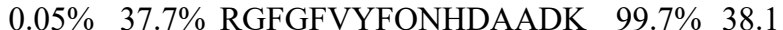

$77 \quad 0.05 \% \quad 37.7 \%$ GFGFVYFQNHDAADK $\quad 99.7 \% \quad 57.2$

$47 \quad 0.05 \% \quad 37.7 \%$ GFGFVYFQNHDAADKAAVVK $\quad 99.7 \% \quad 42.8$

$\begin{array}{lll}0.05 \% & 37.7 \% & \text { AVPKEDIYSGGGGGGSR } \quad 99.7 \% \quad 42.5\end{array}$

$0.05 \% \quad 37.7 \%$ EDIYSGGGGGGSR

$210 \quad 0.23 \% \quad 47.6 \%$ SESPKEPEQLR

$210 \quad 0.23 \% \quad 47.6 \%$ LFIGGLSFETTDESLR $\quad 99.7 \% \quad 46.6$

$210 \quad 0.23 \% \quad 47.6 \%$ SHFEQWGTLTDCVVMR $\quad 99.7 \% \quad 53.5$

$210 \quad 0.23 \% \quad 47.6 \%$ SHFEQWGTLTDCVVMRDPNTK $\quad 98.1 \% \quad 16.9$

$210 \quad 0.23 \% \quad 47.6 \%$ EDSQRPGAHLTVK

$210 \quad 0.23 \% \quad 47.6 \%$ EDSQRPGAHLTVKK

$\begin{array}{llll}210 & 0.23 \% & 47.6 \% & \text { KIFVGGIK }\end{array}$

$210 \quad 0.23 \% \quad 47.6 \%$ IFVGGIKEDTEEHHLR

$99.7 \% 54.0$

$98.0 \% 30.7$

$210 \quad 0.23 \% \quad 47.6 \%$ DYFEQYGK

$210 \quad 0.23 \% \quad 47.6 \%$ IEVIEIMTDR

$\begin{array}{lll}99.6 \% & 22.0 \\ 99.0 \% & 38.4\end{array}$

$\begin{array}{lllll}0.23 \% & 47.6 \% & \text { GFAFVTFDDHDSVDK } \quad 99.7 \% & 64.1\end{array}$

$210 \quad 0.23 \% \quad 47.6 \%$ GFAFVTFDDHDSVDKIVIQK $\quad 99.7 \% \quad 36.2$

$210 \quad 0.23 \% \quad 47.6 \%$ YHTVNGHNCEVR

$210 \quad 0.23 \% \quad 47.6 \%$ YHTVNGHNCEVRK

$210 \quad 0.23 \% \quad 47.6 \%$ GGGFGGNDNFGR

$\begin{array}{llllll}210 & 0.23 \% & 47.6 \% & \text { SSGPYGGGGQYFAKPR } & 99.7 \% & 58.3 \\ 2\end{array}$

$170 \quad 0.19 \% \quad 43.4 \%$ GEEGHDPKEPEQLR

$170 \quad 0.19 \% \quad 43.4 \%$ KLFIGGLSFETTDDSLR

$170 \quad 0.19 \% \quad 43.4 \%$ LFIGGLSFETTDDSLR

$\begin{array}{ll}99.7 \% & 36.6 \\ 99.7 \% & 38.1 \\ 99.7 \% & 32.4\end{array}$

$99.7 \% 32.4$

$\begin{array}{llll}170 & 0.19 \% & 43.4 \% & \text { LFIGGLSFETTDDSLREH } \\ 170 & 0.19 \% & 43.4 \% \text { WGTLTDCVVMR }\end{array}$

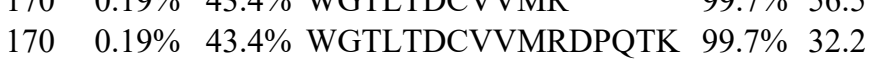


Heterogeneous nuclear ribonucleoprotein A3 GN=HNRNPA3 ROA3_HUMAN $39.60 \quad 100.0 \% \quad 21$ Heterogeneous nuclear ribonucleoprotein A3 GN=HNRNPA3 ROA3_HUMAN $39.60 \quad 100.0 \% \quad 21$ Heterogeneous nuclear ribonucleoprotein A3 GN=HNRNPA3 ROA3_HUMAN $39.60 \quad 100.0 \% \quad 21$ Heterogeneous nuclear ribonucleoprotein $\mathrm{A} 3 \mathrm{GN}=\mathrm{HNRNPA3}$ ROA3_HUMAN $39.60 \quad 100.0 \% 2$ Heterogeneous nuclear ribonucleoprotein A3 GN=HNRNPA3 ROA3_HUMAN $39.60 \quad 100.0 \% \quad 21$ Heterogeneous nuclear ribonucleoprotein $\mathrm{A} 3 \mathrm{GN}=\mathrm{HNRNPA} 3 \mathrm{ROA3}$ _HUMAN $39.60 \quad 100.0 \% \quad 2$ Heterogeneous nuclear ribonucleoprotein A3 GN=HNRNPA3 ROA3_HUMAN $39.60 \quad 100.0 \% \quad 21$ Heterogeneous nuclear ribonucleoprotein A3 GN=HNRNPA3 ROA3_HUMAN $39.60 \quad 100.0 \%$ Heterogeneous nuclear ribonucleoprotein $\mathrm{A} 3 \mathrm{GN}=\mathrm{HNRNPA} 3 \mathrm{ROA} 3$ HUMAN $39.60 \quad 100.0 \% \quad 2$ Heterogeneous nuclear ribonucleoprotein A3 GN=HNRNPA3 ROA3_HUMAN $39.60 \quad 100.0 \% \quad 21$ Heterogeneous nuclear ribonucleoprotein A3 GN=HNRNPA3 ROA3_HUMAN $39.60 \quad 100.0 \% \quad 2$ Heterogeneous nuclear ribonucleoprotein A3 GN=HNRNPA3 ROA3_HUMAN $39.60 \quad 100.0 \%$ Heterogeneous nuclear ribonucleoprotein $\mathrm{A} 3 \mathrm{GN}=\mathrm{HNRNPA} 3$ ROA3_HUMAN $39.60 \quad 100.0 \% \quad 2$ Heterogeneous nuclear ribonucleoprotein $\mathrm{A} 3 \mathrm{GN}=\mathrm{HNRNPA} 3 \mathrm{ROA} 3$ HUMAN $39.60 \quad 100.0 \% \quad 2$ Heterogeneous nuclear ribonucleoprotein $\mathrm{A} 3 \mathrm{GN}=\mathrm{HNRNPA} 3 \mathrm{ROA} 3$ HUMAN $39.60 \quad 100.0 \% \quad 2$ Heterogeneous nuclear ribonucleoprotein A3 GN=HNRNPA3 ROA3_HUMAN $39.60 \quad 100.0 \%$ Heterogeneous nuclear ribonucleoprotein D0 GN=HNRNPD HNRPD HUMAN $38.43 \quad 100.0 \%$ Heterogeneous nuclear ribonucleoprotein D0 GN=HNRNPD HNRPD_HUMAN $38.43 \quad 100.0 \%$ Heterogeneous nuclear ribonucleoprotein D0 GN=HNRNPD HNRPD_HUMAN $38.43 \quad 100.0 \%$ Heterogeneous nuclear ribonucleoprotein D0 GN=HNRNPD HNRPD_HUMAN $38.43 \quad 100.0^{\circ}$ Heterogeneous nuclear ribonucleoprotein D0 GN=HNRNPD HNRPD_HUMAN $38.43 \quad 100.0 \%$ Heterogeneous nuclear ribonucleoprotein D0 GN=HNRNPD HNRPD HUMAN $38.43 \quad 100.0 \%$ Heterogeneous nuclear ribonucleoprotein D0 GN=HNRNPD HNRPD_HUMAN $38.43 \quad 100.0 \%$ Heterogeneous nuclear ribonucleoprotein D0 GN=HNRNPD HNRPD_HUMAN $38.43 \quad 100.0 \%$ Heterogeneous nuclear ribonucleoprotein D0 GN=HNRNPD HNRPD_HUMAN $38.43 \quad 100.0^{\circ}$ Heterogeneous nuclear ribonucleoprotein D0 GN=HNRNPD HNRPD_HUMAN $38.43 \quad 100.0 \%$ Heterogeneous nuclear ribonucleoprotein D0 GN=HNRNPD HNRPD_HUMAN $38.43 \quad 100.0 \%$ Heterogeneous nuclear ribonucleoprotein D0 GN=HNRNPD HNRPD HUMAN $38.43 \quad 100.0 \%$ Heterogeneous nuclear ribonucleoprotein D0 GN=HNRNPD HNRPD_HUMAN $38.43 \quad 100.0 \%$ Heterogeneous nuclear ribonucleoprotein D-like GN=HNRNPDL HNRDL_HUMAN $46.44 \quad 100.0^{\circ} \%$ Heterogeneous nuclear ribonucleoprotein D-like GN=HNRNPDL HNRDL_HUMAN $46.44 \quad 100.0 \%$ Heterogeneous nuclear ribonucleoprotein D-like GN=HNRNPDL HNRDL_HUMAN $46.44 \quad 100.0 \%$ Heterogeneous nuclear ribonucleoprotein D-like GN=HNRNPDL HNRDL_HUMAN $46.44 \quad 100.0^{\circ}$ Heterogeneous nuclear ribonucleoprotein D-like GN=HNRNPDL HNRDL_HUMAN $46.44 \quad 100.0 \%$ Heterogeneous nuclear ribonucleoprotein D-like GN=HNRNPDL HNRDL_HUMAN $46.44 \quad 100.0 \%$ Heterogeneous nuclear ribonucleoprotein D-like GN=HNRNPDL HNRDL_HUMAN $46.44 \quad 100.0 \%$ Heterogeneous nuclear ribonucleoprotein D-like GN=HNRNPDL HNRDL_HUMAN $46.44 \quad 100.0 \%$ Heterogeneous nuclear ribonucleoprotein D-like GN=HNRNPDL HNRDL HUMAN $46.44 \quad 100.0 \%$ Heterogeneous nuclear ribonucleoprotein D-like GN=HNRNPDL HNRDL_HUMAN $46.44 \quad 100.0 \%$ Heterogeneous nuclear ribonucleoprotein D-like GN=HNRNPDL HNRDL_HUMAN $46.44 \quad 100.0 \%$ Heterogeneous nuclear ribonucleoprotein D-like GN=HNRNPDL HNRDL_HUMAN $46.44 \quad 100.0 \%$ Heterogeneous nuclear ribonucleoprotein D-like GN=HNRNPDL HNRDL_HUMAN $46.44 \quad 100.0 \%$ Heterogeneous nuclear ribonucleoprotein D-like GN=HNRNPDL HNRDL HUMAN $46.44100 .0 \%$ Heterogeneous nuclear ribonucleoprotein D-like GN=HNRNPDL HNRDL_HUMAN $46.44 \quad 100.0 \%$ Heterogeneous nuclear ribonucleoprotein D-like GN=HNRNPDL HNRDL_HUMAN $46.44 \quad 100.0 \%$ Heterogeneous nuclear ribonucleoprotein F GN=HNRNPF HNRPF HUMAN $45.67 \quad 100.0 \%$ Heterogeneous nuclear ribonucleoprotein F GN=HNRNPF HNRPF_HUMAN $45.67 \quad 100.0 \%$
$170 \quad 0.19 \% \quad 43.4 \%$ AVSREDSVKPGAHLTVK

$170 \quad 0.19 \% \quad 43.4 \%$ KIFVGGIK

$170 \quad 0.19 \% \quad 43.4 \%$ IFVGGIKEDTEEYNLR

$170 \quad 0.19 \% \quad 43.4 \%$ EDTEEYNLR

$170 \quad 0.19 \% \quad 43.4 \%$ EDTEEYNLRDYFEK

$170 \quad 0.19 \% \quad 43.4 \%$ YGKIETIEVMEDR

$170 \quad 0.19 \% \quad 43.4 \%$ IETIEVMEDR

$170 \quad 0.19 \% \quad 43.4 \%$ IETIEVMEDRQSGK

$170 \quad 0.19 \% \quad 43.4 \%$ RGFAFVTFDDHDTVDK

$170 \quad 0.19 \% \quad 43.4 \%$ GFAFVTFDDHDTVDK

$170 \quad 0.19 \% \quad 43.4 \%$ GFAFVTFDDHDTVDKIVVQK

$170 \quad 0.19 \% \quad 43.4 \%$ YHTINGHNCEVK

$170 \quad 0.19 \% \quad 43.4 \%$ YHTINGHNCEVKK

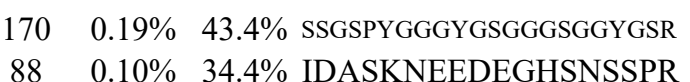

$0.10 \% 34.4 \%$ HSEAATAQREEWK

$0.10 \% \quad 34.4 \%$ DLKDYFSK

$0.10 \% \quad 34.4 \%$ FGEVVDCTLK

$0.10 \% \quad 34.4 \%$ FGEVVDCTLKLDPITGR

$0.10 \% \quad 34.4 \%$ SRGFGFVLFK

$0.10 \% \quad 34.4 \%$ GFGFVLFK

$0.10 \% \quad 34.4 \%$ ESESVDKVMDQK

$0.10 \% \quad 34.4 \%$ IFVGGLSPDTPEEK

$0.10 \% \quad 34.4 \%$ IFVGGLSPDTPEEKIR

$0.10 \% 34.4 \%$ EYFGGFGEVESIELPMDNK

$0.10 \% \quad 34.4 \%$ KYHNVGLSK

$0.10 \% \quad 34.4 \%$ YHNVGLSK

$0.11 \% \quad 31.4 \%$ QLAPLLPSLAPSSAR

$0.11 \% \quad 31.4 \%$ LAGGAAIKGGR

$0.11 \% 31.4 \%$ MFIGGLSWDTSK

$0.11 \% \quad 31.4 \%$ MFIGGLSWDTSKK

$0.11 \% \quad 31.4 \%$ KDLTEYLSR

$0.11 \% 31.4 \%$ DLTEYLSR

$0.11 \% \quad 31.4 \%$ FGEVVDCTIK

$0.11 \% \quad 31.4 \%$ FGEVVDCTIKTDPVTGR

$0.11 \% 31.4 \%$ SRGFGFVLFK

$0.11 \% 31.4 \%$ GFGFVLFK

$0.11 \% 31.4 \%$ DAASVDKVLELK

$0.11 \% \quad 31.4 \%$ VLELKEHK

$0.11 \% \quad 31.4 \%$ VFVGGLSPDTSEEQIK

$0.11 \% 31.4 \%$ GFCFITYTDEEPVK

$0.11 \% \quad 31.4 \%$ GFCFITYTDEEPVKK

$0.11 \% \quad 31.4 \%$ YHQIGSGKCEIK

$0.04 \% \quad 26.5 \%$ QSGEAFVELGSEDDVK

$0.04 \% \quad 26.5 \%$ HSGPNSADSANDGFVR
$99.5 \% \quad 23.4$

$99.7 \% \quad 60.4$

$99.7 \% \quad 58.1$

$98.0 \% \quad 30.7$

$99.7 \% \quad 53.8$

$\begin{array}{lll}99.7 \% & 51.4\end{array}$

$99.7 \% \quad 38.7$

$\begin{array}{lll}99.7 \% & 58.7\end{array}$

$99.7 \% \quad 58.3$

$99.7 \% \quad 27.1$

$99.7 \% \quad 44.0$

$99.7 \% \quad 55.6$

$99.7 \% \quad 51.7$

$99.7 \% \quad 51.0$

$97.7 \% \quad 22.9$

$\begin{array}{rr}99.7 \% & 39.2 \\ 99.7 \% & 55.5\end{array}$

$99.6 \% \quad 25.4$

$\begin{array}{lll}99.0 \% & 35.7\end{array}$

$99.4 \% \quad 53.7$

$99.7 \% \quad 54.3$

$99.7 \% \quad 41.3$

$99.0 \% \quad 43.7$

$99.7 \% \quad 57.8$

$99.7 \% \quad 57.1$

$99.7 \% \quad 59.3$

$99.7 \% \quad 55.9$

$99.7 \% \quad 38.7$

$\begin{array}{ll}99.0 \% & 39.6\end{array}$

$99.6 \% \quad 24.0$

$99.7 \% \quad 49.0$

$99.7 \% \quad 53.3$

$99.7 \% \quad 44.0$

$99.6 \% 32.6$

$99.0 \% \quad 45.8$

$99.4 \% \quad 53.7$

$99.7 \% \quad 53.8$

$99.7 \% \quad 41.3$

$\begin{array}{lll}99.0 \% & 43.7\end{array}$

$99.7 \% \quad 54.1$

$99.0 \% \quad 27.4$

$99.7 \% \quad 56.5$

$99.7 \% \quad 50.3$

$99.7 \% \quad 57.0$

$99.3 \% \quad 21.3$

$99.7 \% \quad 70.3$

$99.7 \% \quad 51.8$
1850.81

1582.78

1234.60

1650.80

1869.88

1713.78

2281.15

1471.67

1599.77

1910.79

1971.86

1542.73

1015.51

1167.57

1919.99

1157.65

914.51

1394.65

1488.76

1757.94

2176.97

1045.58

917.48

1520.88

970.58

1341.65

1469.75

1124.59

996.50

1167.57

1893.94

1157.65

914.51

1287.72

995.59

1705.86

1705.78

1833.87

1419.71

1709.79 1630.72

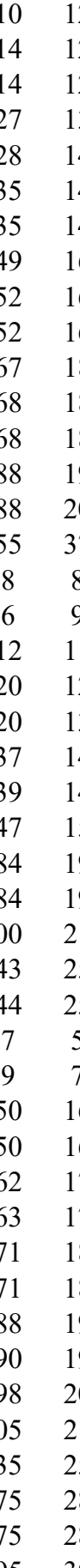

Page 75 
Heterogeneous nuclear ribonucleoprotein F GN=HNRNPF HNRPF_HUMAN $45.67 \quad 100.0 \%$ Heterogeneous nuclear ribonucleoprotein F GN=HNRNPF HNRPF_HUMAN $45.67 \quad 100.0 \%$ Heterogeneous nuclear ribonucleoprotein F GN=HNRNPF HNRPF_HUMAN $45.67 \quad 100.0 \%$ Heterogeneous nuclear ribonucleoprotein $\mathrm{F}$ GN=HNRNPF HNRPF HUMAN $45.67 \quad 100.0 \%$ Heterogeneous nuclear ribonucleoprotein F GN=HNRNPF HNRPF_HUMAN $45.67 \quad 100.0 \%$ Heterogeneous nuclear ribonucleoprotein F GN=HNRNPF HNRPF_HUMAN $45.67 \quad 100.0 \%$ Heterogeneous nuclear ribonucleoprotein F GN=HNRNPF HNRPF_HUMAN $45.67 \quad 100.0 \%$ Heterogeneous nuclear ribonucleoprotein H GN=HNRNPH1 HNRH1_HUMAN $49.23 \quad 100.0 \%$ Heterogeneous nuclear ribonucleoprotein H GN=HNRNPH1 HNRH1_HUMAN $49.23 \quad 100.0 \%$ Heterogeneous nuclear ribonucleoprotein $\mathrm{H}$ GN=HNRNPH1 HNRH1_HUMAN $49.23 \quad 100.0 \%$ Heterogeneous nuclear ribonucleoprotein H GN=HNRNPH1 HNRH1_HUMAN $49.23 \quad 100.0 \%$ teterogeneous nuclear ribonucleoprotein $\mathrm{H}$ GN=HNRNPH1 HNRH1 HUMAN $49.23 \quad 100.0 \%$ Heterogeneous nuclear ribonucleoprotein H GN=HNRNPH1 HNRH1_HUMAN $49.23 \quad 100.0 \%$ Heterogeneous nuclear ribonucleoprotein H GN=HNRNPH1 HNRH1_HUMAN $49.23 \quad 100.0 \%$ Heterogeneous nuclear ribonucleoprotein $\mathrm{H}$ GN=HNRNPH1 HNRH1_HUMAN $49.23 \quad 100.0 \%$ Heterogeneous nuclear ribonucleoprotein $\mathrm{H}$ GN=HNRNPH1 HNRH1_HUMAN $49.23 \quad 100.0 \%$ Heterogeneous nuclear ribonucleoprotein $\mathrm{H}$ GN=HNRNPH1 HNRH1 HUMAN $49.23100 .0 \%$ Heterogeneous nuclear ribonucleoprotein $\mathrm{H}$ GN=HNRNPH1 HNRH1_HUMAN $49.23 \quad 100.0 \%$ Heterogeneous nuclear ribonucleoprotein $\mathrm{H}$ GN=HNRNPH1 HNRH1_HUMAN $49.23 \quad 100.0 \%$ Heterogeneous nuclear ribonucleoprotein $\mathrm{H}$ GN=HNRNPH1 HNRH1_HUMAN $49.23 \quad 100.0 \%$ Heterogeneous nuclear ribonucleoprotein $\mathrm{H}$ GN=HNRNPH1 HNRH1_HUMAN $49.23 \quad 100.0 \%$ Heterogeneous nuclear ribonucleoprotein $\mathrm{H}$ GN=HNRNPH1 HNRH1_HUMAN $49.23 \quad 100.0 \%$ Heterogeneous nuclear ribonucleoprotein $\mathrm{H}$ GN=HNRNPH1 HNRH1_HUMAN $49.23 \quad 100.0 \%$ Heterogeneous nuclear ribonucleoprotein $\mathrm{H}$ GN=HNRNPH1 HNRH1_HUMAN $49.23 \quad 100.0 \%$ Heterogeneous nuclear ribonucleoprotein $\mathrm{H}$ GN=HNRNPH1 HNRH1_HUMAN 49.23 Heterogeneous nuclear ribonucleoprotein $\mathrm{H} 2 \mathrm{GN}=\mathrm{HNRNPH} 2$ HNRH2_HUMAN 49.26 Heterogeneous nuclear ribonucleoprotein $\mathrm{H} 2 \mathrm{GN}=\mathrm{HNRNPH2}$ HNRH2_HUMAN 49.26 Heterogeneous nuclear ribonucleoprotein $\mathrm{H} 2 \mathrm{GN}=\mathrm{HNRNPH} 2 \mathrm{HNRH2}$ HUMAN 49.26 Heterogeneous nuclear ribonucleoprotein $\mathrm{H} 2$ GN=HNRNPH2 HNRH2_HUMAN 49.26 Heterogeneous nuclear ribonucleoprotein $\mathrm{H} 2 \mathrm{GN}=\mathrm{HNRNPH} 2 \mathrm{HNRH} 2$ HUMAN 49.26 Heterogeneous nuclear ribonucleoprotein $\mathrm{H} 2 \mathrm{GN}=\mathrm{HNRNPH} 2 \mathrm{HNRH} 2$ HUMAN 49.26 Heterogeneous nuclear ribonucleoprotein $\mathrm{H} 2 \mathrm{GN}=\mathrm{HNRNPH2}$ HNRH2_HUMAN 49.26 Heterogeneous nuclear ribonucleoprotein $\mathrm{H} 2 \mathrm{GN}=\mathrm{HNRNPH} 2$ HNRH2_HUMAN 49.26 Heterogeneous nuclear ribonucleoprotein $\mathrm{H} 2 \mathrm{GN}=\mathrm{HNRNPH} 2$ HNRH2_HUMAN 49.26 Heterogeneous nuclear ribonucleoprotein $\mathrm{H} 2 \mathrm{GN}=\mathrm{HNRNPH} 2$ HNRH2_HUMAN 49.26 Heterogeneous nuclear ribonucleoprotein $\mathrm{H} 2 \mathrm{GN}=\mathrm{HNRNPH} 2 \mathrm{HNRH2}$ HUMAN 49.26 Heterogeneous nuclear ribonucleoprotein $\mathrm{H} 2 \mathrm{GN}=\mathrm{HNRNPH} 2$ HNRH2_HUMAN 49.26 Heterogeneous nuclear ribonucleoprotein $\mathrm{H} 3 \mathrm{GN}=\mathrm{HNRNPH} 3$ HNRH3 HUMAN 36.99 Heterogeneous nuclear ribonucleoprotein $\mathrm{H} 3 \mathrm{GN}=\mathrm{HNRNPH3}$ HNRH3_HUMAN 36.93 Heterogeneous nuclear ribonucleoprotein $\mathrm{H} 3 \mathrm{GN}=\mathrm{HNRNPH} 3$ HNRH3_HUMAN 36.93 Heterogeneous nuclear ribonucleoprotein $\mathrm{H} 3 \mathrm{GN}=\mathrm{HNRNPH} 3$ HNRH3_HUMAN 36.93 Heterogeneous nuclear ribonucleoprotein $\mathrm{H} 3 \mathrm{GN}=\mathrm{HNRNPH} 3$ HNRH3_HUMAN 36.93 Heterogeneous nuclear ribonucleoprotein $\mathrm{H} 3 \mathrm{GN}=\mathrm{HNRNPH} 3$ HNRH3 HUMAN 36.93 Heterogeneous nuclear ribonucleoprotein $\mathrm{H} 3 \mathrm{GN}=\mathrm{HNRNPH} 3$ HNRH3_HUMAN $36.93 \quad 100.0^{\circ}$ Heterogeneous nuclear ribonucleoprotein $\mathrm{H} 3 \mathrm{GN}=\mathrm{HNRNPH} 3$ HNRH3_HUMAN $36.93 \quad 100.0 \%$ Heterogeneous nuclear ribonucleoprotein $\mathrm{H} 3 \mathrm{GN}=\mathrm{HNRNPH} 3 \mathrm{HNRH} 3$ HUMAN $36.93 \quad 100.0 \%$ Heterogeneous nuclear ribonucleoprotein $\mathrm{H} 3 \mathrm{GN}=\mathrm{HNRNPH} 3 \mathrm{HNRH} 3$ _HUMAN $36.93 \quad 100.0 \%$

$100.0 \%$

$100.0 \%$

$100.0 \%$ $100.0 \%$

$100.0 \%$ $100.0 \%$ $100.0 \%$ $100.0 \%$ $100.0 \%$ $100.0 \%$
$100.0 \%$ $100.0 \%$ $100.0 \%$ $100.0 \%$ $100.0 \%$
26.5\% ITGEAFVQFASQELAEK

$99.7 \% 55.7$ $99.7 \% \quad 38.8$

$99.2 \% \quad 21.1$

$98.3 \% \quad 25.2$

$99.6 \% \quad 26.2$

$0.04 \% \quad 26.5 \%$ SYSDPPLK

$0.04 \% \quad 26.5 \%$ DLSYCLSGMYDHR

$99.7 \% 57.3$

$0.04 \% \quad 26.5 \%$ VHIEIGPDGR

$134 \quad 0.15 \% \quad 47.7 \%$ GLPWSCSADEVQR

$134 \quad 0.15 \% \quad 47.7 \%$ FFSDCKIQNGAQGIR

$134 \quad 0.15 \% \quad 47.7 \%$ IQNGAQGIR

$99.7 \% \quad 45.0 \quad 25.0$

$99.7 \% \quad 50.5 \quad 25.0$

$134 \quad 0.15 \% \quad 47.7 \%$ EGRPSGEAFVELESEDEVK $\quad 99.7 \% \quad 57.5$

$134 \quad 0.15 \% \quad 47.7 \%$ HTGPNSPDTANDGFVR $\quad 99.7 \% \quad 59.8$

$134 \quad 0.15 \% \quad 47.7 \%$ HTGPNSPDTANDGFVRLR $97.6 \% \quad 18.1$

$134 \quad 0.15 \% \quad 47.7 \%$ STGEAFVQFASQEIAEK $\quad 99.7 \% \quad 42.4$

$134 \quad 0.15 \% \quad 47.7 \%$ STGEAFVQFASQEIAEKALK $99.0 \% \quad 20.8$

$134 \quad 0.15 \% \quad 47.7 \%$ IGHRYIEIFK

$134 \quad 0.15 \% \quad 47.7 \%$ YIEIFKSSR

$134 \quad 0.15 \% \quad 47.7 \%$ AEVRTHYDPPR

$99.7 \% \quad 29.7$

$99.7 \% \quad 35.3$

$97.9 \% 19.3$

$99.7 \% \quad 51.6$

$134 \quad 0.15 \% \quad 47.7 \%$ YGDGGSTFQSTTGHCVHMR $\quad 99.7 \% \quad 58.5$

$134 \quad 0.15 \% \quad 47.7 \%$ GLPYRATENDIYNFFSPLNPVR $\quad 99.7 \% \quad 47.9$

$134 \quad 0.15 \% \quad 47.7 \%$ ATENDIYNFFSPLNPVR $\quad 99.7 \% \quad 57.3$

$134 \quad 0.15 \% \quad 47.7 \%$ VHIEIGPDGR

$99.7 \% \quad 40.1$

$100.0 \%$ $100.0 \%$ $100.0 \%$ $100.0 \%$ 10 10
$134 \quad 0.15 \% \quad 47.7 \%$ YVELFLNSTAGASGGAYEHR $99.7 \% \quad 48.0$

$0.00 \% \quad 28.1 \%$ HTGPNSPDTANDGFVR $99.7 \% 59.8$

$0.00 \% \quad 28.1 \%$ HTGPNSPDTANDGFVRLR $\quad 97.6 \% 18.1$

$0.00 \% \quad 28.1 \%$ STGEAFVQFASQEIAEK $\quad 99.7 \% \quad 42.4$

$0.00 \% \quad 28.1 \%$ STGEAFVQFASQEIAEKALK $\quad 99.0 \% \quad 20.8$

$0.00 \% \quad 28.1 \%$ IGHRYIEIFK

$0.00 \% \quad 28.1 \%$ YIEIFKSSR

$0.00 \% \quad 28.1 \%$ AEVRTHYDPPR

$99.7 \% \quad 29.7$

$99.7 \% \quad 35.3$

$97.9 \% \quad 19.3$

$0.00 \% \quad 28.1 \%$ DLNYCFSGMSDHR $\quad 99.7 \% \quad 51.6$

$0.00 \% \quad 28.1 \%$ YGDGGSSFQSTTGHCVHMR $99.7 \% \quad 46.9$

$0.00 \% \quad 28.1 \%$ GLPYRATENDIYNFFSPLNPMR $99.7 \% \quad 27.0$

$0.00 \% \quad 28.1 \%$ ATENDIYNFFSPLNPMR $\quad 99.6 \% 30.6$

$0.00 \% \quad 28.1 \%$ VHIEIGPDGR

$0.08 \% \quad 43.9 \%$ HNGPNDASDGTVR

$99.7 \% \quad 40.1$

$99.7 \% \quad 48.3$

$99.7 \% \quad 58.9$

$99.7 \% \quad 43.7$

$99.0 \% \quad 28.5$

$0.08 \% \quad 43.9 \%$ EIAENALGK

$0.08 \% \quad 43.9 \%$ GFYDPPRR

$0.08 \% \quad 43.9 \%$ ATENDIANFFSPLNPIR

$99.7 \% \quad 57.5$

$99.7 \% \quad 51.2$

$\begin{array}{llllll}0.08 \% & 43.9 \% & \text { ATGEADVEFVTHEDAVAAMSK } & 99.7 \% & 54.5\end{array}$

$0.08 \% \quad 43.9 \%$ YIELFLNSTPGGGSGMGGSGMGGYGR $\quad 99.7 \% \quad 51.6$

$0.08 \% \quad 43.9 \%$ DGMDNQGGYGSVGR $\quad 99.7 \% \quad 47.9$

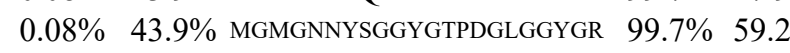

$134 \quad 0.15 \% \quad 47.7 \%$ VTGEADVEFATHEDAVAAMSK $99.7 \% \quad 48.0$
1867.94

1613.82

1721.83

906.46

1632.68

1996.98

1092.58

1504.69

1740.85

956.53

2106.98

1684.77

1953.95

1841.89

2154.11

1275.72

1142.62

1340.67

1601.65

2097.89

2583.30

1996.98

1092.58

2194.00

2142.03

1684.77

1953.95

1841.89

2154.11

1275.72

1142.62

1340.67

1601.65

2083.87

2615.27

2044.94

1092.58

1339.60

1271.63

944.50

1007.5

1918.97

1052.55

2178.00

2554.13

1428.58

2212.90

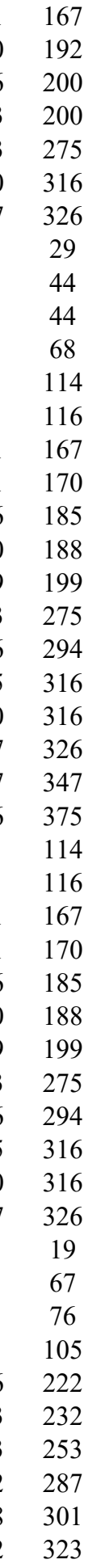

Page 76 of Table S-1-5 
0.08\% $35.0 \%$ RPAEDMEEEQAFKR

$0.08 \% \quad 35.0 \%$ SRNTDEMVELR

$0.08 \% \quad 35.0 \%$ NTDEMVELR

$\begin{array}{llll}99.7 \% & 38.3 & 25.0 & 37.1\end{array}$

$\begin{array}{llll}99.7 \% & 39.0 & 25.0 & 22.8\end{array}$

$99.7 \% \quad 52.0 \quad 25.0 \quad 42.1$

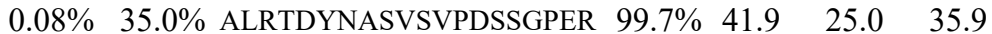

$\begin{array}{lllllll}0.08 \% & 35.0 \% & \text { TDYNASVSVPDSSGPER } & 99.7 \% & 65.5 & 25.0 & 65.5\end{array}$

$0.08 \% \quad 35.0 \%$ ILSISADIETIGEILKK

$99.7 \% \quad 29.4 \quad 25.0 \quad 26.3$

$0.08 \% \quad 35.0 \%$ LLIHQSLAGGIIGVK

$0.08 \% \quad 35.0 \%$ LFQECCPHSTDR

$0.08 \% \quad 35.0 \%$ VVLIGGKPDR

$0.08 \% \quad 35.0 \%$ IILDLISESPIK

$0.08 \% \quad 35.0 \%$ RDYDDMSPR

$0.08 \% \quad 35.0 \%$ DYDDMSPR

$0.08 \% \quad 35.0 \%$ GGDLMAYDR

$0.08 \% \quad 35.0 \%$ GGDLMAYDRR

$99.7 \% \quad 44.8 \quad 25.0 \quad 44.8$

$99.7 \% \quad 57.8 \quad 25.0 \quad 57.8$

$99.7 \% \quad 40.0 \quad 25.0 \quad 23.5$

$99.7 \% \quad 53.3 \quad 25.0 \quad 53.3$

$99.7 \% \quad 41.8 \quad 25.0 \quad 38.1$

$99.0 \% \quad 34.7 \quad 25.0 \quad 34.7$

$99.7 \% \quad 51.0 \quad 25.0 \quad 46.6$

$99.7 \% \quad 31.4 \quad 25.0-16.7$

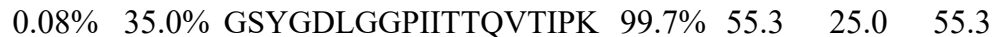

$\begin{array}{lllllll}0.08 \% & 35.0 \% & \text { GSYGDLGGPITTQVTIPKDLAGSIIGK } & 99.7 \% & 44.4 & 25.0 & 44.4\end{array}$

$0.08 \% \quad 35.0 \%$ DLAGSIIGK

$73 \quad 0.08 \% \quad 35.0 \%$ DLAGSIIGKGGQR

$131 \quad 0.14 \% \quad 29.4 \%$ YYGGGSEGGRAPK

$131 \quad 0.14 \% \quad 29.4 \%$ ISRPGDSDDSR

$99.7 \% \quad 40.5$

$99.7 \% \quad 60.6$

$99.7 \% \quad 60.0$

$99.7 \% \quad 36.3$

$\begin{array}{llllll}131 & 0.14 \% & 29.4 \% & \text { KNGVQAMVEFDSVQSAQR } & 99.7 \% & 32.4\end{array}$

$131 \quad 0.14 \% \quad 29.4 \%$ NGVQAMVEFDSVQSAQR $99.7 \% \quad 65.8$

$131 \quad 0.14 \% \quad 29.4 \%$ AKASLNGADIYSGCCTLK $99.7 \% \quad 39.0$

$131 \quad 0.14 \% \quad 29.4 \%$ ASLNGADIYSGCCTLK

$131 \quad 0.14 \% \quad 29.4 \%$ IEYAKPTR

$131 \quad 0.14 \% \quad 29.4 \%$ MGPPVGGHR

$99.7 \% \quad 67.5$ $99.0 \% \quad 50.3$

$131 \quad 0.14 \% \quad 29.4 \%$ VFNVFCLYGNVEK

$99.7 \% \quad 51.8$

$131 \quad 0.14 \% \quad 29.4 \%$ AITHLNNNFMFGQK

$131 \quad 0.14 \% \quad 29.4 \%$ NNRFSTPEQAAK

$131 \quad 0.14 \% \quad 29.4 \%$ FSTPEQAAKNR

$\begin{array}{ll}99.7 \% & 51.7 \\ 99.7 \% & 55.6\end{array}$

$99.7 \% \quad 55.1$

$98.5 \% \quad 18.2$

$\begin{array}{lll}131 & 0.14 \% & 29.4 \% \\ 13 & 0.14 \% & 29.4 \%\end{array}$

$131 \quad 0.14 \% \quad 29.4 \%$ LCFSTAQHAS

$420 \quad 0.46 \% \quad 61.8 \%$ GGNRFEPYANPTK

$420 \quad 0.46 \% \quad 61.8 \%$ FEPYANPTKR

$420 \quad 0.46 \% \quad 61.8 \%$ AFITNIPFDVK

$420 \quad 0.46 \% \quad 61.8 \%$ GCAVVEFK

$420 \quad 0.46 \% \quad 61.8 \%$ AAEVLNKHSLSGRPLK

$420 \quad 0.46 \% \quad 61.8 \%$ HSLSGRPLK

$420 \quad 0.46 \% \quad 61.8 \%$ LGSTVFVANLDYK

$420 \quad 0.46 \% \quad 61.8 \%$ LKEVFSMAGVVVR

$420 \quad 0.46 \% \quad 61.8 \%$ EVFSMAGVVVR

$420 \quad 0.46 \% \quad 61.8 \%$ ADILEDKDGK

$420 \quad 0.46 \% \quad 61.8 \%$ MDERALPK

$420 \quad 0.46 \% \quad 61.8 \%$ GIGMGNIGPAGMGMEGIGFGINK $\quad 99.7 \% \quad 72.4 \quad 25.0 \quad 72.4$

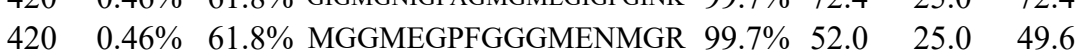

$\begin{array}{llll}99.7 \% & 32.1 & 25.0 & 31.1\end{array}$

$99.7 \% \quad 53.8 \quad 25.0 \quad 53.8$

$99.7 \% \quad 43.7 \quad 25.0 \quad 38.4$

$99.1 \% \quad 20.3 \quad 25.0 \quad 17.6$

$\begin{array}{llll}9.7 \% & 54.0 & 25.0 & 42.2\end{array}$

$\begin{array}{llll}99.7 \% & 26.9 & 25.0 & 26.9\end{array}$

$99.7 \% 56.5 \quad 25.0 \quad 52.6$

$99.7 \% \quad 58.0 \quad 25.0 \quad 54.0$

$99.7 \% \quad 39.9 \quad 25.0 \quad 30.3$

$\begin{array}{lllll}99.7 \% & 40.3 & 25.0 & 35.4\end{array}$

$\begin{array}{lllll}99.7 \% & 40.3 & 25.0 & 35.4 & 13 \\ 99.0 \% & 43.8 & 25.0 & 26.3 & \end{array}$

2.43 $\begin{array}{llll}99.5 \% & 30.0 & 25.0 & 13.2\end{array}$

1222.62

1264.69

909.45

1719.99 

Heterogeneous nuclear ribonucleoprotein M GN=HNRNPM HNRPM_HUMAN $77.52 \quad 100.0 \% \quad 48$ Heterogeneous nuclear ribonucleoprotein M GN=HNRNPM HNRPM_HUMAN $77.52 \quad 100.0 \% \quad 48$ Heterogeneous nuclear ribonucleoprotein M GN=HNRNPM HNRPM_HUMAN $77.52 \quad 100.0 \%$ Heterogeneous nuclear ribonucleoprotein M GN=HNRNPM HNRPM_HUMAN $77.52 \quad 100.0 \% \quad 48$ Heterogeneous nuclear ribonucleoprotein M GN=HNRNPM HNRPM_HUMAN $77.52 \quad 100.0 \% \quad 48$ Heterogeneous nuclear ribonucleoprotein M GN=HNRNPM HNRPM_HUMAN $77.52 \quad 100.0 \% \quad 48$ Heterogeneous nuclear ribonucleoprotein M GN=HNRNPM HNRPM_HUMAN $77.52 \quad 100.0 \% \quad 48$ Heterogeneous nuclear ribonucleoprotein M GN=HNRNPM HNRPM_HUMAN $77.52 \quad 100.0 \% \quad 48$ Heterogeneous nuclear ribonucleoprotein M GN=HNRNPM HNRPM_HUMAN $77.52 \quad 100.0 \% \quad 48$ Heterogeneous nuclear ribonucleoprotein M GN=HNRNPM HNRPM_HUMAN $77.52 \quad 100.0 \% \quad 48$ Heterogeneous nuclear ribonucleoprotein M GN=HNRNPM HNRPM_HUMAN $77.52 \quad 100.0 \% \quad 48$ Heterogeneous nuclear ribonucleoprotein M GN=HNRNPM HNRPM_HUMAN $77.52 \quad 100.0 \% \quad 48$ Heterogeneous nuclear ribonucleoprotein M GN=HNRNPM HNRPM_HUMAN $77.52 \quad 100.0 \% \quad 48$ Heterogeneous nuclear ribonucleoprotein M GN=HNRNPM HNRPM_HUMAN $77.52 \quad 100.0 \% 48$ Heterogeneous nuclear ribonucleoprotein M GN=HNRNPM HNRPM_HUMAN $77.52 \quad 100.0 \% \quad 48$ Heterogeneous nuclear ribonucleoprotein M GN=HNRNPM HNRPM HUMAN $77.52 \quad 100.0 \% 48$ Heterogeneous nuclear ribonucleoprotein M GN=HNRNPM HNRPM_HUMAN $77.52 \quad 100.0 \% \quad 48$ Heterogeneous nuclear ribonucleoprotein M GN=HNRNPM HNRPM_HUMAN $77.52 \quad 100.0 \% \quad 48$ Heterogeneous nuclear ribonucleoprotein M GN=HNRNPM HNRPM_HUMAN $77.52 \quad 100.0 \% 48$ Heterogeneous nuclear ribonucleoprotein M GN=HNRNPM HNRPM_HUMAN $77.52 \quad 100.0 \% \quad 48$ Heterogeneous nuclear ribonucleoprotein M GN=HNRNPM HNRPM_HUMAN $77.52 \quad 100.0 \% \quad 48$ Heterogeneous nuclear ribonucleoprotein M GN=HNRNPM HNRPM_HUMAN $77.52 \quad 100.0 \% \quad 48$ Heterogeneous nuclear ribonucleoprotein M GN=HNRNPM HNRPM_HUMAN $77.52 \quad 100.0 \% \quad 48$ Heterogeneous nuclear ribonucleoprotein M GN=HNRNPM HNRPM_HUMAN $77.52 \quad 100.0 \% \quad 48$ Heterogeneous nuclear ribonucleoprotein M GN=HNRNPM HNRPM_HUMAN $77.52 \quad 100.0 \% \quad 48$ Heterogeneous nuclear ribonucleoprotein M GN=HNRNPM HNRPM_HUMAN $77.52 \quad 100.0 \% \quad 48$ Heterogeneous nuclear ribonucleoprotein M GN=HNRNPM HNRPM_HUMAN $77.52 \quad 100.0 \% 48$ Heterogeneous nuclear ribonucleoprotein M GN=HNRNPM HNRPM_HUMAN $77.52 \quad 100.0 \% \quad 48$ Heterogeneous nuclear ribonucleoprotein M GN=HNRNPM HNRPM HUMAN $77.52 \quad 100.0 \% 48$ Heterogeneous nuclear ribonucleoprotein M GN=HNRNPM HNRPM_HUMAN $77.52 \quad 100.0 \% \quad 48$ Heterogeneous nuclear ribonucleoprotein M GN=HNRNPM HNRPM_HUMAN $77.52 \quad 100.0 \% \quad 48$ Heterogeneous nuclear ribonucleoprotein M GN=HNRNPM HNRPM HUMAN $77.52 \quad 100.0 \%$ Heterogeneous nuclear ribonucleoprotein M GN=HNRNPM HNRPM_HUMAN $77.52 \quad 100.0 \% \quad 48$ Heterogeneous nuclear ribonucleoprotein M GN=HNRNPM HNRPM_HUMAN $77.52 \quad 100.0 \% \quad 48$ Heterogeneous nuclear ribonucleoprotein Q GN=SYNCRIP $\quad$ HNRPQ_HUMAN $\quad 69.60 \quad 100.0 \% \quad 14$ $\begin{array}{lllll}\text { Heterogeneous nuclear ribonucleoprotein Q GN=SYNCRIP } & \text { HNRPQ_HUMAN } & 69.60 & 100.0 \% & 14\end{array}$ Heterogeneous nuclear ribonucleoprotein Q GN=SYNCRIP HNRPQ HUMAN $69.60 \quad 100.0 \%$ $\begin{array}{lllll}\text { Heterogeneous nuclear ribonucleoprotein Q GN=SYNCRIP } & \text { HNRPQ_HUMAN } & 69.60 & 100.0 \% & 14\end{array}$ Heterogeneous nuclear ribonucleoprotein Q GN=SYNCRIP $\quad$ HNRPQ_HUMAN $69.60 \quad 100.0 \% \quad 14$ $\begin{array}{lllll}\text { Heterogeneous nuclear ribonucleoprotein Q GN=SYNCRIP } & \text { HNRPQ_HUMAN } & 69.60 & 100.0 \% & 14\end{array}$ $\begin{array}{lllll}\text { Heterogeneous nuclear ribonucleoprotein Q GN=SYNCRIP } & \text { HNRPQ_HUMAN } & 69.60 & 100.0 \% & 14\end{array}$ Heterogeneous nuclear ribonucleoprotein Q GN=SYNCRIP $\quad$ HNRPQ_HUMAN $69.60 \quad 100.0 \% \quad 14$ $\begin{array}{lllll}\text { Heterogeneous nuclear ribonucleoprotein Q GN=SYNCRIP } & \text { HNRPQ_HUMAN } & 69.60 & 100.0 \% & 14\end{array}$ $\begin{array}{lllll}\text { Heterogeneous nuclear ribonucleoprotein Q GN=SYNCRIP } & \text { HNRPQ_HUMAN } & 69.60 & 100.0 \% & 14\end{array}$ Heterogeneous nuclear ribonucleoprotein Q GN=SYNCRIP HNRPQ HUMAN $69.60 \quad 100.0 \%$ $\begin{array}{lllll}\text { Heterogeneous nuclear ribonucleoprotein Q GN=SYNCRIP } & \text { HNRPQ_HUMAN } & 69.60 & 100.0 \% & 14\end{array}$
$420 \quad 0.46 \% \quad 61.8 \%$ FGSGMNMGR

$420 \quad 0.46 \% \quad 61.8 \%$ INEILSNALK

$420 \quad 0.46 \% \quad 61.8 \%$ INEILSNALKR

$\begin{array}{llll}99.7 \% & 59.2 & 25.0 & 48.2\end{array}$

$99.7 \% \quad 58.3$

$99.7 \% \quad 61.4$

$99.7 \% 57.3$

$420 \quad 0.46 \% \quad 61.8 \%$ QGGGGGGGSVPGIER

$420 \quad 0.46 \% \quad 61.8 \%$ QGGGGGGGSVPGIERMGPGIDR

$420 \quad 0.46 \% \quad 61.8 \%$ MGPGIDRLGGAGMER

$99.7 \% 56.3$

$99.7 \% \quad 42.4$

$99.7 \% \quad 59.9$

$420 \quad 0.46 \% \quad 61.8 \%$ MGAGLGHGMDR

$\begin{array}{llll}420 & 0.46 \% & 61.8 \% & \text { MGAGLGHGMDRVGSEI } \\ 420 & 0.46 \% & 61.8 \% & \text { VGSEIERMGLVMDR }\end{array}$

$420 \quad 0.46 \% \quad 61.8 \%$ MGLVMDRMGSVER

$420 \quad 0.46 \% \quad 61.8 \%$ MGSVERMGSGIER

$420 \quad 0.46 \% \quad 61.8 \%$ MGPLGLDHMASSIER

$420 \quad 0.46 \% \quad 61.8 \%$ MGQTMERIGSGVER

$420 \quad 0.46 \% \quad 61.8 \%$ IGSGVERMGAGMGFGLER

$420 \quad 0.46 \% \quad 61.8 \%$ MGAGMGFGLER

$420 \quad 0.46 \% \quad 61.8 \%$ MAAPIDRVGQTIER

$420 \quad 0.46 \% \quad 61.8 \%$ VGQTIERMGSGVER

$420 \quad 0.46 \% \quad 61.8 \%$ MGPAIERMGLSMER

$420 \quad 0.46 \% \quad 61.8 \%$ MVPAGMGAGLER

$420 \quad 0.46 \% \quad 61.8 \%$ MGPVMDRMATGLER

$420 \quad 0.46 \% \quad 61.8 \%$ MGANNLER

$420 \quad 0.46 \% \quad 61.8 \%$ MGANNLERMGLER

$420 \quad 0.46 \% \quad 61.8 \%$ MGLERMGANSLER

$420 \quad 0.46 \% \quad 61.8 \%$ MGANSLER

$420 \quad 0.46 \% \quad 61.8 \%$ MGANSLERMGLER

$420 \quad 0.46 \% \quad 61.8 \%$ MGPAMGPALGAGIER

$420 \quad 0.46 \% \quad 61.8 \%$ MGLAMGGGGGASFDR

$420 \quad 0.46 \% \quad 61.8 \%$ GNFGGSFAGSFGGAGGHAPGVAR

$420 \quad 0.46 \% \quad 61.8 \%$ GNFGGSFAGSFGGAGGHAPGVARK

$420 \quad 0.46 \% \quad 61.8 \%$ KACQIFVR

$420 \quad 0.46 \% \quad 61.8 \%$ DKFNECGHVLYADIK

$420 \quad 0.46 \% \quad 61.8 \%$ GCGVVKFESPEVAER

$420 \quad 0.46 \% \quad 61.8 \%$ FESPEVAER

$420 \quad 0.46 \% \quad 61.8 \%$ LSGREIDVR

$420 \quad 0.46 \% \quad 61.8 \%$ EIDVRIDR

$66 \quad 0.07 \% \quad 31.9 \%$ EFNEDGALAVLQQFK

$66 \quad 0.07 \% \quad 31.9 \%$ SAFLCGVMK

$99.7 \% \quad 44.0$

$99.5 \% \quad 22.2$

$99.4 \% \quad 20.5$

$99.7 \% \quad 59.7$

$99.3 \% \quad 19.1$

$9.7 \% \quad 53.4$

$99.7 \% \quad 45.0$

$99.7 \% \quad 30.6$

$99.5 \% \quad 22.2$

$99.7 \% \quad 61.0$

$99.7 \% \quad 30.3$

$99.0 \% \quad 71.1$

$99.7 \% \quad 39.1$

$99.7 \% 26.1$

$99.0 \% \quad 67.7$

$99.5 \% \quad 22.0$

$99.7 \% \quad 58.7$

$99.7 \% \quad 58.2$

$99.7 \% \quad 55.3$

$99.7 \% 50.0$

$.0 \% 58.1$

$99.6 \% \quad 22.9$

$99.7 \% \quad 50.9$

$99.7 \% \quad 39.2$

$94.8 \% \quad 24.0$

$98.9 \% \quad 38.6$

$99.7 \% \quad 32.1$

$99.7 \% \quad 38.3$

$\quad 0.07 \% \quad 31.9 \%$ ALLERTGYTLDVTTGQR

$\begin{array}{lll}66 & 0.07 \% & 31.9 \% \\ 66 & 0.07 \% & 31.9 \%\end{array}$

$99.7 \% \quad 56.0$

$99.7 \% \quad 58.1$

$99.7 \% \quad 47.9$

$\begin{array}{llll}66 & 0.07 \% & 31.9 \% & \text { KYGGPPPDSYYGQQPSVGTEIFVGK } \\ 6 & 0.07 \% & 31.9 \% & \text { YGGPPPDSVYSGQQPSVGTEIFVGK }\end{array}$

$66 \quad 0.07 \% \quad 31.9 \%$ DLFEDELVPLFEK

$66 \quad 0.07 \% \quad 31.9 \%$ AGPIWDLR

$66 \quad 0.07 \% \quad 31.9 \%$ LMMDPLTGLNR

$66 \quad 0.07 \% \quad 31.9 \%$ GYAFVTFCTK

66

1114.65

1270.75

1284.63

2026.97

1516.74

1101.49

1871.89

1623.78

1512.70

1424.66

1629.77

1582.73

1855.88

1141.51

1556.82

1534.76

1625.74

1188.59

1595.73

904.43

1522.71

1495.70

877.42

1479.70

1459.70

1415.60

2034.95

2163.05

1021.56

1808.86

1663.81

1063.51

1044.58

1015.55

1708.85

1012.50

1894.00

1311.65

1439.75

2694.34

2566.25

1593.80

927.50

1292.63

$\begin{array}{llll}99.0 \% & 43.1 & 25.0 & 29.5\end{array}$

$\begin{array}{llll}99.7 \% & 47.3 & 25.0 & 39.8\end{array}$

$\begin{array}{llll}99.7 \% & 58.9 & 25.0 & 52.2\end{array}$

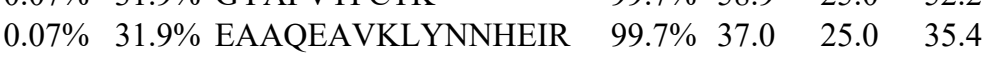

1884.96 
$\begin{array}{lllll}\text { Heterogeneous nuclear ribonucleoprotein Q GN=SYNCRIP } & \text { HNRPQ_HUMAN } & 69.60 & 100.0 \% & 1\end{array}$ Herogen

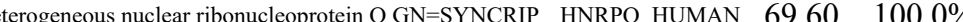
Heterogeneous nuclear ribonucleoprotein Q GN=SYNCRIP HNRPQ_HUMAN $69.60 \quad 100.0 \%$ $\begin{array}{llll}\text { Heterogeneous nuclear ribonucleoprotein Q GN=SYNCRIP } & \text { HNRPQ_HUMAN } & 69.60 & 100.0\end{array}$ Heterogeneous nuclear ribonucleoprotein Q GN=SYNCRIP HNRPQ_HUMAN $69.60 \quad 100.0 \%$ Heterogeneous nuclear ribonucleoprotein Q GN=SYNCRIP HNRPQ_HUMAN $69.60 \quad 100.0 \%$ Heterogeneous nuclear ribonucleoprotein Q GN=SYNCRIP HNRPQ HUMAN 69.60 Hero Heterogeneous nuclear ribonucleoprotein R GN=HNRNPR HNRPR_HUMAN 70.94 Heterogeneous nuclear ribonucleoprotein R GN=HNRNPR HNRPR_HUMAN 70.94 Heterogeneous nuclear ribonucleoprotein R GN=HNRNPR HNRPR_HUMAN 70.94 Heterogeneous nuclear ribonucleoprotein R GN=HNRNPR HNRPR_HUMAN 70.94 Heterogeneous nuclear ribonucleoprotein R GN=HNRNPR HNRPR_HUMAN 70.94 Heterogeneous nuclear ribonucleoprotein R GN=HNRNPR HNRPR_HUMAN 70.9 Heterogeneous nuclear ribonucleoprotein R GN=HNRNPR HNRPR HUMAN 70.94 Heterogeneous nuclear ribonucleoprotein R GN=HNRNPR HNRPR_HUMAN 70.94 Heterogeneous nuclear ribonucleoprotein R GN=HNRNPR HNRPR_HUMAN 70.94 Heterogeneous nuclear ribonucleoprotein R GN=HNRNPR HNRPR_HUMAN 70.94 Heterogeneous nuclear ribonucleoprotein R GN=HNRNPR HNRPR_HUMAN 70.94 Heterogeneous nuclear ribonucleoprotein R GN=HNRNPR HNRPR_HUMAN 70.94 Heterogeneous nuclear ribonucleoprotein R GN=HNRNPR HNRPR_HUMAN 70.94 Heterogeneous nuclear ribonucleoprotein R GN=HNRNPR HNRPR_HUMAN 70.94 Heterogeneous nuclear ribonucleoprotein R GN=HNRNPR HNRPR_HUMAN 70.94 Heterogeneous nuclear ribonucleoprotein R GN=HNRNPR HNRPR_HUMAN 70.94 Heterogeneous nuclear ribonucleoprotein R GN=HNRNPR HNRPR_HUMAN 70.94 Heterogeneous nuclear ribonucleoprotein R GN=HNRNPR HNRPR_HUMAN 70.94 Heterogeneous nuclear ribonucleoprotein R GN=HNRNPR HNRPR_HUMAN 70.94 Heterogeneous nuclear ribonucleoprotein R GN=HNRNPR HNRPR HUMAN 70.94 Heterogeneous nuclear ribonucleoprotein R GN=HNRNPR HNRPR_HUMAN 70.94 Heterogeneous nuclear ribonucleoprotein R GN=HNRNPR HNRPR_HUMAN 70.94 Heterogeneous nuclear ribonucleoprotein R GN=HNRNPR HNRPR_HUMAN 70.94 Heterogeneous nuclear ribonucleoprotein U GN=HNRNPU HNRPU_HUMAN 90.59 Heterogeneous nuclear ribonucleoprotein U GN=HNRNPU HNRPU_HUMAN 90.59 Heterogeneous nuclear ribonucleoprotein U GN=HNRNPU HNRPU_HUMAN 90.59 Heterogeneous nuclear ribonucleoprotein U GN=HNRNPU HNRPU_HUMAN 90.59 Heterogeneous nuclear ribonucleoprotein $\mathrm{U}$ GN=HNRNPU HNRPU HUMAN $90.5{ }^{\circ}$ Heterogeneous nuclear ribonucleoprotein U GN=HNRNPU HNRPU_HUMAN 90.59 Heterogeneous nuclear ribonucleoprotein U GN=HNRNPU HNRPU_HUMAN 90.59 Heterogeneous nuclear ribonucleoprotein $\mathrm{U}$ GN=HNRNPU HNRPU_HUMAN 90.59 Heterogeneous nuclear ribonucleoprotein U GN=HNRNPU HNRPU_HUMAN 90.5 Heterogeneous nuclear ribonucleoprotein $\mathrm{U}$ GN=HNRNPU HNRPU_HUMAN 90.59 Heterogeneous nuclear ribonucleoprotein U GN=HNRNPU HNRPU_HUMAN 90.59 Heterogeneous nuclear ribonucleoprotein $\mathrm{U}$ GN=HNRNPU HNRPUHUMAN 90.5 Heterogeneous nuclear ribonucleoprotein U GN=HNRNPU HNRPU HUMAN 90.5 Heterogeneous nuclear ribonucleoprotein U GN=HNRNPU HNRPU_HUMAN 90.59
16

16

16

16

16

(1)

$\begin{array}{ll}00.0 \% & 14 \\ 00.0 \% & 23\end{array}$

$100.0 \% \quad 23$ $100.0 \% \quad 23$ $100.0 \% \quad 23$ $100.0 \% \quad 23$ $100.0 \% \quad 23$ $100.0 \% \quad 23$ $100.0 \% \quad 23$ $100.0 \% \quad 23$ $100.0 \% \quad 23$ $100.0 \% \quad 23$ $100.0 \% \quad 23$ $100.0 \% \quad 23$ $100.0 \% \quad 23$ $100.0 \% \quad 23$ $100.0 \% \quad 23$ $100.0 \% \quad 23$ $00.0 \% \quad 23$ $100.0 \% \quad 23$ $100.0 \% \quad 23$ $100.0 \% \quad 23$ $100.0 \% \quad 23$ $100.0 \% \quad 23$ $100.0 \% \quad 25$ $100.0 \% \quad 25$ $100.0 \% \quad 25$ $100.0 \% \quad 25$ $100.0 \% \quad 25$ $100.0 \% \quad 25$ $100.0 \% \quad 25$ $100.0 \% \quad 25$ $100.0 \% \quad 25$ $100.0 \% \quad 25$ $100.0 \% \quad 25$ $100.0 \% \quad 25$ $100.0 \% \quad 25$ $100.0 \% \quad 25$
$66 \quad 0.07 \% \quad 31.9 \%$ LYNNHEIR $0.07 \% \quad 31.9 \%$ SGKHIGVCISVANNR

$66 \quad 0.07 \% \quad 31.9 \%$ HIGVCISVANNR

$0.07 \% \quad 31.9 \%$ LFVGSIPK

$66 \quad 0.07 \% \quad 31.9 \%$ TKEQILEEFSK

$0.07 \% \quad 31.9 \%$ EQILEEFSK

$0.07 \% 31.9 \%$ GFCFLEYEDHK

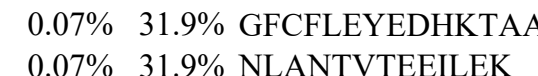

$\begin{array}{llll}16 & 66 & 0.07 \% & 31.9 \% \\ 16 & \text { AFSQFGKLER }\end{array}$

$\begin{array}{lllll}27 & 145 & 0.16 \% & 37.4 \% & \text { EFNEEGALSV } \\ 27 & 145 & 0.16 \% & 37.4 \% & \text { SAFLCGVMK }\end{array}$

$\begin{array}{llll}27 & 145 & 0.16 \% & 37.4 \% \\ 27 & 145 & 0.16 \% & 37.4 \% \text { VQESTKGPDEAK }\end{array}$

$27 \quad 145 \quad 0.16 \% \quad 37.4 \%$ ALLERTGYTLDVTTGQR

$27 \quad 145 \quad 0.16 \% \quad 37.4 \%$ TGYTLDVTTGQR

$27 \quad 145 \quad 0.16 \% \quad 37.4 \%$ TGYTLDVTTGQRK

$\begin{array}{lllll}27 & 145 & 0.16 \% & 37.4 \% & \text { YGGPPDSVYSGVQPGIGTE } \\ 27 & 145 & 0.16 \% & 37.4 \% & \text { DLYEDELVPLFEK }\end{array}$

$27 \quad 145 \quad 0.16 \% \quad 37.4 \%$ AGPIWDLR

$27 \quad 145 \quad 0.16 \% \quad 37.4 \%$ LMMDPLSGQNR

$27 \quad 145 \quad 0.16 \% \quad 37.4 \%$ GYAFITFCGK

$27 \quad 145 \quad 0.16 \% \quad 37.4 \%$ EAAQEAVKLCDSYEIRPGK

$27 \quad 145 \quad 0.16 \% \quad 37.4 \%$ LCDSYEIRPGK

$27 \quad 145 \quad 0.16 \% \quad 37.4 \%$ HLGVCISVANNR

$27 \quad 145 \quad 0.16 \% \quad 37.4 \%$ LFVGSIPK

$27 \quad 145 \quad 0.16 \% \quad 37.4 \%$ TKENILEEFSK

$27 \quad 145 \quad 0.16 \% \quad 37.4 \%$ ENILEEFSK

$27 \quad 145 \quad 0.16 \% \quad 37.4 \%$ GFCFLEYEDHK

$27 \quad 145 \quad 0.16 \% \quad 37.4 \%$ GFCFLEYEDHKSAAQAR

$27 \quad 145 \quad 0.16 \% \quad 37.4 \%$ NLATTVTEEILEK

$27 \quad 145 \quad 0.16 \% \quad 37.4 \%$ SFSEFGKLER

$27 \quad 145 \quad 0.16 \% \quad 37.4 \%$ LKDYAFVHFEDR

$145 \quad 0.16 \% \quad 37.4 \%$ STAYEDYYYHPPPR

$207 \quad 0.23 \% \quad 24.1 \%$ KAEGGGGGGRPGAPAAGDGK $\quad 99.7 \% \quad 34.1$

$207 \quad 0.23 \% \quad 24.1 \%$ AEGGGGGGRPGAPAAGDGK $99.7 \% \quad 37.7$

$207 \quad 0.23 \% \quad 24.1 \%$ AEGGGGGGRPGAPAAGDGKTEQK $\quad 99.7 \% \quad 40.7$

$207 \quad 0.23 \% \quad 24.1 \%$ GYFEYIEENKYSR

$207 \quad 0.23 \% \quad 24.1 \%$ VTEKIPVR

$207 \quad 0.23 \% \quad 24.1 \%$ HLYTKDIDIHEVR

$207 \quad 0.23 \% \quad 24.1 \%$ DIDIHEVR

$207 \quad 0.23 \% \quad 24.1 \%$ NGQDLGVAFK

$207 \quad 0.23 \% \quad 24.1 \%$ NGQDLGVAFKISK

$207 \quad 0.23 \% \quad 24.1 \%$ HAAENPGKYNILGTNTIMDK

$207 \quad 0.23 \% \quad 24.1 \%$ YNILGTNTIMDK

$207 \quad 0.23 \% \quad 24.1 \%$ MMVAGFKK

$207 \quad 0.23 \% \quad 24.1 \%$ QMADTGKLNTLLQR

1058.54

1611.84

1339.69
860.52

860.52

1351.71

1122.57

1444.62

2042.94

1473.78

1182.63

1738.86

1012.50

1288.64

1894.00

1311.65

1439.75

2507.25

1609.80

927.50

1261.60

1163.56

2164.07

1337.65

1339.69

860.52

1337.69

1108.55

1444.62

2028.92

1460.78

1199.61

1539.76

1758.78

1714.91

1666.83

1538.73

2024.97

1697.78

941.58

1638.86

996.51

1048.54

1376.75

2187.09

1398.69

911.48

1588.85 
Heterogeneous nuclear ribonucleoprotein U GN=HNRNPU HNRPU_HUMAN $90.59 \quad 100.0 \% \quad 25$ Heterogeneous nuclear ribonucleoprotein U GN=HNRNPU HNRPU_HUMAN $90.59 \quad 100.0 \% \quad 25$ Heterogeneous nuclear ribonucleoprotein U GN=HNRNPU HNRPU_HUMAN $90.59 \quad 100.0 \% \quad 25$ Heterogeneous nuclear ribonucleoprotein U GN=HNRNPU HNRPU_HUMAN $90.59 \quad 100.0 \% \quad 25$ Heterogeneous nuclear ribonucleoprotein U GN=HNRNPU HNRPU_HUMAN $90.59 \quad 100.0 \% \quad 25$ Heterogeneous nuclear ribonucleoprotein U GN=HNRNPU HNRPU_HUMAN $90.59 \quad 100.0 \% \quad 25$ Heterogeneous nuclear ribonucleoprotein U GN=HNRNPU HNRPU_HUMAN $90.59 \quad 100.0 \% \quad 25$ Heterogeneous nuclear ribonucleoprotein U GN=HNRNPU HNRPU_HUMAN $90.59 \quad 100.0 \% \quad 25$ Heterogeneous nuclear ribonucleoprotein U GN=HNRNPU HNRPU_HUMAN $90.59 \quad 100.0 \% \quad 25$ Heterogeneous nuclear ribonucleoprotein U GN=HNRNPU HNRPU_HUMAN $90.59 \quad 100.0 \% \quad 25$ Heterogeneous nuclear ribonucleoprotein U GN=HNRNPU HNRPU_HUMAN $90.59 \quad 100.0 \% \quad 25$ Heterogeneous nuclear ribonucleoprotein U-like protein 1 GN=HNRNPUL1 HNRL1_HUMAN $95.74 \quad 100.0 \% \quad 10$ Heterogeneous nuclear ribonucleoprotein U-like protein 1 GN=HNRNPUL1 $\quad$ HNRL1_HUMAN $95.74 \quad 100.0 \% \quad 10$ Heterogeneous nuclear ribonucleoprotein U-like protein 1 GN=HNRNPUL1 HNRL1_HUMAN $95.74 \quad 100.0 \% \quad 10$ Heterogeneous nuclear ribonucleoprotein U-like protein $1 \mathrm{GN}=$ HNRNPUL1 HNRL1_HUMAN $95.74 \quad 100.0 \% \quad 10$ Heterogeneous nuclear ribonucleoprotein U-like protein $1 \mathrm{GN}=$ HNRNPUL1 $\quad$ HNRL1_HUMAN $95.74 \quad 100.0 \% \quad 10$ Heterogeneous nuclear ribonucleoprotein U-like protein 1 GN=HNRNPUL1 HNRL1_HUMAN $95.74 \quad 100.0 \% \quad 10$ Heterogeneous nuclear ribonucleoprotein U-like protein 1 GN=HNRNPUL1 $\quad$ HNRL1_HUMAN $95.74 \quad 100.0 \% \quad 10$ $\begin{array}{lllll}\text { Heterogeneous nuclear ribonucleoprotein U-like protein } 1 \mathrm{GN}=\text { HNRNPUL1 } & \text { HNRL1_HUMAN } 95.74 & 100.0 \% & 10\end{array}$ Heterogeneous nuclear ribonucleoprotein U-like protein 1 GN=HNRNPUL1 HNRL1_HUMAN $95.74 \quad 100.0 \% 10$ Heterogeneous nuclear ribonucleoprotein U-like protein 1 GN=HNRNPUL1 HNRL1_HUMAN $95.74 \quad 100.0 \% \quad 10$ Heterogeneous nuclear ribonucleoprotein U-like protein 2 GN=HNRNPUL2 HNRL2_HUMAN $85.11 \quad 100.0 \% \quad 8$ tuclear ribonucleoprotein U-like protein 2 GN=HNRNPUL2 HNRL2_HUMAN $85.11 \quad 100.0 \%$ 作 Teterogeneous nuclear ribonucleoprotein U-like protein 2 GN=HNRNPUL2 HNRL2_HUMAN $85.11 \quad 100.0 \%$ Heterogeneous nuclear ribonucleoprotein U-like protein 2 GN=HNRNPUL2 HNRL2_HUMAN $85.11 \quad 100.0 \%$ Heterogeneous nuclear ribonucleoprotein U-like protein 2 GN=HNRNPUL2 2 HNRL2 HUMAN $85.11 \quad 100.0 \%$ Heterogeneous nuclear ribonucleoprotein U-like protein 2 GN=HNRNPUL2 HNRL2_HUMAN $85.11 \quad 100.0 \%$ Heterogeneous nuclear ribonucleoproteins A2/B1 GN=HNRNPA2B1 ROA2 HUMAN $37.43 \quad 100.0 \%$ Heterogeneous nuclear ribonucleoproteins A2/B1 GN=HNRNPA2B1 ROA2_HUMAN $37.43 \quad 100.0 \%$ Heterogeneous nuclear ribonucleoproteins A2/B1 GN=HNRNPA2B1 ROA2_HUMAN $37.43 \quad 100.0$ Heterogeneous nuclear ribonucleoproteins $\mathrm{A} 2 / \mathrm{B} 1 \mathrm{GN}=\mathrm{HNRNP} 2 \mathrm{~B} 1 \mathrm{ROA2}$ HUMAN $37.43 \quad 100.0$ Heterogeneous nuclear ribonucleoproteins A2/B1 GN=HNRNPA2B1 ROA2_HUMAN $37.43 \quad 100.0^{\circ}$ Heterogeneous nuclear ribonucleoproteins A2/B1 GN=HNRNPA2B1 ROA2_HUMAN $37.43 \quad 100.0^{\circ}$, Heterogeneous nuclear ribonucleoproteins A2/B1 GN=HNRNPA2B1 ROA2_HUMAN $37.43 \quad 100.0^{\circ}$ Heterogeneous nuclear ribonucleoproteins A2/B1 GN=HNRNPA2B1 ROA2_HUMAN $37.43 \quad 100.0^{\circ}$ Heterogeneous nuclear ribonucleoproteins $\mathrm{A} 2 / \mathrm{B} 1 \mathrm{GN}=\mathrm{HNRNPA2B1} \quad \mathrm{ROA} 2$ HUMAN $37.43 \quad 100.0^{\circ}$ Heterogeneous nuclear ribonucleoproteins A2/B1 GN=HNRNPA2B1 $\quad$ ROA2_HUMAN $37.43 \quad 100.0 \% \quad 2$ Heterogeneous nuclear ribonucleoproteins A2/B1 GN=HNRNPA2B1 ROA2_HUMAN $37.43 \quad 100.0 \% \quad 26$ Heterogeneous nuclear ribonucleoproteins A2/B1 GN=HNRNPA2B1 ROA2 HUMAN $37.43 \quad 100.0 \% \quad 26$ Heterogeneous nuclear ribonucleoproteins A2/B1 GN=HNRNPA2B1 $\quad$ ROA2_HUMAN $37.43 \quad 100.0 \% \quad 26$ $\begin{array}{llll}\text { Heterogeneous nuclear ribonucleoproteins A2/B1 GN=HNRNPA2B1 } & \text { ROA2_HUMAN } 37.43 \quad 100.0 \% & 26\end{array}$ Heterogeneous nuclear ribonucleoproteins A2/B1 GN=HNRNPA2B1 $\quad$ ROA2_HUMAN $37.43 \quad 100.0 \% \quad 26$ Heterogeneous nuclear ribonucleoproteins A2/B1 GN=HNRNPA2B1 $\quad$ ROA2_HUMAN $37.43 \quad 100.0 \% \quad 26$ Heterogeneous nuclear ribonucleoproteins A2/B1 GN=HNRNPA2B1 ROA2 HUMAN $37.43 \quad 100.0 \% 26$ Heterogeneous nuclear ribonucleoproteins A2/B1 GN=HNRNPA2B1 $\quad$ ROA2_HUMAN $37.43 \quad 100.0 \% \quad 26$

8

$\begin{array}{llllllll}99.7 \% & 37.1 & 25.0 & 37.1 & 2 & 2 & 0 & 1573.85\end{array}$

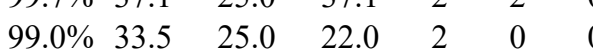

$\begin{array}{lllll}99.7 \% & 54.8 & 25.0 & 50.5 & 2\end{array}$

$\begin{array}{lllll}99.7 \% & 55.5 & 25.0 & 38.7 & 30\end{array}$

$\begin{array}{llll}99.7 \% & 28.7 & 25.0 & 21.9 \\ 99.7 \% & 40.2 & 25.0 & 27.8\end{array}$

$\begin{array}{lllll}99.7 \% & 61.5 & 25.0 & 51.6 & 19\end{array}$

$\begin{array}{lllll}98.6 \% & 22.0 & 25.0 & 15.4 & 1\end{array}$

$\begin{array}{lllll}99.7 \% & 40.0 & 25.0 & 40.0\end{array}$

$\begin{array}{llll}99.7 \% & 46.1 & 25.0 & 31.4\end{array}$

$\begin{array}{lllll}99.7 \% & 58.3 & 25.0 & 49.7 & 7\end{array}$

$\begin{array}{llll}95.0 \% & 13.9 & 25.0 & 13.9\end{array}$

$\begin{array}{llll}99.7 \% & 46.8 & 25.0 & 46.8\end{array}$

$99.7 \% \quad 54.1 \quad 25.0 \quad 54.1$

$99.7 \% \quad 53.1 \quad 25.0 \quad 48.2$

$\begin{array}{llll}99.0 \% & 20.1 & 25.0 & 20.1\end{array}$

$99.7 \% \quad 81.4 \quad 25.0 \quad 71.3$

$\begin{array}{llll}98.5 \% & 18.4 & 25.0 & 16.4\end{array}$

$\begin{array}{llll}95.7 \% & 17.4 & 25.0 & 12.8\end{array}$

$99.7 \% \quad 63.2 \quad 25.0 \quad 63.2$

$\begin{array}{llll}98.3 \% & 20.3 & 25.0 & 16.3\end{array}$

$\begin{array}{llll}99.7 \% & 40.2 & 25.0 & 33.7\end{array}$

$\begin{array}{llll}99.7 \% & 31.1 & 25.0 & 18.6\end{array}$

$\begin{array}{lllll}99.7 \% & 60.7 & 25.0 & 53.5 & 2\end{array}$

$\begin{array}{llll}99.7 \% & 36.0 & 25.0 & 36.0\end{array}$

$\begin{array}{llll}99.7 \% & 53.9 & 25.0 & 53.9\end{array}$

$\begin{array}{lllll}99.7 \% & 77.2 & 25.0 & 69.1 & 2\end{array}$

$\begin{array}{llll}99.7 \% & 28.4 & 25.0 & 24.0\end{array}$

$\begin{array}{lllll}99.7 \% & 32.6 & 25.0 & 28.9 & 2\end{array}$

$\begin{array}{lllll}99.7 \% & 45.5 & 25.0 & 44.4 & 18\end{array}$

$\begin{array}{lllll}99.7 \% & 39.1 & 25.0 & 39.1\end{array}$

$\begin{array}{lllll}99.7 \% & 55.4 & 25.0 & 53.8 & 22 \\ 99.0 \% & 34.9 & 25.0 & 34.9 & 7\end{array}$

$\begin{array}{ccccc}99.0 \% & 34.9 & 25.0 & 34.9 & 7 \\ 99.0 \% & 55.0 & 25.0 & 45.8 & 16\end{array}$

$\begin{array}{llll}99.7 \% & 41.7 & 25.0 & 39.9\end{array}$

$\begin{array}{llll}99.7 \% & 43.7 & 25.0 & 43.7\end{array}$

$\begin{array}{ll}99.5 \% & 28.6\end{array}$

$\begin{array}{llll}99.7 \% & 55.6 & 25.0 & 23.7\end{array}$

$\begin{array}{llll}99.7 \% & 49.4 & 25.0 & 46.8\end{array}$

$\begin{array}{llll}98.0 \% & 30.7 & 25.0 & 0.0\end{array}$

$\begin{array}{llll}99.4 \% & 41.2 & 25.0 & 0.0\end{array}$

$\begin{array}{llll}98.5 \% & 17.5 & 25.0 & 17.5\end{array}$

$\begin{array}{llll}99.7 \% & 37.0 & 25.0 & 33.3\end{array}$

$\begin{array}{llll}99.7 \% & 66.2 & 25.0 & 65.3\end{array}$

$\begin{array}{llll}99.7 \% & 50.7 & 25.0 & 49.3 \\ 99.7 \% & 66.9 & 25.0 & 66.3\end{array}$
947.57

1803.95

1647.84

1803.95

1273.62

1129.53

1257.62

1634.88

1021.57

1266.66

1208.54

1483.77

1341.60

1368.68

912.60

1741.85

1897.95

1183.57

1644.83

1048.51

999.59

1163.57

1623.82

1732.90

1489.77

1827.84

1983.95

1183.52

1057.59

1927.02

1798.92

1087.48

993.49

1491.73

2859.32

1735.95

1338.70

1466.80

861.56

1879.97

1050.44

2220.07

1188.65

1851.87

1695.77 2277.16

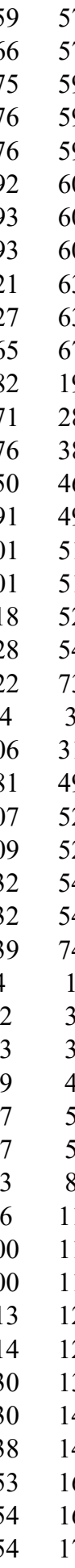


Heterogeneous nuclear ribonucleoproteins A2/B1 GN=HNRNPA2B1 $\quad$ ROA2_HUMAN $37.43 \quad 100.0 \% \quad 26$ $\begin{array}{lllll}\text { Heterogeneous nuclear ribonucleoproteins A2/B1 GN=HNRNPA2B1 } & \text { ROA2_HUMAN } & 37.43 & 100.0 \% & 26\end{array}$ Heterogeneous nuclear ribonucleoproteins A2/B1 GN=HNRNPA2B1 ROA2_HUMAN $37.43 \quad 100.0 \% \quad 26$ $\begin{array}{lllll}\text { Heterogeneous nuclear ribonucleoproteins A2/B1 GN=HNRNPA2B1 } & \text { ROA2_HUMAN } 37.43 \quad 100.0 \% & 26\end{array}$ Heterogeneous nuclear ribonucleoproteins A2/B1 GN=HNRNPA2B1 $\quad$ ROA2_HUMAN $37.43 \quad 100.0 \% \quad 26$ Heterogeneous nuclear ribonucleoproteins A2/B1 GN=HNRNPA2B1 $\quad$ ROA2_HUMAN $37.43 \quad 100.0 \% \quad 26$ $\begin{array}{llll}\text { Heterogeneous nuclear ribonucleoproteins A2/B1 GN=HNRNPA2B1 } & \text { ROA2_HUMAN } 37.43 \quad 100.0 \% & 26\end{array}$ $\begin{array}{llll}\text { Heterogeneous nuclear ribonucleoproteins A2/B1 GN=HNRNPA2B1 } & \text { ROA2_HUMAN } 37.43 \quad 100.0 \% & 26\end{array}$ Heterogeneous nuclear ribonucleoproteins $\mathrm{C} 1 / \mathrm{C} 2 \mathrm{GN}=\mathrm{HNRNPC}$ HNRPC HUMAN $33.67 \quad 100.0 \% \quad 19$ Heterogeneous nuclear ribonucleoproteins $\mathrm{C} 1 / \mathrm{C} 2 \mathrm{GN}=$ HNRNPC HNRPC_HUMAN $33.67 \quad 100.0 \% \quad 19$ Heterogeneous nuclear ribonucleoproteins $\mathrm{Cl} / \mathrm{C} 2 \mathrm{GN}=$ HNRNPC HNRPC_HUMAN $33.67 \quad 100.0 \% \quad 19$ Heterogeneous nuclear ribonucleoproteins $\mathrm{C} 1 / \mathrm{C} 2 \mathrm{GN}=\mathrm{HNRNPC}$ HNRPC HUMAN $33.67 \quad 100.0 \% 19$ Heterogeneous nuclear ribonucleoproteins $\mathrm{C} 1 / \mathrm{C} 2 \mathrm{GN}=\mathrm{HNRNPC}$ HNRPC_HUMAN $33.67 \quad 100.0 \% \quad 19$ Heterogeneous nuclear ribonucleoproteins $\mathrm{Cl} / \mathrm{C} 2 \mathrm{GN}=$ HNRNPC HNRPC_HUMAN $33.67 \quad 100.0 \% \quad 19$ Heterogeneous nuclear ribonucleoproteins $\mathrm{C} 1 / \mathrm{C} 2 \mathrm{GN}=\mathrm{HNRNPC}$ HNRPC_HUMAN $33.67 \quad 100.0 \% \quad 19$ Heterogeneous nuclear ribonucleoproteins $\mathrm{C} 1 / \mathrm{C} 2 \mathrm{GN}=$ HNRNPC HNRPC_HUMAN $33.67 \quad 100.0 \% \quad 19$ Heterogeneous nuclear ribonucleoproteins $\mathrm{C} 1 / \mathrm{C} 2 \mathrm{GN}=\mathrm{HNRNPC}$ HNRPC HUMAN $33.67 \quad 100.0 \% 19$ Heterogeneous nuclear ribonucleoproteins $\mathrm{Cl} / \mathrm{C} 2 \mathrm{GN}=\mathrm{HNRNPC}$ HNRPC_HUMAN $33.67 \quad 100.0 \% \quad 19$ Heterogeneous nuclear ribonucleoproteins $\mathrm{Cl} / \mathrm{C} 2$ GN=HNRNPC HNRPC_HUMAN $33.67 \quad 100.0 \% \quad 19$ Heterogeneous nuclear ribonucleoproteins $\mathrm{Cl} / \mathrm{C} 2 \mathrm{GN}=\mathrm{HNRNPC}$ HNRPC_HUMAN $33.67 \quad 100.0 \% \quad 19$ Heterogeneous nuclear ribonucleoproteins $\mathrm{Cl} / \mathrm{C} 2 \mathrm{GN}=$ HNRNPC HNRPC_HUMAN $33.67 \quad 100.0 \% \quad 19$ Heterogeneous nuclear ribonucleoproteins $\mathrm{C} 1 / \mathrm{C} 2 \mathrm{GN}=\mathrm{HNRNPC}$ HNRPC_HUMAN $33.67 \quad 100.0 \% \quad 19$ Heterogeneous nuclear ribonucleoproteins $\mathrm{C} 1 / \mathrm{C} 2 \mathrm{GN}=\mathrm{HNRNPC}$ HNRPC_HUMAN $33.67 \quad 100.0 \% \quad 19$ Heterogeneous nuclear ribonucleoproteins $\mathrm{C} 1 / \mathrm{C} 2 \mathrm{GN}=\mathrm{HNRNPC}$ HNRPC_HUMAN $33.67 \quad 100.0 \% \quad 19$ Heterogeneous nuclear ribonucleoproteins $\mathrm{Cl} / \mathrm{C} 2 \mathrm{GN}=\mathrm{HNRNPC}$ HNRPC HUMAN $33.67 \quad 100.0 \%$ Heterogeneous nuclear ribonucleoproteins $\mathrm{C} 1 / \mathrm{C} 2 \mathrm{GN}=$ HNRNPC HNRPC_HUMAN $33.67 \quad 100.0 \% \quad 19$ Heterogeneous nuclear ribonucleoproteins $\mathrm{Cl} / \mathrm{C} 2 \mathrm{GN}=\mathrm{HNRNPC}$ HNRPC_HUMAN $33.67 \quad 100.0 \% \quad 19$ High mobility group protein B1 GN=HMGB1 HMGB1_HUMAN $24.89 \quad 100.0 \%$ High mobility group protein B1 GN=HMGB1 HMGB1_HUMAN $24.89 \quad 100.0 \%$ Histone acetyltransferase type B catalytic subunit GN=HAT1 HAT1 HUMAN $49.51 \quad 100.0 \%$ Histone acetyltransferase type B catalytic subunit GN=HAT1 HAT1_HUMAN $49.51 \quad 100.0 \%$ Histone H1.2 GN=HIST1H1C Histone $\mathrm{H} 1.2 \mathrm{GN}=\mathrm{HIST} 1 \mathrm{H} 1 \mathrm{C}$ Histone H1.2 GN=HIST1H1C Histone H1.2 GN=HIST1H1C Histone $\mathrm{H} 1.2 \mathrm{GN}=\mathrm{HIST} 1 \mathrm{H} 1 \mathrm{C}$ Histone $\mathrm{H} 1.2 \mathrm{GN}=\mathrm{HIST} 1 \mathrm{H} 1 \mathrm{C}$ Histone H1.2 GN=HIST1H1C Histone $\mathrm{H} 1.2 \mathrm{GN}=\mathrm{HIST} 1 \mathrm{H} 1 \mathrm{C}$ Histone H1.2 GN=HIST1H1C Histone $\mathrm{H} 1.2 \mathrm{GN}=\mathrm{HIST} 1 \mathrm{H} 1 \mathrm{C}$ Histone $\mathrm{H} 1 \mathrm{x}$ GN=H1FX Histone H1x GN=H1FX Histone $\mathrm{H} 1 \mathrm{x} \mathrm{GN}=\mathrm{H} 1 \mathrm{FX}$ Histone $\mathrm{H} 1 \mathrm{x} \mathrm{GN}=\mathrm{H} 1 \mathrm{FX}$ Histone $\mathrm{H} 1 \mathrm{x}$ GN=H1FX Histone $\mathrm{H} 1 \mathrm{x}$ GN=H1FX H12_HUMAN $21.37 \quad 100.0 \% \quad 10$ H12_HUMAN $21.37 \quad 100.0 \% \quad 10$ H12 HUMAN $21.37 \quad 100.0 \% \quad 10$ H12_HUMAN $21.37 \quad 100.0 \% \quad 10$ H12 HUMAN $21.37 \quad 100.0 \% \quad 10$ H12_HUMAN $21.37 \quad 100.0 \% \quad 10$ H12_HUMAN $21.37 \quad 100.0 \% \quad 10$ H12_HUMAN $21.37 \quad 100.0 \% \quad 10$ H1X_HUMAN $22.49 \quad 100.0 \% \quad 7$ H1X HUMAN $22.49 \quad 100.0 \%$ H1X_HUMAN $22.49 \quad 100.0 \%$ H1X_HUMAN $22.49 \quad 100.0 \%$ H1X HUMAN $22.49 \quad 100.0 \%$ H1X_HUMAN $22.49 \quad 100.0 \%$
$40 \quad 319 \quad 0.35 \% \quad 71.4 \% \quad$ YHTINGHNAEVR $40 \quad 319 \quad 0.35 \% \quad 71.4 \% \quad$ YHTINGHNAEVRK

$40 \quad 319 \quad 0.35 \% \quad 71.4 \%$ ALSRQEMQEVQSSR

$40 \quad 319 \quad 0.35 \% \quad 71.4 \%$ QEMQEVQSSR

$40 \quad 319 \quad 0.35 \% \quad 71.4 \%$ GGNFGFGDSR

$40 \quad 319 \quad 0.35 \% \quad 71.4 \%$ GGGGNFGPGPGSNFR

$40 \quad 319 \quad 0.35 \% \quad 71.4 \%$ GFGDGYNGYGGGPGGGNFGGSPGYGGC

$40 \quad 319 \quad 0.35 \% \quad 71.4 \%$ NMGGPYGGGNYGPGGSGGSGGYGGR

$24 \quad 236 \quad 0.26 \% \quad 52.9 \%$ VFIGNLNTLVVK

$24 \quad 236 \quad 0.26 \% \quad 52.9 \%$ VFIGNLNTLVVKK

$24 \quad 236 \quad 0.26 \% \quad 52.9 \%$ KSDVEAIFSK

$24 \quad 236 \quad 0.26 \% \quad 52.9 \%$ SDVEAIFSK

$24 \quad 236 \quad 0.26 \% \quad 52.9 \%$ SDVEAIFSKYGK

$24 \quad 236 \quad 0.26 \% \quad 52.9 \%$ IVGCSVHK

$24 \quad 236 \quad 0.26 \% \quad 52.9 \%$ GFAFVQYVNER

24

24

24
24

24

24

24

24

24

24

24

24

2

2
2

2
14

14

$236 \quad 0.26 \% \quad 52.9 \%$ VPPPPPIAR

$236 \quad 0.26 \% \quad 52.9 \%$ LKGDDLQAIK

$236 \quad 0.26 \% \quad 52.9 \%$ GDDLQAIKK

$236 \quad 0.26 \% \quad 52.9 \%$ QKVDSLLENLEK

$236 \quad 0.26 \% \quad 52.9 \%$ VDSLLENLEK

$\begin{array}{lll}0.26 \% & 52.9 \% & \text { NDKSEEEQSSSSVK }\end{array}$

$236 \quad 0.26 \% \quad 52.9 \%$ GDDQLELIK

$236 \quad 0.26 \% \quad 52.9 \%$ GDDQLELIKDDEK

$0.00 \% \quad 10.7 \%$ FKDPNAPK

$2 \quad 0.00 \% \quad 10.7 \%$ IKGEHPGLSIGDVAK

$0.00 \% \quad 4.3 \% \quad$ LRDFVLVK

$2 \quad 0.00 \% \quad 4.3 \% \quad$ LCQDLPCFSR

$260 \quad 0.28 \% \quad 36.6 \%$ SETAPAAPAAAPPAEK

$\quad 0.28 \% \quad 36.6 \%$ KASGPPVSELITK

$260 \quad 0.28 \% \quad 36.6 \%$ ASGPPVSELITK

$260 \quad 0.28 \% \quad 36.6 \%$ SGVSLAALK

$260 \quad 0.28 \% \quad 36.6 \%$ SGVSLAALKK

$260 \quad 0.28 \% \quad 36.6 \%$ KALAAAGYDVEK

$260 \quad 0.28 \% \quad 36.6 \%$ ALAAAGYDVEK

$260 \quad 0.28 \% \quad 36.6 \%$ ALAAAGYDVEKNNSR

$260 \quad 0.28 \% \quad 36.6 \%$ SLVSKGTLVQTK

$260 \quad 0.28 \% \quad 36.6 \%$ GTGASGSFKLNK

$9 \quad 0.03 \% \quad 31.9 \%$ SVELEEALPVTTAEGMAK

$29 \quad 0.03 \% \quad 31.9 \%$ YSQLVVETIR

$29 \quad 0.03 \% \quad 31.9 \%$ YSQLVVETIRR

$29 \quad 0.03 \% \quad 31.9 \%$ KVPWFDQQNGR

$29 \quad 0.03 \% \quad 31.9 \%$ ALVQNDTLLQVK

29
$99.7 \% \quad 58.8$

$\begin{array}{llllllll}99.7 \% & 46.8 & 25.0 & 45.8 & 2 & 9 & 0 & 1538.78\end{array}$ $99.7 \% \quad 37.8$ $99.7 \% \quad 58.4$ $99.7 \% \quad 57.6$ $99.7 \% \quad 47.5$

$99.7 \% 55.4$ $99.7 \% 55.8$ $99.7 \% \quad 54.6$ $99.7 \% \quad 61.5$ $99.7 \% \quad 53.8$ $99.7 \% \quad 52.7$ $98.7 \% \quad 18.5$ $99.7 \% \quad 53.4$

$236 \quad 0.26 \% \quad 52.9 \%$ AAVAGEDGRMIAGQVLDINLAAEPK $\quad 99.7 \% \quad 36.6$

$236 \quad 0.26 \% \quad 52.9 \%$ MIAGQVLDINLAAEPK $\quad 99.7 \% \quad 58.2$

$236 \quad 0.26 \% \quad 52.9 \%$ MIAGQVLDINLAAEPKVNR $99.7 \% \quad 33.6$

$236 \quad 0.26 \% \quad 52.9 \%$ SAAEMYGSVTEHPSPSPLLSSSFDLDYDFQR $\quad 99.7 \% \quad 76.1$

$99.7 \% \quad 35.3$

$99.7 \% \quad 36.0$

$99.7 \% \quad 56.6$

$99.7 \% \quad 60.0$

$99.7 \% \quad 53.6$

$99.7 \% \quad 34.2$

$99.7 \% \quad 41.5$

$\begin{array}{lll}99.7 \% & 35.8\end{array}$

$\begin{array}{lll}95.4 \% & 23.5\end{array}$

$99.7 \% \quad 32.3$

$97.0 \% \quad 16.9$

$99.7 \% \quad 33.8$

$98.1 \% 34.6$

$99.7 \% \quad 58.4$

$99.7 \% \quad 56.4$

$99.7 \% \quad 67.4$

$99.7 \% \quad 59.8$

$99.7 \% \quad 46.3$

$99.7 \% \quad 60.9$

$99.7 \% \quad 57.7$

$99.7 \% \quad 56.5$

$99.7 \% \quad 60.2$

$99.7 \% \quad 69.8$

$99.7 \% \quad 32.7$

$99.7 \% \quad 58$.

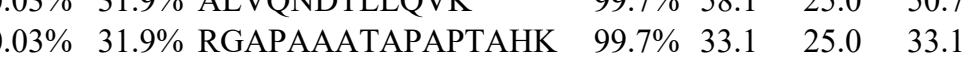

53.2

$.0 \quad 45.8$

$25.0 \quad 47.5$
-0

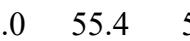

$\begin{array}{lll}55.0 & 55.1 & 22\end{array}$

\begin{tabular}{lll}
25.0 & 54.5 \\
\hline
\end{tabular}

47.8

0
48.8

51.4

$0 \quad 17.1$

\begin{tabular}{lll}
0 & 53.4 \\
\hline
\end{tabular}

20.0

\begin{tabular}{l}
05.6 \\
\hline 5.0
\end{tabular}

$22.7 \quad 0$

$\begin{array}{lll}.0 & 76.1 & 0\end{array}$

$\begin{array}{lll}25.0 & 19.1 & 3\end{array}$

$\begin{array}{ll}25.0 & 44.6\end{array}$

$\begin{array}{lll}.0 & 45.1 & 15\end{array}$

\begin{tabular}{ll}
41.6 \\
\hline
\end{tabular}

$\begin{array}{ll}.0 & 34.2\end{array}$

$\begin{array}{ll}53.0 & 33.3\end{array}$

$\begin{array}{ll}5.0 & 32.3\end{array}$

$\begin{array}{ll}0 & 16.9\end{array}$

$\begin{array}{ll}25.0 & 3.3\end{array}$

$\begin{array}{ll}25.0 & 51.6\end{array}$

$\begin{array}{lll}53.0 & 532\end{array}$

$\begin{array}{ll}5.0 & 42.9\end{array}$

$53.0 \quad 53.0$

0.0
44.9

$\begin{array}{ll}5.0 & 53.2\end{array}$

$25.0 \quad 57.7$

$.0 \quad 50.9$

$\begin{array}{ll}25.0 & 52.8 \\ 5.0 & 23.6\end{array}$

$51.0 \quad 5$

\begin{tabular}{ll}
08.2 \\
\hline
\end{tabular}

\begin{tabular}{ll}
.0 & 24.2 \\
\hline
\end{tabular}

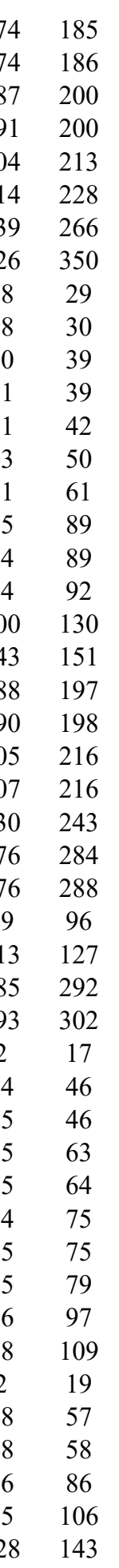

Page 81 of Table S-1-5 
Histone H1x GN=H1FX

Histone H4 GN=HIST1H4A

Histone $\mathrm{H} 4 \mathrm{GN}=\mathrm{HIST} 1 \mathrm{H} 4 \mathrm{~A}$

Histone $\mathrm{H} 4 \mathrm{GN}=\mathrm{HIST} 1 \mathrm{H} 4 \mathrm{~A}$

Histone $\mathrm{H} 4 \mathrm{GN}=\mathrm{HIST} 1 \mathrm{H} 4 \mathrm{~A}$

Histone lysine demethylase PHF8 GN=PHF8 PHF8 _HUMAN $117.87 \quad 100.0 \%$

Histone lysine demethylase PHF8 GN=PHF8 PHF8_HUMAN $117.87 \quad 100.0 \%$ HLA class I histocompatibility antigen, A-2 alpha chain GN=HLA-A 1A02_HUMAN $40.92 \quad 100.0 \%$ HLA class I histocompatibility antigen, A-2 alpha chain GN=HLA-A 1 A02 HUMAN $40.92 \quad 100.0 \%$ HLA class I histocompatibility antigen, A-2 alpha chain GN=HLA-A 1 A02_HUMAN $40.92 \quad 100.0 \%$ Hornerin GN=HRNR

Hornerin GN=HRNR

Hornerin GN=HRNR

Hornerin GN=HRNR

Hornerin GN=HRNR

Hornerin GN=HRNR

Hsp70-binding protein $1 \mathrm{GN}=\mathrm{HSPBP} 1$

Hsp70-binding protein $1 \mathrm{GN}=\mathrm{HSPBP} 1$

Hsp70-binding protein $1 \mathrm{GN}=\mathrm{HSPBP} 1$

Hsp70-binding protein $1 \mathrm{GN}=\mathrm{HSPBP} 1$

Huntingtin GN=HTT

Huntingtin GN=HTT

Huntingtin GN=HTT

Huntingtin GN=HTT

Huntingtin GN=HTT

Huntingtin GN=HTT

Hydroxysteroid dehydrogenase-like protein $2 \mathrm{GN}=\mathrm{HSDL} 2 \mathrm{HSDL} 2$ HUMAN $45.40 \quad 100.0^{\circ}$

Hydroxysteroid dehydrogenase-like protein 2 GN=HSDL2 HSDL2_HUMAN $45.40 \quad 100.0 \%$

Hydroxysteroid dehydrogenase-like protein 2 GN=HSDL2 HSDL2_HUMAN $45.40 \quad 100.0 \%$

Hypoxia up-regulated protein $1 \mathrm{GN}=$ HYOU1 HYOU1 HUMAN $111.34 \quad 100.0 \%$ Hypoxia up-regulated protein $1 \mathrm{GN}=$ HYOU1 HYOU1_HUMAN $111.34 \quad 100.0 \%$ Hypoxia up-regulated protein 1 GN=HYOU1 HYOU1_HUMAN $111.34 \quad 100.0 \%$ Ig kappa chain V-I region Lay OS=Homo sapiens KV113_HUMAN $11.83 \quad 100.0 \%$ Ig kappa chain V-I region Lay OS=Homo sapiens KV113_HUMAN $11.83 \quad 100.0 \%$ Ig kappa chain V-II region RPMI 6410 OS=Homo sapiens KV206_HUMAN $14.71 \quad 100.0 \%$ Ig kappa chain V-II region RPMI 6410 OS=Homo sapiens KV206_HUMAN $14.71 \quad 100.0 \%$ Ig kappa chain V-II region RPMI 6410 OS=Homo sapiens KV206_HUMAN $14.71 \quad 100.0 \%$ Immunoglobulin-binding protein $1 \mathrm{GN}=\mathrm{IGBP} 1 \mathrm{IGBP} 1 \mathrm{HUMAN} 39.22100 .0^{\circ}$ Immunoglobulin-binding protein $1 \mathrm{GN}=\mathrm{IGBP} 1 \mathrm{IGBP} 1$ _HUMAN $39.22 \quad 100.0 \%$ Importin subunit alpha-1 GN=KPNA2 Importin subunit alpha-1 GN=KPNA2 Importin subunit alpha-1 GN=KPNA2 Importin subunit alpha-1 GN=KPNA2 Importin subunit alpha-1 GN=KPNA2 Importin subunit beta-1 GN=KPNB1 Importin subunit beta-1 GN=KPNB1 Importin subunit beta-1 GN=KPNB1
IMA1_HUMAN $57.86 \quad 100.0 \%$ IMA1_HUMAN $57.86 \quad 100.0 \%$ IMA1_HUMAN $57.86 \quad 100.0 \%$ IMA1_HUMAN $57.86 \quad 100.0 \%$ IMA1_HUMAN $57.86 \quad 100.0 \%$ IMB1_HUMAN $97.17 \quad 100.0 \%$ IMB1_HUMAN $97.17 \quad 100.0 \%$ IMB1_HUMAN $97.17 \quad 100.0 \%$
$0.03 \% \quad 31.9 \%$ GAPAAATAPAPTAHK $0.01 \% 38.8 \%$ DNIQGITKPAIR $0.01 \% \quad 38.8 \%$ ISGLIYEETR $0.01 \% \quad 38.8 \%$ VFLENVIR $0.01 \% \quad 38.8 \%$ DAVTYTEHAK $0.00 \% \quad 2.7 \%$ VASIETGLAAAAAK $0.00 \% \quad 2.7 \%$ RPSVGSOSNQAGQGK $0.00 \% \quad 9.3 \%$ FIAVGYVDDTQFVR $0.00 \% \quad 9.3 \%$ FDSDAASQR

$0.00 \% \quad 9.3 \% \quad$ YLENGKETLQR $\begin{array}{llllll}0.05 \% & 4.1 \% & \text { GPYESGSGHSSLGHFGR } & 99.7 \% & 28.7\end{array}$ $\begin{array}{lllllll}0.05 \% & 4.1 \% & \text { SEQHGSSSGSSSSYGQHGSGSR } & 99.7 \% & 48.6\end{array}$

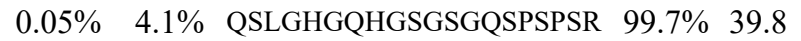
$0.05 \% \quad 4.1 \%$ GPYESGSGHSSGLGHR $99.7 \% \quad 68.3$ $0.05 \% \quad 4.1 \%$ GEQHGSSSGSSSSYGQHGSGSR $\quad 99.7 \% \quad 50.7$ $0.03 \% \quad 11.0 \%$ YLEAGAAGLR $0.03 \% \quad 11.0 \%$ ALFAISCLVR $0.03 \% \quad 11.0 \%$ EQEAGLLQFLR $0.03 \% \quad 11.0 \%$ LDGFSVLMR $0.01 \% \quad 2.4 \%$ TAAGSAVSICQHSR $99.7 \% \quad 57.9$ $99.7 \% \quad 63.6$ $99.7 \% \quad 47.9$ $99.5 \% \quad 28.9$

$0.01 \% \quad 2.4 \% \quad$ LRDGDSTSTLEEHSEGK $0.01 \% \quad 2.4 \%$ AISEEEEEVDPNTQNPK

$99.7 \% \quad 34.4$ $0.01 \% \quad 2.4 \% \quad$ LPLVNSYTR $0.01 \% \quad 2.4 \%$ AVAEPVSR $0.01 \% \quad 2.4 \% \quad$ LLLSEQLSR $0.01 \% \quad 9.6 \%$ LAGCTVFITGASR $99.7 \% \quad 32.4$ $99.7 \% \quad 31.3$ $98.0 \% \quad 16.5$ $99.7 \% 33.8$ $\begin{array}{llll}99.7 \% & 54.3\end{array}$

$0.01 \% \quad 9.6 \%$ LLGTIYTAAEEIEAVGGK $99.7 \% \quad 57.3$ $0.01 \% \quad 9.6 \%$ SGAVEETFR $0.00 \% \quad 3.2 \%$ QADNPHVALYQAR

$0.00 \% \quad 3.2 \%$ TLGGLEMELR

$0.00 \% \quad 3.2 \%$ LAGLFNEQR $99.7 \% \quad 56.3$ $99.1 \% \quad 24.0$ $99.7 \% \quad 32.5$ $99.7 \% \quad 52.9$

$0.01 \% \quad 25.0 \%$ DIQMTQSPSSLSVSVGDR $99.7 \% \quad 29.6$ $0.01 \% \quad 25.0 \%$ LLIYGASTR $0.08 \% \quad 18.0 \%$ LIYKVSNR

$0.08 \% \quad 18.0 \%$ FSGSGSGTDFTLK $0.08 \% \quad 18.0 \%$ FSGSGSGTDFTLKISR $0.00 \% \quad 5.9 \% \quad$ LPELFETGR

$0.00 \% \quad 5.9 \%$ YGALPDQGIAK $99.7 \% \quad 56.0$ $99.0 \% \quad 37.0$ $99.4 \% \quad 64.1$ $99.3 \% 66.1$ $99.3 \% \quad 20.7$ $99.7 \% \quad 48.1$

\section{$0.02 \% \quad 13.8 \%$ GINSSNVENQLQATQAAR $99.7 \% 95.5$} $0.02 \% \quad 13.8 \%$ EKQPPIDNIIR

$99.7 \% \quad 28.3$ $0.02 \% \quad 13.8 \%$ NKNPAPPIDAVEQILPTLVR $0.02 \% \quad 13.8 \%$ TGVVPQLVK $0.02 \% \quad 13.8 \%$ LLGASELPIVTPALR $0.02 \% \quad 6.9 \%$ VLANPGNSQVAR $0.02 \% \quad 6.9 \%$ VAAGLQIK $0.02 \% \quad 6.9 \%$ LAATNALLNSLEFTK

\section{$99.5 \% \quad 22.0$}

$99.7 \% \quad 27.8$

$99.7 \% \quad 44.5$

$99.7 \% \quad 54.9$ $99.0 \% 36.2$ $99.7 \% \quad 44.1$ $\begin{array}{ccc}1331.71 & 129 & 143 \\ 1325.75 & 25 & 36 \\ 1180.62 & 47 & 56 \\ 989.58 & 61 & 68 \\ 1134.54 & 69 & 78 \\ 1272.72 & 902 & 915 \\ 1500.75 & 1019 & 1033 \\ 1629.83 & 46 & 59 \\ 996.44 & 60 & 68 \\ 1350.70 & 195 & 205 \\ 1747.77 & 430 & 448 \\ 1928.85 & 572 & 590 \\ 2152.89 & 970 & 991 \\ 1947.90 & 992 & 1011 \\ 1584.72 & 1038 & 1053 \\ 2122.88 & 1910 & 1931 \\ 1020.55 & 156 & 165 \\ 1149.64 & 211 & 220 \\ 1303.70 & 221 & 231 \\ 1053.54 & 232 & 240 \\ 1444.70 & 269 & 282 \\ 1860.86 & 1714 & 1730 \\ 1928.87 & 2338 & 2354 \\ 1062.59 & 2402 & 2410 \\ 828.46 & 2758 & 2765 \\ 1058.62 & 2885 & 2893 \\ 1352.70 & 8 & 20 \\ 1834.98 & 50 & 67 \\ 995.48 & 307 & 315 \\ 1482.74 & 107 & 119 \\ 1118.59 & 269 & 278 \\ 1047.56 & 283 & 291 \\ 1922.91 & 1 & 18 \\ 993.57 & 46 & 54 \\ 992.59 & 72 & 79 \\ 1303.62 & 87 & 99 \\ 1659.83 & 87 & 102 \\ 1061.56 & 12 & 20 \\ 1132.60 & 277 & 287 \\ 1900.95 & 84 & 101 \\ 1322.74 & 107 & 117 \\ 2185.23 & 239 & 258 \\ 940.58 & 292 & 300 \\ 1549.93 & 301 & 315 \\ 1225.66 & 43 & 54 \\ 799.50 & 55 & 62 \\ 1605.88 & 192 & 206\end{array}$

Page 82 of Table S-1-5 
Importin subunit beta-1 GN=KPNB1 Importin subunit beta-1 GN=KPNB1

Importin-4 GN=IPO4 Importin- $4 \mathrm{GN}=\mathrm{IPO} 4$ Importin-4 GN=IPO4 Importin- $4 \mathrm{GN}=\mathrm{IPO} 4$ Importin-4 GN=IPO4 Importin-5 GN=IPO5 Importin-7 GN=IPO7 Importin-7 GN=IPO7 Importin-7 GN=IPO7 Importin-7 GN=IPO7 Importin-4 GN=IPO4 Importin-4 GN=IPO4 Importin-5 GN=IPO5 Importin-5 GN=IPO5

IMB1 HUMAN $97.17 \quad 100.0 \% \quad 5 \quad 5 \quad-15 \quad 0.02 \% \quad 6.9 \% \quad$ VAALQNLVK IMB1_HUMAN $97.17 \quad 100.0 \%$ IPO4_HUMAN $118.72 \quad 100.0 \%$ IPO4 HUMAN $118.72 \quad 100.0 \%$ IPO4_HUMAN $118.72 \quad 100.0 \%$ IPO4_HUMAN $118.72 \quad 100.0 \%$ IPO4 HUMAN $118.72 \quad 100.0 \%$ IPO4_HUMAN $118.72 \quad 100.0 \%$ IPO4 HUMAN $118.72 \quad 100.0 \%$ IPO5 HUMAN $123.63 \quad 100.0 \%$ IPO5_HUMAN $123.63 \quad 100.0 \%$ IPO5 HUMAN $123.63 \quad 100.0 \%$ IPO7_HUMAN $119.52 \quad 100.0 \%$ IPO7 HUMAN $119.52 \quad 100.0 \%$ IPO7 HUMAN $119.52 \quad 100.0 \%$ IPO7_HUMAN $119.52 \quad 100.0 \%$ 1 GN=HSDL1 HSDL1_HUMAN $37.00 \quad 100.0 \%$ Inactive hydroxysteroid dehydrogenase-like protein $1 \mathrm{GN}=$ HSDL1 HSDL1_HUMAN $37.00 \quad 100.0 \%$ Inactive hydroxysteroid dehydrogenase-like protein 1 GN=HSDL1 HSDL1_HUMAN $37.00 \quad 100.0 \%$ Inactive hydroxysteroid dehydrogenase-like protein $1 \mathrm{GN}=$ HSDL1 HSDL1_HUMAN $37.00 \quad 100.0 \%$ Inactive hydroxysteroid dehydrogenase-like protein $1 \mathrm{GN}=$ HSDL1 HSDL1_HUMAN $37.00 \quad 100.0 \%$ Inactive hydroxysteroid dehydrogenase-like protein $1 \mathrm{GN}=\mathrm{HSDL} 1 \mathrm{HSDL} 1$ HUMAN $37.00 \quad 100.0 \%$ Inorganic pyrophosphatase GN=PPA1 IPYR_HUMAN $32.66 \quad 100.0 \%$ Inorganic pyrophosphatase GN=PPA1 IPYR_HUMAN $32.66 \quad 100.0 \%$ Inosine triphosphate pyrophosphatase GN=ITPA ITPA HUMAN $21.45 \quad 100.0 \%$ Inosine triphosphate pyrophosphatase GN=ITPA ITPA_HUMAN $21.45 \quad 100.0 \%$ Inosine-5'-monophosphate dehydrogenase 2 GN=IMPDH2 IMDH2_HUMAN $55.81 \quad 100.0 \%$ Inosine-5'-monophosphate dehydrogenase $2 \mathrm{GN}=\mathrm{IMPDH} 2 \mathrm{IMDH} 2$ HUMAN $55.81 \quad 100.0 \%$ Inosine-5'-monophosphate dehydrogenase 2 GN=IMPDH2 IMDH2_HUMAN $55.81 \quad 100.0 \%$ Inosine-5'-monophosphate dehydrogenase 2 GN=IMPDH2 IMDH2 HUMAN $55.81 \quad 100.0 \%$ Inosine-5'-monophosphate dehydrogenase $2 \mathrm{GN}=\mathrm{IMPDH} 2$ IMDH2_HUMAN $55.81 \quad 100.0 \%$ Inosine-5'-monophosphate dehydrogenase 2 GN=IMPDH2 IMDH2_HUMAN $55.81 \quad 100.0 \%$

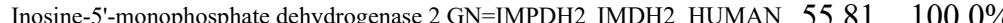
Insulin receptor substrate $4 \mathrm{GN}=\mathrm{IRS} 4$ Insulin receptor substrate $4 \mathrm{GN}=\mathrm{IRS}$ Insulin receptor substrate $4 \mathrm{GN}=\mathrm{IRS} 4$ Insulin receptor substrate $4 \mathrm{GN}=\mathrm{IRS}$ Insulin receptor substrate $4 \mathrm{GN}=\mathrm{IRS}$ Insulin receptor substrate $4 \mathrm{GN}=\mathrm{IRS}$ Insulin receptor substrate $4 \mathrm{GN}=\mathrm{IRS}$ Insulin receptor substrate $4 \mathrm{GN}=\mathrm{IRS}$ Insulin receptor substrate $4 \mathrm{GN}=\mathrm{IRS}$ Insulin receptor substrate $4 \mathrm{GN}=\mathrm{IRS} 4$ Insulin receptor substrate $4 \mathrm{GN}=\mathrm{IRS} 4$ Insulin receptor substrate $4 \mathrm{GN}=\mathrm{IRS}$ Insulin receptor substrate $4 \mathrm{GN}=\mathrm{IRS} 4$ Insulin receptor substrate $4 \mathrm{GN}=\mathrm{IRS} 4$
IRS4_HUMAN $133.77 \quad 100.0 \%$ IRS4 HUMAN $133.77 \quad 100.0 \%$ IRS4_HUMAN $133.77 \quad 100.0 \%$ IRS4_HUMAN $133.77 \quad 100.0 \%$ IRS4 HUMAN $133.77 \quad 100.0 \%$ IRS4_HUMAN $133.77 \quad 100.0 \%$ IRS4_HUMAN $133.77 \quad 100.0 \%$ IRS4 HUMAN $133.77 \quad 100.0 \%$ IRS4_HUMAN $133.77 \quad 100.0 \%$ IRS4 HUMAN $133.77 \quad 100.0 \%$ IRS4_HUMAN $133.77 \quad 100.0 \%$ IRS4_HUMAN $133.77 \quad 100.0 \%$ IRS4_HUMAN $133.77 \quad 100.0 \%$ IRS4_HUMAN $133.77 \quad 100.0 \%$ $0.02 \% \quad 6.9 \% \quad$ LLETTDRPDGHQNNLR $0.02 \% \quad 6.0 \% \quad$ ATEQLQIVLR

$0.02 \% \quad 6.0 \% \quad$ QFAAVLTR

$0.02 \% \quad 6.0 \% \quad$ SLILTALQR

$0.02 \% \quad 6.0 \%$ GLEDPSQVVR

$0.02 \% \quad 6.0 \%$ VVPSYMQAVNR

$0.02 \% \quad 6.0 \% \quad$ LAELCGVLK

$0.02 \% \quad 6.0 \% \quad$ LLMASPTR

$0.01 \% \quad 3.3 \% \quad$ KQAEETYENIPGQSK

$0.01 \% \quad 3.3 \%$ VCDIAAELAR

$0.01 \% \quad 3.3 \% \quad$ SLVEIADTVPK

$0.01 \% \quad 4.1 \%$ YGSPGNVSK

$0.01 \% \quad 4.1 \%$ AFAVGVQQVLLK

$0.01 \% \quad 4.1 \% \quad$ AIFQTIQNR

$0.01 \% \quad 4.1 \%$ QLQDIATLADQRR

$0.01 \% \quad 19.1 \%$ WAVVSGATDGIGK

$0.01 \% \quad 19.1 \%$ AYAEELASR

$0.01 \% \quad 19.1 \%$ GLNIILISR

$0.01 \% \quad 19.1 \%$ NEEKLQVVAK

$0.01 \% \quad 19.1 \%$ AYLDHFSR

$0.01 \% \quad 19.1 \%$ VYAHHAVSTLGISK

$0.00 \% \quad 6.2 \% \quad$ AAPFSLEYR

$0.00 \% \quad 6.2 \% \quad$ YVANLFPYK

$0.00 \% \quad 5.2 \%$ KIVFVTGNAK

$0.00 \% \quad 5.2 \%$ IVFVTGNAK

$0.02 \% \quad 18.1 \%$ GKLPIVNEDDELVAIIAR

$0.02 \% \quad 18.1 \%$ NLIDAGVDALR

$0.02 \% \quad 18.1 \%$ RFGVPVIADGGIQNVGHIAK

$0.02 \% \quad 18.1 \%$ YFSEADKIK

$0.02 \% \quad 18.1 \%$ VAQGVSGAVQDK

$0.05 \% \quad 13.4 \%$ ALCADEYRAR

$0.05 \% \quad 13.4 \%$ FEQFCHLR

$0.05 \% \quad 13.4 \%$ AIGDGEDEMLFTR

$0.05 \% \quad 13.4 \%$ RFVTPSEPVAHSR

$0.05 \% \quad 13.4 \%$ FVTPSEPVAHSR

$0.05 \% \quad 13.4 \%$ RAVSVPASFFR

$0.05 \% \quad 13.4 \%$ LAPSPARPR

$0.05 \% \quad 13.4 \%$ SYFGKLTQSK

$0.05 \% \quad 13.4 \%$ ANPLSLDSAR

$0.05 \% \quad 13.4 \%$ CSEPPPVAR

$0.05 \% \quad 13.4 \%$ LLQEEEQER

$0.05 \% \quad 13.4 \%$ SQSFFAAAR

$0.05 \% \quad 13.4 \%$ AAVSAFPTDSLER

$0.05 \% \quad 13.4 \%$ GAQDVAGGSNPGAHNPSANLAR $\quad 99.7 \% \quad 48.9$

$99.7 \% 34.7$

$99.7 \% \quad 53.8$

$98.2 \% \quad 22.6$

$99.7 \% 32$.

$98.6 \% 21.0$

$99.7 \% 58.7$

$99.0 \% \quad 33.5$

$99.5 \% 21.6$

$99.7 \% \quad 42.0$

$99.7 \% \quad 60.8$

$99.6 \% \quad 24.8$

$99.7 \% \quad 51.7$

$99.7 \% \quad 28.5$

$99.7 \% \quad 52.8$

$99.7 \% \quad 44.8$

$99.7 \% \quad 56.8$

$99.7 \% \quad 50.1$

$99.0 \% \quad 23.5$

$99.7 \% \quad 33.1$

$99.7 \% 54.8$

$98.4 \% \quad 29.0$

$99.7 \% \quad 25.8$

$99.7 \% \quad 49.1$

$99.7 \% 38.4$

$99.7 \% \quad 41.4$

$97.7 \% \quad 21.5$

$99.6 \% \quad 25.6$

$99.7 \% 28.5$

$99.7 \% \quad 27.5$

$99.0 \% \quad 26.6$

$99.7 \% \quad 47.8$

$99.7 \% \quad 34.4$

$99.7 \% \quad 46.6$

$95.2 \% \quad 14.0$

$99.7 \% \quad 32.6$

$99.7 \% \quad 30.4$

$99.7 \% \quad 56.2$

$98.3 \% 17.0$

$99.7 \% \quad 43.8$

$99.7 \% \quad 45.4$

$99.7 \% \quad 42.6$

19
19
878.94

1170.68

905.52

1014.63

1099.57

1263.65

1002.57

904.49

1721.83

1117.57

1171.66

908.45

1272.77

1090.60

1527.82

1260.66

1009.49

998.64

1157.65

1008.49

1482.81

1053.54

1114.59

1076.65

948.55

1965.10

1156.63

2048.14

1100.56

1158.61

1680.90

1915.9

1224.58

1136.53

1453.66

1482.78

1326.68

1236.68

964.57

1158.62

1043.55

1012.49

1173.57

984.49

1363.69 2060.99

243
525
33
62
90
411
761
801
975
41
118
249
283
306
972
1003
81
90
99
109
230
287
18
88
18
18
224
322
375
438
450
455
511
339
384
397
410
410
434
444
623
994
1073
1082
1097
1110
1198


Insulin receptor substrate $4 \mathrm{GN}=\mathrm{IRS} 4$ Insulin receptor substrate $4 \mathrm{GN}=\mathrm{IRS} 4$

in-like growth factor $2 \mathrm{mRNA}$-binding protein $1 \mathrm{GN}=\mathrm{IGF} 2 \mathrm{~B}$

IRS4 HUMAN $133.77 \quad 100.0 \%$ IRS4 HUMAN $133.77 \quad 100.0 \% \quad 16$ $\begin{array}{lllll}\text { Insulin-like growth factor } 2 \text { mRNA-binding protein } 1 \mathrm{GN}=I G F 2 B P 1 & \text { IF2B1_HUMAN } & 63.48 & 100.0 \% & 3\end{array}$ Insulin-like growth factor 2 mRNA-binding protein 1 GN=IGF2BP1 IF2B1_HUMAN $63.48 \quad 100.0 \%$ Insulin-like growth factor 2 mRNA-binding protein $1 \mathrm{GN}=I \mathrm{GF} 2 \mathrm{BP} 1 \quad$ IF2B1_HUMAN $63.48 \quad 100.0 \%$ Insulin-like growth factor 2 mRNA-binding protein $1 \mathrm{GN}=\mathrm{IGF} 2 \mathrm{BP} 1 \quad$ IF2B1_HUMAN $63.48 \quad 100.0 \% \quad 3$ Insulin-like growth factor 2 mRNA-binding protein $1 \mathrm{GN}=\mathrm{IGF} 2 \mathrm{BP} 1 \quad$ IF2B1 HUMAN $63.48 \quad 100.0 \%$ Insulin-like growth factor 2 mRNA-binding protein 1 GN=IGF2BP1 $\quad$ IF2B1_HUMAN $63.48 \quad 100.0 \%$ Insulin-like growth factor 2 mRNA-binding protein $1 \mathrm{GN}=I$ IGF2BP1 $\quad$ IF2B1_HUMAN $63.48 \quad 100.0 \%$ Insulin-like growth factor 2 mRNA-binding protein 1 GN=IGF2BP1 $\quad$ IF2B1_HUMAN $63.48 \quad 100.0 \%$ Insulin-like growth factor 2 mRNA-binding protein 1 GN=IGF2BP1 IF2B1_HUMAN $63.48 \quad 100.0 \%$ Insulin-like growth factor 2 mRNA-binding protein $1 \mathrm{GN}=I$ GF2BP1 $\quad$ IF2B1_HUMAN $63.48 \quad 100.0 \%$ Insulin-like growth factor 2 mRNA-binding protein $1 \mathrm{GN}=I \mathrm{GF} 2 \mathrm{BP} 1 \quad$ IF2B1 HUMAN $63.48 \quad 100.0 \%$ $\begin{array}{llll}\text { Insulin-like growth factor } 2 \text { mRNA-binding protein } 1 \text { GN=IGF2BP1 } & \text { IF2B1_HUMAN } 63.48 \quad 100.0 \% & 3\end{array}$ Insulin-like growth factor 2 mRNA-binding protein $1 \mathrm{GN}=I \mathrm{GF} 2 \mathrm{BP} 1 \quad \mathrm{IF} 2 \mathrm{~B} 1$ HUMAN $63.48 \quad 100.0 \%$ $\begin{array}{llll}\text { Insulin-like growth factor } 2 \text { mRNA-binding protein } 1 \mathrm{GN}=I G F 2 B P 1 & \text { IF2B1_HUMAN } & 63.48 & 100.0 \%\end{array}$ Insulin-like growth factor 2 mRNA-binding protein 1 GN=IGF2BP1 $\quad$ IF2B1_HUMAN $63.48 \quad 100.0 \%$ Insulin-like growth factor 2 mRNA-binding protein $1 \mathrm{GN}=I G F 2 \mathrm{BP} 1 \quad$ IF2B1 HUMAN $63.48 \quad 100.0 \%$ Insulin-like growth factor 2 mRNA-binding protein 1 GN=IGF2BP1 $\quad$ IF2B1_HUMAN $63.48 \quad 100.0 \%$ Insulin-like growth factor 2 mRNA-binding protein $1 \mathrm{GN}=$ IGF2BP1 $\quad$ IF2B1_HUMAN $63.48 \quad 100.0 \%$ Insulin-like growth factor 2 mRNA-binding protein 1 GN=IGF2BP1 $\quad$ IF2B1_HUMAN $63.48 \quad 100.0 \%$ Insulin-like growth factor 2 mRNA-binding protein 1 GN=IGF2BP1 IF2B1_HUMAN $63.48 \quad 100.0 \%$ Insulin-like growth factor 2 mRNA-binding protein 1 GN=IGF2BP1 IF2B1_HUMAN 63.48 Insulin-like growth factor 2 mRNA-binding protein $1 \mathrm{GN}=I \mathrm{GF} 2 \mathrm{BP} 1$ IF2B1_HUMAN $63.48 \quad 100.0 \%$ Insulin-like growth factor 2 mRNA-binding protein 1 GN=IGF2BP1 IF2B1_HUMAN $63.48 \quad 100.0 \%$ Insulin-like growth factor 2 mRNA-binding protein $1 \mathrm{GN}=I$ GF2BP1 $\quad$ IF2B1_HUMAN $63.48 \quad 100.0 \%$ Insulin-like growth factor 2 mRNA-binding protein 1 GN=IGF2BP1 IF2B1_HUMAN $63.48 \quad 100.0 \%$ Insulin-like growth factor 2 mRNA-binding protein $1 \mathrm{GN}=$ IGF2BP1 IF2B1 HUMAN $63.48 \quad 100.0^{\circ}$ Insulin-like growth factor 2 mRNA-binding protein $1 \mathrm{GN}=I$ GF2BP1 $\quad$ IF2B1_HUMAN $63.48 \quad 100.0 \%$ Insulin-like growth factor 2 mRNA-binding protein 1 GN=IGF2BP1 IF2B1_HUMAN 63.48 Insulin-like growth factor 2 mRNA-binding protein 1 GN=IGF2BP1 IF2B1_HUMAN $63.48 \quad 100.0^{\circ}$ Insulin-like growth factor 2 mRNA-binding protein 2 GN=IGF2BP2 IF2B2_HUMAN $66.12 \quad 100.0 \%$ Insulin-like growth factor 2 mRNA-binding protein 2 GN=IGF2BP2 IF2B2_HUMAN $66.12100 .0 \%$ Insulin-like growth factor 2 mRNA-binding protein 2 GN=IGF2BP2 IF2B2_HUMAN $66.12 \quad 100.0 \%$ Insulin-like growth factor 2 mRNA-binding protein 2 GN=IGF2BP2 IF2B2_HUMAN $66.12 \quad 100.0 \%$ Insulin-like growth factor 2 mRNA-binding protein 2 GN=IGF2BP2 IF2B2 HUMAN $66.12 \quad 100.0 \%$ Insulin-like growth factor 2 mRNA-binding protein 2 GN=IGF2BP2 IF2B2_HUMAN $66.12 \quad 100.0 \%$ Insulin-like growth factor 2 mRNA-binding protein 2 GN=IGF2BP2 IF2B2_HUMAN $66.12 \quad 100.0 \%$ Insulin-like growth factor 2 mRNA-binding protein 2 GN=IGF2BP2 IF2B2 HUMAN $66.12 \quad 100.0^{\circ}$ Insulin-like growth factor 2 mRNA-binding protein 3 GN=IGF2BP3 IF2B3_HUMAN $63.71 \quad 100.0 \%$ Insulin-like growth factor 2 mRNA-binding protein 3 GN=IGF2BP3 IF2B3 HUMAN 63.71 100.0\% Insulin-like growth factor 2 mRNA-binding protein 3 GN=IGF2BP3 IF2B3 HUMAN $63.71 \quad 100.0 \%$ Insulin-like growth factor 2 mRNA-binding protein 3 GN=IGF2BP3 IF2B3_HUMAN $63.71 \quad 100.0 \%$ Insulin-like growth factor 2 mRNA-binding protein 3 GN=IGF2BP3 IF2B3 HUMAN $63.71 \quad 100.0 \%$ Insulin-like growth factor 2 mRNA-binding protein 3 GN=IGF2BP3 IF2B3_HUMAN $63.71 \quad 100.0 \%$
44

44

4

44

4

44

4

44

44

44
44

44

44

44

44

44
44
44

4

1

1

31
1

1

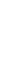

9

9
9
9
9
$46 \quad 0.05 \% \quad 13.4 \%$ GDNQAGGAAAAAAAPEPPPRSR $\quad 99.7 \% \quad 33.8$

$33 \quad 0.15 \% \quad 51.6 \%$ VFAEHKISYSGQFLVK $\begin{array}{llll}7 \% & 35.2 & 25.0 & 35.2\end{array}$

$33 \quad 0.15 \% \quad 51.6 \%$ ISYSGQFLVK

$33 \quad 0.15 \% \quad 51.6 \%$ AIETFSGKVELQGK

$33 \quad 0.15 \% \quad 51.6 \%$ RLEIEHSVPK

- $0.15 \% \quad 51.6 \%$ LNGHQLENHALK

$99.7 \% \quad 57.2$

$99.7 \% \quad 31.8$

$99.7 \% \quad 30.3$

$\begin{array}{lll}0.15 \% & 51.6 \% \text { VSYIPDEQIAQGPENGR }\end{array}$

$.7 \% \quad 52.4$

$133 \quad 0.15 \% \quad 51.6 \%$ QGSPVAAGAPAK $99.7 \% \quad 56.7$

$133 \quad 0.15 \% \quad 51.6 \%$ QGSPVAAGAPAKQQQVDIPLR $\quad 99.7 \% \quad 57.4$

$133 \quad 0.15 \% \quad 51.6 \%$ QQQVDIPLR

$33 \quad 0.15 \% \quad 51.6 \%$ LLVPTQYVGAIIGK

$133 \quad 0.15 \% \quad 51.6 \%$ AISVHSTPEGCSSACK

$133 \quad 0.15 \% \quad 51.6 \%$ MILEIMHK

$133 \quad 0.15 \% \quad 51.6 \%$ DTKTADEVPLK

$133 \quad 0.15 \% \quad 51.6 \%$ TADEVPLK

$133 \quad 0.15 \% \quad 51.6 \%$ TADEVPLKILAHNNFVGR

$133 \quad 0.15 \% \quad 51.6 \%$ ILAHNNFVGR

$33 \quad 0.15 \% \quad 51.6 \%$ ITISSLQDLTLYNPER

$133 \quad 0.15 \% \quad 51.6 \%$ GQHIKQLSR

$133 \quad 0.15 \% \quad 51.6 \%$ IAPPETPDSK

$133 \quad 0.15 \% \quad 51.6 \%$ IAPPETPDSKVR

$133 \quad 0.15 \% \quad 51.6 \%$ MVIITGPPEAQFK

$133 \quad 0.15 \% \quad 51.6 \%$ MVIITGPPEAQFKAQGR

$33 \quad 0.15 \% \quad 51.6 \%$ LKEENFFGPK

$33 \quad 0.15 \% \quad 51.6 \%$ LETHIRVPASAAGR

$33 \quad 0.15 \% \quad 51.6 \%$ TVNELQNLTAAEVVVPR

$33 \quad 0.15 \% \quad 51.6 \%$ DQTPDENDQVIVK

$133 \quad 0.15 \% \quad 51.6 \%$ IIGHFYASQMAQR

$133 \quad 0.15 \% \quad 51.6 \%$ IIGHFYASQMAQRK

$133 \quad 0.15 \% \quad 51.6 \%$ IRDILAQVK

$10 \quad 0.01 \% \quad 16.7 \%$ KLPLAGQVLLK

$99.7 \% \quad 63.6$

$99.7 \% \quad 50.8$

$99.7 \% \quad 55.3$

$99.0 \% \quad 33.3$

$99.7 \% \quad 57.0$

$99.0 \% \quad 44.2$

$99.7 \% \quad 44.0$

$99.7 \% \quad 50.1$

$99.7 \% \quad 34.6$

$99.7 \% \quad 39.5$

$98.8 \% \quad 18.1$

$99.7 \% \quad 32.0$

$99.7 \% \quad 56.0$

$99.7 \% \quad 52.0$

$99.5 \% \quad 21.2$

$99.7 \% \quad 32.5$

$99.7 \% \quad 58.1$

$99.7 \% \quad 57.6$

$99.7 \% \quad 27.5$

$99.7 \% \quad 43.5$

$99.5 \% \quad 25.1$

10

$16.7 \%$ ILVPTQFVGAIIGK

$10 \quad 0.01 \% \quad 16.7 \%$ IAPAEGPDVSER

$10 \quad 0.01 \% \quad 16.7 \%$ MVIITGPPEAQFK

$10 \quad 0.01 \% \quad 16.7 \%$ MVIITGPPEAQFKAQGR

$10 \quad 0.01 \% \quad 16.7 \%$ IIGHFFASQTAQR

$10 \quad 0.01 \% \quad 16.7 \%$ QQEQKYPQGVASQR

$0.03 \% \quad 17.6 \%$ IPVSGPFLVK

$0.03 \% \quad 17.6 \%$ LLVPTQFVGAIIGK

$0.03 \% \quad 17.6 \%$ SITILSTPEGTSAACK

$0.03 \% \quad 17.6 \%$ ILAHNNFVGR

$0.03 \% \quad 17.6 \%$ IAPAEAPDAK

$0.03 \% \quad 17.6 \%$ IAPAEAPDAKVR $\begin{array}{cccc}98.7 \% & 67.8 & 25.0 & 0.0\end{array}$

$\begin{array}{lllll}99.7 \% & 51.5 & 25.0 & 36.8 & 4\end{array}$

$99.7 \% \quad 56.0 \quad 25.0 \quad 49.0$

$\begin{array}{llll}99.7 \% & 52.0 & 25.0 & 52.0\end{array}$

$\begin{array}{llll}99.7 \% & 57.2 & 25.0 & 55.2\end{array}$

$\begin{array}{llll}99.6 \% & 23.8 & 25.0 & 23.8\end{array}$

$\begin{array}{llll}99.7 \% & 29.5 & 25.0 & 27.6\end{array}$

$\begin{array}{llll}98.7 \% & 67.8 & 25.0 & 0.0\end{array}$

$\begin{array}{llll}99.7 \% & 56.5 & 25.0 & 49.8\end{array}$

$\begin{array}{lllll}99.7 \% & 50.1 & 25.0 & 50.1 & 9\end{array}$

$\begin{array}{lllll}99.7 \% & 45.8 & 25.0 & 45.8 & 2\end{array}$

$\begin{array}{llll}99.7 \% & 58.3 & 25.0 & 54.7\end{array}$ $\begin{array}{ccc}1788.86 & 1199 & 1218 \\ 2032.00 & 1199 & 1220 \\ 1875.97 & 4 & 20 \\ 1853.00 & 21 & 36 \\ 1141.63 & 27 & 36 \\ 1506.82 & 53 & 66 \\ 1207.68 & 67 & 76 \\ 1373.73 & 139 & 150 \\ 1872.91 & 151 & 167 \\ 2029.01 & 151 & 168 \\ 1053.57 & 179 & 190 \\ 2131.16 & 179 & 199 \\ 1096.61 & 191 & 199 \\ 1471.89 & 200 & 213 \\ 1690.75 & 243 & 258 \\ 1014.55 & 259 & 266 \\ 1216.64 & 270 & 280 \\ 872.47 & 273 & 280 \\ 1994.08 & 273 & 290 \\ 1140.63 & 281 & 290 \\ 1862.99 & 310 & 325 \\ 1066.61 & 425 & 433 \\ 1054.54 & 441 & 450 \\ 1309.71 & 441 & 452 \\ 1446.77 & 453 & 465 \\ 1842.99 & 453 & 469 \\ 1208.63 & 474 & 483 \\ 1477.82 & 488 & 501 \\ 1853.01 & 509 & 525 \\ 1500.72 & 526 & 538 \\ 1521.76 & 539 & 551 \\ 1649.86 & 539 & 552 \\ 1055.66 & 553 & 561 \\ 1179.78 & 27 & 37 \\ 1934.88 & 172 & 190 \\ 1455.89 & 198 & 211 \\ 1240.62 & 463 & 474 \\ 1446.77 & 475 & 487 \\ 1842.99 & 475 & 491 \\ 1475.78 & 561 & 573 \\ 1646.82 & 584 & 597 \\ 1056.65 & 27 & 36 \\ 1455.89 & 200 & 213 \\ 1635.83 & 243 & 258 \\ 1140.63 & 281 & 290 \\ 982.52 & 441 & 450 \\ 1237.69 & 441 & 452 \\ & & \end{array}$

Page 84 of Table S-1-5 
Insulin-like growth factor 2 mRNA-binding protein 3 GN=IGF2BP3 IF2B3_HUMAN $63.71 \quad 100.0 \%$ Insulin-like growth factor 2 mRNA-binding protein 3 GN=IGF2BP3 $\quad$ IF2B3_HUMAN $63.71 \quad 100.0 \%$ Insulin-like growth factor 2 mRNA-binding protein 3 GN=IGF2BP3 IF2B3_HUMAN $63.71 \quad 100.0 \%$ Insulin-like growth factor 2 mRNA-binding protein 3 GN=IGF2BP3 IF2B3_HUMAN $63.71 \quad 100.0 \%$ Integrator complex subunit $1 \mathrm{GN}=\mathrm{INTS} 1$ INT1_HUMAN $244.30 \quad 100.0 \%$ Integrator complex subunit $1 \mathrm{GN}=\mathrm{INTS} 1 \quad$ INT1_HUMAN $244.30 \quad 100.0 \%$ Integrator complex subunit $1 \mathrm{GN}=\mathrm{INTS} 1 \quad$ INT1_HUMAN $244.30 \quad 100.0 \%$ Integrator complex subunit $1 \mathrm{GN}=\mathrm{INTS} 1 \quad$ INT1_HUMAN $244.30 \quad 100.0 \%$ Integrator complex subunit $1 \mathrm{GN}=\mathrm{INTS} 1$ INT1_HUMAN $244.30 \quad 100.0 \%$ Integrator complex subunit $1 \mathrm{GN}=\mathrm{INTS} 1 \quad$ INT1_HUMAN $244.30 \quad 100.0 \%$ Integrator complex subunit $1 \mathrm{GN}=\mathrm{INTS} 1$ INT1_HUMAN $244.30 \quad 100.0 \%$ Integrator complex subunit $1 \mathrm{GN}=\mathrm{INTS} 1 \quad$ INT1_HUMAN $244.30 \quad 100.0 \%$ Integrator complex subunit $1 \mathrm{GN}=\mathrm{INTS} 1 \quad$ INT1_HUMAN $244.30 \quad 100.0 \%$ Integrator complex subunit $1 \mathrm{GN}=\mathrm{INTS} 1 \quad$ INT1_HUMAN $244.30 \quad 100.0 \%$ Integrator complex subunit $1 \mathrm{GN}=\mathrm{INTS} 1 \quad$ INT1_HUMAN $244.30 \quad 100.0 \%$ Integrator complex subunit $1 \mathrm{GN}=\mathrm{INTS} 1 \quad$ INT1_HUMAN $244.30 \quad 100.0 \%$ Integrator complex subunit $1 \mathrm{GN}=\mathrm{INTS} 1$ INT1_HUMAN $244.30 \quad 100.0 \%$ Integrator complex subunit $11 \mathrm{GN}=\mathrm{CPSF} 3 \mathrm{~L}$ INT11_HUMAN $67.66 \quad 100.0 \%$ Integrator complex subunit $11 \mathrm{GN}=\mathrm{CPSF} 3 \mathrm{~L}$ INT11_HUMAN $67.66 \quad 100.0 \%$ Interferon-induced, double-stranded RNA-activated protein kinase GN=EIIFAK2 E2AK2_HUMAN $62.10 \quad 100.0 \%$ Interferon-induced, double-stranded RNA-activated protein kinase GN=EIF2AK2 E2AK2_HUMAN $62.10 \quad 100.0 \%$ Interferon-induced, double-stranded RNA-activated protein kinase GN=EIF2AK2 $\quad$ E2AK2_HUMAN $62.10 \quad 100.0 \%$ Interferon-inducible double-stranded RNA-dependent protein k kinase activator A GN=PRKRA PRKRA_HUMAN $34.41 \quad 100.0 \%$ Interferen-inducible double-stranded RNA-dependent protein kinase activator A GN=PRKRA PRKRA_HUMAN $34.41 \quad 100.0 \%$

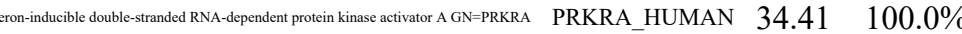
on-mducible double-stranded RNA-dependent protein kinase activator A GN=PRKRA PRKRA_HUMAN $34.41 \quad 100.0 \%$ terferon-inducible double-stranded RNA-dependent protein kinase activator A GN=PRKRA PRKRA_HUMAN $34.41 \quad 100.0 \%$ randed RNA-dependent protein kinase activator A GN=PRKRA PRKRA_HUMAN 34.41 100.0\% 作 RA PRKRA_HUMAN $34.41 \quad 100.0 \%$ PRKRA_HUMAN $34.41 \quad 100.0 \%$ PRKRA_HUMAN $34.41 \quad 100.0 \%$ PRKRA_HUMAN $34.41 \quad 100.0 \%$ $100.0 \%$ $\begin{array}{llll}\text { Interferon-inducible double-stranded RNA-dependent protein kinase activator A GN=PRKRA } & \text { PRKRA_HUMAN } & 34.41 & 100.0 \% \\ \text { Interleukin enhancer-binding factor } 2 \text { GN=ILF2 ILF2_HUMAN } 43.06 & 100.0 \%\end{array}$ Interleukin enhancer-binding factor $2 \mathrm{GN}=\mathrm{ILF} 2 \mathrm{ILF} 2 \mathrm{HUMAN} 43.06 \quad 100.0 \%$ Interleukin enhancer-binding factor 2 GN=ILF2 ILF2_HUMAN $43.06 \quad 100.0 \%$ Interleukin enhancer-binding factor 2 GN=ILF2 ILF2_HUMAN $43.06 \quad 100.0 \%$ Interleukin enhancer-binding factor 2 GN=ILF2 ILF2_HUMAN $43.06 \quad 100.0 \%$ Interleukin enhancer-binding factor 2 GN=ILF2 ILF2_HUMAN $43.06 \quad 100.0 \%$ Interleukin enhancer-binding factor 2 GN=ILF2 ILF2_HUMAN $43.06 \quad 100.0 \%$ Interleukin enhancer-binding factor 2 GN=ILF2 ILF2_HUMAN $43.06 \quad 100.0 \%$ Interleukin enhancer-binding factor 2 GN=ILF2 ILF2_HUMAN $43.06 \quad 100.0 \%$ Interleukin enhancer-binding factor 2 GN=ILF2 ILF2_HUMAN $43.06 \quad 100.0 \%$ Interleukin enhancer-binding factor 2 GN=ILF2 ILF2_HUMAN $43.06 \quad 100.0 \%$
$0.03 \% \quad 17.6 \%$ MVIITGPPEAQFK $0.03 \% \quad 17.6 \%$ MVIITGPPEAQFKAQGR

$0.03 \% \quad 17.6 \%$ ITGHFYACQVAQR

$0.03 \% \quad 17.6 \%$ ALQSGPPQSR

$0.02 \% \quad 6.4 \% \quad$ LSSTPPLSALGR

$0.02 \% \quad 6.4 \% \quad$ LAEAAVAEKR

$0.02 \% \quad 6.4 \%$ SVLLQGEAGR

$0.02 \% \quad 6.4 \%$ SFQNQIAAIQR

$0.02 \% \quad 6.4 \%$ AAAVQADDVEVLK

$0.02 \% \quad 6.4 \% \quad$ LQDLLLGPK

$0.02 \% \quad 6.4 \%$ LGSSQVASR

$0.02 \% \quad 6.4 \%$ LPLFDSVR

$0.02 \% \quad 6.4 \%$ STIMSHLFSK

$0.02 \% \quad 6.4 \% \quad$ SSPEQPIGQGR

$0.02 \% \quad 6.4 \%$ SQDGDTAACSLIQAR

$0.02 \% \quad 6.4 \%$ FITLLADTSDSR

$0.02 \% \quad 6.4 \% \quad$ LMSSAEECCR

$0.00 \% \quad 3.7 \%$ VTPLGAGQDVGR

$0.00 \% \quad 3.7 \%$ SCILVSIAGK

$0.01 \% \quad 6.2 \% \quad$ LAVEILNKEK

$0.01 \% \quad 6.2 \%$ DLKPSNIFLVDTK

$0.01 \% \quad 6.2 \% \quad$ IGDFGLVTSLK

$0.06 \% \quad 41.9 \%$ HRAEAPPLER

$0.06 \% \quad 41.9 \%$ AEAPPLEREDS

$0.06 \% \quad 41.9 \%$ TPIQVLHEYGMK

$59 \quad 0.06 \% \quad 41.9 \%$ NIPVYECER

$59 \quad 0.06 \% \quad 41.9 \%$ SDVQIHVPTFTFR

$59 \quad 0.06 \% \quad 41.9 \%$ VTVGDITCTGEGTSK

$59 \quad 0.06 \% \quad 41.9 \%$ VTVGDITCTGEGTSKK

$59 \quad 0.06 \% \quad 41.9 \%$ AAEAAINILK

$59 \quad 0.06 \% \quad 41.9 \%$ ANASICFAVPDPLMPDPS

$59 \quad 0.06 \% \quad 41.9 \%$ LPEYTLSQEGGPAHK

$59 \quad 0.06 \% \quad 41.9 \%$ LPEYTLSQEGGPAHKR

$59 \quad 0.06 \% \quad 41.9 \%$ REYTTICR

$59 \quad 0.06 \% \quad 41.9 \%$ LESFMETGK

$144 \quad 0.16 \% \quad 39.7 \%$ VKPAPDETSFSEALLK

$144 \quad 0.16 \% \quad 39.7 \%$ VKPAPDETSFSEALLKR

$144 \quad 0.16 \% \quad 39.7 \%$ NQDLAPNSAEQASILSLVTK $99.7 \% \quad 46.8$

$144 \quad 0.16 \% \quad 39.7 \%$ KGTMTTGHNVADLVVILK $99.7 \% \quad 26.1$

$144 \quad 0.16 \% \quad 39.7 \%$ GTMTTGHNVADLVVILK $99.7 \% \quad 55.6$

$144 \quad 0.16 \% \quad 39.7 \%$ ILPTLEAVAALGNK

$144 \quad 0.16 \% \quad 39.7 \%$ ILITTVPPNLR

$144 \quad 0.16 \% \quad 39.7 \%$ ILITTVPPNLRK

$144 \quad 0.16 \% \quad 39.7 \%$ KLDPELHLDIK

$144 \quad 0.16 \% \quad 39.7 \%$ LDPELHLDIK

$144 \quad 0.16 \% \quad 39.7 \%$ VLQSALAAIR
$\% \quad 56.0$

$99.7 \% \quad 49.5$

$9.7 \% \quad 41.8$

$98.6 \% 22.0$

$99.7 \% 40.6$

$99.7 \% 55.5$

$98.6 \% \quad 23.9$

$99.0 \% 33.6$

$99.3 \% \quad 24.8$

$99.7 \% \quad 34.5$

$99.7 \% \quad 51.4$

$99.4 \% \quad 19.3$

$99.7 \% 26.4$

$\begin{array}{lll}99.7 \% & 29.6\end{array}$

$99.7 \% \quad 30.3$

$99.7 \% \quad 51.9$

$99.5 \% 25.8$

$99.7 \% \quad 53.5$

$99.7 \% \quad 55.9$

$\begin{array}{lll}99.7 \% & 32.7\end{array}$

$99.7 \% \quad 55.5$

$99.7 \% \quad 57.9$

$99.7 \% \quad 57.1$

$99.7 \% \quad 41.3$

$99.7 \% \quad 44.0$

$99.0 \% \quad 32.3$

$99.7 \% \quad 54.2$

$\begin{array}{ll}99.7 \% & 55.5\end{array}$

$99.7 \% \quad 48.2$

$99.7 \% \quad 35.0$

$99.7 \% \quad 49.8$

$99.7 \% \quad 38.7$

$99.7 \% \quad 60.8$
1446.77

1842.99

1550.75

1040.55

1198.68

1057.60

1029.57

1275.68

1328.71

996.61

904.48

946.54

1150.59

1155.58

1592.73

1338.69

1242.49

1169.63

1047.59

1156.69

1489.83

1149.65

1175.63

1903.94

1040.49

1431.73

1179.55

1546.80

1524.72

1652.82

1013.60

2045.97

1626.8

1782.91

1098.54

1057.49

1731.92

1888.02

2099.10

1913.05

1768.96

1409.84

1236.77

1364.86

1320.75

1192.66 1041.64 $\begin{array}{ll}53 & 465 \\ 53 & 469 \\ & 551\end{array}$

539

577

$\begin{array}{ll}80 & 91 \\ 92 & 101\end{array}$

$265 \quad 274$

$577 \quad 587$

$683 \quad 695$

$954 \quad 962$

$036 \quad 1043$

$1097 \quad 1106$

$1326 \quad 1336$

$1747 \quad 1761$

0912100

$6 \quad 17$

$\begin{array}{ll}18 & 27 \\ 70 & 79\end{array}$

$70 \quad 79$

$\begin{array}{ll}414 & 426 \\ 430 & 440\end{array}$

$\begin{array}{ll}30 & 440 \\ 6 & 15\end{array}$

$8 \quad 25$

$16 \quad 25$

34

48
57

57
70

70

91

101

142

142
157

157

165
44

44

61

110

111

128
175

175

$175 \quad 186$

$186 \quad 196$

$187 \quad 196$ 
Interleukin enhancer-binding factor $2 \mathrm{GN}=\mathrm{ILF} 2$ ILF2_HUMAN $43.06 \quad 100.0 \%$ Interleukin enhancer-binding factor $2 \mathrm{GN}=\mathrm{ILF} 2 \mathrm{ILF} 2$ _HUMAN $43.06 \quad 100.0 \% \quad 17$ Interleukin enhancer-binding factor 2 GN=ILF2 ILF2_HUMAN $43.06 \quad 100.0 \% \quad 17$ Interleukin enhancer-binding factor 2 GN=ILF2 ILF2 HUMAN $43.06 \quad 100.0 \%$ Interleukin enhancer-binding factor 2 GN=ILF2 ILF2_HUMAN $43.06 \quad 100.0 \% \quad 17$ Interleukin enhancer-binding factor 2 GN=ILF2 ILF2_HUMAN $43.06 \quad 100.0 \%$ Interleukin enhancer-binding factor $3 \mathrm{GN}=$ ILF3 ILF3_HUMAN $95.34 \quad 100.0 \%$ Interleukin enhancer-binding factor $3 \mathrm{GN}=\mathrm{ILF} 3 \mathrm{ILF} 3$ _HUMAN $95.34 \quad 100.0 \%$ Interleukin enhancer-binding factor $3 \mathrm{GN}=\mathrm{ILF} 3 \mathrm{ILF} 3$ HUMAN $95.34 \quad 100.0 \%$ Interleukin enhancer-binding factor $3 \mathrm{GN}=\mathrm{ILF} 3$ ILF3_HUMAN $95.34 \quad 100.0 \% 30$ Interleukin enhancer-binding factor 3 GN=ILF3 ILF3_HUMAN $95.34 \quad 100.0 \% 30$ Interleukin enhancer-binding factor $3 \mathrm{GN}=\mathrm{ILF} 3 \mathrm{ILF} 3$ HUMAN $95.34 \quad 100.0 \%$ Interleukin enhancer-binding factor 3 GN=ILF3 ILF3_HUMAN $95.34 \quad 100.0 \%$ Interleukin enhancer-binding factor 3 GN=ILF3 ILF3_HUMAN $95.34 \quad 100.0 \%$ Interleukin enhancer-binding factor 3 GN=ILF3 ILF3_HUMAN $95.34 \quad 100.0 \%$ Interleukin enhancer-binding factor $3 \mathrm{GN}=$ ILF3 ILF3_HUMAN $95.34 \quad 100.0 \%$ Interleukin enhancer-binding factor $3 \mathrm{GN}=\mathrm{ILF} 3 \mathrm{ILF} 3$ HUMAN $95.34 \quad 100.0 \%$ Interleukin enhancer-binding factor $3 \mathrm{GN}=\mathrm{ILF} 3$ ILF3_HUMAN $95.34 \quad 100.0 \% 30$ Interleukin enhancer-binding factor $3 \mathrm{GN}=$ ILF3 ILF3_HUMAN $95.34 \quad 100.0 \% \quad 30$ Interleukin enhancer-binding factor $3 \mathrm{GN}=\mathrm{ILF} 3 \mathrm{ILF} 3$ HUMAN $95.34 \quad 100.0 \%$ Interleukin enhancer-binding factor $3 \mathrm{GN}=\mathrm{ILF} 3 \mathrm{ILF} 3$ _HUMAN $95.34 \quad 100.0 \%$ Interleukin enhancer-binding factor $3 \mathrm{GN}=\mathrm{ILF} 3$ ILF3 HUMAN $95.34 \quad 100.0 \% 30$ Interleukin enhancer-binding factor $3 \mathrm{GN}=\mathrm{ILF} 3$ ILF3_HUMAN $95.34 \quad 100.0 \% \quad 30$ Interleukin enhancer-binding factor 3 GN=ILF3 ILF3_HUMAN $95.34 \quad 100.0 \%$ Interleukin enhancer-binding factor $3 \mathrm{GN}=\mathrm{ILF} 3 \mathrm{ILF} 3$ HUMAN $95.34 \quad 100.0 \%$ Interleukin enhancer-binding factor 3 GN=ILF3 ILF3_HUMAN $95.34 \quad 100.0 \%$ Interleukin enhancer-binding factor $3 \mathrm{GN}=$ ILF3 ILF3_HUMAN $95.34 \quad 100.0 \%$ Interleukin enhancer-binding factor $3 \mathrm{GN}=\mathrm{ILF} 3$ ILF3_HUMAN $95.34 \quad 100.0 \% 30$ Interleukin enhancer-binding factor $3 \mathrm{GN}=\mathrm{ILF} 3 \mathrm{ILF} 3$ _HUMAN $95.34 \quad 100.0 \%$ Interleukin enhancer-binding factor $3 \mathrm{GN}=\mathrm{ILF} 3 \mathrm{ILF} 3$ HUMAN $95.34 \quad 100.0 \%$ Interleukin enhancer-binding factor $3 \mathrm{GN}=\mathrm{ILF} 3 \mathrm{ILF} 3$ _HUMAN $95.34 \quad 100.0 \% \quad 30$ Interleukin enhancer-binding factor $3 \mathrm{GN}=$ ILF3 ILF3_HUMAN $95.34 \quad 100.0 \%$ Interleukin enhancer-binding factor $3 \mathrm{GN}=\mathrm{ILF} 3 \mathrm{ILF} 3$ HUMAN $95.34 \quad 100.0 \%$ Interleukin enhancer-binding factor $3 \mathrm{GN}=\mathrm{GLF} 3 \mathrm{ILF} 3$ _HUMAN $95.34 \quad 100.0 \%$ Interleukin enhancer-binding factor $3 \mathrm{GN}=\mathrm{ILF} 3 \mathrm{ILF} 3$ HUMAN $95.34 \quad 100.0 \%$ Interleukin enhancer-binding factor $3 \mathrm{GN}=\mathrm{ILF} 3 \mathrm{ILF} 3$ _HUMAN $95.34 \quad 100.0 \%$ Iron-sulfur protein NUBPL GN=NUBPL NUBPL_HUMAN $34.08 \quad 100.0 \%$ Iron-sulfur protein NUBPL GN=NUBPL NUBPL_HUMAN $34.08 \quad 100.0 \%$ Isobutyryl-CoA dehydrogenase, mitochondrial GN=ACAD8 ACAD8_HUMAN $45.07 \quad 100.0 \%$ Isobutyryl-CoA dehydrogenase, mitochondrial GN=ACAD8 ACAD8_HUMAN $45.07 \quad 100.0 \%$ Isocitrate dehydrogenase [NAD] subunit alpha, mitochondrial GN=IDH3A IDH3A_HUMAN 39.59 Isocitrate dehydrogenase [NAD] subunit alpha, mitochondrial GN=IDH3A IDH3A_HUMAN 39.59 socitrate dehydrogenase [NAD] subunit alpha mitochondrial GN=IDH3A IDH3A HUMAN 39.59 locitrate dehydrogenase [NAD] subunit alpha, mitochondrial GN=IDH3A IDH3A_HUMAN 39.59 Isocitrate dehydrogenase $[\mathrm{NAD}]$ subunit alpha, mitochondrial GN=IDH3A IDH3A_HUMAN 39.59 socitrate dehydrogenase [NAD] subunit alpha, mitochondrial GN=IDH3A IDH3A HUMAN 39.59 Isocitrate dehydrogenase [NAD] subunit alpha, mitochondrial GN=IDH3A IDH3A_HUMAN 39.59
$0.16 \% \quad 39.7 \%$ WFEENASQSTVK $144 \quad 0.16 \% \quad 39.7 \%$ QPLALNVAYR

$144 \quad 0.16 \% \quad 39.7 \%$ QPLALNVAYRR

$99.7 \%$

$99.7 \% \quad 30.8$

$\begin{array}{lllll}0.16 \% & 39.7 \% & \text { VHTVMTLEQQDMVCYTAQTLVR } & 99.7 \% & 44.9\end{array}$

$144 \quad 0.16 \% \quad 39.7 \%$ ILSHGGFR

$144 \quad 0.16 \% \quad 39.7 \%$ ILSHGGFRK

$196 \quad 0.21 \% \quad 35.5 \%$ IFVNDDRHVMAK

$196 \quad 0.21 \% \quad 35.5 \%$ GDLDLELVLLCK

$196 \quad 0.21 \% \quad 35.5 \%$ EPPLSLTIHLTSPVVR

$99.0 \% \quad 41.7$

$\begin{array}{llllllll}98.4 \% & 23.2\end{array}$

$99.7 \% \quad 42.4$

$99.7 \% \quad 50.7$

$99.7 \% \quad 33.2$

$196 \quad 0.21 \% \quad 35.5 \%$ VLAGETLSVNDPPDVLDR $99.7 \% \quad 42.4$

$196 \quad 0.21 \% \quad 35.5 \%$ VLAGETLSVNDPPDVLDRQK $96.4 \% \quad 17.0$

$196 \quad 0.21 \% \quad 35.5 \%$ CLAALASLR

$196 \quad 0.21 \% \quad 35.5 \%$ ANGLKSCVIVIR

$196 \quad 0.21 \% \quad 35.5 \%$ VLRDLCTR

$99.7 \% \quad 61.2$

$99.3 \% \quad 42.4$

$99.0 \% \quad 25.3$

$196 \quad 0.21 \% \quad 35.5 \%$ SIGTANRPMGAGEALR

$196 \quad 0.21 \% \quad 35.5 \%$ SIGTANRPMGAGEALRR

$196 \quad 0.21 \% \quad 35.5 \%$ EATDAIGHLDR

$196 \quad 0.21 \% \quad 35.5 \%$ QQREDITQSAQHALR

$196 \quad 0.21 \% \quad 35.5 \%$ EDITQSAQHALR

$196 \quad 0.21 \% \quad 35.5 \%$ LAAFGQLHK

$196 \quad 0.21 \% \quad 35.5 \%$ VLGMDPLPSK

$196 \quad 0.21 \% \quad 35.5 \%$ VLGMDPLPSKMPK

$196 \quad 0.21 \% \quad 35.5 \%$ RPMEEDGEEKSPSK

$196 \quad 0.21 \% \quad 35.5 \%$ LNQLKPGLQYK

$196 \quad 0.21 \% \quad 35.5 \%$ TAKLHVAVK

$196 \quad 0.21 \% \quad 35.5 \%$ VLQDMGLPTGAEGR

$196 \quad 0.21 \% \quad 35.5 \%$ HGKNPVMELNEK

$196 \quad 0.21 \% \quad 35.5 \%$ NPVMELNEK

$196 \quad 0.21 \% \quad 35.5 \%$ YELISETGGSHDKR

$196 \quad 0.21 \% \quad 35.5 \%$ FVMEVEVDGQK

$196 \quad 0.21 \% \quad 35.5 \%$ AYAALAALEK

$196 \quad 0.21 \% \quad 35.5 \%$ LFPDTPLALDANK

$196 \quad 0.21 \% \quad 35.5 \%$ LFPDTPLALDANKK

$196 \quad 0.21 \% \quad 35.5 \%$ FNYSGSGGR

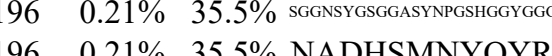

$5 \quad 0.01 \% \quad 10.7 \%$ STTAVNLALALAANDSSK $5 \quad 0.01 \% \quad 10.7 \%$ AIGLLDVDVYGPSVPK $0.00 \% \quad 6.5 \% \quad$ AVIFEDCAVPVANR

$2 \quad 0.00 \% \quad 6.5 \%$ IGSEGQGFLIAVR

$0.02 \% \quad 28.7 \%$ APIQWEER

$0.02 \% \quad 28.7 \%$ NVTAIQGPGGK

$0.02 \% \quad 28.7 \%$ WMIPSEAK

$0.02 \% \quad 28.7 \%$ TPIAAGHPSMNLLLR

$0.02 \% \quad 28.7 \%$ TPYTDVNIVTIR

$0.02 \% \quad 28.7 \%$ LITEGASKR

$0.02 \% \quad 28.7 \%$ IAEFAFEYAR
$97.6 \% 16.3$

$\begin{array}{lll}9.7 \% & 0.6\end{array}$

$99.7 \% \quad 54.1$

$99.7 \% \quad 60.5$

$99.7 \% \quad 38.8$

$99.7 \% \quad 32.3$

$99.5 \% \quad 24.5$

$99.7 \% \quad 35.8$

$99.7 \% \quad 56.5$

$99.7 \% \quad 52.7$

$99.7 \% \quad 58.0$

$99.7 \% \quad 25.8$

$99.7 \% \quad 37.0$

$99.4 \% 22.1$

$99.7 \% \quad 29.4$

$99.7 \% \quad 54.5$

$99.7 \% \quad 37.7$

$99.7 \% \quad 41.3$

$99.7 \% \quad 34.9$

$99.7 \% \quad 59.6$

$99.7 \% \quad 48.7$

$99.7 \% \quad 48.1$

$99.7 \% \quad 63.0$

$99.4 \% \quad 21.8$

$99.7 \% \quad 44.1$

$99.0 \% \quad 43.9$

$99.7 \% \quad 56.0$

$98.0 \% \quad 19.0$

$99.7 \% \quad 53.2$

$99.7 \% \quad 73.3$

$99.7 \% \quad 61.4$

$99.7 \% \quad 74.9$
1425.66

1144.65

1300.75

2655.26

886.49

1014.58

1460.73

1387.75

1759.01

1909.99

2166.14

974.55

1329.77

1032.56

1616.82

1756.92

1197.59

1780.91

1368.69

984.56

1056.58

1444.75

1634.73

1301.76

966.61

1443.73

1411.70

1089.52

1591.77

1296.61

1020.57

1414.76

1542.85

944.42

3012.24

1414.58

1746.92

1642.9

1560.78

1346.74

1028.52

1041.57

977.48

1590.88

1391.75

974.56

1216.60
$60 \quad 269$

319

$320 \quad 327$

$320 \quad 328$

$\begin{array}{ll}6 & 17\end{array}$

$106 \quad 117$

$\begin{array}{ll}62 & 177 \\ 83 & 200\end{array}$

$183 \quad 202$

$203 \quad 211$

$220 \quad 231$

$232 \quad 239$

$258 \quad 274$

298308

$309 \quad 323$

$12 \quad 323$

$333 \quad 342$

$372 \quad 385$

$152 \quad 460$

474

$524 \quad 535$

$527 \quad 535$

$541 \quad 554$

$555 \quad 565$

$578 \quad 587$

$588 \quad 600$

$588 \quad 601$

$807 \quad 815$

$884 \quad 894$

$\begin{array}{ll}89 \\ 100 & 115\end{array}$

$245 \quad 258$

$259 \quad 271$

$59 \quad 66$

$\begin{array}{ll}67 & 77 \\ 78 & 85\end{array}$

$101 \quad 115$

$135 \quad 146$

$170 \quad 178$

$179 \quad 188$ 

Isoleucine--tRNA ligase, cytoplasmic GN=IARS SYIC_HUMAN $144.50 \quad 100.0 \%$ Isoleucine--tRNA ligase, cytoplasmic GN=IARS SYIC_HUMAN $144.50 \quad 100.0 \%$ Isoleucine--tRNA ligase, cytoplasmic GN=IARS SYIC_HUMAN $144.50 \quad 100.0 \%$ Isoleucine--tRNA ligase, cytoplasmic GN=IARS SYIC_HUMAN $144.50 \quad 100.0 \%$ Isoleucine--tRNA ligase, cytoplasmic GN=IARS SYIC_HUMAN $144.50 \quad 100.0 \%$ Isoleucine--tRNA ligase, cytoplasmic GN=IARS SYIC_HUMAN $144.50 \quad 100.0 \%$ Isoleucine--tRNA ligase, cytoplasmic GN=IARS SYIC_HUMAN $144.50 \quad 100.0 \%$ Isoleucine--tRNA ligase, cytoplasmic GN=IARS SYIC_HUMAN $144.50 \quad 100.0 \%$

$0.02 \% \quad 28.7 \%$ MSDGLFLQK

$0.02 \% \quad 28.7 \%$ IEAACFATIK

$0.02 \% \quad 28.7 \%$ IEAACFATIKDGK

$0.02 \% \quad 28.7 \%$ CSDFTEEICR

$0.04 \% \quad 36.4 \%$ IHTPMEYK

$0.04 \% \quad 36.4 \%$ KLDLFANVVHVK

$0.04 \% \quad 36.4 \%$ LDLFANVVHVK

$0.04 \% \quad 36.4 \%$ HNNLDLVIIR

$0.04 \% \quad 36.4 \%$ EQTEGEYSSLEHESAR

$0.04 \% \quad 36.4 \%$ FAFDYATK

$0.04 \% 36.4 \%$ FAFDYATKK

$0.04 \% \quad 36.4 \%$ LGDGLFLQCCEEVAELYPK $99.7 \% 52.5$

$0.04 \% \quad 36.4 \%$ HPFAQAVGR

$0.04 \% \quad 36.4 \%$ NIANPTAMLLSASNMLR

0.04\% $36.4 \%$ HLNLEYHSSMIADAVK

$0.04 \% \quad 36.4 \%$ TRDMGGYSTTTDFIK

$0.04 \% \quad 36.4 \%$ DMGGYSTTTDFIK

$0.04 \% \quad 36.4 \%$ SVIGHLQTK

$0.01 \% \quad 22.1 \%$ TSLDLYANVIHCK

$0.01 \% \quad 22.1 \%$ ENTEGEYSSLEHESVAGVVESLK

$0.01 \% \quad 22.1 \%$ LGDGLFLQCCR

$0.01 \% \quad 22.1 \%$ LHSYATSIR

$0.01 \% \quad 22.1 \%$ AVLASMDNENMHTPDIGGQGTTSEALDVII

$0.05 \% \quad 36.9 \%$ VAKPVVEMDGDEMTR

$0.05 \% \quad 36.9 \%$ LILPHVDIQLK

$0.05 \% \quad 36.9 \%$ YFDLGLPNR

$0.05 \% \quad 36.9 \%$ DQTDDQVTIDSALATQK

$0.05 \% \quad 36.9 \%$ CATITPDEAR

$0.05 \% \quad 36.9 \%$ CATITPDEARVEEFK

$0.05 \% \quad 36.9 \%$ NILGGTVFR

$0.05 \% \quad 36.9 \%$ NILGGTVFREPIICK

$0.05 \% \quad 36.9 \%$ ATDFVADR

$0.05 \% \quad 36.9 \%$ LIDDMVAQVLK

$0.05 \% \quad 36.9 \%$ TIEAEAAHGTVTR

$0.05 \% \quad 36.9 \%$ GKLDGNQDLIR

$0.05 \% \quad 36.9 \%$ VCVETVESGAMTK

$0.05 \% \quad 36.9 \%$ DLAGCIHGLSNVK

$0.05 \% \quad 36.9 \%$ LNEHFLNTTDFLDTIK

$0.03 \% \quad 11.7 \%$ YAHQSGFHVDR

$0.03 \% \quad 11.7 \%$ MGITEYNNQCR

$0.03 \% \quad 11.7 \%$ LLILMEAR

$0.03 \% \quad 11.7 \%$ SDTPLIYK

$0.03 \% \quad 11.7 \%$ VENMVDQLLR

$0.03 \% \quad 11.7 \%$ ESVDHLTIPSR

$0.03 \% \quad 11.7 \%$ NVIVNGLVLASDGQK

$0.03 \% \quad 11.7 \%$ LYLINSPVVR

$0.03 \% \quad 11.7 \%$ FLIQNVLR
$99.7 \% \quad 44.2$

$99.7 \% \quad 62.2$

$99.7 \% \quad 62.3$

$99.7 \% \quad 60.9$

$97.9 \% \quad 21.2$

$99.7 \% \quad 66.3$

$99.7 \% \quad 46$.

$99.7 \% 50$.

$99.7 \% \quad 65.3$

$99.0 \% \quad 23.5$

$99.7 \% \quad 36.9$

$94.6 \% \quad 18.2$

$99.7 \% \quad 70.8$

$99.7 \% \quad 24.8$

$99.4 \% \quad 19.2$

$99.7 \% \quad 46.7$

$99.7 \% \quad 38.0$

$99.7 \% \quad 56.5$

.6\% 28.7

$99.7 \% \quad 53.0$

$99.7 \% \quad 27.4$

$99.7 \% \quad 35.7$

$99.7 \% \quad 62.0$

$99.7 \% \quad 42.8$

$99.7 \% \quad 28.1$

$99.7 \% \quad 68.8$

$99.7 \% \quad 39.8$

$99.3 \% \quad 20.4$

$99.4 \% 25.8$

$99.7 \% \quad 40.3$

$\begin{array}{lll}99.0 \% & 36.3\end{array}$

$99.7 \% \quad 57.6$

$99.7 \% \quad 64.0$

$99.7 \% \quad 55.5$

$99.7 \% \quad 61.2$

$99.7 \% \quad 63.3$

$99.7 \% \quad 25.6$

$99.4 \% \quad 19.4$

$99.7 \% \quad 52.8$

$99.0 \% \quad 37.3$

$98.3 \% \quad 26.3$

$99.7 \% \quad 34.4$

$99.3 \% \quad 20.3$

$99.7 \% \quad 55.7$

$99.7 \% \quad 45.2$

$99.0 \% \quad 40.8$
1123.58

1423.73

1316.52

1018.50

1382.82

1254.72

1206.70

1851.80

962.46

1090.56

2241.06

982.52

1832.94

1843.90

1708.79

1435.6

982.57

1533.77

2493.16

1338.63

1047.56

3302.53

1708.79

1288.80

1094.56

1848.88

1133.53

1765.84

976.56

1716.95

894.43

1260.69

1355.69

1228.66

1426.66

1383.71

1920.97

1316.61

1385.59

974.57

936.50

1232.63

1253.65

1526.85

1173.70 1002.61 
Isoleucine--tRNA ligase, cytoplasmic GN=IARS SYIC_HUMAN $144.50 \quad 100.0 \%$ Isoleucine--tRNA ligase, cytoplasmic GN=IARS SYIC_HUMAN $144.50 \quad 100.0 \%$ Isoleucine--tRNA ligase, cytoplasmic GN=IARS SYIC_HUMAN $144.50 \quad 100.0 \%$ Isoleucine--tRNA ligase, cytoplasmic GN=IARS SYIC HUMAN $144.50 \quad 100.0 \%$ Isoleucine--tRNA ligase, cytoplasmic GN=IARS SYIC_HUMAN $144.50 \quad 100.0 \%$ Isoleucine--tRNA ligase, cytoplasmic GN=IARS SYIC_HUMAN $144.50 \quad 100.0 \%$ Isoleucine--tRNA ligase, cytoplasmic GN=IARS SYIC_HUMAN $144.50 \quad 100.0 \%$ Isoleucine--tRNA ligase, mitochondrial GN=IARS2 SYIM_HUMAN $113.79 \quad 100.0 \%$ Isoleucine--tRNA ligase, mitochondrial GN=IARS2 SYIM HUMAN $113.79 \quad 100.0 \%$ Isoleucine--tRNA ligase, mitochondrial GN=IARS2 SYIM_HUMAN $113.79 \quad 100.0 \%$ Isoleucine--tRNA ligase, mitochondrial GN=IARS2 SYIM_HUMAN $113.79 \quad 100.0 \%$ Isoleucine--tRNA ligase, mitochondrial GN=IARS2 SYIM HUMAN $113.79100 .0 \%$ Isovaleryl-CoA dehydrogenase, mitochondrial GN=IVD IVD_HUMAN $46.32 \quad 100.0 \%$ Isovaleryl-CoA dehydrogenase, mitochondrial GN=IVD IVD_HUMAN $46.32 \quad 100.0 \%$ Junction plakoglobin GN=JUP Junction plakoglobin GN=JUF Junction plakoglobin GN=JUP Junction plakoglobin GN=JUP Junction plakoglobin $\mathrm{GN}=\mathrm{JUP}$ Junction plakoglobin GN=JUP Junction plakoglobin $\mathrm{GN}=\mathrm{JUH}$ Junction plakoglobin GN=JUP

Keratinocyte proline-rich protei Keratinocyte proline-rich protein GN=KPRP KPRP_HUMAN $64.13 \quad 100.0 \%$ Keratinocyte proline-rich protein GN=KPRP KPRP HUMAN $64.13 \quad 100.0 \%$ Ketosamine-3-kinase GN=FN3KRP Ketosamine-3-kinase GN=FN3KRP

PLAK HUMAN $81.75 \quad 100.0 \%$ PLAK_HUMAN $81.75 \quad 100.0 \%$ PLAK HUMAN $81.75 \quad 100.0 \%$ PLAK_HUMAN $81.75 \quad 100.0 \%$ PLAK_HUMAN $81.75 \quad 100.0 \%$ PLAK HUMAN $81.75 \quad 100.0 \%$ PLAK_HUMAN $81.75 \quad 100.0 \%$ PLAK HUMAN $81.75-100.0 \%$ KT3K_HUMAN $34.41 \quad 100.0 \%$ KT3K_HUMAN $34.41 \quad 100.0 \%$

KH domain-containing, RNA-binding, signal transduction-associated protein $1 \mathrm{GN}=\mathrm{KHDRBS1}$ KHDR1 HUMAN $48.23 \quad 100.0 \%$ KHDR1_HUMAN $48.23 \quad 100.0 \%$ KHDR1 HUMAN $48.23 \quad 100.0 \%$ Kinesin-like protein KIF14 GN=KIF14 KIF14_HUMAN $186.50 \quad 100.0 \%$ Kinesin-like protein KIF14 GN=KIF14 KIF14_HUMAN $186.50 \quad 100.0 \%$ Kinesin-like protein KIF20B GN=KIF20B KI20B_HUMAN $210.64 \quad 100.0 \%$ Kinesin-like protein KIF20B GN=KIF20B KI20B_HUMAN $210.64 \quad 100.0 \%$ Kinesin-like protein KIF23 GN=KIF23 KIF23_HUMAN $110.06 \quad 100.0 \%$ Kinesin-like protein KIF23 GN=KIF23 KIF23_HUMAN $110.06 \quad 100.0 \%$ Kinetochore-associated protein $1 \mathrm{GN}=\mathrm{KNTC1}$ KNTC1_HUMAN $250.76 \quad 100.0 \%$ Kinetochore-associated protein $1 \mathrm{GN}=\mathrm{KNTC} 1 \mathrm{KNTC1}$ HUMAN $250.76 \quad 100.0 \%$ Kinetochore-associated protein $1 \mathrm{GN}=\mathrm{KNTC1} \mathrm{KNTC1}$ HUMAN $250.76 \quad 100.0 \%$ Kinetochore-associated protein $1 \mathrm{GN}=\mathrm{KNTC1} \mathrm{KNTC1}$ HUMAN $250.76 \quad 100.0 \%$ Kinetochore-associated protein $1 \mathrm{GN}=\mathrm{KNTC1} \mathrm{KNTC1}$ HUMAN $250.76 \quad 100.0 \%$ Kinetochore-associated protein $1 \mathrm{GN}=\mathrm{KNTC1} \mathrm{KNTC1}$ HUMAN $250.76 \quad 100.0 \%$ Kinetochore-associated protein $1 \mathrm{GN}=\mathrm{KNTC1} \mathrm{KNTC1}$ HUMAN $250.76100 .0 \%$ Kinetochore-associated protein $1 \mathrm{GN}=\mathrm{KNTC1} \mathrm{KNTC1}$ _HUMAN $250.76 \quad 100.0 \%$ Kinetochore-associated protein $1 \mathrm{GN}=\mathrm{KNTC1}$ KNTC1_HUMAN $250.76 \quad 100.0 \%$ KRR1 small subunit processome component homolog GN=KRR1 KRR1 HUMAN $43.67 \quad 100.0 \%$ KRR1 small subunit processome component homolog GN=KRR1 KRR1_HUMAN $43.67 \quad 100.0 \%$

$0.03 \% \quad 11.7 \%$ YIIEELNVR

$0.03 \% \quad 11.7 \%$ YIIEELNVRK

$0.03 \% \quad 11.7 \%$ LRAEPDHMVLGK

$0.03 \% \quad 11.7 \%$ QLSSEELEQFQK

$0.03 \% \quad 11.7 \%$ EVINRIQK

$0.03 \% \quad 11.7 \%$ TQLKGSELEITLTR

$0.03 \% \quad 11.7 \%$ GSELEITLTR

$0.01 \% \quad 6.6 \% \quad$ SYKPVFWSPSSR

$0.01 \% \quad 6.6 \%$ TALAEAELEYNPEHVSR

$0.01 \% \quad 6.6 \%$ FPLLKPSPK

$0.01 \% \quad 6.6 \% \quad$ AVLEEGTDVVIK

$0.01 \% \quad 6.6 \%$ TKDEYLINSQTTEHIVK

$0.00 \% \quad 5.0 \%$ GITAFIVEK

$0.00 \% \quad 5.0 \%$ LYEIGAGTSEVR

$0.02 \% \quad 12.9 \%$ LAEPSQLLK

$0.02 \% \quad 12.9 \%$ LLNDEDPVVVTK

$0.02 \% \quad 12.9 \%$ TMQNTSDLDTAR

$0.02 \% \quad 12.9 \%$ NLSDVATKQEGLESVLK

$0.02 \% \quad 12.9 \%$ HPEAEMAQNSVR

$0.02 \% \quad 12.9 \%$ LNYGIPAIVK

$0.02 \% \quad 12.9 \%$ NEGTATYAAAVLFR

$0.02 \% \quad 12.9 \%$ ISEDKNPDYR

$0.01 \% \quad 5.5 \%$ GRPAVCQPQGR

$0.01 \% \quad 5.5 \%$ RSEPIYNSR

$0.01 \% \quad 5.5 \%$ RLDQCPESPLQR

$0.00 \% \quad 8.4 \%$ LGAQLADLHLDNKK

$0.00 \% \quad 8.4 \%$ GGGQEERPFVAR

$0.01 \% \quad 8.1 \%$ SGSMDPSGAHPSVR

$0.01 \% \quad 8.1 \%$ ILGPQGNTIKR

$0.01 \% \quad 8.1 \%$ GAAPPPPPVPR

$0.00 \% \quad 1.1 \%$ LAAPLLER

$0.00 \% \quad 1.1 \%$ SLENIFAESK

$0.00 \% \quad 1.2 \%$ LIFTYGLTNSGK

$0.00 \% \quad 1.2 \% \quad$ SITNNVSQIK

$0.00 \% \quad 2.7 \%$ NGLLFTYGVTGSGK

$0.00 \% \quad 2.7 \% \quad$ IANTHLNRESSR

$0.01 \% \quad 5.1 \%$ QTLLTNAFVQK

$0.01 \% \quad 5.1 \%$ TYQNLVIEK

$0.01 \% \quad 5.1 \%$ IQQAIENVDFSTAK

$0.01 \% \quad 5.1 \% \quad$ CLTEALPENR

$0.01 \% \quad 5.1 \%$ LALQEEPDHSKEGK

$0.01 \% \quad 5.1 \%$ HKPGSTPEPIAAEVR

$0.01 \% \quad 5.1 \%$ SSTLINKEITK

$0.01 \% \quad 5.1 \%$ SGTEAVLIAHK

$0.01 \% \quad 5.1 \%$ IQNSSGTDYPDIHAAAK

$0.01 \% \quad 13.6 \%$ KTFDPYIIIR

$0.01 \% \quad 13.6 \%$ TFDPYIIIR $\begin{array}{llllllll}99.2 \% & 35.3 & 25.0 & 0.0 & 1 & 0 & 0 & 1148.63\end{array}$

$99.7 \% \quad 33.9 \quad 25.0 \quad 21.5$

$\begin{array}{llll}94.7 \% & 13.5 & 25.0 & 13.5\end{array}$

$99.7 \% \quad 47.5 \quad 25.0 \quad 47.5$

$\begin{array}{llll}99.0 \% & 37.5 & 25.0 & 25.3\end{array}$

$\begin{array}{llll}99.7 \% & 31.7 & 25.0 & 31.7\end{array}$

$97.5 \% \quad 29.7 \quad 25.0 \quad 15.5$

$\begin{array}{llll}95.5 \% & 16.5 & 25.0 & 15.6\end{array}$

$\begin{array}{llll}99.7 \% & 34.2 & 25.0 & 34.2\end{array}$

$99.7 \% \quad 29.1 \quad 25.0 \quad 28.7$

$99.7 \% \quad 46.6 \quad 25.0 \quad 37.1$

$\begin{array}{llll}99.5 \% & 25.0 & 25.0 & 25.0\end{array}$

$99.0 \% \quad 29.5 \quad 25.0 \quad 12.9$

$\begin{array}{llll}99.7 \% & 36.2 & 25.0 & 36.1\end{array}$

$99.7 \% \quad 32.8 \quad 25.0 \quad 21.3$

$\begin{array}{llll}99.7 \% & 57.6 & 25.0 & 52.0\end{array}$

$99.7 \% \quad 30.5 \quad 25.0 \quad 30.5$

$\begin{array}{llll}99.7 \% & 35.8 & 25.0 & 35.8\end{array}$

$\begin{array}{llll}99.5 \% & 21.8 & 25.0 & 18.9\end{array}$

$\begin{array}{llll}99.7 \% & 34.6 & 25.0 & 28.4\end{array}$

$99.7 \% \quad 60.1 \quad 25.0 \quad 52.1$

$\begin{array}{llll}99.3 \% & 25.1 & 25.0 & 23.9\end{array}$

$99.2 \% \quad 19.4 \quad 25.0 \quad 18.5$

$\begin{array}{lllll}99.7 \% & 34.5 & 25.0 & 21.4 & 2\end{array}$

$\begin{array}{llll}98.6 \% & 25.5 & 25.0 & 14.9\end{array}$

$\begin{array}{llll}99.5 \% & 24.5 & 25.0 & 22.3\end{array}$

$\begin{array}{llll}98.3 \% & 20.9 & 25.0 & 14.6\end{array}$

$99.7 \% \quad 41.0 \quad 25.0 \quad 41.0$

$\begin{array}{lllll}99.7 \% & 58.7 & 25.0 & 48.1\end{array}$

$\begin{array}{llll}99.7 \% & 30.5 & 25.0 & 20.5\end{array}$

$\begin{array}{llll}99.0 \% & 23.2 & 25.0 & 23.2\end{array}$

$\begin{array}{llll}99.7 \% & 62.2 & 25.0 & 51.9\end{array}$

$\begin{array}{llll}99.7 \% & 41.2 & 25.0 & 38.8\end{array}$

$\begin{array}{llll}97.9 \% & 21.6 & 25.0 & 14.5\end{array}$

$\begin{array}{llll}99.7 \% & 49.7 & 25.0 & 49.7\end{array}$

$\begin{array}{llll}98.2 \% & 16.6 & 25.0 & 16.6\end{array}$

$\begin{array}{llll}99.7 \% & 29.2 & 25.0 & 29.2\end{array}$

$99.7 \% \quad 39.5 \quad 25.0 \quad 36.7$

$\begin{array}{llll}99.7 \% & 65.5 & 25.0 & 59.7\end{array}$

$\begin{array}{llll}99.7 \% & 36.5 & 25.0 & 26.5\end{array}$

$\begin{array}{llll}99.5 \% & 24.0 & 25.0 & 24.0\end{array}$

$\begin{array}{llll}99.5 \% & 22.2 & 25.0 & 22.2\end{array}$

$\begin{array}{llll}99.7 \% & 33.5 & 25.0 & 24.1\end{array}$

$\begin{array}{llll}99.3 \% & 20.1 & 25.0 & 19.8\end{array}$

$\begin{array}{llll}99.7 \% & 29.0 & 25.0 & 29.0\end{array}$

$\begin{array}{llll}98.7 \% & 17.7 & 25.0 & 17.5\end{array}$

$\begin{array}{llll}99.7 \% & 29.1 & 25.0 & 22.3\end{array}$
1276.73

1365.73

1465.72

999.59

1588.89

1118.61

1440.73

1928.93

1026.63

1272.70

2019.04

977.57

1294.66

998.59

1341.73

1368.61

1830.98

1384.63

1087.65

1483.75

1236.59

1225.62

1121.57

1498.74

1535.85

1302.66

1384.63

1196.71

1055.60

882.54

1137.58

1313.7

1103.61

1413.74

1397.72

1262.71

1107.60

1563.80

1202.58

1580.79

1588.84

1233.71

1125.63

1787.86

1265.73

1137.63

$\begin{array}{cc}69 & 877 \\ 69 & 878 \\ 92 & 903 \\ 18 & 929 \\ 89 & 996 \\ 58 & 1071 \\ 62 & 1071 \\ 39 & 250 \\ 51 & 267 \\ 73 & 281 \\ 34 & 445 \\ 39 & 555 \\ 21 & 229 \\ 99 & 410 \\ 16 & 124 \\ 50 & 161 \\ 92 & 203 \\ 78 & 394 \\ 66 & 477 \\ 78 & 487 \\ 38 & 651 \\ 52 & 661 \\ 67 & 177 \\ 00 & 308 \\ 87 & 398 \\ 03 & 116 \\ 31 & 142 \\ 8 & 31 \\ 76 & 186 \\ 92 & 302 \\ 27 & 434 \\ 66 & 1475 \\ 47 & 158 \\ 74 & 983 \\ 05 & 118 \\ 89 & 300 \\ 17 & 127 \\ 35 & 143 \\ 72 & 185 \\ 90 & 399 \\ 36 & 949 \\ 30 & 1044 \\ 59 & 1669 \\ 46 & 1756 \\ 86 & 1802 \\ 06 & 115 \\ 07 & 115\end{array}$

Page 88 of Table S-1-5 

KRR1 small subunit processome component homolog GN=KRR1 KRR1_HUMAN $43.67 \quad 100.0 \%$ KRR1 small subunit processome component homolog GN=KRR1 KRR1_HUMAN $43.67 \quad 100.0 \%$ KRR1 small subunit processome component homolog GN=KRR1 KRR1 HUMAN $43.67 \quad 100.0 \%$ L-2-hydroxyglutarate dehydrogenase, mitochondrial GN=L2HGDH L2HDH_HUMAN $50.32 \quad 100.0 \%$ L-2-hydroxyglutarate dehydrogenase, mitochondrial GN=L2HGDH L2HDH_HUMAN $50.32 \quad 100.0 \%$ L-2-hydroxyglutarate dehydrogenase, mitochondrial GN=L2HGDH L2HDH_HUMAN $50.32 \quad 100.0 \%$ L-2-hydroxyglutarate dehydrogenase, mitochondrial GN=L2HGDH L2HDH_HUMAN $50.32 \quad 100.0 \%$ L-2-hydroxyglutarate dehydrogenase, mitochondrial GN=L2HGDH L2HDH_HUMAN $50.32 \quad 100.0 \%$ L-2-hydroxyglutarate dehydrogenase, mitochondrial GN=L2HGDH L2HDH_HUMAN $50.32 \quad 100.0 \%$ L-2-hydroxyglutarate dehydrogenase, mitochondrial GN=L2HGDH L2HDH_HUMAN $50.32 \quad 100.0 \%$ L-2-hydroxyglutarate dehydrogenase, mitochondrial GN=L2HGDH L2HDH_HUMAN $50.32 \quad 100.0 \%$ L-2-hydroxyglutarate dehydrogenase, mitochondrial GN=L2HGDH L2HDH_HUMAN $50.32 \quad 100.0 \%$ L-2-hydroxyglutarate dehydrogenase, mitochondrial GN=L2HGDH L2HDH_HUMAN $50.32 \quad 100.0 \%$ L-2-hydroxyglutarate dehydrogenase, mitochondrial GN=L2HGDH L2HDH_HUMAN $50.32 \quad 100.0 \%$ L-2-hydroxyglutarate dehydrogenase, mitochondrial GN=L2HGDH L2HDH_HUMAN $50.32 \quad 100.0 \% \quad 12$ Lactadherin GN=MFGE8 Lactadherin GN=MFGE8 MFGM HUMAN $43.12 \quad 100.0 \%$ MFGM_HUMAN $43.12 \quad 100.0 \%$ Lamina-associated polypeptide 2, isoform alpha GN=TMPO LAP2A_HUMAN $75.49 \quad 100.0 \%$ Lamina-associated polypeptide 2, isoform alpha GN=TMPO LAP2A_HUMAN $75.49 \quad 100.0 \%$ Lamina-associated polypeptide 2, isoform alpha GN=TMPO LAP2A_HUMAN $75.49 \quad 100.0 \%$ Lamina-associated polypeptide 2, isoform alpha GN=TMPO LAP2A_HUMAN $75.49 \quad 100.0 \%$ Lamin-B receptor $\mathrm{GN}=\mathrm{LBR}$ Lamin-B receptor $\mathrm{GN}=\mathrm{LBR}$ Lamin-B receptor $\mathrm{GN}=\mathrm{LBR}$ Lamin-B receptor $\mathrm{GN}=\mathrm{LBR}$ Lamin-B receptor $\mathrm{GN}=\mathrm{LBR}$ Lamin-B receptor $\mathrm{GN}=\mathrm{LBR}$ Lamin-B receptor $\mathrm{GN}=\mathrm{LBR}$ Lamin-B1 GN=LMNB1 Lamin-B1 GN=LMNB1 Lamin-B1 GN=LMNB1 Lamin-B1 GN=LMNB1 Lamin-B1 GN=LMNB1 Lamin-B1 GN=LMNB Lamin-B1 GN=LMNB Lamin-B1 GN=LMNB Lamin-B1 GN=LMNB 1 Lamin-B1 GN=LMNB Lamin-B1 GN=LMNB1 Lamin-B1 GN=LMNB1 Lamin-B1 GN=LMNB1 Lamin-B1 GN=LMNB1 Lamin-B1 GN=LMNB1 Lamin-B1 GN=LMNB Lamin-B1 GN=LMNB Lamin-B1 GN=LMNB1
LBR_HUMAN $70.71 \quad 100.0 \%$ LBR_HUMAN $70.71 \quad 100.0 \%$ LBR HUMAN $70.71 \quad 100.0 \%$ LBR_HUMAN $70.71 \quad 100.0 \%$ LBR_HUMAN $70.71 \quad 100.0 \%$ LBR_HUMAN $70.71 \quad 100.0 \%$ LBR_HUMAN $70.71 \quad 100.0 \%$ LMNB1_HUMAN $66.41 \quad 100.0 \% \quad 25$ LMNB1_HUMAN $66.41 \quad 100.0 \% \quad 25$ LMNB1_HUMAN $\quad 66.41 \quad 100.0 \% \quad 25$ LMNB1 HUMAN $66.41 \quad 100.0 \% \quad 25$ LMNB1_HUMAN $\quad 66.41 \quad 100.0 \% \quad 25$ LMNB1_HUMAN $66.41 \quad 100.0 \% \quad 25$ LMNB1_HUMAN $66.41 \quad 100.0 \% \quad 25$ LMNB1_HUMAN $66.41 \quad 100.0 \% \quad 25$ LMNB1_HUMAN $66.41 \quad 100.0 \% \quad 25$ LMNB1_HUMAN $66.41 \quad 100.0 \% \quad 25$ LMNB1_HUMAN $66.41 \quad 100.0 \% \quad 25$ LMNB1_HUMAN $\quad 66.41 \quad 100.0 \% \quad 25$ LMNB1_HUMAN $66.41 \quad 100.0 \% \quad 25$ LMNB1_HUMAN $66.41 \quad 100.0 \% \quad 25$ LMNB1_HUMAN $66.41 \quad 100.0 \% \quad 25$ LMNB1_HUMAN $66.41 \quad 100.0 \% \quad 25$ LMNB1_HUMAN $66.41 \quad 100.0 \% \quad 25$ LMNB1_HUMAN $\quad 66.41 \quad 100.0 \% \quad 25$
$10 \quad 0.01 \% \quad 13.6 \%$ SVSFEQAVR

$10 \quad 0.01 \% \quad 13.6 \%$ NIHPIYNIK

$10 \quad 0.01 \% \quad 13.6 \%$ LGALTAEEIALK

$0.02 \% \quad 29.4 \%$ HPSLSIGVLEK

$20 \quad 0.02 \% \quad 29.4 \%$ LIVAVEQEEIPR

$0.02 \% \quad 29.4 \%$ GLQNGVPGLR

$0.02 \% \quad 29.4 \%$ LIQQEDIKK

$0.02 \% 29.4 \%$ SIDGMQYPIVIK

$0.02 \% \quad 29.4 \%$ CQYVVTCAGLYSDR

$0.02 \% \quad 29.4 \%$ ISELSGCTPDPR

$0.02 \% \quad 29.4 \%$ GDYLLLKPEK

$0.02 \% \quad 29.4 \%$ GNIYPVPDSR

$0.02 \% \quad 29.4 \%$ LASQNFSYGVTEMYK

$0.02 \% \quad 29.4 \%$ ACFLGATVK

$0.02 \% \quad 29.4 \%$ FIPEITISDILR

$\quad 0.01 \% \quad 5.7 \%$ NFGSVQFVASYK

$10 \quad 0.01 \% \quad 5.7 \% \quad$ NLFETPILAR

$9 \quad 0.01 \% \quad 7.6 \%$ PEFLEDPSVLTK

$0.01 \% \quad 7.6 \%$ NRPPLPAGTNSK

$0.01 \% \quad 7.6 \%$ YGVNPGPIVGTTR

$0.01 \% \quad 7.6 \%$ SSTPLPTISSSAENTR

$0.05 \% \quad 13.3 \%$ KFADGEVVR

$0.05 \% \quad 13.3 \%$ SASASHQADIKEAR

$0.05 \% \quad 13.3 \%$ YNGEPEHIER

$0.05 \% \quad 13.3 \%$ TFEVTPIR

$0.05 \% \quad 13.3 \%$ VVEGTPLIDGR

$0.05 \% \quad 13.3 \%$ NDLSPASSGNAVYDFFIGR

$0.05 \% \quad 13.3 \%$ NPSDPKLAHLK

$0.09 \% \quad 36.3 \%$ AGGPTTPLSPTR

$0.09 \% \quad 36.3 \%$ ALYETELADAR

$0.09 \% \quad 36.3 \%$ ALYETELADARR

$0.09 \% \quad 36.3 \%$ AKLQIELGK

$0.09 \% \quad 36.3 \%$ CKAEHDQLLLNYAK

$0.09 \% \quad 36.3 \%$ KESDLNGAQIK

$0.09 \% \quad 36.3 \%$ ESDLNGAQIK

$0.09 \% \quad 36.3 \%$ LREYEAALNSK

$0.09 \% \quad 36.3 \%$ DAALATALGDKK

$0.09 \% \quad 36.3 \%$ KQLADETLLK

$0.09 \% \quad 36.3 \%$ QLADETLLK

$0.09 \% \quad 36.3 \%$ SMYEEEINETR

$0.09 \% \quad 36.3 \%$ LYKEELEQTYHAK

$0.09 \% \quad 36.3 \%$ LSSEMNTSTVNSAR

$0.09 \% \quad 36.3 \%$ LSSEMNTSTVNSAREELMES

$0.09 \% \quad 36.3 \%$ MRIESLSSQLSNLQK

$0.09 \% \quad 36.3 \%$ IESLSSQLSNLQK

$0.09 \% \quad 36.3 \%$ IQELEDLLAK $\begin{array}{llll}99.7 \% & 31.4 & 25.0 & 24.6\end{array}$

$\begin{array}{llll}99.7 \% & 59.2 & 25.0 & 46.3\end{array}$

$\begin{array}{llll}99.5 \% & 22.9 & 25.0 & 19.9\end{array}$

$99.7 \% \quad 58.1 \quad 25.0 \quad 37.2$

$\begin{array}{llll}99.7 \% & 31.2 & 25.0 & 22.5\end{array}$

$\begin{array}{llll}99.7 \% & 58.3 & 25.0 & 46.2\end{array}$

$\begin{array}{llll}96.8 \% & 20.3 & 25.0 & 12.0\end{array}$

$99.7 \% \quad 35.0 \quad 25.0 \quad 17.2$

$\begin{array}{llll}99.7 \% & 49.8 & 25.0 & 43.3\end{array}$

$\begin{array}{llll}99.7 \% & 84.3 & 25.0 & 83.5\end{array}$

$\begin{array}{llll}99.7 \% & 47.1 & 25.0 & 38.4\end{array}$

$\begin{array}{llll}99.7 \% & 34.8 & 25.0 & 34.8\end{array}$

$\begin{array}{llll}99.7 \% & 34.5 & 25.0 & 25.8\end{array}$

$\begin{array}{llll}99.7 \% & 71.8 & 25.0 & 71.8\end{array}$

$\begin{array}{llll}99.2 \% & 22.4 & 25.0 & 18.9\end{array}$

$\begin{array}{lllll}99.7 \% & 62.6 & 25.0 & 56.0 & 2\end{array}$

$99.7 \% \quad 59.0 \quad 25.0 \quad 52.4$

$99.7 \% \quad 33.0 \quad 25.0 \quad 21.0$

$99.7 \% \quad 32.6 \quad 25.0 \quad 28.5$

$99.7 \% \quad 37.9$

$99.7 \% \quad 51.9$

$99.7 \% \quad 55.5$

$99.7 \% \quad 42.0$

$99.7 \% \quad 54.2$

$96.4 \% \quad 16.0$

$99.0 \% 33.4$

$99.7 \% \quad 51.2$

$99.7 \% \quad 59.8$

$99.6 \% 23.6$

$99.7 \% \quad 58.6$

$99.7 \% \quad 60.4$

$99.7 \% \quad 27.3$

$99.7 \% \quad 50.0$

$99.7 \% \quad 27.2$

$99.7 \% \quad 46.0$

$98.1 \% 24.5$

$99.7 \% \quad 59.6$

$99.7 \% \quad 59.8$

$99.7 \% \quad 48.5$

$99.7 \% \quad 43.5$

$99.7 \% \quad 63.3$

$99.7 \% \quad 32.0$

$99.7 \% \quad 68.4$

$99.7 \% \quad 25.0$

$99.7 \% \quad 33.8$

$99.7 \% \quad 68.3$

$99.7 \% \quad 44.7$
1022.53
1402.73

1402.73

1111.63

1228.71

1179.67

1395.78

1010.57

1114.65

1379.72

1691.75

1331.63

1175.67

1117.56

1753.81

966.51

1416.81

1346.67

1173.66

1374.72

1251.68

1330.71

1647.82

1020.55

1470.73

1243.57

962.53

1155.64

2029.96

1219.68

1154.62

1251.62

1407.72

999.62

1702.86

1202.64

1074.54

1293.68

1173.65

1158.67

1030.58

1400.60

1651.83

1512.70

2403.08

1749.92

1446.78

1171.66

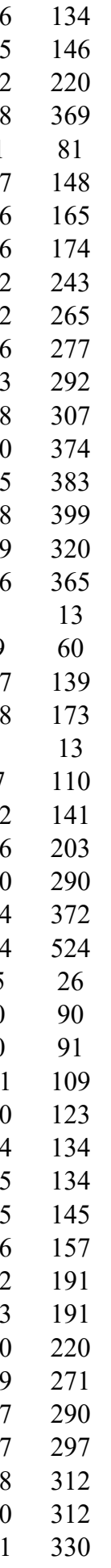

Page 89 of Table S-1-5 
Lamin-B1 GN=LMNB1 Lamin-B1 GN=LMNB Lamin-B1 GN=LMNB Lamin-B1 GN=LMNB1 Lamin-B1 GN=LMNB1 Lamin-B1 GN=LMNB1 Lamin-B2 GN=LMNB2 Lamin-B2 GN=LMNB2 Lamin-B2 GN=LMNB2 Lamin-B2 GN=LMNB2 Lamin-B2 GN=LMNB2 Lamin-B2 GN=LMNB2 Lamin-B2 GN=LMNB2 Lamin-B2 GN=LMNB2 Lamin-B2 GN=LMNB2 Lamin-B2 GN=LMNB2 Lamin-B2 GN=LMNB Lamin-B2 GN=LMNB2 Lamin-B1 GN=LMNB1 Lamin-B2 GN=LMNB2

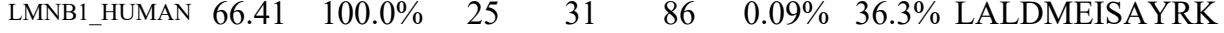
LMNB1_HUMAN $66.41 \quad 100.0 \% \quad 25 \quad 31 \quad 86 \quad 0.09 \% \quad 36.3 \%$ LLEGEEERLK

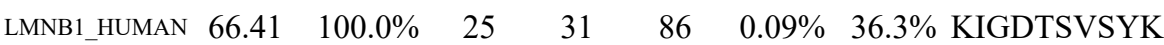
LMNB1_HUMAN $66.41 \quad 100.0 \% \quad 25 \quad 31 \quad 86 \quad 0.09 \% \quad 36.3 \%$ IGDTSVSYK

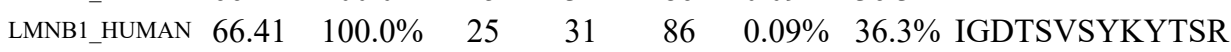

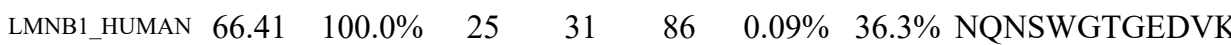
LMNB1_HUMAN $\quad 66.41 \quad 100.0 \% \quad 25$ LMNB2_HUMAN $\quad 67.69 \quad 100.0 \% \quad 12$ LMNB2_HUMAN $67.69 \quad 100.0 \% \quad 12$ LMNB2_HUMAN $67.69 \quad 100.0 \% \quad 12$ LMNB2_HUMAN $67.69 \quad 100.0 \% \quad 12$ LMNB2_HUMAN $\quad 67.69 \quad 100.0 \% \quad 12$ LMNB2_HUMAN $67.69 \quad 100.0 \% \quad 12$ LMNB2_HUMAN $67.69 \quad 100.0 \% \quad 12$ LMNB2_HUMAN $\quad 67.69 \quad 100.0 \% \quad 12$ LMNB2_HUMAN $67.69 \quad 100.0 \% \quad 12$ LMNB2 HUMAN $67.69 \quad 100.0 \% \quad 12$ LMNB2_HUMAN $67.69 \quad 100.0 \% \quad 12$ LMNB2_HUMAN $67.69 \quad 100.0 \% \quad 12$ LMNB2_HUMAN $\quad 67.69 \quad 100.0 \% \quad 12$ APPT ADPPT_HUMAN $35.78 \quad 100.0 \% \quad 2$

La-related protein $1 \mathrm{GN}=\mathrm{LARP} 1$ La-related protein $1 \mathrm{GN}=\mathrm{LARP}$ La-related protein $1 \mathrm{GN}=\mathrm{LARP} 1$ La-related protein $1 \mathrm{GN}=\mathrm{LARP} 1$ La-related protein $1 \mathrm{GN}=\mathrm{LARP} 1$ La-related protein $1 \mathrm{GN}=\mathrm{LARP} 1$ La-related protein $1 \mathrm{GN}=\mathrm{LARP}$ La-related protein $1 \mathrm{GN}=\mathrm{LARP} 1$ La-related protein $1 \mathrm{GN}=\mathrm{LARP} 1$ La-related protein $1 \mathrm{GN}=\mathrm{LARP} 1$ La-related protein $1 \mathrm{GN}=\mathrm{LARP} 1$ La-related protein $1 \mathrm{GN}=\mathrm{LARP} 1$ La-related protein $7 \mathrm{GN}=\mathrm{LARP} 7$ La-related protein $7 \mathrm{GN}=\mathrm{LARP} 7$ La-related protein $7 \mathrm{GN}=\mathrm{LARP} 7$ La-related protein $7 \mathrm{GN}=\mathrm{LARP} 7$ LARP1_HUMAN $123.51 \quad 100.0 \% \quad 12$ $\begin{array}{lll}\text { ADPPI_HUMAN } 35.78 \quad 100.0 \% & 2\end{array}$ LARP1_HUMAN $123.51 \quad 100.0 \% \quad 12$ LARP1_HUMAN $123.51 \quad 100.0 \% \quad 12$ LARP1_HUMAN $123.51 \quad 100.0 \% \quad 12$ LARP1_HUMAN $123.51 \quad 100.0 \% \quad 12$ LARP1_HUMAN $123.51 \quad 100.0 \% \quad 12$ LARP1_HUMAN $123.51 \quad 100.0 \% \quad 12$ LARP1_HUMAN $123.51 \quad 100.0 \% \quad 12$ LARP1_HUMAN $123.51 \quad 100.0 \% \quad 12$ LARP1_HUMAN $123.51 \quad 100.0 \% \quad 12$ LARP1_HUMAN $123.51 \quad 100.0 \% \quad 12$ LARP7_HUMAN $66.90 \quad 100.0 \% \quad 4$ LARP7_HUMAN $66.90 \quad 100.0 \% \quad 4$ LARP7_HUMAN $66.90 \quad 100.0 \% \quad 4$ LARP7 HUMAN $66.90 \quad 100.0 \% \quad 4$ A55 LAT1_HUMAN $55.01 \quad 100.0 \% \quad 2$ A55 LAT1_HUMAN $55.01 \quad 100.0 \% \quad 2$ C LPPRC_HUMAN $157.91 \quad 100.0 \% \quad 16$ RC LPPRC_HUMAN $157.91 \quad 100.0 \% \quad 16$

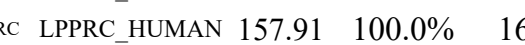
RC LPPRC_HUMAN $157.91 \quad 100.0 \% \quad 16$ RC LPPRC_HUMAN $157.91 \quad 100.0 \% \quad 16$ C LPPRC_HUMAN $157.91 \quad 100.0 \% \quad 16$ $\begin{array}{llll} & \end{array}$
$0.09 \% \quad 36.3 \%$ NQNSWGTGEDVKVILK

$0.04 \% \quad 23.7 \%$ AGGPATPLSPTR

$0.04 \% \quad 23.7 \%$ ALELENDRLLLK

$0.04 \% \quad 23.7 \%$ ISEKEEVTTR

$0.04 \% \quad 23.7 \%$ ALYESELADAR

$0.04 \% \quad 23.7 \%$ ALYESELADARR

$0.04 \% \quad 23.7 \%$ EGELTVAQGR

$0.04 \% \quad 23.7 \%$ GLESDVAELR

$0.04 \% \quad 23.7 \%$ RLVEVDSSR

$0.04 \% \quad 23.7 \%$ LSSDQNDKAASAAR

$0.04 \% \quad 23.7 \%$ LLEGEEERLK

$0.04 \% \quad 23.7 \%$ ATSSSSGSLSATGR

$0.04 \% \quad 23.7 \%$ QVLEGEEIAYKFTPK

$0.04 \% \quad 23.7 \%$ TVLVNADGEEVAMR

$0.00 \% \quad 7.4 \%$ IGQFVFAR

$0.00 \% \quad 7.4 \%$ HQDVPSQDDSKPTQR

$0.03 \% \quad 11.3 \%$ SVQPQSHKPQPTR

$0.03 \% \quad 11.3 \%$ KFDGVEGPR

$0.03 \% \quad 11.3 \%$ QHYQKETESAPGSPR

$0.03 \% \quad 11.3 \%$ ETESAPGSPR

$0.03 \% \quad 11.3 \%$ AVTPVPTKTEEVSNLK

$0.03 \% \quad 11.3 \%$ AKMSAELAK

$0.03 \% \quad 11.3 \%$ FQQVPTDALANK

$0.03 \% \quad 11.3 \%$ SLPTTVPESPNYR

$0.03 \% \quad 11.3 \%$ TPQLKDSSQTSR

$0.03 \% \quad 11.3 \%$ FYPVVKEGR

$0.03 \% \quad 11.3 \%$ YGLECLFR

$0.03 \% \quad 11.3 \%$ YYSYGLEK

$0.01 \% \quad 8.8 \%$ SSAVVELDLEGTR

$0.01 \% \quad 8.8 \% \quad$ TVYVELLPK

$0.01 \% \quad 8.8 \%$ GFAFVEFETKEQAAK

$0.01 \% \quad 8.8 \%$ AIEFLNNPPEEAPR

$0.00 \% \quad 6.3 \% \quad$ ALAAPAAEEKEEAR

$0.00 \% \quad 6.3 \%$ SADGSAPAGEGEGV

$0.04 \% \quad 13.8 \%$ EKDIQEESTFSSR

$0.04 \% \quad 13.8 \%$ SGGLGGSHALLLLR

$0.04 \% \quad 13.8 \%$ MEEANIQPNRVTYQR

$0.04 \% \quad 13.8 \%$ LIASYCNVGDIEGASK

$0.04 \% \quad 13.8 \%$ AGDMENAENILTVMR

$0.04 \% \quad 13.8 \%$ NVQGIIEILK

$0.04 \% \quad 13.8 \%$ SNTLPISLQSIR
$97.4 \% \quad 15.9 \quad 25.0$

$99.7 \% \quad 51.3 \quad 25.0$

$99.7 \% \quad 45.3$

$99.7 \% \quad 55.0$

$\begin{array}{lll}99.7 \% & 60.0 & 25.0\end{array}$

$99.7 \% \quad 52.4$

$99.7 \% \quad 55.6$

$99.7 \% \quad 51.9$

$99.7 \% \quad 66.6$

$99.7 \% \quad 51.7$

$99.7 \% \quad 50.4$

$\begin{array}{lll}98.8 \% & 26.5\end{array}$

$99.7 \% \quad 61.6$

$99.7 \% \quad 64.2$

$\begin{array}{lll}99.7 \% & 36.3\end{array}$

$99.7 \% \quad 51.3$

$99.7 \% \quad 51.3$

$99.7 \% \quad 61.2$

$\begin{array}{lll}99.7 \% & 42.7\end{array}$

$99.7 \% \quad 60.2$

$99.0 \% \quad 56.0$

$98.9 \% \quad 18.8$

$95.5 \% \quad 19.2$

$99.7 \% \quad 44.9$

$96.2 \% \quad 16.9$

$99.7 \% \quad 31.4$

$99.7 \% \quad 30.3$

$98.2 \% \quad 17.7$

$99.7 \% \quad 36.9$

$99.7 \% \quad 33.5$

$99.7 \% \quad 52.0$

$99.7 \% \quad 33.1$

$99.0 \% \quad 45.5$

$99.0 \% 24.1$

$\begin{array}{lll}99.7 \% & 38.7\end{array}$

$99.4 \% \quad 20.9$

$97.1 \% \quad 19.0$

$\begin{array}{lll}99.7 \% & 50.8\end{array}$

$99.7 \% \quad 53.5$

$99.7 \% \quad 62.9$

$99.7 \% \quad 45.3$

$99.7 \% \quad 47.3$

$\begin{array}{lll}97.7 \% & 18.9\end{array}$

$99.7 \% \quad 72.8$

$99.7 \% \quad 28.3$

$99.7 \% \quad 26.6$

$99.7 \% \quad 49.7$
1215.66

1097.58

969.49

1476.73

1334.60

1787.93

1124.61

1426.83

1191.62

1237.61

1393.71

1059.54

1088.56

1060.57

1433.70

1215.66

1268.61

1751.92

1519.74

937.53

1737.82

1489.79

1004.52

1714.8

1030.48

1712.94

948.52

1331.70

1460.74

1347.69

1094.60

1057.5

1022.48

1375.71

1061.62

1701.85

1596.80

1455.74

1701.80

1555.72

1350.79

1848.90

1696.82

1695.77

1126.68

1328.75 $\begin{array}{cc}88 & 379 \\ 80 & 389 \\ 74 & 483 \\ 75 & 483 \\ 75 & 487 \\ 17 & 528 \\ 17 & 532 \\ 9 & 20 \\ 6 & 57 \\ 8 & 67 \\ 4 & 84 \\ 4 & 85 \\ 19 & 128 \\ 52 & 161 \\ 20 & 228 \\ 71 & 284 \\ 74 & 383 \\ 97 & 410 \\ 86 & 500 \\ 42 & 555 \\ 8 & 55 \\ 53 & 267 \\ 86 & 198 \\ 67 & 375 \\ 09 & 523 \\ 14 & 523 \\ 24 & 539 \\ 69 & 677 \\ 42 & 753 \\ 66 & 778 \\ 88 & 799 \\ 00 & 808 \\ 49 & 956 \\ 57 & 964 \\ 6 & 108 \\ 26 & 134 \\ 67 & 181 \\ 82 & 195 \\ 0 & 23 \\ 1 & 48 \\ 5 & 77 \\ 15 & 128 \\ 88 & 202 \\ 03 & 218 \\ 45 & 259 \\ 54 & 463 \\ 30 & 541 \\ & \end{array}$ 

LINE-1 retrotransposable element ORF1 protein GN=L1RE1 LORF1_HUMAN $40.06 \quad 100.0 \%$ LINE-1 retrotransposable element ORF1 protein GN=L1RE1 LORF1 HUMAN $40.06 \quad 100.0 \%$ LINE-1 retrotransposable element ORF1 protein GN=L1RE1 LORF1_HUMAN $40.06 \quad 100.0 \%$ LINE-1 retrotransposable element ORF1 protein GN=L1RE1 LORF1_HUMAN $40.06 \quad 100.0 \%$ LINE-1 retrotransposable element ORF1 protein GN=L1RE1 LORF1_HUMAN $40.06100 .0 \%$ Lipopolysaccharide-responsive and beige-like anchor protein GN=LRBA LRBA_HUMAN $319.11 \quad 100.0 \%$ Lipopolysaccharide-responsive and beige-like anchor protein GN=LRBA LRBA_HUMAN $319.11 \quad 100.0 \%$ Lipopolysaccharide-responsive and beige-like anchor protein GN=LRBA LRBA_HUMAN 319.11 100.0\% Lipopolysaccharide-responsive and beige-like anchor protein GN=LRBA LRBA_HUMAN $319.11 \quad 100.0 \%$ 列 Lipopolysaccharide-responsive and beige-like anchor protein GN=LRBA LRBA_HUMAN $319.11 \quad 100.0 \%$ Lipopolysaccharide-responsive and beige-like anchor protein GN=LRBA LRBA_HUMAN $319.11 \quad 100.0 \%$ Lipopolysaccharide-responsive and beige-like anchor protein GN=LRBA LRBA HUMAN $319.11 \quad 100.0 \%$ L-lactate dehydrogenase A chain GN=LDHA LDHA_HUMAN $36.69 \quad 100.0 \%$ L-lactate dehydrogenase A chain GN=LDHA LDHA_HUMAN $36.69 \quad 100.0 \%$ L-lactate dehydrogenase A chain GN=LDHA LDHA_HUMAN $36.69 \quad 100.0 \%$ L-lactate dehydrogenase A chain GN=LDHA LDHA_HUMAN $36.69 \quad 100.0 \%$ L-lactate dehydrogenase A chain GN=LDHA LDHA HUMAN $36.69 \quad 100.0 \%$ L-lactate dehydrogenase A chain GN=LDHA LDHA_HUMAN $36.69 \quad 100.0 \%$ L-lactate dehydrogenase A chain GN=LDHA LDHA_HUMAN $36.69 \quad 100.0 \%$ L-lactate dehydrogenase A chain GN=LDHA LDHA_HUMAN $36.69 \quad 100.0 \%$ L-lactate dehydrogenase A chain GN=LDHA LDHA_HUMAN $36.69 \quad 100.0 \%$ L-lactate dehydrogenase A chain GN=LDHA LDHA HUMAN $36.69 \quad 100.0 \%$ L-lactate dehydrogenase A chain GN=LDHA LDHA_HUMAN $36.69 \quad 100.0 \%$ L-lactate dehydrogenase A chain GN=LDHA LDHA_HUMAN $36.69 \quad 100.0 \%$ L-lactate dehydrogenase A chain GN=LDHA LDHA_HUMAN $36.69 \quad 100.0 \%$ L-lactate dehydrogenase A chain GN=LDHA LDHA_HUMAN $36.69 \quad 100.0 \%$

18

24

18
18
18

8
8

18
18
18

18

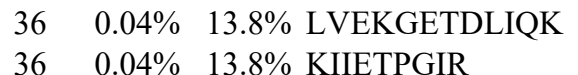

$0.04 \% \quad 13.8 \%$ GFTLNDAANSR

$0.04 \% \quad 13.8 \%$ DYLKEAVTTLK

$0.04 \% \quad 13.8 \%$ TVLDQQQTPSR

$0.04 \% \quad 13.8 \%$ MLNGLEDSIGLSK

$0.04 \% \quad 13.8 \%$ SYVSEKDVTSAK

$0.04 \% \quad 13.8 \%$ ALYEHLTAK

$0.01 \% \quad 12.0 \%$ NLSEVPQCVWR

$0.01 \% \quad 12.0 \%$ ILPEEITNLR

$0.01 \% \quad 12.0 \%$ SVPDEIILLR

$0.01 \% \quad 12.0 \%$ FLALEGNPLR

$0.01 \% \quad 12.0 \%$ VNIHAIITLK

$0.01 \% \quad 12.0 \%$ SNIVTSINFSK

$0.01 \% \quad 12.0 \%$ LQTINLSFNR

$0.00 \% \quad 7.2 \%$ LQQLPADFGR

$0.00 \% \quad 7.2 \% \quad$ LVTLPVSFAQLK

$0.00 \% \quad 1.6 \%$ TGFFEFQAAK

$0.00 \% \quad 1.6 \%$ FDDPLLGPR

$4 \quad 0.02 \% \quad 16.9 \%$ SNYSELREDIQTK

$14 \quad 0.02 \% \quad 16.9 \%$ QANVQIQEIQR

$14 \quad 0.02 \% \quad 16.9 \%$ LTADLSAETLQAR

$14 \quad 0.02 \% \quad 16.9 \%$ LSFISEGEIK

$14 \quad 0.02 \% \quad 16.9 \%$ DFVTTRPALK

$19 \quad 0.02 \% \quad 3.5 \%$ SAAAIALPPIAK

$19 \quad 0.02 \% \quad 3.5 \% \quad$ ATDAQLCLESSPK

$19 \quad 0.02 \% \quad 3.5 \% \quad$ IQNPQILK

$19 \quad 0.02 \% \quad 3.5 \% \quad$ LINDCHGSVSEASSEQK

$19 \quad 0.02 \% \quad 3.5 \% \quad$ VANEAEFILSR

$19 \quad 0.02 \% \quad 3.5 \%$ VGVGTSFGLPQTR

$19 \quad 0.02 \% \quad 3.5 \% \quad$ TSEEFVHINR

$19 \quad 0.02 \% \quad 3.5 \% \quad$ CSGIGDNPGSETAAPR

$117 \quad 0.13 \% \quad 50.0 \%$ DQLIYNLLK

$117 \quad 0.13 \% \quad 50.0 \%$ DQLIYNLLKEEQTPQNK

$117 \quad 0.13 \% \quad 50.0 \%$ ITVVGVGAVGMACAISILMK

$117 \quad 0.13 \% \quad 50.0 \%$ DLADELALVDVIEDK

$117 \quad 0.13 \% \quad 50.0 \%$ LKGEMMDLQHGSLFLR

$117 \quad 0.13 \% \quad 50.0 \%$ GEMMDLQHGSLFLR

$117 \quad 0.13 \% \quad 50.0 \%$ IVSGKDYNVTANSK

$117 \quad 0.13 \% \quad 50.0 \%$ DYNVTANSK

$117 \quad 0.13 \% \quad 50.0 \%$ LVIITAGAR

$117 \quad 0.13 \% \quad 50.0 \%$ FIIPNVVK

$117 \quad 0.13 \% \quad 50.0 \%$ NRVIGSGCNLDSAR

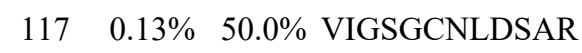

$117 \quad 0.13 \% \quad 50.0 \%$ TLHPDLGTDK

$117 \quad 0.13 \% \quad 50.0 \%$ TLHPDLGTDKDK
$99.6 \% \quad 22.5 \quad 25.0$

$99.7 \% \quad 43.1 \quad 25.0$

$99.7 \% \quad 60.4$

$99.7 \% \quad 68.2$

$99.7 \% \quad 42.7$

$99.7 \% \quad 55.5$

$99.7 \% \quad 50.3$

$99.7 \% \quad 61.6$

$99.7 \% \quad 38.7$

$99.6 \% \quad 26.5$

$99.7 \% \quad 50.6$

$99.7 \% \quad 29.5$

$99.7 \% \quad 42.3$

$99.7 \% \quad 26.8$

$99.7 \% \quad 47.0$

$99.7 \% \quad 43.0$

$99.7 \% \quad 43.4$

$99.6 \% \quad 22.0$

$98.6 \% \quad 18.6$

$99.7 \% \quad 35.2$

$99.7 \% \quad 43.4$

$99.7 \% \quad 40.6$

$99.7 \% \quad 75.6$

$99.7 \% \quad 56.4$

$99.7 \% \quad 27.8$

$99.4 \% \quad 20.2$

$\begin{array}{lll}99.7 \% & 39.5\end{array}$

$99.0 \% 33.0$

$99.6 \% \quad 23.6$

$99.7 \% \quad 55.9$

$99.7 \% \quad 33.2$

$99.7 \% \quad 60.0$

$99.7 \% \quad 36.4$

$99.7 \% \quad 54.0$

$99.7 \% \quad 42.9$

$9.7 \% \quad 48.2$

99.7\% \#\#\#\#

$98.8 \% \quad 18.6$

$99.7 \% \quad 48.2$

$99.7 \% \quad 54.2$

$99.7 \% \quad 53.3$

$99.7 \% \quad 51.5$

$99.0 \% \quad 37.1$

$\begin{array}{ll}99.7 \% & 50.9\end{array}$

$99.7 \% \quad 61.1$

$99.7 \% \quad 30.3$

$97.9 \% \quad 16.2$
1387.68

1197.68

1154.68

1129.64

1121.70

1209.65

1205.66

1144.61

1315.80

1145.56

1029.54

1582.77

1326.71

1388.74

1122.60

1147.65

1122.69

1419.68

953.58

1860.84

1248.66

1318.71

1231.61

1588.70

1119.64

2074.08

2006.08

1657.85

1906.95

1633.78

1495.78

1011.47

913.58

929.58

1518.74

1248.60

1096.56 1339.69 
$\begin{array}{llllllll}\text { L-lactate dehydrogenase A chain GN=LDHA LDHA_HUMAN } & 36.69 & 100.0 \% & 18 & 24 & 117 & 0.13 \% & 50.0 \% \\ \text { QVVESAYEVIK }\end{array}$ L-lactate dehydrogenase A chain GN=LDHA LDHA_HUMAN $36.69 \quad 100.0 \% \quad 18$ L-lactate dehydrogenase A chain GN=LDHA LDHA_HUMAN $36.69 \quad 100.0 \% \quad 18$ -lactate dehydrogenase A chain GN=LDHA LDHA_HUMAN 36.69 L-lactate dehydrogenase B chain GN=LDHB LDHB_HUMAN 36.64 L-lactate dehydrogenase B chain GN=LDHB LDHB_HUMAN 36.64

L-lactate dehydrogenase B chain GN=LDHB LDHB_HUMAN 36.64 L-lactate dehydrogenase B chain GN=LDHB LDHB_HUMAN 36.64 L-lactate dehydrogenase B chain GN=LDHB LDHB_HUMAN 36.64 L-lactate dehydrgenase B chain GN=LDHB LDHB_HUMAN 36.6 L-lactate dehydrogenase B chain GN=LDHB LDHB HUMAN $36.64 \quad 100.0 \%$ L-lactate dehydrogenase B chain GN=LDHB LDHB HUMAN $36.64 \quad 100.0 \%$ L-lactate dehydrogenase B chain GN=LDHB LDHB_HUMAN $36.64 \quad 100.0 \%$ L-lactate dehydrogenase B chain GN=LDHB LDHB_HUMAN $36.64 \quad 100.0 \%$ L-lactate dehydrogenase B chain GN=LDHB LDHB_HUMAN $36.64 \quad 100.0 \%$ L-lactate dehydrogenase B chain GN=LDHB LDHB_HUMAN $36.64 \quad 100.0 \%$ L-lactate dehydrogenase B chain GN=LDHB LDHB HUMAN $36.64 \quad 100.0 \%$ L-lactate dehydrogenase B chain GN=LDHB LDHB_HUMAN $36.64 \quad 100.0 \%$ L-lactate dehydrogenase B chain GN=LDHB LDHB_HUMAN $36.64 \quad 100.0 \%$ L-lactate dehydrogenase B chain GN=LDHB LDHB_HUMAN $36.64 \quad 100.0 \%$ L-lactate dehydrogenase B chain GN=LDHB LDHB_HUMAN $36.64 \quad 100.0 \%$ Long-chain-fatty-acid--CoA ligase $3 \mathrm{GN}=$ ACSL3 ACSL3_HUMAN $80.42 \quad 100.0 \%$ Long-chain-fatty-acid--CoA ligase $3 \mathrm{GN}=$ ACSL3 ACSL3_HUMAN $80.42 \quad 100.0 \%$ Long-chain-fatty-acid--CoA ligase $3 \mathrm{GN}=$ ACSL3 ACSL3_HUMAN $80.42 \quad 100.0 \%$ Lupus La protein $\mathrm{GN}=\mathrm{SSB}$ Lupus La protein $\mathrm{GN}=\mathrm{SSB}$ Lupus La protein $\mathrm{GN}=\mathrm{SSB}$ Lupus La protein $\mathrm{GN}=\mathrm{SSB}$ Lupus La protein $\mathrm{GN}=\mathrm{SSB}$ Lupus La protein $\mathrm{GN}=\mathrm{SSB}$ Lupus La protein $\mathrm{GN}=\mathrm{SSB}$ Lupus La protein $\mathrm{GN}=\mathrm{SSB}$ Lupus La protein $\mathrm{GN}=\mathrm{SSB}$ Lupus La protein $\mathrm{GN}=\mathrm{SSB}$ Lupus La protein $\mathrm{GN}=\mathrm{SSB}$ Lupus La protein $\mathrm{GN}=\mathrm{SSB}$ Lymphoid-specific helicase GN=HELLS Lymphoid-specific helicase GN=HELLS
Lymphoid-specific helicase GN=HELLS Lys-63-specific deubiquitinase BRCC36 GN=BRCC3 BRCC3 HUMAN $36.07 \quad 100.0 \%$ Lys-63-specific deubiquitinase BRCC36 GN=BRCC3 BRCC3_HUMAN $36.07 \quad 100.0 \%$ Lys-63-specific deubiquitinase BRCC36 GN=BRCC3 BRCC3_HUMAN $36.07 \quad 100.0 \%$ Lys-63-specific deubiquitinase BRCC36 GN=BRCC3 BRCC3 HUMAN 36.07 100.0\% Lysine--tRNA ligase GN=KARS Lysine--tRNA ligase $\mathrm{GN}=\mathrm{KARS}$ Lysine--tRNA ligase GN=KARS SYK_HUMAN $68.05 \quad 100.0 \%$ SYK_HUMAN $68.05 \quad 100.0 \%$ SYK HUMAN $68.05 \quad 100.0 \%$ Lysocardiolipin acyltransferase $1 \mathrm{GN}=$ LCLAT1 LCLT1_HUMAN $\quad 48.92 \quad 100.0 \%$

$17 \quad 0.13 \% \quad 50.0 \%$ RVHPVSTMIK

$117 \quad 0.13 \% \quad 50.0 \%$ VTLTSEEEAR

$117 \quad 0.13 \% \quad 50.0 \%$ SADTLWGIQK

$119 \quad 0.13 \% \quad 47.3 \%$ DYSVTANSK

$119 \quad 0.13 \% \quad 47.3 \%$ IVVVTAGVR

$119 \quad 0.13 \% \quad 47.3 \%$ FIIPQIVK

$119 \quad 0.13 \% \quad 47.3 \%$ MVVESAYEVIK

$119 \quad 0.13 \% \quad 47.3 \%$ GLTSVINQK

$119 \quad 0.13 \% \quad 47.3 \%$ LKDDEVAQLK

$119 \quad 0.13 \% \quad 47.3 \%$ KSADTLWDIQK

$119 \quad 0.13 \% \quad 47.3 \%$ SADTLWDIQK

$0.01 \% \quad 5.4 \%$ THYQADIER

LA_HUMAN $46.84 \quad 100.0 \% \quad 12$

LA HUMAN $46.84 \quad 100.0 \% \quad 12$

LA_HUMAN $46.84 \quad 100.0 \% \quad 12$

LA_HUMAN $46.84 \quad 100.0 \% \quad 12$

LA_HUMAN $46.84 \quad 100.0 \% \quad 12$

LA_HUMAN $46.84 \quad 100.0 \% \quad 12$

LA HUMAN $46.84 \quad 100.0 \% \quad 12$

$\begin{array}{ll}\text { LA_HUMAN } 46.84 & 100.0 \%\end{array}$

$46.84 \quad 100.0 \% \quad 12$

$0.03 \% \quad 24.3 \%$ KFVETPGQK

$0.03 \% 24.3 \%$ FVETPGQK

$0.03 \% \quad 24.3 \%$ QKLEEDAEMK

$30 \quad 0.03 \% \quad 24.3 \%$ EGIILFKEK

$0.03 \% \quad 24.3 \%$ DANNGNLQLR

$0.03 \% \quad 24.3 \%$ IIEDQQESLNK

$0.01 \% \quad 3.8 \%$ EVVVYAPLSK

$0.01 \% \quad 3.8 \%$ KQEIFYTAIVNR

$0.01 \% \quad 3.8 \%$ GGQSGLNLSK

$0.01 \% \quad 14.2 \%$ FAYTGTEMR

$0.01 \% \quad 14.2 \%$ VCLESAVELPK

$0.01 \% \quad 14.2 \%$ IHSLTHLDSVTK

$0.01 \% \quad 4.9 \%$ SKIITYIR

$0.01 \% \quad 4.9 \%$ QLFEEQAK

$0.00 \% \quad 4.8 \%$ TTGFTFVVDR
$99.7 \% \quad 58.5$

$99.7 \% \quad 61.8$

$\begin{array}{ll}99.7 \% & 61.8 \\ 99.7 \% & 57.5\end{array}$

$119 \quad 0.13 \% \quad 47.3 \%$ EKLIAPVAEEEATVPNNK

$119 \quad 0.13 \% \quad 47.3 \%$ LIAPVAEEEATVPNNK

$99.7 \% 52.3$

$119 \quad 0.13 \% \quad 47.3 \%$ ITVVGVGQVGMACAISILGK $\quad 99.7 \% \quad 55.3$

$119 \quad 0.13 \% \quad 47.3 \%$ SLADELALVDVLEDK $\quad 99.7 \% \quad 62.7$

$119 \quad 0.13 \% \quad 47.3 \%$ LKGEMMDLQHGSLFLQTPK $99.7 \% 32.1$

$119 \quad 0.13 \% \quad 47.3 \%$ GEMMDLQHGSLFLQTPK $\quad 99.7 \% \quad 50.3$

$119 \quad 0.13 \% \quad 47.3 \%$ IVADKDYSVTANSK $\quad 99.7 \% \quad 57.8$

$119 \quad 0.13 \% \quad 47.3 \%$ HRVIGSGCNLDSAR

$119 \quad 0.13 \% \quad 47.3 \%$ VIGSGCNLDSAR

$0.01 \% \quad 5.4 \% \quad$ IGYSSPQTLADQSSK

$0.01 \% \quad 5.4 \% \quad$ LLLCGGAPLSATTQR

$99.7 \% \quad 37.0$

$99.7 \% \quad 59.9$

$99.0 \% \quad 32.3$

$99.7 \% 37.4$

$99.7 \% \quad 61.1$

$99.7 \% \quad 55.0$

$99.7 \% \quad 56.3$

$99.7 \% \quad 54.9$

$99.7 \% \quad 49.8$

$99.7 \% \quad 66.7$

$99.7 \% \quad 65.2$

$99.7 \% 70.1$

$98.0 \% \quad 18.5$

$99.7 \% 53.4$

$0.03 \% \quad 24.3 \%$ LTTDFNVIVEALSK

$0.03 \% \quad 24.3 \%$ SPSKPLPEVTDEYKNDVK

$0.03 \% \quad 24.3 \%$ GSIFVVFDSIESAK

$0.03 \% \quad 24.3 \%$ GSIFVVFDSIESAKK

$30 \quad 0.03 \% \quad 24.3 \%$ AKDANNGNLQLR

$\quad 0.03 \% \quad 24.3 \%$ IIEDQQESLNKWK

$0.01 \% \quad 14.2 \%$ VLYTCFQSIQAQK

$0.01 \% \quad 4.9 \%$ RGDIIGVQGNPGK 
Lysocardiolipin acyltransferase 1 GN=LCLAT1 LCLT1_HUMAN $48.92 \quad 100.0 \%$ Lysophospholipid acyltransferase $7 \mathrm{GN}=$ MBOAT7 MBOA7_HUMAN $52.77 \quad 100.0 \%$ Lysophospholipid acyltransferase $7 \mathrm{GN}=$ MBOAT7 MBOA7_HUMAN $52.77 \quad 100.0 \%$ Lysophospholipid acyltransferase $7 \mathrm{GN}=$ MBOAT7 MBOA7_HUMAN $52.77 \quad 100.0 \%$ Magnesium transporter protein $1 \mathrm{GN}=$ MAGT1 MAGT1_HUMAN $38.04 \quad 100.0 \%$ Magnesium transporter protein $1 \mathrm{GN}=$ MAGT1 MAGT1_HUMAN $38.04 \quad 100.0 \%$ Magnesium transporter protein $1 \mathrm{GN}=$ MAGT1 MAGT1_HUMAN $38.04 \quad 100.0 \%$ Malate dehydrogenase, mitochondrial GN=MDH2 MDHM_HUMAN $35.50 \quad 100.0 \%$ Malate dehydrogenase, mitochondrial GN=MDH2 MDHM HUMAN $35.50 \quad 100.0 \%$ Malate dehydrogenase, mitochondrial GN=MDH2 MDHM_HUMAN $35.50 \quad 100.0 \%$ Malate dehydrogenase, mitochondrial GN=MDH2 MDHM_HUMAN $35.50 \quad 100.0 \%$ Malate dehydrogenase, mitochondrial GN=MDH2 MDHM HUMAN $35.50 \quad 100.0 \%$ Malate dehydrogenase, mitochondrial GN=MDH2 MDHM_HUMAN $35.50 \quad 100.0 \%$ Malonyl-CoA-acyl carrier protein transacylase, mitochondrial GN=MCAT FABD_HUMAN $42.96 \quad 100.0 \%$ Menyl-CoA-acyl carrier protein transacylase, mitochondrial GN=MCAT FABD HUMAN $42.96 \quad 100.0 \%$ Mannose-1-phosphate guanyltransferase alpha GN=GMPPA GMPPA_HUMAN $46.29 \quad 100.0 \%$ Mannose-1-phosphate guanyltransferase alpha GN=GMPPA GMPPA HUMAN $46.29100 .0 \%$ Mannose-1-phosphate guanyltransferase alpha GN=GMPPA GMPPA_HUMAN $46.29 \quad 100.0 \%$ Mannose-1-phosphate guanyltransferase alpha GN=GMPPA GMPPA_HUMAN $46.29 \quad 100.0 \%$ Mannose-1-phosphate guanyltransferase alpha GN=GMPPA GMPPA_HUMAN $46.29100 .0 \%$ Mannose-1-phosphate guanyltransferase alpha GN=GMPPA GMPPA_HUMAN $46.29 \quad 100.0 \%$ Mannose-1-phosphate guanyltransferase alpha GN=GMPPA GMPPA_HUMAN $46.29 \quad 100.0 \%$ Mannose-P-dolichol utilization defect 1 protein GN=MPDU1 MPU1_HUMAN $26.64 \quad 100.0 \%$ Mannose-P-dolichol utilization defect 1 protein GN=MPDU1 MPU1_HUMAN $26.64100 .0 \%$ MAP7 domain-containing protein 1 GN=MAP7D1 MA7D1_HUMAN $92.82 \quad 100.0^{\circ}$ MAP7 domain-containing protein 1 GN=MAP7D1 MA7D1_HUMAN $92.82 \quad 100.0 \%$ Matrin-3 GN=MATR3

Matrin-3 GN=MATR3 Matrin-3 GN=MATR3 Matrin-3 GN=MATR3 Matrin-3 GN=MATR3 Matrin-3 GN=MATR3 Matrin-3 GN=MATR3 Matrin-3 GN=MATR3 Matrin-3 GN=MATR3 Matrin-3 GN=MATR3 Matrin-3 GN=MATR3 Matrin-3 GN=MATR3 Matrin-3 GN=MATR3 Matrin-3 GN=MATR3 Matrin-3 GN=MATR3 Matrin-3 GN=MATR3 Matrin-3 GN=MATR3 Matrin-3 GN=MATR3 Matrin-3 GN=MATR3 Mediator of DNA damage checkpoint protein $1 \mathrm{GN}=\mathrm{MDC} 1 \mathrm{MDC1}$ _HUMAN $226.66 \quad 100.0 \%$

MATR3_HUMAN $94.63 \quad 100.0 \%$

MATR3_HUMAN $94.63 \quad 100.0 \%$

MATR3 HUMAN $94.63 \quad 100.0 \%$

MATR3_HUMAN $94.63 \quad 100.0 \%$

MATR3_HUMAN $94.63 \quad 100.0 \%$ MATR3 HUMAN $94.63 \quad 100.0^{\circ}$ MATR3_HUMAN $94.63 \quad 100.0 \%$ MATR3_HUMAN $94.63 \quad 100.0 \%$ MATR3 HUMAN $94.63 \quad 100.0 \%$ MATR3_HUMAN $94.63 \quad 100.0 \%$ MATR3 HUMAN $94.63 \quad 100.0 \%$ MATR3_HUMAN $94.63 \quad 100.0 \%$ MATR3_HUMAN $94.63 \quad 100.0 \%$ MATR3 HUMAN $94.63 \quad 100.0 \%$ MATR3_HUMAN $94.63 \quad 100.0 \%$
$0.00 \% \quad 4.8 \% \quad$ YPIDTLPTSK $0.01 \% \quad 8.7 \%$ AGGGPTLQCPPPSSPEK $0.01 \% \quad 8.7 \%$ AASLEYDYETIR $99.7 \% \quad 30.5$ 99.7

$0.01 \% \quad 8.7 \%$ AASQPTSLAPEK

$0.01 \% \quad 8.1 \% \quad$ YSSAFTNR

$0.01 \% \quad 8.1 \%$ RGDTYELQVR

$0.01 \% \quad 8.1 \%$ GFSAEQIAR

$0 \quad 0.01 \% \quad 23.7 \%$ VAVLGASGGIGQPLSLLLK

$10 \quad 0.01 \% \quad 23.7 \%$ IFGVTTLDIVR

$10 \quad 0.01 \% \quad 23.7 \%$ ANTFVAELK

$10 \quad 0.01 \% \quad 23.7 \%$ VNVPVIGGHAGK

$10 \quad 0.01 \% \quad 23.7 \%$ TIIPLISQCTPK

$10 \quad 0.01 \% \quad 23.7 \%$ SQETECTYFSTPLLLGK

$2 \quad 0.00 \% \quad 5.4 \%$ VISGHQEALR

$0.00 \% \quad 5.4 \%$ LLAQQLVSPVK

$0.01 \% \quad 18.8 \%$ AVILIGGPQK

$0.01 \% \quad 18.8 \%$ SAGSALYASR

$0.01 \% \quad 18.8 \%$ GNVYIHPTAK

$0.01 \% \quad 18.8 \%$ VAPSAVLGPNVSIGK

$0.01 \% \quad 18.8 \%$ GVTVGEGVR

$0.01 \% \quad 18.8 \%$ VEGTPSDPNPNDPR

$0.01 \% \quad 18.8 \%$ LLPAITILGCR

$0.00 \% \quad 9.7 \%$ LLVPILLPEK

$0.00 \% \quad 9.7 \%$ GLGLGIVAGSLLVK

$0.00 \% \quad 3.0 \%$ RKPNAGGSPAPVR

$0.00 \% \quad 3.0 \%$ AVVQSPQVTEVL

$0.08 \% \quad 22.3 \%$ SFQQSSLSR

$0.08 \% \quad 22.3 \%$ GPLPLSSQHR MATR3_HUMAN $94.63 \quad 100.0 \% \quad 19$ MATR3_HUMAN $94.63 \quad 100.0 \% \quad 19$ $\begin{array}{llll}\text { MATR_HUMAN } & 94.63 & 100.0 \% & 19 \\ \text { MATR3 HUMAN } & 94.63 & 100.0 \% & 19\end{array}$ $0.08 \% \quad 22.3 \%$ GDADQASNILASFGLSAR $0.08 \% \quad 22.3 \%$ RTEEGPTLSYGR

$0.08 \% \quad 22.3 \%$ TEEGPTLSYGR $0.08 \% \quad 22.3 \%$ TEEGPTLSYGRDGR $0.08 \% \quad 22.3 \%$ MGRGPGPLQER $0.08 \% \quad 22.3 \%$ GPGPLQER $0.08 \% \quad 22.3 \%$ GNLGAGNGNLQGPR $0.08 \% \quad 22.3 \%$ VVHIMDFQR $0.08 \% \quad 22.3 \%$ FDQKQELGR 44.5 $99.7 \% \quad 40.7$ $99.7 \% \quad 32.6$ $99.0 \% \quad 47.6$ $\begin{array}{lll}99.7 \% & 42.8\end{array}$ $99.7 \% \quad 37.9$ $99.7 \% \quad 71.7$ $99.7 \% \quad 34.2$ $99.7 \% \quad 41.0$ $95.1 \% \quad 17.9$ $99.6 \% \quad 25.5$ $99.7 \% \quad 40.9$ $\begin{array}{lll}99.7 \% & 36.1\end{array}$ $99.7 \% \quad 60.8$ $99.7 \% \quad 34.4$ $99.7 \% \quad 43.9$ $96.4 \% 15.1$ $99.7 \% \quad 47.4$ $99.7 \% \quad 44.9$ $\begin{array}{lll}99.7 \% & 49.2\end{array}$ $99.7 \% \quad 29.0$ $99.3 \% 24.1$ $99.7 \% \quad 46.1$ $99.4 \% 25.9$

$99.4 \% \quad 25.6$ $99.7 \% \quad 65.8$ $99.7 \% \quad 37.0$

\section{$\begin{array}{ll}99.7 \% & 50.8 \\ 99.7 \% & 55.2\end{array}$}

$\begin{array}{lll}99.7 \% & 49.2\end{array}$

$99.7 \% \quad 30.3$

$99.7 \% \quad 46.5$

$99.0 \% \quad 41.4$

$99.7 \% \quad 51.5$

$99.7 \% \quad 41.8$ $99.7 \% \quad 46.1$ $0.08 \% \quad 22.3 \%$ VIHLSNLPHSGYSDSAVLK $99.7 \% 30.4$ $0.08 \% \quad 22.3 \%$ LAEPYGKIK $0.08 \% \quad 22.3 \%$ IKNYILMR $99.6 \% 27.6$ $96.6 \% \quad 23.6$ $99.0 \% 25.3$

$0.08 \% \quad 22.3 \%$ LVLRIPNR $0.08 \% \quad 22.3 \%$ IGPYQPNVPVGIDYVIPK $0.08 \% \quad 22.3 \%$ LCSLFYTNEEVAK $0.08 \% \quad 22.3 \%$ NTHCSSLPHYQK $0.08 \% \quad 22.3 \%$ FLNKLAEER $0.01 \% \quad 1.9 \%$ GPLTVEETPR $0.01 \% \quad 1.9 \%$ EGAQVPTGR $\begin{array}{llll}99.7 \% & 54.5 & 25.0 & 49.5\end{array}$ $99.5 \% \quad 26.9 \quad 25.0 \quad 26.3$ $\begin{array}{llll}99.7 \% & 43.0 & 25.0 & 24.6\end{array}$ $99.6 \% \quad 24.6 \quad 25.0 \quad 19.6$ $\begin{array}{llll}99.7 \% & 36.2 & 25.0 & 26.2\end{array}$ 1679.81

1430.68

1199.63

945.44

1236.63

978.50

1793.09

1233.72

992.54

1147.66

1370.77

1973.95

1109.61

1195.74

995.63

982.50

1099.59

1408.82

873.48

1494.68

1226.73

1134.75

1296.83

1306.73

1269.70

1039.52

1091.60

1792.88

1365.68

1209.57

1537.72

1213.6

853.45

1324.67

1144.59

1120.57

2037.08

1018.59

1066.61

980.64

1969.08

1573.76

1471.67

1119.62

1098.58

914.47

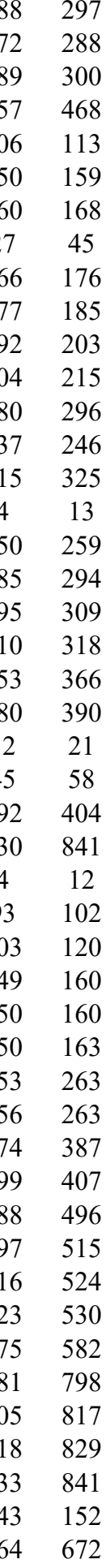

Page 93 of Table S-1-5 
Melanoma-associated antigen D2 GN=MAGED2 MAGD2_HUMAN $64.96 \quad 100.0 \%$ Melanoma-associated antigen D2 GN=MAGED2 MAGD2_HUMAN $64.96 \quad 100.0 \%$ Melanoma-associated antigen D2 GN=MAGED2 MAGD2_HUMAN $64.96 \quad 100.0 \%$ Melanoma-associated antigen D2 GN=MAGED2 MAGD2_HUMAN $64.96 \quad 100.0 \%$ Melanoma-associated antigen D2 GN=MAGED2 MAGD2_HUMAN $64.96 \quad 100.0 \%$ Methionine--tRNA ligase, cytoplasmic GN=MARS SYMC_HUMAN $101.12 \quad 100.0 \%$ Methionine--tRNA ligase, cytoplasmic GN=MARS SYMC_HUMAN $101.12 \quad 100.0 \%$ Methionine--tRNA ligase, cytoplasmic GN=MARS SYMC HUMAN $101.12 \quad 100.0 \%$ Methionine--tRNA ligase, cytoplasmic GN=MARS SYMC_HUMAN $101.12 \quad 100.0 \%$ Methionine--tRNA ligase, cytoplasmic GN=MARS SYMC_HUMAN $101.12 \quad 100.0 \%$ Methionine--tRNA ligase, cytoplasmic GN=MARS SYMC_HUMAN $101.12 \quad 100.0 \%$ Methionine--tRNA ligase, cytoplasmic GN=MARS SYMC_HUMAN $101.12 \quad 100.0 \%$ Methionine--tRNA ligase, cytoplasmic GN=MARS SYMC HUMAN $101.12 \quad 100.0 \%$ Methionyl-tRNA formyltransferase, mitochondrial GN=MTFMT FMT_HUMAN $43.83 \quad 100.0 \%$ Methionyl-tRNA formyltransferase, mitochondrial GN=MTFMT FMT_HUMAN $43.83 \quad 100.0 \%$ Methionyl-tRNA formyltransferase, mitochondrial GN=MTFMT FMT HUMAN $43.83 \quad 100.0 \%$ Methionyl-tRNA formyltransferase, mitochondrial GN=MTFMT FMT_HUMAN $43.83 \quad 100.0 \%$ Methylosome protein $50 \mathrm{GN}=$ WDR77 Methylosome protein $50 \mathrm{GN}=$ WDR77 Methylosome protein $50 \mathrm{GN}=\mathrm{WDR} 77$ Methylosome protein $50 \mathrm{GN}=$ WDR77 Methylosome protein $50 \mathrm{GN}=$ WDR77 Methylosome protein $50 \mathrm{GN}=\mathrm{WDR} 77$ Methylosome protein $50 \mathrm{GN}=\mathrm{WDR} 77$ Methylosome protein $50 \mathrm{GN}=\mathrm{WDR} 77$ Methylosome protein $50 \mathrm{GN}=$ WDR77 Methylosome protein $50 \mathrm{GN}=\mathrm{WDR} 77$ Methylosome protein $50 \mathrm{GN}=\mathrm{WDR} 77$ MEP50_HUMAN $36.72 \quad 100.0 \%$ MEP50 HUMAN $36.72 \quad 100.0 \%$ MEP50_HUMAN $36.72 \quad 100.0 \%$ MEP50 HUMAN $36.72 \quad 100.0 \%$ MEP50_HUMAN $36.72 \quad 100.0 \%$ MEP50_HUMAN $36.72 \quad 100.0 \%$ MEP50 HUMAN $36.72 \quad 100.0 \%$ MEP50_HUMAN $36.72 \quad 100.0 \%$ MEP50_HUMAN $36.72 \quad 100.0 \%$ MEP50_HUMAN $36.72 \quad 100.0 \%$ MEP50_HUMAN $36.72 \quad 100.0 \%$ M thylosome subunit pICln GN=CLNS1A ICLN_HUMAN $26.22 \quad 100.0 \%$ Methylosome subunit pICln GN=CLNS1A ICLN_HUMAN $26.22 \quad 100.0 \%$ Methylosome subunit pICln GN=CLNS1A ICLN_HUMAN $26.22 \quad 100.0 \%$ Methylosome subunit pICln GN=CLNS1A ICLN_HUMAN $26.22 \quad 100.0 \%$ Methylosome subunit pICln GN=CLNS1A ICLN_HUMAN $26.22 \quad 100.0 \%$ Methylthioribose-1-phosphate isomerase GN=MRI1 MTNA_HUMAN $39.15 \quad 100.0 \%$ Methylthioribose-1-phosphate isomerase GN=MRI1 MTNA_HUMAN $39.15 \quad 100.0 \%$ Methylthioribose-1-phosphate isomerase GN=MRI1 MTNA_HUMAN $39.15 \quad 100.0 \%$ Methylthioribose-1-phosphate isomerase GN=MRI1 MTNA_HUMAN $39.15100 .0 \%$ Methylthioribose-1-phosphate isomerase GN=MRI1 MTNA_HUMAN $39.15 \quad 100.0 \%$

$11 \quad 0.01 \% \quad 1.9 \% \quad$ NQLVTPEPTSR

$4 \quad 0.02 \% \quad 21.6 \%$ EEIIPVAAEYDK $0.02 \% 21.6 \%$ KGDEYIINGQK $0.02 \% \quad 21.6 \%$ SDPDPKAPANK $0.02 \% 21.6 \%$ AFTGFIVEADTPGIQIGR $0.02 \% \quad 21.6 \%$ GIVFEDVKVPK $0.02 \% \quad 21.6 \%$ TRPVVAAGAVGLAQR $0.02 \% \quad 21.6 \%$ IYQIYEGTSQIQR $0.01 \% \quad 11.1 \%$ ALEVSEDVKVSK $10 \quad 0.01 \% \quad 11.1 \%$ ATEVSKTPEAR $0.01 \% \quad 11.1 \%$ EAPATQASSTTQLTDTQVLAAENK $10 \quad 0.01 \% \quad 11.1 \%$ VSHVADTKVNTK $10 \quad 0.01 \% \quad 11.1 \%$ GPIAFWAR $0.02 \% \quad 8.6 \%$ KGEDVLGSVR $0.02 \% \quad 8.6 \%$ ALTHIDHSLSR $0.02 \% \quad 8.6 \%$ QPQPSPAEGR $0.02 \% \quad 8.6 \%$ RLEEWLGR $0.02 \% \quad 8.6 \%$ LENDQIESLR $0.02 \% \quad 8.6 \%$ LENDQIESLRQR $0.02 \% \quad 8.6 \%$ ADKNEVAAEVAK $0.02 \% \quad 8.6 \%$ QLAVAEGKPPEAPK $0.01 \% \quad 12.1 \%$ VLFFGTDQFAR $0.01 \% \quad 12.1 \%$ LLNEALILK $0.01 \% \quad 12.1 \%$ LGANMLISVLK $0.01 \% \quad 12.1 \%$ LLDLVEVNSSVLADPK $123 \quad 0.13 \% \quad 32.7 \%$ KETPPPLVPPAAR

$123 \quad 0.13 \% \quad 32.7 \%$ ETPPPLVPPAAR

$23 \quad 0.13 \% \quad 32.7 \%$ EWNLPPNAPACMER

$99.7 \% \quad 36.4$

$98.4 \% \quad 24.5$

$99.7 \% \quad 53.3$

$95.8 \% 16.5$

$99.7 \% \quad 59.5$

$99.7 \% \quad 37.3$

$99.7 \% \quad 50.5$

$99.7 \% 70.0$

$99.7 \% \quad 59.8$

$99.7 \% \quad 54.0$

$98.1 \% \quad 22.2$

$\begin{array}{lll}99.7 \% & 39.6\end{array}$

$99.0 \% \quad 39.5$

$99.7 \% \quad 36.9$

$99.7 \% \quad 36.0$

$99.7 \% \quad 33.3$

$99.0 \% 27$.

$99.7 \% \quad 54.8$

$99.7 \% \quad 25.5$

$99.7 \% \quad 37.2$

$99.7 \% \quad 63.7$

$99.7 \% \quad 42.9$

$97.1 \% \quad 21.0$

$99.7 \% \quad 34.5$

$99.7 \% \quad 60.9$

$99.7 \% \quad 57.2$

$99.7 \% \quad 39.2$

$99.7 \% \quad 41.0$

$0.13 \% \quad 32.7 \%$ YRSDGALLLGASSLSGR $\quad 99.7 \% \quad 57.0$

$3 \quad 0.13 \% \quad 32.7 \%$ SDGALLLGASSLSGR

$99.7 \% \quad 53.9$

$0.13 \% \quad 32.7 \%$ VWDLAQQVVLSSYR

123

$0.13 \% \quad 32.7 \%$ AHAAQVTCVAASPHK

23

123

31

31

31

31

31

27

27

27

$15 \quad 27$

$15 \quad 27$
$0.13 \% \quad 32.7 \%$ DSVFLSCSEDNR

$0.03 \% \quad 31.2 \%$ SFPPPGPAEGLLR

$0.03 \% \quad 31.2 \%$ QQPDTEAVLNGK

$0.03 \% \quad 31.2 \%$ GLGTGTLYIAESR

$0.03 \% \quad 31.2 \%$ DRSDCLGEHLYVMVNAK

$0.03 \% \quad 31.2 \%$ LEGMLSQSVSSQYNMAGVR

$0.03 \% \quad 39.3 \%$ GSLQILDQLLLPK

$0.03 \% \quad 39.3 \%$ DLADVAAR

$0.03 \% \quad 39.3 \%$ EAEREGATEEAVR

$0.03 \% 39.3 \%$ EGATEEAVRER

$0.03 \% \quad 39.3 \%$ VICCTEDMLEK $\begin{array}{lll}99.7 \% & 54.2\end{array}$

$99.7 \% \quad 54.0$

$99.7 \% \quad 47.6$

$99.7 \% \quad 64.4$

$99.7 \% \quad 51.7$

$99.7 \% \quad 33.1$

$99.7 \% \quad 53.7$

$99.7 \% \quad 84.8$

$\begin{array}{ll}.7 \% & 42.8\end{array}$

$99.7 \% \quad 43.5$

$99.0 \% \quad 32.8$

$99.7 \% \quad 44.4$

$99.5 \% 31.0$

$99.6 \% \quad 26.6$
1202.65

1376.69

1264.65

1139.57

1891.99

1230.7

1465.86

1598.82

1303.71

1188.62

2475.22

1298.7

917.50

1059.58

1249.66

1066.53

1058.57

1216.62

1500.78

1244.65

1434.80

1300.67

1026.66

1158.69

1711.95

1372.79

1244.70

1700.75

1722.9

1403.75

2901.39

2466.20

1663.88

1547.77

2957.36

1428.61

1337.72

1299.65

1337.71

2006.94

2072.97

1437.87

830.44

1446.68

1246.60 1397.61

$\begin{array}{cc}85 & 1595 \\ 97 & 1806 \\ 8 & 69 \\ 79 & 189 \\ 07 & 217 \\ 18 & 235 \\ 49 & 259 \\ 80 & 294 \\ 96 & 408 \\ 8 & 59 \\ 6 & 76 \\ 7 & 100 \\ 26 & 137 \\ 20 & 227 \\ 09 & 118 \\ 20 & 130 \\ 05 & 214 \\ 60 & 467 \\ 05 & 814 \\ 05 & 816 \\ 64 & 875 \\ 82 & 895 \\ 0 & 60 \\ 29 & 137 \\ 11 & 221 \\ 85 & 300 \\ 3 & 15 \\ 4 & 15 \\ 6 & 29 \\ 6 & 52 \\ 8 & 52 \\ 19 & 145 \\ 22 & 145 \\ 51 & 164 \\ 65 & 179 \\ 65 & 191 \\ 80 & 191 \\ 6 & 18 \\ 9 & 30 \\ 1 & 43 \\ 9 & 85 \\ 88 & 206 \\ 1 & 23 \\ 02 & 109 \\ 10 & 122 \\ 14 & 124 \\ 25 & 135 \\ & \end{array}$


Methylthioribose-1-phosphate isomerase GN=MRI1 MTNA_HUMAN $39.15 \quad 100.0 \%$ Methylthioribose-1-phosphate isomerase GN=MRI1 MTNA_HUMAN $39.15 \quad 100.0 \%$ Methylthioribose-1-phosphate isomerase GN=MRI1 MTNA_HUMAN $39.15 \quad 100.0 \% \quad 12$ Methylthioribose-1-phosphate isomerase GN=MRI1 MTNA HUMAN $39.15 \quad 100.0 \%$ Methylthioribose-1-phosphate isomerase GN=MRI1 MTNA_HUMAN $39.15 \quad 100.0 \% \quad 12$ Methylthioribose-1-phosphate isomerase GN=MRI1 MTNA_HUMAN $39.15 \quad 100.0 \%$ Methylthioribose-1-phosphate isomerase GN=MRI1 MTNA HUMAN $39.15 \quad 100.0 \%$ MICOS complex subunit MIC27 GN=APOOL MIC27_HUMAN $29.16 \quad 100.0 \%$ MICOS complex subunit MIC27 GN=APOOL MIC27 HUMAN $29.16 \quad 100.0 \%$ MICOS complex subunit MIC27 GN=APOOL MIC27_HUMAN $29.16 \quad 100.0 \%$ MICOS complex subunit MIC27 GN=APOOL MIC27_HUMAN $29.16 \quad 100.0 \%$ MICOS complex subunit MIC27 GN=APOOL MIC27 HUMAN $29.16 \quad 100.0 \%$ MICOS complex subunit MIC60 GN=IMMT MIC60_HUMAN $83.68 \quad 100.0 \%$ MICOS complex subunit MIC60 GN=IMMT MIC60 HUMAN $83.68 \quad 100.0 \%$ MICOS complex subunit MIC60 GN=IMMT MIC60 HUMAN $83.68 \quad 100.0 \%$ MICOS complex subunit MIC60 GN=IMMT MIC60_HUMAN $83.68 \quad 100.0 \%$ MICOS complex subunit MIC60 GN=IMMT MIC60 HUMAN $83.68 \quad 100.0 \%$ Midasin GN=MDN1

Midasin GN=MDN1

Midasin $\mathrm{GN}=\mathrm{MDN} 1$

Midasin GN=MDN1

Midasin GN=MDN1

Midasin GN=MDN1

Midasin GN=MDN1

Midasin GN=MDN1

Midasin GN=MDN1

Midasin $\mathrm{GN}=\mathrm{MDN} 1$

Midasin GN=MDN1 MDN1_HUMAN $632.83 \quad 100.0 \% \quad 12$ MDN1_HUMAN $632.83 \quad 100.0 \% \quad 12$ MDN1_HUMAN $632.83 \quad 100.0 \% \quad 12$ MDN1_HUMAN $632.83 \quad 100.0 \% \quad 12$ MDN1_HUMAN $632.83 \quad 100.0 \% \quad 12$ MDN1_HUMAN $632.83 \quad 100.0 \% \quad 12$ MDN1_HUMAN $632.83 \quad 100.0 \% \quad 12$ MDN1_HUMAN $632.83 \quad 100.0 \% \quad 12$ MDN1_HUMAN $632.83 \quad 100.0 \% \quad 12$ MDN1_HUMAN $632.83 \quad 100.0 \% \quad 12$
Midasin GN=MDN1

15

15

15
7
7

(1)

5
5

5
5
5

5

5
5
5
5

5
12
12
MDN1_HUMAN $632.83 \quad 100.0 \% \quad 12$

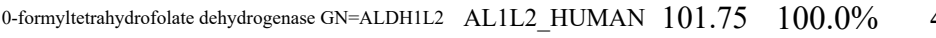
Mitochondrial 10-formyltetrahydrofolate dehydrogenase GN=ALDH1L2 AL1L2_HUMAN $101.75 \quad 100.0 \%$ Mitochondrial 10-formyltetrahydrofolate dehydrogenase GN=ALDH1L2 AL1L2_HUMAN $101.75 \quad 100.0 \%$ Mitochondrial 10-formyltetrahydrofolate dehydrogenase GN=ALDH1L2 AL1L2 HUMAN 101.75 100.0\% Mitochondrial 2-oxoglutarate/malate carrier protein GN=SLC25A11 M2OM_HUMAN $34.06 \quad 100.0 \%$ Mitochondrial 2-oxoglutarate/malate carrier protein GN=SLC25A11 $\quad$ M2OM_HUMAN $34.06 \quad 100.0 \%$ Mitochondrial 2-oxoglutarate/malate carrier protein GN=SLC25A11 M2OM_HUMAN $34.06 \quad 100.0 \%$ Mitochondrial 2-oxoglutarate/malate carrier protein GN=SLC25A11 $\quad$ M2OM_HUMAN $34.06 \quad 100.0 \%$ Mitochondrial 2-oxoglutarate/malate carrier protein GN=SLC25A11 M2OM HUMAN $34.06 \quad 100.0 \%$ Mitochondrial 2-oxoglutarate/malate carrier protein GN=SLC25A11 M2OM_HUMAN $34.06 \quad 100.0 \%$ Mitochondrial 2-oxoglutarate/malate carrier protein GN=SLC25A11 $\quad$ M2OM_HUMAN $34.06 \quad 100.0 \%$ Mitochondrial 2-oxoglutarate/malate carrier protein GN=SLC25A11 $\quad$ M2OM_HUMAN $34.06 \quad 100.0 \% \quad 13$ $\begin{array}{lllll}\text { Mitochondrial 2-oxoglutarate/malate carrier protein GN=SLC25A11 } & \text { M2OM_HUMAN } 34.06 & 100.0 \% & 13\end{array}$ Mitochondrial 2-oxoglutarate/malate carrier protein GN=SLC25A11 $\quad$ M2OM_HUMAN $34.06 \quad 100.0 \% \quad 13$ $\begin{array}{llll}\text { Mitochondrial 2-oxoglutarate/malate carrier protein GN=SLC25A11 } & \text { M2OM_HUMAN } & 34.06 & 100.0 \%\end{array}$ $\begin{array}{lllll}\text { Mitochondrial 2-oxoglutarate/malate carrier protein GN=SLC25A11 } & \text { M2OM_HUMAN } & 34.06 & 100.0 \% & 13\end{array}$ Mitochondrial 2-oxoglutarate/malate carrier protein GN=SLC25A11 $\quad$ M2OM_HUMAN $34.06 \quad 100.0 \% \quad 13$

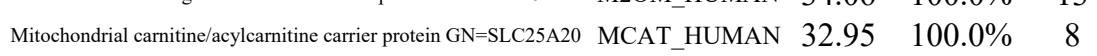

7

$\begin{array}{llll} & \end{array}$ $0.03 \% \quad 39.3 \%$ LEHAFCTETRPYNQGAR $99.7 \% \quad 26.0$ $99.7 \% \quad 48.1$ $99.7 \% \quad 68.5$

$0.03 \% \quad 39.3 \%$ VGTYQLAIVAK

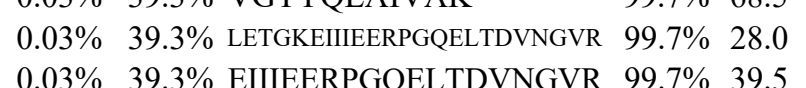

$\begin{array}{lllll}0.03 \% & 39.3 \% & \text { EIIIEERPGQELTDVNGVR } & 99.7 \% & 39.5 \\ 0.03 \% & 39.3 \% & \text { TALTTTISSR } & 99.7 \% & 59.1\end{array}$

$\begin{array}{ll}99.7 \% & 59.1 \\ 99.7 \% & 37.9\end{array}$

$0.01 \% \quad 28.0 \%$ MGVITVSGLAGLVSAR $\quad 99.7 \% \quad 64.0$

$0.01 \% \quad 28.0 \%$ KVYATSQQIFGAVK

$0.01 \% \quad 28.0 \%$ LGSSSEIEVPAK

$0.01 \% \quad 28.0 \%$ HSVPLPTELSSEAK

$0.01 \% \quad 7.3 \%$ YSTSGSSGLTTGK

$10 \quad 0.01 \% \quad 7.3 \%$ ERPPEEVAAR

$0 \quad 0.01 \% \quad 7.3 \% \quad$ TVEGALKER

$10 \quad 0.01 \% \quad 7.3 \% \quad$ VVSQYHELVVQAR

$10 \quad 0.01 \% \quad 7.3 \% \quad$ FVNQLKGESR

$0.03 \% \quad 2.4 \% \quad$ LFLESSDANPVR

$0.03 \% \quad 2.4 \%$ VQLGDQTDSK

$0.03 \% \quad 2.4 \%$ GEPVLLVGETGTGK

$0.03 \% \quad 2.4 \% \quad$ FAASNPCGNIQR

$0.03 \% \quad 2.4 \%$ LNSVLEVEK

$0.03 \% \quad 2.4 \% \quad$ LLEKVEGTVR

$0.03 \% \quad 2.4 \%$ DGQILVYCLNR

$0.03 \% \quad 2.4 \%$ VFTEANLVSVGSK

$0.03 \% \quad 2.4 \%$ TDSQLQGQVLFR

$0.03 \% \quad 2.4 \%$ APAVQDLLTR

$0.03 \% \quad 2.4 \%$ AQDWEENASR

$0.03 \% \quad 2.4 \% \quad$ LNAALATPAK

$0.01 \% \quad 5.7 \% \quad$ NGLVLFGNDGK

$0.01 \% \quad 5.7 \%$ GVINIIPGSGGIAGQR

$0.01 \% \quad 5.7 \%$ LGFTGSTPIGK

$0.01 \% \quad 5.7 \%$ ANSTEYGLASGVFTR

$0.06 \% \quad 46.2 \%$ TSFHALTSILK

$0.06 \% \quad 46.2 \%$ GIYTGLSAGLLR

$0.06 \% \quad 46.2 \%$ LGIYTVLFER

$99.7 \% \quad 43.2$

$99.7 \% \quad 55.7$

$99.5 \% \quad 23.0$

$99.7 \% \quad 56.8$

$99.7 \% \quad 33.6$

$99.7 \% \quad 40.6$

$99.7 \% \quad 38.7$

$94.5 \% \quad 18.0$

$99.7 \% \quad 46.9$

$98.4 \% \quad 20.6$

$99.4 \% \quad 21.5$

$99.7 \% \quad 38.6$

$99.4 \% \quad 26.6$

$99.7 \% \quad 28.0$

$99.7 \% \quad 47.2$

$99.7 \% \quad 50.7$

$99.7 \% \quad 55.7$

$99.7 \% \quad 54.7$

$99.7 \% \quad 42.3$

$99.7 \% \quad 48.3$

$99.7 \% \quad 35.6$

$99.7 \% \quad 52.2$

$99.7 \% \quad 53.6$

$99.7 \% \quad 43.3$

$99.7 \% \quad 50.5$

$99.7 \% \quad 63.4$

$99.7 \% \quad 46.4$

$99.7 \% \quad 57.8$

$0.06 \% \quad 46.2 \%$ LTGADGTPPGFLLK

$99.7 \% \quad 49.2$

$99.7 \% \quad 44.5$

$\begin{array}{lll}99.0 \% & 32.8\end{array}$

$99.7 \% \quad 33.4$

$99.7 \% \quad 42.1$

$0.06 \% \quad 46.2 \%$ ITREEGVLTLWR

$0.06 \% \quad 46.2 \%$ EEGVLTLWR

$0.06 \% \quad 46.2 \%$ AVVVNAAQLASYSQSK

$0.06 \% \quad 46.2 \%$ MIDGKPEYK

$0.06 \% \quad 46.2 \%$ YEGFFSLWK

$0.06 \% \quad 46.2 \%$ GFTPYYAR

$0.02 \% \quad 22.6 \%$ EGITGLYR
2049.96

1029.57

1162.68

2695.43

2167.14

1050.58

2150.22

1546.86

1539.85

1216.64

1494.78

1245.60

1153.60

1002.56

1527.83

1177.63

1347.69

1090.54

1356.74

1334.63

1030.58

1143.67

1350.68

1350.73

1391.73

1083.62

1205.52

969.57

1133.60

1508.85

1077.59

1572.77

1217.69

1220.70

1210.68

1386.76

2289.23

1330.65

946.55

1472.82

1102.59

1635.87

1080.54

1176.57

974.47

908.48 \begin{tabular}{cc}
62 & 186 \\
94 & 210 \\
39 & 249 \\
60 & 270 \\
89 & 312 \\
94 & 312 \\
51 & 360 \\
4 & 52 \\
15 & 130 \\
67 & 180 \\
01 & 212 \\
19 & 232 \\
3 & 45 \\
96 & 205 \\
76 & 284 \\
54 & 366 \\
09 & 718 \\
26 & 137 \\
57 & 366 \\
70 & 683 \\
73 & 984 \\
81 & 1489 \\
17 & 2126 \\
57 & 2467 \\
44 & 2656 \\
30 & 3141 \\
40 & 3349 \\
84 & 3793 \\
06 & 4215 \\
96 & 306 \\
42 & 657 \\
67 & 677 \\
48 & 862 \\
3 & 73 \\
9 & 90 \\
9 & 108 \\
09 & 122 \\
23 & 146 \\
47 & 158 \\
63 & 170 \\
71 & 182 \\
74 & 182 \\
91 & 206 \\
52 & 260 \\
72 & 280 \\
81 & 288 \\
6 & 73 \\
& \\
\hline
\end{tabular}

Page 95 of Table S-1-5 


7
7

8

7
7
7

7
6

6
6
6

6
6

6
6
6

$\begin{array}{cc}6 & 6 \\ 6 & 6 \\ 2 & 15 \\ 12 & 15\end{array}$

12

2

$12 \quad 15$

15

15

1

15

$0.02 \% \quad 22.6 \%$ CLLQIQASSGESK $0.02 \% 22.6 \%$ YTGTLDCAK

0.02\% $22.6 \%$ KLYQEFGIR

$0.02 \% 22.6 \%$ ELIRDEGVTSLYK

$0.02 \% 22.6 \%$ GFNAVMIR

$0.03 \% \quad 49.1 \%$ TDGILALYSGLSASLCR

$0.03 \% \quad 49.1 \%$ QMTYSLTR

$0.03 \% \quad 49.1 \%$ FAIYETVR

$0.03 \% \quad 49.1 \%$ FAIYETVRDR

$0.03 \% \quad 49.1 \%$ GSQGPLPFHEK

$0.03 \% \quad 49.1 \%$ VLLGSVSGLAGGFVGTPADLVNVR

$0.03 \% \quad 49.1 \%$ NYAHALDGLYR

$0.03 \% \quad 49.1 \%$ LFSGATMASSR

$0.03 \% \quad 49.1 \%$ GALVTVGQLSCYDQAK

$0.03 \% \quad 49.1 \%$ GEYQGVFHCAVETAK

$0.03 \% \quad 49.1 \%$ LGPLAFYK

$0.02 \% \quad 21.7 \%$ SEGYFGMYR

$0.02 \% \quad 21.7 \%$ GAAVNLTLVTPEK

$0.02 \% \quad 21.7 \%$ LAANDFFR

$0.02 \% \quad 21.7 \%$ IQLQDAGR

$0.02 \% \quad 21.7 \%$ GLGATLLR

$0.02 \% \quad 21.7 \%$ GVNEDTYSGILDCAR

$0.02 \% \quad 21.7 \%$ HEGPSAFLK

$0.01 \% \quad 15.3 \%$ LGELTGTVK

$0.01 \% \quad 15.3 \%$ ALSQGVESVKK

$0.01 \% \quad 15.3 \%$ EIDDSVLGQTGPYR

$0.01 \% \quad 15.3 \%$ DFKENNVVFNR

$0.01 \% \quad 15.3 \%$ VTDLLGGLFSK

$0.01 \% \quad 15.3 \%$ LLDISASSTEQIL

$0.03 \% \quad 33.4 \%$ RAPDQAAEIGSR

$\begin{array}{lllll}0.03 \% & 33.4 \% & \text { AQGPQQQPGSEGPSYAKK } & 99.4 \% & 22.7\end{array}$

$0.03 \% \quad 33.4 \%$ IPDEFDNDPILVQQLR

$0.03 \% 33.4 \%$ IPDEFDNDPILVQQLRR

$0.03 \% \quad 33.4 \%$ DISCLNRDPAR

$0.03 \% \quad 33.4 \%$ VVVVDCKK

$0.03 \% \quad 33.4 \%$ VLLDLSAFLK

$0.03 \% \quad 33.4 \%$ TIALNGVEDVR

$0.03 \% \quad 33.4 \%$ TVLEHYALEDDPLAAFK

$0.03 \% \quad 33.4 \%$ SNKQNLFLGSLTSR

$0.03 \% \quad 33.4 \%$ QNLFLGSLTSR

$0.01 \% \quad 11.4 \%$ ELFPIQMEGVK

$0.01 \% \quad 11.4 \%$ RPGEEGTVMSLAGK

$0.01 \% \quad 11.4 \%$ MQDTSVSFGYQLDLPK
$99.7 \% \quad 80.8$

$99.3 \% 23.6$

$99.7 \% \quad 48.0$

$98.6 \% \quad 26.4$

$97.5 \% \quad 26.7$

$\begin{array}{ll}99.7 \% & 37.4 \\ 99.0 \% & 51.4\end{array}$

$99.7 \% \quad 46.9$

$99.7 \% \quad 76.9$

$99.0 \% \quad 44.2$

$99.0 \% \quad 32.2$

$99.0 \% 22.1$

$99.7 \% \quad 35.2$

$\begin{array}{lll}99.7 \% & 47.7\end{array}$

$99.7 \% \quad 60.0$

$99.7 \% \quad 59.3$

$99.7 \% \quad 63.0$

$99.0 \% \quad 47.0$

$99.7 \% \quad 41.5$

$99.0 \% \quad 52.7$

$99.0 \% 56.9$

$99.0 \% \quad 30.4$

$99.7 \% \quad 63.3$

$94.7 \% \quad 14.4$

$\begin{array}{ll}99.7 \% & 35.3 \\ 99.7 \% & 42.5\end{array}$

$99.7 \% \quad 39.0$

$99.7 \% \quad 45.4$

$98.9 \% \quad 20.8$

$98.3 \% \quad 19.5$

$\begin{array}{ll}99.7 \% & 49.7 \\ 99.7 \% & 56.2\end{array}$

$99.7 \% \quad 36.7$

$94.6 \% \quad 14.1$

$99.6 \% 32.3$

$99.0 \% \quad 29.9$

$99.7 \% \quad 47.6$

$99.7 \% \quad 60.1$

$\begin{array}{ll}99.7 \% & 36.6 \\ 99.7 \% & 69.8\end{array}$

$99.7 \% \quad 42.9$

$99.7 \% \quad 34.2$

$99.7 \% \quad 37.3$

$99.7 \% \quad 65.2$
1028.47

1153.64

1025.54

858.47

1522.81

907.48

1209.66

1796.92

999.49

998.53

1269.66

1196.61

2298.28

1292.64

1127.55

1709.85

1695.78

908.52

1109.47

1312.75

953.48

900.49

800.50

1669.75

985.51

917.53

1145.65

1549.75

1381.69

1149.65

1389.75

1270.65

1729.81

1857.91

1911.98

2068.08

1316.64

946.54

1118.68

1186.64

1931.98

1564.84

1235.67

1290.68

1447.72

1844.87 
Mitochondrial inner membrane protein OXA1L GN=OXA1L OXA1L_HUMAN $48.55 \quad 100.0 \%$ Mitochondrial inner membrane protein OXA1L GN=OXA1L OXA1L_HUMAN $48.55 \quad 100.0 \%$ Mitochondrial inner membrane protein OXA1L GN=OXA1L OXA1L_HUMAN $48.55 \quad 100.0 \%$ Machondrial inner membrane protein OXAIL GN=OXAIL OXA1L HUMAN $48.55 \quad 100.0 \%$ Mitochondrial ornithine transporter $1 \mathrm{GN}=\mathrm{SLC} 25 \mathrm{~A} 15$ ORNT1_HUMAN $32.74 \quad 100.0 \%$ Mitochondrial ornithine transporter $1 \mathrm{GN}=\mathrm{SLC} 25 \mathrm{~A} 15$ ORNT1_HUMAN $32.74 \quad 100.0 \%$ Mitochondrial ornithine transporter $1 \mathrm{GN}=\mathrm{SLC} 25 \mathrm{~A} 15$ ORNT1_HUMAN $32.74 \quad 100.0 \%$ Mitochondrial ornithine transporter $1 \mathrm{GN}=\mathrm{SLC} 25 \mathrm{~A} 15$ ORNT1_HUMAN $32.74 \quad 100.0 \%$ Mitochondrial ribonuclease P protein 1 GN=TRMT10C MRRP1 HUMAN $47.35100 .0 \%$ Mitochondrial ribonuclease P protein 1 GN=TRMT10C MRRP1_HUMAN $47.35 \quad 100.0 \%$ Mitochondrial ribonuclease P protein 1 GN=TRMT10C MRRP1_HUMAN $47.35 \quad 100.0 \%$ Mitochondrial ribonuclease P protein 1 GN=TRMT10C MRRP1 HUMAN 47.35 Mitochondrial ribonuclease P protein $1 \mathrm{GN}=$ TRMT10C MRRP1_HUMAN 47.35 Mitochondrial ribonuclease P protein $1 \mathrm{GN}=$ TRMT10C MRRP1_HUMAN 47.35 Mitochondrial ribonuclease P protein $1 \mathrm{GN}=$ TRMT10C MRRP1_HUMAN 47.35 Mitochondrial ribonuclease P protein $1 \mathrm{GN}=$ TRMT10C MRRP1_HUMAN 47.3. Mitochondrial ribonuclease P protein $1 \mathrm{GN}=\mathrm{TRMT10C}$ MRRP1 HUMAN 47.3 Mitochondrial ribonuclease P protein $1 \mathrm{GN}=$ TRMT10C MRRP1_HUMAN 47.35 Mitochondrial ribonuclease P protein 1 GN=TRMT10C MRRP1_HUMAN 47.35 Mitochondrial ribonuclease $P$ protein $1 \mathrm{GN}=$ TRMT10C MRRP1_HUMAN 47.34 Mitochondrial ribonuclease P protein $1 \mathrm{GN}=\mathrm{TRMT10C}$ MRRP1_HUMAN 47.3 Mitochondrial ribonuclease $P$ protein $1 \mathrm{GN}=$ TRMT10C MRRP1_HUMAN 47.35 Mitochondrial ribonuclease P protein $1 \mathrm{GN}=$ TRMT10C MRRP1_HUMAN 47.35 Mitochondrial ribonuclease P protein $1 \mathrm{GN}=$ TRMT10C MRRP1_HUMAN 47.35 Mitochondrial ribosome-associated GTPase 1 GN=MTG1 MTG1 HUMAN 37.24 Mitochondrial ribosome-associated GTPase 1 GN=MTG1 MTG1_HUMAN 37.24 Mitochondrial ribosome-associated GTPase 1 GN=MTG1 MTG1_HUMAN 37.24 Mitochondrial ribosome-associated GTPase 1 GN=MTG1 MTG1_HUMAN 37.24 Mitochondrial-processing peptidase subunit beta GN=PMPCB MPPB_HUMAN 54.37 Mitochondrial-processing peptidase subunit beta GN=PMPCB MPPB HUMAN 54.37 Mitotic checkpoint protein BUB3 GN=BUB3 BUB3_HUMAN 37.15 Mitotic checkpoint protein BUB3 GN=BUB3 BUB3_HUMAN 37.15 Mitotic checkpoint protein BUB3 GN=BUB3 BUB3 HUMAN 37.15 Mitotic checkpoint protein BUB3 GN=BUB3 BUB3_HUMAN 37.15 MKI67 FHA domain-interacting nucleolar phosphoprotein GN=NIFK MK67I_HUMAN 34.22 MKI67 FHA domain-interacting nucleolar phosphoprotein GN=NIFK MK67I HUMAN 34.22 MKI67 FHA domain-interacting nucleolar phosphoprotein GN=NIFK MK67I_HUMAN 34.22 MKI67 FHA domain-interacting nucleolar phosphoprotein GN=NIFK MK67I HUMAN 34.22 MKI67 FHA domain-interacting nucleolar phosphoprotein GN=NIFK MK67I_HUMAN 34.22 MKI67 FHA domain-interacting nucleolar phosphoprotein GN=NIFK MK67I_HUMAN 34.22 (1) MK67I HUMAN 34.22

MOB kinase activator $2 \mathrm{GN}=\mathrm{MOB} 2$ MOB kinase activator $2 \mathrm{GN}=\mathrm{MOB} 2$ MOB kinase activator $2 \mathrm{GN}=\mathrm{MOB} 2$ MOB kinase activator $2 \mathrm{GN}=\mathrm{MOB} 2$ MOB kinase activator $2 \mathrm{GN}=\mathrm{MOB} 2$ MOB2_HUMAN $26.93 \quad 100.0 \%$ MOB2 HUMAN $26.93 \quad 100.0 \%$ MOB2_HUMAN $26.93 \quad 100.0 \%$ MOB2_HUMAN $26.93 \quad 100.0 \%$ MOB2 HUMAN $26.93 \quad 100.0 \%$ Monocarboxylate transporter $1 \mathrm{GN}=\mathrm{SLC} 16 \mathrm{~A} 1$ MOT1_HUMAN $53.95 \quad 100.0 \%$

2596.20 $\begin{array}{llllllll}99.7 \% & 50.6 & 25.0 & 35.9 & 2 & 0 & 0 & 1452.72\end{array}$

1103.59

2043.00 
Monocarboxylate transporter $1 \mathrm{GN}=\mathrm{SLC} 16 \mathrm{~A} 1$ MOT1_HUMAN $53.95 \quad 100.0 \%$ Monocarboxylate transporter $1 \mathrm{GN}=\mathrm{SLC} 16 \mathrm{~A} 1$ MOT1_HUMAN $53.95 \quad 100.0 \%$ Monocarboxylate transporter $1 \mathrm{GN}=$ SLC16A1 MOT1_HUMAN $53.95 \quad 100.0 \%$ Monocarboxylate transporter $1 \mathrm{GN}=\mathrm{SLC16A1}$ MOT1 HUMAN $53.95 \quad 100.0 \%$ Monofunctional C1-tetrahydrofolate synthase, mitochondrial GN=MTHFDIL C1TM_HUMAN $105.79 \quad 100.0 \%$ Monofunctional C1-tetrahydrofolate synthase, mitochondrial GN=MTHFDIL C1TM_HUMAN $105.79 \quad 100.0 \%$ mRNA export factor $\mathrm{GN}=\mathrm{RAE} 1$ mRNA export factor $\mathrm{GN}=\mathrm{RAE} 1$ mRNA export factor $\mathrm{GN}=\mathrm{RAE} 1$ mRNA export factor $\mathrm{GN}=\mathrm{RAE} 1$ mRNA export factor $\mathrm{GN}=\mathrm{RAE} 1$ mRNA export factor $\mathrm{GN}=\mathrm{RAE} 1$ mRNA export factor $\mathrm{GN}=\mathrm{RAE}$ RAEIL_HUMAN $40.97 \quad 100.0 \%$ RAEIL HUMAN $40.97 \quad 100.0 \%$ RAE1L_HUMAN $40.97 \quad 100.0 \%$ RAE1L_HUMAN $40.97 \quad 100.0 \%$ RAEIL HUMAN $40.97 \quad 100.0 \%$ RAEIL_HUMAN $40.97 \quad 100.0 \%$ RAEIL HUMAN $40.97 \quad 100.0 \%$ mRNA turnover protein 4 homolog GN=MRTO4 MRT4 HUMAN $27.56 \quad 100.0 \%$ mRNA turnover protein 4 homolog GN=MRTO4 MRT4_HUMAN $27.56 \quad 100.0 \%$ mRNA turnover protein 4 homolog GN=MRTO4 MRT4 HUMAN $27.56 \quad 100.0 \%$ mRNA turnover protein 4 homolog GN=MRTO4 MRT4_HUMAN $27.56 \quad 100.0 \%$ mRNA turnover protein 4 homolog GN=MRTO4 MRT4_HUMAN $27.56 \quad 100.0 \%$ mRNA turnover protein 4 homolog GN=MRTO4 MRT4 HUMAN $27.56 \quad 100.0 \%$ mRNA turnover protein 4 homolog GN=MRTO4 MRT4_HUMAN $27.56 \quad 100.0 \%$ mRNA turnover protein 4 homolog GN=MRTO4 MRT4_HUMAN $27.56 \quad 100.0 \%$ mRNA turnover protein 4 homolog GN=MRTO4 MRT4_HUMAN $27.56 \quad 100.0 \%$ mRNA turnover protein 4 homolog GN=MRTO4 MRT4_HUMAN $27.56 \quad 100.0 \%$ mRNA turnover protein 4 homolog GN=MRTO4 MRT4 HUMAN 27.56 100.0\% Multifunctional protein ADE2 GN=PAICS PUR6_HUMAN $47.08 \quad 100.0 \%$ Multifunctional protein ADE2 GN=PAICS PUR6_HUMAN $47.08 \quad 100.0 \%$ Multiple myeloma tumor-associated protein 2 GN=MMTAG2 MMTA2_HUMAN $29.41 \quad 100.0 \%$ Multiple myeloma tumor-associated protein 2 GN=MMTAG2 MMTA2_HUMAN $29.41 \quad 100.0 \%$ Multiple myeloma tumor-associated protein 2 GN=MMTAG2 MMTA2 HUMAN $29.41 \quad 100.0 \%$ Myb-binding protein 1A GN=MYBBP1A MBB1A_HUMAN $148.86 \quad 100.0 \%$ Myb-binding protein 1A GN=MYBBP1A MBB1A_HUMAN $148.86 \quad 100.0 \%$ Myb-binding protein 1A GN=MYBBP1A MBB1A_HUMAN $148.86 \quad 100.0 \% \quad 25$ Myb-binding protein 1A GN=MYBBP1A MBB1A_HUMAN $148.86 \quad 100.0 \% \quad 25$ Myb-binding protein 1A GN=MYBBP1A MBB1A_HUMAN $148.86 \quad 100.0 \% \quad 25$ Myb-binding protein 1A GN=MYBBP1A MBB1A_HUMAN $148.86 \quad 100.0 \% \quad 25$ Myb-binding protein 1A GN=MYBBP1A MBB1A_HUMAN $148.86 \quad 100.0 \% \quad 25$ Myb-binding protein 1A GN=MYBBP1A MBB1A_HUMAN $148.86 \quad 100.0 \% \quad 25$ Myb-binding protein 1A GN=MYBBP1A MBB1A_HUMAN $148.86 \quad 100.0 \% \quad 25$ Myb-binding protein 1A GN=MYBBP1A MBB1A_HUMAN $148.86 \quad 100.0 \% \quad 25$ Myb-binding protein 1A GN=MYBBP1A MBB1A_HUMAN $148.86 \quad 100.0 \% \quad 25$ Myb-binding protein 1A GN=MYBBP1A MBB1A_HUMAN $148.86 \quad 100.0 \% \quad 25$ Myb-binding protein 1A GN=MYBBP1A MBB1A_HUMAN $148.86 \quad 100.0 \% \quad 25$ Myb-binding protein 1A GN=MYBBP1A MBB1A_HUMAN $148.86 \quad 100.0 \% \quad 25$ Myb-binding protein 1A GN=MYBBP1A MBB1A_HUMAN $148.86 \quad 100.0 \% \quad 25$ Myb-binding protein 1A GN=MYBBP1A MBB1A_HUMAN $148.86 \quad 100.0 \% \quad 25$ Myb-binding protein 1A GN=MYBBP1A MBB1A_HUMAN $148.86 \quad 100.0 \% \quad 25$
$16 \quad 0.02 \% \quad 9.0 \% \quad$ DLHDANTDLIGR $0.02 \% \quad 9.0 \%$ DLHDANTDLIGRHPK $0.02 \% \quad 9.0 \%$ LNDMYGDYK

$99.6 \% \quad 22.0$

$16 \quad 0.02 \% \quad 9.0 \% \quad$ ESKEEETSIDVAGKPNEVTK

$0.00 \% \quad 3.1 \%$ VLDTNDRFLR

$0.00 \% \quad 3.1 \%$ TIAQAVYGAK

$0.00 \% \quad 3.1 \%$ DFILPISDVR

$0.03 \% \quad 20.4 \%$ SSNPMMVLQLPER

$0.03 \% \quad 20.4 \%$ GLIVYQLENQPSEFR

$0.03 \% \quad 20.4 \%$ GLIVYQLENQPSEFRR

$0.03 \% \quad 20.4 \%$ QNKPTGFALGSIEGR

$0.03 \% \quad 20.4 \%$ VAIHYINPPNPAK

$0.03 \% \quad 20.4 \%$ GHEFYNPQK

$0.03 \% \quad 20.4 \%$ NAAEELKPR

$0.03 \% \quad 45.6 \%$ QNLIEELRK

$0.03 \% \quad 45.6 \%$ YLFIFSVANMR

$0.03 \% \quad 45.6 \%$ VMMVALGR

$0.03 \% \quad 45.6 \%$ SPSDEYKDNLHQVSK

$0.03 \% \quad 45.6 \%$ LRGEVGLLFTNR

$0.03 \% \quad 45.6 \%$ GEVGLLFTNR

$0.03 \% \quad 45.6 \%$ TKEEVNEWFTK

$0.03 \% \quad 45.6 \%$ QLGLPTALKR

$0.03 \% \quad 45.6 \%$ GVVTLLSDYEVCK

$0.03 \% \quad 45.6 \%$ EGDVLTPEQAR

$0.03 \% \quad 45.6 \%$ YMWDSQSGR

$0.00 \% \quad 6.6 \% \quad$ VLLQSKDQITAGNAAR

$0.00 \% \quad 6.6 \%$ ACGNFGIPCELR

$0.01 \% \quad 14.1 \%$ EALLAALGYK

$0.01 \% \quad 14.1 \%$ LLGLGSASGSVGR

$0.01 \% \quad 14.1 \%$ VESGGPGTSAASAR

$0.06 \% \quad 19.6 \%$ LITGLGVGR

$0.06 \% \quad 19.6 \%$ LVKDQEALMK

$0.06 \% \quad 19.6 \%$ ALVDILSEVSK

$0.06 \% \quad 19.6 \%$ EVVEQGLLK

$0.06 \% 19.6 \%$ LLGAALPLLTK

$0.06 \% \quad 19.6 \%$ HYGEHVCTAK

$0.06 \% \quad 19.6 \%$ KAQDSSLHMPER

$0.06 \% \quad 19.6 \%$ AQDSSLHMPER

$0.06 \% \quad 19.6 \%$ KPTSQIPETK

$0.06 \% \quad 19.6 \%$ HPFSFPLENQAR

$0.06 \% \quad 19.6 \%$ SVFGHICSHLTPR

$0.06 \% \quad 19.6 \%$ SSSSKQEQDLLHK

$0.06 \% \quad 19.6 \%$ IFTHHLCR

$0.06 \% \quad 19.6 \%$ RYCHDLGER

$0.06 \% \quad 19.6 \%$ AGALHAQVER

$99.7 \% 28.4$

$\begin{array}{ll}99.7 \% & 28.4 \\ 99.7 \% & 35.3\end{array}$

$98.4 \% \quad 18.8$

$99.7 \% \quad 62.2$

$99.7 \% \quad 56.9$

$99.7 \% \quad 57.0$

$99.7 \% \quad 33.4$

$99.7 \% \quad 57.6$

$99.7 \% \quad 26.0$

$99.7 \% \quad 43.1$

$99.6 \% 34.3$

$99.7 \% \quad 46.6$

$99.0 \% \quad 39.2$

$99.7 \% \quad 49.8$

$99.3 \% 19.4$

$99.7 \% \quad 56.6$

$99.7 \% \quad 58.2$

$98.8 \% \quad 23.7$

$99.7 \% \quad 55.0$

$99.7 \% \quad 35.9$

$99.7 \% \quad 28.3$

$99.7 \% \quad 29.5$

$99.7 \% \quad 25.9$

$97.3 \% 20$.

$99.7 \% \quad 54.7$

$99.7 \% \quad 69.2$

$99.7 \% \quad 53.3$

$99.7 \% \quad 43.5$

$99.7 \% \quad 46.8$

$99.6 \% \quad 22.6$

$99.7 \% \quad 44.9$

$99.7 \% \quad 26.8$

$99.7 \% \quad 27.5$

$99.7 \% \quad 30$.

$99.7 \% \quad 34.3$

$99.1 \% 24.1$

$98.4 \% \quad 17.3$

$94.7 \% \quad 21.5$

$99.0 \% 32.5$

$98.4 \% \quad 26.5$

$99.7 \% \quad 29.3$

$0.06 \% \quad 19.6 \%$ GNTAEGCVHETQEKQK

$0.06 \% \quad 19.6 \%$ HQACLLLQK
$99.7 \% \quad 35.9$
1701.87

1134.48

2190.08

1248.67

1021.57

1174.65

1533.74

1792.92

1949.02

1574.83

1433.79

1119.52

1027.55

1142.65

1376.70

876.48

1746.83

1374.79

1105.60

1410.69

1096.68

1482.75

1214.60

1129.47

1684.93

1393.64

1048.60

1173.66

1246.60

885.55

1174.65

1173.67

1014.58

1109.73

1201.54

1398.68

1286.58

1128.63

1442.72

1510.76

1486.75

1083.55

1205.55

1051.56

1815.83

1110.61

$\begin{array}{cc}25 & 236 \\ 25 & 239 \\ 12 & 420 \\ 60 & 479 \\ 76 & 585 \\ 71 & 880 \\ 26 & 935 \\ 60 & 172 \\ 91 & 205 \\ 91 & 206 \\ 25 & 239 \\ 40 & 252 \\ 41 & 349 \\ 57 & 365 \\ 4 & 32 \\ 9 & 49 \\ 2 & 79 \\ 0 & 94 \\ 6 & 107 \\ 8 & 107 \\ 08 & 118 \\ 55 & 164 \\ 65 & 177 \\ 78 & 188 \\ 06 & 214 \\ 1 & 46 \\ 87 & 298 \\ 6 & 85 \\ 18 & 130 \\ 53 & 166 \\ 7 & 85 \\ 49 & 158 \\ 80 & 190 \\ 87 & 295 \\ 08 & 318 \\ 32 & 341 \\ 32 & 443 \\ 33 & 443 \\ 89 & 498 \\ 99 & 510 \\ 72 & 684 \\ 62 & 874 \\ 78 & 885 \\ 88 & 896 \\ 97 & 906 \\ 36 & 951 \\ & 1036 \\ & \end{array}$

Page 98 of Table S-1-5 
$\begin{array}{lllll}\text { Myb-binding protein 1A GN=MYBBP1A } & \text { MBB1A_HUMAN } & 148.86 & 100.0 \% & 25\end{array}$ $\begin{array}{lllll}\text { Myb-binding protein 1A GN=MYBBP1A } & \text { MBB1A_HUMAN } & 148.86 & 100.0 \% & 25\end{array}$ Myb-binding protein 1A GN=MYBBP1A MBB1A_HUMAN $148.86 \quad 100.0 \% \quad 25$ Myb-binding protein 1A GN=MYBBP1A MBB1A_HUMAN $148.86 \quad 100.0 \% \quad 25$ Myb-binding protein 1A GN=MYBBP1A MBB1A_HUMAN $148.86 \quad 100.0 \% \quad 25$ Myb-binding protein 1A GN=MYBBP1A MBB1A_HUMAN $148.86 \quad 100.0 \% \quad 25$ Myb-binding protein 1A GN=MYBBP1A MBB1A_HUMAN $148.86 \quad 100.0 \% \quad 25$ Myelin expression factor $2 \mathrm{GN}=$ MYEF2 $\quad$ MYEF2 HUMAN $64.12 \quad 100.0 \%$ Myelin expression factor 2 GN=MYEF2 MYEF2_HUMAN $64.12 \quad 100.0 \%$ Myelin expression factor 2 GN=MYEF2 $\quad$ MYEF2_HUMAN $64.12 \quad 100.0 \%$ Myelin expression factor $2 \mathrm{GN}=\mathrm{MYEF} 2$ MYEF2 HUMAN $64.12 \quad 100.0 \%$ Myeloid leukemia factor $2 \mathrm{GN}=\mathrm{MLF} 2$ Myeloid leukemia factor $2 \mathrm{GN}=\mathrm{MLF} 2$

Myeloid leukemia factor $2 \mathrm{GN}=\mathrm{MLF} 2$ Myosin-10 GN=MYH10

Myosin-10 GN=MYH10

Myosin-10 GN=MYH10

Myosin-10 GN=MYH10

Myosin-10 GN=MYH10

Myosin-10 GN=MYH10

Myosin-10 GN=MYH10

Myosin-10 GN=MYH10

Myosin-10 GN=MYH10

Myosin-10 GN=MYH10

Myosin-10 GN=MYH10

Myosin-9 GN=MYH9

Myosin-9 GN=MYH9

Myosin-9 GN=MYH9

Myosin- 9 GN=MYH9

Myosin-9 GN=MYH9

$\mathrm{N}$-acetyltransferase $10 \mathrm{GN}=\mathrm{NAT} 10$

$\mathrm{N}$-acetyltransferase $10 \mathrm{GN}=\mathrm{NAT} 10$

$\mathrm{N}$-acetyltransferase $10 \mathrm{GN}=\mathrm{NAT} 10$

$\mathrm{N}$-acetyltransferase $10 \mathrm{GN}=\mathrm{NAT} 10$ MYH10_HUMAN $229.01 \quad 100.0 \%$ MYH10 HUMAN $229.01 \quad 100.0 \%$ MYH10_HUMAN $229.01 \quad 100.0 \%$ MYH10_HUMAN $229.01 \quad 100.0 \%$ MYH10 HUMAN $229.01 \quad 100.0 \%$ MYH10_HUMAN $229.01 \quad 100.0 \%$ MYH10_HUMAN $229.01 \quad 100.0 \%$ MYH10_HUMAN $229.01 \quad 100.0 \%$ MYH10_HUMAN $229.01 \quad 100.0 \%$ MYH10 HUMAN $229.01 \quad 100.0 \%$ MYH10_HUMAN $229.01 \quad 100.0 \%$ MYH9_HUMAN $226.54 \quad 100.0 \%$ MYH9 HUMAN $226.54 \quad 100.0 \%$ MYH9_HUMAN $226.54 \quad 100.0 \%$ MYH9 HUMAN $226.54 \quad 100.0 \%$ MYH9_HUMAN $226.54 \quad 100.0 \%$ NAT10_HUMAN $115.73 \quad 100.0 \%$ NAT10 HUMAN $115.73 \quad 100.0 \%$ NAT10_HUMAN $115.73 \quad 100.0 \%$ NAT10_HUMAN $115.73 \quad 100.0 \%$ Myb-binding protein 1A GN=MYBBP1A MBB1A_HUMAN $148.86 \quad 100.0 \% \quad 25$ NDUAA_HUMAN $40.75 \quad 100.0 \%$

NADH dehydrogenase [ubiquinone] 1 alpha subcomplex subunit 10, mitochondrial GN=NDUFA10 NDUAA_HUMAN $40.75 \quad 100.0 \%$

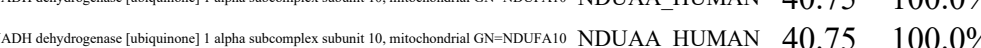
10 NDUAA_HUMAN $40.75 \quad 100.0 \%$ 10 NDUAA_HUMAN $40.75 \quad 100.0 \%$ NDUAA_HUMAN $40.75 \quad 100.0 \%$ 10 NDUAA_HUMAN $40.75 \quad 100.0 \%$ 0 NDUAA_HUMAN $40.75100 .0 \%$ NDUAA_HUMAN $40.75 \quad 100.0 \%$ NDUA9 HUMAN $42.51 \quad 100.0 \%$ NDUA9 HUMAN $42.51 \quad 100.0 \%$
0.06\% $19.6 \%$ TLGVQRPK $0.06 \% \quad 19.6 \%$ EIPSATQSPISK

$0.06 \% \quad 19.6 \%$ AKVPAQANGTPTTK

$0.06 \% \quad 19.6 \%$ SPAPGAPTR

$0.06 \% \quad 19.6 \%$ SPLSALAR

$0.06 \% \quad 19.6 \%$ SPSLLQSGAK

$0.06 \% \quad 19.6 \%$ SPSLLQSGAKK

$0.01 \% \quad 5.8 \%$ LGSAMIGGFAGR

$0.01 \% \quad 5.8 \%$ MGPGIGAILER

$0.01 \% \quad 5.8 \%$ ISGREIDVR

$0.01 \% \quad 5.8 \%$ EIDVRLDR

$0.01 \% \quad 14.9 \%$ VYQETSEMR

$0.01 \% \quad 14.9 \%$ DSDSGLEQMSIGHHIR

$0.01 \% \quad 14.9 \%$ LAIQGPEDSPSR

$0.02 \% \quad 5.8 \%$ AMVNKDDIQK

$0.02 \% \quad 5.8 \%$ EQADFAVEALAK

$0.02 \% \quad 5.8 \%$ NTNPNFVR

$0.02 \% \quad 5.8 \% \quad$ CNGVLEGIR

$0.02 \% \quad 5.8 \%$ ALELDPNLYR

$0.02 \% \quad 5.8 \%$ GDDETLHKNNALK

$0.02 \% \quad 5.8 \% \quad$ QVLALQSQLADTK

$0.02 \% \quad 5.8 \%$ ALAYDKLEK

$0.02 \% \quad 5.8 \%$ ASRDEIFAQSK

$0.02 \% \quad 5.8 \%$ ATISALEAK

$0.02 \% \quad 5.8 \%$ GGPISFSSSR

$0.00 \% \quad 2.7 \%$ NTDQASMPDNTAAQK

$0.00 \% \quad 2.7 \%$ EQADFAIEALAK

$0.00 \% \quad 2.7 \%$ NTNPNFVR

$0.00 \% \quad 2.7 \%$ CNGVLEGIR

$0.00 \% \quad 2.7 \%$ GALALEEKR

$0.01 \% \quad 5.3 \% \quad$ QQSAQSQVSTTAENKTTTTAR

$0.01 \% \quad 5.3 \%$ QSILNSLSR

$0.01 \% \quad 5.3 \%$ IAVHPDYQGMGYGSR

$0.01 \% \quad 5.3 \%$ AGFVPVYLR

$0.02 \% \quad 25.6 \%$ VITVDGNICTGK

$0.02 \% \quad 25.6 \%$ LLQYSDALEHLLTTGQGVVLER

$0.02 \% \quad 25.6 \%$ KQCVDHYNEVK

$0.02 \% \quad 25.6 \%$ QCVDHYNEVK

$0.02 \% \quad 25.6 \%$ ITSAYLQDIENAYK

$0.02 \% \quad 25.6 \%$ ITSAYLQDIENAYKK

$0.02 \% \quad 25.6 \%$ TFLPEMSEK

$0.02 \% \quad 25.6 \%$ KVVEDIEYLK

$0.02 \% \quad 25.6 \%$ YSPGYNTEVGDK

$0.03 \% \quad 39.3 \%$ YVVNHLGR

$0.03 \% \quad 39.3 \%$ MGSQVIIPYR

$0.03 \% \quad 39.3 \%$ VVQHSNVVINLIGR $\begin{array}{llllllll}99.0 \% & 26.3 & 25.0 & 23.5 & 2 & 0 & 0 & 898.55\end{array}$ $\begin{array}{llllllll}99.7 \% & 60.7 & 25.0 & 52.6 & 2 & 0 & 0 & 1257.67\end{array}$

2517.12

1383.76

853.45

814.48

987.55

1115.64

$99.7 \% \quad 40.4 \quad 25.0 \quad 37.3$

$\begin{array}{llll}99.7 \% & 35.7 & 25.0 & 27.8\end{array}$

$99.7 \% \quad 46.8 \quad 25.0 \quad 46.8$

$\begin{array}{llll}99.7 \% & 39.3 & 25.0 & 39.3\end{array}$

$\begin{array}{llll}94.8 \% & 24.0 & 25.0 & 0.0\end{array}$

$98.9 \% \quad 38.6 \quad 25.0 \quad 0.0$

$\begin{array}{llll}99.7 \% & 63.3 & 25.0 & 43.9\end{array}$

$99.7 \% \quad 41.2 \quad 25.0 \quad 41.1$

$99.7 \% \quad 53.5 \quad 25.0 \quad 43.5$

$\begin{array}{llll}99.7 \% & 30.0 & 25.0 & 21.6\end{array}$

$99.7 \% \quad 51.9 \quad 25.0 \quad 51.4$

$\begin{array}{llll}98.6 \% & 22.2 & 25.0 & 15.4\end{array}$

$\begin{array}{llll}99.7 \% & 45.2 & 25.0 & 33.0\end{array}$

$\begin{array}{llll}99.7 \% & 43.2 & 25.0 & 40.8\end{array}$

$\begin{array}{llll}95.3 \% & 14.7 & 25.0 & 13.9\end{array}$

$99.7 \% \quad 70.6 \quad 25.0 \quad 66.8$

$\begin{array}{llll}99.3 \% & 23.7 & 25.0 & 15.9\end{array}$

$\begin{array}{llll}99.7 \% & 29.1 & 25.0 & 26.7\end{array}$

$99.7 \% \quad 36.1 \quad 25.0 \quad 21.4$

$\begin{array}{llll}99.7 \% & 39.5 & 25.0 & 34.6\end{array}$

$\begin{array}{llll}99.7 \% & 44.4 & 25.0 & 44.4\end{array}$

$\begin{array}{llll}99.0 \% & 36.0 & 25.0 & 0.0\end{array}$

$\begin{array}{llll}98.6 \% & 22.2 & 25.0 & 15.4\end{array}$

$\begin{array}{llll}99.7 \% & 45.2 & 25.0 & 33.0\end{array}$

$\begin{array}{llll}99.7 \% & 42.4 & 25.0 & 33.4\end{array}$

$\begin{array}{llll}99.7 \% & 33.2 & 25.0 & 33.2\end{array}$

$99.7 \% \quad 34.9 \quad 25.0 \quad 31.0$

$\begin{array}{llll}99.7 \% & 28.9 & 25.0 & 28.9\end{array}$

$\begin{array}{llll}99.7 \% & 35.5 & 25.0 & 28.3\end{array}$

$99.7 \% \quad 50.7 \quad 25.0 \quad 45.0$

$\begin{array}{llll}99.7 \% & 55.2 & 25.0 & 55.2\end{array}$

$\begin{array}{llll}99.5 \% & 23.1 & 25.0 & 18.0\end{array}$

$\begin{array}{llll}99.0 \% & 18.5 & 25.0 & 18.5\end{array}$

$\begin{array}{llll}99.7 \% & 66.9 & 25.0 & 61.6\end{array}$

$\begin{array}{llll}99.7 \% & 54.1 & 25.0 & 54.1\end{array}$

$\begin{array}{llll}98.6 \% & 20.2 & 25.0 & 17.4\end{array}$

$\begin{array}{llll}99.7 \% & 44.1 & 25.0 & 42.7\end{array}$

$\begin{array}{llll}99.7 \% & 27.2 & 25.0 & 23.8\end{array}$

$99.0 \% \quad 29.0 \quad 25.0 \quad 20.8 \quad 2$

$99.7 \% \quad 41.8 \quad 25.0 \quad 39.6$

$99.7 \% \quad 38.5 \quad 25.0 \quad 38.5$

1136.59

1113.61

1044.58

1015.55

1142.5

1797.82

1269.64

1161.59

1291.65

961.48

1017.51

1203.64

1454.72

1414.79

1050.58

1251.63

903.51

994.50

1607.70

1305.67

961.48

1017.51

986.56

2238.10

1017.57

1666.76

1021.58

1276.66

2455.32

1419.67

1291.57

1628.82

1756.91

1097.52

1235.69

1329.60

957.53

1179.62

1547.90 


\begin{tabular}{|c|c|c|c|c|c|c|c|c|c|c|c|c|c|c|c|c|c|c|}
\hline DH dehydrogenase [ubiquinone] I Ilpha & & 42.51 & $100.0 \%$ & 13 & 15 & 25 & $0.03 \%$ & $39.3 \%$ NFDFEDVFVK & $99.7 \%$ & 39.7 & 25.0 & 21.3 & 2 & 0 & 0 & 1259.59 & 138 & 147 \\
\hline NADH dehydrogenase [ubiquinone] 1 alph subcomplex subunit 9 , mitochondrial GN=NDUFA9 & NDUA9_HUMAN & 42.51 & $100.0 \%$ & 13 & 15 & 25 & $0.03 \%$ & 39.3\% DAFPEAIIVKPSDIFGR & $99.6 \%$ & 24.5 & 25.0 & 24.5 & & 1 & $\Omega$ & 1875.00 & 193 & 209 \\
\hline ADH dehydrogenase [ubiquinone] 1 alpha subcomplex subunit 9 , mitochondral GN=NDUFA 9 & NDUA9_HUMAN & 42.51 & $00.0 \%$ & 13 & 5 & - & $.03 \%$ & $39.3 \%$ FLNSFASMHR & $99.3 \%$ & 25.8 & 25.0 & 18.4 & & 0 & & 1209.58 & 213 & 222 \\
\hline VADH dehydrogenase [ubiquinone] 1 alpha subcomplex subunit 9 , mitochondral GN=NDUFA9 & NDUA9_HUMAN & 42.51 & $100.0 \%$ & 13 & 15 & 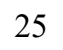 & $.03 \%$ & 39.3\% FGPIPLGSLGWK & $99.6 \%$ & 22.5 & 25.0 & 20.5 & & 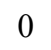 & 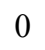 & 1271.71 & 223 & 234 \\
\hline NADH dehydrogenase [ubiquinone]] 1 apha subcomplex subunit 9 , mitochondrial GN=NDUFA9 & NDUA9_HUMAN & 42.51 & $100.0 \%$ & 13 & 5 & 5 & $.03 \%$ & 39.3\% QPVYVVDVSK & $99.7 \%$ & 44.4 & 25.0 & 41.2 & & 0 & 0 & 33.62 & 238 & 247 \\
\hline VADH dehydrogenase [ubiquinone] 1 alpha subcomplex subunit 9 , mitochondrial GN=NDUFA9 & NDUA9_HUMAN & 42.51 & $100.0 \%$ & 13 & 15 & 5 & $0.03 \%$ & $39.3 \%$ GIVNAVKDPDANGK & $99.7 \%$ & 40.7 & 25.0 & 40.6 & & 0 & & 1397.74 & 248 & 261 \\
\hline NADH dehydrogenase [ubiquinone] I alpha subcomplex subunit 9 , mitochondrial GN=NDUFA9 & NDUA9_HUMAN & 42.51 & $100.0 \%$ & 13 & 15 & 5 & $0.03 \%$ & 39.3\% SFAFVGPSR & $99.7 \%$ & 42.6 & 25.0 & 38.7 & & 0 & & 967.50 & 262 & 270 \\
\hline NADH dehydrogenase [ubiquinone] I alph subcomplex subunit 9 , mitochondrial GN=NDUFA9 & NDUA9_HUMAN & 42.51 & $100.0 \%$ & 13 & 15 & 25 & $.03 \%$ & $39.3 \%$ YLLFHLVK & $94.6 \%$ & 14.6 & 25.0 & 14.6 & & 0 & & 1032.62 & 271 & 278 \\
\hline ADH dehydrogenase [ubiquinone] 1 alpha subcomplex subunit 9 , mitochondrial GN=NDUFA9 & NDUA9_HUMAN & 42.51 & $100.0 \%$ & 13 & 15 & 25 & $0.03 \%$ & 39.3\% VFEISPFEPWITR & $99.7 \%$ & 51.6 & 25.0 & 43.7 & & 0 & & .84 & 304 & 316 \\
\hline ADH dehydrogenase [ubiquinone] 1 alpha subcomplex subunit 9 , mitcochondrial GN=NDUFA9 & NDUA9_HUMAN & 42.51 & $100.0 \%$ & 13 & 10 & 25 & $0.03 \%$ & $39.3 \%$ WLSAEIEDVKPAK & $99.7 \%$ & 65.1 & 25.0 & 57.1 & & 0 & & 5.79 & 361 & 373 \\
\hline NADH dehydrogenase [ubiquinone] flavoprotein 1, mitochondrial GN=NDUFV1 & NDUV1_HUMAN & 50.82 & $100.0 \%$ & 3 & 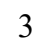 & 6 & $0.01 \%$ & 7.5\% GGAGFPTGLK & $98.7 \%$ & 17.7 & 25.0 & 17.7 & & 0 & & & 89 & 98 \\
\hline NADH dehydrogenase [ubiquinone] flavoprotein 1, mitochondrial GN=NDUFV1 & NDUV1_HUMAN & 50.82 & $100.0 \%$ & 3 & J & 6 & $0.01 \%$ & 7.5\% EAYEAGLIGK & $99.7 \%$ & 30.5 & 25.0 & 26.4 & & 0 & & .55 & 175 & 184 \\
\hline NADH dehydrogenase [ubiquinone] flavoprotein 1, mitochondrial GN=NDUFV1 & NDUV1_HUMAN & 50.82 & $100.0 \%$ & 3 & 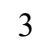 & 6 & $0.01 \%$ & 7.5\% NACGSGYDFDVFVVR & $99.7 \%$ & 49.3 & 25.0 & 49.3 & & 0 & & .76 & 185 & 199 \\
\hline NADH dehydrogenase [ubiquinone] iron-sulfur protein 2, mitochondrial GN=NDUFS2 & NDUS2_HUMAN & 52.55 & $100.0 \%$ & 3 & 4 & 6 & $0.01 \%$ & 9.3\% NITLNFGPQHPAAHGVLR & $99.7 \%$ & 28.5 & 25.0 & 27.9 & & 2 & U & .04 & 79 & 96 \\
\hline NADH dehydrogenase [ubiquinone] iron-sulfur protein 2, mitochondrial GN=NDUFS2 & NDUS2_HUMAN & 52.55 & 100 & 3 & 4 & 6 & $1 \%$ & 9.3\% IIAQCLNK & $99.0 \%$ & 26.0 & 25.0 & 15.0 & & 0 & & & 343 & 350 \\
\hline NADH dehydrogenase [ubiquinone] iron-sulfur protein 2, mitochondrial GN=NDUFS2 & NDUS2_HUMAN & 52.55 & $100.0 \%$ & 3 & 4 & 6 & $\%$ & $9.3 \%$ GEFGV & $99.7 \%$ & 53.0 & 25.0 & 52.9 & & 1 & & 92 & 405 & 421 \\
\hline NADH dehydrogenase [ubiquinone] iron-sulfur protein 3, mitochondrial GN=NDUFS3 & NDUS3_HUMAN & 30.24 & $100.0 \%$ & 3 & J & 4 & $.00 \%$ & RPTVRPR & $99.7 \%$ & 31.1 & 25.0 & 28.9 & & 2 & 0 & .79 & 37 & 50 \\
\hline NADH dehydrogenase [ubiquinone] iron-sulfur protein 3, mitochondrial GN=NDUFS3 & NDUS3_HUMAN & 30.24 & $100.0 \%$ & 3 & J & 4 & $.00 \%$ & $14.4 \% \mathrm{SL}$ & $99.7 \%$ & 40.1 & 25.0 & 40.1 & & 0 & C & & 110 & 122 \\
\hline NADH dehydrogenase [ubiquinone] iron-sulfur protein 3, mitochondrial GN=NDUFS3 & NDUS3_HUMAN & 30.24 & 100. & 3 & 3 & 4 & $.00 \%$ & $14.4 \%$ DFPLSG & $99.4 \%$ & 26.0 & 25.0 & 25.6 & & 0 & & & 201 & 211 \\
\hline NADH-cytochrome b5 reductase $3 \mathrm{GN}=\mathrm{CYB} 5 \mathrm{R} 3$ & NB5R3_HUMAN & 34.24 & 100 & 2 & 2 & 3 & $.00 \%$ & $9.3 \% \quad \mathrm{ST}$ & $99.7 \%$ & 36.8 & 25.0 & 36.5 & & 1 & & .04 & 30 & 46 \\
\hline NADH-cytochrome b5 reductase $3 \mathrm{GN}=\mathrm{CYB} 5 \mathrm{R} 3$ & NB5R3_HUMAN & 34.24 & 10 & 2 & 2 & 3 & $\%$ & $9.3 \% \mathrm{GF}$ & $99.7 \%$ & 62.9 & 25.0 & 52.9 & & 0 & 0 & 62 & 144 & 154 \\
\hline NADH-ubiquinone oxidoreductase 75 kDa subunit, mitochondrial GN=NDUFS1 & NDUS1_HUMAN & 79.47 & $100.0 \%$ & 4 & 4 & 6 & $0.01 \%$ & $5.9 \%$ FASE & $99.7 \%$ & 71.7 & 25.0 & 67.8 & & 0 & & .79 & 185 & 200 \\
\hline NADH-ubiquinone oxidoreductase $75 \mathrm{kDa}$ subunit, mitochondrial GN=NDUFS1 & NDUS1_HUMAN & 79.47 & $100.0 \%$ & 4 & 4 & 6 & $.01 \%$ & $5.9 \% \mathrm{FA}$ & $99.0 \%$ & 25.3 & 25.0 & 19.2 & 1 & 0 & 0 & 52 & 292 & 299 \\
\hline NADH-ubiquinone oxidoreductase 75 kDa subunit, mitochondrial GN=NDUFS1 & NDUS1_HUMAN & 79.47 & 100 & 4 & 4 & 6 & $\%$ & $5.9 \% \mathrm{FE}$ & $98.9 \%$ & 18.8 & 25.0 & 17.5 & & 0 & c & & 409 & 417 \\
\hline NADH-ubiquinone oxidoreductase 75 kDa subunit, mitochondrial GN=NDUFS1 & NDUS1_HUMAN & 79.47 & 100 & 4 & 4 & 6 & $.01 \%$ & $5.9 \% \mathrm{SA}^{\prime}$ & $99.7 \%$ & 33.9 & 25.0 & 32.8 & & 0 & $\mathrm{c}$ & 52 & 593 & 602 \\
\hline NADPH:adrenodoxin oxidoreductase, mitochondrial GN=FDXR & ADRO_HUMAN & 53.84 & $100.0 \%$ & 3 & 3 & 4 & $0 \%$ & $7.5 \%$ TA & $99.4 \%$ & 28.1 & 25.0 & 13.5 & 1 & 0 & 0 & 67 & 283 & 295 \\
\hline NADPH:adrenodoxin oxidoreductase, mitochondrial GN=FDXR & ADRO_HUMAN & 53.84 & 10 & 3 & 3 & 4 & $\%$ & $\%$ LA & $98.4 \%$ & 17.6 & 25.0 & 17.2 & & 1 & 0 & & 328 & 341 \\
\hline NADPH:adrenodoxin oxidoreductase, mitochondrial GN=FDXR & ADRO_HUMAN & 53.84 & 100 & 3 & 3 & 4 & $\%$ & $7.5 \% \quad L G$ & $97.4 \%$ & 21.9 & 25.0 & 12.0 & & 0 & c & 61 & 377 & 386 \\
\hline N-alpha-acetyl & NAA10_HUMAN & 26.46 & & 5 & 5 & 9 & & HGHITSLAVK & & 38.4 & 25.0 & 33.8 & ( & 2 & 0 & & 60 & 78 \\
\hline $\mathrm{N}$-alpha-acetyltransferase $10 \mathrm{GN}=\mathrm{NAA} 10$ & NAA10_HUMAN & 26.46 & 10 & 5 & 5 & 9 & $1 \%$ & $32.8 \%$ AN & $99.4 \%$ & 24.9 & 25.0 & 16.2 & 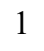 & 0 & 0 & & 97 & 105 \\
\hline $\mathrm{N}$-alpha-acetyltransferase $10 \mathrm{GN}=\mathrm{NAA} 10$ & NAA10_HUMAN & 26.46 & & 5 & & 9 & & $32.8 \%$ AA & $99.7 \%$ & 43.7 & 25.0 & 43.7 & & & & & 7 & 136 \\
\hline tyltransferas & NAA10_HUMAN & 26.46 & & 3 & 5 & 9 & & & & 34.0 & 25.0 & & & 3 & & & 70 & 183 \\
\hline $\mathrm{N}$-alpha-acetyltransferase $10 \mathrm{GN}=\mathrm{NAA} 10$ & NAA10_HUMAN & 26.46 & 100 & 5 & 5 & 9 & $1 \%$ & $32.8 \% \mathrm{GN}$ & $99.7 \%$ & 52.7 & 25.0 & 49.9 & 2 & 0 & . & .70 & 184 & 198 \\
\hline N-alpha-acetyltransferase 15 , NatA auxiliary subunit GN=NAA15 & NAA15_HUMAN & 101.28 & $100.0 \%$ & 6 & 9 & 14 & $.02 \%$ & $7.6 \% \mathrm{YQ}$ & $99.6 \%$ & 25.4 & 25.0 & 25.4 & & 0 & 0 & .80 & 138 & 148 \\
\hline N-alpha-acetyltransferase 15 , NatA auxiliary subunit GN=NAA15 & NAA15_HUMAN & 101.28 & 100 & 6 & 9 & 14 & & $0 \mathrm{RI}$ & & 18.8 & 25.0 & & 2 & 0 & $\mathrm{c}$ & & 295 & 305 \\
\hline $\mathrm{N}$-alpha-acetyltransferase $15, \mathrm{Nat} A$ auxiliary subunit GN=NAA15 & NAA15_HUMAN & 101.28 & $100.0 \%$ & 6 & 9 & 14 & $02 \%$ & $7.6 \% \mathrm{GCF}$ & $99.0 \%$ & 20.9 & 25.0 & 17.5 & 2 & 0 & 0 & .59 & 321 & 330 \\
\hline N-alpha-acetyltransferase 15 , NatA auxiliary subunit GN=NAA15 & NAA15_HUMAN & 101.28 & $100.0 \%$ & 6 & 9 & 14 & $.02 \%$ & $7.6 \% \mathrm{NFI}$ & $99.7 \%$ & 39.2 & 25.0 & 25.4 & & 0 & 0 & 3.61 & 749 & 757 \\
\hline N-alpha-acetyltransferase $15, \mathrm{NatA}$ auxiliary subunit GN=NAA15 & NAA15_HUMAN & 101.28 & 100 & 6 & 9 & 14 & & $7.6 \% \mathrm{NS}$ & $98.4 \%$ & 18.9 & 25.0 & 18.9 & 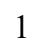 & 1 & ( & .73 & 758 & 770 \\
\hline N-alpha-acetyltransferase $15, \mathrm{NatA}$ auxiliary subunit GN=NAA15 & NAA15_HUMAN & 101.28 & $100.0 \%$ & 6 & 9 & 14 & $.02 \%$ & $7.6 \% \mathrm{MVI}$ & $99.7 \%$ & 29.6 & 25.0 & 29.1 & 3 & 1 & 0 & 2.73 & 771 & 782 \\
\hline Nascent polypeptide-associated complex subunit alpha, muscle-specific form $\mathrm{GN}=\mathrm{NACA}$ & NACAM_HUMAN & 205.42 & $100.0 \%$ & 3 & 3 & 6 & $.01 \%$ & $2.0 \% \mathrm{NILl}$ & $99.7 \%$ & 59.3 & 25.0 & 56.3 & & 0 & 0 & 9.90 & 1964 & 1976 \\
\hline Nascent polypeptide-associated complex subunit alpha, muscle-specific form GN=NACA & NACAM_HUMAN & 205.42 & $100.0 \%$ & 3 & 3 & 6 & & $2.0 \% \mathrm{SPA}$ & $99.7 \%$ & 63.1 & 25.0 & 59.4 & & 0 & 0 & .73 & 1977 & 1990 \\
\hline Nascent polypeptide-associated complex subunit alpha, muscle-specific form GN=NACA & NACAM_HUMAN & 205.42 & $100.0 \%$ & 3 & 3 & 6 & $0.01 \%$ & $2.0 \%$ IEDLSQQAQLAAAEK & $99.7 \%$ & 87.5 & 25.0 & 82.1 & 2 & 0 & 0 & 1614.83 & 1991 & 2005 \\
\hline Nesprin-1 GN=SYNE1 & SYNE1_HUMAN & 1011.10 & $100.0 \%$ & 3 & 3 & 4 & $0.00 \%$ & $0.3 \%$ VQEAILAR & $97.4 \%$ & 19.5 & 25.0 & 13.9 & 1 & 0 & 0 & 899.53 & 4666 & 4673 \\
\hline Nesprin-1 GN=SYNE1 & SYNE1_HUMAN & 1011.10 & 100 & 3 & 3 & 4 & & $0.3 \%$ VLF & $98.5 \%$ & 21.2 & 25.0 & 15.9 & & 0 & 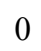 & 7.60 & 6495 & 6504 \\
\hline Nesprin-1 GN=SYNE1 & SYNE1_HUMAN & 1011.10 & $100.0 \%$ & 3 & 3 & 4 & $0.00 \%$ & $0.3 \% \quad$ SSLNEYQPK & $97.3 \%$ & 23.2 & 25.0 & 12.2 & 1 & 0 & 0 & 1065.52 & 6737 & 6745 \\
\hline Neuroblastoma-amplified sequence GN=NBAS & NBAS_HUMAN & 268.58 & $100.0 \%$ & 4 & 4 & 7 & $0.01 \%$ & $1.8 \%$ HGASFIITK & $99.7 \%$ & 26.6 & 25.0 & 18.9 & 0 & 0 & 0 & 973.55 & 46 & 54 \\
\hline Neuroblastoma-amplified sequence GN=NBAS & NBAS_HUMAN & 268.58 & $100.0 \%$ & 4 & 4 & 7 & $0.01 \%$ & $1.8 \%$ SAKDDFTSIIGK & $99.7 \%$ & 47.1 & 25.0 & 47.1 & 2 & 0 & 0 & 1281.67 & 113 & 124 \\
\hline
\end{tabular}


Neuroblastoma-amplified sequence GN=NBAS NBAS_HUMAN $268.58 \quad 100.0 \%$ Neuroblastoma-amplified sequence GN=NBAS NBAS_HUMAN $268.58 \quad 100.0 \%$ Neurofibromin GN=NF1

Neurofibromin GN=NF1

Neurofibromin $\mathrm{GN}=\mathrm{NF} 1$

Neurofibromin GN=NF1

Neurofibromin GN=NF1

Neurofibromin GN=NF1 NF1 HUMAN $319.38 \quad 100.0 \%$ NF1_HUMAN $319.38 \quad 100.0 \%$ NF1 HUMAN $319.38 \quad 100.0 \%$ NF1_HUMAN $319.38 \quad 100.0 \%$ NF1 HUMAN $319.38 \quad 100.0 \%$ NF1_HUMAN $319.38 \quad 100.0 \%$

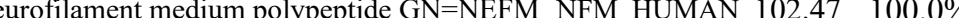
Neurofilament medium polypeptide GN=NEFM NFM_HUMAN $102.47 \quad 100.0 \%$ Neurofilament medium polypeptide GN=NEFM NFM_HUMAN $102.47 \quad 100.0 \%$ Neurofilament medium polypeptide GN=NEFM NFM HUMAN $102.47 \quad 100.0 \%$ Neurofilament medium polypeptide GN=NEFM NFM_HUMAN $102.47 \quad 100.0 \%$ Neurofilament medium polypeptide GN=NEFM NFM_HUMAN $102.47 \quad 100.0 \%$ Neurofilament medium polypeptide GN=NEFM NFM_HUMAN $102.47 \quad 100.0 \%$ Neutral alpha-glucosidase AB GN=GANAB GANAB_HUMAN $106.88 \quad 100.0 \%$ Neutral alpha-glucosidase $\mathrm{AB}$ GN $=$ GANAB GANAB HUMAN $106.88 \quad 100.0^{\circ}$ NF-kappa-B-repressing factor GN=NKRF NKRF_HUMAN $77.67 \quad 100.0 \%$ NF-kappa-B-repressing factor GN=NKRF NKRF_HUMAN $77.67 \quad 100.0 \%$ NF-kappa-B-repressing factor GN=NKRF NKRF HUMAN $77.67 \quad 100.0 \%$ NF-kappa-B-repressing factor GN=NKRF NKRF_HUMAN $77.67 \quad 100.0 \%$ NF-kappa-B-repressing factor GN=NKRF NKRF HUMAN $77.67 \quad 100.0 \%$ NF-kappa-B-repressing factor GN=NKRF NKRF_HUMAN $77.67 \quad 100.0 \%$ NF-kappa-B-repressing factor GN=NKRF NKRF_HUMAN $77.67 \quad 100.0 \%$ Nicotinamide phosphoribosyltransferase GN=NAMPT NAMPT HUMAN $55.52 \quad 100.0 \%$ Nicotinamide phosphoribosyltransferase GN=NAMPT NAMPT_HUMAN $55.52 \quad 100.0 \%$ Ncotinamide/nicotinic acid mononucleotide adenylyltransferase 1 GN=NMNAT1 NMNA1_HUMAN $31.93 \quad 100.0 \%$ 作 Nicotinamide/nicotinic acid mononucleotide adenylytransferase 1 GN=NMNAT1 NMNA1_HUMAN $31.93 \quad 100.0 \%$

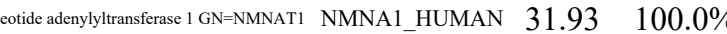
$\begin{array}{ll} & \end{array}$ Nischarin GN=NISCH Nischarin GN=NISCH Nischarin GN=NISCH Nischarin GN=NISCH Nischarin GN=NISCH Nischarin GN=NISCH Non-POU domain-containing octamer-binding protein GN=NONO NONO_HUMAN $54.23 \quad 100.0 \%$ Non-POU domain-containing octamer-binding protein GN=NONO NONO_HUMAN $54.23 \quad 100.0 \%$ Non-POU domain-containing octamer-binding protein GN=NONO NONO_HUMAN $54.23 \quad 100.0 \%$ Non-POU domain-containing octamer-binding protein GN=NONO NONO_HUMAN $54.23 \quad 100.0 \%$ Non-POU domain-containing octamer-binding protein GN=NONO NONO HUMAN $54.23100 .0 \%$ Non-POU domain-containing octamer-binding protein GN=NONO NONO_HUMAN $54.23 \quad 100.0 \%$ Nuclear cap-binding protein subunit $1 \mathrm{GN}=\mathrm{NCBP} 1 \mathrm{NCBP} 1 \_$HUMAN $91.84 \quad 100.0 \%$ Nuclear cap-binding protein subunit $1 \mathrm{GN}=\mathrm{NCBP} 1 \mathrm{NCBP} 1$ HUMAN $91.84 \quad 100.0 \%$ Nuclear cap-binding protein subunit $1 \mathrm{GN}=\mathrm{NCBP} 1 \mathrm{NCBP} 1 \_$HUMAN $91.84 \quad 100.0 \%$
$0.01 \% \quad 1.8 \% \quad$ QVDCALSLIR $0.01 \% \quad 1.8 \% \quad$ IFQHSKPDLQQK

$10 \quad 0.01 \% \quad 2.5 \% \quad$ VAQLAVINSLEK

$0.01 \% \quad 2.5 \%$ QLTESAAIACVK

$10 \quad 0.01 \% \quad 2.5 \% \quad$ AVQGCGAHPAIR

$10 \quad 0.01 \% \quad 2.5 \% \quad$ TLSIFYQAGTSK

$10 \quad 0.01 \% \quad 2.5 \% \quad$ VGSTAVQVTSAER $0.01 \% \quad 2.5 \% \quad$ ALVVFGCISK $0.01 \% \quad 7.9 \%$ VSGSPSSGFR $0.01 \% \quad 7.9 \%$ GSPSTVSSSYKR $0.01 \% \quad 7.9 \%$ LRDDTEAAIR $0.01 \% \quad 7.9 \%$ LTEAAEQNKEAIR $0.01 \% \quad 7.9 \%$ HLREYQDLLNVK $0.01 \% \quad 7.9 \%$ EYQDLLNVK

$0.01 \% \quad 7.9 \%$ ITSEGGDGATKYITK $0.00 \% \quad 2.9 \%$ SIRPGLSPYR

$0.00 \% \quad 2.9 \%$ VVIIGAGKPAAVVLQTK $0.02 \% \quad 13.2 \%$ HLSTCDGQNPPKK $0.02 \% \quad 13.2 \%$ CQNIYLTTGYAGSK $0.02 \% \quad 13.2 \%$ DASGQPIFNASAK $0.02 \% \quad 13.2 \%$ HAAADEALKILQK $0.02 \% \quad 13.2 \%$ TVKYEAAGEAVK $0.02 \% \quad 13.2 \%$ GAVEDVISRNEIQGR $0.02 \% \quad 13.2 \%$ SESHTDLTFSR $0.00 \% \quad 6.1 \% \quad$ AVPEGFVIPR

$0.00 \% \quad 6.1 \%$ GVSSQETAGIGASAHLVNFK

$10 \quad 0.01 \% \quad 23.7 \%$ GIISPVGDAYK

$\quad 0.01 \% \quad 23.7 \%$ VIMAELATK

$10 \quad 0.01 \% \quad 23.7 \%$ WVEVDTWESLQK

$10 \quad 0.01 \% \quad 23.7 \%$ FIYESDVLWK

$10 \quad 0.01 \% \quad 23.7 \%$ YLVPDLVQEYIEK

$10 \quad 0.01 \% \quad 23.7 \%$ NAGVILAPLQR

$10 \quad 0.01 \% \quad 4.3 \% \quad$ EKDLEVYLQK

$10 \quad 0.01 \% \quad 4.3 \% \quad$ LLAAFPGVTPR

$10 \quad 0.01 \% \quad 4.3 \% \quad$ SCCAPSEAVK

$10 \quad 0.01 \% \quad 4.3 \% \quad$ VPLSTVLLDPTR

$\begin{array}{llllllll}99.6 \% & 27.9 & 25.0 & 18.8 & 2 & 0 & 0 & 1174.63\end{array}$ $99.1 \% 23.2$

$99.7 \% \quad 40.2$

$99.4 \% \quad 20.6$

$99.7 \% \quad 26.7$

$99.7 \% \quad 48.6$

$99.7 \% 53.5$

$98.0 \% \quad 21.1$

$99.7 \% 33.8$

$99.7 \% \quad 47.2$

$99.7 \% \quad 39.7$

$99.7 \% \quad 64.5$

$99.7 \% \quad 51.8$

$99.7 \% \quad 48.9$

$99.7 \% \quad 46.1$

$99.7 \% \quad 27.3$

$99.7 \% \quad 27.2$

$99.7 \% \quad 49.6$

$99.7 \% \quad 49.2$

$99.7 \% \quad 56.3$

$99.6 \% \quad 23.3$

$99.7 \% \quad 28.9$

$99.7 \% \quad 48.8$

$98.9 \% \quad 23.0$

$99.7 \% \quad 34.0$

$98.6 \% \quad 22.1$

$99.7 \% \quad 35.4$

$99.7 \% \quad 51.5$

$99.5 \% \quad 25.8$

$99.7 \% \quad 39.1$

$97.4 \% \quad 16.0$

$99.7 \% \quad 38.7$

$99.7 \% 36.1$

$99.7 \% \quad 32.2$

$99.7 \% \quad 37.4$

$99.1 \% \quad 18.7$

$\begin{array}{lllll}0.01 \% & 4.3 \% & \text { TPGTGGSPQGSFADGQPAER } & 99.7 \% & 71.9\end{array}$

$0.01 \% \quad 4.3 \%$ TPGTGGSPQGSFADGQPAERR

$0.03 \% \quad 12.3 \%$ AGEVFIHK

$0.03 \% \quad 12.3 \%$ FACHSASLTVR

$0.03 \% \quad 12.3 \%$ AVVIVDDRGRPSGK

$0.03 \% \quad 12.3 \%$ GIVEFSGKPAAR

$0.03 \% \quad 12.3 \%$ GIVEFSGKPAARK

$0.03 \% \quad 12.3 \%$ AAPGAEFAPNKR

$0.01 \% \quad 4.1 \%$ ANNYNEAVYLVR

$0.01 \% \quad 4.1 \%$ ATNDEIFSILK

$0.01 \% \quad 4.1 \%$ NLFLVIFQR
$25.0 \quad 26.6$

$96.1 \% \quad 20.4 \quad 25.0 \quad 11.4$

$99.7 \% \quad 35.9$

$99.7 \% \quad 25.9$

$99.7 \% \quad 55.4$

$99.7 \% \quad 29.2$

$99.7 \% \quad 61.3$

$99.7 \% \quad 41.0$

$99.7 \% 28.6$

$99.7 \% \quad 40.9$
68.79

1284.75

1290.67

1236.63

1315.69

1304.68

1093.61

980.48

1255.63

1159.61

1472.77

1527.83

1121.58

1540.79

1145.64

1664.05

1481.72

1575.75

1305.64

1407.80

1265.67

1642.85

1279.59

1084.62

1973.01

1119.60

975.55

1519.74

1299.66

1608.85

1151.69

1264.68

1141.67

1108.48

1310.77

1916.87

2072.97

900.49

1248.62

1468.82

1231.68

1359.77

1228.64

1425.71

250.66

1149.68 \begin{tabular}{cc}
9 & 868 \\
2 & 983 \\
7 & 218 \\
5 & 326 \\
0 & 461 \\
89 & 1600 \\
57 & 1769 \\
48 & 2257 \\
7 & 36 \\
3 & 54 \\
5 & 204 \\
9 & 311 \\
0 & 391 \\
3 & 391 \\
1 & 875 \\
2 & 61 \\
2 & 908 \\
3 & 45 \\
6 & 259 \\
3 & 335 \\
9 & 411 \\
8 & 509 \\
5 & 539 \\
6 & 626 \\
8 & 127 \\
7 & 216 \\
6 & 56 \\
7 & 75 \\
9 & 922 \\
6 & 90 \\
6 & 205 \\
8 & 250 \\
2 & 272 \\
9 & 98 \\
9 & 109 \\
3 & 902 \\
6 & 957 \\
16 & 1035 \\
16 & 1036 \\
0 & 107 \\
3 & 153 \\
7 & 190 \\
1 & 202 \\
\hline 7 & 468 \\
\hline
\end{tabular}

Page 101 of Table S-1-5 

Nuclear mitotic apparatus protein 1 GN=NUMA1 NUMA1_HUMAN $238.26 \quad 100.0 \%$ Nuclear mitotic apparatus protein 1 GN=NUMA1 NUMA1_HUMAN $238.26 \quad 100.0 \%$ Nuclear mitotic apparatus protein $1 \mathrm{GN}=$ NUMA1 NUMA1 HUMAN $238.26 \quad 100.0 \%$ Nuclear mitotic apparatus protein 1 GN=NUMA1 NUMA1_HUMAN $238.26 \quad 100.0 \%$ Nuclear mitotic apparatus protein 1 GN=NUMA1 NUMA1_HUMAN $238.26 \quad 100.0 \%$ Nuclear mitotic apparatus protein 1 GN=NUMA1 NUMA1_HUMAN $238.26 \quad 100.0 \%$ Nuclear mitotic apparatus protein 1 GN=NUMA1 NUMA1_HUMAN $238.26 \quad 100.0 \%$ Nuclear mitotic apparatus protein $1 \mathrm{GN}=\mathrm{NUMA} 1$ NUMA1_HUMAN $238.26 \quad 100.0 \%$ Nuclear mitotic apparatus protein $1 \mathrm{GN}=$ NUMA1 NUMA1_HUMAN $238.26 \quad 100.0 \%$ Nuclear mitotic apparatus protein $1 \mathrm{GN}=$ NUMA1 NUMA1_HUMAN $238.26 \quad 100.0 \%$ Nuclear mitotic apparatus protein 1 GN=NUMA1 NUMA1_HUMAN $238.26 \quad 100.0 \%$ Nuclear mitotic apparatus protein 1 GN=NUMA1 NUMA1_HUMAN $238.26 \quad 100.0 \%$ Nuclear mitotic apparatus protein $1 \mathrm{GN}=\mathrm{NUMA} 1$ NUMA1_HUMAN $238.26 \quad 100.0 \%$ Nuclear mitotic apparatus protein $1 \mathrm{GN}=\mathrm{NUMA} 1 \mathrm{NUMA1}$ HUMAN $238.26 \quad 100.0 \%$ Nuclear mitotic apparatus protein 1 GN=NUMA1 NUMA1_HUMAN $238.26 \quad 100.0 \%$ Nuclear mitotic apparatus protein $1 \mathrm{GN}=\mathrm{NUMA} 1$ NUMA1_HUMAN $238.26 \quad 100.0 \%$ Nuclear mitotic apparatus protein 1 GN=NUMA1 NUMA1_HUMAN $238.26 \quad 100.0 \%$ Nuclear mitotic apparatus protein 1 GN=NUMA1 NUMA1_HUMAN $238.26 \quad 100.0 \%$ Nuclear mitotic apparatus protein $1 \mathrm{GN}=$ NUMA1 NUMA1_HUMAN $238.26 \quad 100.0 \%$ Nuclear mitotic apparatus protein 1 GN=NUMA1 NUMA1_HUMAN $238.26 \quad 100.0 \%$ Nuclear mitotic apparatus protein $1 \mathrm{GN}=\mathrm{NUMA1}$ NUMA1_HUMAN $238.26100 .0 \%$ Nuclear mitotic apparatus protein 1 GN=NUMA1 NUMA1_HUMAN $238.26100 .0 \%$ Nuclear mitotic apparatus protein $1 \mathrm{GN}=$ NUMA1 NUMA1_HUMAN $238.26 \quad 100.0 \%$ Nuclear mitotic apparatus protein $1 \mathrm{GN}=\mathrm{NUMA1}$ NUMA1 HUMAN $238.26 \quad 100.0^{\circ}$ Nuclear mitotic apparatus protein 1 GN=NUMA1 NUMA1_HUMAN $238.26 \quad 100.0 \%$ Nuclear mitotic apparatus protein 1 GN=NUMA1 NUMA1_HUMAN $238.26100 .0 \%$ Nuclear mitotic apparatus protein $1 \mathrm{GN}=$ NUMA1 NUMA1_HUMAN $238.26 \quad 100.0 \%$ Nuclear mitotic apparatus protein 1 GN=NUMA1 NUMA1_HUMAN $238.26 \quad 100.0 \%$ Nuclear mitotic apparatus protein $1 \mathrm{GN}=\mathrm{NUMA} 1$ NUMA1_HUMAN $238.26 \quad 100.0^{\circ}$ Nuclear mitotic apparatus protein $1 \mathrm{GN}=$ NUMA1 NUMA1_HUMAN $238.26 \quad 100.0 \%$ Nuclear mitotic apparatus protein 1 GN=NUMA1 NUMA1_HUMAN $238.26 \quad 100.0 \%$ Nuclear mitotic apparatus protein $1 \mathrm{GN}=$ NUMA1 NUMA1_HUMAN $238.26 \quad 100.0 \%$ Nuclear mitotic apparatus protein 1 GN=NUMA1 NUMA1_HUMAN $238.26 \quad 100.0 \%$ Nuclear mitotic apparatus protein $1 \mathrm{GN}=$ NUMA1 NUMA1_HUMAN $238.26100 .0 \%$ Nuclear mitotic apparatus protein $1 \mathrm{GN}=\mathrm{NUMA} 1$ NUMA1_HUMAN $238.26100 .0 \%$ Nuclear mitotic apparatus protein 1 GN=NUMA1 NUMA1_HUMAN $238.26 \quad 100.0 \%$ Nuclear mitotic apparatus protein $1 \mathrm{GN}=$ NUMA1 NUMA1_HUMAN $238.26 \quad 100.0 \%$ Nuclear mitotic apparatus protein 1 GN=NUMA1 NUMA1_HUMAN $238.26 \quad 100.0 \%$ Nuclear mitotic apparatus protein 1 GN=NUMA1 NUMA1_HUMAN $238.26 \quad 100.0 \%$ Nuclear mitotic apparatus protein 1 GN=NUMA1 NUMA1_HUMAN $238.26100 .0 \%$ Nuclear mitotic apparatus protein 1 GN=NUMA1 NUMA1_HUMAN $238.26 \quad 100.0 \%$ Nuclear mitotic apparatus protein 1 GN=NUMA1 NUMA1_HUMAN $238.26100 .0 \%$ Nuclear mitotic apparatus protein $1 \mathrm{GN}=$ NUMA1 NUMA1_HUMAN $238.26 \quad 100.0 \%$ Nuclear pore complex protein Nup107 GN=NUP107 NU107_HUMAN $106.38 \quad 100.0 \%$ Nuclear pore complex protein Nup107 GN=NUP107 NU107_HUMAN $106.38 \quad 100.0 \%$ Nuclear pore complex protein Nup107 GN=NUP107 NU107_HUMAN $106.38 \quad 100.0 \%$
$52 \quad 114 \quad 0.12 \% \quad 22.8 \%$ IIDRIHGTEEGQQILK

$52 \quad 114 \quad 0.12 \% \quad 22.8 \%$ CLEEKNEILQGK

$52 \quad 114 \quad 0.12 \% \quad 22.8 \%$ VEMLETERGQQEAK

$52 \quad 114 \quad 0.12 \% \quad 22.8 \%$ HQVEQLSSSLK

$52 \quad 114 \quad 0.12 \% \quad 22.8 \%$ DSAQTSVTQAQR

$52 \quad 114 \quad 0.12 \% \quad 22.8 \%$ DSAQTSVTQAQREK

$52 \quad 114 \quad 0.12 \% \quad 22.8 \%$ AADALEEQQR

$\begin{array}{llll}52 & 114 & 0.12 \% & 22.8 \% \\ 52 & \text { CISELKAETR }\end{array}$

$52 \quad 114 \quad 0.12 \% \quad 22.8 \%$ VAGIESHSELQISR

$52 \quad 114 \quad 0.12 \% \quad 22.8 \%$ ALQQVQEKEVR

$52 \quad 114 \quad 0.12 \% \quad 22.8 \%$ LADDLSTLQEK

$52 \quad 114 \quad 0.12 \% \quad 22.8 \%$ ELVKEPAR

$52 \quad 114 \quad 0.12 \% \quad 22.8 \%$ AGDRQPEWLEEQQGR

$52 \quad 114 \quad 0.12 \% \quad 22.8 \%$ EAEQMGNELER

$52 \quad 114 \quad 0.12 \% \quad 22.8 \%$ AALMESQGQQQEERGQQER

$52 \quad 114 \quad 0.12 \% \quad 22.8 \%$ GRAQADLALEK

$52 \quad 114 \quad 0.12 \% \quad 22.8 \%$ AQADLALEK

$52 \quad 114 \quad 0.12 \% \quad 22.8 \%$ EKEHASGSGAQSEAAGR

$52 \quad 114 \quad 0.12 \% \quad 22.8 \%$ AEVSKLEQQCQK

$52 \quad 114 \quad 0.12 \% \quad 22.8 \%$ QQEQADSLER

$52 \quad 114 \quad 0.12 \% \quad 22.8 \%$ AQELGHSQSALASAQR

$52 \quad 114 \quad 0.12 \% \quad 22.8 \%$ LLQAETASNSAR

$52 \quad 114 \quad 0.12 \% \quad 22.8 \%$ QELTSQAER

$52 \quad 114 \quad 0.12 \% \quad 22.8 \%$ HLCQQLQAEQAAAEKR

$52 \quad 114 \quad 0.12 \% \quad 22.8 \%$ ELGELIPLRQK

$52 \quad 114 \quad 0.12 \% \quad 22.8 \%$ ASYAEQLSMLK

$52 \quad 114 \quad 0.12 \% \quad 22.8 \%$ ASYAEQLSMLKK

$52 \quad 114 \quad 0.12 \% \quad 22.8 \%$ QFLEVELDQAR

$52 \quad 114 \quad 0.12 \% \quad 22.8 \%$ YVQELAAVR

$52 \quad 114 \quad 0.12 \% \quad 22.8 \%$ LAEVQREAQSTAR

$52 \quad 114 \quad 0.12 \% \quad 22.8 \%$ ELEVMTAKYEGAK

$52 \quad 114 \quad 0.12 \% \quad 22.8 \%$ LADSDQASKVQQQK

$52 \quad 114 \quad 0.12 \% \quad 22.8 \%$ AVQAQGGESQQEAQR

$52 \quad 114 \quad 0.12 \% \quad 22.8 \%$ KQQNQELQEQLR

$52 \quad 114 \quad 0.12 \% \quad 22.8 \%$ QQNQELQEQLR

$52 \quad 114 \quad 0.12 \% \quad 22.8 \%$ LGHELQQAGLK

$52 \quad 114 \quad 0.12 \% \quad 22.8 \%$ TTQIINITMTK

$52 \quad 114 \quad 0.12 \% \quad 22.8 \%$ SAPASQASLR

$52 \quad 114 \quad 0.12 \% \quad 22.8 \%$ RSQAGVSSGAPPGR

$52 \quad 114 \quad 0.12 \% \quad 22.8 \%$ SQAGVSSGAPPGR

$52 \quad 114 \quad 0.12 \% \quad 22.8 \%$ VSLEPHQGPGTPESK

$52 \quad 114 \quad 0.12 \% \quad 22.8 \%$ VSLEPHQGPGTPESKK

$52 \quad 114 \quad 0.12 \% \quad 22.8 \%$ QSMAFSILNTPK

$52 \quad 114 \quad 0.12 \% \quad 22.8 \%$ IATTTASAATAAAIGATPR

$\begin{array}{llll}11 & 0.01 \% & 6.5 \% & \text { SGFGEISSPVIR }\end{array}$

$11 \quad 0.01 \% \quad 6.5 \% \quad$ VLLQASQDENFGNTTPR

$11 \quad 0.01 \% \quad 6.5 \% \quad$ TVVEALFQR $\begin{array}{llll}95.3 \% & 14.5 & 25.0 & 14.5\end{array}$

$99.7 \% \quad 54.0 \quad 25.0 \quad 47.6$

$\begin{array}{llll}99.7 \% & 32.2 & 25.0 & 23.7\end{array}$

$\begin{array}{llll}99.7 \% & 59.6 & 25.0 & 52.6\end{array}$

$\begin{array}{llll}99.7 \% & 59.7 & 25.0 & 51.6\end{array}$

$\begin{array}{llll}99.7 \% & 57.0 & 25.0 & 43.6\end{array}$

$99.7 \% \quad 61.4 \quad 25.0 \quad 52.2$

$\begin{array}{llll}99.7 \% & 51.5 & 25.0 & 31.8\end{array}$

$99.7 \% \quad 57.6 \quad 25.0 \quad 52.5$

$\begin{array}{llll}99.7 \% & 45.2 & 25.0 & 45.2\end{array}$

$\begin{array}{llll}99.7 \% & 47.2 & 25.0 & 35.0\end{array}$

$\begin{array}{llll}99.0 \% & 29.8 & 25.0 & 19.8\end{array}$

$\begin{array}{llll}99.7 \% & 30.6 & 25.0 & 30.6\end{array}$

$\begin{array}{llll}99.7 \% & 31.1 & 25.0 & 31.1\end{array}$

$\begin{array}{llll}99.7 \% & 59.2 & 25.0 & 59.2\end{array}$

$\begin{array}{llll}99.7 \% & 42.9 & 25.0 & 41.3\end{array}$

$99.7 \% \quad 33.3 \quad 25.0-30.1$

$\begin{array}{llll}99.7 \% & 36.6 & 25.0 & 36.6\end{array}$

$\begin{array}{llll}99.7 \% & 47.4 & 25.0 & 47.4\end{array}$

$\begin{array}{llll}99.7 \% & 44.2 & 25.0 & 30.2\end{array}$

$\begin{array}{llll}97.1 \% & 15.7 & 25.0 & 15.7\end{array}$

$99.7 \% \quad 55.5 \quad 25.0 \quad 49.4$

$\begin{array}{llll}99.7 \% & 27.9 & 25.0 & 21.2\end{array}$

$94.5 \% 18$

$99.7 \% \quad 43.6$

$96.6 \% \quad 16.2$

$99.2 \% 31.1$

$99.7 \% \quad 41.5$

$99.3 \% 20.1$

$99.7 \% \quad 46.1$

$99.7 \% \quad 38.4$

$99.7 \% \quad 65.9$

$99.7 \% \quad 43.4$

$99.7 \% \quad 46.5$

$99.7 \% \quad 46.3$

$\begin{array}{lll}99.7 \% & 61.3\end{array}$

$99.7 \% \quad 62.0$

$99.7 \% \quad 37.1$

$99.7 \% \quad 61.6$

$99.7 \% \quad 37.9$

$98.6 \% \quad 17.5$

$99.7 \% \quad 46.5$

$99.6 \% \quad 28.8$

$99.7 \% \quad 26.3$

$99.7 \% \quad 54.8$

$99.7 \% \quad 37.6$
25.0

25.0

25.0

25.0

25.0

25.0

25.0

25.0

25.0

25.0

25.0
25.0

25.0

25.0

25.0

25.0

25.0

25.0

25.0
25.0

25.0

25.0

25.0

460.74

1647.80

1255.66

1291.62

1548.76

1130.54

1206.61

1525.80

1327.73

1232.64

941.54

1798.85

1305.57

2203.02

1171.64

958.52

1671.77

1447.72

1203.56

1653.83

1260.65

1061.52

1880.94

1295.77

1240.62

1368.72

1347.69

1048.58

1458.77

1468.74

1545.79

1586.75

1541.80

1413.71

1193.66

1263.70

987.52

1326.69

1170.59

1562.78

1690.88

1352.69

1715.93

1248.66

1889.94

1062.59 
$10.01 \% \quad 6.5 \% \quad$ AIYAALSGNLK $0.01 \% \quad 6.5 \%$ EADLDVATITK $0.02 \% \quad 6.4 \%$ SFVELSGAER

$0.02 \% \quad 6.4 \%$ SFVELSGAERERPR

$0.02 \% \quad 6.4 \% \quad$ LLLPHPSR

$0.02 \% \quad 6.4 \%$ CYLVTGEGQK

$0.02 \% \quad 6.4 \% \quad$ LQYYDKVLR

$0.02 \% \quad 6.4 \%$ QLVVVLCER

$0.02 \% \quad 6.4 \%$ AGTVMFEYGMR

$0.02 \% \quad 6.4 \% \quad$ RNHDGECTAAPTNR

$0.02 \% \quad 6.4 \% \quad$ LLSTYLER

$0.02 \% \quad 6.4 \% \quad$ KVDAAELLR

$0.05 \% \quad 10.2 \%$ RQPEAVHLLDK

$0.05 \% \quad 10.2 \%$ ASTEGVAIQGQQGTR

$0.05 \% \quad 10.2 \%$ FTDELMEQGLTYK

$0.05 \% \quad 10.2 \%$ QYIATIHSR

$0.05 \% \quad 10.2 \%$ LPGLQATVR

$0.05 \% \quad 10.2 \%$ DLPSADSVQYR

$0.05 \% \quad 10.2 \%$ KADNVVNIAR

$0.05 \% \quad 10.2 \%$ ADNVVNIAR

$0.05 \% \quad 10.2 \%$ ILCCISCNSNIQIK

$0.05 \% \quad 10.2 \%$ LVGDFTHDQSISQK

$0.05 \% \quad 10.2 \%$ SVSGFLHFDTATK

$0.05 \% \quad 10.2 \%$ AQIEQVIANCEHK

$0.05 \% \quad 10.2 \%$ LTAPEDVFSK

$0.05 \% \quad 10.2 \%$ DACDGHEIGR

$0.05 \% \quad 10.2 \%$ ALYTYESK

$0.05 \% \quad 10.2 \%$ IQQGALELLR

$0.05 \% \quad 10.2 \%$ QCLGLLSR

$0.05 \% \quad 10.2 \%$ FGGSDRLR

$0.05 \% \quad 10.2 \%$ LLDIEGLYSK

$0.05 \% \quad 10.2 \%$ YSFIQALVR

$0.01 \% \quad 1.3 \%$ SAQGSSSPVPSMVQK

$0.01 \% \quad 1.3 \% \quad$ ASSTSLTSTQPTK

$0.01 \% \quad 9.6 \%$ DVDVYSQILR

$0.01 \% \quad 9.6 \%$ EADASPASAGICR

$0.01 \% \quad 9.6 \%$ IPLNTEQK

$0.01 \% \quad 9.6 \%$ LGSALSWSIR

$0.01 \% \quad 9.6 \%$ DAAFATLVSDR

$0.01 \% \quad 9.6 \%$ AIIREGSLEGS

$0.03 \% \quad 16.6 \%$ NLQEIQQAGER

$0.03 \% \quad 16.6 \%$ NLQEIQQAGERLR

$0.03 \% \quad 16.6 \%$ TSQETADVKASVLLGSR

$0.03 \% \quad 16.6 \%$ CGDLLAASQVVNR

$0.03 \% \quad 16.6 \%$ LSPATENKLR

$0.03 \% \quad 16.6 \%$ AVYCIIGR

$0.03 \% \quad 16.6 \%$ EALQYFYFLR
$99.7 \% \quad 55.2$

$99.6 \% \quad 25.9 \quad 25.0 \quad 21.2$

$96.2 \% \quad 15.2 \quad 25.0 \quad 15.2$

$99.7 \% \quad 28.9 \quad 25.0 \quad 27.3$

$\begin{array}{llll}99.7 \% & 42.1 & 25.0 & 29.8\end{array}$

$\begin{array}{llll}99.7 \% & 37.3 & 25.0 & 34.2\end{array}$

$99.7 \% \quad 49.7 \quad 25.0 \quad 42.5$

$95.4 \% \quad 14.9 \quad 25.0 \quad 14.9$

$\begin{array}{llll}99.0 \% & 41.5 & 25.0 & 28.2\end{array}$

$99.7 \% \quad 25.3 \quad 25.0 \quad 21.6$

$\begin{array}{llll}99.7 \% & 29.1 & 25.0 & 28.0\end{array}$

$\begin{array}{llll}99.7 \% & 68.1 & 25.0 & 62.9\end{array}$

$\begin{array}{llll}99.7 \% & 57.2 & 25.0 & 56.2\end{array}$

$\begin{array}{llll}99.7 \% & 48.1 & 25.0 & 39.0\end{array}$

$99.7 \% \quad 30.0 \quad 25.0 \quad 21.3$

$\begin{array}{llll}99.7 \% & 61.7 & 25.0 & 48.2\end{array}$

$\begin{array}{llll}99.7 \% & 60.7 & 25.0 & 54.0\end{array}$

$\begin{array}{llll}99.7 \% & 45.5 & 25.0 & 25.0\end{array}$

$99.7 \% \quad 64.5 \quad 25.0 \quad 58.6$

$99.7 \% \quad 40.7 \quad 25.0 \quad 40.7$

$99.7 \% \quad 47.0 \quad 25.0 \quad 47.0$

$\begin{array}{llll}98.6 \% & 30.6 & 25.0 & 29.8\end{array}$

$99.7 \% \quad 33.5 \quad 25.0 \quad 31.0$

$99.7 \% \quad 55.6 \quad 25.0 \quad 55.0$

$\begin{array}{llll}99.0 \% & 35.3 & 25.0 & 19.3\end{array}$

$99.7 \% \quad 48.7 \quad 25.0 \quad 42.4$

$99.0 \% \quad 29.5 \quad 25.0 \quad 12.2$

$\begin{array}{llll}98.7 \% & 27.0 & 25.0 & 11.1\end{array}$

$99.7 \% \quad 40.5 \quad 25.0 \quad 31.7$

$\begin{array}{llll}99.7 \% & 50.4 & 25.0 & 49.3\end{array}$

$\begin{array}{llll}99.7 \% & 38.3 & 25.0 & 38.3\end{array}$

$\begin{array}{llll}99.7 \% & 30.4 & 25.0 & 21.3\end{array}$

$99.7 \% \quad 44.5 \quad 25.0 \quad 43.2$

$99.7 \% \quad 44.6 \quad 25.0=44.6$

$\begin{array}{llll}95.5 \% & 23.5 & 25.0 & 7.6\end{array}$

$\begin{array}{llll}99.7 \% & 67.7 & 25.0 & 53.6\end{array}$

$\begin{array}{llll}99.7 \% & 27.1 & 25.0 & 27.0\end{array}$

$\begin{array}{llll}99.7 \% & 50.4 & 25.0 & 44.8\end{array}$

$99.7 \% \quad 50.4 \quad 25.0 \quad 32.8$

$\begin{array}{llll}99.4 \% & 23.8 & 25.0 & 17.4\end{array}$

$\begin{array}{llll}99.7 \% & 57.8 & 25.0 & 57.8\end{array}$

$\begin{array}{llll}99.7 \% & 60.5 & 25.0 & 52.0\end{array}$

$\begin{array}{lllll}99.7 \% & 44.3 & 25.0 & 27.1 & 2\end{array}$

$\begin{array}{lllll}99.0 \% & 33.2 & 25.0 & 26.0\end{array}$

$\begin{array}{llll}99.7 \% & 36.9 & 25.0 & 31.7\end{array}$
1120.64

1175.62

1094.55

1632.85

932.57

1154.55

1197.66

1115.62

1261.57

1598.71

994.56

1014.59

1305.73

1502.76

1590.74

1088.58

954.57

1250.60

1099.62

971.53

1722.83

1574.78

1409.71

1539.76

1106.57

1129.47

974.48

1140.67

946.51

907.47

1150.64

1096.61

1505.73

1308.66

1207.63

1304.59

942.53

1089.6

1165.58

1131.60

1285.65

1554.83

1761.93

1402.71

1128.64

951.51

1349.69 
Nuclear pore complex protein Nup93 GN=NUP93 NUP93_HUMAN $93.49 \quad 100.0 \%$ Nuclear pore complex protein Nup93 GN=NUP93 NUP93_HUMAN 93.49 Nuclear pore complex protein Nup93 GN=NUP93 NUP93 HUMAN 93.49 Nuclear pore complex protein Nup93 GN=NUP93 NUP93_HUMAN 93.49 Nuclear pore complex protein Nup93 GN=NUP93 NUP93_HUMAN $93.49 \quad 100.0 \%$ Nuclear pore membrane glycoprotein 210 GN=NUP210 PO210_HUMAN $205.11 \quad 100.0 \%$ Nuclear pore membrane glycoprotein 210 GN=NUP210 PO210_HUMAN $205.11 \quad 100.0 \%$ Nuclear pore membrane glycoprotein $210 \mathrm{GN}=\mathrm{NUP} 210 \mathrm{PO} 210$ HUMAN $205.11 \quad 100.0 \%$ Nuclear pore membrane glycoprotein $210 \mathrm{GN}=\mathrm{NUP} 210 \quad$ PO210_HUMAN $205.11 \quad 100.0 \%$ Nuclear receptor coactivator $5 \mathrm{GN}=\mathrm{NCOA} 5$ NCOA5_HUMAN $65.54 \quad 100.0 \%$ Nuclear receptor coactivator $5 \mathrm{GN}=\mathrm{NCOA} 5 \mathrm{NCOA} 5$ HUMAN $65.54 \quad 100.0 \%$ Nuclear receptor coactivator $5 \mathrm{GN}=\mathrm{NCOA} 5$ NCOA5_HUMAN $65.54 \quad 100.0 \%$ Nuclear receptor coactivator $5 \mathrm{GN}=\mathrm{NCOA} 5$ NCOA5_HUMAN $65.54 \quad 100.0 \%$ Nuclear receptor coactivator $5 \mathrm{GN}=\mathrm{NCOA} 5$ NCOA5_HUMAN $65.54 \quad 100.0 \%$ Nuclear RNA export factor 1 GN=NXF1 NXF1_HUMAN $70.19 \quad 100.0 \%$ Nuclear RNA export factor $1 \mathrm{GN}=\mathrm{NXF} 1 \quad$ NXF1 HUMAN $70.19 \quad 100.0 \%$ Nuclease-sensitive element-binding protein $1 \mathrm{GN}=\mathrm{YBX} 1$ YBOX1_HUMAN $35.92 \quad 100.0 \%$ Nuclease-sensitive element-binding protein $1 \mathrm{GN}=$ YBX1 YBOX1_HUMAN $35.92 \quad 100.0 \%$ Nuclease-sensitive element-binding protein $1 \mathrm{GN}=$ YBX1 YBOX1_HUMAN $35.92 \quad 100.0 \%$ Nuclease-sensitive element-binding protein $1 \mathrm{GN}=\mathrm{YBX} 1$ YBOX1_HUMAN $35.92 \quad 100.0 \%$ Nuclease-sensitive element-binding protein $1 \mathrm{GN}=\mathrm{YBX} 1$ YBOX1_HUMAN $35.92 \quad 100.0 \%$ Nuclease-sensitive element-binding protein $1 \mathrm{GN}=\mathrm{YBX} 1$ YBOX1_HUMAN $35.92 \quad 100.0 \%$ Nuclease-sensitive element-binding protein $1 \mathrm{GN}=\mathrm{YBX} 1$ YBOX1_HUMAN $35.92 \quad 100.0 \%$ Nuclease-sensitive element-binding protein $1 \mathrm{GN}=\mathrm{YBX} 1 \mathrm{YBOX} 1$ HUMAN $35.92100 .0 \%$ Nuclease-sensitive element-binding protein $1 \mathrm{GN}=$ YBX1 YBOX1_HUMAN $35.92 \quad 100.0 \%$ Nuclease-sensitive element-binding protein $1 \mathrm{GN}=\mathrm{YBX} 1 \mathrm{YBOX} 1$ HUMAN $35.92 \quad 100.0 \%$ Nucleolar complex protein 2 homolog GN=NOC2L NOC2L_HUMAN $84.92 \quad 100.0 \%$ Nucleolar complex protein 2 homolog GN=NOC2L NOC2L_HUMAN $84.92 \quad 100.0 \%$ Nucleolar complex protein 2 homolog GN=NOC2L NOC2L HUMAN $84.92100 .0 \%$ Nucleolar complex protein 2 homolog GN=NOC2L NOC2L_HUMAN $84.92 \quad 100.0 \%$ Nucleolar complex protein 2 homolog GN=NOC2L NOC2L_HUMAN $84.92 \quad 100.0 \%$ Nucleolar complex protein 2 homolog GN=NOC2L NOC2L HUMAN $84.92 \quad 100.0 \%$ Nucleolar complex protein 2 homolog GN=NOC2L NOC2L_HUMAN $84.92 \quad 100.0 \%$ Nucleolar complex protein 3 homolog GN=NOC3L NOC3L_HUMAN $92.55 \quad 100.0 \%$ Nucleolar complex protein 3 homolog GN=NOC3L NOC3L_HUMAN $92.55100 .0 \%$ Nucleolar complex protein 3 homolog GN=NOC3L NOC3L_HUMAN $92.55 \quad 100.0 \%$ Nucleolar complex protein 4 homolog GN=NOC4L NOC4L HUMAN $58.47 \quad 100.0 \%$ Nucleolar complex protein 4 homolog GN=NOC4L NOC4L_HUMAN $58.47 \quad 100.0 \%$ Nucleolar GTP-binding protein $1 \mathrm{GN}=$ GTPBP4 NOG1_HUMAN $73.97 \quad 100.0 \%$ Nucleolar GTP-binding protein $1 \mathrm{GN}=$ GTPBP4 NOG1 HUMAN $73.97 \quad 100.0 \%$ Nucleolar GTP-binding protein $1 \mathrm{GN}=$ GTPBP4 NOG1_HUMAN $73.97 \quad 100.0 \%$ Nucleolar GTP-binding protein $1 \mathrm{GN}=$ GTPBP4 NOG1_HUMAN $73.97 \quad 100.0 \%$ Nucleolar GTP-binding protein $1 \mathrm{GN}=$ GTPBP4 NOG1_HUMAN $73.97 \quad 100.0 \%$ Nucleolar GTP-binding protein $1 \mathrm{GN}=$ GTPBP4 NOG1_HUMAN $73.97 \quad 100.0 \%$ Nucleolar GTP-binding protein $1 \mathrm{GN}=$ GTPBP4 NOG1 HUMAN $73.97 \quad 100.0 \%$ Nucleolar GTP-binding protein $1 \mathrm{GN}=$ GTPBP4 NOG1_HUMAN $73.97 \quad 100.0 \%$
$0.03 \% \quad 16.6 \%$ FTSDI

$0.03 \% \quad 16.6 \%$ LKNMALSIAER

$0.03 \% \quad 16.6 \%$ LVPLNQESVEER

$0.03 \% \quad 16.6 \%$ TLITFAGMIPYR

$0.03 \% \quad 16.6 \%$ LVQMEVLMN

$0.01 \% \quad 2.6 \%$ GVAIGQTSLTASVTNK

$0.01 \% \quad 2.6 \%$ AVDPTSGQLYGLAR

$0.01 \% \quad 2.6 \%$ VIVAVGDR

$0.01 \% \quad 2.6 \%$ SGSPAVLAFAK

$0.01 \% \quad 8.3 \%$ QYFEEIQR

$0.01 \% \quad 8.3 \%$ RFDAERPVDCSVIVVNK

$\begin{array}{lll}0.01 \% & 8.3 \% & \text { FDAERPVDCSVIVVNK }\end{array}$

$0.01 \% \quad 8.3 \%$ NMPQADAMVLVAR

$0.01 \% \quad 8.3 \%$ MADEAILQER

$0.00 \% \quad 4.4 \%$ AQFFVEDASTASALK

$0.00 \% \quad 4.4 \%$ AKGEIPEVAFMK

$0.03 \% \quad 44.8 \%$ NGYGFINR

$0.03 \% \quad 44.8 \%$ NDTKEDVFVHQTAIK

$0.03 \% \quad 44.8 \%$ GAEAANVTGPGGVPVQGSK

$0.03 \% \quad 44.8 \%$ YAADRNHYR

$\begin{array}{llllllll}99.4 \% & 32.9 & 25.0 & 27.2 & 1 & 0 & 0 & 1191.60\end{array}$

$99.7 \% \quad 37.4 \quad 25.0 \quad 27.4$

$\begin{array}{llll}98.0 \% & 20.9 & 25.0 & 15.2\end{array}$

$99.7 \% \quad 36.3 \quad 25.0 \quad 27.6$

$99.7 \% \quad 52.0 \quad 25.0 \quad 43.2$

$95.4 \% \quad 14.2 \quad 25.0 \quad 14.2$

$\begin{array}{llll}99.7 \% & 43.7 & 25.0 & 43.7\end{array}$

$\begin{array}{llll}99.7 \% & 43.5 & 25.0 & 39.8\end{array}$

$98.6 \% \quad 24.3 \quad 25.0 \quad 15.6$

$99.3 \% \quad 27.0 \quad 25.0 \quad 25.5$

$99.0 \% \quad 42.6$

$99.7 \% \quad 34.1$

$98.4 \% \quad 18.5$

$99.7 \% \quad 28.1$

$99.7 \% \quad 40.0$

$99.7 \% \quad 90.2$

$99.1 \% \quad 20.5$

$99.0 \% \quad 50.9$

$\begin{array}{lll}99.7 \% & 42.3\end{array}$

$99.7 \% \quad 74.1$

$99.4 \% \quad 25.9$

$\begin{array}{lllll}0.03 \% & 44.8 \% & \text { NYQQNYQNSESGEKNEGSESAPEGQAQQR } & 99.7 \% & 61.8\end{array}$

$0.03 \% \quad 44.8 \%$ NEGSESAPEGQAQQR

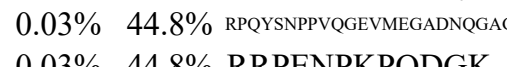

$99.7 \% \quad 73.3$

$99.7 \% \quad 33.3$

$99.6 \% 26.1$

$0.03 \% \quad 44.8 \%$ RPENPKPQDGKETK

$99.7 \% \quad 31.4$

$0.03 \% \quad 44.8 \%$ AADPPAENSSAPEAEQGGAE $\quad 99.7 \% \quad 26.3$

$0.01 \% \quad 9.0 \%$ EAARSPDKPGGSPSASR $\quad 97.8 \% 25.7$

$0.01 \% \quad 9.0 \%$ SPDKPGGSPSASR

$0.01 \% \quad 9.0 \%$ NSVPVTVAMVER

$0.01 \% \quad 9.0 \%$ LFHEVVQAFR

$0.01 \% \quad 9.0 \% \quad$ LSNVNLQEK

$0.01 \% \quad 9.0 \%$ QVQQLLGK

$0.01 \% \quad 9.0 \%$ VQENSAYICSR

$0.01 \% \quad 4.4 \%$ DLSSSEPVHAK

$0.01 \% \quad 4.4 \% \quad$ IRPLTEAEK

$0.01 \% \quad 4.4 \%$ YSSEVATESPLDFTK

$0.00 \% \quad 3.9 \%$ RLEAVLASR

$0.00 \% \quad 3.9 \%$ REPTVSSFYVK

$0.02 \% \quad 12.0 \%$ NLVDNVAKDYVR

$0.02 \% \quad 12.0 \%$ TLLLCGYPNVGK

$0.02 \% \quad 12.0 \%$ SSFINKVTR

$0.02 \% \quad 12.0 \%$ ADVDVQPYAFTTK

$0.02 \% \quad 12.0 \%$ LLAHRVETK

$0.02 \% \quad 12.0 \%$ REDSAPPSSVAR

$0.02 \% \quad 12.0 \%$ EDSAPPSSVAR

$0.02 \% \quad 12.0 \%$ DVSGLRDVK
$99.7 \% \quad 31.5$

$99.7 \% \quad 43.4$

$99.0 \% \quad 22.4$

$99.7 \% \quad 54.1$

$99.7 \% \quad 57.5$

$99.7 \% \quad 32.7$

$99.7 \% \quad 35.7$

$99.7 \% \quad 33.9$

$98.4 \% \quad 23.1$

$99.7 \% \quad 55.4$

$99.7 \% \quad 52.1$

$99.7 \% \quad 38.5$

$\begin{array}{lll}99.7 \% & 54.3\end{array}$

$98.6 \% \quad 17.7$

$99.7 \% \quad 37.8$

$99.2 \% \quad 19.4 \quad 25.0$

$99.7 \% \quad 32.1 \quad 25.0$
1191.60

1261.69

1412.74

1382.75

1092.54

1546.84

1447.75

828.49

1047.58

1112.54

2004.03

1847.93

1447.70

1191.57

1584.79

1335.70

940.46

1744.89

1695.87

1165.55

3257.40

1587.70

3239.53

1421.76

1623.85

1897.80

1669.83

1242.61

1301.69

1245.67

1044.57

913.55

1326.61

1169.58

1056.60

1673.79

1014.6

1312.69

1405.74

1334.7

1051.59

1454.72

1066.64

1271.63

1115.53

988.54

$\begin{array}{cc}69 & 578 \\ 01 & 611 \\ 63 & 673 \\ 19 & 730 \\ 91 & 802 \\ 11 & 819 \\ 48 & 1063 \\ 59 & 1272 \\ 77 & 1584 \\ 25 & 1735 \\ 83 & 190 \\ 91 & 207 \\ 92 & 207 \\ 80 & 292 \\ 16 & 325 \\ 59 & 173 \\ 08 & 619 \\ 0 & 77 \\ 8 & 92 \\ 19 & 137 \\ 38 & 146 \\ 57 & 185 \\ 71 & 185 \\ 05 & 234 \\ 90 & 301 \\ 91 & 304 \\ 05 & 324 \\ 5 & 61 \\ 9 & 61 \\ 45 & 156 \\ 69 & 178 \\ 08 & 516 \\ 69 & 576 \\ 77 & 587 \\ 13 & 123 \\ 75 & 283 \\ 79 & 793 \\ 7 & 25 \\ 22 & 232 \\ 04 & 115 \\ 70 & 181 \\ 82 & 190 \\ 91 & 203 \\ 39 & 347 \\ 55 & 566 \\ 56 & 566 \\ 76 & 584 \\ & \end{array}$

Page 104 of Table S-1-5 
Nucleolar GTP-binding protein 2 GN=GNL2 NOG2_HUMAN $83.66 \quad 100.0 \%$ Nucleolar GTP-binding protein 2 GN=GNL2 NOG2_HUMAN $83.66 \quad 100.0 \%$ Nucleolar GTP-binding protein 2 GN=GNL2 NOG2_HUMAN $83.66 \quad 100.0 \%$ Nucleolar MIF4G domain-containing protein $1 \mathrm{GN}=\mathrm{NOM} 1 \mathrm{NOM1}$ HUMAN $96.26 \quad 100.0 \%$ Nucleolar MIF4G domain-containing protein 1 GN=NOM1 NOM1_HUMAN $96.26 \quad 100.0 \%$ Nucleolar pre-ribosomal-associated protein 1 GN=URB1 NPA1P_HUMAN $254.39 \quad 100.0 \%$ Nucleolar pre-ribosomal-associated protein 1 GN=URB1 NPA1P_HUMAN $254.39100 .0 \%$ Nucleolar pre-ribosomal-associated protein 1 GN=URB1 NPA1P_HUMAN $254.39100 .0 \%$ Nucleolar pre-ribosomal-associated protein $1 \mathrm{GN}=\mathrm{URB} 1 \mathrm{NPA1P}$ HUMAN $254.39100 .0 \%$ Nucleolar pre-ribosomal-associated protein 1 GN=URB1 NPA1P_HUMAN $254.39 \quad 100.0 \%$ Nucleolar pre-ribosomal-associated protein 1 GN=URB1 NPA1P_HUMAN $254.39 \quad 100.0 \%$ Nucleolar pre-ribosomal-associated protein $1 \mathrm{GN}=\mathrm{URB} 1 \mathrm{NPA1P}$ HUMAN $254.39 \quad 100.0 \%$ Nucleolar protein $56 \mathrm{GN}=\mathrm{NOP} 56$ Nucleolar protein $56 \mathrm{GN}=\mathrm{NOP} 56$ Nucleolar protein $56 \mathrm{GN}=\mathrm{NOP} 56$ Nucleolar protein $56 \mathrm{GN}=\mathrm{NOP} 56$ Nucleolar protein $56 \mathrm{GN}=\mathrm{NOP} 56$ Nucleolar protein 56 GN=NOP56 Nucleolar protein $58 \mathrm{GN}=\mathrm{NOP} 58$ Nucleolar protein $58 \mathrm{GN}=\mathrm{NOP} 58$ Nucleolar protein $58 \mathrm{GN}=\mathrm{NOP} 58$ Nucleolar protein $58 \mathrm{GN}=\mathrm{NOP} 58$ Nucleolar protein $58 \mathrm{GN}=\mathrm{NOP} 58$ Nucleolar protein $58 \mathrm{GN}=\mathrm{NOP} 58$ Nucleolar protein $58 \mathrm{GN}=\mathrm{NOP} 58$ Nucleolar protein $58 \mathrm{GN}=\mathrm{NOP} 58$ Nucleolar protein $58 \mathrm{GN}=\mathrm{NOP} 58$ Nucleolar protein $58 \mathrm{GN}=\mathrm{NOP} 58$ Nucleolar protein $7 \mathrm{GN}=\mathrm{NOL} 7$ Nucleolar protein $7 \mathrm{GN}=\mathrm{NOL} 7$ Nucleolar protein $9 \mathrm{GN}=\mathrm{NOP} 9$ Nucleolar protein $9 \mathrm{GN}=\mathrm{NOP} 9$

Nucleolar RNA helicase 2 GN=DDX21 Nucleolar RNA helicase 2 GN=DDX2 Nucleolar RNA helicase 2 GN=DDX2 Nucleolar RNA helicase 2 GN=DDX2 Nucleolar RNA helicase 2 GN=DDX2 Nucleolar RNA helicase 2 GN=DDX2 Nucleolar RNA helicase 2 GN=DDX2 Nucleolar RNA helicase $2 \mathrm{GN}=\mathrm{DDX} 2$ Nucleolar RNA helicase 2 GN=DDX21 Nucleolar RNA helicase $2 \mathrm{GN}=\mathrm{DDX} 2$ Nucleolar RNA helicase 2 GN=DDX21 Nucleolin GN=NCL Nucleolin $\mathrm{GN}=\mathrm{NCL}$

Nucleolin GN=NCL Nucleolin GN=NCL NOP56_HUMAN $66.05 \quad 100.0 \%$ NOP56_HUMAN $66.05 \quad 100.0 \%$ NOP56 HUMAN $66.05 \quad 100.0 \%$ NOP56_HUMAN $66.05 \quad 100.0 \%$ NOP56 HUMAN $66.05 \quad 100.0 \%$ NOP56_HUMAN $66.05 \quad 100.0 \%$ NOP58_HUMAN $59.58 \quad 100.0 \%$ NOP58 HUMAN $59.58 \quad 100.0 \%$ NOP58_HUMAN $59.58 \quad 100.0 \%$ NOP58 HUMAN $59.58 \quad 100.0 \%$ NOP58_HUMAN $59.58 \quad 100.0 \%$ NOP58_HUMAN $59.58 \quad 100.0 \%$ NOP58 HUMAN $59.58 \quad 100.0 \%$ NOP58_HUMAN $59.58 \quad 100.0 \%$ NOP58_HUMAN $59.58 \quad 100.0 \%$ NOP58 HUMAN $59.58 \quad 100.0 \%$ NOL7_HUMAN $29.43 \quad 100.0 \%$ NOL7_HUMAN $29.43 \quad 100.0 \%$ NOP9_HUMAN $69.44 \quad 100.0 \%$ NOP9_HUMAN $69.44 \quad 100.0 \%$ DDX21 HUMAN $87.35 \quad 100.0 \%$ DDX21_HUMAN $87.35 \quad 100.0 \%$ DDX21 HUMAN $87.35 \quad 100.0 \%$ DDX21 HUMAN $87.35 \quad 100.0 \%$ DDX21_HUMAN $87.35 \quad 100.0 \%$ DDX21 HUMAN $87.35 \quad 100.0 \%$ DDX21_HUMAN $87.35 \quad 100.0 \%$ DDX21_HUMAN $87.35 \quad 100.0 \%$ DDX21 HUMAN $87.35 \quad 100.0 \%$ DDX21_HUMAN $87.35 \quad 100.0 \%$ DDX21 HUMAN $87.35 \quad 100.0 \%$ NUCL_HUMAN $76.62 \quad 100.0 \%$ NUCL_HUMAN $76.62 \quad 100.0 \% \quad 18$ NUCL HUMAN $76.62 \quad 100.0 \% \quad 18$ NUCL_HUMAN $76.62 \quad 100.0 \% \quad 18$

\begin{tabular}{|c|c|c|c|c|c|c|}
\hline & & & & & & \\
\hline $0.01 \%$ & $5.1 \%$ & GAFIQLLR & $98.3 \%$ & 37.7 & 25.0 & 6.6 \\
\hline $.01 \%$ & $5.1 \%$ & GGEPDLQTVGK & $99.1 \%$ & 18.3 & 25.0 & 18.3 \\
\hline $00 \%$ & $3.3 \%$ & SGAEEASGHRQDTEER & $99.3 \%$ & 20.9 & 25.0 & 20.9 \\
\hline $00 \%$ & $3.3 \%$ & TRPSAAATAAAR & $99.6 \%$ & 24.0 & 25.0 & 24.0 \\
\hline $.02 \%$ & $3.3 \%$ & LICESLYASGYR & $99.7 \%$ & 44.1 & 25.0 & 39.3 \\
\hline $0.02 \%$ & $3.3 \%$ & TLYTLVTKR & $99.4 \%$ & 24.3 & 5.0 & 24.3 \\
\hline $02 \%$ & $3.3 \%$ & IYEAQPEISR & $99.7 \%$ & 35.6 & 25.0 & 27.2 \\
\hline $0.02 \%$ & $3.3 \%$ & STVENFGQLGR & $99.7 \%$ & 54.8 & 5.0 & 53.7 \\
\hline $0.02 \%$ & $3.3 \%$ & YSEAITQSVLK & $99.7 \%$ & 48.9 & 5.0 & 48.9 \\
\hline $0.02 \%$ & $3.3 \%$ & LCQPSSQEPAKR & $98.0 \%$ & 23.0 & 25.0 & 17.9 \\
\hline $0.02 \%$ & $3.3 \%$ & SVAEHPLSR & $99.7 \%$ & 31.9 & 5.0 & 28.5 \\
\hline $0.02 \%$ & $10.9 \%$ & LLLETHLPSK & $97.4 \%$ & 21.8 & 5.0 & 12.0 \\
\hline $0.02 \%$ & $10.9 \%$ & AQL & $99.3 \%$ & 30.9 & 25.0 & 25.1 \\
\hline $0.02 \%$ & $10.9 \%$ & IIND & $99.7 \%$ & 55.0 & 5.0 & 55.0 \\
\hline $0.02 \%$ & 10.9 & VVs & $99.0 \%$ & 36.8 & 5.0 & 28.7 \\
\hline $0.02 \%$ & $10 \mathrm{~s}$ & LIA & $99.7 \%$ & 48.0 & 25.0 & 47.7 \\
\hline $0.02 \%$ & $10.9 \%$ & YPA & $99.7 \%$ & 70.8 & 5.0 & 55.1 \\
\hline $0.03 \%$ & 21.4 & IVKI & $98.9 \%$ & 26.8 & 5.0 & 25.7 \\
\hline $0.03 \%$ & $21.4 \%$ & $\mathrm{EAl}$ & $99.3 \%$ & 23.6 & 5.0 & 21.5 \\
\hline $0.03 \%$ & $21.4 \%$ & LGC & $99.0 \%$ & 42.4 & 5.0 & 24.8 \\
\hline $0.03 \%$ & $21.4 \%$ & SQI & $99.7 \%$ & 49.5 & 5.0 & 49.5 \\
\hline $0.03 \%$ & $21.4 \%$ & IISI & $99.7 \%$ & 50.5 & 5.0 & 50.5 \\
\hline $0.03 \%$ & $21.4 \%$ & TQI & $99.7 \%$ & 53.5 & 5.0 & 53.5 \\
\hline $0.03 \%$ & 21.4 & LIA & $99.7 \%$ & 47.0 & 5.0 & 47.0 \\
\hline $0.03 \%$ & $21.4 \%$ & HA & $99.7 \%$ & 65.1 & 5.0 & 58.4 \\
\hline $0.03 \%$ & $21.4 \%$ & YGI & $99.7 \%$ & 50.8 & 5.0 & 43.8 \\
\hline $0.03 \%$ & $21.4 \%$ & TYL & $99.7 \%$ & 53.3 & 5.0 & 53.3 \\
\hline $0.00 \%$ & $11.7 \%$ & LTT & $99.6 \%$ & 25.5 & 5.0 & 17.2 \\
\hline $0.00 \%$ & $11.7 \%$ & LYGPGTNR & $98.5 \%$ & 17.6 & 5.0 & 17.6 \\
\hline $0.00 \%$ & $3.3 \%$ & VLD & $99.7 \%$ & 37.8 & 25.0 & 32.1 \\
\hline $0.00 \%$ & $3.3 \%$ & $\mathrm{NV}$ & $95.9 \%$ & 17.1 & 25.0 & 17.1 \\
\hline $0.03 \%$ & $12.5 \%$ & TFH & $99.7 \%$ & 29.5 & .0 & 28.9 \\
\hline $0.03 \%$ & $12.5 \%$ & $\mathrm{GR}$ & $99.7 \%$ & 53.8 & 0 & 53.8 \\
\hline $0.03 \%$ & $12.5 \%$ & $\mathrm{APC}$ & $99.7 \%$ & 37.8 & 25.0 & 37.8 \\
\hline $0.03 \%$ & $12.5 \%$ & MR & $97.7 \%$ & 16.0 & 25.0 & 16.0 \\
\hline $0.03 \%$ & $12.5 \%$ & $\mathrm{NGl}$ & $99.7 \%$ & 52.3 & & 48.8 \\
\hline $0.03 \%$ & $12.5 \%$ & STY & $99.7 \%$ & 54.7 & 25.0 & 50.1 \\
\hline $0.03 \%$ & $12.5 \%$ & IDLIGKK & $99.7 \%$ & 60.7 & 25.0 & 55.6 \\
\hline $0.03 \%$ & $12.5 \%$ & $\mathrm{AA}$ & $99.7 \%$ & 63.6 & & 50.7 \\
\hline $0.03 \%$ & $12.5 \%$ & LVATN & $99.7 \%$ & 79.1 & 25.0 & 75.9 \\
\hline $0.03 \%$ & $12.5 \%$ & TEIIK & $99.7 \%$ & 35.2 & 25.0 & 29.6 \\
\hline $0.03 \%$ & $12.5 \%$ & SFS & $99.0 \%$ & 24.3 & 25.0 & 16.8 \\
\hline $0.12 \%$ & $28.0 \%$ & VAVATPAKK & $99.6 \%$ & 26.0 & 25.0 & 18.2 \\
\hline $0.12 \%$ & $28.0 \%$ & ALVATPGKK & $99.6 \%$ & 25.5 & 25.0 & 25.3 \\
\hline $0.12 \%$ & $28.0 \%$ & QKVEGTEPTTAFNLFVGNLNFNK & $99.7 \%$ & 34.5 & 25.0 & 34.5 \\
\hline $0.12 \%$ & $28.0 \%$ & SAPELKTGISDVFAK & $99.7 \%$ & 31.8 & 25.0 & 31.6 \\
\hline
\end{tabular}

1932.09

917.56

1100.56

1758.76

1143.62

1431.69

1094.66

1205.62

1207.61

1238.66

1400.70

995.53

1150.68

1188.61

1239.58

952.51

1308.76

1376.74

1590.89

1250.64

843.53

1414.70

1226.61

1327.66

1320.80

1324.72

1733.92

1628.71

1204.69

2073.03

1271.71

1006.59

1842.96

1377.83

1164.71

1498.82

1211.67

1252.64

1380.74

913.55

1475.80

1127.67

871.43

884.56

884.56

2568.31 1562.84

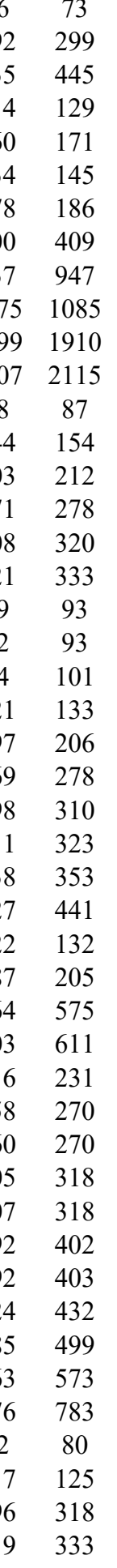


Nucleolin GN=NCL Nucleolin $\mathrm{GN}=\mathrm{NCL}$ Nucleolin $\mathrm{GN}=\mathrm{NCL}$ Nucleolin $\mathrm{GN}=\mathrm{NCL}$ Nucleolin GN=NCL Nucleolin GN=NCL

Nucleolin $\mathrm{GN}=\mathrm{NCL}$ Nucleolin GN $=\mathrm{NCL}$ Nucleolin $\mathrm{GN}=\mathrm{NCL}$ Nucleolin GN=NCL Nucleolin GN $=\mathrm{NCL}$ Nucleolin GN=NCL Nucleolin GN=NCL Nucleolin $\mathrm{GN}=\mathrm{NCL}$

Nucleophosmin GN=NPM Nucleophosmin GN=NPM1 Nucleophosmin GN=NPM1 Nucleophosmin GN=NPM1 Nucleophosmin GN=NPM Nucleophosmin GN=NPM Nucleophosmin GN=NPM1 Nucleoporin NDC1 GN=NDC1 Nucleoporin NDC1 GN=NDC1 Nucleoporin NDC1 GN=NDC1 Nucleoporin NDC1 GN=NDC1 Nucleoporin NDC1 GN=NDC1 Nucleoporin NUP188 homolog GN=NUP188 NU188 HUMAN $196.05 \quad 100.0 \%$ Nucleoporin NUP188 homolog GN=NUP188 NU188_HUMAN $196.05 \quad 100.0 \%$ Nucleoporin NUP188 homolog GN=NUP188 NU188_HUMAN $196.05100 .0 \%$ Nucleoporin NUP188 homolog GN=NUP188 NU188 HUMAN $196.05100 .0 \%$ Nucleoporin-like protein 2 GN=NUPL2 NUPL2_HUMAN $44.87 \quad 100.0 \%$ Nucleoporin-like protein 2 GN=NUPL2 NUPL2_HUMAN $44.87 \quad 100.0 \%$ Nucleoprotein TPR GN=TPR Nucleoprotein TPR GN=TPR TPR HUMAN $267.29 \quad 100.0 \%$ TPR_HUMAN $267.29 \quad 100.0 \%$ Nucleosome assembly protein 1-like $1 \mathrm{GN}=\mathrm{NAP} 1 \mathrm{~L} 1 \mathrm{NP} 1 \mathrm{~L} 1$ HUMAN $45.38 \quad 100.0 \%$ Nucleosome assembly protein 1-like 1 GN=NAP1L1 NP1L1_HUMAN $45.38 \quad 100.0 \%$ Nucleosome assembly protein 1-like 1 GN=NAP1L1 NP1L1_HUMAN $45.38 \quad 100.0 \%$ Origin recognition complex subunit $5 \mathrm{GN}=\mathrm{ORC} 5$ ORC5_HUMAN $50.29 \quad 100.0 \%$ Origin recognition complex subunit $5 \mathrm{GN}=\mathrm{ORC} 5$ ORC5_HUMAN $50.29 \quad 100.0 \%$ Origin recognition complex subunit 5 GN=ORC5 ORC5_HUMAN $50.29 \quad 100.0 \%$ Ornithine aminotransferase, mitochondrial GN=OAT OAT_HUMAN $48.54 \quad 100.0 \%$ Ornithine aminotransferase, mitochondrial GN=OAT OAT_HUMAN $48.54 \quad 100.0 \%$ Ornithine aminotransferase, mitochondrial GN=OAT OAT_HUMAN $48.54 \quad 100.0 \%$ Ornithine aminotransferase, mitochondrial GN=OAT OAT_HUMAN $48.54 \quad 100.0 \%$ Ornithine aminotransferase, mitochondrial GN=OAT OAT_HUMAN $48.54 \quad 100.0 \%$ Ornithine aminotransferase, mitochondrial GN=OAT OAT HUMAN $48.54 \quad 100.0 \%$ Ornithine aminotransferase, mitochondrial GN=OAT OAT_HUMAN $48.54 \quad 100.0 \%$

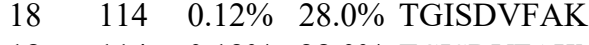

$99.7 \% \quad 46.1$

$114 \quad 0.12 \% \quad 28.0 \%$ TGISDVFAKNDLAVVDVR

$114 \quad 0.12 \% \quad 28.0 \%$ NDLAVVDVR

$114 \quad 0.12 \% \quad 28.0 \%$ ALELTGLK

$114 \quad 0.12 \% \quad 28.0 \%$ VFGNEIKLEKPK

$114 \quad 0.12 \% \quad 28.0 \%$ GIAYIEFK

$114 \quad 0.12 \% \quad 28.0 \%$ SISLYYTGEK

$.7 \% \quad 31.2$

$99.7 \% \quad 59.4$

$98.9 \% \quad 19.2$

$97.6 \% 24.6$

$\begin{array}{lll}98.0 \% & 20.4\end{array}$

$99.7 \% \quad 54.8$

$114 \quad 0.12 \% \quad 28.0 \%$ SISLYYTGEKGQNQDYR $\quad 99.7 \% \quad 26.7$

$114 \quad 0.12 \% \quad 28.0 \%$ TLVLSNLSYSATEETLQEVFEK $\quad 99.7 \% \quad 62.8$

$114 \quad 0.12 \% \quad 28.0 \%$ ATFIKVPQNQNGK

$114 \quad 0.12 \% \quad 28.0 \%$ AIRLELQGPR

$99.7 \% \quad 46.4$

$99.7 \% \quad 63.1$

$99.6 \% \quad 23.7$

\begin{tabular}{lll}
$0.12 \%$ & $28.0 \%$ \\
\hline
\end{tabular}

$114 \quad 0.12 \% \quad 28.0 \%$ GLSEDTTEETLKESFDGSVR

$114 \quad 0.12 \% \quad 28.0 \%$ GFGFVDFNSEEDAK

$\begin{array}{ll}99.7 \% & 41.2 \\ 99.7 \% & 57.3\end{array}$

$99.7 \% \quad 56.7$

$57 \quad 0.06 \% \quad 28.6 \%$ VDNDENEHQLSLR

$\begin{array}{ll}99.7 \% & 56.7 \\ 99.7 \% & 32.3\end{array}$

$\begin{array}{llllll}57 & 0.06 \% & 28.6 \% & \text { DELHIVEAEAMNYEGSPIK } & 99.7 \% & 32.3 \\ 57 & 0.06 \% & 28.6 \% & \text { MSVQPTVSLGGFEITPPVVLR } & 99.7 \% & 47.2\end{array}$

$0.06 \% \quad 28.6 \%$ LLSISGKR

$57 \quad 0.06 \% \quad 28.6 \%$ SAPGGGSKVPQK

$0.06 \% 28.6 \%$ GPSSVEDIK

$57 \quad 0.06 \% \quad 28.6 \%$ GPSSVEDIKAK

$10 \quad 0.01 \% \quad 8.9 \% \quad$ ATAVSRPCAGR

$10 \quad 0.01 \% \quad 8.9 \% \quad$ VLNSNPPPIIK

$10 \quad 0.01 \% \quad 8.9 \% \quad$ LILYQEAAATNGR

$10 \quad 0.01 \% \quad 8.9 \% \quad$ KLNSPEETAFQTPK

$10 \quad 0.01 \% \quad 8.9 \%$ ISGSLVDTSYK

$9 \quad 0.01 \% \quad 2.7 \% \quad$ HTLNPEETSSVVR

$0.01 \% \quad 2.7 \%$ LAFSVTNNVIR

$0.01 \% \quad 2.7 \%$ LAIQLLKR

$\quad 0.01 \% \quad 2.7 \% \quad$ VQRPPSAASAAPSSSK

$0.00 \% \quad 7.3 \% \quad$ YSNVIQPSSFSK

$0.00 \% \quad 7.3 \%$ DQEKPYFSSFDSGASTNRK

$0.00 \% \quad 0.9 \%$ NIEELQQQNQR

$0.00 \% \quad 0.9 \% \quad$ SLESQVENLQK

$0.01 \% \quad 11.5 \%$ LDGLVETPTGYIESLPR

$0.01 \% \quad 11.5 \%$ FYEEVHDLER

$\begin{array}{llll}99.0 \% & 53.7 & 25.0 & 40.3\end{array}$

$99.7 \% \quad 33.4$

$99.7 \% \quad 54.6$

$99.7 \% \quad 59.9$

$97.7 \% \quad 21.0$

$99.6 \% 24.3$

$99.7 \% \quad 59.3$

$97.9 \% \quad 16.6$

$99.7 \% \quad 33.5$

$98.6 \% \quad 24.6$

$99.7 \% \quad 42.1$

$99.0 \% \quad 31.7$

$99.7 \% \quad 31.3$

$99.7 \% \quad 53.4$

$95.0 \% \quad 18.6$

$96.3 \% \quad 17.5$

$99.4 \% \quad 20.8$

$99.7 \% \quad 46.9$

$99.7 \% \quad 43.7$

$0.01 \% \quad 11.5 \%$ NVDLLSDMVQEHDEPILK

$0.01 \% \quad 6.0 \%$ TYVTQTLLK

$0.01 \% \quad 6.0 \%$ NIEPHLKK

$0.01 \% \quad 6.0 \%$ CTVSLDFIR

$0.04 \% \quad 22.3 \%$ TVQGPPTSDDIFER

$0.04 \% \quad 22.3 \%$ SQVDKLTLTSR

$0.04 \% \quad 22.3 \%$ VLPMNTGVEAGETACK

$0.04 \% \quad 22.3 \%$ IVFAAGNFWGR

$\begin{array}{ll}0.04 \% \quad 22.3 \% & \text { NELMKLPSDVVTAVR }\end{array}$

$0.04 \% \quad 22.3 \%$ LPSDVVTAVR

$0.04 \% \quad 22.3 \%$ GKGLLNAIVIK

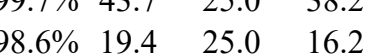

$99.7 \% \quad 35.8 \quad 25.0$

$\begin{array}{llll}99.0 \% & 22.8 & 25.0 & 17.4\end{array}$

$\begin{array}{llll}99.7 \% & 33.2 & 25.0 & 28.2\end{array}$

$99.7 \% \quad 60.9 \quad 25.0 \quad 50.9$

$\begin{array}{llll}99.7 \% & 63.2 & 25.0 & 55.6\end{array}$

$\begin{array}{llll}99.7 \% & 33.3 & 25.0 & 33.3\end{array}$

$\begin{array}{llll}99.7 \% & 54.0 & 25.0 & 54.0\end{array}$

$\begin{array}{lllll}99.7 \% & 36.1 & 25.0 & 36.1 & 2\end{array}$

$99.7 \% \quad 57.9 \quad 25.0 \quad 52.9$

$\begin{array}{llll}99.7 \% & 38.5 & 25.0 & 38.5\end{array}$
1919.02

1000.54

844.51

1401.81

940.51

1160.58

2021.96

2501.27

1444.79

1152.68

1134.65

2200.03

1561.68

1568.73

2161.01

2243.21

873.55

1112.61

931.47

1130.61

1145.58

1191.71

1419.76

1589.82

1169.60

1468.74

1233.69

954.65

1540.81

1356.68

2163.99

1399.69

1274.66

1859.98

1336.62

2111.03

1066.61

978.57

1110.56

1561.75

1247.70

1676.80

1237.65

1687.90

1056.60

1125.74

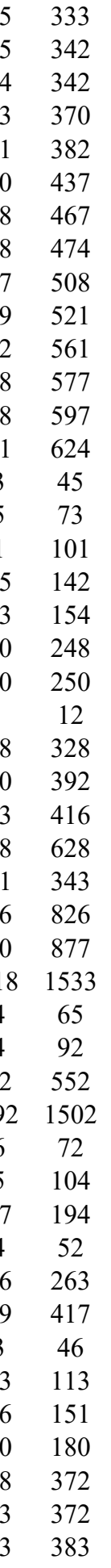

Page 106 of Table S-1-5 

Pachytene checkpoint protein 2 homolog GN=TRIP13 PCH2_HUMAN $48.55 \quad 100.0 \%$ Paired amphipathic helix protein Sin3a GN=SIN3A SIN3A HUMAN $145.18 \quad 100.0 \%$ Paired amphipathic helix protein Sin3a GN=SIN3A SIN3A_HUMAN $145.18 \quad 100.0 \%$ Paired amphipathic helix protein Sin3a GN=SIN3A SIN3A_HUMAN $145.18 \quad 100.0 \%$ PCI domain-containing protein $2 \mathrm{GN}=$ PCID2 PCID2_HUMAN $46.03 \quad 100.0 \%$ PCI domain-containing protein 2 GN=PCID2 PCID2_HUMAN $46.03 \quad 100.0 \%$ PCI domain-containing protein 2 GN=PCID2 PCID2_HUMAN $46.03 \quad 100.0 \%$ PCI domain-containing protein 2 GN=PCID2 PCID2_HUMAN $46.03 \quad 100.0 \%$ PCI domain-containing protein 2 GN=PCID2 PCID2_HUMAN $46.03 \quad 100.0 \%$ PCI domain-containing protein $2 \mathrm{GN}=$ PCID2 PCID2 HUMAN $46.03 \quad 100.0 \%$ PCI domain-containing protein 2 GN=PCID2 PCID2_HUMAN $46.03 \quad 100.0 \%$ PCI domain-containing protein 2 GN=PCID2 PCID2_HUMAN $46.03 \quad 100.0 \%$ PCI domain-containing protein 2 GN=PCID2 PCID2_HUMAN $46.03 \quad 100.0 \%$ Pentatricopeptide repeat domain-containing protein 3, mitochondrial GN=PTCD3 PTCD3_HUMAN 78.55 $100.0 \%$ 3, mitochondrial GN=PTCD3 PTCD3_HUMAN $78.55 \quad 100.0 \%$ Peptidyl-prolyl cis-trans isomerase E GN=PPIE PPIE_HUMAN $33.43 \quad 100.0 \%$ Peptidyl-prolyl cis-trans isomerase E GN=PPIE PPIE_HUMAN $33.43 \quad 100.0 \%$ Peroxiredoxin-1 GN=PRDX1 Peroxiredoxin- 1 GN=PRDX1 Peroxiredoxin-1 GN=PRDX1 Peroxiredoxin-1 GN=PRDX1 Peroxiredoxin- 1 GN=PRDX1 Peroxiredoxin-1 GN=PRDX1 Peroxiredoxin-1 GN=PRDX1

$0.04 \% \quad 22.3 \%$ GLLNAIVIK

$0.04 \% \quad 22.3 \%$ GLLNAIVIKETK

$0.04 \% 22.3 \%$ LRDNGLLAKPTHGDIIR

$99.7 \% \quad 37.7$

$99.4 \% \quad 20.5$

$99.7 \% \quad 35.8$

$99.7 \% \quad 43.2$

$0.00 \% \quad 2.5 \%$ AVAEQVLHSQSR

$99.7 \% \quad 39.4$

$\begin{array}{llll}0.01 \% & 8.8 \% & \text { AGVSISVVHGNLSEEAAK } \quad 99.7 \% \quad 29.2\end{array}$

$0.01 \% \quad 8.8 \%$ FGLFTPGSR

$0.01 \% \quad 8.8 \%$ IESILMSLPLTAR

$0.02 \% \quad 17.1 \%$ NVQSVSIIDTELK

$0.02 \% \quad 17.1 \%$ NVQSVSIIDTELKVK

$0.02 \% \quad 17.1 \%$ VVLLHGPPGTGK

$0.02 \% \quad 17.1 \%$ AGTEPSDAIR

$0.02 \% \quad 17.1 \%$ VVNAVLTQIDQIKR

$0.02 \% \quad 17.1 \%$ QYIGPPSAAAIFK

$0.02 \% \quad 17.1 \%$ LSLLLNDISR

$0.01 \% \quad 2.4 \%$ LLFSNTAAQK

$0.01 \% \quad 2.4 \%$ DKSDSPAIQLR

$0.01 \% \quad 2.4 \%$ SLLESTYQR

$0.02 \% \quad 27.8 \%$ DGASCAELVSFK

$0.02 \% \quad 27.8 \%$ LQMASPEEK

$0.02 \% \quad 27.8 \%$ CTYAVGNHDFIEAYK

$0.02 \% \quad 27.8 \%$ CQTVIVQSFLR

$0.02 \% \quad 27.8 \%$ VFANNADQQLVK

$0.02 \% \quad 27.8 \%$ AIDSSNLKDDYSTAQR

$0.02 \% \quad 27.8 \%$ YHLMQFAEVTR

$0.02 \% 27.8 \%$ AVSEGNLLLLHEALAK

$0.02 \% \quad 27.8 \%$ CGIFLILEK

$0.01 \% \quad 4.9 \%$ VAVLQALASTVNR

$0.01 \% \quad 4.9 \%$ DISEAALKER

$0.01 \% \quad 4.9 \% \quad$ LFDQPGDPLKR

$0.00 \% \quad 4.3 \%$ DSYNLLLVAAR

$0.00 \% \quad 4.3 \%$ ALLPVLAK

$0.00 \% \quad 4.3 \%$ DGLQLLTDMKK

$0.01 \% \quad 8.0 \%$ VAVACNLSGTK

$0.01 \% \quad 8.0 \%$ SALQVLIEMK

$0.01 \% \quad 8.0 \%$ HVFSEEVLAK

$0.00 \% \quad 10.6 \%$ SNPQVYMDIK

$0.00 \% \quad 10.6 \%$ SDVVPMTAENFR

$0.00 \% \quad 10.6 \%$ KFDDENFILK

$0.03 \% \quad 61.3 \%$ IGHPAPNFK

$0.03 \% \quad 61.3 \%$ ATAVMPDGQFK

$0.03 \% \quad 61.3 \%$ DISLSDYKGK

$\begin{array}{lll}99.7 \% & 42.5\end{array}$

$99.7 \% \quad 54.3$

$99.7 \% \quad 47.0$

$99.7 \% \quad 53.2$

$99.7 \% \quad 53.2$

$99.7 \% \quad 35.6$

$99.7 \% \quad 55.2$

$99.7 \% \quad 33.0$

$99.7 \% \quad 68.5$

$99.7 \% \quad 30.3$

$98.2 \% \quad 26.2$

$\begin{array}{lll}99.7 \% & 38.9\end{array}$

$99.7 \% \quad 71.4$

$99.7 \% \quad 30.5$

$98.2 \% \quad 16.8$

$99.7 \% \quad 57.2$

$99.7 \% \quad 39.6$

$99.7 \% \quad 81.7$

$99.7 \% \quad 43.2$

$\begin{array}{lll}99.5 \% & 22.5\end{array}$

$99.7 \% \quad 44.5$

$99.7 \% \quad 52.0$

$97.0 \% \quad 15.1$

$98.4 \% \quad 24.0$

$99.7 \% \quad 33.0$

$98.3 \% \quad 23.1$

$99.2 \% \quad 21.0$

$97.7 \% \quad 20.0$

$99.7 \% \quad 29.9$

$99.5 \% \quad 25.1$

$94.8 \% 16.6$

$99.6 \% 23.6$

$99.7 \% \quad 49.8$

$99.6 \% 26.5$

$99.4 \% \quad 20.1$

$98.3 \% \quad 18.4$

$\begin{array}{lllll}0.03 \% & 61.3 \% & \text { LNCQVIGASVDSHFCHLAWVNTPK } & 99.7 \% & 37.3\end{array}$

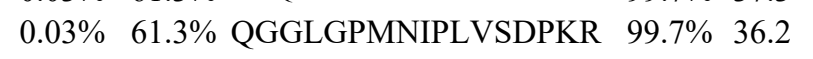

$0.03 \% \quad 61.3 \%$ TIAQDYGVLK

$99.7 \% \quad 61.4$

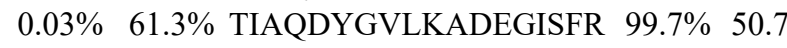

940.62

1298.80

1889.07

1619.89

1324.70

1545.75

1767.92

981.52

1459.82

1445.78

1672.95

1174.69

1016.50

1596.94

1362.74

1143.67

1092.60

1229.65

1096.56

1283.59

1048.50

1787.81

1350.72

1346.71

1783.85

1410.68

1677.95

1092.6

1341.78

1131.60

1285.69

1234.68

824.56

1261.68

1119.58

1131.64

1158.62

1210.58

1381.64

1268.65

980.53

1180.57

1125.58

2753.33

1794.95

1107.60 1983.02 $\begin{array}{cc}75 & 383 \\ 75 & 386 \\ 97 & 413 \\ 99 & 413 \\ 9 & 60 \\ 00 & 1015 \\ 03 & 220 \\ 05 & 413 \\ 14 & 426 \\ 9 & 81 \\ 9 & 83 \\ 74 & 185 \\ 66 & 275 \\ 76 & 289 \\ 17 & 329 \\ 69 & 378 \\ 66 & 875 \\ 36 & 946 \\ 44 & 1052 \\ 1 & 32 \\ 1 & 49 \\ 8 & 82 \\ 3 & 93 \\ 17 & 128 \\ 94 & 209 \\ 74 & 284 \\ 85 & 300 \\ 08 & 316 \\ 8 & 80 \\ 51 & 160 \\ 78 & 388 \\ 20 & 330 \\ 41 & 548 \\ 70 & 580 \\ 3 & 73 \\ 83 & 192 \\ 08 & 317 \\ 38 & 147 \\ 62 & 173 \\ 18 & 227 \\ 8 & 16 \\ 7 & 27 \\ 8 & 37 \\ 9 & 92 \\ 4 & 110 \\ 11 & 120 \\ 11 & 128\end{array}$ 
Peroxiredoxin-1 GN=PRDX1 Peroxiredoxin-1 GN=PRDX1 Peroxiredoxin-1 GN=PRDX1 Peroxiredoxin-1 GN=PRDX1 Peroxiredoxin-2 GN=PRDX2 Peroxiredoxin-2 GN=PRDX2 Peroxiredoxin-2 GN=PRDX2 Peroxiredoxin-2 GN=PRDX2 Peroxiredoxin-2 GN=PRDX2 Peroxiredoxin-2 GN=PRDX2 Peroxiredoxin-2 GN=PRDX2 Peroxiredoxin-2 GN=PRDX2 GN=DECR2 DECR2_HUMAN 30.78 Peroxisomal 2,4-dienoyl-CoA reductase GN=DECR2 DECR2_HUMAN 30.78 Peroxisoma 2,4-dienoyl-CoA teductas GN=DECR2 DECR2 HUMAN 30.78 Peroxisomal biogenesis factor 3 GN=PEX3 PEX3_HUMAN $42.14 \quad 100.0 \%$ Peroxisomal biogenesis factor $3 \mathrm{GN}=\mathrm{PEX} 3$ PEX3 HUMAN $42.14 \quad 100.0 \%$ Peroxisomal membrane protein PEX16 GN=PEX16 PEX16_HUMAN $38.63 \quad 100.0 \%$ Peroxisomal membrane protein PEX16 GN=PEX16 PEX16_HUMAN $38.63 \quad 100.0 \%$ Peroxisomal membrane protein PEX16 GN=PEX16 PEX16_HUMAN $38.63 \quad 100.0 \%$ Peroxisomal membrane protein PEX16 GN=PEX16 PEX16_HUMAN $38.63 \quad 100.0 \%$ Peroxisomal membrane protein PMP34 GN=SLC25A17 PM34 HUMAN $34.57 \quad 100.0 \%$ Peroxisomal membrane protein PMP34 GN=SLC25A17 PM34_HUMAN $34.57 \quad 100.0 \%$ Peroxisomal membrane protein PMP34 GN=SLC25A17 PM34_HUMAN $34.57 \quad 100.0 \%$ Peroxisomal membrane protein PMP34 GN=SLC25A17 PM34_HUMAN $34.57 \quad 100.0 \%$ Peroxisomal multifunctional enzyme type 2 GN=HSD17B4 DHB4_HUMAN $79.69 \quad 100.0 \%$ Peroxisomal multifunctional enzyme type 2 GN=HSD17B4 DHB4_HUMAN $79.69 \quad 100.0 \%$ Peroxisomal multifunctiont enzyme type 2 GN=HSD17B4 DHB4_HUMAN $79.69 \quad 100.0 \%$ Pescadillo homolog GN=PES1 Pescadillo homolog GN=PES1 Pescadillo homolog GN=PES1 PHD finger protein $6 \mathrm{GN}=\mathrm{PHF} 6$ PHD finger protein $6 \mathrm{GN}=\mathrm{PHF} 6$ PHD finger protein $6 \mathrm{GN}=\mathrm{PHF} 6$ PHD finger protein $6 \mathrm{GN}=\mathrm{PHF} 6$ PHD finger protein $6 \mathrm{GN}=\mathrm{PHF} 6$ PHD finger protein $6 \mathrm{GN}=\mathrm{PHF} 6$ PHD finger protein $6 \mathrm{GN}=\mathrm{PHF} 6$ PHD finger protein $6 \mathrm{GN}=\mathrm{PHF} 6$ PHD finger protein $6 \mathrm{GN}=\mathrm{PHF} 6$ Phenylalanine--tRNA ligase aln $\begin{array}{llll}\text { Phenylalanine--tRNA ligase alpha subunit GN=FARSA SYFA_HUMAN } & 57.56 & 100.0 \%\end{array}$ Phenylalanine--tRNA ligase alpha subunit GN=FARSA SYFA HUMAN $57.56 \quad 100.0 \%$ Phenylalanine--tRNA ligase alpha subunit GN=FARSA SYFA_HUMAN $57.56 \quad 100.0 \%$ Phenylalanine--tRNA ligase beta subunit GN=FARSB SYFB_HUMAN $66.12 \quad 100.0 \%$ Phenylalanine--tRNA ligase beta subunit GN=FARSB SYFB_HUMAN $66.12 \quad 100.0 \%$ Phenylalanine--tRNA ligase beta subunit GN=FARSB SYFB_HUMAN $66.12 \quad 100.0 \%$

PHF6 HUMAN $41.29 \quad 100.0 \%$

PHF6 HUMAN $41.29 \quad 100.0 \%$

PHF6_HUMAN $41.29 \quad 100.0 \%$

PHF6 HUMAN $41.29 \quad 100.0 \%$

PHF6 HUMAN $41.29 \quad 100.0 \%$

PHF6_HUMAN $41.29 \quad 100.0 \%$

PHF6_HUMAN $41.29 \quad 100.0 \%$

PHF6_HUMAN $41.29 \quad 100.0 \%$

PHF6_HUMAN $41.29 \quad 100.0 \%$

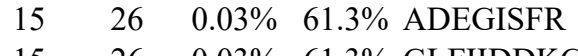

$0.03 \% \quad 61.3 \%$ GLFIIDDKGILR

$0.03 \% \quad 61.3 \%$ QITVNDLPVGR

$0.03 \% \quad 61.3 \%$ LVQAFQFTDK

$0.02 \% \quad 40.4 \%$ IGKPAPDFK

$0.02 \% \quad 40.4 \%$ ATAVVDGAFKEVK

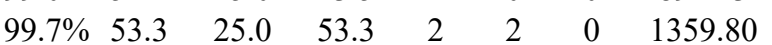

$99.7 \% \quad 61.8 \quad 25.0 \quad 56.6$

$99.7 \% \quad 41.2 \quad 25.0 \quad 41.2$

$99.7 \% \quad 26.2 \quad 25.0 \quad 20.2$

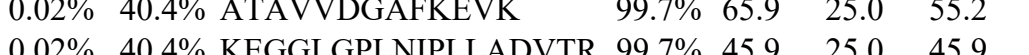

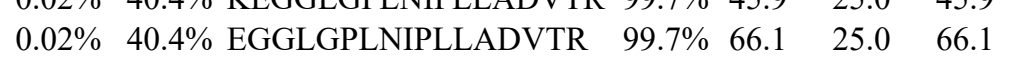

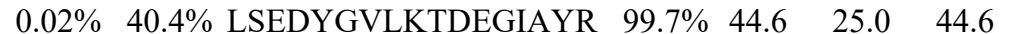

$0.02 \% \quad 40.4 \%$ GLFIIDGK

$0.02 \% \quad 40.4 \%$ GLFIIDGKGVLR

$0.02 \% \quad 40.4 \%$ QITVNDLPVGR

$0.00 \% \quad 14.7 \%$ VAFITGGGSGIGFR

$0.00 \% \quad 14.7 \%$ GQALQVHAGSAK

$0.00 \% \quad 14.7 \%$ VNSLAPGPISGTEGLRR

$0.00 \% \quad 5.6 \%$ EAAEYIAQAR

$0.00 \% \quad 5.6 \%$ HSLSLLDLEQK

$0.01 \% \quad 14.0 \%$ HPAATAQLETAVR

$0.01 \% \quad 14.0 \%$ GFSYLLAGR

$0.01 \% \quad 14.0 \%$ AGLQTSPPIVPLDR

$0.01 \% \quad 14.0 \%$ TLQNTPSLHSR

$0.01 \% \quad 17.3 \%$ FRNEDIVPTNYK

$0.01 \% \quad 17.3 \%$ LSSLDVFIIGAVAK

$99.0 \% 18$.

$99.7 \% \quad 43.3$

$99.7 \% \quad 61.8$

$99.7 \% \quad 46.5$

$99.7 \% \quad 60.7$

$99.4 \% 19.5$

$99.7 \% \quad 51.8$

$99.7 \% \quad 53.9$

$99.7 \% \quad 29.8$

$\begin{array}{lll}99.7 \% & 43.3\end{array}$

$99.7 \% \quad 36.9$

$99.7 \% \quad 38.1$

$99.7 \% \quad 37.3$

$99.7 \% \quad 94.7$

$0.01 \% \quad 17.3 \%$ AIATTVTYPLQTVQSILR

$0.01 \% \quad 17.3 \%$ NILYLLHQR

$0.01 \% \quad 4.9 \%$ VVLVTGAGAGLGR

$0.01 \% \quad 4.9 \% \quad$ AYALAFAER

$0.01 \% \quad 4.9 \%$ GALVVVNDLGGDFK

$0.01 \% \quad 5.1 \%$ GSATNYITR

$0.01 \% \quad 5.1 \%$ LEGQAQAEAK

$0.01 \% \quad 5.1 \%$ LAQEEESEAKR

$100.0 \%$

$0.02 \% \quad 34.0 \%$ DKECGQLLISENQK

$99.7 \% \quad 68.7$

$99.7 \% \quad 48.0$

$99.7 \% \quad 77.5$

$99.7 \% \quad 41.0$

$99.7 \% \quad 63.1$

$99.7 \% \quad 52.4$

$99.7 \% \quad 33.4$

$99.7 \% \quad 37.7$

$99.7 \% \quad 60.1$

$0.02 \% \quad 34.0 \%$ LMCSLCHCPGATIGCDVK $96.6 \% \quad 16.6$

$0.02 \% \quad 34.0 \%$ CGFCHVGEEENEAR

$0.02 \% \quad 34.0 \%$ CMLFSSGTVQLTTTSR

$99.7 \% \quad 42.4$

$99.7 \% \quad 71.8$

$99.7 \% \quad 31.9$

$99.0 \% \quad 50.8$

$99.7 \% \quad 60.2$

$0.02 \% \quad 34.0 \%$ CTLCSQPGATIGCEIK

$0.02 \% \quad 34.0 \%$ TYHYHCGVQDK

$0.01 \% \quad 9.8 \%$ SLQALGEVIEAELR

$0.01 \% \quad 9.8 \%$ VVDSMEDEVQR

$0.01 \% \quad 9.8 \%$ LAQKKPFTPVK

$0.01 \% \quad 9.8 \%$ LDAEPRPPPTQEAA

$0.02 \% \quad 12.4 \%$ DLLFQALGR

$0.02 \% \quad 12.4 \%$ AAGASDVVLYK

$0.02 \% \quad 12.4 \%$ GLQVFKER $\begin{array}{lll}99.7 \% & 28.7\end{array}$

$\begin{array}{llll}99.7 \% & 58.0 & 25.0 & 58.0\end{array}$

$\begin{array}{llll}99.7 \% & 32.2 & 25.0 & 28.9\end{array}$

$94.9 \% \quad 17.1 \quad 25.0 \quad 12.0$

$\begin{array}{llll}99.7 \% & 35.5 & 25.0 & 35.5\end{array}$

$\begin{array}{lllll}99.7 \% & 35.2 & 25.0 & 25.6 & 2\end{array}$

$99.7 \% \quad 41.0 \quad 25.0 \quad 37.2$

$\begin{array}{llll}99.0 \% & 37.4 & 25.0 & 30.8\end{array}$ $\begin{array}{llll}99.7 \% & 74.7 & 25.0 & 68.7\end{array}$

1359.80
1211.67

1196.63

972.55

1334.73

1863.07

1734.98

1928.96

862.50

1287.78

1211.67

1338.72

1166.63

1723.95

1121.56

1282.70

1364.73

983.53

1463.82

1253.66

1495.75

1432.84

1975.12

1169.68

1169.70

1011.53

1403.75

982.50

1044.53

1289.63

1661.82

2094.89

1693.67

1804.86

1041.49

986.60

1794.82

1407.61

2041.03

1527.84

1322.59

1256.77

1491.74

1032.58

1093.59

976.56 
Phenylalanine--tRNA ligase beta subunit GN=FARSB SYFB HUMAN $66.12 \quad 100.0 \%$ Phenylalanine--tRNA ligase beta subunit GN=FARSB SYFB_HUMAN $66.12 \quad 100.0 \%$ Phenylalanine--tRNA ligase beta subunit GN=FARSB SYFB_HUMAN $66.12 \quad 100.0 \%$ Phenylalanine--tRNA ligase beta subunit GN=FARSB SYFB HUMAN $66.12 \quad 100.0 \%$ Phosphate carrier protein, mitochondrial GN=SLC25A3 $\quad$ MPCP_HUMAN $40.10 \quad 100.0 \%$ Phosphate carrier protein, mitochondrial GN=SLC25A3 MPCP_HUMAN $40.10 \quad 100.0 \%$ Phosphate carrier protein, mitochondrial GN=SLC25A3 MPCP_HUMAN $40.10 \quad 100.0 \%$ Phosphate carrier protein, mitochondrial GN=SLC25A3 $\quad$ MPCP_HUMAN $40.10 \quad 100.0 \%$ Phosphate carrier protein, mitochondrial GN=SLC25A3 MPCP_HUMAN $40.10 \quad 100.0 \%$ Phosphate carrier protein, mitochondrial GN=SLC25A3 MPCP_HUMAN $40.10 \quad 100.0 \%$ Phosphate carrier protein, mitochondrial GN=SLC25A3 $\quad$ MPCP_HUMAN $40.10 \quad 100.0 \%$ Phosphate carrier protein, mitochondrial GN=SLC25A3 MPCP_HUMAN $40.10 \quad 100.0 \%$ Phosphate carrier protein, mitochondrial GN=SLC25A3 $\quad$ MPCP_HUMAN $40.10 \quad 100.0 \%$ Phosphate carrier protein, mitochondrial GN=SLC25A3 MPCP_HUMAN 40.10 100.0\% Phosphate carrier protein, mitochondrial GN=SLC25A3 MPCP_HUMAN $40.10 \quad 100.0 \%$ Phosphate carrier protein, mitochondrial GN=SLC25A3 MPCP_HUMAN $40.10 \quad 100.0 \%$ Phosphate carrier protein, mitochondrial GN=SLC25A3 MPCP HUMAN $40.10 \quad 100.0 \%$ Phosphate carrier protein, mitochondrial GN=SLC25A3 MPCP_HUMAN $40.10 \quad 100.0 \%$ Phosphate carrier protein, mitochondrial GN=SLC25A3 MPCP_HUMAN $40.10 \quad 100.0 \%$ Phosphatidate cytidylyltransferase, mitochondrial GN=TAMM41 TAM41_HUMAN $51.07 \quad 100.0 \%$ Phosphatidate cytidylyltransferase, mitochondrial GN=TAMM41 TAM41_HUMAN $51.07 \quad 100.0 \%$ Phosphatidate cytidylyltransferase, mitochondrial GN=TAMM41 TAM41 HUMAN $51.07 \quad 100.0 \%$ Phosphatidylgycerophosphatase and protein-tyrosine phosphatase 1 GN=PTPMTI PTPM1_HUMAN $22.84 \quad 100.0 \%$ $\begin{array}{lll}\text { Phosphatidylglycerophosphatase and protein-tyrosine phosphatase 1 GN=PTPMT1 } & \text { PTPM1_HUMAN } 22.84 \quad 100.0 \%\end{array}$ Phosphatidylinositol 3-kinase regulatory subunit beta GN=PIK3R2 P85B HUMAN 81.55 100.0\% Phosphatidylinositol 3-kinase regulatory subunit beta GN=PIK3R2 P85B_HUMAN $81.55 \quad 100.0 \%$ Phosphatidylinositol 3-kinase regulatory subunit beta GN=PIK3R2 P85B_HUMAN 81.55 Phosphatidylinositol 3-kinase regulatory subunit beta GN=PIK3R2 P85B_HUMAN 81.55 Phosphatidylinositol 3-kinase regulatory subunit beta GN=PIK3R2 P85B_HUMAN 81.5 Phosphatidylinositol 3-kinase regulatory subunit beta GN=PIK3R2 P85B HUMAN 81.5 Phosphatidylinositol 3-kinase regulatory subunit beta GN=PIK3R2 P85B_HUMAN 81.55 Phosphatidylinositol 3-kinase regulatory subunit beta GN=PIK3R2 P85B_HUMAN 81.55 Phosphatidylinositol 3-kinase regulatory subunit beta GN=PIK3R2 P85B_HUMAN 81.55 Phosphatidylinositol 3-kinase regulatory subunit beta GN=PIK3R2 P85B_HUMAN 81.5 Phosphatidylinositol 3-kinase regulatory subunit beta GN=PIK3R2 P85B HUMAN 81.55 Phosphatidylinositol 3-kinase regulatory subunit beta GN=PIK3R2 P85B HUMAN 81.55 Phosphatidylinositol 3-kinase regulatory subunit beta GN=PIK3R2 P85B_HUMAN 81.55 Phosphatidylinositol 4-kinase alpha GN=PI4KA PI4KA_HUMAN $231.33 \quad 100.0 \%$ Phosphatidylinositol 4-kinase alpha GN=PI4KA PI4KA_HUMAN $231.33 \quad 100.0 \%$ Phosphatidylinositol 4-kinase alpha GN=PI4KA PI4KA_HUMAN $231.33 \quad 100.0 \%$ Phosphatidylinositol 4-kinase alpha GN=PI4KA PI4KA_HUMAN $231.33 \quad 100.0 \%$ Phosphatidylinositol 4-phosphate 5-kinase type-1 gamma GN=PIP5K1C PI51C_HUMAN 73.26 $100.0 \%$ Phosphatidylinositol 4-phosphate 5-kinase type-1 gamma GN=PIP5K1C PI51C HUMAN 73.26 100.0\% Phosphatidylserine decarboxylase proenzyme GN=PISD PISD_HUMAN $46.67 \quad 100.0 \%$ Phosphatidylserine decarboxylase proenzyme GN=PISD PISD_HUMAN $46.67 \quad 100.0 \%$ Phosphoacetylglucosamine mutase GN=PGM3 AGM1_HUMAN $59.85 \quad 100.0 \%$ Phosphoacetylglucosamine mutase GN=PGM3 AGM1_HUMAN $59.85 \quad 100.0 \%$

5

3

$0.02 \% \quad 12.4 \%$ LIITEETAK $0.02 \% \quad 12.4 \%$ NIFIECTGTDFTK $0.02 \% \quad 12.4 \%$ VGIRETPENLAK $0.02 \% \quad 12.4 \%$ ASEGPAFFPGR $0.09 \% \quad 34.5 \%$ MQVDPQKYK $0.09 \% \quad 34.5 \%$ GIFNGFSVTLK

$0.09 \% \quad 34.5 \%$ GIFNGFSVTLKEDGVR $0.09 \% \quad 34.5 \%$ GWAPTFLGYSMQGLCK $0.09 \% \quad 34.5 \%$ FGFYEVFK

$0.09 \% \quad 34.5 \%$ VLYSNMLGEENTYLWR $0.09 \% \quad 34.5 \%$ IQTQPGYANTLR $0.09 \% 34.5 \%$ IQTQPGYANTLRDAAI $0.09 \% \quad 34.5 \%$ MYKEEGLK $0.09 \% \quad 34.5 \%$ GVAPLWMR $0.09 \% \quad 34.5 \%$ EKGSSASLVLK $0.09 \% \quad 34.5 \%$ GSSASLVLK $0.09 \% \quad 34.5 \%$ GSSASLVLKR $0.09 \% \quad 34.5 \%$ LPRPPPPEMPESLK $0.09 \% \quad 34.5 \%$ LPRPPPPEMPESLKK $0.01 \% \quad 8.9 \% \quad$ IISVNEDVTLR $0.01 \% \quad 8.9 \%$ ELYGSILQENPQVVYK $0.01 \% \quad 8.9 \%$ LGLSAIVRPSSIR $0.00 \% \quad 10.9 \%$ IDPTVLLGALPLR $0.00 \% \quad 10.9 \%$ QLVQDENVR $0.03 \% \quad 17.4 \%$ AALQALGVAEGGER $0.03 \% \quad 17.4 \%$ FLLQHLGR $0.03 \% \quad 17.4 \%$ APALGPAVR $0.03 \% \quad 17.4 \%$ DASSKIQGEYTLTLR $0.03 \% \quad 17.4 \%$ IQGEYTLTLR $0.03 \% \quad 17.4 \%$ LDTRLLYPVSK $0.03 \% \quad 17.4 \%$ TAIEAFNETIK $0.03 \% \quad 17.4 \%$ CSKEYLER $0.03 \% \quad 17.4 \%$ ILLNSERLK $0.03 \% \quad 17.4 \%$ IAEIHESR $0.03 \% \quad 17.4 \%$ TQAEEMLSGKR $0.03 \% \quad 17.4 \%$ DGTFLIRESSQR $0.03 \% \quad 17.4 \%$ APGPGPPPAAR $0.01 \% \quad 2.2 \% \quad$ FSGTTGQMSDLNK $0.01 \% \quad 2.2 \%$ HVAAIGPR $0.01 \% \quad 2.2 \% \quad$ SNLDITVGSR $0.01 \% \quad 2.2 \% \quad$ FKNTEAIGNEVTR $0.01 \% \quad 4.5 \%$ GVDASGETTYKK $0.01 \% \quad 4.5 \%$ QAQGAQSTSDEKRPVGQK $0.01 \% \quad 6.6 \%$ GVTYSLESFLGPR $0.01 \% \quad 6.6 \%$ GSYNDFSFVTHTNR $0.01 \% \quad 4.1 \%$ VISTTDAER $0.01 \% \quad 4.1 \%$ AFVRPSGTEDVVR $\begin{array}{llllllll}99.1 \% & 20.3 & 25.0 & 19.0 & 2 & 0 & 0 & 1017.58\end{array}$ $\begin{array}{llllllll}99.7 \% & 54.8 & 25.0 & 54.8 & 3 & 0 & 0 & 1545.73\end{array}$ $\begin{array}{llllllll}99.6 \% & 27.5 & 25.0 & 15.2 & 1 & 0 & 0 & 1326.74\end{array}$

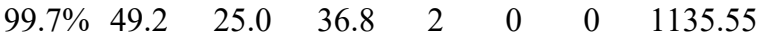
$\begin{array}{llllllll}99.6 \% & 31.7 & 25.0 & 14.2 & 7 & 0 & 0 & 1152.57\end{array}$

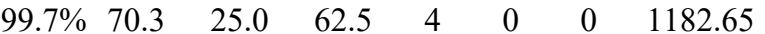

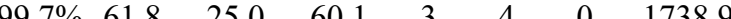

1738.91
1815.86 1036.51

2003.95 1361.72

1843.97

997.50

929.50

1118.64

861.50

1017.61

1587.86

1715.95

1258.70

1879.98

1368.83

1377.85

1100.57

1341.7

983.58

851.51

1681.88

1193.65

1304.76

1236.65

1084.51

1085.67

954.50

1249.62

1408.72

987.54

1385.64

820.48

1061.56

1478.76

$\begin{array}{llllll}99.7 \% & 48.1 & 25.0 & 45.4 & 2 & 0\end{array}$

$\begin{array}{llll}99.7 \% & 26.5 & 25.0 & 19.0\end{array}$

$\begin{array}{llll}99.6 \% & 24.4 & 25.0 & 24.4\end{array}$

1255.62

1914.96

1425.74

1644.74

991.51

$\begin{array}{llll}9.7 \% & 78.7 & 25.0 & 78.1\end{array}$

$\begin{array}{lllll}99.6 \% & 32.3 & 25.0 & 26.7\end{array}$ $\begin{array}{llll}99.7 \% & 43.8 & 25.0 & 43.4\end{array}$

1432.75 
Phosphoglycerate kinase $1 \mathrm{GN}=\mathrm{PGK}$ Phosphoglycerate kinase $1 \mathrm{GN}=\mathrm{PGK} 1$ Phosphoglycerate kinase $1 \mathrm{GN}=\mathrm{PGK} 1$ Phosphoglycerate kinase $1 \mathrm{GN}=\mathrm{PGK} 1$ Phosphoglycerate kinase $1 \mathrm{GN}=\mathrm{PGK} 1$

Phosphoglycerate mutase $1 \mathrm{GN}=\mathrm{PGAM} 1$ Phosphoglycerate mutase $1 \mathrm{GN}=\mathrm{PGAM} 1$ Phosphoglycerate mutase 1 GN=PGAM1

Phosphoglycerate mutase 1 GN=PGAM1 Phosphoglycerate mutase $1 \mathrm{GN}=\mathrm{PGAM} 1$ Phosphoglycerate mutase $1 \mathrm{GN}=$ PGAM1 Phosphoglycolate phosphatase GN=PGP Phosphoglycolate phosphatase GN=PGP

Phosphoglycolate phosphatase GN=PGP Phosphoglycolate phosphatase GN=PGP Phosphoglycolate phosphatase GN=PGP Phospholipase ABHD3 GN=ABHD3 Phospholipase ABHD3 GN=ABHD3
HGVFVGSAMR

$0.02 \% \quad 10.2 \%$ ETPIGLVPK

$5 \quad 0.02 \% \quad 10.2 \%$ EGALDLSGLR

$0.01 \% \quad 13.9 \%$ LTLDKLDVK

$0.01 \% \quad 13.9 \%$ FHVEEEGKGK

$0.01 \% \quad 13.9 \%$ LGDVYVNDAFGTAHR

$0.01 \% \quad 13.9 \%$ AHSSMVGVNLPQK

$0.01 \% \quad 13.9 \%$ VLPGVDALSNI

$0.01 \% \quad 26.4 \%$ HYGGLTGLNK

$0.01 \% \quad 26.4 \%$ YADLTEDQLPSCESLKDTIAR

$0.01 \% \quad 26.4 \%$ ALPFWNEEIVPQIK

$0.01 \% \quad 26.4 \%$ RVLIAAHGNSLR

$0.01 \% \quad 26.4 \%$ VLIAAHGNSLR

$0.01 \% \quad 26.4 \%$ AMEAVAAQGK

$0.01 \% \quad 19.3 \%$ GETAVPGAPEALR

$0.01 \% \quad 19.3 \%$ LGFITNNSSK

$0.01 \% \quad 19.3 \%$ AVVVGFDPHFSYMK

$0.01 \% \quad 19.3 \%$ FIAGTGCLVR

$0.01 \% \quad 19.3 \%$ TILTLTGVSTLGDVK

$0.00 \% \quad 5.9 \% \quad$ KPQLVTGGESFSR

$0.00 \% \quad 5.9 \%$ GVAGENLLTPR

$0.02 \% \quad 37.4 \%$ VFSANSTAACTELAK

$0.02 \% \quad 37.4 \%$ GQDIFIIQTIPR

$0.02 \% \quad 37.4 \%$ NIIGVIPYFPYSK

$0.02 \% 37.4 \%$ AGLTHIITMDLHQK

$0.02 \% 37.4 \%$ EIQGFFSFPVDNLR

$0.02 \% \quad 37.4 \%$ EKPPITVVGDVGGR

$0.02 \% \quad 37.4 \%$ IYVMATHGILSAEAPR

$0.02 \% \quad 37.4 \%$ LIEESSVDEVVVTNTVPHEVQK

$0.02 \% \quad 37.4 \%$ TVDISLILSEAIR

$0.04 \% \quad 32.8 \%$ VQVYQEPNR

$0.04 \% \quad 32.8 \%$ VQVYQEPNRETR

$0.04 \% 32.8 \%$ VQIQESVR

$0.04 \% \quad 32.8 \%$ SIIGVIPYFPYSK

$0.04 \% \quad 32.8 \%$ AGLTHLITMDLHQK

$0.04 \% \quad 32.8 \%$ EIQGFFNIPVDNLR

$0.04 \% 32.8 \%$ SVAAIHPSLEIPMLIPK

$0.04 \% \quad 32.8 \%$ EKPPITVVGDVGGR

$0.04 \% 32.8 \%$ IFVMATHGLLSSDAPR

$0.04 \% \quad 32.8 \%$ TVDISMILSEAIR

$0.02 \% \quad 29.5 \%$ QVVNFGPGPAK

$0.02 \% \quad 29.5 \%$ LPHSVLLEIQK

$0.02 \% \quad 29.5 \%$ GVGISVLEMSHR

$0.02 \% \quad 29.5 \%$ IINNTENLVR
$99.7 \% \quad 28.2$

$99.7 \% \quad 39.5$

$94.6 \% 13.7$

$99.7 \% \quad 45.4$

$96.4 \% 16.6$

$94.8 \% 16$.

$99.7 \% \quad 38.3$

$99.7 \% 29.6$

$99.7 \% \quad 47.7$

$99.7 \% \quad 39.2$

$99.7 \% \quad 49.9$

$99.5 \% \quad 22.4$

$95.5 \% \quad 14.2$

$99.7 \% \quad 52.6$

$99.7 \% \quad 54.5$

$99.7 \% \quad 55.3$

$\begin{array}{lll}99.7 \% & 32.7\end{array}$

$95.1 \% 26.5$

$99.7 \% \quad 37.4$

$99.7 \% 77$.

$99.7 \% \quad 30.4$

$\begin{array}{lll}99.7 \% & 34.9\end{array}$

$99.7 \% \quad 63.8$

$99.7 \% \quad 61.1$

$99.7 \% \quad 38.1$

$96.4 \% 25.9$

$99.7 \% \quad 53.3$

$99.7 \% \quad 46.2$

$99.4 \% \quad 24.3$

$99.7 \% \quad 44.3$

$98.6 \% 17.7$

$99.7 \% \quad 40.1$

$99.3 \% 23.0$

$99.0 \% \quad 45.5$

$99.7 \% \quad 37.9$

$96.4 \% \quad 25.9$

$99.7 \% \quad 32.9$

$95.4 \% \quad 19.8$

$99.7 \% \quad 46$.

$99.7 \% \quad 46.4$

$99.7 \% \quad 49.5$

$99.7 \% \quad 52.9$

$99.7 \% \quad 29.4$

$99.7 \% \quad 46.7$

$99.7 \% \quad 63.3$
1096.50

1629.89

1241.60

060.54

953.57

1030.55

1044.63

1159.57

1634.79

1383.71

1097.62

1059.56

2425.16

1683.91

1306.77

1150.67

975.49

1267.66

1080.57

1612.78

1093.58

1517.88

1405.74

1126.62

1569.76

1400.79

1510.83

1577.85

1668.84

1423.79

1744.91

2451.26

1429.83

1132.57

1518.77

958.53

1483.82

1577.85

1661.86

1832.04

1423.79

1714.89

1447.78

1113.61

1276.76

1284.67 1185.66

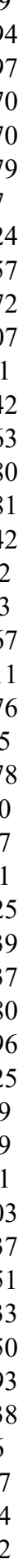

Page 110 of Table S-1-5 
Phosphoserine aminotransferase GN=PSAT1 SERC_HUMAN $40.42 \quad 100.0 \% \quad 1$ Phosphoserine aminotransferase GN=PSAT1 SERC_HUMAN $40.42 \quad 100.0 \%$ Phosphoserine aminotransferase GN=PSAT1 SERC_HUMAN $40.42 \quad 100.0 \%$ Phosphoserine aminotransferase GN=PSAT1 SERC HUMAN $40.42 \quad 100.0^{\circ}$ Phosphoserine aminotransferase GN=PSAT1 SERC_HUMAN $40.42 \quad 100.0 \%$ Phosphoserine aminotransferase GN=PSAT1 SERC_HUMAN $40.42 \quad 100.0 \%$ Phosphotriesterase-related protein GN=PTER PTER_HUMAN $39.02 \quad 100.0 \%$ Phosphotriesterase-related protein GN=PTER PTER_HUMAN $39.02 \quad 100.0 \%$ PIN2/TERF1-interacting telomerase inhibitor 1 GN=PINX1 PINX1 HUMAN $37.04 \quad 100.0 \%$ PIN2/TERF1-interacting telomerase inhibitor 1 GN=PINX1 PINX1_HUMAN $37.04 \quad 100.0 \%$ PIN2/TERF1-interacting telomerase inhibitor 1 GN=PINX1 PINX1_HUMAN $37.04 \quad 100.0 \%$ Plakophilin-2 GN=PKP2 Plakophilin-2 GN=PKP2

PKP2 HUMAN $97.42 \quad 100.0 \%$ PKP2_HUMAN $97.42 \quad 100.0 \%$ AT2B1_HUMAN $138.76 \quad 100.0 \%$ Plasma membrane calcium-transporting ATPase $1 \mathrm{GN}=$ ATP2B1 AT2B1_HUMAN $138.76 \quad 100.0 \%$ Plasma membrane calcium-transporting ATPase $1 \mathrm{GN}=\mathrm{ATP} 2 \mathrm{~B} 1 \quad \mathrm{AT} 2 \mathrm{~B} 1 \_$HUMAN $138.76 \quad 100.0 \%$ Plasminogen activator inhibitor 1 RNA-binding protein GN=SERBP1 PAIRB HUMAN $44.97 \quad 100.0 \%$ PAIRB_HUMAN $44.97 \quad 100.0$ Plectin GN=PLEC Plectin GN=PLEC Plectin GN=PLEC Plectin GN=PLEC Plectin GN=PLEC Plectin GN=PLEC Plectin GN=PLEC Plectin GN=PLEC Plectin GN=PLEC Plectin GN=PLEC Plectin GN=PLEC Plectin GN=PLEC Plectin GN=PLEC Plectin GN=PLEC Plectin GN=PLEC Plectin GN=PLEC Plectin GN=PLEC Plectin GN=PLEC Plectin GN=PLEC Plectin GN=PLEC Plectin GN=PLEC Plectin GN=PLEC Plectin GN=PLEC Plectin GN=PLEC Plectin GN=PLEC Plectin GN=PLEC Plectin $\mathrm{GN}=\mathrm{PLEC}$ Plectin GN=PLEC Plectin GN=PLEC $\begin{array}{lllllllll}4.97 & 100.0 \% & 2 & 2 & 7 & 0.01 \% & 7.4 \% & \text { VGRRPDQQLQGEGK }\end{array}$ PLEC_HUMAN $531.78 \quad 100.0 \%$ PLEC HUMAN $531.78 \quad 100.0 \%$ PLEC_HUMAN $531.78 \quad 100.0 \% \quad 46$ PLEC_HUMAN $531.78 \quad 100.0 \% \quad 46$ PLEC_HUMAN $531.78 \quad 100.0 \% \quad 46$ PLEC_HUMAN $531.78 \quad 100.0 \% \quad 46$ PLEC HUMAN $531.78 \quad 100.0 \% \quad 46$ PLEC_HUMAN $531.78 \quad 100.0 \% \quad 46$ PLEC_HUMAN $531.78 \quad 100.0 \% \quad 46$ PLEC_HUMAN $531.78 \quad 100.0 \% \quad 46$ PLEC_HUMAN $531.78 \quad 100.0 \% \quad 46$ PLEC HUMAN $531.78 \quad 100.0 \% \quad 46$ PLEC HUMAN $531.78 \quad 100.0 \% \quad 46$ PLEC_HUMAN $531.78 \quad 100.0 \% \quad 46$ PLEC HUMAN $531.78 \quad 100.0 \% \quad 46$ PLEC_HUMAN $531.78 \quad 100.0 \% \quad 46$ PLEC_HUMAN $531.78 \quad 100.0 \% \quad 46$ PLEC HUMAN $531.78 \quad 100.0 \% \quad 46$ PLEC_HUMAN $531.78 \quad 100.0 \% \quad 46$ PLEC HUMAN $531.78 \quad 100.0 \% \quad 46$ PLEC_HUMAN $531.78 \quad 100.0 \% \quad 46$ PLEC_HUMAN $531.78 \quad 100.0 \% \quad 46$ PLEC HUMAN $531.78 \quad 100.0 \% \quad 46$ PLEC_HUMAN $531.78 \quad 100.0 \% \quad 46$ PLEC HUMAN $531.78 \quad 100.0 \% \quad 46$ PLEC_HUMAN $531.78 \quad 100.0 \% \quad 46$ PLEC_HUMAN $531.78 \quad 100.0 \% \quad 46$ PLEC HUMAN $531.78 \quad 100.0 \% \quad 46$ PLEC_HUMAN $531.78 \quad 100.0 \% \quad 46$ $0.02 \% \quad 29.5 \%$ NVGSAGV

$0.02 \% \quad 29.5 \%$ DDLLGFALR

$0.02 \% \quad 29.5 \%$ ECPSVLEYK

$0.02 \% \quad 29.5 \%$ ALELNMLSLK

$0.02 \% \quad 29.5 \%$ ASLYNAVTIEDVQK

$0.00 \% \quad 6.6 \%$ VQTVLGLVEPSK

$0.00 \% \quad 6.6 \%$ ILQEAGADISK

$0.01 \% \quad 14.9 \%$ GLGAQEQGATDHIK

$0.01 \% \quad 14.9 \%$ NKPQVPVPGSDISETQV

$0.01 \% \quad 14.9 \%$ ASAQDAGDHVQPPEGR

$0.00 \% \quad 3.5 \%$ IQEQVQQTLAR

$0.00 \% \quad 3.5 \%$ AHLTVGQAAAGGSGNLLTER

$0.00 \% \quad 2.7 \%$ TVIEPMASEGLR

$0.00 \% \quad 2.7 \% \quad$ MVTGDNINTAR

$0.00 \% \quad 2.7 \%$ GIIDSTVSDQR

0.01\% $\quad 7.4 \%$ SAAQAAAQTNSNAAGK

$0.11 \% \quad 10.0 \%$ VPDVQDGVR

$0.11 \% \quad 10.0 \%$ ARSDEGQLSPATR

$0.11 \% \quad 10.0 \%$ SDEGQLSPATR

$0.11 \% \quad 10.0 \%$ IKELQNAGDR

$0.11 \% \quad 10.0 \%$ AVVQLKPR

$0.11 \% \quad 10.0 \%$ LQLEACETR

$0.11 \% \quad 10.0 \%$ GTQGAEEVLR

$0.11 \% \quad 10.0 \%$ HGERDVEVER

$0.11 \% \quad 10.0 \%$ WQAVLAQTDVR

$0.11 \% \quad 10.0 \%$ AQLEPVASPAK

$0.11 \% \quad 10.0 \%$ SIQEELQQLR

$0.11 \% \quad 10.0 \%$ LQLEATER

$0.11 \% \quad 10.0 \%$ GGAEGELQALR

$0.11 \% \quad 10.0 \%$ QVQVALETAQR

$0.11 \% \quad 10.0 \%$ SAEAELQSK

$0.11 \% \quad 10.0 \%$ SAEAELQSKR

$0.11 \% \quad 10.0 \%$ LRLQAEEVAQQK

$0.11 \% \quad 10.0 \%$ QLAEGTAQQR

$0.11 \% \quad 10.0 \%$ LRAETEQGEQQR

$0.11 \% \quad 10.0 \%$ QLLEEELAR

$0.11 \% \quad 10.0 \%$ FRELAEEAAR

$0.11 \% \quad 10.0 \%$ QVEEEILALK

$0.11 \% \quad 10.0 \%$ SKEQAELEAAR

$0.11 \% \quad 10.0 \%$ SLAAEEEAAR

$0.11 \% \quad 10.0 \%$ QLQLAQEAAQK

$0.11 \% \quad 10.0 \%$ QLQLAQEAAQKR

$0.11 \% \quad 10.0 \%$ LKQSAEEQAQAR

$0.11 \% \quad 10.0 \%$ RAQAEQAALR

$0.11 \% \quad 10.0 \%$ AQVEQELTTLR $\begin{array}{llllllll}99.0 \% & 21.4 & 25.0 & 16.7 & 1 & 0 & 0 & 1161.62\end{array}$

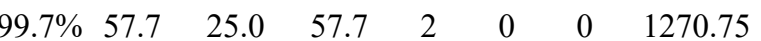

$\begin{array}{llllllll}99.7 \% & 27.8 & 25.0 & 16.9 & 2 & 0 & 0 & 1019.55\end{array}$

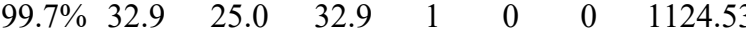

$99.7 \% \quad 56.9 \quad 25.0 \quad 51.5$

$99.7 \% \quad 74.4 \quad 25.0 \quad 71.9$

$99.7 \% \quad 24.3$

$99.7 \% \quad 53.0$

$99.7 \% 34.8$

$25.0 \quad 24.2$

$99.7 \% \quad 54.5$

$98.9 \% \quad 17.9$

$95.7 \% \quad 15.9$

$99.7 \% \quad 30.6$

$99.7 \% \quad 33.2$

$99.7 \% 70.9$

$99.6 \% \quad 22.6$

$99.7 \% \quad 52.9$

$99.7 \% \quad 52.7$

$99.7 \% \quad 32.4$

$99.1 \% \quad 26.1$

$99.0 \% \quad 34.4$

$\begin{array}{lll}99.6 \% & 24.7\end{array}$

$99.7 \% \quad 54.1$

$99.7 \% \quad 26.5$

$\begin{array}{lll}99.7 \% & 49.1\end{array}$

$99.7 \% \quad 35.4$

$99.7 \% \quad 32.2$

$99.0 \% 37.1$

$99.7 \% \quad 63.6$

$99.7 \% \quad 45.7$

$99.7 \% \quad 38.0$

$99.7 \% \quad 51.0$

$\begin{array}{lll}99.7 \% & 32.7\end{array}$

$99.7 \% \quad 47.3$

$99.7 \% \quad 52.1$

$99.3 \% \quad 23.3$

$98.5 \% \quad 21.6$

$99.6 \% \quad 27.9$

$99.7 \% \quad 33.4$

$99.7 \% \quad 55.3$

$99.7 \% 59.5$

$99.7 \% \quad 38.4$

$99.7 \% \quad 48.2$

$99.2 \% \quad 27.8$

$99.7 \% \quad 57.8$

1147.64

1550.81

1269.74

1144.62

1424.71

2080.07

1634.75

1313.72

1923.00

1302.67

1207.57

1190.60

1460.7

1567.83

984.51

1387.69

1160.55

1143.61

910.58

1119.55

1059.54

1225.59

1286.69

1110.62

1243.66

959.52

1100.57

1242.68

962.48

1118.58

1412.79

1101.56

1444.71

1100.59

1191.61

1171.66

1231.63

1046.5

1227.67

1383.77

1358.70

1113.6

1287.69 
Plectin GN=PLEC

Plectin GN=PLEC

Plectin GN=PLEC

Plectin GN=PLEC

Plectin GN=PLEC

Plectin GN=PLEC

Plectin GN=PLEC

Plectin GN=PLEC

Plectin GN=PLEC

Plectin GN=PLEC

Plectin GN=PLEC

Plectin GN=PLEC

Plectin GN=PLEC

Plectin GN=PLEC

Plectin GN=PLEC

Plectin GN=PLEC

Plectin GN=PLEC $\begin{array}{lllll}\text { Poly [ADP-ribose] polymerase 1 GN=PARP1 PARP1_HUMAN } & 113.09 & 100.0 \% & 22 \\ \text { Poly [ADP-ribose] polymerase 1 GN=PARP1 PARP1_HUMAN } & 113.09 & 100.0 \% & 22\end{array}$ Poly [ADP-ribose] polymerase 1 GN=PARP1 PARP1_HUMAN $113.09 \quad 100.0 \% 22$ Poly [ADP-ribose] polymerase 1 GN=PARP1 PARP1_HUMAN $113.09 \quad 100.0 \%$ Poly [ADP-ribose] polymerase 1 GN=PARP1 PARP1_HUMAN $113.09 \quad 100.0 \%$ Poly [ADP-ribose] polymerase 1 GN=PARP1 PARP1_HUMAN $113.09 \quad 100.0 \% 22$ Poly [ADP-ribose] polymerase 1 GN=PARP1 PARP1_HUMAN $113.09 \quad 100.0 \% 22$ Poly [ADP-ribose] polymerase 1 GN=PARP1 PARP1_HUMAN $113.09 \quad 100.0 \% 22$ Poly [ADP-ribose] polymerase 1 GN=PARP1 PARP1_HUMAN $113.09 \quad 100.0 \%$ Poly [ADP-ribose] polymerase 1 GN=PARP1 PARP1_HUMAN $113.09 \quad 100.0 \% 22$ Poly [ADP-ribose] polymerase 1 GN=PARP1 PARP1_HUMAN $113.09 \quad 100.0 \% 22$ Poly [ADP-ribose] polymerase 1 GN=PARP1 PARP1_HUMAN $113.09 \quad 100.0 \%$ Poly [ADP-ribose] polymerase 1 GN=PARP1 PARP1_HUMAN $113.09 \quad 100.0 \% 22$ Poly [ADP-ribose] polymerase $1 \mathrm{GN}=$ PARP1 PARP1_HUMAN $113.09 \quad 100.0 \% 22$ Poly [ADP-ribose] polymerase 1 GN=PARP1 PARP1_HUMAN $113.09 \quad 100.0 \% 22$ Poly [ADP-ribose] polymerase 1 GN=PARP1 PARP1_HUMAN $113.09 \quad 100.0 \% 22$ Poly [ADP-ribose] polymerase 1 GN=PARP1 PARP1_HUMAN $113.09 \quad 100.0 \% 22$ Poly [ADP-ribose] polymerase 1 GN=PARP1 PARP1_HUMAN $113.09 \quad 100.0 \%$ Poly [ADP-ribose] polymerase 1 GN=PARP1 PARP1_HUMAN $113.09 \quad 100.0 \%$ Poly [ADP-ribose] polymerase 1 GN=PARP1 PARP1_HUMAN $113.09 \quad 100.0 \%$ Poly [ADP-ribose] polymerase 1 GN=PARP1 PARP1_HUMAN $113.09 \quad 100.0 \% 22$ Poly [ADP-ribose] polymerase 1 GN=PARP1 PARP1_HUMAN $113.09 \quad 100.0 \% 22$ Poly [ADP-ribose] polymerase 2 GN=PARP2 PARP2_HUMAN $66.21 \quad 100.0 \% \quad 2$ Poly [ADP-ribose] polymerase 2 GN=PARP2 PARP2 HUMAN $66.21 \quad 100.0 \%$ Poly(rC)-binding protein $1 \mathrm{GN}=\mathrm{PCBP} 1$ Poly(rC)-binding protein $1 \mathrm{GN}=\mathrm{PCBP} 1$ Poly(rC)-binding protein $1 \mathrm{GN}=\mathrm{PCBP} 1$ Poly(rC)-binding protein $1 \mathrm{GN}=\mathrm{PCBP} 1$ Poly(rC)-binding protein $1 \mathrm{GN}=\mathrm{PCBP}$. Poly(rC)-binding protein $1 \mathrm{GN}=\mathrm{PCBP} 1$ $\begin{array}{llll}\text { PCBP1_HUMAN } & 37.50 & 100.0 \% & 8\end{array}$ PCBP1_HUMAN $37.50 \quad 100.0 \% \quad 8$ PCBP1_HUMAN $37.50 \quad 100.0 \%$ PCBP1_HUMAN $37.50 \quad 100.0 \% \quad 8$ PCBP1 HUMAN $37.50 \quad 100.0 \% \quad 8$ PCBP1_HUMAN $37.50 \quad 100.0 \% \quad 8$ $\begin{array}{llll}51 & 98 & 0.11 \% & 10.0 \% \\ & \text { LKAEATEAAR }\end{array}$ $\begin{array}{llll}51 & 98 & 0.11 \% & 10.0 \% \text { SQVEEELFSVR }\end{array}$ $\begin{array}{llll}51 \quad 98 & 0.11 \% & 10.0 \% & \text { LSVAAQEAAR }\end{array}$

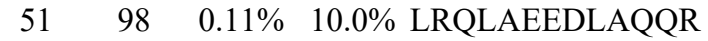

$\begin{array}{llll}51 & 98 & 0.11 \% & 10.0 \% \\ 51 & 98 & 0.11 \% & 10.0 \%\end{array}$ $0.11 \% \quad 10.0 \%$ LAQGHTTVDELAR $0.11 \% \quad 10.0 \%$ VPVDVAYR

$0.11 \% \quad 10.0 \%$ ATVSAPFGK

$0.11 \% \quad 10.0 \%$ IIITVVEEQEQK

$0.11 \% \quad 10.0 \%$ LTVDEAVR

$0.11 \% \quad 10.0 \%$ LYVHEAVK

$0.11 \% \quad 10.0 \%$ LTVEEAVR

$0.11 \% \quad 10.0 \%$ NLVDNITGQR

$0.11 \% \quad 10.0 \%$ LLEAAAQSTK

$0.08 \% \quad 25.1 \%$ CSESIPKDSLR

$0.08 \% 25.1 \%$ AEKTLGDFAAEYAK

$0.08 \% \quad 25.1 \%$ TLGDFAAEYAK

$0.08 \% \quad 25.1 \%$ TLGDFAAEYAKSNR

$0.08 \% \quad 25.1 \%$ KGDEVDGVDEVAK

$0.08 \% 25.1 \%$ QQVPSGESAILDR

$0.08 \% \quad 25.1 \%$ ILTLGKLSR

$0.08 \% \quad 25.1 \%$ LGGKLTGTANK

$0.08 \% \quad 25.1 \%$ ASLCISTKK

$0.08 \% \quad 25.1 \%$ AEPVEVVAPR

$0.08 \% \quad 25.1 \%$ KLTVNPGTK

$0.08 \% \quad 25.1 \%$ SKLPKPVQDLIK

$0.08 \% 25.1 \%$ MIFDVESMKK

$0.08 \% \quad 25.1 \%$ AMVEYEIDLQK

$0.08 \% \quad 25.1 \%$ KPPLLNNADSVQAK

$0.08 \% \quad 25.1 \%$ VVDRDSEEAEIIR

$0.08 \% \quad 25.1 \%$ TTNFAGILSQGLR

$0.08 \% \quad 25.1 \%$ GIYFADMVSK

$0.00 \% \quad 3.8 \%$ GKAPVDPECTAK

$0.00 \% \quad 3.8 \%$ GIYFADMSSK

$0.05 \% \quad 28.7 \%$ EVGSIIGK

$0.05 \% \quad 28.7 \%$ INISEGNCPER

$49 \quad 0.05 \% \quad 28.7 \%$ IITLTGPTNAIFK

$0.05 \% \quad 28.7 \%$ LVVPATQCGSLIGK $\begin{array}{lllll}99.7 \% & 43.4 & 25.0 & 33.2 & 4\end{array}$ $\begin{array}{lllll}99.7 \% & 47.2 & 25.0 & 42.9 & 2\end{array}$ $99.7 \% \quad 66.9 \quad 25.0 \quad 44.2 \quad 2$ $99.7 \% \quad 44.2 \quad 25.0 \quad 41.9$ $\begin{array}{llll}99.4 \% & 20.2 & 25.0 & 19.9\end{array}$

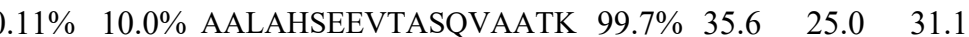

$99.7 \% \quad 43.3$

$99.0 \% \quad 36.8$

$99.7 \% \quad 30.2$

$99.7 \% \quad 43.7$

$99.0 \% \quad 26.7$

$0.11 \% \quad 10.0 \%$ AYSDPSTGEPATYGELQQR $\quad 99.7 \% \quad 50.4$

$96.2 \% \quad 23.8$

$99.0 \% 35.1$

$0.11 \% \quad 10.0 \%$ SSSVGSSSSYPISPAVSR

$99.7 \% 38.3$

$99.6 \% \quad 28.3$

$99.7 \% 28.3$

$99.7 \% \quad 48.3$

$0.08 \% \quad 25.1 \%$ TAEAGGVTGKGQDGIGSK

$99.7 \% \quad 47.0$

$99.7 \% \quad 75.2$

$99.7 \% \quad 58.4$

$99.7 \% \quad 58.3$

$0.08 \% \quad 25.1 \%$ NREELGFRPEYSASQLK

$0.08 \% \quad 25.1 \%$ VVSEDFLQDVSASTK

$97.4 \% \quad 21.9$

$99.7 \% \quad 33.9$

$99.7 \% \quad 62.3$

$99.7 \% \quad 50.2$

$99.7 \% \quad 50.2$

$99.6 \% 24.9$

$99.7 \% \quad 52.8$

$99.7 \% \quad 39.5$

$0.08 \% \quad 25.1 \%$ GGAAVDPDSGLEHSAHVLEK

$\begin{array}{lll}97.5 \% & 17.3\end{array}$

$97.4 \% \quad 22.9$

$99.7 \% \quad 32.8$

$99.7 \% \quad 30.7$

$99.7 \% \quad 62.4$

$99.7 \% \quad 63.2$

$99.7 \% \quad 35.3$

$99.7 \% \quad 57.2$

$99.7 \% \quad 47.9$

$99.7 \% \quad 31.7$

$99.4 \% 20.6$

$99.0 \% \quad 29.3$

$99.7 \% \quad 50.3$

$99.7 \% 54.6$

$99.7 \% \quad 56.5$

$0.05 \% \quad 28.7 \%$ ESTGAQVQVAGDMLPNSTER $99.7 \% \quad 70.1$

$0.05 \% \quad 28.7 \%$ AITIAGVPQSVTECVK

$99.7 \% \quad 44.8$ 
Poly $(\mathrm{rC})$-binding protein $1 \mathrm{GN}=\mathrm{PCBP} 1$ Poly $(\mathrm{rC})$-binding protein $1 \mathrm{GN}=\mathrm{PCBP} 1$ Poly(rC)-binding protein $2 \mathrm{GN}=\mathrm{PCBP} 2$ Poly(rC)-binding protein $2 \mathrm{GN}=\mathrm{PCBP} 2$ Poly(rC)-binding protein $2 \mathrm{GN}=\mathrm{PCBP} 2$ Poly(rC)-binding protein $2 \mathrm{GN}=\mathrm{PCBP} 2$ Poly(rC)-binding protein $2 \mathrm{GN}=\mathrm{PCBP} 2$ Poly(rC)-binding protein $2 \mathrm{GN}=\mathrm{PCBP} 2$ Poly(rC)-binding protein $2 \mathrm{GN}=\mathrm{PCBP} 2$ Poly(rC)-binding protein $2 \mathrm{GN}=\mathrm{PCBP} 2$ Poly(U)-binding-splicing factor PUF60 GN=PUF60 PUF60_HUMAN 59.88 Poly(U)-binding-splicing factor PUF60 GN=PUF60 PUF60_HUMAN 59.88 Poly(U)-binding-splicing factor PUF60 GN=PUF60 PUF60_HUMAN 59.88 Poly(U)-binding-splicing factor PUF60 GN=PUF60 PUF60_HUMAN 59.88 Polyadenylate-binding protein 1 GN=PABPC1 PABP1_HUMAN 70.6? Polyadenylate-binding protein $1 \mathrm{GN}=$ PABPC1 PABP1_HUMAN 70.67 Polyadenylate-binding protein $1 \mathrm{GN}=\mathrm{PABPC} 1$ PABP1_HUMAN 70.67 Polyadenylate-binding protein $1 \mathrm{GN}=\mathrm{PABPC} 1$ PABP1_HUMAN 70.67 Polyadenylate-binding protein $1 \mathrm{GN}=\mathrm{PABPC} 1$ PABP1_HUMAN 70.67 Polyadenylate-binding protein $1 \mathrm{GN}=\mathrm{PABPC1}$ PABP1_HUMAN 70.67 Polyadenylate-binding protein $1 \mathrm{GN}=\mathrm{PABPC} 1$ PABP1_HUMAN 70.67 Polyadenylate-binding protein $1 \mathrm{GN}=\mathrm{PABPC} 1$ PABP1_HUMAN 70.67 Polyadenylate-binding protein $1 \mathrm{GN}=\mathrm{PABPC} 1$ PABP1_HUMAN 70.67 Polyadenylate-binding protein $1 \mathrm{GN}=$ PABPC1 PABP1_HUMAN 70.67 Polyadenylate-binding protein $1 \mathrm{GN}=\mathrm{PABPC} 1 \mathrm{PABP} 1$ HUMAN 70.67 Polyadenylate-binding protein $1 \mathrm{GN}=\mathrm{PABPC} 1$ PABP1_HUMAN 70.67 Polyadenylate-binding protein $1 \mathrm{GN}=$ PABPC1 PABP1_HUMAN 70.67 Polyadenylate-binding protein $1 \mathrm{GN}=\mathrm{PABPC} 1$ PABP1_HUMAN 70.6 Polyadenylate-binding protein $1 \mathrm{GN}=\mathrm{PABPC} 1$ PABP1_HUMAN 70.67 Polyadenylate-binding protein $1 \mathrm{GN}=\mathrm{PABPC} 1$ PABP1_HUMAN 70.67 Polyadenylate-binding protein $1 \mathrm{GN}=\mathrm{PABPC} 1$ PABP1_HUMAN 70.67 Polyadenylate-binding protein $1 \mathrm{GN}=$ PABPC1 PABP1_HUMAN 70.67 Polyadenylate-binding protein $1 \mathrm{GN}=\mathrm{PABPC} 1 \mathrm{PABP} 1$ HUMAN 70.67 Polyadenylate-binding protein $1 \mathrm{GN}=\mathrm{PABPC} 1$ PABP1_HUMAN 70.67 Polyadenylate-binding protein $1 \mathrm{GN}=$ PABPC1 PABP1_HUMAN 70.67 Polyadenylate-binding protein $1 \mathrm{GN}=$ PABPC1 PABP1_HUMAN 70.6 Polyadenylate-binding protein $1 \mathrm{GN}=$ PABPC1 PABP1_HUMAN 70.67 Polyadenylate-binding protein $1 \mathrm{GN}=\mathrm{PABPC} 1$ PABP1_HUMAN 70.67 Polyadenylate-binding protein $1 \mathrm{GN}=$ PABPC1 PABP1_HUMAN 70.67 Polyadenylate-binding protein $1 \mathrm{GN}=\mathrm{PABPC} 1$ PABP1_HUMAN 70.67 Polyadenylate-binding protein $1 \mathrm{GN}=\mathrm{PABPC} 1$ PABP1_HUMAN 70.67 Polyadenylate-binding protein $1 \mathrm{GN}=$ PABPC1 PABP1_HUMAN 70.67 Polyadenylate-binding protein $1 \mathrm{GN}=$ PABPC1 PABP1_HUMAN 70.67 Polyadenylate-binding protein $1 \mathrm{GN}=\mathrm{PABPC} 1$ PABP1_HUMAN 70.67 Polyadenylate-binding protein 2 GN=PABPN1 PABP2_HUMAN 32.75 Polyadenylate-binding protein $2 \mathrm{GN}=$ PABPN1 PABP2_HUMAN 32.75
$100.0 \%$

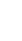

$0.04 \% 31.8 \%$ LVVPASQCGSLIGK

$\begin{array}{llll}216 & 0.24 \% & 42.0 \% & \text { FSPAGPILSIR }\end{array}$

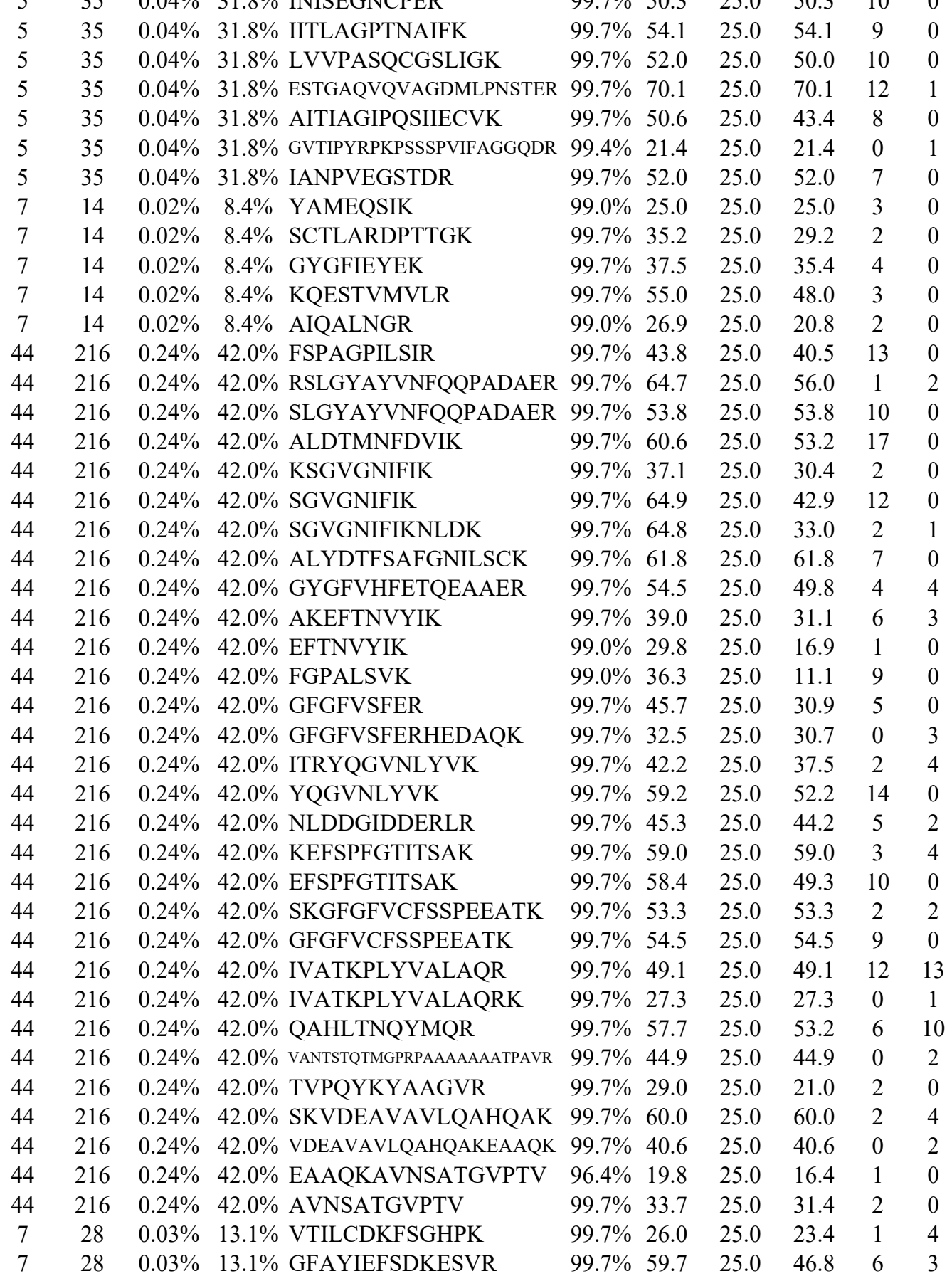

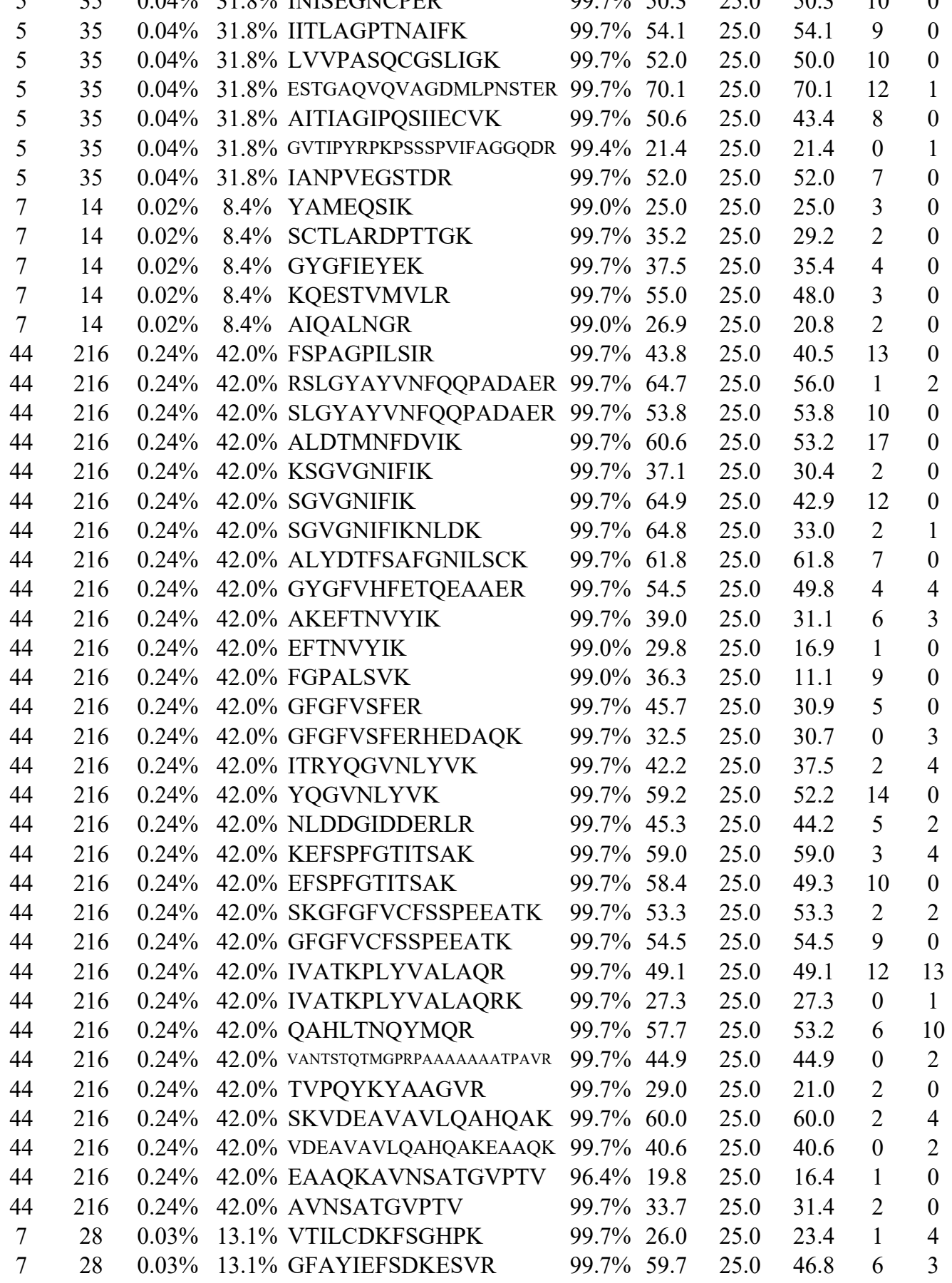

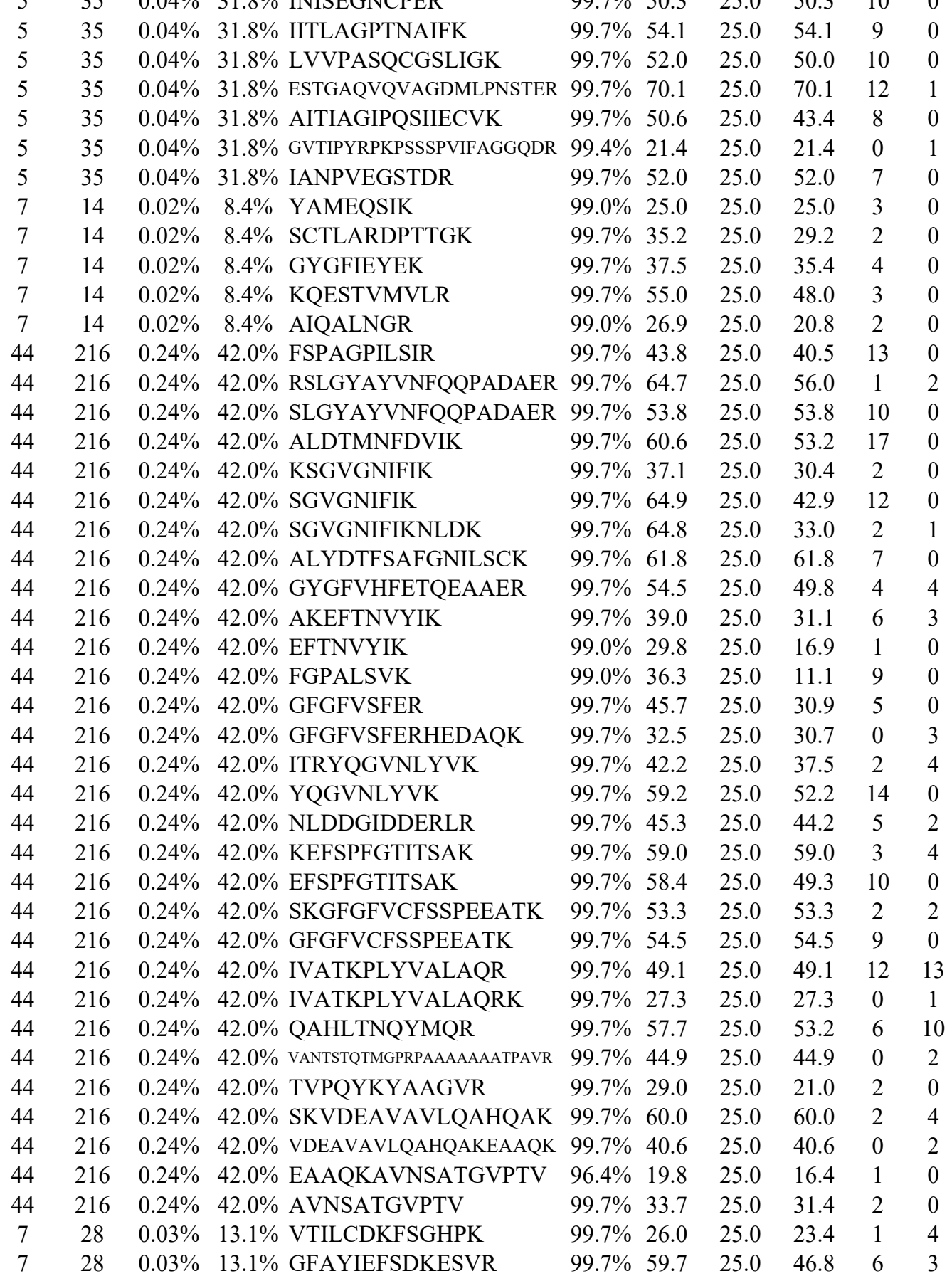

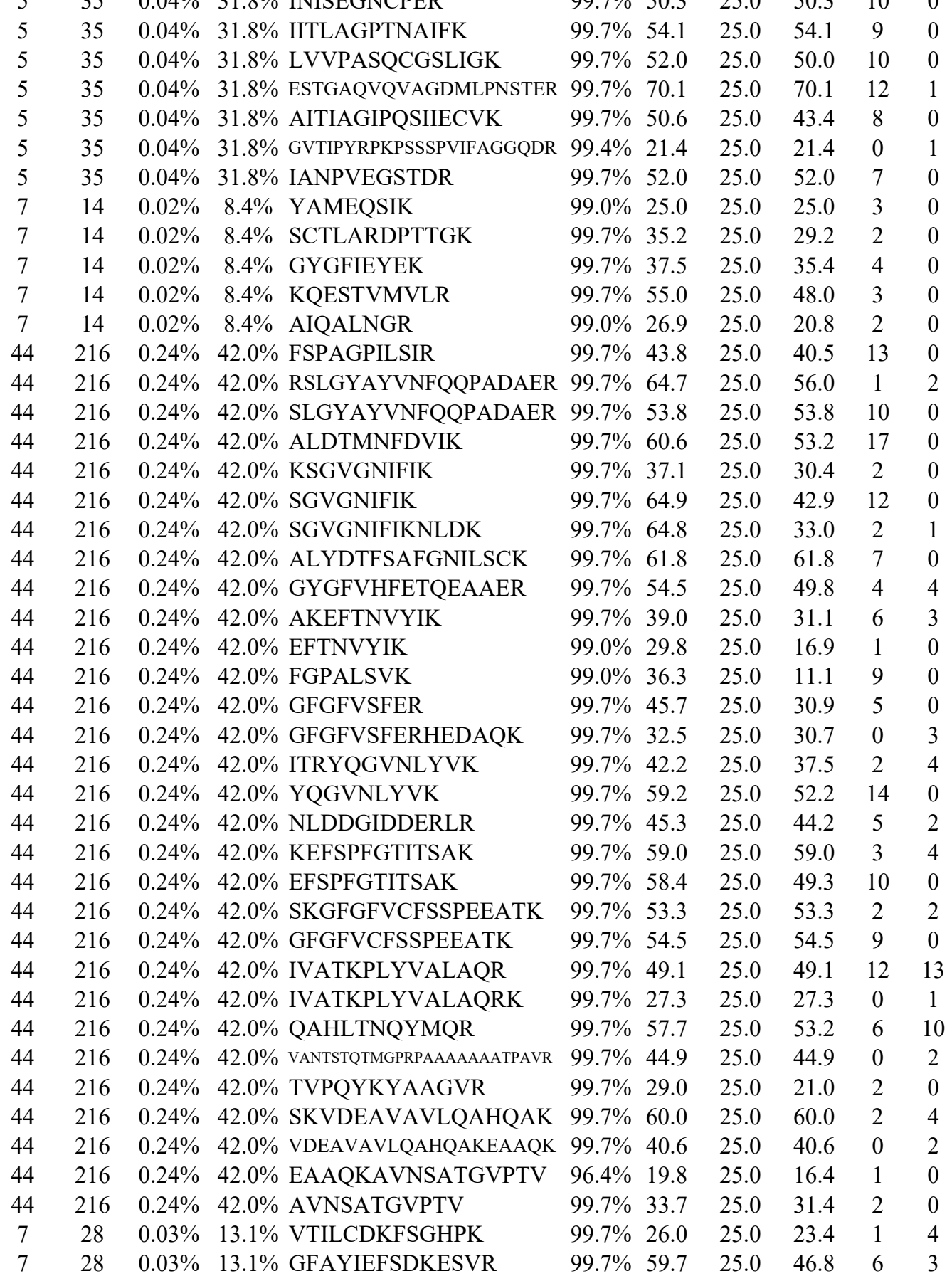

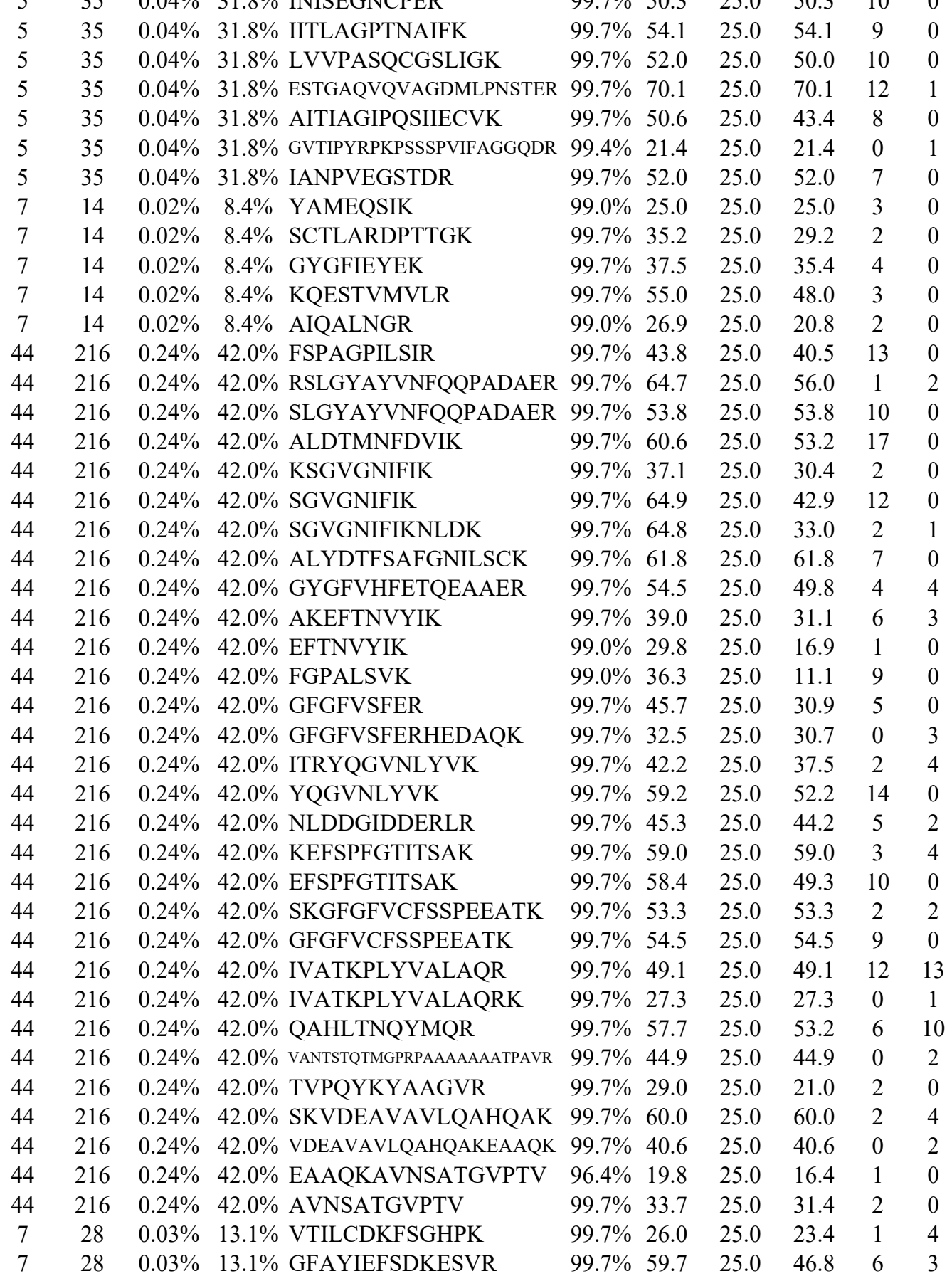

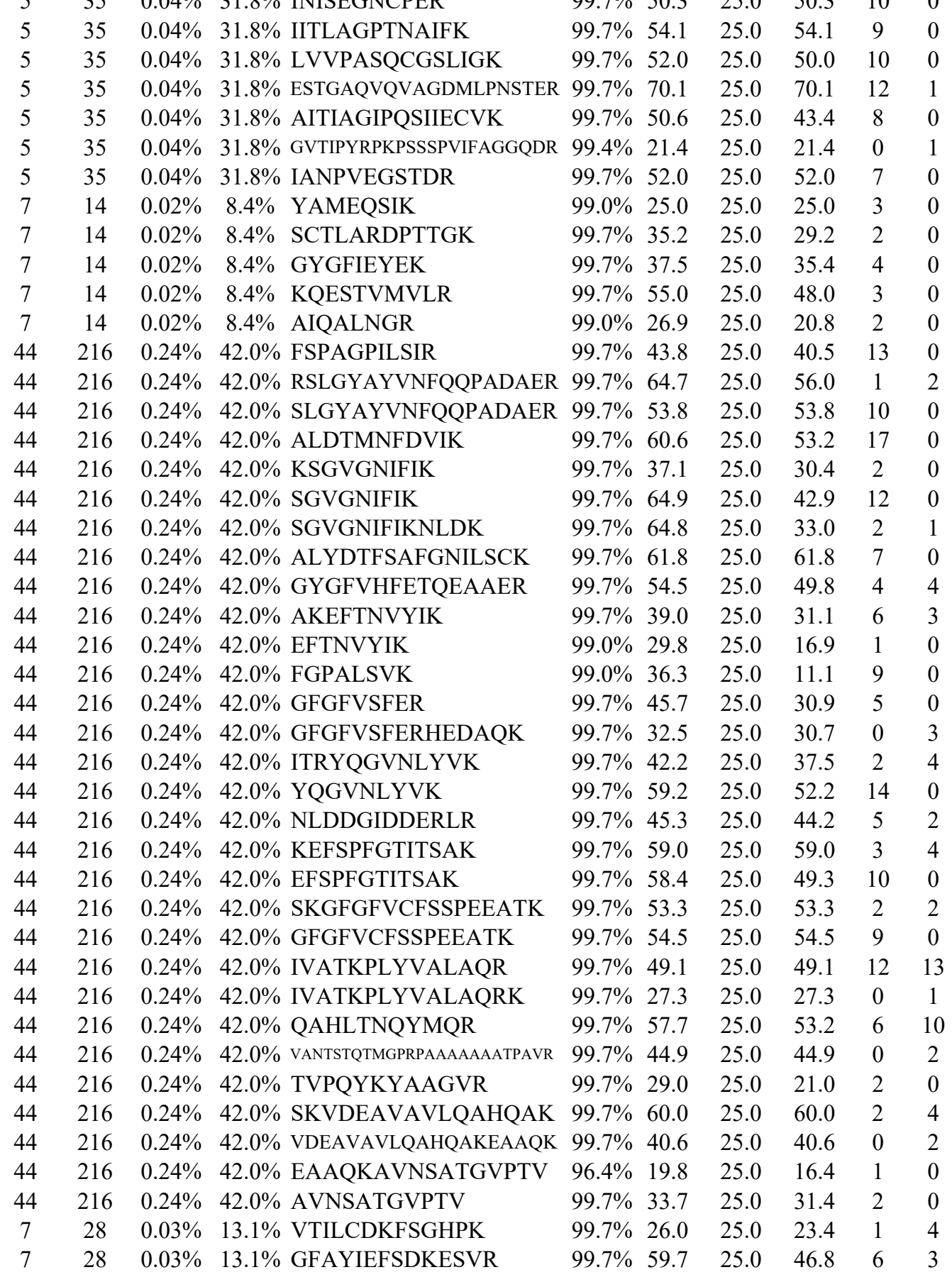

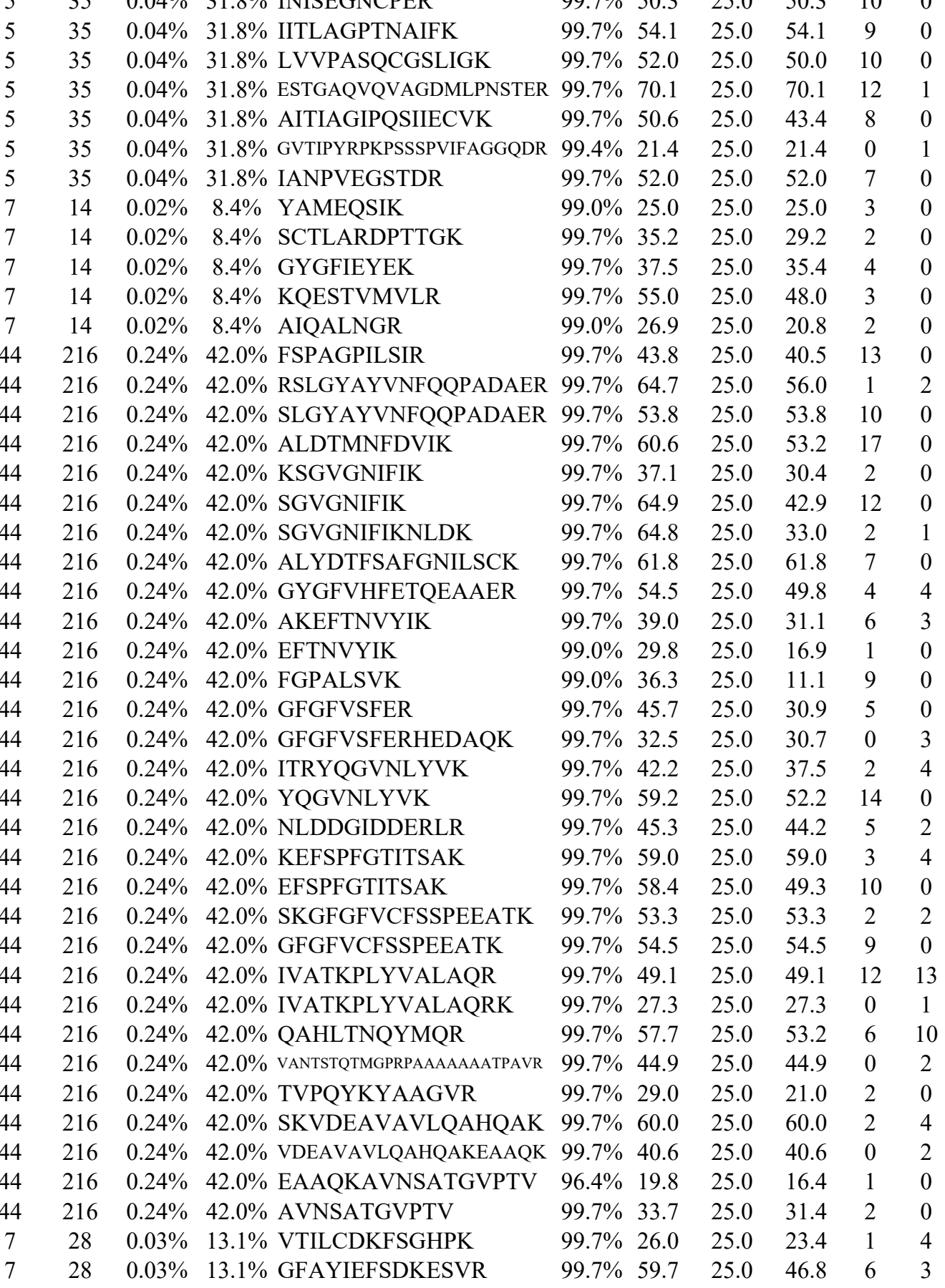

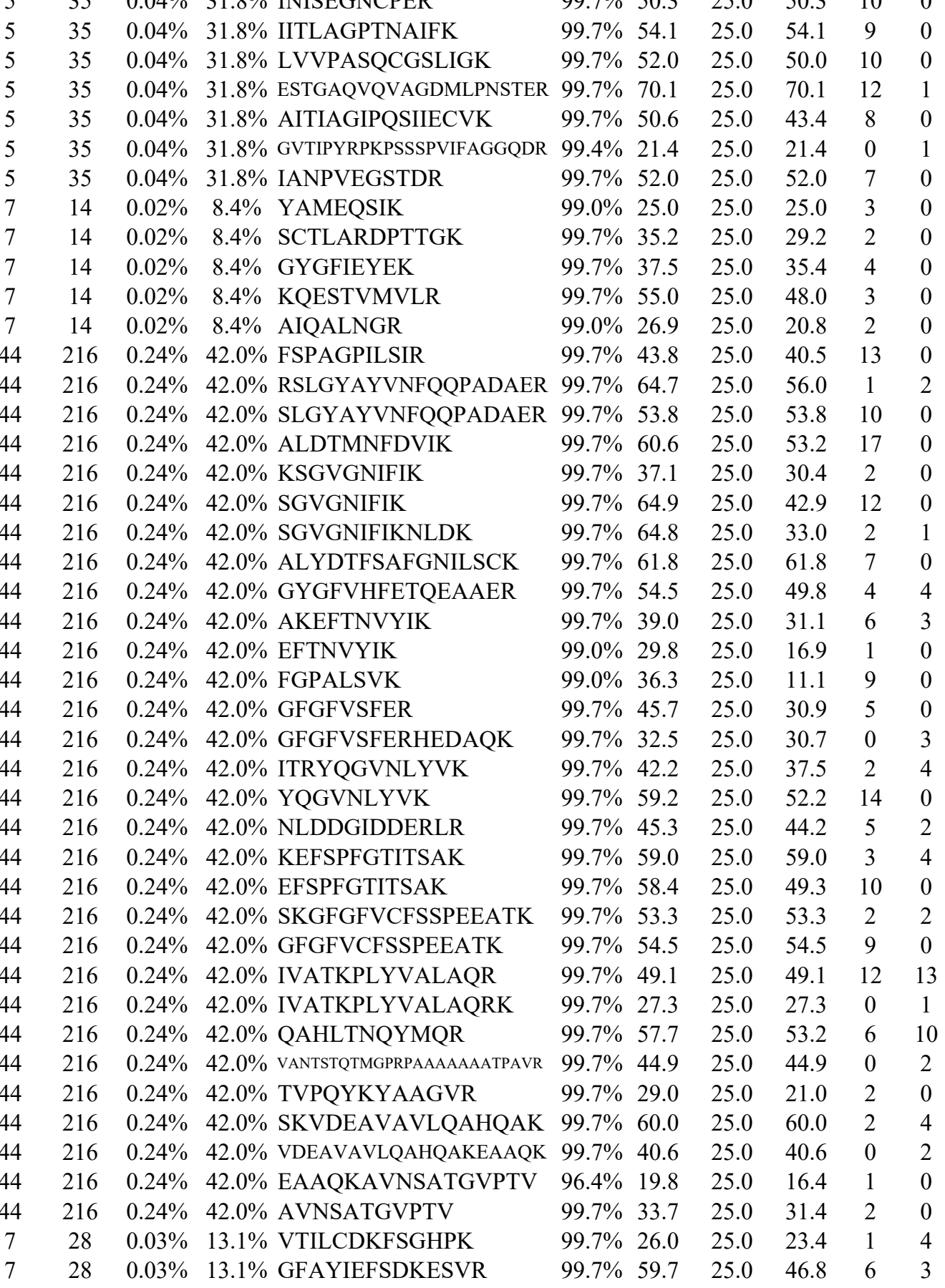

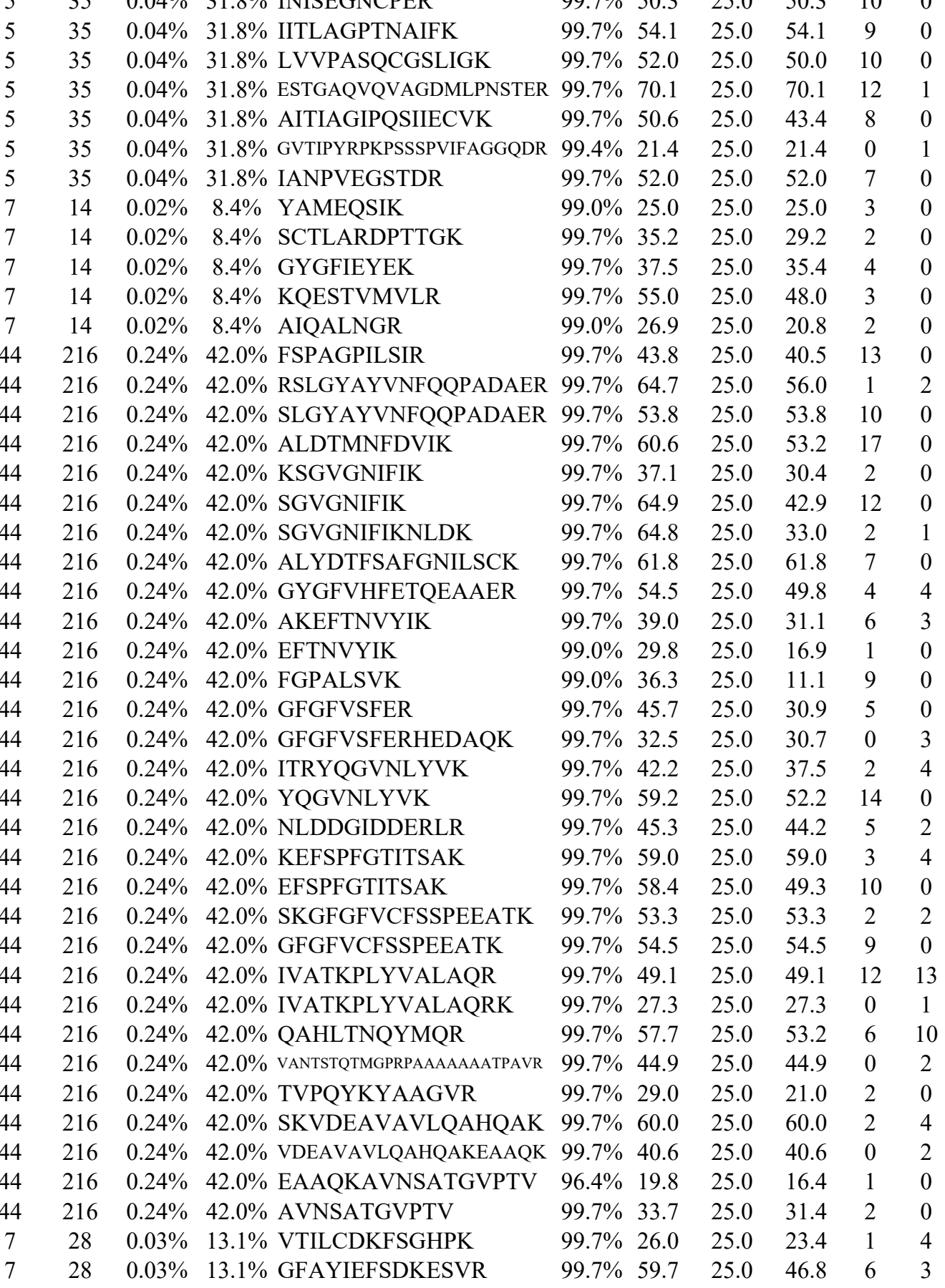

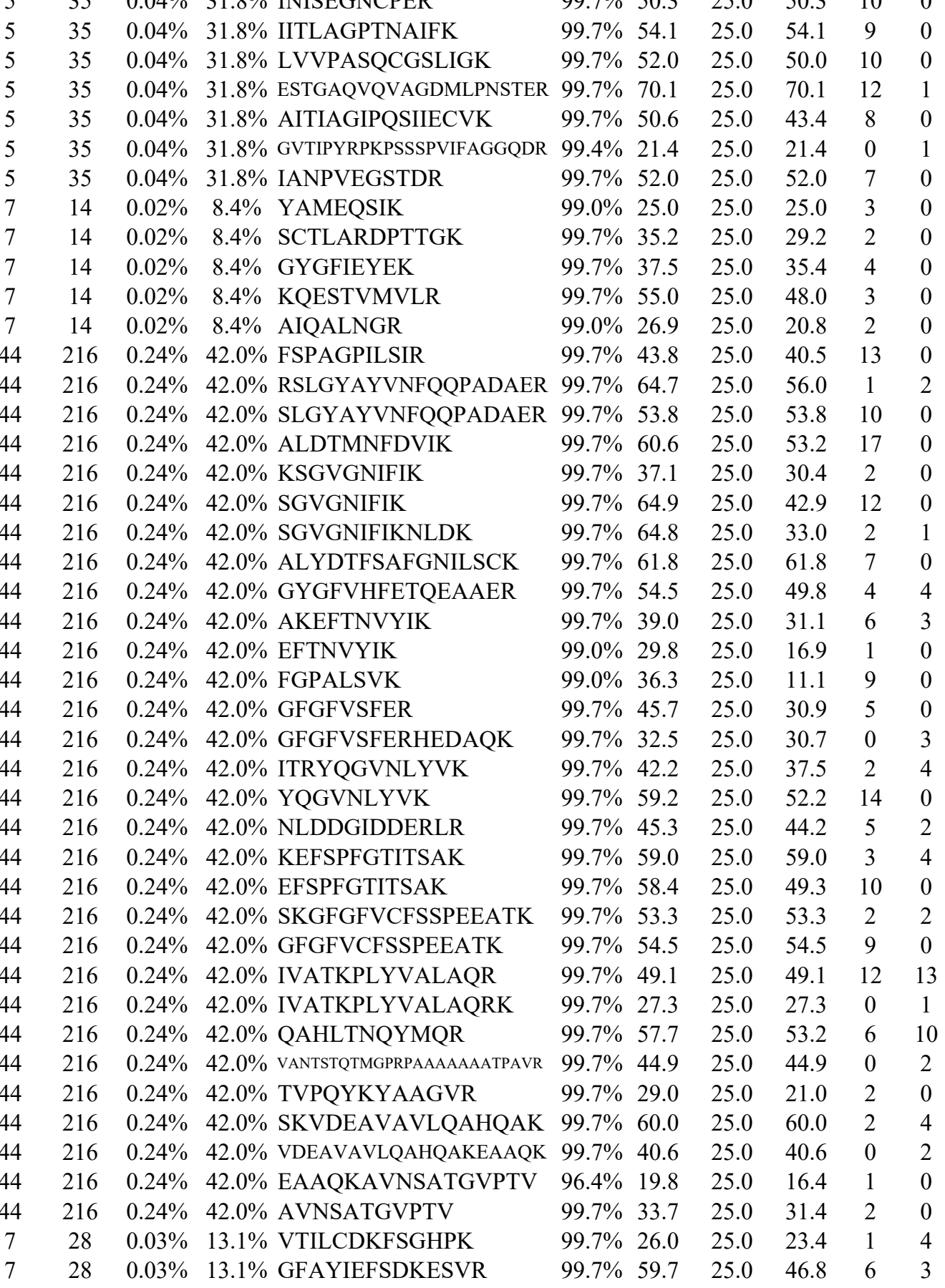

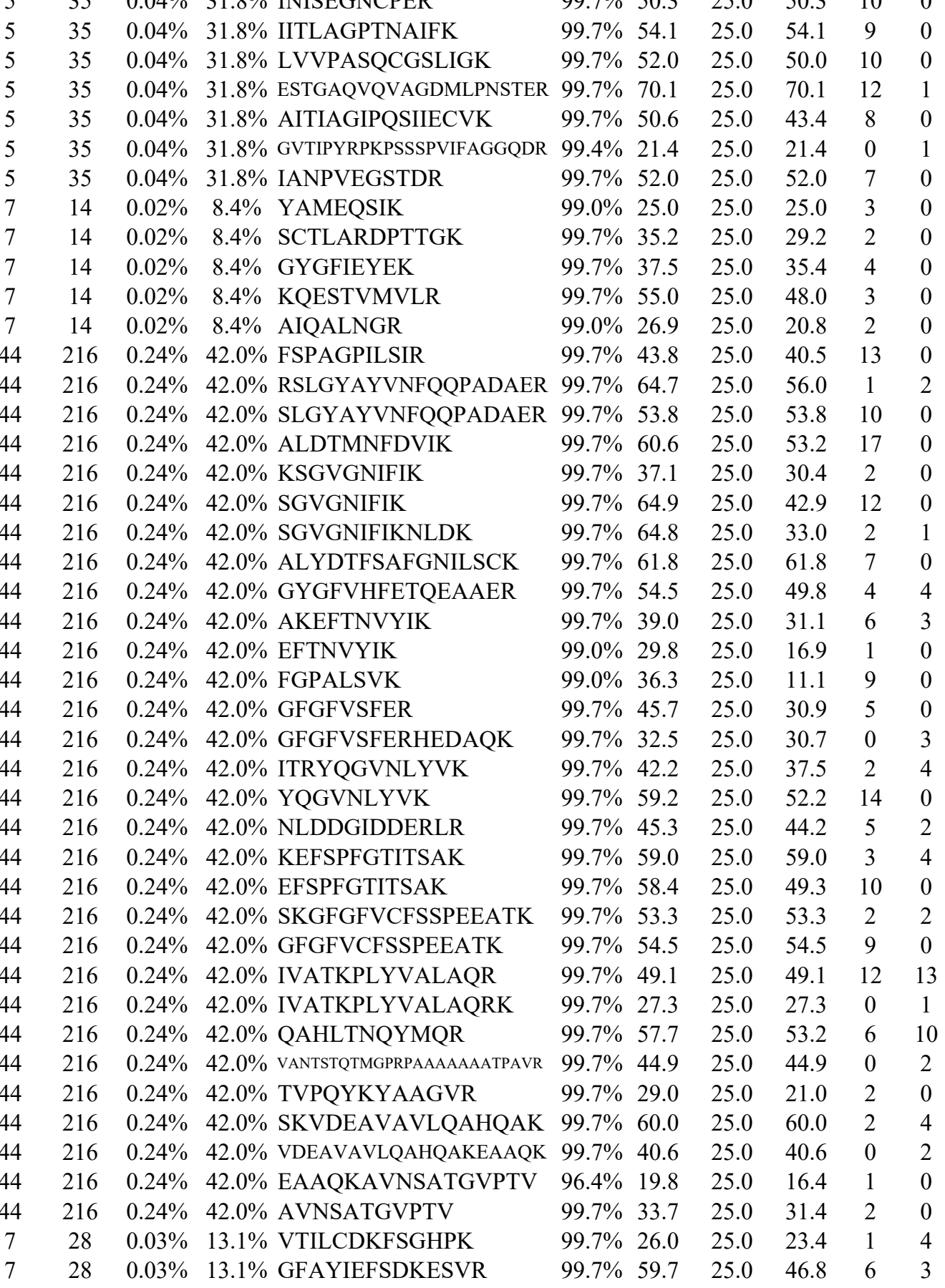

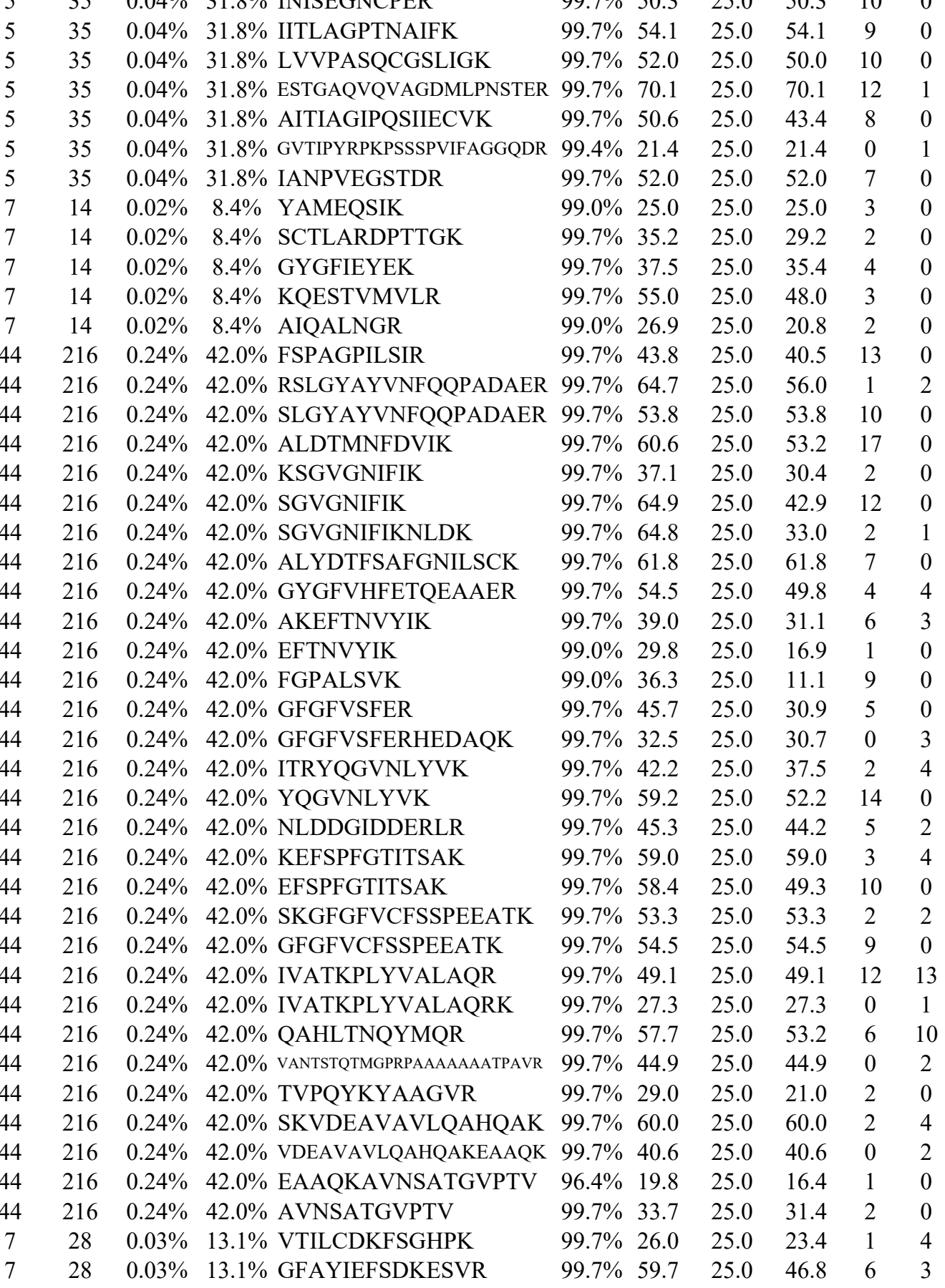

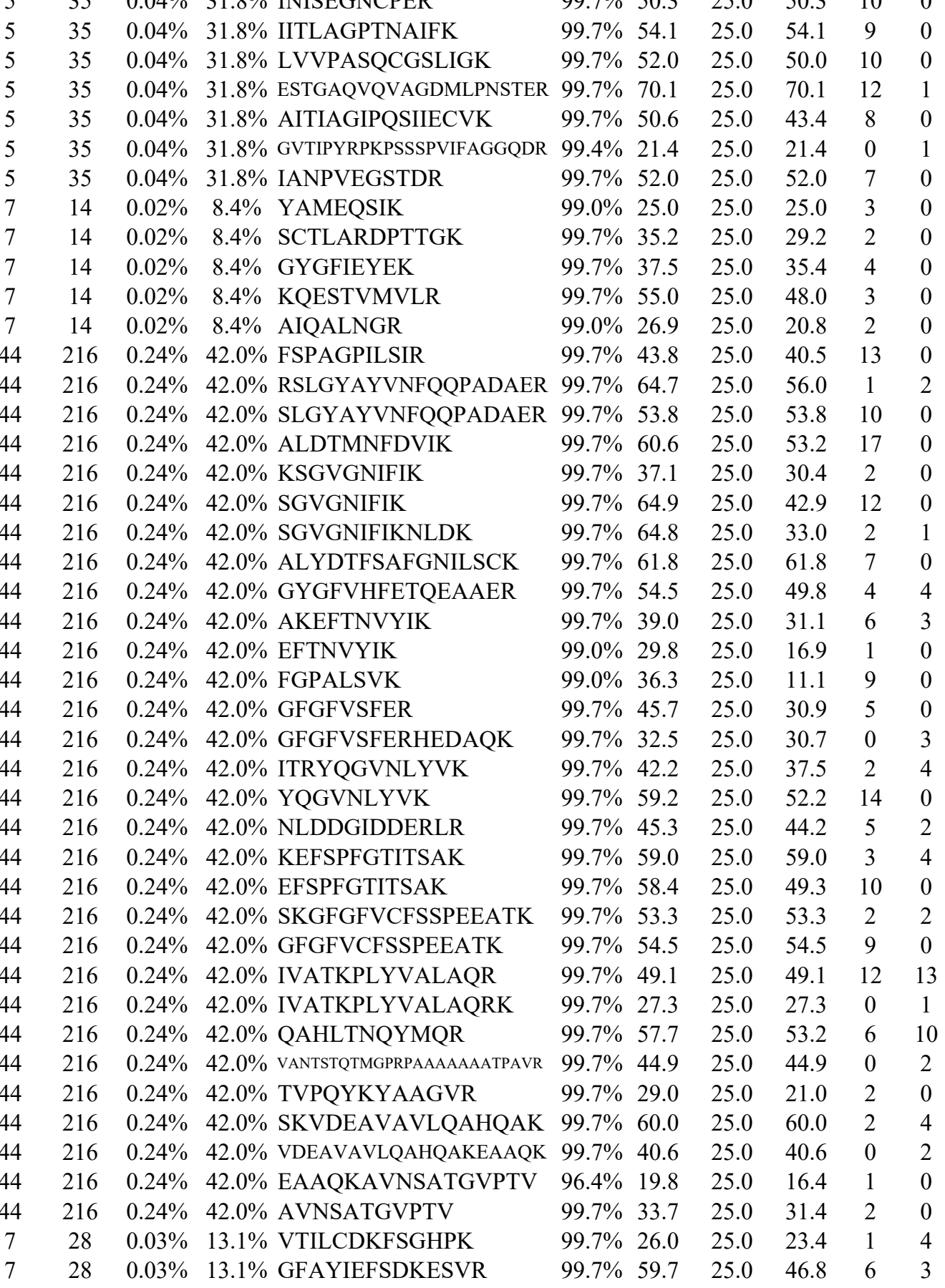

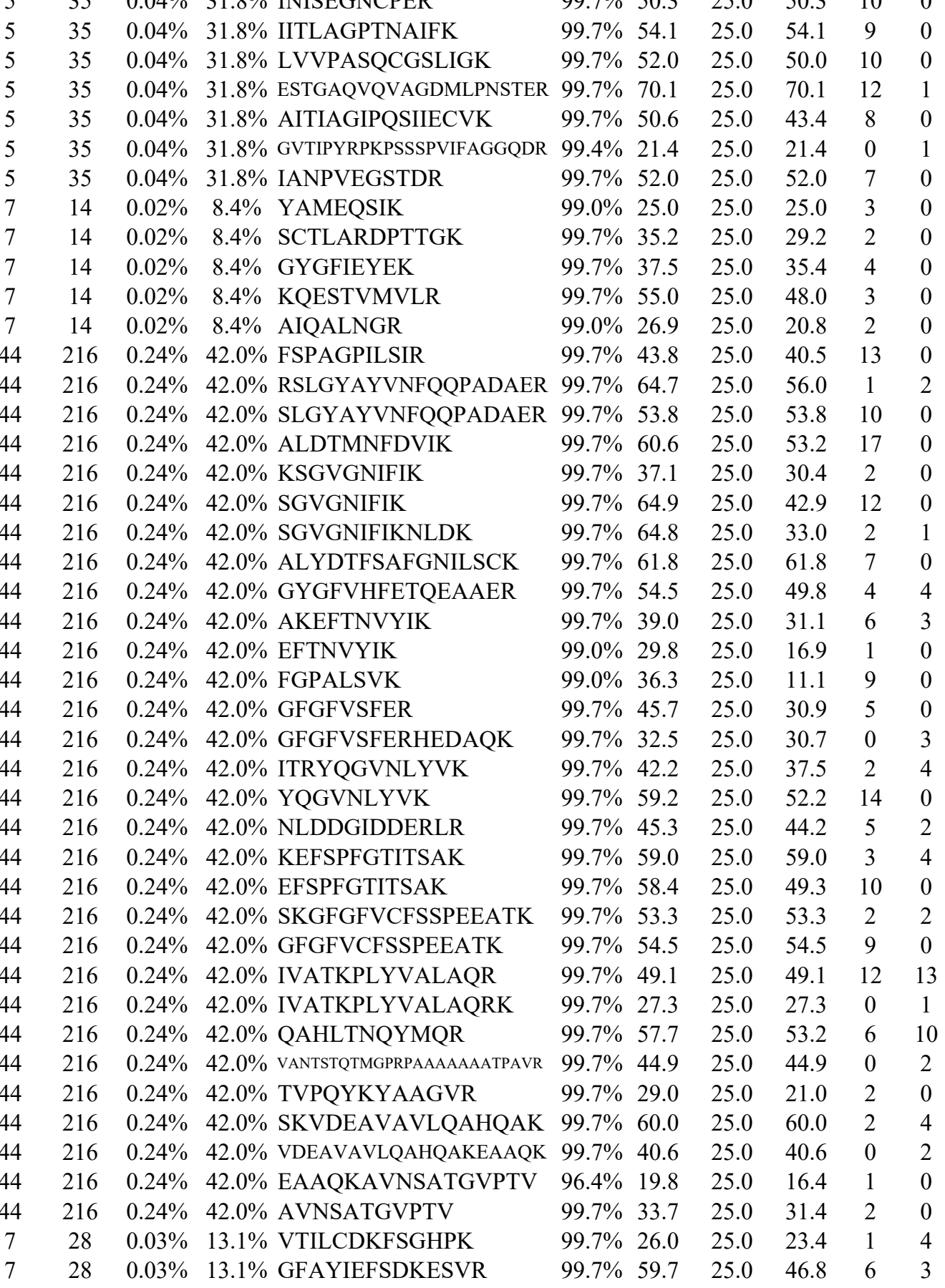

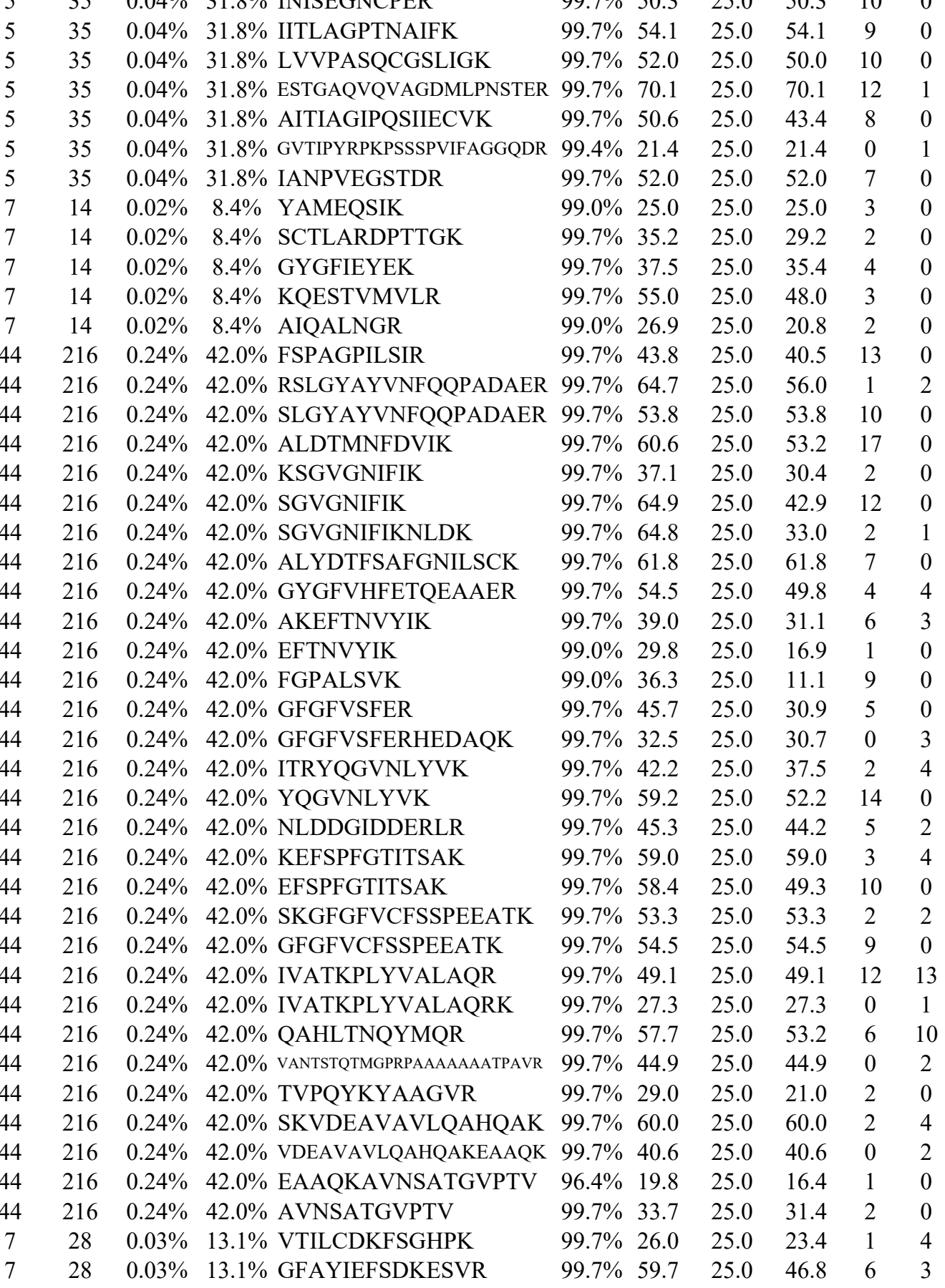

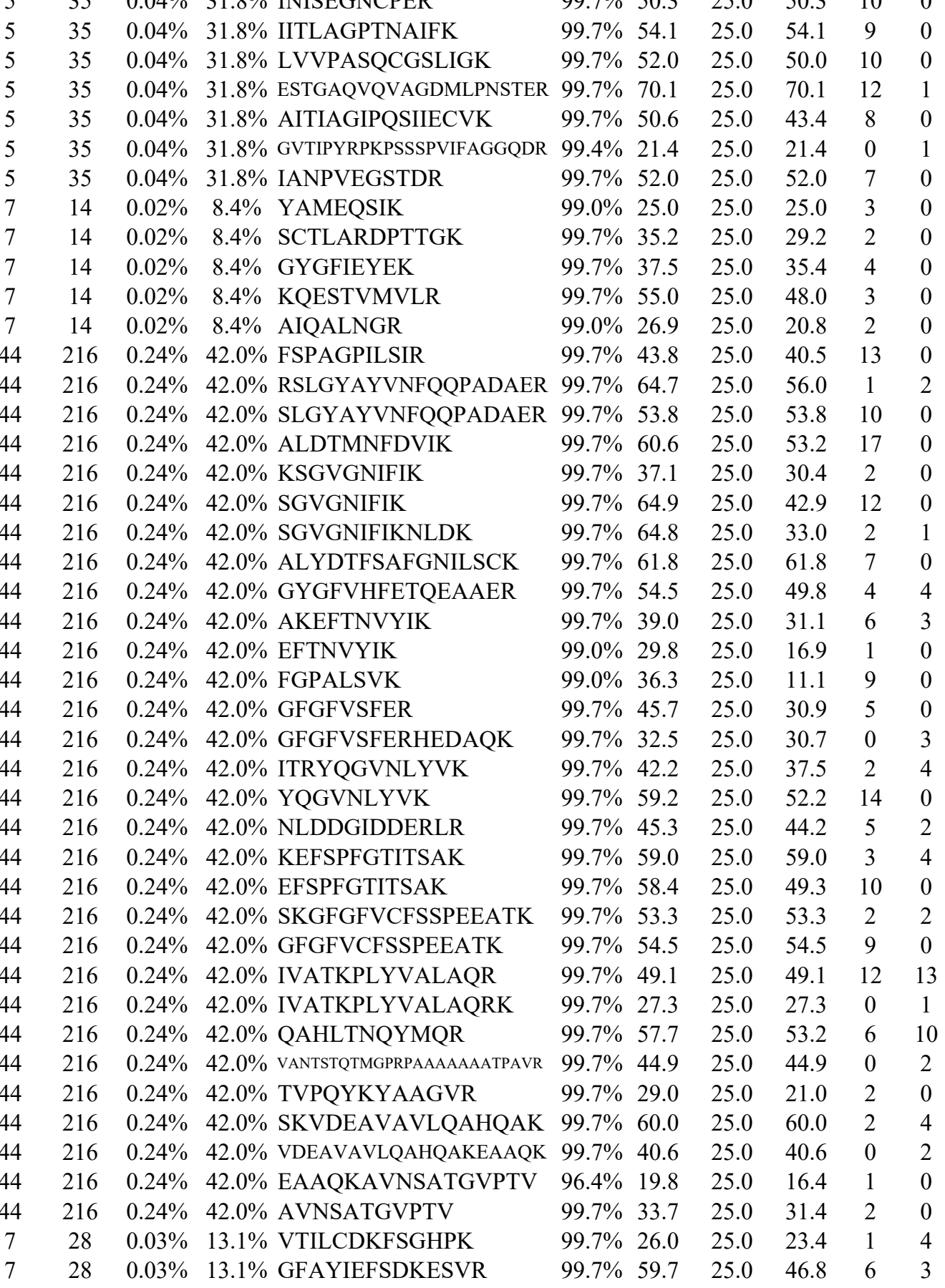

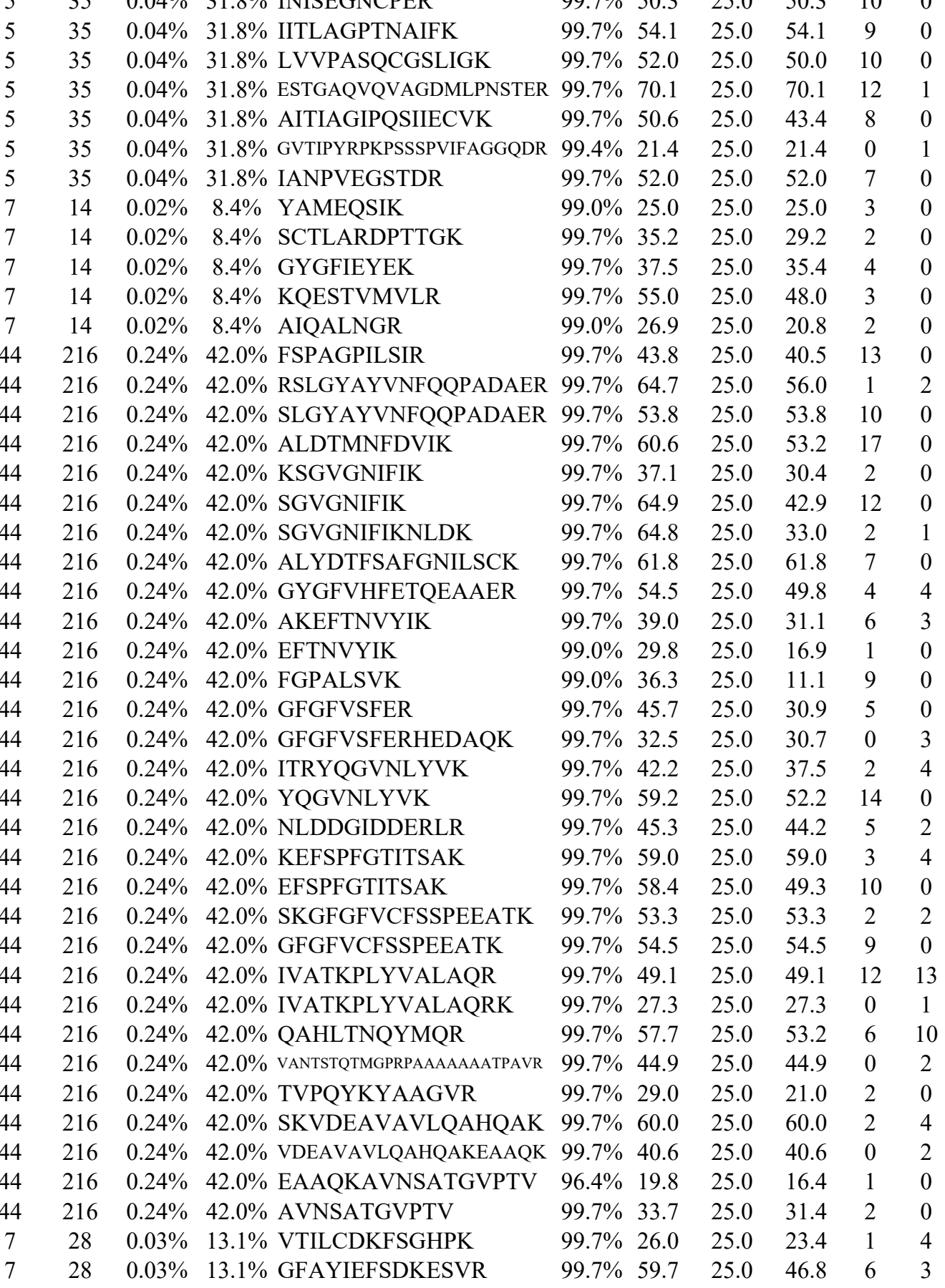

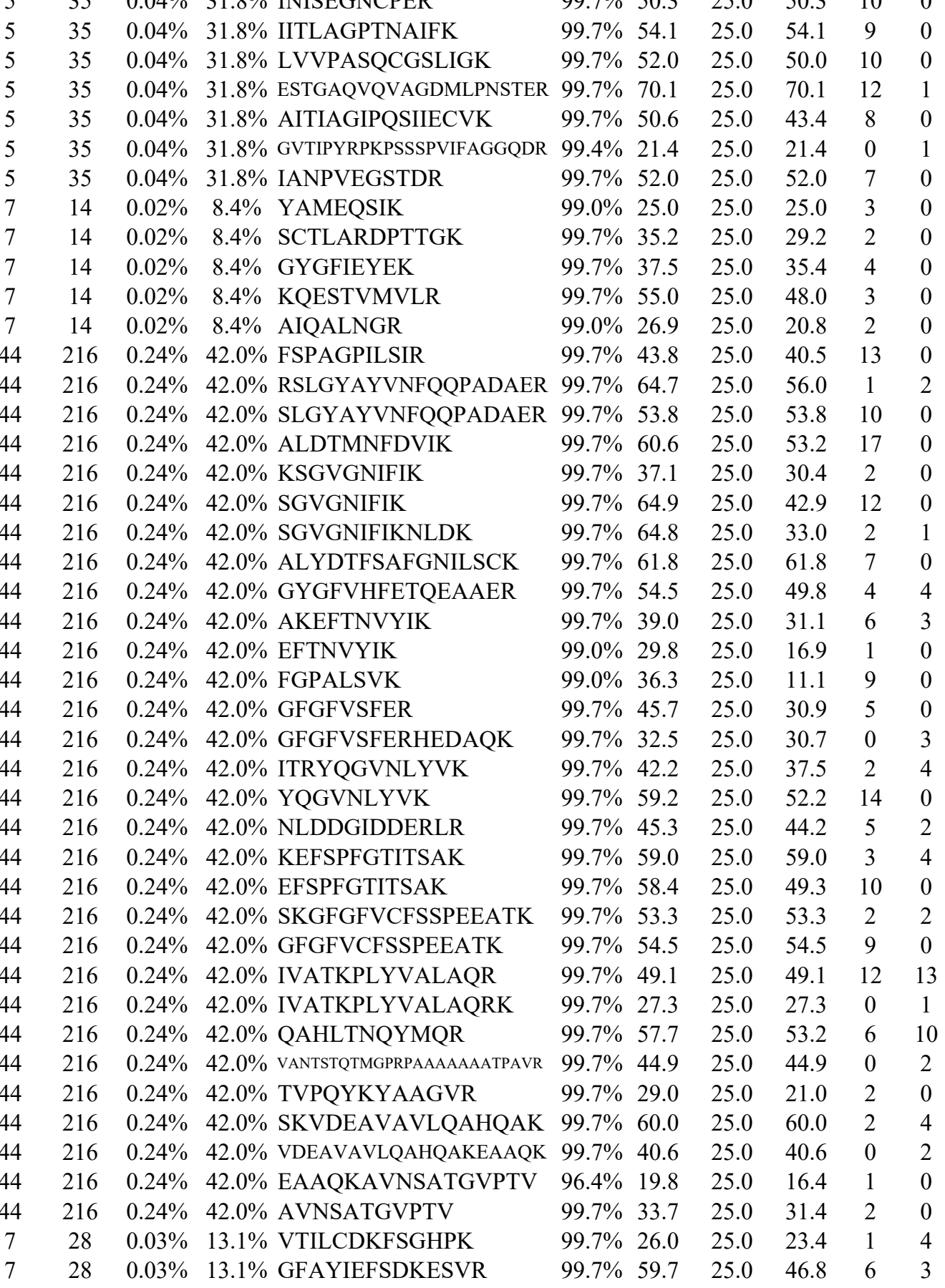

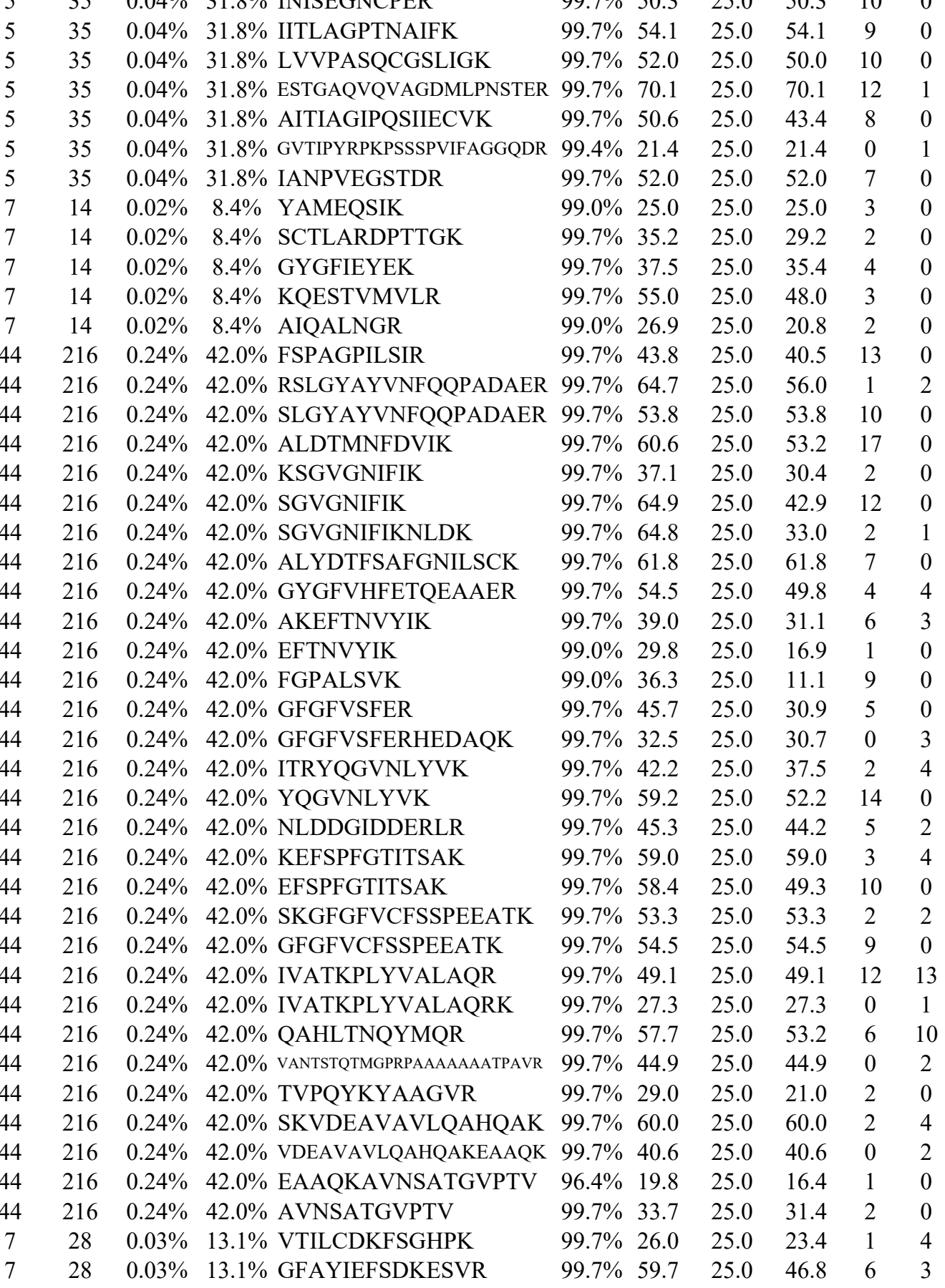

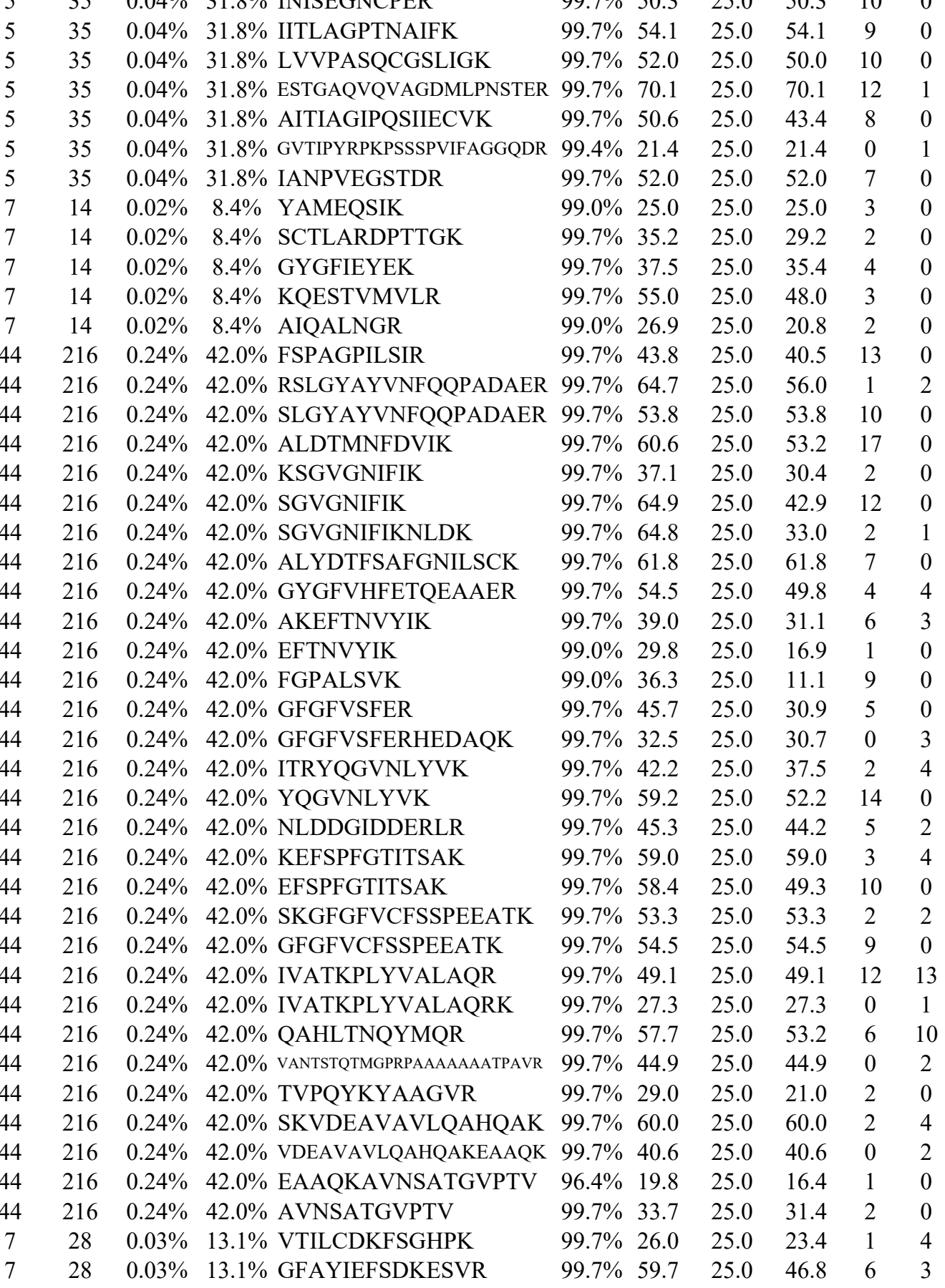

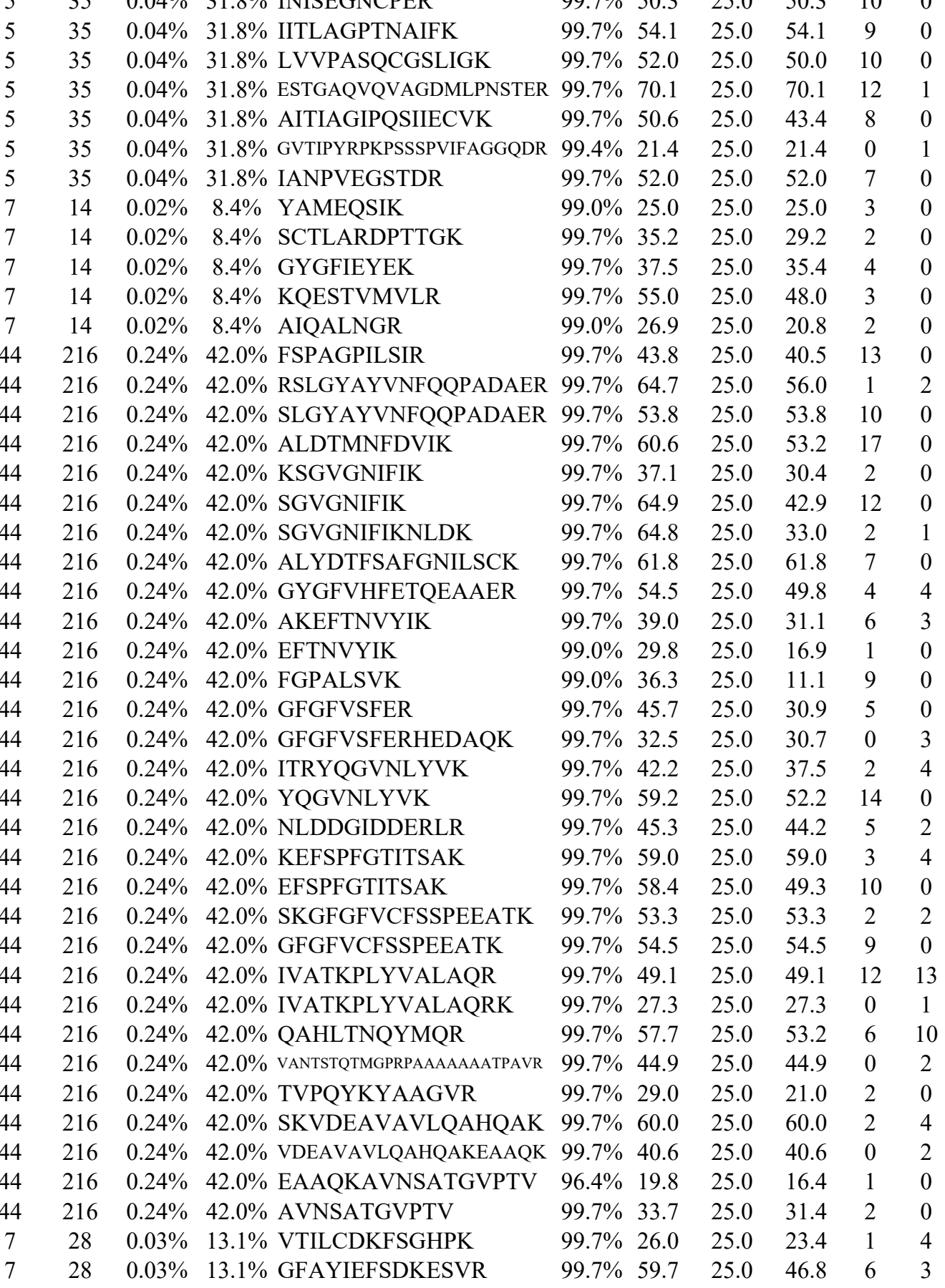

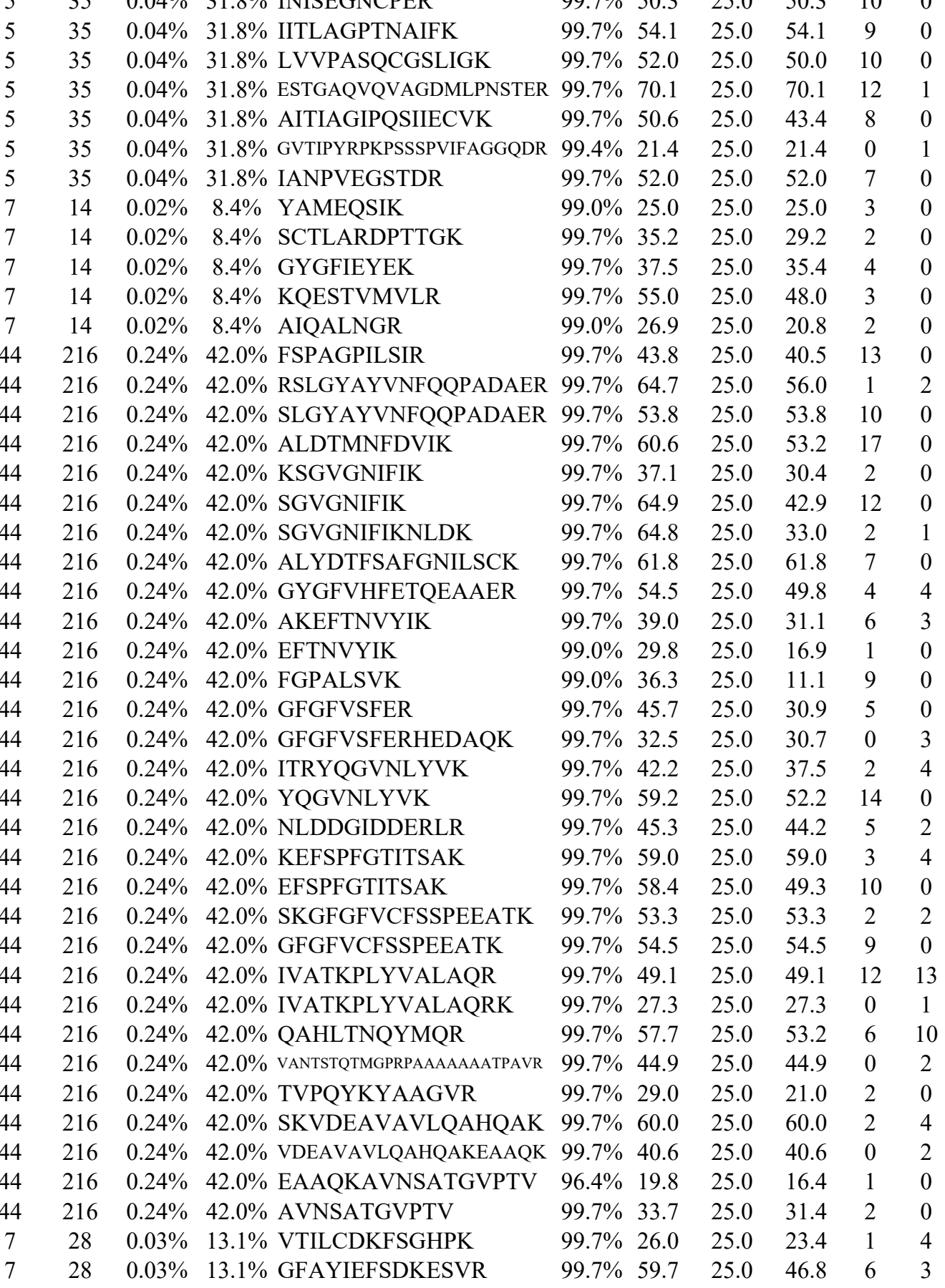

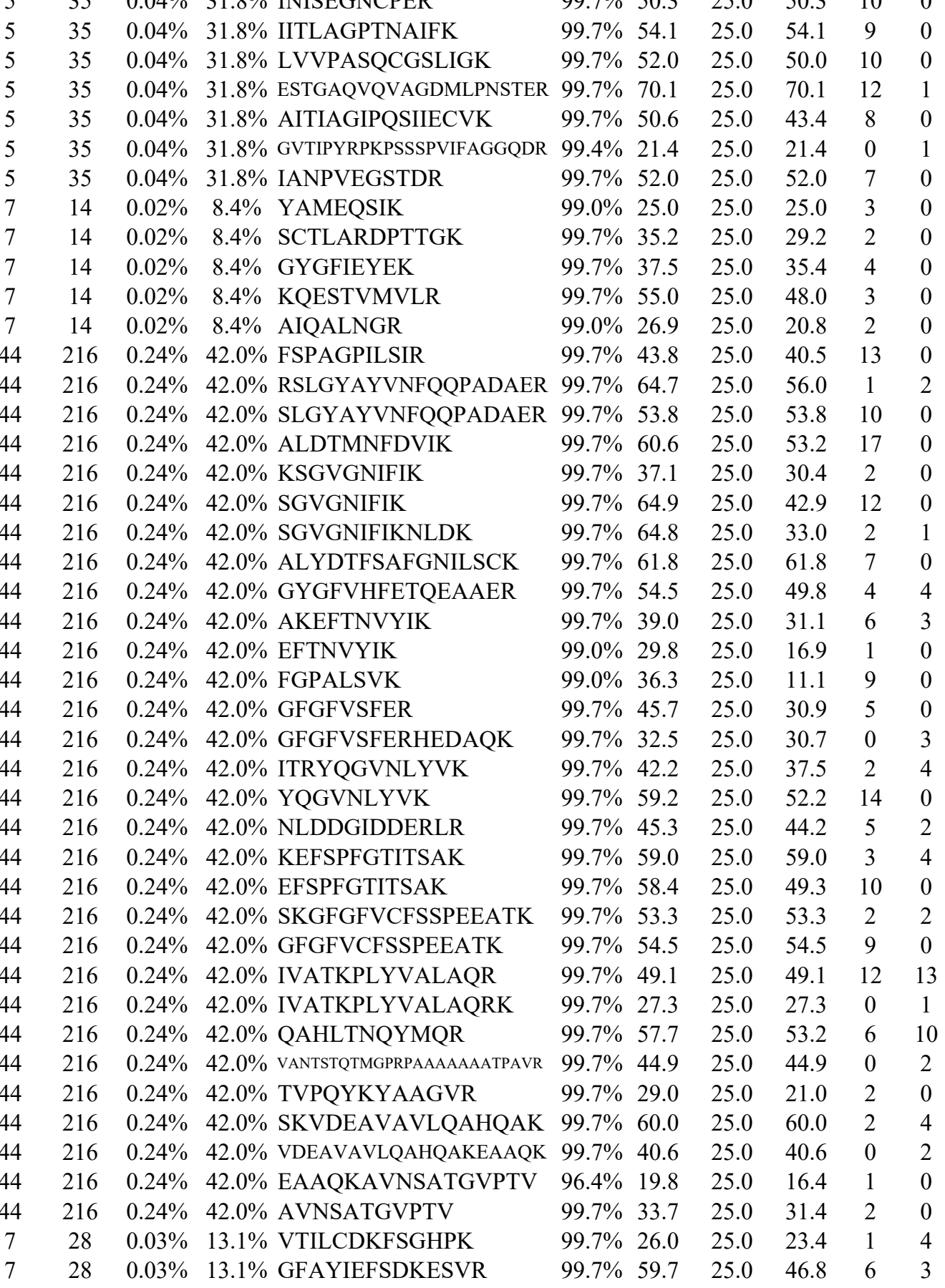

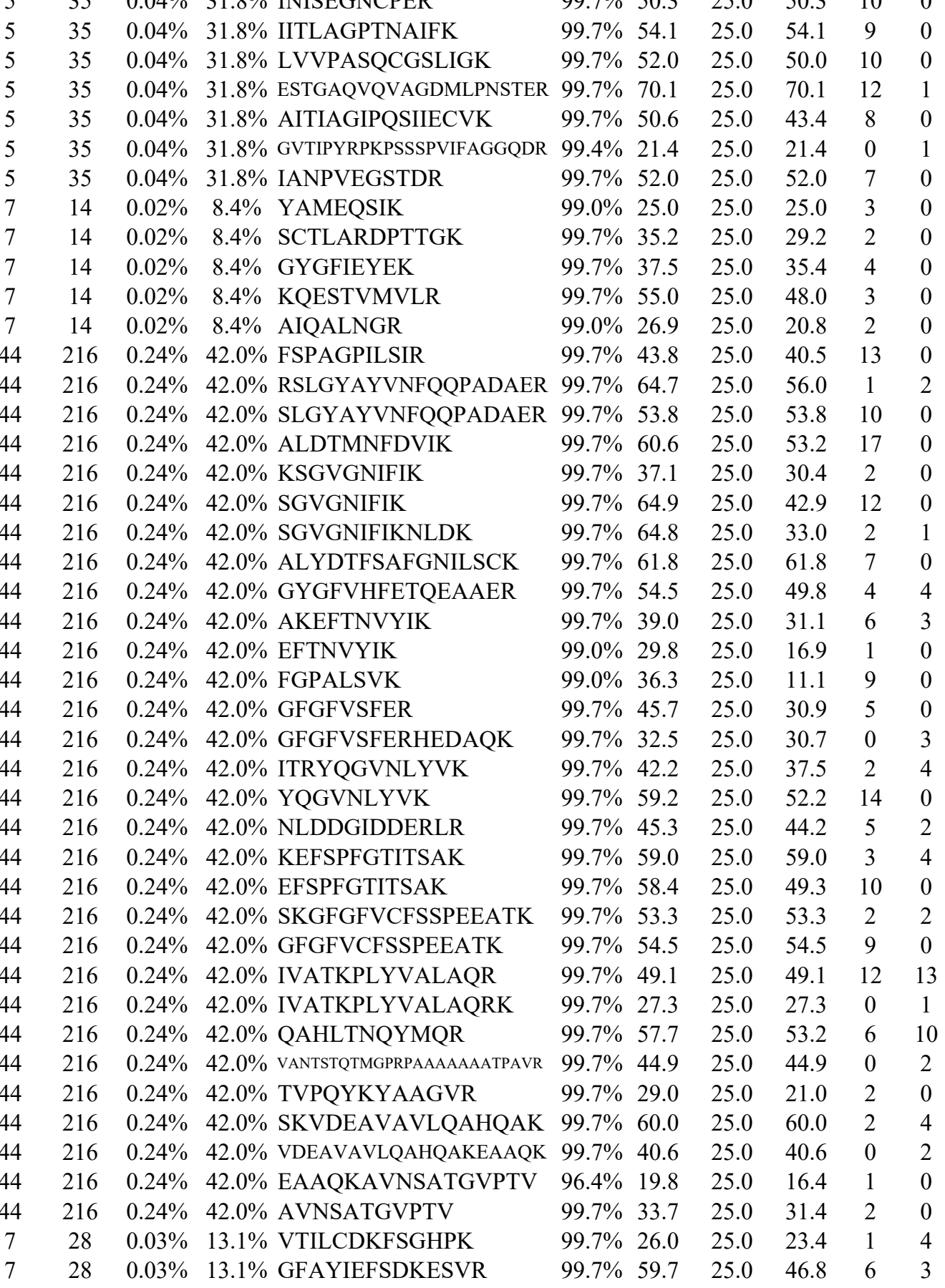

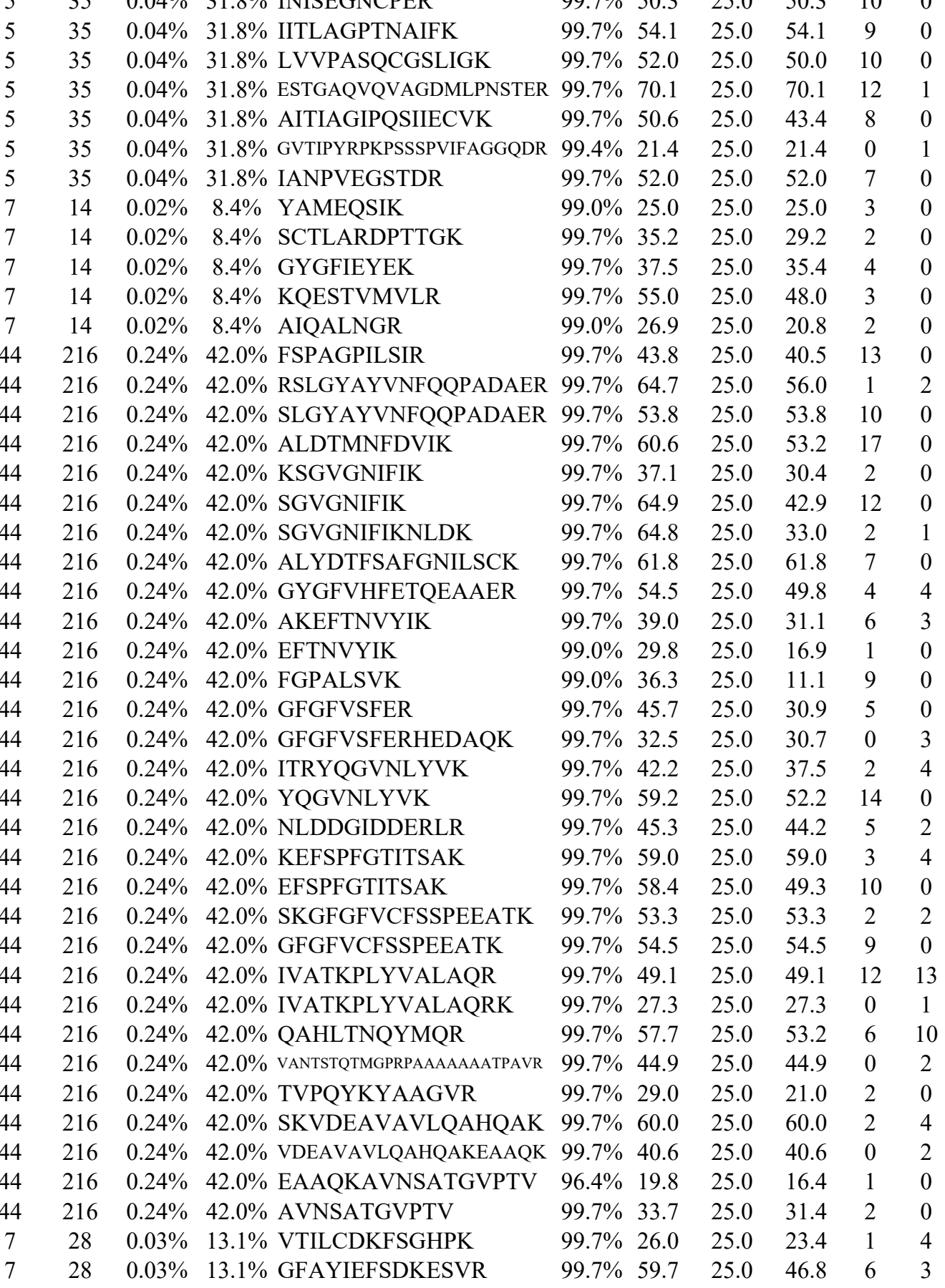

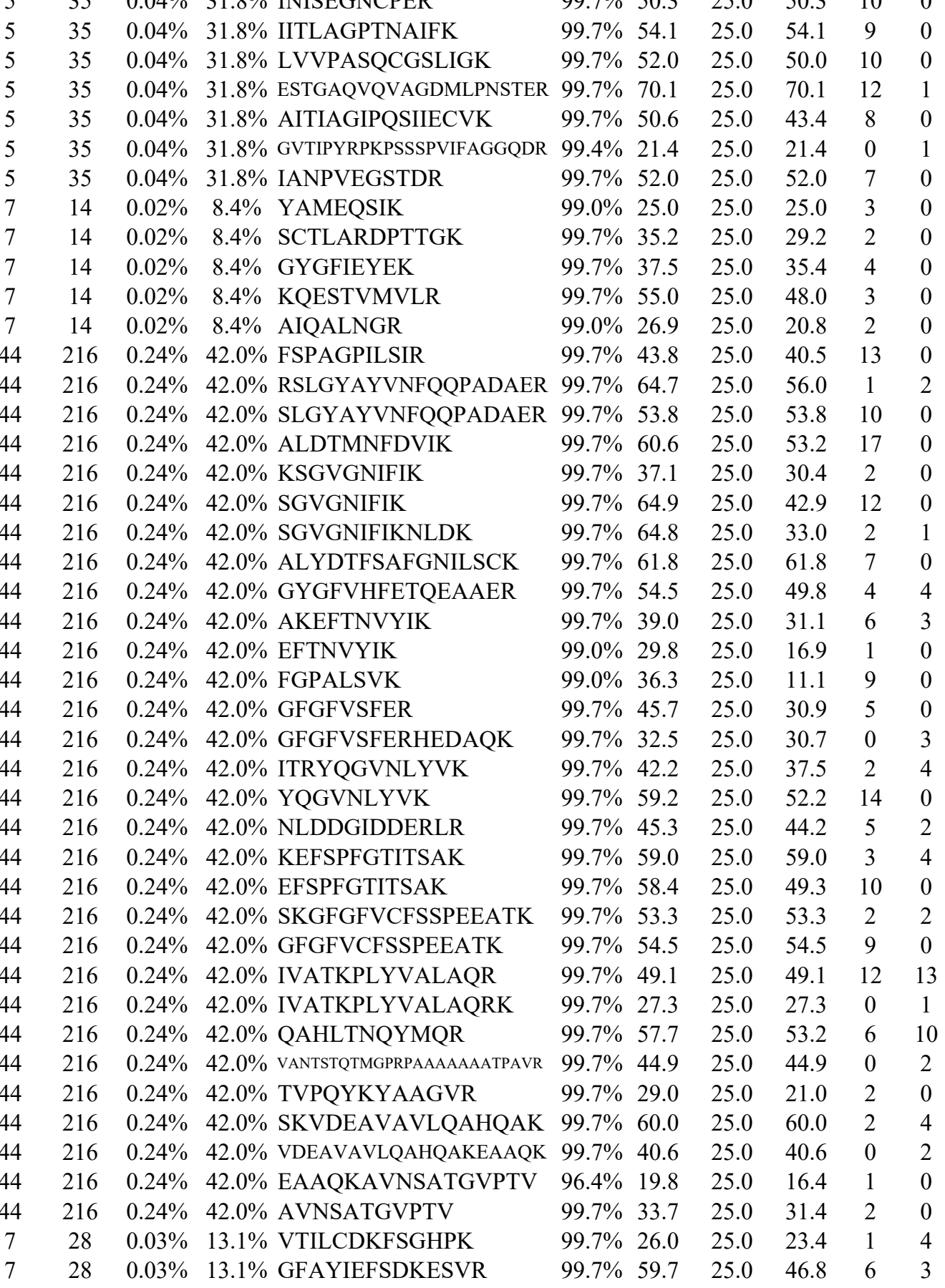

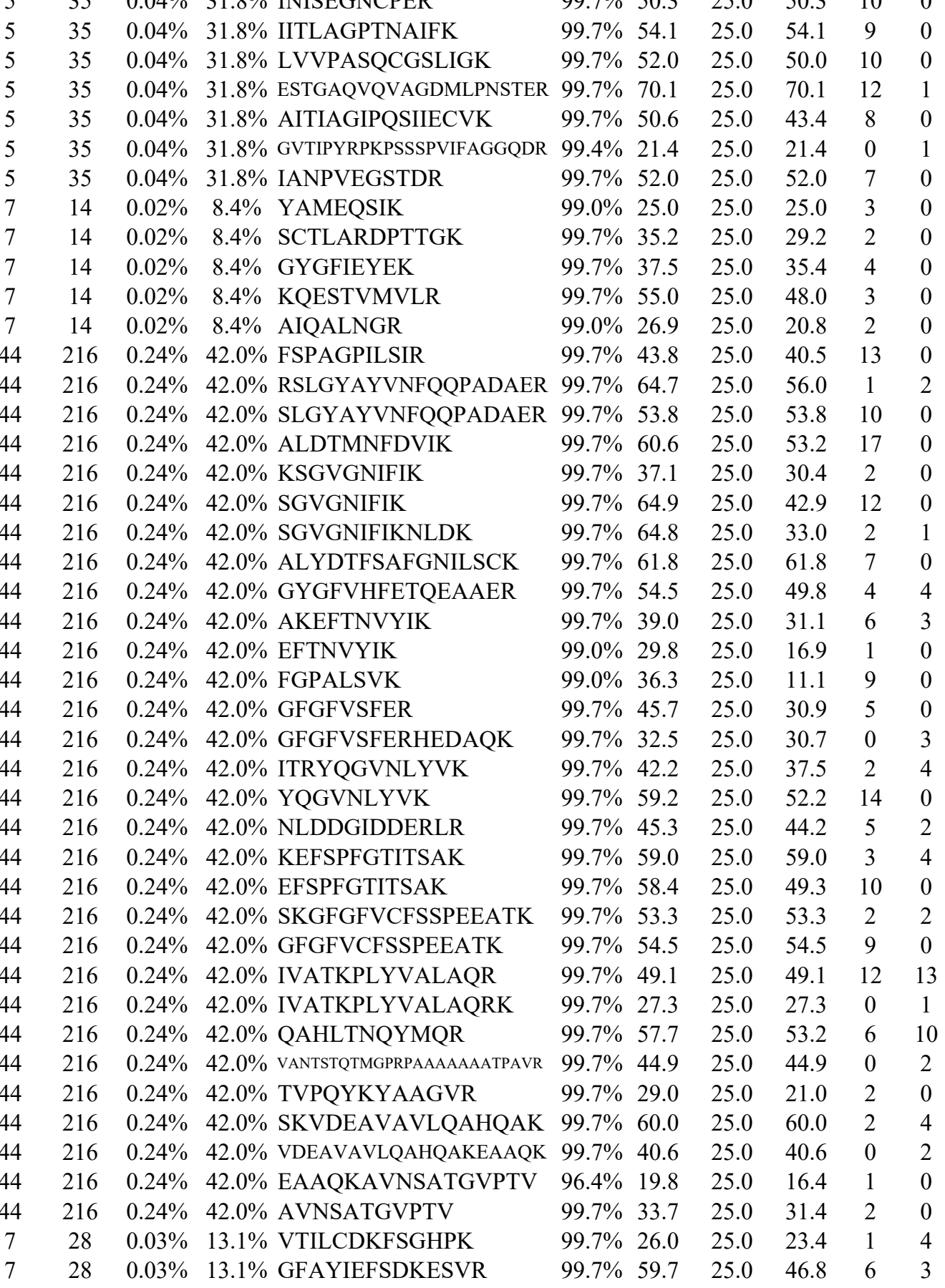

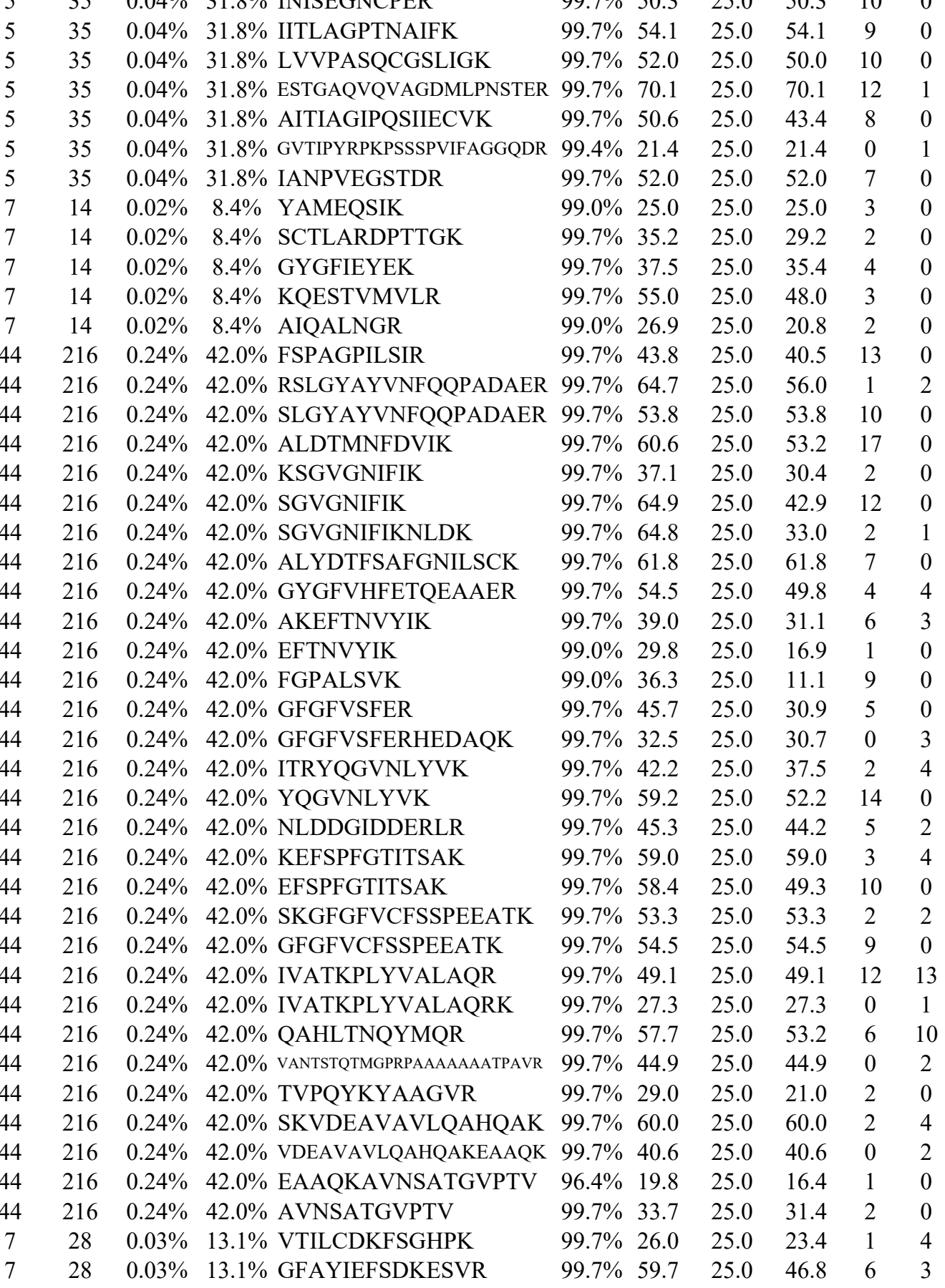

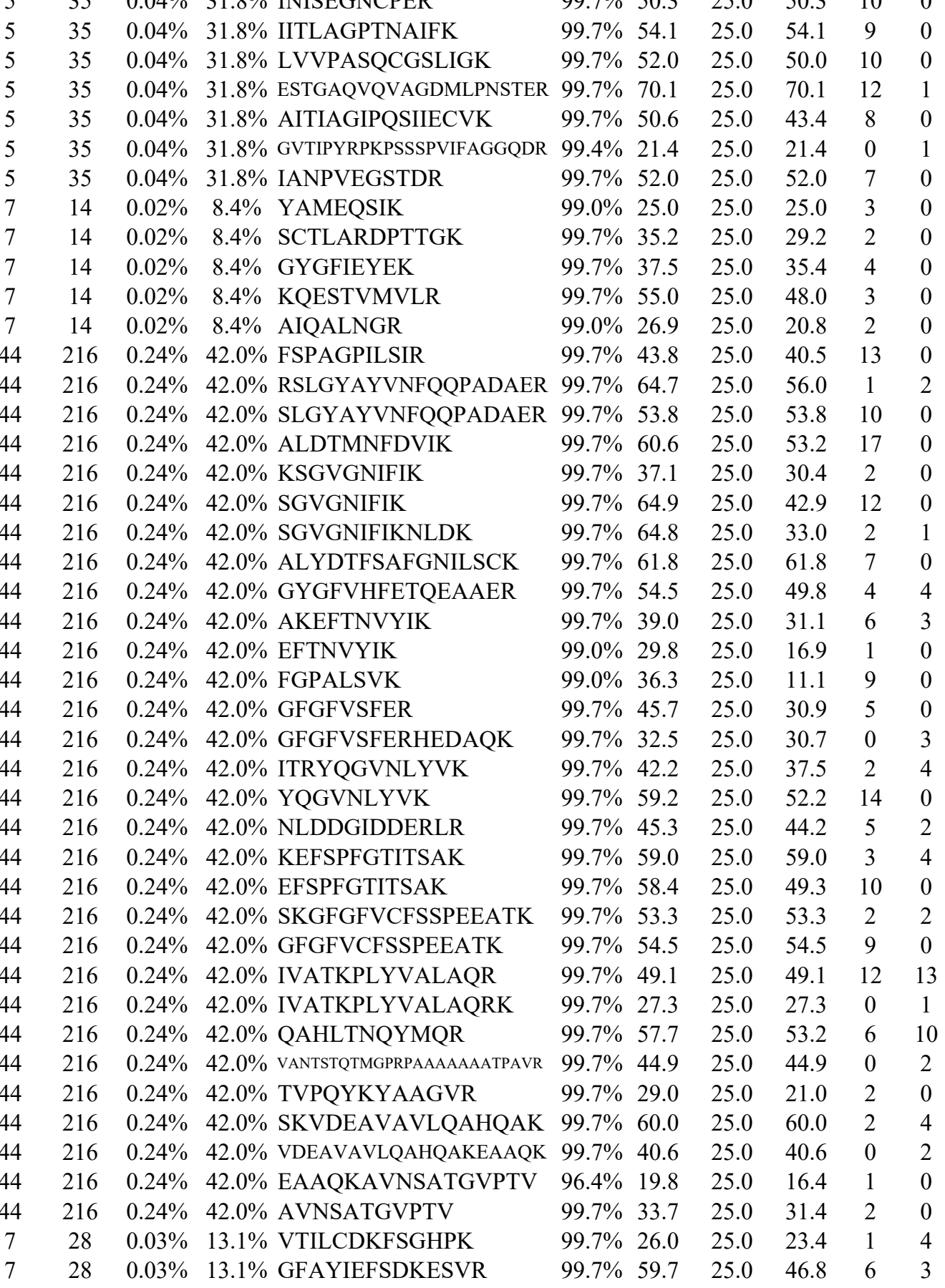

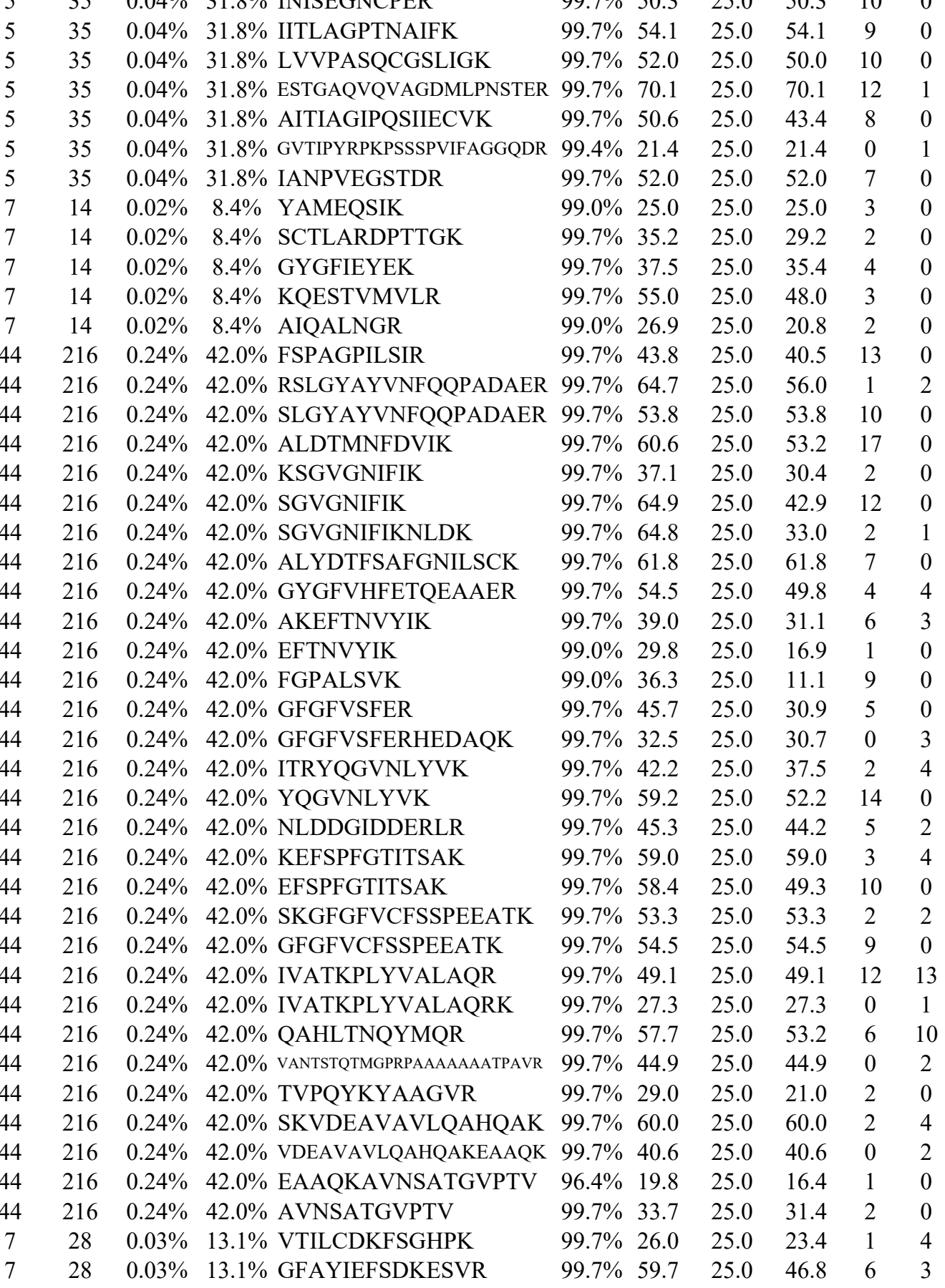

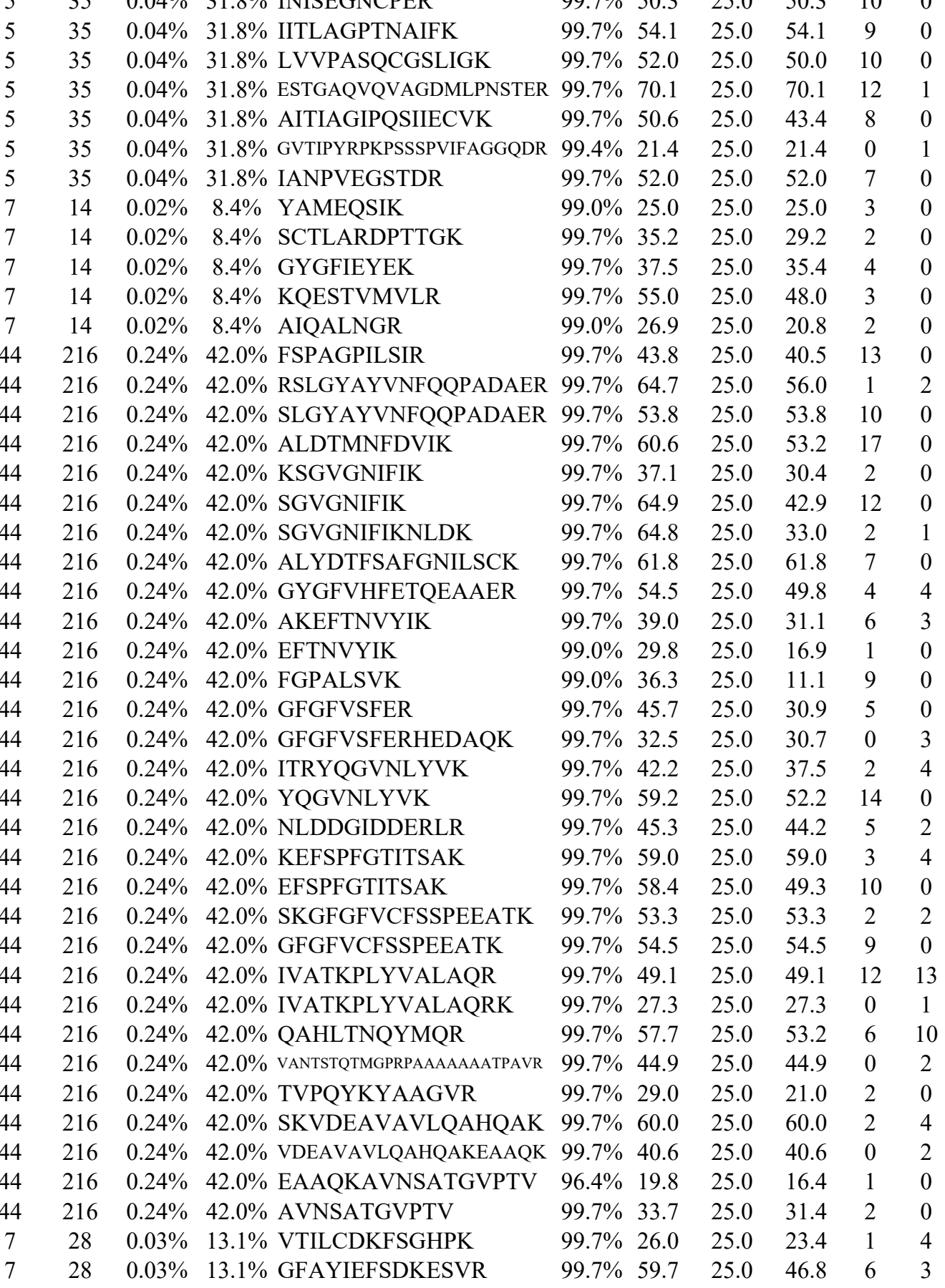

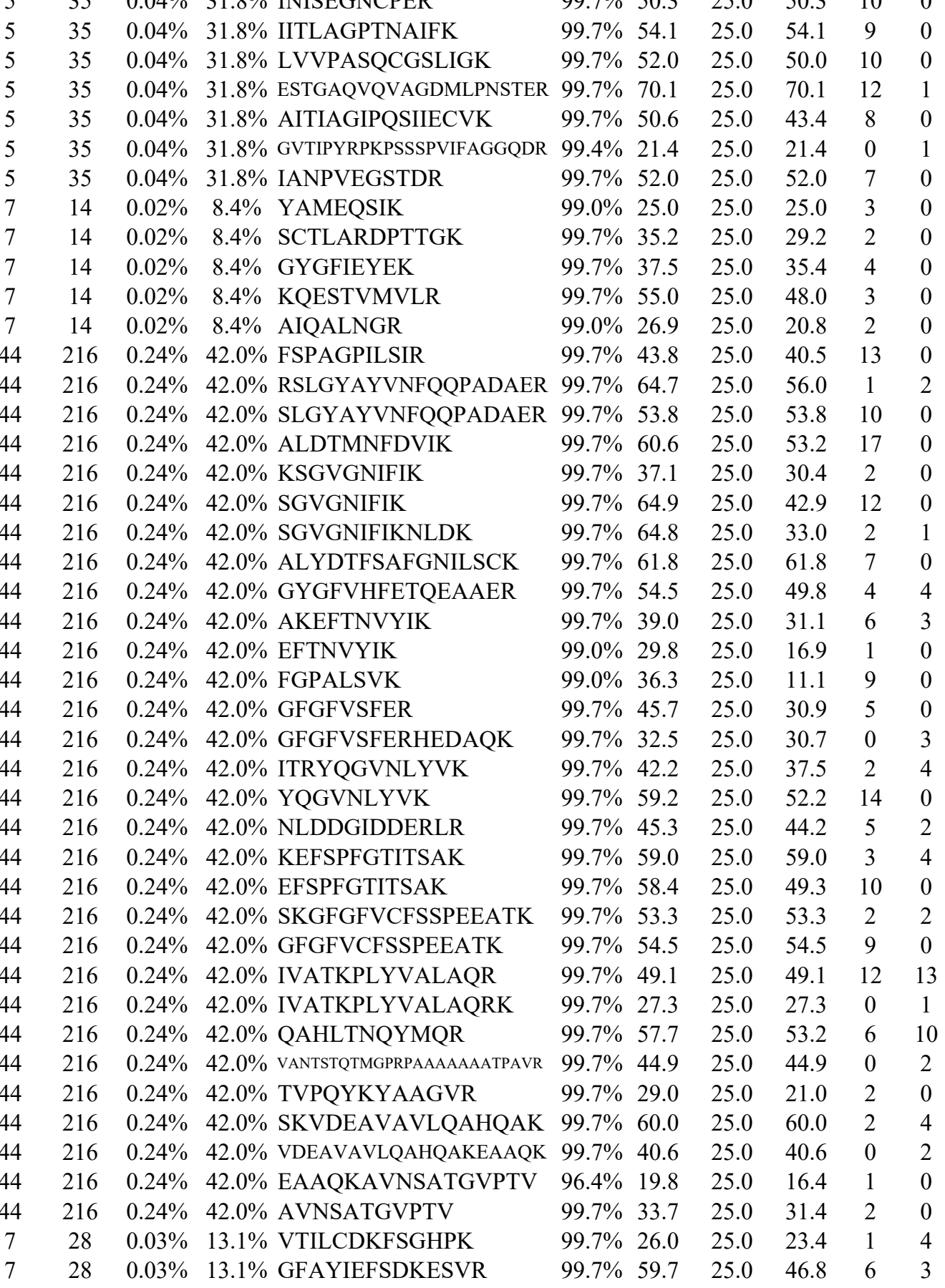

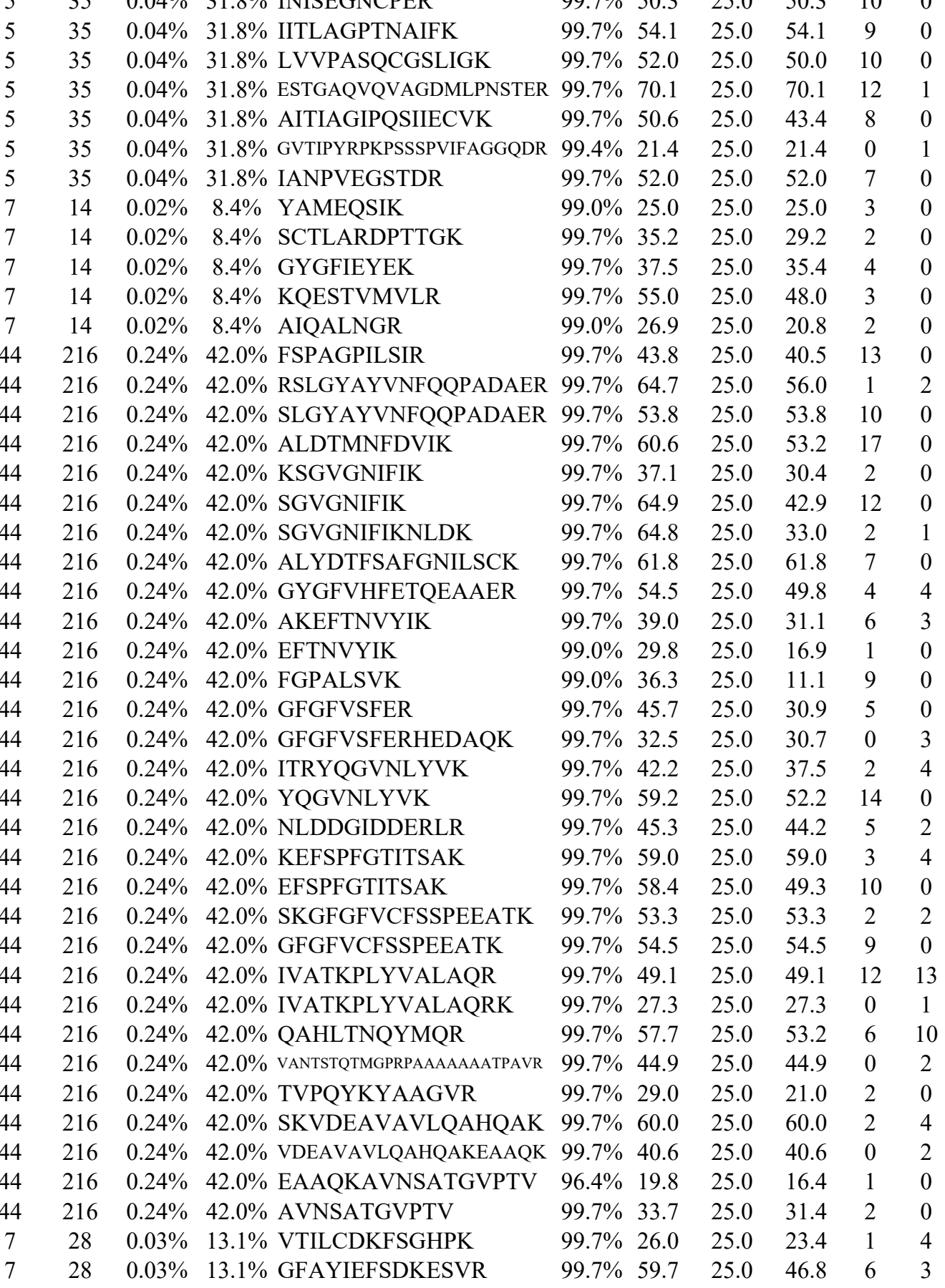

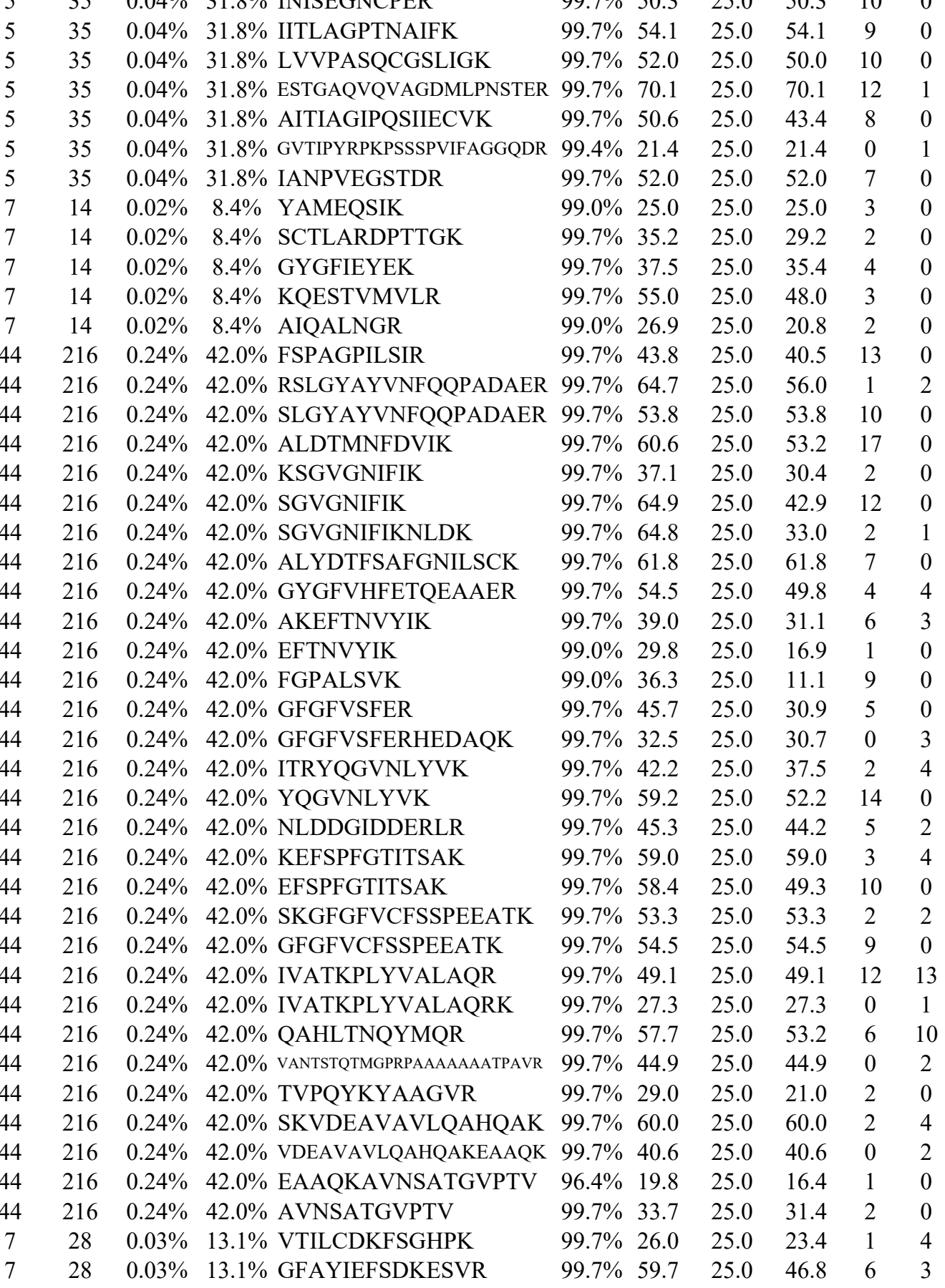

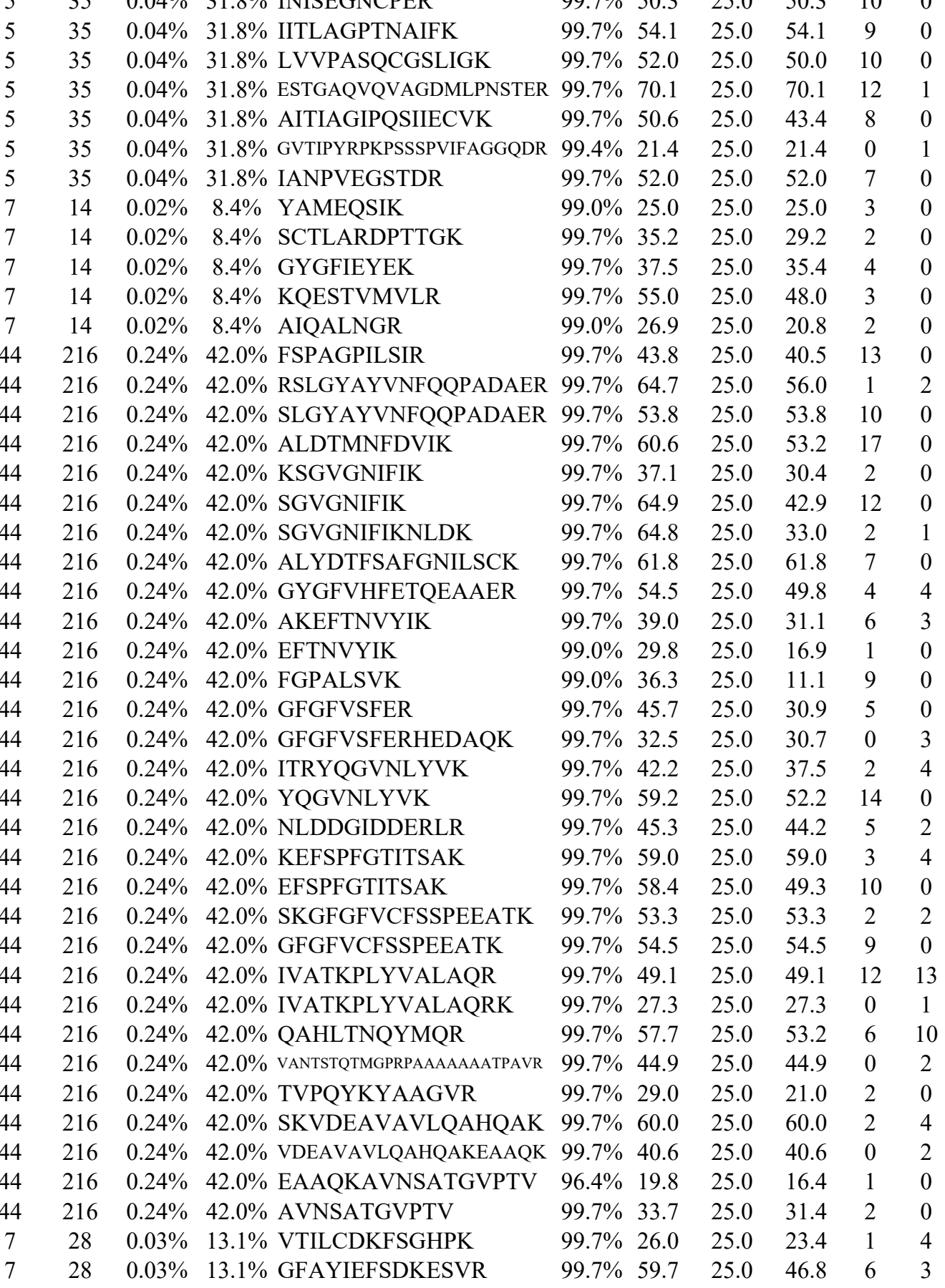

$49 \quad 0.05 \% \quad 28.7 \%$ QGANINEIR $0.05 \% \quad 28.7 \%$ IANPVEGSSGR

$\quad 0.04 \% \quad 31.8 \%$ INISEGNCPER

$0.04 \% \quad 31.8 \%$ IITLAGPTNAIFK

$0.04 \% \quad 31.8 \%$ ESTGAQVQVAGDMLPNST

$0.04 \% \quad 31.8 \%$ AITIAGIPQSIIECVK

$0.04 \% \quad 31.8 \%$ GVTIPYRPKPSSSPVIFAC

$\begin{array}{lll}0.04 \% & 31.8 \% & \text { IANPVEGSTDR } \\ 0.02 \% & 8.4 \% & \text { YAMEQSIK }\end{array}$

$0.02 \% \quad 8.4 \% \quad$ SCTLARDPTTGK

$0.02 \% \quad 8.4 \%$ GYGFIEYEK

$0.02 \% \quad 8.4 \%$ KQESTVMVLR

$0.02 \% \quad 8.4 \%$ AIQALNGR

$216 \quad 0.24 \% \quad 42.0 \%$ RSLGYAYVNFQQPADAER

$\begin{array}{lll}216 & 0.24 \% & 42.0 \% \\ 216 & 0.24 \% & 42.0 \%\end{array}$

$216 \quad 0.24 \% \quad 42.0 \%$ ALDTMNFDVIK

$216 \quad 0.24 \% \quad 42.0 \%$ KSGVGNIFIK

$216 \quad 0.24 \% \quad 42.0 \%$ SGVGNIFIK

$44 \quad 216 \quad 0.24 \% \quad 42.0 \%$ SGVGNIFIKNLDK

$44 \quad 216 \quad 0.24 \% \quad 42.0 \%$ ALYDTFSAFGNILSCK

$44 \quad 216 \quad 0.24 \% \quad 42.0 \%$ GYGFVHFETQEAAER

$44 \quad 216 \quad 0.24 \% \quad 42.0 \%$ AKEFTNVYIK

$44 \quad 216 \quad 0.24 \% \quad 42.0 \%$ EFTNVYIK

$44 \quad 216 \quad 0.24 \% \quad 42.0 \%$ FGPALSVK

$44 \quad 216 \quad 0.24 \% \quad 42.0 \%$ GFGFVSFER

$44 \quad 216 \quad 0.24 \% \quad 42.0 \%$ GFGFVSFERHEDAQK

$44 \quad 216 \quad 0.24 \% \quad 42.0 \%$ ITRYQGVNLYVK

$44 \quad 216 \quad 0.24 \% \quad 42.0 \%$ YQGVNLYVK

$44 \quad 216 \quad 0.24 \% \quad 42.0 \%$ NLDDGIDDERLR

$44 \quad 216 \quad 0.24 \% \quad 42.0 \%$ KEFSPFGTITSAK

$44 \quad 216 \quad 0.24 \% \quad 42.0 \%$ EFSPFGTITSAK

$44 \quad 216 \quad 0.24 \% \quad 42.0 \%$ SKGFGFVCFSSPEEATK

$44 \quad 216 \quad 0.24 \% \quad 42.0 \%$ GFGFVCFSSPEEATK

$44 \quad 216 \quad 0.24 \% \quad 42.0 \%$ IVATKPLYVALAQR

$44 \quad 216 \quad 0.24 \% \quad 42.0 \%$ IVATKPLYVALAQRK
$35 \quad 0.04 \% \quad 31.8 \%$ EVGSIIGK
$99.7 \% \quad 49.1$

$99.7 \% \quad 64.8$

$99.0 \% \quad 29.3$

$99.7 \% \quad 50.3$

$99.7 \% \quad 54.1$

$99.7 \% \quad 52.0$

$99.7 \% 70.1$

$99.7 \% \quad 50.6$

$99.4 \% \quad 21.4$

$99.7 \% \quad 52.0$

$99.0 \% \quad 25.0$

$99.7 \% \quad 35.2$

$99.7 \% \quad 37.5$

$99.7 \% \quad 55.0$

$99.0 \% \quad 26.9$

$99.7 \% \quad 43.8$

$99.7 \% \quad 64.7$
39

$\begin{array}{ll}.0 & 19.5 \\ 25.0 & 50.3\end{array}$

$0 \quad 50.3$

$5.0 \quad 54$

$\begin{array}{ll}0 & 50.0\end{array}$

$\begin{array}{ll}25.0 & 70.1\end{array}$

$\begin{array}{ll}25.0 & 43.4\end{array}$

$\begin{array}{ll}0 & 21.4\end{array}$

52.0

$\begin{array}{ll}25.0 & 25.0\end{array}$

$5.0 \quad 40.5$

$\begin{array}{ll}5.0 & 53.2\end{array}$

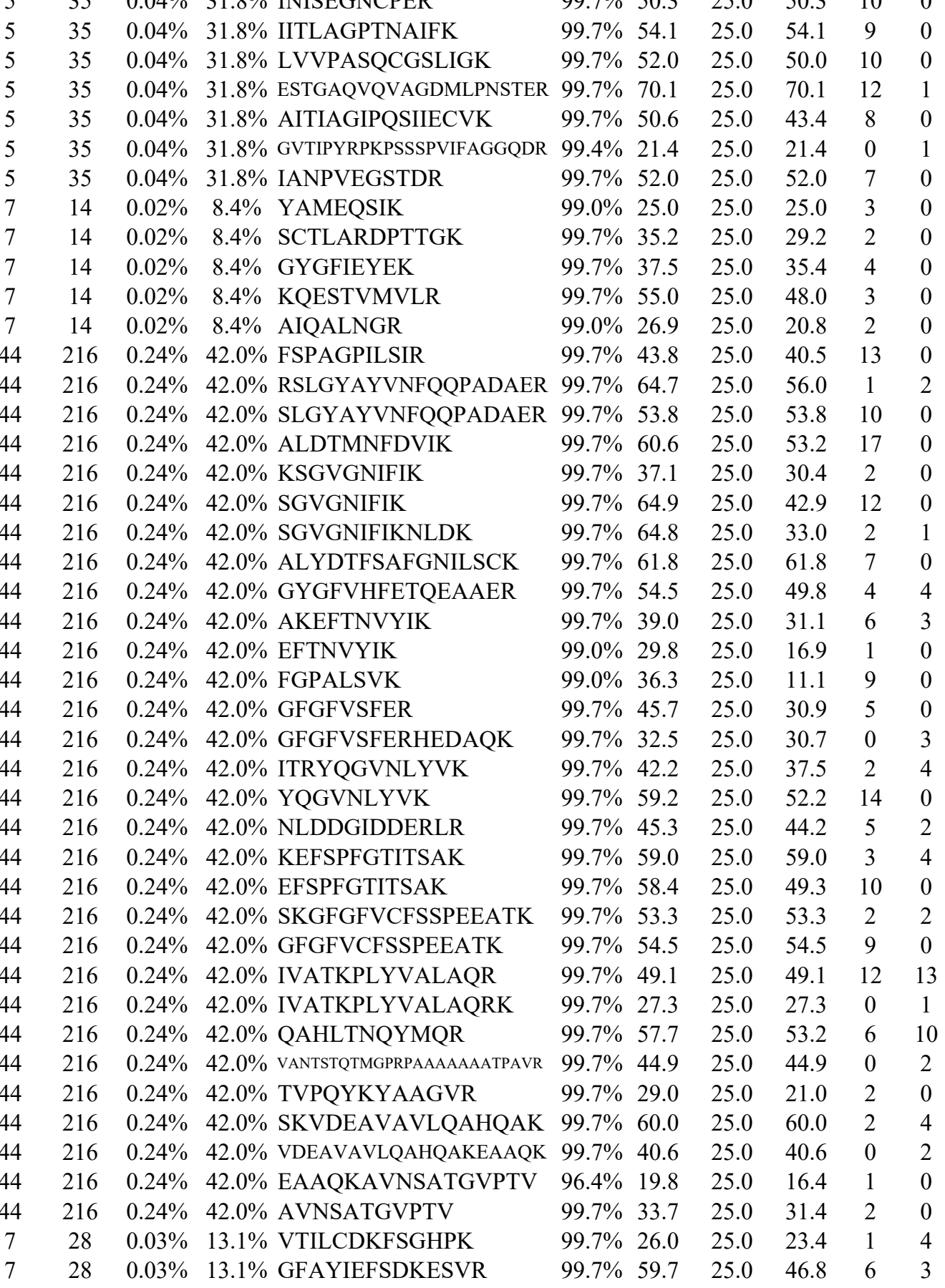

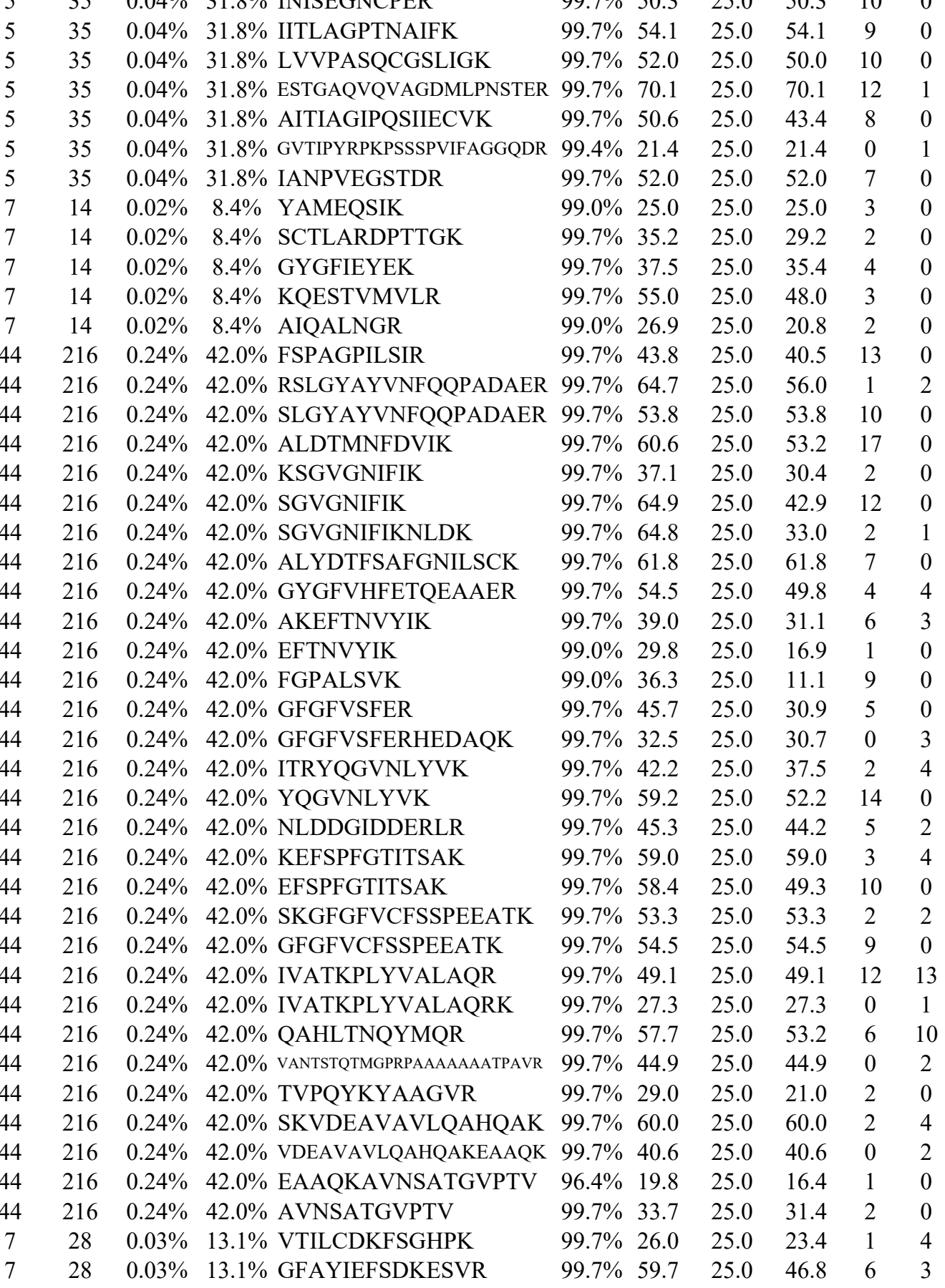

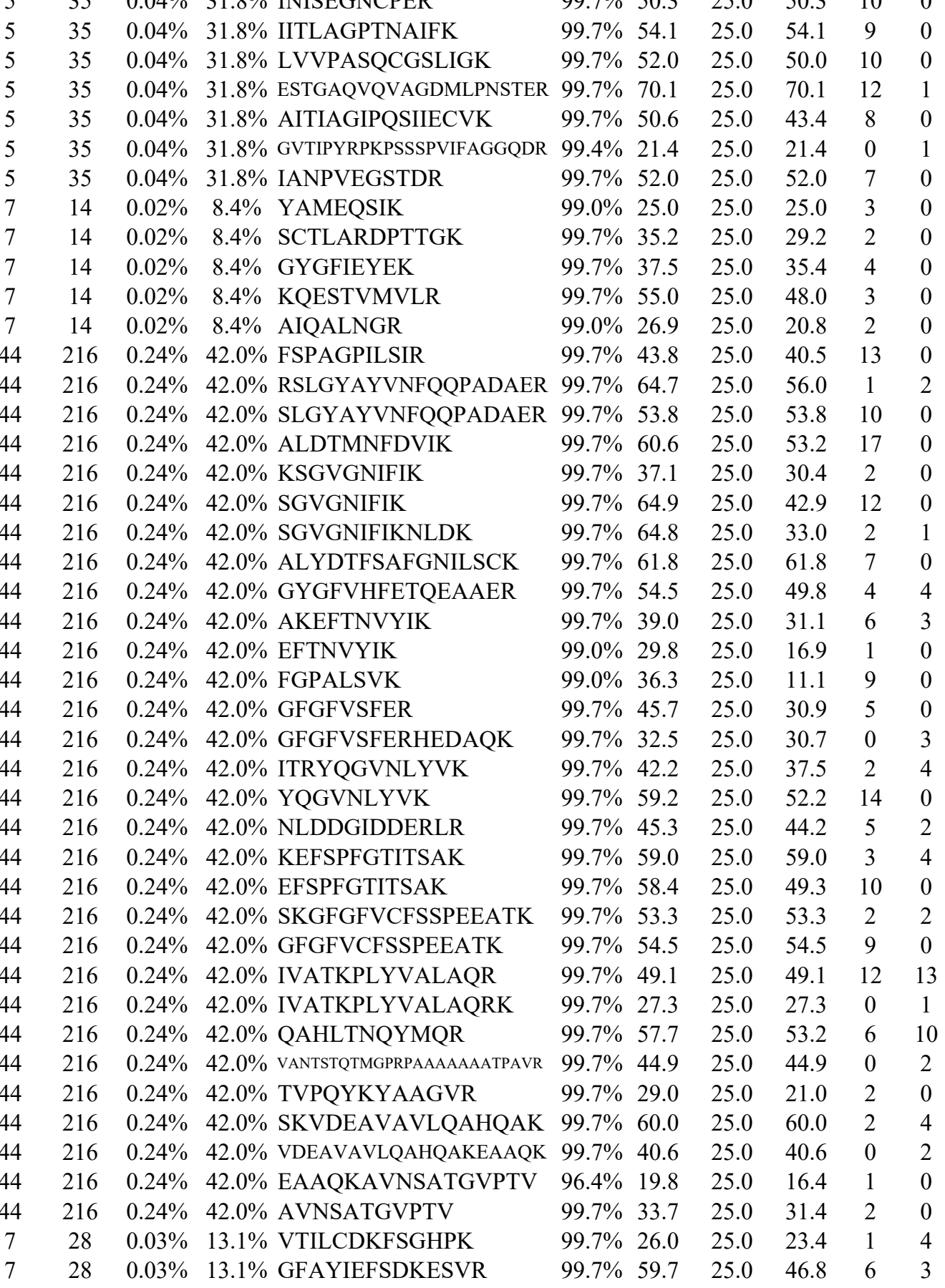

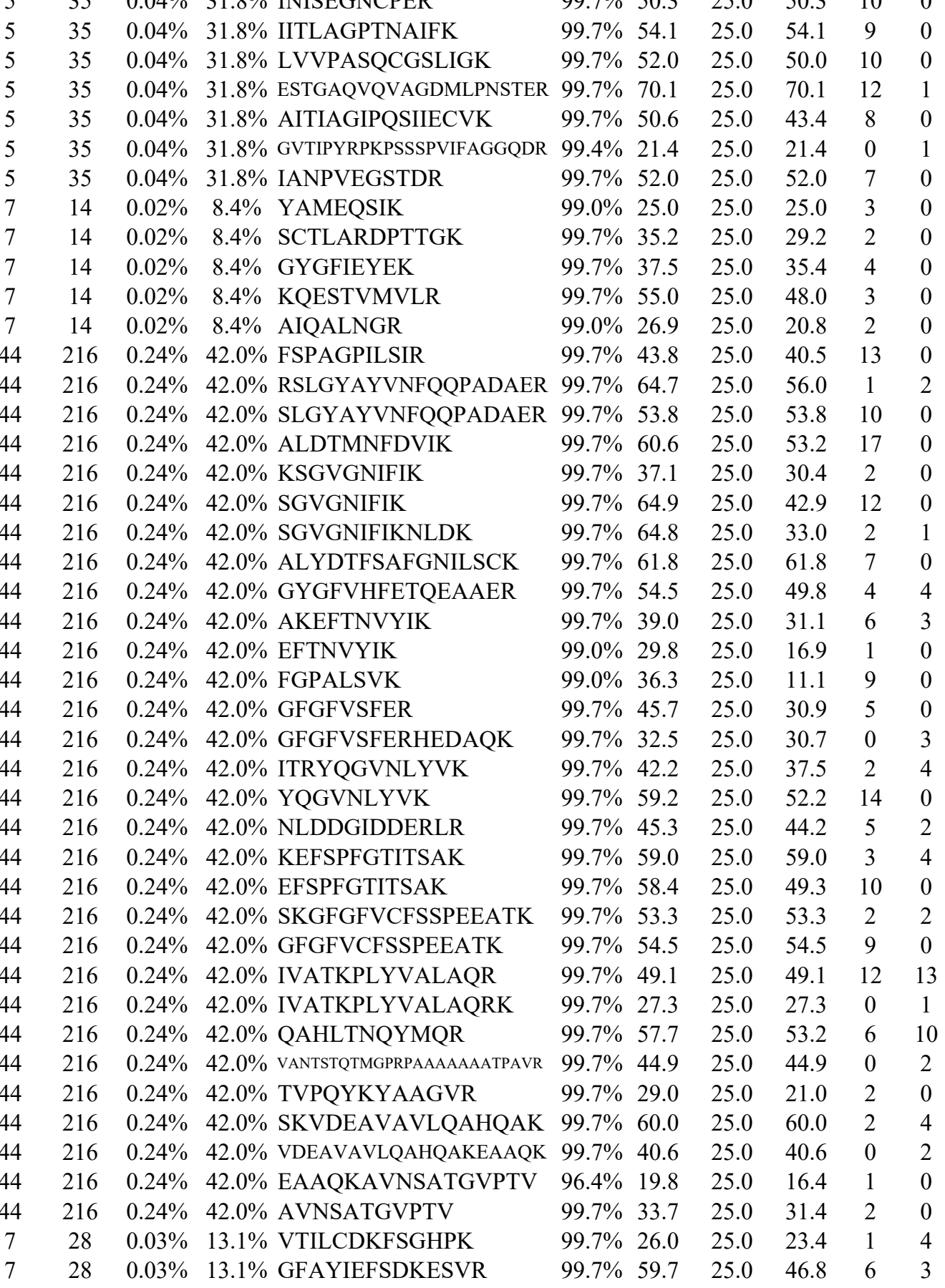

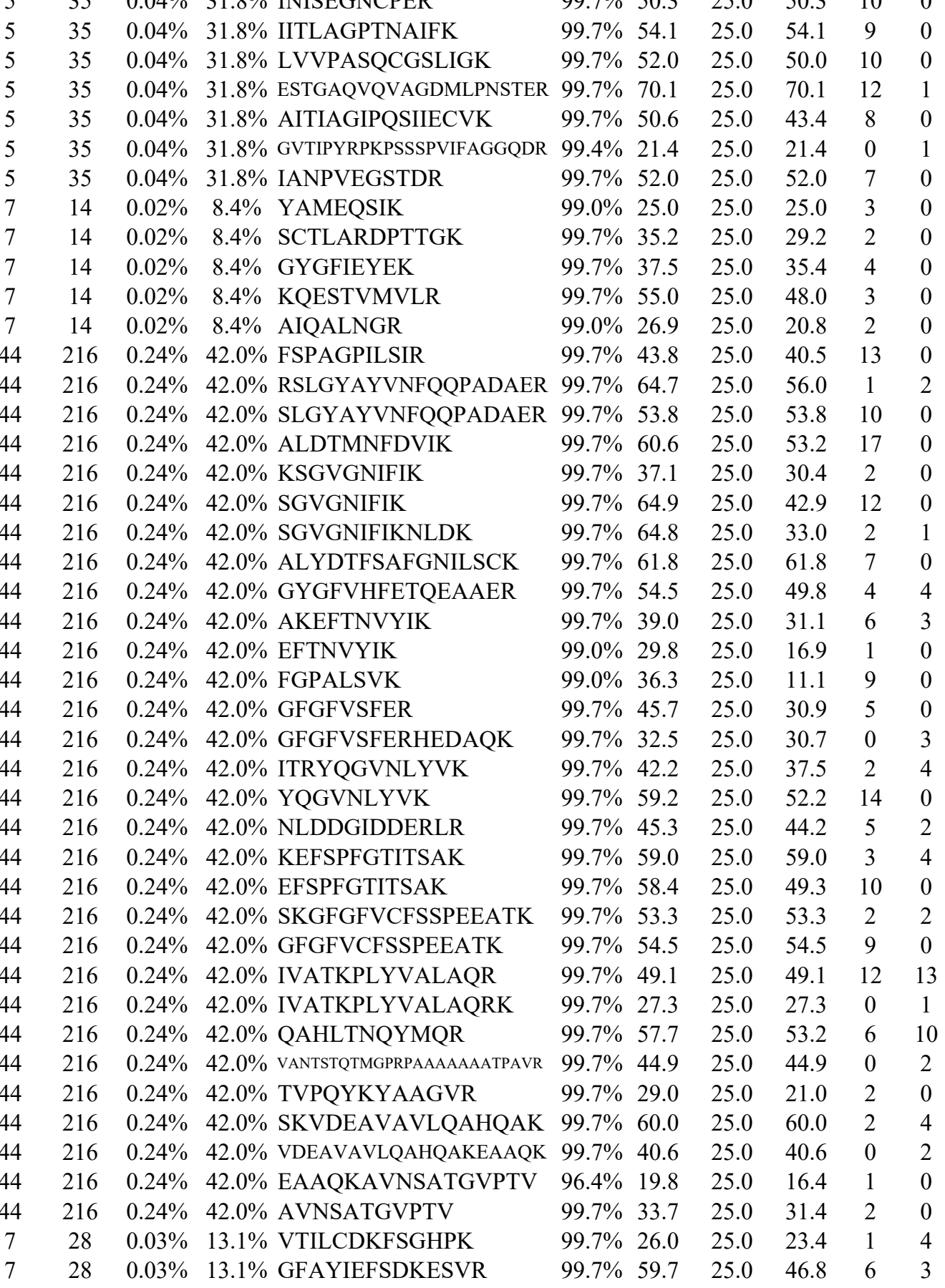

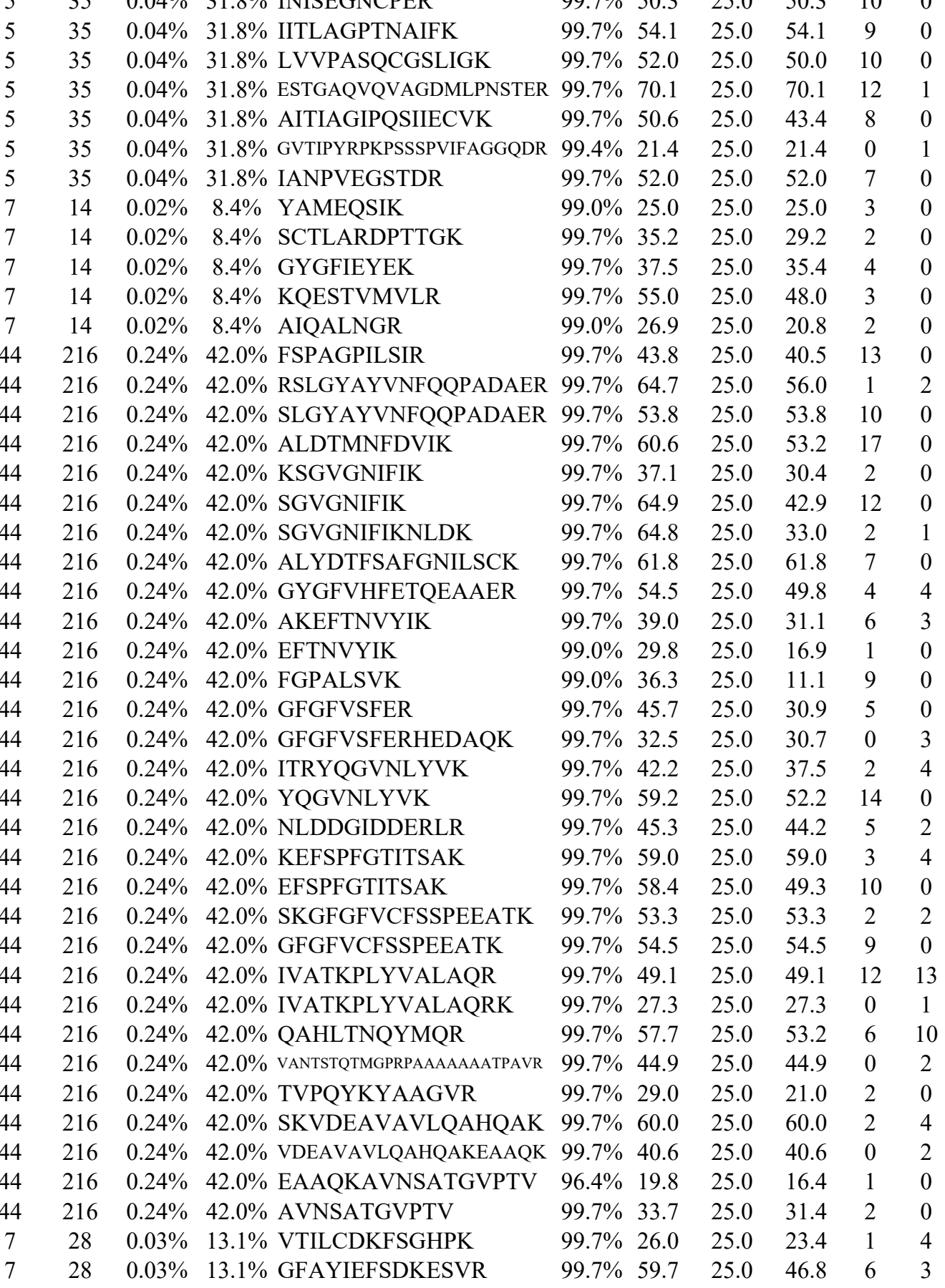

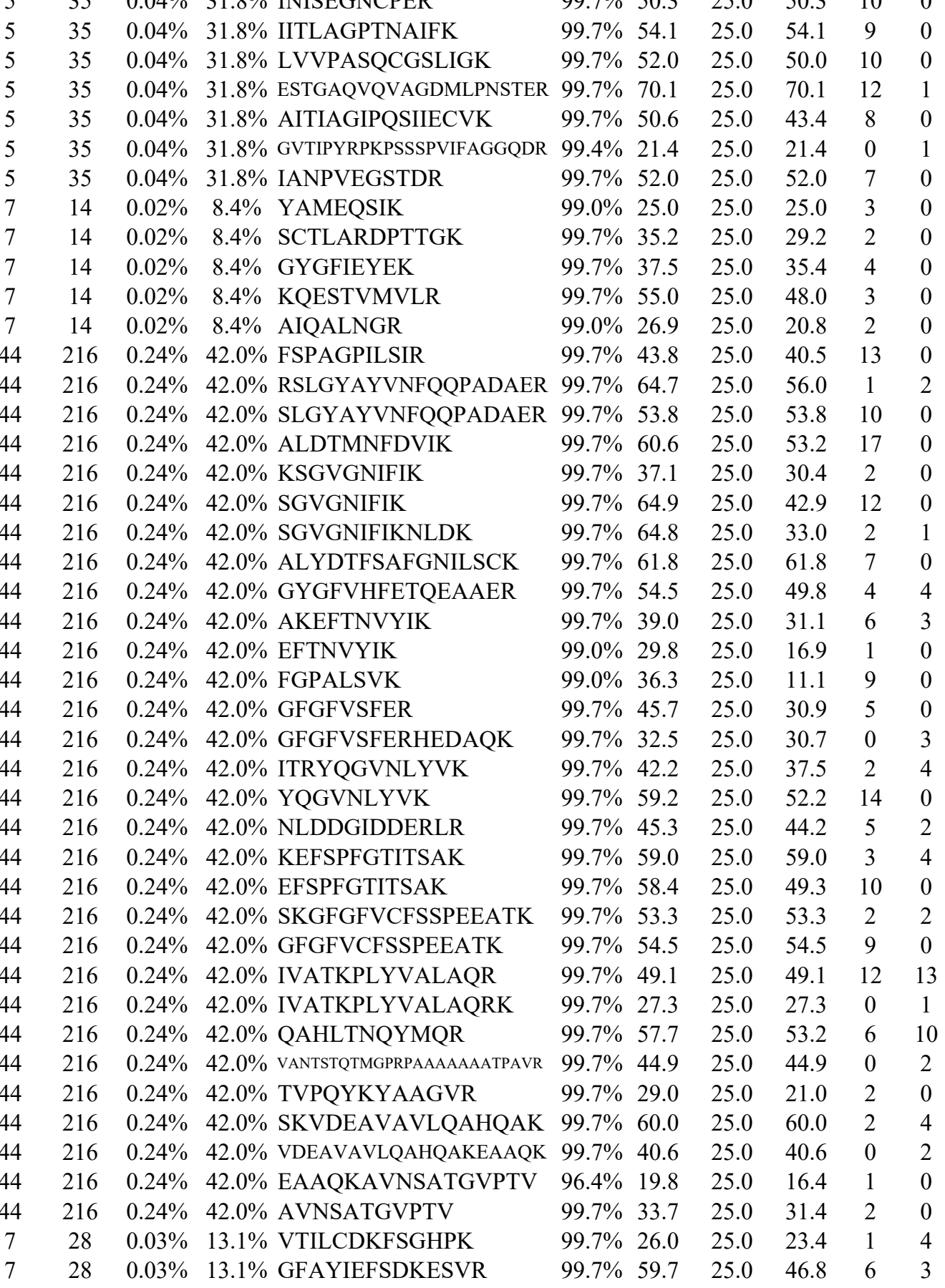

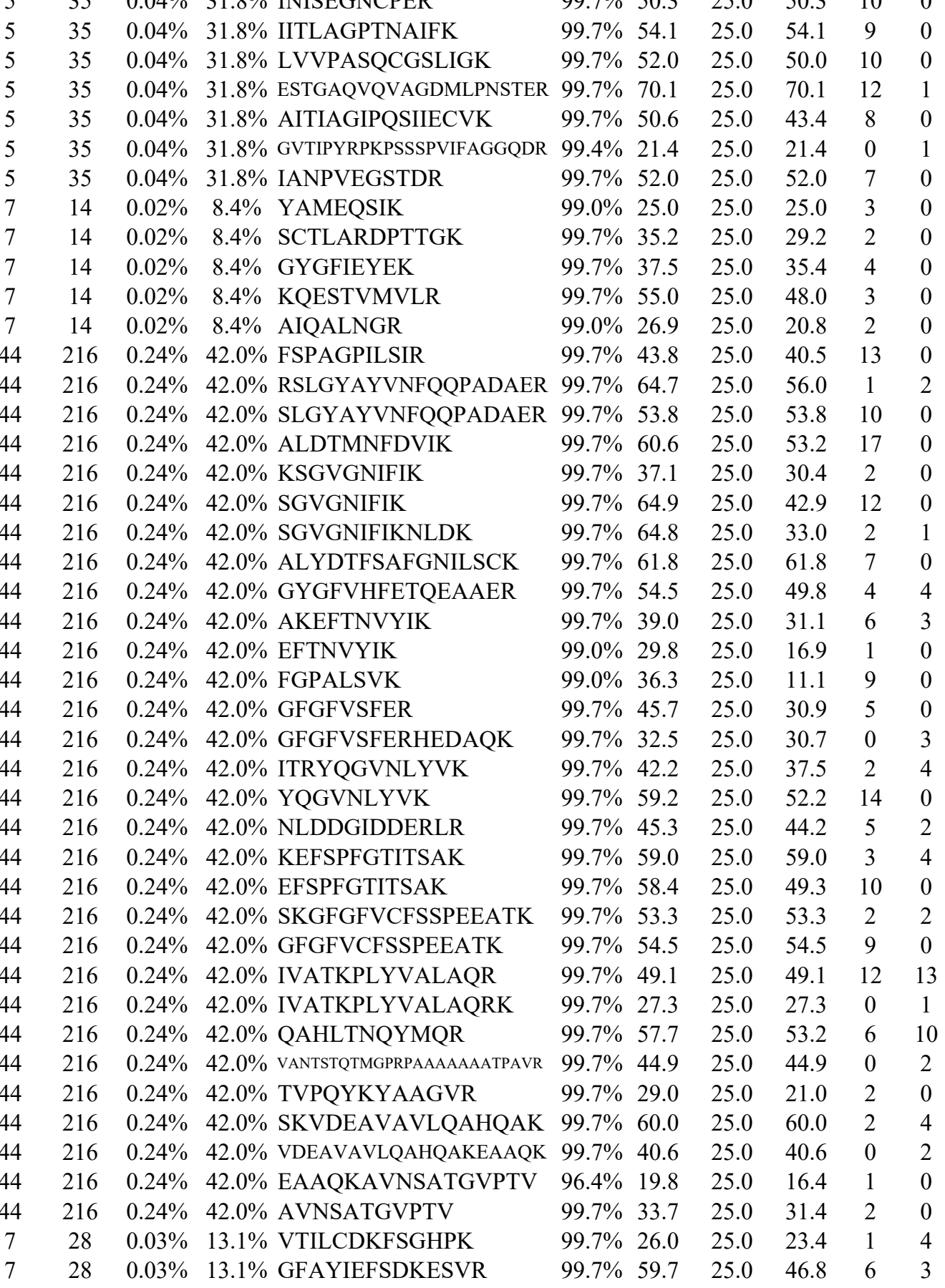

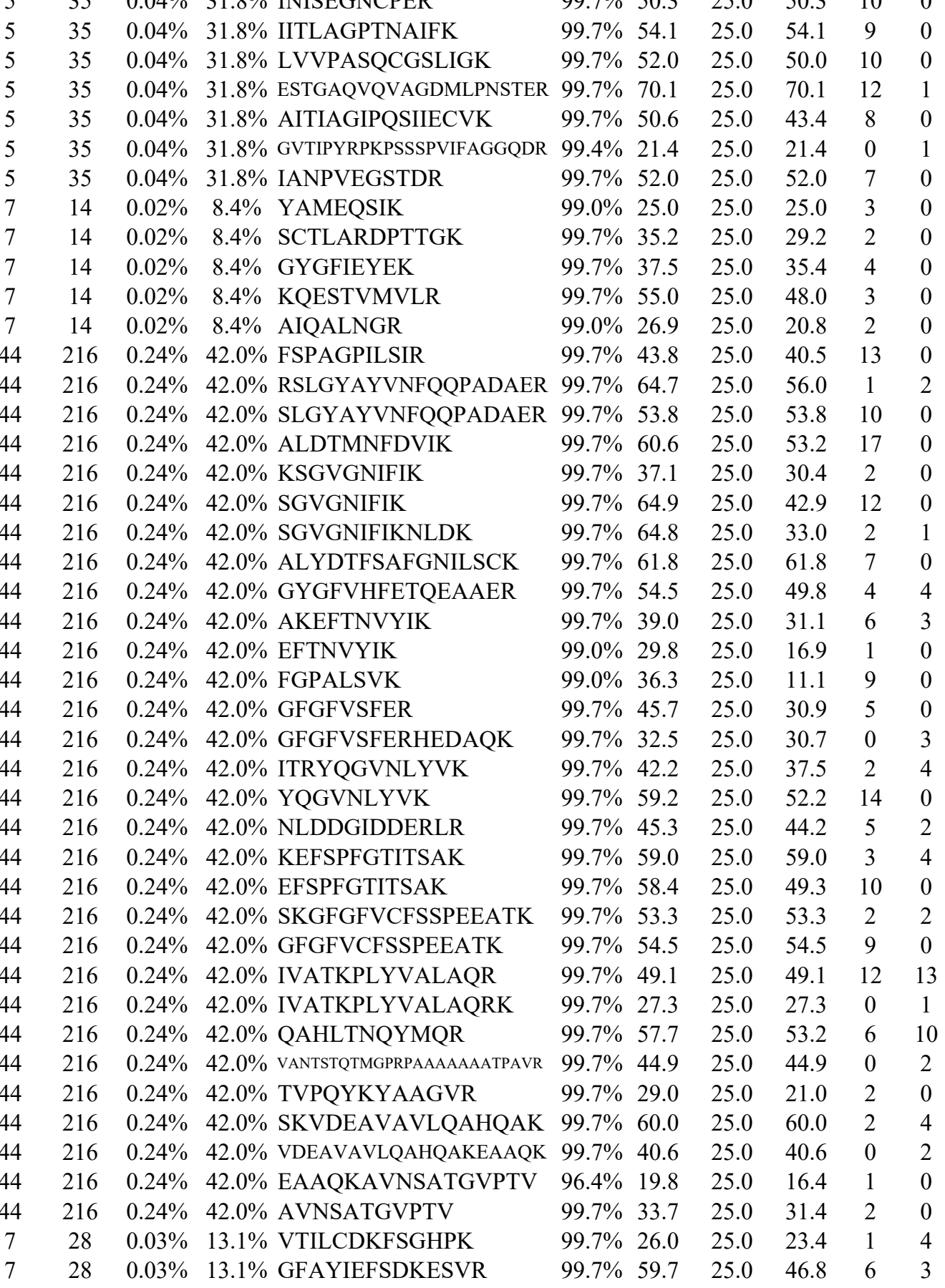

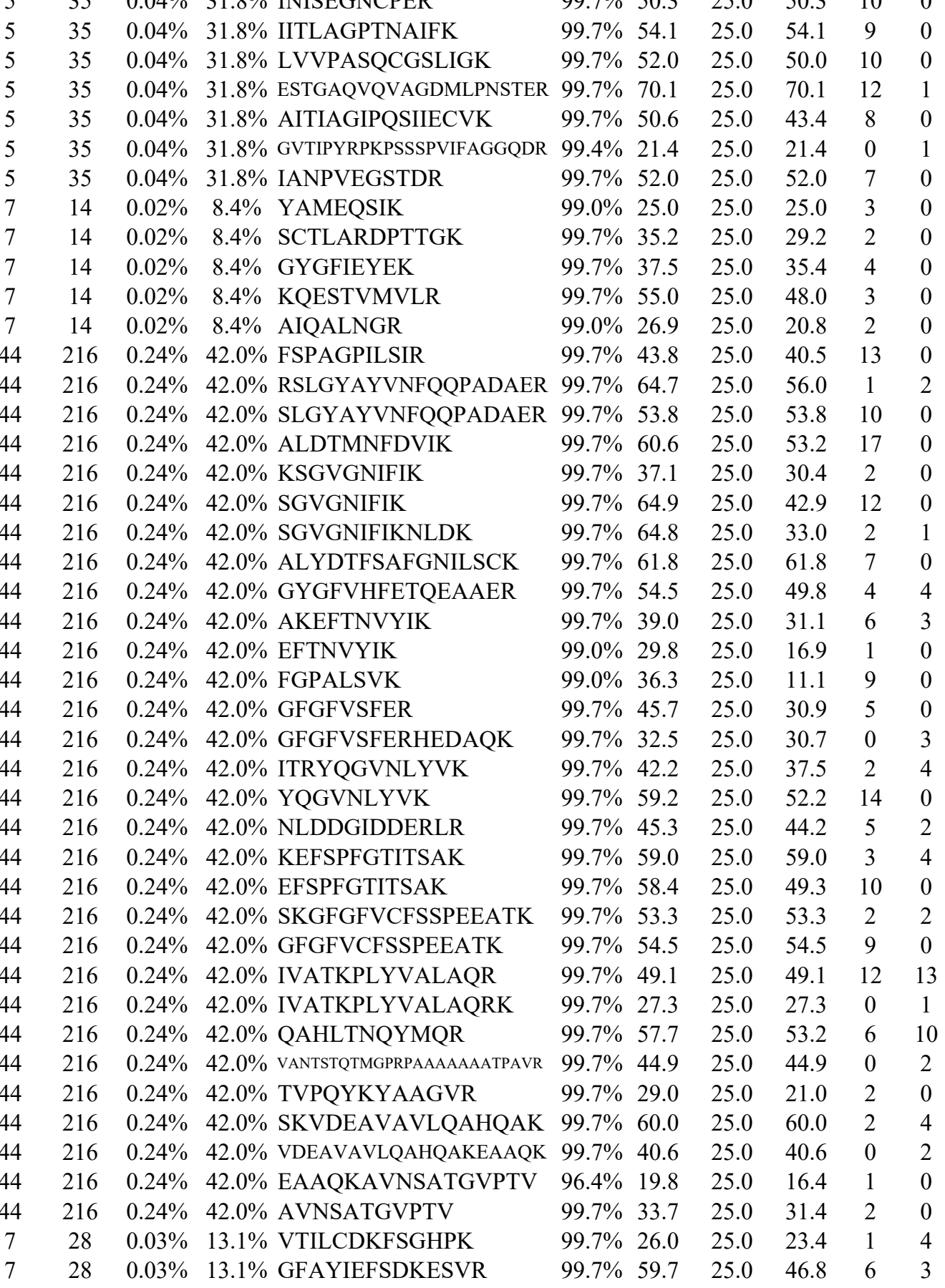

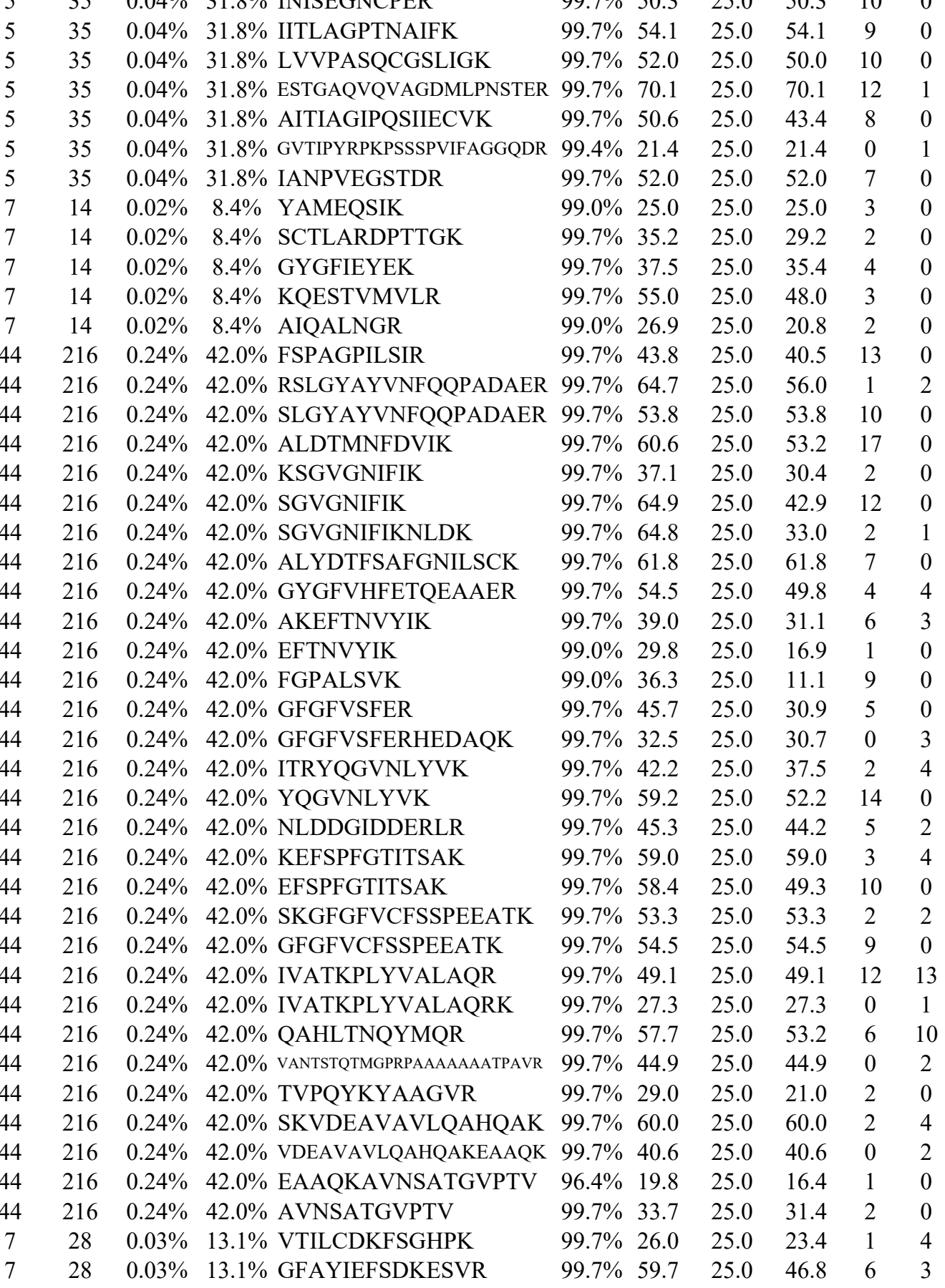

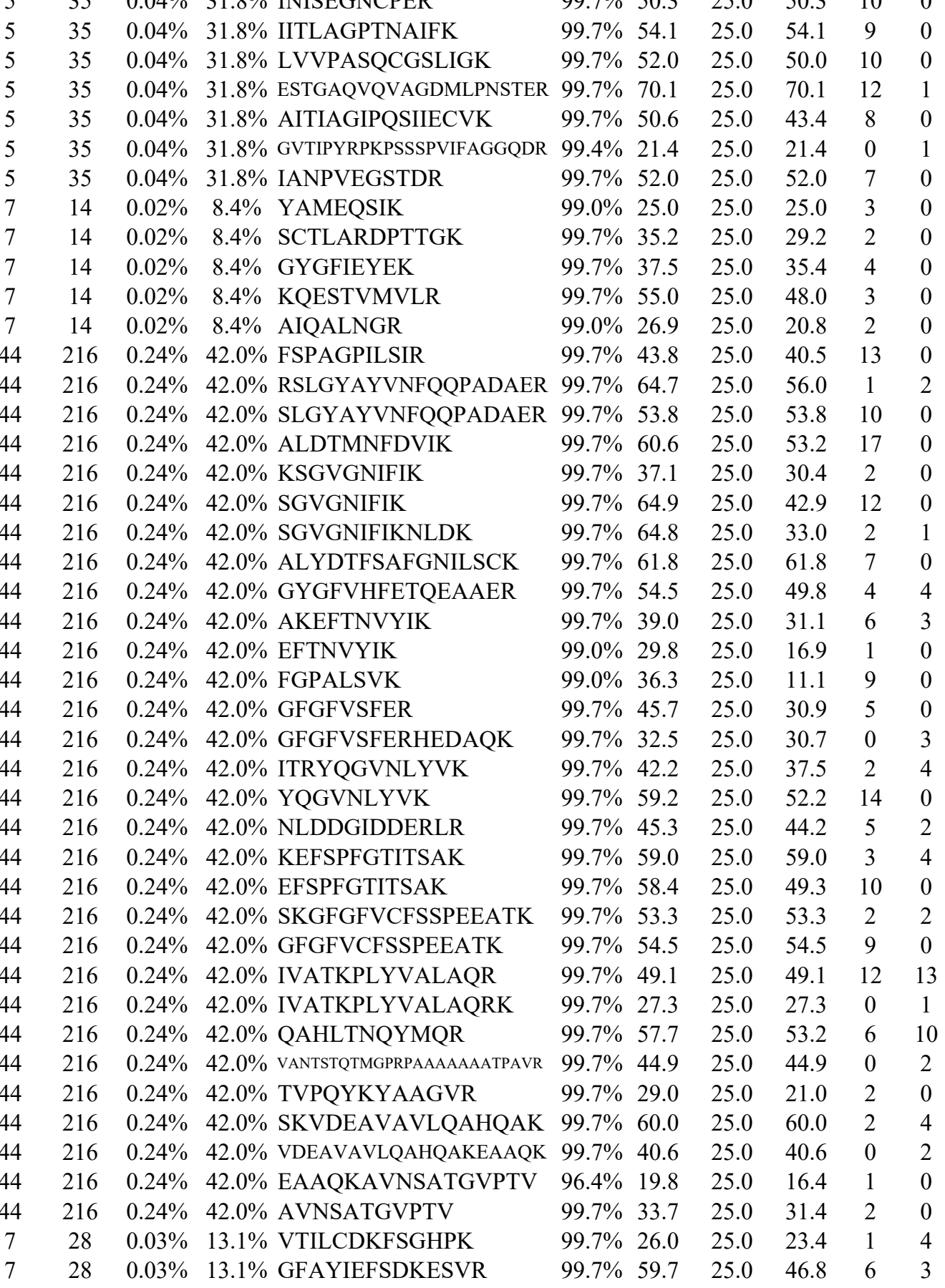

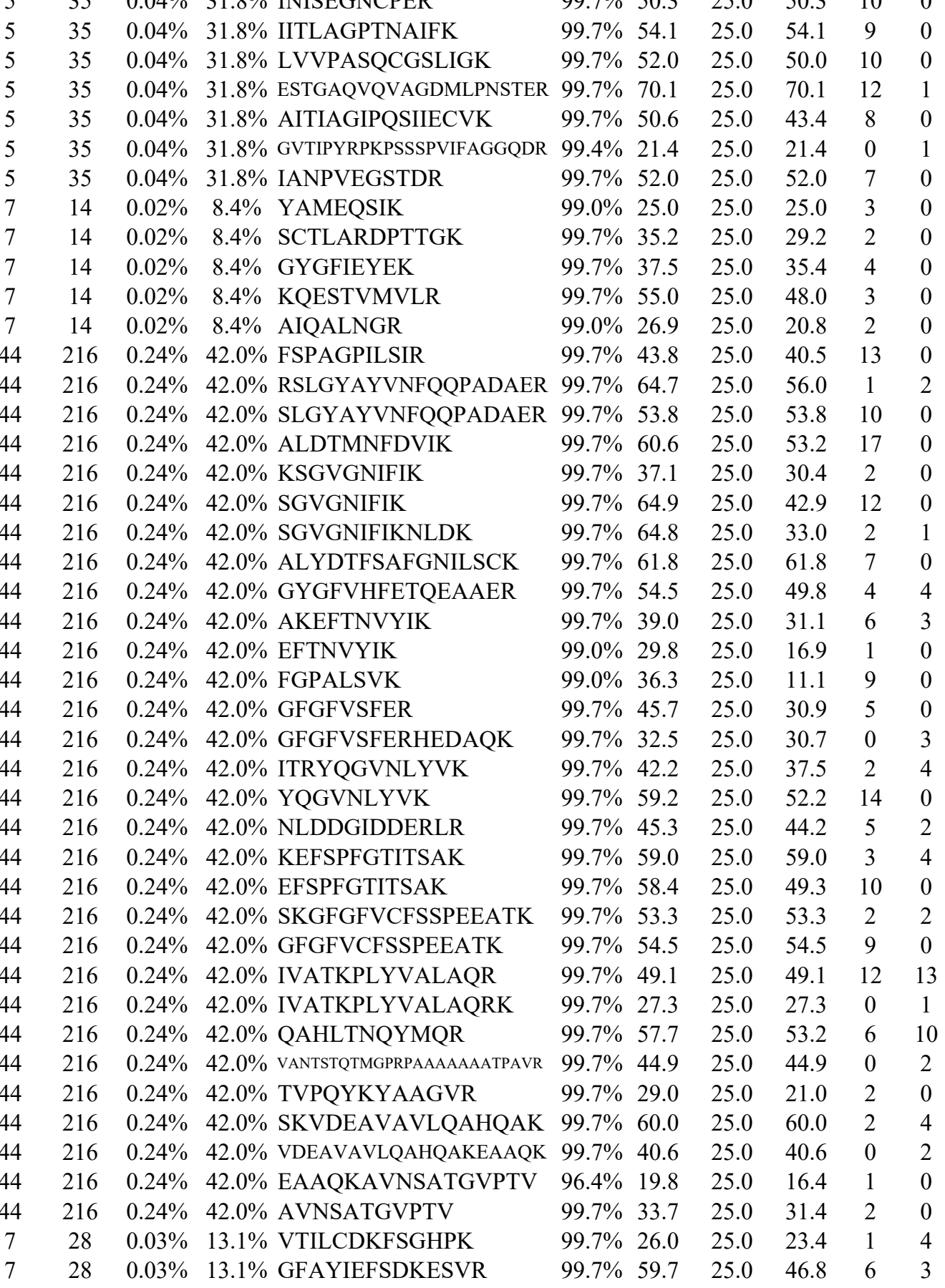

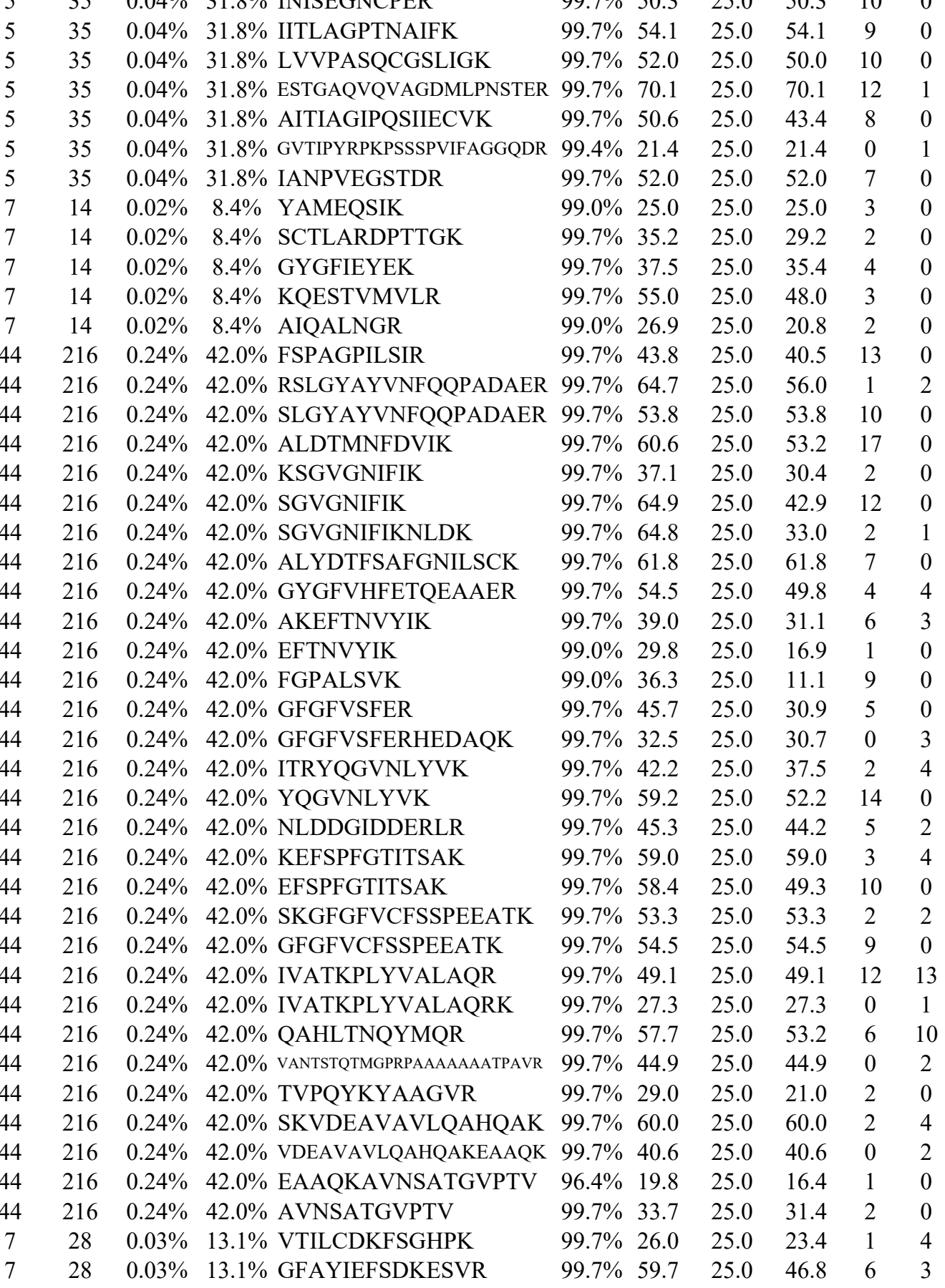

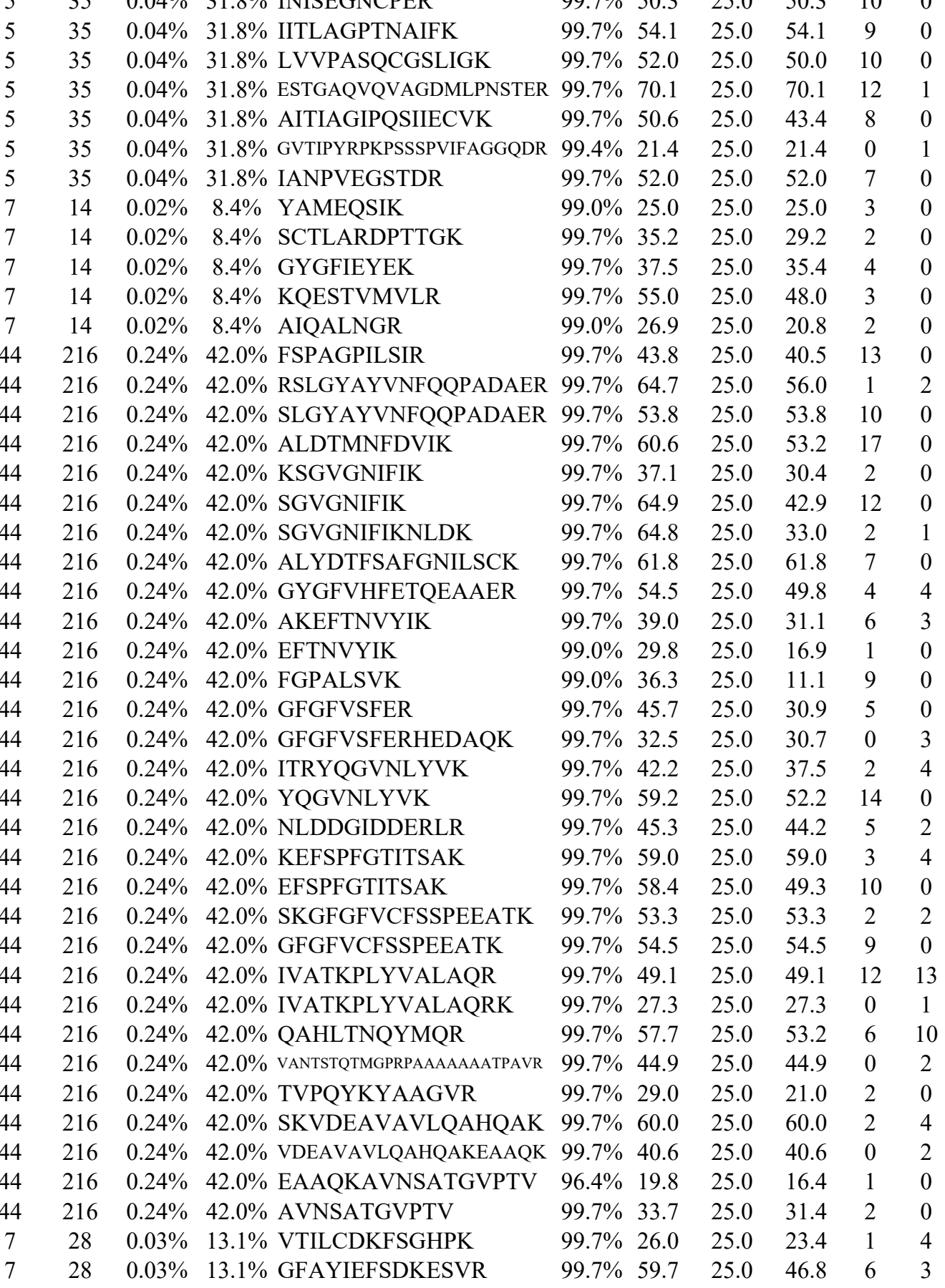

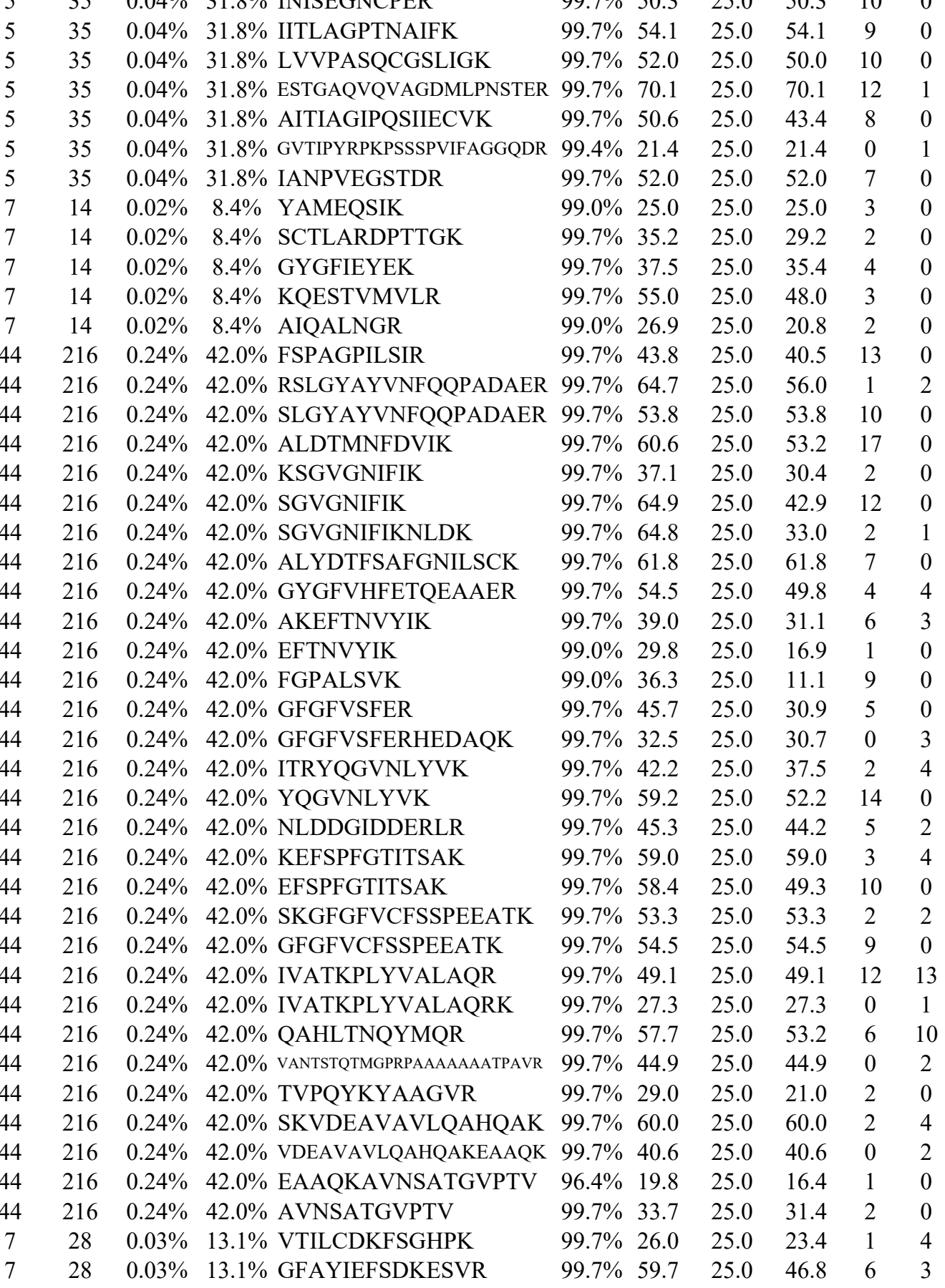

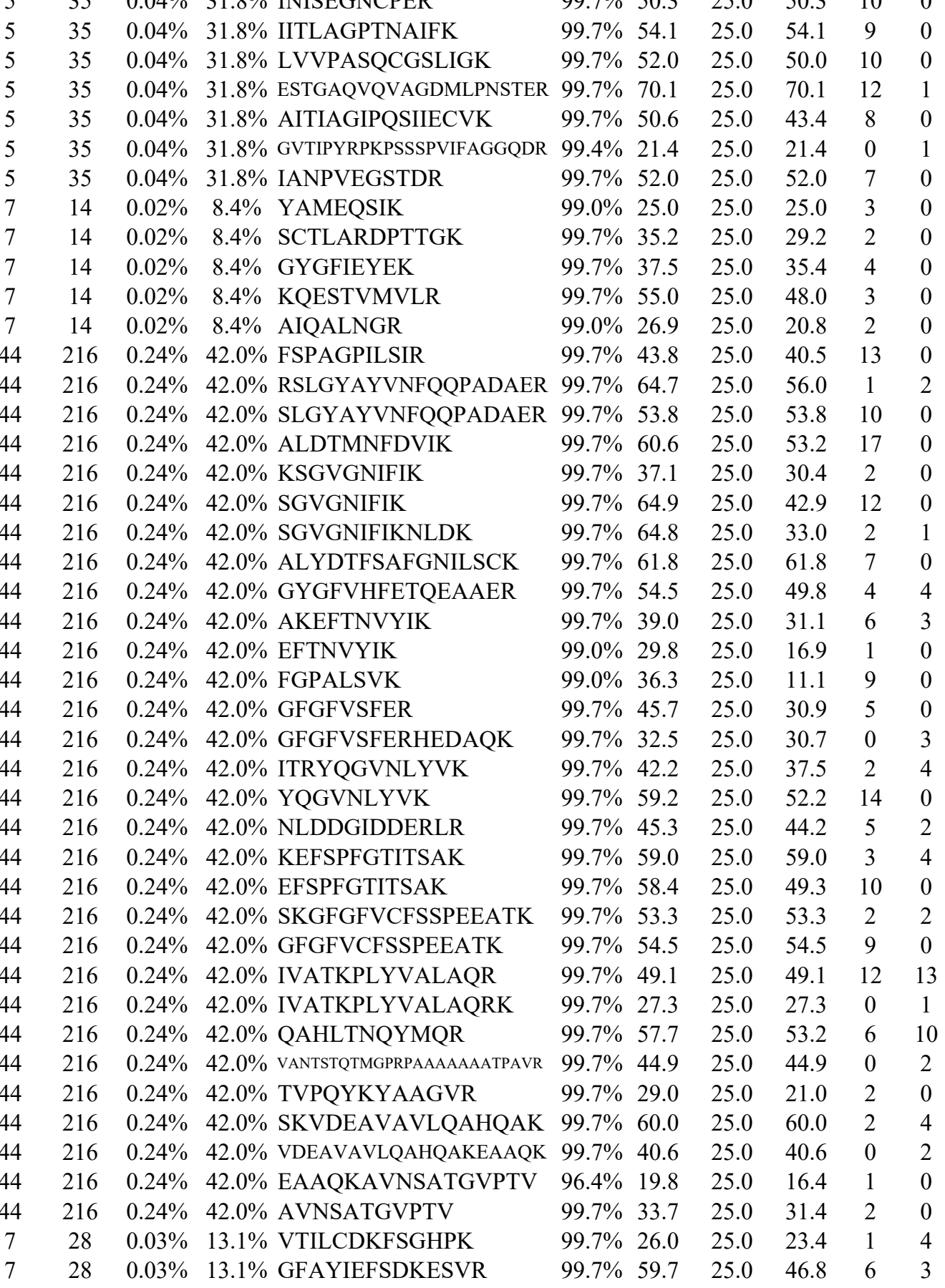

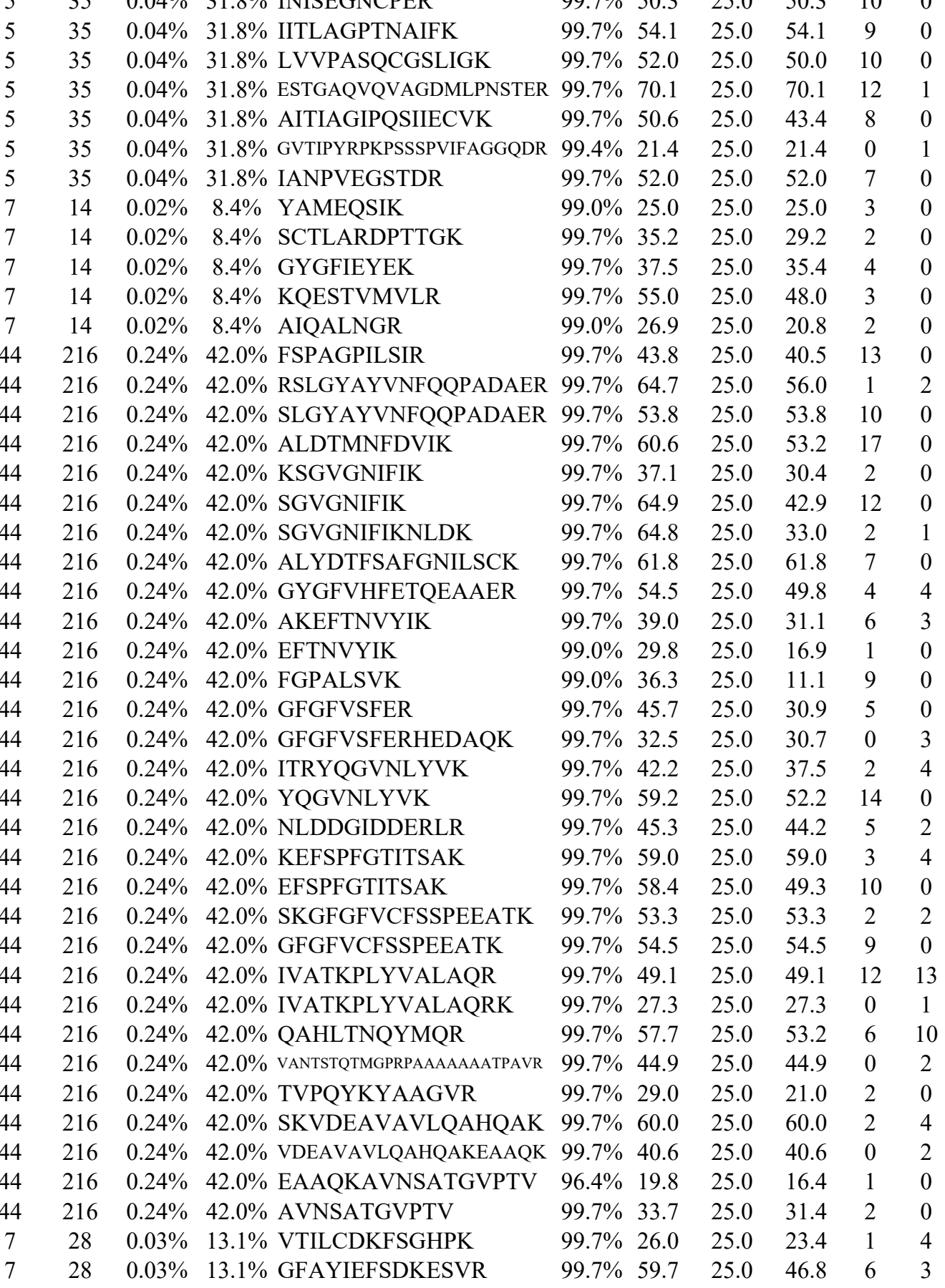

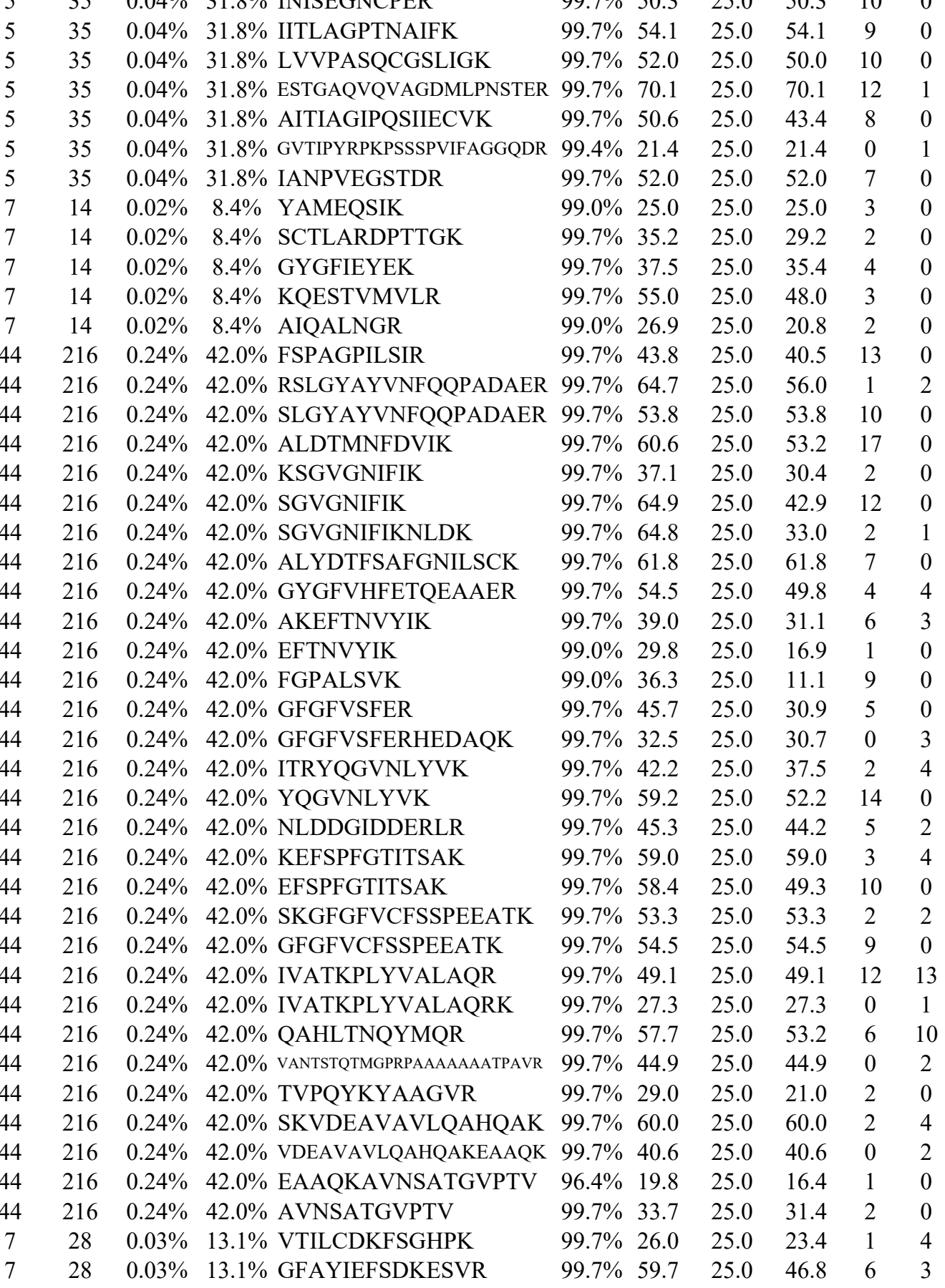

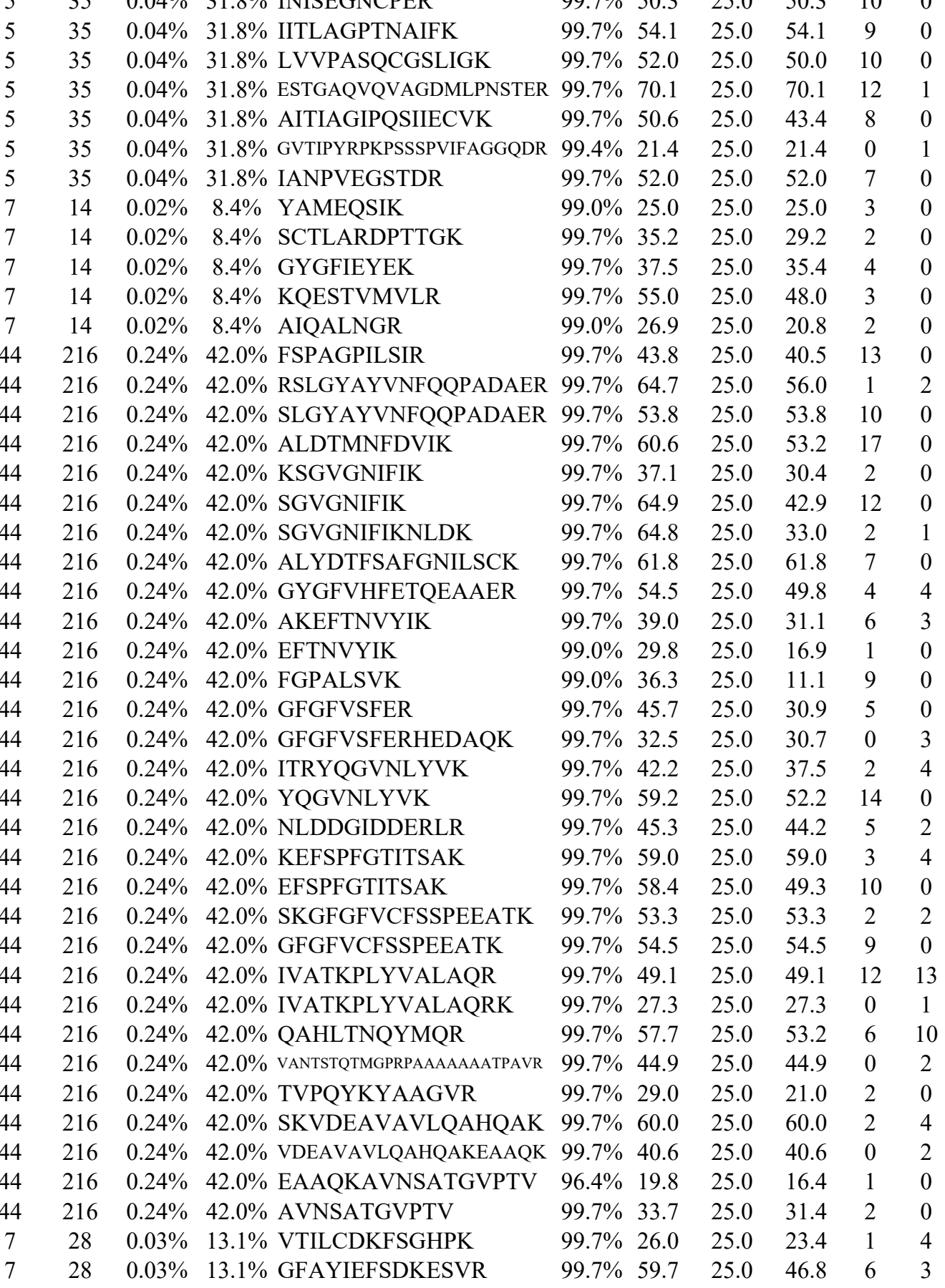

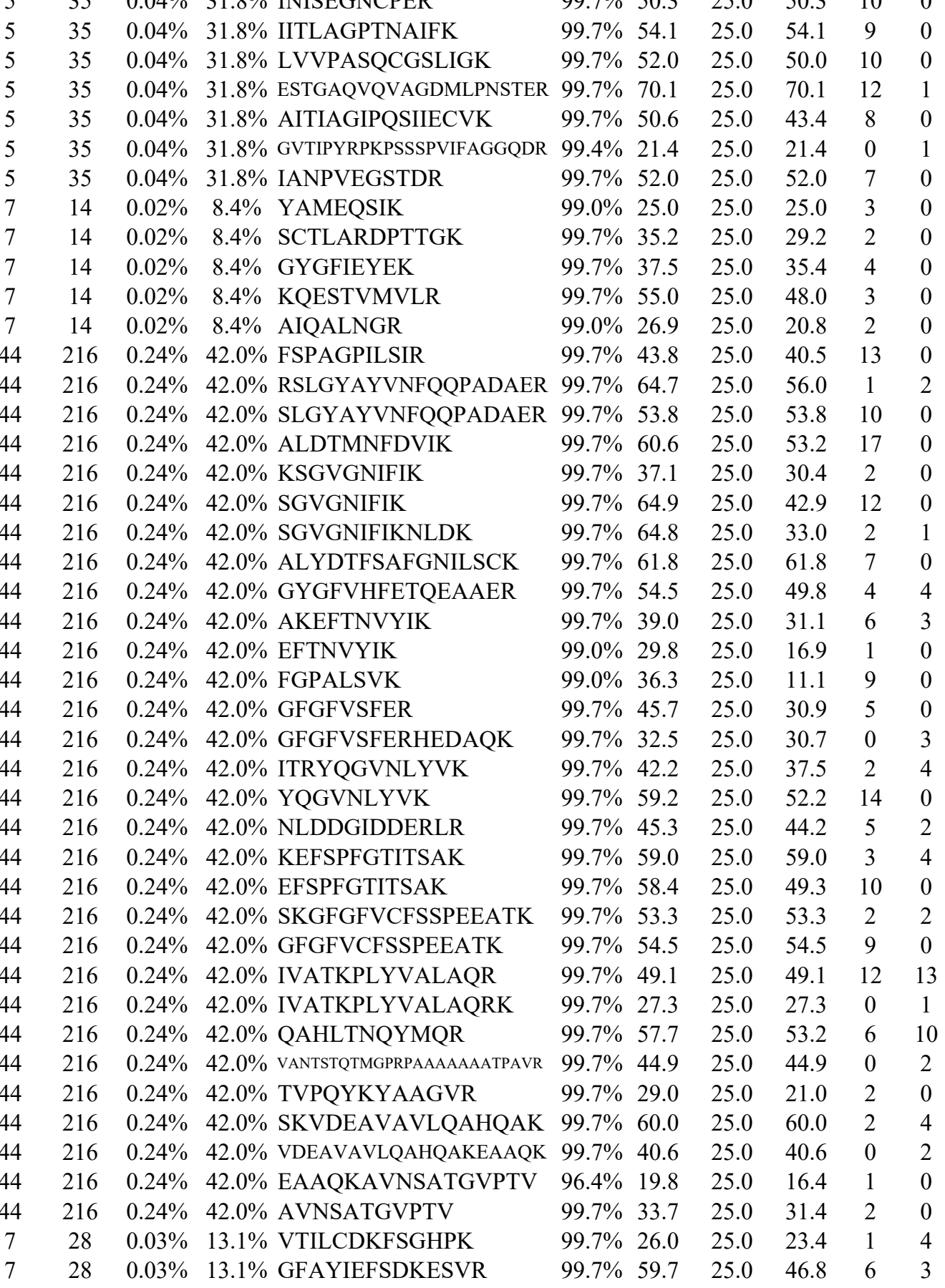

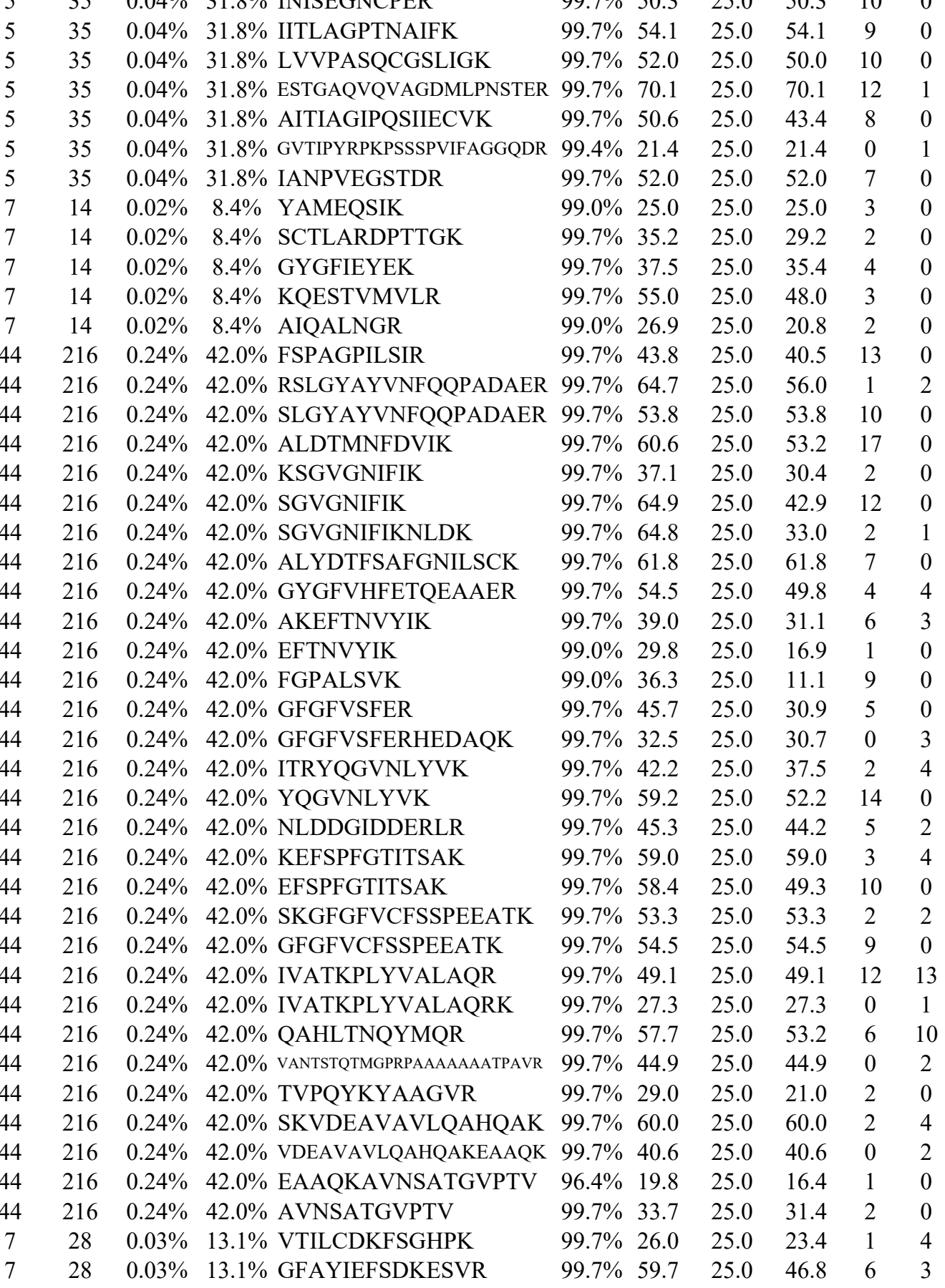

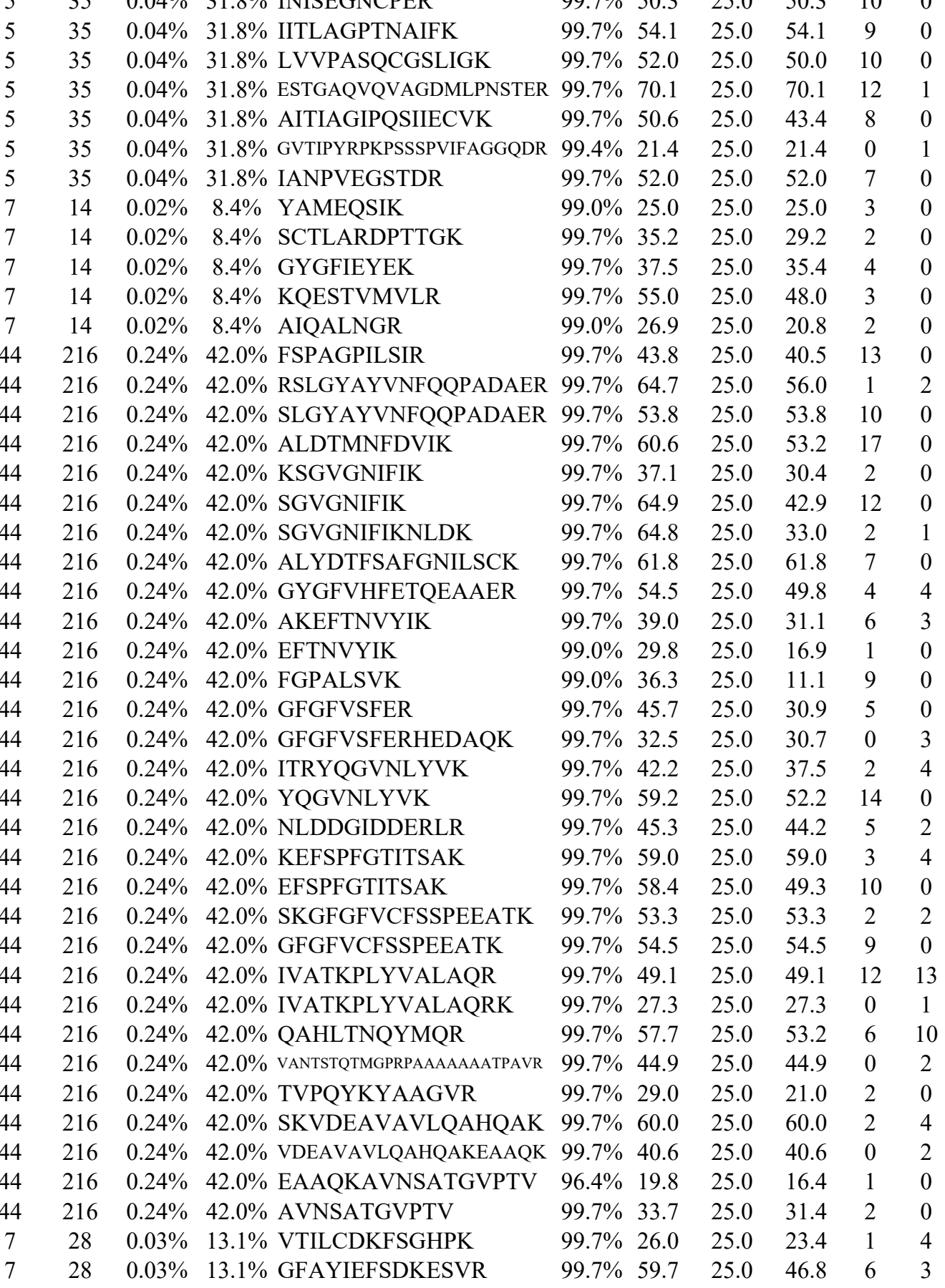

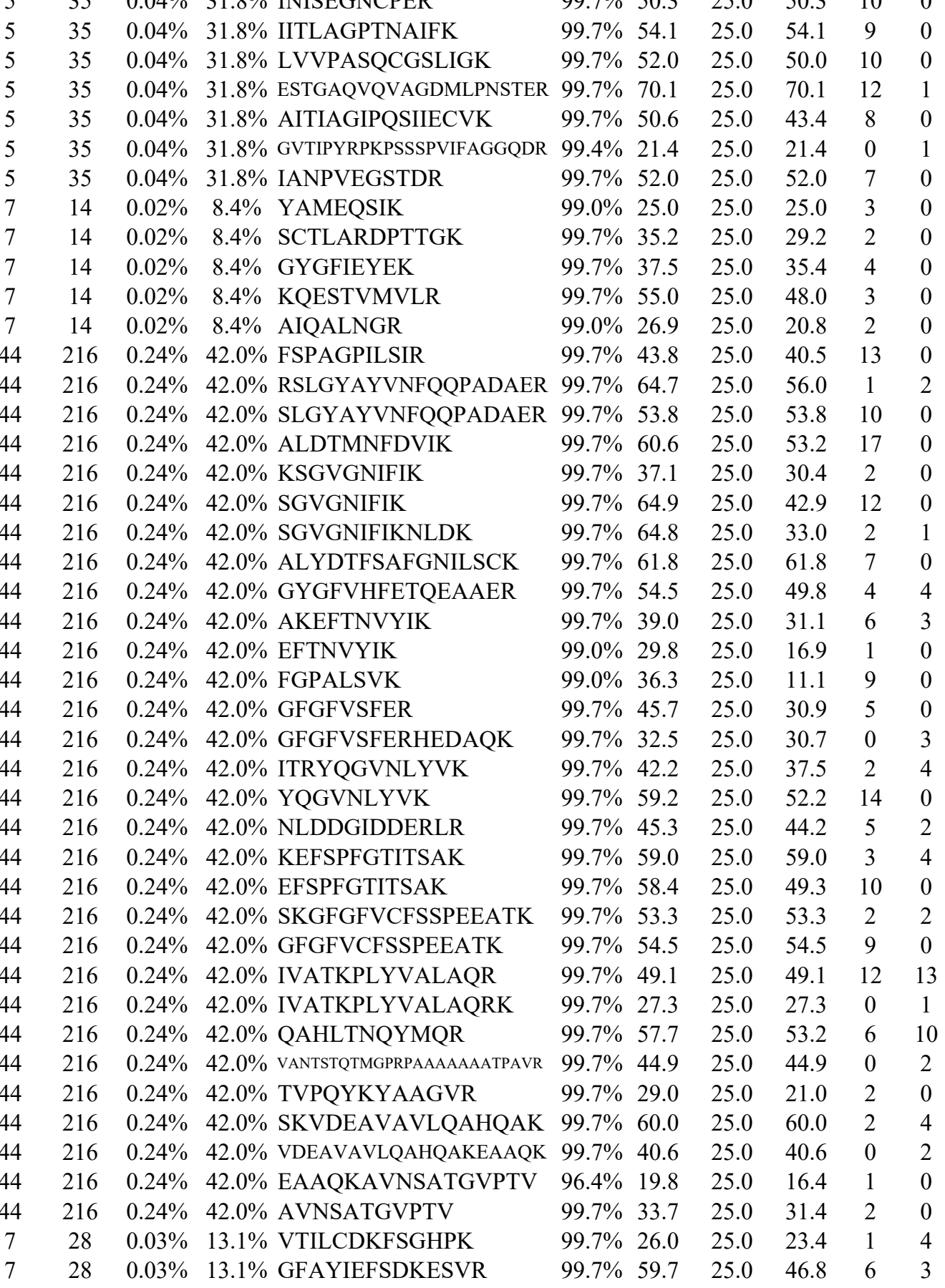

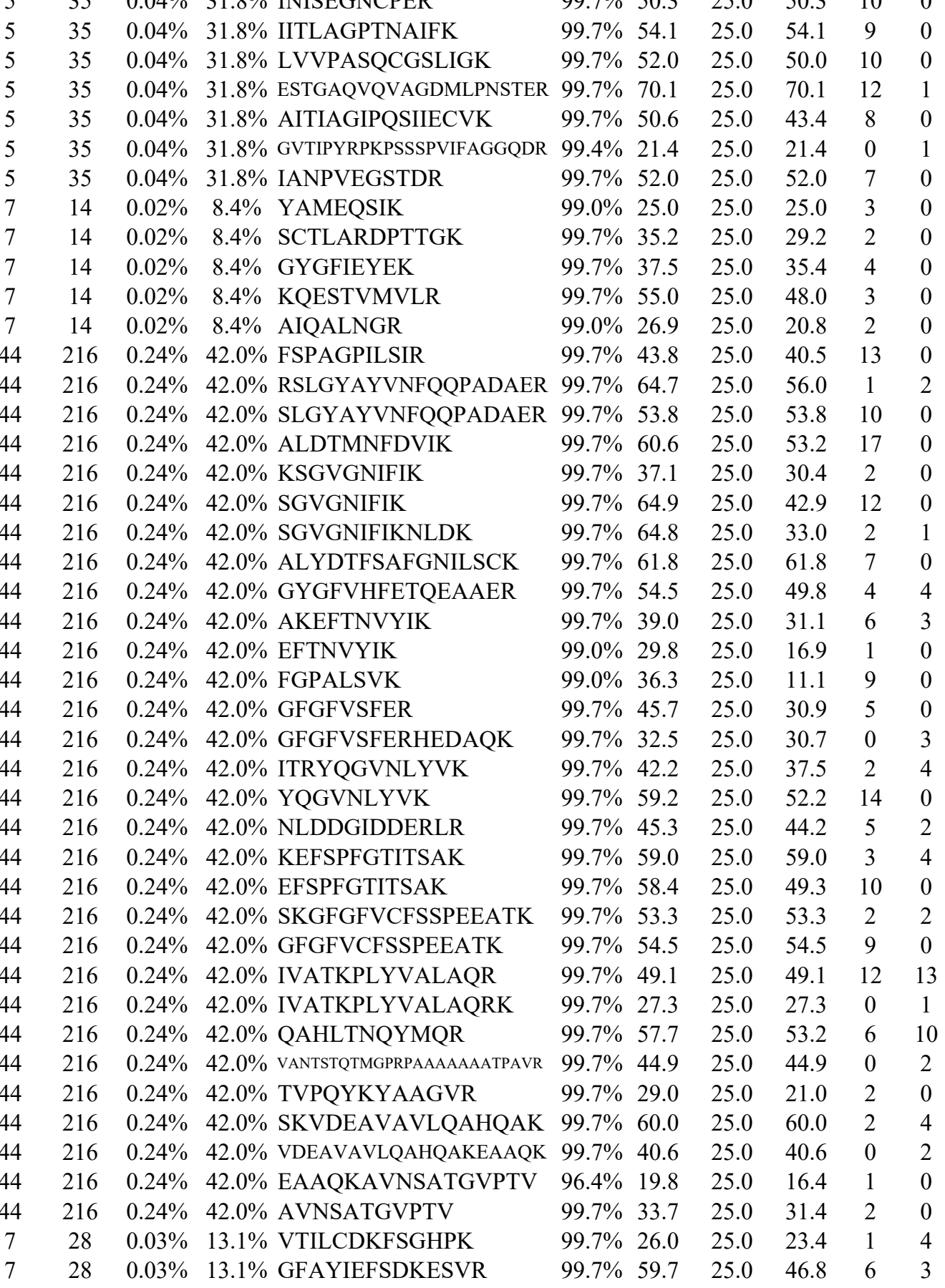

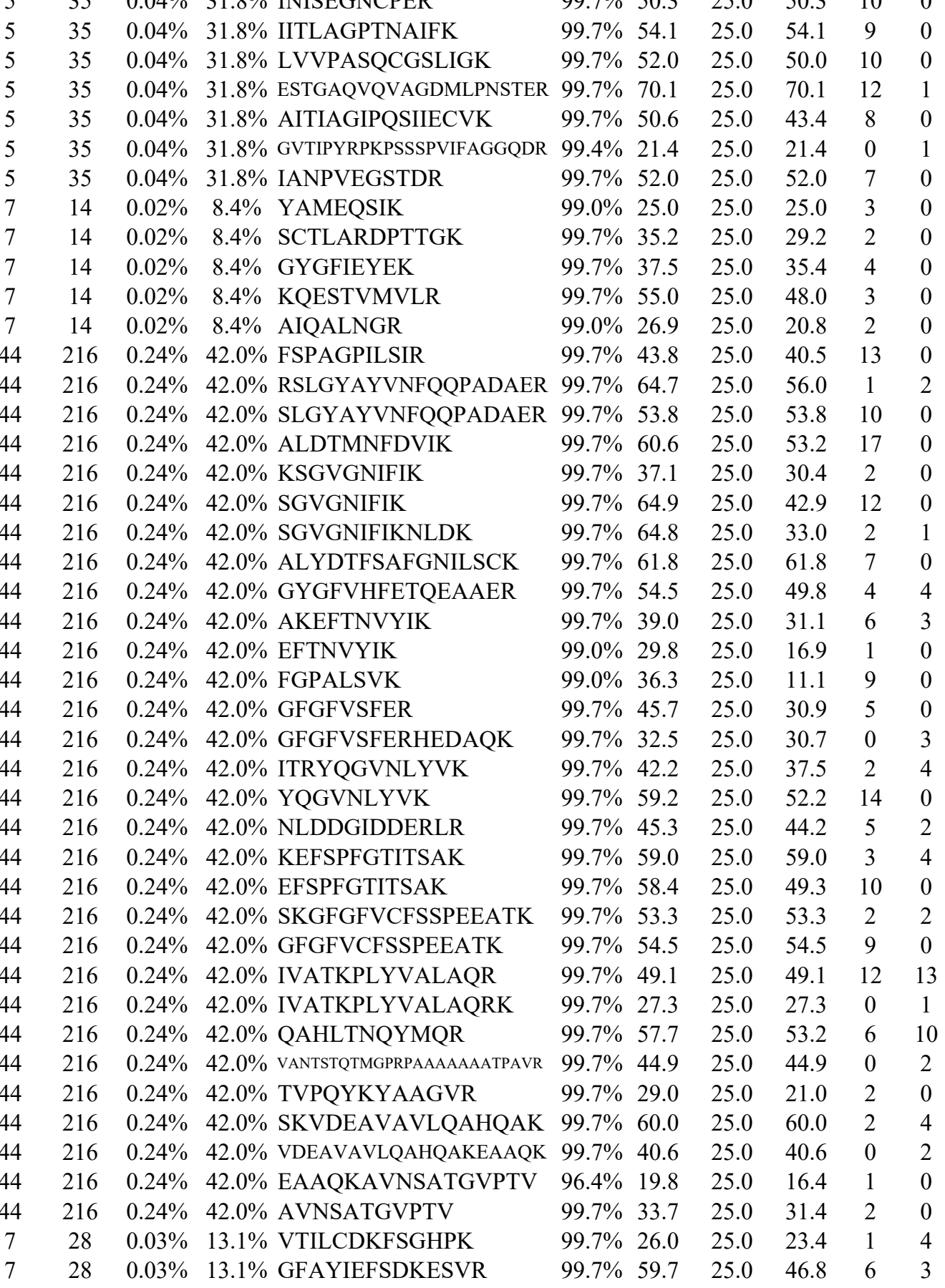

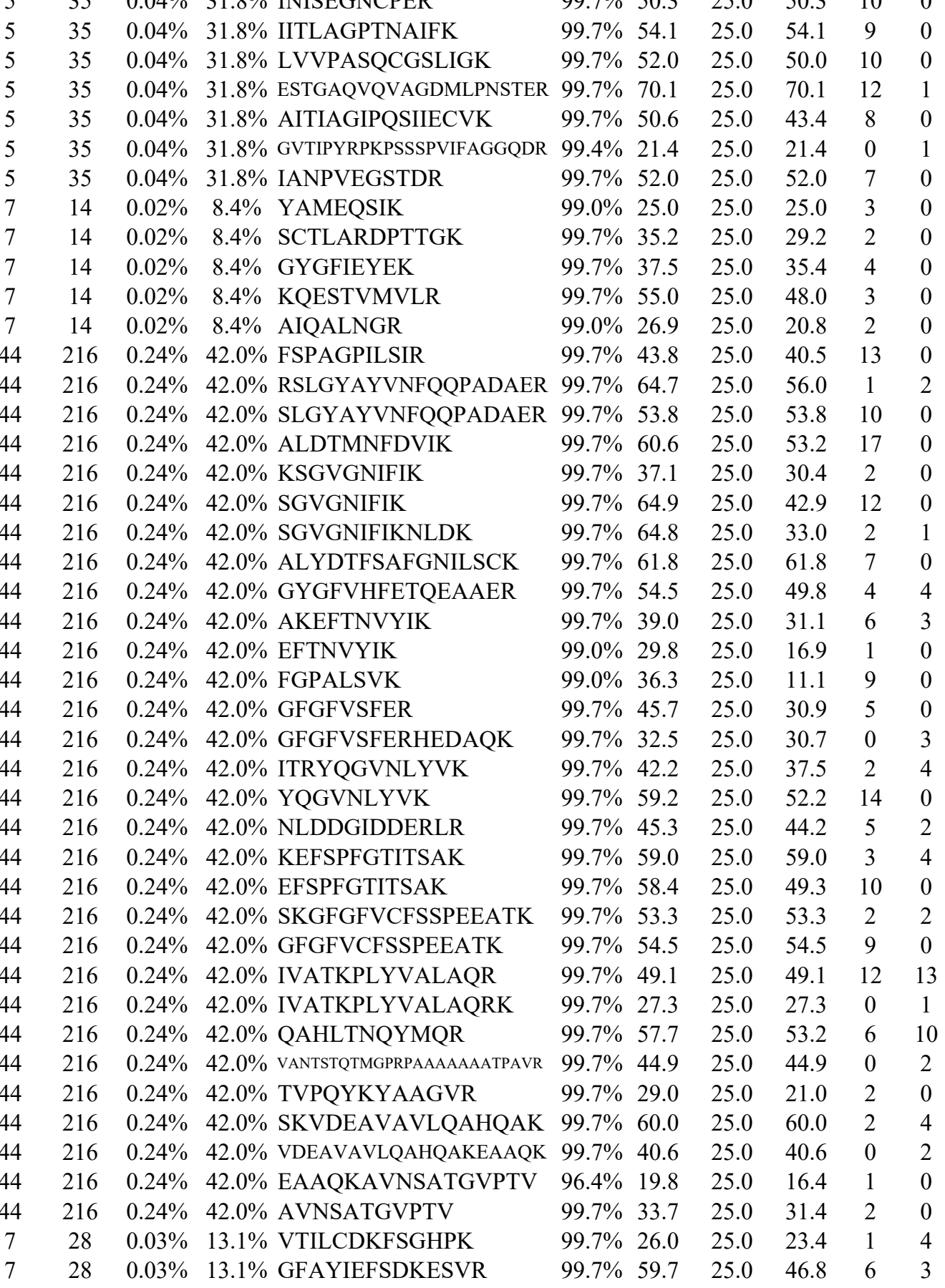

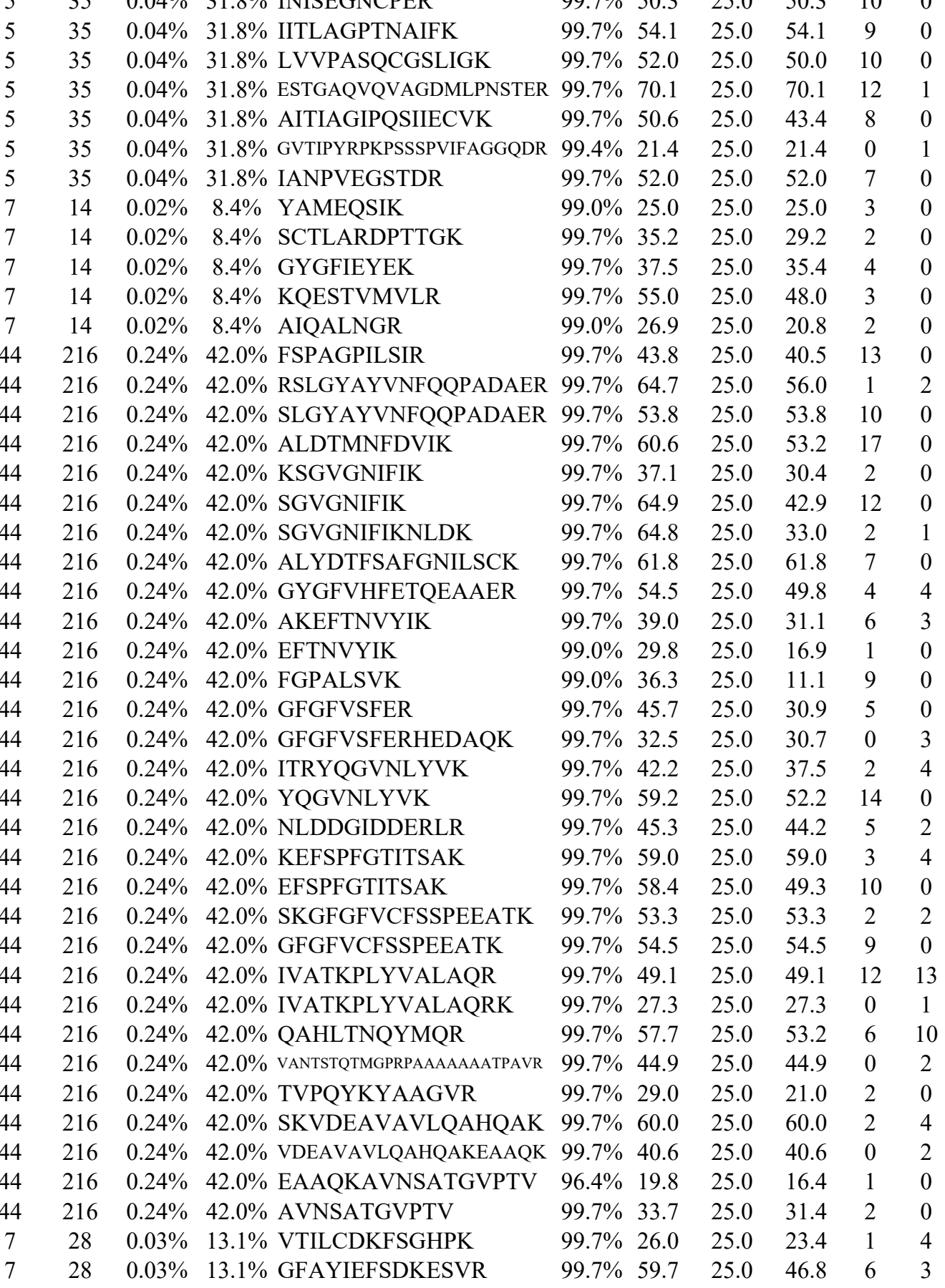

Page 113 of Table S-1-5 
Polyadenylate-binding protein $2 \mathrm{GN}=$ PABPN1 PABP2_HUMAN $32.75 \quad 100.0 \%$ Polyadenylate-binding protein 2 GN=PABPN1 PABP2_HUMAN $32.75 \quad 100.0 \%$ Polyadenylate-binding protein 4 GN=PABPC4 PABP4_HUMAN $70.78 \quad 100.0 \%$ Polyadenylate-binding protein $4 \mathrm{GN}=$ PABPC4 PABP4_HUMAN $70.78 \quad 100.0 \%$ Polyadenylate-binding protein $4 \mathrm{GN}=$ PABPC4 PABP4_HUMAN $70.78 \quad 100.0 \%$ Polyadenylate-binding protein $4 \mathrm{GN}=$ PABPC4 PABP4_HUMAN $70.78 \quad 100.0 \%$ Polyadenylate-binding protein $4 \mathrm{GN}=$ PABPC4 PABP4_HUMAN $70.78 \quad 100.0 \%$ Polyadenylate-binding protein $4 \mathrm{GN}=$ PABPC4 PABP4_HUMAN $70.78 \quad 100.0 \%$ Polyadenylate-binding protein $4 \mathrm{GN}=$ PABPC4 PABP4_HUMAN $70.78 \quad 100.0 \%$ Polyadenylate-binding protein $4 \mathrm{GN}=$ PABPC4 PABP4_HUMAN $70.78 \quad 100.0 \%$ Polyadenylate-binding protein $4 \mathrm{GN}=$ PABPC4 PABP4_HUMAN $70.78 \quad 100.0 \%$ Polyadenylate-binding protein $4 \mathrm{GN}=$ PABPC4 PABP4_HUMAN 70.78 Polyadenylate-binding protein $4 \mathrm{GN}=\mathrm{PABPC} 4$ PABP4_HUMAN 70.78 Polyadenylate-binding protein $4 \mathrm{GN}=\mathrm{PABPC} 4$ PABP4_HUMAN 70.78 Polyadenylate-binding protein $4 \mathrm{GN}=$ PABPC4 PABP4_HUMAN 70.78 Polyadenylate-binding protein $4 \mathrm{GN}=\mathrm{PABPC} 4$ PABP4_HUMAN 70.78 Polyadenylate-binding protein $4 \mathrm{GN}=\mathrm{PABPC} 4$ PABP4 HUMAN 70.78 Polyadenylate-binding protein $4 \mathrm{GN}=$ PABPC4 PABP4_HUMAN 70.78 Polyadenylate-binding protein $4 \mathrm{GN}=$ PABPC4 PABP4_HUMAN 70.78 Polyadenylate-binding protein $4 \mathrm{GN}=$ PABPC4 PABP4_HUMAN 70.78 Polyadenylate-binding protein $4 \mathrm{GN}=\mathrm{PABPC} 4$ PABP4_HUMAN 70.78 Polymerase delta-interacting protein 2 GN=POLDIP2 PDIP2 HUMAN 42.03 Polymerase delta-interacting protein $2 \mathrm{GN}=$ POLDIP2 PDIP2_HUMAN 42.03 Polymerase delta-interacting protein 2 GN=POLDIP2 PDIP2_HUMAN 42.03 Polymerase delta-interacting protein 2 GN=POLDIP2 PDIP2 HUMAN 42.03 Polymerase delta-interacting protein $2 \mathrm{GN}=$ POLDIP2 PDIP2_HUMAN 42.03 Polymerase delta-interacting protein 2 GN=POLDIP2 PDIP2_HUMAN 42.03 Polymerase delta-interacting protein 2 GN=POLDIP2 PDIP2_HUMAN 42.0 Polymerase delta-interacting protein 2 GN=POLDIP2 PDIP2_HUMAN 42.03 Polymerase delta-interacting protein $3 \mathrm{GN}=$ POLDIP3 PDIP3 HUMAN 46.09 Polymerase delta-interacting protein 3 GN=POLDIP3 PDIP3_HUMAN 46.09 Polymerase delta-interacting protein $3 \mathrm{GN}=$ POLDIP3 PDIP3_HUMAN 46.09 Polypyrimidine tract-binding protein $1 \mathrm{GN}=$ =PTBP1 PTBP1_HUMAN 57.22 Polypyrimidine tract-binding protein $1 \mathrm{GN}=$ PTBP1 PTBP1_HUMAN 57.22 Polypyrimidine tract-binding protein $1 \mathrm{GN}=$ PTBP1 PTBP1_HUMAN 57.22 Polypyrimidine tract-binding protein $1 \mathrm{GN}=$ PTBP1 PTBP1_HUMAN 57.22 Polypyrimidine tract-binding protein 1 GN=PTBP1 PTBP1_HUMAN 57.22 Polypyrimidine tract-binding protein $1 \mathrm{GN}=$ =PTBP1 PTBP1_HUMAN 57.22 Polypyrimidine tract-binding protein $1 \mathrm{GN}=$ PTBP1 PTBP1_HUMAN 57.22 Polypyrimidine tract-binding protein $1 \mathrm{GN}=$ PTBP1 PTBP1_HUMAN 57.22 Polypyrimidine tract-binding protein $1 \mathrm{GN}=$ =PTBP1 PTBP1_HUMAN 57.22 Polypyrimidine tract-binding protein $1 \mathrm{GN}=\mathrm{PTBP} 1 \mathrm{PTBP} 1$ HUMAN 57.22 Polypyrimidine tract-binding protein $1 \mathrm{GN}=\mathrm{PTBP} 1$ PTBP1 HUMAN 57.22 Polypyrimidine tract-binding protein $1 \mathrm{GN}=$ PTBP1 PTBP1_HUMAN 57.22 Polypyrimidine tract-binding protein 1 GN=PTBP1 PTBP1_HUMAN 57.22 Polypyrimidine tract-binding protein $1 \mathrm{GN}=$ PTBP1 PTBP1_HUMAN 57.22 Prelamin-A/C GN=LMNA

$100.0 \%$

$100.0 \%$

$100.0 \%$

$00.0 \%$

$100.0 \%$

$100.0 \%$

$100.0 \%$

$00.0 \%$

$00.0 \%$

$100.0 \%$

$100.0 \%$

$100.0 \%$

$100.0 \%$

$100.0 \%$

$100.0 \%$

$100.0 \%$

$100.0 \%$

$100.0 \%$

$100.0 \%$

$100.0 \%$

$00.0 \%$

$100.0 \%$

$00.0 \%$

$100.0 \%$

$100.0 \%$

$100.0 \%$

$100.0 \%$

$100.0 \%$

$100.0 \%$
$0.03 \% \quad 13.1 \%$ TSLALDESLFR $0.03 \% \quad 13.1 \%$ TSLALDESL

$0.05 \% \quad 28.7 \%$ FSPAGPVLSIR

$\begin{array}{lll}99.7 \% & 55.5 & 25.0\end{array}$

$99.7 \% \quad 39.1 \quad 25.0$

$99.7 \% \quad 48.8 \quad 25.0$

QQPADAER $\quad 99.7 \% \quad 64.7$

$0.05 \% \quad 28.7 \%$ SLGYAYVNFQQPADAER $99.7 \% \quad 53.8$

$0.05 \% \quad 28.7 \%$ ALDTMNFDVIK

$99.7 \% \quad 60.6$

$99.7 \% \quad 61.5$

$0.05 \% \quad 28.7 \%$ SGVGNVFIK

$100.0 \% \quad 14$

$100.0 \%$
$0.05 \% \quad 28.7 \%$ ALYDTFSAFGNILSCK

$0.05 \% \quad 28.7 \%$ AKEFTNVYIK

$0.05 \% \quad 28.7 \%$ EFTNVYIK

$0.05 \% \quad 28.7 \%$ GFGFVSYEKHEDANK

$0.05 \% \quad 28.7 \%$ ISRYQGVNLYIK

$0.05 \% \quad 28.7 \%$ YQGVNLYIK

$0.05 \% \quad 28.7 \%$ EFSPFGSITSAK

$0.05 \% \quad 28.7 \%$ SKGFGFVCFSSPEEATK

$0.05 \% \quad 28.7 \%$ GFGFVCFSSPEEATK

$0.05 \% \quad 28.7 \%$ IVGSKPLYVALAQR

$0.05 \% \quad 28.7 \%$ KAHLTNQYMQR

$0.05 \% \quad 28.7 \%$ AHLTNQYMQR

$0.05 \% \quad 28.7 \%$ LFPLIQTMHSNLAGK

$0.05 \% \quad 28.7 \%$ EAAQKVGAVAAATS

$0.02 \% \quad 26.6 \%$ VLETVGVFEVPK

$0.02 \% \quad 26.6 \%$ GVVLFPWQAR

$0.02 \% \quad 26.6 \%$ LYDRDVASAAPEK

$0.02 \% \quad 26.6 \%$ THTYYQVLIDAR

$0.02 \% \quad 26.6 \%$ SQTEAVTFLANHDDSR

$0.02 \% \quad 26.6 \%$ LENLDSDVVQLR

$0.02 \% \quad 26.6 \%$ IFSLSGTLETVR

$0.02 \% \quad 26.6 \%$ GVVGREPVLSK

$0.00 \% \quad 10.0 \%$ KQQTTVPQKPR

$0.00 \% \quad 10.0 \%$ VVQNDAYTAPALPSSIR

$0.00 \% \quad 10.0 \%$ SSGASVTTQPTEFK

$0.06 \% \quad 31.8 \%$ SAGVPSRVIHIR

$99.7 \% \quad 61.8$

$99.7 \% \quad 39.0$

$99.0 \% \quad 29.8$

$99.6 \% \quad 24.7$

$99.1 \% \quad 18.7$

$99.7 \% \quad 49.7$

$99.7 \% \quad 61.9$

$99.7 \% \quad 53.3$

$99.7 \% \quad 54.5$

$99.7 \% \quad 57.5$

$99.7 \% \quad 44.0$

$99.6 \% \quad 26.6$

$99.7 \% \quad 43.6$

$99.7 \% \quad 48.6$

$99.7 \% \quad 92.9$

$99.7 \% \quad 28.8$

$99.7 \% \quad 46.1$

$99.7 \% \quad 52.9$

$99.7 \% \quad 83.7$

$99.7 \% \quad 78.2$

$99.7 \% 80.3$

$99.7 \% \quad 27.0$

$99.6 \% \quad 25.0$

$0.06 \% 31.8 \%$ KLPIDVTEGEVISLGLPFGK

$99.7 \% \quad 32.5$

$99.3 \% \quad 18.8$

$0.06 \% 31.8 \%$ VTNLLMLK

$0.06 \% \quad 31.8 \%$ ELKTDSSPNQAR

$99.0 \% \quad 51.1$

$99.7 \% \quad 32.3$

$\begin{array}{lllll}0.06 \% & 31.8 \% & \text { NNQFQALLQYADPVSAQHAK } & 99.7 \% & 44.0\end{array}$

$0.06 \% \quad 31.8 \%$ IDFSKLTSLNVK

$97.4 \% \quad 17.3$

$0.06 \% \quad 31.8 \%$ IAIPGLAGAGNSVLLVSNLNPER $\quad 99.7 \% \quad 81.7$

$99.0 \% \quad 32.0$

$0.06 \% 31.8 \%$ HQNVQLPR

$\begin{array}{lllll}0.06 \% & 31.8 \% & \text { HQNVQLPREGQEDQGLTK } & 99.5 \% & 26.0 \\ 0.06 \% & 31.8 \% & \text { EGQEDQGLTKDYGNSPLLHR } & 99.7 \% & 54.3\end{array}$

$0.06 \% \quad 31.8 \%$ DYGNSPLHR

$0.06 \% \quad 31.8 \%$ VLFSSNGGVVK

$0.06 \% \quad 31.8 \%$ VSFSKSTI

$99.7 \% \quad 36.3 \quad 25.0 \quad 29.8$

$\begin{array}{llll}99.7 \% & 40.7 & 25.0 & 38.2\end{array}$

$94.9 \% \quad 16.4 \quad 25.0 \quad 13.4$

$0.01 \% \quad 5.7 \%$ SGAQASSTPLSPTR
1251.66

1143.65

2085.01

1928.91

1266.64

920.52

1806.87

1212.66

1013.53

1727.80

1453.82

1097.60

1270.63

1877.87

1662.75

1514.91

1389.71

1277.61

1685.90

1273.67

1316.75

1172.66

1434.72

1479.76

1790.83

1400.74

1322.73

1140.67

1310.75

1801.94

1439.70

1291.76

2112.20

947.56

1345.67

2243.12

1897.89

1364.78

2275.28

991.54

2077.04

2144.00

1058.50

1106.62

868.48

1359.69

\begin{tabular}{c}
238 \\
240 \\
41 \\
67 \\
67 \\
78 \\
104 \\
129 \\
196 \\
196 \\
246 \\
299 \\
299 \\
324 \\
348 \\
348 \\
370 \\
385 \\
385 \\
589 \\
644 \\
72 \\
101 \\
114 \\
141 \\
165 \\
280 \\
297 \\
310 \\
112 \\
246 \\
418 \\
64 \\
84 \\
93 \\
92 \\
146 \\
238 \\
254 \\
266 \\
348 \\
418 \\
428 \\
437 \\
437 \\
482 \\
\hline
\end{tabular}

Page 114 of Table S-1-5 

Pre-mRNA-processing factor 19 GN=PRPF19 PRP19_HUMAN $55.18 \quad 100.0 \%$ Pre-mRNA-processing factor $19 \mathrm{GN}=$ PRPF19 PRP19_HUMAN $55.18 \quad 100.0 \%$ Pre-mRNA-processing factor 19 GN=PRPF19 PRP19_HUMAN $55.18 \quad 100.0 \%$ Pre-mRNA-processing factor 19 GN=PRPF19 PRP19_HUMAN $55.18 \quad 100.0 \%$ Pre-mRNA-processing factor 19 GN=PRPF19 PRP19 HUMAN $55.18 \quad 100.0 \%$ Pre-mRNA-processing factor 19 GN=PRPF19 PRP19_HUMAN $55.18 \quad 100.0 \%$ Pre-mRNA-processing factor 6 GN=PRPF6 PRP6_HUMAN $106.93 \quad 100.0 \%$ Pre-mRNA-processing factor 6 GN=PRPF6 PRP6_HUMAN $106.93 \quad 100.0 \%$ Pre-mRNA-processing factor 6 GN=PRPF6 PRP6_HUMAN $106.93 \quad 100.0 \%$ Pre-mRNA-processing factor 6 GN=PRPF6 PRP6_HUMAN $106.93 \quad 100.0 \%$ Pre-mRNA-processing factor 6 GN=PRPF6 PRP6_HUMAN $106.93 \quad 100.0 \%$ Pre-mRNA-processing-splicing factor 8 GN=PRPF8 PRP8_HUMAN $273.61 \quad 100.0 \%$ Pre-mRNA-processing-splicing factor 8 GN=PRPF8 PRP8 HUMAN $273.61 \quad 100.0 \%$ Pre-mRNA-processing-splicing factor 8 GN=PRPF8 PRP8_HUMAN $273.61 \quad 100.0 \%$ Pre-mRNA-processing-splicing factor 8 GN=PRPF8 PRP8_HUMAN $273.61 \quad 100.0 \%$ Pre-mRNA-processing-splicing factor 8 GN=PRPF8 PRP8_HUMAN $273.61 \quad 100.0 \%$ Pre-mRNA-processing-splicing factor 8 GN=PRPF8 PRP8_HUMAN $273.61 \quad 100.0 \%$ Pre-mRNA-processing-splicing factor 8 GN=PRPF8 PRP8_HUMAN $273.61 \quad 100.0 \%$ Pre-mRNA-processing-splicing factor 8 GN=PRPF8 PRP8_HUMAN $273.61 \quad 100.0 \% 35$ Pre-mRNA-processing-splicing factor 8 GN=PRPF8 PRP8_HUMAN $273.61 \quad 100.0 \%$ Pre-mRNA-processing-splicing factor 8 GN=PRPF8 PRP8_HUMAN $273.61 \quad 100.0 \% \quad 35$ Pre-mRNA-processing-splicing factor 8 GN=PRPF8 PRP8_HUMAN $273.61 \quad 100.0 \% \quad 35$ Pre-mRNA-processing-splicing factor 8 GN=PRPF8 PRP8_HUMAN $273.61 \quad 100.0 \% \quad 35$ Pre-mRNA-processing-splicing factor 8 GN=PRPF8 PRP8_HUMAN $273.61 \quad 100.0 \% \quad 35$ Pre-mRNA-processing-splicing factor $8 \mathrm{GN}=$ PRPF8 PRP8_HUMAN $273.61 \quad 100.0 \%$ Pre-mRNA-processing-splicing factor 8 GN=PRPF8 PRP8_HUMAN $273.61 \quad 100.0 \% \quad 35$ Pre-mRNA-processing-splicing factor 8 GN=PRPF8 PRP8_HUMAN $273.61 \quad 100.0 \% \quad 35$ Pre-mRNA-processing-splicing factor 8 GN=PRPF8 PRP8_HUMAN $273.61 \quad 100.0 \%$ Pre-mRNA-processing-splicing factor 8 GN=PRPF8 PRP8_HUMAN $273.61 \quad 100.0 \% \quad 35$ Pre-mRNA-processing-splicing factor 8 GN=PRPF8 PRP8_HUMAN $273.61 \quad 100.0 \% \quad 35$ Pre-mRNA-processing-splicing factor 8 GN=PRPF8 PRP8_HUMAN $273.61 \quad 100.0 \% \quad 35$ Pre-mRNA-processing-splicing factor 8 GN=PRPF8 PRP8_HUMAN $273.61 \quad 100.0 \% \quad 35$ Pre-mRNA-processing-splicing factor 8 GN=PRPF8 PRP8_HUMAN $273.61 \quad 100.0 \% \quad 35$ Pre-mRNA-processing-splicing factor 8 GN=PRPF8 PRP8_HUMAN $273.61 \quad 100.0 \% \quad 35$ Pre-mRNA-processing-splicing factor 8 GN=PRPF8 PRP8_HUMAN $273.61 \quad 100.0 \% \quad 35$ Pre-mRNA-processing-splicing factor 8 GN=PRPF8 PRP8_HUMAN $273.61 \quad 100.0 \% \quad 35$ Pre-mRNA-processing-splicing factor 8 GN=PRPF8 PRP8_HUMAN $273.61 \quad 100.0 \%$ Pre-mRNA-processing-splicing factor 8 GN=PRPF8 PRP8_HUMAN $273.61 \quad 100.0 \% \quad 35$ Pre-mRNA-processing-splicing factor 8 GN=PRPF8 PRP8_HUMAN $273.61 \quad 100.0 \% \quad 35$ Pre-mRNA-processing-splicing factor 8 GN=PRPF8 PRP8_HUMAN $273.61 \quad 100.0 \% \quad 35$ Pre-mRNA-processing-splicing factor 8 GN=PRPF8 PRP8_HUMAN $273.61 \quad 100.0 \%$ Pre-mRNA-processing-splicing factor 8 GN=PRPF8 PRP8_HUMAN $273.61 \quad 100.0 \% \quad 35$ Pre-mRNA-processing-splicing factor 8 GN=PRPF8 PRP8_HUMAN $273.61 \quad 100.0 \% \quad 35$

$0.02 \% \quad 22.4 \%$ LQDKATVLTTER

$0.02 \% \quad 22.4 \%$ TVPEELVKPEELSK

$0.02 \% 22.4 \%$ SSEQILATLK

$0.02 \% \quad 22.4 \%$ KVTSVVFHPSQDLVFSASPDATIR

$17 \quad 0.02 \% \quad 22.4 \%$ TLQLDNNFEVK

$0.02 \% \quad 22.4 \%$ FIASTGMDR

$0.01 \% \quad 5.3 \%$ IQQQFSDLKR

$0.01 \% \quad 5.3 \% \quad$ LEEVTGKLQVAR

$0.01 \% \quad 5.3 \%$ AVVAQAVR

$0.01 \% \quad 5.3 \%$ AAELETDIRAK

$0.01 \% \quad 5.3 \%$ ESLEALLQR

$22 \quad 0.13 \% \quad 12.9 \%$ YVNGSTYQR

$22.13 \% \quad 12.9 \%$ ALNMAIPGGPK

$40 \quad 122 \quad 0.13 \% \quad 12.9 \%$ RALDIPLVK

$40 \quad 122 \quad 0.13 \% \quad 12.9 \%$ ALDIPLVK

$40 \quad 122 \quad 0.13 \% \quad 12.9 \%$ EHCPAGQPVK

$40 \quad 122 \quad 0.13 \% \quad 12.9 \%$ YYVLNALK

$40 \quad 122 \quad 0.13 \% \quad 12.9 \%$ FGNAFHLCR

$40 \quad 122 \quad 0.13 \% \quad 12.9 \%$ LVVDSHVQYR

$40 \quad 122 \quad 0.13 \% \quad 12.9 \%$ FNTGPVGK

$40 \quad 122 \quad 0.13 \% \quad 12.9 \%$ QRVESHFDLELR

$40 \quad 122 \quad 0.13 \% \quad 12.9 \%$ VESHFDLELR

$40 \quad 122 \quad 0.13 \% \quad 12.9 \%$ LYLKAEQER

$40 \quad 122 \quad 0.13 \% \quad 12.9 \%$ LLILALER

$40 \quad 122 \quad 0.13 \% \quad 12.9 \%$ LKEAYSVK

$40 \quad 122 \quad 0.13 \% \quad 12.9 \%$ IDLTLLNR

$40 \quad 122 \quad 0.13 \% \quad 12.9 \%$ LIVDHNIADYMTAK

$40 \quad 122 \quad 0.13 \% \quad 12.9 \%$ FTADEARDLIQR

$40 \quad 122 \quad 0.13 \% \quad 12.9 \%$ LMKHDVNLGR

$40 \quad 122 \quad 0.13 \% \quad 12.9 \%$ TSYEEFTHK

$40 \quad 122 \quad 0.13 \% \quad 12.9 \%$ QILMASGSTTFTK

$40 \quad 122 \quad 0.13 \% \quad 12.9 \%$ IKIGLNSK

$40 \quad 122 \quad 0.13 \% \quad 12.9 \%$ QTDVGITHFR

$40 \quad 122 \quad 0.13 \% \quad 12.9 \%$ TDFKQYQVLK

$40 \quad 122 \quad 0.13 \% \quad 12.9 \%$ SGLNQIPNR

$40 \quad 122 \quad 0.13 \% \quad 12.9 \%$ ANPALYVLR

$40 \quad 122 \quad 0.13 \% \quad 12.9 \%$ TAEEVAALIR

$40 \quad 122 \quad 0.13 \% \quad 12.9 \%$ SLPVEEQPK

$40 \quad 122 \quad 0.13 \% \quad 12.9 \%$ TISSYTAFSR

$40 \quad 122 \quad 0.13 \% \quad 12.9 \%$ QQIAEIEKQTK

$40 \quad 122 \quad 0.13 \% \quad 12.9 \%$ QTKEQSQLTATQTR

$40 \quad 122 \quad 0.13 \% \quad 12.9 \%$ EQSQLTATQTR

$40 \quad 122 \quad 0.13 \% \quad 12.9 \%$ AISAANLHLR $\begin{array}{llll}99.7 \% & 56.9 & 25.0 & 50.8\end{array}$

$\begin{array}{llll}99.5 \% & 38.8 & 25.0 & 27.0\end{array}$

$\begin{array}{llll}99.7 \% & 58.8 & 25.0 & 55.8\end{array}$

$\begin{array}{llll}99.7 \% & 51.3 & 25.0 & 29.1\end{array}$

$\begin{array}{llll}99.7 \% & 39.3 & 25.0 & 39.3\end{array}$

$\begin{array}{llll}99.7 \% & 41.1 & 25.0 & 30.8\end{array}$

$\begin{array}{llll}99.7 \% & 46.0 & 25.0 & 28.3\end{array}$

$\begin{array}{llll}99.7 \% & 26.1 & 25.0 & 20.4\end{array}$

$99.6 \% \quad 22.6 \quad 25.0 \quad 22.6$

$99.0 \% \quad 53.6 \quad 25.0 \quad 45.6$

$\begin{array}{llll}99.7 \% & 48.5 & 25.0 & 42.2\end{array}$

$\begin{array}{llll}99.7 \% & 40.1 & 25.0 & 23.4\end{array}$

$\begin{array}{llll}95.1 \% & 17.6 & 25.0 & 17.6\end{array}$

$\begin{array}{llll}99.5 \% & 34.3 & 25.0 & 22.5\end{array}$

$99.7 \% \quad 52.4 \quad 25.0 \quad 44.4$

$\begin{array}{llll}99.0 \% & 37.3 & 25.0 & 34.8\end{array}$

$\begin{array}{llll}99.7 \% & 26.6 & 25.0 & 23.8\end{array}$

$\begin{array}{llll}99.0 \% & 31.2 & 25.0 & 25.7\end{array}$

$99.7 \% \quad 65.8 \quad 25.0 \quad 55.2$

$\begin{array}{llll}99.7 \% & 68.1 & 25.0 & 59.8\end{array}$

$\begin{array}{llll}99.0 \% & 36.9 & 25.0 & 23.9\end{array}$

$\begin{array}{lllll}98.9 \% & 21.6 & 25.0 & 16.4\end{array}$

$\begin{array}{llll}99.2 \% & 23.0 & 25.0 & 19.2\end{array}$

$\begin{array}{llll}99.7 \% & 33.2 & 25.0 & 27.6\end{array}$

$\begin{array}{llll}99.0 \% & 48.2 & 25.0 & 24.4\end{array}$

$\begin{array}{llll}99.0 \% & 40.7 & 25.0 & 15.9\end{array}$

$\begin{array}{llll}99.0 \% & 48.0 & 25.0 & 28.8\end{array}$

$\begin{array}{llll}99.7 \% & 40.8 & 25.0 & 40.8\end{array}$

$\begin{array}{llll}99.6 \% & 36.3 & 25.0 & 11.2\end{array}$

$\begin{array}{lllll}99.7 \% & 39.2 & 25.0 & 38.7\end{array}$

$\begin{array}{llll}99.6 \% & 22.3 & 25.0 & 22.3\end{array}$

$99.7 \% \quad 57.9$

$99.0 \% \quad 26.6$

$99.7 \% \quad 58.3$

$99.6 \% \quad 23.5$

$98.4 \% \quad 21.5$

$99.7 \% 35.1$

$99.7 \% \quad 56.4$

$99.7 \% \quad 35.7$

$99.7 \% \quad 51.5$

$99.7 \% \quad 36.8$

$98.1 \% \quad 17.6$

$99.7 \% \quad 44.8$

$99.7 \% \quad 59.2$

872.56

1173.60 
Pre-mRNA-processing-splicing factor 8 GN=PRPF8 PRP8_HUMAN $273.61 \quad 100.0 \% \quad 35$ Pre-mRNA-processing-splicing factor 8 GN=PRPF8 PRP8_HUMAN $273.61 \quad 100.0 \% 35$ Pre-mRNA-processing-splicing factor 8 GN=PRPF8 PRP8_HUMAN $273.61 \quad 100.0 \% \quad 35$ Pre-mRNA-splicing factor ATP-dependent RNA helicase DHX15 GN=DHX15 DHX15 HUMAN $90.94 \quad 100.0 \%$ Pre-mRNA-splicing factor ATP-dependent RNA helicase DHX15 GN=DHX15 DHX15_HUMAN $90.94 \quad 100.0 \%$ Pre-mRNA-splicing factor ATP-dependent RNA helicase DHX15 GN=DHX15 DHX15_HUMAN $90.94 \quad 100.0 \%$ Pre-mRNA-splicing factor ATP-dependent RNA helicase DHX15 GN=DHX15 DHX15 HUMAN $90.94 \quad 100.0 \%$ Pre-mRNA-splicing factor ATP-dependent RNA helicase DHX15 GN=DHX15 DHX15_HUMAN $90.94 \quad 100.0 \%$ Pre-mRNA-splicing factor ISY1 homolog GN=ISY1 ISY1 HUMAN $32.99 \quad 100.0 \%$ Pre-mRNA-splicing factor ISY1 homolog GN=ISY1 ISY1_HUMAN $32.99 \quad 100.0 \%$ Pre-mRNA-splicing factor ISY1 homolog GN=ISY1 ISY1_HUMAN $32.99 \quad 100.0 \%$ Pre-mRNA-splicing factor ISY1 homolog GN=ISY1 ISY1_HUMAN $32.99 \quad 100.0 \%$ Pre-mRNA-splicing factor SPF27 GN=BCAS2 SPF27_HUMAN $26.13 \quad 100.0 \%$ Pre-mRNA-splicing factor SPF27 GN=BCAS2 SPF27_HUMAN $26.13 \quad 100.0 \%$ Pre-mRNA-splicing factor SYF1 GN=XAB2 SYF1_HUMAN $100.01 \quad 100.0 \%$ Pre-mRNA-splicing factor SYF1 GN=XAB2 SYF1_HUMAN $100.01 \quad 100.0 \%$ Pre-mRNA-splicing factor SYF1 GN=XAB2 SYF1 HUMAN $100.01 \quad 100.0 \%$ Pre-mRNA-splicing factor SYF1 GN=XAB2 SYF1_HUMAN $100.01 \quad 100.0 \%$ Pre-mRNA-splicing factor SYF1 GN=XAB2 SYF1_HUMAN $100.01 \quad 100.0 \%$ pre-rRNA processing protein FTSJ3 GN=FTSJ3 SPB1_HUMAN $96.56 \quad 100.0 \%$ pre-rRNA processing protein FTSJ3 GN=FTSJ3 SPB1_HUMAN $96.56 \quad 100.0 \%$ pre-rRNA processing protein FTSJ3 GN=FTSJ3 SPB1 HUMAN $96.56 \quad 100.0 \%$ pre-rRNA processing protein FTSJ3 GN=FTSJ3 SPB1_HUMAN $96.56 \quad 100.0 \%$ Presqualene diphosphate phosphatase GN=PPAPDC2 PPAC2_HUMAN $32.19 \quad 100.0 \%$ Presqualene diphosphate phosphatase GN=PPAPDC2 PPAC2_HUMAN $32.19 \quad 100.0 \%$ Probable 28S rRNA (cytosine(4447)-C(5))-methyltransferase GN=NOP2 NOP2_HUMAN $89.30 \quad 100.0 \%$ Probable 28S rRNA (cytosine(4447)-C(5))-methyltransferase GN=NOP2 NOP2_HUMAN $89.30 \quad 100.0^{\circ}$, Probable 28S rRNA (cytosine(4447)-C(5))-methyltransferase GN=NOP2 NOP2 HUMAN $89.30 \quad 100.0 \%$ Probable 28S rRNA (cytosine(4447)-C(5))-methyltransferase GN=NOP2 NOP2_HUMAN $89.30 \quad 100.0 \%$ Probable 28S rRNA (cytosine(4447)-C(5))-methyltransferase GN=NOP2 NOP2 HUMAN $89.30100 .0 \%$ Probable 28S rRNA (cytosine(4447)-C(5))-methyltransferase GN=NOP2 NOP2_HUMAN $89.30 \quad 100.0 \%$ Probable 28S rRNA (cytosine(4447)-C(5))-methyltransferase GN=NOP2 NOP2_HUMAN $89.30 \quad 100.0 \%$

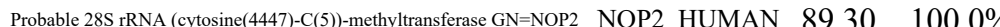
Probable 28S rRNA (cytosine(4447)-C(5))-methyltransferase GN=NOP2 NOP2_HUMAN $89.30 \quad 100.0 \%$ Probable 28S rRNA (cytosine(4447)-C(5))-methyltransferase GN=NOP2 NOP2 HUMAN $89.30 \quad 100.0 \%$ Probable arginine--tRNA ligase, mitochondrial GN=RARS2 SYRM_HUMAN $65.51 \quad 100.0 \%$ Probable arginine--tRNA ligase, mitochondrial GN=RARS2 SYRM_HUMAN $65.51 \quad 100.0 \%$ Probable arginine--tRNA ligase, mitochondrial GN=RARS2 SYRM HUMAN $65.51 \quad 100.0 \%$ Probable arginine--tRNA ligase, mitochondrial GN=RARS2 SYRM_HUMAN $65.51 \quad 100.0 \%$ Probable arginine--tRNA ligase, mitochondrial GN=RARS2 SYRM_HUMAN $65.51 \quad 100.0 \%$ Probable arginine--tRNA ligase, mitochondrial GN=RARS2 SYRM_HUMAN $65.51 \quad 100.0 \%$ Probable arginine--tRNA ligase, mitochondrial GN=RARS2 SYRM_HUMAN $65.51 \quad 100.0 \%$ Probable ATP-dependent RNA helicase DDX17 GN=DDX17 DDX17 HUMAN $80.27100 .0 \%$ Probable ATP-dependent RNA helicase DDX17 GN=DDX17 DDX17_HUMAN $80.27 \quad 100.0 \%$ Probable ATP-dependent RNA helicase DDX17 GN=DDX17 DDX17_HUMAN 80.27 Probable ATP-dependent RNA helicase DDX17 GN=DDX17 DDX17 HUMAN 80.2 Probable ATP-dependent RNA helicase DDX17 GN=DDX17 DDX17_HUMAN 80.27
$40 \quad 122 \quad 0.13 \% \quad 12.9 \%$ FICISDLR

$40 \quad 122 \quad 0.13 \% \quad 12.9 \%$ GYLPSHYER

$0.01 \% \quad 7.0 \%$ HQSFVLVGETGSGK

$0.01 \% \quad 7.0 \%$ VAAMSVAQR

$0.01 \% \quad 7.0 \%$ YGVIILDEAHER

$0.01 \% \quad 7.0 \% \quad$ LQSKEYSQY

$\quad 0.01 \% \quad 16.8 \%$ VAQIQNAGLGEFR

$0.01 \% \quad 16.8 \%$ IRDLNDEINK

$0.01 \% \quad 16.8 \%$ IKELGGPDYGK

$0.00 \% \quad 11.6 \%$ EAAAALVEEETRR

$0.00 \% \quad 11.6 \%$ TIVQLENEIYQIK

$0.01 \% \quad 6.4 \%$ ALPITQHSR

$0.01 \% \quad 6.4 \%$ SSDRLDEAAQR

$0.01 \% \quad 6.4 \%$ LATVVNDERFVSK

$0.01 \% \quad 5.1 \%$ AANPVDFLSK

$0.01 \% \quad 5.1 \% \quad$ ILDPEGLALGAVIASSK

$0.00 \% \quad 6.8 \% \quad$ FEFQSLLSSR

$0.00 \% \quad 6.8 \%$ ATAVDPTCAR

$0.02 \% \quad 13.1 \%$ GAETELVR

$0.02 \% \quad 13.1 \%$ KGPQSLFNAPR

$0.02 \% \quad 13.1 \%$ IQDIVGILR

$0.02 \% \quad 13.1 \%$ NTGVILANDANAER

$0.02 \% \quad 13.1 \%$ NTGVILANDANAERLK

$0.02 \% \quad 13.1 \%$ SVVGNLHR

$0.02 \% \quad 13.1 \%$ GADSELSTVPSVTK

$0.02 \% \quad 13.1 \%$ TQASSSFQDSSQPAGK

$0.01 \% \quad 13.3 \%$ AIACQLSR

$10 \quad 0.01 \% \quad 13.3 \%$ TVLQQVIEDGSK

$10 \quad 0.01 \% \quad 13.3 \%$ IVVEFSSPNVAK

$10 \quad 0.01 \% \quad 13.3 \%$ AAQEFFQR

$10 \quad 0.01 \% \quad 13.3 \%$ GDTGVFLQYTHAR

$10 \quad 0.01 \% \quad 13.3 \%$ TLQIKDSPPEVAGAR

$10 \quad 0.01 \% \quad 13.3 \%$ LLGITPVCR

$16 \quad 42 \quad 0.05 \% \quad 27.8 \%$ NFYVEHPEVAR

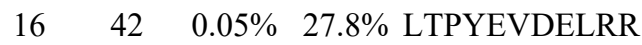

$16 \quad 42 \quad 0.05 \% \quad 27.8 \%$ DMVGIAQTGSGK

$\begin{array}{llll}16 & 42 & 0.05 \% & 27.8 \% \\ 16 & \text { GDGPICLVLAPTR }\end{array}$

$100.0 \% \quad 12$ $100.0 \% \quad 12$
$0.01 \% \quad 7.0 \%$ SNLGSVVLQLKK

$0.01 \% \quad 16.8 \%$ YASETLQAQSEEAR

$0.01 \% \quad 6.4 \%$ YIEFKQGAPKPR

$0.01 \% \quad 6.4 \%$ SHPLPETAVR

$0.01 \% \quad 5.1 \% \quad$ LACDFLAR

$0.01 \% \quad 5.1 \%$ TSVTDFLR

$0.02 \% \quad 13.1 \%$ FLPAVSDENSKR

$0.02 \% \quad 13.1 \%$ GISAGAVQTAGK

$97.3 \% \quad 22.5$

$99.0 \%$

$99.7 \% \quad 31.7$

$99.7 \% \quad 33.9$

$99.7 \% \quad 52.8$

$99.7 \% \quad 35.4$

$99.7 \% \quad 48.0$

$99.7 \% \quad 40.2$

$99.7 \% \quad 62.2$

$96.1 \% \quad 22.8$

$99.7 \% \quad 47.2$

$99.7 \% \quad 66.6$

$97.6 \% \quad 23.5$

$99.7 \% \quad 50.8$

$99.7 \% \quad 33.2$

$99.7 \% 35$.

$95.0 \% 23$.

$99.7 \% \quad 27.4$

$99.7 \% \quad 40.5$

$99.0 \% \quad 24.5$

$99.0 \% \quad 41.7$

$99.7 \% \quad 32.8$

$99.7 \% \quad 53.5$

$99.7 \% \quad 41.7$

$99.6 \% 25.5$

$99.0 \% \quad 31.2$

$99.7 \% \quad 29.8$

$99.7 \% \quad 55.0$

$99.7 \% \quad 49.9$

$99.7 \% \quad 25.9$

$99.7 \% \quad 40.7$

$99.3 \% \quad 23.4$

$99.0 \% \quad 29.8$

$99.7 \% \quad 60.6$

$99.7 \% \quad 43.3$

$99.0 \% \quad 35.3$

$99.7 \% \quad 51.3$

$99.7 \% \quad 58.0$

$99.0 \% \quad 31.5$

$\begin{array}{lll}99.4 \% & 20.8\end{array}$

$99.7 \% 29.1$

$99.7 \% \quad 27.3$

$99.7 \% \quad 45.4$

$97.1 \% \quad 18.0$

$99.7 \% \quad 52.4$

$99.7 \% \quad 36.0$

$0.05 \% \quad 27.8 \%$ ELAQQVQQVADDYGK
$2114 \quad 2121$

$\begin{array}{lll}11.54 & 2250 & 2258 \\ 1445.74 & 153 & 166\end{array}$

$\begin{array}{ccc}948.49 & 196 & 204\end{array}$

$\begin{array}{lll}1414.73 & 254 & 265\end{array}$

$1285.78 \quad 505 \quad 516$

$1145.55 \quad 787 \quad 795$

$\begin{array}{lll}1402.74 & 57 & 69\end{array}$

$\begin{array}{lll}1229.65 & 70 & 79\end{array}$

1176.63

1582.73

1444.74

1590.87

1433.79

1022.57

1106.60

1247.60

1477.80

965.49

938.49

1061.56

1653.94

1213.62

1061.50

874.46

1362.70

1059.58

1214.66

1026.63

1457.73

1698.91

881.50

1390.71

1625.74

918.48

1316.71

1289.71

996.49

1464.72

1581.86

1028.59

1360.66

1390.73

1179.57

1368.73

1691.82
$91 \quad 101$

$267 \quad 280$

$198 \quad 210$

4152

$139 \quad 147$

$158 \quad 167$

$189 \quad 199$

$200 \quad 212$

$252 \quad 259$

$662 \quad 678$

$38 \quad 47$

$48 \quad 57$

$31 \quad 42$

$80 \quad 91$

$92 \quad 102$

$243 \quad 251$

$408 \quad 421$

423

$656 \quad 669$

$670 \quad 685$

111
138

$222 \quad 229$

$457 \quad 469$

$538 \quad 552$

$569 \quad 577$

$133 \quad 143$

$144 \quad 154$

$210 \quad 22$ 
Probable ATP-dependent RNA helicase DDX17 GN=DDX17 DDX17_HUMAN $80.27 \quad 100.0 \%$ Probable ATP-dependent RNA helicase DDX17 GN=DDX17 DDX17_HUMAN $80.27 \quad 100.0 \%$ Probable ATP-dependent RNA helicase DDX17 GN=DDX17 DDX17_HUMAN 80.27 Probable ATP-dependent RNA helicase DDX17 GN=DDX17 DDX17_HUMAN 80.27 Probable ATP-dependent RNA helicase DDX17 GN=DDX17 DDX17_HUMAN 80.27 Probable ATP-dependent RNA helicase DDX17 GN=DDX17 DDX17_HUMAN 80.27 Probable ATP-dependent RNA helicase DDX17 GN=DDX17 DDX17_HUMAN 80.27 Probable ATP-dependent RNA helicase DDX17 GN=DDX17 DDX17_HUMAN 80.27 Probable ATP-dependent RNA helicase DDX17 GN=DDX17 DDX17 HUMAN 80.27 Probable ATP-dependent RNA helicase DDX17 GN=DDX17 DDX17_HUMAN 80.27 Probable ATP-dependent RNA helicase DDX17 GN=DDX17 DDX17_HUMAN 80.27 Probable ATP-dependent RNA helicase DDX17 GN=DDX17 DDX17_HUMAN 80.27 Probable ATP-dependent RNA helicase DDX17 GN=DDX17 DDX17_HUMAN 80.27 Probable ATP-dependent RNA helicase DDX17 GN=DDX17 DDX17_HUMAN 80.27 Probable ATP-dependent RNA helicase DDX17 GN=DDX17 DDX17 HUMAN 80.27 Probable ATP-dependent RNA helicase DDX20 GN=DDX20 DDX20_HUMAN 92.2 Probable ATP-dependent RNA helicase DDX20 GN=DDX20 DDX20_HUMAN 92.24 Probable ATP-dependent RNA helicase DDX23 GN=DDX23 DDX23_HUMAN 95.59 Probable ATP-dependent RNA helicase DDX23 GN=DDX23 DDX23_HUMAN 95.5 Probable ATP-dependent RNA helicase DDX27 GN=DDX27 DDX27_HUMAN 89.84 Probable ATP-dependent RNA helicase DDX27 GN=DDX27 DDX27_HUMAN 89.84 Probable ATP-dependent RNA helicase DDX28 GN=DDX28 DDX28_HUMAN 59.58 Probable ATP-dependent RNA helicase DDX28 GN=DDX28 DDX28_HUMAN 59.58 Probable ATP-dependent RNA helicase DDX28 GN=DDX28 DDX28_HUMAN 59.58 Probable ATP-dependent RNA helicase DDX28 GN=DDX28 DDX28 HUMAN 59.58 Probable ATP-dependent RNA helicase DDX28 GN=DDX28 DDX28_HUMAN 59.58 Probable ATP-dependent RNA helicase DDX28 GN=DDX28 DDX28_HUMAN 59.58 Probable ATP-dependent RNA helicase DDX28 GN=DDX28 DDX28 HUMAN 59.58 Probable ATP-dependent RNA helicase DDX41 GN=DDX41 DDX41_HUMAN 69.84 Probable ATP-dependent RNA helicase DDX41 GN=DDX41 DDX41 HUMAN 69.84 Probable ATP-dependent RNA helicase DDX41 GN=DDX41 DDX41_HUMAN 69.84 Probable ATP-dependent RNA helicase DDX41 GN=DDX41 DDX41_HUMAN 69.84 Probable ATP-dependent RNA helicase DDX46 GN=DDX46 DDX46_HUMAN 117.37 Probable ATP-dependent RNA helicase DDX46 GN=DDX46 DDX46_HUMAN 117.37 Probable ATP-dependent RNA helicase DDX47 GN=DDX47 DDX47_HUMAN 50.65 Probable ATP-dependent RNA helicase DDX47 GN=DDX47 DDX47_HUMAN 50.65 Probable ATP-dependent RNA helicase DDX47 GN=DDX47 DDX47_HUMAN 50.65 Probable ATP-dependent RNA helicase DDX47 GN=DDX47 DDX47_HUMAN 50.65 Probable ATP-dependent RNA helicase DDX47 GN=DDX47 DDX47_HUMAN 50.65 Probable ATP-dependent RNA helicase DDX5 GN=DDX5 DDX5_HUMAN 69.15 Probable ATP-dependent RNA helicase DDX5 GN=DDX5 DDX5_HUMAN 69.15 Probable ATP-dependent RNA helicase DDX5 GN=DDX5 DDX5_HUMAN 69.15 Probable ATP-dependent RNA helicase DDX5 GN=DDX5 DDX5_HUMAN 69.15 Probable ATP-dependent RNA helicase DDX5 GN=DDX5 DDX5 HUMAN 69.1 Probable ATP-dependent RNA helicase DDX5 GN=DDX5 DDX5_HUMAN 69.15 Probable ATP-dependent RNA helicase DDX5 GN=DDX5 DDX5_HUMAN 69.15 Probable ATP-dependent RNA helicase DDX5 GN=DDX5 DDX5_HUMAN 69.15
$100.0 \% \quad 12$

$100.0 \% \quad 12$

$100.0 \% \quad 12$

$100.0 \% \quad 12$

$100.0 \% \quad 12$

$100.0 \% \quad 12$

$100.0 \% \quad 12$

$100.0 \% \quad 12$

$100.0 \% \quad 12$

$100.0 \% \quad 12$

$100.0 \% \quad 12$

$100.0 \% \quad 12$

$100.0 \% \quad 12$

$100.0 \% \quad 2$

$100.0 \% \quad 2$

$100.0 \% \quad 2$

$100.0 \% \quad 2$

$100.0 \%$

$100.0 \%$

$100.0 \%$

$100.0 \%$

$100.0 \%$

$100.0 \%$

$100.0 \%$

$100.0 \%$

$100.0 \%$

$100.0 \%$

$100.0 \%$

$100.0 \%$

$100.0 \%$

$00.0 \%$

$100.0 \%$

$100.0 \%$

$100.0 \%$

$100.0 \%$

$100.0 \% \quad 24$

$100.0 \% \quad 24$

$100.0 \% \quad 24$

$100.0 \% \quad 24$

$100.0 \% \quad 24$

$100.0 \% \quad 24$

$100.0 \% \quad 24$

$100.0 \% \quad 24$
0.05\% 27.8\% LKSTCIYGGAPK

$0.05 \% \quad 27.8 \%$ STCIYGGAPK

$0.05 \% \quad 27.8 \%$ GPQIRDLER

$0.05 \% \quad 27.8 \%$ GVEICIATPGR

$0.05 \% \quad 27.8 \%$ LIDFLESGK

$0.05 \% \quad 27.8 \%$ IVDQIRPDR

$0.05 \% \quad 27.8 \%$ TIIFVETK

$0.05 \% \quad 27.8 \%$ SGKAPILIATDVASR

$0.05 \% \quad 27.8 \%$ APILIATDVASR

$0.05 \% \quad 27.8 \%$ GLDVEDVK

$0.05 \% \quad 27.8 \%$ STNKGTAYTFFTPGNLK

$0.05 \% \quad 27.8 \%$ GTAYTFFTPGNLK

$0.05 \% \quad 27.8 \%$ VLEEANQAINPK

$0.05 \% \quad 27.8 \%$ LMQLVDHRGGGGGGGGR

$0.05 \% \quad 27.8 \%$ SSQSSSQQFSGIGR

$0.01 \% \quad 2.3 \% \quad$ TAQDLSSPR

$0.01 \% \quad 2.3 \%$ VLISTDLTSR

$0.00 \% \quad 2.8 \%$ AGAKDILVATDVAGR

$0.00 \% \quad 2.8 \%$ NIEDYIHR

$0.00 \% \quad 2.8 \%$ AAPDILIATPGR

$0.00 \% \quad 2.8 \%$ ALQEFDLALR

$0.01 \% \quad 13.3 \%$ SPDEPLPVVR

$0.01 \% \quad 13.3 \%$ RPELNQPAR

$0.01 \% \quad 13.3 \%$ GSFADLGLEPR

$0.01 \% \quad 13.3 \%$ AVAQPLGR

$0.01 \% \quad 13.3 \%$ VASPDAVTTITSSK

$0.01 \% \quad 13.3 \%$ VGIFQSFQK

$0.01 \% \quad 13.3 \%$ DILLCTDIASR

$0.01 \% \quad 7.6 \%$ EGPYGLIICPSR

$0.01 \% \quad 7.6 \%$ LLQEDSSPLLR

$0.01 \% \quad 7.6 \%$ SALVKPVTINVGR

$0.01 \% \quad 7.6 \%$ TPPPVLIFAEK

$0.00 \% \quad 2.2 \%$ GAEIIVCTPGR

$0.00 \% \quad 2.2 \%$ GGTILAPTVSAK

$0.01 \% \quad 12.5 \%$ LFALVLTPTR

$0.01 \% \quad 12.5 \%$ KPHIIIATPGR

$0.01 \% \quad 12.5 \%$ LIDHLENTKGFNLR

$9 \quad 0.01 \% \quad 12.5 \%$ LQQYYIFIPSK

$0.01 \% \quad 12.5 \%$ SILLATDVASR

$129 \quad 0.14 \% \quad 33.6 \%$ DRGFGAPR

$129 \quad 0.14 \% \quad 33.6 \%$ FGNPGEKLVK

$129 \quad 0.14 \% \quad 33.6 \%$ NFYQEHPDLAR

$129 \quad 0.14 \% \quad 33.6 \%$ NFYQEHPDLARR

$129 \quad 0.14 \% \quad 33.6 \%$ TAQEVETYR

$129 \quad 0.14 \% \quad 33.6 \%$ TAQEVETYRR

$129 \quad 0.14 \% \quad 33.6 \%$ GDGPICLVLAPTR

$129 \quad 0.14 \% \quad 33.6 \%$ ELAQQVQQVAAEYCR $\begin{array}{lllll}99.7 \% & 59.7 & 25.0 & 53.5 & 6\end{array}$

$99.7 \% \quad 53.6 \quad 25.0 \quad 45.3$

$\begin{array}{llll}99.7 \% & 31.0 & 25.0 & 19.8\end{array}$

$99.7 \% \quad 57.6 \quad 25.0 \quad 39.7$

$\begin{array}{llll}99.7 \% & 32.8 & 25.0 & 29.1\end{array}$

$\begin{array}{lllll}99.4 \% & 21.3 & 25.0 & 18.1\end{array}$

$\begin{array}{llll}99.0 \% & 18.5 & 25.0 & 18.5\end{array}$

$\begin{array}{lllll}99.7 \% & 64.0 & 25.0 & 64.0 & 2\end{array}$

$\begin{array}{lllll}99.7 \% & 55.7 & 25.0 & 55.7 & 20\end{array}$

$\begin{array}{llll}97.5 \% & 20.2 & 25.0 & 14.8\end{array}$

$\begin{array}{llll}99.7 \% & 71.5 & 25.0 & 71.5\end{array}$

$\begin{array}{llll}99.7 \% & 45.6 & 25.0 & 33.5\end{array}$

$\begin{array}{llll}99.7 \% & 54.3 & 25.0 & 48.6\end{array}$

$\begin{array}{llll}.6 \% & 24.0 & 25.0 & 17.8\end{array}$

$\begin{array}{llll}99.7 \% & 43.8 & 25.0 & 43.5\end{array}$

$\begin{array}{llll}99.7 \% & 45.1 & 25.0 & 27.7\end{array}$

$\begin{array}{llll}99.7 \% & 33.3 & 25.0 & 33.3\end{array}$

$\begin{array}{llll}99.7 \% & 56.3 & 25.0 & 47.6\end{array}$

$\begin{array}{llll}99.0 \% & 35.4 & 25.0 & 22.5\end{array}$

$\begin{array}{llll}99.7 \% & 41.5 & 25.0 & 27.2\end{array}$

$\begin{array}{llll}98.9 \% & 27.7 & 25.0 & 20.2\end{array}$

$\begin{array}{llll}99.6 \% & 26.5 & 25.0 & 26.5\end{array}$

$\begin{array}{llll}99.7 \% & 52.4 & 25.0 & 39.8\end{array}$

$\begin{array}{llll}99.7 \% & 52.7 & 25.0 & 44.0\end{array}$

$99.0 \% \quad 24.0 \quad 25.0 \quad 24.0$

$\begin{array}{lllll}99.7 \% & 62.5 & 25.0 & 52.1\end{array}$

$\begin{array}{llll}98.4 \% & 18.9 & 25.0 & 15.9\end{array}$

$\begin{array}{llll}99.7 \% & 37.4 & 25.0 & 37.4\end{array}$

$\begin{array}{llll}96.4 \% & 26.4 & 25.0 & 26.2\end{array}$

$\begin{array}{llll}99.7 \% & 36.2 & 25.0 & 27.9\end{array}$

$\begin{array}{llll}99.7 \% & 35.3 & 25.0 & 35.3\end{array}$

$\begin{array}{llll}99.0 \% & 19.5 & 25.0 & 19.5\end{array}$

$\begin{array}{llll}99.7 \% & 44.5 & 25.0 & 36.2\end{array}$

$\begin{array}{llll}99.7 \% & 41.1 & 25.0 & 29.6\end{array}$

$\begin{array}{llll}99.7 \% & 43.1 & 25.0 & 37.3\end{array}$

$\begin{array}{llll}99.7 \% & 34.9 & 25.0 & 34.9\end{array}$

$97.6 \% \quad 17.6 \quad 25.0 \quad 17.6$

$99.7 \% \quad 35.2 \quad 25.0 \quad 22.2$

$\begin{array}{llll}99.7 \% & 54.9 & 25.0 & 49.1\end{array}$

$\begin{array}{llll}99.0 \% & 22.5 & 25.0 & 17.9\end{array}$

$\begin{array}{llll}99.7 \% & 33.0 & 25.0 & 26.2\end{array}$

$\begin{array}{llll}99.7 \% & 51.5 & 25.0 & 44.8\end{array}$

$\begin{array}{llll}99.6 \% & 25.3 & 25.0 & 20.3\end{array}$

$\begin{array}{llll}99.7 \% & 51.5 & 25.0 & 40.7\end{array}$

$\begin{array}{llll}99.6 \% & 23.6 & 25.0 & 23.6\end{array}$

$\begin{array}{llll}99.7 \% & 36.0 & 25.0 & 33.2\end{array}$

$\begin{array}{llll}99.7 \% & 55.3 & 25.0 & 55.3\end{array}$

3
0
0
0
0
0
0
2
0
0
1
0
0
4
0
0
0
0
0
0
0
0
0
0
0
0
0
0
0
0
4
0
0
0
0
0
2
1
0
0
0
0
0
0
0
0
0
0
0
0
0
0
0
0
0
0

1053.50

1083.59

1172.61

1021.56

1111.62

950.56

1498.86

1226.71

874.45

1846.93

1416.72

1325.71

1623.81

1455.68

974.49

1104.63

1456.81

1059.52

1194.68

1175.64

1108.60

1080.59

1161.59

811.48

1376.73

1053.57

1276.66

1361.69

1270.70

1353.82

1211.70

1172.61

1114.65

1130.69

1202.74

1669.90

1399.76

1145.65

875.45

1088.61

1389.65

1545.76

1096.53

1252.63

1368.73

1792.86 \begin{tabular}{ll}
275 & 284 \\
285 & 293 \\
94 & 3 \\
305 & 3 \\
342 & 3 \\
21 & 428 \\
666 & 480 \\
69 & 4 \\
81 & 488 \\
12 & 528 \\
16 & 5 \\
536 & 5 \\
548 & 564 \\
671 & 684 \\
42 & 50 \\
62 & 371 \\
12 & 726 \\
744 & 751 \\
338 & 3 \\
667 & 676 \\
28 & 37 \\
73 & 81 \\
26 & 136 \\
21 & 228 \\
344 & 3 \\
37 & 4 \\
49 & 459 \\
256 & 267 \\
283 & 293 \\
388 & 400 \\
431 & 441 \\
495 & 505 \\
883 & 894 \\
93 & 102 \\
42 & 152 \\
53 & 166 \\
238 & 2 \\
315 & 325 \\
13 & 20 \\
34 & 43 \\
57 & 67 \\
57 & 68 \\
69 & 77 \\
69 & 78 \\
78 & 177 \\
& 192 \\
\hline
\end{tabular} 
Probable ATP-dependent RNA helicase DDX5 GN=DDX5 DDX5_HUMAN $69.15 \quad 100.0 \% \quad 24$ $\begin{array}{lllll}\text { Probable ATP-dependent RNA helicase DDX5 GN=DDX5 } & \text { DDX5_HUMAN } & 69.15 & 100.0 \% & 24 \\ \text { Probable ATP-dependent RNA helicase DDX5 GN=DDX5 } & \text { DDX5_HUMAN } & 69.15 & 100.0 \% & 24\end{array}$ Probable ATP-dependent RNA helicase DDX5 GN=DDX5 DDX5_HUMAN $69.15 \quad 100.0 \% \quad 24$ Probable ATP-dependent RNA helicase DDX5 GN=DDX5 DDX5 HUMAN $69.15 \quad 100.0 \%$ Probable ATP-dependent RNA helicase DDX5 GN=DDX5 DDX5_HUMAN $69.15 \quad 100.0 \% \quad 24$ Probable ATP-dependent RNA helicase DDX5 GN=DDX5 DDX5_HUMAN $69.15 \quad 100.0 \% 24$ Probable ATP-dependent RNA helicase DDX5 GN=DDX5 DDX5_HUMAN $69.15 \quad 100.0 \% \quad 24$ Probable ATP-dependent RNA helicase DDX5 GN=DDX5 DDX5_HUMAN $69.15 \quad 100.0 \% \quad 24$ Probable ATP-dependent RNA helicase DDX5 GN=DDX5 DDX5_HUMAN $69.15 \quad 100.0 \% \quad 24$ Probable ATP-dependent RNA helicase DDX5 GN=DDX5 DDX5_HUMAN $69.15 \quad 100.0 \% 24$ Probable ATP-dependent RNA helicase DDX5 GN=DDX5 DDX5_HUMAN $69.15 \quad 100.0 \% 24$ Probable ATP-dependent RNA helicase DDX5 GN=DDX5 DDX5_HUMAN $69.15 \quad 100.0 \% 24$ Probable ATP-dependent RNA helicase DDX5 GN=DDX5 DDX5_HUMAN $69.15 \quad 100.0 \% \quad 24$ Probable ATP-dependent RNA helicase DDX5 GN=DDX5 DDX5_HUMAN $69.15 \quad 100.0 \% \quad 24$ Probable ATP-dependent RNA helicase DDX5 GN=DDX5 DDX5_HUMAN $69.15 \quad 100.0 \% \quad 24$ Probable ATP-dependent RNA helicase DDX5 GN=DDX5 DDX5_HUMAN $69.15 \quad 100.0 \% \quad 24$ Probable ATP-dependent RNA helicase DDX52 GN=DDX52 DDX52 HUMAN $67.50 \quad 100.0 \%$ Probable ATP-dependent RNA helicase DDX52 GN=DDX52 DDX52_HUMAN $67.50 \quad 100.0 \%$ Probable ATP-dependent RNA helicase DDX52 GN=DDX52 DDX52_HUMAN $67.50 \quad 100.0 \%$ Probable ATP-dependent RNA helicase DDX56 GN=DDX56 DDX56 HUMAN $61.59 \quad 100.0 \%$ Probable ATP-dependent RNA helicase DDX56 GN=DDX56 DDX56_HUMAN $61.59 \quad 100.0 \%$ Probable ATP-dependent RNA helicase DHX37 GN=DHX37 DHX37 HUMAN $129.55 \quad 100.0 \%$ Probable ATP-dependent RNA helicase DHX37 GN=DHX37 DHX37_HUMAN $129.55 \quad 100.0 \%$ Probable ATP-dependent RNA helicase DHX37 GN=DHX37 DHX37_HUMAN $129.55 \quad 100.0 \%$ Probable ATP-dependent RNA helicase YTHDC2 GN=YTHDC2 YTDC2 HUMAN $160.25 \quad 100.0 \%$ Probable ATP-dependent RNA helicase YTHDC2 GN=YTHDC2 YTDC2_HUMAN $160.25 \quad 100.0 \%$ Probable ATP-dependent RNA helicase YTHDC2 GN=YTHDC2 YTDC2_HUMAN $160.25100 .0 \%$ Probable ATP-dependent RNA helicase YTHDC2 GN=YTHDC2 YTDC2 HUMAN $160.25100 .0 \%$ Probable ATP-dependent RNA helicase YTHDC2 GN=YTHDC2 YTDC2_HUMAN $160.25 \quad 100.0 \%$ Probable ATP-dependent RNA helicase YTHDC2 GN=YTHDC2 YTDC2 HUMAN $160.25100 .0 \%$ Probable ATP-dependent RNA helicase YTHDC2 GN=YTHDC2 YTDC2_HUMAN $160.25 \quad 100.0 \%$ Probable cytosolic iron-sulfur protein assembly protein CIAOI GN=CIAO1 CIAO1_HUMAN $37.84 \quad 100.0 \%$ Probable cytosolic ino-sulfur protin asembly proin CIAOI GN=CIAO1 CIAO1_HUMAN $37.84 \quad 100.0^{\circ}$ Probable cytosolic iron-sulfur protein assembly protein $\mathrm{CIAOI}$ GN=CIAO1 CIAO1_HUMAN $37.84 \quad 100.0 \%$ Probable dimethyladenosine transferase GN=DIMT1 DIM1_HUMAN $35.24 \quad 100.0 \%$ Probable dimethyladenosine transferase GN=DIMT1 DIM1_HUMAN $35.24 \quad 100.0 \%$ Probable dimethyladenosine transferase GN=DIMT1 DIM1_HUMAN $35.24 \quad 100.0 \%$ Probable dimethyladenosine transferase GN=DIMT1 DIM1 HUMAN $35.24 \quad 100.0 \%$ Probable dimethyladenosine transferase GN=DIMT1 DIM1_HUMAN $35.24 \quad 100.0 \%$ Probable dimethyladenosine transferase GN=DIMT1 DIM1_HUMAN $35.24 \quad 100.0 \%$ Probable dimethyladenosine transferase GN=DIMT1 DIM1_HUMAN $35.24 \quad 100.0 \%$ Probable dimethyladenosine transferase GN=DIMT1 DIM1_HUMAN $35.24 \quad 100.0 \%$ Probable dimethyladenosine transferase GN=DIMT1 DIM1_HUMAN $35.24 \quad 100.0 \%$ Probable dimethyladenosine transferase GN=DIMT1 DIM1_HUMAN $35.24 \quad 100.0 \%$ Probable glutamate--tRNA ligase, mitochondrial GN=EARS2 SYEM_HUMAN $58.69 \quad 100.0 \%$ Probable glutamate--tRNA ligase, mitochondrial GN=EARS2 SYEM HUMAN 58.69 Probable glutamate--tRNA ligase, mitochondrial GN=EARS2 SYEM_HUMAN 58.69

4

7

7

7

7
7
3

3

3
3

$29 \quad 0.14 \% \quad 33.6 \%$ LKSTCIYGGAPK

$129 \quad 0.14 \% \quad 33.6 \%$ STCIYGGAPK

$129 \quad 0.14 \% \quad 33.6 \%$ GPQIRDLER

$129 \quad 0.14 \% \quad 33.6 \%$ GVEICIATPGR

$129 \quad 0.14 \% \quad 33.6 \%$ LIDFLECGK

$129 \quad 0.14 \% \quad 33.6 \%$ TTYLVLDEADR

$129 \quad 0.14 \% \quad 33.6 \%$ IVDQIRPDR

$129 \quad 0.14 \% \quad 33.6 \%$ LMEEIMSEKENK

$129 \quad 0.14 \% \quad 33.6 \%$ TIVFVETK

$129 \quad 0.14 \% \quad 33.6 \%$ TIVFVETKR

$129 \quad 0.14 \% \quad 33.6 \%$ APILIATDVASR

$129 \quad 0.14 \% \quad 33.6 \%$ GLDVEDVK

$129 \quad 0.14 \% \quad 33.6 \%$ TGTAYTFFTPNNIK

$129 \quad 0.14 \% \quad 33.6 \%$ QVSDLISVLR

$129 \quad 0.14 \% \quad 33.6 \%$ LLQLVEDR

$129 \quad 0.14 \% \quad 33.6 \%$ LLQLVEDRGSGR

$6 \quad 0.01 \% \quad 5.2 \%$ ELLASAPTGSGK

$6.01 \% \quad 5.2 \%$ ISEGTGFR

$6 \quad 0.01 \% \quad 5.2 \% \quad$ KFDILVTTPNR

$4 \quad 0.00 \% \quad 4.6 \%$ ATGPVVEQAVR

$4 \quad 0.00 \% \quad 4.6 \% \quad$ VANVSAAEDSVSQR

$0.01 \% \quad 2.9 \% \quad$ LSCPITALGR

$0.01 \% \quad 2.9 \% \quad$ TMATFPVAPR

$0.01 \% \quad 2.9 \% \quad$ MQPPTESQVTYLR

$10 \quad 0.01 \% \quad 5.1 \%$ LSQSLGLVSK

$10 \quad 0.01 \% \quad 5.1 \%$ LAAIAVAER

$10 \quad 0.01 \% \quad 5.1 \%$ TTGYTNKEMLK

$10 \quad 0.01 \% \quad 5.1 \% \quad$ MVLCAVVLK

$10 \quad 0.01 \% \quad 5.1 \%$ TQLLGQLR

$10 \quad 0.01 \% \quad 5.1 \%$ FHPASVLSQPQYK

$10 \quad 0.01 \% \quad 5.1 \% \quad$ LASNALQEPSSFR

$5 \quad 0.01 \% \quad 8.9 \%$ MKDSLVLLGR

$0.01 \% \quad 8.9 \%$ SVLSEGHQR

$\begin{array}{llll}0.01 \% & 8.9 \% & \text { CICTLSGFHSR }\end{array}$

$0.02 \% \quad 37.7 \%$ SAGGLMFNTGIGQHILK

$0.02 \% \quad 37.7 \%$ NPLIINSIIDK

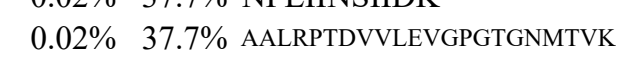

$0.02 \% \quad 37.7 \%$ LVAELHKR

$\begin{array}{lll}0.02 \% & 37.7 \% \text { LQVLVGDVLK }\end{array}$

$0.02 \% \quad 37.7 \%$ LSINTQLLAR

$0.02 \% \quad 37.7 \%$ NNFRPPPK

$0.02 \% \quad 37.7 \%$ SSAVQQLLEK

$0.02 \% \quad 37.7 \%$ SMDIDDFIR

$0.02 \% \quad 37.7 \%$ LLHGFNAEGIHFS

$0.01 \% \quad 8.6 \%$ FAPSPTGFLHLGGLR

$0.01 \% \quad 8.6 \%$ TALYNYIFAK

$0.01 \% \quad 8.6 \%$ EALRNHQTPR $\begin{array}{lllll}99.7 \% & 59.7 & 25.0 & 53.5 & 6\end{array}$

$99.7 \% \quad 53.6 \quad 25.0 \quad 45.3$

$\begin{array}{llll}99.7 \% & 31.0 & 25.0 & 19.8\end{array}$

$99.7 \% \quad 57.6 \quad 25.0 \quad 39.7$

$99.7 \% \quad 46.6 \quad 25.0 \quad 46.0$

$\begin{array}{llll}99.7 \% & 60.4 & 25.0 & 48.9\end{array}$

$\begin{array}{llll}99.4 \% & 21.3 & 25.0 & 18.1\end{array}$

$99.7 \% \quad 35.1 \quad 25.0 \quad 29.1$

$\begin{array}{llll}98.8 \% & 26.4 & 25.0 & 21.0\end{array}$

$\begin{array}{llll}99.7 \% & 28.2 & 25.0 & 28.2\end{array}$

$\begin{array}{lllll}99.7 \% & 55.7 & 25.0 & 55.7 & 20\end{array}$

$\begin{array}{llll}97.5 \% & 20.2 & 25.0 & 14.8\end{array}$

$99.7 \% \quad 51.1 \quad 25.0 \quad 48.7$

$\begin{array}{llll}99.7 \% & 45.2 & 25.0 & 36.6\end{array}$

$99.0 \% \quad 58.8 \quad 25.0 \quad 41.5$

$\begin{array}{llll}99.7 \% & 49.7 & 25.0 & 45.6\end{array}$

$99.7 \% \quad 44.2 \quad 25.0 \quad 38.4$

$99.0 \% \quad 33.6 \quad 25.0 \quad 23.0$

$\begin{array}{llll}99.7 \% & 44.3 & 25.0 & 38.7\end{array}$

$99.7 \% \quad 32.9 \quad 25.0 \quad 28.2$

$\begin{array}{llll}99.7 \% & 67.2 & 25.0 & 62.2\end{array}$

$99.4 \% \quad 27.6 \quad 25.0 \quad 21.5$

$99.7 \% \quad 45.9 \quad 25.0 \quad 40.2$

$\begin{array}{llll}97.7 \% & 21.2 & 25.0 & 13.3\end{array}$

$99.7 \% \quad 61.8 \quad 25.0 \quad 49.8$

$\begin{array}{llll}99.7 \% & 55.9 & 25.0 & 34.3\end{array}$

$\begin{array}{llll}99.5 \% & 21.1 & 25.0 & 21.1\end{array}$

$\begin{array}{llll}98.2 \% & 16.9 & 25.0 & 16.3\end{array}$

$\begin{array}{llll}98.1 \% & 24.1 & 25.0 & 12.4\end{array}$

$98.1 \% \quad 21.4 \quad 25.0 \quad 21.4$

$\begin{array}{llll}98.9 \% & 21.2 & 25.0 & 16.6\end{array}$

$\begin{array}{llll}99.7 \% & 27.8 & 25.0 & 27.8\end{array}$

$\begin{array}{llll}99.7 \% & 40.9 & 25.0 & 26.9\end{array}$

$\begin{array}{llll}98.8 \% & 32.8 & 25.0 & 24.8\end{array}$

$\begin{array}{llll}99.7 \% & 32.1 & 25.0 & 32.1\end{array}$

$\begin{array}{llll}99.7 \% & 71.6 & 25.0 & 67.7\end{array}$

$99.7 \% \quad 41.3$

$\begin{array}{llll}99.0 \% & 28.4 & 25.0 & 21.0\end{array}$

$\begin{array}{llll}99.7 \% & 57.3 & 25.0 & 27.2\end{array}$

$\begin{array}{llll}99.7 \% & 71.1 & 25.0 & 62.4\end{array}$

$\begin{array}{llll}98.9 \% & 22.9 & 25.0 & 22.9\end{array}$

$99.7 \% \quad 57.3 \quad 25.0 \quad 42.0$

$\begin{array}{llll}99.7 \% & 40.7 & 25.0 & 34.2\end{array}$

$\begin{array}{llll}99.7 \% & 37.8 & 25.0 & 37.4\end{array}$

$\begin{array}{llll}95.6 \% & 15.9 & 25.0 & 15.9\end{array}$

$\begin{array}{llll}99.7 \% & 52.0 & 25.0 & 45.0\end{array}$

$\begin{array}{llll}98.3 \% & 21.1 & 25.0 & 15.9\end{array}$
1053.50

1083.59

1172.61

1094.56

1295.65

1111.62

1480.70

936.54

1092.64

1226.71

874.45

1574.79

1129.66

985.57

1342.74

1130.61

866.44

1303.74

1126.62

1432.70

1087.59

1090.57

1565.76

1031.61

913.55

1285.65

1032.59

928.56

1501.78

1419.72

1147.65

1012.52

1337.61

1759.92

1239.73

2241.19

965.59

1083.68

1128.67

969.53

1102.61

1127.50

1441.72

1569.85

1203.64

1221.64

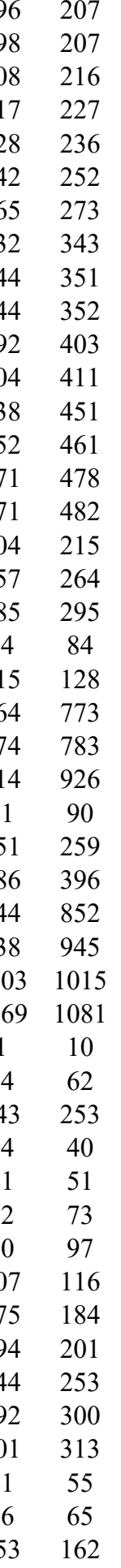

Page 118 of Table S-1-5 
Probable glutamate--tRNA ligase, mitochondrial GN=EARS2 SYEM HUMAN $58.69 \quad 100.0 \%$ Probable methyltransferase-like protein 15 GN=METTL15 MET15_HUMAN $46.12 \quad 100.0 \%$ Probable methyltransferase-like protein 15 GN=METTL15 MET15_HUMAN $46.12 \quad 100.0 \%$ Probable methyltransferase-like protein 15 GN=METTL15 MET15_HUMAN $46.12 \quad 100.0 \%$ Probable methyltransferase-like protein 15 GN=METTL15 MET15_HUMAN $46.12 \quad 100.0 \%$ Probable methyltransferase-like protein 15 GN=METTL15 MET15_HUMAN $46.12 \quad 100.0 \%$ Probable proline--tRNA ligase, mitochondrial GN=PARS2 SYPM_HUMAN $53.26 \quad 100.0 \%$ Probable proline--tRNA ligase, mitochondrial GN=PARS2 SYPM_HUMAN $53.26 \quad 100.0 \%$ Probable rRNA-processing protein EBP2 GN=EBNA1BP2 EBP2 HUMAN $34.85 \quad 100.0 \%$ Probable rRNA-processing protein EBP2 GN=EBNA1BP2 EBP2_HUMAN $34.85 \quad 100.0 \%$ Probable rRNA-processing protein EBP2 GN=EBNA1BP2 EBP2_HUMAN $34.85 \quad 100.0 \%$ Probable rRNA-processing protein EBP2 GN=EBNA1BP2 EBP2_HUMAN $34.85100 .0 \%$ Probable rRNA-processing protein EBP2 GN=EBNA1BP2 EBP2_HUMAN $34.85 \quad 100.0 \%$ Probable rRNA-processing protein EBP2 GN=EBNA1BP2 EBP2_HUMAN $34.85 \quad 100.0 \%$ Probable serine carboxypeptidase CPVL GN=CPVL CPVL_HUMAN $54.17 \quad 100.0 \%$ Probable serine carboxypeptidase CPVL GN=CPVL CPVL_HUMAN $54.17 \quad 100.0 \%$ Probable serine carboxypeptidase CPVL GN=CPVL CPVL HUMAN $54.17 \quad 100.0 \%$ Probable tRNA N6-adenosine threonylcarbamoyltransferase GN=OSGEP OSGEP_HUMAN $36.43 \quad 100.0 \%$ Probable tRNA N6-adenosine threonylcarbamoyltransferase GN=OSGEP OSGEP_HUMAN $36.43 \quad 100.0 \%$ Probable tRNA N6-adenosine threonylcarbamoyltransferase GN=OSGEP OSGEP_HUMAN $36.43 \quad 100.0 \%$ Probable tRNA N6-adenosine threonylcarbamoyltransferase GN=OSGEP OSGEP_HUMAN $36.43 \quad 100.0 \%$ Probable tRNA N6-adenosine threonylcarbamoyltransferase GN=OSGEP OSGEP HUMAN $36.43100 .0 \%$ Probable tRNA N6-adenosine threonylcarbamoyltransferase GN=OSGEP OSGEP_HUMAN $36.43 \quad 100.0 \%$ Probable tRNA N6-adenosine threonylcarbamoyltransferase GN=OSGEP OSGEP_HUMAN $36.43 \quad 100.0 \%$ Probable tRNA pseudouridine synthase 1 GN=TRUB1 TRUB1_HUMAN $37.25 \quad 100.0^{\circ}$ Probable tRNA pseudouridine synthase 1 GN=TRUB1 TRUB1_HUMAN $37.25 \quad 100.0 \%$ Probable tRNA pseudouridine synthase 2 GN=TRUB2 TRUB2_HUMAN $36.70 \quad 100.0 \%$ Probable tRNA pseudouridine synthase 2 GN=TRUB2 TRUB2_HUMAN $36.70 \quad 100.0 \%$ Probable tRNA pseudouridine synthase 2 GN=TRUB2 TRUB2_HUMAN $36.70 \quad 100.0 \%$ Probable ubiquitin carboxyl-terminal hydrolase FAF-X GN=USP9X USP9X_HUMAN $292.28 \quad 100.0^{\circ}$ Probable ubiquitin carboxyl-terminal hydrolase FAF-X GN=USP9X USP9X_HUMAN $292.28 \quad 100.0 \%$ Probable ubiquitin carboxyl-terminal hydrolase FAF-X GN=USP9X USP9X_HUMAN $292.28 \quad 100.0 \%$ Probable ubiquitin carboxyl-terminal hydrolase FAF-X GN=USP9X USP9X_HUMAN $292.28100 .0 \%$ Probable ubiquitin carboxyl-terminal hydrolase FAF-X GN=USP9X USP9X_HUMAN $292.28 \quad 100.0 \%$ Probable ubiquitin carboxyl-terminal hydrolase FAF-X GN=USP9X USP9X_HUMAN $292.28100 .0 \%$ Probable ubiquitin carboxyl-terminal hydrolase FAF-X GN=USP9X USP9X_HUMAN $292.28 \quad 100.0 \%$ Probable ubiquitin carboxyl-terminal hydrolase FAF-X GN=USP9X USP9X_HUMAN $292.28 \quad 100.0 \%$ Probable ubiquitin carboxyl-terminal hydrolase FAF-X GN=USP9X USP9X HUMAN $292.28100 .0 \%$ Probable ubiquitin carboxyl-terminal hydrolase FAF-X GN=USP9X USP9X_HUMAN $292.28 \quad 100.0 \%$ Programmed cell death 6-interacting protein GN=PDCD6IP PDC6I_HUMAN $96.03 \quad 100.0 \%$ Programmed cell death 6-interacting protein GN=PDCD6IP PDC6I_HUMAN 96.03 100.0\% Programmed cell death 6-interacting protein GN=PDCD6IP PDC6I_HUMAN 96.03 $100.0 \%$ Prohibitin GN=PHB Prohibitin GN=PHB Prohibitin GN=PHB Prohibitin $\mathrm{GN}=\mathrm{PHB}$ Prohibitin GN=PHB
$0.02 \% \quad 21.6 \%$ VQTEVLQK

$0.02 \% \quad 21.6 \%$ ESYDDVSSFR

$3 \quad 0.01 \% \quad 32.2 \%$ PAVLGFEGSANK

PHB HUMAN $29.80 \quad 100.0 \%$

PHB_HUMAN $29.80 \quad 100.0 \%$

PHB_HUMAN $29.80 \quad 100.0 \% \quad 20$

PHB HUMAN $29.80 \quad 100.0 \% \quad 20$ PHB_HUMAN $29.80 \quad 100.0 \% \quad 20$
$0.01 \% \quad 8.6 \% \quad$ NMSQEQVAQK

$0.01 \% \quad 17.0 \%$ EQTDQTQAQELHR

$0.01 \% \quad 17.0 \%$ AMLGQFSQAEALLMK

$0.01 \% \quad 17.0 \%$ IFVNNELNELYTGLK

$0.01 \% \quad 17.0 \%$ LVALSFHSLEDR

$0.01 \% \quad 17.0 \%$ VLSPQDQDVQDNPR

$0.00 \% \quad 5.1 \%$ VIDQEMQAIGGQK

$0.00 \% \quad 5.1 \%$ QLPFLLYQVTR

$0.02 \% 21.6 \%$ GLLKPGLNVVLEGPK

$0.02 \% \quad 21.6 \%$ AVDPEDDFQR

$0.02 \% \quad 21.6 \%$ QAQAAVLAVLPR

$0.02 \% \quad 21.6 \%$ RPTDYFAEMAK

$0.01 \% \quad 6.9 \% \quad$ CTEPEDQLYYVK

$0.01 \% \quad 6.9 \%$ FLSLPEVR

$0.01 \% \quad 6.9 \%$ GGGHILPYDQPLR

$0.01 \% \quad 32.2 \%$ TYVTPPGTGFLPGDTAR

$0.01 \% \quad 32.2 \%$ GPGMGAPLVSVAVVAR

$0.01 \% \quad 32.2 \%$ LITGATSPTVLYVSGGNTQVIAYSEHR

$0.01 \% 32.2 \%$ IFGETIDIAVGNCLDR

$0.01 \% \quad 32.2 \%$ LVELPYTVK

$0.01 \% \quad 32.2 \%$ TPLSDSGVTQR

$0.00 \% \quad 6.3 \% \quad$ GPTSAELLNR

$0.00 \% \quad 6.3 \%$ GVLVVGIGSGTK

$0.01 \% \quad 10.0 \%$ DTVELQLLK

$0.01 \% \quad 10.0 \%$ DGFFTLDSALLR

$0.01 \% \quad 10.0 \%$ AATPQVAAELEK

$0.03 \% \quad 4.1 \%$ LVELCVAK

$0.03 \% \quad 4.1 \% \quad$ LLQISSFNGK

$0.03 \% \quad 4.1 \%$ VISSVSYYTHR

$0.03 \% \quad 4.1 \% \quad$ YSHVQEVQER

$0.03 \% \quad 4.1 \%$ VVIQSNDDIASR

$0.03 \% \quad 4.1 \%$ LAQQISDEASR

$0.03 \% \quad 4.1 \%$ HSGDYFTLLR

$0.03 \% \quad 4.1 \%$ ELLAFQTSEK

$0.03 \% \quad 4.1 \%$ VLGGSFADQK

$0.03 \% \quad 4.1 \% \quad$ IIEDCSNSEETVK

$0.01 \% \quad 4.0 \%$ TSEVDLAKPLVK

$0.01 \% \quad 4.0 \%$ TMQGSEVVNVLK

$0.01 \% \quad 4.0 \%$ NIQVSHQEFSK

$95.7 \% \quad 16.6 \quad 25.0 \quad 13.4$

$99.7 \% \quad 46.7 \quad 25.0 \quad 43.0$

$\begin{array}{lllll}99.7 \% & 65.7 & 25.0 & 60.1 & 2\end{array}$

$\begin{array}{ll}99.7 \% & 60.5 \\ 99.7 \% & 53.8\end{array}$

$99.4 \% \quad 45.0$

$0.09 \% \quad 66.5 \%$ FGLALAVAGGVVNSALYNVDAGHR $\quad 99.7 \% \quad 52.8$

$98.4 \% \quad 25.0$

$0.09 \% \quad 66.5 \%$ NVPVITGSKDL

$0.09 \% \quad 66.5 \%$ DLQNVNITLR

$0.09 \% \quad 66.5 \%$ ILFRPVASQLPR
$99.7 \% \quad 50.0$

$99.7 \% \quad 55.0 \quad 25.0 \quad 55.0$

$99.7 \% \quad 47.0 \quad 25.0 \quad 36.2$

$99.7 \% \quad 71.1 \quad 25.0 \quad 59.9$

$99.7 \% \quad 67.2 \quad 25.0 \quad 58.4$

$99.7 \% \quad 34.7 \quad 25.0 \quad 34.7$

$99.6 \% \quad 23.2 \quad 25.0 \quad 23.2$

$\begin{array}{llll}99.7 \% & 53.7 & 25.0 & 53.7\end{array}$

$99.7 \% \quad 32.8 \quad 25.0 \quad 31.1$

$99.7 \% \quad 46.6$

$99.7 \% \quad 32.5$

$99.0 \% \quad 41.0$

$99.7 \% \quad 32.3$

$99.7 \% \quad 60.3$

$99.7 \% \quad 32.4$

$99.7 \% \quad 63.1$

$99.7 \% \quad 28.8$

$99.7 \% \quad 50.9$

$99.7 \% \quad 60.6$

$99.7 \% \quad 55.5$

$\begin{array}{lll}99.7 \% & 31.2\end{array}$

$99.7 \% \quad 55.8$

$98.9 \% \quad 27.4$

$97.9 \% 23.8$

$98.1 \% \quad 21.4$

$99.7 \% \quad 48.0$

$99.5 \% \quad 24.9$

$\begin{array}{lll}99.7 \% & 53.8\end{array}$

$99.7 \% \quad 53.0$

$97.7 \% \quad 20.2$

$99.7 \% \quad 45.6$

$99.7 \% \quad 41.5$

$99.3 \% \quad 22.6$

$99.7 \% \quad 55$.

$99.7 \% \quad 36.6$

1583.74

1669.83

1766.93

1386.74

1610.78

1432.71

1377.79

1533.94

1191.53

1236.74

1344.63

944.54

1204.51

1544.69

960.55

1422.75

1189.62

1749.88

1496.83

2834.47

1792.89

1061.62

1160.59

1057.56

1086.65

1058.61

1354.70

1227.66

931.53

1106.62

1311.67

1274.6

1316.68

1217.61

1208.61

1165.61

1021.53

1523.69

1299.75

1320.68

1316.66

2371.25

914.53

2081.17 $\begin{array}{llllllll}99.7 \% & 63.7 & 25.0 & 52.5 & 4 & 0 & 0 & 1185.66 \\ 99.7 \% & 35.7 & 25.0 & 31.7 & 4 & 5 & 0 & 1396.84\end{array}$

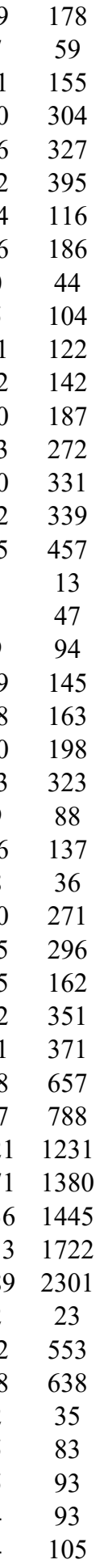

Page 119 of Table S-1-5 
Prohibitin GN=PHB Prohibitin GN=PHB Prohibitin GN=PHB Prohibitin GN=PHB Prohibitin GN=PHB Prohibitin GN=PHB Prohibitin GN=PHB Prohibitin GN=PHB Prohibitin GN=PHB Prohibitin GN=PHB Prohibitin GN=PHB Prohibitin $\mathrm{GN}=\mathrm{PHB}$ Prohibitin GN=PHB Prohibitin GN=PHB

Prohibitin GN=PHB Prohibitin-2 GN=PHB2 Prohibitin-2 GN=PHB2 Prohibitin-2 GN=PHB2 Prohibitin-2 GN=PHB2

Prohibitin-2 GN=PHB2

Prohibitin- 2 GN=PHB2

Prohibitin-2 GN=PHB2

Prohibitin-2 GN=PHB2

Prohibitin-2 GN=PHB2

Prohibitin -2 GN=PHB2

Prohibitin- $2 \mathrm{GN}=\mathrm{PHB} 2$

Prohibitin-2 GN=PHB2

Prohibitin-2 GN=PHB2

Prohibitin-2 GN=PHB2

Prohibitin-2 GN=PHB2 Proliferating cell nuclear antigen GN=PCNA PCNA_HUMAN 28.77 Proliferating cell nuclear antigen GN=PCNA PCNA_HUMAN 28.77 Proliferating cell nuclear antigen GN=PCNA PCNA_HUMAN 28.77 Proliferating cell nuclear antigen GN=PCNA PCNA_HUMAN 28.77 Proliferating cell nuclear antigen GN=PCNA PCNA_HUMAN 28.77 Proliferating cell nuclear antigen GN=PCNA PCNA_HUMAN 28.77 Proliferating cell nuclear antigen GN=PCNA PCNA_HUMAN 28.77 Proliferating cell nuclear antigen GN=PCNA PCNA_HUMAN 28.77 Proliferating cell nuclear antigen GN=PCNA PCNA_HUMAN 28.77 Proline-, glutamic acid-and leucine-rich protein $1 \mathrm{GN}=$ PELP1 PELP1 HUMAN $119.70 \quad 100.0^{\circ}$ Proline-, glutamic acid-and leucine-rich protein 1 GN=PELP1 PELP1_HUMAN $119.70 \quad 100.0 \%$ Proline-, glutamic acid- and leucine-rich protein 1 GN=PELP1 PELP1 HUMAN $119.70 \quad 100.0 \%$ Proteasomal ATPase-associated factor $1 \mathrm{GN}=$ PAAF1 PAAF1_HUMAN $42.19 \quad 100.0 \%$ Proteasomal ATPase-associated factor $1 \mathrm{GN}=$ PAAF1 PAAF1_HUMAN $42.19 \quad 100.0 \%$ Proteasomal ATPase-associated factor $1 \mathrm{GN}=$ PAAF1 PAAF1_HUMAN $42.19 \quad 100.0 \%$ Proteasomal ATPase-associated factor $1 \mathrm{GN}=$ PAAF1 PAAF1_HUMAN $42.19 \quad 100.0 \%$ 24 24 24

24
24
24
24 24

24
24

24

24

24
24
24

24

25

25

25

\begin{tabular}{ll}
25 \\
15 \\
25 \\
\hline
\end{tabular}

25
25

25
25
25

25

$\begin{array}{ll}15 & 25 \\ 15 & 25 \\ 15 & 25\end{array}$

$\begin{array}{ll}15 & 25 \\ 15 & 25 \\ 15 & 25\end{array}$

25
25
25

25

\begin{tabular}{ll}
15 & 25 \\
5 & 25 \\
\hline
\end{tabular}

$\begin{array}{ll}15 & 25 \\ 15 & 25 \\ 15 & 25\end{array}$

25

25
16
16
16

1
16
16

16
16
16

16
16

$\begin{array}{ll}16 \\ 10 \\ 10 & 16\end{array}$

$\begin{array}{ll}0 & 16 \\ 0 & 16 \\ 0 & 16\end{array}$

16

$85 \quad 0.09 \% \quad 66.5 \%$ IFTSIGEDYDER

$99.7 \% \quad 61.6$

$99.7 \% \quad 61.9 \quad 25.0 \quad 47.2$

$0.09 \% \quad 66.5 \%$ FDAGELITQR

$0.09 \% \quad 66.5 \%$ QVSDDLTER

$0.09 \% \quad 66.5 \%$ EFTEAVEAK

$0.09 \% \quad 66.5 \%$ FVVEKAEQQK

$0.09 \% \quad 66.5 \%$ KAAIISAEGDSK

$0.09 \% \quad 66.5 \%$ AAIISAEGDSK

$\begin{array}{lllll}99.7 \% & 55.7 & 25.0 & 37.3 & 4\end{array}$

$\begin{array}{llll}99.7 \% & 43.3 & 25.0 & 43.1\end{array}$

$\begin{array}{llll}99.7 \% & 50.5 & 25.0 & 41.1\end{array}$

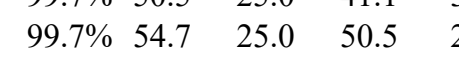

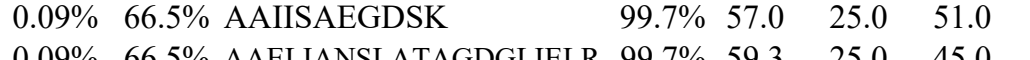

$0.09 \% \quad 66.5 \%$ AAELIANSLATAGDGLIELRK

$0.09 \% \quad 66.5 \%$ KLEAAEDIAYQLSR

$0.09 \% \quad 66.5 \%$ LEAAEDIAYQLSR

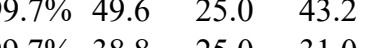

$0.09 \% \quad 66.5 \%$ SRNITYLPAGQSVLLQLPQ

$0.09 \% \quad 66.5 \%$ NITYLPAGQSVLLQLPQ

$0.09 \% \quad 55.9 \%$ LLLGAGAVAYGVR

$0.09 \% \quad 55.9 \%$ ESVFTVEGGHR

$0.09 \% \quad 55.9 \%$ IGGVQQDTILAEGLHFR

$0.09 \% \quad 55.9 \%$ IPWFQYPIIYDIR

$0.09 \% \quad 55.9 \%$ DLQMVNISLR

$0.09 \% \quad 55.9 \%$ VLSRPNAQELPSMYQR

$0.09 \% \quad 55.9 \%$ LGLDYEER

$0.09 \% \quad 55.9 \%$ VLPSIVNEVLK

$0.09 \% \quad 55.9 \%$ FNASQLITQR

$0.09 \% \quad 55.9 \%$ AQVSLLIR

$0.09 \% \quad 55.9 \%$ EYTAAVEAK

$0.09 \% \quad 55.9 \%$ QKIVQAEGEAEAAK

$0.09 \% \quad 55.9 \%$ IVQAEGEAEAAK

$0.09 \% \quad 55.9 \%$ MLGEALSK

$0.09 \% \quad 55.9 \%$ IYLTADNLVLNLQDESFTR

$0.04 \% \quad 52.5 \%$ LVQGSILKK

$0.04 \% \quad 52.5 \%$ SEGFDTYR

$0.04 \% \quad 52.5 \%$ NLAMGVNLTSMSK

$\begin{array}{lll}0.04 \% & 52.5 \% & \text { AEDNADTLALVFEAPNQEK } \\ 0.04 \% & 52.5 \% & \text { LMDLDVEQLGIPEQEYSCVVK }\end{array}$

$\begin{array}{lll}0.04 \% & 52.5 \% & \text { LMDLDVEQLGIPE } \\ 0.04 \% & 52.5 \% & \text { MPSGEFAR }\end{array}$

$0.04 \% \quad 52.5 \%$ DLSHIGDAVVISCAK

$0.04 \% \quad 52.5 \%$ FSASGELGNGNIK

$\begin{array}{lll}0.04 \% & 52.5 \% & \text { FSASGELGNGNIK } \\ 52.5 \% & \text { ATPLSSTVTLSMSADVPLVVEYK }\end{array}$

$\begin{array}{ll}0.04 \% & 52.5 \% \\ 0.01 \% & 2.8 \%\end{array}$

$0.01 \% \quad 2.8 \%$ TGSAVAPVHPPNR

$\begin{array}{lll}0.01 \% & 2.8 \% & \text { LASFFLSR } \\ 0.01 \% & 2.8 \% & \text { NISLHGDGP }\end{array}$

$0.01 \% \quad 14.5 \%$ FLAPYTTFSR

$0.01 \% \quad 14.5 \%$ SITCLDISSR

$6 \quad 0.01 \% \quad 14.5 \%$ GGLGVSSSTDGTMK

$0.01 \% \quad 14.5 \%$ GGILDTAIVDR

$99.7 \% \quad 67.0$

$99.7 \% \quad 71.4$

$99.7 \% \quad 58.8$

$99.7 \% \quad 66.0$

$99.7 \% \quad 48.1$

$99.6 \% \quad 27.0$

$99.7 \% \quad 58.2$

$99.0 \% 54.1$

$\begin{array}{llll}99.7 \% & 32.2\end{array}$

$99.7 \% \quad 59.5$

$99.0 \% \quad 51.2$

$99.7 \% \quad 60.0$

$99.7 \% \quad 57.6$

$\begin{array}{ll}99.7 \% & 68.4 \\ 99.0 \% & 39.3\end{array}$

$\begin{array}{rr}99.7 \% & 49.7\end{array}$

$99.7 \% \quad 38.3$

$\begin{array}{lllll}99.7 \% & 38.3 & 25.0 & 16.2 & 2 \\ 99.0 \% & 41.6 & 25.0 & 34.0 & 2 \\ 99.7 \% & 73.1 & 25.0 & 66.3 & 5\end{array}$

\begin{tabular}{lllll}
$99.7 \%$ & 61.1 & 25.0 & 66.3 & 5 \\
\hline
\end{tabular}

$\begin{array}{lllll}99.7 \% & 54.4 & 25.0 & 54.4 & 2\end{array}$

$\begin{array}{lllll}99.0 \% & 40.4 & 25.0 & 30.7 & 4\end{array}$

$\begin{array}{lllll}99.7 \% & 57.1 & 25.0 & 53.4 & 2 \\ 99.7 \% & 73.7 & 25.0 & 66.0 & 2\end{array}$

$\begin{array}{llll}99.7 \% & 73.7 & 25.0 & 66.0 \\ 99.7 \% & 48.6 & 25.0 & 48.6\end{array}$

$\begin{array}{llll}99.0 \% & 36.9 & 25.0 & 48.6\end{array}$

$99.7 \% \quad 28.9-25.0 \quad 21.8$

$\begin{array}{llll}99.4 \% & 32.3 & 25.0 & 27.3\end{array}$

$\begin{array}{llll}97.4 \% & 15.6 & 25.0 & 15.6\end{array}$

$\begin{array}{llll}99.7 \% & 46.4 & 25.0 & 39.3 \\ 99.7 \% & 38.6 & 25.0 & 29.2\end{array}$

$\begin{array}{llll}99.7 \% & 54.3 \quad 25.0 \quad 34.2\end{array}$

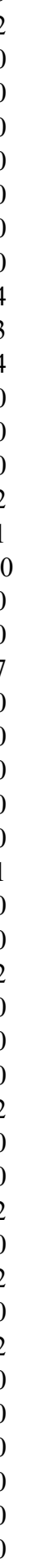

0
0
0
0
0
0
0
0
0
0
0
0
0
0
0
0
0
0
0
0
0
0
0
0
0
0
0
0
0
0
0
0
0
0
0
0
0
0
0
0
0
0
0
0
0
0
0
0
0

1213.74

149.59

1062.51

1023.50

1205.65

1189.64

1061.55

1998.09

2126.18

1606.84

1478.75

2098.17

1855.03

1259.75

1217.59

1853.99

1723.92

1188.64

1888.97

994.48

1210.74

1177.63

899.57

981.49

1471.78

1215.62

864.45

2225.15

985.64

974.42

1381.68

2074.99

2481.19

910.41

1584.81

1293.64

2424.26

884.47

1302.69

940.53

1178.63

1202.62

1151.57

1312.61

Page 120 of Table S-1-5 
Proteasomal ATPase-associated factor 1 GN=PAAF1 PAAF1_HUMAN $42.19 \quad 100.0 \%$ $\begin{array}{lll} & \end{array}$ Proteasomal ubiquitin receptor ADRM1 GN=ADRM1 ADRM1_HUMAN $42.15 \quad 100.0 \%$ Proteasome activator complex subunit $3 \mathrm{GN}=$ PSME3 PSME3 HUMAN $29.51 \quad 100.0 \%$ Proteasome activator complex subunit 3 GN=PSME3 PSME3_HUMAN $29.51 \quad 100.0 \%$ Proteasome activator complex subunit $3 \mathrm{GN}=$ PSME3 PSME3_HUMAN $29.51 \quad 100.0 \%$ Proteasome activator complex subunit $3 \mathrm{GN}=$ PSME3 PSME3_HUMAN $29.51 \quad 100.0 \%$ Proteasome activator complex subunit 3 GN=PSME3 PSME3_HUMAN $29.51 \quad 100.0 \%$ Proteasome subunit alpha type-1 GN=PSMA1 PSA1 HUMAN $29.56 \quad 100.0 \%$ Proteasome subunit alpha type-1 GN=PSMA1 PSA1_HUMAN $29.56 \quad 100.0 \%$ Proteasome subunit alpha type-1 GN=PSMA1 PSA1_HUMAN $29.56 \quad 100.0 \%$ Proteasome subunit alpha type-3 GN=PSMA3 PSA3 HUMAN $28.43 \quad 100.0 \%$ Proteasome subunit alpha type-3 GN=PSMA3 PSA3_HUMAN $28.43 \quad 100.0 \%$ Proteasome subunit alpha type-3 GN=PSMA3 PSA3_HUMAN $28.43 \quad 100.0 \%$ Proteasome subunit alpha type-3 GN=PSMA3 PSA3_HUMAN $28.43 \quad 100.0 \%$ Proteasome subunit alpha type-4 GN=PSMA4 PSA4_HUMAN $29.48 \quad 100.0 \%$ Proteasome subunit alpha type-4 GN=PSMA4 PSA4 HUMAN $29.48 \quad 100.0 \%$ Proteasome subunit alpha type-4 GN=PSMA4 PSA4_HUMAN $29.48 \quad 100.0 \%$ Proteasome subunit alpha type-4 GN=PSMA4 PSA4_HUMAN $29.48 \quad 100.0 \%$ Proteasome subunit alpha type-4 GN=PSMA4 PSA4_HUMAN $29.48 \quad 100.0 \%$ Proteasome subunit alpha type-4 GN=PSMA4 PSA4_HUMAN $29.48 \quad 100.0 \%$ Proteasome subunit alpha type-7 GN=PSMA7 PSA7 HUMAN $27.89 \quad 100.0 \%$ Proteasome subunit alpha type-7 GN=PSMA7 PSA7_HUMAN $27.89 \quad 100.0 \%$ Proteasome subunit alpha type-7 GN=PSMA7 PSA7_HUMAN $27.89 \quad 100.0 \%$ Proteasome-associated protein ECM29 homolog GN=ECM29 ECM29_HUMAN $204.30 \quad 100.0 \%$ Proteasome-associated protein ECM29 homolog GN=ECM29 ECM29_HUMAN 204.30 $100.0 \%$ Proteasome-associated protein ECM29 homolog GN=ECM29 ECM29_HUMAN $204.30 \quad 100.0 \%$ Proteasome-associated protein ECM29 homolog GN=ECM29 ECM29 HUMAN $204.30 \quad 100.0 \%$ Proteasome-associated protein ECM29 homolog GN=ECM29 ECM29_HUMAN $204.30 \quad 100.0 \%$ Proteasome-associated protein ECM29 homolog GN=ECM29 ECM29 HUMAN 204.30 100 $0 \%$ Proteasome-associated protein ECM29 homolog GN=ECM29 ECM29_HUMAN $204.30 \quad 100.0 \%$ Proteasome-associated protein ECM29 homolog GN=ECM29 ECM29_HUMAN $204.30 \quad 100.0 \%$ Proteasome-associated protein ECM29 homolog GN=ECM29 ECM29 HUMAN $204.30 \quad 100.0 \%$ Protein AAR2 homolog GN=AAR2 AAR2_HUMAN $43.47 \quad 100.0 \%$ Protein AAR2 homolog GN=AAR2

AAR2 HUMAN 43.47

$100.0 \%$

$100.0 \%$ $100.0 \%$ $100.0 \%$ $100.0 \%$ $100.0 \%$ $100.0 \%$ $100.0 \%$ $100.0 \%$ $100.0 \%$ $100.0 \%$ $100.0 \%$ $100.0 \%$
$0.01 \% \quad 14.5 \%$ SGAPVLSLLSVR

$0.00 \% \quad 5.9 \%$ VPQCPSGR

$0.00 \% \quad 5.9 \%$ SQSAAVTPSSTTSSTR

$0.01 \% \quad 26.8 \%$ ITSEAEDLVANFFPK

$0.01 \% \quad 26.8 \%$ RLDECEEAFQGTK

$0.01 \% 26.8 \%$ SNQQLVDIIEK

$0.01 \% \quad 26.8 \%$ TVESEAASYLDQISR

$0.01 \% \quad 26.8 \%$ TVTEIDEKEYISLR

$0.00 \% \quad 11.4 \%$ THAVLVALKR

$0.00 \% \quad 11.4 \%$ LVSLIGSK

$0.00 \% \quad 11.4 \%$ ETLPAEQDLTTK

$0.01 \% \quad 16.5 \%$ VFQVEYAMK

$0.01 \% \quad 16.5 \%$ AVENSSTAIGIR

$0.01 \% \quad 16.5 \%$ CKDGVVFGVEK

$0.01 \% \quad 16.5 \%$ SNFGYNIPLK

$0.02 \% \quad 21.8 \%$ TTIFSPEGR

$\quad 0.02 \% \quad 21.8 \%$ LLDEVFFSEK

$0.02 \% \quad 21.8 \%$ QAYTQFGGK

$6 \quad 0.02 \% \quad 21.8 \%$ ATCIGNNSAAAVSMLK

$0.02 \% \quad 21.8 \%$ LSAEKVEIATLTR

$0.02 \% \quad 21.8 \%$ VEIATLTR

$0.00 \% \quad 16.1 \%$ LTVEDPVTVEYITR

$0.00 \% \quad 16.1 \%$ NYTDEAIETDDLTIK

$0.00 \% \quad 16.1 \%$ ALLEVVQSGGK

$0.02 \% \quad 6.3 \% \quad$ LSSTQEGVR

$0.02 \% \quad 6.3 \% \quad$ SASPFNLAEKPK

$0.02 \% \quad 6.3 \%$ TLMSSGQMAPSSSNK

$0.02 \% \quad 6.3 \%$ VKHEVSGETVVFQGGALGK

$0.02 \% \quad 6.3 \% \quad$ KGAAFGFNVIATR

$0.02 \% \quad 6.3 \%$ ALSINTLVK

$0.02 \% \quad 6.3 \% \quad$ ATEQEKAAMDSAR

$0.02 \% \quad 6.3 \% \quad$ AQGAIAMASIAK

$0.02 \% \quad 6.3 \%$ AIACVVTACSAELEK

$0.00 \% \quad 6.5 \%$ MGFFLSLHQR

$0.00 \% \quad 6.5 \%$ QICAFSDVLPVLSMK

$0.02 \% \quad 34.9 \%$ VVLDVGSGTGILCMFAAK

$0.02 \% \quad 34.9 \%$ KVIGIECSSISDYAVK

$0.02 \% \quad 34.9 \%$ VIGIECSSISDYAVK

$0.02 \% \quad 34.9 \%$ GKVEEVELPVEK

$0.02 \% \quad 34.9 \%$ ATLYVTAIEDR

$0.02 \% 34.9 \%$ DVAIKEPLVDVVDPK

$0.02 \% \quad 34.9 \%$ QLVTNACLIK

$0.02 \% \quad 34.9 \%$ VEDLTFTSPFCLQVK

$0.02 \% \quad 34.9 \%$ QTVFYMEDYLTVK

$\begin{array}{llll}9 \% & 55.0 & 25.0 & 54.6\end{array}$

$99.0 \% \quad 33.4$

$99.7 \% \quad 70.9$

$\begin{array}{llll}99.7 \% & 33.4 & 25.0 & 31.9\end{array}$

$\begin{array}{llll}99.7 \% & 56.8 & 25.0 & 48.6\end{array}$

$\begin{array}{llll}99.7 \% & 62.4 & 25.0 & 54.0\end{array}$

$\begin{array}{llll}99.7 \% & 40.3 & 25.0 & 38.7\end{array}$

$99.0 \% \quad 20.1 \quad 25.0 \quad 20.1$

$\begin{array}{llll}98.9 \% & 25.3 & 25.0 & 14.5\end{array}$

$99.5 \% \quad 25.1$

$99.7 \% \quad 40.5$

$99.7 \% \quad 71.6$

$99.7 \% \quad 35.5$

$99.7 \% \quad 37.2$

$99.7 \% \quad 35.8$

$99.7 \% \quad 55.9$

$99.7 \% \quad 40.0$

$99.7 \% \quad 78.2$

$99.7 \% \quad 69.0$

$99.0 \% \quad 38.4$

$99.7 \% 70.6$

$99.7 \% \quad 47.6$

$99.7 \% \quad 56.7$

$99.7 \% \quad 48.1$

$99.7 \% \quad 33.8$

$99.7 \% \quad 69.1$

$99.7 \% \quad 27.1$

$99.5 \% \quad 23.4$

$97.6 \% \quad 25.0$

$99.7 \% \quad 39.6$

$99.7 \% \quad 41.3$

$99.7 \% \quad 46.4$

$99.2 \% \quad 23.5$

$99.7 \% \quad 45.6$

$99.7 \% 72.0$

$\begin{array}{lll}99.7 \% & 43.6\end{array}$

$99.7 \% \quad 73.0$

$99.7 \% \quad 64.8$

$99.7 \% \quad 65.2$

$99.7 \% \quad 46.0$

$99.7 \% \quad 31.2$

$99.3 \% \quad 25.8$

$99.7 \% \quad 58.3$

$0.02 \% \quad 34.9 \%$ TGEEIFGTIGMRPNAK

$99.7 \% \quad 33.3$

$0.16 \% \quad 32.0 \%$ VSSGRDLNCVPEIADTLGAVAK $99.7 \% \quad 59.3$

144

$\begin{array}{llll}0.16 \% & 32.0 \% & \text { DLNCVPEIADTLGAVAK } \quad 99.7 \% \quad 49.5\end{array}$

$\begin{array}{ll}.0 & 25 . \\ .0 & 30 .\end{array}$

62.9
25.0

$\begin{array}{ll}.0 & 27.5\end{array}$

$25.0 \quad 27.3$

$25.0 \quad 24.6$

$.0 \quad 45.8$

$.0 \quad 34.0$

72.0
75.0

$.0 \quad 61.5$

$\begin{array}{ll}.0 & 31.2 \\ 0 & 70.6\end{array}$

$5.0 \quad 47.1$

56.7
56.0

20.0

$\begin{array}{ll}52.0 & 52.2\end{array}$

$25.0 \quad 27.1$

$\begin{array}{ll}5.0 & 17.6\end{array}$

$0 \quad 13.1$

\begin{tabular}{ll}
25.0 & 36.0 \\
\hline
\end{tabular}

$\begin{array}{ll}46.0 & 46.4\end{array}$

$\begin{array}{ll}0.0 & 22.3\end{array}$

$.0 \quad 45.6$

0

0

0
0

(10

0

0

0

00

8.72 900.44

1567.76

1680.85

1582.72

1286.70

1668.81

1695.88

1107.70

816.52

1345.68

1114.56

1217.65

1237.62

1152.60

1007.52

226.63

999.49

1607.79

1430.82

902.53

1634.86

1740.82

1100.63

976.51

1288.69

1541.69

1942.04

1351.75

958.59

1407.65

1131.62

1621.79

1251.63

1723.88

1837.96

1768.92

1640.82

1355.74

1251.66

1636.92

1159.65

1783.89

1652.79

1736.86

2272.16

1785.91 
Protein arginine N-methyltransferase 5 GN=PRMT5 ANM5_HUMAN $72.69 \quad 100.0 \% \quad 25$ Protein arginine N-methyltransferase 5 GN=PRMT5 ANM5_HUMAN $72.69 \quad 100.0 \% \quad 25$ Protein arginine N-methyltransferase 5 GN=PRMT5 ANM5_HUMAN $72.69 \quad 100.0 \% \quad 25$ Protein arginine N-methyltransferase $5 \mathrm{GN}=$ PRMT5 ANM5 HUMAN $72.69 \quad 100.0 \% \quad 25$ Protein arginine N-methyltransferase 5 GN=PRMT5 ANM5_HUMAN $72.69 \quad 100.0 \% \quad 25$ Protein arginine N-methyltransferase 5 GN=PRMT5 ANM5_HUMAN $72.69 \quad 100.0 \% \quad 25$ Protein arginine N-methyltransferase 5 GN=PRMT5 ANM5_HUMAN $72.69 \quad 100.0 \% \quad 25$ Protein arginine N-methyltransferase 5 GN=PRMT5 ANM5_HUMAN $72.69 \quad 100.0 \% \quad 25$ Protein arginine N-methyltransferase $5 \mathrm{GN}=$ PRMT5 ANM5 HUMAN $72.69 \quad 100.0 \% \quad 25$ Protein arginine N-methyltransferase 5 GN=PRMT5 ANM5_HUMAN $72.69 \quad 100.0 \% \quad 25$ Protein arginine N-methyltransferase 5 GN=PRMT5 ANM5_HUMAN $72.69 \quad 100.0 \% \quad 25$ Protein arginine N-methyltransferase 5 GN=PRMT5 ANM5_HUMAN $72.69 \quad 100.0 \% \quad 25$ Protein arginine N-methyltransferase 5 GN=PRMT5 ANM5_HUMAN $72.69 \quad 100.0 \% \quad 25$ $\begin{array}{llll}\text { Protein arginine N-methyltransferase } 5 \text { GN=PRMT5 ANM5_HUMAN } & 72.69 & 100.0 \% & 25\end{array}$ Protein arginine N-methyltransferase 5 GN=PRMT5 ANM5_HUMAN $72.69 \quad 100.0 \% \quad 25$ Protein arginine N-methyltransferase 5 GN=PRMT5 ANM5_HUMAN $72.69 \quad 100.0 \% \quad 25$ Protein arginine N-methyltransferase $5 \mathrm{GN}=$ PRMT5 ANM5 HUMAN $72.69 \quad 100.0 \%$ Protein arginine N-methyltransferase 5 GN=PRMT5 ANM5_HUMAN $72.69 \quad 100.0 \% \quad 25$ Protein arginine N-methyltransferase 5 GN=PRMT5 ANM5_HUMAN $72.69 \quad 100.0 \% \quad 25$ Protein arginine N-methyltransferase $5 \mathrm{GN}=$ =PRMT5 ANM5 HUMAN $72.69 \quad 100.0 \% \quad 25$ Protein arginine N-methyltransferase 5 GN=PRMT5 ANM5_HUMAN $72.69 \quad 100.0 \% \quad 25$ Protein arginine N-methyltransferase 5 GN=PRMT5 ANM5 HUMAN $72.69 \quad 100.0 \% \quad 25$ Protein arginine N-methyltransferase 5 GN=PRMT5 ANM5_HUMAN $72.69 \quad 100.0 \% \quad 25$ Protein CMSS1 GN=CMSS1 Protein CMSS1 GN=CMSS1 Protein CMSS1 GN=CMSS1 Protein CMSS1 GN=CMSS1

Protein DEK GN=DEK Protein DEK GN=DEK Protein DEK GN=DEK Protein DEK GN=DEK Protein DEK GN=DEK Protein DEK GN=DEK Protein diaphanous homolog 1 GN=DIAPH1 DIAP1_HUMAN $141.35100 .0 \%$ Protein diaphanous homolog $1 \mathrm{GN}=$ DIAPH1 DIAP1_HUMAN $141.35 \quad 100.0 \%$ Protein diaphanous homolog 1 GN=DIAPH1 DIAP1_HUMAN $141.35 \quad 100.0 \%$ Protein diaphanous homolog $1 \mathrm{GN}=$ DIAPH1 DIAP1_HUMAN $141.35 \quad 100.0 \%$ Protein ELYS GN=AHCTF 1 Protein ELYS GN=AHCTF Protein flightless- 1 homolog GN=FLII Protein flightless -1 homolog GN=FLII Protein flightless -1 homolog GN=FLII Protein flightless -1 homolog GN=FLII Protein flightless -1 homolog GN=FLII Protein flightless -1 homolog GN=FLII Protein flightless -1 homolog GN=FLII Protein lin-28 homolog B GN=LIN28B CMS1_HUMAN $31.89 \quad 100.0 \%$ CMS1_HUMAN $31.89 \quad 100.0 \% \quad 4$ CMS1_HUMAN $31.89 \quad 100.0 \% \quad 4$ DEK HUMAN $42.68 \quad 100.0 \%$ DEK_HUMAN $42.68 \quad 100.0 \%$ DEK HUMAN $42.68 \quad 100.0 \%$ DEK_HUMAN $42.68 \quad 100.0 \%$

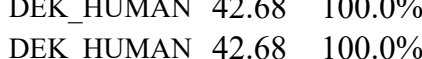
DEK_HUMAN $42.68 \quad 100.0 \%$ ELYS_HUMAN $252.50 \quad 100.0 \%$ FLII_HUMAN $144.76 \quad 100.0 \%$ FLII HUMAN $144.76 \quad 100.0 \%$ FLII_HUMAN $144.76 \quad 100.0 \%$ FLII HUMAN $144.76 \quad 100.0 \%$ FLII_HUMAN $144.76 \quad 100.0 \%$ FLII_HUMAN $144.76 \quad 100.0 \%$ FLII HUMAN $144.76 \quad 100.0 \%$ LN28B_HUMAN $27.08 \quad 100.0 \%$
$30 \quad 144 \quad 0.16 \% \quad 32.0 \%$ QGFDFLCMPVFHPR

$30 \quad 144 \quad 0.16 \% \quad 32.0 \%$ REFIQEPAK

$30 \quad 144 \quad 0.16 \% \quad 32.0 \%$ EFIQEPAK

$30 \quad 144 \quad 0.16 \% \quad 32.0 \%$ EFIQEPAKNRPGPQTR

$30 \quad 144 \quad 0.16 \% \quad 32.0 \%$ SDLLLSGR

$30 \quad 144 \quad 0.16 \% \quad 32.0 \%$ SDLLLSGRDWNTLIVGK

$30 \quad 144 \quad 0.16 \% \quad 32.0 \%$ DWNTLIVGK

$30 \quad 144 \quad 0.16 \% \quad 32.0 \%$ LSPWIRPDSK

$30 \quad 144 \quad 0.16 \% \quad 32.0 \%$ LSPWIRPDSKVEK

$30 \quad 144 \quad 0.16 \% \quad 32.0 \%$ VPLVAPEDLR

$\begin{array}{llll}30 & 144 & 0.16 \% & 32.0 \%\end{array}$ TLCDYSKR

$144 \quad 0.16 \% \quad 32.0 \%$ IAVALEIGADLPSNHVIDR

$144 \quad 0.16 \% \quad 32.0 \%$ AAILPTSIFLTNK

$144 \quad 0.16 \% \quad 32.0 \%$ AAILPTSIFLTNKK

$144 \quad 0.16 \% \quad 32.0 \%$ KGFPVLSK

$144 \quad 0.16 \% \quad 32.0 \%$ DPIKYSQYQQAIYK

$144 \quad 0.16 \% \quad 32.0 \%$ YSQYQQAIYK

$144 \quad 0.16 \% \quad 32.0 \%$ GPLVNASLR

$144 \quad 0.16 \% \quad 32.0 \%$ IKLYAVEK

$144 \quad 0.16 \% \quad 32.0 \%$ DRDPEAQFEMPYVVR

$144 \quad 0.16 \% \quad 32.0 \%$ QPITVREGQTICVR

$144 \quad 0.16 \% \quad 32.0 \%$ EGQTICVR

$144 \quad 0.16 \% \quad 32.0 \%$ EGQTICVRFWR

$7 \quad 0.01 \% \quad 12.5 \%$ ANDLTHSLSSYLK

$7 \quad 0.01 \% \quad 12.5 \%$ RVVHLGVGTPGR $0.01 \% \quad 12.5 \%$ VVHLGVGTPGR $7 \quad 0.02 \% \quad 15.5 \%$ NVGQFSGFPFEK $0.02 \% \quad 15.5 \%$ SICEVLDLER $7 \quad 0.02 \% \quad 15.5 \%$ SGVNSELVK $17 \quad 0.02 \% \quad 15.5 \%$ SGVNSELVKR $17 \quad 0.02 \% \quad 15.5 \%$ LLASANLEEVTMK $17 \quad 0.02 \% \quad 15.5 \%$ VYENYPTYDLTER $0.01 \% \quad 3.5 \%$ SPDELPSAGGDGGK $0.01 \% \quad 3.5 \%$ EMVSQYLYTSK $0.01 \% \quad 3.5 \%$ SAMMYIQELR $0.01 \% \quad 3.5 \%$ LTLTFSAQTK $13 \quad 0.01 \% \quad 0.8 \% \quad$ SVFINNVLSK $0.01 \% \quad 0.8 \% \quad$ SPLYLVSR

$0.01 \% \quad 4.7 \%$ NQLTSLPSAICK

$0.01 \% \quad 4.7 \%$ GAQATLSSTTK

$0.01 \% \quad 4.7 \% \quad$ LLQSLLDTR

$0.01 \% \quad 4.7 \%$ SLEGTEAQVFK

$0.01 \% \quad 4.7 \%$ SLEGTEAQVFKAK

$0.01 \% \quad 4.7 \% \quad$ KAVQGAQQPSLYQIR

$0.01 \% \quad 4.7 \% \quad$ AVQGAQQPSLYQIR $0.01 \% \quad 12.5 \%$ QGGLNLSPLK

$\begin{array}{llllllll}99.7 \% & 37.5 & 25.0 & 21.9 & 1 & 0 & 0 & 1117.60\end{array}$

$\begin{array}{llllllll}99.0 \% & 50.9 & 25.0 & 30.7 & 14 & 0 & 0 & 961.50\end{array}$

$\begin{array}{llllllll}98.9 \% & 21.0 & 25.0 & 21.0 & 2 & 5 & 0 & 1867.98\end{array}$

$\begin{array}{llllllll}99.0 \% & 35.5 & 25.0 & 16.8 & 3 & 0 & 0 & 860.48\end{array}$

1887.03

1045.57

1198.66

1554.86

1108.64

1042.50

2003.09

1388.81

1516.91

875.54

1744.89

1291.63

926.54

963.59

1867.86

1656.89

962.47

1451.72

1448.74

1247.73

1091.63

1026.59

1356.66

1233.61

932.50

1088.61

1434.75

1662.76

1286.59

1348.65

1241.60

1109.62

1120.64

934.54

$\begin{array}{llll}99.7 \% & 50.3 & 25.0 & 46.5\end{array}$

$\begin{array}{llll}99.7 \% & 34.2 & 25.0 & 29.4\end{array}$

$\begin{array}{llll}99.7 \% & 33.7 & 25.0 & 29.7\end{array}$

$\begin{array}{llll}98.6 \% & 17.1 & 25.0 & 17.1\end{array}$

$\begin{array}{llll}99.7 \% & 48.2 & 25.0 & 34.6\end{array}$

$\begin{array}{llll}99.7 \% & 52.8 & 25.0 & 47.4\end{array}$

$\begin{array}{llll}99.7 \% & 38.6 & 25.0 & 29.2\end{array}$

$99.7 \% \quad 54.9 \quad 25.0 \quad 37.0$

$99.7 \% \quad 47.2 \quad 25.0 \quad 47.2$

$\begin{array}{llll}99.2 \% & 19.3 & 25.0 & 19.3\end{array}$

$\begin{array}{llll}99.7 \% & 56.5 & 25.0 & 48.7\end{array}$

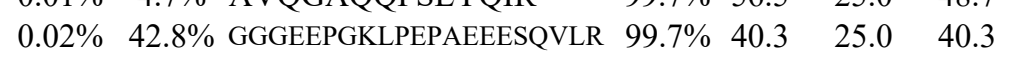

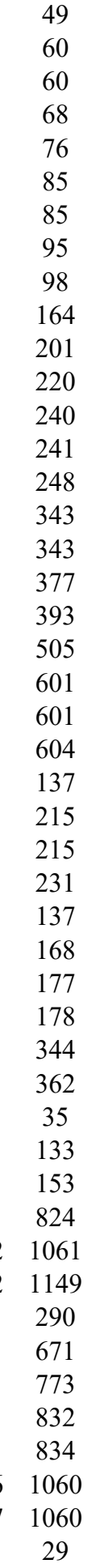

$\begin{array}{ccc}1064.56 & 661 & 671 \\ 1058.62 & 765 & 773 \\ 1208.62 & 822 & 832 \\ 1407.75 & 822 & 834 \\ 1686.93 & 1046 & 1060 \\ 1558.83 & 1047 & 1060 \\ 2208.08 & 9 & 29\end{array}$ 
Protein lin-28 homolog B GN=LIN28B Protein lin-28 homolog B GN=LIN28B Protein lin-28 homolog B GN=LIN28B Protein lin-28 homolog B GN=LIN28B Protein lin-28 homolog B GN=LIN28B Protein lin-28 homolog B GN=LIN28B

Protein LSM14 homolog A GN=LSM14A Protein LSM14 homolog A GN=LSM14A Protein LYRIC GN=MTDH

Protein LYRIC GN=MTDH

Protein pelota homolog GN=PELO

Protein pelota homolog GN=PELO Protein pelota homolog GN=PELO Protein pelota homolog GN=PELO

Protein pelota homolog $\mathrm{GN}=\mathrm{PELO}$ Protein pelota homolog $\mathrm{GN}=\mathrm{PELO}$ Protein pelota homolog $\mathrm{GN}=\mathrm{PELO}$ Protein pelota homolog $\mathrm{GN}=\mathrm{PELO}$ Protein phosphatase $1 \mathrm{~B}$ GN=PPM1B Protein phosphatase 1B GN=PPM1F Protein phosphatase $1 \mathrm{~B}$ GN=PPM1B Protein phosphatase $1 \mathrm{~B}$ GN $=\mathrm{PPM} 1 \mathrm{~B}$ Protein phosphatase 1B GN=PPM1B Protein polybromo- $1 \mathrm{GN}=\mathrm{PBRM} 1$ Protein polybromo- $1 \mathrm{GN}=\mathrm{PBRM} 1$ Protein polybromo-1 GN=PBRM1 Protein PRRC2A GN=PRRC2A Protein PRRC2A GN=PRRC2A Protein PRRC2C GN=PRRC2C Protein PRRC2C GN=PRRC2C Protein RRP5 homolog GN=PDCD11 Protein RRP5 homolog GN=PDCD1 Protein RRP5 homolog GN=PDCD1 Protein RRP5 homolog GN=PDCD1 Protein RRP5 homolog GN=PDCD1 Protein RRP5 homolog GN=PDCD1 Protein RRP5 homolog GN=PDCD1 Protein RRP5 homolog GN=PDCD1 Protein RRP5 homolog GN=PDCD1 Protein RRP5 homolog GN=PDCD1 Protein RRP5 homolog GN=PDCD1 Protein RRP5 homolog GN=PDCD1 Protein RRP5 homolog GN=PDCD1 Protein RRP5 homolog GN=PDCD1 Protein RRP5 homolog GN=PDCD1 Protein RRP5 homolog GN=PDCD11 Protein $\mathrm{S} 100-\mathrm{A} 8 \mathrm{GN}=\mathrm{S} 100 \mathrm{~A} 8$
LN28B HUMAN $27.08 \quad 100.0 \%$ LN28B_HUMAN $27.08 \quad 100.0 \%$ LN28B_HUMAN $27.08 \quad 100.0 \%$ LN28B HUMAN $27.08 \quad 100.0 \%$ LN28B_HUMAN $27.08 \quad 100.0 \%$ LN28B_HUMAN $27.08 \quad 100.0 \%$ LS14A_HUMAN $50.53 \quad 100.0 \%$ \begin{tabular}{ll}
$50.53 \quad 100.0 \%$ \\
\hline
\end{tabular} C $63.84 \quad 100.0 \%$ LYRIC_HUMAN $63.84 \quad 100.0 \%$ PELO_HUMAN $43.36 \quad 100.0 \%$ PELO HUMAN $43.36 \quad 100.0 \%$ PELO_HUMAN $43.36 \quad 100.0 \%$ PELO HUMAN $43.36 \quad 100.0 \%$ PELO HUMAN $43.36 \quad 100.0 \%$ PELO_HUMAN $43.36 \quad 100.0 \%$ PELO HUMAN $43.36 \quad 100.0 \%$ PELO_HUMAN $43.36 \quad 100.0 \%$ PPM1B_HUMAN $52.64 \quad 100.0 \%$ PPM1B HUMAN $52.64 \quad 100.0 \%$ PPM1B_HUMAN $52.64 \quad 100.0 \%$ PPM1B_HUMAN $52.64 \quad 100.0 \%$ PPM1B_HUMAN $52.64 \quad 100.0 \%$ PB1_HUMAN $192.95 \quad 100.0 \%$ PB1 HUMAN $192.95 \quad 100.0 \%$ PB1_HUMAN $192.95 \quad 100.0 \%$ PRC2A_HUMAN $228.87 \quad 100.0 \%$ PRC2A HUMAN $228.87 \quad 100.0 \%$ PRC2C_HUMAN $316.91 \quad 100.0 \%$ PRC2C HUMAN $316.91 \quad 100.0 \%$ RRP5_HUMAN $208.70 \quad 100.0 \%$ RRP5_HUMAN $208.70 \quad 100.0 \%$ RRP5 HUMAN $208.70 \quad 100.0 \%$ RRP5_HUMAN $208.70 \quad 100.0 \%$ RRP5_HUMAN $208.70 \quad 100.0 \%$ RRP5_HUMAN $208.70 \quad 100.0 \%$ RRP5_HUMAN $208.70 \quad 100.0 \%$ RRP5 HUMAN $208.70 \quad 100.0 \%$ RRP5_HUMAN $208.70 \quad 100.0 \%$ RRP5_HUMAN $208.70 \quad 100.0 \%$ RRP5 HUMAN $208.70 \quad 100.0 \%$ RRP5_HUMAN $208.70 \quad 100.0 \%$ RRP5 HUMAN $208.70 \quad 100.0 \%$ RRP5_HUMAN $208.70 \quad 100.0 \%$ RRP5_HUMAN $208.70 \quad 100.0 \%$ RRP5 HUMAN $208.70 \quad 100.0 \%$ S10A8_HUMAN $10.84 \quad 100.0 \%$ $\begin{array}{llllllll}99.7 \% & 60.1 & 25.0 & 57.2 & 5 & 0 & 0 & 1272.62\end{array}$

1866.96

1373.65

1211.61

1603.74

1882.85

1117.63

1227.64

1159.60

1359.74

1536.76

1408.67

1521.79

1294.63

1025.61

1380.73

1709.85

1387.75

1332.70

1233.65

1381.63

1273.67

1050.56

900.49

1064.56

1318.63

1305.66

1119.69

1299.69

1172.63

1322.68

1125.57

1105.64

1193.65

1227.64

1044.54

1081.57

1278.68

1429.75

1148.57

1525.82

1474.76

968.59

995.58

1383.72 $\begin{array}{cccccccc}98.7 \% & 17.8 & 25.0 & 17.8 & 1 & 0 & 0 & 977.61 \\ 99.7 \% & 31.6 & 25.0 & 26.6 & 2 & 0 & 0 & 1272.69\end{array}$

\begin{tabular}{c}
51 \\
68 \\
112 \\
179 \\
193 \\
211 \\
181 \\
253 \\
142 \\
504 \\
60 \\
60 \\
95 \\
95 \\
169 \\
195 \\
265 \\
344 \\
103 \\
142 \\
153 \\
191 \\
369 \\
309 \\
670 \\
1292 \\
466 \\
1223 \\
387 \\
1526 \\
245 \\
337 \\
395 \\
446 \\
457 \\
515 \\
183 \\
560 \\
571 \\
605 \\
701 \\
721 \\
1044 \\
1352 \\
\hline 193 \\
\hline
\end{tabular}

Page 123 of Table S-1-5 
Protein S100-A8 GN=S100A8

Protein SDA1 homolog GN=SDAD1 Protein SDA1 homolog GN=SDAD1 Protein SDA1 homolog GN=SDAD 1 Protein SDA1 homolog GN=SDAD1 Protein SDA1 homolog GN=SDAD1 Protein SEC13 homolog GN=SEC13 Protein SEC13 homolog GN=SEC13 Protein SEC13 homolog GN=SEC13 Protein SET GN=SET Protein SET GN=SET Protein SET GN=SET Protein SET GN=SET Protein SET GN=SET

SET Protein transport protein Sec16A GN=SEC16A SC16A_HUMAN $233.52 \quad 100.0 \%$ Protein transport protein Sec16A GN=SEC16A SC16A HUMAN $233.52 \quad 100.0 \%$ Protein transport protein Sec61 subunit alpha isoform $1 \mathrm{GN}=\mathrm{SEC} 61 \mathrm{~A} 1$ S61A1_HUMAN $52.27 \quad 100.0 \%$ Protein transport protein Sec61 subunit alpha isoform $1 \mathrm{GN}=$ SEC61A1 S61A1_HUMAN $52.27 \quad 100.0 \%$ Protein transport protein Sec61 subunit alpha isoform $1 \mathrm{GN}=\mathrm{SEC} 61 \mathrm{~A} 1$ S61A1_HUMAN $52.27 \quad 100.0 \%$ Protein transport protein Sec61 subunit alpha isoform $1 \mathrm{GN}=\mathrm{SEC} 61 \mathrm{~A} 1$ S61A1_HUMAN $52.27 \quad 100.0 \%$ Protein transport protein Sec61 subunit alpha isoform $1 \mathrm{GN}=\mathrm{SEC} 61 \mathrm{~A} 1$ S61A1_HUMAN $52.27 \quad 100.0 \%$ Protein transport protein Sec61 subunit alpha isoform $1 \mathrm{GN}=\mathrm{SEC} 61 \mathrm{~A} 1$ S61A1_HUMAN $52.27 \quad 100.0 \%$ Protein virilizer homolog GN=KIAA1429 VIR_HUMAN $202.03 \quad 100.0 \%$ Protein virilizer homolog GN=KIAA1429 VIR_HUMAN $202.03 \quad 100.0 \%$ Protein virilizer homolog GN=KIAA1429 VIR_HUMAN $202.03 \quad 100.0 \%$ Protein virilizer homolog GN=KIAA1429 VIR_HUMAN $202.03 \quad 100.0 \%$ Protein virilizer homolog GN=KIAA1429 VIR_HUMAN $202.03 \quad 100.0 \%$ Protein virilizer homolog GN=KIAA1429 VIR_HUMAN $202.03 \quad 100.0 \%$ Protein VPRBP GN=VPRBP Protein VPRBP GN=VPRBP Protein YIF1B GN=YIF1B

Protein YIF1B GN=YIF1B Protein YIPF5 GN=YIPF5 Protein YIPF5 GN=YIPF5

Proto-oncogene tyrosine-protein kinase ROS GN=ROS1 ROS1_HUMAN $263.92 \quad 100.0 \%$ Proto-oncogene tyrosine-protein kinase ROS GN=ROS1 ROS1_HUMAN $263.92 \quad 100.0 \%$ PTB domain-containing engulfment adapter protein $1 \mathrm{GN}=$ GULP1 GULP1 HUMAN $34.49 \quad 100.0 \%$ PTB domain-containing engulfment adapter protein 1 GN=GULP1 GULP1_HUMAN $34.49 \quad 100.0 \%$ Puromycin-sensitive aminopeptidase GN=NPEPPS PSA_HUMAN $103.28 \quad 100.0 \%$ Puromycin-sensitive aminopeptidase GN=NPEPPS PSA_HUMAN $103.28 \quad 100.0 \%$ Puromycin-sensitive aminopeptidase GN=NPEPPS PSA_HUMAN $103.28 \quad 100.0 \%$ Puromycin-sensitive aminopeptidase GN=NPEPPS PSA_HUMAN $103.28100 .0 \%$ Puromycin-sensitive aminopeptidase GN=NPEPPS PSA_HUMAN $103.28 \quad 100.0 \%$ Puromycin-sensitive aminopeptidase GN=NPEPPS PSA_HUMAN $103.28 \quad 100.0 \%$ Puromycin-sensitive aminopeptidase GN=NPEPPS PSA_HUMAN $103.28 \quad 100.0 \%$ Puromycin-sensitive aminopeptidase GN=NPEPPS PSA_HUMAN $103.28 \quad 100.0 \%$
$0.00 \% \quad 23.7 \%$ LLETECPQYIR $0.01 \% \quad 6.1 \%$ DLLVQYATGK $0.01 \% \quad 6.1 \%$ DLLVQYATGKK $0.01 \% \quad 6.1 \% \quad$ TLNPQMLQK $0.01 \% \quad 6.1 \%$ GKPTEASIEAR $0.01 \% \quad 6.1 \% \quad$ VLTQEDFQKIR $0.01 \% \quad 12.1 \%$ NGGQILIADLR $0.01 \% \quad 12.1 \%$ FASGGCDNLIK $0.01 \% \quad 12.1 \%$ GQGSVSASVTEGQQNEQ $0.01 \% \quad 19.3 \%$ LNEQASEEILK $0.01 \% \quad 19.3 \%$ LRQPFFQK $0.01 \% \quad 19.3 \%$ VEVTEFEDIK $0.01 \% \quad 19.3 \%$ IDFYFDENPYFENK $0.01 \% \quad 19.3 \%$ EFHLNESGDPSSK $0.01 \% \quad 1.5 \% \quad$ NPSSAAPVQSR $0.01 \% \quad 1.5 \%$ FGPGGQLIK $0.01 \% \quad 1.5 \%$ TMATMGDTLASR $0.04 \% \quad 9.0 \%$ IIEVGDTPK $0.04 \% \quad 9.0 \%$ IIEVGDTPKDR $0.04 \% \quad 9.0 \%$ AFSPTTVNTGR $0.04 \% \quad 9.0 \% \quad$ YRGQYNTYPIK $0.04 \% \quad 9.0 \%$ GQYNTYPIK $0.04 \% \quad 9.0 \% \quad$ ETSMVHELNR $0.01 \% \quad 3.2 \%$ VNTDGLVLR $0.01 \% \quad 3.2 \%$ TTFEIEISR $0.01 \% \quad 3.2 \%$ VVTAGSAILQK $0.01 \% \quad 3.2 \%$ SAVGHVFSLEK $0.01 \% \quad 3.2 \% \quad$ SPGDSVIR $0.01 \% \quad 3.2 \%$ SEYIEPAKR $0.00 \% \quad 1.5 \%$ LQKADVVAQSR $0.00 \% \quad 1.5 \%$ GLGETATVLTK $0.00 \% \quad 8.0 \% \quad$ YYFAVDTMYVGR $0.00 \% \quad 8.0 \% \quad$ ILADAAAEGVPVR $0.00 \% \quad 8.2 \%$ QYAGYDYSQQGR $0.00 \% \quad 8.2 \%$ TLTVLHPLK $0.00 \% \quad 0.9 \%$ IFILPSGKCCNK $0.00 \% \quad 0.9 \%$ IGDFGLAR $0.00 \% \quad 6.6 \% \quad$ FLGSTEVEQPK $0.00 \% \quad 6.6 \%$ VQDLENQLR $0.04 \% \quad 11.2 \%$ SKYTTPSGEVR $0.04 \% \quad 11.2 \%$ YAAVTQFEATDARR $0.04 \% \quad 11.2 \%$ LNLGTVGFYR $0.04 \% \quad 11.2 \%$ AGIISTVEVLK $0.04 \% \quad 11.2 \%$ SPVYLTVLK $0.04 \% \quad 11.2 \%$ VLGATLLPDLIQK $0.04 \% \quad 11.2 \%$ LSVEGFAVDK $0.04 \% \quad 11.2 \%$ AFFESHPAPSAER
113.56

$99.5 \% \quad 29.2$

$25.0 \quad 41.4 \quad 2$

$99.7 \% \quad 31.6 \quad 25.0 \quad 31.1$

$\begin{array}{llll}99.7 \% & 53.0 & 25.0 & 35.2\end{array}$

$\begin{array}{llll}99.7 \% & 57.9 & 25.0 & 45.9\end{array}$

$99.5 \% \quad 22.0 \quad 25.0 \quad 22.0$

$\begin{array}{llll}99.7 \% & 40.8 & 25.0 & 27.1\end{array}$

$\begin{array}{llll}99.1 \% & 26.5 & 25.0 & 19.4\end{array}$

$\begin{array}{llll}99.7 \% & 38.5 & 25.0 & 25.9\end{array}$

$\begin{array}{llll}99.7 \% & 32.7 & 25.0 & 22.8\end{array}$

$\begin{array}{llll}99.7 \% & 45.2 & 25.0 & 31.3\end{array}$

$\begin{array}{llll}99.7 \% & 36.9 & 25.0 & 36.9\end{array}$

$99.0 \% \quad 30.6 \quad 25.0 \quad 17.5$

$\begin{array}{llll}99.1 \% & 18.8 & 25.0 & 18.0\end{array}$

$99.0 \% \quad 22.2 \quad 25.0 \quad 16.0$

$\begin{array}{llll}99.7 \% & 48.2 & 25.0 & 39.9\end{array}$

$\begin{array}{llll}99.5 \% & 23.4 & 25.0 & 23.4\end{array}$

$\begin{array}{llll}99.7 \% & 57.2 & 25.0 & 55.7\end{array}$

$\begin{array}{llll}99.7 \% & 39.8 & 25.0 & 37.8\end{array}$

$\begin{array}{llll}99.6 \% & 30.2 & 25.0 & 21.0\end{array}$

$\begin{array}{llll}94.9 \% & 25.3 & 25.0 & 20.6\end{array}$

$99.0 \% \quad 33.3 \quad 25.0 \quad 0.0$

$\begin{array}{llll}99.7 \% & 38.6 & 25.0 & 31.0\end{array}$

$96.1 \% \quad 15.7 \quad 25.0 \quad 14.9$

$\begin{array}{llll}99.7 \% & 36.1 & 25.0 & 36.1\end{array}$

$\begin{array}{llll}99.4 \% & 21.7 & 25.0 & 19.1\end{array}$

$\begin{array}{lllll}99.7 \% & 59.2 & 25.0 & 48.0 & 8\end{array}$

$\begin{array}{llll}99.7 \% & 49.6 & 25.0 & 42.6\end{array}$

$\begin{array}{llll}99.7 \% & 35.7 & 25.0 & 31.0\end{array}$

$\begin{array}{lllll}99.7 \% & 41.5 & 25.0 & 41.5 & 4\end{array}$

$99.7 \% \quad 40.6 \quad 25.0 \quad 37.5$

$\begin{array}{llll}99.4 \% & 22.7 & 25.0 & 19.0\end{array}$

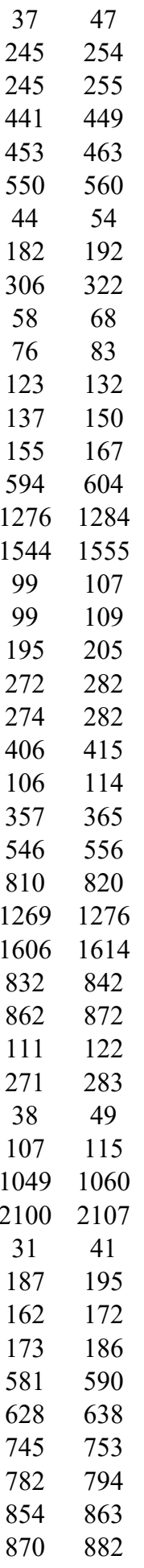

Page 124 of Table S-1-5 

Putative ATP-dependent RNA helicase DHX30 GN=DHX30 DHX30_HUMAN $133.94 \quad 100.0 \%$ Putative ATP-dependent RNA helicase DHX30 GN=DHX30 DHX30_HUMAN $133.94 \quad 100.0 \% 32$ Putative ATP-dependent RNA helicase DHX30 GN=DHX30 DHX30_HUMAN $133.94 \quad 100.0 \% \quad 32$ Putative ATP-dependent RNA helicase DHX30 GN=DHX30 DHX30_HUMAN $133.94 \quad 100.0 \% 32$ Putative ATP-dependent RNA helicase DHX30 GN=DHX30 DHX30_HUMAN $133.94 \quad 100.0 \% 32$ Putative ATP-dependent RNA helicase DHX30 GN=DHX30 DHX30_HUMAN $133.94 \quad 100.0 \% \quad 32$ Putative ATP-dependent RNA helicase DHX30 GN=DHX30 DHX30 HUMAN $133.94 \quad 100.0 \% 32$ Putative ATP-dependent RNA helicase DHX30 GN=DHX30 DHX30_HUMAN $133.94 \quad 100.0 \% 32$ Putative ATP-dependent RNA helicase DHX30 GN=DHX30 DHX30_HUMAN $133.94 \quad 100.0 \% 32$ Putative ATP-dependent RNA helicase DHX30 GN=DHX30 DHX30_HUMAN $133.94 \quad 100.0 \% 32$ Putative ATP-dependent RNA helicase DHX30 GN=DHX30 DHX30_HUMAN $133.94 \quad 100.0 \%$ Putative ATP-dependent RNA helicase DHX30 GN=DHX30 DHX30_HUMAN $133.94 \quad 100.0 \% 32$ Putative ATP-dependent RNA helicase DHX30 GN=DHX30 DHX30_HUMAN $133.94 \quad 100.0 \% 32$ Putative ATP-dependent RNA helicase DHX30 GN=DHX30 DHX30_HUMAN $133.94 \quad 100.0 \% 32$ Putative ATP-dependent RNA helicase DHX30 GN=DHX30 DHX30_HUMAN $133.94 \quad 100.0 \% 32$ Putative ATP-dependent RNA helicase DHX30 GN=DHX30 DHX30_HUMAN $133.94 \quad 100.0 \%$ Putative ATP-dependent RNA helicase DHX30 GN=DHX30 DHX30_HUMAN $133.94 \quad 100.0 \% 32$ Putative ATP-dependent RNA helicase DHX30 GN=DHX30 DHX30_HUMAN $133.94 \quad 100.0 \% 32$ Putative ATP-dependent RNA helicase DHX30 GN=DHX30 DHX30_HUMAN $133.94 \quad 100.0 \% 32$ Putative ATP-dependent RNA helicase DHX30 GN=DHX30 DHX30_HUMAN $133.94 \quad 100.0 \% 32$ Putative ATP-dependent RNA helicase DHX30 GN=DHX30 DHX30_HUMAN $133.94 \quad 100.0 \%$ Putative ATP-dependent RNA helicase DHX30 GN=DHX30 DHX30_HUMAN $133.94 \quad 100.0 \% 32$ Putative ATP-dependent RNA helicase DHX30 GN=DHX30 DHX30_HUMAN $133.94 \quad 100.0 \% 32$ Putative ATP-dependent RNA helicase DHX30 GN=DHX30 DHX30_HUMAN $133.94 \quad 100.0 \%$ Putative ATP-dependent RNA helicase DHX30 GN=DHX30 DHX30_HUMAN $133.94 \quad 100.0 \% 32$ Putative ATP-dependent RNA helicase DHX30 GN=DHX30 DHX30_HUMAN $133.94 \quad 100.0 \% 32$ Putative ATP-dependent RNA helicase DHX30 GN=DHX30 DHX30_HUMAN $133.94 \quad 100.0 \% \quad 32$ Putative ATP-dependent RNA helicase DHX30 GN=DHX30 DHX30 HUMAN $133.94 \quad 100.0 \%$ Putative ATP-dependent RNA helicase DHX30 GN=DHX30 DHX30_HUMAN $133.94 \quad 100.0 \%$ Putative ATP-dependent RNA helicase DHX30 GN=DHX30 DHX30_HUMAN $133.94 \quad 100.0 \%$ Putative ATP-dependent RNA helicase DHX30 GN=DHX30 DHX30_HUMAN $133.94 \quad 100.0 \% 32$ Putative ATP-dependent RNA helicase DHX57 GN=DHX57 DHX57_HUMAN $155.61 \quad 100.0 \%$ Putative ATP-dependent RNA helicase DHX57 GN=DHX57 DHX57_HUMAN $155.61 \quad 100.0 \%$ Putative ATP-dependent RNA helicase DHX57 GN=DHX57 DHX57_HUMAN $155.61 \quad 100.0 \%$ Putative ATP-dependent RNA helicase DHX57 GN=DHX57 DHX57_HUMAN $155.61 \quad 100.0 \%$ Putative helicase MOV-10 GN=MOV10 MOV10 HUMAN $113.68 \quad 100.0 \%$ Putative helicase MOV-10 GN=MOV10 MOV10_HUMAN $113.68 \quad 100.0 \%$ Putative helicase MOV-10 GN=MOV10 MOV10_HUMAN $113.68 \quad 100.0 \% \quad 1$ Putative helicase MOV-10 GN=MOV10 MOV10_HUMAN $113.68 \quad 100.0 \%$ Putative helicase MOV-10 GN=MOV10 MOV10_HUMAN $113.68 \quad 100.0 \%$ Putative helicase MOV-10 GN=MOV10 MOV10_HUMAN $113.68 \quad 100.0 \%$ Putative helicase MOV-10 GN=MOV10 MOV10_HUMAN $113.68 \quad 100.0 \% \quad 12$ Putative helicase MOV-10 GN=MOV10 MOV10_HUMAN $113.68 \quad 100.0 \%$ Putative helicase MOV-10 GN=MOV10 MOV10_HUMAN $113.68 \quad 100.0 \%$ Putative helicase MOV-10 GN=MOV10 MOV10_HUMAN $113.68 \quad 100.0 \% \quad 12$

$10 \quad 35 \quad 0.04 \% \quad 11.2 \%$ DAESIHQYLLQR $82 \quad 0.09 \% \quad 24.5 \%$ NLLNSVIGR $\begin{array}{llll}34 & 82 & 0.09 \% & 24.5 \% \\ 34 & 82 & 0.09 \% & 24.5 \%\end{array}$ $34 \quad 82 \quad 0.09 \% \quad 24.5 \%$ NELFDAAKYR
$0.09 \% \quad 24.5 \%$ QLNPESIRPGGPGGLSR $0.09 \% \quad 24.5 \%$ ALTQFPLPK

$0.09 \% \quad 24.5 \%$ VIQIATSSSTAK

$0.09 \% \quad 24.5 \%$ NLMQFHTVGTK

$0.09 \% \quad 24.5 \%$ LQSDDILPLGK

$0.09 \% \quad 24.5 \%$ TTRIPQLLLER

$0.09 \% \quad 24.5 \%$ IPQLLLER

$0.09 \% \quad 24.5 \%$ CNVIITQPR

$0.09 \% \quad 24.5 \%$ CNVIITQPRR

$0.09 \% \quad 24.5 \%$ RISAVSVAQR

$0.09 \% \quad 24.5 \%$ ISAVSVAQR

$0.09 \% \quad 24.5 \%$ VSHELGPSLRR

$0.09 \% \quad 24.5 \%$ LVLMSATGDNER

$0.09 \% \quad 24.5 \%$ LVLMSATGDNERFSR

$0.09 \% \quad 24.5 \%$ AIFQQPPVGVR

$0.09 \% \quad 24.5 \%$ AIFQQPPVGVRK

$0.09 \% \quad 24.5 \%$ CQSGFAYHLFPR

$0.09 \% \quad 24.5 \%$ TPLENLVLQAK

$0.09 \% \quad 24.5 \%$ TAVEFLSK

$0.09 \% \quad 24.5 \%$ AVDSPNIK

$0.09 \% \quad 24.5 \%$ AIVLAAIFR

$0.09 \% \quad 24.5 \%$ DPFSSSLQNR

$0.09 \% \quad 24.5 \%$ ALLSHDSGSDHLAFVR

$0.09 \% \quad 24.5 \%$ AVAGWEEVLR

$0.09 \% \quad 24.5 \%$ ENYLEENLLYAPSLR

$0.09 \% \quad 24.5 \%$ FKPNSVTYR

$0.09 \% \quad 24.5 \%$ SGNILLHK

$0.09 \% \quad 24.5 \%$ SNGSVFVR

$0.09 \% \quad 24.5 \%$ ATISLSDSDLLR

$0.01 \% \quad 2.2 \%$ QFQSILQER

$0.01 \% \quad 2.2 \%$ RISAISVAER

$0.01 \% \quad 2.2 \% \quad$ ISAISVAER

$0.01 \% \quad 2.2 \% \quad$ YVLQDGSPYMR

$0.02 \% \quad 11.4 \%$ HGVDVEVQGPHEAR

$0.02 \% \quad 11.4 \%$ SLESNPEQLQAMR

$0.02 \% \quad 11.4 \%$ TVTLVEAIK

$0.02 \% \quad 11.4 \%$ VLITTLITAGR

$0.02 \% \quad 11.4 \%$ ETGDPGGQLVLAGDPR

$0.02 \% \quad 11.4 \%$ HGLGYSLLER

$0.02 \% \quad 11.4 \%$ LLTYNSLYK

$0.02 \% \quad 11.4 \%$ KGPDGYDPQFITK

$0.02 \% \quad 11.4 \%$ GPDGYDPQFITK

$0.02 \% \quad 11.4 \%$ SVGVISPYR
$99.7 \% \quad 60.5$ $99.7 \% \quad 37.2$

$\begin{array}{lll}99.7 \% & 45.3\end{array}$

$99.7 \% \quad 44.2$

$99.6 \% 27.5$

$\begin{array}{lll}96.3 \% & 23.1\end{array}$

$99.7 \% \quad 54.0$

$99.7 \% \quad 34.2$

$99.4 \% \quad 28.3$

$95.0 \% \quad 13.9$

$99.0 \% \quad 47.3$

$99.7 \% \quad 45.8$

$99.6 \% \quad 23.8$

$99.7 \% \quad 57.4$

$99.7 \% \quad 53.7$

$97.2 \% \quad 17.3$

$99.7 \% \quad 60.9$

$99.6 \% \quad 23.8$

$\begin{array}{lll}99.7 \% & 57.3\end{array}$

$99.1 \% \quad 19.0$

$99.7 \% \quad 35.4$

$99.7 \% \quad 48.5$

$98.6 \% 19.7$

$\begin{array}{lll}98.4 \% & 24.7\end{array}$

$99.7 \% \quad 50.7$

$99.7 \% \quad 60.9$

$99.7 \% \quad 36.3$

$99.7 \% \quad 38.6$

$99.1 \% \quad 25.7$

$98.8 \% 25.5$

$99.0 \% \quad 43.5$

$99.0 \% \quad 29.6$

$99.7 \% \quad 27.9$

$99.7 \% \quad 32.3$

$98.3 \% \quad 22.9$

$99.7 \% \quad 51.2$

$98.9 \% \quad 22.6$

$99.7 \% \quad 50.6$

$99.7 \% \quad 57.3$

$99.7 \% \quad 32.0$

$99.7 \% \quad 57.3$

$99.7 \% \quad 53.3$

$99.3 \% \quad 20.1$

$99.7 \% \quad 41.3$

$99.7 \% \quad 41.4$

$99.7 \% \quad 45.8$

$99.7 \% \quad 36.3$
1205.67

1291.65

1198.67

1339.81

981.61

1100.59

1256.69

1086.64

930.54

1250.70

1321.64

1711.84

1211.69

1339.78

1482.69

1225.72

894.49

843.46

973.62

1150.55

1724.87

1129.60

1823.92

1111.59

881.52

865.45

1290.69

1148.61

1101.64

945.54

1328.63

1529.75

1502.73

973.59

1157.73

1581.79

1144.6

1114.61

1465.73

1337.64

977.54

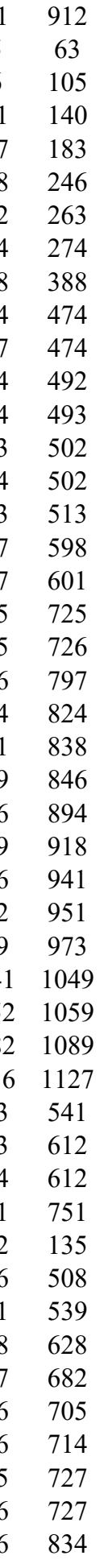


Putative helicase MOV-10 GN=MOV10 MOV10_HUMAN $113.68 \quad 100.0 \% \quad 1$ Putative helicase MOV-10 GN=MOV10 MOV10_HUMAN $113.68 \quad 100.0 \%$ TIмм2зв TI23B HUMAN $21.94-100.0 \%$ TI23B_HUMAN 21.94

TI23B_HUMAN $21.94 \quad 100.0 \%$ Putative oxidoreductase GLYR1 GN=GLYR1 GLYR1_HUMAN $60.56 \quad 100.0 \%$ Putative oxidoreductase GLYR1 GN=GLYR1 GLYR1_HUMAN $60.56 \quad 100.0 \%$ Putative oxidoreductase GLYR1 GN=GLYR1 GLYR1_HUMAN $60.56 \quad 100.0 \%$ Putative RNA-binding protein 15 GN=RBM15 RBM15 HUMAN $107.19 \quad 100.0 \%$ Putative RNA-binding protein 15 GN=RBM15 RBM15_HUMAN $107.19 \quad 100.0 \%$ Putative RNA-binding protein Luc7-like 2 GN=LUC7L2 LC7L2_HUMAN $46.51 \quad 100.0 \%$ Putative RNA-binding protein Luc7-like $2 \mathrm{GN}=$ LUC7L2 LC7L2_HUMAN $46.51 \quad 100.0 \%$ Putative RNA-binding protein Luc7-like 2 GN=LUC7L2 LC7L2_HUMAN $46.51 \quad 100.0 \%$ Putative RNA-binding protein Luc7-like 2 GN=LUC7L2 LC7L2_HUMAN $46.51 \quad 100.0 \%$ Putative RNA-binding protein Luc7-like $2 \mathrm{GN}=$ LUC7L2 LC7L2_HUMAN $46.51 \quad 100.0 \%$ Putative RNA-binding protein Luc7-like 2 GN=LUC7L2 LC7L2_HUMAN $46.51 \quad 100.0 \%$ Putative RNA-binding protein Luc7-like $2 \mathrm{GN}=\mathrm{LUC7} 22$ LC7L2_HUMAN $46.51 \quad 100.0 \%$ Putative RNA-binding protein Luc7-like 2 GN=LUC7L2 LC7L2_HUMAN $46.51 \quad 100.0 \%$ Pyrroline-5-carboxylate reductase 1, mitochondrial GN=PYCR1 P5CR1_HUMAN $33.36 \quad 100.0 \%$ Pyrroline-5-carboxylate reductase 1, mitochondrial GN=PYCR1 P5CR1_HUMAN $33.36 \quad 100.0 \%$ Pyrroline-5-carboxylate reductase 1, mitochondrial GN=PYCR1 P5CR1_HUMAN $33.36 \quad 100.0 \%$ Pyrroline-5-carboxylate reductase 1, mitochondrial GN=PYCR1 P5CR1 HUMAN $33.36100 .0 \%$ Pyrroline-5-carboxylate reductase 1, mitochondrial GN=PYCR1 P5CR1_HUMAN $33.36 \quad 100.0 \%$ Pyrroline-5-carboxylate reductase 1, mitochondrial GN=PYCR1 P5CR1_HUMAN $33.36 \quad 100.0 \%$ Pyrroline-5-carboxylate reductase 1 , mitochondrial GN=PYCR1 P5CR1_HUMAN $33.36 \quad 100.0^{\circ}$ Pyrroline-5-carboxylate reductase 1, mitochondrial GN=PYCR1 P5CR1_HUMAN $33.36 \quad 100.0 \%$ Pyrroline-5-carboxylate reductase 1, mitochondrial GN=PYCR1 P5CR1_HUMAN $33.36 \quad 100.0 \%$ Pyrroline-5-carboxylate reductase 1, mitochondrial GN=PYCR1 P5CR1_HUMAN $33.36 \quad 100.0 \%$ Pyrroline-5-carboxylate reductase 2 GN=PYCR2 P5CR2_HUMAN $33.64 \quad 100.0 \%$ Pyrroline-5-carboxylate reductase $2 \mathrm{GN}=\mathrm{PYCR} 2 \mathrm{P} 5 \mathrm{CR} 2$ HUMAN $33.64100 .0 \%$ Pyrroline-5-carboxylate reductase 2 GN=PYCR2 P5CR2_HUMAN $33.64 \quad 100.0 \%$ Pyrroline-5-carboxylate reductase 2 GN=PYCR2 P5CR2_HUMAN $33.64100 .0 \%$ Pyrroline-5-carboxylate reductase 2 GN=PYCR2 P5CR2_HUMAN $33.64 \quad 100.0 \%$ Pyrroline-5-carboxylate reductase 2 GN=PYCR2 P5CR2_HUMAN $33.64100 .0 \%$ Pyrroline-5-carboxylate reductase 2 GN=PYCR2 P5CR2_HUMAN $33.64 \quad 100.0 \%$ Pyrroline-5-carboxylate reductase 2 GN=PYCR2 P5CR2_HUMAN $33.64 \quad 100.0 \%$ Pyrroline-5-carboxylate reductase 2 GN=PYCR2 P5CR2_HUMAN $33.64 \quad 100.0 \%$ Pyrroline-5-carboxylate reductase $2 \mathrm{GN}=\mathrm{PYCR} 2$ P5CR2 HUMAN $33.64100 .0 \%$ Pyrroline-5-carboxylate reductase 2 GN=PYCR2 P5CR2_HUMAN $33.64 \quad 100.0 \%$ Pyrroline-5-carboxylate reductase 2 GN=PYCR2 P5CR2_HUMAN $33.64100 .0 \%$ Pyrroline-5-carboxylate reductase $2 \mathrm{GN}=\mathrm{PYCR} 2 \mathrm{P} 5 \mathrm{CR} 2$ HUMAN $33.64 \quad 100.0 \%$ Pyrroline-5-carboxylate reductase 2 GN=PYCR2 P5CR2_HUMAN $33.64 \quad 100.0 \%$ Pyrroline-5-carboxylate reductase 3 GN=PYCRL P5CR3 HUMAN $28.66100 .0^{\circ} \%$ Pyrroline-5-carboxylate reductase 3 GN=PYCRL P5CR3_HUMAN $28.66 \quad 100.0 \%$ Pyrroline-5-carboxylate reductase 3 GN=PYCRL P5CR3_HUMAN $28.66 \quad 100.0 \%$ Pyrroline-5-carboxylate reductase $3 \mathrm{GN}=$ PYCRL P5CR3_HUMAN $28.66 \quad 100.0 \%$ Pyrroline-5-carboxylate reductase 3 GN=PYCRL P5CR3_HUMAN $28.66 \quad 100.0 \%$
$0.02 \% \quad 11.4 \%$ SVGVISPYRK

$0.02 \% \quad 11.4 \%$ SVILISTVR

$99.7 \% \quad 32.8$

$99.7 \% \quad 32.7$

$0.01 \% \quad 11.3 \%$ YLVQDTDEFILPTGANK $\quad 99.7 \% \quad 54.9$

$0.01 \% \quad 11.3 \%$ YLVQDTDEFILPTGANKTR $99.7 \% \quad 43.0$

$0.01 \% \quad 11.3 \%$ NVQILNMVTR

$0.01 \% \quad 7.4 \%$ TAEKCDLFIQEGAR

$99.7 \% \quad 57.2$

$99.7 \% \quad 42.5$

$99.7 \% \quad 60.7$

$0.01 \% \quad 7.4 \%$ TSFFLGEVGNAAK

$99.7 \% \quad 53.4$

$0.01 \% \quad 7.4 \%$ ALDQSDNDMSAVYR

$99.7 \% \quad 34.1$

$0.01 \% \quad 4.1 \% \quad$ SSSSSAASDTATSTQRPLR $\quad 99.7 \% \quad 44.3$

$0.03 \% \quad 24.2 \%$ AMLDQLMGTSR

$0.03 \% \quad 24.2 \%$ FSDDRVCK

$0.03 \% \quad 24.2 \%$ SHLLNCCPHDVLSGTR

$0.03 \% \quad 24.2 \%$ LAETQEEISAEVAAK

$0.03 \% \quad 24.2 \%$ VHELNEEIGK

$0.03 \% \quad 24.2 \%$ VEQLGAEGNVEESQK

$0.03 \% \quad 24.2 \%$ NSMPASSFQQQK

$0.03 \% \quad 24.2 \%$ LADHFGGK

$0.02 \% \quad 35.4 \%$ GFTAAGVLAAHK

$0.02 \% \quad 35.4 \%$ CMTNTPVVVR

$99.7 \% \quad 53.6$

$99.0 \% \quad 30.8$

$99.5 \% \quad 22.6$

$99.7 \% \quad 61.8$

$99.7 \% 55.3$

$99.7 \% \quad 57.6$

$99.7 \% \quad 31.2$

$99.0 \% 31.0$

$99.7 \% \quad 55.4$

$99.7 \% \quad 57.1$

$0.02 \% \quad 35.4 \%$ EGATVYATGTHAQVEDGR $\quad 99.7 \% \quad 44.4$

$0.02 \% 35.4 \%$ LGAQALLGAAK

$0.02 \% \quad 35.4 \%$ MLLHSEQHPGQLK

$99.7 \% 71.5$

$99.7 \% \quad 24.6$

$99.7 \% \quad 61.0$

$0.02 \% \quad 35.4 \%$ ELQSMADQEQVSPAAIK $\quad 99.7 \% \quad 40.5$

$0.02 \% \quad 35.4 \%$ ELQSMADQEQVSPAAIKK $97.1 \% \quad 15.2$

$0.02 \% \quad 35.4 \%$ VKLDSPAGTALSPSGHTK $99.7 \% 32.0$

$0.02 \% \quad 35.4 \%$ LDSPAGTALSPSGHTK $\quad 99.7 \% \quad 71.2$

$0.07 \% \quad 42.2 \%$ GFTAAGILSAHK

$99.7 \% \quad 59.8$

$0.07 \% \quad 42.2 \%$ IIASSPEMNLPTVSALR $\quad 99.7 \% \quad 53.6$

$0.07 \% \quad 42.2 \%$ IIASSPEMNLPTVSALRK $\quad 99.5 \% \quad 24.1$

$0.07 \% \quad 42.2 \%$ HIVVSCAAGVTISSVEK $\quad 99.7 \% \quad 48.1$

\begin{tabular}{ll}
$0.07 \%$ & $42.2 \%$ \\
\hline
\end{tabular}

$0.07 \% \quad 42.2 \%$ LMAFQPAPK

$99.7 \% \quad 32.5$

$0.07 \% \quad 42.2 \%$ RLAIQLGAQALLGAAK

$0.07 \% \quad 42.2 \%$ LAIQLGAQALLGAAK

$0.07 \% \quad 42.2 \%$ MLLDSEQHPCQLK

$0.07 \% \quad 42.2 \%$ SLLINAVEASCIR

$99.7 \% \quad 59.5$

$99.6 \% \quad 23.5$

$99.7 \% \quad 61.0$

$99.7 \% \quad 50.1$

$99.0 \% \quad 36.8$

$0.07 \% \quad 42.2 \%$ ISPAALKK

$99.7 \% \quad 57.0$

$0.07 \% \quad 42.2 \%$ VKLESPTVSTLTPSSPGK

$0.07 \% \quad 42.2 \%$ LESPTVSTLTPSSPGK

$0.02 \% \quad 30.7 \%$ RVGFVGAGR

$0.02 \% \quad 30.7 \%$ MAGAIAQGLIR

$99.7 \% \quad 41.0$

$99.7 \% \quad 29.5$

$\begin{array}{ll}0.02 \% & 30.7 \% \text { AGKVEAQHILASAPT } \\ 0.02 \% & 30.7 \% \text { VEAQHILASAPTDR }\end{array}$

$0.02 \% \quad 30.7 \%$ MGMPSSLAHR
$99.7 \% \quad 60.0$

$\begin{array}{llll}99.5 \% & 21.0 & 25.0 & 19.4\end{array}$

$25.0-19.4$

$\begin{array}{llll}99.7 \% & 27.1 & 25.0 & 27.1\end{array}$ 


\section{Pyruvate dehydric} \begin{tabular}{lll} 
ODPA_HUMAN & 43.30 & $100.0 \%$ \\
\hline ODPA_HUMAN & 43.30 & $100.0 \%$
\end{tabular}

Pyruvate kinase PKM GN=PKM

Pyruvate kinase $\mathrm{PKM}$ GN=PKM

Pyruvate kinase $P K M$ GN=PKM

Pyruvate kinase $P K M$ GN=PKN

Pyruvate kinase PKM GN=PKM

Pyruvate kinase $\mathrm{PKM}$ GN=PKM

Pyruvate kinase $\mathrm{PKM}$ GN=PKM

Pyruvate kinase $P K M$ GN=PKM

Pyruvate kinase $\mathrm{PKM}$ GN=PKN

Pyruvate kinase $\mathrm{PKM}$ GN=PKM

Pyruvate kinase $P K M$ GN=PKM

Pyruvate kinase PKM GN=PKM

Pyruvate kinase PKM GN=PKM

Pyruvate kinase $\mathrm{PKM}$ GN=PKM

Pyruvate kinase $\mathrm{PKM}$ GN=PKM

Pyruvate kinase $\mathrm{PKM}$ GN=PKM

Rab-like protein $2 \mathrm{~B}$ GN=RABL2B

Rab-like protein $2 \mathrm{~B} \mathrm{GN}=\mathrm{RABL} 2 \mathrm{~B}$

KPYM_HUMAN $57.94 \quad 100.0 \%$ KPYM HUMAN $57.94 \quad 100.0 \%$ KPYM_HUMAN $57.94 \quad 100.0 \%$ KPYM_HUMAN $57.94 \quad 100.0 \%$ KPYM HUMAN $57.94 \quad 100.0 \%$ KPYM_HUMAN $57.94 \quad 100.0 \%$ KPYM_HUMAN $57.94 \quad 100.0 \%$ KPYM HUMAN $57.94 \quad 100.0 \%$ KPYM_HUMAN $57.94 \quad 100.0 \%$ KPYM HUMAN $57.94 \quad 100.0 \%$ KPYM HUMAN $57.94 \quad 100.0 \%$ KPYM_HUMAN $57.94 \quad 100.0 \%$ KPYM HUMAN $57.94 \quad 100.0 \%$ KPYM_HUMAN $57.94 \quad 100.0 \%$ KPYM_HUMAN $57.94 \quad 100.0 \%$ KPYM HUMAN $57.94 \quad 100.0 \%$ RBL2B_HUMAN $26.10 \quad 100.0 \%$ RBL2B HUMAN $26.10 \quad 100.0 \%$ Rac GTPase-activating protein $1 \mathrm{GN}=$ RACGAP1 RGAP1_HUMAN $71.03 \quad 100.0 \%$ Rac GTPase-activating protein 1 GN=RACGAP1 RGAP1_HUMAN $71.03 \quad 100.0 \%$ Rac GTPase-activating protein $1 \mathrm{GN}=\mathrm{RACGAP} 1$ RGAP1 HUMAN $71.03 \quad 100.0 \%$ Ran GTPase-activating protein $1 \mathrm{GN}=$ RANGAP1 RAGP1_HUMAN $63.54 \quad 100.0 \%$
$0.02 \% \quad 30.7 \%$ IAAQTLLGTAK $0.02 \% \quad 30.7 \%$ MLLHEGQHPAQLR $0.02 \% \quad 30.7 \%$ AATMSAVEAATCR $0.03 \% \quad 27.7 \%$ LEEGPPVTTVLTR

$0.03 \% \quad 27.7 \%$ AHGFTFTR

$0.03 \% \quad 27.7 \%$ EILAELTGR

$0.03 \% \quad 27.7 \%$ LPCIFICENNR

$0.03 \% \quad 27.7 \%$ YGMGTSVER

$0.03 \% \quad 27.7 \%$ AAASTDYYK

$0.03 \% \quad 27.7 \%$ AAASTDYYKR

$0.03 \% \quad 27.7 \%$ RGDFIPGLR

$0.03 \% \quad 27.7 \%$ VDGMDILCVR

$0.03 \% \quad 27.7 \%$ GPILMELQTYR

$0.03 \% \quad 27.7 \%$ TREEIQEVR

$0.03 \% \quad 27.7 \%$ SKSDPIMLLK

$0.02 \% \quad 29.5 \%$ VFLLGEEVAQYDGAYK

$0.02 \% \quad 29.5 \%$ TYYMSGGLQPVPIVFR

$0.02 \% \quad 29.5 \%$ EGVECEVINMR

$0.02 \% \quad 29.5 \%$ TIRPMDMETIEASVMK

$0.02 \% \quad 29.5 \%$ IMEGPAFNFLDAPAVR

$0.02 \% \quad 29.5 \%$ VTGADVPMPYAK

$0.02 \% \quad 29.5 \%$ ILEDNSIPQVK

$0.02 \% \quad 29.5 \%$ DIIFAIKK

$0.00 \% \quad 5.4 \% \quad$ FRLSPAAR

$99.7 \% \quad 64.1$

$99.1 \% \quad 21.4$

$99.7 \% \quad 54.9$

$99.7 \% \quad 59.7$

$98.6 \% 19.6$

$99.7 \% \quad 56.1$

$99.7 \% \quad 52.5$

$99.7 \% \quad 49.9$

$99.6 \% 29.6$

$99.7 \% \quad 66.9$

$99.7 \% \quad 34.5$

$99.7 \% \quad 57.2$

$99.7 \% \quad 54.0$

$99.7 \% \quad 40.3$

$99.3 \% \quad 23.6$

$\begin{array}{lll}99.7 \% & 69.8\end{array}$

$99.7 \% \quad 39.7$

$99.7 \% \quad 52.2$

$99.3 \% \quad 30.0$

$\begin{array}{lll}99.7 \% & 57.3\end{array}$

$99.7 \% \quad 51.6$

$99.7 \% \quad 54.7$

$99.0 \% \quad 30.0$

$94.9 \% \quad 20.4$

$0.00 \% \quad 5.4 \%$ NILEKHSLDASQGTATGPR $\quad 99.7 \% \quad 60.5$

$0.10 \% \quad 40.1 \%$ LDIDSPPITAR

$0.10 \% \quad 40.1 \%$ NTGIICTIGPASR

$0.10 \% \quad 40.1 \%$ SVETLKEMIK

$99.7 \% \quad 57.9$

$99.7 \% \quad 57.1$

$99.7 \% \quad 65.8$

$0.10 \% \quad 40.1 \%$ LNFSHGTHEYHAETIK

$99.7 \% \quad 28.0$

$0.10 \% \quad 40.1 \%$ TATESFASDPILYRPVAVALDTK $\quad 99.7 \% \quad 39.1$

$0.10 \% \quad 40.1 \%$ GSGTAEVELKK

$0.10 \% \quad 40.1 \%$ ITLDNAYMEK

$99.7 \% \quad 53.4$

$99.7 \% \quad 55.1$

$0.10 \% \quad 40.1 \%$ IYVDDGLISLQVK

$99.7 \% \quad 42.9$

$0.10 \% \quad 40.1 \%$ GADFLVTEVENGGSLGSK $99.7 \% \quad 74.4$

$0.10 \% \quad 40.1 \%$ IISKIENHEGVR

$0.10 \% \quad 40.1 \%$ GDLGIEIPAEK

$0.10 \% \quad 40.1 \%$ GDYPLEAVR

$99.7 \% \quad 59.6$

$99.7 \% \quad 51.3$

$99.7 \% \quad 38.5$

$0.10 \% \quad 40.1 \%$ LAPITSDPTEATAVGAVEASFK $\quad 99.7 \% \quad 60.7$

$0.10 \% \quad 40.1 \%$ CCSGAIIVLTK

$0.10 \% \quad 40.1 \%$ APIIAVTRNPQTAR

$0.10 \% \quad 40.1 \%$ VNFAMNVGK

$0.00 \% \quad 11.0 \%$ IICLGDSAVGK

$0.00 \% \quad 11.0 \%$ TILVDFWDTAGQER

$0.01 \% \quad 5.7 \% \quad$ SIGSAVDQGNESIVAK

$0.01 \% \quad 5.7 \%$ NLKEPLLTFR

$0.01 \% \quad 5.7 \%$ TPSSSSLSQR

$0.01 \% \quad 8.0 \%$ TQVAGGQLSFKGK
$99.7 \% \quad 65.8$

$99.7 \% \quad 53.7$

$99.2 \% \quad 25.5$

$99.7 \% \quad 27.5$

$99.7 \% \quad 59.8$

$99.7 \% \quad 56.2$

$99.2 \% \quad 19.4$

$99.7 \% \quad 47.2$

$99.4 \% \quad 25.3$
108

1086.65

1338.61

1411.78

936.47

1001.56

1435.68

999.46

989.46

1145.56

1030.58

1193.57

1320.70

1159.61

1147.64

1801.90

1827.95

1335.60

1899.89

1747.88

1264.62

1255.69

947.59

917.53

1995.03

1197.65

1359.71

1177.65

1883.90

2465.29

1118.61

1197.58

1462.82

1779.88

1394.78

1141.61

1019.52

2175.12

1221.63

1507.87

979.50

1132.60

1650.81

1574.80

1230.72

1049.52

1320.73

\begin{tabular}{cc}
08 & 218 \\
19 & 231 \\
55 & 267 \\
6 & 58 \\
20 & 127 \\
33 & 141 \\
16 & 226 \\
27 & 235 \\
36 & 244 \\
36 & 245 \\
45 & 253 \\
54 & 263 \\
78 & 288 \\
03 & 311 \\
12 & 321 \\
3 & 68 \\
30 & 145 \\
59 & 269 \\
70 & 285 \\
09 & 324 \\
25 & 336 \\
37 & 347 \\
48 & 355 \\
82 & 189 \\
90 & 208 \\
3 & 43 \\
4 & 56 \\
7 & 66 \\
4 & 89 \\
3 & 115 \\
26 & 136 \\
42 & 151 \\
74 & 186 \\
89 & 206 \\
67 & 278 \\
95 & 305 \\
68 & 376 \\
01 & 422 \\
23 & 433 \\
48 & 461 \\
90 & 498 \\
4 & 34 \\
9 & 82 \\
03 & 218 \\
\hline 8 & 437 \\
& 597 \\
\hline 0
\end{tabular}


Ran GTPase-activating protein $1 \mathrm{GN}=$ RANGAP1 RAGP1 HUMAN $63.54 \quad 100.0 \%$ Ran GTPase-activating protein 1 GN=RANGAP1 RAGP1_HUMAN $63.54 \quad 100.0 \%$ Ran GTPase-activating protein 1 GN=RANGAP1 RAGP1_HUMAN $63.54 \quad 100.0 \%$ Ran-specific GTPase-activating protein GN=RANBP1 RANG_HUMAN $23.31 \quad 100.0 \%$ Ran-specific GTPase-activating protein GN=RANBP1 RANG_HUMAN $23.31 \quad 100.0 \%$ Rapamycin-insensitive companion of mTOR GN=RICTOR RICTR_HUMAN $192.22 \quad 100.0 \%$ Rapamycin-insensitive companion of mTOR GN=RICTOR RICTR HUMAN $192.22100 .0 \%$ Rapamycin-insensitive companion of mTOR GN=RICTOR RICTR_HUMAN $192.22 \quad 100.0 \%$ Ras GTPase-activating-like protein IQGAP1 GN=IQGAP1 IQGA1 HUMAN $189.26 \quad 100.0 \%$ Ras GTPase-activating-like protein IQGAP1 GN=IQGAP1 IQGA1_HUMAN $189.26 \quad 100.0 \%$ Ras GTPase-activating-like protein IQGAP1 GN=IQGAP1 IQGA1_HUMAN $189.26 \quad 100.0 \%$ Ras GTPase-activating-like protein IQGAP1 GN=IQGAP1 IQGA1_HUMAN $189.26 \quad 100.0 \%$ Ras GTPase-activating-like protein IQGAP1 GN=IQGAP1 IQGA1_HUMAN $189.26 \quad 100.0 \%$ Ras GTPase-activating-like protein IQGAP1 GN=IQGAP1 IQGA1_HUMAN $189.26 \quad 100.0 \%$ Regulation of nuclear pre-mRNA domain-containing protein $1 \mathrm{~A}$ GN=RPRDIA $\quad$ RPR1A_HUMAN $35.72 \quad 100.0 \%$ Regulation of nuclear pre-mRNA domain-containing protein 1A GN=RPRD1A RPR1A_HUMAN $35.72 \quad 100.0 \%$ Re $\quad$ RPR1A HUMAN $35.72 \quad 100.0 \%$ Regulation of nuclear pre-mRNA domain-containing protein 1A GN=RPRDIA RPR1A_HUMAN $35.72 \quad 100.0 \%$ Regulation of nuclear pre-mRNA domain-containing protein $1 \mathrm{~A}$ GN=RPRD1A $\quad$ RPR1A_HUMAN $35.72 \quad 100.0 \%$ Regulation of nuclear pre-mRNA domain-containing protein $1 \mathrm{~A}$ GN=RPRD1A $\quad$ RPR1A HUMAN $35.72 \quad 100.0 \%$ Regulation of nuclear pre-mRNA domain-contaning protein 1A GN=RPRD1A RPR1A_HUMAN $35.72 \quad 100.0 \%$ Regulator of nonsense transcripts 1 GN=UPF1 RENT1_HUMAN $124.35100 .0 \%$ Regulator of nonsense transcripts 1 GN=UPF1 RENT1_HUMAN $124.35100 .0 \%$ Regulator of nonsense transcripts 1 GN=UPF1 RENT1_HUMAN $124.35 \quad 100.0 \%$ Regulator of nonsense transcripts $1 \mathrm{GN}=\mathrm{UPF} 1$ RENT1_HUMAN $124.35 \quad 100.0 \%$ Regulator of nonsense transcripts 1 GN=UPF1 RENT1_HUMAN $124.35 \quad 100.0 \%$ Regulator of nonsense transcripts 1 GN=UPF1 RENT1_HUMAN $124.35 \quad 100.0 \%$ Regulator of nonsense transcripts 1 GN=UPF1 RENT1_HUMAN $124.35 \quad 100.0 \%$ Regulator of nonsense transcripts 1 GN=UPF1 RENT1_HUMAN $124.35 \quad 100.0 \%$ Regulator of nonsense transcripts 1 GN=UPF1 RENT1 HUMAN $124.35 \quad 100.0 \%$ Regulator of nonsense transcripts 1 GN=UPF1 RENT1_HUMAN $124.35 \quad 100.0 \%$ Regulator of nonsense transcripts 1 GN=UPF1 RENT1_HUMAN $124.35 \quad 100.0 \%$ Regulator of nonsense transcripts 1 GN=UPF1 RENT1_HUMAN $124.35 \quad 100.0 \%$ Renin receptor GN=ATP6AP2 Renin receptor $\mathrm{GN}=\mathrm{ATP} 6 \mathrm{AP}$ RENR_HUMAN $39.01 \quad 100.0 \%$ RENR HUMAN $39.01 \quad 100.0 \%$ Replication factor C subunit $1 \mathrm{GN}=\mathrm{RFC} 1 \quad$ RFC1_HUMAN $128.26 \quad 100.0 \%$ Replication factor C subunit $1 \mathrm{GN}=\mathrm{RFC} 1 \quad$ RFC1_HUMAN $128.26 \quad 100.0 \%$ Replication factor C subunit $1 \mathrm{GN}=\mathrm{RFC} 1 \quad \mathrm{RFC1}$ HUMAN $128.26 \quad 100.0 \%$ Replication factor C subunit $2 \mathrm{GN}=\mathrm{RFC} 2 \mathrm{RFC2}$ _HUMAN $39.16 \quad 100.0 \%$ Replication factor $\mathrm{C}$ subunit $2 \mathrm{GN}=\mathrm{RFC} 2 \mathrm{RFC2}$ HUMAN $39.16 \quad 100.0 \%$ Replication factor $\mathrm{C}$ subunit $2 \mathrm{GN}=\mathrm{RFC} 2 \quad \mathrm{RFC} 2$ _HUMAN $39.16 \quad 100.0 \%$ Replication factor C subunit 2 GN=RFC2 RFC2_HUMAN $39.16 \quad 100.0 \%$ Replication factor C subunit $2 \mathrm{GN}=\mathrm{RFC} 2 \quad \mathrm{RFC} 2 \mathrm{HUMAN} 39.16 \quad 100.0 \%$ Replication factor C subunit 2 GN=RFC2 RFC2_HUMAN $39.16 \quad 100.0 \%$ Replication factor C subunit 2 GN=RFC2 RFC2_HUMAN $39.16 \quad 100.0 \%$ Replication factor C subunit $2 \mathrm{GN}=\mathrm{RFC} 2 \mathrm{RFC2}$ HUMAN $39.16 \quad 100.0 \%$ Replication factor $\mathrm{C}$ subunit $2 \mathrm{GN}=\mathrm{RFC} 2 \mathrm{RFC} 2$ HUMAN $39.16 \quad 100.0 \%$
$0.01 \% \quad 8.0 \% \quad$ VINLNDNTFTEK $0.01 \% \quad 8.0 \%$ SKGAVAIADAIR $0.01 \% \quad 8.0 \%$ HSLLQTLYKV $0.00 \% \quad 10.9 \%$ FASENDLPEWKER $0.00 \% \quad 10.9 \%$ FLNAENAQK $0.00 \% \quad 2.0 \% \quad$ LSDGFVAAEAK

$0.00 \% \quad 2.0 \% \quad$ LTVSSLDYSR

$0.00 \% \quad 2.0 \%$ SLADCNFSYTSSR $0.02 \% \quad 3.8 \%$ LGNFFSPK

$0.02 \% \quad 3.8 \% \quad$ ALQSPALGLR

$0.02 \% \quad 3.8 \%$ NKITLQDVVSHSK

$0.02 \% \quad 3.8 \%$ LIFQMPQNK

$0.02 \% \quad 3.8 \%$ LQQTYAALNSK

$0.02 \% \quad 3.8 \%$ ATFYGEQVDYYK

$0.02 \% \quad 28.5 \%$ LTFLYLANDVIQNSK

$0.02 \% \quad 28.5 \%$ DFAPVIVEAFK

$0.02 \% \quad 28.5 \%$ VLSIWEER

$0.02 \% \quad 28.5 \%$ SVYENDVLEQLK

$0.02 \% \quad 28.5 \%$ ALQDLENAASGDAAVHQR

$\begin{array}{lll}0.02 \% & 28.5 \% & \text { IQSLPDLSR }\end{array}$

$0.03 \% \quad 11.3 \%$ GNTSGSHIVNHLVR

$0.03 \% \quad 11.3 \%$ ADSVVVLLCR

$0.03 \% \quad 11.3 \%$ IPSEQEQLR

$0.03 \% \quad 11.3 \%$ IAYFTLPK

$0.03 \% \quad 11.3 \%$ TVTSATIVYHLAR

$0.03 \% \quad 11.3 \%$ AGLSQSLFER

$0.03 \% \quad 11.3 \%$ LVVLGIRPIR

$0.03 \% \quad 11.3 \%$ AGAKPDQIGIITPYEGQR

$0.03 \% \quad 11.3 \%$ ARYGVIIVGNPK

$0.03 \% \quad 11.3 \%$ YGVIIVGNPK

$0.03 \% \quad 11.3 \%$ KLVNTINPGAR

$0.03 \% \quad 11.3 \%$ AYQHGGVTGLSQY

$0.00 \% \quad 6.0 \%$ SPGSVVFR

$0.00 \% \quad 6.0 \%$ ANSVFEDLSVTLR

$0.01 \% \quad 3.1 \%$ SSADKIGEVSSPK

$0.01 \% \quad 3.1 \%$ FSGKDDGSSFK

$0.01 \% \quad 3.1 \%$ AALLSGPPGVGK

$0.02 \% \quad 38.1 \%$ LNEIVGNEDTVSR

$0.02 \% \quad 38.1 \%$ EGNVPNIIIAGPPGTGK

$0.02 \% \quad 38.1 \%$ TTSILCLAR

$0.02 \% \quad 38.1 \%$ DAMLELNASNDR

$0.02 \% \quad 38.1 \%$ IIILDEADSMTDGAQQALR $99.7 \% \quad 71.8$

$0.02 \% \quad 38.1 \%$ IIILDEADSMTDGAQQALRR

$0.02 \% \quad 38.1 \%$ FALACNASDK

R

$\begin{array}{lll}0.02 \% & 38.1 \% & \text { FALACNASD } \\ 0.1 \% & \text { LTDAQILTR }\end{array}$

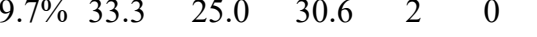

$\begin{array}{llllll}98.9 \% & 18.4 & 25.0 & 18.4 & 1 & 0\end{array}$

$\begin{array}{llll}99.7 \% & 29.8 & 25.0 & 29.8\end{array}$

$99.7 \% \quad 33.5 \quad 25.0 \quad 31.7$

$99.7 \% \quad 56.1 \quad 25.0 \quad 37.5$

$\begin{array}{llll}99.7 \% & 45.9 & 25.0 & 41.8\end{array}$

$99.7 \% \quad 61.9 \quad 25.0 \quad 61.9$

$\begin{array}{llll}98.2 \% & 22.8 & 25.0 & 22.8\end{array}$

$\begin{array}{llll}99.0 \% & 45.3 & 25.0 & 45.3\end{array}$

$\begin{array}{llll}99.7 \% & 29.8 & 25.0 & 26.3\end{array}$

$\begin{array}{llll}97.2 \% & 16.0 & 25.0 & 15.1\end{array}$

$\begin{array}{llll}99.0 \% & 18.5 & 25.0 & 18.5\end{array}$

$99.7 \% \quad 59.1 \quad 25.0 \quad 54.9$

$\begin{array}{llll}99.7 \% & 41.8 & 25.0 & 41.8\end{array}$

$\begin{array}{llll}99.7 \% & 50.2 & 25.0 & 50.2\end{array}$

$\begin{array}{llll}99.7 \% & 31.7 & 25.0 & 24.8\end{array}$

$99.0 \% \quad 24.9 \quad 25.0 \quad 18.8$

$\begin{array}{llll}99.7 \% & 45.9 & 25.0 & 42.9\end{array}$

$99.7 \% \quad 61.6$

$99.7 \% \quad 38.4$

$98.8 \% \quad 25.7$

$99.5 \% \quad 22.3$

$99.7 \% \quad 50.6$

$98.3 \% \quad 20.3$

$99.0 \% 23.0$

$99.7 \% 35.6$

$99.7 \% \quad 56.2$

$99.3 \% \quad 18.7$

$99.7 \% \quad 41.9$

$99.7 \% \quad 26.8$

$99.7 \% \quad 41.4$

$99.7 \% \quad 55.5$

$99.7 \% \quad 37.4$

$97.5 \% \quad 20.5$

$99.7 \% \quad 46.6$

$99.7 \% \quad 38.1$

$98.7 \% \quad 25.1$

$99.7 \% \quad 36.8$

$99.7 \% \quad 65.7$

$99.7 \% \quad 45.6$

$99.7 \% \quad 47.5$

$99.7 \% \quad 59.4$

$99.7 \% \quad 42.5$

$99.7 \% \quad 34.7$

$99.7 \% \quad 69.8$
1171.68

1201.69

1620.77

1034.53

1107.57

1140.59

1507.65

909.48

1025.61

1468.81

1118.60

1236.66

1483.67

1738.94

1235.67

1031.55

1436.73

1865.91

1739.98

1028.57

1490.78

1131.62

1099.57

952.55

1431.80

1107.58

1135.77

1914.01

1286.76

1059.62

1182.70

1380.65

848.46

1450.75

1304.67

1174.54

1066.63

1445.72

1633.89

1034.57

1364.61

2076.03

2232.13

1096.51

2033.05

1030.59
$0 \quad 251$

289

$\begin{array}{cc}578 & 587 \\ 58 & 70\end{array}$

$142 \quad 150$

$364 \quad 374$

$700 \quad 709$

$81 \quad 88$

$327 \quad 336$

$923 \quad 935$

$989 \quad 997$

$1506 \quad 1516$

$1517 \quad 1528$

$57 \quad 71$

$80 \quad 90$

$15 \quad 126$

$169 \quad 186$

$187 \quad 202$

$283 \quad 291$

$149 \quad 162$

$201 \quad 210$

$245 \quad 253$

$342 \quad 349$

$510 \quad 522$

$689 \quad 698$

$699 \quad 708$

811
$877 \quad 888$

$879 \quad 888$

$929 \quad 939$

$117 \quad 1129$

$24 \quad 31$

$140 \quad 152$

$302 \quad 314$

$635 \quad 645$

$47 \quad 59$

$66 \quad 82$

$83 \quad 91$

$100 \quad 111$

$137 \quad 155$

$137 \quad 156$

$\begin{array}{ll}167 & 176 \\ 167 & 184\end{array}$

$193 \quad 201$ 
Replication factor C subunit $2 \mathrm{GN}=\mathrm{RFC} 2 \quad$ RFC2_HUMAN $39.16 \quad 100.0 \% \quad 1$ Replicalion factor C subunit 2 GN=RFC2 $\mathrm{RFC2}_{2}$ HUMAN $39.16 \quad 100.0 \%$ $\begin{array}{lllll}\text { Replication factor C subunit } 2 \mathrm{GN}=\mathrm{RFC} 2 & \mathrm{RFC} 2 \text { HUMAN } & 39.16 & 100.0 \% & 1\end{array}$ Replication factor C subunit $3 \mathrm{GN}=\mathrm{RFC} 3 \quad \mathrm{RFC} 3$ HUMAN $40.56 \quad 100.0 \%$ Replication factor C subunit 3 GN=RFC3 RFC3_HUMAN $40.56 \quad 100.0 \%$ Replication factor C subunit $3 \mathrm{GN}=\mathrm{RFC} 3 \quad \mathrm{RFC} 3$ _HUMAN $40.56 \quad 100.0 \%$ Replication factor C subunit $3 \mathrm{GN}=\mathrm{RFC} 3 \quad$ RFC3_HUMAN $40.56 \quad 100.0 \%$ Replication factor C subunit $3 \mathrm{GN}=\mathrm{RFC} 3 \quad \mathrm{RFC} 3$ _HUMAN $40.56 \quad 100.0 \%$ Replication factor $\mathrm{C}$ subunit $3 \mathrm{GN}=\mathrm{RFC} 3 \mathrm{RFC} 3$ HUMAN $40.56 \quad 100.0 \%$ Replication factor C subunit $3 \mathrm{GN}=\mathrm{RFC} 3 \quad \mathrm{RFC} 3$ _HUMAN $40.56 \quad 100.0 \%$ Replication factor C subunit $3 \mathrm{GN}=\mathrm{RFC} 3 \quad \mathrm{RFC} 3$ _HUMAN $40.56 \quad 100.0 \%$ Replication factor $\mathrm{C}$ subunit $3 \mathrm{GN}=\mathrm{RFC} 3 \mathrm{RFC} 3 \mathrm{HUMAN} 40.56 \quad 100.0^{\circ}$ $\begin{array}{llll}\text { Replication factor C subunit } 3 \mathrm{GN}=\mathrm{RFC} 3 & \mathrm{RFC} 3 \text { _HUMAN } & 40.56 & 100.0 \%\end{array}$ Replication factor C subunit 4 GN=RFC4 RFC4_HUMAN $39.68 \quad 100.0 \%$ Replication factor C subunit $4 \mathrm{GN}=\mathrm{RFC} 4 \quad \mathrm{RFC} 4$ _HUMAN $39.68 \quad 100.0 \%$ Replication factor C subunit 4 GN=RFC4 RFC4_HUMAN $39.68 \quad 100.0 \%$ Replication factor $\mathrm{C}$ subunit $4 \mathrm{GN}=\mathrm{RFC} 4 \mathrm{RFC} 4$ HUMAN $39.68 \quad 100.0 \%$ Replication factor C subunit 4 GN=RFC4 RFC4_HUMAN $39.68 \quad 100.0 \%$ Replication factor C subunit 4 GN=RFC4 RFC4_HUMAN $39.68 \quad 100.0 \%$ Replication factor $\mathrm{C}$ subunit $4 \mathrm{GN}=\mathrm{RFC4}$ RFC4 HUMAN 39.68 Replication factor C subunit $4 \mathrm{GN}=\mathrm{RFC} 4$ RFC4_HUMAN 39.68 Replication factor $\mathrm{C}$ subunit $4 \mathrm{GN}=\mathrm{RFC} 4 \mathrm{RFC} 4 \mathrm{HUMAN} 39.68$ Replication factor $\mathrm{C}$ subunit $4 \mathrm{GN}=\mathrm{RFC} 4$ RFC4_HUMAN 39.68 Replication factor C subunit $4 \mathrm{GN}=\mathrm{RFC} 4$ RFC4_HUMAN 39.68 Replication factor C subunit $5 \mathrm{GN}=\mathrm{RFC} 5$ RFC5_HUMAN 38.50 Replication factor C subunit 5 GN=RFC5 RFC5_HUMAN 38.50 Replication factor C subunit 5 GN=RFC5 RFC5_HUMAN 38.50 Replication factor C subunit 5 GN=RFC5 RFC5_HUMAN 38.50 Replication factor C subunit 5 GN=RFC5 RFC5_HUMAN 38.50 Replication factor C subunit $5 \mathrm{GN}=\mathrm{RFC} 5 \mathrm{RFC5}$ HUMAN 38.50 Replication factor C subunit 5 GN=RFC5 RFC5_HUMAN 38.50 Replication factor C subunit 5 GN=RFC5 RFC5_HUMAN 38.50 Replication factor $\mathrm{C}$ subunit $5 \mathrm{GN}=\mathrm{RFC} 5 \mathrm{RFC5}$ _HUMAN 38.50 Replication factor C subunit 5 GN=RFC5 RFC5_HUMAN 38.50 Replication factor $\mathrm{C}$ subunit $5 \mathrm{GN}=\mathrm{RFC} 5 \mathrm{RFC5}$ _HUMAN 38.50 Replication factor C subunit $5 \mathrm{GN}=\mathrm{RFC} 5$ RFC5_HUMAN 38.50 Replication factor C subunit 5 GN=RFC5 RFC5_HUMAN 38.50 Replication factor C subunit 5 GN=RFC5 RFC5_HUMAN 38.50 Replication initiator $1 \mathrm{GN}=\mathrm{REPIN} 1$ Replication initiator $1 \mathrm{GN}=\mathrm{REPIN} 1$ REPI1_HUMAN 63.57 REPI1_HUMAN 63.57 Replication protein A $32 \mathrm{kDa}$ subunit GN=RPA2 RFA2 HUMAN 29.25 Replication protein A $32 \mathrm{kDa}$ subunit GN=RPA2 RFA2_HUMAN 29.25 Replication protein A $70 \mathrm{kDa}$ DNA-binding subunit GN=RPA1 RFA1_HUMAN 68.14 Replication protein A $70 \mathrm{kDa}$ DNA-binding subunit GN=RPA1 RFA1_HUMAN 68.14 Replication protein A $70 \mathrm{kDa}$ DNA-binding subunit GN=RPA1 RFA1_HUMAN 68.14 Required for meiotic nuclear division protein 1 homolog GN=RMND1 RMND1_HUMAN 51.61 Required for meiotic nuclear division protein 1 homolog GN=RMND1 RMND1_HUMAN 51.61
12 12

12

12

10

10
10

10

10

10

10

10

11
11

11

11

$00.0 \%$

$100.0 \%$

$100.0 \%$

$100.0 \%$

$100.0 \%$

$100.0 \%$

$100.0 \% \quad 14$

$100.0 \% \quad 14$

$100.0 \% \quad 14$

$100.0 \% \quad 14$

$100.0 \% \quad 14$

$100.0 \% \quad 14$

$100.0 \% \quad 14$

$100.0 \% \quad 14$

$100.0 \% \quad 14$

$100.0 \% \quad 14$

$100.0 \% \quad 14$

$100.0 \% \quad 14$

$100.0 \% \quad 14$

$100.0 \%$

$100.0 \%$

$100.0 \%$

$100.0 \%$

$00.0 \%$

$100.0 \%$

$100.0 \%$

$100.0 \%$
$0.02 \% \quad 38.1 \%$ VCDEPHPLLVK

$0.02 \% \quad 38.1 \%$ TFQMAEYLK

$99.7 \% \quad 65.4$

$99.7 \% \quad 31.7$

$0.02 \% \quad 38.1 \%$ IAEGVNSLLQMA

$0.03 \% \quad 29.2 \%$ ELYGVGVEK

$0.03 \% \quad 29.2 \%$ IEHQTITTPSK

$0.03 \% \quad 29.2 \%$ TVAQSQQLETNSQR

$0.03 \% \quad 29.2 \%$ VVLLTEVDK

$0.03 \% \quad 29.2 \%$ VVLLTEVDKLTK

$0.03 \% \quad 29.2 \%$ EGLNLPSQLAHR

$0.03 \% \quad 29.2 \%$ ALLMCEACR

$0.03 \% \quad 29.2 \%$ ETANAIVSQQTPQR

$0.03 \% \quad 29.2 \%$ AIYHLEAFVAK

$0.02 \% \quad 34.2 \%$ GTSISTKPPLTK

$0.02 \% \quad 34.2 \%$ SLEGADLPNLLFYGPPGTGK

$0.02 \% \quad 34.2 \%$ TSTILAAAR

$0.02 \% \quad 34.2 \%$ VLELNASDER

$0.02 \% \quad 34.2 \%$ VKNFAQLTVSGSR

$0.02 \% \quad 34.2 \%$ FCLICNYVSR

$0.02 \% \quad 34.2 \%$ IIEPLTSR

$0.02 \% \quad 34.2 \%$ ISDEGIAYLVK

$0.02 \% \quad 34.2 \%$ VSEGDLRK

$0.02 \% \quad 34.2 \%$ AITFLQSATR

$0.02 \% \quad 34.2 \%$ VITDIAGVIPAEK

$0.04 \% \quad 46.2 \%$ TSTILACAK

$0.04 \% \quad 46.2 \%$ GPILSFASTR

$99.7 \% \quad 55.2$

$99.7 \% \quad 33.3$

$99.6 \% \quad 23.1$

$99.7 \% \quad 35.2$

$99.7 \% \quad 64.7$

$99.7 \% \quad 45.3$

$99.7 \% \quad 61.0$

$99.7 \% \quad 38.7$

$99.7 \% \quad 32.1$

$99.7 \% \quad 52.8$

$99.7 \% \quad 52.2$

$99.7 \% 33.5$

$\begin{array}{lll}99.7 \% & 40.2\end{array}$

$99.7 \% \quad 58.7$

$99.7 \% \quad 49.3$

$99.7 \% \quad 48.0$

$99.7 \% \quad 58.0$

$\begin{array}{lll}95.9 \% & 24.8\end{array}$

$99.7 \% \quad 65.3$

$99.0 \% \quad 39.6$

$99.7 \% \quad 70.4$

$99.7 \% \quad 52.3$

$99.7 \% \quad 45.8$

$99.7 \% \quad 55.2$

$0.04 \% \quad 46.2 \%$ LVILDEADAMTQDAQNALR $99.7 \% \quad 60.8$

$0.04 \% \quad 46.2 \%$ LVILDEADAMTQDAQNALRR $\quad 98.9 \% \quad 18.1$

$0.04 \% \quad 46.2 \%$ FCLICNYLSK

$0.04 \% \quad 46.2 \%$ IIPALQSR

$99.7 \% \quad 55.5$

$99.0 \% \quad 21.4$

$99.7 \% \quad 38.0$

$0.04 \% \quad 46.2 \%$ FGPLTPELMVPR

$0.04 \% \quad 46.2 \%$ ALVTLSSGDMR

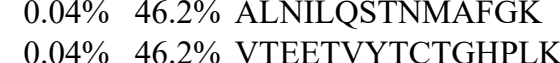

$\begin{array}{ll}99.3 \% & 21.2 \\ 99.7 \% & 52.3\end{array}$

$99.7 \% \quad 58.0$

$99.7 \% 57.6$

$99.0 \% \quad 36.5$

$98.4 \% \quad 22.6$

$99.7 \% \quad 81.5$

$\begin{array}{lll}98.9 \% & 29.8\end{array}$

$0.04 \% \quad 46.2 \%$ IQLSSLIAAFQVTR

$0.00 \% \quad 6.0 \% \quad$ LLSGPSQESPQTLGK

$\begin{array}{ll}99.7 \% & 39.4\end{array}$

$99.7 \% \quad 62.0$

$99.0 \% \quad 55.6$

$99.7 \% \quad 39.3$

$99.7 \% \quad 45.0$

$99.7 \% \quad 47.2$

$99.7 \% \quad 62.6$

$99.7 \% \quad 35.0$

$0.01 \% \quad 12.7 \%$ DAANILVMGVENSAK

$0.01 \% \quad 12.7 \%$ EGDPGTIFFFR
1306.68

1130.56

1771.97

1471.77

993.53

1254.67

1589.79

1015.60

1357.83

1334.72

1123.51

1542.79

1261.69

1229.71

2046.05

903.53

1145.58

1406.78

1331.62

928.55

1207.66

903.49

1107.62

1325.77

964.51

1048.58

2103.04

2259.14

1317.63

897.55

1372.73

2102.00

1149.59

1507.79

1734.84

906.47

847.45

1546.90

1541.82

1868.97

1711.01

905.51

1485.73

1402.79

1282.66

1531.78

1285.62

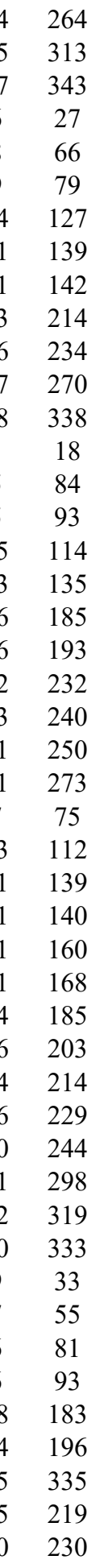

Page 129 of Table S-1-5 
Ribonuclease P protein subunit p38 GN=RPP38 RPP38_HUMAN $31.84 \quad 100.0 \%$ Ribonuclease P protein subunit p38 GN=RPP38 RPP38_HUMAN $31.84 \quad 100.0 \%$ Ribonuclease P protein subunit p38 GN=RPP38 RPP38_HUMAN $31.84 \quad 100.0 \%$ Ribonuclease P protein subunit p38 GN=RPP38 RPP38_HUMAN $31.84 \quad 100.0 \%$ Ribonucleases P/MRP protein subunit POP1 GN=POP1 POP1_HUMAN $114.71 \quad 100.0 \%$ Ribonucleases P/MRP protein subunit POP1 GN=POP1 POP1 HUMAN $114.71 \quad 100.0 \%$ Ribonucleases P/MRP protein subunit POP1 GN=POP1 POP1_HUMAN $114.71 \quad 100.0 \%$ Ribonucleoside-diphosphate reductase subunit M2 B GN=RRM2B RIR2B HUMAN $40.74 \quad 100.0 \%$ Ribonucleoside-diphosphate reductase subunit M2 B GN=RRM2B RIR2B_HUMAN $40.74 \quad 100.0 \%$ Ribonucleoside-diphosphate reductase subunit M2 B GN=RRM2B RIR2B_HUMAN $40.74 \quad 100.0 \%$ Ribose-phosphate pyrophosphokinase $1 \mathrm{GN}=$ PRPS1 PRPS1_HUMAN $34.83 \quad 100.0 \%$ Ribose-phosphate pyrophosphokinase 1 GN=PRPS1 PRPS1_HUMAN $34.83 \quad 100.0 \%$ Ribose-phosphate pyrophosphokinase $1 \mathrm{GN}=$ PRPS1 PRPS1_HUMAN $34.83 \quad 100.0 \%$ Ribose-phosphate pyrophosphokinase $1 \mathrm{GN}=$ PRPS1 PRPS1_HUMAN $34.83 \quad 100.0 \%$ Ribose-phosphate pyrophosphokinase 1 GN=PRPS1 PRPS1_HUMAN $34.83 \quad 100.0 \%$ Ribose-phosphate pyrophosphokinase $1 \mathrm{GN}=$ PRPS1 PRPS1 HUMAN $34.83 \quad 100.0 \%$ Ribose-phosphate pyrophosphokinase $1 \mathrm{GN}=$ PRPS1 PRPS1_HUMAN $34.83 \quad 100.0 \%$ Ribose-phosphate pyrophosphokinase $1 \mathrm{GN}=$ PRPS1 PRPS1_HUMAN $34.83 \quad 100.0 \%$ Ribose-phosphate pyrophosphokinase $2 \mathrm{GN}=$ PRPS2 PRPS2 HUMAN $34.77 \quad 100.0 \%$ Ribose-phosphate pyrophosphokinase 2 GN=PRPS2 PRPS2_HUMAN $34.77 \quad 100.0 \%$ Ribose-phosphate pyrophosphokinase $2 \mathrm{GN}=$ PRPS2 PRPS2_HUMAN $34.77 \quad 100.0 \%$ Ribose-phosphate pyrophosphokinase 2 GN=PRPS2 PRPS2_HUMAN $34.77 \quad 100.0 \%$ Ribose-phosphate pyrophosphokinase 2 GN=PRPS2 PRPS2_HUMAN $34.77 \quad 100.0 \%$ Ribose-phosphate pyrophosphokinase $2 \mathrm{GN}=$ PRPS2 PRPS2 HUMAN $34.77 \quad 100.0^{\circ}$ Ribose-phosphate pyrophosphokinase 2 GN=PRPS2 PRPS2_HUMAN $34.77 \quad 100.0 \%$ Ribose-phosphate pyrophosphokinase 2 GN=PRPS2 PRPS2_HUMAN $34.77 \quad 100.0 \%$ Ribosomal L1 domain-containing protein 1 GN=RSL1D1 RL1D1_HUMAN $54.97 \quad 100.0 \%$ Ribosomal L1 domain-containing protein 1 GN=RSL1D1 RL1D1_HUMAN $54.97 \quad 100.0 \%$ Ribosomal L1 domain-containing protein $1 \mathrm{GN}=$ RSL1D1 RL1D1_HUMAN $54.97 \quad 100.0 \%$ Ribosomal L1 domain-containing protein 1 GN=RSL1D1 RL1D1_HUMAN $54.97 \quad 100.0 \%$ Ribosomal L1 domain-containing protein $1 \mathrm{GN}=$ RSL1D1 RL1D1_HUMAN $54.97 \quad 100.0 \%$ Ribosomal L1 domain-containing protein 1 GN=RSL1D1 RL1D1 HUMAN 54.97

$0.01 \% \quad 12.7 \%$ LNSELDLDDAILEK $0.01 \% \quad 12.7 \%$ IGELFALR $0.01 \% \quad 12.7 \%$ TCQFLSIGR $0.02 \% \quad 38.1 \%$ LTIIVSDPSHCNVLR $0.02 \% \quad 38.1 \%$ LYDVVAVFPK $0.02 \% \quad 38.1 \%$ RPPINVAIDR $0.02 \% \quad 38.1 \%$ GLAFELVYSPAIK $9 \quad 0.02 \% \quad 38.1 \%$ YTISSALNLMQICK $9 \quad 0.02 \% \quad 38.1 \%$ NVIISSAAERPLEIR $0.02 \% 38.1 \%$ AALLHGETR $0.02 \% \quad 38.1 \%$ KPRPSEGDEDCLPASK $0.01 \% \quad 23.7 \%$ TSLNNPYIIR $0.01 \% \quad 23.7 \%$ QLAIGVNEVTR $0.01 \% \quad 23.7 \%$ ELLLVLVCK $0.01 \% \quad 23.7 \%$ SVPACQVPR $0.01 \% \quad 23.7 \%$ IAPVIGLK $0.01 \% \quad 23.7 \%$ NTTDFVDEVR $0.01 \% \quad 23.7 \%$ QASVTLQPLK $0.01 \% \quad 3.8 \%$ NQPTNVTLSSGFVADR $0.01 \% \quad 3.8 \% \quad$ YITASTFAQAR $0.01 \% \quad 3.8 \%$ SSNSLVFQTLPR $0.01 \% \quad 9.7 \% \quad$ FSQEVQVPEAR $0.01 \% \quad 9.7 \%$ EFLFNAIETMPYVK $0.01 \% \quad 9.7 \%$ LLVELGFSK $0.02 \% 35.5 \%$ IFSGSSHQDLSQK $0.02 \% \quad 35.5 \%$ VTAVIPCFPYAR $0.02 \% \quad 35.5 \%$ NCTIVSPDAGGAK $0.02 \% \quad 35.5 \%$ LNVDFALIHK $0.02 \% \quad 35.5 \%$ MVLVGDVKDR $0.02 \% \quad 35.5 \%$ VYAILTHGIFSGPAISR $0.02 \% \quad 35.5 \%$ INNACFEAVVVTNTIPQEDKMK $0.02 \% 35.5 \%$ THNGESVSYLFSHVPL $0.01 \% \quad 31.8 \%$ PNIVLFSGSSHQDLSQR $0.01 \% 31.8 \%$ KFSNQETSVEIGESVR $0.01 \% \quad 31.8 \%$ FSNQETSVEIGESVR $0.01 \% \quad 31.8 \%$ VTAVIPCFPYAR $0.01 \% \quad 31.8 \%$ NCIIVSPDAGGAK $0.01 \% \quad 31.8 \%$ MVLVGDVKDR $0.01 \% \quad 31.8 \%$ VYAILTHGIFSGPAISR $0.01 \% \quad 31.8 \%$ THNGESVSYLFSHVPL $0.02 \% \quad 14.1 \%$ AVDALLTHCK $0.02 \% \quad 14.1 \%$ TVSQIISLQTLKK $0.02 \% \quad 14.1 \%$ RLLPSLIGR $0.02 \% \quad 14.1 \%$ LLPSLIGR $0.02 \% \quad 14.1 \%$ KVPVSVNLLSK $0.02 \% \quad 14.1 \%$ EINDCIGGTVLNISK $0.02 \% \quad 14.1 \%$ TPANEKVEIQK
1013.52

810.54

1195.56

1084.64

1705.85

1228.63

1348.72

1289.65

1717.85

1005.60

1433.70

1393.73

1289.62

1169.67

1131.62

1802.00

2537.24

1786.88

1884.96

1809.90

1681.80

1393.73

1301.65

1131.62

1802.00

1786.88

1127.59

1458.89

1024.66

868.56

1183.74

1632.83 1256.68

$\begin{array}{cc}89 & 302 \\ 53 & 360 \\ 89 & 397 \\ 7 & 91 \\ 9 & 108 \\ 39 & 148 \\ 49 & 161 \\ 68 & 181 \\ 84 & 198 \\ 27 & 235 \\ 47 & 262 \\ 3 & 32 \\ 12 & 122 \\ 28 & 136 \\ 55 & 163 \\ 68 & 175 \\ 85 & 194 \\ 51 & 260 \\ 5 & 30 \\ 01 & 111 \\ 26 & 137 \\ 11 & 121 \\ 53 & 166 \\ 93 & 301 \\ 6 & 18 \\ 5 & 96 \\ 64 & 176 \\ 85 & 194 \\ 05 & 214 \\ 44 & 260 \\ 61 & 282 \\ 03 & 318 \\ 2 & 18 \\ 4 & 49 \\ 5 & 49 \\ 5 & 96 \\ 64 & 176 \\ 05 & 214 \\ 44 & 260 \\ 03 & 318 \\ 9 & 48 \\ 25 & 137 \\ 63 & 171 \\ 64 & 171 \\ 78 & 188 \\ 93 & 207 \\ 75 & 385 \\ & \end{array}$


Ribosomal RNA processing protein 1 homolog A GN=RRP1 RRP1_HUMAN $52.84 \quad 100.0 \%$ Ribosomal RNA processing protein 1 homolog A GN=RRP1 RRP1_HUMAN $52.84 \quad 100.0 \%$ Ribosomal RNA processing protein 1 homolog A GN=RRP1 RRP1_HUMAN $52.84 \quad 100.0 \%$ Ribosomal RNA processing protein 1 homolog A GN=RRP1 RRP1_HUMAN $52.84 \quad 100.0 \%$ Ribosomal RNA processing protein 1 homolog B GN=RRP1B RRP1B_HUMAN $84.43 \quad 100.0 \%$ Ribosomal RNA processing protein 1 homolog B GN=RRP1B RRP1B_HUMAN $84.43 \quad 100.0 \%$ Ribosomal RNA processing protein 1 homolog B GN=RRP1B RRP1B_HUMAN $84.43 \quad 100.0 \%$ Ribosomal RNA processing protein 1 homolog B GN=RRP1B RRP1B_HUMAN $84.43 \quad 100.0 \%$ Ribosomal RNA processing protein 1 homolog B GN=RRP1B RRP1B_HUMAN $84.43 \quad 100.0 \%$ Ribosomal RNA processing protein 1 homolog B GN=RRP1B RRP1B_HUMAN $84.43 \quad 100.0 \%$ Ribosomal RNA processing protein 1 homolog B GN=RRP1B RRP1B_HUMAN $84.43 \quad 100.0 \%$ Ribosomal RNA processing protein 1 homolog B GN=RRP1B RRP1B_HUMAN $84.43 \quad 100.0 \%$ Ribosomal RNA processing protein 1 homolog B GN=RRP1B RRP1B_HUMAN $84.43 \quad 100.0 \%$ Ribosomal RNA processing protein 1 homolog B GN=RRP1B RRP1B_HUMAN $84.43 \quad 100.0 \%$ Ribosomal RNA processing protein 1 homolog B GN=RRP1B RRP1B_HUMAN $84.43 \quad 100.0 \%$ Ribosomal RNA processing protein 1 homolog B GN=RRP1B RRP1B_HUMAN $84.43 \quad 100.0 \%$ Ribosomal RNA processing protein 1 homolog B GN=RRP1B RRP1B_HUMAN $84.43 \quad 100.0 \%$ Ribosomal RNA-processing protein 7 homolog A GN=RRP7A RRP7A_HUMAN $32.33 \quad 100.0 \%$ Ribosomal RNA-processing protein 7 homolog A GN=RRP7A RRP7A_HUMAN $32.33 \quad 100.0 \%$ Ribosome biogenesis protein BMS1 homolog GN=BMS1 BMS1_HUMAN $145.81 \quad 100.0 \%$ Ribosome biogenesis protein BMS1 homolog GN=BMS1 BMS1_HUMAN $145.81 \quad 100.0 \%$ Ribosome biogenesis protein BRX1 homolog GN=BRIX1 BRX1_HUMAN $41.40 \quad 100.0 \%$ Ribosome biogenesis protein BRX1 homolog GN=BRIX1 BRX1_HUMAN $41.40 \quad 100.0 \%$ Ribosome biogenesis protein BRX1 homolog GN=BRIX1 BRX1_HUMAN $41.40 \quad 100.0 \%$ Ribosome biogenesis protein NSA2 homolog GN=NSA2 NSA2_HUMAN $30.07 \quad 100.0 \%$ Ribosome biogenesis protein NSA2 homolog GN=NSA2 NSA2_HUMAN $30.07 \quad 100.0 \%$ Ribosome biogenesis protein NSA2 homolog GN=NSA2 NSA2_HUMAN $30.07 \quad 100.0 \%$ Ribosome biogenesis protein NSA2 homolog GN=NSA2 NSA2_HUMAN $30.07 \quad 100.0 \%$ Ribosome biogenesis protein NSA2 homolog GN=NSA2 NSA2_HUMAN $30.07 \quad 100.0 \%$ Ribosome production factor 2 homolog GN=RPF2 RPF2 HUMAN $35.59 \quad 100.0 \%$ Ribosome production factor 2 homolog GN=RPF2 RPF2_HUMAN $35.59 \quad 100.0 \%$ Ribosome production factor 2 homolog GN=RPF2 RPF2_HUMAN $35.59 \quad 100.0 \%$ Ribosome production factor 2 homolog GN=RPF2 RPF2 HUMAN $35.59 \quad 100.0 \%$ Ribosome production factor 2 homolog GN=RPF2 RPF2_HUMAN $35.59 \quad 100.0 \%$ Ribosome production factor 2 homolog GN=RPF2 RPF2_HUMAN $35.59 \quad 100.0 \%$ Ribosome production factor 2 homolog GN=RPF2 RPF2_HUMAN $35.59 \quad 100.0 \%$ Ribosome production factor 2 homolog GN=RPF2 RPF2_HUMAN $35.59 \quad 100.0 \%$ Ribosome-binding protein $1 \mathrm{GN}=\mathrm{RRBP} 1$ RRBP1 HUMAN $152.47 \quad 100.0 \%$ Ribosome-binding protein $1 \mathrm{GN}=\mathrm{RRBP} 1$ RRBP1_HUMAN $152.47 \quad 100.0 \%$ Ribosome-binding protein $1 \mathrm{GN}=\mathrm{RRBP} 1 \quad$ RRBP1_HUMAN $152.47 \quad 100.0 \%$ Ribosome-binding protein $1 \mathrm{GN}=\mathrm{RRBP} 1$ RRBP1_HUMAN $152.47 \quad 100.0 \%$ Ribosome-binding protein $1 \mathrm{GN}=\mathrm{RRBP} 1$ RRBP1_HUMAN $152.47 \quad 100.0 \%$ Ribosome-binding protein $1 \mathrm{GN}=\mathrm{RRBP} 1$ RRBP1 HUMAN $152.47 \quad 100.0 \%$ RING finger protein 219 GN=RNF219 RN219_HUMAN $81.12 \quad 100.0 \%$ RING finger protein 219 GN=RNF219 RN219_HUMAN $81.12 \quad 100.0 \%$ RISC-loading complex subunit TARBP2 GN=TARBP2 TRBP2_HUMAN $39.04 \quad 100.0 \%$ RISC-loading complex subunit TARBP2 GN=TARBP2 TRBP2_HUMAN $39.04 \quad 100.0 \%$
$0.01 \% \quad 10.8 \%$ LAGNEQVTR

$0.01 \% \quad 10.8 \%$ TKDSLVLNNITR

$\begin{array}{llllllll}99.7 \% & 46.6 & 25.0 & 35.4 & 2 & 0 & 0 & 987.52\end{array}$ $99.7 \% \quad 66.2$

$0.01 \% \quad 10.8 \%$ GVGADPEARAEAGEQPGTAER

$0.01 \% \quad 10.8 \%$ ALLRDQPR

$0.03 \% \quad 16.9 \%$ APAMQPAEIQFAQR

$0.03 \% \quad 16.9 \%$ TKDHTLVQTIAR

$0.03 \% \quad 16.9 \%$ GSPTGGAQLLK

$0.03 \% \quad 16.9 \%$ GSPTGGAQLLKR

$0.03 \% \quad 16.9 \%$ AGPGSLELCGLPSQK

$0.03 \% \quad 16.9 \%$ AKSSTATHPPGPAVQLNK

$0.03 \% \quad 16.9 \%$ SSTATHPPGPAVQLNK

$0.03 \% \quad 16.9 \%$ SSTATHPPGPAVQ

$0.03 \% \quad 16.9 \%$ KVTFGLNR

$0.03 \% \quad 16.9 \%$ TDKSILVSPTGPSR

$0.03 \% \quad 16.9 \%$ SILVSPTGPSR

$0.03 \% \quad 16.9 \%$ VAFDPEQKPLHGVLK

$0.03 \% \quad 16.9 \%$ TPTSSPASSPLVAK

$0.00 \% \quad 7.5 \%$ GPLLVSTESHPVK

$0.00 \% \quad 7.5 \%$ MEHLAQLR

$0.00 \% \quad 1.3 \%$ AFAVQSAVR

$0.00 \% \quad 1.3 \%$ VSLYGYLR

$0.01 \% \quad 11.6 \%$ LFVINEVCEMK

$0.01 \% \quad 11.6 \%$ FLVQNIHTLAELK

$0.01 \% \quad 11.6 \%$ NFQIIEEDAALVEIGPR

$0.01 \% \quad 25.8 \%$ PQNEYIELHR

$0.01 \% \quad 25.8 \%$ TPQGAVPAYLLDR

$0.01 \% \quad 25.8 \%$ VCFVGDGFTR

$0.01 \% \quad 25.8 \%$ NPSSPLYTTLGVITK

$0.01 \% \quad 25.8 \%$ GTVIEVNVSELGLVTQGGK

$0.02 \% \quad 26.5 \%$ KPYGVLYK

$0.02 \% \quad 26.5 \%$ NITRPFEDQTSLEFFSK

$0.02 \% \quad 26.5 \%$ LKSLLIDFFR

$0.02 \% \quad 26.5 \%$ SLLIDFFR

$0.02 \% \quad 26.5 \%$ GPTVSNIR

$0.02 \% \quad 26.5 \%$ IELEEMGPSLDLVLR

$0.02 \% \quad 26.5 \%$ THLASDDLYK

$0.02 \% \quad 26.5 \%$ NISHDTFGTTYGR

$0.02 \% \quad 4.8 \% \quad$ AAILETAPK

$0.02 \% \quad 4.8 \%$ NTDVAQSPEAPKQEAPAK

$0.02 \% \quad 4.8 \%$ EQEITAVQAR

$0.02 \% \quad 4.8 \% \quad$ LQQENSILR

$0.02 \% \quad 4.8 \%$ LQSSEAEVR

$0.02 \% \quad 4.8 \%$ SIEALLEAGQAR

$0.00 \% \quad 4.0 \%$ GSEEDVVSKNQGDSAR

$0.00 \% \quad 4.0 \%$ KIQSSLSSASPSK

$0.01 \% \quad 11.7 \%$ TPISLLQEYGTR

$0.01 \% \quad 11.7 \%$ VTVGDTSCTGQGPSK
$99.7 \% \quad 50.2$

$95.5 \% \quad 21.5$

$99.7 \% \quad 63.6$

$99.7 \% \quad 38.5$

$99.4 \% \quad 28.6$

$99.7 \% \quad 54.0$

$99.7 \% \quad 51.5$

$\begin{array}{lll}99.7 \% & 28.1\end{array}$

$99.7 \% \quad 56.8$

$99.7 \% \quad 28.6$

$99.0 \% \quad 22.2$

$\begin{array}{lll}95.5 \% & 14.3\end{array}$

$99.4 \% \quad 28.7$

$98.4 \% \quad 17.4$

$99.7 \% \quad 48.5$

$\begin{array}{lll}99.7 \% & 51.8\end{array}$

$99.0 \% \quad 27.3$

$99.7 \% \quad 50.7$

$97.8 \% \quad 27.0$

$\begin{array}{lll}99.7 \% & 52.0\end{array}$

$99.7 \% \quad 67.1$

$99.7 \% \quad 45.7$

$99.7 \% \quad 36.3$

$99.3 \% \quad 22.4$

$99.7 \% \quad 52.5$

$99.0 \% \quad 24.2$

$99.7 \% \quad 58.2$

$99.0 \% \quad 33.4$

$99.7 \% \quad 25.8$

$95.5 \% \quad 15.4$

$99.0 \% \quad 33.5$

$99.0 \% \quad 38.8$

$99.7 \% \quad 60.5$

$99.7 \% \quad 40.3$

$99.7 \% \quad 50.8$

$99.7 \% \quad 47.6$

$99.7 \% \quad 39.6$

$99.7 \% \quad 59.4$

$99.3 \% \quad 24.2$

$99.5 \% \quad 25.6$

$99.7 \% \quad 46.4$

$99.4 \% \quad 20.6$

$99.5 \% \quad 26.2$

$99.7 \% \quad 67.8$

$99.7 \% \quad 45.5$
1373.77

2067.97

968.56

1573.78

1382.78

1028.57

1184.67

1513.77

1803.97

1604.84

2192.13

934.55

1457.80

1113.63

1677.93

1342.72

1363.76

997.52

948.53

970.54

1397.68

1525.87

1914.00

1298.65

1400.75

1157.54

1590.87

1900.04

967.56

2059.01

1251.75

1010.57

843.47

1729.90

1162.57

1468.68

913.54

1880.94

1144.60

1100.61

1018.52

1257.68

1677.77

1319.72

1377.74

1493.69

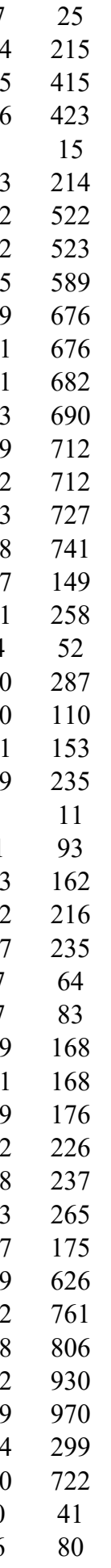

Page 131 of Table S-1-5 
RISC-loading complex subunit TARBP2 GN=TARBP2 TRBP2_HUMAN $39.04 \quad 100.0 \%$ RNA 3'-terminal phosphate cyclase GN=RTCA RTCA_HUMAN $39.34 \quad 100.0 \%$ RNA 3'-terminal phosphate cyclase GN=RTCA RTCA_HUMAN $39.34 \quad 100.0 \%$ RNA 3'-terminal phosphate cyclase GN=RTCA RTCA_HUMAN $39.34 \quad 100.0 \%$ RNA 3'-terminal phosphate cyclase GN=RTCA RTCA_HUMAN $39.34 \quad 100.0 \%$ RNA 3'-terminal phosphate cyclase GN=RTCA RTCA_HUMAN $39.34 \quad 100.0 \%$ RNA 3'-terminal phosphate cyclase GN=RTCA RTCA_HUMAN $39.34 \quad 100.0 \%$ RNA 3'-terminal phosphate cyclase GN=RTCA RTCA_HUMAN $39.34 \quad 100.0 \%$ RNA 3'-terminal phosphate cyclase GN=RTCA RTCA_HUMAN $39.34 \quad 100.0 \%$ RNA 3'-terminal phosphate cyclase-like protein GN=RCL1 RCL1_HUMAN $40.84 \quad 100.0 \%$ RNA 3'-terminal phosphate cyclase-like protein GN=RCL1 RCL1_HUMAN $40.84 \quad 100.0 \%$ RNA binding motif protein, X-linked-like-1 GN=RBMXL1 RMXL1_HUMAN $42.14 \quad 100.0 \%$ RNA binding motif protein, X-linked-like-1 GN=RBMXL1 RMXL1_HUMAN $42.14 \quad 100.0 \%$ RNA binding motif protein, X-linked-like-1 GN=RBMXL1 RMXL1_HUMAN $42.14 \quad 100.0 \%$ RNA binding motif protein, X-linked-like-1 GN=RBMXL1 RMXL1_HUMAN $42.14 \quad 100.0 \%$ RNA binding motif protein, X-linked-like-1 GN=RBMXL1 RMXL1_HUMAN $42.14 \quad 100.0 \%$ RNA binding motif protein, X-linked-like-1 GN=RBMXL1 RMXL1_HUMAN $42.14 \quad 100.0 \%$ RNA binding motif protein, X-linked-like-1 GN=RBMXL1 RMXL1_HUMAN $42.14 \quad 100.0 \%$ RNA binding motif protein, X-linked-like-1 GN=RBMXL1 RMXL1_HUMAN $42.14 \quad 100.0 \%$ RNA binding motif protein, X-linked-like-1 GN=RBMXL1 RMXL1_HUMAN $42.14 \quad 100.0 \%$ RNA binding motif protein, X-linked-like-1 GN=RBMXL1 RMXL1_HUMAN $42.14 \quad 100.0 \%$ RNA binding motif protein, X-linked-like-1 GN=RBMXL1 RMXL1 HUMAN $42.14 \quad 100.0 \%$ RNA binding motif protein, X-linked-like-1 GN=RBMXL1 RMXL1_HUMAN $42.14 \quad 100.0 \%$ RNA binding motif protein, X-linked-like-1 GN=RBMXL1 RMXL1_HUMAN $42.14 \quad 100.0 \%$ RNA binding motif protein, X-linked-like-1 GN=RBMXL1 RMXL1_HUMAN $42.14 \quad 100.0 \%$ RNA binding motif protein, X-linked-like-1 GN=RBMXL1 RMXL1_HUMAN $42.14 \quad 100.0 \%$ RNA binding motif protein, X-linked-like-1 GN=RBMXL1 RMXL1_HUMAN $42.14 \quad 100.0 \%$ RNA binding motif protein, X-linked-like-1 GN=RBMXL1 RMXL1_HUMAN $42.14 \quad 100.0 \%$ RNA binding motif protein, X-linked-like-1 GN=RBMXL1 RMXL1_HUMAN $42.14 \quad 100.0 \%$ RNA binding motif protein, X-linked-like-1 GN=RBMXL1 RMXL1_HUMAN $42.14 \quad 100.0 \%$ RNA binding motif protein, X-linked-like-1 GN=RBMXL1 RMXL1_HUMAN $42.14 \quad 100.0 \%$ RNA binding motif protein, X-linked-like-1 GN=RBMXL1 RMXL1_HUMAN $42.14 \quad 100.0 \%$ RNA binding motif protein, X-linked-like-1 GN=RBMXL1 RMXL1_HUMAN $42.14 \quad 100.0 \%$ RNA binding motif protein, X-linked-like-1 GN=RBMXL1 RMXL1_HUMAN $42.14 \quad 100.0 \%$ RNA binding motif protein, X-linked-like-1 GN=RBMXL1 RMXL1_HUMAN $42.14 \quad 100.0 \%$ RNA binding motif protein, X-linked-like-1 GN=RBMXL1 RMXL1_HUMAN $42.14 \quad 100.0 \%$ RNA binding motif protein, X-linked-like-1 GN=RBMXL1 RMXL1_HUMAN $42.14 \quad 100.0 \%$ RNA polymerase II-associated protein $1 \mathrm{GN}=$ RPAP1 RPAP1_HUMAN $152.76 \quad 100.0 \%$ RNA polymerase II-associated protein $1 \mathrm{GN}=\mathrm{RPAP} 1$ RPAP1_HUMAN $152.76 \quad 100.0 \%$ RNA polymerase-associated protein CTR9 homolog GN=CTR9 CTR9_HUMAN $133.51 \quad 100.0 \%$ RNA polymerase-associated protein CTR9 homolog GN=CTR9 CTR9 HUMAN $133.51 \quad 100.0 \%$ RNA pseudouridylate synthase domain-containing protein $3 \mathrm{GN}=\mathrm{RPUSD} 3$ RUSD3_HUMAN $38.46 \quad 100.0 \%$ RNA pseudouridylate synthase domain-containing protein $3 \mathrm{GN}=\mathrm{RPUSD} 3$ RUSD3_HUMAN $38.46 \quad 100.0 \%$ RNA pseudouridylate synthase domain-containing protein 3 GN=RPUSD3 RUSD3_HUMAN $38.46 \quad 100.0 \%$ RNA pseudouridylate synthase domain-containing protein 3 GN=RPUSD3 RUSD3_HUMAN $38.46 \quad 100.0 \%$ RNA/RNP complex-1-interacting phosphatase GN=DUSP11 DUS11_HUMAN $38.94 \quad 100.0 \%$ RNA/RNP complex-1-interacting phosphatase GN=DUSP11 DUS11_HUMAN $38.94 \quad 100.0 \%$
$0.01 \% \quad 11.7 \%$ SCSLGSLGALGPACCR $0.02 \% \quad 23.0 \%$ VEVDGSIMEGGGQILR $0.02 \% \quad 23.0 \%$ VSTALSCLLGLPLR

$0.02 \% \quad 23.0 \%$ FGFIFNCDIK

$0.02 \% \quad 23.0 \%$ QLNPINLTER

$0.02 \% \quad 23.0 \%$ AFVAGVLPFK

$0.02 \% \quad 23.0 \%$ DMAAAAVR

$0.02 \% \quad 23.0 \%$ EIRDLYVNIQPVQEPK

$0.02 \% \quad 23.0 \%$ DLYVNIQPVQEPK

$0.00 \% \quad 5.4 \% \quad$ LVLSTLSGRPVK

$0.00 \% \quad 5.4 \%$ LLLEEIYR

$0.01 \% \quad 56.4 \%$ LFIGGLNTETNEK

$0.01 \% \quad 56.4 \%$ ALETVFGK

$0.01 \% \quad 56.4 \%$ IVEVLLIKDR

$0.01 \% \quad 56.4 \%$ GFAFVTFESPADAK

$0.01 \% \quad 56.4 \%$ GFAFVTFESPADAKDAAR $0.01 \% 56.4 \%$ VEQATKPSFER

$0.01 \% \quad 56.4 \%$ HGPPPPPR

$0.01 \% \quad 56.4 \%$ GGHMDDGGYSMNFNMSSSR

$0.01 \% \quad 56.4 \%$ GRDSYGGPPR

$0.01 \% \quad 56.4 \%$ DSYGGPPR

$0.01 \% \quad 56.4 \%$ DSYGGPPRR

$0.01 \% \quad 56.4 \%$ RDVYLSPR

$0.01 \% \quad 56.4 \%$ DVYLSPRDDGYSTK

$0.01 \% \quad 56.4 \%$ DDGYSTKDSYSSR

$0.01 \% \quad 56.4 \%$ DSYSSRDYPSSR

$0.01 \% \quad 56.4 \%$ DTRDYAPPPR

$0.01 \% \quad 56.4 \%$ DYAPPPRDYTYR

$0.01 \% \quad 56.4 \%$ DYGHSSSRDDYPSR

$0.01 \% 56.4 \%$ DRDYSDHPSGGSYR

$0.01 \% \quad 56.4 \%$ DYSDHPSGGSYR

$0.01 \% \quad 56.4 \%$ DSYESYGNSR

$0.01 \% \quad 56.4 \%$ GPPPSYGGSSR

$0.01 \% \quad 56.4 \%$ GPPPSYGGSSRYDDYSSSR

$0.01 \% \quad 56.4 \%$ YDDYSSSRDGYGGSR

$0.01 \% 56.4 \%$ DGYGGSRDSYSSSR

$0.01 \% \quad 56.4 \%$ SDLYSSCDR

$0.00 \% \quad 1.5 \% \quad$ SIFAQEIAAR

$0.00 \% \quad 1.5 \%$ ASLLASQALHR

$0.00 \% \quad 1.8 \%$ TNPGCPAEVR

$0.00 \% \quad 1.8 \%$ FDLALAATEAR

$0.01 \% \quad 14.5 \%$ SGPLGDQPFAGLLPK

$0.01 \% \quad 14.5 \%$ NLSREELVDALR

$0.01 \% \quad 14.5 \%$ VGTVLGQR

$0.01 \% \quad 14.5 \%$ DTPVELLAPLPPYFSR

$0.00 \% \quad 9.4 \% \quad$ YYKPEDLPETVPYLK

$0.00 \% \quad 9.4 \%$ IFTVGHQVPDDETIFK
$99.5 \% 21.0$

$99.7 \% \quad 87.1$

$99.7 \% \quad 35.7$

$99.7 \% \quad 47.6$

$99.7 \% \quad 42.8$

$99.7 \% \quad 46.8$

$99.0 \% 31.6$

$99.7 \% \quad 27.7$

$99.7 \% \quad 55.6$

$99.7 \% 37.7$

$99.0 \% \quad 36.8$

$99.7 \% \quad 60.6$

$99.0 \% \quad 27.3$

$99.7 \% \quad 63.7$

$99.7 \% \quad 66.7$

$99.7 \% \quad 40.8$

$99.0 \% 29.0$

$\begin{array}{ll}99.0 \% & 29.0 \\ 99.7 \% & 43.4\end{array}$

$98.6 \% \quad 25.2$

$99.0 \% \quad 48.8$

$98.0 \% \quad 23.3$

$99.0 \% \quad 27.3$

$99.7 \% \quad 63.9$

$99.7 \% \quad 44.9$

$99.7 \% \quad 40.6$

$\begin{array}{lll}99.7 \% & 28.2\end{array}$

$99.7 \% \quad 38.2$

$99.7 \% \quad 42.0$

$99.7 \% \quad 43.2$

$99.2 \% \quad 18.8$

$99.7 \% \quad 55.0$

$99.7 \% \quad 46.5$

$99.7 \% \quad 50.4$

$\begin{array}{lll}99.7 \% & 28.1\end{array}$

$99.7 \% \quad 40.6$

$99.7 \% \quad 25.3$

$99.7 \% \quad 39.0$

$99.7 \% \quad 38.5$

$99.7 \% \quad 33.8$

$99.7 \% \quad 53.6$

$\begin{array}{lll}99.7 \% & 44.8\end{array}$

$98.5 \% \quad 24.9$

$99.0 \% \quad 41.7$

$99.7 \% \quad 31.0$

$99.7 \% 30.1$

$99.6 \% \quad 24.0$ \begin{tabular}{l}
$.0 \quad 86$ \\
\hline
\end{tabular}

45.2

$\begin{array}{ll}0 & 29.8\end{array}$

.0 42.4

$\begin{array}{ll}.0 & 21.1\end{array}$

$\begin{array}{ll}27.0 & 27.7\end{array}$

\begin{tabular}{l}
0 \\
\hline
\end{tabular} 55.6

\begin{tabular}{ll}
0 & 37.2 \\
\hline
\end{tabular}

36.8
25.0

$\begin{array}{ll}36.0 & 48.0\end{array}$

22.6

$\begin{array}{ll}0 & 63.7\end{array}$

$\begin{array}{ll}5.0 & 63.7 \\ 50.4\end{array}$

$\begin{array}{ll}5.0 & 40.8\end{array}$

$\begin{array}{ll}25.0 & 51.2\end{array}$

\begin{tabular}{ll}
5.0 & 25.1 \\
\hline
\end{tabular}

$\begin{array}{ll}5.0 & 43.4\end{array}$

25.0 12.4

\begin{tabular}{ll}
31.5 \\
\hline
\end{tabular}

$\begin{array}{ll}25.0 & 12.6\end{array}$

$\begin{array}{ll}0 & 20.4\end{array}$

$\begin{array}{lll}58.0 & 58.5 & 3\end{array}$

$\begin{array}{ll}.0 & 44.9\end{array}$

38.6

$\begin{array}{ll}25.0 & 18.7\end{array}$

$\begin{array}{ll}.0 & 42.0\end{array}$

$\begin{array}{ll}5.0 & 43.2\end{array}$

$\begin{array}{ll}25.0 & 18.8\end{array}$

54.

$\begin{array}{ll}25.0 & 42.7\end{array}$

$\begin{array}{ll}5.0 & 40.8\end{array}$

$25.0 \quad 28.1$

$\begin{array}{ll}25.0 & 40.6\end{array}$

$\begin{array}{ll}5.0 & 25.3\end{array}$

$\begin{array}{ll}0 & 21.0\end{array}$

\begin{tabular}{ll}
5.0 & 27.4 \\
\hline
\end{tabular}

33.1

\begin{tabular}{ll}
25.0 & 42.5 \\
\hline &
\end{tabular}

$\begin{array}{lll}5.0 & 42.1 & 2\end{array}$

$\begin{array}{ll}25.0 & 18.0\end{array}$

03.5
25.0

\begin{tabular}{ll}
31.0 \\
\hline
\end{tabular}

\begin{tabular}{ll}
27.3 \\
\hline
\end{tabular}

1005.55

1615.76

1480.62

1419.61

1187.58

1513.71

1641.69

1611.68

1340.55

1177.48

1061.50

2034.88

1684.68

1493.63

1102.45

1105.60

1166.66

1100.52

1177.62

1496.81

1414.76

829.49

1814.97

1854.95 1845.94 
RNA-binding motif protein, X chromosome GN=RBMX RBMX_HUMAN $42.33 \quad 100.0 \% \quad 32$ $\begin{array}{llll}\text { RNA-binding motif protein, X chromosome GN=RBMX RBMX_HUMAN } & 42.33 & 100.0 \% & 32 \\ \text { RNA-binding motif protein, X chromosome GN=RBMX RBMX_HUMAN } & 42.33 & 100.0 \% & 32\end{array}$ RNA-binding motif protein, $X$ chromosome GN=RBMX RBMX_HUMAN $42.33 \quad 100.0 \% \quad 32$ RNA-binding motif protein, $X$ chromosome GN=RBMX RBMX_HUMAN $42.33 \quad 100.0 \% 32$ RNA-binding motif protein, $X$ chromosome GN=RBMX RBMX_HUMAN $42.33 \quad 100.0 \% \quad 32$ RNA-binding motif protein, $X$ chromosome GN=RBMX RBMX_HUMAN $42.33 \quad 100.0 \% \quad 32$ RNA-binding motif protein, X chromosome GN=RBMX RBMX_HUMAN $42.33 \quad 100.0 \% \quad 32$ RNA-binding motif protein, $X$ chromosome GN=RBMX RBMX_HUMAN $42.33 \quad 100.0 \% \quad 32$ RNA-binding motif protein, $X$ chromosome GN=RBMX RBMX_HUMAN $42.33 \quad 100.0 \% 32$ RNA-binding motif protein, $X$ chromosome GN=RBMX RBMX_HUMAN $42.33 \quad 100.0 \% \quad 32$ RNA-binding motif protein, $X$ chromosome GN=RBMX RBMX_HUMAN $42.33 \quad 100.0 \% \quad 32$ RNA-binding motif protein, $X$ chromosome GN=RBMX RBMX_HUMAN $42.33 \quad 100.0 \%$ RNA-binding motif protein, $X$ chromosome GN=RBMX RBMX_HUMAN $42.33 \quad 100.0 \%$ RNA-binding motif protein, $X$ chromosome GN=RBMX RBMX_HUMAN $42.33 \quad 100.0 \% \quad 32$ RNA-binding motif protein, $X$ chromosome GN=RBMX RBMX_HUMAN $42.33 \quad 100.0 \% \quad 32$ RNA-binding motif protein, $X$ chromosome GN=RBMX RBMX_HUMAN $42.33 \quad 100.0 \% \quad 32$ RNA-binding motif protein, $X$ chromosome GN=RBMX RBMX_HUMAN $42.33 \quad 100.0 \% 32$ RNA-binding motif protein, $X$ chromosome GN=RBMX RBMX_HUMAN $42.33 \quad 100.0 \% \quad 32$ RNA-binding motif protein, $X$ chromosome GN=RBMX RBMX_HUMAN $42.33 \quad 100.0 \% \quad 32$ RNA-binding motif protein, $X$ chromosome GN=RBMX RBMX_HUMAN $42.33 \quad 100.0 \% \quad 32$ RNA-binding motif protein, $X$ chromosome GN=RBMX RBMX_HUMAN $42.33 \quad 100.0 \% \quad 32$ RNA-binding motif protein, $X$ chromosome GN=RBMX RBMX_HUMAN $42.33 \quad 100.0 \% 32$ RNA-binding motif protein, $X$ chromosome GN=RBMX RBMX_HUMAN $42.33 \quad 100.0 \% \quad 32$ RNA-binding motif protein, $X$ chromosome GN=RBMX RBMX_HUMAN $42.33 \quad 100.0 \% \quad 32$ RNA-binding motif protein, $X$ chromosome GN=RBMX RBMX_HUMAN $42.33 \quad 100.0 \%$ RNA-binding motif protein, $X$ chromosome GN=RBMX RBMX_HUMAN $42.33 \quad 100.0 \% \quad 32$ RNA-binding motif protein, $X$ chromosome GN=RBMX RBMX_HUMAN $42.33 \quad 100.0 \% 32$ RNA-binding motif protein, $X$ chromosome GN=RBMX RBMX_HUMAN $42.33 \quad 100.0 \% \quad 32$ RNA-binding motif protein, $X$ chromosome GN=RBMX RBMX_HUMAN $42.33 \quad 100.0 \% \quad 32$ RNA-binding motif protein, $X$ chromosome GN=RBMX RBMX_HUMAN $42.33 \quad 100.0 \% 32$ RNA-binding motif protein, $X$ chromosome GN=RBMX RBMX_HUMAN $42.33 \quad 100.0 \% \quad 32$ RNA-binding motif protein, $X$ chromosome GN=RBMX RBMX_HUMAN $42.33 \quad 100.0 \%$ RNA-binding motif, single-stranded-interacting protein 1 GN=RBMS1 RBMS1_HUMAN $44.51 \quad 100.0 \%$ $\begin{array}{llll}\text { RNA-binding motif, single-stranded-interacting protein } 1 \text { GN=RBMS1 } & \text { RBMS1_HUMAN } & 44.51 & 100.0 \%\end{array}$ RNA-binding protein $10 \mathrm{GN}=\mathrm{RBM} 10$ RNA-binding protein $10 \mathrm{GN}=\mathrm{RBM} 10$ RNA-binding protein $10 \mathrm{GN}=\mathrm{RBM} 10$ RNA-binding protein $10 \mathrm{GN}=\mathrm{RBM} 10$ RNA-binding protein $10 \mathrm{GN}=\mathrm{RBM} 10$ RNA-binding protein $10 \mathrm{GN}=\mathrm{RBM} 10$ RNA-binding protein $10 \mathrm{GN}=\mathrm{RBM} 10$ RNA-binding protein $10 \mathrm{GN}=\mathrm{RBM} 10$ RNA-binding protein $10 \mathrm{GN}=\mathrm{RBM} 10$ RNA-binding potin 12B GN=RBM RNA-binding protein 12B GN=RBM12B RB12B_HUMAN $118.11 \quad 100.0 \%$ RNA-binding protein 12B GN=RBM12B RB12B_HUMAN $118.11 \quad 100.0 \%$ RNA-binding protein $14 \mathrm{GN}=\mathrm{RBM} 14$

RBM10_HUMAN $103.53 \quad 100.0 \%$

RBM10_HUMAN $103.53 \quad 100.0 \%$ RBM10_HUMAN $103.53 \quad 100.0 \%$ RBM10_HUMAN $103.53 \quad 100.0 \%$ RBM10_HUMAN $103.53 \quad 100.0 \%$ RBM10 HUMAN $103.53 \quad 100.0 \%$ RBM10_HUMAN $103.53 \quad 100.0 \%$ RBM10 HUMAN $103.53 \quad 100$. RB12B_HUMAN $118.11 \quad 100.0 \%$ RBM14_HUMAN $69.49 \quad 100.0 \%$

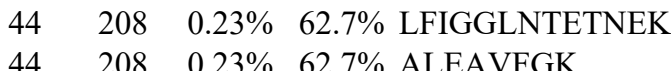

$208 \quad 0.23 \% \quad 62.7 \%$ IVEVLLMK

$208 \quad 0.23 \% \quad 62.7 \%$ IVEVLLMKDR

$208 \quad 0.23 \% \quad 62.7 \%$ GFAFVTFESPADAK

$208 \quad 0.23 \% \quad 62.7 \%$ GFAFVTFESPADAKDAA

$208 \quad 0.23 \% \quad 62.7 \%$ AIKVEQATKPSFESGR

$208 \quad 0.23 \% \quad 62.7 \%$ VEQATKPSFESGR

$208 \quad 0.23 \% \quad 62.7 \%$ RGPPPPPR

$208 \quad 0.23 \% \quad 62.7 \%$ GGHMDDGGYSMNFNMSSSR

$208 \quad 0.23 \% \quad 62.7 \%$ GRDSYGGPPR

$208 \quad 0.23 \% \quad 62.7 \%$ DSYGGPPR

$208 \quad 0.23 \% \quad 62.7 \%$ DSYGGPPRR

$208 \quad 0.23 \% \quad 62.7 \%$ RDVYLSPR

$208 \quad 0.23 \% \quad 62.7 \%$ DVYLSPRDDGYSTK

$208 \quad 0.23 \% \quad 62.7 \%$ DDGYSTKDSYSSR

$208 \quad 0.23 \% \quad 62.7 \%$ DSYSSRDYPSSR

$208 \quad 0.23 \% \quad 62.7 \%$ DTRDYAPPPR

$208 \quad 0.23 \% \quad 62.7 \%$ DYAPPPRDYTYR

$208 \quad 0.23 \% \quad 62.7 \%$ DYGHSSSRDDYPSR

$208 \quad 0.23 \% \quad 62.7 \%$ GYSDRDGYGR

$208 \quad 0.23 \% \quad 62.7 \%$ DRDYSDHPSGGSYR

$208 \quad 0.23 \% \quad 62.7 \%$ DYSDHPSGGSYR

$208 \quad 0.23 \% \quad 62.7 \%$ DSYESYGNSR

$208 \quad 0.23 \% \quad 62.7 \%$ SAPPTRGPPPSYGGSSR

$208 \quad 0.23 \% \quad 62.7 \%$ GPPPSYGGSSR

$208 \quad 0.23 \% \quad 62.7 \%$ GPPPSYGGSSRYDDYSSSR

$208 \quad 0.23 \% \quad 62.7 \%$ YDDYSSSRDGYGGSR

$208 \quad 0.23 \% \quad 62.7 \%$ DGYGGSRDSYSSSR

$208 \quad 0.23 \% \quad 62.7 \%$ DSYSSSRSDLYSSGR

$208 \quad 0.23 \% \quad 62.7 \%$ SDLYSSGRDR

$6 \quad 0.01 \% \quad 7.4 \%$ GYGFVDFDSPAAAQK

$0.01 \% \quad 7.4 \%$ TPPGVSAPTEPLLCK $\begin{array}{llllllll}99.7 \% & 60.6 & 25.0 & 48.0 & 14 & 0 & 0 & 1435.74\end{array}$ $\begin{array}{llllllll}99.0 \% & 39.1 & 25.0 & 28.9 & 2 & 0 & 0 & 834.47\end{array}$ $\begin{array}{llllllll}99.7 \% & 55.0 & 25.0 & 46.5 & 2 & 0 & 0 & 1210.66\end{array}$

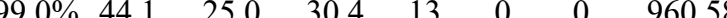
$\begin{array}{llllllll}99.7 \% & 43.3 & 25.0 & 40.7 & 4 & 0 & 0 & 1231.71\end{array}$

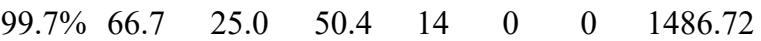

1899.92 1747.93 52.7 $99.7 \% \quad 54.3$

873.51

2097.77

1061.51

848.39

1004.49

1005.55

1615.76

1480.62

1419.61

1187.58

1513.71

1641.69

1145.50

1611.68

1340.55

1177.48

1670.82

1061.50

2034.88

1684.68

1493.63

1666.73

1155.54

1572.73

1566.82

1724.84

1304.63

1328.72

1197.66

1438.71

1126.58

1090.51

1312.72

1196.57

1122.59

1503.82

1047.62

$\begin{array}{llll}95.6 \% & 14.3 & 25.0 & 14.3\end{array}$

$\begin{array}{llll}99.7 \% & 40.7 & 25.0 & 31.7\end{array}$

$\begin{array}{llll}99.6 \% & 24.9 & 25.0 & 24.0\end{array}$

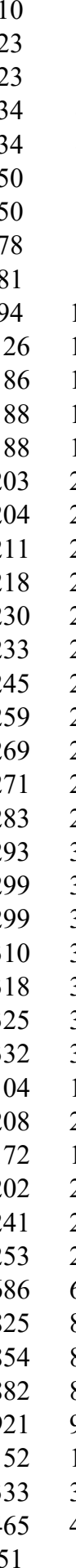


RNA-binding protein $14 \mathrm{GN}=\mathrm{RBM} 14$ RNA-binding protein $14 \mathrm{GN}=\mathrm{RBM} 14$ RNA-binding protein $14 \mathrm{GN}=\mathrm{RBM} 14$ RNA-binding protein $14 \mathrm{GN}=\mathrm{RBM} 14$ RNA-binding protein $14 \mathrm{GN}=\mathrm{RBM} 14$ RNA-binding protein $14 \mathrm{GN}=\mathrm{RBM} 14$ RNA-binding protein $14 \mathrm{GN}=\mathrm{RBM} 14$ RNA-binding protein $14 \mathrm{GN}=\mathrm{RBM} 14$ RNA-binding protein $14 \mathrm{GN}=\mathrm{RBM} 14$ RNA-binding protein $14 \mathrm{GN}=\mathrm{RBM} 14$ RNA-binding protein $14 \mathrm{GN}=\mathrm{RBM} 14$ RNA-binding protein $14 \mathrm{GN}=\mathrm{RBM} 14$ RNA-binding protein $14 \mathrm{GN}=\mathrm{RBM} 14$ RNA-binding protein $14 \mathrm{GN}=\mathrm{RBM} 14$ RNA-binding protein $14 \mathrm{GN}=\mathrm{RBM} 14$ RNA-binding protein $14 \mathrm{GN}=\mathrm{RBM} 14$ RNA-binding protein $14 \mathrm{GN}=\mathrm{RBM} 14$ RNA-binding protein $25 \mathrm{GN}=\mathrm{RBM} 25$ RNA-binding protein $25 \mathrm{GN}=\mathrm{RBM} 25$ RNA-binding protein $39 \mathrm{GN}=\mathrm{RBM} 39$ RNA-binding protein $39 \mathrm{GN}=\mathrm{RBM} 39$ RNA-binding protein $39 \mathrm{GN}=\mathrm{RBM} 39$ RNA-binding protein $39 \mathrm{GN}=\mathrm{RBM} 39$ RNA-binding protein $39 \mathrm{GN}=\mathrm{RBM} 39$ RNA-binding protein $4 \mathrm{GN}=\mathrm{RBM} 4$ RNA-binding protein $4 \mathrm{GN}=\mathrm{RBM} 4$ RNA-binding protein $4 \mathrm{GN}=\mathrm{RBM} 4$ RNA-binding protein $4 \mathrm{GN}=\mathrm{RBM} 4$ RNA-binding protein $4 \mathrm{GN}=\mathrm{RBM} 4$ RNA-binding protein $4 \mathrm{GN}=\mathrm{RBM} 4$ RNA-binding protein $4 \mathrm{GN}=\mathrm{RBM} 4$ RNA-binding protein $4 \mathrm{GN}=\mathrm{RBM} 4$ RNA-binding protein $4 \mathrm{GN}=\mathrm{RBM} 4$ RNA-binding protein $4 \mathrm{GN}=\mathrm{RBM} 4$ RNA-binding protein $4 \mathrm{GN}=\mathrm{RBM} 4$ RNA-binding protein $4 \mathrm{GN}=\mathrm{RBM} 4$ RNA-binding protein $4 \mathrm{GN}=\mathrm{RBM} 4$ RNA-binding protein $4 \mathrm{GN}=\mathrm{RBM} 4$ RNA-binding protein $4 \mathrm{GN}=\mathrm{RBM} 4$ RNA-binding protein $4 \mathrm{~B} \mathrm{GN=RBM4B}$ RNA-binding protein $4 \mathrm{~B} \mathrm{GN}=\mathrm{RBM} 4 \mathrm{~B}$ RNA-binding protein $4 \mathrm{~B}$ GN=RBM4B RNA-binding protein $4 \mathrm{~B}$ GN=RBM4B RNA-binding protein $4 \mathrm{~B}$ GN=RBM4B RNA-binding protein $4 \mathrm{~B}$ GN=RBM4B RNA-binding protein $4 \mathrm{~B} \mathrm{GN}=\mathrm{RBM} 4 \mathrm{~B}$ RNA-binding protein $4 \mathrm{~B} \mathrm{GN}=\mathrm{RBM} 4 \mathrm{~B}$
RBM14_HUMAN $69.49 \quad 100.0 \% \quad 18$ RBM14_HUMAN $69.49 \quad 100.0 \% \quad 18$ RBM14_HUMAN $69.49 \quad 100.0 \% \quad 18$ RBM14 HUMAN $69.49 \quad 100.0 \% \quad 18$ RBM14_HUMAN $69.49 \quad 100.0 \% \quad 18$ RBM14_HUMAN $69.49 \quad 100.0 \% \quad 18$ RBM14_HUMAN $69.49 \quad 100.0 \% \quad 18$ RBM14_HUMAN $69.49 \quad 100.0 \% \quad 18$ RBM14_HUMAN $\quad 69.49 \quad 100.0 \% \quad 18$ RBM14_HUMAN $69.49 \quad 100.0 \% \quad 18$ RBM14_HUMAN $69.49 \quad 100.0 \% \quad 18$ RBM14 HUMAN $69.49 \quad 100.0 \% \quad 18$ RBM14_HUMAN $69.49 \quad 100.0 \% \quad 18$ RBM14_HUMAN $\quad 69.49 \quad 100.0 \% \quad 18$ RBM14 HUMAN $69.49 \quad 100.0 \% \quad 18$ RBM14_HUMAN $69.49 \quad 100.0 \% \quad 18$ RBM14 HUMAN $69.49 \quad 100.0 \% \quad 18$ RBM25_HUMAN $100.19 \quad 100.0 \% \quad 2$ RBM25_HUMAN $100.19 \quad 100.0 \% \quad 2$ RBM39 HUMAN $59.38 \quad 100.0 \% \quad 5$ RBM39_HUMAN $59.38 \quad 100.0 \%$ RBM39 HUMAN $59.38 \quad 100.0 \%$ RBM39_HUMAN $59.38 \quad 100.0 \%$ RBM39_HUMAN $59.38 \quad 100.0 \% \quad 5$ RBM4_HUMAN $40.31 \quad 100.0 \% \quad 15$ RBM4_HUMAN $40.31 \quad 100.0 \% \quad 15$ RBM4_HUMAN $40.31 \quad 100.0 \% \quad 15$ RBM4 HUMAN $40.31 \quad 100.0 \% \quad 15$ RBM4_HUMAN $40.31 \quad 100.0 \% \quad 15$ RBM4 HUMAN $40.31 \quad 100.0 \% \quad 15$ RBM4_HUMAN $40.31 \quad 100.0 \% \quad 15$ RBM4_HUMAN $40.31 \quad 100.0 \% \quad 15$ RBM4 HUMAN $40.31 \quad 100.0 \% \quad 15$ RBM4_HUMAN $40.31 \quad 100.0 \% \quad 15$ RBM4_HUMAN $40.31 \quad 100.0 \% \quad 15$ RBM4 HUMAN $40.31 \quad 100.0 \% \quad 15$ RBM4_HUMAN $40.31 \quad 100.0 \% \quad 15$ RBM4_HUMAN $40.31 \quad 100.0 \% \quad 15$ RBM4_HUMAN $40.31 \quad 100.0 \% \quad 15$ RBM4B_HUMAN $40.15 \quad 100.0 \% \quad 2$ RBM4B HUMAN $40.15 \quad 100.0 \%$ RBM4B_HUMAN $\quad 40.15 \quad 100.0 \% \quad 2$ RBM4B_HUMAN $40.15 \quad 100.0 \% \quad 2$ RBM4B_HUMAN $40.15 \quad 100.0 \%$ RBM4B_HUMAN $40.15 \quad 100.0 \% \quad 2$ RBM4B_HUMAN $\quad 40.15 \quad 100.0 \% \quad 2$ RBM4B_HUMAN $40.15 \quad 100.0 \%$

20
42 42
$0.05 \% \quad 28.6 \%$ IFVGNVSAACTSQELR $0.05 \% \quad 28.6 \%$ AAIAQLNGKEVK $0.05 \% \quad 28.6 \%$ INVELSTK

$0.05 \% \quad 28.6 \%$ INVELSTKGQK

$0.05 \% \quad 28.6 \%$ KGPGLAVQSGDK

$0.05 \% \quad 28.6 \%$ GPGLAVQSGDK

$0.05 \% \quad 28.6 \%$ ASYVAPLTAQPATYR

$0.05 \% \quad 28.6 \%$ AQPSVSLGAAYR

$0.05 \% \quad 28.6 \%$ AQPSASLGVGYR

$0.05 \% \quad 28.6 \%$ TQPMTAQAASYR

$0.05 \% \quad 28.6 \%$ AQPSVSLGAPYR

$0.05 \% \quad 28.6 \%$ TQSSASLAASYAAQQHPQAAASYR

$0.05 \% \quad 28.6 \%$ ASYDDPYKK

$0.05 \% \quad 28.6 \%$ LAELSDYR

$0.05 \% \quad 28.6 \%$ LAELSDYRR

$0.05 \% \quad 28.6 \%$ RLPDAHSDYAR

$0.05 \% \quad 28.6 \%$ YSGSYNDYLR

$0.00 \% \quad 1.8 \%$ LGASNSPGQPNSVK

$0.00 \% \quad 1.8 \%$ LGASNSPGQPNSVKR

$0.01 \% \quad 10.4 \%$ YRSPYSGPK

$0.01 \% \quad 10.4 \%$ TVFCMQLAAR

$0.01 \% \quad 10.4 \%$ DLEEFFSTVGK

$0.01 \% \quad 10.4 \%$ VLGVPIIVQASQAEK

$0.01 \% \quad 10.4 \%$ AAAMANNLQK

$0.03 \% \quad 44.2 \%$ LFIGNLPR

$0.03 \% \quad 44.2 \%$ SLFEQYGK

$0.03 \% \quad 44.2 \%$ VLECDIIK

$0.03 \% \quad 44.2 \%$ NYGFVHIEDK

$0.03 \% \quad 44.2 \%$ NYGFVHIEDKTAAEDAIR

$0.03 \% \quad 44.2 \%$ LHGVNINVEASK

$0.03 \% \quad 44.2 \%$ LHVGNISPTCTNK

$0.03 \% \quad 44.2 \%$ AEDAVEAIR

$0.03 \% \quad 44.2 \%$ GLDNTEFQGK

$0.03 \% \quad 44.2 \%$ GLDNTEFQGKR

$0.03 \% \quad 44.2 \%$ TAPGMGDQSGCYR

$0.03 \% \quad 44.2 \%$ VADLTEQYNEQYGAVR

$0.03 \% \quad 44.2 \%$ ATAPVPTVGEGYGYGHESELSQASAAAR

$0.03 \% \quad 44.2 \%$ NSLYDMAR

$0.03 \% \quad 44.2 \%$ YEREQYADR

$0.00 \% \quad 35.4 \%$ LFIGNLPR

$0.00 \% \quad 35.4 \%$ SLFEQYGK

$0.00 \% \quad 35.4 \%$ VLECDIIK

$0.00 \% \quad 35.4 \%$ NYGFVHIEDK

$0.00 \% \quad 35.4 \%$ NYGFVHIEDKTAAEDAIR

$0.00 \% \quad 35.4 \%$ LHGVNINVEASK

$0.00 \% \quad 35.4 \%$ LHVGNISPTCTNQELR

$0.00 \% \quad 35.4 \%$ AEDAVEAIR
$99.7 \% 59.9$ $99.7 \% \quad 55.8$ $\begin{array}{lll}99.0 \% & 34.3\end{array}$ $99.7 \% 53.1$ $99.7 \% \quad 53.9$ $97.3 \% \quad 16.8$

$99.7 \% \quad 60.8$ $99.7 \% \quad 49.4$ $99.7 \% \quad 56.7$ $99.7 \% \quad 50.8$ $99.7 \% \quad 57.2$ $7 \% 72.0$ $99.3 \% 19.8$ $99.0 \% \quad 22.5$ $99.7 \% \quad 45.2$ $99.7 \% \quad 30.9$ $99.7 \% \quad 64.2$ $99.7 \% \quad 46.0$ $99.4 \% \quad 26.6$ $99.6 \% 25.6$ $99.7 \% \quad 52.9$ $99.7 \% \quad 57.8$ $99.7 \% \quad 31.2$ $99.7 \% \quad 53.5$ $99.0 \% \quad 46.0$ $99.0 \% \quad 33.2$ $99.0 \% \quad 36.5$ $99.7 \% \quad 43.3$

$99.7 \% 52.8$ $9.7 \% 56.6$ $99.7 \% \quad 52.3$ $\begin{array}{lll}99.7 \% & 71.7\end{array}$ $99.7 \% \quad 62.0$ $99.7 \% \quad 54.2$ $99.7 \% \quad 52.8$ $99.7 \% \quad 78.9$ $99.7 \% \quad 61.3$ $99.0 \% 34.1$ $98.8 \% \quad 20.9$ $99.0 \% \quad 46.0$ $99.0 \% \quad 33.2$ $99.0 \% \quad 36.5$ $99.7 \% \quad 43.3$ $99.7 \% \quad 52.8$ $99.7 \% \quad 56.6$ $99.6 \% 23$. $99.7 \% \quad 71.7$
1751.87 1241.72 903.51

1216.69

1156.63

1028.54

1608.84

1219.64

1205.63

1324.63

1245.66

2465.18

1086.5

966.49

1122.59

1300.64

1237.55

1355.69

1511.79

1054.53

1196.59

1271.62

1551.91

1031.53

929.56

971.48

989.53

1221.59

2049.00

1280.70

1440.73

973.49

1108.53

1264.63

1415.57

1855.88

2776.32

969.45

1229.55

929.56

971.48

989.53

1221.59

2049.00

1280.70

1838.92

973.49

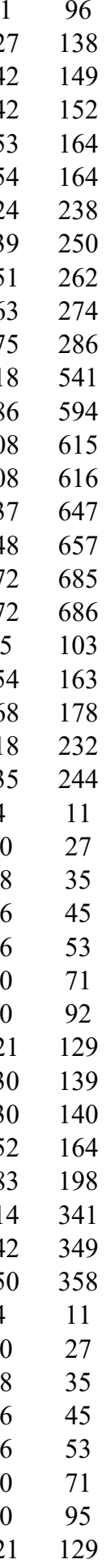


RNA-binding protein $4 \mathrm{~B}$ GN=RBM4B RNA-binding protein $4 \mathrm{~B}$ GN=RBM4B RNA-binding protein $4 \mathrm{~B} \mathrm{GN}=\mathrm{RBM} 4 \mathrm{~B}$ RNA-binding protein $4 \mathrm{~B} \mathrm{GN}=\mathrm{RBM} 4 \mathrm{~B}$ RNA-binding protein $4 \mathrm{~B} \mathrm{GN}=\mathrm{RBM} 4 \mathrm{~B}$ RNA-binding protein $8 \mathrm{~A}$ GN=RBM $8 \mathrm{~A}$ RNA-binding protein $8 \mathrm{~A} \mathrm{GN}=\mathrm{RBM} 8 \mathrm{~A}$ RNA-binding protein Musashi homolog $1 \mathrm{GN}=$ MSII MSIIH_HUMAN $39.12 \quad 100.0 \%$ RNA-binding protein Musashi homolog $1 \mathrm{GN}=$ MSII MSIIH_HUMAN $39.12 \quad 100.0 \%$ RNA-binding protein Musashi homolog $1 \mathrm{GN}=$ MSII MSIIH_HUMAN $39.12 \quad 100.0 \%$ RNA-binding protein Musashi homolog $1 \mathrm{GN}=$ MSII MSIIH_HUMAN $39.12 \quad 100.0 \%$ RNA-binding protein Musashi homolog 2 GN=MSI2 MSI2H_HUMAN $35.20 \quad 100.0 \%$ RNA-binding protein Musashi homolog 2 GN=MSI2 MSI2H_HUMAN $35.20 \quad 100.0 \%$ RNA-binding protein Musashi homolog 2 GN=MSI2 MSI2H_HUMAN $35.20 \quad 100.0 \%$ RNA-binding protein PNO1 GN=PNO1 PNO1_HUMAN $27.93 \quad 100.0 \%$ RNA-binding protein PNO1 GN=PNO1 PNO1_HUMAN $27.93 \quad 100.0 \%$ RNA-binding protein $\mathrm{PNO} 1 \mathrm{GN}=\mathrm{PNO} 1$ RNA-binding protein $\mathrm{PNO} 1 \mathrm{GN}=\mathrm{PNO} 1$ RNA-binding protein $\mathrm{PNO} 1 \mathrm{GN}=\mathrm{PNO} 1$ RNA-binding protein $\mathrm{PNO} 1 \mathrm{GN}=\mathrm{PNO} 1$ RNA-binding protein $\mathrm{PNO} 1 \mathrm{GN}=\mathrm{PNO} 1$ RNA-binding protein $\mathrm{PNO} 1 \mathrm{GN}=\mathrm{PNO} 1$ RNA-binding protein Raly GN=RALY RNA-binding protein Raly GN=RALY RNA-binding protein Raly GN=RALY RNA-binding protein Raly GN=RALY RNA-binding protein Raly GN=RALY RNA-binding protein Raly GN=RALY RNA-binding protein Raly GN=RALY RNA-binding protein Raly GN=RALY RNA-binding protein Raly GN=RALY RNA-binding protein Raly GN=RALY RNA-binding protein Raly GN=RALY RNA-binding protein Raly GN=RALY RNA-binding protein Raly GN=RALY RNA-binding protein Raly GN=RALY RNA-binding protein Raly GN=RALY PNO1_HUMAN $27.93 \quad 100.0 \%$ PNO1_HUMAN $27.93 \quad 100.0 \%$ PNO1_HUMAN $27.93 \quad 100.0 \%$ PNO1_HUMAN $27.93 \quad 100.0 \%$ PNO1_HUMAN $27.93 \quad 100.0 \%$ PNO1_HUMAN $27.93 \quad 100.0 \%$ RALY_HUMAN $32.46 \quad 100.0 \%$ RALY_HUMAN $32.46 \quad 100.0 \%$ RALY HUMAN $32.46 \quad 100.0 \%$ RALY_HUMAN $32.46 \quad 100.0 \%$ RALY_HUMAN $32.46 \quad 100.0 \%$ RALY HUMAN $32.46 \quad 100.0 \%$ RALY_HUMAN $32.46 \quad 100.0 \%$ RALY HUMAN $32.46 \quad 100.0 \%$ RALY_HUMAN $32.46 \quad 100.0 \%$ RALY_HUMAN $32.46 \quad 100.0 \%$ RALY HUMAN $32.46 \quad 100.0 \%$ RALY_HUMAN $32.46 \quad 100.0 \%$ RALY_HUMAN $32.46 \quad 100.0 \%$ RALY HUMAN $32.46 \quad 100.0 \%$ RALY_HUMAN $32.46 \quad 100.0 \%$ R rRNA 2'-O-methyltransferase fibrillarin GN=FBL FBRL_HUMAN $33.78 \quad 100.0 \%$ rRNA 2'-O-methyltransferase fibrillarin GN=FBL FBRL_HUMAN $33.78 \quad 100.0 \%$ rRNA 2'-O-methyltransferase fibrillarin GN=FBL FBRL HUMAN $33.78 \quad 100.0 \%$ rRNA 2'-O-methyltransferase fibrillarin GN=FBL FBRL_HUMAN $33.78 \quad 100.0 \%$ rRNA 2'-O-methyltransferase fibrillarin GN=FBL FBRL_HUMAN $33.78 \quad 100.0 \%$ rRNA 2'-O-methyltransferase fibrillarin GN=FBL FBRL_HUMAN $33.78 \quad 100.0 \%$ rRNA 2'-O-methyltransferase fibrillarin GN=FBL FBRL_HUMAN $33.78 \quad 100.0 \%$ rRNA 2'-O-methyltransferase fibrillarin GN=FBL FBRL_HUMAN $33.78 \quad 100.0 \%$ rRNA 2 '-O-methyltransferase fibrillarin GN=FBL FBRL_HUMAN $33.78 \quad 100.0 \%$
$0.00 \% \quad 35.4 \%$ GLDNTEFQGK $0.00 \% \quad 35.4 \%$ GLDNTEFQGKR

$0.00 \% \quad 35.4 \%$ TAPGMGDQSGCYR

$99.7 \% \quad 62.0$ $99.7 \% \quad 54.2$ $99.7 \% \quad 52.8$ $0.00 \% \quad 35.4 \%$ VADFTEQYNEQYGAVR $\quad 99.7 \% \quad 83.9$ $0.00 \% \quad 35.4 \%$ NSLYDMAR $0.00 \% \quad 7.5 \%$ GRGFGSEEGSR $0.00 \% \quad 7.5 \%$ GFGSEEGSRAR $0.01 \% \quad 15.7 \%$ EYFGQFGEVK $0.01 \% \quad 15.7 \%$ GFGFVTFMDQAGVDK $0.01 \% \quad 15.7 \%$ GFGFVTFESEDIVEK $0.01 \% \quad 15.7 \%$ SYTGLAPGYTYQFPEFR $0.01 \% \quad 12.8 \%$ GFGFVTFADPASVDK $0.01 \% \quad 12.8 \%$ VLGQPHHELDSK $0.01 \% \quad 12.8 \%$ GFGFVTFENEDVVEK $0.02 \% \quad 36.1 \%$ AEEGFTQVTR $0.02 \% \quad 36.1 \%$ QAEQLSAAGEGGDAGR $0.02 \% \quad 36.1 \%$ MDTEEARPAK $0.02 \% \quad 36.1 \%$ KIPVPANR $0.02 \% \quad 36.1 \%$ IFTPIVEHLGLQIR $0.02 \% \quad 36.1 \%$ FTIENVTR $0.02 \% 36.1 \%$ VHILGSFQNIK $0.02 \% 36.1 \%$ TAICNLILGNPPSK $0.07 \% \quad 38.6 \%$ LQASNVTNK $0.07 \% \quad 38.6 \%$ LQASNVTNKNDPK $0.07 \% \quad 38.6 \%$ VFIGNLNTALVK $0.07 \% \quad 38.6 \%$ VFIGNLNTALVKK $0.07 \% \quad 38.6 \%$ KSDVETIFSK $0.07 \% \quad 38.6 \%$ SDVETIFSK $0.07 \% \quad 38.6 \%$ GYAFVQYSNER $99.0 \% \quad 34.1 \quad 25.0 \quad 34.1$ $\begin{array}{llll}99.5 \% & 29.0 & 25.0 & 19.8\end{array}$ $\begin{array}{llll}99.0 \% & 21.3 & 25.0 & 17.0\end{array}$ $99.7 \% \quad 35.5 \quad 25.0 \quad 31.2$ $\begin{array}{llll}99.7 \% & 56.2 & 25.0 & 56.2\end{array}$ $99.7 \% \quad 60.0 \quad 25.0 \quad 53.9$ $\begin{array}{llll}99.7 \% & 45.6 & 25.0 & 45.6\end{array}$ $\begin{array}{llll}99.7 \% & 52.3 & 25.0 & 52.3\end{array}$ $98.2 \% \quad 16.9 \quad 25.0 \quad 16.6$ $99.7 \% \quad 53.0$ $99.7 \% \quad 52.9$ $99.7 \% \quad 83.1$ $99.7 \% \quad 52.8$ $95.9 \% \quad 19.4$ $99.7 \% \quad 51.9$ $99.0 \% \quad 39.4$ $99.7 \% \quad 34.7$ $99.7 \% \quad 59.1$ $99.7 \% \quad 39.7$ $99.7 \% \quad 46.6$ $99.4 \% \quad 68.6$ $97.2 \% \quad 49.2$ $99.7 \% \quad 64.1$ $99.7 \% \quad 48.8$ $99.7 \% \quad 59.9$ $0.07 \% \quad 38.6 \%$ VLAGQTLDINMAGEPKPDRPK $0.07 \% \quad 38.6 \%$ LSPVPVPR $0.07 \% \quad 38.6 \%$ VKTNVPVK $0.07 \% \quad 38.6 \%$ LKSSELQAIK $0.07 \% \quad 38.6 \%$ SSELQAIK $0.07 \% \quad 38.6 \%$ SSELQAIKTELTQIK $0.07 \% \quad 38.6 \%$ SNIDALLSR $0.07 \% \quad 38.6 \%$ LEQIAAEQK $0.05 \% \quad 54.5 \%$ NVMVEPHR $0.05 \% \quad 54.5 \%$ NVMVEPHRHEGVFICR $0.05 \% \quad 54.5 \%$ HEGVFICR $0.05 \% \quad 54.5 \%$ GKEDALVTK $0.05 \% \quad 54.5 \%$ NLVPGESVYGEK $0.05 \% \quad 54.5 \%$ NLVPGESVYGEKR $0.05 \% \quad 54.5 \%$ VSISEGDDKIEYR $\begin{array}{lll}99.7 \% & 49.7\end{array}$ $98.3 \% \quad 23.9$ $\begin{array}{lll}97.7 \% & 22.5\end{array}$ $99.7 \% \quad 38.3$ $99.0 \% \quad 61.6$ $99.7 \% \quad 44.1$ $99.7 \% \quad 56.2$ $99.7 \% \quad 55.2$ $99.0 \% \quad 27.4$

$99.0 \% \quad 22.4$ $99.0 \% \quad 39.5$ $99.7 \% \quad 39.2$ $99.6 \% 24.6$ $99.7 \% \quad 65.8$ $99.7 \% \quad 53.3$ $0.05 \% \quad 54.5 \%$ LAAAILGGVDQIHIKPGAK $99.7 \% \quad 53.0$ $0.05 \% \quad 54.5 \%$ SGRDLINLAK $0.05 \% \quad 54.5 \%$ TNIIPVIEDAR
$99.7 \% \quad 30.5$

$99.3 \% \quad 49.7$

0
0
0
0
0
0
0
0
0
0
0
0
0
0
1
0
0
0
0
0
0
0
2
0
0
0
0
0
0
0
0
0
0
0
0
0
0
0
0
0
0
0
0
0
0
0
0
0
0
0
0
0
0
0
0
0
0
0
0
0
0
0
0
0
0
0
0
0
0
0
0
0
0
0
0
0
0
0
0
0
0
0
0
0
0
0
0

1264.63

1415.57

1889.87

969.45

1138.52

1152.54

1203.57

1634.75

1703.82

1996.94

1557.76

1359.70

1716.81

1137.55

1516.70

1147.54

894.55

1635.96

979.52

1255.72

1497.81

974.53

1428.74

1288.76

1416.86

1153.61

1025.52

1333.62

2266.19

864.53

884.56

1116.66

875.48

1688.94

988.54

1029.56

997.49

1995.96

1017.49

960.54

1291.65

1447.75

1510.74

1872.11

1086.63 1240.69

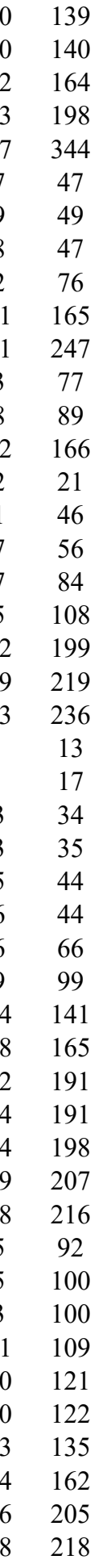


rRNA 2'-O-methyltransferase fibrillarin GN=FBL FBRL_HUMAN $33.78 \quad 100.0 \%$ rRNA 2'-O-methyltransferase fibrillarin GN=FBL FBRL_HUMAN $33.78 \quad 100.0 \%$ rRNA 2'-O-methyltransferase fibrillarin GN=FBL FBRL_HUMAN $33.78 \quad 100.0 \%$ rRNA 2'-O-methyltransferase fibrillarin GN=FBL FBRL_HUMAN $33.78 \quad 100.0 \%$ rRNA 2'-O-methyltransferase fibrillarin GN=FBL FBRL_HUMAN $33.78 \quad 100.0 \%$ rRNA 2'-O-methyltransferase fibrillarin GN=FBL FBRL_HUMAN $33.78 \quad 100.0 \%$ rRNA methyltransferase 3, mitochondrial GN=RNMTL1 MRM3_HUMAN $47.02 \quad 100.0 \%$ rRNA methyltransferase 3, mitochondrial GN=RNMTL1 MRM3_HUMAN $47.02 \quad 100.0 \%$ rRNA methyltransferase 3, mitochondrial GN=RNMTL1 MRM3_HUMAN $47.02 \quad 100.0 \%$ rRNA methyltransferase 3, mitochondrial GN=RNMTL1 MRM3_HUMAN $47.02 \quad 100.0 \%$ rRNA methyltransferase 3, mitochondrial GN=RNMTL1 MRM3_HUMAN $47.02 \quad 100.0 \%$ rRNA methyltransferase 3, mitochondrial GN=RNMTL1 MRM3 HUMAN 47.02 100.0\% RRP12-like protein $\mathrm{GN}=\mathrm{RRP} 12$ RRP12-like protein $\mathrm{GN}=\mathrm{RRP} 12$ RRP12-like protein $\mathrm{GN}=\mathrm{RRP} 12$ RRP12-like protein $\mathrm{GN}=\mathrm{RRP} 12$ RRP12-like protein $\mathrm{GN}=\mathrm{RRP} 12$ RRP12-like protein $\mathrm{GN}=\mathrm{RRP} 12$ RRP12-like protein $\mathrm{GN}=\mathrm{RRP} 12$ RRP12-like protein $\mathrm{GN}=\mathrm{RRP} 12$ RRP12-like protein $\mathrm{GN}=\mathrm{RRP} 12$ RRP12-like protein $\mathrm{GN}=\mathrm{RRP} 12$ RRP12-like protein $\mathrm{GN}=\mathrm{RRP} 12$ $\mathrm{RRP} 12$-like protein $\mathrm{GN}=\mathrm{R} \mathrm{RP} 12$ RRP12-like protein $\mathrm{GN}=\mathrm{RRP} 12$ RRP15-like protein GN=RRP15 RRP15-like protein $\mathrm{GN}=\mathrm{RRP} 15$ RRP15-like protein $\mathrm{GN}=\mathrm{RRP} 15$ RuvB-like $1 \mathrm{GN}=\mathrm{RUVBL} 1$ RuvB-like $1 \mathrm{GN}=$ RUVBL1 RuvB-like 2 GN=RUVBL2 RuvB-like 2 GN=RUVBL2 S1 RNA-binding domain-containing protin $1 \mathrm{GN}=\mathrm{SRBD} 1 \mathrm{SI}$ S1 RNA-binding domain-containing protein 1 GN=SRBD1 SRBD1_HUMAN $111.78 \quad 100.0 \%$ S-adenosylmethionine synthase isoform type-2 GN=MAT2A METK2_HUMAN $43.66 \quad 100.0 \%$ S-adenosylmethionine synthase isoform type-2 GN=MAT2A METK2_HUMAN $43.66 \quad 100.0 \%$ S-adenosylmethionine synthase isoform type-2 GN=MAT2A METK2_HUMAN $43.66 \quad 100.0 \%$ S-adenosylmethionine synthase isoform type-2 GN=MAT2A METK2_HUMAN $43.66 \quad 100.0 \%$ SAFB-like transcription modulator GN=SLTM SLTM_HUMAN $117.15 \quad 100.0 \%$ SAFB-like transcription modulator GN=SLTM SLTM_HUMAN $117.15 \quad 100.0 \%$ SAFB-like transcription modulator GN=SLTM SLTM_HUMAN $117.15 \quad 100.0 \%$ SAFB-like transcription modulator GN=SLTM SLTM_HUMAN $117.15 \quad 100.0 \%$ SAFB-like transcription modulator GN=SLTM SLTM_HUMAN $117.15 \quad 100.0 \%$ Sarcoplasmic/endoplasmic reticulum calcium ATPase $2 \mathrm{GN}=\mathrm{ATP} 2 \mathrm{~A} 2$ AT2A2_HUMAN $114.76 \quad 100.0 \%$ Sarcoplasmic/endoplasmic reticulum calcium ATPase 2 GN=ATP2A2 AT2A2_HUMAN $114.76 \quad 100.0 \%$ Sarcoplasmic/endoplasmic reticulum calcium ATPase 2 GN=ATP2A2 AT2A2_HUMAN $114.76 \quad 100.0 \%$ $16 \quad 23$ (6) 23 16 6

6
RRP12_HUMAN $143.71 \quad 100.0 \%$ RRP15_HUMAN $31.48 \quad 100.0 \%$ RRP15_HUMAN $31.48 \quad 100.0 \%$ RRP15_HUMAN $31.48 \quad 100.0 \%$ RUVB1_HUMAN $50.23 \quad 100.0 \%$ RUVB2 HUMAN $51.16 \quad 100.0 \%$ 2
$0.02 \% \quad 8.9 \%$ GSEFMFEK

$19 \quad 0.02 \% \quad 8.9 \% \quad$ APAHHPAAISTAK

$19 \quad 0.02 \% \quad 8.9 \%$ FCIQEIEK

$19 \quad 0.02 \% \quad 8.9 \% \quad$ SCSETLLR

$19 \quad 0.02 \% \quad 8.9 \% \quad$ CLQSLCDLR

$19 \quad 0.02 \% \quad 8.9 \% \quad$ VTVCQALR

$19 \quad 0.02 \% \quad 8.9 \% \quad$ RAVLETIR

$19 \quad 0.02 \% \quad 8.9 \% \quad$ VLDPASSDFTR

$19 \quad 0.02 \% \quad 8.9 \% \quad$ FGFELVKR

$19 \quad 0.02 \% \quad 8.9 \%$ VLATQPGPGR

$0.01 \% \quad 12.4 \%$ TPESKPTILVK

$0.01 \% \quad 12.4 \%$ GVVQLFNAVQK

$0.01 \% \quad 12.4 \%$ GMDGSTNETASSR

$0.00 \% \quad 5.7 \%$ AVLLAGPPGTGK

$0.00 \% \quad 5.7 \%$ YSVQLLTPANLLAK

$0.00 \% \quad 4.8 \%$ AVLIAGQPGTGK

$0.00 \% \quad 4.8 \%$ VYSLFLDESR

$0.00 \% \quad 2.1 \%$ QLLLTSPVPGR

$0.00 \% \quad 2.1 \%$ SFQQCAGFIR

$0.01 \% \quad 12.7 \%$ TGMILLAGEITSR

$0.01 \% \quad 12.7 \%$ FVIGGPQGDAGLTGR

$0.01 \% \quad 12.7 \%$ NFDLRPGVIVR

6.01\% $12.7 \%$ DLDLKKPIYQR

$0.01 \% \quad 6.3 \%$ CYGIVTMSSSTEVSR

$0.01 \% \quad 6.3 \%$ TELHGQLISVEK

$0.01 \% \quad 6.3 \% \quad$ FGHGSDYSR

$0.01 \% \quad 6.3 \%$ AGAGMITQHSSNASPINR

$0.01 \% \quad 6.3 \%$ IVQISGNSMPR

$0.05 \% \quad 11.1 \%$ NMLFSGTNIAAGK

$\begin{array}{ll}99.7 \% & 39.5 \\ 99.7 \% & 59.9\end{array}$

$0.05 \% \quad 11.1 \%$ AMGVVVATGVNTEIGK

$0.05 \% \quad 11.1 \%$ EFTLEFSR

$0.05 \% \quad 11.1 \%$ SMSVYCTPNKPSR
K $99.7 \%$ \#\#\#\#

$99.7 \% \quad 40.5$

$\begin{array}{lll}99.7 \% & 46.3\end{array}$

$99.7 \% \quad 45.9$

$95.5 \% \quad 14.3$

$99.7 \% \quad 57.6$

$99.7 \% \quad 39.4$

$99.6 \% \quad 31.2$

$\begin{array}{lll}99.7 \% & 39.7\end{array}$

$94.8 \% \quad 13.6$

$95.7 \% \quad 14.4$

$95.7 \% \quad 14.3$

$96.1 \% \quad 18.0$

$97.2 \% \quad 21.1$

$\begin{array}{lll}99.0 \% & 35.8\end{array}$

$99.0 \% \quad 24.4$

$99.7 \% \quad 33.0$

$99.0 \% \quad 42.4$

$99.0 \% \quad 40.7$

$99.7 \% \quad 26.5$

$99.0 \% \quad 38.1$

$99.7 \% \quad 58.7$

$99.6 \% 26.1$

$\begin{array}{lll}99.7 \% & 59.8\end{array}$

$99.7 \% \quad 39.4$

$99.7 \% \quad 35.8$

$99.7 \% 36.8$

$99.7 \% \quad 41.5$

$99.7 \% \quad 36.7$

$99.7 \% \quad 42.5$

$99.7 \% \quad 48.2$

$99.7 \% \quad 49.9$

$99.7 \% \quad 57.4$

$99.2 \% \quad 20.0$

$99.7 \% 27.4$

$99.7 \% \quad 66.1$

$99.7 \% \quad 32.2$

$99.4 \% \quad 20.6$

$\begin{array}{ll}99.7 \% & 26.6 \\ 99.7 \% & 42.4\end{array}$

$99.7 \% \quad 49.5$

$99.7 \% \quad 55.9$

$99.0 \% \quad 24.5$

$99.7 \% \quad 35.3$
2265.13

254.73

1969.92

2098.01

2424.12

1533.85

1317.70

1473.81

1301.64

1273.64

993.57

1282.77

1300.57

1297.70

1169.6

974.43

1271.69

1066.52

965.47

1164.55

946.51

957.58

1207.60

995.57

995.56

1212.72

1202.69

1312.54

1080.64

1530.89

1111.65

1228.62

1180.71

1213.58

1361.75

1444.75

1285.74

1388.79

1676.76

1353.74

1025.44

1811.88

1201.64

1323.67

1561.83

1028.50

1526.71
$45 \quad 255$

$266 \quad 285$

$286 \quad 304$

$305 \quad 318$

$40 \quad 51$

$40 \quad 52$

$72 \quad 8$

$104 \quad 112$

$130 \quad 142$

$21 \quad 32$

$254 \quad 265$

$255 \quad 265$

$274 \quad 286$

$287 \quad 294$

$325 \quad 332$

$659 \quad 666$

711718

$740 \quad 750$

$1015 \quad 1022$

$1129 \quad 1138$

$\begin{array}{ll}104 & 114 \\ 169 & 179\end{array}$

$216 \quad 228$

$65 \quad 76$

$405 \quad 418$

$72 \quad 83$

$429 \quad 438$

$527 \quad 53$

$758 \quad 767$

$62 \quad 74$

$250 \quad 264$

362

$426 \quad 440$

$448 \quad 459$

$755 \quad 763$

9891006

$1007 \quad 1017$

$206 \quad 218$

234
482

$493 \quad 505$ 

Scaffold attachment factor B1 GN=SAFB SAFB1_HUMAN $102.64 \quad 100.0 \%$ Scaffold attachment factor B1 GN=SAFB SAFB1_HUMAN $102.64 \quad 100.0 \%$ Scaffold attachment factor B1 GN=SAFB SAFB1_HUMAN $102.64 \quad 100.0 \%$ Scaffold attachment factor B1 GN=SAFB SAFB1_HUMAN $102.64 \quad 100.0 \%$ Scaffold attachment factor B1 GN=SAFB SAFB1_HUMAN $102.64 \quad 100.0 \%$ Scaffold attachment factor B1 GN=SAFB SAFB1_HUMAN $102.64 \quad 100.0 \%$ Scaffold attachment factor B1 GN=SAFB SAFB1_HUMAN $102.64 \quad 100.0 \%$ Scaffold attachment factor B1 GN=SAFB SAFB1_HUMAN $102.64 \quad 100.0 \%$ Scaffold attachment factor B2 GN=SAFB2 SAFB2_HUMAN $107.47 \quad 100.0 \%$ Scaffold attachment factor B2 GN=SAFB2 SAFB2_HUMAN $107.47 \quad 100.0 \%$ Scaffold attachment factor B2 GN=SAFB2 SAFB2_HUMAN $107.47 \quad 100.0 \%$ Scaffold attachment factor B2 GN=SAFB2 SAFB2_HUMAN $107.47 \quad 100.0 \%$ Scaffold attachment factor B2 GN=SAFB2 SAFB2_HUMAN $107.47 \quad 100.0 \%$ Scaffold attachment factor B2 GN=SAFB2 SAFB2_HUMAN $107.47 \quad 100.0 \%$ Scaffold attachment factor B2 GN=SAFB2 SAFB2 HUMAN $107.47 \quad 100.0 \%$ Scaffold attachment factor B2 GN=SAFB2 SAFB2_HUMAN $107.47 \quad 100.0 \%$ Scaffold attachment factor B2 GN=SAFB2 SAFB2_HUMAN $107.47 \quad 100.0 \%$ Scaffold attachment factor B2 GN=SAFB2 SAFB2 HUMAN $107.47 \quad 100.0 \%$ Scaffold attachment factor B2 GN=SAFB2 SAFB2_HUMAN $107.47 \quad 100.0 \%$ Scaffold attachment factor B2 GN=SAFB2 SAFB2 HUMAN $107.47 \quad 100.0 \%$ SCY1-like protein $2 \mathrm{GN}=\mathrm{SCYL} 2$

SCY1-like protein $2 \mathrm{GN}=\mathrm{SCYL} 2$

$\mathrm{SCY} 1-$ like protein $2 \mathrm{GN}=\mathrm{SCYL} 2$

Sentrin-specific protease $3 \mathrm{GN}=\mathrm{SENP} 3$

Sentrin-specific protease $3 \mathrm{GN}=\mathrm{SENP} 3$

Septin-2 GN=SEPT2

Septin-2 GN=SEPT

Septin-2 GN=SEPT2

Septin $-2 \mathrm{GN}=\mathrm{SEPT} 2$

Septin-2 GN=SEPT2

SCYL2_HUMAN $103.71 \quad 100.0 \%$ SCYL2_HUMAN $103.71 \quad 100.0 \%$ SCYL 2 HUMAN $103.71 \quad 100.0 \%$ SENP3_HUMAN $65.01 \quad 100.0 \%$ SENP3 HUMAN $65.01 \quad 100.0 \%$ SEPT2 HUMAN $41.49 \quad 100.0 \%$ SEPT2_HUMAN $41.49 \quad 100.0 \%$ SEPT2 HUMAN $41.49 \quad 100.0 \%$ SEPT2_HUMAN $41.49 \quad 100.0 \%$ SEPT2_HUMAN $41.49 \quad 100.0 \%$ (100.0\% Serine hydroxymethyltransferase, mitochondrial GN=SHMT2 GLYM_HUMAN $55.99 \quad 100.0 \%$ Serine hydroxymethyltransferase, mitochondrial GN=SHMT2 GLYM HUMAN $55.99100 .0 \%$ Serine hydroxymethyltransferase, mitochondrial GN=SHMT2 GLYM HUMAN $55.99 \quad 100.0 \%$ Serine hydroxymethyltransferase, mitochondrial GN=SHMT2 GLYM HUMAN $55.99 \quad 100.0 \%$ Serine palmitoyltransferase $1 \mathrm{GN}=$ SPTLC1 SPTC1_HUMAN $52.75 \quad 100.0 \%$ Serine palmitoyltransferase $1 \mathrm{GN}=$ SPTLC1 SPTC1_HUMAN $52.75 \quad 100.0 \%$

$13 \quad 43 \quad 0.05 \% \quad 11.1 \%$ GAPEGVIDR

$13 \quad 43 \quad 0.05 \% \quad 11.1 \%$ VGSTKVPMTSGVK

$13 \quad 43 \quad 0.05 \% \quad 11.1 \%$ IGIFGQDEDVTSK

$13 \quad 43 \quad 0.05 \% \quad 11.1 \%$ KAEIGIAMGSGTAVAK

$13 \quad 43 \quad 0.05 \% \quad 11.1 \%$ AEIGIAMGSGTAVAK

$13 \quad 43 \quad 0.05 \% \quad 11.1 \%$ NYLEPGKECVQPATK

$17 \quad 44 \quad 0.05 \% \quad 16.6 \%$ NVDSSGNKSVLMER

17

10

8

$\begin{array}{llll}10 & 19 & 0.02 \% & 14.1 \% \text { NLDTGGNKSVLMER } \\ 10 & 19 & 0.02 \% & 14.1 \% \text { ILDILGETCK }\end{array}$

$\begin{array}{llll}10 & 19 & 0.02 \% & 14.1 \% \\ 10 & 19 & 0.02 \% & 14.1 \%\end{array}$

\section{$\begin{array}{llll}10 & 19 & 0.02 \% & 14.1 \% \\ 10 & 19 & 0.02 \% & 14.1 \%\end{array}$}

$\begin{array}{llll}10 & 19 & 0.02 \% & 14.1 \% \\ 10 & 19 & 0.02 \% & 14.1 \%\end{array}$

$\begin{array}{llll}10 & 19 & 0.02 \% & 14.1 \% \\ 10 & \text { VVGAKVVTNAR }\end{array}$

$10 \quad 19 \quad 0.02 \% \quad 14.1 \%$ CYGFVTMSTSDEATK

\section{$10 \quad 19 \quad 0.02 \% \quad 14.1 \%$ SKGEPVISVK}

$10 \quad 19 \quad 0.02 \% \quad 14.1 \%$ ERLQLECQR

$10 \quad 19 \quad 0.02 \% \quad 14.1 \%$ QQEQLRYEQER

$10 \quad 19 \quad 0.02 \% \quad 14.1 \%$ GLSGPSGPGHMASR

3

3
3

3

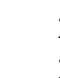

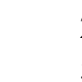

5

5

5
5
5

5
5
5

5
5
5
5
5

$0.00 \% \quad 4.1 \%$ SQFFKGLPK

$0.00 \% \quad 4.1 \% \quad$ NACLQTSSLAVR

$0.00 \% \quad 4.1 \%$ SQQPLKPQVHTPVATVK

$0.00 \% \quad 5.1 \%$ LKSGGGFGPDPGSGTTVPAR

$0.00 \% \quad 5.1 \% \quad$ YLQAEAVKK

$0.01 \% \quad 18.8 \%$ TVQIEASTVEIEER

$0.01 \% \quad 18.8 \%$ LTVVDTPGYGDAINCR

$0.01 \% \quad 18.8 \%$ TIISYIDEQFER

$0.01 \% \quad 18.8 \%$ VNIVPVIAK

$0.01 \% \quad 18.8 \%$ ASIPFSVVGSNQLIEAK

$0.02 \% \quad 12.5 \%$ YYGGAEVVDEIELLCQRR

$0.02 \% \quad 12.5 \%$ TGLIDYNQLALTAR

$0.02 \% \quad 12.5 \%$ LIIAGTSAYAR

$0.02 \% \quad 12.5 \%$ HADIVTTTTHK

$0.02 \% \quad 12.5 \%$ SAITPGGLR

$0.00 \% \quad 5.3 \%$ AAALASLKK

$0.00 \% \quad 5.3 \%$ AACFAIQK
$99.3 \% \quad 25.7$

$98.8 \% 22.6$

$99.7 \% \quad 50.4$

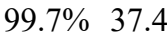

$99.7 \% \quad 44.8$

$99.7 \% \quad 30.2$

$99.7 \% \quad 48.3$

$\begin{array}{ll}99.7 \% & 28.7 \\ 99.7 \% & 51.9\end{array}$

$99.7 \% \quad 51.9$

$99.7 \% \quad 34.0$

$\begin{array}{lll}99.6 \% & 26.0\end{array}$

$99.7 \% \quad 49.9$

$99.7 \% \quad 54.6$

$99.6 \% \quad 25.4$

$99.7 \% \quad 59.5$

$99.6 \% \quad 23.9$

$99.7 \% \quad 32.9$

$\begin{array}{lll}99.7 \% & 26.7\end{array}$

$\begin{array}{lll}99.7 \% & 31.1\end{array}$

$99.7 \% \quad 42.4$

$99.7 \% \quad 51.9$

$99.7 \% \quad 34.0$

$99.7 \% \quad 58.5$

$99.7 \% \quad 54.6$

$99.6 \% \quad 25.4$

$\begin{array}{lll}99.7 \% & 42.7\end{array}$

$\begin{array}{lll}98.8 \% & 18.1\end{array}$

$\begin{array}{lll}98.6 \% & 19.1\end{array}$

$98.5 \% \quad 20.4$

$99.7 \% \quad 26.0$

$96.6 \% \quad 18.7$

$99.7 \% 36.5$

$9.4 \% \quad 19.8$

$99.6 \% \quad 25.6$

$99.7 \% \quad 64.9$

$99.7 \% \quad 54.1$

$99.7 \% \quad 62.3$

$99.7 \% \quad 36.6$

$99.7 \% \quad 51.0$

$\begin{array}{ll}7.7 \% & 19.9\end{array}$

$\begin{array}{lll}99.7 \% & 58.8\end{array}$

$\begin{array}{lll}99.7 \% & 48.7\end{array}$

$96.0 \% \quad 19.9$

$99.2 \% \quad 24.4$

$99.7 \% \quad 27.6$

$99.0 \% \quad 23.4$
915.55

1367.57

1354.67

1136.63

1113.67

1710.74

1586.74

1013.64

1706.74

1056.64

1533.77

1161.62

915.55

1320.69

1136.63

1113.67

1696.72

1043.61

1231.62

1506.73

1326.62

1051.59

1319.67

1858.05

1857.95

1049.60

1603.82

1750.84

1513.75

952.62

1759.96

2170.06

1548.84

1135.65

1223.64

871.50

872.56

908.47 
Serine palmitoyltransferase $1 \mathrm{GN}=$ SPTLC1 SPTC1_HUMAN $52.75 \quad 100.0 \%$ Serine racemase $\mathrm{GN}=\mathrm{SRR}$

Serine racemase $\mathrm{GN}=\mathrm{SRR}$ SRR_HUMAN $36.57 \quad 100.0 \%$ SRR_HUMAN $36.57 \quad 100.0 \%$ Serine/arginine repetitive matrix protin $2 \mathrm{GN}=\mathrm{SRRM} 2$ SRRM2 HUMAN $299.62 \quad 100.0 \%$ Serine/arginine repetitive matrix protein $2 \mathrm{GN}=$ SRRM2 SRRM2_HUMAN $299.62 \quad 100.0 \%$ Serine/arginine repetitive matrix protein $2 \mathrm{GN}=$ SRRM2 SRRM2_HUMAN $299.62 \quad 100.0 \%$ Serine/arginine repetitive matrix protein 2 GN=SRRM2 SRRM2_HUMAN $299.62 \quad 100.0 \%$ Serine/arginine repetitive matrix protein $2 \mathrm{GN}=$ SRRM2 SRRM2_HUMAN $299.62 \quad 100.0 \%$ Serine/arginine repetitive matrix protein $2 \mathrm{GN}=\mathrm{SRRM} 2 \mathrm{SRRM} 2$ HUMAN $299.62100 .0 \%$ Serine/arginine repetitive matrix protein 2 GN=SRRM2 SRRM2_HUMAN $299.62 \quad 100.0 \%$ Serine/arginine repetitive matrix protein $2 \mathrm{GN}=\mathrm{SRRM} 2 \mathrm{SRRM} 2$ HUMAN $299.62 \quad 100.0 \%$ Serine/arginine repetitive matrix protein $2 \mathrm{GN}=\mathrm{SRRM} 2 \mathrm{SRRM} 2$ HUMAN $299.62 \quad 100.0 \%$ Serine/arginine repetitive matrix protein $2 \mathrm{GN}=$ SRRM2 SRRM2_HUMAN $299.62 \quad 100.0 \%$ Serine/arginine repetitive matrix protein $2 \mathrm{GN}=$ SRRM2 SRRM2_HUMAN $299.62 \quad 100.0 \%$ Serine/arginine repetitive matrix protein 2 GN=SRRM2 SRRM2_HUMAN $299.62 \quad 100.0 \%$ Serine/arginine-rich splicing factor $1 \mathrm{GN}=\mathrm{SRSF} 1$ SRSF1_HUMAN $27.75 \quad 100.0 \%$ Serine/arginine-rich splicing factor $1 \mathrm{GN}=\mathrm{SRSF} 1$ SRSF1_HUMAN $27.75100 .0 \%$ Serine/arginine-rich splicing factor $1 \mathrm{GN}=\mathrm{SRSF} 1$ SRSF1_HUMAN $27.75 \quad 100.0 \%$ Serine/arginine-rich splicing factor $1 \mathrm{GN}=$ SRSF1 SRSF1_HUMAN $27.75 \quad 100.0 \%$ Serine/arginine-rich splicing factor $1 \mathrm{GN}=$ SRSF1 SRSF1_HUMAN $27.75 \quad 100.0 \%$ Serine/arginine-rich splicing factor $1 \mathrm{GN}=\mathrm{SRSF} 1$ SRSF1_HUMAN $27.75 \quad 100.0 \%$ Serine/arginine-rich splicing factor $1 \mathrm{GN}=\mathrm{SRSF} 1$ SRSF1_HUMAN $27.75 \quad 100.0 \%$ Serine/arginine-rich splicing factor $1 \mathrm{GN}=\mathrm{SRSF} 1$ SRSF1_HUMAN $27.75 \quad 100.0 \%$ Serine/arginine-rich splicing factor $1 \mathrm{GN}=$ SRSF1 SRSF1_HUMAN $27.75 \quad 100.0 \%$ Serine/arginine-rich splicing factor $1 \mathrm{GN}=\mathrm{SRSF} 1$ SRSF1_HUMAN 27.75 Serine/arginine-rich splicing factor $1 \mathrm{GN}=\mathrm{SRSF} 1$ SRSF1_HUMAN 27.75 Serine/arginine-rich splicing factor $1 \mathrm{GN}=\mathrm{SRSF} 1$ SRSF1_HUMAN 27.75 Serine/arginine-rich splicing factor $1 \mathrm{GN}=$ SRSF1 SRSF1_HUMAN 27.75 Serine/arginine-rich splicing factor $1 \mathrm{GN}=\mathrm{SRSF} 1$ SRSF1_HUMAN 27.75 Serine/arginine-rich splicing factor $1 \mathrm{GN}=\mathrm{SRSF} 1$ SRSF1_HUMAN 27.75 Serine/arginine-rich splicing factor $1 \mathrm{GN}=\mathrm{SRSF} 1$ SRSF1_HUMAN 27.75 Serine/arginine-rich splicing factor $10 \mathrm{GN}=$ SRSF 10 SRS10_HUMAN 31.30 Serine/arginine-rich splicing factor $10 \mathrm{GN}=$ SRSF10 SRS10_HUMAN 31.30 Serine/arginine-rich splicing factor $10 \mathrm{GN}=$ SRSF10 SRS10_HUMAN 31.30 Serine/arginine-rich splicing factor $10 \mathrm{GN}=\mathrm{SRSF} 10$ SRS10 HUMAN 31.3( Serine/arginine-rich splicing factor $10 \mathrm{GN}=$ SRSF10 SRS10_HUMAN 31.30 Serine/arginine-rich splicing factor $2 \mathrm{GN}=\mathrm{SRSF} 2$ SRSF2_HUMAN 25.48 Serine/arginine-rich splicing factor $2 \mathrm{GN}=\mathrm{SRSF} 2$ SRSF2 HUMAN 25.48 Serine/arginine-rich splicing factor $2 \mathrm{GN}=\mathrm{SRSF} 2$ SRSF2_HUMAN 25.48 Serine/arginine-rich splicing factor $3 \mathrm{GN}=\mathrm{SRSF} 3$ SRSF3_HUMAN 19.33 Serine/arginine-rich splicing factor $3 \mathrm{GN}=\mathrm{SRSF} 3$ SRSF3_HUMAN 19.33 Serine/arginine-rich splicing factor $3 \mathrm{GN}=\mathrm{SRSF} 3$ SRSF3_HUMAN 19.33 Serine/arginine-rich splicing factor $3 \mathrm{GN}=\mathrm{SRSF} 3 \mathrm{SRSF} 3$ HUMAN 19.33 Serine/arginine-rich splicing factor $3 \mathrm{GN}=\mathrm{SRSF} 3$ SRSF3_HUMAN $19.33 \quad 100.0^{\circ}$ Serine/arginine-rich splicing factor $3 \mathrm{GN}=\mathrm{SRSF} 3$ SRSF3_HUMAN $19.33 \quad 100.0 \%$ Serine/arginine-rich splicing factor $3 \mathrm{GN}=\mathrm{SRSF} 3$ SRSF3_HUMAN $19.33 \quad 100.0 \%$ Serine/arginine-rich splicing factor $3 \mathrm{GN}=\mathrm{SRSF} 3 \quad \mathrm{SRSF} 3$ _HUMAN $19.33 \quad 100.0 \%$

$100.0 \%$

$100.0 \%$

$100.0 \%$

$100.0 \%$

$100.0 \%$

$100.0 \%$

$100.0 \%$

$100.0 \%$

$100.0 \%$

$100.0 \%$

$100.0 \%$

$100.0 \%$

$00.0 \%$

$100.0 \%$

$100.0 \%$

$100.0 \%$

$00.0 \%$

$0 \%$
$0.00 \% \quad 5.3 \%$ SIALTQAR

$0.00 \% \quad 9.4 \%$ AVVTHSSGNHGQALTYAAK

$0.00 \% \quad 9.4 \%$ QAERPASYQSVSV

$0.05 \% \quad 5.6 \%$ HSLSGSSPGMKDIPR

$0.05 \% \quad 5.6 \%$ SGSESSVDQKTVAR

$99.7 \% \quad 47.6$

$0.08 \% \quad 50.0 \%$ DIEDVFYK

$0.08 \% \quad 50.0 \%$ YGAIRDIDLK

$0.08 \% \quad 50.0 \%$ GGPPFAFVEFEDPR

$0.08 \% \quad 50.0 \%$ GGPPFAFVEFEDPRDAEDAVYGR

$0.08 \% \quad 50.0 \%$ DAEDAVYGR

$0.08 \% \quad 50.0 \%$ DGYDYDGYR

$\begin{array}{ll}99.7 \% & 44.6\end{array}$

18

$\begin{array}{llll}9 & 95 \% & 23.5\end{array}$

$99.7 \% \quad 52.0$

\section{$99.7 \% \quad 52.9$}

$\begin{array}{ll}0.08 \% & 50.0 \% \text { DGTGVVEFVR }\end{array}$

$69 \quad 0.08 \% \quad 50.0 \%$ DGTGVVEFVRK

$0.08 \% \quad 50.0 \%$ KEDMTYAVR

$0.08 \% \quad 50.0 \%$ SHEGETAYIR

$0.03 \% \quad 19.5 \%$ YLRPPNTSLFVR

$0.03 \% \quad 19.5 \%$ YGPIVDVYVPLDFYTR

$0.03 \% \quad 19.5 \%$ GFAYVQFEDVR

$0.03 \% \quad 19.5 \%$ QIEIQFAQGDR

$0.03 \% \quad 19.5 \%$ QIEIQFAQGDRK

$0.01 \% \quad 16.3 \%$ DAEDAMDAMDGAVLDGR $99.7 \% \quad 65.5$

$0.01 \% \quad 16.3 \%$ YGRPPDSHHSR

$99.0 \% \quad 30.9$

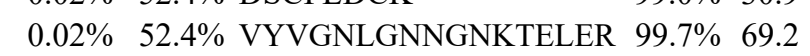

$0.02 \% \quad 52.4 \%$ AFGYYGPLR

$0.02 \% \quad 52.4 \%$ NPPGFAFVEFEDPR

$0.02 \% \quad 52.4 \%$ NPPGFAFVEFEDPRDAADAVR

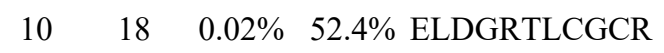

$10 \quad 18 \quad 0.02 \% \quad 52.4 \%$ VRVELSNGEK

$0.02 \% \quad 52.4 \%$ NRGPPPSWGR
$96.8 \% \quad 27.8$

$.7 \% \quad 25.8$

$99.1 \% \quad 26.0$

$99.2 \% \quad 29.5$

$95.9 \% \quad 19.6$

$99.4 \% \quad 21.3$

$99.7 \% \quad 39.2$

$99.7 \% \quad 29.0$

$99.6 \% \quad 23.4$

$99.7 \% \quad 44.3$

$99.7 \% 39.8$

$99.6 \% \quad 25.3$

$99.7 \% \quad 65.8$

$99.0 \% \quad 36.9$

$99.7 \% \quad 56.2$

$99.7 \% \quad 57.4$

$99.0 \% \quad 41.9$

$99.7 \% \quad 33.5$

$99.7 \% \quad 43.2$

$99.7 \% \quad 58.8$

$99.7 \% \quad 55.5$

$99.7 \% \quad 56.1 \quad 25.0 \quad 38.7$

$\begin{array}{lllll}99.7 \% & 34.8 & 25.0 & 31.6 & 0\end{array}$

$\begin{array}{lllll}99.7 \% & 54.1 & 25.0 & 48.3 & 6\end{array}$

$\begin{array}{llll}99.7 \% & 44.7 & 25.0 & 44.7\end{array}$

$99.7 \% \quad 48.1 \quad 25.0 \quad 48.1 \quad 4$

$99.7 \% \quad 51.7$

$99.7 \% \quad 51.9$

$99.7 \% \quad 57.1$

\begin{tabular}{l}
$99.7 \% \quad 25.8$ \\
\hline
\end{tabular}

$99.0 \% \quad 67.8$

$99.7 \% \quad 29.8$

25.0
$25.0 \quad 61.7$

$99.7 \% \quad 56.0$

25.0

859.50

1911.97

1421.70

1019.48

1314.63

1584.78

1450.71

1901.92

1214.59

971.53

1381.74

1238.69

1351.71

1300.7

934.50

1256.70

1257.64

1028.49

1163.64

1564.74

2541.17

995.44

1123.43

1668.90

2224.12

1417.61

2477.14

1078.55

1206.65

1112.54

1162.55

1462.82

1916.98

1330.64

1304.66

1432.75

918.50

1783.7

1308.62

994.40

1876.95

1043.53

1621.76

2320.10

$\begin{array}{llll}99.7 \% & 40.2 & 25.0 & 40.2\end{array}$

$\begin{array}{llll}99.4 \% & 26.9 & 25.0 & 25.7\end{array}$

$\begin{array}{llll}99.7 \% & 60.7 & 25.0 & 52.1\end{array}$

$99.7 \% \quad 31.9 \quad 25.0 \quad 27.3$

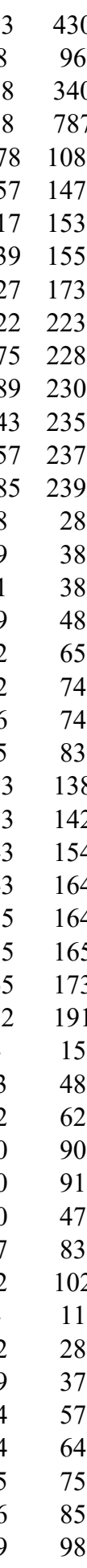

Page 138 of Table S-1-5 

Serine/arginine-rich splicing factor $6 \mathrm{GN}=$ SRSF6 SRSF6_HUMAN $39.59 \quad 100.0 \%$ Serine/arginine-rich splicing factor 6 GN=SRSF6 SRSF6_HUMAN $39.59 \quad 100.0 \%$ Serine/arginine-rich splicing factor $6 \mathrm{GN}=\mathrm{SRSF} 6$ SRSF6 HUMAN $39.59 \quad 100.0 \%$ Serine/arginine-rich splicing factor $6 \mathrm{GN}=\mathrm{SRSF} 6$ SRSF6_HUMAN $39.59 \quad 100.0 \%$ Serine/arginine-rich splicing factor 6 GN=SRSF6 SRSF6_HUMAN $39.59 \quad 100.0 \%$ Serine/arginine-rich splicing factor $6 \mathrm{GN}=$ SRSF6 SRSF6 HUMAN $39.59 \quad 100.0 \%$ Serine/arginine-rich splicing factor 6 GN=SRSF6 SRSF6_HUMAN $39.59 \quad 100.0 \%$ Serine/arginine-rich splicing factor $7 \mathrm{GN}=$ SRSF7 SRSF7_HUMAN $27.37 \quad 100.0 \%$ Serine/arginine-rich splicing factor $7 \mathrm{GN}=$ SRSF7 SRSF7_HUMAN $27.37 \quad 100.0 \%$ Serine/arginine-rich splicing factor $7 \mathrm{GN}=$ SRSF7 SRSF7_HUMAN $27.37 \quad 100.0 \%$ Serine/arginine-rich splicing factor $7 \mathrm{GN}=$ SRSF7 SRSF7_HUMAN $27.37 \quad 100.0 \%$ Serine/arginine-rich splicing factor 7 GN=SRSF7 SRSF7_HUMAN $27.37 \quad 100.0 \%$ Serine/arginine-rich splicing factor $7 \mathrm{GN}=$ SRSF7 SRSF7_HUMAN $27.37 \quad 100.0 \%$ Serine/arginine-rich splicing factor $7 \mathrm{GN}=\mathrm{SRSF} 7$ SRSF7_HUMAN $27.37 \quad 100.0 \%$ Serine/arginine-rich splicing factor 7 GN=SRSF7 SRSF7_HUMAN $27.37 \quad 100.0 \%$ Serine/arginine-rich splicing factor 7 GN=SRSF7 SRSF7_HUMAN $27.37 \quad 100.0 \%$ Serine/arginine-rich splicing factor $7 \mathrm{GN}=\mathrm{SRSF} 7$ SRSF7_HUMAN $27.37 \quad 100.0 \%$ Serine/arginine-rich splicing factor 7 GN=SRSF7 SRSF7_HUMAN $27.37 \quad 100.0 \%$ Serine/arginine-rich splicing factor $9 \mathrm{GN}=$ SRSF9 SRSF9_HUMAN $25.54 \quad 100.0 \%$ Serine/arginine-rich splicing factor 9 GN=SRSF9 SRSF9_HUMAN $25.54 \quad 100.0 \%$ Serine/arginine-rich splicing factor $9 \mathrm{GN}=$ SRSF9 SRSF9_HUMAN $25.54 \quad 100.0 \%$ Serine/arginine-rich splicing factor 9 GN=SRSF9 SRSF9_HUMAN $25.54 \quad 100.0 \%$ Serine/arginine-rich splicing factor 9 GN=SRSF9 SRSF9_HUMAN $25.54 \quad 100.0 \%$ Serine/threonine-protein kinase $38 \mathrm{GN}=\mathrm{STK} 38$ STK38 HUMAN $54.19 \quad 100.0 \%$ Serine/threonine-protein kinase $38 \mathrm{GN}=$ STK38 STK38_HUMAN $54.19 \quad 100.0 \%$ Serine/threonine-protein kinase 38 GN=STK38 STK38_HUMAN $54.19 \quad 100.0 \%$ Serine/threonine-protein kinase $38 \mathrm{GN}=$ STK38 STK38_HUMAN $54.19 \quad 100.0 \%$ Serine/threonine-protein kinase 38-like GN=STK38L ST38L_HUMAN $54.01 \quad 100.0 \%$ Serine/threonine-protein kinase 38-like GN=STK38L ST38L HUMAN $54.01 \quad 100.0 \%$ Serine/threonine-protein kinase 38-like GN=STK38L ST38L_HUMAN $54.01 \quad 100.0 \%$ Serine/threonine-protein kinase 38-like GN=STK38L ST38L_HUMAN $54.01 \quad 100.0 \%$ Serine/threonine-protein kinase 38-like GN=STK38L ST38L HUMAN $54.01 \quad 100.0 \%$ Serine/threonine-protein kinase 38-like GN=STK38L ST38L_HUMAN $54.01 \quad 100.0 \%$ Serine/threonine-protein kinase 38-like GN=STK38L ST38L_HUMAN 54.01 100.0\% Serine/threonine-protein kinase ATR GN=ATR ATR_HUMAN $301.37 \quad 100.0 \%$ Serine/threonine-protein kinase ATR GN=ATR ATR_HUMAN $301.37 \quad 100.0 \%$ Serine/threonine-protein kinase ATR GN=ATR ATR HUMAN $301.37 \quad 100.0 \%$ Serine/threonine-protein kinase ATR GN=ATR ATR_HUMAN $301.37 \quad 100.0 \%$ Serine/threonine-protein kinase MRCK alpha GN=CDC42BPA MRCKA_HUMAN $197.31 \quad 100.0 \%$ . Serine/threonine-protein kinase mTOR GN=MTOR MTOR_HUMAN $288.90 \quad 100.0 \%$

$18 \quad 0.02 \% \quad 52.4 \%$ GPPPSWGR $14 \quad 0.02 \% \quad 14.0 \%$ LIVENLSSR

$14 \quad 0.02 \% \quad 14.0 \%$ QAGEVTFADAHRPK

$14 \quad 0.02 \% \quad 14.0 \%$ LNEGVVEFASYGDLK

$0.05 \% \quad 23.8 \%$ NGYGFVEFEDSR

$49 \quad 0.05 \% \quad 23.8 \%$ DRDGYSYGSR

$11 \quad 49 \quad 0.05 \% \quad 23.8 \%$ TEYRLIVENLSSR

$\begin{array}{lllll}11 & 49 & 0.05 \% & 23.8 \% & \text { LIVENLSSR }\end{array}$

$11 \quad 49 \quad 0.05 \% \quad 23.8 \%$ QAGEVTYADAHK

$11 \quad 49 \quad 0.05 \% \quad 23.8 \%$ QAGEVTYADAHKER

$11 \quad 49 \quad 0.05 \% \quad 23.8 \%$ TNEGVIEFR

$11 \quad 49 \quad 0.05 \% \quad 23.8 \%$ ALDKLDGTEINGR

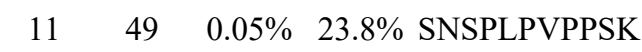

$14 \quad 58 \quad 0.06 \% \quad 39.1 \%$ VYVGNLGTGAGK

$\begin{array}{llll}14 & 58 & 0.06 \% & 39.1 \% \\ 14 & 58 \text { VYGNLGTGAGKGELER }\end{array}$

14

14

14

14

14

1

$0.06 \% 39.1 \%$ VRVELSTGMPR

$\begin{array}{ll}0.06 \% & 39.1 \% \text { VELSTGMPR } \\ 0.06 \% & 39.1 \% \text { RPFDPNDR }\end{array}$

$0.06 \% 39.1 \%$ RPFDPNDRCYECGEK

$0.06 \% \quad 39.1 \%$ GHYAYDCHR

$0.01 \% \quad 24.9 \%$ HGLVPFAFVR

$0.01 \% \quad 24.9 \%$ FEDPRDAEDAIYGR

$0.01 \% \quad 24.9 \%$ NGYDYGQCR

$0.01 \% \quad 24.9 \%$ SHEGETSYIR

$0.00 \% \quad 7.7 \%$ DIKPDNLLLDSKGHVK

$0.00 \% \quad 7.7 \%$ LSDFGLCTGLK

$\begin{array}{lll}0.00 \% & 7.7 \% & \text { LSDFGLCTGL } \\ 0.00 \% & 7.7 \% & \text { RFEGLTAR }\end{array}$

$0.02 \% \quad 14.9 \%$ DIKPDNLLLDAK

$0.02 \% \quad 14.9 \%$ LSDFGLCTGLK

$0.02 \% \quad 14.9 \%$ LSDFGLCTGLKK

$0.02 \% \quad 14.9 \%$ ERPAAIPIEIK

$0.02 \% \quad 14.9 \%$ RFEGLTQR

$0.02 \% \quad 14.9 \%$ GSIPTYMK

$0.01 \% \quad 1.6 \%$ SASVSGAAYTEIR

$0.01 \% \quad 1.6 \%$ LGQLLLSAK

$0.01 \% \quad 1.6 \%$ LAELYVER

$0.01 \% \quad 1.6 \%$ APLNETGEVVNEK

$0.00 \% \quad 1.2 \%$ GAFGEVAVVK

$\begin{array}{llll}99.7 \% & 41.3 & 25.0 & 41.3\end{array}$

$\begin{array}{llll}96.9 \% & 15.8 & 25.0 & 15.8\end{array}$

$99.7 \% \quad 52.9 \quad 25.0 \quad 52.9$

$\begin{array}{llll}99.7 \% & 41.1 & 25.0 & 41.1\end{array}$

$\begin{array}{llll}95.1 \% & 17.1 & 25.0 & 12.3\end{array}$

$97.3 \% \quad 16.4 \quad 25.0 \quad 15.5$

$\begin{array}{llll}99.7 \% & 31.9 & 25.0 & 31.9\end{array}$

$\begin{array}{llll}99.7 \% & 30.0 & 25.0 & 28.8\end{array}$

$\begin{array}{llll}98.5 \% & 18.4 & 25.0 & 18.4\end{array}$

$\begin{array}{llll}94.8 \% & 15.7 & 25.0 & 15.7\end{array}$

$\begin{array}{llll}99.7 \% & 37.3 & 25.0 & 37.1\end{array}$

$\begin{array}{llll}99.7 \% & 32.7 & 25.0 & 32.7\end{array}$

$\begin{array}{llll}99.7 \% & 29.4 & 25.0 & 29.4\end{array}$

$99.7 \% \quad 44.5 \quad 25.0 \quad 41.7$

$\begin{array}{llll}99.7 \% & 54.5 & 25.0 & 50.7\end{array}$

$99.0 \% \quad 41.1 \quad 25.0 \quad 32.3$

$\begin{array}{llll}98.8 \% & 22.6 & 25.0 & 18.7\end{array}$

$\begin{array}{llll}99.7 \% & 44.5 & 25.0 & 41.7\end{array}$

$\begin{array}{llll}99.7 \% & 54.5 & 25.0 & 50.7\end{array}$

$.01 \% \quad 2.3 \%$ VNIGMIDQSR $\begin{array}{llll}9.7 \% & 35.4 & 25.0 & 35.4\end{array}$

$\begin{array}{llll}99.6 \% & 24.1 & 25.0 & 18.8\end{array}$

$\begin{array}{llll}99.0 \% & 39.2 & 25.0 & 23.7\end{array}$

$\begin{array}{llll}99.0 \% & 29.2 & 25.0 & 21.9\end{array}$

$\begin{array}{llll}99.7 \% & 33.3 & 25.0 & 33.3\end{array}$

$\begin{array}{lllll}99.7 \% & 31.4 & 25.0 & 26.5 & 2\end{array}$

$96.0 \% \quad 24.0 \quad 25.0 \quad 8.6$

$\begin{array}{llll}99.7 \% & 43.7 & 25.0 & 34.7\end{array}$

$\begin{array}{llll}99.6 \% & 31.1 & 25.0 & 20.0\end{array}$

$99.7 \% \quad 33.6 \quad 25.0 \quad 26.9$

$\begin{array}{llll}99.7 \% & 37.2 & 25.0 & 29.9\end{array}$

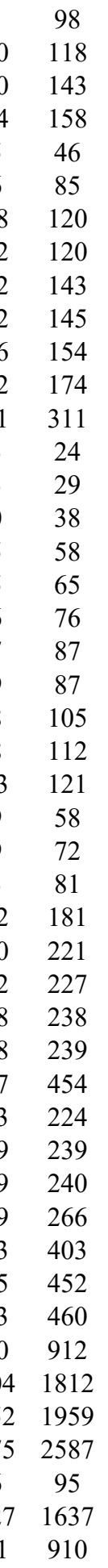


$10 \quad 0.01 \% \quad 2.3 \% \quad$ DASAVSLSESK

$99.7 \% \quad 72.1 \quad 25.0 \quad 56.7 \quad 2 \quad 00$

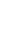

5

6
6
9

9
9
9

8
8
8

9
9
9
9

9

9
10
10

10

$\begin{array}{ll}9 & 10 \\ 9 & 10 \\ 9 & 10\end{array}$

$\begin{array}{ll}9 & 10 \\ 9 & 10 \\ 9 & 10\end{array}$

$10 \quad 0.01 \% \quad 2.3 \%$ SGQGDALASGPVETG $0.01 \% \quad 2.3 \% \quad$ LHVSTINLQK

$0.04 \% \quad 14.6 \%$ MSTPADKVLR

$0.04 \% \quad 14.6 \%$ ATVEQVLDPR

$0.04 \% \quad 14.6 \%$ ATVEQVLDPRTR

$0.04 \% \quad 14.6 \%$ NVQLSESKAR

$0.04 \% \quad 14.6 \%$ DCANVNDFFMR

$0.04 \% \quad 14.6 \%$ HSVAVMTVR

$0.04 \% \quad 14.6 \%$ AMEIASQR

$0.04 \% \quad 14.6 \%$ SSQDHVDEEVFKR

$0.04 \% \quad 14.6 \%$ TLNEVKNYER

$0.01 \% \quad 1.4 \%$ SIEVQLLR

$0.01 \% \quad 1.4 \%$ LLAQCSEVQLGK

$0.01 \% \quad 1.4 \%$ KVVDNASQGEGVR

$0.01 \% \quad 1.4 \%$ HYSVTPLGTR

$0.01 \% \quad 1.4 \%$ YAADINSR

$0.00 \% \quad 3.9 \%$ VLAMSGDPNYLHR

$0.00 \% \quad 3.9 \%$ MAGDPVANVR

$0.00 \% \quad 12.9 \%$ QITQVYGFYDECLRK

$\begin{array}{ll}0.00 \% & 12.9 \% \text { GAGYTFGQDISETFNHANGLTLVSR } \\ 0.01 \% & 23.0 \%\end{array}$

$10 \quad 0.01 \% \quad 23.0 \%$ APLDLDKYVEIAR

$\begin{array}{lll}0.01 \% & 23.0 \% & \text { TGGQVPDTNYIFMGDFVDR } \\ 0.01 \% & 23.0 \% & \text { QITQVYGFYDECQTK }\end{array}$

$\begin{array}{lll}0.01 \% & 23.0 \% & \text { VTNEFVHINNLK }\end{array}$

$0.01 \% \quad 23.0 \%$ CGNIASIMVFK

$0.03 \% \quad 39.1 \%$ QALQLAACGLAGGSAAVLFSAVAVGKPR

$0.03 \% \quad 39.1 \%$ NVESGEEELASK

$0.03 \% \quad 39.1 \%$ HSQYHVDGSLEKDR

$0.03 \% \quad 39.1 \%$ EQAELTGLR

$0.03 \% \quad 39.1 \%$ AIETTDIISR

$0.03 \% \quad 39.1 \%$ QEEDSYEIFICHANVIR

$0.03 \% \quad 39.1 \%$ ALQFPPEGWLR

$0.03 \% \quad 39.1 \%$ TLGDTGFMPPDK

$0.03 \% \quad 27.0 \%$ LNLDSIIGR

$0.03 \% \quad 27.0 \%$ ICGDIHGQYYDLLR

$0.03 \% \quad 27.0 \%$ QSLETICLLLAYK

$\begin{array}{lll}0.03 \% & 27.0 \% & \text { IKYPENFFLLR } \\ 0.03 \% & 27.0 \% \text { YPENFFLLR }\end{array}$

$0.03 \% \quad 27.0 \%$ IYGFYDECK

$0.03 \% \quad 27.0 \%$ AHQVVEDGYEFFAK

$0.03 \% \quad 27.0 \%$ AHQVVEDGYEFFAKR

$\begin{array}{lll}0.03 \% & 27.0 \% & \text { YGQFSGLNPGGRPITPPR } \\ 0.01 \% & 22.6 \% & \text { IVQMTEAEVR }\end{array}$

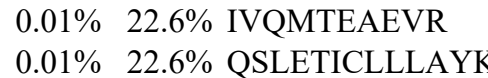

$0.01 \% \quad 22.6 \%$ IKYPENFFLLR $\begin{array}{llll}99.6 \% & 26.0 & 25.0 & 18.2\end{array}$

$\begin{array}{llll}9.6 \% & 22.7 & 25.0 & 21.8\end{array}$

$\begin{array}{llll}99.2 \% & 23.9 & 25.0 & 23.9\end{array}$

$\begin{array}{llll}99.7 \% & 56.8 & 25.0 & 49.9\end{array}$

$\begin{array}{llll}99.7 \% & 35.3 & 25.0 & 35.0\end{array}$

$98.0 \% \quad 19.1 \quad 25.0 \quad 18.1$

$\begin{array}{llll}99.7 \% & 44.4 & 25.0 & 38.3\end{array}$

$\begin{array}{llll}99.7 \% & 48.5 & 25.0 & 48.5\end{array}$

$\begin{array}{llll}99.3 \% & 20.4 & 25.0 & 19.1\end{array}$

$\begin{array}{llll}99.0 \% & 37.7 & 25.0 & 21.9\end{array}$

$\begin{array}{llll}99.7 \% & 55.6 & 25.0 & 51.5\end{array}$

$\begin{array}{llll}98.7 \% & 17.5 & 25.0 & 17.5\end{array}$

$99.0 \% \quad 35.9 \quad 25.0 \quad 13.2$

$\begin{array}{llll}99.7 \% & 38.1 & 25.0 & 32.9\end{array}$

$99.6 \% \quad 24.5 \quad 25.0 \quad 21.2$

$\begin{array}{llll}99.6 \% & 27.4 & 25.0 & 17.9\end{array}$

$\begin{array}{llll}98.3 \% & 17.9 & 25.0 & 17.9\end{array}$

$\begin{array}{llll}99.7 \% & 24.9 & 25.0 & 24.9\end{array}$

$\begin{array}{llll}99.7 \% & 34.9 & 25.0 & 26.9\end{array}$

$\begin{array}{llll}99.7 \% & 28.2 & 25.0 & 28.2\end{array}$

$\begin{array}{llll}99.7 \% & 29.8 & 25.0 & 29.8\end{array}$

$\begin{array}{llll}99.7 \% & 57.7 & 25.0 & 54.0\end{array}$

$\begin{array}{llll}99.7 \% & 50.3 & 25.0 & 40.3\end{array}$

$\begin{array}{llll}99.7 \% & 38.9 & 25.0 & 38.9\end{array}$

$\begin{array}{llll}99.7 \% & 55.5 & 25.0 & 50.2\end{array}$

$\begin{array}{llll}99.7 \% & 50.8 & 25.0 & 41.6\end{array}$

$\begin{array}{llll}99.7 \% & 55.1 & 25.0 & 55.1\end{array}$

$\begin{array}{llll}99.7 \% & 55.5 & 25.0 & 54.6\end{array}$

$\begin{array}{llll}99.7 \% & 28.0 & 25.0 & 24.5\end{array}$

$\begin{array}{llll}99.7 \% & 53.0 & 25.0 & 38.7\end{array}$

$\begin{array}{llll}99.7 \% & 63.4 & 25.0 & 49.2\end{array}$

$\begin{array}{llll}99.7 \% & 46.7 & 25.0 & 46.7\end{array}$

$\begin{array}{llll}97.3 \% & 23.1 & 25.0 & 19.9\end{array}$

$\begin{array}{llll}99.7 \% & 40.9 & 25.0 & 38.3\end{array}$

$\begin{array}{llll}99.7 \% & 35.3 & 25.0 & 30.5\end{array}$

$\begin{array}{llll}99.3 \% & 18.9 & 25.0 & 18.4\end{array}$

$\begin{array}{llll}99.7 \% & 53.9 & 25.0 & 49.8\end{array}$

$\begin{array}{llll}99.3 \% & 21.1 & 25.0 & 20.2\end{array}$

$\begin{array}{llll}97.2 \% & 24.5 & 25.0 & 19.2\end{array}$

$\begin{array}{llll}99.7 \% & 42.9 & 25.0 & 30.7\end{array}$

$\begin{array}{llll}99.7 \% & 55.4 & 25.0 & 53.8\end{array}$

$\begin{array}{llll}99.7 \% & 33.4 & 25.0 & 33.4\end{array}$

$\begin{array}{llll}99.7 \% & 33.8 & 25.0 & 33.8\end{array}$

$\begin{array}{llll}99.7 \% & 59.2 & 25.0 & 47.0\end{array}$

$\begin{array}{llll}99.7 \% & 53.9 & 25.0 & 49.8\end{array}$

$\begin{array}{llll}99.3 \% & 21.1 & 25.0 & 20.2\end{array}$
1058.55

1845.90

1152.67

1133.60

1127.61

1384.75

1131.61

1388.57

1015.54

905.45

1575.74

1265.65

957.57

1345.71

1358.70

1130.60

909.44

1472.73

1045.51

1919.93

2655.28

1502.82

2131.98

1879.85

1427.76

1239.62

2683.47

1291.60

1670.79

1016.54

1118.61

2122.99

1313.70

1278.60

1000.58

1722.83

1551.85

1439.80

1198.63

1194.51

1639.78

1795.88

1914.00

1175.61

1551.85

1439.80 


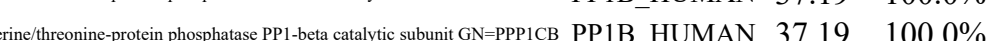
作 hosphatase PPI-beta catalytic subunit GN=PPPICB PP1B HUMAN $37.19 \quad 100.0 \%$ Serine/threonine-protein phosphatase PP1-beta catalytic subunit GN=PPPICB PP1B_HUMAN $37.19 \quad 100.0 \%$ Serine-threonine kinase receptor-associated protein GN=STRAP STRAP_HUMAN $38.44 \quad 100.0 \%$ Serine-threonine kinase receptor-associated protein GN=STRAP STRAP_HUMAN $38.44 \quad 100.0 \%$ Serine-threonine kinase receptor-associated protein GN=STRAP STRAP_HUMAN $38.44 \quad 100.0 \%$ Serine-threonine kinase receptor-associated protein GN=STRAP STRAP HUMAN $38.44100 .0 \%$ Serine-threonine kinase receptor-associated protein GN=STRAP STRAP_HUMAN $38.44 \quad 100.0 \%$ Serine-threonine kinase receptor-associated protein GN=STRAP STRAP_HUMAN $38.44 \quad 100.0 \%$ Serpin $\mathrm{B} 12 \mathrm{GN}=$ SERPINB12 Serpin $B 12$ GN=SERPINB12 Serpin B3 GN=SERPINB3 Serpin $B 3$ GN=SERPINB3 Serpin B6 GN=SERPINB6 Serpin B6 GN=SERPINB6 Serpin B6 GN=SERPINB6 Serpin $\mathrm{H} 1 \mathrm{GN}=$ SERPINH1 Serpin $\mathrm{H} 1 \mathrm{GN}=$ SERPINH1 Serpin $\mathrm{H} 1 \mathrm{GN}=$ SERPINH1 Serpin H1 GN=SERPINH1 Serpin $\mathrm{H} 1 \mathrm{GN}=$ SERPINH1 Serpin $\mathrm{H} 1 \mathrm{GN}=$ SERPINH1 Serpin H1 GN=SERPINH1 Serum albumin $\mathrm{GN}=\mathrm{ALB}$ Serum albumin $\mathrm{GN}=\mathrm{ALB}$

Serum albumin $\mathrm{GN}=\mathrm{ALB}$ Serum albumin $\mathrm{GN}=\mathrm{ALB}$ Serum albumin $\mathrm{GN}=\mathrm{ALB}$ Serum albumin $\mathrm{GN}=\mathrm{ALB}$

SPB12 HUMAN $46.28 \quad 100.0 \%$ SPB12_HUMAN $46.28 \quad 100.0 \%$ SPB3_HUMAN $44.57 \quad 100.0 \%$ SPB6_HUMAN $42.62 \quad 100.0 \%$ SPB6_HUMAN $42.62 \quad 100.0 \%$ SPB6_HUMAN $42.62 \quad 100.0 \%$ SERPH_HUMAN $46.44 \quad 100.0 \%$ SERPH HUMAN $46.44 \quad 100.0 \%$ SERPH_HUMAN $46.44 \quad 100.0 \%$ SERPH_HUMAN $46.44 \quad 100.0 \%$ SERPH_HUMAN $46.44 \quad 100.0 \%$ SERPH_HUMAN $46.44 \quad 100.0 \%$ SERPH HUMAN $46.44 \quad 100.0 \%$ ALBU_HUMAN $69.37 \quad 100.0 \%$ ALBU_HUMAN $69.37 \quad 100.0 \%$ ALBU HUMAN $69.37 \quad 100.0 \%$ ALBU_HUMAN $69.37 \quad 100.0 \%$ ALBU HUMAN $69.37 \quad 100.0 \%$ ALBU_HUMAN $69.37 \quad 100.0 \%$
Sideroflexin- $1 \mathrm{GN}=\mathrm{SFXN} 1$ Sideroflexin-1 GN=SFXN1 Sideroflexin-1 GN=SFXN1 Sideroflexin-1 GN=SFXN1 SPB3 HUMAN $44.57 \quad 100.0 \%$ ACDSB_HUMAN $47.49 \quad 100.0 \%$ B ACDSB_HUMAN $47.49 \quad 100.0 \%$ B ACDSB_HUMAN $47.49 \quad 100.0 \%$ ACDSB_HUMAN $47.49 \quad 100.0 \%$ $100.0 \%$ $100.0 \%$ $100.0 \%$ $100.0 \%$ $100.0 \%$ $100.0 \%$ $100.0 \%$ $100.0 \%$

$0.10 \% \quad 9.2 \% \quad$ KVPQVSTPTLVEVSR

$99.7 \% 042.9$

SFXN1_HUMAN $35.62 \quad 100.0 \%$

SFXN1_HUMAN $35.62 \quad 100.0 \%$ $\begin{array}{lll}11 & 14 & 24 \\ 11 & 14 & 24 \\ 11 & 14 & 2\end{array}$
$0.01 \% \quad 22.6 \%$ YPENFFLLR

$0.01 \% \quad 22.6 \%$ IYGFYDECK

$0.01 \% \quad 22.6 \%$ AHQVVEDGYEFFAK

$0.01 \% \quad 22.6 \%$ AHQVVEDGYEFFAKR

$0.01 \% \quad 22.6 \%$ YQYGGLNSGRPVTPPR

$0.02 \% \quad 25.7 \%$ TVDFTQDSNYLLTGGQDK

$0.02 \% \quad 25.7 \%$ IYDLNKPEAEPK

$0.02 \% \quad 25.7 \%$ SIAFHSAVSLDPIK

$0.02 \% \quad 25.7 \%$ YDYNSGEELESYK

$\begin{array}{lll}0.02 \% & 25.7 \% & \text { FSPDGELYASGSEDGT } \\ 0.02 \% & 25.7 \% & \text { CVLPEEDSGELAKPK }\end{array}$

$0.00 \% \quad 5.9 \%$ IGFIEEVK

$0.00 \% \quad 5.9 \%$ ADLTGISPSPNLYLSK

$0.00 \% \quad 5.6 \% \quad$ INSWVESQTNEK

$0.00 \% \quad 5.6 \%$ GLVLSGVLHK

$0.00 \% \quad 9.8 \%$ IAELLSPGSVDPLTR

$0.00 \% \quad 9.8 \%$ LVLVNAVYFR

$0.00 \% \quad 9.8 \%$ NLGMTDAFELGK

0.02\% $21.1 \%$ KPAAAAAPGTAEK

$0.02 \% \quad 21.1 \%$ SAGLAFSLYQAMAK

$0.02 \% \quad 21.1 \%$ LYGPSSVSFADDFVR

$0.02 \% \quad 21.1 \%$ LLTKEQLK

$0.02 \% \quad 21.1 \%$ GVVEVTHDLQK

$0.02 \% \quad 21.1 \%$ HLAGLGLTEAIDKNK

$0.02 \% \quad 21.1 \%$ DTQSGSLLFIGR

$0.10 \% \quad 9.2 \% \quad$ LVNEVTEFAK

$0.10 \% \quad 9.2 \%$ CASLQKFGER

$0.10 \% \quad 9.2 \% \quad$ YICENQDSISSK

$0.10 \% \quad 9.2 \%$ VPQVSTPTLVEVSR

$0.10 \% \quad 9.2 \%$ CCTESLVNR

$99.7 \% \quad 55.4$

$99.7 \% \quad 33.4$

$\begin{array}{llll}98.8 \% & 26.3\end{array}$

$\begin{array}{ll}9.7 \% & 47.3\end{array}$

$99.7 \% \quad 53.2$

$99.7 \% \quad 41.6$

$99.7 \% \quad 68.4$

$99.7 \% \quad 73$.

$99.7 \% \quad 30.8$

$99.0 \% \quad 27.7$

$96.5 \% \quad 21.2$

$99.7 \% \quad 47.3$

$99.7 \% \quad 38.8$

$99.7 \% \quad 33.6$

$99.1 \% \quad 21.4$

$99.2 \% \quad 18.7$

$99.7 \% \quad 58.8$

$99.7 \% \quad 34.0$

$99.7 \% \quad 54.9$

$99.0 \% \quad 37.3$

$99.7 \% \quad 49.1$

$99.7 \% \quad 41.0$

$99.7 \% \quad 61.7$

$99.7 \% \quad 32.6$

$99.7 \% \quad 32.9$

$99.7 \% \quad 35.3$

$99.7 \% \quad 53.7$

$\begin{array}{lll}99.7 \% & 59.7\end{array}$

$\begin{array}{lll}99.7 \% & 55.3\end{array}$

$0.03 \% \quad 31.2 \%$ KFAQEQIAPLVSTMDENSK $99.2 \% \quad 18.5$

$0.03 \% \quad 31.2 \%$ FAQEQIAPLVSTMDENSK $\quad 99.7 \% \quad 54.1$

$0.03 \% \quad 31.2 \%$ FAQEQIAPLVSTMDENSKMEK

$0.03 \% \quad 31.2 \%$ ATYLPQLTTEK

$0.03 \% \quad 31.2 \%$ ADKEGDYYVLNGSK

$0.03 \% \quad 31.2 \%$ GITSFLVDR

$0.03 \% \quad 31.2 \%$ ASSTCPLTFENVK

$0.03 \% \quad 31.2 \%$ VPEANILGQIGHGYK

$0.03 \% \quad 31.2 \%$ YAIGSLNEGR

$0.03 \% \quad 31.2 \%$ LLEAGKPFIK

$0.03 \% \quad 31.2 \%$ YYASEIAGQTTSK

$0.03 \% \quad 31.2 \%$ IGTIYEGASNIQLNTIAK

$0.03 \% \quad 42.2 \%$ WDQSTFIGR

$0.03 \% \quad 42.2 \%$ ANHFFTVTDPR

$0.03 \% \quad 42.2 \%$ NILLTNEQLESAR
$99.4 \% \quad 20.5$

$99.7 \% \quad 45.3$

$99.7 \% \quad 59.0$

$99.7 \% \quad 36.5$

$99.7 \% \quad 39.5$

$99.7 \% \quad 39.5$

$99.7 \% \quad 59.0$

$99.7 \% \quad 44.5$

$99.7 \% \quad 85.7$

$99.7 \% 74.3$

$99.4 \% \quad 45.7$

$99.7 \% \quad 41.2$

$99.7 \% \quad 84.8$

$99.7 \% \quad 41.9$
119

198.63

1194.51

1639.78

1795.88

1761.90

2001.94

1416.74

1484.81

1596.67

1900.86

1671.83

934.52

1675.89

1434.69

1022.64

1567.87

1193.70

1311.63

1182.65

1457.75

1659.80

972.61

1224.66

1579.88

1293.68

1149.62

1195.59

1443.64

1639.94

1511.84

1138.50

2152.06

2007.97

2428.14

1264.68

1558.74

1007.55

1453.70

1595.85

1079.55

1115.68

1418.68

1906.03

1109.54

1304.64

1500.80 $0.03 \% \quad 42.2 \%$ QGIVPPGLTENELWR \begin{tabular}{cc}
13 & 121 \\
32 & 140 \\
46 & 259 \\
46 & 260 \\
04 & 319 \\
05 & 122 \\
26 & 137 \\
05 & 218 \\
50 & 262 \\
73 & 290 \\
05 & 319 \\
32 & 239 \\
28 & 343 \\
47 & 158 \\
22 & 331 \\
46 & 160 \\
61 & 170 \\
88 & 299 \\
3 & 35 \\
7 & 60 \\
34 & 148 \\
84 & 291 \\
09 & 319 \\
20 & 334 \\
94 & 405 \\
6 & 75 \\
24 & 233 \\
87 & 298 \\
38 & 452 \\
39 & 452 \\
6 & 78 \\
00 & 508 \\
0 & 88 \\
1 & 88 \\
1 & 91 \\
60 & 170 \\
92 & 205 \\
31 & 239 \\
57 & 269 \\
70 & 284 \\
85 & 294 \\
56 & 365 \\
72 & 384 \\
09 & 426 \\
6 & 24 \\
& 35 \\
\hline
\end{tabular}

Page 141 of Table S-1-5 
Sideroflexin- 1 GN=SFXN1 Sideroflexin-1 GN=SFXN1 Sideroflexin- $1 \mathrm{GN}=$ SFXN1 Sideroflexin-1 GN=SFXN1 Sideroflexin-1 GN=SFXN1 Sideroflexin-1 GN=SFXN1 Sideroflexin-1 GN=SFXN1 Sideroflexin-2 GN=SFXN2 Sideroflexin $-2 \mathrm{GN}=\mathrm{SFXN} 2$ Sideroflexin- 4 GN=SFXN4 Sideroflexin- $4 \mathrm{GN}=$ SFXN 4 Sideroflexin- $4 \mathrm{GN}=\mathrm{SFXN} 4$ Sideroflexin- $4 \mathrm{GN}=\mathrm{SFXN} 4$ Sideroflexin- 4 GN=SFXN4

\section{Sideroflexin-4 GN=SFXN4}

SFXN1_HUMAN $35.62 \quad 100.0 \%$ SFXN1_HUMAN $35.62 \quad 100.0 \%$ SFXN1_HUMAN $35.62 \quad 100.0 \%$ SFXN1_HUMAN $35.62 \quad 100.0 \%$ SFXN1_HUMAN $35.62 \quad 100.0 \%$ SFXN1_HUMAN $35.62 \quad 100.0 \%$ SFXN1 HUMAN $35.62 \quad 100.0 \%$ SFXN2_HUMAN $36.23 \quad 100.0 \%$ SFXN2 HUMAN $36.23 \quad 100.0 \%$ SFXN4_HUMAN $38.00 \quad 100.0 \%$ SFXN4_HUMAN $38.00 \quad 100.0 \%$ SFXN4 HUMAN $38.00 \quad 100.0 \%$ SFXN4_HUMAN $38.00 \quad 100.0 \%$ SFXN4_HUMAN $38.00 \quad 100.0 \%$ SFXN4 HUMAN $38.00 \quad 100.0 \%$ Signal recognition Signal recognition particle receptor subunit beta GN=SRPRB SRPRB_HUMAN $29.70 \quad 100.0 \%$ Signal recognition particle receptor subunit beta GN=SRPRB SRPRB_HUMAN $29.70 \quad 100.0 \%$ Signal recognition particle receptor subunit beta GN=SRPRB SRPRB_HUMAN $29.70 \quad 100.0 \%$ Signal recognition particle receptor subunit beta GN=SRPRB SRPRB_HUMAN $29.70 \quad 100.0 \%$ Signal recognition particle receptor subunit beta GN=SRPRB SRPRB_HUMAN $29.70 \quad 100.0 \%$ Signal recognition particle receptor subunit beta GN=SRPRB SRPRB_HUMAN $29.70 \quad 100.0 \%$ Signal recognition particle receptor subunit beta GN=SRPRB SRPRB_HUMAN $29.70 \quad 100.0 \%$ Signal recognition particle receptor subunit beta GN=SRPRB SRPRB HUMAN $29.70 \quad 100.0 \%$ Signal recognition particle receptor subunit beta GN=SRPRB SRPRB_HUMAN $29.70 \quad 100.0 \%$ Signal recognition particle subunit SRP68 GN=SRP68 SRP68_HUMAN $70.73 \quad 100.0 \%$ Signal recognition particle subunit SRP68 GN=SRP68 SRP68_HUMAN $70.73 \quad 100.0 \%$ Signal recognition particle subunit SRP68 GN=SRP68 SRP68_HUMAN $70.73 \quad 100.0 \%$ Signal recognition particle subunit SRP68 GN=SRP68 SRP68 HUMAN $70.73 \quad 100.0 \%$ Signal recognition particle subunit SRP68 GN=SRP68 SRP68_HUMAN $70.73 \quad 100.0 \%$ Signal recognition particle subunit SRP72 GN=SRP72 SRP72_HUMAN $74.61 \quad 100.0 \%$ Signal recognition particle subunit SRP72 GN=SRP72 SRP72_HUMAN $74.61 \quad 100.0 \%$ Signal recognition particle subunit SRP72 GN=SRP72 SRP72_HUMAN $74.61 \quad 100.0 \%$ Signal transducer and activator of transcription $3 \mathrm{GN}=$ STAT3 STAT3_HUMAN $88.07 \quad 100.0 \%$ Signal transducer and activator of transcription $3 \mathrm{GN}=$ STAT3 STAT3_HUMAN $88.07 \quad 100.0 \%$ Sister chromatid cohesion protein PDS5 homolog A GN=PDS5A PDS5A_HUMAN $150.84 \quad 100.0 \%$ Sister chromatid cohesion protein PDS5 homolog A GN=PDS5A PDS5A_HUMAN $150.84 \quad 100.0 \%$ Sister chromatid cohesion protein PDS5 homolog A GN=PDS5A PDS5A_HUMAN $150.84 \quad 100.0 \%$ Sister chromatid cohesion protein PDS5 homolog B GN=PDS5B PDS5B_HUMAN $164.67 \quad 100.0 \%$ Sister chromatid cohesion protein PDS5 homolog B GN=PDS5B PDS5B HUMAN $164.67 \quad 100.0 \%$ Sister chromatid cohesion protein PDS5 homolog B GN=PDS5B PDS5B_HUMAN $164.67 \quad 100.0 \%$ Small proline-rich protein 2E GN=SPRR2E SPR2E_HUMAN $7.85 \quad 100.0 \%$ Small proline-rich protein 2E GN=SPRR2E SPR2E_HUMAN $7.85 \quad 100.0 \%$ Small proline-rich protein 2E GN=SPRR2E SPR2E_HUMAN $7.85 \quad 100.0 \%$ Small subunit processome component 20 homolog GN=UTP20 UTP20_HUMAN $318.40 \quad 100.0 \%$ Small subunit processome component 20 homolog GN=UTP20 UTP20_HUMAN $318.40 \quad 100.0 \%$
$99.0 \% \quad 26.0$

2091.09

$0.03 \% \quad 42.2 \%$ VGIPVTDENGNR

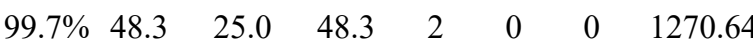

$0.03 \% \quad 42.2 \%$ QAITQVVVSR

$0.03 \% \quad 42.2 \%$ SSMSVTSLEAELQAK

$0.03 \% \quad 42.2 \%$ IQESHPELRR

$0.00 \% \quad 7.8 \%$ LYDSAFHPDTGEK

$0.00 \% \quad 7.8 \% \quad$ YGELEPYVYFNK

$0.01 \% \quad 24.9 \%$ DAVPAFIEPNVR

$\begin{array}{llll}99.6 \% & 80.4 & 25.0 & 80.4\end{array}$

$99.7 \% \quad 34.5 \quad 25.0 \quad 22.9$

$99.3 \% \quad 27.6 \quad 25.0 \quad 27.6$

$99.7 \% \quad 56.0 \quad 25.0 \quad 51.2$

$\begin{array}{llll}99.7 \% & 44.3 & 25.0 & 40.3\end{array}$

$0.01 \% \quad 24.9 \%$ QLLCTNEDVSSPASADQR

$0.01 \% \quad 24.9 \%$ SLATVHPDSSNLIPK

$99.7 \% \quad 53.3$

$99.7 \% \quad 41.9$

$0.01 \% \quad 24.9 \%$ SYTCKPLER

$99.6 \% \quad 26.4$

$0.01 \% \quad 24.9 \%$ GIAVMDKEGNVLGHSR $\quad 99.7 \% \quad 30.5$

$0.01 \% \quad 24.9 \%$ IQSPTEETEIFYHR

$99.7 \% \quad 46.4$

$\begin{array}{lllll}0.03 \% & 48.7 \% & \text { VADGGGAGGTFQPYLDTLR } & 99.7 \% & 72.9\end{array}$

$0.03 \% \quad 48.7 \%$ AVLLVGLCDSGK

$0.03 \% \quad 48.7 \%$ DTQTSITDSCAVYR

$0.03 \% \quad 48.7 \%$ GNSLTLIDLPGHESLR

$99.7 \% \quad 65.0$

$99.7 \% \quad 73.6$

$\begin{array}{lll}99.7 \% & 47.3\end{array}$

$99.7 \% \quad 63.0$

$\begin{array}{ll}0.03 \% & 48.7 \% \\ 0.03 \% & 48.7 \% \text { ATPSFLIACNK }\end{array}$

$0.03 \% \quad 48.7 \%$ LIQQQLEK

$99.7 \% \quad 26.0$

$99.0 \% \quad 48.1$

$0.03 \% \quad 48.7 \%$ LIQQQLEKELNTLR

$99.7 \% \quad 62.5$

$0.03 \% \quad 48.7 \%$ SAAPSTLDSSSTAPAQLGK $99.7 \% \quad 70.9$

$0.03 \% \quad 48.7 \%$ SAAPSTLDSSSTAPAQLGKK $99.6 \% 23.9$

$0.03 \% \quad 48.7 \%$ GDVGSADIQDLEK

$99.7 \% \quad 57.0$

$0.01 \% \quad 13.6 \%$ QVPGGGGGGGSGGGGGSGGGSGGGR $\quad 99.7 \% \quad 33.4$

$0.01 \% \quad 13.6 \%$ GAGGEENKENERPSAGSK $98.9 \% 26.3$

$0.01 \% \quad 13.6 \%$ SGGTEGLLAEKLEALITQTR $99.7 \% 36.6$

$0.01 \% \quad 13.6 \%$ ALLQQQPEDDSKR

$99.7 \% \quad 28.1$

$99.0 \% \quad 42.6$

$99.7 \% \quad 32.5$

$99.7 \% \quad 55.8$

$0.01 \% \quad 5.7 \%$ VLANNSLSFEK

$0.01 \% \quad 5.7 \% \quad$ LTNAEGVEFK

$\begin{array}{llllll}0.01 \% & 5.7 \% & \text { GTQGATAGASSELDASK } & 99.2 \% & \text { \#\#\#\# } \\ 0.00 \% & 3.5 \% & \text { SQGDMQDLNGNNQSVTR } & 99.6 \% & 24.2\end{array}$

$0.00 \% \quad 3.5 \% \quad$ KFNILGTNTK

$0.01 \% \quad 2.9 \%$ STLIPILHQK

$99.7 \% \quad 35.2$

$99.4 \% \quad 20.8$

$\begin{array}{lll}98.9 \% & 22.5\end{array}$

$0.01 \% \quad 2.9 \%$ LAAGSAIMK

$97.6 \% 16.3$

$0.01 \% \quad 2.9 \% \quad$ AAVGQESPGGLEAGNAKAPK

$0.00 \% \quad 2.7 \%$ YALQSAAGKDAAK

$99.7 \% \quad 50.1$

$0.00 \% \quad 2.7 \%$ LAAGSAIVK

$99.1 \% \quad 30.7$

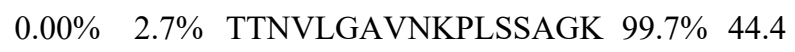

$0.01 \% \quad 48.6 \%$ QPCQPPPVCPTPK

$0.01 \% \quad 48.6 \%$ CPEPCPPPК

$0.01 \% \quad 48.6 \%$ CPPVTPSPPCQPK

$0.00 \% \quad 1.3 \% \quad$ LQANISTGVSK

$0.00 \% \quad 1.3 \%$ LGSESQYSPTPLLK
$99.7 \% \quad 30.7$

$99.7 \% \quad 35.1$

$99.0 \% \quad 23.9$

$97.5 \% 19.1$

$99.7 \% \quad 29.1$
$179 \quad 197$

$203 \quad 214$

1100.64

1596.78

1264.68

1479.68

1521.73

1327.70

1990.91

1578.85

1153.57

1682.86

1749.84

1894.93

1231.67

1616.72

1721.92

1422.77

1264.64

999.58

1725.99

1788.90

1916.99

1346.64

1843.80

1816.84

2087.13

1527.78

838.47

1221.65

1107.57

1550.73

1879.82

1135.65

1149.70

877.48

1851.96

1293.68

829.51

1656.93

1505.72

1081.48

1464.70

1117.62

1519.80 $\begin{array}{ll}224 & 233 \\ 291 & 305\end{array}$

$306 \quad 315$

$73 \quad 85$

$309 \quad 320$

1930

$92 \quad 106$

$156 \quad 164$

$224 \quad 239$

$322 \quad 335$

97
$66 \quad 77$

$91 \quad 104$

$110 \quad 125$

$138 \quad 150$

$171 \quad 181$

$192 \quad 199$

$192 \quad 205$

227

26

$6 \quad 31$

3249

$267 \quad 286$

$405 \quad 417$

$613 \quad 620$

$\begin{array}{cc}74 & 84 \\ 88 & 297\end{array}$

$601 \quad 617$

$181 \quad 197$

$383 \quad 392$

$718 \quad 727$

$890 \quad 898$

$1299 \quad 1318$

888

$1127 \quad 1143$

$10 \quad 22$

$\begin{array}{ll}23 & 31 \\ 54 & 66\end{array}$

$634 \quad 644$ 
列 subunit processome component 20 homolog GN=UTP20 UTP20 HUMAN $318.40 \quad 100.0 \%$ SNW domain-containing protein $1 \mathrm{GN}=\mathrm{SNW} 1 \mathrm{SNW} 1$ HUMAN $61.50 \quad 100.0 \%$ SNW domain-containing protein $1 \mathrm{GN}=\mathrm{SNW} 1 \mathrm{SNW} 1$ HUMAN $61.50 \quad 100.0 \%$ SNW domain-containing protein $1 \mathrm{GN}=\mathrm{SNW} 1 \mathrm{SNW} 1$ HUMAN $61.50 \quad 100.0 \%$ SNW domain-containing protein $1 \mathrm{GN}=\mathrm{SNW} 1 \mathrm{SNW} 1$ _HUMAN $61.50 \quad 100.0 \%$ SNW domain-containing protein $1 \mathrm{GN}=\mathrm{SNW} 1 \mathrm{SNW} 1$ HUMAN $61.50 \quad 100.0 \%$ SNW domain-containing protein $1 \mathrm{GN}=\mathrm{SNW} 1 \mathrm{SNW} 1$ HUMAN $61.50 \quad 100.0 \%$ Sodium/potassium-transporting ATPase subunit alpha-1 GN=ATP1A1 AT1A1_HUMAN $112.90 \quad 100.0 \%$ Sodium/potassium-transporting ATPase subunit alpha-1 GN=ATP1A1 AT1A1 HUMAN $112.90 \quad 100.0 \%$ Sodium/potassium-transporting ATPase subunit alpha-1 GN=ATP1A1 AT1A1_HUMAN $112.90 \quad 100.0 \%$ Sodium/potassium-transporting ATPase subunit alpha-1 GN=ATP1A1 AT1A1_HUMAN $112.90 \quad 100.0 \%$ Sodium/potassium-transporting ATPase subunit alpha-1 GN=ATP1A1 AT1A1_HUMAN $112.90 \quad 100.0 \%$ Sodium/potassium-transporting ATPase subunit alpha-1 GN=ATP1A1 AT1A1_HUMAN $112.90 \quad 100.0 \%$ Sodium/potassium-transporting ATPase subunit alpha-1 GN=ATP1A1 AT1A1_HUMAN $112.90 \quad 100.0 \%$ Sodium/potassium-transporting ATPase subunit beta-3 GN=ATP1B3 AT1B3_HUMAN $31.51 \quad 99.9 \%$ Sodium/potassium-transporting ATPase subunit beta-3 GN=ATP1B3 AT1B3_HUMAN $31.51 \quad 99.9 \%$ Solute carrier family 25 member $40 \mathrm{GN}=\mathrm{SLC} 25 \mathrm{~A} 40$ S2540 HUMAN $38.13 \quad 100.0 \%$ Solute carrier family 25 member $40 \mathrm{GN}=$ SLC25A40 S2540_HUMAN $38.13 \quad 100.0 \%$ Spectrin alpha chain, non-erythrocytic $1 \mathrm{GN}=$ SPTAN1 SPTN1_HUMAN $284.54 \quad 100.0 \%$ Spectrin alpha chain, non-erythrocytic 1 GN=SPTAN1 SPTN1_HUMAN $284.54100 .0 \%$ Spectrin beta chain, non-erythrocytic 1 GN=SPTBN1 SPTB2_HUMAN $274.61 \quad 100.0 \%$ Spectrin beta chain, non-erythrocytic $1 \mathrm{GN}=$ SPTBN1 SPTB2 HUMAN $274.61 \quad 100.0 \%$ Spectrin beta chain, non-erythrocytic $1 \mathrm{GN}=$ SPTBN1 SPTB2_HUMAN $274.61 \quad 100.0 \%$ Spectrin beta chain, non-erythrocytic $1 \mathrm{GN}=$ SPTBN1 SPTB2_HUMAN $274.61 \quad 100.0 \%$ Spectrin beta chain, non-erythrocytic 1 GN=SPTBN1 SPTB2_HUMAN $274.61 \quad 100.0 \%$ Spermatid perinuclear RNA-binding protein GN=STRBP STRBP_HUMAN $73.65 \quad 100.0 \%$ Spermatid perinuclear RNA-binding protein GN=STRBP STRBP_HUMAN $73.65100 .0 \%$ Spermatid perinuclear RNA-binding protein GN=STRBP STRBP HUMAN $73.65 \quad 100.0 \%$ Spermatid perinuclear RNA-binding protein GN=STRBP STRBP_HUMAN $73.65 \quad 100.0 \%$ Spermatid perinuclear RNA-binding protein GN=STRBP STRBP_HUMAN $73.65 \quad 100.0 \%$ Spermatid perinuclear RNA-binding protein GN=STRBP STRBP_HUMAN $73.65 \quad 100.0 \%$ Spermatid perinuclear RNA-binding protein GN=STRBP STRBP_HUMAN $73.65 \quad 100.0 \%$ Spermatid perinuclear RNA-binding protein $\mathrm{GN}=$ STRBP STRBP HUMAN $73.65 \quad 100.0 \%$ Spermidine synthase $\mathrm{GN}=\mathrm{SRM}$ Spermidine synthase $\mathrm{GN}=\mathrm{SRM}$

Spermidine synthase GN=SRM SPEE_HUMAN $33.82 \quad 100.0 \%$ SPEE HUMAN $33.82 \quad 100.0 \%$ SPEE HUMAN $33.82 \quad 100.0 \%$ Sphingomyelin phosphodiesterase 4 GN=SMPD4 NSMA3_HUMAN $93.35100 .0 \%$ Sphingomyelin phosphodiesterase 4 GN=SMPD4 NSMA3 HUMAN $93.35100 .0 \%$ Spindlin-1 GN=SPIN1 Spindlin-1 GN=SPIN1

Spindlin-1 GN=SPIN1 Spindlin-1 GN=SPIN1 Spindlin-1 GN=SPIN1 Spindlin-1 GN=SPIN1 Spindlin-1 GN=SPIN1 SPIN1_HUMAN $29.60 \quad 100.0 \%$ SPIN1_HUMAN $29.60 \quad 100.0 \%$ SPIN1 HUMAN $29.60 \quad 100.0 \%$ SPIN1_HUMAN $29.60 \quad 100.0 \%$ SPIN1_HUMAN $29.60 \quad 100.0 \%$ SPIN1_HUMAN $29.60 \quad 100.0 \%$ SPIN1_HUMAN $29.60 \quad 100.0 \%$ 列 Spliceosome RNA helicase DDX39B GN=DDX39B DX39B_HUMAN $48.99 \quad 100.0 \%$
$0.00 \% \quad 1.3 \%$ LAVSAQSEPAR $0.01 \% \quad 13.1 \%$ SRQTSLVSSR $0.01 \% \quad 13.1 \%$ AADKLAPAQYIR $0.01 \% \quad 13.1 \%$ GYTIPLDKR $0.01 \% \quad 13.1 \%$ GLQTVHINENFAK $0.01 \% \quad 13.1 \%$ LAEALYIADR $0.01 \% \quad 13.1 \%$ TSNEVQYDQRLFNQSK $0.03 \% \quad 8.1 \%$ VDNSSLTGESEPQTR $0.03 \% \quad 8.1 \%$ SPDFTNENPLETR $0.03 \% \quad 8.1 \%$ AVAGDASESALLK $0.03 \% \quad 8.1 \%$ LNIPVSQVNPR $0.03 \% \quad 8.1 \%$ TSPQQKLIIVEGCQR $0.03 \% \quad 8.1 \%$ LIIVEGCQR $0.03 \% \quad 8.1 \%$ ADIGVAMGIAGSDVSK $0.01 \% \quad 10.4 \%$ LFIYNPTTGEFLGR $0.01 \% \quad 10.4 \%$ SDPTSYAGYIEDLKK $0.00 \% \quad 7.1 \% \quad$ LQAQNNPLPK

$0.00 \% \quad 7.1 \% \quad$ FGAVTVISPLELIR

$0.00 \% \quad 1.1 \%$ SQLLGSAHEVQR

$0.00 \% \quad 1.1 \%$ LSDDNTIGKEEIQQR $0.01 \% \quad 2.2 \%$ ELEAENYHDIKR $0.01 \% \quad 2.2 \% \quad$ YKEVAELTR $0.01 \% \quad 2.2 \%$ QALQDTLALYK $0.01 \% \quad 2.2 \% \quad$ VAVVNQIAR $0.01 \% \quad 2.2 \%$ LILEVHQFSR $0.01 \% \quad 12.6 \%$ ANGLKSCVIVLR $0.01 \% \quad 12.6 \%$ LSAFGQIYK $0.01 \% \quad 12.6 \%$ LNQIRPGLQYK $0.01 \% \quad 12.6 \%$ TAKLHVAVK $0.01 \% \quad 12.6 \%$ NPVMELNEK $0.01 \% \quad 12.6 \%$ YELISETGGSHDKR $0.01 \% \quad 12.6 \%$ FVMEVEVDGQK $0.01 \% \quad 12.6 \%$ ASAALAALEK $0.01 \% \quad 8.6 \%$ YQDILVFR $0.01 \% \quad 8.6 \%$ YYNSDVHR $0.01 \% \quad 8.6 \%$ AAFVLPEFAR $0.00 \% \quad 2.8 \%$ YAPDKQAPGSDSQPR $0.00 \% \quad 2.8 \% \quad$ LFVGFLNR

$0.03 \% \quad 42.4 \%$ SRADAGHAGVSANMMK $0.03 \% \quad 42.4 \%$ SSVGPSKPVSQPR

$0.03 \% \quad 42.4 \%$ GTVLDQVPVNPSLYLIK

$0.03 \% \quad 42.4 \%$ YDGFDCVYGLELNKDER $0.03 \% \quad 42.4 \%$ VSALEVLPDR

$0.03 \% \quad 42.4 \%$ ISDAHLADTMIGK

$0.03 \% \quad 42.4 \%$ IMPDSNDSPPAEREPGEVVDSLVGK

$0.02 \% \quad 15.9 \%$ ELAFQISK

$0.02 \% \quad 15.9 \%$ VAVFFGGLSIK
$99.7 \% \quad 57.9$

$99.7 \% \quad 38.0$

$99.7 \% \quad 33.1$

$99.7 \% 35.7$

$99.5 \% \quad 23.3$

$99.7 \% \quad 40.9$

$94.8 \% 13.8$

$99.7 \% \quad 54.0$

$99.7 \% \quad 56.7$

$99.7 \% \quad 66.0$

$99.7 \% \quad 38.5$

$98.6 \% 20.3$

$99.7 \% 37.1$

$\begin{array}{lll}99.7 \% & 46.1\end{array}$

$99.7 \% \quad 39.0$

$\begin{array}{lll}94.6 \% & 13.7\end{array}$

$99.7 \% \quad 39.5$

$99.7 \% \quad 50.9$

$99.6 \% \quad 33.3$

$98.2 \% \quad 16.6$

$99.3 \% \quad 20.5$

$\begin{array}{lll}99.4 \% & 23.7\end{array}$

$99.7 \% \quad 39.1$

$99.7 \% \quad 39.1$

$99.7 \% \quad 37.8$

$\begin{array}{lll}99.3 \% & 42.4\end{array}$

$\begin{array}{lll}99.7 \% & 35.9\end{array}$

$99.7 \% \quad 41.2$

$99.7 \% \quad 52.7$

$99.7 \% \quad 37.0$

$99.4 \% 22$.

$\begin{array}{ll}99.7 \% & 29.4\end{array}$

$99.7 \% \quad 30.2$

$99.0 \% \quad 35.0$

$99.0 \% \quad 40.0$

$99.7 \% \quad 39.8$

$99.7 \% \quad 29.7$

$99.0 \% \quad 20.3$

$99.7 \% 31.0$

$99.7 \% \quad 61.7$

$99.7 \% \quad 42.1$

$99.7 \% \quad 66.1$

$99.7 \% 56.2$

$99.7 \% \quad 28.2$

$99.0 \% \quad 35.0$

$99.7 \% \quad 29.9$

33

0

0
0.8

\begin{tabular}{ll}
.0 & 23.3 \\
\hline
\end{tabular}

$\begin{array}{ll}0 & 38.9\end{array}$

$\begin{array}{ll}0 & 13.8\end{array}$

52.6

$\begin{array}{ll}0 & 52.1\end{array}$

$\begin{array}{ll}0 & 60.1\end{array}$

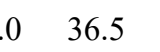

$\begin{array}{ll}0 & 16.3\end{array}$

$\begin{array}{ll}0 & 32.5\end{array}$

$\begin{array}{lll}0 & 46.1 & 2\end{array}$

$\begin{array}{lll} & 39.0 & 4\end{array}$

\begin{tabular}{ll}
0 & 13.7 \\
\hline & 1
\end{tabular}

$\begin{array}{ll}0 & 24.0\end{array}$

\begin{tabular}{ll}
41.2 \\
\hline
\end{tabular}

24.1
25.0

0

$\begin{array}{ll}25.0 & 19.4 \\ 25.0 & 16.5\end{array}$

$\begin{array}{ll}0 & 16.5\end{array}$

0
34.2

$\begin{array}{ll}26.0 & 26.3\end{array}$

0

$5.0 \quad 0.0$

$\begin{array}{ll}5.0 & 32.5\end{array}$

$0 \quad 41.2$

$\begin{array}{ll}5.0 & 47.7\end{array}$

$\begin{array}{ll}0 & 37.0\end{array}$

$\begin{array}{ll}25.0 & 19.7\end{array}$

$\begin{array}{ll}25.0 & 29.4\end{array}$

$0 \quad 25.3$

$\begin{array}{ll}28.0 & 28.9\end{array}$

$\begin{array}{ll}5.0 & 36.1\end{array}$

$\begin{array}{ll}25.0 & 34.0\end{array}$

$\begin{array}{ll}25.0 & 29.7\end{array}$

$\begin{array}{ll}0 & 20.0\end{array}$

$\begin{array}{ll}25.0 & 30.9\end{array}$

$\begin{array}{ll}25.0 & 46.9\end{array}$

\begin{tabular}{ll}
.0 & 46.9 \\
\hline & 31.5
\end{tabular}

$\begin{array}{ll}37.0 & 37.6\end{array}$

$\begin{array}{ll}5.0 & 50.9\end{array}$

$\begin{array}{ll}5.0 & 52.8\end{array}$

$\begin{array}{ll}27.0 & 27.8\end{array}$

$\begin{array}{ll}0 & 24.0\end{array}$

$7-20$ $\begin{array}{ccc}1128.60 & 2251 & 2261 \\ 1120.61 & 29 & 38 \\ 1316.73 & 167 & 178 \\ 1062.59 & 259 & 267 \\ 1470.77 & 274 & 286 \\ 1134.62 & 287 & 296 \\ 1956.94 & 401 & 416 \\ 1619.75 & 213 & 227 \\ 1519.70 & 228 & 240 \\ 1231.65 & 446 & 458 \\ 1236.71 & 648 & 658 \\ 1756.94 & 693 & 707 \\ 1087.59 & 699 & 707 \\ 1490.75 & 728 & 743 \\ 1627.85 & 18 & 31 \\ 1686.82 & 98 & 112 \\ 1122.63 & 43 & 52 \\ 1514.89 & 153 & 166 \\ 1324.70 & 1226 & 1237 \\ 1745.87 & 1830 & 1844 \\ 1516.74 & 487 & 498 \\ 1108.60 & 831 & 839 \\ 1263.69 & 843 & 853 \\ 969.58 & 905 & 913 \\ 1241.70 & 2015 & 2024 \\ 1329.77 & 212 & 223 \\ 1026.56 & 316 & 324 \\ 1329.76 & 395 & 405 \\ 966.61 & 438 & 446 \\ 1089.52 & 513 & 521 \\ 1591.77 & 527 & 540 \\ 1296.61 & 541 & 551 \\ 944.54 & 564 & 573 \\ 1053.57 & 48 & 55 \\ 1053.47 & 278 & 285 \\ 1120.61 & 286 & 295 \\ 1616.77 & 410 & 424 \\ 965.56 & 444 & 451 \\ 1634.74 & 13 & 28 \\ 1325.72 & 38 & 50 \\ 1856.05 & 74 & 90 \\ 2092.93 & 91 & 107 \\ 1098.62 & 108 & 117 \\ 1371.69 & 123 & 135 \\ 2654.26 & 192 & 216 \\ 935.52 & 124 & 131 \\ 1137.67 & 145 & 155 \\ & & \end{array}$

Page 143 of Table S-1-5 
Spliceosome RNA helicase DDX39B GN=DDX39B DX39B_HUMAN $48.99 \quad 100.0 \%$ $\begin{array}{lll} & \end{array}$ Spliceosome RNA helicase DDX39B GN=DDX39B DX39B_HUMAN $48.99 \quad 100.0 \%$ Spliceosome RNA helicase DDX39B GN=DDX39B DX39B_HUMAN $48.99 \quad 100.0^{\circ}$ Spliceosome RNA helicase DDX39B GN=DDX39B DX39B_HUMAN $48.99 \quad 100.0 \%$ Splicing factor 3B subunit $1 \mathrm{GN}=\mathrm{SF} 3 \mathrm{~B} 1 \quad$ SF3B1_HUMAN $145.84 \quad 100.0 \%$ Splicing factor 3B subunit $1 \mathrm{GN}=\mathrm{SF} 3 \mathrm{~B} 1 \quad$ SF3B1_HUMAN $145.84 \quad 100.0 \%$ Splicing factor 3B subunit $1 \mathrm{GN}=\mathrm{SF} 3 \mathrm{~B} 1 \quad$ SF3B1_HUMAN $145.84 \quad 100.0 \%$ Splicing factor 3B subunit $1 \mathrm{GN}=\mathrm{SF} 3 \mathrm{~B} 1 \quad \mathrm{SF} 3 \mathrm{~B} 1$ HUMAN $145.84100 .0 \%$ Splicing factor 3B subunit $1 \mathrm{GN}=$ SF3B1 SF3B1_HUMAN $145.84 \quad 100.0 \%$ Splicing factor 3B subunit $1 \mathrm{GN}=\mathrm{SF} 3 \mathrm{~B} 1 \quad$ SF3B1_HUMAN $145.84 \quad 100.0 \%$ Splicing factor $3 B$ subunit $1 \mathrm{GN}=\mathrm{SF} 3 \mathrm{~B} 1 \quad$ SF3B1_HUMAN $145.84 \quad 100.0^{\circ}$ Splicing factor $3 \mathrm{~B}$ subunit $1 \mathrm{GN}=\mathrm{SF} 3 \mathrm{~B} 1$ Splicing factor $3 \mathrm{~B}$ subunit $1 \mathrm{GN}=\mathrm{SF} 3 \mathrm{~B} 1$

Splicing factor $3 \mathrm{~B}$ subunit $1 \mathrm{GN}=\mathrm{SF} 3 \mathrm{~B} 1$ Splicing factor $3 \mathrm{~B}$ subunit $1 \mathrm{GN}=\mathrm{SF} 3 \mathrm{~B} 1$ Splicing factor $3 \mathrm{~B}$ subunit $1 \mathrm{GN}=\mathrm{SF} 3 \mathrm{~B} 1$ Splicing factor $3 \mathrm{~B}$ subunit $1 \mathrm{GN}=\mathrm{SF} 3 \mathrm{~B} 1$ Splicing factor $3 \mathrm{~B}$ subunit $1 \mathrm{GN}=\mathrm{SF} 3 \mathrm{~B} 1$

Splicing factor $3 \mathrm{~B}$ subunit $1 \mathrm{GN}=\mathrm{SF} 3 \mathrm{~B}$ Splicing factor $3 \mathrm{~B}$ subunit $1 \mathrm{GN}=\mathrm{SF} 3 \mathrm{~B} 1$ Splicing factor $3 \mathrm{~B}$ subunit $1 \mathrm{GN}=\mathrm{SF} 3 \mathrm{~B} 1$

Splicing factor $3 \mathrm{~B}$ subunit $3 \mathrm{GN}=\mathrm{SF} 3 \mathrm{~B} 3$ Splicing factor $3 \mathrm{~B}$ subunit $3 \mathrm{GN}=\mathrm{SF} 3 \mathrm{~B} 3$ Splicing factor $3 \mathrm{~B}$ subunit $3 \mathrm{GN}=\mathrm{SF} 3 \mathrm{~B} 3$ Splicing factor $3 \mathrm{~B}$ subunit $3 \mathrm{GN}=\mathrm{SF} 3 \mathrm{~B} 3$ Splicing factor $3 \mathrm{~B}$ subunit $3 \mathrm{GN}=\mathrm{SF} 3 \mathrm{~B} 3$ SF3B1_HUMAN $145.84 \quad 100.0 \%$ SF3B1_HUMAN $145.84 \quad 100.0 \%$ SF3B1_HUMAN $145.84 \quad 100.0 \%$ SF3B1_HUMAN $145.84 \quad 100.0 \%$ SF3B1 HUMAN $145.84 \quad 100.0 \%$ SF3B1_HUMAN $145.84 \quad 100.0 \%$ SF3B1_HUMAN $145.84 \quad 100.0 \%$ SF3B1_HUMAN $145.84 \quad 100.0 \%$ SF3B1_HUMAN $145.84 \quad 100.0 \%$ SF3B1_HUMAN $145.84 \quad 100.0 \%$ SF3B3_HUMAN $135.58 \quad 100.0 \%$ SF3B3_HUMAN $135.58 \quad 100.0 \%$ SF3B3_HUMAN $135.58 \quad 100.0 \%$ SF3B3_HUMAN $135.58 \quad 100.0 \%$ SF3B3_HUMAN $135.58 \quad 100.0 \%$ $\begin{array}{llll}\text { Splicing factor 3B subunit } 3 \mathrm{GN}=\mathrm{SF} 3 \mathrm{~B} 3 & \text { SF3B3_HUMAN } & 135.58 & 100.0 \% \\ \text { Splicing factor U2AF 35 kDa subunit GN=U2AF1 } & \text { U2AF1_HUMAN } & 27.87 & 100.0 \%\end{array}$ Splicing factor U2AF $35 \mathrm{kDa}$ subunit GN=U2AF1 U2AF1_HUMAN $27.87 \quad 100.0 \%$ Splicing factor U2AF $35 \mathrm{kDa}$ subunit GN=U2AF1 U2AF1_HUMAN $27.87 \quad 100.0 \%$ Splicing factor U2AF $35 \mathrm{kDa}$ subunit GN=U2AF1 U2AF1_HUMAN $27.87 \quad 100.0 \%$ Splicing factor U2AF $35 \mathrm{kDa}$ subunit GN=U2AF1 U2AF1_HUMAN $27.87 \quad 100.0 \%$ Splicing factor U2AF $35 \mathrm{kDa}$ subunit GN=U2AF1 U2AF1_HUMAN $27.87 \quad 100.0 \%$ Splicing factor U2AF $35 \mathrm{kDa}$ subunit GN=U2AF1 U2AF1_HUMAN $27.87 \quad 100.0 \%$ Splicing factor U2AF $65 \mathrm{kDa}$ subunit GN=U2AF2 U2AF2 HUMAN $53.50 \quad 100.0 \%$ Splicing factor U2AF $65 \mathrm{kDa}$ subunit GN=U2AF2 U2AF2_HUMAN $53.50 \quad 100.0 \%$ Splicing factor U2AF $65 \mathrm{kDa}$ subunit GN=U2AF2 U2AF2 HUMAN $53.50 \quad 100.0^{\circ}$ Splicing factor U2AF $65 \mathrm{kDa}$ subunit GN=U2AF2 U2AF2_HUMAN $53.50 \quad 100.0 \%$ Splicing factor U2AF $65 \mathrm{kDa}$ subunit GN=U2AF2 U2AF2_HUMAN $53.50 \quad 100.0 \%$ Splicing factor U2AF $65 \mathrm{kDa}$ subunit GN=U2AF2 U2AF2_HUMAN $53.50 \quad 100.0 \%$ Splicing factor U2AF $65 \mathrm{kDa}$ subunit GN=U2AF2 U2AF2_HUMAN $53.50 \quad 100.0 \%$ Splicing factor U2AF $65 \mathrm{kDa}$ subunit GN=U2AF2 U2AF2 HUMAN $53.50 \quad 100.0 \%$ Splicing factor, proline- and glutamine-rich GN=SFPQ SFPQ_HUMAN $76.15 \quad 100.0 \%$ Splicing factor, proline- and glutamine-rich GN=SFPQ SFPQ_HUMAN $76.15 \quad 100.0 \%$ Splicing factor, proline- and glutamine-rich GN=SFPQ SFPQ_HUMAN $76.15 \quad 100.0 \%$ Splicing factor, proline- and glutamine-rich GN=SFPQ SFPQ_HUMAN $76.15 \quad 100.0 \%$
$20 \quad 0.02 \% \quad 15.9 \%$ NCPHIVVGTPGR

$\begin{array}{lll}0.02 \% & 15.9 \% & \text { NCPHIVVGTPGR } \\ 0.02 \% & 15.9 \% & \text { YQQFKDFQR }\end{array}$

$0.02 \% \quad 15.9 \%$ ILVATNLFGR

$0.04 \% \quad 12.1 \%$ GKGLAAFLK

$0.04 \% \quad 12.1 \%$ QLVDTTVELANK

$0.04 \% \quad 12.1 \%$ VGAAEIISR

$0.04 \% \quad 12.1 \%$ VRQQAADLISR

$0.04 \% \quad 12.1 \%$ QQAADLISR

$0.04 \% \quad 12.1 \%$ AIVNVIGMHK

$0.04 \% \quad 12.1 \%$ VQENCIDLVGR

$0.04 \% \quad 12.1 \%$ IADRGAEYVSAR

$0.04 \% \quad 12.1 \%$ RATVNTFGYIAK

$0.04 \% \quad 12.1 \%$ ATVNTFGYIAK

$0.04 \% \quad 12.1 \%$ VPELNVQNGVLK

$0.04 \% \quad 4.6 \%$ QQEIVVSR

$0.04 \% \quad 4.6 \%$ NFGDQPDIR

$0.04 \% \quad 4.6 \%$ FLAVGLVDNTVR

$0.04 \% \quad 4.6 \%$ SVAGGFVYTYK

$0.03 \% \quad 39.2 \%$ VNCSFYFK

$0.03 \% \quad 39.2 \%$ AVIDLNNR

$0.03 \% \quad 39.2 \%$ QYEMGECTR

$0.02 \% \quad 13.9 \%$ GAKEEHGGLIR

$0.02 \% \quad 13.9 \%$ IFVEFTSVFDCQK

$0.02 \% \quad 13.9 \%$ AMQGLTGR

$0.02 \% \quad 13.9 \%$ AMQGLTGRK

$0.02 \% \quad 13.9 \%$ FANRVVVTK

$0.02 \% \quad 13.9 \%$ YCDPDSYHR

$0.02 \% \quad 13.9 \%$ YCDPDSYHRR

$0.02 \% \quad 11.7 \%$ RPGEKTYTQR

$0.02 \% \quad 11.7 \%$ YGEPGEVFINK

$0.02 \% \quad 11.7 \%$ GFGFIKLESR

$0.02 \% \quad 11.7 \%$ FATHAAALSVR $\begin{array}{llllllll}99.7 \% & 32.8 & 25.0 & 31.9 & 1 & 0 & 0 & 1306.67\end{array}$

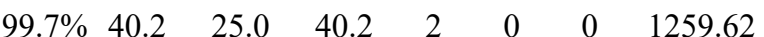

$0.02 \% \quad 15.9 \%$ GLAITFVSDENDAK

$0.04 \% \quad 12.1 \%$ VVNGAAASQPPSK

$0.04 \% \quad 12.1 \%$ VVNGAAASQPPSKR

$0.04 \% \quad 12.1 \%$ WDQTADQTPGATPK

$0.04 \% \quad 12.1 \%$ TDRGGDSIGETPTPGASK

$0.04 \% \quad 12.1 \%$ GGDSIGETPTPGASK

$0.04 \% \quad 12.1 \%$ QCCGTDGVEANYIK

$0.04 \% \quad 4.6 \%$ TVLDPVTGDLSDTR

$0.04 \% \quad 4.6 \%$ TVLDPVTGDLSDTRTR

$0.03 \% \quad 39.2 \%$ NPQNSSQSADGLR

$0.03 \% \quad 39.2 \%$ YGEVEEMNVCDNLGDHLVGNVYVK

$0.03 \% \quad 39.2 \%$ WFNGQPIHAELSPVTDFR

$0.03 \% 39.2 \%$ GGFCNFMHLKPISR

$0.02 \% 13.9 \%$ AFNLVKDSATGLSK
$98.7 \% 25.4$

$99.7 \% \quad 56.3$

$97.2 \% 15.6$

$99.7 \% \quad 30.1$

$99.7 \% \quad 45.5$

$99.7 \% 37.8$

$99.7 \% \quad 36.4$

$99.6 \% \quad 25.8$

$99.7 \% \quad 45.5$

$99.7 \% \quad 58.0$

$99.7 \% \quad 80.5$

$99.7 \% \quad 45.3$

$99.7 \% \quad 40.9$

$\begin{array}{lll}99.7 \% & 39.2\end{array}$

$99.7 \% \quad 54.7$

$99.6 \% \quad 24.0$

$99.7 \% \quad 30.8$

$99.7 \% \quad 67.4$

$99.5 \% \quad 21.4$

$99.0 \% \quad 27.2$

$99.7 \% \quad 38.5$

$99.7 \% \quad 60.2$

$99.7 \% \quad 60.0$

$99.6 \% \quad 25.7$

$99.7 \% \quad 61.0$

$99.0 \% \quad 49.5$

$99.7 \% \quad 58.0$

$99.7 \% 56.6$

$\begin{array}{lll}99.0 \% & 41.8\end{array}$

$7 \% \quad 413$

$99.7 \% \quad 64.8$

$99.7 \% \quad 34.6$

$99.7 \% \quad 53.2$

$99.7 \% \quad 55.7$

$99.7 \% \quad 37.7$

$99.0 \% \quad 40.2$

$99.7 \% \quad 32.2$

$99.7 \% 37.6$

$98.1 \% \quad 16.5$

$99.5 \% 21.3$

$97.0 \% \quad 15.6$

$99.7 \% \quad 34.1$

$99.7 \% \quad 41.2$

$99.7 \% \quad 50.5$
1259.62
1103.66

1912.97

1479.73

1225.65

1381.75

1515.71

1745.83

1373.65

904.56

1614.69

1330.72

915.53

1256.71

1001.54

1097.61

1302.65

1307.67

1340.73

1184.63

1309.75

958.53

1061.50

1303.74

1488.75

1745.90

1191.60

1064.49

1373.64

2769.25

914.51

2114.05

1173.47

1663.82

1166.63

1450.79

1619.78

833.43

961.52

1033.62

1212.47

1368.58

1235.65

1252.62

1153.64

1143.63

$\begin{array}{cc}64 & 175 \\ 30 & 338 \\ 40 & 349 \\ 81 & 398 \\ 85 & 398 \\ 83 & 195 \\ 83 & 196 \\ 00 & 213 \\ 16 & 333 \\ 19 & 333 \\ 40 & 748 \\ 94 & 807 \\ 32 & 843 \\ 44 & 852 \\ 47 & 957 \\ 49 & 957 \\ 99 & 1008 \\ 31 & 1041 \\ 42 & 1053 \\ 75 & 1086 \\ 76 & 1086 \\ 38 & 1149 \\ 7 & 34 \\ 60 & 268 \\ 04 & 615 \\ 77 & 690 \\ 77 & 692 \\ 19 & 929 \\ 6 & 23 \\ 4 & 66 \\ 3 & 116 \\ 26 & 133 \\ 34 & 151 \\ 57 & 165 \\ 66 & 179 \\ 8 & 78 \\ 87 & 300 \\ 32 & 444 \\ 45 & 452 \\ 45 & 453 \\ 54 & 462 \\ 63 & 471 \\ 63 & 472 \\ 87 & 296 \\ 20 & 330 \\ 33 & 342 \\ 66 & 376\end{array}$

Page 144 of Table S-1-5 
Splicing factor, proline- and glutamine-rich GN=SFPQ SFPQ_HUMAN $76.15 \quad 100.0 \%$ Splicing factor, proline- and glutamine-rich GN=SFPQ SFPQ_HUMAN $76.15 \quad 100.0 \%$ Splicing factor, proline- and glutamine-rich GN=SFPQ SFPQ_HUMAN $76.15 \quad 100.0 \%$ Splicing factor, proline- and glutamine-rich GN=SFPQ SFPQ HUMAN $76.15100 .0^{\circ}$ SRSF protein kinase $1 \mathrm{GN}=\mathrm{SRPK} 1$ SRSF protein kinase $1 \mathrm{GN}=\mathrm{SRPK} 1$ SRPK1_HUMAN $74.33 \quad 100.0 \%$ SRPK1_HUMAN $74.33 \quad 100.0 \%$ Stomatin-like protein 2, mitochondrial GN=STOML2 STML2_HUMAN $38.53 \quad 100.0 \%$ Stomatin-like protein 2, mitochondrial GN=STOML2 STML2_HUMAN $38.53 \quad 100.0 \%$ Stomatin-like protein 2, mitochondrial GN=STOML2 STML2_HUMAN $38.53 \quad 100.0 \%$ Stomatin-like protein 2, mitochondrial GN=STOML2 STML2_HUMAN $38.53 \quad 100.0 \%$ Stomatin-like protein 2, mitochondrial GN=STOML2 STML2_HUMAN $38.53 \quad 100.0 \%$ Stomatin-like protein 2, mitochondrial GN=STOML2 STML2_HUMAN $38.53 \quad 100.0 \%$ Stress-70 protein, mitochondrial GN=HSPA9 GRP75_HUMAN $73.68 \quad 100.0 \%$ Stress-70 protein, mitochondrial GN=HSPA9 GRP75_HUMAN $73.68 \quad 100.0 \%$ Stress-70 protein, mitochondrial GN=HSPA9 GRP75_HUMAN $73.68 \quad 100.0 \%$ Stress-70 protein, mitochondrial GN=HSPA9 GRP75_HUMAN $73.68 \quad 100.0 \%$ Stress-70 protein, mitochondrial GN=HSPA9 GRP75_HUMAN $73.68 \quad 100.0 \%$ Stress-70 protein, mitochondrial GN=HSPA9 GRP75_HUMAN $73.68 \quad 100.0 \%$ Stress-70 protein, mitochondrial GN=HSPA9 GRP75_HUMAN $73.68 \quad 100.0 \%$ Stress-70 protein, mitochondrial GN=HSPA9 GRP75_HUMAN $73.68 \quad 100.0 \%$ Stress-70 protein, mitochondrial GN=HSPA9 GRP75_HUMAN $73.68 \quad 100.0 \%$ Stress-70 protein, mitochondrial GN=HSPA9 GRP75_HUMAN $73.68 \quad 100.0 \%$ Stress-70 protein, mitochondrial GN=HSPA9 GRP75_HUMAN $73.68 \quad 100.0 \%$ Stress-70 protein, mitochondrial GN=HSPA9 GRP75_HUMAN $73.68 \quad 100.0 \%$ Stress-70 protein, mitochondrial GN=HSPA9 GRP75 HUMAN $73.68100 .0 \%$ Stress-70 protein, mitochondrial GN=HSPA9 GRP75_HUMAN $73.68 \quad 100.0 \%$ Stress-70 protein, mitochondrial GN=HSPA9 GRP75_HUMAN $73.68 \quad 100.0 \%$ Stress-70 protein, mitochondrial GN=HSPA9 GRP75_HUMAN $73.68 \quad 100.0 \%$ Stress-70 protein, mitochondrial GN=HSPA9 GRP75_HUMAN $73.68 \quad 100.0 \%$ Structural maintenance of chromosomes protein $1 \mathrm{~A}$ GN=SMC1A SMC1A_HUMAN $143.24 \quad 100.0 \%$ Structural maintenance of chromosomes protein $1 \mathrm{~A}$ GN=SMC1A SMC1A_HUMAN $143.24 \quad 100.0 \%$ Structural maintenance of chromosomes protein $1 \mathrm{~A}$ GN=SMC1A SMC1A_HUMAN $143.24 \quad 100.0 \%$ Structural maintenance of chromosomes protein $1 \mathrm{~A}$ GN=SMC1A SMC1A_HUMAN $143.24 \quad 100.0 \%$ Structural maintenance of chromosomes protein $1 \mathrm{~A}$ GN=SMC1A SMC1A_HUMAN $143.24 \quad 100.0 \%$ Structural maintenance of chromosomes protein $1 \mathrm{~A}$ GN=SMC1A SMC1A_HUMAN $143.24 \quad 100.0 \%$ Structural maintenance of chromosomes protein $1 \mathrm{~A}$ GN=SMC1A SMC1A_HUMAN $143.24 \quad 100.0 \%$ Structural maintenance of chromosomes protein $1 \mathrm{~A}$ GN=SMC1A SMC1A_HUMAN $143.24 \quad 100.0 \%$ Structural maintenance of chromosomes protein $1 \mathrm{~A}$ GN=SMC1A SMC1A HUMAN $143.24 \quad 100.0 \%$ Structural maintenance of chromosomes protein $1 \mathrm{~A}$ GN=SMC1A SMC1A_HUMAN $143.24 \quad 100.0 \%$ Structural maintenance of chromosomes protein $1 \mathrm{~A}$ GN=SMC1A SMC1A_HUMAN $143.24 \quad 100.0 \%$ Structural maintenance of chromosomes protein $1 \mathrm{~A}$ GN=SMC1A SMC1A_HUMAN $143.24 \quad 100.0 \%$ Structural maintenance of chromosomes protein $1 \mathrm{~A}$ GN=SMC1A SMC1A_HUMAN $143.24 \quad 100.0 \%$ Structural maintenance of chromosomes protein 1A GN=SMC1A SMC1A_HUMAN $143.24 \quad 100.0 \%$ Structural maintenance of chromosomes protein 1A GN=SMC1A SMC1A_HUMAN $143.24 \quad 100.0 \%$ Structural maintenance of chromosomes protein 2 GN=SMC2 SMC2_HUMAN $135.66 \quad 100.0 \%$ Structural maintenance of chromosomes protein $2 \mathrm{GN}=\mathrm{SMC} 2 \mathrm{SMC} 2$ HUMAN $135.66 \quad 100.0 \%$ Structural maintenance of chromosomes protein $2 \mathrm{GN}=\mathrm{SMC} 2 \mathrm{SMC2}$ _HUMAN $135.66 \quad 100.0 \%$
$14 \quad 0.02 \% \quad 11.7 \%$ AVVIVDDRGR $0.02 \% \quad 11.7 \%$ STGKGIVEFASKPAAR $0.02 \% \quad 11.7 \%$ GIVEFASKPAAR $4 \quad 0.02 \% \quad 11.7 \%$ FGQGGAGPVGGQGPR $0.00 \% \quad 3.5 \%$ STAGNFLVNPLEPK $0.00 \% \quad 3.5 \%$ HFTEDIQTR

$0.01 \% \quad 19.9 \%$ ATVLESEGTR $0.01 \% \quad 19.9 \%$ ESAINVAEGK $0.01 \% \quad 19.9 \%$ ESAINVAEGKK $0.01 \% \quad 19.9 \%$ AEQINQAAGEASAVLAK $0.01 \% \quad 19.9 \%$ APVPGTPDSLSSGSSR $0.01 \% \quad 19.9 \%$ DVQGTDASLDEELDRVK $0.07 \% \quad 26.7 \%$ VLENAEGAR $0.07 \% \quad 26.7 \%$ TTPSVVAFTADGER $0.07 \% \quad 26.7 \%$ QAVTNPNNTFYATK $0.07 \% \quad 26.7 \%$ QAVTNPNNTFYATKR $0.07 \% \quad 26.7 \%$ RYDDPEVQK $0.07 \% \quad 26.7 \%$ NVPFKIVR $0.07 \% \quad 26.7 \%$ ASNGDAWVEAHGK $0.07 \% \quad 26.7 \%$ MKETAENYLGHTAK $0.07 \% \quad 26.7 \%$ NAVITVPAYFNDSQR $0.07 \% \quad 26.7 \%$ QATKDAGQISGLNVLR $0.07 \% \quad 26.7 \%$ DAGQISGLNVLR $0.07 \% \quad 26.7 \%$ ETGVDLTKDNMALQR $0.07 \% \quad 26.7 \%$ AQFEGIVTDLIR $0.07 \% \quad 26.7 \%$ SDIGEVILVGGMTR $0.07 \% \quad 26.7 \%$ VQQTVQDLFGR $0.07 \% \quad 26.7 \%$ VQQTVQDLFGRAPSK $0.07 \% \quad 26.7 \%$ QAASSLQQASLK $0.03 \% \quad 12.5 \%$ LIEIENFK

$0.03 \% \quad 12.5 \%$ FTAIIGPNGSGK $0.03 \% \quad 12.5 \%$ DLIHGAPVGKPAANR $0.03 \% \quad 12.5 \%$ TALFEEISR $0.03 \% \quad 12.5 \%$ SGELAQEYDKR $0.03 \% \quad 12.5 \%$ LIDLCQPTQK $0.03 \% \quad 12.5 \%$ NMDAIIVDSEK $0.03 \% \quad 12.5 \%$ HKTVALDGTLFQK $0.03 \% \quad 12.5 \%$ TVALDGTLFQK $0.03 \% \quad 12.5 \%$ SGVISGGASDLKAK $0.03 \% \quad 12.5 \%$ LTEELKEQMK $0.03 \% \quad 12.5 \%$ YSQSDLEQTKTR $0.03 \% \quad 12.5 \%$ HLALNLQEK $0.03 \% \quad 12.5 \%$ MQDIKLPLSK $0.03 \% \quad 12.5 \%$ LNEQQSVLQR $\begin{array}{lll}0.01 \% & 7.0 \% & \text { ASNLQDLVYKNGQ } \\ 0.01 \% & 7.0 \% & \text { TILEEEITPTIQK } \\ 0.01 \% & 7.0 \% & \text { SLEDALAEAQR }\end{array}$

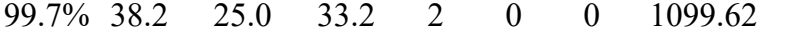
$\begin{array}{llllllll}99.7 \% & 27.4 & 25.0 & 27.4 & 0 & 2 & 0 & 1618.89\end{array}$ $\begin{array}{llllllll}99.7 \% & 42.2 & 25.0 & 42.2 & 3 & 0 & 0 & 1245.70\end{array}$

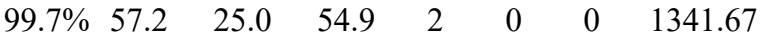
$\begin{array}{llllllll}99.7 \% & 36.4 & 25.0 & 32.1 & 2 & 0 & 0 & 1486.79\end{array}$

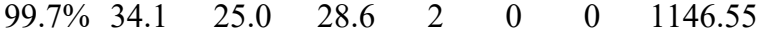

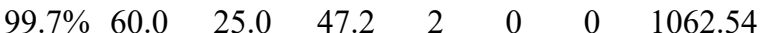

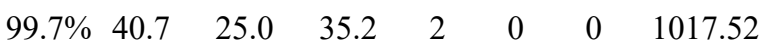

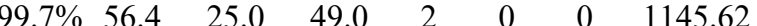

1670.87

1514.74

1889.91

958.50

1450.72

1568.77

1724.87

1149.55

972.60

1341.62

1592.77

1694.85

1670.92

1242.68

1706.84

1361.74

1462.76

1290.68

1673.90

1231.66

1005.56

1161.63

1515.84

1065.56 1295.62

1215.64

1234.60

1457.81

1192.66

1289.71

1248.65

1455.7

1065.61

1172.67

1214.65

1920.02

1514.83 1202.60
0409 $10 \quad 425$ $414 \quad 425$ $667 \quad 681$ 473486 $\begin{array}{ll}507 & 515 \\ 202 & 211\end{array}$ 211 $12 \quad 222$ $234 \quad 250$ $322 \quad 337$ $77 \quad 85$ $86 \quad 99$ $08 \quad 12$ $108 \quad 122$ $127 \quad 135$ $147 \quad 159$ $174 \quad 187$ $188 \quad 202$ $203 \quad 218$ $207 \quad 218$ 307
49 $378 \quad 391$ $395 \quad 405$ 395409 $635 \quad 646$ $6 \quad 13$ $27 \quad 38$ $152 \quad 160$ $161 \quad 171$ $519 \quad 528$ $541 \quad 551$ $636 \quad 648$ $638 \quad 648$ $649 \quad 662$ $681 \quad 690$ $726 \quad 734$ $935 \quad 944$ 0101019 $197 \quad 209$ 298308 

Structural maintenance of chromosomes protein $3 \mathrm{GN}=\mathrm{SMC} 3 \mathrm{SMC} 3$ _HUMAN $141.55100 .0 \%$ Structural maintenance of chromosomes protein $3 \mathrm{GN}=\mathrm{SMC} 3 \mathrm{SMC} 3$ HUMAN $141.55 \quad 100.0 \%$ Structural maintenance of chromosomes protein $3 \mathrm{GN}=\mathrm{SMC} 3 \mathrm{SMC} 3$ _HUMAN $141.55 \quad 100.0 \%$ Structural maintenance of chromosomes protein $3 \mathrm{GN}=\mathrm{SMC} 3 \mathrm{SMC} 3$ _HUMAN $141.55100 .0 \%$ Structural maintenance of chromosomes protein $4 \mathrm{GN}=\mathrm{SMC} 4$ SMC4_HUMAN $147.19100 .0 \%$ Structural maintenance of chromosomes protein $4 \mathrm{GN}=\mathrm{SMC} 4 \mathrm{SMC4}$ _HUMAN $147.19 \quad 100.0 \%$ Structural maintenance of chromosomes protein $4 \mathrm{GN}=\mathrm{SMC} 4$ SMC4_HUMAN $147.19 \quad 100.0 \%$ Structural maintenance of chromosomes protein $4 \mathrm{GN}=\mathrm{SMC} 4$ SMC4_HUMAN $147.19 \quad 100.0 \%$ Structural maintenance of chromosomes protein 4 GN=SMC4 SMC4_HUMAN $147.19 \quad 100.0 \%$ Structural maintenance of chromosomes protein $4 \mathrm{GN}=\mathrm{SMC} 4 \mathrm{SMC} 4$ HUMAN $147.19 \quad 100.0 \%$ Structural maintenance of chromosomes protein $4 \mathrm{GN}=\mathrm{SMC} 4 \mathrm{SMC} 4$ _HUMAN $147.19 \quad 100.0 \%$ Structural maintenance of chromosomes protein $4 \mathrm{GN}=\mathrm{SMC} 4 \mathrm{SMC} 4$ HUMAN $147.19 \quad 100.0 \%$ Structural maintenance of chromosomes protein $4 \mathrm{GN}=\mathrm{SMC} 4 \mathrm{SMC} 4$ HUMAN $147.19100 .0 \%$ Structural maintenance of chromosomes protein $4 \mathrm{GN}=\mathrm{SMC} 4 \mathrm{SMC} 4$ _HUMAN $147.19 \quad 100.0 \%$ Structural maintenance of chromosomes protein $4 \mathrm{GN}=\mathrm{SMC} 4 \mathrm{SMC} 4$ HUMAN $147.19 \quad 100.0 \%$ Structural maintenance of chromosomes protein $4 \mathrm{GN}=$ SMC4 SMC4_HUMAN $147.19100 .0 \%$ Structural maintenance of chromosomes protein $4 \mathrm{GN}=\mathrm{SMC} 4 \mathrm{SMC} 4$ _HUMAN $147.19 \quad 100.0 \%$ Structural maintenance of chromosomes protein $4 \mathrm{GN}=\mathrm{SMC} 4$ SMC4 HUMAN $147.19 \quad 100.0^{\circ}$ Structural maintenance of chromosomes protein $4 \mathrm{GN}=\mathrm{SMC} 4 \mathrm{SMC4}$ _HUMAN $147.19 \quad 100.0 \%$ Structural maintenance of chromosomes protein $4 \mathrm{GN}=\mathrm{SMC} 4$ SMC4_HUMAN $147.19 \quad 100.0 \%$ Structural maintenance of chromosomes protein $4 \mathrm{GN}=\mathrm{SMC} 4 \mathrm{SMC} 4 \mathrm{HUMAN} 147.19 \quad 100.0 \%$ Succinyl-CoA ligase [ADP/GDP-forming] subunit alpha, mitochondrial GN=SUCLG1 SUCA_HUMAN $36.25 \quad 100.0 \%$ Succinyl-CoA ligase [ADP/GDP-forming] subunit alpha, mitochondrial GN=SUCLG1 SUCA HUMAN $36.25 \quad 100.0 \%$ Succinyl-COA ligase [ADP/GDP-forming] subunit apha, mitochondrial GN=SUCLGI SUCA_HUMAN $36.25 \quad 100.0 \%$ Succinyl-CoA ligase [ADP/GDP-forming] subunit apha, mitochondrial GN=SUCLG1 SUCA_HUMAN $36.25 \quad 100.0 \%$ 作 Succinyl-COA ligase [ADP/GDP-forming] subunit alpha, mitochondrial GN=SUCLG1 SUCA_HUMAN $36.25 \quad 100.0 \%$ Succinyl-CoA ligase [ADP/GDP-forming] subunit alpha, mitochondral GN=SUCLG1 SUCA_HUMAN $36.25 \quad 100.0 \%$ Succinyl-COA ligase [ADP-forming] subunit beta, mitochondrial GN=SUCLA2 SUCB1_HUMAN $50.32 \quad 100.0 \%$ Succinyl-COA ligase [ADP-forming] subunit beta, mitochondrial GN=SUCLA2 SUCB1_HUMAN $50.32 \quad 100.0 \%$ Secinyl-CoA ligase [ADP-forming] subunit beta, mitochondrial GN=SUCLA2 SUCB1_HUMAN $50.32 \quad 100.0 \%$ Succinyl-CoA ligase [ADP-forming] subunit beta, mitochondrial GN=SUCLA2 SUCB1_HUMAN $50.32 \quad 100.0 \%$ Succinyl-COA ligase [ADP-forming] subunit beta, mitochondrial GN=SUCLA2 SUCB1_HUMAN $50.32 \quad 100.0 \%$ igecinyl-CoA ligase [ADP-forming] subunit beta, mitochondrial GN=SUCLA2 SUCB1 HUMAN $50.32100 .0 \%$ Succinyl-CoA ligase [ADP-forming] subunit beta, mitochondrial GN=SUCLA2 SUCB1_HUMAN $50.32 \quad 100.0 \%$ Succinyl-CoA ligase [ADP-forming] subunit beta, mitochondrial GN=SUCLA2 SUCB1 HUMAN $50.32 \quad 100.0 \%$ Succinyl-COA ligase [ADP-forming] subunit beta, mitochondrial GN=SUCLA2 SUCB1_HUMAN $50.32 \quad 100.0 \%$ Succinyl-CoA ligase [ADP-forming] subunit beta, mitochondrial GN=SUCLA2 SUCB1_HUMAN $50.32100 .0 \%$ Succinyl-CoA ligase [GDP-forming] subunit beta, mitochondrial GN=SUCLG2 SUCB2 HUMAN $46.51 \quad 100.0 \%$

$0.01 \% \quad 7.0 \% \quad$ LYNVVVDTEVTGK $0.01 \% \quad 7.0 \%$ YTIIPLNK $0.01 \% \quad 7.0 \%$ SQAASILTK

$0.01 \% \quad 7.0 \%$ TKFVDGVSTVAR $0.02 \% \quad 6.6 \%$ QVIIQGFR $0.02 \% \quad 6.6 \%$ LALLHEGTGPR $0.02 \% \quad 6.6 \% \quad$ INQMATAPDSQR $0.02 \% \quad 6.6 \%$ LAQATQERTDLYAK $0.02 \% \quad 6.6 \%$ SMEVSTQLAR $0.02 \% \quad 6.6 \%$ GALTGGYYDTR $0.02 \% \quad 6.6 \%$ ALDQFVNFSEQKEK $0.03 \% \quad 13.7 \%$ FSCIIGPNGSGK $0.03 \% \quad 13.7 \%$ TFKDVGNLLR $0.03 \% \quad 13.7 \%$ SNNIINETTTR $0.03 \% \quad 13.7 \%$ HNTAVSQLTK $30 \quad 0.03 \% \quad 13.7 \%$ EALIAASETLKER $0.03 \% \quad 13.7 \%$ GKVLDAIIQEK $0.03 \% \quad 13.7 \%$ VLDAIIQEK $30 \quad 0.03 \% \quad 13.7 \%$ KMTEIQTPENTPR $0.03 \% \quad 13.7 \%$ MTEIQTPENTPR $30 \quad 0.03 \% \quad 13.7 \%$ AMQIQEQKVQLEER $30 \quad 0.03 \% \quad 13.7 \%$ NTLEKFTASIQR $0.03 \% \quad 13.7 \%$ QLDECASAITK $30 \quad 0.03 \% \quad 13.7 \%$ NTNAAEESLPEIQKEHR $\quad 0.03 \% \quad 13.7 \%$ VIQENEHALQK $\quad 0.03 \% \quad 13.7 \%$ VAELDKITYER $30 \quad 0.03 \% \quad 13.7 \%$ IFNLSGGEK $0.03 \% \quad 13.7 \%$ SVAVNPKEIASK $0.03 \% \quad 24.9 \%$ QHLYVDKNTK $0.03 \% \quad 24.9 \%$ IICQGFTGK $0.03 \% \quad 24.9 \%$ QGTFHSQQALEYGTK $0.03 \% \quad 24.9 \%$ LVGGTTPGK $0.03 \% \quad 24.9 \%$ GGQTHLGLPVFNTVK $0.03 \% \quad 24.9 \%$ LIGPNCPGVINPGECK $0.03 \% \quad 24.9 \%$ MGHAGAIIAGGK $0.03 \% \quad 22.2 \%$ SPDEAYAIAK $0.03 \% \quad 22.2 \%$ GKGTFESGLK $0.03 \% \quad 22.2 \%$ IVFSPEEAK

$0.03 \% \quad 22.2 \%$ ICNQVLVCER $0.03 \% \quad 22.2 \%$ EQALQLAQK $0.03 \% \quad 22.2 \%$ INFDSNSAYR $0.03 \% \quad 22.2 \%$ CDVIAQGIVMAVK $0.03 \% \quad 22.2 \%$ DLEIKIPVVVR $0.03 \% \quad 22.2 \%$ ILACDDLDEAAR $0.03 \% \quad 22.2 \%$ LSEIVTLAK $0.04 \% \quad 34.0 \%$ FFVADTANEALEAAK $0.04 \% \quad 34.0 \%$ FFVADTANEALEAAKR
1098.59

1430.79

1213.72

1028.60

1544.77

1416.68

1729.89

1407.76

1235.59

1965.96

1308.69

1336.71

964.51

1242.71

1245.66

1023.53

1694.81

829.48

1567.86

1724.85

1098.57

1064.53

1023.55

1019.54

1290.63

1028.57

1186.55

1403.74

1280.79

1361.64

973.59

1596.79 1752.89 

SUMO-activating enzyme subunit $1 \mathrm{GN}=\mathrm{SAE} 1 \mathrm{SAE} 1$ HUMAN $38.45 \quad 100.0 \%$ SUMO-activating enzyme subunit $1 \mathrm{GN}=$ SAE1 SAE1_HUMAN $38.45 \quad 100.0 \%$ Superkiller viralicidic activity 2-like $2 \mathrm{GN}=$ SKIV2L2 SK2L2 HUMAN $117.81 \quad 100.0 \%$ Superkiller viralicidic activity 2-like 2 GN=SKIV2L2 SK2L2_HUMAN $117.81 \quad 100.0 \%$ Superkiller viralicidic activity 2-like 2 GN=SKIV2L2 SK2L2_HUMAN $117.81 \quad 100.0 \%$ Superkiller viralicidic activity 2-like 2 GN=SKIV2L2 SK2L2 HUMAN $117.81 \quad 100.0 \%$ Superkiller viralicidic activity 2-like 2 GN=SKIV2L2 SK2L2_HUMAN $117.81 \quad 100.0 \%$ Superkiller viralicidic activity 2-like 2 GN=SKIV2L2 SK2L2_HUMAN $117.81 \quad 100.0 \%$ Suppressor of SWI4 1 homolog GN=PPAN SSF1_HUMAN $53.19 \quad 100.0 \%$ Suppressor of SWI4 1 homolog GN=PPAN SSF1_HUMAN $53.19 \quad 100.0 \%$ Suppressor of SWI4 1 homolog GN=PPAN SSF1 HUMAN $53.19100 .0 \%$ SURP and G-patch domain-containing protein 2 GN=SUGP2 SUGP2_HUMAN $120.21 \quad 100.0 \%$ SURP and G-patch domain-containing protein 2 GN=SUGP2 SUGP2_HUMAN $120.21 \quad 100.0 \%$ SURP and G-patch domain-containing protein $2 \mathrm{GN}=\mathrm{SUGP} 2$ SUGP2 HUMAN $120.21 \quad 100.0 \%$ SURP and G-patch domain-containing protein 2 GN=SUGP2 SUGP2_HUMAN $120.21 \quad 100.0 \%$ SURP and G-patch domain-containing protein 2 GN=SUGP2 SUGP2 HUMAN $120.21 \quad 100.0^{\circ}$ Survival motor neuron protein GN=SMN1 SMN_HUMAN $31.85 \quad 100.0 \%$ Survival motor neuron protein GN=SMN1 SMN_HUMAN $31.85 \quad 100.0 \%$ Survival motor neuron protein GN=SMN1 SMN_HUMAN $31.85 \quad 100.0 \%$

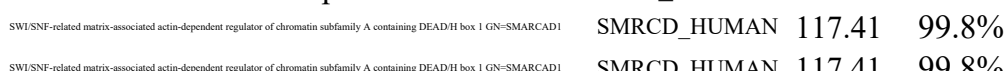

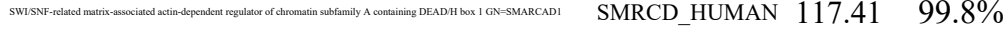

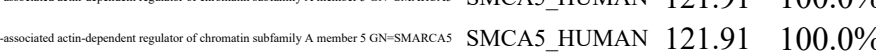
SMCA5 HUMAN $121.91 \quad 100.0 \%$ SMCA5_HUMAN $121.91 \quad 100.0 \%$ SMCA5_HUMAN $121.91 \quad 100.0 \%$ SMCA5_HUMAN $121.91 \quad 100.0 \%$ STX18_HUMAN $38.67 \quad 100.0 \%$ STX18 HUMAN $38.67 \quad 100.0 \%$ STX18 HUMAN $38.67 \quad 100.0 \%$ STX18_HUMAN $38.67 \quad 100.0 \%$

\section{Syntaxin-18 GN=STX18}

Syntaxin-18 GN=STX18

Syntaxin-18 GN=STX18

Syntaxin-18 GN=STX18

$100.0 \%$

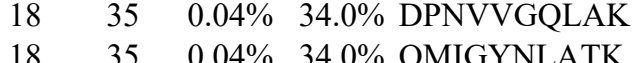

$\begin{array}{lll}35 & 0.04 \% & 34.0 \% \\ 35 & 0.04 \% & 34.0 \%\end{array}$

$0.04 \% \quad 34.0 \%$ ETYLAILMDR

$0.04 \% \quad 34.0 \%$ EQIDIFEGIK

$0.04 \% \quad 34.0 \%$ EQIDIFEGIKDSQAQR

$0.04 \% \quad 34.0 \%$ MAENLGFVGPLK

$0.04 \% \quad 34.0 \%$ INFDDNAEFR

$0.04 \% \quad 34.0 \%$ EAQVYQAFK

$0.04 \% \quad 34.0 \%$ ELELKVPLVVR

$0.04 \% \quad 34.0 \%$ LEGTNVQEAQK

$99.7 \% \quad 34.7$

$99.7 \% \quad 44.9$

$99.7 \% \quad 57.9$

$99.7 \% \quad 54.7$

$99.7 \% \quad 26.0$

$99.7 \% \quad 48.5$

$99.7 \% \quad 57.2$

$99.7 \% \quad 56.2$

$99.7 \% \quad 45.2$

$99.7 \% \quad 39.0$

$99.7 \% \quad 59.5$

$0.04 \% \quad 34.0 \%$ ILNNSGLPITSAIDLEDAAK $\quad 99.7 \% \quad 55.4$

$0.04 \% \quad 34.0 \%$ ILNNSGLPITSAIDLEDAAKK

$0.00 \% \quad 6.1 \%$ NLILAGVK

$0.00 \% \quad 6.1 \% \quad$ VSQGVEDGPDTK

$0.00 \% \quad 6.1 \%$ VSQGVEDGPDTKR

$0.01 \% \quad 5.6 \% \quad$ VIFTSPIK

$0.01 \% \quad 5.6 \%$ SFYQFQHYR

$0.01 \% \quad 5.6 \%$ VIQKVEAFEHR

$0.01 \% \quad 5.6 \%$ KAQIAIDIK

$0.01 \% \quad 5.6 \%$ LTEQLAGPLR

$0.01 \% \quad 5.6 \%$ MTDVFEGSIIR

$0.01 \% \quad 6.6 \%$ VMEPLTASR

$0.01 \% \quad 6.6 \%$ VNLNTIKR

$0.01 \% \quad 6.6 \% \quad$ VGGSDEEASGIPSR

$0.02 \% \quad 4.1 \% \quad$ APSSLSDAVPQR

$0.02 \% \quad 4.1 \%$ RATTGTQTLLSSGTR

$0.02 \% \quad 4.1 \%$ ATTGTQTLLSSGTR

$0.02 \% \quad 4.1 \%$ VGMIPAPK

$0.02 \% \quad 4.1 \% \quad$ RVCLIQEPK

$0.01 \% \quad 11.6 \%$ NGDICETSGKPK

$0.01 \% \quad 11.6 \%$ ETCVVVYTGYGNR

$0.01 \% \quad 11.6 \%$ LGPGKPGLK

$0.00 \% \quad 2.2 \%$ SADEQSIYEKER

$0.00 \% \quad 2.2 \%$ VGQTKEVLVIK

$0.01 \% \quad 5.2 \%$ SVCLIGDKEQR

$0.01 \% \quad 5.2 \%$ YLVIDEAHR

$0.01 \% \quad 5.2 \%$ VLIFSQMTR

$0.01 \% \quad 5.2 \% \quad$ TAEMNEKLSK

$0.01 \% \quad 5.2 \% \quad$ TIGYKVPR

$0.01 \% \quad 5.2 \%$ ALDTKIGR

$0.01 \% \quad 15.5 \%$ EVISHIGK

$0.01 \% \quad 15.5 \%$ TCSEAIQQLR

$0.01 \% \quad 15.5 \%$ TEAHKEIHSQQVK

$0.01 \% \quad 15.5 \%$ VSQSPSKDSEENPATEERPEK

$0.00 \% \quad 3.0 \%$ SQLLILDR

$0.00 \% \quad 3.0 \% \quad$ ISEQTYQLSR
$99.0 \% \quad 29.3$

$94.8 \% \quad 14.7$

$99.7 \% \quad 37.5$

$94.9 \% \quad 14.5$

$99.7 \% \quad 41.5$

$99.7 \% \quad 44.8$

$98.3 \% \quad 19.5$

$99.7 \% \quad 63.7$

$99.7 \% \quad 41.4$

$99.3 \% \quad 30.5$

$\begin{array}{lll}99.0 \% & 29.7\end{array}$

$99.7 \% \quad 42.8$

$99.7 \% \quad 56.4$

$98.7 \% \quad 21.4$

$99.7 \% \quad 63.7$

$99.0 \% \quad 22.8$

$97.5 \% \quad 18.2$

$99.7 \% \quad 38.7$

$\begin{array}{lll}99.7 \% & 42.8\end{array}$

$99.3 \% \quad 24.9$

$98.9 \% \quad 27.8$

$95.0 \% \quad 17.7$

$99.7 \% \quad 53.1$

$99.7 \% \quad 36.8$

$99.7 \% \quad 34.1$

$99.7 \% \quad 27.7$

$\begin{array}{lll}99.0 \% & 25.4\end{array}$

$99.0 \% \quad 31.5$

$98.6 \% \quad 21.1$

$99.7 \% \quad 59.8$

$99.6 \% 24.0$

$99.7 \% \quad 26.6$

$99.0 \% \quad 31.3$

$99.7 \% \quad 31.1$
1138.59

1203.64

1240.62

1191.63

1876.94

1291.67

1240.56

1083.55

1294.81

1216.62

2055.10

2183.19

827.54

1231.58

1387.68

904.55

1275.59

1355.74

999.62

1097.63

1283.63

1003.52

957.58

1360.63

1227.63

1549.83

1393.73

812.47

1142.6

1305.61

1517.71

866.55

1454.68

1213.75

1304.66

1115.58

1094.60

1150.58

933.55

873.52

882.50

1205.59

1534.80

2344.09

957.57

1224.62

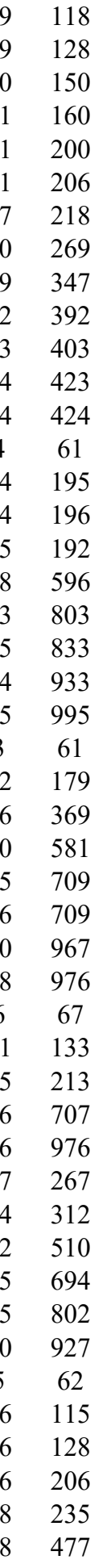


TAR DNA-binding protein 43 GN=TARDBP TADBP_HUMAN $44.74 \quad 100.0 \%$ TAR DNA-binding protein 43 GN=TARDBP TADBP_HUMAN $44.74 \quad 100.0 \%$ TAR DNA-binding protein 43 GN=TARDBP TADBP_HUMAN $44.74 \quad 100.0 \%$ Target of rapamycin complex subunit LST8 GN=MLST8 LST8 HUMAN $35.88 \quad 100.0^{\circ}$ Target of rapamycin complex subunit LST8 GN=MLST8 LST8_HUMAN $35.88 \quad 100.0 \%$ Target of rapamycin complex subunit LST8 GN=MLST8 LST8_HUMAN $35.88 \quad 100.0 \%$ TATA-binding protein-associated factor 172 GN=BTAF1 BTAF1_HUMAN $206.89 \quad 100.0 \%$ TATA-binding protein-associated factor $172 \mathrm{GN}=\mathrm{BTAF} 1$ BTAF1_HUMAN $206.89 \quad 100.0 \%$ TATA-binding protein-associated factor 172 GN=BTAF1 BTAF1 HUMAN $206.89 \quad 100.0 \%$ TATA-binding protein-associated factor $172 \mathrm{GN}=\mathrm{BTAF} 1$ BTAF1_HUMAN $206.89 \quad 100.0 \%$ TATA-binding protein-associated factor 172 GN=BTAF1 BTAF1_HUMAN $206.89 \quad 100.0 \%$ TATA-binding protein-associated factor 2N GN=TAF15 RBP56 HUMAN $61.83100 .0 \%$ TATA-binding protein-associated factor 2N GN=TAF15 RBP56_HUMAN $61.83 \quad 100.0 \%$ TATA-binding protein-associated factor 2N GN=TAF15 RBP56_HUMAN $61.83 \quad 100.0 \%$ TBC1 domain family member $15 \mathrm{GN}=\mathrm{TBC} 1 \mathrm{D} 15$ TBC15_HUMAN $79.49 \quad 100.0 \%$ $\mathrm{TBC} 1$ domain family member $15 \mathrm{GN}=\mathrm{TBC} 1 \mathrm{D} 15 \mathrm{TBC} 15$ _HUMAN $79.49 \quad 100.0 \%$ T-complex protein 1 subunit alpha GN=TCP1 TCPA HUMAN 60.35 T-complex protein 1 subunit alpha GN=TCP1 TCPA_HUMAN 60.35 T-complex protein 1 subunit alpha GN=TCP1 TCPA_HUMAN 60.35 T-complex protein 1 subunit alpha GN=TCP1 TCPA_HUMAN 60.35 T-complex protein 1 subunit alpha GN=TCP1 TCPA_HUMAN 60.35 T-complex protein 1 subunit alpha GN=TCP1 TCPA_HUMAN 60.35 T-complex protein 1 subunit alpha GN=TCP1 TCPA_HUMAN 60.35 T-complex protein 1 subunit alpha GN=TCP1 TCPA_HUMAN 60.3s T-complex protein 1 subunit alpha GN=TCP1 TCPA_HUMAN 60.35 T-complex protein 1 subunit alpha GN=TCP1 TCPA_HUMAN 60.35 T-complex protein 1 subunit alpha GN=TCP1 TCPA_HUMAN 60.3s T-complex protein 1 subunit alpha GN=TCP1 TCPA_HUMAN 60.35 T-complex protein 1 subunit alpha GN=TCP1 TCPA_HUMAN 60.3s T-complex protein 1 subunit alpha GN=TCP1 TCPA HUMAN 60.3 T-complex protein 1 subunit alpha GN=TCP1 TCPA_HUMAN 60.35 T-complex protein 1 subunit alpha GN=TCP1 TCPA_HUMAN 60.3 T-complex protein 1 subunit alpha GN=TCP1 TCPA_HUMAN 60.35 T-complex protein 1 subunit alpha GN=TCP1 TCPA_HUMAN 60.35 T-complex protein 1 subunit alpha GN=TCP1 TCPA_HUMAN 60.35 T-complex protein 1 subunit alpha GN=TCP1 TCPA_HUMAN 60.35 T-complex protein 1 subunit alpha GN=TCP1 TCPA_HUMAN 60.3s T-complex protein 1 subunit alpha GN=TCP1 TCPA_HUMAN 60.3 T-complex protein 1 subunit alpha GN=TCP1 TCPA_HUMAN 60.35 T-complex protein 1 subunit alpha GN=TCP1 TCPA_HUMAN 60.35 T-complex protein 1 subunit alpha GN=TCP1 TCPA_HUMAN 60.35 T-complex protein 1 subunit alpha GN=TCP1 TCPA_HUMAN 60.35 T-complex protein 1 subunit alpha GN=TCP1 TCPA_HUMAN 60.35 T-complex protein 1 subunit beta GN=CCT2 TCPB_HUMAN 57.49 T-complex protein 1 subunit beta GN=CCT2 TCPB_HUMAN 57.49 T-complex protein 1 subunit beta $\mathrm{GN}=\mathrm{CCT} 2$ TCPB_HUMAN 57.49 T-complex protein 1 subunit beta $\mathrm{GN}=\mathrm{CCT} 2$ TCPB_HUMAN 57.49 $100.0 \%$ $100.0 \%$ $100.0 \%$ $100.0 \%$
$0.01 \% \quad 10.1 \%$ KMDETDASSAVK $0.01 \% \quad 10.1 \%$ GISVHISNAEPK

$99.7 \% \quad 42.1$ $99.7 \% \quad 54.2$ $0.01 \% \quad 10.1 \%$ FGGNPGGFGNQGGFGNSR $99.7 \% \quad 72.7$ $0.00 \% \quad 14.7 \%$ TVQHQDSQVNALEVTPDR $\quad 99.7 \% \quad 38.0$ $0.00 \% \quad 14.7 \%$ SMIAAAGYQHIR $99.7 \% \quad 56.2$ $0.00 \% \quad 14.7 \%$ FSPDSTLLATCSADQ $0.01 \% \quad 3.1 \%$ AAAQQLGEVVK $0.01 \% \quad 3.1 \%$ IAAGQAVEAIVK $0.01 \% \quad 3.1 \%$ IANVVINQSANDSK

$0.01 \% \quad 3.1 \%$ AVTLAVQPR $0.01 \% \quad 3.1 \%$ NTIDINNFDGK $0.01 \% \quad 8.5 \%$ GEATVSFDDPPSAK $99.7 \% \quad 67.4$ $99.7 \% \quad 32.6$ $\begin{array}{lll}99.7 \% & 80.8\end{array}$ $99.7 \% 34.0$ $99.7 \% \quad 36.6$ $99.7 \% \quad 45.0$ $99.7 \% \quad 57.8$

$\begin{array}{llllll}0.01 \% & 8.5 \% & \text { SGGGYGGDRSSGGGYSGDR } & 99.7 \% & 50.1\end{array}$ $0.01 \% \quad 8.5 \%$ SGGGYGGDRGGGYGGDR $99.7 \% \quad 31.6$

$0.00 \% \quad 3.3 \%$ TNDQDGLISGILR $0.00 \% \quad 3.3 \%$ VTNYIFDSLR $0.09 \% \quad 41.7 \%$ SQNVMAAASIANIVK $0.09 \% \quad 41.7 \%$ SSLGPVGLDK $0.09 \% \quad 41.7 \%$ LLEVEHPAAK $0.09 \% \quad 41.7 \%$ NADELVKQK $0.09 \% \quad 41.7 \%$ QKIHPTSVISGYR $0.09 \% \quad 41.7 \%$ IHPTSVISGYR $0.09 \% \quad 41.7 \%$ YTDIRGQPR $0.09 \% \quad 41.7 \%$ YPVNSVNILK $0.09 \% \quad 41.7 \%$ IACLDFSLQK $0.09 \% \quad 41.7 \%$ IACLDFSLQKTK $0.09 \% \quad 41.7 \%$ LGVQVVITDPEKLDQIR $0.09 \% \quad 41.7 \%$ ICDDELILIK

$0.09 \% \quad 41.7 \%$ ICDDELILIKNTK $0.09 \% \quad 41.7 \%$ TSASIILR

$0.09 \% \quad 41.7 \%$ GANDFMCDEMER $0.09 \% \quad 41.7 \%$ SLHDALCVVK $0.09 \% \quad 41.7 \%$ SLHDALCVVKR $0.09 \% \quad 41.7 \%$ EQLAIAEFAR $99.7 \% \quad 27.0$ $99.7 \% \quad 31.4$ $99.7 \% \quad 83.1$ $99.5 \% \quad 28.5$ $99.7 \% \quad 61.5$ $99.7 \% \quad 39.1$ $99.4 \% \quad 25.9$ $99.6 \% 23.4$ $99.6 \% 24.4$ $99.7 \% \quad 35.3$ $99.7 \% \quad 53.5$ $98.0 \% 22.1$ $100.0 \% \quad 27$ $100.0 \% \quad 27$ $100.0 \%$ $100.0 \% \quad 27$ $100.0 \% \quad 27$ $100.0 \% \quad 27$ $100.0 \% \quad 27$ $100.0 \% \quad 27$ $100.0 \% \quad 27$ $100.0 \% \quad 27$ $100.0 \% \quad 27$ $100.0 \% \quad 27$ $100.0 \% \quad 27$ $100.0 \% \quad 27$ $100.0 \% \quad 27$ $100.0 \% \quad 27$

$\begin{array}{ccc}1297.59 & 84 & 95 \\ 1251.67 & 252 & 263 \\ 1726.77 & 276 & 293 \\ 2037.00 & 37 & 54 \\ 1317.67 & 55 & 66 \\ 2001.89 & 228 & 245 \\ 1113.63 & 24 & 34 \\ 1169.69 & 60 & 71 \\ 1472.77 & 249 & 262 \\ 954.57 & 745 & 753 \\ 1250.60 & 1059 & 1069 \\ 1420.66 & 284 & 297 \\ 1748.72 & 423 & 441 \\ 1544.65 & 451 & 467 \\ 1401.73 & 27 & 39 \\ 1227.64 & 253 & 262 \\ 1532.81 & 19 & 33 \\ 972.54 & 34 & 43 \\ 1106.62 & 64 & 73 \\ 1044.57 & 103 & 111 \\ 1485.82 & 110 & 122 \\ 1229.66 & 112 & 122 \\ 1105.58 & 181 & 189 \\ 1146.65 & 190 & 199 \\ 1194.62 & 234 & 243 \\ 1423.76 & 234 & 245 \\ 1923.09 & 248 & 264 \\ 1231.66 & 356 & 365 \\ 1574.85 & 356 & 368 \\ 860.52 & 371 & 378 \\ 1474.54 & 379 & 390 \\ 1141.60 & 391 & 400 \\ 1297.70 & 391 & 401 \\ 1147.61 & 434 & 443 \\ 2353.30 & 444 & 466 \\ 2622.48 & 444 & 468 \\ 1680.86 & 467 & 480 \\ 1411.67 & 469 & 480 \\ 1539.77 & 469 & 481 \\ 1355.74 & 485 & 496 \\ 1545.83 & 497 & 510 \\ 1188.66 & 500 & 510 \\ 1205.69 & 516 & 526 \\ 1275.59 & 14 & 25 \\ 870.54 & 182 & 189 \\ 1492.88 & 190 & 203 \\ 2041.05 & 205 & 223\end{array}$


T-complex protein 1 subunit beta GN=CCT2 TCPB_HUMAN $57.49 \quad 100.0 \%$ T-complex protein 1 subunit delta GN=CCT4 TCPD_HUMAN $57.93 \quad 100.0 \% \quad 20$ T-complex protein 1 subunit delta GN=CCT4 TCPD_HUMAN $57.93 \quad 100.0 \% \quad 20$ T-complex protein 1 subunit delta GN=CCT4 TCPD HUMAN $57.93 \quad 100.0 \%$ T-complex protein 1 subunit delta GN=CCT4 TCPD_HUMAN $57.93 \quad 100.0 \% \quad 20$ T-complex protein 1 subunit delta GN=CCT4 TCPD_HUMAN $57.93 \quad 100.0 \% \quad 20$ T-complex protein 1 subunit delta GN=CCT4 TCPD_HUMAN $57.93 \quad 100.0 \% \quad 20$ T-complex protein 1 subunit delta GN=CCT4 TCPD_HUMAN $57.93 \quad 100.0 \% \quad 20$ T-complex protein 1 subunit delta GN=CCT4 TCPD_HUMAN $57.93 \quad 100.0 \%$ T-complex protein 1 subunit delta GN=CCT4 TCPD_HUMAN $57.93 \quad 100.0 \% \quad 20$ T-complex protein 1 subunit delta GN=CCT4 TCPD_HUMAN $57.93 \quad 100.0 \% \quad 20$ T-complex protein 1 subunit delta GN=CCT4 TCPD_HUMAN $57.93 \quad 100.0 \% \quad 20$ T-complex protein 1 subunit delta GN=CCT4 TCPD_HUMAN $57.93 \quad 100.0 \% \quad 20$ T-complex protein 1 subunit delta GN=CCT4 TCPD_HUMAN $57.93 \quad 100.0 \% \quad 20$ T-complex protein 1 subunit delta GN=CCT4 TCPD_HUMAN $57.93 \quad 100.0 \% \quad 20$ T-complex protein 1 subunit delta GN=CCT4 TCPD_HUMAN $57.93 \quad 100.0 \% \quad 20$ T-complex protein 1 subunit delta GN=CCT4 TCPD HUMAN $57.93 \quad 100.0 \% \quad 20$ T-complex protein 1 subunit delta GN=CCT4 TCPD_HUMAN $57.93 \quad 100.0 \% \quad 20$ T-complex protein 1 subunit delta GN=CCT4 TCPD_HUMAN $57.93 \quad 100.0 \% \quad 20$ T-complex protein 1 subunit delta GN=CCT4 TCPD_HUMAN $57.93 \quad 100.0 \% 20$ T-complex protein 1 subunit delta GN=CCT4 TCPD_HUMAN $57.93 \quad 100.0 \% \quad 20$ T-complex protein 1 subunit epsilon GN=CCT5 TCPE HUMAN $59.67 \quad 100.0 \%$ T-complex protein 1 subunit epsilon GN=CCT5 TCPE_HUMAN $59.67 \quad 100.0 \%$ T-complex protein 1 subunit epsilon GN=CCT5 TCPE_HUMAN $59.67 \quad 100.0 \%$ T-complex protein 1 subunit epsilon GN=CCT5 TCPE HUMAN $59.67 \quad 100.0 \%$ T-complex protein 1 subunit epsilon GN=CCT5 TCPE_HUMAN $59.67 \quad 100.0 \%$ T-complex protein 1 subunit epsilon GN=CCT5 TCPE_HUMAN $59.67 \quad 100.0 \%$ T-complex protein 1 subunit epsilon GN=CCT5 TCPE_HUMAN $59.67 \quad 100.0 \%$ T-complex protein 1 subunit epsilon GN=CCT5 TCPE_HUMAN $59.67 \quad 100.0 \%$ T-complex protein 1 subunit epsilon $\mathrm{GN}=\mathrm{CCT} 5 \mathrm{TCPE}$ HUMAN $59.67 \quad 100.0 \%$ T-complex protein 1 subunit eta GN=CCT7 TCPH_HUMAN $59.37 \quad 100.0 \%$ T-complex protein 1 subunit eta $\mathrm{GN}=\mathrm{CCT} 7 \mathrm{TCPH} \_$HUMAN $59.37 \quad 100.0 \%$ T-complex protein 1 subunit gamma GN=CCT3 TCPG HUMAN $60.54 \quad 100.0 \%$ T-complex protein 1 subunit gamma GN=CCT3 TCPG_HUMAN $60.54 \quad 100.0 \%$ T-complex protein 1 subunit gamma GN=CCT3 TCPG_HUMAN $60.54 \quad 100.0 \%$ T-complex protein 1 subunit gamma GN=CCT3 TCPG_HUMAN $60.54 \quad 100.0 \%$ T-complex protein 1 subunit gamma GN=CCT3 TCPG_HUMAN $60.54 \quad 100.0 \%$ T-complex protein 1 subunit gamma GN=CCT3 TCPG_HUMAN $60.54 \quad 100.0 \%$ T-complex protein 1 subunit gamma GN=CCT3 TCPG_HUMAN $60.54 \quad 100.0 \%$ T-complex protein 1 subunit gamma GN=CCT3 TCPG_HUMAN $60.54 \quad 100.0 \%$ T-complex protein 1 subunit gamma GN=CCT3 TCPG_HUMAN $60.54 \quad 100.0 \%$ T-complex protein 1 subunit gamma GN=CCT3 TCPG_HUMAN $60.54 \quad 100.0 \%$ T-complex protein 1 subunit gamma $\mathrm{GN}=\mathrm{CCT} 3 \mathrm{TCPG}$ HUMAN $60.54100 .0 \%$ T-complex protein 1 subunit gamma GN=CCT3 TCPG_HUMAN $60.54 \quad 100.0 \%$ T-complex protein 1 subunit gamma GN=CCT3 TCPG_HUMAN $60.54 \quad 100.0 \%$ T-complex protein 1 subunit gamma GN=CCT3 TCPG HUMAN $60.54 \quad 100.0 \%$ T-complex protein 1 subunit gamma GN=CCT3 TCPG_HUMAN $60.54 \quad 100.0 \%$
$10 \quad 0.01 \% \quad 11.6 \%$ HGINCFINR$$
63
$$
$0.06 \% \quad 28.3 \%$ ANITAIRR $0.06 \% \quad 28.3 \%$ EILSEVER $\begin{array}{llllll}99.7 \% & 33.0 & 25.0 & 27.7 & 2 & 0\end{array}$ $\begin{array}{llllll}99.7 \% & 34.5 & 25.0 & 30.3 & 2 & 2\end{array}$ $99.0 \% \quad 41.9 \quad 25.0 \quad 26.5 \quad 2$ $\begin{array}{llll}99.7 \% & 42.1 & 25.0 & 32.9\end{array}$ $\begin{array}{llll}99.1 \% & 20.2 & 25.0 & 20.2\end{array}$ $\begin{array}{llll}99.7 \% & 57.1 & 25.0 & 49.6\end{array}$ $\begin{array}{llll}99.7 \% & 58.8 & 25.0 & 44.5\end{array}$ $\begin{array}{llll}99.7 \% & 37.8 & 25.0 & 37.8\end{array}$ $\begin{array}{lllll}99.7 \% & 55.3 & 25.0 & 55.1 & 11\end{array}$ $\begin{array}{lllll}99.0 \% & 26.6 & 25.0 & 20.0\end{array}$ $\begin{array}{lllll}99.7 \% & 30.6 & 25.0 & 25.7 & 4\end{array}$ $\begin{array}{llll}99.7 \% & 58.8 & 25.0 & 53.2\end{array}$ $\begin{array}{llll}99.7 \% & 29.5 & 25.0 & 29.5\end{array}$ $\begin{array}{lllll}99.7 \% & 51.5 & 25.0 & 42.3 & 2\end{array}$ $\begin{array}{lllll}99.4 \% & 57.9 & 25.0 & 0.0 & 2\end{array}$ $\begin{array}{lllll}99.7 \% & 51.6 & 25.0 & 51.6 & 14\end{array}$ $\begin{array}{lllll}99.6 \% & 27.7 & 25.0 & 26.7\end{array}$ $\begin{array}{llll}99.7 \% & 37.1 & 25.0 & 37.1\end{array}$ $\begin{array}{llll}99.7 \% & 44.3 & 25.0 & 44.3\end{array}$ $\begin{array}{lllll}99.7 \% & 56.7 & 25.0 & 48.0 & 2\end{array}$ $\begin{array}{llll}99.0 \% & 26.2 & 25.0 & 18.9\end{array}$ $\begin{array}{llll}95.8 \% & 19.7 & 25.0 & 12.5\end{array}$ $\begin{array}{lllll}99.7 \% & 31.4 & 25.0 & 23.3\end{array}$ $\begin{array}{lllll}99.7 \% & 79.8 & 25.0 & 75.5 & 4\end{array}$ $\begin{array}{llll}99.7 \% & 46.5 & 25.0 & 40.4\end{array}$ $\begin{array}{llll}99.7 \% & 32.2 & 25.0 & 29.7\end{array}$ $\begin{array}{llll}97.2 \% & 23.6 & 25.0 & 10.5\end{array}$ $\begin{array}{lllll}99.4 \% & 57.9 & 25.0 & 0.0 & 2\end{array}$ $\begin{array}{llll}98.6 \% & 17.4 & 25.0 & 17.4\end{array}$ $\begin{array}{llll}99.7 \% & 40.5 & 25.0 & 37.3\end{array}$ $0.02 \% \quad 15.7 \%$ KQQISLATQMVR $0.02 \% \quad 15.7 \%$ QQISLATQMVR

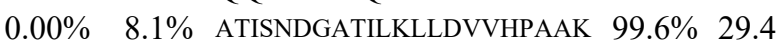
$0.00 \% \quad 8.1 \%$ SQDAEVGDGTTSVTLLAAEFLK $99.7 \% \quad 82.6$ $0.06 \% \quad 28.3 \%$ EIQVQHPAAK $0.06 \% \quad 28.3 \%$ ALDDMISTLK $0.06 \% \quad 28.3 \%$ ALDDMISTLKK $0.06 \% \quad 28.3 \%$ MVQFEENGRK $0.06 \% \quad 28.3 \%$ IPGGIIEDSCVLR $0.06 \% \quad 28.3 \%$ GVMINKDVTHPR $0.06 \% \quad 28.3 \%$ IVLLDSSLEYK $0.06 \% \quad 28.3 \%$ IVLLDSSLEYKK $0.06 \% \quad 28.3 \%$ GISDLAQHYLMR $0.06 \% \quad 28.3 \%$ GASKEILSEVER $0.06 \% \quad 28.3 \%$ NLQDAMQVCR $0.06 \% \quad 28.3 \%$ AMTGVEQWPYR $0.06 \% \quad 28.3 \%$ AVAQALEVIPR \begin{tabular}{llll}
$99.7 \%$ & 47.6 & 25.0 & 82.6 \\
\hline & 25.0 & 37.3
\end{tabular}

$\begin{array}{llll}99.7 \% & 32.5 & 25.0 & 24.5\end{array}$

$\begin{array}{llll}99.7 \% & 50.8 & 25.0 & 49.3\end{array}$

$\begin{array}{llll}99.6 \% & 25.0 & 25.0 & 19.0\end{array}$

$\begin{array}{lllll}99.7 \% & 46.0 & 25.0 & 34.0 & 2\end{array}$

$\begin{array}{llll}99.7 \% & 43.1 & 25.0 & 42.2\end{array}$

$\begin{array}{llll}99.7 \% & 56.8 & 25.0 & 47.7\end{array}$

$\begin{array}{lllll}99.7 \% & 35.5 & 25.0 & 35.5 & 2\end{array}$

$\begin{array}{llll}99.7 \% & 52.3 & 25.0 & 51.5\end{array}$

$\begin{array}{lllll}99.0 \% & 25.8 & 25.0 & 17.7 & 2\end{array}$

$\begin{array}{lllll}99.7 \% & 52.7 & 25.0 & 45.1 & 2\end{array}$

$\begin{array}{llll}99.0 \% & 32.3 & 25.0 & 11.8\end{array}$

$\begin{array}{lllll}99.0 \% & 32.3 & 25.0 & 11.8 & 1 \\ 99.7 \% & 59.0 & 25.0 & 51.2 & 4\end{array}$

$\begin{array}{llll}99.7 \% & 47.0 & 25.0 & 46.5\end{array}$

$\begin{array}{lllll}99.7 \% & 62.8 & 25.0 & 58.1 & 12\end{array}$
1130.55

1517.78

837.45

1298.74

1456.78

1357.73

1189.65

1545.88

1346.75

933.58

1145.63

1456.78

1658.93

1344.71

1183.63

1550.89

2300.26

1318.58

1380.73

1372.78

931.48

874.51

1001.53

1093.53

1391.74

1713.86

989.54

1183.63

1402.78

1274.69

2247.27

2252.13

1120.6

1106.58

1234.67

1237.60

1428.75

1366.73

1279.71

1407.81

1419.7

914.55

1317.70

974.52

1250.56

1337.63

1166.69

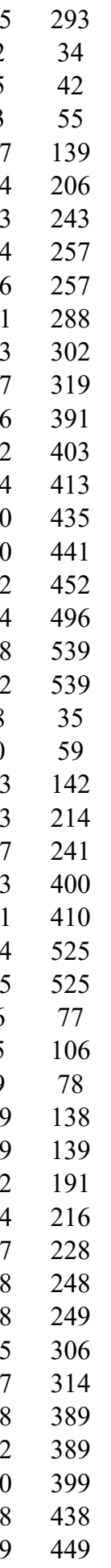


T-complex protein 1 subunit gamma GN=CCT3 TCPG_HUMAN $60.54 \quad 100.0 \% \quad 1$ T-complex protein 1 subunit gamma GN=CCT3 TCPG_HUMAN $60.54 \quad 100.0 \%$ T-complex protein 1 subunit gamma GN=CCT3 TCPG_HUMAN $60.54 \quad 100.0 \%$ T-complex protein 1 subunit theta GN=CCT8 TCPQ HUMAN $59.62 \quad 100.0 \%$ T-complex protein 1 subunit theta GN=CCT8 TCPQ_HUMAN $59.62 \quad 100.0 \%$ T-complex protein 1 subunit theta $\mathrm{GN}=\mathrm{CCT} 8$ TCPQ_HUMAN $59.62 \quad 100.0 \%$ T-complex protein 1 subunit theta GN=CCT8 TCPQ HUMAN $59.62 \quad 100.0 \%$ T-complex protein 1 subunit theta GN=CCT8 TCPQ_HUMAN $59.62 \quad 100.0 \%$ T-complex protein 1 subunit zeta GN=CCT6A TCPZ HUMAN $58.03 \quad 100.0 \%$ T-complex protein 1 subunit zeta GN=CCT6A TCPZ_HUMAN $58.03 \quad 100.0 \%$ T-complex protein 1 subunit zeta GN=CCT6A TCPZ_HUMAN $58.03 \quad 100.0 \%$ T-complex protein 1 subunit zeta GN=CCT6A TCPZ_HUMAN $58.03 \quad 100.0 \%$ T-complex protein 1 subunit zeta GN=CCT6A TCPZ_HUMAN $58.03 \quad 100.0 \%$ T-complex protein 1 subunit zeta GN=CCT6A TCPZ_HUMAN $58.03 \quad 100.0 \%$ T-complex protein 1 subunit zeta GN=CCT6A TCPZ_HUMAN $58.03 \quad 100.0 \%$ T-complex protein 1 subunit zeta GN=CCT6A TCPZ_HUMAN $58.03 \quad 100.0 \%$ T-complex protein 1 subunit zeta GN=CCT6A TCPZ HUMAN $58.03 \quad 100.0 \%$ T-complex protein 1 subunit zeta GN=CCT6A TCPZ_HUMAN $58.03 \quad 100.0 \%$ T-complex protein 1 subunit zeta GN=CCT6A TCPZ_HUMAN $58.03 \quad 100.0 \%$ T-complex protein 1 subunit zeta GN=CCT6A TCPZ HUMAN $58.03 \quad 100.0 \%$ T-complex protein 1 subunit zeta GN=CCT6A TCPZ_HUMAN $58.03 \quad 100.0 \%$ T-complex protein 1 subunit zeta GN=CCT6A TCPZ HUMAN $58.03 \quad 100.0 \%$ TELO2-interacting protein 1 homolog GN=TTI1 TTI1_HUMAN $122.07 \quad 100.0 \%$ TELO2-interacting protein 1 homolog GN=TTI1 TTI1_HUMAN $122.07 \quad 100.0 \%$ Testis-expressed sequence 10 protein GN=TEX10 TEX10_HUMAN $105.68100 .0 \%$ Testis-expressed sequence 10 protein GN=TEX10 TEX10_HUMAN $105.68 \quad 100.0 \%$ Testis-expressed sequence 10 protein GN=TEX10 TEX10_HUMAN $105.68 \quad 100.0 \%$ Testis-expressed sequence 10 protein GN=TEX10 TEX10 HUMAN $105.68100 .0 \%$ Tetratricopeptide repeat protein $37 \mathrm{GN}=\mathrm{TTC} 37$ TTC37_HUMAN $175.49 \quad 100.0 \%$ Tetratricopeptide repeat protein $37 \mathrm{GN}=\mathrm{TTC} 37$ TTC37 HUMAN $175.49 \quad 100.0 \%$ Tetratricopeptide repeat protein 37 GN=TTC37 TTC37_HUMAN $175.49 \quad 100.0 \%$ Tetratricopeptide repeat protein 37 GN=TTC37 TTC37_HUMAN $175.49 \quad 100.0 \%$ Tetratricopeptide repeat protein $37 \mathrm{GN}=$ TTC37 TTC37_HUMAN $175.49100 .0 \%$ Tetratricopeptide repeat protein $37 \mathrm{GN}=\mathrm{TTC} 37$ TTC37_HUMAN $175.49 \quad 100.0 \%$ TGF-beta-activated kinase 1 and MAP3K7-binding protein $1 \mathrm{GN}=\mathrm{TAB} 1$ TAB1_HUMAN $54.64 \quad 100.0 \%$ TGF-beta-activated kinase 1 and MAP3K7-binding protein $1 \mathrm{GN}=\mathrm{TAB} 1 \mathrm{TAB} 1$ HUMAN $54.64 \quad 100.0 \%$ TGF-beta-activated kinase 1 and MAP3K7-binding protein $1 \mathrm{GN}=\mathrm{TAB} 1 \quad \mathrm{TAB} 1$ HUMAN $54.64 \quad 100.0 \%$ Thioredoxin domain-containing protein $5 \mathrm{GN}=$ TXNDC5 TXND5 HUMAN $47.63 \quad 100.0 \%$ Thioredoxin domain-containing protein 5 GN=TXNDC5 TXND5_HUMAN $47.63 \quad 100.0 \%$ THO complex subunit $2 \mathrm{GN}=\mathrm{THOC} 2$ THO complex subunit $2 \mathrm{GN}=\mathrm{THOC}$ THO complex subunit $2 \mathrm{GN}=\mathrm{THOC} 2$ THO complex subunit $2 \mathrm{GN}=\mathrm{THOC} 2$ THO complex subunit $2 \mathrm{GN}=\mathrm{THOC} 2$ THO complex subunit $3 \mathrm{GN}=\mathrm{THOC} 3$ THO complex subunit $3 \mathrm{GN}=\mathrm{THOC} 3$ THO complex subunit $3 \mathrm{GN}=\mathrm{THOC} 3$ THOC2_HUMAN $182.78 \quad 100.0 \%$ THOC2_HUMAN $182.78 \quad 100.0 \%$ THOC3_HUMAN $38.77 \quad 100.0 \%$ THOC3_HUMAN $38.77 \quad 100.0 \%$

(2)

5

$4 \quad 18$

18
18
18

18
18
18

18

$\begin{array}{ll}4 & 18 \\ 4 & 18\end{array}$

18

18

\begin{tabular}{ll}
14 & 18 \\
14 & 18 \\
4 & 18 \\
\hline 4 & 18
\end{tabular}

18
18
18

18
18

$\begin{array}{ll}2 & 2 \\ 4 & 4\end{array}$

4
4
4

$\begin{array}{ccccl}4 & 6 & 0.01 \% & 4.1 \% & \text { FLQALADGSSR } \\ 4 & 6 & 0.01 \% & 4.1 \% & \text { AVYTLYQQR } \\ 4 & 6 & 0.01 \% & 4.1 \% & \text { SLQATALR } \\ 6 & 11 & 0.01 \% & 4.0 \% & \text { SGPGLIGLGIK } \\ 6 & 11 & 0.01 \% & 4.0 \% & \text { IVDNLGASGNSLYQR } \\ 6 & 11 & 0.01 \% & 4.0 \% & \text { AALNELLK }\end{array}$

$\begin{array}{ccccl}4 & 6 & 0.01 \% & 4.1 \% & \text { FLQALADGSSR } \\ 4 & 6 & 0.01 \% & 4.1 \% & \text { AVYTLYQQR } \\ 4 & 6 & 0.01 \% & 4.1 \% & \text { SLQATALR } \\ 6 & 11 & 0.01 \% & 4.0 \% & \text { SGPGLIGLGIK } \\ 6 & 11 & 0.01 \% & 4.0 \% & \text { IVDNLGASGNSLYQR } \\ 6 & 11 & 0.01 \% & 4.0 \% & \text { AALNELLK }\end{array}$

6
6
3

3
2
2
5

2
5
5

5 THOC3_HUMAN $38.77 \quad 100.0 \%$
$59 \quad 0.06 \% \quad 28.3 \%$ TLIQNCGASTIR $59 \quad 0.06 \% \quad 28.3 \%$ IDDIVSGHK

$59 \quad 0.06 \% \quad 28.3 \%$ IDDIVSGHKK

$0.01 \% \quad 10.9 \%$ HFSGLEEAVYR

$0.01 \% \quad 10.9 \%$ QYGNEVFLAK

$0.01 \% \quad 10.9 \%$ AIADTGANVVVTGGK

$0.01 \% \quad 10.9 \%$ LVPGGGATEIELAK

$0.01 \% \quad 10.9 \%$ FAEAFEAIPR

$90.04 \% \quad 26.4 \%$ TLNPKAEVAR

$39 \quad 0.04 \% \quad 26.4 \%$ AQAALAVNISAAR

$39 \quad 0.04 \% \quad 26.4 \%$ MLVSGAGDIKLTK

$0.04 \% \quad 26.4 \%$ QADLYISEGLHPR

$0.04 \% \quad 26.4 \%$ IITEGFEAAK

$0.04 \% \quad 26.4 \%$ IITEGFEAAKEK

$0.04 \% \quad 26.4 \%$ ALQFLEEVKVSR

$0.04 \% \quad 26.4 \%$ EMDRETLIDVAR

$0.04 \% \quad 26.4 \%$ HKSETDTSLIR

$0.04 \% \quad 26.4 \%$ SETDTSLIR

$0.04 \% \quad 26.4 \%$ GLVLDHGAR

$0.04 \% \quad 26.4 \%$ VCGDSDKGFVVINQK

$0.04 \% \quad 26.4 \%$ EGIVALRR

$0.00 \% \quad 2.0 \%$ DAPLAVLR

$0.00 \% \quad 2.0 \%$ LAGSLVTQAPISAR

$0.01 \% \quad 4.1 \% \quad$ LQNATPTNFK

$0.01 \% \quad 4.1 \%$ FLQALADGSSR

$0.01 \% \quad 4.1 \%$ AVYTLYQQR

$0.01 \% \quad 4.1 \%$ SLQATALR

$0.01 \% \quad 4.0 \%$ IVDNLGASGNSLYQR

$11-0.01 \% \quad 4.0 \% \quad$ VVYQPGYPK

$11 \quad 0.01 \% \quad 4.0 \% \quad$ ALELNQRLSSQ

$0.01 \% \quad 7.7 \% \quad$ VLLQAFDVVER

$0.01 \% \quad 7.7 \%$ IHSDTFASGGER

$\begin{array}{lll}0.00 \% & 4.6 \% & \text { IAEVDCTAER }\end{array}$

$0.00 \% \quad 4.6 \%$ FVLSQAKDEL

$0.02 \% \quad 3.1 \%$ GSPVNALQNK

$0.02 \% \quad 3.1 \%$ LTKENVKPSGR

$0.02 \% \quad 3.1 \%$ FVELVHQQK

$0.02 \% \quad 3.1 \%$ VLNLGQALER

$0.02 \% \quad 3.1 \% \quad$ TTVPNAESK

$0.01 \% \quad 6.0 \%$ YVLGMQELFR

$0.01 \% \quad 6.0 \%$ TASVFLLEK

$\begin{array}{lll}0.01 \% & 6.0 \% & \text { TASVFLLEKDR }\end{array}$ $\begin{array}{llllllll}99.7 \% & 57.7 & 25.0 & 49.0 & 2 & 0 & 0 & 1333.69\end{array}$

$99.7 \% \quad 38.4 \quad 25.0-34.3-2$

$99.6 \% \quad 28.9 \quad 25.0 \quad 17.5$

$99.6 \% \quad 23.8 \quad 25.0 \quad 23.8$

$\begin{array}{llll}99.7 \% & 37.1 & 25.0 & 34.2\end{array}$

$\begin{array}{llll}99.7 \% & 78.3 & 25.0 & 69.5\end{array}$

$99.0 \% \quad 23.8 \quad 25.0 \quad 15.8$

$\begin{array}{lllll}99.7 \% & 54.4 & 25.0 & 49.2 & 2\end{array}$

$99.7 \% \quad 55.4 \quad 25.0 \quad 55.4$

$\begin{array}{lllll}99.7 \% & 39.5 & 25.0 & 39.5 & 3\end{array}$

$\begin{array}{lllll}99.7 \% & 66.7 & 25.0 & 61.0 & 2\end{array}$

$\begin{array}{lllll}99.7 \% & 52.3 & 25.0 & 49.6 & 3\end{array}$

$\begin{array}{llll}99.7 \% & 45.5 & 25.0 & 23.1\end{array}$

$\begin{array}{llll}99.7 \% & 60.8 & 25.0 & 56.9\end{array}$

$\begin{array}{llll}99.7 \% & 52.2 & 25.0 & 52.2\end{array}$

$\begin{array}{lllll}99.7 \% & 41.5 & 25.0 & 26.6 & 2\end{array}$

$95.0 \% \quad 16.6 \quad 25.0 \quad 12.4$

$\begin{array}{lllll}99.7 \% & 35.0 & 25.0 & 27.2\end{array}$

$99.7 \% \quad 45.5 \quad 25.0 \quad 35.6$

$\begin{array}{llll}99.7 \% & 46.0 & 25.0 & 40.9\end{array}$

$\begin{array}{llll}99.7 \% & 39.7 & 25.0 & 15.5\end{array}$

$\begin{array}{lllll}98.9 \% & 26.1 & 25.0 & 12.7 & 2\end{array}$

$\begin{array}{llll}99.0 \% & 31.1 & 25.0 & 21.8\end{array}$

$\begin{array}{lllll}99.7 \% & 44.8 & 25.0 & 44.8 & 2\end{array}$

$\begin{array}{lllll}99.7 \% & 37.1 & 25.0 & 34.5\end{array}$

$99.7 \% \quad 41.2 \quad 25.0 \quad 41.2$

$\begin{array}{llll}99.7 \% & 67.1 & 25.0 & 58.4\end{array}$

$\begin{array}{llll}99.0 \% & 43.8 & 25.0 & 27.5\end{array}$

$\begin{array}{lllll}99.7 \% & 36.8 & 25.0 & 25.2 & 2\end{array}$

$99.7 \% \quad 70.6 \quad 25.0 \quad 70.6$

$\begin{array}{llll}99.0 \% & 25.0 & 25.0 & 15.6\end{array}$

$\begin{array}{llll}99.0 \% & 39.0 & 25.0 & 32.3\end{array}$

$\begin{array}{llll}99.7 \% & 33.3 & 25.0 & 33.3\end{array}$

$\begin{array}{llll}99.4 \% & 27.6 & 25.0 & 27.6\end{array}$

$99.7 \% \quad 44.9 \quad 25.0 \quad 44.9$

$\begin{array}{llll}98.8 \% & 18.7 & 25.0 & 18.0\end{array}$

$\begin{array}{llll}99.7 \% & 40.7 & 25.0 & 40.7\end{array}$

$99.7 \% \quad 31.9 \quad 25.0 \quad 31.9$

$\begin{array}{llll}9.7 \% & 31.0 & 25.0 & 31.0\end{array}$

$\begin{array}{lllll}99.7 \% & 37.9 & 25.0 & 37.9 & 6\end{array}$

$\begin{array}{llll}99.7 \% & 39.6 & 25.0 & 29.9\end{array}$

$\begin{array}{llll}97.6 \% & 16.4 & 25.0 & 16.4\end{array}$

$\begin{array}{lllll}99.7 \% & 45.9 & 25.0 & 45.0 & 1\end{array}$

$\begin{array}{llll}99.4 \% & 23.8 & 25.0 & 16.8\end{array}$

$\begin{array}{llll}99.7 \% & 56.2 & 25.0 & 56.2\end{array}$

$\begin{array}{ll}0 & 0 \\ 0 & 0 \\ 0 & 0 \\ 0 & 0 \\ 0 & 0 \\ 0 & 0 \\ 0 & 0 \\ 0 & 0 \\ 0 & 0 \\ 2 & 0 \\ 4 & 0 \\ 0 & 0 \\ 0 & 0 \\ 0 & 0 \\ 2 & 0 \\ 1 & 0 \\ 0 & 0 \\ 0 & 0 \\ 2 & 0 \\ 0 & 0 \\ 0 & 0 \\ 0 & 0 \\ 0 & 0 \\ 0 & 0 \\ 0 & 0 \\ 0 & 0 \\ 0 & 0 \\ 0 & 0 \\ 0 & 0 \\ 0 & 0 \\ 0 & 0 \\ 0 & 0 \\ 0 & 0 \\ 0 & 0 \\ 0 & 0 \\ 0 & 0 \\ 0 & 0 \\ 0 & 0 \\ 0 & 0 \\ 1 & 0 \\ 0 & 0 \\ 0 & 0 \\ 0 & 0 \\ 0 & 0 \\ 0 & 0 \\ 1 & 0 \\ & \end{array}$

$\begin{array}{ccc}1333.69 & 450 & 461 \\ 983.52 & 519 & 527 \\ 1111.61 & 519 & 528 \\ 1307.64 & 21 & 31 \\ 1168.60 & 172 & 181 \\ 1372.74 & 282 & 296 \\ 1354.76 & 408 & 421 \\ 1150.59 & 441 & 450 \\ 1098.63 & 6 & 15 \\ 1255.71 & 16 & 28 \\ 1348.75 & 46 & 58 \\ 1498.77 & 105 & 117 \\ 1078.58 & 118 & 127 \\ 1335.72 & 118 & 129 \\ 1418.80 & 130 & 141 \\ 1447.72 & 142 & 153 \\ 1286.67 & 198 & 208 \\ 1021.52 & 200 & 208 \\ 937.52 & 209 & 217 \\ 1665.83 & 281 & 295 \\ 1262.66 & 296 & 307 \\ 913.56 & 308 & 315 \\ 854.51 & 921 & 928 \\ 1383.80 & 956 & 969 \\ 1133.60 & 25 & 34 \\ 1164.60 & 234 & 244 \\ 1141.60 & 505 & 513 \\ 859.50 & 591 & 598 \\ 1011.62 & 271 & 281 \\ 1606.82 & 335 & 349 \\ 871.52 & 1143 & 1150 \\ 934.51 & 1202 & 1209 \\ 1050.56 & 1508 & 1516 \\ 1258.68 & 1554 & 1564 \\ 1288.73 & 105 & 115 \\ 1276.59 & 337 & 348 \\ 1699.85 & 387 & 402 \\ 1163.54 & 376 & 385 \\ 1149.62 & 423 & 432 \\ 1027.55 & 406 & 415 \\ 1228.70 & 556 & 566 \\ 1127.62 & 999 & 1007 \\ 1112.64 & 1137 & 1146 \\ 946.48 & 1344 & 1352 \\ 1271.65 & 34 & 43 \\ 1007.58 & 78 & 86 \\ 1278.71 & 78 & 88 \\ & & \end{array}$

Page 150 of Table S-1-5 
THO complex subunit $4 \mathrm{GN}=\mathrm{ALYREF}$ THO complex subunit $4 \mathrm{GN}=\mathrm{ALYREF}$ THO complex subunit $4 \mathrm{GN}=\mathrm{ALYREF}$ THO complex subunit $4 \mathrm{GN}=\mathrm{ALYREF}$ THO complex subunit $4 \mathrm{GN}=\mathrm{ALYREF}$ THUMP domain-containing protein $3 \mathrm{GN}=$ THUN THUMP THUMP domain-containing protein 3 GN=THUMPD3 THUM__HUMAN $57.00 \quad 100.0 \%$ Thyroid hormone receptor-associated protein 3 GN=THRAP3 TR150_HUMAN $108.67 \quad 100.0 \%$ Thyroid hormone receptor-associated protein $3 \mathrm{GN}=$ THRAP3 TR150_HUMAN $108.67 \quad 100.0 \%$ Thyroid hormone receptor-associated protein $3 \mathrm{GN}=$ THRAP3 TR150_HUMAN $108.67 \quad 100.0 \%$ Thyroid hormone receptor-associated protein $3 \mathrm{GN}=$ THRAP3 TR150_HUMAN $108.67 \quad 100.0 \%$ Thyroid hormone receptor-associated protein $3 \mathrm{GN}=$ THRAP3 TR150_HUMAN $108.67 \quad 100.0 \%$ Thyroid hormone receptor-associated protein $3 \mathrm{GN}=$ THRAP3 TR150_HUMAN $108.67 \quad 100.0 \%$ Thyroid hormone receptor-associated protein 3 GN=THRAP3 TR150_HUMAN $108.67 \quad 100.0 \%$ Thyroid hormone receptor-associated protein $3 \mathrm{GN}=\mathrm{THRAP3}$ TR150_HUMAN $108.67 \quad 100.0 \%$ Thyroid hormone receptor-associated protein $3 \mathrm{GN}=$ THRAP3 TR150 HUMAN $108.67 \quad 100.0 \%$ Thyroid hormone receptor-associated protein $3 \mathrm{GN}=$ THRAP3 TR150_HUMAN $108.67 \quad 100.0 \%$ Thyroid hormone receptor-associated protein 3 GN=THRAP3 TR150_HUMAN $108.67 \quad 100.0 \%$ Thyroid hormone receptor-associated protein $3 \mathrm{GN}=$ THRAP3 TR150_HUMAN $108.67 \quad 100.0 \%$ Thyroid hormone receptor-associated protein 3 GN=THRAP3 TR150_HUMAN $108.67 \quad 100.0 \%$ Thyroid hormone receptor-associated protein 3 GN=THRAP3 TR150_HUMAN $108.67 \quad 100.0 \%$ Thyroid transcription factor 1-associated protein $26 \mathrm{GN}=\mathrm{CCDC} 59$ TAP26_HUMAN $28.67 \quad 100.0 \%$ Thyroid transcription factor 1-associated protein $26 \mathrm{GN}=\mathrm{CCDC} 59$ TAP26_HUMAN $28.67 \quad 100.0 \%$ Thyroid transcription factor 1 -associated protein $26 \mathrm{GN}=\mathrm{CCDC} 59$ TAP26 HUMAN $28.67 \quad 100.0 \%$ Tight junction protein $\mathrm{ZO}-1 \mathrm{GN}=\mathrm{TJP} 1$ Tight junction protein $\mathrm{ZO}-1 \mathrm{GN}=\mathrm{TJP} 1$

Tight junction protein $\mathrm{ZO}-1 \mathrm{GN}=\mathrm{TJP} 1$ Tight junction protein $\mathrm{ZO}-1 \mathrm{GN}=\mathrm{TJP} 1$ TP53-regulating kinase $\mathrm{GN}=\mathrm{TP} 53 \mathrm{RK}$ TP53-regulating kinase $\mathrm{GN}=\mathrm{TP} 53 \mathrm{RK}$ TP53-regulating kinase $\mathrm{GN}=\mathrm{TP} 53 \mathrm{RK}$ TP53-regulating kinase $\mathrm{GN}=\mathrm{TP} 53 \mathrm{RK}$ TP53-regulating kinase $\mathrm{GN}=\mathrm{TP} 53 \mathrm{RK}$ ZO1_HUMAN $195.46 \quad 100.0 \%$ ZO1_HUMAN $195.46 \quad 100.0 \%$ ZO1 HUMAN $195.46 \quad 100.0 \%$ ZO1_HUMAN $195.46 \quad 100.0 \%$ PRPK HUMAN $28.16 \quad 100.0 \%$ PRPK_HUMAN $28.16 \quad 100.0 \%$ PRPK_HUMAN $28.16 \quad 100.0 \%$ PRPK HUMAN $28.16 \quad 100.0 \%$ PRPK_HUMAN $28.16 \quad 100.0 \%$ TraB domain-containing protein GN=TRABD TRABD_HUMAN $42.32 \quad 100.0 \%$ TraB domain-containing protein GN=TRABD TRABD_HUMAN $42.32 \quad 100.0 \%$ TraB domain-containing protein GN=TRABD TRABD_HUMAN $42.32 \quad 100.0 \%$ TraB domain-containing protein GN=TRABD TRABD_HUMAN $42.32 \quad 100.0 \%$ TraB domain-containing protein GN=TRABD TRABD_HUMAN $42.32 \quad 100.0 \%$ Trafficking protein particle complex subunit 5 GN=TRAPPC5 TPPC5_HUMAN $20.78 \quad 99.6 \%$ Trafficking protein particle complex subunit 5 GN=TRAPPC5 TPPC5_HUMAN $20.78 \quad 99.6 \%$ Transcription activator BRG1 GN=SMARCA4 SMCA4_HUMAN $184.65 \quad 100.0 \%$ Transcription activator BRG1 GN=SMARCA4 SMCA4_HUMAN $184.65 \quad 100.0 \%$ Transcription activator BRG1 GN=SMARCA4 SMCA4_HUMAN $184.65 \quad 100.0 \%$ Transcription activator BRG1 GN=SMARCA4 SMCA4_HUMAN $184.65 \quad 100.0 \%$ Transcription activator BRG1 GN=SMARCA4 SMCA4_HUMAN $184.65 \quad 100.0 \%$ Transcription activator BRG1 GN=SMARCA4 SMCA4_HUMAN $184.65 \quad 100.0 \%$
$19 \quad 0.02 \% \quad 35.0 \%$ MDMSLDDIIK

$\begin{array}{llllllll}99.7 \% & 35.5 & 25.0 & 25.7 & 2 & 0 & 0 & 1180.56\end{array}$

$0.02 \% \quad 35.0 \%$ QLPDKWQHDLFDSGF

$99.7 \% \quad 56.3$

$19 \quad 0.02 \% \quad 35.0 \%$ SLGTADVHFER

$\begin{array}{lllll}0.02 \% & 35.0 \% & \text { QYNGVPLDGRPMNIQLVTSQIDAQR } & 99.7 \% & 33.8 \\ 0.02 \% & 35.0 \% & \text { QQLSAEELDAQLDAYNAR } & 99.7 \% & 58.6\end{array}$

$\begin{array}{ccc}0.02 \% & 35.0 \% & \text { QQLSAEELDAQLDAYN } \\ 0.01 \% & 6.5 \% & \text { AGEKHCFTSNEAAR }\end{array}$

$99.5 \% \quad 21.6$

$0.01 \% \quad 6.5 \%$ AANNIASLLTK

$99.7 \% 35.6$

$0.01 \% \quad 6.5 \%$ AAVYVLIR

$99.0 \% \quad 44.7$

$0.06 \% \quad 14.6 \%$ ASESSKPWPDATYGTGSASR $\quad 99.7 \% 31.1$

$0.06 \% \quad 14.6 \%$ ASAVSELSPR

$0.06 \% \quad 14.6 \%$ ASAVSELSPRER

$0.06 \% \quad 14.6 \%$ SPALKSPLQSVVVR

$0.06 \% \quad 14.6 \%$ SPLQSVVVR

$0.06 \% \quad 14.6 \%$ SPLQSVVVRR

$0.06 \% \quad 14.6 \%$ EESAASGGAAYTK

$0.06 \% 14.6 \%$ GSFSDTGLGDGK

$0.06 \% \quad 14.6 \%$ VIGANKNQEEEK

$0.06 \% \quad 14.6 \%$ KTEELEEESFPER

$0.06 \% \quad 14.6 \%$ GFVPEKNFR

$0.06 \% \quad 14.6 \%$ VTAYKAVQEK

$0.06 \% \quad 14.6 \%$ SIFQHIQSAQSQR

$0.06 \% \quad 14.6 \%$ IDISPSTFRK

$0.01 \% \quad 12.4 \%$ GEGVSTVGYR

$0.01 \% \quad 12.4 \%$ HLYLAEEER

$0.01 \% \quad 12.4 \%$ AQEEYEQIQAK

$0.01 \% \quad 2.5 \%$ MSARAAAAK

$0.01 \% \quad 2.5 \%$ SVASSQPAKPTK

$0.01 \% \quad 2.5 \%$ EISQDSLAAR

$0.01 \% \quad 2.5 \%$ DGNIQEGDVVLK

$99.7 \% \quad 53.2$

$99.7 \% \quad 30.6$

$99.7 \% \quad 31.6$

$99.7 \% \quad 57.2$

$96.0 \% \quad 21.2$

$99.7 \% \quad 32.5$

$99.7 \% \quad 61.4$

$99.7 \% \quad 35.2$

$98.5 \% 16.9$

$99.7 \% \quad 32.4$

$99.5 \% \quad 30.5$

$99.7 \% \quad 76.2$

$96.1 \% \quad 15.8$

$99.7 \% \quad 59.2$

$99.7 \% \quad 44.3$

$99.7 \% \quad 66.2$

$99.2 \% \quad 35.8$

$\begin{array}{lll}99.7 \% & 37.8\end{array}$

$99.7 \% \quad 51.3$

$94.5 \% 17.1$

$0.01 \% \quad 23.3 \%$ ATTPADGEEPAPEAEALAAAR $\quad 99.7 \% \quad 41.4$

$0.01 \% \quad 23.3 \%$ FLSGLELVK

$0.01 \% \quad 23.3 \%$ DYIQSTMETEK

$99.5 \% \quad 26.6$

$99.7 \% 33.0$

$99.7 \% \quad 48.4$

$\begin{array}{lll}0.01 \% & 23.3 \% & \text { TPQGLSNLAK } \\ 0.01 \% & 23.3 \% & \text { TIGQVLAR }\end{array}$

$0.01 \% \quad 18.9 \%$ TVTQLVAEDGSR

$99.0 \% \quad 37.5$

$99.7 \% \quad 56.7$

$97.9 \% 22.9$

$99.0 \% \quad 23.6$

$0.01 \% \quad 18.9 \%$ EAQELSLEK

$99.4 \% \quad 21.3$

$0.01 \% \quad 18.9 \%$ TASLVLSLPAAQYCLQR

$0.00 \% \quad 9.0 \%$ VLDALVAR

$0.00 \% \quad 9.0 \%$ VLGALLFVK

$0.03 \% \quad 7.5 \%$ ITPIQKPR

$0.03 \% \quad 7.5 \%$ RDTALETALNAK

$0.03 \% \quad 7.5 \%$ DTALETALNAK

$0.03 \% \quad 7.5 \%$ AVATYHANTER

$0.03 \% \quad 7.5 \%$ LMAEDEEGYRK

$0.03 \% \quad 7.5 \%$ ILTGTDAPK $\begin{array}{llll}96.6 \% & 15.5 & 25.0 & 15.1\end{array}$

$\begin{array}{llll}96.6 \% & 16.2 & 25.0 & 16.2\end{array}$

$99.0 \% \quad 20.4 \quad 25.0 \quad 20.4$

$\begin{array}{llll}99.7 \% & 36.2 & 25.0 & 27.4\end{array}$

$99.7 \% \quad 51.8 \quad 25.0 \quad 42.1$

$\begin{array}{llll}99.5 \% & 23.5 & 25.0 & 17.8\end{array}$

$99.6 \% \quad 24.1 \quad 25.0 \quad 24$

$\begin{array}{llll}98.0 \% & 22.5 & 25.0 & 12.7\end{array}$
2703.28

1231.61

2813.44

2034.97

1577.71

1115.64

904.56

2054.94

1016.54

1301.68

1480.88

984.58

1140.68

1241.56

1140.52

1358.69

1622.75

1093.58

1136.63

1529.78

1163.64

1024.51

1159.57

1336.64

876.47

1200.66

1089.55

1286.66

2037.97

1005.60

1360.59

1028.57

857.52

1275.65

1680.83

1046.54

1915.93

1891.01

856.53

959.63

952.59

1302.70

1146.60

1232.60

1340.62

915.51
1
107
155
189
253
247
369
484
235
245
247
261
261
262
346
387
467
498
522
532
621
688
28
103
182
18
2
239
23
4
4
134
144
152
739
133
369
73

(1) 
Transcription activator BRG1 GN=SMARCA4 SMCA4_HUMAN $184.65 \quad 100.0 \%$ Transcription activator BRG1 GN=SMARCA4 SMCA4_HUMAN $184.65 \quad 100.0 \%$ Transcription activator BRG1 GN=SMARCA4 SMCA4_HUMAN $184.65 \quad 100.0 \%$ Transcription activator BRGI GN=SMARCA4 SMCA4_HUMAN $184.65 \quad 100.0 \%$ Transcription activator BRG1 GN=SMARCA4 SMCA4_HUMAN $184.65 \quad 100.0 \%$ Transcription activator BRG1 GN=SMARCA4 SMCA4_HUMAN $184.65100 .0 \%$ Transcription activator BRG1 GN=SMARCA4 SMCA4_HUMAN $184.65100 .0 \%$ Transcription elongation factor, mitochondrial GN=TEFM TEFM_HUMAN $41.68 \quad 100.0 \%$ Transcription elongation factor, mitochondrial GN=TEFM TEFM HUMAN $41.68 \quad 100.0 \%$ Transcription elongation factor, mitochondrial GN=TEFM TEFM_HUMAN $41.68 \quad 100.0 \%$ Transcription factor A, mitochondrial GN=TFAM TFAM_HUMAN $29.10 \quad 100.0 \%$ Transcription factor A, mitochondrial GN=TFAM TFAM HUMAN $29.10 \quad 100.0 \%$ Transcriptional activator protein Pur-alpha GN=PURA PURA_HUMAN $34.91 \quad 100.0 \%$ Transcriptional activator protein Pur-alpha GN=PURA PURA_HUMAN $34.91 \quad 100.0 \%$ Transcriptional activator protein Pur-alpha GN=PURA PURA HUMAN $34.91 \quad 100.0 \%$ Transcriptional activator protein Pur-alpha GN=PURA PURA_HUMAN $34.91 \quad 100.0 \%$ Transcriptional activator protein Pur-alpha GN=PURA PURA_HUMAN $34.91 \quad 100.0 \%$ Transcriptional activator protein Pur-beta GN=PURB PURB_HUMAN $33.24 \quad 100.0 \%$ Transcriptional activator protein Pur-beta GN=PURB PURB_HUMAN $33.24 \quad 100.0 \%$ Transcriptional activator protein Pur-beta GN=PURB PURB HUMAN $33.24 \quad 100.0 \%$ Transcriptional adapter 1 GN=TADA1 TADA1_HUMAN $37.38 \quad 100.0 \%$ Transcriptional adapter 1 GN=TADA1 TADA1_HUMAN $37.38 \quad 100.0 \%$ Transducin beta-like protein 3 GN=TBL3 TBL3_HUMAN $89.03 \quad 100.0 \%$ Transducin beta-like protein 3 GN=TBL3 TBL3_HUMAN $89.03 \quad 100.0 \%$ Transformation/transcription domain-associated protein GN=TRRAP TRRAP_HUMAN $437.60 \quad 100.0 \%$ Transformation/transcription domain-associated protein GN=TRRAP TRRAP_HUMAN $437.60 \quad 100.0 \%$ Transformation/transcription domain-associated protein GN=TRRAP TRRAP_HUMAN $437.60 \quad 100.0 \%$ Transformation/transcription domain-associated protein GN=TRRAP TRRAP HUMAN $437.60 \quad 100.0 \%$ Transformation/transcription domain-associated protein GN=TRRAP TRRAP_HUMAN $437.60 \quad 100.0 \%$ Transformation/transcription domain-associated protein GN=TRRAP TRRAP HUMAN 437.60 100.0\% Transformation/transcription domain-associated protein GN=TRRAP TRRAP_HUMAN $437.60 \quad 100.0 \%$ Transformation/transcription domain-associated protein GN=TRRAP TRRAP_HUMAN $437.60 \quad 100.0 \%$ Transformation/transcription domain-associated protein GN=TRRAP TRRAP HUMAN $437.60 \quad 100.0 \%$ Transformation/transcription domain-associated protein GN=TRRAP TRRAP_HUMAN $437.60 \quad 100.0 \%$ Transformer-2 protein homolog alpha GN=TRA2A TRA2A_HUMAN $32.69 \quad 100.0 \%$ Transformer- 2 protein homolog alpha GN=TRA2A TRA2A_HUMAN $32.69 \quad 100.0 \%$ Transformer-2 protein homolog alpha GN=TRA2A TRA2A_HUMAN $32.69 \quad 100.0 \%$ Transformer-2 protein homolog alpha GN=TRA2A TRA2A HUMAN $32.69 \quad 100.0^{\circ}$ Transformer-2 protein homolog alpha GN=TRA2A TRA2A_HUMAN $32.69 \quad 100.0 \%$ Transformer-2 protein homolog alpha GN=TRA2A TRA2A_HUMAN $32.69 \quad 100.0 \%$ Transformer-2 protein homolog alpha GN=TRA2A TRA2A_HUMAN $32.69 \quad 100.0 \%$ Transformer-2 protein homolog alpha GN=TRA2A TRA2A_HUMAN $32.69 \quad 100.0 \%$ Transformer-2 protein homolog alpha GN=TRA2A TRA2A_HUMAN $32.69100 .0 \%$ Transformer-2 protein homolog beta GN=TRA2B TRA2B_HUMAN $33.67 \quad 100.0 \%$ Transformer-2 protein homolog beta GN=TRA2B TRA2B_HUMAN $33.67 \quad 100.0 \%$ Transformer-2 protein homolog beta GN=TRA2B TRA2B HUMAN $33.67 \quad 100.0 \%$ Transformer-2 protein homolog beta GN=TRA2B TRA2B_HUMAN $33.67 \quad 100.0 \%$

(1)

2

2
5
5

7

5

5
5
5

5
3

3
3
3

3

2
2
2

2
2
10

$24 \quad 0.03 \% \quad 7.5 \% \quad$ YMIVDEGHR $0.03 \% \quad 7.5 \%$ LTQVLNTHYVAPR

$0.03 \% \quad 7.5 \%$ CDMSALQR

$0.03 \% \quad 7.5 \% \quad$ LCTVNSVEEK

$0.03 \% \quad 7.5 \% \quad$ YKLNVDQK

$0.03 \% \quad 7.5 \%$ VIQAGMFDQK

$0.03 \% \quad 7.5 \%$ DSDAGSSTPTTSTR

$0.00 \% \quad 8.3 \%$ SINIVEHR

$0.00 \% \quad 8.3 \% \quad$ AVNSIISIVFGTR

$0.00 \% \quad 8.3 \%$ QFLFDSILK

$0.00 \% \quad 6.9 \% \quad$ KPVSSYLR

$0.00 \% \quad 6.9 \% \quad$ ELTLLGKPK

$0.01 \% \quad 23.9 \%$ YYMDLKENQR

$0.01 \% \quad 23.9 \%$ GPGLGSTQGQTIALPAQGLIEFR

$0.01 \% \quad 23.9 \%$ LIDDYGVEEEPAELPEGTSLTVDNKR

$0.01 \% \quad 23.9 \%$ FFFDVGSNK

$0.01 \% \quad 23.9 \%$ VSEVKPTYR

$0.01 \% \quad 11.5 \%$ GGGGGPCGFQPASR

$0.01 \% \quad 11.5 \%$ GGGEQETQELASK

$0.01 \% \quad 11.5 \%$ VSEVKPSYR

$0.00 \% \quad 7.5 \%$ NLSEALGDNVK

$0.00 \% \quad 7.5 \% \quad$ YAFGSNVTPQPYLK

$0.00 \% \quad 3.3 \% \quad$ FKTNYAVER

$0.00 \% \quad 3.3 \%$ NTAPDNGPILLQAQTTQR

$0.02 \% \quad 2.7 \%$ APGEAQFIPNK

$0.02 \% \quad 2.7 \%$ AIETALDCLK

$0.02 \% \quad 2.7 \%$ TIPNVIISHR

$0.02 \% \quad 2.7 \% \quad$ EVTSPNSTVR

$0.02 \% \quad 2.7 \% \quad$ DVLAANPNR

$0.02 \% \quad 2.7 \% \quad$ VWVSENFQER

$0.02 \% \quad 2.7 \%$ GLSVDSAQEVKR

$0.02 \% \quad 2.7 \%$ TATGAISAVFGR

$0.02 \% \quad 2.7 \%$ VIYEGLTNYEK

$0.02 \% \quad 2.7 \%$ VVAVSPQMR

$0.05 \% \quad 33.0 \%$ ANPDPNTCLGVFGLSLYTTER

$0.05 \% \quad 33.0 \%$ YGPLSGVNVVYDQR

$0.05 \% \quad 33.0 \%$ GFAFVYFER

$0.05 \% \quad 33.0 \%$ IDDSKEAMER

$0.05 \% \quad 33.0 \%$ ANGMELDGRR

$0.05 \% \quad 33.0 \%$ IRVDYSITK

$0.05 \% \quad 33.0 \%$ GYDRYEDYDYR

$0.05 \% \quad 33.0 \%$ RSPSPYYSR

$0.05 \% \quad 33.0 \%$ SPSPYYSR

$0.08 \% \quad 38.5 \%$ ANPDPNCCLGVFGLSLYTTER

$0.08 \% \quad 38.5 \%$ DLREVFSK

$0.08 \% 38.5 \%$ YGPIADVSIVYDQQSR

$0.08 \% \quad 38.5 \%$ YGPIADVSIVYDQQSRR $\begin{array}{lllll}97.3 \% & 16.8 & 25.0 & 16.8 & 1\end{array}$

$99.7 \% \quad 55.6$

$99.0 \% \quad 29.5$

$99.7 \% \quad 42.7$

$99.0 \% \quad 20.6$

$99.7 \% \quad 42.8$

$99.7 \% \quad 64.3$

$99.0 \% \quad 26.4$

$99.7 \% \quad 48.2$

$99.4 \% \quad 20.5$

$97.6 \% \quad 26.1$

$99.7 \% \quad 37.6$

$99.7 \% \quad 41.7$

$99.7 \% 55.6$

$99.7 \% \quad 43.1$

$99.6 \% \quad 24.7$

$99.7 \% \quad 32.8$

$\begin{array}{lll}99.7 \% & 58.3\end{array}$

$99.7 \% \quad 44.4$

$99.0 \% \quad 28.3$

$99.7 \% \quad 31.5$

$99.6 \% \quad 27.4$

$9.7 \% 67.6$

$99.7 \% \quad 36.3$

$\begin{array}{lll}99.7 \% & 31.8\end{array}$

$99.7 \% \quad 40.9$

$99.7 \% \quad 31.9$

$\begin{array}{lll}99.7 \% & 29.7\end{array}$

$99.7 \% \quad 49.5$

$99.7 \% \quad 54.9$

$99.7 \% \quad 51.0$

$98.3 \% \quad 18.6$

$99.7 \% \quad 74.3$

$99.7 \% \quad 54.3$

$99.7 \% \quad 55.7$

$99.7 \% \quad 60.4$

$97.0 \% \quad 18.7$

$99.7 \% \quad 57.6$

$\begin{array}{lll}99.3 \% & 22.9\end{array}$

$99.7 \% \quad 48.0$

$99.0 \% \quad 47.0$

$\begin{array}{ll}99.7 \% & 58.5\end{array}$

$99.0 \% \quad 33.1$

$99.7 \% \quad 55.8$

$99.7 \% \quad 45.3$
1511.83

980.43

1178.57

1007.55

1136.58

1382.60

967.53

1376.79

1110.62

949.55

998.62

1359.64

2311.24

2889.40

1060.51

1078.59

1304.58

1333.62

1064.57

1159.60

1584.81

1127.58

1938.00

1171.61

1133.59

1149.67

1089.55

969.51

1293.62

1288.69

1150.62

1328.67

1002.54

2325.12

1566.79

1135.56

1193.55

1118.54

1094.62

1514.62

1112.55

956.45

2384.10

993.54

1810.90

1967.00 

Transformer-2 protein homolog beta GN=TRA2B TRA2B_HUMAN $33.67 \quad 100.0 \%$ Transformer-2 protein homolog beta GN=TRA2B TRA2B_HUMAN $33.67 \quad 100.0 \%$ Translation initiation factor eIF-2B subunit alpha GN=EIF2B1 EI2BA HUMAN $33.71 \quad 100.0 \%$ Translation initiation factor eIF-2B subunit alpha GN=EIF2B1 EI2BA_HUMAN $33.71 \quad 100.0 \%$ Translation initiation factor eIF-2B subunit alpha GN=EIF2B1 EI2BA_HUMAN $33.71 \quad 100.0 \%$ Translation initiation factor eIF-2B subunit alpha GN=EIF2B1 EI2BA HUMAN $33.71 \quad 100.0 \%$ Translation initiation factor eIF-2B subunit alpha GN=EIF2B1 EI2BA_HUMAN $33.71 \quad 100.0 \%$ Translation initiation factor eIF-2B subunit alpha GN=EIF2B1 EI2BA HUMAN $33.71 \quad 100.0 \%$ Translation initiation factor eIF-2B subunit alpha GN=EIF2B1 EI2BA_HUMAN $33.71 \quad 100.0 \%$ Translation initiation factor eIF-2B subunit beta GN=EIF2B2 EI2BB_HUMAN $38.99 \quad 100.0 \%$ Translation initiation factor eIF-2B subunit beta GN=EIF2B2 EI2BB HUMAN $38.99 \quad 100.0 \%$ Translation initiation factor eIF-2B subunit beta GN=EIF2B2 EI2BB_HUMAN $38.99 \quad 100.0 \%$ Translation initiation factor eIF-2B subunit beta GN=EIF2B2 EI2BB_HUMAN $38.99 \quad 100.0 \%$ Translation initiation factor eIF-2B subunit delta GN=EIF2B4 EI2BD HUMAN $57.56 \quad 100.0 \%$ Translation initiation factor eIF-2B subunit delta GN=EIF2B4 EI2BD_HUMAN $57.56 \quad 100.0 \%$ Translation initiation factor eIF-2B subunit delta GN=EIF2B4 EI2BD_HUMAN $57.56 \quad 100.0 \%$ Translation initiation factor eIF-2B subunit gamma GN=EIF2B3 EI2BG HUMAN $50.24 \quad 100.0 \%$ Translation initiation factor elF-2B subunit gamma GN=EIF2B3 EI2BG_HUMAN $50.24 \quad 100.0 \%$ Translational activator GCN1 GN=GCN1L1 GCN1L HUMAN $292.76100 .0 \%$ Translational activator GCN1 GN=GCN1L1 GCN1L_HUMAN $292.76 \quad 100.0 \%$ Translational activator GCN1 GN=GCN1L1 GCN1L_HUMAN $292.76 \quad 100.0 \%$ Translational activator GCN1 GN=GCN1L1 GCN1L_HUMAN $292.76 \quad 100.0 \%$ Translational activator GCN1 GN=GCN1L1 GCN1L_HUMAN $292.76 \quad 100.0 \%$ Translational activator GCN1 GN=GCN1L1 GCN1L HUMAN $292.76 \quad 100.0^{\circ} \%$ Translational activator GCN1 GN=GCN1L1 GCN1L_HUMAN $292.76 \quad 100.0 \%$ Translational activator GCN1 GN=GCN1L1 GCN1L_HUMAN $292.76 \quad 100.0 \%$ Translational activator GCN1 GN=GCN1L1 GCN1L_HUMAN $292.76 \quad 100.0 \%$ Translational activator GCN1 GN=GCN1L1 GCN1L_HUMAN $292.76 \quad 100.0 \%$ Translational activator GCN1 GN=GCN1L1 GCN1L_HUMAN $292.76 \quad 100.0 \% \quad 35$ Translational activator GCN1 GN=GCN1L1 GCN1L_HUMAN $292.76 \quad 100.0 \% \quad 35$ Translational activator GCN1 GN=GCN1L1 GCN1L_HUMAN $292.76 \quad 100.0 \%$ Translational activator GCN1 GN=GCN1L1 GCN1L HUMAN $292.76 \quad 100.0 \% \quad 35$ Translational activator GCN1 GN=GCN1L1 GCN1L_HUMAN $292.76 \quad 100.0 \%$ Translational activator GCN1 GN=GCN1L1 GCN1L_HUMAN $292.76 \quad 100.0 \% \quad 35$ Translational activator GCN1 GN=GCN1L1 GCN1L_HUMAN $292.76 \quad 100.0 \% \quad 35$ Translational activator GCN1 GN=GCN1L1 GCN1L_HUMAN $292.76 \quad 100.0 \%$ Translational activator GCN1 GN=GCN1L1 GCN1L_HUMAN $292.76 \quad 100.0 \%$ Translational activator GCN1 GN=GCN1L1 GCN1L_HUMAN $292.76 \quad 100.0 \% \quad 35$ Translational activator GCN1 GN=GCN1L1 GCN1L_HUMAN $292.76 \quad 100.0 \%$ Translational activator GCN1 GN=GCN1L1 GCN1L_HUMAN $292.76 \quad 100.0 \%$ Translational activator GCN1 GN=GCN1L1 GCN1L_HUMAN $292.76 \quad 100.0 \% \quad 35$

$\begin{array}{llll}13 & 71 & 0.08 \% & 38.5 \% \\ 13 & 71 & 0.08 \% & \text { GFAFVYFENVDDAK }\end{array}$ $99.7 \% \quad 58.8$

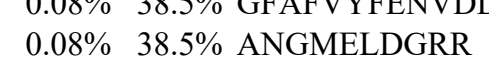
13 $13 \quad 71 \quad 0.08 \% \quad 38.5 \%$ IRVDFSITK

$\begin{array}{llll}13 & 71 & 0.08 \% & 38.5 \% \\ 13 & 71 & 0.08 \% & 38.5 \% \text { ADDRDYYSR }\end{array}$

$13 \quad 71 \quad 0.08 \% \quad 38.5 \%$ AAQDRDQIYR

$\begin{array}{llll}13 & 71 & 0.08 \% & 38.5 \%\end{array}$

$13 \quad 71 \quad 0.08 \% \quad 38.5 \%$ SPSPYYSR

$14 \quad 0.02 \% \quad 28.5 \%$ SQMKEDPDMASA

$4 \quad 0.02 \% \quad 28.5 \%$ DKGETIQGLR

$14 \quad 0.02 \% \quad 28.5 \%$ FISLASLEYSDYSK

$14 \quad 0.02 \% \quad 28.5 \%$ DGATILTHAYSR

$14 \quad 0.02 \% \quad 28.5 \%$ VLEAAVAAK

$14 \quad 0.02 \% \quad 28.5 \%$ IGTNQMAVCAK

$14 \quad 0.02 \% \quad 28.5 \%$ AQNKPFYVVAESFK

$6 \quad 0.01 \% \quad 13.7 \%$ SDESDQQESLHK

$6 \quad 0.01 \% \quad 13.7 \%$ TILANGALR

$6 \quad 0.01 \% \quad 13.7 \%$ AVTGTHTLALAAK

$6 \quad 0.01 \% \quad 13.7 \%$ LSPQFPNEEDSFHK

$5 \quad 0.01 \% \quad 7.7 \%$ ELPESGIQLGTPR

$0.01 \% \quad 7.7 \%$ LGLQYSQGLVSGSNAR

$0.01 \% \quad 7.7 \%$ VGTAQLALVAR

$0.00 \% \quad 4.9 \% \quad$ KGQDSIEPVPGQK

$0.00 \% \quad 4.9 \% \quad$ SLDIYSFIK

$119 \quad 0.13 \% \quad 13.6 \%$ AADTQVSETLKR

$44 \quad 119 \quad 0.13 \% \quad 13.6 \%$ NLLHSLQSSGIGSK

$44 \quad 119 \quad 0.13 \% \quad 13.6 \%$ SALLDFYMK

$44 \quad 119 \quad 0.13 \% \quad 13.6 \%$ LMDEAVLALR

$44 \quad 119 \quad 0.13 \% \quad 13.6 \%$ LSVADSQAEAK

$44 \quad 119 \quad 0.13 \% \quad 13.6 \%$ ALVAVLLSR

$44 \quad 119 \quad 0.13 \% \quad 13.6 \%$ HLDQIIPR

$44 \quad 119 \quad 0.13 \% \quad 13.6 \%$ SIIQSAQQDSIKK

$44 \quad 119 \quad 0.13 \% \quad 13.6 \%$ GIKEEVQLTSK

$44 \quad 119 \quad 0.13 \% \quad 13.6 \%$ ALGTLVSHVTLR

$44 \quad 119 \quad 0.13 \% \quad 13.6 \%$ VDENGPELLPR

$44 \quad 119 \quad 0.13 \% \quad 13.6 \%$ QAGAEALSQAVAR

$44 \quad 119 \quad 0.13 \% \quad 13.6 \%$ LMEIYQEK

$44 \quad 119 \quad 0.13 \% \quad 13.6 \%$ CGLALALNK

$44 \quad 119 \quad 0.13 \% \quad 13.6 \%$ NAPNDASYDAVR

$44 \quad 119 \quad 0.13 \% \quad 13.6 \%$ LMQQLLESDKYAER

$44 \quad 119 \quad 0.13 \% \quad 13.6 \%$ KGAAYGLAGLVK

$44 \quad 119 \quad 0.13 \% \quad 13.6 \%$ GAAYGLAGLVK

$44 \quad 119 \quad 0.13 \% \quad 13.6 \%$ AVMSNLSAHGVK

$44 \quad 119 \quad 0.13 \% \quad 13.6 \%$ LTEVLTDSHVK

$44 \quad 119 \quad 0.13 \% \quad 13.6 \%$ LTEVLTDSHVKVQK

$44 \quad 119 \quad 0.13 \% \quad 13.6 \%$ ASLLDPVPEVR

$44 \quad 119 \quad 0.13 \% \quad 13.6 \%$ LMPEIVATASK
$1.0 \%$

$99.7 \% 43.6$

$99.7 \% \quad 30.0$

$99.7 \% \quad 43.4$

$99.7 \% \quad 48.0$

$99.0 \% \quad 47.0$

$99.7 \% \quad 30.8$

$99.7 \% \quad 37.0$

$99.7 \% \quad 96.1$

$99.7 \% \quad 49.4$

$99.7 \% \quad 46.9$

$99.5 \% \quad 21.3$

$99.7 \% \quad 28.6$

$99.7 \% \quad 48.4$

$98.8 \% 31.3$

$99.7 \% \quad 60.7$

$\begin{array}{lll}99.4 \% & 20.8\end{array}$

$96.2 \% \quad 14.7$

$99.7 \% \quad 40.2$

$99.7 \% \quad 63.9$

$99.7 \% \quad 36.5$

$\begin{array}{lll}97.4 \% & 17.5\end{array}$

$99.7 \% \quad 39.7$

$99.7 \% \quad 62.8$

$99.7 \% \quad 33.5$

$99.7 \% \quad 55.5$

$99.7 \% \quad 58.4$

$99.7 \% \quad 59.3$

$98.5 \% \quad 19.2$

$97.3 \% 19.3$

$99.7 \% \quad 50.4$

$99.7 \% \quad 50.2$

$99.7 \% \quad 26.9$

$99.7 \% \quad 66.9$

$99.0 \% \quad 41.1$

$99.7 \% \quad 30.5$

$99.7 \% \quad 54.5$

$99.6 \% \quad 24.4$

$99.7 \% \quad 33.8$

$99.7 \% \quad 47.5$

$99.7 \% \quad 58.0$

$99.7 \% \quad 63.8$

$99.5 \% \quad 21.5$

$99.7 \% \quad 44.3$

$99.7 \% \quad 28.6$
949.93

1118.54

1078.63

1309.54

1235.61

1112.55

956.45

1851.86

1116.60

1622.79

1304.66

871.52

1192.58

1627.85

1402.61

928.56

1253.72

1674.78

1396.74

1649.86

1098.66

1382.73

1085.59

1318.70

1440.78

1103.54

1146.62

1118.57

941.61

991.57

1445.80

1231.69

1266.75

1238.64

1271.67

1053.53

959.53

1292.59

1723.87

1147.68

1019.59

1213.64

1241.67

1596.90

1195.67

1159.64 $\begin{array}{cc}0 & 173 \\ 0 & 176 \\ 9 & 188 \\ 9 & 197 \\ 9 & 238 \\ 2 & 261 \\ 3 & 271 \\ 4 & 271 \\ 2 & 28 \\ 7 & 46 \\ 5 & 88 \\ 1 & 132 \\ 7 & 145 \\ 0 & 220 \\ 1 & 234 \\ 0 & 111 \\ 8 & 246 \\ 7 & 259 \\ 4 & 287 \\ 6 & 88 \\ 0 & 225 \\ 8 & 428 \\ 4 & 146 \\ 0 & 268 \\ & 13 \\ 8 & 101 \\ 1 & 229 \\ 4 & 323 \\ 9 & 509 \\ 8 & 576 \\ 5 & 712 \\ 77 & 789 \\ 9 & 829 \\ 5 & 926 \\ 27 & 1037 \\ 77 & 1189 \\ 01 & 1208 \\ 35 & 1243 \\ 05 & 1316 \\ 81 & 1394 \\ 95 & 1406 \\ 96 & 1406 \\ 85 & 1496 \\ 43 & 1553 \\ 35 & 1674 \\ 1745\end{array}$

Page 153 of Table S-1-5 
Translational activator GCN1 GN=GCN1L1 GCN1L_HUMAN $292.76 \quad 100.0 \% \quad 35$ Translational activator GCN1 GN=GCN1L1 GCN1L_HUMAN $292.76 \quad 100.0 \% \quad 35$ Translational activator GCN1 GN=GCN1L1 GCN1L_HUMAN $292.76 \quad 100.0 \%$ Translational activator GCN1 GN=GCN1L1 GCN1L HUMAN $292.76 \quad 100.0 \%$ Translational activator GCN1 GN=GCN1L1 GCN1L_HUMAN $292.76 \quad 100.0 \% \quad 35$ Translational activator GCN1 GN=GCN1L1 GCN1L_HUMAN $292.76 \quad 100.0 \%$ Translational activator GCN1 GN=GCN1L1 GCN1L_HUMAN $292.76 \quad 100.0 \%$ Translational activator GCN1 GN=GCN1L1 GCN1L_HUMAN $292.76 \quad 100.0 \% \quad 35$ Translational activator GCN1 GN=GCN1L1 GCN1L_HUMAN $292.76 \quad 100.0 \%$ Translational activator GCN1 GN=GCN1L1 GCN1L_HUMAN $292.76 \quad 100.0 \% \quad 35$ Translational activator GCN1 GN=GCN1L1 GCN1L_HUMAN $292.76 \quad 100.0 \%$ Translational activator GCN1 GN=GCN1L1 GCN1L_HUMAN $292.76 \quad 100.0 \%$ Transmembrane protein 126A GN=TMEM126A T126A_HUMAN $21.53 \quad 100.0 \%$ Transmembrane protein 126A GN=TMEM126A T126A_HUMAN $21.53 \quad 100.0 \%$ Transmembrane protein 126A GN=TMEM126A T126A_HUMAN $21.53 \quad 100.0 \%$ Transmembrane protein 126A GN=TMEM126A T126A_HUMAN $21.53 \quad 100.0 \%$ Transmembrane protein $201 \mathrm{GN}=$ TMEM201 TM201_HUMAN $72.24 \quad 100.0 \%$ Transmembrane protein 201 GN=TMEM201 TM201_HUMAN $72.24 \quad 100.0 \%$ Transmembrane protein 201 GN=TMEM201 TM201_HUMAN $72.24 \quad 100.0 \%$ Transmembrane protein 33 GN=TMEM33 TMM33_HUMAN $27.98 \quad 10$ Transmembrane protein 33 GN=TMEM33 TMM33_HUMAN $27.98 \quad 100.0 \%$ Transmembrane protein $33 \mathrm{GN}=$ TMEM33 TMM33 HUMAN $27.98 \quad 100.0 \%$ Transmembrane protein 33 GN=TMEM33 TMM33_HUMAN 27.98 Transportin-1 GN=TNPO1

Transportin-1 GN=TNPO1 Transportin-1 GN=TNPO1 Transportin-1 GN=TNPO1 $\begin{array}{llll} & \end{array}$ Tricarboxylate transport protein, mitochondrial GN=SLC25A1 TXTP HUMAN 34.01 100.0\% Tricarboxylate transport protein, mitochondrial GN=SLC25A1 TXTP_HUMAN $34.01 \quad 100.0 \%$ Tricarboxylate transport protein, mitochondrial GN=SLC25A1 TXTP_HUMAN $34.01 \quad 100.0 \%$ Tricarboxylate transport protein, mitochondrial GN=SLC25A1 TXTP HUMAN 34.01 100.0\% Tricarboxylate transport protein, mitochondrial GN=SLC25A1 TXTP_HUMAN $34.01 \quad 100.0 \%$ Tricarboxylate transport protein, mitochondrial GN=SLC25A1 TXTP_HUMAN $34.01 \quad 100.0 \%$ Tricarboxylate transport protein, mitochondrial GN=SLC25A1 TXTP_HUMAN $34.01 \quad 100.0 \%$ Tricarboxylate transport protein, mitochondrial GN=SLC25A1 TXTP_HUMAN $34.01 \quad 100.0 \%$ Tricarboxylate transport protein, mitochondrial GN=SLC25A1 TXTP HUMAN $34.01 \quad 100.0^{\circ}$ Trifunctional enzyme subunit alpha, mitochondrial GN=HADHA ECHA_HUMAN $83.00 \quad 100.0 \%$ Trifunctional enzyme subunit alpha, mitochondrial GN=HADHA ECHA_HUMAN $83.00 \quad 100.0 \%$ Trifunctional enzyme subunit alpha, mitochondrial GN=HADHA ECHA HUMAN $83.00 \quad 100.0 \%$ Trifunctional enzyme subunit alpha, mitochondrial GN=HADHA ECHA_HUMAN $83.00 \quad 100.0 \%$ Trifunctional enzyme subunit alpha, mitochondrial GN=HADHA ECHA HUMAN $83.00100 .0 \%$ Trifunctional enzyme subunit alpha, mitochondrial GN=HADHA ECHA_HUMAN $83.00 \quad 100.0 \%$ Trifunctional enzyme subunit alpha, mitochondrial GN=HADHA ECHA_HUMAN $83.00 \quad 100.0 \%$ Trifunctional enzyme subunit alpha, mitochondrial GN=HADHA ECHA HUMAN $83.00 \quad 100.0 \%$ Trifunctional enzyme subunit beta, mitochondrial GN=HADHB ECHB_HUMAN $51.30 \quad 100.0 \%$
$119 \quad 0.13 \% \quad 13.6 \%$ VDIAPHVR

$\begin{array}{cccccccc}99.0 \% & 35.4 & 25.0 & 35.4 & 2 & 0 & 0 & 906.52\end{array}$ $99.7 \% \quad 50.8$

$99.2 \% \quad 21.5$

$119 \quad 0.13 \% \quad 13.6 \%$ ALADENEFVRDTALR $99.7 \% \quad 55.5$

$119 \quad 0.13 \% \quad 13.6 \%$ MTTETASEDDN

$119 \quad 0.13 \% \quad 13.6 \%$ VLAGLYMGR

$119 \quad 0.13 \% \quad 13.6 \%$ SDTQ

$119 \quad 0.13 \% \quad 13.6 \%$ LTTPPVNTR

$119 \quad 0.13 \% \quad 13.6 \%$ ADYTSHLR

$119 \quad 0.13 \% \quad 13.6 \%$ EGVLTGSPEQKEEAAK

$119 \quad 0.13 \% \quad 13.6 \%$ HHIETGGGQLPAK

$119 \quad 0.13 \% \quad 13.6 \%$ QGEEVFQSLSK

$0.01 \% \quad 20.5 \%$ KINQLPEAER

$0.01 \% \quad 20.5 \%$ YQSALLPHK

$0.01 \% \quad 20.5 \%$ GNILSYWIR

$0.01 \% \quad 20.5 \%$ ALQLSEPGKEIH

$6 \quad 0.01 \% \quad 4.7 \%$ EEGRYDEEVEVYR

$0.01 \% \quad 4.7 \%$ ALLLSHQFK

$0.01 \% \quad 4.7 \%$ SPVQVILLR

$10 \quad 0.01 \% \quad 19.0 \%$ ALLANALTSALR

$10 \quad 0.01 \% \quad 19.0 \%$ GSNSLPLLR

$10 \quad 0.01 \% \quad 19.0 \%$ SVLDKLSANQQNILK

$10 \quad 0.01 \% \quad 19.0 \%$ LCLQSIAFISR

$7 \quad 0.01 \% \quad 5.4 \% \quad$ ESQSPDTTIQR

$0.01 \% \quad 5.4 \%$ SLSGLILKNNVK

$0.01 \% \quad 5.4 \%$ ATVGILITTIASK

$0.01 \% \quad 5.4 \%$ TLLENTAITIGR

$0.04 \% \quad 32.2 \%$ TQLQLDER

$0.04 \% \quad 32.2 \%$ SHGVLGLYR

$0.04 \% \quad 32.2 \%$ GLSSLLYGSIPK

$0.04 \% \quad 32.2 \%$ FGMFEFLSNHMR

$0.04 \% \quad 32.2 \%$ VKFIHDQTSPNPK

$0.04 \% \quad 32.2 \%$ FIHDQTSPNPK

$0.04 \% \quad 32.2 \%$ EQGLKGTYQGLTATVLK

$0.04 \% \quad 32.2 \%$ GTYQGLTATVLK

$0.04 \% \quad 32.2 \%$ FFVMTSLR

$0.04 \% \quad 32.2 \%$ MQGLEAHKYR

$0.04 \% \quad 32.2 \%$ NTWDCGLQILK

$0.02 \% \quad 13.2 \%$ TLQEVTQLSQEAQR

$0.02 \% \quad 13.2 \%$ TILKDATLTALDR

$0.02 \% \quad 13.2 \%$ DATLTALDRGQQQVFK

$0.02 \% \quad 13.2 \%$ DTSASAVAVGLKQGK

$0.02 \% \quad 13.2 \%$ VIIVVKDGPGFYTTR

$0.02 \% \quad 13.2 \%$ ILQEGVDPK

$0.02 \% \quad 13.2 \%$ HVAEDLGKVFGER

$0.02 \% \quad 13.2 \%$ FGGGNPELLTQMVSK

$0.02 \% \quad 20.0 \%$ TLAKPNIR
$99.7 \% \quad 35.5$

$99.7 \% \quad 46.9$

$99.0 \% \quad 54.9$

$94.8 \% \quad 18.9$

$99.0 \% \quad 31.8$

$99.7 \% \quad 51.0$

$99.7 \% \quad 56.1$

$99.7 \% \quad 34.1$

$99.4 \% \quad 30.4$

$98.7 \% \quad 17.5$

$99.7 \% \quad 29.9$

$99.7 \% \quad 42.2$

$99.7 \% \quad 34.2$

$99.7 \% \quad 28.4$

$\begin{array}{lll}99.7 \% & 48.2\end{array}$

$99.7 \% \quad 72.8$

$99.7 \% \quad 41.0$

$99.7 \% \quad 57.3$

$99.7 \% \quad 57.5$

$99.5 \% \quad 24.1$

$99.7 \% \quad 43.6$

$99.7 \% \quad 37.8$

$\begin{array}{lll}99.7 \% & 57.7\end{array}$

$99.0 \% \quad 50.2$

$99.7 \% \quad 46.1$

$99.7 \% \quad 64.3$

$99.5 \% \quad 20.9$

$\begin{array}{lll}99.2 \% & 26.1\end{array}$

$99.7 \% \quad 56.8$

$98.4 \% \quad 17.1$

$99.7 \% \quad 53.9$

$99.0 \% \quad 50.8$

$\begin{array}{lll}97.4 \% & 19.4\end{array}$

$99.7 \% \quad 44.8$

$99.7 \% \quad 58.7$

$\begin{array}{lll}99.5 \% & 23.9\end{array}$

$98.8 \% 29.8$

$99.7 \% \quad 48.2$

$99.7 \% \quad 42.8$

$99.7 \% \quad 35.4$

$97.3 \% \quad 17.4$

$99.7 \% \quad 55.7$

$99.0 \% \quad 20.0$
1719.87

2046.86

1198.73

995.53

917.51

998.56

962.47

1672.84

1344.70

1251.62

1197.66

1056.58

1121.6

1321.71

1672.74

1056.62

1024.65

1213.73

956.55

1670.94

1307.71

1261.60

1285.78

1287.79

1301.74

1002.52

1001.55

1234.70

1531.68

1510.80

1283.64

1807.00

1251.69

1000.53

1232.62

1347.67

1630.84

1430.82

1790.94

1431.78

1664.94

998.55

1456.75

593.79

1593.79
912.56

$\begin{array}{cc}46 & 1753 \\ 85 & 1794 \\ 85 & 1799 \\ 53 & 1871 \\ 72 & 1882 \\ 85 & 1893 \\ 94 & 1901 \\ 84 & 2092 \\ 84 & 2191 \\ 70 & 2285 \\ 38 & 2550 \\ 24 & 2634 \\ 0 & 29 \\ 33 & 141 \\ 42 & 150 \\ 84 & 195 \\ 42 & 154 \\ 84 & 192 \\ 10 & 218 \\ 8 & 69 \\ 35 & 143 \\ 44 & 158 \\ 31 & 241 \\ 9 & 39 \\ 4 & 85 \\ 16 & 128 \\ 74 & 785 \\ 1 & 58 \\ 7 & 85 \\ 6 & 97 \\ 02 & 113 \\ 48 & 160 \\ 50 & 160 \\ 74 & 190 \\ 79 & 190 \\ 99 & 206 \\ 48 & 257 \\ 58 & 268 \\ 12 & 125 \\ 87 & 399 \\ 91 & 406 \\ 20 & 534 \\ 35 & 549 \\ 61 & 569 \\ 98 & 610 \\ 11 & 625 \\ 5 & 52 \\ & \end{array}$

Page 154 of Table S-1-5 

tRNA (cytosine(34)-C(5))-methyltransferase GN=NSUN2 NSUN2 HUMAN $86.47 \quad 100.0 \%$ tRNA (cytosine(34)-C(5))-methyltransferase GN=NSUN2 NSUN2_HUMAN $86.47 \quad 100.0 \%$ tRNA (cytosine(34)-C(5))-methyltransferase GN=NSUN2 NSUN2 HUMAN $86.47 \quad 100.0 \%$ tRNA pseudouridine synthase A, mitochondrial GN=PUS1 TRUA_HUMAN $47.47 \quad 100.0 \%$ tRNA pseudouridine synthase A, mitochondrial GN=PUS1 TRUA_HUMAN $47.47 \quad 100.0 \%$ tRNA pseudouridine synthase-like $1 \mathrm{GN}=$ PUSL1 PUSL1 HUMAN $33.23 \quad 100.0 \%$ tRNA pseudouridine synthase-like 1 GN=PUSL1 PUSL1_HUMAN $33.23 \quad 100.0 \%$ tRNA selenocysteine 1-associated protein $1 \mathrm{GN}=$ TRNAU1AP TSAP1 HUMAN $32.50 \quad 100.0 \%$ tRNA selenocysteine 1-associated protein $1 \mathrm{GN}=\mathrm{TRNAU1AP} \quad$ TSAP1_HUMAN $32.50 \quad 100.0 \%$ tRNA-splicing ligase RtcB homolog GN=RTCB RTCB_HUMAN $55.21 \quad 100.0 \%$ tRNA-splicing ligase RtcB homolog GN=RTCB RTCB HUMAN $55.21 \quad 100.0 \%$ tRNA-splicing ligase RtcB homolog GN=RTCB RTCB_HUMAN $55.21 \quad 100.0 \%$ tRNA-splicing ligase RtcB homolog GN=RTCB RTCB_HUMAN $55.21 \quad 100.0 \%$ Tuberin GN=TSC2

Tuberin $\mathrm{GN}=\mathrm{TSC} 2$

Tuberin $\mathrm{GN}=\mathrm{TSC} 2$

Tubulin alpha- $1 \mathrm{~A}$ chain GN=TUBA1A Tubulin alpha-1A chain GN=TUBA1A Tubulin alpha-1A chain GN=TUBA1A Tubulin alpha-1A chain GN=TUBA1A Tubulin alpha-1A chain GN=TUBA1A Tubulin alpha-1A chain GN=TUBA1A Tubulin alpha-1A chain GN=TUBA1A Tubulin alpha-1A chain GN=TUBA1A Tubulin alpha-1A chain GN=TUBA1A TSC2 HUMAN $200.61 \quad 100.0 \%$ TSC2_HUMAN $200.61 \quad 100.0 \%$ TSC2 HUMAN $200.61 \quad 100.0 \%$ TBA1A_HUMAN $50.14 \quad 100.0 \%$ TBA1A_HUMAN $50.14 \quad 100.0 \%$ TBA1A_HUMAN $50.14 \quad 100.0 \%$ TBA1A_HUMAN $50.14 \quad 100.0 \%$ TBA1A_HUMAN $50.14 \quad 100.0 \%$ TBA1A HUMAN $50.14 \quad 100.0 \%$ TBA1A_HUMAN $50.14 \quad 100.0 \%$ TBA1A HUMAN $50.14 \quad 100.0 \%$ TBA1A_HUMAN $50.14 \quad 100.0 \%$

$0.02 \% \quad 20.0 \%$ NVVVVDGVR $0.02 \% \quad 20.0 \%$ AALTGLLHR $0.02 \% \quad 20.0 \%$ EAALGAGFSDK $0.02 \% \quad 20.0 \%$ KLMLDLNK $0.02 \% \quad 20.0 \%$ LAAAFAVSR $0.02 \% \quad 20.0 \%$ DNGIRPSSLEQMAK

$0.02 \% \quad 20.0 \%$ ALAMGYKPK $0.02 \% \quad 20.0 \%$ TKVGLPPLEK $0.02 \% \quad 20.0 \%$ VGLPPLEK

$0.02 \% \quad 20.0 \%$ LVMAAANR

$0.02 \% \quad 7.5 \% \quad$ AFTKPEEACSFILSADFPALVVK

$0.02 \% \quad 7.5 \%$ ASGLAAGKGVIVAK

$0.02 \% \quad 7.5 \%$ IKDTVLQR

$0.02 \% \quad 7.5 \%$ AIAFLQQPR

$0.02 \% \quad 7.5 \%$ IYSHSLLPVLR

$0.02 \% \quad 7.5 \%$ AAVAGLDKAER

$0.00 \% \quad 5.5 \%$ APEEFELLSK

$0.00 \% \quad 5.5 \%$ AVINTVPYDVVHR

$0.00 \% \quad 4.2 \%$ HLEAAALLSER

$0.00 \% \quad 4.2 \%$ NADGLIVASR

$0.02 \% \quad 6.1 \%$ ILDMCAAPGSK

$0.02 \% \quad 6.1 \%$ IATRGAEQLAEGGR

$0.02 \% \quad 6.1 \%$ GAEQLAEGGR

$0.02 \% \quad 6.1 \% \quad$ ILLTQENPFFR

$0.02 \% \quad 6.1 \% \quad$ KLSSETYSQAK

$0.00 \% \quad 5.2 \%$ TIEDDLVSALVR

$0.00 \% \quad 5.2 \%$ APGLGLVLER

$0.00 \% \quad 8.6 \%$ LNSVEPVR

$0.00 \% \quad 8.6 \%$ TDAGVHALSNAAHLDVQR

$0.00 \% \quad 7.7 \%$ AFATMGETVMSVK

$0.00 \% \quad 7.7 \% \quad$ FTDELEQKR

$0.01 \% \quad 9.1 \%$ QIGNVAALPGIVHR

$0.01 \% \quad 9.1 \%$ MLQADPNKVSAR

$0.01 \% \quad 9.1 \%$ VEQHVVDGKER

$0.01 \% \quad 9.1 \%$ LRPIAVIKG

$0.00 \% \quad 1.6 \%$ DFVPFITK

$0.00 \% \quad 1.6 \%$ LVTVTTSVGTGTR

$0.00 \% \quad 1.6 \%$ SPSGLRPR $\begin{array}{llllllll}99.7 \% & 54.8 & 25.0 & 40.8 & 2 & 0 & 0 & 951.57\end{array}$

$\begin{array}{llllllll}99.7 \% & 52.5 & 25.0 & 52.1 & 2 & 0 & 0 & 1065.52\end{array}$

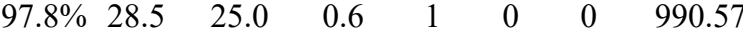

$\begin{array}{llllllll}99.7 \% & 55.0 & 25.0 & 46.3 & 4 & 0 & 0 & 905.52\end{array}$

$\begin{array}{llllllll}98.7 \% & 18.6 & 25.0 & 17.4 & 2 & 0 & 0 & 1561.76\end{array}$

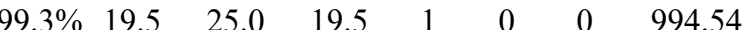

$\begin{array}{llllllll}99.7 \% & 30.0 & 25.0 & 30.0 & 2 & 0 & 0 & 1081.66\end{array}$

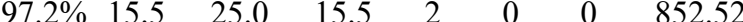

$\begin{array}{llllllll}99.0 \% & 41.0 & 25.3 & 32.6 & 2 & 0 & 0 & 845.47\end{array}$
TIGGGDDSFNTFFSETGAGK $99.7 \% \quad 54.3$

$\begin{array}{llll}67.8 \% & \text { TIGGGDDSFNTFFSETGAGKHVPR } \quad 99.7 \% & 53.2\end{array}$

$0.01 \% \quad 67.8 \%$ AVFVDLEPTVIDEVR $\quad 99.7 \% 56.6$

$0.01 \% \quad 67.8 \%$ QLFHPEQLITGKEDAANNYAR $99.7 \% \quad 54.3$

$0.01 \% \quad 67.8 \%$ GHYTIGKEIIDLVLDR

$0.01 \% \quad 67.8 \%$ EIIDLVLDR

$99.7 \% \quad 52.3$

$99.7 \% \quad 59.6$

$99.7 \% \quad 35.3$

$0.01 \% \quad 67.8 \%$ KLADQCTGLQGFLVFHSFGGGTGSGFtSLLMER $\quad 99.7 \% \quad 41.1$
845.47
2540.31

1241.76

972.58

1043.60

1297.76

1100.61

1162.60

1482.81

1209.66

1015.55

1162.56

1428.76

987.49

1377.75

1241.64

1330.72

1024.62

913.51

1874.95

1403.65

1165.58

1444.84

1329.69

1295.67

966.65

966.53

1291.72

869.50

8290

$\begin{array}{ll}18 & 128 \\ 81 & 188\end{array}$

$230 \quad 238$

$8 \quad 291$

$326 \quad 334$

416

$437 \quad 444$

$126 \quad 148$

$149 \quad 162$

$250 \quad 257$

$425 \quad 433$

$845 \quad 855$

$285 \quad 294$

$339 \quad 351$

$368 \quad 377$

$180 \quad 190$

$306 \quad 315$

29
40
40

$111 \quad 122$

$328 \quad 337$

$51 \quad 58$

$65 \quad 82$

$22 \quad 34$

$144 \quad 152$

$199 \quad 210$

$358 \quad 368$

$497 \quad 505$

$907 \quad 914$

10661078

$1452 \quad 1459$

2007.89

2497.17

1701.9

2280.19

2415.2

1842.01

1085.62

1354.81

3534.71 
Tubulin alpha-1A chain GN=TUBA1A Tubulin alpha-1A chain GN=TUBA1A Tubulin alpha-1A chain $\mathrm{GN}=\mathrm{TUBA} 1 \mathrm{~A}$ Tubulin alpha-1A chain $\mathrm{GN}=\mathrm{TUBA} 1 \mathrm{~A}$ Tubulin alpha-1A chain GN=TUBA1A Tubulin alpha-1A chain $\mathrm{GN}=$ TUBA1A

Tubulin alpha-1A chain $\mathrm{GN}=\mathrm{TUBA} 1 \mathrm{~A}$ Tubulin alpha- $1 \mathrm{~A}$ chain $\mathrm{GN}=\mathrm{TUBA} 1 \mathrm{~A}$ Tubulin alpha-1A chain $\mathrm{GN}=\mathrm{TUBA} 1 \mathrm{~A}$ Tubulin alpha-1A chain GN=TUBA1A Tubulin alpha-1A chain GN=TUBA1A Tubulin alpha-1A chain $\mathrm{GN}=\mathrm{TUBA} 1 \mathrm{~A}$ Tubulin alpha-1A chain GN=TUBA1A Tubulin alpha-1A chain $\mathrm{GN}=$ TUBA1A Tubulin alpha-1A chain GN=TUBA1A Tubulin alpha-1A chain GN=TUBA1A Tubulin alpha-1A chain GN=TUBA1A Tubulin alpha-1A chain GN=TUBA1A Tubulin alpha-1B chain $\mathrm{GN}=$ TUBA1B

Tubulin alpha-1B chain $\mathrm{GN}=\mathrm{TUBA} 1 \mathrm{~B}$ Tubulin alpha-1B chain GN=TUBA1B Tubulin alpha-1B chain GN=TUBA1B Tubulin alpha-1B chain GN=TUBA1B Tubulin alpha-1B chain GN=TUBA1B Tubulin alpha-1B chain GN=TUBA1B Tubulin alpha-1B chain $\mathrm{GN}=\mathrm{TUBA} 1 \mathrm{~B}$ Tubulin alpha-1B chain GN=TUBA1B Tubulin alpha-1B chain GN=TUBA1B Tubulin alpha-1B chain GN=TUBA1B Tubulin alpha-1B chain $\mathrm{GN}=\mathrm{TUBA} 1 \mathrm{~B}$ Tubulin alpha-1B chain GN=TUBA1B Tubulin alpha-1B chain GN=TUBA1B Tubulin alpha-1B chain GN=TUBA1B Tubulin alpha-1B chain GN=TUBA1B Tubulin alpha-1B chain GN=TUBA1B Tubulin alpha-1B chain GN=TUBA1B Tubulin alpha-1B chain GN=TUBA1B Tubulin alpha-1B chain GN=TUBA1B Tubulin alpha-1B chain GN=TUBA1B Tubulin alpha-1B chain GN=TUBA1B Tubulin alpha-1B chain $\mathrm{GN}=\mathrm{TUBA} 1 \mathrm{~B}$ Tubulin alpha-1B chain GN=TUBA1B Tubulin alpha-1B chain GN=TUBA1B Tubulin alpha-1B chain GN=TUBA1B Tubulin alpha-1B chain GN=TUBA1B Tubulin beta chain $\mathrm{GN}=\mathrm{TUBH}$ Tubulin beta chain $\mathrm{GN}=\mathrm{TUBB}$ \begin{tabular}{lllllll} 
TBA1A_HUMAN 50.14 & $100.0 \%$ & 3 & 3 & 12 & $0.01 \%$ & $67.8 \%$ \\
\hline
\end{tabular} TBA1A_HUMAN $50.14 \quad 100.0 \%$ TBA1A HUMAN $50.14 \quad 100.0 \%$ TBA1A_HUMAN $50.14 \quad 100.0 \%$ TBA1A_HUMAN $50.14 \quad 100.0 \%$ TBA1A HUMAN $50.14 \quad 100.0 \%$ TBA1A_HUMAN $50.14 \quad 100.0 \%$ TBA1A HUMAN $50.14 \quad 100.0 \%$ TBA1A HUMAN $50.14 \quad 100.0 \%$ TBA1A_HUMAN $50.14 \quad 100.0 \%$ TBA1A HUMAN $50.14 \quad 100.0 \%$ TBA1A_HUMAN $50.14 \quad 100.0 \%$ TBA1A_HUMAN $50.14 \quad 100.0 \%$ TBA1A HUMAN $50.14 \quad 100.0 \%$ TBA1A_HUMAN $50.14 \quad 100.0 \%$ TBA1A_HUMAN $50.14 \quad 100.0 \%$ TBA1A HUMAN $50.14 \quad 100.0 \%$ TBA1B_HUMAN $50.15 \quad 100.0 \%$ TBA1B HUMAN $50.15 \quad 100.0 \% \quad 27$ TBA1B_HUMAN $50.15 \quad 100.0 \% \quad 27$ TBA1B_HUMAN $50.15 \quad 100.0 \% \quad 27$ TBA1B_HUMAN $50.15 \quad 100.0 \% \quad 27$ TBA1B_HUMAN $50.15 \quad 100.0 \% \quad 27$ TBA1B_HUMAN $50.15 \quad 100.0 \% \quad 27$ TBA1B_HUMAN $50.15 \quad 100.0 \% \quad 27$ TBA1B_HUMAN $50.15 \quad 100.0 \% \quad 27$ TBA1B HUMAN $50.15 \quad 100.0 \% \quad 27$ TBA1B_HUMAN $50.15 \quad 100.0 \% \quad 27$ TBA1B HUMAN $50.15 \quad 100.0 \% \quad 27$ TBA1B_HUMAN $50.15 \quad 100.0 \% \quad 27$ TBA1B_HUMAN $50.15 \quad 100.0 \% \quad 27$ TBA1B HUMAN $50.15 \quad 100.0 \% \quad 27$ TBA1B_HUMAN $50.15 \quad 100.0 \% \quad 27$ TBA1B HUMAN $50.15 \quad 100.0 \% \quad 27$ TBA1B_HUMAN $50.15 \quad 100.0 \% \quad 27$ TBA1B_HUMAN $50.15 \quad 100.0 \% \quad 27$ TBA1B HUMAN $50.15 \quad 100.0 \% \quad 27$ TBA1B_HUMAN $50.15 \quad 100.0 \% \quad 27$ TBA1B_HUMAN $50.15 \quad 100.0 \% \quad 27$ TBA1B HUMAN $50.15 \quad 100.0 \% \quad 27$ TBA1B_HUMAN $50.15 \quad 100.0 \% \quad 27$ TBA1B_HUMAN $50.15 \quad 100.0 \% \quad 27$ TBA1B_HUMAN $50.15 \quad 100.0 \% \quad 27$ TBA1B_HUMAN $50.15 \quad 100.0 \% \quad 27$ TBB5 HUMAN $49.67 \quad 100.0 \% \quad 33$ TBB5_HUMAN $49.67 \quad 100.0 \% \quad 33$

$320 \quad 0.35 \% \quad 67.8 \%$ EIIDLVLDR

$320 \quad 0.35 \% \quad 67.8 \%$ LSVDYGKK

$320 \quad 0.35 \% \quad 67.8 \%$ DVNAAIATIK
$0.01 \% \quad 67.8 \%$ LIGQIVSSITASLR

$99.7 \% \quad 53.9$

$25.0 \quad 79.9$

$0.01 \% \quad 67.8 \%$ IHFPLATYAPVISAEK

$99.7 \% \quad 49.7$

$0.01 \% \quad 67.8 \%$ HGKYMACCLLYR

$99.7 \% \quad 57.6$

25.0

$0.01 \% \quad 67.8 \%$ YMACCLLYR

$0.01 \% \quad 67.8 \%$ GDVVPKDVNAAIATIK

$99.7 \% \quad 38.5$

$25.0 \quad 57.6$

67.8\% DVNAAIATIK

$0.01 \% \quad 67.8 \%$ DVNAAIATIKTK

$99.7 \% \quad 60.0$

$99.7 \% \quad 55.4$

$0.01 \% \quad 67.8 \%$ TIQFVDWCPTGFK

$99.7 \% \quad 56.9$

$0.01 \% \quad 67.8 \%$ TIOFVDWCPTGFKVGINYQPPTVVPGGDLAK $99.7 \% \quad 47.4$

$0.01 \% \quad 67.8 \%$ VGINYQPPTVVPGGDLAK $99.7 \% 53.6$

$\begin{array}{lllll}0.01 \% & 67.8 \% & \text { VGINYQPPTVVPGGDLAKVQR } & 99.3 \% & 30.7\end{array}$

$0.01 \% \quad 67.8 \%$ AVCMLSNTTAIAEAWAR $99.7 \% \quad 43.7$

$0.01 \% \quad 67.8 \%$ LDHKFDLMYAK

$99.7 \% \quad 35.5$

$320 \quad 0.35 \% \quad 67.8 \%$ TIGGGDDSFNTFFSETGAGK $\quad 99.7 \% \quad 54.3$

$320 \quad 0.35 \% \quad 67.8 \%$ TIGGGDDSFNTFFSETGAGKHVPR $99.7 \% \quad 53.2$

$320 \quad 0.35 \% \quad 67.8 \%$ AVFVDLEPTVIDEVR $\quad 99.7 \% \quad 56.6$

$320 \quad 0.35 \% \quad 67.8 \%$ AVFVDLEPTVIDEVRTGTYR $99.7 \% \quad 47.0$

$320 \quad 0.35 \% \quad 67.8 \%$ QLFHPEQLITGKEDAANNYAR $\quad 99.7 \% \quad 54.3$

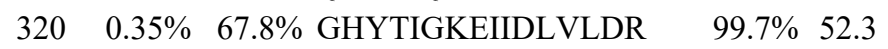

$320 \quad 0.35 \% \quad 67.8 \%$ EIIDLVLDRIR

$99.7 \% \quad 59.6$

$99.7 \% \quad 35.3$

$320 \quad 0.35 \% \quad 67.8 \%$ RNLDIERPTYTNLNR

$320 \quad 0.35 \% \quad 67.8 \%$ NLDIERPTYTNLNR

$99.0 \% \quad 48.2$

$99.2 \% \quad 22.2$

$99.7 \% \quad 55.5$

$99.7 \% \quad 55.2$

$320 \quad 0.35 \% \quad 67.8 \%$ LISQIVSSITASLR

$99.7 \% \quad 79.9$

$320 \quad 0.35 \% \quad 67.8 \%$ IHFPLATYAPVISAEK $\quad 99.7 \% \quad 53.9$

$320 \quad 0.35 \% \quad 67.8 \%$ AYHEQLSVAEITNACFEPANQMVK $\quad 99.7 \% \quad 49.7$

$320 \quad 0.35 \% \quad 67.8 \%$ HGKYMACCLLYR

$99.7 \% \quad 57.6$

$99.7 \% \quad 38.5$

$99.7 \% \quad 60.0$

$99.7 \% \quad 60.0$

$320 \quad 0.35 \% \quad 67.8 \%$ DVNAAIATIKTK

$99.7 \% \quad 55.4$

$99.7 \% \quad 54.9$

$320 \quad 0.35 \% \quad 67.8 \%$ SIOFVDWCPTGFKVGINYOPPTVVPGGDLAK $\quad 99.7 \% \quad 59.0$

$320 \quad 0.35 \% \quad 67.8 \%$ VGINYQPPTVVPGGDLAK $\quad 99.7 \% \quad 53.6$

$320 \quad 0.35 \% \quad 67.8 \%$ VGINYQPPTVVPGGDLAKVQR $99.3 \% \quad 30.7$

$320 \quad 0.35 \% \quad 67.8 \%$ AVCMLSNTTAIAEAWAR $99.7 \% \quad 43.7$

$\begin{array}{llllll}320 & 0.35 \% & 67.8 \% & \text { LDHKFDLMYAK } & 99.7 \% & 35.5 \\ 453 & 0.49 \% & 71.2 \% & \text { MREIVHIQAGQCGNQIGAK } & 99.4 \% & 57.4\end{array}$

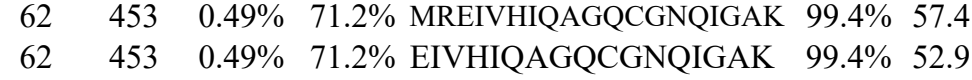

2409.2

$216 \quad 229$

$230 \quad 243$

$244 \quad 264$

1587.72

1249.55

1610.91

1015.58

1244.72

1598.77

3404.74

1824.99

2208.21

1864.90

1396.69

2007.89

2497.17

1701.91

2280.19

2415.21

1842.01

1085.62

1354.81

3534.71

909.50

1874.98

1718.88

1487.88

2409.21

1756.96

2766.29

1587.72

1249.55

1610.91

1015.58

1244.72

1584.75

3390.72

1824.99

2208.21

1864.90

1396.69

2110.06

1822.92 
Tubulin beta chain GN=TUBB Tubulin beta chain GN=TUBE

Tubulin beta chain $\mathrm{GN}=\mathrm{TUBB}$

Tubulin beta chain $\mathrm{GN}=\mathrm{TUB}$

Tubulin beta chain $\mathrm{GN}=\mathrm{TUBB}$

Tubulin beta chain $\mathrm{GN}=\mathrm{TUBB}$

Tubulin beta chain GN=TUBE

Tubulin beta chain GN=TUBF

Tubulin beta chain $\mathrm{GN}=\mathrm{TUB}$

Tubulin beta chain $\mathrm{GN}=\mathrm{TUBB}$

Tubulin beta chain $\mathrm{GN}=\mathrm{TUBB}$

Tubulin beta chain $\mathrm{GN}=\mathrm{TUB}$

Tubulin beta chain GN=TUBB

Tubulin beta chain $\mathrm{GN}=\mathrm{TUBB}$

Tubulin beta chain $\mathrm{GN}=\mathrm{TUBB}$

Tubulin beta chain $\mathrm{GN}=\mathrm{TUBH}$

Tubulin beta chain $\mathrm{GN}=\mathrm{TUBB}$

Tubulin beta chain GN=TUBB

Tubulin beta chain $\mathrm{GN}=\mathrm{TUBB}$

Tubulin beta chain $\mathrm{GN}=\mathrm{TUBB}$

Tubulin beta chain GN=TUBE

Tubulin beta chain GN=TUBB

Tubulin beta chain GN=TUBB

Tubulin beta chain $\mathrm{GN}=\mathrm{TUBB}$

Tubulin beta chain $\mathrm{GN}=\mathrm{TUB}$

Tubulin beta chain $\mathrm{GN}=\mathrm{TUBB}$

Tubulin beta chain $\mathrm{GN}=\mathrm{TUBB}$

Tubulin beta chain GN=TUBB

Tubulin beta chain $\mathrm{GN}=\mathrm{TUBB}$

Tubulin beta chain $\mathrm{GN}=\mathrm{TUB}$

Tubulin beta chain GN=TUBB

Tubulin beta-2A chain GN=TUBB2A

Tubulin beta-2A chain $\mathrm{GN}=\mathrm{TUBB} 2$

Tubulin beta- $2 A$ chain $\mathrm{GN}=\mathrm{TUBB} 2 \mathrm{~A}$

Tubulin beta- $2 \mathrm{~A}$ chain $\mathrm{GN}=\mathrm{TUBB} 2 \mathrm{~F}$

Tubulin beta-2A chain $\mathrm{GN}=\mathrm{TUBB} 2 \mathrm{~A}$

Tubulin beta- $2 A$ chain $\mathrm{GN}=\mathrm{TUBB} 2 \mathrm{~A}$

Tubulin beta- $2 A$ chain $\mathrm{GN}=\mathrm{TUBB} 2 \mathrm{~A}$

Tubulin beta- $2 A$ chain $\mathrm{GN}=\mathrm{TUBB} 2 \mathrm{~A}$

Tubulin beta-2A chain $\mathrm{GN}=\mathrm{TUBB} 2 \mathrm{~A}$

Tubulin beta- $2 A$ chain $\mathrm{GN}=\mathrm{TUBB} 2 A$

Tubulin beta- $2 A$ chain $\mathrm{GN}=\mathrm{TUBB} 2$

Tubulin beta- $2 A$ chain $\mathrm{GN}=\mathrm{TUBB} 2 \mathrm{~A}$

Tubulin beta-2A chain GN=TUBB2A

Tubulin beta- $2 A$ chain $\mathrm{GN}=\mathrm{TUBB} 2 \mathrm{~A}$

Tubulin beta- $2 \mathrm{~A}$ chain $\mathrm{GN}=\mathrm{TUBB} 2$

Tubulin beta- $2 \mathrm{~A}$ chain $\mathrm{GN}=\mathrm{TUBB} 2 \mathrm{~A}$

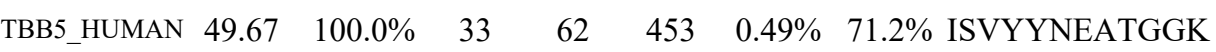

$\begin{array}{llllllll}99.7 \% & 54.3 & 25.0 & 54.3 & 17 & 0 & 0 & 1301.64\end{array}$ TBB5 HUMAN $49.67 \quad 100.0 \% \quad 33$ TBB5 HUMAN $49.67 \quad 100.0 \% \quad 33$ TBB5_HUMAN $49.67 \quad 100.0 \% \quad 33$ TBB5_HUMAN $49.67 \quad 100.0 \% \quad 33$ TBB5 HUMAN $49.67 \quad 100.0 \% \quad 33$ TBB5_HUMAN $49.67 \quad 100.0 \% \quad 33$ TBB5 HUMAN $49.67 \quad 100.0 \% \quad 33$ TBB5_HUMAN $49.67 \quad 100.0 \% \quad 33$ TBB5_HUMAN $49.67 \quad 100.0 \% \quad 33$ TBB5 HUMAN $49.67 \quad 100.0 \% \quad 33$ TBB5_HUMAN $49.67 \quad 100.0 \% \quad 33$ TBB5 HUMAN $49.67 \quad 100.0 \% \quad 33$ TBB5 HUMAN $49.67 \quad 100.0 \% \quad 33$ TBB5_HUMAN $49.67 \quad 100.0 \% \quad 33$ TBB5 HUMAN $49.67 \quad 100.0 \% \quad 33$ TBB5_HUMAN $49.67 \quad 100.0 \% \quad 33$ TBB5_HUMAN $49.67 \quad 100.0 \% \quad 33$ TBB5 HUMAN $49.67 \quad 100.0 \% \quad 33$ TBB5_HUMAN $49.67 \quad 100.0 \% \quad 33$ TBB5 HUMAN $49.67 \quad 100.0 \% \quad 33$ TBB5 HUMAN $49.67 \quad 100.0 \% \quad 33$ TBB5 HUMAN $49.67 \quad 100.0 \% \quad 33$ TBB5 HUMAN $49.67 \quad 100.0 \% \quad 33$ TBB5_HUMAN $49.67 \quad 100.0 \% \quad 33$ TBB5_HUMAN $49.67 \quad 100.0 \% \quad 33$ TBB5 HUMAN $49.67 \quad 100.0 \% \quad 33$ TBB5_HUMAN $49.67 \quad 100.0 \% \quad 33$ TBB5 HUMAN $49.67 \quad 100.0 \% \quad 33$ TBB5 HUMAN $49.67 \quad 100.0 \% \quad 33$ TBB2A_HUMAN $49.91 \quad 100.0 \% \quad 5$ TBB2A HUMAN $49.91 \quad 100.0 \% \quad 5$ TBB2A_HUMAN $49.91 \quad 100.0 \% \quad 5$ TBB2A_HUMAN $49.91 \quad 100.0 \%$ TBB2A HUMAN $49.91 \quad 100.0 \%$ TBB2A_HUMAN $49.91 \quad 100.0 \%$ TBB2A HUMAN $49.91 \quad 100.0 \%$ TBB2A_HUMAN $49.91 \quad 100.0 \%$ TBB2A_HUMAN $49.91 \quad 100.0 \%$ TBB2A_HUMAN $49.91 \quad 100.0 \%$ TBB2A_HUMAN $49.91 \quad 100.0 \%$ TBB2A HUMAN $49.91 \quad 100.0 \%$ TBB2A HUMAN $49.91 \quad 100.0 \%$ TBB2A_HUMAN $49.91 \quad 100.0 \%$ TBB2A HUMAN $49.91 \quad 100.0 \%$ TBB2A_HUMAN $49.91 \quad 100.0 \%$ $453 \quad 0.49 \% \quad 71.2 \%$ ISVYYNEATGGKYVPR $7 \% 64.9$

$453 \quad 0.49 \% \quad 71.2 \%$ AILVDLEPGTMDSVR

QSGAGNNWAK $99.7 \% \quad 56.8$

$\begin{array}{lllllll}62 & 453 & 0.49 \% & 71.2 \% & \text { GHYTEGAELVDSVLDVVR } & 99.7 \% & 38.7\end{array}$

62

62

62

62

62

62

62

62

62

62

62

$62 \quad 453 \quad 0.49 \% \quad 71.2 \%$ ALTVPELTQQVFDAKNMMAACDPR

$62 \quad 453 \quad 0.49 \% \quad 71.2 \%$ NMMAACDPR

$62 \quad 453 \quad 0.49 \% \quad 71.2 \%$ NMMAACDPRHGR

$62 \quad 453 \quad 0.49 \% \quad 71.2 \%$ HGRYLTVAAVFR

$\begin{array}{lllll}62 & 453 & 0.49 \% & 71.2 \% & \text { YLTVAAVFR }\end{array}$

$62 \quad 453 \quad 0.49 \% \quad 71.2 \%$ YLTVAAVFRGR

$62 \quad 453 \quad 0.49 \% \quad 71.2 \%$ MSMKEVDEQMLNVQNK

$62 \quad 453 \quad 0.49 \% \quad 71.2 \%$ EVDEQMLNVQNK

$62 \quad 453 \quad 0.49 \% \quad 71.2 \%$ NSSYFVEWIPNNVK

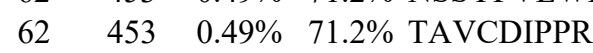

$62 \quad 453 \quad 0.49 \% \quad 71.2 \%$ TAVCDIPPRGLK

$453 \quad 0.49 \% \quad 71.2 \%$ MAVTFIGNSTAIQELFK

$62 \quad 453 \quad 0.49 \% \quad 71.2 \%$ MAVTFIGNSTAIQELFKR

$62 \quad 453 \quad 0.49 \% \quad 71.2 \%$ ISEQFTAMFR

$62 \quad 453 \quad 0.49 \% \quad 71.2 \%$ ISEQFTAMFRR

22

22

$\begin{array}{ll}99.7 \% & 48.5 \\ 99.2 \% & 62.7\end{array}$

$99.0 \% \quad 39.6$

$99.7 \% \quad 58.9$

$99.7 \% \quad 45.3$

$\begin{array}{lll}99.7 \% & 44.2\end{array}$

$99.7 \% \quad 39.9$

$99.7 \% \quad 53.5$

$99.7 \% \quad 61.2$

$99.7 \% \quad 44.0$

$99.7 \% \quad 59.0$

$99.7 \% \quad 33.4$

$99.7 \% \quad 37.1$

$\begin{array}{lll}97.6 \% & 24.9\end{array}$

$99.7 \% \quad 60.5$

$99.7 \% \quad 60.1$

$99.7 \% \quad 54.2$

$99.7 \% \quad 50.8$

$99.7 \% \quad 60.9$

$99.7 \% \quad 41.3$

$99.7 \% \quad 50.9$

$\begin{array}{lll}99.7 \% & 39.3\end{array}$

$99.7 \% \quad 59.7$

$99.7 \% \quad 59.3$

$99.4 \% 24.9$

0.02\% 60.2\% EIVHIQAGQCGNQIGAK $99.4 \% 52.9$

$0.02 \% \quad 60.2 \%$ INVYYNEAAGNK

$99.7 \% \quad 45.4$

$99.7 \% \quad 58.0$

$\begin{array}{lllll}0.02 \% & 60.2 \% & \text { SGPFGIFRPDNFVGQSGAGNNWAK } \quad 99.7 \% & 56.8\end{array}$

$0.02 \% \quad 60.2 \%$ GHYTEGAELVDSVLDVVR $99.7 \% \quad 38.7$

$0.02 \% \quad 60.2 \%$ GHYTEGAELVDSVLDVVRK $\quad 99.7 \% \quad 48.5$

$0.02 \% \quad 60.2 \%$ IREEYPDR

$99.0 \% \quad 39.6$

02\% $60.2 \%$ LITPTYDLNHLVSAT

$0.02 \% \quad 60.2 \%$ FPGQLNADLRK

$0.02 \% \quad 60.2 \%$ KLAVNMVPFPR

$0.02 \% \quad 60.2 \%$ LAVNMVPFPR

$0.02 \% \quad 60.2 \%$ LHFFMPGFAPLTSR

$0.02 \% \quad 60.2 \%$ ALTVPELTQQMFDSK

$0.02 \% \quad 60.2 \%$ NMMAACDPR

\section{$99.7 \% \quad 45.3$}

$99.7 \% \quad 44.2$

$99.7 \% \quad 39.9$

$99.7 \% \quad 53.5$

$99.7 \% \quad 61.2$

$99.7 \% \quad 44.0$

$99.7 \% \quad 45.1$

$99.7 \% \quad 37.1$

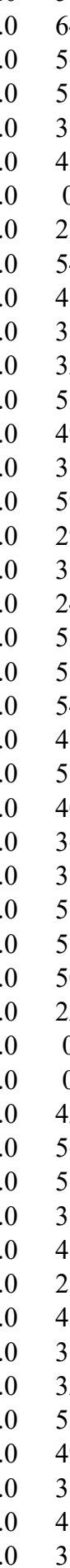

64.9

816.92

1615.84

2798.34

1958.98

2087.08

3327.53

1077.53

1335.70

2724.33

1130.60

1258.69

1271.73

1143.63

1636.83

1659.90

2738.29

1065.43

1447.60

1389.77

1039.59

1252.72

1971.88

1446.69

1696.83

1028.52

1326.72

1869.98

2042.07

1245.59

1401.69

2110.06

1822.92

1355.66

1615.84

2798.34

1958.98

2087.08

1077.53

2724.33

1130.60

1258.69

1271.73

1143.63

1636.83

1723.86 1065.43 
Tubulin beta- $2 \mathrm{~A}$ chain $\mathrm{GN}=\mathrm{TUBB} 2 \mathrm{~A}$ Tubulin beta-2A chain $\mathrm{GN}=\mathrm{TUBB} 2 \mathrm{~A}$ Tubulin beta-2A chain $\mathrm{GN}=\mathrm{TUBB} 2 \mathrm{~A}$ Tubulin beta-2A chain $\mathrm{GN}=\mathrm{TUBB} 2 \mathrm{~A}$ Tubulin beta- $2 \mathrm{~A}$ chain $\mathrm{GN}=\mathrm{TUBB} 2 \mathrm{~A}$ Tubulin beta- $2 \mathrm{~A}$ chain $\mathrm{GN}=\mathrm{TUBB} 2 \mathrm{~A}$

Tubulin beta- $2 \mathrm{~A}$ chain $\mathrm{GN}=\mathrm{TUBB} 2 \mathrm{~A}$ Tubulin beta- $2 \mathrm{~A}$ chain $\mathrm{GN}=\mathrm{TUBB} 2 \mathrm{~A}$ Tubulin beta- $2 \mathrm{~A}$ chain $\mathrm{GN}=\mathrm{TUBB} 2 \mathrm{~A}$ Tubulin beta- $2 \mathrm{~A}$ chain $\mathrm{GN}=\mathrm{TUBB} 2 \mathrm{~A}$ Tubulin beta- $2 \mathrm{~A}$ chain $\mathrm{GN}=\mathrm{TUBB} 2 \mathrm{~A}$ Tubulin beta- $2 \mathrm{~A}$ chain $\mathrm{GN}=\mathrm{TUBB} 2 \mathrm{~A}$ Tubulin beta- $2 \mathrm{~A}$ chain $\mathrm{GN}=\mathrm{TUBB} 2 \mathrm{~A}$ Tubulin beta-4A chain $\mathrm{GN}=\mathrm{TUBB} 4 \mathrm{~A}$

Tubulin beta-4A chain $\mathrm{GN}=\mathrm{TUBB} 4 \mathrm{~A}$

Tubulin beta- $4 \mathrm{~A}$ chain $\mathrm{GN}=\mathrm{TUBB} 4 \mathrm{~A}$

Tubulin beta-4A chain $\mathrm{GN}=\mathrm{TUBB} 4 \mathrm{~A}$

Tubulin beta- $4 \mathrm{~A}$ chain $\mathrm{GN}=\mathrm{TUBB} 4 \mathrm{~A}$

Tubulin beta-4A chain $\mathrm{GN}=\mathrm{TUBB} 4 \mathrm{~A}$

Tubulin beta- $4 \mathrm{~A}$ chain $\mathrm{GN}=\mathrm{TUBB} 4 \mathrm{~A}$

Tubulin beta-4A chain GN=TUBB4A

Tubulin beta- $4 \mathrm{~A}$ chain $\mathrm{GN}=\mathrm{TUBB} 4 \mathrm{~A}$

Tubulin beta- $4 \mathrm{~A}$ chain $\mathrm{GN}=\mathrm{TUBB} 4 \mathrm{~A}$

Tubulin beta- $4 \mathrm{~A}$ chain $\mathrm{GN}=\mathrm{TUBB} 4 \mathrm{~A}$

Tubulin beta- $4 \mathrm{~A}$ chain $\mathrm{GN}=\mathrm{TUBB} 4 \mathrm{~A}$

Tubulin beta-4A chain GN=TUBB4A

Tubulin beta- $4 \mathrm{~A}$ chain $\mathrm{GN}=\mathrm{TUBB} 4 \mathrm{~A}$

Tubulin beta-4A chain $\mathrm{GN}=\mathrm{TUBB} 4 \mathrm{~A}$

Tubulin beta-4A chain GN=TUBB4A

Tubulin beta- $4 \mathrm{~A}$ chain $\mathrm{GN}=\mathrm{TUBB} 4 \mathrm{~A}$

Tubulin beta- $4 \mathrm{~A}$ chain $\mathrm{GN}=\mathrm{TUBB} 4 \mathrm{~A}$

Tubulin beta- $4 \mathrm{~A}$ chain $\mathrm{GN}=\mathrm{TUBB} 4 \mathrm{~A}$

Tubulin beta- $4 \mathrm{~A}$ chain $\mathrm{GN}=\mathrm{TUBB} 4 \mathrm{~A}$

Tubulin beta- $4 \mathrm{~A}$ chain $\mathrm{GN}=\mathrm{TUBB} 4 \mathrm{~A}$

Tubulin beta- $4 \mathrm{~A}$ chain $\mathrm{GN}=\mathrm{TUBB} 4 \mathrm{~A}$

Tubulin beta-4A chain $\mathrm{GN}=\mathrm{TUBB} 4 \mathrm{~A}$

Tubulin beta- $4 \mathrm{~A}$ chain $\mathrm{GN}=\mathrm{TUBB} 4 \mathrm{~A}$

Tubulin beta-4A chain $\mathrm{GN}=\mathrm{TUBB} 4 \mathrm{~A}$

Tubulin beta- $4 \mathrm{~A}$ chain $\mathrm{GN}=\mathrm{TUBB} 4 \mathrm{~A}$

Tubulin beta-4B chain $\mathrm{GN}=\mathrm{TUBB} 4 \mathrm{~B}$

Tubulin beta- $4 \mathrm{~B}$ chain $\mathrm{GN}=\mathrm{TUBB} 4 \mathrm{~B}$

Tubulin beta- $4 \mathrm{~B}$ chain $\mathrm{GN}=\mathrm{TUBB} 4 \mathrm{~B}$

Tubulin beta-4B chain $\mathrm{GN}=\mathrm{TUBB} 4 \mathrm{~B}$

Tubulin beta- $4 \mathrm{~B}$ chain $\mathrm{GN}=\mathrm{TUBB} 4 \mathrm{~B}$

Tubulin beta-4B chain $\mathrm{GN}=\mathrm{TUBB} 4 \mathrm{~B}$

Tubulin beta- $4 \mathrm{~B}$ chain $\mathrm{GN}=\mathrm{TUBB} 4 \mathrm{~B}$

Tubulin beta-4B chain $\mathrm{GN}=\mathrm{TUBB} 4 \mathrm{~B}$

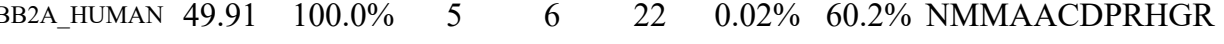
TBB2A_HUMAN $49.91 \quad 100.0 \%$ TBB2A_HUMAN $49.91 \quad 100.0 \%$ TBB2A HUMAN $49.91 \quad 100.0 \%$ TBB2A_HUMAN $49.91 \quad 100.0 \%$ TBB2A_HUMAN $49.91 \quad 100.0 \%$ TBB2A HUMAN $49.91 \quad 100.0 \%$ TBB2A_HUMAN $49.91 \quad 100.0 \%$ TBB2A HUMAN $49.91 \quad 100.0 \%$ TBB2A HUMAN $49.91 \quad 100.0 \%$ TBB2A_HUMAN $49.91 \quad 100.0 \%$ TBB2A HUMAN $49.91 \quad 100.0 \%$ TBB2A_HUMAN $49.91 \quad 100.0 \%$ TBB4A_HUMAN $49.59 \quad 100.0 \%$ TBB4A HUMAN $49.59 \quad 100.0 \%$ TBB4A_HUMAN $49.59 \quad 100.0 \%$ TBB4A HUMAN $49.59 \quad 100.0 \%$ TBB4A HUMAN $49.59 \quad 100.0 \%$ TBB4A_HUMAN $49.59 \quad 100.0 \%$ TBB4A HUMAN $49.59 \quad 100.0 \%$ TBB4A_HUMAN $49.59 \quad 100.0 \%$ TBB4A HUMAN $49.59 \quad 100.0 \%$ TBB4A_HUMAN $49.59 \quad 100.0 \%$ TBB4A_HUMAN $49.59 \quad 100.0 \%$ TBB4A HUMAN $49.59 \quad 100.0 \%$ TBB4A_HUMAN $49.59 \quad 100.0 \%$ TBB4A_HUMAN $49.59 \quad 100.0 \%$ TBB4A HUMAN $49.59 \quad 100.0 \%$ TBB4A_HUMAN $49.59 \quad 100.0 \%$ TBB4A HUMAN $49.59 \quad 100.0 \%$ TBB4A_HUMAN $49.59 \quad 100.0 \%$ TBB4A_HUMAN $49.59 \quad 100.0 \%$ TBB4A_HUMAN $49.59 \quad 100.0 \%$ TBB4A_HUMAN $49.59 \quad 100.0 \%$ TBB4A_HUMAN $49.59 \quad 100.0 \%$ TBB4A_HUMAN $49.59 \quad 100.0 \%$ TBB4A_HUMAN $49.59 \quad 100.0 \%$ TBB4A HUMAN $49.59 \quad 100.0 \%$ TBB4A_HUMAN $49.59 \quad 100.0 \%$ TBB4B_HUMAN $49.83 \quad 100.0 \%$ TBB4B HUMAN $49.83 \quad 100.0 \%$ TBB4B_HUMAN $49.83 \quad 100.0 \%$ TBB4B HUMAN $49.83 \quad 100.0 \%$ TBB4B HUMAN $49.83 \quad 100.0 \%$ TBB4B_HUMAN $49.83 \quad 100.0 \%$ TBB4B HUMAN $49.83 \quad 100.0 \%$ TBB4B_HUMAN $49.83 \quad 100.0 \%$

$0.02 \% \quad 60.2 \%$ HGRYLTVAAIFR

$0.02 \% \quad 60.2 \%$ YLTVAAIFR

$0.02 \% \quad 60.2 \%$ YLTVAAIFRGR

$0.02 \% \quad 60.2 \%$ EVDEQMLNVQNK

$0.02 \% \quad 60.2 \%$ NSSYFVEWIPNNVK

$0.02 \% \quad 60.2 \%$ TAVCDIPPR

$0.02 \% \quad 60.2 \%$ TAVCDIPPRGLK

$0.02 \% \quad 60.2 \%$ ISEQFTAMFR

$0.02 \% \quad 60.2 \%$ ISEQFTAMFRR

$0.01 \% \quad 62.2 \%$ IMNTFSVVPSPK

$0.01 \% \quad 62.2 \%$ FPGQLNADLR

$0.01 \% \quad 62.2 \%$ FPGQLNADLRK

$0.01 \% \quad 62.2 \%$ KLAVNMVPFPR

$0.01 \% \quad 62.2 \%$ LAVNMVPFPR

$0.01 \% \quad 62.2 \%$ LHFFMPGFAPLTSR

$0.01 \% \quad 62.2 \%$ NMMAACDPR

$0.01 \% \quad 62.2 \%$ NMMAACDPRHGR

$0.01 \% \quad 62.2 \%$ HGRYLTVAAVFR

$0.01 \% \quad 62.2 \%$ YLTVAAVFR

$0.01 \% \quad 62.2 \%$ YLTVAAVFRGR

$0.01 \% \quad 62.2 \%$ NSSYFVEWIPNNVK

$0.01 \% \quad 62.2 \%$ TAVCDIPPR

$0.01 \% \quad 62.2 \%$ TAVCDIPPRGLK

$0.01 \% \quad 62.2 \%$ ISEQFTAMFR

$0.01 \% \quad 62.2 \%$ ISEQFTAMFRR

$0.06 \% \quad 71.0 \%$ INVYYNEATGGK
$0.02 \% \quad 60.2 \%$ MSMKEVDEQMLNVQNK

$0.02 \% \quad 60.2 \%$ MSATFIGNSTAIQELFK

$0.02 \% \quad 60.2 \%$ MSATFIGNSTAIQELFKR

$\begin{array}{llllllll}97.6 \% & 24.9 & 25.0 & 24.9 & 0 & 1 & 0 & 1447.60\end{array}$ $99.7 \% \quad 52.6$

$99.7 \% \quad 53.2$

$99.6 \% 23.3$

$99.7 \% \quad 50.8$

$\begin{array}{lll}99.7 \% & 60.9\end{array}$

$99.7 \% \quad 41.3$

$99.7 \% \quad 50.9$

$99.7 \% \quad 39.3$

$99.4 \% \quad 42.7$

$\begin{array}{lll}99.5 \% & 50.8\end{array}$

$99.7 \% \quad 59.3$

$99.4 \% \quad 24.9$

$0.01 \% \quad 62.2 \%$ MREIVHLQAGQCGNQIGAK $99.4 \% 57.4$

$0.01 \% \quad 62.2 \%$ EIVHLQAGQCGNQIGAK $\quad 99.4 \% 52.9$

$\begin{array}{lllll}0.01 \% & 62.2 \% & \text { AVLVDLEPGTMDSVR } \quad 99.7 \% & 58.9\end{array}$

$0.01 \% \quad 62.2 \%$ SGPFGQIFRPDNFVFGQSGAGNNWAK $\quad 99.7 \% \quad 56.8$

$0.01 \% \quad 62.2 \%$ GHYTEGAELVDAVLDVVRK $99.0 \% 19.2$

$0.01 \% \quad 62.2 \%$ EAESCDCLQGFQLTHSLGGGTGSGMGTLLISK $99.2 \% 62.7$

$99.7 \% \quad 58.9$

$\begin{array}{lllll}0.01 \% & 62.2 \% & \text { LTTPTYGDLNHLVSATMSGVTTCLR } & 99.7 \% & 45.3\end{array}$

$0.01 \% \quad 62.2 \%$ ALTVPELTQQMFDAK

$99.7 \% \quad 44.2$

$99.7 \% \quad 39.9$

$99.7 \% \quad 53.5$

$99.7 \% \quad 61.2$

$99.7 \% \quad 44.0$

$99.7 \% \quad 51.6$

$99.7 \% \quad 37.1$

$97.6 \% \quad 24.9$

$99.7 \% \quad 60.5$

$99.7 \% \quad 60.1$

$99.7 \% \quad 54.2$

$99.7 \% \quad 41.3$

$99.7 \% \quad 50.9$

$99.7 \% 39.3$

$0.01 \% \quad 62.2 \%$ MAATFIGNSTAIQELFK $\quad 99.3 \% 81.2$

$\begin{array}{lllll}0.01 \% & 62.2 \% & \text { MAATFIGNSTAIQELFKR } & 99.3 \% & 19.1\end{array}$

$99.7 \% \quad 59.3$

$99.4 \% \quad 24.9$

0.06\% $71.0 \%$ MREIVHLQAGQCGNQIGAK $99.4 \% 57.4$

$0.06 \% \quad 71.0 \%$ EIVHLQAGQCGNQIGAK $\quad 99.4 \% 52.9$

$99.7 \% \quad 61.2$

$0.06 \% \quad 71.0 \%$ INVYYNEATGGKYVPR $\quad 99.7 \% \quad 69.2$

$0.06 \% \quad 71.0 \%$ AVLVDLEPGTMDSVR $\quad 99.7 \% \quad 58.9$

$\begin{array}{lllll}0.06 \% & 71.0 \% & \text { SGPFGIFRPDNFVFGQSGAGNNWAK } \quad 99.7 \% \quad 56.8\end{array}$

$0.06 \% \quad 71.0 \%$ GHYTEGAELVDSVLDVVR $99.7 \% \quad 38.7$

$0.06 \% \quad 71.0 \%$ GHYTEGAELVDSVLDVVRK $99.7 \% \quad 48.5$
1403.79

1053.61

1266.73

1971.88

1446.69

1696.83

1028.52

1326.72

1857.94

2014.04

1245.59

1401.69

2110.06

1822.92

1617.82

2798.34

2071.08

3327.53

1335.70

2724.33

1130.60

1258.69

1271.73

1143.63

1636.83

1691.87

1065.43

1447.60

1389.77

1039.59

1252.72

1696.83

1028.52

1326.72

1857.94

1998.05

1245.59

1401.69

2110.06

1822.92

1328.65

1843.93

1617.82

2798.34

1958.98 2087.08

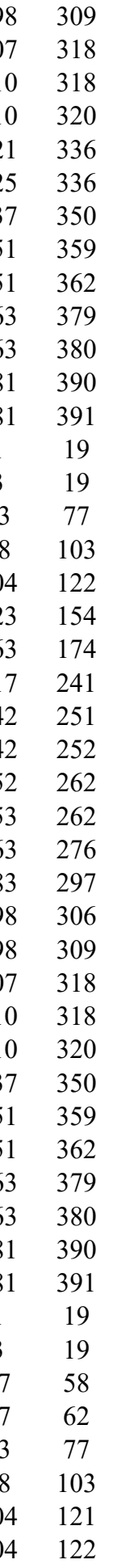

Page 158 of Table S-1-5 
Tubulin beta- $4 \mathrm{~B}$ chain $\mathrm{GN}=\mathrm{TUBB} 4 \mathrm{~B}$ Tubulin beta- $4 \mathrm{~B}$ chain $\mathrm{GN}=\mathrm{TUBB} 4 \mathrm{~B}$ Tubulin beta- $4 \mathrm{~B}$ chain $\mathrm{GN}=\mathrm{TUBB} 4 \mathrm{~B}$ Tubulin beta- $4 \mathrm{~B}$ chain $\mathrm{GN}=\mathrm{TUBB} 4 \mathrm{~B}$ Tubulin beta- $4 \mathrm{~B}$ chain $\mathrm{GN}=\mathrm{TUBB} 4 \mathrm{~B}$ Tubulin beta- $4 \mathrm{~B}$ chain $\mathrm{GN}=\mathrm{TUBB} 4 \mathrm{~B}$

Tubulin beta- $4 \mathrm{~B}$ chain $\mathrm{GN}=\mathrm{TUBB} 4 \mathrm{~B}$ Tubulin beta- $4 \mathrm{~B}$ chain $\mathrm{GN}=\mathrm{TUBB} 4 \mathrm{~B}$ Tubulin beta- $4 \mathrm{~B}$ chain $\mathrm{GN}=\mathrm{TUBB} 4 \mathrm{~B}$ Tubulin beta- $4 \mathrm{~B}$ chain $\mathrm{GN}=\mathrm{TUBB} 4 \mathrm{~B}$ Tubulin beta $-4 \mathrm{~B}$ chain $\mathrm{GN}=\mathrm{TUBB} 4 \mathrm{~B}$ Tubulin beta- $4 \mathrm{~B}$ chain $\mathrm{GN}=\mathrm{TUBB} 4 \mathrm{~B}$ Tubulin beta- $4 \mathrm{~B}$ chain $\mathrm{GN}=\mathrm{TUBB} 4 \mathrm{~B}$ Tubulin beta- $4 \mathrm{~B}$ chain $\mathrm{GN}=\mathrm{TUBB} 4 \mathrm{~B}$

Tubulin beta- $4 \mathrm{~B}$ chain $\mathrm{GN}=\mathrm{TUBB} 4 \mathrm{~B}$

Tubulin beta $-4 \mathrm{~B}$ chain $\mathrm{GN}=\mathrm{TUBB} 4 \mathrm{~B}$

Tubulin beta- $4 \mathrm{~B}$ chain $\mathrm{GN}=\mathrm{TUBB} 4 \mathrm{~B}$

Tubulin beta- $4 \mathrm{~B}$ chain $\mathrm{GN}=\mathrm{TUBB} 4 \mathrm{~B}$

Tubulin beta $-4 \mathrm{~B}$ chain $\mathrm{GN}=\mathrm{TUBB} 4 \mathrm{~B}$

Tubulin beta $-4 \mathrm{~B}$ chain $\mathrm{GN}=\mathrm{TUBB} 4 \mathrm{E}$

Tubulin beta- $4 \mathrm{~B}$ chain GN=TUBB4B

Tubulin beta- $4 \mathrm{~B}$ chain $\mathrm{GN}=\mathrm{TUBB} 4 \mathrm{~B}$

Tubulin beta- $4 \mathrm{~B}$ chain $\mathrm{GN}=\mathrm{TUBB} 4 \mathrm{~B}$

Tubulin beta $-4 \mathrm{~B}$ chain $\mathrm{GN}=\mathrm{TUBB} 4 \mathrm{~B}$

Tubulin beta- 6 chain GN=TUBB 6

Tubulin beta -6 chain GN=TUBB 6

Tubulin beta- 6 chain GN=TUBB 6

Tubulin beta- 6 chain $\mathrm{GN}=$ TUBB 6

Tubulin beta- 6 chain GN=TUBB6

Tubulin beta- 6 chain $\mathrm{GN}=\mathrm{TUBB} 6$

Tubulin beta -6 chain GN=TUBB 6

Tubulin beta -6 chain GN=TUBB 6

Tubulin beta- 6 chain GN=TUBB 6

Tubulin beta- 6 chain GN=TUBB6

Tubulin beta- 6 chain GN=TUBB 6

Tubulin beta -6 chain GN=TUBB6

Tubulin beta- 6 chain GN=TUBB6

Tubulin beta- 6 chain $\mathrm{GN}=$ TUBB 6

Tubulin gamma- 1 chain GN=TUBG 1

Tubulin gamma-1 chain $\mathrm{GN}=\mathrm{TUBG}$

Tubulin gamma- 1 chain $\mathrm{GN}=\mathrm{TUBG}$

Tubulin gamma- 1 chain GN=TUBG1

Tubulin-specific chaperone D GN=TBCD TBCD_HUMAN $132.60 \quad 100.0^{\circ}$

Tubulin-specific chaperone D GN=TBCD TBCD_HUMAN $132.60 \quad 100.0 \%$ Tubulin-specific chaperone D GN=TBCD TBCD_HUMAN $132.60 \quad 100.0 \%$ Tuftelin-interacting protein 11 GN=TFIP11 TFP11_HUMAN $96.82 \quad 100.0 \%$ Tuftelin-interacting protein 11 GN=TFIP11 TFP11_HUMAN $96.82 \quad 100.0 \%$
$49.83 \quad 100.0 \%$ TBB $49.83 \quad 100.0 \%$ _ TBB4B_HUMAN $49.83 \quad 100.0 \%$ TBB4B_HUMAN $49.83 \quad 100.0 \%$ BBB4B HUMAN $49.83 \quad 100.0 \%$ TBB4B_HUMAN $49.83 \quad 100.0 \%$ BB4B HUMAN $49.83 \quad 100.0 \%$ TBB4B_HUMAN $49.83 \quad 100.0 \%$ TBB4B_HUMAN $49.83 \quad 100.0 \%$ TBB4B HUMAN $49.83 \quad 100.0 \%$ TBB4B_HUMAN $49.83 \quad 100.0 \%$ BB4B_HUMAN $49.83 \quad 100.0 \%$ TBB4B HUMAN $49.83 \quad 100.0 \%$ $\begin{array}{lll} & 100.0 \%\end{array}$ TBB4B HUMAN $49.83 \quad 100.0 \%$ TBB4B_HUMAN $49.83 \quad 100.0 \%$ TBB4B_HUMAN $49.83 \quad 100.0 \%$ TBB4B_HUMAN $49.83 \quad 100.0 \%$ TBB4B_HUMAN $49.83 \quad 100.0 \%$ TBB4B_HUMAN $49.83 \quad 100.0 \%$ BBB4B_HUMAN $49.83 \quad 100.0 \%$ TBB6_HUMAN $49.86 \quad 100.0 \%$ TBB6_HUMAN $49.86 \quad 100.0 \%$ BB6_HUMAN $49.86 \quad 100.0 \%$ TBB6_HUMAN $49.86 \quad 100.0 \%$ TBB6_HUMAN $49.86 \quad 100.0 \%$ TBB6 HUMAN $49.86 \quad 100.0 \%$ TBB6 HUMAN $49.86 \quad 100.0 \%$ TBB6_HUMAN $49.86 \quad 100.0 \%$ TBB6 HUMAN $49.86 \quad 100.0 \%$ TBB6_HUMAN $49.86 \quad 100.0 \%$ TBB6 HUMAN $49.86 \quad 100.0 \%$ TBB6_HUMAN $49.86 \quad 100.0 \%$ TBB6_HUMAN $49.86 \quad 100.0 \%$ TBB6 HUMAN $49.86 \quad 100.0 \%$ TBG1_HUMAN $51.17 \quad 100.0 \%$ TBG1 HUMAN $51.17 \quad 100.0 \%$ TBG1_HUMAN $51.17 \quad 100.0 \%$ TBG1_HUMAN $51.17 \quad 100.0 \%$ TBG1_HUMAN $51.17 \quad 100.0$

13
13
13
13
13
13
13
13
13
13
13
13
13
13
13
13
13
13
13
13
13
13
13
6

58 $\begin{array}{lll}0.06 \% & 71.0 \% & 71.0 \% \\ 0.06 & \text { IREEYPDR }\end{array}$

$\begin{array}{lll}0.06 \% & 71.0 \% & \text { IREEYPDR } \\ 0.06 \% & 71.0 \% \text { IMTSVVPSPK }\end{array}$ $99.0 \% \quad 39.6$ $99.7 \% \quad 58.9$

0.06\% $71.0 \%$ LTTPTYGDLNHLVSAT

$\begin{array}{lll}0.06 \% & 71.0 \% & \text { FPGQLNADLRK }\end{array}$

$0.06 \% \quad 71.0 \%$ KLAVNMVPFPR

$0.06 \% \quad 71.0 \%$ LAVNMVPFPR

$0.06 \% \quad 71.0 \%$ LHFFMPGFAPLTSR

$0.06 \% \quad 71.0 \%$ ALTVPELTQQMFDAK

$0.06 \% \quad 71.0 \%$ NMMAACDPR

$0.06 \% \quad 71.0 \%$ NMMAACDPRHGR

$0.06 \% \quad 71.0 \%$ HGRYLTVAAVFR

$0.06 \% \quad 71.0 \%$ YLTVAAVFR

$0.06 \% \quad 71.0 \%$ YLTVAAVFRGR

$0.06 \% \quad 71.0 \%$ MSMKEVDEQMLNVQNK

$0.06 \% \quad 71.0 \%$ EVDEQMLNVQNK

$0.06 \% \quad 71.0 \%$ NSSYFVEWIPNNVK

$0.06 \% \quad 71.0 \%$ TAVCDIPPR

$0.06 \% \quad 71.0 \%$ TAVCDIPPRGLK

$\begin{array}{llll}99.7 \% & 45.3 & 25.0 & 45.3\end{array}$

$99.7 \% \quad 44.2 \quad 25.0 \quad 31.2 \quad 3$

$99.7 \% \quad 39.9$

$99.7 \% \quad 53.5$

$99.7 \% \quad 61.2$

$99.7 \% \quad 44.0$

$99.7 \% \quad 51.6$

$99.7 \% \quad 37.1$

$97.6 \% 24.9$

$99.7 \% \quad 60.5$

$99.7 \% \quad 60.1$

$99.7 \% \quad 54.2$

$0.06 \% \quad 71.0 \%$ MSATFIGNSTAIQELFK

$0.06 \% \quad 71.0 \%$ MSATFIGNSTAIQELFKR

$0.06 \% \quad 71.0 \%$ ISEQFTAMFR

$0.06 \% \quad 71.0 \%$ ISEQFTAMFRR

$0.01 \% \quad 32.3 \%$ INVYYNESSSQKYVPR

$0.01 \% \quad 32.3 \%$ AALVDLEPGTMDSVR

$0.01 \% 32.3 \%$ GHYTEGAELVDAVLDVVRK

$0.01 \% 32.3 \%$ FPGQLNADLR

$0.01 \% \quad 32.3 \%$ FPGQLNADLRK

$0.01 \% \quad 32.3 \%$ KLAVNMVPFPR

$0.01 \% \quad 32.3 \%$ LAVNMVPFPR

$10 \quad 0.01 \% \quad 32.3 \%$ LHFFMPGFAPLTSR

$10 \quad 0.01 \% \quad 32.3 \%$ ALTVPELTQQMFDAR

$0.01 \% \quad 32.3 \%$ NMMAACDPR

$0 \quad 0.01 \% \quad 32.3 \%$ NMMAACDPRHGR

$\quad 0.01 \% \quad 32.3 \%$ NSSYFVEWIPNNVK

$10 \quad 0.01 \% \quad 32.3 \%$ MASTFIGNSTAIQELFK

$99.7 \% 50.8$

$99.7 \% \quad 60.9$

$99.7 \% \quad 41.3$

$99.7 \% \quad 50.9$

$99.7 \% \quad 39.3$

$99.4 \% \quad 42.7$

$99.5 \% 50.8$

$99.4 \% \quad 24.9$

$99.7 \% \quad 30.7$

$99.7 \% \quad 35.2$

$99.0 \% \quad 19.2$

$99.7 \% \quad 44.2$

$99.7 \% \quad 39.9$

$99.7 \% 53.5$

$99.7 \% \quad 61.2$

$99.7 \% \quad 44.0$

$99.7 \% \quad 49.1$

$99.7 \% \quad 37.1$

$\begin{array}{lll}97.6 \% & 24.9\end{array}$

$99.7 \% \quad 41.3$

$0.01 \% \quad 32.3 \%$ MASTFIGNSTAIQELFKR

$99.3 \% \quad 69.2$

$0.01 \% \quad 10.6 \%$ AVLLDLEPR

$10 \quad 0.01 \% \quad 10.6 \%$ VIHSILNSPYAK

$99.7 \% \quad 48.0$

$99.7 \% \quad 44.7$

$0.01 \% \quad 10.6 \%$ LTQNADCVVVLDNTALNR $99.7 \% \quad 38.0$

$\begin{array}{lll}99.7 \% & 29.0 & 25 .\end{array}$

$99.7 \% \quad 55.0$

$99.7 \% 58.1$

$99.7 \% \quad 41.6$

$99.7 \% \quad 35.1$

$97.3 \% \quad 21.8$
$0.01 \% \quad 2.5 \%$ DAAAVLVSR

$0.00 \% \quad 2.5 \%$ NAQGIINPIEAK

$0.00 \% \quad 2.5 \%$ LEPLYSPIR
$0.01 \% \quad 2.5 \%$ LQQVLTGLR
3327.53

1077.53

1335.70

2724.33

1130.60

1258.69

1271.73

1143.63

1636.83

1691.87

1065.43

1447.60

1389.77

1039.59

1252.72

1971.88

1446.69

1696.83

1028.52

1326.72

1857.94

2014.04

1245.59

1401.69

1946.96

1589.78

2071.08

1130.60

1258.69

1271.73

1143.63

1636.83

1719.87

1065.43

1447.60

1696.83

1873.94

2014.04

1025.60

1341.75

2016.02

1027.53

901.51

1220.60

1027.63

1267.70

1267.70
1087.61

$55 \quad 162$

$63 \quad 174$

$242 \quad 251$

$242 \quad 252$

$252 \quad 262$

$253 \quad 262$

$283 \quad 297$

$298 \quad 306$

$298 \quad 309$

$307 \quad 318$

$310 \quad 318$

$310 \quad 320$

$325 \quad 336$

$337 \quad 350$

$351 \quad 359$

$351 \quad 362$

$363 \quad 379$

$363 \quad 380$

$381 \quad 390$

$381 \quad 391$

$\begin{array}{ll}47 & 62 \\ 63 & 77\end{array}$

$104 \quad 122$ 
Tyrosine--tRNA ligase, cytoplasmic GN=YARS SYYC_HUMAN $59.15 \quad 100.0 \%$ Tyrosine--tRNA ligase, cytoplasmic GN=YARS SYYC_HUMAN $59.15 \quad 100.0 \%$ Tyrosine--tRNA ligase, cytoplasmic GN=YARS SYYC HUMAN $59.15 \quad 100.0 \%$ Tyrosine--tRNA ligase, cytoplasmic GN=YARS SYYC_HUMAN $59.15 \quad 100.0 \%$ Tyrosine--tRNA ligase, cytoplasmic GN=YARS SYYC_HUMAN $59.15 \quad 100.0 \%$ U1 small nuclear ribonucleoprotein $70 \mathrm{kDa}$ GN=SNRNP70 RU17 HUMAN $51.56 \quad 100.0 \%$ U1 small nuclear ribonucleoprotein $70 \mathrm{kDa}$ GN=SNRNP70 RU17_HUMAN $51.56 \quad 100.0 \%$ U1 small nuclear ribonucleoprotein $70 \mathrm{kDa}$ GN=SNRNP70 RU17_HUMAN $51.56 \quad 100.0 \%$ U1 small nuclear ribonucleoprotein $70 \mathrm{kDa} \mathrm{GN=SNRNP70}$ RU17_HUMAN $51.56 \quad 100.0 \%$ U1 small nuclear ribonucleoprotein $70 \mathrm{kDa}$ GN=SNRNP70 RU17_HUMAN $51.56 \quad 100.0 \%$ U2 small nuclear ribonucleoprotein $A^{\prime}$ GN=SNRPA1 RU2A HUMAN $28.42 \quad 100.0 \%$ U2 small nuclear ribonucleoprotein A' GN=SNRPA1 RU2A_HUMAN $28.42 \quad 100.0 \%$ U2 small nuclear ribonucleoprotein $A^{\prime}$ GN=SNRPA1 RU2A_HUMAN $28.42 \quad 100.0 \%$ U2 small nuclear ribonucleoprotein A' GN=SNRPA1 RU2A_HUMAN $28.42 \quad 100.0 \%$ U2 small nuclear ribonucleoprotein A' GN=SNRPA1 RU2A_HUMAN $28.42 \quad 100.0 \%$ U2 small nuclear ribonucleoprotein A' GN=SNRPA1 RU2A HUMAN $28.42 \quad 100.0 \%$ U2 small nuclear ribonucleoprotein A' GN=SNRPA1 RU2A_HUMAN $28.42 \quad 100.0 \%$ U2 small nuclear ribonucleoprotein A' GN=SNRPA1 RU2A_HUMAN $28.42 \quad 100.0 \%$ U3 small nucleolar ribonucleoprotein protein IMP4 GN=IMP4 IMP4 HUMAN $33.76 \quad 100.0 \%$ U3 small nucleolar ribonucleoprotein protein IMP4 GN=IMP4 IMP4_HUMAN $33.76 \quad 100.0 \%$ U4/U6 small nuclear ribonucleoprotein Prp31 GN=PRPF31 PRP31_HUMAN $55.46 \quad 100.0 \%$ U4/U6 small nuclear ribonucleoprotein Prp31 GN=PRPF31 PRP31_HUMAN $55.46 \quad 100.0 \%$ U4/U6 small nuclear ribonucleoprotein Prp31 GN=PRPF31 PRP31_HUMAN 55.46 $100.0 \%$ U4/U6 small nuclear ribonucleoprotein Prp31 GN=PRPF31 PRP31_HUMAN 55.46 100.0\% U4/U6 small nuclear ribonucleoprotein Prp31 GN=PRPF31 PRP31_HUMAN 55.46 100.0\% U4/U6 small nuclear ribonucleoprotein Prp31 GN=PRPF31 PRP31_HUMAN $55.46 \quad 100.0 \%$ U4/U6 small nuclear ribonucleoprotein Prp31 GN=PRPF31 PRP31_HUMAN 55.46 $100.0^{\circ}$ U4/U6 small nuclear ribonucleoprotein Prp31 GN=PRPF31 PRP31_HUMAN $55.46 \quad 100.0 \%$ U4/U6 small nuclear ribonucleoprotein Prp31 GN=PRPF31 PRP31_HUMAN $55.46 \quad 100.0 \%$ U4/U6 small nuclear ribonucleoprotein Prp31 GN=PRPF31 PRP31_HUMAN $55.46 \quad 100.0 \%$ U4/U6 small nuclear ribonucleoprotein Prp31 GN=PRPF31 PRP31_HUMAN 55.46 100.0\% U4/U6 small nuclear ribonucleoprotein Prp31 GN=PRPF31 PRP31 HUMAN 55.46 $100.0^{\circ}$ U4/U6 small nuclear ribonucleoprotein Prp31 GN=PRPF31 PRP31_HUMAN 55.46 $100.0 \%$ U4/U6 small nuclear ribonucleoprotein Prp4 GN=PRPF4 PRP4_HUMAN $58.45 \quad 100.0 \%$ U4/U6 small nuclear ribonucleoprotein Prp4 GN=PRPF4 PRP4 HUMAN $58.45 \quad 100.0 \%$ U5 small nuclear ribonucleoprotein $200 \mathrm{kDa}$ helicase GN=SNRNP200 U520_HUMAN $244.51 \quad 100.0 \%$ U5 small nuclear ribonucleoprotein $200 \mathrm{kDa}$ helicase GN=SNRNP200 U520 HUMAN $244.51 \quad 100.0 \%$ U5 small nuclear ribonucleoprotein $200 \mathrm{kDa}$ helicase GN=SNRNP200 U520_HUMAN $244.51 \quad 100.0 \%$ U5 small nuclear ribonucleoprotein $200 \mathrm{kDa}$ helicase GN=SNRNP200 U520_HUMAN $244.51 \quad 100.0 \%$ U5 small nuclear ribonucleoprotein $200 \mathrm{kDa}$ helicase GN=SNRNP200 U520_HUMAN $244.51 \quad 100.0 \%$

\begin{tabular}{llll}
$0.00 \%$ & $7.1 \%$ & SDPQLIVQLR \\
\hline & $0.00 \%$ & $7.1 \%$ & EGLYEQAFQLLR
\end{tabular} EGLYEQAFQLLR

$14 \quad 0.02 \% \quad 16.3 \%$ EYTLDVYR

$16.3 \%$ LSSVVTQHDSKK

$0.02 \% \quad 16.3 \%$ YLPALGYSKR

$0.02 \% \quad 16.3 \%$ NSVEVALNK

$0.02 \% \quad 16.3 \%$ LASAAYPDPSK

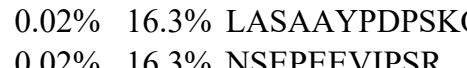

$0.02 \% \quad 16.3 \%$ IDVGEAEPR

$0.02 \% \quad 16.3 \%$ GQPDEELKPK

$0.01 \% \quad 8.7 \%$ RQQEVETELK

$0.01 \% \quad 8.7 \%$ VNYDTTESK

$0.01 \% \quad 8.7 \%$ EFEVYGPIKR

$0.01 \% \quad 8.7 \%$ RGGADVNIR

$0.01 \% \quad 8.7 \%$ GGADVNIR

$\begin{array}{llllllll}99.4 \% & 26.4 & 25.0 & 16.1 & 1 & 0 & 0 & 1168.67\end{array}$

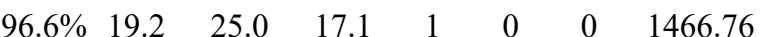

$\begin{array}{llllllll}99.0 \% & 26.3 & 25.0 & 20.4 & 1 & 0 & 0 & 1058.52\end{array}$

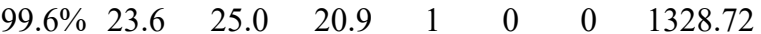

$\begin{array}{llll}99.7 \% & 33.3 & 25.0 & 29.8\end{array}$

$99.7 \% \quad 46.9 \quad 25.0 \quad 41.0$

$99.7 \% \quad 57.6 \quad 25.0 \quad 55.1$

$99.7 \% \quad 42.0$

$99.7 \% \quad 51.9$

$95.1 \% \quad 18.9$

$97.5 \% \quad 24.3$

$99.7 \% \quad 34.5$

$98.2 \% \quad 16.6$

$99.7 \% \quad 56.2$

$99.0 \% \quad 30.7$

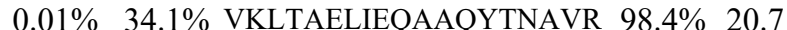

$0.01 \% \quad 34.1 \%$ LTAELIEQAAQYTNAVR

$0.01 \% \quad 34.1 \%$ TLLVNNNR

$0.01 \% \quad 34.1 \%$ SLTYLSILR

$0.01 \% \quad 34.1 \%$ TFNPGAGLPTDK

$0.01 \% \quad 34.1 \%$ GGPSPGDVEAIK

$0.01 \% \quad 34.1 \%$ NAIANASTLAEVER

$0.01 \% \quad 34.1 \%$ LKGLLQSGQIPGR

$0.00 \% \quad 6.2 \% \quad$ LIPTELRR

$0.00 \% \quad 6.2 \% \quad$ NVELTEVGPR

$0.03 \% \quad 25.9 \%$ ASEVMGPVEAAPEYR

$0.03 \% \quad 25.9 \%$ TVKELGNSLDK

$0.03 \% \quad 25.9 \%$ HRIYEYVESR

$0.03 \% \quad 25.9 \%$ IYEYVESR

$0.03 \% \quad 25.9 \%$ IMGVAGGLTNLSK

$0.03 \% \quad 25.9 \%$ MPACNIMLLGAQR

$0.03 \% \quad 25.9 \%$ VDSFHESTEGK

$0.03 \% \quad 25.9 \%$ QVKPLPAPLDGQR

$0.03 \% \quad 25.9 \%$ LGLTEIRK

$0.03 \% \quad 25.9 \%$ VRQTQVNEATK

$0.03 \% \quad 25.9 \%$ QTQVNEATKAR

$0.03 \% 25.9 \%$ TLQKQSVVYGGK

$0.03 \% \quad 25.9 \%$ YFSSMAEFLK

$0.00 \% \quad 4.6 \% \quad$ LHKEIPETTR

$0.00 \% \quad 4.6 \%$ GHNTNVGAIVFHPK

$0.10 \% \quad 13.0 \%$ ANSNLVLQADR

$0.10 \% \quad 13.0 \%$ FYDDAIVSQK

$0.10 \% \quad 13.0 \%$ FYDDAIVSQKK

$0.10 \% \quad 13.0 \%$ KADEVLEILK

$0.10 \% \quad 13.0 \%$ ADEVLEILK

$0.10 \% \quad 13.0 \%$ YAQAGFEGFK $\begin{array}{ccccc}99.7 \% & 55.1 & 25.0 & 55.1 & 1 \\ 96.6 \% & 26.6 & 25.0 & 8.9 & 1 \\ 99.7 \% & 47.3 & 25.0 & 36.4 & 2 \\ 99.7 \% & 41.6 & 25.0 & 35.2 & 2 \\ 99.7 \% & 53.0 & 25.0 & 41.3 & 2 \\ 99.7 \% & 87.2 & 25.0 & 84.3 & 2 \\ 99.1 \% & 20.1 & 25.0 & 20.1 & 0 \\ 99.0 \% & 31.2 & 25.0 & 17.7 & 2 \\ 99.7 \% & 41.0 & 25.0 & 27.0 & 2 \\ 99.7 \% & 57.1 & 25.0 & 52.4 & 4 \\ 99.1 \% & 31.5 & 25.0 & 9.4 & 2 \\ 97.2 \% & 16.7 & 25.0 & 16.7 & 0 \\ 99.0 \% & 54.1 & 25.0 & 36.4 & 2 \\ 99.7 \% & 55.3 & 25.0 & 41.7 & 4 \\ 99.7 \% & 39.4 & 25.0 & 30.1 & 1 \\ 99.6 \% & 22.5 & 25.0 & 22.5 & 1 \\ 99.3 \% & 19.3 & 25.0 & 19.3 & 1 \\ 99.0 \% & 55.6 & 25.0 & 40.1 & 2 \\ 99.7 \% & 59.9 & 25.0 & 59.6 & 4 \\ 99.7 \% & 28.3 & 25.0 & 23.1 & 1 \\ 99.7 \% & 43.2 & 25.0 & 42.5 & 2 \\ 99.7 \% & 35.7 & 25.0 & 34.6 & 2 \\ 99.2 \% & 19.4 & 25.0 & 19.4 & 0 \\ 99.7 \% & 28.9 & 25.0 & 22.3 & 0 \\ 99.7 \% & 53.6 & 25.0 & 46.2 & 3 \\ 99.7 \% & 72.9 & 25.0 & 67.7 & 2 \\ 99.7 \% & 30.5 & 25.0 & 29.8 & 1 \\ 99.7 \% & 64.7 & 25.0 & 50.6 & 3 \\ 99.7 \% & 50.2 & 25.0 & 40.1 & 2 \\ 99.7 \% & 57.0 & 25.0 & 55.7 & 8\end{array}$
259

128

$136 \quad 147$

1167.65

973.53

1119.57

1818.94

1256.61

985.50

1140.59

1259.66

1056.48

1237.66

957.52

801.42

2118.16

1890.99

943.53

1065.63

1217.62

1126.57

1458.75

1366.82

997.62

1113.59

1621.75

1203.66

1351.68

1058.52

1276.69

1490.73

1235.55

1418.81

929.58

1273.69

1245.65

1307.73

1238.58

1223.67

1490.79

1200.63

1185.58

1313.67

1157.68

1029.58

1117.53 $\begin{array}{ll}198 & 2 \\ 311 & 3\end{array}$

$336 \quad 346$

$336 \quad 352$

$357 \quad 367$

392400

$475 \quad 484$

$\begin{array}{ll}78 & 87\end{array}$

$110 \quad 118$

$122 \quad 131$

$201 \quad 209$

20

$4 \quad 20$

$68 \quad 75$

$114 \quad 122$

$180 \quad 191$

$194 \quad 205$

$206 \quad 219$

$220 \quad 232$

$41 \quad 48$

$241 \quad 250$

$138 \quad 148$

$202 \quad 211$

$204 \quad 211$

$231 \quad 243$

$244 \quad 256$

$305 \quad 315$

$339 \quad 351$

$407 \quad 417$

$409 \quad 419$

$427 \quad 438$

$479 \quad 488$

$198 \quad 207$

$271 \quad 284$

25
$275 \quad 284$

$285 \quad 294$

$286 \quad 294$

$\begin{array}{ll}286 & 294 \\ 470 & 479\end{array}$ 
5 small nuclear ribonucleoprotein $200 \mathrm{kDa}$ helicase GN=SNRNP200 U520_HUMAN $244.51 \quad 100.0 \% \quad 31$ I5 small nuclear ribonucleoprotein $200 \mathrm{kDa}$ helicase GN=SNRNP200 U520_HUMAN $244.51 \quad 100.0 \% \quad 31$ U5 small nuclear ribonucleoprotein $200 \mathrm{kDa}$ helicase GN=SNRNP200 U520_HUMAN $244.51 \quad 100.0 \%$ U5 small nuclear ribonucleoprotein $200 \mathrm{kDa}$ helicase GN=SNRNP200 U520_HUMAN $244.51 \quad 100.0 \%$ U5 small nuclear ribonucleoprotein $200 \mathrm{kDa}$ helicase GN=SNRNP200 U520_HUMAN $244.51 \quad 100.0 \%$ U5 small nuclear ribonucleoprotein $200 \mathrm{kDa}$ helicase GN=SNRNP200 U520_HUMAN $244.51 \quad 100.0 \%$ U5 small nuclear ribonucleoprotein $200 \mathrm{kDa}$ helicase GN=SNRNP200 U520_HUMAN $244.51 \quad 100.0 \%$ U5 small nuclear ribonucleoprotein $200 \mathrm{kDa}$ helicase GN=SNRNP200 U520_HUMAN $244.51 \quad 100.0 \%$ U5 small nuclear ribonucleoprotein $200 \mathrm{kDa}$ helicase GN=SNRNP200 U520 HUMAN $244.51 \quad 100.0 \%$ U5 small nuclear ribonucleoprotein $200 \mathrm{kDa}$ helicase GN=SNRNP200 U520_HUMAN $244.51 \quad 100.0 \%$ U5 small nuclear ribonucleoprotein $200 \mathrm{kDa}$ helicase GN=SNRNP200 U520_HUMAN $244.51 \quad 100.0 \%$ U5 small nuclear ribonucleoprotein $200 \mathrm{kDa}$ helicase GN=SNRNP200 U520 HUMAN $244.51 \quad 100.0 \%$ U5 small nuclear ribonucleoprotein $200 \mathrm{kDa}$ helicase GN=SNRNP200 U520_HUMAN $244.51 \quad 100.0 \%$ U5 small nuclear ribonucleoprotein $200 \mathrm{kDa}$ helicase GN=SNRNP200 U520_HUMAN $244.51 \quad 100.0 \%$ U5 small nuclear ribonucleoprotein $200 \mathrm{kDa}$ helicase GN=SNRNP200 U520 HUMAN $244.51 \quad 100.0 \%$ U5 small nuclear ribonucleoprotein $200 \mathrm{kDa}$ helicase GN=SNRNP200 U520_HUMAN $244.51 \quad 100.0 \%$ U5 small nuclear ribonucleoprotein $200 \mathrm{kDa}$ helicase GN=SNRNP200 U520 HUMAN $244.51 \quad 100.0 \%$ U5 small nuclear ribonucleoprotein $200 \mathrm{kDa}$ helicase GN=SNRNP200 U520 HUMAN $244.51 \quad 100.0 \%$ U5 small nuclear ribonucleoprotein $200 \mathrm{kDa}$ helicase GN=SNRNP200 U520_HUMAN $244.51 \quad 100.0 \%$ U5 small nuclear ribonucleoprotein $200 \mathrm{kDa}$ helicase GN=SNRNP200 U520_HUMAN $244.51 \quad 100.0 \%$ U5 small nuclear ribonucleoprotein $200 \mathrm{kDa}$ helicase GN=SNRNP200 U520_HUMAN $244.51 \quad 100.0 \%$ U5 small nuclear ribonucleoprotein $200 \mathrm{kDa}$ helicase GN=SNRNP200 U520_HUMAN $244.51 \quad 100.0 \%$ U5 small nuclear ribonucleoprotein $200 \mathrm{kDa}$ helicase GN=SNRNP200 U520_HUMAN $244.51 \quad 100.0 \%$ U5 small nuclear ribonucleoprotein $200 \mathrm{kDa}$ helicase GN=SNRNP200 U520_HUMAN $244.51 \quad 100.0 \%$ U5 small nuclear ribonucleoprotein $200 \mathrm{kDa}$ helicase GN=SNRNP200 U520 HUMAN $244.51 \quad 100.0 \%$ U5 small nuclear ribonucleoprotein $40 \mathrm{kDa}$ protein GN=SNRNP40 SNR40_HUMAN $39.31 \quad 100.0 \%$ U5 small nuclear ribonucleoprotein $40 \mathrm{kDa}$ protein GN=SNRNP40 SNR40_HUMAN $39.31 \quad 100.0 \%$ U5 small nuclear ribonucleoprotein $40 \mathrm{kDa}$ protein GN=SNRNP40 SNR40 HUMAN $39.31 \quad 100.0 \%$ U5 small nuclear ribonucleoprotein $40 \mathrm{kDa}$ protein GN=SNRNP40 SNR40_HUMAN $39.31 \quad 100.0 \%$ U5 small nuclear ribonucleoprotein $40 \mathrm{kDa}$ protein GN=SNRNP40 SNR40 HUMAN $39.31 \quad 100.0 \%$ U5 small nuclear ribonucleoprotein $40 \mathrm{kDa}$ protein GN=SNRNP40 SNR40_HUMAN $39.31 \quad 100.0 \%$ U5 small nuclear ribonucleoprotein $40 \mathrm{kDa}$ protein GN=SNRNP40 SNR40_HUMAN $39.31 \quad 100.0 \%$ UAP56-interacting factor GN=FYTTD1 UIF HUMAN $35.82 \quad 100.0^{\circ}$ UAP56-interacting factor GN=FYTTD1 UIF_HUMAN $35.82 \quad 100.0 \%$ UAP56-interacting factor GN=FYTTD1 UIF HUMAN $35.82 \quad 100.0 \%$ UAP56-interacting factor GN=FYTTD1 UIF_HUMAN $35.82 \quad 100.0 \%$ UAP56-interacting factor GN=FYTTD1 UAP56-interacting factor GN=FYTTD1 UAP56-interacting factor GN=FYTTD1 UAP56-interacting factor GN=FYTTD1

UAP56-interacting factor $\mathrm{GN}=\mathrm{FYTTD} 1$ . UIF HUMAN $35.82 \quad 100.0 \%$ UIF_HUMAN $35.82 \quad 100.0 \%$ UIF_HUMAN $35.82 \quad 100.0 \%$ UIF HUMAN $35.82 \quad 100.0 \%$ Ubiquitin carboxyl-terminal hydrolase $24 \mathrm{GN}=$ USP24 UBP24_HUMAN $294.37 \quad 100.0 \%$ Ubiquitin carboxyl-terminal hydrolase 24 GN=USP24 UBP24 HUMAN 294.37 100.0\% Ubiquitin carboxyl-terminal hydrolase 24 GN=USP24 UBP24_HUMAN $294.37 \quad 100.0 \%$ Ubiquitin carboxyl-terminal hydrolase 24 GN=USP24 UBP24_HUMAN $294.37 \quad 100.0 \%$ Ubiquitin carboxyl-terminal hydrolase 24 GN=USP24 UBP24 HUMAN $294.37 \quad 100.0 \%$ Ubiquitin thioesterase OTUB1 GN=OTUB1 OTUB1_HUMAN $31.28 \quad 100.0 \%$

37

37

37

37

37
37

31

1

31
7

7
7

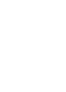

9
9
9
9

9
9
9

9

9
9
5

9
5
5
5

$\begin{array}{llll}9.10 \% & 13.0 \% & \text { NIEMTQEDVR }\end{array}$

FQIMNEIVYEK

$0.10 \% \quad 13.0 \%$ DTLGLFLR

$0.10 \% \quad 13.0 \%$ EGSASTEVLR

$0.10 \% \quad 13.0 \%$ GTQVYSPEK

$91 \quad 0.10 \% \quad 13.0 \%$ TGNFQVTELGR

$91 \quad 0.10 \% \quad 13.0 \%$ VFSLSSEFK

$91 \quad 0.10 \% \quad 13.0 \%$ EEEKLELQK

$91 \quad 0.10 \% \quad 13.0 \%$ VPIPVKESIEEPSAK

$91 \quad 0.10 \% \quad 13.0 \%$ ESIEEPSAK

$91 \quad 0.10 \% \quad 13.0 \%$ KLPEEVVK

$91 \quad 0.10 \% \quad 13.0 \%$ TICAEFAILR

$91 \quad 0.10 \% \quad 13.0 \%$ MLLQSSEGR

$91 \quad 0.10 \% \quad 13.0 \%$ KVVLLTGETSTDLK

$91 \quad 0.10 \% \quad 13.0 \%$ VVLLTGETSTDLK

$91 \quad 0.10 \% \quad 13.0 \%$ IVALSSSLSNAK

$91 \quad 0.10 \% \quad 13.0 \%$ LLSMAKPVYHAITK

$91 \quad 0.10 \% \quad 13.0 \%$ KPVIVFVPSR

$91 \quad 0.10 \% \quad 13.0 \%$ MTQNPNYYNLQGISHR

$91 \quad 0.10 \% \quad 13.0 \%$ TNLLLQAHLSR

$91 \quad 0.10 \% \quad 13.0 \%$ SNSLISIK

$91 \quad 0.10 \% \quad 13.0 \%$ SNSLISIKR

$11 \quad 0.01 \% \quad 21.8 \%$ FHPNGSTLASAGFDR

$11 \quad 0.01 \% \quad 21.8 \%$ TVAVWDSETGER

$11 \quad 0.01 \% \quad 21.8 \%$ LKGHTSFVNSCYPAR

$11 \quad 0.01 \% \quad 21.8 \%$ GHTSFVNSCYPAR

$11 \quad 0.01 \% \quad 21.8 \%$ GPQLVCTGSDDGTVK

$11 \quad 0.01 \% \quad 21.8 \%$ IFQGNVHNFEK

$11 \quad 0.01 \% \quad 21.8 \%$ FVYVWDTTSR

$17 \quad 0.02 \% \quad 35.8 \%$ LVGATATSSPPPK

$17 \quad 0.02 \% \quad 35.8 \%$ LLQQSGAQQFR

$17 \quad 0.02 \% \quad 35.8 \%$ RPNGVITGLAAR

$17 \quad 0.02 \% \quad 35.8 \%$ KNNIPANFTR

$0.02 \% 35.8 \%$ GVPLQFDINSVGK

$0.02 \% 35.8 \%$ QTGMTLNER

$0.01 \% \quad 2.0 \%$ CLLASTYLAR

$0.01 \% \quad 2.0 \%$ VLYNLEVLSSK

$0.01 \% \quad 2.0 \% \quad$ SSSGFVGLR

$0.01 \% \quad 2.0 \%$ VYDQTNPYTDVR

$0.01 \% \quad 2.0 \%$ VAVATILEK $\begin{array}{llllllll}99.7 \% & 43.6 & 25.0 & 40.5 & 4 & 0 & 0 & 1208.59\end{array}$

$\begin{array}{llllllll}99.7 \% & 59.4 & 25.0 & 59.4 & 2 & 0 & 0 & 1297.65\end{array}$

$\begin{array}{llll}99.7 \% & 53.5 & 25.0 & 41.9\end{array}$

$99.7 \% \quad 57.5 \quad 25.0 \quad 54.2$

$99.7 \% \quad 50.8 \quad 25.0 \quad 50.4$

$\begin{array}{llll}99.0 \% & 19.5 & 25.0 & 19.5\end{array}$

$\begin{array}{llll}99.7 \% & 53.5 & 25.0 & 43.6\end{array}$

$\begin{array}{lllll}99.7 \% & 36.6 & 25.0 & 35.3 & 2\end{array}$

$\begin{array}{llll}99.7 \% & 51.9 & 25.0 & 46.9\end{array}$

$\begin{array}{llll}99.7 \% & 31.9 & 25.0 & 24.9\end{array}$

$\begin{array}{llll}98.1 \% & 20.6 & 25.0 & 14.4\end{array}$

$\begin{array}{llll}99.7 \% & 35.8 & 25.0 & 35.8\end{array}$

$\begin{array}{llll}99.7 \% & 33.4 & 25.0 & 18.7\end{array}$

$\begin{array}{llll}98.1 \% & 23.4 & 25.0 & 12.5\end{array}$

$\begin{array}{llll}99.7 \% & 40.4 & 25.0 & 34.3\end{array}$

$\begin{array}{llll}99.7 \% & 39.8 & 25.0 & 31.5\end{array}$

$\begin{array}{lllll}99.7 \% & 26.2 & 25.0 & 26.2\end{array}$

$\begin{array}{llll}99.7 \% & 57.5 & 25.0 & 57.5\end{array}$

$\begin{array}{llll}99.7 \% & 73.7 & 25.0 & 73.7\end{array}$

$\begin{array}{llll}98.8 \% & 19.4 & 25.0 & 19.4\end{array}$

$\begin{array}{llll}99.7 \% & 51.9 & 25.0 & 49.0\end{array}$

$\begin{array}{llll}99.6 \% & 24.1 & 25.0 & 24.1\end{array}$

$\begin{array}{llll}99.7 \% & 52.3 & 25.0 & 52.3\end{array}$

$\begin{array}{llll}98.8 \% & 19.1 & 25.0 & 17.0\end{array}$

$99.7 \% \quad 49.2 \quad 25.0 \quad 24.7$

$\begin{array}{llll}99.5 \% & 24.6 & 25.0 & 24.6\end{array}$

$\begin{array}{llll}99.7 \% & 37.6 & 25.0 & 35.4\end{array}$

$\begin{array}{llll}99.7 \% & 32.2 & 25.0 & 31.7\end{array}$

$\begin{array}{llll}99.3 \% & 22.7 & 25.0 & 22.7\end{array}$

$\begin{array}{llll}99.7 \% & 48.4 & 25.0 & 48.4\end{array}$

$\begin{array}{llll}99.7 \% & 51.3 & 25.0 & 41.2\end{array}$

$99.7 \% \quad 33.0 \quad 25.0 \quad 30.8$

$\begin{array}{llll}99.7 \% & 42.7 & 25.0 & 38.1\end{array}$

$\begin{array}{llll}99.7 \% & 50.4 & 25.0 & 38.3\end{array}$

$\begin{array}{llll}99.2 \% & 18.8 & 25.0 & 18.8\end{array}$

$\begin{array}{llll}99.4 \% & 26.0 & 25.0 & 15.3\end{array}$

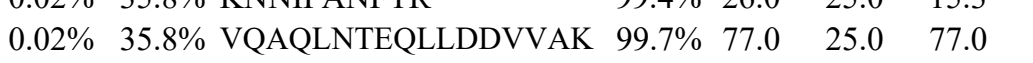

$\begin{array}{lllllll}0.02 \% & 35.8 \% & \text { VQAQLNTEQLLDDVVAKR } & 99.7 \% & 29.0 & 25.0 & 28.1\end{array}$

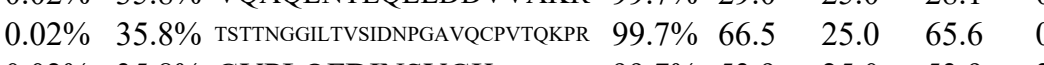

$0.01 \% \quad 17.0 \%$ IQQEIAVQNPLVSER $\begin{array}{lllll}99.7 \% & 53.9 & 25.0 & 53.9 & 2\end{array}$

$98.7 \% \quad 29.1 \quad 25.0 \quad 9.3$

$99.7 \% \quad 49.7 \quad 25.0 \quad 42.0$

$99.7 \% \quad 37.0 \quad 25.0 \quad 37.0$

$99.7 \% \quad 40.7 \quad 25.0 \quad 22.6$

$\begin{array}{llll}97.1 \% & 21.1 & 25.0 & 11.9\end{array}$

$99.7 \% \quad 26.9 \quad 25.0 \quad 22.3$ $\begin{array}{llll}99.7 \% & 88.2 & 25.0 & 79.2\end{array}$
1234.57

1429.70

1198.67

934.54

1048.53

1008.50

1221.62

1043.54

1145.61

1622.90

989.48

941.57

1193.63

1020.51

1503.86

1375.77

1189.68

1587.89

1141.71

1951.91

1265.73

861.50

1017.6

1576.75

1349.63

1736.85

1495.67

1533.72

1332.67

1273.62

1225.68

1275.68

1224.72

1174.63

1884.01

2040.11

2911.49

1373.74

1049.50

1167.62

1264.71

909.48

1470.69

943.58

1723.93 
Ubiquitin thioesterase OTUB1 GN=OTUB1 OTUB1_HUMAN $31.28 \quad 100.0 \%$ Ubiquitin thioesterase OTUB1 GN=OTUB1 OTUB1_HUMAN $31.28 \quad 100.0 \%$ Ubiquitin thioesterase OTUB1 GN=OTUB1 OTUB1_HUMAN $31.28 \quad 100.0 \%$ Ubiquitin-40S ribosomal protein S27a GN=RPS27A RS27A_HUMAN $17.97 \quad 100.0^{\circ}$ Ubiquitin-40S ribosomal protein S27a GN=RPS27A RS27A_HUMAN $17.97 \quad 100.0 \%$ Ubiquitin-40S ribosomal protein S27a GN=RPS27A RS27A_HUMAN $17.97 \quad 100.0 \%$ Ubiquitin-40S ribosomal protein S27a GN=RPS27A RS27A HUMAN $17.97 \quad 100.0 \%$ Ubiquitin-40S ribosomal protein S27a GN=RPS27A RS27A_HUMAN $17.97 \quad 100.0 \%$ Ubiquitin-40S ribosomal protein S27a GN=RPS27A RS27A HUMAN $17.97 \quad 100.0^{\circ}$ Ubiquitin-like modifier-activating enzyme 1 GN=UBA1 UBA1_HUMAN $117.85 \quad 100.0 \%$ Ubiquitin-like modifier-activating enzyme $1 \mathrm{GN}=\mathrm{UBA} 1$ UBA1_HUMAN $117.85 \quad 100.0 \%$ Ubiquitin-protein ligase E3A GN=UBE3A UBE3A HUMAN $100.69100 .0 \%$ Ubiquitin-protein ligase E3A GN=UBE3A UBE3A_HUMAN $100.69 \quad 100.0 \%$ Ubiquitin-protein ligase E3A GN=UBE3A UBE3A_HUMAN $100.69100 .0 \%$ Uncharacterized protein C19orf52 GN=C19orf52 CS052 HUMAN $29.23 \quad 100.0 \%$ Uncharacterized protein C19orf52 GN=C19orf52 CS052_HUMAN $29.23 \quad 100.0 \%$ Uncharacterized protein $\mathrm{C} 3$ orf17 $\mathrm{GN}=\mathrm{C} 3$ orf17 $\mathrm{CC} 017$ HUMAN $64.55 \quad 100.0 \%$ Uncharacterized protein $\mathrm{C} 3$ orf $17 \mathrm{GN}=\mathrm{C} 3$ orf17 $\quad$ CC017_HUMAN $64.55 \quad 100.0 \%$ Unconventional myosin-Ib GN=MYO1B MYO1B_HUMAN $131.99 \quad 100.0 \%$ Unconventional myosin-Ib GN=MYO1B MYO1B HUMAN $131.99 \quad 100.0 \%$ Unconventional myosin-Ib GN=MYO1B MYO1B_HUMAN $131.99 \quad 100.0 \%$ Unconventional myosin-Id GN=MYO1D MYO1D_HUMAN $116.21 \quad 100.0 \%$ Unconventional myosin-Id GN=MYO1D MYO1D_HUMAN $116.21 \quad 100.0 \%$ Unconventional myosin-Id GN=MYO1D MYO1D_HUMAN $116.21 \quad 100.0 \%$ Unconventional myosin-Va GN=MYO5A MYO5A_HUMAN $215.41 \quad 100.0 \%$ Unconventional myosin-Va GN=MYO5A MYO5A_HUMAN $215.41 \quad 100.0 \%$ Unconventional myosin-Va GN=MYO5A MYO5A_HUMAN $215.41 \quad 100.0 \%$ Unconventional myosin-Va GN=MYO5A MYO5A_HUMAN $215.41 \quad 100.0 \%$ Unconventional myosin-Va GN=MYO5A MYO5A_HUMAN $215.41 \quad 100.0 \%$ Unconventional myosin-Vb GN=MYO5B MYO5B HUMAN $213.68 \quad 100.0 \%$ Unconventional myosin- $\mathrm{Vb}$ GN=MYO5B MYO5B_HUMAN $213.68 \quad 100.0 \%$ Unhealthy ribosome biogenesis protein 2 homolog GN=URB2 URB2_HUMAN $170.55 \quad 100.0 \%$ Unhealthy ribosome biogenesis protein 2 homolog GN=URB2 URB2 HUMAN $170.55100 .0 \%$ UPF0428 protein CXorf56 GN=CXorf56 CX056_HUMAN $25.62 \quad 100.0 \%$ UPF0428 protein CXorf56 GN=CXorf56 CX056_HUMAN $25.62 \quad 100.0 \%$ UPF0488 protein $\mathrm{C} 8$ orf33 $\mathrm{GN}=\mathrm{C} 8$ orf33 $\quad$ CH033_HUMAN $24.99 \quad 100.0 \%$ UPF0488 protein C8orf33 $\mathrm{GN}=\mathrm{C} 8$ orf33 $\quad$ CH033_HUMAN $24.99 \quad 100.0 \%$ UPF0488 protein $\mathrm{C} 8$ orf33 $\mathrm{GN}=\mathrm{C} 8$ orf33 3 CH033 HUMAN $24.99 \quad 100.0^{\circ}$ UPF0488 protein C8orf33 $\mathrm{GN}=\mathrm{C} 8$ orf33 $\quad$ CH033_HUMAN $24.99 \quad 100.0 \%$ UPF0488 protein $\mathrm{C} 8$ orf33 $\mathrm{GN}=\mathrm{C} 8$ orf33 3 CH033 HUMAN $24.99100 .0 \%$ $\mathrm{UPF} 0488$ protein $\mathrm{C} 8 \mathrm{or} 33 \mathrm{GN}=\mathrm{C} 8 \mathrm{OP}$ Uridine-cytidine kinase $2 \mathrm{GN}=\mathrm{UCK} 2$ Uridine-cytidine kinase $2 \mathrm{GN}=\mathrm{UCK}$ Uridine-cytidine kinase $2 \mathrm{GN}=\mathrm{UCK} 2$ Uridine-cytidine kinase $2 \mathrm{GN}=\mathrm{UCK} 2$ CH033 HUMAN $24.99 \quad 100.0 \%$ UCK2_HUMAN $29.30 \quad 100.0 \%$ UCK2 HUMAN $29.30 \quad 100.0 \%$ UCK2_HUMAN $29.30 \quad 100.0 \%$ UCK2_HUMAN $29.30 \quad 100.0 \%$ Uridine-cytidine kinase-like $1 \mathrm{GN}=\mathrm{UCKL} 1 \mathrm{UCKL} 1$ HUMAN $61.14 \quad 100.0 \%$ Uridine-cytidine kinase-like $1 \mathrm{GN}=\mathrm{UCKL} 1$ UCKL1_HUMAN $\quad 61.14 \quad 100.0 \%$
$0.01 \% \quad 17.0 \%$ EYAEDDNIYQQK

$0.01 \% \quad 17.0 \%$ LLTSGYLQR

$0.01 \% \quad 17.0 \%$ FFEHFIEGGR

$\begin{array}{llllllll}99.7 \% & 48.0 & 25.0 & 48.0 & 1 & 0 & 0 & 1515.66\end{array}$

$\begin{array}{llllllll}99.7 \% & 53.3 & 25.0 & 44.0 & 2 & 0 & 0 & 1050.59\end{array}$

$99.7 \% \quad 37.7 \quad 25.0 \quad 37.7 \quad 2$

$0.11 \% \quad 39.1 \%$ TITLEVEPSDTIENVK

$99.7 \% \quad 55.3$

$0.11 \% \quad 39.1 \%$ TITLEVEPSDTIENVKAK

$0.11 \% \quad 39.1 \%$ IQDKEGIPPDQQR

$0.11 \% 39.1 \%$ LIFAGKQLEDGR

$0.11 \% \quad 39.1 \%$ TLSDYNIQK

$0.11 \% \quad 39.1 \%$ ESTLHLVLR

$0.01 \% \quad 2.2 \%$ LQTSSVLVSGLR

$0.01 \% \quad 2.2 \% \quad$ LKSDTAAAAVR

$0.01 \% \quad 4.3 \%$ IGDSSQGDNNLQK

$0.01 \% \quad 4.3 \%$ NLVNDDDAIVAASK

$0.01 \% \quad 4.3 \%$ VDPLETELGVK

$0.01 \% \quad 6.5 \%$ ESEAFVQR

$0.01 \% \quad 6.5 \%$ VLDVGFVGR

$0.00 \% \quad 3.9 \%$ ASEETLLGISK

$0.00 \% \quad 3.9 \%$ EIQQFSQGTRK

$0.00 \% \quad 3.1 \%$ VSTTLNVAQAYYAR

$0.00 \% \quad 3.1 \%$ SLFPEGNPAK

$0.00 \% \quad 3.1 \%$ SSALVIQSYIR

$0.01 \% \quad 3.3 \%$ SNCVLEAFGNAK

$0.01 \% \quad 3.3 \%$ RPLTAATLFK

$0.01 \% \quad 3.3 \%$ SIPASDLPQVR

$0.01 \% \quad 3.0 \%$ NQSIIVSGESGAGK

$0.01 \% \quad 3.0 \%$ LGNADNFNYTK

$0.01 \% \quad 3.0 \%$ AGQVAYLEK

$0.01 \% \quad 3.0 \%$ NLILELKPR

$0.01 \% \quad 3.0 \%$ HADYLNDDQKVR

$0.00 \% \quad 1.2 \%$ NQSIIVSGESGAGK

$0.00 \% \quad 1.2 \%$ AGQVAYLEK

$0.00 \% \quad 1.5 \%$ VAEFSLSGSQR

$0.00 \% \quad 1.5 \% \quad$ SLDSSTPLPIVR

$0.00 \% \quad 11.3 \%$ NAPVTFIVDGAVVK

$0.00 \% \quad 11.3 \%$ EVADSYAQNAK

$0.01 \% 24.5 \%$ AHPLGDEGGTASK

$0.01 \% \quad 24.5 \%$ AHPLGDEGGTASKK

$0.01 \% \quad 24.5 \%$ QKEQAIGAIR

$0.01 \% \quad 24.5 \%$ AAAYSAQVQPVDGATR

$0.01 \% \quad 24.5 \%$ AAAYSAQVQPVDGATRK

$0.01 \% \quad 24.5 \%$ ATLDMPDEEFRFNF

$0.01 \% \quad 18.0 \%$ IVQLLGQNEVDYR

$0.01 \% \quad 18.0 \%$ QVVILSQDSFYR

$0.01 \% \quad 18.0 \%$ TVQIPVYDFVSHSR

$0.01 \% \quad 18.0 \%$ YADVIIPR

$0.00 \% \quad 4.2 \%$ EAFAIGLGGGSASGK

$0.00 \% \quad 4.2 \%$ LADIVVPR $\begin{array}{llll}99.7 \% & 30.4 & 25.0 & 30.4\end{array}$

$\begin{array}{lllll}99.7 \% & 61.6 & 25.0 & 61.6 & 37\end{array}$

$\begin{array}{llll}99.1 \% & 20.3 & 25.0 & 20.3\end{array}$

$99.7 \% \quad 55.5 \quad 25.0 \quad 46.1 \quad 20$

$99.7 \% \quad 55.8 \quad 25.0 \quad 45.0$

$\begin{array}{llll}99.7 \% & 52.4 & 25.0 & 51.7\end{array}$

$\begin{array}{llll}99.7 \% & 43.8 & 25.0 & 38.2\end{array}$

$99.7 \% \quad 38.7 \quad 25.0 \quad 38.7$

$\begin{array}{lllll}99.7 \% & 48.8 & 25.0 & 45.8 & 2\end{array}$

$\begin{array}{llll}99.3 \% & 21.8 & 25.0 & 17.6\end{array}$

$99.0 \% \quad 26.1 \quad 25.0 \quad 17.2$

$\begin{array}{llll}99.7 \% & 50.8 & 25.0 & 41.8\end{array}$

$99.7 \% \quad 54.1 \quad 25.0 \quad 54.1$

$\begin{array}{llll}99.4 \% & 29.9 & 25.0 & 12.7\end{array}$

$\begin{array}{llll}99.7 \% & 62.7 & 25.0 & 59.4\end{array}$

$\begin{array}{llll}94.6 \% & 16.1 & 25.0 & 12.4\end{array}$

$\begin{array}{lllll}99.7 \% & 41.7 & 25.0 & 31.5 & 2\end{array}$

$99.7 \% \quad 73.7$

$97.8 \% \quad 18.2$

$99.7 \% \quad 26.6$

$99.6 \% \quad 28.5$

$99.7 \% \quad 32.5$

$99.7 \% \quad 35.2$

$99.7 \% \quad 30.1$

$97.5 \% 15.7$

$99.6 \% \quad 28.5$

$99.7 \% \quad 35.2$

$99.7 \% \quad 34.5$

$99.7 \% \quad 53.7$

$99.7 \% \quad 49.2$

$99.7 \% \quad 35.5$

$99.7 \% \quad 33.5$

$99.7 \% \quad 29.4$

$99.7 \% 37.8$

$99.7 \% \quad 69.8$

$99.7 \% \quad 33.6$

$99.7 \% 37.0$

$99.7 \% \quad 40.6$

$99.7 \% \quad 84.0$

$99.7 \% 26.1$

$99.0 \% \quad 46.2$

$99.6 \% \quad 39.9$

$99.0 \% \quad 44.7$
1987.06

1523.78

1346.74

1081.55

1067.62

1259.73

1102.62

1375.65

1444.73

1199.65

965.47

961.55

1147.62

1321.69

1556.81

1059.55

1236.69

1309.62

1117.67

1182.65

1346.69

1256.59

978.53

1095.69

1473.71

1346.69

978.53

1180.60

1284.72

1429.81

1195.56

1239.60

1367.69

1113.64

1604.80

1732.90

1894.83

1546.82

1454.76

1647.85

946.54

1321.67

882.54 
Vacuolar protein sorting-associated protein 26A GN=VPS26A VP26A_HUMAN $38.17 \quad 100.0 \%$ Vacuolar protein sorting-associated protein 26A GN=VPS26A VP26A_HUMAN $38.17 \quad 100.0 \%$ Vacuolar protein sorting-associated protein 26A GN=VPS26A VP26A_HUMAN $38.17 \quad 100.0 \%$ Vacuolar protein sorting-associated protein 26A GN=VPS26A VP26A_HUMAN $38.17 \quad 100.0 \%$ Very-long-chain (3R)-3-hydroxyacyl-CoA dehydratase $3 \mathrm{GN}=\mathrm{HACD} 3$ HACD3_HUMAN $43.16 \quad 100.0 \%$ Very-long-chain (3R)-3-hydroxyacyl-CoA dehydratase 3 GN=HACD3 HACD3_HUMAN $43.16 \quad 100.0 \%$ Very-long-chain (3R)-3-hydroxyacyl-CoA dehydratase $3 \mathrm{GN}=\mathrm{HACD} 3$ HACD3_HUMAN $43.16 \quad 100.0 \%$ Very-long-chain (3R)-3-hydroxyacyl-CoA dehydratase 3 GN=HACD3 HACD3_HUMAN $43.16 \quad 100.0 \%$ Very-long-chain (3R)-3-hydroxyacyl-CoA dehydratase 3 GN=HACD3 HACD3_HUMAN $43.16 \quad 100.0 \%$ Very-long-chain 3-oxoacyl-CoA reductase GN=HSD17B12 DHB12_HUMAN $34.33 \quad 100.0 \%$ Very-long-chain 3-oxoacyl-CoA reductase GN=HSD17B12 DHB12_HUMAN $34.33 \quad 100.0 \%$ Very-long-chain 3-oxoacyl-CoA reductase GN=HSD17B12 DHB12_HUMAN $34.33 \quad 100.0 \%$ Very-long-chain 3-oxoacyl-CoA reductase GN=HSD17B12 DHB12_HUMAN $34.33 \quad 100.0 \%$ Very-long-chain 3-oxoacyl-CoA reductase GN=HSD17B12 DHB12_HUMAN $34.33 \quad 100.0 \%$ Very-long-chain 3-oxoacyl-CoA reductase GN=HSD17B12 DHB12_HUMAN $34.33 \quad 100.0 \%$ Very-long-chain 3-oxoacyl-CoA reductase GN=HSD17B12 DHB12_HUMAN $34.33 \quad 100.0 \%$ Very-long-chain 3-oxoacyl-CoA reductase GN=HSD17B12 DHB12_HUMAN $34.33 \quad 100.0 \%$ Very-long-chain 3-oxoacyl-CoA reductase GN=HSD17B12 DHB12_HUMAN $34.33 \quad 100.0 \%$ Very-long-chain enoyl-CoA reductase GN=TECR TECR_HUMAN $36.04 \quad 100.0 \%$ Very-long-chain enoyl-CoA reductase GN=TECR TECR_HUMAN $36.04 \quad 100.0 \%$ Very-long-chain enoyl-CoA reductase GN=TECR TECR_HUMAN $36.04 \quad 100.0 \%$ Vesicle-fusing ATPase GN=NSF

Vesicle-fusing ATPase $\mathrm{GN}=\mathrm{NSF}$

Vesicle-fusing ATPase $\mathrm{GN}=\mathrm{NSF}$

Vesicle-fusing ATPase GN=NSF

Vesicle-fusing ATPase $\mathrm{GN}=\mathrm{NSF}$

Vesicle-fusing ATPase GN=NSF

Vimentin GN=VIM

Vimentin GN=VIM

Vimentin GN=VIM

Vimentin GN=VIM

Vimentin $\mathrm{GN}=\mathrm{VIM}$

Vimentin GN=VIM

Vimentin GN=VIM

Vimentin GN=VIM

Vimentin GN=VIM

Vimentin $\mathrm{GN}=\mathrm{VIM}$

Vimentin GN=VIM

Vimentin GN=VIM

Vimentin GN=VIM

Vimentin GN=VIM

Vimentin GN=VIM

Vimentin GN=VIM

Vimentin GN=VIM

Vimentin $\mathrm{GN}=\mathrm{VIM}$

Vimentin GN=VIM

Vimentin GN=VIM
NSF HUMAN $82.60 \quad 100.0 \%$

NSF_HUMAN $82.60 \quad 100.0 \%$ NSF_HUMAN $82.60 \quad 100.0 \%$ NSF HUMAN $82.60 \quad 100.0 \%$ NSF_HUMAN $82.60 \quad 100.0 \%$ NSF_HUMAN $82.60 \quad 100.0 \%$ VIME_HUMAN $53.65 \quad 100.0 \%$ VIME_HUMAN $53.65 \quad 100.0 \%$ VIME_HUMAN $53.65 \quad 100.0 \%$ VIME_HUMAN $53.65 \quad 100.0 \%$ VIME_HUMAN $53.65 \quad 100.0 \%$ VIME_HUMAN $53.65 \quad 100.0 \%$ VIME_HUMAN $53.65 \quad 100.0 \%$ VIME HUMAN $53.65 \quad 100.0 \%$ VIME_HUMAN $53.65 \quad 100.0 \%$ VIME HUMAN $53.65 \quad 100.0 \%$ VIME_HUMAN $53.65 \quad 100.0 \%$ VIME_HUMAN $53.65 \quad 100.0 \%$ VIME HUMAN $53.65 \quad 100.0 \%$ VIME_HUMAN $53.65 \quad 100.0 \%$ VIME_HUMAN $53.65 \quad 100.0 \%$ VIME_HUMAN $53.65 \quad 100.0 \%$ VIME_HUMAN $53.65 \quad 100.0 \%$ VIME_HUMAN $53.65 \quad 100.0 \%$ VIME_HUMAN $53.65 \quad 100.0 \%$ VIME_HUMAN $53.65 \quad 100.0 \%$
$0.01 \% \quad 17.1 \%$ HYLFYDGESVSGK $0.01 \% \quad 17.1 \%$ ELALPGELTQSR

$6 \quad 0.01 \% \quad 17.1 \%$ EITGIGPSTTTETETIAK $0.01 \% \quad 17.1 \%$ LFLAGYDPTPTMR $0.02 \% \quad 11.3 \%$ QVNITVQK

$16 \quad 0.02 \% \quad 11.3 \%$ KVSQWWER

$16 \quad 0.02 \% \quad 11.3 \%$ LESEGSPETLTNLR

$16 \quad 0.02 \% \quad 11.3 \%$ LESEGSPETLTNLRK

$16 \quad 0.02 \% \quad 11.3 \%$ FSFTLPYPVK

$14 \quad 31 \quad 0.03 \% \quad 35.9 \%$ ISYSLFTALR

$14 \quad 31 \quad 0.03 \% \quad 35.9 \%$ SYAEELAK

$14 \quad 31 \quad 0.03 \% \quad 35.9 \%$ LDQVSSEIKEK

$14 \quad 31 \quad 0.03 \% \quad 35.9 \%$ TIAVDFASEDIYDKIK

$14 \quad 31 \quad 0.03 \% \quad 35.9 \%$ MININILSVCK

$14 \quad 31 \quad 0.03 \% \quad 35.9 \%$ MTQLVLPGMVER

$14 \quad 31 \quad 0.03 \% \quad 35.9 \%$ TFVDFFSQCLHEEYR

$14 \quad 31 \quad 0.03 \% \quad 35.9 \%$ GVFVQSVLPYFVATK

$14 \quad 31 \quad 0.03 \% \quad 35.9 \%$ KPTLDKPSPETFVK

$15 \quad 0.02 \% \quad 10.1 \%$ SLKDEDVLQK

$15 \quad 0.02 \% \quad 10.1 \%$ LPVGTTATLYFR

$15 \quad 0.02 \% \quad 10.1 \%$ LLETLFVHR

$18 \quad 0.02 \% \quad 7.7 \%$ GILLYGPPGCGK

$18 \quad 0.02 \% \quad 7.7 \% \quad$ NFSGAELEGLVR

$18 \quad 0.02 \% \quad 7.7 \% \quad$ VLDDGELLVQQTK

$18 \quad 0.02 \% \quad 7.7 \% \quad$ LLDYVPIGPR

$18 \quad 0.02 \% \quad 7.7 \% \quad$ KLLIIGTTSR

$18 \quad 0.02 \% \quad 7.7 \% \quad$ LLIIGTTSR

$59 \quad 225 \quad 0.25 \% \quad 75.1 \%$ MFGGPGTASRPSSSR

\begin{tabular}{llll}
59 & 225 & $0.25 \%$ & $75.1 \%$ \\
\hline & SYVTTSTR
\end{tabular}

$59 \quad 225 \quad 0.25 \% \quad 75.1 \%$ TYSLGSALRPSTSR

$59 \quad 225 \quad 0.25 \% \quad 75.1 \%$ SLYASSPGGVYATR

$59 \quad 225 \quad 0.25 \% \quad 75.1 \%$ LRSSVPGVR

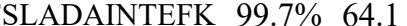

$59 \quad 225 \quad 0.25 \% \quad 75.1 \%$ LLQDSVDFSLADAINTEFKNTR

$59 \quad 225 \quad 0.25 \% \quad 75.1 \%$ TNEKVELQELNDR

$59 \quad 225 \quad 0.25 \% \quad 75.1 \%$ VELQELNDR

$59 \quad 225 \quad 0.25 \% \quad 75.1 \%$ FANYIDKVR

$59 \quad 225 \quad 0.25 \% \quad 75.1 \%$ ILLAELEQLK

$59 \quad 225 \quad 0.25 \% \quad 75.1 \%$ ILLAELEQLKGQGK

$59225 \quad 0.25 \% \quad 75.1 \%$ LGDLYEEEMR

$59 \quad 225 \quad 0.25 \% \quad 75.1 \%$ QVDQLTNDK

$59 \quad 225 \quad 0.25 \% \quad 75.1 \%$ QVDQLTNDKAR

$59 \quad 225 \quad 0.25 \% \quad 75.1 \%$ VEVERDNLAEDIMR

$59 \quad 225 \quad 0.25 \% \quad 75.1 \%$ EEAENTLQSFR

$59 \quad 225 \quad 0.25 \% \quad 75.1 \%$ QDVDNASLAR

$59225 \quad 0.25 \% \quad 75.1 \%$ KVESLQEEIAFLK

$59225 \quad 0.25 \% \quad 75.1 \%$ DVRQQYESVAAK
$99.4 \% \quad 28.4 \quad 25.0 \quad 28.4$

$99.7 \% \quad 58.0 \quad 25.0 \quad 53.6$

$\begin{array}{llll}9.7 \% & 44.4 & 25.0 & 44.4\end{array}$

$99.0 \% \quad 32.7 \quad 25.0 \quad 26.2$

$\begin{array}{llll}95.1 \% & 17.5 & 25.0 & 12.5\end{array}$

$99.7 \% \quad 70.2 \quad 25.0 \quad 68.7$

$\begin{array}{llll}97.9 \% & 19.4 & 25.0 & 14.8\end{array}$

$99.7 \% \quad 24.4 \quad 25.0 \quad 21.4$

$99.7 \% \quad 78.1 \quad 25.0 \quad 68.2$

$\begin{array}{lllll}99.0 \% & 28.4 & 25.0 & 20.1 & 2\end{array}$

$\begin{array}{llll}94.7 \% & 20.7 & 25.0 & 13.6\end{array}$

$99.7 \% \quad 70.6 \quad 25.0 \quad 70.6 \quad 2$

$99.7 \% \quad 66.1 \quad 25.0 \quad 62.8$

$\begin{array}{llll}99.7 \% & 55.9 & 25.0 & 46.5\end{array}$

$\begin{array}{llll}99.7 \% & 47.2 & 25.0 & 47.2\end{array}$

$\begin{array}{lllll}99.7 \% & 48.1 & 25.0 & 48.1\end{array}$

$99.7 \% \quad 30.0 \quad 25.0 \quad 28.5$

$\begin{array}{llll}99.7 \% & 46.2 & 25.0 & 40.6\end{array}$

$\begin{array}{llll}99.7 \% & 65.7 & 25.0 & 65.7\end{array}$

$\begin{array}{llll}99.7 \% & 39.7 & 25.0 & 26.7\end{array}$

$\begin{array}{llll}99.7 \% & 34.9 & 25.0 & 24.6\end{array}$

$\begin{array}{llll}99.7 \% & 58.8 & 25.0 & 41.3\end{array}$

$\begin{array}{llll}99.7 \% & 54.6 & 25.0 & 54.6\end{array}$

$\begin{array}{llll}99.7 \% & 39.1 & 25.0 & 39.1\end{array}$

$\begin{array}{lllll}99.7 \% & 42.6 & 25.0 & 35.7 & 2\end{array}$

$\begin{array}{llll}99.7 \% & 45.6 & 25.0 & 37.9\end{array}$

$99.7 \% \quad 54.0 \quad 25.0 \quad 41.8$

$\begin{array}{lllll}99.0 \% & 38.1 & 25.0 & 29.5 & 8\end{array}$

$\begin{array}{llll}99.7 \% & 40.1 & 25.0 & 40.1\end{array}$

$\begin{array}{llll}99.7 \% & 54.5 & 25.0 & 54.5\end{array}$

$\begin{array}{lllll}99.7 \% & 29.7 & 25.0 & 17.6 & 2\end{array}$

$\begin{array}{llll}99.7 \% & 55.7 & 25.0 & 55.7\end{array}$

$99.7 \% \quad 41.1 \quad 25.0 \quad 31.7$

$\begin{array}{llll}99.4 \% & 25.4 & 25.0 & 25.4\end{array}$

$\begin{array}{llll}99.7 \% & 60.2 & 25.0 & 51.6\end{array}$

$\begin{array}{llll}99.7 \% & 47.1 & 25.0 & 38.7\end{array}$

$\begin{array}{llll}99.7 \% & 55.3 & 25.0 & 55.3\end{array}$

$\begin{array}{llll}99.7 \% & 47.0 & 25.0 & 47.0\end{array}$

$\begin{array}{llll}99.7 \% & 45.3 & 25.0 & 36.8\end{array}$

$\begin{array}{llll}99.7 \% & 56.3 & 25.0 & 40.0\end{array}$

$99.6 \% \quad 31.3 \quad 25.0 \quad 31.3$

$\begin{array}{llll}99.7 \% & 34.7 & 25.0 & 34.7\end{array}$

$\begin{array}{lllll}99.7 \% & 55.1 & 25.0 & 44.2 & 8\end{array}$

$\begin{array}{llll}99.7 \% & 58.4 & 25.0 & 55.9\end{array}$

$\begin{array}{llll}99.7 \% & 54.4 & 25.0 & 48.4\end{array}$

$\begin{array}{ll}0 & 0 \\ 0 & 0 \\ 0 & 0 \\ 0 & 0 \\ 0 & 0 \\ 0 & 0 \\ 0 & 0 \\ 1 & 0 \\ 0 & 0 \\ 0 & 0 \\ 0 & 0 \\ 0 & 0 \\ 1 & 0 \\ 0 & 0 \\ 0 & 0 \\ 2 & 0 \\ 0 & 0 \\ 2 & 0 \\ 0 & 0 \\ 0 & 0 \\ 0 & 0 \\ 0 & 0 \\ 0 & 0 \\ 0 & 0 \\ 0 & 0 \\ 0 & 0 \\ 0 & 0 \\ 4 & 0 \\ 0 & 0 \\ 6 & 0 \\ 0 & 0 \\ 0 & 0 \\ 1 & 0 \\ 3 & 0 \\ 2 & 0 \\ 0 & 0 \\ 0 & 0 \\ 0 & 0 \\ 3 & 0 \\ 0 & 0 \\ 0 & 0 \\ 2 & 0 \\ 5 & 0 \\ 0 & 0 \\ 0 & 0 \\ 6 & 0 \\ 0 & 0 \\ & 0\end{array}$

1313.71

1848.94

1497.74

929.54

1118.57

1545.78

1673.87

1198.65

1170.65

910.45

1275.68

1827.94

1304.71

1373.73

1977.88

1654.92

1586.88

1174.63

1338.74

1127.66

1231.65

1291.66

1457.78

1142.66

1101.70

973.60

1510.71

914.46

1495.79

1428.71

970.58

2126.07

2497.26

1587.80

1115.57

1125.61

1169.71

1539.91

1254.57

1060.53

1287.67

1688.83

1323.62

1088.53

1533.85

1393.71 
Vimentin GN=VIM

Vimentin GN=VIM

Vimentin GN=VIM

Vimentin GN=VIM

Vimentin GN=VIM

Vimentin GN=VIM

Vimentin GN=VIM

Vimentin GN=VIM

Vimentin GN=VIM

Vimentin GN=VIM

Vimentin GN=VIM

Vimentin GN=VIM

Vimentin GN=VIM

Vimentin GN=VIM

Vimentin GN=VIM

Vimentin GN=VIM

Vimentin GN=VIM
Vimentin GN=VIM

Vimentin GN=VIM

Vimentin GN=VIM

$\begin{array}{lllllll}\text { VIME HUMAN } 53.65 & 100.0 \% & 40 & 59 & 225 & 0.25 \% & 75.1 \% \\ \text { VIMEYESVAAK }\end{array}$

VIME_HUMAN $53.65 \quad 100.0 \% \quad 40 \quad 59 \quad 225 \quad 0.25 \% \quad 75.1 \%$ NLQEAEEWYK

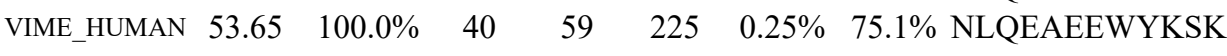

VIME_HUMAN $53.65 \quad 100.0 \% \quad 40 \quad 59 \quad 225 \quad 0.25 \% \quad 75.1 \%$ FADLSEAANR

VIME_HUMAN $53.65 \quad 100.0 \% \quad 40$

VIME_HUMAN $53.65 \quad 100.0 \% \quad 40$

VIME HUMAN $53.65 \quad 100.0 \% \quad 40$

VIME_HUMAN $53.65 \quad 100.0 \% \quad 40$

VIME HUMAN $53.65 \quad 100.0 \% \quad 40$

VIME_HUMAN $53.65 \quad 100.0 \% \quad 40$

VIME_HUMAN $53.65 \quad 100.0 \% \quad 40$

VIME HUMAN $53.65 \quad 100.0 \% \quad 40$

VIME_HUMAN $53.65 \quad 100.0 \% \quad 40$

VIME_HUMAN $53.65 \quad 100.0 \% \quad 40$

VIME_HUMAN $53.65 \quad 100.0 \% \quad 40$

VIME_HUMAN $53.65 \quad 100.0 \% \quad 40$

VIME HUMAN $53.65 \quad 100.0 \% \quad 40$

VIME_HUMAN $53.65 \quad 100.0 \% \quad 40$

VIME_HUMAN $53.65 \quad 100.0 \% \quad 40$

VIME HUMAN $53.65 \quad 100.0 \% \quad 40$

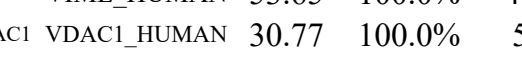

Voltage-dependent anion-selective channel protein $1 \mathrm{GN}=\mathrm{VDACl}$ VDAC1_HUMAN $30.77 \quad 100.0 \%$

Voltage-dependent anion-selective channel protein $1 \mathrm{GN}=\mathrm{VDACl}$ VDAC1_HUMAN $30.77 \quad 100.0 \%$

Voltage-dependent anion-selective channel protein $1 \mathrm{GN}=\mathrm{VDAC1}$ VDAC1_HUMAN 30.77

Voltage-dependent anion-selective channel protein $1 \mathrm{GN}=\mathrm{VDAC1}$ VDAC1_HUMAN 30.77

Voltage-dependent anion-selective channel protein $1 \mathrm{GN}=\mathrm{VDAC} 1$ VDAC1_HUMAN 30.77

Voltage-dependent anion-selective channel protein $2 \mathrm{GN}=\mathrm{VDAC2}$ VDAC2_HUMAN 31.57

Voltage-dependent anion-selective channel protein $2 \mathrm{GN}=\mathrm{VDAC2}$ VDAC2 HUMAN 31.57

Voltage-dependent anion-selective channel protein $2 \mathrm{GN}=\mathrm{VDAC2}$ VDAC2_HUMAN 31.57

Voltage-dependent anion-selective channel protein $2 \mathrm{GN}=\mathrm{VDAC2}$ VDAC2 $\mathrm{HUMAN} 31.5$

Voltage-dependent anion-selective channel protein $2 \mathrm{GN}=\mathrm{VDAC2}$ VDAC2_HUMAN 31.57

Voltage-dependent anion-selective channel protein $2 \mathrm{GN}=\mathrm{VDAC2}$ VDAC2_HUMAN 31.57

Voltage-dependent anion-selective channel protein $2 \mathrm{GN}=\mathrm{VDAC2}$ VDAC2_HUMAN 31.57

Voltage-dependent anion-selective channel protein 2 GN=VDAC2 VDAC2_HUMAN 31.57

Voltage-dependent anion-selective channel protein $2 \mathrm{GN}=\mathrm{VDAC} 2$ VDAC2 HUMAN 31.57

Voltage-dependent anion-selective channel protein $2 \mathrm{GN}=\mathrm{VDAC2}$ VDAC2_HUMAN 31.5

Voltage-dependent anion-selective channel protein $3 \mathrm{GN}=\mathrm{VDAC} 3$ VDAC3_HUMAN 30.66

Voltage-dependent anion-selective channel protein $3 \mathrm{GN}=\mathrm{VDAC} 3$ VDAC3_HUMAN 30.66

Voltage-dependent anion-selective channel protein $3 \mathrm{GN}=\mathrm{VDAC} 3$ VDAC3_HUMAN 30.66

Voltage-dependent anion-selective channel protein $3 \mathrm{GN}=\mathrm{VDAC} 3$ VDAC3_HUMAN 30.66

Voltage-dependent anion-selective channel protein $3 \mathrm{GN}=\mathrm{VDAC} 3$ VDAC3_HUMAN 30.66

Voltage-dependent anion-selective channel protein $3 \mathrm{GN}=\mathrm{VDAC} 3$ VDAC3_HUMAN 30.66

voltage-dependent anion-selective channel protein $3 \mathrm{GN}=\mathrm{VDAC} 3$ VDAC3 HUMAN 30.66

Voltage-deped

Voltage-dependent anion-selective channel protein $3 \mathrm{GN}=\mathrm{VDAC} 3$ VDAC3_HUMAN 30.66

Voltage-dependent anion-selective channel protein $3 \mathrm{GN}=\mathrm{VDAC} 3$ VDAC3 HUMAN 30.66

Voltage-dependent anion-selective channel protein $3 \mathrm{GN}=\mathrm{VDAC} 3$ VDAC3_HUMAN 30.66

$100.0 \%$

$00.0 \%$

$100.0 \%$

$100.0 \% \quad 10$

$100.0 \% \quad 10$

$100.0 \% \quad 10$

$100.0 \% \quad 10$

$100.0 \% \quad 10$

$100.0 \% \quad 10$

$100.0 \% \quad 10$

$100.0 \% \quad 10$

$100.0 \% \quad 10$

$100.0 \% \quad 10$

$100.0 \% \quad 12$

$00.0 \% \quad 12$

$100.0 \% \quad 12$

$100.0 \% \quad 12$

$100.0 \% \quad 12$

$100.0 \% \quad 12$

$100.0 \% \quad 12$

$100.0 \% \quad 12$

$100.0 \% \quad 12$

$\begin{array}{lllll}59 & 225 & 0.25 \% & 75.1 \% & \text { FADLSEAANR } \\ 59 & 225 & 0.25 \% & 75.1 \% & \text { FADLSEAANRNNDALR }\end{array}$

$59225 \quad 0.25 \% \quad 75.1 \%$ QVQSLTCEVDALK

$59225 \quad 0.25 \% \quad 75.1 \%$ LQDEIQNMKEEMAR

$59225 \quad 0.25 \% \quad 75.1 \%$ HLREYQDLLNVK

$59 \quad 225 \quad 0.25 \% \quad 75.1 \%$ EYQDLLNVK

$\begin{array}{llll}59 & 225 & 0.25 \% & 75.1 \% \\ 59 & \text { MALDIEIATYR }\end{array}$

$59-225 \quad 0.25 \% \quad 75.1 \%$ MALDIEIATYRK

$59 \quad 225 \quad 0.25 \% \quad 75.1 \%$ KLLEGEESR

$59 \quad 225 \quad 0.25 \% \quad 75.1 \%$ LLEGEESRISLPLPNFSSLNLR

$59 \quad 225 \quad 0.25 \% \quad 75.1 \%$ ISLPLPNFSSLNLR

$59 \quad 225 \quad 0.25 \% \quad 75.1 \%$ ISLPLPNFSSLNLRETNLDSLPLVDTHSK

$\begin{array}{lll}0.25 \% & 75.1 \% & \text { ETNLDSLPLVDTHSKR }\end{array}$

$225 \quad 0.25 \% \quad 75.1 \%$ TLLIKTVETR

. $25 \%$ 75.1\% DGQVINETSQHHDDLE

$0.01 \% \quad 30.0 \%$ LTFDSSFSPNTGK

$13 \quad 0.01 \% \quad 30.0 \%$ YQIDPDACFSAK

$40 \quad 0.04 \% \quad 43.5 \%$ WCEYGLTFTEK

$40 \quad 0.04 \% \quad 43.5 \%$ WNTDNTLGTEIAIEDQICQGLK

$40 \quad 0.04 \% \quad 43.5 \%$ LTFDTTFSPNTGKK

$40 \quad 0.04 \% \quad 43.5 \%$ NNFAVGYR

$\begin{array}{lllll}11 & 40 & 0.04 \% & 43.5 \% & \text { YQLDPTASISAK }\end{array}$

$1140 \quad 0.04 \% \quad 43.5 \%$ LTLSALVDGK

$\begin{array}{lll}49 & 0.05 \% \quad 53.4 \% \text { GYGFGMVK }\end{array}$

17

$0.05 \% \quad 53.4 \%$ VCNYGLTFTQK

$17 \quad 49 \quad 0.05 \% \quad 53.4 \%$ LTLDTIFVPNTGKK

$100.0 \% \quad 12$

$0.05 \% \quad 53.4 \%$ LSQNNFALGYK

$\begin{array}{llll}99.7 \% & 31.8 & 25.0 & 31.8\end{array}$

$\begin{array}{lllll}99.7 \% & 31.8 & 25.0 & 31.8 & 2 \\ 99.7 \% & 65.3 & 25.0 & 59.0 & 2\end{array}$

$99.7 \% \quad 59.0 \quad 25.0 \quad 45.7$

$99.7 \% \quad 60.0$

$\begin{array}{ll}97.7 \% & 25.2\end{array}$

$99.7 \% \quad 51.8$

$99.7 \% \quad 48.9$

$99.7 \% \quad 49.2$

$99.7 \% \quad 43.1$

$99.7 \% \quad 57.4$

$99.7 \% \quad 47.8$

$99.7 \% 51.8$

$\begin{array}{ll}99.7 \% & 40.6 \\ 99.7 \% & 29.2\end{array}$

75.1\% TVETRGQVINETSQHHDDLE $99.7 \% \quad 45.8$

$99.7 \% \quad 60.3$

99.1\% \#\#\#\#

$99.4 \% \quad 19.7$

$99.7 \% \quad 60.1$

$99.7 \% \quad 54.1$

$99.7 \% \quad 54.9$

$99.4 \% \quad 56.7$

$\begin{array}{lll}97.9 \% & 23.3\end{array}$

$99.7 \% \quad 24.6$

$\begin{array}{lll}99.7 \% & 59.2\end{array}$

$\begin{array}{ll}99.7 \% & 59.2 \\ 99.7 \% & 59.4\end{array}$

$\begin{array}{ll}99.7 \% & 42.5 \\ 99.0 \% & 48.2\end{array}$

$\begin{array}{ll}99.0 \% & 48.2\end{array}$

$\begin{array}{lllllll}11 & 40 & 0.04 \% & 43.5 \% & \text { TGDFQLHTNVNDGTEFGGSIYQK } & 99.7 \% & 52.8 \\ 11 & 40 & 0.04 \% & 43.5 \% & \text { YQLDPTASISAK } & 99.7 \% & 48.8\end{array}$

$\begin{array}{ll}99.7 \% & 48.8 \\ 99.7 \% & 60.8\end{array}$

$99.7 \% \quad 59.9$

$99.0 \% \quad 39.0$

$\begin{array}{ll}99.7 \% & 83.7\end{array}$

$99.7 \% \quad 56.6$ $99.7 \% \quad 52.5$

$99.7 \% \quad 44.1$

$99.7 \% \quad 58.3$

$99.7 \% \quad 48.3$

\begin{tabular}{rrr}
$99.7 \%$ & 56.2 \\
\hline $\mathrm{QK}$ & $99.7 \%$ & 53.4
\end{tabular}

$\begin{array}{lllllll}17 & 49 & 0.05 \% & 53.4 \% & \text { AADFQLHTHVNDGTEFGGSIYQK } & 99.7 \% & 53.4 \\ 17 & 49 & 0.05 \% & 53.4 \% & \text { IETSINLAWTAGSNNTR } & 99.7 \% & 90.6 \\ 17 & 49 & 0.05 \% & 53.4 \% & \text { VNNASLIGLGYTQTLRPGVK } & 99.7 \% & 53.6\end{array}$

5.0

60.0

11.
38.7

$0 \quad 102$

1023.51

309.61

1524.73

1093.53

1776.86

1490.75

2377.17

1766.81

1527.83

1121.58

1311.66

1423.76

1060.56

2484.35

1570.90

3220.72

824.95

1173.72

2423.11

1836.80

2176.05

1400.67

1213.62

1414.63

2103.18

1030.61

824.47

1433.64

2519.21

428.70

556.80

940.46

2528.17

1293.67

2103.16

1016.60

874.41

990.84

1621.80

1330.65

1907.88

1418.79

546.88

254.65

1847.92

2101.18 

V-type proton ATPase subunit d 1 GN=ATP6V0D1 VA0D1_HUMAN $40.33 \quad 100.0 \%$ V-type proton ATPase subunit H GN=ATP6V1H VATH_HUMAN $55.88 \quad 100.0 \%$ V-type proton ATPase subunit H GN=ATP6V1H VATH_HUMAN $55.88 \quad 100.0 \%$ WD repeat-containing protein $1 \mathrm{GN}=$ WDR1 WDR1_HUMAN $66.19 \quad 100.0 \%$ WD repeat-containing protein $1 \mathrm{GN}=$ WDR1 WDR1_HUMAN $66.19 \quad 100.0 \%$ WD repeat-containing protein $1 \mathrm{GN}=$ WDR1 WDR1_HUMAN $66.19 \quad 100.0 \%$ WD repeat-containing protein $18 \mathrm{GN}=$ WDR18 WDR 18 HUMAN $47.41 \quad 100.0 \%$ WD repeat-containing protein 18 GN=WDR18 WDR18_HUMAN $47.41 \quad 100.0 \%$ WD repeat-containing protein 5 GN=WDR5 WDR5_HUMAN $36.59 \quad 100.0 \%$ WD repeat-containing protein 5 GN=WDR5 WDR5 HUMAN $36.59 \quad 100.0 \%$ WD repeat-containing protein 5 GN=WDR5 WDR5_HUMAN $36.59 \quad 100.0 \%$ WD repeat-containing protein 5 GN=WDR5 WDR5 HUMAN $36.59 \quad 100.0 \%$ WD repeat-containing protein 5 GN=WDR5 WDR5_HUMAN $36.59 \quad 100.0 \%$ WD repeat-containing protein 82 GN=WDR82 WDR82_HUMAN $35.08 \quad 100.0 \%$ WD repeat-containing protein $82 \mathrm{GN}=$ WDR82 WDR82_HUMAN $35.08 \quad 100.0 \%$ WD repeat-containing protein 82 GN=WDR82 WDR82_HUMAN $35.08 \quad 100.0 \%$ WD repeat-containing protein $82 \mathrm{GN}=$ WDR82 WDR82_HUMAN $35.08 \quad 100.0 \%$ WD repeat-containing protein 82 GN=WDR82 WDR82_HUMAN $35.08 \quad 100.0 \%$ WD repeat-containing protein 82 GN=WDR82 WDR82_HUMAN $35.08 \quad 100.0 \%$ WD repeat-containing protein 82 GN=WDR82 WDR82 HUMAN $35.08 \quad 100.0 \%$ X-ray repair cross-complementing protein $5 \mathrm{GN}=\mathrm{XRCC} 5 \mathrm{XRCC} 5$ HUMAN $82.71 \quad 100.0 \%$ X-ray repair cross-complementing protein $5 \mathrm{GN}=$ XRCC5 XRCC5_HUMAN $82.71 \quad 100.0 \%$ X-ray repair cross-complementing protein $5 \mathrm{GN}=\mathrm{XRCC} 5$ XRCC5_HUMAN $82.71 \quad 100.0 \%$ X-ray repair cross-complementing protein $5 \mathrm{GN}=\mathrm{XRCC} 5$ XRCC5_HUMAN $82.71 \quad 100.0 \%$ $\mathrm{X}$-ray repair cross-complementing protein $5 \mathrm{GN}=\mathrm{XRCC} 5 \mathrm{XRCC} 5$ HUMAN $82.71 \quad 100.0 \%$ X-ray repair cross-complementing protein $5 \mathrm{GN}=\mathrm{XRCC} 5 \mathrm{XRCC} 5$ HUMAN $82.71 \quad 100.0 \%$ X-ray repair cross-complementing protein $5 \mathrm{GN}=\mathrm{XRCC} 5$ XRCC5_HUMAN $82.71 \quad 100.0 \%$ X-ray repair cross-complementing protein $5 \mathrm{GN}=\mathrm{XRCC} 5 \mathrm{XRCC} 5$ HUMAN $82.71 \quad 100.0 \%$ X-ray repair cross-complementing protein $6 \mathrm{GN}=\mathrm{XRCC} 6 \mathrm{XRCC6}$ _HUMAN $69.85 \quad 100.0 \%$ X-ray repair cross-complementing protein $6 \mathrm{GN}=\mathrm{XRCC} 6$ XRCC6_HUMAN $69.85 \quad 100.0 \%$ X-ray repair cross-complementing protein $6 \mathrm{GN}=\mathrm{XRCC} 6$ XRCC6 HUMAN $69.85 \quad 100.0 \%$ X-ray repair cross-complementing protein $6 \mathrm{GN}=\mathrm{XRCC6}$ XRCC6_HUMAN $69.85 \quad 100.0 \%$ X-ray repair cross-complementing protein $6 \mathrm{GN}=\mathrm{XRCC} 6 \mathrm{XRCC} 6$ HUMAN $69.85 \quad 100.0 \%$ X-ray repair cross-complementing protein $6 \mathrm{GN}=\mathrm{XRCC} 6 \mathrm{XRCC6}$ _HUMAN $69.85 \quad 100.0 \%$ X-ray repair cross-complementing protein $6 \mathrm{GN}=\mathrm{XRCC6}$ XRCC6_HUMAN $69.85 \quad 100.0 \%$ X-ray repair cross-complementing protein $6 \mathrm{GN}=\mathrm{XRCC} 6$ XRCC6_HUMAN $69.85 \quad 100.0 \%$ X-ray repair cross-complementing protein $6 \mathrm{GN}=\mathrm{XRCC} 6 \mathrm{XRCC6}$ _HUMAN $69.85 \quad 100.0 \%$

$49 \quad 0.05 \% \quad 53.4 \%$ LTLSALIDGK $0.01 \% \quad 3.9 \%$ VNAGTLAVLQR $0.01 \% \quad 3.9 \%$ RLSQYPNENLHSAVTK $0.01 \% \quad 3.9 \% \quad$ DTTVQTLTLQPSVK $0.01 \% \quad 3.9 \%$ IILDNLQAK

$0.01 \% \quad 3.9 \%$ RGELEPQLGSPQQKPK $0.01 \% \quad 11.1 \%$ AYLESFYK

$0.01 \% \quad 11.1 \%$ LYPEGLAQLAR

$0.01 \% \quad 11.1 \%$ NVADYYPEYK

$0.01 \% \quad 11.1 \%$ AKIDNYIPIF

$0.00 \% \quad 5.0 \%$ GAVDAAVPTNIIAAK

$0.00 \% \quad 5.0 \%$ VSIFFDYAR

$0.01 \% \quad 4.8 \%$ VFASLPQVER

$0.01 \% \quad 4.8 \%$ YEYQPFAGK

$0.01 \% \quad 4.8 \%$ IAVVGEGREK

$0.00 \% \quad 4.6 \%$ VATSSLDQTVK

$0.00 \% \quad 4.6 \%$ VTELEDEVR

$0.01 \% \quad 19.5 \%$ FTLAGHTK

$0.01 \% \quad 19.5 \%$ TLPAHSDPVSAVHFNR

$0.01 \% \quad 19.5 \%$ DGSLIVSSSYDGLCR

$0.01 \% \quad 19.5 \%$ TLIDDDNPPVSFVK

$0.01 \% \quad 19.5 \%$ YILAATLDNTLK

$0.02 \% \quad 26.5 \%$ YTHAANTVVYSSNK

$0.02 \% \quad 26.5 \%$ YLSLHDNK

$0.02 \% \quad 26.5 \%$ YLSLHDNKYIR

$0.02 \% \quad 26.5 \%$ VVALSMSPVDDT

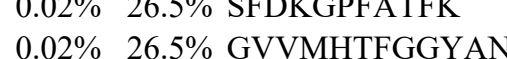

$0.02 \% \quad 26.5 \%$ HTGPITCLQFNPK

$0.02 \% \quad 8.7 \%$ KVITMFVQR

$0.02 \% \quad 8.7 \%$ VITMFVQR

$0.02 \% \quad 8.7 \%$ HIEIFTDLSSR

$0.02 \% \quad 8.7 \%$ CFSVLGFCK

$0.02 \% \quad 8.7 \% \quad$ FFMGNQVLK

$0.02 \% \quad 8.7 \%$ LFQCLLHR

$0.02 \% \quad 8.7 \% \quad$ SQIPLSKIK

$0.02 \% \quad 8.7 \% \quad$ IKTLFPLIEAK

$0.04 \% \quad 20.2 \%$ DSLIFLVDASK

$0.04 \% \quad 20.2 \%$ NIYVLQELDNPGAK

$0.04 \% \quad 20.2 \%$ NIYVLQELDNPGAKR

$0.04 \% \quad 20.2 \%$ ILELDQFKGQQGQK

$0.04 \% \quad 20.2 \%$ IMLFTNEDNPHGNDSAK

$0.04 \% \quad 20.2 \%$ TFNTSTGGLLLPSDTKR

$0.04 \% \quad 20.2 \%$ CLEKEVAALCR

$0.04 \% \quad 20.2 \%$ IMATPEQVGK

$0.04 \% \quad 20.2 \%$ SDSFENPVLQQHFR $\begin{array}{llllllll}99.4 \% & 56.7 & 25.0 & 0.0 & 5 & 0 & 0 & 1030.61\end{array}$

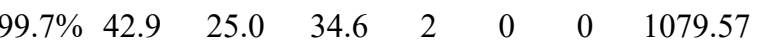

$\begin{array}{llllllll}99.7 \% & 59.3 & 25.0 & 50.0 & 2 & 0 & 0 & 1141.67\end{array}$

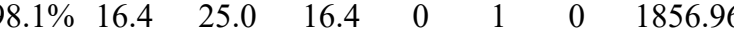

$\begin{array}{llllllll}99.4 \% & 22.0 & 25.0 & 21.0 & 2 & 0 & 0 & 1530.84\end{array}$

$99.4 \% \quad 28.1 \quad 25.0 \quad 27.8$

$\begin{array}{llll}99.7 \% & 29.5 & 25.0 & 29.5\end{array}$

$\begin{array}{llll}96.2 \% & 19.9 & 25.0 & 12.9\end{array}$

$\begin{array}{llll}99.7 \% & 50.1 & 25.0 & 40.1\end{array}$

$99.7 \% \quad 44.7 \quad 25.0 \quad 44.7$

$99.7 \% \quad 37.0 \quad 25.0 \quad 32.8$

$\begin{array}{llll}99.5 \% & 21.5 & 25.0 & 19.7\end{array}$

$99.7 \% \quad 50.4 \quad 25.0 \quad 49.1$

$\begin{array}{llll}99.7 \% & 39.7 & 25.0 & 39.7\end{array}$

$\begin{array}{llll}99.1 \% & 20.8 & 25.0 & 20.8\end{array}$

$\begin{array}{lllll}99.5 \% & 30.3 & 25.0 & 15.5\end{array}$

$99.7 \% \quad 38.5 \quad 25.0 \quad 29.6$

$\begin{array}{llll}99.5 \% & 26.0 & 25.0 & 15.9\end{array}$

$\begin{array}{llll}98.7 \% & 25.0 & 25.0 & 13.2\end{array}$

$\begin{array}{llll}99.7 \% & 41.6 & 25.0 & 38.0\end{array}$

$\begin{array}{llll}99.7 \% & 57.3 & 25.0 & 57.3\end{array}$

$\begin{array}{llll}99.7 \% & 70.3 & 25.0 & 62.9\end{array}$

$\begin{array}{llll}99.7 \% & 60.3 & 25.0 & 60.3\end{array}$

$\begin{array}{lllll}99.7 \% & 67.2 & 25.0 & 67.2 & 2\end{array}$

$\begin{array}{llll}99.0 \% & 38.1 & 25.0 & 19.9\end{array}$

$\begin{array}{llll}98.5 \% & 17.8 & 25.0 & 17.2\end{array}$

$\begin{array}{llll}99.7 \% & 55.3 & 25.0 & 55.3\end{array}$

$\begin{array}{llll}99.7 \% & 49.4 & 25.0 & 41.1\end{array}$

$\begin{array}{llll}98.6 \% & 20.3 & 25.0 & 19.2\end{array}$

$\begin{array}{llll}99.6 \% & 28.7 & 25.0 & 25.2\end{array}$

$\begin{array}{llll}97.2 \% & 16.1 & 25.0 & 16.1\end{array}$

$\begin{array}{lllll}99.0 \% & 41.2 & 25.0 & 31.6 & 4\end{array}$

$99.7 \% \quad 43.6 \quad 25.0 \quad 36.8$

$\begin{array}{llll}99.7 \% & 36.8 & 25.0 & 35.2\end{array}$

$\begin{array}{llll}99.4 \% & 23.6 & 25.0 & 17.5\end{array}$

$\begin{array}{llll}99.0 \% & 36.5 & 25.0 & 25.6\end{array}$

$\begin{array}{llll}99.5 \% & 22.5 & 25.0 & 19.6\end{array}$

$99.7 \% \quad 30.4 \quad 25.0 \quad 30.4$

$99.7 \% \quad 55.1 \quad 25.0 \quad 51.9$

$\begin{array}{llll}99.7 \% & 61.0 & 25.0 & 61.0\end{array}$

$\begin{array}{llll}99.7 \% & 54.9 & 25.0 & 54.9\end{array}$

$99.7 \% \quad 52.6 \quad 25.0 \quad 43.5 \quad 2$

$\begin{array}{llll}99.7 \% & 42.2 & 25.0 & 40.5\end{array}$

$\begin{array}{llll}99.7 \% & 48.5 & 25.0 & 48.5\end{array}$

$99.7 \% \quad 33.6 \quad 25.0 \quad 33.6 \quad 2$

$\begin{array}{llll}99.7 \% & 49.8 & 25.0 & 43.3\end{array}$

$\begin{array}{llll}99.7 \% & 33.3 & 25.0 & 28.5\end{array}$
1027.61

1791.97

1020.50

1230.68

1261.57

1193.66

1410.80

1117.57

1145.63

1102.52

1057.60

1148.62

1089.54

874.48

1747.89

1628.76

1559.80

1335.75

1554.75

989.51

1421.75

2081.05

1244.63

1467.70

1512.76

1121.65

1009.55

1317.68

1117.52

1099.56

1086.59

1013.64

1272.79

1207.66

1573.82

1729.92

1631.88

1918.86

1807.96

1348.67

1089.56

1703.81

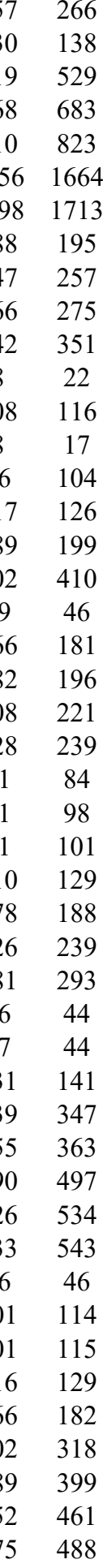


$0.00 \% \quad 21.0 \%$ AGEAPTENPAPPTQQSSAE

$0.01 \% \quad 7.4 \%$ LGSTEVASNVPK

$\begin{array}{llll}99.7 \% & 39.6 & 25.0 & 39.6\end{array}$

$\begin{array}{lll}9.7 \% & 58.0 \quad 25.0\end{array}$

YTH domain-containing family protein $2 \mathrm{GN}=$ YTHDF2 YTHD2 HUMAN $62.33100 .0 \%$ YTH domain-containing family protein $2 \mathrm{GN}=$ YTHDF2 YTHD2_HUMAN $62.33 \quad 100.0 \%$ YTH domain-containing family protein $2 \mathrm{GN}=$ YTHDF2 YTHD2 HUMAN $62.33100 .0 \%$ YTH domain-containing protein $1 \mathrm{GN}=$ YTHDC1 $\quad$ YTDC1_HUMAN $84.70 \quad 100.0 \%$ YTH domain-containing protein $1 \mathrm{GN}=$ YTHDC1 YTDC1_HUMAN $84.70 \quad 100.0 \%$ YTH domain-containing protein $1 \mathrm{GN}=$ YTHDC1 YTDC1 HUMAN $84.70 \quad 100.0 \%$ YTH domain-containing protein $1 \mathrm{GN}=$ YTHDC1 YTDC1_HUMAN $84.70 \quad 100.0 \%$ YTH domain-containing protein $1 \mathrm{GN}=$ YTHDC1 YTDC1_HUMAN $84.70 \quad 100.0 \%$ Zinc finger $\mathrm{CCCH}$ domain-containing protein $11 \mathrm{~A} \mathrm{GN}=\mathrm{ZC} 3 \mathrm{H} 11 \mathrm{~A}$ ZC11A_HUMAN $89.13 \quad 100.0 \%$ Zinc finger $\mathrm{CCCH}$ domain-containing protein $11 \mathrm{~A} \mathrm{GN}=\mathrm{ZC} 3 \mathrm{H} 11 \mathrm{~A}$ ZC11A_HUMAN $89.13 \quad 100.0 \%$ Zinc finger $\mathrm{CCCH}$ domain-containing protein $13 \mathrm{GN}=\mathrm{ZC} 3 \mathrm{H} 13 \mathrm{ZC} 3 \mathrm{HD}$ HUMAN $196.64100 .0 \%$ Zinc finger CCCH domain-containing protein $13 \mathrm{GN}=\mathrm{ZC} 3 \mathrm{H} 13$ ZC3HD_HUMAN $196.64 \quad 100.0 \%$ Zinc finger CCCH domain-containing protein $13 \mathrm{GN}=\mathrm{ZC} 3 \mathrm{H} 13$ ZC3HD_HUMAN $196.64100 .0 \%$ Zinc finger $\mathrm{CCCH}$ domain-containing protein $13 \mathrm{GN}=\mathrm{ZC} 3 \mathrm{H} 13 \mathrm{ZC} 3 \mathrm{HD}$ HUMAN $196.64100 .0 \%$ Zinc finger CCCH domain-containing protein $13 \mathrm{GN}=\mathrm{ZC} 3 \mathrm{H} 13$ ZC3HD_HUMAN $196.64 \quad 100.0 \%$ Zinc finger $\mathrm{CCCH}$ domain-containing protein $18 \mathrm{GN}=\mathrm{ZC} 3 \mathrm{H} 18 \mathrm{ZCH} 18$ HUMAN $106.38 \quad 100.0 \%$ Zinc finger $\mathrm{CCCH}$ domain-containing protein $18 \mathrm{GN}=\mathrm{ZC} 3 \mathrm{H} 18 \mathrm{ZCH} 18$ HUMAN $106.38100 .0 \%$ Zinc finger $\mathrm{CCCH}$ domain-containing protein $18 \mathrm{GN}=\mathrm{ZC} 3 \mathrm{H} 18 \mathrm{ZCH} 18 \_H U M A N \quad 106.38 \quad 100.0 \%$ Zinc finger $\mathrm{CCCH}$ domain-containing protein $18 \mathrm{GN}=\mathrm{ZC} 3 \mathrm{H} 18 \mathrm{ZCH} 18$ HUMAN $106.38100 .0 \%$ Zinc finger $\mathrm{CCCH}$ domain-containing protein $8 \mathrm{GN}=\mathrm{ZC} 3 \mathrm{H} 8 \mathrm{ZC} 3 \mathrm{H} 8$ _HUMAN $33.58 \quad 100.0 \%$ Zinc finger $\mathrm{CCCH}$ domain-containing protein $8 \mathrm{GN}=\mathrm{ZC} 3 \mathrm{H} 8 \mathrm{ZC} 3 \mathrm{H} 8$ _HUMAN $33.58 \quad 100.0 \%$ Zinc finger CCCH-type antiviral protein $1 \mathrm{GN}=\mathrm{ZC} 3 \mathrm{HAV} 1 \mathrm{ZCCHV}$ HUMAN $101.43 \quad 100.0 \%$ Zinc finger CCCH-type antiviral protein $1 \mathrm{GN}=\mathrm{ZC} 3 \mathrm{HAV} 1$ ZCCHV_HUMAN $101.43 \quad 100.0 \%$ Zinc finger CCCH-type antiviral protein $1 \mathrm{GN}=\mathrm{ZC} 3 \mathrm{HAV} 1 \mathrm{ZCCHV}$ HUMAN $101.43 \quad 100.0 \%$ Zinc finger CCCH-type antiviral protein $1 \mathrm{GN}=\mathrm{ZC} 3 \mathrm{HAV} 1 \mathrm{ZCCHV} \_H U M A N \quad 101.43 \quad 100.0 \%$ Zinc finger CCCH-type antiviral protein $1 \mathrm{GN}=Z \mathrm{ZC} 3 \mathrm{HAV} 1 \mathrm{ZCCHV} \_H U M A N \quad 101.43 \quad 100.0 \%$ Zinc finger CCCH-type antiviral protein $1 \mathrm{GN}=\mathrm{ZC} 3 \mathrm{HAV} 1 \mathrm{ZCCHV}$ HUMAN $101.43 \quad 100.0 \%$ Zinc finger $\mathrm{CCHC}$ domain-containing protein $3 \mathrm{GN}=\mathrm{ZCCHC} 3 \mathrm{ZCHC} 3$ _HUMAN $43.62 \quad 100.0 \%$ Zinc finger $\mathrm{CCHC}$ domain-containing protein $3 \mathrm{GN}=\mathrm{ZCCHC} 3 \mathrm{ZCHC} 3$ HUMAN $43.62100 .0 \%$ Zinc finger $\mathrm{CCHC}$ domain-containing protein $3 \mathrm{GN}=\mathrm{ZCCHC} 3 \mathrm{ZCHC} 3$ HUMAN $43.62 \quad 100.0 \%$ Zinc finger CCHC domain-containing protein $3 \mathrm{GN}=\mathrm{ZCCHC} 3 \mathrm{ZCHC} 3$ _HUMAN $43.62 \quad 100.0 \%$ Zinc finger CCHC domain-containing protein $3 \mathrm{GN}=\mathrm{ZCCHC} 3 \mathrm{ZCHC} 3$ HUMAN $43.62100 .0 \%$ Zinc finger CCHC domain-containing protein $3 \mathrm{GN}=\mathrm{ZCCHC} 3 \mathrm{ZCHC} 3$ _HUMAN $43.62 \quad 100.0 \%$ Zinc finger CCHC-type and RNA-binding motif-containing protein $1 \mathrm{GN}=Z C R B 1 \quad$ ZCRB1_HUMAN $24.59 \quad 100.0 \%$ 作 Zinc finger protein $346 \mathrm{GN}=\mathrm{ZNF} 346$ Zinc finger protein $346 \mathrm{GN}=\mathrm{ZNF} 346$ Zinc finger protein $346 \mathrm{GN}=\mathrm{ZNF} 346$ Zinc finger protein $346 \mathrm{GN}=\mathrm{ZNF} 346$ Zinc finger protein $346 \mathrm{GN}=\mathrm{ZNF} 346$ Zinc finger protein $346 \mathrm{GN}=\mathrm{ZNF} 346$ ZN346_HUMAN $32.93 \quad 100.0 \%$ ZN346 HUMAN $32.93 \quad 100.0 \%$ ZN346 HUMAN $32.93 \quad 100.0 \%$ ZN346_HUMAN $32.93 \quad 100.0 \%$ ZN346 HUMAN $32.93 \quad 100.0 \%$ ZN346_HUMAN $32.93 \quad 100.0 \%$

$0.01 \% \quad 7.4 \%$ SYSEDDIHR

$0.01 \% \quad 7.4 \%$ LENNENKPVTNSR

$0.01 \% \quad 7.4 \%$ DTQEVPLEK

$0.02 \% \quad 8.5 \% \quad$ QLVSKPLSSSVSNNKR

$0.02 \% \quad 8.5 \%$ SATEYKNEEYQR

$0.02 \% \quad 8.5 \%$ GISPIVFDR

$\begin{array}{lll}0.02 \% & 8.5 \% & \text { SGSSASESYAGSEK }\end{array}$

$0.02 \% \quad 8.5 \%$ SNNHENVSLAK

$0.00 \% \quad 2.8 \% \quad$ LSVQSNPSPQLR

$0.00 \% \quad 2.8 \% \quad$ TVVLPPIVASR

$0.01 \% \quad 3.5 \%$ LGPSTGSTAETQCR

$0.01 \% \quad 3.5 \%$ TSAVSSPLLDQQR

$0.01 \% \quad 3.5 \% \quad$ TPSPSYQR

$0.01 \% \quad 3.5 \%$ LLSQVVRPQESR

$0.01 \% \quad 3.5 \%$ ASLLSNLGPCCK

$0.01 \% \quad 4.7 \%$ GGQYENFR

$0.01 \% \quad 4.7 \% \quad$ SSSYSSYSSR

$\begin{array}{llll}99.4 \% & 20.4 & 25.0 & 20.4\end{array}$

$\begin{array}{llll}99.5 \% & 22.8 & 25.0 & 22.8\end{array}$

$\begin{array}{llll}97.3 \% & 16.4 & 25.0 & 16.4\end{array}$

$\begin{array}{llll}99.7 \% & 54.7 & 25.0 & 54.7\end{array}$

$\begin{array}{llll}99.7 \% & 45.8 & 25.0 & 45.8\end{array}$

$\begin{array}{llll}98.4 \% & 25.7 & 25.0 & 11.5\end{array}$

$\begin{array}{llll}99.7 \% & 43.3 & 25.0 & 43.3\end{array}$

$\begin{array}{llll}99.7 \% & 56.0 & 25.0 & 55.5\end{array}$

$\begin{array}{llll}95.5 \% & 20.4 & 25.0 & 10.8\end{array}$

$\begin{array}{llll}99.7 \% & 32.2 & 25.0 & 32.2\end{array}$

$99.7 \% \quad 59.5 \quad 25.0 \quad 59.5$

$\begin{array}{llll}99.7 \% & 51.8 & 25.0 & 46.4\end{array}$

$\begin{array}{llll}95.7 \% & 22.3 & 25.0 & 12.1\end{array}$

$\begin{array}{llll}99.7 \% & 27.4 & 25.0 & 25.8\end{array}$

$\begin{array}{llll}99.7 \% & 55.1 & 25.0 & 53.2\end{array}$

$99.0 \% \quad 24.9 \quad 25.0 \quad 24.4$

$99.7 \% \quad 41.4 \quad 25.0 \quad 35.7$

$0.01 \% \quad 4.7 \%$ TLSGSGSGSGSSYSGSSSR

$0.01 \% \quad 4.7 \%$ AVEDAIAR

$0.00 \% \quad 6.2 \% \quad$ ELQQYIQAR

$0.00 \% \quad 6.2 \% \quad$ FYVQGYCTR

$0.02 \% \quad 8.7 \% \quad$ FVVLETGGEAGITR

$0.02 \% \quad 8.7 \% \quad$ ASLEDAPVDDLTR

$0.02 \% \quad 8.7 \%$ KFTYLGSQDR

$0.02 \% \quad 8.7 \%$ ATDLGGTSQAGTSQR

$0.02 \% \quad 8.7 \%$ TVFSPTLPAAR

$0.02 \% \quad 8.7 \%$ SSLGSLQTPEAVTTR

$0.01 \% \quad 19.3 \%$ ICFQGDEGACPTR

$0.01 \% \quad 19.3 \%$ DFVVGALILR

$99.7 \% \quad 68.0$

$95.3 \% \quad 20.1$

$99.7 \% \quad 38.4$

$96.1 \% \quad 14.9$

$99.7 \% \quad 84.1$

$99.7 \% \quad 61.5$

$99.6 \% \quad 30.8$

$99.7 \% \quad 67.7$

$99.1 \% \quad 22.8$

$99.7 \% \quad 45.1$

$99.7 \% \quad 58.9$

$99.7 \% \quad 48.3$

$0.01 \% \quad 19.3 \%$ SIGMDPSDIYAVIQIPGSR

$0.01 \% \quad 19.3 \%$ SAEKLALFLR

$99.1 \% \quad 24.3$

$99.4 \% 20.0$

$0.01 \% \quad 19.3 \%$ KGIVCNLCGK

HH

$0.00 \% \quad 13.4 \%$ STVYVSNLPFSLTNNDLYR

$0.00 \% \quad 13.4 \%$ NMLGEREPPK

$0.02 \% \quad 27.6 \%$ NQCLFTNTQCK

$0.02 \% \quad 27.6 \%$ VCCALLISESQK

$0.02 \% \quad 27.6 \%$ YLAIHGMETLKGETK

$0.02 \% \quad 27.6 \%$ LADPAVTDFPAGK

$0.02 \% \quad 27.6 \%$ IVLNSIEQYQAHVSGFK

$0.02 \% \quad 27.6 \%$ TVASSLGQIPMQR

$\begin{array}{lllll}99.3 \% & 20.0 & 25.0 & 19.9 & 1 \\ 99.7 \% & 51.7 & 25.0 & 51.7 & 3 \\ 99.7 \% & 57.4 & 25.0 & 54.9 & 2 \\ 99.7 \% & 30.6 & 25.0 & 29.7 & 0 \\ 99.7 \% & 46.7 & 25.0 & 46.7 & 4 \\ 99.7 \% & 38.9 & 25.0 & 38.1 & 2 \\ 99.7 \% & 48.1 & 25.0 & 31.9 & 4\end{array}$

1691.85 940.46

1744.89

3559.67

1881.85

1201.64

1121.49

1514.76

1058.54

1743.97

1517.69

1003.56

1346.57

1212.60

1325.72

1151.71

1464.67

1401.73

935.46

1411.80

1319.64

970.44

1110.47

1707.74

844.45

1148.61

1193.54

1448.77

1401.69

1214.62

1449.69

1159.65

1546.8

1510.64

1102.66

2035.02

1147.68

1148.59

1531.80

2203.10

1170.59

1413.63

1407.70

1690.88

1301.67

1933.02 1387.74

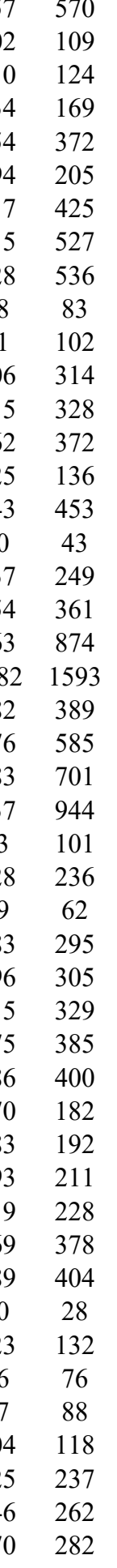

Page 166 of Table S-1-5 
Zinc finger protein $512 \mathrm{GN}=\mathrm{ZNF} 512$ Zinc finger protein $512 \mathrm{GN}=\mathrm{ZNF} 512$ Zinc finger protein $512 \mathrm{GN}=\mathrm{ZNF} 512$ Zinc finger protein $512 \mathrm{GN}=\mathrm{ZNF} 512$ Zinc finger protein $638 \mathrm{GN}=\mathrm{ZNF} 638$ Zinc finger protein $638 \mathrm{GN}=\mathrm{ZNF} 638$ Zinc finger protein $768 \mathrm{GN}=\mathrm{ZNF} 768$ Zinc finger protein $768 \mathrm{GN}=\mathrm{ZNF} 768$ Zinc finger protein OZF GN=ZNF146 Zinc finger protein OZF GN=ZNF146 Zinc finger RNA-binding protein $\mathrm{GN}=Z$ ZFR ZFR_HUMAN $117.01 \quad 100.0 \%$ Zinc finger RNA-binding protein GN=ZFR ZFR_HUMAN $117.01 \quad 100.0 \%$ Zinc finger RNA-binding protein GN=ZFR ZFR_HUMAN $117.01 \quad 100.0 \%$ Zinc finger RNA-binding protein GN=ZFR ZFR_HUMAN $117.01 \quad 100.0 \%$ Zinc finger RNA-binding protein GN=ZFR ZFR_HUMAN $117.01 \quad 100.0 \%$ Zinc finger RNA-binding protein GN=ZFR ZFR HUMAN $117.01 \quad 100.0 \%$ Zinc finger RNA-binding protein GN=ZFR ZFR_HUMAN $117.01 \quad 100.0 \%$ Zinc transporter $7 \mathrm{GN}=\mathrm{SLC} 30 \mathrm{~A} 7$ Zinc transporter $7 \mathrm{GN}=\mathrm{SLC} 30 \mathrm{~A} 7$ Zinc transporter $7 \mathrm{GN}=\mathrm{SLC} 30 \mathrm{~A} 7$ ZNT7_HUMAN $41.63 \quad 100.0 \%$

ZN512_HUMAN $64.68 \quad 100.0 \%$ $64.68-100.0 \%$ ZN638_HUMAN $220.63 \quad 100.0 \%$ ZN638_HUMAN $220.63 \quad 100.0 \%$ ZN768 HUMAN $60.23 \quad 100.0 \%$ ZN768_HUMAN $60.23 \quad 100.0 \%$ OZF HUMAN $33.31 \quad 100.0 \%$ OZF HUMAN $33.31 \quad 100.0 \%$ ZNT7_HUMAN $41.63 \quad 100.0 \%$ ZNT7_HUMAN $41.63 \quad 100.0 \%$ $\begin{array}{llllll}0.01 \% & 9.4 \% & \text { LGAVPATSGPTTFKQQR } & 97.5 \% & 15.8 & 25.0\end{array}$ $0.01 \% \quad 9.4 \% \quad$ IKPAATSHVEGSGGVSAK $\quad 99.3 \% \quad 20.0$ $0.01 \% \quad 9.4 \%$ AGLAYHLR $99.0 \% \quad 47.5$ $0.01 \% \quad 9.4 \%$ VLQDLVPDDR $99.7 \% \quad 35.9$ $0.01 \% \quad 1.3 \%$ TSSGTKPSVKPTSATK $0.01 \% \quad 1.3 \%$ YIETTPLTIK

$0.01 \% \quad 3.7 \%$ AFADSSYLLR $0.01 \% \quad 3.7 \%$ AFGDSSYLLR

$0.00 \% \quad 8.2 \%$ LFECNECGK

$0.00 \% \quad 8.2 \% \quad$ SHTGEKPYGCNECGK

$99.4 \% \quad 20.1$

$\begin{array}{llll}99.7 \% & 31.7\end{array}$

$99.7 \% \quad 57.3$

$99.7 \% \quad 50.2$

$96.8 \% 19.4$

$99.2 \% \quad 29.4$

$\begin{array}{llll}0.02 \% & 10.4 \% & \text { AGYSQGATQYTQAQQTR } & 99.7 \% \quad 60.4\end{array}$

$0.02 \% \quad 10.4 \%$ GLTTTGNSSENSTSNTK $\quad 99.7 \% \quad 66.0$

$0.02 \% \quad 10.4 \%$ VSAVPTNMAAKK

$99.4 \% \quad 19.9$

$99.7 \% \quad 28.7$

$99.7 \% \quad 39.5$

$0.02 \% \quad 10.4 \%$

$0.02 \% \quad 10.4 \%$ CLDALAALR

$0.02 \% \quad 10.4 \%$ ANGLQSCVIIIR

$0.02 \% \quad 10.4 \%$ AISSASSPQSPGDALR

$0.00 \% \quad 10.9 \%$ TPPLLENSLPQCYQR

$0.00 \% \quad 10.9 \%$ LIVAPDADAR $0.00 \% \quad 10.9 \%$ WILSQTHNIFTQAGVR
$99.7 \% \quad 50.7$

$99.7 \% \quad 43.4$

$99.7 \% \quad 45.3$

$\begin{array}{lll}99.7 \% & 39.3\end{array}$

$96.8 \% \quad 20.7$

$96.8 \% \quad 16.3$
1758.95

1695.90

900.51

1169.62

1576.85

1178.67

1142.58

1128.57

1156.48

1723.72

1858.87

1682.82

1232.67

1721.99

1600.87

1002.54

1343.75

1543.77

1815.9

1040.57

1040.57 1870.99

21
100
307
376
627
740
334
362
79
247
208
484
496
627
818
907
927
969
311
349
365


14-3-3 protein gamma $\mathrm{GN}=\mathrm{YWHAG}$ 14-3-3 protein gamma $\mathrm{GN}=\mathrm{YWHAG}$ 14-3-3 protein gamma $\mathrm{GN}=\mathrm{YWHAG}$ 14-3-3 protein gamma $\mathrm{GN}=\mathrm{YWHAG}$ 14-3-3 protein gamma GN=YWHAG 14-3-3 protein gamma $\mathrm{GN}=\mathrm{YWHAG}$ 14-3-3 protein theta $\mathrm{GN}=\mathrm{YWHAQ}$ 14-3-3 protein theta $\mathrm{GN}=\mathrm{YWHAQ}$ 14-3-3 protein theta $\mathrm{GN}=\mathrm{YWHAQ}$ 14-3-3 protein theta $\mathrm{GN}=\mathrm{YWHAQ}$ 14-3-3 protein theta $\mathrm{GN}=\mathrm{YWHAQ}$ 14-3-3 protein theta $\mathrm{GN}=\mathrm{YWHAQ}$ 14-3-3 protein theta $\mathrm{GN}=\mathrm{YWHAQ}$ 14-3-3 protein theta $\mathrm{GN}=\mathrm{YWHAQ}$ 14-3-3 protein zeta/delta GN=YWHAZ 14-3-3 protein zeta/delta $\mathrm{GN}=\mathrm{YWHAZ}$ 14-3-3 protein zeta/delta $\mathrm{GN}=\mathrm{YWHAZ}$ 14-3-3 protein zeta/delta GN $=Y W H A Z$ 14-3-3 protein zeta/delta $\mathrm{GN}=\mathrm{YWHAZ}$ 14-3-3 protein zeta/delta GN=YWHAZ 14-3-3 protein zeta/delta $\mathrm{GN}=\mathrm{YWHAZ}$ 14-3-3 protein zeta/delta GN=YWHAZ 14-3-3 protein theta $\mathrm{GN}=\mathrm{YWHAQ}$

1433G_HUMAN $28.30 \quad 100.0 \%$ 1433G_HUMAN $28.30 \quad 100.0 \%$ 1433G_HUMAN $28.30 \quad 100.0 \%$ 1433G HUMAN $28.30 \quad 100.0 \%$ 1433G_HUMAN $28.30 \quad 100.0 \%$ 1433G_HUMAN $28.30 \quad 100.0 \%$ 1433T HUMAN $27.77 \quad 100.0 \%$ 1433T_HUMAN $27.77 \quad 100.0 \%$ 1433T HUMAN $27.77 \quad 100.0 \%$ 1433T_HUMAN $27.77 \quad 100.0 \%$ 1433T_HUMAN $27.77 \quad 100.0 \%$ 1433T_HUMAN $27.77 \quad 100.0 \%$ 1433T_HUMAN $27.77 \quad 100.0 \%$ 1433T_HUMAN $27.77 \quad 100.0 \%$ 1433T HUMAN $27.77 \quad 100.0 \%$ 1433Z_HUMAN $27.75 \quad 100.0 \%$ 1433Z HUMAN $27.75 \quad 100.0 \%$ 1433Z_HUMAN $27.75 \quad 100.0 \%$ 1433Z_HUMAN $27.75 \quad 100.0 \%$ $1433 Z$ HUMAN $27.75 \quad 100.0 \%$ 1433Z_HUMAN $27.75 \quad 100.0 \%$ 1433Z HUMAN $27.75 \quad 100.0 \%$ 1433Z_HUMAN $27.75 \quad 100.0 \%$ PLCE_HUMAN $42.07 \quad 100.0 \%$ 1-acyl-sn-glycerol-3-phosphate acyltransferase epsilon GN=AGPAT5 PLCE HUMAN $42.07 \quad 100.0 \%$ 2',3'-cyclic-nucleotide 3'-phosphodiesterase GN=CNP CN37_HUMAN $47.58 \quad 100.0 \%$ 2',3'-cyclic-nucleotide 3'-phosphodiesterase GN=CNP CN37_HUMAN $47.58 \quad 100.0 \%$ 2',3'-cyclic-nucleotide 3'-phosphodiesterase GN=CNP CN37_HUMAN $47.58 \quad 100.0 \%$ 2',3'-cyclic-nucleotide 3 '-phosphodiesterase GN=CNP CN37_HUMAN $47.58 \quad 100.0 \%$ 2',3'-cyclic-nucleotide 3'-phosphodiesterase GN=CNP CN37 HUMAN $47.58 \quad 100.0 \%$ 2',3'-cyclic-nucleotide 3 '-phosphodiesterase GN=CNP CN37_HUMAN $47.58 \quad 100.0 \%$ 2',3'-cyclic-nucleotide 3 '-phosphodiesterase GN=CNP CN37_HUMAN 47.58 2',3'-cyclic-nucleotide 3'-phosphodiesterase GN=CNP CN37_HUMAN 47.58 $26 \mathrm{~S}$ protease regulatory subunit 10B GN=PSMC6 PRS10_HUMAN 44.17 $26 \mathrm{~S}$ protease regulatory subunit 10B GN=PSMC6 PRS10_HUMAN 44.17 $26 \mathrm{~S}$ protease regulatory subunit 10B GN=PSMC6 PRS10_HUMAN 44.17 26S protease regulatory subunit 10B GN=PSMC6 PRS10_HUMAN 44.1' $26 \mathrm{~S}$ protease regulatory subunit 10B GN=PSMC6 PRS10 HUMAN 44.17 $26 \mathrm{~S}$ protease regulatory subunit $10 \mathrm{~B}$ GN=PSMC6 PRS10_HUMAN 44.17 $26 \mathrm{~S}$ protease regulatory subunit 10B GN=PSMC6 PRS10_HUMAN 44.1 $26 \mathrm{~S}$ protease regulatory subunit $10 \mathrm{~B}$ GN=PSMC6 PRS10 HUMAN 44.17 $26 \mathrm{~S}$ protease regulatory subunit 10B GN=PSMC6 PRS10_HUMAN 44.17 $26 \mathrm{~S}$ protease regulatory subunit 10B GN=PSMC6 PRS10 HUMAN 44.17 $26 \mathrm{~S}$ protease regulatory subunit $10 \mathrm{~B}$ GN=PSMC6 PRS10_HUMAN 44.17 $26 \mathrm{~S}$ protease regulatory subunit 10B GN=PSMC6 PRS10_HUMAN 44.17 $26 \mathrm{~S}$ protease regulatory subunit 10B GN=PSMC6 PRS10 HUMAN 44.1? $26 \mathrm{~S}$ protease regulatory subunit 10B GN=PSMC6 PRS10_HUMAN 44.17
$16 \quad 0.02 \% \quad 27.1 \%$ NVTELNEPLSNEER $0.02 \% \quad 27.1 \%$ NLLSVAYK $0.02 \% \quad 27.1 \%$ VISSIEQK $0.02 \% \quad 27.1 \%$ YLAEVATGEK $0.02 \% \quad 27.1 \%$ YLAEVATGEKR $0.02 \% \quad 27.1 \%$ AYSEAHEISK $0.01 \% \quad 35.5 \%$ YDDMATCMK $0.01 \% \quad 35.5 \%$ AVTEQGAELSNEER $0.01 \% 35.5 \%$ NLLSVAYK

$0.01 \% \quad 35.5 \%$ VISSIEQK $0.01 \% \quad 35.5 \%$ EKVESELR $0.01 \% \quad 35.5 \%$ YLAEVACGDDRK

$0.01 \% \quad 35.5 \%$ QTIDNSQGAYQEAFDISKK $0.01 \% \quad 35.5 \%$ KEMQPTHPIR

$0.01 \% \quad 35.5 \%$ EMQPTHPIR

$0.03 \% \quad 35.1 \%$ LAEQAERYDDMAACMK $0.03 \% \quad 35.1 \%$ SVTEQGAELSNEER $0.03 \% \quad 35.1 \%$ NLLSVAYK $0.03 \% \quad 35.1 \%$ VVSSIEQKTEGAEK $0.03 \% \quad 35.1 \%$ FLIPNASQAESK $0.03 \% 35.1 \%$ YLAEVAAGDDKK $0.03 \% 35.1 \%$ KEMQPTHPIR $0.03 \% \quad 35.1 \%$ EMQPTHPIR $0.00 \% \quad 5.8 \%$ LLSAFLPAR $0.00 \% \quad 5.8 \%$ VLSASQAFAAQR $0.02 \% \quad 19.2 \%$ LDEDLAAYCR $0.02 \% \quad 19.2 \%$ ILVLDDTNHER $0.02 \% \quad 19.2 \%$ NQWQLSADDLKK $0.02 \% \quad 19.2 \%$ AGQVFLEELGNHK $0.02 \% \quad 19.2 \%$ RPPGVLHCTTK $0.02 \% \quad 19.2 \%$ APGAEEYAQQDVLK 0.02\% $19.2 \%$ APGAEEYAQQDVLKK $0.02 \% \quad 19.2 \%$ AIFTGYYGK $0.06 \% \quad 46.8 \%$ DKALQDYR $0.06 \% \quad 46.8 \%$ LLEHKEIDGR $0.06 \% \quad 46.8 \%$ ALQSVGQIVGEVLK $0.06 \% \quad 46.8 \%$ QLTEEKFIVK $0.06 \% \quad 46.8 \%$ VALDMTTLTIMR $0.06 \% \quad 46.8 \%$ ELREVIELPLTNPELFQR $0.06 \% \quad 46.8 \%$ EVIELPLTNPELFQR $0.06 \% \quad 46.8 \%$ GCLLYGPPGTGK $0.06 \% \quad 46.8 \%$ AVASQLDCNFLK $0.06 \% \quad 46.8 \%$ VVSSSIVDK $0.06 \% \quad 46.8 \%$ VVSSSIVDKYIGESAR $0.06 \% \quad 46.8 \%$ RFSEGTSADR $0.06 \% \quad 46.8 \%$ FSEGTSADR $0.06 \% \quad 46.8 \%$ FSEGTSADREIQR $\begin{array}{llllllll}99.7 \% & 79.7 & 25.0 & 77.7 & 2 & 0 & 0 & 1643.79\end{array}$

907.52

$99.0 \% \quad 40.9$

$99.0 \% \quad 35.2$

$99.7 \% \quad 60.0$

$99.7 \% \quad 54.0$

$99.7 \% \quad 59.0$

$95.0 \% \quad 19.5$

$\begin{array}{lll}99.7 \% & 69.4\end{array}$

$99.0 \% \quad 40.9$

$99.0 \% \quad 35.2$

$98.2 \% \quad 24.9$

$99.7 \% \quad 54.4$

$\begin{array}{ll}99.7 \% & 53.9 \\ 99.7 \% & 28.9\end{array}$

$99.7 \% \quad 43.8$

$99.7 \% \quad 39.0$

$99.7 \% \quad 79.1$

$99.0 \% \quad 40.9$

$99.7 \% \quad 65.5$

$99.7 \% \quad 47.5$

$99.7 \% \quad 54.2$

$99.7 \% \quad 28.9$

$99.7 \% \quad 43.8$

$99.7 \% \quad 36.9$

$99.7 \% \quad 53.6$

$99.7 \% \quad 40.3$

$\begin{array}{lll}99.7 \% & 43.3\end{array}$

$99.4 \% \quad 22.8$

$99.7 \% \quad 77.9$

$98.7 \% \quad 21.9$

$99.7 \% \quad 57.0$

$99.6 \% \quad 26.2$

$99.7 \% \quad 33.2$

$99.0 \% \quad 27.5$

$99.7 \% \quad 29.6$

$99.7 \% \quad 54.2$

$96.7 \% \quad 17.8$

$99.7 \% \quad 42.0$

$99.7 \% \quad 34$.

$99.7 \% \quad 48.2$

$99.7 \% \quad 48.8$

$99.7 \% \quad 51.5$

$99.7 \% \quad 43.0$

$99.7 \% \quad 61.0$

$99.1 \% \quad 29.9$

$99.7 \% \quad 58.3$

$99.7 \% \quad 35.1$

$100.0 \% \quad 20$

$\begin{array}{cc}29 & 42 \\ 43 & 50 \\ 2 & 69 \\ 33 & 142 \\ 33 & 143 \\ 53 & 162 \\ 9 & 27 \\ 28 & 41 \\ 42 & 49 \\ 1 & 68 \\ 4 & 91 \\ 28 & 139 \\ 40 & 158 \\ 58 & 167 \\ 59 & 167 \\ 2 & 27 \\ 28 & 41 \\ 42 & 49 \\ 61 & 74 \\ 04 & 115 \\ 28 & 139 \\ 58 & 167 \\ 59 & 167 \\ 37 & 45 \\ 84 & 195 \\ 03 & 112 \\ 18 & 128 \\ 65 & 176 \\ 05 & 217 \\ 45 & 255 \\ 62 & 275 \\ 62 & 276 \\ 92 & 400 \\ 6 & 13 \\ 6 & 25 \\ 49 & 62 \\ 43 & 72 \\ 43 & 109 \\ 44 & 161 \\ 47 & 161 \\ 69 & 180 \\ 86 & 197 \\ 98 & 206 \\ 98 & 213 \\ & 251 \\ & 255\end{array}$


26S protease regulatory subunit 10B GN=PSMC6 PRS10_HUMAN $44.17 \quad 100.0 \%$ 26S protease regulatory subunit 10B GN=PSMC6 PRS10_HUMAN $44.17 \quad 100.0 \% \quad 20$ 26S protease regulatory subunit 10B GN=PSMC6 PRS10_HUMAN $44.17 \quad 100.0 \% \quad 2$ $26 \mathrm{~S}$ protease regulatory subunit 10B GN=PSMC6 PRS10 HUMAN $44.17 \quad 100.0 \%$ $26 \mathrm{~S}$ protease regulatory subunit 10B GN=PSMC6 PRS10_HUMAN $44.17 \quad 100.0 \% \quad 20$ $26 \mathrm{~S}$ protease regulatory subunit 10B GN=PSMC6 PRS10_HUMAN $44.17 \quad 100.0 \% \quad 2$ $26 \mathrm{~S}$ protease regulatory subunit $4 \mathrm{GN}=\mathrm{PSMC} 1 \mathrm{PRS} 4$ HUMAN $49.19 \quad 100.0 \%$ $26 \mathrm{~S}$ protease regulatory subunit $4 \mathrm{GN}=$ PSMC1 PRS4_HUMAN $49.19 \quad 100.0 \%$ $26 \mathrm{~S}$ protease regulatory subunit $4 \mathrm{GN}=\mathrm{PSMC} 1 \mathrm{PRS} 4 \mathrm{HUMAN} 49.19$ $26 \mathrm{~S}$ protease regulatory subunit $4 \mathrm{GN}=\mathrm{PSMC1}$ PRS4 HUMAN 49.19 26S protease regulatory subunit $4 \mathrm{GN}=\mathrm{PSMC1}$ PRS4_HUMAN $49.1 \mathrm{~S}$ $26 \mathrm{~S}$ protease regulatory subunit $6 \mathrm{~A}$ GN=PSMC3 $\mathrm{PRS} 6 \mathrm{~A}$ HUMAN 49.21

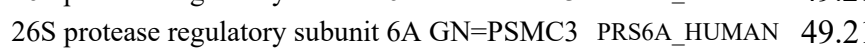
$26 \mathrm{~S}$ protease regulatory subunit $6 \mathrm{~A}$ GN=PSMC3 $\mathrm{PRS6A}$ HUMAN 49.21 $26 \mathrm{~S}$ protease regulatory subunit $6 \mathrm{~A} \mathrm{GN}=\mathrm{PSMC} 3$ PRS6A HUMAN 49.2 $26 \mathrm{~S}$ protease regulatory subunit $6 \mathrm{~A}$ GN=PSMC3 $\mathrm{PRS} 6 \mathrm{~A} \_$HUMAN 49.21 $26 \mathrm{~S}$ protease regulatory subunit $6 \mathrm{~A} \mathrm{GN}=\mathrm{PSMC} 3$ PRS6A HUMAN 49.2 $26 \mathrm{~S}$ protease regulatory subunit $6 \mathrm{~A}$ GN=PSMC3 $\mathrm{PRS6A}$ HUMAN 49.21 $26 \mathrm{~S}$ protease regulatory subunit $6 \mathrm{~B} \mathrm{GN}=\mathrm{PSMC} 4 \mathrm{PRS} 6 \mathrm{~B} \_\mathrm{HUMAN} 47.37$ $26 \mathrm{~S}$ protease regulatory subunit $6 \mathrm{~B} \mathrm{GN}=\mathrm{PSMC} 4 \mathrm{PRS} 6 \mathrm{~B}$ HUMAN 47.37 $26 \mathrm{~S}$ protease regulatory subunit $6 \mathrm{~B}$ GN=PSMC4 PRS6B_HUMAN 47.37 $26 \mathrm{~S}$ protease regulatory subunit $6 \mathrm{~B} \mathrm{GN}=\mathrm{PSMC} 4 \mathrm{PRS} 6 \mathrm{~B}$ HUMAN 47.37 $26 \mathrm{~S}$ protease regulatory subunit $6 \mathrm{~B} \mathrm{GN}=\mathrm{PSMC} 4 \mathrm{PRS} 6 \mathrm{~B}$ HUMAN 47.37 $26 \mathrm{~S}$ protease regulatory subunit $7 \mathrm{GN}=\mathrm{PSMC} 2$ PRS7 HUMAN 48.64 $26 \mathrm{~S}$ protease regulatory subunit $7 \mathrm{GN}=\mathrm{PSMC} 2 \mathrm{PRS} 7 \mathrm{HUMAN} 48.64$ $26 \mathrm{~S}$ protease regulatory subunit $7 \mathrm{GN}=\mathrm{PSMC} 2 \mathrm{PRS} 7$ _HUMAN 48.64 $26 \mathrm{~S}$ protease regulatory subunit $7 \mathrm{GN}=\mathrm{PSMC} 2 \mathrm{PRS} 7$ HUMAN 48.64 $26 \mathrm{~S}$ protease regulatory subunit $7 \mathrm{GN}=\mathrm{PSMC} 2 \mathrm{PRS} 7$ HUMAN 48.64 $26 \mathrm{~S}$ protease regulatory subunit $7 \mathrm{GN}=\mathrm{PSMC} 2$ PRS7_HUMAN 48.64 $26 \mathrm{~S}$ protease regulatory subunit $7 \mathrm{GN}=\mathrm{PSMC} 2 \mathrm{PRS} 7 \mathrm{HUMAN} 48.64$ $26 \mathrm{~S}$ protease regulatory subunit $7 \mathrm{GN}=$ PSMC2 PRS7_HUMAN 48.64 $26 \mathrm{~S}$ protease regulatory subunit $7 \mathrm{GN}=\mathrm{PSMC} 2 \mathrm{PRS} 7$ HUMAN 48.64 $26 \mathrm{~S}$ protease regulatory subunit $7 \mathrm{GN}=\mathrm{PSMC} 2 \mathrm{PRS} 7$ HUMAN 48.64 $26 \mathrm{~S}$ protease regulatory subunit $7 \mathrm{GN}=\mathrm{PSMC} 2$ PRS7_HUMAN 48.64 $26 \mathrm{~S}$ protease regulatory subunit $7 \mathrm{GN}=\mathrm{PSMC} 2 \mathrm{PRS} 7$ HUMAN 48.64 $26 \mathrm{~S}$ protease regulatory subunit $8 \mathrm{GN}=\mathrm{PSMC} 5$ PRS8_HUMAN 45.63 $26 \mathrm{~S}$ protease regulatory subunit $8 \mathrm{GN}=\mathrm{PSMC} 5$ PRS8_HUMAN 45.63 $26 \mathrm{~S}$ protease regulatory subunit $8 \mathrm{GN}=\mathrm{PSMC} 5 \mathrm{PRS} 8 \mathrm{HUMAN} 45.63$ $26 \mathrm{~S}$ protease regulatory subunit $8 \mathrm{GN}=$ PSMC5 PRS8_HUMAN 45.63 $26 \mathrm{~S}$ protease regulatory subunit $8 \mathrm{GN}=$ PSMC5 PRS8_HUMAN 45.63 26S protease regulatory subunit $8 \mathrm{GN}=\mathrm{PSMC} 5$ PRS 8 HUMAN 45.63 $26 \mathrm{~S}$ protease regulatory subunit $8 \mathrm{GN}=\mathrm{PSMC} 5 \mathrm{PRS} 8$ _HUMAN 45.63 $26 \mathrm{~S}$ protease regulatory subunit $8 \mathrm{GN}=\mathrm{PSMC} 5 \mathrm{PRS} 8$ HUMAN 45.63 $26 \mathrm{~S}$ protease regulatory subunit $8 \mathrm{GN}=$ PSMC5 $5 R 8^{2}$ HUMAN $45.63 \quad 100.0^{\circ}$ $26 \mathrm{~S}$ protease regulatory subunit $8 \mathrm{GN}=\mathrm{PSMC} 5 \mathrm{PRS} 8$ _HUMAN $45.63 \quad 100.0 \%$ $26 \mathrm{~S}$ protease regulatory subunit $8 \mathrm{GN}=\mathrm{PSMC} 5 \mathrm{PRS} 8$ _HUMAN $45.63100 .0 \%$ 26S proteasome non-ATPase regulatory subunit 1 GN=PSMD1 PSMD1_HUMAN $105.84 \quad 100.0 \%$

$$
\begin{aligned}
& 11 \\
& 11 \\
& 11
\end{aligned}
$$

\section{$0.01 \% 22.6 \%$ GVLMYGPPG}

22.6\% LAGPQLVQMFIGDGAK $0.01 \% 22.6 \%$ EKAPSIIFIDELDAIGTK $0.01 \% 22.6 \%$ VIAATNRVDILDPALLR $0.01 \% \quad 22.6 \%$ KMNVSPDVNYEELAR AVCVEAGMIALR

$0.01 \% \quad 9.1 \%$ VVGSEFVQK $0.01 \% \quad 9.1 \%$ VVGSEFVQKYLGEGPR $0.01 \% \quad 9.1 \%$ RLIFSTITSK $0.01 \% \quad 9.1 \%$ LIFSTITSK $0.03 \% \quad 27.5 \%$ PDYLGADQRK $0.03 \% 27.5 \%$ ALDEGDIALLK $0.03 \% \quad 27.5 \%$ ALDEGDIALLKTYGQSTYSR $0.03 \% 27.5 \%$ TYGQSTYSR $0.03 \% 27.5 \%$ FVNLGIEPPK $0.03 \% \quad 27.5 \%$ FVNLGIEPPKGVLLFGPPGTGK $0.03 \% 27.5 \%$ AVANRTDACFIR $0.03 \% \quad 27.5 \%$ VIGSELVQK $0.03 \% \quad 27.5 \%$ VIGSELVQKYVGEGAR $0.03 \% 27.5 \%$ ACLIFFDEIDAIGGAR $0.03 \% \quad 27.5 \%$ LCPNSTGAEIR $0.03 \% \quad 27.5 \%$ SVCTEAGMFAIR $0.03 \% \quad 35.7 \%$ LQAQRNELNAK $0.03 \% 35.7 \%$ LLREELQLLQEQGSYVGEVVR $0.03 \% \quad 35.7 \%$ FVVDVDKNIDINDVT $0.03 \% \quad 35.7 \%$ GVLLYGPPGTGK $0.03 \% \quad 35.7 \%$ AVAHHTDCTFIR $0.03 \% 35.7 \%$ VSGSELVQK $0.03 \% \quad 35.7 \%$ VSGSELVQKFIGEGAR $0.03 \% 35.7 \%$ LEGGSGGDSEVQR $0.03 \% \quad 35.7 \%$ IAELMPGASGAEVK $0.03 \% \quad 35.7 \%$ RVHVTQEDFEMAVAK $0.00 \% \quad 2.5 \%$ LLHVAVSDVNDDVRR
$99.7 \% \quad 41.2$ $98.6 \% 22.3$ $99.0 \% \quad 34.7$

$\begin{array}{lllll}99.7 \% & 74.6 & 25.0 & 67.7\end{array}$

$\begin{array}{llll}99.7 \% & 55.5 & 25.0 & 53.1\end{array}$

$\begin{array}{llll}99.7 \% & 52.8 & 25.0 & 52.8\end{array}$

$\begin{array}{llll}99.7 \% & 27.8 & 25.0 & 21.2\end{array}$

$\begin{array}{ccccc}99.2 \% & 51.8 & 25.0 & 0.0 & 2\end{array}$

$\begin{array}{llll}99.7 \% & 58.1 & 25.0 & 53.3\end{array}$

$\begin{array}{llll}99.3 \% & 23.3 & 25.0 & 23.3\end{array}$ $\begin{array}{llll}99.0 \% & 44.8 & 25.0 & 31.1\end{array}$

$96.2 \% \quad 17.7 \quad 25.0 \quad 13.4$ $\begin{array}{llll}99.6 \% & 26.4 & 25.0 & 26.3\end{array}$

$\begin{array}{llll}99.7 \% & 54.3 & 25.0 & 54.3\end{array}$

$\begin{array}{llll}99.6 \% & 24.2 & 25.0 & 24.2\end{array}$

$\begin{array}{llll}99.7 \% & 35.1 & 25.0 & 35.1\end{array}$

$\begin{array}{llll}99.7 \% & 37.0 & 25.0 & 28.4\end{array}$

$\begin{array}{llll}99.7 \% & 28.5 & 25.0 & 23.3\end{array}$

$\begin{array}{llll}99.7 \% & 38.5 & 25.0 & 38.5\end{array}$

$\begin{array}{llll}99.7 \% & 28.7 & 25.0 & 26.7\end{array}$

$\begin{array}{llll}99.7 \% & 39.2 & 25.0 & 39.2\end{array}$

$\begin{array}{llll}99.7 \% & 29.4 & 25.0 & 29.0\end{array}$

$\begin{array}{llll}99.5 \% & 23.5 & 25.0 & 19.4\end{array}$

$99.7 \% \quad 30.5 \quad 25.0 \quad 20.1$

$99.7 \% \quad 57.0 \quad 25.0 \quad 47.9$

$\begin{array}{llll}99.7 \% & 51.3 & 25.0 & 51.3\end{array}$

$\begin{array}{llll}99.7 \% & 36.9 & 25.0 & 31.0\end{array}$

$\begin{array}{llll}99.5 \% & 29.8 & 25.0 & 15.9\end{array}$ $\begin{array}{llll}99.7 \% & 28.3 & 25.0 & 24.4\end{array}$ $\begin{array}{llll}96.9 \% & 24.1 & 25.0 & 10.0\end{array}$ $\begin{array}{llll}98.9 \% & 23.8 & 25.0 & 23.8\end{array}$ $99.7 \% \quad 82.1 \quad 25.0 \quad 82.1$ $\begin{array}{llll}99.7 \% & 46.2 & 25.0 & 41.9\end{array}$ $\begin{array}{llll}99.7 \% & 53.8 & 25.0 & 43.5\end{array}$ $\begin{array}{llll}99.7 \% & 54.2 & 25.0 & 49.8\end{array}$ 
26S proteasome non-ATPase regulatory subunit $1 \mathrm{GN}=\mathrm{PSMD} 1$ PSMD1_HUMAN $105.84 \quad 100.0 \%$ $26 \mathrm{~S}$ proteasome non-ATPase regulatory subunit $13 \mathrm{GN}=\mathrm{PSMD} 13$ PSD13_HUMAN $42.95 \quad 100.0 \%$ 26S proteasome non-ATPase regulatory subunit $13 \mathrm{GN}=\mathrm{PSMD} 13$ PSD13_HUMAN $42.95 \quad 100.0 \%$ $26 \mathrm{~S}$ proteasome non-ATPase regulatory subunit $13 \mathrm{GN}=\mathrm{PSMD} 13$ PSD13 HUMAN $42.95100 .0 \%$ 26S proteasome non-ATPase regulatory subunit $13 \mathrm{GN}=$ PSMD13 PSD13_HUMAN $42.95 \quad 100.0 \%$ 26S proteasome non-ATPase regulatory subunit $13 \mathrm{GN}=$ PSMD13 PSD13_HUMAN $42.95 \quad 100.0 \%$ 26S proteasome non-ATPase regulatory subunit 13 GN=PSMD13 PSD13_HUMAN $42.95 \quad 100.0 \%$ 26S proteasome non-ATPase regulatory subunit $13 \mathrm{GN}=$ PSMD13 PSD13_HUMAN $42.95 \quad 100.0 \%$ $26 \mathrm{~S}$ proteasome non-ATPase regulatory subunit $14 \mathrm{GN}=$ PSMD14 PSDE_HUMAN $34.58 \quad 100.0 \%$ 26 s proteasome non-ATPase regulatory subunit $14 \mathrm{GN}=$ PSMD14 PSDE_HUMAN $34.58 \quad 100.0 \%$ 26S proteasome non-ATPase regulatory subunit 2 GN=PSMD2 PSMD2_HUMAN $100.20 \quad 100.0 \%$ 26S proteasome non-ATPase regulatory subunit 2 GN=PSMD2 PSMD2_HUMAN $100.20100 .0 \%$ 26S proteasome non-ATPase regulatory subunit 2 GN=PSMD2 PSMD2_HUMAN $100.20 \quad 100.0 \%$ $26 \mathrm{~S}$ proteasome non-ATPase regulatory subunit 2 GN=PSMD2 PSMD2_HUMAN $100.20 \quad 100.0 \%$ $26 \mathrm{~S}$ proteasome non-ATPase regulatory subunit 2 GN=PSMD2 PSMD2_HUMAN $100.20 \quad 100.0 \%$ 26S proteasome non-ATPase regulatory subunit $3 \mathrm{GN}=$ PSMD3 PSMD3_HUMAN $60.98 \quad 100.0 \%$ $26 \mathrm{~S}$ proteasome non-ATPase regulatory subunit $3 \mathrm{GN}=\mathrm{PSMD} 3$ PSMD3 HUMAN $60.98 \quad 100.0 \%$ 26S proteasome non-ATPase regulatory subunit 3 GN=PSMD3 PSMD3_HUMAN $60.98 \quad 100.0 \%$ 26S proteasome non-ATPase regulatory subunit 3 GN=PSMD3 PSMD3_HUMAN $60.98 \quad 100.0 \%$ $26 \mathrm{~S}$ proteasome non-ATPase regulatory subunit $3 \mathrm{GN}=\mathrm{PSMD} 3$ PSMD3_HUMAN $60.98 \quad 100.0 \%$ 26S proteasome non-ATPase regulatory subunit $3 \mathrm{GN}=$ PSMD3 PSMD3_HUMAN $60.98 \quad 100.0 \%$ $26 \mathrm{~S}$ proteasome non-ATPase regulatory subunit $3 \mathrm{GN}=\mathrm{PSMD} 3$ PSMD3_HUMAN $60.98 \quad 100.0 \%$ 26S proteasome non-ATPase regulatory subunit $3 \mathrm{GN}=$ PSMD3 PSMD3_HUMAN $60.98 \quad 100.0 \%$ 26S proteasome non-ATPase regulatory subunit $3 \mathrm{GN}=\mathrm{PSMD} 3$ PSMD3_HUMAN $60.98 \quad 100.0 \%$ 26S proteasome non-ATPase regulatory subunit $3 \mathrm{GN}=$ PSMD3 PSMD3_HUMAN $60.98 \quad 100.0 \%$ 26S proteasome non-ATPase regulatory subunit 3 GN=PSMD3 PSMD3_HUMAN $60.98 \quad 100.0 \%$ 26S proteasome non-ATPase regulatory subunit 3 GN=PSMD3 PSMD3_HUMAN 60.98 26S proteasome non-ATPase regulatory subunit 3 GN=PSMD3 PSMD3_HUMAN 60.98 26S proteasome non-ATPase regulatory subunit $3 \mathrm{GN}=\mathrm{PSMD} 3$ PSMD3_HUMAN 60.98 26 S proteasome non-ATPase regulatory subunit $3 \mathrm{GN}=\mathrm{PSMD} 3$ PSMD3_HUMAN 60.98 26S proteasome non-ATPase regulatory subunit 3 GN=PSMD3 PSMD3_HUMAN 60.98 26S proteasome non-ATPase regulatory subunit $3 \mathrm{GN}=$ PSMD3 PSMD3_HUMAN 60.98 26S proteasome non-ATPase regulatory subunit 3 GN=PSMD3 PSMD3_HUMAN 60.98 26S proteasome non-ATPase regulatory subunit 3 GN=PSMD3 PSMD3_HUMAN 60.98 265 proteasome non-ATPase regulatory subunit 3 GN=PSMD3 PSMD3_HUMAN 60.98 26S proteasome non-ATPase regulatory subunit 3 GN=PSMD3 PSMD3_HUMAN 60.98 26S proteasome non-ATPase regulatory subunit 3 GN=PSMD3 PSMD3_HUMAN 60.98 $26 \mathrm{~S}$ proteasome non-ATPase regulatory subunit $3 \mathrm{GN}=\mathrm{PSMD} 3$ PSMD3 HUMAN 60.9 26S proteasome non-ATPase regulatory subunit 3 GN=PSMD3 PSMD3_HUMAN 60.9 26S proteasome non-ATPase regulatory subunit $4 \mathrm{GN}=$ PSMD 4 PSMD4_HUMAN 40.74 26S proteasome non-ATPase regulatory subunit 4 GN=PSMD4 PSMD4_HUMAN 40.7 26S proteasome non-ATPase regulatory subunit $4 \mathrm{GN}=$ PSMD4 PSMD4_HUMAN $40.74100 .0^{\circ}$ $26 \mathrm{~S}$ proteasome non-ATPase regulatory subunit $4 \mathrm{GN}=$ PSMD4 PSMD4_HUMAN $40.74 \quad 100.0 \%$ 26S proteasome non-ATPase regulatory subunit 4 GN=PSMD4 PSMD4_HUMAN $40.74 \quad 100.0 \%$ 26S proteasome non-ATPase regulatory subunit $4 \mathrm{GN}=\mathrm{PSMD} 4$ PSMD4_HUMAN $40.74 \quad 100.0 \%$ 26S proteasome non-ATPase regulatory subunit $4 \mathrm{GN}=$ PSMD4 PSMD4_HUMAN $40.74 \quad 100.0 \%$ 26S proteasome non-ATPase regulatory subunit 6 GN=PSMD6 PSMD6_HUMAN $45.53 \quad 100.0 \%$
$3 \quad 0.00 \% \quad 2.5 \% \quad$ VLTMPETCR $0.02 \% \quad 20.2 \%$ SSDEAVILCK

$0.02 \% \quad 20.2 \%$ LNIGDLQVTK $0.02 \% \quad 20.2 \%$ YYQTIGNHASYYK $0.02 \% \quad 20.2 \%$ QLTFEEIAK $0.02 \% \quad 20.2 \%$ VLDLQQIK

$0.01 \% \quad 12.6 \%$ VIDVFAMPQSGTGVSVEAVDPV

$0.01 \% \quad 12.6 \%$ AVAVVVDPIQSVK

$0.01 \% \quad 6.4 \% \quad$ SSTTSMTSVPKPLK

$0.01 \% \quad 6.4 \%$ CALGVFRK

$0.01 \% \quad 6.4 \%$ LNILDTLSK

$0.01 \% \quad 6.4 \%$ VGQAVDVVGQAGKPK

$0.06 \% \quad 44.0 \%$ RLNHYVLYK

$0.06 \% \quad 44.0 \%$ LNHYVLYK

$0.06 \% \quad 44.0 \%$ AVQGFFTSNNATR

$0.06 \% \quad 44.0 \%$ ISDDLMQK

$0.06 \% \quad 44.0 \%$ RALDLVAAK

$0.06 \% \quad 44.0 \%$ ALDLVAAK

$\quad 0.06 \% \quad 44.0 \%$ VYEFLDKLDVVR

$50 \quad 0.06 \% \quad 44.0 \%$ HDADGQATLLNLLLR

$50 \quad 0.06 \% \quad 44.0 \%$ NYLHYSLYDQAEK

$50 \quad 0.06 \% \quad 44.0 \%$ SVFPEQANNNEWAR

$50 \quad 0.06 \% \quad 44.0 \%$ IKAIQLEYSEAR

$50 \quad 0.06 \% \quad 44.0 \%$ AIQLEYSEAR

$50 \quad 0.06 \% \quad 44.0 \%$ APQHTAVGFK

$50 \quad 0.06 \% \quad 44.0 \%$ SLMPYFLLTQAVR

$50 \quad 0.06 \% \quad 44.0 \%$ FNQVLDQFGEK

$50 \quad 0.06 \% \quad 44.0 \%$ MISLSYSR

$50 \quad 0.06 \% \quad 44.0 \%$ ISLADIAQK

$50 \quad 0.06 \% \quad 44.0 \%$ LQLDSPEDAEFIVAK

$50 \quad 0.06 \% \quad 44.0 \%$ AIRDGVIEASINHEK

$50 \quad 0.06 \% \quad 44.0 \%$ DGVIEASINHEK

$0.06 \% \quad 44.0 \%$ SYNKDLESAEER

$0.03 \% \quad 19.6 \%$ ILSKLHTVQPK

$0.03 \% \quad 19.6 \%$ GKITFCTGIR

$0.03 \% \quad 19.6 \%$ ITFCTGIR

$0.03 \% \quad 19.6 \%$ NAMGSLASQATK

$0.04 \% \quad 45.0 \%$ PLENLEEEGLPK
$0.02 \% \quad 20.2 \%$ ITVNEVELLVMK

$0.01 \% \quad 6.4 \%$ FGGSGSQVDSAR

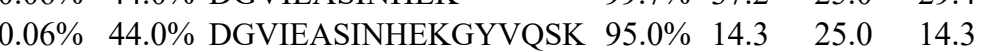

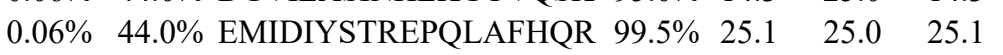

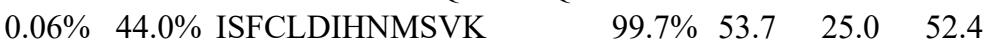

$99.7 \%$ 43.4 $25.0 \quad 37.5$

$\begin{array}{ll}0.03 \% & 19.6 \% \\ 0.03 \% & 19.6 \% \text { NGDFLPTRLQAQQDAVNIVCHSK }\end{array}$

$99.7 \%$

$99.7 \% \quad 35.6$

25.0

$99.7 \% \quad 43.2 \quad 25.0 \quad 39.9$

$99.0 \% \quad 26.4 \quad 25.0 \quad 19.1$

$\begin{array}{llll}99.7 \% & 36.5 & 25.0 & 34.4 \\ 99.7 \% & 59.4 & 25.0 & 47.0\end{array}$

122.53

1606.81

1121.55

1100.63

1607.75

1078.58

1387.79

956.58

2707.37

1324.78

1479.77

950.52

1167.54

1016.60

1452.82

1205.68

1049.58

1412.69

965.46

956.59

800.49

1495.82

1649.90

1643.77

1661.77

1420.78

1179.60

1055.56

1554.84

1324.65

956.49

958.56

1674.86

1651.88

1311.65

1973.99

2234.10

1563.77

1440.66

2611.30

1710.86

1263.78

1152.62

967.50

1973.06

1194.58 $\begin{array}{llllllll}99.7 \% & 61.5 & 25.0 & 61.5 & 2 & 0 & 0 & 1367.71\end{array}$

$\begin{array}{cc}91 & 899 \\ 6 & 99 \\ 06 & 115 \\ 23 & 132 \\ 62 & 174 \\ 90 & 298 \\ 02 & 313 \\ 40 & 347 \\ 9 & 94 \\ 40 & 152 \\ 4 & 97 \\ 51 & 258 \\ 58 & 369 \\ 04 & 712 \\ 46 & 860 \\ 07 & 115 \\ 08 & 115 \\ 16 & 128 \\ 87 & 194 \\ 01 & 209 \\ 02 & 209 \\ 17 & 228 \\ 42 & 256 \\ 57 & 269 \\ 74 & 287 \\ 95 & 306 \\ 97 & 306 \\ 16 & 325 \\ 56 & 368 \\ 75 & 385 \\ 09 & 416 \\ 17 & 425 \\ 26 & 440 \\ 41 & 455 \\ 44 & 455 \\ 44 & 461 \\ 62 & 479 \\ 80 & 492 \\ 00 & 511 \\ 8 & 40 \\ 6 & 40 \\ 1 & 81 \\ 2 & 91 \\ 4 & 91 \\ 09 & 126 \\ 54 & 365 \\ 2 & 13 \\ & \end{array}$



26S proteasome non-ATPase regulatory subunit 6 GN=PSMD6 $\quad$ PSMD6_HUMAN $45.53 \quad 100.0 \% \quad 1$ 26S proteasome non-ATPase regulatory subunit 6 GN=PSMD6 PSMD6_HUMAN $45.53 \quad 100.0 \%$ 26S proteasome non-ATPase regulatory subunit 6 GN=PSMD6 PSMD6_HUMAN $45.53 \quad 100.0 \%$ 26S proteasome non-ATPase regulatory subunit 6 GN=PSMD6 PSMD6_HUMAN $45.53 \quad 100.0 \% \quad 1$ ' 26S proteasome non-ATPase regulatory subunit 6 GN=PSMD6 PSMD6_HUMAN $45.53 \quad 100.0 \% \quad 1$ ' 26S proteasome non-ATPase regulatory subunit 6 GN=PSMD6 PSMD6_HUMAN $45.53 \quad 100.0 \% \quad 17$ 26S proteasome non-ATPase regulatory subunit 6 GN=PSMD6 $\quad$ PSMD6_HUMAN $45.53 \quad 100.0 \% \quad 1$ 26S proteasome non-ATPase regulatory subunit $6 \mathrm{GN}=$ PSMD6 $\quad$ PSMD6 HUMAN $45.53 \quad 100.0 \% \quad 1$ 26S proteasome non-ATPase regulatory subunit 6 GN=PSMD6 PSMD6_HUMAN $45.53 \quad 100.0 \% \quad 17$ 26S proteasome non-ATPase regulatory subunit 6 GN=PSMD6 PSMD6_HUMAN $45.53 \quad 100.0 \% \quad 1$ ' $26 \mathrm{~S}$ proteasome non-ATPase regulatory subunit $6 \mathrm{GN}=$ PSMD6 PSMD6 HUMAN 45.53 26S proteasome non-ATPase regulatory subunit 6 GN=PSMD6 PSMD6_HUMAN 45.53 26S proteasome non-ATPase regulatory subunit 6 GN=PSMD6 PSMD6_HUMAN 45.53 26S proteasome non-ATPase regulatory subunit 6 GN=PSMD6 PSMD6_HUMAN 45.53 26S proteasome non-ATPase regulatory subunit 6 GN=PSMD6 PSMD6_HUMAN 45.53 26S proteasome non-ATPase regulatory subunit $7 \mathrm{GN}=\mathrm{PSMD} 7 \mathrm{PSMD} 7$ HUMAN 37.03 26S proteasome non-ATPase regulatory subunit 7 GN=PSMD7 PSMD7_HUMAN 37.03 26S proteasome non-ATPase regulatory subunit 8 GN=PSMD8 PSMD8_HUMAN 39.61 26S proteasome non-ATPase regulatory subunit 8 GN=PSMD8 PSMD8 HUMAN 39.61 $28 \mathrm{~S}$ ribosomal protein S18b, mitochondrial GN=MRPS18B RT18B_HUMAN 29.40 $28 \mathrm{~S}$ ribosomal protein S18b, mitochondrial GN=MRPS18B RT18B_HUMAN 29.40 28S ribosomal protein S18b, mitochondrial GN=MRPS18B RT18B_HUMAN 29.40 $28 \mathrm{~S}$ ribosomal protein S18b, mitochondrial GN=MRPS18B RT18B_HUMAN 29.40 $28 \mathrm{~S}$ ribosomal protein $\mathrm{S} 2$, mitochondrial GN=MRPS2 RT02_HUMAN 33.25 $28 \mathrm{~S}$ ribosomal protein S2, mitochondrial GN=MRPS2 RT02_HUMAN 33.25 $28 \mathrm{~S}$ ribosomal protein S2, mitochondrial GN=MRPS2 RT02_HUMAN 33.25 $28 \mathrm{~S}$ ribosomal protein $\mathrm{S} 2$, mitochondrial GN=MRPS2 RT02_HUMAN 33.25 $28 \mathrm{~S}$ ribosomal protein $\mathrm{S} 2$, mitochondrial GN=MRPS2 RT02_HUMAN 33.25 $28 \mathrm{~S}$ ribosomal protein $\mathrm{S} 2$, mitochondrial GN=MRPS2 RT02 HUMAN 33.2 $28 \mathrm{~S}$ ribosomal protein S2, mitochondrial GN=MRPS2 RT02_HUMAN 33.25 $28 \mathrm{~S}$ ribosomal protein S22, mitochondrial GN=MRPS22 RT22_HUMAN 41.28 $28 \mathrm{~S}$ ribosomal protein S22, mitochondrial GN=MRPS22 RT22_HUMAN 41.28 $28 \mathrm{~S}$ ribosomal protein S22, mitochondrial GN=MRPS22 RT22_HUMAN 41.28 $28 \mathrm{~S}$ ribosomal protein S22, mitochondrial GN=MRPS22 RT22_HUMAN 41.28 $28 \mathrm{~S}$ ribosomal protein S22, mitochondrial GN=MRPS22 RT22_HUMAN 41.28 $28 \mathrm{~S}$ ribosomal protein S22, mitochondrial GN=MRPS22 RT22_HUMAN 41.2 $28 \mathrm{~S}$ ribosomal protein S22, mitochondrial GN=MRPS22 RT22 HUMAN 41.28 $28 \mathrm{~S}$ ribosomal protein S22, mitochondrial GN=MRPS22 RT22_HUMAN 41.28 $28 \mathrm{~S}$ ribosomal protein S22, mitochondrial GN=MRPS22 RT22_HUMAN 41.28 $28 \mathrm{~S}$ ribosomal protein S22, mitochondrial GN=MRPS22 RT22 HUMAN 41.2 $28 \mathrm{~S}$ ribosomal protein S22, mitochondrial GN=MRPS22 RT22_HUMAN 41.28 $28 \mathrm{~S}$ ribosomal protein S22, mitochondrial GN=MRPS22 RT22_HUMAN 41.28 $28 \mathrm{~S}$ ribosomal protein S23, mitochondrial GN=MRPS23 RT23_HUMAN 21.77 $28 \mathrm{~S}$ ribosomal protein S23, mitochondrial GN=MRPS23 RT23_HUMAN 21.77 $28 \mathrm{~S}$ ribosomal protein S23, mitochondrial GN=MRPS23 RT23_HUMAN 21.77 $28 \mathrm{~S}$ ribosomal protein S27, mitochondrial GN=MRPS27 RT27_HUMAN 47.61
$100.0 \% \quad 17$ $100.0 \% \quad 17$ $100.0 \% \quad 17$ $100.0 \% \quad 17$ $100.0 \% \quad 17$ $100.0 \% \quad 2$ $100.0 \%$ $100.0 \%$ $100.0 \% \quad 2$ $100.0 \%$ $100.0 \%$ $00.0 \%$ $100.0 \%$ $100.0 \%$ $100.0 \%$ $100.0 \%$ $100.0 \%$ $100.0 \%$ $100.0 \%$ $100.0 \%$ $100.0 \% \quad 12$ $100.0 \% \quad 12$ $100.0 \% \quad 12$ $100.0 \% \quad 12$ $100.0 \% \quad 12$ $100.0 \% \quad 12$ $100.0 \% \quad 12$ $100.0 \% \quad 12$ $100.0 \% \quad 12$ $100.0 \% \quad 12$ $100.0 \% \quad 12$ $100.0 \% \quad 12$ $100.0 \%$ $100.0 \%$ $100.0 \%$ $100.0 \%$
$0.04 \% \quad 45.0 \%$ FLLSLPEHR

$0.04 \% \quad 45.0 \%$ GDAAVRDELMAAVR

$0.04 \% \quad 45.0 \%$ SLDWQIDVDLLNK

$0.04 \% \quad 45.0 \%$ NLGESEIR

$0.04 \% \quad 45.0 \%$ NLGESEIRDAMMAK

$0.04 \% \quad 45.0 \%$ IGDKEGALTAFR

$0.04 \% \quad 45.0 \%$ LDIVFYLLR

$0.04 \% \quad 45.0 \%$ IGLFYMDNDLITR

$0.04 \% \quad 45.0 \%$ GAEILEVLHSLPAVR

$0.04 \% \quad 45.0 \%$ QYLFSLYECR

$0.04 \% \quad 45.0 \%$ IHAYSQLLESYR

$0.04 \% \quad 45.0 \%$ IDKVNEIVETNRPDSK

$0.04 \% \quad 45.0 \%$ VNEIVETNRPDSK

$0.04 \% \quad 45.0 \%$ KGDLLLNR

$0.00 \% \quad 7.7 \%$ DIKDTTVGTLSQR

$0.00 \% \quad 7.7 \%$ SVVALHNLINNK

$0.00 \% \quad 4.9 \%$ DIQTNVYIK

$0.00 \% \quad 4.9 \% \quad$ ILFFNTPK

$0.01 \% \quad 21.7 \%$ YLESEEYQER

$0.01 \% \quad 21.7 \%$ VVGNPCPICR

$\begin{array}{lll}0.01 \% & 21.7 \% & \text { LYQGHLQEESGPPPESMPK } \\ 0.01 \% & 21.7 \% & \text { TPAEASSTGQTGPQSAL }\end{array}$

$0.01 \% 22.6 \%$ HSDFFNVK

$0.01 \% 22.6 \%$ FMEPYIFGSR

$0.01 \% \quad 22.6 \%$ LLFGPTVR

$0.01 \% \quad 22.6 \%$ LFQTAITR

$0.01 \% \quad 22.6 \%$ RQQVEALYR

$0.01 \% 22.6 \%$ QQVEALYR

$0.01 \% \quad 22.6 \%$ LQGQKEPGDQGPAHPPGADMSHSL

$0.05 \% \quad 35.8 \%$ MTGLNLQK

$0.05 \% 35.8 \%$ TFKPAIQELKPPTYK

$0.05 \% \quad 35.8 \%$ LMTQAQLEEATR

$0.05 \% \quad 35.8 \%$ VPINDVLAEDK

$0.05 \% \quad 35.8 \%$ VPINDVLAEDKILEGTETTK

$0.05 \% \quad 35.8 \%$ YVFTDISYSIPHR

$0.05 \% \quad 35.8 \%$ MIQVYFPK

$0.05 \% \quad 35.8 \%$ ILTPIIFKEENLR

$0.05 \% \quad 35.8 \%$ KIDGLLIDQIQR

$0.05 \% \quad 35.8 \%$ IDGLLIDQIQR

$0.05 \% \quad 35.8 \%$ DQAAEGINLIK

$0.05 \% \quad 35.8 \%$ GAYIELTLQTYQEALSR

$0.01 \% \quad 17.4 \%$ LETVGSIFSR

$0.01 \% \quad 17.4 \%$ AKFYSVYGSGQR

0.01\% $17.4 \%$ ALLAEGVILRR

$0.03 \% \quad 30.9 \%$ KLPVSSLTISR $\begin{array}{llll}99.7 \% & 34.6 & 25.0 & 34.6\end{array}$ $\begin{array}{llll}99.7 \% & 39.7 & 25.0 & 32.5\end{array}$ $\begin{array}{llll}99.6 \% & 25.6 & 25.0 & 22.9\end{array}$ $\begin{array}{lllll}99.7 \% & 35.9 & 25.0 & 35.9 & 2\end{array}$ $\begin{array}{lllll}99.7 \% & 66.2 & 25.0 & 60.3\end{array}$ $\begin{array}{llll}99.0 \% & 22.4 & 25.0 & 19.5\end{array}$

$\begin{array}{llll}99.7 \% & 42.2 & 25.0 & 42.1\end{array}$ $\begin{array}{lllll}99.7 \% & 41.6 & 25.0 & 37.2 & 2\end{array}$ $99.7 \% \quad 50.6 \quad 25.0 \quad 28.0$

$\begin{array}{llll}99.7 \% & 53.1 & 25.0 & 53.1\end{array}$

$\begin{array}{lllll}99.7 \% & 41.5 & 25.0 & 41.5 & 2\end{array}$

$99.7 \% \quad 49.5 \quad 25.0 \quad 45.4$

$\begin{array}{llll}99.7 \% & 57.6 & 25.0 & 47.5\end{array}$

$99.7 \% \quad 31.7 \quad 25.0 \quad 31.7$

$\begin{array}{llll}99.6 \% & 31.4 & 25.0 & 15.4\end{array}$

$\begin{array}{lllll}99.0 \% & 46.1 & 25.0 & 38.1 & 2\end{array}$

$\begin{array}{llll}99.7 \% & 67.1 & 25.0 & 50.5\end{array}$

$\begin{array}{llll}99.7 \% & 47.9 & 25.0 & 39.7\end{array}$

$\begin{array}{llll}99.0 \% & 25.2 & 25.0 & 19.4\end{array}$

$\begin{array}{llll}96.4 \% & 21.2 & 25.0 & 10.9\end{array}$

$\begin{array}{llll}99.7 \% & 50.8 & 25.0 & 49.6\end{array}$

$\begin{array}{llll}99.7 \% & 60.0 & 25.0 & 58.7\end{array}$

PK 99.70

$99.7 \%$ $99.7 \% \quad 51.4$

$99.6 \% \quad 25.5$

$96.6 \% \quad 22.7$

$99.0 \% \quad 55.2$

$99.7 \% \quad 29.7$ $99.0 \% \quad 40.4$

$99.0 \% 18.8$ $99.0 \% \quad 33.8$ $99.7 \% \quad 29.8$ $99.7 \% \quad 69.2$ $99.7 \% \quad 55.6$ $99.7 \% \quad 32.8$ $\begin{array}{ll}99.7 \% & 54.6 \\ 99.0 \% & 41.6\end{array}$ $99.2 \% \quad 20.7$ $99.7 \% \quad 44.8$ $\begin{array}{lll}99.7 \% & 59.8\end{array}$ $99.7 \% \quad 61.8$ $99.7 \% \quad 48.3$ $99.7 \% \quad 60.2$ $\begin{array}{lll}99.7 \% & 47.8\end{array}$ $98.3 \% 17.6$ $99.7 \% \quad 53.0$

1963.01

1111.63
1473.75

1604.67

1558.81

917.47

1564.75

1277.69

1151.68

1586.79

1603.92

1378.65

1479.76

1856.97

1500.77

928.56

1433.76

1321.76

1093.59

979.56

1345.59

1171.57

2140.00

1602.76

993.48

1262.59

902.55

949.55

1162.63

1006.53 
$28 \mathrm{~S}$ ribosomal protein S27, mitochondrial GN=MRPS27 RT27 HUMAN $47.61 \quad 100.0 \%$ $28 \mathrm{~S}$ ribosomal protein S27, mitochondrial GN=MRPS27 RT27_HUMAN $47.61 \quad 100.0 \%$ $28 \mathrm{~S}$ ribosomal protein S27, mitochondrial GN=MRPS27 RT27_HUMAN $47.61 \quad 100.0 \% \quad 1$ $28 \mathrm{~S}$ ribosomal protein S27, mitochondrial GN=MRPS27 RT27_HUMAN $47.61 \quad 100.0 \%$ $28 \mathrm{~S}$ ribosomal protein S27, mitochondrial GN=MRPS27 RT27_HUMAN $47.61 \quad 100.0 \%$ $28 \mathrm{~S}$ ribosomal protein S27, mitochondrial GN=MRPS27 RT27_HUMAN $47.61 \quad 100.0 \% \quad 13$ $28 \mathrm{~S}$ ribosomal protein S27, mitochondrial GN=MRPS27 RT27_HUMAN $47.61 \quad 100.0 \% \quad 13$ $28 \mathrm{~S}$ ribosomal protein S27, mitochondrial GN=MRPS27 RT27_HUMAN $47.61 \quad 100.0 \% \quad 13$ $28 \mathrm{~S}$ ribosomal protein S27, mitochondrial GN=MRPS27 RT27 HUMAN $47.61 \quad 100.0 \% \quad 1$ $28 \mathrm{~S}$ ribosomal protein S27, mitochondrial GN=MRPS27 RT27_HUMAN $47.61 \quad 100.0 \% \quad 1$ $28 \mathrm{~S}$ ribosomal protein S27, mitochondrial GN=MRPS27 RT27_HUMAN $47.61 \quad 100.0 \% \quad 1$ $28 \mathrm{~S}$ ribosomal protein S27, mitochondrial GN=MRPS27 RT27 HUMAN $47.61 \quad 100.0 \%$ $28 \mathrm{~S}$ ribosomal protein S29, mitochondrial GN=DAP3 RT29_HUMAN $45.57 \quad 100.0 \%$ $28 \mathrm{~S}$ ribosomal protein S29, mitochondrial GN=DAP3 RT29_HUMAN $45.57 \quad 100.0 \%$ $28 \mathrm{~S}$ ribosomal protein $\mathrm{S} 29$, mitochondrial GN=DAP3 RT29 HUMAN $45.57 \quad 100.0 \%$ $28 \mathrm{~S}$ ribosomal protein S29, mitochondrial GN=DAP3 RT29_HUMAN $45.57 \quad 100.0 \%$ $28 \mathrm{~S}$ ribosomal protein $\mathrm{S} 29$, mitochondrial GN=DAP3 RT29 HUMAN $45.57 \quad 100.0 \%$ $28 \mathrm{~S}$ ribosomal protein S29, mitochondrial GN=DAP3 RT29_HUMAN $45.57 \quad 100.0 \%$ $28 \mathrm{~S}$ ribosomal protein S29, mitochondrial GN=DAP3 RT29_HUMAN $45.57 \quad 100.0 \%$ $28 \mathrm{~S}$ ribosomal protein $\mathrm{S} 29$, mitochondrial GN=DAP3 RT29 HUMAN 45.57 $28 \mathrm{~S}$ ribosomal protein $\mathrm{S} 29$, mitochondrial GN=DAP3 RT29_HUMAN 45.57 28S ribosomal protein S31, mitochondrial GN=MRPS31 RT31_HUMAN 45.32 28S ribosomal protein S31, mitochondrial GN=MRPS31 RT31 HUMAN 45.32 28S ribosomal protein S31, mitochondrial GN=MRPS31 RT31_HUMAN 45.32 $28 \mathrm{~S}$ ribosomal protein $\mathrm{S} 31$, mitochondrial GN=MRPS31 RT31_HUMAN 45.32 28 S ribosomal protein S34, mitochondrial GN=MRPS34 RT34_HUMAN 25.65 $28 \mathrm{~S}$ ribosomal protein S34, mitochondrial GN=MRPS34 RT34_HUMAN 25.6 28S ribosomal protein S34, mitochondrial GN=MRPS34 RT34 HUMAN 25.6. $28 \mathrm{~S}$ ribosomal protein S35, mitochondrial GN=MRPS35 RT35_HUMAN 36.8 $28 \mathrm{~S}$ ribosomal protein $\mathrm{S} 35$, mitochondrial GN=MRPS35 RT35 HUMAN 36.8 $28 \mathrm{~S}$ ribosomal protein $\mathrm{S} 35$, mitochondrial GN=MRPS35 RT35_HUMAN 36.85 $28 \mathrm{~S}$ ribosomal protein $\mathrm{S} 35$, mitochondrial GN=MRPS35 RT35_HUMAN 36.8 . $28 \mathrm{~S}$ ribosomal protein S35, mitochondrial GN=MRPS35 RT35 HUMAN 36.8 $28 \mathrm{~S}$ ribosomal protein $\mathrm{S} 35$, mitochondrial GN=MRPS35 RT35_HUMAN 36.8 _ $28 \mathrm{~S}$ ribosomal protein S35, mitochondrial GN=MRPS35 RT35 HUMAN 36.8 $28 \mathrm{~S}$ ribosomal protein $\mathrm{S} 5$, mitochondrial GN=MRPS5 RT05 HUMAN 48.0 28S ribosomal protein S5, mitochondrial GN=MRPS5 RT05_HUMAN 48.01 $28 \mathrm{~S}$ ribosomal protein $\mathrm{S} 5$, mitochondrial GN=MRPS5 RT05 HUMAN 48.01 $28 \mathrm{~S}$ ribosomal protein S5, mitochondrial GN=MRPS5 RT05_HUMAN 48.01 28S ribosomal protein S5, mitochondrial GN=MRPS5 RT05_HUMAN 48.01 $28 \mathrm{~S}$ ribosomal protein $\mathrm{S} 5$, mitochondrial GN=MRPS5 RT05 HUMAN 48.01 $28 \mathrm{~S}$ ribosomal protein S5, mitochondrial GN=MRPS5 RT05_HUMAN 48.01 $28 \mathrm{~S}$ ribosomal protein $\mathrm{S} 5$, mitochondrial GN=MRPS5 RT05_HUMAN 48.01 $28 \mathrm{~S}$ ribosomal protein S5, mitochondrial GN=MRPS5 RT05_HUMAN $48.01 \quad 100.0^{\circ}$ $28 \mathrm{~S}$ ribosomal protein S9, mitochondrial GN=MRPS9 RT09_HUMAN $45.84 \quad 100.0^{\circ}$ $28 \mathrm{~S}$ ribosomal protein S9, mitochondrial GN=MRPS9 RT09 HUMAN $45.84100 .0^{\circ}$ $28 \mathrm{~S}$ ribosomal protein S9, mitochondrial GN=MRPS9 RT09_HUMAN $45.84 \quad 100.0 \%$
$0.03 \% \quad 30.9 \%$ LIDNISSR

$99.0 \% \quad 37.8$

$\begin{array}{lll}99.7 \% & 33.2\end{array}$

$97.5 \% \quad 20.3$

$99.7 \% \quad 50.5$

$99.7 \% \quad 54.3$

$99.7 \% \quad 43.9$

$99.7 \% \quad 41.5$

$\begin{array}{ll}99.7 \% & 69.2 \\ 99.7 \% & 52.4\end{array}$

$\begin{array}{ll}0.03 \% & 30.9 \% \\ 0.03 \% & 30.9 \%\end{array}$

$0.03 \% \quad 30.9 \%$ LVEQLDIEETEQSK

$99.7 \% \quad 70.8$

$0.03 \% \quad 30.9 \%$ IESEGLLSLTTQLVK

$0.03 \% \quad 23.1 \%$ TFSEACLMVR

$0.03 \% \quad 23.1 \%$ NTSFAYPAIR

$0.03 \% \quad 23.1 \%$ DLLQSSYNK

$0.03 \% \quad 23.1 \%$ FDQPLEASTWLK

$0.03 \% \quad 23.1 \%$ GSPLGEVVEQGITR

$0.03 \% \quad 23.1 \%$ NATDAVGIVLK

$0.03 \% \quad 23.1 \%$ KAYLPQELLGK

$0.03 \% \quad 23.1 \%$ AYLPQELLGK

$0.03 \% \quad 23.1 \%$ ELLFLSNANPSLLER

$0.01 \% \quad 13.4 \%$ GMKVELSTVNVR

$0 \quad 0.01 \% \quad 13.4 \%$ SELLSQLQQHEEESR

$0.01 \% \quad 13.4 \%$ ISFSNIISDMK

$10 \quad 0.01 \% \quad 13.4 \%$ IQFDEGYDNYPGQEK

$0.01 \% \quad 13.8 \%$ LPLFGLGR

$6 \quad 0.01 \% \quad 13.8 \%$ VRPDYTAQNLDHGK

$0.01 \% \quad 13.8 \%$ AWGILTFK

$0.01 \% \quad 27.6 \%$ TPGNERPPR

$3 \quad 0.01 \% \quad 27.6 \%$ EGNLELLK

$0.01 \% \quad 27.6 \%$ HFPIEIDSTDYVSSGPSVR

$0.01 \% \quad 27.6 \%$ LSSLNLDDHAK

$0.01 \% \quad 27.6 \%$ NILETLLQMK

$0.01 \% \quad 27.6 \%$ NMEINKEELLGTK

$99.7 \% \quad 36.1$

$99.7 \% \quad 60.9$

$99.7 \% \quad 59.4$

$99.7 \% \quad 51.5$

$99.0 \% \quad 35.9$

$0.01 \% \quad 27.6 \%$ SVVSLKNEEENENSISQYK

$0.02 \% \quad 22.6 \%$ GQIIGEGR

$0.02 \% \quad 22.6 \%$ NGAVQTIAQR

$0.02 \% \quad 22.6 \%$ NVFTMTAK

$0.02 \% \quad 22.6 \%$ VLVAVGNGK

$0.02 \% \quad 22.6 \%$ GAAGFSIGK

$0.02 \% \quad 22.6 \%$ AVHHLHYIER

$0.02 \% \quad 22.6 \%$ YEDHTIFHDISLR

$0.02 \% \quad 22.6 \%$ VSGSINMLSLTQGLFR

$0.02 \% \quad 22.6 \%$ EECGPLPIVVASPR

$0.03 \% \quad 24.0 \%$ ETYTEDFIKK

$0.03 \% \quad 24.0 \%$ QIEEFNIGK

$0.03 \% \quad 24.0 \%$ QIEEFNIGKR
$99.7 \% \quad 54.9$

$99.7 \% \quad 46.3$

$99.7 \% \quad 47.9$

$99.7 \% \quad 44.7$

$99.7 \% \quad 64.3$

$99.7 \% \quad 44.5$

$99.1 \% \quad 28.8$

$99.7 \% \quad 78.4$

$\begin{array}{lll}97.0 \% & 23.4\end{array}$

$99.7 \% \quad 67.7$

$\begin{array}{lll}99.7 \% & 37.3\end{array}$

$97.3 \% \quad 22.7$

$98.1 \% \quad 17.7$

$99.0 \% \quad 37.5$

$\begin{array}{lll}99.7 \% & 29.3\end{array}$

$99.7 \% \quad 68.8$

$99.7 \% \quad 39.0$

1358.71

1127.67

1660.83

2560.31

1630.93

1213.57

1139.58

1067.54

1434.73

1441.76

1100.63

1259.74

1131.64

1715.93

1348.73

1812.87

1270.63

1802.79

872.54

1613.80

935.54

1023.53

915.51

2106.01

1212.62

1202.68

1518.78

2197.06

829.45

1057.57

911.47

856.53

807.44

1274.68

1645.80

1738.92

1523.79

1273.63 $\begin{array}{llllllll}99.7 \% & 32.2 & 25.0 & 20.4 & 3 & 0 & 0 & 1273.63 \\ 99.7 \% & 41.0 & 25.0 & 32.0 & 2 & 0 & 0 & 1077.56 \\ 99.7 \% & 41.1 & 25.0 & 24.1 & 3 & 1 & 0 & 1233.66\end{array}$

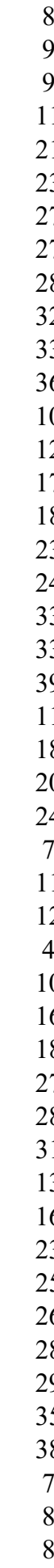

Page 6 of Table S-1- 6 
$28 \mathrm{~S}$ ribosomal protein S9, mitochondrial GN=MRPS9 RT09_HUMAN $45.84 \quad 100.0 \%$ $28 \mathrm{~S}$ ribosomal protein $\mathrm{S} 9$, mitochondrial GN=MRPS9 RT09_HUMAN $45.84 \quad 100.0 \%$ $28 \mathrm{~S}$ ribosomal protein S9, mitochondrial GN=MRPS9 RT09_HUMAN $45.84 \quad 100.0 \%$ $28 \mathrm{~S}$ ribosomal protein $\mathrm{S} 9$, mitochondrial GN=MRPS9 RT09 HUMAN $45.84 \quad 100.0 \%$ $28 \mathrm{~S}$ ribosomal protein S9, mitochondrial GN=MRPS9 RT09_HUMAN $45.84 \quad 100.0 \%$ $28 \mathrm{~S}$ ribosomal protein S9, mitochondrial GN=MRPS9 RT09_HUMAN $45.84 \quad 100.0 \%$ $28 \mathrm{~S}$ ribosomal protein $\mathrm{S} 9$, mitochondrial GN=MRPS9 RT09_HUMAN $45.84 \quad 100.0 \%$ 2-amino-3-ketobutyrate coenzyme A ligase, mitochondrial GN=GCAT $\quad \mathrm{KBL} \_$HUMAN $45.29 \quad 100.0 \%$ 2-amino-3-ketobutyrate coenzyme A ligase, mitochondrial GN=GCAT KBL HUMAN 45.29 2-amino-3-ketobutyrate coenzyme A ligase, mitochondrial GN=GCAT KBL_HUMAN 45.29 2-amino-3-ketobutyrate coenzyme A ligase, mitochondrial $\mathrm{GN}=\mathrm{GCAT} \quad \mathrm{KBL}$ HUMAN 45.29 2-amino-3-ketobutyrate coenzyme A ligase, mitochondrial GN=GCAT KBL HUMAN 45.29 2-amino-3-ketobutyrate coenzyme A ligase, mitochondrial GN=GCAT KBL_HUMAN 45.29 2-amino-3-ketobutyrate coenzyme A ligase, mitochondrial GN=GCAT KBL_HUMAN 45.29 2-amino-3-ketobutyrate coenzyme A ligase, mitochondrial GN=GCAT KBL HUMAN 45.29 2-amino-3-ketobutyrate coenzyme A ligase, mitochondrial GN=GCAT KBL_HUMAN 45.29 2-amino-3-ketobutyrate coenzyme A ligase, mitochondrial GN=GCAT KBL HUMAN 45.29 2-amino-3-ketobutyrate coenzyme A ligase, mitochondrial GN=GCAT KBL_HUMAN 45.29 2-methoxy-6-polyprenyl-1,4-benzoquinol methylase, mitochondrial GN=COQ5 COQ5_HUMAN 37.14 2-methoxy-6-polyprenyl-1,4-benzoquinol methylase, mitochondrial GN=COQ5 COQ5 HUMAN 37.14 2-methoxy-6-polyprenyl-1,4-benzoquinol methylase, mitochondrial GN=COQ5 COQ5_HUMAN 37.14 2-oxoisovalerate dehydrogenase subunit beta, mitochondrial GN=BCKDHB ODBB_HUMAN 43.12 2-oxoisovalerate dehydrogenase subunit beta, mitochondrial GN=BCKDHB ODBB_HUMAN 43.12 $3^{\prime}\left(2^{\prime}\right), 5^{\prime}$-bisphosphate nucleotidase $1 \mathrm{GN}=\mathrm{BPNT} 1$ BPNT1_HUMAN 33.39 $3^{\prime}\left(2^{\prime}\right), 5^{\prime}$-bisphosphate nucleotidase $1 \mathrm{GN}=$ BPNT1 BPNT1_HUMAN 33.39 3'(2'),5'-bisphosphate nucleotidase $1 \mathrm{GN}=$ BPNT1 BPNT1_HUMAN 33.3 39S ribosomal protein L12, mitochondrial GN=MRPL12 RM12_HUMAN 21.35 39 S ribosomal protein L12, mitochondrial GN=MRPL12 RM12_HUMAN 21.3 39S ribosomal protein $\mathrm{L} 15$, mitochondrial $\mathrm{GN}=\mathrm{MRPL} 15 \mathrm{RM} 15$ HUMAN 33.42 39S ribosomal protein L15, mitochondrial GN=MRPL15 RM15_HUMAN 33.42 39S ribosomal protein L15, mitochondrial GN=MRPL15 RM15_HUMAN 33.42 39S ribosomal protein L15, mitochondrial GN=MRPL15 RM15 HUMAN 33.42 39S ribosomal protein L15, mitochondrial GN=MRPL15 RM15_HUMAN 33.42 39S ribosomal protein L15, mitochondrial GN=MRPL15 RM15_HUMAN 33.42 39 S ribosomal protein $\mathrm{L} 15$, mitochondrial GN=MRPL15 RM15_HUMAN 33.42 39S ribosomal protein L15, mitochondrial GN=MRPL15 RM15_HUMAN 33.42 39S ribosomal protein L19, mitochondrial GN=MRPL19 RM19 HUMAN 33.54 39S ribosomal protein L19, mitochondrial GN=MRPL19 RM19_HUMAN 33.54 39S ribosomal protein L19, mitochondrial GN=MRPL19 RM19_HUMAN 33.54 39S ribosomal protein L19, mitochondrial GN=MRPL19 RM19 HUMAN 33.54 39S ribosomal protein L19, mitochondrial GN=MRPL19 RM19_HUMAN 33.54 39S ribosomal protein $\mathrm{L} 2$, mitochondrial GN=MRPL2 RM02 HUMAN 33.30 39 S ribosomal protein $\mathrm{L} 2$, mitochondrial GN=MRPL2 RM02_HUMAN 33.30 39S ribosomal protein L24, mitochondrial GN=MRPL24 RM24_HUMAN 24.92 39S ribosomal protein L24, mitochondrial GN=MRPL24 RM24_HUMAN 24.92 39S ribosomal protein L3, mitochondrial GN=MRPL3 RM03_HUMAN 38.63
$0.03 \% \quad 24.0 \%$ AIAYLFPSGLFEK $0.03 \% \quad 24.0 \%$ HPEQIFPR $0.03 \% \quad 24.0 \%$ LSDLDYMQFIR $0.03 \% \quad 24.0 \%$ LLTSQCGAAEEEFVQR $0.03 \% \quad 24.0 \%$ EQLMFPFHFVDR $0.03 \% 24.0 \%$ LGKHDVTCTVSGGGR $0.03 \% \quad 24.0 \%$ HDVTCTVSGGGR $0.03 \% \quad 37.7 \%$ GILEGELEGIR $0.03 \% \quad 37.7 \%$ FICGTQSIHK

$0.03 \% \quad 37.7 \%$ HLDMADLEAK $\begin{array}{lll}0.03 \% & 37.7 \% & \text { ALGGASGGYTTGPGPLVSLLR } \quad 99.7 \% \quad 54.2\end{array}$ $0.03 \% \quad 37.7 \%$ ALDLLMGSNTIVQSMAAK $99.7 \% 55.0$ $0.03 \% \quad 37.7 \%$ MADDMLKR $0.03 \% \quad 37.7 \%$ GIFVIGFSYPVVPK $0.03 \% \quad 37.7 \%$ VQISAVHSEEDIDR $0.03 \% \quad 37.7 \%$ CVEAFVEVGR $0.01 \% \quad 10.7 \%$ VYQVFESVAK $0.01 \% \quad 10.7 \%$ FLNYVQSQHQR $0.01 \% \quad 10.7 \%$ NVTHIDQALQEAHR $0.01 \% \quad 6.6 \%$ SGDLFNCGSLTIR $0.01 \% \quad 6.6 \%$ EKLGVSCEVIDLR $0.01 \% \quad 6.6 \% \quad$ LGVSCEVIDLR $0.01 \% \quad 8.8 \%$ LVASAYSIAQK $0.01 \% \quad 8.8 \%$ IIQLIEGK $0.01 \% \quad 8.8 \%$ NYDYYASR $0.00 \% \quad 11.6 \%$ LTEAKPVDKVK $0.00 \% \quad 11.6 \%$ NYIQGINLVQAK $0.02 \% \quad 32.1 \%$ VSLANLKPNPGSK $0.02 \% \quad 32.1 \%$ LGFEGGQTPFYIR $0.02 \% \quad 32.1 \%$ LQYLIDLGR $0.02 \% \quad 32.1 \%$ GVTIQPLKR $0.02 \% \quad 32.1 \%$ NGGVVTTAFYDPR $0.02 \% 32.1 \%$ SLDIVCKPVPFFLR $0.02 \% \quad 32.1 \%$ GYLADPAKFPEAR $0.02 \% \quad 32.1 \%$ ILKPTDENLLK $0.01 \% \quad 13.4 \%$ FLSPEFIPR

$0 \quad 0.01 \% \quad 13.4 \%$ VTTADPYASGK

$10 \quad 0.01 \% \quad 13.4 \%$ GLGATFILR

$10 \quad 0.01 \% \quad 13.4 \%$ RLDDSLLYLR

$10 \quad 0.01 \% \quad 13.4 \%$ LDDSLLYLR $0.00 \% \quad 8.5 \%$ SADIALVAGGSR $0.00 \% \quad 8.5 \%$ QMQVLETCVATVGR $0.00 \% \quad 9.7 \%$ GTMIPSEAPLLHR $0.00 \% \quad 9.7 \% \quad$ KPTEIEWR $0.01 \% \quad 19.8 \%$ QLVSDEDKAQLASK
$99.7 \% \quad 52.2$ $98.7 \% \quad 22.6$ $\begin{array}{lll}99.7 \% & 38.2\end{array}$ $99.7 \% 65$. $99.2 \% \quad 20.5$ $96.7 \% \quad 24$ $99.7 \% \quad 46.3$ $99.7 \% \quad 70.9$ $99.7 \% \quad 45.3$ $99.7 \% \quad 45.3$ $99.7 \% \quad 54.8$ $99.7 \% \quad 30.5$ $99.7 \% \quad 68.7$ $99.7 \% \quad 39.6$ $99.7 \% \quad 48.2$ $99.7 \% \quad 46.8$ $99.7 \% \quad 59.2$ $96.7 \% \quad 22.3$ $99.7 \% \quad 57.3$ $99.7 \% \quad 45.0$ $99.0 \% 34$. $99.0 \% \quad 29.4$ $97.1 \% \quad 17.1$ $99.7 \% \quad 35.0$ $99.7 \% 36.2$ $99.7 \% \quad 44.6$ $99.7 \% \quad 49.3$ $99.4 \% \quad 22.2$ $99.7 \% \quad 37.0$ $\begin{array}{lll}99.7 \% & 29.8\end{array}$ $99.7 \% \quad 49.8$ $98.6 \% \quad 22.4$ $99.3 \% \quad 22.1$ $99.7 \% \quad 37.2$ $99.7 \% \quad 55.2$ $99.7 \% \quad 31.1$ $99.7 \% 53$. $99.7 \% \quad 58.6$ $99.7 \% \quad 43.7$ $99.7 \% \quad 31.3$ $99.0 \% 37.2$ $99.2 \% \quad 26.3$
1023.54

1416.68

1837.88

1581.75

1543.76

1245.56

1185.65

1190.60

1142.55

2299.06

2204.15

1944.06

1878.97

979.47

1522.87

1597.78

1165.57

1169.62

1419.7

1631.82

1439.69

1517.80

1260.66

1150.65

913.57

1051.45

1227.73

1360.76

1324.76

1484.75

1090.63

1011.63

1396.69

1690.94

1434.74

1283.76

1105.60

1109.55

947.57

1263.71

1107.60

1116.60

1591.79

1437.75

1058.56 1531.80

$\begin{array}{cc}07 & 119 \\ 27 & 134 \\ 13 & 223 \\ 28 & 243 \\ 11 & 322 \\ 23 & 337 \\ 26 & 337 \\ 9 & 39 \\ 04 & 113 \\ 78 & 187 \\ 24 & 244 \\ 45 & 265 \\ 66 & 286 \\ 09 & 326 \\ 62 & 369 \\ 70 & 383 \\ 90 & 403 \\ 04 & 413 \\ 8 & 77 \\ 24 & 134 \\ 21 & 234 \\ 71 & 183 \\ 93 & 305 \\ 95 & 305 \\ 1 & 21 \\ 25 & 232 \\ 90 & 297 \\ 34 & 144 \\ 51 & 162 \\ 2 & 34 \\ 5 & 77 \\ 01 & 109 \\ 26 & 134 \\ 70 & 182 \\ 83 & 196 \\ 21 & 233 \\ 82 & 292 \\ 5 & 83 \\ 19 & 129 \\ 44 & 152 \\ 82 & 191 \\ 83 & 191 \\ 36 & 147 \\ 33 & 246 \\ 06 & 118 \\ & 136 \\ & \\ 32\end{array}$

Page 7 of Table S-1-6 
S ribosomal protein L3, mitochondrial GN=MRPL3 RM03 HUMAN $38.63 \quad 100.0 \%$ 39S ribosomal protein $\mathrm{L} 3$, mitochondrial GN=MRPL3 RM03_HUMAN $38.63 \quad 100.0 \%$ 39S ribosomal protein L3, mitochondrial GN=MRPL3 RM03_HUMAN $38.63 \quad 100.0 \%$ 39S ribosomal protein $\mathrm{L} 3$, mitochondrial GN=MRPL3 RM03 HUMAN $38.63 \quad 100.0 \%$ 39S ribosomal protein L3, mitochondrial GN=MRPL3 RM03_HUMAN $38.63 \quad 100.0 \%$ 39S ribosomal protein $\mathrm{L} 37$, mitochondrial GN=MRPL37 RM37_HUMAN $48.12 \quad 100.0 \%$ 39S ribosomal protein $\mathrm{L} 37$, mitochondrial GN=MRPL37 RM37_HUMAN $48.12 \quad 100.0 \%$ 39S ribosomal protein $\mathrm{L} 37$, mitochondrial GN=MRPL37 RM37_HUMAN $48.12 \quad 100.0 \%$ 39S ribosomal protein $\mathrm{L} 37$, mitochondrial GN=MRPL37 RM37 HUMAN $48.12 \quad 100.0 \%$ $39 \mathrm{~S}$ ribosomal protein $\mathrm{L} 37$, mitochondrial GN=MRPL37 RM37_HUMAN $48.12 \quad 100.0 \%$ 39S ribosomal protein L37, mitochondrial GN=MRPL37 RM37_HUMAN $48.12 \quad 100.0 \%$ 39S ribosomal protein L37, mitochondrial GN=MRPL37 RM37_HUMAN $48.12 \quad 100.0 \%$ 39S ribosomal protein L37, mitochondrial GN=MRPL37 RM37_HUMAN $48.12 \quad 100.0 \%$ 39S ribosomal protein L37, mitochondrial GN=MRPL37 RM37_HUMAN $48.12 \quad 100.0 \%$ 39S ribosomal protein $\mathrm{L} 37$, mitochondrial GN=MRPL37 RM37 HUMAN $48.12 \quad 100.0 \%$ 39S ribosomal protein L38, mitochondrial GN=MRPL38 RM38_HUMAN $44.60 \quad 100.0 \%$ $39 \mathrm{~S}$ ribosomal protein $\mathrm{L} 38$, mitochondrial GN=MRPL38 RM38 HUMAN $44.60 \quad 100.0 \%$ 39S ribosomal protein L38, mitochondrial GN=MRPL38 RM38_HUMAN $44.60 \quad 100.0 \%$ 39S ribosomal protein L38, mitochondrial GN=MRPL38 RM38_HUMAN $44.60 \quad 100.0 \%$ 39 S ribosomal protein $\mathrm{L} 38$, mitochondrial GN=MRPL38 RM38 HUMAN $44.60 \quad 100.0 \%$ 39S ribosomal protein $\mathrm{L} 38$, mitochondrial GN=MRPL38 RM38_HUMAN $44.60 \quad 100.0 \%$ 39S ribosomal protein L38, mitochondrial GN=MRPL38 RM38 HUMAN $44.60 \quad 100.0 \%$ 39S ribosomal protein L39, mitochondrial GN=MRPL39 RM39_HUMAN $38.71 \quad 100.0 \%$ 39S ribosomal protein L39, mitochondrial GN=MRPL39 RM39_HUMAN $38.71 \quad 100.0 \%$ 39S ribosomal protein L39, mitochondrial GN=MRPL39 RM39 HUMAN $38.71 \quad 100.0 \%$ 39S ribosomal protein L39, mitochondrial GN=MRPL39 RM39_HUMAN $38.71 \quad 100.0 \%$ 39S ribosomal protein L39, mitochondrial GN=MRPL39 RM39_HUMAN $38.71 \quad 100.0 \%$ 39S ribosomal protein $\mathrm{L} 39$, mitochondrial GN=MRPL39 RM39 HUMAN $38.71 \quad 100.0 \%$ 39S ribosomal protein L4, mitochondrial GN=MRPL4 RM04_HUMAN $34.92 \quad 100.0 \%$ 39S ribosomal protein $\mathrm{L} 4$, mitochondrial GN=MRPL4 RM04 HUMAN $34.92 \quad 100.0 \%$ 39S ribosomal protein L4, mitochondrial GN=MRPL4 RM04_HUMAN $34.92 \quad 100.0 \%$ 39S ribosomal protein L44, mitochondrial GN=MRPL44 RM44_HUMAN $37.54 \quad 100.0 \%$ 39S ribosomal protein $\mathrm{L} 44$, mitochondrial GN=MRPL44 RM44 HUMAN $37.54 \quad 100.0 \%$ 39S ribosomal protein L44, mitochondrial GN=MRPL44 RM44_HUMAN $37.54 \quad 100.0 \%$ 39S ribosomal protein L44, mitochondrial GN=MRPL44 RM44_HUMAN $37.54 \quad 100.0 \%$ 39S ribosomal protein L44, mitochondrial GN=MRPL44 RM44_HUMAN $37.54 \quad 100.0 \%$ 39S ribosomal protein L44, mitochondrial GN=MRPL44 RM44_HUMAN $37.54 \quad 100.0 \%$ 39S ribosomal protein L44, mitochondrial GN=MRPL44 RM44 HUMAN $37.54 \quad 100.0 \%$ 39S ribosomal protein L44, mitochondrial GN=MRPL44 RM44_HUMAN $37.54 \quad 100.0 \%$ 39S ribosomal protein L44, mitochondrial GN=MRPL44 RM44_HUMAN $37.54 \quad 100.0 \%$ $39 \mathrm{~S}$ ribosomal protein $\mathrm{L} 45$, mitochondrial GN=MRPL45 RM45 HUMAN $35.35 \quad 100.0 \%$ 39S ribosomal protein $\mathrm{L} 45$, mitochondrial GN=MRPL45 RM45_HUMAN $35.35 \quad 100.0 \%$ 39S ribosomal protein $\mathrm{L} 46$, mitochondrial GN=MRPL46 RM46 HUMAN $31.71 \quad 100.0 \%$ 39S ribosomal protein L46, mitochondrial GN=MRPL46 RM46_HUMAN $31.71 \quad 100.0 \%$ 39S ribosomal protein L46, mitochondrial GN=MRPL46 RM46_HUMAN $31.71 \quad 100.0 \%$ 3-ketoacyl-CoA thiolase, mitochondrial GN=ACAA2 THIM_HUMAN $41.92 \quad 100.0 \%$ 3-ketoacyl-CoA thiolase, mitochondrial GN=ACAA2 THIM_HUMAN $41.92 \quad 100.0 \%$
11- $0.01 \% \quad 19.8 \%$ RPGAVATY

$0.01 \% \quad 19.8 \%$ LPAYKDLGK

$0.02 \% \quad 29.3 \%$ VYEIPGLEPITFAGK

$0.02 \% \quad 29.3 \%$ TKLIEGLPEK

$0.02 \% \quad 29.3 \%$ LIEGLPEK

$0.02 \% \quad 29.3 \%$ VLSLVDDPR

$0.02 \% \quad 29.3 \%$ NHIENQDECVLNVISHAR

$0.02 \% \quad 29.3 \%$ ETYCPVIVDNLIQLCK

$0.02 \% \quad 29.3 \%$ ESLLLQVR

$0.02 \% \quad 29.3 \%$ MILFAFGSALAQAR

$0.02 \% \quad 29.3 \%$ VLEQPVVVQSVGTDGR

$0.02 \% \quad 29.3 \%$ VVVEPVGPVGFKPETFRK

$0.02 \% \quad 22.6 \%$ IDIGLPPPK

$0.02 \% \quad 22.6 \%$ KQAIQELR

$0.02 \% \quad 22.6 \%$ TASVPLDAVR

$0.02 \% \quad 22.6 \%$ LAEYYGLYR

$0.02 \% \quad 22.6 \%$ DLFHGATFVPR

$\begin{array}{lllll}0.02 \% & 22.6 \% & \text { VAEGQVTCPYLPPFPAR } & 99.7 \% & 41.8\end{array}$

$0.02 \% \quad 22.6 \%$ QDQPIDFSEDARPSPCYQLAQR $99.7 \% \quad 44.0$

$0.01 \% \quad 21.3 \%$ TDPGTVFVMNK

$0.01 \% \quad 21.3 \%$ AFKDEYMVNLVR

$0.01 \% \quad 21.3 \%$ DLPFETLEVEAK

$0.01 \% \quad 21.3 \%$ VALEIFQHSK

$0.01 \% \quad 21.3 \%$ IGDFIDVSEGPLIPR

$0.01 \% \quad 21.3 \%$ RFQGVSLPVHLR

$0.01 \% \quad 14.5 \%$ ATENPEQVASEGLPEPVLR

$0.01 \% \quad 14.5 \%$ KVELPVPTHR

$0.01 \% \quad 14.5 \%$ VGLADLHPDVFATAPR

$0.02 \% \quad 32.2 \%$ LQENFSLDLLK

$0.02 \% \quad 32.2 \%$ TAFVNSCYIK

$0.02 \% \quad 32.2 \%$ EAVLLNLK

$99.7 \% \quad 26.7$

$96.3 \% \quad 18.7$

$99.7 \% \quad 36.3$

$99.7 \% 33.5$

$99.7 \% 53.6$

$99.7 \% \quad 29.5$

$99.7 \% \quad 56.9$

$99.2 \% \quad 19.7$

$99.7 \% \quad 44.4$

$99.7 \% \quad 58.2$

$99.7 \% \quad 33.8$

$99.0 \% \quad 34.5$

$0.02 \% \quad 32.2 \%$ NLVDFLTGEEVVCHVAR $99.7 \% 58.1$

$0.02 \% \quad 32.2 \%$ IINPMGLLVEELK

$99.0 \% \quad 22.1$

$\begin{array}{llll}0.02 \% & 32.2 \% & \text { QSGGTTALPLYFVGLYCDKK } \quad 97.4 \% & 20.4\end{array}$

$0.02 \% \quad 32.2 \%$ LIAEGPGETVLVAEEEAAR $99.7 \% \quad 83.9$

$0.02 \% \quad 32.2 \%$ KLYGFTENR

$0.02 \% \quad 32.2 \%$ LYGFTENR

$0.00 \% \quad 12.1 \%$ IKDYDANFK

$99.7 \% \quad 45.3$

$99.0 \% \quad 39.2$

$99.7 \% \quad 34.5$

$0.00 \% \quad 12.1 \%$ TVMIPGPQLKPEEEYEEAQGEAQKPQLA

$0.01 \% \quad 12.9 \%$ SLYSDHELR

$0.01 \% \quad 12.9 \%$ TLATLSENNMEAK

$0.01 \% \quad 12.9 \%$ ALLLTGDFSQAGNK

$0.00 \% \quad 5.5 \%$ DFTATDLSEFAAK

$0.00 \% \quad 5.5 \%$ ETPALTINR $\begin{array}{llll}99.7 \% & 44.9 & 25.0 & 27.3\end{array}$

$\begin{array}{llll}99.7 \% & 54.2 & 25.0 & 50.0\end{array}$

$\begin{array}{llll}99.7 \% & 66.2 & 25.0 & 66.2\end{array}$

$\begin{array}{llll}99.7 \% & 34.2 & 25.0 & 26.8\end{array}$

$99.7 \% \quad 33.0 \quad 25.0 \quad 29.1$
1788.98

863.47

1227.67

1169.64

1004.58

1633.88

1127.67

898.52

1013.56

2148.03

1964.98

957.57

1511.80

1682.91

1985.12

949.57

985.58

1028.57

1147.58

1259.65

1901.96

2621.21

1208.60

1500.75

1390.7

1171.65

1627.87

1408.82

2036.03

1175.69

1678.89

1319.72

1202.59

899.56

1957.98

1484.84

2218.12

1954.01

1127.58

999.49

1113.56

3126.53

1119.54

1437.69

1434.76

1415.67

1014.56

\begin{tabular}{cc}
17 & 131 \\
42 & 150 \\
57 & 166 \\
39 & 250 \\
04 & 312 \\
9 & 63 \\
26 & 135 \\
28 & 135 \\
36 & 144 \\
45 & 162 \\
74 & 189 \\
16 & 223 \\
13 & 326 \\
35 & 350 \\
96 & 413 \\
8 & 96 \\
07 & 114 \\
27 & 136 \\
51 & 159 \\
60 & 170 \\
45 & 261 \\
75 & 296 \\
3 & 83 \\
57 & 168 \\
13 & 224 \\
25 & 234 \\
57 & 271 \\
96 & 307 \\
1 & 49 \\
0 & 59 \\
7 & 92 \\
9 & 89 \\
0 & 99 \\
13 & 120 \\
55 & 171 \\
34 & 246 \\
60 & 279 \\
80 & 298 \\
03 & 311 \\
04 & 311 \\
25 & 133 \\
79 & 306 \\
2 & 90 \\
91 & 203 \\
36 & 249 \\
& 38 \\
\hline
\end{tabular}

Page 8 of Table S-1- 6 
40S ribosomal protein $\mathrm{S} 11 \mathrm{GN}=\mathrm{RPS} 11$ $40 \mathrm{~S}$ ribosomal protein $\mathrm{S} 11 \mathrm{GN}=\mathrm{RPS} 11$ $40 \mathrm{~S}$ ribosomal protein $\mathrm{S} 2 \mathrm{GN}=\mathrm{RPS} 2$ $40 \mathrm{~S}$ ribosomal protein $\mathrm{S} 2 \mathrm{GN}=\mathrm{RPS} 2$ $40 \mathrm{~S}$ ribosomal protein $\mathrm{S} 2 \mathrm{GN}=\mathrm{RPS} 2$ $40 \mathrm{~S}$ ribosomal protein $\mathrm{S} 2 \mathrm{GN}=\mathrm{RPS} 2$ $40 \mathrm{~S}$ ribosomal protein $\mathrm{S} 2 \mathrm{GN}=\mathrm{RPS} 2$ $40 \mathrm{~S}$ ribosomal protein $\mathrm{S} 2 \mathrm{GN}=\mathrm{RPS} 2$ $40 \mathrm{~S}$ ribosomal protein $\mathrm{S} 2 \mathrm{GN}=\mathrm{RPS} 2$ $40 \mathrm{~S}$ ribosomal protein $\mathrm{S} 2 \mathrm{GN}=\mathrm{RPS} 2$ $40 \mathrm{~S}$ ribosomal protein $\mathrm{S} 2 \mathrm{GN}=\mathrm{RPS} 2$ $40 \mathrm{~S}$ ribosomal protein $\mathrm{S} 2 \mathrm{GN}=\mathrm{RPS} 2$ $40 \mathrm{~S}$ ribosomal protein $\mathrm{S} 2 \mathrm{GN}=\mathrm{RPS} 2$ $40 \mathrm{~S}$ ribosomal protein $\mathrm{S} 2 \mathrm{GN}=\mathrm{RPS} 2$ $40 \mathrm{~S}$ ribosomal protein $\mathrm{S} 2 \mathrm{GN}=\mathrm{RPS} 2$ $40 \mathrm{~S}$ ribosomal protein $\mathrm{S} 2 \mathrm{GN}=\mathrm{RPS} 2$ 40S ribosomal protein $\mathrm{S} 3 \mathrm{GN}=\mathrm{RPS} 3$ $40 \mathrm{~S}$ ribosomal protein $\mathrm{S} 3 \mathrm{GN}=\mathrm{RPS} 3$ $40 \mathrm{~S}$ ribosomal protein $\mathrm{S} 3 \mathrm{GN}=\mathrm{RPS} 3$ $40 \mathrm{~S}$ ribosomal protein $\mathrm{S} 3 \mathrm{GN}=\mathrm{RPS} 3$ $40 \mathrm{~S}$ ribosomal protein $\mathrm{S} 3 \mathrm{GN}=\mathrm{RPS} 3$ $40 \mathrm{~S}$ ribosomal protein $\mathrm{S} 3 \mathrm{GN}=\mathrm{RPS} 3$ $40 \mathrm{~S}$ ribosomal protein $\mathrm{S} 3 \mathrm{GN}=\mathrm{RPS} 3$ $40 \mathrm{~S}$ ribosomal protein $\mathrm{S} 3 \mathrm{GN}=\mathrm{RPS} 3$ $40 \mathrm{~S}$ ribosomal protein $\mathrm{S} 3 \mathrm{GN}=\mathrm{RPS} 3$ $40 \mathrm{~S}$ ribosomal protein $\mathrm{S} 3 \mathrm{GN}=\mathrm{RPS} 3$ $40 \mathrm{~S}$ ribosomal protein $\mathrm{S} 3 \mathrm{GN}=\mathrm{RPS} 3$ $40 \mathrm{~S}$ ribosomal protein $\mathrm{S} 3 \mathrm{GN}=\mathrm{RPS} 3$ $40 \mathrm{~S}$ ribosomal protein $\mathrm{S} 3 \mathrm{GN}=\mathrm{RPS} 3$ $40 \mathrm{~S}$ ribosomal protein $\mathrm{S} 3 \mathrm{GN}=\mathrm{RPS} 3$ $40 \mathrm{~S}$ ribosomal protein $\mathrm{S} 3 \mathrm{GN}=\mathrm{RPS} 3$ $40 \mathrm{~S}$ ribosomal protein $\mathrm{S} 3 \mathrm{GN}=\mathrm{RPS} 3$ $40 \mathrm{~S}$ ribosomal protein $\mathrm{S} 3 \mathrm{GN}=\mathrm{RPS} 3$ $40 \mathrm{~S}$ ribosomal protein $\mathrm{S} 3 \mathrm{GN}=\mathrm{RPS} 3$ $40 \mathrm{~S}$ ribosomal protein $\mathrm{S} 3 \mathrm{GN}=\mathrm{RPS} 3$ $40 \mathrm{~S}$ ribosomal protein $\mathrm{S} 3 \mathrm{GN}=\mathrm{RPS} 3$ $40 \mathrm{~S}$ ribosomal protein $\mathrm{S} 3 \mathrm{a} \mathrm{GN}=\mathrm{RPS} 3 \mathrm{~A}$ $40 \mathrm{~S}$ ribosomal protein $\mathrm{S} 3 \mathrm{a} \mathrm{GN}=\mathrm{RPS} 3 \mathrm{~A}$ $40 \mathrm{~S}$ ribosomal protein $\mathrm{S} 3 \mathrm{a} \mathrm{GN}=\mathrm{RPS} 3 \mathrm{~A}$ $40 \mathrm{~S}$ ribosomal protein $\mathrm{S} 3 \mathrm{a} \mathrm{GN}=\mathrm{RPS} 3 \mathrm{~A}$ $40 \mathrm{~S}$ ribosomal protein $\mathrm{S} 3 \mathrm{a} \mathrm{GN}=\mathrm{RPS} 3 \mathrm{~A}$ $40 \mathrm{~S}$ ribosomal protein $\mathrm{S} 3 \mathrm{a} \mathrm{GN}=\mathrm{RPS} 3 \mathrm{~A}$ $40 \mathrm{~S}$ ribosomal protein $\mathrm{S} 3 \mathrm{a} \mathrm{GN}=\mathrm{RPS} 3 \mathrm{~A}$ $40 \mathrm{~S}$ ribosomal protein $\mathrm{S} 3 \mathrm{a} \mathrm{GN}=\mathrm{RPS} 3 \mathrm{~A}$ $40 \mathrm{~S}$ ribosomal protein $\mathrm{S} 3 \mathrm{a} \mathrm{GN}=\mathrm{RPS} 3 \mathrm{~A}$ $40 \mathrm{~S}$ ribosomal protein $\mathrm{S} 3 \mathrm{a} \mathrm{GN}=\mathrm{RPS} 3 \mathrm{~A}$ $40 \mathrm{~S}$ ribosomal protein $\mathrm{S} 3 \mathrm{a} \mathrm{GN}=\mathrm{RPS} 3 \mathrm{~A}$ $\begin{array}{llllllll}\text { RS11_HUMAN } & 18.43 & 100.0 \% & 2 & 4 & 6 & 0.01 \% & 13.9 \% \\ \text { AYQKQPTIFQNK }\end{array}$

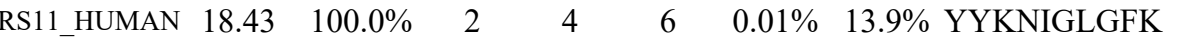
RS2_HUMAN $31.33 \quad 100.0 \% \quad 14 \quad 17 \quad 67 \quad 0.08 \% \quad 53.2 \%$ AEDKEWMPVTK RS2 HUMAN $31.33 \quad 100.0 \% \quad 14 \quad 17 \quad 67 \quad 0.08 \% \quad 53.2 \%$ SLEEIYLFSLPIK RS2 HUMAN $31.33 \quad 100.0 \%$ RS2 HUMAN $31.33 \quad 100.0 \%$ RS2_HUMAN $31.33 \quad 100.0 \% \quad 14$ RS2_HUMAN $31.33 \quad 100.0 \% \quad 14$ RS2 HUMAN $31.33 \quad 100.0 \% \quad 14$ RS2_HUMAN $31.33 \quad 100.0 \% \quad 14$ RS2_HUMAN $31.33 \quad 100.0 \% \quad 14$ RS2 HUMAN $31.33 \quad 100.0 \% \quad 14$ RS2_HUMAN $31.33 \quad 100.0 \% \quad 14$ RS2_HUMAN $31.33 \quad 100.0 \% \quad 14$ RS2_HUMAN $31.33 \quad 100.0 \% \quad 14$ RS2_HUMAN $31.33 \quad 100.0 \% \quad 14$ RS3 HUMAN $26.69 \quad 100.0 \% \quad 20$ RS3_HUMAN $26.69 \quad 100.0 \% \quad 20$ RS3_HUMAN $26.69 \quad 100.0 \% \quad 20$ RS3 HUMAN $26.69 \quad 100.0 \% \quad 20$ RS3_HUMAN $26.69 \quad 100.0 \% \quad 20$ RS3 HUMAN $26.69 \quad 100.0 \% \quad 20$ RS3_HUMAN $26.69 \quad 100.0 \% \quad 20$ RS3_HUMAN $26.69 \quad 100.0 \% \quad 20$ RS3 HUMAN $26.69 \quad 100.0 \% \quad 20$ RS3_HUMAN $26.69 \quad 100.0 \% \quad 20$ RS3_HUMAN $26.69 \quad 100.0 \% \quad 20$ RS3 HUMAN $26.69 \quad 100.0 \% \quad 20$ RS3_HUMAN $26.69 \quad 100.0 \% \quad 20$ RS3 HUMAN $26.69 \quad 100.0 \% \quad 20$ RS3_HUMAN $26.69 \quad 100.0 \% \quad 20$ RS3_HUMAN $26.69 \quad 100.0 \% \quad 20$ RS3 HUMAN $26.69 \quad 100.0 \% \quad 20$ RS3_HUMAN $26.69 \quad 100.0 \% \quad 20$ RS3_HUMAN $26.69 \quad 100.0 \% \quad 20$ RS3 HUMAN $26.69 \quad 100.0 \% \quad 20$ RS3A_HUMAN $29.95 \quad 100.0 \% \quad 19$ RS3A HUMAN $29.95 \quad 100.0 \% \quad 19$ RS3A_HUMAN $29.95 \quad 100.0 \% \quad 19$ RS3A_HUMAN $29.95 \quad 100.0 \% \quad 19$ RS3A_HUMAN $29.95 \quad 100.0 \% \quad 19$ RS3A_HUMAN $29.95 \quad 100.0 \% \quad 19$ RS3A_HUMAN $29.95 \quad 100.0 \% \quad 19$ RS3A_HUMAN $29.95 \quad 100.0 \% \quad 19$ RS3A_HUMAN $29.95 \quad 100.0 \% \quad 19$ RS3A_HUMAN $29.95 \quad 100.0 \% \quad 19$ RS3A_HUMAN $29.95 \quad 100.0 \% \quad 19$ $0.08 \% \quad 53.2 \%$ LSIVPVRR

$0.08 \% \quad 53.2 \%$ IGKPHTVPCK

$0.08 \% \quad 53.2 \%$ GTGIVSAPVPK $0.08 \% \quad 53.2 \%$ GCTATLGNFAK $0.08 \% \quad 53.2 \%$ ATFDAISK $0.08 \% \quad 53.2 \%$ TYSYLTPDLWK $0.08 \% \quad 53.2 \%$ SPYQEFTDHLVK $0.08 \% \quad 53.2 \%$ TQAPAVATT $0.09 \% \quad 69.5 \%$ KFVADGIFK $0.09 \% \quad 69.5 \%$ FVADGIFK $0.09 \% \quad 69.5 \%$ AELNEFLTR $0.09 \% \quad 69.5 \%$ VTPTRTEIIILATR $0.09 \% \quad 69.5 \%$ TEIIILATR

$0.09 \% \quad 69.5 \%$ IRELTAVVQK $0.09 \% \quad 69.5 \%$ ELTAVVQK $0.09 \% \quad 69.5 \%$ ELTAVVQKR $0.09 \% \quad 69.5 \%$ GLCAIAQAESLR $0.09 \% \quad 69.5 \%$ YKLLGGLAVR $0.09 \% \quad 69.5 \%$ LLGGLAVRR $0.09 \% \quad 69.5 \%$ RACYGVLR $0.09 \% \quad 69.5 \%$ FIMESGAK $0.09 \% \quad 69.5 \%$ GCEVVVSGK $0.09 \% \quad 69.5 \%$ IMLPWDPTGK $0.09 \% \quad 69.5 \%$ KPLPDHVSIVEPK $0.09 \% \quad 69.5 \%$ DEILPTTPISEQK $\begin{array}{lll}0.08 \% & 67.0 \% & \text { VVDPFSKK } \\ 0.08 \% & 67.0 \% & \text { APAMFNIR }\end{array}$

$0.08 \% \quad 67.0 \%$ LITEDVQGK

$0.08 \% \quad 67.0 \%$ LFCVGFTK

$0.08 \% \quad 67.0 \%$ TSYAQHQQVR $\begin{array}{llllllll}99.7 \% & 37.8 & 25.0 & 37.8 & 2 & 1 & 0 & 1465.78\end{array}$

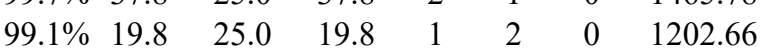

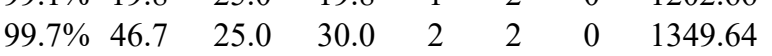

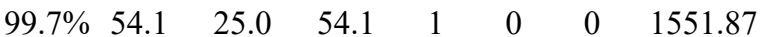

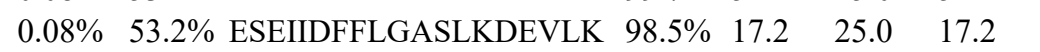

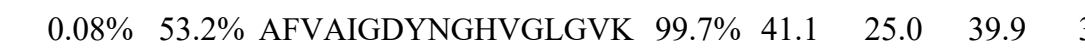
$99.0 \% \quad 41.3 \quad 25.0 \quad 20.5$ $\begin{array}{llll}99.7 \% & 38.5 & 25.0 & 30.4\end{array}$ $\begin{array}{llll}99.7 \% & 37.7 & 25.0 & 37.7\end{array}$

$0.08 \% \quad 53.2 \%$ KLLMMAGIDDCYTSAR $0.08 \% \quad 53.2 \%$ LLMMAGIDDCYTSAR $0.09 \% \quad 69.5 \%$ ELAEDGYSGVEVR $0.09 \% \quad 69.5 \%$ FGFPEGSVELYAEK $0.09 \% \quad 69.5 \%$ GGKPEPPAMPQPVPTA $\begin{array}{llll}99.7 \% & 43.0 & 25.0 & 43.0\end{array}$ $\begin{array}{lllll}99.7 \% & 52.3 & 25.0 & 52.3 & 2\end{array}$ $\begin{array}{llll}99.7 \% & 57.6 & 25.0 & 53.3\end{array}$ $99.0 \% \quad 41.5 \quad 25.0 \quad 28.3$ $\begin{array}{llll}99.7 \% & 48.3 & 25.0 & 48.3\end{array}$ $99.7 \% \quad 51.5 \quad 25.0 \quad 49.2$ $\begin{array}{lllll}97.4 \% & 18.5 & 25.0 & 17.1 & 1\end{array}$ $99.7 \% \quad 42.5 \quad 25.0 \quad 31.4$ $\begin{array}{llll}99.0 \% & 39.3 & 25.0 & 36.8\end{array}$ $\begin{array}{llll}99.7 \% & 59.3 & 25.0 & 45.1\end{array}$ $\begin{array}{llll}99.7 \% & 68.1 & 25.0 & 57.8\end{array}$ $\begin{array}{llll}99.5 \% & 24.1 & 25.0 & 23.8\end{array}$ $99.7 \% \quad 55.1 \quad 25.0 \quad 55.1$ $\begin{array}{llll}99.7 \% & 40.7 & 25.0 & 32.7\end{array}$ $\begin{array}{lllll}99.0 \% & 46.0 & 25.0 & 34.9 & 2\end{array}$ $\begin{array}{llll}99.7 \% & 49.4 & 25.0 & 36.3\end{array}$ $\begin{array}{llll}99.7 \% & 52.3 & 25.0 & 52.3\end{array}$ $\begin{array}{llll}99.7 \% & 56.3 & 25.0 & 41.1\end{array}$ $\begin{array}{llll}99.7 \% & 30.9 & 25.0 & 30.9\end{array}$ $99.1 \% \quad 21.6 \quad 25.0 \quad 17.9$ $\begin{array}{llll}96.9 \% & 23.3 & 25.0 & 10.2\end{array}$ $\begin{array}{llll}99.0 \% & 43.0 & 25.0 & 18.3\end{array}$ $\begin{array}{llll}99.7 \% & 58.5 & 25.0 & 54.2\end{array}$ $99.4 \% \quad 24.4 \quad 25.0 \quad 18.6$ $\begin{array}{llll}99.7 \% & 36.8 & 25.0 & 36.8\end{array}$ $99.7 \% \quad 68.1 \quad 25.0 \quad 50.2$ $\begin{array}{llll}99.7 \% & 46.0 & 25.0 & 38.5\end{array}$ $\begin{array}{llll}97.2 \% & 22.2 & 25.0 & 13.5\end{array}$ $99.0 \% \quad 52.2 \quad 25.0 \quad 46.0$

2153.14 1716.91

939.61

1136.62

1025.60

1876.86

1748.77

1139.55

852.45

1386.69

1463.72

859.45

1024.58

896.49

1092.57

1423.67

1583.95

1029.63

1156.70

887.52

1043.62

1572.76

1288.67

1089.68

954.62

994.53

898.43

934.47

1173.60

1458.83

1470.77

1589.80

919.52

919.48

1951.98

2080.07

1002.55

$\begin{array}{lllllll}0.08 \% & 67.0 \% & \text { VFEVSLADLQNDEVAFRK } & 99.7 \% & 58.6 & 25.0 & 51.3\end{array}$

\begin{tabular}{ll}
$0.08 \%$ & $67.0 \%$ NCLTNFHGMDLTR \\
\hline
\end{tabular}

$0.08 \% \quad 67.0 \%$ KWQTMIEAHVDVK

$99.7 \% \quad 53.5$

$99.7 \% \quad 56.0 \quad 25.0 \quad 56.0$

$\begin{array}{llll}99.5 \% & 23.9 & 25.0 & 23.2\end{array}$

$99.0 \% \quad 55.4 \quad 25.0 \quad 38.8$

$99.0 \% \quad 47.1 \quad 25.0 \quad 32.1 \quad 5$

$99.7 \% \quad 73.6 \quad 25.0 \quad 65.2$

$0.08 \% \quad 67.0 \%$ EVQTNDLKEVVNK

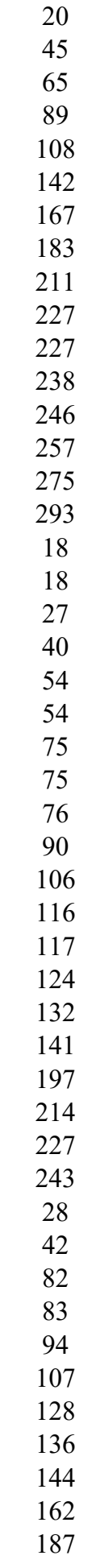


$40 \mathrm{~S}$ ribosomal protein $\mathrm{S} 3 \mathrm{a} \mathrm{GN}=\mathrm{RPS} 3 \mathrm{~A}$ $40 \mathrm{~S}$ ribosomal protein $\mathrm{S} 3 \mathrm{a} \mathrm{GN}=\mathrm{RPS} 3 \mathrm{~A}$ $40 \mathrm{~S}$ ribosomal protein $\mathrm{S} 3 \mathrm{a} \mathrm{GN}=\mathrm{RPS} 3 \mathrm{~A}$ $40 \mathrm{~S}$ ribosomal protein $\mathrm{S} 3 \mathrm{a} \mathrm{GN}=\mathrm{RPS} 3 \mathrm{~A}$ $40 \mathrm{~S}$ ribosomal protein $\mathrm{S} 3 \mathrm{a} \mathrm{GN}=\mathrm{RPS} 3 \mathrm{~A}$ $40 \mathrm{~S}$ ribosomal protein $\mathrm{S} 3 \mathrm{a} \mathrm{GN}=\mathrm{RPS} 3 \mathrm{~A}$ $40 \mathrm{~S}$ ribosomal protein $\mathrm{S} 3 \mathrm{a} \mathrm{GN}=\mathrm{RPS} 3 \mathrm{~A}$ $\begin{array}{lll}40 \mathrm{~S} \text { ribosomal protein } \mathrm{S} 3 \mathrm{a} \text { GN=RPS3A } & \text { RS3A_HUMAN } & 29.95 \\ 40 \mathrm{~S} \text { ribosomal protein } \mathrm{S} 4, \mathrm{X} \text { isoform GN=RPS4X RS4X_HUMAN } & 29.60\end{array}$ $40 \mathrm{~S}$ ribosomat protein $\mathrm{S} 4, \mathrm{X}$ isoform GN=RPS4X RS4X HUMAN 29 40S ribosomal protein S4, X isoform GN=RPS4X RS4X_HUMAN 29.60 40S ribosomal protein S4, X isoform GN=RPS4X RS4X_HUMAN 29.60 $40 \mathrm{~S}$ ribosomal protein S4, X isoform GN=RPS4X RS4X_HUMAN 29.60 40S ribosomal protein $\mathrm{S} 4, \mathrm{X}$ isoform GN=RPS4X RS4X_HUMAN 29.60 $40 \mathrm{~S}$ ribosomal protein $\mathrm{S} 4, \mathrm{X}$ isoform GN=RPS4X RS4X_HUMAN 29.60 40S ribosomal protein S4, X isoform GN=RPS4X RS4X_HUMAN 29.60 $40 \mathrm{~S}$ ribosomal protein $\mathrm{S} 4, \mathrm{X}$ isoform GN=RPS4X RS4X HUMAN 29.60 40S ribosomal protein S4, X isoform GN=RPS4X RS4X_HUMAN 29.60 40S ribosomal protein S4, X isoform GN=RPS4X RS4X_HUMAN 29.60 40 S ribosomal protein S4, X isoform GN=RPS4X RS4X_HUMAN 29.60 40S ribosomal protein S4, X isoform GN=RPS4X RS4X_HUMAN 29.60 40S ribosomal protein $\mathrm{S} 4, \mathrm{X}$ isoform GN=RPS4X RS4X HUMAN 29.60 40S ribosomal protein $\mathrm{S} 5 \mathrm{GN}=\mathrm{RPS} 5$ $40 \mathrm{~S}$ ribosomal protein $\mathrm{S} 5 \mathrm{GN}=\mathrm{RPS} 5$ $40 \mathrm{~S}$ ribosomal protein $\mathrm{S} 5 \mathrm{GN}=\mathrm{RPS} 5$ $40 \mathrm{~S}$ ribosomal protein $\mathrm{S} 5 \mathrm{GN}=\mathrm{RPS} 5$ $40 \mathrm{~S}$ ribosomal protein $\mathrm{S} 5 \mathrm{GN}=\mathrm{RPS} 5$ $40 \mathrm{~S}$ ribosomal protein $\mathrm{S} 6 \mathrm{GN}=\mathrm{RPS} 6$ $40 \mathrm{~S}$ ribosomal protein $\mathrm{S} 6 \mathrm{GN}=\mathrm{RPS} 6$ $40 \mathrm{~S}$ ribosomal protein $\mathrm{S} 6 \mathrm{GN}=\mathrm{RPS} 6$ $40 \mathrm{~S}$ ribosomal protein $\mathrm{S} 6 \mathrm{GN}=\mathrm{RPS} 6$ $40 \mathrm{~S}$ ribosomal protein $\mathrm{S} 6 \mathrm{GN}=\mathrm{RPS} 6$ $40 \mathrm{~S}$ ribosomal protein $\mathrm{S} 6 \mathrm{GN}=\mathrm{RPS} 6$ $40 \mathrm{~S}$ ribosomal protein $\mathrm{S} 6 \mathrm{GN}=\mathrm{RPS} 6$ $40 \mathrm{~S}$ ribosomal protein $\mathrm{S} 6 \mathrm{GN}=\mathrm{RPS} 6$ 40S ribosomal protein $\mathrm{S} 6 \mathrm{GN}=\mathrm{RPS} 6$ $40 \mathrm{~S}$ ribosomal protein $\mathrm{S} 6 \mathrm{GN}=\mathrm{RPS} 6$ 40S ribosomal protein $\mathrm{S} 6 \mathrm{GN}=\mathrm{RPS} 6$ 40S ribosomal protein $\mathrm{S} 7 \mathrm{GN}=\mathrm{RPS} 7$ $40 \mathrm{~S}$ ribosomal protein $\mathrm{S} 7 \mathrm{GN}=\mathrm{RPS} 7$ $40 \mathrm{~S}$ ribosomal protein $\mathrm{S} 7 \mathrm{GN}=\mathrm{RPS} 7$ $40 \mathrm{~S}$ ribosomal protein $\mathrm{S} 7 \mathrm{GN}=\mathrm{RPS} 7$ $40 \mathrm{~S}$ ribosomal protein $\mathrm{S} 7 \mathrm{GN}=\mathrm{RPS} 7$ $40 \mathrm{~S}$ ribosomal protein $\mathrm{S} 7 \mathrm{GN}=\mathrm{RPS} 7$ $40 \mathrm{~S}$ ribosomal protein $\mathrm{S} 8 \mathrm{GN}=\mathrm{RPS} 8$ $40 \mathrm{~S}$ ribosomal protein $\mathrm{S} 8 \mathrm{GN}=\mathrm{RPS} 8$ $40 \mathrm{~S}$ ribosomal protein $\mathrm{S} 8 \mathrm{GN}=\mathrm{RPS} 8$
$100.0 \%$ RS5_HUMAN $22.88 \quad 100.0 \%$ RS5_HUMAN $22.88 \quad 100.0 \% \quad 5$ RS5 HUMAN $22.88 \quad 100.0 \% \quad 5$ RS5_HUMAN $22.88 \quad 100.0 \% \quad 5$ RS5_HUMAN $22.88 \quad 100.0 \%$ RS6 HUMAN $28.68 \quad 100.0 \% \quad 11$ RS6_HUMAN $28.68 \quad 100.0 \% \quad 11$ RS6 HUMAN $28.68 \quad 100.0 \% \quad 11$ RS6_HUMAN $28.68 \quad 100.0 \% \quad 11$ RS6_HUMAN $28.68 \quad 100.0 \% \quad 11$ RS6 HUMAN $28.68 \quad 100.0 \% \quad 11$ RS6_HUMAN $28.68 \quad 100.0 \% \quad 11$ RS6_HUMAN $28.68 \quad 100.0 \% \quad 11$ RS6 HUMAN $28.68 \quad 100.0 \% \quad 11$ RS6_HUMAN $28.68 \quad 100.0 \% \quad 11$ RS6 HUMAN $28.68 \quad 100.0 \% \quad 11$ RS7_HUMAN $22.13 \quad 100.0 \% \quad 6$ RS7_HUMAN $22.13 \quad 100.0 \%$ RS7 HUMAN $22.13 \quad 100.0 \%$ RS7_HUMAN $22.13 \quad 100.0 \%$ RS7 HUMAN $22.13 \quad 100.0 \%$ RS7_HUMAN $22.13 \quad 100.0 \%$ RS8_HUMAN $24.21 \quad 100.0 \% \quad 12$ RS8_HUMAN $24.21 \quad 100.0 \% \quad 12$ RS8_HUMAN $24.21 \quad 100.0 \% \quad 12$
$0.08 \% \quad 67.0 \%$ ADGYEPPVQESV

$0.09 \% \quad 49.0 \%$ LTGVFAPRPSTGPHK

$0.09 \% \quad 49.0 \%$ LKYALTGDEVK

$0.09 \% \quad 49.0 \%$ YALTGDEVK

$0.09 \% \quad 49.0 \%$ YALTGDEVKK

$0.09 \% \quad 49.0 \%$ ITPEEAKYK

$0.09 \% \quad 49.0 \%$ GIPHLVTHDAR

$0.09 \% \quad 49.0 \%$ TIRYPDPLIK

$\begin{array}{llll}99.7 \% & 51.5 & 25.0 & 51.1 \\ 99.7 \% & 33.1 & 25.0 & 31.9\end{array}$

$99.7 \% \quad 52.9 \quad 25.0 \quad 44.0$

$99.7 \% \quad 51.2 \quad 25.0 \quad 40.0$

$99.7 \% \quad 59.0 \quad 25.0 \quad 47.0$

$\begin{array}{llll}99.5 \% & 27.8 & 25.0 & 16.9\end{array}$

$\begin{array}{llll}99.7 \% & 52.7 & 25.0 & 48.1\end{array}$

$99.7 \% \quad 34.6 \quad 25.0 \quad 25.2$

$\begin{array}{llll}99.7 \% & 41.5 & 25.0 & 40.9\end{array}$

$0.09 \% \quad 49.0 \%$ VNDTIQIDLETGK

$99.7 \%$

$0.09 \% \quad 49.0 \%$ FDTGNLCMVTGGANLGR

$0.09 \% \quad 49.0 \%$ ERHPGSFDVVHVK

$0.09 \% \quad 49.0 \%$ HPGSFDVVHVK

$0.09 \% \quad 49.0 \%$ DANGNSFATR

$0.09 \% \quad 49.0 \%$ LSNIFVIGK

$0.09 \% \quad 49.0 \%$ GNKPWISLPR

$0.01 \% \quad 16.7 \%$ YLPHSAGR

$0.01 \% \quad 16.7 \%$ KAQCPIVER

$0.01 \% \quad 16.7 \%$ AQCPIVER

$0.01 \% \quad 16.7 \%$ QAVDVSPLR

$0.01 \% \quad 16.7 \%$ EAAFRNIK

$0.06 \% \quad 34.9 \%$ MKLNISFPATGCQK

$\begin{array}{llll}99.7 \% & 52.4 & 25.0 & 52.4\end{array}$

$\begin{array}{llll}99.7 \% & 51.9 & 25.0 & 51.9\end{array}$

$99.7 \% \quad 56.9 \quad 25.0 \quad 48.2$

$\begin{array}{lllll}99.7 \% & 59.8 & 25.0 & 53.4 & 15\end{array}$

$\begin{array}{llll}99.7 \% & 38.7 & 25.0 & 38.7\end{array}$

$99.0 \% \quad 28.9 \quad 25.0 \quad 25.8$

$\begin{array}{lllll}99.7 \% & 29.7 & 25.0 & 23.4 & 2\end{array}$

$99.0 \% \quad 39.7 \quad 25.0 \quad 24.5$

$\begin{array}{llll}99.7 \% & 47.2 & 25.0 & 35.9\end{array}$

$\begin{array}{llll}94.8 \% & 21.2 & 25.0 & 11.3\end{array}$

$\begin{array}{llll}99.7 \% & 53.8 & 25.0 & 47.7\end{array}$

$0.06 \% 34.9 \%$ LNISFPATGCQK

$0.06 \% 34.9 \%$ LIEVDDER

$\begin{array}{llll}99.7 \% & 52.3 & 25.0 & 48.2\end{array}$

$99.0 \% \quad 47.8 \quad 25.0 \quad 42.9$

$\begin{array}{llll}99.7 \% & 49.5 & 25.0 & 27.1\end{array}$

$0.06 \% \quad 34.9 \%$ LIEVDDERK

$\begin{array}{ll}99.7 \% & 54.2\end{array}$

$\begin{array}{llllll}0.06 \% & 34.9 \% & \text { MATEVAADALGEEWKGYVVR } & 99.7 \% & 54.8\end{array}$

$\begin{array}{lllll}0.06 \% & 34.9 \% & \text { GCIVDANLSVLNLVIVK } & 99.7 \% & 67.5\end{array}$

$0.06 \% 34.9 \%$ GEKDIPGLTDTTVPR

$99.7 \% \quad 54.9$

$99.7 \% \quad 56.8$

$99.3 \% \quad 22.5$

$99.7 \% \quad 57.6$

$99.0 \% \quad 37.0$

$99.7 \% \quad 53.8$

$99.0 \% \quad 32.5$

$99.0 \% \quad 29.4$

$99.0 \% 26.3$

$25.0 \quad 54.2$

$\begin{array}{ll}5.0 & 54.8 \\ 25.0 & 65.9\end{array}$

$0.06 \% 34.9 \%$ DIPGLTDTTVPRR

$0.06 \% \quad 34.9 \%$ LFNL SKEDDVR

$0.01 \% \quad 29.9 \%$ ELNITAAKEIEVGGGR

$0.01 \% \quad 29.9 \%$ SFQKIQVR

$0.01 \% \quad 29.9 \%$ HVVFIAQR

$0.01 \% \quad 29.9 \%$ RILPKPTR

$\begin{array}{ll}99.3 \% & 20.1\end{array}$

$0.01 \% \quad 29.9 \%$ AQQNNVEHKVETFSGVYK

$0.06 \% 53.4 \%$ KYELGRPAANTK

$99.7 \% \quad 54.5$

$99.7 \% \quad 46.3$

$\begin{array}{lll}0.06 \% & 53.4 \% & \text { LDVGNFSWGSECCTR }\end{array}$

$99.7 \% \quad 60.3$
1290.58

1564.86

$200 \quad 214$

$223 \quad 240$

$228 \quad 240$

$250 \quad 264$

$253 \quad 264$

1236.68

995.50

1123.60

1078.58

1215.66

1215.71

1445.75

1782.83

1506.78

1221.64

1052.48

990.60

1167.66

900.47

1100.59

972.49

984.55

948.53

1610.80

1335.67

988.49

1116.59

1620.76

2211.08

1827.04

1598.84

1284.68

1440.78

1335.69

859.49

1656.89

1005.58

969.56

980.64

2078.03

1347.74

1219.64

1787.75 
$40 \mathrm{~S}$ ribosomal protein $\mathrm{S} 8 \mathrm{GN}=\mathrm{RPS} 8$ $40 \mathrm{~S}$ ribosomal protein $\mathrm{S} 8 \mathrm{GN}=\mathrm{RPS} 8$ $40 \mathrm{~S}$ ribosomal protein $\mathrm{S} 8 \mathrm{GN}=\mathrm{RPS} 8$ $40 \mathrm{~S}$ ribosomal protein $\mathrm{S} 8 \mathrm{GN}=\mathrm{RPS} 8$ $40 \mathrm{~S}$ ribosomal protein $\mathrm{S} 8 \mathrm{GN}=\mathrm{RPS} 8$ $40 \mathrm{~S}$ ribosomal protein $\mathrm{S} 8 \mathrm{GN}=\mathrm{RPS} 8$ $40 \mathrm{~S}$ ribosomal protein $\mathrm{S} 8 \mathrm{GN}=\mathrm{RPS} 8$ $40 \mathrm{~S}$ ribosomal protein $\mathrm{S} 8 \mathrm{GN}=\mathrm{RPS} 8$ $40 \mathrm{~S}$ ribosomal protein $\mathrm{S} 8 \mathrm{GN}=\mathrm{RPS} 8$ $40 \mathrm{~S}$ ribosomal protein $\mathrm{S} 9 \mathrm{GN}=\mathrm{RPS} 9$ $40 \mathrm{~S}$ ribosomal protein $\mathrm{S} 9 \mathrm{GN}=\mathrm{RPS} 9$ $40 \mathrm{~S}$ ribosomal protein $\mathrm{S} 9 \mathrm{GN}=\mathrm{RPS} 9$ $40 \mathrm{~S}$ ribosomal protein $\mathrm{S} 9 \mathrm{GN}=\mathrm{RPS} 9$ $40 \mathrm{~S}$ ribosomal protein $\mathrm{S} 9 \mathrm{GN}=\mathrm{RPS} 9$ $40 \mathrm{~S}$ ribosomal protein $\mathrm{S} 9 \mathrm{GN}=\mathrm{RPS} 9$ $40 \mathrm{~S}$ ribosomal protein $\mathrm{S} 9 \mathrm{GN}=\mathrm{RPS} 9$ 40S ribosomal protein $\mathrm{S} 9 \mathrm{GN}=\mathrm{RPS} 9$ $40 \mathrm{~S}$ ribosomal protein $\mathrm{S} 9 \mathrm{GN}=\mathrm{RPS} 9$ $40 \mathrm{~S}$ ribosomal protein $\mathrm{SA}$ GN=RPSA $40 \mathrm{~S}$ ribosomal protein $\mathrm{SA} \mathrm{GN}=\mathrm{RPSA}$ $40 \mathrm{~S}$ ribosomal protein $\mathrm{SA} \mathrm{GN}=\mathrm{RPSA}$ $40 \mathrm{~S}$ ribosomal protein $\mathrm{SA}$ GN=RPSA $40 \mathrm{~S}$ ribosomal protein $\mathrm{SA} G \mathrm{GN}=\mathrm{RPSA}$ $40 \mathrm{~S}$ ribosomal protein $\mathrm{SA}$ GN=RPSA 40S ribosomal protein $\mathrm{SA} G \mathrm{GN}=\mathrm{RPSA}$ $40 \mathrm{~S}$ ribosomal protein $\mathrm{SA} \mathrm{GN}=\mathrm{RPSA}$ $5 '-3$ ' exoribonuclease $1 \mathrm{GN}=\mathrm{XRN} 1$
RS8_HUMAN $24.21 \quad 100.0 \% \quad 12$ RS8_HUMAN $24.21 \quad 100.0 \% \quad 12$ RS8_HUMAN $24.21 \quad 100.0 \% \quad 12$ RS8_HUMAN $24.21 \quad 100.0 \% \quad 12$ RS8_HUMAN $24.21 \quad 100.0 \% \quad 12$ RS8_HUMAN $24.21 \quad 100.0 \% \quad 12$ RS8 HUMAN $24.21 \quad 100.0 \% \quad 12$ RS8_HUMAN $24.21 \quad 100.0 \% \quad 12$ RS8_HUMAN $24.21 \quad 100.0 \% \quad 12$ RS9_HUMAN $22.59 \quad 100.0 \% \quad 9$ RS9_HUMAN $22.59 \quad 100.0 \% \quad 9$ RS9 HUMAN $22.59 \quad 100.0 \% \quad 9$ RS9_HUMAN $22.59 \quad 100.0 \% \quad 9$ RS9 HUMAN $22.59 \quad 100.0 \%$ RS9 HUMAN $22.59 \quad 100.0 \%$ RS9_HUMAN $22.59 \quad 100.0 \%$ RS9 HUMAN $22.59 \quad 100.0 \%$ RS9_HUMAN $22.59 \quad 100.0 \%$ RSSA_HUMAN $32.85 \quad 100.0 \%$ RSSA HUMAN $32.85 \quad 100.0 \%$ RSSA_HUMAN $32.85 \quad 100.0 \%$ RSSA HUMAN $32.85 \quad 100.0 \%$ RSSA HUMAN $32.85 \quad 100.0 \%$ RSSA_HUMAN $32.85 \quad 100.0 \%$ RSSA HUMAN $32.85 \quad 100.0 \%$ RSSA_HUMAN $32.85 \quad 100.0 \% \quad 8$ XRN1_HUMAN $194.11 \quad 100.0 \%$ XRN1_HUMAN $194.11 \quad 100.0 \%$ 5'-AMP-activated protein kinase subunit gamma-1 GN=PRKAG1 AAKG1_HUMAN $37.58 \quad 100.0 \%$ 5'-AMP-activated protein kinase subunit gamma-1 GN=PRKAG1 AAKG1 HUMAN $37.58 \quad 100.0 \%$ 5'-AMP-activated protein kinase subunit gamma-1 GN=PRKAG1 AAKG1_HUMAN $37.58 \quad 100.0 \%$ 5'-AMP-activated protein kinase subunit gamma-1 GN=PRKAG1 AAKG1_HUMAN $37.58 \quad 100.0 \%$ 5'-AMP-activated protein kinase subunit gamma-1 GN=PRKAG1 AAKG1_HUMAN $37.58 \quad 100.0 \%$ 5'-AMP-activated protein kinase subunit gamma-1 GN=PRKAG1 AAKG1_HUMAN $37.58 \quad 100.0 \%$ 5'-AMP-activated protein kinase subunit gamma-1 GN=PRKAG1 AAKG1_HUMAN $37.58 \quad 100.0 \%$ 5'-AMP-activated protein kinase subunit gamma-1 GN=PRKAG1 AAKG1_HUMAN $37.58 \quad 100.0 \%$ 5-methylcytosine rRNA methyltransferase NSUN4 GN=NSUN4 NSUN4_HUMAN $43.09 \quad 100.0 \%$ 5-methylcytosine rRNA methyltransferase NSUN4 GN=NSUN4 NSUN4 HUMAN $43.09 \quad 100.0 \%$ 5-methylcytosine rRNA methyltransferase NSUN4 GN=NSUN4 NSUN4_HUMAN $43.09 \quad 100.0 \%$ 5-methylcytosine rRNA methyltransferase NSUN4 GN=NSUN4 NSUN4_HUMAN $43.09 \quad 100.0 \%$ $60 \mathrm{kDa}$ heat shock protein, mitochondrial GN=HSPD1 CH60 HUMAN $61.06 \quad 100.0 \%$ $60 \mathrm{kDa}$ heat shock protein, mitochondrial GN=HSPD1 CH60_HUMAN $61.06 \quad 100.0 \%$ $60 \mathrm{kDa}$ heat shock protein, mitochondrial GN=HSPD1 CH60 HUMAN $61.06 \quad 100.0 \%$ $60 \mathrm{kDa}$ heat shock protein, mitochondrial GN=HSPD1 CH60_HUMAN $61.06 \quad 100.0 \%$ $60 \mathrm{kDa}$ heat shock protein, mitochondrial GN=HSPD1 $\mathrm{CH} 60$ HUMAN 61.06 100.0\% $60 \mathrm{kDa}$ heat shock protein, mitochondrial GN=HSPD1 CH60 HUMAN $61.06 \quad 100.0 \%$ $60 \mathrm{kDa}$ heat shock protein, mitochondrial GN=HSPD1 CH60_HUMAN $61.06 \quad 100.0 \%$ $\begin{array}{lll}0.06 \% & 53.4 \% & \text { TRIIDVVYNASNNELVR } \\ 0.06 \% & 53.4 \% & \text { IIDVVYNASNNELVR }\end{array}$

$0.06 \% 53.4 \%$ NCIVLIDSTPYR

$0.06 \% \quad 53.4 \%$ LTPEEEEILNK

$0.06 \% \quad 53.4 \%$ ISSLLEEQFQQGK

$0.06 \% \quad 53.4 \%$ LLACIASRPGQCGR

$0.06 \% \quad 53.4 \%$ ADGYVLEGK

$0.06 \% 53.4 \%$ ADGYVLEGKELEFYLR

$0.02 \% 35.1 \%$ SRLDQELK

$0.02 \% \quad 35.1 \%$ ELLTLDEKDPR

$0.02 \% \quad 35.1 \%$ RLFEGNALLR

$0.02 \% \quad 35.1 \%$ LFEGNALLR

$0.02 \% \quad 35.1 \%$ LFEGNALLRR

$0.02 \% \quad 35.1 \%$ IGVLDEGK

$0.02 \% 35.1 \%$ RLQTQVFK

$0.02 \% \quad 35.1 \%$ LDSQKHIDFSLR

$0.02 \% \quad 35.1 \%$ SPYGGGRPGR

$0.02 \% \quad 25.8 \%$ KSDGIYIINLK

$0.02 \% \quad 25.8 \%$ SDGIYIINLK

$0.02 \% \quad 25.8 \%$ SDGIYIINLKR

$0.02 \% \quad 25.8 \%$ AIVAIENPADVSVISSR

$0.02 \% \quad 25.8 \%$ FAAATGATPIAGR

$0.02 \% \quad 25.8 \%$ FTPGTFTNQIQAAFR

$0.02 \% \quad 25.8 \%$ LLVVTDPR

$0.02 \% \quad 25.8 \%$ YVDIAIPCNNK

$0.00 \% \quad 1.1 \%$ LGVSGYLVSR

$0.00 \% \quad 1.1 \%$ FTGSIFIGR

$0.01 \% \quad 22.1 \%$ LVVFDTSLQVKK

$3 \quad 0.01 \% \quad 22.1 \%$ AFFALVTNGVR

$0.01 \% \quad 22.1 \%$ VSALPVVDEK

$0.01 \% \quad 22.1 \%$ VSALPVVDEKGR

$0.01 \% \quad 22.1 \%$ FDVINLAAEK

$0.01 \% \quad 22.1 \%$ TYNNLDVSVTK

$0.01 \% \quad 22.1 \%$ SHYFEGVLK

$0.01 \% \quad 22.1 \%$ LVEAEVHR

$0.01 \% \quad 10.7 \%$ VSLLSEQK

$0.01 \% \quad 10.7 \%$ TLALLQTGCCR

$0.01 \% \quad 10.7 \%$ NLAANDLSPSR

$0.01 \% \quad 10.7 \%$ VLVDVPCTTDR

$0.05 \% \quad 37.0 \%$ TVIIEQSWGSPK

$0.05 \% \quad 37.0 \%$ VTKDGVTVAK

$97.5 \% 20.7$

$\begin{array}{ll}99.7 \% & 27.4 \\ 99.7 \% & 56.5\end{array}$

$99.7 \% \quad 54.5$

$99.7 \% \quad 56.1$

$99.7 \% \quad 41.9$

$99.7 \% \quad 34.5$

$99.7 \% \quad 59.6$

$99.7 \% \quad 31.9$

$99.0 \% \quad 31.1$

$97.7 \% \quad 16.9$

$99.7 \% \quad 49.8$

$99.7 \% \quad 43.7$

$99.3 \% \quad 23.3$

$99.0 \% \quad 34.2$

$99.0 \% \quad 27.5$

$99.7 \% \quad 52.9$

$99.7 \% \quad 33.5$

$99.7 \% \quad 44.2$

$99.7 \% \quad 46.8$

$99.6 \% \quad 30.5$

$99.7 \% \quad 67.8$

$99.7 \% \quad 48.3$

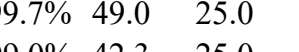

$\begin{array}{llll}99.7 \% & 47.0 & 25.0 & 47.0\end{array}$

$\begin{array}{llll}99.7 \% & 38.3 & 25.0 & 38.3\end{array}$

$99.1 \% \quad 26.2 \quad 25.0 \quad 19.3$

$\begin{array}{llll}99.7 \% & 38.6 & 25.0 & 38.6\end{array}$

$99.7 \% \quad 60.4 \quad 25.0 \quad 60.4$

$\begin{array}{llll}99.7 \% & 34.4 & 25.0 & 26.9\end{array}$

$\begin{array}{llll}99.7 \% & 52.3 & 25.0 & 45.0\end{array}$

$99.7 \% \quad 40.3 \quad 25.0 \quad 35.1$

$\begin{array}{llll}99.7 \% & 54.0 & 25.0 & 49.4\end{array}$

$\begin{array}{llll}98.3 \% & 18.6 & 25.0 & 17.5\end{array}$

$\begin{array}{llll}99.0 \% & 38.6 & 25.0 & 36.9\end{array}$

$99.0 \% \quad 41.2 \quad 25.0 \quad 24.4 \quad 2$

$99.7 \% \quad 44.5 \quad 25.0 \quad 33.2$

$\begin{array}{llll}99.7 \% & 48.2 & 25.0 & 34.5\end{array}$

$99.7 \% \quad 40.1 \quad 25.0 \quad 40.1$

$99.7 \% \quad 69.9 \quad 25.0 \quad 63.1$

$\begin{array}{lllll}99.7 \% & 63.9 & 25.0 & 47.0 & 2\end{array}$

$\begin{array}{lll}0.05 \% & 37.0 \% & \text { LVQDVANNTNEEAGG } \\ 0.05 \% & 37.0 \% & \text { SIAKEGFEK }\end{array}$

$\begin{array}{ll}0.05 \% & 37.0 \% \text { GANPVEIR }\end{array}$

$0.05 \% \quad 37.0 \%$ GANPVEIRR

$0.05 \% \quad 37.0 \%$ GVITVKDGK $\begin{array}{llll}9.7 \% & 44.9 & 25.0 & 44.9\end{array}$

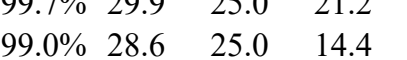

$\begin{array}{llll}99.7 \% & 47.8 & 25.0 & 42.1\end{array}$

$99.4 \% \quad 22.4 \quad 25.0 \quad 20.0$
1915.84

1976.06

1718.91

1450.74

1314.68

1506.78

1558.79

951.48

1901.96

988.54

1328.71

1188.68

1032.58

1188.68

830.46

1019.60

1458.77

1003.51

1263.73

1135.64

1291.74

1740.95

1203.65

1698.86

912.55

1306.65

1050.59

997.55

1376.81

1194.66

1056.59

1269.72

1119.60

1253.64

1079.55

952.52

903.51

1292.65

1157.59

1274.64

1344.72

1017.59

2560.25

1008.54

855.47

1011.57

916.55
75
92
9
1
139
170
184
193
200
30
69
79
79
80
91
116
162
172
52
52
53
80
102
117
128
166
930
939
59
70
234
236
253
264
278
299
72
198
209
262
72
8
121
130

Page 11 of Table S-1- 6 

$\begin{array}{lllllllll}60 \mathrm{kDa} \text { heat shock protein, mitochondrial GN=HSPD1 } & \mathrm{CH} 60 \text { HUMAN } & 61.06 & 100.0 \% & 19 & 26 & 45 & 0.05 \% & 37.0 \% \text { GYISPYFINTSK } \\ 60 \mathrm{kDa} \text { heat shock protein, mitochondrial GN=HSPD1 } & \text { CH60_HUMAN } & 61.06 & 100.0 \% & 19 & 26 & 45 & 0.05 \% & 37.0 \% \text { GYISPYFINTSKGQK }\end{array}$ $60 \mathrm{kDa}$ heat shock protein, mitochondrial GN=HSPD1 CH60_HUMAN $\quad 61.06 \quad 100.0 \% \quad 19$ $60 \mathrm{kDa}$ heat shock protein, mitochondrial GN=HSPD1 CH60 HUMAN $61.06 \quad 100.0 \%$ $60 \mathrm{kDa}$ heat shock protein, mitochondrial GN=HSPD1 CH60_HUMAN $61.06 \quad 100.0 \% \quad 19$ $60 \mathrm{kDa}$ heat shock protein, mitochondrial GN=HSPD1 CH60_HUMAN $61.06 \quad 100.0 \% \quad 19$ $60 \mathrm{kDa}$ heat shock protein, mitochondrial GN=HSPD1 CH60_HUMAN $61.06 \quad 100.0 \% \quad 19$ $60 \mathrm{kDa}$ heat shock protein, mitochondrial GN=HSPD1 CH60_HUMAN $61.06 \quad 100.0 \% \quad 19$ $60 \mathrm{kDa}$ heat shock protein, mitochondrial GN=HSPD1 CH60 HUMAN $61.06 \quad 100.0 \% \quad 19$ $60 \mathrm{kDa}$ heat shock protein, mitochondrial GN=HSPD1 CH60_HUMAN $61.06 \quad 100.0 \% \quad 19$ $60 \mathrm{kDa}$ heat shock protein, mitochondrial GN=HSPD1 CH60_HUMAN $61.06 \quad 100.0 \% \quad 1$ $60 \mathrm{kDa}$ heat shock protein, mitochondrial GN=HSPD1 CH60_HUMAN 61.06 $60 \mathrm{~S}$ acidic ribosomal protein P0 GN=RPLP0 RLA0_HUMAN 34.27 60S acidic ribosomal protein P0 GN=RPLP0 RLA0_HUMAN 34.27 $60 \mathrm{~S}$ acidic ribosomal protein P0 GN=RPLP0 RLA0_HUMAN 34.27 $60 \mathrm{~S}$ acidic ribosomal protein P0 GN=RPLP0 RLA0_HUMAN 34.2 $60 \mathrm{~S}$ acidic ribosomal protein P0 GN=RPLP0 RLA0 HUMAN 34.27 $60 \mathrm{~S}$ acidic ribosomal protein P0 GN=RPLP0 RLA0_HUMAN 34.27 $60 \mathrm{~S}$ acidic ribosomal protein P0 GN=RPLP0 RLA0_HUMAN 34.27 $60 \mathrm{~S}$ acidic ribosomal protein $\mathrm{P} 0 \mathrm{GN}=\mathrm{RPLP0}$ RLA0 HUMAN 34.27 $60 \mathrm{~S}$ acidic ribosomal protein P0 GN=RPLP0 RLA0_HUMAN 34.27 $60 \mathrm{~S}$ acidic ribosomal protein P0 GN=RPLP0 RLA0 HUMAN 34.27 $60 \mathrm{~S}$ acidic ribosomal protein $\mathrm{P} 0 \mathrm{GN}=\mathrm{RPLP0}$ RLA0 HUMAN 34.27 $60 \mathrm{~S}$ acidic ribosomal protein P0 GN=RPLP0 RLA0_HUMAN 34.27 $60 \mathrm{~S}$ acidic ribosomal protein $\mathrm{P} 0 \mathrm{GN}=\mathrm{RPLP0}$ RLA0 HUMAN 34.27 $60 \mathrm{~S}$ acidic ribosomal protein P0 GN=RPLP0 RLA0_HUMAN 34.27 $60 \mathrm{~S}$ acidic ribosomal protein P0 GN=RPLP0 RLA0 HUMAN 34.27 $60 \mathrm{~S}$ ribosomal protein L10 GN=RPL10 RL10 HUMAN 24.60 $60 \mathrm{~S}$ ribosomal protein $\mathrm{L} 10 \mathrm{GN}=\mathrm{RPL} 10$ $60 \mathrm{~S}$ ribosomal protein $\mathrm{L} 10 \mathrm{GN}=\mathrm{RPL} 10$ $60 \mathrm{~S}$ ribosomal protein $\mathrm{L} 10 \mathrm{GN}=\mathrm{RPL} 10$ $60 \mathrm{~S}$ ribosomal protein $\mathrm{L} 10 \mathrm{GN}=\mathrm{RPL} 10$ $60 \mathrm{~S}$ ribosomal protein $\mathrm{L} 10 \mathrm{GN}=\mathrm{RPL} 10$ $60 \mathrm{~S}$ ribosomal protein $\mathrm{L} 10 \mathrm{GN}=\mathrm{RPL} 10$ $60 \mathrm{~S}$ ribosomal protein $\mathrm{L} 10 \mathrm{GN}=\mathrm{RPL} 10$ $60 \mathrm{~S}$ ribosomal protein $\mathrm{L} 10 \mathrm{GN}=\mathrm{RPL} 10$ $60 \mathrm{~S}$ ribosomal protein $\mathrm{L} 10 \mathrm{GN}=\mathrm{RPL} 10$ $60 \mathrm{~S}$ ribosomal protein $\mathrm{L} 10 \mathrm{GN}=\mathrm{RPL} 10$ $60 \mathrm{~S}$ ribosomal protein $\mathrm{L} 10 \mathrm{GN}=\mathrm{RPL} 10$ $60 \mathrm{~S}$ ribosomal protein $\mathrm{L} 10 \mathrm{GN}=\mathrm{RPL} 10$ $60 \mathrm{~S}$ ribosomal protein L10a GN=RPL10A RL10__HUMAN 24.60 60S ribosomal protein L10a GN=RPL10A RL10A_HUMAN 24.83 60 S ribosomal protei $60 \mathrm{~S}$ ribosomal protein L10a GN=RPL10A RL10A_HUMAN $24.83 \quad 100.0 \%$ 60S ribosomal protein L10a GN=RPL10A RL10A_HUMAN 24.83 $60 \mathrm{~S}$ ribosomal protein L10a GN=RPL10A RL10A_HUMAN 24.83
$100.0 \% \quad 19$ $100.0 \% \quad 15$ $100.0 \% \quad 15$ $100.0 \% \quad 15$ $100.0 \% \quad 15$ $100.0 \% \quad 15$ $100.0 \% \quad 15$ $100.0 \% \quad 15$ $100.0 \% \quad 15$ $100.0 \% \quad 15$ $100.0 \% \quad 15$ $100.0 \% \quad 15$ $100.0 \% \quad 15$ $100.0 \% \quad 15$ $100.0 \% \quad 15$ $100.0 \% \quad 15$ $100.0 \% \quad 13$ $100.0 \% \quad 13$ $100.0 \% \quad 13$ $100.0 \% \quad 13$ $100.0 \% \quad 13$ $100.0 \% \quad 13$ $100.0 \% \quad 13$ $100.0 \% \quad 13$ $100.0 \% \quad 13$ $100.0 \% \quad 13$ $100.0 \% \quad 13$ $100.0 \% \quad 13$ $100.0 \% \quad 13$ $100.0 \% \quad 9$ $100.0 \%$ $100.0 \% \quad 9$ $100.0 \%$ $100.0 \%$ $100.0 \%$
$0.08 \% \quad 59.6 \%$ GHLENNPALEK

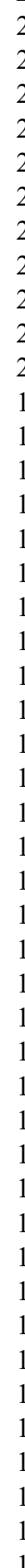

26
26

26

26

26
26

26

26

26

26

19
19

19

19

19

19
19

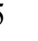

$0.05 \% \quad 37.0 \%$ CEFQDAYVLLSEK

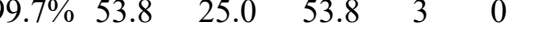

$\begin{array}{llllll}99.7 \% & 38.1 & 25.0 & 38.1 & 1 & 1\end{array}$

$0.05 \% \quad 37.0 \%$ ISSIQSIVPALEIANAHR

$0.05 \% \quad 37.0 \%$ VGLQVVAVK

$0.05 \% \quad 37.0 \%$ VGEVIVTKDDAMLLK

$99.7 \% \quad 56.8$

$\begin{array}{llll}99.7 \% & 72.6 & 25.0 & 30.7\end{array}$

$99.7 \% \quad 50.2$

$99.7 \% \quad 55.7$

$0.05 \% \quad 37.0 \%$ LSDGVAVLK

$99.7 \% \quad 72.8$

$0.05 \% \quad 37.0 \%$ AAVEEGIVLGGGCALLR $\quad 99.7 \% \quad 41.8$

$0.05 \% \quad 37.0 \%$ TLKIPAMTIAK

$0.05 \% \quad 37.0 \%$ NAGVEGSLIVEK

$0.05 \% \quad 37.0 \%$ GIIDPTKVVR

$0.08 \% \quad 59.6 \%$ IIQLLDDYPK

$0.08 \% \quad 59.6 \%$ CFIVGADNVGSK

$0.08 \% \quad 59.6 \%$ GNVGFVFTK

$0.08 \% \quad 59.6 \%$ GNVGFVFTKEDLTEIR

$0.08 \% \quad 59.6 \%$ EDLTEIRDMLLANK

$0.08 \% \quad 59.6 \%$ DMLLANKVPAAAR

$0.08 \% \quad 59.6 \%$ AGAIAPCEVTVPAQNTGLGPEK

$0.08 \% 59.6 \%$ TSFFQALGITTK

$0.08 \% \quad 59.6 \%$ GTIEILSDVQLIK

$99.7 \% 26.8$

$99.7 \% \quad 67.8$

$99.7 \% \quad 45.1$

$99.7 \% \quad 57.7$

$\begin{array}{lll}99.7 \% & 33.7\end{array}$

$\begin{array}{lll}99.7 \% & 59.8\end{array}$

$99.7 \% \quad 49.2$

$99.7 \% \quad 53.2$

$99.7 \% \quad 41.5$

$99.7 \% \quad 59.1$

$99.7 \% \quad 55.6$

$\begin{array}{lll}99.7 \% & 47.7\end{array}$

$99.7 \% \quad 60.7$

$0.08 \% \quad 59.6 \%$ NVASVCLQIGYPTVASVPHSIINGYK $\quad 99.7 \% \quad 39.6$

$0.08 \% \quad 59.6 \%$ VLALSVETDYTFPLAEK $\quad 99.7 \% \quad 52.3$

$0.08 \% \quad 59.6 \%$ VLALSVETDYTFPLAEKVK $99.7 \% \quad 29.4$

$0.08 \% \quad 59.6 \%$ AFLADPSAFVAAAPVAAATTAAPAAAAAPAK

$99.7 \% \quad 51.2$

$0.08 \% \quad 59.6 \%$ AFLADPSAFVAAAPVAAATTAAPAAAAAPAKVEAK

$0.04 \% \quad 52.8 \%$ GVPDAKIR

$0.04 \% \quad 52.8 \%$ IRIFDLGR

$0.04 \% \quad 52.8 \%$ ICANKYMVK

$0.04 \% \quad 52.8 \%$ SCGKDGFHIR

$0.04 \% 52.8 \%$ VRLHPFHVIR

$0.04 \% \quad 52.8 \%$ INKMLSCAGADR

$0.04 \% \quad 52.8 \%$ MLSCAGADR

$0.04 \% \quad 52.8 \%$ GAFGKPQGTVAR

$0.04 \% \quad 52.8 \%$ VHIGQVIMSIR

$0.04 \% \quad 52.8 \%$ LQNKEHVIEALR

$0.04 \% \quad 52.8 \%$ EHVIEALR

$0.04 \% \quad 52.8 \%$ FNADEFEDMVAEKR

$0.04 \% \quad 52.8 \%$ RLIPDGCGVK

$0.02 \% \quad 39.2 \%$ VSRDTLYEAVR

$0.02 \% \quad 39.2 \%$ DTLYEAVR

$99.7 \% \quad 32.3$

$99.0 \% 27.9$

$99.0 \% \quad 37.2$

$99.1 \% 28.0$

$99.7 \% \quad 44.6$

$99.7 \% \quad 35.5$

$99.7 \% \quad 40.8$

$99.5 \% \quad 26.4$

$99.7 \% \quad 56.9$

$99.7 \% \quad 47.3$

$99.7 \% \quad 31.0$

$99.0 \% \quad 23.7$

$97.2 \% \quad 22.4$

$99.7 \% \quad 28.8$

$99.6 \% 27.2$

$99.0 \% \quad 40.8$

$0.02 \% \quad 39.2 \%$ DTLYEAVREVLHGNQR

$0.02 \% \quad 39.2 \%$ FSVCVLGDQQHCDEAK

$9.7 \% \quad 44.3$

$0.02 \% \quad 39.2 \%$ KYDAFLASESLIK

$99.7 \% \quad 27.2$

$0.02 \% \quad 39.2 \%$ ILGPGLNK

$98.2 \% \quad 35.0$

$0.02 \% \quad 39.2 \%$ AGKFPSLLTHNENMVAK $98.6 \% \quad 18.5$
1919.07

912.59

1630.91

901.54

960.51

1684.91

1186.72

1215.66

1097.67

1217.68

1266.61

1221.62

968.52

1824.95

1660.86

1369.76

2180.10

1313.71

1428.83

2787.45

1896.00

2123.16

2752.47

3179.71

855.50

989.59

1142.57

1176.56

1273.76

1351.65

980.43

1188.65

1252.72

1449.82

966.54

1700.76

1114.60

1308.69

966.49

1899.97

1892.83

1484.80

811.50

1872.96 $\begin{array}{cc}22 & 233 \\ 22 & 236 \\ 37 & 249 \\ 51 & 268 \\ 93 & 301 \\ 45 & 359 \\ 97 & 405 \\ 21 & 429 \\ 30 & 446 \\ 71 & 481 \\ 82 & 493 \\ 17 & 526 \\ 17 & 26 \\ 27 & 38 \\ 57 & 77 \\ 34 & 92 \\ 34 & 99 \\ 93 & 106 \\ 00 & 112 \\ 13 & 134 \\ 35 & 146 \\ 50 & 162 \\ 21 & 246 \\ 48 & 264 \\ 48 & 266 \\ 67 & 297 \\ 67 & 301 \\ 25 & 32 \\ 31 & 38 \\ 70 & 78 \\ 79 & 88 \\ 39 & 98 \\ 99 & 110 \\ 02 & 110 \\ 17 & 128 \\ 29 & 139 \\ 42 & 153 \\ 46 & 153 \\ 76 & 189 \\ 89 & 198 \\ 5 & 15 \\ 8 & 15 \\ 8 & 23 \\ 53 & 78 \\ 06 & 118 \\ 23 & 130 \\ 31 & 147\end{array}$

Page 12 of Table S-1-6 
60S ribosomal protein L10a GN=RPL10A RL10A_HUMAN $24.83 \quad 100.0 \%$ $\begin{array}{llll} & \end{array}$ $60 \mathrm{~S}$ ribosomal protein $\mathrm{L} 11 \mathrm{GN}=\mathrm{RPL} 11$ $60 \mathrm{~S}$ ribosomal protein $\mathrm{L} 11 \mathrm{GN}=\mathrm{RPL} 11$ $60 \mathrm{~S}$ ribosomal protein $\mathrm{L} 11 \mathrm{GN}=\mathrm{RPL} 11$ $60 \mathrm{~S}$ ribosomal protein $\mathrm{L} 11 \mathrm{GN}=\mathrm{RPL} 11$ $60 \mathrm{~S}$ ribosomal protein $\mathrm{L} 11 \mathrm{GN}=\mathrm{RPL} 11$ $60 \mathrm{~S}$ ribosomal protein $\mathrm{L} 11 \mathrm{GN}=\mathrm{RPL} 11$ $60 \mathrm{~S}$ ribosomal protein $\mathrm{L} 13 \mathrm{GN}=\mathrm{RPL} 13$ $60 \mathrm{~S}$ ribosomal protein $\mathrm{L} 13 \mathrm{GN}=\mathrm{RPL} 13$ $60 \mathrm{~S}$ ribosomal protein $\mathrm{L} 13 \mathrm{GN}=\mathrm{RPL} 13$ $60 \mathrm{~S}$ ribosomal protein $\mathrm{L} 13 \mathrm{GN}=\mathrm{RPL} 13$ $60 \mathrm{~S}$ ribosomal protein $\mathrm{L} 13 \mathrm{GN}=\mathrm{RPL} 13$ $60 \mathrm{~S}$ ribosomal protein $\mathrm{L} 13 \mathrm{GN}=\mathrm{RPL} 13$ $60 \mathrm{~S}$ ribosomal protein $\mathrm{L} 13 \mathrm{GN}=\mathrm{RPL} 13$ $60 \mathrm{~S}$ ribosomal protein $\mathrm{L} 13 \mathrm{GN}=\mathrm{RPL} 13$ $60 \mathrm{~S}$ ribosomal protein $\mathrm{L} 13 \mathrm{GN}=\mathrm{RPL} 13$ $60 \mathrm{~S}$ ribosomal protein $\mathrm{L} 13 \mathrm{GN}=\mathrm{RPL} 13$ $60 \mathrm{~S}$ ribosomal protein $\mathrm{L} 13 \mathrm{GN}=\mathrm{RPL} 13$ 60S ribosomal protein L13a GN=RPL13A RL13A_HUMAN 23.58 $60 \mathrm{~S}$ ribosomal protein L13a GN=RPL13A RL13A_HUMAN 23.58 60S ribosomal protein L13a GN=RPL13A RL13A_HUMAN 23.58 $60 \mathrm{~S}$ ribosomal protein L13a GN=RPL13A RL13A_HUMAN 23.58 60S ribosomal protein L13a GN=RPL13A RL13A_HUMAN 23.58 60S ribosomal protein L13a GN=RPL13A RL13A_HUMAN 23.58 $60 \mathrm{~S}$ ribosomal protein $\mathrm{L} 14 \mathrm{GN}=\mathrm{RPL} 14$ $60 \mathrm{~S}$ ribosomal protein $\mathrm{L} 14 \mathrm{GN}=\mathrm{RPL} 14$ $60 \mathrm{~S}$ ribosomal protein $\mathrm{L} 14 \mathrm{GN}=\mathrm{RPL} 14$ $60 \mathrm{~S}$ ribosomal protein $\mathrm{L} 15 \mathrm{GN}=\mathrm{RPL} 15$ $60 \mathrm{~S}$ ribosomal protein $\mathrm{L} 15 \mathrm{GN}=\mathrm{RPL} 15$ $60 \mathrm{~S}$ ribosomal protein $\mathrm{L} 15 \mathrm{GN}=\mathrm{RPL} 15$ $60 \mathrm{~S}$ ribosomal protein $\mathrm{L} 15 \mathrm{GN}=\mathrm{RPL} 15$ $60 \mathrm{~S}$ ribosomal protein $\mathrm{L} 17 \mathrm{GN}=\mathrm{RPL} 17$ $60 \mathrm{~S}$ ribosomal protein $\mathrm{L} 17 \mathrm{GN}=\mathrm{RPL} 17$ $60 \mathrm{~S}$ ribosomal protein $\mathrm{L} 17 \mathrm{GN}=\mathrm{RPL} 17$ $60 \mathrm{~S}$ ribosomal protein $\mathrm{L} 17 \mathrm{GN}=\mathrm{RPL} 17$ $60 \mathrm{~S}$ ribosomal protein $\mathrm{L} 17 \mathrm{GN}=\mathrm{RPL} 17$ $60 \mathrm{~S}$ ribosomal protein $\mathrm{L} 17 \mathrm{GN}=\mathrm{RPL} 17$ $60 \mathrm{~S}$ ribosomal protein $\mathrm{L} 17 \mathrm{GN}=\mathrm{RPL} 17$ $60 \mathrm{~S}$ ribosomal protein $\mathrm{L} 17 \mathrm{GN}=\mathrm{RPL} 17$ $60 \mathrm{~S}$ ribosomal protein $\mathrm{L} 18 \mathrm{GN}=\mathrm{RPL} 18$ $60 \mathrm{~S}$ ribosomal protein $\mathrm{L} 18 \mathrm{GN}=\mathrm{RPL} 18$ $60 \mathrm{~S}$ ribosomal protein $\mathrm{L} 18 \mathrm{GN}=\mathrm{RPL} 18$ $60 \mathrm{~S}$ ribosomal protein $\mathrm{L} 18 \mathrm{GN}=\mathrm{RPL} 18$ $60 \mathrm{~S}$ ribosomal protein $\mathrm{L} 18 \mathrm{GN}=\mathrm{RPL} 18$ $60 \mathrm{~S}$ ribosomal protein $\mathrm{L} 18 \mathrm{GN}=\mathrm{RPL} 18$ 60 S ribosomal protein L18a GN=RPL18A RL18A_HUMAN $20.76 \quad 100.0 \%$
RLII_HUMAN $20.25 \quad 100.0 \%$ RL11_HUMAN $20.25 \quad 100.0 \%$ RL11_HUMAN $20.25 \quad 100.0 \%$ RL11_HUMAN $20.25 \quad 100.0 \%$ RL11_HUMAN $20.25 \quad 100.0 \%$ RL13 HUMAN $24.26 \quad 100.0 \%$ RL13_HUMAN $24.26 \quad 100.0 \%$ RL13 HUMAN $24.26 \quad 100.0 \%$ RL13_HUMAN $24.26 \quad 100.0 \%$ RL13_HUMAN $24.26 \quad 100.0 \%$ RL13 HUMAN $24.26 \quad 100.0 \%$ RL13_HUMAN $24.26 \quad 100.0 \%$ RL13_HUMAN $24.26 \quad 100.0 \%$ RL13 HUMAN $24.26 \quad 100.0 \%$ $100.0 \%$ $100.0 \%$ $100.0 \%$ $100.0 \%$ $00.0 \%$ $00.0 \%$ $100.0 \%$ RL14_HUMAN $23.43 \quad 100.0 \%$ RL14_HUMAN $23.43 \quad 100.0 \%$ RL14 HUMAN $23.43 \quad 100.0 \%$ RL15_HUMAN $24.15 \quad 100.0 \%$ RL15 HUMAN $24.15 \quad 100.0 \%$ RL15_HUMAN $24.15 \quad 100.0 \%$ RL15_HUMAN $24.15 \quad 100.0 \%$ RL17 HUMAN $21.40 \quad 100.0 \%$ RL17_HUMAN $21.40 \quad 100.0 \%$ RL17_HUMAN $21.40 \quad 100.0 \%$ RL17_HUMAN $21.40 \quad 100.0 \%$ RL17_HUMAN $21.40 \quad 100.0 \%$ RL17_HUMAN $21.40 \quad 100.0 \%$ RL17_HUMAN $21.40 \quad 100.0 \%$ RL17_HUMAN $21.40 \quad 100.0 \%$ RL18 HUMAN $21.64 \quad 100.0 \%$ RL18_HUMAN $21.64 \quad 100.0 \%$ RL18 HUMAN $21.64 \quad 100.0 \%$ RL18_HUMAN $21.64 \quad 100.0 \%$ RL18 HUMAN $21.64 \quad 100.0 \%$ RL18 HUMAN $21.64 \quad 100.0 \%$
$0.02 \% \quad 39.2 \%$ FPSLLTHNENMVAK $0.02 \% 39.2 \%$ VLCLAVAVGHVK $0.01 \% \quad 26.4 \%$ VLEQLTGQTPVFSK $0.01 \% \quad 26.4 \%$ NEKIAVHCTVR

$0.01 \% \quad 26.4 \%$ IAVHCTVR

$0.01 \% \quad 26.4 \%$ GAKAEEILEK

$0.01 \% \quad 26.4 \%$ AEEILEKGLK

$0.01 \% \quad 26.4 \%$ YDGIILPGK

$0.09 \% \quad 35.1 \%$ RVATWFNQPAR

$0.09 \% \quad 35.1 \%$ VATWFNQPAR

$0.09 \% \quad 35.1 \%$ VATWFNQPARK

$0.09 \% \quad 35.1 \%$ GFSLEELR

$0.09 \% \quad 35.1 \%$ TIGISVDPR

$0.09 \% \quad 35.1 \%$ TIGISVDPRR

$0.09 \% \quad 35.1 \%$ NKSTESLQANVQR

$0.09 \% \quad 35.1 \%$ STESLQANVQR

$0.09 \% \quad 35.1 \%$ SKLILFPR

$0.09 \% \quad 35.1 \%$ LATQLTGPVMPVR

$0.09 \% \quad 35.1 \%$ VITEEEKNFK

$0.02 \% \quad 27.1 \%$ CEGINISGNFYR

$0.02 \% \quad 27.1 \%$ GQAALDRLK

$0.02 \% \quad 27.1 \%$ VFDGIPPPYDKK

$0.02 \% \quad 27.1 \%$ MVVPAALK

$0.02 \% \quad 27.1 \%$ MVVPAALKVVR

$0.02 \% \quad 27.1 \%$ YQAVTATLEEK

$0.03 \% \quad 14.9 \%$ VAYVSFGPHAGK

$0.03 \% \quad 14.9 \%$ LVAIVDVIDQNR

$0.03 \% \quad 14.9 \%$ MTDFDRFK

$0.02 \% \quad 18.1 \%$ AKQGYVIYR

$0.02 \% \quad 18.1 \%$ GATYGKPVHHGVNQLK

$0.02 \% \quad 18.1 \%$ SLQSVAEER

$0.02 \% \quad 18.1 \%$ SLQSVAEERAGR

$0.02 \% 33.2 \%$ VRYSLDPENPTK

$0.02 \% \quad 33.2 \%$ YSLDPENPTK

$0.02 \% \quad 33.2 \%$ YSLDPENPTKSCK

$0.02 \% 33.2 \%$ ETAQAIKGMHIR

$0.02 \% \quad 33.2 \%$ YLKDVTLQK

$0.02 \% \quad 33.2 \%$ SAEFLLHMLK

$0.02 \% \quad 33.2 \%$ EQIVPKPEEEVAQK

$0.02 \% \quad 33.2 \%$ EQIVPKPEEEVAQKK

$0.03 \% \quad 27.1 \%$ TNSTFNQVVLK

$0.03 \% \quad 27.1 \%$ TNSTFNQVVLKR

$0.03 \% \quad 27.1 \%$ TAVVVGTITDDVR

$0.03 \% \quad 27.1 \%$ GCGTVLLSGPR

$0.03 \% 27.1 \%$ GCGTVLLSGPRK

$0.03 \% 27.1 \%$ APGTPHSHTKPYVR

$0.03 \% 57.4 \%$ ASGTLREYK $\begin{array}{lllll}95.7 \% & 14.9 & 25.0 & 14.4 & 0\end{array}$

$\begin{array}{lllll}99.7 \% & 46.3 & 25.0 & 46.3 & 2\end{array}$

$\begin{array}{lllll}99.7 \% & 52.2 & 25.0 & 51.6 & 2\end{array}$

$\begin{array}{llll}99.4 \% & 28.0 & 25.0 & 15.9\end{array}$

$\begin{array}{lllll}99.0 \% & 34.2 & 25.0 & 25.3\end{array}$

$\begin{array}{llll}99.7 \% & 46.4 & 25.0 & 32.6\end{array}$

$\begin{array}{llll}99.7 \% & 39.6 & 25.0 & 34.7\end{array}$

$\begin{array}{lllll}99.7 \% & 51.6 & 25.0 & 51.6 & 3\end{array}$

$\begin{array}{lllll}99.7 \% & 43.9 & 25.0 & 36.5 & 2\end{array}$

$\begin{array}{llll}99.7 \% & 46.6 & 25.0 & 35.7\end{array}$

$\begin{array}{llll}98.7 \% & 22.2 & 25.0 & 16.1\end{array}$

$\begin{array}{lllll}99.0 \% & 49.2 & 25.0 & 36.7 & 8\end{array}$

$\begin{array}{lllll}99.7 \% & 46.7 & 25.0 & 33.7 & 19\end{array}$

$\begin{array}{llll}97.3 \% & 24.9 & 25.0 & 12.6\end{array}$

$\begin{array}{llll}99.7 \% & 53.6 & 25.0 & 33.7\end{array}$

$\begin{array}{lllll}99.7 \% & 58.0 & 25.0 & 51.1 & 12\end{array}$

$\begin{array}{llll}99.0 \% & 50.3 & 25.0 & 50.3\end{array}$

$\begin{array}{llll}99.7 \% & 49.2 & 25.0 & 48.7\end{array}$

$\begin{array}{llll}99.7 \% & 52.0 & 25.0 & 39.8\end{array}$

$\begin{array}{llll}99.7 \% & 63.5 & 25.0 & 63.5\end{array}$

$\begin{array}{llll}99.7 \% & 44.9 & 25.0 & 32.8\end{array}$

$\begin{array}{llll}97.4 \% & 17.5 & 25.0 & 17.5\end{array}$

$\begin{array}{llll}98.7 \% & 18.0 & 25.0 & 18.0\end{array}$

$\begin{array}{lllll}99.7 \% & 44.8 & 25.0 & 44.8 & 2\end{array}$

$\begin{array}{llll}99.4 \% & 24.6 & 25.0 & 21.4\end{array}$

$\begin{array}{llll}99.7 \% & 42.9 & 25.0 & 42.9\end{array}$

$\begin{array}{lllll}99.7 \% & 51.9 & 25.0 & 51.9 & 16\end{array}$

$\begin{array}{lllll}99.0 \% & 26.0 & 25.0 & 26.0\end{array}$

$\begin{array}{llll}99.7 \% & 32.6 & 25.0 & 24.3\end{array}$

$\begin{array}{llll}99.7 \% & 34.7 & 25.0 & 34.7\end{array}$

$\begin{array}{llll}99.7 \% & 56.4 & 25.0 & 46.1\end{array}$

$\begin{array}{llll}99.7 \% & 29.5 & 25.0 & 29.5\end{array}$

$\begin{array}{llll}99.7 \% & 29.3 & 25.0 & 29.3\end{array}$

$\begin{array}{llll}99.7 \% & 32.6 & 25.0 & 32.5\end{array}$

$\begin{array}{llll}99.7 \% & 51.0 & 25.0 & 46.1\end{array}$

$\begin{array}{llll}99.7 \% & 29.7 & 25.0 & 22.4\end{array}$

$\begin{array}{lllll}99.7 \% & 43.2 & 25.0 & 33.0 & 2\end{array}$

$\begin{array}{llll}98.9 \% & 20.1 & 25.0 & 17.4\end{array}$

$\begin{array}{llll}99.7 \% & 29.3 & 25.0 & 26.1\end{array}$

$\begin{array}{lllll}95.6 \% & 15.6 & 25.0 & 13.8\end{array}$

$\begin{array}{lllll}99.7 \% & 59.5 & 25.0 & 53.3\end{array}$

$\begin{array}{lllll}99.7 \% & 55.4 & 25.0 & 49.6 & 2\end{array}$

$\begin{array}{llll}99.7 \% & 62.6 & 25.0 & 58.4\end{array}$

$\begin{array}{llll}99.7 \% & 57.8 & 25.0 & 49.5\end{array}$

$\begin{array}{lllll}99.7 \% & 48.3 & 25.0 & 32.1 & 2\end{array}$

$\begin{array}{llll}99.7 \% & 31.3 & 25.0 & 31.3\end{array}$

$\begin{array}{llll}99.7 \% & 32.7 & 25.0 & 23.0\end{array}$

$\begin{array}{ll}0 & 161 \\ 0 & 12 \\ 0 & 154 \\ 0 & 132 \\ 0 & \\ 0 & 108 \\ 0 & 112 \\ 0 & \\ 0 & 137 \\ 0 & 118 \\ 0 & 131 \\ 0 & \\ 0 & \\ 0 & 111 \\ 0 & 147 \\ 0 & 123 \\ 0 & 973 \\ 0 & 139 \\ 0 & 123 \\ 0 & 142 \\ 0 & 97 \\ 0 & 137 \\ 0 & 82 \\ 0 & 119 \\ 0 & 125 \\ 0 & 123 \\ 0 & 135 \\ 0 & 107 \\ 0 & 109 \\ 0 & 170 \\ 0 & 101 \\ 0 & 130 \\ 0 & 141 \\ 0 & 116 \\ 0 & 153 \\ 0 & 137 \\ 0 & 110 \\ 0 & 120 \\ 0 & 162 \\ 0 & 175 \\ 0 & 125 \\ 0 & 140 \\ 0 & 134 \\ 0 & 111 \\ 0 & 124 \\ 0 & 154 \\ 0 & 102\end{array}$

1265.74

1546.85

1326.69

955.51

1087.60

1129.65

975.55

1345.71

1189.61

1317.71

950.49

957.54

1113.64

1474.76

1232.62

973.62

1398.78

1236.65

1429.65

971.56

1375.73

828.50

1198.73

1252.64

1232.64

1354.77

1075.49

1097.61

1705.91

1018.52

1302.68

1418.73

1163.56

1538.72

1370.72

1107.64

1204.64

1623.86

1751.95

1250.67

1406.78

1345.73

1116.58

1244.68

1547.81

1024.54 \begin{tabular}{c}
147 \\
173 \\
52 \\
75 \\
75 \\
85 \\
88 \\
178 \\
31 \\
31 \\
32 \\
82 \\
101 \\
102 \\
116 \\
116 \\
129 \\
158 \\
177 \\
49 \\
103 \\
115 \\
125 \\
128 \\
159 \\
23 \\
35 \\
111 \\
63 \\
93 \\
105 \\
108 \\
13 \\
13 \\
16 \\
42 \\
55 \\
96 \\
167 \\
168 \\
49 \\
50 \\
91 \\
143 \\
144 \\
168 \\
11 \\
\hline
\end{tabular}

Page 13 of Table S-1- 6 
60S ribosomal protein L18a GN=RPL18A RL18A_HUMAN $20.76 \quad 100.0 \%$ (18) 60 S ribosomal protein L18a GN=RPL18A RL18A_HUMAN $20.76 \quad 100.0 \%$ 60 S ribosomal protein L18a GN=RPL18A RL18A HUMAN 20.76 60 S ribosomal protein L18a GN=RPL18A RL18A_HUMAN $20.76 \quad 100.0 \%$ 60S ribosomal protein L18a GN=RPL18A RL18A_HUMAN $20.76 \quad 100.0 \%$ 60S ribosomal protein L18a GN=RPL18A RL18A_HUMAN $20.76 \quad 100.0 \%$ $60 \mathrm{~S}$ ribosomal protein L18a GN=RPL18A RL18A_HUMAN $20.76 \quad 100.0 \%$ $60 \mathrm{~S}$ ribosomal protein L18a GN=RPL18A RL18A HUMAN $20.76 \quad 100.0 \%$ 60S ribosomal protein L18a GN=RPL18A RL18A_HUMAN $20.76100 .0 \%$ $60 \mathrm{~S}$ ribosomal protein $\mathrm{L} 19 \mathrm{GN}=\mathrm{RPL} 19$ $60 \mathrm{~S}$ ribosomal protein $\mathrm{L} 19 \mathrm{GN}=\mathrm{RPL} 19$ $60 \mathrm{~S}$ ribosomal protein $\mathrm{L} 19 \mathrm{GN}=\mathrm{RPL} 19$ $60 \mathrm{~S}$ ribosomal protein $\mathrm{L} 19 \mathrm{GN}=\mathrm{RPL} 19$ $60 \mathrm{~S}$ ribosomal protein $\mathrm{L} 21 \mathrm{GN}=\mathrm{RPL} 21$ $60 \mathrm{~S}$ ribosomal protein $\mathrm{L} 21 \mathrm{GN}=\mathrm{RPL} 21$ $60 \mathrm{~S}$ ribosomal protein $\mathrm{L} 21 \mathrm{GN}=\mathrm{RPL} 21$ $60 \mathrm{~S}$ ribosomal protein $\mathrm{L} 21 \mathrm{GN}=\mathrm{RPL} 21$ $60 \mathrm{~S}$ ribosomal protein $\mathrm{L} 21 \mathrm{GN}=\mathrm{RPL} 21$ $60 \mathrm{~S}$ ribosomal protein $\mathrm{L} 21 \mathrm{GN}=\mathrm{RPL} 21$ RL19 HUMAN 23.47 RL19 HUMAN 23.47 RL19_HUMAN 23.47 RL19 HUMAN 23.47 RL21_HUMAN 18.57 RL21_HUMAN 18.57 RL21 HUMAN 18.57 RL21 HUMAN 18.57 RL21_HUMAN 18.57 RL21 HUMAN 18.57 60S ribosomal protein L23a GN=RPL23A RL23A_HUMAN 17.70 60S ribosomal protein L23a GN=RPL23A RL23A_HUMAN 17.70 60S ribosomal protein L23a GN=RPL23A RL23A_HUMAN 17.70 60S ribosomal protein L23a GN=RPL23A RL23A_HUMAN 17.70 60S ribosomal protein L23a GN=RPL23A RL23A_HUMAN 17.70 $60 \mathrm{~S}$ ribosomal protein $\mathrm{L} 24 \mathrm{GN}=\mathrm{RPL} 24$ $60 \mathrm{~S}$ ribosomal protein $\mathrm{L} 24 \mathrm{GN}=\mathrm{RPL} 24$ $60 \mathrm{~S}$ ribosomal protein $\mathrm{L} 24 \mathrm{GN}=\mathrm{RPL} 24$ $60 \mathrm{~S}$ ribosomal protein $\mathrm{L} 24 \mathrm{GN}=\mathrm{RPL} 24$ $60 \mathrm{~S}$ ribosomal protein $\mathrm{L} 24 \mathrm{GN}=\mathrm{RPL} 24$ $60 \mathrm{~S}$ ribosomal protein $\mathrm{L} 24 \mathrm{GN}=\mathrm{RPL} 24$ $60 \mathrm{~S}$ ribosomal protein $\mathrm{L} 24 \mathrm{GN}=\mathrm{RPL} 24$ $60 \mathrm{~S}$ ribosomal protein $\mathrm{L} 27 \mathrm{a} \mathrm{GN}=\mathrm{RPL} 27 \mathrm{~A}$ RL27A HUMAN 16.56 $60 \mathrm{~S}$ ribosomal protein L27a GN=RPL27A RL27A_HUMAN 16.56 60S ribosomal protein L27a GN=RPL27A RL27A_HUMAN 16.56 $60 \mathrm{~S}$ ribosomal protein $\mathrm{L} 28 \mathrm{GN}=\mathrm{RPL} 28$ $60 \mathrm{~S}$ ribosomal protein $\mathrm{L} 28 \mathrm{GN}=\mathrm{RPL} 28$ $60 \mathrm{~S}$ ribosomal protein $\mathrm{L} 29 \mathrm{GN}=\mathrm{RPL} 29$ $60 \mathrm{~S}$ ribosomal protein $\mathrm{L} 29 \mathrm{GN}=\mathrm{RPL} 29$ $60 \mathrm{~S}$ ribosomal protein $\mathrm{L} 29 \mathrm{GN}=\mathrm{RPL} 29$ $60 \mathrm{~S}$ ribosomal protein $\mathrm{L} 29 \mathrm{GN}=\mathrm{RPL} 29$ $60 \mathrm{~S}$ ribosomal protein $\mathrm{L} 29 \mathrm{GN}=\mathrm{RPL} 29$ $60 \mathrm{~S}$ ribosomal protein $\mathrm{L} 3 \mathrm{GN}=\mathrm{RPL} 3$ $60 \mathrm{~S}$ ribosomal protein $\mathrm{L} 3 \mathrm{GN}=\mathrm{RPL} 3$ $60 \mathrm{~S}$ ribosomal protein $\mathrm{L} 3 \mathrm{GN}=\mathrm{RPL} 3$ $60 \mathrm{~S}$ ribosomal protein $\mathrm{L} 3 \mathrm{GN}=\mathrm{RPL} 3$ $60 \mathrm{~S}$ ribosomal protein $\mathrm{L} 3 \mathrm{GN}=\mathrm{RPL} 3$

RL24_HUMAN $17.78 \quad 100.0 \%$ RL24_HUMAN $17.78 \quad 100.0 \%$ RL24_HUMAN $17.78 \quad 100.0 \%$ RL24_HUMAN $17.78 \quad 100.0 \%$ RL24_HUMAN $17.78 \quad 100.0 \%$ $\begin{array}{lll}\text { RL24_HUMAN } & 17.78 & 100.0 \% \\ \text { RL24_HUMAN } & 17.78 & 100.0 \%\end{array}$ $00.0 \%$ $100.0 \%$
$100.0 \%$ $100.0 \%$ RL28 HUMAN $15.75 \quad 100.0 \%$ RL28_HUMAN $15.75 \quad 100.0 \%$ RL29_HUMAN $17.75 \quad 100.0 \%$ RL29_HUMAN $17.75 \quad 100.0 \%$ RL29_HUMAN $17.75 \quad 100.0 \%$ RL29 HUMAN $17.75 \quad 100.0 \%$ RL29_HUMAN $17.75 \quad 100.0 \%$ RL3 HUMAN $46.11 \quad 100.0 \%$
$13 \quad 24 \quad 0.03 \% \quad 57.4 \%$ CHTPPLYR $0.03 \% 57.4 \%$ MRIFAPNHVVAK $0.03 \% \quad 57.4 \%$ IFAPNHVVAK $0.03 \% \quad 57.4 \%$ SSGEIVYCGQVFEK $0.03 \% \quad 57.4 \%$ VKNFGIWLR $0.03 \% \quad 57.4 \%$ VEEIAASKCR $0.03 \% 57.4 \%$ IKFPLPHR

$0.03 \% \quad 57.4 \%$ FTTKRPNTFF $0.01 \% \quad 13.3 \%$ RLASSVLR $0.01 \% \quad 13.3 \%$ ILMEHIHK

$0.01 \% \quad 13.3 \%$ LLADQAEAR

$0.01 \% \quad 13.3 \%$ LLADQAEARR

$0.01 \% \quad 32.5 \%$ HGVVPLATYMR

$0.01 \% 32.5 \%$ HGVVPLATYMRIYK

$0.01 \% \quad 32.5 \%$ VYNVTQHAVGIVVNK

$0.01 \% \quad 32.5 \%$ VYNVTQHAVGIVVNKQVK

$0.01 \% \quad 32.5 \%$ GTWVQLKR

$0.01 \% 32.5 \%$ QPAPPREAHFVR

$0.01 \% \quad 28.8 \%$ EAPAPPKAEAK

$0.01 \% \quad 28.8 \%$ KLYDIDVAK

$0.01 \% \quad 28.8 \%$ VNTLIRPDGEKK

$0.01 \% \quad 28.8 \%$ LAPDYDALDVANK

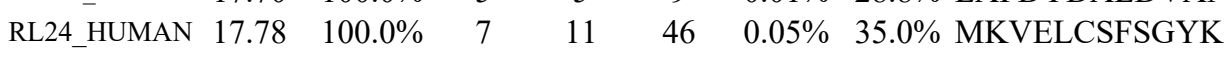
RL3_HUMAN $46.11 \quad 100.0 \% \quad 22$ RL3_HUMAN $46.11 \quad 100.0 \% \quad 22$ RL3 HUMAN $46.11 \quad 100.0 \% \quad 22$ RL3_HUMAN $46.11 \quad 100.0 \% \quad 22$ $0.04 \% \quad 24.5 \%$ LAYIAHPK $0.04 \% \quad 24.5 \%$ DQTKAQAAAPASVPAQAPK

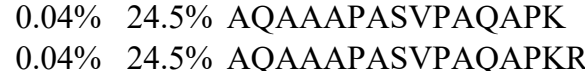
$0.11 \% \quad 44.7 \%$ HGSLGFLPR $0.11 \% \quad 44.7 \%$ SFPKDDPSKPVHLTAFLGYK $0.11 \% \quad 44.7 \%$ DDPSKPVHLTAFLGYK $0.11 \% \quad 44.7 \%$ AGMTHIVR $0.11 \% \quad 44.7 \%$ AGMTHIVREVDRPGSK $0.03 \% \quad 57.4 \%$ DLTTAGAVTQCYR $0.03 \% \quad 57.4 \%$ AHSIQIMKVEEIAASK

$0.01 \% \quad 28.8 \%$ VNTLIRPDGEK

$\begin{array}{lllllll}77.1 & 25.0 & 14.1 & 1 & 0 & 0 & 1043.51\end{array}$

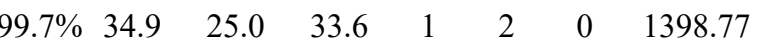
$\begin{array}{llllllll}99.7 \% & 45.9 & 25.0 & 32.9 & 2 & 0 & 0 & 1095.63\end{array}$

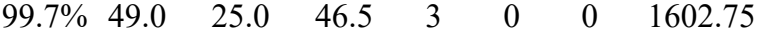
$\begin{array}{llllllll}99.7 \% & 28.5 & 25.0 & 28.5 & 2 & 0 & 0 & 1132.66\end{array}$

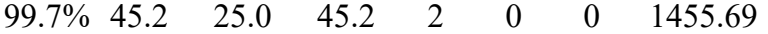

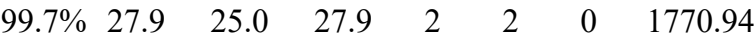
$\begin{array}{llllllll}99.7 \% & 38.9 & 25.0 & 38.9 & 2 & 0 & 0 & 1162.59\end{array}$

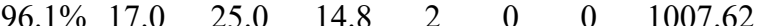

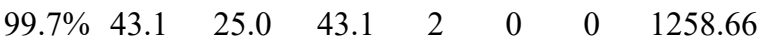
$\begin{array}{llllllll}99.0 \% & 34.1 & 25.0 & 21.7 & 1 & 0 & 0 & 901.56\end{array}$

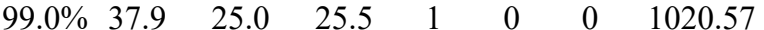
$99.4 \% \quad 31.7$ $99.7 \% \quad 28.2$ $97.6 \% \quad 17.6$ $99.7 \% \quad 66.8$ $\begin{array}{llll}99.7 \% & 48.0 & 25.0 & 48.0\end{array}$ $\begin{array}{llll}99.0 \% & 47.2 & 25.0 & 31.4\end{array}$ $\begin{array}{llll}99.7 \% & 28.2 & 25.0 & 18.8\end{array}$ $99.7 \% \quad 42.9 \quad 25.0 \quad 39.9$ $\begin{array}{llll}99.7 \% & 31.8 & 25.0 & 26.1\end{array}$ $\begin{array}{llll}99.7 \% & 50.0 & 25.0 & 40.7\end{array}$ $\begin{array}{llll}99.3 \% & 21.3 & 25.0 & 21.3\end{array}$ $\begin{array}{llll}97.9 \% & 22.7 & 25.0 & 22.7\end{array}$ $\begin{array}{llll}99.7 \% & 55.1 & 25.0 & 47.2\end{array}$ $\begin{array}{llll}99.7 \% & 43.6 & 25.0 & 42.3\end{array}$ $99.0 \% \quad 41.1 \quad 25.0 \quad 33.4$ $\begin{array}{llll}99.0 \% & 46.5 & 25.0 & 35.5\end{array}$ $\begin{array}{llll}99.7 \% & 36.7 & 25.0 & 25.7\end{array}$ $\begin{array}{llll}99.7 \% & 51.8 & 25.0 & 41.5\end{array}$ $\begin{array}{llll}99.7 \% & 66.0 & 25.0 & 64.5\end{array}$ $\begin{array}{llll}99.7 \% & 51.4 & 25.0 & 39.3\end{array}$ $\begin{array}{llll}99.7 \% & 51.3 & 25.0 & 51.3\end{array}$ $\begin{array}{llll}99.7 \% & 28.4 & 25.0 & 26.5\end{array}$ $\begin{array}{llll}99.7 \% & 39.7 & 25.0 & 31.2\end{array}$ $\begin{array}{llll}99.7 \% & 40.4 & 25.0 & 39.7\end{array}$ $\begin{array}{llll}99.7 \% & 28.8 & 25.0 & 28.8\end{array}$ $\begin{array}{llll}99.0 \% & 36.5 & 25.0 & 33.7\end{array}$ $\begin{array}{lll}1.6 & 25.0 & 41.6\end{array}$ $99.7 \% \quad 46.5$ $25.0 \quad 45.9$ $\begin{array}{ll}99.7 \% & 50.1 \\ 99.5 \% & 23.6\end{array}$

$99.0 \% 48.7$
$99.7 \% \quad 33.1$

29
41
41
70
83
111
136
138
157
176
16
144
162
163
32
35
78
81
130
142
18
123
134
135
152
12
35
35
43
56
93
94
105
105
114
20
33
79
103
149
149
150
19
50
50
58
66

Page 14 of Table S-1-6 
$60 \mathrm{~S}$ ribosomal protein $\mathrm{L} 3 \mathrm{GN}=\mathrm{RPL} 3$ $60 \mathrm{~S}$ ribosomal protein $\mathrm{L} 3 \mathrm{GN}=\mathrm{RPL} 3$ $60 \mathrm{~S}$ ribosomal protein $\mathrm{L} 3 \mathrm{GN}=\mathrm{RPL} 3$ $60 \mathrm{~S}$ ribosomal protein $\mathrm{L} 3 \mathrm{GN}=\mathrm{RPL} 3$ $60 \mathrm{~S}$ ribosomal protein $\mathrm{L} 3 \mathrm{GN}=\mathrm{RPL} 3$ $60 \mathrm{~S}$ ribosomal protein $\mathrm{L} 3 \mathrm{GN}=\mathrm{RPL} 3$ $60 \mathrm{~S}$ ribosomal protein $\mathrm{L} 3 \mathrm{GN}=\mathrm{RPL} 3$ $60 \mathrm{~S}$ ribosomal protein $\mathrm{L} 3 \mathrm{GN}=\mathrm{RPL} 3$ $60 \mathrm{~S}$ ribosomal protein $\mathrm{L} 3 \mathrm{GN}=\mathrm{RPL} 3$ $60 \mathrm{~S}$ ribosomal protein $\mathrm{L} 3 \mathrm{GN}=\mathrm{RPL} 3$ $60 \mathrm{~S}$ ribosomal protein $\mathrm{L} 3 \mathrm{GN}=\mathrm{RPL} 3$ $60 \mathrm{~S}$ ribosomal protein $\mathrm{L} 3 \mathrm{GN}=\mathrm{RPL} 3$ $60 \mathrm{~S}$ ribosomal protein $\mathrm{L} 3 \mathrm{GN}=\mathrm{RPL} 3$ $60 \mathrm{~S}$ ribosomal protein $\mathrm{L} 3 \mathrm{GN}=\mathrm{RPL} 3$ $60 \mathrm{~S}$ ribosomal protein $\mathrm{L} 3 \mathrm{GN}=\mathrm{RPL} 3$ $60 \mathrm{~S}$ ribosomal protein $\mathrm{L} 3 \mathrm{GN}=\mathrm{RPL} 3$ $60 \mathrm{~S}$ ribosomal protein $\mathrm{L} 3 \mathrm{GN}=\mathrm{RPL} 3$ $60 \mathrm{~S}$ ribosomal protein L34 GN=RPL34 $60 \mathrm{~S}$ ribosomal protein $\mathrm{L} 34 \mathrm{GN}=\mathrm{RPL} 34$ $60 \mathrm{~S}$ ribosomal protein $\mathrm{L} 4 \mathrm{GN}=\mathrm{RPL} 4$ $60 \mathrm{~S}$ ribosomal protein $\mathrm{L} 4 \mathrm{GN}=\mathrm{RPL} 4$ $60 \mathrm{~S}$ ribosomal protein $\mathrm{L} 4 \mathrm{GN}=\mathrm{RPL} 4$ $60 \mathrm{~S}$ ribosomal protein $\mathrm{L} 4 \mathrm{GN}=\mathrm{RPL} 4$ $60 \mathrm{~S}$ ribosomal protein $\mathrm{L} 4 \mathrm{GN}=\mathrm{RPL} 4$ $60 \mathrm{~S}$ ribosomal protein $\mathrm{L} 4 \mathrm{GN}=\mathrm{RPL} 4$ $60 \mathrm{~S}$ ribosomal protein $\mathrm{L} 4 \mathrm{GN}=\mathrm{RPL} 4$ $60 \mathrm{~S}$ ribosomal protein $\mathrm{L} 4 \mathrm{GN}=\mathrm{RPL} 4$ $60 \mathrm{~S}$ ribosomal protein $\mathrm{L} 4 \mathrm{GN}=\mathrm{RPL} 4$ $60 \mathrm{~S}$ ribosomal protein $\mathrm{L} 4 \mathrm{GN}=\mathrm{RPL} 4$ $60 \mathrm{~S}$ ribosomal protein $\mathrm{L} 4 \mathrm{GN}=\mathrm{RPL} 4$ $60 \mathrm{~S}$ ribosomal protein $\mathrm{L} 4 \mathrm{GN}=\mathrm{RPL} 4$ $60 \mathrm{~S}$ ribosomal protein $\mathrm{L} 4 \mathrm{GN}=\mathrm{RPL} 4$ $60 \mathrm{~S}$ ribosomal protein $\mathrm{L} 4 \mathrm{GN}=\mathrm{RPL} 4$ $60 \mathrm{~S}$ ribosomal protein $\mathrm{L} 4 \mathrm{GN}=\mathrm{RPL} 4$ $60 \mathrm{~S}$ ribosomal protein $\mathrm{L} 4 \mathrm{GN}=\mathrm{RPL} 4$ $60 \mathrm{~S}$ ribosomal protein $\mathrm{L} 4 \mathrm{GN}=\mathrm{RPL} 4$ $60 \mathrm{~S}$ ribosomal protein $\mathrm{L} 4 \mathrm{GN}=\mathrm{RPL} 4$ $60 \mathrm{~S}$ ribosomal protein $\mathrm{L} 4 \mathrm{GN}=\mathrm{RPL} 4$ $60 \mathrm{~S}$ ribosomal protein $\mathrm{L} 4 \mathrm{GN}=\mathrm{RPL} 4$ $60 \mathrm{~S}$ ribosomal protein $\mathrm{L} 4 \mathrm{GN}=\mathrm{RPL} 4$ $60 \mathrm{~S}$ ribosomal protein $\mathrm{L} 4 \mathrm{GN}=\mathrm{RPL} 4$ $60 \mathrm{~S}$ ribosomal protein $\mathrm{L} 4 \mathrm{GN}=\mathrm{RPL} 4$ $60 \mathrm{~S}$ ribosomal protein $\mathrm{L} 4 \mathrm{GN}=\mathrm{RPL} 4$ $60 \mathrm{~S}$ ribosomal protein $\mathrm{L} 4 \mathrm{GN}=\mathrm{RPL} 4$ $60 \mathrm{~S}$ ribosomal protein $\mathrm{L} 4 \mathrm{GN}=\mathrm{RPL} 4$ $60 \mathrm{~S}$ ribosomal protein $\mathrm{L} 4 \mathrm{GN}=\mathrm{RPL} 4$ $60 \mathrm{~S}$ ribosomal protein $\mathrm{L} 5 \mathrm{GN}=\mathrm{RPL} 5$

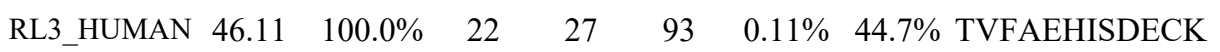
RL3_HUMAN $46.11 \quad 100.0 \% \quad 22 \quad 27 \quad 93 \quad 0.11 \% \quad 44.7 \%$ TVFAEHISDECKR RL3_HUMAN $46.11 \quad 100.0 \% \quad 22$ RL3 HUMAN $46.11 \quad 100.0 \% \quad 22$ RL3_HUMAN $46.11 \quad 100.0 \% \quad 22$ RL3_HUMAN $46.11 \quad 100.0 \% \quad 22$ RL3 HUMAN $46.11 \quad 100.0 \% \quad 22$ RL3_HUMAN $46.11 \quad 100.0 \% \quad 22$ RL3 HUMAN $46.11 \quad 100.0 \% \quad 22$ RL3_HUMAN $46.11 \quad 100.0 \% \quad 22$ RL3_HUMAN $46.11 \quad 100.0 \% \quad 22$ RL3 HUMAN $46.11 \quad 100.0 \% \quad 22$ RL3_HUMAN $46.11 \quad 100.0 \% \quad 22$ RL3_HUMAN $46.11 \quad 100.0 \% \quad 22$ RL3_HUMAN $46.11 \quad 100.0 \% \quad 22$ RL3_HUMAN $46.11 \quad 100.0 \% \quad 22$ RL3 HUMAN $46.11 \quad 100.0 \% \quad 22$ RL34_HUMAN $13.29 \quad 100.0 \% \quad 2$ RL34_HUMAN $13.29 \quad 100.0 \% \quad 2$ RL4 HUMAN $47.70 \quad 100.0 \% \quad 27$ RL4_HUMAN $47.70 \quad 100.0 \% \quad 27$ RL4 HUMAN $47.70 \quad 100.0 \% \quad 27$ RL4_HUMAN $47.70 \quad 100.0 \% \quad 27$ RL4_HUMAN $47.70 \quad 100.0 \% \quad 27$ RL4 HUMAN $47.70 \quad 100.0 \% \quad 27$ RL4_HUMAN $47.70 \quad 100.0 \% \quad 27$ RL4_HUMAN $47.70 \quad 100.0 \% \quad 27$ RL4 HUMAN $47.70 \quad 100.0 \% \quad 27$ RL4_HUMAN $47.70 \quad 100.0 \% \quad 27$ RL4 HUMAN $47.70 \quad 100.0 \% \quad 27$ RL4_HUMAN $47.70 \quad 100.0 \% \quad 27$ RL4_HUMAN $47.70 \quad 100.0 \% \quad 27$ RL4 HUMAN $47.70 \quad 100.0 \% \quad 27$ RL4_HUMAN $47.70 \quad 100.0 \% \quad 27$ RL4_HUMAN $47.70 \quad 100.0 \% \quad 27$ RL4 HUMAN $47.70 \quad 100.0 \% \quad 27$ RL4_HUMAN $47.70 \quad 100.0 \% \quad 27$ RL4 HUMAN $47.70 \quad 100.0 \% \quad 27$ RL4_HUMAN $47.70 \quad 100.0 \% \quad 27$ RL4_HUMAN $47.70 \quad 100.0 \% \quad 27$ RL4 HUMAN $47.70 \quad 100.0 \% \quad 27$ RL4_HUMAN $47.70 \quad 100.0 \% \quad 27$ RL4 HUMAN $47.70 \quad 100.0 \% \quad 27$ RL4 HUMAN $47.70 \quad 100.0 \% \quad 27$ RL4_HUMAN $47.70 \quad 100.0 \% \quad 27$ RL4 HUMAN $47.70 \quad 100.0 \% \quad 27$ RL5_HUMAN $34.36 \quad 100.0 \% \quad 17$

$\begin{array}{llll}27 & 93 & 0.11 \% & 44.7 \% \text { IGQGYLIK } \\ 27 & 93 & 0.11 \% & 44.7 \% \text { IGQGYLIKDGK }\end{array}$

$27 \quad 93 \quad 0.11 \% \quad 44.7 \%$ NNASTDYDLSDK

$0.11 \% \quad 44.7 \%$ KSLLVQTK

$27 \quad 93 \quad 0.11 \% \quad 44.7 \%$ SLLVQTKR

$27 \quad 93 \quad 0.11 \% \quad 44.7 \%$ ALEKIDLK

$27 \quad 93 \quad 0.11 \% \quad 44.7 \%$ IDLKFIDTTSK

$27 \quad 93 \quad 0.11 \% \quad 44.7 \%$ FIDTTSKFGHGR

$93 \quad 0.11 \% \quad 44.7 \%$ AFMGPLKK

$0.00 \% \quad 8.6 \%$ RLSYNTASNK

$0.00 \% \quad 8.6 \% \quad$ LSYNTASNK

$160 \quad 0.18 \% \quad 52.9 \%$ NVTLPAVFK

$160 \quad 0.18 \% \quad 52.9 \%$ SGQGAFGNMCR

$160 \quad 0.18 \% \quad 52.9 \%$ EAVLLLKK

$160 \quad 0.18 \% \quad 52.9 \%$ GPCIIYNEDNGIIK

$160 \quad 0.18 \% \quad 52.9 \%$ NIPGITLLNVSK

$160 \quad 0.18 \% \quad 52.9 \%$ LAPGGHVGR

$160 \quad 0.18 \% \quad 52.9 \%$ FCIWTESAFR

$160 \quad 0.18 \% \quad 52.9 \%$ KLDELYGTWR

$160 \quad 0.18 \% \quad 52.9 \%$ SNYNLPMHK

$160 \quad 0.18 \% \quad 52.9 \%$ MINTDLSR

$160 \quad 0.18 \% \quad 52.9 \%$ IMLKLNPYAK

$160 \quad 0.18 \% \quad 52.9 \%$ AAAAAAALQAK

$160 \quad 0.18 \% \quad 52.9 \%$ AAVAGKKPVVGK
$0.11 \% \quad 44.7 \%$ ERLEQQVPVNQVFGQDEMIDVIGVTK $\quad 99.7 \% \quad 52.5$

$25.0 \quad 27.3$

$0.11 \% \quad 44.7 \%$ LEQQVPVNQVFGQDEMIDVIGVTK $99.7 \% \quad 39.3$

$99.0 \% \quad 49.5$

$25.0 \quad 39.3$

$99.7 \% \quad 56.8 \quad 25.0 \quad 52.7$

$\begin{array}{llll}99.7 \% & 52.0 & 25.0 & 52.0\end{array}$

$99.0 \% \quad 36.3 \quad 25.0 \quad 28.2$

$99.0 \% \quad 39.4 \quad 25.0 \quad 34.9$

$99.0 \% \quad 35.1 \quad 25.0 \quad 19.6$

$\begin{array}{llll}99.7 \% & 49.2 & 25.0 & 42.8\end{array}$

$\begin{array}{llll}95.4 \% & 23.8 & 25.0 & 23.1\end{array}$

$99.0 \% \quad 32.4 \quad 25.0 \quad 24.9$

$\begin{array}{llll}98.2 \% & 17.4 & 25.0 & 17.0\end{array}$

$99.4 \% \quad 29.8 \quad 25.0 \quad 19.4$

$99.7 \% \quad 32.4 \quad 25.0 \quad 31.4$

$\begin{array}{llll}99.7 \% & 29.2 & 25.0 & 29.2\end{array}$

$\begin{array}{llll}99.0 \% & 19.4 & 25.0 & 19.4\end{array}$

$160 \quad 0.18 \% \quad 52.9 \%$ APIRPDIVNFVHTNLRK

$160 \quad 0.18 \% \quad 52.9 \%$ QPYAVSELAGHQTSAESWGTGR $99.7 \%$

$\begin{array}{llll}99.7 \% & 28.5 & 25.0 & 28.5 \\ 99.7 \% & 53.2 & 25.0 & 53.2\end{array}$

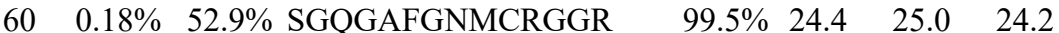

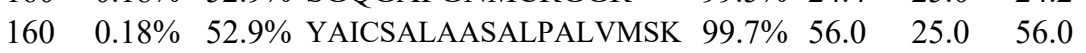

$160 \quad 0.18 \% \quad 52.9 \%$ TKEAVLLLK

$160 \quad 0.18 \% \quad 52.9 \%$ RGPCIIYNEDNGIIK

$160 \quad 0.18 \% \quad 52.9 \%$ AFRNIPGITLLNVSK

$160 \quad 0.18 \% \quad 52.9 \%$ NIPGITLLNVSKLNILK

$160 \quad 0.18 \% \quad 52.9 \%$ AASLKSNYNLPMHK

$\begin{array}{llll}99.7 \% & 31.3 & 25.0 & 24.7\end{array}$

$99.0 \% \quad 37.5 \quad 25.0 \quad 19.3$

$99.7 \% \quad 54.1 \quad 25.0 \quad 50.3$

$99.7 \% \quad 54.2 \quad 25.0 \quad 54.1$

$99.7 \% \quad 45.0 \quad 25.0 \quad 42.6$

$\begin{array}{llll}99.7 \% & 64.7 & 25.0 & 62.6\end{array}$

$99.7 \% \quad 59.6 \quad 25.0 \quad 59.6$

$\begin{array}{llll}99.7 \% & 51.5 & 25.0 & 40.5\end{array}$

$99.7 \% \quad 41.8 \quad 25.0 \quad 35.0$

$99.7 \% \quad 42.3 \quad 25.0 \quad 42.3$

$99.6 \% \quad 23.8 \quad 25.0 \quad 23.8$

$99.7 \% \quad 48.4 \quad 25.0 \quad 48.4$

$\begin{array}{llllllll}160 & 0.18 \% & 52.9 \% & \text { SNYNLPMHKMINTDLSR } & 99.1 \% & 19.9 & 25.0 & 19.2\end{array}$

$\begin{array}{llll}99.0 \% & 54.9 & 25.0 & 41.8\end{array}$

$99.7 \% \quad 39.8 \quad 25.0 \quad 33.3$

$96.9 \% \quad 18.6 \quad 25.0 \quad 14.7$

$160 \quad 0.18 \% \quad 52.9 \%$ VDKAAAAAAALQAK

$99.7 \% \quad 47.9$

$99.7 \% \quad 56.8$

$25.0 \quad 46.9$

$160 \quad 0.18 \% \quad 52.9 \%$ AAAAAAALQAKSDEK

$\begin{array}{llll}99.5 \% & 25.0 & 25.0 & 25.0\end{array}$

$99.7 \% \quad 54.0 \quad 25.0 \quad 54.0$
2987.51

2702.37

1237.63

891.53

$162 \quad 169$

$177 \quad 193$

$178 \quad 193$

$\begin{array}{ll}199 & 224 \\ 201 & 224\end{array}$

251261

$349 \quad 356$

$944.59 \quad 350 \quad 357$

$929.57 \quad 359 \quad 366$

$\begin{array}{lll}1280.71 & 363 & 373\end{array}$

$1365.69 \quad 367 \quad 378$

$907.51 \quad 387 \quad 394$

$1153.60 \quad 10 \quad 19$

997.49

988.58

1862.04

1990.13

2332.10

1184.49

1470.63

1953.02

1014.66

913.61

1761.90

1605.79

1642.96

1268.76

1850.15

863.48

1316.61

1280.66

1589.81

1119.53

2065.98

949.48

1083.65

1206.69

1298.74

956.55

1415.75

1124.72

1692.89 
$60 \mathrm{~S}$ ribosomal protein $\mathrm{L} 5 \mathrm{GN}=\mathrm{RPL} 5$ $60 \mathrm{~S}$ ribosomal protein $\mathrm{L} 5 \mathrm{GN}=\mathrm{RPL} 5$ $60 \mathrm{~S}$ ribosomal protein $\mathrm{L} 5 \mathrm{GN}=\mathrm{RPL} 5$ $60 \mathrm{~S}$ ribosomal protein $\mathrm{L} 5 \mathrm{GN}=\mathrm{RPL} 5$ $60 \mathrm{~S}$ ribosomal protein $\mathrm{L} 5 \mathrm{GN}=\mathrm{RPL} 5$ $60 \mathrm{~S}$ ribosomal protein $\mathrm{L} 5 \mathrm{GN}=\mathrm{RPL} 5$ $60 \mathrm{~S}$ ribosomal protein $\mathrm{L} 5 \mathrm{GN}=\mathrm{RPL} 5$ $60 \mathrm{~S}$ ribosomal protein $\mathrm{L} 5 \mathrm{GN}=\mathrm{RPL} 5$ $60 \mathrm{~S}$ ribosomal protein $\mathrm{L} 5 \mathrm{GN}=\mathrm{RPL} 5$ $60 \mathrm{~S}$ ribosomal protein $\mathrm{L} 5 \mathrm{GN}=\mathrm{RPL} 5$ $60 \mathrm{~S}$ ribosomal protein $\mathrm{L} 5 \mathrm{GN}=\mathrm{RPL} 5$ $60 \mathrm{~S}$ ribosomal protein $\mathrm{L} 5 \mathrm{GN}=\mathrm{RPL} 5$ $60 \mathrm{~S}$ ribosomal protein L5 GN=RPL5 $60 \mathrm{~S}$ ribosomal protein $\mathrm{L} 5 \mathrm{GN}=\mathrm{RPL} 5$ $60 \mathrm{~S}$ ribosomal protein $\mathrm{L} 5 \mathrm{GN}=\mathrm{RPL} 5$ $60 \mathrm{~S}$ ribosomal protein $\mathrm{L} 5 \mathrm{GN}=\mathrm{RPL} 5$ $60 \mathrm{~S}$ ribosomal protein $\mathrm{L} 6 \mathrm{GN}=\mathrm{RPL} 6$ $60 \mathrm{~S}$ ribosomal protein $\mathrm{L} 6 \mathrm{GN}=\mathrm{RPL} 6$ $60 \mathrm{~S}$ ribosomal protein $\mathrm{L} 6 \mathrm{GN}=\mathrm{RPL} 6$ $60 \mathrm{~S}$ ribosomal protein $\mathrm{L} 6 \mathrm{GN}=\mathrm{RPL} 6$ $60 \mathrm{~S}$ ribosomal protein $\mathrm{L} 6 \mathrm{GN}=\mathrm{RPL} 6$ $60 \mathrm{~S}$ ribosomal protein $\mathrm{L} 6 \mathrm{GN}=\mathrm{RPL} 6$ $60 \mathrm{~S}$ ribosomal protein $\mathrm{L} 6 \mathrm{GN}=\mathrm{RPL} 6$ $60 \mathrm{~S}$ ribosomal protein $\mathrm{L} 6 \mathrm{GN}=\mathrm{RPL} 6$ $60 \mathrm{~S}$ ribosomal protein $\mathrm{L} 6 \mathrm{GN}=\mathrm{RPL} 6$ $60 \mathrm{~S}$ ribosomal protein $\mathrm{L} 6 \mathrm{GN}=\mathrm{RPL} 6$ $60 \mathrm{~S}$ ribosomal protein $\mathrm{L} 6 \mathrm{GN}=\mathrm{RPL} 6$ $60 \mathrm{~S}$ ribosomal protein $\mathrm{L} 6 \mathrm{GN}=\mathrm{RPL} 6$ $60 \mathrm{~S}$ ribosomal protein $\mathrm{L} 6 \mathrm{GN}=\mathrm{RPL} 6$ $60 \mathrm{~S}$ ribosomal protein $\mathrm{L} 6 \mathrm{GN}=\mathrm{RPL} 6$ $60 \mathrm{~S}$ ribosomal protein $\mathrm{L} 6 \mathrm{GN}=\mathrm{RPL} 6$ $60 \mathrm{~S}$ ribosomal protein $\mathrm{L} 6 \mathrm{GN}=\mathrm{RPL} 6$ $60 \mathrm{~S}$ ribosomal protein $\mathrm{L} 6 \mathrm{GN}=\mathrm{RPL} 6$ $60 \mathrm{~S}$ ribosomal protein $\mathrm{L} 7 \mathrm{GN}=\mathrm{RPL} 7$ $60 \mathrm{~S}$ ribosomal protein $\mathrm{L} 7 \mathrm{GN}=\mathrm{RPL} 7$ $60 \mathrm{~S}$ ribosomal protein $\mathrm{L} 7 \mathrm{GN}=\mathrm{RPL} 7$ $60 \mathrm{~S}$ ribosomal protein $\mathrm{L} 7 \mathrm{GN}=\mathrm{RPL} 7$ $60 \mathrm{~S}$ ribosomal protein $\mathrm{L} 7 \mathrm{GN}=\mathrm{RPL} 7$ $60 \mathrm{~S}$ ribosomal protein $\mathrm{L} 7 \mathrm{GN}=\mathrm{RPL} 7$ $60 \mathrm{~S}$ ribosomal protein $\mathrm{L} 7 \mathrm{GN}=\mathrm{RPL} 7$ $60 \mathrm{~S}$ ribosomal protein $\mathrm{L} 7 \mathrm{GN}=\mathrm{RPL} 7$ $60 \mathrm{~S}$ ribosomal protein $\mathrm{L} 7 \mathrm{GN}=\mathrm{RPL} 7$ $60 \mathrm{~S}$ ribosomal protein $\mathrm{L} 7 \mathrm{GN}=\mathrm{RPL} 7$ $60 \mathrm{~S}$ ribosomal protein $\mathrm{L} 7 \mathrm{GN}=\mathrm{RPL} 7$ $60 \mathrm{~S}$ ribosomal protein $\mathrm{L} 7 \mathrm{GN}=\mathrm{RPL} 7$ $60 \mathrm{~S}$ ribosomal protein $\mathrm{L} 7 \mathrm{GN}=\mathrm{RPL} 7$ $60 \mathrm{~S}$ ribosomal protein $\mathrm{L} 7 \mathrm{a} \mathrm{GN}=\mathrm{RPL} 7 \mathrm{~A}$ \begin{tabular}{lllllll} 
RL5_HUMAN 34.36 & $100.0 \%$ & 17 & 31 & 87 & $0.10 \%$ & $48.8 \%$ \\
\hline
\end{tabular}

$99.7 \% \quad \begin{array}{rllllll}53.8 & 25.0 & 38.8 & 3 & 0 & 0 & 1222.63\end{array}$

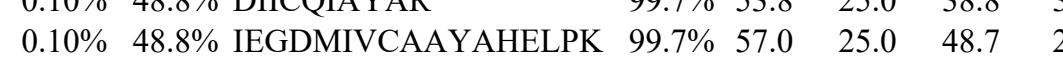
RL5_HUMAN $34.36 \quad 100.0 \% \quad 17$ RL5_HUMAN $34.36 \quad 100.0 \% \quad 17$ RL5 HUMAN $34.36 \quad 100.0 \% \quad 17$ RL5_HUMAN $34.36 \quad 100.0 \% \quad 17$ RL5_HUMAN $34.36 \quad 100.0 \% \quad 17$ RL5_HUMAN $34.36 \quad 100.0 \% \quad 17$ RL5_HUMAN $34.36 \quad 100.0 \% \quad 17$ $\begin{array}{lll}\text { RL5 HUMAN } 34.36 & 100.0 \% & 17\end{array}$ RL5_HUMAN $34.36 \quad 100.0 \% \quad 17$ RL5_HUMAN $34.36 \quad 100.0 \% \quad 17$ RL5 HUMAN $34.36 \quad 100.0 \% \quad 17$ RL5_HUMAN $34.36 \quad 100.0 \% \quad 17$ RL5_HUMAN $34.36 \quad 100.0 \% \quad 17$ RL5_HUMAN $34.36 \quad 100.0 \% \quad 17$ RL5_HUMAN $34.36 \quad 100.0 \% \quad 17$ $\begin{array}{lll}\text { RL6 HUMAN } 32.73 \quad 100.0 \% & 17\end{array}$ RL6_HUMAN $32.73 \quad 100.0 \% \quad 17$ RL6_HUMAN $32.73 \quad 100.0 \% \quad 17$

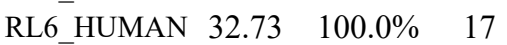
RL6_HUMAN $32.73 \quad 100.0 \% \quad 17$ RL6 HUMAN $32.73 \quad 100.0 \% \quad 17$ RL6_HUMAN $32.73 \quad 100.0 \% \quad 17$ RL6_HUMAN $32.73 \quad 100.0 \% \quad 17$ RL6 HUMAN $32.73 \quad 100.0 \% \quad 17$ RL6_HUMAN $32.73 \quad 100.0 \% \quad 17$ RL6_HUMAN $32.73 \quad 100.0 \% \quad 17$ RL6 HUMAN $32.73 \quad 100.0 \% \quad 17$ RL6_HUMAN $32.73 \quad 100.0 \% \quad 17$ RL6 HUMAN $32.73 \quad 100.0 \% \quad 17$ RL6_HUMAN $32.73 \quad 100.0 \% \quad 17$ RL6_HUMAN $32.73 \quad 100.0 \% \quad 17$ $\begin{array}{lll}\text { RL6 HUMAN } 32.73 & 100.0 \% & 17\end{array}$ RL7_HUMAN $29.23 \quad 100.0 \% \quad 13$

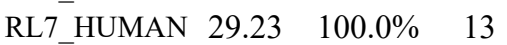
RL7 HUMAN $29.23 \quad 100.0 \% \quad 13$ RL7_HUMAN $29.23 \quad 100.0 \% \quad 13$ RL7 HUMAN $29.23 \quad 100.0 \% \quad 13$ RL7_HUMAN $29.23 \quad 100.0 \% \quad 13$ RL7_HUMAN $29.23 \quad 100.0 \% \quad 13$ RL7_HUMAN $29.23 \quad 100.0 \% \quad 13$ RL7_HUMAN $29.23 \quad 100.0 \% \quad 13$ RL7 HUMAN $29.23 \quad 100.0 \% \quad 13$ RL7_HUMAN $29.23 \quad 100.0 \% \quad 13$ RL7_HUMAN $29.23 \quad 100.0 \% \quad 13$ RL7_HUMAN $29.23 \quad 100.0 \% \quad 13$ RL7A_HUMAN $30.00 \quad 100.0 \% \quad 18$
$0.10 \% \quad 48.8 \%$ VGLTNYAAAYCTGLLLAR

$0.10 \% \quad 48.8 \%$ TTTGNKVFGALK

$0.10 \% \quad 48.8 \%$ GAVDGGLSIPHSTK

$0.10 \% \quad 48.8 \%$ GAVDGGLSIPHSTKR

$99.7 \% \quad 40.7$

$\begin{array}{lllll}99.7 \% & 56.5 & 25.0 & 50.4\end{array}$

$\begin{array}{llll}99.7 \% & 33.6 & 25.0 & 33.0\end{array}$

$\begin{array}{llll}99.7 \% & 43.8 & 25.0 & 30.0\end{array}$

$\begin{array}{lllll}99.7 \% & 33.2 & 25.0 & 27.4 & 3\end{array}$

$0.10 \% \quad 48.8 \%$ RFPGYDSESK

$0.10 \% \quad 48.8 \%$ FPGYDSESK

$99.7 \% 46.7$

$0.10 \% \quad 48.8 \%$ FPGYDSESKEFNAEVHR

$0.10 \% \quad 48.8 \%$ EFNAEVHR

$0.10 \% \quad 48.8 \%$ EFNAEVHRK

$0.10 \% \quad 48.8 \%$ HIMGQNVADYMR

$0.10 \% \quad 48.8 \%$ YLMEEDEDAYKK

$0.10 \% \quad 48.8 \%$ NSVTPDMMEEMYK

$0.10 \% \quad 48.8 \%$ NSVTPDMMEEMYKK

$0.10 \% \quad 48.8 \%$ AHAAIRENPVYEK

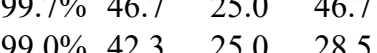

$\begin{array}{llll}99.7 \% & 37.4 & 25.0 & 30.0\end{array}$

$\begin{array}{llll}99.7 \% & 53.5 & 25.0 & 46.5\end{array}$

$\begin{array}{llll}99.7 \% & 55.8 & 25.0 & 51.5\end{array}$

$99.7 \% \quad 51.7 \quad 25.0 \quad 51.7$

$\begin{array}{llll}99.7 \% & 51.7 & 25.0 & 51.7\end{array}$

$\begin{array}{llll}98.4 \% & 22.1 & 25.0 & 14.8\end{array}$

$\begin{array}{lllll}99.7 \% & 86.5 & 25.0 & 76.5\end{array}$

$0.10 \% \quad 48.3 \%$ EKVLATVTKPVGGDK

$\begin{array}{llll}99.7 \% & 53.8\end{array}$

$0.10 \% \quad 48.3 \%$ VLATVTKPVGGDKNGGT

$99.3 \% 21.7$

$0.10 \% \quad 48.3 \%$ YYPTEDVPR

$0.10 \% \quad 48.3 \%$ YYPTEDVPRK

$0.10 \% \quad 48.3 \%$ KPFSQHVR

$99.7 \% \quad 60.8$

$99.7 \% 33.7$

$99.0 \% \quad 41.4$

$99.7 \% \quad 62.3$

$0.10 \% \quad 48.3 \%$ ASITPGTILIILTGR

$\begin{array}{lll}99.7 \% & 62.3 \\ 99.7 \% & 53.7\end{array}$

$99.0 \% 36.3$

$\begin{array}{llll}99.0 \% & 32.3\end{array}$

$99.7 \% \quad 39.6$

$99.7 \% \quad 61.2$

$99.7 \% \quad 34.8$

$99.7 \% \quad 46.8$

$99.7 \% \quad 58.0$

$\begin{array}{llll}99.7 \% & 54.6\end{array}$

$\begin{array}{llll}99.7 \% & 54.8\end{array}$

$99.7 \% \quad 34.9$

$99.7 \% \quad 48.1$

$99.7 \% \quad 50.2$

$\begin{array}{llll}99.7 \% & 36.8\end{array}$

$99.7 \% \quad 38.7$

$99.7 \% \quad 34.8$

$99.0 \% \quad 49.1$

$99.7 \% \quad 42.0$

$99.7 \% \quad 62.0$

$99.7 \% \quad 60.4$

$98.4 \% \quad 20.0$

$\begin{array}{lll}99.7 \% & 48.4\end{array}$

$0.05 \% \quad 39.5 \%$ EALNALW

$0.05 \% \quad 39.5 \%$ TTHFVEGGDAGNR

$\begin{array}{lll}99.7 \% & 60.3\end{array}$

$0.06 \% \quad 45.1 \%$ KVAPAPAVVK
1932.92

1927.01

1236.69

1338.70

1494.80

1185.55

1029.45

2011.91

1001.48

1129.57

1434.66

1533.68

1574.65

1702.75

1497.78

1541.89

1284.75

1769.99

1139.54

1267.63

998.55

1525.93

1764.07

866.50

994.50

1122.59

1332.61

1589.74

1195.60

970.56

1158.66

1446.77

1210.70

1320.69

1192.60

1322.76

1053.57

1662.89

965.53

1121.63

1326.79

1170.68

1265.63

1360.62

2115.98

979.63

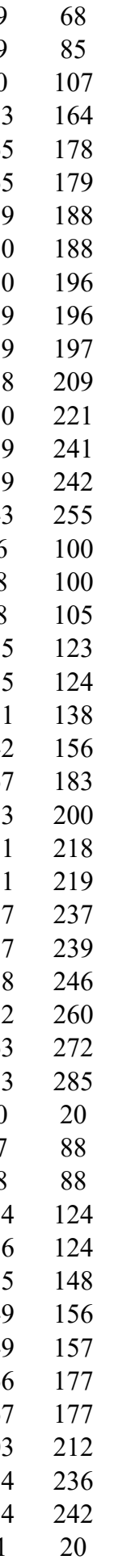

Page 16 of Table S-1- 6 
$60 \mathrm{~S}$ ribosomal protein $\mathrm{L} 7 \mathrm{a} \mathrm{GN}=\mathrm{RPL} 7 \mathrm{~A}$ $60 \mathrm{~S}$ ribosomal protein $\mathrm{L} 7 \mathrm{a} \mathrm{GN}=\mathrm{RPL} 7 \mathrm{~A}$ $60 \mathrm{~S}$ ribosomal protein $\mathrm{L} 7 \mathrm{a} \mathrm{GN}=\mathrm{RPL7A}$ $60 \mathrm{~S}$ ribosomal protein $\mathrm{L} 7 \mathrm{a} \mathrm{GN}=\mathrm{RPL} 7 \mathrm{~A}$ $60 \mathrm{~S}$ ribosomal protein $\mathrm{L} 7 \mathrm{a} \mathrm{GN}=\mathrm{RPL7A}$ $60 \mathrm{~S}$ ribosomal protein $\mathrm{L} 7 \mathrm{a} \mathrm{GN}=\mathrm{RPL} 7 \mathrm{~A}$ $60 \mathrm{~S}$ ribosomal protein $\mathrm{L} 7 \mathrm{a} \mathrm{GN}=\mathrm{RPL} 7 \mathrm{~A}$ $60 \mathrm{~S}$ ribosomal protein $\mathrm{L} 7 \mathrm{a} \mathrm{GN}=\mathrm{RPL} 7 \mathrm{~A}$ $60 \mathrm{~S}$ ribosomal protein $\mathrm{L} 7 \mathrm{a} \mathrm{GN}=\mathrm{RPL} 7 \mathrm{~A}$ $60 \mathrm{~S}$ ribosomal protein $\mathrm{L} 7 \mathrm{a} \mathrm{GN}=\mathrm{RPL7A}$ $60 \mathrm{~S}$ ribosomal protein $\mathrm{L} 7 \mathrm{a} \mathrm{GN}=\mathrm{RPL} 7 \mathrm{~A}$ $60 \mathrm{~S}$ ribosomal protein $\mathrm{L} 7 \mathrm{a} \mathrm{GN}=\mathrm{RPL} 7 \mathrm{~A}$ $60 \mathrm{~S}$ ribosomal protein $\mathrm{L} 7 \mathrm{a} \mathrm{GN}=\mathrm{RPL} 7 \mathrm{~A}$ $60 \mathrm{~S}$ ribosomal protein $\mathrm{L} 7 \mathrm{a} \mathrm{GN}=\mathrm{RPL} 7 \mathrm{~A}$ $60 \mathrm{~S}$ ribosomal protein $\mathrm{L} 7 \mathrm{a} \mathrm{GN}=\mathrm{RPL} 7 \mathrm{~A}$ $60 \mathrm{~S}$ ribosomal protein $\mathrm{L} 7 \mathrm{a} \mathrm{GN}=\mathrm{RPL} 7 \mathrm{~A}$ $60 \mathrm{~S}$ ribosomal protein $\mathrm{L} 7 \mathrm{a} \mathrm{GN}=\mathrm{RPL} 7 \mathrm{~A}$ $60 \mathrm{~S}$ ribosomal protein $\mathrm{L} 7$-like $1 \mathrm{GN}=\mathrm{RPL} 7 \mathrm{LI}$ $60 \mathrm{~S}$ ribosomal protein $\mathrm{L} 7$-like $1 \mathrm{GN}=\mathrm{RPL7L1}$ RL7L_HUMAN $28.66 \quad 100.0 \%$ $60 \mathrm{~S}$ ribosomal protein L7-like $1 \mathrm{GN}=$ RPL7L1 RL7L_HUMAN $28.66 \quad 100.0 \%$ $60 \mathrm{~S}$ ribosomal protein L7-like $1 \mathrm{GN}=\mathrm{RPL} 7 \mathrm{~L} 1$ RL7L_HUMAN $28.66 \quad 100.0 \%$ $60 \mathrm{~S}$ ribosomal protein $\mathrm{L} 7$-like $1 \mathrm{GN}=\mathrm{RPL} 7 \mathrm{~L} 1 \mathrm{RL} 7 \mathrm{~L}$ HUMAN $28.66 \quad 100.0 \%$ $60 \mathrm{~S}$ ribosomal protein $\mathrm{L} 8 \mathrm{GN}=\mathrm{RPL} 8$ $60 \mathrm{~S}$ ribosomal protein $\mathrm{L} 8 \mathrm{GN}=\mathrm{RPL} 8$ $60 \mathrm{~S}$ ribosomal protein $\mathrm{L} 8 \mathrm{GN}=\mathrm{RPL} 8$ $60 \mathrm{~S}$ ribosomal protein $\mathrm{L} 8 \mathrm{GN}=\mathrm{RPL} 8$ $60 \mathrm{~S}$ ribosomal protein $\mathrm{L} 8 \mathrm{GN}=\mathrm{RPL} 8$ $60 \mathrm{~S}$ ribosomal protein $\mathrm{L} 8 \mathrm{GN}=\mathrm{RPL} 8$ $60 \mathrm{~S}$ ribosomal protein $\mathrm{L} 8 \mathrm{GN}=\mathrm{RPL} 8$ $60 \mathrm{~S}$ ribosomal protein $\mathrm{L} 8 \mathrm{GN}=\mathrm{RPL} 8$ $60 \mathrm{~S}$ ribosomal protein $\mathrm{L} 8 \mathrm{GN}=\mathrm{RPL} 8$ $60 \mathrm{~S}$ ribosomal protein $\mathrm{L} 9 \mathrm{GN}=\mathrm{RPL} 9$ $60 \mathrm{~S}$ ribosomal protein $\mathrm{L} 9 \mathrm{GN}=\mathrm{RPL} 9$ $60 \mathrm{~S}$ ribosomal protein $\mathrm{L} 9 \mathrm{GN}=\mathrm{RPL} 9$ $60 \mathrm{~S}$ ribosomal protein $\mathrm{L} 9 \mathrm{GN}=\mathrm{RPL} 9$ $60 \mathrm{~S}$ ribosomal protein $\mathrm{L} 9 \mathrm{GN}=\mathrm{RPL} 9$ 60 S ribosomal protein $\mathrm{L} 9 \mathrm{GN}=\mathrm{RPL} 9$ $60 \mathrm{~S}$ ribosomal protein $\mathrm{L} 9 \mathrm{GN}=\mathrm{RPL} 9$

RL8_HUMAN $28.02 \quad 100.0 \%$ RL8_HUMAN $28.02 \quad 100.0 \%$ RL8 HUMAN $28.02 \quad 100.0 \%$ RL8_HUMAN $28.02 \quad 100.0 \%$ RL8_HUMAN $28.02 \quad 100.0 \%$ RL8 HUMAN $28.02 \quad 100.0 \%$ RL8_HUMAN $28.02 \quad 100.0 \%$ RL8 HUMAN $28.02 \quad 100.0 \%$ RL8_HUMAN $28.02 \quad 100.0 \%$ RL9_HUMAN $21.86 \quad 100.0 \%$ RL9 HUMAN $21.86 \quad 100.0 \%$ RL9_HUMAN $21.86 \quad 100.0 \%$ RL9_HUMAN $21.86 \quad 100.0 \%$ RL9_HUMAN $21.86 \quad 100.0 \%$ RL9_HUMAN $21.86 \quad 100.0 \%$ RL9 HUMAN $21.86 \quad 100.0 \%$ $78 \mathrm{kDa}$ glucose-regulated protein GN=HSPA5 GRP78_HUMAN $72.33 \quad 100.0 \%$ $\begin{array}{lllll}78 \mathrm{kDa} \text { glucose-regulated protein GN=HSPA5 GRP78_HUMAN } & 72.33 & 100.0 \% & 1\end{array}$ $78 \mathrm{kDa}$ glucose-regulated protein GN=HSPA5 GRP78_HUMAN $72.33 \quad 100.0 \%$ $78 \mathrm{kDa}$ glucose-regulated protein GN=HSPA5 GRP78_HUMAN $72.33 \quad 100.0 \% \quad 12$ $78 \mathrm{kDa}$ glucose-regulated protein GN=HSPA5 GRP78_HUMAN $72.33 \quad 100.0 \%$ $78 \mathrm{kDa}$ glucose-regulated protein GN=HSPA5 GRP78_HUMAN $72.33 \quad 100.0 \%$ $78 \mathrm{kDa}$ glucose-regulated protein GN=HSPA5 GRP78_HUMAN $72.33 \quad 100.0 \% \quad 12$ $78 \mathrm{kDa}$ glucose-regulated protein GN=HSPA5 GRP78_HUMAN $72.33 \quad 100.0 \% \quad 12$ $\begin{array}{lllll}78 \mathrm{kDa} \text { glucose-regulated protein GN=HSPA5 GRP78_HUMAN } & 72.33 & 100.0 \% & 12\end{array}$
$0.06 \% \quad 45.1 \%$ KVVNPLFEK

$0.06 \% \quad 45.1 \%$ VVNPLFEK

$0.06 \% \quad 45.1 \%$ NFGIGQDIQPK

$0.06 \% \quad 45.1 \%$ VPPAINQFTQALDR

$0.06 \% \quad 45.1 \%$ QTATQLLK

$0.06 \% \quad 45.1 \%$ AGVNTVTTLVENK

$0.06 \% \quad 45.1 \%$ AGVNTVTTLVENKK

$0.06 \% \quad 45.1 \%$ KMGVPYCIIK

$0.06 \% \quad 45.1 \%$ MGVPYCIIK

$0.06 \% \quad 45.1 \%$ KTCTTVAFTQVNSEDK

$0.06 \% \quad 45.1 \%$ TCTTVAFTQVNSEDK

$0.06 \% \quad 45.1 \%$ TCTTVAFTQVNSEDKGALAK

$0.06 \% \quad 45.1 \%$ TNYNDRYDEIR

$0.06 \% \quad 45.1 \%$ RHWGGNVLGPK

$0.06 \% \quad 45.1 \%$ HWGGNVLGPK

$0.01 \% \quad 20.3 \%$ KIPLVPENLLK

$0.01 \% \quad 20.3 \%$ LESFLHDSWR

$0.01 \% \quad 20.3 \%$ IDGVSLLVQR

$0.01 \% \quad 20.3 \%$ IFSGVFVK

$0.01 \% \quad 20.3 \%$ EMGTPGYRGER

$0.04 \% \quad 32.3 \%$ GIVKDIIHDPGR

$0.04 \% 32.3 \%$ DIIHDPGR

$\begin{array}{llll}9.7 \% & 33.0 & 25.0 & 33.0\end{array}$

$\begin{array}{llll}98.9 \% & 18.5 & 25.0 & 18.5\end{array}$

$\begin{array}{llll}99.7 \% & 38.7 & 25.0 & 22.9\end{array}$

$99.0 \% \quad 32.0 \quad 25.0 \quad 31.2$

$\begin{array}{llll}99.7 \% & 58.6 & 25.0 & 50.2\end{array}$

$99.7 \% \quad 42.4 \quad 25.0 \quad 39.4$

$99.0 \% \quad 46.6 \quad 25.0 \quad 26.9$

$\begin{array}{llll}99.7 \% & 60.1 & 25.0 & 60.1\end{array}$

$\begin{array}{llll}99.7 \% & 60.9 & 25.0 & 60.9\end{array}$

$\begin{array}{llll}99.7 \% & 35.5 & 25.0 & 29.4\end{array}$

$\begin{array}{llll}97.8 \% & 18.0 & 25.0 & 15.8\end{array}$

$\begin{array}{llll}99.7 \% & 37.0 & 25.0 & 34.0\end{array}$

$\begin{array}{llll}99.7 \% & 72.8 & 25.0 & 72.8\end{array}$

$\begin{array}{llll}99.7 \% & 39.8 & 25.0 & 39.8\end{array}$

$\begin{array}{llll}99.7 \% & 37.3 & 25.0 & 31.1\end{array}$

$99.5 \% \quad 25.1 \quad 25.0 \quad 24.9$

$\begin{array}{llll}99.7 \% & 39.2 & 25.0 & 39.2\end{array}$

$\begin{array}{llll}99.1 \% & 19.5 & 25.0 & 19.5\end{array}$

$\begin{array}{llll}97.5 \% & 29.8 & 25.0 & 16.5\end{array}$

$99.7 \% \quad 72.8 \quad 25.0 \quad 51.8$

$\begin{array}{llll}99.0 \% & 27.9 & 25.0 & 18.5\end{array}$

$\begin{array}{llll}98.8 \% & 19.8 & 25.0 & 18.7\end{array}$

$\begin{array}{llll}99.7 \% & 48.4 & 25.0 & 48.4\end{array}$

$\begin{array}{llll}99.0 \% & 35.2 & 25.0 & 24.8\end{array}$

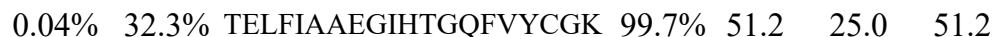

$0.04 \% \quad 32.3 \%$ ASGNYATVISHNPETK

$99.7 \% \quad 55.9$

$0.04 \% \quad 32.3 \%$ ASGNYATVISHNPETKK

$0.04 \% \quad 32.3 \%$ VKLPSGSK

$0.04 \% \quad 32.3 \%$ AVVGVVAGGGR

$99.7 \% \quad 57.3$

$99.0 \% 34.1$

$99.7 \% \quad 53.3$

0.04\% 32.3\% AVVGVVAGGGRIDKPILK $99.7 \% \quad 32.2$

$0.04 \% \quad 32.3 \%$ KVGLIAAR

$99.0 \% \quad 56.9$

$\begin{array}{lllll}0.02 \% & 38.5 \% & \text { TILSNQTVDIPENVDITLKGR } & 99.7 \% & 48.2\end{array}$

$0.02 \% \quad 38.5 \%$ TVIVKGPR

$0.02 \% \quad 38.5 \%$ DFNHINVELSLLGKK

$0.02 \% \quad 38.5 \%$ TICSHVQNMIK

$0.02 \% \quad 38.5 \%$ KFLDGIYVSEK

$99.0 \% 30.1$

$99.7 \% \quad 42.3$

$99.7 \% \quad 35.2$

$99.7 \% 34.6$

$99.7 \% \quad 54.8$

$0.02 \% \quad 38.5 \%$ FLDGIYVSEKGTVQQADE $99.7 \% \quad 30.1$

$0.04 \% \quad 24.3 \%$ VEIIANDQGNR

$0.04 \% \quad 24.3 \%$ ITPSYVAFTPEGER

$99.3 \% \quad 60.5$

$99.7 \% \quad 54.6$

$99.7 \% \quad 63.6$

$0.04 \% \quad 24.3 \%$ NQLTSNPENTVFDAK

$0.04 \% \quad 24.3 \%$ NQLTSNPENTVFDAKR

$99.7 \% \quad 66.9$

$0.04 \% \quad 24.3 \%$ TKPYIQVDIGGGQTK

$\begin{array}{lll}99.7 \% & 38.3\end{array}$

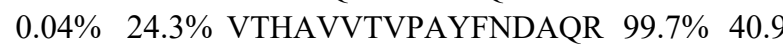

$0.04 \% \quad 24.3 \%$ QATKDAGTIAGLNVMR

$0.04 \% \quad 24.3 \%$ DAGTIAGLNVMR

$99.7 \% \quad 69.3$

$99.7 \% \quad 63.9$
851.53

979.63

1073.64

945.54

1216.63

1569.84

902.53

1345.73

1473.83

1224.65

1096.55

1828.87

1700.78

2141.05

1458.66

1220.66

1064.56

1263.80

1289.63

1099.65

896.52

1268.57

1319.74

922.47

2241.10

1688.82

1816.92

815.50

941.55

1749.07

827.55

2326.26

869.56

1726.95

1346.66

1298.70

1170.60

1998.97

1228.63

1566.78

1677.81

1833.91

1604.86

1887.97

1645.87

1217.63

1659.90

20
2
34
34
48
89
97
150
15
185
185
2
2
2
234
245
245
18
61
105
122
237
54
54
92
144
145
155
174
181
241
23
31
5
197
187
184
184
97
9

Page 17 of Table S-1- 
$\begin{array}{lllll}78 \mathrm{kDa} \text { glucose-regulated protein GN=HSPA5 GRP78_HUMAN } & 72.33 & 100.0 \% & 1\end{array}$ $78 \mathrm{kDa}$ glucose-regulated protein GN=HSPA5 GRP78_HUMAN $72.33 \quad 100.0 \%$ $78 \mathrm{kDa}$ glucose-regulated protein GN=HSPA5 GRP78_HUMAN $72.33 \quad 100.0 \% \quad 1$ $78 \mathrm{kDa}$ glucose-regulated protein GN=HSPA5 GRP78_HUMAN $72.33 \quad 100.0 \%$ $78 \mathrm{kDa}$ glucose-regulated protein GN=HSPA5 GRP78_HUMAN $72.33 \quad 100.0 \%$ 7-dehydrocholesterol reductase GN=DHCR7 DHCR7_HUMAN $54.49 \quad 100.0 \%$ 7-dehydrocholesterol reductase GN=DHCR7 DHCR7_HUMAN $54.49 \quad 100.0 \%$ 7-dehydrocholesterol reductase GN=DHCR7 DHCR7_HUMAN $54.49 \quad 100.0 \%$ 7-dehydrocholesterol reductase GN=DHCR7 DHCR7 HUMAN $54.49 \quad 100.0 \%$ 7-dehydrocholesterol reductase GN=DHCR7 DHCR7_HUMAN $54.49 \quad 100.0 \%$ 7-dehydrocholesterol reductase GN=DHCR7 DHCR7_HUMAN $54.49 \quad 100.0 \%$ $7 \mathrm{SK}$ snRNA methylphosphate capping enzyme GN=MEPCE MEPCE HUMAN $74.36 \quad 100.0 \%$ 7SK snRNA methylphosphate capping enzyme GN=MEPCE MEPCE_HUMAN $74.36 \quad 100.0 \%$ Acetolactate synthase-like protein GN=ILVBL ILVBL_HUMAN $67.87 \quad 100.0 \%$ Acetolactate synthase-like protein GN=ILVBL ILVBL_HUMAN $67.87 \quad 100.0 \%$ Acetolactate synthase-like protein GN=ILVBL ILVBL_HUMAN $67.87 \quad 100.0 \%$ Acetolactate synthase-like protein GN=ILVBL ILVBL HUMAN $67.87 \quad 100.0 \%$ Acetolactate synthase-like protein GN=ILVBL ILVBL_HUMAN $67.87 \quad 100.0 \%$ Acetolactate synthase-like protein GN=ILVBL ILVBL_HUMAN $67.87 \quad 100.0 \%$ Acetyl-CoA acetyltransferase, mitochondrial GN=ACAT1 THIL HUMAN $45.20 \quad 100.0 \%$ Acetyl-CoA acetyltransferase, mitochondrial GN=ACAT1 THIL_HUMAN $45.20 \quad 100.0 \%$ Acetyl-CoA acetyltransferase, mitochondrial GN=ACAT1 THIL_HUMAN $45.20 \quad 100.0 \%$ Acetyl-CoA acetyltransferase, mitochondrial GN=ACAT1 THIL_HUMAN $45.20 \quad 100.0 \%$ Acetyl-CoA acetyltransferase, mitochondrial GN=ACAT1 THIL_HUMAN $45.20 \quad 100.0 \%$ Acetyl-CoA acetyltransferase, mitochondrial GN=ACAT1 THIL HUMAN $45.20 \quad 100.0 \%$ Acetyl-CoA acetyltransferase, mitochondrial GN=ACAT1 THIL_HUMAN $45.20 \quad 100.0 \%$ Acetyl-CoA carboxylase $1 \mathrm{GN}=$ ACACA ACACA_HUMAN $265.56 \quad 100.0 \%$ Acetyl-CoA carboxylase $1 \mathrm{GN}=\mathrm{ACACA} \quad$ ACACA_HUMAN $265.56 \quad 100.0 \%$ Acidic fibroblast growth factor intracellular-binding protein GN=FIBP FIBP_HUMAN $41.88 \quad 100.0 \%$ Acidic fibroblast growth factor intracellular-binding protein GN=FIBP $\quad$ FIBP HUMAN $41.88 \quad 100.0 \%$ Acidic fibroblast growth factor intracellular-binding protein GN=FIBP FIBP_HUMAN $41.88 \quad 100.0 \%$ Acidic fibroblast growth factor intracellular-binding protein GN=FIBP FIBP_HUMAN $41.88 \quad 100.0 \%$ Acidic fibroblast growth foctor intrellular binding protein GN=FIBP FIBP HUMAN $41.88 \quad 100.0^{\circ}$ $\begin{array}{lll}\text { Acidic fibroblast growth factor intracellular-binding protein GN=FIBP } & \text { FIBP_HUMAN } 41.88 \quad 100.0 \%\end{array}$ Actin, alpha skeletal muscle GN=ACTA1 ACTS_HUMAN $42.05 \quad 100.0 \%$ Actin, alpha skeletal muscle GN=ACTA1 ACTS_HUMAN $42.05 \quad 100.0 \%$ Actin, alpha skeletal muscle GN=ACTA1 ACTS_HUMAN $42.05 \quad 100.0 \%$ Actin, alpha skeletal muscle GN=ACTA1 ACTS_HUMAN $42.05 \quad 100.0 \%$ Actin, alpha skeletal muscle GN=ACTA1 ACTS_HUMAN $42.05 \quad 100.0 \%$ Actin, alpha skeletal muscle GN=ACTA1 ACTS_HUMAN $42.05 \quad 100.0 \%$ Actin, alpha skeletal muscle GN=ACTA1 ACTS_HUMAN $42.05 \quad 100.0 \%$ Actin, alpha skeletal muscle GN=ACTA1 ACTS_HUMAN $42.05 \quad 100.0 \%$ Actin, alpha skeletal muscle GN=ACTA1 ACTS HUMAN $42.05 \quad 100.0 \%$ Actin, alpha skeletal muscle GN=ACTA1 ACTS_HUMAN $42.05 \quad 100.0 \%$ Actin, alpha skeletal muscle GN=ACTA1 ACTS_HUMAN $42.05 \quad 100.0 \%$ Actin, alpha skeletal muscle GN=ACTA1 ACTS_HUMAN $42.05 \quad 100.0 \%$ Actin, alpha skeletal muscle GN=ACTA1 ACTS_HUMAN $42.05 \quad 100.0 \%$ $\begin{array}{llll}15 & 35 & 0.04 \% & 24.3 \% \\ 15 & 35 & 0.04 \% & 24.3 \% \text { SDIDEIVLVGGSTR }\end{array}$ $99.7 \% \quad 40.9$ $0.04 \% \quad 24.3 \%$ KSQIFSTASDNQPTVTIK

\section{(1)}

$99.7 \% \quad 30.1$

$0.04 \% \quad 24.3 \%$ SQIFSTASDNQPTVTIK

$99.7 \% \quad 58.1$

$99.7 \% \quad 37.3$

GERPLTK

$0.04 \% \quad 24.3 \%$ ELEEIVQPIISK

$0.02 \% \quad 15.2 \%$ SLDGVTNDR

$99.7 \% \quad 53.0$

$99.7 \% \quad 53.3$

$0.02 \% \quad 15.2 \%$ FLPGYVGGIQEGAVTPAGVVNK $\quad 99.7 \% \quad 55.5$

$0.02 \% \quad 15.2 \%$ GYFFPTSAR

$0.02 \% \quad 15.2 \%$ VIECSYTSADGQR

$99.7 \% \quad 46.0$

$99.7 \% \quad 54.0$

$99.7 \% \quad 52.4$

$99.0 \% \quad 26.9$

$0.02 \% \quad 15.2 \%$ YTAAVPYR

$\begin{array}{lllll}0.00 \% & 4.4 \% & \text { ESPGAAATSSSGPQAQQHR } & 97.2 \% & 19.6 \\ 0.00 \% & 4.4 \% & \text { SCFPASLTASR } & 99.7 \% & 27.7\end{array}$

$0.02 \% \quad 16.3 \%$ LSGTVGVAAVTAGPGLTNTVTAVK $\quad 99.7 \% \quad 56.2$

$0.02 \% \quad 16.3 \%$ GALQAVDQLSLFRPLCK $99.1 \% 20.2$

$0.02 \% \quad 16.3 \%$ AAVETLGVPCFLGGMAR $99.7 \% \quad 50.6$

$0.02 \% \quad 16.3 \%$ EQVPSLGSNVACGLAYTDYHK $99.7 \% 35.3$

$0.02 \% \quad 16.3 \%$ GLLLSRENEDQVVK

$0.02 \% \quad 16.3 \%$ TDFRDGSIAV

$0.01 \% \quad 20.8 \%$ EVVIVSATR

$0.01 \% 20.8 \%$ TPIGSFLGSLSLLPATK

$0.01 \% \quad 20.8 \%$ LGSIAIQGAIEK

$95.8 \% \quad 18.6$

$99.6 \% \quad 25.2$

$99.7 \% \quad 57.5$

$99.7 \% \quad 63.7$

$99.7 \% \quad 58.7$

$0.01 \% \quad 20.8 \%$ EAYMGNVLQGGEGQAPTR $99.7 \% \quad 48.0$

$0.01 \% \quad 20.8 \%$ IHMGSCAENTAK

$0.01 \% \quad 20.8 \%$ NEQDAYAINSYTR

$99.3 \% \quad 21.8$

$99.7 \% \quad 69.6$

$0.01 \% \quad 20.8 \%$ LNVTPLAR

$0.00 \% \quad 1.2 \%$ AIGIGAYLVR

$99.0 \% 39.6$

$99.5 \% \quad 28.5$

$0.00 \% \quad 1.2 \%$ TIQVENSHLILTGAGALNK $\quad 99.7 \% \quad 34.4$

$99.7 \% \quad 52.7$

$99.7 \% \quad 29.8$

$99.7 \% \quad 51.5$

$99.3 \% \quad 27.5$

$99.7 \% \quad 38.1$

$99.7 \% \quad 28.4$

$\begin{array}{lll}99.7 \% & 55.9\end{array}$

$99.7 \% \quad 48.3$

$99.7 \% \quad 48.2$

$0.00 \% \quad 35.8 \%$ AVFPSIVGRPR

$0.00 \% \quad 35.8 \%$ HQGVMVGMGQK

$0.00 \% \quad 35.8 \%$ HQGVMVGMGQKDSYVGDEAQSK

$0.00 \% \quad 35.8 \%$ DSYVGDEAQSK

$0.00 \% \quad 35.8 \%$ DSYVGDEAQSKR

$0.00 \% \quad 35.8 \%$ YPIEHGIITNWDDMEK

$0.00 \% \quad 35.8 \%$ IWHHTFYNELR

$0.00 \% \quad 35.8 \%$ LDLAGRDLTDYLMK

$0.00 \% \quad 35.8 \%$ DLTDYLMK

$0.00 \% \quad 35.8 \%$ GYSFVTTAER

$0.00 \% \quad 35.8 \%$ SYELPDGQVITIGNER

$0.00 \% \quad 35.8 \%$ MQKEITALAPSTMK

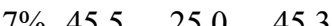

$\begin{array}{llll}99.7 \% & 54.2 & 25.0 & 54.2\end{array}$

$99.7 \% \quad 53.4 \quad 25.0 \quad 50.7$

$\begin{array}{llll}98.6 \% & 17.7 & 25.0 & 17.7\end{array}$

$\begin{array}{llll}99.7 \% & 34.1 & 25.0 & 32.7\end{array}$

$\begin{array}{llll}99.7 \% & 42.8 & 25.0 & 39.5\end{array}$

$\begin{array}{llll}99.0 \% & 49.2 & 25.0 & 39.2\end{array}$

$99.6 \% \quad 27.6 \quad 25.0 \quad 21.6$

$\begin{array}{llll}99.7 \% & 59.2 & 25.0 & 50.3\end{array}$

$99.7 \% \quad 60.4 \quad 25.0 \quad 51.6$

0
0
0
0
0
0
0
0
0
0
0
0
0
0
0
0
0
0
0
0
0
0
0
0
0
0
0
0
0
0
0
0
0
0
0
0
0
0
0
0
0
0
0
0
0
0
0
0
0
0
0
0
0

1836.93

1397.79

976.47

2173.17

1045.51

1485.66

1204.68

940.49

1866.87

1196.57

2184.22

1916.04

1748.88

2309.09

1599.87

1080.53

973.57

1701.98

1199.70

1877.88

1318.59

1544.70

883.54

1032.62

1979.09

1280.59

1841.95

1400.70

1478.86

1371.66

1077.58

976.45

1198.71

1187.57

2383.07

1198.52

1354.62

1960.9

1515.75

1639.84

998.49

1130.55

1790.89

1548.81 $\begin{array}{cc}354 & 367 \\ 477 & 464 \\ 448 & 464 \\ 65 & 474 \\ 622 & 633 \\ 14 & 22 \\ 21 & 142 \\ 99 & 207 \\ 377 & 389 \\ 394 & 404 \\ 62 & 469 \\ 68 & 86 \\ 521 & 531 \\ 11 & 134 \\ 58 & 174 \\ 306 & 322 \\ 557 & 577 \\ 586 & 599 \\ 623 & 632 \\ 41 & 49 \\ 50 & 66 \\ 67 & 78 \\ 88 & 105 \\ 91 & 202 \\ 209 & 221 \\ 304 & 311 \\ 824 & 1833 \\ 838 & 1856 \\ 96 & 105 \\ 53 & 168 \\ 72 & 183 \\ 246 & 258 \\ 269 & 280 \\ 301 & 309 \\ 21 & 30 \\ 31 & 41 \\ 42 & 52 \\ 42 & 63 \\ 53 & 63 \\ 53 & 64 \\ 71 & 86 \\ 87 & 97 \\ 80 & 193 \\ 86 & 193 \\ 99 & 208 \\ 241 & 256 \\ 315 & 328 \\ & \end{array}$

Page 18 of Table S-1-6 
Actin, alpha skeletal muscle GN=ACTA1 ACTS_HUMAN $42.05 \quad 100.0 \%$ Actin, alpha skeletal muscle GN=ACTA1 ACTS_HUMAN $42.05 \quad 100.0 \%$ Actin, alpha skeletal muscle GN=ACTA1 ACTS_HUMAN $42.05 \quad 100.0 \%$ Actin, alpha skeletal muscle GN=ACTAI ACTS HUMAN $42.05 \quad 100.0 \%$ Actin, cytoplasmic $1 \mathrm{GN}=\mathrm{ACTB}$ Actin, cytoplasmic $1 \mathrm{GN}=\mathrm{ACTB}$ Actin, cytoplasmic $1 \mathrm{GN}=\mathrm{ACTB}$ Actin, cytoplasmic $1 \mathrm{GN}=\mathrm{ACTE}$ Actin, cytoplasmic $1 \mathrm{GN}=\mathrm{ACTH}$ Actin, cytoplasmic $1 \mathrm{GN}=\mathrm{ACTB}$ Actin, cytoplasmic $1 \mathrm{GN}=\mathrm{ACTB}$ Actin, cytoplasmic $1 \mathrm{GN}=\mathrm{ACTB}$ Actin, cytoplasmic $1 \mathrm{GN}=\mathrm{ACTE}$ Actin, cytoplasmic $1 \mathrm{GN}=\mathrm{ACTB}$ Actin, cytoplasmic $1 \mathrm{GN}=\mathrm{ACTB}$ Actin, cytoplasmic $1 \mathrm{GN}=\mathrm{ACTB}$ Actin, cytoplasmic $1 \mathrm{GN}=\mathrm{ACTB}$ Actin, cytoplasmic $1 \mathrm{GN}=\mathrm{ACTB}$ Actin, cytoplasmic $1 \mathrm{GN}=\mathrm{ACTB}$ Actin, cytoplasmic $1 \mathrm{GN}=\mathrm{ACTB}$ Actin, cytoplasmic $1 \mathrm{GN}=\mathrm{ACTB}$ Actin, cytoplasmic $1 \mathrm{GN}=\mathrm{ACTB}$ Actin, cytoplasmic $1 \mathrm{GN}=\mathrm{ACTB}$ Actin, cytoplasmic $1 \mathrm{GN}=\mathrm{ACTB}$ Actin, cytoplasmic $1 \mathrm{GN}=\mathrm{ACTB}$ Actin, cytoplasmic $1 \mathrm{GN}=\mathrm{ACTB}$ Actin, cytoplasmic $1 \mathrm{GN}=\mathrm{ACTB}$ Actin, cytoplasmic $1 \mathrm{GN}=\mathrm{ACTB}$ Actin, cytoplasmic $1 \mathrm{GN}=\mathrm{ACTB}$ Actin, cytoplasmic $1 \mathrm{GN}=\mathrm{ACTB}$ Actin-related protein $2 \mathrm{GN}=\mathrm{ACTR} 2$ Actin-related protein $2 \mathrm{GN}=\mathrm{ACTR} 2$ Actin-related protein $2 \mathrm{GN}=\mathrm{ACTR} 2$ Actin-related protein $2 \mathrm{GN}=\mathrm{ACTR} 2$ Actin-related protein $2 \mathrm{GN}=\mathrm{ACTR} 2$ ACTB_HUMAN $41.74 \quad 100.0 \% \quad 26$ ACTB_HUMAN $41.74 \quad 100.0 \% \quad 26$ ACTB HUMAN $41.74 \quad 100.0 \% \quad 26$ ACTB_HUMAN $41.74 \quad 100.0 \% \quad 26$ ACTB HUMAN $41.74 \quad 100.0 \% \quad 26$ ACTB_HUMAN $41.74 \quad 100.0 \% \quad 26$ ACTB_HUMAN $41.74 \quad 100.0 \% \quad 26$ ACTB HUMAN $41.74 \quad 100.0 \% \quad 26$ ACTB_HUMAN $41.74 \quad 100.0 \% \quad 26$ ACTB_HUMAN $41.74 \quad 100.0 \% \quad 26$ ACTB_HUMAN $41.74 \quad 100.0 \% \quad 26$ ACTB_HUMAN $41.74 \quad 100.0 \% \quad 26$ ACTB HUMAN $41.74 \quad 100.0 \% \quad 26$ ACTB_HUMAN $41.74 \quad 100.0 \% \quad 26$ ACTB_HUMAN $41.74 \quad 100.0 \% \quad 26$ ACTB HUMAN $41.74 \quad 100.0 \% \quad 26$ ACTB_HUMAN $41.74 \quad 100.0 \% \quad 26$ ACTB_HUMAN $41.74 \quad 100.0 \% \quad 26$ ACTB_HUMAN $41.74 \quad 100.0 \% \quad 26$ ACTB_HUMAN $41.74 \quad 100.0 \% \quad 26$ ACTB HUMAN $41.74 \quad 100.0 \% \quad 26$ ACTB_HUMAN $41.74 \quad 100.0 \% \quad 26$ ACTB_HUMAN $41.74 \quad 100.0 \% \quad 26$ ACTB HUMAN $41.74 \quad 100.0 \% \quad 26$ ACTB_HUMAN $41.74 \quad 100.0 \% \quad 26$ ACTB HUMAN $41.74 \quad 100.0 \% \quad 26$ ARP2_HUMAN $44.76 \quad 100.0 \% \quad 5$ ARP2_HUMAN $44.76 \quad 100.0 \% \quad 5$ ARP2_HUMAN $44.76 \quad 100.0 \%$ ARP2_HUMAN $44.76 \quad 100.0 \%$ ARP2 HUMAN $44.76 \quad 100.0 \% \quad 5$ Activating signal cointegrator 1 complex subunit $3 \mathrm{GN}=\mathrm{ASCC} 3 \mathrm{ASCC} 3$ HUMAN $251.47 \quad 100.0 \%$ Activating signal cointegrator 1 complex subunit $3 \mathrm{GN}=\mathrm{ASCC} 3$ ASCC3_HUMAN $251.47 \quad 100.0 \%$ Activating signal cointegrator 1 complex subunit $3 \mathrm{GN}=\mathrm{ASCC} 3 \mathrm{ASCC} 3$ HUMAN $251.47 \quad 100.0 \%$ Activating signal cointegrator 1 complex subunit $3 \mathrm{GN}=\mathrm{ASCC} 3 \mathrm{ASCC} 3$ HUMAN $251.47 \quad 100.0 \%$ Activating signal cointegrator 1 complex subunit $3 \mathrm{GN}=\mathrm{ASCC} 3$ ASCC3_HUMAN $251.47 \quad 100.0 \%$ Activating signal cointegrator 1 complex subunit $3 \mathrm{GN}=\mathrm{ASCC} 3 \mathrm{ASCC} 3 \mathrm{HUMAN} 251.47 \quad 100.0 \%$ Activating signal cointegrator 1 complex subunit $3 \mathrm{GN}=\mathrm{ASCC} 3 \mathrm{ASCC} 3$ _HUMAN $251.47 \quad 100.0 \%$ Activating signal cointegrator 1 complex subunit $3 \mathrm{GN}=\mathrm{ASCC} 3 \mathrm{ASCC} 3$ HUMAN $251.47 \quad 100.0 \%$ Activating signal cointegrator 1 complex subunit $3 \mathrm{GN}=\mathrm{ASCC} 3 \mathrm{ASCC} 3$ HUMAN $251.47 \quad 100.0 \%$ Activating signal cointegrator 1 complex subunit $3 \mathrm{GN}=\mathrm{ASCC} 3$ ASCC3_HUMAN $251.47 \quad 100.0 \%$ Activating signal cointegrator 1 complex subunit $3 \mathrm{GN}=\mathrm{ASCC} 3 \mathrm{ASCC} 3$ HUMAN $251.47 \quad 100.0 \%$ Activator of $90 \mathrm{kDa}$ heat shock protein ATPase homolog $1 \mathrm{GN}=\mathrm{AHSA}$ AHSA1_HUMAN $38.27 \quad 100.0 \%$

$0.00 \% \quad 35.8 \%$ EITALAPSTMK $0.00 \% 35.8 \%$ EITALAPS

$0.00 \% \quad 35.8 \%$ IKIIAPPER

$0.00 \% \quad 35.8 \%$ IIAPPERK

$47 \quad 247 \quad 0.28 \% \quad 63.5 \%$ AGFAGDDAPR

$47 \quad 247 \quad 0.28 \% \quad 63.5 \%$ AVFPSIVGRPR

$47 \quad 247 \quad 0.28 \% \quad 63.5 \%$ HQGVMVGMGQK

$47 \quad 247 \quad 0.28 \% \quad 63.5 \%$ HQGVMVGMGQKDSYVGDEAQSK

$47 \quad 247 \quad 0.28 \% \quad 63.5 \%$ DSYVGDEAQSK

$47 \quad 247 \quad 0.28 \% \quad 63.5 \%$ DSYVGDEAQSKR

$47 \quad 247 \quad 0.28 \% \quad 63.5 \%$ IWHHTFYNELR

$247 \quad 0.28 \% \quad 63.5 \%$ VAPEEHPVLLTEAPLNPK

$\begin{array}{llll}247 & 0.28 \% & 63.5 \% & \text { VAPEEHPVLLTEAPLNPKANR } \\ 247 & 0.28 \% & 63.5 \% & \text { TTGIVMDSGDGVTHTVPIYEGYALPHAILR }\end{array}$

$247 \quad 0.28 \% \quad 63.5 \%$ LDLAGRDLTDYLMK

$247 \quad 0.28 \% \quad 63.5 \%$ DLTDYLMK

$247 \quad 0.28 \% \quad 63.5 \%$ ILTERGYSFTTTAER

$247 \quad 0.28 \% \quad 63.5 \%$ GYSFTTTAER

$247 \quad 0.28 \% \quad 63.5 \%$ GYSFTTTAEREIVR

$247 \quad 0.28 \% \quad 63.5 \%$ LCYVALDFEQEMATAASSSSLEK

$247 \quad 0.28 \% \quad 63.5 \%$ SYELPDGQVITIGNER

$\begin{array}{llll}247 & 0.28 \% & 63.5 \% & \text { KDLYANTVLSGGTTMYPGIADR } \\ 247 & 0.28 \% & 63.5 \% & \text { DLYANTVLSGGTTMYPGIADR }\end{array}$

$\begin{array}{llll}247 & 0.28 \% & 63.5 \% & \text { DLYANTVLSGGTTMYPGIAD } \\ 247 & 0.28 \% & 63.5 \% & \text { MQKEITALAPSTMK }\end{array}$

$247 \quad 0.28 \% \quad 63.5 \%$ EITALAPSTMK

$247 \quad 0.28 \% \quad 63.5 \%$ EITALAPSTMKIK

$247 \quad 0.28 \% \quad 63.5 \%$ IKIIAPPER

$247 \quad 0.28 \% \quad 63.5 \%$ IIAPPERK

$247 \quad 0.28 \% \quad 63.5 \%$ QEYDESGPSIVHR

$247 \quad 0.28 \% \quad 63.5 \%$ QEYDESGPSIVHRK

$14 \quad 0.02 \% \quad 17.0 \%$ HLWDYTFGPEK

$14 \quad 0.02 \% \quad 17.0 \%$ ILLTEPPMNPTK

$14 \quad 0.02 \% \quad 17.0 \%$ GYAFNHSADFETVR

$14 \quad 0.02 \% \quad 17.0 \%$ LCYVGYNIEQEQK

$14 \quad 0.02 \% \quad 17.0 \%$ HIVLSGGSTMYPGLPSR

$30 \quad 0.03 \% \quad 5.2 \% \quad$ IQREQALLNAR

$30 \quad 0.03 \% \quad 5.2 \%$ RLEPLGIIVK

$30 \quad 0.03 \% \quad 5.2 \%$ ANPLAYGISHK

$30 \quad 0.03 \% \quad 5.2 \% \quad$ AYQIDPTLRK

$30 \quad 0.03 \% \quad 5.2 \% \quad$ TGYFSSTDLGR

$30 \quad 0.03 \% \quad 5.2 \% \quad$ TVAAELAIFR

$30 \quad 0.03 \% \quad 5.2 \%$ VFNKYPTSK

$30 \quad 0.03 \% \quad 5.2 \%$ AVYIAPLK

$\begin{array}{lllll}11 & 30 & 0.03 \% & 5.2 \% & \text { TNFISSHTEKPVR }\end{array}$

$11 \quad 30 \quad 0.03 \% \quad 5.2 \%$ AGRPQFDDQGK

$11 \quad 30 \quad 0.03 \% \quad 5.2 \%$ VSDSLTDLALK

$10 \quad 19 \quad 0.02 \% \quad 24.9 \%$ ADATNVNNWHWTER $\begin{array}{lllll}99.7 \% & 58.1 & 25.0 & 53.8 & 28\end{array}$

$\begin{array}{llll}99.7 \% & 28.3 & 25.0 & 28.3\end{array}$

$\begin{array}{lllll}99.7 \% & 36.8 & 25.0 & 36.8 & 2\end{array}$

$99.0 \% \quad 42.5 \quad 25.0 \quad 31.6$

$99.7 \% \quad 55.9 \quad 25.0 \quad 45.4$

$\begin{array}{llll}99.7 \% & 48.3 & 25.0 & 48.3\end{array}$

$\begin{array}{llll}99.7 \% & 48.2 & 25.0 & 26.7\end{array}$

$\begin{array}{llll}99.7 \% & 45.5 & 25.0 & 45.3\end{array}$

$\begin{array}{llll}99.7 \% & 54.2 & 25.0 & 54.2\end{array}$

$\begin{array}{llll}99.7 \% & 53.4 & 25.0 & 50.7\end{array}$

$\begin{array}{llll}99.7 \% & 34.1 & 25.0 & 32.7\end{array}$

$\begin{array}{llll}99.7 \% & 42.1 & 25.0 & 32.6\end{array}$

$\begin{array}{llll}9.7 \% & 23.3 & 25.0 & 21.8\end{array}$

$\begin{array}{llll}7 \% & 50.8 & 25.0 & 50.8\end{array}$

$\begin{array}{llll}99.7 \% & 42.8 & 25.0 & 39.5\end{array}$

$\begin{array}{llll}99.0 \% & 49.2 & 25.0 & 39.2\end{array}$

$\begin{array}{llll}99.7 \% & 41.3 & 25.0 & 41.3\end{array}$

$99.7 \% \quad 59.3 \quad 25.0 \quad 52.7$

$99.7 \% \quad 29.1$

$99.7 \% \quad 54.6$

$99.7 \% \quad 59.2$

25.0

22.1

\begin{tabular}{lll}
0 & 48.9 \\
\hline & 48.9
\end{tabular}

$99.7 \% \quad 60.4$

$99.7 \% \quad 58.1$

$99.7 \% \quad 28.3$

$99.7 \% \quad 36.8$

$99.0 \% \quad 42.5$

$99.7 \% \quad 43.5$

$99.3 \% \quad 21.5$

$99.4 \% 22.1$

$99.7 \% \quad 50.8$

$99.7 \% \quad 55.1$

$99.7 \% \quad 55.4$

$\begin{array}{lll}99.2 \% & 19.5\end{array}$

$97.2 \% \quad 15.8$

$99.7 \% \quad 34.0$

$98.0 \% \quad 21.7$

$97.9 \% \quad 16.5$

$99.7 \% \quad 52.3$

$\begin{array}{lll}99.7 \% & 54.2\end{array}$

$99.7 \% \quad 40.8$

$95.2 \% \quad 18.9$

$99.7 \% \quad 33.5$

$99.7 \% \quad 35.0$

$99.7 \% \quad 44.7$

$99.7 \% \quad 33.5$
1418.79

1036.65

923.57

976.45

1198.71

1187.57

2383.07

1198.52

1354.62

1515.75

1954.06

2295.25

3183.61

1639.84

998.49

1744.89

1132.53

1629.82

2566.17

1790.89

2359.16

2215.07

1548.81

1177.61

1418.79

1036.65

923.57

1516.70

1644.80

1392.66

1353.74

1613.73

1643.77

1787.91

1311.75

1137.74

1170.63

1204.67

1203.56

1090.63

1083.58

874.54

1515.79

1218.59

1161.64

1713.77

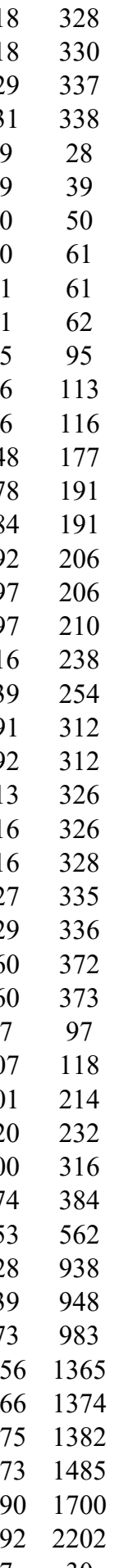

Page 19 of Table S-1-6 
Activator of $90 \mathrm{kDa}$ heat shock protein ATPase homolog $1 \mathrm{GN}=\mathrm{AHSA} 1$ AHSA1_HUMAN $38.27 \quad 100.0 \%$ Activator of $90 \mathrm{kDa}$ heat shock protein ATPase homolog $1 \mathrm{GN}=\mathrm{AHSAl}$ AHSA1_HUMAN $38.27 \quad 100.0 \%$ Activator of $90 \mathrm{kDa}$ heat shock protein ATPase homolog $1 \mathrm{GN}=\mathrm{AHSA} 1$ AHSA1_HUMAN $38.27 \quad 100.0 \%$ Activator of $90 \mathrm{kDa}$ heat shock protein ATPase homolog $1 \mathrm{GN}=\mathrm{AHSA} 1$ AHSA1 HUMAN $38.27 \quad 100.0^{\circ}$ Activator of $90 \mathrm{kDa}$ heat shock protein ATPase homolog $1 \mathrm{GN}=\mathrm{AHSA}$ AHSA1_HUMAN $38.27 \quad 100.0 \%$ Activator of $90 \mathrm{kDa}$ heat shock protein ATPase homolog $1 \mathrm{GN}=\mathrm{AHSA} 1$ AHSA1_HUMAN $38.27 \quad 100.0 \%$ Activator of basal transcription $1 \mathrm{GN}=\mathrm{ABT} 1 \mathrm{ABT1}$ _HUMAN $31.08 \quad 100.0 \%$ Activator of basal transcription $1 \mathrm{GN}=\mathrm{ABT1}$ ABT1_HUMAN $31.08 \quad 100.0 \%$ Activator of basal transcription $1 \mathrm{GN}=\mathrm{ABT} 1 \mathrm{ABT} 1$ HUMAN $31.08 \quad 100.0 \%$ Activator of basal transcription $1 \mathrm{GN}=\mathrm{ABT} 1 \mathrm{ABT1}$ _HUMAN $31.08 \quad 100.0 \%$ Activator of basal transcription $1 \mathrm{GN}=\mathrm{ABT} 1 \mathrm{ABT}{ }_{-}$HUMAN $31.08 \quad 100.0 \%$ Acyl-CoA dehydrogenase family member 9, mitochondrial GN=ACAD9 ACAD9_HUMAN $68.76 \quad 100.0 \%$ Acyl-CoA dehydrogenase family member 9, mitochondrial GN=ACAD9 ACAD9_HUMAN $68.76 \quad 100.0 \%$ Acyl-CoA dehydrogenase family member 9, mitochondrial GN=ACAD9 ACAD9_HUMAN $68.76 \quad 100.0 \%$ Acyl-CoA dehydrogenase family member 9, mitochondrial GN=ACAD9 ACAD9_HUMAN $68.76 \quad 100.0 \%$ Acyl-coenzyme A thioesterase $8 \mathrm{GN}=$ ACOT8 ACOT8_HUMAN $35.91 \quad 100.0 \%$ Acyl-coenzyme A thioesterase $8 \mathrm{GN}=\mathrm{ACOT} 8$ ACOT8 HUMAN $35.91 \quad 100.0 \%$ Acyl-coenzyme A thioesterase $8 \mathrm{GN}=$ ACOT8 ACOT8_HUMAN $35.91 \quad 100.0 \%$ Acyl-coenzyme A thioesterase $8 \mathrm{GN}=$ ACOT 8 ACOT__HUMAN $35.91 \quad 100.0 \%$ Acyl-coenzyme A thioesterase $8 \mathrm{GN}=$ ACOT8 ACOT8_HUMAN $35.91 \quad 100.0 \%$ Acyl-coenzyme A thioesterase 9, mitochondrial GN=ACOT9 ACOT9_HUMAN $49.90 \quad 100.0 \%$ Acyl-coenzyme A thioesterase 9, mitochondrial GN=ACOT9 ACOT9_HUMAN $49.90 \quad 100.0 \%$ Acyl-coenzyme A thioesterase 9, mitochondrial GN=ACOT9 ACOT9_HUMAN $49.90 \quad 100.0 \%$ Adenylate kinase 4, mitochondrial GN=AK4 KAD4_HUMAN $25.27 \quad 100.0 \%$ Adenylate kinase 4, mitochondrial GN=AK4 KAD4_HUMAN $25.27 \quad 100.0 \%$ Adenylate kinase 4, mitochondrial GN=AK4 KAD4_HUMAN $25.27 \quad 100.0 \%$ Adenylate kinase 4, mitochondrial GN=AK4 KAD4_HUMAN $25.27 \quad 100.0 \%$ Adenylate kinase 4, mitochondrial GN=AK4 KAD4_HUMAN $25.27 \quad 100.0 \%$ Adenylosuccinate lyase GN=ADSL Adenylosuccinate lyase $\mathrm{GN}=\mathrm{ADSL}$

ADP/ATP translocase $1 \mathrm{GN}=\mathrm{SLC} 25 \mathrm{~A} 4$ $\mathrm{ADP} / \mathrm{ATP}$ translocase $1 \mathrm{GN}=\mathrm{SLC} 25 \mathrm{~A} 4$ ADP/ATP translocase $1 \mathrm{GN}=\mathrm{SLC} 25 \mathrm{~A} 4$ ADP/ATP translocase $1 \mathrm{GN}=\mathrm{SLC} 25 \mathrm{~A} 4$ $\mathrm{ADP} / \mathrm{ATP}$ translocase $1 \mathrm{GN}=\mathrm{SLC} 25 \mathrm{~A} 4$ $\mathrm{ADP} / \mathrm{ATP}$ translocase $1 \mathrm{GN}=\mathrm{SLC} 25 \mathrm{~A} 4$ $\mathrm{ADP} / \mathrm{ATP}$ translocase $1 \mathrm{GN}=\mathrm{SLC} 25 \mathrm{~A}$ ADP/ATP translocase $1 \mathrm{GN}=\mathrm{SLC} 25 \mathrm{~A} 4$ ADP/ATP translocase $1 \mathrm{GN}=\mathrm{SLC} 25 \mathrm{~A} 4$ $\mathrm{ADP} / \mathrm{ATP}$ translocase $1 \mathrm{GN}=\mathrm{SLC} 25 \mathrm{~A} 4$ $\mathrm{ADP} / \mathrm{ATP}$ translocase $1 \mathrm{GN}=\mathrm{SLC} 25 \mathrm{~A} 4$ ADP/ATP translocase $1 \mathrm{GN}=\mathrm{SLC} 25 \mathrm{~A} 4$ $\mathrm{ADP} / \mathrm{ATP}$ translocase $1 \mathrm{GN}=\mathrm{SLC} 25 \mathrm{~A} 4$ $\mathrm{ADP} / \mathrm{ATP}$ translocase $1 \mathrm{GN}=\mathrm{SLC} 25 \mathrm{~A} 4$ $\mathrm{ADP} / \mathrm{ATP}$ translocase $1 \mathrm{GN}=\mathrm{SLC} 25 \mathrm{~A} 4$ ADP/ATP translocase $2 \mathrm{GN}=\mathrm{SLC} 25 \mathrm{~A} 5$ ADP/ATP translocase $2 \mathrm{GN}=\mathrm{SLC} 25 \mathrm{~A} 5$ PUR8_HUMAN $54.89 \quad 100.0 \%$ PUR8 HUMAN $54.89 \quad 100.0 \%$ ADT1_HUMAN $33.07 \quad 100.0 \%$ ADT1_HUMAN $33.07 \quad 100.0 \%$ ADT1_HUMAN $33.07 \quad 100.0 \%$ ADT1_HUMAN $33.07 \quad 100.0 \%$ ADT1_HUMAN $33.07 \quad 100.0 \%$ ADT1_HUMAN $33.07 \quad 100.0 \%$ ADT1_HUMAN $33.07 \quad 100.0 \%$ ADT1_HUMAN $33.07 \quad 100.0 \%$ ADT1_HUMAN $33.07 \quad 100.0 \%$ ADT1_HUMAN $33.07 \quad 100.0 \%$ ADT1_HUMAN $33.07 \quad 100.0 \%$ ADT1_HUMAN $33.07 \quad 100.0 \%$ ADT1_HUMAN $33.07 \quad 100.0 \%$ ADT1_HUMAN $33.07 \quad 100.0 \%$ ADT2 HUMAN $32.85 \quad 100.0 \%$ ADT2_HUMAN $32.85 \quad 100.0 \%$ ADT1_HUMAN $33.07 \quad 100.0 \%$ \begin{tabular}{llll}
10 & 19 & $0.02 \%$ & $24.9 \%$ \\
10 & 19 & $0.02 \%$ & $24.9 \%$ \\
\hline
\end{tabular}

5

4

4

4

4

4
5
5

5

5

5
2
2

2

4

$4 \begin{array}{ll}4 & -1 \\ 4 & 4\end{array}$

4

4
4
4

4

4
4
4

4

$\begin{array}{ll}4 & 4 \\ 4 & 4 \\ 4 & 4\end{array}$

$\begin{array}{cc}4 & 4 \\ 21 & 28 \\ 21 & 28\end{array}$

$19 \quad 0.02 \% \quad 24.9 \%$ EAMGIYISTLK

$19 \quad 0.02 \% \quad 24.9 \%$ GIPAPEEERTR

$0.02 \% \quad 24.9 \%$ QTFGYGAR

$10 \quad 0.01 \% \quad 19.1 \%$ NLLSAYGEVGR

$10 \quad 0.01 \% \quad 19.1 \%$ VFFQAEDR

$10 \quad 0.01 \% \quad 19.1 \%$ LRAEVAQAK

$10 \quad 0.01 \% \quad 19.1 \%$ ETDFYLQSVER

$6 \quad 0.01 \% \quad 9.7 \%$ AFAKELFLGK

$6 \quad 0.01 \% \quad 9.7 \%$ LIEMTAEYACTR

$0.01 \% \quad 9.7 \%$ ILLIFEGTNEILR

$0.01 \% \quad 19.4 \%$ LPVLYQVER

$0.01 \% \quad 19.4 \%$ TGSSFSVRSVK

$0.01 \% \quad 19.4 \%$ VKPQVSESKL

$0.01 \% \quad 6.6 \% \quad$ YLTVQNTVR

$0.01 \% \quad 6.6 \% \quad$ IAFSSTSLLK

$0.01 \% \quad 6.6 \%$ SLEICHPQER

$0.01 \% \quad 24.7 \%$ AVILGPPGSGK

$0.01 \% \quad 24.7 \%$ SLLVPDHVITR

$0.01 \% \quad 24.7 \%$ LMMSELENR

$0.01 \% \quad 24.7 \%$ DVAKPVIELYK

$0.00 \% \quad 3.9 \%$ LADFAKER

$0.00 \% \quad 3.9 \%$ AFIITGQTYTR

$0.01 \% \quad 41.9 \%$ TAVAPIER

$0.01 \% \quad 41.9 \%$ TAVAPIERVK

$0.01 \% \quad 41.9 \%$ VKLLLQVQHASK

$0.01 \% \quad 41.9 \%$ LLLQVQHASK

$0.01 \% \quad 41.9 \%$ EQGFLSFWR

$0.01 \% \quad 41.9 \%$ GNLANVIR

$0.01 \% \quad 41.9 \%$ YFPTQALNFAFK

$0.01 \% \quad 41.9 \%$ QLFLGGVDR

$0.01 \% \quad 41.9 \%$ TRLAADVGK

$0.01 \% \quad 41.9 \%$ EFHGLGDCIIK

$0.01 \% \quad 41.9 \%$ AAYFGVYDTAK

$0.01 \% \quad 41.9 \%$ GAWSNVLR $\begin{array}{llllllll}99.7 \% & 63.8 & 25.0 & 51.2 & 2 & 0 & 0 & 1088.53\end{array}$

$\begin{array}{llllllll}99.7 \% & 53.4 & 25.0 & 44.9 & 4 & 0 & 0 & 1225.65\end{array}$

2136.99

$0.02 \% \quad 24.9 \%$ FHMVDGNVSGEFTDLVPEK $99.7 \% \quad 41.8$

$10 \quad 0.01 \% \quad 19.1 \%$ VAASLHNTPMGAR

$0.01 \% \quad 9.7 \%$ LASGEHIAAFCLTEPASGSDAASIR

$0.01 \% \quad 19.4 \%$ LFGGQIVGQALVAAAK

$0.01 \% \quad 19.4 \%$ QDGVLAVTCAQEGVIR

$0.01 \% \quad 24.7 \%$ GVLHQFSGTETNK

$0.01 \% \quad 41.9 \%$ DFLAGGVAAAVSK

$0.01 \% \quad 41.9 \%$ KGADIMYTGTVDCWR

$0.01 \% \quad 41.9 \%$ GADIMYTGTVDCWR

$0.11 \% \quad 48.0 \%$ DFLAGGVAAAISK

$0.11 \% \quad 48.0 \%$ TAVAPIER $\begin{array}{llll}9.0 \% & 30.1 & 25.0 & 18.0\end{array}$

$\begin{array}{llll}99.7 \% & 57.5 & 25.0 & 50.2\end{array}$

$\begin{array}{lllll}99.0 \% & 46.3 & 25.0 & 27.6 & 2\end{array}$

$\begin{array}{llll}99.6 \% & 24.8 & 25.0 & 24.8\end{array}$

$\begin{array}{llll}99.7 \% & 27.2 & 25.0 & 21.4\end{array}$

$99.7 \% \quad 64.1 \quad 25.0 \quad 64.1 \quad 2$

$\begin{array}{llll}99.7 \% & 32.9 & 25.0 & 32.9\end{array}$

$\begin{array}{lllll}99.7 \% & 36.8 & 25.0 & 35.2 & 0\end{array}$

$\begin{array}{lllll}99.7 \% & 48.6 & 25.0 & 48.6 & 1\end{array}$

$\begin{array}{llll}99.7 \% & 50.3 & 25.0 & 50.3\end{array}$

$\begin{array}{lllll}99.7 \% & 45.0 & 25.0 & 45.0 & 2\end{array}$

$\begin{array}{llll}99.7 \% & 49.8 & 25.0 & 48.0\end{array}$

$\begin{array}{llll}94.8 \% & 18.3 & 25.0 & 10.6\end{array}$

$\begin{array}{llll}99.7 \% & 70.0 & 25.0 & 70.0\end{array}$

$95.9 \% \quad 16.0 \quad 25.0 \quad 14.9$

$\begin{array}{llll}97.6 \% & 21.0 & 25.0 & 21.0\end{array}$

$99.7 \% \quad 38.1 \quad 25.0 \quad 38.1$

$\begin{array}{llll}99.4 \% & 26.2 & 25.0 & 26.2\end{array}$

$\begin{array}{lllll}99.7 \% & 34.3 & 25.0 & 19.0 & 2\end{array}$

$\begin{array}{llll}99.5 \% & 23.2 & 25.0 & 23.2\end{array}$

$99.7 \% \quad 50.0 \quad 25.0 \quad 50.0$

$\begin{array}{llll}99.7 \% & 46.4 & 25.0 & 35.5\end{array}$

$99.7 \% \quad 56.2 \quad 25.0 \quad 55.5$

$\begin{array}{llll}99.0 \% & 46.8 & 25.0 & 36.9\end{array}$

$99.7 \% \quad 38.8 \quad 25.0 \quad 35.1$

$\begin{array}{llll}99.7 \% & 91.4 & 25.0 & 88.7\end{array}$

$\begin{array}{lllll}99.0 \% & 41.9 & 25.0 & 29.8 & 10\end{array}$

$\begin{array}{llll}99.7 \% & 28.6 & 25.0 & 28.6\end{array}$

$\begin{array}{llll}99.7 \% & 32.8 & 25.0 & 30.2\end{array}$

$\begin{array}{lllll}99.7 \% & 54.2 & 25.0 & 46.3 & 13\end{array}$

$\begin{array}{llll}99.7 \% & 31.7 & 25.0 & 27.1\end{array}$

$\begin{array}{lllll}99.0 \% & 37.8 & 25.0 & 27.8 & 2\end{array}$

$\begin{array}{llll}99.7 \% & 33.8 & 25.0 & 24.1\end{array}$

$\begin{array}{lllll}99.7 \% & 55.0 & 25.0 & 36.8 & 2\end{array}$

$\begin{array}{lllll}94.9 \% & 23.6 & 25.0 & 2.4 & 1\end{array}$

$\begin{array}{lllll}99.7 \% & 40.0 & 25.0 & 33.3 & 2\end{array}$

$\begin{array}{llll}99.7 \% & 45.8 & 25.0 & 45.8\end{array}$

$\begin{array}{llll}99.7 \% & 39.1 & 25.0 & 39.1\end{array}$

$\begin{array}{llll}99.7 \% & 55.0 & 25.0 & 55.0\end{array}$

$\begin{array}{llll}99.0 \% & 58.4 & 25.0 & 37.3 \\ 99.7 \% & 67.5 & 25.0 & 64.5\end{array}$

$\begin{array}{llll}99.0 \% & 41.9 & 25.0 & 29.8\end{array}$
1254.64

899.44

1178.62

1011.49

1324.68

985.58

1386.65

1123.65

2531.22

1457.68

1530.89

1542.90

1116.64

1154.62

1715.87

1114.65

1093.60

1066.61

1268.61

995.59

1249.73

1122.53

1274.74

1417.71

949.51

1270.68

1205.65

856.49

1083.65

1363.84

1136.68

1169.57

856.50

1446.74

1004.55

930.54

1288.64

1205.58

1788.80

1644.71

902.48

1219.67

Page 20 of Table S-1-6 
ADP/ATP translocase $2 \mathrm{GN}=\mathrm{SLC} 25 \mathrm{~A} 5$ ADP/ATP translocase 2 GN=SLC25A5 $\mathrm{ADP} / \mathrm{ATP}$ translocase $2 \mathrm{GN}=\mathrm{SLC} 25 \mathrm{~A} 5$ ADP/ATP translocase $2 \mathrm{GN}=\mathrm{SLC} 25 \mathrm{~A} 5$ ADP/ATP translocase $2 \mathrm{GN}=\mathrm{SLC} 25 \mathrm{~A} 5$ $\mathrm{ADP} / \mathrm{ATP}$ translocase $2 \mathrm{GN}=\mathrm{SLC} 25 \mathrm{~A} 5$ ADP/ATP translocase $2 \mathrm{GN}=\mathrm{SLC} 25 \mathrm{~A} 5$ ADP/ATP translocase $2 \mathrm{GN}=\mathrm{SLC} 25 \mathrm{~A} 5$ ADP/ATP translocase $2 \mathrm{GN}=\mathrm{SLC} 25 \mathrm{~A} 5$ ADP/ATP translocase $2 \mathrm{GN}=\mathrm{SLC} 25 \mathrm{~A} 5$ ADP/ATP translocase $2 \mathrm{GN}=\mathrm{SLC} 25 \mathrm{~A} 5$ ADP/ATP translocase $2 \mathrm{GN}=\mathrm{SLC} 25 \mathrm{~A} 5$ $\mathrm{ADP} / \mathrm{ATP}$ translocase $2 \mathrm{GN}=\mathrm{SLC} 25 \mathrm{~A} 5$ ADP/ATP translocase $2 \mathrm{GN}=\mathrm{SLC} 25 \mathrm{~A} 5$ ADP/ATP translocase $2 \mathrm{GN}=\mathrm{SLC} 25 \mathrm{~A} 5$ ADP/ATP translocase $2 \mathrm{GN}=\mathrm{SLC} 25 \mathrm{~A} 5$ ADP/ATP translocase $2 \mathrm{GN}=\mathrm{SLC} 25 \mathrm{~A} 5$ ADP/ATP translocase $2 \mathrm{GN}=\mathrm{SLC} 25 \mathrm{~A} 5$ $\mathrm{ADP} / \mathrm{ATP}$ translocase $2 \mathrm{GN}=\mathrm{SLC} 25 \mathrm{~A} 5$ ADP/ATP translocase $3 \mathrm{GN}=\mathrm{SLC} 25 \mathrm{~A} 6$ $\mathrm{ADP} / \mathrm{ATP}$ translocase $3 \mathrm{GN}=\mathrm{SLC} 25 \mathrm{~A} 6$ $\mathrm{ADP} / \mathrm{ATP}$ translocase $3 \mathrm{GN}=\mathrm{SLC} 25 \mathrm{~A} 6$ $\mathrm{ADP} / \mathrm{ATP}$ translocase $3 \mathrm{GN}=\mathrm{SLC} 25 \mathrm{~A} 6$ ADP/ATP translocase $3 \mathrm{GN}=\mathrm{SLC} 25 \mathrm{~A} 6$ ADP/ATP translocase $3 \mathrm{GN}=\mathrm{SLC} 25 \mathrm{~A} 6$ $\mathrm{ADP} / \mathrm{ATP}$ translocase $3 \mathrm{GN}=\mathrm{SLC} 25 \mathrm{~A} 6$ ADP/ATP translocase $3 \mathrm{GN}=\mathrm{SLC} 25 \mathrm{~A} 6$ ADP/ATP translocase $3 \mathrm{GN}=\mathrm{SLC} 25 \mathrm{~A} 6$ ADP/ATP translocase $3 \mathrm{GN}=\mathrm{SLC} 25 \mathrm{~A} 6$ $\mathrm{ADP} / \mathrm{ATP}$ translocase $3 \mathrm{GN}=\mathrm{SLC} 25 \mathrm{~A} 6$ ADP/ATP translocase $3 \mathrm{GN}=\mathrm{SLC} 25 \mathrm{~A} 6$ $\mathrm{ADP} / \mathrm{ATP}$ translocase $3 \mathrm{GN}=\mathrm{SLC} 25 \mathrm{~A} 6$ $\mathrm{ADP} / \mathrm{ATP}$ translocase $3 \mathrm{GN}=\mathrm{SLC} 25 \mathrm{~A} 6$ $\mathrm{ADP} / \mathrm{ATP}$ translocase $3 \mathrm{GN}=\mathrm{SLC} 25 \mathrm{~A} 6$ ADP/ATP translocase $3 \mathrm{GN}=\mathrm{SLC} 25 \mathrm{~A} 6$ $\mathrm{ADP} / \mathrm{ATP}$ translocase $3 \mathrm{GN}=\mathrm{SLC} 25 \mathrm{~A} 6$ $\mathrm{ADP} / \mathrm{ATP}$ translocase $3 \mathrm{GN}=\mathrm{SLC} 25 \mathrm{~A} 6$ Aflatoxin B1 aldehyde reductase member 2 GN=AKR7A2 ARK72_HUMAN 39.59 AH receptor-interacting protein GN=AIP AIP_HUMAN 37.64 AH receptor-interacting protein $\mathrm{GN}=\mathrm{AIP}$ AIP HUMAN 37.64 A-kinase anchor protein 8-like GN=AKAP8L AKP8L_HUMAN $71.65 \quad 100.0 \%$ A-kinase anchor protein 8-like GN=AKAP8L AKP8L HUMAN $71.65 \quad 100.0 \%$ Aladin GN=AAAS Aladin GN=AAAS Aladin GN=AAAS AAAS_HUMAN $59.57 \quad 100.0 \%$ AAAS_HUMAN $59.57 \quad 100.0 \%$ AAAS HUMAN $59.57 \quad 100.0 \%$ Alanine--tRNA ligase, mitochondrial GN=AARS2 SYAM_HUMAN $107.34 \quad 100.0 \%$ ADT3_HUMAN $32.87 \quad 100.0 \%$ ADT3 HUMAN $32.87 \quad 100.0 \%$ ADT3 HUMAN $32.87 \quad 100.0 \%$ ADT3 HUMAN $32.87 \quad 100.0 \%$ ADT3 HUMAN $32.87 \quad 100.0 \%$ $\begin{array}{lll}\text { ADT_HUMAN } & 32.87 & 100.0 \% \\ \text { ADT3 HUMAN } & 32.87 & 100.0 \%\end{array}$ ADT3 HUMAN $32.87 \quad 100.0 \%$ ADT3_HUMAN $32.87 \quad 100.0 \%$ ADT3_HUMAN $32.87 \quad 100.0 \%$ ADT3 HUMAN $32.87 \quad 100.0 \%$ $100.0 \%$ $00.0 \%$ $0.0 \%$ $0.11 \% \quad 48.0 \%$ VKLLLQVQHASK $0.11 \% \quad 48.0 \%$ LLLQVQHASK

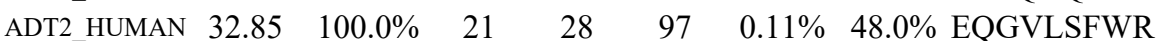

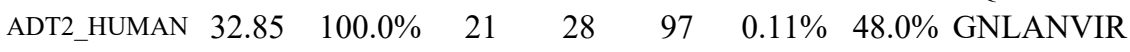
$\begin{array}{llllllll}\text { ADT2_HUMAN } & 32.85 & 100.0 \% & 21 & 28 & 97 & 0.11 \% & 48.0 \% \\ \text { YFPTQALNFAFK }\end{array}$ ADT2 HUMAN $32.85 \quad 100.0 \%$ ADT2_HUMAN $32.85 \quad 100.0 \% \quad 21$ ADT2_HUMAN $32.85 \quad 100.0 \% \quad 21$ ADT2 HUMAN $32.85 \quad 100.0 \% \quad 21$ ADT2 HUMAN $32.85 \quad 100.0 \% \quad 21$ ADT2 HUMAN $32.85 \quad 100.0 \% \quad 2$ ADT2 HUMAN $32.85 \quad 100.0 \% \quad 21$ _ $32.85 \quad 100.0 \% \quad 21$ ADT3 HUMAN $32.87 \quad 100.0 \%$ ADT3_HUMAN $32.87 \quad 100.0 \%$ $28 \quad 97 \quad 0.11 \% \quad 48.0 \%$ YKQIFLGGVDK $28 \quad 97 \quad 0.11 \% \quad 48.0 \%$ QIFLGGVDK

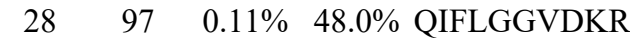
$28 \quad 97 \quad 0.11 \% \quad 48.0 \%$ TRLAADVGK $\begin{array}{llll}28 & 97 \quad 0.11 \% & 48.0 \% & \text { LAADVGKAGAER }\end{array}$ $28 \quad 97 \quad 0.11 \% \quad 48.0 \%$ GLGDCLVK $\begin{array}{llll}28 & 97 & 0.11 \% & 48.0 \% \\ 28 & 97 G D C L V K I Y K\end{array}$ $28 \quad 97 \quad 0.11 \% \quad 48.0 \%$ AAYFGIYDTAK $28 \quad 97 \quad 0.11 \% \quad 48.0 \%$ KGTDIMYTGTLDCWR $\begin{array}{llll}28 & 97 \quad 0.11 \% & 48.0 \% & \text { GTDIMYTGTLDCWR }\end{array}$ $28 \quad 97 \quad 0.11 \% \quad 48.0 \%$ GTDIMYTGTLDCWRK $28 \quad 97 \quad 0.11 \% \quad 48.0 \%$ DEGGKAFFK $28 \quad 97 \quad 0.11 \% \quad 48.0 \%$ GAWSNVLR

$19 \quad 0.02 \% \quad 46.3 \%$ DFLAGGIAAAISK

$19 \quad 0.02 \% \quad 46.3 \%$ TAVAPIER

$19 \quad 0.02 \% \quad 46.3 \%$ TAVAPIERVK

$19 \quad 0.02 \% \quad 46.3 \%$ VKLLLQVQHASK

$19 \quad 0.02 \% \quad 46.3 \%$ LLLQVQHASK

$19 \quad 0.02 \% \quad 46.3 \%$ EQGVLSFWR

$19 \quad 0.02 \% \quad 46.3 \%$ GNLANVIR

$19 \quad 0.02 \% \quad 46.3 \%$ YFPTQALNFAFK

$19 \quad 0.02 \% \quad 46.3 \%$ YKQIFLGGVDK

$19 \quad 0.02 \% \quad 46.3 \%$ QIFLGGVDK

$19 \quad 0.02 \% \quad 46.3 \%$ TRLAADVGK

$19 \quad 0.02 \% \quad 46.3 \%$ LAADVGKSGTER

$19 \quad 0.02 \% \quad 46.3 \%$ GLGDCLVK

$19 \quad 0.02 \% \quad 46.3 \%$ AAYFGVYDTAK

$19 \quad 0.02 \% \quad 46.3 \%$ KGADIMYTGTVDCWR

$19 \quad 0.02 \% \quad 46.3 \%$ GADIMYTGTVDCWR

$19 \quad 0.02 \% \quad 46.3 \%$ DEGGKAFFK

$19 \quad 0.02 \% \quad 46.3 \%$ GAWSNVLR

$0.00 \% \quad 9.5 \%$ FYAYNPLAGGLLTGK

$0.00 \% \quad 9.5 \% \quad$ ALQAAYGASAPSVTSAALR

$0.00 \% \quad 7.6 \%$ AVPLIHQEGNR

$0.00 \% \quad 7.6 \%$ VLELDPALAPVVSR

$0.00 \% \quad 3.3 \%$ SGRPMASGYGR

$0.00 \% \quad 3.3 \%$ SILNNKLISK

$0.00 \% \quad 6.6 \%$ VYNASSTIVPSLK

$0.00 \% \quad 6.6 \% \quad$ ILATTPSAVFR

$0.00 \% \quad 6.6 \% \quad$ VQDGKPVILLFR

$0.01 \% \quad 4.9 \%$ LVPSASVRPR

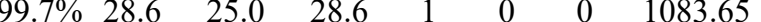

1363.84

1136.68

1121.57

$\begin{array}{cccccccc}99.0 \% & 37.8 & 25.0 & 27.8 & 2 & 0 & 0 & 856.50 \\ 99.7 \% & 33.8 & 25.0 & 24.1 & 3 & 0 & 0 & 1446.74\end{array}$

$\begin{array}{llllllll}99.7 \% & 33.8 & 25.0 & 24.1 & 3 & 0 & 0 & 1446.74 \\ 99.7 \% & 41.8 & 25.0 & 33.6 & 2 & 0 & 0 & 1267.70\end{array}$

$\begin{array}{llllllll}99.7 \% & 43.3 & 25.0 & 29.7 & 4 & 0 & 0 & 976.55\end{array}$

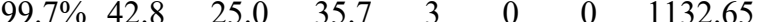

$\begin{array}{llllllll}94.9 \% & 23.6 & 25.0 & 2.4 & 1 & 0 & 0 & 930.54\end{array}$

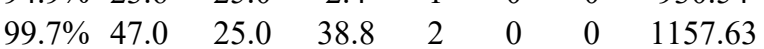

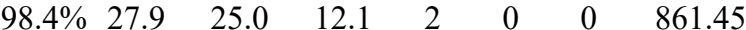

$99.0 \% \quad 20.7 \quad 25.0 \quad 20.7$

$99.7 \% \quad 58.1 \quad 25.0 \quad 48.7$

$99.7 \% \quad 50.6 \quad 25.0 \quad 50.6$

$99.7 \% \quad 46.1 \quad 25.0 \quad 45.3 \quad 4$

$99.7 \% \quad 31.2 \quad 25.0 \quad 31.2$

$\begin{array}{llll}99.7 \% & 43.3 & 25.0 & 33.5\end{array}$

$99.0 \% \quad 58.4 \quad 25.0 \quad 37.3$

$99.7 \% \quad 69.1 \quad 25.0 \quad 52.5$

$99.0 \% \quad 41.9 \quad 25.0 \quad 29.8$

$\begin{array}{llll}99.7 \% & 28.6 & 25.0 & 28.6\end{array}$

$99.7 \% \quad 32.8 \quad 25.0 \quad 30.2$

$99.7 \% \quad 54.2 \quad 25.0 \quad 46.3 \quad 13$

$\begin{array}{llll}99.7 \% & 57.7 & 25.0 & 43.7\end{array}$

$99.0 \% \quad 37.8 \quad 25.0 \quad 27.8$

$\begin{array}{llll}99.7 \% & 33.8 & 25.0 & 24.1\end{array}$

$\begin{array}{llll}99.7 \% & 41.8 & 25.0 & 33.6\end{array}$

$\begin{array}{llll}99.7 \% & 43.3 & 25.0 & 29.7\end{array}$

$94.9 \% \quad 23.6 \quad 25.0 \quad 2.4$

$\begin{array}{llll}99.7 \% & 34.6 & 25.0 & 26.3\end{array}$

$\begin{array}{llll}98.4 \% & 27.9 & 25.0 & 12.1\end{array}$

$\begin{array}{llll}99.7 \% & 45.8 & 25.0 & 45.8\end{array}$

$\begin{array}{llll}99.7 \% & 39.1 & 25.0 & 39.1\end{array}$

$\begin{array}{llll}99.7 \% & 55.0 & 25.0 & 55.0\end{array}$

$\begin{array}{llll}99.7 \% & 43.3 & 25.0 & 33.5\end{array}$

$\begin{array}{lllll}99.0 \% & 58.4 & 25.0 & 37.3 & 8\end{array}$

$\begin{array}{llll}99.7 \% & 49.0 & 25.0 & 46.5\end{array}$

$\begin{array}{llll}99.7 \% & 43.1 & 25.0 & 43.1\end{array}$

$\begin{array}{llll}99.7 \% & 41.1 & 25.0 & 37.0\end{array}$

$\begin{array}{lllll}99.7 \% & 48.7 & 25.0 & 48.7\end{array}$

$\begin{array}{llll}99.7 \% & 26.7 & 25.0 & 26.7\end{array}$

$99.7 \% \quad 42.6 \quad 25.0 \quad 27.6$

$\begin{array}{llll}99.4 \% & 24.6 & 25.0 & 18.7\end{array}$

$\begin{array}{lllll}99.7 \% & 40.8 & 25.0 & 40.0 & 2\end{array}$

$\begin{array}{llll}99.0 \% & 19.2 & 25.0 & 19.2\end{array}$

$\begin{array}{llll}98.2 \% & 19.0 & 25.0 & 16.6\end{array}$

1265.69

1219.60

1832.83

1688.74

1832.83

998.49

902.48

1233.68

856.49

1083.65

1363.84

1136.68

1121.57

856.50

1446.74

1267.70

976.55

930.54

1203.63

861.45

1205.58

1788.80

1644.71

998.49

902.48

1584.84

1804.96

1233.67

1478.86

1154.54

1129.69

1378.76

1175.68

1384.83

1081.65 
Aldose reductase $\mathrm{GN}=\mathrm{AKR} 1 \mathrm{~B} 1$ Alkyldihydroxyacetonephosphate synthase, peroxisomal GN=AGPS ADAS_HUMAN $72.91 \quad 100.0 \%$ Akyldihydroxyacetonephosphate synthase, peroxisomal GN=AGPS ADAS HUMAN $72.91 \quad 100.0^{\circ}$

Alpha-centractin GN=ACTR1A Alpha-centractin GN=ACTR1A

Alpha-centractin $\mathrm{GN}=\mathrm{ACTR} 1 \mathrm{~A}$ Alpha-centractin GN=ACTR1A Alpha-centractin GN=ACTR1A Alpha-centractin GN=ACTR1A Alpha-centractin GN=ACTR1A Alpha-centractin GN=ACTR1A Alpha-enolase $\mathrm{GN}=\mathrm{ENO} 1$ Alpha-enolase $\mathrm{GN}=\mathrm{ENO} 1$

Alpha-enolase $\mathrm{GN}=\mathrm{ENO} 1$ Alpha-enolase $\mathrm{GN}=\mathrm{ENO}$ Alpha-enolase $\mathrm{GN}=\mathrm{ENO} 1$ Alpha-enolase $\mathrm{GN}=\mathrm{ENO} 1$ Alpha-enolase $\mathrm{GN}=\mathrm{ENO}$ Alpha-enolase $\mathrm{GN}=\mathrm{ENO} 1$ Alpha-internexin GN=INA Alpha-internexin GN=INA Alpha-internexin GN=INA Alpha-internexin GN=INA Alpha-internexin GN=INA Alpha-internexin GN=INA Alpha-internexin GN=INA Alpha-internexin GN=INA Alpha-internexin GN=INA Alpha-internexin GN=INA Alpha-internexin GN=INA Alpha-internexin GN=INA Alpha-internexin GN=INA
ALDR_HUMAN $35.85 \quad 100.0 \%$ ALDR_HUMAN $35.85 \quad 100.0 \%$ ALDR HUMAN $35.85 \quad 100.0 \%$

$0.01 \% \quad 4.9 \% \quad$ AGQEDVLFPVAR

$10 \quad 0.01 \% \quad 12.0 \%$ LAPALATGNTVVMK

$10 \quad 0.01 \% \quad 12.0 \%$ VLGYIQLGQK

$10 \quad 0.01 \% \quad 12.0 \%$ VLGYIQLGQKEGAK

$10 \quad 0.01 \% \quad 12.0 \%$ IAKEEIFGPVQPLFK

$10 \quad 0.01 \% \quad 12.0 \%$ YGLAAAVFTR

$10 \quad 0.01 \% \quad 12.0 \%$ TVTIKVPQK

$8 \quad 0.01 \% \quad 14.6 \%$ SPPGQVTEAVK

$0.00 \% \quad 3.5 \%$ TIISLDTSQMNR

ACTZ_HUMAN $42.62 \quad 100.0 \%$ ACTZ_HUMAN $42.62 \quad 100.0 \%$ ACTZ HUMAN $42.62 \quad 100.0 \%$ ACTZ_HUMAN $42.62 \quad 100.0 \%$ ACTZ HUMAN $42.62 \quad 100.0 \%$ ACTZ HUMAN $42.62 \quad 100.0 \%$ ACTZ_HUMAN $42.62 \quad 100.0 \%$ ACTZ HUMAN $42.62 \quad 100.0 \%$ ENOA_HUMAN $47.17 \quad 100.0 \%$ ENOA_HUMAN $47.17 \quad 100.0 \%$ ENOA_HUMAN $47.17 \quad 100.0 \%$ ENOA_HUMAN $47.17 \quad 100.0 \%$ ENOA HUMAN $47.17 \quad 100.0 \%$ ENOA_HUMAN $47.17 \quad 100.0 \%$ ENOA_HUMAN $47.17 \quad 100.0 \%$ ENOA HUMAN $47.17 \quad 100.0 \%$ AINX_HUMAN $55.39 \quad 100.0 \%$ AINX_HUMAN $55.39 \quad 100.0 \%$ AINX_HUMAN $55.39 \quad 100.0 \%$ AINX_HUMAN $55.39 \quad 100.0 \%$ AINX_HUMAN $55.39 \quad 100.0 \%$ AINX_HUMAN $55.39 \quad 100.0 \%$ AINX_HUMAN $55.39 \quad 100.0 \%$ AINX HUMAN $55.39 \quad 100.0 \%$ AINX_HUMAN $55.39 \quad 100.0 \%$ AINX HUMAN $55.39 \quad 100.0 \%$ AINX_HUMAN $55.39 \quad 100.0 \%$ AINX_HUMAN $55.39 \quad 100.0 \%$ AINX HUMAN $55.39 \quad 100.0 \%$ AIMP1_HUMAN $34.35 \quad 100.0 \%$

$0.03 \% \quad 28.1 \%$ ALEAELAALRQR $0.01 \% \quad 4.9 \%$ TGAVGDLVIIGDR $0.01 \% \quad 4.9 \% \quad$ LLAVTGEQAQQAR $0.00 \% \quad 2.7 \%$ VAFCGAPEEGR $0.00 \% \quad 2.7 \%$ EALLVANGTPR

$0.01 \% \quad 14.6 \%$ REELFIVSK

$0.01 \% \quad 14.6 \%$ YKPAVNQIECHPYLTQEK

$0.01 \% \quad 14.6 \%$ TTAQVLIR

$0.00 \% \quad 3.5 \%$ GVQFAPFSTCR

$99.7 \% \quad 61.5$ $99.7 \% \quad 57.7$

$99.7 \% \quad 69.7$

$99.7 \% \quad 29.9$

$99.7 \% \quad 32.4$

$99.7 \% \quad 49.5$

$99.4 \% \quad 21.8$

$99.7 \% \quad 50.2$

$99.7 \% \quad 29.1$

$99.7 \% \quad 60.9$

$99.3 \% \quad 31.3$

$99.7 \% \quad 33.6$

$99.5 \% \quad 28.3$

$97.4 \% \quad 17.4$

$99.0 \% \quad 57.1$

$99.7 \% \quad 32.1$

$99.7 \% \quad 38.5$

$99.7 \% \quad 51.2$

$0.02 \% \quad 25.0 \%$ AGFAGDQIPK

$\begin{array}{ll}99.7 \% & 35.7\end{array}$

$0.02 \% \quad 25.0 \%$ YCFPNYVGRPK

$0.02 \% \quad 25.0 \%$ VMAGALEGDIFIGPK

$0.02 \% \quad 25.0 \%$ IDIAGRDVSR

$0.02 \% \quad 25.0 \%$ EGYDFHSSSEFEIVK

$0.02 \% \quad 25.0 \%$ AQYYLPDGSTIEIGPSR

$98.7 \% \quad 19.9$

$99.3 \% \quad 59.9$

$99.6 \% \quad 25.5$

$97.3 \% \quad 15.9$

$99.7 \% \quad 46.4$

$0.02 \% \quad 25.0 \%$ TLFSNIVLSGGSTLFK

$99.7 \% \quad 86.0$

$0.03 \% \quad 21.2 \%$ EIFDSRGNPTVEVDLFTSK

$0.03 \% \quad 21.2 \%$ GNPTVEVDLFTSK

$0.03 \% \quad 21.2 \%$ FGANAILGVSLAVCK

$0.03 \% \quad 21.2 \%$ IGAEVYHNLK

$0.03 \% \quad 21.2 \%$ YISPDQLADLYK

$99.7 \% \quad 47.8$

$99.7 \% \quad 54.4$

$99.7 \% \quad 60.0$

$99.7 \% \quad 46.2$

$\begin{array}{lllll}0.03 \% & 21.2 \% & \text { FTASAGIQVVGDDLTVTNPK } \quad 99.7 \% & 59.9\end{array}$

$0.03 \% \quad 21.2 \%$ FTASAGIQVVGDDLTVTNPKR $99.7 \% \quad 46.8$

$\begin{array}{lll}0.03 \% & 21.2 \% & \text { VNQIGSVTESLQACK } \quad 99.2 \% \quad 57.2\end{array}$

$0.03 \% \quad 28.1 \%$ LSGAGGAGGFR

$99.7 \% \quad 55.0$

$0.03 \% \quad 28.1 \%$ SNVASSAACSSASSLGLGLAYR $99.7 \% 57.7$

$0.03 \% \quad 28.1 \%$ RPPASDGLDLSQAAAR

$0.03 \% \quad 28.1 \%$ ALEAELAALR

$0.03 \% \quad 28.1 \%$ AQLEEASSAR

$0.03 \% \quad 28.1 \%$ DVDGATLAR

$0.03 \% \quad 28.1 \%$ AQYESLAAK

$0.03 \% \quad 28.1 \%$ FANLNEQAAR

$0.03 \% \quad 28.1 \%$ TIEIEGLRGANESLER

$0.03 \% \quad 28.1 \%$ HLREYQDLLNVK

$0.03 \% \quad 28.1 \%$ EYQDLLNVK

$0.03 \% \quad 28.1 \%$ SNIEETTISSQKI

$0.02 \% \quad 35.6 \%$ GAEADQIIEYLK
$99.7 \% 53.6$

$99.7 \% \quad 57.4$

$97.3 \% \quad 16.4$

$99.7 \% \quad 66.7$

$99.7 \% \quad 27.1$

$95.9 \% \quad 29.0$

$99.7 \% \quad 67.0$

$\begin{array}{lll}99.7 \% & 30.4\end{array}$

$99.7 \% \quad 59.8$

$99.7 \% \quad 46.4$

$99.7 \% \quad 55.3$

$99.7 \% \quad 68.7$
1301.68

1285.71

1384.75

192.54

1140.64

1385.78

1118.66

1503.85

1715.97

1068.58

1013.64

1112.59

1120.64

2218.10

901.55

1378.70

1269.60

1003.52

2385.18

1400.68

1517.80

1101.60

1773.80

1866.92

1683.93

2154.07

1406.72

1519.83

1143.62

1425.73

2033.06

2189.16

1633.82

949.49

2129.03

1624.84

1056.60

1340.76

1061.52

917.47

980.50

1133.57

1786.93

1527.83

1121.58

1449.74

1349.69

$\begin{array}{cc}81 & 592 \\ 57 & 769 \\ 78 & 790 \\ 46 & 256 \\ 14 & 424 \\ 96 & 209 \\ 70 & 379 \\ 70 & 383 \\ 12 & 426 \\ 42 & 451 \\ 07 & 515 \\ 3 & 33 \\ 0 & 78 \\ 78 & 195 \\ 44 & 251 \\ 54 & 265 \\ 56 & 566 \\ 3 & 32 \\ 3 & 43 \\ 3 & 43 \\ 7 & 61 \\ 83 & 192 \\ 01 & 215 \\ 39 & 255 \\ 93 & 308 \\ 0 & 28 \\ 6 & 28 \\ 06 & 120 \\ 84 & 193 \\ 70 & 281 \\ 07 & 326 \\ 07 & 327 \\ 44 & 358 \\ 9 & 39 \\ 6 & 67 \\ 8 & 83 \\ 21 & 130 \\ 21 & 132 \\ 52 & 161 \\ 02 & 210 \\ 70 & 278 \\ 91 & 300 \\ 23 & 338 \\ 75 & 386 \\ 78 & 386 \\ 87 & 499 \\ 5 & 26\end{array}$



Anaphase-promoting complex subunit 7 GN=ANAPC7 APC7_HUMAN $66.86 \quad 100.0 \%$ Anaphase-promoting complex subunit $7 \mathrm{GN}=$ ANAPC7 APC7_HUMAN $66.86 \quad 100.0 \%$ Anaphase-promoting complex subunit $7 \mathrm{GN}=\mathrm{ANAPC} 7$ APC7_HUMAN $66.86 \quad 100.0 \%$ Anaphase-promoting complex subunit $7 \mathrm{GN}=\mathrm{ANAPC} 7$ APC7_HUMAN $66.86 \quad 100.0 \%$ Anaphase-promoting complex subunit $7 \mathrm{GN}=$ ANAPC7 APC7 HUMAN $66.86 \quad 100.0 \%$ Ancient ubiquitous protein $1 \mathrm{GN}=$ AUP1 AUP1_HUMAN $53.03 \quad 100.0 \%$ Ancient ubiquitous protein $1 \mathrm{GN}=$ AUP1 AUP1_HUMAN $53.03 \quad 100.0 \%$ Ancient ubiquitous protein $1 \mathrm{GN}=\mathrm{AUP} 1 \quad$ AUP1_HUMAN $53.03 \quad 100.0 \%$ Ancient ubiquitous protein $1 \mathrm{GN}=$ AUP1 AUP1_HUMAN $53.03 \quad 100.0 \%$ Ancient ubiquitous protein $1 \mathrm{GN}=\mathrm{AUP} 1 \quad$ AUP1_HUMAN $53.03 \quad 100.0 \%$ Ancient ubiquitous protein $1 \mathrm{GN}=$ AUP1 AUP1_HUMAN $53.03 \quad 100.0 \%$ Ancient ubiquitous protein $1 \mathrm{GN}=\mathrm{AUP} 1 \quad$ AUP1_HUMAN $53.03 \quad 100.0 \%$ Annexin A2 GN=ANXA2 Annexin A2 GN=ANXA2 Annexin A6 GN=ANXA6 Annexin A6 GN=ANXA6 Antigen KI-67 GN=MKI67 Antigen $\mathrm{KI}-67 \mathrm{GN}=\mathrm{MKI} 67$ ANXA2 HUMAN $38.61 \quad 100.0 \%$ ANXA2_HUMAN $38.61 \quad 100.0 \%$ ANXA6_HUMAN $75.88 \quad 100.0 \%$ ANXA6_HUMAN $75.88 \quad 100.0 \%$ KI67_HUMAN $358.70 \quad 100.0 \%$ KI67_HUMAN $358.70 \quad 100.0 \%$ AP-1 complex subunit gamma-1 GN=AP1G1 AP1G1_HUMAN $91.35 \quad 100.0 \%$ AP-1 complex subunit gamma-1 GN=AP1G1 AP1G1_HUMAN $91.35 \quad 100.0 \%$ AP-1 complex subunit gamma-1 GN=AP1G1 AP1G1_HUMAN $91.35 \quad 100.0 \%$ AP-1 complex subunit gamma-1 GN=AP1G1 AP1G1_HUMAN $91.35 \quad 100.0 \%$ AP-1 complex subunit mu-1 GN=AP1M1 AP1M1_HUMAN $48.59 \quad 100.0 \%$ AP-1 complex subunit mu-1 GN=AP1M1 AP1M1_HUMAN $48.59 \quad 100.0 \%$ AP-1 complex subunit mu-1 GN=AP1M1 AP1M1_HUMAN $48.59 \quad 100.0 \%$ AP-1 complex subunit mu-1 GN=AP1M1 AP1M1_HUMAN $48.59 \quad 100.0 \%$ AP-1 complex subunit mu-1 GN=AP1M1 AP1M1_HUMAN $48.59 \quad 100.0 \%$

$\begin{array}{llll}12 & 20 & 0.02 \% & 35.6 \% \\ 12 & \text { AILQATLREEK }\end{array}$

$99.7 \% \quad 44.5$

$0.02 \% \quad 35.6 \%$ KQQSIAGSADSKPIDVSR

$12 \quad 20$

$0.02 \% \quad 35.6 \%$ IGCIITAR

$99.7 \% \quad 48.8$

$99.7 \% \quad 58.9$

$99.0 \% \quad 57.3$

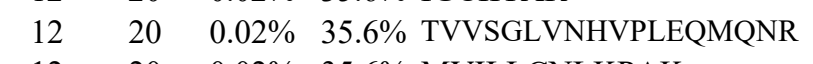

$12 \quad 20 \quad 0.02 \% \quad 35.6 \%$ MVILLCNLKPAK

$\begin{array}{lll}99.7 \% & 43.1\end{array}$

$0.02 \% \quad 35.6 \%$ IEILAPPNGSVPGDR

$96.1 \% 34.7$

$96.1 \% \quad 15.1$

20

\section{0}

$$
10
$$

11.7\% GMDVYGYLLAR

11.7\% EGRLEDVENLGCR

$9 \quad 0.01 \% \quad 11.7 \%$ VQEAIIHFR

$9 \quad 0.01 \% \quad 11.7 \%$ EQKYEDGIALLR

$17 \quad 0.02 \% \quad 17.6 \%$ GELVESLKR

\section{$0.02 \% \quad 17.6 \%$ LPPTPLLLFPEEEATNGR}

$0.02 \% \quad 17.6 \%$ QLGEANEEFALR

$0.02 \% \quad 17.6 \%$ VKEVLPHVPLGVIQR

$0.02 \% \quad 17.6 \%$ EVLPHVPLGVIQR

$0.02 \% \quad 17.6 \%$ GTQSLPTASASK

$0.02 \% \quad 17.6 \%$ FPSSGPVTPQPTALTFAK

$0.01 \% \quad 6.8 \%$ GVDEVTIVNILTNR

$\begin{array}{lll}0.01 \% & 6.8 \% & \text { QDIAFAYQR } \\ 0.00 \% & 3.3 \% & \text { DAFVAIVQSVK }\end{array}$

$0.00 \% \quad 3.3 \%$ GAGTDEKTLTR

$0.00 \% \quad 0.8 \%$ SGASEANLIVAK

$0.00 \% \quad 0.8 \%$ SPQSDPADTPTNTK

$0.01 \% \quad 3.8 \%$ KAALCAVHVIR

$0.01 \% \quad 3.8 \%$ AALCAVHVIR

$0.01 \% \quad 3.8 \%$ VLAINILGR

$0.01 \% \quad 3.8 \%$ TVQTDHNAVQR

$0.02 \% \quad 25.5 \%$ HNNLYLVATSK

$0.02 \% \quad 25.5 \%$ ILQEYITQEGHK

$0.02 \% \quad 25.5 \%$ VFLSGMPELR

$0.02 \% \quad 25.5 \%$ LGLNDKVLFDNTGR $\begin{array}{ll}99.7 \% & 42.0 \\ 99.7 \% & 47.4\end{array}$ $\begin{array}{llll}99.7 \% & 39.9 & 25.0 & 47.4\end{array}$ $\begin{array}{lllll}9.7 \% & 54.6 & 25.0 & 54.6 & 2\end{array}$ $\begin{array}{llll}99.7 \% & 28.6 & 25.0 & 25.6\end{array}$ $\begin{array}{lllll}99.7 \% & 52.5 & 25.0 & 47.5 & 2\end{array}$ $\begin{array}{llll}99.7 \% & 61.7 & 25.0 & 52.9\end{array}$ $\begin{array}{llll}99.7 \% & 43.0 & 25.0 & 20.0\end{array}$ $\begin{array}{lllll}99.7 \% & 36.2 & 25.0 & 36.2 & 1\end{array}$ $99.7 \% \quad 42.6 \quad 25.0 \quad 36.0$ $\begin{array}{llll}95.2 \% & 18.7 & 25.0 & 10.6\end{array}$ $\begin{array}{llll}99.6 \% & 27.5 & 25.0 & 20.8\end{array}$ $99.7 \% \quad 43.6 \quad 25.0 \quad 37.0$ $\begin{array}{ccc}1271.73 & 36 & 46 \\ 1886.99 & 137 & 154 \\ 1758.90 & 138 & 154 \\ 903.51 & 159 & 166 \\ 2037.05 & 188 & 205 \\ 1399.82 & 206 & 217 \\ 1534.82 & 236 & 250 \\ 1917.96 & 251 & 267 \\ 2597.26 & 34 & 58 \\ 1294.71 & 148 & 159 \\ 1938.91 & 199 & 215 \\ 1086.60 & 216 & 224 \\ 1464.72 & 305 & 317 \\ 1233.63 & 341 & 352 \\ 1267.64 & 430 & 440 \\ 1620.83 & 680 & 694 \\ 1173.59 & 919 & 929 \\ 1020.59 & 1040 & 1048 \\ 1168.65 & 1608 & 1617 \\ 1121.59 & 254 & 263 \\ 1257.63 & 307 & 317 \\ 1546.73 & 318 & 330 \\ 1611.94 & 365 & 379 \\ 1112.62 & 389 & 397 \\ 1434.76 & 489 & 500 \\ 1030.59 & 202 & 210 \\ 1994.06 & 217 & 234 \\ 1376.68 & 298 & 309 \\ 1684.03 & 370 & 384 \\ 1456.86 & 372 & 384 \\ 1147.60 & 414 & 425 \\ 1845.97 & 426 & 443 \\ 1542.85 & 50 & 63 \\ 1111.55 & 69 & 77 \\ 1176.66 & 588 & 598 \\ 1148.59 & 614 & 624 \\ 1159.63 & 648 & 659 \\ 1458.67 & 1861 & 1874 \\ 1237.72 & 156 & 166 \\ 1109.62 & 157 & 166 \\ 968.63 & 307 & 315 \\ 1268.63 & 335 & 345 \\ 1259.67 & 62 & 72 \\ 1458.76 & 130 & 141 \\ 1164.61 & 202 & 211 \\ 1561.83 & 212 & 225 \\ 1745.86 & 230 & 243 \\ & & \end{array}$ 
AP-1 complex subunit mu-1 GN=AP1M1 AP1M1_HUMAN $48.59 \quad 100.0 \%$ AP-1 complex subunit mu-1 GN=AP1M1 AP1M1_HUMAN $48.59 \quad 100.0 \%$ AP-1 complex subunit mu-1 GN=AP1M1 AP1M1_HUMAN $48.59 \quad 100.0 \%$ AP-1 complex subunit mu-1 GN=AP1M1 AP1M1_HUMAN $48.59 \quad 100.0 \%$ AP-2 complex subunit alpha-1 GN=AP2A1 AP2A1_HUMAN $107.55 \quad 100.0 \%$ AP-2 complex subunit alpha-1 GN=AP2A1 AP2A1_HUMAN $107.55 \quad 100.0 \%$ AP-2 complex subunit mu GN=AP2M1 AP2M1_HUMAN $49.66 \quad 100.0 \%$ AP-2 complex subunit mu GN=AP2M1 AP2M1_HUMAN $49.66 \quad 100.0 \%$ AP-2 complex subunit mu GN=AP2M1 AP2M1 HUMAN $49.66 \quad 100.0 \%$ AP-2 complex subunit mu GN=AP2M1 AP2M1_HUMAN $49.66 \quad 100.0 \%$ AP-2 complex subunit mu GN=AP2M1 AP2M1_HUMAN $49.66 \quad 100.0 \%$ AP-2 complex subunit mu GN=AP2M1 AP2M1_HUMAN $49.66 \quad 100.0 \%$ AP-3 complex subunit delta-1 GN=AP3D1 AP3D1_HUMAN $130.16 \quad 100.0 \%$ AP-3 complex subunit delta-1 GN=AP3D1 AP3D1_HUMAN $130.16 \quad 100.0 \%$ AP-3 complex subunit delta-1 GN=AP3D1 AP3D1_HUMAN $130.16 \quad 100.0 \%$ AP-3 complex subunit delta-1 GN=AP3D1 AP3D1_HUMAN $130.16 \quad 100.0 \%$ AP-3 complex subunit delta-1 GN=AP3D1 AP3D1_HUMAN $130.16 \quad 100.0 \%$ AP-3 complex subunit delta-1 GN=AP3D1 AP3D1_HUMAN $130.16 \quad 100.0 \%$ AP-3 complex subunit delta-1 GN=AP3D1 AP3D1_HUMAN $130.16 \quad 100.0 \%$ Apoptosis-inducing factor 1, mitochondrial GN=AIFM1 AIFM1_HUMAN $66.90 \quad 100.0 \%$ Apoptosis-inducing factor 1, mitochondrial GN=AIFM1 AIFM1_HUMAN $66.90 \quad 100.0 \%$ Apoptosis-inducing factor 1, mitochondrial GN=AIFM1 AIFM1_HUMAN $66.90 \quad 100.0 \%$ Apoptosis-inducing factor 1, mitochondrial GN=AIFM1 AIFM1_HUMAN $66.90 \quad 100.0 \%$ Apoptosis-inducing factor 1, mitochondrial GN=AIFM1 AIFM1_HUMAN $66.90 \quad 100.0 \%$ Apoptosis-inducing factor 1, mitochondrial GN=AIFM1 AIFM1_HUMAN $66.90 \quad 100.0 \%$ Apoptosis-inducing factor 1, mitochondrial GN=AIFM1 AIFM1_HUMAN $66.90 \quad 100.0 \%$ Apoptotic chromatin condensation inducer in the nucleus GN=ACIN1 ACINU_HUMAN $151.86 \quad 100.0 \%$ Apoptotic chromatin condensation inducer in the nucleus GN=ACIN1 ACINU_HUMAN $151.86 \quad 100.0 \%$ Apoptotic chromatin condensation inducer in the nucleus $\mathrm{GN}=\mathrm{ACIN} 1$ ACINU_HUMAN $151.86 \quad 100.0 \%$ Apoptotic chromatin condensation inducer in the nucleus $\mathrm{GN}=\mathrm{ACIN} 1$ ACINU_HUMAN $151.86 \quad 100.0 \%$ Apoptotic chromatin condensation inducer in the nucleus $\mathrm{GN}=\mathrm{ACIN} 1 \quad \mathrm{ACINU} \_$HUMAN $151.86 \quad 100.0 \%$ Apoptotic chromatin condensation inducer in the nucleus $\mathrm{GN}=\mathrm{ACIN} 1$ ACINU_HUMAN $151.86 \quad 100.0 \%$ Apoptotic chromatin condensation inducer in the nucleus GN=ACIN1 ACINU_HUMAN $151.86 \quad 100.0 \%$ Apoptotic chromatin condensation inducer in the nucleus GN=ACIN1 ACINU_HUMAN $151.86 \quad 100.0 \%$ Apoptotic chromatin condensation inducer in the nucleus $\mathrm{GN}=\mathrm{ACIN} 1$ ACINU_HUMAN $151.86 \quad 100.0 \%$ Apoptotic chromatin condensation inducer in the nucleus GN=ACIN1 ACINU_HUMAN $151.86 \quad 100.0 \%$ Arginase-1 GN=ARG1

Arginase- $1 \mathrm{GN}=\mathrm{ARG} 1$ ARGI1_HUMAN $34.74 \quad 100.0 \%$ ARGI1 HUMAN $34.74 \quad 100.0 \%$ Arginine--tRNA ligase, cytoplasmic GN=RARS SYRC_HUMAN $75.38 \quad 100.0 \%$ Arginine--tRNA ligase, cytoplasmic GN=RARS SYRC_HUMAN $75.38 \quad 100.0 \%$ Arginine--tRNA ligase, cytoplasmic GN=RARS SYRC_HUMAN $75.38 \quad 100.0 \%$ Arginine--tRNA ligase, cytoplasmic GN=RARS SYRC_HUMAN $75.38 \quad 100.0 \%$ Arginine--tRNA ligase, cytoplasmic GN=RARS SYRC_HUMAN $75.38 \quad 100.0 \%$ Arginine--tRNA ligase, cytoplasmic GN=RARS SYRC_HUMAN $75.38 \quad 100.0 \%$ Arginine--tRNA ligase, cytoplasmic GN=RARS SYRC_HUMAN $75.38 \quad 100.0 \%$ Arginine--tRNA ligase, cytoplasmic GN=RARS SYRC_HUMAN $75.38 \quad 100.0 \%$ Arginine--tRNA ligase, cytoplasmic GN=RARS SYRC_HUMAN $75.38 \quad 100.0 \%$

(1)

6

$\begin{array}{ccccl}2 & 4 & 0.00 \% & 2.2 \% & \text { EMGEAFAADIPR } \\ 2 & 4 & 0.00 \% & 2.2 \% & \text { ALQVGCLLR } \\ 6 & 10 & 0.01 \% & 13.3 \% & \text { NAVDAFRVNVIHAR }\end{array}$

$10 \quad 0.01 \% \quad 13.3 \%$ NAVDAFRVNVIHAR

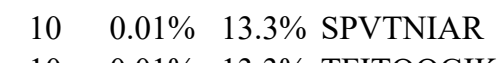

$10 \quad 0.01 \% \quad 13.3 \%$ TFITQQGIK

$10 \quad 0.01 \% \quad 13.3 \%$ LSKFDSER

$10 \quad 0.01 \% \quad 13.3 \%$ SNFKPSLLAQK

$10 \quad 0.01 \% \quad 13.3 \%$ SGIYETRC

$12 \quad 0.01 \% \quad 6.8 \%$ LFGALTPLEPR

$12 \quad 0.01 \% \quad 6.8 \% \quad$ ALDLLYGMVSK

$12 \quad 0.01 \% \quad 6.8 \%$ ASCILQLVK

$12 \quad 0.01 \% \quad 6.8 \%$ HRPSEADEEELAR

$12 \quad 0.01 \% \quad 6.8 \% \quad$ KQEQANNPFYIK

$12 \quad 0.01 \% \quad 6.8 \%$ GMELSVLDSLNAR

$12 \quad 0.01 \% \quad 6.8 \% \quad$ MSFQNLLAK

$13 \quad 0.01 \% \quad 14.8 \%$ ISGLGLTPEQK

$13 \quad 0.01 \% \quad 14.8 \%$ ELWFSDDPNVTK

$13 \quad 0.01 \% \quad 14.8 \%$ LNDGSQITYEK

$13 \quad 0.01 \% \quad 14.8 \%$ CLIATGGTPR

$13 \quad 0.01 \% \quad 14.8 \%$ SLSAIDRAGAEVK

$0.01 \% \quad 14.8 \%$ ALGTEVIQLFPEKGNMGK

$0.01 \% \quad 14.8 \%$ VMPNAIVQSVGVSSGK

$0.04 \% \quad 7.8 \%$ VTDLKAALEQR

$0.04 \% \quad 7.8 \%$ GALMLENLQK

$0.04 \% \quad 7.8 \%$ SSSISEEKGDSDDEKPR

$0.04 \% \quad 7.8 \%$ SQEQEVLER

$0.04 \% \quad 7.8 \%$ RLSQPESAEK

$0.04 \% \quad 7.8 \%$ GVPAGNSDTEGGQPGR

$0.04 \% \quad 7.8 \%$ WGASTATTQK

$0.04 \% \quad 7.8 \% \quad$ VTLGDTLTR

$0.04 \% \quad 7.8 \%$ VTLGDTLTRR

$0.04 \% \quad 7.8 \%$ SGVSITIDDPVR

$0.00 \% \quad 3.7 \%$ GGVEEGPTVLR

$0.00 \% \quad 3.7 \%$ GGVEEGPTVLRK

$0.03 \% \quad 21.5 \%$ NMINIISR

$0.03 \% \quad 21.5 \%$ AAYPDLENPPLLVTPSQQAK

$0.03 \% \quad 21.5 \%$ EIAENITK

$0.03 \% \quad 21.5 \%$ VIVDFSSPNIAK

$0.03 \% \quad 21.5 \%$ STIIGESISR

$0.03 \% \quad 21.5 \%$ AYQCVVLLQGK

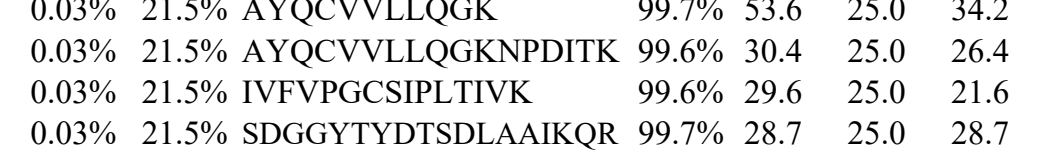

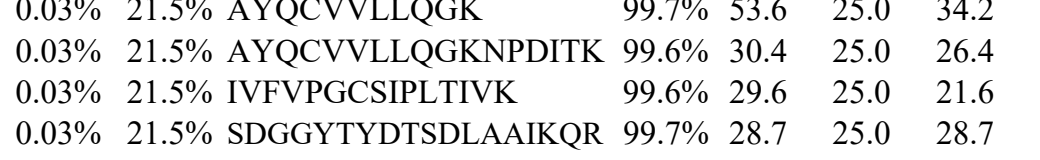

$\begin{array}{llll}99.7 \% & 28.1 & 25.0 & 28.1\end{array}$

$\begin{array}{llll}99.7 \% & 49.5 & 25.0 & 46.2\end{array}$

$\begin{array}{lllll}99.7 \% & 41.3 & 25.0 & 41.3 & 2\end{array}$

$\begin{array}{llll}99.7 \% & 57.9 & 25.0 & 45.9\end{array}$

$\begin{array}{llll}99.7 \% & 34.6 & 25.0 & 34.6\end{array}$

$\begin{array}{llll}98.7 \% & 22.9 & 25.0 & 15.8\end{array}$

$99.7 \% \quad 32.0 \quad 25.0 \quad 32.0$

$\begin{array}{lllll}99.0 \% & 36.0 & 25.0 & 28.7 & 2\end{array}$

$\begin{array}{llll}99.7 \% & 46.2 & 25.0 & 37.3\end{array}$

$\begin{array}{llll}99.0 \% & 39.1 & 25.0 & 26.8\end{array}$

$\begin{array}{llll}99.7 \% & 32.1 & 25.0 & 28.2\end{array}$

$99.0 \% \quad 44.2 \quad 25.0 \quad 44.2$

$99.7 \% \quad 28.7 \quad 25.0 \quad 20.0$

$\begin{array}{llll}99.7 \% & 51.3 & 25.0 & 51.3\end{array}$

$\begin{array}{llll}99.7 \% & 61.6 & 25.0 & 49.7\end{array}$

$\begin{array}{llll}99.7 \% & 35.3 & 25.0 & 35.3\end{array}$

$\begin{array}{llll}96.5 \% & 18.9 & 25.0 & 13.2\end{array}$

$\begin{array}{llll}99.7 \% & 36.2 & 25.0 & 36.2\end{array}$

$\begin{array}{llll}99.7 \% & 55.4 & 25.0 & 44.8\end{array}$

$99.7 \% \quad 41.0 \quad 25.0 \quad 37.2$

$\begin{array}{llll}99.7 \% & 29.7 & 25.0 & 29.7\end{array}$

$\begin{array}{llll}99.7 \% & 61.8 & 25.0 & 48.3\end{array}$

$\begin{array}{lllll}99.7 \% & 39.0 & 25.0 & 33.6 & 2\end{array}$

$\begin{array}{llll}96.8 \% & 18.6 & 25.0 & 17.5\end{array}$

$\begin{array}{llll}99.7 \% & 37.4 & 25.0 & 30.6\end{array}$

$\begin{array}{llll}99.7 \% & 34.8 & 25.0 & 24.8\end{array}$

$\begin{array}{llll}98.4 \% & 21.1 & 25.0 & 21.1\end{array}$

$\begin{array}{llll}99.7 \% & 45.0 & 25.0 & 39.8\end{array}$

$\begin{array}{llll}99.2 \% & 26.0 & 25.0 & 15.4\end{array}$

$\begin{array}{llll}99.7 \% & 56.0 & 25.0 & 52.5\end{array}$

$99.7 \% \quad 41.7 \quad 25.0 \quad 34.6$

$\begin{array}{llll}99.7 \% & 43.6 & 25.0 & 32.4\end{array}$

$\begin{array}{llll}99.7 \% & 30.2 & 25.0 & 22.1\end{array}$

$\begin{array}{llll}99.7 \% & 57.0 & 25.0 & 48.7\end{array}$

$\begin{array}{llll}99.7 \% & 34.3 & 25.0 & 22.0\end{array}$

$99.2 \% \quad 21.4 \quad 25.0 \quad 21.4$

$\begin{array}{llll}98.7 \% & 26.4 & 25.0 & 11.6\end{array}$

$\begin{array}{llll}99.7 \% & 41.5 & 25.0 & 41.5\end{array}$

$\begin{array}{llll}99.0 \% & 31.9 & 25.0 & 21.8\end{array}$

$\begin{array}{llll}99.7 \% & 53.5 & 25.0 & 44.7\end{array}$

$\begin{array}{llll}99.7 \% & 55.8 & 25.0 & 45.2\end{array}$

$\begin{array}{llll}99.7 \% & 53.6 & 25.0 & 34.2\end{array}$

$\begin{array}{lll}99.6 \% & 30.4\end{array}$

$99.6 \% 29.6$

$99.7 \% 28.7$ $\begin{array}{llll}99.7 \% & 58.5 & 25.0 & 51.8\end{array}$

$\begin{array}{ccc}2118.05 & 305 & 324 \\ 1657.86 & 380 & 393 \\ 1370.67 & 411 & 421 \\ 1599.78 & 411 & 423 \\ 1322.60 & 142 & 153 \\ 1029.59 & 936 & 944 \\ 1581.86 & 27 & 40 \\ 857.48 & 45 & 52 \\ 1035.58 & 131 & 139 \\ 981.50 & 254 & 261 \\ 1232.70 & 309 & 319 \\ 985.44 & 428 & 435 \\ 1213.69 & 244 & 254 \\ 1209.65 & 360 & 370 \\ 1031.59 & 572 & 580 \\ 1538.72 & 655 & 667 \\ 1479.76 & 673 & 684 \\ 1404.72 & 963 & 975 \\ 1051.56 & 1079 & 1087 \\ 1142.64 & 99 & 109 \\ 1450.69 & 178 & 189 \\ 1267.62 & 245 & 255 \\ 1045.55 & 256 & 265 \\ 1316.72 & 266 & 278 \\ 1948.02 & 325 & 342 \\ 1572.84 & 363 & 378 \\ 1243.70 & 77 & 87 \\ 1116.61 & 104 & 113 \\ 1865.84 & 206 & 222 \\ 1117.55 & 328 & 336 \\ 1144.60 & 708 & 717 \\ 1498.69 & 832 & 847 \\ 1050.52 & 851 & 860 \\ 975.55 & 971 & 979 \\ 1131.65 & 971 & 980 \\ 1258.66 & 987 & 998 \\ 1113.59 & 22 & 32 \\ 1241.69 & 22 & 33 \\ 976.52 & 72 & 79 \\ 2152.13 & 90 & 109 \\ 917.49 & 136 & 143 \\ 1289.71 & 194 & 205 \\ 1062.58 & 214 & 223 \\ 1278.69 & 290 & 300 \\ 1947.04 & 290 & 306 \\ 1642.96 & 363 & 377 \\ 1960.92 & 378 & 395 \\ & & \\ 130\end{array}$

Page 24 of Table S-1- 6 
Arginine--tRNA ligase, cytoplasmic GN=RARS SYRC HUMAN $75.38 \quad 100.0 \%$ Arginine--tRNA ligase, cytoplasmic GN=RARS SYRC_HUMAN $75.38 \quad 100.0 \%$ Arginine--tRNA ligase, cytoplasmic GN=RARS SYRC_HUMAN $75.38 \quad 100.0 \% \quad 1$ Asparagine synthetase [glutamine-hydrolyzing] GN=ASNS ASNS HUMAN $64.37 \quad 100.0 \%$ Asparagine synthetase [glutamine-hydrolyzing] GN=ASNS ASNS_HUMAN $64.37 \quad 100.0 \%$ Asparagine synthetase [glutamine-hydrolyzing] GN=ASNS ASNS_HUMAN $64.37 \quad 100.0 \%$ Asparagine synthetase [glutamine-hydrolyzing] GN=ASNS ASNS HUMAN $64.37 \quad 100.0 \%$ Asparagine synthetase [glutamine-hydrolyzing] GN=ASNS ASNS_HUMAN $64.37 \quad 100.0 \%$ Asparagine synthetase [glutamine-hydrolyzing] GN=ASNS ASNS HUMAN $64.37 \quad 100.0 \%$ Asparagine synthetase [glutamine-hydrolyzing] GN=ASNS ASNS_HUMAN $64.37 \quad 100.0 \%$ Asparagine synthetase [glutamine-hydrolyzing] GN=ASNS ASNS_HUMAN $64.37 \quad 100.0 \%$ Aspartate aminotransferase, mitochondrial GN=GOT2 AATM HUMAN $47.52 \quad 100.0 \%$ Aspartate aminotransferase, mitochondrial GN=GOT2 AATM_HUMAN $47.52 \quad 100.0 \%$ Aspartate aminotransferase, mitochondrial GN=GOT2 AATM_HUMAN $47.52 \quad 100.0 \%$ Aspartate aminotransferase, mitochondrial $\mathrm{GN}=\mathrm{GOT} 2$ AATM_HUMAN $47.52 \quad 100.0 \%$ Aspartate aminotransferase, mitochondrial GN=GOT2 AATM_HUMAN $47.52 \quad 100.0 \%$ Aspartate aminotransferase, mitochondrial GN=GOT2 AATM HUMAN $47.52 \quad 100.0 \%$ Aspartate aminotransferase, mitochondrial GN=GOT2 AATM_HUMAN $47.52 \quad 100.0 \%$ Aspartate--tRNA ligase, cytoplasmic GN=DARS SYDC_HUMAN $57.14 \quad 100.0 \%$ Aspartate--tRNA ligase, cytoplasmic GN=DARS SYDC HUMAN $57.14 \quad 100.0 \%$ Aspartate--tRNA ligase, cytoplasmic GN=DARS SYDC_HUMAN $57.14 \quad 100.0 \%$ Aspartate--tRNA ligase, cytoplasmic GN=DARS SYDC HUMAN $57.14 \quad 100.0 \%$ Aspartate--tRNA ligase, cytoplasmic GN=DARS SYDC_HUMAN $57.14 \quad 100.0 \%$ Aspartate--tRNA ligase, cytoplasmic GN=DARS SYDC_HUMAN $57.14 \quad 100.0 \%$ Aspartate--tRNA ligase, cytoplasmic GN=DARS SYDC HUMAN 57.14 100.0\% Aspartate--tRNA ligase, cytoplasmic GN=DARS SYDC_HUMAN $57.14 \quad 100.0 \%$ Ataxin-10 GN=ATXN10

Ataxin-10 GN=ATXN10

Ataxin-10 GN=ATXN10

Ataxin-10 GN=ATXN10

ATX10 HUMAN $53.49 \quad 100.0 \%$

ATX10 HUMAN $53.49 \quad 100.0 \%$

ATX10_HUMAN $53.49 \quad 100.0 \%$

ATX10 HUMAN $53.49 \quad 100.0 \%$

$100.0 \% \quad 33$

$100.0 \% \quad 33$

$100.0 \% \quad 33$ $100.0 \% \quad 33$ $100.0 \% \quad 33$ $100.0 \%$ $100.0 \% \quad 33$ $100.0 \% \quad 33$ $100.0 \% \quad 33$ $100.0 \% \quad 33$ $100.0 \% \quad 33$ $100.0 \% \quad 33$ $100.0 \% \quad 33$ $100.0 \% \quad 33$ $100.0 \% \quad 33$ $100.0 \% \quad 33$ $100.0 \% \quad 33$

7

7

$\begin{array}{ll}7 & 7 \\ 7 & 7 \\ 8 & 8 \\ 8 & 8\end{array}$

$\begin{array}{ll}8 & 8 \\ 8 & 8 \\ 8 & 8\end{array}$

8

8
8
8
8

8
8

8

$\begin{array}{ll}8 & 8 \\ 4 & 4 \\ 4 & 4\end{array}$

4

4
4

4

40

40

4

40

40

40

40

40
40

40
40
40
40
$0.03 \% \quad 21.5 \%$ LANIDEEMLQK $0.03 \% \quad 21.5 \%$ GFDILGIKPVQR

$0.02 \% \quad 16.9 \%$ LAVVDPLFGMQPIR

$0.02 \% \quad 16.9 \%$ AMTEDGFLAVCSEAK

$0.02 \% \quad 16.9 \%$ ILFNNAVK

$0.02 \% \quad 16.9 \%$ IGCLLSGGLDSSLVAATLLK

$0.02 \% \quad 16.9 \%$ ELYLFDVLR

$0.02 \% \quad 16.9 \%$ EAFSDGITSVK

$0.02 \% \quad 16.9 \%$ TKEGYYYR

$8 \quad 0.02 \% \quad 16.9 \%$ WINATDPSAR

$0.01 \% \quad 16.3 \%$ ASAELALGENSEVLK

$0.01 \% \quad 16.3 \%$ FVTVQTISGTGALR

$0.01 \% \quad 16.3 \%$ DAGMQLQGYR

$0.01 \% \quad 16.3 \%$ VGAFTMVCK

$0.01 \% \quad 16.3 \%$ IAAAILNTPDLR

$0.01 \% \quad 16.3 \%$ IAAAILNTPDLRK

$0.01 \% \quad 16.3 \%$ TQLVSNLKK

$10 \quad 0.01 \% \quad 17.4 \%$ FAANINKESIVDVEGVVR

$10 \quad 0.01 \% \quad 17.4 \%$ ESIVDVEGVVR

$10 \quad 0.01 \% \quad 17.4 \%$ IGSCTQQDVELHVQK

$10 \quad 0.01 \% \quad 17.4 \%$ GFVEIQTPK

$10 \quad 0.01 \% \quad 17.4 \%$ NNAYLAQSPQLYK

$10 \quad 0.01 \% \quad 17.4 \%$ FQTEIQTVNK

$10 \quad 0.01 \% \quad 17.4 \%$ IHDPQLLTER

$10 \quad 0.01 \% \quad 17.4 \%$ VTMLFLGLHNVR

$7 \quad 0.01 \% \quad 10.3 \%$ ALTALFKEQR

$0.01 \% \quad 10.3 \%$ NACIECSVNQNSIR

$0.01 \% \quad 10.3 \%$ ITSDEPLTKDDIPVFLR

$0.01 \% \quad 10.3 \%$ LIGNLCYK

$184 \quad 0.21 \% \quad 56.6 \%$ TGTAEMSSILEER

$184 \quad 0.21 \% \quad 56.6 \%$ ILGADTSVDLEETGR

$184 \quad 0.21 \% \quad 56.6 \%$ ILGADTSVDLEETGRVLSIGDGIAR

$184 \quad 0.21 \% \quad 56.6 \%$ VLSIGDGIAR

$184 \quad 0.21 \% \quad 56.6 \%$ NVQAEEMVEFSSGLK

$184 \quad 0.21 \% \quad 56.6 \%$ GMSLNLEPDNVGVVVFGNDK

$184 \quad 0.21 \% \quad 56.6 \%$ TGAIVDVPVGEELLGR

$184 \quad 0.21 \% \quad 56.6 \%$ VVDALGNAIDGK

$184 \quad 0.21 \% \quad 56.6 \%$ VVDALGNAIDGKGPIGSK

$184 \quad 0.21 \% \quad 56.6 \%$ VGLKAPGIIPR

$184 \quad 0.21 \% \quad 56.6 \%$ ISVREPMQTGIK

$184 \quad 0.21 \% \quad 56.6 \%$ AVDSLVPIGR

$184 \quad 0.21 \% \quad 56.6 \%$ AVDSLVPIGRGQR

$184 \quad 0.21 \% \quad 56.6 \%$ GQRELIIGDR

$184 \quad 0.21 \% \quad 56.6 \%$ ELIIGDRQTGK

$40 \quad 184 \quad 0.21 \% \quad 56.6 \%$ TSIAIDTIINQK

$40 \quad 184 \quad 0.21 \% \quad 56.6 \%$ TSIAIDTIINQKR $\begin{array}{llll}99.7 \% & 45.8 & 25.0 & 40.7 \\ 99.7 \% & 55.3 & 25.0 & 52.7\end{array}$

$99.7 \% \quad 28.0 \quad 25.0 \quad 28.0$

$99.7 \% \quad 55.4 \quad 25.0 \quad 55.4$

$99.7 \% \quad 54.9 \quad 25.0 \quad 54.9$

$99.0 \% \quad 42.9 \quad 25.0 \quad 7.9$

$\begin{array}{llll}99.7 \% & 29.5 & 25.0 & 29.5\end{array}$

$\begin{array}{llll}9.7 \% & 62.4 & 25.0 & 56.4 \\ 99.7 \% & 47.8 & 25.0 & 47.8\end{array}$

$99.0 \% \quad 29.0 \quad 25.0 \quad 24.0$

$\begin{array}{lllll}99.7 \% & 32.2 & 25.0 & 32.2 & 2\end{array}$

$99.7 \% \quad 51.7 \quad 25.0 \quad 51.7$

$99.7 \% \quad 98.0 \quad 25.0 \quad 91.3 \quad 2$

$99.3 \% \quad 28.1 \quad 25.0 \quad 17.6$

$99.7 \% \quad 27.9 \quad 25.0 \quad 25.3$

$99.7 \% \quad 58.4 \quad 25.0 \quad 45.7$

$99.7 \% \quad 37.2 \quad 25.0 \quad 37.2$

$99.2 \% \quad 20.6 \quad 25.0 \quad 20.6$

$99.5 \% \quad 22.9$

$98.5 \% 21.3$

$99.0 \% \quad 18.7$

$99.7 \% \quad 29.5$

$99.7 \% \quad 49.2$

$\begin{array}{lll}99.6 \% & 26.3\end{array}$

$99.7 \% \quad 30.4$

$99.7 \% \quad 46.8$

$\begin{array}{lll}99.7 \% & 40.8\end{array}$

$99.7 \% \quad 55.2$

$99.7 \% \quad 27.9$

$99.0 \% \quad 19.6$

$99.7 \% \quad 68.6$

$99.7 \% \quad 71.6$

$9.7 \% \quad 52.5$

$99.7 \% \quad 59.8$

$99.7 \% \quad 60.4$

$99.7 \% 52.9$

$\begin{array}{ll}99.7 \% & 56.6 \\ 99.7 \% & 52.4\end{array}$

$99.7 \% \quad 57.5$

$99.7 \% \quad 53.8$

$\begin{array}{lll}99.7 \% & 44.4\end{array}$

$99.7 \% \quad 55.3$

$\begin{array}{lll}99.7 \% & 30.0\end{array}$

$99.7 \% \quad 27.5$

$99.7 \% \quad 48.0$

$99.7 \% \quad 58.5$

$99.7 \% \quad 49.0$
1319.65

1342.78

1571.86

1644.72

918.54

1988.11

1167.64

1153.57

1079.52

1130.56

1530.80

1449.81

1138.53

1012.50

1267.74

1395.83

1030.63

1960.05

1201.64

1741.85

1018.56

1509.77

1207.63

1221.66

1399.79

1176.67

1664.75

1959.04

980.52

1423.67

1575.79

2557.35

1000.58

1667.79

2120.03

1624.89

1171.63

1710.94

1120.72

1358.75

1026.59

1367.78

1156.64

1229.69

1316.74

1472.84 \begin{tabular}{ll}
547 & 557 \\
648 & 659 \\
50 & 63 \\
48 & 162 \\
237 & 244 \\
253 & 272 \\
396 & 404 \\
468 & 478 \\
12 & 5 \\
541 & 550 \\
08 & 122 \\
26 & 139 \\
71 & 180 \\
288 & 296 \\
36 & 337 \\
26 & 338 \\
356 & 364 \\
04 & 121 \\
11 & 121 \\
27 & 141 \\
214 & 222 \\
242 & 254 \\
321 & 330 \\
432 & 441 \\
476 & 487 \\
28 & 37 \\
90 & 103 \\
254 & 270 \\
377 & 384 \\
46 & 58 \\
59 & 73 \\
59 & 83 \\
74 & 83 \\
89 & 103 \\
04 & 123 \\
34 & 149 \\
50 & 161 \\
50 & 167 \\
72 & 182 \\
83 & 194 \\
95 & 204 \\
95 & 207 \\
205 & 2 \\
208 & 2 \\
219 & 230 \\
219 & 231 \\
& \\
\hline
\end{tabular}

Page 25 of Table S-1-6 
ATP synthase subunit alpha, mitochondrial GN=ATP5A1 ATPA_HUMAN $59.75 \quad 100.0 \% \quad 33$ ATP synthase subunit alpha, mitochondrial GN=ATP5A1 ATPA_HUMAN $59.75 \quad 100.0 \% 33$ ATP synthase subunit alpha, mitochondrial GN=ATP5A1 ATPA_HUMAN $59.75 \quad 100.0 \% 33$ ATP synthase subunit alpha, mitochondrial GN=ATP5A1 ATPA_HUMAN $59.75 \quad 100.0 \% 33$ ATP synthase subunit alpha, mitochondrial GN=ATP5A1 ATPA_HUMAN $59.75 \quad 100.0 \%$ ATP synthase subunit alpha, mitochondrial GN=ATP5A1 ATPA_HUMAN $59.75 \quad 100.0 \% 33$ ATP synthase subunit alpha, mitochondrial GN=ATP5A1 ATPA_HUMAN $59.75 \quad 100.0 \% 33$ ATP synthase subunit alpha, mitochondrial GN=ATP5A1 ATPA_HUMAN $59.75 \quad 100.0 \% 33$ ATP synthase subunit alpha, mitochondrial GN=ATP5A1 ATPA_HUMAN $59.75 \quad 100.0 \% 33$ ATP synthase subunit alpha, mitochondrial GN=ATP5A1 ATPA_HUMAN $59.75 \quad 100.0 \%$ ATP synthase subunit alpha, mitochondrial GN=ATP5A1 ATPA_HUMAN $59.75 \quad 100.0 \% \quad 33$ ATP synthase subunit alpha, mitochondrial GN=ATP5A1 ATPA_HUMAN 59.75 ATP synthase subunit alpha, mitochondrial GN=ATP5A1 ATPA_HUMAN 59.75 ATP synthase subunit alpha, mitochondrial GN=ATP5A1 ATPA_HUMAN 59.75 ATP synthase subunit alpha, mitochondrial GN=ATP5A1 ATPA_HUMAN 59.75 ATP synthase subunit alpha, mitochondrial GN=ATP5A1 ATPA_HUMAN 59.75 ATP synthase subunit beta, mitochondrial GN=ATP5B ATPB HUMAN 56.56 ATP synthase subunit beta, mitochondrial GN=ATP5B ATPB_HUMAN 56.56 ATP synthase subunit beta, mitochondrial GN=ATP5B ATPB_HUMAN 56.56 ATP synthase subunit beta, mitochondrial GN=ATP5B ATPB HUMAN 56.56 ATP synthase subunit beta, mitochondrial GN=ATP5B ATPB_HUMAN 56.56 ATP synthase subunit beta, mitochondrial GN=ATP5B ATPB_HUMAN 56.56 ATP synthase subunit beta, mitochondrial GN=ATP5B ATPB HUMAN 56.56 ATP synthase subunit beta, mitochondrial GN=ATP5B ATPB_HUMAN 56.56 ATP synthase subunit beta, mitochondrial GN=ATP5B ATPB_HUMAN 56.56 ATP synthase subunit beta, mitochondrial GN=ATP5B ATPB_HUMAN 56.56 ATP synthase subunit beta, mitochondrial GN=ATP5B ATPB_HUMAN 56.56 ATP synthase subunit beta, mitochondrial GN=ATP5B ATPB HUMAN 56.56 ATP synthase subunit beta, mitochondrial GN=ATP5B ATPB_HUMAN 56.56 ATP synthase subunit beta, mitochondrial GN=ATP5B ATPB HUMAN 56.56 ATP synthase subunit beta, mitochondrial GN=ATP5B ATPB_HUMAN 56.56 ATP synthase subunit gamma, mitochondrial GN=ATP5C1 ATPG_HUMAN 33.00 ATP synthase subunit gamma, mitochondrial GN=ATP5C1 ATPG_HUMAN 33.00 ATP synthase subunit gamma, mitochondrial GN=ATP5C1 ATPG_HUMAN 33.00 ATP synthase subunit gamma, mitochondrial GN=ATP5C1 ATPG_HUMAN 33.00 ATP synthase subunit gamma, mitochondrial GN=ATP5C1 ATPG_HUMAN 33.00 ATP synthase subunit gamma, mitochondrial GN=ATP5C1 ATPG_HUMAN 33.00 ATP synthase subunit gamma, mitochondrial GN=ATP5C1 ATPG_HUMAN 33.00 ATP synthase subunit gamma, mitochondrial GN=ATP5C1 ATPG_HUMAN 33.00 ATP synthase subunit gamma, mitochondrial GN=ATP5C1 ATPG_HUMAN 33.00 ATP synthase subunit $\mathrm{O}$, mitochondrial GN=ATP5O ATPO HUMAN 23.28 ATP synthase subunit $\mathrm{O}$, mitochondrial GN=ATP5O ATPO_HUMAN 23.28 ATP synthase subunit $\mathrm{O}$, mitochondrial GN=ATP5O ATPO HUMAN 23.28 ATP synthase subunit $\mathrm{O}$, mitochondrial GN=ATP5O ATPO_HUMAN 23.28 ATP synthase subunit O, mitochondrial GN=ATP5O ATPO_HUMAN 23.28 ATPase family AAA domain-containing protein 1 GN=ATAD1 ATAD1_HUMAN 40.75 ATPase family AAA domain-containing protein 1 GN=ATAD1 ATAD1_HUMAN 40.75 $\begin{array}{llll}99.7 \% & 59.6 & 25.0 & 52.6\end{array}$ $99.0 \% \quad 46.8 \quad 25.0 \quad 23.7$ $99.7 \% \quad 54.8$ $99.7 \% \quad 33.7$ $97.3 \% \quad 15.9$ $\begin{array}{llll}99.7 \% & 51.4\end{array}$ $99.7 \% \quad 55.9$ $184 \quad 0.21 \% \quad 56.6 \%$ HALIIYDDLSK $99.7 \% \quad 29.1$ $84 \quad 0.21 \% \quad 56.6 \%$ QAVAYRQMSLLLR $99.7 \% \quad 31.8$ $\begin{array}{ll}99.7 \% & 58.6 \\ 99.7 \% & 37.7\end{array}$

$84 \quad 0.21 \% \quad 56.6 \%$ EAYPGDVFYLHSR
$184 \quad 0.21 \% \quad 56.6 \%$ EAYPGDVFYLHSRLLER

$184 \quad 0.21 \% \quad 56.6 \%$ GIRPAINVGLSVSR

$184 \quad 0.21 \% \quad 56.6 \%$ GVRLTELLK

$184 \quad 0.21 \% \quad 56.6 \%$ GYLDKLEPSK

$99.7 \% 51$.

$\begin{array}{lll}98.3 \% & 27.3\end{array}$ $99.7 \% \quad 35.2$

$184 \quad 0.21 \% \quad 56.6 \%$ FENAFLSHVVSQHQALLGTIR $99.7 \% \quad 53.5$

$184 \quad 0.21 \% \quad 56.6 \%$ LKEIVTNFLAGFEA $99.7 \% \quad 56.3$

$108 \quad 0.12 \% \quad 39.3 \%$ ETRLVLEVAQHLGESTVR

$108 \quad 0.12 \% \quad 39.3 \%$ LVLEVAQHLGESTVR

$108 \quad 0.12 \% \quad 39.3 \%$ TIAMDGTEGLVR

$99.7 \% 29.6$

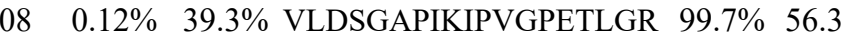

$108 \quad 0.12 \% \quad 39.3 \%$ IMNVIGEPIDERGPIK

$108 \quad 0.12 \% \quad 39.3 \%$ VVDLLAPYAK

$108 \quad 0.12 \% \quad 39.3 \%$ IGLFGGAGVGK

$108 \quad 0.12 \% \quad 39.3 \%$ TVLIMELINNVAK

$108 \quad 0.12 \% \quad 39.3 \%$ AHGGYSVFAGVGER

$108 \quad 0.12 \% \quad 39.3 \%$ VALVYGQMNEPPGAR

$108 \quad 0.12 \% \quad 39.3 \%$ VALTGLTVAEYFR

$108 \quad 0.12 \% \quad 39.3 \%$ FTQAGSEVSALLGR

$108 \quad 0.12 \% \quad 39.3 \%$ AIAELGIYPAVDPLDSTSR

$108 \quad 0.12 \% \quad 39.3 \%$ IMDPNIVGSEHYDVAR

$108 \quad 0.12 \% \quad 39.3 \%$ FLSQPFQVAEVFTGHMGK

$27 \quad 0.03 \% \quad 32.2 \%$ IYGLGSLALYEK

$0.03 \% \quad 32.2 \%$ HLLIGVSSDR

$0.03 \% \quad 32.2 \%$ GLCGAIHSSIAK

$0.03 \% \quad 32.2 \%$ SEVATLTAAGK

$0.03 \% \quad 32.2 \%$ EVMLVGIGDK

$0.03 \% \quad 32.2 \%$ EVMLVGIGDKIR

$0.03 \% \quad 32.2 \%$ THSDQFLVAFK

$0.03 \% \quad 32.2 \%$ ELIEIISGAAALD

$0.01 \% \quad 20.2 \%$ VAQILKEPK

$0.01 \% \quad 20.2 \%$ VAASVLNPYVK

$11 \quad 0.01 \% \quad 20.2 \%$ VAASVLNPYVKR

$11 \quad 0.01 \% \quad 20.2 \%$ SLNDITAKER

$11 \quad 0.01 \% \quad 20.2 \%$ TDPSILGGMIVR

$0.00 \% \quad 5.5 \%$ NEVVGLIFR

$4 \quad 0.00 \% \quad 5.5 \%$ LAAAVFSLAIK

\section{$\begin{array}{lll}99.3 \% & 25.3\end{array}$} $99.7 \% \quad 53.6$

$99.7 \% \quad 46.1$

$99.7 \% \quad 57.8$ $99.7 \% \quad 44.7$

$99.7 \% \quad 58.3$

$99.7 \% \quad 33.4$

$99.7 \% \quad 50.7$

$\begin{array}{ll}99.7 \% & 56.8 \\ 99.7 \% & 35.6\end{array}$

$99.7 \% \quad 32.3$

$99.7 \% \quad 74.9$

$99.7 \% \quad 45.7$

$99.7 \% \quad 45.7$

$99.7 \% \quad 52.5$

$99.7 \% \quad 37.1$

$99.7 \% \quad 55.2$

$99.7 \% \quad 75.3$

$99.7 \% \quad 64.6$

$99.7 \% \quad 64.3$

$99.7 \% \quad 32.7$

$99.7 \% \quad 42.6$

$99.7 \% \quad 52.3$

$99.7 \% \quad 62.9$

$99.7 \% \quad 34.2$

$99.7 \% \quad 39.9$

$99.7 \% \quad 53.1$
$0.03 \% \quad 32.2 \%$ NASEMIDKLTLTFNR
1701.88

1287.69

1976.06

1564.86

2117.07

1553.74

2065.05

1438.85

1028.65

1149.62

2367.26

1551.84

2037.11

1650.92

1262.64

1919.10

1796.96

1088.64

975.56

1457.84

1406.68

1601.81

1439.79

1435.75

1988.03

1831.86

2023.01

1326.73

1096.6

1213.64

1047.57

1076.57

1345.75

1292.66

1768.89

1314.72

1025.64

1160.67

1316.77

1146.61

1274.68

1046.60 1103.68 $\begin{array}{cc}42 & 252 \\ 54 & 261 \\ 54 & 262 \\ 62 & 270 \\ 02 & 316 \\ 06 & 316 \\ 06 & 322 \\ 17 & 329 \\ 30 & 347 \\ 35 & 347 \\ 35 & 351 \\ 03 & 416 \\ 64 & 472 \\ 94 & 503 \\ 07 & 527 \\ 40 & 553 \\ 72 & 109 \\ 95 & 109 \\ 10 & 121 \\ 25 & 143 \\ 44 & 159 \\ 89 & 198 \\ 02 & 212 \\ 13 & 225 \\ 26 & 239 \\ 65 & 279 \\ 82 & 294 \\ 11 & 324 \\ 88 & 406 \\ 07 & 422 \\ 63 & 480 \\ 68 & 79 \\ 91 & 100 \\ 01 & 112 \\ 16 & 126 \\ 27 & 136 \\ 27 & 138 \\ 44 & 154 \\ 63 & 277 \\ 86 & 298 \\ 55 & 73 \\ 74 & 84 \\ 74 & 85 \\ 91 & 100 \\ 77 & 188 \\ 14 & 22 \\ 73 & 183\end{array}$ 

ATPase family AAA domain-containing protein 3A GN=ATAD3A ATD3A_HUMAN $71.37 \quad 100.0 \% \quad 24$ ATPase family AAA domain-containing protein 3A GN=ATAD3A ATD3A_HUMAN $71.37 \quad 100.0 \% \quad 24$ ATPase family AAA domain-contining protein $3 \mathrm{~A}$ GN=ATAD3A ATD3A HUMAN $71.37 \quad 100.0 \%$ ATPase family AAA domain-containing protein 3A GN=ATAD3A ATD3A_HUMAN $71.37 \quad 100.0 \% \quad 24$ ATPase family AAA domain-containing protein 3A GN=ATAD3A ATD3A_HUMAN $71.37 \quad 100.0 \% \quad 24$ ATPase family AAA domain-containing protein 3A GN=ATAD3A ATD3A_HUMAN $71.37 \quad 100.0 \% \quad 24$ ATPase family AAA domain-containing protein 3A GN=ATAD3A ATD3A_HUMAN $71.37 \quad 100.0 \% \quad 24$ ATPase family AAA domain-containing protein $3 \mathrm{~A}$ GN=ATAD3A ATD3A HUMAN $71.37 \quad 100.0 \%$ ATPase family AAA domain-containing protein 3A GN=ATAD3A ATD3A_HUMAN $71.37 \quad 100.0 \% \quad 24$ ATPase family AAA domain-containing protein 3A GN=ATAD3A ATD3A_HUMAN $71.37 \quad 100.0 \% \quad 24$ ATPase family AAA domain-containing protein 3A GN=ATAD3A ATD3A_HUMAN 71.37 ATPase family AAA domain-containing protein 3A GN=ATAD3A ATD3A_HUMAN 71.37 ATPase family AAA domain-containing protein 3A GN=ATAD3A ATD3A_HUMAN 71.37 ATPase family AAA domain-containing protein $3 \mathrm{~A}$ GN=ATAD3A ATD3A HUMAN 71.37 ATPase family AAA domain-containing protein 3A GN=ATAD3A ATD3A_HUMAN 71.3 ATPase family AAA domain-containing protein $3 \mathrm{~A}$ GN=ATAD3A ATD3A HUMAN 71.37 ATPase family AAA domain-containing protein 3A GN=ATAD3A ATD3A_HUMAN 71.37 ATPase family AAA domain-containing protein $3 \mathrm{~A}$ GN=ATAD3A ATD3A_HUMAN 71.37 ATPase family AAA domain-containing protein 3A GN=ATAD3A ATD3A_HUMAN 71.37 ATPase family AAA domain-containing protein 3A GN=ATAD3A ATD3A_HUMAN 71.37 ATPase family AAA domain-containing protein 3A GN=ATAD3A ATD3A_HUMAN 71.37 ATPase family AAA domain-containing protein $3 \mathrm{~A}$ GN=ATAD3A ATD3A_HUMAN 71.37 ATPase family AAA domain-containing protein 3A GN=ATAD3A ATD3A_HUMAN 71.3 ATPase family AAA domain-containing protein $3 \mathrm{~B}$ GN=ATAD3B $\quad$ ATD3B_HUMAN 72.57 ATPase family AAA domain-containing protein $3 \mathrm{~B}$ GN=ATAD3B ATD3B_HUMAN 72.57 ATPase family AAA domain-containing protein 3B GN=ATAD3B ATD3B_HUMAN 72.57 ATPase family AAA domain-containing protein 3B GN=ATAD3B ATD3B HUMAN 72.57 ATPase family AAA domain-containing protein $3 \mathrm{~B}$ GN=ATAD3B ATD3B_HUMAN $72.5^{\circ}$ ATPase family AAA domain-containing protein 3B GN=ATAD3B ATD3B_HUMAN 72.57 ATPase family AAA domain-containing protein $3 \mathrm{~B}$ GN=ATAD3B ATD3B_HUMAN 72.57 ATPase family AAA domain-containing protein 3B GN=ATAD3B ATD3B_HUMAN 72.57 ATPase family AAA domain-containing protein 3B GN=ATAD3B ATD3B_HUMAN 72.57 ATPase family AAA domain-containing protein $3 \mathrm{~B}$ GN=ATAD3B ATD3B_HUMAN 72.57 ATPase family AAA domain-containing protein 3B GN=ATAD3B ATD3B_HUMAN 72.57 ATPase family AAA domain-containing protein $3 \mathrm{~B}$ GN=ATAD3B $\quad$ ATD3B HUMAN 72.57 ATPase family AAA domain-containing protein $3 \mathrm{~B}$ GN=ATAD3B ATD3B_HUMAN $72.5^{\circ}$ ATPase family AAA domain-containing protein 3B GN=ATAD3B ATD3B_HUMAN 72.57 ATPase family AAA domain-containing protein 3B GN=ATAD3B ATD3B_HUMAN 72.57 ATPase family AAA domain-containing protein 3B GN=ATAD3B ATD3B_HUMAN $72.5^{\circ}$ ATPase family AAA domain-containing protein $3 \mathrm{~B} G \mathrm{GN}=\mathrm{ATAD} 3 \mathrm{~B} \quad \mathrm{ATD} 3 \mathrm{~B}$ HUMAN $725^{\circ}$ ATPase family AAA domain-containing protein 3B GN=ATAD3B ATD3B_HUMAN $72.5^{\circ}$ ATPase family AAA domain-containing protein 3B GN=ATAD3B ATD3B HUMAN 72.57

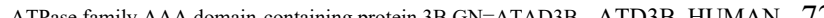
ATPase family AAA domain-containing protein $3 \mathrm{~B}$ GN=ATAD3B ATD3B HUMAN 72.57 ATP-binding cassette sub-family $B$ member 7 , mitochondrial $\mathrm{GN}=\mathrm{ABCB} 7 \quad \mathrm{ABCB} 7$ HUMAN 82.64 $\begin{array}{lll}A & \\ \text { ATP-binding cassette sub-family B member } 7 \text {, mitochondrial } \mathrm{GN}=\mathrm{ABCB} 7 \mathrm{ABCB} 7 \text { HUMAN } & 82.64\end{array}$

(2)

3
3

3

3

3

3
3
3

3

3
3
3

3

$\begin{array}{lll}0.08 \% & 38.5 \% & \text { GLGDRPAPK } \\ 0.08 \% & 38.5 \% & \text { DKWSNFDPT }\end{array}$

$0.08 \% \quad 38.5 \%$ AQYQDKLAR

$0.08 \% \quad 38.5 \%$ ATVEREMELR

$0.08 \% \quad 38.5 \%$ ENADIIREQIR

$0.08 \% \quad 38.5 \%$ AAEHRQTVLESIR

$0.08 \% \quad 38.5 \%$ QTVLESIR

$0.08 \% \quad 38.5 \%$ TAGTLFGEGFR

$0.08 \% \quad 38.5 \%$ NATLVAGRFIEAR

$0.08 \% 38.5 \%$ LGKPSLVR

$0.08 \% \quad 38.5 \%$ ITVLEALR

$0.08 \% \quad 38.5 \%$ ITVLEALRHPIQVSR

$0.08 \% \quad 38.5 \%$ LLSRPQDALEGVVLSPSL

$0.08 \% \quad 38.5 \%$ VRDIAIATR

$0.08 \% 38.5 \%$ NILMYGPPGTGK

$0.08 \% \quad 38.5 \%$ LALHSGMDYAIMTGGDVAPMGR

$0.08 \% \quad 38.5 \%$ LFDWANTSR

$0.08 \% \quad 38.5 \%$ MYFDKYVLKPATEGK

$0.08 \% \quad 38.5 \%$ LKLAQFDYGR

$0.08 \% 38.5 \%$ LAQFDYGR

$0.08 \% 38.5 \%$ LAQFDYGRK

$0.08 \% \quad 38.5 \%$ LTEGMSGR

$0.08 \% \quad 38.5 \%$ AEGPGRGDEPSPS

$0.01 \% 31.2 \%$ GLGDRPAPK

$0.01 \% \quad 31.2 \%$ DKWSNFDPTGLER

$0.01 \% \quad 31.2 \%$ TLSEETRQHQAR

$0.01 \% \quad 31.2 \%$ AQYQDKLAR

$0.01 \% \quad 31.2 \%$ ATVEREMELR

$0.01 \% \quad 31.2 \%$ ENADIIREQIR

$0.01 \% \quad 31.2 \%$ QTVLESIR

$0.01 \% \quad 31.2 \%$ TAGTLFGEGFR

$0.01 \% \quad 31.2 \%$ LGKPSLVR

$0.01 \% \quad 31.2 \%$ ITVLEALR

$0.01 \% \quad 31.2 \%$ ITVLEALRHPIQVSR

$0.01 \% \quad 31.2 \%$ VRDIAIATR

$0.01 \% \quad 31.2 \%$ HILLYGPPGTGK

$0.01 \% \quad 31.2 \%$ LALHSGMDYAIMTGGDVAPMGR

$0.01 \% \quad 31.2 \%$ LFDWANTSR

$0.01 \% \quad 31.2 \%$ ATEEISKDLR

$0.01 \% \quad 31.2 \%$ LHFDNCVLKPATEGK

$0.01 \% \quad 31.2 \%$ LKLAQFDYGR

$0.01 \% \quad 31.2 \%$ LAQFDYGR

$\begin{array}{lll}0.01 \% & 31.2 \% & \text { LAQFDYGRK }\end{array}$

$0.01 \% 31.2 \%$ LTEGMSGR

$0.00 \% \quad 2.9 \%$ VAISLGFLGGAK

$0.00 \% \quad 2.9 \%$ AGAAFFNEVR
$99.7 \% \quad 52.7 \quad 25.0 \quad 43.9$

$\begin{array}{llll}99.7 \% & 33.6 & 25.0 & 33.5\end{array}$

$\begin{array}{llll}99.7 \% & 33.7 & 25.0 & 30.0\end{array}$

$99.7 \% \quad 60.2 \quad 25.0 \quad 51.5$

$\begin{array}{llll}99.7 \% & 34.0 & 25.0 & 16.8\end{array}$

$99.7 \% \quad 37.0 \quad 25.0 \quad 26.4$

$99.7 \% \quad 34.6 \quad 25.0 \quad 34.6$

$\begin{array}{llll}99.0 \% & 50.1 & 25.0 & 30.5\end{array}$

$99.7 \% \quad 56.7 \quad 25.0 \quad 56.7$

$97.7 \% \quad 19.0 \quad 25.0 \quad 14.6$

$\begin{array}{llll}99.0 \% & 42.4 & 25.0 & 29.3\end{array}$

$99.0 \% \quad 47.1 \quad 25.0 \quad 33.9$

$\begin{array}{llll}99.7 \% & 38.1 & 25.0 & 38.1\end{array}$

$\begin{array}{llll}99.7 \% & 33.6 & 25.0 & 33.4\end{array}$

$99.7 \% \quad 40.0 \quad 25.0 \quad 36.3$

$\begin{array}{llll}99.7 \% & 60.7 & 25.0 & 49.9\end{array}$

$\begin{array}{llll}7.7 \% & 29.3 & 25.0 & 28.5\end{array}$

$99.7 \% \quad 45.9 \quad 25.0 \quad 34.0$

$\begin{array}{llll}99.7 \% & 39.9 & 25.0 & 39.9\end{array}$

$\begin{array}{llll}99.7 \% & 52.5 & 25.0 & 52.5\end{array}$

$99.0 \% \quad 51.2 \quad 25.0 \quad 27.2$

$99.7 \% \quad 31.1 \quad 25.0 \quad 31.1$

$\begin{array}{llll}99.0 \% & 49.3 & 25.0 & 45.1\end{array}$

$\begin{array}{llll}99.7 \% & 42.4 & 25.0 & 41.2\end{array}$

$\begin{array}{llll}99.7 \% & 52.7 & 25.0 & 43.9\end{array}$

$\begin{array}{llll}99.7 \% & 33.6 & 25.0 & 33.5\end{array}$

$\begin{array}{llll}99.7 \% & 33.7 & 25.0 & 30.0\end{array}$

$\begin{array}{llll}99.7 \% & 60.2 & 25.0 & 51.5\end{array}$

$99.7 \% \quad 34.0 \quad 25.0 \quad 16.8$

$\begin{array}{llll}99.7 \% & 37.0 & 25.0 & 26.4\end{array}$

$\begin{array}{llll}99.0 \% & 50.1 & 25.0 & 30.5\end{array}$

$\begin{array}{llll}99.7 \% & 56.7 & 25.0 & 56.7\end{array}$

$\begin{array}{llll}99.0 \% & 42.4 & 25.0 & 29.3\end{array}$

$\begin{array}{llll}99.0 \% & 47.1 & 25.0 & 33.9\end{array}$

$\begin{array}{llll}99.7 \% & 38.1 & 25.0 & 38.1\end{array}$

$\begin{array}{llll}99.7 \% & 40.0 & 25.0 & 36.3\end{array}$

$\begin{array}{llll}99.7 \% & 46.2 & 25.0 & 38.2\end{array}$

$\begin{array}{llll}9.7 \% & 29.3 & 25.0 & 28.5\end{array}$

$\begin{array}{llll}99.7 \% & 45.9 & 25.0 & 34.0\end{array}$

$\begin{array}{llll}99.7 \% & 48.9 & 25.0 & 22.4\end{array}$

$\begin{array}{llll}99.3 \% & 21.4 & 25.0 & 21.2\end{array}$

$\begin{array}{llll}99.7 \% & 52.5 & 25.0 & 52.5\end{array}$

$\begin{array}{llll}99.0 \% & 51.2 & 25.0 & 27.2\end{array}$

$\begin{array}{lllll}99.7 \% & 31.1 & 25.0 & 31.1 & 2\end{array}$

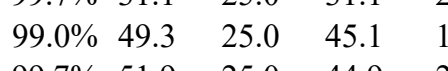

$\begin{array}{llll}99.7 \% & 51.9 & 25.0 & 44.9\end{array}$

$\begin{array}{llll}97.4 \% & 25.3 & 25.0 & 21.9\end{array}$

\begin{tabular}{|c|c|c|c|c|c|}
\hline & & & & & \\
\hline 33.7 & 25.0 & 30.0 & 0 & 4 & 0 \\
\hline 60.2 & 25.0 & 51.5 & 4 & 0 & \\
\hline 34.0 & 25.0 & 16.8 & 2 & 2 & \\
\hline 37.0 & 25.0 & 26.4 & 3 & 1 & 0 \\
\hline 34.6 & 25.0 & 34.6 & 2 & 2 & \\
\hline 50.1 & 25.0 & 30.5 & 3 & 0 & \\
\hline 56.7 & 25.0 & 56.7 & 6 & 0 & 0 \\
\hline $6 \quad 19.0$ & 25.0 & 14.6 & 1 & 0 & \\
\hline 42.4 & 25.0 & 29.3 & 3 & 0 & \\
\hline 47.1 & 25.0 & 33.9 & 4 & 0 & 0 \\
\hline $\begin{array}{ll}6 & 38.1\end{array}$ & 25.0 & 38.1 & 0 & 2 & 0 \\
\hline 33.6 & 25.0 & 33.4 & 0 & 2 & \\
\hline 40.0 & 25.0 & 36.3 & 5 & 0 & 0 \\
\hline 60.7 & 25.0 & 49.9 & 4 & 0 & 0 \\
\hline 29.3 & 25.0 & 28.5 & 0 & 1 & \\
\hline 645.9 & 25.0 & 34.0 & 4 & 0 & 0 \\
\hline 39.9 & 25.0 & 39.9 & 1 & 2 & 0 \\
\hline 52.5 & 25.0 & 52.5 & 2 & 2 & \\
\hline 51.2 & 25.0 & 27.2 & 3 & 0 & 0 \\
\hline 31.1 & 25.0 & 31.1 & 2 & 0 & 0 \\
\hline 49.3 & 25.0 & 45.1 & 1 & 0 & 0 \\
\hline 642.4 & 25.0 & 41.2 & 4 & 0 & 0 \\
\hline 52.7 & 25.0 & 43.9 & 1 & 0 & 0 \\
\hline 33.6 & 25.0 & 33.5 & 1 & 0 & 0 \\
\hline 33.7 & 25.0 & 30.0 & 0 & 4 & 0 \\
\hline 60.2 & 25.0 & 51.5 & 4 & 0 & 0 \\
\hline 34.0 & 25.0 & 16.8 & 2 & 2 & 0 \\
\hline 37.0 & 25.0 & 26.4 & 3 & 1 & 0 \\
\hline 50.1 & 25.0 & 30.5 & 3 & 0 & 0 \\
\hline 56.7 & 25.0 & 56.7 & 6 & 0 & 0 \\
\hline 42.4 & 25.0 & 29.3 & 3 & 0 & 0 \\
\hline 47.1 & 25.0 & 33.9 & 4 & 0 & 0 \\
\hline 38.1 & 25.0 & 38.1 & 0 & 2 & 0 \\
\hline 40.0 & 25.0 & 36.3 & 5 & 0 & 0 \\
\hline 46.2 & 25.0 & 38.2 & 2 & 0 & 0 \\
\hline 29.3 & 25.0 & 28.5 & 0 & 1 & 0 \\
\hline 45.9 & 25.0 & 34.0 & 4 & 0 & 0 \\
\hline 48.9 & 25.0 & 22.4 & 2 & 0 & 0 \\
\hline 21.4 & 25.0 & 21.2 & 0 & 2 & 0 \\
\hline 52.5 & 25.0 & 52.5 & 2 & 2 & 0 \\
\hline 51.2 & 25.0 & 27.2 & 3 & 0 & 0 \\
\hline 31.1 & 25.0 & 31.1 & 2 & 0 & 0 \\
\hline 49.3 & 25.0 & 45.1 & 1 & 0 & 0 \\
\hline 51.9 & 25.0 & 44.9 & 2 & 0 & 0 \\
\hline 20 & 25.0 & 21.9 & 1 & 0 & 0 \\
\hline
\end{tabular}

Page 27 of Table S-1-6 
ATP-binding cassette sub-family D member $3 \mathrm{GN}=\mathrm{ABCD} 3 \quad \mathrm{ABCD} 3$ _HUMAN $75.48 \quad 100.0 \%$ ATP-binding cassette sub-family D member $3 \mathrm{GN}=\mathrm{ABCD} 3 \mathrm{ABCD} 3$ HUMAN $75.48 \quad 100.0 \%$ ATP-binding cassette sub-family D member $3 \mathrm{GN}=\mathrm{ABCD} 3 \quad \mathrm{ABCD} 3$ _HUMAN $75.48 \quad 100.0 \%$ ATP-binding cassette sub-family E member $1 \mathrm{GN}=\mathrm{ABCE} 1 \mathrm{ABCE} 1$ HUMAN $67.32 \quad 100.0^{\circ}$ ATP-binding cassette sub-family E member $1 \mathrm{GN}=\mathrm{ABCE} 1 \mathrm{ABCE} 1$ _HUMAN $67.32 \quad 100.0 \%$ ATP-binding cassette sub-family E member $1 \mathrm{GN}=\mathrm{ABCE} 1$ ABCE1_HUMAN $67.32 \quad 100.0 \%$ ATP-binding cassette sub-family F mer $2 \mathrm{GN}=\mathrm{ABCF} 2 \mathrm{ABCF} 2 \mathrm{HUMAN} 71.29 \quad 100.0 \%$ ATP-binding cassette sub-family F member $2 \mathrm{GN}=\mathrm{ABCF} 2 \mathrm{ABCF} 2$ _HUMAN $71.29 \quad 100.0 \%$ ATP-citrate synthase $\mathrm{GN}=\mathrm{ACLY}$ ATP-citrate synthase $\mathrm{GN}=\mathrm{ACLY}$ ATP-citrate synthase $\mathrm{GN}=\mathrm{ACLY}$ ATP-citrate synthase $\mathrm{GN}=\mathrm{ACLY}$ ATP-citrate synthase GN=ACLY ATP-citrate synthase $\mathrm{GN}=\mathrm{ACLY}$ ATP-citrate synthase GN=ACLY ATP-citrate synthase GN=ACLY ATP-citrate synthase $\mathrm{GN}=\mathrm{ACLY}$ ATP-citrate synthase $\mathrm{GN}=\mathrm{ACLY}$ ATP-citrate synthase $\mathrm{GN}=\mathrm{ACLY}$ ATP-citrate synthase $\mathrm{GN}=\mathrm{ACLY}$ ATP-citrate synthase $\mathrm{GN}=\mathrm{ACLY}$ ATP-citrate synthase $\mathrm{GN}=\mathrm{ACLY}$ ATP-citrate synthase GN=ACLY ATP-citrate synthase $\mathrm{GN}=\mathrm{ACLY}$ ATP-citrate synthase GN=ACLY ATP-citrate synthase GN=ACLY ATP-citrate synthase $\mathrm{GN}=\mathrm{ACLY}$ ATP-citrate synthase GN=ACLY ATP-citrate synthase GN=ACLY ATP-citrate synthase $\mathrm{GN}=\mathrm{ACL}$ ATP-dependet 6-phospofuctokna, livertype GN=PFK ATP-dependent 6-phosphofructokinase, liver type GN=PFKL PFKAL_HUMAN 85.02 $100.0 \%$ ATP-dependent 6-phosphofructokinase, liver type GN=PFKL PFKAL HUMAN 85.02 $100.0 \%$ ATP-dependent 6-phosphofructokinase, muscle type GN=PFKM PFKAM_HUMAN $85.18 \quad 100.0 \%$ ATP-dependent 6-phosphofructokinase, muscle type GN=PFKM PFKAM_HUMAN $85.18 \quad 100.0 \%$ ATP-dependent 6-phosphofructokinase, muscle type GN=PFKM PFKAM_HUMAN $85.18 \quad 100.0 \%$ $\begin{array}{llll}\text { ATP-dependent 6-phosphofructokinase, platelet type GN=PFKP PFKAP_HUMAN } 85.60 & 100.0 \%\end{array}$ ATP-dependent 6-phosphofructokinase, platelet type GN=PFKP PFKAP HUMAN $85.60100 .0^{\circ}$ ATP-dependent 6-phosphofructokinase, platelet type GN=PFKP PFKAP_HUMAN $85.60 \quad 100.0 \%$ ATP-dependent 6-phosphofructokinase, platelet type GN=PFKP PFKAP_HUMAN $85.60 \quad 100.0 \%$ ATP-dependent 6-phosphofructokinase, platelet type GN=PFKP PFKAP HUMAN 85.60 100.0\% ATP-dependent 6-phosphofructokinase, platelet type GN=PFKP PFKAP_HUMAN $85.60 \quad 100.0 \%$ ATP-dependent Clp protease ATP-hinding subunit clpX-like, mitochondrial GN=CLPX CLPX_HUMAN $69.22100 .0 \%$ ATP-dependent Clp protease ATP-binding subunit clpX--ilike, mitochondrial GN=CLPX CLPX_HUMAN $69.22 \quad 100.0 \%$ ATP-dependent Clp protease ATP-binding subunit clpX-like, mitochondrial GN=CLPX CLPX_HUMAN $69.22 \quad 100.0 \%$ TTP-dependent Clp protease ATP-binding subunit elpX-like, mitochondrial GN=CLPX CLPX HUMAN 69.22 100.0\% ATP-dependent Clp protease ATP-binding subunit clpX-like, mitochondrial GN=CLPX CLPX_HUMAN $69.22 \quad 100.0 \%$
$0.01 \% \quad 6.1 \% \quad$ AVVDKVFFSR $0.01 \% \quad 6.1 \%$ STHSELLEDYYQSGR $0.01 \% \quad 6.1 \%$ SGANVLICGPNGCGK $0.01 \% \quad 5.3 \%$ LCIEVTPQSK $0.01 \% \quad 5.3 \% \quad$ FACAVVCIQK $0.01 \% \quad 5.3 \%$ VAETANEEEVKK $0.00 \% \quad 3.2 \%$ SMLLSAIGKR $0.00 \% \quad 3.2 \%$ LVDEEPQLTK

$69 \quad 0.08 \% \quad 22.3 \%$ AISEQTGKELLYK

$69 \quad 0.08 \% \quad 22.3 \%$ FICTTSAIQNR

$69 \quad 0.08 \% \quad 22.3 \%$ LGQEATVGK

$69 \quad 0.08 \% \quad 22.3 \%$ LGQEATVGKATGFLK

$69 \quad 0.08 \% \quad 22.3 \%$ DGVYVLDLAAK

$69 \quad 0.08 \% \quad 22.3 \%$ VDATADYICK

$69 \quad 0.08 \% \quad 22.3 \%$ SGASLKLTLLNPK

$69 \quad 0.08 \% \quad 22.3 \%$ TILSLMTR

$69 \quad 0.08 \% \quad 22.3 \%$ RGGPNYQEGLR

$69 \quad 0.08 \% \quad 22.3 \%$ GGPNYQEGLR

$69 \quad 0.08 \% \quad 22.3 \%$ TASFSESRADEVAPAK

$69 \quad 0.08 \% \quad 22.3 \%$ AKPAMPQDSVPSPR

$69 \quad 0.08 \% \quad 22.3 \%$ SAYDSTMETMNYAQIR

$69 \quad 0.08 \% \quad 22.3 \%$ TIAIIAEGIPEALTR

$69 \quad 0.08 \% \quad 22.3 \%$ IGNTGGMLDNILASK

$69 \quad 0.08 \% \quad 22.3 \%$ LYRPGSVAYVSR

$69 \quad 0.08 \% \quad 22.3 \%$ SGGMSNELNNIISR

$69 \quad 0.08 \% \quad 22.3 \%$ YQDTPGVK

$69 \quad 0.08 \% \quad 22.3 \%$ NQALKEAGVFVPR

$69 \quad 0.08 \% \quad 22.3 \%$ LIMGIGHR

$69 \quad 0.08 \% \quad 22.3 \%$ VQILKDYVR

$69 \quad 0.08 \% \quad 22.3 \%$ SMGFIGHYLDQKR

$0.01 \% \quad 5.8 \%$ AIGVLTSGGDAQGMNAAVR

$0.01 \% \quad 5.8 \%$ GGTPSAFDRILSSK

$0.01 \% \quad 5.8 \%$ AVAFSPVTELKK

$0.00 \% \quad 4.0 \%$ VGIFTGAR

$0.00 \% \quad 4.0 \% \quad$ AAYNLVKR

$0.00 \% \quad 4.0 \% \quad$ LGYDTRVTVLGHVQR

$0.01 \% \quad 9.2 \%$ FLEHLSGAGK

$0.01 \% \quad 9.2 \%$ AIGVLTSGGDAQGMNAAVR

$0.01 \% \quad 9.2 \%$ AACNLLQR

$0.01 \% \quad 9.2 \%$ SFAGNLNTYKR

$0.01 \% \quad 9.2 \%$ SAVRVGIADGHR

$0.01 \% \quad 9.2 \%$ NVIFQPVAELKK

$16 \quad 0.02 \% \quad 15.5 \%$ SIIKEPESAAEAVK

$0.02 \% \quad 15.5 \%$ SNILLLGPTGSGK

$0.02 \% \quad 15.5 \%$ TLLAQTLAK

$0.02 \% \quad 15.5 \%$ LLQDANYNVEK

$0.02 \% \quad 15.5 \%$ DVGGEGVQQGLLK

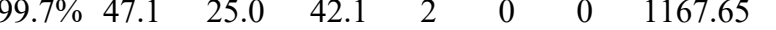

1784.81

1503.70

1174.6

$99.3 \% \quad 25.5 \quad 25.0 \quad 25.5$

$99.7 \% \quad 41.0 \quad 25.0 \quad 36.6$

$\begin{array}{llll}99.7 \% & 36.2 & 25.0 & 29.6\end{array}$

$\begin{array}{llll}99.2 \% & 30.5 & 25.0 & 29.0\end{array}$

$\begin{array}{lllll}99.7 \% & 31.7 & 25.0 & 21.0 & 3\end{array}$

$\begin{array}{llll}99.7 \% & 57.7 & 25.0 & 51.9\end{array}$

$\begin{array}{llll}99.7 \% & 50.9 & 25.0 & 45.4\end{array}$

$\begin{array}{llll}99.7 \% & 57.0 & 25.0 & 47.6\end{array}$

$99.7 \% \quad 41.6 \quad 25.0 \quad 41.6$

$\begin{array}{llll}99.5 \% & 23.3 & 25.0 & 23.3\end{array}$

$\begin{array}{llll}99.7 \% & 38.9 & 25.0 & 37.1\end{array}$

$99.7 \% \quad 33.1 \quad 25.0 \quad 26.4$

$99.0 \% \quad 46.9 \quad 25.0 \quad 41.1$

$99.7 \% \quad 47.7 \quad 25.0 \quad 37.1$

$\begin{array}{llll}99.2 \% & 39.7 & 25.0 & 9.1\end{array}$

$\begin{array}{llll}99.7 \% & 48.0 & 25.0 & 48.0\end{array}$

$\begin{array}{llll}99.7 \% & 32.7 & 25.0 & 32.6\end{array}$

$\begin{array}{lllll}99.7 \% & 55.2 & 25.0 & 54.2 & 2\end{array}$

$\begin{array}{llll}99.7 \% & 49.3 & 25.0 & 45.0\end{array}$

$\begin{array}{llll}99.7 \% & 49.8 & 25.0 & 49.8\end{array}$

$\begin{array}{lllll}99.7 \% & 35.3 & 25.0 & 27.3 & 2\end{array}$

$99.7 \% \quad 59.1 \quad 25.0 \quad 51.0$

$\begin{array}{llll}99.0 \% & 44.7 & 25.0 & 30.4\end{array}$

$99.7 \% \quad 55.4 \quad 25.0 \quad 55.2$

$\begin{array}{llll}99.0 \% & 29.1 & 25.0 & 21.8\end{array}$

$\begin{array}{lllll}99.7 \% & 39.5 & 25.0 & 31.7 & 2\end{array}$

$\begin{array}{llll}97.5 \% & 16.1 & 25.0 & 16.1\end{array}$

99.6\% \#\#\#\# 25.0 \#\#\#\#

$\begin{array}{llll}99.7 \% & 38.4 & 25.0 & 27.2\end{array}$

$99.7 \% \quad 33.3 \quad 25.0 \quad 30.9$

$99.0 \% \quad 25.0 \quad 25.0 \quad 20.9$

$99.0 \% \quad 24.4 \quad 25.0 \quad 24.4$

$\begin{array}{llll}99.7 \% & 34.3 & 25.0 & 32.3\end{array}$

$\begin{array}{llll}99.3 \% & 25.1 & 25.4 & 15.9\end{array}$

25.0 \#\#\#\#

$\begin{array}{lllll}97.5 \% & 27.6 & 25.0 & 8.4 & 2\end{array}$

$\begin{array}{llll}99.7 \% & 57.6 & 25.0 & 51.3\end{array}$

$\begin{array}{lllll}99.7 \% & 29.3 & 25.0 & 27.2\end{array}$

$\begin{array}{llll}99.7 \% & 32.4 & 25.0 & 32.4\end{array}$

$99.7 \% \quad 37.7 \quad 25.0 \quad 25.4$

$\begin{array}{llll}99.7 \% & 66.7 & 25.0 & 64.2\end{array}$

$99.7 \% \quad 44.5 \quad 25.0 \quad 41.6$

$\begin{array}{llll}99.7 \% & 37.3 & 25.0 & 26.5\end{array}$

$99.7 \% \quad 53.8 \quad 25.0 \quad 49.5$ $\begin{array}{cc}57 & 66 \\ 48 & 362 \\ 65 & 479 \\ 37 & 46 \\ 25 & 234 \\ 33 & 344 \\ 25 & 134 \\ 09 & 618 \\ 5 & 17 \\ 18 & 28 \\ 39 & 97 \\ 39 & 103 \\ 10 & 220 \\ 21 & 230 \\ 60 & 272 \\ 22 & 329 \\ 79 & 389 \\ 80 & 389 \\ 53 & 468 \\ 70 & 483 \\ 77 & 592 \\ 93 & 607 \\ 36 & 650 \\ 51 & 662 \\ 63 & 676 \\ 04 & 711 \\ 76 & 788 \\ 69 & 976 \\ 87 & 995 \\ 666 & 1078 \\ 17 & 35 \\ 02 & 315 \\ 16 & 727 \\ 40 & 47 \\ 01 & 108 \\ 87 & 301 \\ 16 & 25 \\ 26 & 44 \\ 10 & 117 \\ 86 & 396 \\ 31 & 442 \\ 26 & 737 \\ 45 & 158 \\ 87 & 299 \\ 00 & 308 \\ 39 & 349 \\ 74 & 386 \\ & \end{array}$ 
ATP-dependent RNA helicase A GN=DHX9 DHX9_HUMAN $140.96 \quad 100.0 \%$ ATP-dependent RNA helicase A GN=DHX9 DHX9_HUMAN $140.96 \quad 100.0 \%$ ATP-dependent RNA helicase A GN=DHX9 DHX9 HUMAN $140.96 \quad 100.0 \%$ ATP-dependent RNA helicase A GN=DHX9 DHX9_HUMAN $140.96 \quad 100.0 \%$ ATP-dependent RNA helicase A GN=DHX9 DHX9_HUMAN $140.96 \quad 100.0 \%$ ATP-dependent RNA helicase A GN=DHX9 DHX9_HUMAN $140.96 \quad 100.0 \%$ ATP-dependent RNA helicase A GN=DHX9 DHX9_HUMAN $140.96 \quad 100.0 \%$ ATP-dependent RNA helicase A GN=DHX9 DHX9_HUMAN $140.96 \quad 100.0 \% \quad 43$ ATP-dependent RNA helicase A GN=DHX9 DHX9_HUMAN $140.96 \quad 100.0 \%$ ATP-dependent RNA helicase A GN=DHX9 DHX9_HUMAN $140.96 \quad 100.0 \%$ ATP-dependent RNA helicase A GN=DHX9 DHX9_HUMAN $140.96 \quad 100.0 \% \quad 43$ ATP-dependent RNA helicase A GN=DHX9 DHX9_HUMAN $140.96 \quad 100.0 \% \quad 43$ ATP-dependent RNA helicase A GN=DHX9 DHX9_HUMAN $140.96 \quad 100.0 \% \quad 43$ ATP-dependent RNA helicase A GN=DHX9 DHX9_HUMAN $140.96 \quad 100.0 \%$ ATP-dependent RNA helicase A GN=DHX9 DHX9_HUMAN $140.96 \quad 100.0 \%$ ATP-dependent RNA helicase A GN=DHX9 DHX9_HUMAN $140.96 \quad 100.0 \%$ ATP-dependent RNA helicase A GN=DHX9 DHX9_HUMAN $140.96 \quad 100.0 \%$ ATP-dependent RNA helicase A GN=DHX9 DHX9_HUMAN $140.96 \quad 100.0 \% \quad 43$ ATP-dependent RNA helicase A GN=DHX9 DHX9_HUMAN $140.96 \quad 100.0 \% 43$ ATP-dependent RNA helicase A GN=DHX9 DHX9_HUMAN $140.96 \quad 100.0 \% \quad 43$ ATP-dependent RNA helicase A GN=DHX9 DHX9_HUMAN $140.96 \quad 100.0 \%$ ATP-dependent RNA helicase A GN=DHX9 DHX9_HUMAN $140.96 \quad 100.0 \% \quad 43$ ATP-dependent RNA helicase A GN=DHX9 DHX9_HUMAN $140.96 \quad 100.0 \% \quad 43$ ATP-dependent RNA helicase A GN=DHX9 DHX9_HUMAN $140.96 \quad 100.0 \% \quad 43$ ATP-dependent RNA helicase A GN=DHX9 DHX9_HUMAN $140.96 \quad 100.0 \% \quad 43$ ATP-dependent RNA helicase A GN=DHX9 DHX9_HUMAN $140.96 \quad 100.0 \% \quad 43$ ATP-dependent RNA helicase A GN=DHX9 DHX9_HUMAN $140.96 \quad 100.0 \%$ ATP-dependent RNA helicase A GN=DHX9 DHX9_HUMAN $140.96 \quad 100.0 \% \quad 43$ ATP-dependent RNA helicase A GN=DHX9 DHX9_HUMAN $140.96 \quad 100.0 \% \quad 43$ ATP-dependent RNA helicase A GN=DHX9 DHX9_HUMAN $140.96 \quad 100.0 \% \quad 43$ ATP-dependent RNA helicase A GN=DHX9 DHX9_HUMAN $140.96 \quad 100.0 \%$ ATP-dependent RNA helicase A GN=DHX9 DHX9_HUMAN $140.96 \quad 100.0 \% \quad 43$ ATP-dependent RNA helicase A GN=DHX9 DHX9_HUMAN $140.96 \quad 100.0 \% \quad 43$

$0.02 \% \quad 15.5 \%$ LLEGTIVNVPEKNSR $.02 \% \quad 15.5 \%$ YLGFGTPSNLGK 0.02\% $15.5 \%$ RAAAAADLANR $0.01 \% \quad 13.7 \%$ GQATDIAIQAEEIMK $0.01 \% \quad 13.7 \%$ QSLQVIESAMER $0.33 \% \quad 33.0 \%$ KMTPSYEIR 0.33\% $33.0 \%$ MTPSYEIR

$288 \quad 0.33 \% \quad 33.0 \%$ GANLKDYYSR

$288 \quad 0.33 \% \quad 33.0 \%$ ARLNQYFQK

$288 \quad 0.33 \% \quad 33.0 \%$ LNQYFQKEK

$288 \quad 0.33 \% \quad 33.0 \%$ IQGEYKYTQVGPDHNR

$288 \quad 0.33 \% \quad 33.0 \%$ YTQVGPDHNR

$288 \quad 0.33 \% \quad 33.0 \%$ SFIAEMTIYIK

$288 \quad 0.33 \% \quad 33.0 \%$ KLAAQSCALSLVR

$288 \quad 0.33 \% \quad 33.0 \%$ LAAQSCALSLVR

$288 \quad 0.33 \% \quad 33.0 \%$ QLYHLGVVEAYSGLTK

$288 \quad 0.33 \% \quad 33.0 \%$ LAQFEPSQR

$288 \quad 0.33 \% \quad 33.0 \%$ TTQVPQFILDDFIQNDR

$288 \quad 0.33 \% \quad 33.0 \%$ AAECNIVVTQPR

$288 \quad 0.33 \% \quad 33.0 \%$ AAECNIVVTQPRR

$288 \quad 0.33 \% \quad 33.0 \%$ RISAVSVAER

$288 \quad 0.33 \% \quad 33.0 \%$ ISAVSVAER

$288 \quad 0.33 \% \quad 33.0 \%$ GEEPGKSCGYSVR

$288 \quad 0.33 \% \quad 33.0 \%$ GISHVIVDEIHER

$288 \quad 0.33 \% \quad 33.0 \%$ DVVQAYPEVR

$288 \quad 0.33 \% \quad 33.0 \%$ HLEMNPHFGSHR

$288 \quad 0.33 \% \quad 33.0 \%$ YQILPLHSQIPR

$288 \quad 0.33 \% \quad 33.0 \%$ YQILPLHSQIPREEQR

$288 \quad 0.33 \% \quad 33.0 \%$ KVFDPVPVGVTK

$288 \quad 0.33 \% \quad 33.0 \%$ VFDPVPVGVTK

$288 \quad 0.33 \% \quad 33.0 \%$ VRPGFCFHLCSR

$288 \quad 0.33 \% \quad 33.0 \%$ LETHMTPEMFR

$288 \quad 0.33 \% \quad 33.0 \%$ TPLHEIALSIK

$288 \quad 0.33 \% \quad 33.0 \%$ LGGIGQFLAK

$288 \quad 0.33 \% \quad 33.0 \%$ ELDALDANDELTPLGR

$288 \quad 0.33 \% \quad 33.0 \%$ ILAKLPIEPR

$288 \quad 0.33 \% \quad 33.0 \%$ MGGEEAEIR

$288 \quad 0.33 \% \quad 33.0 \%$ KILTTEGR

$288 \quad 0.33 \% \quad 33.0 \%$ ILTTEGRNALIHK

$288 \quad 0.33 \% \quad 33.0 \%$ YPSPFFVFGEK

$288 \quad 0.33 \% \quad 33.0 \%$ LQISHEAAACITGLR

$288 \quad 0.33 \% \quad 33.0 \%$ AAMEALVVEVTK

$288 \quad 0.33 \% \quad 33.0 \%$ QPAIISQLDPVNER
$99.7 \% \quad 28.4$

$\begin{array}{llll}97.7 \% & 16.8 & 25.0 & 16.8 \\ 99.7 \% & 32.5 & 25.0 & 32.5\end{array}$

$\begin{array}{llll}99.7 \% & 92.5 & 25.0 & 86.7\end{array}$

$\begin{array}{llll}99.7 \% & 47.8 & 25.0 & 47.8\end{array}$

$99.7 \% \quad 51.4 \quad 25.0 \quad 28.8$

$99.0 \% \quad 33.9 \quad 25.0 \quad 32.1$

$\begin{array}{llll}99.2 \% & 30.9 & 25.0 & 30.9\end{array}$

$\begin{array}{lllll}99.0 \% & 52.2 & 25.0 & 40.2 & 20\end{array}$

$\begin{array}{llll}99.7 \% & 37.7 & 25.0 & 37.7\end{array}$

$\begin{array}{llll}99.7 \% & 54.8 & 25.0 & 42.8\end{array}$

$\begin{array}{llll}99.3 \% & 22.0 & 25.0 & 18.2\end{array}$

$99.7 \% \quad 51.4 \quad 25.0 \quad 30.1$

$\begin{array}{llll}99.7 \% & 29.8 & 25.0 & 29.3\end{array}$

$99.7 \% \quad 46.4 \quad 25.0 \quad 34.4$

$\begin{array}{llll}99.7 \% & 52.6 & 25.0 & 48.8\end{array}$

$99.7 \% \quad 50.5 \quad 25.0 \quad 50.5$

$\begin{array}{lllll}99.7 \% & 57.8 & 25.0 & 50.2 & 22\end{array}$

$\begin{array}{llll}99.7 \% & 45.7 & 25.0 & 45.7\end{array}$

$\begin{array}{lllll}99.7 \% & 53.9 & 25.0 & 51.1 & 8\end{array}$

$\begin{array}{llll}99.7 \% & 54.7 & 25.0 & 49.9\end{array}$

$\begin{array}{llll}99.7 \% & 46.0 & 25.0 & 41.1\end{array}$

$\begin{array}{llll}99.1 \% & 22.8 & 25.0 & 20.6\end{array}$

$\begin{array}{llll}99.7 \% & 58.4 & 25.0 & 46.5\end{array}$

$\begin{array}{llll}99.7 \% & 61.1 & 25.0 & 47.3\end{array}$

$\begin{array}{llll}99.7 \% & 33.5 & 25.0 & 33.5\end{array}$

$\begin{array}{llll}99.7 \% & 61.7 & 25.0 & 61.7\end{array}$

$\begin{array}{llll}99.7 \% & 60.5 & 25.0 & 54.8\end{array}$

$\begin{array}{llll}99.5 \% & 26.8 & 25.0 & 26.8\end{array}$

$\begin{array}{llll}99.7 \% & 39.5 & 25.0 & 24.5\end{array}$

$\begin{array}{llll}98.6 \% & 18.6 & 25.0 & 17.1\end{array}$

$\begin{array}{llll}99.7 \% & 58.5 & 25.0 & 58.5\end{array}$

$\begin{array}{llll}99.7 \% & 49.1 & 25.0 & 49.1\end{array}$

$\begin{array}{llll}99.7 \% & 41.7 & 25.0 & 41.7\end{array}$

$99.7 \% \quad 28.9 \quad 25.0 \quad 26.1$

$\begin{array}{lllll}99.7 \% & 54.3 & 25.0 & 50.0\end{array}$

$\begin{array}{lllll}99.7 \% & 56.6 & 25.0 & 49.1 & 26\end{array}$

$\begin{array}{lllll}99.7 \% & 55.7 & 25.0 & 40.6 & 2\end{array}$

$\begin{array}{lllll}99.7 \% & 32.3 & 25.0 & 32.3 & 4\end{array}$

$99.7 \% \quad 44.2 \quad 25.0 \quad 36.9$

$\begin{array}{lllll}99.0 \% & 30.0 & 25.0 & 13.1 & 3\end{array}$

$\begin{array}{lllll}99.7 \% & 31.4 & 25.0 & 31.4\end{array}$

$\begin{array}{llll}99.7 \% & 28.2 & 25.0 & 23.8\end{array}$

$\begin{array}{llll}99.7 \% & 26.8 & 25.0 & 26.8\end{array}$

$\begin{array}{llll}99.7 \% & 57.1 & 25.0 & 54.0\end{array}$

$\begin{array}{llll}99.7 \% & 46.0 & 25.0 & 41.0\end{array}$
1124.58

996.48

1838.91

1025.54

2162.97

1186.59

1167.63

1197.63

1904.93

1186.56

1331.69

1416.80

1288.70

1777.95

1075.55

2050.02

1357.69

1513.79

1087.62

931.52

1425.64

1503.79

1175.61

1461.68

1464.83

2007.08

1285.75

1157.66

1535.74

1391.64

1221.72

1003.59

1741.86

1149.74

991.45

917.54

1465.85

1317.65

1639.86

1260.69 1579.84 $\begin{array}{cc}87 & 401 \\ 38 & 449 \\ 52 & 462 \\ 75 & 185 \\ 86 & 200 \\ 15 & 226 \\ 6 & 24 \\ 7 & 24 \\ 6 & 71 \\ 4 & 71 \\ 21 & 141 \\ 42 & 151 \\ 83 & 191 \\ 85 & 193 \\ 94 & 209 \\ 00 & 209 \\ 10 & 220 \\ 36 & 248 \\ 37 & 248 \\ 49 & 264 \\ 15 & 323 \\ 18 & 434 \\ 35 & 446 \\ 35 & 447 \\ 47 & 456 \\ 48 & 456 \\ 62 & 474 \\ 04 & 516 \\ 29 & 538 \\ 69 & 680 \\ 81 & 692 \\ 81 & 696 \\ 97 & 708 \\ 98 & 708 \\ 68 & 779 \\ 85 & 795 \\ 96 & 806 \\ 10 & 819 \\ 38 & 853 \\ 54 & 863 \\ 30 & 938 \\ 11 & 1018 \\ 12 & 1024 \\ 38 & 1048 \\ 90 & 1104 \\ 05 & 1116 \\ 17 & 1130\end{array}$ 
ATP-dependent RNA helicase A GN=DHX9 DHX9_HUMAN $140.96 \quad 100.0 \% \quad 4$ ATP-dependent RNA helicase A GN=DHX9 DHX9_HUMAN $140.96 \quad 100.0 \%$ ATP-dependent RNA helicase DDX18 GN=DDX18 DDX18_HUMAN $75.41 \quad 100.0 \%$ ATP-dependent RNA helicase DDX18 GN=DDX18 DDX18 HUMAN 75.41 $100.0^{\circ}$ ATP-dependent RNA helicase DDX18 GN=DDX18 DDX18_HUMAN $75.41 \quad 100.0 \%$ ATP-dependent RNA helicase DDX18 GN=DDX18 DDX18_HUMAN $75.41 \quad 100.0 \%$ ATP-dependent RNA helicase DDX19A GN=DDX19A DD19A HUMAN $53.98 \quad 100.0 \%$ ATP-dependent RNA helicase DDX19A GN=DDX19A DD19A_HUMAN $53.98 \quad 100.0 \%$ ATP-dependent RNA helicase DDX24 GN=DDX24 DDX24 HUMAN $96.33 \quad 100.0 \%$ ATP-dependent RNA helicase DDX24 GN=DDX24 DDX24_HUMAN $96.33 \quad 100.0 \%$ ATP-dependent RNA helicase DDX39A GN=DDX39A DX39A_HUMAN $49.13 \quad 100.0 \%$ ATP-dependent RNA helicase DDX39A GN=DDX39A DX39A_HUMAN $49.13100 .0 \%$ ATP-dependent RNA helicase DDX39A GN=DDX39A DX39A_HUMAN $49.13 \quad 100.0 \%$ ATP-dependent RNA helicase DDX39A GN=DDX39A DX39A_HUMAN $49.13 \quad 100.0 \%$ ATP-dependent RNA helicase DDX39A GN=DDX39A DX39A_HUMAN $49.13 \quad 100.0 \%$ ATP-dependent RNA helicase DDX39A GN=DDX39A DX39A_HUMAN $49.13 \quad 100.0 \%$ ATP-dependent RNA helicase DDX39A GN=DDX39A DX39A HUMAN $49.13 \quad 100.0 \%$ ATP-dependent RNA helicase DDX3X GN=DDX3X DDX3X_HUMAN $73.25 \quad 100.0 \%$ ATP-dependent RNA helicase DDX3X GN=DDX3X DDX3X_HUMAN 73.25 ATP-dependent RNA helicase DDX3X GN=DDX3X DDX3X HUMAN 73.25 ATP-dependent RNA helicase DDX3X GN=DDX3X DDX3X_HUMAN 73.25 ATP-dependent RNA helicase DDX3X GN=DDX3X DDX3X_HUMAN 73.25 ATP-dependent RNA helicase DDX3X GN=DDX3X DDX3X_HUMAN 73.25 ATP-dependent RNA helicase DDX3X GN=DDX3X DDX3X_HUMAN 73.25 ATP-dependent RNA helicase DDX3X GN=DDX3X DDX3X_HUMAN 73.25 ATP-dependent RNA helicase DDX3X GN=DDX3X DDX3X_HUMAN 73.25 ATP-dependent RNA helicase DDX3X GN=DDX3X DDX3X_HUMAN 73.25 ATP-dependent RNA helicase DDX3X GN=DDX3X DDX3X_HUMAN 73.2 ATP-dependent RNA helicase DDX3X GN=DDX3XDDX3X_HUMAN 73.25 ATP-dependent RNA helicase DDX3X GN=DDX3X DDX3X_HUMAN 73.25 ATP-dependent RNA helicase DDX3X GN=DDX3X DDX3X_HUMAN 73.25 ATP-dependent RNA helicase DDX3X GN=DDX3X DDX3X_HUMAN 73.25 ATP-dependent RNA helicase DDX3X GN=DDX3X DDX3X_HUMAN 73.25 ATP-dependent RNA helicase DDX3X GN=DDX3X DDX3X_HUMAN 73.25 ATP-dependent RNA helicase DDX3X GN=DDX3X DDX3X_HUMAN 73.25 ATP-dependent RNA helicase DDX50 GN=DDX50 DDX50_HUMAN 82.57 ATP-dependent RNA helicase DDX50 GN=DDX50 DDX50_HUMAN 82.57 ATP-dependent RNA helicase DDX50 GN=DDX50 DDX50_HUMAN 82.57 ATP-dependent RNA helicase DDX50 GN=DDX50 DDX50_HUMAN 82.57 ATP-dependent RNA helicase DDX50 GN=DDX50 DDX50_HUMAN 82.57 ATP-dependent RNA helicase DDX54 GN=DDX54 DDX54_HUMAN 98.60 ATP-dependent RNA helicase DDX54 GN=DDX54 DDX54_HUMAN 98.60 ATP-dependent RNA helicase DDX54 GN=DDX54 DDX54_HUMAN 98.60 ATP-dependent RNA helicase DHX36 GN=DHX36 DHX36_HUMAN $114.76 \quad 100.0 \%$ ATP-dependent RNA helicase DHX36 GN=DHX36 DHX36_HUMAN $114.76 \quad 100.0 \%$ ATP-dependent RNA helicase DHX36 GN=DHX36 DHX36_HUMAN $114.76100 .0 \%$ ATP-dependent RNA helicase DHX8 GN=DHX8 DHX8_HUMAN $139.32 \quad 100.0 \%$

5
5
5
2
2

2

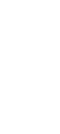

2
2
2
2

2

2

3
3

3
21
21

$100.0 \% \quad 18$

$\begin{array}{ll}100.0 \% & 18 \\ 100.0 \% & 18\end{array}$

$100.0 \% \quad 18$

$100.0 \% \quad 18$

$100.0 \% \quad 18$

$100.0 \% \quad 18$

$100.0 \% \quad 18$

$100.0 \% \quad 18$

$100.0 \% \quad 18$

$100.0 \% \quad 18$

$100.0 \% \quad 18$

$100.0 \% \quad 18$

$100.0 \% \quad 18$

$100.0 \% \quad 18$

$100.0 \% \quad 18$

$100.0 \% \quad 18$

$100.0 \%$

$100.0 \%$

$100.0 \%$

$100.0 \%$

$100.0 \%$

$100.0 \%$

$.0 \% \quad 3$

\begin{tabular}{ll}
$0 \%$ & 2 \\
\hline & 2
\end{tabular}

21

$\begin{array}{llll}288 & 0.33 \% & 33.0 \% & \text { YGDGPRPPK }\end{array}$

$0.01 \% \quad 7.2 \% \quad$ NGTGVLILSPTR

$0.01 \% \quad 7.2 \%$ LGNGINIIVATPGR

$0.01 \% \quad 7.2 \%$ QTMLFSATQTR

$0.01 \% \quad 7.2 \% \quad$ SAQEAYKSYIR

$0.01 \% \quad 7.3 \%$ SNLVDNTNQVEVLQRDPNSPLYSVK

$0.01 \% \quad 7.3 \%$ VLVTTNVCAR

$0.00 \% \quad 2.9 \% \quad$ TSEIYVHR

$0.00 \% \quad 2.9 \% \quad$ KPKEPQPEQPQPSTSAN

$0.01 \% \quad 15.0 \%$ ELAFQISK

$0.01 \% \quad 15.0 \%$ NCPHVVVGTPGR

$0.01 \% \quad 15.0 \%$ GMAQEERLSR

$0.01 \% \quad 15.0 \%$ YQQFKDFQR

$0.01 \% \quad 15.0 \%$ RILVATNLFGR

$0.01 \% \quad 15.0 \%$ ILVATNLFGR

$0.01 \% \quad 15.0 \%$ GLAITFVSDENDAK

$50 \quad 0.06 \% \quad 26.6 \%$ SSFFSDRGSGSR

$50 \quad 0.06 \% \quad 26.6 \%$ YTRPTPVQK

$50 \quad 0.06 \% \quad 26.6 \%$ DLMACAQTGSGK

$50 \quad 0.06 \% \quad 26.6 \%$ KQYPISLVLAPTR

$50 \quad 0.06 \% \quad 26.6 \%$ QYPISLVLAPTR

$50 \quad 0.06 \% \quad 26.6 \%$ ELAVQIYEEAR

$50 \quad 0.06 \% \quad 26.6 \%$ ELAVQIYEEARK

$0.06 \% \quad 26.6 \%$ VRPCVVYGGADIGQQIR

$\begin{array}{ll}0.06 \% & 26.6 \% \text { IVEQDTMPPKGVR }\end{array}$

$0.06 \% \quad 26.6 \%$ HTMMFSATFPK

$50 \quad 0.06 \% \quad 26.6 \%$ VGSTSENITQK

$50 \quad 0.06 \% \quad 26.6 \%$ VVWVEESDKR

$50 \quad 0.06 \% \quad 26.6 \%$ DREEALHQFR

$50 \quad 0.06 \% \quad 26.6 \%$ SGKSPILVATAVAAR

$50 \quad 0.06 \% \quad 26.6 \%$ SPILVATAVAAR

$50 \quad 0.06 \% \quad 26.6 \%$ VGNLGLATSFFNER

$50 \quad 0.06 \% \quad 26.6 \%$ DYRQSSGASSSSFSSSR

$50 \quad 0.06 \% \quad 26.6 \%$ QSSGASSSSFSSSR

$0.01 \% \quad 6.1 \%$ NGIDILVGTPGR

$0.01 \% \quad 6.1 \%$ SRYEQVDLVGK

$0.01 \% \quad 6.1 \%$ VLVATNVAAR

$0.01 \% \quad 6.1 \% \quad$ KLSSNAVSQITR

$0.01 \% \quad 6.1 \%$ LSSNAVSQITR

$0.01 \% \quad 4.0 \%$ CSTLIVTDLAAR

$0.01 \% \quad 4.0 \%$ VADNAQQQYVR

$0.01 \% \quad 4.0 \% \quad$ SRPAPSPESIKR

$0.00 \% \quad 3.7 \%$ SSGGGYGGGPAGGHGGNR

$0.00 \% \quad 3.7 \%$ ISAISVAER

$0.00 \% \quad 3.7 \%$ AVICAGLYPK

$0.02 \% \quad 7.1 \%$ NGAEFTDSLISNLLR
$99.7 \% \quad 49.3$

$99.7 \% \quad 53.8$

$99.7 \% \quad 34.2$

$99.3 \% \quad 20.2$

$99.7 \% \quad 46.5$

$99.7 \% \quad 45.2$

$99.7 \% 55.3$

$99.7 \% \quad 34.6$

$99.0 \% \quad 32.8$

$99.7 \% \quad 29.0$

$\begin{array}{ll}9.0 \% & 27.8 \\ 99.7 \% & 59.5\end{array}$

$99.7 \% \quad 32.9$

$96.7 \% \quad 19.1$

$99.6 \% 25.8$

$99.7 \% \quad 59.0$

$99.7 \% \quad 36.3$

$98.1 \% \quad 20.2$

$99.7 \% \quad 37.1$

$99.7 \% \quad 46.3$

$99.7 \% \quad 43.2$

$\begin{array}{lll}99.7 \% & 30.9\end{array}$

$99.7 \% \quad 54.3$

$99.7 \% \quad 79.1$

$99.7 \% \quad 29.0$

$99.7 \% \quad 30.0$

$97.9 \% \quad 22.7$

$99.7 \% \quad 55.2$

$98.5 \% \quad 17.5$

$99.7 \% \quad 38.5$

$\begin{array}{lll}99.7 \% & 31.5\end{array}$

$99.7 \% \quad 53.4$

$99.7 \% \quad 55.5$

$99.7 \% \quad 50.0$

$99.7 \% \quad 78.5$

$\begin{array}{lll}99.7 \% & 59.7\end{array}$

$99.7 \% \quad 26.6$

$99.7 \% \quad 35.5$

$99.7 \% \quad 40.5$

$99.7 \% \quad 46.2$

$99.7 \% \quad 62.1$

$99.7 \% \quad 53.5$

$99.7 \% \quad 47.2$

$\begin{array}{lll}99.5 \% & 23.7\end{array}$

$\begin{array}{ll}99.7 \% & 55.8 \\ 99.7 \% & 32.3\end{array}$

$99.7 \% \quad 70.2$

1888.01

986.51

1227.71

1394.8

1283.64

1315.66

2829.44

1132.61

1004.52

1862.92

935.52

1292.65

1176.58

1259.62

1259.76

1103.66

1479.73

1289.59

1089.61

1254.55

1485.88

1357.78

1320.68

1448.77

1887.99

1485.77

1329.60

1163.59

1246.64

1300.64

1440.85

1168.70

1524.78

1795.78

1361.59

1211.67

1293.68

1013.61

1303.73

1175.64

1319.70

1291.64

1324.73

1501.65

945.54

1091.59

1649.85

Page 30 of Table S-1-6 
ATP-dependent RNA helicase DHX8 GN=DHX8 DHX8 HUMAN $139.32 \quad 100.0 \%$ ATP-dependent RNA helicase DHX8 GN=DHX8 DHX8_HUMAN $139.32 \quad 100.0 \%$ ATP-dependent RNA helicase DHX8 GN=DHX8 DHX8_HUMAN $139.32 \quad 100.0 \%$ ATP-dependent RNA helicase DHX8 GN=DHX8 DHX8 HUMAN $139.32 \quad 100.0 \%$ ATP-dependent RNA helicase DHX8 GN=DHX8 DHX8_HUMAN $139.32 \quad 100.0 \%$ ATP-dependent RNA helicase DHX8 GN=DHX8 DHX8_HUMAN $139.32 \quad 100.0 \%$ ATP-dependent RNA helicase DHX8 GN=DHX8 DHX8_HUMAN $139.32100 .0 \%$ Atypical kinase ADCK3, mitochondrial GN=ADCK3 ADCK3_HUMAN $71.95 \quad 100.0 \%$ Atypical kinase ADCK3, mitochondrial GN=ADCK3 ADCK3 HUMAN $71.95 \quad 100.0 \%$ Aurora kinase $\mathrm{B}$ GN $=\mathrm{AURKB}$ Aurora kinase $\mathrm{B}$ GN $=\mathrm{AURKB}$ AURKB_HUMAN $39.31 \quad 100.0 \%$ AURKB_HUMAN $39.31 \quad 100.0 \%$ A Baculoviral IAP repeat-containing protein $6 \mathrm{GN}=\mathrm{BIRC} 6$ BIRC6_HUMAN $530.25 \quad 100.0 \%$ Bcl-2-associated transcription factor $1 \mathrm{GN}=\mathrm{BCLAF} 1 \mathrm{BCLF} 1$ HUMAN $106.13 \quad 100.0 \%$ Bcl-2-associated transcription factor $1 \mathrm{GN}=\mathrm{BCLAF} 1 \mathrm{BCLF} 1$ HUMAN $106.13 \quad 100.0 \%$ Bcl-2-associated transcription factor $1 \mathrm{GN}=\mathrm{BCLAF} 1$ BCLF1_HUMAN $106.13 \quad 100.0 \%$ Bcl-2-associated transcription factor $1 \mathrm{GN}=\mathrm{BCLAF} 1 \mathrm{BCLF} 1$ HUMAN $106.13 \quad 100.0 \%$ Bcl-2-associated transcription factor $1 \mathrm{GN}=\mathrm{BCLAF} 1 \mathrm{BCLF} 1$ HUMAN $106.13 \quad 100.0 \%$ Bcl-2-associated transcription factor 1 GN=BCLAF1 BCLF1_HUMAN $106.13 \quad 100.0 \%$ Bcl-2-associated transcription factor $1 \mathrm{GN}=\mathrm{BCLAF} 1 \mathrm{BCLF} 1$ HUMAN $106.13 \quad 100.0 \%$ Bcl-2-associated transcription factor $1 \mathrm{GN}=\mathrm{BCLAF} 1 \mathrm{BCLF} 1$ _HUMAN $106.13 \quad 100.0 \%$ Bcl-2-associated transcription factor $1 \mathrm{GN}=\mathrm{BCLAF} 1 \mathrm{BCLF} 1$ HUMAN $106.13100 .0 \%$ Bcl-2-associated transcription factor $1 \mathrm{GN}=\mathrm{BCLAF} 1 \mathrm{BCLF} 1$ _HUMAN $106.13 \quad 100.0 \%$ Beta-galactosidase $\mathrm{GN}=\mathrm{GLB} 1$ Beta-galactosidase $\mathrm{GN}=\mathrm{GLB} 1$ Beta-galactosidase $\mathrm{GN}=\mathrm{GLB}$ Beta-galactosidase $\mathrm{GN}=\mathrm{GLB} 1$ Beta-galactosidase $\mathrm{GN}=\mathrm{GLB}$ Beta-galactosidase $\mathrm{GN}=\mathrm{GLB} 1$ Beta-galactosidase $\mathrm{GN}=\mathrm{GLB} 1$ Beta-galactosidase $\mathrm{GN}=\mathrm{GLB} 1$ Beta-galactosidase $\mathrm{GN}=\mathrm{GLB} 1$

Beta-galactosidase $\mathrm{GN}=\mathrm{GLB} 1$ BGAL_HUMAN $76.08 \quad 100.0 \%$ BGAL HUMAN $76.08 \quad 100.0 \%$ BGAL_HUMAN $76.08 \quad 100.0 \%$ BGAL HUMAN $76.08 \quad 100.0 \%$ BGAL HUMAN $76.08 \quad 100.0 \%$ BGAL_HUMAN $76.08 \quad 100.0 \%$ BGAL_HUMAN $76.08 \quad 100.0 \%$ BGAL_HUMAN $76.08 \quad 100.0 \%$ BGAL_HUMAN $76.08 \quad 100.0 \%$ BGAL HUMAN $76.08 \quad 100.0 \%$ Bifunctional glutamate/proline--tRNA ligase GN=EPRS SYEP_HUMAN $170.59 \quad 100.0 \%$ Bifunctional glutamate/proline--tRNA ligase GN=EPRS SYEP HUMAN $170.59 \quad 100.0 \%$ Bifunctional glutamate/proline--tRNA ligase GN=EPRS SYEP_HUMAN $170.59 \quad 100.0 \%$ Bifunctional glutamate/proline--tRNA ligase GN=EPRS SYEP_HUMAN $170.59 \quad 100.0 \%$ Bifunctional glutamate/proline--tRNA ligase GN=EPRS SYEP HUMAN $170.59100 .0 \%$ Bifunctional glutamate/proline--tRNA ligase GN=EPRS SYEP_HUMAN $170.59 \quad 100.0 \%$ Bifunctional glutamate/proline--tRNA ligase GN=EPRS SYEP_HUMAN $170.59 \quad 100.0 \%$ Bifunctional glutamate/proline--tRNA ligase GN=EPRS SYEP HUMAN $170.59 \quad 100.0 \%$ Bifunctional glutamate/proline--tRNA ligase GN=EPRS SYEP_HUMAN $170.59 \quad 100.0 \%$ Bifunctional glutamate/proline--tRNA ligase GN=EPRS SYEP HUMAN $170.59 \quad 100.0 \%$ Bifunctional glutamate/proline--tRNA ligase GN=EPRS SYEP_HUMAN $170.59 \quad 100.0 \%$ Bifunctional glutamate/proline--tRNA ligase GN=EPRS SYEP_HUMAN $170.59 \quad 100.0 \%$ Bifunctional glutamate/proline--tRNA ligase GN=EPRS SYEP HUMAN $170.59 \quad 100.0 \%$ Bifunctional glutamate/proline--tRNA ligase GN=EPRS SYEP_HUMAN $170.59 \quad 100.0 \%$ $0.02 \% \quad 7.1 \%$ VANVADVVSKGQR

$0.02 \% \quad 7.1 \%$ LIVTSATLDAVK

$0.02 \% \quad 7.1 \%$ IFDPAPPGSR

$0.02 \% \quad 7.1 \%$ TGIDQLVVTPISQAQAK

$0.02 \% \quad 7.1 \%$ TNLASTVLSLK

$0.02 \% \quad 7.1 \%$ AICSGFFR

$0.00 \% \quad 5.9 \%$ LANFGGLAVGLGFGALAEVAKK

$0.00 \% \quad 5.9 \%$ AVLGSSPFLSEANAER

$0.01 \% \quad 6.4 \%$ SNVQPTAAPGQK

$0.01 \% \quad 6.4 \%$ IYLILEYAPR

$0.00 \% \quad 0.4 \%$ KFLSDIVR

$0.00 \% \quad 0.4 \%$ SNLDTEVTTAK

$0.03 \% \quad 11.8 \%$ KAEGEPQEESPLK

$0.03 \% \quad 11.8 \%$ TIAPQNAPR

$0.03 \% \quad 11.8 \%$ SSFYPDGGDQETAK

$98.6 \% \quad 25.6$

$99.7 \% \quad 37.7$

$99.7 \% \quad 29.8$

$99.7 \% \quad 29.7$

$99.7 \% \quad 48.3$

$99.7 \% 58.5$

$98.6 \% 23.4$

$99.7 \% 54.6$

$99.4 \% \quad 22.4$

$\begin{array}{lll}99.7 \% & 46.8\end{array}$

$95.0 \% \quad 26.1$

$99.7 \% \quad 41.2$

$98.1 \% \quad 17.3$

$99.5 \% \quad 27.7$

$99.7 \% \quad 47.9$

$\begin{array}{lllll}0.03 \% & 11.8 \% & \text { SSFYPDGGDQETAKTGK } & 98.0 \% & 20.9\end{array}$

$0.03 \% \quad 11.8 \%$ SVLADQGKSFATASHR

$0.03 \% \quad 11.8 \%$ NTEEEGLKYK

$0.03 \% \quad 11.8 \%$ ETQSPEQVKSEK

$0.03 \% \quad 11.8 \%$ STFREESPLR

$0.03 \% \quad 11.8 \%$ SIFDHIKLPQASK

$0.03 \% \quad 11.8 \%$ SAAMTLNER

$0.02 \% \quad 19.4 \%$ MFEIDYSR

$0.02 \% \quad 19.4 \%$ DSFLKDGQPFR

$0.02 \% \quad 19.4 \%$ YISGSIHYSR

$0.02 \% \quad 19.4 \%$ TEAVASSLYDILAR

$0.02 \% \quad 19.4 \%$ TVGAALDILCPSGPIK

$0.02 \% \quad 19.4 \%$ SLYPLTFIQVK

$0.02 \% \quad 19.4 \%$ QHYGFVLYR

$0.02 \% \quad 19.4 \%$ TTLPQDCSNPAPLSSPLNGVHDR

$0.02 \% \quad 19.4 \%$ AYVAVDGIPQGVLER

$0.02 \% \quad 19.4 \%$ AGATLDLLVENMGR

$0.07 \% \quad 20.3 \%$ FVELPGAEMGK

$0.07 \% \quad 20.3 \%$ AALLNQHYQVNFK

$0.07 \% \quad 20.3 \%$ AALLNQHYQVNFKGK

$0.07 \% \quad 20.3 \%$ YAEKLIQEGK

$0.07 \% \quad 20.3 \%$ GSQFGQSCCLR

$0.07 \% \quad 20.3 \%$ LNLNNTVLSK

$0.07 \% \quad 20.3 \%$ LNLNNTVLSKR

$0.07 \% \quad 20.3 \%$ KVIDPVAPR

$0.07 \% \quad 20.3 \%$ VIDPVAPR

$0.07 \% \quad 20.3 \%$ NPEVGLKPVWYSPK

$0.07 \% \quad 20.3 \%$ GDIIQLQR

$0.07 \% \quad 20.3 \%$ VAVQGDVVR

$0.07 \% \quad 20.3 \%$ VAVQGDVVRELK

$99.7 \% \quad 45$.

$99.7 \% \quad 44.1$

$99.7 \% \quad 28.3$

$97.3 \% \quad 16.9$

$98.8 \% 27.0$

$97.1 \% \quad 23.3$

$97.4 \% \quad 20.1$

$99.7 \% \quad 34.0$

$99.7 \% \quad 63.4$

$99.7 \% \quad 60.2$

$99.7 \% 47$.

$99.7 \% \quad 51.2$

$99.5 \% \quad 23.7$

$99.7 \% \quad 59.5$

$99.7 \% \quad 63.8$

$99.7 \% \quad 66.9$

$99.7 \% \quad 28.5$

$99.5 \% 23.4$

$96.0 \% 15$.

$99.7 \% \quad 37.9$

$99.7 \% \quad 46.9$

$99.7 \% \quad 54.5$

$99.7 \% \quad 54.0$

$99.3 \% \quad 21.7$

$99.0 \% \quad 44.2$

$99.7 \% \quad 27.6$

$99.0 \% \quad 39.9$

$99.7 \% \quad 50.0$

$99.7 \% \quad 39.0$

$\begin{array}{llll}0.07 \% & 20.3 \% & \text { TGQEYKPGNPPAEIGQNISSNSSASILESK } \quad 99.7 \% \quad 42.5\end{array}$ $\begin{array}{ll}.0 & 37.7\end{array}$

29.0

$\begin{array}{ll}.0 & 27.7\end{array}$

\begin{tabular}{ll}
48.3 \\
\hline
\end{tabular}

\begin{tabular}{ll}
47.0 \\
\hline
\end{tabular}

$.0 \quad 18.5$

66.9

\begin{tabular}{ll}
0 & 22.4 \\
\hline & 34.8
\end{tabular}

$\begin{array}{lll}34.0 & 2 \\ 25.0 & 8.8 & \end{array}$

$\begin{array}{ll}25.0 & 8.8\end{array}$

8.8
37.8

\begin{tabular}{ll}
17.3 \\
\hline
\end{tabular}

$25.0 \quad 17.4$

\begin{tabular}{lll}
30.6 \\
\hline
\end{tabular}

$\begin{array}{ll}25.0 & 45.1\end{array}$

$\begin{array}{ll}33.0 & 33.8\end{array}$

$\begin{array}{ll}25.0 & 15.9\end{array}$

$\begin{array}{ll}20.0 & 20.2\end{array}$

20.1

\begin{tabular}{ll}
0 & 34.0 \\
\hline
\end{tabular}

$\begin{array}{lll}25.0 & 57.0 & 2\end{array}$

$\begin{array}{ll}25.0 & 47.1\end{array}$

$\begin{array}{lll}0.0 & 51.2 & 2\end{array}$

$\begin{array}{ll}0 & 20.9\end{array}$

$\begin{array}{ll}25.0 & 63.8\end{array}$

$\begin{array}{ll}5.0 & 54.6\end{array}$

$\begin{array}{ll}5.0 & 18.9\end{array}$

$25.0 \quad 22.0$

$\begin{array}{ll}25.0 & 15.1 \\ 25.0 & 22.0\end{array}$

$\begin{array}{ll}22.0 & 46.9\end{array}$

\begin{tabular}{ll}
5.0 & 48.5 \\
\hline &
\end{tabular}

$\begin{array}{ll}5.0 & 39.8\end{array}$

$\begin{array}{ll}25.0 & 21.7\end{array}$

\begin{tabular}{ll}
5.0 & 44.2 \\
\hline
\end{tabular}

\begin{tabular}{ll}
5.0 & 27.6 \\
\hline
\end{tabular}

$\begin{array}{ll}25.0 & 21.0 \\ 25.0\end{array}$
1342.74

1230.73

1056.55

1768.98

1146.67

957.46

2103.20

1647.83

1197.62

1250.71

977.58

1178.59

1441.72

967.53

1501.64

1787.81

1674.86

1210.60

1389.69

1221.62

1483.83

992.48

1060.48

1309.65

1182.59

1508.80

1611.88

1308.76

1182.61

2476.19

1586.85

1475.75

1193.59

1545.82

1730.93

1178.64

1299.56

1115.64

1271.74

994.60

866.51

1613.87

942.54

942.54

1312.76 3103.52 $\begin{array}{cc}06 & 315 \\ 06 & 318 \\ 13 & 724 \\ 24 & 833 \\ 69 & 885 \\ 23 & 933 \\ 06 & 1113 \\ 14 & 235 \\ 47 & 262 \\ 5 & 56 \\ 50 & 159 \\ 83 & 1390 \\ 01 & 2311 \\ 68 & 180 \\ 04 & 312 \\ 19 & 332 \\ 19 & 335 \\ 14 & 429 \\ 30 & 439 \\ 93 & 504 \\ 25 & 534 \\ 87 & 599 \\ 23 & 631 \\ 1 & 38 \\ 9 & 49 \\ 0 & 59 \\ 86 & 299 \\ 84 & 399 \\ 00 & 410 \\ 11 & 419 \\ 20 & 442 \\ 43 & 457 \\ 69 & 482 \\ 87 & 197 \\ 17 & 229 \\ 17 & 231 \\ 79 & 288 \\ 29 & 339 \\ 26 & 435 \\ 26 & 436 \\ 98 & 506 \\ 99 & 506 \\ 36 & 549 \\ 67 & 674 \\ 57 & 765 \\ 57 & 768 \\ 95 & 824 \\ & \end{array}$

Page 31 of Table S-1-6 
$\mathrm{CAD}$ protein $\mathrm{GN}=\mathrm{CAD}$

$\mathrm{CAD}$ protein $\mathrm{GN}=\mathrm{CAD}$

$\mathrm{CAD}$ protein $\mathrm{GN}=\mathrm{CAD}$

$\mathrm{CAD}$ protein $\mathrm{GN}=\mathrm{CAD}$

$\mathrm{CAD}$ protein $\mathrm{GN}=\mathrm{CAD}$

$\mathrm{CAD}$ protein $\mathrm{GN}=\mathrm{CAD}$

$\mathrm{CAD}$ protein $\mathrm{GN}=\mathrm{CAD}$

$\mathrm{CAD}$ protein $\mathrm{GN}=\mathrm{CAD}$

$\mathrm{CAD}$ protein $\mathrm{GN}=\mathrm{CAD}$

$\mathrm{CAD}$ protein $\mathrm{GN}=\mathrm{CAD}$

$\mathrm{CAD}$ protein $\mathrm{GN}=\mathrm{CAD}$

$\mathrm{CAD}$ protein $\mathrm{GN}=\mathrm{CAD}$

$\mathrm{CAD}$ protein $\mathrm{GN}=\mathrm{CAD}$

$\mathrm{CAD}$ protein $\mathrm{GN}=\mathrm{CAD}$

$\mathrm{CAD}$ protein $\mathrm{GN}=\mathrm{CAD}$

$\mathrm{CAD}$ protein $\mathrm{GN}=\mathrm{CAD}$

$\mathrm{CAD}$ protein $\mathrm{GN}=\mathrm{CAD}$

$\mathrm{CAD}$ protein $\mathrm{GN}=\mathrm{CAD}$

$\mathrm{CAD}$ protein $\mathrm{GN}=\mathrm{CAD}$

$\mathrm{CAD}$ protein $\mathrm{GN}=\mathrm{CAD}$

$\mathrm{CAD}$ protein $\mathrm{GN}=\mathrm{CAD}$

$\mathrm{CAD}$ protein $\mathrm{GN}=\mathrm{CAD}$

$\mathrm{CAD}$ protein $\mathrm{GN}=\mathrm{CAD}$

$\mathrm{CAD}$ protein $\mathrm{GN}=\mathrm{CAD}$

$\mathrm{CAD}$ protein $\mathrm{GN}=\mathrm{CAD}$
$\mathrm{CAD}$ protein $\mathrm{GN}=\mathrm{CAD}$

$\mathrm{CAD}$ protein $\mathrm{GN}=\mathrm{CAD}$

$\mathrm{CAD}$ protein $\mathrm{GN}=\mathrm{CAD}$

$\mathrm{CAD}$ protein $\mathrm{GN}=\mathrm{CAD}$

PYR1_HUMAN $242.98 \quad 100.0 \% \quad 30$ PYR1_HUMAN $242.98 \quad 100.0 \% \quad 30$ PYR1_HUMAN $242.98 \quad 100.0 \% \quad 30$ PYR1 HUMAN $242.98 \quad 100.0 \% \quad 30$ PYR1_HUMAN $242.98 \quad 100.0 \% \quad 30$ PYR1_HUMAN $242.98 \quad 100.0 \% \quad 30$ PYR1_HUMAN $242.98 \quad 100.0 \% \quad 30$ PYR1_HUMAN $242.98 \quad 100.0 \% \quad 30$ PYR1_HUMAN $242.98 \quad 100.0 \% \quad 30$ PYR1_HUMAN $242.98 \quad 100.0 \% \quad 30$ PYR1_HUMAN $242.98 \quad 100.0 \% \quad 30$ PYR1_HUMAN $242.98 \quad 100.0 \% \quad 30$ PYR1_HUMAN $242.98 \quad 100.0 \% \quad 30$ PYR1_HUMAN $242.98 \quad 100.0 \% \quad 30$ PYR1_HUMAN $242.98 \quad 100.0 \% \quad 30$ PYR1_HUMAN $242.98 \quad 100.0 \% \quad 30$ PYR1 HUMAN $242.98 \quad 100.0 \% \quad 30$ PYR1_HUMAN $242.98 \quad 100.0 \% \quad 30$ PYR1_HUMAN $242.98 \quad 100.0 \% \quad 30$ PYR1_HUMAN $242.98 \quad 100.0 \% \quad 30$ PYR1_HUMAN $242.98 \quad 100.0 \% \quad 30$ PYR1_HUMAN $242.98 \quad 100.0 \% \quad 30$ PYR1_HUMAN $242.98 \quad 100.0 \% \quad 30$ PYR1_HUMAN $242.98 \quad 100.0 \% \quad 30$ PYR1 HUMAN $242.98 \quad 100.0 \% \quad 30$ PYR1_HUMAN $242.98 \quad 100.0 \% \quad 30$ PYR1_HUMAN $242.98 \quad 100.0 \% \quad 30$ PYR1_HUMAN $242.98 \quad 100.0 \% \quad 30$ PYR1_HUMAN $242.98 \quad 100.0 \% \quad 30$ Calcium-binding mitochondrial carrier protein Aralar2 GN=SLC25A13 $\mathrm{CMC}_{2}$ HUMAN $74.18 \quad 100.0 \% \quad 19$
$0.01 \% \quad 4.5 \%$ APLDASDSGR

$0.01 \% \quad 4.5 \%$ GKLSSSFSSR

$0.00 \% \quad 4.1 \% \quad$ IFASNLKER

$0.00 \% \quad 4.1 \%$ FYNLVLLPR

$0.02 \% \quad 12.2 \%$ APAEILNGKEISAQIR

$0.02 \% \quad 12.2 \%$ GDLNDCFIPCTPK

$0.02 \% \quad 12.2 \%$ VVGDVAYDEAKER

$0.02 \% \quad 12.2 \%$ TPVPSDIDISR

$0.02 \% \quad 12.2 \%$ VLLSALER

$0.02 \% \quad 12.2 \%$ VLLSALERLK

$0.02 \% \quad 12.2 \%$ LVPSVNGVRR

$0.02 \% \quad 12.2 \%$ FSDIQIRR

$0.02 \% \quad 12.2 \%$ VLDTNDRFLR

$0.02 \% \quad 12.2 \%$ GALALAQAVQR

$0.02 \% \quad 12.2 \%$ THLSLSHNPEQK

$0.11 \% \quad 14.6 \%$ VFNTGGAPR

$0.11 \% \quad 14.6 \%$ ILALDCGLK

$0.11 \% \quad 14.6 \%$ ATGYPLAYVAAK

$0.11 \% \quad 14.6 \%$ LALGIPLPELR

$0.11 \% \quad 14.6 \%$ SFEEAFQK

$0.11 \% \quad 14.6 \%$ IIAHAQLLEQHR

$0.11 \% \quad 14.6 \%$ TPHVLVLGSGVYR

$0.11 \% \quad 14.6 \%$ VLGTSPEAIDSAENR

$0.11 \% \quad 14.6 \%$ ELSDLESAR

$0.11 \% \quad 14.6 \%$ FLSSAAAVSK

$0.11 \% \quad 14.6 \%$ TLGVDLVALATR

$0.11 \% \quad 14.6 \%$ VPQFSFSR

$0.11 \% \quad 14.6 \%$ KNILLTIGSYK

$0.11 \% \quad 14.6 \%$ NILLTIGSYK

$0.11 \% \quad 14.6 \%$ NKSELLPTVR

$0.11 \% \quad 14.6 \%$ SELLPTVR

$0.11 \% \quad 14.6 \%$ LFVEALGQIGPAPPLK

$0.11 \% \quad 14.6 \%$ ASDPGLPAEEPKEK

$0.11 \% \quad 14.6 \%$ TSSSFAAAMAR

$0.11 \% \quad 14.6 \%$ LGGAVLSFSEATSSVQK

$0.11 \% \quad 14.6 \%$ YVAPPSLR

$0.11 \% \quad 14.6 \%$ VNEISVEVDSDPR

$0.11 \% \quad 14.6 \%$ MALLATVLGRF

$0.05 \% \quad 28.1 \%$ YLNIFGESQPNPK

$0.05 \% \quad 28.1 \%$ TVELLSGVVDQTK
$99.0 \% \quad 23.1 \quad 25.0$

$99.7 \% \quad 29.5$

$99.7 \% \quad 43.1 \quad 25.0 \quad 34.7$

$\begin{array}{llll}99.7 \% & 32.1 & 25.0 & 27.2\end{array}$

$\begin{array}{llll}99.7 \% & 29.7 & 25.0 & 29.7\end{array}$

$\begin{array}{llll}99.7 \% & 34.0 & 25.0 & 34.0\end{array}$

$99.7 \% \quad 68.9 \quad 25.0 \quad 68.6$

$\begin{array}{lllll}99.7 \% & 37.7 & 25.0 & 33.2\end{array}$

$99.0 \% \quad 39.7 \quad 25.0 \quad 25.0$

$\begin{array}{llll}99.7 \% & 30.7 & 25.0 & 30.7\end{array}$

$\begin{array}{llll}99.2 \% & 19.7 & 25.0 & 19.0\end{array}$

$99.0 \% \quad 29.6 \quad 25.0 \quad 18.2$

$99.3 \% \quad 25.1 \quad 25.0 \quad 18.3$

$99.7 \% \quad 66.6 \quad 25.0 \quad 40.1$

$\begin{array}{llll}99.5 \% & 23.2 & 25.0 & 23.2\end{array}$

$\begin{array}{llll}99.7 \% & 45.8 & 25.0 & 38.8\end{array}$

$95.5 \% \quad 19.7 \quad 25.0 \quad 11.8$

$\begin{array}{llll}97.9 \% & 19.1 & 25.0 & 16.0\end{array}$

$\begin{array}{llll}99.7 \% & 47.5 & 25.0 & 47.5\end{array}$

$\begin{array}{llll}99.7 \% & 58.3 & 25.0 & 58.3\end{array}$

$\begin{array}{llll}96.4 \% & 16.4 & 25.0 & 15.3\end{array}$

$99.0 \% \quad 40.7 \quad 25.0 \quad 35.6$

$\begin{array}{llll}99.7 \% & 40.7 & 25.0 & 40.7\end{array}$

$\begin{array}{lllll}99.7 \% & 41.5 & 25.0 & 41.5 & 2\end{array}$

$99.7 \% \quad 52.0$

$99.7 \% \quad 28.2$

$99.0 \% \quad 30.5$

$99.7 \% \quad 41.2$

$\begin{array}{llll}99.7 \% & 40.8 & 25.0 & 40.8\end{array}$

$\begin{array}{llll}99.7 \% & 54.8 & 25.0 & 54.8\end{array}$

$\begin{array}{llll}99.7 \% & 36.8 & 25.0 & 29.7\end{array}$

$\begin{array}{lllll}99.6 \% & 29.6 & 25.0 & 22.1 & 2\end{array}$

$\begin{array}{llll}99.7 \% & 58.5 & 25.0 & 50.7\end{array}$

$\begin{array}{llll}99.0 \% & 47.5 & 25.0 & 38.5\end{array}$

$\begin{array}{llll}99.6 \% & 23.8 & 25.0 & 23.8\end{array}$

$\begin{array}{llll}99.7 \% & 34.0 & 25.0 & 29.8\end{array}$

$\begin{array}{lllll}99.7 \% & 36.4 & 25.0 & 25.6 & 2\end{array}$

$\begin{array}{llll}98.3 \% & 17.8 & 25.0 & 17.8\end{array}$

$\begin{array}{llll}99.7 \% & 49.4 & 25.0 & 49.4\end{array}$

$\begin{array}{llll}99.7 \% & 39.1 & 25.0 & 36.5\end{array}$

$\begin{array}{llll}99.7 \% & 55.9 & 25.0 & 46.7\end{array}$

$\begin{array}{lll}988.47 & 1098 & 1107\end{array}$ $236 \quad 244$ $\begin{array}{lll}1709.95 & 2 & 17\end{array}$ $\begin{array}{lll}1536.68 & 138 & 150\end{array}$ $1450.72 \quad 252 \quad 264$ $1199.63 \quad 314 \quad 324$ $900.55 \quad 355 \quad 362$ $1141.73 \quad 355 \quad 364$ $\begin{array}{lll}1096.66 & 479 & 488\end{array}$ $\begin{array}{lll}1034.57 & 489 & 496\end{array}$ $\begin{array}{lll}1248.67 & 533 & 542\end{array}$ $1097.64 \quad 794 \quad 804$

$\begin{array}{lll}1390.71 & 867 & 878\end{array}$ $\begin{array}{rrr}918.48 & 169 & 177\end{array}$ $\begin{array}{lll}1002.57 & 178 \quad 186\end{array}$ $\begin{array}{lll}1676.92 & 178 & 191\end{array}$ $\begin{array}{lll}1394.70 & 275 & 287\end{array}$ $\begin{array}{lll}1257.62 & 359 & 371\end{array}$ $1827.98 \quad 501 \quad 516$ $916.56 \quad 548 \quad 555$ $\begin{array}{lll}1224.66 & 697 & 708\end{array}$ $\begin{array}{lll}1191.75 & 709 & 719\end{array}$ $2100.99 \quad 720 \quad 739$ 1020.51 985.46

1428.81 1397.79

1019.50

980.54

1228.73

967.50

1249.75

1121.66

1156.67

914.53

1649.96 1467.73

1115.51 1680.88 $98.6 \% \quad 19.6$ $99.7 \% \quad 58.7$

$\begin{array}{ll}25.0 & 51.2 \\ 25.0 & 19.5\end{array}$
$\begin{array}{llll}99.7 \% & 49.4 & 25.0 & 49.4\end{array}$ $\begin{array}{llll}99.7 \% & 58.5 & 25.0 & 58.5\end{array}$ $\begin{array}{llll}99.7 \% & 53.7 & 25.0 & 46.8\end{array}$ 

Calcium-binding mitochondrial carrier protein Aralar2 GN=SLC25A13 CMC2_HUMAN $74.18 \quad 100.0 \%$ Calcium-binding mitochondrial carrier protein Aralar2 GN=SLC25A13 CMC2_HUMAN $74.18 \quad 100.0 \%$ Calcium-binding mitochondrial carrier protein Aralar2 $\mathrm{GN}=\mathrm{SLC} 25 \mathrm{~A} 13 \mathrm{CMC} 2 \mathrm{HUMAN} 74.18 \quad 100.0 \%$ Calcium-binding mitochondrial carrier protein Aralar2 $\mathrm{GN}=\mathrm{SLC} 25 \mathrm{~A} 13 \mathrm{CMC} 2$ HUMAN $74.18 \quad 100.0 \%$ Calcium-binding mitochondrial carrier protein Aralar2 GN=SLC25A13 $\quad$ CMC2_HUMAN $74.18 \quad 100.0 \%$ Calcium-binding mitochondrial carrier protein Aralar2 $\mathrm{GN}=\mathrm{SLC} 25 \mathrm{~A} 13 \mathrm{CMC} 2$ HUMAN $74.18 \quad 100.0 \%$ Calcium-binding mitochondrial carrier protein Aralar2 GN=SLC25A13 CMC2_HUMAN 74.18 $100.0 \%$ Calcium-binding mitochondrial carrier protein Aralar2 GN=SLC25A13 CMC2 HUMAN $74.18 \quad 100.0 \%$ Calcium-binding mitochondrial carrier protein Aralar2 $\mathrm{GN}=\mathrm{SLC} 25 \mathrm{~A} 13 \mathrm{CMC} 2$ HUMAN $74.18 \quad 100.0 \%$ Calcium-binding mitochondrial carrier protein Aralar2 GN=SLC25A13 CMC2_HUMAN $74.18 \quad 100.0 \%$ Calcium-binding mitochondrial carrier protein Aralar2 $\mathrm{GN}=\mathrm{SLC25A13} \mathrm{CMC2}$ HUMAN $74.18 \quad 100.0 \%$ Calcium-binding mitochondrial carrier protein Aralar2 $\mathrm{GN}=\mathrm{SLC} 25 \mathrm{~A} 13 \mathrm{CMC} 2$ HUMAN $74.18 \quad 100.0 \%$ Calcium-binding mitochondrial carrier protein Aralar2 GN=SLC25A13 CMC2_HUMAN $74.18 \quad 100.0 \%$ Calcium-binding mitochondrial carrier protein Aralar2 GN=SLC25A13 CMC2_HUMAN $74.18 \quad 100.0 \%$ Calcium-binding mitochondrial carrier protein Aralar2 $\mathrm{GN}=\mathrm{SLC} 25 \mathrm{~A} 13 \mathrm{CMC} 2$ HUMAN $74.18 \quad 100.0 \%$ Calcium-binding mitochondrial carrier protein Aralar2 GN=SLC25A13 CMC2 HUMAN 74.18 Calcium-binding mitochondrial carrier protein SCaMC-1 GN=SLC25A24 SCMC1_HUMAN $53.36 \quad 100.0 \%$ Calcium-binding mitochondrial carrier protein SCaMC-1 GN=SLC25A24 SCMC1_HUMAN $53.36 \quad 100.0 \%$ Calcium-binding mitochondrial carrier protein SCaMC-1 GN=SLC25A24 SCMC1_HUMAN $53.36 \quad 100.0^{\circ}$ Calcium-binding mitochondrial carrier protein SCaMC-1 GN=SLC25A24 SCMC1_HUMAN $53.36 \quad 100.0 \%$ Calcium-binding mitochondrial carrier protein SCaMC-1 GN=SLC25A24 SCMC1 HUMAN $53.36100 .0^{\circ}$ Calcium-binding mitochondrial carrier protein SCaMC-1 GN=SLC25A24 SCMC1_HUMAN $53.36 \quad 100.0 \%$ Calcium-binding mitochondrial carrier protein SCaMC-1 GN=SLC25A24 SCMC1_HUMAN $53.36 \quad 100.0 \%$ Calcium-binding nit Calcyclin-binding protein GN=CACYBP $\quad$ CYBP_HUMAN $26.21 \quad 100.0 \%$ Calcyclin-binding protein GN=CACYBP CYBP_HUMAN $26.21 \quad 100.0 \%$ Calmodulin-regulated spectrin-associated protein 3 GN=CAMSAP3 CAMP3_HUMAN $134.75100 .0 \%$ Calmodulin-regulated spectrin-associated protein 3 GN=CAMSAP3 CAMP3_HUMAN $134.75 \quad 100.0 \%$ cAMP-dependent protein kinase catalytic subunit beta GN=PRKACB KAPCB HUMAN $40.62 \quad 100.0^{\circ}$ cAMP-dependent protein kinase catalytic subunit beta GN=PRKACB $\quad$ KAPCB_HUMAN $40.62 \quad 100.0 \%$ cAMP-dependent protein kinase catalytic subunit beta GN=PRKACB KAPCB_HUMAN $40.62 \quad 100.0 \%$ AMP-dependent protein kinse catalytic subunit beta GN=PRKACB KAPCB_HUMAN $40.62 \quad 100.0 \%$ cAMP-dependent protein kinase catalytic subunit beta GN=PRKACB KAPCB_HUMAN $40.62 \quad 100.0 \%$ Cancer-related nucleoside-triphosphatase GN=NTPCR NTPCR_HUMAN $20.71 \quad 100.0 \%$ Cancer-related nucleoside-triphosphatase GN=NTPCR NTPCR_HUMAN $20.71 \quad 100.0 \%$ Carbonic anhydrase $2 \mathrm{GN}=\mathrm{CA} 2$ CAH2_HUMAN $29.25 \quad 100.0 \%$ CAH2 HUMAN $29.25 \quad 100.0 \%$ Carbonyl reductase [NADPH] $1 \mathrm{GN}=\mathrm{CBR} 1$ CBR1_HUMAN $30.37 \quad 100.0 \%$ Carbonyl reductase [NADPH] $1 \mathrm{GN}=\mathrm{CBR} 1$ CBR1_HUMAN $30.37 \quad 100.0 \%$ Carbonyl reductase [NADPH] $1 \mathrm{GN}=\mathrm{CBR} 1$ CBR1_HUMAN $30.37 \quad 100.0 \%$ Carbonyl reductase [NADPH] 1 GN=CBR1 CBR1_HUMAN $30.37 \quad 100.0 \%$ Casein kinase I isoform alpha GN=CSNK1A1 KC1A HUMAN $38.92 \quad 100.0 \%$ Casein kinase I isoform alpha GN=CSNK1A1 KC1A_HUMAN $38.92 \quad 100.0 \%$ Casein kinase I isoform alpha GN=CSNK1A1 KC1A_HUMAN $38.92 \quad 100.0 \%$ Casein kinase II subunit alpha GN=CSNK2A1 CSK21 HUMAN $45.14 \quad 100.0 \%$ Casein kinase II subunit alpha GN=CSNK2A1 CSK21_HUMAN $45.14 \quad 100.0 \%$

21

2

2

2

9 21

1921

21

19

9

19
19

19
19

8

8

5

2

2

$\begin{array}{ll}2 & 2 \\ 4 & 5 \\ 4 & 5\end{array}$

5
5
5
5

5

3

3

3

$\begin{array}{llll}40 & 0.05 \% & 28.1 \% & \text { DVEVTKEEFVLAAQK } \\ 40 & 0.05 \% & 28.1 \% & \text { MTLADIER }\end{array}$

40

$40 \quad 0.05 \% \quad 28.1 \%$ ASGDSARPVLLQVAESAYR

$40 \quad 0.05 \% \quad 28.1 \%$ STGSFVGELMYK

$40 \quad 0.05 \% \quad 28.1 \%$ YEGFFGLYR

$40 \quad 0.05 \% \quad 28.1 \%$ AIKLTVNDFVR

$40 \quad 0.05 \% \quad 28.1 \%$ LTVNDFVR

$40 \quad 0.05 \% \quad 28.1 \%$ LQVAGEITTGPR

$40 \quad 0.05 \% \quad 28.1 \%$ VSALSVVR

$40 \quad 0.05 \% \quad 28.1 \%$ DLGFFGIYK

$40 \quad 0.05 \% \quad 28.1 \%$ DLGFFGIYKGAK

$40 \quad 0.05 \% \quad 28.1 \%$ TRLQVAAR

$40 \quad 0.05 \% \quad 28.1 \%$ AGQTTYSGVIDCFR

$40 \quad 0.05 \% \quad 28.1 \%$ AGQTTYSGVIDCFRK

$40 \quad 0.05 \% \quad 28.1 \%$ ILREEGPK

$40 \quad 0.05 \% \quad 28.1 \%$ INLPAPNPDHVGGYK

$40 \quad 0.05 \% \quad 28.1 \%$ LAVATFAGIENK

$3 \quad 0.03 \% \quad 17.2 \%$ QLLAGGIAGAVSR

$0.03 \% \quad 17.2 \%$ TSTAPLDRLK

$0.03 \% \quad 17.2 \%$ SDKMNIFGGFR

$0.03 \% \quad 17.2 \%$ LLTEEGQKIGTFER

$0.03 \% \quad 17.2 \%$ TGQYSGIYDCAK

$0.03 \% \quad 17.2 \%$ TGQYSGIYDCAKK

$0.03 \% \quad 17.2 \%$ HEGLGAFYK

$0.03 \% \quad 17.2 \%$ IISKEGIPGLYR

$0.00 \% \quad 7.5 \%$ SKIETEIK

$0.00 \% \quad 7.5 \%$ TDTVLILCR

$0.00 \% \quad 2.2 \% \quad$ ASPAAPADGAAPAQPSIR

$0.00 \% \quad 2.2 \%$ SAFLQVQPR

$0.01 \% \quad 13.7 \%$ TLGTGSFGR

$0.01 \% \quad 13.7 \%$ ATEQYYAMK

$0.01 \% \quad 13.7 \%$ ILQAVNFPFLVR

$0.01 \% \quad 13.7 \%$ NLLQVDLTK

$0.01 \% \quad 13.7 \%$ KVEAPFIPK

$0.00 \% \quad 12.1 \%$ HVFLTGPPGVGK

$0.00 \% \quad 12.1 \%$ GKPLALVEEIR

$0.00 \% \quad 7.3 \% \quad$ VVDVLDSIK

$0.00 \% \quad 7.3 \%$ SADFTNFDPR

$0.01 \% \quad 15.9 \%$ LFSGDVVLTAR

$0.01 \% \quad 15.9 \%$ GQAAVQQLQAEGLSPR

$0.01 \% \quad 15.9 \%$ SCSPELQQK

$0.01 \% \quad 15.9 \%$ IGVTVLSR

$0.00 \% \quad 11.9 \%$ HPQLLYESK

$0.00 \% \quad 11.9 \%$ LFLIDFGLAK

$\begin{array}{lllllll}0.00 \% & 11.9 \% & \text { AAQQAASSSGQGQQAQTPTGK } & 99.7 \% & 49.7 & 25.0 & 49.7 \\ 0.00 \% & 11.5 \% & \text { GGPNIITLADIVKDPVSR } & 97.7 \% & 16.3 & 25.0 & 16.3\end{array}$

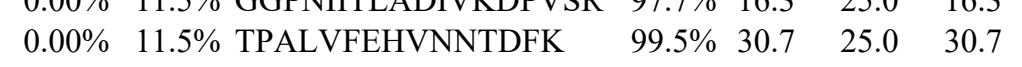

$\begin{array}{llll}38.7 & 25.0 & 38.7 & 1\end{array}$ $99.7 \% \quad 38.9$

$99.7 \% \quad 34.8 \quad-25.0,43.7$

$\begin{array}{llll}99.0 \% & 43.4 & 25.0 & 36.3\end{array}$

$\begin{array}{lllll}99.7 \% & 60.3 & 25.0 & 49.7 & 2\end{array}$

$\begin{array}{lllll}99.0 \% & 66.4 & 25.0 & 59.3 & 2\end{array}$

$\begin{array}{llll}99.7 \% & 30.2 & 25.0 & 29.0\end{array}$

$\begin{array}{lllll}99.7 \% & 39.2 & 25.0 & 30.9 & 2\end{array}$

$\begin{array}{llll}99.0 \% & 29.9 & 25.0 & 13.9 \\ 99.7 \% & 65.9 & 25.0 & 65.9\end{array}$

$\begin{array}{llll}99.7 \% & 69.7 & 25.0 & 69.7\end{array}$

$\begin{array}{llll}99.0 \% & 43.2 & 25.0 & 33.7\end{array}$

$\begin{array}{llll}99.7 \% & 33.3 & 25.0 & 29.1 \\ 99.7 \% & 73.5 & 25.0 & 71.5\end{array}$

$\begin{array}{llll}99.7 \% & 52.6 & 25.0 & 52.6\end{array}$

$\begin{array}{lllll}99.7 \% & 34.8 & 25.0 & 28.0 & 2\end{array}$

$99.6 \% \quad 24.0 \quad 25.0 \quad 19.9$

$\begin{array}{llll}99.7 \% & 78.7 & 25.0 & 70.7\end{array}$

$\begin{array}{llll}99.7 \% & 61.2 & 25.0 & 61.2\end{array}$

$\begin{array}{llll}99.7 \% & 28.5 & 25.0 & 28.5\end{array}$

$\begin{array}{llll}99.7 \% & 39.1 & 25.0 & 39.1\end{array}$

$\begin{array}{llll}98.6 \% & 21.5 & 25.0 & 17.2\end{array}$

$\begin{array}{llll}99.7 \% & 65.7 & 25.0 & 49.5\end{array}$

$\begin{array}{llll}99.7 \% & 33.2 & 25.0 & 33.2 \\ 99.7 \% & 29.1 & 25.0 & 21.9\end{array}$

$\begin{array}{llll}99.7 \% & 42.2 & 25.0 & 33.8\end{array}$

$\begin{array}{llll}99.5 \% & 28.5 & 25.0 & 28.5\end{array}$

$\begin{array}{llll}99.7 \% & 55.0 & 25.0 & 55.0\end{array}$

$\begin{array}{llll}99.3 \% & 32.8 & 25.0 & 20.2\end{array}$

$\begin{array}{llll}99.7 \% & 43.5 & 25.0 & 31.6\end{array}$

$\begin{array}{llll}99.7 \% & 34.8 & 25.0 & 34.8\end{array}$

$\begin{array}{llll}99.7 \% & 29.3 & 25.0 & 29.3\end{array}$

$\begin{array}{llll}99.6 \% & 27.5 & 25.0 & 25.2 \\ 99.7 \% & 46.2 & 25.0 & 35.3\end{array}$

$99.7 \% \quad 61.6 \quad 25.0 \quad 55.4$

$\begin{array}{llll}96.3 \% & 16.8 & 25.0 & 14.6\end{array}$

$\begin{array}{cccc}99.0 \% & 41.0 & 25.0 & 0.0\end{array}$

$98.6 \% \quad 22.6 \quad 25.0 \quad 19.0$ $\begin{array}{llll}99.7 \% & 28.3 & 25.0 & 28.3\end{array}$

$\begin{array}{lllll}99.7 \% & 77.8 & 25.0 & 71.3 & 3\end{array}$
948.48

1990.04

1334.63

1151.55

1275.74

963.53

1241.69

830.51

1059.55

1315.70

914.55

1574.73

1702.82

941.54

1591.82

1233.68

1212.71

1101.63

1287.62

1620.86

1362.60

1490.69

1021.51

1345.78

947.54

1090.59

1647.85

1045.58

895.46

1120.50

1416.84

1043.61

1028.61

1208.68

1224.73

987.57

1169.52

1177.66

1652.87

1076.50

844.53

1114.59

1136.67

2001.96

1865.05

1731.87 
Casein kinase II subunit alpha GN=CSNK2A1 CSK21_HUMAN $45.14 \quad 100.0 \%$ Casein kinase II subunit alpha' GN=CSNK2A2 CSK22_HUMAN $41.21 \quad 100.0 \%$ Casein kinase II subunit alpha' GN=CSNK2A2 CSK22_HUMAN $41.21 \quad 100.0 \%$ Casein kinase II subunit alpha' GN=CSNK2A2 CSK22 HUMAN $41.21 \quad 100.0^{\circ}$ Casein kinase II subunit alpha' GN=CSNK2A2 CSK22_HUMAN $41.21 \quad 100.0 \%$ Cat eye syndrome critical region protein $5 \mathrm{GN}=$ CECR5 CECR5_HUMAN $46.32 \quad 100.0 \%$ Cat eye syndrome critical region protein $5 \mathrm{GN}=$ CECR5 CECR5_HUMAN $46.32 \quad 100.0 \%$ Cat eye syndrome critical region protein $5 \mathrm{GN}=\mathrm{CECR} 5$ CECR5_HUMAN $46.32 \quad 100.0 \%$ Cat eye syndrome critical region protein $5 \mathrm{GN}=$ CECR5 CECR5_HUMAN $46.32 \quad 100.0 \%$ Cat eye syndrome critical region protein $5 \mathrm{GN}=$ CECR5 CECR5_HUMAN $46.32 \quad 100.0 \%$ Cat eye syndrome critical region protein $5 \mathrm{GN}=\mathrm{CECR} 5$ CECR5_HUMAN $46.32 \quad 100.0 \%$ Cat eye syndrome critical region protein $5 \mathrm{GN}=$ CECR5 CECR5_HUMAN $46.32 \quad 100.0 \%$ Cat eye syndrome critical region protein $5 \mathrm{GN}=\mathrm{CECR} 5$ CECR5_HUMAN $46.32 \quad 100.0 \%$ Cat eye syndrome critical region protein $5 \mathrm{GN}=$ CECR5 CECR5_HUMAN $46.32100 .0 \%$ Cat eye syndrome critical region protein 5 GN=CECR5 CECR5_HUMAN $46.32 \quad 100.0 \%$ Catenin delta-1 GN=CTNND1

Catenin delta-1 GN $=\mathrm{CTNND} 1$

CTND1_HUMAN $108.17 \quad 100.0 \%$

CTND1 HUMAN $108.17 \quad 100.0 \%$

CCAAT/enhancer-binding protein zeta GN=CEBPZ CEBPZ_HUMAN $120.98 \quad 100.0 \%$ CCAAT/enhancer-binding protein zeta GN=CEBPZ CEBPZ_HUMAN $120.98 \quad 100.0 \%$ CCAAT/enhancer-binding protein zeta GN=CEBPZ CEBPZ_HUMAN $120.98 \quad 100.0 \%$ CCR4-NOT transcription complex subunit $1 \mathrm{GN}=\mathrm{CNOT1}$ CNOT1_HUMAN $266.94 \quad 100.0 \%$ CCR4-NOT transcription complex subunit $1 \mathrm{GN}=\mathrm{CNOT1}$ CNOT1_HUMAN $266.94 \quad 100.0 \%$ CCR4-NOT transcription complex subunit $1 \mathrm{GN}=\mathrm{CNOT} 1$ CNOT1_HUMAN $266.94 \quad 100.0 \%$ CCR4-NOT transcription complex subunit $1 \mathrm{GN}=\mathrm{CNOT1}$ CNOT1_HUMAN $266.94 \quad 100.0 \%$ CCR4-NOT transcription complex subunit $1 \mathrm{GN}=\mathrm{CNOT1}$ CNOT1_HUMAN $266.94 \quad 100.0 \%$ CCR4-NOT transcription complex subunit 8 GN=CNOT8 CNOT8_HUMAN $33.54 \quad 100.0 \%$ CCR4-NOT transcription complex subunit $8 \mathrm{GN}=$ CNOT8 CNOT8_HUMAN $33.54 \quad 100.0 \%$ Cell cycle and apoptosis regulator protein $2 \mathrm{GN}=$ CCAR2 CCAR2_HUMAN $102.90 \quad 100.0 \%$ Cell cycle and apoptosis regulator protein $2 \mathrm{GN}=\mathrm{CCAR} 2$ CCAR2_HUMAN $102.90 \quad 100.0 \%$ Cell cycle and apoptosis regulator protein $2 \mathrm{GN}=\mathrm{CCAR} 2$ CCAR2 HUMAN $102.90 \quad 100.0 \%$ Cell differentiation protein RCD1 homolog GN=RQCD1 RCD1_HUMAN $33.63 \quad 100.0 \%$ Cell differentiation protein RCD1 homolog GN=RQCD1 RCD1_HUMAN $33.63 \quad 100.0 \%$ Cell differentiation protein RCD1 homolog GN=RQCD1 RCD1 HUMAN $33.63 \quad 100.0 \%$ Cell division cycle 5-like protein $\mathrm{GN}=\mathrm{CDC} 5 \mathrm{~L}$ CDC5L_HUMAN $92.25 \quad 100.0 \%$ Cell division cycle 5-like protein $\mathrm{GN}=\mathrm{CDC} 5 \mathrm{~L} \quad \mathrm{CDC} 5 \mathrm{~L} \_$HUMAN $92.25 \quad 100.0 \%$ Cell division cycle 5-like protein GN=CDC5L CDC5L_HUMAN $92.25 \quad 100.0 \%$ Cell division cycle 5-like protein $\mathrm{GN}=\mathrm{CDC} 5 \mathrm{~L} \quad \mathrm{CDC} 5 \mathrm{~L} \_$HUMAN $92.25 \quad 100.0 \%$ Cell division cycle 5-like protein GN=CDC5L CDC5L HUMAN $92.25 \quad 100.0 \%$ Cell division cycle 5-like protein GN=CDC5L CDC5L_HUMAN $92.25 \quad 100.0 \%$ Cell division cycle 5-like protein GN=CDC5L CDC5L_HUMAN $92.25 \quad 100.0 \%$ Cell division cycle 5-like protein $\mathrm{GN}=\mathrm{CDC} 5 \mathrm{~L} \quad \mathrm{CDC} 5 \mathrm{~L} \_$HUMAN $92.25 \quad 100.0 \%$ Cell division cycle protein 23 homolog GN=CDC23 CDC23_HUMAN $68.84 \quad 100.0 \%$ Cell division cycle protein 23 homolog $\mathrm{GN}=\mathrm{CDC} 23 \mathrm{CDC} 23$ HUMAN $68.84 \quad 100.0 \%$ Cell growth-regulating nucleolar protein GN=LYAR LYAR_HUMAN $43.62 \quad 100.0 \%$ Cell growth-regulating nucleolar protein GN=LYAR LYAR_HUMAN $43.62 \quad 100.0 \%$ Cell growth-regulating nucleolar protein GN=LYAR LYAR_HUMAN $43.62 \quad 100.0 \%$ Cell growth-regulating nucleolar protein GN=LYAR LYAR_HUMAN $43.62 \quad 100.0 \%$
$0.00 \% \quad 11.5 \%$ QLYQTLTDYDIR

$0.01 \% \quad 13.4 \%$ VYAEVNSLR

$0.01 \% \quad 13.4 \%$ YSEVFEAINITNNER

$0.01 \% \quad 13.4 \%$ LIDTVKDPVSK

$0.01 \% \quad 13.4 \%$ VLGTEELYGYLK

$0.03 \% \quad 29.1 \%$ RLVNSQGQLR

$0.03 \% \quad 29.1 \%$ LVNSQGQLR

$0.03 \% \quad 29.1 \%$ VPVVFVTNAGNILQHSK

$0.03 \% \quad 29.1 \%$ LFSEYHEK

$0.03 \% \quad 29.1 \%$ MLVSGQGPVMENAQGLGFR

$0.03 \% \quad 29.1 \%$ NVVTVDELR

$0.03 \% \quad 29.1 \%$ MAFPLLDMVDLER

$0.03 \% \quad 29.1 \%$ IEGVLLLGEPVR

$0.03 \% \quad 29.1 \%$ ATHDGAPELGAGGTR

$0.03 \% \quad 29.1 \%$ NPQSTEPVLGGGEPPFHGHR

$0.00 \% \quad 2.4 \%$ GSLASLDSLRK

$0.00 \% \quad 2.4 \%$ SDFQVNLNNASR

$0.01 \% \quad 3.8 \%$ NRPEPHSDENGSTTPK

$0.01 \% \quad 3.8 \%$ MLSALLTGVNR

$0.01 \% \quad 3.8 \%$ GKENTDSVVMQPK

$0.01 \% \quad 2.1 \%$ SLDLIESLLR

$0.01 \% \quad 2.1 \%$ LAEVGQYEQVK

$0.01 \% \quad 2.1 \% \quad$ NLDEQLSAPK

$0.01 \% \quad 2.1 \% \quad$ SLLEVVVLSR

$0.01 \% \quad 2.1 \% \quad$ NLILSAFPR

$0.00 \% \quad 7.5 \%$ SSIDYQYQLLR

$0.00 \% \quad 7.5 \%$ LYGLGTGVAQK

$0.00 \% \quad 3.4 \%$ VQTLSNQPLLK

$0.00 \% \quad 3.4 \%$ VVTQNICQYR

$0.00 \% \quad 3.4 \%$ LTPLQLEIQR

$0.00 \% \quad 11.0 \%$ LTSLGVIGALVK

$0.00 \% \quad 11.0 \%$ IMESGSELSK

$0.00 \% \quad 11.0 \%$ NLQEGQVTDPR

$0.02 \% \quad 12.2 \%$ TIAPIIGR

$0.02 \% \quad 12.2 \%$ AAGIEIQK

$0.02 \% \quad 12.2 \%$ GVDYNAEIPFEK

$\begin{array}{llllll}0.02 \% & 12.2 \% & \text { ESDLPSAILQTSGVSEFTK } & 99.7 \% & 55.8\end{array}$

$0.02 \% \quad 12.2 \%$ LVLPAPQISDAELQEVVK $99.7 \% \quad 29.2$

$0.02 \% \quad 12.2 \%$ VGQASEIAR

$0.02 \% \quad 12.2 \%$ SGTTPKPVINSTPGR

$0.02 \% \quad 12.2 \%$ ILLGGYQSR

$0.00 \% \quad 3.4 \%$ QLLLIAGLTR

$0.00 \% \quad 3.4 \%$ AYFDVKEYDR

$0.01 \% \quad 19.5 \%$ VFFTCNACGESVK

$0.01 \% \quad 19.5 \%$ VFFTCNACGESVKK

$0.01 \% \quad 19.5 \%$ CISEDQKYGGK

$0.01 \% \quad 19.5 \%$ ISELIKRPNVSPK
$9.7 \% \quad 39.6$

$99.7 \% \quad 61.3$

$99.7 \% \quad 46.7$

$99.7 \% \quad 30.6$

$99.7 \% \quad 49.4$

$98.6 \% \quad 20.4$

$99.7 \% \quad 57.8$

$99.7 \% 54.1$

$99.7 \%$

$99.7 \% \quad 45.8$

$99.7 \% \quad 60.6$

$99.7 \% \quad 44.3$

$99.7 \% \quad 52.8$

$96.4 \% 15.0$

$99.7 \% \quad 62.3$

$99.7 \% \quad 45.5$

$98.2 \% \quad 26.3$

$99.7 \% \quad 43.6$

$99.7 \% \quad 41.5$

$99.7 \% 49$.

$99.6 \% \quad 31.4$

$99.7 \% \quad 59.8$

$99.7 \% \quad 39.1$

$99.7 \% \quad 42.0$

$99.7 \% \quad 51.0$

$98.9 \% \quad 25.5$

$99.7 \% \quad 32.0$

$96.9 \% \quad 25.4$

$99.7 \% \quad 51.6$

$98.0 \% \quad 16.9$

$98.0 \% \quad 22.0$

$99.6 \% 27.7$

$99.7 \% \quad 56.3$

$99.7 \% \quad 58.4$

$99.7 \% \quad 42.6$

$99.7 \% \quad 47.6$

$99.7 \% \quad 30.6$

$99.7 \% \quad 41.4$

$98.5 \% \quad 20.0$

$99.7 \% \quad 40.0$

$98.6 \% \quad 18$
1528.76

1050.56

1798.86

1214.70

1384.74

1170.67

1014.57

1823.02

1052.50

1990.98

1044.57

1565.77

1294.77

1409.68

2113.02

1146.65

1364.66

1765.81

1174.66

1432.7

1158.67

1263.66

1114.57

1114.68

1030.60

1385.71

1106.62

1240.73

1280.64

1210.72

1170.75

1096.52

1256.62

840.53

829.48

1381.66

2009.01

1949.10

930.50

1511.82

1006.57

1097.70

1305.61

1518.67

1646.77

1284.59

1480.88

6

260

$73 \quad 8$

448

$83 \quad 99$

132

$153 \quad 161$

$162 \quad 174$

$189 \quad 200$

$332 \quad 346$

$345 \quad 355$

$143 \quad 158$

781

$450 \quad 459$

$1311 \quad 1320$

$1641 \quad 1650$

$2130 \quad 2138$

$56 \quad 66$

$259 \quad 269$

$113 \quad 123$

$748 \quad 757$

896905

$137 \quad 148$

$82 \quad 292$

$84 \quad 91$

$193 \quad 200$

$207 \quad 218$

$95 \quad 312$

$313 \quad 321$

$427 \quad 441$

$719 \quad 727$

$35 \quad 44$

101

14

15

8193 
Cell growth-regulating nucleolar protein GN=LYAR LYAR_HUMAN $43.62 \quad 100.0 \%$ Cell growth-regulating nucleolar protein GN=LYAR LYAR_HUMAN $43.62 \quad 100.0 \%$ Cell growth-regulating nucleolar protein GN=LYAR LYAR_HUMAN $43.62 \quad 100.0 \%$ Cellular tumor antigen p53 GN=TP53 Cellular tumor antigen $\mathrm{p} 53 \mathrm{GN}=\mathrm{TP} 53$ Cellular tumor antigen $\mathrm{p} 53 \mathrm{GN}=\mathrm{TP} 53$ Cellular tumor antigen $\mathrm{p} 53 \mathrm{GN}=\mathrm{TP} 53$ Cellular tumor antigen p53 GN=TP53 Centromere protein $\mathrm{V} \mathrm{GN}=\mathrm{CENPV}$

Centromere protein $\mathrm{V}$ GN $=\mathrm{CENPV}$ Centromere protein $\mathrm{V}$ GN $=\mathrm{CENPV}$ Centromere protein $\mathrm{V}$ GN $=\mathrm{CENPV}$ Centromere protein $\mathrm{V}$ GN $=\mathrm{CENPV}$ Centromere protein $\mathrm{V}$ GN $=\mathrm{CENPV}$ P53 HUMAN $43.65 \quad 100.0 \%$ P53_HUMAN $43.65 \quad 100.0 \%$ P53_HUMAN $43.65 \quad 100.0 \%$ P53 HUMAN $43.65 \quad 100.0 \%$ P53_HUMAN $43.65 \quad 100.0 \%$ CENPV HUMAN $29.95 \quad 100.0 \%$ CENPV_HUMAN $29.95 \quad 100.0 \%$ CENPV_HUMAN $29.95 \quad 100.0 \%$ CENPV HUMAN $29.95 \quad 100.0 \%$ CENPV_HUMAN $29.95 \quad 100.0 \%$ CENPV_HUMAN $29.95 \quad 100.0 \%$ Centromere/kinetochore protein Zw10 homolog GN=ZW10 ZW10_HUMAN $88.83 \quad 100.0 \%$ Centromere/kinetochore protein Zw10 homolog GN=ZW10 ZW10_HUMAN $88.83 \quad 100.0 \%$ Charged multivesicular body protein $4 \mathrm{~b}$ GN=CHMP4B CHM4B_HUMAN $24.95 \quad 100.0 \%$ Charged multivesicular body protein 4b GN=CHMP4B CHM4B_HUMAN $24.95 \quad 100.0 \%$ Charged multivesicular body protein $4 \mathrm{~b}$ GN=CHMP4B CHM4B_HUMAN $24.95 \quad 100.0 \%$ Charged multivesicular body protein $4 \mathrm{~b}$ GN=CHMP4B CHM4B_HUMAN $24.95 \quad 100.0 \%$ Chitobiosyldiphosphodolichol beta-mannosyltransferase GN=ALG1 ALG1_HUMAN $52.52 \quad 100.0 \%$ Chitobiosyldiphosphodolichol beta-mannosyltransferase GN=ALG1 ALG1_HUMAN $52.52 \quad 100.0 \%$ Chloride intracellular channel protein $1 \mathrm{GN}=$ CLIC1 CLIC1_HUMAN $26.92 \quad 100.0 \%$ Chloride intracellular channel protein $1 \mathrm{GN}=\mathrm{CLIC1}$ CLIC1_HUMAN $26.92 \quad 100.0 \%$ Chloride intracellular channel protein $1 \mathrm{GN}=$ CLIC1 CLIC1_HUMAN $26.92 \quad 100.0 \%$ Chloride intracellular channel protein $4 \mathrm{GN}=\mathrm{CLIC} 4$ CLIC4_HUMAN $28.77 \quad 100.0 \%$ Chloride intracellular channel protein 4 GN=CLIC4 CLIC4_HUMAN $28.77 \quad 100.0 \%$ Chromatin target of PRMT1 protein GN=CHTOP CHTOP_HUMAN $26.40 \quad 100.0 \%$ Chromatin target of PRMT1 protein GN=CHTOP CHTOP_HUMAN $26.40 \quad 100.0 \%$ Chromatin target of PRMT1 protein GN=CHTOP CHTOP_HUMAN $26.40 \quad 100.0 \%$ Chromatin target of PRMT1 protein GN=CHTOP CHTOP_HUMAN $26.40 \quad 100.0 \%$ Chromodomain-helicase-DNA-binding protein $1 \mathrm{GN}=\mathrm{CHD} 1 \mathrm{CHD} 1 \_H U M A N \quad 196.69 \quad 100.0 \%$ Chromodomain-helicase-DNA-binding protein $1 \mathrm{GN}=\mathrm{CHD} 1 \mathrm{CHD} 1 \mathrm{HUMAN} 196.69100 .0 \%$ Chromodomain-helicase-DNA-binding protein 1-like GN=CHDIL CHD1L_HUMAN $100.99 \quad 100.0 \%$ Chromodomain-helicase-DNA-binding protein 1-like GN=CHD1L CHD1L_HUMAN $100.99 \quad 100.0 \%$ Chromodomain-helicase-DNA-binding protein 1-like GN=CHDIL CHD1L_HUMAN $100.99 \quad 100.0 \%$ Chromodomain-helicase-DNA-binding protein 4 GN=CHD4 CHD4_HUMAN $218.01 \quad 100.0 \%$ Chromodomain-helicase-DNA-binding protein $4 \mathrm{GN}=\mathrm{CHD} 4$ CHD4_HUMAN $218.01 \quad 100.0 \%$ Chromosome transmission fidelity protein 18 homolog GN=CHTF18 CTF18_HUMAN $107.38 \quad 100.0 \%$ Chromosome transmission fidelity protein 18 homolog GN=CHTF18 CTF 18 _HUMAN $107.38 \quad 100.0 \%$ Citrate synthase, mitochondrial $\mathrm{GN}=\mathrm{C}$ Citrate synthase, mitochondrial $\mathrm{GN}=\mathrm{CS}$ Citron Rho-interacting kinase $\mathrm{GN}=\mathrm{CIT}$ Citron Rho-interacting kinase $\mathrm{GN}=\mathrm{CIT}$ Citron Rho-interacting kinase $\mathrm{GN}=\mathrm{CIT}$

Citron Rho-interacting kinase $\mathrm{GN}=\mathrm{CIT}$ Citron Rho-interacting kinase $\mathrm{GN}=\mathrm{CIT}$
CISY_HUMAN $51.71 \quad 100.0 \%$ CISY_HUMAN $51.71 \quad 100.0 \%$ CTRO HUMAN $231.44 \quad 100.0 \%$ CTRO_HUMAN $231.44 \quad 100.0 \%$ CTRO_HUMAN $231.44 \quad 100.0 \%$ CTRO HUMAN $231.44 \quad 100.0 \%$ CTRO_HUMAN $231.44 \quad 100.0 \%$
$0.01 \% \quad 19.5 \%$ VRELLEQISAFDNVPR $0.01 \% \quad 19.5 \%$ VKDAVEQQGEVK $0.01 \% \quad 19.5 \%$ ISKNPTFK

$0.02 \% \quad 14.8 \%$ TYQGSYGFR

$0.02 \% \quad 14.8 \%$ LGFLHSGTAK

$0.02 \% \quad 14.8 \%$ SVTCTYSPALNK

$0.02 \% \quad 14.8 \%$ ALPNNTSSSPQPK

$0.02 \% \quad 14.8 \%$ KKPLDGEYFTLQIR

$99.7 \% \quad 46.2$ $99.7 \% \quad 39.1$

$98.4 \% \quad 18.1$

$99.7 \% 27.2$

$99.7 \% 37.6$

$99.7 \% \quad 45.0$

$99.7 \% \quad 41.6$

$\begin{array}{lll}99.7 \% & 32.9\end{array}$

$0.02 \% \quad 33.8 \%$ SGASGASAAPAASAAAA

$0.02 \% \quad 33.8 \%$ LLLDTFEYQGLVK

$0.02 \% \quad 33.8 \%$ GAEHITTYTFNTHK

$0.02 \% \quad 33.8 \%$ CGVQSFYTPR

$0.02 \% \quad 33.8 \%$ SNPGGFGIAPHCLDEGTVR

$0.00 \% \quad 3.0 \% \quad$ FLKGDTTDLLK

$0.00 \% \quad 3.0 \% \quad$ NLMTSEIHNTVK

$0.01 \% \quad 22.8 \%$ GGPTPQEAIQR

$0.01 \% \quad 22.8 \%$ KIEQELTAAK

$0.01 \% \quad 22.8 \%$ QLAQIDGTLSTIEFQR

$0.01 \% \quad 22.8 \%$ EALENANTNTEVLK

$0.00 \% \quad 5.2 \%$ LGSMHSPFR

$0.00 \% \quad 5.2 \%$ SAFTERDAGSGLVTR

$0.01 \% \quad 13.3 \%$ GVTFNVTTVDTK

$0.01 \% \quad 13.3 \%$ NSNPALNDNLEK

$0.01 \% \quad 13.3 \%$ YLSNAYAR

$0.00 \% \quad 7.9 \%$ NSRPEANEALER

$0.00 \% \quad 7.9 \% \quad$ YLTNAYSR

$0.03 \% \quad 21.0 \%$ NKQPTPVNIR

$0.03 \% \quad 21.0 \%$ ASMQQQQQLASAR

$0.03 \% \quad 21.0 \%$ LAQQMENRPSVQAALK

$0.03 \% \quad 21.0 \%$ EQLDNQLDAYMSK

$0.00 \% \quad 1.1 \%$ LKNDDSLLYK

$0.00 \% \quad 1.1 \%$ VLIFSQMVR

$0.01 \% \quad 3.3 \%$ GGQAPGFLLR

$0.01 \% \quad 3.3 \%$ SFEQLVNLQK

$0.01 \% \quad 3.3 \%$ GGLFTALEKR

$0.00 \% \quad 1.2 \%$ VLIFSQMTK

$0.00 \% \quad 1.2 \%$ VGGNIEVLGFNAR

$0.00 \% \quad 2.3 \%$ TTLAHVIAR

$0.00 \% \quad 2.3 \% \quad$ ITFPSSQQEAQNR

$0.00 \% \quad 4.1 \%$ AYAQGISR

$0.00 \% \quad 4.1 \% \quad$ IVPNVLLEQGK

$0.01 \% \quad 3.5 \%$ NPLDAGAAEPIASR

$0.01 \% \quad 3.5 \%$ SPFAEGTSAR

$1 \quad 0.01 \% \quad 3.5 \%$ SESVVSGLDSPAK

$0.01 \% \quad 3.5 \%$ LAAEEFKR

$0.01 \% \quad 3.5 \%$ LIDFLQAK $\begin{array}{llll}9.7 \% & 59.2 & 25.0 & 57.5\end{array}$

$\begin{array}{llll}99.7 \% & 54.7 & 25.0 & 40.4\end{array}$

$\begin{array}{llll}99.7 \% & 53.3 & 25.0 & 46.4\end{array}$

$99.7 \% \quad 56.9 \quad 25.0 \quad 56.9$

$\begin{array}{llll}99.7 \% & 63.9 & 25.0 & 63.9\end{array}$

$\begin{array}{llll}99.7 \% & 56.9 & 25.0 & 53.9\end{array}$

$99.2 \% \quad 24.2 \quad 25.0 \quad 19.6$

$\begin{array}{lllll}99.7 \% & 52.8 & 25.0 & 45.5 & 2\end{array}$

$99.7 \% \quad 52.9 \quad 25.0 \quad 47.5$

$\begin{array}{llll}99.7 \% & 34.3 & 25.0 & 30.9\end{array}$

$\begin{array}{llll}99.7 \% & 38.7 & 25.0 & 38.7\end{array}$

$99.7 \% \quad 78.5 \quad 25.0 \quad 73.6$

$\begin{array}{llll}99.7 \% & 27.5 & 25.0 & 23.2\end{array}$

$99.7 \% \quad 32.8 \quad 25.0 \quad 32.8$

$99.7 \% \quad 74.6 \quad 25.0 \quad 58.2$

$\begin{array}{llll}99.7 \% & 63.1 & 25.0 & 56.1\end{array}$

$99.0 \% \quad 33.6 \quad 25.0 \quad 25.5$

$\begin{array}{llll}99.5 \% & 27.1 & 25.0 & 24.3\end{array}$

$\begin{array}{llll}99.0 \% & 31.3 & 25.0 & 27.6\end{array}$

$\begin{array}{llll}99.7 \% & 32.9 & 25.0 & 30.4\end{array}$

$\begin{array}{llll}99.7 \% & 68.8 & 25.0 & 54.0\end{array}$

$\begin{array}{llll}99.7 \% & 40.7 & 25.0 & 28.7\end{array}$

$\begin{array}{llll}99.7 \% & 53.6 & 25.0 & 53.6\end{array}$

$\begin{array}{llll}95.2 \% & 19.0 & 25.0 & 17.8\end{array}$

$\begin{array}{llll}99.7 \% & 31.2 & 25.0 & 30.6\end{array}$

$\begin{array}{llll}99.7 \% & 39.7 & 25.0 & 21.3\end{array}$

$99.7 \% \quad 47.7 \quad 25.0 \quad 34.6$

$99.7 \% \quad 52.8 \quad 25.0 \quad 48.4$

$\begin{array}{llll}99.7 \% & 31.5 & 25.0 & 23.2\end{array}$

$99.7 \% \quad 43.4 \quad 25.0 \quad 43.4$

$\begin{array}{llll}99.7 \% & 36.4 & 25.0 & 36.4\end{array}$

$\begin{array}{llll}99.7 \% & 52.5 & 25.0 & 47.9\end{array}$

$\begin{array}{llll}95.0 \% & 22.9 & 25.0 & 7.8\end{array}$

$\begin{array}{llll}99.3 \% & 19.9 & 25.0 & 19.5\end{array}$

$\begin{array}{llll}99.7 \% & 60.2 & 25.0 & 52.1\end{array}$

$\begin{array}{llll}99.7 \% & 41.8 & 25.0 & 19.8\end{array}$

$\begin{array}{llll}99.7 \% & 47.9 & 25.0 & 39.8\end{array}$

$99.0 \% \quad 35.6 \quad 25.0 \quad 17.6$

$\begin{array}{llll}99.0 \% & 19.2 & 25.0 & 19.2\end{array}$
1886.01

\begin{tabular}{|c|c|c|c|c|c|c|}
\hline 39.1 & 25.0 & 27.5 & 1 & 0 & 0 & 1329 \\
\hline 18.1 & 25.0 & 18.0 & 2 & 0 & 0 & \\
\hline 27.2 & 25.0 & 27.2 & 1 & 0 & 0 & 107 \\
\hline 37.6 & 25.0 & 30.9 & 3 & 0 & 0 & 103 \\
\hline 45.0 & 25.0 & 45.0 & 5 & 0 & 0 & 13 \\
\hline 41.6 & 25.0 & 38.2 & 4 & 0 & 0 & 13 \\
\hline 32.9 & 25.0 & 28.7 & 0 & 2 & 0 & 170 \\
\hline 59.2 & 25.0 & 57.5 & 2 & 2 & 0 & 198 \\
\hline 54.7 & 25.0 & 40.4 & 2 & 3 & 0 & 145 \\
\hline 53.3 & 25.0 & 46.4 & 5 & 0 & 0 & 153 \\
\hline 56.9 & 25.0 & 56.9 & 1 & 2 & 0 & 161 \\
\hline 63.9 & 25.0 & 63.9 & 2 & 0 & 0 & 121 \\
\hline 56.9 & 25.0 & 53.9 & 1 & 2 & 0 & 19 \\
\hline 24.2 & 25.0 & 19.6 & 1 & 0 & 0 & 125 \\
\hline 52.8 & 25.0 & 45.5 & 2 & 0 & 0 & 140 \\
\hline 52.9 & 25.0 & 47.5 & 2 & 0 & 0 & 115 \\
\hline 34.3 & 25.0 & 30.9 & 1 & 0 & 0 & 113 \\
\hline 38.7 & 25.0 & 38.7 & 2 & 0 & 0 & 181 \\
\hline 78.5 & 25.0 & 73.6 & 1 & 0 & 0 & 154 \\
\hline 27.5 & 25.0 & 23.2 & 1 & 0 & 0 & 104 \\
\hline 32.8 & 25.0 & 32.8 & 1 & 0 & 0 & 156 \\
\hline 74.6 & 25.0 & 58.2 & 1 & 0 & 0 & 128 \\
\hline 63.1 & 25.0 & 56.1 & 2 & 0 & 0 & 132 \\
\hline 33.6 & 25.0 & 25.5 & 2 & 0 & 0 & \\
\hline 27.1 & 25.0 & 24.3 & 1 & 0 & 0 & 138 \\
\hline 31.3 & 25.0 & 27.6 & 2 & 0 & 0 & \\
\hline 32.9 & 25.0 & 30.4 & 4 & 0 & 0 & 116 \\
\hline 68.8 & 25.0 & 54.0 & 8 & 0 & 0 & 146 \\
\hline 40.7 & 25.0 & 28.7 & 2 & 7 & 0 & 179 \\
\hline 53.6 & 25.0 & 53.6 & 4 & 0 & 0 & 155 \\
\hline 19.0 & 25.0 & 17.8 & 1 & 0 & 0 & 120 \\
\hline 31.2 & 25.0 & 30.6 & 3 & 0 & 0 & 109 \\
\hline 39.7 & 25.0 & 21.3 & 2 & 0 & 0 & 101 \\
\hline 47.7 & 25.0 & 34.6 & 2 & 0 & 0 & 120 \\
\hline 52.8 & 25.0 & 48.4 & 2 & 0 & 0 & 109 \\
\hline 31.5 & 25.0 & 23.2 & 1 & 0 & 0 & 106 \\
\hline 43.4 & 25.0 & 43.4 & 2 & 0 & 0 & 134 \\
\hline 36.4 & 25.0 & 36.4 & 1 & 0 & 0 & 98 \\
\hline 52.5 & 25.0 & 47.9 & 1 & 0 & 0 & 15 \\
\hline 22.9 & 25.0 & 7.8 & 1 & 0 & 0 & 86 \\
\hline 19.9 & 25.0 & 19.5 & 2 & 0 & 0 & 120 \\
\hline 60.2 & 25.0 & 52.1 & 2 & 0 & 0 & 138 \\
\hline 41.8 & 25.0 & 19.8 & 1 & 0 & 0 & 102 \\
\hline 47.9 & 25.0 & 39.8 & 1 & 0 & 0 & $12^{\circ}$ \\
\hline 35.6 & 25.0 & 17.6 & 1 & 0 & 0 & \\
\hline 19.2 & 25.0 & 19.2 & 2 & 0 & 0 & \\
\hline
\end{tabular}

Page 36 of Table S-1-6 
Citron Rho-interacting kinase $\mathrm{GN}=\mathrm{CIT}$ Citron Rho-interacting kinase $\mathrm{GN}=\mathrm{CIT}$ Clathrin heavy chain $1 \mathrm{GN}=\mathrm{CLTC}$ Clathrin heavy chain $1 \mathrm{GN}=\mathrm{CLTC}$ Clathrin heavy chain $1 \mathrm{GN}=\mathrm{CLTC}$ Clathrin heavy chain $1 \mathrm{GN}=\mathrm{CLTC}$ Clathrin heavy chain $1 \mathrm{GN}=\mathrm{CLTC}$ Clathrin heavy chain $1 \mathrm{GN}=\mathrm{CLTC}$ Clathrin heavy chain $1 \mathrm{GN}=\mathrm{CLTC}$ Clathrin heavy chain $1 \mathrm{GN}=\mathrm{CLTC}$ Clathrin heavy chain $1 \mathrm{GN}=\mathrm{CLTC}$ Clathrin heavy chain $1 \mathrm{GN}=\mathrm{CLTC}$ Clathrin heavy chain $1 \mathrm{GN}=\mathrm{CLTC}$ Clathrin heavy chain $1 \mathrm{GN}=\mathrm{CLTC}$ Clathrin heavy chain $1 \mathrm{GN}=\mathrm{CLTC}$ Clathrin heavy chain $1 \mathrm{GN}=\mathrm{CLTC}$ Clathrin heavy chain $1 \mathrm{GN}=\mathrm{CLTC}$ Clathrin heavy chain $1 \mathrm{GN}=\mathrm{CLTC}$ Clathrin heavy chain $1 \mathrm{GN}=\mathrm{CLTC}$ Clathrin heavy chain $1 \mathrm{GN}=\mathrm{CLTC}$ Clathrin heavy chain $1 \mathrm{GN}=\mathrm{CLTC}$ Clathrin heavy chain $1 \mathrm{GN}=\mathrm{CLTC}$ Clathrin heavy chain $1 \mathrm{GN}=\mathrm{CLTC}$ Clathrin heavy chain $1 \mathrm{GN}=\mathrm{CLTC}$ Clathrin heavy chain $1 \mathrm{GN}=\mathrm{CLTC}$
CTRO HUMAN $231.44 \quad 100.0 \%$ CTRO_HUMAN $231.44 \quad 100.0 \%$ CLH1_HUMAN $191.62 \quad 100.0 \%$ CLH1 HUMAN $191.62 \quad 100.0 \% \quad 23$ CLH1_HUMAN $191.62 \quad 100.0 \% \quad 23$ CLH1_HUMAN $191.62 \quad 100.0 \% \quad 23$ CLH1_HUMAN $191.62 \quad 100.0 \% \quad 23$ CLH1_HUMAN $191.62 \quad 100.0 \% \quad 23$ CLH1 HUMAN $191.62 \quad 100.0 \%$ CLH1_HUMAN $191.62 \quad 100.0 \% \quad 23$ CLH1_HUMAN $191.62 \quad 100.0 \% \quad 23$ CLH1_HUMAN $191.62 \quad 100.0 \% \quad 23$ CLH1_HUMAN $191.62 \quad 100.0 \% \quad 23$ CLH1_HUMAN $191.62 \quad 100.0 \% \quad 23$ CLH1_HUMAN $191.62 \quad 100.0 \% \quad 23$ CLH1_HUMAN $191.62 \quad 100.0 \% \quad 23$ CLH1 HUMAN $191.62 \quad 100.0 \% \quad 23$ CLH1_HUMAN $191.62 \quad 100.0 \% \quad 23$ CLH1_HUMAN $191.62 \quad 100.0 \% \quad 23$ CLH1 HUMAN $191.62 \quad 100.0 \% \quad 23$ CLH1_HUMAN $191.62 \quad 100.0 \% \quad 23$ CLH1_HUMAN $191.62 \quad 100.0 \% \quad 23$ CLH1_HUMAN $191.62 \quad 100.0 \% \quad 23$ CLH1_HUMAN $191.62 \quad 100.0 \% \quad 23$ CLH1_HUMAN $191.62 \quad 100.0 \% \quad 23$ SF1 CPSF1_HUMAN $160.89 \quad 100.0 \% \quad 7$ CPSF1_HUMAN $160.89 \quad 100.0 \%$ CPSF__HUMAN $160.89 \quad 100.0 \%$ CPSF1_HUMAN $160.89 \quad 100.0 \%$ CPSF1_HUMAN $160.89 \quad 100.0 \%$ CPSF6 HUMAN $59.21 \quad 100.0 \%$ F6 CPSF6_HUMAN $59.21 \quad 100.0 \%$ CPSF6 HUMAN $59.21 \quad 100.0 \%$ CPSF6_HUMAN $59.21 \quad 100.0 \%$ COPA HUMAN $138.35 \quad 100.0 \%$ COPA_HUMAN $138.35 \quad 100.0 \%$ COPA_HUMAN $138.35 \quad 100.0 \%$ COPA HUMAN $138.35 \quad 100.0 \%$ COPA_HUMAN $138.35 \quad 100.0 \%$ COPA HUMAN $138.35 \quad 100.0 \%$ COPA HUMAN $138.35 \quad 100.0 \%$ COPA_HUMAN $138.35 \quad 100.0 \%$ COPA HUMAN $138.35 \quad 100.0 \%$ COPA_HUMAN $138.35 \quad 100.0 \% \quad 19$

0

$0.06 \% \quad 16.4 \%$ VSQPIEGHAASFAQFK $\quad 97.5 \%$

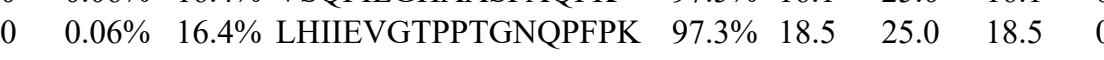

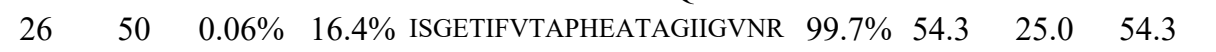

$\begin{array}{lllllllll}26 & 50 & 0.06 \% & 16.4 \% & \text { NNLAGAEELFAR } & 99.7 \% & 47.1 & 25.0 & 44.6\end{array}$

$\begin{array}{lllllllll}26 & 50 & 0.06 \% & 16.4 \% & \text { KFNALFAQGNYSEAAK } & 99.7 \% & 57.8 & 25.0 & 52.0\end{array}$

$\begin{array}{llllllllll}26 & 50 & 0.06 \% & 16.4 \% & \text { SVDPTLALSVYLR } & 99.7 \% & 46.5 & 25.0 & 46.5 & 2\end{array}$

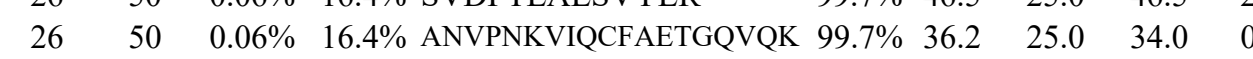

$26 \quad 50 \quad 0.06 \% \quad 16.4 \%$ VIQCFAETGQVQK

$99.6 \% 24.4$

$99.7 \% \quad 47.6$

$99.1 \% \quad 29.3$

$99.2 \% \quad 24.9$

$99.7 \% \quad 29.1$

$99.7 \% \quad 53.2$

$98.5 \% \quad 22.1$

$99.7 \% \quad 45.7$

$99.7 \% \quad 52.8$

$\begin{array}{lll}0.06 \% & 16.4 \% & \text { FLRENPYYDSR } \\ 0.06 \% & 16.4 \% & \text { ESYVETELIFALAK }\end{array}$

$0.06 \% \quad 16.4 \%$ LLYNNVSNFGR

$99.7 \% \quad 53.0$
$99.7 \%$

$\quad 0.06 \% \quad 16.4 \%$ LASTLVHLGEYQAAVDGAR

$50 \quad 0.06 \% \quad 16.4 \%$ VANVELYYR

$0.06 \% \quad 16.4 \%$ VKQLPLVKPYLR

$99.7 \% \quad 63.8$

$99.5 \% \quad 27.9$

$98.5 \% \quad 18.3$

$0.04 \% \quad 6.4 \% \quad$ LSVVEYDPGTHDLK

$99.5 \% \quad 23.8$

$99.7 \% \quad 39.7$

$0.04 \% \quad 6.4 \%$ SSFLPSYIIDVR

$0.04 \% \quad 6.4 \%$ VLVDSSFGQPTTQGEAR

$0.04 \% \quad 6.4 \%$ EVLLVALGSR

$0.04 \% \quad 6.4 \%$ VYAVATSTNTPCAR

$0.04 \% \quad 6.4 \%$ NVLDGELLNR

$0.01 \% \quad 9.1 \%$ GFALVGVGSEASSK

$0.01 \% \quad 9.1 \%$ GFALVGVGSEASSKK

$0.01 \% \quad 9.1 \%$ RELHGQNPVVTPCNK

$0.01 \% \quad 9.1 \%$ QFLSQFEMQSR

$0.01 \% \quad 9.1 \%$ AISSSAISR

$0.05 \% \quad 18.7 \%$ NLSPGAVESDVR

$\begin{array}{lllll}99.7 \% & 55.2 & 25.0 & 55.2 & 8\end{array}$

$\begin{array}{llll}99.7 \% & 58.1 & 25.0 & 50.4\end{array}$

$\begin{array}{llll}99.7 \% & 63.8 & 25.0 & 54.3\end{array}$

$\begin{array}{llll}99.7 \% & 39.9 & 25.0 & 36.0\end{array}$

$\begin{array}{llll}99.7 \% & 46.0 & 25.0 & 44.2\end{array}$

$\begin{array}{lllll}99.7 \% & 36.8 & 25.0 & 26.4 & 2\end{array}$

$\begin{array}{llll}99.7 \% & 44.8 & 25.0 & 41.1\end{array}$

$\begin{array}{llll}99.7 \% & 46.2 & 25.0 & 38.7\end{array}$

$\begin{array}{lllll}99.7 \% & 43.8 & 25.0 & 29.5 & 2\end{array}$

$99.7 \% \quad 63.4 \quad 25.0 \quad 53.0$

$0.05 \% \quad 18.7 \%$ QLDFNSSKDVAVMQLR

$0.05 \% \quad 18.7 \%$ ASNLENSTYDLYTIPK

$99.5 \% 22.8$

$99.7 \% \quad 60.0$

$\begin{array}{lll}99.7 \% & 26.7\end{array}$

$25.0 \quad 22.8$

$0.05 \% \quad 18.7 \%$ DADSQNPDAPEGKR

$0.05 \% \quad 18.7 \%$ SSGLTAVWVAR

$0.05 \% \quad 18.7 \%$ NLKNEITK

$4 \quad 0.05 \% \quad 18.7 \%$ DADSITLFDVQQKR

$44 \quad 0.05 \% \quad 18.7 \%$ KLDALCNIHENIR

$44 \quad 0.05 \% \quad 18.7 \%$ YAVTTGDHGIIR

$98.1 \% 25.4$

$99.7 \% \quad 46.2$

$\begin{array}{lll}99.5 \% & 23.4\end{array}$

$99.7 \% \quad 55.5$

$99.7 \% \quad 47.9$

1058.56

1252.66

1337.69

1465.78

1844.97

1716.87

1945.05

2353.25

1304.66

1758.88

1433.80

2131.10

1507.76

1620.84

1059.58

1110.67

1776.83

1334.63

1459.70

1612.85

1296.67

1971.03

1126.59

1453.93

1572.79

1739.82

1396.75

1791.89

1056.64

1510.73

1142.62

1308.68

1436.77

1748.89

1400.66

891.49

1243.63

1850.94

1828.90

1499.67

1146.63

959.55

1635.83

1595.83

1302.68 $0.05 \% \quad 18.7 \%$ TLDLPIYVTR
8641872

$87 \quad 96$

$177 \quad 188$

$177 \quad 189$

$189 \quad 205$

$190 \quad 205$

$\begin{array}{ll}228 & 245 \\ 298 & 320\end{array}$

$355 \quad 366$

$367 \quad 382$

$469 \quad 481$

$482 \quad 500$

$488 \quad 500$

$626 \quad 638$

38
$857 \quad 865$

$866 \quad 881$

$882 \quad 892$

$893 \quad 903$

11661179

$1216 \quad 1226$

$1227 \quad 1245$

$\begin{array}{ll}398 & 1406 \\ 442 & 1453\end{array}$

$103 \quad 116$

$167 \quad 182$

$183 \quad 194$

$817 \quad 833$

$848 \quad 857$

10331046

$1397 \quad 1406$

$125 \quad 138$

$125 \quad 139$

$147 \quad 161$

$162 \quad 172$

$423 \quad 431$

$171 \quad 182$

$343 \quad 358$

$383 \quad 398$

$399 \quad 412$

413423

$468 \quad 481$

$517 \quad 529$

$551 \quad 562$

Page 37 of Table S-1-6 
Coatomer subunit alpha $\mathrm{GN}=\mathrm{COPA}$ Coatomer subunit alpha $\mathrm{GN}=\mathrm{COPA}$ Coatomer subunit alpha $\mathrm{GN}=\mathrm{COPA}$ Coatomer subunit alpha $\mathrm{GN}=\mathrm{COPA}$ Coatomer subunit alpha $\mathrm{GN}=\mathrm{COPA}$ Coatomer subunit alpha $\mathrm{GN}=\mathrm{COPA}$ Coatomer subunit alpha $\mathrm{GN}=\mathrm{COPA}$ Coatomer subunit alpha $\mathrm{GN}=\mathrm{COPA}$ Coatomer subunit alpha $\mathrm{GN}=\mathrm{COPA}$ Coatomer subunit beta $\mathrm{GN}=\mathrm{COPB} 1$ Coatomer subunit beta $\mathrm{GN}=\mathrm{COPB} 1$ Coatomer subunit beta $\mathrm{GN}=\mathrm{COPB} 1$ Coatomer subunit beta $\mathrm{GN}=\mathrm{COPB} 1$ Coatomer subunit beta $\mathrm{GN}=\mathrm{COPB} 1$ Coatomer subunit beta' $\mathrm{GN}=\mathrm{COPB} 2$ Coatomer subunit beta' $\mathrm{GN}=\mathrm{COPB} 2$ Coatomer subunit delta $\mathrm{GN}=\mathrm{ARCN} 1$ Coatomer subunit delta $\mathrm{GN}=\mathrm{ARCN} 1$ Coatomer subunit delta $\mathrm{GN}=\mathrm{ARCN}$ Coatomer subunit delta $\mathrm{GN}=\mathrm{ARCN} 1$ Coatomer subunit delta $\mathrm{GN}=\mathrm{ARCN} 1$ Coatomer subunit delta $\mathrm{GN}=\mathrm{ARCN} 1$ Coatomer subunit delta $\mathrm{GN}=\mathrm{ARCN} 1$ Coatomer subunit delta $\mathrm{GN}=\mathrm{ARCN} 1$ Coatomer subunit delta $\mathrm{GN}=\mathrm{ARCN} 1$ Coatomer subunit epsilon $\mathrm{GN}=\mathrm{COPE}$ Coatomer subunit epsilon $\mathrm{GN}=\mathrm{COPE}$ Coatomer subunit epsilon $\mathrm{GN}=\mathrm{COPE}$ Coatomer subunit epsilon $\mathrm{GN}=\mathrm{COPE}$ Coatomer subunit gamma-1 GN=COPG1 Coatomer subunit gamma-1 GN=COPG1 Coatomer subunit gamma-1 GN=COPG1 Coatomer subunit gamma-1 GN=COPG1 COPG1_HUMAN $97.72 \quad 100.0 \%$ Coatomer subunit gamma-1 GN=COPG1 COPG1_HUMAN $97.72 \quad 100.0 \%$ Coiled-coil domain-containing protein $137 \mathrm{GN}=\mathrm{CCDC} 137 \quad$ CC137_HUMAN $33.23 \quad 100.0 \%$ Coiled-coil domain-containing protein $137 \mathrm{GN}=\mathrm{CCDC} 137 \quad \mathrm{CC} 137$ HUMAN $33.23 \quad 100.0 \%$ Coiled-coil domain-containing protein $137 \mathrm{GN}=\mathrm{CCDC} 137 \quad \mathrm{CC} 137$ _HUMAN $33.23 \quad 100.0 \%$ Coiled-coil domain-containing protein $47 \mathrm{GN}=\mathrm{CCDC} 47 \mathrm{CCD} 47$ HUMAN $55.87 \quad 100.0 \%$ Coiled-coil domain-containing protein $47 \mathrm{GN}=\mathrm{CCDC} 47$ CCD47_HUMAN $55.87 \quad 100.0 \%$ Coiled-coil domain-containing protein $47 \mathrm{GN}=\mathrm{CCDC} 47$ CCD47_HUMAN $55.87 \quad 100.0 \%$ Complement component $1 \mathrm{Q}$ subcomponent-binding protein, mitochondral GN=ClQBP $\mathrm{C} 1 \mathrm{QBP}$ HUMAN $31.36 \quad 100.0 \%$ CIQBP_HUMAN $31.36 \quad 100.0 \%$ Condensin complex subunit $1 \mathrm{GN}=\mathrm{NCAPD} 2 \mathrm{CND} 1$ HUMAN $157.19 \quad 100.0 \%$ Condensin complex subunit $1 \mathrm{GN}=\mathrm{NCAPD} 2$ CND1_HUMAN $157.19 \quad 100.0 \%$ Condensin complex subunit $1 \mathrm{GN}=\mathrm{NCAPD} 2 \mathrm{CND} 1$ HUMAN $157.19 \quad 100.0 \%$ $0.05 \% \quad 18.7 \%$ KYDEVLH $0.05 \% \quad 18.7 \%$ LVGQSIIAYLQK

$\begin{array}{llllllll}99.7 \% & 31.3 & 25.0 & 31.3 & 2 & 2 & 0 & 1437.80\end{array}$ $99.7 \% \quad 31.7$ $99.7 \% \quad 79.8$ $99.7 \% \quad 51.9$ $99.0 \% \quad 19.7$ $\begin{array}{llll}99.7 \% & 32.8\end{array}$ $99.7 \% \quad 54.8$ $0.05 \% \quad 18.7 \%$ GFFEGTIASKGK $0.05 \% \quad 18.7 \%$ QLFLQTYAR

$0.05 \% \quad 18.7 \%$ LLELGPKPEVAQQTR

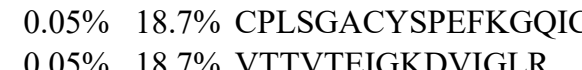
$0.01 \% \quad 6.2 \%$ DLQHPNEFIR $0.01 \% \quad 6.2 \%$ NAVLAIYTIYR $0.01 \% \quad 6.2 \% \quad$ NVEELVIVLKK $25.0 \quad 42.1$ $\begin{array}{llll}99.7 \% & 64.9 & 25.0 & 58.6\end{array}$ $\begin{array}{llll}99.7 \% & 37.3 & 25.0 & 28.8\end{array}$ $\begin{array}{llll}99.7 \% & 57.5 & 25.0 & 54.7\end{array}$ $99.7 \% \quad 35.0 \quad 25.0 \quad 35.0$

$0.01 \% \quad 6.2 \%$ EAGELKPEEEITVGPVQK $0.01 \% \quad 6.2 \% \quad$ LEEEKLSQK

$0.00 \% \quad 2.1 \%$ HSEVQQANLK $0.00 \% \quad 2.1 \%$ TYLPSQVSR $0.02 \% \quad 18.6 \%$ VLLAAAVCTK $0.02 \% \quad 18.6 \%$ TRIEGLLAAFPK $0.02 \% \quad 18.6 \%$ NSNILEDLETLR

$0.02 \% \quad 18.6 \%$ VAPAPARPSGPSK $0.02 \% \quad 18.6 \%$ LFTAESLIGLKNPEK $0.02 \% \quad 18.6 \%$ SFPVNSDVGVLK

$0.02 \% \quad 18.6 \%$ KNYCNIQVTK $0.02 \% \quad 18.6 \%$ NYCNIQVTK $0.02 \% \quad 18.6 \%$ VTQVDGNSPVR $97.0 \% \quad 15.7$ $\begin{array}{lll}95.5 \% & 23.5\end{array}$ $99.7 \% \quad 37.5$ $99.1 \% \quad 19.0$ $99.7 \% \quad 58.4$ $99.4 \% \quad 20.9$ $99.7 \% \quad 58.8$ $99.7 \% \quad 27.0$ $94.7 \% \quad 15.3$ $95.3 \% 19.0$ $99.7 \% 31.0$ $99.7 \% \quad 46.7$ $99.7 \% \quad 60.2$

$\begin{array}{lll}0.01 \% & 18.8 \% & \text { APPAPGPASGGSGEVDELFDVK } \quad 99.7 \% \quad 74.0\end{array}$

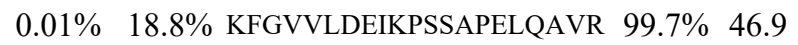
$0.01 \% \quad 18.8 \%$ FGVVLDEIKPSSAPELQAVR $99.7 \% \quad 55.2$ $0.01 \% \quad 18.8 \%$ ENDFDRLVLQYAPSA $99.7 \% \quad 40.6$ $99.0 \% \quad 44.5$ $96.9 \% \quad 18.9$ $99.7 \% \quad 74.6$ $99.5 \% \quad 23.2$ $99.1 \% 22.6$ $99.1 \% \quad 26.1$ $95.6 \% \quad 18.7$ $99.7 \% \quad 39.3$ $99.7 \% \quad 41.8$ $99.2 \% \quad 23.5$ $99.7 \% \quad 31.5$ $99.7 \% \quad 38.0$ $95.7 \% \quad 19.9$ $99.7 \% \quad 66.6$ $\begin{array}{lll}25.0 & 35.0 & 2 \\ 25.0 & 15.7 & 0 \\ 25.0 & 6.4\end{array}$ $0.01 \% \quad 8.6 \%$ VFNETPINPRK $0.01 \% \quad 8.6 \%$ SIATLAITTLLK $\begin{array}{lll}0.01 \% & 8.6 \% & \text { ILHLLGQEGPK } \\ 0.01 \% & 8.6 \% & \text { TTNPSKYIR }\end{array}$ $0.01 \% \quad 8.6 \%$ SVPLATAPMAEQR $0.01 \% \quad 8.6 \%$ TLEEAVGNIVK $\begin{array}{lll}0.01 \% & 11.1 \% \text { NQDEQEIPFR } \\ 0.01 \% & 11.1 \% \text { KGESDGAYIHR }\end{array}$ $0.01 \% \quad 11.1 \%$ AADRLEQELLR $0.00 \% \quad 6.2 \% \quad$ VCCEGMLIQLR $0.00 \% \quad 6.2 \%$ RQDLLNVLAR $0.00 \% \quad 6.2 \% \quad$ ARVEENFLK $0.01 \% \quad 12.1 \%$ AFVDFLSDEIKEER

$0.01 \% \quad 12.1 \%$ VEEQEPELTSTPNFVVEVIK $0.02 \% \quad 9.9 \%$ SGGVNQYVVQEVLSIK $0.02 \% \quad 9.9 \% \quad$ LLENPTINHQK $0.02 \% \quad 9.9 \%$ FQAVVALAVGR
$99.7 \% \quad 51.5$ $99.7 \% \quad 31.5$ $99.7 \% \quad 54.3$

(1)

1289.67

1332.79

1241.65

1139.62

1678.95

2129.96

1600.93

1268.64

1296.73

1283.79

1953.02

1103.59

1153.60

1050.56

1045.61

1315.77

1416.73

1234.69

1659.93

1261.68

1267.65

1139.55

1171.6

2097.01

2283.27

2155.18

1737.84

873.48

1314.72

1244.78

1204.7

1079.58

1386.70

1172.65

1275.60

1232.60

1313.72

1378.66

1197.7

1105.60

1697.84

2287.17

1719.93

1306.71 1130.67

$\begin{array}{cc}89 & 600 \\ 07 & 616 \\ 20 & 631 \\ 16 & 825 \\ 16 & 827 \\ 57 & 965 \\ 28 & 1142 \\ 85 & 1202 \\ 03 & 1217 \\ 08 & 117 \\ 54 & 164 \\ 52 & 362 \\ 96 & 513 \\ 47 & 655 \\ 19 & 328 \\ 60 & 768 \\ 2 & 11 \\ 7 & 38 \\ 3 & 84 \\ 12 & 224 \\ 37 & 351 \\ 52 & 363 \\ 76 & 485 \\ 77 & 485 \\ 86 & 496 \\ 2 & 23 \\ 5 & 85 \\ 6 & 85 \\ 94 & 308 \\ 5 & 32 \\ 3 & 43 \\ 39 & 350 \\ 55 & 465 \\ 66 & 474 \\ 78 & 590 \\ 96 & 806 \\ 7 & 66 \\ 18 & 128 \\ 83 & 193 \\ 13 & 223 \\ 27 & 236 \\ 11 & 419 \\ 1 & 94 \\ 55 & 174 \\ 0 & 35 \\ 05 & 215 \\ 02 & 412 \\ & \end{array}$

Page 38 of Table S-1-6 
Condensin complex subunit 1 GN=NCAPD2 CND1_HUMAN $157.19 \quad 100.0 \%$ Condensin complex subunit 1 GN=NCAPD2 CND1_HUMAN $157.19 \quad 100.0 \%$ Condensin complex subunit 1 GN=NCAPD2 CND1_HUMAN $157.19 \quad 100.0 \%$ Condensin complex subunit $1 \mathrm{GN}=$ NCAPD2 CND1_HUMAN $157.19100 .0 \%$ Condensin complex subunit $1 \mathrm{GN}=\mathrm{NCAPD} 2 \mathrm{CND} 1$ HUMMAN $157.19 \quad 100.0 \%$ Condensin complex subunit $1 \mathrm{GN}=\mathrm{NCAPD} 2$ CND1_HUMAN $157.19 \quad 100.0 \%$ Condensin complex subunit $1 \mathrm{GN}=\mathrm{NCAPD} 2$ CND1_HUMAN $157.19 \quad 100.0 \%$ Condensin complex subunit $1 \mathrm{GN}=\mathrm{NCAPD} 2 \mathrm{CND} 1$ HUMMAN $157.19 \quad 100.0 \%$ Condensin complex subunit $3 \mathrm{GN}=\mathrm{NCAPG}$ CND3_HUMAN $114.34100 .0 \%$ Condensin complex subunit 3 GN=NCAPG CND3_HUMAN $114.34 \quad 100.0 \%$ Condensin-2 complex subunit D3 GN=NCAPD3 CNDD3_HUMAN $168.89 \quad 100.0 \%$ Condensin-2 complex subunit D3 GN=NCAPD3 CNDD3_HUMAN $168.89100 .0 \%$ Condensin-2 complex subunit D3 GN=NCAPD3 CNDD3_HUMAN $168.89100 .0 \%$ Constitutive coactivator of PPAR-gamma-like protein $1 \mathrm{GN}=$ FAM120A F120A HUMAN $121.89 \quad 100.0 \%$ Constitutive coactivator of PPAR-gamma-like protein $1 \mathrm{GN}=$ FAM120A F120A_HUMAN $121.89100 .0 \%$ Constitutive coactivator of PPAR-gamma-like protein 1 GN=FAM120A F120A_HUMAN $121.89 \quad 100.0 \%$ 作 $121.89 \quad 100.0 \%$ COP9 signalosome complex subunit $3 \mathrm{GN}=\mathrm{COPS} 3$ CSN3_HUMAN $47.87 \quad 100.0 \%$ COP9 signalosome complex subunit $3 \mathrm{GN}=$ COPS3 CSN3_HUMAN $47.87 \quad 100.0 \%$ COP9 signalosome complex subunit $4 \mathrm{GN}=\mathrm{COPS} 4 \mathrm{CSN} 4$ HUMAN $46.27 \quad 100.0 \%$ COP9 signalosome complex subunit $4 \mathrm{GN}=\mathrm{COPS} 4 \mathrm{CSN} 4$ _HUMAN $46.27 \quad 100.0 \%$ COP9 signalosome complex subunit $4 \mathrm{GN}=\mathrm{COPS} 4 \mathrm{CSN} 4$ HUMAN $46.27 \quad 100.0 \%$ COP9 signalosome complex subunit 7a GN=COPS7A CSN7A_HUMAN $30.28 \quad 100.0 \%$ COP9 signalosome complex subunit 7a GN=COPS7A CSN7A_HUMAN $30.28 \quad 100.0 \%$ Core histone macro-H2A.1 GN=H2AFY H2AY HUMAN $39.62 \quad 100.0 \%$ Core histone macro-H2A.1 GN=H2AFY H2AY_HUMAN $39.62 \quad 100.0 \%$ Core histone macro-H2A.1 GN=H2AFY H2AY HUMAN $39.62 \quad 100.0 \%$ Cornifin-B GN=SPRR1B Cornifin-B GN=SPRR1B Creatine kinase $\mathrm{B}$-type $\mathrm{GN}=\mathrm{CKB}$ Creatine kinase B-type $\mathrm{GN}=\mathrm{CKB}$ Creatine kinase B-type $\mathrm{GN}=\mathrm{CKB}$ Creatine kinase B-type $\mathrm{GN}=\mathrm{CKB}$ Creatine kinase $\mathrm{B}$-type $\mathrm{GN}=\mathrm{CKB}$ Creatine kinase B-type $\mathrm{GN}=\mathrm{CKB}$ Creatine kinase $\mathrm{B}$-type $\mathrm{GN}=\mathrm{CKB}$ Creatine kinase B-type $\mathrm{GN}=\mathrm{CKB}$ Creatine kinase $\mathrm{B}$-type $\mathrm{GN}=\mathrm{CKB}$ Creatine kinase B-type $\mathrm{GN}=\mathrm{CKB}$ Creatine kinase B-type $\mathrm{GN}=\mathrm{CKB}$ Crk-like protein $\mathrm{GN}=\mathrm{CRKI}$ Crk-like protein $\mathrm{GN}=\mathrm{CRKI}$ Crk-like protein $\mathrm{GN}=\mathrm{CRKL}$ Crk-like protein $\mathrm{GN}=\mathrm{CRKL}$ SPR1B HUMAN 9.89 SPR1B_HUMAN $9.89 \quad 100.0 \%$ KCRB HUMAN $42.65 \quad 100.0 \%$ KCRB_HUMAN $42.65 \quad 100.0 \%$ KCRB_HUMAN $42.65 \quad 100.0 \%$ KCRB HUMAN $42.65 \quad 100.0 \%$ KCRB_HUMAN $42.65 \quad 100.0 \%$ KCRB HUMAN $42.65 \quad 100.0 \%$ KCRB HUMAN $42.65 \quad 100.0 \%$ KCRB_HUMAN $42.65 \quad 100.0 \%$ KCRB HUMAN $42.65 \quad 100.0 \%$ KCRB_HUMAN $42.65 \quad 100.0 \%$ KCRB_HUMAN $42.65 \quad 100.0 \%$ CRKL HUMAN $33.78 \quad 100.0 \%$ CRKL_HUMAN $33.78 \quad 100.0 \%$ CRKL HUMAN $33.78 \quad 100.0 \%$ CRKL_HUMAN $33.78 \quad 100.0 \%$ Crooked neck-like protein $1 \mathrm{GN}=$ CRNKL1 CRNL1_HUMAN $100.45 \quad 100.0 \%$ Crooked neck-like protein $1 \mathrm{GN}=\mathrm{CRNKL} 1$ CRNL1_HUMAN $100.45 \quad 100.0 \%$ Crooked neck-like protein $1 \mathrm{GN}=\mathrm{CRNKL} 1 \mathrm{CRNL} 1$ HUMAN $100.45 \quad 100.0 \%$
$0.02 \% \quad 9.9 \% \quad$ ESTGNMVTGQT

$0.02 \% \quad 9.9 \% \quad$ KITEAIGIISK

$0.02 \% \quad 9.9 \%$ EAVLNAYR

$0.02 \% \quad 9.9 \%$ CSSVMLLGMMAR

$0.02 \% \quad 9.9 \%$ DLAYCVSQLPLTER

$0.02 \% \quad 9.9 \%$ AIIDEFEQKLR

$9 \quad 0.02 \% \quad 9.9 \% \quad$ YQPLASTASDNDFVTPEPR

$0.00 \% \quad 2.0 \% \quad$ IQAVLALSR

$0.00 \% \quad 2.0 \%$ AVLSCIAPSAK

$0.01 \% \quad 2.9 \%$ APLAVTSQVINCR

$0.01 \% \quad 2.9 \% \quad$ FLVQEIMFDR

$\begin{array}{lllll}0.01 \% & 2.9 \% & \text { ASAGHVAVSSPTPETGPLQR } & 99.7 \% & 32.2\end{array}$

4

4

$0.00 \% \quad 6.6 \%$ AMDQEITVNPQFVQK

$0.00 \% \quad 8.4 \%$ VISFEEQVASIR

$0.00 \% \quad 8.4 \%$ AVIEHNLLSASK

$0.00 \% \quad 8.4 \%$ IASQMITEGR

$0.00 \% \quad 9.5 \%$ VTGQNQEQFLLLAK

$0.00 \% \quad 9.5 \%$ ELAESDFASTFR

$0.00 \% \quad 11.0 \%$ AGVIFPVGR

$0.00 \% \quad 11.0 \%$ AASADSTTEGTPADGFTVLSTK

$0.00 \% \quad 11.0 \%$ EFVEAVLELR

$0.00 \% \quad 18.0 \%$ VPEPCHPK

$0.00 \% \quad 18.0 \%$ VPEPCQPK

$0.04 \% \quad 36.0 \%$ PFSNSHNALK

$0.04 \% 36.0 \%$ VLTPELYAELR

$0.04 \% 36.0 \%$ VLTPELYAELRAK

$0.04 \% 36.0 \%$ LAVEALSSLDGDLAGR

$0.04 \% 36.0 \%$ TFLVWVNEEDHLR

$0.04 \% 36.0 \%$ GGNMKEVFTR

$0.04 \% \quad 36.0 \%$ FCTGLTQIETLFK

$99.7 \% \quad 42.5$

$\begin{array}{llll}99.3 \% & 20.2\end{array}$

$99.7 \% \quad 41.9$

$99.7 \% 52.6$

$99.1 \% \quad 22.8$

$99.7 \% 33.1$

$\begin{array}{lll}98.1 \% & 25.5 \\ 2\end{array}$

$99.7 \% 56.5$

$\begin{array}{llll}99.7 \% & 48.7\end{array}$

$99.0 \% \quad 24.2$

$\begin{array}{llllll}99.0 \% & 25.7\end{array}$

$99.7 \% 61.8$

$99.7 \% \quad 56.6$

$99.7 \% \quad 48.2$

$99.7 \% 79.4$

$94.5 \% \quad 19.0$

$98.1 \% \quad 21.0$

$99.7 \% \quad 60.3$

$\begin{array}{llllllll}0.04 \% & 36.0 \% & \text { RGTGGVDTAAVGGVFDVSNADR } & 99.7 \% & 55.2\end{array}$

$0.04 \% \quad 36.0 \%$ LGFSEVELVQMVVDGVK $99.7 \% \quad 68.7$

$0.04 \% \quad 36.0 \%$ LLIEMEQR

$99.0 \% \quad 48.1$

$0.04 \% \quad 36.0 \%$ LEQGQAIDDLMPAQK

$\begin{array}{lllll}99.7 \% & 63.3\end{array}$

$0.01 \% \quad 19.1 \%$ DSSTCPGDYVLSVSENSR $99.7 \% \quad 48.7$

$0.01 \% \quad 19.1 \%$ VSHYIINSLPNRR

$0.01 \% \quad 19.1 \%$ IHYLDTTTLIEPAPR

$0.01 \% \quad 19.1 \%$ TALALEVGDIVK

$0.01 \% \quad 3.3 \%$ TFEDNIRK $\begin{array}{llllllll}99.7 \% & 37.0 & 25.0 & 23.2 & 2 & 0 & 0 & 1227.66\end{array}$

$\begin{array}{llll}9.7 \% & 32.2 & 25.0 & 32.2 \\ 99.0 \% & 47.5 & 25.0 & 32.2\end{array}$

$\begin{array}{rrrr}99.7 \% & 37.8 & 25.0 & 32.2 \\ 9 & 25.0 & 37.8\end{array}$

$\begin{array}{llll}99.7 \% & 39.4 & 25.0 & 37.8 \\ 99.0 & 37.1\end{array}$

$\begin{array}{llll}99.7 \% & 45.1 & 25.0 & 42.6\end{array}$

$\begin{array}{llll}99.7 \% & 29.2 & 25.0 & 29.2\end{array}$

$\begin{array}{lllll}99.7 \% & 59.0 & 25.0 & 43.4\end{array}$

$\begin{array}{llll}99.7 \% & 41.1 & 25.0 & 35.1\end{array}$

$\begin{array}{lllll}99.7 \% & 48.4 & 25.0 & 48.4\end{array}$

$\begin{array}{llll}98.4 \% & 22.4 & 25.0 & 18.3\end{array}$

$\begin{array}{llllllll}0.01 \% & 5.4 \% & \text { VAAASGHCGAFSGSDSSR } & 99.7 \% & 44.2 & 25.0 & 32.2 & 0\end{array}$

$\begin{array}{rrrrr}99.7 \% & 44.2 & 25.0 & 44.2 \\ 99.7 \% & 40.5 & 25.0 & 27.4\end{array}$

$\begin{array}{lllllll}0.01 \% & 5.4 \% & \text { NQAAIQGRPPYAASAEEVAK } & 99.7 \% & 32.2 & 25.0 & 31.9\end{array}$

$\begin{array}{llllllll}0.01 \% & 5.4 \% & \text { EAALEAAVLNKEE } & 99.7 \% & 40.3 & 25.0 & 36.3 \\ 0.00 \% & 6.6 \% & \text { TFLTLSLQDMASR } & 99.7 \% & 78.4 & 25.0 & 78.4\end{array}$

$0.01 \% \quad 3.3 \%$ GIEDIIVSK

$0.01 \% \quad 3.3 \%$ AIYELAISQPR $\begin{array}{llll}7.5 & 25.0 & 15.4 & 0\end{array}$

$99.0 \% \quad 24.2 \quad 25.0 \quad 59.1$

$99.7 \% \quad 51.0 \quad 25.0 \quad 45.7$ $\begin{array}{llll}99.7 \% & 44.3 & 25.0 & 35.0 \\ 99.7 \% & 59.1 & 25.0 & 59.1\end{array}$

$\begin{array}{llll}99.0 \% & 24.2 & 25.0 & 17.1 \\ 99.7 \% & 39.4 & 25.0 & 34.7\end{array}$
1527.68
1172.73

935.49

1355.63

1664.83

1361.74

2107.99

970.60

1116.61

1428.76

1297.66

1962.00

1723.75

941.58

2071.06

1386.71

1482.76

1747.87

1377.74

1281.72

1105.57

1588.87

1372.64

915.54

2127.01

1204.66

963.47

954.47

1114.56

1303.73

1502.86

1586.84

1657.83

1154.56

1557.80

2121.03

1864.97

1047.55

1672.82

1972.86

1568.87

1739.93

1228.71

1022.53

973.56

1260.69 $\begin{array}{cc}41 & 452 \\ 84 & 597 \\ 33 & 643 \\ 91 & 698 \\ 72 & 783 \\ 25 & 1238 \\ 80 & 1290 \\ 25 & 1343 \\ 60 & 168 \\ 98 & 208 \\ 19 & 331 \\ 43 & 452 \\ 20 & 1339 \\ 12 & 929 \\ 87 & 995 \\ 10 & 1029 \\ 06 & 1118 \\ 13 & 325 \\ 92 & 406 \\ 6 & 107 \\ 03 & 314 \\ 38 & 347 \\ 7 & 20 \\ 4 & 65 \\ 9 & 27 \\ 68 & 189 \\ 40 & 249 \\ 5 & 52 \\ 3 & 60 \\ 2 & 11 \\ 3 & 43 \\ 3 & 45 \\ 57 & 172 \\ 24 & 236 \\ 43 & 252 \\ 53 & 265 \\ 20 & 341 \\ 42 & 358 \\ 59 & 366 \\ 67 & 381 \\ 0 & 57 \\ 8 & 70 \\ 0 & 104 \\ 54 & 265 \\ 30 & 237 \\ 67 & 475 \\ 61 & 671 \\ & \end{array}$

Page 39 of Table S-1- 6 


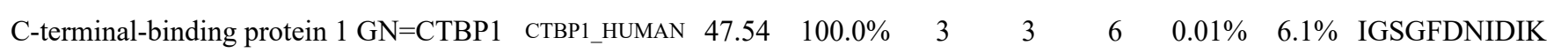

C-terminal-binding protein $1 \mathrm{GN}=\mathrm{CTBP} 1$ CTBP1_HUMAN $47.54 \quad 100.0 \%$ C-terminal-binding protein $1 \mathrm{GN}=\mathrm{CTBP} 1 \quad$ CTBP1_HUMAN $47.54 \quad 100.0 \%$ CTP synthase $1 \mathrm{GN}=\mathrm{CTPS} 1$

CTP synthase $1 \mathrm{GN}=\mathrm{CTPS} 1$

CTP synthase $1 \mathrm{GN}=\mathrm{CTPS} 1$

CTP synthase $1 \mathrm{GN}=\mathrm{CTPS} 1$

CTP synthase $1 \mathrm{GN}=\mathrm{CTPS} 1$

CTP synthase $1 \mathrm{GN}=\mathrm{CTPS} 1$

CTP synthase $1 \mathrm{GN}=\mathrm{CTPS} 1$

CTP synthase $1 \mathrm{GN}=\mathrm{CTPS} 1$

CTP synthase $1 \mathrm{GN}=\mathrm{CTPS} 1$

CTP synthase $1 \mathrm{GN}=\mathrm{CTPS} 1$

$\begin{array}{llll}\text { Cullin-associated NEDD8-dissociated protein } 1 \mathrm{GN}=\mathrm{CAND} 1 \text { CAND1_HUMAN } & 136.38 & 100.0 \% \\ \text { CYRG1_HUMAN } & 66.69 & 100.0 \%\end{array}$

Cullin-associated NEDD8-dissociated protein 1 GN=CAND1 CAND1_HUMAN $136.38 \quad 100.0 \%$ Cullin-associated NEDD8-dissociated protein $1 \mathrm{GN}=\mathrm{CAND} 1$ CAND1_HUMAN $136.38 \quad 100.0 \%$ Cullin-associated NEDD8-dissociated protein $1 \mathrm{GN}=$ CAND1 CAND1 HUMAN $136.38100 .0 \%$ Cullin-associated NEDD8-dissociated protein 1 GN=CAND1 CAND1_HUMAN $136.38 \quad 100.0 \%$ Cullin-associated NEDD8-dissociated protein 1 GN=CAND1 CAND1_HUMAN $136.38 \quad 100.0 \%$ Cullin-associated NEDD8-dissociated protein $1 \mathrm{GN}=$ CAND1 CAND1_HUMAN $136.38 \quad 100.0 \%$ Cullin-associated NEDD8-dissociated protein $1 \mathrm{GN}=$ CAND1 CAND1_HUMAN $136.38 \quad 100.0 \%$ Cullin-associated NEDD8-dissociated protein $1 \mathrm{GN}=$ CAND1 CAND1_HUMAN $136.38 \quad 100.0 \%$ Cullin-associated NEDD8-dissociated protein $1 \mathrm{GN}=$ CAND1 CAND1_HUMAN $136.38 \quad 100.0 \%$ Cullin-associated NEDD8-dissociated protein 1 GN=CAND1 CAND1_HUMAN $136.38 \quad 100.0 \%$ Cullin-associated NEDD8-dissociated protein 2 GN=CAND2 CAND2_HUMAN $135.26100 .0 \%$ Cullin-associated NEDD8-dissociated protein 2 GN=CAND2 CAND2_HUMAN $135.26 \quad 100.0 \%$ Cullin-associated NEDD8-dissociated protein 2 GN=CAND2 CAND2_HUMAN $135.26 \quad 100.0 \%$ Cyclin-dependent kinase $1 \mathrm{GN}=\mathrm{CDK} 1$ Cyclin-dependent kinase $1 \mathrm{GN}=\mathrm{CDK} 1$ Cyclin-dependent kinase $1 \mathrm{GN}=\mathrm{CDK} 1$ Cyclin-dependent kinase $1 \mathrm{GN}=\mathrm{CDK} 1$ Cyclin-dependent kinase $1 \mathrm{GN}=\mathrm{CDK} 1$ Cyclin-dependent kinase $1 \mathrm{GN}=\mathrm{CDK} 1$ Cyclin-dependent kinase $1 \mathrm{GN}=\mathrm{CDK} 1$ Cyclin-dependent kinase $1 \mathrm{GN}=\mathrm{CDK} 1$ Cyclin-dependent kinase $1 \mathrm{GN}=\mathrm{CDK} 1$ Cyclin-dependent kinase $1 \mathrm{GN}=\mathrm{CDK} 1$ Cyclin-dependent kinase $1 \mathrm{GN}=\mathrm{CDK} 1$ Cyclin-dependent kinase $1 \mathrm{GN}=\mathrm{CDK} 1$ Cyclin-dependent kinase $2 \mathrm{GN}=\mathrm{CDK} 2$ Cyclin-dependent kinase $2 \mathrm{GN}=\mathrm{CDK} 2$ Cyclin-dependent kinase $2 \mathrm{GN}=\mathrm{CDK} 2$ Cyclin-dependent kinase $2 \mathrm{GN}=\mathrm{CDK} 2$ Cyclin-dependent kinase $2 \mathrm{GN}=\mathrm{CDK} 2$ Cyclin-dependent kinase $2 \mathrm{GN}=\mathrm{CDK} 2$ Cyclin-dependent kinase $2 \mathrm{GN}=\mathrm{CDK} 2$ Cyclin-dependent kinase $9 \mathrm{GN}=\mathrm{CDK} 9$
CDK1 HUMAN $34.10 \quad 100.0 \%$ CDK1_HUMAN $34.10 \quad 100.0 \%$ CDK1 HUMAN $34.10 \quad 100.0 \%$ CDK1_HUMAN $34.10 \quad 100.0 \%$ CDK1_HUMAN $34.10 \quad 100.0 \%$ CDK1_HUMAN $34.10 \quad 100.0 \%$ CDK1_HUMAN $34.10 \quad 100.0 \%$ CDK1_HUMAN $34.10 \quad 100.0 \%$ CDK1_HUMAN $34.10 \quad 100.0 \%$ CDK1_HUMAN $34.10 \quad 100.0 \%$ CDK1_HUMAN $34.10 \quad 100.0 \%$ CDK1_HUMAN $34.10 \quad 100.0 \%$ CDK2_HUMAN $33.93 \quad 100.0 \%$ CDK2 HUMAN $33.93 \quad 100.0 \%$ CDK2_HUMAN $33.93 \quad 100.0 \%$ CDK2 HUMAN $33.93 \quad 100.0 \%$ CDK2_HUMAN $33.93 \quad 100.0 \%$ CDK2_HUMAN $33.93 \quad 100.0 \%$ CDK2_HUMAN $33.93 \quad 100.0 \%$ CDK9_HUMAN $42.78 \quad 100.0 \%$$$
\begin{array}{lllll}
99.7 \% & 74.5 & 25.0 & 42.1 &
\end{array}
$$$$
\begin{array}{llll}
99.7 \% & 74.5 & 25.0 & 42.1 \\
99.7 \% & 58.2 & 25.0 & 55.5
\end{array}
$$

$\begin{array}{llll}99.7 \% & 58.2 & 25.0 & 55.5\end{array}$

$\begin{array}{lllll}99.7 \% & 54.0 & 25.0 & 53.2 & 2\end{array}$

$\begin{array}{lllll}99.7 \% & 40.9 & 25.0 & 40.9 & 2\end{array}$

$\begin{array}{llll}99.0 \% & 52.1 & 25.0 & 0.0\end{array}$

$\begin{array}{lllll}99.7 \% & 43.5 & 25.0 & 41.3 & 2\end{array}$

$\begin{array}{lllll}99.7 \% & 69.8 & 25.0 & 64.7 & 2\end{array}$

$\begin{array}{llll}99.7 \% & 36.9 & 25.0 & 35.2\end{array}$
$30.2 \%$ IRLDTETEGVPST 0.01\% $30.2 \%$ LADFGLAR

$\begin{array}{ll}0.01 \% & 30.2 \% \\ 0.01 \% & 12.4 \%\end{array}$ $0.01 \% \quad 12.4 \%$ IGQGTFGEVFK 
Cyclin-dependent kinase $9 \mathrm{GN}=\mathrm{CDK} 9$ Cyclin-dependent kinase $9 \mathrm{GN}=\mathrm{CDK} 9$ Cyclin-dependent kinase $9 \mathrm{GN}=\mathrm{CDK} 9$ Cyclin-dependent kinase $9 \mathrm{GN}=\mathrm{CDK} 9$ Cyclin-dependent-like kinase 5 GN=CDK5 CDK5_HUMAN $33.31 \quad 100.0 \%$ Cyclin-dependent-like kinase $5 \mathrm{GN}=\mathrm{CDK} 5$ CDK5_HUMAN $33.31 \quad 100.0 \%$ Cyclin-dependent-like kinase $5 \mathrm{GN}=\mathrm{CDK} 5$ CDK5_HUMAN $33.31 \quad 100.0 \%$ Cyclin-G-associated kinase GN=GAK Cyclin-G-associated kinase $\mathrm{GN}=\mathrm{GAK}$ Cystathionine beta-synthase $\mathrm{GN}=\mathrm{CBS}$ Cystathionine beta-synthase $\mathrm{GN}=\mathrm{CBS}$ Cystathionine beta-synthase $\mathrm{GN}=\mathrm{CBS}$ MAN $42.78 \quad 100.0 \%$ CDK9_HUMAN $42.78 \quad 100.0 \%$ CBS_HUMAN $60.59 \quad 100.0 \%$ CBS_HUMAN $60.59 \quad 100.0 \%$ CBS HUMAN $60.59 \quad 100.0 \%$

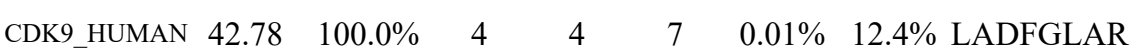
GAK_HUMAN $143.19 \quad 100.0 \%$ GAK HUMAN $143.19 \quad 100.0 \%$ Cytochrome b-c 1 complex subunit 1, mitochondrial GN=UQCRC1 QCR1_HUMAN $52.65 \quad 100.0 \%$ Cytochrome b-c1 complex subunit 1, mitochondrial GN=UQCRC1 QCR1_HUMAN $52.65 \quad 100.0 \%$ Cytochrome b-c1 complex subunit 1, mitochondrial GN=UQCRC1 QCR1_HUMAN $52.65 \quad 100.0 \%$ Cytochrome b-c1 complex subunit 1, mitochondrial GN=UQCRC1 QCR1_HUMAN $52.65100 .0 \%$ Cytochrome b-c1 complex subunit 2, mitochondrial GN=UQCRC2 QCR2_HUMAN $48.44 \quad 100.0 \%$ Cytochrome b-c1 complex subunit 2, mitochondrial GN=UQCRC2 QCR2_HUMAN $48.44 \quad 100.0 \%$ Cytochrome b-c1 complex subunit 2, mitochondrial GN=UQCRC2 QCR2_HUMAN $48.44 \quad 100.0 \%$ Cytochrome b-c1 complex subunit 2, mitochondrial GN=UQCRC2 QCR2_HUMAN $48.44 \quad 100.0 \%$ Cytochrome b-c1 complex subunit 2, mitochondrial GN=UQCRC2 QCR2_HUMAN $48.44 \quad 100.0 \%$ Cytochrome b-c1 complex subunit 2, mitochondrial GN=UQCRC2 QCR2_HUMAN $48.44 \quad 100.0 \%$ Cytochrome b-c1 complex subunit 2, mitochondrial GN=UQCRC2 QCR2_HUMAN $48.44 \quad 100.0 \%$ Cytochrome b-c1 complex subunit 2, mitochondrial GN=UQCRC2 QCR2_HUMAN $48.44 \quad 100.0 \%$ Cytochrome b-c1 complex subunit 2, mitochondrial GN=UQCRC2 QCR2_HUMAN $48.44 \quad 100.0 \%$ Cytochrome b-c1 complex subunit 2, mitochondrial GN=UQCRC2 QCR2_HUMAN $48.44 \quad 100.0 \%$ Cytochrome b-c1 complex subunit 2, mitochondrial GN=UQCRC2 QCR2_HUMAN $48.44 \quad 100.0 \%$ \begin{tabular}{lll} 
Cytochrome b-c1 complex subunit 2, mitochondrial GN=UQCRC2 QCR2_HUMAN $48.44 \quad 100.0 \%$ \\
\hline Cy
\end{tabular} Cytoplasmic dynein 1 heavy chain $1 \mathrm{GN}=\mathrm{DYNC1H} 1$ DYHC1_HUMAN $532.41 \quad 100.0 \%$ Cytoplasmic dynein 1 heavy chain $1 \mathrm{GN}=$ DYNC1H1 DYHC1_HUMAN $532.41 \quad 100.0 \%$ Cytoplasmic dynein 1 heavy chain $1 \mathrm{GN}=\mathrm{DYNC1H} 1$ DYHC1_HUMAN $532.41 \quad 100.0 \%$ Cytoplasmic dynein 1 heavy chain $1 \mathrm{GN}=\mathrm{DYNC1H} 1$ DYHC1_HUMAN $532.41 \quad 100.0 \%$ Cytoplasmic dynein 1 heavy chain $1 \mathrm{GN}=\mathrm{DYNC1H} 1$ DYHC1_HUMAN $532.41 \quad 100.0 \%$ Cytoplasmic dynein 1 heavy chain $1 \mathrm{GN}=\mathrm{DYNC1H} 1$ DYHC1_HUMAN $532.41 \quad 100.0 \%$ Cytoplasmic dynein 1 heavy chain $1 \mathrm{GN}=\mathrm{DYNC1H} 1$ DYHC1_HUMAN $532.41 \quad 100.0 \%$ Cytoplasmic dynein 1 heavy chain $1 \mathrm{GN}=\mathrm{DYNC1H} 1$ DYHC1_HUMAN $532.41 \quad 100.0 \%$ Cytoplasmic dynein 1 heavy chain $1 \mathrm{GN}=\mathrm{DYNC} 1 \mathrm{H} 1$ DYHC1_HUMAN $532.41 \quad 100.0 \%$ Cytoplasmic dynein 1 heavy chain $1 \mathrm{GN}=\mathrm{DYNC} 1 \mathrm{H} 1$ DYHC1_HUMAN $532.41 \quad 100.0 \%$ Cytoplasmic dynein 1 heavy chain $1 \mathrm{GN}=\mathrm{DYNC1H} 1$ DYHC1_HUMAN $532.41 \quad 100.0 \%$ $\begin{array}{lllll}\text { Cytoplasmic dynein } 1 \text { heavy chain } 1 \mathrm{GN}=\mathrm{DYNC} 1 \mathrm{H} 1 & \text { DYHC1_HUMAN } & 532.41 & 100.0 \% & 6\end{array}$ Cytoplasmic dynein 1 heavy chain $1 \mathrm{GN}=\mathrm{DYNC1H} 1$ DYHC1_HUMAN $532.41 \quad 100.0 \%$ Cytoplasmic dynein 1 heavy chain $1 \mathrm{GN}=\mathrm{DYNC1H} 1$ DYHC1_HUMAN $532.41 \quad 100.0 \%$ Cytoplasmic dynein 1 heavy chain $1 \mathrm{GN}=$ DYNC1H1 DYHC1_HUMAN $532.41 \quad 100.0 \% \quad 65$ Cytoplasmic dynein 1 heavy chain $1 \mathrm{GN}=\mathrm{DYNC1H} 1$ DYHC1_HUMAN $532.41 \quad 100.0 \% \quad 65$ Cytoplasmic dynein 1 heavy chain $1 \mathrm{GN}=\mathrm{DYNC1H} 1$ DYHC1_HUMAN $532.41 \quad 100.0 \%$ Cytoplasmic dynein 1 heavy chain $1 \mathrm{GN}=\mathrm{DYNC1H} 1$ DYHC1_HUMAN $532.41 \quad 100.0 \% \quad 65$

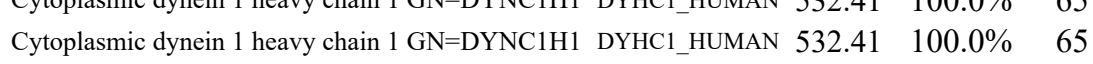

$0.01 \% \quad 12.4 \%$ GSQITQQSTNQSR

$0.01 \% \quad 12.4 \%$ NPATTNQTEFER

$0.01 \% \quad 12.4 \%$ NPATTNQTEFERVF

$0.00 \% \quad 10.3 \%$ IGEGTYGTVFK

$0.00 \% \quad 10.3 \%$ DLKPQNLLINR

$0.00 \% \quad 10.3 \%$ LADFGLAR

$0.00 \% \quad 1.6 \%$ ALVEEEITR

$0.00 \% \quad 1.6 \%$ AVVMTPVPLFSK

$0.01 \% \quad 6.9 \%$ PSETPQAEVGPTGCPHR

$0.01 \% \quad 6.9 \% \quad$ SNDEEAFTFAR

$0.01 \% \quad 6.9 \%$ AAQELQEGQR

$0.01 \% \quad 11.2 \%$ ALSKDLPK

$0.01 \% \quad 11.2 \%$ ADLTEYLSTHYKAPR

$0.01 \% \quad 11.2 \%$ LCTSATESEVAR

$\begin{array}{lllll}0.01 \% & 11.2 \% & \text { NALVSHLDGTTPVCEDIGR } & 99.7 \% & 29.0\end{array}$

$0.04 \% \quad 34.9 \%$ AGSRYEDFSNLGTTHLLR $99.7 \% \quad 38.7$

$0.04 \% \quad 34.9 \%$ YEDFSNLGTTHLLR

$0.04 \% 34.9 \%$ LTSSLTTK

$0.04 \% \quad 34.9 \%$ GASSFKITR

$\begin{array}{lllll}0.04 \% & 34.9 \% & \text { AVAFQNPQTHVIENLHAAAYR } & 99.7 \% & 34.7\end{array}$

$0.04 \% \quad 34.9 \%$ NALANPLYCPDYR

17

17

17
17
$0.04 \% \quad 34.9 \%$ VTSEELHYFVQNHFTSAR

$0.04 \% \quad 34.9 \%$ MALIGLGVSHPVLK

$0.04 \% \quad 34.9 \%$ QVAEQFLNMR

$\begin{array}{lll}31 & 0.04 \% & 34.9 \% \\ 3 & 0.04 \% & 34.9 \%\end{array}$

$99.7 \% \quad 38.5$

$99.7 \% \quad 56.2$

$99.7 \% \quad 58.0$

$99.7 \% \quad 51.4$

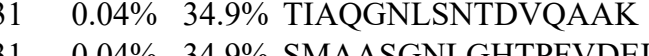

$255 \quad 0.29 \% \quad 13.6 \%$ FLSDPQVHTVLVER

$255 \quad 0.29 \% \quad 13.6 \%$ SNSLAFIK

$255 \quad 0.29 \% \quad 13.6 \%$ TPVIDADKPVSSQLR

$255 \quad 0.29 \% \quad 13.6 \%$ ESPEVLLTLDILK

$255 \quad 0.29 \% \quad 13.6 \%$ DLSSQLLK

$255 \quad 0.29 \% \quad 13.6 \%$ LRDQLGTAK

$255 \quad 0.29 \% \quad 13.6 \%$ GAIREYQTQLIQR

$255 \quad 0.29 \% \quad 13.6 \%$ EYQTQLIQR

$255 \quad 0.29 \% \quad 13.6 \%$ VQYPQSQACK

$255 \quad 0.29 \% \quad 13.6 \%$ LKQDGDSFR

$255 \quad 0.29 \% \quad 13.6 \%$ IFTIESTR

$255 \quad 0.29 \% \quad 13.6 \%$ TFSEILNR

$255 \quad 0.29 \% \quad 13.6 \%$ MVVLSLPR

$255 \quad 0.29 \% \quad 13.6 \%$ IVQEDRAVESR

$255 \quad 0.29 \% \quad 13.6 \%$ QNLDALLNQLK

$255 \quad 0.29 \% \quad 13.6 \%$ LRQYASYEFVQR

$255 \quad 0.29 \% \quad 13.6 \%$ QYASYEFVQR

$255 \quad 0.29 \% \quad 13.6 \%$ HLLPVETQR

$255 \quad 0.29 \% \quad 13.6 \%$ ALGEYLER
$99.7 \% \quad 67.2$

$98.4 \% \quad 17.2$

$\begin{array}{lll}99.7 \% & 43.0\end{array}$

$99.7 \% \quad 46.5$

862.48

1434.69

1407.65

1653.79

1171.60

1323.77

862.48

1059.57

1288.73

1819.84

1286.56

1129.56

871.52

1764.89

1323.62

2054.00

2037.01

1665.82

850.49

966.54

2350.21

1566.74

2165.04

1434.85

1235.62

1450.74

1630.84

1745.82

1639.88

879.49

1625.89

1469.85

903.51

1001.57

1575.86

1178.62

1208.57

1065.53

966.53

979.52

914.55

1301.68

1269.72

1559.80

1290.61

1092.62

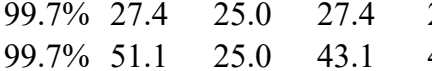

$\begin{array}{llll}99.6 \% & 25.8 & 25.0 & 25.8\end{array}$

$\begin{array}{llll}99.0 \% & 33.7 & 25.0 & 28.9\end{array}$

950.49 

Cytoplasmic dynein 1 heavy chain $1 \mathrm{GN}=$ DYNC1H1 DYHC1_HUMAN $532.41 \quad 100.0 \% \quad 65$ Cytoplasmic dynein 1 heavy chain $1 \mathrm{GN}=$ DYNC1H1 DYHC1_HUMAN $532.41 \quad 100.0 \% \quad 65$ Cytoplasmic dynein 1 heavy chain $1 \mathrm{GN}=\mathrm{DYNC1H} 1$ DYHC1_HUMAN $532.41 \quad 100.0 \% \quad 65$

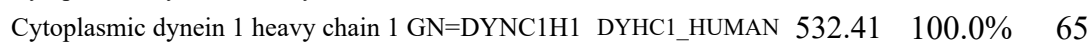
Cytoplasmic dynein 1 heavy chain $1 \mathrm{GN}=$ DYNC1H1 DYHC1_HUMAN $532.41 \quad 100.0 \% \quad 65$ Cytoplasmic dynein 1 heavy chain $1 \mathrm{GN}=$ DYNC1H1 DYHC1_HUMAN $532.41 \quad 100.0 \% \quad 65$ Cytoplasmic dynein 1 heavy chain $1 \mathrm{GN}=\mathrm{DYNC} 1 \mathrm{H} 1$ DYHC1_HUMAN $532.41 \quad 100.0 \% \quad 65$ Cytoplasmic dynein 1 heavy chain $1 \mathrm{GN}=\mathrm{DYNC1H} 1$ DYHC1_HUMAN $532.41 \quad 100.0 \% \quad 65$ Cytoplasmic dynein 1 heavy chain $1 \mathrm{GN}=\mathrm{DYNC} 1 \mathrm{H} 1$ DYHC1_HUMAN $532.41 \quad 100.0 \% \quad 65$ $\begin{array}{lllll}\text { Cytoplasmic dynein } 1 \text { heavy chain } 1 \mathrm{GN}=\mathrm{DYNC} 1 \mathrm{H} 1 & \text { DYHC1_HUMAN } & 532.41 & 100.0 \% & 65\end{array}$ Cytoplasmic dynein 1 heavy chain $1 \mathrm{GN}=$ DYNC1H1 DYHC1_HUMAN $532.41 \quad 100.0 \% \quad 65$ $\begin{array}{llll}\text { Cytoplasmic dynein } 1 \text { heavy chain } 1 \mathrm{GN}=\mathrm{DYNC} 1 \mathrm{H} 1 & \mathrm{DYHC1} \text { HUMAN } 532.41 & 100.0 \% & 65\end{array}$ Cytoplasmic dynein 1 heavy chain 1 GN=DYNC1H1 DYHC1_HUMAN $532.41 \quad 100.0 \% \quad 65$ Cytoplasmic dynein 1 heavy chain $1 \mathrm{GN}=$ DYNC1H1 DYHC1_HUMAN $532.41 \quad 100.0 \% \quad 65$ Cytoplasmic dynein 1 heavy chain $1 \mathrm{GN}=\mathrm{DYNC1H} 1$ DYHC1_HUMAN $532.41 \quad 100.0 \% \quad 65$ Cytoplasmic dynein 1 heavy chain $1 \mathrm{GN}=$ DYNC1H1 DYHC1_HUMAN $532.41 \quad 100.0 \% \quad 65$ Cytoplasmic dynein 1 heavy chain $1 \mathrm{GN}=\mathrm{DYNC1H} 1$ DYHC1_HUMAN $532.41 \quad 100.0 \% \quad 65$ Cytoplasmic dynein 1 heavy chain $1 \mathrm{GN}=$ DYNC1H1 DYHC1_HUMAN $532.41 \quad 100.0 \% \quad 65$ Cytoplasmic dynein 1 heavy chain $1 \mathrm{GN}=\mathrm{DYNC1H} 1$ DYHC1_HUMAN $532.41 \quad 100.0 \% \quad 65$ Cytoplasmic dynein 1 heavy chain $1 \mathrm{GN}=\mathrm{DYNC} 1 \mathrm{H} 1$ DYHC1_HUMAN $532.41 \quad 100.0 \% \quad 65$ Cytoplasmic dynein 1 heavy chain $1 \mathrm{GN}=$ DYNC1H1 DYHC1_HUMAN $532.41 \quad 100.0 \% \quad 65$ Cytoplasmic dynein 1 heavy chain $1 \mathrm{GN}=$ DYNC1H1 DYHC1_HUMAN $532.41 \quad 100.0 \% \quad 65$ Cytoplasmic dynein 1 heavy chain $1 \mathrm{GN}=$ DYNC1H1 DYHC1_HUMAN $532.41 \quad 100.0 \% \quad 65$ Cytoplasmic dynein 1 heavy chain $1 \mathrm{GN}=$ DYNC1H1 DYHC1_HUMAN $532.41 \quad 100.0 \% \quad 65$ Cytoplasmic dynein 1 heavy chain $1 \mathrm{GN}=\mathrm{DYNC1H} 1$ DYHC1_HUMAN $532.41 \quad 100.0 \% \quad 65$ Cytoplasmic dynein 1 heavy chain $1 \mathrm{GN}=$ DYNC1H1 DYHC1_HUMAN $532.41 \quad 100.0 \% \quad 65$ Cytoplasmic dynein 1 heavy chain $1 \mathrm{GN}=\mathrm{DYNC1H} 1$ DYHC1_HUMAN $532.41 \quad 100.0 \% \quad 65$ Cytoplasmic dynein 1 heavy chain $1 \mathrm{GN}=\mathrm{DYNC} 1 \mathrm{H} 1$ DYHC1_HUMAN $532.41 \quad 100.0 \% \quad 65$ Cytoplasmic dynein 1 heavy chain $1 \mathrm{GN}=\mathrm{DYNC1H} 1$ DYHC1_HUMAN $532.41 \quad 100.0 \% \quad 65$ Cytoplasmic dynein 1 heavy chain $1 \mathrm{GN}=\mathrm{DYNC} 1 \mathrm{H} 1$ DYHC1_HUMAN $532.41 \quad 100.0 \% \quad 65$

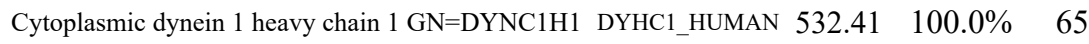
Cytoplasmic dynein 1 heavy chain $1 \mathrm{GN}=\mathrm{DYNC1H} 1$ DYHC1_HUMAN $532.41 \quad 100.0 \% \quad 65$

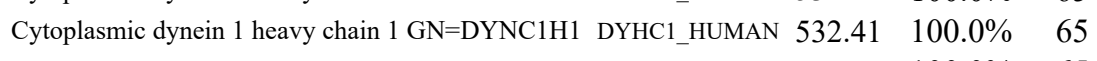
Cytoplasmic dynein 1 heavy chain 1 GN=DYNC1H1 DYHC1_HUMAN $532.41 \quad 100.0 \% \quad 65$ $\begin{array}{lllll}\text { Cytoplasmic dynein } 1 \text { heavy chain } 1 \mathrm{GN}=\mathrm{DYNC1H} 1 & \text { DYHC1_HUMAN } 532.41 & 100.0 \% & 65\end{array}$ Cytoplasmic dynein 1 heavy chain $1 \mathrm{GN}=$ DYNC1H1 DYHC1_HUMAN $532.41 \quad 100.0 \% \quad 65$ Cytoplasmic dynein 1 heavy chain $1 \mathrm{GN}=$ DYNC1H1 DYHC1_HUMAN $532.41 \quad 100.0 \% \quad 65$

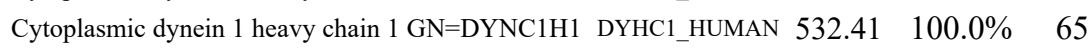
Cytoplasmic dynein 1 heavy chain $1 \mathrm{GN}=$ DYNC1H1 DYHC1_HUMAN $532.41 \quad 100.0 \% \quad 65$ Cytoplasmic dynein 1 heavy chain $1 \mathrm{GN}=$ DYNC1H1 DYHC1_HUMAN $532.41 \quad 100.0 \% \quad 65$ Cytoplasmic dynein 1 heavy chain $1 \mathrm{GN}=\mathrm{DYNC1H} 1$ DYHC1_HUMAN $532.41 \quad 100.0 \% \quad 65$ Cytoplasmic dynein 1 heavy chain $1 \mathrm{GN}=$ DYNC1H1 DYHC1_HUMAN $532.41 \quad 100.0 \%$ $\begin{array}{llll}\text { Cytoplasmic dynein } 1 \text { heavy chain } 1 \mathrm{GN}=\mathrm{DYNC} 1 \mathrm{H} 1 & \text { DYHC1_HUMAN } & 532.41 & 100.0 \%\end{array} 65$ Cytoplasmic dynein 1 heavy chain $1 \mathrm{GN}=\mathrm{DYNC1H} 1$ DYHC1_HUMAN $532.41 \quad 100.0 \% \quad 65$ Cytoplasmic dynein 1 heavy chain $1 \mathrm{GN}=\mathrm{DYNC} 1 \mathrm{H} 1$ DYHC1_HUMAN $532.41 \quad 100.0 \% \quad 65$ $\begin{array}{lllll}\text { Cytoplasmic dynein } 1 \text { light intermediate chain } 1 \text { GN=DYNCILI1 } & \text { DC1L1_HUMAN } & 56.58 & 100.0 \% & 3\end{array}$
$74 \quad 255 \quad 0.29 \% \quad 13.6 \%$ ALGEYLERER $74 \quad 255 \quad 0.29 \% \quad 13.6 \%$ TPVSITEHPK

$74 \quad 255 \quad 0.29 \% \quad 13.6 \%$ LLAESVTEVEIFGK $255 \quad 0.29 \% \quad 13.6 \%$ SFEWLSQMR

$255 \quad 0.29 \% \quad 13.6 \%$ LGGSPFGPAGTGK

$255 \quad 0.29 \% \quad 13.6 \%$ LGGSPFGPAGTGKTESVK

$255 \quad 0.29 \% \quad 13.6 \%$ ALGHQLGR

$255 \quad 0.29 \% \quad 13.6 \%$ TSAPITCELLNK

$255 \quad 0.29 \% \quad 13.6 \%$ SNLPDNLKK

$255 \quad 0.29 \% \quad 13.6 \%$ SVLVSAGNVK

$255 \quad 0.29 \% \quad 13.6 \%$ SVLVSAGNVKR

$255 \quad 0.29 \% \quad 13.6 \%$ AISKDHLYGTLDPNTR

$255 \quad 0.29 \% \quad 13.6 \%$ SIPLDEGEDEAQR

$255 \quad 0.29 \% \quad 13.6 \%$ SIPLDEGEDEAQRR

$255 \quad 0.29 \% \quad 13.6 \%$ AELGEYIRR

$255 \quad 0.29 \% \quad 13.6 \%$ VPQIEVETHK

$255 \quad 0.29 \% \quad 13.6 \%$ TMTLFSALR

$255 \quad 0.29 \% \quad 13.6 \%$ TFDHYCEYR

$255 \quad 0.29 \% \quad 13.6 \%$ TSDQTWVKLER

$255 \quad 0.29 \% \quad 13.6 \%$ IQFVGACNPPTDPGR

$255 \quad 0.29 \% \quad 13.6 \%$ FTQDTQPHYIYSPR

$255 \quad 0.29 \% \quad 13.6 \%$ IWAHEALR

$255 \quad 0.29 \% \quad 13.6 \%$ WTDENIDTVALK

$255 \quad 0.29 \% \quad 13.6 \%$ QPQGHLLLIGVSGAGK

$255 \quad 0.29 \% \quad 13.6 \%$ AATSPALFNR

$255 \quad 0.29 \% \quad 13.6 \%$ SMANPPAAVK

$255 \quad 0.29 \% \quad 13.6 \%$ NYMSNPSYNYEIVNR

$255 \quad 0.29 \% \quad 13.6 \%$ ASLACGPMVK

$255 \quad 0.29 \% \quad 13.6 \%$ TEYLSNADERLR

$255 \quad 0.29 \% \quad 13.6 \%$ TSFLDDAFRK

$255 \quad 0.29 \% \quad 13.6 \%$ SSLQSQCLNEVLK

$255 \quad 0.29 \% \quad 13.6 \%$ LQGEFQLR

$255 \quad 0.29 \% \quad 13.6 \%$ SLLQALNEVK

$255 \quad 0.29 \% \quad 13.6 \%$ SLLQALNEVKGR

$255 \quad 0.29 \% \quad 13.6 \%$ DLFQVAFNR

$255 \quad 0.29 \% \quad 13.6 \%$ GNEIVLSAGSTPR

$255 \quad 0.29 \% \quad 13.6 \%$ IQGLTVEQAEAVVR

$255 \quad 0.29 \% \quad 13.6 \%$ LFLTMEINPK

$255 \quad 0.29 \% \quad 13.6 \%$ IFVFEPPPGVK

$255 \quad 0.29 \% \quad 13.6 \%$ TFSSIPVSR

$255 \quad 0.29 \% \quad 13.6 \%$ KYEFGESDLR

$255 \quad 0.29 \% \quad 13.6 \%$ LLNTFLER

$255 \quad 0.29 \% \quad 13.6 \%$ VLLTTQGVDMISK

$255 \quad 0.29 \% \quad 13.6 \%$ TLINELVK

$255 \quad 0.29 \% \quad 13.6 \%$ IKQLQNISLAAASGGAK

$255 \quad 0.29 \% \quad 13.6 \%$ QLQNISLAAASGGAK

$6 \quad 0.01 \% \quad 10.1 \%$ NVLLLGEDGAGKTSLIR $\begin{array}{lllll}99.7 \% & 37.6 & 25.0 & 28.3 & 2\end{array}$

$\begin{array}{llll}99.7 \% & 52.4 & 25.0 & 45.0\end{array}$

$\begin{array}{llll}99.7 \% & 63.5 & 25.0 & 63.5\end{array}$

$99.7 \% \quad 34.3 \quad 25.0 \quad 34.3$

$\begin{array}{llll}99.7 \% & 55.7 & 25.0 & 53.8\end{array}$

$\begin{array}{llll}99.5 \% & 23.3 & 25.0 & 21.4\end{array}$

$\begin{array}{llll}99.0 \% & 36.3 & 25.0 & 28.9\end{array}$

$\begin{array}{llll}99.7 \% & 50.6 & 25.0 & 44.7\end{array}$

$\begin{array}{llll}95.6 \% & 22.1 & 25.0 & 8.9\end{array}$

$\begin{array}{llll}99.7 \% & 34.9 & 25.0 & 26.8\end{array}$

$\begin{array}{llll}99.7 \% & 53.5 & 25.0 & 53.5\end{array}$

$97.7 \% \quad 16.1 \quad 25.0$

$99.7 \%$

$99.7 \% \quad 39.7$

$99.7 \% \quad 28.2$

$99.7 \% \quad 58.2$

$99.7 \% \quad 53.3$

$99.7 \% \quad 33.0$

$99.7 \% \quad 38.8$

$99.7 \% \quad 65.3$

$99.7 \% \quad 61.0$

$99.0 \% \quad 33.1$

$99.7 \% \quad 45.3$

$99.2 \% \quad 20.9$

$99.7 \% \quad 45.1$

$99.7 \% \quad 34.1$

$99.7 \% \quad 53.8$

$99.7 \% \quad 28.0$

$99.4 \% \quad 22.2$

$99.7 \% \quad 46.5$

$99.7 \% \quad 50.6$

$99.0 \% \quad 41.3$

$99.7 \% \quad 40.3$

$99.7 \% \quad 40.0$

$99.7 \% \quad 48.2$

$99.7 \% \quad 58.0$

$99.7 \% \quad 67.5$

$99.7 \% \quad 38.2$

$99.7 \% \quad 33.6$

$99.5 \% \quad 23.2$

$99.7 \% \quad 48.1$

$99.0 \% \quad 34.1$

$99.7 \% \quad 52.6$

$98.6 \% \quad 25.6$

$95.2 \% \quad 14.4$

$99.7 \% 39.1$

$99.2 \% \quad 21.3$
$0 \quad 123$
-

1534.84

1199.55

1145.60

1689.88

851.48

1346.70

1028.57

973.57

1129.67

1800.92

1458.67

1614.77

1106.60

1179.64

1055.56

1290.52

1362.70

1628.79

1752.83

995.54

1404.70

1574.90

1047.56

985.51

1863.83

1049.51

1466.72

1199.61

1505.76

990.54

1114.65

1327.77

1109.57

1300.69

1512.84

1205.66

1229.69

993.54

1243.60

1005.57

1404.78

929.57

1669.96

1428.78

1756.00
$1716 \quad 1729$

18351843

$1900 \quad 1912$

$900 \quad 1917$

$1918 \quad 1925$

$2026 \quad 2034$

$2095 \quad 2104$

$2095 \quad 2105$

$2258 \quad 2273$

$2384 \quad 2396$

$2384 \quad 2397$

$2512 \quad 2520$

$602 \quad 2561$

26342642

$695 \quad 2705$ $2784 \quad 2797$ $2824 \quad 2831$ $2845 \quad 2856$ 2943 33093318 $3370 \quad 3384$ $3612 \quad 3621$ $3706 \quad 3718$ $3734 \quad 3741$ $3748 \quad 3757$ $3748 \quad 3759$ $3862 \quad 3870$ 39113923 \begin{tabular}{ll}
924 & 3937 \\
\hline & 4133
\end{tabular} $4160 \quad 4168$ $4204 \quad 4213$ $4264 \quad 4271$ $4330 \quad 4342$ $4450 \quad 4457$ $4486 \quad 4502$ $4488 \quad 4502$ $69 \quad 85$ 
Cytoplasmic dynein 1 light intermediate chain $1 \mathrm{GN}=$ DYNC1LI1 DC1L1 HUMAN $56.58 \quad 100.0 \%$ Cytoplasmic dynein 1 light intermediate chain 1 GN=DYNCILI1 DC1L1_HUMAN $56.58 \quad 100.0 \%$ Cytoplasmic dynein 2 heavy chain $1 \mathrm{GN}=\mathrm{DYNC} 2 \mathrm{H} 1$ DYHC2_HUMAN $492.63 \quad 100.0 \%$ Cytoplasmic dynein 2 heavy chain $1 \mathrm{GN}=\mathrm{DYNC} 2 \mathrm{H} 1$ DYHC2_HUMAN $492.63 \quad 100.0 \%$ Cytoplasmic dynein 2 heavy chain $1 \mathrm{GN}=\mathrm{DYNC} 2 \mathrm{H} 1$ DYHC2_HUMAN $492.63 \quad 100.0 \%$ Cytoplasmic dynein 2 heavy chain $1 \mathrm{GN}=\mathrm{DYNC} 2 \mathrm{H} 1$ DYHC2_HUMAN $492.63 \quad 100.0 \%$ Cytoplasmic dynein 2 heavy chain $1 \mathrm{GN}=\mathrm{DYNC} 2 \mathrm{H} 1$ DYHC2_HUMAN $492.63 \quad 100.0 \%$ Cytoplasmic dynein 2 heavy chain $1 \mathrm{GN}=\mathrm{DYNC} 2 \mathrm{H} 1 \quad$ DYHC2_HUMAN $492.63 \quad 100.0 \%$ Cytoplasmic FMR1-interacting protein $1 \mathrm{GN}=$ CYFIP1 CYFP1 HUMAN $145.19100 .0 \%$ Cytoplasmic FMR1-interacting protein 1 GN=CYFIP1 CYFP1_HUMAN $145.19 \quad 100.0 \%$ Cytoplasmic FMR1-interacting protein 1 GN=CYFIP1 CYFP1_HUMAN $145.19 \quad 100.0 \%$ Cytoplasmic FMR1-interacting protein $1 \mathrm{GN}=$ CYFIP1 CYFP1_HUMAN $145.19 \quad 100.0 \%$ Cytoplasmic FMR1-interacting protein 1 GN=CYFIP1 CYFP1_HUMAN $145.19 \quad 100.0 \%$ Cytoplasmic FMR1-interacting protein $1 \mathrm{GN}=$ CYFIP1 CYFP1_HUMAN $145.19 \quad 100.0 \%$ Cytoplasmic FMR1-interacting protein 2 GN=CYFIP2 CYFP2_HUMAN $148.40 \quad 100.0 \%$ Cytoplasmic FMR1-interacting protein 2 GN=CYFIP2 CYFP2_HUMAN $148.40 \quad 100.0 \%$ Cytoplasmic FMR1-interacting protein $2 \mathrm{GN}=$ CYFIP2 CYFP2 HUMAN $148.40 \quad 100.0 \%$ Cytoplasmic FMR1-interacting protein 2 GN=CYFIP2 CYFP2_HUMAN $148.40 \quad 100.0 \%$ Cytoplasmic tRNA 2-thiolation protein $1 \mathrm{GN}=\mathrm{CTU} 1$ CTU1_HUMAN $36.45 \quad 100.0 \%$ Cytoplasmic tRNA 2-thiolation protein $1 \mathrm{GN}=\mathrm{CTU} 1$ CTU1_HUMAN $36.45 \quad 100.0 \%$ Cytoskeleton-associated protein 5 GN=CKAP5 CKAP5_HUMAN $225.50 \quad 100.0 \%$ Cytoskeleton-associated protein $5 \mathrm{GN}=\mathrm{CKAP} 5$ CKAP5_HUMAN $225.50 \quad 100.0 \%$ Cytoskeleton-associated protein 5 GN=CKAP5 CKAP5_HUMAN $225.50 \quad 100.0 \%$ Cytoskeleton-associated protein 5 GN=CKAP5 CKAP5_HUMAN $225.50 \quad 100.0 \%$ Cytoskeleton-associated protein $5 \mathrm{GN}=\mathrm{CKAP} 5$ CKAP5 HUMAN $225.50 \quad 100.0 \%$ Cytoskeleton-associated protein 5 GN=CKAP5 CKAP5_HUMAN $225.50 \quad 100.0 \%$ Cytoskeleton-associated protein $5 \mathrm{GN}=\mathrm{CKAP} 5$ CKAP5_HUMAN $225.50 \quad 100.0 \%$ Cytoskeleton-associated protein $5 \mathrm{GN}=\mathrm{CKAP} 5$ CKAP5_HUMAN $225.50 \quad 100.0 \%$ Cytoskeleton-associated protein 5 GN=CKAP5 CKAP5_HUMAN $225.50 \quad 100.0 \%$ Cytosolic acyl coenzyme A thioester hydrolase GN=ACOT7 BACH HUMAN $41.80 \quad 100.0 \%$ Cytosolic acyl coenzyme A thioester hydrolase GN=ACOT7 $\quad$ BACH_HUMAN $41.80 \quad 100.0 \%$ Cytosolic Fe-S cluster assembly factor NUBP2 GN=NUBP2 NUBP2_HUMAN $28.83 \quad 100.0 \%$ Cytosolic Fe-S cluster assembly factor NUBP2 GN=NUBP2 NUBP2 HUMAN $28.83 \quad 100.0 \%$ D-3-phosphoglycerate dehydrogenase GN=PHGDH SERA_HUMAN $56.65 \quad 100.0 \%$ D-3-phosphoglycerate dehydrogenase GN=PHGDH SERA HUMAN $56.65 \quad 100.0 \%$ D-3-phosphoglycerate dehydrogenase GN=PHGDH SERA_HUMAN $56.65 \quad 100.0 \%$ D-3-phosphoglycerate dehydrogenase GN=PHGDH SERA_HUMAN $56.65 \quad 100.0 \%$ D-3-phosphoglycerate dehydrogenase GN=PHGDH SERA HUMAN $56.65100 .0 \%$ D-3-phosphoglycerate dehydrogenase GN=PHGDH SERA_HUMAN $56.65 \quad 100.0 \%$ D-3-phosphoglycerate dehydrogenase GN=PHGDH SERA_HUMAN $56.65100 .0 \%$ D-3-phosphoglycerate dehydrogenase GN=PHGDH SERA HUMAN $56.65 \quad 100.0 \%$ D-3-phosphoglycerate dehydrogenase GN=PHGDH SERA_HUMAN $56.65 \quad 100.0 \%$ D-3-phosphoglycerate dehydrogenase GN=PHGDH SERA HUMAN $56.65100 .0 \%$ D-3-phosphoglycerate dehydrogenase GN=PHGDH SERA_HUMAN $56.65 \quad 100.0 \%$ D-3-phosphoglycerate dehydrogenase GN=PHGDH SERA_HUMAN $56.65100 .0 \%$ D-3-phosphoglycerate dehydrogenase GN=PHGDH SERA HUMAN $56.65 \quad 100.0 \%$ D-3-phosphoglycerate dehydrogenase GN=PHGDH SERA_HUMAN $56.65 \quad 100.0 \%$

6

6
6
6

6
6
6

2

2
2
2

2
2
2

2
9

9

9

9

9

9
9
9
9

9

9

2

2
2
2

2

$\begin{array}{ll}18 & 2 \\ 18 & 2 \\ 18 & 2\end{array}$

$\begin{array}{ll}18 & 20 \\ 18 & 20 \\ 18 & 20\end{array}$

$18 \quad 20$

$18 \quad 20$

18
18
18

18

\begin{tabular}{|c|c|c|c|c|c|c|}
\hline $0.01 \%$ & $10.1 \%$ & KPVTVSPTTPTSPTEGEAS & $99.6 \%$ & 26.1 & 25.0 & 26.1 \\
\hline $0.01 \%$ & $1.7 \%$ & TVAGGGLETISNLK & $99.7 \%$ & 50.2 & 25.0 & 37.7 \\
\hline $0.01 \%$ & $1.7 \%$ & VTTLTTHAGIR & $99.7 \%$ & 28.6 & 25.0 & 23.7 \\
\hline $0.01 \%$ & $1.7 \%$ & SLNEFLEEKR & $99.7 \%$ & 29.5 & 25.0 & 29.5 \\
\hline $0.01 \%$ & $1.7 \%$ & SLEGEVVPFK & $99.7 \%$ & 28.3 & 5.0 & 28.3 \\
\hline $0.01 \%$ & $1.7 \%$ & SGTTQNANESHIVVQALR & $99.3 \%$ & 21.4 & 5.0 & 21.4 \\
\hline $0.01 \%$ & $1.7 \%$ & IAEEVVKIEER & $99.4 \%$ & 28.3 & 25.0 & 22.2 \\
\hline $0.01 \%$ & $5.8 \%$ & YSNSEVVTGSGR & $99.7 \%$ & 61.2 & 5.0 & 57.2 \\
\hline $0.01 \%$ & $5.8 \%$ & SGFDIKVPR & $99.7 \%$ & 54.9 & 5.0 & 47.2 \\
\hline $0.01 \%$ & $5.8 \%$ & RAVGPSSTQLYMVR & $99.7 \%$ & 28.4 & 25.0 & 28.4 \\
\hline $0.01 \%$ & $5.8 \%$ & EANHNVSAPYGR & $97.9 \%$ & 16.5 & 5.0 & 16.5 \\
\hline $0.01 \%$ & $5.8 \%$ & DKQPNAQPQYLHGSK & $98.3 \%$ & 17.0 & 25.0 & 16.8 \\
\hline $0.01 \%$ & $5.8 \%$ & LGTPQQIAIAR & $99.7 \%$ & 57.9 & 25.0 & 44.7 \\
\hline $0.00 \%$ & $3.7 \%$ & EANHNVSAPYGR & $97.9 \%$ & 16.5 & 25.0 & 16.5 \\
\hline $0.00 \%$ & $3.7 \%$ & TAIPFTQEPQR & $99.7 \%$ & 37.0 & 25.0 & 30.2 \\
\hline $0.00 \%$ & $3.7 \%$ & LGTPQQIAIAR & $99.7 \%$ & 57.9 & 25.0 & 44.7 \\
\hline $0.00 \%$ & $3.7 \%$ & SVETDSSTVEHVR & $99.7 \%$ & 66.3 & 25.0 & 66.3 \\
\hline $0.00 \%$ & $8.9 \%$ & LLPPGAVVAVGASGGK & $95.7 \%$ & 14.9 & 25.0 & 14.9 \\
\hline $0.00 \%$ & $8.9 \%$ & GGGLGSPGEGGALPR & $99.7 \%$ & 40.4 & 25.0 & 35.8 \\
\hline $0.01 \%$ & $4.9 \%$ & FVTDSNAVVQLK & $99.7 \%$ & 48.1 & 25.0 & 42.1 \\
\hline $0.01 \%$ & $4.9 \%$ & TTGEVVSGVVSK & $99.7 \%$ & 51.7 & 25.0 & 40.2 \\
\hline $0.01 \%$ & $4.9 \%$ & LIAVEIYR & $99.0 \%$ & 21.3 & 25.0 & 21.3 \\
\hline $0.01 \%$ & $4.9 \%$ & LEAGDYADLVK & $99.7 \%$ & 33.8 & 25.0 & 23.1 \\
\hline $0.01 \%$ & $4.9 \%$ & LHIVALIAQK & $98.3 \%$ & 20.8 & 5.0 & 16.0 \\
\hline $0.01 \%$ & $4.9 \%$ & TALAAT & $99.7 \%$ & 48.1 & 25.0 & 36.3 \\
\hline $0.01 \%$ & $4.9 \%$ & MQGQSPPAPTR & $97.9 \%$ & 23.5 & 25.0 & 13.3 \\
\hline $0.01 \%$ & $4.9 \%$ & AQNISSNANMLR & $99.7 \%$ & 39.3 & 25.0 & 33.1 \\
\hline $0.01 \%$ & $4.9 \%$ & NSSQFI & $99.7 \%$ & 40.8 & 25.0 & 40.8 \\
\hline $0.00 \%$ & $7.1 \%$ & VLEVPPVVYSR & $99.1 \%$ & 21.5 & 25.0 & 21.5 \\
\hline $0.00 \%$ & $7.1 \%$ & AASAFFTYVSLSQEGR & $99.7 \%$ & 53.0 & 25.0 & 53.0 \\
\hline $0.00 \%$ & $7.8 \%$ & HIILVLSGK & $99.7 \%$ & 29.4 & 25.0 & 25.5 \\
\hline $0.00 \%$ & $7.8 \%$ & STISTELALALR & $99.7 \%$ & 43.4 & 25.0 & 43.4 \\
\hline $0.05 \%$ & $35.8 \%$ & ILQDGGLQVVEK & $99.7 \%$ & 54.7 & 25.0 & 50.9 \\
\hline $0.05 \%$ & $35.8 \%$ & SATKVTADVINAAEK & $99.7 \%$ & 46.8 & 25.0 & 44.2 \\
\hline $0.05 \%$ & $35.8 \%$ & VTADVINAAEK & $99.7 \%$ & 55.9 & 25.0 & 48.3 \\
\hline $0.05 \%$ & $35.8 \%$ & VTADVINAAEKLQVVGR & $99.7 \%$ & 48.6 & 25.0 & 46.2 \\
\hline $0.05 \%$ & $35.8 \%$ & AGTGVDNVDLEAATR & $99.7 \%$ & 62.5 & 25.0 & 47.8 \\
\hline $0.05 \%$ & $35.8 \%$ & AGTGVDNVDLEAATRK & $99.7 \%$ & 60.3 & 25.0 & 60.3 \\
\hline $0.05 \%$ & $35.8 \%$ & TLGILGLGR & $99.7 \%$ & 46.8 & 25.0 & 40.3 \\
\hline $0.05 \%$ & $35.8 \%$ & IGREVATR & $98.5 \%$ & 28.2 & 25.0 & 12.9 \\
\hline $0.05 \%$ & $35.8 \%$ & GGIVDEGALLR & $99.7 \%$ & 63.7 & 25.0 & 46.3 \\
\hline $0.05 \%$ & $35.8 \%$ & ALQSGQCAGAALDVFTEEPPRDR & $99.7 \%$ & 33.8 & 25.0 & 33.8 \\
\hline $0.05 \%$ & $35.8 \%$ & ALVDHENVISCPHLGASTK & $99.7 \%$ & 44.9 & 25.0 & 44.9 \\
\hline $0.05 \%$ & $35.8 \%$ & ALVDHENVISCPHLGASTKEAQSR & $99.7 \%$ & 27.1 & 25.0 & 27.1 \\
\hline $0.05 \%$ & $35.8 \%$ & CGEEIAVQFVDMVKGK & $99.7 \%$ & 58.3 & 25.0 & 58.3 \\
\hline $0.05 \%$ & $35.8 \%$ & GTIQVITQGTSLK & $99.7 \%$ & 60.9 & 25.0 & 60.9 \\
\hline
\end{tabular}

\begin{tabular}{|c|c|c|c|}
\hline 0 & 1586.84 & 412 & 428 \\
\hline 0 & 1885.94 & 505 & 523 \\
\hline 0 & 1359.75 & 999 & 1012 \\
\hline 0 & 1169.66 & 1388 & 1398 \\
\hline 0 & 1264.65 & 1414 & 1423 \\
\hline 0 & 1104.59 & 1478 & 1487 \\
\hline 0 & 1924.98 & 1886 & 1903 \\
\hline 0 & 1314.73 & 2960 & 2970 \\
\hline 0 & 1255.59 & 366 & 377 \\
\hline 0 & 1018.57 & 541 & 549 \\
\hline 0 & 1580.82 & 550 & 563 \\
\hline 0 & 1314.62 & 827 & 838 \\
\hline 0 & 1710.86 & 878 & 892 \\
\hline 0 & 1167.68 & 1066 & 1076 \\
\hline 0 & 1314.62 & 851 & 862 \\
\hline 0 & 1287.67 & 891 & 901 \\
\hline 0 & 1167.68 & 1090 & 1100 \\
\hline 0 & 1445.69 & 1252 & 1264 \\
\hline 0 & 1392.82 & 47 & 62 \\
\hline 0 & 1281.65 & 195 & 209 \\
\hline 0 & 1320.72 & 56 & 67 \\
\hline 0 & 1162.63 & 85 & 96 \\
\hline 0 & 976.58 & 186 & 193 \\
\hline 0 & 1193.61 & 312 & 322 \\
\hline 0 & 1105.71 & 662 & 671 \\
\hline 0 & 1084.61 & 762 & 772 \\
\hline 0 & 1169.57 & 812 & 822 \\
\hline 0 & 1318.65 & 1442 & 1453 \\
\hline 0 & 1491.69 & 1871 & 1882 \\
\hline 0 & 1257.72 & 173 & 183 \\
\hline 0 & 1733.85 & 325 & 340 \\
\hline 0 & 979.63 & 15 & 23 \\
\hline 0 & 1274.73 & 29 & 40 \\
\hline 0 & 1298.73 & 22 & 33 \\
\hline 0 & 1517.82 & 55 & 69 \\
\hline 0 & 1130.61 & 59 & 69 \\
\hline 0 & 1783.01 & 59 & 75 \\
\hline 0 & 1488.73 & 76 & 90 \\
\hline 0 & 1616.82 & 76 & 91 \\
\hline 0 & 899.57 & 147 & 155 \\
\hline 0 & 901.52 & 156 & 163 \\
\hline 0 & 1099.61 & 237 & 247 \\
\hline 0 & 2488.19 & 248 & 270 \\
\hline 0 & 2048.02 & 271 & 289 \\
\hline 0 & 2619.29 & 271 & 294 \\
\hline 0 & 1809.89 & 295 & 310 \\
\hline 0 & 1345.77 & 352 & 364 \\
\hline
\end{tabular}

Page 43 of Table S-1-6 
D-3-phosphoglycerate dehydrogenase GN=PHGDH SERA_HUMAN $56.65 \quad 100.0 \%$ D-3-phosphoglycerate dehydrogenase GN=PHGDH SERA_HUMAN $56.65 \quad 100.0 \% \quad 18$ D-3-phosphoglycerate dehydrogenase GN=PHGDH SERA_HUMAN $56.65 \quad 100.0 \% \quad 18$ D-3-phosphoglycerate dehydrogenase GN=PHGDH SERA_HUMAN $56.65 \quad 100.0 \%$ DBIRD complex subunit ZNF326 GN=ZNF326 ZN326_HUMAN $65.65 \quad 100.0 \%$ DBIRD complex subunit ZNF326 GN=ZNF326 ZN326_HUMAN $65.65 \quad 100.0 \% \quad 10$ DBIRD complex subunit ZNF326 GN=ZNF326 ZN326 HUMAN $65.65 \quad 100.0 \% \quad 10$ DBIRD complex subunit ZNF326 GN=ZNF326 ZN326_HUMAN $65.65 \quad 100.0 \%$ DBIRD complex subunit ZNF326 GN=ZNF326 ZN326 HUMAN $65.65 \quad 100.0 \%$ DBIRD complex subunit ZNF326 GN=ZNF326 ZN326_HUMAN $65.65 \quad 100.0 \% \quad 10$ DBIRD complex subunit ZNF326 GN=ZNF326 ZN326_HUMAN $65.65 \quad 100.0 \% \quad 1$ DBIRD complex subunit ZNF326 GN=ZNF326 ZN326 HUMAN $65.65 \quad 100.0 \%$ DBIRD complex subunit ZNF326 GN=ZNF326 ZN326_HUMAN 65.65 DBIRD complex subunit ZNF326 GN=ZNF326 ZN326 HUMAN 65.65 DDB1- and CUL4-associated factor 7 GN=DCAF7 DCAF7 HUMAN 38.93 DDB1- and CUL4-associated factor 7 GN=DCAF7 DCAF7_HUMAN 38.93 DDB1- and CUL4-associated factor 7 GN=DCAF7 DCAF7 HUMAN 38.93 DDB1- and CUL4-associated factor 7 GN=DCAF7 DCAF7 HUMAN 38.93 DDB1- and CUL4-associated factor 7 GN=DCAF7 DCAF7_HUMAN 38.93 DDRGK domain-containing protein 1 GN=DDRGK1 DDRGK HUMAN 35.61 DDRGK domain-containing protein 1 GN=DDRGK1 DDRGK_HUMAN $35.61 \quad 100.0^{\circ}$ Dedicator of cytokinesis protein $1 \mathrm{GN}=$ DOCK1 DOCK1_HUMAN $215.35 \quad 100.0 \%$ Dedicator of cytokinesis protein $1 \mathrm{GN}=$ DOCK1 DOCK1_HUMAN $215.35 \quad 100.0 \%$ Dedicator of cytokinesis protein $11 \mathrm{GN}=$ DOCK11 DOC11_HUMAN $237.68 \quad 100.0 \%$ Dedicator of cytokinesis protein $11 \mathrm{GN}=$ DOCK11 DOC11 HUMAN $237.68100 .0 \%$ Dedicator of cytokinesis protein $4 \mathrm{GN}=$ DOCK4 DOCK4_HUMAN $225.21 \quad 100.0 \%$ Dedicator of cytokinesis protein 4 GN=DOCK4 DOCK4_HUMAN $225.21 \quad 100.0 \%$ Dedicator of cytokinesis protein $4 \mathrm{GN}=$ DOCK4 DOCK4_HUMAN $225.21 \quad 100.0 \%$ Dehydrogenase/reductase SDR family member 4 GN=DHRS4 DHRS4_HUMAN $29.54 \quad 100.0 \%$ Dehydrogenase/reductase SDR family member 4 GN=DHRS4 DHRS4 HUMAN $29.54 \quad 100.0 \%$ Dehydrogenase/reductase SDR family member 7B GN=DHRS7B DRS7B_HUMAN $35.12 \quad 100.0 \%$ Dehydrogenase/reductase SDR family member 7B GN=DHRS7B DRS7B_HUMAN $35.12 \quad 100.0 \%$ Delta-1-pyrroline-5-carboxylate synthase GN=ALDH18A1 P5CS HUMAN 87.30 100.0\% Delta-1-pyrroline-5-carboxylate synthase GN=ALDH18A1 P5CS_HUMAN 87.30 $100.0 \%$ Delta-1-pyrroline-5-carboxylate synthase GN=ALDH18A1 P5CS HUMAN 87.30 $100.0 \%$ Delta-1-pyrroline-5-carboxylate synthase GN=ALDH18A1 P5CS HUMAN 87.30 100.0\% Delta-1-pyrroline-5-carboxylate synthase GN=ALDH18A1 P5CS_HUMAN 87.30 $100.0 \%$ Delta-1-pyrroline-5-carboxylate synthase GN=ALDH18A1 P5CS_HUMAN 87.30 100.0\% Delta-1-pyrroline-5-carboxylate synthase GN=ALDH18A1 P5CS_HUMAN $87.30 \quad 100.0 \%$ Deoxynucleoside triphosphate triphosphohydrolase SAMHDI GN=SAMHD1 SAMH1_HUMAN $72.20 \quad 100.0 \%$ Deris Deoxynucleoside triphosphate triphosphohydrolase SAMHDI GN=SAMHDI SAMH1_HUMAN $72.20 \quad 100.0 \%$ Desmoglein-1 GN=DSG1 Desmoglein-1 GN=DSG1 Desmoplakin GN=DSP Desmoplakin GN=DSP Desmoplakin GN=DSP
10

10

10
10

10
10

10
10

10

2
$\begin{array}{lll}\text { DSG1_HUMAN } & 113.75 & 100.0 \% \\ \text { DSG1_HUMAN } & 113.75 & 100.0 \%\end{array}$ DESP_HUMAN $331.78 \quad 100.0 \%$ DESP_HUMAN $331.78 \quad 100.0 \% \quad 19$ DESP_HUMAN $331.78 \quad 100.0 \% \quad 19$
0.05\% $35.8 \%$ NAGNCLSPAVIVGLLK $0.05 \% \quad 35.8 \%$ EASKQADVNLVNAK

$0.05 \% \quad 35.8 \%$ QADVNLVNAK

$0.05 \% \quad 35.8 \%$ DLPLLLFR

$0.02 \% \quad 17.7 \%$ FGPYESYDSR

$19 \quad 0.02 \% \quad 17.7 \%$ SSLGGRDLYR

$19 \quad 0.02 \% \quad 17.7 \%$ SGYGFNEPEQSR

$19 \quad 0.02 \% \quad 17.7 \%$ FGGSYGGR

$19 \quad 0.02 \% \quad 17.7 \%$ FGGSYGGRFESSYR

$19 \quad 0.02 \% \quad 17.7 \%$ NSLDSFGGR

$19 \quad 0.02 \% \quad 17.7 \%$ NQGGSSWEAPYSR

$19 \quad 0.02 \% \quad 17.7 \%$ STNVTVAAAR

$19 \quad 0.02 \% \quad 17.7 \%$ MAFTCSFCK

$19 \quad 0.02 \% \quad 17.7 \%$ ESVLTATSILNNPIVK

$10 \quad 0.01 \% \quad 18.7 \%$ VQLVGLDEESSEFICR

$10 \quad 0.01 \% \quad 18.7 \%$ NTFDHPYPTTK

$10 \quad 0.01 \% \quad 18.7 \%$ GVYPDLLATSGDYLR

$10 \quad 0.01 \% \quad 18.7 \%$ VNLVSGHVK

$10 \quad 0.01 \% \quad 18.7 \%$ DMFASVGADGSVR

$0.00 \% \quad 8.6 \%$ VAQPGPLEPEEPR

$0.00 \% \quad 8.6 \%$ VVLLEDLASQVGLR

$0.00 \% \quad 1.2 \%$ AHEIASKQVEER

$0.00 \% \quad 1.2 \%$ SNTSLLQQNLR

$0.00 \% \quad 1.0 \%$ SYASTPELRK

$0.00 \% \quad 1.0 \% \quad$ LTGLSEISLR

$0.01 \% \quad 1.9 \%$ GIFLGNNNQAMK

$0.01 \% \quad 1.9 \%$ TVESQLYTNPDSR

$0.01 \% \quad 1.9 \%$ ESGVSLIATVTR

$0.00 \% \quad 8.3 \%$ RLAQDGAHVVVSSR

$0.00 \% \quad 8.3 \%$ TLAIELAPR

$0.00 \% \quad 8.3 \%$ NAVVVITGATSGLGK

$0.00 \% \quad 8.3 \%$ YGVMDTTTAQGR

$10 \quad 0.01 \% \quad 9.6 \%$ LGSAVVTR

$10 \quad 0.01 \% \quad 9.6 \% \quad$ LRHEILLSQSVR

$10 \quad 0.01 \% \quad 9.6 \% \quad$ NLNGTLHELLR

$10 \quad 0.01 \% \quad 9.6 \%$ MLATLEPEQR

$10 \quad 0.01 \% \quad 9.6 \% \quad$ MIDLIIPR

$10 \quad 0.01 \% \quad 9.6 \%$ GSSQLVRDIQK

$10 \quad 0.01 \% \quad 9.6 \%$ GKDHVVSDFSEHGSLK

$6 \quad 0.01 \% \quad 5.3 \%$ GGFEEPVLLK

$0.01 \% \quad 5.3 \%$ SFLYEIVSNKR

$0.01 \% \quad 5.3 \% \quad$ YVGETQPTGQIK

$0.00 \% \quad 2.3 \%$ IHSDCAANQQVTYR

$0.00 \% \quad 2.3 \%$ ESSNVVVTER

$99.7 \% \quad 46.2$

$99.7 \% \quad 61.9$

$0.04 \% \quad 7.0 \%$ AESGPDLRYEVTSGGGGTSR

$0.04 \% \quad 7.0 \%$ AELIVQPELK

$0.04 \% \quad 7.0 \% \quad$ YGDGIQLTR
$99.7 \% \quad 39.4$

$99.0 \% \quad 36.2$

$99.7 \% \quad 43.4$

$98.4 \% \quad 21.5$

$99.7 \% \quad 55.9$

$99.0 \% \quad 36.2$

$99.4 \% \quad 21.5$

$99.7 \% \quad 46.5$

$99.7 \% \quad 54.5$

$99.7 \% \quad 36.4$

$99.7 \% \quad 36.7$

$99.7 \% \quad 57.7$

$99.7 \% \quad 64.7$

$99.7 \% \quad 59.0$

$99.7 \% \quad 67.7$

$99.7 \% \quad 40.8$

$99.7 \% \quad 54.4$

$99.7 \% \quad 29.1$

$99.7 \% \quad 68.3$

$95.2 \% \quad 17.4$

$99.7 \% \quad 38.6$

$99.7 \% \quad 27.0$

$99.7 \% \quad 67.5$

$99.5 \% \quad 26.3$

$99.7 \% \quad 66.9$

$99.7 \% \quad 62.7$

$99.1 \% \quad 20.5$

$99.7 \% \quad 43$.

$99.7 \% \quad 78.9$

$99.7 \% \quad 74.3$

$99.0 \% \quad 34.5$

$99.7 \% \quad 26.1$

$99.7 \% \quad 28.4$

$99.4 \% 30.1$

$97.4 \% \quad 18.5$

$99.7 \% \quad 32.7$

$99.7 \% \quad 37.0$

$99.7 \% \quad 38.6$

$99.7 \% \quad 64.7$

$94.8 \% \quad 22.5$

$99.7 \% \quad 41.9$

$99.7 \% 30.8$

1071.58

986.60

1220.52

1123.59

1370.60

800.37

1569.71

952.45

1438.63

989.54

1151.47

1698.96

1880.91

1320.62

639.83

952.56

1311.60

1418.73

1511.88

1396.72

1273.69

1151.61

1088.63

1306.66

1509.72

1232.68

1494.81

983.59

1386.80

1315.59

802.48

1450.85

1279.71

1203.60

970.58

230.68

1741.85

1088.60

1355.73

1320.68

1662.77

1119.56

1995.94

1139.67

$99.7 \% \quad 38.1$

$99.7 \% \quad 29.9$ 
DNA ligase $3 \mathrm{GN}=\mathrm{LIG} 3$ DNA ligase 3 GN=LIG3

DNA mismatch repair protein Msh2 GN=MSH2 MSH2_HUMAN $104.75100 .0 \%$ DNA mismatch repair protein Msh2 GN=MSH2 MSH2 HUMAN $104.75100 .0 \%$ DNA mismatch repair protein Msh2 GN=MSH2 MSH2_HUMAN $104.75 \quad 100.0 \%$ DNA mismatch repair protein Msh2 GN=MSH2 MSH2_HUMAN $104.75 \quad 100.0 \%$ DNA mismatch repair protein Msh2 GN=MSH2 MSH2_HUMAN $104.75 \quad 100.0 \%$ DNA mismatch repair protein Msh6 GN=MSH6 MSH6_HUMAN $152.79 \quad 100.0 \%$ DNA mismatch repair protein Msh6 GN=MSH6 MSH6_HUMAN $152.79 \quad 100.0 \%$ DNA mismatch repair protein Msh6 GN=MSH6 MSH6_HUMAN $152.79 \quad 100.0 \%$ DNA mismatch repair protein Msh6 GN=MSH6 MSH6_HUMAN $152.79 \quad 100.0 \%$ DNA mismatch repair protein Msh6 GN=MSH6 MSH6_HUMAN $152.79 \quad 100.0 \%$ DNA mismatch repair protein Msh6 GN=MSH6 MSH6_HUMAN $152.79 \quad 100.0 \%$ DNA mismatch repair protein Msh6 GN=MSH6 MSH6_HUMAN $152.79 \quad 100.0 \%$ DNA mismatch repair protein Msh6 GN=MSH6 MSH6_HUMAN $152.79 \quad 100.0 \%$ DNA mismatch repair protein Msh6 GN=MSH6 MSH6_HUMAN $152.79100 .0 \%$ DNA mismatch repair protein Msh6 GN=MSH6 MSH6 HUMAN $152.79100 .0 \%$ DNA mismatch repair protein Msh6 GN=MSH6 MSH6_HUMAN $152.79 \quad 100.0 \%$ DNA mismatch repair protein Msh6 GN=MSH6 MSH6_HUMAN $152.79 \quad 100.0 \%$ DNA mismatch repair protein Msh6 GN=MSH6 MSH6 HUMAN $152.79 \quad 100.0 \%$ DNA polymerase alpha catalytic subunit GN=POLA1 DPOLA_HUMAN $165.92 \quad 100.0 \%$ DNA polymerase alpha catalytic subunit GN=POLA1 DPOLA HUMAN $165.92 \quad 100.0 \%$ DNA polymerase delta catalytic subunit GN=POLD1 DPOD1_HUMAN $123.63 \quad 100.0 \%$ DNA polymerase delta catalytic subunit GN=POLD1 DPOD1_HUMAN $123.63 \quad 100.0 \%$ DNA polymerase delta catalytic subunit GN=POLD1 DPOD1_HUMAN $123.63100 .0 \%$ DNA polymerase delta catalytic subunit GN=POLD1 DPOD1_HUMAN $123.63 \quad 100.0 \%$ DNA polymerase delta catalytic subunit GN=POLD1 DPOD1_HUMAN $123.63 \quad 100.0 \%$ DNA polymerase delta catalytic subunit GN=POLD1 DPOD1_HUMAN $123.63 \quad 100.0 \%$ DNA polymerase epsilon catalytic subunit A GN=POLE DPOE1_HUMAN $261.52 \quad 100.0 \%$ DNA polymerase epsilon catalytic subunit A GN=POLE DPOE1 HUMAN $261.52 \quad 100.0 \%$ DNA polymerase epsilon catalytic subunit A GN=POLE DPOE1_HUMAN $261.52 \quad 100.0 \%$ DNA polymerase epsilon catalytic subunit A GN=POLE DPOE1_HUMAN $261.52 \quad 100.0 \%$ DNA polymerase epsilon catalytic subunit A GN=POLE DPOE1_HUMAN $261.52 \quad 100.0 \%$ DNA polymerase epsilon catalytic subunit A GN=POLE DPOE1_HUMAN $261.52 \quad 100.0 \%$ DNA polymerase epsilon catalytic subunit A GN=POLE DPOE1_HUMAN $261.52 \quad 100.0 \%$ DNA repair protein RAD50 GN=RAD50 RAD50_HUMAN $153.90 \quad 100.0 \%$ DNA repair protein RAD50 GN=RAD50 RAD50_HUMAN $153.90 \quad 100.0 \%$ DNA repair protein RAD50 GN=RAD50 RAD50_HUMAN $153.90 \quad 100.0 \%$ DNA repair protein RAD50 GN=RAD50 RAD50_HUMAN $153.90 \quad 100.0 \%$ DNA repair protein RAD50 GN=RAD50 RAD50_HUMAN $153.90 \quad 100.0 \%$ DNA repair protein RAD50 GN=RAD50 RAD50_HUMAN $153.90 \quad 100.0 \%$ DNA repair protein RAD50 GN=RAD50 RAD50_HUMAN $153.90 \quad 100.0 \%$ DNA repair protein RAD50 GN=RAD50 RAD50_HUMAN $153.90 \quad 100.0 \%$ DNA repair protein RAD50 GN=RAD50 RAD50_HUMAN $153.90 \quad 100.0 \%$ DNA repair protein RAD50 GN=RAD50 RAD50_HUMAN $153.90 \quad 100.0 \%$ DNA repair protein RAD50 GN=RAD50 RAD50_HUMAN $153.90 \quad 100.0 \%$ DNA repair protein RAD50 GN=RAD50 RAD50_HUMAN $153.90 \quad 100.0 \%$
$0.00 \% \quad 1.8 \%$ TQIIQDFLRK $0.00 \% \quad 1.8 \%$ NLQDVVER $0.01 \% \quad 5.4 \% \quad$ NLQSVVLSK $0.01 \% \quad 5.4 \%$ QVGVGYVDSIQR $0.01 \% \quad 5.4 \%$ GGILITER $0.01 \% \quad 5.4 \% \quad$ LTSLNEEYTK $0.01 \% \quad 5.4 \%$ NNSFVNEIISR $0.02 \% \quad 10.4 \%$ SPALSDANKASAR $0.02 \% \quad 10.4 \%$ VHVQFFDDSPTR $0.02 \% \quad 10.4 \%$ QATSISSETKNTLR $0.02 \% \quad 10.4 \%$ AYGVCFVDTSLGK $0.02 \% \quad 10.4 \%$ IHNVGSPLK $0.02 \% \quad 10.4 \%$ AIMYEETTYSK $0.02 \% \quad 10.4 \%$ IIGIMEEVADGFK $0.02 \% \quad 10.4 \%$ QVISLQTK $0.02 \% \quad 10.4 \%$ YQLEIPENFTTR $0.02 \% \quad 10.4 \%$ LANLINAEER $0.02 \% \quad 10.4 \%$ LANLPEEVIQK $0.02 \% \quad 10.4 \%$ EVCLASER $0.02 \% \quad 10.4 \%$ LLTLIKEL $0.00 \% \quad 1.5 \%$ AAYAGGLVLDPK $0.00 \% \quad 1.5 \%$ SGYSEVNLSK $0.01 \% \quad 5.8 \%$ ELNLAISR $0.01 \% \quad 5.8 \%$ VLSFDIECAGR $0.01 \% \quad 5.8 \%$ LGLTEDQFIR $0.01 \% \quad 5.8 \%$ IFEPILGEGR $0.01 \% \quad 5.8 \%$ VGGLLAFAK $0.01 \% \quad 5.8 \%$ TVLSHQGAVCEFCQPR $0.01 \% \quad 3.3 \% \quad$ KLEDYGEQK $0.01 \% \quad 3.3 \% \quad$ SSSLQDFDIR $0.01 \% \quad 3.3 \%$ SLAQFSYLEPGSIR $0.01 \% \quad 3.3 \%$ ALFGIFIPSQR $0.01 \% \quad 3.3 \%$ ASVFVLDTVR $0.01 \% \quad 3.3 \%$ FLLAYKEER $0.01 \% \quad 3.3 \%$ LGSSVIYANFNR $0.03 \% \quad 14.1 \%$ VAQETDVRAQIR $0.03 \% \quad 14.1 \%$ LQFRDVNGELIAVQR $0.03 \% \quad 14.1 \%$ CAEIDREMISSLGVSK $0.03 \% \quad 14.1 \%$ ACEIRDQITSK $0.03 \% \quad 14.1 \%$ SYENELDPLKNR $0.03 \% \quad 14.1 \%$ LKEIEHNLSK $0.03 \% \quad 14.1 \%$ IMKLDNEIK $0.03 \% \quad 14.1 \%$ LLNQEKSELLVEQGR $0.03 \% \quad 14.1 \%$ IIELKSEILSK $0.03 \% \quad 14.1 \%$ LQGIDLDR $0.03 \% \quad 14.1 \%$ KLIQDQQEQIQHLK $0.03 \% \quad 14.1 \%$ WLQDNLTLR
1535.80

1416.68

964.56

1335.61

1421.73

916.55

1510.75

1142.62

1253.71

963.46

942.62

1174.65

1083.53

915.53

1266.61

1191.64

1130.62

875.54

1888.88

1109.55

1167.56

1567.81

1248.71

1106.62

1168.64

1340.70

1385.75

1757.97

1794.87

1320.66

1477.73

1210.68

1103.61

1755.96

1272.78

929.51

1748.97 1158.63 $\begin{array}{cc}83 & 292 \\ 46 & 453 \\ 74 & 82 \\ 60 & 171 \\ 20 & 227 \\ 56 & 565 \\ 19 & 929 \\ 14 & 26 \\ 29 & 140 \\ 25 & 338 \\ 55 & 567 \\ 25 & 833 \\ 42 & 852 \\ 71 & 883 \\ 89 & 896 \\ 77 & 988 \\ 15 & 1024 \\ 305 & 1315 \\ 335 & 1342 \\ 353 & 1360 \\ 37 & 848 \\ 444 & 1453 \\ 67 & 174 \\ 12 & 322 \\ 30 & 639 \\ 69 & 978 \\ 99 & 1007 \\ 17 & 1032 \\ 42 & 1050 \\ 16 & 1125 \\ 472 & 1485 \\ 498 & 1508 \\ 10 & 1519 \\ 771 & 1579 \\ 559 & 1870 \\ 72 & 83 \\ 34 & 98 \\ 33 & 148 \\ 20 & 230 \\ 43 & 254 \\ 55 & 264 \\ 65 & 273 \\ 38 & 352 \\ 42 & 452 \\ 16 & 823 \\ 51 & 864 \\ 17 & 1025 \\ & \end{array}$ 
DNA repair protein RAD50 GN=RAD50 RAD50_HUMAN $153.90 \quad 100.0 \%$ DA repair protein RAD50 GN=RAD50 RAD50_HUMAN $153.90100 .0 \%$ DNA repair protein RAD50 GN=RAD50 RAD50_HUMAN $153.90 \quad 100.0 \%$ DNA repair protein RAD50 GN=RAD50 RAD50_HUMAN $153.90 \quad 100.0 \%$ DNA repair protein RAD51 homolog 2 GN=RAD51B RA51B_HUMAN $42.20 \quad 100.0 \%$ DNA repair protein RAD51 homolog 2 GN=RAD51B RA51B_HUMAN $42.20 \quad 100.0 \%$ DNA repair protein RAD51 homolog 3 GN=RAD51C RA51C HUMAN $42.19 \quad 100.0 \%$ DNA repair protein RAD51 homolog 3 GN=RAD51C RA51C_HUMAN $42.19 \quad 100.0 \%$ DNA repair protein RAD51 homolog 3 GN=RAD51C RA51C HUMAN $42.19 \quad 100.0 \%$ DNA replication licensing factor MCM3 GN=MCM3 MCM3_HUMAN $90.98 \quad 100.0 \%$ DNA replication licensing factor MCM3 GN=MCM3 MCM3_HUMAN $90.98 \quad 100.0 \%$ DNA replication licensing factor MCM3 GN=MCM3 MCM3 HUMAN $90.98 \quad 100.0 \%$ DNA replication licensing factor MCM3 GN=MCM3 MCM3_HUMAN $90.98 \quad 100.0 \%$ DNA replication licensing factor MCM3 GN=MCM3 MCM3_HUMAN $90.98 \quad 100.0 \%$ DNA replication licensing factor MCM3 GN=MCM3 MCM3_HUMAN $90.98 \quad 100.0 \%$ DNA replication licensing factor MCM3 GN=MCM3 MCM3_HUMAN $90.98 \quad 100.0 \%$ DNA replication licensing factor $\mathrm{MCM} 3 \mathrm{GN}=\mathrm{MCM} 3 \mathrm{MCM} 3$ HUMAN $90.98 \quad 100.0 \%$ DNA replication licensing factor MCM4 GN=MCM4 MCM4_HUMAN $96.56 \quad 100.0 \%$ DNA replication licensing factor MCM4 GN=MCM4 MCM4_HUMAN $96.56 \quad 100.0 \%$ DNA replication licensing factor MCM4 GN=MCM4 MCM4 HUMAN $96.56 \quad 100.0 \%$ DNA replication licensing factor MCM4 GN=MCM4 MCM4_HUMAN $96.56 \quad 100.0 \%$ DNA replication licensing factor MCM4 GN=MCM4 MCM4 HUMAN $96.56 \quad 100.0 \%$ DNA replication licensing factor MCM4 GN=MCM4 MCM4_HUMAN $96.56 \quad 100.0 \%$ DNA replication licensing factor MCM5 GN=MCM5 MCM5_HUMAN $82.29 \quad 100.0 \%$ DNA replication licensing factor MCM5 GN=MCM5 MCM5 HUMAN 82.29 DNA replication licensing factor MCM5 GN=MCM5 MCM5_HUMAN 82.29 DNA replication licensing factor MCM5 GN=MCM5 MCM5_HUMAN 82.29 DNA replication licensing factor MCM5 GN=MCM5 MCM5 HUMAN 82.2 DNA replication licensing factor MCM5 GN=MCM5 MCM5_HUMAN 82.29 DNA replication licensing factor MCM5 GN=MCM5 MCM5 HUMAN 82.29 DNA replication licensing factor MCM6 GN=MCM6 MCM6_HUMAN 92.89 DNA replication licensing factor MCM6 GN=MCM6 MCM6_HUMAN 92.89 DNA replication licensing factor MCM6 GN=MCM6 MCM6 HUMAN 92.89 DNA replication licensing factor MCM6 GN=MCM6 MCM6_HUMAN 92.89 DNA replication licensing factor MCM6 GN=MCM6 MCM6 HUMAN 92.85 DNA replicalion licening factor $\mathrm{MCM} 6 \mathrm{GN}=\mathrm{MCM} 6 \mathrm{MCM}$ DNA replication licensing factor MCM7 GN=MCM7 MCM7 HUMAN 81.31 DNA replication licensing factor MCM7 GN=MCM7 MCM7 HUMAN 81.31 DNA replication licensing factor MCM7 GN=MCM7 MCM7_HUMAN 81.31 DNA replication licensing factor MCM7 GN=MCM7 MCM7_HUMAN 81.3 DNA replication licensing factor MCM7 GN=MCM7 MCM7_HUMAN 81.3 DNA replication licensing factor MCM7 GN=MCM7 MCM7_HUMAN 81.3 DNA replication licensing factor MCM7 GN=MCM7 MCM7_HUMAN 81.3 DNA replication licensing factor MCM7 GN=MCM7 MCM7_HUMAN $81.31 \quad 100.0^{\circ}$ DNA replication licensing factor MCM7 GN=MCM7 MCM7_HUMAN $81.31 \quad 100.0 \%$ DNA replication licensing factor MCM7 GN=MCM7 MCM7 HUMAN $81.31 \quad 100.0 \%$ DNA replication licensing factor MCM7 GN=MCM7 MCM7_HUMAN $81.31 \quad 100.0 \%$

2

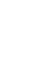

3

(2)

8
8
8

8
8

8
8

$0.02 \% \quad 9.3 \%$ TVLIACNVK

$\begin{array}{lll}0.02 \% & 9.3 \% & \text { SKDIFDQLAK } \\ 0.02 \% & 9.3 \% & \text { YVLCTAPR }\end{array}$

$99.7 \% \quad 66.2$

$25.0 \quad 31.7$

$14 \quad 0.02 \% \quad 9.3 \%$ GSSGVGLTAAVTTDQETGER

$0.01 \% \quad 6.8 \% \quad$ ATPAQTPRSEDAR

$0.01 \% \quad 6.8 \%$ QRPDLGSAQK

$0.01 \% \quad 6.8 \%$ IAEPSVCGR

$0.01 \% \quad 6.8 \%$ AVPIRVNPR

$0.01 \% \quad 6.8 \%$ AGIICQLNAR

$0.01 \% \quad 6.8 \%$ GMVSAYPR

$0.02 \% \quad 10.4 \%$ SFAGAVSPQEEEEFRR

$0.02 \% \quad 10.4 \%$ LAALPNVYEVISK

$0.02 \% \quad 10.4 \%$ SIAPSIFGGTDMKK

$0.02 \% \quad 10.4 \%$ AIACLLFGGSR

$0.02 \% \quad 10.4 \%$ AIACLLFGGSRK

$0.02 \% \quad 10.4 \%$ CSPIGVYTSGK

$0.02 \% \quad 10.4 \%$ LSAEAAEKLK

$95.5 \% \quad 15.2$

$99.5 \% \quad 22.6$

$98.1 \% \quad 23.6$

$96.8 \% \quad 19.6$

$99.7 \% \quad 63.1$

$99.0 \% \quad 22.6$

$97.6 \% \quad 16.7$

$99.7 \% \quad 26.6$

$98.2 \% \quad 24.0$

$99.7 \% \quad 63.1$

$99.7 \% \quad 46.2$

$99.5 \% \quad 25.4$

$99.7 \% \quad 42.4$

$99.3 \% \quad 27.6$

$0.02 \% \quad 7.2 \%$ FLLDTNKSR

$0.02 \% \quad 7.2 \%$ VSGVDGYETEGIRGLR

$0.02 \% \quad 7.2 \%$ HVEEFSPR

$99.7 \% 53.2$

$\begin{array}{ll}99.0 \% & 32.7 \\ 99.7 \% & 53.2\end{array}$

$0.02 \% \quad 7.2 \%$ TSILAAANPISGHYDR

$\begin{array}{ll}99.7 \% & 53.2 \\ 99.7 \% & 30.1\end{array}$

$\begin{array}{llll}0.02 \% & 7.2 \% & \text { TSILAAANPIS } \\ 0.02 \% & 7.2 \% & \text { LGFSEYCR }\end{array}$

$0.04 \% \quad 21.6 \%$ SPQNQYPAELMR

$0.04 \% \quad 21.6 \%$ ADSVGKLVTVR

$0.04 \% \quad 21.6 \%$ SITVLVEGENTR

$0.04 \% \quad 21.6 \%$ ALLLLLVGGVDQSPR

$99.0 \% \quad 46.6$

$99.7 \% \quad 40.6$

$\begin{array}{lll}99.7 \% & 60.1\end{array}$

$99.7 \% \quad 49.6$

$99.7 \% \quad 33.7$

$99.7 \% \quad 36.1$

$\begin{array}{lll}0.04 \% & 21.6 \% & \text { GNINICLMGDI } \\ 0.04 \% & 21.6 \% & \text { SQLLSYIDR }\end{array}$

$99.2 \% \quad 27.4$

$\begin{array}{lllll}0.04 \% & 21.6 \% & \text { SQYTTGRGSSGVGLTAAVLR } & 99.7 \% & 39.8\end{array}$

$99.7 \% \quad 63.2$

$99.7 \% \quad 64.7$

$99.7 \% \quad 55.4$

$99.7 \% \quad 57.5$

1714.89

884.59

1205.58

1206.56

1176.57

1270.77

1300.73

1256.72

1348.75

1137.55

1055.62

1211.72

1062.50

1017.58

1164.63

979.50

1935.93

1399.69

1099.59

988.49

1021.63

1115.60

896.43

1838.87

1416.81

1467.75

1164.62

1292.71

1168.57

1059.60

1093.60

1707.87

1000.48

1685.86

1900.99

1031.46

1433.68

1144.67

1317.70

1550.93

1574.77

1094.58

1981.05

1187.67

$0.04 \% \quad 21.6 \%$ AGILTTLNAR

$0.04 \% \quad 21.6 \%$ CSILAAANPAYGR

$0.04 \% \quad 21.6 \%$ SLEQNIQLPAALLSR
1214

1312

$206 \quad 217$

1324

$55 \quad 65$

$278 \quad 289$

$38 \quad 46$

$47 \quad 56$

$144 \quad 152$

$258 \quad 266$

$292 \quad 301$

$357 \quad 364$

$372 \quad 391$

$18 \quad 30$

$114 \quad 123$

$396 \quad 404$

$601 \quad 610$

$725 \quad 732$

$325 \quad 337$

$338 \quad 351$

$352 \quad 362$

$352 \quad 363$

$397 \quad 407$

$574 \quad 583$

$191 \quad 199$

285
415

$497 \quad 512$

$497 \quad 514$

$715 \quad 722$

$121 \quad 132$

$154 \quad 164$

$252 \quad 263$

$353 \quad 367$

$373 \quad 387$

$401 \quad 420$

$401 \quad 420$

$472 \quad 481$

$500 \quad 514$ 


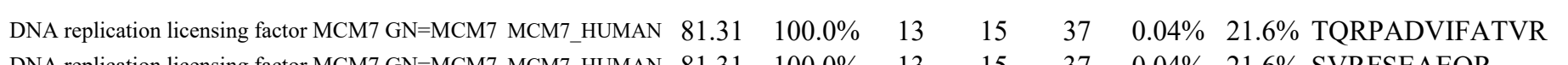
DNA topoisomerase $1 \mathrm{GN}=\mathrm{TOP} 1$ DNA topoisomerase $1 \mathrm{GN}=\mathrm{TOP} 1$ DNA topoisomerase $1 \mathrm{GN}=\mathrm{TOP} 1$ DNA topoisomerase $1 \mathrm{GN}=\mathrm{TOP} 1$

DNA topoisomerase $1 \mathrm{GN}=\mathrm{TOP} 1$ TOP1_HUMAN $90.73 \quad 100.0 \%$ TOP1 HUMAN $90.73 \quad 100.0 \%$ TOP1_HUMAN $90.73 \quad 100.0 \%$ TOP1_HUMAN $90.73 \quad 100.0 \%$ TOP1_HUMAN $90.73 \quad 100.0 \%$ DNA topoisomerase 2-alpha GN=TOP2A TOP2A_HUMAN $174.39 \quad 100.0 \% \quad 3$ DNA topoisomerase 2-alpha GN=TOP2A TOP2A_HUMAN $174.39 \quad 100.0 \%$ DNA topoisomerase 2-alpha GN=TOP2A TOP2A_HUMAN $174.39 \quad 100.0 \%$ DNA topoisomerase 2-alpha GN=TOP2A $\quad$ TOP2A_HUMAN $174.39 \quad 100.0 \% \quad 32$ DNA topoisomerase 2-alpha GN=TOP2A $\quad$ TOP2A_HUMAN $174.39 \quad 100.0 \% 32$ DNA topoisomerase 2-alpha GN=TOP2A $\quad$ TOP2A_HUMAN $174.39 \quad 100.0 \% \quad 32$ DNA topoisomerase 2-alpha GN=TOP2A TOP2A_HUMAN $174.39 \quad 100.0 \% 32$ DNA topoisomerase 2-alpha GN=TOP2A TOP2A_HUMAN $174.39 \quad 100.0 \% \quad 32$ DNA topoisomerase 2-alpha GN=TOP2A TOP2A_HUMAN $174.39 \quad 100.0 \% \quad 32$ DNA topoisomerase 2-alpha GN=TOP2A TOP2A_HUMAN $174.39 \quad 100.0 \% 32$ DNA topoisomerase 2-alpha GN=TOP2A TOP2A_HUMAN $174.39 \quad 100.0 \%$ DNA topoisomerase 2-alpha GN=TOP2A TOP2A_HUMAN $174.39 \quad 100.0 \% 32$ DNA topoisomerase 2-alpha GN=TOP2A $\quad$ TOP2A_HUMAN $174.39 \quad 100.0 \% 32$ DNA topoisomerase 2-alpha GN=TOP2A TOP2A_HUMAN $174.39 \quad 100.0 \% \quad 32$ DNA topoisomerase 2-alpha GN=TOP2A $\quad$ TOP2A_HUMAN $174.39 \quad 100.0 \% 32$ DNA topoisomerase 2-alpha GN=TOP2A $\quad$ TOP2A_HUMAN $174.39 \quad 100.0 \% 32$ DNA topoisomerase 2-alpha GN=TOP2A $\quad$ TOP2A_HUMAN $174.39 \quad 100.0 \% 32$ DNA topoisomerase 2-alpha GN=TOP2A TOP2A_HUMAN $174.39 \quad 100.0 \% 32$ DNA topoisomerase 2-alpha GN=TOP2A TOP2A_HUMAN $174.39 \quad 100.0 \% \quad 32$ DNA topoisomerase 2-alpha GN=TOP2A $\quad$ TOP2A_HUMAN $174.39 \quad 100.0 \% 32$ DNA topoisomerase 2-alpha GN=TOP2A $\quad$ TOP2A_HUMAN $174.39 \quad 100.0 \% 32$ DNA topoisomerase 2-alpha GN=TOP2A $\quad$ TOP2A_HUMAN $174.39 \quad 100.0 \% \quad 32$ DNA topoisomerase 2-alpha GN=TOP2A TOP2A HUMAN $174.39 \quad 100.0 \% 32$ DNA topoisomerase 2-alpha GN=TOP2A TOP2A_HUMAN $174.39 \quad 100.0 \% \quad 32$ DNA topoisomerase 2-alpha GN=TOP2A $\quad$ TOP2A_HUMAN $174.39 \quad 100.0 \% 32$ DNA topoisomerase 2-alpha GN=TOP2A $\quad$ TOP2A_HUMAN $174.39 \quad 100.0 \% 32$ DNA topoisomerase 2-alpha GN=TOP2A TOP2A_HUMAN $174.39 \quad 100.0 \% \quad 32$ DNA topoisomerase 2-alpha GN=TOP2A $\quad$ TOP2A_HUMAN $174.39 \quad 100.0 \% 32$ DNA topoisomerase 2-alpha GN=TOP2A TOP2A_HUMAN $174.39 \quad 100.0 \% 32$ DNA topoisomerase 2-alpha GN=TOP2A $\quad$ TOP2A_HUMAN $174.39 \quad 100.0 \% \quad 32$ DNA topoisomerase 2-alpha GN=TOP2A TOP2A_HUMAN $174.39 \quad 100.0 \% 32$ DNA topoisomerase 2-alpha GN=TOP2A TOP2A_HUMAN $174.39 \quad 100.0 \%$ DNA topoisomerase 2-beta $\mathrm{GN}=\mathrm{TOP} 2 \mathrm{~B}$ DNA topoisomerase 2-beta $\mathrm{GN}=\mathrm{TOP} 2 \mathrm{~B}$ DNA topoisomerase 2-beta $\mathrm{GN}=\mathrm{TOP} 2 \mathrm{H}$ DNA topoisomerase 2-beta $\mathrm{GN}=\mathrm{TOP} 2 \mathrm{~B}$ DNA topoisomerase 2-beta $\mathrm{GN}=\mathrm{TOP} 2 \mathrm{~B}$ DNA topoisomerase 2-beta $\mathrm{GN}=\mathrm{TOP} 2 \mathrm{~B}$ DNA topoisomerase 2-beta $\mathrm{GN}=\mathrm{TOP} 2 \mathrm{~B}$ DNA topoisomerase 2-beta $\mathrm{GN}=\mathrm{TOP} 2 \mathrm{~B}$
TOP2B_HUMAN $183.27 \quad 100.0 \% \quad 13$ TOP2B_HUMAN $183.27 \quad 100.0 \% \quad 13$ TOP2B_HUMAN $183.27 \quad 100.0 \% \quad 13$ TOP2B HUMAN $183.27 \quad 100.0 \% \quad 13$ TOP2B_HUMAN $183.27 \quad 100.0 \% \quad 13$ TOP2B_HUMAN $183.27 \quad 100.0 \% \quad 13$ TOP2B_HUMAN $183.27 \quad 100.0 \% \quad 13$ TOP2B_HUMAN $183.27 \quad 100.0 \% \quad 13$
$0.04 \% \quad 21.6 \%$ SVRFSEAEQR

$0.01 \% \quad 6.5 \%$ AEEVATFFAK

$0.01 \% \quad 6.5 \% \quad$ IMPEDIIINCSK

$0.01 \% \quad 6.5 \%$ VPSPPPGHK

$0.01 \% \quad 6.5 \% \quad$ YIMLNPSSR

$0.01 \% \quad 6.5 \% \quad$ AVAILCNHQR

$0.08 \% \quad 19.3 \%$ IFDEILVNAADNK

$0.08 \% \quad 19.3 \%$ IFDEILVNAADNKQR

$0.08 \% \quad 19.3 \%$ GIPVVEHKVEK

$0.08 \% \quad 19.3 \%$ LCNIFSTK

$0.08 \% \quad 19.3 \%$ LCNIFSTKFTVETASR

$0.08 \% \quad 19.3 \%$ FTVETASR

$0.08 \% \quad 19.3 \%$ RAYDIAGSTK

$0.08 \% \quad 19.3 \%$ AYDIAGSTKDVK

$0.08 \% \quad 19.3 \%$ GFQQISFVNSIATSK

$0.08 \% \quad 19.3 \%$ GGRHVDYVADQIVTK

$0.08 \% \quad 19.3 \%$ HVDYVADQIVTK

$0.08 \% \quad 19.3 \%$ SFGSTCQLSEK

$0.08 \% \quad 19.3 \%$ SFGSTCQLSEKFIK

$0.08 \% \quad 19.3 \%$ NSTECTLILTEGDSAK

$0.08 \% \quad 19.3 \%$ TLAVSGLGVVGR

$0.08 \% \quad 19.3 \%$ DKYGVFPLR

$0.08 \% \quad 19.3 \%$ QIMENAEINNIIK

$0.08 \% \quad 19.3 \%$ IVGLQYKK

$0.08 \% \quad 19.3 \%$ NYEDEDSLKTLR

$0.08 \% \quad 19.3 \%$ FLEEFITPIVK

$0.08 \% \quad 19.3 \%$ YSGPEDDAAISLAFSK

$0.08 \% \quad 19.3 \%$ YSGPEDDAAISLAFSKK

$0.08 \% \quad 19.3 \%$ KVLFTCFK

$0.08 \% \quad 19.3 \%$ YIFTMLSSLAR

$0.08 \% \quad 19.3 \%$ LMDGEEPLPMLPSYK

$0.08 \% \quad 19.3 \%$ MTEEKLAEAER

$0.08 \% \quad 19.3 \%$ FILEKIDGK

$0.08 \% \quad 19.3 \%$ IDGKIIIENKPK

$0.08 \% \quad 19.3 \%$ IIIENKPK

$0.08 \% \quad 19.3 \%$ TQMAEVLPSPR

$0.08 \% \quad 19.3 \%$ DPALNSGVSQKPDPAK

$0.03 \% \quad 13.4 \%$ EVTFVPGLYK

$0.03 \% \quad 13.4 \%$ IFDEILVNAADNK

$0.03 \% \quad 13.4 \%$ IFDEILVNAADNKQR

$0.03 \% \quad 13.4 \%$ GIPVVEHKVEK

$0.03 \% \quad 13.4 \%$ LCNIFSTK

$0.03 \% \quad 13.4 \%$ RAYDLAGSCR

$0.03 \% \quad 13.4 \%$ HVDYVVDQVVGK

$0.03 \% \quad 13.4 \%$ AGVSVKPFQVK
$0.08 \% \quad 19.3 \%$ EVTFVPGLYK $\begin{array}{lllllll}99.7 \% & 42.8 & 25.0 & 32.1 & 3 & 0 & 0\end{array}$ $\begin{array}{llllll}99.7 \% & 35.7 & 25.0 & 18.5 & 2 & 2\end{array}$

$99.7 \% \quad 40.5 \quad 25.0 \quad 34.2$

$\begin{array}{llll}95.9 \% & 15.7 & 25.0 & 15.1\end{array}$

$94.6 \% \quad 15.6 \quad 25.0 \quad 14.7$

$\begin{array}{llll}98.7 \% & 22.5 & 25.0 & 16.1\end{array}$

$\begin{array}{llll}99.7 \% & 50.1 & 25.0 & 39.5\end{array}$

$96.0 \% \quad 18.0 \quad 25.0 \quad 15.3$

$\begin{array}{llll}99.7 \% & 52.3 & 25.0 & 49.1\end{array}$

$\begin{array}{llll}99.7 \% & 60.3 & 25.0 & 53.2\end{array}$

$\begin{array}{llll}99.7 \% & 27.5 & 25.0 & 27.5\end{array}$

$99.0 \% \quad 40.9 \quad 25.0 \quad 35.5$

$\begin{array}{llll}99.7 \% & 37.5 & 25.0 & 37.5\end{array}$

$99.0 \% \quad 49.6 \quad 25.0 \quad 41.8$

$\begin{array}{llll}99.7 \% & 46.9 & 25.0 & 38.7\end{array}$

$\begin{array}{llll}99.7 \% & 38.8 & 25.0 & 37.9\end{array}$

$99.7 \% \quad 42.9 \quad 25.0 \quad 40.6$

$\begin{array}{llll}99.7 \% & 31.4 & 25.0 & 26.6\end{array}$

$\begin{array}{llll}99.7 \% & 67.6 & 25.0 & 61.9\end{array}$

$\begin{array}{llll}99.7 \% & 58.8 & 25.0 & 53.9\end{array}$

$\begin{array}{llll}99.7 \% & 37.5 & 25.0 & 37.0\end{array}$

$99.7 \% \quad 67.1 \quad 25.0 \quad 45.3$

$\begin{array}{llll}99.7 \% & 57.1 & 25.0 & 51.4\end{array}$

$\begin{array}{llll}99.3 \% & 23.7 & 25.0 & 18.9\end{array}$

$\begin{array}{llll}99.7 \% & 46.9 & 25.0 & 38.3\end{array}$

$\begin{array}{llll}99.0 \% & 27.0 & 25.0 & 25.6\end{array}$

$\begin{array}{llll}99.7 \% & 56.5 & 25.0 & 49.6\end{array}$

$99.7 \% \quad 49.9 \quad 25.0 \quad 49.2$

$\begin{array}{llll}99.7 \% & 49.2 & 25.0 & 49.2\end{array}$

$99.7 \% \quad 37.6 \quad 25.0 \quad 37.6$

$\begin{array}{llll}99.0 \% & 22.0 & 25.0 & 17.7\end{array}$

$\begin{array}{lllll}99.7 \% & 60.1 & 25.0 & 60.1 & 4\end{array}$

$\begin{array}{llll}99.7 \% & 37.4 & 25.0 & 31.6\end{array}$

$\begin{array}{llll}99.1 \% & 18.9 & 25.0 & 18.9\end{array}$

$\begin{array}{llll}97.5 \% & 20.6 & 25.0 & 14.5\end{array}$

$99.1 \% \quad 19.0 \quad 25.0 \quad 19.0$

$94.9 \% \quad 15.5 \quad 25.0 \quad 13.0$

$99.7 \% \quad 47.7 \quad 25.0 \quad 37.3$

$\begin{array}{llll}99.7 \% & 32.6 & 25.0 & 32.5\end{array}$

$\begin{array}{llll}96.0 \% & 18.0 & 25.0 & 15.3\end{array}$

$\begin{array}{llll}99.7 \% & 52.3 & 25.0 & 49.1\end{array}$

$\begin{array}{lllll}99.7 \% & 60.3 & 25.0 & 53.2 & 2\end{array}$

$\begin{array}{llll}99.7 \% & 27.5 & 25.0 & 27.5\end{array}$

$\begin{array}{llll}99.0 \% & 40.9 & 25.0 & 35.5\end{array}$

$\begin{array}{llll}99.5 \% & 25.1 & 25.0 & 21.8\end{array}$

$\begin{array}{llll}99.7 \% & 37.2 & 25.0 & 35.8\end{array}$

$\begin{array}{llll}99.2 \% & 26.1 & 25.0 & 17.8\end{array}$
1208.6

1208.60

1112.56

1448.7

915.50

1096.55

1181.62

1152.63

1461.76

1745.92

1234.72

982.50

1873.95

910.46

1081.56

1267.65

1626.85

1657.87

1387.72

1243.56

1631.81

1738.82

1128.67

1094.60

1529.80

948.59

1482.71

1335.76

1670.79

1798.89

1042.58

1301.69

1719.83

1306.63

1062.62

1367.83

954.60

1228.64

1623.83

1152.63

1461.76

1745.92

1234.72

982.50

1168.55

1357.71

1159.68 


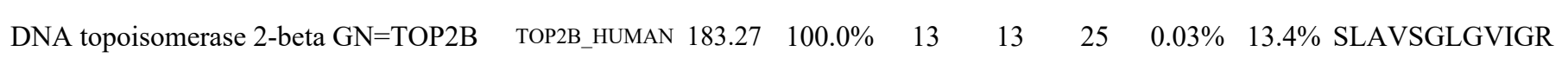

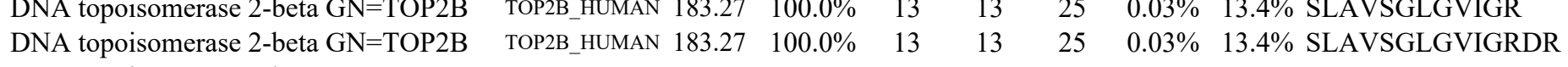
DNA topoisomerase 2-beta GN=TOP2B DNA topoisomerase 2-beta $\mathrm{GN}=\mathrm{TOP} 2 \mathrm{~B}$ DNA topoisomerase 2-beta GN=TOP2B DNA topoisomerase 2-beta GN=TOP2B DNA topoisomerase 2-beta $\mathrm{GN}=\mathrm{TOP} 2 \mathrm{~B}$ DNA topoisomerase 2-beta $\mathrm{GN}=\mathrm{TOP} 2 \mathrm{~B}$ DNA topoisomerase 2-beta $\mathrm{GN}=\mathrm{TOP} 2 \mathrm{~B}$ DNA topoisomerase 2-beta $\mathrm{GN}=\mathrm{TOP} 2 \mathrm{~B}$ DNA topoisomerase 2-beta GN=TOP2B DNA topoisomerase 2-beta GN=TOP2B DNA topoisomerase 2-beta GN=TOP2B TOP2B_HUMAN $183.27 \quad 100.0 \% \quad 13$ TOP2B HUMAN $183.27 \quad 100.0 \% \quad 13$ TOP2B_HUMAN $183.27 \quad 100.0 \% \quad 13$ TOP2B_HUMAN $183.27 \quad 100.0 \% \quad 13$ TOP2B_HUMAN $183.27 \quad 100.0 \% \quad 13$ TOP2B_HUMAN $183.27 \quad 100.0 \% \quad 13$ TOP2B HUMAN $183.27 \quad 100.0 \% \quad 13$ TOP2B_HUMAN $183.27 \quad 100.0 \% \quad 13$ TOP2B_HUMAN $183.27 \quad 100.0 \% \quad 13$ TOP2B_HUMAN $183.27 \quad 100.0 \% \quad 13$ TOP2B_HUMAN $183.27 \quad 100.0 \% \quad 13$ DC PRKDC_HUMAN $469.10 \quad 100.0 \% \quad 103$

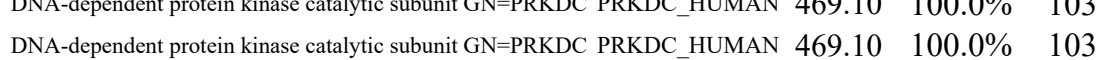
DNA-dependent protein kinase catalytic subunit GN=PRKDC PRKDC_HUMAN $469.10 \quad 100.0 \% \quad 103$ DNA-dependent protein kinase catalytic subunit GN=PRKDC PRKDC HUMAN $469.10 \quad 100.0 \% \quad 103$ DNA-dependent protein kinase catalytic subunit GN=PRKDC PRKDC_HUMAN $469.10 \quad 100.0 \% \quad 103$ DNA-dependent protein kinase catalytic subunit GN=PRKDC PRKDC_HUMAN $469.10 \quad 100.0 \% \quad 103$ DNA-dependent protein kinase catalytic subunit GN=PRKDC PRKDC_HUMAN $469.10 \quad 100.0 \% \quad 103$ DNA-dependent protein kinase catalytic subunit GN=PRKDC PRKDC_HUMAN $469.10 \quad 100.0 \% \quad 103$ DNA-dependent protein kinase catalytic subunit GN=PRKDC PRKDC_HUMAN $469.10 \quad 100.0 \% \quad 103$ $\begin{array}{llll}\text { DNA-dependent protein kinase catalytic subunit GN=PRKDC PRKDC_HUMAN } & 469.10 & 100.0 \% & 103\end{array}$ DNA-dependent protein kinase catalytic subunit GN=PRKDC PRKDC_HUMAN $469.10 \quad 100.0 \% \quad 103$ DNA-dependent protein kinase catalytic subunit GN=PRKDC PRKDC_HUMAN $469.10 \quad 100.0 \% \quad 103$ DNA-dependent protein kinase catalytic subunit GN=PRKDC PRKDC_HUMAN $469.10 \quad 100.0 \% \quad 103$ DNA-dependent protein kinase catalytic subunit GN=PRKDC PRKDC_HUMAN $469.10 \quad 100.0 \%$ DNA-dependent protein kinase catalytic subunit GN=PRKDC PRKDC_HUMAN $469.10 \quad 100.0 \% \quad 103$ DNA-dependent protein kinase catalytic subunit GN=PRKDC PRKDC_HUMAN $469.10 \quad 100.0 \% \quad 103$ DNA-dependent protein kinase catalytic subunit GN=PRKDC PRKDC HUMAN $469.10 \quad 100.0 \% \quad 103$ DNA-dependent protein kinase catalytic subunit GN=PRKDC PRKDC_HUMAN $469.10 \quad 100.0 \% \quad 103$ DNA-dependent protein kinase catalytic subunit GN=PRKDC PRKDC_HUMAN $469.10 \quad 100.0 \% \quad 103$ DNA-dependent protein kinase catalytic subunit GN=PRKDC PRKDC_HUMAN $469.10 \quad 100.0 \% \quad 103$ DNA-dependent protein kinase catalytic subunit GN=PRKDC PRKDC_HUMAN $469.10 \quad 100.0 \% \quad 103$ DNA-dependent protein kinase catalytic subunit GN=PRKDC PRKDC_HUMAN $469.10 \quad 100.0 \% \quad 103$ DNA-dependent protein kinase catalytic subunit GN=PRKDC PRKDC_HUMAN $469.10 \quad 100.0 \% \quad 103$ DNA-dependent protein kinase catalytic subunit GN=PRKDC PRKDC_HUMAN $469.10 \quad 100.0 \% \quad 103$ DNA-dependent protein kinase catalytic subunit GN=PRKDC PRKDC_HUMAN $469.10 \quad 100.0 \% \quad 103$ DNA-dependent protein kinase catalytic subunit GN=PRKDC PRKDC_HUMAN $469.10 \quad 100.0 \% \quad 103$ $\begin{array}{llll}\text { DNA-dependent protein kinase catalytic subunit GN=PRKDC PRKDC_HUMAN } & 469.10 & 100.0 \% & 103\end{array}$ DNA-dependent protein kinase catalytic subunit GN=PRKDC PRKDC HUMAN $469.10 \quad 100.0 \% \quad 103$ DNA-dependent protein kinase catalytic subunit GN=PRKDC PRKDC_HUMAN $469.10 \quad 100.0 \% \quad 103$ DNA-dependent protein kinase catalytic subunit GN=PRKDC PRKDC HUMAN $469.10 \quad 100.0 \% \quad 103$ DNA-dependent protein kinase catalytic subunit GN=PRKDC PRKDC_HUMAN $469.10 \quad 100.0 \% \quad 103$ DNA-dependent protein kinase catalytic subunit GN=PRKDC PRKDC_HUMAN $469.10 \quad 100.0 \% \quad 103$ DNA-dependent protein kinase catalytic subunit GN=PRKDC PRKDC_HUMAN $469.10 \quad 100.0 \% \quad 103$ DNA-dependent protein kinase catalytic subunit GN=PRKDC PRKDC_HUMAN $469.10 \quad 100.0 \% \quad 103$
$0.03 \% \quad 13.4 \%$ QIMENAEINNIIK

$0.03 \% \quad 13.4 \%$ IVGLQYKK

$0.03 \% \quad 13.4 \%$ SYDDAESLKTLR

$0.03 \% \quad 13.4 \%$ HGFLEEFITPIVK

$0.03 \% \quad 13.4 \%$ YAGPEDDAAITLAFSK

$0.03 \% \quad 13.4 \%$ LHGLPEQFLYGTATK

$0.03 \% \quad 13.4 \%$ SIPSLVDGFKPGQR

$0.03 \% \quad 13.4 \%$ KVLFTCFK

$0.03 \% \quad 13.4 \%$ LLFPAVDDNLLK

$0.03 \% \quad 13.4 \%$ DLIQMLVQR

$519 \quad 0.59 \% \quad 25.1 \%$ LQETLSAADR

$519 \quad 0.59 \% \quad 25.1 \%$ CGAALAGHQLIR

$519 \quad 0.59 \% \quad 25.1 \%$ IAPYSVEIK

$519 \quad 0.59 \% \quad 25.1 \%$ NTCTSVYTKDR

$519 \quad 0.59 \% \quad 25.1 \%$ TQMTSAVREPK

$519 \quad 0.59 \% \quad 25.1 \%$ LPVLAGCLK

$519 \quad 0.59 \% \quad 25.1 \%$ GLSSLLCNFTK

$\begin{array}{lll}519 & 0.59 \% & 25.1 \% \\ 5 M E E D P Q T S R\end{array}$

$519 \quad 0.59 \% \quad 25.1 \%$ AIRPQIDLKR

$519 \quad 0.59 \% \quad 25.1 \%$ YAVPSAGLR

$519 \quad 0.59 \% \quad 25.1 \%$ AALSALESFLK

$519 \quad 0.59 \% \quad 25.1 \%$ NVDSNNKELSIAIR

$519 \quad 0.59 \% \quad 25.1 \%$ GYGLFAGPCK

$519 \quad 0.59 \% \quad 25.1 \%$ VFLALAAK

$519 \quad 0.59 \% \quad 25.1 \%$ NCISTVVHQGLIR

$519 \quad 0.59 \% \quad 25.1 \%$ ICSKPVVLPK

$519 \quad 0.59 \% \quad 25.1 \%$ GPESESEDHRASGEVR

$519 \quad 0.59 \% \quad 25.1 \%$ IKYFEGVSPK

$519 \quad 0.59 \% \quad 25.1 \%$ FGKEVAVK

$519 \quad 0.59 \% \quad 25.1 \%$ AYVPALQMAFK

$519 \quad 0.59 \% \quad 25.1 \%$ TSALSDETKNNWEVSALSR

$519 \quad 0.59 \% \quad 25.1 \%$ NNWEVSALSR

$519 \quad 0.59 \% \quad 25.1 \%$ GFNKVVLK

$\begin{array}{lll}519 & 0.59 \% & 25.1 \% \\ & \text { NLSSNEAISLEEIR }\end{array}$

$519 \quad 0.59 \% \quad 25.1 \%$ NLSSNEAISLEEIRIR

$519 \quad 0.59 \% \quad 25.1 \%$ VVQMLGSLGGQINK

$519 \quad 0.59 \% \quad 25.1 \%$ NLLTVTSSDEMMK

$519 \quad 0.59 \% \quad 25.1 \%$ SYVAWDREK

$519 \quad 0.59 \% \quad 25.1 \%$ LSFAVPFR

$519 \quad 0.59 \% \quad 25.1 \%$ VTELALTASDR

$519 \quad 0.59 \% \quad 25.1 \%$ VTELALTASDRQTK

$519 \quad 0.59 \% \quad 25.1 \%$ RTFPVLLR

$519 \quad 0.59 \% \quad 25.1 \%$ LACDVDQVTR

$519 \quad 0.59 \% \quad 25.1 \%$ LYSLALHPNAFKR
$99.7 \% \quad 71.9$

$\begin{array}{lll}95.1 \% & 22.2\end{array}$

$\begin{array}{lll}97.4 \% & 18.2\end{array}$

$99.7 \% \quad 46.9$

$99.0 \% \quad 27.0$

$\begin{array}{lll}99.7 \% & 52.2\end{array}$

$99.7 \% \quad 40.8$

$99.7 \% \quad 63.7$

$99.0 \% \quad 20.9$

$99.7 \% \quad 34.5$

$99.0 \% \quad 22.0$

$99.7 \% \quad 29.5$

$99.7 \% \quad 48.4$

$99.7 \% \quad 48.0$

$99.7 \% \quad 47.5$

$99.7 \% \quad 35.6$

$99.7 \% \quad 36.6$

$99.5 \% \quad 25.2$

$99.7 \% 51.1$

$99.7 \% \quad 50.3$

$99.5 \% \quad 24.5$

$99.7 \% \quad 50.4$

$99.7 \% \quad 46.5$

$99.7 \% \quad 47.7$

$99.7 \% \quad 57.3$

$99.7 \% \quad 39.9$

$98.9 \% \quad 24.6$

$99.7 \% \quad 50.9$

$99.3 \% \quad 28.2$

$99.7 \% \quad 49.3$

$99.7 \% \quad 33.4$

$99.0 \% \quad 63.2$

$99.6 \% \quad 25.6$

$99.7 \% 30.1$

$\begin{array}{lll}99.7 \% & 43.0\end{array}$

$99.0 \% \quad 36.7$

$99.7 \% \quad 45.8$

$95.6 \% \quad 14.2$

$99.7 \% \quad 56.9$

$99.7 \% \quad 44.4$

$99.7 \% \quad 42.6$

$99.0 \% \quad 50.6$

$99.7 \% \quad 62.0$

$99.7 \% \quad 51.2$

$99.0 \% \quad 35.9$

$99.7 \% \quad 60.0$

$97.3 \% \quad 19.6$
1399.80

1122.61

1529.80

948.59

1397.69

1529.84

1668.81

1674.89

1500.82

1042.58

1357.77

1115.62

1103.57

1266.67

1019.58

1344.62

1247.64

970.58

1239.64

1179.49

1209.74

933.52

1149.65

1572.83

1069.51

832.53

1496.80

1140.68

1741.77

1167.64

877.51

1238.66

2108.03

1175.58

904.56

1574.80

1843.99

1459.79

1500.69

1153.56

936.53

1175.63

1532.83

1001.63

1176.57

1529.86 $\begin{array}{cc}88 & 499 \\ 88 & 501 \\ 00 & 508 \\ 21 & 533 \\ 34 & 541 \\ 42 & 553 \\ 88 & 600 \\ 61 & 676 \\ 98 & 712 \\ 35 & 748 \\ 49 & 756 \\ 37 & 848 \\ 93 & 1101 \\ 5 & 24 \\ 5 & 36 \\ 00 & 108 \\ 09 & 119 \\ 06 & 216 \\ 17 & 225 \\ 26 & 236 \\ 37 & 246 \\ 55 & 264 \\ 65 & 273 \\ 11 & 321 \\ 51 & 364 \\ 65 & 374 \\ 64 & 471 \\ 77 & 489 \\ 90 & 499 \\ 00 & 515 \\ 80 & 689 \\ 10 & 717 \\ 47 & 757 \\ 02 & 820 \\ 11 & 820 \\ 25 & 832 \\ 39 & 852 \\ 39 & 854 \\ 55 & 868 \\ 69 & 881 \\ 82 & 890 \\ 92 & 899 \\ 14 & 924 \\ 14 & 927 \\ 64 & 971 \\ & \end{array}$

Page 49 of Table S-1- 6 

DNA-dependentrin DNA-dependent protein kinase catalytic subunit GN=PRKDC PRKDC_HUMAN $469.10 \quad 100.0 \% \quad 103$ DNA-dependent protein kinase catalytic subunit GN=PRKDC PRKDC_HUMAN $469.10 \quad 100.0 \% \quad 103$ DNA-dependent protein kinase catalytic subunit GN=PRKDC PRKDC_HUMAN $469.10 \quad 100.0 \% \quad 103$ DNA-dependent protein kinase catalytic subunit GN=PRKDC PRKDC_HUMAN $469.10 \quad 100.0 \% \quad 103$ DNA-dependent protein kinase catalytic subunit GN=PRKDC PRKDC_HUMAN $469.10 \quad 100.0 \% \quad 103$ DNA-dependent protein kinase catalytic subunit GN=PRKDC PRKDC_HUMAN $469.10 \quad 100.0 \% \quad 103$ DNA-dependent protein kinase catalytic subunit GN=PRKDC PRKDC HUMAN $469.10 \quad 100.0 \% \quad 103$ DNA-dependent protein kinase catalytic subunit GN=PRKDC PRKDC_HUMAN $469.10 \quad 100.0 \% \quad 103$ DNA-dependent protein kinase catalytic subunit GN=PRKDC PRKDC_HUMAN $469.10 \quad 100.0 \% \quad 103$ DNA-dependent protein kinase catalytic subunit GN=PRKDC PRKDC_HUMAN $469.10 \quad 100.0 \% \quad 103$ DNA-dependent protein kinase catalytic subunit GN=PRKDC PRKDC_HUMAN $469.10 \quad 100.0 \% \quad 103$ DNA-dependent protein kinase catalytic subunit GN=PRKDC PRKDC_HUMAN $469.10 \quad 100.0 \% \quad 103$ DNA-dependent protein kinase catalytic subunit GN=PRKDC PRKDC_HUMAN $469.10 \quad 100.0 \% \quad 103$ DNA-dependent protein kinase catalytic subunit GN=PRKDC PRKDC_HUMAN $469.10 \quad 100.0 \% \quad 103$ DNA-dependent protein kinase catalytic subunit GN=PRKDC PRKDC HUMAN $469.10 \quad 100.0 \% \quad 103$ DNA-dependent protein kinase catalytic subunit GN=PRKDC PRKDC_HUMAN $469.10 \quad 100.0 \% \quad 103$ DNA-dependent protein kinase catalytic subunit GN=PRKDC PRKDC_HUMAN $469.10 \quad 100.0 \% \quad 103$ DNA-dependent protein kinase catalytic subunit GN=PRKDC PRKDC_HUMAN $469.10 \quad 100.0 \% \quad 103$ DNA-dependent protein kinase catalytic subunit GN=PRKDC PRKDC_HUMAN $469.10 \quad 100.0 \% \quad 103$ DNA-dependent protein kinase catalytic subunit GN=PRKDC PRKDC HUMAN $469.10 \quad 100.0 \% \quad 103$ DNA-dependent protein kinase catalytic subunit GN=PRKDC PRKDC_HUMAN $469.10 \quad 100.0 \% \quad 103$ $\begin{array}{llll}\text { DNA-dependent protein kinase catalytic subunit GN=PRKDC PRKDC_HUMAN } & 469.10 & 100.0 \% & 103\end{array}$ DNA-dependent protein kinase catalytic subunit GN=PRKDC PRKDC_HUMAN $469.10 \quad 100.0 \% \quad 103$ DNA-dependent protein kinase catalytic subunit GN=PRKDC PRKDC_HUMAN $469.10 \quad 100.0 \% \quad 103$ DNA-dependent protein kinase catalytic subunit GN=PRKDC PRKDC_HUMAN $469.10 \quad 100.0 \% \quad 103$ DNA-dependent protein kinase catalytic subunit GN=PRKDC PRKDC_HUMAN $469.10 \quad 100.0 \% \quad 103$ $\begin{array}{llll}\text { DNA-dependent protein kinase catalytic subunit GN=PRKDC PRKDC_HUMAN } & 469.10 & 100.0 \% & 103\end{array}$ DNA-dependent protein kinase catalytic subunit GN=PRKDC PRKDC HUMAN $469.10 \quad 100.0 \% \quad 103$ DNA-dependent protein kinase catalytic subunit GN=PRKDC PRKDC_HUMAN $469.10 \quad 100.0 \% \quad 103$ DNA-dependent protein kinase catalytic subunit GN=PRKDC PRKDC_HUMAN $469.10 \quad 100.0 \% \quad 103$ DNA-dependent protein kinase catalytic subunit GN=PRKDC PRKDC HUMAN $469.10 \quad 100.0 \% \quad 103$ DNA-dependent protein kinase catalytic subunit GN=PRKDC PRKDC_HUMAN $469.10 \quad 100.0 \% \quad 103$ DNA-dependent protein kinase catalytic subunit GN=PRKDC PRKDC_HUMAN $469.10 \quad 100.0 \% \quad 103$ DNA-dependent protein kinase catalytic subunit GN=PRKDC PRKDC_HUMAN $469.10 \quad 100.0 \% \quad 103$ DNA-dependent protein kinase catalytic subunit GN=PRKDC PRKDC_HUMAN $469.10 \quad 100.0 \% \quad 103$ DNA-dependent protein kinase catalytic subunit GN=PRKDC PRKDC HUMAN $469.10 \quad 100.0 \% \quad 103$ DNA-dependent protein kinase catalytic subunit GN=PRKDC PRKDC_HUMAN $469.10 \quad 100.0 \% \quad 103$ $\begin{array}{llll}\text { DNA-dependent protein kinase catalytic subunit GN=PRKDC PRKDC_HUMAN } & 469.10 & 100.0 \% & 103\end{array}$ DNA-dependent protein kinase catalytic subunit GN=PRKDC PRKDC_HUMAN $469.10 \quad 100.0 \% \quad 103$ DNA-dependent protein kinase catalytic subunit GN=PRKDC PRKDC_HUMAN $469.10 \quad 100.0 \% \quad 103$ DNA-dependent protein kinase catalytic subunit GN=PRKDC PRKDC HUMAN $469.10 \quad 100.0 \% \quad 103$ DNA-dependent protein kinase catalytic subunit GN=PRKDC PRKDC_HUMAN $469.10 \quad 100.0 \% \quad 103$ DNA-dependent protein kinase catalytic subunit GN=PRKDC PRKDC_HUMAN $469.10 \quad 100.0 \% \quad 103$ DNA-dependent protein kinase catalytic subunit GN=PRKDC PRKDC_HUMAN $469.10 \quad 100.0 \% \quad 103$ DNA-dependent protein kinase catalytic subunit GN=PRKDC PRKDC_HUMAN $469.10 \quad 100.0 \% \quad 103$
$26 \quad 519 \quad 0.59 \% \quad 25.1 \%$ LGASLAFNNIYR

$519 \quad 0.59 \% \quad 25.1 \%$ SLGTIQQCCDAIDHLCR

$519 \quad 0.59 \% \quad 25.1 \%$ FVPLLPGNR

$99.7 \% \quad 45.0$

$519 \quad 0.59 \% \quad 25.1 \%$ TVGALQVLGTEA

$519 \quad 0.59 \% \quad 25.1 \%$ CFGTGAAGNR

$519 \quad 0.59 \% \quad 25.1 \%$ TSPQEGERYNYSK

$519 \quad 0.59 \% \quad 25.1 \%$ DLCNTHLMR

$519 \quad 0.59 \% \quad 25.1 \%$ SRLAAVVSACK

$519 \quad 0.59 \% \quad 25.1 \%$ LAAVVSACK

$519 \quad 0.59 \% \quad 25.1 \%$ QCLPSLDLSCK

$519 \quad 0.59 \% \quad 25.1 \%$ LATTILQHWK

$519 \quad 0.59 \% \quad 25.1 \%$ MAVLALLAK

$\begin{array}{lll}519 & 0.59 \% & 25.1 \% \\ 5 N N Y V D C M K K\end{array}$

$519 \quad 0.59 \% \quad 25.1 \%$ LNESTFDTQITK

$519 \quad 0.59 \% \quad 25.1 \%$ LNESTFDTQITKK

$519 \quad 0.59 \% \quad 25.1 \%$ ILDVMYSR

$519 \quad 0.59 \% \quad 25.1 \%$ LPKDDVHAK

$519 \quad 0.59 \% \quad 25.1 \%$ INQVFHGSCITEGNELTK

$519 \quad 0.59 \% \quad 25.1 \%$ SLGPPQGEEDSVPR

$519 \quad 0.59 \% \quad 25.1 \%$ LGNPIVPLNIR

$519 \quad 0.59 \% \quad 25.1 \%$ SKDFVQVMR

$519 \quad 0.59 \% \quad 25.1 \%$ VCLDIIYK

$519 \quad 0.59 \% \quad 25.1 \%$ LPSNTLDR

$\begin{array}{llll}519 & 0.59 \% & 25.1 \% & \text { STVLTPMFVET } \\ 519 & 0.59 \% & 25.1 \% & \text { WPVAGQIR }\end{array}$

$\begin{array}{llll}519 & 0.59 \% & 25.1 \% & \text { ATQQQHDF } \\ 519 & 0.59 \% & 25.1 \% & \text { SVGPDFGK }\end{array}$

$519 \quad 0.59 \% \quad 25.1 \%$ SVGPDFGKK

$519 \quad 0.59 \% \quad 25.1 \%$ LGLPGDEVDNK

$519 \quad 0.59 \% \quad 25.1 \%$ LGLPGDEVDNKVK

$\begin{array}{llll}519 & 0.59 \% & 25.1 \% & \text { MKQDAQVVLYR }\end{array}$

$\begin{array}{llll}519 & 0.59 \% & 25.1 \% & \text { QDAQVVLYR }\end{array}$

$519 \quad 0.59 \% \quad 25.1 \%$ HGDLPDIQIK

$519 \quad 0.59 \% \quad 25.1 \%$ HSSLITPLQAVAQR

$\begin{array}{llll}519 & 0.59 \% & 25.1 \% & \text { HSSLITPLQAVAQRD } \\ 519 & 0.59 \% & 25.1 \% & \text { TLSEKNITQK }\end{array}$

$\begin{array}{llll}519 & 0.59 \% & 25.1 \% & \text { TLSEKNNITQ } \\ 519 & 0.59 \% & 25.1 \% & \text { LLEEALLR }\end{array}$

$519 \quad 0.59 \% \quad 25.1 \%$ LLPAELPAKR

$519 \quad 0.59 \% \quad 25.1 \%$ SIGEYDVLR

$519 \quad 0.59 \% \quad 25.1 \%$ GIFTSEIGTK

$519 \quad 0.59 \% \quad 25.1 \%$ QITQSALLAEAR

$519 \quad 0.59 \% \quad 25.1 \%$ QGNLSSQVPLK

$519 \quad 0.59 \% \quad 25.1 \%$ QGNLSSQVPLKR

$519 \quad 0.59 \% \quad 25.1 \%$ LLNTWTNRYPDAK

$519 \quad 0.59 \% \quad 25.1 \%$ KQNNFSLAMK

$519 \quad 0.59 \% \quad 25.1 \%$ SRSQGCSEQVLTVLK

$519 \quad 0.59 \% \quad 25.1 \%$ SQGCSEQVLTVLK
$99.6 \% \quad 26.1 \quad 25.0$

$99.7 \% \quad 50.0$

$99.7 \% \quad 55.1$

$99.7 \% \quad 44.7$

$99.7 \% \quad 42.7$

$99.7 \% \quad 29.5$

$99.7 \% \quad 45.3$

$99.7 \% \quad 54.6$

$99.7 \% \quad 42.0$

$99.7 \% \quad 38.1$

$99.7 \% \quad 34.0$

$99.7 \% \quad 56.5$

$99.7 \% \quad 53.3$

$99.0 \% \quad 51.2$

$\begin{array}{lll}99.7 \% & 36.9\end{array}$

$99.7 \% \quad 44.5$

$\begin{array}{lll}99.7 \% & 48.7\end{array}$

$99.7 \% \quad 34.1$

$99.7 \% \quad 30.9$

$\begin{array}{lll}99.0 \% & 32.8\end{array}$

$99.0 \% \quad 46.2$

$99.0 \% \quad 29.2$

$98.8 \% \quad 24.6$

$99.1 \% \quad 20.0$

$99.7 \% \quad 50.0$

$99.7 \% \quad 57.0$

$99.7 \% \quad 34.8$

$99.7 \% \quad 56.7$

$99.7 \% \quad 31.6$ $\begin{array}{llll}97.9 \% & 16.3 & 25.0 & 28.5\end{array}$ $\begin{array}{lll}16.3 & 25.0 & 16.3\end{array}$ $\begin{array}{llll}99.7 \% & 39.0 & 25.0 & 31.2\end{array}$ $\begin{array}{llll}99.0 \% & 55.2 & 25.0 & 49.9\end{array}$ $99.7 \% \quad 35.9 \quad 25.0 \quad 35.9$ $\begin{array}{llll}99.7 \% & 53.2 & 25.0 & 51.3\end{array}$ $\begin{array}{llll}99.7 \% & 46.8 & 25.0 & 46.5\end{array}$ $\begin{array}{llll}99.7 \% & 61.0 & 25.0 & 49.7\end{array}$ $\begin{array}{llll}97.6 \% & 18.8 & 25.0 & 15.4\end{array}$ $99.7 \% \quad 39.3 \quad 25.0 \quad 28.7$ $\begin{array}{llll}99.3 \% & 23.4 & 25.0 & 20.9\end{array}$ $99.5 \% \quad 31.0 \quad 25.0 \quad 25.3$ $\begin{array}{llll}99.7 \% & 41.2 & 25.0 & 35.9\end{array}$ $99.7 \% \quad 61.0 \quad 25.0 \quad 50.2$
Page 50 of Table S-1-6 
DNA-dependent protein kinase catalytic subunit GN=PRKDC PRKDC_HUMAN $469.10 \quad 100.0 \% \quad 103$ DNA-dependent protein kinase catalytic subunit GN=PRKDC PRKDC_HUMAN $469.10 \quad 100.0 \% \quad 103$ DNA-dependent protein kinase catalytic subunit GN=PRKDC PRKDC_HUMAN $469.10 \quad 100.0 \% \quad 103$ DNA-dependent protein kinase catalytic subunit GN=PRKDC PRKDC_HUMAN $469.10 \quad 100.0 \% \quad 103$ DNA-dependent protein kinase catalytic subunit GN=PRKDC PRKDC_HUMAN $469.10 \quad 100.0 \% \quad 103$ DNA-dependent protein kinase catalytic subunit GN=PRKDC PRKDC_HUMAN $469.10 \quad 100.0 \% \quad 103$ DNA-dependent protein kinase catalytic subunit GN=PRKDC PRKDC_HUMAN $469.10 \quad 100.0 \% \quad 103$ DNA-dependent protein kinase catalytic subunit GN=PRKDC PRKDC_HUMAN $469.10 \quad 100.0 \% \quad 10$ DNA-dependent protein kinase catalytic subunit GN=PRKDC PRKDC_HUMAN $469.10 \quad 100.0 \% 10$ DNA-dependent protein kinase catalytic subunit GN=PRKDC PRKDC_HUMAN $469.10 \quad 100.0 \% \quad 10$ DNA-dependent protein kinase catalytic subunit GN=PRKDC PRKDC_HUMAN $469.10 \quad 100.0 \% \quad 10$ DNA-dependent protein kinase catalytic subunit GN=PRKDC PRKDC_HUMAN $469.10 \quad 100.0 \% 103$ $\begin{array}{llll}\text { DNA-dependent protein kinase catalytic subunit GN=PRKDC PRKDC_HUMAN } & 469.10 & 100.0 \% & 103\end{array}$ DNA-dependent protein kinase catalytic subunit GN=PRKDC PRKDC_HUMAN $469.10 \quad 100.0 \% \quad 10$ DNA-dependent protein kinase catalytic subunit GN=PRKDC PRKDC_HUMAN $469.10 \quad 100.0 \% \quad 103$ DNA-dependent protein kinase catalytic subunit GN=PRKDC PRKDC_HUMAN $469.10 \quad 100.0 \%$ DNA-dependent protein kinase catalytic subunit GN=PRKDC PRKDC_HUMAN $469.10 \quad 100.0 \%$ DNA-dependent protein kinase catalytic subunit GN=PRKDC PRKDC_HUMAN $469.10 \quad 100.0 \% \quad 103$ $\begin{array}{llll}\text { DNA-dependent protein kinase catalytic subunit GN=PRKDC PRKDC_HUMAN } & 469.10 & 100.0 \% & 103\end{array}$ DNA-dependent protein kinase catalytic subunit GN=PRKDC PRKDC HUMAN $469.10 \quad 100.0 \% \quad 103$ DNA-dependent protein kinase catalytic subunit GN=PRKDC PRKDC_HUMAN $469.10 \quad 100.0 \% \quad 103$ DNA-dependent protein kinase catalytic subunit GN=PRKDC PRKDC_HUMAN $469.10 \quad 100.0 \% \quad 103$ DNA-directed RNA polymerase I subunit RPA1 GN=POLR1A RPA1_HUMAN $194.81 \quad 100.0 \%$ DNA-directed RNA polymerase I subunit RPA1 GN=POLR1A RPA1_HUMAN $194.81 \quad 100.0 \%$ DNA-directed RNA polymerase I subunit RPA34 GN=CD3EAP RPA34_HUMAN $54.99 \quad 100.0 \%$ DNA-directed RNA polymerase I subunit RPA34 GN=CD3EAP RPA34_HUMAN $54.99 \quad 100.0 \%$ DNA-directed RNA polymerase II subunit RPB1 GN=POLR2A RPB1_HUMAN $217.18 \quad 100.0 \%$ DNA-directed RNA polymerase II subunit RPB1 GN=POLR2A RPB1_HUMAN $217.18 \quad 100.0 \%$ DNA-directed RNA polymerase II subunit RPB1 GN=POLR2A RPB1_HUMAN $217.18 \quad 100.0 \%$ DNA-directed RNA polymerase III subunit RPC1 GN=POLR3A RPC1 HUMAN $155.65100 .0 \%$ DNA-directed RNA polymerase III subunit RPC1 GN=POLR3A RPC1_HUMAN $155.65 \quad 100.0 \%$ DNA-directed RNA polymerase III subunit RPC1 GN=POLR3A RPC1_HUMAN $155.65100 .0 \%$ DNA-directed RNA polynos I and II subunit RPACl GN=POLRIC RPAC1_HUMAN $39.25 \quad 100.0 \%$ DNA-directed RNA polymerases I and III subunit RPACI GN=POLRIC RPAC1_HUMAN $39.25 \quad 100.0 \%$ DNA-directed RNA polymerases I and III subunit RPAC1 GN=POLRIC RPAC1_HUMAN $39.25100 .0 \%$ DNA-directed RNA polymerases I and III subunit RPAC1 GN=POLR1C RPAC1_HUMAN $39.25100 .0 \%$ DNA-directed RNA polymerases I and III subunit RPAC1 GN=POLRIC RPAC1_HUMAN $39.25 \quad 100.0 \%$ DnaJ homolog subfamily A member $1 \mathrm{GN}=$ DNAJA1 DNJA1_HUMAN $44.87 \quad 100.0^{\circ}$ DnaJ homolog subfamily A member 1 GN=DNAJA1 DNJA1_HUMAN $44.87 \quad 100.0 \%$ DnaJ homolog subfamily A member $2 \mathrm{GN}=$ DNAJA2 DNJA2_HUMAN $45.75 \quad 100.0 \%$ DnaJ homolog subfamily A member 2 GN=DNAJA2 DNJA2 HUMAN $45.75 \quad 100.0 \%$ DnaJ homolog subfamily A member 2 GN=DNAJA2 DNJA2_HUMAN $45.75 \quad 100.0 \%$ DnaJ homolog subfamily A member 3, mitochondrial GN=DNAJA3 DNJA3 HUMAN $52.49 \quad 100.0 \%$ DnaJ homolog subfamily A member 3, mitochondrial GN=DNAJA3 DNJA3_HUMAN $52.49 \quad 100.0 \%$ DnaJ homolog subfamily A member 3, mitochondrial GN=DNAJA3 DNJA3_HUMAN $52.49 \quad 100.0 \%$ DnaJ homolog subfamily A member 3, mitochondrial GN=DNAJA3 DNJA3_HUMAN $52.49 \quad 100.0 \%$ DnaJ homolog subfamily A member 3, mitochondrial GN=DNAJA3 DNJA3_HUMAN $52.49 \quad 100.0 \%$

(2)

3

3
3
3
3

$\begin{array}{ll}3 & 3 \\ 3 & 3 \\ 3 & 3\end{array}$

3

3
5
5

3
6
6

6
6
6

2

2

3

3

3
3
3
11

1

$\begin{array}{ll}9 & 1 \\ 9 & 1 \\ 9 & 1 \\ 9 & 1\end{array}$

$519 \quad 0.59 \% \quad 25.1 \%$ DQNILLGTTYR

$519 \quad 0.59 \% \quad 25.1 \%$ ALKLNSNEAR

$519 \quad 0.59 \% \quad 25.1 \%$ NIEKMYER

$519 \quad 0.59 \% \quad 25.1 \%$ MYAALGDPK

$519 \quad 0.59 \% \quad 25.1 \%$ APGLGAFRR

$519 \quad 0.59 \% \quad 25.1 \%$ KFIQTFGK

$519 \quad 0.59 \% \quad 25.1 \%$ EFDKHFGK

$519 \quad 0.59 \% \quad 25.1 \%$ NELEIPGQYDGR

$519 \quad 0.59 \% \quad 25.1 \%$ VTVMASLR

$519 \quad 0.59 \% \quad 25.1 \%$ GHDEREHPFLVK

$519 \quad 0.59 \% \quad 25.1 \%$ TYSVVPMTSR

$519 \quad 0.59 \% \quad 25.1 \%$ APPCEYKDWLTK

$519 \quad 0.59 \% \quad 25.1 \%$ GANRTETVTSFR

$519 \quad 0.59 \% \quad 25.1 \%$ TETVTSFR

$519 \quad 0.59 \% \quad 25.1 \%$ VPADLLKR

$519 \quad 0.59 \% \quad 25.1 \%$ MSTSPEAFLALR

$519 \quad 0.59 \% \quad 25.1 \%$ APAFRDYVAVAR

$519 \quad 0.59 \% \quad 25.1 \%$ AQEPESGLSEETQVK

$519 \quad 0.59 \% \quad 25.1 \%$ CLMDQATDPNILGR

$0.00 \% \quad 1.1 \%$ GYLTPTSAR

$2 \quad 0.00 \% \quad 1.1 \%$ GAFLSYSQK

$4 \quad 0.00 \% \quad 5.1 \%$ FCAFGGNPPVTGPR

$0.00 \% \quad 5.1 \%$ SALAPNLLTSGK

$0.00 \% \quad 2.1 \%$ TPSLTVFLLGQSAR

$0.00 \% \quad 2.1 \% \quad$ YSPTSPTYSPTTPK

$0.00 \% \quad 2.1 \% \quad$ YSPTSPTYSPTSPK

$0.01 \% \quad 2.9 \% \quad$ LAPVYLSNR

$0.01 \% \quad 2.9 \%$ GFSIGIGDVTPGQGLLK

$6 \quad 0.01 \% \quad 2.9 \% \quad$ SLEDLCSQYDLTVR

$10 \quad 0.01 \% \quad 17.6 \%$ VVLGEFGVR

$10 \quad 0.01 \% \quad 17.6 \%$ ILLAEVPTMAVEK

$10 \quad 0.01 \% \quad 17.6 \%$ NQGDEEGTEIDTLQFR

$10 \quad 0.01 \% \quad 17.6 \%$ DSSDPNELYVNHK

$10 \quad 0.01 \% \quad 17.6 \%$ FSPVATASYR

$4 \quad 0.00 \% \quad 5.8 \% \quad$ NVICDKCEGR

$0.00 \% \quad 5.8 \%$ TIVITSHPGQIVK

$0.01 \% \quad 8.0 \%$ ELYDRYGEQGLR

$0.01 \% \quad 8.0 \%$ NVLCSACSGQGGK

$0.01 \% \quad 8.0 \%$ VIEPGCVR

$0.03 \% \quad 19.2 \%$ KAYYQLAK

$0.03 \% \quad 19.2 \%$ GGPTVDPEELFR

$0.03 \% \quad 19.2 \%$ GVNKEFTVNIMDTCER

$\begin{array}{llllll}0.03 \% & 19.2 \% \text { GSIIISPCVVCR } & 99.7 \% & 41.6 & 25.0 & 26.4 \\ 0.03 \% & 19.2 \% \text { RVMIPVPAGVEDGQTVR } & 99.7 \% & 36.4 & 25.0 & 35.8\end{array}$ $\begin{array}{llll}99.7 \% & 45.8 & 25.0 & 47.2\end{array}$

$99.7 \%-45.7-25.0-39.6$

$99.0 \% \quad 26.6 \quad 25.0 \quad 18.8$

$\begin{array}{llll}99.7 \% & 29.2 & 25.0 & 29.2\end{array}$

$\begin{array}{llll}99.7 \% & 28.0 & 25.0 & 20.1\end{array}$

$\begin{array}{llll}99.0 \% & 31.9 & 25.0 & 16.7\end{array}$

$\begin{array}{llll}97.7 \% & 19.9 & 25.0 & 16.0\end{array}$

$\begin{array}{llll}99.7 \% & 39.0 & 25.0 & 37.9\end{array}$

$\begin{array}{llll}99.0 \% & 33.8 & 25.0 & 23.8\end{array}$

$\begin{array}{llll}98.7 \% & 18.1 & 25.0 & 17.5\end{array}$

$99.7 \% \quad 27.2 \quad 25.0 \quad 27.2$

$\begin{array}{llll}98.6 \% & 21.1 & 25.0 & 15.7\end{array}$

$\begin{array}{llll}99.7 \% & 38.2 & 25.0 & 31.3\end{array}$

$99.0 \% \quad 45.6 \quad 25.0 \quad 41.9$

$\begin{array}{llll}99.0 \% & 58.6 & 25.0 & 43.0\end{array}$

$\begin{array}{llll}99.7 \% & 40.8 & 25.0 & 39.6\end{array}$

$\begin{array}{llll}99.7 \% & 39.9 & 25.0 & 29.2\end{array}$

$\begin{array}{llll}99.7 \% & 59.2 & 25.0 & 52.3\end{array}$

$99.7 \% \quad 52.3 \quad 25.0 \quad 52.3$

$\begin{array}{llll}99.6 \% & 26.2 & 25.0 & 21.4\end{array}$

$\begin{array}{llll}98.3 \% & 25.2 & 25.0 & 13.2\end{array}$

$\begin{array}{llll}99.7 \% & 52.5 & 25.0 & 52.5\end{array}$

$\begin{array}{llll}99.7 \% & 33.5 & 25.0 & 23.0\end{array}$

$\begin{array}{llll}99.7 \% & 47.0 & 25.0 & 47.0\end{array}$

$\begin{array}{llll}99.7 \% & 46.2 & 25.0 & 46.2\end{array}$

$\begin{array}{lllll}99.7 \% & 35.0 & 25.0 & 33.1 & 2\end{array}$

$\begin{array}{llll}99.3 \% & 27.5 & 25.0 & 24.0\end{array}$

$\begin{array}{lllll}99.7 \% & 45.8 & 25.0 & 45.8 & 2\end{array}$

$\begin{array}{lllll}99.7 \% & 54.5 & 25.0 & 46.3 & 2\end{array}$

$\begin{array}{llll}94.8 \% & 22.5 & 25.0 & 4.0\end{array}$

$\begin{array}{lllll}99.7 \% & 44.1 & 25.0 & 44.1 & 4\end{array}$

$99.7 \% \quad 71.6 \quad 25.0 \quad 71.6$

$\begin{array}{llll}99.7 \% & 36.1 & 25.0 & 36.1\end{array}$

$\begin{array}{lllll}99.7 \% & 38.2 & 25.0 & 30.9 & 2\end{array}$

$\begin{array}{llll}99.7 \% & 30.9 & 25.0 & 26.8\end{array}$

$\begin{array}{llll}99.7 \% & 59.1 & 25.0 & 54.7\end{array}$

$\begin{array}{llll}99.7 \% & 26.9 & 25.0 & 26.9\end{array}$

$99.7 \% \quad 63.6 \quad 25.0 \quad 63.6$

$\begin{array}{llll}99.0 \% & 24.4 & 25.0 & 19.4\end{array}$

$\begin{array}{llll}96.9 \% & 25.9 & 25.0 & 10.3\end{array}$

$\begin{array}{llll}99.7 \% & 51.5 & 25.0 & 51.5\end{array}$

$\begin{array}{llll}99.7 \% & 34.1 & 25.0 & 32.1\end{array}$

$\begin{array}{ll}99.7 \% & 36.4\end{array}$
0

0

0

0

$\begin{array}{ll}0 & 0 \\ 0 & 0 \\ 0 & 0\end{array}$

$\begin{array}{lll}68.90 & 3303 & 3318 \\ 008.10 & 3319 & 3335\end{array}$

$1293.68 \quad 3325 \quad 3335$

$2381.22 \quad 3359 \quad 3380$

$1115.62 \quad 3453 \quad 3462$

$1082.53 \quad 3605 \quad 3612$

$965.48 \quad 3613 \quad 3621$

$944.54 \quad 3622 \quad 3630$

$968.56 \quad 3631 \quad 3638$

$\begin{array}{lll}1007.49 & 3639 & 3646\end{array}$

$\begin{array}{lll}390.66 & 3697 & 3708\end{array}$

$1463.74 \quad 3742 \quad 3753$

$\begin{array}{lll}156.57 & 3790 & 3799\end{array}$

$\begin{array}{lll}1507.73 & 3834 & 3845\end{array}$

$\begin{array}{lll}338.68 & 3861 & 3872\end{array}$

38653872

$911.57 \quad 3878 \quad 3885$

$\begin{array}{lll}338.67 & 3890 & 3901\end{array}$

$\begin{array}{lll}335.72 & 4071 \quad 4082\end{array}$

$\begin{array}{llll}1631.78 & 4091 & 4105\end{array}$

$619.75 \quad 4106 \quad 4119$

$965.51 \quad 254 \quad 262$

$\begin{array}{lll}1000.51 & 1087 & 1095\end{array}$

$\begin{array}{lll}476.71 & 149 & 162\end{array}$

$\begin{array}{lll}1171.67 & 163 & 174\end{array}$

$\begin{array}{lll}1489.84 & 1136 & 1149\end{array}$

$\begin{array}{lll}1526.74 & 1874 & 1887\end{array}$

$\begin{array}{lll}1512.72 & 1909 & 1922\end{array}$

$\begin{array}{lll}1032.58 & 686 & 694\end{array}$

$1658.91 \quad 695 \quad 711$

$1698.80 \quad 878 \quad 891$

$\begin{array}{lll}975.56 & 14 & 22\end{array}$

$\begin{array}{lll}1429.80 & 79 & 91\end{array}$

$851.84 \quad 126 \quad 141$

$1517.69 \quad 155 \quad 167$

$\begin{array}{lll}1098.56 & 225 & 234\end{array}$

$\begin{array}{lll}250.56 & 131 & 140\end{array}$

$\begin{array}{ccc}1392.82 & 284 & 296 \\ 1498.73 & 64 & 75\end{array}$

$1337.59 \quad 140 \quad 152$

$929.49 \quad 303 \quad 310$

$984.55 \quad 111 \quad 118$

$\begin{array}{lll}1316.65 & 176 \quad 187\end{array}$

$1928.88 \quad 223 \quad 238$

$1360.71 \quad 282 \quad 293$

Page 51 of Table S-1- 
DnaJ homolog subfamily A member 3, mitochondrial GN=DNAJA3 DNJA3_HUMAN $52.49 \quad 100.0 \%$ DnaJ homolog subfamily A member 3, mitochondrial GN=DNAJA3 DNJA3_HUMAN $52.49 \quad 100.0 \%$ DnaJ homolog subfamily A member 3, mitochondrial GN=DNAJA3 DNJA3_HUMAN $52.49 \quad 100.0 \%$ DnaJ homolog subfamily A member 3, mitochondrial GN=DNAJA3 DNJA3 HUMAN $52.49 \quad 100.0 \%$ DnaJ homolog subfamily B member $1 \mathrm{GN}=$ DNAJB1 DNJB1_HUMAN $38.05 \quad 100.0 \%$ DnaJ homolog subfamily B member $1 \mathrm{GN}=$ DNAJB1 DNJB1_HUMAN $38.05 \quad 100.0 \%$ DnaJ homolog subfamily B member 11 GN=DNAJB11 DJB11_HUMAN $40.51 \quad 100.0 \%$ DnaJ homolog subfamily B member 11 GN=DNAJB11 DJB11_HUMAN $40.51 \quad 100.0 \%$ DnaJ homolog subfamily B member 11 GN=DNAJB11 DJB11_HUMAN $40.51 \quad 100.0 \%$ DnaJ homolog subfamily B member 11 GN=DNAJB11 DJB11_HUMAN $40.51 \quad 100.0 \%$ DnaJ homolog subfamily B member 12 GN=DNAJB12 DJB12_HUMAN $41.82 \quad 100.0 \%$ DnaJ homolog subfamily B member 12 GN=DNAJB12 DJB12_HUMAN $41.82 \quad 100.0 \%$ DnaJ homolog subfamily B member 12 GN=DNAJB12 DJB12_HUMAN $41.82 \quad 100.0 \%$ DnaJ homolog subfamily B member 6 GN=DNAJB6 DNJB6_HUMAN $36.09 \quad 100.0 \%$ DnaJ homolog subfamily B member 6 GN=DNAJB6 DNJB6_HUMAN $36.09 \quad 100.0 \%$ DnaJ homolog subfamily B member $6 \mathrm{GN}=$ DNAJB6 DNJB6_HUMAN $36.09 \quad 100.0 \%$ DnaJ homolog subfamily B member 6 GN=DNAJB6 DNJB6 HUMAN $36.09 \quad 100.0 \%$ DnaJ homolog subfamily B member 6 GN=DNAJB6 DNJB6_HUMAN $36.09 \quad 100.0 \%$ DnaJ homolog subfamily C member $10 \mathrm{GN}=$ DNAJC10 DJC10_HUMAN $91.08 \quad 100.0 \%$ DnaJ homolog subfamily C member 10 GN=DNAJC10 DJC10_HUMAN $91.08 \quad 100.0 \%$ DnaJ homolog subfamily C member $10 \mathrm{GN}=$ DNAJC10 DJC10_HUMAN $91.08 \quad 100.0 \%$ DnaJ homolog subfamily C member $10 \mathrm{GN}=$ DNAJC10 DJC10 HUMAN $91.08 \quad 100.0 \%$ DnaJ homolog subfamily C member $10 \mathrm{GN}=$ DNAJC10 DJC10_HUMAN $91.08 \quad 100.0 \%$ DnaJ homolog subfamily C member 11 GN=DNAJC11 DJC11_HUMAN $63.28 \quad 100.0 \%$ DnaJ homolog subfamily C member $11 \mathrm{GN}=$ DNAJC11 DJC11_HUMAN $63.28 \quad 100.0 \%$ DnaJ homolog subfamily C member 11 GN=DNAJC11 DJC11_HUMAN $63.28 \quad 100.0 \%$ DnaJ homolog subfamily C member 11 GN=DNAJC11 DJC11_HUMAN $63.28 \quad 100.0 \%$ DnaJ homolog subfamily C member 11 GN=DNAJC11 DJC11_HUMAN $63.28 \quad 100.0 \%$ DnaJ homolog subfamily C member 11 GN=DNAJC11 DJC11_HUMAN $63.28 \quad 100.0 \%$ DnaJ homolog subfamily C member 11 GN=DNAJC11 DJC11 HUMAN $63.28 \quad 100.0 \%$ DnaJ homolog subfamily C member 11 GN=DNAJC11 DJC11_HUMAN $63.28 \quad 100.0 \%$ DnaJ homolog subfamily C member 11 GN=DNAJC11 DJC11_HUMAN $63.28 \quad 100.0 \%$ DnaJ homolog subfamily C member $13 \mathrm{GN}=$ DNAJC13 DJC13 HUMAN $254.42 \quad 100.0 \%$ DnaJ homolog subfamily C member 13 GN=DNAJC13 DJC13_HUMAN $254.42 \quad 100.0 \%$ DnaJ homolog subfamily C member 13 GN=DNAJC13 DJC13_HUMAN $254.42 \quad 100.0 \%$ DnaJ homolog subfamily C member $13 \mathrm{GN}=$ DNAJC13 DJC13_HUMAN $254.42 \quad 100.0 \%$ DnaJ homolog subfamily C member 13 GN=DNAJC13 DJC13_HUMAN $254.42 \quad 100.0 \%$ DnaJ homolog subfamily C member $13 \mathrm{GN}=$ DNAJC13 DJC13_HUMAN $254.42 \quad 100.0 \%$ DnaJ homolog subfamily C member 13 GN=DNAJC13 DJC13_HUMAN $254.42 \quad 100.0 \%$ DnaJ homolog subfamily C member $13 \mathrm{GN}=$ DNAJC13 DJC13_HUMAN $254.42 \quad 100.0 \%$ DnaJ homolog subfamily C member 13 GN=DNAJC13 DJC13_HUMAN $254.42 \quad 100.0 \%$ DnaJ homolog subfamily C member 13 GN=DNAJC13 DJC13_HUMAN $254.42 \quad 100.0 \%$ Dolichol-phosphate mannosyltransferase subunit 1 GN=DPM1 DPM1_HUMAN $29.64100 .0 \%$ Dolichol-phosphate mannosyltransferase subunit 1 GN=DPM1 DPM1_HUMAN $29.64 \quad 100.0 \%$ Dolichol-phosphate mannosyltransferase subunit 1 GN=DPM1 DPM1_HUMAN $29.64 \quad 100.0 \%$ Dolichol-phosphate mannosyltransferase subunit 1 GN=DPM1 DPM1_HUMAN $29.64 \quad 100.0 \%$ Dolichol-phosphate mannosyltransferase subunit 1 GN=DPM1 DPM1_HUMAN $29.64 \quad 100.0 \%$

(1)

(1)

3

3

3
5
5
5

5
5
5
5

5
5
5

5
5
5

5
5

5
5
5

5
9
9

9

9

9

9

9

9
9
9

9

9

10
10
10

10
10

10

10
10

\begin{tabular}{|c|c|c|c|c|}
\hline $3 \%$ & $.2 \% \mathrm{~V}$ & $.7 \% \quad 53.5$ & 25.0 & 50.6 \\
\hline $0.03 \%$ & 19.2\% INSYGYGDHYIHIK & $99.7 \% \quad 41.2$ & 25.0 & 40.0 \\
\hline $0.03 \%$ & 19.2\% REAGEDEEGFLSK & $99.7 \% \quad 37.2$ & 25.0 & 37.2 \\
\hline $0.03 \%$ & 19.2\% EAGEDEEGFLSK & $99.5 \% \quad 23.8$ & 25.0 & 23.8 \\
\hline $0.00 \%$ & $8.2 \%$ NPFDTFFGQR & $98.6 \% \quad 22.8$ & 25.0 & 19.5 \\
\hline $0.00 \%$ & 8.2\% EGDQTSNNIPADIVFVLK & $99.6 \% \quad 25.8$ & 5.0 & 21.1 \\
\hline $0.01 \%$ & 15.1\% LALQLHPDRNPDDPQAQEK & $99.7 \% \quad 39.1$ & 5.0 & 39.1 \\
\hline $0.01 \%$ & 15.1\% FQMTQEVVCDECPNVK & $99.7 \% \quad 57.7$ & 5.0 & 57.7 \\
\hline $0.01 \%$ & 15.1\% TLEVEIEPGVR & $99.7 \% \quad 50.0$ & 5.0 & 38.0 \\
\hline $0.01 \%$ & $15.1 \%$ EQLTEEAR & $97.9 \% \quad 24.2$ & 5.0 & 18.0 \\
\hline $0.00 \%$ & 9.6\% GYTAEQVAAVK & $96.5 \% \quad 19.4$ & 5.0 & 14.2 \\
\hline $0.00 \%$ & 9.6\% AIGTAYAVLSNPEK & $99.7 \% \quad 47.0$ & 5.0 & 47.0 \\
\hline $0.00 \%$ & $9.6 \%$ NVEDDYIANLR & $99.7 \% \quad 53.1$ & 5.0 & 53.1 \\
\hline $0.02 \%$ & 20.2\% VDYYEVLGVQR & $99.7 \% \quad 67.1$ & 25.0 & 50.1 \\
\hline $0.02 \%$ & 20.2\% QVAEAYEVLSDAK & $99.7 \% \quad 72.3$ & 5.0 & 67.1 \\
\hline $0.02 \%$ & 20.2\% VEVEEDGQLK & $99.7 \% \quad 26.8$ & 5.0 & 23.8 \\
\hline $0.02 \%$ & $20.2 \%$ SLTINGVADDDALAEER & $99.7 \% \quad 60.8$ & 25.0 & 60.8 \\
\hline $0.02 \%$ & $20.2 \%$ APGPWDPLASAAGLK & $99.7 \% \quad 31.3$ & 5.0 & 31.3 \\
\hline $0.01 \%$ & 7.2\% IGAVNCGDDRMLCR & $99.7 \% \quad 31.2$ & 5.0 & 28.7 \\
\hline $0.01 \%$ & $7.2 \%$ ALLPELRR & $98.5 \% \quad 21.8$ & 25.0 & 17.1 \\
\hline $0.01 \%$ & $7.2 \%$ ASNLLYGQLK & $99.7 \% \quad 54.2$ & 5.0 & 42.8 \\
\hline $0.01 \%$ & 7.2\% AGKVDCQAYAQTCQK & $99.7 \% \quad 36.1$ & 25.0 & 36.1 \\
\hline $0.01 \%$ & 7.2\% NFQEEQINTR & $99.6 \% \quad 39.6$ & 25.0 & 18.6 \\
\hline $0.02 \%$ & $18.8 \%$ EASSEELKAAYR & $99.6 \% \quad 28.4$ & 25.0 & 25.6 \\
\hline $0.02 \%$ & $18.8 \%$ AIYDIYGKR & $99.7 \% \quad 53.8$ & 25.0 & 52.1 \\
\hline $0.02 \%$ & $18.8 \%$ CFVTTNCALQFSSR & $99.7 \% \quad 74.7$ & 25.0 & 74.7 \\
\hline $0.02 \%$ & 18.8\% GIRPGLTTVLAR & $99.7 \% \quad 37.0$ & 25.0 & 37.0 \\
\hline $0.02 \%$ & 18.8\% AGFFGTVVEYGAER & $99.7 \% \quad 76.0$ & 25.0 & 69.7 \\
\hline $0.02 \%$ & 18.8\% AGFFGTVVEYGAERK & $99.2 \% \quad 22.1$ & 25.0 & 22.0 \\
\hline $0.02 \%$ & $18.8 \%$ HSVLGAAVSVGVPQGVSLK & $99.7 \% \quad 37.7$ & 25.0 & 37.7 \\
\hline $0.02 \%$ & $18.8 \%$ VIDVTVPLQCLVK & $99.7 \% \quad 38.2$ & 25.0 & 36.5 \\
\hline $0.02 \%$ & $18.8 \%$ DSKLILTEASK & $99.6 \% \quad 25.0$ & 25.0 & 24.4 \\
\hline $0.02 \%$ & 4.9\% GQGTEFNLTFR & $99.7 \% \quad 49.4$ & 25.0 & 44.4 \\
\hline $0.02 \%$ & 4.9\% AIIEEGDKEIATK & $99.7 \% \quad 41.8$ & 25.0 & 31.3 \\
\hline $0.02 \%$ & 4.9\% ENINQKPVVLR & $97.0 \% \quad 15.7$ & 25.0 & 15.7 \\
\hline $0.02 \%$ & $4.9 \%$ IAAHLADFTPR & $99.7 \% \quad 32.2$ & 25.0 & 31.5 \\
\hline $0.02 \%$ & 4.9\% AYEFLCTK & $98.6 \% \quad 22.5$ & 25.0 & 15.2 \\
\hline $0.02 \%$ & $4.9 \%$ TQSILFNR & $97.7 \% \quad 18.4$ & 25.0 & 16.9 \\
\hline $0.02 \%$ & 4.9\% SEETNQQEVANSLAK & $99.7 \% \quad 76.8$ & 25.0 & 70.3 \\
\hline $0.02 \%$ & 4.9\% VEMALEALR & $99.7 \% \quad 43.4$ & 25.0 & 22.7 \\
\hline $0.02 \%$ & 4.9\% MTADKLIGPK & $95.9 \% \quad 19.6$ & 25.0 & 15.7 \\
\hline $0.02 \%$ & 4.9\% RADTVGLACEAINR & $99.7 \% \quad 37.7$ & 25.0 & 32.7 \\
\hline $0.02 \%$ & 28.5\% YSVLLPTYNER & $99.4 \% \quad 22.1$ & 25.0 & 21.8 \\
\hline $0.02 \%$ & 28.5\% DVAEQLEK & $99.0 \% \quad 27.0$ & 25.0 & 15.6 \\
\hline $0.02 \%$ & 28.5\% LGLGTAYIHGMK & $99.7 \% \quad 42.0$ & 25.0 & 41.9 \\
\hline $0.02 \%$ & $28.5 \%$ FIPEFIRK & $98.0 \% \quad 24.5$ & 25.0 & 10.8 \\
\hline $0.02 \%$ & 28.5\% QKEGNFDIVSGTR & $99.7 \% \quad 31.6$ & 25.0 & 26.8 \\
\hline
\end{tabular}



Dual specificity protein phosphatase $9 \mathrm{GN}=$ DUSP9 DUS9_HUMAN $41.87 \quad 100.0 \%$ Dual specificity protein phosphatase 9 GN=DUSP9 DUS9_HUMAN $41.87 \quad 100.0 \%$ Dual specificity protein phosphatase $9 \mathrm{GN}=$ DUSP9 DUS9 HUMAN $41.87 \quad 100.0 \%$ Dynactin subunit $1 \mathrm{GN}=\mathrm{DCTN} 1$

0.01\% $7.9 \%$ NTLLIAGLQAR

$0.01 \% \quad 7.9 \%$ YSQTGNYELAVALSR

$0.01 \% \quad 7.9 \%$ WVFKEEGVLR

$0.01 \% \quad 14.2 \%$ VTAEVVLAHLGGGSTSR

$0.01 \% \quad 14.2 \%$ LPVALDPGAK

$0.01 \% \quad 14.2 \%$ YDYQRQPDSGISSIR

$0.01 \% \quad 14.2 \%$ NIEIDSPYEISR

$0.01 \% \quad 14.2 \%$ ALTSEIALLQSR

$0.01 \% \quad 14.2 \%$ SAVEAERLVAGK

$0.01 \% \quad 14.2 \%$ IDHILDAL

$0.00 \% \quad 7.7 \%$ ETLPSIWDSPTK

$0.00 \% \quad 7.7 \%$ QLSVVVPSYNEEK

$0.02 \% \quad 17.2 \%$ NLPVNFEVAR

$0.02 \% \quad 17.2 \%$ VSVGEFVGEGEGK

$0.02 \% \quad 17.2 \%$ NAAIAVLEELK

$0.02 \% \quad 17.2 \%$ NAAIAVLEELKK

$0.02 \% \quad 17.2 \%$ LPPLPAVER

$0.02 \% \quad 17.2 \%$ TKPIVKPQTSPEYGQGINPISR

$0.02 \% \quad 17.2 \%$ LAQIQQAK

$0.02 \% \quad 17.2 \%$ LAQIQQAKK

$0.02 \% \quad 17.2 \%$ EKEPEYTLLTER

$0.02 \% \quad 17.2 \%$ VPQAQPTKPALK

$0.01 \% \quad 9.3 \% \quad$ VSVGEFSAEGEGNSKK

$0.01 \% \quad 9.3 \%$ AGPEYGQGMNPISR

$0.01 \% \quad 9.3 \%$ LAQIQQAK

$0.01 \% \quad 9.3 \% \quad$ LAQIQQAKK

$0.01 \% \quad 9.3 \%$ VGNEVATGTGPNKK

$0.01 \% \quad 4.2 \% \quad$ NTNSVPETAPAAIPETKR

$0.01 \% \quad 4.2 \% \quad$ AMTILLEEAK

$0.01 \% \quad 4.2 \% \quad$ YLNTNPVGGLLEYAR

$0.01 \% \quad 4.2 \%$ VSIYDSKR

$0.00 \% \quad 4.5 \%$ RLEAFLTQK

$0.00 \% \quad 4.5 \% \quad$ LNQPGTPTR

$0.01 \% \quad 14.1 \%$ GAYGVVEK

$0.01 \% \quad 14.1 \%$ DVKPSNVLINK

$0.01 \% \quad 14.1 \%$ MCDFGISGYLVDSVAK

$0.01 \% \quad 14.1 \%$ QVVEEPSPQLPADR

$0.00 \% \quad 8.3 \%$ FTLNPNPTGVQNPHIER

$0.00 \% \quad 8.3 \%$ LCDFGISGQLVDSIAK

$0.01 \% \quad 13.5 \%$ SRELYESAR

$0.01 \% \quad 13.5 \%$ FQAECPHLCETSLAGR

$0.01 \% \quad 13.5 \%$ ASFPVQILPNLYLGSAR

$0.01 \% \quad 13.5 \%$ DSANLESLAK

$0.02 \% \quad 10.5 \%$ GTVAYVGATLFATGK $\begin{array}{llllllll}99.7 \% & 52.3 & 25.0 & 42.5 & 1 & 0 & 0 & 1194.58\end{array}$ $\begin{array}{llllllll}99.7 \% & 34.2 & 25.0 & 32.0 & 2 & 0 & 0 & 1404.67\end{array}$

$99.7 \% \quad 56.8$

$99.7 \% \quad 63.9$

$99.7 \% \quad 99.4$

$99.7 \% \quad 32.9$

$99.7 \% \quad 46.3$

$99.1 \% \quad 19.9$

$99.7 \% \quad 40.6$

$99.7 \% 57.2$

$99.7 \% \quad 46.7$

$99.7 \% 58.8$

$97.4 \% 16$.

$99.7 \% \quad 38.9$

$99.7 \% \quad 40.1$

$96.2 \% \quad 19.2$

$99.7 \% \quad 65.6$

$99.7 \% \quad 46.1$

$99.7 \% \quad 54.9$

$98.5 \% \quad 17.5$

$99.7 \% 50.7$

$99.0 \% \quad 50.0$

$99.7 \% \quad 51.4$

$99.6 \% \quad 28.0$

$99.7 \% \quad 36.9$

$99.7 \% \quad 32.2$

$99.7 \% \quad 48.8$

$99.0 \% 50.0$

$99.7 \% \quad 51.4$

$98.1 \% \quad 21.0$

$\begin{array}{ll}99.5 \% & 23.4 \\ 95.4 \% & 20.8\end{array}$

$99.7 \% \quad 54.8$

$\begin{array}{llll}99.4 \% & 23.4 & 25.0 & 17.8\end{array}$

$99.6 \% \quad 25.2 \quad 25.0 \quad 25.2$

$\begin{array}{llll}97.4 \% & 24.2 & 25.0 & 9.9\end{array}$

$99.6 \% \quad 23.6 \quad 25.0 \quad 22.3$

$\begin{array}{llll}99.7 \% & 52.5 & 25.0 & 52.5\end{array}$

$\begin{array}{llll}99.7 \% & 38.0 & 25.0 & 38.0\end{array}$

$\begin{array}{llll}99.0 \% & 19.3 & 25.0 & 18.4\end{array}$

$99.7 \% \quad 60.0 \quad 25.0 \quad 46.0$

$99.0 \% \quad 28.6 \quad 25.0 \quad 16.6$

$\begin{array}{llll}95.0 \% & 17.9 & 25.0 & 12.2\end{array}$

$\begin{array}{lllll}99.7 \% & 36.8 & 25.0 & 36.8 & 2\end{array}$

$\begin{array}{llll}99.7 \% & 39.6 & 25.0 & 27.5\end{array}$ $\begin{array}{llll}99.7 \% & 60.3 & 25.0 & 56.8\end{array}$
1404.67
1176.66

1169.70

1671.83

1262.69

1653.89

980.58

1784.86

1435.71

1301.74

1229.68

909.50

1373.69

1491.77

1158.63

1293.63

1170.67

1298.77

991.59

2410.31

899.53

1027.63

1507.76

1277.76

1624.78

1476.69

899.53

1027.63

1371.72

1895.98

1118.61

1679.88

967.52

1105.64

983.53

822.44

1226.7

1777.81

1564.80

1933.99

1722.87

1110.55

1875.85

1846.02

1047.53 1455.78

\begin{tabular}{cc}
37 & 147 \\
06 & 216 \\
41 & 251 \\
40 & 250 \\
83 & 297 \\
98 & 307 \\
9 & 65 \\
17 & 126 \\
64 & 278 \\
80 & 391 \\
25 & 536 \\
65 & 576 \\
00 & 607 \\
4 & 65 \\
6 & 78 \\
97 & 206 \\
20 & 232 \\
40 & 250 \\
40 & 251 \\
52 & 260 \\
69 & 290 \\
91 & 298 \\
91 & 299 \\
00 & 311 \\
56 & 367 \\
43 & 258 \\
98 & 311 \\
12 & 319 \\
12 & 320 \\
46 & 359 \\
68 & 385 \\
65 & 574 \\
22 & 736 \\
09 & 1116 \\
3 & 61 \\
89 & 397 \\
3 & 80 \\
90 & 200 \\
06 & 221 \\
80 & 293 \\
9 & 75 \\
45 & 260 \\
9 & 37 \\
30 & 145 \\
01 & 217 \\
18 & 227 \\
2 & 56 \\
& \\
\hline
\end{tabular}

Page 53 of Table S-1-6 
Dynactin subunit $1 \mathrm{GN}=\mathrm{DCTN} 1$ Dynactin subunit $1 \mathrm{GN}=\mathrm{DCTN} 1$ Dynactin subunit $1 \mathrm{GN}=\mathrm{DCTN} 1$ Dynactin subunit $1 \mathrm{GN}=\mathrm{DCTN} 1$ Dynactin subunit $1 \mathrm{GN}=\mathrm{DCTN} 1$ Dynactin subunit $1 \mathrm{GN}=\mathrm{DCTN} 1$ Dynactin subunit $1 \mathrm{GN}=\mathrm{DCTN} 1$ Dynactin subunit $1 \mathrm{GN}=\mathrm{DCTN} 1$ Dynactin subunit $1 \mathrm{GN}=\mathrm{DCTN} 1$

Dynamin-2 GN=DNM2

Dynamin-2 GN=DNM2

Dynamin -2 GN=DNM2

Dynamin-2 GN=DNM2

Dynein assembly factor 5, axonemal GN=DNAAF5 DAAF5 HUMAN 93.52 $100.0 \%$

Dynein assembly factor 5, axonemal GN=DNAAF5 DAAF5_HUMAN $93.52 \quad 100.0 \%$ Dynein assembly factor 5, axonemal GN=DNAAF5 DAAF5_HUMAN $93.52 \quad 100.0 \%$ Dynein assembly factor 5, axonemal GN=DNAAF5 DAAF5 HUMAN $93.52 \quad 100.0 \%$ E3 SUMO-protein ligase RanBP2 GN=RANBP2 RBP2_HUMAN $358.20 \quad 100.0 \%$ E3 SUMO-protein ligase RanBP2 GN=RANBP2 RBP2_HUMAN $358.20 \quad 100.0 \%$ E3 SUMO-protein ligase RanBP2 GN=RANBP2 RBP2 HUMAN $358.20 \quad 100.0 \%$ E3 SUMO-protein ligase RanBP2 GN=RANBP2 RBP2_HUMAN $358.20 \quad 100.0 \%$ E3 SUMO-protein ligase RanBP2 GN=RANBP2 RBP2 HUMAN $358.20 \quad 100.0 \%$ E3 ubiquitin-protein ligase HERC2 GN=HERC2 HERC2_HUMAN $527.22 \quad 100.0 \%$ E3 ubiquitin-protein ligase HERC2 GN=HERC2 HERC2_HUMAN $527.22 \quad 100.0 \%$ E3 ubiquitin-protein ligase HUWE1 GN=HUWE1 HUWE1_HUMAN $481.89 \quad 100.0 \%$ E3 ubiquitin-protein ligase HUWE1 GN=HUWE1 HUWE1_HUMAN $481.89 \quad 100.0 \%$ E3 ubiquitin-protein ligase HUWE1 GN=HUWE1 HUWE1_HUMAN $481.89 \quad 100.0 \%$ E3 ubiquitin-protein ligase HUWE1 GN=HUWE1 HUWE1_HUMAN $481.89 \quad 100.0 \%$ E3 ubiquitin-protein ligase HUWE1 GN=HUWE1 HUWE1_HUMAN $481.89 \quad 100.0 \%$ E3 ubiquitin-protein ligase HUWE1 GN=HUWE1 HUWE1_HUMAN $481.89 \quad 100.0 \%$ E3 ubiquitin-protein ligase HUWE1 GN=HUWE1 HUWE1_HUMAN $481.89 \quad 100.0 \%$ E3 ubiquitin-protein ligase HUWE1 GN=HUWE1 HUWE1_HUMAN $481.89 \quad 100.0 \%$ E3 ubiquitin-protein ligase HUWE1 GN=HUWE1 HUWE1_HUMAN $481.89 \quad 100.0 \%$ E3 ubiquitin-protein ligase HUWE1 GN=HUWE1 HUWE1_HUMAN $481.89 \quad 100.0 \%$ E3 ubiquitin-protein ligase HUWE1 GN=HUWE1 HUWE1_HUMAN $481.89 \quad 100.0 \% 24$ E3 ubiquitin-protein ligase HUWE1 GN=HUWE1 HUWE1_HUMAN $481.89 \quad 100.0 \% 24$ E3 ubiquitin-protein ligase HUWE1 GN=HUWE1 HUWE1_HUMAN $481.89 \quad 100.0 \%$ E3 ubiquitin-protein ligase HUWE1 GN=HUWE1 HUWE1_HUMAN $481.89 \quad 100.0 \% 24$ E3 ubiquitin-protein ligase HUWE1 GN=HUWE1 HUWE1_HUMAN $481.89 \quad 100.0 \% \quad 24$ E3 ubiquitin-protein ligase HUWE1 GN=HUWE1 HUWE1_HUMAN $481.89 \quad 100.0 \% \quad 24$ E3 ubiquitin-protein ligase HUWE1 GN=HUWE1 HUWE1_HUMAN $481.89 \quad 100.0 \% \quad 24$ E3 ubiquitin-protein ligase HUWE1 GN=HUWE1 HUWE1_HUMAN $481.89 \quad 100.0 \% \quad 24$ E3 ubiquitin-protein ligase HUWE1 GN=HUWE1 HUWE1_HUMAN $481.89 \quad 100.0 \% \quad 24$ E3 ubiquitin-protein ligase HUWE1 GN=HUWE1 HUWE1_HUMAN $481.89 \quad 100.0 \% \quad 24$ E3 ubiquitin-protein ligase HUWE1 GN=HUWE1 HUWE1_HUMAN $481.89 \quad 100.0 \% \quad 24$ E3 ubiquitin-protein ligase HUWE1 GN=HUWE1 HUWE1_HUMAN $481.89 \quad 100.0 \% \quad 24$ E3 ubiquitin-protein ligase HUWE1 GN=HUWE1 HUWE1_HUMAN $481.89 \quad 100.0 \% \quad 24$
$0.02 \% \quad 10.5 \%$ KYFTCDEGHGIFVR $0.02 \% \quad 10.5 \%$ MQEQQADLQR $0.02 \% \quad 10.5 \%$ IKGEELSEANVR $0.02 \% \quad 10.5 \%$ DSPLLLQQISAMR $0.02 \% \quad 10.5 \%$ LHISQLQHENSILK $0.02 \% \quad 10.5 \%$ ASLASLPPLHVAK $0.02 \% \quad 10.5 \%$ LSHEGPGSELPAGALYR $0.02 \% \quad 10.5 \%$ SPSAQLMEQVAQLK $0.02 \% \quad 10.5 \%$ VTFSCAAGFGQR

$0.01 \% \quad 4.5 \%$ GISPVPINLR $0.01 \% \quad 4.5 \%$ EVDPQGLR $0.01 \% \quad 4.5 \%$ GYIGVVNR $0.01 \% \quad 4.5 \%$ EISYAIKNIHGVR $0.01 \% \quad 4.7 \%$ LLPGLEADSKPGR $0.01 \% \quad 4.7 \%$ CLSDPAEGCR $0.01 \% \quad 4.7 \% \quad$ LLPALAAR $0.01 \% \quad 4.7 \% \quad$ LFDDVPQVR $0.01 \% \quad 2.1 \% \quad$ YIASVQGSTPSPR $0.01 \% \quad 2.1 \% \quad$ IIDDSDSNLSVVK $0.01 \% \quad 2.1 \%$ FGISEPGNQEK $0.01 \% \quad 2.1 \%$ IAVAVLEETTR $0.01 \% \quad 2.1 \%$ SNNSETSSVAQSGSESKVEPK $0.00 \% \quad 0.5 \%$ SLNVSSSVNQASR $0.00 \% \quad 0.5 \%$ AAGLESAATIR $0.09 \% \quad 6.9 \%$ TPTEAPADCR $0.09 \% \quad 6.9 \% \quad$ TLTSIVHLER $0.09 \% \quad 6.9 \% \quad$ AIQDPAFSDGIR $0.09 \% \quad 6.9 \%$ GLQSFVQCQPFER $0.09 \% \quad 6.9 \% \quad$ ADGTATAPPPR $0.09 \% \quad 6.9 \%$ SILTLSHEPK

$0.09 \% \quad 6.9 \% \quad$ SHHAASTTTAPTPAAR $0.09 \% \quad 6.9 \% \quad$ AALPLTTSDTK $0.09 \% \quad 6.9 \% \quad$ YLQSNSNNWR $0.09 \% \quad 6.9 \%$ HIIEDPCTLR $0.09 \% \quad 6.9 \%$ SAATSGAGSTTSGVVSGSLGSR $0.09 \% \quad 6.9 \%$ GSGTASDDEFENLR $0.09 \% \quad 6.9 \%$ KGLVNDLAR $0.09 \% \quad 6.9 \% \quad$ IVNQPSSLFGSK

$0.09 \% \quad 6.9 \%$ HADHSSLTLGSGSSTTR $0.09 \% \quad 6.9 \% \quad$ AGSSTPGDAPPAVAEVQGR $0.09 \% \quad 6.9 \%$ DSAVAISGADSR $0.09 \% \quad 6.9 \% \quad$ NLCYHAQTR $0.09 \% \quad 6.9 \%$ SSESELCIETPK $0.09 \% \quad 6.9 \%$ TNIFQIQR $0.09 \% \quad 6.9 \%$ HVLDTLIQLAK $0.09 \% \quad 6.9 \% \quad$ LGSSGLGSASSIQAAVR $\begin{array}{lllll}0.09 \% & 6.9 \% & \text { RQQQAATSESSQSEASVR } & 99.0 \% & 25.4\end{array}$

$99.5 \% \quad 23.5$

$99.7 \% 53$. $99.7 \% 33.3$

$98.7 \% \quad 17.9$ $99.5 \% \quad 22.3$

$\begin{array}{lll}99.7 \% & 41.8\end{array}$ $99.7 \% \quad 79.4$ $99.7 \% \quad 42.6$ $99.7 \% \quad 34.8$ $99.0 \% \quad 34.5$ $99.0 \% \quad 30.8$ $99.0 \% \quad 28.0$ $99.7 \% \quad 26.6$ $99.7 \% 26.7$ $\begin{array}{lll}95.6 \% & 16.4\end{array}$ $99.7 \% \quad 41.5$ $99.7 \% \quad 49.1$ $\begin{array}{lll}97.8 \% & 36.4\end{array}$ $98.8 \% \quad 21.0$ $99.7 \% \quad 50.0$

$99.1 \% 23.2$ $\begin{array}{ll}99.7 \% & 52.7\end{array}$ $99.4 \% \quad 32.0$ $99.7 \% \quad 41.6$ $99.7 \% \quad 33.1$ $99.7 \% \quad 38.7$ $99.7 \% \quad 43.6$ $99.7 \% \quad 29.9$ $99.7 \% \quad 41.5$ $99.5 \% \quad 25.5$ $99.7 \% \quad 31.2$ $99.2 \% \quad 20.5$ $99.7 \% \quad 28.2$ $\begin{array}{lll}99.7 \% & 74.9\end{array}$ $99.7 \% \quad 60.3$ $99.7 \% \quad 28.9$ $99.7 \% \quad 40.2$ $99.7 \% \quad 53.4$ $99.6 \% \quad 24.5$ $99.7 \% \quad 29.6$ $99.0 \% \quad 42.9$ $99.0 \% \quad 42.9$
1728.82 1262.58

1344.71

1471.79

1659.92

1303.77

1753.89

1529.80

1300.61

1065.64

913.47

877.49

1499.83

1352.75

1164.48

824.54

1088.57

1362.70

1404.72

1205.58

1201.68

2152.00

1348.68

1059.58

1117.49

1168.67

1289.65

1595.76

1053.53

1124.63

1576.78

1117.61

1281.60

1253.63

1896.93

1497.65

985.58

1276.69

1713.82

1766.87

1148.55

1162.54

1379.64

1019.56

1250.75

1560.83 1949.93 
E3 ubiquitin-protein ligase HUWE1 GN=HUWE1 HUWE1_HUMAN $481.89 \quad 100.0 \% \quad 24 \quad 25 \quad 82 \quad 0.09 \% \quad 6.9 \%$ FLQFVTGTSK E3 ubiquitin-protein ligase MYCBP2 GN=MYCBP2 MYCB2_HUMAN $510.08 \quad 100.0 \%$ E3 ubiquitin-protein ligase MYCBP2 GN=MYCBP2 MYCB2_HUMAN $510.08 \quad 100.0 \%$ 3 ubiquitin-protein ligase MYCBP2 GN=MYCBP2 MYCB2 HUMAN $510.08 \quad 100.0 \%$ E3 ubiquitin-protein ligase MYCBP2 GN=MYCBP2 MYCB2_HUMAN $510.08 \quad 100.0 \%$ E3 ubiquitin-protein ligase MYCBP2 GN=MYCBP2 MYCB2_HUMAN $510.08 \quad 100.0 \%$ E3 ubiquitin-protein ligase MYCBP2 GN=MYCBP2 MYCB2_HUMAN $510.08 \quad 100.0 \%$ E3 ubiquitin-protein ligase RING2 GN=RNF2 RING2_HUMAN $37.66 \quad 100.0 \%$ E3 ubiquitin-protein ligase RING2 GN=RNF2 RING2 HUMAN $37.66 \quad 100.0 \%$ E3 ubiquitin-protein ligase RING2 GN=RNF2 RING2_HUMAN $37.66 \quad 100.0 \%$ E3 ubiquitin-protein ligase TRIM21 GN=TRIM21 RO52_HUMAN $54.17 \quad 100.0 \%$ E3 ubiquitin-protein ligase TRIM21 GN=TRIM21 RO52 HUMAN $54.17 \quad 100.0 \%$ E3 ubiquitin-protein ligase TRIM21 GN=TRIM21 RO52_HUMAN $54.17 \quad 100.0 \%$ E3 ubiquitin-protein ligase TRIM21 GN=TRIM21 RO52 HUMAN $54.17 \quad 100.0 \%$ E3 ubiquitin-protein ligase TRIM21 GN=TRIM21 RO52_HUMAN $54.17 \quad 100.0 \%$ E3 ubiquitin-protein ligase TRIM21 GN=TRIM21 RO52_HUMAN $54.17 \quad 100.0 \%$ E3 ubiquitin-protein ligase TRIM21 GN=TRIM21 RO52 HUMAN $54.17 \quad 100.0 \%$ E3 ubiquitin-protein ligase TRIP12 GN=TRIP12 TRIPC_HUMAN $220.44 \quad 100.0 \%$ E3 ubiquitin-protein ligase TRIP12 GN=TRIP12 TRIPC_HUMAN $220.44 \quad 100.0 \%$ E3 ubiquitin-protein ligase TRIP12 GN=TRIP12 TRIPC HUMAN $220.44 \quad 100.0 \%$ E3 ubiquitin-protein ligase UBR4 GN=UBR4 UBR4_HUMAN $573.84 \quad 100.0 \%$ E3 ubiquitin-protein ligase UBR4 GN=UBR4 UBR4_HUMAN $573.84 \quad 100.0 \%$ E3 ubiquitin-protein ligase UBR4 GN=UBR4 UBR4_HUMAN $573.84 \quad 100.0 \%$ E3 ubiquitin-protein ligase UBR4 GN=UBR4 UBR4_HUMAN $573.84 \quad 100.0 \%$ E3 ubiquitin-protein ligase UBR4 GN=UBR4 UBR4 HUMAN $573.84 \quad 100.0 \%$ E3 ubiquitin-protein ligase UBR4 GN=UBR4 UBR4_HUMAN $573.84 \quad 100.0 \%$ E3 ubiquitin-protein ligase UBR4 GN=UBR4 UBR4_HUMAN $573.84 \quad 100.0 \%$ E3 ubiquitin-protein ligase UBR4 GN=UBR4 UBR4_HUMAN $573.84 \quad 100.0 \%$ EH domain-containing protein $1 \mathrm{GN}=\mathrm{EHD} 1$ EHD1_HUMAN $60.63 \quad 100.0 \%$ EH domain-containing protein $1 \mathrm{GN}=\mathrm{EHD} 1$ EHD1 HUMAN $60.63 \quad 100.0 \%$ EH domain-containing protein $1 \mathrm{GN}=$ EHD1 EHD1_HUMAN $60.63 \quad 100.0 \%$ EH domain-containing protein $1 \mathrm{GN}=$ EHD1 EHD1_HUMAN $60.63 \quad 100.0 \%$ ELAV-like protein $1 \mathrm{GN}=\mathrm{ELAVL} 1$ ELAV-like protein $1 \mathrm{GN}=\mathrm{ELAVL}$ ELAV-like protein $1 \mathrm{GN}=\mathrm{ELAVL}$ : ELAV-like protein $1 \mathrm{GN}=\mathrm{ELAVL}$ ELAV-like protein $1 \mathrm{GN}=\mathrm{ELAVL}$ ELAV-like protein $1 \mathrm{GN}=$ ELAVL1 ELAV-like protein $1 \mathrm{GN}=\mathrm{ELAVL} 1$ ELAV-like protein $1 \mathrm{GN}=\mathrm{ELAVL}$ ELAV-like protein $1 \mathrm{GN}=\mathrm{ELAVL}$ ELAV-like protein $1 \mathrm{GN}=\mathrm{ELAVL}$ ELAV-like protein $1 \mathrm{GN}=\mathrm{ELAVL}$ ELAV-like protein $1 \mathrm{GN}=$ ELAVL1 ELAV-like protein $1 \mathrm{GN}=\mathrm{ELAVL}$ ELAV-like protein $1 \mathrm{GN}=\mathrm{ELAVL}$. ELAV-like protein $1 \mathrm{GN}=\mathrm{ELAVL}$ : ELAV1 HUMAN $36.09 \quad 100.0 \%$ ELAV1_HUMAN $36.09 \quad 100.0 \%$ ELAV1 HUMAN $36.09 \quad 100.0 \%$ ELAV1_HUMAN $36.09 \quad 100.0 \%$ ELAV1_HUMAN $36.09 \quad 100.0 \%$ ELAV1_HUMAN $36.09 \quad 100.0 \%$ ELAV1_HUMAN $36.09 \quad 100.0 \%$ ELAV1_HUMAN $36.09 \quad 100.0 \%$ ELAV1_HUMAN $36.09 \quad 100.0 \%$ ELAV1_HUMAN $36.09 \quad 100.0 \%$ ELAV1_HUMAN $36.09 \quad 100.0 \%$ ELAV1_HUMAN $36.09 \quad 100.0 \%$ ELAV1_HUMAN $36.09 \quad 100.0 \%$ ELAV1 HUMAN $36.09 \quad 100.0 \%$ ELAV1_HUMAN $36.09 \quad 100.0 \%$
$0.01 \% \quad 1.4 \%$ TVQNSGYGPK

$0.01 \% \quad 1.4 \%$ LITSQVFGK

$0.01 \% \quad 1.4 \%$ GTTITGTAGTTVGK

$0.00 \% \quad 11.0 \%$ FCADCIITALR

$0.00 \% \quad 11.0 \%$ SLRPDPNFDALISK

$0.00 \% \quad 11.0 \%$ TSGNATVDHLSK

$0.02 \% \quad 14.7 \%$ GGGSVCPVCR

$0.02 \% \quad 14.7 \%$ QLANMVNNLK

$99.6 \% 25.4$

$99.7 \% \quad 40.5$

$99.7 \% \quad 29.9$

$95.7 \% \quad 14.5$

$99.1 \% 21.8$

$99.2 \% \quad 26.9$

$0.02 \% \quad 14.7 \%$ QLANMVNNLKEISQEAR

$0.02 \% \quad 14.7 \%$ SRIHAEFVQQK

$\begin{array}{ll}99.7 \% & 27.4 \\ 99.7 \% & 37.2\end{array}$

$0.02 \% \quad 14.7 \%$ IHAEFVQQK

$99.7 \% \quad 42.7$

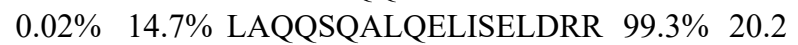

$0.02 \% \quad 14.7 \%$ LGDTQQSIPGNEER

$0.01 \% \quad 2.1 \%$ KPNPLANSNTSGYSESK

$0.01 \% \quad 2.1 \%$ SSFLASLNPK

$0.01 \% \quad 2.1 \%$ LSTQSNSNNIEPAR

$0.02 \% \quad 1.6 \%$ IQIGTQAIER

$0.02 \% \quad 1.6 \%$ SLLASLHTSR

$0.02 \% \quad 1.6 \%$ ACAEIAAQR

$0.02 \% \quad 1.6 \%$ TINLYYNNR

$0.02 \% \quad 1.6 \%$ TVQAIVELK

$0.02 \% \quad 1.6 \%$ ELLEYDLQQR

$0.02 \% \quad 1.6 \%$ TSVQPTFTASQYR

$0.02 \% \quad 1.6 \%$ QVLFTPATQAAR

$0.01 \% \quad 8.8 \%$ HLIEQDFPGMR

$0.01 \% \quad 8.8 \%$ LNAFGNAFLNR

$0.01 \% \quad 8.8 \%$ LLDTVDDMLANDIAR

$0.01 \% \quad 8.8 \%$ SKLPNTVLGK

$99.7 \% \quad 42.9$

$95.6 \% \quad 21.4$

$\begin{array}{lll}99.7 \% & 63.8\end{array}$

$99.7 \% \quad 29.5$

$99.7 \% \quad 45.7$

$99.7 \% \quad 46.6$

$99.7 \% 30.6$

$99.6 \% 25.6$

$99.7 \% \quad 41.9$

$99.7 \% \quad 36.8$

$99.7 \% \quad 55.5$

$98.8 \% 23.1$

$99.7 \% \quad 27.9$

$99.7 \% \quad 61.5$

$99.7 \% \quad 68.7$

$99.6 \% \quad 24.7$

$101 \quad 0.11 \% \quad 59.8 \%$ TNLIVNYLPQNMTQDELR $99.7 \% \quad 52.6$

$101 \quad 0.11 \% \quad 59.8 \%$ SLFSSIGEVESAK

$99.7 \% \quad 53.1$

$101 \quad 0.11 \% \quad 59.8 \%$ DKVAGHSLGYGFVNYVTAK $99.7 \% \quad 61.0$

$101 \quad 0.11 \% \quad 59.8 \%$ VAGHSLGYGFVNYVTAK $99.7 \% \quad 49.6$

$101 \quad 0.11 \% \quad 59.8 \%$ AINTLNGLR

$101 \quad 0.11 \% \quad 59.8 \%$ VSYARPSSEVIK

$101 \quad 0.11 \% \quad 59.8 \%$ DANLYISGLPR

$101 \quad 0.11 \% \quad 59.8 \%$ TMTQKDVEDMFSR

$101 \quad 0.11 \% \quad 59.8 \%$ DVEDMFSR

$101 \quad 0.11 \% \quad 59.8 \%$ VLVDQTTGLSR

$101 \quad 0.11 \% \quad 59.8 \%$ GVAFIRFDK

$101 \quad 0.11 \% \quad 59.8 \%$ SEAEEAITSFNGHKPPGSSEPITVK

$101 \quad 0.11 \% \quad 59.8 \%$ FAANPNQNK

$101 \quad 0.11 \% \quad 59.8 \%$ NVALLSQLYHSPAR

$101 \quad 0.11 \% \quad 59.8 \%$ NVALLSQLYHSPARR
$99.7 \% \quad 53.2$

$99.7 \% \quad 34.0$

$99.7 \% \quad 41.7$

$99.7 \% \quad 49.3$

$99.0 \% \quad 41.6$

$99.7 \% \quad 59.3$

$99.7 \% \quad 37.5$

$99.7 \% \quad 53.7$

$99.7 \% \quad 32.2$

$99.7 \% \quad 64.8$

$98.3 \% \quad 20.2$
$127.61 \quad 4296 \quad 4305$

$\begin{array}{lll}143.63 & 24 & 33\end{array}$

\begin{tabular}{ccc}
996.51 & 349 & 358 \\
\hline
\end{tabular}

$\begin{array}{lll}1030.63 & 1871 & 1880\end{array}$

$1050.52 \quad 2035 \quad 2044$

$\begin{array}{lll}992.58 & 3866 & 3874\end{array}$

$1264.67 \quad 4087 \quad 4100$

$1339.65 \quad 71 \quad 81$

$\begin{array}{lll}1572.84 & 99 & 112\end{array}$

$1229.61 \quad 250 \quad 261$

1048.47

1160.6

1958.01

1342.72

1099.59

2098.13

1543.73

1793.87

1063.58

1530.75

1128.64

1084.61

989.48

1170.59

1000.60

1306.66

1485.73

1302.72

1342.66

1236.65

1674.84

1056.64

2162.09

1353.69

2026.04

1782.92

971.56

1335.73

1218.65

1619.70

1014.42

1188.66

1052.59

2612.28

1003.50

1568.85

1724.96 
ELAV-like protein $1 \mathrm{GN}=\mathrm{ELAVL} 1$ ELAV-like protein $1 \mathrm{GN}=$ ELAVL1 ELAV-like protein $1 \mathrm{GN}=\mathrm{ELAVL} 1$ ELAV-like protein $2 \mathrm{GN}=\mathrm{ELAVL} 2$ ELAV-like protein $2 \mathrm{GN}=\mathrm{ELAVL} 2$ ELAV-like protein $2 \mathrm{GN}=\mathrm{ELAVL} 2$ ELAV-like protein $2 \mathrm{GN}=\mathrm{ELAVL} 2$ ELAV-like protein $2 \mathrm{GN}=\mathrm{ELAVL} 2$ ELAV-like protein $2 \mathrm{GN}=\mathrm{ELAVL} 2$ ELAV-like protein $2 \mathrm{GN}=$ ELAVL2 ELAV-like protein $2 \mathrm{GN}=\mathrm{ELAVL} 2$ ELAV-like protein $2 \mathrm{GN}=\mathrm{ELAVL} 2$ ELAV-like protein $2 \mathrm{GN}=\mathrm{ELAVL} 2$ ELAV-like protein $2 \mathrm{GN}=\mathrm{ELAVL} 2$ ELAV-like protein $2 \mathrm{GN}=\mathrm{ELAVL} 2$ ELAV-like protein $2 \mathrm{GN}=\mathrm{ELAVL} 2$ ELAV-like protein $2 \mathrm{GN}=\mathrm{ELAVL} 2$

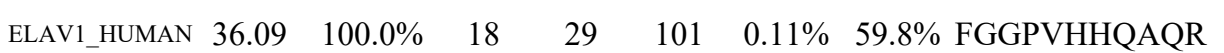

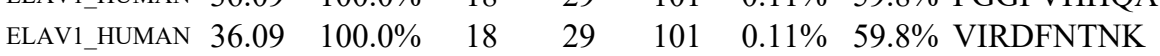

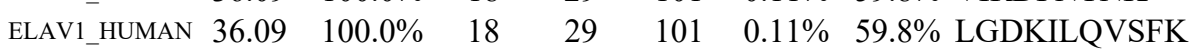

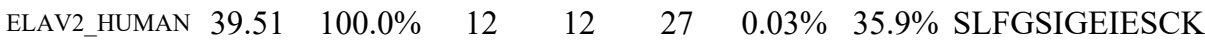
$\begin{array}{llllllll}\text { ELAV2_HUMAN } & 39.51 & 100.0 \% & 12 & 12 & 27 & 0.03 \% & 35.9 \% \\ \text { AINTLNGLR }\end{array}$

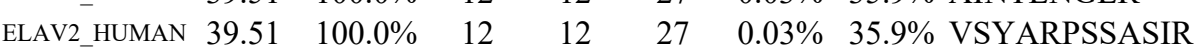

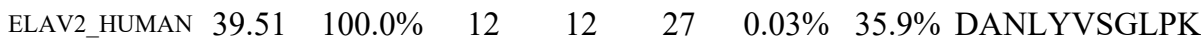

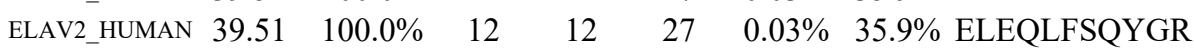

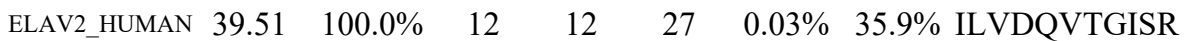

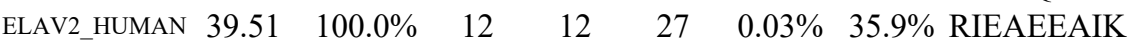

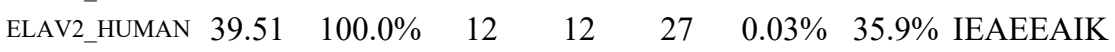
ELAV2 HUMAN $39.51 \quad 100.0 \% \quad 12$ ELAV2_HUMAN $39.51 \quad 100.0 \% \quad 12$ ELAV2_HUMAN $39.51 \quad 100.0 \% \quad 12$ ELAV2_HUMAN $39.51 \quad 100.0 \% \quad 12$ ELAV2_HUMAN $39.51 \quad 100.0 \% \quad 12$ ELAV2_HUMAN $39.51 \quad 100.0 \% \quad 12$

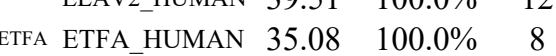
$\begin{array}{ll}100.0 \% & 8 \\ 100.0 \% & 8 \\ 100.0 \% & 8\end{array}$ $100.0 \% \quad 8$ $100.0 \% \quad 8$ $100.0 \%$ $100.0 \%$ $100.0 \%$ $100.0 \%$ $100.0 \%$ $100.0 \%$ $100.0 \%$ $100.0 \%$ $100.0 \%$ $100.0 \%$ $\begin{array}{ll}7.84 & 100.0 \%\end{array}$ \begin{tabular}{l}
$100.0 \%$ \\
\hline
\end{tabular} \begin{tabular}{ll}
$100.0 \%$ \\
\hline
\end{tabular} \begin{tabular}{ll}
$100.0 \%$ \\
\hline
\end{tabular} \begin{tabular}{ll}
$100.0 \%$ \\
\hline
\end{tabular} \begin{tabular}{ll}
$100.0 \%$ \\
\hline
\end{tabular} $\begin{array}{ll}96 & 100.0 \%\end{array}$ $14 \quad 100.0 \%$ $14 \quad 100.0 \%$ $100.0 \%$ $14 \quad 100.0 \%$ $14 \quad 100.0 \%$ $14 \quad 100.0 \%$ $\begin{array}{ll}4 & 100.0 \%\end{array}$ $100.0 \%$ $\begin{array}{llll}12 & 27 & 0.03 \% & 35.9 \% \\ 12 & \text { GLNGQKPPGATEPITVK }\end{array}$

$\begin{array}{lllll}12 & 27 & 0.03 \% & 35.9 \% & \text { TNQAILSQLYQSPNR }\end{array}$

$\begin{array}{lllll}12 & 27 & 0.03 \% & 35.9 \% & \text { TNQAILSQLYQSPNRR }\end{array}$

$\begin{array}{llll}12 & 27 & 0.03 \% & 35.9 \% \\ 12 & \text { RYPGPLAQQAQR }\end{array}$

$\begin{array}{llll}12 & 27 & 0.03 \% & 35.9 \% \\ 12 & \text { YPGPLAQQAQR }\end{array}$

$\begin{array}{lllll}12 & 27 & 0.03 \% & 35.9 \% & \text { VIRDFNTNK }\end{array}$

$16 \quad 0.02 \% \quad 34.8 \%$ LGGEVSCLVAGTK

$\begin{array}{lll}16 & 0.02 \% & 34.8 \% \\ 16 & \text { VLVAQHDVYK }\end{array}$

$16 \quad 0.02 \% \quad 34.8 \%$ GLLPEELTPLILATQK

$\begin{array}{lll}16 & 0.02 \% & 34.8 \% \\ 16 & 0.02 \% & \text { LEVAPISDIIAIK }\end{array}$

$\begin{array}{lll}16 & 0.02 \% & 34.8 \% \\ 16 & \text { GTSFDAAATSGGSASSEK }\end{array}$

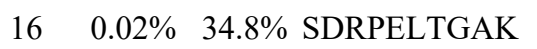

$\begin{array}{lllllllll}16 & 0.02 \% & 34.8 \% & \text { ALVDAGFVPNDMQVGQTGK } & 99.7 \% & 43.8\end{array}$

$\begin{array}{llll}16 & 0.02 \% & 35.3 \% & \text { TGVVTDGVK }\end{array}$

$16 \quad 0.02 \% \quad 35.3 \%$ EVIAVSCGPAQCQETIR

$\begin{array}{lll}16 & 0.02 \% \quad 35.3 \% & \text { TALAMGADR }\end{array}$

$\begin{array}{llll}16 & 0.02 \% & 35.3 \% & \text { LGPLQVAR }\end{array}$

$16 \quad 0.02 \% \quad 35.3 \%$ EKVDLVLLGK

$\begin{array}{llll}16 & 0.02 \% & 35.3 \% & \text { EIDGGLETLR }\end{array}$

$\begin{array}{lll}16 & 0.02 \% & 35.3 \% \\ 16 & \text { LSVISVEDPPQR }\end{array}$

$\begin{array}{lll}16 & 0.02 \% & 35.3 \% \\ 16 & \text { TAGVKVETTEDLVAK }\end{array}$

$16 \quad 0.02 \% \quad 35.3 \%$ VETTEDLVAK

$\begin{array}{lll}7 & 0.01 \% & 13.3 \% \\ 7 & 0.01 \% & \text { IFDTYVGAQR }\end{array}$

$0.01 \% \quad 13.3 \%$ IENSLTYSK

$\begin{array}{lll}7 & 0.01 \% & 13.3 \% \\ 7 & 0.0 \% & \text { MCLLQITGYK }\end{array}$

$7 \quad 0.01 \% \quad 13.3 \%$ QLYLDVESVR

$\begin{array}{llll}231 & 0.26 \% & 35.3 \% & \text { THINIVVIGHVDSGK }\end{array}$

$231 \quad 0.26 \% \quad 35.3 \%$ STTTGHLIYK

$231 \quad 0.26 \% \quad 35.3 \%$ YYVTIIDAPGHR

$99.7 \% 32.8$

$99.7 \% \quad 70.3$

$99.7 \% 37.4$

$99.0 \% 71.2$

$99.7 \% 34.6$

$99.7 \% \quad 56.5$

$99.7 \% \quad 46.6$

$99.4 \% 21.9$

$99.7 \% \quad 45.1$

$99.7 \% \quad 59.1$

$99.7 \% \quad 44.8$

$99.7 \% \quad 46.0$

$99.7 \% 34.8$

$99.7 \% \quad 52.9$

$99.7 \% 44.5$

$99.7 \% 53.8$

$99.7 \% \quad 32.0$

$231 \quad 0.26 \% \quad 35.3 \%$ YYVTIIDAPGHRDFIK

$\begin{array}{llll}99.7 \% & 34.5\end{array}$

$231 \quad 0.26 \% \quad 35.3 \%$ EHALLAYTLGVK

$231 \quad 0.26 \% \quad 35.3 \%$ QLIVGVNK

$231 \quad 0.26 \% \quad 35.3 \%$ YEEIVKEVSTYIK

$99.7 \% \quad 60.3$

$\begin{array}{lll}99.0 \% & 41.4\end{array}$

$99.7 \% 37.8$

$99.0 \% 34.8$
1106.60

1247.74

1426.69

971.56

1293.69

1176.63

1369.67

1200.69

1058.58

902.48

1706.94

1732.90

1889.00

1384.74

1228.64

1106.60

1290.67

1171.65

1736.02

1381.83

1630.72

1073.56

1812.96

1920.91

875.48

1917.92

905.45

853.53

1113.69

1102.57

1339.72

1560.85

1104.58

1169.60

1054.54

1242.62

1221.65

1588.88

1120.60

1404.73

1908.00

1871.01

1314.74

870.54

1600.85 967.55 $\begin{array}{cc}07 & 217 \\ 75 & 283 \\ 10 & 320 \\ 7 & 69 \\ 6 & 104 \\ 12 & 123 \\ 24 & 134 \\ 40 & 150 \\ 56 & 166 \\ 76 & 184 \\ 77 & 184 \\ 85 & 201 \\ 10 & 224 \\ 10 & 225 \\ 25 & 236 \\ 26 & 236 \\ 07 & 315 \\ 7 & 59 \\ 6 & 85 \\ 6 & 101 \\ 27 & 139 \\ 70 & 187 \\ 07 & 216 \\ 33 & 249 \\ 50 & 268 \\ 7 & 35 \\ 0 & 76 \\ 7 & 85 \\ 9 & 106 \\ 15 & 124 \\ 65 & 174 \\ 22 & 233 \\ 34 & 248 \\ 39 & 248 \\ 4 & 43 \\ 7 & 55 \\ 7 & 106 \\ 07 & 116 \\ 6 & 20 \\ 1 & 30 \\ 5 & 96 \\ 5 & 100 \\ 30 & 146 \\ 35 & 146 \\ 47 & 154 \\ 67 & 179 \\ 73 & 180 \\ & \end{array}$

Page 56 of Table S-1-6 


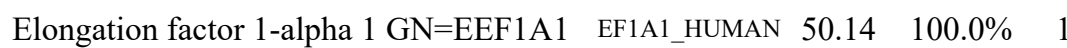
Elongation factor 1-alpha $1 \mathrm{GN}=\mathrm{EEF} 1 \mathrm{~A} 1 \quad$ EF1A1_HUMAN $50.14 \quad 100.0 \%$ Elongation factor 1-alpha $1 \mathrm{GN}=\mathrm{EEF} 1 \mathrm{~A} 1 \quad$ EF1A1_HUMAN $50.14 \quad 100.0 \% \quad 16$ Elongation factor 1-alpha $1 \mathrm{GN}=\mathrm{EEF} 1 \mathrm{~A} 1 \mathrm{EF} 1 \mathrm{~A} 1 \mathrm{HUMAN} \quad 50.14 \quad 100.0 \%$ Elongation factor 1-alpha $1 \mathrm{GN}=\mathrm{EEF} 1 \mathrm{~A} 1 \quad$ EF1A1_HUMAN $50.14 \quad 100.0 \% \quad 16$ Elongation factor 1-alpha 1 GN=EEF1A1 EF1A1_HUMAN $50.14 \quad 100.0 \% \quad 16$ Elongation factor 1-alpha $1 \mathrm{GN}=\mathrm{EEF} 1 \mathrm{~A} 1$ EF1A1 HUMAN $50.14 \quad 100.0 \%$ Elongation factor 1-delta GN=EEF1D Elongation factor 1-delta GN=EEF1D Elongation factor 1-delta GN=EEF1D Elongation factor 1-delta GN=EEF1D Elongation factor 1-gamma GN=EEF1G Elongation factor 1-gamma GN=EEF1G Elongation factor 1-gamma GN=EEF1G Elongation factor 1-gamma GN=EEF1G Elongation factor 1-gamma GN=EEF1G Elongation factor 1-gamma GN=EEF1G Elongation factor 1-gamma GN=EEF1G Elongation factor $2 \mathrm{GN}=\mathrm{EEF} 2$

Elongation factor $2 \mathrm{GN}=\mathrm{EEF} 2$ Elongation factor $2 \mathrm{GN}=\mathrm{EEF} 2$ Elongation factor $2 \mathrm{GN}=\mathrm{EEF} 2$ Elongation factor $2 \mathrm{GN}=\mathrm{EEF} 2$ Elongation factor $2 \mathrm{GN}=\mathrm{EEF} 2$ Elongation factor $2 \mathrm{GN}=\mathrm{EEF} 2$ Elongation factor $2 \mathrm{GN}=\mathrm{EEF} 2$ Elongation factor $2 \mathrm{GN}=\mathrm{EEF} 2$ Elongation factor $2 \mathrm{GN}=\mathrm{EEF} 2$ Elongation factor $2 \mathrm{GN}=\mathrm{EEF} 2$ Elongation factor $2 \mathrm{GN}=\mathrm{EEF} 2$ Elongation factor $2 \mathrm{GN}=\mathrm{EEF} 2$ Elongation factor $2 \mathrm{GN}=\mathrm{EEF} 2$ Elongation factor $2 \mathrm{GN}=\mathrm{EEF} 2$ Elongation factor $2 \mathrm{GN}=\mathrm{EEF} 2$ Elongation factor $2 \mathrm{GN}=\mathrm{EEF} 2$ Elongation factor Tu, mitochondial GN=TUFM Elongation factor Tu, mitochondrial GN=TUFM EFTU HUMAN $49.54 \quad 100.0 \%$ Elongation factor Tu, mitochondrial GN=TUFM EFTU HUMAN $49.54 \quad 100.0 \%$ Elongation factor Tu, mitochondrial GN=TUFM EFTU_HUMAN $49.54 \quad 100.0 \% \quad 20$ Elongation factor Tu, mitochondrial GN=TUFM EFTU_HUMAN $49.54 \quad 100.0 \%$ Elongation factor $\mathrm{Tu}$, mitochondrial GN=TUFM EFTU_HUMAN $49.54 \quad 100.0 \% 20$ Elongation factor Tu, mitochondrial GN=TUFM EFTU_HUMAN $49.54 \quad 100.0 \% \quad 20$ Elongation factor Tu, mitochondrial GN=TUFM EFTU HUMAN $49.54 \quad 100.0 \%$ Elongation factor Tu, mitochondrial GN=TUFM EFTU_HUMAN $49.54 \quad 100.0 \% 20$ Elongation factor Tu, mitochondrial GN=TUFM EFTU_HUMAN $49.54 \quad 100.0 \%$ Elongation factor Tu, mitochondrial GN=TUFM EFTU HUMAN $49.54 \quad 100.0 \% \quad 20$ Elongation factor Tu, mitochondrial GN=TUFM EFTU_HUMAN $49.54 \quad 100.0 \% \quad 20$

EF1D HUMAN $31.12 \quad 100.0 \%$ EF1D_HUMAN $31.12 \quad 100.0 \%$ EF1D_HUMAN $31.12 \quad 100.0 \%$ EF1G_HUMAN $50.12 \quad 100.0 \%$ \begin{tabular}{lll} 
& \\
EF1G_HUMAN & 50.12 & $100.0 \%$ \\
\hline
\end{tabular} EF1G HUMAN $50.12 \quad 100.0 \%$ _ $50.12 \quad 100.0 \%$ \begin{tabular}{ll}
$50.12 \quad 100.0 \%$ \\
\hline
\end{tabular} EF2 HUMAN $95.34 \quad 100.0 \%$ EF2 HUMAN $95.34 \quad 100.0 \%$ \begin{tabular}{lll} 
& \\
\hline
\end{tabular} EF2 HUMAN $95.34 \quad 100.0 \%$ EF2_HUMAN $95.34 \quad 100.0 \% \quad 17$ EF2 HUMAN $95.34 \quad 100.0 \% \quad 17$ $\begin{array}{llll}\text { EF2 HUMAN } & 95.34 & 100.0 \% & 17\end{array}$ EF2 HUMAN $95.34 \quad 100.0 \% \quad 17$ $\begin{array}{llll}\text { EF2_HUMAN } & 95.34 & 100.0 \% & 17 \\ \text { EF2_HUMAN } & 95.34 & 100.0 \% & 17\end{array}$ EF2_HUMAN $95.34 \quad 100.0 \% \quad 17$ EF2_HUMAN $95.34 \quad 100.0 \% \quad 17$ EF2 HUMAN $95.34 \quad 100.0 \% \quad 17$ $\begin{array}{llll}\text { EF2_HUMAN } & 95.34 & 100.0 \% & 17 \\ & & \end{array}$
$231 \quad 0.26 \% \quad 35.3 \%$ SGDAAIVDMVPGKPMCVESFSDYPPLGR

$\begin{array}{llll}231 & 0.26 \% & 35.3 \% & \text { DMRQTVAVGVIK }\end{array}$

$99.7 \% \quad 41.9$

$231 \quad 0.26 \% \quad 35.3 \%$ QTVAVGVIK

$99.7 \% \quad 54.6$

$10 \quad 0.01 \% \quad 20.6 \%$ SLAGSSGPGASSGTSGDHGELVVR

$10 \quad 0.01 \% \quad 20.6 \%$ IASLEVENQSLR

$10 \quad 0.01 \% \quad 20.6 \%$ ATAPQTQHVSPMR $99.7 \% \quad 43.7$ $99.7 \% \quad 46.0$ $99.4 \% 23.8$ $95.3 \% \quad 15.0$ $6 \quad 0.02 \% \quad 16.9 \%$ AFKALIAAQYSGAQVR $0.02 \% \quad 16.9 \%$ ALIAAQYSGAQVR $0.02 \% \quad 16.9 \%$ VLSAPPHFHFGQTNR $99.4 \% 22.5$ $99.7 \% \quad 64.5$ $\begin{array}{lll}98.8 \% & 19.8\end{array}$ $99.0 \% \quad 28.1$ $99.7 \% \quad 55.8$ $99.7 \% \quad 44.5$ $99.7 \% \quad 46.0$ $99.7 \% \quad 64.7$ $\begin{array}{lll}99.7 \% & 51.5\end{array}$ $99.7 \% \quad 36.3$ $99.7 \% \quad 53.5$ $99.7 \% \quad 48.3$ $99.7 \% \quad 60.5$ $98.7 \% \quad 18.4$ $96.6 \% \quad 19.0$ $98.3 \% \quad 17.9$ $99.7 \% \quad 53.8$ $99.7 \% \quad 63.5$ $99.7 \% \quad 37.3$ $99.7 \% \quad 49.0$ $99.7 \% \quad 33.8$ $99.7 \% \quad 53.2$

$\begin{array}{ll}.0 & 48.9\end{array}$
\begin{tabular}{ll}
32.1 \\
\hline
\end{tabular}

1439.7

973.58

1693.94

1347.74

1707.87

975.53

1245.69

1241.65

1572.82

1091.58

1123.57

1430.74

1013.50

1107.64

1362.81

1402.81

1274.71

890.51

1351.76

1594.76

1208.50

$0.08 \% \quad 18.5 \%$ EGALCEENMR

$0.08 \% \quad 18.5 \%$ GGGQIIPTAR

$0.08 \% \quad 18.5 \%$ RCLYASVLTAQPR

$0.08 \% \quad 18.5 \%$ CLYASVLTAQPR

$\begin{array}{lllll}0.08 \% & 18.5 \% & \text { GHVFEESQVAGTPMFVVK } & 99.7 \% & 31.0 \\ 0.08 \% & 18.5 \% & \text { AYLPVNESFGFTADLR } & 99.7 \% & 54.5\end{array}$

$99.7 \% \quad 28.4$

$0.11 \% \quad 45.6 \%$ TTLTAAITK

$0.11 \% \quad 45.6 \%$ ILAEGGGAKFK

$0.11 \% \quad 45.6 \%$ YEEIDNAPEERAR

$99.7 \% \quad 38.2$

$\begin{array}{llll}99.7 \% & 34.7 & 25.0 & 34.3\end{array}$

$0.11 \% \quad 45.6 \%$ ARGITINAAHVEYSTAAR $\quad 99.7 \% \quad 52.8$

$0.11 \% \quad 45.6 \%$ GITINAAHVEYSTAAR $\quad 99.7 \% \quad 58.9$

$25.0 \quad 52.1$

$0.11 \% \quad 45.6 \%$ HYAHTDCPGHADYVK

$25.0 \quad 52.9$

$0.11 \% \quad 45.6 \%$ QIGVEHVVVYVNK

$99.7 \% \quad 49.5$

$25.0 \quad 35.7$

$0.11 \% \quad 45.6 \%$ LLDAVDTYIPVPAR

$99.7 \% \quad 54.2$

$25.0 \quad 41.3$

$0.11 \% \quad 45.6 \%$ DLEKPFLLPVEAVYSVPGR $99.7 \% \quad 41.0$

$25.0 \quad 54.2$

$0.11 \% \quad 45.6 \%$ DLEKPFLLPVEAVYSVPGRGTVVTGTLER $\quad 99.6 \% 26.1$

$99.7 \% \quad 55.7$

1378.71

1961.98

1799.90

1809.94

919.55

1090.63

1591.73

1901.00

1673.86

1770.77

1483.83

1542.85

2129.16

3142.72 1032.57 $\begin{array}{cc}248 & 255 \\ 256 & 266 \\ 256 & 290 \\ 267 & 290 \\ 396 & 423 \\ 428 & 439 \\ 431 & 439 \\ 60 & 83 \\ 84 & 95 \\ 124 & 136 \\ 233 & 241 \\ 15 & 30 \\ 18 & 30 \\ 31 & 45 \\ 174 & 181 \\ 202 & 212 \\ 286 & 295 \\ 401 & 414 \\ 2 & 10 \\ 33 & 42 \\ 236 & 249 \\ 240 & 249 \\ 416 & 426 \\ 416 & 428 \\ 439 & 449 \\ 440 & 449 \\ 499 & 506 \\ 507 & 519 \\ 581 & 594 \\ 589 & 698 \\ 717 & 726 \\ 727 & 739 \\ 728 & 739 \\ 768 & 785 \\ 786 & 801 \\ 54 & 70 \\ 71 & 79 \\ 80 & 90 \\ 92 & 104 \\ 103 & 120 \\ 105 & 120 \\ 121 & 135 \\ 170 & 182 \\ 239 & 252 \\ & 271 \\ \end{array}$ 
Elongation factor Tu, mitochondrial GN=TUFM EFTU HUMAN $49.54 \quad 100.0 \% \quad 20$ Elongation factor Tu, mitochondrial GN=TUFM EFTU_HUMAN $49.54 \quad 100.0 \% \quad 20$ Elongation factor Tu, mitochondrial GN=TUFM EFTU_HUMAN $49.54 \quad 100.0 \% 20$ Elongation factor Tu, mitochondrial GN=TUFM EFTU HUMAN $49.54 \quad 100.0 \%$ Elongation factor Tu, mitochondrial GN=TUFM EFTU_HUMAN $49.54 \quad 100.0 \% \quad 20$ Elongation factor Tu, mitochondrial GN=TUFM EFTU_HUMAN $49.54 \quad 100.0 \% 20$ Elongation factor $\mathrm{Tu}$, mitochondrial GN=TUFM EFTU_HUMAN $49.54 \quad 100.0 \% 20$ Elongation factor Tu, mitochondrial GN=TUFM EFTU_HUMAN $49.54 \quad 100.0 \% \quad 20$ Elongator complex protein $1 \mathrm{GN}=$ IKBKAP ELP1_HUMAN $150.26 \quad 100.0 \%$ Elongator complex protein 1 GN=IKBKAP ELP1_HUMAN $150.26100 .0 \%$ Emerin GN=EMD

Emerin GN=EMD

Emerin GN=EMD

Emerin $\mathrm{GN}=\mathrm{EMD}$

Emerin GN=EMD

Emerin GN=EMD

Emerin $\mathrm{GN}=\mathrm{EMD}$

Emerin $\mathrm{GN}=\mathrm{EMD}$

Emerin GN=EMD

Emerin $\mathrm{GN}=\mathrm{EMD}$

EMD HUMAN $28.99 \quad 100.0 \%$

EMD HUMAN $28.99 \quad 100.0 \%$

EMD_HUMAN $28.99 \quad 100.0 \% \quad 10$ EMD_HUMAN $28.99 \quad 100.0 \% \quad 10$ EMD HUMAN $28.99 \quad 100.0 \% \quad 10$ EMD_HUMAN $28.99 \quad 100.0 \% \quad 10$ EMD_HUMAN $28.99 \quad 100.0 \% \quad 10$ EMD_HUMAN $28.99 \quad 100.0 \% \quad 10$ EMD_HUMAN $28.99 \quad 100.0 \% \quad 10$ EMD HUMAN $28.99 \quad 100.0 \% \quad 10$ Enoyl-CoA hydratase, mitochondrial GN=ECHS1 ECHM_HUMAN $31.39 \quad 100.0 \% \quad 2$ Enoyl-CoA hydratase, mitochondrial GN=ECHS1 ECHM_HUMAN $31.39 \quad 100.0 \% \quad 2$ ER membrane protein complex subunit 2 GN=EMC2 EMC2_HUMAN $34.83 \quad 100.0 \%$ ER membrane protein complex subunit $2 \mathrm{GN}=\mathrm{EMC} 2$ EMC2_HUMAN $34.83 \quad 100.0 \%$; ER membrane protein complex subunit $3 \mathrm{GN}=\mathrm{EMC} 3$ EMC3 HUMAN $29.95 \quad 100.0 \%$ ER membrane protein complex subunit $3 \mathrm{GN}=\mathrm{EMC} 3$ EMC3_HUMAN $29.95 \quad 100.0 \%$ Erlin-1 GN=ERLIN

Erlin-1 GN=ERLIN Erlin-1 GN=ERLIN Erlin-1 GN=ERLIN1 Erlin-1 GN=ERLIN1 Erlin-1 GN=ERLIN Erlin-1 GN=ERLIN Erlin-1 GN=ERLIN 1 Erlin-2 GN=ERLIN 2 Erlin-2 GN=ERLIN2 Erlin-2 GN=ERLIN 2 Erlin-2 GN=ERLIN 2 Erlin-2 GN=ERLIN2 Erlin-2 GN=ERLIN 2 Erlin-2 GN=ERLIN 2 Erlin-2 GN=ERLIN 2 Erlin-2 GN=ERLIN 2 Erlin-2 GN=ERLIN2 Erlin-2 GN=ERLIN 2 Erlin-2 GN=ERLIN 2 Erlin-2 GN=ERLIN2 ERLN1_HUMAN $38.93 \quad 100.0 \%$ ERLN1_HUMAN $38.93 \quad 100.0 \%$ ERLN1_HUMAN $38.93 \quad 100.0 \%$ ERLN1_HUMAN $38.93 \quad 100.0 \%$ ERLN1 HUMAN $38.93 \quad 100.0 \%$ ERLN1_HUMAN $38.93 \quad 100.0 \%$ ERLN1_HUMAN $38.93 \quad 100.0 \%$ ERLN1_HUMAN $38.93 \quad 100.0 \%$ ERLN2 HUMAN $37.84 \quad 100.0 \%$ ERLN2 HUMAN $37.84 \quad 100.0 \%$ ERLN2_HUMAN $37.84 \quad 100.0 \%$ ERLN2 HUMAN $37.84 \quad 100.0 \%$ ERLN2_HUMAN $37.84 \quad 100.0 \%$ ERLN2_HUMAN $37.84 \quad 100.0 \%$ ERLN2 HUMAN $37.84 \quad 100.0 \%$ ERLN2_HUMAN $37.84 \quad 100.0 \% \quad 16$ ERLN2 HUMAN $37.84 \quad 100.0 \% \quad 16$ ERLN2 HUMAN $37.84 \quad 100.0 \% \quad 16$ ERLN2_HUMAN $37.84 \quad 100.0 \% \quad 16$ ERLN2 HUMAN $37.84 \quad 100.0 \% \quad 16$ ERLN2_HUMAN $37.84 \quad 100.0 \% \quad 16$
$98 \quad 0.11 \% \quad 45.6 \%$ KGDECELLGHSK $0.11 \% \quad 45.6 \%$ GDECELLGHSK

$0.11 \% \quad 45.6 \%$ TVVTGIEMFHK

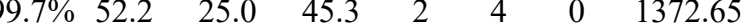
$97.2 \% \quad 20.4$

$99.7 \% \quad 54.2$

$0.11 \% \quad 45.6 \%$ SLERAEAGDNLGALVR

$0.11 \% \quad 45.6 \%$ AEAGDNLGALVR

$0.11 \% \quad 45.6 \%$ GLVMVKPGSIKPHQK

$0.11 \% \quad 45.6 \%$ VEAQVYILSK

$0.11 \% \quad 45.6 \%$ VEAQVYILSKEEGGR

$0.00 \% \quad 1.4 \%$ VFLGNVETFIK

$0.00 \% \quad 1.4 \%$ FTIDKYLK

$0.02 \% \quad 46.5 \%$ RYNIPHGPVVGSTR

$0.02 \% \quad 46.5 \%$ YNIPHGPVVGSTR

$0.02 \% \quad 46.5 \%$ KIFEYETQR

$0.02 \% \quad 46.5 \%$ LSPPSSSAASSYSFSDLNSTR

$0.02 \% \quad 46.5 \%$ GDADMYDLPK

$0.02 \% \quad 46.5 \%$ KEDALLYQSK

$0.02 \% \quad 46.5 \%$ GYNDDYYEESYFTTR

$0.02 \% \quad 46.5 \%$ TYGEPESAGPSR

$0.02 \% \quad 46.5 \%$ DSAYQSITHYRPVSASR

$0.02 \% \quad 46.5 \%$ APGAGLGQDR

$0.00 \% \quad 8.6 \%$ NNTVGLIQLNRPK

$0.00 \% \quad 8.6 \%$ SLAMEMVLTGDR

$0.00 \% \quad 8.4 \%$ ILQEDPTNTAAR

$0.00 \% \quad 8.4 \%$ YTQGGLENLELSR

$0.00 \% \quad 10.0 \%$ AGPELLLDSNIR

$0.00 \% \quad 10.0 \%$ LTQEQVSDSQVLIR

$19 \quad 0.02 \% \quad 26.0 \%$ SVQTTLQTDEVK

$0.02 \% \quad 26.0 \%$ DLNLMAPGLTIQAVR

$0.02 \% \quad 26.0 \%$ VVEKEAETER

$0.02 \% \quad 26.0 \%$ ISEIEDAAFLAR

$0.02 \% \quad 26.0 \%$ ADAEYYAAHK

$0.02 \% \quad 26.0 \%$ LTPEYLELKK

$0.02 \% \quad 26.0 \%$ ESSLPSKEALEPSGENVIQN

$0.02 \% \quad 26.0 \%$ EALEPSGENVIQNK

$0.07 \% \quad 42.8 \%$ IEEGHIGVYYR

$0.07 \% \quad 42.8 \%$ SVQTTLQTDEVK

$0.07 \% \quad 42.8 \%$ LALQQDLTSMAPGLVIQAVR

$0.07 \% \quad 42.8 \%$ VTKPNIPEAIR

$0.07 \% \quad 42.8 \%$ VTKPNIPEAIRR

$0.07 \% \quad 42.8 \%$ NYELMESEK

$0.07 \% \quad 42.8 \%$ NYELMESEKTK

$0.07 \% \quad 42.8 \%$ VVEKEAETER

$0.07 \% \quad 42.8 \%$ ALIEAEKVAQVAEITYGQK

$0.07 \% \quad 42.8 \%$ VAQVAEITYGQK

$0.07 \% \quad 42.8 \%$ KISEIEDAAFLAR

$0.07 \% \quad 42.8 \%$ ISEIEDAAFLAR

$0.07 \% \quad 42.8 \%$ AKADAECYTAMK
$98.1 \% \quad 16.9$

$99.7 \% \quad 63.6$

$99.7 \% \quad 49.6$

$95.6 \% \quad 17.2$

$99.0 \% 21.6$

$99.7 \% \quad 29.3$

$99.7 \% \quad 56.5$

$99.7 \% \quad 48.4$

$99.7 \% \quad 95.7$

$99.7 \% \quad 57.0$

$99.7 \% \quad 53.8$

$99.7 \% \quad 56.2$

$99.7 \% \quad 36.4$

$99.7 \% \quad 48.0$

$99.7 \% \quad 68.7$

$99.7 \% \quad 55.9$

$99.7 \% \quad 50.8$

$99.7 \% \quad 65.2$

$99.7 \% \quad 49.6$

$99.7 \% \quad 59.6$

$99.7 \% \quad 60.5$

$99.7 \% \quad 58.6$

$99.7 \% \quad 50.4$

$99.7 \% \quad 83.3$

$99.7 \% \quad 54.6$

$99.1 \% \quad 23.3$

$99.7 \% \quad 43.9$

$99.7 \% \quad 59.0$

$99.7 \% \quad 61.1$

$99.7 \% \quad 60.5$

$99.7 \% \quad 48.5$

$99.7 \% \quad 36.3$

$98.6 \% \quad 19.8$

$99.3 \% \quad 32.1$

$99.7 \% \quad 59.6$

$99.7 \% \quad 50.4$

$99.7 \% \quad 30.0$

$99.7 \% \quad 54.7$

$99.7 \% \quad 71.8$

$99.7 \% \quad 83.3$

$99.7 \% \quad 58.3$
020.4

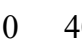

0
57.7

59.5

$\begin{array}{ll}.0 & 16.9\end{array}$

$\begin{array}{ll}0 & 58.8\end{array}$

38.0

0.0
13.2

$\begin{array}{ll}.0 & 18.7\end{array}$

\begin{tabular}{ll}
.0 & 29.3 \\
\hline
\end{tabular}

$\begin{array}{ll}0 & 55.3\end{array}$

.039.

$\begin{array}{ll}0 & 95.7\end{array}$

$\begin{array}{ll}25.0 & 29.7\end{array}$

$\begin{array}{ll}5.0 & 46.8\end{array}$

$0 \quad 53.8$

$\begin{array}{ll}25.0 & 43.5\end{array}$

\begin{tabular}{ll}
35.8 \\
\hline
\end{tabular}

$0 \quad 42.2$

66.

\begin{tabular}{ll}
49.5 \\
\hline
\end{tabular}

$\begin{array}{ll}25.0 & 35.3\end{array}$

$\begin{array}{ll}5.0 & 61.7\end{array}$

$\begin{array}{ll}5.0 & 43.8\end{array}$

39.6

50.9

$\begin{array}{ll}25.0 & 49.7\end{array}$

5.044 .9

$\begin{array}{ll}0 & 69.9\end{array}$

$\begin{array}{ll}25.0 & 54.6\end{array}$

$\begin{array}{ll}25.0 & 20.5\end{array}$

$\begin{array}{ll}0 & 37.0\end{array}$

$5.0 \quad 57.4$

. 44

50.9

$\begin{array}{ll}5.0 & 48.5\end{array}$

$\begin{array}{ll}36.0 & 36.3\end{array}$

17.0
25.0

8.0

$\begin{array}{ll}5.0 & 51.3\end{array}$

$\begin{array}{ll}5.0 & 44.9\end{array}$

$\begin{array}{ll}3.0 & 30.0\end{array}$

$\begin{array}{ll}5.0 & 52.9 \\ 25.0 & 66.5\end{array}$

$\begin{array}{lll}25.0 & 66.5 & 2\end{array}$

$\begin{array}{ll}25.0 & 69.9\end{array}$

$.0 \quad 52.4$

0
1
2
0
0
1
0
5
0
0
0
2
2
2
0
0
0
0
0
0
0
0
2
0
0
0
0
0
0
0
0
0
0
0
0
0
0
0
0
0
0
0
0
0
0
0
1
3
0
0
0
0
0
0
0
0
0
0
0
0
0
0
0
0
0
0
0

1244.56

1261.66

1670.88

1185.62

1618.95

1149.65

1677.88

1266.71

1027.58

1552.83

1396.73

1213.62

2161.00

1140.49

1194.64

1922.77

1250.56

1937.95

941.48

1466.84

1322.64

1328.68

1479.74

1297.71

1615.87

1348.70

1627.88

1189.61

1334.70

1138.52

1233.71

2256.14

1527.77

1335.67

1348.70

2140.18

1237.73

1393.83

1142.50

1371.65

1189.61

2061.12

1306.70

1462.79

1334.70

1358.61 
Erlin-2 GN=ERLIN2 Erlin-2 GN=ERLIN2 Erlin-2 GN=ERLIN2 Erythrocyte band 7 integral membrane protein GN=STOM STOM_HUMAN 31.73 Eythrocyte band 7 integral membe 31.7 Ethylmalonyl-CoA decarboxylase GN=ECHDC1 ECHD1_HUMAN $33.70 \quad 100.0 \%$ Ethylmalonyl-CoA decarboxylase GN=ECHDC1 ECHD1_HUMAN $33.70 \quad 100.0 \%$ Ethylmalonyl-CoA decarboxylase GN=ECHDC1 ECHD1_HUMAN $33.70 \quad 100.0 \%$ Ethylmalonyl-CoA decarboxylase GN=ECHDC1 ECHD1_HUMAN $33.70 \quad 100.0 \%$ Ethylmalonyl-CoA decarboxylase GN=ECHDC1 ECHD1_HUMAN $33.70 \quad 100.0 \%$ Eukaryotic initiation factor 4A-I GN=EIF4A1 IF4A1_HUMAN $46.16 \quad 100.0 \%$ Eukaryotic initiation factor 4A-I GN=EIF4A1 IF4A1_HUMAN $46.16 \quad 100.0 \%$ Eukaryotic initiation factor 4A-I GN=EIF4A1 IF4A1_HUMAN $46.16 \quad 100.0 \%$ Eukaryotic initiation factor 4A-I GN=EIF4A1 IF4A1_HUMAN $46.16 \quad 100.0 \%$ Eukaryotic initiation factor 4A-I GN=EIF4A1 IF4A1_HUMAN $46.16 \quad 100.0 \%$ Eukaryotic initiation factor 4A-I GN=EIF4A1 IF4A1_HUMAN $46.16 \quad 100.0 \%$ Eukaryotic initiation factor 4A-I GN=EIF4A1 IF4A1 HUMAN $46.16 \quad 100.0 \%$ Eukaryotic initiation factor 4A-I GN=EIF4A1 IF4A1_HUMAN $46.16 \quad 100.0 \%$ Eukaryotic initiation factor 4A-I GN=EIF4A1 IF4A1_HUMAN $46.16 \quad 100.0 \%$ Eukaryotic initiation factor 4A-I GN=EIF4A1 IF4A1_HUMAN $46.16 \quad 100.0 \%$ Eukaryotic initiation factor 4A-I GN=EIF4A1 IF4A1_HUMAN $46.16 \quad 100.0 \%$ Eukaryotic initiation factor 4A-III GN=EIF4A3 IF4A3_HUMAN $46.87 \quad 100.0 \%$ Eukaryotic initiation factor 4A-III GN=EIF4A3 IF4A3_HUMAN $46.87 \quad 100.0 \%$ Eukaryotic initiation factor 4A-III GN=EIF4A3 IF4A3_HUMAN $46.87 \quad 100.0 \%$ Eukaryotic initiation factor 4A-III GN=EIF4A3 IF4A3 HUMAN $46.87 \quad 100.0 \%$ Eukaryotic initiation factor 4A-III GN=EIF4A3 IF4A3_HUMAN $46.87 \quad 100.0 \%$ Eukaryotic initiation factor 4A-III GN=EIF4A3 IF4A3_HUMAN $46.87 \quad 100.0 \%$ Eukaryotic initiation factor 4A-III GN=EIF4A3 IF4A3_HUMAN $46.87 \quad 100.0 \%$ Eukaryotic translation initiation factor 2 subunit 1 GN=EIF2S1 IF2A_HUMAN $36.11 \quad 100.0 \%$ Eukaryotic translation initiation factor 2 subunit $1 \mathrm{GN}=\mathrm{EIF} 2 \mathrm{~S} 1 \mathrm{IF} 2 \mathrm{~A}$ HUMAN $36.11 \quad 100.0 \%$ Eukaryotic translation initiation factor 2 subunit $1 \mathrm{GN}=$ EIF2S1 IF2A_HUMAN $36.11 \quad 100.0 \%$ Eukaryotic translation initiation factor 2 subunit $1 \mathrm{GN}=\mathrm{EIF} 2 \mathrm{~S} 1 \mathrm{IF} 2 \mathrm{~A} \_$HUMAN $36.11 \quad 100.0 \%$ Eukaryotic translation initiation factor 3 subunit A GN=EIF3A EIF3A_HUMAN $166.57 \quad 100.0 \%$ Eukaryotic translation initiation factor 3 subunit A GN=EIF3A EIF3A_HUMAN $166.57 \quad 100.0 \%$ Eukaryotic translation initiation factor 3 subunit A GN=EIF3A EIF3A_HUMAN $166.57 \quad 100.0 \%$ Eukaryotic translation initiation factor 3 subunit A GN=EIF3A EIF3A_HUMAN $166.57 \quad 100.0 \%$ Eukaryotic translation initiation factor 3 subunit A GN=EIF3A EIF3A_HUMAN $166.57 \quad 100.0 \%$ Eukaryotic translation initiation factor 3 subunit A GN=EIF3A EIF3A HUMAN $166.57 \quad 100.0 \%$ Eukaryotic translation initiation factor 3 subunit A GN=EIF3A EIF3A_HUMAN $166.57 \quad 100.0 \%$ Eukaryotic translation initiation factor 3 subunit A GN=EIF3A EIF3A_HUMAN $166.57 \quad 100.0 \%$ Eukaryotic translation initiation factor 3 subunit A GN=EIF3A EIF3A_HUMAN $166.57 \quad 100.0 \%$ Eukaryotic translation initiation factor 3 subunit A GN=EIF3A EIF3A_HUMAN $166.57 \quad 100.0 \%$ Eukaryotic translation initiation factor 3 subunit A GN=EIF3A EIF3A HUMAN $166.57 \quad 100.0 \%$ Eukaryotic translation initiation factor 3 subunit A GN=EIF3A EIF3A_HUMAN $166.57 \quad 100.0 \%$ Eukaryotic translation initiation factor 3 subunit A GN=EIF3A EIF3A_HUMAN $166.57 \quad 100.0 \%$ Eukaryotic translation initiation factor 3 subunit A GN=EIF3A EIF3A_HUMAN $166.57 \quad 100.0 \%$ Eukaryotic translation initiation factor 3 subunit A GN=EIF3A EIF3A_HUMAN $166.57 \quad 100.0 \%$
C6 $62 \quad 0.07 \% \quad 42.8 \%$ ADAECYTAMK

$0.07 \% \quad 42.8 \%$ LTPEYLQLMK

$0.07 \% \quad 42.8 \%$ DIPNMFMDSAGSVSK

$0.00 \% \quad 6.9 \% \quad$ LLAQTTLR

$0.00 \% \quad 6.9 \%$ VIAAEGEMNASR

$3 \quad 0.01 \% \quad 19.5 \%$ EDNGIGILTLNNPSR

$0.01 \% \quad 19.5 \%$ VIELENWTEGK

$\begin{array}{lll}3 & 0.01 \% & 19.5 \% \\ \text { NTFSSGSDLNAVK }\end{array}$

$13 \quad 0.01 \% \quad 19.5 \%$ SLEEAQEWLK

$0.01 \% \quad 19.5 \%$ QFIQGPPEVIR

$0.05 \% \quad 32.5 \%$ GIYAYGFEKPSAIQQR

\begin{tabular}{llll}
$9.7 \%$ & 55.2 & 25.0 & 52.5 \\
$99.7 \%$ & 36.5 & 25.0 & 33.3 \\
\hline
\end{tabular}

$\begin{array}{llll}99.7 \% & 36.5 & 25.0 & 33.3\end{array}$

$99.7 \% \quad 41.5 \quad 25.0 \quad 41.5$

$99.0 \% \quad 42.3 \quad 25.0 \quad 32.0$

$\begin{array}{llll}99.7 \% & 62.0 & 25.0 & 55.8\end{array}$

$\begin{array}{llll}99.7 \% & 51.2 & 25.0 & 48.9\end{array}$

$\begin{array}{llll}99.7 \% & 53.3 & 25.0 & 49.3\end{array}$

$99.7 \% \quad 57.6 \quad 25.0 \quad 51.8$

$\begin{array}{lllll}99.7 \% & 37.3 & 25.0 & 25.8\end{array}$

$99.7 \% \quad 43.7 \quad 25.0 \quad 33.1$

$\begin{array}{lllllll}0.05 \% & 32.5 \% & \text { ALPCIKGYDVIAQAQSGTGK } & 99.1 \% & 57.1 & 25.0 & 49.5 \\ 0.05 \% & 32.5 \% & \text { GYDVIAQAQSGTGK } & 99.7 \% & 66.6 & 25.0 & 0.0\end{array}$

$0.05 \% \quad 32.5 \%$ GYDVIAQAQSGTGK

$0.05 \% \quad 32.5 \%$ ELAQQIQK

$99.0 \% \quad 32.7$

$\begin{array}{ll}25.0 & 0.0 \\ 25.0 & 66 \\ 25.0 & 24.6\end{array}$

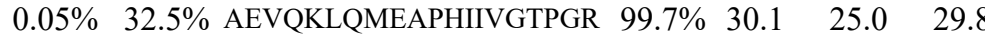

$0.05 \% 32.5 \%$ LQMEAPHIIVGTPGR

$0.05 \% 32.5 \%$ MFVLDEADEMLSR

$99.7 \% \quad 29.9$

$99.7 \% \quad 57.4$

$99.3 \% 21.3$

$0.05 \% 32.5 \%$ GFKDQIYDIFQK

$0.05 \% 32.5 \%$ VLITTDLLAR

$99.7 \% 56.6$

$0.05 \% \quad 32.5 \%$ GIDVQQVSLVINYDLPTNR $\quad 99.7 \% \quad 47.3$

$0.05 \% \quad 32.5 \%$ GVAINMVTEEDKR

$0.02 \% \quad 17.8 \%$ GIYAYGFEKPSAIQQR

$0.02 \% \quad 17.8 \%$ GRDVIAQSQSGTGK

$0.02 \% \quad 17.8 \%$ ELAVQIQK

$\begin{array}{lll}16.02 \% & 17.8 \% \text { KLDYGQHVVAGTPGR }\end{array}$

$0.02 \% \quad 17.8 \%$ LDYGQHVVAGTPGR

$0.02 \% \quad 17.8 \%$ GFKEQIYDVYR

$0.02 \% \quad 17.8 \%$ KGVAINFVK

$0.01 \% \quad 13.7 \%$ RLTPQAVK

$0.01 \% \quad 13.7 \%$ AGLNCSTENMPIK

$0.01 \% \quad 13.7 \%$ GVFNVQMEPK

$0.01 \% \quad 13.7 \%$ VVTDTDETELAR

$0.06 \% \quad 18.2 \%$ PAYFQRPENALKR

$0.06 \% \quad 18.2 \%$ ANEFLEVGK

$0.06 \% \quad 18.2 \%$ ANEFLEVGKK

$0.06 \% \quad 18.2 \%$ YLELCVDLRK

$0.06 \% \quad 18.2 \%$ NICQQVNIK

$0.06 \% \quad 18.2 \%$ MHLSQIQR

$0.06 \% \quad 18.2 \%$ AVEDIHGLFSLSK

$54 \quad 0.06 \% \quad 18.2 \%$ SGNALFHASTLHR

$0.06 \% \quad 18.2 \%$ KNLTQDEMQR

$0.06 \% \quad 18.2 \%$ NLTQDEMQR

$0.06 \% \quad 18.2 \%$ VLLATLSIPITPER

$0.06 \% \quad 18.2 \%$ VLLATLSIPITPERTDIAR

$0.06 \% \quad 18.2 \%$ LLDMDGIIVEK

$0.06 \% \quad 18.2 \%$ RLATLLGLQAPPTR

$0.06 \% \quad 18.2 \%$ LATLLGLQAPPTR
$99.7 \% \quad 35.8$

$99.7 \% \quad 57.1$

$99.7 \% \quad 35.7$

$99.0 \% \quad 35.7$

$99.7 \% \quad 36.3$

$99.7 \% \quad 34.2$

$99.6 \% 25.1$

$99.7 \% \quad 32.6$

$98.5 \% \quad 23.1$

$99.5 \% \quad 27.5$

$99.7 \% \quad 48.0$

$99.7 \% \quad 86.4$

$99.7 \% 28.1$

$99.7 \% \quad 38.1$

$98.6 \% \quad 18.5$

$99.7 \% \quad 30.8$

$99.7 \% \quad 34.5$

$96.7 \% \quad 19.5$

$99.7 \% \quad 49.9$

$99.7 \% \quad 49.2$

$99.7 \% 26.5$

$99.7 \% \quad 44.1$

$99.3 \% \quad 21.2$

$99.7 \% \quad 27.8$

$99.7 \% \quad 53.9$

$99.7 \% 26.8$

$99.7 \% \quad 36.0$
115

0

0



Eukaryotic translation initiation factor 3 subunit A GN=EIF3A EIF3A_HUMAN $166.57 \quad 100.0 \% \quad 27$ Eukaryotic translation initiation factor 3 subunit A GN=EIF3A EIF3A_HUMAN $166.57 \quad 100.0 \% \quad 27$ Eukaryotic translation initiation factor 3 subunit A GN=EIF3A EIF3A_HUMAN $166.57 \quad 100.0 \%$ Eukaryotic translation initiation factor 3 subunit A GN=EIF3A EIF3A_HUMAN $166.57 \quad 100.0 \% \quad 27$ Eukaryotic translation initiation factor 3 subunit A GN=EIF3A EIF3A_HUMAN $166.57 \quad 100.0 \% \quad 27$ Eukaryotic translation initiation factor 3 subunit A GN=EIF3A EIF3A_HUMAN $166.57 \quad 100.0 \% \quad 27$ Eukaryotic translation initiation factor 3 subunit A GN=EIF3A EIF3A_HUMAN $166.57 \quad 100.0 \% \quad 27$ Eukaryotic translation initiation factor 3 subunit A GN=EIF3A EIF3A_HUMAN $166.57 \quad 100.0 \%$ Eukaryotic translation initiation factor 3 subunit A GN=EIF3A EIF3A_HUMAN $166.57 \quad 100.0 \% \quad 27$ Eukaryotic translation initiation factor 3 subunit A GN=EIF3A EIF3A_HUMAN $166.57 \quad 100.0 \% \quad 2$ Eukaryotic translation initiation factor 3 subunit A GN=EIF3A EIF3A_HUMAN $166.57 \quad 100.0 \% \quad 27$ Eukaryotic translation initiation factor 3 subunit B GN=EIF3B EIF3B_HUMAN $92.48 \quad 100.0 \%$ Eukaryotic translation initiation factor 3 subunit B GN=EIF3B EIF3B_HUMAN $92.48 \quad 100.0 \%$ Eukaryotic translation initiation factor 3 subunit B GN=EIF3B EIF3B_HUMAN $92.48 \quad 100.0 \%$ Eukaryotic translation initiation factor 3 subunit B GN=EIF3B EIF3B_HUMAN $92.48 \quad 100.0 \%$ Eukaryotic translation initiation factor 3 subunit $\mathrm{B}$ GN=EIF3B EIF3B HUMAN $92.48 \quad 100.0 \%$ Eukaryotic translation initiation factor 3 subunit B GN=EIF3B EIF3B_HUMAN $92.48 \quad 100.0 \%$ Eukaryotic translation initiation factor 3 subunit B GN=EIF3B EIF3B_HUMAN $92.48 \quad 100.0 \%$ Eukaryotic translation initiation factor 3 subunit $\mathrm{C}$ GN=EIF3C EIF3C HUMAN $105.35 \quad 100.0 \%$ Eukaryotic translation initiation factor 3 subunit C GN=EIF3C EIF3C_HUMAN $105.35 \quad 100.0 \%$ Eukaryotic translation initiation factor 3 subunit D GN=EIF3D EIF3D HUMAN $63.97 \quad 100.0 \%$ Eukaryotic translation initiation factor 3 subunit D GN=EIF3D EIF3D_HUMAN $63.97 \quad 100.0 \%$ Eukaryotic translation initiation factor 3 subunit D GN=EIF3D EIF3D_HUMAN $63.97 \quad 100.0 \%$ Eukaryotic translation initiation factor 3 subunit D GN=EIF3D EIF3D_HUMAN $63.97 \quad 100.0^{\circ}$ Eukaryotic translation initiation factor 3 subunit D GN=EIF3D EIF3D_HUMAN $63.97 \quad 100.0 \%$ Eukaryotic translation initiation factor 3 subunit D GN=EIF3D EIF3D_HUMAN $63.97 \quad 100.0 \%$ Eukaryotic translation initiation factor 3 subunit D GN=EIF3D EIF3D HUMAN $63.97 \quad 100.0 \%$ Eukaryotic translation initiation factor 3 subunit D GN=EIF3D EIF3D_HUMAN $63.97 \quad 100.0 \%$ Eukaryotic translation initiation factor 3 subunit D GN=EIF3D EIF3D HUMAN $63.97 \quad 100.0^{\circ} \%$ Eukaryotic translation initiation factor 3 subunit E GN=EIF3E EIF3E_HUMAN $52.22 \quad 100.0 \%$ Eukaryotic translation initiation factor 3 subunit E GN=EIF3E EIF3E_HUMAN $52.22 \quad 100.0 \%$ Eukaryotic translation initiation factor 3 subunit $\mathrm{E}$ GN=EIF3E EIF3E HUMAN $52.22 \quad 100.0^{\circ}$ Eukaryotic translation initiation factor 3 subunit E GN=EIF3E EIF3E_HUMAN $52.22 \quad 100.0 \%$ Eukaryotic translation initiation factor 3 subunit E GN=EIF3E EIF3E_HUMAN $52.22 \quad 100.0 \%$ Eukaryotic translation initiation factor 3 subunit E GN=EIF3E EIF3E_HUMAN $52.22 \quad 100.0 \%$ Eukaryotic translation initiation factor 3 subunit E GN=EIF3E EIF3E_HUMAN $52.22 \quad 100.0 \%$ Eukaryotic translation initiation factor 3 subunit E GN=EIF3E EIF3E_HUMAN $52.22 \quad 100.0 \%$ Eukaryotic translation initiation factor 3 subunit E GN=EIF3E EIF3E_HUMAN $52.22 \quad 100.0 \%$ Eukaryotic translation initiation factor 3 subunit $\mathrm{E}$ GN=EIF3E EIF3E_HUMAN $52.22 \quad 100.0 \%$ Eukaryotic translation initiation factor 3 subunit $\mathrm{E}$ GN=EIF3E EIF3E HUMAN $52.22 \quad 100.0 \%$ Eukaryotic translation initiation factor 3 subunit $\mathrm{E}$ GN=EIF3E EIF3E_HUMAN $52.22 \quad 100.0 \%$ Eukaryotic translation initiation factor 3 subunit $\mathrm{E}$ GN=EIF3E EIF3E HUMAN $52.22100 .0 \%$ Eukaryotic translation initiation factor 3 subunit $\mathrm{E}$ GN=EIF3E EIF3E_HUMAN $52.22 \quad 100.0 \%$ Eukaryotic translation initiation factor 3 subunit E GN=EIF3E EIF3E_HUMAN $52.22 \quad 100.0 \%$ Eukaryotic translation initiation factor 3 subunit $\mathrm{F}$ GN=EIF3F EIF3F HUMAN $37.56 \quad 100.0 \%$ Eukaryotic translation initiation factor 3 subunit F GN=EIF3F EIF3F_HUMAN $37.56 \quad 100.0 \%$

7

2

2
9

9

$\begin{array}{ll}5 & 18 \\ 15 & 18\end{array}$

$54 \quad 0.06 \% \quad 18.2 \%$ IGLINDMVR $0.06 \% \quad 18.2 \%$ LLQQVSQIYQSIEFSR $0.06 \% \quad 18.2 \%$ LTSLVPFVDAFQLER $0.06 \% \quad 18.2 \%$ TLSFGSDLNYATR $0.06 \% \quad 18.2 \%$ NQLTAMSSVLAK $0.06 \% \quad 18.2 \%$ ILQEHEQIKK

$0.06 \% \quad 18.2 \%$ RLEEIPLIK

$0.06 \% \quad 18.2 \%$ MLEDRDLFVMR

$0.06 \% \quad 18.2 \%$ RLGDSSLSR

$0.06 \% \quad 18.2 \%$ LGDSSLSR

$0.06 \% \quad 18.2 \%$ GLDDDRGPR

$0.06 \% \quad 18.2 \%$ NMDDDRLSR

$0.02 \% \quad 8.9 \% \quad$ AQAVSEDAGGNEGR

$0.02 \% \quad 8.9 \%$ AQAVSEDAGGNEGRAAEAEPR

$0.02 \% \quad 8.9 \%$ GTYLATFHQR

$0.02 \% \quad 8.9 \% \quad$ VTLMQLPTR

$0.02 \% \quad 8.9 \%$ GTQGVVTNFEIFR

$0.02 \% \quad 8.9 \%$ FAVLHGEAPR

$0.02 \% \quad 8.9 \%$ ISVSFYHVK

$0.00 \% \quad 2.4 \%$ SIVDKEGVPR

$0.00 \% \quad 2.4 \%$ AKELLGQGLLLR

$0.04 \% \quad 19.7 \%$ VADWTGATYQDKR

$0.04 \% \quad 19.7 \%$ NMLQFNLQILPK

$0.04 \% \quad 19.7 \%$ IFHTVTTTDDPVIR

$0.04 \% \quad 19.7 \%$ IFHTVTTTDDPVIRK

$0.04 \% \quad 19.7 \%$ SVYSWDIVVQR

$0.04 \% \quad 19.7 \%$ NLAMEATYINHNFSQQCLR

$0.04 \% \quad 19.7 \%$ LGDDIDLIVR

$0.04 \% \quad 19.7 \%$ GAVIATELKNNSYK

$0.04 \% \quad 19.7 \%$ WTCCALLAGSEYLK

$0.05 \% \quad 29.4 \%$ NLYSDDIPHALR

$0.05 \% \quad 29.4 \%$ RTTVVAQLK

$0.05 \% \quad 29.4 \%$ TTVVAQLK

$0.05 \% \quad 29.4 \%$ TTVVAQLKQLQAETEPIVK

$0.05 \% \quad 29.4 \%$ QLQAETEPIVK

$0.05 \% \quad 29.4 \%$ MFEDPETTR

$0.05 \% \quad 29.4 \%$ VLVPATDR

$\begin{array}{ll}99.7 \% & 50.3 \\ 99.7 \% & 53.2\end{array}$

$99.7 \% \quad 53.2$

$99.7 \% \quad 69.6$

$99.7 \% \quad 65.7$

$99.7 \% \quad 52.2$

$98.6 \% 19.6$

$96.5 \% \quad 18.5$

$99.4 \% \quad 22.9$

$97.3 \% \quad 28.0$

$99.0 \% 55.9$

$95.5 \% \quad 14.5$

$99.7 \% \quad 30.3$

$99.7 \% \quad 63.9$

$99.7 \% \quad 27.6$

$99.7 \% \quad 49.3$

$99.7 \% \quad 37.5$

$99.7 \% \quad 52.2$

$99.7 \% \quad 44.0$

$99.6 \% \quad 29.9$

$\begin{array}{lll}99.5 \% & 25.0\end{array}$

$99.7 \% \quad 41.9$

$99.7 \% \quad 38.2$

$99.7 \% \quad 64.6$

$99.7 \% \quad 43.6$

$99.7 \% \quad 30.3$

$99.7 \% \quad 54.6$

$99.7 \% \quad 30.4$

$99.7 \% \quad 59.1$

$99.7 \% \quad 62.5$

$99.7 \% \quad 40.5$

$98.8 \% \quad 23.4$

$99.7 \% \quad 30.1$

$98.9 \% \quad 30.3$

$\begin{array}{ll}99.7 \% & 51.7 \\ 99.7 \% & 38.8\end{array}$

$99.7 \% \quad 38.6$

$99.0 \% \quad 27.9$

$0.05 \% \quad 29.4 \%$ LKETIDNNSVSSPLQSLQQR $99.7 \% \quad 41.0$

$0.05 \% \quad 29.4 \%$ YLTTAVITNK

$\begin{array}{lll}0.05 \% & 29.4 \% & \text { YLTTAVITNKDVR }\end{array}$

$99.7 \% \quad 47.9$

$99.7 \% \quad 61.9$

$95.0 \% \quad 19.5$

$99.7 \% \quad 47.2$

$\begin{array}{ll}0.05 \% & 29.4 \% \text { QVLKDLVK } \\ 0.05 \% & 29.4 \% \text { LFIFETFCR }\end{array}$

$\begin{array}{lllll}0.05 \% & 29.4 \% & \text { LGHVVMGNNAVSPYQQVIEK } & 99.7 \% & 27.8 \\ 0.05 \% & 29.4 \% & \text { LGHVVMGNNAVSPYQQVIEKTK } & 99.7 \% & 35.1 \\ 0.05 \% & 29.4 \% & \text { SQMLAMNIEK } & 99.7 \% & 54.9\end{array}$

$0.05 \% \quad 29.4 \%$ SQMLAMNIEK

$\begin{array}{ll}99.7 \% & 54.9 \\ 99.6 \% & 24.8\end{array}$

$\begin{array}{lllll}0.00 \% & 9.8 \% & \text { EAPNPIHLTVDTSLQNGR } & 99.6 \% & 24.8 \\ 0.00 \% & 9.8 \% & \text { VIGLSSDLQQVGGASAR } & 99.7 \% & 92.4\end{array}$
1939.03

1734.94

1444.7

1278.67

1265.72

1110.69

1440.70

990.53

834.43

1000.48

1121.50

1360.61

2084.96

1193.61

1058.60

1467.76

1096.59

1079.59

1099.61

1310.82

1510.73

1474.81

1614.85

1742.94

1351.70

2310.08

1128.63

1507.81

1671.79

1413.71

1015.63

859.52

2096.20

1255.69

1125.49

870.50

2257.18

1123.64

1493.83

942.60

1232.61

2199.12

2428.27

1196.57

1962.00

1657.89 $\begin{array}{cc}68 & 376 \\ 39 & 454 \\ 55 & 469 \\ 90 & 502 \\ 21 & 532 \\ 24 & 633 \\ 03 & 711 \\ 53 & 763 \\ 77 & 885 \\ 78 & 885 \\ 72 & 1080 \\ 42 & 1150 \\ 21 & 134 \\ 21 & 141 \\ 46 & 355 \\ 93 & 501 \\ 36 & 548 \\ 77 & 586 \\ 87 & 595 \\ 5 & 104 \\ 42 & 653 \\ 2 & 54 \\ 13 & 124 \\ 23 & 236 \\ 23 & 237 \\ 61 & 271 \\ 11 & 329 \\ 65 & 374 \\ 18 & 431 \\ 35 & 448 \\ 0 & 71 \\ 4 & 82 \\ 5 & 82 \\ 5 & 93 \\ 3 & 93 \\ 4 & 102 \\ 56 & 163 \\ 92 & 211 \\ 56 & 265 \\ 56 & 268 \\ 72 & 279 \\ 38 & 346 \\ 88 & 407 \\ 88 & 409 \\ 15 & 424 \\ 93 & 210 \\ 62 & 278 \\ & \end{array}$

Page 60 of Table S-1-6 
Eukaryotic translation initiation factor 3 subunit $\mathrm{G} \mathrm{GN=EIF3G} \mathrm{EIF3G} \mathrm{HUMAN} 35.61 \quad 100.0 \%$ Eukaryotic translation initiation factor 3 subunit G GN=EIF3G EIF3G_HUMAN $35.61 \quad 100.0 \%$ Eukaryotic translation initiation factor 3 subunit $\mathrm{H}$ GN=EIF3H EIF3H_HUMAN $39.93 \quad 100.0 \%$ Eukaryotic translation initiation factor 3 subunit $\mathrm{H}$ GN=EIF3H EIF3H_HUMAN $39.93 \quad 100.0 \%$ Eukaryotic translation initiation factor 3 subunit $\mathrm{H}$ GN=EIF3H EIF3H_HUMAN $39.93 \quad 100.0 \%$ Eukaryotic translation initiation factor 3 subunit $\mathrm{H}$ GN=EIF3H EIF3H_HUMAN $39.93 \quad 100.0 \%$ Eukaryotic translation initiation factor 3 subunit $\mathrm{H}$ GN=EIF3H EIF3H_HUMAN $39.93 \quad 100.0 \%$ Eukaryotic translation initiation factor 3 subunit I GN=EIF3I EIF3I_HUMAN $36.50 \quad 100.0 \%$ Eukaryotic translation initiation factor 3 subunit I GN=EIF3I EIF3I HUMAN $36.50 \quad 100.0 \%$ Eukaryotic translation initiation factor 3 subunit I GN=EIF3I EIF3I_HUMAN $36.50 \quad 100.0 \%$ Eukaryotic translation initiation factor 3 subunit I GN=EIF3I EIF3I_HUMAN $36.50 \quad 100.0 \%$ Eukaryotic translation initiation factor 3 subunit I GN=EIF3I EIF3I HUMAN $36.50 \quad 100.0 \%$ Eukaryotic translation initiation factor 3 subunit I GN=EIF3I EIF3I_HUMAN $36.50 \quad 100.0 \%$ Eukaryotic translation initiation factor 3 subunit I GN=EIF3I EIF3I HUMAN $36.50 \quad 100.0 \%$ Eukaryotic translation initiation factor 3 subunit I GN=EIF3I EIF3I_HUMAN $36.50 \quad 100.0 \%$ Eukaryotic translation initiation factor 3 subunit I GN=EIF3I EIF3I_HUMAN $36.50 \quad 100.0 \%$ Eukaryotic translation initiation factor 3 subunit I GN=EIF3I EIF3I HUMAN $36.50 \quad 100.0 \%$ Eukaryotic translation initiation factor 3 subunit I GN=EIF3I EIF3I_HUMAN $36.50 \quad 100.0 \%$ Eukaryotic translation initiation factor 3 subunit L GN=EIF3L EIF3L_HUMAN $66.73 \quad 100.0 \%$ Eukaryotic translation initiation factor 3 subunit L GN=EIF3L EIF3L_HUMAN $66.73 \quad 100.0 \%$ Eukaryotic translation initiation factor 3 subunit $\mathrm{L}$ GN=EIF3L EIF3L_HUMAN $66.73 \quad 100.0 \%$ Eukaryotic translation initiation factor 3 subunit L GN=EIF3L EIF3L_HUMAN $66.73 \quad 100.0 \%$ Eukaryotic translation initiation factor 3 subunit $\mathrm{L}$ GN=EIF3L EIF3L_HUMAN $66.73 \quad 100.0 \%$ Eukaryotic translation initiation factor 3 subunit L GN=EIF3L EIF3L_HUMAN $66.73 \quad 100.0 \%$ Eukaryotic translation initiation factor 3 subunit L GN=EIF3L EIF3 L HUMAN $66.73 \quad 100.0 \%$ Eukaryotic translation initiation factor 3 subunit $\mathrm{L}$ GN=EIF3L EIF3L_HUMAN $66.73 \quad 100.0 \%$ Eukaryotic translation initiation factor 3 subunit L GN=EIF3L EIF3L_HUMAN $66.73 \quad 100.0 \%$ Eukaryotic translation initiation factor 3 subunit $\mathrm{L}$ GN=EIF3L EIF3L_HUMAN $66.73 \quad 100.0 \%$ Eukaryotic translation initiation factor 3 subunit L GN=EIF3L EIF3L_HUMAN $66.73 \quad 100.0 \%$ Eukaryotic translation initiation factor 3 subunit L GN=EIF3L EIF3L_HUMAN $66.73 \quad 100.0 \%$ Eukaryotic translation initiation factor 3 subunit $\mathrm{L}$ GN=EIF3L EIF3L_HUMAN $66.73 \quad 100.0 \%$ Eukaryotic translation initiation factor 3 subunit L GN=EIF3L EIF3L_HUMAN $66.73 \quad 100.0 \%$ Eukaryotic translation initiation factor 3 subunit L GN=EIF3L EIF3L HUMAN $66.73 \quad 100.0 \%$ Eukaryotic translation initiation factor 3 subunit M GN=EIF3M EIF3M_HUMAN $42.50 \quad 100.0 \%$ Eukaryotic translation initiation factor 3 subunit M GN=EIF3M EIF3M_HUMAN $42.50 \quad 100.0 \%$ Eukaryotic translation initiation factor 3 subunit M GN=EIF3M EIF3M_HUMAN $42.50 \quad 100.0 \%$ Eukaryotic translation initiation factor 3 subunit M GN=EIF3M EIF3M_HUMAN $42.50 \quad 100.0 \%$ Eukaryotic translation initiation factor 4 gamma $1 \mathrm{GN}=\mathrm{EIF} 4 \mathrm{G} 1 \quad$ IF4G1 HUMAN $175.49 \quad 100.0^{\circ}$ Eukaryotic translation initiation factor 4 gamma $1 \mathrm{GN}=\mathrm{EIF} 4 \mathrm{G} 1 \quad$ IF4G1_HUMAN $175.49 \quad 100.0 \%$ Eukaryotic translation initiation factor 4 gamma 1 GN=EIF4G1 IF4G1_HUMAN $175.49 \quad 100.0 \%$ Eukaryotic translation initiation factor 4 gamma $1 \mathrm{GN}=\mathrm{EIF} 4 \mathrm{G} 1$ IF4G1_HUMAN $175.49 \quad 100.0 \%$ Eukaryotic translation initiation factor 4 gamma 2 GN=EIF4G2 IF4G2_HUMAN $102.37 \quad 100.0 \%$ Eukaryotic translation initiation factor 4 gamma 2 GN=EIF4G2 IF4G2 HUMAN $102.37 \quad 100.0 \%$ Eukaryotic translation initiation factor 4 gamma 2 GN=EIF4G2 IF4G2_HUMAN $102.37 \quad 100.0 \%$ Eukaryotic translation initiation factor 4 gamma 2 GN=EIF4G2 IF4G2_HUMAN $102.37 \quad 100.0 \%$ Earyotic translation initiation factor 4 gamma $2 \mathrm{GN}=\mathrm{EIF} 4 \mathrm{G} 2 \quad \mathrm{IF} 4 \mathrm{G} 2$ HUMAN $102.37 \quad 100.0 \%$ Eukaryotic translation initiation factor 4B GN=EIF4B IF4B_HUMAN $69.15 \quad 100.0 \%$
$0.00 \% \quad 7.2 \%$ LPGELEPVQATQNK $0.00 \% \quad 7.2 \%$ GFAFISFHR

$99.7 \% \quad 35.7$ $99.7 \% \quad 31.8$

$0.01 \% \quad 14.8 \%$ KEGTGSTATSSSSTAGAAGK $\quad 99.7 \% \quad 51.7$ $0.01 \% \quad 14.8 \%$ EGTGSTATSSSSTAGAAGK $\quad 99.7 \% \quad 64.1$

$0.01 \% \quad 14.8 \%$ QVQIDGLVVLK

$0.01 \% \quad 14.8 \%$ EFTAQNLGK

$0.01 \% \quad 14.8 \%$ LFMAQALQEYNN

$0.03 \% \quad 35.1 \%$ SITQIKYNR

$0.03 \% \quad 35.1 \%$ EGDLLFTVAK

$0.03 \% \quad 35.1 \%$ HVLTGSADNSCR

$0.03 \% \quad 35.1 \%$ SGEVLVNVK

$0.03 \% \quad 35.1 \%$ SGEVLVNVKEHSR

$0.03 \% \quad 35.1 \%$ QINDIQLSR

$0.03 \% \quad 35.1 \%$ DMTMFVTASK

$0.03 \% \quad 35.1 \%$ LFDSTTLEHQK

$0.03 \% \quad 35.1 \%$ FFHLAFEEEFGR

$0.03 \% 35.1 \%$ GHFGPINSVAFHPDGK

$0.03 \% \quad 35.1 \%$ SYSSGGEDGYVR

$0.05 \% \quad 28.2 \%$ NFIQYFHK

$99.7 \% \quad 38.5$

$99.7 \% \quad 49.0$

$99.7 \% \quad 56.4$

$99.7 \% \quad 43.7$

$99.7 \% \quad 63.5$

$99.0 \% \quad 29.4$

$0.05 \% \quad 28.2 \%$ TVSDLIDQKVYELQASR $\quad 99.7 \% \quad 51.6$

$0.05 \% \quad 28.2 \%$ VSGGPSLEQR

$0.05 \% \quad 28.2 \%$ KSEEEIDFLR

$99.7 \% \quad 44.2$

$99.7 \% \quad 52.8$

$0.05 \% \quad 28.2 \%$ SEEEIDFLR

$0.05 \% \quad 28.2 \%$ LHSLLGDYYQAIK

$0.05 \% \quad 28.2 \%$ VLENIELNKK

$0.05 \% \quad 28.2 \%$ VFANILLYIQR

$0.05 \% \quad 28.2 \%$ IDESIHLQLR

$0.05 \% \quad 28.2 \%$ VFSDEVQQQAQLSTIR

$0.05 \% \quad 28.2 \%$ SFLKLYTTMPVAK

$0.05 \% \quad 28.2 \%$ LYTTMPVAK

$0.05 \% \quad 28.2 \%$ LAGFLDLTEQEFR

$0.05 \% \quad 28.2 \%$ RYGDFFIR

$0.01 \% \quad 13.4 \%$ YTVYCSLIK

$0.01 \% \quad 13.4 \%$ LLYEALVDCKK

$0.01 \% \quad 13.4 \%$ VMVELLGSYTEDNASQAR

$0.01 \% \quad 13.4 \%$ LLTFMGMAVENK

$0.01 \% \quad 4.5 \%$ ITKPGSIDSNNQLFAPGGR $99.7 \%$

$0.01 \% \quad 4.5 \% \quad$ GSSGGSGAKPSDAASEAARPATSTLNR $\quad 99.7 \% \quad 42.0$

$0.01 \% \quad 4.5 \% \quad$ FSALQQAVPTESTDNRR

$0.01 \% \quad 4.5 \%$ HGVESTLER

$0.01 \% \quad 5.4 \%$ TAGNSEFLGK

$0.01 \% \quad 5.4 \%$ KAFLDNGPK

$0.01 \% \quad 5.4 \%$ TNPPLIQEKPAK

$0.01 \% \quad 5.4 \%$ HFLPEMLSK

$0.01 \% \quad 5.4 \%$ SYLAQFAAR

$0.04 \% \quad 17.5 \%$ SILPTAPR
$99.7 \% \quad 44.1$

$99.7 \% \quad 28.1$

$99.6 \% 25.8$

$99.7 \% \quad 36.2$

$98.0 \% \quad 16.4$

$99.7 \% \quad 49.4$

$99.0 \% \quad 26.7$
$98.5 \% \quad 18.7$

$97.7 \% \quad 21.5$

$99.7 \% 60.8$

$99.7 \% \quad 42.6$

$99.7 \% \quad 38.9$

$99.7 \% \quad 54.8$

$99.7 \% \quad 30.7$

$99.7 \% \quad 38.8$

$99.7 \% \quad 52.3$

$99.7 \% \quad 58.7$

$\begin{array}{ll}0 & 22.3\end{array}$

$0 \quad 50$

$\begin{array}{ll}0 & 62.9\end{array}$

$0 \quad 18.6$

14.2

$\begin{array}{ll}32.6 \\ 25.0 & 37.7\end{array}$

$\begin{array}{lll}0 & 37.7 & 2\end{array}$

$\begin{array}{lll}0 & 49.0 & 2\end{array}$

$\begin{array}{lll}0 & 49.1 \quad 2\end{array}$

$\begin{array}{ll}.0 & 42.0\end{array}$

$\begin{array}{lll}.0 & 18.0 \quad 2\end{array}$

$\begin{array}{lll}38.0 & 38.9 & 3\end{array}$

$\begin{array}{ll}43.1 \\ 35.0 & 30.7\end{array}$

\begin{tabular}{ll}
38.7 \\
\hline
\end{tabular}

$\begin{array}{ll}25.0 & 49.9\end{array}$

$\begin{array}{ll}25.0 & 16.8\end{array}$

51.6

51.8

$0 \quad 38.8$

39.6

$\begin{array}{lll}5.0 & 99.9 & 2\end{array}$

$\begin{array}{llll}99.0 \% & 26.3 & 25.0 & 20.1\end{array}$

$\begin{array}{lllll}99.7 \% & 32.8 & 25.0 & 31.7 & 2\end{array}$

$\begin{array}{llll}9.7 \% & 28.3 & 25.0 & 28.3\end{array}$

$\begin{array}{ll}28.3 \\ 25.0 & 23.9\end{array}$

$\begin{array}{ll}23.0 & 42.5\end{array}$

$\begin{array}{ll}33.0 & 33.5\end{array}$

$\begin{array}{ll}25.0 & 42.0\end{array}$

44.1

$\begin{array}{ll}.0 & 44.1 \\ .0 & 36.1\end{array}$

$28.0 \quad 28$

$\begin{array}{ll}0 & 20.7\end{array}$

\begin{tabular}{ll}
0 & 36.2 \\
\hline
\end{tabular}

$\begin{array}{ll}2.0 & 16.4\end{array}$

$\begin{array}{ll}.0 & 16.4 \\ 0 & 32.7\end{array}$

$\begin{array}{ll}25.0 & 14.3\end{array}$

0
0
2
0
0
0
0
0
0
0
0
1
0
2
2
0
0
0
1
1
2
0
0
0
0
2
0
0
0
2
0
0
0
0
0
0
1
0
0
0
0
0
0
2
0
1
0
1
0
0
0
0
0
0
0
0
0
0
0
0
0
0
0
0
0
0
0
0
0
0
0

1755.84

1627.74

1211.74

1007.52

1441.68

1122.63

1092.59

1316.60

944.54

1453.78

1086.59

1162.51

1318.66

1528.72

1679.83

1276.54

1096.56

1965.03

1029.53

1265.64

1137.54

2113.97

1520.81

1199.70

1349.79

1223.67

1848.95

1498.83

1039.55

1538.79

1073.55

1146.59

1351.73

1998.94

1353.69

1972.02

2503.21

1919.96

1027.52

1023.51

989.54

1335.76

1101.58

1026.54

854.51

$\begin{array}{cc}96 & 209 \\ 81 & 289 \\ 5 & 24 \\ 6 & 24 \\ 8 & 48 \\ 32 & 340 \\ 41 & 352 \\ 2 & 20 \\ 1 & 30 \\ 6 & 77 \\ 77 & 185 \\ 77 & 189 \\ 90 & 198 \\ 99 & 208 \\ 14 & 224 \\ 69 & 280 \\ 83 & 298 \\ 99 & 310 \\ 4 & 61 \\ 2 & 78 \\ 44 & 153 \\ 07 & 216 \\ 08 & 216 \\ 43 & 262 \\ 80 & 292 \\ 93 & 302 \\ 35 & 345 \\ 82 & 391 \\ 46 & 461 \\ 62 & 474 \\ 66 & 474 \\ 75 & 487 \\ 38 & 545 \\ 21 & 129 \\ 67 & 177 \\ 84 & 201 \\ 79 & 290 \\ 72 & 1090 \\ 96 & 1122 \\ 23 & 1139 \\ 81 & 1289 \\ 2 & 41 \\ 13 & 321 \\ 21 & 532 \\ 76 & 584 \\ 41 & 649 \\ 1 & 78 \\ & \end{array}$



Eukaryotic translation initiation factor 4B GN=EIF4B IF4B_HUMAN $69.15 \quad 100.0 \%$ Eukaryotic translation initiation factor 6 GN=EIF6 IF6 HUMAN $26.60 \quad 100.0 \%$ Eukaryotic translation initiation factor 6 GN=EIF6 IF6_HUMAN $26.60 \quad 100.0 \%$ Exocyst complex component 4 GN=EXOC4 EXOC4_HUMAN $110.50 \quad 100.0 \%$ Exocyst complex component 4 GN=EXOC4 EXOC4_HUMAN $110.50100 .0 \%$ Exosome complex component MTR3 GN=EXOSC6 EXOs6_HUMAN $28.24 \quad 100.0 \%$ Exosome complex component MTR3 GN=EXOSC6 EXOS6_HUMAN $28.24 \quad 100.0 \%$ Exosome complex component MTR3 GN=EXOSC6 EXOS6_HUMAN $28.24 \quad 100.0 \%$ Exosome complex component MTR3 GN=EXOSC6 EXOS6_HUMAN $28.24 \quad 100.0 \%$ Exosome complex component MTR3 GN=EXOSC6 EXOS6 HUMAN $28.24 \quad 100.0 \%$ Exosome complex component RRP43 GN=EXOSC8 EXOS8_HUMAN $30.04 \quad 100.0 \%$ Exosome complex component RRP43 GN=EXOSC8 EXOS8_HUMAN $30.04 \quad 100.0 \%$ Exosome complex component RRP43 GN=EXOSC8 EXOS8 HUMAN $30.04 \quad 100.0 \%$ Exosome complex component RRP43 GN=EXOSC8 EXOS8_HUMAN $30.04 \quad 100.0 \%$ Exosome complex exonuclease RRP44 GN=DIS3 RRP44_HUMAN $109.01 \quad 100.0 \%$ Exosome complex exonuclease RRP44 GN=DIS3 RRP44_HUMAN $109.01 \quad 100.0 \%$ Exosome complex exonuclease RRP44 GN=DIS3 RRP44_HUMAN $109.01 \quad 100.0 \%$ Exosome complex exonuclease RRP44 GN=DIS3 RRP44_HUMAN $109.01 \quad 100.0 \%$ Exosome complex exonuclease RRP44 GN=DIS3 RRP44_HUMAN $109.01 \quad 100.0 \%$ Exportin-1 GN=XPO1

Exportin-1 GN=XPO1 Exportin-1 GN=XPO1 Exportin-1 GN=XPO1 Exportin-1 GN=XPO1 Exportin-1 GN=XPO1 Exportin-1 GN=XPO1 Exportin-1 GN=XPO1 Exportin-1 GN=XPO1 Exportin-1 GN=XPO1 Exportin-1 GN=XPO1 Exportin-1 GN=XPO1 Exportin-2 GN=CSE1L Exportin-2 GN=CSE1L

Exportin-2 GN=CSE1L Exportin-2 GN=CSE1L Exportin-2 GN=CSE1L Exportin-2 GN $=\mathrm{CSE} 1 \mathrm{~L}$ Exportin-2 GN=CSE1L Exportin-2 GN=CSE1L Exportin-2 GN=CSE1L XPO1_HUMAN $123.39 \quad 100.0 \%$ XPO1_HUMAN $123.39 \quad 100.0 \%$ XPO1_HUMAN $123.39 \quad 100.0 \%$ XPO1_HUMAN $123.39 \quad 100.0 \%$ XPO1_HUMAN $123.39 \quad 100.0 \%$ XPO1_HUMAN $123.39 \quad 100.0 \%$ XPO1_HUMAN $123.39 \quad 100.0 \%$ XPO1_HUMAN $123.39 \quad 100.0 \%$ XPO1_HUMAN $123.39 \quad 100.0 \%$ XPO1 HUMAN $123.39 \quad 100.0 \%$ XPO1_HUMAN $123.39 \quad 100.0 \%$ XPO1 HUMAN $123.39 \quad 100.0 \%$ XPO2_HUMAN $110.42 \quad 100.0 \%$ XPO2_HUMAN $110.42 \quad 100.0 \%$ XPO2_HUMAN $110.42 \quad 100.0 \%$ XPO2_HUMAN $110.42 \quad 100.0 \%$ XPO2 HUMAN $110.42 \quad 100.0 \%$ XPO2_HUMAN $110.42 \quad 100.0 \%$ XPO2_HUMAN $110.42 \quad 100.0 \%$ XPO2 HUMAN $110.42 \quad 100.0 \%$ XPO2_HUMAN $110.42 \quad 100.0 \%$

$0.04 \% \quad 17.5 \%$ GLNISAVR 12

5

2
2
2

2
2
2

12

12
12
12

12
12
12

12
12
12

12
12
10

12
10
10

$\begin{array}{lllll}0.00 \% & 3.0 \% & \text { KFLDTSHYSTAGSSSVR } \quad 99.7 \% & 29.9\end{array}$

$0.00 \% \quad 3.0 \%$ STTQVADSGYQR

$10 \quad 0.01 \% \quad 20.2 \%$ GSAYLEAGGTK

$10 \quad 0.01 \% \quad 20.2 \%$ VLCAVSGPR

$\begin{array}{lll}99.7 \% & 29.3\end{array}$

$99.7 \% \quad 59.3$

$99.7 \% \quad 54.1$

$0.01 \% \quad 20.2 \%$ GGGPAGAGGEAPAALR $\quad 99.7 \% \quad 64.9$

$10 \quad 0.01 \% \quad 20.2 \%$ LGLEGCQR

$10 \quad 0.01 \% \quad 20.2 \%$ LYPVLQQSLVR

$\begin{array}{lll}0.01 \% & 18.8 \% & \text { TVEPLEYYR }\end{array}$

\section{$\begin{array}{lll}99.0 \% & 37.4\end{array}$}

$99.7 \% \quad 51.3$

$95.7 \% \quad 24.2$

$\begin{array}{llll}0.01 \% & 18.8 \% & \text { TTTVNIGSISTADGSALVK } \quad 99.7 \% \quad 86.3\end{array}$

$0.01 \% \quad 18.8 \%$ LGNTTVICGVK

$0.01 \% \quad 18.8 \%$ AEFAAPSTDAPDK

$10 \quad 0.01 \% \quad 5.1 \%$ SGTYLQGTFR

$10 \quad 0.01 \% \quad 5.1 \%$ RGTTVYLCEK

$10 \quad 0.01 \% \quad 5.1 \%$ GALTLSSPEVR

$10 \quad 0.01 \% \quad 5.1 \%$ NLEIKTDTAK

$10 \quad 0.01 \% \quad 5.1 \%$ YADVIVHR

$4 \quad 23 \quad 0.03 \% \quad 13.2 \%$ PAIMTMLADHAAR

$423 \quad 0.03 \% \quad 13.2 \%$ YYGLQILENVIK

$14 \quad 23 \quad 0.03 \% \quad 13.2 \%$ YVVGLIIK

$14 \quad 23 \quad 0.03 \% \quad 13.2 \%$ TSSDPTCVEKEK

$14 \quad 23 \quad 0.03 \% \quad 13.2 \%$ TSESLCQNNMVILK

$0.03 \% \quad 13.2 \%$ IYLDMLNVYK

$0.03 \% \quad 13.2 \%$ LISGWVSR

$0.03 \% \quad 13.2 \%$ SAFPHLQDAQVK

$0.04 \% \quad 9.3 \%$ TLDPDPAIR

$0.04 \% \quad 9.3 \%$ QLSDAISIIGR

$0.04 \% \quad 9.3 \%$ DLEGSDIDTRR

$0.04 \% \quad 9.3 \%$ SANVNEFPVLK

$0.04 \% \quad 9.3 \%$ TGNIPALVR

$0.04 \% \quad 9.3 \%$ LLQAFLER

$0.04 \% \quad 9.3 \%$ KICAVGITK

$0.04 \% \quad 9.3 \%$ ICAVGITK

$0.04 \% \quad 9.3 \%$ EHDPVGQMVNNPK

\section{$97.5 \% \quad 26.1$}

$99.7 \% \quad 40.9$

$99.7 \% \quad 33.5$

$\begin{array}{lll}99.7 \% & 37.0\end{array}$

$99.0 \% \quad 37.8$

$94.6 \% \quad 14.6$

$95.8 \% \quad 19.1$

$95.9 \% \quad 20.8$

$\begin{array}{lll}99.7 \% & 36.9\end{array}$

$99.7 \% \quad 57.5$

$99.0 \% \quad 55.1$

$99.7 \% \quad 42.4$

$97.9 \% \quad 17.5$

$99.7 \% \quad 38.2$
$99.7 \% \quad 27.5$
829.49

1783.79

1531.82

1816.83

1914.87

2390.08

1680.73

1294.64

1142.62

1534.75

1842.90

1312.61

1053.52

958.51

1308.67

932.46

1315.77

1169.58

1834.98

1161.63

1319.61

1129.56

1226.62

1129.62

1132.62

972.53

1429.69

1452.81

904.59

1380.63

1636.80

2027.03

1199.66

1370.75

1293.74

1287.67

917.52

1340.70

997.53

1172.66

1276.61

1217.65

940.56

989.58

989.58

861.49 1480.69

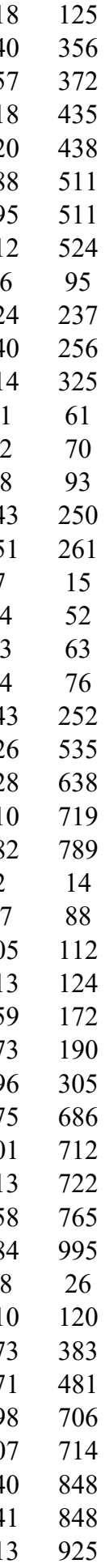


Exportin-2 GN=CSE1L Exportin-7 GN=XPO7 Exportin-7 GN=XPO7 Exportin-7 GN=XPO7 Exportin-7 GN=XPO7 Exportin-7 GN=XPO7

Exportin-7 GN=XPO7 Exportin-T GN=XPOT Exportin- $\mathrm{T}$ GN=XPOT

Exportin-T GN=XPOT FACT complex subunit SPT16 GN=SUPT16H SP16H HUMAN $119.92 \quad 100.0 \%$ FACT complex subunit SPT16 GN=SUPT16H SP16H_HUMAN $119.92 \quad 100.0 \%$ FACT complex subunit SPT16 GN=SUPT16H SP16H_HUMAN $119.92 \quad 100.0 \%$ F-actin-capping protein subunit alpha-1 GN=CAPZA1 CAZA1_HUMAN $32.92 \quad 100.0 \%$ F-actin-capping protein subunit alpha-1 GN=CAPZA1 CAZA1_HUMAN $32.92 \quad 100.0 \%$ F-actin-capping protein subunit alpha-1 GN=CAPZA1 CAZA1_HUMAN $32.92 \quad 100.0 \%$ F-actin-capping protein subunit alpha-2 GN=CAPZA2 CAZA2 HUMAN $32.95 \quad 100.0 \%$ F-actin-capping protein subunit alpha-2 GN=CAPZA2 CAZA2_HUMAN $32.95 \quad 100.0 \%$ F-actin-capping protein subunit alpha-2 GN=CAPZA2 CAZA2_HUMAN $32.95 \quad 100.0 \%$ F-actin-capping protein subunit beta GN=CAPZB CAPZB_HUMAN $31.35 \quad 100.0 \%$ F-actin-capping protein subunit beta GN=CAPZB CAPZB_HUMAN $31.35 \quad 100.0 \%$ Fanconi anemia group D2 protein GN=FANCD2 FACD2_HUMAN $164.13 \quad 100.0 \%$ Fanconi anemia group D2 protein GN=FANCD2 FACD2_HUMAN $164.13 \quad 100.0 \%$ Fanconi anemia group D2 protein GN=FANCD2 FACD2_HUMAN $164.13 \quad 100.0 \%$ Fanconi anemia group D2 protein GN=FANCD2 FACD2_HUMAN $164.13100 .0 \%$ Fanconi anemia group D2 protein GN=FANCD2 FACD2_HUMAN $164.13 \quad 100.0 \%$ Fanconi anemia group I protein GN=FANCI FANCI_HUMAN $149.33 \quad 100.0 \%$ Fanconi anemia group I protein GN=FANCI FANCI_HUMAN $149.33 \quad 100.0 \%$ Fanconi anemia group I protein GN=FANCI FANCI_HUMAN $149.33 \quad 100.0 \%$ Fanconi anemia group I protein GN=FANCI FANCI_HUMAN $149.33100 .0 \%$ Fanconi anemia group I protein GN=FANCI FANCI_HUMAN $149.33 \quad 100.0 \%$ Fanconi anemia group I protein GN=FANCI FANCI_HUMAN $149.33 \quad 100.0 \%$ Fanconi anemia group I protein GN=FANCI FANCI_HUMAN $149.33 \quad 100.0 \%$ Fanconi anemia group I protein GN=FANCI FANCI_HUMAN $149.33 \quad 100.0 \%$ Fanconi anemia group I protein GN=FANCI FANCI_HUMAN $149.33 \quad 100.0 \%$ Fanconi anemia group I protein GN=FANCI FANCI_HUMAN $149.33 \quad 100.0 \%$ Fanconi anemia group I protein GN=FANCI FANCI_HUMAN $149.33 \quad 100.0 \%$ Fanconi anemia group I protein GN=FANCI FANCI_HUMAN $149.33 \quad 100.0 \%$ Fanconi anemia group I protein GN=FANCI FANCI_HUMAN $149.33 \quad 100.0 \%$ Far upstream element-binding protein 2 GN=KHSRP FUBP2_HUMAN $73.12 \quad 100.0 \%$ Far upstream element-binding protein 2 GN=KHSRP FUBP2_HUMAN $73.12 \quad 100.0 \%$ Far upstream element-binding protein 2 GN=KHSRP FUBP2_HUMAN $73.12 \quad 100.0 \%$ Far upstream element-binding protein 2 GN=KHSRP FUBP2 HUMAN $73.12 \quad 100.0 \%$ Far upstream element-binding protein 2 GN=KHSRP FUBP2_HUMAN $73.12 \quad 100.0 \%$ Far upstream element-binding protein 3 GN=FUBP3 FUBP3_HUMAN $61.64 \quad 100.0 \%$ Far upstream element-binding protein $3 \mathrm{GN}=$ FUBP3 FUBP3_HUMAN $61.64 \quad 100.0 \%$ Far upstream element-binding protein 3 GN=FUBP3 FUBP3_HUMAN $61.64 \quad 100.0 \%$
$0.04 \% \quad 9.3 \% \quad$ IHLAQSLHK

$0.01 \% \quad 5.7 \%$ ALVEFTNSPDCLSK

$0.01 \% \quad 5.7 \%$ TNNPLPLEQR

$0.01 \% \quad 5.7 \% \quad$ LAASVPYVK

$0.01 \% \quad 5.7 \%$ VLQLMNLTDSR

$0.01 \% \quad 5.7 \%$ TTFYTALGR

$0.01 \% \quad 5.7 \%$ GIAFAFNAK

$0.01 \% \quad 2.8 \%$ ALAYFEQLK

$0.01 \% \quad 2.8 \%$ ASALQDMMR

$0.01 \% \quad 2.8 \%$ SRTAYLFSR

$0.01 \% \quad 4.6 \%$ GNENANGAPAITLLIR

$0.01 \% \quad 4.6 \%$ NEGNIFPNPEATFVK

$\begin{array}{ccc}0.01 \% & 4.6 \% & \text { APGEQTVPALNLQNAFR } \\ 0.01 \% & 15.0 \% & \text { FITHAPPGEFNEVFNDVR }\end{array}$

$0.01 \% \quad 15.0 \%$ FITHAPPGEFNE

$0.01 \% \quad 15.0 \%$ LLLNNDNLLR

$0.01 \% \quad 15.0 \%$ FTITPPTAQVVGVLK

$0.00 \% \quad 11.5 \%$ LLLNNDNLLR

$0.00 \% \quad 11.5 \%$ TSVETALR

$0.00 \% \quad 11.5 \%$ FTITPSTTQVVGILK

$0.00 \% \quad 8.7 \%$ SGSGTMNLGGSLTR

$0.00 \% \quad 8.7 \%$ STLNEIYFGK

$0.01 \% \quad 3.9 \%$ TGESQNQLAVDQIAFQK

$0.01 \% \quad 3.9 \%$ SESPSLTQER

$0.01 \% \quad 3.9 \%$ LVSPLCLAPYFR

$0.01 \% \quad 3.9 \%$ NIGFSHLQQR

$0.01 \% \quad 3.9 \%$ TLELLVCR

$0.02 \% \quad 12.2 \%$ GSPCSEEAGTLR

$0.02 \% \quad 12.2 \%$ SFKDLQLLQGSK

$0.02 \% \quad 12.2 \%$ TIETSPSLSR

$0.02 \% \quad 12.2 \%$ AMFANQLDAR

$0.02 \% \quad 12.2 \%$ SAVAGFLLLLK

$0.02 \% \quad 12.2 \%$ CLSQQADVR

$0.02 \% \quad 12.2 \%$ YAVNVALQK

$0.02 \% \quad 12.2 \%$ IFQNLCDITR

$0.02 \% \quad 12.2 \%$ SISLLCLEGLQK

$0.02 \% \quad 12.2 \%$ IFSAVQQFYQPK

$0.02 \% \quad 12.2 \%$ TAAPTVCLLVLSQAEK

$0.02 \% \quad 12.2 \%$ LKGQVSQETLSEEASSQATLPNQPVEK

$0.02 \% \quad 12.2 \%$ EKPAAVATAMAR

$0.01 \% \quad 8.2 \%$ DAFADAVQR

$0.01 \% \quad 8.2 \% \quad$ SVSLTGAPESVQK

$0.01 \% \quad 8.2 \%$ GGETIKQLQER

$0.01 \% \quad 8.2 \%$ IGGGIDVPVPR

$0.01 \% \quad 8.2 \%$ AINQQTGAFVEISR

$0.02 \% \quad 19.8 \%$ RPLDDGVGNQLGAL

$0.02 \% \quad 19.8 \%$ GGETIKQLQER

$\begin{array}{llll}0.02 \% & 19.8 \% \text { GGETIKQLQER } & 99.7 \% & 41.3 \\ 0.02 \% & 19.8 \% \text { MVMIQDGPLPTGADKPLR } & 96.9 \% & 15.9\end{array}$
$99.7 \% 51.7$

$99.1 \% \quad 21.9$

$99.5 \% 23.8$

$99.7 \% \quad 28.9$

$\begin{array}{lll}99.7 \% & 40.9\end{array}$

$98.7 \% \quad 21.1$

$95.7 \% \quad 14.3$

$99.2 \% \quad 23.9$

$99.7 \% \quad 28.0$

$95.6 \% \quad 15.5$

$\begin{array}{lll}99.7 \% & 46.7\end{array}$

$99.7 \% \quad 38.3$

$\begin{array}{ll}99.7 \% & 58.1 \\ 99.7 \% & 58.6\end{array}$

$99.7 \% \quad 64.3$

$99.7 \% \quad 58.6$

$98.1 \% \quad 25.0$

$99.7 \% \quad 59.2$

$99.7 \% \quad 55.9$

$98.6 \% 21.1$

$\begin{array}{ll}7 \% & 36.3\end{array}$

$\begin{array}{ll}95.2 \% & 20.1 \\ 99.7 \% & 50.0\end{array}$

$99.7 \% 27.7$

$99.0 \% \quad 43.4$

$99.0 \% \quad 19.3$

$\begin{array}{lll}99.7 \% & 52.8\end{array}$

$99.7 \% \quad 44.9$

$\begin{array}{lll}99.3 \% & 20.2\end{array}$

$98.5 \% \quad 18.0$

$\begin{array}{lll}99.7 \% & 35.4\end{array}$

$99.7 \% \quad 40.3$

$99.7 \% \quad 47.6$

$99.7 \% \quad 55.8$

$99.7 \% \quad 70.3$

$99.7 \% \quad 51.2$

$9.1 \% 20$.

$\begin{array}{lll}99.7 \% & 28.7\end{array}$

$99.2 \% \quad 22.7$

$99.7 \% \quad 41.3$

$99.7 \% \quad 57.0$

$99.7 \% \quad 58.9$

$\begin{array}{lll}99.7 \% & 40.2\end{array}$

$\begin{array}{ll}99.7 \% & 41.3 \\ 96.9 \% & 15.9\end{array}$
$98.2 \% \quad 17.2$
1046.61

1580.76

1181.63

947.56

1305.68

1029.54

938.51

1082.59

1054.47

1100.58

1623.88

1676.83

1825.96

2089.01

1197.70

1570.92

1197.70

876.48

1604.93

1353.64

1171.60

1876.94

1133.54

1435.78

1199.63

1003.56

1263.56

1363.76

1090.57

1136.55

1131.71

1076.52

1005.57

1279.65

1360.75

1455.76

1700.93

2898.47

1231.65

992.48

1302.69

1258.68

1079.62

1533.80

1945.04

1258.68 1939.01 
Far upstream element-binding protein $3 \mathrm{GN}=\mathrm{FUBP} 3$ FUBP3 HUMAN $61.64 \quad 100.0 \%$ Far upstream element-binding protein $3 \mathrm{GN}=\mathrm{FUBP} 3$ FUBP3_HUMAN $61.64 \quad 100.0 \%$ Far upstream element-binding protein $3 \mathrm{GN}=\mathrm{FUBP} 3$ FUBP3_HUMAN $61.64 \quad 100.0 \%$ ar upstream element-binding protein $3 \mathrm{GN}=\mathrm{FUBP} 3$ FUBP3 HUMAN $61.64 \quad 100.0 \%$ Far upstream element-binding protein $3 \mathrm{GN}=$ FUBP3 FUBP3_HUMAN $61.64 \quad 100.0 \%$ Far upstream element-binding protein $3 \mathrm{GN}=$ FUBP3 FUBP3_HUMAN $61.64 \quad 100.0 \%$ Farnesyl pyrophosphate synthase GN=FDPS FPPS_HUMAN $48.28 \quad 100.0 \%$ Farnesyl pyrophosphate synthase GN=FDPS FPPS_HUMAN $48.28 \quad 100.0 \%$ Farnesyl pyrophosphate synthase GN=FDPS FPPS HUMAN $48.28 \quad 100.0 \%$ Farnesyl pyrophosphate synthase GN=FDPS FPPS_HUMAN $48.28 \quad 100.0 \%$ FAST kinase domain-containing protein 2 GN=FASTKD2 FAKD2_HUMAN $81.47 \quad 99.9 \%$ FAST kinase domain-containing protein $2 \mathrm{GN}=$ FASTKD2 FAKD2 HUMAN $81.47 \quad 99.9 \%$ FAST kinase domain-containing protein 3 GN=FASTKD3 FAKD3_HUMAN $75.69 \quad 100.0 \%$ FAST kinase domain-containing protein 3 GN=FASTKD3 FAKD3_HUMAN $75.69 \quad 100.0 \%$ FAST kinase domain-containing protein $5 \mathrm{GN}=$ FASTKD5 FAKD5 HUMAN $86.58 \quad 100.0 \%$ FAST kinase domain-containing protein 5 GN=FASTKD5 FAKD5_HUMAN $86.58 \quad 100.0 \%$ FAST kinase domain-containing protein $5 \mathrm{GN}=$ FASTKD5 FAKD5 HUMAN $86.58 \quad 100.0 \%$ Fatty acid synthase GN=FASN Fatty acid synthase GN=FASN Fatty acid synthase GN=FASN Fatty acid synthase GN=FASI Fatty acid synthase GN=FASN Fatty acid synthase GN=FASN Fatty acid synthase GN=FASN Fatty acid synthase GN=FASN Fatty acid synthase GN=FASN Fatty acid synthase GN=FASN Fatty acid synthase GN=FASN Fatty acid synthase GN=FASN Fatty acid synthase GN=FASN Fatty acid synthase GN=FASN Fatty acid synthase GN=FASN Fatty acid synthase GN=FASN Fatty acid synthase GN=FAS Fatty acid synthase GN=FASN Fatty acid synthase GN=FASN Fatty acid synthase GN=FASI Fatty acid synthase GN=FASN Fatty acid synthase GN=FASN F-box only protein $22 \mathrm{GN}=\mathrm{FBXO} 22$ F-box only protein $22 \mathrm{GN}=\mathrm{FBXO} 22$ FAS HUMAN $273.43 \quad 100.0 \%$ FAS_HUMAN $273.43 \quad 100.0 \%$ FAS HUMAN $273.43 \quad 100.0 \% \quad 22$ FAS_HUMAN $273.43 \quad 100.0 \% \quad 22$ FAS HUMAN $273.43 \quad 100.0 \% \quad 22$ FAS_HUMAN $273.43 \quad 100.0 \% \quad 22$ FAS_HUMAN $273.43 \quad 100.0 \% \quad 22$ FAS HUMAN $273.43 \quad 100.0 \% \quad 22$ FAS_HUMAN $273.43 \quad 100.0 \% \quad 22$ FAS_HUMAN $273.43 \quad 100.0 \% \quad 22$ FAS HUMAN $273.43 \quad 100.0 \% \quad 22$ FAS_HUMAN $273.43 \quad 100.0 \% \quad 22$ FAS HUMAN $273.43 \quad 100.0 \% \quad 22$ FAS_HUMAN $273.43 \quad 100.0 \% \quad 22$ FAS_HUMAN $273.43 \quad 100.0 \% \quad 22$ FAS HUMAN $273.43 \quad 100.0 \% \quad 22$ FAS_HUMAN $273.43 \quad 100.0 \% \quad 22$ FAS HUMAN $273.43 \quad 100.0 \% \quad 22$ FAS HUMAN $273.43 \quad 100.0 \% \quad 22$ FAS_HUMAN $273.43 \quad 100.0 \% \quad 22$ FAS HUMAN $273.43 \quad 100.0 \% \quad 22$ FAS HUMAN $273.43 \quad 100.0 \% \quad 22$ FBX22_HUMAN $44.51 \quad 100.0 \% \quad 2$ FBX22 HUMAN $44.51 \quad 100.0 \% \quad 2$ F-box/LRR-repeat protein 12 GN=FBXL12 FXL12_HUMAN $37.03 \quad 100.0 \%$ F-box/LRR-repeat protein 12 GN=FBXL12 FXL12_HUMAN $37.03 \quad 100.0 \%$ F-box/LRR-repeat protein $12 \mathrm{GN}=$ FBXL12 FXL12_HUMAN $37.03 \quad 100.0 \%$ Ferrochelatase, mitochondrial GN=FECH HEMH_HUMAN $47.86 \quad 100.0 \%$ Ferrochelatase, mitochondrial GN=FECH HEMH HUMAN $47.86 \quad 100.0 \%$ Filaggrin $\mathrm{GN}=\mathrm{FLG}$
$98.6 \% \quad 31.9$ $99.7 \% \quad 57.1$ $99.7 \% \quad 60.7$ $99.7 \% \quad 38.7$ $94.9 \% \quad 18.1$ $\begin{array}{lll}99.7 \% & 39.6\end{array}$

$0.02 \% \quad 19.8 \%$ IQFKPDDGISPER $0.02 \% \quad 19.8 \%$ SINQQSGAHVELQR $0.02 \% \quad 19.8 \%$ GVPQQIEVAR

$98.5 \% \quad 17.3$

$0.01 \% \quad 11.9 \%$ VLTEDEMGHPEIGDAIAR $0.01 \% \quad 11.9 \%$ LKEVLEYNAIGGK $0.01 \% \quad 11.9 \%$ GLTVVVAFR $0.01 \% \quad 11.9 \%$ ATPEQYQILK $0.00 \% \quad 3.9 \%$ VAVLCVSR $99.7 \% 56$. $99.7 \% \quad 36.6$ $99.7 \% \quad 35.7$ $99.0 \% \quad 31.2$

$0.00 \% \quad 3.9 \%$ TKIYSVEALPVAAVNVQSTQ $\quad 98.0 \% \quad 26.9$ $0.00 \% \quad 2.7 \% \quad$ IGLTNLLGAR $0.00 \% \quad 2.7 \%$ ELVEYLQR $0.01 \% \quad 3.7 \% \quad$ ASTLQLGSPR $0.01 \% \quad 3.7 \%$ EATPAENVAK $0.01 \% \quad 3.7 \%$ LAVQFTNR $0.06 \% \quad 9.8 \%$ AGLYGLPR $0.06 \% \quad 9.8 \%$ FDASFFGVHPK $0.06 \% \quad 9.8 \%$ AFDTAGNGYCR $0.06 \% \quad 9.8 \%$ SEGVVAVLLTK $0.06 \% \quad 9.8 \%$ SEGVVAVLLTKK $0.06 \% \quad 9.8 \%$ VGDPQELNGITR $0.06 \% \quad 9.8 \%$ ALCATRQEPLLIGSTK $0.06 \% \quad 9.8 \%$ QEPLLIGSTK

$0.06 \% \quad 9.8 \%$ LQVVDQPLPVR

$0.06 \% \quad 9.8 \%$ TGTVSLEVR

$0.06 \% \quad 9.8 \%$ HGLYLPTR $99.7 \% \quad 68.9$ $99.0 \% \quad 47.3$ $99.7 \% \quad 62.8$ $99.7 \% \quad 50.5$ $99.0 \% \quad 34.8$ $\begin{array}{lll}99.0 \% & 35.7\end{array}$ $99.7 \% \quad 37.7$ $99.7 \% \quad 38.4$ $99.7 \% \quad 51.2$ $98.7 \% \quad 19.0$ $99.7 \% \quad 53.8$ $99.7 \% \quad 30.6$ $98.8 \% 19.7$ $99.7 \% \quad 35.9$ $\begin{array}{lll}96.4 \% & 16.8\end{array}$ $99.0 \% 22.6$

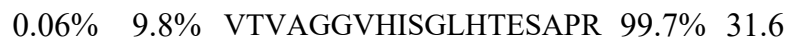
$0.06 \% \quad 9.8 \%$ AALQEELQLCK

$0.06 \% \quad 9.8 \%$ GLVQALQTK $0.06 \% \quad 9.8 \%$ VVEVLAGHGHLYSR $0.06 \% \quad 9.8 \%$ SFYGSTLFLCR $0.06 \% \quad 9.8 \%$ VLQGDLVMNVYR $99.7 \% \quad 43.1$ $99.7 \% \quad 38.7$ $99.0 \% \quad 27.8$ $99.7 \% \quad 41.6$ $99.7 \% \quad 45.8$ $0.06 \% \quad 9.8 \%$ VVVQVLAEEPEAVLK $99.7 \% \quad 57.7$

$0.06 \% \quad 9.8 \% \quad$ QGVQVQVSTSNISSLEGAR $\quad 99.7 \% \quad 61.8$ $0.06 \% \quad 9.8 \%$ EDGLAQQQTQLNLR $0.06 \% \quad 9.8 \%$ SLLVNPEGPTLMR $0.06 \% \quad 9.8 \%$ LSIPTYGLQCTR $0.00 \% \quad 6.0 \% \quad$ STFVLSNLAEVVER $0.00 \% \quad 6.0 \% \quad$ VVAEELENVR $0.01 \% \quad 12.6 \%$ VPAFRDEHLQGLTR $0.01 \% \quad 12.6 \%$ SLVLGGTYR $99.7 \% \quad 61.8$ $99.7 \% \quad 48.0$ $99.7 \% \quad 29.0$ $99.7 \% \quad 49.3$ $99.5 \% \quad 35.5$ $99.7 \% \quad 26.4$ $99.7 \% \quad 29.2$

$0.01 \% \quad 12.6 \%$ VTETGLDAGLQELSYLQR $\quad 99.7 \% 58$ $0.00 \% \quad 7.6 \%$ GDPYPQEVSATVQK $99.7 \% \quad 43.3$

$0.00 \% \quad 7.6 \%$ ALADLVHSHIQSNELCSK $99.2 \% \quad 26.3$ $99.7 \% \quad 47.0$ $0.00 \% \quad 0.5 \%$ LAQAYYESTR 1204.60

931.57

1501.76

1566.80

1096.61

1968.93

1433.80

961.58

1190.64

903.51

2118.14

1027.63

1049.56

1029.57

1029.52

948.53

846.48

1251.62

1231.52

1115.67

1243.76

1298.67

1757.96

1085.62

1263.74

961.53

956.53

1888.00

1302.67

957.57

1536.83

1350.65

1406.75

1622.94

1960.01

1613.82

1442.77

1408.73

1563.84

1157.62

1638.87

965.54

1993.02

1518.74

2022.01 
Filaggrin $\mathrm{GN}=\mathrm{FLG}$

Filamin-A GN=FLNA

Filamin-A GN=FLNA

Filamin-A GN=FLNA

Filamin-A GN=FLNA

Filamin-A GN=FLNA

Filamin-A GN=FLNA

Filamin-A GN=FLNA

Filamin-A GN=FLNA

Filamin-A GN=FLNA

Filamin-A GN=FLNA

Filamin-A GN=FLNA

Filamin-A GN=FLNA

Filamin-A GN=FLNA

Filamin-A GN=FLNA

Filamin-A GN=FLNA

Filamin-B GN=FLNB

Filamin-B GN=FLNB

Filamin-B GN=FLNB

Focadhesin GN=FOCAD

Focadhesin GN=FOCAD

Four and a half LIM domains protein $1 \mathrm{GN}=\mathrm{FHL} 1 \mathrm{FHL} 1$ HUMAN $36.26 \quad 100.0 \%$

Four and a half LIM domains protein $1 \mathrm{GN}=\mathrm{FHL} 1$ FHL1_HUMAN $36.26 \quad 100.0 \%$ Fragile X mental retardation protein 1 GN=FMR1 FMR1_HUMAN $71.17 \quad 100.0 \%$ Fragile X mental retardation protein $1 \mathrm{GN}=\mathrm{FMR} 1$ FMR1_HUMAN $71.17 \quad 100.0 \%$ Fragile X mental retardation protein 1 GN=FMR1 FMR1_HUMAN $71.17 \quad 100.0 \%$ Fragile X mental retardation syndrome-related protein 2 GN=FXR2 FXR2_HUMAN $74.22 \quad 100.0 \%$ Fragile X mental retardation syndrome-related protein 2 GN=FXR2 FXR2_HUMAN $74.22 \quad 100.0 \%$ Fragile X mental retardation syndrome-related protein 2 GN=FXR2 $\quad$ FXR2_HUMAN $74.22 \quad 100.0 \%$ Fragile $X$ mental retardation syndrome-related protein 2 GN=FXR2 FXR2 HUMAN $74.22 \quad 100.0 \%$ Fragile X mental retardation syndrome-related protein 2 GN=FXR2 $\quad$ FXR2_HUMAN $74.22 \quad 100.0 \%$ Fructose-bisphosphate aldolase A GN=ALDOA ALDOA_HUMAN $39.42 \quad 100.0 \%$ Fructose-bisphosphate aldolase A GN=ALDOA ALDOA_HUMAN $39.42 \quad 100.0 \%$ Fructose-bisphosphate aldolase A GN=ALDOA ALDOA_HUMAN $39.42 \quad 100.0 \%$ Fructose-bisphosphate aldolase A GN=ALDOA ALDOA_HUMAN $39.42 \quad 100.0 \%$ Fructose-bisphosphte aldolase A GN=ALDOA ALDOA_HUMAN 39.42 100.0\% Galactokinase $\mathrm{GN}=\mathrm{GALK} 1$ Galactokinase GN=GALK1 Galactokinase GN=GALK1 Galactokinase GN $=$ GALK1 Galactokinase GN=GALK 1 Galactokinase $\mathrm{GN}=\mathrm{GALK} 1$ Galactokinase GN=GALK1 Galactokinase $\mathrm{GN}=\mathrm{GALK} 1$ Galactokinase $\mathrm{GN}=\mathrm{GALK} 1$ Galactokinase $\mathrm{GN}=\mathrm{GALK} 1$ Galectin-7 GN=LGALS7 GALK1_HUMAN $42.27 \quad 100.0 \%$ GALK1 HUMAN $42.27 \quad 100.0 \%$ GALK1_HUMAN $42.27 \quad 100.0 \%$ GALK1_HUMAN $42.27 \quad 100.0 \%$ GALK1_HUMAN $42.27 \quad 100.0 \%$ GALK1_HUMAN $42.27 \quad 100.0 \%$ GALK1_HUMAN $42.27 \quad 100.0 \%$ GALK1_HUMAN $42.27 \quad 100.0 \%$ GALK1_HUMAN $42.27 \quad 100.0 \%$ GALK1_HUMAN $42.27 \quad 100.0 \%$ LEG7_HUMAN $15.07 \quad 100.0 \%$
$0.00 \% \quad 0.5 \% \quad$ ENLPISGHK

$98.6 \% \quad 21.1$

$\begin{array}{lllll}0.04 \% & 7.3 \% & \text { VTAQGPGLEPSGNIANK } \quad 99.7 \% \quad 53.0\end{array}$

$0.04 \% \quad 7.3 \%$ SPYTVTVGQACNPSACR $99.7 \% \quad 56.9$

$0.04 \% \quad 7.3 \%$ TGVAVNKPAEFTVDAK

$0.04 \% \quad 7.3 \%$ SPFSVAVSPSLDLSK

$\begin{array}{ll}99.3 \% & 20.2 \\ 99.7 \% & 51.5\end{array}$

$99.7 \% 72.9$

$0.04 \% \quad 7.3 \%$ AFGPGLQGGSAGSPAR

$0.04 \% \quad 7.3 \%$ AHVVPCFDASK

$0.04 \% \quad 7.3 \% \quad$ YGGQPVPNFPSK

$95.6 \% \quad 15.8$

$99.3 \% 19.5$

$99.7 \% \quad 44.8$

$97.9 \% \quad 22.6$

$\begin{array}{lll}0.04 \% & 7.3 \% & \text { ALTQTGGPHVK }\end{array}$

$99.7 \% \quad 58.3$

$\begin{array}{lllll}0.04 \% & 7.3 \% & \text { GAGTGGLGLAVEGPSEAK } & 99.7 \% & 58.3 \\ 0.04 \% & 7.3 \% & \text { ANLPQSFQVDTSK } & 99.7 \% & 39.9\end{array}$

$0.04 \% \quad 7.3 \%$ AGVAPLQVK

$0.04 \% \quad 7.3 \%$ KGEITGEVR

$0.04 \% \quad 7.3 \%$ TPCEEILVK

$0.00 \% \quad 1.2 \% \quad$ IQQNTFTR

$0.00 \% \quad 1.2 \%$ VKVEPAVDTSR

$0.00 \% \quad 1.2 \%$ VAVTEGCQPSR

$0.00 \% \quad 1.3 \%$ TVAGIPNFILK

$0.00 \% \quad 1.3 \%$ SYSGENTASAIAR

$0.00 \% \quad 7.1 \%$ AIVAGDQNVEYK

$0.00 \% \quad 7.1 \%$ QVIGTGSFFPK

$0.01 \% \quad 4.8 \%$ LIQEIVDKSGVVR

$0.01 \% \quad 4.8 \%$ VGPNAPEEK

$0.01 \% \quad 4.8 \% \quad$ LQIDEQLR

$0.01 \% \quad 9.1 \% \quad$ LRPVNPNPLATK

$0.01 \% \quad 9.1 \%$ VIQEIVDKSGVVR

$\begin{array}{llll}99.3 \% & 21.3\end{array}$

$99.2 \% \quad 29.0$

$99.7 \% \quad 32.3$

$98.6 \% \quad 21.1$

$99.7 \% \quad 36.9$

$99.7 \% \quad 54.2$

$99.6 \% \quad 25.5$

$99.7 \% \quad 44.2$

$99.7 \% \quad 50.1$

$99.4 \% \quad 24.2$

$99.7 \% \quad 44.3$

$99.6 \% \quad 25.7$

$99.0 \% \quad 26.6$

$99.7 \% \quad 46.9$

$99.7 \% \quad 60.7$

$99.0 \% \quad 26.6$

$9.1 \%$ LQIDEQLR

$0.01 \% \quad 9.1 \%$ AGYSTDESSSSSLHATR

$0.01 \% \quad 9.1 \%$ GPPPAPRPTSR

$0.01 \% \quad 17.3 \%$ ELSDIAHR

$0.01 \% \quad 17.3 \%$ GILAADESTGSIAK

$98.3 \% 21.0$

$99.0 \% \quad 30.5$

$99.7 \% \quad 80.5$

$99.7 \% \quad 29.2$

$0.01 \% \quad 17.3 \%$ ADDGRPFPQVIK

$99.7 \% \quad 38.5$

$0.01 \% \quad 17.3 \%$ AAQEEYVKR

$99.7 \% \quad 56.5$

$99.7 \% \quad 41.1$

$0.02 \% \quad 29.6 \%$ QPQVAELLAEAR

$99.7 \% \quad 37.0$

$\begin{array}{lllll}0.02 \% & 29.6 \% & \text { AFREEFGAEPELAVSAPGR } & 99.7 \% & 37.0 \\ 0.02 \% & 29.6 \% & \text { KDGLVSLLTTSEGADEPQR } & 99.7 \% & 50.1\end{array}$

$0.02 \% \quad 29.6 \%$ LQFPLPTAQR

$0.02 \% \quad 29.6 \%$ GHALLIDCR

$0.02 \% \quad 29.6 \%$ SLETSLVPLSDPK

$0.02 \% \quad 29.6 \%$ LAVLITNSNVR

$0.02 \% \quad 29.6 \%$ HSLASSEYPVR

$0.02 \% \quad 29.6 \%$ HSLASSEYPVRR

$0.02 \% \quad 29.6 \%$ EVQLEELEAAR

$\begin{array}{lll}99.5 \% & 24.8\end{array}$

$99.7 \% \quad 49.1$

$99.7 \% \quad 57.5$

$99.7 \% \quad 64.4$

$99.7 \% \quad 56.2$

$99.4 \% \quad 22.4$

$99.7 \% \quad 66.2$

$99.0 \% \quad 27.4$ $0.01 \% \quad 25.0 \%$ GLVPPNASR
994.53

1007.53

1652.86

1867.84

1646.87

1533.82

1429.72

1230.59

1290.65

1225.57

1108.61

1570.81

1434.72

882.54

988.54

1088.57

1007.53

1200.66

1203.58

1172.70

1326.63

1306.66

1180.64

1455.85

940.47

1014.56

1319.78

1441.84

1014.56

1755.78

1132.62

940.48

1332.70

1342.71

2123.09

1093.56

1324.72

2033.0

2016.02

1170.66

1054.55

1385.75

1199.71

1245.62

1401.72

1286.66
45

$384 \quad 400$

$468 \quad 484$

$685 \quad 700$

$59 \quad 973$

$1152 \quad 1162$

$235 \quad 1246$

$1273 \quad 1283$

$\begin{array}{rr}284 & 1294 \\ 382 & 1399\end{array}$

$\begin{array}{ll}1465 & 1477\end{array}$

$1478 \quad 1486$

$1801 \quad 1809$

$2599 \quad 2607$

$17 \quad 24$

$1220 \quad 1230$

$20 \quad 1330$

$1028 \quad 1040$

$134 \quad 144$

$303 \quad 315$

$345 \quad 353$

$435 \quad 442$

$122 \quad 133$

$313 \quad 325$

$379 \quad 386$

$407 \quad 423$

$491 \quad 501$

$15 \quad 22$

$88 \quad 99$

$154 \quad 173$

$323 \quad 331$

$\begin{array}{cc}6 & 17 \\ 19 & 37\end{array}$

$69 \quad 87$

$88 \quad 97$

$196 \quad 204$

$205 \quad 217$

$218 \quad 228$

$229 \quad 239$

$229 \quad 240$ 
$0.02 \% \quad 23.1 \%$ TCGLINSVK

$14 \quad 0.02 \% \quad 23.1 \%$ FYQASTSELYGK

$\begin{array}{llll}99.7 \% & 29.9 & 2 & 2\end{array}$

621.79

$0.02 \% \quad 23.1 \%$ ETTPFYPR

$14 \quad 0.02 \% \quad 23.1 \%$ VHVTVDLK

$0.02 \% \quad 23.1 \%$ YYRPTEVDFLQGDCTK

$99.7 \% 58.5$

991.52

1393.66

1010.49

$\begin{array}{llllllll}99.0 \% & 42.3 & 25.0 & 35.3 & 2 & 0 & 0 & 910.54\end{array}$

910.54
1991.92

$0.02 \% \quad 23.1 \%$ VAFDELVR

$0.01 \% \quad 3.0 \%$ GLTQIQSR

$0.01 \% \quad 3.0 \%$ LLETVIDVSTADR

$0.01 \% \quad 3.0 \%$ SIAEGIGPEER

$0.00 \% \quad 2.1 \%$ TVIESSPESPVTITEPYR

$0.00 \% \quad 2.1 \%$ CYLGATCAYDAAK

$0.02 \% \quad 5.2 \%$ LYQYMLNAGLAK

$0.02 \% \quad 5.2 \%$ GISQAEIR

$0.02 \% \quad 5.2 \% \quad$ YISCVFAEESDLSR

$0.02 \% \quad 5.2 \%$ NLIIEAVTNLR

$0.02 \% \quad 5.2 \% \quad$ NLSEEGLLR

$99.7 \% \quad 36.2$

948.51

$\begin{array}{llllllll}99.0 \% & 35.7 & 25.0 & 20.9 & 2 & 0 & 0 & 902.51\end{array}$

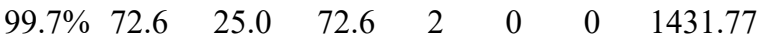

$\begin{array}{llllllll}99.0 \% & 20.7 & 25.0 & 20.7 & 1 & 0 & 0 & 1157.58\end{array}$

$\begin{array}{llllllll}99.7 \% & 33.5 & 25.0 & 33.5 & 2 & 0 & 0 & 2005.01\end{array}$

$\begin{array}{llllllll}99.0 \% & 20.9 & 25.0 & 20.9 & 1 & 0 & 0 & 1463.63\end{array}$

$\begin{array}{llllllll}98.4 \% & 20.2 & 25.0 & 16.9 & 1 & 0 & 0 & 1384.73\end{array}$

$\begin{array}{llllllll}99.0 \% & 32.2 & 25.0 & 17.8 & 1 & 0 & 0 & 873.48\end{array}$

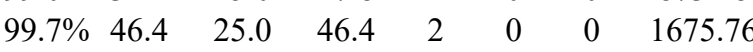

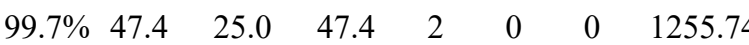

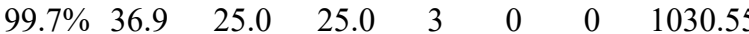

$0.02 \% \quad 5.2 \%$ TTVIQDGIKK

$99.4 \% \quad 25.4$

1030.55

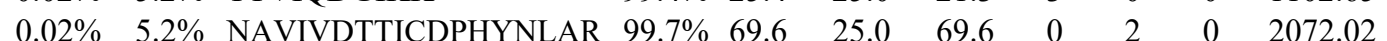

$0.02 \% \quad 5.2 \%$ IASNVLNTK

$0.02 \% \quad 5.2 \%$ NPQAYLNYK

$99.7 \% \quad 43.6$

959.55

$0.02 \% \quad 5.2 \%$ SYQSFQTFR

$97.3 \% 16.0$

1110.56

$0.02 \% \quad 21.4 \%$ MLPTLGGEEGVSR

$99.7 \% \quad 42.9$

$99.7 \% \quad 64.2$

$0.02 \% \quad 21.4 \%$ FSTSSLLLR

$99.7 \% \quad 48.5$

$0.02 \% \quad 21.4 \%$ EGYNNPPISGENLIGLSR

$0.02 \% \quad 21.4 \%$ ANISVHPDKLK

$0.02 \% \quad 21.4 \%$ IYQVLDFRIR

$0.02 \% \quad 21.4 \%$ HGYAPSDLPVK

$0.02 \% \quad 21.4 \%$ STYNYSLPITVK

$0.02 \% \quad 21.4 \%$ STYNYSLPITVKK

$0.02 \% \quad 21.4 \%$ TSDELRDTMSLMIR

$0.02 \% \quad 21.4 \%$ SKRPALFSSSAK

$0.01 \% \quad 5.2 \%$ IVAFENAFER

$0.01 \% \quad 5.2 \%$ VLVSPTNPPGATSSCQK

$\begin{array}{llll}99.6 \% & 26.0\end{array}$

$97.4 \% \quad 21.1$

$99.7 \% \quad 39.4$

$\begin{array}{lllllll}98.4 \% & 18.1\end{array}$

$\begin{array}{llll}99.7 \% & 30.7\end{array}$

$96.4 \% \quad 19.7$

$99.3 \% \quad 27.1$

$99.7 \% \quad 61.8$

$0.01 \% \quad 5.2 \%$ LGFISKHELYSR

$0.01 \% \quad 5.2 \%$ LVKELEGVITK

$0.00 \% \quad 6.7 \%$ SDAPDTLLLEK

$0.00 \% \quad 6.7 \%$ HADYIASYGSK

$0.00 \% \quad 4.2 \%$ DVLAHQVPNAK

$0.00 \% \quad 4.2 \%$ LRVQQAALR

$0.00 \% \quad 4.2 \% \quad$ AHYEAEIKNSQEAQK

$0.00 \% \quad 4.2 \%$ STSEENIGIK

$0.00 \% \quad 4.9 \%$ NLDPMPSEGKK

$0.00 \% \quad 4.9 \%$ AGLSNYGNPR

$\begin{array}{rrrr}9.7 \% & 48.9 & 25.0 & 48.9 \\ 99.7 \% & 31.4 & 25.0 & 31.4\end{array}$

$\begin{array}{lllll}99.6 \% & 27.3 & 25.0 & 23.6\end{array}$

$\begin{array}{llll}99.7 \% & 47.2 & 25.0 & 34 .\end{array}$

$\begin{array}{llll}99.3 \% & 22.5 & 25.0 & 22.5\end{array}$

$99.7 \% \quad 51.5 \quad 25.0 \quad 51.2$

$\begin{array}{llll}97.9 \% & 17.1 & 25.0 & 16.5\end{array}$

$\begin{array}{llll}98.0 \% & 17.7 & 25.0 & 17.7\end{array}$

$\begin{array}{llll}99.6 \% & 26.7 & 25.0 & 24.4\end{array}$

$\begin{array}{llll}95.2 \% & 14.0 & 25.0 & 14.0\end{array}$

$99.7 \% \quad 47.0 \quad 25.0 \quad 34.4$

Glucose-6-phosphate translocase GN=SLC37A4 G6PT1 HUMAN $46.36 \quad 100.0 \%$

Glucose-6-phosphate translocase GN=SLC37A4 G6PT1_HUMAN $46.36 \quad 100.0 \%$

(n)

1163.55

1345.68

1023.58

1929.97

1221.70

1322.76

1183.61

1385.73

1513.83

1667.81

1278.72

1195.61

1742.87

1449.78

1228.75

1201.63

1211.57

1191.65

1054.65

1745.85

1077.54

1231.60 1048.52 

Glutamine--tRNA ligase $\mathrm{GN}=\mathrm{QARS}$ Glutamine--tRNA ligase GN=QARS Glutamine--tRNA ligase GN=QARS SYQ_HUMAN 87.80 SYQ HUMAN 87.80 SYQ_HUMAN $87.80 \quad 100.0 \%$ Glutaminyl-peptide cyclotransferase GN=QPCT QPCT_HUMAN $40.88 \quad 100.0 \%$ Glutaminyl-peptide cyclotransferase GN=QPCT QPCT_HUMAN $40.88 \quad 100.0 \%$ Glutaminyl-peptide cyclotransferase-like protein GN=QPCTL QPCTL_HUMAN $42.93 \quad 100.0 \%$ Glutaminyl-peptide cyclotransferase-like protein GN=QPCTL QPCTL HUMAN $42.93100 .0 \%$ Glutaminyl-peptide cyclotransferase-like protein GN=QPCTL QPCTL_HUMAN $42.93 \quad 100.0 \%$ Glutaminyl-peptide cyclotransferase-like protein GN=QPCTL QPCTL_HUMAN $42.93 \quad 100.0 \%$ Gutaminyl-peptide cyclotransferase-like protein GN=QPCTL QPCTL HUMAN $42.93 \quad 100.0^{\circ}$ Glutaminyl-peptide cyclotransferase-like protein GN=QPCTL QPCTL_HUMAN $42.93 \quad 100.0 \%$ Glutaminyl-peptide cyclotransferase-like protein GN=QPCTL QPCTL_HUMAN $42.93 \quad 100.0 \%$ Glutaminyl-peptide cyclotransferase-like protein GN=QPCTL QPCTL HUMAN $42.93 \quad 100.0 \%$ Glutaminyl-peptide cyclotransferase-like protein GN=QPCTL QPCTL_HUMAN $42.93 \quad 100.0 \%$ Glutaminyl-peptide cyclotransferase-like protein GN=QPCTL QPCTL HUMAN $42.93 \quad 100.0 \%$ Glutaminyl-peptide cyclotransferase-like protein GN=QPCTL QPCTL_HUMAN $42.93 \quad 100.0 \%$ Glutaredoxin-3 GN=GLRX3

Glutaredoxin-3 GN=GLRX WXI.43 $100.0 \%$ GLRX3 HUMAN $37.43 \quad 100.0 \%$ GLRX__HUMAN $37.43 \quad 100.0 \%$ Glutaredoxin-3 GN=GLRX G3P HUMAN $36.05 \quad 100.0 \%$ Glyceraldehyde-3-phosphate dehydrogenase GN=GAPDH G3P HUMAN $36.05 \quad 100.0 \%$ Glyceraldehyde-3-phosphate dehydrogenase GN=GAPDH G3P HUMAN $36.05100 .0 \%$ Glyceraldehyde-3-phosphate dehydrogenase GN=GAPDH G3P HUMAN $36.05 \quad 100.0 \%$ Glyceraldehyde-3-phosphate dehydrogenase GN=GAPDH G3P_HUMAN $36.05 \quad 100.0 \%$ Glyceraldehyde-3-phosphate dehydrogenase GN=GAPDH G3P_HUMAN $36.05 \quad 100.0 \%$ Glyceraldehyde-3-phosphate dehydrogenase GN=GAPDH G3P HUMAN $36.05 \quad 100.0 \%$ Glycerol-3-phosphate dehydrogenase 1-like protein GN=GPDIL GPD1L_HUMAN $38.42 \quad 100.0 \%$ Glycerol-3-phosphate dehydrogenase 1-like protein GN=GPDIL GPDIL HUMAN $38.42100 .0 \%$ Glycerol-3-phosphate dehydrogenase 1-like protein GN=GPDIL GPD1L_HUMAN $38.42 \quad 100.0 \%$ Glycerol-3-phosphate dehydrogenase 1-like protein GN=GPDIL GPD1L_HUMAN 38.42 100.0\% Glycerol-3-phosphate dehydrogenase 1-like protein GN=GPD1L GPDIL HUMAN $38.42 \quad 100.0 \%$ Glycerol-3-phosphate dehydrogenase 1-like protein GN=GPDIL GPD1L_HUMAN $38.42 \quad 100.0 \%$ Glycerol-3-phosphate dehydrogenase 1-like protein GN=GPDIL GPD1L_HUMAN 38.42 100.0\% Glycerol-3-phosphate dehydrogenase 1-like protein GN=GPDIL GPD1L_HUMAN $38.42 \quad 100.0 \%$ Glycogen phosphorylase, liver form GN=PYGL PYGL_HUMAN 97.15 $100.0 \%$ Glycogen phosphorylase, liver form GN=PYGL PYGL HUMAN $97.15 \quad 100.0 \%$ Glycogen phosphorylase, liver form GN=PYGL PYGL_HUMAN 97.15 $100.0 \%$ Glycogen phosphorylase, liver form GN=PYGL PYGL_HUMAN 97.15 100.0\% Glycogen phosphorylase, liver form GN=PYGL PYGL HUMAN 97.15 100.0\% Glycogen phosphorylase, liver form GN=PYGL PYGL_HUMAN 97.15 $100.0 \%$ Glyoxylate reductase/hydroxypyruvate reductase GN=GRHPR GRHPR_HUMAN $35.67100 .0 \%$ Glyoxylate reductase/hydroxypyruvate reductase GN=GRHPR GRHPR_HUMAN $35.67 \quad 100.0 \%$ Golgi phosphoprotein $3 \mathrm{GN}=\mathrm{GOLPH} 3 \quad$ GOLP3_HUMAN $33.81 \quad 100.0 \%$ Golgi phosphoprotein $3 \mathrm{GN}=\mathrm{GOLPH} 3 \quad$ GOLP3 HUMAN $33.81 \quad 100.0 \%$
$0.00 \% \quad 8.4 \% \quad$ INPDEREEMK $0.00 \% \quad 8.4 \%$ LFIVESNSSSSTR $0.01 \% \quad 3.6 \%$ AINFNFGYAK

$0.01 \% \quad 3.6 \%$ ANNGICFLR

$0.01 \% \quad 3.6 \%$ FSEGEATLR

$0.01 \% \quad 6.9 \%$ YPGSPGSYAAR

$0.01 \% \quad 6.9 \%$ SFSNIISTLNPTAK

$0.05 \% \quad 23.6 \%$ GLMEPLLPPK

$0.05 \% \quad 23.6 \%$ RTEELPLGR

$0.05 \% \quad 23.6 \%$ TEELPLGR

$0.05 \% \quad 23.6 \%$ ELRVPLIGSLPEAR

$0.05 \% \quad 23.6 \%$ VPLIGSLPEAR

$0.05 \% \quad 23.6 \%$ RVVGQLDPQR

$0.05 \% \quad 23.6 \%$ VVGQLDPQR

$0.05 \% \quad 23.6 \%$ TPGSPGNLQVR

$0.05 \% \quad 23.6 \%$ KFLEATLR

$0.05 \% \quad 23.6 \%$ HLTLACHYDSK

$0.05 \% \quad 23.6 \%$ HLAQLMESIPHSPGPTR

$0.01 \% \quad 9.3 \%$ ELPQVSFVK

$0.01 \% \quad 9.3 \%$ LDGAHAPELTK

$0.01 \% \quad 9.3 \%$ GELVGGLDIVK

$0.04 \% \quad 26.9 \%$ LVINGNPITIFQER

$0.04 \% \quad 26.9 \%$ LVINGNPITIFQERDPSK

$0.04 \% \quad 26.9 \%$ IISNASCTTNCLAPLAK

$0.04 \% \quad 26.9 \%$ GALQNIIPASTGAAK

$0.04 \% \quad 26.9 \%$ VPTANVSVVDLTCR

$0.04 \% \quad 26.9 \%$ LISWYDNEFGYSNR

$0.04 \% \quad 26.9 \%$ VVDLMAHMASKE

$0.01 \% \quad 25.6 \%$ KLTDIINNDHENVK

$0.01 \% \quad 25.6 \%$ ICDEITGR

$0.01 \% \quad 25.6 \%$ KALGITLIK

$0.01 \% \quad 25.6 \%$ GIDEGPEGLK

$0.01 \% \quad 25.6 \%$ ELLQTPNFR

$0.01 \% \quad 25.6 \%$ ITVVDDADTVELCGALK

$0.01 \% \quad 25.6 \%$ LGLMEMIAFAR

$0.01 \% \quad 25.6 \%$ LQGPQTSAEVYR

$0.02 \% \quad 8.2 \%$ GIVGVENVAELKK

$0.02 \% \quad 8.2 \%$ FSQFLETEYKVK

$0.02 \% \quad 8.2 \% \quad$ VIFLENYR

$0.02 \% \quad 8.2 \% \quad$ LVIDQIDNGFFSPK

$0.02 \% \quad 8.2 \%$ VFADYEAYVK

$0.02 \% \quad 8.2 \%$ NIAASGKFSSDR

$0.00 \% \quad 10.4 \%$ ILDAAGANLK

$0.00 \% \quad 10.4 \%$ IAAAGLDVTSPEPLPTNHPLLTLK

$0.00 \% \quad 8.4 \%$ GCMLIELALR

$0.00 \% \quad 8.4 \%$ SDAPTGDVLLDEALK

$0.01 \% \quad 4.7 \% \quad$ LNLYAASLR $\begin{array}{llllllll}95.1 \% & 17.5 & 25.0 & 13.0 & 1 & 0 & 0 & 1260.59\end{array}$

1426.72

$99.7 \% \quad 39.2$

$99.7 \% \quad 53.8$

$99.7 \% \quad 37.7$

$99.7 \% \quad 39.1$

$\begin{array}{llll}97.5 \% & 19.3 & 25.0 & 14.9\end{array}$

$\begin{array}{lllll}99.7 \% & 33.4 & 25.0 & 33.4 & 3\end{array}$

$99.7 \% \quad 47.9 \quad 25.0 \quad 47.9$

$\begin{array}{llll}98.9 \% & 28.9 & 25.0 & 11.7\end{array}$

$99.7 \% \quad 46.0 \quad 25.0 \quad 32.2$

$99.7 \% \quad 55.9 \quad 25.0 \quad 47.6$

$\begin{array}{llll}99.0 \% & 39.7 & 25.0 & 13.0\end{array}$

$99.7 \% \quad 54.6 \quad 25.0 \quad 50.4$

$\begin{array}{llll}99.7 \% & 41.7 & 25.0 & 41.7\end{array}$

$\begin{array}{lllll}99.7 \% & 33.4 & 25.0 & 25.4 & 2\end{array}$

$\begin{array}{llll}99.7 \% & 33.4 & 25.0 & 29.3\end{array}$

$\begin{array}{llll}99.7 \% & 50.7 & 25.0 & 34.8\end{array}$

$99.7 \% \quad 49.1 \quad 25.0 \quad 45.2$

$\begin{array}{llll}99.7 \% & 38.4 & 25.0 & 35.9\end{array}$

$\begin{array}{llll}99.7 \% & 55.3 & 25.0 & 55.3\end{array}$

$\begin{array}{llll}99.7 \% & 53.2 & 25.0 & 51.3\end{array}$

$\begin{array}{llll}99.7 \% & 75.6 & 25.0 & 69.7\end{array}$

$\begin{array}{llll}99.7 \% & 51.8 & 25.0 & 51.8\end{array}$

$\begin{array}{llll}99.7 \% & 51.7 & 25.0 & 48.2\end{array}$

$\begin{array}{llll}99.7 \% & 26.4 & 25.0 & 26.4\end{array}$

$99.0 \% \quad 52.8 \quad 25.0 \quad 43.4$

$\begin{array}{llll}95.4 \% & 14.5 & 25.0 & 14.5\end{array}$

$\begin{array}{lllll}99.7 \% & 37.0 & 25.0 & 30.9\end{array}$

$\begin{array}{llll}97.9 \% & 26.8 & 25.0 & 9.1\end{array}$

$\begin{array}{lllll}99.7 \% & 67.0 & 25.0 & 67.0 & 2\end{array}$

$\begin{array}{llll}99.7 \% & 37.5 & 25.0 & 27.9\end{array}$

$\begin{array}{llll}99.7 \% & 48.7 & 25.0 & 48.7\end{array}$

$\begin{array}{lllll}99.7 \% & 58.5 & 25.0 & 56.6 & 2\end{array}$

$99.7 \% \quad 29.2 \quad 25.0 \quad 29.2$

$\begin{array}{llll}99.0 \% & 34.1 & 25.0 & 34.1\end{array}$

$\begin{array}{llll}99.7 \% & 39.3 & 25.0 & 39.2\end{array}$

$\begin{array}{llll}95.8 \% & 15.3 & 25.0 & 15.3\end{array}$

$\begin{array}{lllll}99.7 \% & 56.2 & 25.0 & 53.1 & 2\end{array}$

$\begin{array}{llll}99.7 \% & 44.5 & 25.0 & 33.2\end{array}$

$\begin{array}{llll}99.7 \% & 36.8 & 25.0 & 36.8\end{array}$

$\begin{array}{llll}99.7 \% & 46.8 & 25.0 & 30.2\end{array}$

$\begin{array}{llll}99.7 \% & 61.6 & 25.0 & 60.5\end{array}$

$99.6 \% \quad 26.0 \quad 25.0 \quad 19.0$
1144.58

1064.53

1009.49

1125.53

1492.80

107

$293 \quad 301$

395403

88

$1110.62 \quad 17 \quad 26$

1070.60

914.49

1549.91

1151.68

1167.66

1011.56

1125.60

977.58

1344.64

1886.95

1046.59

1151.61

1099.64

1613.90

2041.11

1833.92

1411.79

1530.79

1763.80

1330.65

1652.86

963.46

956.65

1014.51

1117.60

1818.92

1251.66

1348.69

1355.79

1518.78

1053.57

1592.83

1204.59

1252.63

985.57

2468.38

1175.63

1543.79

1020.58 

H/ACA ribonucleoprotein complex subunit $1 \mathrm{GN}=\mathrm{GAR} 1 \mathrm{GAR} 1$ HUMAN $22.35100 .0 \%$ $\mathrm{H} / \mathrm{ACA}$ ribonucleoprotein complex subunit $4 \mathrm{GN}=\mathrm{DKC1} \mathrm{DKC1}$ _HUMAN $57.68 \quad 100.0 \%$ $\mathrm{H} / \mathrm{ACA}$ ribonucleoprotein complex subunit $4 \mathrm{GN}=\mathrm{DKC1} \mathrm{DKC1}$ HUMAN $57.68100 .0 \%$ $\mathrm{H} / \mathrm{ACA}$ ribonucleoprotein complex subunit $4 \mathrm{GN}=\mathrm{DKCl}$ DKC1_HUMAN $57.68 \quad 100.0 \%$ HCLS1-associated protein X-1 GN=HAX1 HAX1_HUMAN $31.62 \quad 100.0 \%$ HCLS1-associated protein X-1 GN=HAX1 HAX1 HUMAN $31.62 \quad 100.0 \%$ HCLS1-associated protein X-1 GN=HAX1 HAX1_HUMAN $31.62 \quad 100.0 \%$

$\begin{array}{llll}6 \% & \text { KACGDSTLTQITAGLDPVGR } & 99.7 \% & 31.5\end{array}$ $99.7 \% \quad 64.8$ $99.7 \% \quad 55.8$ $99.7 \% \quad 54.6$ $99.7 \% \quad 73.2$ $\begin{array}{lll}99.3 \% & 49.8\end{array}$ $99.7 \% \quad 39.5$ $\begin{array}{lll}98.3 \% & 18.5\end{array}$ $99.7 \% \quad 60.0$ $99.7 \% \quad 50.5$ $99.7 \% \quad 55.8$ $99.0 \% \quad 42.2$ $99.7 \% \quad 47.9$ $\begin{array}{lll}99.7 \% & 32.1\end{array}$ $99.3 \% \quad 49.8$ $\begin{array}{lll}95.3 \% & 17.3\end{array}$ $99.7 \% \quad 48.5$ $\begin{array}{lll}99.7 \% & 37.8\end{array}$ $99.7 \% \quad 27.4$ $99.7 \% \quad 37.6$ $95.7 \% \quad 18.0$ $\begin{array}{lll}98.3 \% & 20.8\end{array}$ $99.7 \% \quad 69.0$ $99.7 \% \quad 51.0$ $0.02 \% \quad 31.9 \%$ LWDLTTGTTTR $0.02 \% \quad 31.9 \%$ DVLSVAFSSDNR $0.02 \% 31.9 \%$ YTVQDESHSEWVSCVR $0.02 \% \quad 31.9 \%$ FSPNSSNPIIVSCGWDK $0.02 \% 31.9 \%$ HLYTLDGGDIINALCFSPNR $0.02 \% 31.9 \%$ IIVDELKQEVISTSSK $0.02 \% 31.9 \%$ VWQVTIGTR $0.03 \% \quad 12.0 \%$ KLVLILNK $0.03 \% \quad 12.0 \%$ ELPTVVFR $0.03 \% \quad 12.0 \%$ LLGGFQETCSK $0.03 \% \quad 12.0 \%$ VGVIGFPNVGK $0.03 \% \quad 12.0 \%$ GGIPNVEGAAK $0.03 \% \quad 12.0 \%$ SGFNLEELEKNNAQSIR $0.01 \% \quad 8.1 \%$ TIESYCQDVLR $0.01 \% \quad 8.1 \%$ CSVPVDQASESLLK $0.01 \% \quad 8.1 \%$ SSLINSLKR $0.01 \% \quad 8.1 \%$ IADAIENKTTVYK $0.00 \% \quad 10.1 \%$ VDEIFGQLR

$0.00 \% \quad 10.1 \%$ FYIDPYKLLPLQR $0.01 \% \quad 7.2 \%$ SQQSAGKEYVGIVR $0.01 \% \quad 7.2 \%$ LHNAIEGGTQLSR $0.01 \% \quad 7.2 \%$ APQVVAEAAK $0.02 \% 35.8 \%$ GFFGFPGPR $0.02 \% \quad 35.8 \%$ DSMLKYPDSHQPR
$99.7 \% \quad 51.1$

$99.7 \% \quad 72.3$

$\begin{array}{ll}99.7 \% & 39.8 \\ 99.7 \% & 52.0\end{array}$

$99.7 \% \quad 41.7$ $99.0 \% \quad 29.5$

$\begin{array}{lll}99.0 \% & 35.7\end{array}$

$99.7 \% \quad 28.8$

$99.7 \% \quad 56.3$

$99.7 \% \quad 30.6$

$99.0 \% \quad 25.0$

$99.7 \% \quad 52.3$

$\begin{array}{lll}99.7 \% & 42.8\end{array}$

$99.7 \% \quad 37.2$

$99.7 \% \quad 50.9$

$99.7 \% \quad 39.3$

$98.7 \% \quad 17.9$

$99.7 \% \quad 64.0 \quad 25$.

$99.7 \% \quad 43.0$

$99.7 \% \quad 36.7$

$99.7 \% \quad 37.7$

$98.6 \% \quad 24.3$

$99.7 \% \quad 38.2$
1119.62

878.44

1096.48

1761.91

1380.72

909.42

1110.52

1586.72

1057.63

1519.74

1094.61

1147.71

1258.66

1087.64

861.42

1057.63

1264.65

1309.64

1981.87

1907.90

2276.11

1789.00

1059.59

940.66

960.55

1239.60

1086.63

1012.54

1948.97

1383.66

1532.76

1017.6

1465.79

1076.57

1665.94

1521.80

1395.73

983.55

981.49

972.56 1573.74

42
42
78
89
209
46
100
100
142
176
179
192
205
257
330
53
199
211
293
347
52
210
3


HCLS1-associated protein X-1 GN=HAX1 HAX1_HUMAN $31.62 \quad 100.0 \%$ HCLS1-associated protein X-1 GN=HAX1 HAX1_HUMAN $31.62 \quad 100.0 \%$ HCLS1-associated protein X-1 GN=HAX1 HAX1_HUMAN $31.62 \quad 100.0 \%$ HCLS1-associated protein X-1 GN=HAX1 HAX1_HUMAN $31.62 \quad 100.0 \%$ HCLS1-associated protein X-1 GN=HAX1 HAX1_HUMAN $31.62 \quad 100.0 \%$ HCLS1-associated protein X-1 GN=HAX1 HAX1_HUMAN $31.62 \quad 100.0 \%$ HEAT repeat-containing protein 1 GN=HEATR1 HEAT1_HUMAN $242.38 \quad 100.0 \%$ HEAT repeat-containing protein 1 GN=HEATR1 HEAT1_HUMAN $242.38 \quad 100.0 \%$ HEAT repeat-containing protein 1 GN=HEATR1 HEAT1_HUMAN $242.38 \quad 100.0 \%$ HEAT repeat-containing protein 1 GN=HEATR1 HEAT1_HUMAN $242.38 \quad 100.0 \%$ HEAT repeat-containing protein $1 \mathrm{GN}=$ HEATR1 HEAT1_HUMAN $242.38 \quad 100.0 \%$ HEAT repeat-containing protein 1 GN=HEATR1 HEAT1_HUMAN $242.38 \quad 100.0 \%$ HEAT repeat-containing protein 1 GN=HEATR1 HEAT1_HUMAN $242.38 \quad 100.0 \%$ HEAT repeat-containing protein 1 GN=HEATR1 HEAT1_HUMAN $242.38 \quad 100.0 \%$ HEAT repeat-containing protein 1 GN=HEATR1 HEAT1_HUMAN $242.38 \quad 100.0 \%$ HEAT repeat-containing protein 1 GN=HEATR1 HEAT1_HUMAN $242.38 \quad 100.0 \%$ HEAT repeat-containing protein 1 GN=HEATR1 HEAT1_HUMAN $242.38 \quad 100.0 \%$ HEAT repeat-containing protein 5B GN=HEATR5B HTR5B_HUMAN $224.31 \quad 100.0 \%$ HEAT repeat-containing protein 5B GN=HEATR5B HTR5B_HUMAN $224.31 \quad 100.0 \%$ HEAT repeat-containing protein 5B GN=HEATR5B HTR5B_HUMAN $224.31 \quad 100.0 \%$ Heat shock $70 \mathrm{kDa}$ protein $1 \mathrm{~A} / 1 \mathrm{~B}$ GN=HSPA1A HSP71_HUMAN $70.05 \quad 100.0 \%$ Heat shock $70 \mathrm{kDa}$ protein $1 \mathrm{~A} / 1 \mathrm{~B}$ GN=HSPA1A HSP71 HUMAN $70.05 \quad 100.0 \%$ Heat shock $70 \mathrm{kDa}$ protein 1A/1B GN=HSPA1A HSP71_HUMAN $70.05 \quad 100.0 \%$ Heat shock $70 \mathrm{kDa}$ protein 1A/1B GN=HSPA1A HSP71_HUMAN $70.05 \quad 100.0 \%$ Heat shock $70 \mathrm{kDa}$ protein $1 \mathrm{~A} / 1 \mathrm{~B}$ GN=HSPA1A HSP71 HUMAN $70.05 \quad 100.0^{\circ}$ Heat shock $70 \mathrm{kDa}$ protein $1 \mathrm{~A} / 1 \mathrm{~B}$ GN=HSPA1A HSP71_HUMAN $70.05 \quad 100.0 \%$ Heat shock $70 \mathrm{kDa}$ protein 1A/1B GN=HSPA1A HSP71_HUMAN $70.05 \quad 100.0 \%$ Heat shock $70 \mathrm{kDa}$ protein 1A/1B GN=HSPA1A HSP71_HUMAN $70.05 \quad 100.0 \%$ Heat shock $70 \mathrm{kDa}$ protein $1 \mathrm{~A} / 1 \mathrm{~B}$ GN=HSPA1A HSP71_HUMAN $70.05 \quad 100.0 \%$ Heat shock $70 \mathrm{kDa}$ protein $1 \mathrm{~A} / 1 \mathrm{~B}$ GN=HSPA1A HSP71 HUMAN $70.05 \quad 100.0 \%$ Heat shock $70 \mathrm{kDa}$ protein 1A/1B GN=HSPA1A HSP71_HUMAN $70.05 \quad 100.0 \%$ Heat shock $70 \mathrm{kDa}$ protein 1A/1B GN=HSPA1A HSP71_HUMAN $70.05 \quad 100.0 \%$ Heat shock $70 \mathrm{kDa}$ protein $1 \mathrm{~A} / 1 \mathrm{~B}$ GN=HSPA1A HSP71 HUMAN $70.05 \quad 100.0 \%$ Heat shock $70 \mathrm{kDa}$ protein $1 \mathrm{~A} / 1 \mathrm{~B}$ GN=HSPA1A HSP71_HUMAN $70.05 \quad 100.0 \%$ Heat shock $70 \mathrm{kDa}$ protein 1A/1B GN=HSPA1A HSP71_HUMAN $70.05 \quad 100.0 \%$ Heat shock $70 \mathrm{kDa}$ protein 1A/1B GN=HSPA1A HSP71_HUMAN $70.05 \quad 100.0 \%$ Heat shock $70 \mathrm{kDa}$ protein 1A/1B GN=HSPA1A HSP71_HUMAN $70.05 \quad 100.0 \%$ Heat shock $70 \mathrm{kDa}$ protein $1 \mathrm{~A} / 1 \mathrm{~B}$ GN=HSPA1A HSP71 HUMAN $70.05 \quad 100.0^{\circ}$ Heat shock $70 \mathrm{kDa}$ protein $1 \mathrm{~A} / 1 \mathrm{~B}$ GN=HSPA1A HSP71_HUMAN $70.05 \quad 100.0 \%$ Heat shock $70 \mathrm{kDa}$ protein $1 \mathrm{~A} / 1 \mathrm{~B}$ GN=HSPA1A HSP71_HUMAN $70.05 \quad 100.0 \%$ Heat shock $70 \mathrm{kDa}$ protein $1 \mathrm{~A} / 1 \mathrm{~B}$ GN=HSPA1A HSP71_HUMAN $70.05100 .0 \%$ Heat shock $70 \mathrm{kDa}$ protein 1A/1B GN=HSPA1A HSP71_HUMAN $70.05 \quad 100.0 \%$ Heat shock $70 \mathrm{kDa}$ protein 1A/1B GN=HSPA1A HSP71 HUMAN $70.05 \quad 100.0 \%$ Heat shock $70 \mathrm{kDa}$ protein $1 \mathrm{~A} / 1 \mathrm{~B}$ GN=HSPA1A HSP71_HUMAN $70.05 \quad 100.0 \%$ Heat shock $70 \mathrm{kDa}$ protein 1A/1B GN=HSPA1A HSP71_HUMAN $70.05 \quad 100.0 \%$ Heat shock $70 \mathrm{kDa}$ protein 1A/1B GN=HSPA1A HSP71_HUMAN $70.05 \quad 100.0 \%$ Heat shock $70 \mathrm{kDa}$ protein 1A/1B GN=HSPA1A HSP71_HUMAN $70.05 \quad 100.0 \%$ $\begin{array}{lllll}10 & 16 & 0.02 \% & 35.8 \% & \text { YPDSHQPR }\end{array}$

$16 \quad 0.02 \% \quad 35.8 \%$ IFGGVLESDAR

10

10
10

10
10

10

(11

1

1

11

11

3

30

30

30

30
30

30

30
30

30

30
30

30
30

30

30

30

30
30

30

30
30
30

30

30
30

30

30
30

30

30

30

30 $30 \quad 4$

$0.02 \% \quad 35.8 \%$ TREDNDLDSQVSQEGLGPVLQPQPK

$0.02 \% \quad 35.8 \%$ ITKPDGIVEER

$\begin{array}{lll}0.02 \% & 35.8 \% & \text { TVVDSEGRTETTVTR }\end{array}$

$0.02 \% \quad 35.8 \%$ TETTVTRHEADSSPR

$0.02 \% \quad 5.2 \%$ VFAEYPGSSAQLR

$0.02 \% \quad 5.2 \%$ LLESKYPR

$0.02 \% \quad 5.2 \% \quad$ LIGVANQK

$0.02 \% \quad 5.2 \% \quad$ LDDTYSFQVINK

$0.02 \% \quad 5.2 \%$ VVESGGPEILK

$0.02 \% \quad 5.2 \%$ GLVGNPLPSVR

$0.02 \% \quad 5.2 \%$ ALDLLNNK

$0.02 \% \quad 5.2 \% \quad$ EGEEEQAINR

$0.02 \% \quad 5.2 \% \quad$ ITSEMGSASQANIR

$0.02 \% \quad 5.2 \% \quad$ TLATTLAPR

$0.02 \% \quad 5.2 \%$ VLLPAIKK

$0.00 \% \quad 1.9 \%$ AVEAVVNDTSGENK

$0.00 \% \quad 1.9 \% \quad$ VFAADCLCR

$0.00 \% \quad 1.9 \% \quad$ STSVNLNQASGAVGSAK

$44 \quad 340 \quad 0.38 \% \quad 42.7 \%$ VEIIANDQGNR

$44 \quad 340 \quad 0.38 \% \quad 42.7 \%$ TTPSYVAFTDTER

$44 \quad 340 \quad 0.38 \% \quad 42.7 \%$ NQVALNPQNTVFDAK

$44 \quad 340 \quad 0.38 \% \quad 42.7 \%$ NQVALNPQNTVFDAKR

$44 \quad 340 \quad 0.38 \% \quad 42.7 \%$ HWPFQVINDGDKPK

$44 \quad 340 \quad 0.38 \% \quad 42.7 \%$ VQVSYKGETK

$44 \quad 340 \quad 0.38 \% \quad 42.7 \%$ AFYPEEISSMVLTK

$44 \quad 340 \quad 0.38 \% \quad 42.7 \%$ QATKDAGVIAGLNVLR

$44 \quad 340 \quad 0.38 \% \quad 42.7 \%$ DAGVIAGLNVLR

$44 \quad 340 \quad 0.38 \% \quad 42.7 \%$ IINEPTAAAIAYGLDR

$44 \quad 340 \quad 0.38 \% \quad 42.7 \%$ ATAGDTHLGGEDFDNR

$44 \quad 340 \quad 0.38 \% \quad 42.7 \%$ LVNHFVEEFKR

$44 \quad 340 \quad 0.38 \% \quad 42.7 \%$ ARFEELCSDLFR

$44 \quad 340 \quad 0.38 \% \quad 42.7 \%$ FEELCSDLFR

$44 \quad 340 \quad 0.38 \% \quad 42.7 \%$ STLEPVEK

$44 \quad 340 \quad 0.38 \% \quad 42.7 \%$ LDKAQIHDLVLVGGSTR

$44 \quad 340 \quad 0.38 \% \quad 42.7 \%$ AQIHDLVLVGGSTR

$44 \quad 340 \quad 0.38 \% \quad 42.7 \%$ AQIHDLVLVGGSTRIPK

$44 \quad 340 \quad 0.38 \% \quad 42.7 \%$ LLQDFFNGR

$44 \quad 340 \quad 0.38 \% \quad 42.7 \%$ LLQDFFNGRDLNK

$44 \quad 340 \quad 0.38 \% \quad 42.7 \%$ AMTKDNNLLGR

$44 \quad 340 \quad 0.38 \% \quad 42.7 \%$ ANKITITNDK

$44 \quad 340 \quad 0.38 \% \quad 42.7 \%$ ITITNDKGR

$44 \quad 340 \quad 0.38 \% \quad 42.7 \%$ LSKEEIER

$44 \quad 340 \quad 0.38 \% \quad 42.7 \%$ MVQEAEKYK

$44 \quad 340 \quad 0.38 \% \quad 42.7 \%$ YKAEDEVQR

$44 \quad 340 \quad 0.38 \% \quad 42.7 \%$ VSAKNALESYAFNMK
$99.0 \% 30.0$

$99.7 \% \quad 69.4$

$99.7 \% \quad 47.1$

$99.3 \% \quad 20.0$

$99.7 \% \quad 38.0$

$\begin{array}{lll}99.7 \% & 27.4\end{array}$

$95.1 \% 16.5$

$99.0 \% \quad 26.9$

$98.7 \% \quad 29.1$

$99.7 \% \quad 44.9$

$99.7 \% \quad 43.3$

$99.7 \% \quad 34.1$

$94.8 \% \quad 17.2$

$\begin{array}{lll}99.7 \% & 32.3\end{array}$

$99.7 \% \quad 51.8$

$99.7 \% \quad 44.1$

$99.0 \% \quad 25.4$

$99.7 \% \quad 31.7$

$99.4 \% \quad 36.1$

$99.7 \% \quad 62.9$

$99.7 \% \quad 55.4$

$99.7 \% \quad 59.5$

$99.7 \% \quad 75.1$

$99.7 \% \quad 35.8$

$99.7 \% \quad 42.4$

$99.7 \% \quad 55.2$

$99.7 \% 56.5$

$99.7 \% \quad 58.3$

$99.7 \% \quad 46.8$

$\begin{array}{lll}99.7 \% & 52.8\end{array}$

$99.7 \% \quad 39.9$

$\begin{array}{lll}99.7 \% & 51.1\end{array}$

$99.7 \% \quad 50.5$

$99.0 \% \quad 32.5$

$99.7 \% \quad 54.5$

$99.7 \% \quad 54.6$

$99.7 \% \quad 32.5$

$\begin{array}{lll}99.7 \% & 59.8\end{array}$

$99.7 \% \quad 53.1$

$99.7 \% \quad 54.5$

$99.4 \% \quad 26.1$

$\begin{array}{lll}99.7 \% & 56.7\end{array}$

$\begin{array}{lll}99.0 \% & 59.0\end{array}$

$99.7 \% \quad 34.7$

$99.7 \% \quad 42.0$

$99.7 \% \quad 49.9$

999.46

999.46

1163.61

2750.36

1256.68

1650.83

1686.80

1424.72

1005.57

842.51

1442.72

1127.63

1108.65

900.52

1174.53

1464.71

943.56

881.62

1432.69

1111.50

1590.81

1228.63

1487.70

1658.85

1814.95

1680.85

1138.61

1630.80

1625.93

1197.70

1687.90

1675.73

1417.76

1542.74

1315.60

902.48

1822.02

1465.81

1804.04

1109.57

1579.82

1232.64

1117.62

1017.57

1003.54

1141.56

1137.55

1688.83

Page 70 of Table S-1-6 
Heat shock $70 \mathrm{kDa}$ protein 1A/1B GN=HSPA1A HSP71_HUMAN $70.05 \quad 100.0 \% \quad 30$ Heat shock $70 \mathrm{kDa}$ protein 1A/1B GN=HSPA1A HSP71_HUMAN $70.05 \quad 100.0 \% \quad 30$ Heat shock $70 \mathrm{kDa}$ protein 1A/1B GN=HSPA1A HSP71_HUMAN $70.05 \quad 100.0 \% 30$ Heat shock $70 \mathrm{kDa}$ protein $4 \mathrm{GN}=\mathrm{HSPA} 4$ HSP74 HUMAN $94.33 \quad 100.0 \%$ Heat shock $70 \mathrm{kDa}$ protein $4 \mathrm{GN}=\mathrm{HSPA} 4$ HSP74_HUMAN $94.33 \quad 100.0 \%$ Heat shock $70 \mathrm{kDa}$ protein $4 \mathrm{GN}=$ HSPA4 HSP74_HUMAN $94.33 \quad 100.0 \%$ Heat shock $70 \mathrm{kDa}$ protein $4 \mathrm{GN}=$ HSPA4 HSP74_HUMAN $94.33 \quad 100.0 \%$ Heat shock $70 \mathrm{kDa}$ protein $4 \mathrm{GN}=\mathrm{HSPA} 4 \quad$ HSP74_HUMAN $94.33 \quad 100.0 \%$ Heat shock $70 \mathrm{kDa}$ protein $4 \mathrm{GN}=\mathrm{HSPA} 4$ HSP74_HUMAN $94.33 \quad 100.0 \%$ Heat shock $70 \mathrm{kDa}$ protein 4L GN=HSPA4L HS74L_HUMAN $94.51 \quad 100.0 \%$ Heat shock $70 \mathrm{kDa}$ protein 4L GN=HSPA4L HS74L_HUMAN $94.51 \quad 100.0 \%$ Heat shock $70 \mathrm{kDa}$ protein 4L GN=HSPA4L HS74L_HUMAN $94.51 \quad 100.0 \%$ Heat shock $70 \mathrm{kDa}$ protein 4L GN=HSPA4L HS74L_HUMAN $94.51 \quad 100.0 \%$ Heat shock cognate $71 \mathrm{kDa}$ protein GN=HSPA8 HSP7C_HUMAN $70.90 \quad 100.0 \%$ Heat shock cognate $71 \mathrm{kDa}$ protein GN=HSPA8 HSP7C_HUMAN $70.90 \quad 100.0 \%$ Heat shock cognate $71 \mathrm{kDa}$ protein GN=HSPA8 HSP7C_HUMAN $70.90 \quad 100.0 \% \quad 2$ Heat shock cognate $71 \mathrm{kDa}$ protein GN=HSPA8 HSP7C HUMAN $70.90 \quad 100.0 \%$ Heat shock cognate $71 \mathrm{kDa}$ protein GN=HSPA8 HSP7C_HUMAN $70.90 \quad 100.0 \% \quad 24$ Heat shock cognate $71 \mathrm{kDa}$ protein GN=HSPA8 HSP7C_HUMAN $70.90 \quad 100.0 \% \quad 24$ Heat shock cognate $71 \mathrm{kDa}$ protein GN=HSPA8 HSP7C_HUMAN $70.90 \quad 100.0 \%$ Heat shock cognate $71 \mathrm{kDa}$ protein GN=HSPA8 HSP7C_HUMAN $70.90 \quad 100.0 \% \quad 24$ Heat shock cognate $71 \mathrm{kDa}$ protein GN=HSPA8 HSP7C HUMAN $70.90 \quad 100.0 \%$ Heat shock cognate $71 \mathrm{kDa}$ protein GN=HSPA8 HSP7C_HUMAN $70.90 \quad 100.0 \%$ Heat shock cognate $71 \mathrm{kDa}$ protein GN=HSPA8 HSP7C_HUMAN $70.90 \quad 100.0 \% \quad 24$ Heat shock cognate $71 \mathrm{kDa}$ protein GN=HSPA8 HSP7C HUMAN $70.90 \quad 100.0 \%$ Heat shock cognate $71 \mathrm{kDa}$ protein GN=HSPA8 HSP7C_HUMAN $70.90 \quad 100.0 \% \quad 24$ Heat shock cognate $71 \mathrm{kDa}$ protein GN=HSPA8 HSP7C_HUMAN $70.90 \quad 100.0 \%$ Heat shock cognate $71 \mathrm{kDa}$ protein GN=HSPA8 HSP7C_HUMAN $70.90 \quad 100.0 \% \quad 24$ Heat shock cognate $71 \mathrm{kDa}$ protein GN=HSPA8 HSP7C_HUMAN $70.90 \quad 100.0 \% \quad 24$ Heat shock cognate $71 \mathrm{kDa}$ protein GN=HSPA8 HSP7C HUMAN $70.90 \quad 100.0 \%$ Heat shock cognate $71 \mathrm{kDa}$ protein GN=HSPA8 HSP7C_HUMAN $70.90 \quad 100.0 \% \quad 24$ Heat shock cognate $71 \mathrm{kDa}$ protein GN=HSPA8 HSP7C_HUMAN $70.90 \quad 100.0 \%$ Heat shock cognate $71 \mathrm{kDa}$ protein GN=HSPA8 HSP7C HUMAN $70.90 \quad 100.0 \%$ Heat shock cognate $71 \mathrm{kDa}$ protein GN=HSPA8 HSP7C_HUMAN $70.90 \quad 100.0 \%$ Heat shock cognate $71 \mathrm{kDa}$ protein GN=HSPA8 HSP7C_HUMAN $70.90 \quad 100.0 \%$ Heat shock cognate $71 \mathrm{kDa}$ protein GN=HSPA8 HSP7C_HUMAN $70.90 \quad 100.0 \% \quad 24$ Heat shock cognate $71 \mathrm{kDa}$ protein GN=HSPA8 HSP7C_HUMAN $70.90 \quad 100.0 \%$ Heat shock cognate $71 \mathrm{kDa}$ protein GN=HSPA8 HSP7C HUMAN $70.90 \quad 100.0 \%$ Heat shock cognate $71 \mathrm{kDa}$ protein GN=HSPA8 HSP7C_HUMAN $70.90 \quad 100.0 \% \quad 24$ Heat shock cognate $71 \mathrm{kDa}$ protein GN=HSPA8 HSP7C_HUMAN $70.90 \quad 100.0 \%$ Heat shock cognate $71 \mathrm{kDa}$ protein GN=HSPA8 HSP7C_HUMAN $70.90 \quad 100.0 \% \quad 24$ Heat shock protein $105 \mathrm{kDa}$ GN=HSPH1 HS105_HUMAN $96.87 \quad 100.0 \%$ Heat shock protein $105 \mathrm{kDa}$ GN=HSPH1 HS105 HUMAN $96.87 \quad 100.0 \%$ Heat shock protein $105 \mathrm{kDa}$ GN=HSPH1 HS105_HUMAN $96.87 \quad 100.0 \%$ Heat shock protein $105 \mathrm{kDa}$ GN=HSPH1 HS105_HUMAN $96.87 \quad 100.0 \%$ Heat shock protein $105 \mathrm{kDa}$ GN=HSPH1 HS105_HUMAN $96.87 \quad 100.0 \%$ Heat shock protein $105 \mathrm{kDa}$ GN=HSPH1 HS105_HUMAN $96.87 \quad 100.0 \%$
$44 \quad 340 \quad 0.38 \% \quad 42.7 \%$ NALESYAFNMK

$44 \quad 340 \quad 0.38 \% \quad 42.7 \%$ SAVEDEGLK

$44 \quad 340 \quad 0.38 \% \quad 42.7 \%$ GGSGSGPTIEEVD

$7 \quad 0.01 \% \quad 8.8 \%$ AGGIETIANEYSDR $0.01 \% \quad 8.8 \%$ NTVQGFKR

$0.01 \% \quad 8.8 \%$ AFSDPFVEAEK

$0.01 \% \quad 8.8 \% \quad$ VLATAFDTTLGGR

$0.01 \% \quad 8.8 \%$ ELSTTLNADEAVTR

$0.01 \% \quad 8.8 \%$ GCALQCAILSPAFK

$0.00 \% \quad 5.6 \%$ SQIVTNVR

$0.00 \% \quad 5.6 \%$ SFDDPIVQTER

$0.00 \% \quad 5.6 \%$ DISTTLNADEAVAR

$0.00 \% \quad 5.6 \%$ GCALQCAILSPAFK

$199 \quad 0.22 \% \quad 38.2 \%$ VEIIANDQGNR

$199 \quad 0.22 \% \quad 38.2 \%$ TTPSYVAFTDTER

$199 \quad 0.22 \% \quad 38.2 \%$ NQVAMNPTNTVFDAK

$199 \quad 0.22 \% \quad 38.2 \%$ NQVAMNPTNTVFDAKR

$199 \quad 0.22 \% \quad 38.2 \%$ VQVEYKGETK

$199 \quad 0.22 \% \quad 38.2 \%$ SFYPEEVSSMVLTK

$199 \quad 0.22 \% \quad 38.2 \%$ MKEIAEAYLGK

$199 \quad 0.22 \% \quad 38.2 \%$ EIAEAYLGK

$199 \quad 0.22 \% \quad 38.2 \%$ TVTNAVVTVPAYFNDSQR

$199 \quad 0.22 \% \quad 38.2 \%$ TVTNAVVTVPAYFNDSQRQATK

$199 \quad 0.22 \% \quad 38.2 \%$ QATKDAGTIAGLNVLR

$199 \quad 0.22 \% \quad 38.2 \%$ DAGTIAGLNVLR

$199 \quad 0.22 \% \quad 38.2 \%$ IINEPTAAAIAYGLDK

$199 \quad 0.22 \% \quad 38.2 \%$ IINEPTAAAIAYGLDKK

$199 \quad 0.22 \% \quad 38.2 \%$ STAGDTHLGGEDFDNR

$199 \quad 0.22 \% \quad 38.2 \%$ MVNHFIAEFK

$199 \quad 0.22 \% \quad 38.2 \%$ ARFEELNADLFR

$199 \quad 0.22 \% \quad 38.2 \%$ FEELNADLFR

$199 \quad 0.22 \% \quad 38.2 \%$ GTLDPVEK

$199 \quad 0.22 \% \quad 38.2 \%$ LDKSQIHDIVLVGGSTR

$199 \quad 0.22 \% \quad 38.2 \%$ SQIHDIVLVGGSTR

$199 \quad 0.22 \% \quad 38.2 \%$ LLQDFFNGK

$199 \quad 0.22 \% \quad 38.2 \%$ LLQDFFNGKELNK

$199 \quad 0.22 \% \quad 38.2 \%$ ITITNDKGR

$199 \quad 0.22 \% \quad 38.2 \%$ LSKEDIER

$199 \quad 0.22 \% \quad 38.2 \%$ MVQEAEKYK

$199 \quad 0.22 \% \quad 38.2 \%$ NSLESYAFNMK

$199 \quad 0.22 \% \quad 38.2 \%$ VCNPIITK

$9 \quad 0.01 \% \quad 8.7 \% \quad$ NQQITHANNTVSNFKR

$9 \quad 0.01 \% \quad 8.7 \%$ VLGTAFDPFLGGK

$\begin{array}{lll}0.01 \% & 8.7 \% & \text { DISTTLNADEAVAR }\end{array}$

$0.01 \% \quad 8.7 \%$ GCALQCAILSPAFK

$\quad 0.01 \% \quad 8.7 \% \quad$ FQEAEERPK

$9 \quad 0.01 \% \quad 8.7 \%$ SLDQDPVVR

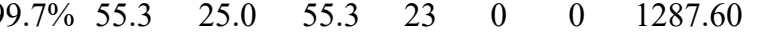

947.47

1204.53

1495.70

949.52

1239.59

$\begin{array}{llllllll}99.7 \% & 54.7 & 25.0 & 50.1 & 3 & 0 & 0 & 1321.71 \\ 99.7 \% & 48.9 & 25.0 & 43.3 & 1 & 0 & 0 & 1519.76\end{array}$

$\begin{array}{llllllll}99.7 \% & 54.7 & 25.0 & 50.1 & 3 & 0 & 0 & 1321.71 \\ 99.7 \% & 48.9 & 25.0 & 43.3 & 1 & 0 & 0 & 1519.76\end{array}$

$99.5 \% \quad 28.1 \quad 25.0 \quad 24.0$

$\begin{array}{llll}99.0 \% & 40.7 & 25.0 & 31.2\end{array}$

$\begin{array}{lllll}99.7 \% & 58.2 & 25.0 & 52.3\end{array}$

$99.7 \% \quad 60.0 \quad 25.0 \quad 50.1$

$\begin{array}{llll}99.5 \% & 28.1 & 25.0 & 24.0\end{array}$

$\begin{array}{llll}99.3 \% & 60.5 & 25.0 & 0.0\end{array}$

$99.7 \% 55.4$

$99.7 \% \quad 62.6$

$99.7 \% \quad 54.5$

$99.7 \% \quad 55.5$

$99.7 \% \quad 55.2$

$99.7 \% \quad 63.8$

$99.7 \% \quad 32.1$

$99.7 \% \quad 45.9$

$99.7 \% \quad 28.6$

$99.7 \% \quad 43.5$

$99.7 \% \quad 60.0$

$99.7 \% \quad 63.9$

$99.7 \% \quad 50.2$

$99.7 \% \quad 48.4$

$99.7 \% \quad 49.9$

$99.7 \% \quad 49.9$

$99.7 \% \quad 46.0$

$99.0 \% \quad 33.1$

$99.7 \% \quad 53.0$

$99.7 \% \quad 40.6$

$99.7 \% \quad 42.9$

$99.7 \% \quad 52.5$

$99.7 \% \quad 56.7$

$99.0 \% \quad 59.5$

$99.7 \% \quad 34.7$

$99.7 \% 52.6$

$98.6 \% \quad 28.4$

$99.7 \% \quad 27.9$

$99.2 \% \quad 21.2$

$99.7 \% \quad 60.0$

$99.5 \% \quad 28.1$

$98.8 \% \quad 24.9$

$96.2 \% \quad 21.2$

916.52

1306.63

1475.73

1535.77

1228.63

1487.70

1649.80

1821.89

1180.62

1632.78

1252.66

993.53

1982.00

2410.24

1627.91

1199.67

1659.90

1787.99

1691.73

1235.62

1480.75

1253.62

858.46

1838.01

1481.8

1081.57

1565.83

1017.57

989.53

1141.56

1303.60

944.52

1871.95

1321.72

1475.73

1535.77

1133.56

1028.54 
Heat shock protein $75 \mathrm{kDa}$, mitochondrial GN=TRAP1 TRAP1_HUMAN $80.11 \quad 100.0 \%$ Heat shock protein $75 \mathrm{kDa}$, mitochondrial GN=TRAP1 TRAP1_HUMAN $80.11 \quad 100.0 \%$ Heat shock protein $75 \mathrm{kDa}$, mitochondrial GN=TRAP1 TRAP1_HUMAN $80.11 \quad 100.0 \%$ Heat shock protein $75 \mathrm{kDa}$, mitochondrial GN=TRAP1 TRAP1_HUMAN $80.11 \quad 100.0 \%$ Heat shock protein $75 \mathrm{kDa}$, mitochondrial GN=TRAP1 TRAP1_HUMAN $80.11 \quad 100.0 \%$ Heat shock protein $75 \mathrm{kDa}$, mitochondrial GN=TRAP1 TRAP1_HUMAN $80.11 \quad 100.0 \%$ Heat shock protein $75 \mathrm{kDa}$, mitochondrial GN=TRAP1 TRAP1_HUMAN $80.11 \quad 100.0 \%$ Heat shock protein beta-1 GN=HSPB1 HSPB1_HUMAN $22.78 \quad 100.0 \%$ Heat shock protein beta-1 GN=HSPB1 HSPB1_HUMAN $22.78 \quad 100.0 \%$ Heat shock protein HSP 90-alpha GN=HSP90AA1 HS90A_HUMAN $84.66 \quad 100.0 \%$ Heat shock protein HSP 90-alpha GN=HSP90AA1 HS90A_HUMAN $84.66 \quad 100.0 \%$ Heat shock protein HSP 90-alpha GN=HSP90AA1 HS90A_HUMAN $84.66 \quad 100.0 \%$ Heat shock protein HSP 90-alpha GN=HSP90AA1 HS90A_HUMAN $84.66 \quad 100.0 \%$ Heat shock protein HSP 90-alpha GN=HSP90AA1 HS90A_HUMAN $84.66 \quad 100.0 \%$ Heat shock protein HSP 90-alpha GN=HSP90AA1 HS90A_HUMAN $84.66 \quad 100.0 \%$ Heat shock protein HSP 90-alpha GN=HSP90AA1 HS90A_HUMAN $84.66 \quad 100.0 \%$ Heat shock protein HSP 90-alpha GN=HSP90AA1 HS90A_HUMAN $84.66 \quad 100.0 \%$ Heat shock protein HSP 90-alpha GN=HSP90AA1 HS90A_HUMAN $84.66 \quad 100.0 \%$ Heat shock protein HSP 90-alpha GN=HSP90AA1 HS90A_HUMAN $84.66 \quad 100.0 \%$ Heat shock protein HSP 90-alpha GN=HSP90AA1 HS90A_HUMAN $84.66 \quad 100.0 \%$ Heat shock protein HSP 90-alpha GN=HSP90AA1 HS90A_HUMAN $84.66 \quad 100.0 \%$ Heat shock protein HSP 90-beta GN=HSP90AB1 HS90B_HUMAN 83.27 Heat shock protein HSP 90-beta GN=HSP90AB1 HS90B_HUMAN 83.27 Heat shock protein HSP 90-beta GN=HSP90AB1 HS90B_HUMAN 83.27 Heat shock protein HSP 90-beta GN=HSP90AB1 HS90B_HUMAN 83.27 Heat shock protein HSP 90-beta GN=HSP90AB1 HS90B_HUMAN 83.27 Heat shock protein HSP 90-beta GN=HSP90AB1 HS90B_HUMAN 83.27 Heat shock protein HSP 90-beta GN=HSP90AB1 HS90B_HUMAN 83.27 Heat shock protein HSP 90-beta GN=HSP90AB1 HS90B_HUMAN 83.27 Heat shock protein HSP 90-beta GN=HSP90AB1 HS90B_HUMAN 83.27 Heat shock protein HSP 90-beta GN=HSP90AB1 HS90B_HUMAN 83.27 Heat shock protein HSP 90-beta GN=HSP90AB1 HS90B_HUMAN 83.27 Heat shock protein HSP 90-beta GN=HSP90AB1 HS90B_HUMAN 83.27 Heat shock protein HSP 90-beta GN=HSP90AB1 HS90B_HUMAN 83.27 Heat shock protein HSP 90-beta GN=HSP90AB1 HS90B_HUMAN 83.27 Heat shock protein HSP 90-beta GN=HSP90AB1 HS90B_HUMAN 83.27 Heat shock protein HSP 90-beta GN=HSP90AB1 HS90B_HUMAN 83.27 Heat shock protein HSP 90-beta GN=HSP90AB1 HS90B_HUMAN 83.27 Heat shock protein HSP 90-beta GN=HSP90AB1 HS90B_HUMAN 83.27 Heat shock protein HSP 90-beta GN=HSP90AB1 HS90B_HUMAN 83.27 Heat shock protein HSP 90-beta GN=HSP90AB1 HS90B_HUMAN 83.27 Heat shock protein HSP 90-beta GN=HSP90AB1 HS90B_HUMAN 83.27 Heat shock protein HSP 90-beta GN=HSP90AB1 HS90B HUMAN 83.27 Heat shock protein HSP 90-beta GN=HSP90AB1 HS90B_HUMAN 83.27 Heat shock protein HSP 90-beta GN=HSP90AB1 HS90B_HUMAN 83.27 Heat shock protein HSP 90-beta GN=HSP90AB1 HS90B_HUMAN 83.27 Heat shock protein HSP 90-beta GN=HSP90AB1 HS90B_HUMAN 83.27
$9 \quad 0.01 \% \quad 10.1 \%$ AFLDALQNQAEASSK $0.01 \% \quad 10.1 \%$ TDAPLNIR $0.01 \% \quad 10.1 \%$ GVVDSEDIPLNLSR $0.01 \% \quad 10.1 \%$ ELLQESALIR $0.01 \% \quad 10.1 \%$ ELLQESALIRK $0.01 \% \quad 10.1 \%$ NIYYLCAPNR $0.01 \% \quad 10.1 \%$ AQLLQPTLEINPR $0.01 \% \quad 9.8 \%$ LFDQAFGLPR $0.01 \% \quad 9.8 \%$ AQLGGPEAAK

$10 \quad 0.01 \% \quad 18.3 \%$ ELISNSSDALDKIR

$10 \quad 0.01 \% \quad 18.3 \%$ YESLTDPSKLDSGK

$10 \quad 0.01 \% \quad 18.3 \%$ TLTIVDTGIGMTK

$10 \quad 0.01 \% \quad 18.3 \%$ ADLINNLGTIAK

$10 \quad 0.01 \% \quad 18.3 \%$ VILHLKEDQTEYLEER

$10 \quad 0.01 \% \quad 18.3 \%$ EKYIDQEELNK

$10 \quad 0.01 \% \quad 18.3 \%$ YIDQEELNK

$10 \quad 0.01 \% \quad 18.3 \%$ HFSVEGQLEFR

$10 \quad 0.01 \% \quad 18.3 \%$ RAPFDLFENR

$10 \quad 0.01 \% \quad 18.3 \%$ NNIKLYVR

$10 \quad 0.01 \% \quad 18.3 \%$ GVVDSEDLPLNISR

$10 \quad 0.01 \% \quad 18.3 \%$ DQVANSAFVER

$162 \quad 0.18 \% \quad 37.6 \%$ ELISNASDALDK

$162 \quad 0.18 \% \quad 37.6 \%$ ELISNASDALDKIR

$162 \quad 0.18 \% \quad 37.6 \%$ YESLTDPSKLDSGK

$162 \quad 0.18 \% \quad 37.6 \%$ IDIIPNPQER

$162 \quad 0.18 \% \quad 37.6 \%$ TLTLVDTGIGMTK

$162 \quad 0.18 \% \quad 37.6 \%$ ADLINNLGTIAK

$162 \quad 0.18 \% \quad 37.6 \%$ ADHGEPIGRGTK

$162 \quad 0.18 \% \quad 37.6 \%$ VILHLKEDQTEYLEER

$162 \quad 0.18 \% \quad 37.6 \%$ EKYIDQEELNK

$162 \quad 0.18 \% \quad 37.6 \%$ YIDQEELNK

$162 \quad 0.18 \% \quad 37.6 \%$ NPDDITQEEYGEFYK

$162 \quad 0.18 \% \quad 37.6 \%$ HFSVEGQLEFR

$162 \quad 0.18 \% \quad 37.6 \%$ ALLFIPRR

$162 \quad 0.18 \% \quad 37.6 \%$ RAPFDLFENK

$162 \quad 0.18 \% \quad 37.6 \%$ APFDLFENK

$162 \quad 0.18 \% \quad 37.6 \%$ NNIKLYVR

$162 \quad 0.18 \% \quad 37.6 \%$ GVVDSEDLPLNISR

$\begin{array}{llll}162 & 0.18 \% & 37.6 \% & \text { FYEAFSKNLK }\end{array}$

$162 \quad 0.18 \% \quad 37.6 \%$ NLKLGIHEDSTNR

$162 \quad 0.18 \% \quad 37.6 \%$ LGIHEDSTNR

$162 \quad 0.18 \% \quad 37.6 \%$ LGIHEDSTNRR

$162 \quad 0.18 \% \quad 37.6 \%$ YHTSQSGDEMTSLSEYVSR

$162 \quad 0.18 \% \quad 37.6 \%$ SIYYITGESK

$162 \quad 0.18 \% \quad 37.6 \%$ EQVANSAFVER

$162 \quad 0.18 \% \quad 37.6 \%$ EFDGKSLVSVTK
$99.0 \% \quad 34.3$

$99.2 \% 65.1$

$\begin{array}{lll}0.0 & 16 & 0\end{array}$

$99.7 \% \quad 41.5 \quad 25.0 \quad 31.0$

$\begin{array}{llll}99.7 \% & 35.4 & 25.0 & 33.4\end{array}$

$99.7 \% \quad 43.2 \quad 25.0 \quad 43.2$

$\begin{array}{llll}99.7 \% & 57.4 & 25.0 & 49.8\end{array}$

$99.7 \% \quad 32.4 \quad 25.0 \quad 32.4$

$\begin{array}{llll}99.7 \% & 60.1 & 25.0 & 50.5\end{array}$

$\begin{array}{llll}99.7 \% & 39.7 & 25.0 & 31.3\end{array}$

$99.2 \% \quad 65.9 \quad 25.0 \quad 0.0$

$\begin{array}{llll}99.7 \% & 61.0 & 25.0 & 50.0\end{array}$

$\begin{array}{llll}99.7 \% & 35.2 & 25.0 & 35.2\end{array}$

$97.9 \% \quad 22.9 \quad 25.0 \quad 15.6$

$99.7 \% \quad 55.1 \quad 25.0 \quad 40.6$

$99.7 \% \quad 33.6 \quad 25.0 \quad 33.6$

$\begin{array}{llll}99.7 \% & 30.1 & 25.0 & 29.6\end{array}$

$\begin{array}{llll}99.0 \% & 41.5 & 25.0 & 33.0\end{array}$

$99.2 \% \quad 65.1 \quad 25.0 \quad 0.0$

$\begin{array}{llll}99.7 \% & 38.8 & 25.0 & 34.8\end{array}$

$\begin{array}{llll}98.3 \% & 28.9 & 25.0 & 24.1\end{array}$

$\begin{array}{llll}99.7 \% & 53.2 & 25.0 & 42.2\end{array}$

$\begin{array}{llll}99.7 \% & 39.7 & 25.0 & 31.3\end{array}$

$\begin{array}{lllll}99.7 \% & 44.9 & 25.0 & 43.7\end{array}$

$99.7 \% \quad 61.0$

$99.2 \% \quad 29.7$

$99.7 \% \quad 35.2$

$97.9 \% \quad 22.9$

$99.7 \% \quad 55.1$

$99.7 \% \quad 57.4$

$99.7 \% \quad 33.6$

$95.5 \% \quad 16.7$

$99.7 \% \quad 31.1$

$99.7 \% \quad 37.3$

$99.0 \% \quad 41.5$

$99.2 \% \quad 65.1$

$98.8 \% \quad 20.6$

$99.7 \% \quad 31.4$

$99.7 \% \quad 43.5$

$99.7 \% \quad 28.4$

$100.0 \% \quad 28$

$100.0 \% \quad 28$

$100.0 \%$

$100.0 \% \quad 28$

1560.82

1539.75

1349.73

1242.71

2015.04

1408.70

1151.56

1348.66

1264.64

1019.60

1513.79

1235.60

1275.64

1544.83

1539.75

1194.65

1349.73

1242.71

1237.63

2015.04

1408.70

1151.56

1847.80

1348.66

985.63

1236.64

1080.54

1019.60

1513.79

1246.65

1496.78

1141.56

1297.66

2192.94

1160.58

1249.62

1309.70 1835.81 
Heat shock protein HSP 90-beta GN=HSP90AB1 $\quad$ HS90B_HUMAN $83.27 \quad 100.0 \%$ Heat shock protein HSP 90-beta GN=HSP90AB1 HS90B_HUMAN $83.27 \quad 100.0 \%$ Helicase SKI2W GN=SKIV2I Helicase SKI2W GN=SKIV2I Helicase SKI2W GN=SKIV2I Helicase-like transcription factor GN=HLTF HLTF_HUMAN $113.93 \quad 100.0 \%$ Helicase-like transcription factor GN=HLTF HLTF_HUMAN $113.93 \quad 100.0 \%$ Hermansky-Pudlak syndrome 6 protein GN=HPS6 HPS6_HUMAN $82.98 \quad 100.0 \%$ Hermansky-Pudlak syndrome 6 protein GN=HPS6 HPS6 HUMAN $82.98 \quad 100.0 \%$ Heterochromatin protein 1-binding protein $3 \mathrm{GN}=\mathrm{HP} 1 \mathrm{BP} 3 \mathrm{HP} 1 \mathrm{~B} 3$ _HUMAN $61.21 \quad 100.0 \%$ Heterochromatin protein 1-binding protein $3 \mathrm{GN}=\mathrm{HP} 1 \mathrm{BP} 3 \mathrm{HP1B} 3$ _HUMAN $61.21 \quad 100.0 \%$ Heterochromatin protein 1-binding protein $3 \mathrm{GN}=\mathrm{HP} 1 \mathrm{BP} 3 \mathrm{HP} 1 \mathrm{~B} 3$ HUMAN $61.21 \quad 100.0^{\circ}$ Heterochromatin protein 1-binding protein $3 \mathrm{GN}=\mathrm{HP} 1 \mathrm{BP} 3 \mathrm{HP} 1 \mathrm{~B} 3$ _HUMAN $61.21 \quad 100.0 \%$ Heterochromatin protein 1-binding protein $3 \mathrm{GN}=\mathrm{HP} 1 \mathrm{BP} 3 \mathrm{HP} 1 \mathrm{~B} 3$ _HUMAN $61.21 \quad 100.0 \%$ Heterochromatin protein 1-binding protein $3 \mathrm{GN}=\mathrm{HP} 1 \mathrm{BP} 3$ HP1B3_HUMAN $61.21 \quad 100.0 \%$ Heterochromatin protein 1-binding protein $3 \mathrm{GN}=\mathrm{HP} 1 \mathrm{BP} 3 \mathrm{HP} 1 \mathrm{~B} 3$ _HUMAN $61.21 \quad 100.0 \%$ Heterochromatin protein 1-binding protein $3 \mathrm{GN}=\mathrm{HP} 1 \mathrm{BP} 3 \mathrm{HP} 1 \mathrm{~B} 3$ HUMAN $61.21100 .0 \%$ Heterogeneous nuclear ribonucleoprotein A/B GN=HNRNPAB ROAA_HUMAN $36.23 \quad 100.0 \%$ Heterogeneous nuclear ribonucleoprotein A/B GN=HNRNPAB ROAA_HUMAN 36.23 Heterogeneous nuclear ribonucleoprotein A/B GN=HNRNPAB ROAA HUMAN 36.23 Heterogeneous nuclear ribonucleoprotein A/B GN=HNRNPAB ROAA_HUMAN 36.23 Heterogeneous nuclear ribonucleoprotein A/B GN=HNRNPAB ROAA_HUMAN 36.23 Heterogeneous nuclear ribonucleoprotein A/B GN=HNRNPAB ROAA_HUMAN 36.2 Heterogeneous nuclear ribonucleoprotein A/B GN=HNRNPAB ROAA_HUMAN 36.2 ? Heterogeneous nuclear ribonucleoprotein A/B GN=HNRNPAB ROAA_HUMAN 36.23 Heterogeneous nuclear ribonucleoprotein A/B GN=HNRNPAB ROAA_HUMAN 36.23 Heterogeneous nuclear ribonucleoprotein A/B GN=HNRNPAB ROAA_HUMAN 36.23 Heterogeneous nuclear ribonucleoprotein $\mathrm{A} / \mathrm{B}$ GN=HNRNPAB ROAA HUMAN 36.23 Heterogeneous nuclear ribonucleoprotein A0 GN=HNRNPA0 ROA0_HUMAN 30.8 Heterogeneous nuclear ribonucleoprotein $\mathrm{A} 0$ GN=HNRNPA0 ROA0_HUMAN 30.84 Heterogeneous nuclear ribonucleoprotein A0 GN=HNRNPA0 ROA0_HUMAN 30.84 Heterogeneous nuclear ribonucleoprotein $\mathrm{A} 0 \mathrm{GN}=\mathrm{HNRNPA0}$ ROA0_HUMAN 30.84 Heterogeneous nuclear ribonucleoprotein A0 GN=HNRNPA0 ROA0_HUMAN 30.84 Heterogeneous nuclear ribonucleoprotein A0 GN=HNRNPA0 ROA0_HUMAN 30.84 Heterogeneous nuclear ribonucleoprotein A0 GN=HNRNPA0 ROA0_HUMAN 30.84 Heterogeneous nuclear ribonucleoprotein A0 GN=HNRNPA0 ROA0_HUMAN 30.84 Heterogeneous nuclear ribonucleoprotein A0 GN=HNRNPA0 ROA0_HUMAN 30.8 Heterogeneous nuclear ribonucleoprotein A0 GN=HNRNPA0 ROA0 HUMAN 30.84 Heterogeneous nuclear ribonucleoprotein A1 GN=HNRNPA1 ROA1_HUMAN 38.75 Heterogeneous nuclear ribonucleoprotein A1 GN=HNRNPA1 ROA1_HUMAN 38.75 Heterogeneous nuclear ribonucleoprotein A1 GN=HNRNPA1 ROA1_HUMAN 38.75 Heterogeneous nuclear ribonucleoprotein A1 GN=HNRNPA1 ROA1_HUMAN 38.7 . Heterogeneous nuclear ribonucleoprotein A1 GN=HNRNPA1 ROA1_HUMAN 38.7 Heterogeneous nuclear ribonucleoprotein A1 GN=HNRNPA1 ROA1_HUMAN 38.75 Heterogeneous nuclear ribonucleoprotein A1 GN=HNRNPA1 ROA1_HUMAN 38.7 . Heterogeneous nuclear ribonucleoprotein $\mathrm{Al} \mathrm{GN}=\mathrm{HNRNPA1} \mathrm{ROA1}$ HUMAN 38.7 Heterogeneous nuclear ribonucleoprotein A1 GN=HNRNPA1 ROA1_HUMAN 38.75
$100.0 \%$

$100.0 \%$ $100.0 \%$ $100.0 \%$ $100.0 \%$ $100.0 \%$ $100.0 \%$ $100.0 \%$ $100.0 \% \quad 10$ $100.0 \%$ $100.0 \%$ $100.0 \%$ $100.0 \%$ $100.0 \%$ $100.0 \%$ $100.0 \%$ $100.0 \%$ $100.0 \%$ $100.0 \%$ $100.0 \%$ $100.0 \%$ $100.0 \% \quad 20$ $100.0 \% \quad 20$ $100.0 \% \quad 20$ $100.0 \% \quad 20$ $100.0 \% \quad 20$ $100.0 \% \quad 20$ $100.0 \% \quad 20$ $100.0 \% \quad 20$

3

\section{$4 \quad 0.00 \% \quad 3.2 \%$ GDTVSASPCSAPLAR}

$4 \quad 0.00 \% \quad 3.2 \%$ TQGELFLLLDSR

$0.00 \% \quad 3.2 \%$ GLDPTGTVILLCK

$0.00 \% \quad 3.1 \%$ VILDEGHAIRNPNAQQTK

$0.00 \% \quad 3.1 \%$ AGGVGLNLSAASR

$0.00 \% \quad 3.5 \%$ LLSDLSAFGGAAR

$\quad 0.00 \% \quad 3.5 \%$ TLEPSGEASTSLGR

$0.03 \% \quad 11.6 \%$ SGASVVAIRK

$0.03 \% \quad 11.6 \%$ GKGASGSFVVVQK

$0.03 \% \quad 11.6 \%$ GASGSFVVVQK

$0.03 \% \quad 11.6 \%$ LEDVLPLAFTR

$0.03 \% \quad 11.6 \%$ EASYSLIR

$0.03 \% \quad 11.6 \%$ KYVSQYYPK

$0.03 \% \quad 11.6 \%$ AVERGQLEQITGK

$0.03 \% \quad 11.6 \%$ GQLEQITGK

$\begin{array}{ll}0.07 \% & 28.0 \% \text { MFVGGLSWDTSK }\end{array}$

$0.07 \% \quad 28.0 \%$ MFVGGLSWDTSKK

$0.07 \% \quad 28.0 \%$ DLKDYFTK

$0.07 \% \quad 28.0 \%$ FGEVVDCTIK

$0.07 \% \quad 28.0 \%$ FGEVVDCTIKMDPNTGR

$0.07 \% \quad 28.0 \%$ GFGFILFK

$0.07 \% \quad 28.0 \%$ EYFGEFGEIEAIELPMDPK

$0.07 \% \quad 28.0 \%$ RGFVFITFK

$0.07 \% \quad 28.0 \%$ GFVFITFK

$0.07 \% \quad 28.0 \%$ GFVFITFKEEEPVK

$0.07 \% \quad 28.0 \%$ EVYQQQQYGSGGR

$0.05 \% \quad 37.4 \%$ LFIGGLNVQTSESGLR

$0.05 \% \quad 37.4 \%$ GHFEAFGTLTDCVVVVNPQTK

$0.05 \% \quad 37.4 \%$ KLFVGGLK

$0.05 \% \quad 37.4 \%$ GDVAEGDLIEHFSQFGTVEK

$0.05 \% \quad 37.4 \%$ AEIIADKQSGK

$0.05 \% \quad 37.4 \%$ RGFGFVYFQNHDAADK

$0.05 \% \quad 37.4 \%$ GFGFVYFQNHDAADK

37.4\% AVPKEDIYSGGGGGGSR $99.7 \% \quad 51.9$

$45 \quad 0.05 \% \quad 37.4 \%$ EDIYSGGGGGGSR

$180 \quad 0.20 \% \quad 48.9 \%$ SESPKEPEQLR

$180 \quad 0.20 \% \quad 48.9 \%$ KLFIGGLSFETTDESLR

$99.7 \% \quad 80.2$

$180 \quad 0.20 \% \quad 48.9 \%$ LFIGGLSFETTDESLR

$\begin{array}{ll}99.7 \% & 45.6 \\ 99.7 \% & 41.2\end{array}$

$99.7 \% \quad 66.8$

$180 \quad 0.20 \% \quad 48.9 \%$ SHFEQWGTLTDCVVMR $\quad 99.7 \% \quad 51.2$

$180 \quad 0.20 \% \quad 48.9 \%$ SHFEQWGTLTDCVVMRDPNTK $99.6 \% 24.2$

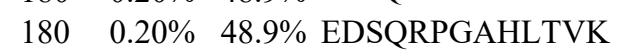

$180 \quad 0.20 \% \quad 48.9 \%$ EDSQRPGAHLTVKK

$180 \quad 0.20 \% \quad 48.9 \%$ KIFVGGIK

$180 \quad 0.20 \% \quad 48.9 \%$ IFVGGIKEDTEEHHLR

1343.63

1471.73

1029.53

1167.57

1954.90

928.53

2230.03

1114.64

958.54

1669.88

1499.69

1690.91

2319.14

861.56

2178.04

1159.63

1871.88

1715.78

2184.09

1606.78

1211.53

1299.65

1913.00

1784.91

1965.89

2521.16

1437.74

1565.84

861.56 1879.97 
Heterogeneous nuclear ribonucleoprotein A1 GN=HNRNPA1 ROA1_HUMAN $38.75 \quad 100.0 \% \quad 20$ $\begin{array}{llll}\text { Heterogeneous nuclear ribonucleoprotein A1 GN=HNRNPA1 ROA1_HUMAN } & 38.75 & 100.0 \% & 20\end{array}$ Heterogeneous nuclear ribonucleoprotein A1 GN=HNRNPA1 ROA1_HUMAN $38.75 \quad 100.0 \% \quad 20$ Heterogeneous nuclear ribonucleoprotein A1 GN=HNRNPA1 ROA1_HUMAN $38.75 \quad 100.0 \% 20$ Heterogeneous nuclear ribonucleoprotein A1 GN=HNRNPA1 ROA1_HUMAN $38.75 \quad 100.0 \% \quad 20$ Heterogeneous nuclear ribonucleoprotein A1 GN=HNRNPA1 ROA1_HUMAN $38.75 \quad 100.0 \% 20$ Heterogeneous nuclear ribonucleoprotein A1 GN=HNRNPA1 ROA1_HUMAN $38.75 \quad 100.0 \% \quad 20$ Heterogeneous nuclear ribonucleoprotein A1 GN=HNRNPA1 ROA1_HUMAN $38.75 \quad 100.0 \% \quad 20$ Heterogeneous nuclear ribonucleoprotein A1 GN=HNRNPA1 ROA1 HUMAN $38.75 \quad 100.0 \% \quad 20$ $\begin{array}{llll}\text { Heterogeneous nuclear ribonucleoprotein A1 GN=HNRNPA1 ROA1_HUMAN } & 38.75 & 100.0 \% & 20\end{array}$ Heterogeneous nuclear ribonucleoprotein A1 GN=HNRNPA1 ROA1_HUMAN $38.75 \quad 100.0 \% 20$ Heterogeneous nuclear ribonucleoprotein A1 GN=HNRNPA1 ROA1_HUMAN $38.75 \quad 100.0 \% 20$ $\begin{array}{lllll}\text { Heterogeneous nuclear ribonucleoprotein A1 GN=HNRNPA1 ROA1_HUMAN } & 38.75 & 100.0 \% & 20\end{array}$ Heterogeneous nuclear ribonucleoprotein $\mathrm{A} 3 \mathrm{GN}=\mathrm{HNRNPA} 3$ ROA3_HUMAN $39.60 \quad 100.0 \% 20$ Heterogeneous nuclear ribonucleoprotein $\mathrm{A} 3 \mathrm{GN}=$ HNRNPA3 ROA3_HUMAN $39.60 \quad 100.0 \% 20$ $\begin{array}{lllll}\text { Heterogeneous nuclear ribonucleoprotein } \mathrm{A} 3 \mathrm{GN}=\mathrm{HNRNPA} 3 & \mathrm{ROA} 3 \text { HUMAN } & 39.60 & 100.0 \% & 20\end{array}$ Heterogeneous nuclear ribonucleoprotein $\mathrm{A} 3 \mathrm{GN}=\mathrm{HNRNPA} 3 \mathrm{ROA} 3$ HUMAN $39.60 \quad 100.0 \%$ Heterogeneous nuclear ribonucleoprotein A3 GN=HNRNPA3 ROA3_HUMAN $39.60 \quad 100.0 \% \quad 20$ Heterogeneous nuclear ribonucleoprotein A3 GN=HNRNPA3 ROA3_HUMAN $39.60 \quad 100.0 \% 20$ Heterogeneous nuclear ribonucleoprotein $\mathrm{A} 3 \mathrm{GN}=\mathrm{HNRNPA} 3 \mathrm{ROA} 3$ HUMAN $39.60 \quad 100.0 \% 20$ Heterogeneous nuclear ribonucleoprotein A3 GN=HNRNPA3 ROA3_HUMAN $39.60 \quad 100.0 \% \quad 20$ Heterogeneous nuclear ribonucleoprotein $\mathrm{A} 3 \mathrm{GN}=\mathrm{HNRNPA} 3 \mathrm{ROA} 3$ HUMAN $39.60 \quad 100.0 \% \quad 20$ Heterogeneous nuclear ribonucleoprotein A3 GN=HNRNPA3 ROA3_HUMAN $39.60 \quad 100.0 \% 20$ Heterogeneous nuclear ribonucleoprotein $\mathrm{A} 3 \mathrm{GN}=\mathrm{HNRNPA} 3 \mathrm{ROA} 3$ HUMAN $39.60 \quad 100.0 \% \quad 20$ Heterogeneous nuclear ribonucleoprotein $\mathrm{A} 3 \mathrm{GN}=\mathrm{HNRNPA} 3 \mathrm{ROA} 3$ HUMAN $39.60 \quad 100.0 \%$ $\begin{array}{lllll}\text { Heterogeneous nuclear ribonucleoprotein A3 GN=HNRNPA3 } & \text { ROA3_HUMAN } & 39.60 & 100.0 \% & 20\end{array}$ Heterogeneous nuclear ribonucleoprotein A3 GN=HNRNPA3 ROA3_HUMAN $39.60 \quad 100.0 \% \quad 20$ Heterogeneous nuclear ribonucleoprotein A3 GN=HNRNPA3 ROA3_HUMAN $39.60 \quad 100.0 \% 20$ $\begin{array}{lllll}\text { Heterogeneous nuclear ribonucleoprotein } \mathrm{A} 3 \mathrm{GN}=\mathrm{HNRNPA} 3 & \mathrm{ROA} 3 \text { HUMAN } & 39.60 & 100.0 \% & 20\end{array}$ Heterogeneous nuclear ribonucleoprotein $\mathrm{A} 3 \mathrm{GN}=\mathrm{HNRNPA} 3 \mathrm{ROA} 3$ HUMAN $39.60 \quad 100.0 \% \quad 20$

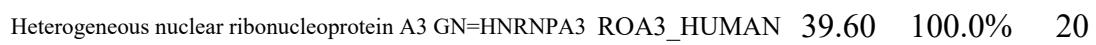
Heterogeneous nuclear ribonucleoprotein A3 GN=HNRNPA3 ROA3_HUMAN $39.60 \quad 100.0 \% \quad 20$ Heterogeneous nuclear ribonucleoprotein $\mathrm{A} 3 \mathrm{GN}=\mathrm{HNRNPA} 3 \mathrm{ROA} 3$ HUMAN $39.60 \quad 100.0 \% \quad 20$ Heterogeneous nuclear ribonucleoprotein A3 GN=HNRNPA3 ROA3_HUMAN $39.60 \quad 100.0 \% \quad 20$ Heterogeneous nuclear ribonucleoprotein D0 GN=HNRNPD HNRPD_HUMAN $38.43 \quad 100.0 \% \quad 12$ Heterogeneous nuclear ribonucleoprotein D0 GN=HNRNPD HNRPD_HUMAN $38.43 \quad 100.0 \% 12$ Heterogeneous nuclear ribonucleoprotein D0 GN=HNRNPD HNRPD_HUMAN $38.43 \quad 100.0 \% \quad 12$ Heterogeneous nuclear ribonucleoprotein D0 GN=HNRNPD HNRPD_HUMAN $38.43 \quad 100.0 \% 12$ Heterogeneous nuclear ribonucleoprotein D0 GN=HNRNPD HNRPD_HUMAN $38.43 \quad 100.0 \% \quad 12$ Heterogeneous nuclear ribonucleoprotein D0 GN=HNRNPD HNRPD_HUMAN $38.43 \quad 100.0 \% 12$ Heterogeneous nuclear ribonucleoprotein D0 GN=HNRNPD HNRPD HUMAN $38.43 \quad 100.0 \% \quad 12$ Heterogeneous nuclear ribonucleoprotein D0 GN=HNRNPD HNRPD_HUMAN $38.43 \quad 100.0 \% \quad 12$ Heterogeneous nuclear ribonucleoprotein D0 GN=HNRNPD HNRPD HUMAN $38.43 \quad 100.0 \%$ Heterogeneous nuclear ribonucleoprotein D0 GN=HNRNPD HNRPD_HUMAN $38.43 \quad 100.0 \% \quad 12$ Heterogeneous nuclear ribonucleoprotein D0 GN=HNRNPD HNRPD_HUMAN $38.43 \quad 100.0 \% \quad 12$ Heterogeneous nuclear ribonucleoprotein D0 GN=HNRNPD HNRPD HUMAN $38.43 \quad 100.0 \%$ $\begin{array}{llll}\text { Heterogeneous nuclear ribonucleoprotein D0 GN=HNRNPD HNRPD_HUMAN } & 38.43 & 100.0 \% & 12\end{array}$
$0.20 \% \quad 48.9 \%$ IEVIEIMTDR

$180 \quad 0.20 \% \quad 48.9 \%$ IEVIEIMTDRGSGK

$180 \quad 0.20 \% \quad 48.9 \%$ RGFAFVTFDDHDSVDK

$180 \quad 0.20 \% \quad 48.9 \%$ GFAFVTFDDHDSVDK

$180 \quad 0.20 \% \quad 48.9 \%$ GFAFVTFDDHDSVDKIVIQK

$180 \quad 0.20 \% \quad 48.9 \%$ YHTVNGHNCEVR

$180 \quad 0.20 \% \quad 48.9 \%$ YHTVNGHNCEVRK

$180 \quad 0.20 \% \quad 48.9 \%$ GGGFGGNDNFGR

$\begin{array}{llllll} & 0.20 \% & 48.9 \% & \text { SSGPYGGGGQYFAKPR } & 99.7 \% & 57.4\end{array}$

$\begin{array}{llllll}180 & 0.20 \% & 48.9 \% & \text { NQGGYGGSSSSSSYGSGRR } & 95.5 \% & 14.4\end{array}$

$148 \quad 0.17 \% \quad 43.1 \%$ GEEGHDPKEPEQLR

$99.7 \% \quad 42.4$

$148 \quad 0.17 \% \quad 43.1 \%$ KLFIGGLSFETTDDSLR $\quad 99.7 \% \quad 52.5$

$148 \quad 0.17 \% \quad 43.1 \%$ LFIGGLSFETTDDSLR $\quad 99.7 \% \quad 79.8$

$148 \quad 0.17 \% \quad 43.1 \%$ LFIGGLSFETTDDSLREHFEK $99.7 \% \quad 45.3$

$148 \quad 0.17 \% \quad 43.1 \%$ WGTLTDCVVMR

$99.7 \% \quad 54.3$

$148 \quad 0.17 \% \quad 43.1 \%$ WGTLTDCVVMRDPQTK $99.7 \% \quad 44.8$

$148 \quad 0.17 \% \quad 43.1 \%$ AVSREDSVKPGAHLTVK 99.7\% 26.2

$148 \quad 0.17 \% \quad 43.1 \%$ EDSVKPGAHLTVK

$148 \quad 0.17 \% \quad 43.1 \%$ EDSVKPGAHLTVKK

$148 \quad 0.17 \% \quad 43.1 \%$ KIFVGGIK

$148 \quad 0.17 \% \quad 43.1 \%$ IFVGGIKEDTEEYNLR

$148 \quad 0.17 \% \quad 43.1 \%$ EDTEEYNLR

$148 \quad 0.17 \% \quad 43.1 \%$ EDTEEYNLRDYFEK

$148 \quad 0.17 \% \quad 43.1 \%$ YGKIETIEVMEDR

$148 \quad 0.17 \% \quad 43.1 \%$ IETIEVMEDR

$148 \quad 0.17 \% \quad 43.1 \%$ IETIEVMEDRQSGK

$99.7 \% \quad 58.0$

$99.7 \% \quad 41.5$

$98.6 \% \quad 35.5$

$99.7 \% \quad 57.7$

$99.7 \% \quad 46.9$

$99.7 \% \quad 41.9$

$99.7 \% \quad 53.9$

$99.7 \% \quad 59.5$

$99.7 \% \quad 37.3$

$99.7 \% \quad 47.2$

$39 \quad 148 \quad 0.17 \% \quad 43.1 \%$ GFAFVTFDDHDTVDK

$148 \quad 0.17 \% \quad 43.1 \%$ GFAFVTFDDHDTVDKIVVQK

$148 \quad 0.17 \% \quad 43.1 \% \quad$ YHTINGHNCEVK

$99.7 \% 33.3$

$99.5 \% \quad 26.3$

$39-148 \quad 0.17 \% \quad 43.1 \%$ YHTINGHNCEVKK

$\begin{array}{ll}99.5 \% & 26.3 \\ 99.7 \% & 79.3\end{array}$

$\begin{array}{llllll}148 & 0.17 \% & 43.1 \% & \text { SSGSPYGGGYGSGGGSGGYGSR } & 99.7 \% & 79.3 \\ 86 & 0.10 \% & 38.3 \% & \text { IDASKNEEDEGHSNSSPR } & 99.7 \% & 50.8\end{array}$

$\begin{array}{llllll}86 & 0.10 \% & 38.3 \% & \text { IDASKNEEDEGHSNSSPR } & 99.7 \% & 50.8 \\ 86 & 0.10 \% & 38.3 \% & \text { MFIGGLSWDTTK } & 99.7 \% & 60.9\end{array}$

$\begin{array}{ll}99.7 \% & 60.9 \\ 99.7 \% & 36.8\end{array}$

$99.0 \% \quad 28.4$

$99.3 \% \quad 55.7$

$0.10 \% \quad 38.3 \%$ DLKDYFSK

$\begin{array}{lll}0.10 \% & 38.3 \% & \text { FGEVVDCTLK }\end{array}$

$99.7 \% \quad 54.2$

$99.7 \% \quad 39.0$

$99.0 \% \quad 36.0$

$99.7 \% \quad 56.1$

$99.7 \% \quad 59.7$

$\begin{array}{rr}99.7 \% & 59.7 \\ 99.7 \% & 59.4\end{array}$

$0.10 \% \quad 38.3 \%$ ESESVDKVMDQK

$0.10 \% \quad 38.3 \%$ IFVGGLSPDTPEEK

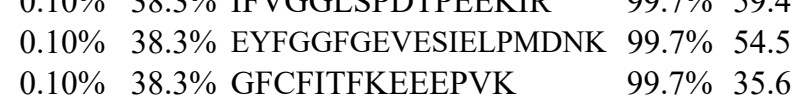



Heterogeneous nuclear ribonucleoprotein D0 GN=HNRNPD HNRPD_HUMAN $38.43 \quad 100.0 \%$ Heterogeneous nuclear ribonucleoprotein D-like GN=HNRNPDL HNRDL_HUMAN $46.44 \quad 100.0 \% \quad 15$ Heterogeneous nuclear ribonucleoprotein D-like GN=HNRNPDL HNRDL_HUMAN $46.44 \quad 100.0 \%$ Heterogeneous nuclear ribonucleoprotein D-like GN=HNRNPDL HNRDL_HUMAN $46.44 \quad 100.0 \% \quad 15$ Heterogeneous nuclear ribonucleoprotein D-like GN=HNRNPDL HNRDL_HUMAN $46.44 \quad 100.0 \% \quad 15$ Heterogeneous nuclear ribonucleoprotein D-like GN=HNRNPDL HNRDL_HUMAN $46.44 \quad 100.0 \% \quad 15$ Heterogeneous nuclear ribonucleoprotein D-like GN=HNRNPDL HNRDL_HUMAN $46.44 \quad 100.0 \% \quad 15$ Heterogeneous nuclear ribonucleoprotein D-like GN=HNRNPDL HNRDL HUMAN $46.44 \quad 100.0 \% \quad 15$ Heterogeneous nuclear ribonucleoprotein D-like GN=HNRNPDL HNRDL_HUMAN $46.44 \quad 100.0 \% \quad 15$ Heterogeneous nuclear ribonucleoprotein D-like GN=HNRNPDL HNRDL_HUMAN $46.44 \quad 100.0 \% \quad 1$; Heterogeneous nuclear ribonucleoprotein D-like GN=HNRNPDL HNRDL_HUMAN $46.44 \quad 100.0 \% \quad 15$ Heterogeneous nuclear ribonucleoprotein D-like GN=HNRNPDL HNRDL_HUMAN $46.44 \quad 100.0 \% \quad 15$ Heterogeneous nuclear ribonucleoprotein D-like GN=HNRNPDL HNRDL_HUMAN $46.44 \quad 100.0 \% 15$ Heterogeneous nuclear ribonucleoprotein D-like GN=HNRNPDL HNRDL_HUMAN $46.44 \quad 100.0 \% \quad 15$ Heterogeneous nuclear ribonucleoprotein D-like GN=HNRNPDL HNRDL_HUMAN $46.44 \quad 100.0 \% \quad 15$ Heterogeneous nuclear ribonucleoprotein D-like GN=HNRNPDL HNRDL HUMAN $46.44 \quad 100.0 \% \quad 15$ Heterogeneous nuclear ribonucleoprotein F GN=HNRNPF HNRPF_HUMAN $45.67 \quad 100.0 \%$ Heterogeneous nuclear ribonucleoprotein F GN=HNRNPF HNRPF_HUMAN $45.67 \quad 100.0 \%$ Heterogeneous nuclear ribonucleoprotein $\mathrm{F}$ GN=HNRNPF HNRPF_HUMAN $45.67 \quad 100.0 \%$ Heterogeneous nuclear ribonucleoprotein F GN=HNRNPF HNRPF_HUMAN $45.67 \quad 100.0 \%$ Heterogeneous nuclear ribonucleoprotein F GN=HNRNPF HNRPF HUMAN $45.67 \quad 100.0 \%$ Heterogeneous nuclear ribonucleoprotein F GN=HNRNPF HNRPF_HUMAN $45.67 \quad 100.0 \%$ Heterogeneous nuclear ribonucleoprotein F GN=HNRNPF HNRPF_HUMAN $45.67 \quad 100.0 \%$ Heterogeneous nuclear ribonucleoprotein $\mathrm{F}$ GN=HNRNPF HNRPF HUMAN $45.60^{\circ}$ Heterogeneous nuclear ribonucleoprotein $\mathrm{F}$ GN=HNRNPF HNRPF_HUMAN 45.67 Heterogeneous nuclear ribonucleoprotein F GN=HNRNPF HNRPF_HUMAN 45.67 Heterogeneous nuclear ribonucleoprotein $\mathrm{F}$ GN=HNRNPF HNRPF HUMAN $45.6^{\circ}$ Heterogeneous nuclear ribonucleoprotein $\mathrm{H}$ GN=HNRNPH1 HNRH1_HUMAN 49.2 ? Heterogeneous nuclear ribonucleoprotein $\mathrm{H}$ GN=HNRNPH1 HNRH1_HUMAN 49.23 Heterogeneous nuclear ribonucleoprotein H GN=HNRNPH1 HNRH1_HUMAN 49.23 Heterogeneous nuclear ribonucleoprotein $\mathrm{H}$ GN=HNRNPH1 HNRH1_HUMAN 49.23 Heterogeneous nuclear ribonucleoprotein $\mathrm{H}$ GN=HNRNPH1 HNRH1_HUMAN 49.23 Heterogeneous nuclear ribonucleoprotein $\mathrm{H}$ GN=HNRNPH1 HNRH1_HUMAN 49.23 Heterogeneous nuclear ribonucleoprotein H GN=HNRNPH1 HNRH1_HUMAN 49.23 Heterogeneus dear 49.23 Heterogeneous nuclear ribonucleoprotein H GN=HNRNPH1 HNRH1_HUMAN $49.23 \quad 100.0 \%$ Heterogeneous nuclear ribonucleoprotein $\mathrm{H}$ GN=HNRNPH1 HNRH1 HUMAN $49.23100 .0 \%$ Heterogeneous nuclear ribonucleoprotein $\mathrm{H}$ GN=HNRNPH1 HNRH1_HUMAN $49.23 \quad 100.0 \%$ Heterogeneous nuclear ribonucleoprotein H GN=HNRNPH1 HNRH1_HUMAN 49.23 Heterogeneous nuclear ribonucleoprotein $\mathrm{H}$ GN=HNRNPH1 HNRH1_HUMAN 49.23 Heterogeneous nuclear ribonucleoprotein H GN=HNRNPH1 HNRH1_HUMAN 49.23 Heterogeneous nuclear ribonucleoprotein $\mathrm{H}$ GN=HNRNPH1 HNRH1_HUMAN 49.23 Heterogeneous ncloar Heterogeneous nuclear ribonucleoprotein $\mathrm{H}$ GN=HNRNPH1 $\quad$ HNRH1_HUMAN $49.23 \quad 100.0 \%$ Heterogeneous nuclear ribonucleoprotein $\mathrm{H}$ GN=HNRNPH1 HNRH1_HUMAN $49.23 \quad 100.0 \% \quad 2$ Heterogeneous nuclear ribonucleoprotein $\mathrm{H}$ GN=HNRNPH1 HNRH1_HUMAN $49.23 \quad 100.0 \%$

$100.0 \%$

$100.0 \%$

$100.0 \%$

$100.0 \%$

$100.0 \%-20$

$100.0 \% \quad 20$

$100.0 \% \quad 20$

$00.0 \% \quad 20$ $100.0 \% \quad 20$

$0 \% \quad 20$ $.0 \% \quad 20$ $100.0 \% \quad 20$ $100.0 \% \quad 20$ $100.0 \% \quad 20$ $0 \% \quad 20$
$0.09 \% \quad 31.4 \%$ DLTEYLSR

$0.09 \% \quad 31.4 \%$ FGEVVDCTIK

$99.7 \% \quad 47.8$

$99.7 \% \quad 39.0$

$99.0 \% \quad 36.0$

$99.7 \% \quad 66.8$

$99.0 \% \quad 29.2$

$99.7 \% \quad 49.9$

$99.7 \% \quad 38.7$

$99.7 \% \quad 62.1$

$99.7 \% \quad 41.5$

$0.09 \% \quad 31.4 \%$ GFCFITYTDEEPVK

$0.09 \% \quad 31.4 \%$ GFCFITYTDEEPVK

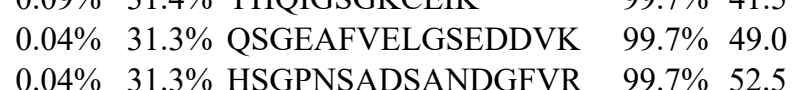

$\begin{array}{lllll}0.04 \% & 31.3 \% & \text { HSGPNSADSANDGFVR } & 99.7 \% & 52.5 \\ 0.04 \% & 31.3 \% & \text { HSGPNSADSANDGFVRLR } & 99.5 \% & 24.8\end{array}$

$\begin{array}{lllll}0.04 \% & 31.3 \% & \text { ITGEAFVQFASQELAEK } & 99.7 \% & 72.8\end{array}$

$0.04 \% \quad 31.3 \%$ IGHRYIEVFK

$\begin{array}{lll}94.7 \% & 20.1\end{array}$

$0.04 \% \quad 31.3 \%$ YIEVFKSSQEEVR

$99.7 \% \quad 55.2$ $00.0 \% \quad 20$ 20
20

20

$20-27$

$34 \quad 0.0$


Heterogeneous nuclear ribonucleoprotein H GN=HNRNPH1 $\quad$ HNRH1_HUMAN $49.23 \quad 100.0 \% \quad 20$ Heterogeneous nuclear ribonucleoprotein $\mathrm{H} 2 \mathrm{GN}=\mathrm{HNRNPH} 2 \mathrm{HNRH} 2$ HUMAN $49.26 \quad 100.0 \%$ Heterogeneous nuclear ribonucleoprotein $\mathrm{H} 2 \mathrm{GN}=\mathrm{HNRNPH} 2 \mathrm{HNRH} 2$ HUMAN $49.26 \quad 100.0 \%$ Heterogeneous nuclear ribonucleoprotein $\mathrm{H} 2 \mathrm{GN}=\mathrm{HNRNPH} 2 \mathrm{HNRH} 2$ HUMAN $49.26 \quad 100.0 \%$ Heterogeneous nuclear ribonucleoprotein $\mathrm{H} 2 \mathrm{GN}=\mathrm{HNRNPH} 2 \mathrm{HNRH2}$ HUMAN $49.26 \quad 100.0 \%$ Heterogeneous nuclear ribonucleoprotein $\mathrm{H} 2 \mathrm{GN}=\mathrm{HNRNPH} 2 \mathrm{HNRH2}$ HUMAN $49.26 \quad 100.0 \%$ Heterogeneous nuclear ribonucleoprotein $\mathrm{H} 2 \mathrm{GN}=\mathrm{HNRNPH} 2 \mathrm{HNRH} 2$ HUMAN $49.26 \quad 100.0 \%$ Heterogeneous nuclear ribonucleoprotein $\mathrm{H} 2 \mathrm{GN}=\mathrm{HNRNPH} 2 \mathrm{HNRH} 2$ HUMAN $49.26 \quad 100.0 \%$ Heterogeneous nuclear ribonucleoprotein $\mathrm{H} 2 \mathrm{GN}=\mathrm{HNRNPH} 2$ HNRH2 HUMAN $49.26 \quad 100.0 \%$ Heterogeneous nuclear ribonucleoprotein $\mathrm{H} 2 \mathrm{GN}=\mathrm{HNRNPH} 2 \mathrm{HNRH2}$ HUMAN $49.26 \quad 100.0 \%$ Heterogeneous nuclear ribonucleoprotein $\mathrm{H} 2 \mathrm{GN}=\mathrm{HNRNPH} 2 \mathrm{HNRH} 2$ HUMAN $49.26 \quad 100.0 \%$ Heterogeneous nuclear ribonucleoprotein $\mathrm{H} 3 \mathrm{GN}=\mathrm{HNRNPH} 3$ HNRH3 HUMAN 36.93 Heterogeneous nuclear ribonucleoprotein $\mathrm{H} 3 \mathrm{GN}=\mathrm{HNRNPH} 3$ HNRH3_HUMAN 36.93 Heterogeneous nuclear ribonucleoprotein $\mathrm{H} 3 \mathrm{GN}=\mathrm{HNRNPH} 3$ HNRH3_HUMAN 36.93 Heterogeneous nuclear ribonucleoprotein $\mathrm{H} 3 \mathrm{GN}=\mathrm{HNRNPH3}$ HNRH3_HUMAN 36.93 Heterogeneous nuclear ribonucleoprotein $\mathrm{H} 3 \mathrm{GN}=\mathrm{HNRNPH3}$ HNRH3_HUMAN 36.93 Heterogeneous nuclear ribonucleoprotein $\mathrm{H} 3 \mathrm{GN}=\mathrm{HNRNPH} 3 \mathrm{HNRH} 3$ HUMAN 36.93 Heterogeneous nuclear ribonucleoprotein $\mathrm{H3}$ GN=HNRNPH3 HNRH3_HUMAN 36.93 Heterogeneous nuclear ribonucleoprotein $\mathrm{H} 3 \mathrm{GN}=\mathrm{HNRNPH} 3$ HNRH3_HUMAN 36.93 Heterogeneous nuclear ribonucleoprotein $\mathrm{H} 3 \mathrm{GN}=\mathrm{HNRNPH} 3$ HNRH3_HUMAN 36.93 Heterogeneous nuclear ribonucleoprotein $\mathrm{H} 3$ GN=HNRNPH3 HNRH3_HUMAN 36.93 Heterogeneous nuclear ribonucleoprotein $\mathrm{K}$ GN=HNRNPK HNRPK_HUMAN 50.98 Heterogeneous nuclear ribonucleoprotein K GN=HNRNPK HNRPK_HUMAN 50.98 Heterogeneous nuclear ribonucleoprotein K GN=HNRNPK HNRPK_HUMAN 50.98 Heterogeneous nuclear ribonucleoprotein K GN=HNRNPK HNRPK_HUMAN 50.98 Heterogeneous nuclear ribonucleoprotein $\mathrm{K}$ GN=HNRNPK HNRPK_HUMAN 50.98 Heterogeneous nuclear ribonucleoprotein K GN=HNRNPK HNRPK_HUMAN 50.98 Heterogeneous nuclear ribonucleoprotein $\mathrm{K}$ GN=HNRNPK HNRPK_HUMAN 50.98 Heterogeneous nuclear ribonucleoprotein K GN=HNRNPK HNRPK_HUMAN 50.98 Heterogeneous nuclear ribonucleoprotein K GN=HNRNPK HNRPK_HUMAN 50.98 Heterogeneous nuclear ribonucleoprotein K GN=HNRNPK HNRPK_HUMAN 50.98 Heterogeneous nuclear ribonucleoprotein K GN=HNRNPK HNRPK_HUMAN 50.98 Heterogeneous nuclear ribonucleoprotein K GN=HNRNPK HNRPK_HUMAN 50.98 Heterogeneous nuclear ribonucleoprotein $\mathrm{K}$ GN=HNRNPK HNRPK_HUMAN 50.98 Heterogeneous nuclear ribonucleoprotein K GN=HNRNPK HNRPK_HUMAN 50.98 Heterogeneous nuclear ribonucleoprotein $\mathrm{K}$ GN=HNRNPK HNRPK HUMAN 50.98 Heterogeneous nuclear ribonucleoprotein K GN=HNRNPK HNRPK_HUMAN 50.9 Heterogeneous nuclear ribonucleoprotein $\mathrm{K}$ GN=HNRNPK HNRPK_HUMAN 50.9 Heterogeneous nuclear ribonucleoprotein $\mathrm{K}$ GN=HNRNPK HNRPK_HUMAN 50.98 Heterogeneous nuclear ribonucleoprotein L GN=HNRNPL HNRPL_HUMAN 64.13 Heterogeneous nuclear ribonucleoprotein L GN=HNRNPL HNRPL_HUMAN 64.13 Heterogeneous nuclear ribonucleoprotein L GN=HNRNPL HNRPL_HUMAN 64.1. Heterogeneous nuclear ribonucleoprotein L GN=HNRNPL HNRPL HUMAN 64.13 Heterogeneos ducler iboclo Heterogeneous nuclear ribonucleoprotein $\mathrm{L}$ GN=HNRNPL HNRPL HUMAN $64.13 \quad 100.0 \%$ Heterogeneous nuclear ribonucleoprotein L GN=HNRNPL HNRPL_HUMAN $64.13 \quad 100.0 \%$ Heterogeneous nuclear ribonucleoprotein L GN=HNRNPL HNRPL_HUMAN $64.13 \quad 100.0 \%$
$100.0 \%$ $100.0 \%$ $100.0 \%$ $100.0 \%$ $100.0 \%$ $100.0 \% \quad 10$ $100.0 \%$ $100.0 \%$ $100.0 \% \quad 10$ $100.0 \% \quad 10$ $00.0 \% \quad 18$ $100.0 \% \quad 18$ $100.0 \% \quad 18$ $100.0 \% \quad 18$ $100.0 \% \quad 18$ $100.0 \% \quad 18$ $100.0 \% \quad 18$ $100.0 \% \quad 18$ $100.0 \% \quad 18$ $100.0 \% \quad 18$ $100.0 \% \quad 18$ $100.0 \% \quad 18$ $100.0 \% \quad 18$ $00.0 \% \quad 18$ $100.0 \% \quad 18$ $100.0 \% \quad 18$ $100.0 \% \quad 18$ $100.0 \% \quad 18$ $100.0 \% \quad 19$ $100.0 \% \quad 19$ $100.0 \% \quad 19$ $0 \% \quad 19$ 19 19 $19 \quad 35$

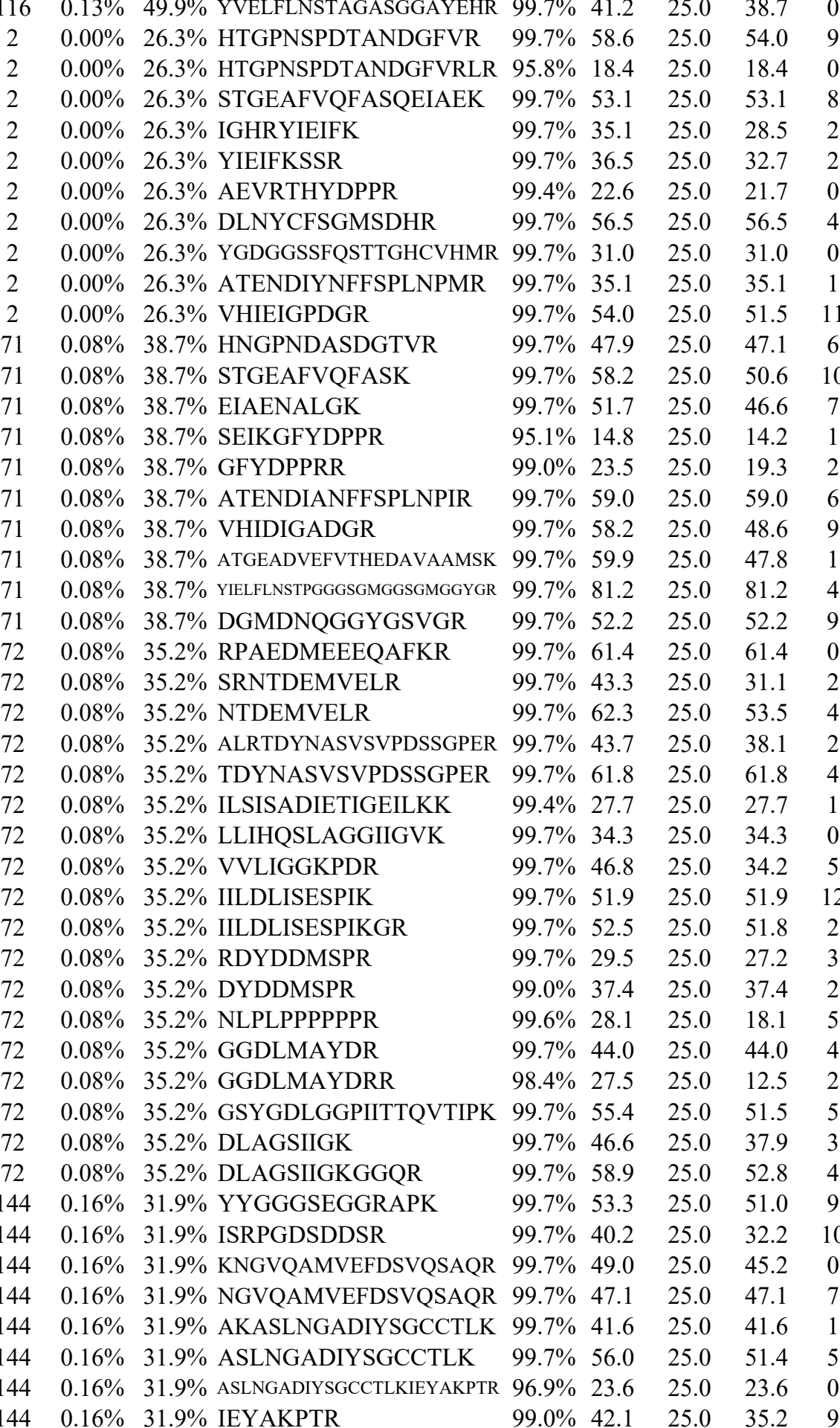

2142.03 684.77 1953.95 1841.89 1275.72

2044.94

1092.58

1339.60

1271.63

944.50

1308.66

1007.51

1918.97

1052.55

2194.00

2554.13

1412.59

1735.81

1349.65

1106.51

2121.02

1780.80

1843.08

1518.94

1053.64

1340.80

1553.93

1154.49

998.39

1194.70

1013.44

1153.54

1917.03

873.50

1271.71

1298.61

1204.56

1993.98

1865.88

1928.92

1729.79

2688.31

977.54

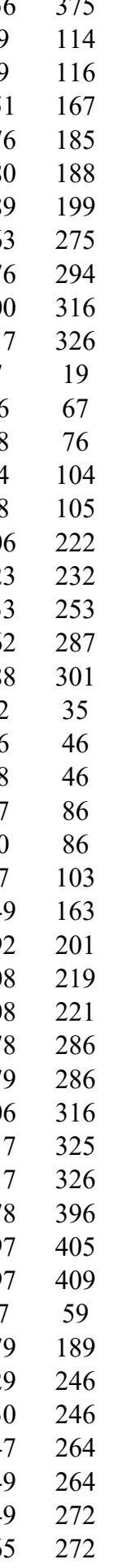

Page 76 of Table S-1-6 

Heterogeneous nuclear ribonucleoprotein L GN=HNRNPL HNRPL_HUMAN $64.13 \quad 100.0 \% \quad 19$ teterogeneous nuclear ribonucleoprotein M GN=HNRNPM HNRPM HUMAN $77.52 \quad 100.0 \%$ Heterogeneous nuclear ribonucleoprotein M GN=HNRNPM HNRPM_HUMAN $77.52 \quad 100.0 \% \quad 48$ Heterogeneous nuclear ribonucleoprotein M GN=HNRNPM HNRPM_HUMAN $77.52 \quad 100.0 \% \quad 48$ Heterogeneous nuclear ribonucleoprotein M GN=HNRNPM HNRPM_HUMAN $77.52 \quad 100.0 \% 48$ Heterogeneous nuclear ribonucleoprotein M GN=HNRNPM HNRPM_HUMAN $77.52 \quad 100.0 \% \quad 48$ Heterogeneous nuclear ribonucleoprotein M GN=HNRNPM HNRPM_HUMAN $77.52 \quad 100.0 \% \quad 48$ Heterogeneous nuclear ribonucleoprotein M GN=HNRNPM HNRPM_HUMAN $77.52 \quad 100.0 \% \quad 48$ Heterogeneous nuclear ribonucleoprotein M GN=HNRNPM HNRPM_HUMAN $77.52 \quad 100.0 \% 48$ 年 Heterogeneous nuclear ribonucleoprotein M GN=HNRNPM HNRPM_HUMAN $77.52 \quad 100.0 \% \quad 48$ Heterogeneous nuclear ribonucleoprotein M GN=HNRNPM HNRPM_HUMAN $77.52 \quad 100.0 \% 48$ Heterogeneous nuclear ribonucleoprotein M GN=HNRNPM HNRPM_HUMAN $77.52 \quad 100.0 \% 48$ Heterogeneous nuclear ribonucleoprotein M GN=HNRNPM HNRPM_HUMAN $77.52 \quad 100.0 \% 48$ Heterogeneous nuclear ribonucleoprotein M GN=HNRNPM HNRPM HUMAN $77.52 \quad 100.0 \%$ Heterogeneous nuclear ribonucleoprotein M GN=HNRNPM HNRPM_HUMAN $77.52 \quad 100.0 \% \quad 48$ Heterogeneous nuclear ribonucleoprotein M GN=HNRNPM HNRPM_HUMAN $77.52 \quad 100.0 \% \quad 48$ Heterogeneous nuclear ribonucleoprotein M GN=HNRNPM HNRPM_HUMAN $77.52 \quad 100.0 \% 48$ Heterogeneous nuclear ribonucleoprotein M GN=HNRNPM HNRPM_HUMAN $77.52 \quad 100.0 \% \quad 48$ Heterogeneous nuclear ribonucleoprotein M GN=HNRNPM HNRPM_HUMAN $77.52 \quad 100.0 \% 48$ Heterogeneous nuclear ribonucleoprotein M GN=HNRNPM HNRPM_HUMAN $77.52 \quad 100.0 \% \quad 48$ Heterogeneous nuclear ribonucleoprotein M GN=HNRNPM HNRPM_HUMAN $77.52 \quad 100.0 \% 48$ 年 $\begin{array}{llll}\text { Heterogeneous nuclear ribonucleoprotein M GN=HNRNPM HNRPM_HUMAN } & 77.52 & 100.0 \% & 48\end{array}$ Heterogeneous nuclear ribonucleoprotein M GN=HNRNPM HNRPM_HUMAN $77.52 \quad 100.0 \% \quad 48$ Heterogeneous nuclear ribonucleoprotein M GN=HNRNPM HNRPM HUMAN $77.52 \quad 100.0 \% 48$ Heterogeneous nuclear ribonucleoprotein M GN=HNRNPM HNRPM_HUMAN $77.52 \quad 100.0 \% \quad 48$ Heterogeneous nuclear ribonucleoprotein M GN=HNRNPM HNRPM HUMAN $77.52 \quad 100.0 \% \quad 48$ Heterogeneous nuclear ribonucleoprotein M GN=HNRNPM HNRPM_HUMAN $77.52 \quad 100.0 \% \quad 48$ Heterogeneous nuclear ribonucleoprotein M GN=HNRNPM HNRPM_HUMAN $77.52 \quad 100.0 \% \quad 48$ Heterogeneous nuclear ribonucleoprotein M GN=HNRNPM HNRPM HUMAN $77.52 \quad 100.0 \% 48$ Heterogeneous nuclear ribonucleoprotein M GN=HNRNPM HNRPM_HUMAN $77.52 \quad 100.0 \% \quad 48$ Heterogeneous nuclear ribonucleoprotein M GN=HNRNPM HNRPM_HUMAN $77.52 \quad 100.0 \% 48$ Heterogeneous nuclear ribonucleoprotein M GN=HNRNPM HNRPM_HUMAN $77.52 \quad 100.0 \% 48$ Heterogeneous nuclear ribonucleoprotein M GN=HNRNPM HNRPM_HUMAN $77.52 \quad 100.0 \% 48$ Heterogeneous nuclear ribonucleoprotein M GN=HNRNPM HNRPM HUMAN $77.52 \quad 100.0 \%$ Heterogeneous nuclear ribonucleoprotein M GN=HNRNPM HNRPM_HUMAN $77.52 \quad 100.0 \% \quad 48$

$35 \quad 144 \quad 0.16 \% \quad 31.9 \%$ MGPPVGGHR

$144 \quad 0.16 \% \quad 31.9 \%$ MNCDRVFNVFCLYGNVEK

$144 \quad 0.16 \% \quad 31.9 \%$ VFNVFCLYGNVEK

$99.7 \% \quad 40.5$

$99.2 \% 26.4$

5.0

$\begin{array}{lllll}35 & 144 & 0.16 \% & 31.9 \% & \text { VFNVFCLYGNVEKVK } \\ 35 & 144 & 0.16 \% & 31.9 \% \text { SKPGAAMVEMADGYAVD }\end{array}$

$144 \quad 0.16 \% \quad 31.9 \%$ AITHLNNNFMFGQK

$99.7 \% \quad 57.3$

$99.7 \% \quad 61.4$

$144 \quad 0.16 \% \quad 31.9 \%$ QPAIMPGQSYGLEDGSCSYKDFSESR $\quad 99.6 \% \quad 25.4$

$144 \quad 0.16 \% \quad 31.9 \%$ NNRFSTPEQAAK

$144 \quad 0.16 \% \quad 31.9 \%$ FSTPEQAAK

$144 \quad 0.16 \% \quad 31.9 \%$ NPNGPYPYTLK

$144 \quad 0.16 \% \quad 31.9 \%$ LCFSTAQHAS

$424 \quad 0.48 \% \quad 63.2 \%$ GGNRFEPYANPTK

$424 \quad 0.48 \% \quad 63.2 \%$ FEPYANPTKR

$424 \quad 0.48 \% \quad 63.2 \%$ AFITNIPFDVK

$99.7 \% 53.1$

$99.7 \% \quad 31.6$

$99.7 \% \quad 36.2$

$99.7 \% \quad 55.3$

$99.7 \% \quad 40.9$

$97.4 \% \quad 20.0$

$99.7 \% \quad 55.3$

$424 \quad 0.48 \% \quad 63.2 \%$ VGEVTYVELLMDAEGK

$424 \quad 0.48 \% \quad 63.2 \%$ GCAVVEFK

$424 \quad 0.48 \% \quad 63.2 \%$ AAEVLNKHSLSGRPLK

$424 \quad 0.48 \% \quad 63.2 \%$ HSLSGRPLK

$424 \quad 0.48 \% \quad 63.2 \%$ LGSTVFVANLDYK

$424 \quad 0.48 \% \quad 63.2 \%$ LKEVFSMAGVVVR

$424 \quad 0.48 \% \quad 63.2 \%$ EVFSMAGVVVR

$424 \quad 0.48 \% \quad 63.2 \%$ ADILEDKDGK

$424 \quad 0.48 \% \quad 63.2 \%$ MDERALPK

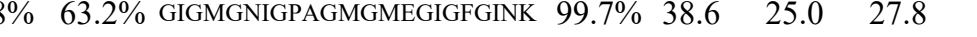

. $03.2 \%$ MGGMEGPFGGGMENMGR

$424 \quad 0.48 \% \quad 63.2 \%$ FGSGMNMGR

$424 \quad 0.48 \% \quad 63.2 \%$ INEILSNALK

$424 \quad 0.48 \% \quad 63.2 \%$ INEILSNALKR

$99.7 \% \quad 59.8$

$99.7 \% 54.2$

$424 \quad 0.48 \% \quad 63.2 \%$ QGGGGGGGSVPGIER

$99.7 \% \quad 56.7$

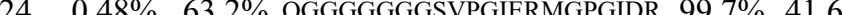

$424 \quad 0.48 \% \quad 63.2 \%$ MGPGIDRLGGAGMER

$424 \quad 0.48 \% \quad 63.2 \%$ MGAGLGHGMDR

$99.7 \% \quad 56.9$

$99.7 \% \quad 51.6$

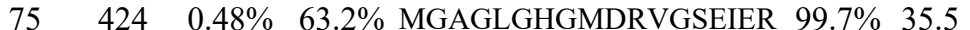

$424 \quad 0.48 \% \quad 63.2 \%$ VGSEIERMGLVMDR

$424 \quad 0.48 \% \quad 63.2 \%$ MGLVMDRMGSVER

$424 \quad 0.48 \% \quad 63.2 \%$ MGSVERMGSGIER

$424 \quad 0.48 \% \quad 63.2 \%$ MGPLGLDHMASSIER

$99.7 \% \quad 51.5$

$99.7 \% \quad 36.2$

$99.7 \% \quad 29.0$

$99.7 \% \quad 55.8$

$98.7 \% 18$.

4. $0.48 \% \quad 63.2 \%$ MGQTMERIGSGVER

$\begin{array}{llll}424 & 0.48 \% & 63.2 \% & \text { IGSGVERMGAGMGF } \\ 424 & 0.48 \% & 63.2 \% & \text { MGAGMGFGLER }\end{array}$

$424 \quad 0.48 \% \quad 63.2 \%$ MAAPIDRVGQTIER

$424 \quad 0.48 \% \quad 63.2 \%$ VGQTIERMGSGVER

$424 \quad 0.48 \% \quad 63.2 \%$ MGPAIERMGLSMER

$424 \quad 0.48 \% \quad 63.2 \%$ MVPAGMGAGLER

$424 \quad 0.48 \% \quad 63.2 \%$ MGPVMDRMATGLER

$424 \quad 0.48 \% \quad 63.2 \%$ MGANNLER

$424 \quad 0.48 \% \quad 63.2 \%$ MGANNLERMGLER \begin{tabular}{llll}
$99.7 \%$ & 42.5 & 25.0 & 42.0 \\
\hline
\end{tabular}

$99.7 \% \quad 57.6 \quad 25.0 \quad 43.6 \quad 21$

$99.7 \% \quad 34.7 \quad 25.0 \quad 34.7$

$99.7 \% \quad 38.0 \quad 25.0 \quad 35.7$

$\begin{array}{llll}99.7 \% & 29.2 & 25.0 & 28.9\end{array}$

$\begin{array}{llll}99.7 \% & 55.4 & 25.0 & 45.0\end{array}$

$99.7 \%$ 45.0 $25.0 \quad 40.1$

$\begin{array}{llll}99.0 \% & 71.1 & 25.0 & 60.3\end{array}$

$99.7 \% \quad 34.7 \quad 25.0 \quad 32.4$
907.46

2265.03

1588.78

1815.95

1899.86

1650.81

2925.27

1362.68

978.49

1263.64

1121.50

1450.7

1222.62

1264.69

1752.87

909.45

1719.99

994.58

1426.76

1450.8

1193.63

1103.56

959.50

2210.04

1746.67

956.41

1114.65

1270.75

1284.63

2026.97

1548.73

1117.49

1887.88

1623.78

1512.70

1440.66

1629.77

1582.73

1855.88

1141.51

1556.82

1534.76

1625.74

1188.59

1563.74

904.43

1522.71

\begin{tabular}{ll}
345 & 353 \\
394 & 411 \\
399 & 4 \\
399 & 4 \\
17 & 434 \\
435 & 448 \\
56 & 481 \\
482 & 493 \\
485 & 493 \\
59 & 579 \\
80 & 589 \\
57 & 69 \\
61 & 70 \\
73 & 83 \\
5 & 110 \\
13 & 120 \\
128 & 143 \\
135 & 143 \\
202 & 214 \\
220 & 232 \\
222 & 232 \\
233 & 242 \\
278 & 285 \\
323 & 345 \\
346 & 362 \\
363 & 371 \\
372 & 381 \\
372 & 382 \\
389 & 403 \\
389 & 410 \\
404 & 418 \\
419 & 429 \\
419 & 436 \\
430 & 443 \\
437 & 449 \\
444 & 456 \\
457 & 471 \\
472 & 485 \\
479 & 496 \\
486 & 496 \\
497 & 5 \\
504 & 517 \\
518 & 531 \\
532 & 543 \\
544 & 557 \\
558 & 565 \\
558 & 570 \\
& \\
\hline
\end{tabular}


Heterogeneous nuclear ribonucleoprotein M GN=HNRNPM HNRPM_HUMAN $77.52 \quad 100.0 \% \quad 48$ Heterogeneous nuclear ribonucleoprotein M GN=HNRNPM HNRPM_HUMAN $77.52 \quad 100.0 \% \quad 48$ Heterogeneous nuclear ribonucleoprotein M GN=HNRNPM HNRPM_HUMAN $77.52 \quad 100.0 \% \quad 48$ Heterogeneous nuclear ribonucleoprotein M GN=HNRNPM HNRPM_HUMAN $77.52 \quad 100.0 \%$ Heterogeneous nuclear ribonucleoprotein M GN=HNRNPM HNRPM_HUMAN $77.52 \quad 100.0 \% \quad 48$ Heterogeneous nuclear ribonucleoprotein M GN=HNRNPM HNRPM_HUMAN $77.52 \quad 100.0 \% \quad 48$ Heroren $77.52 \quad 100.0 \%$ Heterogeneous nuclear ribonucleoprotein M GN=HNRNPM HNRPM_HUMAN $77.52 \quad 100.0 \% \quad 48$ Heterogeneous nuclear ribonucleoprotein M GN=HNRNPM HNRPM_HUMAN $77.52 \quad 100.0 \% \quad 48$ Heterogeneous nuclear ribonucleoprotein M GN=HNRNPM HNRPM_HUMAN $77.52 \quad 100.0 \% \quad 48$ Heterogeneous nuclear ribonucleoprotein M GN=HNRNPM HNRPM_HUMAN $77.52 \quad 100.0 \% \quad 48$ Heterogeneous nuclear ribonucleoprotein M GN=HNRNPM HNRPM_HUMAN $77.52 \quad 100.0 \% \quad 48$ $\begin{array}{lllll}\text { Heterogeneous nuclear ribonucleoprotein Q GN=SYNCRIP } & \text { HNRPQ_HUMAN } & 69.60 & 100.0 \% & 15\end{array}$ Heterogeneous nuclear ribonucleoprotein Q GN=SYNCRIP $\quad$ HNRPQ_HUMAN $69.60 \quad 100.0 \% \quad 15$

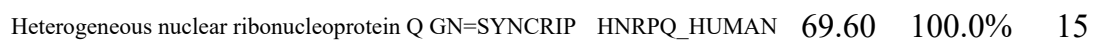
$\begin{array}{lllll}\text { Heterogeneous nuclear ribonucleoprotein Q GN=SYNCRIP } & \text { HNRPQ_HUMAN } & 69.60 & 100.0 \% & 15\end{array}$ Heterogeneous nuclear ribonucleoprotein Q GN=SYNCRIP HNRPQ HUMAN $69.60 \quad 100.0 \%$ Heterogeneous nuclear ribonucleoprotein Q GN=SYNCRIP $\quad$ HNRPQ_HUMAN $69.60 \quad 100.0 \% \quad 15$ $\begin{array}{lllll}\text { Heterogeneous nuclear ribonucleoprotein Q GN=SYNCRIP } & \text { HNRPQ_HUMAN } & 69.60 & 100.0 \% & 15\end{array}$ Heterogeneous nuclear ribonucleoprotein Q GN=SYNCRIP $\quad$ HNRPQ_HUMAN $69.60 \quad 100.0 \% \quad 15$ $\begin{array}{lllll}\text { Heterogeneous nuclear ribonucleoprotein Q GN=SYNCRIP } & \text { HNRPQ_HUMAN } & 69.60 & 100.0 \% & 15\end{array}$ Heterogeneous nuclear ribonucleoprotein Q GN=SYNCRIP HNRPQ HUMAN $69.60 \quad 100.0 \% \quad 15$ $\begin{array}{lllll}\text { Heterogeneous nuclear ribonucleoprotein Q GN=SYNCRIP } & \text { HNRPQ_HUMAN } & 69.60 & 100.0 \% & 15\end{array}$ Heterogeneous nuclear ribonucleoprotein Q GN=SYNCRIP $\quad$ HNRPQ_HUMAN $69.60 \quad 100.0 \% \quad 15$ Heterogeneous nuclear ribonucleoprotein Q GN=SYNCRIP HNRPQ HUMAN $69.60 \quad 100.0 \%$ $\begin{array}{lllll}\text { Heterogeneous nuclear ribonucleoprotein Q GN=SYNCRIP } & \text { HNRPQ_HUMAN } & 69.60 & 100.0 \% & 15\end{array}$ Heterogeneous nuclear ribonucleoprotein Q GN=SYNCRIP $\quad$ HNRPQ_HUMAN $69.60 \quad 100.0 \% \quad 15$ Heterogeneous nuclear ribonucleoprotein Q GN=SYNCRIP HNRPQ_HUMAN $69.60 \quad 100.0 \% \quad 15$ $\begin{array}{lllll}\text { Heterogeneous nuclear ribonucleoprotein Q GN=SYNCRIP } & \text { HNRPQ_HUMAN } & 69.60 & 100.0 \% & 15\end{array}$ Heterogeneous nuclear ribonucleoprotein Q GN=SYNCRIP HNRPQ HUMAN $69.60 \quad 100.0 \%$ $\begin{array}{lllll}\text { Heterogeneous nuclear ribonucleoprotein Q GN=SYNCRIP } & \text { HNRPQ_HUMAN } & 69.60 & 100.0 \% & 15\end{array}$ Heterogeneous nuclear ribonucleoprotein Q GN=SYNCRIP $\quad$ HNRPQ_HUMAN $69.60 \quad 100.0 \% \quad 15$ Heterogeneous nuclear ribonucleoprotein Q GN=SYNCRIP HNRPQ HUMAN $69.60 \quad 100.0 \% \quad 15$ $\begin{array}{lllll}\text { Heterogeneous nuclear ribonucleoprotein Q GN=SYNCRIP } & \text { HNRPQ_HUMAN } & 69.60 & 100.0 \% & 15\end{array}$ Heterogeneous nuclear ribonucleoprotein Q GN=SYNCRIP $\quad$ HNRPQ_HUMAN $69.60 \quad 100.0 \% \quad 15$ Heterogeneous nuclear ribonucleoprotein R GN=HNRNPR HNRPR_HUMAN $70.94 \quad 100.0 \% 20$ Heterogeneous nuclear ribonucleoprotein R GN=HNRNPR HNRPR_HUMAN $70.94 \quad 100.0 \% \quad 20$ Heterogeneous nuclear ribonucleoprotein R GN=HNRNPR HNRPR_HUMAN $70.94 \quad 100.0 \%$ Heterogeneous nuclear ribonucleoprotein R GN=HNRNPR HNRPR_HUMAN $70.94 \quad 100.0 \% \quad 20$ Heterogeneous nuclear ribonucleoprotein R GN=HNRNPR HNRPR_HUMAN $70.94 \quad 100.0 \% \quad 20$ Heterogeneous nuclear ribonucleoprotein R GN=HNRNPR HNRPR_HUMAN $70.94 \quad 100.0 \% 20$ Heterogeneous nuclear ribonucleoprotein R GN=HNRNPR HNRPR_HUMAN $70.94 \quad 100.0 \% \quad 20$ Heterogeneous nuclear ribonucleoprotein R GN=HNRNPR HNRPR_HUMAN $70.94 \quad 100.0 \%$ Heterogeneous nuclear ribonucleoprotein R GN=HNRNPR HNRPR_HUMAN $70.94 \quad 100.0 \% 20$ Heterogeneous nuclear ribonucleoprotein R GN=HNRNPR HNRPR_HUMAN $70.94 \quad 100.0 \% \quad 20$ Heterogeneous nuclear ribonucleoprotein R GN=HNRNPR HNRPR HUMAN $70.94 \quad 100.0 \% 20$ Heterogeneous nuclear ribonucleoprotein R GN=HNRNPR HNRPR_HUMAN $70.94 \quad 100.0 \% \quad 20$
$75 \quad 424 \quad 0.48 \% \quad 63.2 \%$ MGLERMGANSLER $424 \quad 0.48 \% \quad 63.2 \%$ MGANSLER

$424 \quad 0.48 \% \quad 63.2 \%$ MGANSLERMGLER $424 \quad 0.48 \% \quad 63.2 \%$ MGPAMGPALGAGIER

$424 \quad 0.48 \% \quad 63.2 \%$ MGLAMGGGGGASFDR

$424 \quad 0.48 \% \quad 63.2 \%$ GNFGGSFAGSFGGAGGHAPGVAR

$424 \quad 0.48 \% \quad 63.2 \%$ GNFGGSFAGSFGGAGGHAPGVARK

$424 \quad 0.48 \% \quad 63.2 \%$ KACQIFVR

$424 \quad 0.48 \% \quad 63.2 \%$ DKFNECGHVLYADIK

$424 \quad 0.48 \% \quad 63.2 \%$ GCGVVKFESPEVAER

$424 \quad 0.48 \% \quad 63.2 \%$ FESPEVAER

$66 \quad 0.07 \% \quad 34.7 \%$ EFNEDGALAVLQQFK

$66 \quad 0.07 \% \quad 34.7 \%$ SAFLCGVMK

$0.07 \% \quad 34.7 \%$ ALLERTGYTLDVTTGQR

$0.07 \% \quad 34.7 \%$ TGYTLDVTTGQR

$0.07 \% \quad 34.7 \%$ TGYTLDVTTGQRK

$\begin{array}{ll}0.07 \% & 34.7 \% \text { KYGGPPDSVYSGQQPSVGTEIFVGK }\end{array}$

$0.07 \% \quad 34.7 \%$ DLFEDELVPLFEK

$0.07 \% \quad 34.7 \%$ AGPIWDLR

$0.07 \% \quad 34.7 \%$ LMMDPLTGLNR

$0.07 \% \quad 34.7 \%$ GYAFVTFCTK

$\begin{array}{llll}0.07 \% & 34.7 \% & \text { EAAQEAVKLYNNHEIR }\end{array}$

$0.07 \% \quad 34.7 \%$ LYNNHEIR

$6 \quad 0.07 \% \quad 34.7 \%$ SGKHIGVCISVANNR

$66 \quad 0.07 \% \quad 34.7 \%$ HIGVCISVANNR

$66 \quad 0.07 \% \quad 34.7 \%$ LFVGSIPK

$66 \quad 0.07 \% \quad 34.7 \%$ TKEQILEEFSK

$66 \quad 0.07 \% \quad 34.7 \%$ EQILEEFSK

$0.07 \% \quad 34.7 \%$ VTEGLTDVILYHQPDDK

18

$0.07 \% \quad 34.7 \%$ GFCFLEYEDHKTAAQAR $99.7 \% \quad 42.3$

$0.07 \% \quad 34.7 \%$ NLANTVTEEILEK

\begin{tabular}{llll}
18 & 66 & $0.07 \%$ & $34.7 \%$ \\
\hline & AFSQFGKLER
\end{tabular}

$25 \quad 147 \quad 0.17 \% \quad 33.8 \%$ SAFLCGVMK

$25 \quad 147 \quad 0.17 \% \quad 33.8 \%$ VQESTKGPDEAK

$147 \quad 0.17 \% \quad 33.8 \%$ ALLERTGYTLDVTTGQR

$147 \quad 0.17 \% \quad 33.8 \%$ TGYTLDVTTGQR

$147 \quad 0.17 \% \quad 33.8 \%$ TGYTLDVTTGQRK

$147 \quad 0.17 \% \quad 33.8 \%$ YGGPPPDSVYSGVQPGIGTEV

$147 \quad 0.17 \% \quad 33.8 \%$ DLYEDELVPLFEK

$147 \quad 0.17 \% \quad 33.8 \%$ AGPIWDLR

$147 \quad 0.17 \% \quad 33.8 \%$ LMMDPLSGQNR

$147 \quad 0.17 \% \quad 33.8 \%$ GYAFITFCGK

$147 \quad 0.17 \% \quad 33.8 \%$ LCDSYEIRPGK

$\begin{array}{lllll}25 & 147 & 0.17 \% & 33.8 \% & \text { HLGVCISVANNR }\end{array}$
$99.7 \% \quad 26.7$

$99.7 \% \quad 36.8$

$99.7 \% \quad 59.1$

$99.7 \% \quad 46.3$

$99.7 \% \quad 39.5$

$99.7 \% \quad 63.1$

$99.7 \% \quad 54.7$

$99.7 \% \quad 56.5$

149

1495.70

2163.05

1663.81

1012.50

2566.25

1884.96

1122.57

$\begin{array}{llll}99.0 \% & 57.5 & 25.0 & 44.5\end{array}$

$99.7 \% \quad 44.9 \quad 25.0 \quad 37.5$

$\begin{array}{lllll}99.7 \% & 62.9 & 25.0 & 56.7 & 12\end{array}$

$\begin{array}{llll}99.7 \% & 49.9 & 25.0 & 38.3\end{array}$

$\begin{array}{llll}99.3 \% & 57.8 & 25.0 & 0.0\end{array}$
877.42

1479.70

1459.70

1415.60

2144.95

2034.95

1021.56

1808.86

1063.51

1708.85

1894.00

1311.65

1439.75

2694.34

1593.80

927.50

1260.64

1193.57

1058.54

1611.84

1339.69

860.52

1351.71

1942.98

1444.62

2042.94

1473.78

1182.63

1012.50

1288.64

1894.00

1311.65

1439.75

2507.25

1609.80

927.50

1261.60

$571 \quad 578$

$592 \quad 606$

$607 \quad 621$

$\begin{array}{ll}607 & 627 \\ 628 & 650\end{array}$

$628 \quad 650$

$651-658$

$671 \quad 685$

707

$67 \quad 81$

$92 \quad 100$

$126 \quad 142$

$131 \quad 142$

$131 \quad 143$

$143 \quad 168$

$44-168$

$185 \quad 192$

$193 \quad 203$

$204 \quad 213$

$214 \quad 229$

229

$230 \quad 244$

$233 \quad 244$

$255 \quad 265$

$257 \quad 265$

$266 \quad 282$

$287 \quad 297$

$287 \quad 303$

$344 \quad 356$

$357 \quad 366$

$95 \quad 103$

$115 \quad 126$

$129 \quad 145$

$134 \quad 145$

$134 \quad 146$

$147 \quad 171$

$175 \quad 187$

$188 \quad 195$

196206

$\begin{array}{lll}1163.56 & 207 & 216\end{array}$

$\begin{array}{lll}1337.65 & 225 & 235\end{array}$

$1339.69 \quad 236 \quad 247$ 
Heterogeneous nuclear ribonucleoprotein R GN=HNRNPR HNRPR_HUMAN $70.94 \quad 100.0 \% \quad 20$ Heterogeneous nuclear ribonucleoprotein R GN=HNRNPR HNRPR_HUMAN $70.94 \quad 100.0 \% \quad 20$ Heterogeneous nuclear ribonucleoprotein R GN=HNRNPR HNRPR_HUMAN $70.94 \quad 100.0 \% \quad 20$ Heterogeneous nuclear ribonucleoprotein R GN=HNRNPR HNRPR_HUMAN $70.94 \quad 100.0 \%$ Heterogeneous nuclear ribonucleoprotein R GN=HNRNPR HNRPR_HUMAN $70.94 \quad 100.0 \% \quad 20$ Heterogeneous nuclear ribonucleoprotein R GN=HNRNPR HNRPR_HUMAN $70.94 \quad 100.0 \% \quad 20$ Heterogeneous nuclear ribonucleoprotein R GN=HNRNPR HNRPR_HUMAN $70.94 \quad 100.0 \% \quad 20$ Heterogeneous nuclear ribonucleoprotein R GN=HNRNPR HNRPR_HUMAN $70.94 \quad 100.0 \% \quad 20$ Heterogeneous nuclear ribonucleoprotein U GN=HNRNPU HNRPU_HUMAN $90.59 \quad 100.0 \%$ Heterogeneous nuclear ribonucleoprotein U GN=HNRNPU HNRPU_HUMAN $90.59 \quad 100.0 \% \quad 24$ Heterogeneous nuclear ribonucleoprotein U GN=HNRNPU HNRPU_HUMAN $90.59 \quad 100.0 \% \quad 24$ Heterogeneous nuclear ribonucleoprotein U GN=HNRNPU HNRPU_HUMAN $90.59 \quad 100.0 \% \quad 24$ Heterogeneous nuclear ribonucleoprotein U GN=HNRNPU HNRPU_HUMAN $90.59 \quad 100.0 \% \quad 24$ Heterogeneous nuclear ribonucleoprotein U GN=HNRNPU HNRPU_HUMAN $90.59 \quad 100.0 \% \quad 24$ Heterogeneous nuclear ribonucleoprotein U GN=HNRNPU HNRPU_HUMAN $90.59 \quad 100.0 \% \quad 24$ Heterogeneous nuclear ribonucleoprotein U GN=HNRNPU HNRPU_HUMAN $90.59 \quad 100.0 \% \quad 24$ Heterogeneous nuclear ribonucleoprotein U GN=HNRNPU HNRPU HUMAN $90.59 \quad 100.0 \%$ Heterogeneous nuclear ribonucleoprotein U GN=HNRNPU HNRPU_HUMAN $90.59 \quad 100.0 \% \quad 24$ Heterogeneous nuclear ribonucleoprotein U GN=HNRNPU HNRPU_HUMAN $90.59 \quad 100.0 \% \quad 24$ Heterogeneous nuclear ribonucleoprotein U GN=HNRNPU HNRPU_HUMAN $90.59 \quad 100.0 \% \quad 24$ Heterogeneous nuclear ribonucleoprotein U GN=HNRNPU HNRPU_HUMAN $90.59 \quad 100.0 \% \quad 24$ Heterogeneous nuclear ribonucleoprotein U GN=HNRNPU HNRPU_HUMAN $90.59 \quad 100.0 \% \quad 24$ Heterogeneous nuclear ribonucleoprotein U GN=HNRNPU HNRPU_HUMAN $90.59 \quad 100.0 \% 24$ Heterogeneous nuclear ribonucleoprotein U GN=HNRNPU HNRPU_HUMAN $90.59 \quad 100.0 \% \quad 24$ Heterogeneous nuclear ribonucleoprotein U GN=HNRNPU HNRPU HUMAN $90.59 \quad 100.0 \%$ Heterogeneous nuclear ribonucleoprotein U GN=HNRNPU HNRPU_HUMAN $90.59 \quad 100.0 \% \quad 24$ Heterogeneous nuclear ribonucleoprotein U GN=HNRNPU HNRPU_HUMAN $90.59 \quad 100.0 \% \quad 24$ Heterogeneous nuclear ribonucleoprotein U GN=HNRNPU HNRPU_HUMAN $90.59 \quad 100.0 \% \quad 24$ Heterogeneous nuclear ribonucleoprotein U GN=HNRNPU HNRPU_HUMAN $90.59 \quad 100.0 \% \quad 24$ Heterogeneous nuclear ribonucleoprotein U GN=HNRNPU HNRPU HUMAN $90.59 \quad 100.0 \%$ Heterogeneous nuclear ribonucleoprotein U GN=HNRNPU HNRPU_HUMAN $90.59 \quad 100.0 \% \quad 24$ Heterogeneous nuclear ribonucleoprotein U GN=HNRNPU HNRPU_HUMAN $90.59 \quad 100.0 \% \quad 24$ Heterognous 列 Heterogeneous nuclear ribonucleoprotein U-like protein 1 GN=HNRNPUL1 HNRL1_HUMAN $95.74 \quad 100.0 \%$ Heterogeneous nuclear ribonucleoprotein U-like protein 1 GN=HNRNPUL1 HNRL1_HUMAN $95.74 \quad 100.0 \%$ Heterogeneous nuclear ribonucleoprotein U-like protein 1 GN=HNRNPUL1 HNRL1_HUMAN $95.74 \quad 100.0 \%$ Heterogeneous nuclear ribonucleoprotein U-like protein 1 GN=HNRNPUL1 HNRL1_HUMAN $95.74 \quad 100.0 \%$ Heterogeneous nuclear ribonucleoprotein U-like protein 1 GN=HNRNPUL1 HNRL1 HUMAN $95.74100 .0 \%$ Herogeneous nuclear ribonucleoprotein U-like protein 1 GN=HNRNPUL1 HNRL1_HUMAN $95.74 \quad 100.0 \%$ in U-like protein $2 \mathrm{GN}=\mathrm{HNRNPUL2}$ HNRL2 HUMAN $85.11 \quad 100.0 \%$ in U-like protein $2 \mathrm{GN}=\mathrm{HNRNPUL2}$ HNRL2 HUMAN $85.11 \quad 100.0 \%$ U-like protein 2 GN=HNRNPUL2 HNRL2 HUMAN $85.11 \quad 100.0 \%$ Ulike pod 2 GN=HNRNPUL2 HNRL2 HUMAN $85.11 \quad 100.0 \%$ in U-like protein 2 GN=HNRNPUL2 HNRL2_HUMAN $85.11 \quad 100.0 \%$
$25 \quad 147 \quad 0.17 \% \quad 33.8 \%$ GFCFLEYEDHK

$147 \quad 0.17 \% \quad 33.8 \%$ GFCFLEYEDHKSAAQAR $\quad 99.7 \% \quad 48.8$

$147 \quad 0.17 \% \quad 33.8 \%$ NLATTVTEEILEK

$147 \quad 0.17 \% \quad 33.8 \%$ SFSEFGKLER

$99.7 \% \quad 58.9$

$99.7 \% 53.8$

$99.7 \% \quad 42.0$

$147 \quad 0.17 \% \quad 33.8 \%$ LKDYAFVHFEDR

$99.7 \% \quad 40.7$

99.7\% 47.3

$206 \quad 0.23 \% \quad 24.0 \%$ KAEGGGGGGRPGAPAAGDGK $\quad 99.7 \% \quad 31.5$

$206 \quad 0.23 \% \quad 24.0 \%$ AEGGGGGGRPGAPAAGDGK $\quad 99.2 \% \quad 23.9$

$206 \quad 0.23 \% \quad 24.0 \%$ AEGGGGGGRPGAPAAGDGKTEQK $\quad 99.7 \% \quad 49.0$

$206 \quad 0.23 \% \quad 24.0 \%$ GYFEYIEENKYSR

$206 \quad 0.23 \% \quad 24.0 \%$ VTEKIPVR

$206 \quad 0.23 \% \quad 24.0 \%$ HLYTKDIDIHEVR

$206 \quad 0.23 \% \quad 24.0 \%$ DIDIHEVR

$206 \quad 0.23 \% \quad 24.0 \%$ NGQDLGVAFK

$206 \quad 0.23 \% \quad 24.0 \%$ NGQDLGVAFKISK

$99.7 \% \quad 57.6$

$99.0 \% \quad 50.6$

$99.7 \% \quad 35.7$

$99.0 \% 58.6$

$99.7 \% \quad 52.0$

$99.7 \% \quad 58.5$

$206 \quad 0.23 \% \quad 24.0 \%$ HAAENPGKYNILGTN

$206 \quad 0.23 \% \quad 24.0 \%$ YNILGTNTIMDK

$206 \quad 0.23 \% \quad 24.0 \%$ MMVAGFKK

$206 \quad 0.23 \% \quad 24.0 \%$ QMADTGKLNTLLQR

$206 \quad 0.23 \% \quad 24.0 \%$ APQCLGKFIEIAAR

$206 \quad 0.23 \% \quad 24.0 \%$ RNFILDQTNVSAAAQR

$206 \quad 0.23 \% \quad 24.0 \%$ NFILDQTNVSAAAQR

$206 \quad 0.23 \% \quad 24.0 \%$ NFILDQTNVSAAAQRR

$206 \quad 0.23 \% \quad 24.0 \%$ KMCLFAGFQR

$206 \quad 0.23 \% \quad 24.0 \%$ MCLFAGFQR

$206 \quad 0.23 \% \quad 24.0 \%$ MCLFAGFQRK

$206 \quad 0.23 \% \quad 24.0 \%$ AEVEGKDLPEHAVLK

$206 \quad 0.23 \% \quad 24.0 \%$ DLPEHAVLK

$206 \quad 0.23 \% \quad 24.0 \%$ LLEQYKEESK

$37 \quad 0.04 \% \quad 11.2 \%$ HLPSTEPDPHVVR

$37 \quad 0.04 \% \quad 11.2 \%$ NCAVEFNFGQR

$37 \quad 0.04 \% \quad 11.2 \%$ KYNILGTNAIMDK

$37 \quad 0.04 \% \quad 11.2 \%$ YNILGTNAIMDK

$37 \quad 0.04 \% \quad 11.2 \%$ YNILGTNAIMDKMR

$37 \quad 0.04 \% \quad 11.2 \%$ LIQIAARK

$37 \quad 0.04 \% \quad 11.2 \%$ NYILDQTNVYGSAQR

$37 \quad 0.04 \% \quad 11.2 \%$ KMRPFEGFQR

$0.04 \% \quad 11.2 \%$ AIVICPTDEDLKDR

$0.04 \% \quad 11.2 \%$ NPPGASTYNK

$3 \quad 0.01 \% \quad 9.8 \%$ GLKVDLAQR

$13 \quad 0.01 \% \quad 9.8 \% \quad$ EGCTEVSLLR

$13 \quad 0.01 \% \quad 9.8 \%$ YNVLGAETVLNQMR

$13 \quad 0.01 \% \quad 9.8 \%$ SRDLLVQQASQCLSK

$13 \quad 0.01 \% \quad 9.8 \% \quad$ NFILDQCNVYNSGQR

\section{$99.7 \% \quad 55.7$}

$99.7 \% \quad 58.2$

$99.0 \% \quad 41.5$

$\begin{array}{lll}99.7 \% & 37.7\end{array}$

$99.7 \% \quad 54.8$

$99.7 \% \quad 56.6$

$99.7 \% \quad 51.0$

$99.7 \% \quad 33.4$

$99.7 \% \quad 44.8$

$99.7 \% \quad 51.0$

$98.7 \% \quad 20.5$

$99.7 \% 38.0$

$99.7 \% \quad 40.2$

$99.7 \% \quad 60.4$

$99.7 \% \quad 35.0$

$99.7 \% \quad 54.1$

$99.5 \% \quad 26.4$

$99.7 \% \quad 55.5$

$98.2 \% \quad 19.4$

$99.0 \% \quad 24.7$

$99.7 \% \quad 88.5$

$99.3 \% \quad 22.1$

$99.7 \% \quad 32.5$

$99.7 \% \quad 28.1$

$99.7 \% \quad 49.8$

$99.7 \% \quad 34.4$

$99.7 \% \quad 37.8$

$99.7 \% \quad 39.1$

$99.7 \% \quad 58.3$
860.52

337.69

1444.62

2028.92

1460.78

1199.61

1539.76

1758.78

1714.91

1666.83

1538.73

2024.97

1697.78

941.58

1638.86

996.51

1048.54

1376.75

2203.08

1398.69

911.48

1588.85

1573.85

1803.95

1647.84

1803.95

1273.62

1145.52

1257.62

1634.88

1021.57

1266.66

1483.77

1341.60

1496.78

1368.68

1671.82

912.60

1741.85

1311.66

1644.83

1048.51

999.59

1163.57

1623.82

1732.90 1827.84

$\begin{array}{cc}48 & 255 \\ 58 & 268 \\ 90 & 300 \\ 90 & 306 \\ 47 & 359 \\ 60 & 369 \\ 73 & 384 \\ 28 & 441 \\ 87 & 204 \\ 15 & 234 \\ 16 & 234 \\ 16 & 238 \\ 56 & 268 \\ 40 & 347 \\ 48 & 360 \\ 53 & 360 \\ 24 & 433 \\ 24 & 436 \\ 17 & 536 \\ 25 & 536 \\ 37 & 544 \\ 45 & 558 \\ 59 & 572 \\ 75 & 590 \\ 76 & 590 \\ 76 & 591 \\ 92 & 601 \\ 93 & 601 \\ 93 & 602 \\ 21 & 635 \\ 27 & 635 \\ 65 & 674 \\ 71 & 283 \\ 76 & 386 \\ 49 & 461 \\ 50 & 461 \\ 50 & 463 \\ 91 & 498 \\ 01 & 515 \\ 17 & 526 \\ 28 & 541 \\ 22 & 731 \\ 4 & 32 \\ 06 & 315 \\ 81 & 494 \\ 07 & 521 \\ 32 & 546 \\ & \end{array}$

Page 79 of Table S-1-6 

$13 \quad 0.01 \% \quad 9.8 \%$ NYYGYQGYR

$283 \quad 0.32 \% \quad 66.6 \%$ TLETVPLER

$283 \quad 0.32 \% \quad 66.6 \%$ KLFIGGLSFETTEESLR

$283 \quad 0.32 \% \quad 66.6 \%$ LFIGGLSFETTEESLR

$283 \quad 0.32 \% \quad 66.6 \%$ NYYEQWGK

$283 \quad 0.32 \% \quad 66.6 \%$ LTDCVVMR

$283 \quad 0.32 \% \quad 66.6 \%$ LTDCVVMRDPASK

$283 \quad 0.32 \% \quad 66.6 \%$ AVAREESGKPGAHVT

$283 \quad 0.32 \% \quad 66.6 \%$ EESGKPGAHVTVKK

$283 \quad 0.32 \% \quad 66.6 \%$ KLFVGGIK

$283 \quad 0.32 \% \quad 66.6 \%$ LFVGGIKEDTEEHHLR

$283 \quad 0.32 \% \quad 66.6 \%$ DYFEEYGK

$283 \quad 0.32 \% \quad 66.6 \%$ DYFEEYGKIDTIEIITDR

$283 \quad 0.32 \% \quad 66.6 \%$ IDTIEIITDR

$283 \quad 0.32 \% \quad 66.6 \%$ RGFGFVTFDDHDPVDK

$283 \quad 0.32 \% \quad 66.6 \%$ GFGFVTFDDHDPVDK

$283 \quad 0.32 \% \quad 66.6 \%$ GFGFVTFDDHDPVDKIVLQK

$283 \quad 0.32 \% \quad 66.6 \%$ YHTINGHNAEVR

$283 \quad 0.32 \% \quad 66.6 \%$ YHTINGHNAEVRK

$283 \quad 0.32 \% \quad 66.6 \%$ ALSRQEMQEVQSSR

$283 \quad 0.32 \% \quad 66.6 \%$ QEMQEVQSSR

$283 \quad 0.32 \% \quad 66.6 \%$ GGNFGFGDSR

$283 \quad 0.32 \% \quad 66.6 \%$ GGGGNFGPGPGSNFR

$283 \quad 0.32 \% \quad 66.6 \%$ GGGGNFGPGPGSNFRGGSDGYGSGR

$\begin{array}{llll}283 & 0.32 \% & 66.6 \% & \text { GFGDGYNGYGGGPGGGNFGGSGYGGGR } \\ 283 & 0.32 \% & 66.6 \% & \text { NMGGPYGGGNYGPGGSGGSGGYGGR }\end{array}$

$235 \quad 0.27 \% \quad 39.5 \%$ VFIGNLNTLVVK

$235 \quad 0.27 \% \quad 39.5 \%$ VFIGNLNTLVVKK

$235 \quad 0.27 \% \quad 39.5 \%$ KSDVEAIFSK

$235 \quad 0.27 \% \quad 39.5 \%$ SDVEAIFSK

$235 \quad 0.27 \% \quad 39.5 \%$ SDVEAIFSKYGK

$235 \quad 0.27 \% \quad 39.5 \%$ IVGCSVHK

$235 \quad 0.27 \% \quad 39.5 \%$ GFAFVQYVNER

$235 \quad 0.27 \% \quad 39.5 \%$ MIAGQVLDINLAAEPK

$235 \quad 0.27 \% \quad 39.5 \%$ MIAGQVLDINLAAEPKVNR

$235 \quad 0.27 \% \quad 39.5 \%$ VPPPPPIAR

$235 \quad 0.27 \% \quad 39.5 \%$ LKGDDLQAIK

$235 \quad 0.27 \% \quad 39.5 \%$ GDDLQAIKK

$235 \quad 0.27 \% \quad 39.5 \%$ QKVDSLLENLEK

$235 \quad 0.27 \% \quad 39.5 \%$ VDSLLENLEK

$235 \quad 0.27 \% \quad 39.5 \%$ VDSLLENLEKIEK

$235 \quad 0.27 \% \quad 39.5 \%$ NDKSEEEQSSSSVK

$235 \quad 0.27 \% \quad 39.5 \%$ GDDQLELIK

$2 \quad 0.00 \% \quad 10.7 \%$ FKDPNAPK

$2 \quad 0.00 \% \quad 10.7 \%$ IKGEHPGLSIGDVAK
$98.2 \% \quad 20.0 \quad 25.0$ $99.7 \% \quad 31.8 \quad 25.0$ $99.7 \% \quad 48.7$ $99.7 \% \quad 41.5$ $99.0 \% \quad 31.8 \quad 25.0 \quad 28.2$ $99.0 \% \quad 52.0 \quad 25.0 \quad 43.8$ $\begin{array}{llll}99.7 \% & 57.3 & 25.0 & 44.5\end{array}$ $\begin{array}{llll}99.3 \% & 25.3 & 25.0 & 25.3\end{array}$ $99.7 \% \quad 54.0 \quad 25.0 \quad 48.5$ $\begin{array}{llll}99.7 \% & 42.7 & 25.0 & 36.9\end{array}$ $\begin{array}{llll}98.6 \% & 35.5 & 25.0 & 0.0\end{array}$ $99.3 \% \quad 51.0 \quad 25.0 \quad 0.0$ $\begin{array}{llll}99.0 \% & 19.3 & 25.0 & 19.3\end{array}$

$\begin{array}{llll}99.7 \% & 40.8 & 25.0 & 36.5\end{array}$ $99.7 \% \quad 64.6 \quad 25.0 \quad 56.7$

$\begin{array}{llll}99.7 \% & 49.2 & 25.0 & 48.6\end{array}$

$\begin{array}{llll}99.7 \% & 60.6 & 25.0 & 60.6\end{array}$

$99.7 \% \quad 58.5$

$99.7 \% \quad 55.3$

$99.7 \% \quad 45.0$

$99.7 \% \quad 53.4$

$99.7 \% \quad 55.1$

$99.7 \% \quad 51.0$

$\begin{array}{ll}.7 \% & 47.8\end{array}$

$.7 \% \quad 53.2$

$99.7 \% \quad 57.3$

$99.7 \% \quad 54.6$

$99.7 \% \quad 58.0$

$99.7 \% \quad 54.8$

$99.7 \% \quad 53.7$

$99.0 \% \quad 20.5$

$99.7 \% \quad 58.2$

$99.7 \% \quad 52.1$

\section{$99.4 \% \quad 21.9$}

$99.7 \% \quad 31.8$

$99.3 \% \quad 27.1$

$99.7 \% \quad 36.8$

$99.7 \% \quad 60.9$

$99.7 \% \quad 58.5$

$99.7 \% 57.0$

$99.7 \% \quad 42.8$

$99.7 \% \quad 55.0$

$98.9 \% \quad 26.2$

$99.1 \% \quad 21.3$
1183.52

1057.59

1927.02

1798.92

1087.48

993.49

1491.73

1735.95

1338.70

1466.80

861.56

1879.97

1050.44

2220.07

1188.65

1851.87

1695.77

2277.16

1410.69

1538.78

1664.80

1221.55

1013.44

1377.63

2270.99

2495.04

2205.90

1316.79

1444.89

1123.60

995.50

1343.68

899.48

1329.66

1682.91

2068.12

943.57

1100.63

987.55

1415.77

1159.62

1529.84

1553.69

1030.54

916.49

1520.84 
Histone deacetylase $1 \mathrm{GN}=\mathrm{HDAC} 1$ Histone deacetylase $1 \mathrm{GN}=\mathrm{HDAC} 1$ Histone deacetylase $1 \mathrm{GN}=\mathrm{HDAC} 1$ Histone H1.2 GN=HIST1H1C Histone H1.2 GN=HIST1H1C Histone H1.2 GN=HIST1H1C Histone H1.2 GN=HIST1H1C Histone H1.2 GN=HIST1H1C Histone H1.2 GN=HIST1H1C Histone H1.2 GN=HIST1H1C Histone H1.2 GN=HIST1H1C Histone H1.2 GN=HIST1H1C Histone H1.2 GN=HIST1H1C Histone $\mathrm{H} 1 \mathrm{x} \mathrm{GN}=\mathrm{H} 1 \mathrm{FX}$

Histone H1x GN=H1FX Histone $\mathrm{H} 1 \mathrm{x}$ GN=H1FX Histone $\mathrm{H} 1 \mathrm{x}$ GN=H1FX Histone $\mathrm{H} 1 \mathrm{x} \mathrm{GN}=\mathrm{H} 1 \mathrm{FX}$ Histone $\mathrm{H} 4 \mathrm{GN}=\mathrm{HIST} 1 \mathrm{H} 4 \mathrm{~A}$

Histone $\mathrm{H} 4 \mathrm{GN}=\mathrm{HIST} 1 \mathrm{H} 4 \mathrm{~A}$ Histone $\mathrm{H} 4 \mathrm{GN}=\mathrm{HIST} 1 \mathrm{H} 4 \mathrm{~A}$

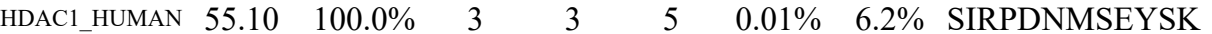
HDAC1_HUMAN $55.10 \quad 100.0 \%$ HDAC1_HUMAN $55.10 \quad 100.0 \%$ H12 HUMAN $21.37 \quad 100.0 \%$ H12_HUMAN $21.37 \quad 100.0 \%$ H12_HUMAN $21.37 \quad 100.0 \%$ H12 HUMAN $21.37 \quad 100.0 \%$ H12_HUMAN $21.37 \quad 100.0 \%$ H12_HUMAN $21.37 \quad 100.0 \%$ H12_HUMAN $21.37 \quad 100.0 \%$ H12_HUMAN $21.37 \quad 100.0 \%$ H12 HUMAN $21.37 \quad 100.0 \%$ H12_HUMAN $21.37 \quad 100.0 \%$ H1X_HUMAN $22.49 \quad 100.0 \%$ H1X HUMAN $22.49 \quad 100.0 \%$ H1X_HUMAN $22.49 \quad 100.0 \%$ H1X HUMAN $22.49 \quad 100.0 \%$ H1X_HUMAN $22.49 \quad 100.0 \%$ H4 HUMAN $11.37 \quad 100.0 \%$ H4 HUMAN $11.37 \quad 100.0 \%$ H4_HUMAN $11.37 \quad 100.0 \%$ DOT1L_HUMAN $184.86 \quad 100.0 \%$ Histone-lysine N-methyltransferase, H3 lysine-79 specific GN=DOTIL DOT1L_HUMAN $184.86 \quad 100.0 \%$ HLA class I histocompatibility antigen, A-2 alpha chain GN=HLA-A 1A02_HUMAN 40.92 100.0\% HLA class I histocompatibility antigen, A-2 alpha chain GN=HLA-A 1 A02 HUMAN $40.92 \quad 100.0 \%$ HLA class I histocompatibility antigen, A-2 alpha chain GN=HLA-A 1 A02_HUMAN $40.92 \quad 100.0 \%$ HLA class I histocompatibility antigen, $\mathrm{Cw}-7$ alpha chain GN=HLA-C 1 C07_HUMAN $40.65 \quad 100.0 \%$ HLA class I histocompatibility antigen, $\mathrm{Cw}-7$ alpha chain GN=HLA-C $1 \mathrm{C} 07$ HUMAN $40.65 \quad 100.0 \%$ HLA class I histocompatibility antigen, $\mathrm{Cw}-7$ alpha chain GN=HLA-C 1 C07_HUMAN $40.65 \quad 100.0 \%$ Hornerin GN=HRNR Hornerin GN=HRNR Hornerin GN=HRNR Hornerin GN=HRNR Hornerin GN=HRNR Hornerin $\mathrm{GN}=\mathrm{HRNR}$

Hsp70-binding protein $1 \mathrm{GN}=\mathrm{HSPBP} 1$ Hsp70-binding protein $1 \mathrm{GN}=\mathrm{HSPBP} 1$ Hsp70-binding protein $1 \mathrm{GN}=\mathrm{HSPBP} 1$ Hsp70-binding protein $1 \mathrm{GN}=\mathrm{HSPBP} 1$ Huntingtin GN=HTT

Huntingtin $\mathrm{GN}=\mathrm{HT}$ Huntingtin GN=HT1 Huntingtin GN=HTT Huntingtin GN=HTT Huntingtin $\mathrm{GN}=\mathrm{HT}]$ Huntingtin GN=HT1
HORN HUMAN $282.37 \quad 100.0 \%$ HORN_HUMAN $282.37 \quad 100.0 \%$ HORN_HUMAN $282.37 \quad 100.0 \%$ HORN HUMAN $282.37 \quad 100.0 \%$ HORN_HUMAN $282.37 \quad 100.0 \%$ HORN HUMAN $282.37 \quad 100.0 \%$ HPBP1_HUMAN $39.47 \quad 100.0 \%$ HPBP1 HUMAN $39.47 \quad 100.0 \%$ HPBP1_HUMAN $39.47 \quad 100.0 \%$ HD HUMAN $347.60 \quad 100.0 \%$ HD HUMAN $347.60 \quad 100.0 \%$ HD_HUMAN $347.60 \quad 100.0 \%$ HD HUMAN $347.60 \quad 100.0 \%$ HD HUMAN $347.60 \quad 100.0 \%$ HD_HUMAN $347.60 \quad 100.0 \%$ HD HUMAN $347.60 \quad 100.0 \%$ HPBP1_HUMAN $39.47 \quad 100.0 \%$

$256 \quad 0.29 \% \quad 36.6 \%$ KASGPPVSELITK $0.01 \% \quad 6.2 \% \quad$ YGEYFPGTGDLR

$\begin{array}{llllllll}99.7 \% & 34.5 & 25.0 & 21.9 & 2 & 0 & 0 & 1426.66\end{array}$ $98.2 \% \quad 23.0$

$5 \quad 0.01 \% \quad 6.2 \% \quad$ YGEYFPGTGDLRDIGAGK $256 \quad 0.29 \% \quad 36.6 \%$ SETAPAAPAAAPPAEK

$256 \quad 0.29 \% \quad 36.6 \%$ ASGPPVSELITK

$256 \quad 0.29 \% \quad 36.6 \%$ SGVSLAALK

$256 \quad 0.29 \% \quad 36.6 \%$ SGVSLAALKK

$256 \quad 0.29 \% \quad 36.6 \%$ KALAAAGYDVEK

$256 \quad 0.29 \% \quad 36.6 \%$ ALAAAGYDVEK

$256 \quad 0.29 \% \quad 36.6 \%$ ALAAAGYDVEKNNSR

$256 \quad 0.29 \% \quad 36.6 \%$ SLVSKGTLVQTK

$256 \quad 0.29 \% \quad 36.6 \%$ GTGASGSFKLNK

$23 \quad 0.03 \% \quad 18.3 \%$ YSQLVVETIR

$23 \quad 0.03 \% \quad 18.3 \%$ YSQLVVETIRR

$23 \quad 0.03 \% \quad 18.3 \%$ ALVQNDTLLQVK

$23 \quad 0.03 \% \quad 18.3 \%$ RGAPAAATAPAPTAHK

$23 \quad 0.03 \% \quad 18.3 \%$ GAPAAATAPAPTAHK

$6 \quad 0.01 \% \quad 31.1 \%$ DNIQGITKPAIR

$6 \quad 0.01 \% \quad 31.1 \%$ ISGLIYEETR

$6 \quad 0.01 \% \quad 31.1 \%$ DAVTYTEHAK

$2 \quad 0.00 \% \quad 1.4 \% \quad$ LNTRPSTGLLR

$0.00 \% \quad 1.4 \%$ INSRNLSDIGTIMR

$0.00 \% \quad 9.9 \%$ FIAVGYVDDTQFVR

$0.00 \% \quad 9.9 \%$ FDSDAASQR

$0.00 \% \quad 9.9 \%$ WAAVVVPSGQEQR

$0.00 \% \quad 9.8 \%$ FISVGYVDDTQFVR

$0.00 \% \quad 9.8 \%$ FDSDAASPR

$0.00 \% \quad 9.8 \%$ WAAVVVPSGQEQR

$0.05 \% \quad 4.1 \%$ GSGSGQSPSSGQHGTGFGR $\quad 99.7 \% \quad 32.4$

$\begin{array}{llll}0.05 \% & 4.1 \% & \text { GPYESGSGHSSGLGHQESR } & 99.7 \% \quad 32.5\end{array}$

$\begin{array}{llllll}.05 \% & 4.1 \% & \text { SEQHGSSSGSSSSYGQHGSGSR } & 99.7 \% & 39.2\end{array}$

$0.05 \% \quad 4.1 \%$ QSLGHGQHGSGSGQSPSPSR $\quad 99.7 \% \quad 43.1$

$0.05 \% \quad 4.1 \%$ GPYESGSGHSSGLGHR $\quad 99.7 \% \quad 38.9$

$0.05 \% \quad 4.1 \%$ GEQHGSSSGSSSSYGQHGSGSR

$0.02 \% \quad 11.0 \%$ YLEAGAAGLR

$0.02 \% \quad 11.0 \%$ ALFAISCLVR

$0.02 \% \quad 11.0 \%$ EQEAGLLQFLR

$0.02 \% \quad 11.0 \%$ LDGFSVLMR

$0.01 \% \quad 2.8 \%$ TAAGSAVSICQHSR

$0.01 \% \quad 2.8 \%$ VIAAVSHELITSTTR

$98.3 \% \quad 17.0$

$99.7 \% \quad 39.8$

$99.7 \% \quad 57.5$

$99.7 \% \quad 61.3$

$99.7 \% \quad 47.2$

$99.7 \% \quad 49.9$

$99.7 \% \quad 53.9$

$0.01 \% \quad 2.8 \% \quad$ LRDGDSTSTLEEHSEGK

$99.7 \% \quad 33.2$

$99.7 \% \quad 38.6$

$96.1 \% \quad 18.7$

$97.6 \% \quad 17.2$

$98.7 \% 31.0$

$99.0 \% \quad 30.3$
$0.01 \% \quad 2.8 \%$ LPLVNSYTR

$0.01 \% \quad 2.8 \%$ AVAEPVSR

$0.00 \% \quad 5.8 \%$ ALLEVLGR
1374.63

1915.92

1478.75

1326.76

1198.67

845.51

973.60

1235.66

1107.57

1578.79

1260.75

1166.62

1207.67

1363.77

1341.77

1487.8

1331.71

1325.75

1180.62

1134.54

1227.72

1589.84

1629.83

996.44

1426.74

1645.82

965.43

1426.74

1747.77

1928.85

2152.89

1947.90

1584.72

2122.88

1020.55

1149.64

1303.70

1053.54

1444.70

1597.89

1860.86

1928.87

1062.59

828.46

1058.62

870.54

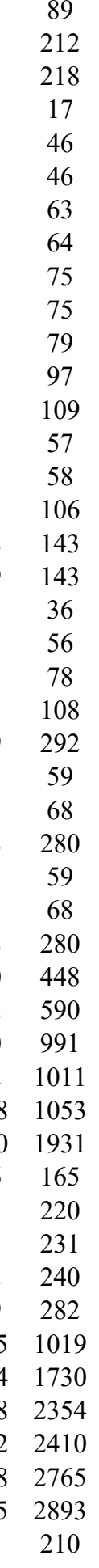


Hydroxyacylglutathione hydrolase, mitochondrial GN=HAGH GLO2_HUMAN $33.81 \quad 100.0 \%$ Hydroxysteroid dehydrogenase-like protein $2 \mathrm{GN}=$ HSDL2 HSDL2_HUMAN $45.40 \quad 100.0 \%$ Hydroxysteroid dehydrogenase-like protein 2 GN=HSDL2 HSDL2_HUMAN $45.40 \quad 100.0 \%$ droxysteroid dehydrogenase-like protein $2 \mathrm{GN}=\mathrm{HSDL} 2 \mathrm{HSDL} 2 \mathrm{HUMAN} 45.40$ Hydroxysteroid dehydrogenase-like protein 2 GN=HSDL2 HSDL2_HUMAN $45.40 \quad 100.0 \%$ Hydroxysteroid dehydrogenase-like protein 2 GN=HSDL2 HSDL2_HUMAN $45.40 \quad 100.0 \%$ Hypoxia up-regulated protein $1 \mathrm{GN}=$ HYOU1 HYOU1_HUMAN $111.34100 .0 \%$ Hypoxia up-regulated protein $1 \mathrm{GN}=$ HYOU1 HYOU1_HUMAN $111.34 \quad 100.0 \%$ Hypoxia up-regulated protein $1 \mathrm{GN}=$ HYOU1 HYOU1 HUMAN $111.34 \quad 100.0 \%$ Hypoxia up-regulated protein $1 \mathrm{GN}=$ HYOU1 HYOU1_HUMAN $111.34 \quad 100.0 \%$ Ig kappa chain V-I region Lay OS=Homo sapiens KV113_HUMAN $11.83 \quad 100.0 \%$ Ig kappa chain V-I region Lay OS=Homo sapiens KV113 HUMAN $11.83 \quad 100.0 \%$ Ig kappa chain V-II region RPMI 6410 OS=Homo sapiens KV206_HUMAN $14.71 \quad 100.0 \%$ Ig kappa chain V-II region RPMI 6410 OS=Homo sapiens KV206_HUMAN $14.71 \quad 100.0 \%$ Ig kappa chain V-II region RPMI 6410 OS=Homo sapiens KV206 HUMAN $14.71 \quad 100.0 \%$ Immunoglobulin lambda-like polypeptide 5 GN=IGLL5 IGLL5_HUMAN $23.06 \quad 99.8 \%$ Immunoglobulin lambda-like polypeptide 5 GN=IGLL5 IGLL5 HUMAN $23.06 \quad 99.8 \%$ Immunoglobulin-binding protein $1 \mathrm{GN}=\mathrm{IGBP} 1 \mathrm{IGBP} 1$ HUMAN $39.22 \quad 100.0 \%$ Immunoglobulin-binding protein $1 \mathrm{GN}=$ IGBP1 IGBP1_HUMAN $39.22 \quad 100.0 \%$ Importin subunit alpha-1 GN=KPNA2 Importin subunit alpha-1 GN=KPNA2 Importin subunit alpha- $1 \mathrm{GN}=\mathrm{KPNA} 2$ Importin subunit alpha-1 GN=KPNA2 Importin subunit alpha-1 GN=KPNA2 Importin subunit alpha-5 GN=KPNA1 Importin subunit alpha- 5 GN=KPNA1 Importin subunit alpha- $5 \mathrm{GN}=\mathrm{KPNA} 1$ Importin subunit beta- $1 \mathrm{GN}=\mathrm{KPNB} 1$ Importin subunit beta- $1 \mathrm{GN}=\mathrm{KPNB} 1$ Importin subunit beta-1 GN=KPNB1 Importin subunit beta- $1 \mathrm{GN}=\mathrm{KPNB} 1$ Importin subunit beta- $1 \mathrm{GN}=\mathrm{KPNB} 1$ Importin subunit beta-1 $\mathrm{GN}=\mathrm{KPNB} 1$ Importin-11 GN=IPO11 Importin-11 GN=IPO1 Importin-11 GN=IPO11 Importin-4 GN=IPO Importin- $4 \mathrm{GN}=\mathrm{IPO} 4$ Importin- $4 \mathrm{GN}=\mathrm{IPO} 4$ Importin- $4 \mathrm{GN}=\mathrm{IPO} 4$ Importin-4 GN=IPO4 Importin-4 GN=IPO Importin- $4 \mathrm{GN}=\mathrm{IPO} 4$ Importin-5 GN=IPO5 Importin-5 GN=IPO Importin-5 GN=IPO5 Importin-7 GN=IPO7

IMA1_HUMAN $57.86 \quad 100.0 \%$ IMA1_HUMAN $57.86 \quad 100.0 \%$ IMA1_HUMAN $57.86 \quad 100.0 \%$ IMA1_HUMAN $57.86 \quad 100.0 \%$ IMA1_HUMAN $57.86 \quad 100.0 \%$ IMA5 HUMAN $60.22 \quad 100.0 \%$ IMA5_HUMAN $60.22 \quad 100.0 \%$ IMA5_HUMAN $60.22 \quad 100.0 \%$ IMB1_HUMAN $97.17 \quad 100.0 \%$ IMB1_HUMAN $97.17 \quad 100.0 \%$ IMB1 HUMAN $97.17 \quad 100.0 \%$ IMB1_HUMAN $97.17 \quad 100.0 \%$ IMB1_HUMAN $97.17 \quad 100.0 \%$ IMB1_HUMAN $97.17 \quad 100.0 \%$ IPO11_HUMAN $112.54 \quad 100.0 \%$ IPO11_HUMAN $112.54 \quad 100.0 \%$ IPO11 HUMAN $112.54 \quad 100.0 \%$ IPO4_HUMAN $118.72 \quad 100.0 \%$ IPO4 HUMAN $118.72 \quad 100.0 \%$ IPO4_HUMAN $118.72 \quad 100.0 \%$ IPO4_HUMAN $118.72 \quad 100.0 \%$ IPO4_HUMAN $118.72 \quad 100.0 \%$ IPO4_HUMAN $118.72 \quad 100.0 \%$ IPO4_HUMAN $118.72 \quad 100.0 \%$ IPO5 HUMAN $123.63 \quad 100.0 \%$ IPO5_HUMAN $123.63 \quad 100.0 \%$ IPO5 HUMAN $123.63 \quad 100.0 \%$ IPO7_HUMAN $119.52 \quad 100.0 \%$
$0.00 \% \quad 5.8 \%$ HVEPGNAAIR $0.01 \% \quad 16.0 \%$ LAGCTVFITGASR $0.01 \% \quad 16.0 \%$ DGANIVIAAK $\begin{array}{llllll}99.7 \% & 38.3 & 25.0 & 38.3 & 2 & 0\end{array}$

AEEIEAVGGK $99.7 \% \quad 43.2$ $0.01 \% \quad 16.0 \%$ KVDIIADAAYSIFQKPK

$0.01 \% \quad 16.0 \%$ SGAVEETFR

$0.01 \% \quad 4.5 \%$ QADNPHVALYQAR

$0.01 \% \quad 4.5 \%$ TLGGLEMELR

$0.01 \% \quad 4.5 \% \quad$ LAGLFNEQR

$0.01 \% \quad 4.5 \%$ DAVVYPILVEFTR

$0.01 \% \quad 25.0 \%$ DIQMTQSPSSLSVSVGDR

$0.01 \% \quad 25.0 \%$ LLIYGASTR

$0.09 \% \quad 18.0 \%$ LIYKVSNR

$0.09 \% \quad 18.0 \%$ FSGSGSGTDFTLK

$0.09 \% \quad 18.0 \%$ FSGSGSGTDFTLKISR

$0.00 \% \quad 10.7 \%$ VTVLGQPK

$0.00 \% \quad 10.7 \%$ SYSCQVTHEGSTVEK

$0.00 \% \quad 5.9 \% \quad$ LPELFETGR

$0.00 \% \quad 5.9 \% \quad$ YGALPDQGIAK
$0.01 \% \quad 14.2 \%$ GINSSNVENQLQATQAAR

$0.01 \% \quad 14.2 \%$ EKQPPIDNIIR

$0.01 \% \quad 14.2 \%$ NLTWTLSNLCR

$0.01 \% \quad 14.2 \%$ NKNPAPPIDAVEQILPTLVR

$0.01 \% \quad 14.2 \%$ LLGASELPIVTPALR

$0.00 \% \quad 8.7 \% \quad$ LLSKEPNPPIDEVISTPGVVAR

$0.00 \% \quad 8.7 \%$ NAVWALSNLCR

$0.00 \% \quad 8.7 \%$ IVQVALNGLENILR

$0.02 \% \quad 8.6 \%$ AAVENLPTFLVELSR

$0.02 \% \quad 8.6 \%$ VLANPGNSQVAR

$0.02 \% \quad 8.6 \%$ VAAGLQIK

$0.02 \% \quad 8.6 \%$ LAATNALLNSLEFTK

$0.02 \% \quad 8.6 \% \quad$ VAALQNLVK

$0.02 \% \quad 8.6 \%$ LLETTDRPDGHQNNLR

$0.01 \% \quad 3.4 \%$ VAPHALSEEEKTTLR

$0.01 \% \quad 3.4 \%$ ALLTFYHVTK

$0.01 \% \quad 3.4 \%$ NYAYKPSK

$0.02 \% \quad 6.3 \% \quad$ ATEQLQIVLR

$0.02 \% \quad 6.3 \% \quad$ SLILTALQR

$0.02 \% \quad 6.3 \%$ GLEDPSQVVR

$0.02 \% \quad 6.3 \% \quad$ VVPSYMQAVNR

$0.02 \% \quad 6.3 \% \quad$ LAELCGVLK

$0.02 \% \quad 6.3 \%$ VRDNICGALAR

$0.02 \% \quad 6.3 \% \quad$ LLMASPTR

$0.01 \% \quad 3.2 \%$ VCDIAAELAR

$0.01 \% \quad 3.2 \% \quad$ FLFDSVSSQNVGLR

$0.01 \% \quad 3.2 \% \quad$ SLVEIADTVPK

$0.01 \% \quad 5.2 \% \quad$ YGSPGNVSK $\begin{array}{llll}99.5 \% & 25.8 & 25.0 & 20.2\end{array}$ $99.7 \% \quad 42.4$ $99.7 \% \quad 33.0$

$99.7 \% \quad 49.4$

$99.7 \% \quad 38.0$

$98.3 \% \quad 17.3$

$99.7 \% \quad 27.2$

$99.7 \% \quad 66.5$

$99.7 \% \quad 34.5$

971.55

1907.06

995.48

1482.74

1118.59

1047.56

1521.83

1922.91

993.57

1303.62

841.51

1711.76

1061.56

1132.60

1322.74

1377.69

2185.23

1549.93

2331.29

1303.66

1551.92

1658.9

1605.88

955.59

1878.94

1680.89

1192.67

1170.68

1014.63

1099.57

1263.65

1244.65

1117.57

$\begin{array}{llll}99.0 \% & 27.0 & 25.0 & 21.0\end{array}$

$\begin{array}{llll}99.7 \% & 50.1 & 25.0 & 34.8\end{array}$

$\begin{array}{llll}99.7 \% & 46.0 & 25.0 & 45.5\end{array}$

$\begin{array}{llll}99.7 \% & 59.2 & 25.0 & 53 .\end{array}$
1063.56
1352.70

1834.98

992.59

1659.83

1900.95

1225.66

799.50

970.50

1002.57

904.49

242
20
42
67
236
315
119
278
291
451
18
54
79
99
102
112
206
20
287
101
117
238
258
315
130
241
452
42
54
62
206
243
525
91
156
337
33
90
411
761
801
967
975
118
148
249

$\begin{array}{lll}908.45 & 275 & 283\end{array}$ 
Importin-7 GN=IPO7 Importin-7 GN=IPO7 Importin-7 GN=IPO7 Importin-7 GN=IPO7
IPO7_HUMAN $119.52 \quad 100.0 \% \quad 5 \quad 5 \quad 6 \quad 6 \quad 0.01 \% \quad 5.2 \% \quad$ EYNEFAEVFLK IPO7_HUMA IPO7_HUMAN $119.52 \quad 100.0 \%$ IPO7 HUMAN $119.52 \quad 100.0 \%$ Inactive hydroxysteroid dehydrogenase-like protein 1 GN=HSDL1 HSDL1_HUMAN $37.00 \quad 100.0 \%$ Inactive hydroxysteroid dehydrogenase-like protein $1 \mathrm{GN}=$ HSDL1 HSDL1_HUMAN $37.00 \quad 100.0 \%$ Inactive hydroxysteroid dehydrogenase-like protein $1 \mathrm{GN}=\mathrm{HSDL} 1 \mathrm{HSDL} 1$ HUMAN $37.00 \quad 100.0 \%$ Inactive hydroxysteroid dehydrogenase-like protein $1 \mathrm{GN}=$ HSDL1 HSDL1_HUMAN $37.00 \quad 100.0 \%$ Inactive hydroxysteroid dehydrogenase-like protein $1 \mathrm{GN}=\mathrm{HSDL} 1 \mathrm{HSDL} 1$ HUMAN $37.00 \quad 100.0 \%$ Inactive hydroxysteroid dehydrogenase-like protein $1 \mathrm{GN}=\mathrm{HSDL} 1$ HSDL1_HUMAN $37.00 \quad 100.0 \%$ Inorganic pyrophosphatase GN=PPA1 IPYR_HUMAN $32.66 \quad 100.0 \%$ Inorganic pyrophosphatase $\mathrm{GN}=\mathrm{PPA} 1$

IPYR HUMAN $32.66 \quad 100.0 \%$ Inosine-5'-monophosphate dehydrogenase $2 \mathrm{GN}=\mathrm{IMPDH} 2$ IMDH2_HUMAN $55.81 \quad 100.0 \%$ Inosine-5'-monophosphate dehydrogenase 2 GN=IMPDH2 IMDH2_HUMAN $55.81 \quad 100.0 \%$ Inosine-5'-monophosphate dehydrogenase 2 GN=IMPDH2 IMDH2_HUMAN $55.81 \quad 100.0 \%$ Inosine-5'-monophosphate dehydrogenase 2 GN=IMPDH2 IMDH2_HUMAN $55.81 \quad 100.0 \%$ Inosine-5'-monophosphate dehydrogenase $2 \mathrm{GN}=\mathrm{IMPDH} 2 \mathrm{IMDH} 2$ HUMAN $55.81 \quad 100.0 \%$ Inosine-5'-monophosphate dehydrogenase 2 GN=IMPDH2 IMDH2_HUMAN $55.81 \quad 100.0 \%$ Inosine-5'-monophosphate dehydrogenase 2 GN=IMPDH2 IMDH2_HUMAN $55.81 \quad 100.0 \%$ Insulin receptor substrate $4 \mathrm{GN}=\mathrm{IRS} 4$ Insulin receptor substrate $4 \mathrm{GN}=\mathrm{IRS}$ Insulin receptor substrate $4 \mathrm{GN}=\mathrm{IRS} 4$ Insulin receptor substrate $4 \mathrm{GN}=\mathrm{IRS} 4$ Insulin receptor substrate $4 \mathrm{GN}=\mathrm{IRS}$ Insulin receptor substrate $4 \mathrm{GN}=\mathrm{IRS} 4$ Insulin receptor substrate $4 \mathrm{GN}=\mathrm{IRS} 4$ Insulin receptor substrate $4 \mathrm{GN}=\mathrm{IRS}$ Insulin receptor substrate $4 \mathrm{GN}=\mathrm{IRS} 4$ Insulin receptor substrate $4 \mathrm{GN}=\mathrm{IRS}$ Insulin receptor substrate $4 \mathrm{GN}=\mathrm{IRS} 4$ Insulin receptor substrate $4 \mathrm{GN}=\mathrm{IRS} 4$ Insulin receptor substrate $4 \mathrm{GN}=\mathrm{IRS} 4$ Insulin receptor substrate $4 \mathrm{GN}=\mathrm{IRS} 4$ Insulin receptor substrate $4 \mathrm{GN}=\mathrm{IRS} 4$ Insulin receptor substrate $4 \mathrm{GN}=\mathrm{IRS} 4$ Insulin receptor substrate $4 \mathrm{GN}=\mathrm{IRS} 4$ Insulin receptor substrate $4 \mathrm{GN}=\mathrm{IRS}$ Insulin receptor substrate $4 \mathrm{GN}=\mathrm{IRS} 4$ Insulin receptor substrate $4 \mathrm{GN}=\mathrm{IRS} 4$ Insulin receptor substrate $4 \mathrm{GN}=\mathrm{IRS} 4$ Insulin receptor substrate $4 \mathrm{GN}=\mathrm{IRS} 4$ Insulin receptor substrate $4 \mathrm{GN}=\mathrm{IRS} 4$ IRS4_HUMAN $133.77 \quad 100.0 \%$ IRS4 HUMAN $133.77 \quad 100.0 \%$ IRS4 HUMAN $133.77 \quad 100.0 \%$ IRS4_HUMAN $133.77 \quad 100.0 \%$ IRS4 HUMAN $133.77 \quad 100.0 \% \quad 23$ IRS4_HUMAN $133.77 \quad 100.0 \% \quad 23$ IRS4_HUMAN $133.77 \quad 100.0 \% \quad 23$ IRS4 HUMAN $133.77 \quad 100.0 \% \quad 23$ IRS4_HUMAN $133.77 \quad 100.0 \% \quad 23$ IRS4 HUMAN $133.77 \quad 100.0 \% \quad 23$ IRS4_HUMAN $133.77 \quad 100.0 \% \quad 23$ IRS4_HUMAN $133.77 \quad 100.0 \% \quad 23$ IRS4 HUMAN $133.77 \quad 100.0 \% \quad 23$ IRS4_HUMAN $133.77 \quad 100.0 \% \quad 23$ IRS4_HUMAN $133.77 \quad 100.0 \% \quad 23$ IRS4 HUMAN $133.77 \quad 100.0 \% \quad 23$ IRS4_HUMAN $133.77 \quad 100.0 \% \quad 23$ IRS4 HUMAN $133.77 \quad 100.0 \% \quad 23$ IRS4_HUMAN $133.77 \quad 100.0 \% \quad 23$ IRS4_HUMAN $133.77 \quad 100.0 \% \quad 23$ IRS4 HUMAN $133.77 \quad 100.0 \% \quad 23$ IRS4_HUMAN $133.77 \quad 100.0 \% \quad 23$ IF2B1_HUMAN $63.48 \quad 100.0 \% \quad 33$ $\begin{array}{lllll} & \end{array}$ Insulin-like growth factor 2 mRNA-binding protein $1 \mathrm{GN}=$ IGF2BP1 $\quad$ IF2B1_HUMAN $63.48 \quad 100.0 \% \quad 33$ Insulin-like growth factor 2 mRNA-binding protein $1 \mathrm{GN}=I G F 2 \mathrm{BP} 1 \quad$ IF2B1 HUMAN $63.48 \quad 100.0 \%$ $\begin{array}{lllll}\text { Insulin-like growth factor } 2 \text { mRNA-binding protein } 1 \text { GN=IGF2BP1 } & \text { IF2B1_HUMAN } & 63.48 & 100.0 \% & 33\end{array}$ $0.01 \% \quad 5.2 \%$ AFAVGVQQVLLK $0.01 \% \quad 5.2 \%$ AIFQTIQNR

$0.01 \% \quad 5.2 \%$ QLQDIATLADQRR

$11 \quad 0.01 \% \quad 17.6 \%$ WAVVSGATDGIGK

$11 \quad 0.01 \% \quad 17.6 \%$ AYAEELASR

$0.01 \% \quad 17.6 \%$ GLNIILISR

$0.01 \% \quad 17.6 \%$ NEEKLQVVAK

$0.01 \% \quad 17.6 \%$ AYLDHFSR

$0.01 \% \quad 17.6 \%$ ALQYEYASK

$0.00 \% \quad 10.7 \%$ AAPFSLEYR

$0.00 \% \quad 10.7 \%$ VIAINVDDPDAANYNDINDVKR $99.4 \% \quad 21.6$

$0.02 \% \quad 18.5 \%$ NRDYPLASK

$0.02 \% \quad 18.5 \%$ DKYPNLQVIGGNVVTAAQAK

$0.02 \% \quad 18.5 \%$ NLIDAGVDALR

$0.02 \% \quad 18.5 \%$ RFGVPVIADGGIQNVGI

$0.02 \% \quad 18.5 \%$ VAQGVSGAVQDK

$0.02 \% \quad 18.5 \%$

$0.02 \% \quad 18.5 \%$ TSSAQVEGGVHSLHSYEK $99.7 \% 34.7$

$0.06 \% \quad 22.0 \%$ YFVLKLETADAPAR $\quad 96.2 \% \quad 15.2$

$0.06 \% \quad 22.0 \%$ LETADAPARLEYYENAR $99.7 \% 36.9$

$0.06 \% \quad 22.0 \%$ AAAAAAAAAASGAAIPPLIPPR $\quad 99.2 \% \quad 24.0$

$0.06 \% \quad 22.0 \%$ VITLYQCFSVSQR

$0.06 \% \quad 22.0 \%$ LCLTDEEVVFVR

$0.06 \% 22.0 \%$ CGHSEQYFFLEVGR

$0.06 \% 22.0 \%$ ALCADEYRAR

$0.06 \% \quad 22.0 \%$ AIGDGEDEMLFTR

$0.06 \% \quad 22.0 \%$ RFVTPSEPVAHSR

$0.06 \% \quad 22.0 \%$ FVTPSEPVAHSR

$0.06 \% \quad 22.0 \%$ LAPSPARPR

$0.06 \% \quad 22.0 \%$ SYFGKLTQSK

$99.7 \% \quad 37.9$

$99.7 \% \quad 59.9$

$99.7 \% \quad 31.9$

$99.7 \% \quad 29.7$

$99.7 \% \quad 59.4$

$99.7 \% \quad 48.3$

$99.7 \% \quad 42.2$

$99.7 \% \quad 27.0$

$99.7 \% \quad 30.2$

$\begin{array}{llll}0.06 \% & 22.0 \% & \text { SSPLGQNDNSEYVPMLPGK } \quad 99.7 \% & 29.3\end{array}$

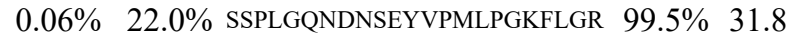

$0.06 \% 22.0 \%$ EADSSSDYVNMDFTKR

$0.06 \% 22.0 \%$ ANPLSLDSAR

$0.06 \% \quad 22.0 \%$ LLQEEEQER

$0.06 \% \quad 22.0 \%$ SQSFFAAAR

$0.06 \% \quad 22.0 \%$ AAVSAFPTDSLER

$\begin{array}{ll}99.7 \% & 30.0 \\ 99.7 \% & 54.0\end{array}$

$99.7 \% \quad 32.6$

$99.7 \% \quad 55.1$

$99.7 \% \quad 46.8$

$0.06 \% \quad 22.0 \%$ WFQPVANAADAEAVR $\quad 99.7 \% \quad 47.9$

$\begin{array}{llll}0.06 \% & 22.0 \% & \text { GAQDVAGGSNPGAHNPSANLAR } \quad 99.7 \% & 41.1\end{array}$

$\begin{array}{lllll}0.06 \% & 22.0 \% & \text { GDNQAGGAAAAAAAPEPPPRSR } & 99.7 \% & 38.1\end{array}$

54.4\% LYIGNLNESVTPADLEK

$99.7 \% \quad 56.2$

$99.7 \% \quad 30.8$

$99.7 \% \quad 49.0$

$48 \quad 167 \quad 0.19 \% \quad 54.4 \%$ ISYSGQFLVK

$\begin{array}{ll}98.8 \% & 18.4 \\ 96.4 \% & 15.9\end{array}$
388.67

1272.77

1090.60

1527.82

1260.66

1009.49

998.64

1157.65

1008.49

1072.53

1053.54

2444.21

1063.55

2086.13

1156.63

2048.14

1158.61

1680.90

1915.91

1593.86

1981.96

1899.08

1600.82

1479.75

1728.78

1224.58

1453.66

1482.78

1326.68

964.57

1158.62

2048.96

2522.23

1864.80

1043.55

1173.57

984.49

1363.69

1644.81

2060.99

1788.86

2032.00

1875.97

1853.00

1141.63

1928.79

852.45

$\begin{array}{cc}84 & 294 \\ 95 & 306 \\ 64 & 972 \\ 91 & 1003 \\ 9 & 81 \\ 2 & 90 \\ 1 & 99 \\ 00 & 109 \\ 23 & 230 \\ 31 & 239 \\ 0 & 18 \\ 56 & 177 \\ 30 & 238 \\ 92 & 311 \\ 12 & 322 \\ 56 & 375 \\ 39 & 450 \\ 39 & 455 \\ 94 & 511 \\ 5 & 108 \\ 00 & 116 \\ 24 & 145 \\ 47 & 159 \\ 56 & 267 \\ 85 & 298 \\ 30 & 339 \\ 85 & 397 \\ 98 & 410 \\ 99 & 410 \\ 36 & 444 \\ 14 & 623 \\ 17 & 835 \\ 17 & 839 \\ 14 & 929 \\ 85 & 994 \\ 74 & 1082 \\ 89 & 1097 \\ 98 & 1110 \\ 62 & 1176 \\ 77 & 1198 \\ 99 & 1218 \\ 99 & 1220 \\ 4 & 20 \\ 1 & 36 \\ 7 & 36 \\ 7 & 52 \\ 3 & 60 \\ & \end{array}$




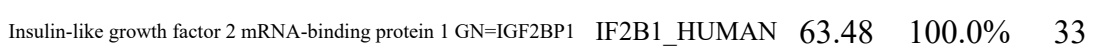
$\begin{array}{lllll}\text { Insulin-like growth factor } 2 \text { mRNA-binding protein } 1 \text { GN=IGF2BP1 } & \text { IF2B1_HUMAN } & 63.48 & 100.0 \% & 33\end{array}$

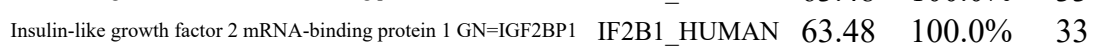
Insulin-like growth factor 2 mRNA-binding protein 1 GN=IGF2BP1 IF2B1_HUMAN $63.48 \quad 100.0 \%$ Insulin-like growth factor 2 mRNA-binding protein 1 GN=IGF2BP1 $\quad$ IF2B1_HUMAN $63.48 \quad 100.0 \%$ $\begin{array}{lllll}\text { Insulin-like growth factor } 2 \text { mRNA-binding protein } 1 \text { GN=IGF2BP1 } & \text { IF2B1_HUMAN } & 63.48 & 100.0 \% & 33\end{array}$ Insulin-like growth factor 2 mRNA-binding protein $1 \mathrm{GN}=$ IGF2BP1 $\quad$ IF2B1_HUMAN $63.48 \quad 100.0 \%$ Insulin-like growth factor 2 mRNA-binding protein 1 GN=IGF2BP1 $\quad$ IF2B1_HUMAN $63.48 \quad 100.0 \% \quad 33$ Insulin-like growth factor 2 mRNA-binding protein 1 GN=IGF2BP1 $\quad$ IF2B1_HUMAN $63.48 \quad 100.0 \% 33$ $\begin{array}{llll}\text { Insulin-like growth factor } 2 \text { mRNA-binding protein } 1 \text { GN=IGF2BP1 } & \text { IF2B1_HUMAN } & 63.48 & 100.0 \%\end{array} 3$ Insulin-like growth factor 2 mRNA-binding protein 1 GN=IGF2BP1 $\quad$ IF2B1_HUMAN $63.48 \quad 100.0 \% 33$ Insulin-like growth factor 2 mRNA-binding protein 1 GN=IGF2BP1 $\quad$ IF2B1_HUMAN $63.48 \quad 100.0 \% \quad 33$ Insulin-like growth factor 2 mRNA-binding protein 1 GN=IGF2BP1 $\quad$ IF2B1_HUMAN $63.48 \quad 100.0 \% \quad 33$ Insulin-like growth factor 2 mRNA-binding protein 1 GN=IGF2BP1 $\quad$ IF2B1_HUMAN $63.48 \quad 100.0 \% \quad 33$ Insulin-like growth factor 2 mRNA-binding protein 1 GN=IGF2BP1 $\quad$ IF2B1_HUMAN $63.48 \quad 100.0 \%$ Insulin-like growth factor 2 mRNA-binding protein 1 GN=IGF2BP1 $\quad$ IF2B1_HUMAN $63.48 \quad 100.0 \%$ Insulin-like growth factor 2 mRNA-binding protein $1 \mathrm{GN}=I \mathrm{GF} 2 \mathrm{BP} 1 \quad \mathrm{IF} 2 \mathrm{~B} 1$ HUMAN $63.48 \quad 100.0 \%$ Insulin-like growth factor 2 mRNA-binding protein $1 \mathrm{GN}=$ IGF2BP1 $\quad$ IF2B1_HUMAN $63.48 \quad 100.0 \%$ Insulin-like growth factor 2 mRNA-binding protein 1 GN=IGF2BP1 IF2B1_HUMAN $63.48 \quad 100.0 \%$ Insulin-like growth factor 2 mRNA-binding protein 1 GN=IGF2BP1 $\quad$ IF2B1_HUMAN $63.48 \quad 100.0 \% 33$ Insulin-like growth factor 2 mRNA-binding protein $1 \mathrm{GN}=$ IGF2BP1 1 IF2B1_HUMAN $63.48 \quad 100.0 \%$ Insulin-like growth factor 2 mRNA-binding protein 1 GN=IGF2BP1 $\quad$ IF2B1_HUMAN $63.48 \quad 100.0 \%$ Insulin-like growth factor 2 mRNA-binding protein 1 GN=IGF2BP1 $\quad$ IF2B1_HUMAN $63.48 \quad 100.0 \% \quad 33$ Insulin-like growth factor 2 mRNA-binding protein 1 GN=IGF2BP1 $\quad$ IF2B1_HUMAN $63.48 \quad 100.0 \%$ Insulin-like growth factor 2 mRNA-binding protein $1 \mathrm{GN}=$ IGF2BP1 IF2B1 HUMAN $63.48 \quad 100.0 \%$ Insulin-like growth factor 2 mRNA-binding protein 1 GN=IGF2BP1 $\quad$ IF2B1_HUMAN $63.48 \quad 100.0 \%$ Insulin-like growth factor 2 mRNA-binding protein 1 GN=IGF2BP1 $\quad$ IF2B1_HUMAN $63.48 \quad 100.0 \%$ Insulin-like growth factor 2 mRNA-binding protein 1 GN=IGF2BP1 $\quad$ IF2B1_HUMAN $63.48 \quad 100.0 \% \quad 33$ Insulin-like growth factor 2 mRNA-binding protein 2 GN=IGF2BP2 IF2B2_HUMAN $66.12 \quad 100.0 \%$ Insulin-like growth factor 2 mRNA-binding protein 2 GN=IGF2BP2 IF2B2 HUMAN $66.12 \quad 100.0 \%$ Insulin-like growth factor 2 mRNA-binding protein 2 GN=IGF2BP2 IF2B2_HUMAN $66.12 \quad 100.0 \%$ Insulin-like growth factor 2 mRNA-binding protein 2 GN=IGF2BP2 IF2B2_HUMAN $66.12 \quad 100.0 \%$ Insulin-like growth factor 2 mRNA-binding protein 2 GN=IGF2BP2 IF2B2 HUMAN $66.12 \quad 100.0 \%$ Insulin-like growth factor 2 mRNA-binding protein 2 GN=IGF2BP2 IF2B2_HUMAN $66.12 \quad 100.0 \%$ Insulin-like growth factor 2 mRNA-binding protein 2 GN=IGF2BP2 IF2B2_HUMAN $66.12 \quad 100.0 \%$ Insulin-like growth factor 2 mRNA-binding protein 2 GN=IGF2BP2 IF2B2_HUMAN $66.12 \quad 100.0 \%$ Insulin-like growth factor 2 mRNA-binding protein 2 GN=IGF2BP2 IF2B2_HUMAN $66.12 \quad 100.0 \%$ Insulin-like growth factor 2 mRNA-binding protein 3 GN=IGF2BP3 IF2B3 HUMAN $63.71 \quad 100.0^{\circ}$ Insulin-like growth factor 2 mRNA-binding protein 3 GN=IGF2BP3 $\quad$ IF2B3_HUMAN $63.71 \quad 100.0 \%$ Insulin-like growth factor 2 mRNA-binding protein 3 GN=IGF2BP3 IF2B3_HUMAN $63.71 \quad 100.0 \%$ Insulin-like growth factor 2 mRNA-binding protein $3 \mathrm{GN}=\mathrm{IGF} 2 \mathrm{BP} 3 \quad$ IF2B3 HUMAN $63.71 \quad 100.0 \%$ Insulin-like growth factor 2 mRNA-binding protein $3 \mathrm{GN}=\mathrm{IGF} 2 \mathrm{BP} 3 \quad$ IF2B3_HUMAN $63.71 \quad 100.0 \%$ Insulin-like growth factor 2 mRNA-binding protein 3 GN=IGF2BP3 IF2B3 HUMAN $63.71 \quad 100.0 \%$ Insulin-like growth factor 2 mRNA-binding protein 3 GN=IGF2BP3 IF2B3_HUMAN $63.71 \quad 100.0 \%$ Insulin-like growth factor 2 mRNA-binding protein 3 GN=IGF2BP3 IF2B3_HUMAN $63.71 \quad 100.0 \%$ Insulin-like growth factor 2 mRNA-binding protein $3 \mathrm{GN}=\mathrm{IGF} 2 \mathrm{BP} 3 \quad \mathrm{IF} 2 \mathrm{~B} 3$ HUMAN $63.71 \quad 100.0 \%$ Insulin-like growth factor 2 mRNA-binding protein 3 GN=IGF2BP3 $\quad$ IF2B3_HUMAN $63.71 \quad 100.0 \%$
$167 \quad 0.19 \% \quad 54.4 \%$ LNGHQLENHALK

$99.7 \% \quad 58.1$

$167 \quad 0.19 \% \quad 54.4 \%$ VSYIPDEQIAQGPENGR

$167 \quad 0.19 \% \quad 54.4 \%$ VSYIPDEQIAQGPENGRR

$\begin{array}{ll}99.0 \% & 24.8 \\ 99.7 \% & 55.5\end{array}$

$167 \quad 0.19 \% \quad 54.4 \%$ QGSPVAAGAPAK

$99.7 \% 55.5$ 48

.

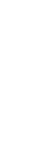

6
8

8
8

.

$167 \quad 0.19 \% \quad 54.4 \%$ QGSPVAAGAPAKQQQVDIPLR

$167 \quad 0.19 \% \quad 54.4 \%$ QQQVDIPLR

$167 \quad 0.19 \% \quad 54.4 \%$ LLVPTQYVGAIIGK

$167 \quad 0.19 \% \quad 54.4 \%$ AISVHSTPEGCSSACK

$167 \quad 0.19 \% \quad 54.4 \%$ MILEIMHK

$167 \quad 0.19 \% \quad 54.4 \%$ DTKTADEVPLK

$167 \quad 0.19 \% \quad 54.4 \%$ TADEVPLK

$167 \quad 0.19 \% \quad 54.4 \%$ TADEVPLKILAHNNFVGR

$167 \quad 0.19 \% \quad 54.4 \%$ ILAHNNFVGR

$167 \quad 0.19 \% \quad 54.4 \%$ ITISSLQDLTLYNPER

$167 \quad 0.19 \% \quad 54.4 \%$ GQHIKQLSR

$167 \quad 0.19 \% \quad 54.4 \%$ IAPPETPDSK

$167 \quad 0.19 \% \quad 54.4 \%$ IAPPETPDSKVR

$167 \quad 0.19 \% \quad 54.4 \%$ MVIITGPPEAQFK

$167 \quad 0.19 \% \quad 54.4 \%$ MVIITGPPEAQFKAQGR

$167 \quad 0.19 \% \quad 54.4 \%$ LKEENFFGPK

$167 \quad 0.19 \% \quad 54.4 \%$ LETHIRVPASAAGR

$167 \quad 0.19 \% \quad 54.4 \% \quad$ TVNELQNLTAAEVVVPR

$167 \quad 0.19 \% \quad 54.4 \%$ DQTPDENDQVIVK

$167 \quad 0.19 \% \quad 54.4 \%$ IIGHFYASQMAQR

$167 \quad 0.19 \% \quad 54.4 \%$ IIGHFYASQMAQRK

$167 \quad 0.19 \% \quad 54.4 \%$ IRDILAQVK

$15 \quad 0.02 \% \quad 19.5 \%$ KLPLAGQVLLK

$0.02 \% \quad 19.5 \%$ GDHSSREQGHAPGGTSQAR

$5 \quad 0.02 \% \quad 19.5 \%$ ILVPTQFVGAIIGK

$15 \quad 0.02 \% \quad 19.5 \%$ IAPAEGPDVSER

$15 \quad 0.02 \% \quad 19.5 \%$ MVIITGPPEAQFK

$15 \quad 0.02 \% \quad 19.5 \%$ MVIITGPPEAQFKAQGR

$15 \quad 0.02 \% \quad 19.5 \% \quad$ TVNELQNLTSAEVIVPR

$15 \quad 0.02 \% \quad 19.5 \%$ IIGHFFASQTAQR

$15 \quad 0.02 \% \quad 19.5 \%$ QQEQKYPQGVASQR

$24 \quad 0.03 \% \quad 19.9 \%$ IPVSGPFLVK

$24 \quad 0.03 \% \quad 19.9 \%$ LLVPTQFVGAIIGK

$\begin{array}{llll}10 & 24 & 0.03 \% & 19.9 \% \\ 10 & 24 & 0.03 \% & 19.9 \%\end{array}$

$10 \quad 24 \quad 0.03 \% \quad 19.9 \%$ ILAHNNFVGR

$10 \quad 24 \quad 0.03 \% \quad 19.9 \%$ IAPAEAPDAK

$10 \quad 24 \quad 0.03 \% \quad 19.9 \%$ IAPAEAPDAKVR

$10 \quad 24 \quad 0.03 \% \quad 19.9 \%$ MVIITGPPEAQFK

$10 \quad 24 \quad 0.03 \% \quad 19.9 \%$ MVIITGPPEAQFKAQGR

$10 \quad 24 \quad 0.03 \% \quad 19.9 \%$ DQTPDENDQVVVK

$10 \quad 24 \quad 0.03 \% \quad 19.9 \%$ ITGHFYACQVAQR $\begin{array}{llll}9.7 \% & 44.1 & 25.0 & 44.1\end{array}$

$\begin{array}{llll}99.7 \% & 53.5 & 25.0 & 53.5\end{array}$

$\begin{array}{llll}99.0 \% & 34.0 & 25.0 & 21.5\end{array}$

$\begin{array}{llll}99.7 \% & 36.9 & 25.0 & 24.9\end{array}$

$\begin{array}{llll}99.0 \% & 37.8 & 25.0 & 21.4\end{array}$

$\begin{array}{llll}99.7 \% & 31.0 & 25.0 & 30.7\end{array}$

$\begin{array}{llll}99.7 \% & 51.1 & 25.0 & 50.7\end{array}$

$\begin{array}{lllll}99.7 \% & 54.2 & 25.0 & 47.6 & 2\end{array}$

$99.7 \% \quad 35.5 \quad 25.0 \quad 30.1$

$98.1 \% \quad 17.0 \quad 25.0 \quad 17.0 \quad 3$

$\begin{array}{llll}99.7 \% & 49.2 & 25.0 & 44.0\end{array}$

$99.7 \% \quad 53.3 \quad 25.0 \quad 43.6$

$\begin{array}{llll}99.7 \% & 53.6 & 25.0 & 53.3\end{array}$

$99.7 \% \quad 32.2 \quad 25.0 \quad 29.1$

$\begin{array}{llll}99.7 \% & 38.5 & 25.0 & 36.4\end{array}$

$\begin{array}{llll}99.7 \% & 45.3 & 25.0 & 44.6\end{array}$

$\begin{array}{llll}99.7 \% & 45.5 & 25.0 & 37.0\end{array}$

$\begin{array}{llll}99.7 \% & 55.8 & 25.0 & 49.8\end{array}$

$\begin{array}{llll}99.5 \% & 23.5 & 25.0 & 22.8\end{array}$

$99.7 \% \quad 46.8 \quad 25.0 \quad 28.0$

$\begin{array}{lllll}99.7 \% & 29.1 & 25.0 & 21.6 & 2\end{array}$

$\begin{array}{llll}99.7 \% & 36.6 & 25.0 & 36.6\end{array}$

$\begin{array}{cccc}99.7 \% & 47.7 & 25.0 & 44.8\end{array}$

$99.7 \% \quad 53.3 \quad 25.0 \quad 43.6$

$\begin{array}{lllll}99.7 \% & 53.6 & 25.0 & 53.3 & 4\end{array}$

$\begin{array}{lllll}99.7 \% & 51.4 & 25.0 & 46.5 & 2\end{array}$

$\begin{array}{llll}99.7 \% & 51.4 & 25.0 & 49.1\end{array}$

$\begin{array}{llll}98.2 \% & 18.6 & 25.0 & 18.6\end{array}$

$99.7 \% \quad 30.9 \quad 25.0 \quad 29.8$

$\begin{array}{lllll}99.0 \% & 42.4 & 25.0 & 0.0 & 4\end{array}$

$\begin{array}{lllll}99.7 \% & 51.0 & 25.0 & 42.7 & 4\end{array}$

$\begin{array}{llll}99.7 \% & 51.1 & 25.0 & 50.7\end{array}$

$\begin{array}{lllll}99.7 \% & 37.3 & 25.0 & 37.3 & 2\end{array}$

$\begin{array}{lllll}99.7 \% & 50.4 & 25.0 & 46.2 & 3\end{array}$

$\begin{array}{lllll}99.7 \% & 53.3 & 25.0 & 43.6 & 9\end{array}$

$\begin{array}{lllll}99.7 \% & 53.6 & 25.0 & 53.3 & 4\end{array}$

$\begin{array}{llll}99.7 \% & 53.3 & 25.0 & 45.5\end{array}$

$\begin{array}{llll}99.7 \% & 57.7 & 25.0 & 52.2\end{array}$
1506.82

506.82

207.68

1373.73

1872.91

2029.01

1053.57

2131.16

1096.61

1471.89

1690.75

1014.55

1216.64

872.47

1994.08

1140.63

1862.99

1066.61

1054.54

1309.71

1430.77

1842.99

1208.63

1477.82

1853.01

1500.72

1521.76

1649.86

1055.66

1179.78

1934.88

1455.89

1240.62

1430.77

1842.99

1883.02

1475.78

1646.82

1056.65

1455.89

1635.83

1140.63

982.52

1237.69

1430.77

1842.99

1486.70

1550.75

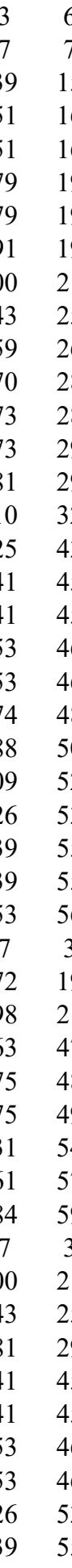


Insulin-like growth factor 2 mRNA-binding protein 3 GN=IGF2BP3 IF2B3_HUMAN $63.71 \quad 100.0 \%$ Integrator complex subunit $1 \mathrm{GN}=\mathrm{INTS} 1 \quad$ INT1_HUMAN $244.30 \quad 100.0 \%$ Integrator complex subunit $1 \mathrm{GN}=\mathrm{INTS} 1 \quad$ INT1_HUMAN $244.30 \quad 100.0 \%$ Integrator complex subunit $1 \mathrm{GN}=\mathrm{INTS} 1 \quad$ INT1_HUMAN $244.30 \quad 100.0 \%$ Integrator complex subunit $1 \mathrm{GN}=\mathrm{INTS} 1$ INT1_HUMAN $244.30 \quad 100.0 \%$ Integrator complex subunit $1 \mathrm{GN}=\mathrm{INTS} 1 \quad$ INT1_HUMAN $244.30 \quad 100.0 \%$ Integrator complex subunit $1 \mathrm{GN}=\mathrm{INTS} 1 \quad$ INT1_HUMAN $244.30 \quad 100.0 \%$ Integrator complex subunit $1 \mathrm{GN}=\mathrm{INTS} 1 \quad$ INT1_HUMAN $244.30 \quad 100.0 \%$ Integrator complex subunit $1 \mathrm{GN}=\mathrm{INTS} 1 \quad$ INT1_HUMAN $244.30 \quad 100.0 \%$ Integrator complex subunit $1 \mathrm{GN}=\mathrm{INTS} 1 \quad$ INT1_HUMAN $244.30 \quad 100.0 \%$ Integrator complex subunit $1 \mathrm{GN}=\mathrm{INTS} 1 \quad$ INT1_HUMAN $244.30 \quad 100.0 \%$ Integrator complex subunit $1 \mathrm{GN}=\mathrm{INTS} 1 \quad$ INT1_HUMAN $244.30 \quad 100.0 \%$ $\begin{array}{llll}\text { Interferon-induced, double-stranded RNA-activated protein kinase GN=EIF2AK2 } & \text { E2AK2_HUMAN } & 62.10 & 100.0 \% \\ \text { Interferon-induced, double-stranded RNA-activated protein kinase GN=EIF2AK2 } & \text { E2AK2_HUMAN } & 62.10 & 100.0 \%\end{array}$ Interferon-induced, double-stranded RNA-activated protein kinase GN=EIF2AK2 E2AK2_HUMAN $62.10 \quad 100.0 \%$ Interferon-inducible double-stranded RNA-dependent protein kinase activator A GN=PRKRA PRKRA_HUMAN $34.41 \quad 100.0 \%$ 列 $\begin{array}{lll} & \end{array}$ RARRA_HUMAN $34.41 \quad 100.0 \%$ RA PRKRA_HUMAN $34.41 \quad 100.0 \%$ PRERA_HUMAN $34.41 \quad 100.0 \%$ A PRKRA_HUMAN $34.41 \quad 100.0 \%$ RRA PRKRA_HUMAN $34.41 \quad 100.0 \%$ PRKRA_HUMAN $34.41 \quad 100.0 \%$ PRKRA_HUMAN $34.41 \quad 100.0 \%$ PRKRA_HUMAN $34.41 \quad 100.0 \%$ PRKRA_HUMAN $34.41 \quad 100.0 \%$

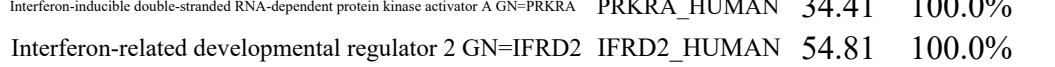
Interferon-related developmental regulator $2 \mathrm{GN}=\mathrm{IFRD} 2 \mathrm{IFRD} 2$ HUMAN $54.81 \quad 100.0 \%$ Interleukin enhancer-binding factor $2 \mathrm{GN}=\mathrm{ILF} 2$ ILF2_HUMAN $43.06 \quad 100.0 \% \quad 20$ Interleukin enhancer-binding factor 2 GN=ILF2 ILF2_HUMAN $43.06 \quad 100.0 \% \quad 2$ Interleukin enhancer-binding factor $2 \mathrm{GN}=\mathrm{ILF} 2$ ILF2_HUMAN $43.06 \quad 100.0 \% \quad 20$ Interleukin enhancer-binding factor 2 GN=ILF2 ILF2_HUMAN $43.06 \quad 100.0 \% \quad 20$ Interleukin enhancer-binding factor 2 GN=ILF2 ILF2_HUMAN $43.06 \quad 100.0 \% 20$ Interleukin enhancer-binding factor 2 GN=ILF2 ILF2_HUMAN $43.06 \quad 100.0 \% \quad 20$ Interleukin enhancer-binding factor 2 GN=ILF2 ILF2_HUMAN $43.06 \quad 100.0 \% \quad 20$ Interleukin enhancer-binding factor $2 \mathrm{GN}=\mathrm{ILF} 2 \mathrm{ILF} 2 \mathrm{HUMAN} \quad 43.06 \quad 100.0 \%$ Interleukin enhancer-binding factor 2 GN=ILF2 ILF2_HUMAN $43.06 \quad 100.0 \% \quad 20$ Interleukin enhancer-binding factor 2 GN=ILF2 ILF2_HUMAN $43.06 \quad 100.0 \%$ Interleukin enhancer-binding factor 2 GN=ILF2 ILF2_HUMAN $43.06 \quad 100.0 \% \quad 2$ Interleukin enhancer-binding factor 2 GN=ILF2 ILF2_HUMAN $43.06 \quad 100.0 \%$ Interleukin enhancer-binding factor 2 GN=ILF2 ILF2_HUMAN $43.06 \quad 100.0 \%$ Interleukin enhancer-binding factor $2 \mathrm{GN}=\mathrm{ILF} 2 \mathrm{ILF} 2$ _HUMAN $43.06 \quad 100.0 \% \quad 20$ Interleukin enhancer-binding factor 2 GN=ILF2 ILF2_HUMAN $43.06 \quad 100.0 \%$ Interleukin enhancer-binding factor 2 GN=ILF2 ILF2 HUMAN $43.06 \quad 100.0 \%$ Interleukin enhancer-binding factor 2 GN=ILF2 ILF2_HUMAN $43.06 \quad 100.0 \% \quad 20$

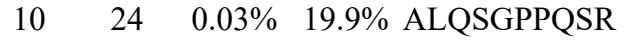

$0.02 \% \quad 5.3 \%$ LAEAAVAEKR

$0.02 \% \quad 5.3 \%$ SVLLQGEAGR

$0.02 \% \quad 5.3 \%$ RQPIDNVSR

$0.02 \% \quad 5.3 \% \quad$ SFQNQIAAIQR

$0.02 \% \quad 5.3 \% \quad$ ILVIGLSR

$0.02 \% \quad 5.3 \%$ AAAVQADDVEVLK

$0.02 \% \quad 5.3 \%$ LQDLLLGPK

$0.02 \% \quad 5.3 \%$ LGSSQVASR

$0.02 \% \quad 5.3 \% \quad$ SSPEQPIGQGR

$0.02 \% \quad 5.3 \%$ SQDGDTAACSLIQAR

$0.02 \% \quad 5.3 \% \quad$ LMSSAEECCR

$0.01 \% \quad 6.7 \%$ LAVEILNKEK

$0.01 \% \quad 6.7 \% \quad$ LAYLQILSEETSVK

$0.01 \% \quad 6.7 \%$ DLKPSNIFLVDTK

$0.06 \% \quad 41.9 \%$ HRAEAPPLER

$0.06 \% \quad 41.9 \%$ EDSGTFSLGK

$0.06 \% \quad 41.9 \%$ TPIQVLHEYGMK

$0.06 \% \quad 41.9 \%$ NIPVYECER

$0.06 \% \quad 41.9 \%$ SDVQIHVPTFTFR

$0.06 \% \quad 41.9 \%$ VTVGDITCTGEGTSK

$0.06 \% \quad 41.9 \%$ VTVGDITCTGEGTSKK

$0.06 \% \quad 41.9 \%$ AAEAAINILK

$0.06 \% \quad 41.9 \%$ ANASICFAVPDPLMPDP

$0.06 \% \quad 41.9 \%$ LPEYTLSQEGGPAHK

$0.06 \% \quad 41.9 \%$ LPEYTLSQEGGPAHKR

$0.06 \% \quad 41.9 \%$ REYTTICR

$0.06 \% \quad 41.9 \%$ LESFMETGK

$0.00 \% \quad 4.4 \% \quad$ LLPDFLLER

$0.00 \% \quad 4.4 \% \quad$ LPQLLSSESVNLR

$138 \quad 0.16 \% \quad 48.2 \%$ VKPAPDETSFSEALLK

$138 \quad 0.16 \% \quad 48.2 \%$ VKPAPDETSFSEALLKR

$0.16 \% \quad 48.2 \%$ RNQDLAPNSAEQASILSLVTK $99.7 \% 66.6$

138

$138 \quad 0.16 \% \quad 48.2 \%$ GTMTTGHNVADLVVILK $99.7 \% \quad 56.3$

$138 \quad 0.16 \% \quad 48.2 \%$ ILPTLEAVAALGNK

$99.7 \% \quad 60.3$

KVVESLR $99.7 \% \quad 46.3$

$138 \quad 0.16 \% \quad 48.2 \%$ AQDPSEVLTMLTNETGFEISSSDATVK $\quad 99.7 \% \quad 46.3$

$138 \quad 0.16 \% \quad 48.2 \%$ ILITTVPPNLR

$138 \quad 0.16 \% \quad 48.2 \%$ ILITTVPPNLRK

$138 \quad 0.16 \% \quad 48.2 \%$ KLDPELHLDIK

$138 \quad 0.16 \% \quad 48.2 \%$ LDPELHLDIK

$138 \quad 0.16 \% \quad 48.2 \%$ VLQSALAAIR

$138 \quad 0.16 \% \quad 48.2 \%$ WFEENASQSTVK

$138 \quad 0.16 \% \quad 48.2 \%$ QPLALNVAYR

$138 \quad 0.16 \% \quad 48.2 \%$ QPLALNVAYRR

\section{$99.7 \% \quad 43.5$}

$99.4 \% \quad 21.5$

$99.7 \% \quad 54.9$

$99.7 \% \quad 38.3$

$99.7 \% \quad 65.5$

$99.7 \% \quad 58.4$

$99.7 \% \quad 46.8$

$99.5 \% \quad 23.5$
1040.55

1057.60

1029.57

1084.59

1275.68

870.58

1328.71

996.61

904.48

1155.58

1592.73

1242.49

1156.69

1593.87

1489.83

1175.63

1040.49

1431.73

1179.55

1546.80

1524.72

1652.82

1013.60

2029.97

1626.81

1782.91

1098.54

1057.49

1115.65

1455.82

1731.92

1888.02

2255.20

2099.10

1897.06

1768.96

1409.84

2093.23

2886.36

1236.77

1364.86

1320.75

1192.66

1041.64

1425.66

1144.65

1300.75 $\begin{array}{cc}68 & 577 \\ 92 & 101 \\ 65 & 274 \\ 40 & 348 \\ 77 & 587 \\ 56 & 663 \\ 83 & 695 \\ 54 & 962 \\ 79 & 987 \\ 326 & 1336 \\ 747 & 1761 \\ 091 & 2100 \\ 70 & 79 \\ 60 & 173 \\ 14 & 426 \\ 6 & 15 \\ 16 & 25 \\ 34 & 45 \\ 48 & 56 \\ 57 & 69 \\ 70 & 84 \\ 70 & 85 \\ 91 & 100 \\ 01 & 119 \\ 42 & 156 \\ 42 & 157 \\ 57 & 164 \\ 65 & 173 \\ 71 & 179 \\ 29 & 341 \\ 44 & 59 \\ 44 & 60 \\ 60 & 80 \\ 61 & 80 \\ 10 & 127 \\ 11 & 127 \\ 28 & 141 \\ 28 & 147 \\ 48 & 174 \\ 75 & 185 \\ 75 & 186 \\ 86 & 196 \\ 87 & 196 \\ 97 & 206 \\ 10 & 221 \\ 60 & 269 \\ 60 & 270\end{array}$

Page 85 of Table S-1-6 
Interleukin enhancer-binding factor 2 GN=ILF2 ILF2_HUMAN $43.06 \quad 100.0 \% \quad 20$ Interleukin enhancer-binding factor 2 GN=ILF2 ILF2_HUMAN $43.06 \quad 100.0 \% \quad 20$ Interleukin enhancer-binding factor 2 GN=ILF2 ILF2_HUMAN $43.06 \quad 100.0 \% 20$ Interleukin enhancer-binding factor $3 \mathrm{GN}=\mathrm{ILF} 3 \mathrm{ILF} 3$ HUMAN $95.34 \quad 100.0 \%$ Interleukin enhancer-binding factor $3 \mathrm{GN}=\mathrm{ILF} 3 \mathrm{ILF} 3$ _HUMAN $95.34 \quad 100.0 \% \quad 29$ Interleukin enhancer-binding factor 3 GN=ILF3 ILF3_HUMAN $95.34 \quad 100.0 \% 29$ Interleukin enhancer-binding factor 3 GN=ILF3 ILF3_HUMAN $95.34 \quad 100.0 \% 29$ Interleukin enhancer-binding factor $3 \mathrm{GN}=\mathrm{ILF} 3$ ILF3_HUMAN $95.34 \quad 100.0 \% \quad 29$ Interleukin enhancer-binding factor $3 \mathrm{GN}=\mathrm{ILF} 3 \mathrm{ILF} 3$ HUMAN $95.34 \quad 100.0 \%$ Interleukin enhancer-binding factor $3 \mathrm{GN}=\mathrm{ILF} 3 \mathrm{ILF} 3$ _HUMAN $95.34 \quad 100.0 \% \quad 29$ Interleukin enhancer-binding factor 3 GN=ILF3 ILF3_HUMAN $95.34 \quad 100.0 \% 29$ Interleukin enhancer-binding factor 3 GN=ILF3 ILF3_HUMAN $95.34 \quad 100.0 \% 29$ Interleukin enhancer-binding factor $3 \mathrm{GN}=\mathrm{ILF} 3 \mathrm{ILF} 3$ _HUMAN $95.34 \quad 100.0 \% \quad 29$ Interleukin enhancer-binding factor 3 GN=ILF3 ILF3_HUMAN $95.34 \quad 100.0 \% \quad 29$ Interleukin enhancer-binding factor 3 GN=ILF3 ILF3_HUMAN $95.34 \quad 100.0 \% 29$ Interleukin enhancer-binding factor 3 GN=ILF3 ILF3_HUMAN $95.34 \quad 100.0 \% \quad 29$ Interleukin enhancer-binding factor $3 \mathrm{GN}=$ ILF3 ILF3 HUMAN $95.34 \quad 100.0 \%$ Interleukin enhancer-binding factor $3 \mathrm{GN}=\mathrm{ILF} 3 \mathrm{ILF} 3$ _HUMAN $95.34 \quad 100.0 \% \quad 29$ Interleukin enhancer-binding factor 3 GN=ILF3 ILF3_HUMAN $95.34 \quad 100.0 \% 29$ Interleukin enhancer-binding factor 3 GN=ILF3 ILF3_HUMAN $95.34 \quad 100.0 \% 29$ Interleukin enhancer-binding factor $3 \mathrm{GN}=\mathrm{ILF} 3 \mathrm{ILF} 3$ _HUMAN $95.34 \quad 100.0 \% \quad 29$ Interleukin enhancer-binding factor $3 \mathrm{GN}=$ ILF3 ILF3_HUMAN $95.34 \quad 100.0 \%$ Interleukin enhancer-binding factor 3 GN=ILF3 ILF3_HUMAN $95.34 \quad 100.0 \% \quad 29$ Interleukin enhancer-binding factor $3 \mathrm{GN}=$ ILF3 ILF3_HUMAN $95.34 \quad 100.0 \%$ Interleukin enhancer-binding factor $3 \mathrm{GN}=\mathrm{ILF} 3 \mathrm{ILF} 3$ HUMAN $95.34 \quad 100.0 \%$ Interleukin enhancer-binding factor 3 GN=ILF3 ILF3_HUMAN $95.34 \quad 100.0 \% \quad 29$ Interleukin enhancer-binding factor $3 \mathrm{GN}=$ ILF3 ILF3_HUMAN $95.34 \quad 100.0 \%$ Interleukin enhancer-binding factor $3 \mathrm{GN}=$ ILF3 ILF3_HUMAN $95.34 \quad 100.0 \%$ Interleukin enhancer-binding factor $3 \mathrm{GN}=\mathrm{ILF} 3 \mathrm{ILF} 3$ _HUMAN $95.34 \quad 100.0 \%$ Interleukin enhancer-binding factor $3 \mathrm{GN}=\mathrm{ILF} 3$ ILF3 HUMAN $95.34 \quad 100.0 \%$ Interleukin enhancer-binding factor $3 \mathrm{GN}=\mathrm{ILF} 3 \mathrm{ILF} 3$ _HUMAN $95.34 \quad 100.0 \% 29$ Interleukin enhancer-binding factor $3 \mathrm{GN}=$ ILF3 ILF3_HUMAN $95.34 \quad 100.0 \% 29$ $\begin{array}{llll}\text { Intron-binding protein aquarius } \mathrm{GN}=\mathrm{AQR} & \mathrm{AQR} \text { HUMAN } & 171.30 & 100.0 \%\end{array}$ Intron-binding protein aquarius GN=AQR AQR_HUMAN $171.30 \quad 100.0 \%$ Isocitrate dehydrogenase [NAD] subunit alpha, mitochondrial GN=IDH3A IDH3A_HUMAN $39.59 \quad 100.0 \%$ Isocitrate dehydrogenase [NAD] subunit alpha, mitochondrial GN=IDH3A IDH3A_HUMAN $39.59 \quad 100.0 \%$ Isocitrate dehydrogenase [NAD] subunit alpha, mitochondrial GN=IDH3A IDH3A_HUMAN 39.59 Isocitrate dehydrogenase $[\mathrm{NAD}]$ subunit alpha mitochondrial $\mathrm{GN}=[\mathrm{DH} 3 \mathrm{~A}$ IDH3A_HUMAN 39.59 Isocitrate dehydrogenase [NAD] subunit alpha, mitochondrial GN=IDH3A IDH3A_HUMAN 39.59 Isocitrate dehydrogenase [NAD] subunit alpha, mitochondrial GN=IDH3A IDH3A_HUMAN 39.59 Isocitrate dehydrogenase [NAD] subunit alpha, mitochondrial GN=IDH3A IDH3A_HUMAN 39.59 Isocitrate dehydrogenase [NAD] subunit alpha, mitochondrial GN=IDH3A IDH3A_HUMAN 39.59 Isocitrate dehydrogenase [NAD] subunit alpha, mitochondrial GN=IDH3A IDH3A_HUMAN 39.59 Isocitrate dehydrogenase [NAD] subunit beta, mitochondrial GN=IDH3B IDH3B_HUMAN 42.18 Isocitrate dehydrogenase [NAD] subunit beta, mitochondrial GN=IDH3B IDH3B_HUMAN 42.18
35 35
35

42
42

42

42

42
42

42

4

42

42

42
42
42

4

42
42

42
42

42
42
42

42

42

42

4

42

10

1
10
10

1

11
11
11

11
$\% \%$

$38 \quad 0.16 \% \quad 48.2 \%$ ILSHGGFR

$38 \quad 0.16 \% \quad 48.2 \%$ ILSHGGFRK

$84 \quad 0.21 \% \quad 34.2 \%$ IFVNDDRHVMAK

34.2\% GDLDLELVLLCK

$184 \quad 0.21 \% \quad 34.2 \%$ EKPTTALLDK

$184 \quad 0.21 \% \quad 34.2 \%$ VLAGETLSVNDPPDVLDR

$184 \quad 0.21 \% \quad 34.2 \%$ CLAALASLR

$184 \quad 0.21 \% \quad 34.2 \%$ ANGLKSCVIVIR

$184 \quad 0.21 \% \quad 34.2 \%$ SIGTANRPMGAGEALR

$184 \quad 0.21 \% \quad 34.2 \%$ SIGTANRPMGAGEALRR

$184 \quad 0.21 \% \quad 34.2 \%$ EATDAIGHLDR

$184 \quad 0.21 \% \quad 34.2 \%$ QQREDITQSAQHALR

$184 \quad 0.21 \% \quad 34.2 \%$ EDITQSAQHALR

$184 \quad 0.21 \% \quad 34.2 \%$ LAAFGQLHK

$184 \quad 0.21 \% \quad 34.2 \%$ VLGMDPLPSK

$184 \quad 0.21 \% \quad 34.2 \%$ VLGMDPLPSKMPK

$184 \quad 0.21 \% \quad 34.2 \%$ RPMEEDGEEKSPSK

$184 \quad 0.21 \% \quad 34.2 \%$ LNQLKPGLQYK

$184 \quad 0.21 \% \quad 34.2 \%$ TAKLHVAVK

$184 \quad 0.21 \% \quad 34.2 \%$ VLQDMGLPTGAEGR

$184 \quad 0.21 \% \quad 34.2 \%$ HGKNPVMELNEK

$184 \quad 0.21 \% \quad 34.2 \%$ NPVMELNEK

$184 \quad 0.21 \% \quad 34.2 \%$ GLKYELISETGGSHDK

$184 \quad 0.21 \% \quad 34.2 \%$ YELISETGGSHDKR

$84 \quad 0.21 \% \quad 34.2 \%$ FVMEVEVDGQK

$184 \quad 0.21 \% \quad 34.2 \%$ VAKAYAALAALEK

$184 \quad 0.21 \% \quad 34.2 \%$ AYAALAALEK

$184 \quad 0.21 \% \quad 34.2 \%$ LFPDTPLALDANK

$184 \quad 0.21 \% \quad 34.2 \%$ FNYSGSGGR

$184 \quad 0.21 \% \quad 34.2 \%$ SGGNSYGSGGASYNPGSHGGYGGG

$184 \quad 0.21 \% \quad 34.2 \%$ NADHSMNYQYR

$0.00 \% \quad 1.6 \% \quad$ YSNMEQSLFTR

$3 \quad 0.00 \% \quad 1.6 \%$ VGVPTVDLDAQGR

$19 \quad 0.02 \% \quad 24.3 \%$ NVTAIQGPGGK

$19 \quad 0.02 \% \quad 24.3 \%$ TPIAAGHPSMNLLLR

$19 \quad 0.02 \% \quad 24.3 \%$ TPYTDVNIVTIR

$19 \quad 0.02 \% \quad 24.3 \%$ LITEGASKR

$19 \quad 0.02 \% \quad 24.3 \%$ IAEFAFEYAR

$19 \quad 0.02 \% \quad 24.3 \%$ MSDGLFLQK

$19 \quad 0.02 \% \quad 24.3 \%$ IEAACFATIK

$19 \quad 0.02 \% \quad 24.3 \%$ IEAACFATIKDGK

$19 \quad 0.02 \% \quad 24.3 \%$ CSDFTEEICR

$0.04 \% \quad 26.5 \%$ GELASYDMR

$0.04 \% \quad 26.5 \%$ SLPGYMTR

$0.04 \% \quad 26.5 \%$ HNNLDLVIIR

$0.04 \% \quad 26.5 \%$ EQTEGEYSSLEHESAR
$99.0 \%$

$99.3 \% \quad 28.1$

$99.7 \% \quad 57.3$

$99.7 \% \quad 45.6$

$96.5 \% 21.2$

$99.7 \% \quad 57$.

$99.7 \% \quad 61.1$

$99.1 \% \quad 37.8$

$99.3 \% \quad 21.1$

$99.7 \% \quad 60.7$

$99.7 \% \quad 55.2$

$99.7 \% \quad 58.7$

$99.7 \% \quad 45.3$

$99.7 \% \quad 42.6$

$97.5 \% \quad 16.3$

$99.7 \% \quad 28.0$

$99.7 \% \quad 48.3$

$99.7 \% \quad 42.0$

$99.7 \% \quad 53.0$

$99.7 \% \quad 30.6$

$99.7 \% \quad 38.4$

$99.0 \% \quad 24.4$

$99.7 \% \quad 32.0$

$99.7 \% \quad 40.1$

$\begin{array}{lll}99.7 \% & 29.4\end{array}$

$99.7 \% \quad 59.1$

$\begin{array}{lll}99.7 \% & 50.8\end{array}$

$99.7 \% \quad 36.1$

$99.7 \% \quad 53.0$

$\begin{array}{lll}99.7 \% & 44.3\end{array}$

$98.6 \% \quad 26.2$

$99.7 \% \quad 61.9$

$99.7 \% \quad 47.8$

$99.7 \% \quad 42.7$

$99.7 \% \quad 68.4$

$99.7 \% \quad 39.3$

$99.7 \% \quad 67.3$

$\begin{array}{lll}99.7 \% & 35.3\end{array}$

$99.7 \% \quad 62.1$

$99.7 \% \quad 66.8$

$99.7 \% \quad 54.2$

$99.5 \% \quad 25.2$

$95.5 \% \quad 15.3$

$99.7 \% \quad 60.8$

$99.7 \% \quad 53.0$ $\begin{array}{ll}0 & 53.5\end{array}$

\begin{tabular}{l}
04.6 \\
\hline
\end{tabular}

$\begin{array}{ll}0 & 11.2\end{array}$

57.1
25.0

$\begin{array}{ll}0.0 & 0.0 \\ & \end{array}$

$\begin{array}{ll}0.0 & 20.1\end{array}$

\begin{tabular}{ll}
31.5 \\
\hline
\end{tabular}

$\begin{array}{ll}53.0 & 43.0\end{array}$

51.0

$\begin{array}{ll}25.0 & 46.3\end{array}$

52.0
25.0

$\begin{array}{ll}0 & 15.6\end{array}$

$\begin{array}{lll} & 35.7 & 12\end{array}$

35.7
41.2

\begin{tabular}{ll}
49.7 \\
\hline
\end{tabular}

$\begin{array}{ll}0 & 30.6\end{array}$

24.0
25.0

$\begin{array}{ll}0 & 29.6\end{array}$

0
29.6

$\begin{array}{ll}29.0 & 29.4\end{array}$

$\begin{array}{ll}.0 & 44.7\end{array}$

$\begin{array}{ll}25.0 & 49.7\end{array}$

$\begin{array}{ll}.0 & 28.8\end{array}$

\begin{tabular}{ll}
53.0 \\
\hline
\end{tabular}

$\begin{array}{ll}5.0 & 44.3\end{array}$

$\begin{array}{ll}26.0 & 26.2\end{array}$

\begin{tabular}{ll}
52.5 \\
\hline
\end{tabular}

\begin{tabular}{ll}
57.5 \\
\hline
\end{tabular}

\begin{tabular}{ll}
60.3 \\
\hline
\end{tabular}

\begin{tabular}{ll}
25.0 & 60.5 \\
\hline
\end{tabular}

\begin{tabular}{ll}
5.0 & 24.5 \\
\hline &
\end{tabular}

15
15

$\begin{array}{ccccc}25.0 & 49.3 & 0 & 4 & 0 \\ 25.0 & 27.1 & 3 & 0 & 0 \\ 25.0 & 13.5 & 4 & 0 & 0 \\ 25.0 & 53.5 & 5 & 15 & 0 \\ 25.0 & 45.6 & 6 & 0 & 0 \\ 25.0 & 11.2 & 1 & 0 & 0 \\ 25.0 & 57.1 & 6 & 0 & 0 \\ 25.0 & 46.9 & 6 & 0 & 0 \\ 25.0 & 0.0 & 3 & 0 & 0 \\ 25.0 & 20.1 & 0 & 1 & 0 \\ 25.0 & 31.5 & 0 & 6 & 0 \\ 25.0 & 43.0 & 4 & 0 & 0 \\ 25.0 & 51.9 & 0 & 8 & 0 \\ 25.0 & 46.3 & 5 & 4 & 0 \\ 25.0 & 35.0 & 10 & 0 & 0 \\ 25.0 & 42.0 & 7 & 0 & 0 \\ 25.0 & 15.6 & 2 & 1 & 0 \\ 25.0 & 28.0 & 0 & 2 & 0 \\ 25.0 & 35.7 & 12 & 8 & 0 \\ 25.0 & 41.2 & 4 & 0 & 0 \\ 25.0 & 49.7 & 11 & 0 & 0 \\ 25.0 & 30.6 & 1 & 6 & 0 \\ 25.0 & 32.3 & 2 & 0 & 0 \\ 25.0 & 24.4 & 0 & 2 & 0 \\ 25.0 & 29.6 & 1 & 2 & 0 \\ 25.0 & 29.6 & 4 & 0 & 0 \\ 25.0 & 29.4 & 1 & 0 & 0 \\ 25.0 & 44.7 & 17 & 0 & 0 \\ 25.0 & 49.7 & 3 & 0 & 0 \\ 25.0 & 28.8 & 2 & 0 & 0 \\ 25.0 & 53.0 & 0 & 5 & 0 \\ 25.0 & 44.3 & 5 & 6 & 0 \\ 25.0 & 26.2 & 1 & 0 & 0 \\ 25.0 & 52.5 & 2 & 0 & 0 \\ 25.0 & 47.5 & 2 & 0 & 0 \\ 25.0 & 37.3 & 2 & 2 & 0 \\ 25.0 & 60.3 & 2 & 0 & 0 \\ 25.0 & 28.6 & 2 & 0 & 0 \\ 25.0 & 60.5 & 2 & 0 & 0 \\ 25.0 & 24.5 & 2 & 0 & 0 \\ 25.0 & 55.0 & 2 & 0 & 0 \\ 25.0 & 62.8 & 2 & 0 & 0 \\ 25.0 & 50.0 & 1 & 0 & 0 \\ 25.0 & 25.2 & 1 & 0 & 0 \\ 25.0 & 14.4 & 1 & 0 & 0 \\ 25.0 & 49.2 & 2 & 0 & 0 \\ & 51.9 & 2 & 2 & 0 \\ 25 & & & \end{array}$

$\begin{array}{ccccc}25.0 & 49.3 & 0 & 4 & 0 \\ 25.0 & 27.1 & 3 & 0 & 0 \\ 25.0 & 13.5 & 4 & 0 & 0 \\ 25.0 & 53.5 & 5 & 15 & 0 \\ 25.0 & 45.6 & 6 & 0 & 0 \\ 25.0 & 11.2 & 1 & 0 & 0 \\ 25.0 & 57.1 & 6 & 0 & 0 \\ 25.0 & 46.9 & 6 & 0 & 0 \\ 25.0 & 0.0 & 3 & 0 & 0 \\ 25.0 & 20.1 & 0 & 1 & 0 \\ 25.0 & 31.5 & 0 & 6 & 0 \\ 25.0 & 43.0 & 4 & 0 & 0 \\ 25.0 & 51.9 & 0 & 8 & 0 \\ 25.0 & 46.3 & 5 & 4 & 0 \\ 25.0 & 35.0 & 10 & 0 & 0 \\ 25.0 & 42.0 & 7 & 0 & 0 \\ 25.0 & 15.6 & 2 & 1 & 0 \\ 25.0 & 28.0 & 0 & 2 & 0 \\ 25.0 & 35.7 & 12 & 8 & 0 \\ 25.0 & 41.2 & 4 & 0 & 0 \\ 25.0 & 49.7 & 11 & 0 & 0 \\ 25.0 & 30.6 & 1 & 6 & 0 \\ 25.0 & 32.3 & 2 & 0 & 0 \\ 25.0 & 24.4 & 0 & 2 & 0 \\ 25.0 & 29.6 & 1 & 2 & 0 \\ 25.0 & 29.6 & 4 & 0 & 0 \\ 25.0 & 29.4 & 1 & 0 & 0 \\ 25.0 & 44.7 & 17 & 0 & 0 \\ 25.0 & 49.7 & 3 & 0 & 0 \\ 25.0 & 28.8 & 2 & 0 & 0 \\ 25.0 & 53.0 & 0 & 5 & 0 \\ 25.0 & 44.3 & 5 & 6 & 0 \\ 25.0 & 26.2 & 1 & 0 & 0 \\ 25.0 & 52.5 & 2 & 0 & 0 \\ 25.0 & 47.5 & 2 & 0 & 0 \\ 25.0 & 37.3 & 2 & 2 & 0 \\ 25.0 & 60.3 & 2 & 0 & 0 \\ 25.0 & 28.6 & 2 & 0 & 0 \\ 25.0 & 60.5 & 2 & 0 & 0 \\ 25.0 & 24.5 & 2 & 0 & 0 \\ 25.0 & 55.0 & 2 & 0 & 0 \\ 25.0 & 62.8 & 2 & 0 & 0 \\ 25.0 & 50.0 & 1 & 0 & 0 \\ 25.0 & 25.2 & 1 & 0 & 0 \\ 25.0 & 14.4 & 1 & 0 & 0 \\ 25.0 & 49.2 & 2 & 0 & 0 \\ & 51.9 & 2 & 2 & 0 \\ 25 & & & \end{array}$

886.49

1014.58

1460.73

1387.75

1115.63

1909.99

974.55

1329.77

1616.82

1756.92

1197.59

1780.91

1368.69

984.56

1056.58

1444.75

1634.73

1301.76

966.61

1459.72

1395.71

1089.52

1733.87

1591.77

1280.62

1318.77

1020.57

1414.76

944.42

3012.24

1414.58

1375.63

1326.70

1041.57

1590.88

1391.75

974.56

1216.60

1054.52

1123.58

1423.73

1316.52

1057.46

940.46

1206.70

1851.80

Page 86 of Table S-1-6 

socitrate dehydrogenase [NAD] subunit beta, mitochondrial GN=IDH3B IDH3B_HUMAN $42.18 \quad 100.0 \%$ Isocitrate dehydrogenase $[\mathrm{NAD}]$ subunit beta, mitochondrial GN=IDH3B IDH3B_HUMAN $42.18 \quad 100.0 \%$ socitrate dehydrogenase $[\mathrm{NAD}]$ subunit beta, mitochondrial GN=IDH3B $\mathrm{IDH} 3 \mathrm{~B}$ HUMAN $42.18 \quad 100.0 \%$ Isocitrate dehydrogenase [NAD] subunit beta, mitochondrial GN=IDH3B IDH3B_HUMAN $42.18 \quad 100.0 \%$ Isocitrate dehydrogenase [NAD] subunit beta, mitochondrial GN=IDH3B IDH3B_HUMAN $42.18 \quad 100.0 \%$ Isocitrate dehydrogenase [NAD] subunit beta, mitochondrial GN=IDH3B $\quad$ IDH3B HUMAN $42.18 \quad 100.0 \%$ Isocitrate dehydrogenase [NAD] subunit gamma, mitochondrial GN=IDH3G IDH3G_HUMAN $42.79 \quad 100.0^{\circ}$ Isocitrate dehydrogenase [NAD] subunit gamma, mitochondrial GN=IDH3G IDH3G HUMAN 42.79 Isocitrate dehydrogenase [NAD] subunit gamma, mitochondrial GN=IDH3G IDH3G_HUMAN 42.79 Isocitrate dehydrogenase [NAD] subunit gamma, mitochondrial GN=IDH3G IDH3G HUMAN 42.79 Isocitrate dehydrogenase [NADP], mitochondrial GN=IDH2 IDHP_HUMAN 50.91 Isocitrate dehydrogenase [NADP], mitochondrial GN=IDH2 IDHP_HUMAN 50.91 Isocitrate dehydrogenase [NADP], mitochondrial GN=IDH2 IDHP HUMAN 50.91 Isocitrate dehydrogenase [NADP], mitochondrial GN=IDH2 IDHP_HUMAN 50.91 Isocitrate dehydrogenase [NADP], mitochondrial GN=IDH2 IDHP HUMAN 50.91 Isocitrate dehydrogenase [NADP], mitochondrial GN=IDH2 IDHP_HUMAN 50.91 Isocitrate dehydrogenase [NADP], mitochondrial GN=IDH2 IDHP_HUMAN 50.91 cocitrate dehydroge Isocitrate dehydrogenase [NADP], mitochondrial GN=IDH2 IDHP_HUMAN $50.91 \quad 100.0 \%$ Isocitrate dehydrogenase [NADP], mitochondrial GN=IDH2 IDHP_HUMAN $50.91 \quad 100.0 \%$ Isocitrate dehydrogenase [NADP], mitochondrial GN=IDH2 IDHP_HUMAN $50.91 \quad 100.0 \%$ Isocitrate dehydrogenase [NADP], mitochondrial GN=IDH2 IDHP_HUMAN $50.91 \quad 100.0 \%$ Isocitrate dehydrogenase [NADP], mitochondrial GN=IDH2 IDHP HUMAN 50.91 $100.0^{\circ}$ Isocitrate dehydrogenase [NADP], mitochondrial GN=IDH2 IDHP_HUMAN $50.91 \quad 100.0 \%$ Isocitrate dehydrogenase [NADP], mitochondrial GN=IDH2 IDHP_HUMAN $50.91 \quad 100.0 \%$ Isocitrate dehydrogenase [NADP], mitochondrial GN=IDH2 IDHP_HUMAN $50.91 \quad 100.0 \%$ Isocitrate dehydrogenase [NADP], mitochondrial GN=IDH2 IDHP_HUMAN $50.91 \quad 100.0 \%$ Isoleucine--tRNA ligase, cytoplasmic GN=IARS SYIC HUMAN $144.50 \quad 100.0 \%$ Isoleucine--tRNA ligase, cytoplasmic GN=IARS SYIC_HUMAN $144.50 \quad 100.0 \% \quad 21$ Isoleucine--tRNA ligase, cytoplasmic GN=IARS SYIC_HUMAN $144.50 \quad 100.0 \% \quad 21$ Isoleucine--tRNA ligase, cytoplasmic GN=IARS SYIC HUMAN $144.50 \quad 100.0 \% 21$ Isoleucine--tRNA ligase, cytoplasmic GN=IARS SYIC_HUMAN $144.50 \quad 100.0 \% \quad 21$ Isoleucine--tRNA ligase, cytoplasmic GN=IARS SYIC_HUMAN $144.50 \quad 100.0 \%$ Isoleucine--tRNA ligase, cytoplasmic GN=IARS SYIC_HUMAN $144.50 \quad 100.0 \% \quad 21$ Isoleucine--tRNA ligase, cytoplasmic GN=IARS SYIC_HUMAN $144.50 \quad 100.0 \% \quad 2$ Isoleucine--tRNA ligase, cytoplasmic GN=IARS SYIC HUMAN $144.50 \quad 100.0 \%$ Isoleucine--tRNA ligase, cytoplasmic GN=IARS SYIC_HUMAN $144.50 \quad 100.0 \% \quad 21$ Isoleucine--tRNA ligase, cytoplasmic GN=IARS SYIC_HUMAN $144.50 \quad 100.0 \%$ Isoleucine--tRNA ligase, cytoplasmic GN=IARS SYIC_HUMAN $144.50 \quad 100.0 \%$ Isoleucine--tRNA ligase, cytoplasmic GN=IARS SYIC_HUMAN $144.50 \quad 100.0 \%$ Isoleucine--tRNA ligase, cytoplasmic GN=IARS SYIC_HUMAN $144.50 \quad 100.0 \%$ Isoleucine--tRNA ligase, cytoplasmic GN=IARS SYIC_HUMAN $144.50 \quad 100.0 \% \quad 21$ Isoleucine--tRNA ligase, cytoplasmic GN=IARS SYIC_HUMAN $144.50 \quad 100.0 \% \quad 2$ Isoleucine--tRNA ligase, cytoplasmic GN=IARS SYIC HUMAN $144.50 \quad 100.0 \% \quad 2$ Isoleucine--tRNA ligase, cytoplasmic GN=IARS SYIC_HUMAN $144.50 \quad 100.0 \% \quad 21$
$0.04 \% \quad 26.5 \%$ FAFDYATK $0.04 \% \quad 26.5 \%$ FAFDYAT

$0.04 \% \quad 26.5 \%$ HPFAQAVGR

$\begin{array}{llllllll}99.0 \% & 31.7 & 25.0 & 28.5 & 2 & 0 & 0 & 962.46\end{array}$ $99.7 \% \quad 35.5 \quad 25.0 \quad 29.2$

$0.04 \% \quad 26.5 \%$ NIANPTAMLLSASNMLR $0.04 \% \quad 26.5 \%$ TRDMGGYSTTTDFIK

$0.04 \% \quad 26.5 \%$ DMGGYSTTTDFIK

$0.04 \% \quad 26.5 \%$ SVIGHLQTK

$0.01 \% \quad 13.0 \%$ TSLDLYANVIHCK

$0.01 \% \quad 13.0 \%$ SLPGVVTR

$0.01 \% \quad 13.0 \%$ HKDIDILIVR

$0.01 \% \quad 13.0 \%$ LGDGLFLQCCR

$0.01 \% \quad 13.0 \%$ LHSYATSIR

$0.06 \% \quad 42.0 \%$ VAKPVVEMDGDEMTR

$0.06 \% \quad 42.0 \%$ LILPHVDIQLK

$0.06 \% \quad 42.0 \%$ YFDLGLPNR

$0.06 \% \quad 42.0 \%$ DQTDDQVTIDSALATQK

$0.06 \% \quad 42.0 \%$ CATITPDEAR

$0.06 \% \quad 42.0 \%$ CATITPDEARVEEFK

$0.06 \% \quad 42.0 \%$ NILGGTVFREPIICK

$0.06 \% \quad 42.0 \%$ LVPGWTKPITIGR

$0.06 \% \quad 42.0 \%$ ATDFVADR

$0.06 \% \quad 42.0 \%$ LIDDMVAQVLK

$0.06 \% \quad 42.0 \%$ SSGGFVWACK

$0.06 \% \quad 42.0 \%$ TIEAEAAHGTVTR

$0.06 \% \quad 42.0 \%$ GKLDGNQDLIR

$0.06 \% \quad 42.0 \%$ LDGNQDLIR

$0.06 \% \quad 42.0 \%$ VCVETVESGAMTK

$0.06 \% \quad 42.0 \%$ DLAGCIHGLSNVK

$0.06 \% \quad 42.0 \%$ LNEHFLNTTDFLDTIK

$0.04 \% \quad 19.2 \%$ YAHQSGFHVDR

$0.04 \% \quad 19.2 \%$ MGITEYNNQCR

$0.04 \% \quad 19.2 \%$ LLILMEAR

$0.04 \% \quad 19.2 \%$ SDTPLIYK

$0.04 \% \quad 19.2 \%$ VENMVDQLLR

$0.04 \% \quad 19.2 \%$ ISDLHRESVDHLTIPSR

$0.04 \% \quad 19.2 \%$ NVIVNGLVLASDGQK

$0.04 \% \quad 19.2 \%$ NYPDPVSIIQK

$0.04 \% \quad 19.2 \%$ YGADALRLYLINSPVVR

$0.04 \% \quad 19.2 \%$ LYLINSPVVR

$0.04 \% \quad 19.2 \%$ LQKEEEIEFLYNENTVR

$0.04 \% \quad 19.2 \%$ FVDILTNWYVR

$0.04 \% \quad 19.2 \%$ YIIEELNVR

$0.04 \% \quad 19.2 \%$ LRAEPDHMVLGK

$0.04 \% \quad 19.2 \%$ QLSSEELEQFQK

$0.04 \% \quad 19.2 \%$ EVINRIQK

0.04\% 19.2\% CNLVPTDEITVYYK

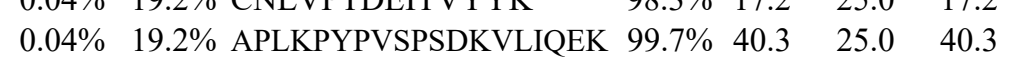

$\begin{array}{llll}99.5 \% & 30.2 & 25.0 & 25.0\end{array}$

$\begin{array}{llll}9.7 \% & 52.8 & 25.0 & 52.8\end{array}$

$\begin{array}{llll}99.7 \% & 39.7 & 25.0 & 35.8\end{array}$

$\begin{array}{llll}99.7 \% & 57.8 & 25.0 & 52.4\end{array}$

$99.7 \% \quad 31.5 \quad 25.0 \quad 31.5$

$\begin{array}{lllll}99.7 \% & 49.3 & 25.0 & 48.7 & 2\end{array}$

$98.8 \% \quad 23.1 \quad 25.0 \quad 16.2$

$99.7 \% \quad 32.2 \quad 25.0 \quad 32.2$

$\begin{array}{llll}99.7 \% & 51.4 & 25.0 & 51.4\end{array}$

$\begin{array}{llll}97.2 \% & 22.4 & 25.0 & 11.4\end{array}$

$\begin{array}{llll}99.7 \% & 53.2 & 25.0 & 53.2\end{array}$

$99.7 \% \quad 48.3 \quad 25.0 \quad 29.0$

$99.7 \% \quad 37.3 \quad 25.0 \quad 31.1$

99.6\% \#\#\#\#

$\begin{array}{lll}99.7 \% & 44.7\end{array}$

$99.3 \% \quad 20.6$

$\begin{array}{lll}99.7 \% & 48.3\end{array}$

$97.2 \% \quad 18.0$

$99.0 \% \quad 36.8$

$99.7 \% \quad 50.5$

$99.7 \% \quad 57.3$

$99.7 \% \quad 77.8$

$99.7 \% \quad 58.3$

$99.7 \% \quad 40.5$

$99.7 \% \quad 90.1$

$99.7 \% \quad 65.6$

$99.7 \% \quad 46.5$

$99.3 \% 20.5$

$99.7 \% \quad 53.1$

$99.0 \% \quad 52.5$

$99.0 \% 26.1$

$99.6 \% 25.6$

$99.7 \% \quad 47.4$

$99.7 \% \quad 65.2$

$96.8 \% \quad 18.9$

$99.7 \% \quad 33.2$

$99.7 \% \quad 38.1$

$99.2 \% \quad 20.8$

$99.7 \% \quad 46.6$

$99.6 \% \quad 51.1$

$99.7 \% \quad 34.2$

$99.7 \% \quad 56.0$

$99.0 \% \quad 26.4$

$98.3 \% \quad 17.2$

$23 \quad 39$ $\begin{array}{cc}200 & 207 \\ 200 & 208 \\ 309 & 317 \\ 318 & 334 \\ 360 & 374 \\ 362 & 374 \\ 375 & 383 \\ 137 & 149 \\ 150 & 157 \\ 158 & 167 \\ 227 & 237 \\ 341 & 349 \\ 46 & 60 \\ 70 & 80 \\ 81 & 89 \\ 90 & 106 \\ 113 & 122 \\ 113 & 127 \\ 141 & 155 \\ 160 & 172 \\ 181 & 188 \\ 289 & 299 \\ 300 & 309 \\ 341 & 353 \\ 383 & 393 \\ 385 & 393 \\ 401 & 413 \\ 414 & 426 \\ 427 & 442 \\ 71 & 81 \\ 111 & 121 \\ 255 & 262 \\ 403 & 410 \\ 419 & 428 \\ 495 & 511 \\ 586 & 600 \\ 607 & 617 \\ 618 & 634 \\ 625 & 634 \\ 670 & 686 \\ 726 & 736 \\ 869 & 877 \\ 892 & 903 \\ 918 & 929 \\ 989 & 996 \\ 1001 & 1014 \\ & 1057 \\ & \\ 3039\end{array}$

Page 87 of Table S-1-6 
Isoleucine--tRNA ligase, cytoplasmic GN=IARS SYIC_HUMAN $144.50 \quad 100.0 \% \quad 2$ Isoleucine--tRNA ligase, cytoplasmic GN=IARS SYIC_HUMAN $144.50 \quad 100.0 \%$ Isoleucine--tRNA ligase, cytoplasmic GN=IARS SYIC_HUMAN $144.50 \quad 100.0 \% \quad 2$ Isoleucine--tRNA ligase, mitochondrial GN=IARS2 SYIM HUMAN $113.79 \quad 100.0 \%$ Isoleucine--tRNA ligase, mitochondrial GN=IARS2 SYIM_HUMAN $113.79 \quad 100.0 \%$ Isoleucine--tRNA ligase, mitochondrial GN=IARS2 SYIM_HUMAN $113.79 \quad 100.0 \%$ Isoleucine--tRNA ligase, mitochondrial GN=IARS2 SYIM HUMAN $113.79 \quad 100.0 \%$ Isovaleryl-CoA dehydrogenase, mitochondrial GN=IVD IVD_HUMAN $46.32 \quad 100.0 \%$ Isovaleryl-CoA dehydrogenase, mitochondrial GN=IVD IVD HUMAN $46.32 \quad 100.0 \%$ Junction plakoglobin GN=JUP Junction plakoglobin GN=JUP

Junction plakoglobin GN=JUP PLAK HUMAN $81.75 \quad 100.0 \%$ PLAK_HUMAN $81.75 \quad 100.0 \%$ PLAK_HUMAN $81.75 \quad 100.0 \%$ Katanin p60 ATPase-containing subunit A1 GN=KATNA1 KTNA1_HUMAN $55.97 \quad 100.0 \%$ Katanin p60 ATPase-containing subunit A1 GN=KATNA1 KTNA1_HUMAN $55.97 \quad 100.0 \%$ Katanin p60 ATPase-containing subunit A1 GN=KATNA1 KTNA1 HUMAN $55.97 \quad 100.0 \%$ Kelch-like ECH-associated protein 1 GN=KEAP1 KEAP1_HUMAN $69.66 \quad 100.0 \%$ Kelch-like ECH-associated protein $1 \mathrm{GN}=\mathrm{KEAP} 1 \mathrm{KEAP} 1$ HUMAN $69.66 \quad 100.0 \%$ Keratinocyte proline-rich protein GN=KPRP KPRP_HUMAN $64.13 \quad 100.0 \%$ Keratinocyte proline-rich protein GN=KPRP KPRP_HUMAN $64.13 \quad 100.0 \%$ Keratinocyte proline-rich protein GN=KPRP KPRP_HUMAN $64.13 \quad 100.0 \%$ Ketosamine-3-kinase GN=FN3KRP Ketosamine-3-kinase GN=FN3KRP KT3K_HUMAN $34.41 \quad 100.0 \%$ KT3K HUMAN $34.41 \quad 100.0 \%$ KHDR1 HUMAN $48.23 \quad 100.0 \%$ KHDR1_HUMAN $48.23 \quad 100.0 \%$ KHDR1_HUMAN $48.23 \quad 100.0 \%$ KHDR1_HUMAN $48.23 \quad 100.0 \%$ KIF14_HUMAN $186.50 \quad 100.0 \%$ $\begin{array}{llll}\text { Kinesin-like protein KIF14 GN=KIF14 } & \text { KIF14_HUMAN } 186.50 & 100.0 \% \\ \text { Kinesin-like protein KIF14 GN=KIF14 } & \text { KIF14_HUMAN } 186.50 & 100.0 \% \\ \text { Kinesin-like protein KIF14 GN=KIF14 } & \text { KIF14_HUMAN } 186.50 & 100.0 \%\end{array}$ $\begin{array}{llll}\text { Kinesin-like protein KIF14 GN=KIF14 } & \text { KIF14_HUMAN } 186.50 & 100.0 \% \\ \text { Kinesin-like protein KIF14 GN=KIF14 } & \text { KIF14_HUMAN } 186.50 & 100.0 \% \\ \text { Kinesin-like protein KIF14 GN=KIF14 } & \text { KIF14_HUMAN } 186.50 & 100.0 \%\end{array}$ Kinesin-like protein Kinetochore-associated protein $1 \mathrm{GN}=\mathrm{KNTC1} \mathrm{KNTC1}{ }_{-} \mathrm{HUMAN} 250.76 \quad 100.0 \%$ Kinetochore-associated protein $1 \mathrm{GN}=\mathrm{KNTC1} \mathrm{KNTC1}$ HUMAN $250.76 \quad 100.0 \%$ Kinetochore-associated protein $1 \mathrm{GN}=\mathrm{KNTC1} \mathrm{KNTC1}$ HUMAN $250.76100 .0 \%$ Kinetochore-associated protein $1 \mathrm{GN}=\mathrm{KNTC1}$ KNTC1_HUMAN $250.76 \quad 100.0 \%$ Kinetochore-associated protein $1 \mathrm{GN}=\mathrm{KNTC1} \mathrm{KNTC1}$ HUMAN $250.76100 .0 \%$ KRR1 small subunit processome component homolog GN=KRR1 KRR1_HUMAN $43.67 \quad 100.0 \%$ KRR1 small subunit processome component homolog GN=KRR1 KRR1_HUMAN $43.67 \quad 100.0 \%$ L-2-hydroxyglutarate dehydrogenase, mitochondrial GN=L2HGDH L2HDH HUMAN $50.32100 .0 \%$ L-2-hydroxyglutarate dehydrogenase, mitochondrial GN=L2HGDH L2HDH_HUMAN $50.32 \quad 100.0 \%$ L-2-hydroxyglutarate dehydrogenase, mitochondrial GN=L2HGDH L2HDH_HUMAN $50.32 \quad 100.0 \%$ L-2-hydroxyglutarate dehydrogenase, mitochondrial GN=L2HGDH L2HDH HUMAN $50.32100 .0 \%$ L-2-hydroxyglutarate dehydrogenase, mitochondrial GN=L2HGDH L2HDH_HUMAN $50.32 \quad 100.0 \%$ L-2-hydroxyglutarate dehydrogenase, mitochondrial GN=L2HGDH L2HDH HUMAN $50.32100 .0 \%$ L-2-hydroxyglutarate dehydrogenase, mitochondrial GN=L2HGDH L2HDH_HUMAN $50.32 \quad 100.0 \%$ L-2-hydroxyglutarate dehydrogenase, mitochondrial GN=L2HGDH L2HDH_HUMAN $50.32100 .0 \%$ L-2-hydroxyglutarate dehydrogenase, mitochondrial GN=L2HGDH L2HDH HUMAN $50.32100 .0 \%$ L-2-hydroxyglutarate dehydrogenase, mitochondrial GN=L2HGDH L2HDH_HUMAN $50.32 \quad 100.0 \%$
19.2\% TQLKGSELEITLTR

$0.01 \% \quad 5.4 \%$ TALAEAELEYNPEHVSR

$0.01 \% \quad 5.4 \%$ FPLLKPSPK

$0.01 \% \quad 5.4 \%$ AVLEEGTDVVIK

$0.01 \% \quad 5.4 \%$ TKDEYLINSQTTEHIVK

$0.00 \% \quad 5.2 \%$ TDLAAVPASR

$0.00 \% \quad 5.2 \%$ LYEIGAGTSEVR

$0.00 \% \quad 4.7 \%$ LAEPSQLLK

$0.00 \% \quad 4.7 \% \quad$ LLNDEDPVVVTK

$0.00 \% \quad 4.7 \%$ ALMGSPQLVAAVVR

$0.01 \% \quad 6.7 \% \quad$ DIISQNPNVR

$0.01 \% \quad 6.7 \% \quad$ TTFFNVSSSTLTSK

$0.01 \% \quad 6.7 \% \quad$ SVSAADIER

$0.00 \% \quad 3.4 \% \quad$ IGVGVAVLNR

$0.00 \% \quad 3.4 \%$ SALGITVHQGR

$0.01 \% \quad 5.5 \%$ GRPAVCQPQGR

$0.01 \% \quad 5.5 \%$ RSEPIYNSR

$0.01 \% \quad 5.5 \%$ RLDQCPESPLQR

$0.00 \% \quad 8.4 \%$ LGAQLADLHLDNKK

$0.00 \% \quad 8.4 \%$ GGGQEERPFVAR

$0.02 \% \quad 10.8 \%$ SGSMDPSGAHPSVR

$0.02 \% \quad 10.8 \%$ QTPSRQPPLPHR

$0.02 \% \quad 10.8 \%$ ILGPQGNTIKR

$0.02 \% \quad 10.8 \%$ GAAPPPPPVPR

$0.01 \% \quad 1.9 \% \quad$ LAAPLLER

$0.01 \% \quad 1.9 \% \quad$ INLIDLAGSER

$0.01 \% \quad 1.9 \%$ VISALSEQANQR

$\begin{array}{llll}0.01 \% & 3.6 \% & \text { TYQNLVIEK }\end{array}$

$10 \quad 0.01 \% \quad 3.6 \% \quad$ IQQAIENVDFSTAK

$10 \quad 0.01 \% \quad 3.6 \%$ LALQEEPDHSKEGK

$\quad 0.01 \% \quad 3.6 \%$ HKPGSTPEPIAAEVR

$10 \quad 0.01 \% \quad 3.6 \%$ SGTEAVLIAHK

$10 \quad 0.01 \% \quad 3.6 \%$ IQNSSGTDYPDIHAAAK $0.00 \% \quad 6.0 \%$ GLLEESSFATLFPK

$0.00 \% \quad 6.0 \%$ TFDPYIIIR

$0.02 \% \quad 27.2 \%$ HPSLSIGVLEK

$0.02 \% \quad 27.2 \%$ LIVAVEQEEIPR

$0.02 \% \quad 27.2 \%$ LIQQEDIKK

$0.02 \% \quad 27.2 \%$ SIDGMQYPIVIK

$0.02 \% \quad 27.2 \%$ CQYVVTCAGLYSDR

$0.02 \% \quad 27.2 \%$ ISELSGCTPDPR

$0.02 \% \quad 27.2 \%$ GDYLLLKPEK

$0.02 \% \quad 27.2 \%$ GNIYPVPDSR

$0.02 \% \quad 27.2 \%$ LASQNFSYGVTEMYK

$0.02 \% \quad 27.2 \%$ ACFLGATVK
$99.7 \% \quad 35.6$

$99.7 \% \quad 34.5$

$99.7 \% \quad 60.9$

$99.7 \% 28.9$

$99.4 \% \quad 45.9$

$99.7 \% \quad 64.5$

$97.2 \% 24.8$

$\begin{array}{lll}99.7 \% & 43.8\end{array}$

$99.7 \% \quad 42.8$

$99.7 \% \quad 43.6$

$99.7 \% \quad 55.3$

$99.7 \% 41.6$

$99.7 \% \quad 36.3$

$96.9 \% \quad 19.8$

$99.7 \% 29.1$

$\begin{array}{lll}99.7 \% & 31.3\end{array}$

$99.7 \% \quad 32.6$

$99.4 \% \quad 22.5$

$96.8 \% \quad 21.6$

$99.7 \% \quad 37.3$

$95.0 \% \quad 14.3$

$99.7 \% \quad 51.0$

$99.7 \% \quad 32.2$

$\begin{array}{lll}98.7 \% & 22.7\end{array}$

$99.7 \% \quad 46.0$

$99.7 \% \quad 69.2$

$99.7 \% \quad 40.4$

$99.7 \% \quad 58.8$

$99.3 \% \quad 20.6$

$99.7 \% 30.5$

$99.5 \% \quad 22.9$

$99.7 \% \quad 28.6$

$99.7 \% \quad 47.7$

$99.7 \% \quad 36.6$

$99.7 \% \quad 40.4$

$99.7 \% \quad 55.9$

$99.4 \% 28$.

$99.7 \% \quad 66.5$

$99.7 \% \quad 43.6$

$99.7 \% \quad 66.3$

$99.7 \% \quad 41.7$

$99.7 \% \quad 36.0$

$99.7 \% \quad 39.5$

$\begin{array}{lll}97.7 \% & 21.8\end{array}$
1118.61

2118.10

1928.93

1026.63

1272.70

2019.04

1000.54

1294.66

998.59

1341.73

1427.80

1155.6

1519.76

947.48

997.62

1138.63

1225.62

1121.57

1498.74

1535.85

1302.66

1400.62

1413.77

1196.71

1055.60

882.54

1200.66

1315.70

1107.60

1563.80

1580.79

1588.84

1125.63

1787.86

1538.81

1137.63

1179.67

1395.78

1114.65

1363.73

1691.75

1331.63

1175.67

1117.56

1753.81

966.51 $\begin{array}{cc}58 & 1071 \\ 62 & 1071 \\ 27 & 1244 \\ 51 & 267 \\ 73 & 281 \\ 34 & 445 \\ 39 & 555 \\ 11 & 220 \\ 99 & 410 \\ 16 & 124 \\ 50 & 161 \\ 78 & 191 \\ 98 & 207 \\ 68 & 281 \\ 72 & 480 \\ 61 & 470 \\ 55 & 565 \\ 67 & 177 \\ 00 & 308 \\ 87 & 398 \\ 03 & 116 \\ 31 & 142 \\ 8 & 31 \\ 2 & 43 \\ 76 & 186 \\ 92 & 302 \\ 27 & 434 \\ 99 & 609 \\ 36 & 647 \\ 35 & 143 \\ 72 & 185 \\ 36 & 949 \\ 30 & 1044 \\ 46 & 1756 \\ 86 & 1802 \\ 3 & 66 \\ 07 & 115 \\ 1 & 81 \\ 37 & 148 \\ 66 & 174 \\ 32 & 243 \\ 52 & 265 \\ 66 & 277 \\ 83 & 292 \\ 98 & 307 \\ 60 & 374 \\ 75 & 383 \\ & \end{array}$

Page 88 of Table S-1-6 
L-2-hydroxyglutarate dehydrogenase, $\mathrm{mi}$
Lactadherin GN=MFGE8
Lactadherin GN=MFGE8

Lactadherin GN=MFGE\&

Lactadherin GN=MFGE 8

Lactadherin GN=MFGE8

Lamina-associated polypeptide 2, isoform alpha GN=TMPO LAP2A_HUMAN $75.49 \quad 100.0 \%$

Lamina-associated polypeptide 2, isoform alpha GN=TMPO LAP2A HUMAN $75.49 \quad 100.0 \%$

Lamina-associated polypeptide 2, isoform alpha GN=TMPO LAP2A_HUMAN $75.49 \quad 100.0 \%$

Lamina-associated polypeptide 2, isoform alpha GN=TMPO LAP2A HUMAN $75.49100 .0 \%$

Lamina-associated polypeptide 2, isoform alpha GN=TMPO LAP2A_HUMAN $75.49 \quad 100.0 \%$

Lamin-B receptor $\mathrm{GN}=\mathrm{LBR}$

amin- $\mathrm{B}$ receptor $\mathrm{GN}=\mathrm{LBR}$

Lamin-B receptor $\mathrm{GN}=\mathrm{LBR}$

Lamin-B receptor $\mathrm{GN}=\mathrm{LBR}$

Lamin-B receptor $\mathrm{GN}=\mathrm{LBR}$

Lamin-B receptor $\mathrm{GN}=\mathrm{LBR}$

Lamin-B receptor $\mathrm{GN}=\mathrm{LBR}$

Lamin-B receptor $\mathrm{GN}=\mathrm{LBR}$

Lamin-B receptor $\mathrm{GN}=\mathrm{LBR}$

Lamin-B1 GN=LMNB

Lamin-B1 GN=LMNB

Lamin-B1 GN=LMNB

Lamin-B1 GN=LMNB1

Lamin-B1 GN=LMNB

Lamin-B1 GN=LMNB

Lamin-B1 GN=LMNB

Lamin-B1 GN=LMNB

Lamin-B1 GN=LMNB1

Lamin-B1 GN=LMNB1

Lamin-B1 GN=LMNB

Lamin-B1 GN=LMNB

Lamin-B1 GN=LMNB

Lamin-B1 GN=LMNB

Lamin-B1 GN=LMNB

Lamin-B1 GN=LMNB

Lamin-B1 GN=LMNB1

Lamin-B1 GN=LMNB

Lamin-B1 GN=LMNB

Lamin-B1 GN=LMNB1

Lamin-B1 GN=LMNB

Lamin-B1 GN=LMNB

Lamin-B1 GN=LMNB1

Lamin-B1 GN=LMNB

Lamin-B1 GN=LMNB1

Lamin-B1 GN=LMNB

Lamin-B1 GN=LMNB1

Lamin-B2 GN=LMNB2
LBR_HUMAN $70.71 \quad 100.0 \%$

LBR HUMAN $70.71 \quad 100.0 \%$

LBR_HUMAN $70.71 \quad 100.0 \%$

LBR_HUMAN $70.71 \quad 100.0 \%$

LBR HUMAN $70.71 \quad 100.0 \%$

LBR_HUMAN $70.71 \quad 100.0 \%$

LBR_HUMAN $70.71 \quad 100.0 \%$

LBR HUMAN $70.71 \quad 100.0 \%$

LBR_HUMAN $70.71 \quad 100.0 \%$

LMNB1 HUMAN $66.41 \quad 100.0 \% \quad 27$

LMNB1_HUMAN $\quad 66.41 \quad 100.0 \% \quad 27$

LMNB1_HUMAN $66.41 \quad 100.0 \% \quad 27$

LMNB1_HUMAN $66.41 \quad 100.0 \% \quad 27$

LMNB1_HUMAN $66.41 \quad 100.0 \% \quad 27$

LMNB1 HUMAN $66.41 \quad 100.0 \% \quad 27$

LMNB1_HUMAN $66.41 \quad 100.0 \% \quad 27$

LMNB1_HUMAN $66.41 \quad 100.0 \% \quad 27$

LMNB1_HUMAN $66.41 \quad 100.0 \% \quad 27$

LMNB1_HUMAN $\quad 66.41 \quad 100.0 \% \quad 27$

LMNB1 HUMAN $66.41 \quad 100.0 \% \quad 27$

LMNB1_HUMAN $66.41 \quad 100.0 \% \quad 27$

LMNB1_HUMAN $66.41 \quad 100.0 \% \quad 27$ LMNB1 HUMAN $66.41 \quad 100.0 \% \quad 27$ LMNB1_HUMAN $66.41 \quad 100.0 \% \quad 27$ LMNB1_HUMAN $66.41 \quad 100.0 \% \quad 27$ LMNB1_HUMAN $66.41 \quad 100.0 \% \quad 27$ LMNB1_HUMAN $66.41 \quad 100.0 \% \quad 27$ LMNB1 HUMAN $66.41 \quad 100.0 \% \quad 27$ LMNB1_HUMAN $66.41 \quad 100.0 \% \quad 27$ LMNB1_HUMAN $66.41 \quad 100.0 \% \quad 27$ LMNB1_HUMAN $66.41 \quad 100.0 \% \quad 27$ LMNB1_HUMAN $66.41 \quad 100.0 \% \quad 27$ LMNB1_HUMAN $66.41 \quad 100.0 \% \quad 27$ LMNB1_HUMAN $66.41 \quad 100.0 \% \quad 27$ LMNB1_HUMAN $\quad 66.41 \quad 100.0 \% \quad 27$ LMNB1 HUMAN $66.41 \quad 100.0 \% \quad 27$ LMNB2_HUMAN $67.69 \quad 100.0 \% \quad 11$
$0.02 \% \quad 27.2 \%$ FIPEITISDILR

$0.01 \% \quad 12.4 \%$ LASHEYLK

$99.7 \% \quad 35.8$

$99.0 \% \quad 35.0$

$10 \quad 0.01 \% \quad 12.4 \%$ NAVHVNLFETPVEAQYVR

$10 \quad 0.01 \% \quad 12.4 \%$ NFGSVQFVASYK

$\quad 0.01 \% \quad 12.4 \%$ NLFETPILAR

$0.01 \% \quad 9.9 \%$ PEFLEDPSVLTK

$0.01 \% \quad 9.9 \%$ SELVANNVTLPAGEQR

$0.01 \% \quad 9.9 \% \quad$ NRPPLPAGTNSK

$0.01 \% \quad 9.9 \%$ YGVNPGPIVGTTR

$0.01 \% \quad 9.9 \%$ SSTPLPTISSSAENTR

$0.05 \% \quad 15.9 \%$ KFADGEVVR

$0.05 \% \quad 15.9 \%$ SASASHQADIKEAR

$0.05 \% \quad 15.9 \%$ LTPLILKPFGNSISR

$0.05 \% \quad 15.9 \%$ YNGEPEHIER

$0.05 \% \quad 15.9 \%$ TFEVTPIR

$0.05 \% \quad 15.9 \%$ VVEGTPLIDGR

$0.05 \% \quad 15.9 \%$ VVEGTPLIDGRR

$0.05 \% \quad 15.9 \%$ NDLSPASSGNAVYDFFIGR

$0.05 \% \quad 15.9 \%$ NPSDPKLAHLK

$0.09 \% \quad 37.9 \%$ AGGPTTPLSPTR

$0.09 \% \quad 37.9 \%$ ALYETELADAR

0.09\% 37.9\% ALYETELADARR

$0.09 \% \quad 37.9 \%$ ALDDTARER

$0.09 \% \quad 37.9 \%$ AKLQIELGK

$0.09 \% \quad 37.9 \%$ CKAEHDQLLLNYAK

$0.09 \% \quad 37.9 \%$ AEHDQLLLNYAK

$0.09 \% \quad 37.9 \%$ KESDLNGAQIK

$0.09 \% \quad 37.9 \%$ ESDLNGAQIK

$0.09 \% \quad 37.9 \%$ LREYEAALNSK

$0.09 \% \quad 37.9 \%$ EYEAALNSK

$0.09 \% \quad 37.9 \%$ DAALATALGDKK

$0.09 \% \quad 37.9 \%$ KQLADETLLK

$0.09 \% \quad 37.9 \%$ QLADETLLK

$0.09 \% \quad 37.9 \%$ SMYEEEINETR

$0.09 \% \quad 37.9 \%$ LYKEELEQTYHAK

$0.09 \% \quad 37.9 \%$ LSSEMNTSTVNSAREELMESR

$0.09 \% \quad 37.9 \%$ MRIESLSSQLSNLQK

$0.09 \% \quad 37.9 \%$ IESLSSQLSNLQK

$0.09 \% \quad 37.9 \%$ IQELEDLLAK

$0.09 \% \quad 37.9 \%$ LALDMEISAYRK

$0.09 \% \quad 37.9 \%$ LLEGEEERLK

$0.09 \% \quad 37.9 \%$ KIGDTSVSYK

$0.09 \% \quad 37.9 \%$ IGDTSVSYK

$0.09 \% \quad 37.9 \%$ IGDTSVSYKYTSR

$0.09 \% \quad 37.9 \%$ NQNSWGTGEDVK

$0.09 \% \quad 37.9 \%$ NQNSWGTGEDVKV

$0.04 \% \quad 24.2 \%$ AGGPATPLSPTR
$99.7 \% \quad 50.8$

$99.0 \% \quad 39.0$

$99.0 \% 21$.

$94.6 \% 14.2$

$99.7 \% 29$.

$99.7 \% \quad 57.0$

$99.7 \% \quad 61.7$

$99.7 \% \quad 41.2$

$99.7 \% \quad 36.2$

$99.7 \% \quad 34.3$

$99.7 \% \quad 32.2$

$99.0 \% 33.0$

$99.7 \% \quad 42.0$

$97.3 \% \quad 17.1$

$99.7 \% 55.1$

$\begin{array}{lll}98.1 \% & 16.9\end{array}$

$99.7 \% \quad 54.6$

$99.7 \% \quad 63.2$

$\begin{array}{lll}99.7 \% & 33.8\end{array}$

$95.2 \% \quad 23.5$

$99.7 \% \quad 52.4$

$99.7 \% \quad 34.0$

$\begin{array}{lll}99.3 \% & 22.2\end{array}$

$99.7 \% \quad 38.1$

$98.9 \% 22.7$

$99.7 \% 55.6$

$99.0 \% 25.4$

$99.7 \% \quad 58.6$

$99.7 \% \quad 41.3$

$99.7 \% 39.7$

$99.7 \% \quad 51.8$

$99.7 \% \quad 48.4$

$99.7 \% \quad 33.2$

$99.7 \% \quad 29.7$

$99.7 \% \quad 55.7$

$99.7 \% 47$.

$97.2 \% \quad 17.2$

$99.7 \% \quad 56.5$

$99.7 \% 38.1$

$99.7 \% \quad 59.2$

$99.7 \% \quad 63.5$

$99.7 \% \quad 48.5$

$99.7 \% \quad 56.1$

$99.7 \% \quad 51.9$
1416.81
960.51

960.51
2086.07

1346.67

1173.66

1374.72

1697.88

1251.68

1330.71

1647.82

1020.55

1470.73

1655.98

1243.57

962.53

1155.64

1311.74

2029.96

1219.68

1154.62

1251.62

1407.72

1046.52

999.62

1702.86

1414.73

1202.64

1074.54

1293.68

1024.49

1173.65

1158.67

1030.58

1400.60

1651.83

2403.08

1749.92

1446.78

1171.66

1409.75

1215.66

1097.58

969.49

1476.73

1334.60

1787.93

1124.61

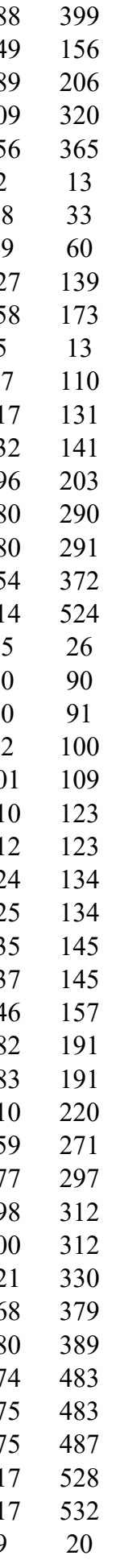

Page 89 of Table S-1-6 
Lamin-B2 GN=LMNB2 Lamin-B2 GN=LMNB2 Lamin-B2 GN=LMNB2 Lamin-B2 GN=LMNB2 Lamin-B2 GN=LMNB2 Lamin-B2 GN=LMNB2 Lamin-B2 GN=LMNB2 Lamin-B2 GN=LMNB2 Lamin-B2 GN=LMNB2 Lamin-B2 GN=LMNB2 Lamin-B2 GN=LMNB2
LMNB2_HUMAN $67.69 \quad 100.0 \% \quad 11 \quad 12 \quad 32 \quad 0.04 \% \quad 24.2 \%$ ALELENDRLLLK LMNB2_HUMAN $67.69 \quad 100.0 \% \quad 11 \quad 12 \quad 32 \quad 0.04 \% \quad 24.2 \%$ ISEKEEVTTR

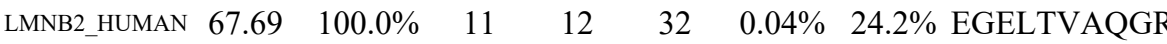

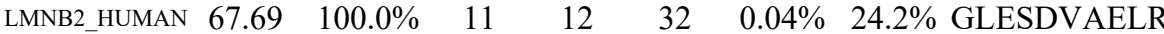

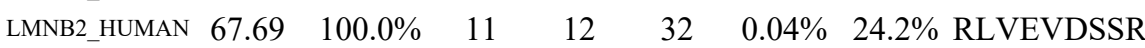

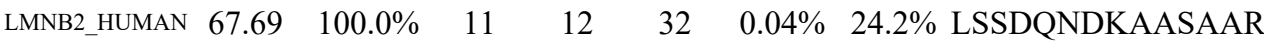

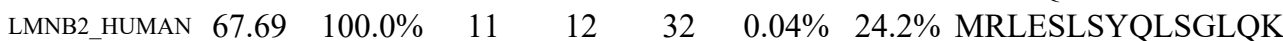

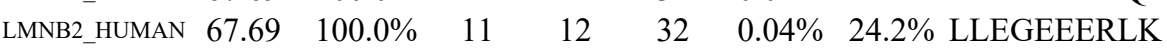

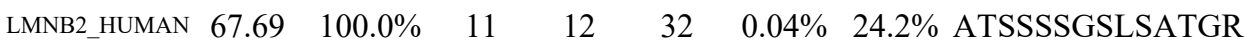

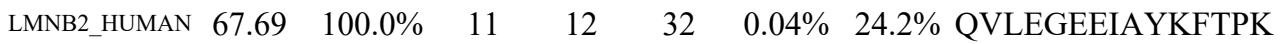

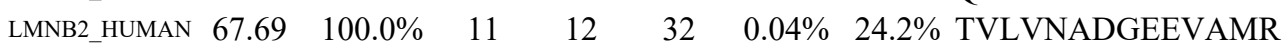
$0.01 \% \quad 7.4 \%$ IGQFVFAR

$0.01 \% \quad 7.4 \%$ HQDVPSQDDSKPTQR $0.04 \% \quad 11.7 \%$ SVQPQSHKPQPTR

$0.04 \% \quad 11.7 \%$ THFDYQFGYR $0.04 \% \quad 11.7 \%$ KFDGVEGPR $0.04 \% \quad 11.7 \%$ QHYQKETESAPGSPR $0.04 \% \quad 11.7 \%$ AVTPVPTKTEEVSNLK $0.04 \% \quad 11.7 \%$ AKMSAELAK $0.04 \% \quad 11.7 \%$ SLPTTVPESPNYR $0.04 \% \quad 11.7 \%$ TPQLKDSSQTSR $0.04 \% \quad 11.7 \%$ FYPVVKEGR $0.04 \% \quad 11.7 \%$ LGIGQSQEMNTLFR $0.04 \% \quad 11.7 \%$ YGLECLFR $0.00 \% \quad 4.0 \%$ TVYVELLPK

$0.00 \% \quad 4.0 \%$ AIEFLNNPPEEAPR $0.00 \% \quad 6.3 \%$ ALAAPAAEEKEEAR $0.00 \% \quad 6.3 \%$ SADGSAPAGEGEGVTLQR $0.00 \% \quad 2.2 \%$ SADDSLSGVVR $0.00 \% \quad 2.2 \%$ APVVAIAVLDGR $0.04 \% \quad 13.5 \%$ EKDIQEESTFSSR $0.04 \% \quad 13.5 \%$ SGGLGGSHALLLLR $0.04 \% \quad 13.5 \%$ MEEANIQPNRVTYQR $0.04 \% \quad 13.5 \%$ LIASYCNVGDIEGASK $0.04 \% \quad 13.5 \%$ NVQGIIEILK $0.04 \% \quad 13.5 \%$ SNTLPISLQSIR $0.04 \% \quad 13.5 \%$ SSLLLGFRR $0.04 \% \quad 13.5 \%$ LVEKGETDLIQK $0.04 \% \quad 13.5 \%$ KIIETPGIR $39 \quad 0.04 \% \quad 13.5 \%$ KGAYDIFLNAK $0.04 \% \quad 13.5 \%$ GAYDIFLNAK $0.04 \% \quad 13.5 \%$ GFTLNDAANSR $39 \quad 0.04 \% \quad 13.5 \%$ DYLKEAVTTLK $39 \quad 0.04 \% \quad 13.5 \%$ TVLDQQQTPSR $39 \quad 0.04 \% \quad 13.5 \%$ MLNGLEDSIGLSK $39 \quad 0.04 \% \quad 13.5 \%$ SYVSEKDVTSAK $39 \quad 0.04 \% \quad 13.5 \%$ ALYEHLTAK $\begin{array}{lllll}99.7 \% & 35.9 & 25.0 & 35.9 & 1\end{array}$ $\begin{array}{lllll}99.7 \% & 44.3 & 25.0 & 28.5 & 2\end{array}$ $\begin{array}{lllll}99.7 \% & 46.6 & 25.0 & 33.1 & 4\end{array}$ $99.7 \% \quad 67.8 \quad 25.0 \quad 48.5$ $\begin{array}{llll}99.7 \% & 36.3 & 25.0 & 26.6\end{array}$ $\begin{array}{llll}96.5 \% & 18.8 & 25.0 & 18.8\end{array}$ $\begin{array}{llll}98.5 \% & 18.0 & 25.0 & 18.0\end{array}$ $\begin{array}{lllll}99.7 \% & 56.5 & 25.0 & 47.6 & 3\end{array}$ $99.7 \% \quad 51.9 \quad 25.0 \quad 44.9$ $\begin{array}{llll}97.9 \% & 20.4 & 25.0 & 14.3\end{array}$

$\begin{array}{llll}99.7 \% & 81.2 & 25.0 & 81.2\end{array}$ $99.0 \% \quad 42.2 \quad 25.0 \quad 30.8$ $\begin{array}{llll}99.7 \% & 51.5 & 25.0 & 51.5\end{array}$ $95.9 \% \quad 18.0 \quad 25.0 \quad 14.5$ $99.7 \% \quad 31.0 \quad 25.0 \quad 30.6$ $\begin{array}{llll}99.7 \% & 38.9 & 25.0 & 29.2\end{array}$ $99.4 \% \quad 26.4 \quad 25.0 \quad 24.6$ $\begin{array}{llll}99.7 \% & 34.2 & 25.0 & 33.8\end{array}$ $\begin{array}{llll}99.7 \% & 29.9 & 25.0 & 29.9\end{array}$ $\begin{array}{llll}99.7 \% & 35.9 & 25.0 & 33.2\end{array}$ $99.7 \% \quad 41.4 \quad 25.0 \quad 41.4$ $99.7 \% \quad 29.6 \quad 25.0 \quad 28.5$ $99.7 \% \quad 51.3 \quad 25.0 \quad 51.3$ $\begin{array}{lllll}99.0 \% & 43.1 & 25.0 & 41.5 & 2\end{array}$ $99.3 \% \quad 20.1 \quad 25.0 \quad 20.1$ $\begin{array}{llll}99.7 \% & 48.4 & 25.0 & 48.4\end{array}$ $\begin{array}{llll}99.7 \% & 47.5 & 25.0 & 47.5\end{array}$ $\begin{array}{llll}99.7 \% & 69.6 & 25.0 & 69.6\end{array}$ $\begin{array}{llll}99.7 \% & 51.9 & 25.0 & 44.2\end{array}$ $\begin{array}{llll}99.7 \% & 53.5 & 25.0 & 53.5\end{array}$ $\begin{array}{llll}99.7 \% & 67.2 & 25.0 & 60.1\end{array}$ $\begin{array}{lllll}99.7 \% & 49.5 & 25.0 & 42.8 & 2\end{array}$ $\begin{array}{llll}99.5 \% & 27.5 & 25.0 & 21.9\end{array}$ $\begin{array}{lllll}99.7 \% & 80.7 & 25.0 & 76.3 & 2\end{array}$ $\begin{array}{llll}99.7 \% & 39.5 & 25.0 & 39.0\end{array}$ $\begin{array}{llll}99.7 \% & 57.2 & 25.0 & 37.5\end{array}$ $\begin{array}{llll}95.7 \% & 22.4 & 25.0 & 8.6\end{array}$ $\begin{array}{lllll}96.5 \% & 21.3 & 25.0 & 11.8 & 0\end{array}$ $\begin{array}{llll}96.5 \% & 22.6 & 25.0 & 9.8\end{array}$ $\begin{array}{llll}99.2 \% & 29.8 & 25.0 & 29.8\end{array}$ $\begin{array}{llll}99.7 \% & 53.8 & 25.0 & 49.6\end{array}$ $\begin{array}{lllll}99.7 \% & 54.7 & 25.0 & 51.8 & 2\end{array}$ $\begin{array}{lllll}99.7 \% & 55.2 & 25.0 & 49.5 & 2\end{array}$ $\begin{array}{llll}99.7 \% & 51.5 & 25.0 & 42.8\end{array}$ $\begin{array}{lllll}99.7 \% & 46.2 & 25.0 & 38.3 & 2\end{array}$ $\begin{array}{llll}99.7 \% & 59.7 & 25.0 & 55.5\end{array}$ $\begin{array}{llll}99.7 \% & 44.8 & 25.0 & 29.7\end{array}$

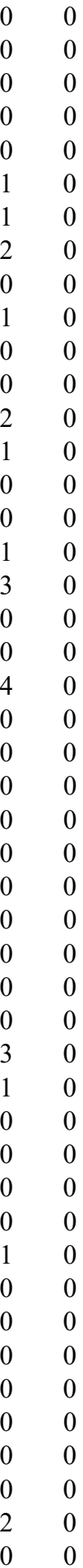

191.62

1059.54

1088.56

1060.57

1433.70

1752.93

1215.66

1268.61

1751.92

1503.75

937.53

1737.82

1489.79

1333.60

1004.52

1714.81

1712.94

948.52

1460.74

1347.69

1094.60

1593.81

1057.51

1061.62

1596.80

1455.74

1701.80

1105.55

1180.70

1555.72

1350.79

1848.90

1696.82

1126.68

1328.75

1048.63

1372.77

1026.63

1239.67

1111.58

1165.56

1280.71

1272.65

1392.70

1313.66 1045.57 
Leucine-rich repeat-containing protein 40 GN=LRRC40 LRC40_HUMAN $68.25 \quad 100.0 \%$ Leucine-rich repeat-containing protein $40 \mathrm{GN}=$ LRRC40 LRC40_HUMAN $68.25 \quad 100.0 \%$ Leucine-rich repeat-containing protein $40 \mathrm{GN}=$ LRRC40 LRC40_HUMAN 68.25 Leucine-rich repeat-containing protein $40 \mathrm{GN}=$ LRRC40 LRC40_HUMAN 68.25 Leucine-rich repeat-containing protein 40 GN=LRRC40 LRC40_HUMAN 68.25 Leucine-rich repeat-containing protein $40 \mathrm{GN}=$ LRRC40 LRC40_HUMAN 68.25 Leucine-rich repeat-containing protein $40 \mathrm{GN}=$ LRRC40 LRC40_HUMAN 68.25 Leucine-rich repeat-containing protein 59 GN=LRRC59 LRC59_HUMAN 34.93 Leucine-rich repeat-containing protein 59 GN=LRRC59 LRC59 HUMAN 34.93 Leucine--tRNA ligase, cytoplasmic GN=LARS SYLC_HUMAN $134.47 \quad 100.0 \%$ Leucine--tRNA ligase, cytoplasmic GN=LARS SYLC_HUMAN $134.47 \quad 100.0 \%$ LINE-1 retrotransposable element ORF1 protein GN=L1RE1 LORF1_HUMAN $40.06 \quad 100.0 \%$ LINE-1 retrotransposable element ORF1 protein GN=L1RE1 LORF1_HUMAN $40.06 \quad 100.0 \%$ LINE-1 retrotransposable element ORF1 protein GN=L1RE1 LORF1_HUMAN $40.06 \quad 100.0 \%$ LINE-1 retrotransposable element ORF1 protein GN=L1RE1 LORF1_HUMAN $40.06 \quad 100.0 \%$ LINE-1 retrotransposable element ORF1 protein GN=L1RE1 LORF1_HUMAN $40.06 \quad 100.0 \%$ Lipopolysaccharide-responsive and beige-like anchor protein GN=LRBA LRBA HUMAN $319.11 \quad 100.0 \%$ Lipopolysaccharide-responsive and beige-like anchor protein GN=LRBA LRBA_HUMAN $319.11 \quad 100.0 \%$ Lipopolysaccharide-responsive and beige-like anchor protein GN=LRBA LRBA_HUMAN $319.11 \quad 100.0 \%$ Lipopolysaccharide-responsive and beige-like anchor protein GN=LRBA LRBA_HUMAN $319.11 \quad 100.0 \%$ Lipopolysaccharide-responsive and beige-like anchor protein GN=LRBA LRBA_HUMAN $319.11 \quad 100.0 \%$ Lipopolysaccharide-responsive and beige-like anchor protein GN=LRBA LRBA_HUMAN $319.11 \quad 100.0 \%$ Lipopolysaccharide-responsive and beige-like anchor protein GN=LRBA LRBA_HUMAN $319.11 \quad 100.0 \%$ L-lactate dehydrogenase A chain GN=LDHA LDHA_HUMAN $36.69 \quad 100.0 \%$ L-lactate dehydrogenase A chain GN=LDHA LDHA_HUMAN 36.69 L-lactate dehydrogenase A chain GN=LDHA LDHA_HUMAN 36.69 L-lactate dehydrogenase A chain GN=LDHA LDHA_HUMAN 36.69 L-lactate dehydrogenase A chain GN=LDHA LDHA_HUMAN 36.69 L-lactate dehydrogenase A chain GN=LDHA LDHA_HUMAN 36.69 L-lactate dehydrogenase A chain GN=LDHA LDHA_HUMAN 36.69 L-lactate dehydrogenase A chain GN=LDHA LDHA_HUMAN 36.69 L-lactate dehydrogenase A chain GN=LDHA LDHA_HUMAN 36.69 L-lactate dehydrogenase A chain GN=LDHA LDHA_HUMAN 36.69 L-lactate dehydrogenase A chain GN=LDHA LDHA_HUMAN 36.69 L-lactate dehydrogenase A chain GN=LDHA LDHA_HUMAN 36.69 L-lactate dehydrogenase A chain GN=LDHA LDHA_HUMAN 36.69 L-lactate dehydrogenase A chain GN=LDHA LDHA_HUMAN 36.69 L-lactate dehydrogenase A chain GN=LDHA LDHA_HUMAN 36.69 L-lactate dehydrogenase A chain GN=LDHA LDHA_HUMAN 36.69 L-lactate dehydrogenase A chain GN=LDHA LDHA_HUMAN 36.69 L-lactate dehydrogenase A chain GN=LDHA LDHA_HUMAN 36.69 L-lactate dehydrogenase A chain GN=LDHA LDHA_HUMAN 36.69 L-lactate dehydrogenase A chain GN=LDHA LDHA_HUMAN 36.69 L-lactate dehydrogenase B chain GN=LDHB LDHB_HUMAN $36.64 \quad 100.0 \%$ L-lactate dehydrogenase B chain GN=LDHB LDHB_HUMAN $36.64 \quad 100.0 \%$ L-lactate dehydrogenase B chain GN=LDHB LDHB HUMAN $36.64 \quad 100.0 \%$ L-lactate dehydrogenase B chain GN=LDHB LDHB_HUMAN $36.64 \quad 100.0 \%$
13

25

$\begin{array}{llll}122 & 0.14 \% & 47.6 \% & \text { DQLIYNLLK } \\ 122 & 0.14 \% & 47.6 \% & \text { DQLIYNLLKEEQTPQNK }\end{array}$

$\begin{array}{lll}122 & 0.14 \% & 47.6 \% \\ 122 & 0.14 \% & 47.6 \% \text { DQLIYNLLKEEQTPQNK } \\ 122 & 0.14 \% & 47.6 \% \text { LKGEMGAVGMACAISILMK }\end{array}$

$122 \quad 0.14 \% \quad 47.6 \%$ LKGEMMDLQHGSLFLR

$122 \quad 0.14 \% \quad 47.6 \%$ GEMMDLQHGSLFLR

$122 \quad 0.14 \% \quad 47.6 \%$ IVSGKDYNVTANSK

$122 \quad 0.14 \% \quad 47.6 \%$ DYNVTANSK

$122 \quad 0.14 \% \quad 47.6 \%$ LVIITAGAR

$122 \quad 0.14 \% \quad 47.6 \%$ FIIPNVVK

$22 \quad 0.14 \% \quad 47.6 \%$ VIGSGCNLDSAR

$122 \quad 0.14 \% \quad 47.6 \%$ TLHPDLGTDK

$122 \quad 0.14 \% \quad 47.6 \%$ EVHKQVVESAYEVIK

$122 \quad 0.14 \% \quad 47.6 \%$ QVVESAYEVIK

$122 \quad 0.14 \% \quad 47.6 \%$ RVHPVSTMIK

$122 \quad 0.14 \% \quad 47.6 \%$ VHPVSTMIK

$122 \quad 0.14 \% \quad 47.6 \%$ VTLTSEEEAR

$122 \quad 0.14 \% \quad 47.6 \%$ VTLTSEEEARLK

$122 \quad 0.14 \% \quad 47.6 \%$ KSADTLWGIQK

$122 \quad 0.14 \% \quad 47.6 \%$ SADTLWGIQK

$122 \quad 0.14 \% \quad 47.6 \%$ SADTLWGIQKELQF

$99 \quad 0.11 \% \quad 49.4 \%$ EKLIAPVAEEEATVPNNK

$99 \quad 0.11 \% \quad 49.4 \%$ LIAPVAEEEATVPNNK

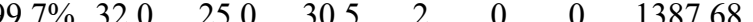
$\begin{array}{llllllll}99.7 \% & 32.6 & 25.0 & 24.9 & 2 & 0 & 0 & 1197.68\end{array}$ $\begin{array}{llllllll}99.0 \% & 28.5 & 25.0 & 19.7 & 1 & 0 & 0 & 899.49\end{array}$

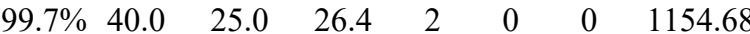
$\begin{array}{llllllll}99.7 \% & 61.2 & 25.0 & 42.1 & 3 & 0 & 0 & 1129.64\end{array}$ $\begin{array}{llllllll}98.9 \% & 18.7 & 25.0 & 18.7 & 1 & 0 & 0 & 1121.70\end{array}$

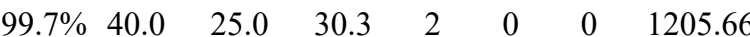
$\begin{array}{llllllll}99.7 \% & 27.8 & 25.0 & 26.5 & 2 & 0 & 0 & 1144.61\end{array}$

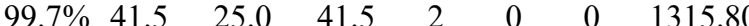
$99.7 \% \quad 50.4 \quad 25.0 \quad 46.8$ $\begin{array}{lllll}99.7 \% & 42.5 & 25.0 & 34.3 & 2\end{array}$ $98.0 \% \quad 36.7 \quad 25.0-6.3$ $\begin{array}{llll}99.7 \% & 51.8 & 25.0 & 48.7\end{array}$ $\begin{array}{llll}99.7 \% & 76.7 & 25.0 & 68.6\end{array}$ $99.7 \% \quad 50.7 \quad 25.0 \quad 23.3$ $\begin{array}{lllll}99.7 \% & 32.9 & 25.0 & 25.9 & 2\end{array}$ $99.7 \% \quad 37.3 \quad 25.0 \quad 26.4$ $\begin{array}{llll}99.7 \% & 58.4 & 25.0 & 54.2\end{array}$ $\begin{array}{llll}98.9 \% & 23.6 & 25.0 & 23.6\end{array}$ $99.4 \% \quad 24.7 \quad 25.0 \quad 24.7$ $\begin{array}{llll}99.7 \% & 47.2 & 25.0 & 44.2\end{array}$ $99.5 \% \quad 23.5 \quad 25.0 \quad 23.5$ $98.9 \% \quad 22.5 \quad 25.0 \quad 17.6$ $99.0 \% \quad 37.0$ $99.7 \% \quad 56.5$ $99.5 \% \quad 24.8$ $99.7 \% \quad 59.2$ $99.7 \% \quad 64.8$ $99.7 \% 52.6$ $99.7 \% \quad 58.4$ $\begin{array}{lll}99.0 \% & 42.2\end{array}$ $99.7 \% \quad 58.0$ $99.7 \% \quad 29.2$ $99.7 \% \quad 51.6$ $99.7 \% \quad 64.8$ $99.4 \% \quad 27.5$ $97.3 \% \quad 17.4$ $99.7 \% \quad 55.5$ $99.7 \% \quad 65.6$ $\begin{array}{lll}99.7 \% & 36.4\end{array}$ $99.7 \% \quad 57.7$ $\begin{array}{lll}99.6 \% & 26.2\end{array}$ 0. $\begin{array}{lll}99.7 \% & 56.0 \\ 99.7 \% & 54.4 \\ 99.7 \% & 66.9 & 2\end{array}$ $99.7 \% \quad 66.9$
1145.56

1029.54

1582.77

1326.71

1388.74

1122.60

1147.65

1122.69

1419.68

953.58

1860.84

1248.66

1318.71

1231.61

1119.64

2074.08

2006.08

1906.95

1633.78

1495.78

1011.47

913.58

929.58

1248.60

1096.56

1757.94

1264.68

1167.67

1011.57

1134.56

1375.74

1246.68

1118.58

1635.84

1952.03

1694.90

1989.09 1629.86 
L-lactate dehydrogenase B chain GN=LDHB LDHB_HUMAN $36.64 \quad 100.0 \%$ L-lactate dehydrogenase B chain GN=LDHB LDHB_HUMAN $36.64 \quad 100.0 \%$ L-lactate dehydrogenase B chain GN=LDHB LDHB_HUMAN $36.64 \quad 100.0 \%$ L-lactate dehydrogenase B chain GN=LDHB LDHB HUMAN $36.64 \quad 100.0 \%$ L-lactate dehydrogenase B chain GN=LDHB LDHB_HUMAN $36.64 \quad 100.0 \%$ L-lactate dehydrogenase B chain GN=LDHB LDHB_HUMAN $36.64 \quad 100.0 \%$ L-lactate dehydrogenase B chain GN=LDHB LDHB_HUMAN $36.64 \quad 100.0 \%$ L-lactate dehydrogenase B chain GN=LDHB LDHB_HUMAN $36.64 \quad 100.0 \%$ L-lactate dehydrogenase B chain GN=LDHB LDHB_HUMAN $36.64 \quad 100.0 \%$ L-lactate dehydrogenase B chain GN=LDHB LDHB_HUMAN $36.64 \quad 100.0 \%$ L-lactate dehydrogenase B chain GN=LDHB LDHB_HUMAN $36.64 \quad 100.0 \%$ -lactate dehydrogenase B chain GN=LDHB LDHB_HUMAN $36.64 \quad 100.0^{\circ}$ L-lactate dehydrogenase B chain GN=LDHB LDHB_HUMAN $36.64 \quad 100.0 \%$ Long-chain fatty acid transport protein $4 \mathrm{GN}=\mathrm{SLC} 27 \mathrm{~A} 4$ S27A4_HUMAN $72.07 \quad 100.0 \%$ Long-chain fatty acid transport protein $4 \mathrm{GN}=\mathrm{SLC} 27 \mathrm{~A} 4 \mathrm{~S} 27 \mathrm{~A} 4$ _HUMAN $72.07 \quad 100.0 \%$ Long-chain-fatty-acid--CoA ligase $3 \mathrm{GN}=$ ACSL3 ACSL3_HUMAN $80.42 \quad 100.0 \%$ Long-chain-fatty-acid--CoA ligase $3 \mathrm{GN}=$ ACSL3 ACSL3_HUMAN $80.42 \quad 100.0 \%$ Long-chain-fatty-acid--CoA ligase $3 \mathrm{GN}=$ ACSL3 ACSL3_HUMAN $80.42 \quad 100.0 \%$ Long-chain-fatty-acid--CoA ligase $3 \mathrm{GN}=$ ACSL3 ACSL3_HUMAN $80.42 \quad 100.0 \%$ Long-chain-fatty-acid-CoA ligase $3 \mathrm{GN}=$ ACSL 3 ACSL3 HUMAN $80.42 \quad 100.0 \%$ Lupus La protein $\mathrm{GN}=\mathrm{SSB}$ Lupus La protein $\mathrm{GN}=\mathrm{SSB}$ Lupus La protein $\mathrm{GN}=\mathrm{SSB}$ Lupus La protein $\mathrm{GN}=\mathrm{SSB}$ Lupus La protein $\mathrm{GN}=\mathrm{SSB}$ Lupus La protein $\mathrm{GN}=\mathrm{SSB}$ Lupus La protein $\mathrm{GN}=\mathrm{SSB}$ Lupus La protein $\mathrm{GN}=\mathrm{SSB}$ Lupus La protein $\mathrm{GN}=\mathrm{SSB}$

Lymphoid-specific helicase GN=HELLS LA_HUMAN $46.84 \quad 100.0 \%$ LA HUMAN $46.84 \quad 100.0 \%$ LA HUMAN $46.84 \quad 100.0 \%$ LA HUMAN $46.84 \quad 100.0 \%$ LA HUMAN $46.84 \quad 100.0 \%$ LA_HUMAN $46.84 \quad 100.0 \%$ LA HUMAN $46.84 \quad 100.0 \%$ LA HUMAN $46.84 \quad 100.0 \%$ LA_HUMAN $46.84 \quad 100.0 \%$ HELLS HUMAN $97.08 \quad 100.0 \%$ Lymphoid-specific helicase GN=HELLS HELLS_HUMAN $97.08 \quad 100.0 \%$ Lys-63-specific deubiquitinase BRCC36 GN=BRCC3 BRCC3_HUMAN $36.07 \quad 100.0 \%$ Lys-63-specific deubiquitinase BRCC36 GN=BRCC3 BRCC3_HUMAN $36.07 \quad 100.0 \%$ Lys-63-specific deubiquitinase BRCC36 GN=BRCC3 BRCC3_HUMAN $36.07 \quad 100.0 \%$ Lys-63-specific deubiquitinase BRCC36 GN=BRCC3 BRCC3_HUMAN $36.07 \quad 100.0 \%$ Lys-63-specific deubiquitinase BRCC36 GN=BRCC3 BRCC3_HUMAN $36.07 \quad 100.0 \%$ Lysine--tRNA ligase $\mathrm{GN}=\mathrm{KARS}$ Lysine--tRNA ligase $\mathrm{GN}=\mathrm{KARS}$ Lysine--tRNA ligase GN=KARS SYK_HUMAN $68.05 \quad 100.0 \%$ SYK HUMAN $68.05 \quad 100.0 \%$ SYK_HUMAN $68.05 \quad 100.0 \%$ Lysophospholipid acyltransferase $7 \mathrm{GN}=$ MBOAT7 MBOA7_HUMAN $52.77 \quad 100.0 \%$ Lysophospholipid acyltransferase $7 \mathrm{GN}=$ MBOAT7 MBOA7_HUMAN $52.77 \quad 100.0 \%$ Lysophospholipid acyltransferase $7 \mathrm{GN}=$ MBOAT7 MBOA7_HUMAN $52.77 \quad 100.0 \%$ Major centromere autoantigen B GN=CENPB CENPB_HUMAN $65.17 \quad 100.0 \%$ Major centromere autoantigen B GN=CENPB CENPB_HUMAN $65.17 \quad 100.0 \%$ Malate dehydrogenase, mitochondrial GN=MDH2 MDHM_HUMAN $35.50 \quad 100.0 \%$ Malate dehydrogenase, mitochondrial GN=MDH2 MDHM HUMAN $35.50 \quad 100.0 \%$ Malate dehydrogenase, mitochondrial GN=MDH2 MDHM_HUMAN $35.50 \quad 100.0 \%$

5
5
5

5
5
5

$\begin{array}{ll}5 & 5 \\ 5 & 5 \\ 5 & 5\end{array}$

10

$\begin{array}{ll}9 & 10 \\ 9 & 10 \\ 9 & 10\end{array}$

$\begin{array}{ll}9 & 10 \\ 9 & 10 \\ 9 & 10\end{array}$

9

10

10

10 \\ $\begin{array}{lll}99 & 0.11 \% & 49.4 \% \\ 9 & \text { FIIPQIVK }\end{array}$ \\ $99 \quad 0.11 \% \quad 49.4 \%$ HRVIGSGCNLDSAR}

$99 \quad 0.11 \% \quad 49.4 \%$ VIGSGCNLDSAR

$99 \quad 0.11 \% \quad 49.4 \%$ MVVESAYEVIK

$99 \quad 0.11 \% \quad 49.4 \%$ IHPVSTMVK

$99 \quad 0.11 \% \quad 49.4 \%$ GLTSVINQK

$99 \quad 0.11 \% \quad 49.4 \%$ LKDDEVAQLK

$99 \quad 0.11 \% \quad 49.4 \%$ KSADTLWDIQK

$99 \quad 0.11 \% \quad 49.4 \%$ SADTLWDIQK

$6 \quad 0.01 \% \quad 3.1 \% \quad$ TVPILFASTVR

$0.01 \% \quad 3.1 \%$ ILSFVYPIR

$9 \quad 0.01 \% \quad 8.6 \%$ AKPVNSKPDSAYR

$9 \quad 0.01 \% \quad 8.6 \%$ LKDIVSLVPR

$\begin{array}{lll}0.01 \% & 8.6 \% & \text { IGYSSPQTLADQSSK }\end{array}$

$0.01 \% \quad 8.6 \% \quad$ LLLCGGAPLSATTQR

$0.01 \% \quad 8.6 \%$ THYQADIER

$24 \quad 0.03 \% \quad 23.5 \%$ ICHQIEYYFGDFNLPR

$24 \quad 0.03 \% \quad 23.5 \%$ LTTDFNVIVEALSK

$0.03 \% \quad 23.5 \%$ SPSKPLPEVTDEYKNDVK

$24 \quad 0.03 \% \quad 23.5 \%$ GSIFVVFDSIESAK

$4 \quad 0.03 \% \quad 23.5 \%$ GSIFVVFDSIESAKK

$0.03 \% \quad 23.5 \%$ QKLEEDAEMK

$2 \quad 0.03 \% \quad 23.5 \%$ AKDANNGNLQLR

$0.03 \% \quad 23.5 \%$ DANNGNLQLR

$0.03 \% \quad 23.5 \%$ IIEDQQESLNK

$0.00 \% \quad 2.6 \% \quad$ KQEIFYTAIVNR

$0.00 \% \quad 2.6 \%$ GGQSGLNLSK

$0.01 \% \quad 17.4 \%$ FAYTGTEMR

$0.01 \% \quad 17.4 \%$ TVAEKVDAVR

$0.01 \% \quad 17.4 \%$ VLYTCFQSIQAQK

$0.01 \% \quad 17.4 \%$ VCLESAVELPK

$0.01 \% \quad 17.4 \%$ IHSLTHLDSVTK

$0.00 \% \quad 4.9 \%$ RGDIIGVQGNPGK

$0.00 \% \quad 4.9 \% \quad$ SKIITYIR

$0.00 \% \quad 4.9 \%$ QLFEEQAK

$0.01 \% \quad 8.7 \%$ AGGGPTLQCPPPSSPEK

$0.01 \% \quad 8.7 \%$ AASLEYDYETIR

$0.01 \% \quad 8.7 \%$ AASQPTSLAPEK

$0.00 \% \quad 3.8 \%$ HGVVSCSGVAR

$0.00 \% \quad 3.8 \%$ LAAQSLDTSGLR

$0.01 \% \quad 27.8 \%$ VAVLGASGGIGQPLSLLLK

$0.01 \% \quad 27.8 \%$ IFGVTTLDIVR

$0.01 \% \quad 27.8 \%$ ANTFVAELK $9.7 \% \quad 58.8$

$\begin{array}{llll}99.3 \% & 22.1\end{array}$

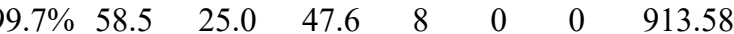

$\begin{array}{llllllll}99.0 \% & 38.9 & 25.0 & 29.6 & 4 & 0 & 0 & 957.61\end{array}$

$\begin{array}{llllllll}99.7 \% & 44.3 & 25.0 & 40.2 & 1 & 3 & 0 & 1541.76\end{array}$

$\begin{array}{llllllll}99.7 \% & 58.0 & 25.0 & 50.8 & 24 & 0 & 0 & 1248.60\end{array}$

$\begin{array}{llllllll}99.7 \% & 58.7 & 25.0 & 54.7 & 14 & 0 & 0 & 1283.66\end{array}$

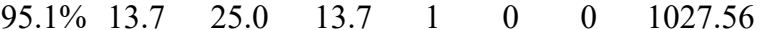

$\begin{array}{llllllll}99.7 \% & 55.3 & 25.0 & 32.4 & 7 & 0 & 0 & 959.55\end{array}$

$\begin{array}{llllllll}99.7 \% & 61.2 & 25.0 & 44.9 & 4 & 0 & 0 & 1158.64\end{array}$

$\begin{array}{llllllll}99.7 \% & 49.0 & 25.0 & 41.7 & 2 & 0 & 0 & 1304.68\end{array}$

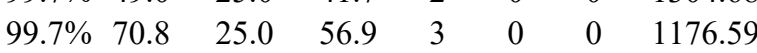

$\begin{array}{llllllll}99.7 \% & 32.6 & 25.0 & 32.6 & 4 & 0 & 0 & 1203.71\end{array}$

$\begin{array}{llllllll}97.0 \% & 25.6 & 25.0 & 11.1 & 2 & 0 & 0 & 1107.66\end{array}$

$\begin{array}{llllllll}99.7 \% & 40.7 & 25.0 & 39.6 & 1 & 0 & 0 & 1432.75\end{array}$

$\begin{array}{llllllll}99.7 \% & 37.3 & 25.0 & 28.5 & 2 & 0 & 0 & 1139.71\end{array}$

$\begin{array}{llllllll}99.7 \% & 69.6 & 25.0 & 69.6 & 2 & 0 & 0 & 1581.78\end{array}$

$\begin{array}{llllllll}99.7 \% & 69.0 & 25.0 & 61.3 & 2 & 0 & 0 & 1557.84\end{array}$

$\begin{array}{llllllll}99.7 \% & 33.9 & 25.0 & 30.8 & 2 & 0 & 0 & 1132.54\end{array}$

$\begin{array}{llllllll}94.7 \% & 16.9 & 25.0 & 16.0 & 0 & 1 & 0 & 2071.97\end{array}$

$\begin{array}{llllllll}99.7 \% & 32.2 & 25.0 & 32.1 & 5 & 0 & 0 & 1549.85\end{array}$

2046.04

1498.78

1626.87

$\begin{array}{llll}99.5 \% & 24.4 & 25.0 & 23.1\end{array}$

$\begin{array}{llll}98.9 \% & 24.5 & 25.0 & 15.3\end{array}$

$99.7 \% \quad 73.1 \quad 25.0 \quad 73.1 \quad 2$

$\begin{array}{llll}99.7 \% & 50.3 & 25.0 & 40.3\end{array}$

$\begin{array}{lllll}99.7 \% & 57.8 & 25.0 & 46.8 & 3\end{array}$

$\begin{array}{llll}99.7 \% & 60.7 & 25.0 & 60.7\end{array}$

$\begin{array}{lllll}99.4 \% & 23.5 & 25.0 & 17.9 & 2\end{array}$

$\begin{array}{llll}99.4 \% & 26.2 & 25.0 & 25.9\end{array}$

$\begin{array}{llll}99.7 \% & 43.9 & 25.0 & 22.1\end{array}$

$\begin{array}{lllll}99.7 \% & 64.5 & 25.0 & 61.0 & 2\end{array}$

$\begin{array}{lllll}99.7 \% & 32.8 & 25.0 & 22.0 & 1\end{array}$

$\begin{array}{llll}98.6 \% & 17.8 & 25.0 & 17.8\end{array}$

$\begin{array}{lllll}99.7 \% & 36.4 & 25.0 & 35.4 & 1\end{array}$

$\begin{array}{llll}99.0 \% & 25.1 & 25.0 & 25.1\end{array}$

$\begin{array}{llll}99.0 \% & 35.4 & 25.0 & 17.6\end{array}$

$\begin{array}{lllll}99.6 \% & 24.2 & 25.0 & 24.2 & 2\end{array}$

$\begin{array}{llll}99.7 \% & 44.4 & 25.0 & 38.0\end{array}$

$98.7 \% \quad 21.3 \quad 25.0 \quad 17.2$

$\begin{array}{llll}99.7 \% & 43.1 & 25.0 & 43.1\end{array}$

$\begin{array}{llll}97.3 \% & 16.8 & 25.0 & 16.8\end{array}$

$\begin{array}{lllll}99.7 \% & 80.7 & 25.0 & 80.7 & 2\end{array}$

$\begin{array}{llll}99.7 \% & 57.7 & 25.0 & 50.7\end{array}$

$\begin{array}{llll}99.7 \% & 43.2 & 25.0 & 30.4\end{array}$

1236.58

1313.69

1114.56

1316.67

1481.81

960.51

1091.48

1087.61

1585.80

1244.66

1350.74

1310.72

993.61

992.50

1679.81

1430.68

1199.63

1128.56

1231.66

1793.09

1233.72

992.54 
Malate dehydrogenase, mitochondrial GN=MDH2 MDHM_HUMAN $35.50 \quad 100.0 \%$ Malate dehydrogenase, mitochondrial GN=MDH2 MDHM_HUMAN $35.50 \quad 100.0 \%$ Malate dehydrogenase, mitochondrial GN=MDH2 MDHM_HUMAN $35.50 \quad 100.0 \%$ Malate dehydrogenase, mitochondrial GN=MDH2 MDHM HUMAN $35.50 \quad 100.0^{\circ}$ Malonyl-CoA-acyl carrier protein transacylase, mitochondrial GN=MCAT FABD_HUMAN $42.96 \quad 100.0 \%$ Malonyl-CoA-acyl carrier protein transacylase, mitochondrial GN=MCAT FABD_HUMAN $42.96 \quad 100.0 \%$ Malonyl-CoA-acyl carrier protein transacylase, mitochondrial GN=MCAT FABD_HUMAN $42.96 \quad 100.0 \%$ Mannose-1-phosphate guanyltransferase alpha GN=GMPPA GMPPA_HUMAN $46.29 \quad 100.0 \%$ Mannose-1-phosphate guanyltransferase alpha GN=GMPPA GMPPA_HUMAN $46.29 \quad 100.0 \%$ Mannose-1-phosphate guanyltransferase alpha GN=GMPPA GMPPA_HUMAN $46.29 \quad 100.0 \%$ Mannose-1-phosphate guanyltransferase alpha GN=GMPPA GMPPA_HUMAN $46.29 \quad 100.0 \%$ Mannose-1-phosphate guanyltransferase alpha GN=GMPPA GMPPA_HUMAN 46.29 Mannose-1-phosphate guanyltransferase alpha GN=GMPPA GMPPA_HUMAN 46.29 Mannose-1-phosphate guanyltransferase alpha GN=GMPPA GMPPA_HUMAN 46.29 Mannose-1-phosphate guanyltransferase beta GN=GMPPB GMPPB HUMAN $39.83 \quad 100.0 \%$ Mannose-1-phosphate guanyltransferase beta GN=GMPPB GMPPB_HUMAN $39.83 \quad 100.0 \%$ Mannose-1-phosphate guanyltransferase beta GN=GMPPB GMPPB HUMAN $39.83 \quad 100.0 \%$ Matrin-3 GN=MATR3

Matrin-3 GN=MATR3

Matrin-3 GN=MATR3

Matrin-3 GN=MATR3

Matrin-3 GN=MATR3

Matrin-3 GN=MATR3

Matrin-3 GN=MATR3

Matrin-3 GN=MATR3

Matrin-3 GN=MATR3

Matrin-3 GN=MATR3

Matrin-3 GN=MATR3

Matrin-3 GN=MATR3

Matrin-3 GN=MATR3

Matrin-3 GN=MATR3

Matrin-3 GN=MATR3

Matrin-3 GN=MATR3

Matrin-3 GN=MATR3

Matrin-3 GN=MATR3

Matrin-3 GN=MATR3

Matrin-3 GN=MATR3

Matrin-3 GN=MATR3

Matrin-3 GN=MATR3

Mediator of DNA damage checkpoint protein $1 \mathrm{GN}=\mathrm{MDC1}$ MDC1_HUMAN $226.66 \quad 100.0 \%$ Mediator of DNA damage checkpoint protein $1 \mathrm{GN}=\mathrm{MDC1}$ MDC1_HUMAN $226.66100 .0 \%$ Mediator of DNA damage checkpoint protein $1 \mathrm{GN}=\mathrm{MDC1}$ MDC1_HUMAN $226.66 \quad 100.0 \%$ Mediator of DNA damage checkpoint protein $1 \mathrm{GN}=\mathrm{MDC} 1$ MDC1_HUMAN $226.66100 .0 \%$ Medium-chain specific acyl-COA dehydrogenase, mitochondrial GN=ACADM ACADM_HUMAN $46.59 \quad 100.0 \%$ Medium-chain specific acyl-CoA dehydrogenase, mitochondrial GN=ACADM ACADM_HUMAN $46.59 \quad 100.0 \%$ Medium-chain specific acyl-CoA dehydrogenase, mitochondrial GN=ACADM ACADM HUMAN $46.59 \quad 100.0 \%$ Medium-chain specific acyl-CoA dehydrogenase, mitochondrial GN=ACADM ACADM_HUMAN $46.59 \quad 100.0 \%$
$13 \quad 0.01 \% \quad 27.8 \%$ VNVPVIGGHAGK

$0.01 \% \quad 27.8 \%$ AGAGSATLSMAYAGAR

$0.01 \% \quad 27.8 \%$ SQETECTYFSTPLLLGK

$0.01 \% 27.8 \%$ MISDAIPELK

$0.00 \% \quad 7.7 \%$ FNFACLEAR

$0.00 \% \quad 7.7 \%$ VISGHQEALR

$0.00 \% \quad 7.7 \% \quad$ LLAQQLVSPVK

$0.01 \% \quad 18.8 \%$ AVILIGGPQK

$0.01 \% \quad 18.8 \%$ SAGSALYASR

$0.01 \% \quad 18.8 \%$ GNVYIHPTAK

$0.01 \% \quad 18.8 \%$ VAPSAVLGPNVSIGK

$0.01 \% \quad 18.8 \%$ GVTVGEGVR

$0.01 \% \quad 18.8 \%$ VEGTPSDPNPNDPR

$0.01 \% \quad 18.8 \%$ LLPAITILGCR

$0.00 \% \quad 11.4 \%$ ALILVGGYGTR

$0.00 \% \quad 11.4 \%$ YGVVVCEADTGR

$99.7 \% \quad 39.5$

$99.7 \% 29.0$

$99.7 \% \quad 42.5$

$99.5 \% 25.1$

$99.7 \% 55.6$

$99.7 \% \quad 29.8$

$99.7 \% \quad 42.0$

$99.5 \% \quad 24.3$

$97.8 \% 26.2$

$99.7 \% 51.1$

$99.7 \% \quad 38.6$

$99.7 \% \quad 39.2$

$99.7 \% \quad 48.3$

$99.7 \% \quad 54.2$

$0.00 \% \quad 11.4 \%$ LCSGPGIVGNVLVDPSAR $\quad 99.7 \% \quad 62.9$

$0.08 \% \quad 24.4 \%$ SFQQSSLSR

$0.08 \% \quad 24.4 \%$ GPLPLSSQHR

$99.7 \% \quad 51.7$

$99.7 \% \quad 39.6$

MATR3_HUMAN $94.63 \quad 100.0 \% \quad 22$ MATR__HUMAN $94.63 \quad 100.0 \% \quad 22$ MATR3 HUMAN $94.63 \quad 100.0 \% \quad 22$ MATR3_HUMAN $94.63 \quad 100.0 \% \quad 22$ MATR3 HUMAN $94.63 \quad 100.0 \% \quad 22$ MATR3_HUMAN $94.63 \quad 100.0 \% \quad 22$ MATR3_HUMAN $94.63 \quad 100.0 \% \quad 22$ MATR3_HUMAN $94.63 \quad 100.0 \% \quad 22$ MATR3 HUMAN $94.63 \quad 100.0 \% \quad 22$ MATR3_HUMAN $94.63 \quad 100.0 \% \quad 22$ MATR3_HUMAN $94.63 \quad 100.0 \% \quad 22$ MATR3 HUMAN $94.63 \quad 100.0 \% \quad 22$ MATR3_HUMAN $94.63 \quad 100.0 \% \quad 22$ MATR3_HUMAN $94.63 \quad 100.0 \% \quad 22$ MATR3_HUMAN $94.63 \quad 100.0 \% \quad 22$ MATR3 HUMAN $94.63 \quad 100.0 \% \quad 22$ MATR3 HUMAN $94.63 \quad 100.0 \% \quad 22$

$0.08 \% \quad 24.4 \%$ GDADQASNILASFGLSAR

$0.08 \% \quad 24.4 \%$ RTEEGPTLSYGR

$0.08 \% \quad 24.4 \%$ TEEGPTLSYGR

$0.08 \% \quad 24.4 \%$ TEEGPTLSYGRDGR

$0.08 \% \quad 24.4 \%$ MGRGPGPLQER

$0.08 \% \quad 24.4 \%$ GPGPLQER

$0.08 \% \quad 24.4 \%$ GNLGAGNGNLQGPR

$99.7 \% \quad 53.2$

$99.7 \% \quad 55.8$

$99.5 \% \quad 23.4$

$99.7 \% \quad 44.6$

$99.0 \% \quad 34.3$

$99.7 \% \quad 60.9$

$0.08 \% \quad 24.4 \%$ GNLGAGNGNLQGPRHMQK $99.6 \% 24.5$

$0.08 \% 24.4 \%$ VVHIMDFQR

$99.7 \% \quad 32.0$

$99.7 \% \quad 48.4$

$0.08 \% \quad 24.4 \%$ FDQKQELGR

$0.08 \% \quad 24.4 \%$ LAEPYGKIK

$0.08 \% \quad 24.4 \%$ IKNYILMR

$0.08 \% \quad 24.4 \%$ VDLSEKYK

$0.08 \% \quad 24.4 \%$ LVLRIPNR

$0.08 \% 24.4 \%$ IPNRGIDLLK

$0.08 \% 24.4 \%$ IGPYQPNVPVGIDYVIPK

$0.08 \% \quad 24.4 \%$ LCSLFYTNEEVAK

$0.08 \% \quad 24.4 \%$ NTHCSSLPHYQK

$0.08 \% \quad 24.4 \%$ FLNKLAEER

$0.01 \% \quad 2.6 \%$ GPLTVEETPR

$0.01 \% \quad 2.6 \%$ EGAQVPTGR

$\begin{array}{lll}0.01 \% & 2.6 \% & \text { NQLVTPEPTSR }\end{array}$

$0.01 \% \quad 2.6 \%$ TPEPVVPTAPEPHPTTSTDQPVTPK

$0.02 \% \quad 23.0 \%$ KGDEYIINGQK

$0.02 \% \quad 23.0 \%$ ANWYFLLAR

$0.02 \% \quad 23.0 \%$ SDPDPKAPANK

$0.02 \% \quad 23.0 \%$ AFTGFIVEADTPGIQIGR
$97.2 \% \quad 22.4$

$95.7 \% \quad 16.2$

$99.0 \% 23.6$

$99.0 \% \quad 26.8$

$95.0 \% \quad 16.6$

$99.3 \% 31.2$

$99.7 \% \quad 58.2$

$98.9 \% \quad 21.9$

$99.7 \% \quad 54.5$

$98.4 \% 17.6$

$99.3 \% 27.1$

$99.7 \% \quad 35.8$

$99.7 \% \quad 28.1$

$99.7 \% \quad 48.0$

$99.4 \% \quad 25.8$

$96.5 \% 23.0$

$99.7 \% \quad 46.9$
.0

39.0

$\begin{array}{ll}0 & 22.1\end{array}$

$\begin{array}{ll}.0 & 28.8\end{array}$

$\begin{array}{ll}.0 & 24.2\end{array}$

$0 \quad 54.4$

29.0
25.0

24.3
25.0

$\begin{array}{ll}5.0 & 26.2\end{array}$

\begin{tabular}{ll}
39.5 \\
\hline
\end{tabular}

21.0

38.0

\begin{tabular}{ll}
38.3 \\
\hline
\end{tabular}

51.1

$\begin{array}{ll}.0 & 62.9\end{array}$

.035 .1

$\begin{array}{ll}34.0 & 34.8\end{array}$

$\begin{array}{ll}.0 & 51.7\end{array}$

\begin{tabular}{ll}
40.8 \\
\hline
\end{tabular}

\begin{tabular}{ll}
.0 & 45.5 \\
\hline &
\end{tabular}

$\begin{array}{ll}25.0 & 42.5\end{array}$

$\begin{array}{ll}3.0 & 33.9\end{array}$

51.5
25.0

$\begin{array}{ll}24.0 & 24.5\end{array}$

$\begin{array}{ll}0 & 29.8\end{array}$

\begin{tabular}{ll}
37.9 \\
\hline
\end{tabular}

$.0 \quad 31.4$

$\begin{array}{ll}0 & 13.4\end{array}$

$\begin{array}{ll}.0 & 14.1\end{array}$

$\begin{array}{ll}.0 & 22.5\end{array}$

.026 .8

$\begin{array}{ll}25.0 \quad 13.0 \\ 25.0 & 31.2\end{array}$

\begin{tabular}{l}
$25.0 \quad 31.2$ \\
\hline 5.0
\end{tabular}

\begin{tabular}{ll}
5.0 & 54.2 \\
\hline
\end{tabular}

21.9

$5.0 \quad 42.6$

$\begin{array}{ll}25.0 & 17.6\end{array}$

$\begin{array}{ll}5.0 & 16.6\end{array}$

$\begin{array}{ll}29.0 & 29.3\end{array}$

$\begin{array}{ll}28.0 & 28.1\end{array}$

$\begin{array}{ll}25.0 & 35.1 \\ 25.0 & 25.8\end{array}$

\begin{tabular}{ll}
25.0 & 25.8 \\
\hline 5.0 & 10.2
\end{tabular} $242 \quad 257$ $280 \quad 296$ $315 \quad 324$ $\begin{array}{ll}204 & 212 \\ 237 & 246\end{array}$ $315 \quad 325$ $4 \quad 13$ $250 \quad 259$ $285 \quad 294$ 318 $353 \quad 366$ $380 \quad 390$ 313 $144 \quad 155$

$\begin{array}{cc}4 & 12 \\ 93 & 102\end{array}$

$103 \quad 120$

$149 \quad 160$

$150 \quad 160$

$150 \quad 163$

$56 \quad 263$

$374 \quad 387$

$374 \quad 391$

$399 \quad 407$

$488 \quad 496$

$497 \quad 515$

$516 \quad 524$

$66 \quad 573$

$575 \quad 582$

$579 \quad 588$

$781 \quad 798$

$805 \quad 817$

$818 \quad 829$

$833 \quad 841$

$143 \quad 152$

$664 \quad 672$

$1585 \quad 1595$

$1608 \quad 1632$

$179 \quad 189$

$198 \quad 206$

$\begin{array}{lll}1139.57 & 207 & 217 \\ 1891.99 & 218 & 235\end{array}$ 
Methionine--tRNA ligase, cytoplasmic GN=MARS SYMC_HUMAN $101.12 \quad 100.0 \%$ Methionine--tRNA ligase, cytoplasmic GN=MARS SYMC_HUMAN $101.12 \quad 100.0 \%$ Methionyl-tRNA formyltransferase, mitochondrial GN=MTFMT FMT HUMAN $43.83 \quad 100.0 \%$ Methionyl-tRNA formyltransferase, mitochondrial GN=MTFMT FMT_HUMAN $43.83 \quad 100.0 \%$ Methionyl-tRNA formyltransferase, mitochondrial GN=MTFMT FMT_HUMAN $43.83 \quad 100.0 \%$ Methylosome protein $50 \mathrm{GN}=$ WDR77 Methylosome protein $50 \mathrm{GN}=$ WDR77 Methylosome protein $50 \mathrm{GN}=\mathrm{WDR} 77$ Methylosome protein $50 \mathrm{GN}=$ WDR77 Methylosome protein $50 \mathrm{GN}=$ WDR77 Methylosome protein $50 \mathrm{GN}=$ WDR77 Methylosome protein $50 \mathrm{GN}=$ WDR77 Methylosome protein $50 \mathrm{GN}=\mathrm{WDR} 77$ Methylosome protein $50 \mathrm{GN}=$ WDR77 Methylosome protein $50 \mathrm{GN}=$ WDR77 Methylosome protein $50 \mathrm{GN}=$ WDR77 Methylosome protein $50 \mathrm{GN}=$ WDR77 Methylosome protein $50 \mathrm{GN}=\mathrm{WDR} 77$ MEP50_HUMAN $36.72 \quad 100.0 \%$ MEP50_HUMAN $36.72 \quad 100.0 \%$ MEP50_HUMAN $36.72 \quad 100.0 \%$ MEP50_HUMAN $36.72 \quad 100.0 \%$ MEP50_HUMAN $36.72 \quad 100.0 \%$ MEP50 HUMAN $36.72 \quad 100.0 \%$ MEP50_HUMAN $36.72 \quad 100.0 \%$ MEP50 HUMAN $36.72 \quad 100.0 \%$ MEP50 HUMAN $36.72 \quad 100.0 \%$ MEP50_HUMAN $36.72 \quad 100.0 \%$ MEP50 HUMAN $36.72 \quad 100.0 \%$ MEP50 HUMAN $36.72 \quad 100.0 \%$ MEP50_HUMAN $36.72 \quad 100.0 \%$ ethylosome subunit $\mathrm{pIC} \ln \mathrm{GN}=\mathrm{CLNS} 1 \mathrm{~A}$ ICLN HUMAN $26.22 \quad 100.0 \%$ Methylosome subunit pICln GN=CLNS1A ICLN_HUMAN $26.22 \quad 100.0 \%$ Methylosome subunit pICln GN=CLNS1A ICLN HUMAN $26.22 \quad 100.0 \%$ Methylosome subunit pICln GN=CLNS1A ICLN_HUMAN $26.22 \quad 100.0 \%$ Methylosome subunit pICln GN=CLNS1A ICLN_HUMAN $26.22 \quad 100.0 \%$ Methylthioribose-1-phosphate isomerase GN=MRI1 MTNA HUMAN $39.15 \quad 100.0 \%$ Methylthioribose-1-phosphate isomerase GN=MRI1 MTNA_HUMAN $39.15 \quad 100.0 \%$ Methylthioribose-1-phosphate isomerase GN=MRI1 MTNA_HUMAN $39.15 \quad 100.0 \%$ Methylthioribose-1-phosphate isomerase GN=MRI1 MTNA_HUMAN $39.15 \quad 100.0 \%$ Methylthioribose-1-phosphate isomerase GN=MRI1 MTNA_HUMAN $39.15 \quad 100.0 \%$ Methylthioribose-1-phosphate isomerase GN=MRI1 MTNA_HUMAN $39.15 \quad 100.0 \%$ Methylthioribose-1-phosphate isomerase GN=MRI1 MTNA_HUMAN $39.15 \quad 100.0 \%$ Methylthioribose-1-phosphate isomerase GN=MRI1 MTNA_HUMAN $39.15 \quad 100.0 \%$ Methylthioribose-1-phosphate isomerase GN=MRI1 MTNA HUMAN $39.15 \quad 100.0 \%$ Methylthioribose-1-phosphate isomerase GN=MRI1 MTNA_HUMAN $39.15 \quad 100.0 \%$

$16 \quad 0.02 \% \quad 23.0 \%$ GIVFEDVKVPK

$\begin{array}{lll}16 & 0.02 \% & 23.0 \% \\ 16 & 0.02 \% & 23.0 \%\end{array}$

$16 \quad 0.02 \% \quad 23.0 \%$ IYQIYEGTSQIQR

$0.01 \% \quad 7.1 \%$ ALEVSEDVKVSK

$0.01 \% \quad 7.1 \%$ ATEVSKTPEAR

$0.01 \% \quad 7.1 \%$ VSHVADTKVNTK

$0.01 \% \quad 7.1 \%$ GPIAFWAR

$0.02 \% \quad 9.9 \% \quad$ KGEDVLGSVR

$0.02 \% \quad 9.9 \% \quad$ ALTHIDHSLSR

$0.02 \% \quad 9.9 \% \quad$ QPQPSPAEGR

$0.02 \% \quad 9.9 \%$ RLEEWLGR

$0.02 \% \quad 9.9 \%$ HGNQYIQVNEPWKR

$0.02 \% \quad 9.9 \%$ LENDQIESLR

$0.02 \% \quad 9.9 \% \quad$ ADKNEVAAEVAK

$0.02 \% \quad 9.9 \%$ QLAVAEGKPPEAPK

$0.01 \% \quad 9.8 \%$ VLFFGTDQFAR

$0.01 \% \quad 9.8 \%$ LGANMLISVLK

$0.01 \% \quad 9.8 \%$ LLDLVEVNSSVLADPK

$132 \quad 0.15 \% \quad 44.4 \%$ KETPPPLVPPAAR

$132 \quad 0.15 \% \quad 44.4 \%$ ETPPPLVPPAAR

$132 \quad 0.15 \% \quad 44.4 \%$ EWNLPPNAPACMER

$132 \quad 0.15 \% \quad 44.4 \%$ YRSDGALLLGASSLSGR

$132 \quad 0.15 \% \quad 44.4 \%$ SDGALLLGASSLSGR

$0.15 \% \quad 44.4 \%$ CWAGSLWLFK

$132 \quad 0.15 \% \quad 44.4 \%$ DPCAAPNEGFCSAGVQTEAGVADLTWVGE

$0.15 \% \quad 44.4 \%$ FCKYEHDDIVSTVSVLSSGTQAVSGSK

132

132

$0.15 \% \quad 44.4 \%$ VWDLAQQVVLSSYR

$0.15 \% \quad 44.4 \%$ AHAAQVTCVAASPHK

$32 \quad 0.15 \% \quad 44.4 \%$ AHAAQVTCVAASPHKDSVFLSCSEDNR

$132 \quad 0.15 \% \quad 44.4 \%$ DSVFLSCSEDNR

$0.03 \% \quad 31.2 \%$ SFPPPGPAEGLLR

$0.03 \% \quad 31.2 \%$ QQPDTEAVLNGK

$0.03 \% \quad 31.2 \%$ GLGTGTLYIAESR

$0.03 \% \quad 31.2 \%$ DRSDCLGEHLYVMVNAK

$0.03 \% \quad 31.2 \%$ LEGMLSQSVSSQYNMAGVR

$0.02 \% \quad 41.5 \%$ GSLQILDQLLLPK

$0.02 \% \quad 41.5 \%$ YEAVGSVHQAWEAIR

$0.02 \% \quad 41.5 \%$ DLADVAAR

$0.02 \% \quad 41.5 \%$ EAEREGATEEAVR

$0.02 \% \quad 41.5 \%$ VICCTEDMLEK

$.7 \% \quad 39.4$

$98.7 \% \quad 22.9$

$99.7 \% \quad 64.2$

$99.7 \% \quad 66.4$

$99.7 \% \quad 40.5$

$99.3 \% 21.0$

$99.0 \% \quad 43.3$

$99.7 \% 39.7$

$99.7 \% \quad 50.8$

$\begin{array}{lll}99.7 \% & 32.9\end{array}$

$99.0 \% \quad 34.9$

$99.2 \% \quad 23.8$

$99.7 \% \quad 48.0$

$99.7 \% \quad 43.5$

$99.7 \% \quad 59.0$

$99.7 \% \quad 31.7$

$99.7 \% \quad 59.1$

$99.7 \% \quad 46.7$

$99.7 \% \quad 47.3$

$99.6 \% \quad 26.7$

$99.7 \% \quad 55.3$

$99.7 \% \quad 58.4$

$99.7 \% \quad 55.3$

$99.7 \% \quad 31.0$

$99.7 \% \quad 54.4$

$99.7 \% \quad 49.6$

$99.7 \% \quad 55.3$

$99.7 \% \quad 54.9$

$99.7 \% \quad 71.6$

$\begin{array}{ll}9.7 \% & 53.2 \\ 9.7 \% & 45.0\end{array}$

$99.7 \% \quad 60.9$

$99.7 \% \quad 79.4$

$99.7 \% \quad 46.0$

$99.7 \% \quad 52.3$

$99.7 \% \quad 36.6$

$99.0 \% \quad 29.4$

$99.7 \% \quad 41.1$

$97.4 \% \quad 21.3$

$0.02 \% \quad 41.5 \%$ VTVLTHCNTGALATAGYGTALGVIR $\quad 99.7 \% \quad 44.1$

$0.02 \% \quad 41.5 \%$ LEHAFCTETRPYNQGAR

$0.02 \% \quad 41.5 \%$ GVSAVVVGADR

$\begin{array}{llll}99.3 \% & 20.3\end{array}$

$0.02 \% \quad 41.5 \%$ VGTYQLAIVAK

$99.7 \% \quad 67.6$

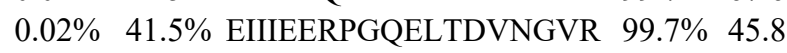

1465.86

1030.52

1598.82

1303.71

1188.62

1298.71

917.50

1059.58

1249.66

1066.53

1058.57

1768.89

1216.62

1244.65

1434.80

1300.67

1158.69

1711.95

1372.79

1244.70

1684.76

1722.91

1403.75

1267.63

3164.41

2901.39

2466.20

1663.88

1547.77

2957.36

1428.61

1337.72

1299.65

1337.71

2006.94

2088.97

1437.87

1715.85

830.44

1446.68

1397.61

2516.33

2049.96

1029.57

1162.68

2167.14

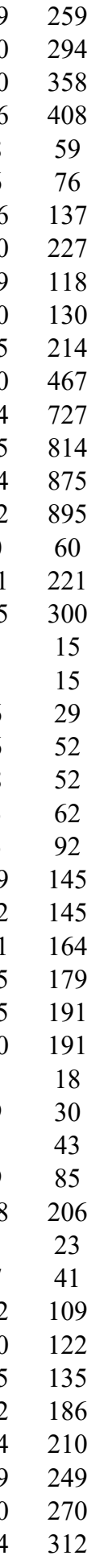

Page 94 of Table S-1-6 
Methylthioribose-1-phosphate isomerase GN=MRI1 MTNA_HUMAN $39.15 \quad 100.0 \%$ MICOS complex subunit MIC60 GN=IMMT MIC60 HUMAN $83.68 \quad 100.0 \%$ MICOS complex subunit MIC60 GN=IMMT MIC60_HUMAN $83.68 \quad 100.0 \%$ MICOS complex subunit MIC60 GN=IMMT MIC60_HUMAN $83.68 \quad 100.0^{\circ}$ MICOS complex subunit MIC60 GN=IMMT MIC60_HUMAN $83.68 \quad 100.0 \%$ MICOS complex subunit MIC60 GN=IMMT MIC60_HUMAN $83.68 \quad 100.0 \%$ Midasin GN=MDN1 Midasin GN=MDN1 Midasin GN=MDN1

Midasin GN=MDN1

Midasin GN=MDN1

Midasin GN=MDN1

Midasin GN=MDN1

Midasin $\mathrm{GN}=\mathrm{MDN} 1$

Midasin GN=MDN1

Midasin GN=MDN1

Midasin GN=MDN1

Midasin GN=MDN1

Midasin GN=MDN1

Midasin GN=MDN1

MDN1_HUMAN $632.83 \quad 100.0 \%$ MDN1_HUMAN $632.83 \quad 100.0 \%$ MDN1 HUMAN $632.83 \quad 100.0 \%$ MDN1_HUMAN $632.83 \quad 100.0 \%$ MDN1_HUMAN $632.83 \quad 100.0 \%$ MDN1_HUMAN $632.83 \quad 100.0 \%$ MDN1_HUMAN $632.83 \quad 100.0 \%$ MDN1_HUMAN $632.83 \quad 100.0 \%$ MDN1 HUMAN $632.83 \quad 100.0 \%$ MDN1_HUMAN $632.83 \quad 100.0 \%$ MDN1_HUMAN $632.83 \quad 100.0 \%$ MDN1_HUMAN $632.83 \quad 100.0 \%$ MDN1_HUMAN $632.83 \quad 100.0 \%$ MDN1_HUMAN $632.83 \quad 100.0 \%$ Minor histocompatibility antigen H13 GN=HM13 HM13_HUMAN $41.49 \quad 100.0 \%$ Minor histocompatibility antigen H13 GN=HM13 HM13 HUMAN $41.49 \quad 100.0 \%$ Mitochondrial 10-formyltetrahydrofolate dehydrogenase GN=ALDHIL2 AL1L2_HUMAN $101.75 \quad 100.0 \%$ Mitochondrial 10-formyltetrahydrofolate dehydrogenase GN=ALDHIL2 AL1L2_HUMAN $101.75 \quad 100.0 \%$ Mitochondrial 10-formyltetrahydrofolate dehydrogenase GN=ALDH1L2 AL1L2_HUMAN $101.75 \quad 100.0 \%$ Mitochondrial 10-formyltetrahydrofolate dehydrogenase GN=ALDHIL2 AL1L2_HUMAN $101.75 \quad 100.0 \%$ Mitochondrial 2-oxoglutarate/malate carrier protein GN=SLC25A11 M2OM_HUMAN $34.06 \quad 100.0 \%$ Mitochondrial 2-oxoglutarate/malate carrier protein GN=SLC25A11 M2OM HUMAN $34.06 \quad 100.0 \%$ Mitochondrial 2-oxoglutarate/malate carrier protein GN=SLC25A11 M2OM_HUMAN $34.06 \quad 100.0 \%$ Mitochondrial 2-oxoglutarate/malate carrier protein GN=SLC25A11 M2OM HUMAN $34.06 \quad 100.0 \%$ Mitochondrial 2-oxoglutarate/malate carrier protein GN=SLC25A11 M2OM_HUMAN $34.06 \quad 100.0 \%$ Mitochondrial 2-oxoglutarate/malate carrier protein GN=SLC25A11 M2OM_HUMAN $34.06 \quad 100.0 \%$ Mitochondrial 2-oxoglutarate/malate carrier protein GN=SLC25A11 M2OM HUMAN $34.06 \quad 100.0 \%$ Mitochondrial 2-oxoglutarate/malate carrier protein GN=SLC25A11 M2OM_HUMAN $34.06 \quad 100.0 \%$ Mitochondrial carnitine/acylcarnitine carrier protein GN=SLC25A20 MCAT HUMAN $32.95100 .0 \%$ Mitochondrial carnitine/acylcarnitine carrier protein GN=SLC25A20 MCAT_HUMAN $32.95 \quad 100.0 \%$ Mitochondrial carnitine/acylcarnitine carrier protein GN=SLC25A20 MCAT_HUMAN $32.95 \quad 100.0 \%$ Mitochondrial carnitine/acylcarnitine carrier protein GN=SLC25A20 MCAT HUMAN $32.95100 .0 \%$ Mitochondrial carnitine/acylcarnitine carrier protein GN=SLC25A20 MCAT_HUMAN $32.95 \quad 100.0 \%$ Mitochondrial carnitine/acylcarnitine carrier protein GN=SLC25A20 MCAT_HUMAN $32.95 \quad 100.0 \%$ Mitochondrial carnitine/acylcarnitine carrier protein GN=SLC25A20 MCAT_HUMAN $32.95100 .0 \%$ Mitochondrial dicarboxylate carrier GN=SLC25A10 DIC_HUMAN $31.28 \quad 100.0 \%$ Mitochondrial dicarboxylate carrier GN=SLC25A10 DIC_HUMAN $31.28 \quad 100.0 \%$ Mitochondrial dicarboxylate carrier GN=SLC25A10 DIC_HUMAN $31.28 \quad 100.0 \%$ Mitochondrial dicarboxylate carrier GN=SLC25A10 DIC_HUMAN $31.28 \quad 100.0 \%$ Mitochondrial dicarboxylate carrier GN=SLC25A10 DIC HUMAN $31.28 \quad 100.0 \%$ Mitochondrial dicarboxylate carrier GN=SLC25A10 DIC_HUMAN $31.28 \quad 100.0 \%$
$0.02 \% \quad 41.5 \%$ TALTTTISSR $0.01 \% \quad 7.4 \%$ YSTSGSSGLTTGK $0.01 \% \quad 7.4 \%$ ERPPEEVAAR $0.01 \% \quad 7.4 \%$ TVEGALKER $0.01 \% \quad 7.4 \%$ VVSQYHELVVQAR $0.01 \% \quad 7.4 \%$ GVYSEETLRAR $0.03 \% \quad 2.8 \% \quad$ YFKDTSPVFQR $0.03 \% \quad 2.8 \% \quad$ LFLESSDANPVR $0.03 \% \quad 2.8 \% \quad$ FLQQEQSVFR $0.03 \% \quad 2.8 \%$ GEPVLLVGETGTGK $0.03 \% \quad 2.8 \%$ FAASNPCGNIQR $0.03 \% \quad 2.8 \% \quad$ LLEKVEGTVR $0.03 \% \quad 2.8 \%$ DGQILVYCLNR $0.03 \% \quad 2.8 \%$ VFTEANLVSVGSK $0.03 \% \quad 2.8 \%$ TDSQLQGQVLFR $0.03 \% \quad 2.8 \%$ APAVQDLLTR $0.03 \% \quad 2.8 \%$ SHVLCKGELDQR $0.03 \% \quad 2.8 \%$ AQDWEENASR $0.03 \% \quad 2.8 \% \quad$ LNAALATPAK $0.03 \% \quad 2.8 \%$ VLAAVQAAR $0.00 \% \quad 5.8 \%$ NASDMPETITSR $0.00 \% \quad 5.8 \%$ LVFPQDLLEK $0.01 \% \quad 5.7 \%$ NGLVLFGNDGK $0.01 \% \quad 5.7 \%$ GVINIIPGSGGIAGQR $0.01 \% \quad 5.7 \%$ LGFTGSTPIGK $0.01 \% \quad 5.7 \%$ ANSTEYGLASGVFTR $0.02 \% \quad 29.3 \%$ TSFHALTSILK $0.02 \% \quad 29.3 \%$ LGIYTVLFER $0.02 \% \quad 29.3 \%$ LTGADGTPPGFLLK $0.02 \% \quad 29.3 \%$ MTADGRLPADQR $0.02 \% \quad 29.3 \%$ NVFNALIR $0.02 \% \quad 29.3 \%$ ITREEGVLTLWR $0.02 \% \quad 29.3 \%$ AVVVNAAQLASYSQSK $0.02 \% \quad 29.3 \%$ MIDGKPEYK $0.01 \% \quad 20.3 \%$ EGITGLYR $0.01 \% \quad 20.3 \%$ CLLQIQASSGESK $0.01 \% \quad 20.3 \%$ YTGTLDCAK $0.01 \% \quad 20.3 \%$ KLYQEFGIR $0.01 \% \quad 20.3 \%$ LYQEFGIR $0.01 \% \quad 20.3 \%$ RVSELSAPR $0.01 \% \quad 20.3 \%$ ELIRDEGVTSLYK $0.03 \% \quad 37.6 \%$ VHLQTQQEVK $0.03 \% 37.6 \%$ QMTYSLTR $0.03 \% \quad 37.6 \%$ FAIYETVR $0.03 \% \quad 37.6 \%$ FAIYETVRDR $0.03 \% \quad 37.6 \%$ GSQGPLPFHEK $0.03 \% \quad 37.6 \%$ NYAHALDGLYR
$99.4 \% \quad 25.0$

$99.7 \% \quad 44.1$

$99.7 \% \quad 40.6$

$99.7 \% \quad 32.2$

$96.7 \% \quad 23.2$

$99.7 \% \quad 48.6$

$99.7 \% \quad 52.3$

$99.7 \% \quad 43.5$

$99.7 \% \quad 45.2$

$99.7 \% \quad 31.1$

$99.7 \% \quad 48.9$

$99.7 \% \quad 56.3$

$99.7 \% \quad 51.8$

$99.7 \% \quad 51.2$

$95.5 \% \quad 18.1$

$99.7 \% \quad 45.5$

$99.7 \% \quad 45.4$

$99.7 \% \quad 48.7$

$99.2 \% \quad 20.5$

$99.5 \% 25.4$

$99.1 \% 23.1$

$99.7 \% \quad 44.5$

$99.7 \% \quad 48.4$

$99.7 \% \quad 45.6$

$99.7 \% \quad 52.1$

$99.7 \% \quad 52.3$

$99.7 \% \quad 45.2$

$99.2 \% \quad 20.9$

$99.0 \% \quad 34.0$

$99.5 \% \quad 24.2$

$99.7 \% \quad 52.1$

$99.7 \% \quad 27.2$

$99.0 \% 30.1$

$99.7 \% \quad 87.0$

$99.6 \% \quad 26.3$

$99.7 \% \quad 49.9$

$98.4 \% \quad 28.9$

$99.7 \% \quad 39.9$

$99.7 \% \quad 34.5$

$99.7 \% \quad 48.2$

$99.0 \% \quad 41.8$

$99.0 \% \quad 39.3$

$99.6 \% 27.1$

$99.7 \% \quad 36.2$

$99.7 \% \quad 51.2$
1245.60

1153.60

1002.56

1527.83

1280.66

1387.70

1347.69

1281.66

1356.74

1334.63

1143.67

1350.68

1350.73

1391.73

1083.62

1441.72

1205.52

969.57

898.55

1321.61

1201.68

1133.60

1508.85

1077.59

1572.77

1217.69

1210.68

1386.76

1346.65

946.55

1472.82

1635.87

1096.53

908.48

1420.71

1028.47

1153.64

1025.54

1014.57

1522.8

1209.66

999.49

998.53

1269.66

1196.61

1292.64 $\begin{array}{cc}51 & 360 \\ 3 & 45 \\ 96 & 205 \\ 76 & 284 \\ 54 & 366 \\ 24 & 634 \\ 15 & 125 \\ 26 & 137 \\ 55 & 164 \\ 70 & 683 \\ 73 & 984 \\ 17 & 2126 \\ 57 & 2467 \\ 44 & 2656 \\ 30 & 3141 \\ 40 & 3349 \\ 08 & 3519 \\ 84 & 3793 \\ 06 & 4215 \\ 09 & 5517 \\ 2 & 73 \\ 42 & 251 \\ 96 & 306 \\ 42 & 657 \\ 67 & 677 \\ 48 & 862 \\ 3 & 73 \\ 9 & 108 \\ 09 & 122 \\ 47 & 158 \\ 63 & 170 \\ 71 & 182 \\ 91 & 206 \\ 52 & 260 \\ 6 & 73 \\ 36 & 148 \\ 49 & 157 \\ 58 & 166 \\ 59 & 166 \\ 93 & 211 \\ 55 & 267 \\ 2 & 41 \\ 1 & 78 \\ 9 & 86 \\ 9 & 88 \\ & 150\end{array}$

Page 95 of Table S-1-6 
Mitochondrial glutamate carrier $1 \mathrm{GN}=\mathrm{SLC} 25 \mathrm{~A} 22 \mathrm{GHC} 1 \mathrm{HUMAN} 34.47 \quad 100.0 \%$ Mitochondrial glutamate carrier $1 \mathrm{GN}=\mathrm{SLC} 25 \mathrm{~A} 22 \mathrm{GHC1}$ _HUMAN $34.47 \quad 100.0 \%$ Mitochondrial glutamate carrier $1 \mathrm{GN}=\mathrm{SLC} 25 \mathrm{~A} 22 \mathrm{GHC} 1$ HUMAN $34.47 \quad 100.0 \%$

Mitochondrial import inner membrane translocase subunit TIM44 GN=TIMM44 TIM44_HUMAN $51.36 \quad 100.0 \%$

Mitochondrial import inner membrane translocase subunit TIM44 GN=TIMM44 TIM44_HUMAN $51.36 \quad 100.0 \%$ Mitochondrial ornithine transporter $1 \mathrm{GN}=$ SLC25A15 ORNT1_HUMAN 32.74 Mitochondrial ornithine transporter $1 \mathrm{GN}=\mathrm{SLC} 25 \mathrm{~A} 15$ ORNT1 HUMAN 32.74 Mitochondrial ornithine transporter 1 GN=SLC25A15 ORNT1_HUMAN 32.74 Mitochondrial ornithine transporter $1 \mathrm{GN}=\mathrm{SLC} 25 \mathrm{~A} 15$ ORNT1_HUMAN 32.74 Mitochondrial ribonuclease P protein $1 \mathrm{GN}=$ TRMT10C MRRP1 HUMAN 47.35 Mitochondrial ribonuclease P protein $1 \mathrm{GN}=$ TRMT10C MRRP1_HUMAN 47.3. Mitochondrial ribonuclease P protein $1 \mathrm{GN}=$ TRMT10C MRRP1_HUMAN 47.3 Mitochondral ibonuclease P potin 1 GN=TRMT10C MRRP1_HUMAN 47.3 Mitochondrial ribonuclease P protein $1 \mathrm{GN}=$ TRMT10C MRRP1_HUMAN 47.3 Mitochondrial ribonuclease P protein $1 \mathrm{GN}=$ TRMT10C MRRP1_HUMAN 47.3

4

4

4

4
4
4

2

2

\begin{tabular}{ll}
15 \\
12 & 15 \\
12 & 15 \\
\hline & 15
\end{tabular}

15
15
12

15

$12-15$

12

12
12
12

12
12
12

2

6
6
6

6
6
6
6

$\begin{array}{cc}4 & 4 \\ 4 & 4 \\ 21 & 23\end{array}$

4
23

$\begin{array}{ll}1 & 23 \\ 1 & 23 \\ 1 & 23\end{array}$

23

23

$0.03 \% \quad 37.6 \%$ LFSGATMASSR $0.03 \% \quad 37.6 \%$ GALVTVGQLSCYDQAK

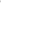

$0.03 \% 37.6 \%$ LGPLAFYK

$0.03 \% \quad 37.6 \%$ NFGIKVPS

$0.01 \% \quad 11.8 \%$ GAAVNLTLVTPEK

$0.01 \% \quad 11.8 \%$ LAANDFFR

$0.01 \% \quad 11.8 \%$ IQLQDAGR

$0.01 \% \quad 11.8 \%$ HEGPSAFLK

$0.01 \% \quad 10.2 \%$ RLEESDVLQEAR

$0.01 \% \quad 10.2 \%$ LGELTGTVK

$0.01 \% \quad 10.2 \%$ ALSQGVESVKK

$0.01 \% \quad 10.2 \%$ EIDDSVLGQTGPYR

$0.04 \% \quad 31.2 \%$ RAPDQAAEIGSR

$0.04 \% \quad 31.2 \%$ APDQAAEIGSR

$\begin{array}{lllll}0.04 \% & 31.2 \% & \text { AQGPQQQPGSEGPSYAKK } & 99.7 \% & 32.0\end{array}$

$11 \quad 0.01 \% \quad 11.0 \%$ ASSEMALYQK $\begin{array}{lll}0.04 \% & 31.2 \% & \text { IPDEFDNDPILVQQLR }\end{array}$

$\quad 0.04 \% \quad 31.2 \%$ IPDEFDNDPILVQQLRR

$0.04 \% \quad 31.2 \%$ DISCLNRDPAR

$0.04 \% \quad 31.2 \%$ VLLDLSAFLK

$0.04 \% \quad 31.2 \%$ TIALNGVEDVR

$0.04 \% \quad 31.2 \%$ TVLEHYALEDDPLAAFK

$0.04 \% \quad 31.2 \%$ SNKQNLFLGSLTSR

$0.04 \% \quad 31.2 \%$ QNLFLGSLTSR

$0.02 \% \quad 21.3 \%$ ELFPIQMEGVK

$19 \quad 0.02 \% \quad 21.3 \%$ FVNWQVDGEYR

$0.02 \% \quad 21.3 \%$ RPGEEGTVMSLAGK

$19 \quad 0.02 \% \quad 21.3 \%$ MQDTSVSFGYQLDLPK

$19 \quad 0.02 \% \quad 21.3 \%$ GSVDSNWIVGATLEK

$0.02 \% \quad 21.3 \%$ FQCGFGLTIG

$11 \quad 0.01 \% \quad 11.0 \%$ CLIFPLIVTGQR

$1 \quad 0.01 \% \quad 11.0 \%$ LAGDHIEYYK

$11 \quad 0.01 \% \quad 11.0 \%$ EGFLESFK

$11 \quad 0.01 \% \quad 11.0 \%$ NQLELAAR

$0.01 \% \quad 12.0 \%$ GLTDCCLK

$0.01 \% \quad 12.0 \%$ TYSQVGFR

$0.01 \% \quad 12.0 \%$ SQNTVWSVIK

$0.01 \% \quad 12.0 \%$ KLMMNQLEAY

$\quad 0.06 \% \quad 53.8 \%$ SSVQEECVSTISSSK

$\begin{array}{lll}0.06 \% & 53.8 \% \text { SSVQEECVSTISSSKDEDPLAATR }\end{array}$

$0.06 \% \quad 53.8 \%$ EVPEHITEEELK

$0.06 \% \quad 53.8 \%$ TLMECVSNTAK

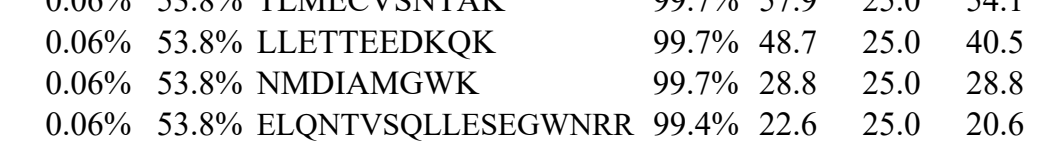

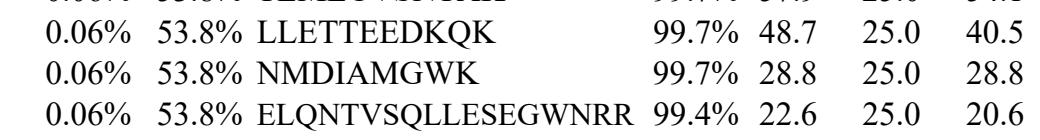

$\begin{array}{llll}99.7 \% & 54.9 & 25.0 & 54.7\end{array}$

$\begin{array}{lllll}99.7 \% & 27.0 & 25.0 & 26.1 & 0\end{array}$

$\begin{array}{llll}97.9 \% & 19.2 & 25.0 & 14.9\end{array}$

$\begin{array}{lllll}99.7 \% & 40.0 & 25.0 & 40.0 & 2\end{array}$

$\begin{array}{lllll}99.7 \% & 73.4 & 25.0 & 62.7 & 2\end{array}$

$\begin{array}{lllll}99.7 \% & 46.3 & 25.0 & 46.3 & 2 \\ 99.7 \% & 67.7 & 25.0 & 63.7 & 2\end{array}$

$\begin{array}{llll}99.7 \% & 46.1 & 25.0 & 37.5\end{array}$

$\begin{array}{llll}99.7 \% & 41.2 & 25.0 & 40.7\end{array}$

$\begin{array}{lllll}99.7 \% & 51.8 & 25.0 & 51.8 & 2\end{array}$

$\begin{array}{lllll}99.7 \% & 54.9 & 25.0 & 54.4\end{array}$

$\begin{array}{ccccc}99.7 \% & 52.8 & 25.0 & 49.1 & 4\end{array}$

$\begin{array}{llll}99.7 \% & 45.6 & 25.0 & 45.6 \\ 99.7 \% & 27.5 & 25.0 & 27.5\end{array}$

$\begin{array}{llll}99.7 \% & 27.5 & 25.0 & 27.5 \\ 99.7 \% & 35.4 & 25.0 & 29.4\end{array}$

$\begin{array}{llll}99.7 \% & 46.5 & 25.0 & 40.2\end{array}$

$\begin{array}{llll}99.7 \% & 43.3 & 25.0 & 35.2\end{array}$

$\begin{array}{llll}95.1 \% & 21.5 & 25.0 & 8.5\end{array}$

$\begin{array}{llll}99.0 \% & 41.9 & 25.0 & 11.7\end{array}$

$\begin{array}{llll}99.0 \% & 21.3 & 25.0 & 17.4\end{array}$

$\begin{array}{llll}99.0 \% & 31.3 & 25.0 & 14.7\end{array}$

$\begin{array}{llll}99.7 \% & 61.1 & 25.0 & 50.4 \\ 95.6 \% & 14.3 & 25.0 & 14.3\end{array}$

$\begin{array}{llll}99.7 \% & 33.0 & 25.0 & 33.0\end{array}$

$\begin{array}{llll}99.7 \% & 55.8 & 25.0 & 52.4\end{array}$

$\begin{array}{llll}99.7 \% & 42.3 & 25.0 & 29.2\end{array}$

$\begin{array}{llll}99.7 \% & 57.9 & 25.0 & 54.1\end{array}$

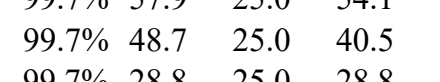

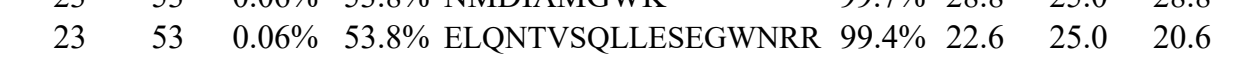

$100.0 \% \quad 2$

$\begin{array}{ccccc}0 & 0 & 1143.55 & 160 & 170 \\ 0 & 0 & 1709.85 & 171 & 186 \\ 2 & 0 & 1695.78 & 232 & 246 \\ 0 & 0 & 908.52 & 247 & 254 \\ 0 & 0 & 861.48 & 280 & 287 \\ 0 & 0 & 1312.75 & 68 & 80 \\ 0 & 0 & 953.48 & 84 & 91 \\ 0 & 0 & 900.49 & 129 & 136 \\ 0 & 0 & 985.51 & 278 & 286 \\ 1 & 0 & 1444.74 & 90 & 101 \\ 0 & 0 & 917.53 & 122 & 130 \\ 0 & 0 & 1145.65 & 178 & 188 \\ 0 & 0 & 1549.75 & 189 & 202 \\ 2 & 0 & 1270.65 & 32 & 43 \\ 0 & 0 & 1114.55 & 33 & 43 \\ 0 & 0 & 1729.81 & 48 & 64 \\ 2 & 0 & 1857.91 & 48 & 65 \\ 0 & 0 & 1911.98 & 98 & 113 \\ 2 & 0 & 2068.08 & 98 & 114 \\ 2 & 0 & 1316.64 & 233 & 243 \\ 0 & 0 & 1118.68 & 275 & 284 \\ 0 & 0 & 1186.64 & 285 & 295 \\ 2 & 0 & 1931.98 & 296 & 312 \\ 2 & 0 & 1564.84 & 332 & 345 \\ 0 & 0 & 1235.67 & 335 & 345 \\ 0 & 0 & 1290.68 & 92 & 102 \\ 0 & 0 & 1412.66 & 185 & 195 \\ 4 & 0 & 1431.73 & 240 & 253 \\ 0 & 0 & 1844.87 & 294 & 309 \\ 0 & 0 & 1575.80 & 316 & 330 \\ 0 & 0 & 1099.52 & 352 & 361 \\ 0 & 0 & 1416.80 & 153 & 164 \\ 0 & 0 & 1208.59 & 188 & 197 \\ 0 & 0 & 1127.54 & 198 & 207 \\ 0 & 0 & 956.47 & 359 & 366 \\ 0 & 0 & 914.51 & 387 & 394 \\ 0 & 0 & 966.44 & 46 & 53 \\ 0 & 0 & 957.48 & 54 & 61 \\ 0 & 0 & 1161.63 & 149 & 158 \\ 0 & 0 & 1240.61 & 292 & 301 \\ 0 & 0 & 1627.75 & 72 & 86 \\ 4 & 0 & 2596.20 & 72 & 95 \\ 0 & 0 & 1452.72 & 107 & 118 \\ 0 & 0 & 1253.59 & 119 & 129 \\ 0 & 0 & 1333.68 & 165 & 175 \\ 0 & 0 & 1065.49 & 186 & 194 \\ 1 & 0 & 2159.08 & 219 & 236\end{array}$

Page 96 of Table S-1-6 

Mitochondrial ribonuclease P protein 1 GN=TRMT10C MRRP1_HUMAN $47.35 \quad 100.0 \% \quad 21$ Mitochondrial ribonuclease P protein $1 \mathrm{GN}=$ TRMT10C MRRP1_HUMAN $47.35 \quad 100.0 \%$ Mitochondrial ribonuclease P protein $1 \mathrm{GN}=$ TRMT10C MRRP1 HUMAN $47.35 \quad 100.0 \%$ Mitochondrial ribonuclease P protein 1 GN=TRMT10C MRRP1_HUMAN $47.35 \quad 100.0 \% \quad 21$ Mitochondrial ribonuclease P protein $1 \mathrm{GN}=$ TRMT10C MRRP1_HUMAN $47.35 \quad 100.0 \%$ Mitochondrial ribonuclease P protein $1 \mathrm{GN}=$ TRMT10C MRRP1_HUMAN $47.35 \quad 100.0 \%$ Mitochondrial ribonuclease P protein 1 GN=TRMT10C MRRP1_HUMAN $47.35 \quad 100.0 \%$ Mitochondrial ribonuclease P protein $1 \mathrm{GN}=$ TRMT10C MRRP1 HUMAN 47.35 Mitochondrial ribonuclease P protein $1 \mathrm{GN}=$ TRMT10C MRRP1_HUMAN 47.35 Mitochondrial ribonuclease P protein 1 GN=TRMT10C MRRP1_HUMAN 47.35 Mitochondrial ribonuclease P protein $1 \mathrm{GN}=\mathrm{TRMT10C}$ MRRP1 HUMAN 47.3 Mitochondrial ribonuclease P protein $1 \mathrm{GN}=$ TRMT10C MRRP1_HUMAN 47.35 Mitochondrial ribonuclease P protein $1 \mathrm{GN}=$ TRMT10C MRRP1_HUMAN 47.35 Mitochondrial ribonuclease $P$ protein $3 \mathrm{GN}=\mathrm{KIAA} 0391$ MRRP3 HUMAN 67.3 Mitochondrial ribonuclease P protein $3 \mathrm{GN}=\mathrm{KIAA} 0391 \quad$ MRRP3_HUMAN 67.3 Mitochondrial ribosome-associated GTPase $1 \mathrm{GN}=\mathrm{MTG} 1$ MTG1 HUMAN 37.2 Mitochondrial ribosome-associated GTPase $1 \mathrm{GN}=\mathrm{MTG} 1$ MTG1_HUMAN 37.24 Mitochondrial ribosome-associated GTPase 1 GN=MTG1 MTG1_HUMAN 37.2 Mitogen-activated protein kinase $1 \mathrm{GN}=$ MAPK1 MK01_HUMAN 41.3 Mitogen-activated protein kinase $1 \mathrm{GN}=\mathrm{MAPK} 1$ MK01_HUMAN 41.3 Mitogen-activated protein kinase $1 \mathrm{GN}=\mathrm{MAPK} 1$ MK01 HUMAN 41.3 Mitotic checkpoint protein BUB3 GN=BUB3 BUB3_HUMAN Mitotic checkpoint protein BUB3 GN=BUB3 BUB3_HUMAN 37.1 Mitotic checkpoint protein BUB3 GN=BUB3 BUB3 HUMAN 37.1 Mitotic checkpoint protein BUB3 GN=BUB3 BUB3_HUMAN 37.15 MKI67 FHA domain-interacting nucleolar phosphoprotein GN=NIFK MK67I_HUMAN 34.22 MKI67 FHA domain-interacting nucleolar phosphoprotein GN=NIFK MK67I HUMAN 34.22 MKI67 FHA domain-interacting nucleolar phosphoprotein GN=NIFK MK67I_HUMAN 34.22 MKI67 FHA domain-interacting nucleolar phosphoprotein GN=NIFK MK67I HUMAN 34.22 MKI67 FHA domain-interacting nucleolar phosphoprotein GN=NIFK MK67I_HUMAN 34.22 MKI67 FHA domain-interacting nucleolar phosphoprotein GN=NIFK MK67I_HUMAN 34.22 MKI67 FHA domain-interacting nucleolar phosphoprotein GN=NIFK MK67I HUMAN 34.22 MMS19 nucleotide excision repair protein homolog GN=MMS19 MMS19_HUMAN 113.29 MMS19 nucleotide excision repair protein homolog GN=MMS19 MMS19_HUMAN 113.29

MOB kinase activator $2 \mathrm{GN}=\mathrm{MOB} 2$ MOB kinase activator $2 \mathrm{GN}=\mathrm{MOB} 2$ MOB2 HUMAN $26.93 \quad 100.0 \%$ Monocarboxylate transporter $1 \mathrm{GN}=$ SLC16A1 MOT1_HUMAN $53.95 \quad 100.0 \%$ Monocarboxylate transporter $1 \mathrm{GN}=\mathrm{SLC} 16 \mathrm{~A} 1 \mathrm{MOT1}$ _HUMAN $53.95 \quad 100.0 \%$ Monocarboxylate transporter $1 \mathrm{GN}=\mathrm{SLC16A1}$ MOT1 HUMAN $53.95 \quad 100.0 \%$ mRNA export factor $\mathrm{GN}=\mathrm{RAE} 1$ mRNA export factor $\mathrm{GN}=\mathrm{RAE} 1$ mRNA export factor $\mathrm{GN}=\mathrm{RAE} 1$ mRNA export factor $\mathrm{GN}=\mathrm{RAE}$ : mRNA export factor $\mathrm{GN}=\mathrm{RAE} 1$ mRNA export factor $\mathrm{GN}=\mathrm{RAE} 1$ MOB2_HUMAN $26.93 \quad 100.0 \%$ MOB2 HUMAN $26.93 \quad 100.0 \%$

(3)

(a)

3

(1)

4

4

4

7

7
7
7

$\begin{array}{ll}7 & 9 \\ 7 & 9\end{array}$

9
9

$\begin{array}{ll}7 & 9 \\ 7 & 9 \\ 7 & 9\end{array}$

$\begin{array}{ll}7 & 9 \\ 7 & 9 \\ 2 & 2\end{array}$

2

2
2
3
3

2

3

3
3
3

$\begin{array}{ll}3 & 3 \\ 3 & 3 \\ 8 & 11 \\ 8 & 11\end{array}$

3

$\begin{array}{ll}8 & 1 \\ 8 & 11 \\ 8 & 11 \\ 8 & 11\end{array}$
$\begin{array}{llll}\text { RAE1L_HUMAN } & 40.97 & 100.0 \% & 8\end{array}$ RAE1L_HUMAN $40.97 \quad 100.0 \%$ RAE1L_HUMAN $40.97 \quad 100.0 \%$
$0.06 \% \quad 53.8 \%$ NVDPFHIYFCNLK

$0.06 \% 53.8 \%$ LLLTSTEK

$0.06 \% \quad 53.8 \%$ SHVDLFPK

$\begin{array}{llllllll}99.7 \% & 43.8 & 25.0 & 40.0 & 2 & 0 & 0 & 1666.80\end{array}$

$99.0 \% \quad 40.3$

$99.0 \% \quad 24.7$

$0.06 \% \quad 53.8 \%$ DSIIYLTADSPNVMTTFR $99.7 \% \quad 61.8$

$0.06 \% \quad 53.8 \%$ HDKVYVIGSFVDK

$98.9 \% \quad 19.9$

$99.7 \% \quad 41.9$

$0.06 \% \quad 53.8 \%$ VYVIGSFVDK

$0.06 \% \quad 53.8 \%$ VYVIGSFVDKSMQPGTSLAK

$0.06 \% \quad 53.8 \%$ SMQPGTSLAK

$0.06 \% \quad 53.8 \%$ RLNLATECLPLDK

$0.06 \% 53.8 \%$ LNLATECLPLDK

$0.06 \% \quad 53.8 \%$ YLQWEIGNK

$0.06 \% 53.8 \%$ NLTLDQMIR

$0.06 \% 53.8 \%$ NNGNWQEALQFVPK

$0.06 \% \quad 53.8 \%$ HTGFLEISQHSQEFINR

$0.00 \% \quad 5.2 \%$ SRPPFDVVIDGLNVAK

$0.00 \% \quad 5.2 \%$ ESQLLLNVVSQLAK

$0.01 \% \quad 9.3 \%$ LVDCIIEVHDAR

$0.01 \% \quad 9.3 \%$ MDLADLTEQQK

$0.01 \% \quad 9.3 \%$ DFLQTFRR

$0.01 \% \quad 7.5 \%$ GQVFDVGPR

$0.01 \% \quad 7.5 \%$ YIHSANVLHR

$0.01 \% \quad 7.5 \%$ ICDFGLAR

$0.01 \% \quad 14.6 \%$ LNQPPEDGISSVK

$0.01 \% \quad 14.6 \%$ VYTLSVSGDR

$0.01 \% \quad 14.6 \%$ QGYVLSSIEGR

$0.01 \% \quad 14.6 \%$ VAVEYLDPSPEVQK

$6 \quad 0.02 \% \quad 24.2 \%$ GYAFVEFESEDVAK

$0.02 \% \quad 24.2 \%$ IVAETMNNYLFGER

$0.02 \% \quad 24.2 \%$ KGIDYDFPSLILQK

$0.02 \% \quad 24.2 \%$ GIDYDFPSLILQK

$0.02 \% \quad 24.2 \%$ KVSGTLDTPEK

$0.02 \% \quad 24.2 \%$ VSGTLDTPEK

$0.02 \% \quad 24.2 \%$ TVDSQGPTPVCTPTFLER

$0.00 \% \quad 1.8 \%$ AVLASTPR

$0.00 \% \quad 1.8 \%$ LLQAAAGASAR

$0.01 \% \quad 8.9 \%$ KAYLEPEHTK

$0.01 \% \quad 8.9 \%$ AYLEPEHTK

$0.01 \% \quad 8.9 \% \quad$ LVTDEDVFPTK

$3 \quad 0.01 \% \quad 7.0 \%$ DLHDANTDLIGR

$0.01 \% \quad 7.0 \%$ DLHDANTDLIGRHPK

$0.01 \% \quad 7.0 \%$ ESKEEETSIDVAGKPNEVTK

$0.03 \% \quad 22.3 \%$ APNYSCVMTGSWDK

$0.03 \% \quad 22.3 \%$ SSNPMMVLQLPER

$0.03 \% \quad 22.3 \%$ GLIVYQLENQPSEFR

$0.03 \% \quad 22.3 \%$ GLIVYQLENQPSEFRR

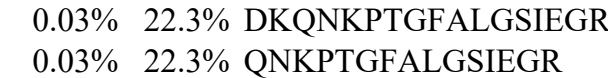

$9.7 \% \quad 44.0$

$\begin{array}{lll}99.7 \% & 47.8\end{array}$

$99.2 \% \quad 20.4$

$\begin{array}{lll}99.7 \% & 54.8\end{array}$

$99.7 \% \quad 45.2$

$99.7 \% \quad 41.9$

$99.7 \% \quad 48.7$

$\begin{array}{lll}99.7 \% & 37.8\end{array}$

$99.4 \% \quad 22.9$

$96.9 \% \quad 23.8$

$99.1 \% \quad 23.0$

$99.7 \% \quad 42.4$

$99.0 \% \quad 28.1$

$99.7 \% \quad 37.1$

$98.7 \% \quad 26.3$

$99.0 \% \quad 37.5$

$\begin{array}{lll}99.7 \% & 30.3\end{array}$

$99.7 \% \quad 30.2$

$99.7 \% \quad 36.2$

$99.7 \% \quad 36.5$

$99.7 \% \quad 56.0$

$99.7 \% \quad 58.8$

$99.5 \% \quad 23.4$

$99.7 \% \quad 44.7$

$99.7 \% \quad 57.6$

$99.7 \% \quad 63.1$

$\begin{array}{ll}99.7 \% & 58.1\end{array}$

$99.7 \% \quad 72.7$

$\begin{array}{lll}99.7 \% & 28.2\end{array}$

$97.5 \% \quad 24.3$

$99.7 \% \quad 61.0$

$99.7 \% \quad 56.1$

$96.1 \% \quad 14.9$

$99.7 \% \quad 37.5$

$\begin{array}{ll}99.0 \% & 30.6 \\ 99.7 \% & 45.6\end{array}$

$99.7 \% \quad 57.2$

$99.7 \% \quad 40.0$

$99.7 \% \quad 36.2$

$99.7 \% \quad 33.0$
942.50

2044.01

1506.80

1126.61

2143.11

1019.52

1542.83

1386.73

1150.59

1103.59

1644.81

2043.00

1726.95

1541.89

1439.73

1307.62

1082.57

974.51

1209.65

951.47

1383.71

1096.56

1208.63

1573.81

1590.73

1656.81

1636.89

1508.80

1174.63

1046.54

2004.97

814.48

1028.58

1215.64

1087.54

1263.65

1339.66

1701.87

2190.08

1615.69

1533.74

1792.92

1949.02

1817.95

1574.83 $\begin{array}{cc}37 & 249 \\ 69 & 276 \\ 77 & 284 \\ 85 & 302 \\ 03 & 315 \\ 06 & 315 \\ 06 & 325 \\ 16 & 325 \\ 28 & 340 \\ 29 & 340 \\ 41 & 349 \\ 50 & 358 \\ 65 & 378 \\ 81 & 397 \\ 00 & 415 \\ 22 & 435 \\ 48 & 59 \\ 85 & 95 \\ 04 & 311 \\ 16 & 24 \\ 39 & 148 \\ 65 & 172 \\ 9 & 21 \\ 40 & 149 \\ 92 & 202 \\ 03 & 216 \\ 87 & 100 \\ 01 & 114 \\ 79 & 192 \\ 80 & 192 \\ 16 & 226 \\ 17 & 226 \\ 27 & 244 \\ 47 & 254 \\ 74 & 384 \\ 23 & 32 \\ 24 & 32 \\ 21 & 131 \\ 25 & 236 \\ 25 & 239 \\ 60 & 479 \\ 38 & 151 \\ 60 & 172 \\ 91 & 205 \\ 91 & 206 \\ 23 & 239 \\ 25 & 239 \\ & \end{array}$

Page 97 of Table S-1-6 
mRNA export factor $\mathrm{GN}=\mathrm{RAE} 1$ mRNA export factor $\mathrm{GN}=\mathrm{RAE} 1$ mRNA turnover protein 4 homolog GN=MRTO4 MRT4_HUMAN $27.56 \quad 100.0 \%$ mRNA turnover protein 4 homolog GN=MRTO4 MRT4 HUMAN $27.56 \quad 100.0 \%$ mRNA turnover protein 4 homolog GN=MRTO4 MRT4_HUMAN $27.56 \quad 100.0 \%$ mRNA turnover protein 4 homolog GN=MRTO4 MRT4_HUMAN $27.56 \quad 100.0 \%$ Multifunctional protein ADE2 GN=PAICS PUR6_HUMAN $47.08 \quad 100.0 \%$ Multifunctional protein ADE2 GN=PAICS PUR6_HUMAN $47.08 \quad 100.0 \%$ Multiple myeloma tumor-associated protein $2 \mathrm{GN}=$ MMTAG2 MMTA2_HUMAN $29.41 \quad 100.0 \%$ Multiple myeloma tumor-associated protein 2 GN=MMTAG2 MMTA2_HUMAN $29.41 \quad 100.0 \%$ Multiple myeloma tumor-associated protein 2 GN=MMTAG2 MMTA2_HUMAN $29.41 \quad 100.0 \%$ Myb-binding protein 1A GN=MYBBP1A MBB1A_HUMAN $148.86 \quad 100.0 \%$ Myb-binding protein 1A GN=MYBBP1A MBB1A_HUMAN $148.86 \quad 100.0 \%$ Myb-binding protein 1A GN=MYBBP1A MBB1A_HUMAN $148.86 \quad 100.0 \%$ Myb-binding protein 1A GN=MYBBP1A MBB1A_HUMAN $148.86 \quad 100.0 \%$ Myb-binding protein 1A GN=MYBBP1A MBB1A_HUMAN $148.86 \quad 100.0 \%$ Myb-binding protein 1A GN=MYBBP1A MBB1A HUMAN $148.86 \quad 100.0 \%$ Myb-binding protein 1A GN=MYBBP1A MBB1A_HUMAN $148.86 \quad 100.0 \%$ Myb-binding protein 1A GN=MYBBP1A MBB1A_HUMAN $148.86 \quad 100.0 \%$ Myb-binding protein 1A GN=MYBBP1A MBB1A_HUMAN $148.86 \quad 100.0 \%$ Myb-binding protein 1A GN=MYBBP1A MBB1A_HUMAN $148.86 \quad 100.0 \%$ Myb-binding protein 1A GN=MYBBP1A $\quad$ MBB1A_HUMAN $148.86 \quad 100.0 \% 38$ $\begin{array}{lllll}\text { Myb-binding protein 1A GN=MYBBP1A } & \text { MBB1A_HUMAN } & 148.86 & 100.0 \% & 38\end{array}$ Myb-binding protein 1A GN=MYBBP1A MBB1A_HUMAN $148.86 \quad 100.0 \% \quad 38$ Myb-binding protein 1A GN=MYBBP1A MBB1A_HUMAN $148.86 \quad 100.0 \% \quad 38$ Myb-binding protein 1A GN=MYBBP1A MBB1A_HUMAN $148.86 \quad 100.0 \% \quad 38$ Myb-binding protein 1A GN=MYBBP1A MBB1A_HUMAN $148.86 \quad 100.0 \% \quad 38$ Myb-binding protein 1A GN=MYBBP1A MBB1A_HUMAN $148.86 \quad 100.0 \% \quad 38$ Myb-binding protein 1A GN=MYBBP1A MBB1A_HUMAN $148.86 \quad 100.0 \%$ Myb-binding protein 1A GN=MYBBP1A MBB1A HUMAN $148.86 \quad 100.0 \% \quad 38$ Myb-binding protein 1A GN=MYBBP1A MBB1A_HUMAN $148.86 \quad 100.0 \% \quad 38$ $\begin{array}{lllll}\text { Myb-binding protein 1A GN=MYBBP1A } & \text { MBB1A_HUMAN } & 148.86 & 100.0 \% & 38\end{array}$ Myb-binding protein 1A GN=MYBBP1A $\quad$ MBB1A_HUMAN $148.86 \quad 100.0 \% 38$ $\begin{array}{lllll}\text { Myb-binding protein 1A GN=MYBBP1A } & \text { MBB1A_HUMAN } & 148.86 & 100.0 \% & 38\end{array}$ Myb-binding protein 1A GN=MYBBP1A MBB1A_HUMAN $148.86 \quad 100.0 \% 38$ Myb-binding protein 1A GN=MYBBP1A MBB1A_HUMAN $148.86 \quad 100.0 \% \quad 38$ Myb-binding protein 1A GN=MYBBP1A MBB1A_HUMAN $148.86 \quad 100.0 \%$ Myb-binding protein 1A GN=MYBBP1A MBB1A_HUMAN $148.86 \quad 100.0 \% 38$ Myb-binding protein 1A GN=MYBBP1A MBB1A_HUMAN $148.86 \quad 100.0 \% \quad 38$ Myb-binding protein 1A GN=MYBBP1A MBB1A_HUMAN $148.86 \quad 100.0 \% \quad 38$ Myb-binding protein 1A GN=MYBBP1A MBB1A_HUMAN $148.86 \quad 100.0 \% \quad 38$ Myb-binding protein 1A GN=MYBBP1A MBB1A_HUMAN $148.86 \quad 100.0 \%$ Myb-binding protein 1A GN=MYBBP1A MBB1A_HUMAN $148.86 \quad 100.0 \% \quad 38$ Myb-binding protein 1A GN=MYBBP1A MBB1A_HUMAN $148.86 \quad 100.0 \% \quad 38$ Myb-binding protein 1A GN=MYBBP1A MBB1A_HUMAN $148.86 \quad 100.0 \% \quad 38$ Myb-binding protein 1A GN=MYBBP1A MBB1A_HUMAN $148.86 \quad 100.0 \% 38$ Myb-binding protein 1A GN=MYBBP1A MBB1A_HUMAN $148.86 \quad 100.0 \% \quad 38$
$0.01 \% \quad 14.6 \%$ GEVGLLFTNR

$0.01 \% \quad 14.6 \%$ YTEMDYAR

$0.00 \% \quad 5.9 \% \quad$ VLLQSKDQITAGNAAR $0.00 \% \quad 5.9 \%$ IATGSFLKR $0.01 \% \quad 15.6 \%$ ENYLGNSLMAPVGR $0.01 \% \quad 15.6 \%$ LLGLGSASGSVGR $0.01 \% \quad 15.6 \%$ VESGGPGTSAASAR $0.09 \% \quad 28.0 \%$ LAATEKLLEYLR $0.09 \% \quad 28.0 \%$ LITGLGVGR $0.09 \% \quad 28.0 \%$ LVKDQEALMK $0.09 \% \quad 28.0 \%$ ALVDILSEVSK $0.09 \% \quad 28.0 \%$ KLVGSVNLFSDENVPR $0.09 \% \quad 28.0 \%$ LVGSVNLFSDENVPR $0.09 \% \quad 28.0 \%$ KLPAIALDLLR $0.09 \% \quad 28.0 \%$ LPAIALDLLR

$0.09 \% \quad 28.0 \%$ EVVEQGLLK $0.09 \% \quad 28.0 \%$ LLGAALPLLTK $0.09 \% \quad 28.0 \%$ EQLHLVMQGDVIR $0.09 \% \quad 28.0 \%$ HYGEHVCTAK $0.09 \% \quad 28.0 \%$ KAQDSSLHMPER $0.09 \% \quad 28.0 \%$ AQDSSLHMPER $0.09 \% \quad 28.0 \%$ KPTSQIPETK $0.09 \% \quad 28.0 \%$ HPFSFPLENQAR $98.2 \% \quad 17.1 \quad 25.0 \quad 16.6$ $99.7 \% \quad 37.0 \quad 25.0 \quad 37.0$ $\begin{array}{llll}99.6 \% & 27.7 & 25.0 & 27.7\end{array}$ $\begin{array}{llll}96.4 \% & 22.8 & 25.0 & 22.8\end{array}$ $99.7 \% \quad 70.1 \quad 25.0 \quad 62.2$ $\begin{array}{llll}99.7 \% & 59.6 & 25.0 & 59.6\end{array}$ $99.7 \% \quad 66.7 \quad 25.0 \quad 52.6$ $99.7 \% \quad 61.5 \quad 25.0 \quad 52.7$ $99.7 \% \quad 40.3 \quad 25.0 \quad 31.2$ $\begin{array}{llll}99.7 \% & 49.2 & 25.0 & 49.2\end{array}$ $\begin{array}{llll}99.7 \% & 53.3 & 25.0 & 53.3\end{array}$ $99.7 \% \quad 71.4 \quad 25.0 \quad 67.8$ $\begin{array}{llll}99.6 \% & 26.4 & 25.0 & 26.4\end{array}$ $\begin{array}{llll}99.7 \% & 45.0 & 25.0 & 28.7\end{array}$ $\begin{array}{llll}98.8 \% & 33.4 & 25.0 & 21.7\end{array}$ $\begin{array}{llll}99.7 \% & 37.1 & 25.0 & 37.1\end{array}$ $98.0 \% \quad 18.0 \quad 25.0 \quad 17.5$ $99.5 \% \quad 23.7 \quad 25.0 \quad 20.3$ $\begin{array}{llll}95.4 \% & 23.7 & 25.0 & 14.8\end{array}$ $99.7 \% \quad 43.7 \quad 25.0 \quad 43.7$ $\begin{array}{llll}99.7 \% & 29.5 & 25.0 & 23.5\end{array}$ $99.7 \% \quad 35.2 \quad 25.0 \quad 35.2$ $0.09 \% \quad 28.0 \%$ SPAESCDLLGDIQTCIR $0.09 \% \quad 28.0 \%$ SPAESCDLLGDIQTCIRK $0.09 \% \quad 28.0 \%$ SVFGHICSHLTPR $0.09 \% \quad 28.0 \%$ SSSSKQEQDLLHK $0.09 \% \quad 28.0 \%$ IFTHHLCR $0.09 \% \quad 28.0 \%$ RYCHDLGER $0.09 \% \quad 28.0 \%$ AGALHAQVER $\begin{array}{llll}99.7 \% & 34.5 & 25.0 & 34.5\end{array}$ $98.4 \% \quad 19.1 \quad 25.0 \quad 17.6$ $99.7 \% \quad 31.9 \quad 25.0 \quad 19.6$ $99.0 \% \quad 32.9 \quad 25.0 \quad 22.8$ $97.0 \% \quad 20.3 \quad 25.0 \quad 13.1$ $99.7 \% \quad 41.0 \quad 25.0 \quad 28.4$

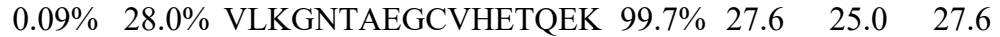
$0.09 \% \quad 28.0 \%$ GNTAEGCVHETQEK

$99.7 \% \quad 46.7$ $\begin{array}{lllll}0.09 \% & 28.0 \% & \text { AGTDPSHMPTGPQAASCLDLNLVTR } & 99.7 \% & 51.9\end{array}$ $0.09 \% \quad 28.0 \%$ VYSTALSSFLTK $0.09 \% \quad 28.0 \%$ VYSTALSSFLTKR $0.09 \% \quad 28.0 \%$ HQACLLLQK

$0.09 \% \quad 28.0 \%$ TLGVQRPK $0.09 \% \quad 28.0 \%$ DAKEIPSATQSPISK $0.09 \% \quad 28.0 \%$ EIPSATQSPISK $\begin{array}{lll}6.9 & 25.0 & 50.4\end{array}$ $99.7 \% \quad 55.4 \quad 25.0 \quad 55.4$ $\begin{array}{llll}99.7 \% & 39.4 & 25.0 & 29.8\end{array}$ $99.0 \% \quad 26.4 \quad 25.0 \quad 26.4$ $\begin{array}{llll}99.2 \% & 20.5 & 25.0 & 19.2\end{array}$ $99.7 \% \quad 50.5 \quad 25.0-41.1$ $\begin{array}{llll}1 \% & 23.0 & 25.0 & 23.0\end{array}$ $0.09 \% \quad 28.0 \%$ AKVPAQANGTPTTK $0.09 \% \quad 28.0 \%$ SPAPGAPTR $0.09 \% \quad 28.0 \%$ SPLSALAR $\begin{array}{ll}99.1 \% & 23.0 \\ 99.3 \% & 25.6\end{array}$ $99.7 \% \quad 39.2$ $99.0 \% \quad 49.2$

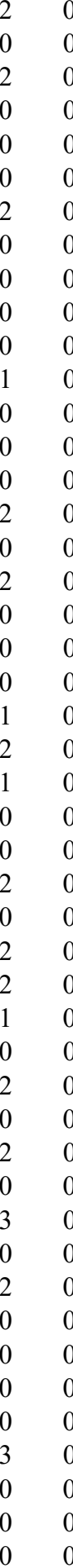

1173.66

1246.60

1419.82

885.55

1174.65

1173.67

1773.95

1645.85

1222.79

1094.69

1014.58

1109.73

1537.82

1201.54

1414.67

1286.58

1128.63

1442.72

1934.90

2062.99

1510.76

1486.75

1083.55

1205.55

1051.56

1899.92

1559.68

2625.24

1316.71

1472.81

1110.61

898.55

1571.83

1257.67

2517.12

1383.76

853.45

814.48

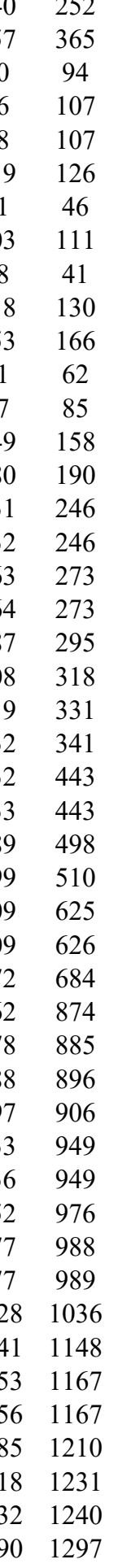


Myb-binding protein 1A GN=MYBBP1A MBB1A_hUMAN $148.86 \quad 100.0 \%$ Myb-binding protein 1A GN=MYBBP1A MBB1A_HUMAN $148.86 \quad 100.0 \% \quad 38$ Myelin expression factor 2 GN=MYEF2 MYEF2_HUMAN $64.12 \quad 100.0 \%$ Myelin expression factor $2 \mathrm{GN}=\mathrm{MYEF} 2$ Myeloid leukemia factor $2 \mathrm{GN}=\mathrm{MLF} 2$ Myeloid leukemia factor $2 \mathrm{GN}=\mathrm{MLF} 2$

Myeloid leukemia factor $2 \mathrm{GN}=\mathrm{MLF} 2$ Myosin-10 GN=MYH10

Myosin-10 GN=MYH10

Myosin-10 GN=MYH10

Myosin-10 GN=MYH10

Myosin-10 GN=MYH10

Myosin-10 GN=MYH10

Myosin-10 GN=MYH10

Myosin-10 GN=MYH10

Myosin-10 GN=MYH10

Myosin-10 GN=MYH10

Myosin-10 GN=MYH10

Myosin-10 GN=MYH10

Myosin- $10 \mathrm{GN}=\mathrm{MYH} 10$

Myosin-9 GN=MYH9

Myosin-9 GN=MYH9

Myosin-9 GN=MYH9

Myosin-9 GN=MYH9

Myosin-9 GN=MYH9

Myosin-9 GN=MYH9

Myosin-9 GN=MYH9

$\mathrm{N}$-acetyltransferase $10 \mathrm{GN}=\mathrm{NAT} 1 \mathrm{C}$

$\mathrm{N}$-acetyltransferase $10 \mathrm{GN}=\mathrm{NAT} 10$

$\mathrm{N}$-acetyltransferase $10 \mathrm{GN}=\mathrm{NAT} 10$

$\mathrm{N}$-acetyltransferase $10 \mathrm{GN}=\mathrm{NAT} 10$

$\mathrm{N}$-acetyltransferase $10 \mathrm{GN}=\mathrm{NAT} 10$

N-acylneuraminate cytidylyltransferase GN=CMAS NEUA_HUMAN $48.38 \quad 100.0 \%$

NADH dehydrogenase [ubiquinone] I alpha subcomplex subunit 10, mitochondral GN=NDUFAl0 NDUAA_HUMAN $40.75 \quad 100.0 \%$

NADH dehydrogenases [ubiquinone] 1 alpha subcomplex subunit 10, mitochondral GN=NDUFA10 NDUAA_HUMAN $40.75 \quad 100.0 \%$

NADH dechydrogenase [ubiquinone] 1 alpha subcomplex subunit 10, mitcochondral GN=NDUFA10 NDUAA_HUMAN $40.75 \quad 100.0 \%$

NDUAA_HUMAN $40.75 \quad 100.0 \%$ NDUAA HUMAN $40.75 \quad 100.0 \%$ NDUA9_HUMAN $42.51 \quad 100.0 \%$ NDUA9 HUMAN $42.51 \quad 100.0 \%$ NDUA9 HUMAN $42.51 \quad 100.0 \%$ NDUA9_HUMAN $42.51 \quad 100.0 \%$ NDUA9 HUMAN $42.51 \quad 100.0 \%$

$.0 \% \quad 12$
$0.09 \% \quad 28.0 \%$ SPSLLQSGAKK

$0.00 \% \quad 3.7 \%$ MGPGIGAILER

$0.00 \% \quad 3.7 \% \quad$ IGSKGNQIFVR

$0.01 \% \quad 14.9 \%$ VYQETSEMR

$0.01 \% \quad 14.9 \%$ DSDSGLEQMSIGHHIR

$0.01 \% \quad 14.9 \%$ LAIQGPEDSPSR

$0.02 \% \quad 6.7 \% \quad$ AMVNKDDIQK

$0.02 \% \quad 6.7 \% \quad$ VIQYLAHVASSHK

$13 \quad 20 \quad 0.02 \% \quad 6.7 \% \quad$ NTDQASMPENTVAQK

$13 \quad 20 \quad 0.02 \% \quad 6.7 \%$ EQADFAVEALAK

$\begin{array}{lllll}13 & 20 & 0.02 \% & 6.7 \% & \text { CNGVLEGIR }\end{array}$

$\begin{array}{lllll}13 & 20 & 0.02 \% & 6.7 \% & \text { ALELDPNLYR }\end{array}$

$13 \quad 20 \quad 0.02 \% \quad 6.7 \% \quad$ QVLALQSQLADTK

$13 \quad 20 \quad 0.02 \% \quad 6.7 \% \quad$ ALAYDKLEK

$13 \quad 20 \quad 0.02 \% \quad 6.7 \%$ FDQLLAEEK

$13 \quad 20 \quad 0.02 \% \quad 6.7 \% \quad$ ASRDEIFAQSK

$13 \quad 20 \quad 0.02 \% \quad 6.7 \%$ FKATISALEAK

$\begin{array}{lllll}13 & 20 & 0.02 \% & 6.7 \% & \text { ATISALEAK }\end{array}$

$0.02 \% \quad 6.7 \%$ GGPISFSSSR

$0.01 \% \quad 3.9 \% \quad$ NTDQASMPDNTAAQK

$0.01 \% \quad 3.9 \%$ EQADFAIEALAK

$0.01 \% \quad 3.9 \%$ TVGQLYKEQLAK

$0.01 \% \quad 3.9 \% \quad$ CNGVLEGIR

$0.01 \% \quad 3.9 \%$ FDQLLAEEK

$0.01 \% \quad 3.9 \%$ GALALEEKR

$0.01 \% \quad 3.9 \%$ VKLQEMEGTVK

$0.01 \% \quad 6.2 \% \quad$ ILIENGVAER

$0.01 \% \quad 6.2 \%$ QQSAQSQVSTTAENKTTTTAR

$0.01 \% \quad 6.2 \% \quad$ QSILNSLSR

$0.01 \% \quad 6.2 \%$ IAVHPDYQGMGYGSR

$0.01 \% \quad 6.2 \% \quad$ AGFVPVYLR

$0.00 \% \quad 7.1 \%$ GVEKPPHLAALILAR

$0.00 \% \quad 7.1 \%$ VGLSGAPADACSTAQK

$0.01 \% \quad 19.2 \%$ VITVDGNICTGK

$0.01 \% \quad 19.2 \%$ KQCVDHYNEVK

$0.01 \% \quad 19.2 \%$ ITSAYLQDIENAYK

$0.01 \% \quad 19.2 \%$ TFLPEMSEK

$0.01 \% \quad 19.2 \%$ KVVEDIEYLK

$0.01 \% \quad 19.2 \%$ VVEDIEYLK

$0.01 \% \quad 19.2 \%$ YSPGYNTEVGDK

$0.02 \% \quad 35.5 \%$ YVVNHLGR

$0.02 \% \quad 35.5 \%$ MGSQVIIPYR

$19 \quad 0.02 \% \quad 35.5 \%$ NFDFEDVFVK

$19 \quad 0.02 \% \quad 35.5 \%$ DAFPEAIIVKPSDIFGR

$0.02 \% \quad 35.5 \%$ FLNSFASMHR

$0.02 \% \quad 35.5 \%$ FGPIPLGSLGWK $\begin{array}{lllll}99.7 \% & 54.8 & 25.0 & 45.6 & 3\end{array}$

$\begin{array}{llll}99.7 \% & 29.6 & 25.0 & 29.6\end{array}$

$99.7 \% \quad 48.9 \quad 25.0 \quad 45.2 \quad$

$99.7 \% \quad 27.7 \quad 25.0 \quad 27.7$

$\begin{array}{llll}99.7 \% & 35.7 & 25.0 & 27.0\end{array}$

$\begin{array}{llll}99.7 \% & 32.5 & 25.0 & 32.5\end{array}$

$\begin{array}{llll}99.7 \% & 60.6 & 25.0 & 50.5\end{array}$

$\begin{array}{llll}99.1 \% & 26.6 & 25.0 & 14.2\end{array}$

$\begin{array}{llll}98.0 \% & 16.8 & 25.0 & 16.3\end{array}$

$\begin{array}{llll}99.7 \% & 47.7 & 25.0 & 47.7\end{array}$

$99.7 \% \quad 51.1 \quad 25.0 \quad 48.3$

$99.7 \% \quad 31.8 \quad 25.0 \quad 21.2$

$\begin{array}{llll}99.7 \% & 40.8 & 25.0 & 40.8\end{array}$

$\begin{array}{llll}99.7 \% & 49.4 & 25.0 & 49.4\end{array}$

$\begin{array}{llll}99.6 \% & 26.8 & 25.0 & 18.9\end{array}$

$\begin{array}{llll}99.7 \% & 31.7 & 25.0 & 27.9\end{array}$

$99.7 \% \quad 37.1 \quad 25.0 \quad 34.5$

$\begin{array}{llll}99.7 \% & 39.7 & 25.0 & 22.1\end{array}$

$\begin{array}{llll}99.7 \% & 35.8 & 25.0 & 20.0\end{array}$

$\begin{array}{llll}99.7 \% & 44.2 & 25.0 & 36.2\end{array}$

$\begin{array}{llll}99.7 \% & 28.2 & 25.0 & 28.2\end{array}$

$99.1 \% \quad 44.9 \quad 25.0 \quad 0.0$

$\begin{array}{llll}99.6 \% & 25.0 & 25.0 & 25.0\end{array}$

$99.7 \% \quad 31.8 \quad 25.0 \quad 21.2$

$\begin{array}{lllll}99.7 \% & 31.7 & 25.0 & 27.9\end{array}$

$\begin{array}{llll}99.7 \% & 40.6 & 25.0 & 20.9\end{array}$

$\begin{array}{llll}94.7 \% & 18.3 & 25.0 & 11.3\end{array}$

$\begin{array}{llll}98.0 \% & 17.3 & 25.0 & 17.3\end{array}$

$99.7 \% \quad 33.9$

$99.7 \% \quad 59.2$

$99.7 \% \quad 37.5$

$99.7 \% \quad 26.1$

$99.7 \% \quad 48.5$

$99.7 \% \quad 43.3$

$99.7 \% \quad 48.7$

$98.6 \% \quad 22.8$

$99.7 \% \quad 54.0$

$97.3 \% \quad 22.8$

$99.7 \% \quad 42.3$

$99.7 \% \quad 51.1$

$95.5 \% \quad 16.8$

$99.0 \% \quad 37.0$

$99.7 \% \quad 34.4$

$99.4 \% \quad 32.6$

$97.2 \% \quad 20.1$

$99.6 \% \quad 28.1$

$97.9 \% \quad 16.8$
987.55

1115.64

1113.61

1218.70

1158.51

1797.82

1269.64

1161.59

1452.80

1633.75

1291.65

1017.51

1203.64

1414.79

1050.58

1092.56

1251.63

1178.68

903.51

994.50

1607.70

1305.67

1377.77

1017.51

1092.56

986.56

1261.68

1113.63

2238.10

1017.57

1666.76

1021.58

1584.96

1532.74

1276.66

1419.67

1628.82

1081.52

1235.69

1107.59

1329.60

957.53

1179.62

1259.59

1875.00

1209.58

1271.71 


\begin{tabular}{|c|c|c|c|c|c|c|c|c|c|c|c|c|c|c|c|c|c|c|}
\hline HH dehydrogenase [ubiquinionen] 1 alpha subcomplex subunit 9 , mitochondrala GN & 9 NDUA9 & 42.51 & $100.0 \%$ & 12 & 12 & 19 & $0.02 \%$ & 35.5\% QPVYVVDVSK & $99.7 \%$ & 48.7 & 25.0 & 45.8 & 2 & 0 & 0 & 1133.62 & 238 & 247 \\
\hline VADH dehydrogenase [ubiquirone]] 1 alpha subcomplex subunit 9 , mitcochondrial GN=NDUFA 9 & 9 NDUA9_HUMAN & 42.51 & $100.0 \%$ & 12 & 12 & 19 & $0.02 \%$ & $35.5 \%$ GIVNAVKDPDANGK & $99.7 \%$ & 32.3 & 25.0 & 28.0 & 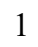 & 0 & , & 1397.74 & 248 & 261 \\
\hline IDH dehydrogenase [ubiquinonee] I alpha subcomplex subunit 9 , mitochondrial GN=NDUFAS & 9 NDUA9_HUMAN & 42.51 & $100.0 \%$ & 12 & 2 & 19 & $0.02 \%$ & $35.5 \%$ SFAFVGPSR & $99.7 \%$ & 42.3 & 25.0 & 35.0 & & 0 & & & 262 & 270 \\
\hline NADH dehydrogenase [ubiquinone] 1 alpha subcomplex subunit 9 , mitochondrial GN=NDUFA & 9 NDUA9_HUMAN & 42.51 & $100.0 \%$ & 12 & 12 & 19 & $.02 \%$ & $35.5 \%$ YLLFHLVK & $96.4 \%$ & 21.2 & 25.0 & 12.8 & & 0 & & 1032.62 & 271 & 278 \\
\hline NADH dehydrogenase [ubiquinone] 1 alpha subcomplex subunit 9 , mitochondrial GN=NDUFA & 9 NDUA9_HUMAN & 42.51 & $100.0 \%$ & 12 & 12 & 19 & $.02 \%$ & $35.5 \%$ VFEISPFEPWITR & $99.7 \%$ & 68.7 & 25.0 & 58.0 & & & & 1620.84 & 304 & 316 \\
\hline NADH dehydrogenase [ubiquinone] 1 alpha subcomplex subunit 9 , mitochondrial GN=NDUFA & 9 NDUA9_HUMAN & 42.51 & $100.0 \%$ & 12 & 12 & 19 & $0.02 \%$ & $35.5 \%$ WLSAEIEDVKPAK & $99.7 \%$ & 53.2 & 25.0 & 53.2 & & 0 & 0 & 85.79 & 361 & 373 \\
\hline $\mathrm{NADH}$ dehydrogenase [ubiquinone] iron-sulfur protein 2, mitochondrial GN=NDUFS2 & 2 NDUS2_HUMAN & 52.55 & $100.0 \%$ & 3 & 4 & 7 & $0.01 \%$ & 9.3\% NITLNFGPQHPAAHGVLR & $99.7 \%$ & 30.2 & 25.0 & 30.2 & & ? & 0 & 1942.04 & 79 & 96 \\
\hline NADH dehydrogenase [ubiquinone] iron-sulfur protein 2, mitochondrial GN=NDUFS2 & 2 NDUS2_HUMAN & 52.55 & $100.0 \%$ & J & 4 & 7 & $0.01 \%$ & 9.3\% IIAQCLNK & $99.0 \%$ & 24.6 & 25.0 & 15.6 & & & & 959.53 & 343 & 350 \\
\hline VADH dehydrogenase [ubiquinone] iron-sulfur protein 2, mitochondrial GN=NDUFS2 & 2 NDUS2_HUMAN & 52.55 & $100.0 \%$ & 3 & 4 & 7 & $0.01 \%$ & 9.3\% GEFGVYLVSDGSSRPYR & $99.7 \%$ & 57.8 & 25.0 & 57.1 & & & & 1888.92 & 405 & 421 \\
\hline NADH-cytochrome b5 reductase $3 \mathrm{GN}=\mathrm{CYB} 5 \mathrm{R} 3$ & NB5R3_HUMAN & 34.24 & $100.0 \%$ & 4 & 4 & 5 & $0.01 \%$ & 18.6\% STPAITLESPDIKYPLR & $99.2 \%$ & 21.0 & 25.0 & 21.0 & 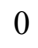 & & 0 & 1901.04 & 30 & 46 \\
\hline NADH-cytochrome b5 reductase $3 \mathrm{GN}=\mathrm{CYB} 5 \mathrm{R} 3$ & NB5R3_HUMAN & 34.24 & $100.0 \%$ & 4 & 4 & 5 & $0.01 \%$ & $18.6 \%$ VYFKDTHPK & $97.7 \%$ & 20.2 & 25.0 & 15.8 & & 0 & & .59 & 112 & 120 \\
\hline NADH-cytochrome b5 reductase $3 \mathrm{GN}=\mathrm{CYB} 5 \mathrm{R} 3$ & NB5R3_HUMAN & 34.24 & $100.0 \%$ & 4 & 4 & 5 & $.01 \%$ & $18.6 \%$ GPSC & $99.7 \%$ & 53.0 & 25.0 & 50.4 & & 0 & & .62 & 144 & 154 \\
\hline NADH-cytochrome b5 reductase $3 \mathrm{GN}=\mathrm{CYB} 5 \mathrm{R} 3$ & NB5R3_HUMAN & 34.24 & $100.0 \%$ & 4 & 4 & 5 & $.01 \%$ & $18.6 \%$ SVGMIAGGTGITPMLQVIR & $99.7 \%$ & 41.0 & 25.0 & 27.9 & & 0 & & .04 & 174 & 192 \\
\hline NADH-ubiquinone oxidoreductase $75 \mathrm{kDa}$ subunit, mitochondrial GN=NDUFS1 & NDUS1_HUMAN & 79.47 & $100.0 \%$ & 4 & 4 & 6 & $0.01 \%$ & $6.2 \%$ GWNILTNSEK & $98.7 \%$ & 24.4 & 25.0 & 15.3 & 1 & 0 & & .59 & 99 & 108 \\
\hline NADH-ubiquinone oxidoreductase 75 kDa subunit, mitochondrial GN=NDUFS1 & NDUS1_HUMAN & 79.47 & $100.0 \%$ & 4 & 4 & 6 & $0.01 \%$ & $6.2 \%$ FASEIAGVDDLC & $99.7 \%$ & 88.1 & 25.0 & 82.7 & & & & 79 & 185 & 200 \\
\hline NADH-ubiquinone oxidoreductase 75 kDa subunit, mitochondrial GN=NDUFS1 & NDUS1_HUMAN & 79.47 & 100 & 4 & 4 & 6 & $.01 \%$ & $6.2 \%$ FE & $99.7 \%$ & 32.9 & 25.0 & 21.4 & 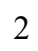 & 0 & & .55 & 409 & 417 \\
\hline NADH-ubiquinone oxidoreductase $75 \mathrm{kDa}$ subunit, mitochondrial GN=NDUFS1 & 1 NDUS1_HUMAN & 79.47 & $100.0 \%$ & 4 & 4 & 6 & $1 \%$ & $6.2 \% \mathrm{SA}$ & $99.7 \%$ & 37.1 & 25.0 & 31.1 & & 0 & 0 & .52 & 593 & 602 \\
\hline NADPH:adrenodoxin oxidoreductase, mitochondrial GN=FDXR & ADRO_HUMAN & 53.84 & $100.0 \%$ & 3 & 4 & 5 & $0.01 \%$ & $7.7 \% \mathrm{FGV}$ & $95.7 \%$ & 26.7 & 25.0 & 21.9 & & 0 & & & 80 & 90 \\
\hline NADPH:adrenodoxin oxidoreductase, mitochondrial GN=FDXR & ADRO_HUMAN & 53.84 & $100.0 \%$ & 3 & 4 & 5 & $.01 \%$ & $7.7 \%$ TAT & $99.7 \%$ & 31.8 & 25.0 & 21.5 & 2 & 0 & 0 & & 283 & 295 \\
\hline NADPH:adrenodoxin oxidoreductase, mitochondrial GN=FDXR & ADRO_HUMAN & 53.84 & $100.0 \%$ & 3 & 4 & 5 & $1 \%$ & JVDEATR & $99.7 \%$ & 34.6 & 25.0 & 34.6 & & & 0 & & 328 & 341 \\
\hline $\mathrm{N}$-alpha-acetyltransferase $10 \mathrm{GN}=\mathrm{NAA} 10$ & NAA10_HUMAN & 26.46 & 10 & 6 & 8 & 11 & $\%$ & $38.3 \% \mathrm{MEE}$ & $99.7 \%$ & 31.8 & 25.0 & 28.3 & & & & & 60 & 78 \\
\hline $\mathrm{N}$-alpha-acetyltransferase $10 \mathrm{GN}=\mathrm{NAA} 10$ & NAA10_HUMAN & 26.46 & $\%$ & 6 & 8 & 11 & $1 \%$ & $38.3 \% \mathrm{AN}$ & $99.7 \%$ & 38.6 & 25.0 & 31.4 & 1 & ( & & & 97 & 105 \\
\hline $\mathrm{N}$-alpha-acetyltransferase $10 \mathrm{GN}=\mathrm{NAA} 10$ & NAA10_HUMAN & 26.46 & $\%$ & 6 & 8 & 11 & $\%$ & $38.3 \%$ AA & $99.7 \%$ & 42.0 & 25.0 & 42.0 & & & 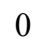 & & 117 & 136 \\
\hline $\mathrm{N}$-alpha-acetyltransferase $10 \mathrm{GN}=\mathrm{NAA} 10$ & NAA10_HUMAN & 26.46 & 10( & 6 & 8 & 11 & & $38.3 \% \mathrm{YY}$ & $99.7 \%$ & 37.4 & 25.0 & 37.4 & & & & & 137 & 149 \\
\hline $\mathrm{N}$-alpha-acetyltransferase $10 \mathrm{GN}=\mathrm{NAA} 10$ & NAA10_HUMAN & 26.46 & $\%$ & 6 & 8 & 11 & $\%$ & $\% \mathrm{HV}$ & $99.7 \%$ & 43.4 & 25.0 & 43.4 & 1 & ( & & & 170 & 183 \\
\hline $\mathrm{N}$-alpha-acetyltransferase $10 \mathrm{GN}=\mathrm{NAA} 10$ & NAA10_HUMAN & 26.46 & $\%$ & 6 & 8 & 11 & $\%$ & $38.3 \%$ GN & $99.7 \%$ & 40.1 & 25.0 & 37.8 & 2 & & ( & & 184 & 198 \\
\hline $\mathrm{N}$-alpha-acetyltransferase 15 , NatA auxiliary subunit GN=NAA15 & NAA15_HUMAN & 101.28 & 100 & 8 & 9 & 15 & $0.02 \%$ & $9.8 \% \mathrm{YQ}$ & $97.5 \%$ & 25.7 & 25.0 & 25.7 & 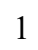 & & 0 & 80 & 138 & 148 \\
\hline $\mathrm{N}$-alpha-acetyltransferase 15 , NatA auxiliary subunit $\mathrm{GN}=\mathrm{NAA} 15$ & NAA15_HUMAN & 101.28 & $100.0 \%$ & 8 & 9 & 15 & $2 \%$ & $9.8 \% \mathrm{LE}$ & $99.7 \%$ & 44.4 & 25.0 & 40.4 & 2 & 0 & 0 & .51 & 240 & 248 \\
\hline $\mathrm{N}$-alpha-acetyltransferase 15 , NatA auxiliary subunit $\mathrm{GN}=\mathrm{NAA} 15$ & NAA15_HUMAN & 101.28 & 100 & 8 & 9 & 15 & $\%$ & $\%$ Al & $96.6 \%$ & 16.2 & 25.0 & 15.2 & . & 0 & 0 & & 267 & 276 \\
\hline N-alpha-acetyltransferase 15 , NatA auxiliary subunit GN=NAA15 & NAA15_HUMAN & 101.28 & $100.0 \%$ & 8 & 9 & 15 & $2 \%$ & $9.8 \% \mathrm{RLI}$ & $99.7 \%$ & 53.1 & 25.0 & 45.9 & the & & c & 73 & 295 & 305 \\
\hline $\mathrm{N}$-alpha-acetyltransferase $15, \mathrm{NatA}$ auxiliary subunit $\mathrm{GN}=\mathrm{NAA} 15$ & NAA15_HUMAN & 101.28 & $100.0 \%$ & 8 & 9 & 15 & $.02 \%$ & $9.8 \% \mathrm{GC}$ & $97.5 \%$ & 15.9 & 25.0 & 15.9 & 2 & 0 & 0 & 59 & 321 & 330 \\
\hline $\mathrm{N}$-alpha-acetyltransferase 15 , NatA auxiliary subunit GN=NAA15 & NAA15_HUMAN & 101.28 & 100 & 8 & 9 & 15 & $\%$ & $\% \mathrm{NF}$ & $99.7 \%$ & 34.2 & 25.0 & 21.3 & 2 & 0 & 0 & & 749 & 757 \\
\hline $\mathrm{N}$-alpha-acetyltransferase 15 , NatA auxiliary subunit $\mathrm{GN}=\mathrm{NAA} 15$ & NAA15_HUMAN & 101.28 & $100.0 \%$ & 8 & 9 & 15 & $\%$ & $9.8 \% \mathrm{NS}$ & $99.1 \%$ & 23.1 & 25.0 & 23.1 & t & & $\mathrm{C}$ & & 758 & 770 \\
\hline $\mathrm{N}$-alpha-acetyltransferase 15 , NatA auxiliary subunit GN=NAA15 & NAA15_HUMAN & 101.28 & 100 & 8 & 9 & 15 & & QKR & & 27.9 & 25.0 & 19.4 & 2 & & 0 & & 771 & 782 \\
\hline Nascent polypeptide-associated complex subunit alpha, muscle-specific form GN=NACA & NACAM_HUMAN & 205.42 & $100.0 \%$ & 3 & 3 & 6 & $\%$ & $2.0 \%$ NIL & $99.7 \%$ & 59.6 & 25.0 & 59.6 & 2 & 0 & 0 & 90 & 1964 & 1976 \\
\hline Nascent polypeptide-associated complex subunit alpha, muscle-specific form GN=NACA & NACAM_HUMAN & 205.42 & $100.0 \%$ & 3 & 3 & 6 & & $2.0 \% \mathrm{SPA}$ & $99.7 \%$ & 69.3 & 25.0 & 69.3 & 2 & & 0 & & 1977 & 1990 \\
\hline ascent polypeptide-associated complex subunit alpha, muscle-specific form GN=NACA & NACAM_HUMAN & 205.42 & & 3 & 3 & 6 & & $2.0 \%$ IED & $99.7 \%$ & \#\#\# & 25.0 & 98.7 & 2 & 0 & 0 & & 1991 & 2005 \\
\hline Nck-associated protein $1 \mathrm{GN}=\mathrm{NCKAP} 1$ & NCKP1_HUMAN & 128.79 & $100.0 \%$ & 2 & 2 & 3 & $0.00 \%$ & $1.9 \% \mathrm{AAl}$ & $99.4 \%$ & 25.2 & 25.0 & 19.1 & 1 & 0 & 0 & .61 & 306 & 315 \\
\hline Nck-associated protein $1 \mathrm{GN}=\mathrm{NCKAP} 1$ & NCKP1_HUMAN & 128.79 & $100.0 \%$ & 2 & 2 & 3 & & $1.9 \% \quad \mathrm{IG}$ & $99.7 \%$ & 28.1 & 25.0 & 28.1 & 2 & 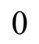 & 0 & .64 & 1069 & 1079 \\
\hline Neurofibromin GN=NF1 & NF1_HUMAN & 319.38 & & 3 & 3 & 6 & & $\% \mathrm{~V}$ & & 45.6 & 25.0 & 45.6 & & 0 & $\mathrm{C}$ & & 207 & 218 \\
\hline Neurofibromin GN=NF1 & NF1_HUMAN & 319.38 & $100.0 \%$ & 3 & 3 & 6 & $1 \%$ & $1.3 \%$ TLS & $99.7 \%$ & 42.5 & 25.0 & 42.5 & 2 & 0 & 0 & .69 & 1589 & 1600 \\
\hline Neurofibromin GN=NF1 & NF1_HUMAN & 319.38 & $100.0 \%$ & 3 & 3 & 6 & $01 \%$ & $1.3 \%$ VGS & $99.7 \%$ & 43.8 & 25.0 & 43.8 & & 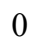 & 0 & .68 & 1757 & 1769 \\
\hline Neurofilament medium polypeptide GN=NEFM & NFM_HUMAN & 102.47 & & 6 & 7 & 16 & & $9.2 \%$ VSG & $99.7 \%$ & 37.3 & 25.0 & 27.9 & & 0 & 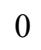 & & 27 & 36 \\
\hline Neurofilament medium polypeptide GN=NEFM & NFM_HUMAN & 102.47 & $100.0 \%$ & 6 & 7 & 16 & $0.02 \%$ & $9.2 \%$ GSP & $99.7 \%$ & 35.8 & 25.0 & 34.3 & 4 & 0 & 0 & 1255.63 & 43 & 54 \\
\hline Neurofilament medium polypeptide $\mathrm{GN}=\mathrm{NEFM}$ & NFM_HUMAN & 102.47 & $100.0 \%$ & 6 & 7 & 16 & $0.02 \%$ & $9.2 \%$ LRDDTEAAIR & $99.7 \%$ & 44.0 & 25.0 & 36.5 & 0 & 0 & 0 & 1159.61 & 195 & 204 \\
\hline Neurofilament medium polypeptide GN=NEFM & NFM_HUMAN & 102.47 & $100.0 \%$ & 6 & 7 & 16 & & 9.2\% VQSLQDEVAFLR & $99.7 \%$ & 55.5 & 25.0 & 45.2 & & 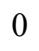 & & & 224 & 235 \\
\hline Neurofilament medium polypeptide GN=NEFM & NFM_HUMAN & 102.47 & $100.0 \%$ & 6 & 7 & 16 & $0.02 \%$ & 9.2\% LTEAAEQNKEAIR & $99.7 \%$ & 44.4 & 25.0 & 44.4 & 2 & 1 & 0 & 1472.77 & 299 & 311 \\
\hline
\end{tabular}


Neurofilament medium polypeptide GN=NEFM NFM_HUMAN $102.47 \quad 100.0 \%$ Neurofilament medium polypeptide GN=NEFM NFM_HUMAN $102.47 \quad 100.0 \%$ Neurofilament medium polypeptide GN=NEFM NFM_HUMAN $102.47 \quad 100.0 \%$ Neutral alpha-glucosidase AB GN=GANAB GANAB HUMAN $106.88 \quad 100.0 \%$ Neutral alpha-glucosidase AB GN=GANAB GANAB_HUMAN $106.88 \quad 100.0 \%$ NF-kappa-B-repressing factor GN=NKRF NKRF_HUMAN $77.67 \quad 100.0 \%$ NF-kappa-B-repressing factor GN=NKRF NKRF_HUMAN $77.67 \quad 100.0 \%$ NF-kappa-B-repressing factor GN=NKRF NKRF_HUMAN $77.67 \quad 100.0 \%$ NF-kappa-B-repressing factor GN=NKRF NKRF HUMAN $77.67 \quad 100.0 \%$ NF-kappa-B-repressing factor GN=NKRF NKRF_HUMAN $77.67 \quad 100.0 \%$ NF-kappa-B-repressing factor GN=NKRF NKRF_HUMAN $77.67 \quad 100.0 \%$ Nicotinamide phosphoribosyltransferase GN=NAMPT NAMPT_HUMAN $55.52 \quad 100.0 \%$ Nicotinamide phosphoribosyltransferase GN=NAMPT NAMPT_HUMAN $55.52 \quad 100.0 \%$ Nicotinamide phosphoribosyltransferase GN=NAMPT NAMPT_HUMAN $55.52 \quad 100.0 \%$ Nen $100.0 \%$ Nischarin GN=NISCH Nischarin GN=NISCH Nischarin GN=NISCH

Nischarin GN=NISCH NISCH_HUMAN $166.63 \quad 100.0 \%$ NISCH_HUMAN $166.63 \quad 100.0 \%$ NISCH HUMAN $166.63 \quad 100.0 \%$ Non-POU domain-containing octamer-binding protein GN=NONO NONO_HUMAN $54.23 \quad 100.0 \%$ Non-POU domain-containing octamer-binding protein GN=NONO NONO_HUMAN $54.23 \quad 100.0 \%$ Non-POU domain-containing octamer-binding protein GN=NONO NONO_HUMAN $54.23 \quad 100.0 \%$ Non-POU domain-containing octamer-binding protein GN=NONO NONO_HUMAN $54.23 \quad 100.0 \%$ Non-POU domain-containing octamer-binding protein GN=NONO NONO_HUMAN $54.23 \quad 100.0 \%$ Non-POU domain-containing octamer-binding protein GN=NONO NONO_HUMAN $54.23 \quad 100.0 \%$ Non-POU domain-containing octamer-binding protein GN=NONO NONO_HUMAN $54.23 \quad 100.0 \%$ Nuclear cap-binding protein subunit $1 \mathrm{GN}=\mathrm{NCBP} 1 \mathrm{NCBP} 1$ HUMAN $91.84 \quad 100.0 \%$ Nuclear cap-binding protein subunit 1 GN=NCBP1 NCBP1_HUMAN $91.84 \quad 100.0 \%$ Nuclear cap-binding protein subunit $1 \mathrm{GN}=\mathrm{NCBP} 1 \mathrm{NCBP} 1$ HUMAN $91.84 \quad 100.0 \%$ Nuclear cap-binding protein subunit $1 \mathrm{GN}=\mathrm{NCBP} 1 \mathrm{NCBP} 1$ HUMAN $91.84 \quad 100.0 \%$ Nuclear mitotic apparatus protein 1 GN=NUMA1 NUMA1_HUMAN $238.26 \quad 100.0 \%$ Nuclear mitotic apparatus protein 1 GN=NUMA1 NUMA1_HUMAN $238.26 \quad 100.0 \%$ Nuclear mitotic apparatus protein 1 GN=NUMA1 NUMA1_HUMAN $238.26 \quad 100.0 \%$ Nuclear mitotic apparatus protein 1 GN=NUMA1 NUMA1_HUMAN $238.26 \quad 100.0 \%$ Nuclear mitotic apparatus protein 1 GN=NUMA1 NUMA1_HUMAN $238.26 \quad 100.0 \%$ Nuclear mitotic apparatus protein 1 GN=NUMA1 NUMA1_HUMAN $238.26 \quad 100.0 \%$ Nuclear mitotic apparatus protein 1 GN=NUMA1 NUMA1 HUMAN $238.26 \quad 100.0 \%$ Nuclear mitotic apparatus protein 1 GN=NUMA1 NUMA1_HUMAN $238.26 \quad 100.0 \%$ Nuclear mitotic apparatus protein $1 \mathrm{GN}=\mathrm{NUMA1}$ NUMA1_HUMAN $238.26 \quad 100.0 \%$ Nuclear mitotic apparatus protein 1 GN=NUMA1 NUMA1_HUMAN $238.26 \quad 100.0 \%$ Nuclear mitotic apparatus protein 1 GN=NUMA1 NUMA1_HUMAN $238.26 \quad 100.0 \%$ Nuclear mitotic apparatus protein 1 GN=NUMA1 NUMA1_HUMAN $238.26 \quad 100.0 \%$ Nuclear mitotic apparatus protein 1 GN=NUMA1 NUMA1_HUMAN $238.26 \quad 100.0 \%$ Nuclear mitotic apparatus protein 1 GN=NUMA1 NUMA1_HUMAN $238.26 \quad 100.0 \%$ Nuclear mitotic apparatus protein 1 GN=NUMA1 NUMA1 HUMAN $238.26 \quad 100.0 \%$ Nuclear mitotic apparatus protein 1 GN=NUMA1 NUMA1_HUMAN $238.26 \quad 100.0 \%$
$16 \quad 0.02 \% \quad 9.2 \% \quad$ HLREYQDLLNVK $0.02 \% \quad 9.2 \%$ EYQDLLNVK $0.02 \% \quad 9.2 \%$ ITSEGGDGATKYITK $0.00 \% \quad 2.0 \%$ SIRPGLSPYR $0.00 \% \quad 2.0 \%$ FRIDELEPR $0.02 \% \quad 11.2 \%$ HLSTCDGQNPPKK $0.02 \% \quad 11.2 \%$ DASGQPIFNASAK $0.02 \% \quad 11.2 \%$ HAAADEALKILQK $0.02 \% \quad 11.2 \%$ TVKYEAAGEAVK $0.02 \% \quad 11.2 \%$ GAVEDVISRNEIQGR $0.02 \% \quad 11.2 \%$ SESHTDLTFSR $0.01 \% \quad 7.9 \%$ AVPEGFVIPR

$0.01 \% \quad 7.9 \%$ GVSSQETAGIGASAHLVNFK $0.01 \% \quad 7.9 \% \quad$ SYSFDEIRK

$0.00 \% \quad 7.9 \%$ GIISPVGDAYK $0.00 \% \quad 7.9 \%$ NAGVILAPLQR $0.01 \% \quad 2.9 \%$ SCCAPSEAVK $0.01 \% \quad 2.9 \%$ VPLSTVLLDPTR $0.01 \% \quad 2.9 \% \quad$ TPGTGGSPQGSFADGQPAER $0.03 \% \quad 15.3 \%$ AGEVFIHK $0.03 \% \quad 15.3 \%$ FACHSASLTVR $0.03 \% \quad 15.3 \%$ AVVIVDDRGRPSGK $0.03 \% \quad 15.3 \%$ GIVEFSGKPAAR $0.03 \% \quad 15.3 \%$ GIVEFSGKPAARK $0.03 \% \quad 15.3 \%$ FAQPGSFEYEYAMR $0.03 \% \quad 15.3 \%$ AAPGAEFAPNKR $0.01 \% \quad 5.6 \%$ ANNYNEAVYLVR $0.01 \% \quad 5.6 \% \quad$ KTCAAQLVSYPGK $0.01 \% \quad 5.6 \%$ FVREVLEK $0.01 \% \quad 5.6 \%$ ATNDEIFSILK $0.11 \% \quad 23.0 \%$ IIDRIHGTEEGQQILK $0.11 \% 23.0 \%$ CLEEKNEILQGK $0.11 \% \quad 23.0 \%$ VEMLETERGQQEAK $0.11 \% \quad 23.0 \%$ HQVEQLSSSLK $0.11 \% \quad 23.0 \%$ DSAQTSVTQAQR $0.11 \% \quad 23.0 \%$ DSAQTSVTQAQREK $0.11 \% \quad 23.0 \%$ RAADALEEQQR $0.11 \% \quad 23.0 \%$ AADALEEQQR $0.11 \% \quad 23.0 \%$ CISELKAETR $\begin{array}{llll}99.7 \% & 48.4 & 25.0 & 29.2\end{array}$

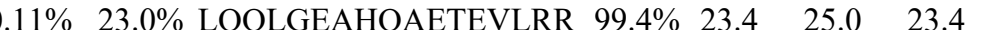
$0.11 \% \quad 23.0 \%$ VAGIESHSELQISR $0.11 \% \quad 23.0 \%$ ALQQVQEKEVR $0.11 \% \quad 23.0 \%$ LADDLSTLQEK $0.11 \% \quad 23.0 \%$ MAATSKEVAR $0.11 \% \quad 23.0 \%$ ELVKEPAR $0.11 \% \quad 23.0 \%$ AGDRQPEWLEEQQGR
$99.7 \% 59.8$ $99.7 \% \quad 46.4$ $99.7 \% 33.4$ $99.5 \% 23.6$ $99.3 \% \quad 20.9$ $99.7 \% 38$. $99.7 \% \quad 52.5$ $99.7 \% \quad 34.0$ $99.2 \% \quad 20.5$

$99.7 \% \quad 42.7$ $99.7 \% \quad 41.8$ $98.2 \% \quad 19.6$

$95.0 \% \quad 16.9$ $99.7 \% \quad 33.7$ $96.9 \% \quad 22.3$ $99.7 \% \quad 27.3$ $99.7 \% \quad 40.5$ $99.7 \% \quad 48.7$ $99.7 \% \quad 47.0$ $98.6 \% 17.7$ $98.0 \% \quad 23.6$ $99.7 \% \quad 37.3$ $99.7 \% \quad 31.1$ $99.7 \% \quad 57.5$ $99.7 \% \quad 33.3$ $\begin{array}{lll}96.9 \% & 16.0\end{array}$ $99.7 \% \quad 50.3$ $99.7 \% \quad 46.5$ $99.7 \% \quad 31.8$ $97.1 \% 27$. $99.7 \% \quad 39.2$ $99.2 \% \quad 20.5$ $99.7 \% 48$ $99.7 \% 36$. $99.7 \% \quad 59.1$ $99.7 \% \quad 57.5$ $99.7 \% \quad 34.5$ $99.0 \% \quad 20$.

$99.7 \% \quad 65.3$ $99.7 \% \quad 44.3$ $99.7 \% \quad 48.5$ $99.7 \% \quad 71.3 \quad 25.0 \quad 53.2$ $\begin{array}{llll}99.7 \% & 43.5 & 25.0 & 34.2\end{array}$ $\begin{array}{llll}99.0 \% & 29.9 & 25.0 & 20.6\end{array}$ $\begin{array}{llll}99.7 \% & 44.2 \quad 25.0 & 38.4\end{array}$

0
0
0
0
0
0
0
0
0
0
0
0
0
0
0
0
0
0
0
0
0
0
0
0
0
0
0
0
0
0
0
0
0
0
0
0
0
0
0
0
0
0
0
0

1121.58

1540.79

1145.64

1174.62

1481.72

1305.64

1407.80

1265.67

1642.85

1279.59

1084.62

1973.01

1144.56

1119.60

1151.69

1108.48

1310.77

1916.87

2072.97

900.49

1248.62

1468.82

1231.68

1359.77

1695.75

1228.64

1425.71

1422.74

1019.59

1250.66

1850.01

1460.74

1647.80

1255.66

1291.62

1548.76

1286.64

1130.54

1206.61

1978.05

1525.80

1327.73

1232.64

1063.56

941.54

1798.85 $\begin{array}{cc}80 & 391 \\ 83 & 391 \\ 61 & 875 \\ 2 & 61 \\ 01 & 109 \\ 3 & 45 \\ 23 & 335 \\ 99 & 411 \\ 98 & 509 \\ 25 & 539 \\ 16 & 626 \\ 18 & 127 \\ 97 & 216 \\ 70 & 478 \\ 6 & 56 \\ 62 & 272 \\ 93 & 902 \\ 46 & 957 \\ 16 & 1035 \\ 16 & 1036 \\ 00 & 107 \\ 43 & 153 \\ 77 & 190 \\ 91 & 202 \\ 91 & 203 \\ 57 & 270 \\ 57 & 468 \\ 18 & 129 \\ 30 & 342 \\ 48 & 455 \\ 12 & 522 \\ 9 & 54 \\ 75 & 386 \\ 36 & 449 \\ 51 & 561 \\ 32 & 643 \\ 32 & 645 \\ 24 & 734 \\ 25 & 734 \\ 35 & 744 \\ 71 & 787 \\ 56 & 869 \\ 84 & 894 \\ 98 & 908 \\ 09 & 918 \\ 36 & 943 \\ 44 & 958 \\ & \end{array}$ 
Nuclear mitotic apparatus protein 1 GN=NUMA1 NUMA1_HUMAN $238.26 \quad 100.0 \% \quad 4$ Nuclear mitotic apparatus protein 1 GN=NUMA1 NUMA1_HUMAN $238.26 \quad 100.0 \%$ Nuclear mitotic apparatus protein 1 GN=NUMA1 NUMA1_HUMAN $238.26 \quad 100.0 \%$ Nuclear mitotic apparatus protein $1 \mathrm{GN}=\mathrm{NUMA1}$ NUMA1_HUMAN $238.26 \quad 100.0^{\circ}$ Nuclear mitotic apparatus protein 1 GN=NUMA1 NUMA1_HUMAN $238.26 \quad 100.0 \%$ Nuclear mitotic apparatus protein 1 GN=NUMA1 NUMA1_HUMAN $238.26 \quad 100.0 \%$ Nuclear mitotic apparatus protein $1 \mathrm{GN}=$ NUMA1 NUMA1_HUMAN $238.26 \quad 100.0 \%$ Nuclear mitotic apparatus protein 1 GN=NUMA1 NUMA1_HUMAN $238.26 \quad 100.0 \%$ Nuclear mitotic apparatus protein $1 \mathrm{GN}=\mathrm{NUMA} 1$ NUMA1 HUMAN $238.26 \quad 100.0^{\circ}$ Nuclear mitotic apparatus protein $1 \mathrm{GN}=$ NUMA1 NUMA1_HUMAN $238.26 \quad 100.0 \%$ Nuclear mitotic apparatus protein $1 \mathrm{GN}=$ NUMA1 NUMA1_HUMAN $238.26 \quad 100.0 \%$ Nuclear mitotic apparatus protein $1 \mathrm{GN}=$ NUMA1 NUMA1_HUMAN $238.26 \quad 100.0 \%$ Nuclear mitotic apparatus protein 1 GN=NUMA1 NUMA1_HUMAN $238.26 \quad 100.0 \%$ Nuclear mitotic apparatus protein $1 \mathrm{GN}=\mathrm{NUMA} 1$ NUMA1_HUMAN $238.26 \quad 100.0 \%$ Nuclear mitotic apparatus protein $1 \mathrm{GN}=$ NUMA1 NUMA1 HUMAN $238.26 \quad 100.0 \%$ Nuclear mitotic apparatus protein 1 GN=NUMA1 NUMA1_HUMAN $238.26 \quad 100.0 \%$ Nuclear mitotic apparatus protein $1 \mathrm{GN}=\mathrm{NUMA} 1$ NUMA1_HUMAN $238.26 \quad 100.0 \%$ Nuclear mitotic apparatus protein 1 GN=NUMA1 NUMA1_HUMAN $238.26 \quad 100.0 \%$ Nuclear mitotic apparatus protein 1 GN=NUMA1 NUMA1_HUMAN $238.26100 .0 \%$ Nuclear mitotic apparatus protein $1 \mathrm{GN}=$ NUMA1 NUMA1_HUMAN $238.26 \quad 100.0 \%$ Nuclear mitotic apparatus protein 1 GN=NUMA1 NUMA1_HUMAN $238.26 \quad 100.0 \%$ Nuclear mitotic apparatus protein $1 \mathrm{GN}=\mathrm{NUMA1}$ NUMA1_HUMAN $238.26100 .0 \%$ Nuclear mitotic apparatus protein 1 GN=NUMA1 NUMA1_HUMAN $238.26 \quad 100.0 \%$ Nuclear mitotic apparatus protein $1 \mathrm{GN}=\mathrm{NUMA} 1$ NUMA1_HUMAN $238.26 \quad 100.0 \%$ Nuclear mitotic apparatus protein $1 \mathrm{GN}=\mathrm{NUMA} 1$ NUMA1 HUMAN $238.26 \quad 100.0 \%$ Nuclear mitotic apparatus protein 1 GN=NUMA1 NUMA1_HUMAN $238.26 \quad 100.0 \%$ Nuclear mitotic apparatus protein 1 GN=NUMA1 NUMA1_HUMAN $238.26100 .0 \%$ Nuclear mitotic apparatus protein $1 \mathrm{GN}=$ NUMA1 NUMA1_HUMAN $238.26 \quad 100.0 \%$ Nuclear pore complex protein Nup107 GN=NUP107 NU107_HUMAN $106.38 \quad 100.0 \%$ Nuclear pore complex protein Nup107 GN=NUP107 NU107 HUMAN $106.38 \quad 100.0^{\circ}$ Nuclear pore complex protein Nup107 GN=NUP107 NU107_HUMAN $106.38 \quad 100.0 \%$ Nuclear pore complex protein Nup107 GN=NUP107 NU107_HUMAN $106.38 \quad 100.0 \%$ Nuclear pore complex protein Nup107 GN=NUP107 NU107 HUMAN $106.38 \quad 100.0 \%$ Nuclear pore complex protein Nup155 GN=NUP155 NU155_HUMAN $155.20 \quad 100.0 \%$ Nuclear pore complex protein Nup155 GN=NUP155 NU155 HUMAN $155.20 \quad 100.0 \%$ Nuclear pore complex protein Nup160 GN=NUP160 NU160_HUMAN $162.13 \quad 100.0 \%$ Nuclear pore complex protein Nup160 GN=NUP160 NU160_HUMAN $162.13100 .0 \%$ Nuclear pore complex protein Nup160 GN=NUP160 NU160 HUMAN $162.13 \quad 100.0^{\circ}$ Nuclear pore complex protein Nup160 GN=NUP160 NU160_HUMAN $162.13 \quad 100.0 \%$ Nuclear pore complex protein Nup160 GN=NUP160 NU160_HUMAN $162.13100 .0 \%$ Nuclear pore complex protein Nup160 GN=NUP160 NU160_HUMAN $162.13 \quad 100.0 \%$ Nuclear pore complex protein Nup160 GN=NUP160 NU160_HUMAN $162.13 \quad 100.0 \%$ Nuclear pore complex protein Nup160 GN=NUP160 NU160 HUMAN $162.13 \quad 100.0 \%$ Nuclear pore complex protein Nup160 GN=NUP160 NU160_HUMAN $162.13 \quad 100.0 \%$ Nuclear pore complex protein Nup160 GN=NUP160 NU160_HUMAN $162.13 \quad 100.0 \%$ Nuclear pore complex protein Nup160 GN=NUP160 NU160 HUMAN $162.13 \quad 100.0 \%$ Nuclear pore complex protein Nup205 GN=NUP205 NU205_HUMAN $227.93 \quad 100.0 \%$

.

5
2
2

2
11
11

11
11
11

$98 \quad 0.11 \% \quad 23.0 \%$ EAEQMGNELER

. $0.1 \% 23.0 \%$ GRAQADLALEK

$0.11 \% 23.0 \%$ AQADLALEK

$0.11 \% 23.0 \%$ EKEHASGSGAQSEAAGR
$0.11 \% 23.7$
$0.11 \%$ AEVSKLEQQCQK

$0.11 \% 23.0 \%$ QQEQADSLER

$0.11 \% 23.0 \%$ AQELGHSQSALASAQR

$0.11 \% 23.0 \%$ LLQAETASNSAR

$0.11 \% \quad 23.0 \%$ HLCQQLQAEQAAAEKR

$0.11 \% 23.0 \%$ ASYAEQLSMLK

$0.11 \% 23.0 \%$ YVQELAAVR

$0.11 \% 23.0 \%$ YVQELAAVRADAETR

$0.11 \% 23.0 \%$ ELEVMTAKYEGAK

$0.11 \% 23.0 \%$ LADSDQASKVQQQK

$0.11 \% 23.0 \%$ AVQAQGGESQQEAQR

$0.11 \% \quad 23.0 \%$ KQQNQELQEQLR

$0.11 \% 23.0 \%$ QQNQELQEQLR

$0.11 \% 23.0 \%$ LGHELQQAGLK

$0.11 \% \quad 23.0 \%$ FQVATDALK

$0.11 \% \quad 23.0 \%$ TTQIINITMTK

$0.11 \% \quad 23.0 \%$ SAPASQASLR

$0.11 \% 23.0 \%$ RSQAGVSSGAPPGR

$0.11 \% \quad 23.0 \%$ SQAGVSSGAPPGR

$0.11 \% \quad 23.0 \%$ VSLEPHQGPGTPESK

$0.11 \% 23.0 \%$ QSMAFSILNTPK

$0.11 \% \quad 23.0 \%$ KLGNSLLR

$0.11 \% \quad 23.0 \%$ IATTTASAATAAAIGATPR

$0.01 \% \quad 6.5 \%$ SGFGEISSPVIR

$0.01 \% \quad 6.5 \%$ VLLQASQDENFGNTTPR

$0.01 \% \quad 6.5 \%$ TVVEALFQR

$0.01 \% \quad 6.5 \%$ AIYAALSGNLK

$0.01 \% \quad 6.5 \%$ EADLDVATITK

$0.00 \% \quad 2.0 \%$ VASVSQNAIVSAAGNIAR

$0.00 \% \quad 2.0 \%$ LLEVYDQLFK

$0.02 \% \quad 7.9 \% \quad$ SFVELSGAER

$0.02 \% \quad 7.9 \%$ SFVELSGAERERPR

$0.02 \% \quad 7.9 \% \quad$ LLLPHPSR

$\begin{array}{lllll}12 & 20 & 0.02 \% & 7.9 \% & \text { GFNPAQPLNIR }\end{array}$

$\begin{array}{lllll}12 & 20 & 0.02 \% & 7.9 \% & \text { MNLTQLYGSNTA }\end{array}$

$\begin{array}{lllll}12 & 20 & 0.02 \% & 7.9 \% & \text { TAPLLLSYYLIK } \\ 12 & 20 & 0.02 \% & 7.9 \% & \text { CYLVTGEGQK }\end{array}$

$\begin{array}{lllll}12 & 20 & 0.02 \% & 7.9 \% & \text { SEDGEIVSTPR }\end{array}$

$\begin{array}{lllll}12 & 20 & 0.02 \% & 7.9 \% & \text { QLVVVLCER }\end{array}$

$\begin{array}{lllll}12 & 20 & 0.02 \% & 7.9 \% & \text { QGNCYLAALNCLR }\end{array}$

$\begin{array}{lllll}12 & 20 & 0.02 \% & 7.9 \% & \text { LLSTYLER }\end{array}$

$\begin{array}{lllll}25 & 52 & 0.06 \% & 12.0 \% & \text { RQPEAVHLLDK }\end{array}$ $\begin{array}{llll}94.7 \% & 14.6 & 25.0 & 14.6\end{array}$ $\begin{array}{lll}7 \% & 36.9\end{array}$ $99.7 \% \quad 36.5$ $99.7 \% 58$. $\begin{array}{lll}99.7 \% & 40.3\end{array}$ . $99.7 \% \quad 66.9$ $99.7 \% \quad 61.2$ $99.7 \% \quad 44.8$ $98.7 \% \quad 20.2$ $99.7 \% \quad 39.5$ $98.8 \% \quad 25.8$ $99.7 \% \quad 89.6$ $99.7 \% \quad 41.6$ $99.7 \% \quad 49.4$ $99.7 \% \quad 52.4$ $98.0 \% \quad 28.0$ $99.7 \% \quad 61.0$ $99.7 \% \quad 58.9$ $97.9 \% \quad 22.8$ $99.7 \% \quad 56.5$ $\begin{array}{lll}99.7 \% & 30.7\end{array}$ $99.7 \% \quad 33.2$ $97.1 \% \quad 24.5$ $\begin{array}{ll}3 \% & 16.5\end{array}$ $\begin{array}{lll}-1 & -1 \\ 9 & -0 \% & 24.2 \\ 99.7 \% & 92.8\end{array}$ $99.5 \% \quad 24.6$ $\begin{array}{lll}99.7 \% & 49.3\end{array}$ $99.7 \% \quad 58.3$ $99.7 \% \quad 41.8$ $\begin{array}{lll}99.1 \% & 29.9\end{array}$ $99.7 \% \quad 58.6$ $99.3 \% \quad 23.8$ $96.8 \% \quad 16.6$ $99.4 \% \quad 21.2$

$$
\text { R } 99.7
$$

$99.7 \% \quad 44.0$ $99.7 \% \quad 31.0$ $\begin{array}{lll}99.7 \% & 48.3\end{array}$ $99.7 \% \quad 43.9$ $99.7 \% \quad 35.8$ $99.0 \% \quad 59.9$ $99.7 \% \quad 29.9$ 2203.02 1171.64

958.52

1671.77

1447.72

1203.56

1653.83

1260.65

1880.94

1240.62

1048.58

1691.87

1468.74

1545.79

1586.75

1541.80

1413.71

1193.66

992.54

1279.69

987.52

1326.69

1170.59

1562.78

1352.69

900.56

1715.93

1248.66

1889.94

1062.59

1120.64

1175.62

1727.94

1267.69

1094.55

1632.85

932.57

1226.66

2076.98

1394.83

1154.55

1189.57

1115.62

1552.74

994.56 1305.73 $\begin{array}{ll}066 & 1004 \\ 014 & 1024\end{array}$

$1016 \quad 1024$

$1098 \quad 1114$

$1127 \quad 1138$

11391148

11751190

$271 \quad 1282$

$1365 \quad 1380$

$431 \quad 1441$

$1476 \quad 1490$

$1504 \quad 1516$

$1558 \quad 1571$

$1574 \quad 1588$

$1625 \quad 1636$

$1626 \quad 1636$

$\begin{array}{ll}655 \quad 1665 \\ 700 & 1708\end{array}$

$1811 \quad 1821$

$1840 \quad 1849$

18861899

$1887 \quad 1899$

$990 \quad 2004$

$2058 \quad 2065$

20902108

$4 \quad 15$

$251 \quad 259$

$426 \quad 436$

$627 \quad 637$

$315 \quad 332$

12991308

$44 \quad 53$

$\begin{array}{cc}44 & 57 \\ 164 & 171\end{array}$

690700

$701 \quad 718$

$766 \quad 777$

$916 \quad 925$

10361044

$1121 \quad 1133$

$1291 \quad 1298$ 
Nuclear pore complex protein Nup205 GN=NUP205 NU205_HUMAN $227.93 \quad 100.0 \% \quad 24$ $\begin{array}{llll}\text { Nuclear pore complex protein Nup205 GN=NUP205 NU205_HUMAN } 227.93 & 100.0 \% & 24\end{array}$ Nuclear pore complex protein Nup205 GN=NUP205 NU205_HUMAN $227.93 \quad 100.0 \% \quad 24$ Nuclear pore complex protein Nup205 GN=NUP205 NU205 HUMAN $227.93 \quad 100.0 \% 24$ Nuclear pore complex protein Nup205 GN=NUP205 NU205_HUMAN $227.93 \quad 100.0 \% \quad 24$ Nuclear pore complex protein Nup205 GN=NUP205 NU205_HUMAN $227.93 \quad 100.0 \% \quad 24$ Nuclear pore complex protein Nup205 GN=NUP205 NU205_HUMAN $227.93 \quad 100.0 \% 24$ Nuclear pore complex protein Nup205 GN=NUP205 NU205_HUMAN $227.93 \quad 100.0 \% \quad 24$ Nuclear pore complex protein Nup205 GN=NUP205 NU205 HUMAN $227.93 \quad 100.0 \%$ Nuclear pore complex protein Nup205 GN=NUP205 NU205_HUMAN $227.93 \quad 100.0 \% \quad 24$ Nuclear pore complex protein Nup205 GN=NUP205 NU205_HUMAN $227.93 \quad 100.0 \%$ Nuclear pore complex protein Nup205 GN=NUP205 NU205_HUMAN $227.93 \quad 100.0 \% \quad 24$ Nuclear pore complex protein Nup205 GN=NUP205 NU205_HUMAN $227.93 \quad 100.0 \% \quad 24$ Nuclear pore complex protein Nup205 GN=NUP205 NU205_HUMAN $227.93 \quad 100.0 \% 24$ Nuclear pore complex protein Nup205 GN=NUP205 NU205_HUMAN $227.93 \quad 100.0 \% \quad 24$ Nuclear pore complex protein Nup205 GN=NUP205 NU205_HUMAN $227.93 \quad 100.0 \% \quad 24$ Nuclear pore complex protein Nup205 GN=NUP205 NU205 HUMAN $227.93 \quad 100.0 \%$ Nuclear pore complex protein Nup205 GN=NUP205 NU205_HUMAN $227.93 \quad 100.0 \% \quad 24$ Nuclear pore complex protein Nup205 GN=NUP205 NU205_HUMAN $227.93 \quad 100.0 \% \quad 24$ Nuclear pore complex protein Nup205 GN=NUP205 NU205_HUMAN $227.93 \quad 100.0 \% 24$ Nuclear pore complex protein Nup205 GN=NUP205 NU205_HUMAN $227.93 \quad 100.0 \% \quad 24$ Nuclear pore complex protein Nup205 GN=NUP205 NU205_HUMAN $227.93 \quad 100.0 \% \quad 24$ Nuclear pore complex protein Nup205 GN=NUP205 NU205_HUMAN $227.93 \quad 100.0 \% \quad 24$ Nuclear pore complex protein Nup214 GN=NUP214 NU214_HUMAN $213.62 \quad 100.0 \%$ Nuclear pore complex protein Nup214 GN=NUP214 NU214 HUMAN $213.62 \quad 100.0 \%$ Nuclear pore complex protein Nup214 GN=NUP214 NU214_HUMAN $213.62 \quad 100.0 \%$ Nuclear pore complex protein Nup85 GN=NUP85 NUP85_HUMAN $75.02 \quad 100.0 \%$ Nuclear pore complex protein Nup85 GN=NUP85 NUP85 HUMAN $75.02 \quad 100.0 \%$ Nuclear pore complex protein Nup85 GN=NUP85 NUP85_HUMAN $75.02 \quad 100.0 \%$ Nuclear pore complex protein Nup85 GN=NUP85 NUP85 HUMAN 75.02 $100.0 \%$ Nuclear pore complex protein Nup85 GN=NUP85 NUP85_HUMAN $75.02 \quad 100.0 \%$ Nuclear pore complex protein Nup93 GN=NUP93 NUP93_HUMAN $93.49 \quad 100.0 \%$ Nuclear pore complex protein Nup93 GN=NUP93 NUP93 HUMAN $93.49 \quad 100.0^{\circ}$ Nuclear pore complex protein Nup93 GN=NUP93 NUP93_HUMAN $93.49 \quad 100.0 \%$ Nuclear pore complex protein Nup93 GN=NUP93 NUP93 HUMAN $93.49 \quad 100.0 \%$ Nuclear pore complex protein Nup93 GN=NUP93 NUP93_HUMAN $93.49 \quad 100.0 \%$ Nuclear pore complex protein Nup93 GN=NUP93 NUP93_HUMAN $93.49 \quad 100.0 \%$ Nuclear pore complex protein Nup93 GN=NUP93 NUP93 HUMAN $93.49 \quad 100.0 \%$ Nuclear pore complex protein Nup93 GN=NUP93 NUP93_HUMAN $93.49 \quad 100.0 \%$ Nuclear pore complex protein Nup93 GN=NUP93 NUP93_HUMAN $93.49100 .0 \%$ Nuclear pore complex protein Nup93 GN=NUP93 NUP93_HUMAN $93.49 \quad 100.0 \%$ Nuclear pore membrane glycoprotein $210 \mathrm{GN}=\mathrm{NUP} 210$ PO210_HUMAN $205.11 \quad 100.0 \%$ Nuclear pore membrane glycoprotein $210 \mathrm{GN}=\mathrm{NUP} 210 \mathrm{PO} 210$ HUMAN $205.11 \quad 100.0 \%$ Nuclear pore membrane glycoprotein $210 \mathrm{GN}=\mathrm{NUP} 210 \quad$ PO210_HUMAN $205.11 \quad 100.0 \%$ Nuclear receptor coactivator 5 GN=NCOA5 NCOA5_HUMAN $65.54 \quad 100.0 \%$ Nuclear receptor coactivator $5 \mathrm{GN}=\mathrm{NCOA} 5$ NCOA5_HUMAN $65.54 \quad 100.0 \%$ Nuclear receptor coactivator 5 GN=NCOA5 NCOA5_HUMAN $65.54 \quad 100.0 \%$
$0.06 \% \quad 12.0 \%$ EVSDLIKECR

$0.06 \% \quad 12.0 \%$ QYIATIHSR

$0.06 \% \quad 12.0 \%$ LPGLQATVR

$0.06 \% \quad 12.0 \%$ DLPSADSVQYR

$0.06 \% \quad 12.0 \%$ KADNVVNIAR

$0.06 \% \quad 12.0 \%$ ADNVVNIAR

$0.06 \% \quad 12.0 \%$ YLYHGNTNPELA

$0.06 \% \quad 12.0 \%$ LVGDFTHDQSISQK

$0.06 \% \quad 12.0 \%$ SVSGFLHFDTATK

$0.06 \% \quad 12.0 \%$ DILQDVHDK

$0.06 \% \quad 12.0 \%$ LTAPEDVFSK

$0.06 \% 12.0 \%$ DACDGHEIGR

$0.06 \% \quad 12.0 \%$ ALYTYESK

$0.06 \% 12.0 \%$ IQQGALELLR

$0.06 \% \quad 12.0 \%$ QCLGLLSR

$0.06 \% \quad 12.0 \%$ FGGSDRLR

$0.06 \% 12.0 \%$ FQDDNVEGDKVSK

$0.06 \% \quad 12.0 \%$ KLLDIEGLYSK

$0.06 \% 12.0 \%$ LLDIEGLYSK

$0.06 \% \quad 12.0 \%$ YSFIQALVR

$0.01 \% \quad 2.4 \%$ SHLVHGSSPGVMGTSVATSASK

$0.01 \% \quad 2.4 \%$ TPHPVLTPVAANQAK

$0.01 \% \quad 2.4 \%$ ASSTSLTSTQPTK

$0.01 \% \quad 7.9 \% \quad$ DVDVYSQILR

$0.01 \% \quad 7.9 \%$ EADASPASAGICR

$0.01 \% \quad 7.9 \%$ IPLNTEQK

$0.01 \% \quad 7.9 \%$ LGSALSWSIR

$0.01 \% \quad 7.9 \%$ AIIREGSLEGS

$0.02 \% \quad 12.7 \%$ NLQEIQQAGER

$0.02 \% \quad 12.7 \%$ NLQEIQQAGERLR

$0.02 \% \quad 12.7 \%$ TSQETADVKASVLLGSR

$0.02 \% \quad 12.7 \%$ SSLDNIEMAYAR

$0.02 \% \quad 12.7 \%$ CGDLLAASQVVNR

$0.02 \% \quad 12.7 \%$ LSPATENKLR

$0.02 \% \quad 12.7 \%$ AVYCIIGR

$0.02 \% \quad 12.7 \%$ FTSDTKPIINK

$0.02 \% \quad 12.7 \%$ LKNMALSIAER

$0.02 \% \quad 12.7 \%$ LVQMEVLMN

$0.00 \% \quad 1.9 \%$ GVAIGQTSLTASVTNK

$0.00 \% \quad 1.9 \%$ VIVAVGDR

$0.00 \% \quad 1.9 \%$ SGSPAVLAFAK

$0.01 \% \quad 8.3 \%$ QYFEEIQR

$0.01 \% \quad 8.3 \%$ GGSPFAIVITQQHQIHR

$0.01 \% \quad 8.3 \%$ NMPQADAMVLVAR
$99.7 \% \quad 72.5$ $99.7 \% \quad 45.3$

$99.4 \% \quad 22.6$

$99.7 \% \quad 45.2$

$99.7 \% \quad 47.4$

$99.7 \% \quad 51.6$

$99.7 \% \quad 47.5$

$99.7 \% \quad 45.4$

$99.3 \% \quad 20.4$

$99.7 \% \quad 38.0$

$96.3 \% \quad 17.9$

$99.7 \% \quad 43.5$

$96.8 \% \quad 17.9$

$99.7 \% \quad 41.9$

$99.7 \% \quad 43.6$

$99.0 \% \quad 30.6$

$99.7 \% \quad 62.2$

$99.0 \% \quad 24.9$

$99.0 \% \quad 31.0$

$98.2 \% \quad 19.6$

$99.7 \% \quad 31.0$

$\begin{array}{lll}99.7 \% & 55.7\end{array}$

$99.7 \% \quad 47.6$

$99.2 \% \quad 20.4$

$94.8 \% \quad 18.5$

$99.7 \% \quad 29.2$

$\begin{array}{lll}99.7 \% & 57.7\end{array}$

$99.7 \% \quad 49.4$

$95.0 \% \quad 20.4$

$99.7 \% \quad 73.9$

$99.7 \% \quad 45.8$

$99.7 \% \quad 52.4$

$\begin{array}{lll}95.8 \% & 20.2\end{array}$

$\begin{array}{ll}99.7 \% & 56.4\end{array}$

$99.7 \% \quad 62.8$

$99.7 \% \quad 54.6$

$99.7 \% \quad 48.7$

$99.0 \% \quad 31.0$

$99.6 \% \quad 30.1$

$99.7 \% \quad 30.7$

$99.3 \% \quad 20.9$

$99.7 \% \quad 65.9$

$94.7 \% \quad 17.6$

$99.7 \% \quad 32.5$

$99.0 \% \quad 34.4$

$96.2 \% \quad 17.3$

$99.7 \% \quad 45.1$ \begin{tabular}{ll}
71.1 \\
\hline
\end{tabular} 45.3

02.6
25.0

35.3

$\begin{array}{ll}0 & 46.8\end{array}$

46.8
47.2

$\begin{array}{ll}0 & 27.9\end{array}$

$\begin{array}{ll}25.0 & 20.4\end{array}$

$\begin{array}{ll}25.0 & 38.0\end{array}$

$\begin{array}{ll}2.0 & 13.7\end{array}$

$\begin{array}{ll}.0 & 43.5\end{array}$

$\begin{array}{ll} & 17.9\end{array}$

$\begin{array}{ll}0 & 37.3\end{array}$

$\begin{array}{ll}25.0 & 43.6\end{array}$

20.8
25.0

$\begin{array}{ll}.0 & 57.8\end{array}$

\begin{tabular}{ll}
5.0 & 16.4 \\
\hline
\end{tabular}

\begin{tabular}{ll}
5.0 & 15.4 \\
\hline
\end{tabular}

$\begin{array}{ll}0 & 15.4 \\ 0 & 19.5\end{array}$

$\begin{array}{ll}25.0 & 30.6\end{array}$

$\begin{array}{ll}.0 & 48.4\end{array}$

48.4
47.2

$\begin{array}{ll}20.4 \\ 25.0 & 15.3\end{array}$

$\begin{array}{ll}.0 & 20.4 \\ 0 & 15.3\end{array}$

20.1

$5.0 \quad 49.6$

$\begin{array}{cc}25.0 & 49.0 \\ 25.0 & 55.6\end{array}$

$\begin{array}{cc}.0 & 8.6 \\ .0 & 55.4 \\ .0 & 45.8\end{array}$

$\begin{array}{ll}26.0 & 45.8 \\ 25.0 & 10.7\end{array}$

$\begin{array}{ll}.0 & 26.9 \\ .0 & 10.7\end{array}$

$\begin{array}{ll}.0 & 10.7\end{array}$

$\begin{array}{ll}5.0 & 54.4\end{array}$

\begin{tabular}{ll}
02.8 \\
\hline
\end{tabular}

$\begin{array}{ll}25.0 & 35.6 \\ 25.0 & 18.9\end{array}$

$\begin{array}{ll}25.0 & 18.9 \\ 25.0 & 25.7\end{array}$

$\begin{array}{ll}5.0 & 30.7 \\ 25.0 & 20.9\end{array}$

$\begin{array}{ll}20.0 & 20.9 \\ 25.0 & 58.2\end{array}$

$\begin{array}{ll}55.0 & 11.8\end{array}$

$\begin{array}{ll}5.0 & 30.8\end{array}$

$\begin{array}{lll}25.0 & 30.8 & 2 \\ 25.0 & 26.4 & 2 \\ 25.0 & 17.3 & 0\end{array}$

0
0
0
0
0
0
0
0
0
1
0
0
1
0
0
0
0
0
0
0
0
0
0
0
2
0
0
0
0
0
0
0
0
1
0
0
1
0
0
0
0
0
0
0
0
0
0
0
0
0
0
0
0
0
0
0
0
0
0
0
0
0
0
0
0
0
0
0

1248.63

1088.58

954.57

1250.60

1099.62

971.53

1953.93

1722.83

1574.78

1409.71

1082.55

1106.57

1129.47

974.48

1140.67

946.51 
Nucleolar GTP-binding protein $1 \mathrm{GN}=$ GTPBP4 NOG1_HUMAN $73.97 \quad 100.0 \%$ Nucleolar GTP-binding protein $1 \mathrm{GN}=$ GTPBP4 NOG1_HUMAN $73.97 \quad 100.0 \%$ Nucleolar GTP-binding protein $1 \mathrm{GN}=$ GTPBP4 NOG1_HUMAN $73.97 \quad 100.0 \%$ Nucleolar GTP-binding protein 1 GN=GTPBP4 NOG1_HUMAN $73.97 \quad 100.0 \%$ Nucleolar GTP-binding protein 2 GN=GNL2 NOG2_HUMAN $83.66 \quad 100.0 \%$ Nucleolar GTP-binding protein 2 GN=GNL2 NOG2 HUMAN $83.66100 .0 \%$ Nucleolar pre-ribosomal-associated protein 1 GN=URB1 NPA1P_HUMAN $254.39100 .0 \%$ Nucleolar pre-ribosomal-associated protein $1 \mathrm{GN}=$ URB1 NPA1P_HUMAN $254.39100 .0 \%$ Nucleolar pre-ribosomal-associated protein 1 GN=URB1 NPA1P_HUMAN $254.39100 .0 \%$ Nucleolar pre-ribosomal-associated protein 1 GN=URB1 NPA1P_HUMAN $254.39100 .0 \%$ Nucleolar pre-ribosomal-associated protein $1 \mathrm{GN}=$ URB1 NPA1P HUMAN $254.39 \quad 100.0^{\circ}$ Nucleolar pre-ribosomal-associated protein 1 GN=URB1 NPA1P_HUMAN $254.39 \quad 100.0 \%$ Nucleolar protein $56 \mathrm{GN}=\mathrm{NOP} 56$ Nucleolar protein $56 \mathrm{GN}=\mathrm{NOP} 56$ Nucleolar protein $56 \mathrm{GN}=\mathrm{NOP} 56$ Nucleolar protein $56 \mathrm{GN}=\mathrm{NOP} 56$ Nucleolar protein $56 \mathrm{GN}=\mathrm{NOP} 56$ Nucleolar protein $56 \mathrm{GN}=\mathrm{NOP} 56$ Nucleolar protein $58 \mathrm{GN}=\mathrm{NOP} 58$ Nucleolar protein $58 \mathrm{GN}=\mathrm{NOP} 58$ NOP56_HUMAN $66.05 \quad 100.0 \%$ NOP56_HUMAN $66.05 \quad 100.0 \%$ NOP56_HUMAN $66.05 \quad 100.0 \%$ NOP56 HUMAN $66.05 \quad 100.0 \%$ NOP56 HUMAN $66.05 \quad 100.0 \%$ NOP56_HUMAN $66.05 \quad 100.0 \%$ NOP58 HUMAN $59.58 \quad 100.0 \%$ NOP58_HUMAN $59.58 \quad 100.0 \%$

$0.01 \% \quad 8.3 \%$ MADEAILQER $0.00 \% \quad 5.3 \% \quad$ AQFFVEDASTASALK

$0.00 \% \quad 5.3 \%$ SCMAATLR

$0.00 \% \quad 5.3 \% \quad$ ILNLSGNELK

$0.03 \% \quad 43.5 \%$ NGYGFINR

$0.03 \% \quad 43.5 \%$ NDTKEDVFVHQTAIK

$0.03 \% \quad 43.5 \%$

$0.03 \% \quad 43.5 \%$ GAEAANVTGPGGVPVQGSK

$0.03 \% \quad 43.5 \%$ YAADRNHYR

$0.03 \% \quad 43.5 \%$ NYQQNYQNSESGEK

$0.03 \% \quad 43.5 \%$ NYQQNYQNSESGEKNEGSESAPEGQAQQ

$0.03 \% \quad 43.5 \%$ NEGSESAPEGQAQQR

$0.03 \% \quad 43.5 \%$ RPQYSNPPVQGEVMEGADNQGAGEQGRPV

$0.03 \% \quad 43.5 \%$ RPENPKPQDGKETK

$0.01 \% \quad 6.4 \%$ EAARSPDKPGGSPSASR

$0.01 \% \quad 6.4 \%$ SPDKPGGSPSASR

$0.01 \% \quad 6.4 \%$ NSVPVTVAMVER

$0.01 \% \quad 6.4 \%$ LFHEVVQAFR

$0.01 \% \quad 6.4 \% \quad$ LSNVNLQEK

$0.01 \% \quad 2.9 \%$ DLSSSEPVHAK

$0.01 \% \quad 2.9 \% \quad$ IRPLTEAEK

$0.01 \% \quad 2.9 \%$ IRPLTEAEKSTK

$0.01 \% \quad 5.6 \%$ RLEAVLASR

$0.01 \% \quad 5.6 \%$ ELALSALLK

$0.01 \% \quad 5.6 \%$ REPTVSSFYVK

$10 \quad 0.01 \% \quad 10.6 \%$ NLVDNVAKDYVR

$10 \quad 0.01 \% \quad 10.6 \%$ TLLLCGYPNVGK

$10 \quad 0.01 \% \quad 10.6 \%$ ADVDVQPYAFTTK

$10 \quad 0.01 \% \quad 10.6 \%$ LLAHRVETK

$10 \quad 0.01 \% \quad 10.6 \%$ REDSAPPSSVAR

$10 \quad 0.01 \% \quad 10.6 \%$ DVSGLRDVK

$0.00 \% \quad 3.6 \%$ IIKPLQYQSTVASGTVAR

$0.00 \% \quad 3.6 \%$ GAFIQLLR

$3 \quad 0.01 \% \quad 2.9 \% \quad$ LICESLYASGYR

$13 \quad 0.01 \% \quad 2.9 \% \quad$ IYEAQPEISR

$0.01 \% \quad 2.9 \%$ STVENFGQLGR

$0.01 \% \quad 2.9 \% \quad$ YSEAITQSVLK

$3 \quad 0.01 \% \quad 2.9 \% \quad$ LCQPSSQEPAKR

$0.01 \% \quad 2.9 \%$ SVAEHPLSR

$19 \quad 0.02 \% \quad 11.3 \%$ AQLGLGHSYSR

$19 \quad 0.02 \% \quad 11.3 \%$ IINDNATYCR

$19 \quad 0.02 \% \quad 11.3 \%$ VVSLSEYR

$19 \quad 0.02 \% \quad 11.3 \%$ LIAHAGSLTNLAK

$19 \quad 0.02 \% \quad 11.3 \%$ YPASTVQILGAEK

$19 \quad 0.02 \% \quad 11.3 \%$ YGLIFHSTFIGR

$40.04 \% \quad 31.2 \%$ IVKEAHEPLAVADAK $0.04 \% \quad 31.2 \%$ EAHEPLAVADAK
$99.7 \% \quad 54.3$

$99.7 \% \quad 88.7$

$98.0 \% \quad 18.7$

$96.2 \% \quad 21.1$

$99.0 \% \quad 37.7$

$99.7 \% \quad 37.0$

$99.7 \% \quad 52.4$

$99.7 \% \quad 38.7$

$99.7 \% \quad 57.7$

$99.7 \% \quad 47.6$

$99.7 \% \quad 54.0$

$99.7 \% \quad 42.2$

$\begin{array}{lll}99.7 \% & 36.3\end{array}$

$99.7 \% \quad 31.0$

$99.7 \% \quad 33.4$

$99.7 \% \quad 34.5$

$99.7 \% \quad 34.9$

$99.7 \% \quad 44.2$

$99.7 \% \quad 56.4$

$99.7 \% \quad 27.3$

$\begin{array}{lll}99.7 \% & 26.4\end{array}$

$99.7 \% \quad 31.9$

$99.7 \% \quad 41.7$

$96.6 \% \quad 19.8$

$99.7 \% \quad 53.4$

$99.7 \% \quad 61.9$

$99.7 \% \quad 61.6$

$99.1 \% \quad 19.5$

$98.8 \% 26.7$

$98.1 \% \quad 27.5$

$99.7 \% \quad 35.7$

$98.4 \% \quad 41.2$

$99.7 \% \quad 29.9$

$\begin{array}{lll}99.7 \% & 38.3\end{array}$

$99.7 \% \quad 62.8$

$99.7 \% \quad 39.4$

$99.7 \% \quad 29.4$

$98.0 \% \quad 22.7$

$99.7 \% \quad 43.1$

$99.7 \% \quad 55.9$

$99.0 \% \quad 41.0$

$\begin{array}{lll}99.7 \% & 46.5\end{array}$

$99.7 \% \quad 47.7$

$99.7 \% \quad 28.7$

$99.5 \% \quad 26.2$

$95.9 \% \quad 22.2$
1584.79

909.43

1100.63

940.46

1744.89

3472.67

1695.87

1165.55

1688.71

3257.40

1587.70

3239.53

1623.85

1669.83

1242.61

1301.69

1245.67

1044.57

1169.58

1056.60

1372.78

1014.61

957.60

1312.69

1405.74

1334.71

1454.72

1066.64

1271.63

988.54

1932.09

917.56

1431.69

1205.62

1207.61

1238.66

1400.70

995.53

1188.61

1239.58

952.51

1308.76

1376.74

1410.75

1590.89

1250.64

$\begin{array}{cc}16 & 325 \\ 59 & 173 \\ 51 & 258 \\ 95 & 304 \\ 0 & 77 \\ 8 & 92 \\ 02 & 137 \\ 19 & 137 \\ 38 & 146 \\ 57 & 170 \\ 57 & 185 \\ 71 & 185 \\ 05 & 234 \\ 91 & 304 \\ 5 & 61 \\ 9 & 61 \\ 45 & 156 \\ 69 & 178 \\ 08 & 516 \\ 13 & 123 \\ 75 & 283 \\ 75 & 286 \\ 7 & 25 \\ 16 & 124 \\ 22 & 232 \\ 04 & 115 \\ 70 & 181 \\ 91 & 203 \\ 39 & 347 \\ 55 & 566 \\ 76 & 584 \\ 6 & 73 \\ 92 & 299 \\ 34 & 145 \\ 00 & 409 \\ 37 & 947 \\ 75 & 1085 \\ 99 & 1910 \\ 07 & 2115 \\ 44 & 154 \\ 03 & 212 \\ 71 & 278 \\ 08 & 320 \\ 21 & 333 \\ 48 & 359 \\ & 93\end{array}$

Page 104 of Table S-1- 
Nucleolar protein $58 \mathrm{GN}=\mathrm{NOP} 58$ Nucleolar protein $58 \mathrm{GN}=\mathrm{NOP} 58$ Nucleolar protein $58 \mathrm{GN}=\mathrm{NOP} 58$ Nucleolar protein $58 \mathrm{GN}=\mathrm{NOP} 58$ Nucleolar protein $58 \mathrm{GN}=\mathrm{NOP} 58$ Nucleolar protein $58 \mathrm{GN}=\mathrm{NOP} 58$ Nucleolar protein $58 \mathrm{GN}=\mathrm{NOP} 58$ Nucleolar protein $58 \mathrm{GN}=\mathrm{NOP} 58$ Nucleolar protein $58 \mathrm{GN}=\mathrm{NOP} 58$ Nucleolar protein $58 \mathrm{GN}=\mathrm{NOP} 58$ Nucleolar protein $58 \mathrm{GN}=\mathrm{NOP} 58$ Nucleolar protein $7 \mathrm{GN}=\mathrm{NOL} 7$ Nucleolar protein $7 \mathrm{GN}=\mathrm{NOL} 7$ Nucleolar protein $7 \mathrm{GN}=\mathrm{NOL} 7$

Nucleolar protein $7 \mathrm{GN}=\mathrm{NOL} 7$

Nucleolar RNA helicase 2 GN=DDX2 Nucleolar RNA helicase 2 GN=DDX2 Nucleolar RNA helicase 2 GN=DDX2 1 Nucleolar RNA helicase $2 \mathrm{GN}=\mathrm{DDX} 2$ Nucleolar RNA helicase 2 GN=DDX2 Nucleolar RNA helicase 2 GN=DDX21 Nucleolar RNA helicase $2 \mathrm{GN}=\mathrm{DDX} 2$ Nucleolar RNA helicase 2 GN=DDX2 1 Nucleolar RNA helicase 2 GN=DDX2 Nucleolar RNA helicase 2 GN=DDX2 Nucleolar RNA helicase 2 GN=DDX2 Nucleolar RNA helicase $2 \mathrm{GN}=\mathrm{DDX} 2$ Nucleolar RNA helicase $2 \mathrm{GN}=\mathrm{DDX} 2$ Nucleolar RNA helicase 2 GN=DDX2 1 Nucleolar RNA helicase 2 GN=DDX21 Nucleolin GN=NCL Nucleolin $\mathrm{GN}=\mathrm{NCL}$

Nucleolin GN=NCL

Nucleolin GN=NCL

Nucleolin $\mathrm{GN}=\mathrm{NCL}$

Nucleolin $\mathrm{GN}=\mathrm{NCL}$

Nucleolin $\mathrm{GN}=\mathrm{NCL}$

Nucleolin $\mathrm{GN}=\mathrm{NCL}$

Nucleolin GN=NCL

Nucleolin $\mathrm{GN}=\mathrm{NCL}$

Nucleolin $\mathrm{GN}=\mathrm{NCL}$

Nucleolin GN=NCL

Nucleolin $\mathrm{GN}=\mathrm{NCL}$

Nucleolin GN=NCL

Nucleolin $\mathrm{GN}=\mathrm{NCL}$

Nucleophosmin GN=NPM

Nucleophosmin GN=NPM1 \begin{tabular}{lllllll} 
NOP58_HUMAN 59.58 & $100.0 \%$ & 13 & 18 & 34 & $0.04 \%$ & $31.2 \%$ \\
\hline
\end{tabular}

$0.04 \% 31.2 \%$ SQMDGLIPGVEPR

NOP58_HUMAN $59.58 \quad 100.0 \% \quad 13$

NOP58_HUMAN $59.58 \quad 100.0 \% \quad 13$

NOP58 HUMAN $59.58 \quad 100.0 \% \quad 13$

NOP58_HUMAN $59.58 \quad 100.0 \% \quad 13$

NOP58_HUMAN $59.58 \quad 100.0 \% \quad 13$

NOP58 HUMAN $59.58 \quad 100.0 \% \quad 13$

NOP58_HUMAN $59.58 \quad 100.0 \% \quad 13$

NOP58 HUMAN $59.58 \quad 100.0 \% \quad 13$

NOP58_HUMAN $59.58 \quad 100.0 \% \quad 13$

NOP58_HUMAN $59.58 \quad 100.0 \% \quad 13$

NOL7 HUMAN $29.43 \quad 100.0 \% \quad 4$

NOL7_HUMAN $29.43 \quad 100.0 \% \quad 4$

NOL7 HUMAN $29.43 \quad 100.0 \% \quad 4$

NOL7 HUMAN $29.43 \quad 100.0 \%$

DDX21_HUMAN $87.35 \quad 100.0 \% \quad 15$

DDX21_HUMAN $87.35 \quad 100.0 \% \quad 15$

DDX21_HUMAN $87.35 \quad 100.0 \% \quad 15$

DDX21_HUMAN $87.35 \quad 100.0 \% \quad 15$

DDX21 HUMAN $87.35 \quad 100.0 \% \quad 15$

DDX21_HUMAN $87.35 \quad 100.0 \% \quad 15$

DDX21 HUMAN $87.35 \quad 100.0 \% \quad 15$

DDX21_HUMAN $87.35 \quad 100.0 \% \quad 15$

DDX21_HUMAN $87.35 \quad 100.0 \% \quad 15$

DDX21 HUMAN $87.35 \quad 100.0 \% \quad 15$

DDX21_HUMAN $87.35 \quad 100.0 \% \quad 15$

DDX21_HUMAN $87.35 \quad 100.0 \% \quad 15$

DDX21 HUMAN $87.35 \quad 100.0 \% \quad 15$

DDX21_HUMAN $87.35 \quad 100.0 \% \quad 15$

DDX21 HUMAN $87.35 \quad 100.0 \% \quad 15$

NUCL_HUMAN $76.62 \quad 100.0 \% \quad 15$

NUCL_HUMAN $76.62 \quad 100.0 \% \quad 15$

NUCL HUMAN $76.62 \quad 100.0 \% \quad 15$

NUCL_HUMAN $76.62 \quad 100.0 \% \quad 15$

NUCL_HUMAN $76.62 \quad 100.0 \% \quad 15$

NUCL HUMAN $76.62 \quad 100.0 \% \quad 15$

NUCL_HUMAN $76.62 \quad 100.0 \% \quad 15$

NUCL HUMAN $76.62 \quad 100.0 \% \quad 15$

NUCL_HUMAN $76.62 \quad 100.0 \% \quad 15$

NUCL_HUMAN $76.62 \quad 100.0 \% \quad 15$

NUCL HUMAN $76.62 \quad 100.0 \% \quad 15$

NUCL_HUMAN $76.62 \quad 100.0 \% \quad 15$

NUCL_HUMAN $76.62 \quad 100.0 \% \quad 15$

NUCL_HUMAN $76.62 \quad 100.0 \% \quad 15$

NUCL_HUMAN $76.62 \quad 100.0 \% \quad 15$

NPM HUMAN $32.58 \quad 100.0 \% \quad 7$

NPM_HUMAN $32.58 \quad 100.0 \% \quad 7$

$0.04 \% \quad 31.2 \%$ IISDNLTYCK

$0.04 \% \quad 31.2 \%$ TQLYEYLQNR

$0.04 \% \quad 31.2 \%$ LIAHAGSLLNLAK

$0.04 \% \quad 31.2 \%$ HAASTVQILGAEK

$0.01 \% \quad 21.0 \%$ KLLPDTILEK

$0.01 \% \quad 21.0 \%$ LTTASQTNIKK

$100 \quad 0.11 \% \quad 22.1 \%$ VAVATPAKK

$100 \quad 0.11 \% \quad 22.1 \%$ ALVATPGKK

$0.11 \% \quad 22.1 \%$ TGISDVFAK

$100 \quad 0.11 \% \quad 22.1 \%$ NDLAVVDVR

$100 \quad 0.11 \% \quad 22.1 \%$ ALELTGLK

$100 \quad 0.11 \% \quad 22.1 \%$ ATFIKVPQNQNGK

$100 \quad 0.11 \% \quad 22.1 \%$ SQPSKTLFVK
$0.04 \% \quad 31.2 \%$ LSELLPEEVEAEVK

$99.7 \% 56.9$

$99.7 \% \quad 49.4$

$0.04 \% \quad 31.2 \%$ YGLIYHASLVGQTSPK

$\begin{array}{llll}99.7 \% & 56.2 & 25.0 & 51.7\end{array}$

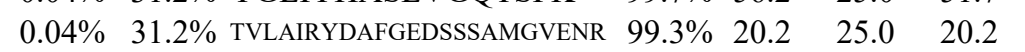

$34 \quad 0.04 \% \quad 31.2 \%$ TYDPSGDSTLPTCSK

$99.7 \% \quad 58.2$

$97.7 \% \quad 26.6$

$99.5 \% \quad 28.7$

$99.7 \% \quad 33.0$

$0.01 \% \quad 21.0 \%$ QQAAQAFIHNSLYGPGINR

$99.7 \% \quad 46.6$

$0.05 \% \quad 19.3 \%$ KAEPSEVDMNSPK

$99.7 \% \quad 49.5$

$0.05 \% \quad 19.3 \%$ VTKNEEPSEEEIDAPKPK $95.6 \% \quad 18.5$

$99.4 \% \quad 24.0$

$99.7 \% \quad 59.2$

$99.7 \% \quad 38.6$

$95.1 \% \quad 13.7$

$99.7 \% \quad 59.7$

$99.7 \% 36.6$

$99.7 \% \quad 47.2$

$99.7 \% \quad 46.0$

$99.7 \% \quad 29.0$

$99.7 \% \quad 74.5$

$99.7 \% \quad 27.5$

$95.5 \% \quad 23.2$

$99.0 \% \quad 24.5$

$99.7 \% \quad 27.7$

$99.7 \% \quad 27.7$

$99.7 \% \quad 47.0$

$100 \quad 0.11 \% \quad 22.1 \%$ SAPELKTGISDVFAK

$98.9 \% \quad 18.9$

$99.7 \% \quad 46.8$

$100 \quad 0.11 \% \quad 22.1 \%$ TGISDVFAKNDLAVVDVR $\quad 99.7 \% \quad 41.7$

$99.7 \% \quad 59.0$

$99.0 \% \quad 24.6$

$99.7 \% \quad 45.0$

$99.7 \% \quad 37.5$

$99.7 \% \quad 49.8$

$99.7 \% \quad 29.7$

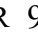

$\begin{array}{ll}99.7 \% & 31.9 \\ 99.7 \% & 40.1\end{array}$

$99.7 \% \quad 49.8$

$100 \quad 0.11 \% \quad 22.1 \%$ GFGFVDFNSEEDAK

$45 \quad 0.05 \% \quad 28.6 \%$ DELHIVEAEAMNYEGSPIK $99.7 \% \quad 36.7$
1584.84

1327.66

1320.80

1320.80
1324.72

121

$222 \quad 235$

278
310

$2504.17 \quad 366 \quad 388$

427441

$112 \quad 121$

$1204.69 \quad 122 \quad 132$

$2073.03 \quad 187 \quad 205$

$\begin{array}{lll}1559.83 & 224 & 237\end{array}$

1447.67

2040.01

1842.96

1377.83

1164.71

1514.81

1211.67

1252.64

1380.74

913.55

1317.66

1475.80

1127.67

1126.54

871.43

884.56

884.56

2568.3

1562.84

937.50

1919.02

1000.54

844.51

1160.58

2021.96

1444.79

1152.68

1134.65

2200.03

1561.68

1568.73

2161.01 
Nucleophosmin GN=NPM1 Nucleophosmin GN=NPM1 Nucleophosmin GN=NPM1 Nucleophosmin GN=NPM1 Nucleophosmin GN=NPM1 Nucleoporin NDC1 GN=NDC1

Nucleoporin $\mathrm{NDC} 1 \mathrm{GN}=\mathrm{NDC} 1$ Nucleoporin NDC1 GN=NDC1 Nucleoporin NDC1 GN=NDC1

Nucleoporin NUP188 homolog GN ucleoporin NUP188 homolog GN=NUP188 NU188_HUMAN $196.05 \quad 100.0 \%$ Nucleoporin NUP188 homolog GN=NUP188 NU188_HUMAN $196.05 \quad 100.0 \%$ Nucleoporin NUP188 homolog GN=NUP188 NU188_HUMAN $196.05 \quad 100.0 \%$ Nucleoporin NUP188 homolog GN=NUP188 NU188_HUMAN $196.05100 .0 \%$ Nucleoporin NUP188 homolog GN=NUP188 NU188_HUMAN $196.05 \quad 100.0 \%$ Nucleoporin NUP188 homolog GN=NUP188 NU188_HUMAN $196.05 \quad 100.0 \%$ Nucleoporin NUP188 homolog GN=NUP188 NU188 HUMAN $196.05100 .0 \%$ Nucleoporin NUP188 homolog GN=NUP188 NU188_HUMAN $196.05 \quad 100.0 \%$ Nucleoporin NUP188 homolog GN=NUP188 NU188_HUMAN $196.05 \quad 100.0 \%$ Nucleoporin-like protein 2 GN=NUPL 2 NUPL2 HUMAN $44.87-100.0^{\circ}$ Nucleoporin-like protein 2 GN=NUPL2 Nucleoporin-like protein $2 \mathrm{GN}=\mathrm{NUPL} 2$ Nucleoprotein TPR GN=TPR Nucleoprotein TPR GN=TPR Nucleosome assembly protein 1-like $1 \mathrm{GN}=\mathrm{NAP} 1 \mathrm{~L} 1$ NP1L1_HUMAN $45.38 \quad 100.0 \%$ Nucleosome assembly protein 1-like $1 \mathrm{GN}=$ NAP1L1 NP1L1_HUMAN $45.38 \quad 100.0 \%$ Nucleosome assembly protein 1-like 1 GN=NAP1L1 NP1L1_HUMAN $45.38 \quad 100.0 \%$ Origin recognition complex subunit $5 \mathrm{GN}=\mathrm{ORC} 5$ ORC5 HUMAN $50.29100 .0 \%$ Origin recognition complex subunit $5 \mathrm{GN}=\mathrm{ORC} 5$ ORC5_HUMAN $50.29 \quad 100.0 \%$ Ornithine aminotransferase, mitochondrial GN=OAT OAT_HUMAN $48.54 \quad 100.0 \%$ Ornithine aminotransferase, mitochondrial $\mathrm{GN}=\mathrm{OAT}$ OAT HUMAN $48.54 \quad 100.0 \%$ Ornithine aminotransferase, mitochondrial GN=OAT OAT_HUMAN $48.54 \quad 100.0 \%$ Ornithine aminotransferase, mitochondrial GN=OAT OAT_HUMAN $48.54 \quad 100.0 \%$ Ornithine aminotransferase, mitochondrial GN=OAT OAT_HUMAN $48.54 \quad 100.0 \%$ Ornithine aminotransferase, mitochondrial GN=OAT OAT_HUMAN $48.54 \quad 100.0 \%$ Ornithine aminotransferase, mitochondrial GN=OAT OAT HUMAN $48.54 \quad 100.0 \%$ Ornithine aminotransferase, mitochondrial GN=OAT OAT_HUMAN $48.54 \quad 100.0 \%$ Ornithine aminotransferase, mitochondrial GN=OAT OAT_HUMAN $48.54 \quad 100.0 \%$ Ornithine aminotransferase, mitochondrial GN=OAT OAT_HUMAN $48.54 \quad 100.0 \%$ Ornithine aminotransferase, mitochondrial GN=OAT OAT_HUMAN $48.54 \quad 100.0 \%$ Ornithine aminotransferase, mitochondrial GN=OAT OAT_HUMAN $48.54 \quad 100.0 \%$ Ornithine aminotransferase, mitochondrial GN=OAT OAT_HUMAN $48.54 \quad 100.0 \%$ Ornithine aminotransferase, mitochondrial GN=OAT OAT_HUMAN $48.54 \quad 100.0 \%$ Ornithine aminotransferase, mitochondrial GN=OAT OAT HUMAN $48.54 \quad 100.0 \%$ Ornithine aminotransferase, mitochondrial GN=OAT OAT_HUMAN $48.54 \quad 100.0 \%$
$0.05 \% \quad 28.6 \%$ MSVQPTVSLGGFEITPPVVLR $99.7 \% 52.8$ $99.0 \% \quad 52.2$ $99.7 \% \quad 48.6$ $99.7 \% \quad 59.4$ $99.7 \% \quad 60.5$ $\begin{array}{llll}99.5 \% & 23.8\end{array}$ $99.7 \% \quad 66.6$ $\begin{array}{lll}99.7 \% & 26.9\end{array}$ $99.7 \% \quad 34.6$

$0.05 \% \quad 28.6 \%$ SAPGGGSKV

$0.05 \% \quad 28.6 \%$ GPSSVEDIKAK

$0.01 \% \quad 7.3 \%$ ATAVSRPCAGR

$0.01 \% \quad 7.3 \%$ LILYQEAAATNGR

$0.01 \% \quad 7.3 \% \quad$ KLNSPEETAFQTPK

$0.01 \% \quad 7.3 \%$ ISGSLVDTSYK

$99.0 \% \quad 22.3$

$0.02 \% \quad 7.4 \% \quad$ LLEGLSYYKPPSPSSAEK

$0.02 \% \quad 7.4 \%$ HTLNPEETSSVVR

$95.4 \% \quad 20.9$

$99.5 \% \quad 25.1$

$99.7 \% \quad 47.8$

$99.0 \% 37.8$

$99.7 \% \quad 27.8$

$99.7 \% \quad 45.0$

$99.7 \% \quad 39.0$

$99.6 \% 25.5$

$99.7 \% \quad 34.8$

$0.02 \% \quad 7.4 \%$ GAPSSPATGVLPSPQGK

$0.01 \% \quad 9.9 \%$ AICQFFLQGR

$0.01 \% \quad 9.9 \%$ DQEKPYFSSFDSGASTNRK

$0.01 \% \quad 9.9 \%$ IPLKPPPLELLNV

$0.00 \% \quad 0.8 \%$ REITSLHER

$0.00 \% \quad 0.8 \%$ SLESQVENLQK

$0.00 \% \quad 5.6 \%$ AGEIIEIINK

$0.00 \% \quad 5.6 \%$ LLGPANSGVAR

$0.01 \% \quad 11.5 \%$ LDGLVETPTGYIESLPR

$99.7 \% \quad 26.4$

$99.7 \% \quad 28.3$

$96.0 \% 24.4$

$96.0 \% \quad 26.0$

$99.7 \% 35.6$

$99.7 \% \quad 43.9$

$99.7 \% \quad 43.3$

$99.7 \% \quad 40.5$

$0.01 \% \quad 11.5 \%$ FYEEVHDLER

$99.7 \% 26.8$

$99.5 \% \quad 24.2$

$0.00 \% \quad 3.9 \% \quad$ TYVTQTLLK

$0.00 \% \quad 3.9 \%$ NIEPHLKK

$95.9 \% \quad 20.5$

$99.7 \% \quad 45.8$

$40 \quad 0.05 \% \quad 39.2 \%$ TVQGPPTSDDIFER

$94.5 \% \quad 22.5$

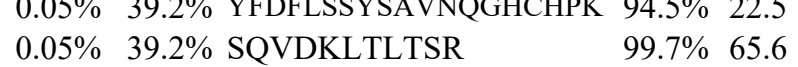

$0.05 \% \quad 39.2 \%$ AFYNNVLGEYEEYITK

$99.7 \% \quad 53.3$

$99.7 \% \quad 38.3$

$99.7 \% \quad 53.8$

$40 \quad 0.05 \% \quad 39.2 \%$ IVFAAGNFWGR

$\begin{array}{lllll}0.05 \% & 39.2 \% & \text { ELCTRHQVLFIADEIQTGLAR } & 99.7 \% & 65.3 \\ 0.05 \% & 39.2 \% & \text { HQVLFIADEIQTGLAR } & 99.7 \% & 50.8\end{array}$

$40 \quad 0.05 \% \quad 39.2 \%$ WLAVDYENVRPDIVLLGK

$99.7 \% \quad 35.2$

$99.5 \% \quad 24.4$

$99.7 \% \quad 56.9$

$99.7 \% \quad 37.3$

$99.7 \% 39.0$

$99.7 \% \quad 52.7$

$0.05 \% \quad 39.2 \%$ GKGLLNAIVIK

$0.05 \% \quad 39.2 \%$ GLLNAIVIK

$40 \quad 0.05 \% \quad 39.2 \%$ GLLNAIVIKETK

$99.7 \% \quad 44.1$

$\begin{array}{lll}0.05 \% & 39.2 \% & \text { LRDNGLLAKPTHGDIIR } \\ 0.05 \% & 39.2 \% & \text { DNGLLAKPTHGDIIR }\end{array}$

$99.7 \% \quad 36.9$

\begin{tabular}{ll}
52.8 \\
\hline
\end{tabular}

58.0

$0 \quad 53.3$

$\begin{array}{ll}25.0 & 48.0\end{array}$

$\begin{array}{ll}0 & 20.4 \\ -0 & -1\end{array}$

$0 \quad 66.5$

26.9

$\begin{array}{ll}.0 & 31.8\end{array}$

22.3

$\begin{array}{ll}25.0 & 19.5\end{array}$

$\begin{array}{ll}25.0 & 21.7\end{array}$

$\begin{array}{ll}.0 & 47.8\end{array}$

$\begin{array}{ll}0 & 29.4\end{array}$

$25.0 \quad 27.4$

$45.0 \quad 45.0$

$\begin{array}{ll}25.0 & 22.7 \\ 25.0 & 55.6\end{array}$

$55.0 \quad 55.6$

$\begin{array}{ll}25.0 & 15.8\end{array}$

$\begin{array}{ll}5.0 & 26.4\end{array}$

$\begin{array}{ll}5.0 & 28.3\end{array}$

$\begin{array}{cc}7.9 \\ 25.0 & 19.2\end{array}$

020.1

$\begin{array}{ll}5.0 & 32.9\end{array}$

$\begin{array}{ll}5.0 & 43.3\end{array}$

$\begin{array}{ll}25.0 & 31.3\end{array}$

$\begin{array}{ll}5.0 & 23.2\end{array}$

$0 \quad 19.8$

$25.0 \quad 11.4$

$\begin{array}{ll}.0 & 34.0\end{array}$

$25.0 \quad 22.5$

$25.0 \quad 55.4$

$25.0 \quad 52.7$

$25.0 \quad 38.3$

$25.0 \quad 50.9$

$25.0 \quad 43.4$

$25.0 \quad 35.2$

$25.0 \quad 23.6$

$25.0 \quad 51.6$

$\begin{array}{ll}57.0 & 37.3\end{array}$

20
1130.61

1145.58

1419.76

1589.82

1169.60

1966.02

1468.74

1344.76

1233.69

954.65

1248.68

1425.82

1540.81

1223.66

1550.82

1239.63

2163.99

1442.90

1140.61

1274.66

1099.64

1054.60

1859.98

1336.62

2095.04

1066.61

978.57

1561.75

2257.01

1247.70

1952.93

1676.80

1237.65

2470.29

1810.98

2100.15

1687.90

1056.60

1125.74

940.62

1298.80

1889.07

1619.89 
OTU domain-containing protein 4 GN=OTUD4 OTUD4_HUMAN $124.04 \quad 100.0 \%$ OTU domain-containing protein 4 GN=OTUD4 OTUD4_HUMAN $124.04 \quad 100.0 \%$ Oxygen-dependent coproporphyrinogen-III oxidase, mitochondrial GN=CPOX HEM6_HUMAN $50.15 \quad 100.0 \%$ Oxygen-dependent coproporphyrinogen-III oxidase, mitochondrial GN=CPOX HEM6_HUMAN $50.15100 .0 \%$ Oxygen-dependent coproporphyrinogen-III oxidase, mitochondrial GN=CPOX HEM6_HUMAN $50.15 \quad 100.0 \%$ Oxygen-dependent coproporphyrinogen-III oxidase, mitochondrial GN=CPOX HEM6_HUMAN $50.15 \quad 100.0 \%$ dent coproporphyrinogen-III oxidase, mitochondrial GN=CPOX HEM6 HUMAN $50.15 \quad 100.0 \%$ Pachytene checkpoint protein 2 homolog GN=TRIP13 PCH2_HUMAN $48.55 \quad 100.0 \%$ Pachytene checkpoint protein 2 homolog GN=TRIP13 PCH2 HUMAN $48.55 \quad 100.0 \%$ Pachytene checkpoint protein 2 homolog GN=TRIP13 PCH2_HUMAN $48.55 \quad 100.0 \%$ Pachytene checkpoint protein 2 homolog GN=TRIP13 PCH2_HUMAN $48.55 \quad 100.0 \%$ Pachytene checkpoint protein 2 homolog GN=TRIP13 PCH2 HUMAN $48.55 \quad 100.0 \%$ Paired amphipathic helix protein Sin3a GN=SIN3A SIN3A_HUMAN $145.18 \quad 100.0 \%$ Paired amphipathic helix protein Sin3a GN=SIN3A SIN3A_HUMAN $145.18100 .0 \%$ Parafibromin $\mathrm{GN}=\mathrm{CDC} 73$ Parafibromin $\mathrm{GN}=\mathrm{CDC} 73$ CDC73 HUMAN $60.58 \quad 100.0 \%$ CDC73_HUMAN $60.58 \quad 100.0 \%$ 作 2 GN=PCID2 PCID2 HUMAN $46.03 \quad 100.0 \%$ PCI domain-containing protein 2 GN=PCID2 PCID2_HUMAN $46.03 \quad 100.0 \%$ PCI domain-containing protein 2 GN=PCID2 PCID2_HUMAN $46.03 \quad 100.0 \%$ PCI domain-containing protein $2 \mathrm{GN}=\mathrm{PCID} 2 \mathrm{PCID} 2$ HUMAN $46.03 \quad 100.0 \%$ PCI domain-containing protein 2 GN=PCID2 PCID2_HUMAN $46.03 \quad 100.0 \%$ PCI domain-containing protein $2 \mathrm{GN}=$ PCID2 PCID2 HUMAN $46.03 \quad 100.0 \%$ PCI domain-containing protein 2 GN=PCID2 PCID2_HUMAN $46.03 \quad 100.0 \%$ PCI domain-containing protein $2 \mathrm{GN}=\mathrm{PCID} 2$ PCID2_HUMAN $46.03 \quad 100.0 \%$ Pentatricopeptide repeat domain-containing protein 3, mitochondrial GN=PTCD3 $\mathrm{PTCD} 3 \mathrm{HUMAN} 78.55100 .0 \%$

$100.0 \%$ $100.0 \%$ $100.0 \%$ $100.0 \%$ $100.0 \%$ $100.0 \%$ $100.0 \%$ $100.0 \%$ $100.0 \%$ $100.0 \%$ PRDX1 HUMAN $22.11 \quad 100.0 \%$ PRDX1_HUMAN $22.11 \quad 100.0 \%$ PRDX6 HUMAN $25.04 \quad 100.0 \%$ PRDX6_HUMAN $25.04 \quad 100.0 \%$ R2 DECR2_HUMAN $30.78 \quad 100.0 \%$ $100.0 \%$ $100.0 \%$ $100.0 \%$ $100.0 \%$ $100.0 \%$ $100.0 \%$
$0.00 \% \quad 2.5 \% \quad$ AVAEQVLHSQSR

$\begin{array}{llllllll}99.7 \% & 61.8 & 25.0 & 59.2 & 2 & 0 & 0 & 1324.70\end{array}$

$3 \quad 0.00 \% \quad 2.5 \%$ TAADVVSPGANSVDS

Q99.7\% 34.2

$0.01 \% \quad 14.8 \%$ ATSLGRPEEEEDELAHR $\quad 99.5 \% \quad 26.0$

$0.01 \% \quad 14.8 \%$ AGVSISVVHGNLSEEAAK

$0.01 \% \quad 14.8 \%$ YVEFNLLYDR

$0.01 \% \quad 14.8 \%$ FGLFTPGSR

$0.01 \% \quad 14.8 \%$ IESILMSLPLTAR

$0.01 \% \quad 11.8 \%$ NVQSVSIIDTELK

$1 \quad 0.01 \% \quad 11.8 \%$ NVQSVSIIDTELKVK

$11 \quad 0.01 \% \quad 11.8 \%$ VVLLHGPPGTGK

$11 \quad 0.01 \% \quad 11.8 \%$ VVNAVLTQIDQIKR

$0.01 \% \quad 11.8 \%$ LSLLLNDISR

$0.00 \% \quad 1.7 \% \quad$ LLFSNTAAQK

$0.00 \% \quad 1.7 \%$ DKSDSPAIQLR

$0.00 \% \quad 3.8 \%$ SAPLEIGLQR

$0.00 \% \quad 3.8 \%$ NIFAILQSVK

$0.02 \% \quad 20.3 \%$ DGASCAELVSFK

$0.02 \% \quad 20.3 \%$ LQMASPEEK

$16 \quad 0.02 \% \quad 20.3 \%$ CQTVIVQSFLR

$0.02 \% \quad 20.3 \%$ VFANNADQQLVK

$0.02 \% \quad 20.3 \%$ VFANNADQQLVKK

$0.02 \% \quad 20.3 \%$ YHLMQFAEVTR

$99.7 \% \quad 31.1 \quad 25.0 \quad 31.1$

$99.7 \% \quad 52.3$

$99.7 \% \quad 44.3$

$99.7 \% \quad 45.5$

$99.7 \% 32.0$

$99.7 \% \quad 32.6$

$99.7 \% \quad 63.0$

$99.7 \% \quad 50.5$

$99.6 \% \quad 24.4$

$\begin{array}{lll}99.7 \% & 42.7\end{array}$

$99.7 \% \quad 43.3$

$99.7 \% \quad 47.9$

$99.7 \% \quad 55.9$

$99.7 \% \quad 41.3$

$99.7 \% \quad 62.1$

$99.7 \% \quad 52.4$

$99.6 \% \quad 26.2$

$99.7 \% \quad 37.2$

$98.0 \% \quad 18.5$

$99.7 \% \quad 30.7$

$99.7 \% \quad 36.8$

$99.7 \% \quad 32.5$

$99.7 \% \quad 27.9$

$99.7 \% \quad 36.3$

$99.7 \% \quad 44.3$

$99.7 \% \quad 37.8$

$99.7 \% \quad 38.1$

$98.5 \% \quad 25.7$

$97.3 \% \quad 25.1$

$98.2 \% \quad 20.5$

$99.5 \% \quad 24.4$

$99.7 \% \quad 47.4$

$99.7 \% \quad 36.3$

$0.01 \% \quad 14.6 \%$ TIAQDYGVLK

$0.01 \% \quad 14.6 \%$ LVQAFQFTDK

$99.7 \% \quad 77.5$

$98.8 \% \quad 21.4$

$99.7 \% \quad 53.4$

$99.7 \% \quad 35.4$

$99.0 \% 33.7$

$99.7 \% \quad 47.4$

$99.7 \% \quad 37.3$

$99.7 \% \quad 27.2$

$99.7 \% \quad 38.8$

$99.7 \% \quad 43.1$

1596.94

1143.67

1346.71

1158.62

$0.00 \% \quad 6.8 \% \quad$ FRNEDIVPTNYK

$0.00 \% \quad 6.8 \%$ NILYLLHQR
1545.75

1938.92

1767.92

1331.66

981.52

1459.82

1445.78

1672.95

1174.69

1092.60

1229.65

1083.62

1132.67

1283.59

1032.50

1350.72

1474.80

1410.68

1677.95

1092.61

1131.60

1285.69

1050.52

1043.54

1234.68

1119.58

1131.64

1000.59

1108.54

980.53

1107.60

1196.63

2098.09

1007.56

1166.63

1058.58

871.50

1364.73

983.53

1463.82

1495.75

60 $1000 \quad 1015$

$110 \quad 126$

$203 \quad 220$

$392 \quad 401$

$414 \quad 426$

$69 \quad 81$

$69 \quad 83$

$174 \quad 185$

$\begin{array}{ll}76 \\ 69 & 378\end{array}$

$866 \quad 875$

$936 \quad 946$

$111 \quad 120$

$248 \quad 257$

$21 \quad 32$

$41 \quad 49$

$17 \quad 128$

$117 \quad 129$

$274 \quad 284$

$285 \quad 300$

$308 \quad 316$

$151 \quad 160$

$378 \quad 388$

$557 \quad 565$

$105 \quad 113$

$320 \quad 330$

$\begin{array}{ll}63 & 73\end{array}$

$183 \quad 192$

$308 \quad 317$

$474 \quad 482$

483493

$8 \quad 16$

$111 \quad 120$

$159 \quad 168$

$2 \quad 22$

$133 \quad 141$

$171 \quad 182$

$220 \quad 230$

$231 \quad 238$

$18 \quad 30$

$31 \quad 39$

$133 \quad 146$

$136 \quad 147$

$1169.68 \quad 249 \quad 257$ 
Peroxisomal multifunctional enzyme type 2 GN=HSD17B4 DHB4_HUMAN $79.69100 .0 \%$ Peroxisomal multifunctional enzyme type 2 GN=HSD17B4 DHB4_HUMAN $79.69100 .0 \%$ Peroxisomal multifunctional enzyme type $2 \mathrm{GN}=\mathrm{HSD} 17 \mathrm{~B} 4$ DHB4_HUMAN $79.69 \quad 100.0 \%$ Peroxisomal multifunctional enzyme type $2 \mathrm{GN}=\mathrm{HSD} 17 \mathrm{~B} 4 \mathrm{DHB} 4 \mathrm{HUMAN} 79.69100 .0^{\circ}$ Pescadillo homolog GN=PES1 Pescadillo homolog GN=PES Pescadillo homolog GN=PES Pescadillo homolog GN=PES1 PHD finger protein $6 \mathrm{GN}=\mathrm{PHF} 6$ PHD finger protein $6 \mathrm{GN}=\mathrm{PHF} 6$ PHD finger protein $6 \mathrm{GN}=\mathrm{PHF} 6$ PHD finger protein $6 \mathrm{GN}=\mathrm{PHF} 6$ PHD finger protein $6 \mathrm{GN}=\mathrm{PHF} 6$ PHD finger protein $6 \mathrm{GN}=\mathrm{PHF} 6$ PHD finger protein $6 \mathrm{GN}=\mathrm{PHF} 6$ PHD finger protein $6 \mathrm{GN}=\mathrm{PHF} 6$ PHD finger protein $6 \mathrm{GN}=\mathrm{PHF} 6$ PESC_HUMAN $68.00 \quad 100.0 \%$ PESC HUMAN $68.00 \quad 100.0 \%$ PESC HUMAN $68.00 \quad 100.0 \%$ PESC_HUMAN $68.00 \quad 100.0 \%$ PHF6 HUMAN $41.29 \quad 100.0 \%$ PHF6 HUMAN $41.29 \quad 100.0 \%$ PHF6 HUMAN $41.29 \quad 100.0 \%$ PHF6 HUMAN $41.29 \quad 100.0^{\circ}$ PHF6_HUMAN $41.29 \quad 100.0 \%$ PHF6 HUMAN $41.29 \quad 100.0 \%$ PHF6 HUMAN $41.29 \quad 100.0 \%$ PHF6_HUMAN $41.29 \quad 100.0 \%$ PHF6 HUMAN $41.29 \quad 100.0 \%$ Phenylalanine--tRNA ligase alpha subunit GN=FARSA SYFA_HUMAN $57.56 \quad 100.0 \%$ Phenylalanine--tRNA ligase alpha subunit GN=FARSA SYFA_HUMAN $57.56 \quad 100.0 \%$ Phenylalanine--tRNA ligase alpha subunit GN=FARSA SYFA HUMAN $57.56 \quad 100.0 \%$ Phenylalanine--tRNA ligase beta subunit GN=FARSB SYFB_HUMAN $66.12 \quad 100.0 \%$ Phenylalanine--tRNA ligase beta subunit GN=FARSB SYFB HUMAN $66.12100 .0 \%$ Phenylalanine--tRNA ligase beta subunit GN=FARSB SYFB_HUMAN $66.12 \quad 100.0 \%$ Phenylalanine--tRNA ligase beta subunit GN=FARSB SYFB_HUMAN $66.12 \quad 100.0 \%$ Phenylalanine--tRNA ligase beta subunit GN=FARSB SYFB HUMAN $66.12 \quad 100.0 \%$ Phenylalanine--tRNA ligase beta subunit GN=FARSB SYFB_HUMAN $66.12 \quad 100.0 \%$ Phosphate carrier protein, mitochondrial GN=SLC25A3 MPCP_HUMAN $40.10 \quad 100.0 \%$ Phosphate carrier protein, mitochondrial GN=SLC25A3 MPCP_HUMAN $40.10 \quad 100.0 \%$ Phosphate carrier protein, mitochondrial GN=SLC25A3 MPCP_HUMAN $40.10 \quad 100.0 \%$ Phosphate carrier protein, mitochondrial GN=SLC25A3 MPCP HUMAN $40.10 \quad 100.0 \%$ Phosphate carrier protein, mitochondrial GN=SLC25A3 MPCP_HUMAN $40.10 \quad 100.0 \%$ Phosphate carrier protein, mitochondrial GN=SLC25A3 $\quad$ MPCP_HUMAN $40.10 \quad 100.0 \%$ Phosphate carrier protein, mitochondrial GN=SLC25A3 MPCP HUMAN $40.10 \quad 100.0^{\circ}$ Phosphate carrier protein, mitochondrial GN=SLC25A3 MPCP_HUMAN $40.10 \quad 100.0 \%$ Phosphate carrier protein, mitochondrial GN=SLC25A3 MPCP_HUMAN $40.10 \quad 100.0 \%$ Phosphate carrier protein, mitochondrial GN=SLC25A3 MPCP_HUMAN $40.10 \quad 100.0 \%$ Phosphate carrier protein, mitochondrial GN=SLC25A3 MPCP_HUMAN $40.10 \quad 100.0 \%$ Phosphate carrier protein, mitochondrial GN=SLC25A3 MPCP HUMAN 40.10 100.0\% Phosphatidate cytidylyltransferase, mitochondrial GN=TAMM41 TAM41_HUMAN $51.07 \quad 100.0 \%$ Phosphatidate cytidylyltransferase, mitochondrial GN=TAMM41 TAM41_HUMAN $51.07 \quad 100.0 \%$ Phosphatidylinositol 3-kinase regulatory subunit beta GN=PIK3R2 P85B HUMAN $81.55 \quad 100.0 \%$ Phosphatidylinositol 3-kinase regulatory subunit beta GN=PIK3R2 P85B_HUMAN $81.55 \quad 100.0 \%$ Phosphatidylinositol 3-kinase regulatory subunit beta GN=PIK3R2 P85B_HUMAN $81.55 \quad 100.0 \%$ Phosphatidylinositol 3-kinase regulatory subunit beta GN=PIK3R2 P85B_HUMAN $81.55 \quad 100.0 \%$ Phosphatidylinositol 3-kinase regulatory subunit beta GN=PIK3R2 P85B_HUMAN 81.55 100.0\% Phosphatidylinositol 3-kinase regulatory subunit beta GN=PIK3R2 P85B HUMAN $81.55 \quad 100.0 \%$ Phosphatidylinositol 3-kinase regulatory subunit beta GN=PIK3R2 P85B_HUMAN $81.55 \quad 100.0 \%$
$0.01 \% \quad 6.5 \%$ VVLVTGAGAGLGR $0.01 \% \quad 6.5 \%$ AYALAFAER $0.01 \% \quad 6.5 \%$ GALVVVNDLGGDFK $0.01 \% \quad 6.5 \% \quad$ IDVVVNNAGILR $0.01 \% \quad 6.8 \%$ GSATNYITR $0.01 \% \quad 6.8 \%$ LEGQAQAEAK $0.01 \% \quad 6.8 \% \quad$ LAALSASLAR $0.01 \% \quad 6.8 \%$ LAQEEESEAKR $0.02 \% \quad 32.1 \%$ DKECGQLLISENQK $0.02 \% \quad 32.1 \%$ TYHYHCALHDK $0.02 \% \quad 32.1 \%$ CGFCHVGEEENEAR $0.02 \% 32.1 \%$ CMLFSSGTVQLTTTSR $0.02 \% \quad 32.1 \%$ AEFGDFDIK $0.02 \% \quad 32.1 \%$ TVLQEIKR

$0.02 \% \quad 32.1 \%$ CTLCSQPGATIGCEIK $0.02 \% \quad 32.1 \%$ TYHYHCGVQDK $0.01 \% \quad 8.3 \%$ THSQGGYGSQGYKYNWK $0.01 \% \quad 8.3 \% \quad$ LAQKKPFTPVK $0.01 \% \quad 8.3 \% \quad$ LDAEPRPPPTQEAA $0.01 \% \quad 10.9 \%$ DLLFQALGR $0.01 \% \quad 10.9 \%$ AAGASDVVLYK $0.01 \% \quad 10.9 \%$ GLQVFKER $0.01 \% \quad 10.9 \%$ NIFIECTGTDFTK $0.01 \% \quad 10.9 \%$ VGIRETPENLAK $0.01 \% \quad 10.9 \%$ ASEGPAFFPGR $0.06 \% \quad 25.4 \%$ MQVDPQKYK $0.06 \% \quad 25.4 \%$ GIFNGFSVTLK $0.06 \% \quad 25.4 \%$ GIFNGFSVTLKEDGVR $0.06 \% 25.4 \%$ FGFYEVFK

$0.06 \% \quad 25.4 \%$ IQTQPGYANTLR $0.06 \% 25.4 \%$ IQTQPGYANTLRDAAPK $0.06 \% 25.4 \%$ MYKEEGLK $0.06 \% \quad 25.4 \%$ GVAPLWMR $0.06 \% 25.4 \%$ EKGSSASLVLK

$0.06 \% \quad 25.4 \%$ GSSASLVLK $0.06 \% \quad 25.4 \%$ GSSASLVLKR $0.06 \% \quad 25.4 \%$ LPRPPPPEMPESLK $0.00 \% \quad 6.0 \% \quad$ IISVNEDVTLR $0.00 \% \quad 6.0 \% \quad$ ELYGSILQENPQVVYK $0.04 \% \quad 19.9 \%$ AALQALGVAEGGER $0.04 \% \quad 19.9 \%$ TGLDSESHYRPELPAPR $0.04 \% \quad 19.9 \%$ FLLQHLGR $0.04 \% \quad 19.9 \%$ APALGPAVR $0.04 \% \quad 19.9 \%$ ALGATFGPLLLR $0.04 \% \quad 19.9 \%$ DASSKIQGEYTLTLR $0.04 \% \quad 19.9 \%$ IQGEYTLTLR $\begin{array}{llllllll}99.7 \% & 53.5 & 25.0 & 46.3 & 2 & 0 & 0 & 1169.70\end{array}$

1011.53

$\begin{array}{llllllll}99.7 \% & 72.1 & 25.0 & 63.5 & 1 & 0 & 0 & 1403.75\end{array}$

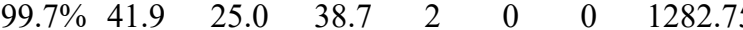

$\begin{array}{llllllll}99.7 \% & 53.4 & 25.0 & 44.8 & 2 & 0 & 0 & 982.50\end{array}$

$\begin{array}{llllllll}99.7 \% & 33.3 & 25.0 & 19.8 & 1 & 0 & 0 & 1044.53\end{array}$

$99.7 \% \quad 49.1 \quad 25.0$

$\begin{array}{llll}99.7 \% & 41.7 & 25.0 & 41.7\end{array}$

$99.7 \% \quad 58.5 \quad 25.0 \quad 49.7$

$99.0 \% \quad 24.5 \quad 25.0 \quad 24.5$

$99.7 \% \quad 50.3 \quad 25.0 \quad 50.3$

$99.7 \% \quad 78.2 \quad 25.0 \quad 78.2$

$\begin{array}{llll}99.7 \% & 33.5 & 25.0 & 18.9\end{array}$

$99.0 \% \quad 42.5 \quad 25.0 \quad 12.4$

$\begin{array}{llll}99.7 \% & 30.8 & 25.0 & 30.8\end{array}$

$\begin{array}{llll}99.6 \% & 24.8 & 25.0 & 24.8\end{array}$

$\begin{array}{llll}9.7 \% & 59.8 & 25.0 & 59.8\end{array}$

$\begin{array}{lll}17.0 & 25.0 & 17.3\end{array}$

$\begin{array}{llll}99.7 \% & 40.3 & 25.0 & 40.3\end{array}$

$\begin{array}{llll}99.7 \% & 48.4 & 25.0 & 30.0\end{array}$

$99.7 \% \quad 39.4 \quad 25.0 \quad 36.6$

$\begin{array}{llll}99.0 \% & 40.7 & 25.0 & 34.1\end{array}$

$\begin{array}{lllll}99.7 \% & 66.9 & 25.0 & 66.9 & 2\end{array}$

$\begin{array}{llll}99.5 \% & 23.7 & 25.0 & 23.7\end{array}$

$\begin{array}{llll}99.7 \% & 57.0 & 25.0 & 46.5\end{array}$

$99.7 \% \quad 31.4 \quad 25.0 \quad 22.4$

$\begin{array}{llll}99.7 \% & 57.1 & 25.0 & 51.9\end{array}$

$\begin{array}{llll}99.7 \% & 36.0 & 25.0 & 33.0\end{array}$

$99.0 \% \quad 31.9 \quad 25.0 \quad 22.2$

$\begin{array}{llll}99.7 \% & 60.2 & 25.0 & 45.6\end{array}$

$\begin{array}{llll}98.4 \% & 18.4 & 25.0 & 16.8\end{array}$

$99.0 \% \quad 39.1 \quad 25.0 \quad 24.5$

$\begin{array}{llll}99.0 \% & 31.5 & 25.0 & 13.6\end{array}$

$\begin{array}{llll}99.7 \% & 38.3 & 25.0 & 29.9\end{array}$

$99.7 \% \quad 44.9 \quad 25.0 \quad 28.0$

$\begin{array}{llll}99.7 \% & 56.3 & 25.0 & 42.3\end{array}$

$99.7 \% \quad 43.5 \quad 25.0 \quad 42.6$

$\begin{array}{llll}99.7 \% & 28.6 & 25.0 & 28.6\end{array}$

$\begin{array}{llll}99.7 \% & 67.5 & 25.0 & 67.3\end{array}$

$\begin{array}{llll}99.7 \% & 59.4 & 25.0 & 56.3\end{array}$

$\begin{array}{llll}98.2 \% & 27.4 & 25.0 & 26.4\end{array}$

$\begin{array}{llll}99.0 \% & 45.0 & 25.0 & 37.7\end{array}$

$99.7 \% \quad 31.5 \quad 25.0 \quad 31.5$

$\begin{array}{lllll}99.7 \% & 26.7 & 25.0 & 26.7 & 2\end{array}$

$\begin{array}{llll}99.2 \% & 26.3 & 25.0 & 26.3\end{array}$

$\begin{array}{llll}99.7 \% & 36.9 & 25.0 & 28.6\end{array}$

$\begin{array}{cc}1 & 23 \\ 4 & 32 \\ 3 & 46 \\ 3 & 104 \\ 2 & 20 \\ 50 & 259 \\ 76 & 285 \\ 24 & 534 \\ 5 & 38 \\ 02 & 112 \\ 12 & 225 \\ 42 & 257 \\ 58 & 266 \\ 67 & 274 \\ 80 & 295 \\ 00 & 310 \\ 48 & 365 \\ 99 & 315 \\ 39 & 349 \\ 95 & 508 \\ 9 & 17 \\ 4 & 64 \\ 3 & 90 \\ 50 & 262 \\ 18 & 329 \\ 37 & 547 \\ 3 & 101 \\ 02 & 112 \\ 02 & 117 \\ 38 & 145 \\ 90 & 201 \\ 90 & 206 \\ 07 & 214 \\ 19 & 226 \\ 94 & 304 \\ 96 & 304 \\ 96 & 305 \\ 42 & 355 \\ 40 & 150 \\ 14 & 229 \\ 6 & 49 \\ 38 & 154 \\ 24 & 231 \\ 36 & 244 \\ 45 & 256 \\ 56 & 370 \\ 61 & 370 \\ & \end{array}$

Page 108 of Table S-1-6 

$\begin{array}{llllllllll}\text { Phosphatidylinositol 3-kinase regulatory subunit beta GN=PIK3R2 } & \text { P85B_HUMAN } & 81.55 & 100.0 \% & 14 & 16 & 31 & 0.04 \% & 19.9 \% & \text { TAIEAFNETIK }\end{array}$ Phosphatidylinositol 3-kinase regulatory subunit beta GN=PIK3R2 P85B_HUMAN $81.55 \quad 100.0 \%$ Phosphatidylinositol 3-kinase regulatory subunit beta GN=PIK3R2 P85B_HUMAN 81.55 Phosphatidylinositol 3-kinase regulatory subunit beta GN=PIK3R2 P85B_HUMAN 81.55 Phosphatidylinositol 3-kinase regulatory subunit beta GN=PIK3R2 P85B_HUMAN 81.55 Phosphatidylinositol 3-kinase regulatory subunit beta GN=PIK3R2 P85B_HUMAN 81.55 Phosphatidylinositol 4-kinase alpha GN=PI4KA PI4KA_HUMAN $231.33 \quad 100.0 \%$ Phosphatidylinositol 4-kinase alpha GN=PI4KA PI4KA_HUMAN $231.33 \quad 100.0 \%$ Phosphatidylinositol 4-kinase alpha GN=PI4KA PI4KA_HUMAN $231.33 \quad 100.0 \%$ Phosphatidylserine decarboxylase proenzyme GN=PISD PISD_HUMAN $46.67 \quad 100.0 \%$ Phosphatidylserine decarboxylase proenzyme GN=PISD PISD_HUMAN $46.67 \quad 100.0 \%$ Phosphatidylserine decarboxylase proenzyme GN=PISD PISD_HUMAN $46.67 \quad 100.0 \%$ Phosphatidylserine decarboxylase proenzyme GN=PISD PISD_HUMAN $46.67 \quad 100.0 \%$ Phosphoacetylglucosamine mutase GN=PGM3 AGM1_HUMAN $59.85 \quad 100.0 \%$ Phosphoacetylglucosamine mutase GN=PGM3 AGM1_HUMAN $59.85 \quad 100.0 \%$ Phosphoacetylglucosamine mutase GN=PGM3 AGM1_HUMAN $59.85 \quad 100.0 \%$ Phosphoenolpyruvate carboxykinase [GTP], mitochondrial GN=PCK2 $\quad$ PCKGM_HUMAN $70.73 \quad 100.0 \%$ $\begin{array}{llll}\text { Phosphoenolpyruvate carboxykinase }[\mathrm{GTP}] \text {, mitochondrial GN=PCK2 } & \text { PCKGM_HUMAN } 70.73 \quad 100.0 \%\end{array}$ $\begin{array}{llll}\text { Phosphoenolpyruvate carboxykinase [GTP], mitochondrial GN=PCK2 } & \text { PCKGM_HUMAN } 70.73 \quad 100.0 \%\end{array}$ Phosphoenolpyruvate carboxykinase [GTP], mitochondrial GN=PCK2 PCKGM_HUMAN $70.73 \quad 100.0 \%$ Phosphoenolpyruvate carboxykinase [GTP], mitochondrial GN=PCK2 PCKGM_HUMAN $70.73 \quad 100.0 \%$

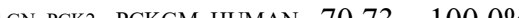
Phosphoglycerate kinase $1 \mathrm{GN}=\mathrm{PGK}$ Phosphoglycerate kinase $1 \mathrm{GN}=\mathrm{PGK} 1$ Phosphoglycerate kinase $1 \mathrm{GN}=\mathrm{PGK} 1$ Phosphoglycerate mutase 1 GN=PGAM1 Phosphoglycerate mutase $1 \mathrm{GN}=\mathrm{PGAM} 1$ PGAMIPhosphoglycerate mutase 1 GN=PGAM1 PGAM1_HUMAN 28.80 Phosphoglycerate mutase $1 \mathrm{GN}=$ PGAM1 PGAM1_HUMAN 28.80 Phosphoglycerate mutase 1 GN=PGAM1 PGAM1_HUMAN 28.80 Phosphoglycolate phosphatase GN=PGP PGP_HUMAN 34.01 Phosphoglycolate phosphatase GN=PGP PGP_HUMAN 34.01 Phosphoglycolate phosphatase GN=PGP PGP_HUMAN 34.01 Phosphoribosyl pyrophosphate synthase-associated protein 1 GN=PRPSAP1 KPRA_HUMAN 39.39 Phosphoribosyl pyrophosphte Phosphoribosyl pyrophosphate synthase-associated protein 1 GN=PRPSAP1 KPRA_HUMAN 39.39 Phosphoribosyl pyrophosphate synthase-associated protein 1 GN=PRPSAP1 KPRA_HUMAN 39.39 Phosphoribosyl pyrophosphate synthase-associated protein 1 GN=PRPSAP1 KPRA_HUMAN 39.39 Phosphoribosyl pyrophosphate synthase-associated protein 1 GN=PRPSAPI KPRA_HUMAN 39.39 Phosphoribosyl pyrophosphate synthase-associated protein 1 GN=PRPSAP1 $\quad$ KPRA_HUMAN $39.39100 .0^{\circ}$ Phosphoribosyl pyrophosphate synthase-associated protein 2 GN=PRPSAP2 KPRB_HUMAN $40.93 \quad 100.0 \%$ Phosphoribosyl pyrophosphate synthase-associated protein 2 GN=PRPSAP2 KPRB HUMAN $40.93 \quad 100.0 \%$ Phosphoribosyl pyrophosphate synthase-associated protein 2 GN=PRPSAP2 KPRB_HUMAN $40.93 \quad 100.0 \%$ hosphoribosyl pyrophosphate synthase-associated protein 2 GN=PRPSAP2 KPRB_HUMAN $40.93 \quad 100.0^{\circ}$

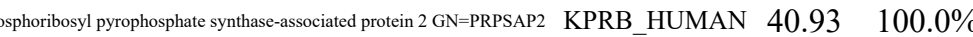
Phosphoribosyl pyrophosphate synthase-associated protein 2 GN=PRPSAP2 KPRB_HUMAN $40.93 \quad 100.0 \%$ $\begin{array}{llll}16 & 31 & 0.04 \% & 19.9 \% \\ 16 & 31 & 0.04 \% & 19.9 \%\end{array}$

$16 \quad 31 \quad 0.04 \% \quad 19.9 \%$ IAEIHESR

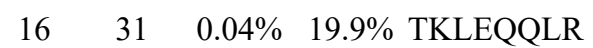

$16 \quad 31 \quad 0.04 \% \quad 19.9 \%$ TQAEEMLSGKR

$\begin{array}{llll}16 & 31 & 0.04 \% & 19.9 \% \\ & 3 & \text { DGTFLIRESSQR }\end{array}$

$0.00 \% \quad 1.6 \%$ TSSVSSISQVSPER

$0.00 \% \quad 1.6 \%$ HVAAIGPR

$0.00 \% \quad 1.6 \%$ SNLDITVGSR

$10 \quad 0.01 \% \quad 11.2 \%$ LNQVELPHWLR

$10 \quad 0.01 \% \quad 11.2 \%$ ILNFGQVK

$10 \quad 0.01 \% \quad 11.2 \%$ GVTYSLESFLGPR

$10 \quad 0.01 \% \quad 11.2 \%$ GSYNDFSFVTHTNR

$10 \quad 0.01 \% \quad 5.5 \% \quad$ MGLLAVLR

$10 \quad 0.01 \% \quad 5.5 \% \quad$ VISTTDAER

$10 \quad 0.01 \% \quad 5.5 \%$ AFVRPSGTEDVVR

$13 \quad 0.01 \% \quad 10.2 \%$ YNNCWLAR

$13 \quad 0.01 \% \quad 10.2 \%$ LGTPVLQALGDGDFVK

$13 \quad 0.01 \% \quad 10.2 \%$ YVAAAFPSACGK

$0.01 \% \quad 10.2 \%$ HGVFVGSAMR

$13 \quad 0.01 \% \quad 10.2 \%$ ETPIGLVPK

$3 \quad 0.01 \% \quad 10.2 \%$ EGALDLSGLR

$0.01 \% \quad 10.3 \%$ ACANPAAGSVILLENLR

$0.01 \% \quad 10.3 \%$ LGDVYVNDAFGTAHR

$0.01 \% \quad 10.3 \%$ VLPGVDALSNI

$0.01 \% \quad 16.9 \%$ HGESAWNLENR

$0.01 \% \quad 16.9 \%$ HYGGLTGLNK

$0.01 \% \quad 16.9 \%$ RVLIAAHGNSLR

$0.01 \% \quad 16.9 \%$ VLIAAHGNSLR

$0.01 \% \quad 16.9 \%$ AMEAVAAQGK

$0.01 \% \quad 10.3 \%$ GETAVPGAPEALR

$0.01 \% \quad 10.3 \%$ LGFITNNSSK

$0.01 \% \quad 10.3 \%$ FIAGTGCLVR

$17 \quad 0.02 \% \quad 29.2 \%$ VFSANSTAACTELAK

$0.02 \% \quad 29.2 \%$ GQDIFIIQTIPR

$0.02 \% \quad 29.2 \%$ NIIGVIPYFPYSK

$0.02 \% \quad 29.2 \%$ AGLTHIITMDLHQK

$0.02 \% \quad 29.2 \%$ EIQGFFSFPVDNLR

$0.02 \% \quad 29.2 \%$ EKPPITVVGDVGGR

$0.02 \% \quad 29.2 \%$ LIEESSVDEVVVTNTVPHEVQK

$0.04 \% \quad 33.9 \%$ VQVYQEPNR

$0.04 \% 33.9 \%$ VQVYQEPNRETR

$0.04 \% \quad 33.9 \%$ VQIQESVR

$0.04 \% \quad 33.9 \%$ GKDVFIIQTVSK

$0.04 \% \quad 33.9 \%$ SIIGVIPYFPYSK

$0.04 \% \quad 33.9 \%$ AGLTHLITMDLHQK \begin{tabular}{llllll}
$99.6 \%$ & 25.3 & 25.0 & 21.7 & 2 & 2 \\
\hline
\end{tabular}

$\begin{array}{llllll}95.7 \% & 16.0 & 25.0 & 16.0 & 2 & 0\end{array}$

$\begin{array}{llll}99.7 \% & 43.8 & 25.0 & 31.5\end{array}$

$99.0 \% \quad 46.1 \quad 25.0 \quad 23.6 \quad 2$

$\begin{array}{llll}99.0 \% & 29.5 & 25.0 & 16.2\end{array}$

$\begin{array}{llll}99.7 \% & 53.3 & 25.0 & 46.3\end{array}$

$\begin{array}{llll}99.7 \% & 35.0 & 25.0 & 26.2\end{array}$

$99.7 \% \quad 33.6 \quad 25.0 \quad 33.6$

$95.0 \% \quad 13.8 \quad 25.0 \quad 13.8$

$\begin{array}{llll}99.7 \% & 52.5 & 25.0 & 49.8\end{array}$

$\begin{array}{llll}99.4 \% & 25.0 & 25.0 & 24.0\end{array}$

$99.0 \% \quad 38.3 \quad 25.0 \quad 14.1$

$\begin{array}{llll}99.7 \% & 48.8 & 25.0 & 46.3\end{array}$

$\begin{array}{llll}99.7 \% & 78.4 & 25.0 & 78.4\end{array}$

$99.0 \% \quad 54.4 \quad 25.0 \quad 40.1$

$\begin{array}{lllll}99.7 \% & 39.9 & 25.0 & 28.8\end{array}$

$99.7 \% \quad 44.8 \quad 25.0 \quad 40.0$

$\begin{array}{llll}95.4 \% & 21.0 & 25.0 & 14.2\end{array}$

$\begin{array}{lllll}99.7 \% & 63.8 & 25.0 & 63.3 & 2\end{array}$

$\begin{array}{llll}99.7 \% & 30.6 & 25.0 & 30.6\end{array}$

$\begin{array}{lllll}99.7 \% & 36.5 & 25.0 & 31.3 & 2\end{array}$

$\begin{array}{llll}98.3 \% & 17.2 & 25.0 & 17.2\end{array}$

$\begin{array}{llll}99.7 \% & 52.8 & 25.0 & 48.1\end{array}$

$\begin{array}{llll}99.7 \% & 44.1 & 25.0 & 41.3\end{array}$

$\begin{array}{llll}99.7 \% & 32.9 & 25.0 & 31.7\end{array}$

$\begin{array}{llll}99.7 \% & 35.6 & 25.0 & 33.9\end{array}$

$\begin{array}{llll}95.4 \% & 18.4 & 25.0 & 18.4\end{array}$

$\begin{array}{llll}99.7 \% & 39.2 & 25.0 & 28.4\end{array}$

$\begin{array}{llll}99.7 \% & 28.0 & 25.0 & 28.0\end{array}$

$99.7 \% \quad 51.4 \quad 25.0 \quad 51.4$

$\begin{array}{llll}99.7 \% & 56.7 & 25.0 & 49.6\end{array}$

$\begin{array}{llll}99.7 \% & 42.1 & 25.0 & 30.7\end{array}$

$\begin{array}{llll}99.7 \% & 44.2 & 25.0 & 27.8\end{array}$

$\begin{array}{llll}99.7 \% & 39.0 & 25.0 & 21.3\end{array}$

$\begin{array}{llll}99.7 \% & 53.5 & 25.0 & 53.5\end{array}$

$\begin{array}{llll}99.7 \% & 59.2 & 25.0 & 55.9\end{array}$

$\begin{array}{llll}99.6 \% & 25.5 & 25.0 & 25.5\end{array}$

$99.0 \% \quad 45.1 \quad 25.0 \quad 0.0$

$\begin{array}{llll}99.7 \% & 53.8 & 25.0 & 53.8\end{array}$

$\begin{array}{llll}99.7 \% & 42.6 & 25.0 & 40.8\end{array}$

$\begin{array}{llll}99.7 \% & 41.2 & 25.0 & 38.3\end{array}$

$\begin{array}{llll}99.7 \% & 39.9 & 25.0 & 35.7\end{array}$

$\begin{array}{llll}99.4 \% & 21.9 & 25.0 & 19.2\end{array}$

$\begin{array}{llll}99.0 \% & 48.2 & 25.0 & 33.6\end{array}$

$\begin{array}{llll}99.7 \% & 65.4 & 25.0 & 65.4\end{array}$

$\begin{array}{llll}99.7 \% & 44.4 & 25.0 & 38.5\end{array}$

$99.0 \% \quad 45.1 \quad 25.0 \quad 0.0$
1236.65

1085.67

954.50

1015.59

1249.62

1408.72

1463.73

820.48

1061.56

1404.77

918.54

1425.74

1644.74

872.54

991.51

1432.75

1096.50

1629.89

1241.60

1060.54

953.57

1030.55

1768.94

1634.79

1097.62

1312.60

1059.56

1306.77

1150.67

975.49

1267.66

1080.57

1093.58

1569.76

1400.79

1510.83

1577.85

1668.84

1423.79

2451.26

1132.57

1518.77

958.53

1334.77

1483.82

1577.85

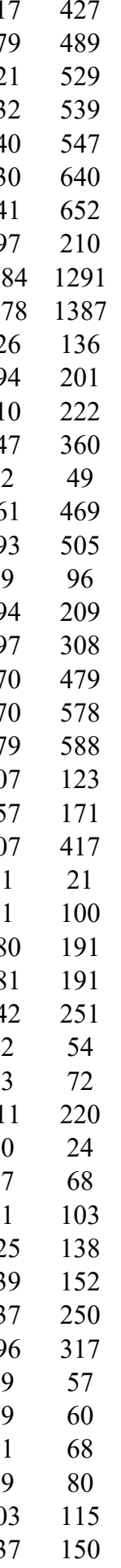

Page 109 of Table S-1- 

\begin{tabular}{ll}
$100.0 \%$ \\
\hline
\end{tabular} Phosphoserine aminotransferase GN=PSAT1 SERC_HUMAN $40.42 \quad 100.0 \%$ Phosphoserine aminotransferase GN=PSAT1 SERC_HUMAN $40.42 \quad 100.0 \%$ Phosphoserine aminotransferase GN=PSAT1 SERC_HUMAN $40.42 \quad 100.0 \%$ Phosphoserine aminotransferase GN=PSAT1 SERC_HUMAN $40.42 \quad 100.0 \%$ Phosphoserine aminotransferase GN=PSAT1 SERC_HUMAN $40.42 \quad 100.0 \%$ Phosphoserine aminotransferase GN=PSAT1 SERC_HUMAN $40.42 \quad 100.0 \%$ Phosphoserine aminotransferase GN=PSAT1 SERC_HUMAN $40.42 \quad 100.0 \%$ Phosphoserine aminotransferase GN=PSAT1 SERC_HUMAN $40.42 \quad 100.0 \%$ Phosphoserine aminotransferase GN=PSAT1 SERC_HUMAN $40.42 \quad 100.0 \%$ Phosphoserine aminotransferase GN=PSAT1 SERC_HUMAN $40.42 \quad 100.0 \%$ Phosphoserine aminotransferase GN=PSAT1 SERC_HUMAN $40.42 \quad 100.0 \%$ PIN2/TERF1-interacting telomerase inhibitor 1 GN=PINX1 PINX1_HUMAN $37.04 \quad 100.0 \%$ PIN2/TERF1-interacting telomerase inhibitor 1 GN=PINX1 PINX1_HUMAN $37.04 \quad 100.0 \%$ PIN2/TERF1-interacting telomerase inhibitor 1 GN=PINX1 PINX1_HUMAN $37.04 \quad 100.0 \%$ Plasma membrane calcium-transporting ATPase 1 GN=ATP2B1 AT2B1_HUMAN $138.76 \quad 100.0 \%$ Plasma membrane calcium-transporting ATPase $1 \mathrm{GN}=\mathrm{ATP} 2 \mathrm{~B} 1 \quad$ AT2B1_HUMAN $138.76 \quad 100.0 \%$ Plasma membrane calcium-transporting ATPase 1 GN=ATP2B1 AT2B1_HUMAN $138.76 \quad 100.0 \%$ Plasma membrane calcium-transporting ATPase 1 GN=ATP2B1 AT2B1_HUMAN $138.76 \quad 100.0 \%$ Plasminogen activator inhibitor 1 RNA-binding protein GN=SERBP1 PAIRB_HUMAN $44.97 \quad 100.0 \%$ $\begin{array}{lll}\text { Plasminogen activator inhibitor } 1 \text { RNA-binding protein GN=SERBP1 } & \text { PAIRB_HUMAN } 44.97 \quad 100.0 \%\end{array}$ Plectin GN=PLEC Plectin GN $=$ PLEC Plectin GN=PLEC Plectin GN=PLEC Plectin GN=PLEC Plectin GN=PLEC Plectin GN=PLEC Plectin GN=PLEC Plectin GN=PLEC Plectin GN=PLEC Plectin GN=PLEC Plectin GN=PLEC Plectin GN=PLEC Plectin GN=PLEC Plectin GN=PLEC Plectin GN=PLEC Plectin GN=PLEC Plectin GN=PLEC Plectin GN=PLEC Plectin GN=PLEC Plectin GN=PLEC Plectin GN=PLEC Plectin GN=PLEC PLEC HUMAN $531.78 \quad 100.0 \% \quad 51$ PLEC_HUMAN $531.78 \quad 100.0 \% \quad 51$ PLEC_HUMAN $531.78 \quad 100.0 \% \quad 51$ PLEC_HUMAN $531.78 \quad 100.0 \% \quad 51$ PLEC_HUMAN $531.78 \quad 100.0 \% \quad 51$ PLEC HUMAN $531.78 \quad 100.0 \% \quad 51$ PLEC_HUMAN $531.78 \quad 100.0 \% \quad 51$ PLEC_HUMAN $531.78 \quad 100.0 \% \quad 51$ PLEC_HUMAN $531.78 \quad 100.0 \% \quad 51$ PLEC_HUMAN $531.78 \quad 100.0 \% \quad 51$ PLEC_HUMAN $531.78 \quad 100.0 \% \quad 51$ PLEC_HUMAN $531.78 \quad 100.0 \% \quad 51$ PLEC_HUMAN $531.78 \quad 100.0 \% \quad 51$ PLEC HUMAN $531.78 \quad 100.0 \% \quad 51$ PLEC_HUMAN $531.78 \quad 100.0 \% \quad 51$ PLEC_HUMAN $531.78 \quad 100.0 \% \quad 51$ PLEC_HUMAN $531.78 \quad 100.0 \% \quad 51$ PLEC_HUMAN $531.78 \quad 100.0 \% \quad 51$ PLEC_HUMAN $531.78 \quad 100.0 \% \quad 51$ PLEC_HUMAN $531.78 \quad 100.0 \% \quad 51$ PLEC_HUMAN $531.78 \quad 100.0 \% \quad 51$ PLEC_HUMAN $531.78 \quad 100.0 \% \quad 51$ PLEC_HUMAN $531.78 \quad 100.0 \% \quad 51$
$0.04 \% \quad 33.9 \%$ EIQGFFNIPVDNLR

$0.04 \% \quad 33.9 \%$ EKPPITVVGDVGGR

$99.7 \% \quad 52.2$

$99.7 \% \quad 42.6$

$0.04 \% 33.9 \%$ RIEESAIDEVVVTNTIPHEVQK $99.7 \% \quad 37.3$

$0.02 \% \quad 35.1 \%$ QVVNFGPGPAK

$0.02 \% \quad 35.1 \%$ LPHSVLLEIQK

$0.02 \% \quad 35.1 \%$ GVGISVLEMSHR

$0.02 \% \quad 35.1 \%$ ELLAVPDNYK

$99.7 \% \quad 46.6$

$99.7 \% \quad 28.9$

$99.7 \% \quad 38$

$99.7 \% \quad 27.4$

$0.02 \% \quad 35.1 \%$ GAVLVCDMSSNFLSKPVDVSK

$0.02 \% \quad 35.1 \%$ FGVIFAGAQK

$0.02 \% \quad 35.1 \%$ NVGSAGVTVVIVR

$0.02 \% \quad 35.1 \%$ DDLLGFALR

$0.02 \% \quad 35.1 \%$ ECPSVLEYK

$0.02 \% \quad 35.1 \%$ ALELNMLSLK

$0.02 \% \quad 35.1 \%$ ASLYNAVTIEDVQK

$0.01 \% \quad 14.9 \%$ GLGAQEQGATDHIK

\% 17.3

$99.7 \% \quad 39.4$

$99.7 \% \quad 60.0$

$99.7 \% \quad 46.4$

$99.5 \% \quad 23.0$

$99.7 \% \quad 50.6$

$99.7 \% \quad 82.8$

$99.7 \% \quad 43.8$

$\begin{array}{lllll}0.01 \% & 14.9 \% & \text { NKPQVPVPGSDISETQVER } & 99.7 \% & 60.4\end{array}$

$0.01 \% \quad 14.9 \%$ ASAQDAGDHVQPPEGR

$0.00 \% \quad 3.7 \%$ TVIEPMASEGLR

$0.00 \% \quad 3.7 \% \quad$ MVTGDNINTAR

$0.00 \% \quad 3.7 \%$ GIIDSTVSDQR

$0.00 \% \quad 3.7 \% \quad$ SSLYEGLEKPESR

$\begin{array}{ll}99.3 \% & 20.2 \\ 99.7 \% & 27.8\end{array}$

$99.7 \% \quad 32.5$

$99.7 \% \quad 38.2$

$99.4 \% 23.0$

$0.01 \% \quad 7.4 \%$ SAAQAAAQTNSNAAGK

$0.01 \% \quad 7.4 \%$ VGRRPDQQLQGEGK

$0.10 \% \quad 11.0 \%$ VPDVQDGVR

$0.10 \% \quad 11.0 \%$ GLHQSIEEFR

$0.10 \% \quad 11.0 \%$ SDEGQLSPATR

$0.10 \% \quad 11.0 \%$ IKELQNAGDR

$0.10 \% \quad 11.0 \%$ AVVQLKPR

$0.10 \% \quad 11.0 \%$ LQLEACETR

$0.10 \% \quad 11.0 \%$ GTQGAEEVLR

$0.10 \% \quad 11.0 \%$ HGERDVEVER

$0.10 \% \quad 11.0 \%$ WQAVLAQTDVR

$0.10 \% \quad 11.0 \%$ AQLEPVASPAK

$0.10 \% \quad 11.0 \%$ SIQEELQQLR

$0.10 \% \quad 11.0 \%$ LQLEATER

$0.10 \% \quad 11.0 \%$ GGAEGELQALR

$0.10 \% \quad 11.0 \%$ ARQVQVALETAQR

$0.10 \% \quad 11.0 \%$ QVQVALETAQR

$0.10 \% \quad 11.0 \%$ SAEAELQSK

$0.10 \% \quad 11.0 \%$ SAEAELQSKR

$0.10 \% \quad 11.0 \%$ LRLQAEEVAQQK

$0.10 \% \quad 11.0 \%$ QLAEGTAQQR

$0.10 \% \quad 11.0 \%$ LAAEQELIR

$0.10 \% \quad 11.0 \%$ LRAETEQGEQQR

$0.10 \% \quad 11.0 \%$ QLLEEELAR

$0.10 \% \quad 11.0 \%$ LAAIGEATR
$99.7 \% \quad 59.3$

$99.7 \% \quad 32.7$

$99.7 \% \quad 38.9$

$98.2 \% \quad 19.1$

$99.7 \% \quad 43.0$

$99.7 \% \quad 33.3$

$99.0 \% \quad 26.7$

$\begin{array}{lll}99.7 \% & 28.7\end{array}$

$99.7 \% \quad 43.6$

$99.7 \% \quad 30.0$

$99.7 \% \quad 44.2$

$99.7 \% \quad 42.2$

$\begin{array}{lll}95.9 \% & 23.1\end{array}$

$99.0 \% \quad 36.3$

$99.7 \% \quad 51.2$

$99.7 \% \quad 31.1$

$99.7 \% \quad 62.1$

$99.7 \% \quad 43.4$

$99.7 \% \quad 45.0$

$99.7 \% \quad 34.4$

$99.7 \% \quad 40.7$

$99.7 \% \quad 43.4$

$99.7 \% \quad 41.6$

$99.4 \% 23.8$

$98.8 \% \quad 34.0$
1423.79

1714.89

2506.3

1113.61

1276.76

1284.67

1161.62

2253.13

1037.58

1270.75

1019.55

1124.53

1131.64

1550.81

1424.71

2080.07

1634.75

1302.67

1207.57

1190.60

1494.74

1460.71

1567.83

984.51

1215.61

1160.55

1143.6

910.58

1119.55

1059.54

1225.59

1286.69

1110.62

1243.66

959.52

1100.57

1469.82

1242.68

962.48

1118.58

1412.79

1101.56

1042.59

1444.71

1100.59

901.51 $\begin{array}{cc}1 & 164 \\ 0 & 263 \\ 3 & 308 \\ 9 & 330 \\ & 16 \\ 7 & 27 \\ 4 & 45 \\ 2 & 71 \\ 0 & 190 \\ 1 & 200 \\ 1 & 213 \\ 4 & 222 \\ 3 & 231 \\ 4 & 333 \\ 33 & 356 \\ 4 & 57 \\ 1 & 209 \\ 2 & 287 \\ 5 & 646 \\ 6 & 716 \\ 9 & 789 \\ 64 & 1176 \\ 3 & 68 \\ 99 & 122 \\ 2 & 410 \\ 7 & 706 \\ 4 & 724 \\ 9 & 818 \\ 77 & 934 \\ 31 & 1139 \\ 34 & 1243 \\ 04 & 1313 \\ 25 & 1335 \\ 28 & 1438 \\ 54 & 1563 \\ 96 & 1603 \\ 06 & 1616 \\ 97 & 1709 \\ 99 & 1709 \\ 10 & 1718 \\ 10 & 1719 \\ 81 & 1792 \\ 36 & 1845 \\ 56 & 1854 \\ & 1866 \\ & \\ 67\end{array}$

Page 110 of Table S-1-6 
Plectin GN=PLEC Plectin GN=PLEC Plectin GN=PLEC Plectin GN=PLEC Plectin GN=PLEC Plectin GN=PLEC

Plectin GN=PLEC Plectin GN=PLEC Plectin GN=PLEC Plectin GN=PLEC Plectin GN=PLEC Plectin GN=PLEC Plectin GN=PLEC Plectin GN=PLEC

Plectin GN=PLEC Plectin GN=PLEC Plectin GN=PLEC Plectin GN=PLEC Plectin GN=PLEC

Plectin GN=PLEC Plectin GN=PLEC Plectin GN=PLEC Plectin GN=PLEC Plectin GN=PLEC Plectin GN=PLEC Plectin GN=PLEC Plectin GN=PLEC Plectin GN=PLEC Poly [ADP-ribose] polymerase 1 GN=PARP1 PARP1 HUMAN $113.09 \quad 100.0 \%$ Poly [ADP-ribose] polymerase 1 GN=PARP1 PARP1_HUMAN $113.09 \quad 100.0 \% \quad 22$ Poly [ADP-ribose] polymerase 1 GN=PARP1 PARP1_HUMAN $113.09 \quad 100.0 \% 22$ Poly [ADP-ribose] polymerase 1 GN=PARP1 PARP1_HUMAN $113.09 \quad 100.0 \% 22$ Poly [ADP-ribose] polymerase 1 GN=PARP1 PARP1_HUMAN $113.09 \quad 100.0 \%$ Poly [ADP-ribose] polymerase 1 GN=PARP1 PARP1_HUMAN $113.09 \quad 100.0 \%$ Poly [ADP-ribose] polymerase 1 GN=PARP1 PARP1_HUMAN $113.09 \quad 100.0 \%$ Poly [ADP-ribose] polymerase 1 GN=PARP1 PARP1_HUMAN $113.09 \quad 100.0 \% 22$ Poly [ADP-ribose] polymerase 1 GN=PARP1 PARP1_HUMAN $113.09 \quad 100.0 \% 22$ Poly [ADP-ribose] polymerase 1 GN=PARP1 PARP1_HUMAN $113.09 \quad 100.0 \% 22$ Poly [ADP-ribose] polymerase 1 GN=PARP1 PARP1_HUMAN $113.09 \quad 100.0 \% 22$ Poly [ADP-ribose] polymerase 1 GN=PARP1 PARP1_HUMAN $113.09 \quad 100.0 \% 22$ Poly [ADP-ribose] polymerase 1 GN=PARP1 PARP1_HUMAN $113.09 \quad 100.0 \%$ Poly [ADP-ribose] polymerase 1 GN=PARP1 PARP1_HUMAN $113.09 \quad 100.0 \% 22$ Poly [ADP-ribose] polymerase 1 GN=PARP1 PARP1_HUMAN $113.09 \quad 100.0 \% 22$ Poly [ADP-ribose] polymerase 1 GN=PARP1 PARP1_HUMAN $113.09 \quad 100.0 \% 22$ Poly [ADP-ribose] polymerase 1 GN=PARP1 PARP1_HUMAN $113.09 \quad 100.0 \% 22$ Poly [ADP-ribose] polymerase 1 GN=PARP1 PARP1_HUMAN $113.09 \quad 100.0 \%$ $\begin{array}{llll}54 & 88 & 0.10 \% & 11.0 \% \\ 54 & \text { LAEDEAFQR }\end{array}$ \begin{tabular}{llll}
54 & 88 & $0.10 \%$ & $11.0 \%$ \\
\hline & QVEEEILALK
\end{tabular} $\begin{array}{lllll}54 & 88 & 0.10 \% & 11.0 \% & \text { SKEQAELEAAR }\end{array}$ $\begin{array}{lllll}54 & 88 & 0.10 \% & 11.0 \% & \text { SLAAEEEAAR }\end{array}$ $\begin{array}{llll}54 & 88 & 0.10 \% & 11.0 \% \\ & & \text { QLQLAQEAAQK }\end{array}$ $\begin{array}{llll}54 & 88 & 0.10 \% & 11.0 \% \\ 54 & \text { LKQSAEEQAQAR }\end{array}$ $54 \quad 88 \quad 0.10 \% \quad 11.0 \%$ RAQAEQAALR $\begin{array}{lllll}54 & 88 & 0.10 \% & 11.0 \% & \text { AQVEQELTTLR }\end{array}$ $\begin{array}{lllll}54 & 88 & 0.10 \% & 11.0 \% & \text { LKAEATEAAR }\end{array}$

$\begin{array}{llll}54 & 88 & 0.10 \% & 11.0 \% \text { SQVEEELFSVR }\end{array}$

$\begin{array}{llll}54 & 88 & 0.10 \% & 11.0 \% \\ 54 S V A A Q E A A R\end{array}$

\begin{tabular}{llll}
54 & 88 & $0.10 \%$ & $11.0 \%$ \\
\hline & LRQLAEEDLAQQR
\end{tabular}

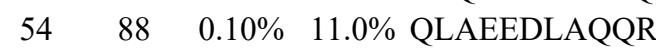

$\begin{array}{llll}54 & 88 & 0.10 \% & 11.0 \% \\ 54 & \text { QAEEIGEKLHR }\end{array}$

54

54

54

54

54

54 54

54

54

54

54

$0.10 \% \quad 11.0 \%$ LAQGHTTVDELAR

$0.10 \% \quad 11.0 \%$ VPVDVAYR

$0.10 \% \quad 11.0 \%$ ATVSAPFGK

$0.10 \% \quad 11.0 \%$ IIITVVEEQEQK

$0.10 \% \quad 11.0 \%$ SLVPAAELLESR

$0.10 \% \quad 11.0 \%$ LTVDEAVR

$0.10 \% \quad 11.0 \%$ ARQEELYSELQAR

$0.10 \% \quad 11.0 \%$ VPVDVAYQR

$0.10 \% \quad 11.0 \%$ ELIPTEEALR

$0.10 \% \quad 11.0 \%$ LTVEEAVR

$0.10 \% \quad 11.0 \%$ LLEAAAQSTK

$0.10 \% \quad 25.5 \%$ CSESIPKDSLR

$0.10 \% \quad 25.5 \%$ TLGDFAAEYAK

$0.10 \% \quad 25.5 \%$ KGDEVDGVDEVAK

$0.10 \% \quad 25.5 \%$ QQVPSGESAILDR

$0.10 \% \quad 25.5 \%$ ILTLGKLSR

$0.10 \% \quad 25.5 \%$ LGGKLTGTANK

$0.10 \% \quad 25.5 \%$ ASLCISTKK

$0.10 \% \quad 25.5 \%$ AEPVEVVAPR

$0.10 \% \quad 25.5 \%$ VFSATLGLVDIVK

$0.10 \% \quad 25.5 \%$ SKLPKPVQDLIK

$0.10 \% \quad 25.5 \%$ MIFDVESMKK

$0.10 \% \quad 25.5 \%$ AMVEYEIDLQK $\begin{array}{lllll}99.7 \% & 44.2 & 25.0 & 34.5 & 1\end{array}$ $99.7 \% \quad 54.4 \quad 25.0 \quad 44.3$ $\begin{array}{lllll}99.7 \% & 54.9 & 25.0 & 46.7 & 2\end{array}$ $\begin{array}{llll}99.7 \% & 46.8 & 25.0 & 36.0\end{array}$ $\begin{array}{llll}99.7 \% & 28.2 & 25.0 & 26.5\end{array}$ $99.7 \% \quad 49.6 \quad 25.0 \quad 48.5$ $99.7 \% \quad 38.0 \quad 25.0 \quad 31.8$ $99.7 \% \quad 68.1 \quad 25.0 \quad 62.4 \quad 2$ $\begin{array}{llll}99.7 \% & 44.5 & 25.0 & 43.5\end{array}$ $\begin{array}{llll}99.7 \% & 41.3 & 25.0 & 38.2\end{array}$ $99.7 \% \quad 70.0 \quad 25.0 \quad 45.1$ $\begin{array}{llll}99.6 \% & 28.5 & 25.0 & 17.2\end{array}$ $\begin{array}{llll}99.7 \% & 34.3 & 25.0 & 33.5\end{array}$ $\begin{array}{llll}99.6 \% & 26.8 & 25.0 & 23.5\end{array}$

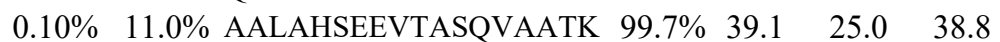

$0.10 \% \quad 11.0 \%$ APVPASELLASGVLSR

$0.10 \% \quad 11.0 \%$ SSSVGSSSSYPISPAVSR

$99.7 \% \quad 47.3$

$99.0 \% \quad 41.3$

$95.3 \% 14.1$

$99.7 \% \quad 46.6$

$96.1 \% 22.6$

$99.0 \% 26.1$

$99.7 \% \quad 44.6$

$99.7 \% \quad 44.8$

$99.7 \% \quad 27.0$

$98.5 \% \quad 20.8$

$99.0 \% \quad 31.0$

$99.7 \% \quad 38.4$

$98.7 \% \quad 24.1$

$99.7 \% \quad 50.5$

$0.10 \% \quad 25.5 \%$ TAEAGGVTGKGQDGIGSK $\quad 99.7 \% \quad 45.1$

$0.10 \% \quad 25.5 \%$ AEKTLGDFAAEYAK

$99.7 \% \quad 74.7$

$99.7 \% \quad 50.5$

$99.7 \% \quad 68.3$

$0.10 \% \quad 25.5 \%$ TLGDFAAEYAKSNR

$0.10 \% \quad 25.5 \%$ NREELGFRPEYSASQLK

$0.10 \% \quad 25.5 \%$ VVSEDFLQDVSASTK

$0.10 \% \quad 25.5 \%$ GGAAVDPDSGLEHSAHVLEK

$0.10 \% \quad 25.5 \%$ KPPLLNNADSVQAK $\begin{array}{lll}99.5 \% & 23.2\end{array}$

$99.7 \% \quad 34.5$

$99.7 \% \quad 65.8$

$99.7 \% \quad 44.9$

$99.7 \% \quad 62.0$

$99.7 \% \quad 26.2$

$99.7 \% \quad 51.4$

$99.7 \% \quad 51.0$

$99.7 \% \quad 29.0$

$99.7 \% \quad 25.7$

$98.2 \% \quad 22.8$

$99.7 \% \quad 58.9$

$99.7 \% \quad 50.5$

(0)

$231.63 \quad 2098 \quad 2108$

$046.51 \quad 2130 \quad 2139$

$\begin{array}{lll}1227.67 & 2172 & 2182\end{array}$

$\begin{array}{lll}358.70 & 2254 & 2265\end{array}$

$\begin{array}{lll}113.61 & 2286 & 2295\end{array}$

$\begin{array}{lll}1287.69 & 2319 & 2329 \\ 1059.58 & 2349 & 2358\end{array}$

$\begin{array}{lll}1322.66 & 2361 & 2371\end{array}$

$\begin{array}{lll}1015.55 & 2420 & 2429\end{array}$

$1569.83 \quad 2430 \quad 2442$

$1300.65 \quad 2432 \quad 2442$

$309.69 \quad 2546 \quad 2556$

$\begin{array}{lll}1783.92 & 2744 & 2761\end{array}$

$1410.73 \quad 2809 \quad 2821$

$\begin{array}{lll}18.50 & 2961 \quad 2968\end{array}$

$\begin{array}{lll}877.48 & 3045 & 3053\end{array}$

$\begin{array}{lll}428.79 & 3095 & 3106\end{array}$

$284.72 \quad 3116 \quad 3127$

$902.49 \quad 3213 \quad 3220$

$\begin{array}{lll}592.80 & 3356 & 3368\end{array}$

$1566.89 \quad 3447 \quad 3462$

$\begin{array}{lll}046.56 & 3620 & 3628 \\ 170.64 & 3926 & 3935\end{array}$

$\begin{array}{llll}916.51 & 4122 & 4129\end{array}$

$1754.86 \quad 4384 \quad 4401$

$\begin{array}{lll}1031.57 & 4600 & 4609\end{array}$

$1291.63 \quad 24 \quad 34$

$1632.82 \quad 88 \quad 105$

$\begin{array}{lcc}1513.75 & 106 & 119\end{array}$

$\begin{array}{lll}1185.58 & 109 & 119\end{array}$

$\begin{array}{lll}1542.75 & 109 & 122\end{array}$

$2024.02 \quad 166 \quad 182$

$\begin{array}{lll}360.66 & 209 & 221\end{array}$

$1399.72 \quad 270 \quad 282$

$1000.65 \quad 395 \quad 403$

$059.62 \quad 415 \quad 425$

$1007.56 \quad 426 \quad 434$

$1624.81 \quad 453 \quad 467$

$\begin{array}{lll}1066.59 & 487 & 496\end{array}$

$\begin{array}{lll}1988.97 & 529 & 548\end{array}$

$361.80 \quad 552 \quad 564$

$\begin{array}{lll}1365.85 & 663 & 674\end{array}$

$\begin{array}{lll}1227.61 & 675 & 684\end{array}$

$\begin{array}{lll}1354.66 & 685 & 695\end{array}$ 
Poly [ADP-ribose] polymerase 1 GN=PARP1 PARP1_HUMAN $113.09 \quad 100.0 \% \quad 22$

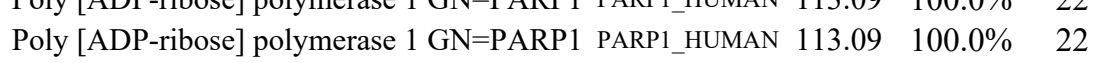
Poly [ADP-ribose] polymerase 1 GN=PARP1 PARP1_HUMAN $113.09 \quad 100.0 \% 22$ Poly(rC)-binding protein $1 \mathrm{GN}=\mathrm{PCBP}$ Poly(rC)-binding protein $1 \mathrm{GN}=\mathrm{PCBP} 1$ Poly(rC)-binding protein $1 \mathrm{GN}=\mathrm{PCBP} 1$ Poly $(\mathrm{rC})$-binding protein $1 \mathrm{GN}=\mathrm{PCBP} 1$ Poly $(\mathrm{rC})$-binding protein $1 \mathrm{GN}=\mathrm{PCBP} 1$ Poly $(\mathrm{rC})$-binding protein $1 \mathrm{GN}=\mathrm{PCBP}$ Poly $(\mathrm{rC})$-binding protein $1 \mathrm{GN}=\mathrm{PCBP} 1$ Poly $(\mathrm{rC})$-binding protein $1 \mathrm{GN}=\mathrm{PCBP} 1$ Poly(rC)-binding protein $2 \mathrm{GN}=\mathrm{PCBP} 2$ Poly $(\mathrm{rC})$-binding protein $2 \mathrm{GN}=\mathrm{PCBP} 2$ Poly(rC)-binding protein $2 \mathrm{GN}=\mathrm{PCBP} 2$ Poly(rC)-binding protein $2 \mathrm{GN}=\mathrm{PCBP} 2$ Poly $(\mathrm{rC})$-binding protein $2 \mathrm{GN}=\mathrm{PCBP} 2$ Poly(rC)-binding protein $2 \mathrm{GN}=\mathrm{PCBP} 2$ Poly(rC)-binding protein $2 \mathrm{GN}=\mathrm{PCBP} 2$ Poly(rC)-binding protein $2 \mathrm{GN}=\mathrm{PCBP} 2$ PCBP1 HUMAN $37.50 \quad 100.0 \%$ PCBP1_HUMAN $37.50 \quad 100.0 \%$ PCBP1_HUMAN $37.50 \quad 100.0 \%$ PCBP1_HUMAN $37.50-100.0 \%$ PCBP1_HUMAN $37.50 \quad 100.0 \%$ PCBP1_HUMAN $37.50 \quad 100.0 \%$ PCBP1_HUMAN $37.50 \quad 100.0 \%$ PCBP1_HUMAN $37.50 \quad 100.0 \%$ PCBP2 HUMAN $38.58 \quad 100.0 \%$ PCBP2_HUMAN $38.58 \quad 100.0 \%$ PCBP2_HUMAN $38.58 \quad 100.0 \%$ PCBP2 HUMAN $38.58 \quad 100.0 \%$ PCBP2_HUMAN $38.58 \quad 100.0 \%$ PCBP2 HUMAN $38.58 \quad 100.0 \%$ PCBP2_HUMAN $38.58 \quad 100.0 \%$ PCBP2_HUMAN $38.58 \quad 100.0 \%$ Poly(U)-binding-splicing factor PUF60 GN=PUF60 PUF60_HUMAN $59.88 \quad 100.0 \%$ Poly(U)-binding-splicing factor PUF60 GN=PUF60 PUF60_HUMAN $59.88 \quad 100.0 \%$ Poly(U)-binding-splicing factor PUF60 GN=PUF60 PUF60 HUMAN $59.88 \quad 100.0 \%$ Poly(U)-binding-splicing factor PUF60 GN=PUF60 PUF60_HUMAN $59.88 \quad 100.0 \%$ Poly(U)-binding-splicing factor PUF60 GN=PUF60 PUF60_HUMAN $59.88 \quad 100.0 \%$ Poly(U)-binding-splicing factor PUF60 GN=PUF60 PUF60 HUMAN $59.88100 .0 \%$ Polyadenylate-binding protein $1 \mathrm{GN}=$ PABPC1 PABP1_HUMAN $70.67 \quad 100.0 \%$ Polyadenylate-binding protein $1 \mathrm{GN}=$ PABPC1 PABP1_HUMAN $70.67 \quad 100.0 \%$ Polyadenylate-binding protein $1 \mathrm{GN}=$ PABPC1 1 PABP1_HUMAN $70.67 \quad 100.0 \% 3$ Polyadenylate-binding protein $1 \mathrm{GN}=$ PABPC1 PABP1_HUMAN $70.67 \quad 100.0 \% \quad 32$ Polyadenylate-binding protein $1 \mathrm{GN}=$ PABPC1 PABP1_HUMAN $70.67 \quad 100.0 \%$ Polyadenylate-binding protein $1 \mathrm{GN}=\mathrm{PABPC} 1 \mathrm{PABP} 1$ HUMAN $70.67 \quad 100.0 \% \quad 32$ Polyadenylate-binding protein $1 \mathrm{GN}=$ PABPC1 PABP1_HUMAN $70.67 \quad 100.0 \% \quad 32$ Polyadenylate-binding protein $1 \mathrm{GN}=$ PABPC1 PABP1_HUMAN $70.67 \quad 100.0 \% \quad 32$ Polyadenylate-binding protein $1 \mathrm{GN}=$ PABPC1 PABP1_HUMAN $70.67 \quad 100.0 \% \quad 32$ Polyadenylate-binding protein $1 \mathrm{GN}=$ PABPC1 1 PABP1_HUMAN $70.67 \quad 100.0 \% 32$ Polyadenylate-binding protein $1 \mathrm{GN}=$ PABPC1 PABP1_HUMAN $70.67 \quad 100.0 \% \quad 32$ Polyadenylate-binding protein $1 \mathrm{GN}=$ PABPC1 PABP1_HUMAN $70.67 \quad 100.0 \% \quad 32$ Polyadenylate-binding protein $1 \mathrm{GN}=$ PABPC1 PABP1_HUMAN $70.67 \quad 100.0 \% \quad 32$ Polyadenylate-binding protein $1 \mathrm{GN}=$ PABPC1 PABP1_HUMAN $70.67 \quad 100.0 \% \quad 32$ Polyadenylate-binding protein $1 \mathrm{GN}=\mathrm{PABPC} 1 \quad \mathrm{PABP} 1$ HUMAN $70.67 \quad 100.0 \% \quad 32$ Polyadenylate-binding protein $1 \mathrm{GN}=$ PABPC1 PABP1_HUMAN $70.67 \quad 100.0 \% 32$ Polyadenylate-binding protein $1 \mathrm{GN}=$ PABPC1 PABP1_HUMAN $70.67 \quad 100.0 \%$ Polyadenylate-binding protein $1 \mathrm{GN}=$ PABPC1 PABP1_HUMAN $70.67 \quad 100.0 \% \quad 32$ Polyadenylate-binding protein $1 \mathrm{GN}=$ PABPC1 PABP1_HUMAN $70.67 \quad 100.0 \% \quad 32$ Polyadenylate-binding protein $1 \mathrm{GN}=$ PABPC1 PABP1_HUMAN $70.67 \quad 100.0 \%$ Polyadenylate-binding protein $1 \mathrm{GN}=$ PABPC1 PABP1_HUMAN $70.67 \quad 100.0 \%$ Polyadenylate-binding protein $1 \mathrm{GN}=$ PABPC1 1 PABP1_HUMAN $70.67 \quad 100.0 \% \quad 32$
$29 \quad 85 \quad 0.10 \% \quad 25.5 \%$ VVDRDSEEAEIIR $85 \quad 0.10 \% \quad 25.5 \%$ GIYFADMVSK $0.06 \% \quad 28.7 \%$ EVGSIIGK

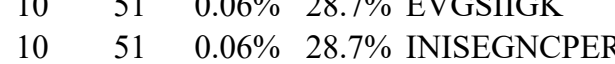

$10 \quad 51 \quad 0.06 \% \quad 28.7 \%$ IITLTGPTNAIFK

$\begin{array}{lll}9.7 \% & 27.5 & 25.0\end{array}$

$99.7 \%$ 49.9 $99.0 \% \quad 28.4$

$99.7 \% 55$. $99.7 \% \quad 49.3$

$99.7 \% \quad 60.0$

$0.06 \% \quad 28.7 \%$ LVVPATQCGSLIGK

$\begin{array}{ll}99.7 \% & 60.0 \\ 99.7 \% & 55.2\end{array}$

$99.7 \% \quad 51.0$

$99.7 \% 55.6$

$99.7 \% \quad 67.3$

$99.0 \% \quad 28.4$

$99.7 \% 55.1$

$99.7 \% \quad 53.0$

$99.7 \% \quad 56.8$

$0.04 \% \quad 31.8 \%$ INISEGNCPER

$0.04 \% \quad 31.8 \%$ IITLAGPTNAIFK

$0.04 \% 31.8 \%$ LVVPASQCGSLIGK

$99.7 \% \quad 55.2$

$99.7 \% \quad 53.0$

$0.04 \% \quad 31.8 \%$ AITIAGIPQSIIECVK

$0.04 \% \quad 31.8 \%$ GVTIPYRPKPSSSPVIFAGGQDR

$34 \quad 0.04 \% \quad 31.8 \%$ IANPVEGSTDR

$0.02 \% \quad 12.7 \%$ LGLPPLTPEQQEALQK

$0.02 \% \quad 12.7 \%$ YAMEQSIK

$19 \quad 0.02 \% \quad 12.7 \%$ VYVGSIYYELGEDTIR

$0.02 \% \quad 12.7 \%$ SCTLARDPTTGK

$19 \quad 0.02 \% \quad 12.7 \%$ GYGFIEYEK

$19 \quad 0.02 \% \quad 12.7 \%$ KQESTVMVLR

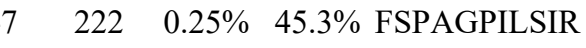

$47 \quad 222 \quad 0.25 \% \quad 45.3 \%$ VCRDMITR

$\begin{array}{ll}99.7 \% & 33.2 \\ 99.7 \% & 54.0\end{array}$

$99.7 \% \quad 29.0$

$99.0 \% \quad 24.9$

$99.7 \% \quad 63.5$

$99.7 \% \quad 38.3$

$99.7 \% \quad 40.9$

$99.7 \% \quad 48.4$

$99.7 \% \quad 38.4$

$97.9 \% \quad 23.9$
$222 \quad 0.25 \% \quad 45.3 \%$ RSLGYAYVNFQQPADAER

$222 \quad 0.25 \% \quad 45.3 \%$ SLGYAYVNFQQPADAER $222 \quad 0.25 \% \quad 45.3 \%$ ALDTMNFDVIK

$2220.25 \% \quad 45.3 \%$ KSGVGNIFIK

$222 \quad 0.25 \% \quad 45.3 \%$ SGVGNIFIKNLDK

$222 \quad 0.25 \% \quad 45.3 \%$ ALYDTFSAFGNILSCK

$222 \quad 0.25 \% \quad 45.3 \%$ GYGFVHFETQEAAER

$222 \quad 0.25 \% \quad 45.3 \%$ AKEFTNVYIK

$222 \quad 0.25 \% \quad 45.3 \%$ EFTNVYIK

$0.25 \% \quad 45.3 \%$ FGPALSVK

$222 \quad 0.25 \% \quad 45.3 \%$ GFGFVSFER

$222 \quad 0.25 \% \quad 45.3 \%$ GFGFVSFERHEDAQK

$222 \quad 0.25 \% \quad 45.3 \%$ AVDEMNGKELNGK

$0.25 \% \quad 45.3 \%$ ITRYQGVNLYVK

$222 \quad 0.25 \% \quad 45.3 \%$ YQGVNLYVK

$222 \quad 0.25 \% \quad 45.3 \%$ NLDDGIDDERLR

$222 \quad 0.25 \% \quad 45.3 \%$ KEFSPFGTITSAK

$222 \quad 0.25 \% \quad 45.3 \%$ EFSPFGTITSAK

$222 \quad 0.25 \% \quad 45.3 \%$ SKGFGFVCFSSPEEATK
$99.7 \% 54$.

$99.7 \% \quad 58.8$

$99.7 \% \quad 38.8$

$99.7 \% \quad 61.7$

$\begin{array}{lll}99.7 \% & 54.2\end{array}$

$99.7 \% \quad 45.8$

$99.7 \% \quad 55.2$

$99.7 \% \quad 35.9$

$99.0 \% \quad 31.9$

$99.0 \% \quad 54.7$

$99.7 \% \quad 42.8$

$99.6 \% \quad 23.8$

$99.5 \% \quad 31.4$

$99.7 \% \quad 51.3$

$99.7 \% \quad 49.8$

$99.7 \% \quad 42.8$

$99.7 \% \quad 42.5$

$99.7 \% \quad 58.6$

$99.7 \% \quad 56.9$
530.78

1377.75

1146.55

802.47

1288.60

1388.82

1442.80

2105.98

1672.89

1014.53

1086.55

802.47

1288.60

1358.80

1428.79

2105.98

1712.96

2429.29

1158.58

1761.97

969.47

1876.93

1306.64

1105.52

1190.66

1157.67

1050.52

2085.0

1928.91

1266.64

1062.63

934.54

1404.78

1806.87

1740.80

1212.66

1013.53

818.48

1045.51

1753.83

1420.67

1453.82

1083.58

1430.69

1412.74

1284.65

1284.65
1877.87

\begin{tabular}{cc}
03 & 815 \\
66 & 878 \\
94 & 903 \\
4 & 31 \\
7 & 57 \\
8 & 70 \\
02 & 115 \\
25 & 144 \\
45 & 160 \\
98 & 306 \\
15 & 325 \\
4 & 31 \\
7 & 57 \\
8 & 70 \\
02 & 115 \\
25 & 144 \\
45 & 160 \\
77 & 199 \\
23 & 333 \\
4 & 69 \\
3 & 80 \\
31 & 146 \\
54 & 265 \\
68 & 276 \\
58 & 467 \\
1 & 41 \\
2 & 49 \\
0 & 67 \\
1 & 67 \\
8 & 78 \\
5 & 104 \\
6 & 104 \\
6 & 108 \\
14 & 129 \\
39 & 153 \\
87 & 196 \\
89 & 196 \\
14 & 221 \\
32 & 240 \\
32 & 246 \\
47 & 259 \\
88 & 299 \\
91 & 299 \\
00 & 311 \\
12 & 324 \\
13 & 324 \\
32 & 348 \\
& \\
\hline 0
\end{tabular}

Page 112 of Table S-1-6 
Polypyrimidine tract-binding protein $1 \mathrm{GN}=$ PTBP1 PTBP1_HUMAN $57.22 \quad 100.0 \% \quad 1$ Polypyrimidine tract-binding protein $1 \mathrm{GN}=$ PTBP1 PTBP1_HUMAN $57.22 \quad 100.0 \%$ Polypyrimidine tract-binding protein $1 \mathrm{GN}=$ PTBP1 PTBP1_HUMAN $57.22 \quad 100.0 \% \quad 1$ Polypyrimidine tract-binding protein $1 \mathrm{GN}=\mathrm{PTBP} 1$ PTBP1_HUMAN $57.22 \quad 100.0 \%$ Polypyrimidine tract-binding protein $1 \mathrm{GN}=$ PTBP1 PTBP1_HUMAN $57.22 \quad 100.0 \%$ Polypyrimidine tract-binding protein $1 \mathrm{GN}=$ PTBP1 PTBP1_HUMAN $57.22 \quad 100.0 \%$ Polypyrimidine tract-binding protein $1 \mathrm{GN}=$ PTBP1 PTBP1_HUMAN $57.22 \quad 100.0 \%$ Polypyrimidine tract-binding protein $1 \mathrm{GN}=$ PTBP1 PTBP1_HUMAN $57.22 \quad 100.0 \%$ Polypyrimidine tract-binding protein $1 \mathrm{GN}=$ PTBP1 PTBP1 HUMAN $57.22 \quad 100.0 \%$ Polypyrimidine tract-binding protein $1 \mathrm{GN}=$ PTBP1 PTBP1_HUMAN $57.22 \quad 100.0 \%$ Polypyrimidine tract-binding protein $1 \mathrm{GN}=$ =PTBP1 PTBP1_HUMAN $57.22 \quad 100.0 \% \quad 13$ Polypyrimidine tract-binding protein $1 \mathrm{GN}=$ PTBP1 PTBP1_HUMAN $57.22 \quad 100.0 \%$ Polypyrimidine tract-binding protein 1 GN=PTBP1 PTBP1_HUMAN $57.22 \quad 100.0 \%$ Prelamin-A/C GN=LMNA

Prelamin-A/C GN=LMNA

Prelamin-A/C GN=LMN

Prelamin-A/C GN=LMN

Prelamin-A/C GN=LMNA

LMNA_HUMAN $74.14 \quad 100.0 \%$

LMNA HUMAN $74.14 \quad 100.0 \%$ LMNA_HUMAN $74.14 \quad 100.0 \%$ LMNA HUMAN $74.14 \quad 100.0 \%$ LMNA HUMAN $74.14 \quad 100.0 \%$ Pre-mRNA 3'-end-processing factor FIP1 GN=FIP1L1 FIP1_HUMAN $66.53 \quad 100.0 \%$ Pre-mRNA 3'-end-processing factor FIP1 GN=FIP1L1 FIP1 HUMAN $66.53 \quad 100.0 \%$ Pre-mRNA-processing factor 19 GN=PRPF19 PRP19_HUMAN $55.18 \quad 100.0 \%$ Pre-mRNA-processing factor $19 \mathrm{GN}=$ PRPF19 PRP19 HUMAN $55.18 \quad 100.0 \%$ Pre-mRNA-processing factor 19 GN=PRPF19 PRP19_HUMAN $55.18 \quad 100.0 \%$ Pre-mRNA-processing factor 19 GN=PRPF19 PRP19_HUMAN $55.18 \quad 100.0 \%$ Pre-mRNA-processing factor $19 \mathrm{GN}=\mathrm{PRPF} 19$ PRP19 HUMAN $55.18 \quad 100.0 \%$ Pre-mRNA-processing factor 19 GN=PRPF19 PRP19_HUMAN $55.18 \quad 100.0 \%$ Pre-mRNA-processing factor $19 \mathrm{GN}=$ PRPF19 PRP19_HUMAN $55.18 \quad 100.0 \%$ Pre-mRNA-processing factor 6 GN=PRPF6 PRP6_HUMAN $106.93100 .0 \%$ Pre-mRNA-processing factor 6 GN=PRPF6 PRP6_HUMAN $106.93 \quad 100.0 \%$ Pre-mRNA-processing factor $6 \mathrm{GN}=$ PRPF6 PRP6 HUMAN $106.93 \quad 100.0 \%$ Pre-mRNA-processing factor 6 GN=PRPF6 PRP6_HUMAN $106.93 \quad 100.0 \%$ Pre-mRNA-processing factor 6 GN=PRPF6 PRP6_HUMAN $106.93 \quad 100.0 \%$ Pre-mRNA-processing factor 6 GN=PRPF6 PRP6 HUMAN $106.93 \quad 100.0 \%$ Pre-mRNA-processing factor 6 GN=PRPF6 PRP6_HUMAN $106.93 \quad 100.0 \%$ Pre-mRNA-processing-splicing factor $8 \mathrm{GN}=$ PRPF8 PRP8_HUMAN $273.61 \quad 100.0 \%$ Pre-mRNA-processing-splicing factor $8 \mathrm{GN}=$ PRPF8 PRP8 HUMAN $273.61 \quad 100.0 \%$ Pre-mRNA-processing-splicing factor 8 GN=PRPF8 PRP8_HUMAN $273.61 \quad 100.0 \%$ Pre-mRNA-processing-splicing factor 8 GN=PRPF8 PRP8 HUMAN $273.61 \quad 100.0 \%$ Pre-mRNA-processing-splicing factor 8 GN=PRPF8 PRP8_HUMAN $273.61 \quad 100.0 \%$ Pre-mRNA-processing-splicing factor 8 GN=PRPF8 PRP8_HUMAN $273.61100 .0 \%$ Pre-mRNA-processing-splicing factor $8 \mathrm{GN}=$ PRPF8 PRP8 HUMAN $273.61 \quad 100.0 \%$ Pre-mRNA-processing-splicing factor 8 GN=PRPF8 PRP8_HUMAN 273.61 $100.0 \%$ Pre-mRNA-processing-splicing factor 8 GN=PRPF8 PRP8 HUMAN $273.61 \quad 100.0 \%$ Pre-mRNA-processing-splicing factor $8 \mathrm{GN}=$ =PRPF8 PRP8 HUMAN $273.61 \quad 100.0 \%$ Pre-mRNA-processing-splicing factor 8 GN=PRPF8 PRP8_HUMAN $273.61 \quad 100.0 \%$ Pre-mRNA-processing-splicing factor 8 GN=PRPF8 PRP8 HUMAN $273.61 \quad 100.0 \%$ Pre-mRNA-processing-splicing factor 8 GN=PRPF8 PRP8_HUMAN $273.61 \quad 100.0 \%$ $\begin{array}{llll}16 & 39 & 0.04 \% & 31.8 \% \\ 16 & 39 & 0.04 \% & 31.8 \%\end{array}$ $\begin{array}{llllllll}99.7 \% & 28.8 & 25.0 & 28.8 & 0 & 2 & 0 & 1291.76\end{array}$ 947.56

1345.67 2243.12

1897.89

1364.78 2275.28

991.54

2144.00

1058.50

1106.62

868.48

1359.69

1293.64

1752.86

1699.97

1491.75

1629.83

1473.73

988.58

1374.76

1782.99

1597.87

1614.84

1320.68

1013.47

1262.69

1342.77

813.49

1017.52

1216.65

1058.58

1344.77

1084.58

1024.65

868.55

1122.54

983.56

1121.53

1215.65

819.44

1149.63

940.62

$\begin{array}{llllllll}99.0 \% & 34.1 & 25.0 & 23.4 & 1 & 0 & 0 & 937.54 \\ 99.0 \% & 53.1 & 25.0 & 33.2 & 4 & 0 & 0 & 957.57\end{array}$

$\begin{array}{llllllll}99.0 \% & 34.1 & 25.0 & 23.4 & 1 & 0 & 0 & 937.54 \\ 99.0 \% & 53.1 & 25.0 & 33.2 & 4 & 0 & 0 & 957.57\end{array}$

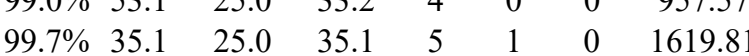

64
84
92
146
238
254
266
348
418
437
437
482
531
25
90
296
311
541
344
344
128
187
206
206
303
439
497
147
329
367
387
389
599
802
278
428
428
442
460
548
565
623
790

845

Page 114 of Table S-1-6 
Pre-mRNA-processing-splicing factor 8 GN=PRPF8 PRP8_HUMAN $273.61 \quad 100.0 \% \quad 36$ Pre-mRNA-processing-splicing factor 8 GN=PRPF8 PRP8_HUMAN $273.61 \quad 100.0 \% 36$ Pre-mRNA-processing-splicing factor 8 GN=PRPF8 PRP8_HUMAN $273.61 \quad 100.0 \% \quad 36$ Pre-mRNA-processing-splicing factor 8 GN=PRPF8 PRP8_HUMAN $273.61 \quad 100.0 \% \quad 36$ Pre-mRNA-processing-splicing factor 8 GN=PRPF8 PRP8_HUMAN $273.61 \quad 100.0 \% \quad 36$ Pre-mRNA-processing-splicing factor 8 GN=PRPF8 PRP8_HUMAN $273.61 \quad 100.0 \% \quad 36$ Pre-mRNA-processing-splicing factor 8 GN=PRPF8 PRP8_HUMAN $273.61 \quad 100.0 \% 36$ Pre-mRNA-processing-splicing factor 8 GN=PRPF8 PRP8_HUMAN $273.61 \quad 100.0 \% \quad 36$ Pre-mRNA-processing-splicing factor 8 GN=PRPF8 PRP8 HUMAN $273.61 \quad 100.0 \% 36$ Pre-mRNA-processing-splicing factor 8 GN=PRPF8 PRP8_HUMAN $273.61 \quad 100.0 \% 36$ Pre-mRNA-processing-splicing factor 8 GN=PRPF8 PRP8_HUMAN $273.61 \quad 100.0 \% 36$ Pre-mRNA-processing-splicing factor 8 GN=PRPF8 PRP8_HUMAN $273.61 \quad 100.0 \% 36$ Pre-mRNA-processing-splicing factor 8 GN=PRPF8 PRP8_HUMAN $273.61 \quad 100.0 \% \quad 36$ Pre-mRNA-processing-splicing factor 8 GN=PRPF8 PRP8_HUMAN $273.61 \quad 100.0 \% \quad 36$ Pre-mRNA-processing-splicing factor 8 GN=PRPF8 PRP8_HUMAN $273.61 \quad 100.0 \% \quad 36$ Pre-mRNA-processing-splicing factor 8 GN=PRPF8 PRP8_HUMAN $273.61 \quad 100.0 \% 36$ Pre-mRNA-processing-splicing factor $8 \mathrm{GN}=$ PRPF8 PRP8_HUMAN $273.61 \quad 100.0 \% 3$ Pre-mRNA-processing-splicing factor 8 GN=PRPF8 PRP8_HUMAN $273.61 \quad 100.0 \% \quad 36$ Pre-mRNA-processing-splicing factor 8 GN=PRPF8 PRP8_HUMAN $273.61 \quad 100.0 \% \quad 36$ Pre-mRNA-processing-splicing factor 8 GN=PRPF8 PRP8_HUMAN $273.61 \quad 100.0 \% 36$ Pre-mRNA-processing-splicing factor 8 GN=PRPF8 PRP8_HUMAN $273.61 \quad 100.0 \% \quad 36$ Pre-mRNA-processing-splicing factor 8 GN=PRPF8 PRP8_HUMAN $273.61 \quad 100.0 \% 36$ Pre-mRNA-processing-splicing factor 8 GN=PRPF8 PRP8_HUMAN $273.61 \quad 100.0 \% \quad 36$ Pre-mRNA-splicing factor ATP-dependent RNA helicase DHX15 GN=DHX15 DHX15_HUMAN $90.94 \quad 100.0 \%$ Pre-mRNA-splicing factor ATP-dependent RNA helicase DHX15 GN=DHX15 DHX15 HUMAN $90.94 \quad 100.0 \%$ Pre-mRNA-splicing factor ATP-dependent RNA helicase DHX15 GN=DHX15 DHX15_HUMAN $90.94 \quad 100.0 \%$ Pre-mRNA-splicing factor ATP-dependent RNA helicase DHX15 GN=DHX15 DHX15_HUMAN $90.94 \quad 100.0 \%$ Pre-mRNA-splicing factor ATP-dependent RNA helicase DHX15 GN=DHX15 DHX15 HUMAN $90.94 \quad 100.0 \%$ Pre-mRNA-splicing factor ATP-dependent RNA helicase DHX15 GN=DHX15 DHX15_HUMAN $90.94 \quad 100.0 \%$ Pre-mRNA-splicing factor ISY1 homolog GN=ISY1 ISY1_HUMAN $32.99 \quad 100.0 \%$ Pre-mRNA-splicing factor ISY1 homolog GN=ISY1 ISY1_HUMAN $32.99 \quad 100.0 \%$ Pre-mRNA-splicing factor ISY1 homolog GN=ISY1 ISY1_HUMAN $32.99 \quad 100.0 \%$ Pre-mRNA-splicing factor ISY1 homolog GN=ISY1 ISY1_HUMAN $32.99 \quad 100.0 \%$ Pre-mRNA-splicing factor SYF1 GN=XAB2 SYF1_HUMAN $100.01 \quad 100.0 \%$ Pre-mRNA-splicing factor SYF1 GN=XAB2 SYF1 HUMAN $100.01 \quad 100.0 \%$ Pre-mRNA-splicing factor SYF1 GN=XAB2 SYF1_HUMAN $100.01 \quad 100.0 \%$ Pre-mRNA-splicing factor SYF1 GN=XAB2 SYF1_HUMAN $100.01 \quad 100.0 \%$ Pre-mRNA-splicing factor SYF1 GN=XAB2 SYF1_HUMAN $100.01 \quad 100.0 \%$ pre-rRNA processing protein FTSJ3 GN=FTSJ3 SPB1_HUMAN $96.56 \quad 100.0 \%$ pre-rRNA processing protein FTSJ3 GN=FTSJ3 SPB1_HUMAN $96.56 \quad 100.0 \%$ pre-rRNA processing protein FTSJ3 GN=FTSJ3 SPB1_HUMAN $96.56 \quad 100.0 \%$ pre-rRNA processing protein FTSJ3 GN=FTSJ3 SPB1_HUMAN $96.56 \quad 100.0 \%$ pre-rRNA processing protein FTSJ3 GN=FTSJ3 SPB1 HUMAN $96.56 \quad 100.0 \%$ Probable 28S rRNA (cytosine(4447)-C(5))-methyltransferase GN=NOP2 NOP2_HUMAN $89.30 \quad 100.0 \%$ Probable 28S rRNA (cytosine(4447)-C(5))-methyltransferase GN=NOP2 NOP2_HUMAN $89.30 \quad 100.0 \%$ Probable 28S rRNA (cytosine(4447)-C(5))-methyltransferase GN=NOP2 NOP2_HUMAN $89.30 \quad 100.0 \%$ Probable 28S rRNA (cytosine(4447)-C(5))-methyltransferase GN=NOP2 NOP2_HUMAN $89.30 \quad 100.0 \%$
$111 \quad 0.13 \% \quad 14.5 \%$ FTADEARDLIQR

$111-0.13 \% \quad 14.5 \%$ YLTEHPDPNNENIVGYNR

$111 \quad 0.13 \% \quad 14.5 \%$ YLTEHPDPNNENIVGYNNKK

$111 \quad 0.13 \% \quad 14.5 \%$ TSYEEFTHK

$111 \quad 0.13 \% \quad 14.5 \%$ QILMASGSTTFTK

$111 \quad 0.13 \% \quad 14.5 \%$ QTDVGITHFR

$111 \quad 0.13 \% \quad 14.5 \%$ TDFKQYQVLK

$111 \quad 0.13 \% \quad 14.5 \%$ ASGFEESMK

$111 \quad 0.13 \% \quad 14.5 \%$ SGLNQIPNR

$111 \quad 0.13 \% \quad 14.5 \%$ SGLNQIPNRR

$111 \quad 0.13 \% \quad 14.5 \%$ ANPALYVLR

$111 \quad 0.13 \% \quad 14.5 \%$ SLPVEEQPK

$111 \quad 0.13 \% \quad 14.5 \%$ GSELQLPFQACLKVEK

$111 \quad 0.13 \% \quad 14.5 \%$ TISSYTAFSR

$111 \quad 0.13 \% \quad 14.5 \%$ QQIAEIEKQTK

$111 \quad 0.13 \% \quad 14.5 \%$ QTKEQSQLTATQTR

$111 \quad 0.13 \% \quad 14.5 \%$ EQSQLTATQTR

$111 \quad 0.13 \% \quad 14.5 \%$ HGDEIITSTTSNYETQTFSSK

$111 \quad 0.13 \% \quad 14.5 \%$ AISAANLHLR

$111 \quad 0.13 \% \quad 14.5 \%$ KFICISDLR

$111 \quad 0.13 \% \quad 14.5 \%$ FICISDLR

$111 \quad 0.13 \% \quad 14.5 \%$ AQIAGYLYGVSPPDNPQVK

$111 \quad 0.13 \% \quad 14.5 \%$ GYLPSHYER

$15 \quad 0.02 \% \quad 8.6 \%$ HRLDLGEDYPSGK

$15 \quad 0.02 \% \quad 8.6 \% \quad$ VAAMSVAQR

$15 \quad 0.02 \% \quad 8.6 \%$ YGVIILDEAHER

$15 \quad 0.02 \% \quad 8.6 \% \quad$ IRVESLLVTAISK

$15 \quad 0.02 \% \quad 8.6 \% \quad$ SNLGSVVLQLKK

$15 \quad 0.02 \% \quad 8.6 \%$ LQSKEYSQY

$9 \quad 0.01 \% \quad 16.8 \%$ VAQIQNAGLGEFR

$9 \quad 0.01 \% \quad 16.8 \%$ IRDLNDEINK

$9 \quad 0.01 \% \quad 16.8 \%$ IKELGGPDYGK

$9 \quad 0.01 \% \quad 16.8 \%$ YASETLQAQSEEAR

$11 \quad 0.01 \% \quad 6.4 \%$ YIEFKQGAPKPR

$11 \quad 0.01 \% \quad 6.4 \% \quad$ SHPLPETAVR

$11 \quad 0.01 \% \quad 6.4 \% \quad$ SSDRLDEAAQR

$11 \quad 0.01 \% \quad 6.4 \%$ LATVVNDERFVSK

$13 \quad 0.01 \% \quad 6.7 \%$ LACDFLAR

$13 \quad 0.01 \% \quad 6.7 \%$ AEGYAEGDLTLYHR

$13 \quad 0.01 \% \quad 6.7 \% \quad$ TSVTDFLR

$13 \quad 0.01 \% \quad 6.7 \% \quad$ AANPVDFLSK

$13 \quad 0.01 \% \quad 6.7 \% \quad$ ILDPEGLALGAVIASSK

$0.01 \% \quad 8.1 \%$ GAETELVR

$0.01 \% \quad 8.1 \%$ KGPQSLFNAPR

$0.01 \% \quad 8.1 \%$ IQDIVGILR

$0.01 \% \quad 8.1 \%$ NTGVILANDANAERLK
$11 \quad 0.01 \% \quad 6.4 \% \quad$ ALPITQHSR $\begin{array}{ll}98.5 \% & 21.7\end{array}$

$99.7 \% \quad 29.2$

$95.5 \% \quad 18.2$

$99.7 \% \quad 50.6$

$99.7 \% \quad 50.7$

$99.7 \% \quad 27.7$

$97.9 \% \quad 22.7$

$99.7 \% \quad 35.4$

$96.9 \% \quad 17.1$

$99.7 \% \quad 44.5$

$99.7 \% \quad 30.1$

$95.6 \% \quad 15.5$

$99.7 \% \quad 41.3$

$95.5 \% \quad 15.5$

$99.6 \% \quad 26.0$

$99.7 \% \quad 55.6$

$99.7 \% \quad 28.3$

$\begin{array}{lll}99.7 \% & 54.7\end{array}$

$97.2 \% \quad 16.4$

$99.0 \% \quad 44.4$

$9.7 \% \quad 38.5$

$99.7 \% \quad 33.3$

$99.7 \% \quad 51.6$

$99.7 \% \quad 59.0$

$99.7 \% \quad 37.5$

$99.7 \% \quad 50.6$

$99.7 \% \quad 56.2$

$99.7 \% \quad 26.7$

$99.7 \% \quad 51.7$

$\begin{array}{lll}98.7 \% & 25.0\end{array}$

$99.7 \% \quad 43.5$

$99.7 \% \quad 52.9$

$99.1 \% \quad 26.2$

$99.7 \% \quad 33.1$

$\begin{array}{lll}99.7 \% & 27.7\end{array}$

$99.7 \% \quad 30.4$

$\begin{array}{lll}99.7 \% & 57.9\end{array}$

$99.0 \% \quad 40.8$

$99.7 \% \quad 34.8$

$99.0 \% \quad 53.5$

$99.3 \% \quad 23.0$

$99.7 \% \quad 65.1$

$98.4 \% \quad 28.3$

$99.5 \% \quad 26.3$

$99.7 \% \quad 27.5$

$99.5 \% \quad 22.5$
143

(14)



Probable ATP-dependent RNA helicase DDX28 GN=DDX28 DDX28_HUMAN $59.58 \quad 100.0 \%$ Probable ATP-dependent RNA helicase DDX28 GN=DDX28 DDX28 HUMAN $59.58 \quad 100.0 \%$ Probable ATP-dependent RNA helicase DDX28 GN=DDX28 DDX28_HUMAN $59.58 \quad 100.0 \%$ Probable ATP-dependent RNA helicase DDX28 GN=DDX28 DDX28_HUMAN $59.58 \quad 100.0 \%$ Probable ATP-dependent RNA helicase DDX41 GN=DDX41 DDX41_HUMAN $69.84 \quad 100.0 \%$ Probable ATP-dependent RNA helicase DDX41 GN=DDX41 DDX41_HUMAN $69.84 \quad 100.0 \%$ Probable ATP-dependent RNA helicase DDX46 GN=DDX46 DDX46_HUMAN $117.37 \quad 100.0 \%$ Probable ATP-dependent RNA helicase DDX46 GN=DDX46 DDX46_HUMAN $117.37 \quad 100.0 \%$

$0.01 \% \quad 8.1 \%$ SVVGNLHR $0.01 \% \quad 8.1 \%$ GADSELSTVPSVTK $0.01 \% \quad 8.1 \%$ AIACQLSR $0.01 \% \quad 8.1 \%$ TVLQQVIEDGSK $0.01 \% \quad 8.1 \%$ IVVEFSSPNVAK $0.01 \% \quad 8.1 \%$ TLQIKDSPPEVAGAR $0.05 \% \quad 25.5 \%$ NFYVEHPEVAR $0.05 \% \quad 25.5 \%$ LTPYEVDELR $0.05 \% \quad 25.5 \%$ LTPYEVDELRR $0.05 \% \quad 25.5 \%$ DMVGIAQTGSGK $47 \quad 0.05 \% \quad 25.5 \%$ GDGPICLVLAPTR $0.05 \% \quad 25.5 \%$ ELAQQVQQVADDYGK $0.05 \% \quad 25.5 \%$ LKSTCIYGGAPK $0.05 \% \quad 25.5 \%$ STCIYGGAPK $0.05 \% \quad 25.5 \%$ GPQIRDLER $0.05 \% 25.5 \%$ GVEICIATPGR $0.05 \% 25.5 \%$ LIDFLESGK $0.05 \% \quad 25.5 \%$ TIIFVETK $0.05 \% \quad 25.5 \%$ SGKAPILIATDVASR $0.05 \% \quad 25.5 \%$ APILIATDVASR $0.05 \% \quad 25.5 \%$ STNKGTAYTFFTPGNLK $0.05 \% 25.5 \%$ GTAYTFFTPGNLK $0.05 \% \quad 25.5 \%$ VLEEANQAINPK $\begin{array}{lll}0.05 \% & 25.5 \% & \text { LMQLVDHRGGGGGGGC } \\ 0.05 \% & 25.5 \% & \text { SSQSSSQQFSGIGR }\end{array}$ $\begin{array}{lll}0.01 \% & 2.3 \% & \text { TAQDLSSPR }\end{array}$ $0.01 \% \quad 2.3 \%$ VLISTDLTSR $0.00 \% \quad 2.8 \%$ AGAKDILVATDVAGR $0.00 \% \quad 2.8 \%$ NIEDYIHR $0.00 \% \quad 2.8 \%$ AAPDILIATPGR $0.00 \% \quad 2.8 \%$ ALQEFDLALR $0.03 \% 25.0 \%$ SPDEPLPVVR $0.03 \% \quad 25.0 \%$ RPELNQPAR $0.03 \% 25.0 \%$ LSSKGSFADLGLEPR $0.03 \% 25.0 \%$ GSFADLGLEPR $0.03 \% \quad 25.0 \%$ TLSYLLPLLQR $0.03 \% \quad 25.0 \%$ LLGQPSLDSLPIPAPR $0.03 \% \quad 25.0 \%$ GLVLVPSRELAQQVR $0.03 \% \quad 25.0 \%$ AVAQPLGR $0.03 \% \quad 25.0 \%$ VASPDAVTTITSSK $0.03 \% \quad 25.0 \%$ VGIFQSFQK $\begin{array}{ll}0.03 \% & 25.0 \% \text { DILLCTDIASR }\end{array}$ $0.03 \% \quad 25.0 \%$ SLPGLASSVKEPLPQAT $0.00 \% \quad 3.9 \% \quad$ LLQEDSSPLLR $0.00 \% \quad 3.9 \%$ SALVKPVTINVGR $0.00 \% \quad 4.1 \%$ VVTVVTTKK $0.00 \% \quad 4.1 \%$ GAEIIVCTPGR
1163.57

1368.73

1691.82

1294.68

1053.50

1083.59

1172.61

1021.56

950.56

1498.86

1226.71

1846.93

1416.72

1325.71

1639.81

1455.68

974.49

1104.63

1456.81

1059.52

1194.68

1175.64

1108.60

1080.59

1576.83

1161.59

1316.79

1673.96

1664.98

811.48

1376.73

$\begin{array}{llllllll}99.7 \% & 36.2 & 25.0 & 36.0 & 2 & 0 & 0 & 1053.57 \\ 98.4 \% & 17.7 & 25.0 & 17.7 & 1 & 0 & 0 & 1276.66\end{array}$

$\begin{array}{llllllll}99.7 \% & 47.0 & 25.0 & 47.0 & 2 & 0 & 0 & 1694.93\end{array}$

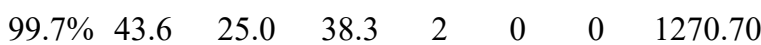
$\begin{array}{llllllll}99.5 \% & 22.4 & 25.0 & 22.4 & 0 & 1 & 0 & 1353.82\end{array}$ $\begin{array}{llllllll}99.3 \% & 23.6 & 25.0 & 23.6 & 1 & 0 & 0 & 974.62\end{array}$ $\begin{array}{llllllll}99.7 \% & 29.0 & 25.0 & 29.0 & 1 & 0 & 0 & 1172.61\end{array}$ 
Probable ATP-dependent RNA helicase DDX46 GN=DDX46 DDX46_HUMAN $117.37 \quad 100.0 \%$ Probable ATP-dependent RNA helicase DDX46 GN=DDX46 DDX46_HUMAN $117.37 \quad 100.0 \%$ Probable ATP-dependent RNA helicase DDX47 GN=DDX47 DDX47_HUMAN $50.65 \quad 100.0 \%$ Probable ATP-dependent RNA helicase DDX47 GN=DDX47 DDX47 HUMAN $50.65100 .0 \%$ Probable ATP-dependent RNA helicase DDX47 GN=DDX47 DDX47_HUMAN $50.65 \quad 100.0 \%$ Probable ATP-dependent RNA helicase DDX5 GN=DDX5 DDX5_HUMAN $69.15 \quad 100.0 \%$ Probable ATP-dependent RNA helicase DDX5 GN=DDX5 DDX5_HUMAN $69.15 \quad 100.0 \%$ Probable ATP-dependent RNA helicase DDX5 GN=DDX5 DDX5_HUMAN $69.15 \quad 100.0 \% \quad 2$ Probable ATP-dependent RNA helicase DDX5 GN=DDX5 DDX5 HUMAN $69.15 \quad 100.0 \% 2$ Probable ATP-dependent RNA helicase DDX5 GN=DDX5 DDX5_HUMAN $69.15 \quad 100.0 \% \quad 2$ Probable ATP-dependent RNA helicase DDX5 GN=DDX5 DDX5_HUMAN $69.15 \quad 100.0 \% \quad 2$ Probable ATP-dependent RNA helicase DDX5 GN=DDX5 DDX5_HUMAN $69.15 \quad 100.0 \% \quad 2$ Probable ATP-dependent RNA helicase DDX5 GN=DDX5 DDX5_HUMAN $69.15 \quad 100.0 \%$ Probable ATP-dependent RNA helicase DDX5 GN=DDX5 DDX5_HUMAN $69.15 \quad 100.0 \% \quad 2$ Probable ATP-dependent RNA helicase DDX5 GN=DDX5 DDX5_HUMAN $69.15 \quad 100.0 \% \quad 2$ Probable ATP-dependent RNA helicase DDX5 GN=DDX5 DDX5_HUMAN $69.15 \quad 100.0 \%$ Probable ATP-dependent RNA helicase DDX5 GN=DDX5 DDX5 HUMAN $69.15 \quad 100.0 \% \quad 2$ Probable ATP-dependent RNA helicase DDX5 GN=DDX5 DDX5_HUMAN $69.15 \quad 100.0 \% \quad 2$ Probable ATP-dependent RNA helicase DDX5 GN=DDX5 DDX5_HUMAN $69.15 \quad 100.0 \% \quad 2$ Probable ATP-dependent RNA helicase DDX5 GN=DDX5 DDX5 HUMAN $69.15 \quad 100.0 \%$ Probable ATP-dependent RNA helicase DDX5 GN=DDX5 DDX5_HUMAN $69.15 \quad 100.0 \% \quad 2$ Probable ATP-dependent RNA helicase DDX5 GN=DDX5 DDX5_HUMAN $69.15 \quad 100.0 \% \quad 2$ Probable ATP-dependent RNA helicase DDX5 GN=DDX5 DDX5_HUMAN $69.15 \quad 100.0 \% \quad 2$ Probable ATP-dependent RNA helicase DDX5 GN=DDX5 DDX5_HUMAN $69.15 \quad 100.0 \% \quad 2$ Probable ATP-dependent RNA helicase DDX5 GN=DDX5 DDX5 HUMAN $69.15 \quad 100.0 \%$ Probable ATP-dependent RNA helicase DDX5 GN=DDX5 DDX5_HUMAN $69.15 \quad 100.0 \%$ Probable ATP-dependent RNA helicase DDX52 GN=DDX52 DDX52_HUMAN $67.50 \quad 100.0 \%$ Probable ATP-dependent RNA helicase DDX52 GN=DDX52 DDX52_HUMAN 67.50 Probable ATP-dependent RNA helicase DDX52 GN=DDX52 DDX52_HUMAN 67.50 Probable ATP-dependent RNA helicase DDX56 GN=DDX56 DDX56_HUMAN 61.59 Probable ATP-dependent RNA helicase DDX56 GN=DDX56 DDX56_HUMAN 61.59 Probable ATP-dependent RNA helicase DDX56 GN=DDX56 DDX56_HUMAN 61.55 Probable ATP-dependent RNA helicase DDX56 GN=DDX56 DDX56_HUMAN 61.59 Probable ATP-dependent RNA helicase DDX56 GN=DDX56 DDX56_HUMAN 61.59 Probable ATP-dependent RNA helicase DHX37 GN=DHX37 DHX37_HUMAN 129.55 Probable ATP-dependent RNA helicase DHX37 GN=DHX37 DHX37_HUMAN 129.55100 .0 Probable ATP-dependent RNA helicase DHX37 GN=DHX37 DHX37_HUMAN $129.55100 .0 \%$ Probable ATP-dependent RNA helicase YTHDC2 GN=YTHDC2 YTDC2 HUMAN $160.25100 .0^{\circ}$ Probable ATP-dependent RNA helicase YTHDC2 GN=YTHDC2 YTDC2_HUMAN $160.25 \quad 100.0 \%$ Probable ATP-dependent RNA helicase YTHDC2 GN=YTHDC2 YTDC2_HUMAN $160.25 \quad 100.0 \%$ Probable ATP-dependent RNA helicase YTHDC2 GN=YTHDC2 YTDC2_HUMAN $160.25 \quad 100.0 \%$ Probable ATP-dependent RNA helicase YTHDC2 GN=YTHDC2 YTDC2_HUMAN $160.25100 .0 \%$ Probable ATP-dependent RNA helicase YTHDC2 GN=YTHDC2 YTDC2 HUMAN $160.25100 .0 \%$ Probable cytosolic iron-sulfur protein assembly protein $\mathrm{CIAO1} \mathrm{GN}=\mathrm{CIAO} \quad \mathrm{CIAO}$ _HUMAN $37.84 \quad 100.0 \%$ Probable cytosolic iron-sulfur protein assembly protein $\mathrm{CIAO1} \mathrm{GN}=\mathrm{CIAO} 1$ CIAO1_HUMAN $37.84 \quad 100.0 \%$ Probable dimethyladenosine transferase GN=DIMT1 DIM1_HUMAN $35.24 \quad 100.0 \%$ Probable dimethyladenosine transferase GN=DIMT1 DIM1_HUMAN $35.24 \quad 100.0 \%$
$0.00 \% \quad 4.1 \%$ LLVATSVAAR $0.00 \% \quad 4.1 \%$ GGTILAPTVSAK $0.01 \% \quad 7.9 \%$ KPHIIIATPGR

$0.01 \% \quad 7.9 \%$ LIDHLENTKGFNLR $0.01 \% \quad 7.9 \%$ SILLATDVASR

$132 \quad 0.15 \% \quad 29.5 \%$ FGNPGEKLVK

$132 \quad 0.15 \% \quad 29.5 \%$ NFYQEHPDLAR

$132 \quad 0.15 \% \quad 29.5 \%$ NFYQEHPDLARR

$132 \quad 0.15 \% \quad 29.5 \%$ TAQEVETYR

$132 \quad 0.15 \% \quad 29.5 \%$ TAQEVETYRR

$132 \quad 0.15 \% \quad 29.5 \%$ GDGPICLVLAPTR

$132 \quad 0.15 \% \quad 29.5 \%$ ELAQQVQQVAAEYCR

$132 \quad 0.15 \% \quad 29.5 \%$ LKSTCIYGGAPK

$132 \quad 0.15 \% \quad 29.5 \%$ STCIYGGAPK

$132 \quad 0.15 \% \quad 29.5 \%$ GPQIRDLER

$132 \quad 0.15 \% \quad 29.5 \%$ GVEICIATPGR

$132 \quad 0.15 \% \quad 29.5 \%$ LIDFLECGK

$132 \quad 0.15 \% \quad 29.5 \%$ TTYLVLDEADR

$132 \quad 0.15 \% \quad 29.5 \%$ LMEEIMSEKENK

$132 \quad 0.15 \% \quad 29.5 \%$ TIVFVETK

$132 \quad 0.15 \% \quad 29.5 \%$ TIVFVETKR

$132 \quad 0.15 \% \quad 29.5 \%$ APILIATDVASR

$132 \quad 0.15 \% \quad 29.5 \%$ TGTAYTFFTPNNIK

$132 \quad 0.15 \% \quad 29.5 \%$ QVSDLISVLR

$132 \quad 0.15 \% \quad 29.5 \%$ LLQLVEDR

$132 \quad 0.15 \% \quad 29.5 \%$ LLQLVEDRGSGR

$4 \quad 0.00 \% \quad 5.7 \%$ ELLASAPTGSGK

$0.00 \% \quad 5.7 \%$ ISEGTGFR

$0.00 \% \quad 5.7 \%$ AITFFTEDDKPLLR

$0.01 \% \quad 11.0 \%$ AIPLALEGKDLLAR

$0.01 \% \quad 11.0 \%$ GLVLVPTKELAR

$0.01 \% \quad 11.0 \%$ VANVSAAEDSVSQR

$0.01 \% \quad 11.0 \%$ SLLFVNTLER

$0.01 \% \quad 11.0 \%$ ASDPEAGVAR

$0.00 \% \quad 2.8 \%$ TMATFPVAPR

$0.00 \% \quad 2.8 \%$ QIVTAGLGDHLAR

$0.00 \% \quad 2.8 \%$ FLLEGQVFR

$0.01 \% \quad 4.4 \%$ LSQSLGLVSK

$0.01 \% \quad 4.4 \% \quad$ LAAIAVAER

$0.01 \% \quad 4.4 \%$ TLLTFCTNGVLLR

$0.01 \% \quad 4.4 \%$ TTGYTNKEMLK

$0.01 \% \quad 4.4 \%$ SFDALNFVTMLK

$0.01 \% \quad 4.4 \%$ NLEISQQK

$0.01 \% \quad 7.4 \% \quad$ SVLSEGHQR

$0.01 \% \quad 7.4 \%$ SVAWAPSGNLLATCSR

$0.03 \% \quad 48.9 \%$ SAGGLMFNTGIGQHILK

$0.03 \% \quad 48.9 \%$ NPLIINSIIDK $\begin{array}{llllllll}99.7 \% & 42.8 & 25.0 & 27.9 & 1 & 0 & 0 & 1000.61\end{array}$

1114.65

$99.6 \% 26.3$

$99.5 \% 23.1$

$99.7 \% \quad 44.8$

$\begin{array}{lll}99.7 \% & 41.4\end{array}$

$99.7 \% \quad 55.2$

$99.7 \% \quad 30.2$

$99.7 \% \quad 45.4$

$99.7 \% \quad 29.9$

$99.7 \% \quad 40.2$

$99.7 \% \quad 56.8$

$99.7 \% \quad 55.7$

$99.7 \% \quad 58.8$

$99.6 \% \quad 27.9$

$99.7 \% \quad 64.4$

$99.7 \% \quad 51.3$

$99.7 \% \quad 41.0$

$99.7 \% \quad 41.0$

$99.0 \% \quad 29.8$

$99.7 \% \quad 35.2$

$99.7 \% \quad 54.5$

$99.7 \% \quad 58.9$

$99.7 \% \quad 54.6$

$99.0 \% \quad 58.4$

$99.7 \% \quad 54.3$

$99.7 \% \quad 38.9$

$99.0 \% \quad 29.2$

$99.7 \% \quad 33.7$

$94.7 \% \quad 14.6$

$99.5 \% \quad 22.6$

$\begin{array}{lll}99.7 \% & 76.4\end{array}$

$99.7 \% \quad 36.3$

$97.7 \% \quad 22.5$

$99.7 \% \quad 34.4$

$99.7 \% \quad 30.2$

$98.5 \% \quad 20.3$

$99.7 \% \quad 66.2$

$99.7 \% \quad 51.7$

$99.7 \% \quad 38.9$

$97.4 \% \quad 17.1$

$99.7 \% \quad 56.3$

$96.0 \% \quad 19.7$

$99.7 \% \quad 43.6$

$99.7 \% \quad 44.1$

$99.7 \% \quad 27.1$

$99.7 \% \quad 53.0$ $\begin{array}{lll}1669.90 & 153 & 166\end{array}$

$1145.65 \quad 315 \quad 325$

$1088.61 \quad 34 \quad 43$

1389.65

1545.76

1096.53

1252.63

1368.73

1792.86

1294.68

1053.50

1083.59

1172.61

1094.56

1295.65

1480.70

936.54

1092.64

1226.71

1574.79

1129.66

985.57

1342.74

1130.61

866.44

1665.88

1479.89

1295.80

1432.70

1191.67

972.47

1090.57

1350.75

1108.62

1031.61

913.55

1507.83

1285.65

1385.71

959.52

1012.52

1689.84

1743.92

1239.73 
Probable dimethyladenosine transferase GN=DIMT1 DIM1_HUMAN $35.24 \quad 100.0 \%$ Probable dimethyladenosine transferase GN=DIMT1 DIM1 HUMAN $35.24 \quad 100.0 \%$ Probable dimethyladenosine transferase GN=DIMT1 DIM1_HUMAN $35.24 \quad 100.0 \%$ Probable dimethyladenosine transferase GN=DIMT1 DIM1_HUMAN $35.24 \quad 100.0 \%$ Probable dimethyladenosine transferase GN=DIMT1 DIM1_HUMAN $35.24 \quad 100.0 \%$ Probable dimethyladenosine transferase GN=DIMT1 DIM1_HUMAN $35.24 \quad 100.0 \%$ Probable dimethyladenosine transferase GN=DIMT1 DIM1 HUMAN $35.24 \quad 100.0 \%$ Probable dimethyladenosine transferase GN=DIMT1 DIM1_HUMAN $35.24 \quad 100.0 \%$ Probable dimethyladenosine transferase GN=DIMT1 DIM1 HUMAN $35.24 \quad 100.0 \%$ Probable dimethyladenosine transferase GN=DIMT1 DIM1_HUMAN $35.24 \quad 100.0 \%$ Probable dimethyladenosine transferase GN=DIMT1 DIM1_HUMAN $35.24 \quad 100.0 \%$ Probable glutamate--tRNA ligase, mitochondrial GN=EARS2 SYEM HUMAN $58.69 \quad 100.0 \%$ Probable glutamate--tRNA ligase, mitochondrial GN=EARS2 SYEM_HUMAN $58.69 \quad 100.0 \%$ Probable methyltransferase-like protein 15 GN=METTL15 MET15_HUMAN $46.12 \quad 100.0 \%$ Probable methyltransferase-like protein 15 GN=METTL15 MET15 HUMAN $46.12 \quad 100.0 \%$ Probable methyltransferase-like protein 15 GN=METTL15 MET15_HUMAN $46.12 \quad 100.0 \%$ Probable methyltransferase-like protein $15 \mathrm{GN}=$ METTL15 MET15 HUMAN $46.12 \quad 100.0 \%$ Probable methyltransferase-like protein 15 GN=METTL15 MET15_HUMAN $46.12 \quad 100.0 \%$ Probable rRNA-processing protein EBP2 GN=EBNA1BP2 EBP2_HUMAN $34.85 \quad 100.0 \%$ Probable rRNA-processing protein EBP2 GN=EBNA1BP2 EBP2 HUMAN $34.85 \quad 100.0 \%$ Probable rRNA-processing protein EBP2 GN=EBNA1BP2 EBP2_HUMAN $34.85 \quad 100.0 \%$ Probable rRNA-processing protein EBP2 GN=EBNA1BP2 EBP2 HUMAN $34.85 \quad 100.0 \%$ Probable rRNA-processing protein EBP2 GN=EBNA1BP2 EBP2_HUMAN $34.85 \quad 100.0 \%$ Probable rRNA-processing protein EBP2 GN=EBNA1BP2 EBP2_HUMAN $34.85100 .0 \%$ Probable rRNA-processing protein EBP2 GN=EBNA1BP2 EBP2 HUMAN 34.85 bable tRNA N6-adenosine threonylcarbamoyltransferase GN=OSGEP OSGEP_HUMAN 36.43 Probable tRNA N6-adenosine threonylcarbamoyltransferase GN=OSGEP OSGEP_HUMAN 36.4 Probable tRNA N6-adenosine threonylcarbamoyltransferase GN=OSGEP OSGEP HUMAN 36.4 Probable tRNA N6-adenosine threonylcarbamoyltransferase GN=OSGEP OSGEP_HUMAN 36.4 Probable tRNA N6-adenosine threonylerbamoyltransferase GN=OSGEP OSGEP HUMAN 36.4 Probable tRNA N6-adenosine threonylcarbamoyltransferase GN=OSGEP OSGEP HUMAN 36.43 Probable tRNA N6-adenosine threonylcarbamoyltransferase GN=OSGEP OSGEP_HUMAN 36.43 Probable tRNA N6-adenosine threonylcarbamoyltransferase GN=OSGEP OSGEP HUMAN 36.43 Probable tRNA pseudouridine synthase 2 GN=TRUB2 TRUB2_HUMAN 36.70 Probable tRNA pseudouridine synthase 2 GN=TRUB2 TRUB2_HUMAN 36.70 Probable ubiquitin carboxyl-terminal hydrolase FAF-X GN=USP9X USP9X_HUMAN 292.28 Probable ubiquitin carboxyl-terminal hydrolase FAF-X GN=USP9X USP9X_HUMAN $292.28 \quad 100.0^{\circ}$ Probable ubiquitin carboxyl-erminal hydrolase FAF-X GN=USP9X USP9X_HUMAN $292.28 \quad 100.0^{\circ}$ Probable ubiquitin carboxyl-terminal hydrolase FAF-X GN=USP9X USP9X_HUMAN $292.28 \quad 100.0 \%$ Probable ubiquitin carboxyl-terminal hydrolase FAF-X GN=USP9X USP9X_HUMAN $292.28 \quad 100.0 \%$ Probable ubiquitin carboxyl-terminal hydrolase FAF-X GN=USP9X USP9X HUMAN $292.28 \quad 100.0 \%$ Probable ubiquitin carboxyl-terminal hydrolase FAF-X GN=USP9X USP9X_HUMAN $292.28 \quad 100.0 \%$ Probable ubiquitin carboxyl-terminal hydrolase FAF-X GN=USP9X USP9X HUMAN $292.28 \quad 100.0 \%$ Programmed cell death 6-interacting protein GN=PDCD6IP PDC6I_HUMAN $96.03 \quad 100.0 \%$ Programmed cell death 6-interacting protein GN=PDCD6IP PDC6I_HUMAN 96.03 $100.0 \%$ Programmed cell death 6-interacting protein GN=PDCD6IP PDC6I HUMAN $96.03 \quad 100.0^{\circ}$ Prohibitin $\mathrm{GN}=\mathrm{PHB}$ $29.80 \quad 100.0 \%$

6

\begin{tabular}{lll}
$0.01 \%$ & $17.0 \%$ EQTDQTQAQELHR \\
\hline & $17.0 \%$ IFVNNELNELYTGLK
\end{tabular}

$$
\begin{array}{lll}
0.01 \% & 17.0 \% & \text { FLLGISMTER }
\end{array}
$$

$0.01 \% \quad 17.0 \%$ TSQLGSDHENTEEVSMR

$0.01 \% \quad 17.0 \%$ VLSPQDQDVQDNPR

$0.02 \% \quad 24.2 \%$ ELQDAFSR

$0.02 \% \quad 24.2 \%$ GLLKPGLNVVLEGPK

$0.02 \% \quad 24.2 \%$ AVDPEDDFQR

$0.02 \% \quad 24.2 \%$ QAQAAVLAVLPR

$0.02 \% \quad 24.2 \%$ RPTDYFAEMAK

$0.02 \% \quad 24.2 \%$ VQTEVLQK

$0.02 \% \quad 24.2 \%$ ESYDDVSSFR

$0.02 \% \quad 37.0 \%$ PAVLGFEGSANK

$0.02 \% \quad 37.0 \%$ TYVTPPGTGFLPGDTAR

$0.02 \% 37.0 \%$ GPGMGAPLVSVAVVAR

$\begin{array}{lll}0.02 \% & 37.0 \% & \text { LITGATSPTVLYVSGGNTQVIAYSEHR } \\ 0.02 \% & 37.0 \% & \text { IFGETIDIAVGNCLDR }\end{array}$

$0.02 \% \quad 37.0 \%$ ISNDPSPGYNIEQMAK

$0.02 \% \quad 37.0 \%$ LVELPYTVK

$0.02 \% \quad 37.0 \%$ TPLSDSGVTQR

$0.00 \% \quad 6.3 \%$ DTVELQLLK

$0.00 \% \quad 6.3 \% \quad$ AATPQVAAELEK

$0.03 \% \quad 3.5 \% \quad$ LLQISSFNGK

$0.03 \% \quad 3.5 \% \quad$ VVIQSNDDIASR

$0.03 \% \quad 3.5 \% \quad$ NNFLPNADMETR

$0.03 \% \quad 3.5 \% \quad$ LLLTAIGYGHVR

$0.03 \% \quad 3.5 \%$ HSGDYFTLLR

$0.03 \% \quad 3.5 \%$ ELLAFQTSEK

$\begin{array}{lll}0.03 \% & 3.5 \% & \text { VLGGSFADQK } \\ 0.03 \% & 3.5 \% & \text { IIEDCSNSEETVK }\end{array}$

$0.01 \% \quad 4.0 \%$ TSEVDLAKPLVK

$0.01 \% \quad 4.0 \%$ TMQGSEVVNVLK

$0.01 \% \quad 4.0 \%$ NIQVSHQEFSK

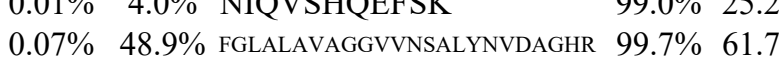

$99.3 \% 21.9$

$99.7 \% \quad 66.2$

$99.7 \% \quad 41.8$

$99.7 \% \quad 68.6$

$98.8 \% \quad 25.7$

$99.7 \% \quad 32.9$

$99.7 \% \quad 42.6$

$99.7 \% \quad 69.1$

$99.7 \% \quad 31.5$

$98.0 \% \quad 27.6$

$99.7 \% \quad 58.5$

$99.7 \% \quad 46.9$

$99.7 \% 79.1$

$99.7 \% 53.8$

$98.3 \% \quad 17.2$

$99.5 \% \quad 28.3$

$99.7 \% \quad 66.4$

$99.7 \% \quad 49.9$

$99.7 \% \quad 39.4$

$99.3 \% \quad 22.9$

$99.7 \% \quad 53.4$

$99.5 \% \quad 23.0$

$99.7 \% \quad 36.6$

$99.5 \% \quad 24.9$

$99.7 \% \quad 31.5$

$99.7 \% \quad 48.0$

$99.5 \% \quad 25.3$

$99.7 \% \quad 55.6$

$99.0 \% \quad 25.2$ $\begin{array}{ll}99.7 \% & 37.6 \\ 99.0 \% & 57.8\end{array}$

$\begin{array}{lll}99.7 \% & 57.1\end{array}$

$99.7 \% \quad 44.9$

$99.7 \% \quad 71.2$

$99.0 \% \quad 34.9$

$99.7 \% \quad 32.0$

$99.7 \% \quad 30.2$

$99.7 \% \quad 57.3$

$99.7 \% \quad 51.8$

$\begin{array}{lll}99.6 \% & 24.7\end{array}$

$99.7 \% \quad 39.8$

$\begin{array}{lll}99.7 \% & 29.4\end{array}$

\begin{tabular}{|c|c|c|c|c|c|c|c|}
\hline 0020 & 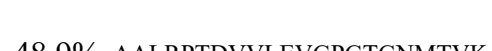 & 70 & 276 & 580 & 276 & 0 & 1 \\
\hline $0.03 \%$ & $48.9 \%$ AALRPTDVVLE & $99.7 \%$ & 37.6 & 25.0 & 37.6 & 0 & 1 \\
\hline $0.03 \%$ & 48.9\% LVAELHKR & $99.0 \%$ & 57.8 & 25.0 & 36.0 & 2 & \\
\hline $0.03 \%$ & 48.9\% LQVLVGDVLK & $99.7 \%$ & 57.1 & 25.0 & 36.8 & 2 & 0 \\
\hline $0.03 \%$ & 48.9\% LVAKPGDKL & $99.7 \%$ & 44.9 & 25.0 & 43.9 & 0 & 2 \\
\hline $0.03 \%$ & 48.9\% LSINTQLLA & $99.7 \%$ & 71.2 & 25.0 & 60.0 & 2 & \\
\hline $0.03 \%$ & 48.9\% NNFRPPPK & $99.0 \%$ & 34.9 & 25.0 & 18.8 & 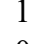 & \\
\hline $0.03 \%$ & 48.9\% NNFRPPPKVESSVVR & $99.7 \%$ & 32.0 & 25.0 & 28.2 & 0 & 1 \\
\hline $0.03 \%$ & $48.9 \%$ NPPPPINFQEW & $99.7 \%$ & 30.2 & 25.0 & 29.9 & 2 & \\
\hline $0.03 \%$ & $48.9 \%$ SSAVQQLLE & $99.7 \%$ & 57.3 & 25.0 & 40.5 & 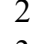 & 0 \\
\hline $0.03 \%$ & 48.9\% SMDIDDFIR & $99.7 \%$ & 51.8 & 25.0 & 42.1 & 3 & 0 \\
\hline $0.03 \%$ & 48.9\% LLHGFNAEGIH & $99.6 \%$ & 24.7 & 25.0 & 24.7 & 0 & \\
\hline $0.00 \%$ & $3.8 \%$ TALYNYIFAK & $99.7 \%$ & 39.8 & 25.0 & 33.0 & 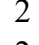 & \\
\hline $0.00 \%$ & $3.8 \%$ NMSQEQVAQK & $99.7 \%$ & 29.4 & 25.0 & 29.4 & 2 & 0 \\
\hline $0.01 \%$ & $17.0 \%$ EQTDQTQAQELHR & $99.3 \%$ & 21.9 & 25.0 & 21.9 & ( & 0 \\
\hline $0.01 \%$ & $17.0 \%$ IFVNNELNEL & $99.7 \%$ & 66.2 & 25.0 & 62.4 & 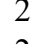 & 0 \\
\hline $0.01 \%$ & 17.0\% FLLGISMTER & $99.7 \%$ & 41.8 & 25.0 & 33.9 & 2 & 0 \\
\hline $0.01 \%$ & $17.0 \%$ TSQLGSDHENTEEVS & $99.7 \%$ & 27.4 & 25.0 & 27.4 & 0 & 2 \\
\hline $0.01 \%$ & $17.0 \%$ VLSPQDQD & $99.7 \%$ & 68.6 & 25.0 & 67.3 & 2 & 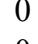 \\
\hline $0.02 \%$ & $24.2 \%$ ELQDAFSR & $98.8 \%$ & 25.7 & 25.0 & 13.2 & 1 & 0 \\
\hline $0.02 \%$ & $24.2 \%$ GLLKPGLNVV] & $99.7 \%$ & 32.9 & 25.0 & 32.9 & 0 & 2 \\
\hline $0.02 \%$ & 24.2\% AVDPEDDFQR & $99.7 \%$ & 42.6 & 25.0 & 41.4 & 3 & 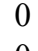 \\
\hline $0.02 \%$ & $24.2 \%$ QAQAAVLAVLP & $99.7 \%$ & 69.1 & 25.0 & 64.7 & 2 & 0 \\
\hline $0.02 \%$ & 24.2\% RPTDYFAEN & $99.7 \%$ & 31.5 & 25.0 & 27.7 & 2 & 0 \\
\hline $0.02 \%$ & $24.2 \%$ VQTEVLQK & $98.0 \%$ & 27.6 & 25.0 & 6.5 & 1 & 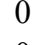 \\
\hline $0.02 \%$ & $24.2 \%$ ESYDDVSSFR & $99.7 \%$ & 54.2 & 25.0 & 54.2 & 4 & 0 \\
\hline $0.02 \%$ & 37.0\% PAVLGFEGSANK & $99.7 \%$ & 58.5 & 25.0 & 57.9 & 2 & 0 \\
\hline $0.02 \%$ & $37.0 \%$ TYVTPPGTGFLPGDTAR & $99.7 \%$ & 46.9 & 25.0 & 45.8 & 2 & 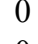 \\
\hline $0.02 \%$ & $37.0 \%$ GPGMGAPLVSVAVVAR & $99.7 \%$ & 79.1 & 25.0 & 79.1 & 2 & 0 \\
\hline $0.02 \%$ & $37.0 \%$ LITGATSPTVLYVSGGNTQVIAYS & $99.7 \%$ & 44.7 & 25.0 & 43.0 & 0 & 1 \\
\hline $0.02 \%$ & $37.0 \%$ IFGETIDIAVGNCLDR & $99.7 \%$ & 53.8 & 25.0 & 53.8 & 2 & 0 \\
\hline $0.02 \%$ & $37.0 \%$ ISNDPSPGYN & $98.3 \%$ & 17.2 & 25.0 & 17.2 & 1 & 0 \\
\hline $0.02 \%$ & $37.0 \%$ LVELPYTVK & $99.5 \%$ & 28.3 & 25.0 & 24.6 & 2 & 0 \\
\hline $0.02 \%$ & $37.0 \%$ TPLSDSGVTC & $99.7 \%$ & 66.4 & 25.0 & 49.1 & 2 & 0 \\
\hline $0.00 \%$ & $6.3 \%$ DTVELQLLK & $99.7 \%$ & 49.9 & 25.0 & 42.4 & 1 & 0 \\
\hline $0.00 \%$ & $6.3 \%$ AATPQVAAEI & $99.7 \%$ & 39.4 & 25.0 & 25.8 & 2 & 0 \\
\hline $0.03 \%$ & $3.5 \%$ LLQISSFNGK & $99.3 \%$ & 22.9 & 25.0 & 18.8 & 1 & 0 \\
\hline $0.03 \%$ & $3.5 \%$ VVIQSNDDIASR & $99.7 \%$ & 53.4 & 25.0 & 53.4 & 8 & 0 \\
\hline $0.03 \%$ & $3.5 \%$ NNFLPNADMETR & $99.5 \%$ & 23.0 & 25.0 & 23.0 & 1 & 0 \\
\hline $0.03 \%$ & $3.5 \%$ LLLTAIGYGHY & $99.7 \%$ & 36.6 & 25.0 & 36.6 & 2 & 2 \\
\hline $0.03 \%$ & $3.5 \%$ HSGDYFTLLR & $99.5 \%$ & 24.9 & 25.0 & 22.7 & 5 & 0 \\
\hline $0.03 \%$ & $3.5 \%$ ELLAFQTSEK & $99.7 \%$ & 51.1 & 25.0 & 51.1 & 6 & 0 \\
\hline $0.03 \%$ & $3.5 \%$ VLGGSFADQK & $99.7 \%$ & 31.5 & 25.0 & 29.4 & 2 & 0 \\
\hline $0.03 \%$ & $3.5 \%$ IIEDCSNSEETVK & $99.7 \%$ & 48.0 & 25.0 & 16.1 & 1 & 0 \\
\hline $0.01 \%$ & $4.0 \%$ TSEVDLAKPLVK & $99.5 \%$ & 25.3 & 25.0 & 21.4 & 2 & 0 \\
\hline $0.01 \%$ & $4.0 \%$ TMQGSEVVNVI & $99.7 \%$ & 55.6 & 25.0 & 53.0 & 3 & 0 \\
\hline
\end{tabular}

2241.19

965.59

1083.68

1419.78

1128.67

969.53

1725.94

1878.95

1102.6

1111.51

1441.72

1203.64

1162.55

1583.74

1766.93

1166.62

1935.84

1610.78

965.47

1533.94

1191.53

1236.74

1328.63

944.54

1204.51

1189.62

1749.88

1496.83

2834.47

1792.89

1763.83

1061.62

1160.59

1058.61

1227.66

1106.62

1316.68

1437.64

1312.77

1208.61

1165.61

1021.53

1523.69

1299.75

1320.68

1316.66 2371.25

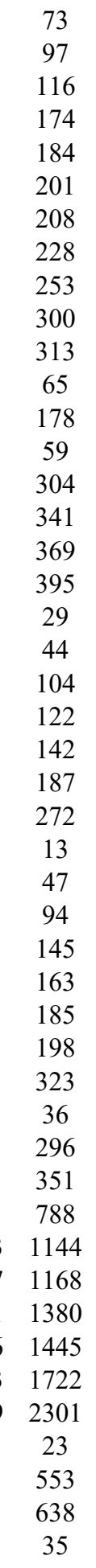

Page 118 of Table S-1-6 
Prohibitin GN=PHB Prohibitin GN=PHB Prohibitin GN $=$ PHB Prohibitin GN=PHB Prohibitin GN=PHB Prohibitin GN=PHB Prohibitin GN=PHB Prohibitin GN=PHB Prohibitin GN=PHB Prohibitin GN=PHB Prohibitin GN=PHB Prohibitin GN=PHB Prohibitin-2 GN=PHB2 Prohibitin-2 GN=PHB2

Prohibitin-2 GN=PHB2

Prohibitin-2 GN=PHB2

Prohibitin-2 GN=PHB2

Prohibitin- 2 GN=PHB2

Prohibitin-2 GN=PHB2

Prohibitin-2 GN=PHB2

Prohibitin-2 GN=PHB2

Prohibitin-2 GN=PHB2

Prohibitin-2 GN=PHB2

Prohibitin-2 GN=PHB2

Prohibitin-2 GN=PHB2

Prohibitin-2 GN=PHB2

Prohibitin-2 GN=PHB2

Prohibitin-2 GN=PHB2

$\begin{array}{lll}\text { Prohibitin-2 GN=PHB2 PHB2_HUMAN } & 33.30 \\ \text { Proliferating cell nuclear antigen GN=PCNA PCNA_HUMAN } & 28.77\end{array}$

Proliferating cell nuclear antigen GN=PCNA PCNA_HUMAN 28.77

Proliferating cell nuclear antigen GN=PCNA PCNA_HUMAN 28.77

Proliferating cell nuclear antigen GN=PCNA PCNA_HUMAN 28.77

Proliferating cell nuclear antigen GN=PCNA PCNA_HUMAN 28.77

Proliferating cell nuclear antigen GN=PCNA PCNA_HUMAN 28.77

Proliferating cell nuclear antigen GN=PCNA PCNA_HUMAN 28.77

Proliferating cell nuclear antigen GN=PCNA PCNA_HUMAN 28.77

Proliferating cell nuclear antigen GN=PCNA PCNA_HUMAN 28.77

Proliferating cell nuclear antigen GN=PCNA PCNA_HUMAN 28.77

Proliferating cell nuclear antigen GN=PCNA PCNA_HUMAN 28.77

Proliferating cell nuclear antigen GN=PCNA PCNA_HUMAN 28.77

Proline-, glutamic acid-and leucine-rich protein 1 GN=PELP1 PELP1_HUMAN $119.70 \quad 100.0 \%$

Proline-, glutamic acid-and leucine-rich protein 1 GN=PELP1 PELP1_HUMAN $119.70 \quad 100.0 \%$

Proline-, glutamic acid-and leucine-rich protein 1 GN=PELP1 PELP1_HUMAN $119.70 \quad 100.0 \%$ Proline-, glutamic acid- and leucine-rich protein 1 GN=PELP1 PELP1_HUMAN $119.70 \quad 100.0 \%$ Proteasomal ATPase-associated factor $1 \mathrm{GN}=$ PAAF1 PAAF1_HUMAN $42.19 \quad 100.0 \%$ Proteasomal ATPase-associated factor $1 \mathrm{GN}=$ PAAF1 PAAF1_HUMAN $42.19 \quad 100.0 \%$ $\begin{array}{llll}16 & 62 & 0.07 \% & 48.9 \% \text { DLQNVNITLR } \\ 16 & 62 & 0.07 \% & 48.9 \% \text { ILFRPVASQLPR }\end{array}$

16

16

16
16
16

16

13

16

16

16
26
26

26
26
26

26

26

26

26

26
26

26
26
26

26
26

26

26

26

26

26

26
26
26

26
26
18

18

18
12
18

18
18
18

18
18

18
18
18

18

18
18
18

18
18
12

$0.07 \% \quad 48.9 \%$ IFTSIGEDYDER

$0.07 \% \quad 48.9 \%$ VLPSITTEILK

$0.07 \% \quad 48.9 \%$ FDAGELITQR

$0.07 \% \quad 48.9 \%$ QVSDDLTER

$0.07 \% \quad 48.9 \%$ EFTEAVEAK

$0.07 \% \quad 48.9 \%$ AAIISAEGDSK

$0.08 \% \quad 60.5 \%$ DLQMVNISLR

$0.08 \% \quad 60.5 \%$ LGLDYEER

$0.08 \% \quad 60.5 \%$ FNASQLITQR

$0.08 \% \quad 60.5 \%$ AQVSLLIR

$0.08 \% \quad 60.5 \%$ EYTAAVEAK

$0.08 \% \quad 60.5 \%$ MLGEALSK

$0.04 \% 53.6 \%$ LVQGSILK

$0.04 \% \quad 53.6 \%$ LVQGSILKK

$0.04 \% \quad 53.6 \%$ SEGFDTYR

$\begin{array}{ll}0.04 \% & 53.6 \% \\ 0.04 \% & 53.6 \% \text { MPDLDVEQLGIPEQ MPAR }\end{array}$

$0.04 \% \quad 53.6 \%$ IADMGHLK
$0.07 \% \quad 48.9 \%$ FVVEKAEQQK

$0.07 \% \quad 48.9 \%$ KAAIISAEGDSK

$0.07 \% \quad 48.9 \%$ KLEAAEDIAYQLSR

$0.07 \% \quad 48.9 \%$ LEAAEDIAYQLSR

$0.08 \% \quad 60.5 \%$ LLLGAGAVAYGVR

$0.08 \% \quad 60.5 \%$ ESVFTVEGGHR

$\quad 0.08 \% \quad 60.5 \%$ IGGVQQDTILAEGLHFR

$0.08 \% \quad 60.5 \%$ IPWFQYPIIYDIR

$0.08 \% \quad 60.5 \%$ ISSPTGSKDLQMVNISLR

$0.08 \% \quad 60.5 \%$ VLSRPNAQELPSMYQR

$0.08 \% \quad 60.5 \%$ VLPSIVNEVLK

$0.08 \% \quad 60.5 \%$ QKIVQAEGEAEAAK

$0.08 \% \quad 60.5 \%$ IVQAEGEAEAAK

$0.08 \% \quad 60.5 \%$ MLGEALSKNPGYIK

$0.08 \% \quad 60.5 \%$ IYLTADNLVLNLQDESFTR

$0.04 \% \quad 53.6 \%$ CDRNLAMGVNLTSMSK

$\begin{array}{ll}0.04 \% & 53.6 \% \text { NLAMGVNLTSMSK }\end{array}$

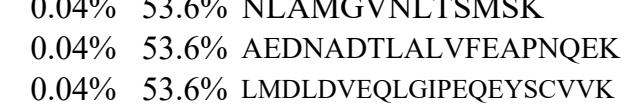

$0.04 \% 53.6 \%$ DLSHIGDAVVISCAK

$\begin{array}{ll}0.04 \% & 53.6 \% \\ 0.04 \% & 53.6 \% \text { FSASGELGNGNIK }\end{array}$

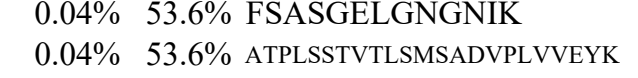$$
\begin{array}{lll}
0.01 \% & 4.3 \% & \text { TGSAVAPVH } \\
0.01 \% & 4.3 \% & \text { LASFFLSR }
\end{array}
$$

$0.01 \% \quad 4.3 \%$ NISLHGDGPLR

$0.01 \% \quad 4.3 \%$ GSPDGSLQTGKPSAPK

$0.01 \% \quad 11.5 \%$ SIHISCPK

$0.01 \% \quad 11.5 \%$ GGLGVSSSTDGTMK

$\begin{array}{llll}97.3 \% & 24.1 & 25.0 & 10.1 \\ 99.7 \% & 29.2 & 25.0 & 29.2\end{array}$

$99.0 \% \quad 41.8$

$99.7 \% \quad 60.0$

$\begin{array}{lll}99.7 \% & 88.2 \\ 99.7 \% & 55.4\end{array}$

$99.0 \% \quad 40.2$

$\begin{array}{lll}96.6 \% & 18.8 \\ 99.0 \% & 50.8\end{array}$

$\begin{array}{lll}99.0 \% & 50.8-25.0 & 37.3\end{array}$

$\begin{array}{llll}99.7 \% & 29.0 & 25.0 & 27.7\end{array}$

$\begin{array}{llll}97.1 \% & 15.8 & 25.0 & 15.8 \\ 97.3 \% & 24.1 & 25.0 & 10.1\end{array}$

$\begin{array}{ccc}1185.66 & 84 & 93 \\ 1396.84 & 94 & 105 \\ 1444.66 & 106 & 117 \\ 1213.74 & 118 & 128 \\ 1149.59 & 134 & 143 \\ 1062.51 & 149 & 157 \\ 1023.50 & 178 & 186 \\ 1205.65 & 198 & 207 \\ 1189.64 & 208 & 219 \\ 1061.55 & 209 & 219 \\ 1606.84 & 240 & 253 \\ 1478.75 & 241 & 253 \\ 1259.75 & 25 & 37 \\ 1217.59 & 38 & 48 \\ 1853.99 & 55 & 71 \\ 1723.92 & 72 & 84 \\ 1946.04 & 90 & 107 \\ 1188.64 & 98 & 107 \\ 1888.97 & 108 & 123 \\ 994.48 & 124 & 131 \\ 1210.74 & 132 & 142 \\ 1177.63 & 148 & 157 \\ 899.57 & 158 & 165 \\ 981.49 & 192 & 200 \\ 1471.78 & 223 & 236 \\ 1215.62 & 225 & 236 \\ 864.45 & 237 & 244 \\ 1536.81 & 237 & 250 \\ 2225.15 & 271 & 289 \\ 857.55 & 6 & 13 \\ 985.64 & 6 & 14 \\ 974.42 & 54 & 61 \\ 1796.85 & 62 & 77 \\ 1397.68 & 65 & 77 \\ 2074.99 & 92 & 110 \\ 2465.19 & 118 & 138 \\ 910.41 & 139 & 146 \\ 1584.81 & 150 & 164 \\ 1293.64 & 169 & 181 \\ 2408.26 & 218 & 240 \\ 884.47 & 241 & 248 \\ 1302.69 & 49 & 61 \\ 940.53 & 217 & 224 \\ 1178.63 & 355 & 365 \\ 1526.78 & 480 & 495 \\ 941.49 & 66 & 73 \\ 1296.61 & 104 & 117\end{array}$

Page 119 of Table S-1-6 
Proteasomal ATPase-associated factor 1 GN=PAAF1 PAAF1_HUMAN $42.19 \quad 100.0 \%$ Proteasomal ATPase-associated factor $1 \mathrm{GN}=$ PAAF1 PAAF1_HUMAN $42.19 \quad 100.0 \%$ Proteasomal ubiquitin receptor ADRM1 GN=ADRM1 ADRM1_HUMAN $42.15 \quad 100.0 \%$ Proteasomal ubiquitin receptor ADRM1 GN=ADRM1 ADRM1_HUMAN $42.15 \quad 100.0 \%$ Proteasome activator complex subunit 3 GN=PSME3 PSME3_HUMAN $29.51 \quad 100.0 \%$ Proteasome activator complex subunit $3 \mathrm{GN}=$ PSME3 PSME3_HUMAN $29.51 \quad 100.0 \%$ Proteasome subunit alpha type-1 GN=PSMA1 PSA1_HUMAN $29.56 \quad 100.0 \%$ Proteasome subunit alpha type-1 GN=PSMA1 PSA1_HUMAN $29.56 \quad 100.0 \%$ Proteasome subunit alpha type-1 GN=PSMA1 PSA1_HUMAN $29.56 \quad 100.0 \%$ Proteasome subunit alpha type-3 GN=PSMA3 PSA3_HUMAN $28.43 \quad 100.0 \%$ Proteasome subunit alpha type-3 GN=PSMA3 PSA3_HUMAN $28.43 \quad 100.0 \%$ Proteasome subunit alpha type-3 GN=PSMA3 PSA3_HUMAN $28.43 \quad 100.0 \%$ Proteasome subunit alpha type-3 GN=PSMA3 PSA3_HUMAN $28.43 \quad 100.0 \%$ Proteasome subunit alpha type-4 GN=PSMA4 PSA4_HUMAN $29.48 \quad 100.0 \%$ Proteasome subunit alpha type-4 GN=PSMA4 PSA4_HUMAN $29.48 \quad 100.0 \%$ Proteasome subunit alpha type-4 GN=PSMA4 PSA4_HUMAN $29.48 \quad 100.0 \%$ Proteasome subunit alpha type-4 GN=PSMA4 PSA4 HUMAN $29.48 \quad 100.0 \%$ Proteasome subunit alpha type-4 GN=PSMA4 PSA4_HUMAN $29.48 \quad 100.0 \%$ Proteasome subunit alpha type-4 GN=PSMA4 PSA4_HUMAN $29.48 \quad 100.0 \%$ Proteasome subunit alpha type-4 GN=PSMA4 PSA4_HUMAN $29.48 \quad 100.0 \%$ Proteasome subunit alpha type-5 GN=PSMA5 PSA5_HUMAN $26.41 \quad 100.0 \%$ Proteasome subunit alpha type-5 GN=PSMA5 PSA5_HUMAN $26.41 \quad 100.0 \%$ Proteasome-associated protein ECM29 homolog GN=ECM29 ECM29_HUMAN $204.30 \quad 100.0 \%$ Proteasome-associated protein ECM29 homolog GN=ECM29 ECM29_HUMAN $204.30 \quad 100.0 \%$ Proteasome-associated protein ECM29 homolog GN=ECM29 ECM29_HUMAN $204.30 \quad 100.0 \%$ Proteasome-associated protein ECM29 homolog GN=ECM29 ECM29_HUMAN $204.30 \quad 100.0 \%$ Proteasome-associated protein ECM29 homolog GN=ECM29 ECM29_HUMAN $204.30 \quad 100.0 \%$ Proteasome-associated protein ECM29 homolog GN=ECM29 ECM29_HUMAN 204.30 $100.0 \%$ Proteasome-associated protein ECM29 homolog GN=ECM29 ECM29_HUMAN $204.30 \quad 100.0 \%$ Proteasome-associated protein ECM29 homolog GN=ECM29 ECM29 HUMAN 204.30 100.0\% Proteasome-associated protein ECM29 homolog GN=ECM29 ECM29_HUMAN $204.30 \quad 100.0 \%$ Proteasome-associated protein ECM29 homolog GN=ECM29 ECM29_HUMAN $204.30 \quad 100.0 \%$ Proteasome-associated protein ECM29 homolog GN=ECM29 ECM29_HUMAN $204.30 \quad 100.0 \%$ Proteasome-associated protein ECM29 homolog GN=ECM29 ECM29_HUMAN 204.30 100.0\% Proteasome-associated protein ECM29 homolog GN=ECM29 ECM29_HUMAN $204.30 \quad 100.0 \%$ Proteasome-associated protein ECM29 homolog GN=ECM29 ECM29_HUMAN 204.30 100.0\% Proteasome-associated protein ECM29 homolog GN=ECM29 ECM29_HUMAN 204.30 100.0\% Proteasome-associated protein ECM29 homolog GN=ECM29 ECM29 HUMAN $204.30100 .0 \%$ Protein arginine N-methyltransferase $1 \mathrm{GN}=$ PRMT1 ANM1_HUMAN $41.52 \quad 100.0 \%$ Protein arginine N-methyltransferase 1 GN=PRMT1 ANM1_HUMAN $41.52 \quad 100.0 \%$ Protein arginine N-methyltransferase 1 GN=PRMT1 ANM1_HUMAN $41.52 \quad 100.0 \%$ Protein arginine N-methyltransferase 1 GN=PRMT1 ANM1_HUMAN $41.52 \quad 100.0 \%$ Protein arginine N-methyltransferase $1 \mathrm{GN}=$ PRMT1 ANM1_HUMAN $41.52 \quad 100.0 \%$ Protein arginine N-methyltransferase 1 GN=PRMT1 ANM1_HUMAN $41.52 \quad 100.0 \%$ Protein arginine N-methyltransferase 1 GN=PRMT1 ANM1_HUMAN $41.52 \quad 100.0 \%$ Protein arginine N-methyltransferase $1 \mathrm{GN}=$ PRMT1 ANM1_HUMAN $41.52 \quad 100.0 \%$ Protein arginine N-methyltransferase 1 GN=PRMT1 ANM1_HUMAN $41.52 \quad 100.0 \%$
$0.01 \% \quad 11.5 \%$ GGILDTAIVDR $0.01 \% \quad 11.5 \%$ SGAPVLSLLSVR $0.00 \% \quad 5.9 \%$ VPQCPSGR

$0.00 \% \quad 5.9 \%$ SQSAAVTPSSTTSSTR $0.00 \% \quad 9.8 \%$ SNQQLVDIIEK $0.00 \% \quad 9.8 \%$ TVTEIDEKEYISLR

$0.00 \% \quad 11.0 \%$ THAVLVALK $0.00 \% \quad 11.0 \%$ LVSLIGSK $0.00 \% \quad 11.0 \%$ ETLPAEQDLTTK $0.01 \% \quad 16.5 \%$ VFQVEYAMK $0.01 \% \quad 16.5 \%$ AVENSSTAIGIR $0.01 \% \quad 16.5 \%$ CKDGVVFGVEK $0.01 \% \quad 16.5 \%$ SNFGYNIPLK $0.02 \% \quad 26.1 \%$ TTIFSPEGR $0.02 \% \quad 26.1 \%$ LLDEVFFSEK $0.02 \% \quad 26.1 \%$ QAYTQFGGK $0.02 \% \quad 26.1 \%$ ATCIGNNSAAAVSMLK $0.02 \% \quad 26.1 \%$ QDYKEGEMTLK $0.02 \% \quad 26.1 \%$ LSAEKVEIATLTR $0.02 \% \quad 26.1 \%$ VEIATLTR $0.00 \% \quad 12.0 \%$ GVNTFSPEGR $0.00 \% \quad 12.0 \%$ AIGSASEGAQSSLQEVYHK $0.04 \% \quad 11.3 \%$ LSSTQEGVR $0.04 \% \quad 11.3 \%$ SASPFNLAEKPK $0.04 \% \quad 11.3 \%$ HSVATAADLELKSK $0.04 \% \quad 11.3 \%$ VYLGDIPLKTK $0.04 \% \quad 11.3 \%$ TLMSSGQMAPSSSNK $0.04 \% \quad 11.3 \%$ NGPLPIPSEGSGFTK $0.04 \% \quad 11.3 \%$ VKHEVSGETVVFQGGALGK $0.04 \% \quad 11.3 \%$ KGAAFGFNVIATR $0.04 \% \quad 11.3 \%$ AGEQLAPFLPQLVPR $0.04 \% \quad 11.3 \%$ ESSCLALNDLLR $0.04 \% \quad 11.3 \%$ ALSINTLVK $0.04 \% \quad 11.3 \%$ ATEQEKAAMDSAR $0.04 \% \quad 11.3 \%$ LYLQELITITQK $0.04 \% \quad 11.3 \%$ AQGAIAMASIAK $0.04 \% \quad 11.3 \%$ AIACVVTACSAELEK $0.04 \% \quad 11.3 \%$ IVAISCAADILK $0.03 \% \quad 42.4 \%$ VVLDVGSGTGILCMFAAK $0.03 \% \quad 42.4 \%$ KVIGIECSSISDYAVK $0.03 \% \quad 42.4 \%$ VIGIECSSISDYAVK $0.03 \% \quad 42.4 \%$ ANKLDHVVTIIK $0.03 \% \quad 42.4 \%$ GKVEEVELPVEK $0.03 \% \quad 42.4 \%$ ATLYVTAIEDR $0.03 \% \quad 42.4 \%$ DVAIKEPLVDVVDPK $0.03 \% \quad 42.4 \%$ QLVTNACLIK

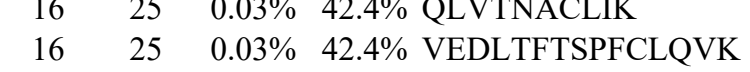

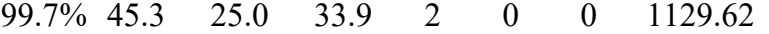

1198.72
900.44

$\begin{array}{llllllll}99.0 \% & 23.1 & 25.0 & 22.6 & 2 & 0 & 0 & 900.44\end{array}$

$\begin{array}{llllllll}99.7 \% & 65.6 & 25.0 & 65.6 & 2 & 0 & 0 & 1567.76\end{array}$

$\begin{array}{llllllll}99.7 \% & 49.0 & 25.0 & 43.1 & 2 & 0 & 0 & 1286.70\end{array}$

$\begin{array}{llllllll}99.2 \% & 19.4 & 25.0 & 18.8 & 0 & 1 & 0 & 1695.88\end{array}$

$\begin{array}{llllllll}99.4 \% & 23.7 & 25.0 & 23.7 & 1 & 0 & 0 & 951.60\end{array}$

$\begin{array}{llllllll}98.3 \% & 18.9 & 25.0 & 18.2 & 1 & 0 & 0 & 816.52\end{array}$

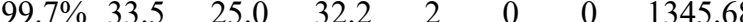

$\begin{array}{llllllll}99.7 \% & 39.8 & 25.0 & 39.4 & 2 & 0 & 0 & 1114.56\end{array}$

$99.7 \% \quad 70.0 \quad 25.0 \quad 57.8$

$99.7 \% \quad 36.8 \quad 25.0 \quad 23.5$

$\begin{array}{llll}99.7 \% & 34.6 & 25.0 & 22.1\end{array}$

$99.5 \% \quad 30.6 \quad 25.0 \quad 18.1$

$99.7 \% \quad 63.0 \quad 25.0 \quad 61.8$

$\begin{array}{llll}99.7 \% & 38.2 & 25.0 & 29.3\end{array}$

$\begin{array}{llll}99.7 \% & 63.3 & 25.0 & 60.4\end{array}$

$\begin{array}{llll}99.2 \% & 30.2 & 25.0 & 20.6\end{array}$

$\begin{array}{llll}99.7 \% & 45.3 & 25.0 & 45.3\end{array}$

$99.0 \% \quad 48.7 \quad 25.0 \quad 37.1$

$\begin{array}{llll}99.7 \% & 31.6 & 25.0 & 21.0\end{array}$

$\begin{array}{llll}95.5 \% & 15.6 & 25.0 & 13.6\end{array}$

$\begin{array}{llll}99.2 \% & 30.8 & 25.0 & 12.0\end{array}$

$\begin{array}{lllll}99.7 \% & 31.6 & 25.0 & 27.8 & 2\end{array}$

$\begin{array}{llll}97.6 \% & 16.0 & 25.0 & 16.0\end{array}$

$\begin{array}{llll}99.3 \% & 25.8 & 25.0 & 25.5\end{array}$

$\begin{array}{llll}99.7 \% & 52.3 & 25.0 & 52.3\end{array}$

$\begin{array}{llll}97.2 \% & 16.2 & 25.0 & 16.2\end{array}$

$\begin{array}{llll}99.7 \% & 50.8 & 25.0 & 50.8\end{array}$

$\begin{array}{llll}99.7 \% & 42.0 & 25.0 & 35.1\end{array}$

$\begin{array}{llll}99.5 \% & 26.9 & 25.0 & 19.6\end{array}$

$\begin{array}{llll}99.7 \% & 36.6 & 25.0 & 25.5\end{array}$

$\begin{array}{llll}99.7 \% & 32.4 & 25.0 & 19.2\end{array}$

$99.7 \% \quad 44.1 \quad 25.0 \quad 44.1$

$\begin{array}{llll}99.7 \% & 45.7 & 25.0 & 45.7\end{array}$

$\begin{array}{llll}99.7 \% & 44.1 & 25.0 & 30.3\end{array}$

$\begin{array}{llll}99.7 \% & 67.9 & 25.0 & 67.9\end{array}$

$\begin{array}{llll}99.7 \% & 55.5 & 25.0 & 49.5\end{array}$

$\begin{array}{llll}99.7 \% & 90.1 & 25.0 & 68.5\end{array}$

$\begin{array}{llll}99.7 \% & 55.2 & 25.0 & 55.2\end{array}$

$\begin{array}{llll}99.7 \% & 95.8 & 25.0 & 95.8\end{array}$

$\begin{array}{llll}99.7 \% & 28.9 & 25.0 & 28.9\end{array}$

$99.7 \% \quad 65.0 \quad 25.0 \quad 59.7$

$\begin{array}{llll}99.7 \% & 70.9 & 25.0 & 64.9\end{array}$

$\begin{array}{llll}99.7 \% & 46.8 & 25.0 & 46.8\end{array}$

$99.7 \% \quad 43.4 \quad 25.0 \quad 34.4$

$\begin{array}{llll}99.7 \% & 35.2 & 25.0 & 34.2\end{array}$

1217.65

1237.62

1152.60

1007.52

1226.63

999.49

1623.78

1341.64

1430.82

902.53

1063.52

1961.96

976.51

1288.69

1469.80

1246.74

1557.69

1500.77

1942.04

1351.75

1635.92

1390.70

958.59

1407.65

1462.85

1131.62

1621.79

1273.72

1837.96

1768.92

1640.82

1350.81

1355.74

1251.66

1636.92

1159.65 
Protein arginine N-methyltransferase 1 GN=PRMT1 ANM1_HUMAN $41.52 \quad 100.0 \% \quad 12$ $\begin{array}{llll}\text { Protein arginine N-methyltransferase } 1 \text { GN=PRMT1 ANM1_HUMAN } & 41.52 & 100.0 \% & 12\end{array}$ Protein arginine N-methyltransferase 1 GN=PRMT1 ANM1_HUMAN $41.52 \quad 100.0 \% \quad 12$ Protein arginine N-methyltransferase 5 GN=PRMT5 ANM5 HUMAN $72.69 \quad 100.0 \%$ Protein arginine N-methyltransferase 5 GN=PRMT5 ANM5_HUMAN $72.69 \quad 100.0 \% \quad 24$ Protein arginine N-methyltransferase 5 GN=PRMT5 ANM5_HUMAN $72.69 \quad 100.0 \% 24$ Protein arginine N-methyltransferase 5 GN=PRMT5 ANM5_HUMAN $72.69 \quad 100.0 \% \quad 24$ Protein arginine N-methyltransferase 5 GN=PRMT5 ANM5_HUMAN $72.69 \quad 100.0 \% \quad 24$ Protein arginine N-methyltransferase $5 \mathrm{GN}=$ PRMT5 ANM5 HUMAN $72.69 \quad 100.0 \%$ Protein arginine N-methyltransferase 5 GN=PRMT5 ANM5_HUMAN $72.69 \quad 100.0 \% \quad 24$ Protein arginine N-methyltransferase 5 GN=PRMT5 ANM5_HUMAN $72.69 \quad 100.0 \% \quad 24$ Protein arginine N-methyltransferase 5 GN=PRMT5 ANM5 HUMAN $72.69 \quad 100.0 \% 24$ Protein arginine N-methyltransferase 5 GN=PRMT5 ANM5_HUMAN $72.69 \quad 100.0 \% \quad 24$ Protein arginine N-methyltransferase 5 GN=PRMT5 ANM5_HUMAN $72.69 \quad 100.0 \% 24$ Protein arginine N-methyltransferase 5 GN=PRMT5 ANM5_HUMAN $72.69 \quad 100.0 \% 24$ $\begin{array}{llll}\text { Protein arginine N-methyltransferase 5 GN=PRMT5 } & \text { ANM5_HUMAN } 72.69 & 100.0 \% & 24\end{array}$ Protein arginine N-methyltransferase $5 \mathrm{GN}=$ =PRMT5 ANM5 HUMAN $72.69 \quad 100.0 \% \quad 24$ Protein arginine N-methyltransferase 5 GN=PRMT5 ANM5_HUMAN $72.69 \quad 100.0 \% \quad 24$ Protein arginine N-methyltransferase 5 GN=PRMT5 ANM5_HUMAN $72.69 \quad 100.0 \% 24$ Protein arginine N-methyltransferase 5 GN=PRMT5 ANM5 HUMAN $72.69 \quad 100.0 \% 24$ Protein arginine N-methyltransferase 5 GN=PRMT5 ANM5_HUMAN $72.69 \quad 100.0 \% \quad 24$ Protein arginine N-methyltransferase 5 GN=PRMT5 ANM5_HUMAN $72.69 \quad 100.0 \% \quad 24$ Protein arginine N-methyltransferase 5 GN=PRMT5 ANM5_HUMAN $72.69 \quad 100.0 \% 24$ Protein arginine N-methyltransferase 5 GN=PRMT5 ANM5_HUMAN $72.69 \quad 100.0 \% \quad 24$ Protein arginine N-methyltransferase $5 \mathrm{GN}=$ PRMT5 ANM5 HUMAN $72.69 \quad 100.0 \%$ Protein arginine N-methyltransferase 5 GN=PRMT5 ANM5_HUMAN $72.69 \quad 100.0 \% \quad 24$ Protein arginine N-methyltransferase 5 GN=PRMT5 ANM5_HUMAN $72.69 \quad 100.0 \%$ Protein CMSS1 GN $=\mathrm{CMSS}$ Protein CMSS1 GN=CMSS Protein CMSS1 GN $=\mathrm{CMSS}$ Protein CMSS1 GN=CMSS1 Protein DEK GN=DEK Protein DEK GN=DEK Protein DEK GN=DEK Protein DEK GN=DEK Protein DEK GN=DEK Protein DEK GN=DEK Protein diaphanous homolog $1 \mathrm{GN}=$ DIAPH1 DIAP1_HUMAN $141.35 \quad 100.0 \%$ Protein diaphanous homolog 1 GN=DIAPH1 DIAP1_HUMAN $141.35 \quad 100.0 \%$ Protein diaphanous homolog 1 GN=DIAPH1 DIAP1_HUMAN $141.35 \quad 100.0 \%$ Protein diaphanous homolog 1 GN=DIAPH1 DIAP1_HUMAN $141.35 \quad 100.0 \%$ Protein diaphanous homolog $1 \mathrm{GN}=$ DIAPH1 DIAP1_HUMAN $141.35 \quad 100.0 \%$ Protein disulfide-isomerase A4 GN=PDIA4 PDIA4_HUMAN $72.93 \quad 100.0 \%$ Protein disulfide-isomerase A4 GN=PDIA4 PDIA4 HUMAN $72.93 \quad 100.0 \%$ Protein ELYS GN=AHCTF1 CMS1_HUMAN $31.89 \quad 100.0 \%$ CMS1_HUMAN $31.89 \quad 100.0 \%$ DEK_HUMAN $42.68 \quad 100.0 \%$ DEK_HUMAN $42.68 \quad 100.0 \%$ DEK_HUMAN $42.68 \quad 100.0 \%$ DEK_HUMAN $42.68 \quad 100.0 \%$ DEK_HUMAN $42.68 \quad 100.0 \%$ ELYS_HUMAN $252.50 \quad 100.0 \%$
$0.03 \% \quad 42.4 \%$ TGFSTSPESPYTHWK

$0.03 \% \quad 42.4 \%$ QTVFYMEDYLTVK

$99.7 \% \quad 27.2$

$99.7 \% \quad 40.4$

$0.03 \% \quad 42.4 \%$ TGEEIFGTIGMRPNAK

$163 \quad 0.18 \% \quad 35.3 \%$ VSSGRDLNCVPEIADTLGAVAK

$163 \quad 0.18 \% \quad 35.3 \%$ DLNCVPEIADTLGAVAK

$163 \quad 0.18 \% \quad 35.3 \%$ EFIQEPAK

$163 \quad 0.18 \% \quad 35.3 \%$ EFIQEPAKNRPGPQTR

$163 \quad 0.18 \% \quad 35.3 \%$ SDLLLSGR

$163 \quad 0.18 \% \quad 35.3 \%$ SDLLLSGRDWNTLIVGK

$163 \quad 0.18 \% \quad 35.3 \%$ DWNTLIVGK

$163 \quad 0.18 \% \quad 35.3 \%$ LSPWIRPDSK

$163 \quad 0.18 \% \quad 35.3 \%$ LSPWIRPDSKVEK

$163 \quad 0.18 \% \quad 35.3 \%$ VPLVAPEDLR

$163 \quad 0.18 \% \quad 35.3 \%$ TLCDYSKR

$163 \quad 0.18 \% \quad 35.3 \%$ IAVALEIGADLPSNHVIDR

$163 \quad 0.18 \% \quad 35.3 \%$ AAILPTSIFLTNK

$163 \quad 0.18 \% \quad 35.3 \%$ AAILPTSIFLTNKK

$163 \quad 0.18 \% \quad 35.3 \%$ KGFPVLSK

$163 \quad 0.18 \% \quad 35.3 \%$ YSQYQQAIYK

$98.5 \% \quad 18.2$

$99.0 \% 42.1$

$99.7 \% \quad 29.3$

$99.0 \% \quad 35.0$

$99.7 \% \quad 47.3$

$99.7 \% \quad 48.6$

$99.0 \% \quad 20.3$

$99.7 \% \quad 36.5$

$99.7 \% \quad 52.0$

$99.0 \% \quad 45.3$

$99.7 \% 52.1$

$99.7 \% \quad 53.9$

$99.7 \% \quad 47.2$

$99.0 \% \quad 56.8$

$99.7 \% 51.1$

$163 \quad 0.18 \% \quad 35.3 \%$ VPEEEKDTNVQVLMVLGAGR

$163 \quad 0.18 \% \quad 35.3 \%$ GPLVNASLR

$163 \quad 0.18 \% \quad 35.3 \%$ IKLYAVEK

$99.7 \% 55.3$

$99.0 \% 37.0$

0.18\% $35.3 \%$ DDGVSIPGEYTSFLAPISSSK

$163 \quad 0.18 \% \quad 35.3 \%$ QPITVREGQTICVR

$163 \quad 0.18 \% \quad 35.3 \%$ EGQTICVR

$163 \quad 0.18 \% \quad 35.3 \%$ EGQTICVRFWR

$0.01 \% \quad 12.5 \%$ ANDLTHSLSSYLK

$0.01 \% \quad 12.5 \%$ RVVHLGVGTPGR

$0.01 \% \quad 12.5 \%$ VVHLGVGTPGR

$0.01 \% \quad 12.5 \%$ QGGLNLSPLK

$0.02 \% \quad 15.5 \%$ NVGQFSGFPFEK

$0.02 \% \quad 15.5 \%$ SICEVLDLER

$0.02 \% \quad 15.5 \%$ SGVNSELVK

$7 \quad 0.02 \% \quad 15.5 \%$ SGVNSELVKR

$0.02 \% \quad 15.5 \%$ LLASANLEEVTMK

$0.02 \% \quad 15.5 \%$ VYENYPTYDLTER

$4 \quad 0.02 \% \quad 6.5 \% \quad$ SPDELPSAGGDGGK

$0.02 \% \quad 6.5 \%$ EMVSQYLYTSK

$0.02 \% \quad 6.5 \%$ SAMMYIQELR

$0.02 \% \quad 6.5 \% \quad$ KLYKPEVQLR

$0.02 \% \quad 6.5 \% \quad$ LTLTFSAQTK

$0.02 \% \quad 6.5 \%$ TAQNLSIFLGSFR

$0.02 \% \quad 6.5 \%$ NAGAFGFNISFLCK

$0.00 \% \quad 3.6 \%$ IDATSASVLASR

$0.00 \% \quad 3.6 \%$ VDATAETDLAK

$0.01 \% \quad 0.8 \% \quad$ SVFINNVLSK
$99.7 \% \quad 35.2$

$99.0 \% \quad 42.5$

$99.2 \% \quad 20.0$

$99.7 \% \quad 27.5$

$99.7 \% \quad 39.4$

$99.7 \% \quad 49.1$

$99.7 \% \quad 54.0$

$99.7 \% \quad 47.0$

$99.7 \% \quad 60.4$

$99.5 \% \quad 31.7$

$99.7 \% \quad 61.2$

$99.7 \% \quad 63.0$

$99.7 \% \quad 50.6$

$99.7 \% \quad 30.4$

$99.7 \% \quad 34.8$

$99.7 \% \quad 57.0$

$99.5 \% 25.5$

$99.7 \% \quad 31.5$

$99.7 \% \quad 38.6$

$99.7 \% \quad 57.5$

$99.7 \% \quad 47.8$

$99.4 \% \quad 24.1$

$99.7 \% \quad 45.7$
636.79

1736.86

2272.16

1785.91

1766.81

961.50

1867.98

860.48

1887.03

1045.57

1198.66

1554.86

1108.64

1042.50

2003.09

1388.81

1516.91

875.54

1291.63

2184.13

926.54

963.59

2170.06

1656.89

962.47

1451.72

1448.74

1247.73

1091.63

1026.59

1356.66

1233.61

932.50

1088.61

1434.75

1662.76

1286.59

1348.65

1241.60

1273.76

1109.62

1453.78

1545.75

1190.64

1133.57

1120.64

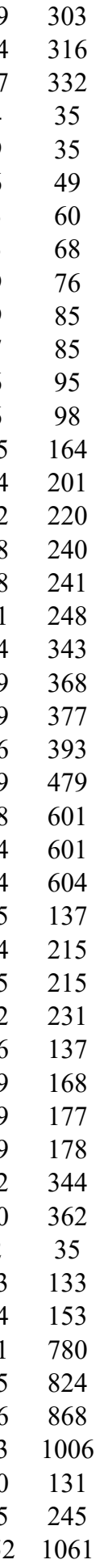

Page 121 of Table S-1-6 
Protein ELYS GN=AHCTF1 Protein FAM207A GN=FAM207A Protein FAM207A GN=FAM207A Protein FAM45B GN=FAM45B Protein FAM45B GN=FAM45B Protein flightless-1 homolog GN=FLII Protein flightless-1 homolog GN=FLII Protein flightless-1 homolog GN=FLII Protein flightless-1 homolog GN=FLII Protein flightless- 1 homolog GN=FLII Protein flightless-1 homolog GN=FLII Protein flightless-1 homolog GN=FLII Protein flightless-1 homolog GN=FLII Protein lin-28 homolog B GN=LIN28B Protein lin-28 homolog B GN=LIN28B Protein lin-28 homolog B GN=LIN28B Protein lin-28 homolog B GN=LIN28B Protein lin-28 homolog B GN=LIN28B Protein lin-28 homolog B GN=LIN28B Protein lin-28 homolog B GN=LIN28B Protein LTV1 homolog GN=LTV1 Protein LTV1 homolog GN=LTV1 Protein LYRIC GN=MTDH Protein LYRIC GN=MTDH

Protein MON2 homolog $\mathrm{GN}=\mathrm{MON} 2$ Protein MON2 homolog GN=MON2 Protein MON2 homolog GN=MON2 Protein MON2 homolog GN=MON2 Protein MON2 homolog GN=MON2 Protein O-GlcNAcase GN=MGEA5 Protein O-GlcNAcase GN=MGEA5 Protein pelota homolog GN=PELO Protein pelota homolog GN=PELO Protein pelota homolog GN=PELO Protein pelota homolog $\mathrm{GN}=\mathrm{PELO}$ Protein phosphatase 1B GN=PPM1B Protein phosphatase 1B GN=PPM1B Protein phosphatase $1 \mathrm{~B} \mathrm{GN}=\mathrm{PPM} 1 \mathrm{~B}$ Protein phosphatase $1 \mathrm{~B}$ GN=PPM1B Protein polybromo-1 GN=PBRM1

Protein polybromo-1 GN=PBRM1 Protein polybromo- $1 \mathrm{GN}=\mathrm{PBRM} 1$ Protein polybromo-1 GN=PBRM1 Protein PRRC2A GN=PRRC2A Protein PRRC2A GN=PRRC2A

Protein RRP5 homolog GN=PDCD11 Protein RRP5 homolog GN=PDCD11
ELYS HUMAN $252.50 \quad 100.0 \% \quad 2 \quad 2 \quad 2 \quad 7 \quad 0.01 \% \quad 0.8 \% \quad$ SPLYLVSR F207A_HUMAN $25.46 \quad 100.0 \% \quad 2 \quad 25 \quad 5 \quad 0.01 \% \quad 10.0 \%$ ATVVVGDLHPLR F207A_HUMAN $25.46 \quad 100.0 \%$ FA45B_HUMAN $40.52 \quad 100.0 \%$ FA45B_HUMAN $40.52 \quad 100.0 \%$ FLII_HUMAN $144.76 \quad 100.0 \%$ FLII HUMAN $144.76 \quad 100.0 \%$ FLII_HUMAN $144.76 \quad 100.0 \%$ FLII HUMAN $144.76 \quad 100.0 \%$ FLII_HUMAN $144.76 \quad 100.0 \%$ FLII_HUMAN $144.76 \quad 100.0 \%$ FLII HUMAN $144.76 \quad 100.0 \%$ FLII_HUMAN $144.76 \quad 100.0 \%$ LN28B_HUMAN $27.08 \quad 100.0 \%$ LN28B_HUMAN $27.08 \quad 100.0 \%$ LN28B_HUMAN $27.08 \quad 100.0 \%$ LN28B HUMAN $27.08 \quad 100.0 \%$ LN28B_HUMAN $27.08 \quad 100.0 \%$ LN28B_HUMAN $27.08 \quad 100.0 \%$ LN28B HUMAN $27.08 \quad 100.0 \%$ LTV1_HUMAN $54.86 \quad 100.0 \%$ LTV1_HUMAN $54.86 \quad 100.0 \%$ LYRIC_HUMAN $63.84 \quad 100.0 \%$ LYRIC_HUMAN $63.84 \quad 100.0 \%$ MON2_HUMAN $190.36 \quad 100.0 \%$ MON2_HUMAN $190.36 \quad 100.0 \%$ MON2_HUMAN $190.36 \quad 100.0 \%$ MON2 HUMAN $190.36 \quad 100.0 \%$ MON2_HUMAN $190.36 \quad 100.0 \%$ OGA HUMAN $102.92 \quad 100.0 \%$ OGA_HUMAN $102.92 \quad 100.0 \%$ PELO_HUMAN $43.36 \quad 100.0 \%$ PELO HUMAN $43.36 \quad 100.0 \%$ PELO_HUMAN $43.36 \quad 100.0 \%$ PELO_HUMAN $43.36 \quad 100.0 \%$ PPM1B HUMAN $52.64 \quad 100.0 \%$ PPM1B_HUMAN $52.64 \quad 100.0 \%$ PPM1B HUMAN $52.64 \quad 100.0 \%$ PPM1B_HUMAN $52.64 \quad 100.0 \%$ PB1_HUMAN $192.95 \quad 100.0 \%$ PB1 HUMAN $192.95 \quad 100.0 \%$ PB1_HUMAN $192.95 \quad 100.0 \%$ PB1_HUMAN $192.95 \quad 100.0 \%$ PRC2A HUMAN $228.87 \quad 100.0 \%$ PRC2A_HUMAN $228.87 \quad 100.0 \%$ RRP5 HUMAN $208.70 \quad 100.0 \%$ RRP5_HUMAN $208.70 \quad 100.0 \%$

$0.02 \% \quad 42.8 \%$ MGFGFISMINR
$98.9 \% \quad 19.5$

$99.7 \% \quad 40.2$

$99.7 \% \quad 47.3$

$99.7 \% \quad 32.6$

$0.00 \% \quad 7.8 \%$ IEAVQEFTR

$94.8 \% \quad 14.4$ $99.6 \% 38.5$

$0.01 \% \quad 7.5 \%$ NQLTSLPSAICK $97.1 \% \quad 16.6$

$0.01 \% \quad 7.5 \%$ LAGASPATVAAAAAAGSGPKDPMA

$0.01 \% \quad 7.5 \%$ GAQATLSSTTK

$0.01 \% \quad 7.5 \%$ LLQSLLDTR

$0.01 \% \quad 7.5 \%$ SLEGTEAQVFKAK

$0.01 \% \quad 7.5 \%$ ADLTALFLPR

$0.01 \% \quad 7.5 \%$ KAVQGAQQPSLYQIR

$0.01 \% \quad 7.5 \% \quad$ AVQGAQQPSLYQIR

$99.7 \% 39$.

$99.7 \% \quad 40.2$

$99.7 \% \quad 43.7$

$99.7 \% \quad 49.3$

$99.7 \% \quad 26.8$

$99.7 \% \quad 59.0$

$0.02 \% \quad 42.8 \%$ GGGEEPGKLPEPAEEESQVLR

$99.7 \% \quad 51.2$

$0.02 \% \quad 42.8 \%$ EGSPLDIPVDVFVHQSK $\quad 95.4 \% \quad 18.1$

$0.02 \% \quad 42.8 \%$ VTGPGGSPCLGSER

$0.02 \% \quad 42.8 \%$ NVAQPPASSQGR

$99.7 \% \quad 63.3$

$99.7 \% \quad 32.0$

$0.02 \% \quad 42.8 \%$ QEAESQPCTSTLPR

$99.7 \% \quad 58.5$

$0.02 \% \quad 42.8 \%$ EVGGGHGCTSPPFPQEAR $\quad 99.7 \% \quad 34.1$

$0.00 \% \quad 5.3 \%$ SQRDPLAADESAPQR

$0.00 \% \quad 5.3 \%$ TGIPLNVLPK

$0.00 \% \quad 4.1 \%$ TVEVAEGEAVR

$0.00 \% \quad 4.1 \%$ TISTSDPAEVLVK

$0.01 \% \quad 3.0 \% \quad$ ITQLCLAAIQR

$0.01 \% \quad 3.0 \% \quad$ YLLQPLGDFSR

$0.01 \% \quad 3.0 \%$ SLEVVVDLYQK

$0.01 \% \quad 3.0 \%$ VLSIGLPVAR

$0.01 \% \quad 3.0 \%$ MALSVLLKR

$0.00 \% \quad 2.0 \%$ GGLAGEFQR

$0.00 \% \quad 2.0 \% \quad$ KVTDPSVAK

$0.01 \% \quad 9.6 \%$ KVQTESSTGSVGSNR

$0.01 \% \quad 9.6 \%$ VQTESSTGSVGSNR

$0.01 \% \quad 9.6 \%$ AKVEVNIPR

$0.01 \% \quad 9.6 \%$ LVDSVKENAGTVR

$0.01 \% \quad 9.8 \%$ SGSALELSVENVK

$0.01 \% \quad 9.8 \%$ SGSTAVGVMISPK

$0.01 \% \quad 9.8 \%$ IQNAGGSVMIQR

$0.01 \% \quad 9.8 \%$ NVIEAVYSR

$0.01 \% \quad 2.3 \%$ GSLGEERNPTSK

$0.01 \% \quad 2.3 \%$ LNEVYEAVK

$0.01 \% \quad 2.3 \%$ VGDCVFIK

$0.01 \% \quad 2.3 \%$ VVDDEIYYFR

$0.00 \% \quad 1.2 \%$ QSSSEISLAVER

$0.00 \% \quad 1.2 \%$ GVGSGGQGPPPPR

$0.06 \% \quad 12.8 \%$ CVVSSLGITDR

$0.06 \% \quad 12.8 \%$ VGQYLNCIVEK

1159.60

1359.74

1286.73

1308.69

1292.71

1024.65

1030.64

934.47

944.54

1536.76

1408.67

1025.61

1387.75

1332.70

1233.65

1289.66

1050.56

1274.63

1064.56

937.48

1318.63

1305.66

1162.60

1206.61

1322.68 
Protein RRP5 homolog GN=PDCD11 Protein RRP5 homolog GN=PDCD11 Protein RRP5 homolog GN=PDCD11 Protein RRP5 homolog GN=PDCD1 Protein RRP5 homolog GN=PDCD11 Protein RRP5 homolog GN=PDCD1 Protein RRP5 homolog GN=PDCD1 1 Protein RRP5 homolog GN=PDCD1 Protein RRP5 homolog GN=PDCD11 Protein RRP5 homolog GN=PDCD1 Protein RRP5 homolog GN=PDCD1 Protein RRP5 homolog GN=PDCD11 Protein RRP5 homolog GN=PDCD1 Protein RRP5 homolog GN=PDCD11 Protein RRP5 homolog GN=PDCD11 Protein RRP5 homolog GN=PDCD1 Protein RRP5 homolog GN=PDCD1 Protein RRP5 homolog GN=PDCD1 Protein SDA1 homolog GN=SDAD 1 Protein SDA1 homolog GN=SDAD1 Protein SDA1 homolog GN=SDAD1 Protein SDA1 homolog GN=SDAD1 Protein SDA1 homolog GN=SDAD1 Protein SEC13 homolog GN=SEC13 Protein SEC13 homolog GN=SEC13 Protein SEC13 homolog GN=SEC13 Protein SET GN=SET

Protein SET GN=SET

Protein SET GN=SET

Protein SET GN=SET

Protein SET GN=SET

Protein TBRG4 GN=TBRG4

Protein TBRG4 GN=TBRG4

$\begin{array}{lrll}\text { Protein TBRG4 GN=TBRG4 } & \text { TBRG4_HUMAN } & 70.74 & 100.0 \% \\ \text { Protein timeless homolog GN=TIMELESS TIM HUMAN } & 138.66 & 100.0 \%\end{array}$

Protein timeless homolog GN=TIMELESS TIM_HUMAN $138.66 \quad 100.0 \%$ Protein transport protein Sec16A GN=SEC16A SC16A_HUMAN $233.52 \quad 100.0 \%$ Protein transport protein Sec16A GN=SEC16A SC16A_HUMAN $233.52 \quad 100.0 \%$ Protein transport protein Sec16A GN=SEC16A SC16A_HUMAN $233.52 \quad 100.0 \%$ Protein transport protein Sec61 subunit alpha isoform 1 GN=SEC61A1 S61A1_HUMAN $52.27 \quad 100.0 \%$ Protein transport protein Sec61 subunit alpha isoform $1 \mathrm{GN}=\mathrm{SEC} 61 \mathrm{~A} 1$ S61A1_HUMAN $52.27 \quad 100.0 \%$ Protein transport protein Sec61 subunit alpha isoform 1 GN=SEC61A1 S61A1_HUMAN $52.27 \quad 100.0 \%$ Protein transport protein Sec61 subunit alpha isoform $1 \mathrm{GN}=\mathrm{SEC} 61 \mathrm{~A} 1$ S61A1 HUMAN $52.27 \quad 100.0^{\circ}$ Protein transport protein Sec61 subunit alpha isoform $1 \mathrm{GN}=\mathrm{SEC} 61 \mathrm{~A} 1$ S61A1_HUMAN $52.27 \quad 100.0 \%$ Protein transport protein Sec61 subunit alpha isoform $1 \mathrm{GN}=\mathrm{SEC} 61 \mathrm{A1}$ S61A1_HUMAN $52.27 \quad 100.0 \%$ Protein unc-45 homolog A GN=UNC45A UN45A_HUMAN $103.08 \quad 100.0 \%$ Protein unc-45 homolog A GN=UNC45A UN45A_HUMAN $103.08 \quad 100.0 \%$

20

$100.0 \% \quad 20$ $\begin{array}{lll} & \end{array}$ RRP5_HUMAN $208.70 \quad 100.0 \% \quad 20$ RRP5 HUMAN $208.70 \quad 100.0 \% \quad 20$ RRP5 HUMAN $208.70 \quad 100.0 \% \quad 20$ RRP5 HUMAN $208.70 \quad 100.0 \% \quad 20$ RRP5 HUMAN $208.70 \quad 100.0 \% \quad 20$ RRP5 HUMAN $208.70 \quad 100.0 \% \quad 20$ RRP5_HUMAN $208.70 \quad 100.0 \%$ RRP5 HUMAN $208.70 \quad 100.0 \% \quad 20$ DAl_HUMAN $79.88 \quad 100.0 \%$ SDA1_HUMAN $79.88 \quad 100.0 \%$ SDA1 HUMAN $79.88 \quad 100.0 \%$ SEC13_HUMAN $35.54 \quad 100.0 \%$ SEC13 HUMAN $35.54 \quad 100.0 \%$ SET_HUMAN $33.49 \quad 100.0 \%$ SET HUMAN $33.49 \quad 100.0 \%$ SET_HUMAN $33.49 \quad 100.0 \%$ SET_HUMAN $33.49 \quad 100.0 \%$ TBRG4_HUMAN $70.74 \quad 100.0 \%$ TBRG4_HUMAN $70.74 \quad 100.0 \%$ 3 2 3 6 6 6 6
2
$49 \quad 0.06 \% \quad 12.8 \%$ ACILCVHPR

$49 \quad 0.06 \% \quad 12.8 \%$ TSIIEAQYLR

$20 \quad 49 \quad 0.06 \% \quad 12.8 \%$ YHDIEPGAVVK

$20 \quad 49 \quad 0.06 \% \quad 12.8 \%$ VLLCDPEAK

$20 \quad 49 \quad 0.06 \% \quad 12.8 \%$ FYNNVQGLVPK

$20 \quad 49 \quad 0.06 \% \quad 12.8 \%$ VVVLNCEPSKER

$20 \quad 49 \quad 0.06 \% \quad 12.8 \%$ TKDGLEVAVLPHNIR

$20 \quad 49 \quad 0.06 \% \quad 12.8 \%$ VLCLSQSEGR

$\begin{array}{llll}20 & 49 & 0.06 \% & 12.8 \% \\ 20 & \text { KPALVSTVEGGQDPK }\end{array}$

$20 \quad 49 \quad 0.06 \% \quad 12.8 \%$ TTEPGVTGLLLAVEGPAAK

$20 \quad 49 \quad 0.06 \% \quad 12.8 \%$ IPLLLTSLSFK

$20 \quad 49 \quad 0.06 \% \quad 12.8 \%$ VTPNEGLTVSFPFGK

$20 \quad 49 \quad 0.06 \% \quad 12.8 \%$ CYILSTADNVLTLSLR

$20 \quad 49 \quad 0.06 \% \quad 12.8 \%$ LGPSVVGLAR

$20 \quad 49 \quad 0.06 \% \quad 12.8 \%$ SEKFQEAGELYNR

$20 \quad 49 \quad 0.06 \% \quad 12.8 \%$ AIFENTLSTYPK

$20 \quad 49 \quad 0.06 \% \quad 12.8 \%$ VIHLSLAPK

$9 \quad 0.01 \% \quad 6.6 \%$ DLLVQYATGK

$9 \quad 0.01 \% \quad 6.6 \%$ DLLVQYATGKK

$9 \quad 0.01 \% \quad 6.6 \% \quad$ GKPTEASIEAR

$9 \quad 0.01 \% \quad 6.6 \% \quad$ VLTQEDFQKIR

$9 \quad 0.01 \% \quad 6.6 \% \quad$ TNPFSSSTNKEK

$0.01 \% \quad 12.1 \%$ NGGQILIADLR

$0.01 \% \quad 12.1 \%$ FASGGCDNLIK

$0.01 \% \quad 12.1 \%$ GQGSVSASVTEGQQNEQ

$10 \quad 0.01 \% \quad 19.3 \%$ LNEQASEEILK

$10 \quad 0.01 \% \quad 19.3 \%$ LRQPFFQK

$10 \quad 0.01 \% \quad 19.3 \%$ VEVTEFEDIK

$10 \quad 0.01 \% \quad 19.3 \%$ IDFYFDENPYFENK

$10 \quad 0.01 \% \quad 19.3 \%$ EFHLNESGDPSSK

$3 \quad 0.00 \% \quad 6.5 \%$ VLVMLAAQSR

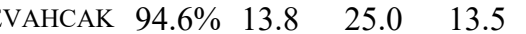

$0.00 \% \quad 6.5 \% \quad$ KAVAEELAK

$0.00 \% \quad 2.7 \%$ SADFAELEVLR

$0.00 \% \quad 2.7 \%$ AAASLSQPEEEQKLQPELQPK

$0.01 \% \quad 1.8 \%$ NPSSAAPVQSR

$0.01 \% \quad 1.8 \%$ FGPGGQLIK

$0.01 \% \quad 1.8 \%$ LLPSAPQTLPDGPLASPAR

$0.04 \% \quad 9.0 \%$ IIEVGDTPK

$0.04 \% \quad 9.0 \%$ IIEVGDTPKDR

$\begin{array}{lll}0.04 \% & 9.0 \% & \text { AFSPTTVNTGR }\end{array}$

$0.04 \% \quad 9.0 \% \quad$ YRGQYNTYPIK

$0.04 \% \quad 9.0 \%$ GQYNTYPIK

$0.04 \% \quad 9.0 \%$ ETSMVHELNR

$0.00 \% \quad 2.9 \%$ TVATLSILGTR

$0.00 \% \quad 2.9 \%$ ALIPLALEGTDVGQTK $\begin{array}{llll}99.7 \% & 58.0 & 25.0 & 50.0\end{array}$

$\begin{array}{llll}99.7 \% & 29.0 & 25.0 & 18.5\end{array}$

$\begin{array}{llll}99.7 \% & 49.4 & 25.0 & 32.8\end{array}$

$\begin{array}{llll}99.7 \% & 44.1 & 25.0 & 39.3\end{array}$

$\begin{array}{llll}99.7 \% & 37.7 & 25.0 & 32.0\end{array}$

$99.7 \% \quad 31.0 \quad 25.0 \quad 31.0$

$\begin{array}{llll}99.7 \% & 49.5 & 25.0 & 45.9\end{array}$

$99.1 \% \quad 19.5 \quad 25.0 \quad 19.5$

$\begin{array}{llll}99.7 \% & 50.0 & 25.0 & 49.4\end{array}$

$\begin{array}{llll}99.7 \% & 54.9 & 25.0 & 42.4\end{array}$

\begin{tabular}{llll}
$\%$ & 50.2 & 25.0 & 50.2 \\
\hline
\end{tabular}

$\begin{array}{lllll}99.7 \% & 48.0 & 25.0 & 48.0 & 2\end{array}$

$\begin{array}{llll}99.7 \% & 34.3 & 25.0 & 34.3\end{array}$

$\begin{array}{llll}99.7 \% & 61.8 & 25.0 & 57.4\end{array}$

$\begin{array}{llll}99.7 \% & 35.4 & 25.0 & 32.8\end{array}$

$\begin{array}{llll}99.7 \% & 49.0 & 25.0 & 48.7\end{array}$

$\begin{array}{llll}99.6 \% & 25.1 & 25.0 & 25.1\end{array}$

$\begin{array}{llll}99.7 \% & 35.7 & 25.0 & 25.6\end{array}$

$\begin{array}{llll}99.7 \% & 46.3 & 25.0 & 41.1\end{array}$

$\begin{array}{llll}99.7 \% & 33.4 & 25.0 & 25.9\end{array}$

$\begin{array}{llll}99.7 \% & 33.8 & 25.0 & 30.5\end{array}$

$\begin{array}{llll}97.6 \% & 16.0 & 25.0 & 16.0\end{array}$

$\begin{array}{lllll}99.7 \% & 59.1 & 25.0 & 51.1\end{array}$

$99.7 \% \quad 43.4 \quad 25.0 \quad 24.8$

$\begin{array}{llll}99.7 \% & 36.9 & 25.0 & 36.9\end{array}$

$\begin{array}{llll}99.7 \% & 47.5 & 25.0 & 33.8\end{array}$

$99.0 \% \quad 36.4 \quad 25.0 \quad 24.9$

$\begin{array}{lllll}99.7 \% & 60.8 & 25.0 & 53.5 & 3\end{array}$

$\begin{array}{llll}99.7 \% & 55.1 & 25.0 & 55.1\end{array}$

$\begin{array}{llll}99.7 \% & 55.6 & 25.0 & 54.2 \\ 99.7 \% & 58.0 & 25.0 & 50.0\end{array}$

$\begin{array}{llll}94.6 \% & 13.8 & 25.0 & 13.5 \\ 94.6 \% & 23.7 & 25.0 & 11.3\end{array}$

$\begin{array}{llll}99.5 \% & 27.1 & 25.0 & 26.2\end{array}$

$\begin{array}{llll}98.6 \% & 17.9 & 25.0 & 17.9\end{array}$

$\begin{array}{llll}99.7 \% & 37.8 & 25.0 & 37.0\end{array}$

$\begin{array}{llll}99.7 \% & 35.3 & 25.0 & 26.1\end{array}$

$\begin{array}{llll}99.7 \% & 51.1 & 25.0 & 51.1\end{array}$

$\begin{array}{llll}99.7 \% & 30.9 & 25.0 & 29.9\end{array}$

$\begin{array}{llll}99.7 \% & 46.0 & 25.0 & 32.5\end{array}$

$\begin{array}{llll}99.7 \% & 56.4 & 25.0 & 45.6\end{array}$

$\begin{array}{llll}98.8 \% & 18.3 & 25.0 & 18.3\end{array}$

$\begin{array}{llll}99.7 \% & 35.4 & 25.0 & 26.4\end{array}$

$\begin{array}{llll}99.0 \% & 25.0 & 25.0 & 15.8\end{array}$

$\begin{array}{llll}98.3 \% & 20.2 & 25.0 & 20.2\end{array}$

$99.6 \% \quad 24.3 \quad 25.0 \quad 24.3$
0
0
0
0
0
0
0
1
0
0
0
0
0
0
0
1
0
0
0
0
0
0
0
0
0
0
0
0
0
0
0
0
0
0
0
0
0
0
0
1
0
0
0
0
0
0
0
0
0
0
0
1105.64

1193.65

1227.64

1044.54

1278.68

1429.75

1661.93

1148.57

1525.82

1824.01

1231.77

1592.83

1838.97

968.59

1570.75

1383.72

977.61

1107.60

1235.70

1158.61

1376.75

1339.65

1169.66

1181.56

1705.76

1273.66

1063.60

1208.60

1840.81

1446.65

1087.63

2330.17

958.56

1249.64

2321.20

1113.56

916.53

1901.05

971.54

1242.67

1150.59

1402.71

1083.55

1231.57

1131.67

1131.67
1625.91
86
895
74

457

$507 \quad 515$

$61 \quad 571$

$\begin{array}{ll}594 & 605 \\ 647 & 661\end{array}$

$692 \quad 701$

$707 \quad 721$

$982 \quad 1000$

$283 \quad 1298$

$1343 \quad 1352$

$1704 \quad 1716$

$1782 \quad 1793$

$1821 \quad 1829$

$245 \quad 254$

$245 \quad 255$

463
550
560

$634 \quad 645$

$44 \quad 54$

$182 \quad 192$

$306 \quad 322$

58
76

$123 \quad 132$

$137 \quad 150$

$155 \quad 167$

$261 \quad 270$

$316 \quad 337$

$623 \quad 631$

$247 \quad 257$

10941114

$594 \quad 604$

1284

17711789

$99 \quad 107$

$99 \quad 109$

$\begin{array}{ll}205 \\ 272 & 282\end{array}$

$274 \quad 282$

$406 \quad 415$

$230 \quad 240$

$\begin{array}{ll}692 & 707\end{array}$ 
Protein virilizer homolog GN=KIAA1429 VIR HUMAN $202.03 \quad 100.0 \%$ Protein virilizer homolog GN=KIAA1429 VIR_HUMAN $202.03 \quad 100.0 \%$ Protein virilizer homolog GN=KIAA1429 VIR_HUMAN $202.03 \quad 100.0 \%$ Protein virilizer homolog GN=KIAA1429 VIR HUMAN $202.03 \quad 100.0 \%$ Protein virilizer homolog GN=KIAA1429 VIR_HUMAN $202.03 \quad 100.0 \%$ Protein virilizer homolog GN=KIAA1429 VIR_HUMAN $202.03 \quad 100.0 \%$ Protein VPRBP GN=VPRBP Protein VPRBP GN=VPRBP VPRBP HUMAN $169.01 \quad 100.0 \%$ VPRBP_HUMAN $169.01 \quad 100.0 \%$ Proto-oncogene tyrosine-protein kinase Src GN=SRC SRC HUMAN $59.84 \quad 100.0 \%$ Proto-oncogene tyrosine-protein kinase Src GN=SRC SRC_HUMAN $59.84 \quad 100.0 \%$ Pumilio homolog 1 GN=PUM1

Pumilio homolog 1 GN=PUM1 PUM1_HUMAN $126.47 \quad 100.0 \%$ PUM1 HUMAN $126.47 \quad 100.0 \%$ Puromycin-sensitive aminopeptidase GN=NPEPPS PSA_HUMAN $103.28 \quad 100.0 \%$ Puromycin-sensitive aminopeptidase GN=NPEPPS PSA_HUMAN $103.28100 .0 \%$ Puromycin-sensitive aminopeptidase GN=NPEPPS PSA_HUMAN $103.28 \quad 100.0 \%$ Puromycin-sensitive aminopeptidase GN=NPEPPS PSA_HUMAN $103.28 \quad 100.0 \%$ Puromycin-sensitive aminopeptidase GN=NPEPPS PSA HUMAN $103.28 \quad 100.0 \%$ Puromycin-sensitive aminopeptidase GN=NPEPPS PSA_HUMAN $103.28 \quad 100.0 \%$ Puromycin-sensitive aminopeptidase GN=NPEPPS PSA_HUMAN $103.28 \quad 100.0 \%$ Puromycin-sensitive aminopeptidase GN=NPEPPS PSA_HUMAN $103.28 \quad 100.0 \%$ Puromycin-sensitive aminopeptidase GN=NPEPPS PSA_HUMAN $103.28 \quad 100.0 \%$ Puromycin-sensitive aminopeptidase GN=NPEPPS PSA HUMAN $103.28 \quad 100.0 \%$ Puromycin-sensitive aminopeptidase GN=NPEPPS PSA_HUMAN $103.28 \quad 100.0 \%$ Puromycin-sensitive aminopeptidase GN=NPEPPS PSA_HUMAN $103.28 \quad 100.0 \%$ Putative ATP-dependent RNA helicase DHX30 GN=DHX30 DHX30_HUMAN $133.94 \quad 100.0 \%$ Putative ATP-dependent RNA helicase DHX30 GN=DHX30 DHX30_HUMAN $133.94 \quad 100.0 \%$ Putative ATP-dependent RNA helicase DHX30 GN=DHX30 DHX30_HUMAN $133.94 \quad 100.0 \%$ Putative ATP-dependent RNA helicase DHX30 GN=DHX30 DHX30_HUMAN $133.94 \quad 100.0 \%$ Putative ATP-dependent RNA helicase DHX30 GN=DHX30 DHX30_HUMAN $133.94 \quad 100.0 \% \quad 28$ Putative ATP-dependent RNA helicase DHX30 GN=DHX30 DHX30 HUMAN $133.94 \quad 100.0 \% \quad 28$ Putative ATP-dependent RNA helicase DHX30 GN=DHX30 DHX30_HUMAN $133.94 \quad 100.0 \% \quad 28$ Putative ATP-dependent RNA helicase DHX30 GN=DHX30 DHX30_HUMAN $133.94 \quad 100.0 \% 28$ Putative ATP-dependent RNA helicase DHX30 GN=DHX30 DHX30_HUMAN $133.94 \quad 100.0 \% \quad 28$ Putative ATP-dependent RNA helicase DHX30 GN=DHX30 DHX30_HUMAN $133.94 \quad 100.0 \% \quad 28$ Putative ATP-dependent RNA helicase DHX30 GN=DHX30 DHX30_HUMAN $133.94 \quad 100.0 \%$ Putative ATP-dependent RNA helicase DHX30 GN=DHX30 DHX30_HUMAN $133.94 \quad 100.0 \% \quad 28$ Putative ATP-dependent RNA helicase DHX30 GN=DHX30 DHX30_HUMAN $133.94 \quad 100.0 \%$ Putative ATP-dependent RNA helicase DHX30 GN=DHX30 DHX30 HUMAN $133.94 \quad 100.0 \% 28$ Putative ATP-dependent RNA helicase DHX30 GN=DHX30 DHX30_HUMAN $133.94 \quad 100.0 \% \quad 28$ Putative ATP-dependent RNA helicase DHX30 GN=DHX30 DHX30_HUMAN $133.94 \quad 100.0 \% \quad 28$ Putative ATP-dependent RNA helicase DHX30 GN=DHX30 DHX30_HUMAN $133.94 \quad 100.0 \% \quad 28$ Putative ATP-dependent RNA helicase DHX30 GN=DHX30 DHX30_HUMAN $133.94 \quad 100.0 \% \quad 28$ Putative ATP-dependent RNA helicase DHX30 GN=DHX30 DHX30_HUMAN $133.94 \quad 100.0 \% \quad 28$ Putative ATP-dependent RNA helicase DHX30 GN=DHX30 DHX30_HUMAN $133.94 \quad 100.0 \% 28$ Putative ATP-dependent RNA helicase DHX30 GN=DHX30 DHX30_HUMAN $133.94 \quad 100.0 \%$ Putative ATP-dependent RNA helicase DHX30 GN=DHX30 DHX30_HUMAN $133.94 \quad 100.0 \% 28$ Putative ATP-dependent RNA helicase DHX30 GN=DHX30 DHX30_HUMAN $133.94 \quad 100.0 \% \quad 28$ $\quad 0.01 \% \quad 3.2 \%$ TTFEIEISR

$10 \quad 0.01 \% \quad 3.2 \% \quad$ VVTAGSAILQK

$10 \quad 0.01 \% \quad 3.2 \%$ SAVGHVFSLEK

$10 \quad 0.01 \% \quad 3.2 \% \quad$ SPGDSVIR

$10 \quad 0.01 \% \quad 3.2 \%$ SEYIEPAKR

$0.00 \% \quad 1.5 \%$ LQKADVVAQSR

$0.00 \% \quad 1.5 \%$ GLGETATVLTK

$0.00 \% \quad 3.9 \%$ AANILVGENLVCK

$0.00 \% \quad 3.9 \%$ VADFGLAR

$0.00 \% \quad 1.9 \%$ DSLTGSSDLYKR

$0.00 \% \quad 1.9 \%$ YISAAPGAEAK

$0.05 \% \quad 14.7 \%$ SKYTTPSGEVR

$0.05 \% \quad 14.7 \%$ YAAVTQFEATDARR

$0.05 \% \quad 14.7 \%$ VYTPVGKAEQGK

$0.05 \% \quad 14.7 \%$ FALEVAAK

$0.05 \% \quad 14.7 \%$ LNLGTVGFYR

$0.05 \% \quad 14.7 \%$ LGLQNDLFSLAR

$0.05 \% \quad 14.7 \%$ AGIISTVEVLK

$0.05 \% \quad 14.7 \%$ SPVYLTVLK

$0.05 \% \quad 14.7 \%$ VLGATLLPDLIQK

$0.05 \% \quad 14.7 \%$ LSVEGFAVDK

$0.05 \% \quad 14.7 \%$ AFFESHPAPSAER

$0.05 \% \quad 14.7 \%$ DAESIHQYLLQR

$0.08 \% \quad 21.4 \%$ NLLNSVIGR

$0.08 \% \quad 21.4 \%$ SVEVEGYGSK

$0.08 \% 21.4 \%$ NELFDAAKYR

$0.08 \% \quad 21.4 \%$ QLNPESIRPGGPGGLSR

$0.08 \% \quad 21.4 \%$ VIQIATSSSTAK

$0.08 \% \quad 21.4 \%$ NLMQFHTVGTK

$0.08 \% \quad 21.4 \%$ LQSDDILPLGK

$0.08 \% \quad 21.4 \%$ TTRIPQLLLER

$0.08 \% \quad 21.4 \%$ IPQLLLER

$0.08 \% \quad 21.4 \%$ CNVIITQPR

$0.08 \% \quad 21.4 \%$ RISAVSVAQR

$0.08 \% \quad 21.4 \%$ ISAVSVAQR

$0.08 \% \quad 21.4 \%$ VSHELGPSLRR

$0.08 \% \quad 21.4 \%$ LVLMSATGDNER

$0.08 \% \quad 21.4 \%$ LVLMSATGDNERFSR

$0.08 \% \quad 21.4 \%$ AIFQQPPVGVR

$0.08 \% \quad 21.4 \%$ AIFQQPPVGVRK

$0.08 \% \quad 21.4 \%$ TPLENLVLQAK

$0.08 \% \quad 21.4 \%$ IHMPEKTAVEFLSK

$0.08 \% \quad 21.4 \%$ TAVEFLSK

$0.08 \% \quad 21.4 \%$ AIVLAAIFR

$0.08 \% 21.4 \%$ DPFSSSLQNR

$0.08 \% \quad 21.4 \%$ ALLSHDSGSDHLAFVR

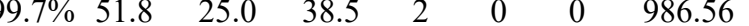

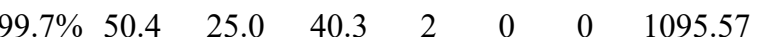

$\begin{array}{llllllll}99.7 \% & 48.6 & 25.0 & 36.8 & 2 & 0 & 0 & 1086.65\end{array}$

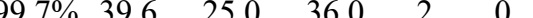

$99.0 \% \quad 31.7 \quad 25.0 \quad 23.8$

$99.4 \% \quad 22.4 \quad 25.0 \quad 18.9$

$99.7 \% \quad 47.0 \quad 25.0 \quad 47.0$

$99.7 \% \quad 42.1 \quad 25.0 \quad 25.1 \quad 2$

$99.7 \% \quad 33.3 \quad 25.0 \quad 29.9$

$99.0 \% \quad 32.9 \quad 25.0 \quad(9.8)$

$99.7 \% \quad 34.2 \quad 25.0 \quad 31.1 \quad 3$

$99.7 \% \quad 32.2 \quad 25.0 \quad 32.2$

$99.7 \% \quad 35.5 \quad 25.0 \quad 35.5$

$99.5 \% \quad 25.4 \quad 25.0 \quad 22.2$

$\begin{array}{llll}97.5 \% & 18.1 & 25.0 & 17.4\end{array}$

$99.0 \% \quad 24.2 \quad 25.0 \quad 17.5$

$99.7 \% \quad 38.0 \quad 25.0 \quad 27.9$

$99.7 \% \quad 58.4 \quad 25.0 \quad 48.1$

$99.7 \% \quad 46.8 \quad 25.0 \quad 41.2$

$99.7 \% \quad 39.5 \quad 25.0 \quad 36.3$

$99.7 \% \quad 41.7 \quad 25.0 \quad 41.7$

$99.7 \% \quad 33.8 \quad 25.0 \quad 27.6$

$\begin{array}{llll}99.1 \% & 19.0 & 25.0 & 19.0\end{array}$

$99.7 \% \quad 53.6 \quad 25.0 \quad 48.3$

$99.7 \% \quad 36.9 \quad 25.0-27.3$

$\begin{array}{llll}99.7 \% & 60.7 & 25.0 & 60.2\end{array}$

$\begin{array}{llll}99.7 \% & 45.2 & 25.0 & 30.6\end{array}$

$\begin{array}{llll}98.9 \% & 18.8 & 25.0 & 18.3\end{array}$

$\begin{array}{llll}99.7 \% & 56.2 & 25.0 & 50.6\end{array}$

$\begin{array}{llll}99.7 \% & 44.8 & 25.0 & 32.9\end{array}$

$\begin{array}{llll}97.6 \% & 24.7 & 25.0 & 10.4\end{array}$

$\begin{array}{llll}96.6 \% & 17.7 & 25.0 & 17.7\end{array}$

$99.0 \% \quad 50.7 \quad 25.0-37.8$

$\begin{array}{llll}99.7 \% & 57.8 & 25.0 & 46.2\end{array}$

$\begin{array}{llll}99.7 \% & 50.8 & 25.0 & 22.7\end{array}$

$99.7 \% \quad 71.1 \quad 25.0 \quad 32.5$

$98.0 \% \quad 16.9 \quad 25.0 \quad 16.9$

$99.7 \% \quad 54.9 \quad 25.0 \quad 49.5$

$\begin{array}{llll}99.7 \% & 29.0 & 25.0 & 28.6\end{array}$

$\begin{array}{llll}99.7 \% & 53.8 & 25.0 & 53.8\end{array}$

$\begin{array}{lllll}97.8 \% & 26.1 & 25.0 & 26.0\end{array}$

$\begin{array}{llll}99.7 \% & 52.9 & 25.0 & 52.9\end{array}$

$\begin{array}{llll}99.7 \% & 31.8 & 25.0 & 31.8\end{array}$

$\begin{array}{llll}97.3 \% & 16.6 & 25.0 & 15.7\end{array}$

$\begin{array}{llll}99.7 \% & 49.7 & 25.0 & 49.7\end{array}$

$99.7 \% \quad 42.6 \quad 25.0 \quad 36.3$

$\begin{array}{llll}99.7 \% & 31.2 & 25.0 & 31.2\end{array}$
1214.69

1214.69
1089.62

1400.76

848.46

1341.66

1077.56

1224.62

1598.79

1276.69

848.49

1139.62

1346.74

1129.68

1019.61

1380.85

1064.56

1445.68

1472.75

985.58

1054.51

1226.62

1734.92

1205.67

1275.65

1198.67

1339.81

981.61

1100.59

1086.64

930.54

1250.70

1321.64

1711.84

1211.69

1339.78

1225.72

1645.86

894.49

973.62

1150.55

1724.87 
Putative ATP-dependent RNA helicase DHX30 GN=DHX30 DHX30_HUMAN $133.94 \quad 100.0 \% \quad 28$ Putative ATP-dependent RNA helicase DHX30 GN=DHX30 DHX30_HUMAN $133.94 \quad 100.0 \% \quad 28$ Putative ATP-dependent RNA helicase DHX30 GN=DHX30 DHX30_HUMAN $133.94 \quad 100.0 \% \quad 28$ Putative ATP-dependent RNA helicase DHX30 GN=DHX30 DHX30_HUMAN $133.94 \quad 100.0 \% \quad 28$ Putative ATP-dependent RNA helicase DHX30 GN=DHX30 DHX30_HUMAN $133.94 \quad 100.0 \% \quad 28$ Putative ATP-dependent RNA helicase DHX33 GN=DHX33 DHX33_HUMAN $78.88 \quad 100.0 \%$ Putative ATP-dependent RNA helicase DHX33 GN=DHX33 DHX33_HUMAN $78.88 \quad 100.0 \%$ Putative ATP-dependent RNA helicase DHX57 GN=DHX57 DHX57_HUMAN $155.61 \quad 100.0 \%$ Putative ATP-dependent RNA helicase DHX57 GN=DHX57 DHX57_HUMAN $155.61 \quad 100.0 \%$ Putative ATP-dependent RNA helicase DHX57 GN=DHX57 DHX57_HUMAN $155.61 \quad 100.0 \%$ Putative ATP-dependent RNA helicase DHX57 GN=DHX57 DHX57_HUMAN $155.61 \quad 100.0 \%$ Putative ATP-dependent RNA helicase DHX57 GN=DHX57 DHX57_HUMAN $155.61 \quad 100.0 \%$ Putative helicase MOV-10 GN=MOV10 MOV10_HUMAN $113.68 \quad 100.0 \%$ Putative helicase MOV-10 GN=MOV10 MOV10_HUMAN $113.68 \quad 100.0 \%$ Putative helicase MOV-10 GN=MOV10 MOV10_HUMAN $113.68 \quad 100.0 \%$ Putative helicase MOV-10 GN=MOV10 MOV10_HUMAN $113.68 \quad 100.0 \%$ Putative helicase MOV-10 GN=MOV10 MOV10_HUMAN $113.68 \quad 100.0 \%$ Putative helicase MOV-10 GN=MOV10 MOV10_HUMAN $113.68 \quad 100.0 \%$ Putative helicase MOV-10 GN=MOV10 MOV10_HUMAN $113.68 \quad 100.0 \%$ Putative helicase MOV-10 GN=MOV10 MOV10_HUMAN $113.68 \quad 100.0 \%$ Putative helicase MOV-10 GN=MOV10 MOV10_HUMAN $113.68 \quad 100.0 \%$ Putative methyltransferase NSUN3 GN=NSUN3 NSUN3_HUMAN $38.25 \quad 100.0 \%$ Putative methyltransferase NSUN3 GN=NSUN3 NSUN3_HUMAN $38.25 \quad 100.0 \%$ Putative oxidoreductase GLYR1 GN=GLYR1 GLYR1_HUMAN $60.56 \quad 100.0 \%$ Putative oxidoreductase GLYR1 GN=GLYR1 GLYR1_HUMAN $60.56 \quad 100.0 \%$ Putative oxidoreductase GLYR1 GN=GLYR1 GLYR1_HUMAN $60.56 \quad 100.0 \%$ Putative oxidoreductase GLYR1 GN=GLYR1 GLYR1_HUMAN $60.56 \quad 100.0 \%$ Putative oxidoreductase GLYR1 GN=GLYR1 GLYR1_HUMAN $60.56 \quad 100.0 \%$ Putative RNA-binding protein 15 GN=RBM15 RBM15_HUMAN $107.19 \quad 100.0 \%$ Putative RNA-binding protein 15 GN=RBM15 RBM15 HUMAN $107.19 \quad 100.0 \%$ Putative RNA-binding protein Luc7-like 2 GN=LUC7L2 LC7L2_HUMAN $46.51 \quad 100.0 \%$ Putative RNA-binding protein Luc7-like 2 GN=LUC7L2 LC7L2_HUMAN $46.51 \quad 100.0 \%$ Putative RNA-binding protein Luc7-like 2 GN=LUC7L2 LC7L2_HUMAN $46.51 \quad 100.0 \%$ Putative RNA-binding protein Luc7-like 2 GN=LUC7L2 LC7L2_HUMAN $46.51 \quad 100.0 \%$ Putative RNA-binding protein Luc7-like 2 GN=LUC7L2 LC7L2_HUMAN $46.51 \quad 100.0 \%$ Putative RNA-binding protein Luc7-like 2 GN=LUC7L2 LC7L2_HUMAN $46.51 \quad 100.0 \%$ Putative RNA-binding protein Luc7-like 2 GN=LUC7L2 LC7L2_HUMAN $46.51 \quad 100.0 \%$ Putative transferase CAF17, mitochondrial GN=IBA57 CAF17_HUMAN $38.16 \quad 100.0 \%$ Putative transferase CAF17, mitochondrial GN=IBA57 CAF17_HUMAN $38.16 \quad 100.0 \%$ Pyrroline-5-carboxylate reductase 1, mitochondrial GN=PYCR1 P5CR1_HUMAN $33.36 \quad 100.0 \%$ Pyrroline-5-carboxylate reductase 1, mitochondrial GN=PYCR1 P5CR1_HUMAN $33.36 \quad 100.0 \%$ Pyrroline-5-carboxylate reductase 1, mitochondrial GN=PYCR1 P5CR1_HUMAN $33.36 \quad 100.0 \%$ Pyrroline-5-carboxylate reductase 1, mitochondrial GN=PYCR1 P5CR1_HUMAN $33.36 \quad 100.0 \%$ $\begin{array}{llll}\text { Pyrroline-5-carboxylate reductase 1, mitochondrial GN=PYCR1 P5CR1_HUMAN } 33.36 & 100.0 \%\end{array}$ Pyrroline-5-carboxylate reductase 1, mitochondrial GN=PYCR1 P5CR1_HUMAN $33.36 \quad 100.0 \%$ Pyrroline-5-carboxylate reductase 1, mitochondrial GN=PYCR1 P5CR1_HUMAN $33.36 \quad 100.0 \%$ $\begin{array}{lll}\text { Pyrroline-5-carboxylate reductase 1, mitochondrial GN=PYCR1 P5CR1_HUMAN } 33.36 & 100.0 \%\end{array}$
$30-75 \quad 0.08 \% \quad 21.4 \%$ SNGSVFVR

$\begin{array}{llll}30 & 75 & 0.08 \% & 21.4 \% \\ 2 & \text { ATISLSDSDLLR }\end{array}$

$0.00 \% \quad 2.6 \%$ GQLLAQLR

$0.00 \% \quad 2.6 \%$ RVAAISLATR

$0.01 \% \quad 4.1 \% \quad$ YSDPPVNFLPVPSR

$0.01 \% \quad 4.1 \%$ VANIICTQPR

$0.01 \% \quad 4.1 \%$ ISAISVAER

$0.01 \% \quad 4.1 \%$ LLYCTTGVLLR

$0.01 \% \quad 4.1 \%$ QFTELLSDIGFAR

$19 \quad 0.02 \% \quad 8.9 \%$ HGVDVEVQGPHEAR

$19 \quad 0.02 \% \quad 8.9 \% \quad$ SLESNPEQLQAMR

$19 \quad 0.02 \% \quad 8.9 \% \quad$ VLITTLITAGR

$19 \quad 0.02 \% \quad 8.9 \%$ HGLGYSLLER

$19 \quad 0.02 \% \quad 8.9 \% \quad$ LLTYNSLYK

$19 \quad 0.02 \% \quad 8.9 \% \quad$ KGPDGYDPQFITK

$19 \quad 0.02 \% \quad 8.9 \% \quad$ SVGVISPYR

$19 \quad 0.02 \% \quad 8.9 \% \quad$ SVGVISPYRK

$19 \quad 0.02 \% \quad 8.9 \% \quad$ SVILISTVR

$2 \quad 0.00 \% \quad 6.5 \% \quad$ VLDLCAAPGGK

$0.00 \% \quad 6.5 \% \quad$ NLPLLQIELLR

$0.01 \% \quad 12.8 \%$ FQQAVDAVEEFLR

$0.01 \% \quad 12.8 \%$ TAEKCDLFIQEGAR

$0.01 \% \quad 12.8 \%$ DLVLGPSGVLQGIRPGK

$0.01 \% \quad 12.8 \%$ TSFFLGEVGNAAK

$0.01 \% \quad 12.8 \%$ ALDQSDNDMSAVYR

$\begin{array}{lll}0.01 \% & 4.1 \% & \text { SSGAASSAPGGGDGAEYKTLK } \\ 0.01 \% & 4.1 \% & \text { SSSSSAASDTATSTQRPLR }\end{array}$

$7 \quad 0.02 \% \quad 19.4 \%$ AMLDQLMGTSR

$17 \quad 0.02 \% \quad 19.4 \%$ ADYEIASK

$17 \quad 0.02 \% \quad 19.4 \%$ LAETQEEISAEVAAK

$0.02 \% \quad 19.4 \%$ VHELNEEIGK

$17 \quad 0.02 \% \quad 19.4 \%$ VEQLGAEGNVEESQK

$0.02 \% \quad 19.4 \%$ LADHFGGK

$0.02 \% \quad 19.4 \%$ LHLGFIEIR

$0.00 \% \quad 7.0 \% \quad$ LLTQDEGPALVPGGR

$0.00 \% \quad 7.0 \% \quad$ YLQGVPEGVR

$6 \quad 0.02 \% \quad 31.0 \%$ GFTAAGVLAAHK

$0.02 \% \quad 31.0 \%$ CMTNTPVVVR

$0.02 \% \quad 31.0 \%$ EGATVYATGTHAQVEDGR

$0.02 \% \quad 31.0 \%$ LGAQALLGAAK

$0.02 \% \quad 31.0 \%$ SLLINAVEASCIR

$\begin{array}{ll}99.7 \% & 48.0 \\ 99.7 \% & 55.4\end{array}$

$0.02 \% \quad 31.0 \%$ VKLDSPAGTALSPSGHTK $99.7 \% \quad 38.8$

$0.02 \% \quad 31.0 \%$ LDSPAGTALSPSGHTK $\begin{array}{ll}99.7 \% & 39.3 \\ 99.7 \% & 31.5\end{array}$

$99.0 \% \quad 42.7$

$99.0 \% \quad 32.4$

$99.7 \% \quad 28.6$

$\begin{array}{lllll}99.0 \% & 22.3\end{array}$

$99.0 \% \quad 20.3$

$94.8 \% 19.7$

$9.7 \% 48.6$

$99.7 \% \quad 55.8$

$\begin{array}{lll}99.7 \% & 36.7 \\ 99.7 \% & 48.4\end{array}$

$99.7 \% \quad 47.3$

$99.7 \% \quad 53.4$

$99.7 \% \quad 72.1$

$99.1 \% \quad 25.5$

$99.7 \% \quad 31.8$

$99.7 \% \quad 28.6$

$\begin{array}{ll}98.0 \% & 20.7 \\ 99.7 \% & 34.3\end{array}$

$99.7 \% \quad 48.0$

$99.7 \% \quad 34.6$

$99.7 \% \quad 27.9$

$99.7 \% \quad 58.5$

$99.7 \% \quad 52.5$

$99.7 \% \quad 68.5$

$\begin{array}{ll}99.7 \% & 72.5 \\ 99.7 \% & 55.8\end{array}$

$\begin{array}{ll}99.7 \% & 55.8 \\ 99.7 \% & 27.3\end{array}$

$99.0 \% \quad 45.7$

$\begin{array}{lll}99.7 \% & 43.8\end{array}$

$99.7 \% \quad 48.5$

$99.7 \% \quad 54.0$

$99.0 \% \quad 31.9$

$99.7 \% \quad 26.6$

$99.4 \% \quad 24.9$

$98.6 \% \quad 17.6$

$99.7 \% \quad 58.4$

$99.7 \% \quad 34.8$

$\begin{array}{ll}99.7 \% & 51.0\end{array}$
881.52

865.45

1290.69

898.55

1057.65

1587.82

1171.63

945.54

1308.73

1496.77

1529.75

1518.72

1157.73

1144.61

1114.61

1465.73

977.54

1105.64

987.62

1100.58

1321.82

1551.78

1637.80

1706.00

1340.68

1584.70

1910.91

1909.92

1238.59

896.44

1588.81

1167.60

1616.78

844.43

1097.65

1522.82

1117.60

1142.63

1176.59

1861.87

1012.62

1445.78

1844.91

1765.94

1538.78 $\begin{array}{ll}041 & 1049 \\ 052 & 1059\end{array}$

$082 \quad 1089$

$116 \quad 1127$

88
138

$129 \quad 138$

$\begin{array}{ll}432 & 445 \\ 593 & 602\end{array}$

$604 \quad 612$

$641 \quad 651$

1651177

$122 \quad 135$

$496 \quad 508$

$618 \quad 628$

$696 \quad 705$

$706 \quad 714$

$715 \quad 727$

$826 \quad 834$

$\begin{array}{ll}874 & 882 \\ 8726\end{array}$

$135 \quad 145$

$238 \quad 248$

312

$339 \quad 355$

$423 \quad 435$

$536 \quad 549$

$153 \quad 173$

$9 \quad 19$

$\begin{array}{ll}69 & 76 \\ & \end{array}$

$126 \quad 135$

$140 \quad 154$

$206 \quad 213$

$214 \quad 222$

$198 \quad 212$

$224 \quad 233$

$18 \quad 29$

$20 \quad 129$

$205 \quad 215$

$252 \quad 215$

$252 \quad 264$

287
290
207

307 
Pyrroline-5-carboxylate reductase 2 GN=PYCR2 P5CR2_HUMAN $33.64 \quad 100.0 \% \quad 1$ Pyrroline-5-carboxylate reductase $2 \mathrm{GN}=\mathrm{PYCR} 2 \quad \mathrm{P} 5 \mathrm{CR} 2$ HUMAN $33.64 \quad 100.0 \%$ Pyrroline-5-carboxylate reductase 2 GN=PYCR2 P5CR2_HUMAN $33.64 \quad 100.0 \%$ Pyrroline-5-carboxylate reductase 2 GN=PYCR2 P5CR2_HUMAN $33.64 \quad 100.0 \%$ Pyrroline-5-carboxylate reductase 2 GN=PYCR2 P5CR2_HUMAN $33.64 \quad 100.0 \%$ Pyrroline-5-carboxylate reductase 2 GN=PYCR2 P5CR2_HUMAN $33.64 \quad 100.0 \%$ Pyrroline-5-carboxylate reductase 2 GN=PYCR2 P5CR2_HUMAN $33.64 \quad 100.0 \%$ Pyrroline-5-carboxylate reductase 2 GN=PYCR2 P5CR2_HUMAN $33.64 \quad 100.0 \%$ Pyrroline-5-carboxylate reductase 2 GN=PYCR2 P5CR2 HUMAN $33.64 \quad 100.0 \%$ Pyrroline-5-carboxylate reductase 2 GN=PYCR2 P5CR2_HUMAN $33.64 \quad 100.0 \%$ Pyrroline-5-carboxylate reductase 2 GN=PYCR2 P5CR2_HUMAN $33.64 \quad 100.0 \%$ Pyrroline-5-carboxylate reductase $2 \mathrm{GN}=\mathrm{PYCR} 2$ P5CR2 HUMAN $33.64 \quad 100.0 \%$ Pyrroline-5-carboxylate reductase 2 GN=PYCR2 P5CR2_HUMAN $33.64 \quad 100.0 \%$ Pyrroline-5-carboxylate reductase 2 GN=PYCR2 P5CR2_HUMAN $33.64 \quad 100.0 \%$ Pyrroline-5-carboxylate reductase 2 GN=PYCR2 P5CR2_HUMAN $33.64 \quad 100.0 \%$ Pyrroline-5-carboxylate reductase 2 GN=PYCR2 P5CR2_HUMAN $33.64 \quad 100.0 \%$ Pyrroline-5-carboxylate reductase 3 GN=PYCRL P5CR3 HUMAN $28.66 \quad 100.0 \%$ Pyrroline-5-carboxylate reductase 3 GN=PYCRL P5CR3_HUMAN $28.66 \quad 100.0 \%$ Pyrroline-5-carboxylate reductase 3 GN=PYCRL P5CR3_HUMAN 28.66 100.0\% Pyrroline-5-carboxylate reductase 3 GN=PYCRL P5CR3 HUMAN $28.66 \quad 100.0 \%$ Pyrroline-5-carboxylate reductase $3 \mathrm{GN}=$ PYCRL P5CR3_HUMAN $28.66100 .0 \%$ Pyrroline-5-carboxylate reductase 3 GN=PYCRL P5CR3 HUMAN $28.66100 .0 \%$

Prywate dehy El component subent pha, somatic form, mitochondrial GN=PDHA ODPA_HUMAN 43.30 13 $00.0 \% \quad 13$ $100.0 \% \quad 13$ $100.0 \% \quad 13$ $100.0 \% \quad 13$ $\begin{array}{lllll}\text { Pyruvate dehydrogenase El component subunit alpha, somatic fom, mitochondral GN=PDHAI } & \text { ODPA_HUMAN } & 43.30 & 100.0 \% & 13 \\ \text { Pyruvate dehydrogenase E1 component subunit beta, mitchondrial GN=PDHB } & \text { ODPB_HUMAN } & 39.23 & 100.0 \% & 7\end{array}$ Pyruvate dehydrogenase El component subunit beta, mitochondrial GN=PDHB ODPB_HUMAN $39.23 \quad 100.0 \%$ Pyruvate dehydrogenase E1 component subunit beta, mitochondrial GN=PDHB ODPB HUMAN $39.23 \quad 100.0 \%$ Pyruvate dehydrogenase E1 component subunit beta, mitochondrial GN=PDHB ODPB_HUMAN $39.23 \quad 100.0 \%$ Pyruvate dehydrogenase E1 component subunit beta, mitochondrial GN=PDHB ODPB_HUMAN $39.23 \quad 100.0 \%$ Pyruvate dehydrogenase E1 component subunit beta, mitochondrial GN=PDHB ODPB HUMAN $39.23 \quad 100.0 \%$ Pyruvate dehydrogenase El component subunit beta, mitochondrial GN=PDHB ODPB_HUMAN $39.23 \quad 100.0 \%$ Pyruvate dehydrogenase protein $X$ component, mitochondrial GN=PDHX ODPX HUMAN $54.12 \quad 100.0 \%$ Pyruvate dehydrogenase protein $X$ component, mitochondrial GN=PDHX ODPX_HUMAN $54.12 \quad 100.0 \%$ Pyruvate kinase $\mathrm{PKM}$ GN=PKM Pyruvate kinase $P K M$ GN=PKM Pyruvate kinase $\mathrm{PKM}$ GN=PKM KPYM_HUMAN $57.94 \quad 100.0 \% \quad 25$ KPYM_HUMAN $57.94 \quad 100.0 \% \quad 25$ KPYM_HUMAN $57.94 \quad 100.0 \% \quad 25$

$0.08 \% \quad 40.9 \%$ GFTAAGILSAHK

$0.08 \% \quad 40.9 \%$ IIASSPEMNLPTVSALR

$0.08 \% \quad 40.9 \%$ IIASSPEMNLPTVSALRK

$99.7 \% \quad 62.6$

$99.7 \% \quad 52.4$

$0.08 \% \quad 40.9 \%$ KMGVNLTR

$0.08 \% \quad 40.9 \%$ HIVVSCAAGVTISSVEK $\quad 99.7 \% \quad 46.7$

$0.08 \% \quad 40.9 \%$ HIVVSCAAGVTISSVEKK

$0.08 \% \quad 40.9 \%$ KLMAFQPAPK

$0.08 \% \quad 40.9 \%$ LMAFQPAPK

$0.08 \% \quad 40.9 \%$ RLAIQLGAQALLGAAK

$0.08 \% \quad 40.9 \%$ LAIQLGAQALLGAAK

$0.08 \% \quad 40.9 \%$ SLLINAVEASCIR

$0.08 \% \quad 40.9 \%$ TRELQSMADQEK

$0.08 \% \quad 40.9 \%$ ELQSMADQEK

$0.08 \% \quad 40.9 \%$ ISPAALKK

$0.08 \% \quad 40.9 \%$ VKLESPTVSTLTPSSPGK

$0.08 \% \quad 40.9 \%$ LESPTVSTLTPSSPGK

$0.02 \% \quad 25.9 \%$ RVGFVGAGR

$0.02 \% \quad 25.9 \%$ MAGAIAQGLIR

$0.02 \% \quad 25.9 \%$ VEAQHILASAPTDR

$0.02 \% \quad 25.9 \%$ IAAQTLLGTAK

$0.02 \% \quad 25.9 \%$ MLLHEGQHPAQLR

$0.02 \% \quad 25.9 \%$ AATMSAVEAATCR

$0.04 \% \quad 34.9 \%$ LEEGPPVTTVLTR

$0.04 \% \quad 34.9 \%$ AHGFTFTR

$0.04 \% \quad 34.9 \%$ EILAELTGR

$0.04 \% \quad 34.9 \%$ NFYGGNGIVGAQVPLGAGIALACK

$0.04 \% \quad 34.9 \%$ LPCIFICENNR

$0.04 \% \quad 34.9 \%$ YGMGTSVER

$0.04 \% \quad 34.9 \%$ AAASTDYYK

$0.04 \% \quad 34.9 \%$ AAASTDYYKR

$0.04 \% \quad 34.9 \%$ RGDFIPGLR

$0.04 \% \quad 34.9 \%$ VDGMDILCVR

$0.04 \% \quad 34.9 \%$ GPILMELQTYR

$0.04 \% \quad 34.9 \%$ YHGHSMSDPGVSYR

$0.04 \% \quad 34.9 \%$ TREEIQEVR

$0.02 \% \quad 25.1 \%$ VFLLGEEVAQYDGAYK

$0.02 \% \quad 25.1 \%$ TYYMSGGLQPVPIVFR

$0.02 \% \quad 25.1 \%$ EGVECEVINMR

$0.02 \% \quad 25.1 \%$ IMEGPAFNFLDAPAVR

$0.02 \% \quad 25.1 \%$ VTGADVPMPYAK

$0.02 \% \quad 25.1 \%$ ILEDNSIPQVK

$0.02 \% \quad 25.1 \%$ DIIFAIKK

$\begin{array}{ll}9.7 \% & 40.4 \\ 99.7 \% & 49.6\end{array}$

$99.7 \% \quad 45.2$

$99.7 \% \quad 53.2$

$99.7 \% \quad 63.8$

$99.7 \% \quad 48.0$

$99.1 \% \quad 24.0$

$99.7 \% \quad 47.4$

$99.0 \% 27.8$

$99.7 \% \quad 58.9$

$99.7 \% \quad 47.8$

$99.7 \% \quad 38.1$

$99.7 \% \quad 63.7$

$99.7 \% \quad 59.4$

$99.7 \% \quad 73.6$

$97.0 \% \quad 15.9$

$99.7 \% \quad 61.4$

$99.7 \% \quad 52.8$

$99.0 \% \quad 22.9$

$99.7 \% \quad 45.1$

$99.7 \% \quad 49.9$

$99.7 \% \quad 55.3$

$99.7 \% \quad 36.2$

$99.7 \% \quad 47.6$

$99.7 \% \quad 39.7$

$99.7 \% \quad 55.1$

$99.7 \% 54.1$

$99.7 \% \quad 34.4$

$99.7 \% \quad 38.1$

$99.7 \% \quad 69.3$

$99.7 \% \quad 53.2$

$99.7 \% \quad 48.1$

$99.7 \% \quad 57.7$

$99.7 \% \quad 50.6$

$99.7 \% \quad 52.7$

$98.7 \% \quad 25.8$

$0.00 \% \quad 3.8 \%$ NILEKHSLDASQGTATGPR

$0.00 \% \quad 3.8 \%$ HSLDASQGTATGPR

$0.14 \% \quad 55.6 \%$ LDIDSPPITAR

$0.14 \% \quad 55.6 \%$ NTGIICTIGPASR

0.14\% $55.6 \%$ SVETLKEMIK
$99.7 \% \quad 58.2$

$99.7 \% \quad 55.8$

$\begin{array}{lll}99.7 \% & 45.7\end{array}$

52.4

$\begin{array}{ll}0 & 18.2\end{array}$

10.6

$\begin{array}{ll}0 & 46.7\end{array}$

$\begin{array}{ll}0 & 40.4\end{array}$

$\begin{array}{ll}.0 & 36.7\end{array}$

$\begin{array}{ll}56.0 & 36.8\end{array}$

$\begin{array}{ll}0 & 53.2\end{array}$

$\begin{array}{ll}.0 & 63.8\end{array}$

$\begin{array}{ll}0 & 48.0\end{array}$

18.8

\begin{tabular}{ll}
39.7 \\
\hline
\end{tabular}

\begin{tabular}{ll}
24.4 \\
\hline
\end{tabular}

$5.0 \quad 54.1$

\begin{tabular}{ll}
36.7 \\
\hline
\end{tabular}

$\begin{array}{ll}28.0 & 28.7\end{array}$

$\begin{array}{ll}0 & 54.3\end{array}$

$\begin{array}{ll}.0 & 58.8\end{array}$

$\begin{array}{ll}0 & 71.9\end{array}$

\begin{tabular}{ll}
15.9 \\
\hline
\end{tabular}

$\begin{array}{ll}0 & 40.1\end{array}$

\begin{tabular}{ll}
52.8 \\
\hline
\end{tabular}

$\begin{array}{ll}5.0 & 17.3\end{array}$

$\begin{array}{ll}0 & 34.6\end{array}$

38.7

$\begin{array}{ll}5.0 & 49.9 \\ 25.0 & 45.2\end{array}$

\begin{tabular}{ll}
0 & 45.2 \\
\hline
\end{tabular}

$\begin{array}{lll}0 & 36.2 & 2\end{array}$

$\begin{array}{ll}25.0 & 45.9\end{array}$

$\begin{array}{lll} & 28.0 & 2 \\ .0 & 49.1 & 4\end{array}$

$54.0 \quad 54.1 \quad 4$

$\begin{array}{ll}5.0 & 30.0\end{array}$

$\begin{array}{ll}25.0 & 20.2\end{array}$

$\begin{array}{ll}.0 & 66.3 \\ 25.0 & 45.8\end{array}$

$\begin{array}{ll}5.0 & 45.8 \\ 25.0 & 48.1\end{array}$

$\begin{array}{ll}0 & 48.1\end{array}$

57.7
25.0

25.044 .0

$\begin{array}{lll}53.0 & 43.6\end{array}$

$\begin{array}{ll}5.0 & 12.4\end{array}$

$\begin{array}{ll}5.0 & 37.3\end{array}$

$\begin{array}{ll}3.0 & 30.1\end{array}$

$\begin{array}{lll}.0 & 49.4 & 2\end{array}$

$\begin{array}{ll}0 & 48.9\end{array}$

0
0
3
0
4
2
0
0
4
0
0
0
0
0
0
2
0
0
0
0
2
0
0
1
0
0
0
0
0
0
0
0
0
2
0
0
0
0
0
0
0
0
0
0
0
0
0
0
0
0
0
0
0
0
0
0
0
0
0
0
0
0
0
0
0
0
0
0

1828.01

1600.84

918.53

1116.62

1507.79

1086.65

1545.80

1338.61

1411.78

936.47

1001.56

2347.22

1435.68

1015.45

989.46

1145.56

1030.58

1177.57

1320.70

1592.69

1159.61

1801.90

1827.95

1351.60

1763.88

1248.63

1255.69

947.59

1995.03

1397.68

1197.65

1359.7

1193.64 
Pyruvate kinase $\mathrm{PKM}$ GN=PKM Pyruvate kinase $\mathrm{PKM}$ GN=PKM Pyruvate kinase $P K M$ GN=PKM Pyruvate kinase $\mathrm{PKM}$ GN=PKM Pyruvate kinase $\mathrm{PKM}$ GN=PKM Pyruvate kinase $P K M$ GN=PKM Pyruvate kinase $\mathrm{PKM}$ GN=PKM Pyruvate kinase $\mathrm{PKM}$ GN=PKM Pyruvate kinase $\mathrm{PKM}$ GN=PKM Pyruvate kinase $P K M$ GN=PKM Pyruvate kinase $\mathrm{PKM}$ GN=PKM Pyruvate kinase $\mathrm{PKM}$ GN=PKM Pyruvate kinase $\mathrm{PKM}$ GN=PKM Pyruvate kinase $\mathrm{PKM}$ GN=PKM Pyruvate kinase $\mathrm{PKM}$ GN=PKM Pyruvate kinase $\mathrm{PKM}$ GN=PKM Pyruvate kinase $\mathrm{PKM}$ GN=PKM Pyruvate kinase $\mathrm{PKM}$ GN=PKM Pyruvate kinase $\mathrm{PKM}$ GN=PKM Pyruvate kinase $\mathrm{PKM}$ GN=PKM Pyruvate kinase $\mathrm{PKM}$ GN=PKM Pyruvate kinase $\mathrm{PKM}$ GN=PKM Q9UN72-DECOY Q9UN72-DECOY Rab3 GTPase-activating protein non-catalytic subunit GN=RAB3GAP2 Rab3 GTPase-activating protein non-catalytic subunit $\mathrm{GN}=\mathrm{RAB} 3 \mathrm{GAP} 2$ Rab-like protein $3 \mathrm{GN}=\mathrm{RABL} 3$ Rab-like protein $3 \mathrm{GN}=\mathrm{RABL} 3$ Rac GTPase-activating protein $1 \mathrm{GN}=\mathrm{RACGAP} 1$ RGAP1_HUMAN $71.03 \quad 100.0^{\circ}$ Rac GTPase-activating protein $1 \mathrm{GN}=\mathrm{RACGAP} 1$ RGAP1 HUMAN $71.03 \quad 100.0 \%$ Rac GTPase-activating protein 1 GN=RACGAP1 RGAP1_HUMAN $71.03 \quad 100.0 \%$ Ran GTPase-activating protein $1 \mathrm{GN}=$ RANGAP1 RAGP1_HUMAN $63.54 \quad 100.0 \%$ Ran GTPase-activating protein $1 \mathrm{GN}=\mathrm{RANGAP} 1$ RAGP1 HUMAN $63.54 \quad 100.0 \%$ Ran GTPase-activating protein 1 GN=RANGAP1 RAGP1_HUMAN $63.54 \quad 100.0 \%$ Ran GTPase-activating protein $1 \mathrm{GN}=$ RANGAP1 RAGP1_HUMAN $63.54 \quad 100.0 \%$ Ran-specific GTPase-activating protein GN=RANBP1 RANG_HUMAN $23.31 \quad 100.0 \%$ Ran-specific GTPase-activating protein GN=RANBP1 RANG_HUMAN $23.31 \quad 100.0 \%$ Ran-specific GTPase-activating protein GN=RANBP1 RANG HUMAN $23.31 \quad 100.0 \%$ Rapamycin-insensitive companion of mTOR GN=RICTOR RICTR_HUMAN $192.22 \quad 100.0 \%$ Rapamycin-insensitive companion of mTOR GN=RICTOR RICTR_HUMAN $192.22 \quad 100.0 \%$ Rapamycin-insensitive companion of mTOR GN=RICTOR RICTR_HUMAN $192.22 \quad 100.0 \%$ Ras GTPase-activating-like protein IQGAP1 GN=IQGAP1 IQGA1_HUMAN $189.26 \quad 100.0 \%$ Ras GTPase-activating-like protein IQGAP1 GN=IQGAP1 IQGA1 HUMAN $189.26 \quad 100.0 \%$ Ras GTPase-activating-like protein IQGAP1 GN=IQGAP1 IQGA1_HUMAN $189.26 \quad 100.0 \%$ Ras GTPase-activating-like protein IQGAP1 GN=IQGAP1 IQGA1_HUMAN $189.26 \quad 100.0 \%$ Ras GTPase-activating-like protein IQGAP1 GN=IQGAP1 IQGA1 HUMAN $189.26 \quad 100.0 \%$ Ras GTPase-activating-like protein IQGAP1 GN=IQGAP1 IQGA1_HUMAN $189.26 \quad 100.0 \%$ 35

(2)

35

35

35

3

3
3
3
3

$\begin{array}{ll}3 & 3 \\ 3 & 3 \\ 8 & 9\end{array}$

3

$126 \quad 0.14 \% \quad 55.6 \%$ GSGTAEVELKK

$126 \quad 0.14 \% \quad 55.6 \%$ ITLDNAYMEK

$126 \quad 0.14 \% \quad 55.6 \%$ IYVDDGLISLQVK

$99.7 \% \quad 31.5$

$\begin{array}{ll}99.7 \% & 52.9\end{array}$

$99.7 \% \quad 46.4$

$126 \quad 0.14 \% \quad 55.6 \%$ IYVDDGLISLQVKQK

$99.7 \% 53.2$

$99.7 \% \quad 51.6$

$26 \quad 0.14 \% \quad 55.6 \%$ QKGADFLVTEVENGGSLGSK $99.7 \% \quad 61.0$

$126 \quad 0.14 \% \quad 55.6 \%$ GADFLVTEVENGGSLGSK $99.7 \% \quad 89.1$

$126 \quad 0.14 \% \quad 55.6 \%$ GADFLVTEVENGGSLGSKK $99.7 \% \quad 47.6$

$126 \quad 0.14 \% \quad 55.6 \%$ GVNLPGAAVDLPAVSEK $99.7 \% \quad 50.9$

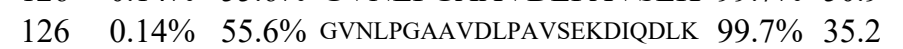

$126 \quad 0.14 \% \quad 55.6 \%$ IISKIENHEGVR

$126 \quad 0.14 \% \quad 55.6 \%$ RFDEILEASDGIMVAR

$126 \quad 0.14 \% \quad 55.6 \%$ GDLGIEIPAEK

$99.7 \% \quad 57.8$

$126 \quad 0.14 \% \quad 55.6 \%$ GDLGIEIPAEKVFLAQK $\quad 99.7 \% \quad 29.7$

$126 \quad 0.14 \% \quad 55.6 \%$ AGKPVICATQMLESMIK

$\begin{array}{ll}99.7 \% & 29.7 \\ 99.7 \% & 45.9\end{array}$

$99.7 \% \quad 50.4$

$\begin{array}{lll}0.14 \% & 55.6 \% \text { GDYPLEAVR }\end{array}$

$99.4 \% \quad 23.8$

$126 \quad 0.14 \% \quad 55.6 \%$ EAEAAIYHLQLFEELRR

$126 \quad 0.14 \% \quad 55.6 \%$ LAPITSDPTEATAVGAVEASFK

$126 \quad 0.14 \% \quad 55.6 \%$ CCSGAIIVLTK

$126 \quad 0.14 \% \quad 55.6 \%$ APIIAVTRNPQTAR

$126 \quad 0.14 \% \quad 55.6 \%$ VNFAMNVGK

$0.00 \% \quad 0.0 \% \quad$ ALSAAKVPR

$0.00 \% \quad 0.0 \% \quad$ GLTVIVVGR

$0.00 \% \quad 1.6 \%$ VAQFLVIYAPR

$0.00 \% \quad 1.6 \%$ VSSLQAEPLPR

$0.00 \% \quad 9.8 \%$ VHDYKEGTPEEK

$0.00 \% \quad 9.8 \%$ YLAAGSSNAVK

$0.01 \% \quad 5.5 \%$ SIGSAVDQGNESIVAK

$0.01 \% \quad 5.5 \%$ GLTETGLYR

$0.01 \% \quad 5.5 \% \quad$ TPSSSSLSQR

$0.01 \% \quad 8.7 \%$ TQVAGGQLSFKGK

$0.01 \% \quad 8.7 \% \quad$ QVEVINFGDCLVR

$0.01 \% \quad 8.7 \%$ AFNSSSFNSNTFLTR

$0.01 \% \quad 8.7 \%$ HSLLQTLYKV

$0.01 \% \quad 16.4 \%$ TLEEDEEELFK

$0.01 \% \quad 16.4 \%$ FASENDLPEWKER

$0.01 \% \quad 16.4 \%$ FLNAENAQK

$0.00 \% \quad 1.8 \%$ LSDGFVAAEAK

$0.00 \% \quad 1.8 \% \quad$ LTVSSLDYSR

$0.00 \% \quad 1.8 \%$ ILTAATDACR

$0.02 \% \quad 5.3 \% \quad$ LGNFFSPK

$0.02 \% \quad 5.3 \%$ ALQSPALGLR

$0.02 \% \quad 5.3 \%$ LAAVALINAAIQK

$0.02 \% \quad 5.3 \%$ TLQALQIPAAK

$0.02 \% \quad 5.3 \% \quad$ NKITLQDVVSHSK

$0.02 \% \quad 5.3 \%$ LIFQMPQNK $\begin{array}{llll}99.7 \% & 54.0 & 25.0 & 54.0\end{array}$

$\begin{array}{llll}99.7 \% & 66.0 & 25.0 & 61.7\end{array}$

$\begin{array}{lllll}99.7 \% & 39.9 & 25.0 & 39.9 & 2\end{array}$

$\begin{array}{llll}97.7 \% & 16.4 & 25.0 & 16.4\end{array}$

$\begin{array}{llll}98.8 \% & 18.6 & 25.0 & 18.6\end{array}$

$\begin{array}{llll}96.6 \% & 19.5 & 25.0 & 13.1\end{array}$

$\begin{array}{llll}99.7 \% & 29.8 & 25.0 & 29.8\end{array}$

$\begin{array}{llll}99.5 \% & 23.4 & 25.0 & 23.4\end{array}$

$99.0 \% \quad 18.7 \quad 25.0 \quad 18.7$

$\begin{array}{llll}95.6 \% & 19.0 & 25.0 & 12.9\end{array}$

$\begin{array}{lllll}99.7 \% & 54.2 & 25.0 & 54.2 & 2\end{array}$

$99.5 \% \quad 26.6 \quad 25.0 \quad 18.1$

$99.7 \% \quad 39.5 \quad 25.0 \quad 30.2$

$99.7 \% \quad 39.6 \quad 25.0 \quad 39.6$

$\begin{array}{llll}99.7 \% & 51.5 & 25.0 & 47.2\end{array}$

$\begin{array}{llll}99.7 \% & 35.9 & 25.0 & 35.8\end{array}$

$\begin{array}{llll}99.7 \% & 33.9 & 25.0 & 33.9\end{array}$

$\begin{array}{llll}98.5 \% & 25.6 & 25.0 & 25.6\end{array}$

$\begin{array}{llll}99.7 \% & 32.1 & 25.0 & 29.3\end{array}$

$\begin{array}{llll}99.7 \% & 44.1 & 25.0 & 28.6\end{array}$

$\begin{array}{llll}99.7 \% & 31.7 & 25.0 & 26.9\end{array}$

$\begin{array}{llll}99.7 \% & 31.8 & 25.0 & 31.8\end{array}$

$\begin{array}{llll}99.6 \% & 27.3 & 25.0 & 19.4\end{array}$

$\begin{array}{llll}99.0 \% & 45.6 & 25.0 & 45.6\end{array}$

$\begin{array}{llll}99.7 \% & 42.5 & 25.0 & 35.6\end{array}$

$99.7 \% \quad 41.6 \quad 25.0 \quad 40.7$

$\begin{array}{llll}99.7 \% & 40.1 & 25.0 & 37.0\end{array}$

$\begin{array}{llll}99.7 \% & 27.7 & 25.0 & 27.7\end{array}$

$\begin{array}{llll}99.7 \% & 31.2 & 25.0 & 24.7\end{array}$
2465.29

1118.61

1197.58

1462.82

1718.97

2036.03

1779.88

1907.97

1636.89

2349.27

1394.78

1821.92

1141.61

1828.02

1908.96

1019.52

2088.09

2175.12

1221.63

1507.87

979.50

912.56

913.58

1276.74

1196.66

1431.68

1080.57

1574.80

1009.53

1049.52

1320.73

1548.78

1692.80

1201.69

1381.64

1620.77

1034.53

1107.57

1140.59

1091.55

909.48

1025.61

1295.80

1153.69

1468.81

1118.60 \begin{tabular}{|c}
\hline 115 \\
136 \\
151 \\
186 \\
188 \\
206 \\
206 \\
207 \\
224 \\
230 \\
278 \\
294 \\
305 \\
311 \\
336 \\
376 \\
400 \\
422 \\
433 \\
461 \\
498 \\
\hline \\
0 \\
4
\end{tabular}

Page 127 

Regulator of nonsense transcripts 1 GN=UPF1 RENT1_HUMAN $124.35 \quad 100.0 \%$ Regulator of nonsense transcripts 1 GN=UPF1 RENT1_HUMAN $124.35 \quad 100.0 \%$ Regulator of nonsense transcripts 1 GN=UPF1 RENT1_HUMAN $124.35 \quad 100.0 \%$ Regulator of nonsense transcripts 1 GN=UPF1 RENT1_HUMAN $124.35 \quad 100.0 \%$ Regulator of nonsense transcripts 1 GN=UPF1 RENT1_HUMAN $124.35100 .0 \%$ Regulator of nonsense transcripts 1 GN=UPF1 RENT1_HUMAN $124.35 \quad 100.0 \%$ Regulator of nonsense transcripts 1 GN=UPF1 RENT1_HUMAN $124.35 \quad 100.0 \%$ Regulator of nonsense transcripts 1 GN=UPF1 RENT1_HUMAN $124.35100 .0 \%$ Regulator of nonsense transcripts 1 GN=UPF1 RENT1_HUMAN $124.35 \quad 100.0 \%$ Regulator of nonsense transcripts 1 GN=UPF1 RENT1_HUMAN $124.35 \quad 100.0 \%$ Regulatory-associated protein of mTOR GN=RPTOR RPTOR_HUMAN $149.04 \quad 100.0 \%$ Regulatory-associated protein of mTOR GN=RPTOR RPTOR_HUMAN $149.04 \quad 100.0 \%$ Regulatory-associated protein of mTOR GN=RPTOR RPTOR_HUMAN $149.04 \quad 100.0 \%$ Replication factor C subunit $1 \mathrm{GN}=\mathrm{RFC} 1 \quad \mathrm{RFC1}$ HUMAN $128.26 \quad 100.0 \%$ Replication factor C subunit $1 \mathrm{GN}=\mathrm{RFC} 1 \quad \mathrm{RFC1}$ _HUMAN $128.26 \quad 100.0 \%$ Replication factor C subunit $1 \mathrm{GN}=\mathrm{RFC} 1 \quad \mathrm{RFC} 1$ HUMAN $128.26 \quad 100.0 \%$ Replication factor C subunit 2 GN=RFC2 RFC2_HUMAN $39.16 \quad 100.0 \%$ Replication factor $\mathrm{C}$ subunit $2 \mathrm{GN}=\mathrm{RFC} 2 \quad \mathrm{RFC} 2$ HUMAN $39.16 \quad 100.0 \%$ Replication factor $\mathrm{C}$ subunit $2 \mathrm{GN}=\mathrm{RFC} 2 \quad \mathrm{RFC} 2$ HUMAN $39.16 \quad 100.0 \%$ Replication factor C subunit 2 GN=RFC2 RFC2_HUMAN $39.16 \quad 100.0 \%$ Replication factor C subunit $2 \mathrm{GN}=\mathrm{RFC} 2 \quad \mathrm{RFC} 2 \mathrm{HUMAN} 39.16 \quad 100.0 \%$ Replication factor C subunit 2 GN=RFC2 RFC2_HUMAN $39.16 \quad 100.0 \%$ Replication factor C subunit $2 \mathrm{GN}=\mathrm{RFC} 2$ RFC2_HUMAN $39.16 \quad 100.0 \%$ Replication factor C subunit 2 GN=RFC2 RFC2_HUMAN $39.16 \quad 100.0 \%$ Replication factor C subunit $2 \mathrm{GN}=\mathrm{RFC} 2 \mathrm{RFC2}$ _HUMAN $39.16 \quad 100.0 \%$ Replication factor $\mathrm{C}$ subunit $2 \mathrm{GN}=\mathrm{RFC} 2 \mathrm{RFC} 2 \mathrm{HUMAN} 39.16 \quad 100.0 \%$ Replication factor $\mathrm{C}$ subunit $2 \mathrm{GN}=\mathrm{RFC} 2 \quad \mathrm{RFC} 2$ HUMAN $39.16 \quad 100.0 \%$ Replication factor C subunit $2 \mathrm{GN}=\mathrm{RFC} 2 \mathrm{RFC} 2$ HUMAN $39.16 \quad 100.0 \%$ Replication factor $\mathrm{C}$ subunit $3 \mathrm{GN}=\mathrm{RFC} 3 \mathrm{RFC} 3 \mathrm{HUMAN} 40.56 \quad 100.0 \%$ Replication factor C subunit $3 \mathrm{GN}=\mathrm{RFC} 3 \quad \mathrm{RFC} 3$ _HUMAN $40.56 \quad 100.0 \%$ Replication factor $\mathrm{C}$ subunit $3 \mathrm{GN}=\mathrm{RFC} 3$ RFC3_HUMAN $40.56 \quad 100.0 \%$ Replication factor C subunit $3 \mathrm{GN}=\mathrm{RFC} 3$ RFC3_HUMAN $40.56 \quad 100.0 \%$ Replication factor C subunit $3 \mathrm{GN}=\mathrm{RFC} 3 \quad \mathrm{RFC} 3$ _HUMAN $40.56 \quad 100.0 \%$ Replication factor C subunit $3 \mathrm{GN}=\mathrm{RFC} 3 \quad \mathrm{RFC} 3$ HUMAN $40.56 \quad 100.0 \%$ Replication factor C subunit 3 GN=RFC3 RFC3_HUMAN $40.56 \quad 100.0 \%$ Replication factor C subunit $3 \mathrm{GN}=\mathrm{RFC} 3 \quad \mathrm{RFC} 3$ _HUMAN $40.56 \quad 100.0 \%$ Replication factor C subunit $3 \mathrm{GN}=\mathrm{RFC} 3 \quad \mathrm{RFC} 3$ HUMAN $40.56 \quad 100.0 \%$ Replication factor C subunit 3 GN=RFC3 RFC3_HUMAN $40.56 \quad 100.0 \%$

$0.02 \% \quad 23.4 \%$ LTFLYLANDVIQNSK

$0.02 \% 23.4 \%$ DFAPVIVEAFK

$0.02 \% \quad 23.4 \%$ VLSIWEER

$0.02 \% \quad 23.4 \%$ SVYENDVLEQLK

$99.7 \% 35$

$\begin{array}{lll}99.7 \% & 30.9\end{array}$

$99.2 \% 25.6$

$99.0 \% \quad 48.0$

$\begin{array}{lll}99.7 \% & 40.9\end{array}$

$0.02 \% \quad 23.4 \%$ ALQDLENAASGDAAVHQR $\quad 99.7 \% \quad 46.7$

$0.02 \% \quad 23.4 \%$ IQSLPDLSR

$0.02 \% \quad 11.3 \%$ GNTSGSHIVNHLVR

$0.02 \% \quad 11.3 \%$ ADSVVVLLCR

$0.02 \% \quad 11.3 \%$ IPSEQEQLR

$0.02 \% \quad 11.3 \%$ IAYFTLPK

$0.02 \% \quad 11.3 \%$ TVTSATIVYHLAR

$0.02 \% \quad 11.3 \%$ AGLSQSLFER

$0.02 \% \quad 11.3 \%$ LVVLGIRPIR

$98.3 \% 22.3$

$99.7 \% \quad 28.9$

$99.7 \% 35.0$

$97.1 \% \quad 21.8$

$99.0 \% 32.7$

$99.7 \% \quad 42.8$

$99.7 \% \quad 59.4$

$\begin{array}{lll}96.2 \% & 16.3\end{array}$

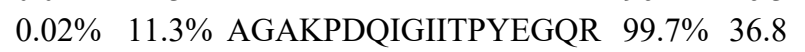

$0.02 \% \quad 11.3 \%$ ARYGVIIVGNPK

$0.02 \% \quad 11.3 \%$ KLVNTINPGAR

$0.02 \% \quad 11.3 \%$ AYQHGGVTGLSQY

$0.00 \% \quad 2.5 \% \quad$ SYNCTPVSSPR

$0.00 \% \quad 2.5 \%$ SVSSYGNIR

$0.00 \% \quad 2.5 \%$ SLIVAGLGDGSIR

$0.01 \% \quad 3.2 \%$ SSADKIGEVSSPK

$0.01 \% \quad 3.2 \% \quad$ IIDEDGLLNLIR

$0.01 \% \quad 3.2 \%$ AALLSGPPGVGK

$0.02 \% \quad 34.2 \%$ APGSAGHYELPWVEK

$0.02 \% \quad 34.2 \%$ LNEIVGNEDTVSR

$99.6 \% \quad 25.7$

$99.7 \% \quad 57.2$

$99.7 \% 38.6$

$99.7 \% \quad 41.4$

$99.5 \% \quad 30.0$

$96.0 \% \quad 16.4$

$99.7 \% \quad 29.9$

$99.7 \% \quad 56.9$

$99.4 \% 26.5$

$99.3 \% \quad 21.9$

$99.7 \% \quad 72.9$

$99.7 \% \quad 64.2$

$99.7 \% \quad 43.0$

$0.02 \% \quad 34.2 \%$ TTSILCLAR

$\begin{array}{lllll}0.02 \% & 34.2 \% & \text { IIILDEADSMTDGAQQALR } & 99.7 \% & 59.0 \\ 0.02 \% & 34.2 \% & \text { IIILDEADSMTDGAQQALRR } & 99.7 \% & 29.0\end{array}$

$0.02 \% \quad 34.2 \%$ FALACNASDK $99.7 \% \quad 46.1$

$0.02 \% \quad 34.2 \%$ FALACNASDKIIEPIQSR

$0.02 \% \quad 34.2 \%$ IIEPIQSR

$0.02 \% \quad 34.2 \%$ LTDAQILTR

$0.02 \% \quad 34.2 \%$ VCDEPHPLLVK

$0.02 \% \quad 34.2 \%$ TFQMAEYLK

$0.03 \% \quad 34.8 \%$ LDYHKEQAAQLR

$0.03 \% \quad 34.8 \%$ ELYGVGVEK

$0.03 \% \quad 34.8 \%$ LRIEHQTITTPSK

$0.03 \% \quad 34.8 \%$ IEHQTITTPSK

$0.03 \% 34.8 \%$ VVIQEMLK

$0.03 \% \quad 34.8 \%$ TVAQSQQLETNSQR

$0.03 \% \quad 34.8 \%$ VVLLTEVDK

$0.03 \% \quad 34.8 \%$ VVLLTEVDKLTK

$0.03 \% 34.8 \%$ LILCCNSTSK

$0.03 \% \quad 34.8 \%$ EGLNLPSQLAHR
$99.7 \% \quad 39.6$

$99.0 \% \quad 28.1$

$99.7 \% \quad 61.1$

$99.7 \% \quad 44.9$

$99.7 \% \quad 36.3$

$99.7 \% \quad 42.0$

$99.7 \% \quad 37.9$

$99.4 \% \quad 26.0$

$99.5 \% 25.3$

$97.3 \% \quad 25.1$

$99.7 \% \quad 81.9$

$99.7 \% \quad 34.8$

$99.7 \% \quad 67.2$

$99.7 \% \quad 35.6$

$99.7 \% \quad 45.8$
1031.55

1436.73

1865.91

1028.57

1490.78

1131.62

1099.57

952.55

1431.80

1107.58

1135.77

1914.01

1286.76

1182.70

1380.65

1267.57

982.50

1257.72

1304.67

1383.78

1066.63

1640.81

1445.72

1633.89

1034.57

2060.03

2232.13

1096.51

2033.05

955.56

1030.59

1306.68

1130.56

1471.77

993.53

1523.85

1254.67

975.55

1589.79

1015.60

1357.83

1195.58

1334.72
$17 \quad 1528$

$80 \quad 90$

$107 \quad 114$

$115 \quad 126$

$169 \quad 186$

$283 \quad 291$

$149 \quad 162$

$201 \quad 210$

$245 \quad 253$

$342 \quad 349$

$510 \quad 522$

699708

$794 \quad 811$

$877 \quad 888$

$929 \quad 939$

$117 \quad 1129$

$\begin{array}{ll}719 & 727\end{array}$

1791191

$302 \quad 314$

$469 \quad 480$

$646 \quad 657$

$27 \quad 41$

82

$83 \quad 91$

$137 \quad 155$

$137 \quad 156$

$\begin{array}{ll}67 & 176 \\ 67 & 184\end{array}$

$177 \quad 184$

$193 \quad 201$

$254 \quad 264$

$305 \quad 313$

$58 \quad 66$

$\begin{array}{ll}67 & 79 \\ 69 & 79\end{array}$

113
$14 \quad 127$

$\begin{array}{ll}114 & 127\end{array}$

$131 \quad 142$

$161 \quad 170$

$203 \quad 214$ 


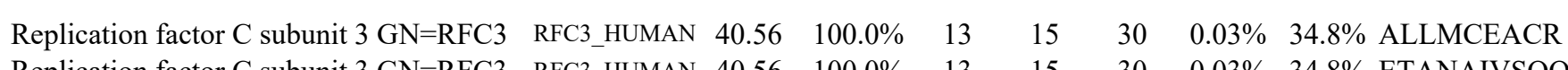
$\begin{array}{lllll}\text { Replication factor C subunit } 3 \mathrm{GN}=\mathrm{RFC} 3 & \mathrm{RFC} 3 \text { _HUMAN } & 40.56 & 100.0 \% & 1\end{array}$ Replication factor C subunit $4 \mathrm{GN}=\mathrm{RFC} 4 \quad \mathrm{RFC} 4$ _HUMAN $39.68 \quad 100.0 \%$ Replication factor C subunit 4 GN=RFC4 RFC4_HUMAN $39.68 \quad 100.0 \% \quad 12$ Replication factor C subunit 4 GN=RFC4 $\quad$ RFC4_HUMAN $39.68 \quad 100.0 \% \quad 1$ Replication factor C subunit $4 \mathrm{GN}=\mathrm{RFC} 4 \quad \mathrm{RFC} 4$ _HUMAN $39.68 \quad 100.0 \% \quad 12$ Replication factor C subunit 4 GN=RFC4 RFC4_HUMAN $39.68 \quad 100.0 \% \quad 12$ Replication factor C subunit $4 \mathrm{GN}=\mathrm{RFC} 4 \quad \mathrm{RFC} 4 \mathrm{HUMAN} \quad 39.68 \quad 100.0 \% \quad 1$ Replication factor C subunit $4 \mathrm{GN}=\mathrm{RFC} 4 \quad \mathrm{RFC} 4$ _HUMAN $39.68 \quad 100.0 \% \quad 12$ $\begin{array}{lllll}\text { Replication factor } \mathrm{C} \text { subunit } 4 \mathrm{GN}=\mathrm{RFC} 4 & \mathrm{RFC} 4 \text { _HUMAN } & 39.68 & 100.0 \% & 1\end{array}$ Replication factor $\mathrm{C}$ subunit $4 \mathrm{GN}=\mathrm{RFC} 4 \mathrm{RFC4}$ HUMAN $39.68 \quad 100.0 \%$ Replication factor C subunit 4 GN=RFC4 $\quad$ RFC4_HUMAN $39.68 \quad 100.0 \% \quad 12$ Replication factor $\mathrm{C}$ subunit $4 \mathrm{GN}=\mathrm{RFC} 4 \quad \mathrm{RFC} 4$ _HUMAN $39.68 \quad 100.0 \%$ Replication factor C subunit $4 \mathrm{GN}=\mathrm{RFC} 4 \quad \mathrm{RFC} 4$ _HUMAN $39.68 \quad 100.0 \% \quad 12$ Replication factor C subunit $5 \mathrm{GN}=\mathrm{RFC} 5 \quad \mathrm{RFC} 5$ _HUMAN $38.50 \quad 100.0 \%$ Replication factor $\mathrm{C}$ subunit $5 \mathrm{GN}=\mathrm{RFC} 5 \mathrm{RFC} 5$ HUMAN $38.50 \quad 100.0 \%$ Replication factor C subunit 5 GN=RFC5 $\quad$ RFC5_HUMAN $38.50 \quad 100.0 \% \quad 12$ Replication factor C subunit 5 GN=RFC5 $\quad$ RFC5_HUMAN $38.50 \quad 100.0 \% \quad 12$ Replication factor C subunit $5 \mathrm{GN}=\mathrm{RFC} 5 \quad$ RFC5_HUMAN $38.50 \quad 100.0 \%$ Replication factor C subunit 5 GN=RFC5 RFC5_HUMAN $38.50 \quad 100.0 \%$ Replication factor C subunit $5 \mathrm{GN}=\mathrm{RFC} 5 \mathrm{RFC} 5$ HUMAN $38.50 \quad 100.0 \%$ Replication factor C subunit 5 GN=RFC5 RFC5_HUMAN $38.50 \quad 100.0 \%$ Replication factor C subunit 5 GN=RFC5 RFC5_HUMAN $38.50 \quad 100.0 \%$ Replication factor $\mathrm{C}$ subunit $5 \mathrm{GN}=\mathrm{RFC} 5 \mathrm{RFC5}$ HUMAN $38.50 \quad 100.0 \%$ Replication factor C subunit 5 GN=RFC5 $\quad$ RFC5_HUMAN $38.50 \quad 100.0 \% \quad 12$ Replication factor C subunit $5 \mathrm{GN}=\mathrm{RFC} 5 \quad$ RFC5_HUMAN $38.50 \quad 100.0 \%$ Replication initiator $1 \mathrm{GN}=\mathrm{REPIN}$ Replication initiator $1 \mathrm{GN}=\mathrm{REPIN}$ Replication initiator $1 \mathrm{GN}=\mathrm{REPIN}$ REPI1 HUMAN REPI_HUMAN 63.57 REPI1 HUMAN 63.57

$100.0 \%$ $100.0 \%$ $100.0 \%$ $99.8 \%$ $99.8 \%$ $100.0 \%$ $100.0 \%$ $100.0 \%$ $100.0 \%$ $100.0 \%$ $\begin{array}{llll}\text { tein } 1 \text { homolog GN=RMND1 } & \text { RMND1_HUMAN } & 51.61 & 100.0 \% \\ \text { tein } 1 \text { homolog GN=RMND1 } & \text { RMND1_HUMAN } & 51.61 & 100.0 \%\end{array}$ Replication protein A $32 \mathrm{kDa}$ subunit GN=RPA2 RFA2_HUMAN 29.2 Replication protein A $70 \mathrm{kDa}$ DNA-binding subunit GN=RPA1 RFA1 HUMAN 68.1 Replication protein A $70 \mathrm{kDa}$ DNA-binding subunit GN=RPA1 RFA1_HUMAN 68.1 Replication protein A 70 kDa DNA-binding subunit GN=RPA1 RFA1_HUMAN 68.14 Required for meiotic nuclear division protein 1 homolog GN=RMND1 RMND1_HUMAN 51.61 Ribonuclease 3 GN=DROSHA Ribonuclease $3 \mathrm{GN}=$ DROSHA RNC_HUMAN $159.32 \quad 100.0 \%$ RNC HUMAN $159.32 \quad 100.0 \%$ Ribonuclease P protein subunit $\mathrm{p} 30 \mathrm{GN}=\mathrm{RPP} 30$ RPP30 HUMAN $29.32 \quad 100.0 \%$ Ribonuclease P protein subunit p30 GN=RPP30 RPP30_HUMAN $29.32 \quad 100.0 \%$ Ribonuclease P protein subunit $\mathrm{p} 30 \mathrm{GN}=\mathrm{RPP} 30$ RPP30 HUMAN $29.32 \quad 100.0 \%$ Ribonuclease P protein subunit p30 GN=RPP30 RPP30_HUMAN $29.32 \quad 100.0 \%$ Ribonuclease P protein subunit $\mathrm{p} 30 \mathrm{GN}=\mathrm{RPP} 30$ RPP30_HUMAN $29.32 \quad 100.0 \%$ Ribonuclease P protein subunit $\mathrm{p} 30 \mathrm{GN}=\mathrm{RPP} 30$ RPP30 HUMAN $29.32 \quad 100.0 \%$ Ribonuclease P protein subunit p38 GN=RPP38 RPP38_HUMAN $31.84 \quad 100.0 \%$ $0.03 \% \quad 34.8 \%$ ETANAIVSQQTPQR $0.03 \% \quad 34.8 \%$ AIYHLEAFVAK

$0.03 \% \quad 36.1 \%$ GTSISTKPPLTK

$99.7 \% 52.2$

$0.03 \% \quad 36.1 \%$ SLEGADLPNLLFYGPPGTGK

$0.03 \% \quad 36.1 \%$ TSTILAAAR

$0.03 \% \quad 36.1 \%$ ELFGPELFR

$0.03 \% \quad 36.1 \%$ VLELNASDER

$0.03 \% 36.1 \%$ VLELNASDERGIQVVR

$0.03 \% \quad 36.1 \%$ VKNFAQLTVSGSR

$0.03 \% \quad 36.1 \%$ FCLICNYVSR

$0.03 \% \quad 36.1 \%$ ISDEGIAYLVK

$0.03 \% \quad 36.1 \%$ VSEGDLRK

$0.03 \% \quad 36.1 \%$ AITFLQSATR

$0.03 \% \quad 36.1 \%$ VITDIAGVIPAEK

$0.03 \% \quad 41.5 \%$ TSTILACAK

$0.03 \% \quad 41.5 \%$ GPILSFASTR

$99.7 \% \quad 58.6$

$99.7 \% \quad 47.5$

$99.7 \% \quad 61.5$

$99.7 \% 38.8$

$99.7 \% 31.6$

$99.7 \% \quad 44.6$

$99.7 \% \quad 60.4$

$99.0 \% \quad 47.8$

$\begin{array}{lll}99.7 \% & 51.8\end{array}$

$99.7 \% \quad 64.3$

$99.7 \% \quad 35.7$

$99.7 \% \quad 62.1$

$0.03 \% \quad 41.5 \%$ LVILDEADAMTQDAQNALR $99.7 \% \quad 75.6$

$0.03 \% \quad 41.5 \%$ VIEKFTENTR

$0.03 \% \quad 41.5 \%$ FCLICNYLSK

$0.03 \% \quad 41.5 \%$ IIPALQSR

$0.03 \% \quad 41.5 \%$ FGPLTPELMVPR

$0.03 \% \quad 41.5 \%$ ALVTLSSGDMRR

$0.03 \% \quad 41.5 \%$ ALNILQSTNMAFGK

$0.03 \% \quad 41.5 \%$ VTEETVYTCTGHPLK

$0.03 \% \quad 41.5 \%$ VDFPSSVR

$0.03 \% \quad 41.5 \%$ IQLSSLIAAFQVTR

$0.01 \% \quad 8.3 \% \quad$ LLSGPSQESPQTLGK

$99.7 \% \quad 33.7$

$98.4 \% \quad 18.0$

$99.7 \% \quad 47.3$

$95.6 \% \quad 22.2$

$99.7 \% \quad 59.1$

$99.7 \% \quad 66.4$

$99.0 \% \quad 37.7$

$99.7 \% \quad 59.5$

$\begin{array}{lll}94.7 \% & 24.8\end{array}$

$0.01 \% \quad 8.3 \%$ GLRQQGTSVAQSGAQAPG

$0.01 \% \quad 8.3 \%$ VHVAEALEEAAAK

$0.00 \% \quad 4.4 \%$ HAEKAPTNIVYK

$0.00 \% \quad 4.4 \%$ APTNIVYK

$0.01 \% \quad 6.5 \%$ AAGPSLSHTSGGTQSK

$0.01 \% \quad 6.5 \%$ VVPIASLTPYQSK

$0.01 \% \quad 6.5 \%$ SYEDATKITVR

$0.01 \% \quad 7.6 \%$ DAANILVMGVENSAK

$0.01 \% \quad 7.6 \%$ EGDPGTIFFFR

$0.01 \% \quad 7.6 \%$ IGELFALR

$0.00 \% \quad 1.6 \%$ GINTLINIMSR

$0.00 \% \quad 1.6 \%$ TLQTVGPSHAR

$0.01 \% 28.0 \%$ LYDVVAVFPK

$0.01 \% \quad 28.0 \%$ RPPINVAIDR

$0.01 \% \quad 28.0 \%$ GLAFELVYSPAIK

$0.01 \% \quad 28.0 \%$ NVIISSAAERPLEIR

$0.01 \% \quad 28.0 \%$ KTAFGIISTVK

$0.01 \% \quad 28.0 \%$ KPRPSEGDEDCLPASK

$0.01 \% \quad 20.5 \%$ TSLNNPYIIR
$94.9 \% \quad 16.3$

$99.0 \% \quad 36.5$

$99.7 \% \quad 48.9$

$99.6 \% \quad 25.7$

$\begin{array}{lll}99.7 \% & 40.7\end{array}$

$99.7 \% \quad 50.9$

$99.7 \% \quad 36.5$

$99.0 \% \quad 65.2$

$98.4 \% \quad 20.6$

$99.7 \% \quad 39.7$

$99.7 \% \quad 51.3$

$99.7 \% \quad 34.3$

$99.7 \% \quad 36.5$

$97.7 \% \quad 20.6$

$99.7 \% \quad 37.3$

$99.7 \% \quad 34.3$

$99.7 \% \quad 58.8$

\section{$99.7 \% \quad 41.8$}

1139.50

1542.79

1261.69

2046.05

903.53

1107.58

1145.58

1797.98

1406.78

1331.62

1207.66

903.49

1107.62

1325.77

964.51

1048.58

2103.04

1236.66

1317.63

897.55

1372.73

1321.69

1507.79

1734.84

906.47

1546.90

1541.82

1868.97

1337.7

1370.74

905.51

1485.73

1402.79

1282.66

1531.78

1285.62

918.54

1231.68

1166.63

1150.65

1150.67

1407.79

1667.94

1164.70

1785.84

1190.65

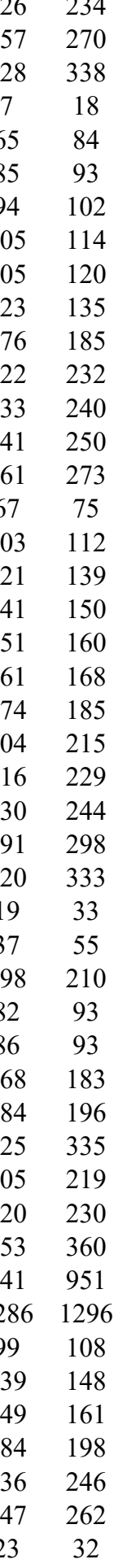

Page 129 of Table S-1-6 
Ribonuclease P protein subunit p38 GN=RPP38 RPP38 HUMAN $31.84 \quad 100.0 \%$ Ribonuclease P protein subunit $\mathrm{p} 38 \mathrm{GN}=\mathrm{RPP} 38$ RPP38_HUMAN $31.84 \quad 100.0 \%$ Ribonuclease P protein subunit p38 GN=RPP38 RPP38_HUMAN $31.84 \quad 100.0 \%$ Ribonuclease P protein subunit $\mathrm{p} 38 \mathrm{GN}=\mathrm{RPP} 38$ RPP38 HUMAN $31.84 \quad 100.0 \%$ Ribonuclease P protein subunit p38 GN=RPP38 RPP38_HUMAN $31.84 \quad 100.0 \%$ Ribonucleases P/MRP protein subunit POP1 GN=POP1 POP1_HUMAN $114.71 \quad 100.0 \%$ Ribonucleases P/MRP protein subunit POP1 GN=POP1 POP1_HUMAN $114.71 \quad 100.0 \%$ Ribonucleases P/MRP protein subunit POP1 GN=POP1 POP1_HUMAN $114.71 \quad 100.0 \%$ Ribonucleases P/MRP protein subunit POP1 GN=POP1 POP1_HUMAN $114.71 \quad 100.0 \%$ Ribonucleoside-diphosphate reductase subunit M2 B GN=RRM2B RIR2B_HUMAN $40.74 \quad 100.0 \%$ Ribonucleoside-diphosphate reductase subunit M2 B GN=RRM2B RIR2B_HUMAN $40.74 \quad 100.0 \%$

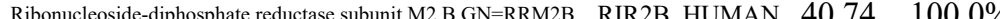
Ribose-phosphate pyrophosphokinase $1 \mathrm{GN}=$ PRPS1 PRPS1_HUMAN $34.83 \quad 100.0 \%$ Ribose-phosphate pyrophosphokinase 1 GN=PRPS1 PRPS1 HUMAN $34.83 \quad 100.0 \%$ Ribose-phosphate pyrophosphokinase $1 \mathrm{GN}=$ PRPS1 PRPS1_HUMAN $34.83 \quad 100.0 \%$ Ribose-phosphate pyrophosphokinase 1 GN=PRPS1 PRPS1_HUMAN $34.83 \quad 100.0 \%$ Ribose-phosphate pyrophosphokinase $1 \mathrm{GN}=$ PRPS1 PRPS1_HUMAN $34.83 \quad 100.0 \%$ Ribose-phosphate pyrophosphokinase 1 GN=PRPS1 PRPS1_HUMAN $34.83 \quad 100.0 \%$ Ribose-phosphate pyrophosphokinase $1 \mathrm{GN}=$ PRPS1 PRPS1_HUMAN $34.83 \quad 100.0 \%$ Ribose-phosphate pyrophosphokinase $2 \mathrm{GN}=$ PRPS2 PRPS2 HUMAN $34.77 \quad 100.0 \%$ Ribose-phosphate pyrophosphokinase 2 GN=PRPS2 PRPS2_HUMAN $34.77 \quad 100.0 \%$ Ribose-phosphate pyrophosphokinase 2 GN=PRPS2 PRPS2 HUMAN $34.77 \quad 100.0 \%$ Ribose-phosphate pyrophosphokinase 2 GN=PRPS2 PRPS2_HUMAN $34.77 \quad 100.0 \%$ Ribose-phosphate pyrophosphokinase 2 GN=PRPS2 PRPS2_HUMAN $34.77 \quad 100.0 \%$ Ribose-phosphate pyrophosphokinase 2 GN=PRPS2 PRPS2 HUMAN $34.77 \quad 100.0 \%$ Ribose-phosphate pyrophosphokinase 2 GN=PRPS2 PRPS2_HUMAN $34.77 \quad 100.0 \%$ Ribosomal L1 domain-containing protein 1 GN=RSL1D1 RL1D1_HUMAN $54.97 \quad 100.0 \%$ Ribosomal L1 domain-containing protein 1 GN=RSL1D1 RL1D1 HUMAN $54.97 \quad 100.0 \%$ Ribosomal L1 domain-containing protein $1 \mathrm{GN}=$ RSL1D1 RL1D1_HUMAN $54.97 \quad 100.0 \%$ Ribosomal L1 domain-containing protein $1 \mathrm{GN}=\mathrm{RSL} 1 \mathrm{D} 1 \mathrm{RL} 1 \mathrm{D} 1$ HUMAN $54.97100 .0 \%$ Ribosomal L1 domain-containing protein 1 GN=RSL1D1 RL1D1_HUMAN $54.97 \quad 100.0 \%$ Ribosomal L1 domain-containing protein 1 GN=RSL1D1 RL1D1_HUMAN $54.97 \quad 100.0 \%$ Ribosomal L1 domain-containing protein $1 \mathrm{GN}=$ RSL1D1 RL1D1 HUMAN $54.97100 .0 \%$ Ribosomal L1 domain-containing protein 1 GN=RSL1D1 RL1D1_HUMAN $54.97 \quad 100.0 \%$ Ribosomal protein S6 kinase alpha-3 GN=RPS6KA3 KS6A3_HUMAN $83.74 \quad 100.0 \%$ Ribosomal protein S6 kinase alpha-3 GN=RPS6KA3 KS6A3_HUMAN $83.74 \quad 100.0 \%$ Ribosomal RNA processing protein 1 homolog A GN=RRP1 RRP1_HUMAN $52.84 \quad 100.0 \%$ Ribosomal RNA processing protein 1 homolog A GN=RRP1 RRP1_HUMAN $52.84 \quad 100.0^{\circ}$ Ribosomal RNA processing protein 1 homolog A GN=RRP1 RRP1_HUMAN $52.84 \quad 100.0 \%$ Ribosomal RNA processing protein 1 homolog A GN=RRP1 RRP1_HUMAN $52.84 \quad 100.0 \%$ Ribosomal RNA processing protein 1 homolog B GN=RRP1B RRP1B HUMAN $84.43100 .0 \%$ Ribosomal RNA processing protein 1 homolog B GN=RRP1B RRP1B_HUMAN $84.43 \quad 100.0 \%$ Ribosomal RNA processing protein 1 homolog B GN=RRP1B RRP1B HUMAN $84.43 \quad 100.0 \%$ Ribosomal RNA processing protein 1 homolog B GN=RRP1B RRP1B_HUMAN $84.43 \quad 100.0 \%$ Ribosomal RNA processing protein 1 homolog B GN=RRP1B RRP1B_HUMAN 84.43 $100.0 \%$ Ribosomal RNA processing protein 1 homolog $B$ GN=RRP1B RRP1B HUMAN $84.43 \quad 100.0 \%$ Ribosomal RNA processing protein 1 homolog B GN=RRP1B RRP1B_HUMAN $84.43 \quad 100.0 \%$
$10 \quad 0.01 \% \quad 20.5 \%$ QLAIGVNEVTR

$\quad 0.01 \% \quad 20.5 \%$ ELLLVLVCK

$10 \quad 0.01 \% \quad 20.5 \%$ IAPVIGLK

$10 \quad 0.01 \% \quad 20.5 \%$ NTTDFVDEVR

$10 \quad 0.01 \% \quad 20.5 \%$ QASVTLQPLK $\begin{array}{lll}0.01 \% & 5.2 \% & \text { VNPHSLPDPEVNE } \\ 0.01 \% & 5.2 \% & \text { AGPEGTSQEIPK }\end{array}$

$\begin{array}{lll}0.01 \% & 5.2 \% & \text { AGPEGTSQEIPK } \\ 0.01 \% & 5.2 \% & \text { YITASTFAQAR }\end{array}$

$0.01 \% \quad 5.2 \%$ SSNSLVFQTLPR

$0.01 \% \quad 8.3 \%$ FSQEVQVPEAR

$0.01 \% \quad 8.3 \%$ QYIEFVADR

$0.01 \% \quad 8.3 \%$ LLVELGFSK

$0.02 \% \quad 23.9 \%$ IFSGSSHQDLSQK

$0.02 \% \quad 23.9 \%$ VTAVIPCFPYAR

$0.02 \% \quad 23.9 \%$ NCTIVSPDAGGAK

$0.02 \% \quad 23.9 \%$ NCTIVSPDAGGAKR

$0.02 \% \quad 23.9 \%$ LNVDFALIHK

$0.02 \% \quad 23.9 \%$ MVLVGDVKDR

$0.02 \% \quad 23.9 \%$ VYAILTHGIFSGPAISR

$0.01 \% \quad 30.2 \%$ PNIVLFSGSSHQDLSQR

$0.01 \% \quad 30.2 \%$ VADRLGLELGK

$0.01 \% \quad 30.2 \%$ KFSNQETSVEIGESVR

$0.01 \% \quad 30.2 \%$ VTAVIPCFPYAR

$0.01 \% \quad 30.2 \%$ NCIIVSPDAGGAK

$0.01 \% \quad 30.2 \%$ MVLVGDVKDR

$0.01 \% \quad 30.2 \%$ VYAILTHGIFSGPAISR

$0.02 \% \quad 18.0 \%$ AVDALLTHCK

$0.02 \% \quad 18.0 \%$ TVSQIISLQTLKK

$0.02 \% \quad 18.0 \%$ LLSSFDFFLTDAR

$0.02 \% \quad 18.0 \%$ RLLPSLIGR

$0.02 \% \quad 18.0 \%$ LLPSLIGR

$0.02 \% \quad 18.0 \%$ EINDCIGGTVLNISK

$0.02 \% \quad 18.0 \%$ ATNESEDEIPQLVPIGK

$0.02 \% \quad 18.0 \%$ TPANEKVEIQK

$0.00 \% \quad 2.8 \%$ GGELLDKILR

$0.00 \% \quad 2.8 \%$ NQSPVLEPVGR

$0.01 \% \quad 8.9 \%$ VQLPPEIQLAQR

$0.01 \% \quad 8.9 \% \quad$ LAGNEQVTR

$0.01 \% \quad 8.9 \%$ TKDSLVLNNITR

$0.01 \% \quad 8.9 \%$ ALLRDQPR

$0.03 \% 13.5 \%$ APAMQPAEIQFAQR

$0.03 \% \quad 13.5 \%$ TKDHTLVQTIAR

$0.03 \% \quad 13.5 \%$ GSPTGGAQLLK

$0.03 \% \quad 13.5 \%$ GSPTGGAQLLKR

$0.03 \% \quad 13.5 \%$ AGPGSLELCGLPSQK

$9.7 \% \quad 56.4$

$99.7 \% 42.3$

$\begin{array}{lll}99.0 \% & 20.3\end{array}$

$99.7 \% \quad 54.9$

$99.0 \% \quad 20.7$

$98.7 \% \quad 17.9$

$97.3 \% \quad 28.7$

$99.7 \% \quad 41.9$

$99.7 \% \quad 58.2$

$99.7 \% \quad 53.5$

$99.3 \% \quad 20.8$

$99.2 \% \quad 19.9$

$99.7 \% \quad 58.6$

$99.7 \% \quad 43.5$

$99.7 \% 51.6$

$98.4 \% \quad 20.9$

$99.7 \% \quad 34.7$

$99.7 \% \quad 50.7$

$99.7 \% \quad 46.6$

$99.7 \% \quad 36.0$

$99.6 \% \quad 29.4$

$99.6 \% \quad 26.3$

$99.7 \% \quad 43.5$

$99.7 \% \quad 57.8$

$99.7 \% \quad 50.7$

$99.7 \% \quad 46.6$

$99.7 \% \quad 33.2$

$99.7 \% \quad 40.3$

$99.7 \% \quad 64.2$

$99.7 \% \quad 33.8$

$99.0 \% \quad 33.3$

$99.7 \% \quad 60.3$

$99.5 \% \quad 30.5$

$99.7 \% \quad 37.9$

$99.3 \% \quad 27.0$

$99.2 \% \quad 19.5$

$\begin{array}{lll}97.3 \% & 22.1\end{array}$

$99.7 \% \quad 52.3$

$99.7 \% \quad 60.6$

$\begin{array}{lll}96.9 \% & 20.5\end{array}$

$99.7 \% \quad 64.1$

$99.7 \% \quad 45.4$

$99.7 \% \quad 40.0$

$99.7 \% \quad 59.6$

$99.7 \% \quad 45.2$

$\begin{array}{lllll}0.03 \% & 13.5 \% & \text { AKSSTATHPPGPAVQLNK } & 99.3 \% & 21.5\end{array}$

$0.03 \% \quad 13.5 \%$ SSTATHPPGPAVQLNK
46.9

19.4

18.1

$\begin{array}{ll}0 & 17.9\end{array}$

20.2

$.0 \quad 38.0$

$\begin{array}{ll}25.0 & 43.5\end{array}$

$\begin{array}{lll}45.0 & 43.7\end{array}$

$\begin{array}{lll}20.8 & 2\end{array}$

$\begin{array}{lll}.0 & 52.4 & 2\end{array}$

$\begin{array}{lll}25.0 & 37.1 & 2\end{array}$

\begin{tabular}{ll}
41.4 \\
\hline
\end{tabular}

$\begin{array}{ll}5.0 & 20.9\end{array}$

$\begin{array}{ll}0 & 34.7\end{array}$

$\begin{array}{ll}.0 & 48.9\end{array}$

$\begin{array}{ll}4.0 & 46.6\end{array}$

35.3

\begin{tabular}{ll}
16.3 \\
\hline
\end{tabular}

$\begin{array}{ll}0 & 19.8\end{array}$

$\begin{array}{lll}.0 & 37.1 & 2\end{array}$

$\begin{array}{lll}25.0 & 57.3 \quad 2\end{array}$

$.0 \quad 48.9$

\begin{tabular}{l}
46.6 \\
\hline
\end{tabular}

$\begin{array}{ll}25.0 & 33.2\end{array}$

$\begin{array}{ll}5.0 & 40.3\end{array}$

$\begin{array}{lll}25.0 & 64.2 & 2\end{array}$

$.0 \quad 26.9$

\begin{tabular}{ll}
5.0 & 19.1 \\
\hline
\end{tabular}

$\begin{array}{ll}5.0 & 51.3\end{array}$

.0 30.5

\begin{tabular}{ll}
27.7 \\
\hline
\end{tabular}

$.0 \quad 18.4$

$\begin{array}{ll}5.0 & 19.5\end{array}$

$\begin{array}{ll}25.0 & 13.0\end{array}$

$\begin{array}{ll}0 & 40.5\end{array}$

$\begin{array}{ll}5.0 & 50.9\end{array}$

$\begin{array}{ll}25.0 & 15.1\end{array}$

\begin{tabular}{ll}
0 & 61.4 \\
\hline
\end{tabular}

$\begin{array}{lll}5.0 & 43.8 \quad 2\end{array}$

$\begin{array}{lll}26.0 & 26.0\end{array}$

$\begin{array}{lll} & \\ 25.0 & 48.9 & 2\end{array}$

$\begin{array}{lll}5.0 & 45.2 & 2\end{array}$

$25.0 \quad 21.5$

\begin{tabular}{ll}
40.5 \\
\hline
\end{tabular} $\begin{array}{ccc}1199.67 & 112 & 122 \\ 1086.66 & 128 & 136 \\ 810.54 & 168 & 175 \\ 1195.56 & 185 & 194 \\ 1084.64 & 251 & 260 \\ 1963.94 & 61 & 78 \\ 1213.61 & 89 & 100 \\ 1228.63 & 101 & 111 \\ 1348.72 & 126 & 137 \\ 1289.65 & 111 & 121 \\ 1140.57 & 284 & 292 \\ 1005.60 & 293 & 301 \\ 1433.70 & 6 & 18 \\ 1393.73 & 85 & 96 \\ 1289.62 & 164 & 176 \\ 1445.72 & 164 & 177 \\ 1169.67 & 185 & 194 \\ 1131.62 & 205 & 214 \\ 1802.00 & 244 & 260 \\ 1884.96 & 2 & 18 \\ 1170.68 & 19 & 29 \\ 1809.90 & 34 & 49 \\ 1393.73 & 85 & 96 \\ 1301.65 & 164 & 176 \\ 1131.62 & 205 & 214 \\ 1802.00 & 244 & 260 \\ 1127.59 & 39 & 48 \\ 1458.89 & 125 & 137 \\ 1531.78 & 148 & 160 \\ 1024.66 & 163 & 171 \\ 868.56 & 164 & 171 \\ 1632.83 & 193 & 207 \\ 1839.93 & 357 & 373 \\ 1256.68 & 375 & 385 \\ 1113.66 & 498 & 507 \\ 1195.64 & 713 & 723 \\ 1391.80 & 5 & 16 \\ 987.52 & 17 & 25 \\ 1373.77 & 204 & 215 \\ 968.56 & 416 & 423 \\ 1573.78 & 2 & 15 \\ 1382.78 & 203 & 214 \\ 1028.57 & 512 & 522 \\ 1184.67 & 512 & 523 \\ 1513.77 & 575 & 589 \\ 1803.97 & 659 & 676 \\ 1604.84 & 661 & 676\end{array}$

Page 130 of Table S-1-6 
Ribosomal RNA processing protein 1 homolog B GN=RRP1B RRP1B_HUMAN $84.43 \quad 100.0 \%$ Ribosomal RNA processing protein 1 homolog B GN=RRP1B RRP1B_HUMAN $84.43 \quad 100.0 \%$ Ribosomal RNA processing protein 1 homolog B GN=RRP1B RRP1B_HUMAN $84.43 \quad 100.0 \%$ Ribosome biogenesis protein BMS1 homolog GN=BMS1 BMS1_HUMAN $145.81 \quad 100.0 \%$ Ribosome biogenesis protein BMS1 homolog GN=BMS1 BMS1_HUMAN $145.81 \quad 100.0 \%$ Ribosome biogenesis protein BMS1 homolog GN=BMS1 BMS1_HUMAN $145.81 \quad 100.0 \%$ Ribosome biogenesis protein BMS1 homolog GN=BMS1 BMS1_HUMAN $145.81 \quad 100.0 \%$ Ribosome biogenesis protein BRX1 homolog GN=BRIX1 BRX1_HUMAN $41.40 \quad 100.0 \%$ Ribosome biogenesis protein BRX1 homolog GN=BRIX1 BRX1_HUMAN $41.40 \quad 100.0 \%$ Ribosome biogenesis protein BRX1 homolog GN=BRIX1 BRX1_HUMAN $41.40 \quad 100.0 \%$ Ribosome biogenesis protein BRX1 homolog GN=BRIX1 BRX1_HUMAN $41.40 \quad 100.0 \%$ Ribosome biogenesis protein NSA2 homolog GN=NSA2 NSA2_HUMAN $30.07 \quad 100.0 \%$ Ribosome biogenesis protein NSA2 homolog GN=NSA2 NSA2_HUMAN $30.07 \quad 100.0 \%$ Ribosome maturation protein SBDS GN=SBDS SBDS_HUMAN $28.76 \quad 100.0 \%$ Ribosome maturation protein SBDS GN=SBDS SBDS_HUMAN $28.76 \quad 100.0 \%$ Ribosome production factor 2 homolog GN=RPF2 RPF2_HUMAN $35.59 \quad 100.0 \%$ Ribosome production factor 2 homolog GN=RPF2 RPF2 HUMAN $35.59 \quad 100.0 \%$ Ribosome production factor 2 homolog GN=RPF2 RPF2_HUMAN $35.59 \quad 100.0 \%$ Ribosome production factor 2 homolog GN=RPF2 RPF2_HUMAN $35.59 \quad 100.0 \%$ Ribosome production factor 2 homolog GN=RPF2 RPF2_HUMAN $35.59 \quad 100.0 \%$ Ribosome production factor 2 homolog GN=RPF2 RPF2_HUMAN $35.59 \quad 100.0 \%$ Ribosome production factor 2 homolog GN=RPF2 RPF2 HUMAN $35.59 \quad 100.0 \%$ Ribosome-binding protein $1 \mathrm{GN}=\mathrm{RRBP} 1$ RRBP1_HUMAN $152.47 \quad 100.0 \%$ Ribosome-binding protein $1 \mathrm{GN}=\mathrm{RRBP} 1$ RRBP1_HUMAN $152.47 \quad 100.0 \%$ Ribosome-binding protein $1 \mathrm{GN}=\mathrm{RRBP} 1$ RRBP1_HUMAN $152.47 \quad 100.0 \%$ Ribosome-binding protein 1 GN=RRBP1 RRBP1_HUMAN $152.47 \quad 100.0 \%$ Ribosome-binding protein $1 \mathrm{GN}=\mathrm{RRBP} 1 \quad$ RRBP1_HUMAN $152.47 \quad 100.0 \%$ RING finger protein $219 \mathrm{GN}=\mathrm{RNF} 219 \quad$ RN219_HUMAN $81.12 \quad 100.0 \%$ RING finger protein $219 \mathrm{GN}=\mathrm{RNF} 219 \quad$ RN219_HUMAN $81.12 \quad 100.0 \%$ RISC-loading complex subunit TARBP2 GN=TARBP2 TRBP2 HUMAN $39.04 \quad 100.0 \%$ RISC-loading complex subunit TARBP2 GN=TARBP2 TRBP2_HUMAN $39.04 \quad 100.0 \%$ RISC-loading complex subunit TARBP2 GN=TARBP2 TRBP2_HUMAN $39.04 \quad 100.0 \%$ RNA 3'-terminal phosphate cyclase GN=RTCA RTCA_HUMAN $39.34 \quad 100.0 \%$ RNA 3'-terminal phosphate cyclase GN=RTCA RTCA_HUMAN $39.34 \quad 100.0 \%$ RNA 3'-terminal phosphate cyclase GN=RTCA RTCA_HUMAN $39.34 \quad 100.0 \%$ RNA 3'-terminal phosphate cyclase GN=RTCA RTCA_HUMAN $39.34 \quad 100.0 \%$ RNA 3'-terminal phosphate cyclase GN=RTCA RTCA_HUMAN $39.34 \quad 100.0 \%$ RNA 3'-terminal phosphate cyclase GN=RTCA RTCA HUMAN $39.34 \quad 100.0 \%$ RNA 3'-terminal phosphate cyclase GN=RTCA RTCA_HUMAN $39.34 \quad 100.0 \%$ RNA 3'-terminal phosphate cyclase GN=RTCA RTCA_HUMAN $39.34 \quad 100.0 \%$ RNA 3'-terminal phosphate cyclase-like protein GN=RCL1 RCL1_HUMAN $40.84 \quad 100.0 \%$ RNA 3'-terminal phosphate cyclase-like protein GN=RCL1 RCL1_HUMAN $40.84 \quad 100.0 \%$ RNA 3'-terminal phosphate cyclase-like protein GN=RCL1 RCL1_HUMAN $40.84 \quad 100.0 \%$ RNA 3'-terminal phosphate cyclase-like protein GN=RCL1 RCL1_HUMAN $40.84 \quad 100.0 \%$ RNA binding motif protein, X-linked-like-1 GN=RBMXL1 RMXL1_HUMAN $42.14 \quad 100.0 \%$ RNA binding motif protein, X-linked-like-1 GN=RBMXL1 RMXL1_HUMAN $42.14 \quad 100.0 \%$ RNA binding motif protein, X-linked-like-1 GN=RBMXL1 RMXL1_HUMAN $42.14 \quad 100.0 \%$ $\begin{array}{lll}0.03 \% & 13.5 \% & \text { SSTATHPPGPAVQL } \\ 0.03 \% & 13.5 \% & \text { SILVSPTGPSR }\end{array}$

$0.03 \% \quad 13.5 \%$ TPTSSPASSPLVAK

$0.01 \% \quad 3.0 \%$ AFAVQSAVR

$0.01 \% \quad 3.0 \% \quad$ STLIQCLIR

$0.01 \% \quad 3.0 \% \quad$ KAAEAFLR

$0.01 \% \quad 3.0 \%$ IAATGVVLDLDK

$0.01 \% \quad 16.4 \%$ LFVINEVCEMK

$0.01 \% \quad 16.4 \%$ FLVQNIHTLAELK

$0.01 \% \quad 16.4 \%$ SQPFVDHVFTFTILDNR

$0.01 \% \quad 16.4 \%$ NFQIIEEDAALVEIGPR

$0.00 \% \quad 8.9 \% \quad$ TPQGAVPAYLLDR

$0.00 \% \quad 8.9 \%$ VCFVGDGFTR

$0.00 \% \quad 7.2 \%$ LTNVAVVR

$0.00 \% \quad 7.2 \%$ GEVQVSDKER

$0.02 \% \quad 25.8 \%$ KPYGVLYK

$0.02 \% \quad 25.8 \%$ NITRPFEDQTSLEFFSK

$0.02 \% \quad 25.8 \%$ SLLIDFFR

$0.02 \% \quad 25.8 \%$ GPTVSNIR

$0.02 \% \quad 25.8 \%$ IELEEMGPSLDLVLR

$0.02 \% \quad 25.8 \%$ THLASDDLYK

$0.02 \% \quad 25.8 \%$ NISHDTFGTTYGR

$0.02 \% \quad 4.1 \%$ AAILETAPK

$0.02 \% \quad 4.1 \%$ NTDVAQSPEAPKQEAPAK

$0.02 \% \quad 4.1 \%$ EQEITAVQAR

$0.02 \% \quad 4.1 \%$ LQSSEAEVR

$0.02 \% \quad 4.1 \%$ SIEALLEAGQAR

$0.00 \% \quad 3.0 \%$ FAVAALQSK

$0.00 \% \quad 3.0 \%$ KIQSSLSSASPSK

$0.00 \% \quad 11.7 \%$ TPISLLQEYGTR

$0.00 \% \quad 11.7 \%$ VTVGDTSCTGQGPSK

$0.00 \% \quad 11.7 \%$ SCSLGSLGALGPACCR

$0.02 \% \quad 23.0 \%$ VEVDGSIMEGGGQILR

$0.02 \% \quad 23.0 \%$ VSTALSCLLGLPLR

$0.02 \% \quad 23.0 \%$ FGFIFNCDIK

$0.02 \% \quad 23.0 \%$ QLNPINLTER

$0.02 \% \quad 23.0 \%$ AFVAGVLPFK

$0.02 \% \quad 23.0 \%$ DMAAAAVR

$0.02 \% \quad 23.0 \%$ EIRDLYVNIQPVQEPK

$0.02 \% \quad 23.0 \%$ DLYVNIQPVQEPK

$0.01 \% \quad 11.5 \%$ LVLSTLSGRPVK

$0.01 \% \quad 11.5 \%$ DFEASFIR

$0.01 \% \quad 11.5 \%$ GVTNDQVDPSVDVLK

$0.01 \% \quad 11.5 \%$ LLLEEIYR

$10 \quad 0.01 \% \quad 56.4 \%$ LFIGGLNTETNEK

$10 \quad 0.01 \% \quad 56.4 \%$ ALETVFGK

$10 \quad 0.01 \% \quad 56.4 \%$ GFAFVTFESPADAK $\begin{array}{lll}95.7 \% & 20.7\end{array}$ $99.7 \% \quad 31.8$

$99.7 \% \quad 56.8$

$99.7 \% \quad 57.7$

$99.7 \% \quad 37.2$

$97.6 \% \quad 27.1$

$99.7 \% 36.2$

$99.7 \% 44$.

$99.7 \% 71$.

$99.4 \% \quad 22.2$

$99.7 \% \quad 70.7$

$99.7 \% \quad 28.2$

$99.7 \% \quad 30.0$

$99.0 \% \quad 37.8$

$99.7 \% \quad 39.8$

$99.0 \% \quad 28.2$

$99.7 \% \quad 32.5$

$98.9 \% 23.0$

$99.0 \% 33.1$

$99.7 \% \quad 54.5$

$99.7 \% \quad 44.0$

$\begin{array}{lll}99.7 \% & 53.7\end{array}$

$99.7 \% \quad 47.0$

$99.7 \% 33.6$

$99.7 \% \quad 59.5$

$99.6 \% \quad 25.0$

$\begin{array}{lll}99.7 \% & 37.7\end{array}$

$97.6 \% \quad 22.3$

$99.5 \% \quad 26.6$

$99.7 \% \quad 68.3$

$99.7 \% \quad 40.9$

$98.9 \% \quad 18.5$

$99.7 \% \quad 66.8$

$99.7 \% \quad 44.0$

$99.7 \% \quad 61.5$

$99.7 \% \quad 49.0$

$99.7 \% \quad 39.6$

$99.0 \% \quad 44.1$

$99.5 \% \quad 25.7$

$99.7 \% \quad 54.2$

$99.7 \% \quad 41.9$

$99.0 \% \quad 35.1$

$99.7 \% \quad 40.3$

$99.0 \% \quad 49.9$

$99.7 \% \quad 61.3$

$97.7 \% \quad 19.4$

$99.7 \% \quad 63.9$
2192.13

1113.63

1342.72

948.53

1103.62

905.52

1214.70

1381.69

1525.87

2036.02

1914.00

1400.75

1157.54

871.54

1146.58

967.56

2059.01

1010.57

843.47

1729.90

1162.57

1468.68

913.54

1880.94

1144.60

1018.52

1257.68

934.54

1319.72

1377.74

1493.69

1665.75

1659.84

1499.86

1260.61

1197.66

1048.62

804.40

1941.04

1542.82

1269.79

984.48

1585.81

1048.60

1435.74

864.48

1486.72
682
712
741
52
104
681
1019
110
153
214
235
93
162
19
100
64
83
168
176
226
237
265
175
626
761
930
970
225
722
41
80
296
21
35
156
186
205
216
236
236
31
53
133
289
22
30
63

Page 131 of Table S-1-6 
RNA binding motif protein, X-linked-like-1 GN=RBMXL1 RMXL1_HUMAN $42.14 \quad 100.0 \%$ RNA binding motif protein, X-linked-like-1 GN=RBMXL1 RMXL1_HUMAN $42.14 \quad 100.0 \%$ RNA binding motif protein, X-linked-like-1 GN=RBMXL1 RMXL1_HUMAN $42.14 \quad 100.0 \%$ RNA binding motif protein, X-linked-like-1 GN=RBMXL1 RMXL1_HUMAN $42.14 \quad 100.0 \%$ RNA binding motif protein, X-linked-like-1 GN=RBMXL1 RMXL1_HUMAN $42.14 \quad 100.0 \%$ RNA binding motif protein, X-linked-like-1 GN=RBMXL1 RMXL1_HUMAN $42.14 \quad 100.0 \%$ RNA binding motif protein, X-linked-like-1 GN=RBMXL1 RMXL1_HUMAN $42.14 \quad 100.0 \%$ RNA binding motif protein, X-linked-like-1 GN=RBMXL1 RMXL1_HUMAN $42.14 \quad 100.0 \%$ RNA binding motif protein, X-linked-like-1 GN=RBMXL1 RMXL1_HUMAN $42.14 \quad 100.0 \%$ RNA binding motif protein, X-linked-like-1 GN=RBMXL1 RMXL1_HUMAN $42.14 \quad 100.0 \%$ RNA binding motif protein, X-linked-like-1 GN=RBMXL1 RMXL1_HUMAN $42.14 \quad 100.0 \%$ RNA binding motif protein, X-linked-like-1 GN=RBMXL1 RMXL1_HUMAN $42.14 \quad 100.0 \%$ RNA binding motif protein, X-linked-like-1 GN=RBMXL1 RMXL1_HUMAN $42.14 \quad 100.0 \%$ RNA binding motif protein, X-linked-like-1 GN=RBMXL1 RMXL1_HUMAN $42.14 \quad 100.0 \%$ RNA binding motif protein, X-linked-like-1 GN=RBMXL1 RMXL1_HUMAN $42.14 \quad 100.0 \%$ RNA binding motif protein, X-linked-like-1 GN=RBMXL1 RMXL1_HUMAN $42.14 \quad 100.0 \%$ RNA binding motif protein, X-linked-like-1 GN=RBMXL1 RMXL1 HUMAN $42.14 \quad 100.0 \%$ RNA binding motif protein, X-linked-like-1 GN=RBMXL1 RMXL1_HUMAN $42.14 \quad 100.0 \%$ RNA binding motif protein, X-linked-like-1 GN=RBMXL1 RMXL1_HUMAN $42.14 \quad 100.0 \%$ RNA binding motif protein, X-linked-like-1 GN=RBMXL1 RMXL1_HUMAN $42.14 \quad 100.0 \%$ RNA binding motif protein, X-linked-like-1 GN=RBMXL1 RMXL1_HUMAN $42.14 \quad 100.0 \%$ RNA binding motif protein, X-linked-like-1 GN=RBMXL1 RMXL1_HUMAN $42.14 \quad 100.0 \%$ RNA binding protein fox-1 homolog 2 GN=RBFOX2 RFOX2_HUMAN $41.37 \quad 100.0 \%$ RNA binding protein fox-1 homolog 2 GN=RBFOX2 RFOX2_HUMAN $41.37 \quad 100.0 \%$ RNA/RNP complex-1-interacting phosphatase GN=DUSP11 DUS11 HUMAN $38.94 \quad 100.0 \%$ RNA/RNP complex-1-interacting phosphatase GN=DUSP11 DUS11_HUMAN $38.94 \quad 100.0 \%$ RNA/RNP complex-1-interacting phosphatase GN=DUSP11 DUS11_HUMAN $38.94 \quad 100.0 \%$ RNA/RNP complex-1-interacting phosphatase GN=DUSP11 DUS11_HUMAN $38.94 \quad 100.0 \%$ RNA-binding motif protein, $X$ chromosome GN=RBMX RBMX_HUMAN $42.33 \quad 100.0 \%$ RNA-binding motif protein, $X$ chromosome GN=RBMX RBMX HUMAN $42.33 \quad 100.0 \%$ RNA-binding motif protein, $X$ chromosome GN=RBMX RBMX_HUMAN $42.33 \quad 100.0 \%$ RNA-binding motif protein, $X$ chromosome GN=RBMX RBMX_HUMAN $42.33 \quad 100.0 \%$ RNA-binding motif protein, $X$ chromosome GN=RBMX RBMX HUMAN $42.33 \quad 100.0 \%$ RNA-binding motif protein, $X$ chromosome GN=RBMX RBMX_HUMAN $42.33 \quad 100.0 \%$ RNA-binding motif protein, $X$ chromosome GN=RBMX RBMX HUMAN $42.33 \quad 100.0 \%$ RNA-binding motif protein, $X$ chromosome GN=RBMX RBMX_HUMAN $42.33 \quad 100.0 \%$ RNA-binding motif protein, $X$ chromosome GN=RBMX RBMX_HUMAN $42.33 \quad 100.0 \%$ RNA-binding motif protein, $X$ chromosome GN=RBMX RBMX HUMAN $42.33 \quad 100.0 \%$ RNA-binding motif protein, $X$ chromosome GN=RBMX RBMX_HUMAN $42.33 \quad 100.0 \%$ RNA-binding motif protein, $X$ chromosome GN=RBMX RBMX_HUMAN $42.33 \quad 100.0 \%$ RNA-binding motif protein, $X$ chromosome GN=RBMX RBMX_HUMAN $42.33 \quad 100.0 \%$ RNA-binding motif protein, $X$ chromosome GN=RBMX RBMX_HUMAN $42.33 \quad 100.0 \%$ RNA-binding motif protein, $X$ chromosome GN=RBMX RBMX HUMAN $42.33 \quad 100.0 \%$ RNA-binding motif protein, $X$ chromosome GN=RBMX RBMX_HUMAN $42.33 \quad 100.0 \%$ RNA-binding motif protein, $X$ chromosome GN=RBMX RBMX_HUMAN $42.33 \quad 100.0 \%$ RNA-binding motif protein, $X$ chromosome GN=RBMX RBMX HUMAN $42.33 \quad 100.0 \%$ RNA-binding motif protein, $X$ chromosome GN=RBMX RBMX_HUMAN $42.33 \quad 100.0 \%$
$99.7 \% \quad 56.7$

$99.7 \% \quad 60.7$

$99.0 \% \quad 26.7$

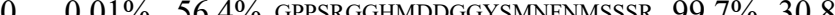

$10 \quad 0.01 \% \quad 56.4 \%$ GGHMDDGGYSMNFNMSSSR $99.7 \% \quad 52.9$

$10 \quad 0.01 \% \quad 56.4 \%$ RSAPSGLVR

$10 \quad 0.01 \% \quad 56.4 \%$ GRDSYGGPPR

$10 \quad 0.01 \% \quad 56.4 \%$ DSYGGPPR

$10 \quad 0.01 \% \quad 56.4 \%$ RDVYLSPR

$10 \quad 0.01 \% \quad 56.4 \%$ DVYLSPRDDGYSTK

$10 \quad 0.01 \% \quad 56.4 \%$ DDGYSTKDSYSSR

$10 \quad 0.01 \% \quad 56.4 \%$ DSYSSRDYPSSR

$10 \quad 0.01 \% \quad 56.4 \%$ DYAPPPRDYTYR

$10 \quad 0.01 \% \quad 56.4 \%$ DYGHSSSRDDYPSR

$10 \quad 0.01 \% \quad 56.4 \%$ DRDYSDHPSGGSYR

$10 \quad 0.01 \% \quad 56.4 \%$ DYSDHPSGGSYR

$10 \quad 0.01 \% \quad 56.4 \%$ DSYESYGNSR

$10 \quad 0.01 \% \quad 56.4 \%$ GPPPSYGGSSR $\begin{array}{ll}99.6 \% & 30.3 \\ 99.3 \% & 46.6\end{array}$

$\begin{array}{ll}99.3 \% & 46.6 \\ 99.0 \% & 49.7\end{array}$

$99.0 \% 49.7$

$99.7 \% \quad 41.7$

$99.7 \% \quad 44.2$

$99.7 \% \quad 31.3$

$99.7 \% \quad 38.2$

$99.7 \% \quad 30.0$

$99.7 \% \quad 38.0$

$99.2 \% \quad 22.5$

$99.7 \% \quad 52.5$

$99.7 \% \quad 55.4$

$0 \quad 0.01 \% \quad 56.4 \%$ GPPPSYGGSSRYDDYSSSR

$10 \quad 0.01 \% \quad 56.4 \%$ YDDYSSSRDGYGGSR

$10 \quad 0.01 \% \quad 56.4 \%$ DGYGGSRDSYSSSR

$10 \quad 0.01 \% \quad 56.4 \%$ SDLYSSCDR

$0.00 \% \quad 5.1 \% \quad$ RLHVSNIPFR

$0.00 \% \quad 5.1 \%$ KIEVNNATAR

$0.01 \% \quad 18.2 \%$ LAPEECFSPLDLFNK

$0.01 \% \quad 18.2 \%$ YYKPEDLPETVPYLK

$0.01 \% \quad 18.2 \%$ IFTVGHQVPDDETIFK

$0.01 \% \quad 18.2 \%$ HFHTQTQSLQQSVR

$217 \quad 0.25 \% \quad 65.0 \%$ LFIGGLNTETNEK

$217 \quad 0.25 \% \quad 65.0 \%$ LFIGGLNTETNEKALEAVFGK

$217 \quad 0.25 \% \quad 65.0 \%$ ALEAVFGK

$217 \quad 0.25 \% \quad 65.0 \%$ ALEAVFGKYGR

$217 \quad 0.25 \% \quad 65.0 \%$ IVEVLLMK

$217 \quad 0.25 \% \quad 65.0 \%$ IVEVLLMKDR

$217 \quad 0.25 \% \quad 65.0 \%$ GFAFVTFESPADAK

$217 \quad 0.25 \% \quad 65.0 \%$ GFAFVTFESPADAKDAAR

$217 \quad 0.25 \% \quad 65.0 \%$ AIKVEQATKPSFESGR

$217 \quad 0.25 \% \quad 65.0 \%$ VEQATKPSFESGR

$217 \quad 0.25 \% \quad 65.0 \%$ RGPPPPPR

$99.7 \% \quad 29.6$

$99.7 \% \quad 33.7$

$99.7 \% \quad 45.9$

$99.7 \% \quad 42.0$

$99.4 \% \quad 20.9$

$99.3 \% \quad 22.1$

$99.7 \% \quad 33.1$

$96.0 \% \quad 15.4$

$98.5 \% 18.0$

$99.7 \% \quad 37.0$

$99.7 \% \quad 61.3$

$99.7 \% 54.6$

$99.0 \% \quad 43.1$

$\begin{array}{lll}99.7 \% & 50.0\end{array}$

$99.0 \% \quad 45.5$

$\begin{array}{lll}99.7 \% & 35.8\end{array}$

$99.7 \% \quad 63.9$

$99.7 \% \quad 56.7$

$99.7 \% \quad 52.7$

$99.7 \% \quad 57.5$

$99.0 \% 57.8$

$217 \quad 0.25 \% \quad 65.0 \%$ GPPSRGGHMDDGGYSMNFNMSSSR $\quad 99.7 \% \quad 30.8$

$217 \quad 0.25 \% \quad 65.0 \%$ GGHMDDGGYSMNFNMSSSR $99.7 \% \quad 52.9$

$99.3 \% \quad 46.6$

$99.0 \% \quad 49.7$

$98.9 \% \quad 24.4$

$99.7 \% \quad 41.7$

$99.7 \% \quad 44.2$

$99.7 \% \quad 31.3$
1899.92

1291.66

854.46

2592.03

2097.77

942.55

1061.51

848.39

1005.55

1615.76

1480.62

1419.61

1513.71

1641.69

1611.68

1340.55

1177.48

1061.50

2034.88

1684.68

1493.63

1102.45

1238.71

1115.62

1779.86

1854.95

1845.94

1696.85

1435.74

2251.20

834.47

1210.66

944.59

1231.71

1486.72

1899.92

1747.93

1435.72

873.51

2592.03

2097.77

1061.51

848.39

1005.55

1615.76

1480.62

1419.61

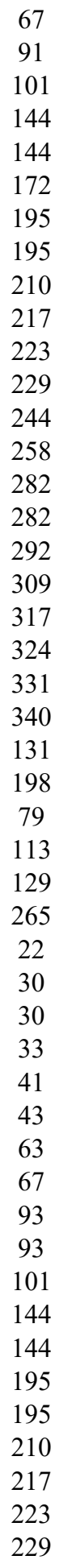


RNA-binding motif protein, X chromosome GN=RBMX RBMX_HUMAN $42.33 \quad 100.0 \% \quad 33$ $\begin{array}{lllll}\text { RNA-binding motif protein, } X \text { chromosome GN=RBMX } & \text { RBMX_HUMAN } & 42.33 & 100.0 \% & 33 \\ \text { RNA-binding motif protein, X chromosome GN=RBMX RBMX_HUMAN } & 42.33 & 100.0 \% & 33\end{array}$ RNA-binding motif protein, $X$ chromosome GN=RBMX RBMX_HUMAN $42.33 \quad 100.0 \% \quad 33$ RNA-binding motif protein, $X$ chromosome GN=RBMX RBMX HUMAN $42.33 \quad 100.0 \%$ RNA-binding motif protein, $X$ chromosome GN=RBMX RBMX_HUMAN $42.33 \quad 100.0 \%$ RNA-binding motif protein, $X$ chromosome GN=RBMX RBMX_HUMAN $42.33 \quad 100.0 \% \quad 33$ RNA-binding motif protein, $X$ chromosome GN=RBMX RBMX_HUMAN $42.33 \quad 100.0 \% 33$ RNA-binding motif protein, $X$ chromosome GN=RBMX RBMX_HUMAN $42.33 \quad 100.0 \% \quad 33$ RNA-binding motif protein, $X$ chromosome GN=RBMX RBMX HUMAN $42.33 \quad 100.0 \% 33$ RNA-binding motif protein, $X$ chromosome GN=RBMX RBMX_HUMAN $42.33 \quad 100.0 \%$ RNA-binding motif protein, $X$ chromosome GN=RBMX RBMX_HUMAN $42.33 \quad 100.0 \% \quad 33$ RNA-binding motif protein, $X$ chromosome GN=RBMX RBMX HUMAN $42.33 \quad 100.0 \%$ RNA-binding motif protein, $X$ chromosome GN=RBMX RBMX_HUMAN $42.33 \quad 100.0 \% \quad 33$ RNA-binding motif protein, $X$ chromosome GN=RBMX RBMX_HUMAN $42.33 \quad 100.0 \% \quad 33$ RNA-binding protein $10 \mathrm{GN}=\mathrm{RBM} 10$ RNA-binding protein $10 \mathrm{GN}=\mathrm{RBM} 10$ RNA-binding protein $10 \mathrm{GN}=\mathrm{RBM} 10$ RNA-binding protein $10 \mathrm{GN}=\mathrm{RBM} 10$ RNA-binding protein $10 \mathrm{GN}=\mathrm{RBM} 10$ RNA-binding protein $10 \mathrm{GN}=\mathrm{RBM} 10$ RNA-binding protein $10 \mathrm{GN}=\mathrm{RBM} 10$ RNA-binding protein $10 \mathrm{GN}=\mathrm{RBM} 10$ RNA-binding protein $10 \mathrm{GN}=\mathrm{RBM} 10$ RNA-binding protein $12 \mathrm{~B}$ GN=RBM12B RNA-binding protein $12 \mathrm{~B} \mathrm{GN=RBM12 \textrm {B }}$ RNA-binding protein $14 \mathrm{GN}=\mathrm{RBM} 14$ RNA-binding protein $14 \mathrm{GN}=\mathrm{RBM} 14$ RNA-binding protein $14 \mathrm{GN}=\mathrm{RBM} 14$
RNA-binding protein $14 \mathrm{GN}=\mathrm{RBM} 14$ RNA-binding protein $14 \mathrm{GN}=\mathrm{RBM} 14$ RNA-binding protein $14 \mathrm{GN}=\mathrm{RBM} 14$ RNA-binding protein $14 \mathrm{GN}=\mathrm{RBM} 14$ RNA-binding protein $14 \mathrm{GN}=\mathrm{RBM} 14$ RNA-binding protein $14 \mathrm{GN}=\mathrm{RBM} 14$ RNA-binding protein $14 \mathrm{GN}=\mathrm{RBM} 14$ RNA-binding protein $14 \mathrm{GN}=\mathrm{RBM} 14$ RNA-binding protein $14 \mathrm{GN}=\mathrm{RBM} 14$ RNA-binding protein $14 \mathrm{GN}=\mathrm{RBM} 14$ RNA-binding protein $14 \mathrm{GN}=\mathrm{RBM} 14$ RNA-binding protein $25 \mathrm{GN}=\mathrm{RBM} 25$ RNA-binding protein $25 \mathrm{GN}=\mathrm{RBM} 25$ RNA-binding protein $39 \mathrm{GN}=\mathrm{RBM} 39$ RNA-binding protein $39 \mathrm{GN}=\mathrm{RBM} 39$ RNA-binding protein $39 \mathrm{GN}=\mathrm{RBM} 39$ RNA-binding protein $39 \mathrm{GN}=\mathrm{RBM} 39$ RNA-binding protein $39 \mathrm{GN}=\mathrm{RBM} 39$ RNA-binding protein $39 \mathrm{GN}=\mathrm{RBM} 39$ RBM10 HUMAN $103.53 \quad 100.0 \%$ RBM10_HUMAN $103.53 \quad 100.0 \%$ RBM10 HUMAN $103.53 \quad 100.0 \% \quad 9$ RBM10 HUMAN $103.53 \quad 100.0 \%$ RBM10_HUMAN $103.53 \quad 100.0 \%$ RBM10 HUMAN $103.53 \quad 100.0 \%$ RBM10_HUMAN $103.53 \quad 100.0 \%$ RBM10 HUMAN $103.53 \quad 100.0 \%$ RBM10 HUMAN $103.53 \quad 100.0 \%$ RB12B_HUMAN $118.11 \quad 100.0 \%$ BB12B HUMAN $118.11-100.0 \%$ RBM14_HUMAN $69.49 \quad 100.0 \%$ RBM14_HUMAN $69.49 \quad 100.0 \%$ RBM14 HUMAN $69.49 \quad 100.0 \%$ RBM14_HUMAN $69.49 \quad 100.0 \%$ RBM14_HUMAN $69.49 \quad 100.0 \%$ RBM14 HUMAN $69.49 \quad 100.0 \%$ RBM14_HUMAN $69.49 \quad 100.0 \%$ RBM14 HUMAN $69.49 \quad 100.0 \%$ RBM14_HUMAN $\quad 69.49 \quad 100.0 \% \quad 14$ RBM14_HUMAN $69.49 \quad 100.0 \% \quad 14$ RBM14 HUMAN $69.49 \quad 100.0 \% \quad 14$ RBM14_HUMAN $69.49 \quad 100.0 \% \quad 14$ RBM14 HUMAN $69.49 \quad 100.0 \% \quad 14$ RBM14_HUMAN $69.49 \quad 100.0 \% \quad 14$ RBM25_HUMAN $100.19 \quad 100.0 \%$ RBM25 HUMAN $100.19 \quad 100.0 \%$ RBM39_HUMAN $59.38 \quad 100.0 \%$ RBM39 HUMAN $59.38 \quad 100.0 \%$ RBM39 HUMAN $59.38 \quad 100.0 \%$ RBM39_HUMAN $59.38 \quad 100.0 \%$ RBM39 HUMAN $59.38 \quad 100.0 \%$ RBM39_HUMAN $59.38 \quad 100.0 \%$
$46 \quad 217 \quad 0.25 \% \quad 65.0 \%$ DYAPPPRDYTYR $46 \quad 217 \quad 0.25 \% \quad 65.0 \%$ DYGHSSSRDDYPSR

$46 \quad 217 \quad 0.25 \% \quad 65.0 \%$ GYSDRDGYGR

$46 \quad 217 \quad 0.25 \% \quad 65.0 \%$ DRDYSDHPSGGSYR

$46 \quad 217 \quad 0.25 \% \quad 65.0 \%$ DYSDHPSGGSYR

$46 \quad 217 \quad 0.25 \% \quad 65.0 \%$ DSYESYGNSR

$46 \quad 217 \quad 0.25 \% \quad 65.0 \%$ SAPPTRGPPPSYGGSSR

$46 \quad 217 \quad 0.25 \% \quad 65.0 \%$ GPPPSYGGSSR

$46 \quad 217 \quad 0.25 \% \quad 65.0 \%$ GPPPSYGGSSRYDDYSSSR

$46 \quad 217 \quad 0.25 \% \quad 65.0 \%$ YDDYSSSRDGYGGSR

$46 \quad 217 \quad 0.25 \% \quad 65.0 \%$ DGYGGSRDSYSSSR

$46 \quad 217 \quad 0.25 \% \quad 65.0 \%$ DSYSSSRSDLYSSGR

$46 \quad 217 \quad 0.25 \% \quad 65.0 \%$ SDLYSSGRDR

$46 \quad 217 \quad 0.25 \% \quad 65.0 \%$ GLPPSMER

$10 \quad 26 \quad 0.03 \% \quad 12.7 \%$ GFAFVEFSHLQDATR

$0.03 \% \quad 12.7 \%$ DGLGSDNIGSR

$0.03 \% \quad 12.7 \%$ QGIVTPIEAQTR

$0.03 \% \quad 12.7 \%$ TMVTRFNEAQ

$0.00 \% \quad 1.8 \%$ AENPYLFLR

$0.00 \% \quad 1.8 \%$ FLGTEVLLR

$0.05 \% \quad 25.1 \%$ IFVGNVSAACTSQELR

$0.05 \% \quad 25.1 \%$ AAIAQLNGKEVK

$0.05 \% \quad 25.1 \%$ INVELSTK

$0.05 \% \quad 25.1 \%$ INVELSTKGQK

$0.05 \% \quad 25.1 \%$ KGPGLAVQSGDK

$0.05 \% \quad 25.1 \%$ ASYVAPLTAQPATYR

$0.05 \% \quad 25.1 \%$ AQPSVSLGAAYR

$0.05 \% \quad 25.1 \%$ AQPSASLGVGYR

$0.05 \% \quad 25.1 \%$ TQPMTAQAASYR

$0.05 \% \quad 25.1 \%$ AQPSVSLGAPYR

$0.05 \% \quad 25.1 \%$ LAELSDYRR

$0.05 \% \quad 25.1 \%$ RLPDAHSDYAR

$0.05 \% \quad 25.1 \%$ YSGSYNDYLR

$0.00 \% \quad 1.8 \%$ LGASNSPGQPNSVK

$0.00 \% \quad 1.8 \%$ LGASNSPGQPNSVKR

$0.01 \% \quad 10.8 \%$ YRSPYSGPK

$1 \quad 0.01 \% \quad 10.8 \%$ TVFCMQLAAR

$11 \quad 0.01 \% \quad 10.8 \%$ DLEEFFSTVGK

$\begin{array}{lll}11 & 0.01 \% \quad 10.8 \% \text { VLGVPIIVQASQAEK }\end{array}$ $\begin{array}{llllll}\% & 38.2 & 25.0 & 32.8 & 2 & 0\end{array}$

$\begin{array}{llll}99.7 \% & 30.0 & 25.0 & 30.0\end{array}$

$\begin{array}{lllll}99.6 \% & 27.7 & 25.0 & 26.1 & 4\end{array}$

$\begin{array}{lllll}99.7 \% & 38.0 & 25.0 & 38.0 & 2\end{array}$

$\begin{array}{llll}99.2 \% & 22.5 & 25.0 & 22.4\end{array}$

$\begin{array}{llll}99.7 \% & 52.5 & 25.0 & 52.5\end{array}$

$\begin{array}{llll}99.7 \% & 34.6 & 25.0 & 30.7\end{array}$

$99.7 \% \quad 55.4 \quad 25.0 \quad 53.8$

$\begin{array}{llll}99.7 \% & 29.6 & 25.0 & 29.6 \\ 99.7 \% & 33.7 & 25.0 & 32.8\end{array}$

$\begin{array}{llll}99.7 \% & 45.9 & 25.0 & 45.9\end{array}$

$99.7 \% \quad 49.6 \quad 25.0 \quad 49.6$

$\begin{array}{llll}99.4 \% & 24.6 & 25.0 & 17.2\end{array}$

$99.0 \% \quad 32.2 \quad 25.0 \quad 27.1$

$99.7 \% \quad 44.2 \quad 25.0 \quad 44.2$

$99.7 \% \quad 49.9 \quad 25.0 \quad 34.4$

$\begin{array}{llll}99.7 \% & 50.9 & 25.0 & 44.7\end{array}$

$\begin{array}{llll}99.7 \% & 64.7 & 25.0 & 59.3\end{array}$

$98.9 \% \quad 18.9 \quad 25.0 \quad 18.9$

$\begin{array}{llll}99.7 \% & 45.7 & 25.0 & 39.7\end{array}$

$\begin{array}{llll}99.7 \% & 58.2 & 25.0 & 46.4\end{array}$

$98.5 \% \quad 17.5$

$99.7 \% \quad 38.0$

$\begin{array}{llll}99.7 \% & 43.7 & 25.0 & 35.4\end{array}$

$0.05 \% \quad 25.1 \%$ TQSSASLAASYAAQQHPQAAASYR

$99.7 \%$ \#\#\#\# $25.0 \quad 97.1 \quad 2$

$\begin{array}{llll}99.7 \% & 38.3 & 25.0 & 33.9\end{array}$

$\begin{array}{llll}99.0 \% & 37.4 & 25.0 & 29.5\end{array}$

$99.7 \% \quad 48.0 \quad 25.0 \quad 42.1 \quad 2$

$\begin{array}{llll}99.7 \% & 55.1 & 25.0 & 55.1\end{array}$

$99.7 \% \quad 63.7 \quad 25.0 \quad 61.4$

$\begin{array}{lllll}99.7 \% & 58.2 & 25.0 & 50.2 & 2\end{array}$

$\begin{array}{llll}99.7 \% & 55.4 & 25.0 & 51.8\end{array}$

$\begin{array}{llll}99.7 \% & 54.7 & 25.0 & 52.1\end{array}$

$\begin{array}{llll}99.7 \% & 45.9 & 25.0 & 43.5\end{array}$

$99.7 \% \quad 55.6 \quad 25.0 \quad 55.6$

$\begin{array}{lllll}99.7 \% & 43.7 & 25.0 & 30.7 & 3\end{array}$

$\begin{array}{llll}99.7 \% & 30.8 & 25.0 & 30.2\end{array}$

$99.7 \% \quad 48.9 \quad 25.0 \quad 47.5$

$\begin{array}{llll}99.7 \% & 33.4 & 25.0 & 33.4\end{array}$

$\begin{array}{llll}99.7 \% & 40.0 & 25.0 & 37.2\end{array}$

$\begin{array}{llll}99.6 \% & 26.2 & 25.0 & 19.0\end{array}$

$99.7 \% \quad 53.4 \quad 25.0 \quad 47.6$

$\begin{array}{llll}99.6 \% & 28.0 & 25.0 & 22.7\end{array}$

$\begin{array}{llll}99.7 \% & 32.7 & 25.0 & 32.7\end{array}$

$\begin{array}{lll}99.4 \% & 23.1\end{array}$

$99.7 \% \quad 47.7$

151

0

0

13.71

1145.50

1611.68

1340.55

1177.48

1670.82

1061.50

2034.88

1684.68

1493.63

1666.73

1155.54

902.44

1724.84

1328.72

1197.66

1438.71

1669.83

1090.51

1312.72

1973.95

1196.57

1122.59

1047.62

1751.87

1241.72

903.51

1216.69

1156.63

1608.84

1219.64

1205.63

1340.63

1245.66

2465.18

1122.59

1300.64

1237.55

1355.69

1511.79

1054.53

1196.59

1271.62

1551.91

1822.05

1031.53 
RNA-binding protein $4 \mathrm{GN}=\mathrm{RBM} 4$ RNA-binding protein $4 \mathrm{GN}=\mathrm{RBM} 4$ RNA-binding protein $4 \mathrm{GN}=\mathrm{RBM} 4$ RNA-binding protein $4 \mathrm{GN}=\mathrm{RBM} 4$ RNA-binding protein $4 \mathrm{GN}=\mathrm{RBM} 4$ RNA-binding protein $4 \mathrm{GN}=\mathrm{RBM} 4$ RNA-binding protein $4 \mathrm{GN}=\mathrm{RBM} 4$ RNA-binding protein $4 \mathrm{GN}=\mathrm{RBM} 4$ RNA-binding protein $4 \mathrm{GN}=\mathrm{RBM} 4$ RNA-binding protein $4 \mathrm{GN}=\mathrm{RBM} 4$ RNA-binding protein $4 \mathrm{GN}=\mathrm{RBM} 4$ RNA-binding protein $4 \mathrm{GN}=\mathrm{RBM} 4$ RNA-binding protein $4 \mathrm{GN}=\mathrm{RBM} 4$ RNA-binding protein $4 \mathrm{GN}=\mathrm{RBM} 4$ RNA-binding protein $4 \mathrm{GN}=\mathrm{RBM} 4$ RNA-binding protein $4 \mathrm{GN}=\mathrm{RBM} 4$ RNA-binding protein $4 \mathrm{GN}=\mathrm{RBM} 4$ RNA-binding protein $4 \mathrm{~B} \mathrm{GN}=\mathrm{RBM} 4 \mathrm{~B}$ RNA-binding protein $4 \mathrm{~B}$ GN=RBM4B RNA-binding protein $4 \mathrm{~B} \mathrm{GN}=\mathrm{RBM} 4 \mathrm{~B}$ RNA-binding protein $4 \mathrm{~B}$ GN=RBM $4 \mathrm{~B}$ RNA-binding protein $4 \mathrm{~B} \mathrm{GN}=\mathrm{RBM} 4 \mathrm{~B}$ RNA-binding protein $4 \mathrm{~B} \mathrm{GN}=\mathrm{RBM} 4 \mathrm{~B}$ RNA-binding protein $4 \mathrm{~B} \mathrm{GN}=\mathrm{RBM} 4 \mathrm{~B}$ RNA-binding protein $4 \mathrm{~B} \mathrm{GN}=\mathrm{RBM} 4 \mathrm{~B}$ RNA-binding protein $4 \mathrm{~B} \mathrm{GN}=\mathrm{RBM} 4 \mathrm{~B}$ RNA-binding protein $4 \mathrm{~B} \mathrm{GN}=\mathrm{RBM} 4 \mathrm{~B}$ RNA-binding protein $4 \mathrm{~B}$ GN=RBM4B RNA-binding protein $4 \mathrm{~B}$ GN=RBM4B RNA-binding protein $4 \mathrm{~B} \mathrm{GN}=\mathrm{RBM} 4 \mathrm{~B}$ RNA-binding protein $4 \mathrm{~B} \mathrm{GN}=\mathrm{RBM} 4 \mathrm{~B}$ RNA-binding protein $4 \mathrm{~B} \mathrm{GN}=\mathrm{RBM} 4 \mathrm{~B}$ RNA-binding protein Musashi homolog $1 \mathrm{GN}=\mathrm{MSI} 1 \mathrm{MS1H}$ HUMAN $39.12 \quad 100 \%$ RNA-binding protein Musashi homolog 1 GN=MSII MSIIH_HUMAN $39.12 \quad 100.0 \%$ RNA-binding protein Musashi homolog $1 \mathrm{GN}=$ MSI1 MSIIH_HUMAN $39.12 \quad 100.0 \%$ RNA-binding protein Musashi homolog $1 \mathrm{GN}=$ MSI1 MSIIH_HUMAN $39.12 \quad 100.0 \%$ RNA-binding protein Musashi homolog 2 GN=MSI2 MSI2H_HUMAN $35.20 \quad 100.0 \%$ RNA-binding protein Musashi homolog $2 \mathrm{GN}=\mathrm{MSI} 2 \mathrm{MSI2H}$ HUMAN $35.20 \quad 100.0 \%$ RNA-binding protein $\mathrm{PNO} 1 \mathrm{GN}=\mathrm{PNO} 1$ RNA-binding protein $\mathrm{PNO} 1 \mathrm{GN}=\mathrm{PNO} 1$ RNA-binding protein $\mathrm{PNO} 1 \mathrm{GN}=\mathrm{PNO} 1$ RNA-binding protein Raly GN=RALY RNA-binding protein Raly GN=RALY RNA-binding protein Raly GN=RALY RNA-binding protein Raly GN=RALY RNA-binding protein Raly GN=RALY RNA-binding protein Raly GN=RALY RBM4B HUMAN $40.15 \quad 100.0 \%$ PNO1 HUMAN $27.93 \quad 100.0 \%$ PNO1_HUMAN $27.93 \quad 100.0 \%$ RALY_HUMAN $32.46 \quad 100.0 \%$
RBM4 HUMAN $40.31 \quad 100.0 \% \quad 17 \quad 21 \quad 38 \quad 0.04 \% \quad 49.2 \%$ LFIGNLPR

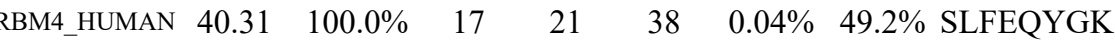
RBM4 HUMAN $40.31 \quad 100.0 \% \quad 17$ RBM4_HUMAN $40.31 \quad 100.0 \% \quad 17$ RBM4_HUMAN $40.31 \quad 100.0 \% \quad 17$ RBM4 HUMAN $40.31 \quad 100.0 \% \quad 17$ RBM4_HUMAN $40.31 \quad 100.0 \% \quad 17$ RBM4_HUMAN $40.31 \quad 100.0 \% \quad 17$ RBM4_HUMAN $\quad 40.31 \quad 100.0 \% \quad 17$ RBM4_HUMAN $40.31 \quad 100.0 \% \quad 17$ RBM4 HUMAN $40.31 \quad 100.0 \% \quad 17$ RBM4_HUMAN $40.31 \quad 100.0 \% \quad 17$ RBM4_HUMAN $40.31 \quad 100.0 \% \quad 17$ RBM4_HUMAN $40.31 \quad 100.0 \% \quad 17$ RBM4_HUMAN $40.31 \quad 100.0 \% \quad 17$ RBM4 HUMAN $40.31 \quad 100.0 \% \quad 17$ RBM4B_HUMAN $40.15 \quad 100.0 \% \quad 2$ RBM4B_HUMAN $40.15 \quad 100.0 \% \quad 2$ RBM4B HUMAN $40.15 \quad 100.0 \% \quad 2$ $\begin{array}{lll}\text { RBMA_HUMAN } & 40.15 & 100.0 \%\end{array}$ RBM4B_HUMAN $40.15 \quad 100.0 \%$ RBM4B_HUMAN $\quad 40.15 \quad 100.0 \% \quad 2$ RBM4B HUMAN $40.15 \quad 100.0 \% \quad 2$ RBM4B_HUMAN $\quad 40.15 \quad 100.0 \% \quad 2$ RBM4B_HUMAN $40.15 \quad 100.0 \% \quad 2$ RBM4B_HUMAN $40.15 \quad 100.0 \% \quad 2$ RBM4B_HUMAN $40.15 \quad 100.0 \% \quad 2$ RBM4B HUMAN $40.15 \quad 100.0 \% \quad 2$ $\begin{array}{lll}\text { RBM4B_HUMAN } & 40.15 & 100.0 \%\end{array}$ RALY_HUMAN $32.46 \quad 100.0 \% \quad 17$ RALY_HUMAN $32.46 \quad 100.0 \% \quad 17$ RALY_HUMAN $32.46 \quad 100.0 \% \quad 17$ RALY_HUMAN $32.46 \quad 100.0 \% \quad 17$ RALY_HUMAN $32.46 \quad 100.0 \% \quad 17$

$0.04 \% \quad 49.2 \%$ VLECDIIK

$0.00 \% \quad 40.4 \%$ LFIGNLPR

$0.00 \% \quad 40.4 \%$ SLFEQYGK

$0.00 \% \quad 40.4 \%$ VLECDIIK

$19 \quad 61 \quad 0.07 \% \quad 42.8 \%$ SDVETIFSK

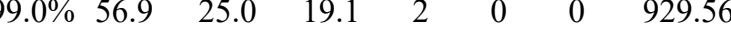
$\begin{array}{llllllll}99.0 \% & 31.6 & 25.0 & 24.8 & 2 & 0 & 0 & 971.48\end{array}$ $\begin{array}{llllllll}99.0 \% & 33.7 & 25.0 & 18.8 & 2 & 0 & 0 & 989.53\end{array}$ $\begin{array}{llllllll}99.7 \% & 45.2 & 25.0 & 30.8 & 1 & 0 & 0 & 1221.59\end{array}$ $0.04 \% \quad 49.2 \%$ NYGFVHIEDK

$0.04 \% \quad 49.2 \%$ NYGFVHIEDKTAAEDAIR $0.04 \% \quad 49.2 \%$ LHGVNINVEASK

$0.04 \% \quad 49.2 \%$ LHVGNISPTCTNK $0.04 \% \quad 49.2 \%$ DYAFVHMER

$0.04 \% \quad 49.2 \%$ AEDAVEAIR

$0.04 \% \quad 49.2 \%$ GLDNTEFQGK

$0.04 \% \quad 49.2 \%$ GLDNTEFQGKR

$0.04 \% \quad 49.2 \%$ MHVQLSTSR

$99.7 \% \quad 46.5$

$99.7 \% \quad 40.2 \quad 25.0 \quad 34.3$

$99.7 \% \quad 35.1 \quad 25.0 \quad 35.1 \quad 2$ $99.7 \% \quad 51.9 \quad 25.0 \quad 31.8$ $\begin{array}{llll}99.7 \% & 50.2 & 25.0 & 46.0\end{array}$ $99.7 \% \quad 39.0 \quad 25.0 \quad 29.5$ $\begin{array}{lllll}99.7 \% & 32.9 & 25.0 & 30.9\end{array}$ $0.04 \% \quad 49.2 \%$ TAPGMGDQSGCYR $\begin{array}{llll}99.7 \% & 27.3\end{array}$

$0.04 \% \quad 49.2 \%$ VADLTEQYNEQYGAVR

$0.04 \% \quad 49.2 \%$ ATAPVPTVGEGYGYGHESELSQASAAAR

$0.04 \% \quad 49.2 \%$ NSLYDMAR

$0.04 \% \quad 49.2 \%$ YEREQYADR

$0.00 \% \quad 40.4 \%$ NYGFVHIEDK

$99.7 \%$

$99.0 \% \quad 20.7$

$98.9 \% \quad 18.6$

$99.0 \% \quad 56.9$

$99.0 \% 31.6$

$99.0 \% \quad 33.7$

$99.7 \% \quad 45.2$

$0.00 \% \quad 40.4 \%$ NYGFVHIEDKTAAEDAIR

$0.00 \% \quad 40.4 \%$ LHGVNINVEASK

$0.00 \% \quad 40.4 \%$ LHVGNISPTCTNQELR

$0.00 \% \quad 40.4 \%$ DYAFVHMER

$0.00 \% \quad 40.4 \%$ AEDAVEAIR

$0.00 \% \quad 40.4 \%$ GLDNTEFQGK

$0.00 \% \quad 40.4 \%$ GLDNTEFQGKR

$0.00 \% \quad 40.4 \%$ MHVQLSTSR

$0.00 \% \quad 40.4 \%$ TAPGMGDQSGCYR

$0.00 \% \quad 40.4 \%$ VADFTEQYNEQYGAVR

$0.00 \% \quad 40.4 \%$ NSLYDMAR

$10 \quad 0.01 \% \quad 15.7 \%$ EYFGQFGEVK

$0.01 \% \quad 15.7 \%$ GFGFVTFMDQAGVDK

$0.01 \% \quad 15.7 \%$ GFGFVTFESEDIVEK

$0.01 \% \quad 15.7 \%$ SYTGLAPGYTYQFPEFR

$0.01 \% \quad 9.2 \%$ GFGFVTFADPASVDK

$0.01 \% \quad 9.2 \%$ GFGFVTFENEDVVEK

$0.01 \% \quad 14.7 \%$ AEEGFTQVTR

$0.01 \% \quad 14.7 \%$ QAEQLSAAGEGGDAGR

$0.01 \% \quad 14.7 \%$ VHILGSFQNIK

$0.07 \% \quad 42.8 \%$ LQASNVTNK

$61 \quad 0.07 \% \quad 42.8 \%$ LQASNVTNKNDPK

$19 \quad 61 \quad 0.07 \% \quad 42.8 \%$ VFIGNLNTALVK

$19 \quad 61 \quad 0.07 \% \quad 42.8 \%$ VFIGNLNTALVKK

$19 \quad 61 \quad 0.07 \% \quad 42.8 \%$ KSDVETIFSK $\begin{array}{llll}99.7 \% & 54.7 & 25.0 & 42.5\end{array}$

$\begin{array}{llll}99.7 \% & 32.0 & 25.0 & 23.7\end{array}$

$99.7 \% \quad 35.1 \quad 25.0 \quad 35.1$

$99.7 \% \quad 51.9 \quad 25.0 \quad 31.8$

$\begin{array}{llll}99.7 \% & 50.2 & 25.0 & 46.0\end{array}$

$\begin{array}{lllll}99.7 \% & 39.0 & 25.0 & 29.5\end{array}$

$99.7 \% \quad 32.9 \quad 25.0 \quad 30.9$

$\begin{array}{llll}99.7 \% & 78.9 & 25.0 & 78.9\end{array}$

$\begin{array}{llll}99.0 \% & 20.7 & 25.0 & 19.9\end{array}$

$99.7 \% \quad 35.2 \quad 25.0 \quad 34.7$

$99.7 \% \quad 55.1 \quad 25.0 \quad 55.1$

$99.7 \% \quad 53.0 \quad 25.0 \quad 50.1$

$\begin{array}{llll}99.7 \% & 64.3 & 25.0 & 64.3\end{array}$

$\begin{array}{llll}99.7 \% & 44.8 & 25.0 & 40.2\end{array}$

$\begin{array}{llll}99.7 \% & 56.8 & 25.0 & 50.8\end{array}$

$99.7 \% \quad 55.4 \quad 25.0 \quad 44.9$

$\begin{array}{llll}99.7 \% & 47.1 & 25.0 & 45.3\end{array}$

$99.4 \% \quad 25.2 \quad 25.0 \quad 25.2$

$\begin{array}{llll}99.7 \% & 39.5 & 25.0 & 32.9\end{array}$

$\begin{array}{llll}99.7 \% & 39.5 & 25.0 & 27.8\end{array}$

$\begin{array}{llll}99.2 \% & 66.5 & 25.0 & 0.0\end{array}$

$\begin{array}{lllll}99.2 \% & 64.3 & 25.0 & 0.0 & 2\end{array}$

$\begin{array}{llll}99.7 \% & 58.3 & 25.0 & 45.0\end{array}$

$\begin{array}{llll}99.7 \% & 57.5 & 25.0 & 39.5\end{array}$ $\begin{array}{llll}9.7 \% & 46.5 & 25.0 & 46.5\end{array}$

$\begin{array}{llll}99.7 \% & 27.3 & 25.0 & 27.3\end{array}$

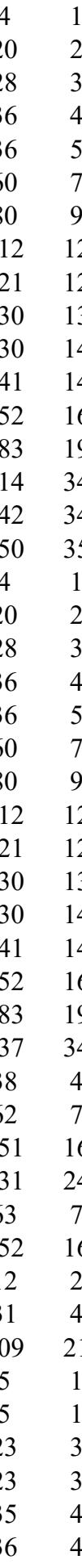

Page 134 of Table S-1- 6 
RNA-binding protein Raly GN=RALY RNA-binding protein Raly GN=RALY RNA-binding protein Raly GN=RALY RNA-binding protein Raly GN=RALY RNA-binding protein Raly GN=RALY RNA-binding protein Raly GN=RALY RNA-binding protein Raly GN=RALY RNA-binding protein Raly GN=RALY RNA-binding protein Raly GN=RALY RNA-binding protein Raly GN=RALY

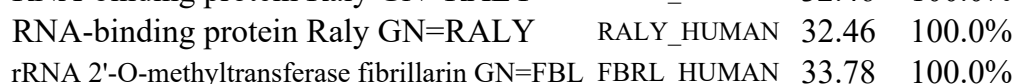
$\begin{array}{llll}\text { rRNA } 2 '-O-\text {-methyltransferase fibrillarin GN=FBL FBRL_HUMAN } & 33.78 & 100.0 \% & 1\end{array}$ rRNA 2'-O-methyltransferase fibrillarin GN=FBL FBRL_HUMAN $33.78 \quad 100.0 \% \quad 1$ rRNA 2'-O-methyltransferase fibrillarin GN=FBL FBRL_HUMAN $33.78 \quad 100.0 \%$ rRNA 2'-O-methyltransferase fibrillarin GN=FBL FBRL_HUMAN $33.78 \quad 100.0 \%$ rRNA 2'-O-methyltransferase fibrillarin GN=FBL FBRL HUMAN $33.78 \quad 100.0 \%$ $\begin{array}{llll}\text { rRNA 2'-O-methyltransferase fibrillarin GN=FBL FBRL_HUMAN } & 33.78 & 100.0 \%\end{array}$ rRNA 2'-O-methyltransferase fibrillarin GN=FBL FBRL_HUMAN $33.78 \quad 100.0 \%$ rRNA 2'-O-methyltransferase fibrillarin GN=FBL FBRL_HUMAN $33.78 \quad 100.0 \%$ rRNA 2'-O-methyltransferase fibrillarin GN=FBL FBRL_HUMAN $33.78 \quad 100.0 \%$ rRNA 2'-O-methyltransferase fibrillarin GN=FBL FBRL HUMAN $33.78 \quad 100.0 \%$ rRNA 2'-O-methyltransferase fibrillarin GN=FBL FBRL_HUMAN $33.78 \quad 100.0 \%$ rRNA 2'-O-methyltransferase fibrillarin GN=FBL FBRL_HUMAN $33.78 \quad 100.0 \%$ rRNA 2'-O-methyltransferase fibrillarin GN=FBL FBRL_HUMAN $33.78 \quad 100.0 \%$ rRNA 2'-O-methyltransferase fibrillarin GN=FBL FBRL_HUMAN $33.78 \quad 100.0 \%$ rRNA 2'-O-methyltransferase fibrillarin GN=FBL FBRL_HUMAN $33.78 \quad 100.0 \%$ rRNA methyltransferase 3, mitochondrial GN=RNMTL1 MRM3_HUMAN $47.02 \quad 100.0 \%$ rRNA methyltransferase 3, mitochondrial GN=RNMTL1 MRM3_HUMAN $47.02 \quad 100.0 \%$ rRNA methyltransferase 3, mitochondrial GN=RNMTL1 MRM3 HUMAN $47.02 \quad 100.0 \%$ rRNA methyltransferase 3, mitochondrial GN=RNMTL1 MRM3_HUMAN $47.02 \quad 100.0 \%$ RRP12-like protein GN=RRP12 RRP12-like protein $\mathrm{GN}=\mathrm{RRP} 12$ RRP12-like protein GN=RRP12 RRP12-like protein $\mathrm{GN}=\mathrm{RRP} 12$ RRP12-like protein $\mathrm{GN}=\mathrm{RRP} 12$ RRP12-like protein $\mathrm{GN}=\mathrm{RRP} 12$ RRP12-like protein GN=RRP12 RRP12-like protein $\mathrm{GN}=\mathrm{RRP} 12$ RRP12-like protein GN=RRP12 RRP15-like protein GN=RRP15 RRP15-like protein GN=RRP15 RRP15-like protein GN=RRP15 RRP15-like protein GN=RRP15 RuvB-like 1 GN=RUVBL1 RuvB-like 1 GN=RUVBL1 S1 RNA-binding domain-containing protein $1 \mathrm{GN}=$ SRBD1 SRBD1_HUMAN $111.78 \quad 100.0 \%$ RRP12 HUMAN $143.71 \quad 100.0 \%$ RRP12_HUMAN $143.71 \quad 100.0 \%$ RRP12_HUMAN $143.71 \quad 100.0 \%$ RRP12 HUMAN $143.71 \quad 100.0 \%$ RRP12_HUMAN $143.71 \quad 100.0 \%$ RRP12 HUMAN $143.71 \quad 100.0 \%$ RRP12_HUMAN $143.71 \quad 100.0 \%$ RRP12 HUMAN $143.71 \quad 100.0 \%$ RRP15_HUMAN $31.48 \quad 100.0 \%$ RRP15 HUMAN $31.48 \quad 100.0 \%$ RRP15_HUMAN $31.48 \quad 100.0 \%$ $\begin{array}{lll}\text { RRP15_HUMAN } & 31.48 & 100.0 \% \\ \text { RUVB1_HUMAN } & 50.23 & 100.0 \%\end{array}$ RUVB1 HUMAN $50.23 \quad 100.0 \%$
$19 \quad 61 \quad 0.07 \% \quad 42.8 \%$ GYAFVQYSNER $\begin{array}{llllllll}99.7 \% & 63.7 & 25.0 & 59.1 & 4 & 0 & 0 & 1333.62\end{array}$ $99.7 \% \quad 41.8$ $0.07 \% \quad 42.8 \%$ AAVLGENGR $99.7 \% \quad 46.6$ $99.0 \% 32.3$ $99.0 \% \quad 29.8$ $99.2 \% \quad 20.2$ $99.7 \% \quad 47.5$ $99.0 \% \quad 69.6$ $99.7 \% \quad 50.3$ $99.7 \% 53.8$ $99.7 \% \quad 53.6$ $99.0 \% \quad 27.8$ $99.0 \% \quad 41.1$ $\begin{array}{lll}99.7 \% & 31.7\end{array}$ $99.6 \% 26.0$ $99.7 \% \quad 50.8$ $99.7 \% \quad 63.6$

5

5
5
10
RRP15_HUMAN $31.48 \quad 100.0 \%$

\section{$\begin{array}{lllll}10 & 16 & 0.02 \% & 8.1 \% & \text { GCQAEADRAEVSR }\end{array}$}

$\begin{array}{lllll}10 & 16 & 0.02 \% & 8.1 \% & \text { RAVLETIR }\end{array}$

$\begin{array}{lllll}10 & 16 & 0.02 \% & 8.1 \% & \text { VAVTVMDVAHLAK }\end{array}$

$10 \quad 16 \quad 0.02 \% \quad 8.1 \%$ VLATQPGPGR

$0.01 \% \quad 15.2 \%$ TPESKPTILVK

$0.01 \% \quad 15.2 \%$ GVVQLFNAVQK

$0.01 \% \quad 15.2 \%$ KDFISVLR

$0.01 \% \quad 15.2 \%$ GMDGSTNETASSR

$0.00 \% \quad 5.7 \%$ AVLLAGPPGTGK

$0.00 \% \quad 5.7 \%$ YSVQLLTPANLLAK

AK

$\begin{array}{llll}99.7 \% & 39.3 & 25.0 & 32.1\end{array}$

$\begin{array}{llll}99.7 \% & 30.6 & 25.0 & 23.6\end{array}$

$\begin{array}{llll}99.3 \% & 60.0 & 25.0 & 0.0\end{array}$

$\begin{array}{rrrr}97.7 \% & 16.4 & 25.0 & 15.9\end{array}$

$\begin{array}{llll}99.7 \% & 56.5 & 25.0 & 51.7\end{array}$

$\begin{array}{llll}99.7 \% & 53.5 & 25.0 & 29.8\end{array}$

99.7\% 96.9

$\begin{array}{ll}29.8 \\ 25.0 & 96\end{array}$

$\begin{array}{llll}99.7 \% & 80.6 & 25.0 & 80.6\end{array}$

$\begin{array}{llll}99.7 \% & 45.0 & 25.0 & 45.0\end{array}$

$\begin{array}{lllll}99.7 \% & 71.5 & 25.0 & 71.5 & 2\end{array}$

$\begin{array}{llll}99.7 \% & 27.6 & 25.0 & 26.9\end{array}$

$\begin{array}{lllll}99.7 \% & 58.9 & 25.0 & 44.6 & 2\end{array}$

$\begin{array}{llll}99.7 \% & 32.4 & 25.0 & 20.5\end{array}$

$\begin{array}{llll}99.7 \% & 47.3 & 25.0 & 35.0\end{array}$

$\begin{array}{llll}97.5 \% & 16.0 & 25.0 & 16.0\end{array}$

$\begin{array}{llll}99.7 \% & 51.0 & 25.0 & 51.0\end{array}$

$\begin{array}{llll}99.0 \% & 25.5 & 25.0 & 19.0\end{array}$

$\begin{array}{llll}99.7 \% & 45.2 & 25.0 & 40.4\end{array}$

$99.0 \% \quad 38.6 \quad 25.0 \quad 27.9$

$99.7 \% \quad 26.4 \quad 25.0 \quad 26.4$

$\begin{array}{llll}99.0 \% & 48.4 & 25.0 & 31.1\end{array}$

$\begin{array}{lllll}99.7 \% & 51.3 & 25.0 & 51.3 & 2\end{array}$

$99.7 \% \quad 37.6 \quad 25.0 \quad 27.7 \quad 2$

$\begin{array}{llll}97.5 \% & 22.9 & 25.0 & 13.4\end{array}$

$99.7 \% \quad 55.5 \quad 25.0 \quad 53.4 \quad 2$

$\begin{array}{llll}96.1 \% & 20.9 & 25.0 & 11.1\end{array}$

$\begin{array}{llll}99.7 \% & 68.9 & 25.0 & 68.9\end{array}$

$\begin{array}{lllll}99.7 \% & 41.3 & 25.0 & 35.3 & 2\end{array}$

$\begin{array}{lllll}99.7 \% & 31.5 & 25.0 & 31.5 & 2\end{array}$

$0.00 \% \quad 3.3 \% \quad$ ILYNSLNDSFKR

$\begin{array}{llll}97.7 \% & 19.8 & 25.0 & 15.1\end{array}$

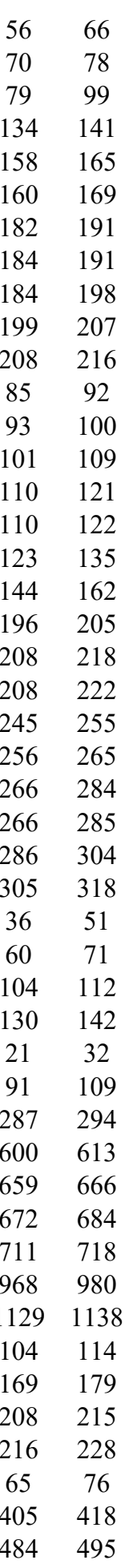

(⿻) 

Scaffold attachment factor B1 GN=SAFB SAFB1_HUMAN $102.64 \quad 100.0 \%$ Scaffold attachment factor B1 GN=SAFB SAFB1_HUMAN $102.64 \quad 100.0 \%$ Scaffold attachment factor B1 GN=SAFB SAFB1_HUMAN $102.64 \quad 100.0 \%$ Scaffold attachment factor B1 GN=SAFB SAFB1_HUMAN $102.64 \quad 100.0 \%$ Scaffold attachment factor B1 GN=SAFB SAFB1_HUMAN $102.64 \quad 100.0 \%$ Scaffold attachment factor B1 GN=SAFB SAFB1_HUMAN $102.64 \quad 100.0 \%$ Scaffold attachment factor B1 GN=SAFB SAFB1_HUMAN $102.64 \quad 100.0 \%$ Scaffold attachment factor B1 GN=SAFB SAFB1_HUMAN $102.64 \quad 100.0 \%$ Scaffold attachment factor B1 GN=SAFB SAFB1_HUMAN $102.64 \quad 100.0 \%$ Scaffold attachment factor B1 GN=SAFB SAFB1_HUMAN $102.64 \quad 100.0 \%$ Scaffold attachment factor B1 GN=SAFB SAFB1_HUMAN $102.64 \quad 100.0 \%$ Scaffold attachment factor B1 GN=SAFB SAFB1_HUMAN $102.64 \quad 100.0 \%$ Scaffold attachment factor B2 GN=SAFB2 SAFB2_HUMAN $107.47 \quad 100.0 \%$ Scaffold attachment factor B2 GN=SAFB2 SAFB2_HUMAN $107.47 \quad 100.0 \%$ Scaffold attachment factor B2 GN=SAFB2 SAFB2_HUMAN $107.47 \quad 100.0 \%$ Scaffold attachment factor B2 GN=SAFB2 SAFB2 HUMAN $107.47 \quad 100.0 \%$ Scaffold attachment factor B2 GN=SAFB2 SAFB2_HUMAN $107.47 \quad 100.0 \%$ Scaffold attachment factor B2 GN=SAFB2 SAFB2_HUMAN $107.47 \quad 100.0 \%$ Scaffold attachment factor B2 GN=SAFB2 SAFB2_HUMAN $107.47 \quad 100.0 \%$ Scaffold attachment factor B2 GN=SAFB2 SAFB2_HUMAN $107.47 \quad 100.0 \%$

$0.00 \% \quad 3.3 \% \quad$ QLLLTSPVPGR $0.00 \% \quad 3.3 \%$ SFQQCAGFIR

$0.00 \% \quad 4.7 \%$ AEVASFVADR $0.00 \% \quad 4.7 \%$ ALAVDAAFR

$0.01 \% \quad 12.4 \%$ TGMILLAGEITSR $0.01 \% \quad 12.4 \%$ AVVPAKYLDEDTIYHLQPSGR $0.01 \% \quad 12.4 \%$ YLDEDTIYHLQPSGR $0.01 \% \quad 12.4 \%$ FVIGGPQGDAGLTGR $0.01 \% \quad 4.0 \%$ TELHGQLISVEK $0.01 \% \quad 4.0 \%$ AGAGMITQHSSNASPINR $0.01 \% \quad 4.0 \%$ IVQISGNSMPR $0.05 \% \quad 19.3 \%$ STTLRVDQSILTGESVSVIK $0.05 \% \quad 19.3 \%$ NMLFSGTNIAAGK $0.05 \% \quad 19.3 \%$ AMGVVVATGVNTEIGK $0.05 \% \quad 19.3 \%$ VGEATETALTCLVEK $0.05 \% \quad 19.3 \%$ EFTLEFSR

$0.05 \% \quad 19.3 \%$ SMSVYCTPNKPSR

$0.05 \% \quad 19.3 \%$ VGSTKVPMTSGVK

$0.05 \% \quad 19.3 \%$ CLALATHDNPLRR

$0.05 \% \quad 19.3 \%$ VIMITGDNKGTAVAICR $0.05 \% \quad 19.3 \%$ IGIFGQDEDVTSK

$0.05 \% \quad 19.3 \%$ AFTGREFDELNPSAQR $0.05 \% \quad 19.3 \%$ KAEIGIAMGSGTAVAK $0.05 \% \quad 19.3 \%$ AEIGIAMGSGTAVAK $0.05 \% \quad 19.3 \%$ ISLPVILMDETLK $0.05 \% \quad 19.3 \%$ NYLEPGKECVQPATK $0.05 \% \quad 17.4 \%$ VIDLRAELR

$0.05 \% \quad 17.4 \%$ NVDSSGNKSVLMER

$0.05 \% \quad 17.4 \%$ AIEDEGGNPDEIEITSEGNKK $0.05 \% \quad 17.4 \%$ ILDILGETCK

$0.05 \% \quad 17.4 \%$ ADSLLAVVK $0.05 \% \quad 17.4 \%$ NFWVSGLSSTTR $0.05 \% \quad 17.4 \%$ ATDLKNLFSK $0.05 \% \quad 17.4 \%$ VVGAKVVTNAR $0.05 \% \quad 17.4 \%$ CYGFVTMSTAEEATK $0.05 \% \quad 17.4 \%$ SKGVPVISVK $0.05 \% \quad 17.4 \%$ AALDERYHSDFNR $0.05 \% \quad 17.4 \%$ SMMGEREGQHYPER $0.05 \% \quad 17.4 \%$ DGWGGYGSDKR $0.02 \% \quad 17.4 \%$ VIDLRAELK $0.02 \% \quad 17.4 \%$ NLDTGGNKSVLMER $0.02 \% \quad 17.4 \%$ AVKEEGQDPDEIGIELEATS $0.02 \% \quad 17.4 \%$ ILDILGETCK $0.02 \% \quad 17.4 \%$ ADSLLAVVK $0.02 \% \quad 17.4 \%$ NLWVSGLSSTTR $0.02 \% \quad 17.4 \%$ ATDLKNLFSK $0.02 \% \quad 17.4 \%$ VVGAKVVTNAR
$9.7 \% \quad 44.6$ $\begin{array}{lll}99.7 \% & 45.0\end{array}$ $99.7 \% \quad 40.9$ $99.7 \% \quad 53.1$ $99.7 \% \quad 45.5$ $99.7 \% \quad 42.2$ $99.0 \% 34.1$ $99.7 \% \quad 41.6$ $99.7 \% 32.6$ $99.5 \% \quad 23.8$ $99.2 \% \quad 21.5$ $99.7 \% \quad 53.0$ $97.6 \% \quad 15.9$ $99.7 \% \quad 36.7$ $99.7 \% \quad 61.1$ $98.7 \% \quad 22.6$ $99.7 \% \quad 31.6$ $\begin{array}{lll}99.7 \% & 29.2\end{array}$ $99.7 \% \quad 58.1$

\section{$99.6 \% \quad 25.5$} $99.7 \% \quad 35.3$ $99.7 \% \quad 72.0$ $99.7 \% \quad 55.3$ $99.7 \% \quad 47.6$ $99.7 \% \quad 34.1$ $\begin{array}{lll}99.7 \% & 49.2\end{array}$ $\begin{array}{lll}99.7 \% & 29.2\end{array}$ $\begin{array}{lll}99.7 \% & 25.7\end{array}$ $99.3 \% \quad 22.0$ $99.3 \% \quad 20.9$ $99.3 \% \quad 26.3$ $\begin{array}{lll}99.7 \% & 62.1\end{array}$

\section{$99.7 \% \quad 42.8$} $99.7 \% \quad 35.3$ $99.7 \% \quad 72.0$ $99.7 \% \quad 55.1$ $99.7 \% \quad 47.6$ $99.7 \% \quad 34.1$
1811.88

1201.64

2133.18

1323.67

1561.83

1620.82

1028.50

1526.7

1290.71

1536.81

1818.96

1408.70

1837.88

1503.82

1375.73

1471.84

1733.85

1084.65

1535.75

2245.05

1161.62

915.55

1354.67

1136.63

1113.67

1710.74

1013.64

1593.74

1706.74

1197.53

1056.64

1533.77

2258.10

1161.62

915.55

1320.69

1136.63

1113.67 
Scaffold attachment factor B2 GN=SAFB2 SAFB2_HUMAN $107.47 \quad 100.0 \%$ Scaffold attachment factor B2 GN=SAFB2 SAFB2_HUMAN $107.47 \quad 100.0 \%$ Scaffold attachment factor B2 GN=SAFB2 SAFB2_HUMAN $107.47 \quad 100.0 \%$ Scaffold attachment factor B2 GN=SAFB2 SAFB2 HUMAN $107.47 \quad 100.0 \%$ Scaffold attachment factor B2 GN=SAFB2 SAFB2_HUMAN $107.47 \quad 100.0 \%$ Scaffold attachment factor B2 GN=SAFB2 SAFB2_HUMAN $107.47 \quad 100.0 \%$ SCY1-like protein $2 \mathrm{GN}=\mathrm{SCYL} 2$ SCY1-like protein $2 \mathrm{GN}=\mathrm{SCYL} 2$ Septin-2 GN=SEPT2

Septin-2 GN=SEPT2

Septin-2 GN=SEPT2

Septin-2 GN=SEPT2

Septin-2 GN=SEPT2

Septin-9 GN=SEPT9

Septin-9 GN=SEPT9 SCYL2_HUMAN $103.71 \quad 100.0 \%$ SCYL2_HUMAN $103.71 \quad 100.0 \%$ SEPT2 HUMAN $41.49 \quad 100.0 \%$ SEPT2_HUMAN $41.49 \quad 100.0 \%$ SEPT2_HUMAN $41.49 \quad 100.0 \%$ SEPT2_HUMAN $41.49 \quad 100.0 \%$ SEPT2_HUMAN $41.49 \quad 100.0 \%$ SEPT9_HUMAN $65.40 \quad 100.0 \%$ SEPT9_HUMAN $65.40 \quad 100.0 \%$ Serine hydroxymethyltransferase, mitochondrial GN=SHMT2 GLYM_HUMAN $55.99 \quad 100.0 \%$ Serine hydroxymethyltransferase, mitochondrial GN=SHMT2 GLYM_HUMAN $55.99 \quad 100.0 \%$ Serine hydroxymethyltransferase, mitochondrial GN=SHMT2 GLYM_HUMAN $55.99 \quad 100.0 \%$ Serine hydroxymethyltransferase, mitochondrial GN=SHMT2 GLYM_HUMAN $55.99 \quad 100.0 \%$ Serine palmitoyltransferase $1 \mathrm{GN}=$ SPTLC1 SPTC1_HUMAN $52.75 \quad 99.9 \%$ Serine palmitoyltransferase $1 \mathrm{GN}=$ SPTLC1 SPTC1_HUMAN $52.75 \quad 99.9 \%$ Serine/arginine repetitive matrix protein 2 GN=SRRM2 SRRM2_HUMAN $299.62 \quad 100.0 \%$ Serine/arginine repetitive matrix protein 2 GN=SRRM2 SRRM2_HUMAN $299.62 \quad 100.0 \%$ Serine/arginine repetitive matrix protein 2 GN=SRRM2 SRRM2_HUMAN $299.62 \quad 100.0 \%$ Serine/arginine repetitive matrix protein 2 GN=SRRM2 SRRM2_HUMAN $299.62 \quad 100.0 \%$ Serine/arginine repetitive matrix protein $2 \mathrm{GN}=\mathrm{SRRM} 2 \mathrm{SRRM} 2$ HUMAN $299.62 \quad 100.0 \%$ Serine/arginine repetitive matrix protein $2 \mathrm{GN}=\mathrm{SRRM} 2 \mathrm{SRRM} 2$ HUMAN $299.62 \quad 100.0 \%$ Serine/arginine repetitive matrix protein 2 GN=SRRM2 SRRM2_HUMAN $299.62 \quad 100.0 \%$ Serine/arginine repetitive matrix protein $2 \mathrm{GN}=\mathrm{SRRM} 2 \mathrm{SRRM} 2$ HUMAN $299.62 \quad 100.0 \%$ Serine/arginine repetitive matrix protein $2 \mathrm{GN}=$ SRRM2 SRRM2_HUMAN $299.62 \quad 100.0 \%$ Serine/arginine repetitive matrix protein $2 \mathrm{GN}=\mathrm{SRRM} 2 \mathrm{SRRM} 2$ HUMAN $299.62 \quad 100.0 \%$ Serine/arginine repetitive matrix protein 2 GN=SRRM2 SRRM2_HUMAN $299.62 \quad 100.0 \%$ Serine/arginine repetitive matrix protein 2 GN=SRRM2 SRRM2_HUMAN $299.62 \quad 100.0 \%$ Serine/arginine repetitive matrix protein 2 GN=SRRM2 SRRM2_HUMAN $299.62 \quad 100.0 \%$ Serine/arginine-rich splicing factor $1 \mathrm{GN}=\mathrm{SRSF} 1$ SRSF1_HUMAN $27.75 \quad 100.0 \%$ Serine/arginine-rich splicing factor $1 \mathrm{GN}=\mathrm{SRSF} 1$ SRSF1_HUMAN $27.75 \quad 100.0 \%$ Serine/arginine-rich splicing factor $1 \mathrm{GN}=\mathrm{SRSF} 1$ SRSF1_HUMAN $27.75 \quad 100.0 \%$ Serine/arginine-rich splicing factor $1 \mathrm{GN}=\mathrm{SRSF} 1$ SRSF1_HUMAN $27.75 \quad 100.0 \%$ Serine/arginine-rich splicing factor $1 \mathrm{GN}=\mathrm{SRSF} 1$ SRSF1_HUMAN $27.75 \quad 100.0 \%$ Serine/arginine-rich splicing factor $1 \mathrm{GN}=\mathrm{SRSF} 1$ SRSF1_HUMAN $27.75 \quad 100.0 \%$ Serine/arginine-rich splicing factor $1 \mathrm{GN}=\mathrm{SRSF} 1$ SRSF1_HUMAN $27.75 \quad 100.0 \%$ Serine/arginine-rich splicing factor $1 \mathrm{GN}=\mathrm{SRSF} 1$ SRSF1_HUMAN $27.75 \quad 100.0 \%$ Serine/arginine-rich splicing factor $1 \mathrm{GN}=\mathrm{SRSF} 1$ SRSF1_HUMAN $27.75 \quad 100.0 \%$ Serine/arginine-rich splicing factor $1 \mathrm{GN}=\mathrm{SRSF} 1$ SRSF1_HUMAN $27.75 \quad 100.0 \%$ Serine/arginine-rich splicing factor $1 \mathrm{GN}=\mathrm{SRSF} 1$ SRSF1_HUMAN $27.75 \quad 100.0 \%$ Serine/arginine-rich splicing factor $10 \mathrm{GN}=$ SRSF10 SRS10_HUMAN $31.30 \quad 100.0 \%$ $\begin{array}{llll}\text { Serine/arginine-rich splicing factor } 10 \mathrm{GN}=\mathrm{SRSF} 10 & \text { SRS10_HUMAN } & 31.30 & 100.0 \%\end{array}$

(2)

$0.00 \% \quad 3.6 \%$ VTADVTSAVMGNPVTR $\begin{array}{lll}0.00 \% & 3.6 \% & \text { VTADVTSAVMGNPVTR } \\ 0.00 \% & 3.6 \% & \text { SQQPLKPQVHTPVATVK }\end{array}$ $0.01 \% \quad 18.8 \%$ TVQIEASTVEIEER $0.01 \% \quad 18.8 \%$ LTVVDTPGYGDAINCR $0.01 \% \quad 18.8 \%$ TIISYIDEQFER $0.01 \% \quad 18.8 \%$ VNIVPVIAK $0.01 \% \quad 18.8 \%$ ASIPFSVVGSNQLIEAK $0.00 \% \quad 3.4 \% \quad$ YLQEEVNINR

$0.00 \% \quad 3.4 \%$ VVNIVPVIAK $0.02 \% \quad 8.9 \%$ TGLIDYNQLALTAR $0.02 \% \quad 8.9 \%$ LIIAGTSAYAR $0.02 \% \quad 8.9 \%$ HADIVTTTTHK $0.02 \% \quad 8.9 \%$ SAITPGGLR $0.00 \% \quad 3.4 \%$ AACFAIQK $0.00 \% \quad 3.4 \%$ SIALTQAR $0.04 \% \quad 6.4 \% \quad$ SLSGSSPCPK

$0.04 \% \quad 6.4 \%$ SKDSLVQSCPGSLSLCAGVK

$0.04 \% \quad 6.4 \%$ SGSESSVDQKTVAR

$0.04 \% \quad 6.4 \%$ SGSSQELDVKPSASPQEL

$0.04 \% \quad 6.4 \%$ SPSVSSPEPAEK

$0.04 \% \quad 6.4 \%$ TAPAANLASR

$0.04 \% \quad 6.4 \%$ TPAIPTAVNLADSR

$0.04 \% \quad 6.4 \%$ TPAAAAAMNLASPR

$0.04 \% \quad 6.4 \%$ TAVAPSAVNLADPR

$0.04 \% \quad 6.4 \% \quad$ TPTAPAVNLAGAR

$0.04 \% \quad 6.4 \%$ SAHATAPVNIAGSR

$0.04 \% \quad 6.4 \%$ TAAALAPASLTSAR

$0.04 \% \quad 6.4 \%$ VPLSAYER

$0.06 \% \quad 41.9 \%$ IYVGNLPPDIR

$0.06 \% \quad 41.9 \%$ TKDIEDVFYK

$0.06 \% \quad 41.9 \%$ DIEDVFYK

$0.06 \% \quad 41.9 \%$ YGAIRDIDLK

$0.06 \% \quad 41.9 \%$ GGPPFAFVEFEDPRDAEDAVYGR

$0.06 \% \quad 41.9 \%$ DGYDYDGYR

$0.06 \% \quad 41.9 \%$ EAGDVCYADVYR

$0.06 \% \quad 41.9 \%$ DGTGVVEFVR

$0.06 \% \quad 41.9 \%$ DGTGVVEFVRK

$0.06 \% \quad 41.9 \%$ KEDMTYAVR

$0.06 \% \quad 41.9 \%$ SHEGETAYIR

$0.03 \% \quad 19.5 \%$ YLRPPNTSLFVR

$0.03 \% \quad 19.5 \%$ YGPIVDVYVPLDFYTR
$99.7 \% \quad 67.7$

$99.7 \% \quad 29.7$

$95.4 \% \quad 19.3$

$96.8 \% \quad 16.4$

$99.3 \% \quad 20.9$

$99.7 \% \quad 41.3$

$\% \quad 61.2$

$99.7 \% \quad 68.0$

$99.7 \% \quad 83.9$

$99.7 \% \quad 60.0$

$96.2 \% \quad 22.0$

$99.7 \% \quad 46.4$

$\begin{array}{lll}97.3 \% & 16.9\end{array}$

$99.7 \% \quad 31.9$

$99.7 \% \quad 57.0$

$99.7 \% \quad 46.2$

$99.7 \% \quad 29.4$

$\begin{array}{lll}99.4 \% & 29.6\end{array}$

$97.4 \% \quad 20.2$

$\begin{array}{ll}99.2 \% & 20.9 \\ 99.7 \% & 31.2\end{array}$

$\begin{array}{ll}99.4 \% & 25.9\end{array}$

$99.7 \% \quad 31.3$

$98.6 \% 25.6$

$99.7 \% \quad 38.3$

$98.3 \% 23.4$

$99.7 \% \quad 38.6$

$99.7 \% \quad 31.2$

$99.7 \% \quad 30.3$

$99.7 \% \quad 58.1$

$99.0 \% \quad 26.4$

$99.7 \% \quad 54.4$

$99.7 \% \quad 61.6$

$99.0 \% \quad 22.5$

$99.7 \% \quad 41.5$

$99.7 \% \quad 39.4$

$99.7 \% \quad 43.0$

$99.7 \% \quad 46.7$

$99.7 \% \quad 56.0$

$99.7 \% \quad 26.8$

$99.7 \% \quad 58.1$

$99.7 \% \quad 53.5$

$99.7 \% \quad 35.5$

$99.7 \% \quad 42.9$ 10.5 20.9

$\begin{array}{ll}0 & 41.3\end{array}$

$\begin{array}{ll}0.0 & 50.8\end{array}$

$\begin{array}{ll}5.0 & 19.5\end{array}$

$\begin{array}{ll}0 & 65.4\end{array}$

$\begin{array}{ll}0 & 83.7\end{array}$

50.0

$\begin{array}{ll}0.0 & 9.7\end{array}$

$\begin{array}{ll}25.0 & 43.5\end{array}$

$\begin{array}{ll}0 & 16.9\end{array}$

$\begin{array}{ll}0 & 31.9\end{array}$

\begin{tabular}{ll}
54.0 & 54.9 \\
\hline &
\end{tabular}

$\begin{array}{ll}.0 & 45.8\end{array}$

$\begin{array}{ll}0 & 21.9\end{array}$

\begin{tabular}{l}
13.5 \\
\hline
\end{tabular}

$8.0 \quad 8.4$

$\begin{array}{ll}0 & 14.9\end{array}$

$\begin{array}{ll}25.0 & 20.9\end{array}$

$\begin{array}{ll}25.0 & 25.5\end{array}$

$\begin{array}{ll}0 & 25.9\end{array}$

\begin{tabular}{ll}
27.1 \\
\hline
\end{tabular}

$\begin{array}{ll}23.0 & 23.7\end{array}$

37.4
25.0

\begin{tabular}{ll}
15.5 \\
\hline
\end{tabular}

. 38.6

\begin{tabular}{ll}
22.4 \\
\hline
\end{tabular}

$\begin{array}{ll}0 & 53.1\end{array}$

\begin{tabular}{ll}
22.9 \\
\hline
\end{tabular}

$\begin{array}{ll}5.0 & 52.0\end{array}$

$\begin{array}{ll}5.0 & 59.6\end{array}$

$25.0 \quad 21.8$

$\begin{array}{ll}0 & 28.8\end{array}$

$\begin{array}{ll}5.0 & 39.1\end{array}$

5.043 .0

$\begin{array}{ll}0 & 46.7\end{array}$

$\begin{array}{ll}5.0 & 44.4\end{array}$

$\begin{array}{ll}5.0 & 25.8\end{array}$

$\begin{array}{ll}5.0 & 50.7\end{array}$

$\begin{array}{ll}25.0 & 48.7\end{array}$

$\begin{array}{ll}25.0 & 35.5\end{array}$

$.0 \quad 42.9$

1231.62

1506.73

1197.53

1310.63

1633.82

1858.05

1603.82

1750.84

1513.75

952.62

1759.96

1277.65

1051.69

1548.84

1135.65

1223.64

871.50

908.47

859.50

1019.48

2093.04

1450.71

1901.92

1214.59

971.53

1425.77

1357.69

1381.74

1238.69

1351.71

1300.72

934.50

1256.70

1257.64

1028.49

1163.64

2541.17

1123.43

1417.61

1078.55

1206.65

1128.54

1162.55

1462.82

1916.98 $\begin{array}{cc}49 & 463 \\ 77 & 586 \\ 66 & 674 \\ 15 & 725 \\ 20 & 830 \\ 84 & 897 \\ 5 & 30 \\ 98 & 714 \\ 8 & 91 \\ 7 & 112 \\ 17 & 128 \\ 75 & 183 \\ 33 & 249 \\ 90 & 399 \\ 36 & 445 \\ 01 & 214 \\ 20 & 230 \\ 70 & 280 \\ 17 & 425 \\ 90 & 197 \\ 23 & 430 \\ 78 & 787 \\ 21 & 1040 \\ 17 & 1530 \\ 39 & 1556 \\ 27 & 1738 \\ 22 & 2231 \\ 47 & 2260 \\ 61 & 2274 \\ 75 & 2288 \\ 89 & 2301 \\ 43 & 2356 \\ 57 & 2370 \\ 85 & 2392 \\ 8 & 28 \\ 9 & 38 \\ 1 & 38 \\ 9 & 48 \\ 2 & 74 \\ 5 & 83 \\ 43 & 154 \\ 55 & 164 \\ 55 & 165 \\ 65 & 173 \\ 82 & 191 \\ 4 & 15 \\ 3 & 48 \\ & \end{array}$

Page 137 of Table S-1-6 
Serine/arginine-rich splicing factor $3 \mathrm{GN}=\mathrm{SRSF} 3$ SRSF3_HUMAN $19.33 \quad 100.0 \%$ Serine/arginine-rich splicing factor $3 \mathrm{GN}=\mathrm{SRSF} 3$ SRSF3_HUMAN $19.33 \quad 100.0 \%$ Serine/arginine-rich splicing factor $3 \mathrm{GN}=\mathrm{SRSF} 3 \mathrm{SRSF} 3$ HUMAN $19.33 \quad 100.0 \%$ Serine/arginine-rich splicing factor $3 \mathrm{GN}=\mathrm{SRSF} 3 \quad$ SRSF3_HUMAN $19.33 \quad 100.0 \%$ Serine/arginine-rich splicing factor $3 \mathrm{GN}=\mathrm{SRSF} 3$ SRSF3_HUMAN $19.33 \quad 100.0 \%$ Serine/arginine-rich splicing factor $3 \mathrm{GN}=\mathrm{SRSF} 3$ SRSF3_HUMAN $19.33 \quad 100.0 \%$ Serine/arginine-rich splicing factor 5 GN=SRSF5 SRSF5_HUMAN $31.26 \quad 100.0 \%$ Serine/arginine-rich splicing factor 5 GN=SRSF5 SRSF5_HUMAN $31.26 \quad 100.0 \%$ Serine/arginine-rich splicing factor 5 GN=SRSF5 SRSF5_HUMAN $31.26 \quad 100.0 \%$ Serine/arginine-rich splicing factor 5 GN=SRSF5 SRSF5_HUMAN $31.26 \quad 100.0 \%$ Serine/arginine-rich splicing factor 6 GN=SRSF6 SRSF6 HUMAN $39.59100 .0 \%$ Serine/arginine-rich splicing factor 6 GN=SRSF6 SRSF6_HUMAN $39.59 \quad 100.0 \%$ Serine/arginine-rich splicing factor $6 \mathrm{GN}=$ SRSF6 SRSF6_HUMAN $39.59 \quad 100.0 \%$ Serine/arginine-rich splicing factor 6 GN=SRSF6 SRSF6_HUMAN $39.59 \quad 100.0 \%$ Serine/arginine-rich splicing factor 6 GN=SRSF6 SRSF6_HUMAN $39.59 \quad 100.0 \%$ Serine/arginine-rich splicing factor 6 GN=SRSF6 SRSF6 HUMAN $39.59 \quad 100.0 \%$ Serine/arginine-rich splicing factor 6 GN=SRSF6 SRSF6_HUMAN $39.59 \quad 100.0 \%$ Serine/arginine-rich splicing factor 6 GN=SRSF6 SRSF6_HUMAN $39.59 \quad 100.0 \%$ Serine/arginine-rich splicing factor 7 GN=SRSF7 SRSF7_HUMAN 27.37 Serine/arginine-rich splicing factor $7 \mathrm{GN}=\mathrm{SRSF} 7$ SRSF7_HUMAN 27.37 Serine/arginine-rich splicing factor $7 \mathrm{GN}=$ SRSF7 SRSF7_HUMAN 27.37 Serine/arginine-rich splicing factor 7 GN=SRSF7 SRSF7_HUMAN 27.37 Serine/arginine-rich splicing factor $7 \mathrm{GN}=\mathrm{SRSF} 7$ SRSF7_HUMAN 27.37 Serine/arginine-rich splicing factor $7 \mathrm{GN}=$ SRSF7 SRSF7_HUMAN 27.37 Serine/arginine-rich splicing factor 7 GN=SRSF7 SRSF7_HUMAN 27.37 Serine/arginine-rich splicing factor $7 \mathrm{GN}=$ SRSF7 SRSF7_HUMAN 27.37 Serine/arginine-rich splicing factor $7 \mathrm{GN}=$ SRSF7 SRSF7 HUMAN 27.37 Serine/arginine-rich splicing factor $7 \mathrm{GN}=$ SRSF7 SRSF7_HUMAN 27.37 Serine/arginine-rich splicing factor 9 GN=SRSF9 SRSF9_HUMAN 25.54 Serine/arinine-rich splicing factor 9 GN=SRSF9 SRSF_HUMAN Serine/arginine-rich splicing factor 9 GN=SRSF9 SRSF9_HUMAN $25.54 \quad 100.0 \%$ Serine/arginine-rich splicing factor $9 \mathrm{GN}=$ SRSF9 SRSF9 HUMAN $25.54 \quad 100.0 \%$ Serine/arginine-rich splicing factor 9 GN=SRSF9 SRSF9_HUMAN $25.54 \quad 100.0 \%$ Serine/arginine-rich splicing factor 9 GN=SRSF9 SRSF9_HUMAN $25.54 \quad 100.0 \%$ Serine/arginine-rich splicing factor $9 \mathrm{GN}=$ SRSF9 SRSF9_HUMAN $25.54 \quad 100.0 \%$ Serine/threonine-protein kinase 38 GN=STK38 STK38_HUMAN $54.19 \quad 100.0 \%$ Serine/threonine-protein kinase $38 \mathrm{GN}=\mathrm{STK} 38$ STK38 HUMAN $54.19 \quad 100.0 \%$ Serine/threonine-protein kinase 38 GN=STK38 STK38_HUMAN $54.19 \quad 100.0 \%$ Serine/threonine-protein kinase 38 GN=STK38 STK38_HUMAN $54.19 \quad 100.0 \%$ Serine/threonine-protein kinase $38 \mathrm{GN}=$ STK38 STK38_HUMAN $54.19 \quad 100.0 \%$ Serine/threonine-protein kinase 38-like GN=STK38L ST38L_HUMAN $54.01 \quad 100.0 \%$

$25 \quad 0.03 \% \quad 19.5 \%$ GFAYVQFEDVR $0.03 \% \quad 19.5 \%$ QIEIQFAQGDR $0.03 \% \quad 19.5 \%$ QIEIQFAQGDRK

$\begin{array}{llllllll}99.7 \% & 41.0 & 25.0 & 38.5 & 1 & 0 & 0 & 1330.64\end{array}$ $99.7 \%$

$0.01 \% \quad 16.3 \%$ VGDVYIPR $\begin{array}{ll}99.7 \% & 56.4 \\ 99.7 \% & 29.5\end{array}$ $0.01 \% \quad 16.3 \%$ YGRPPDSHHSR $99.7 \% \quad 29.5$

$0.01 \% \quad 36.6 \%$ VYVGNLGNNGNKTELER $99.7 \% 33.1$ $0.01 \% \quad 36.6 \%$ AFGYYGPLR $0.01 \% \quad 36.6 \%$ NPPGFAFVEFEDPR

$0.01 \% \quad 36.6 \%$ VRVELSNGEK $0.01 \% \quad 36.6 \%$ NRGPPPSWGR $0.01 \% \quad 36.6 \%$ GPPPSWGR $0.02 \% \quad 18.0 \%$ LIVENLSSR $0.02 \% \quad 18.0 \%$ VSWQDLKDFMR $0.02 \% \quad 18.0 \%$ QAGEVTFADAHRPK $0.02 \% \quad 18.0 \%$ LNEGVVEFASYGDLK $0.06 \% \quad 20.3 \%$ DRDGYSYGSR $0.06 \% \quad 20.3 \%$ TEYRLIVENLSSR $0.06 \% \quad 20.3 \%$ LIVENLSSR

$0.06 \% \quad 20.3 \%$ QAGEVTYADAHK $0.06 \% \quad 20.3 \%$ QAGEVTYADAHKER $0.06 \% \quad 20.3 \%$ TNEGVIEFR

$0.06 \% \quad 20.3 \%$ ALDKLDGTEINGR $0.06 \% \quad 20.3 \%$ SNSPLPVPPSK $0.05 \% \quad 34.5 \%$ VYVGNLGTGAGK $99.7 \% \quad 31.7$ $99.7 \% \quad 41.6$ $99.7 \% \quad 44.5$ $99.7 \% \quad 40.3$ $95.3 \% \quad 18.3$ $99.7 \% \quad 54.6$ $99.7 \% \quad 31.6$ $99.7 \% \quad 40.2$ $99.7 \% \quad 62.3$ $99.7 \% \quad 34.0$ $\begin{array}{lll}99.7 \% & 29.2\end{array}$ $99.7 \% \quad 54.6$ $99.7 \% \quad 54.5$ $99.7 \% \quad 45.1$ $\begin{array}{lll}99.7 \% & 58.7\end{array}$ $99.7 \% 55.1$ $99.7 \% \quad 32.7$ $99.7 \% \quad 60.6$

$0.05 \% \quad 34.5 \%$ VYVGNLGTGAGKGELER $0.05 \% \quad 34.5 \%$ AFSYYGPLR

$0.05 \% \quad 34.5 \%$ NPPGFAFVEFEDPR

$99.7 \% \quad 55.1$

$99.7 \% \quad 55.9$

$99.7 \% \quad 41.6$

$\begin{array}{lll}0.05 \% & 34.5 \% & \text { NPPGFAFVEFEDPRDAEDAVR } \quad 99.7 \% \quad 34.3\end{array}$

$0.05 \% \quad 34.5 \%$ VRVELSTGMPR

$0.05 \% 34.5 \%$ VELSTGMPR

$0.05 \% \quad 34.5 \%$ RPFDPNDR

$0.05 \% \quad 34.5 \%$ RPFDPNDRCYECGEK

$0.05 \% \quad 34.5 \%$ GHYAYDCHR

$0.02 \% \quad 33.5 \%$ IYVGNLPTDVR

$0.02 \% 33.5 \%$ HGLVPFAFVR

$0.02 \% \quad 33.5 \%$ NGYDYGQCR

$0.02 \% 33.5 \%$ EAGDVCYADVQK

$0.02 \% \quad 33.5 \%$ DGVGMVEYLR

$0.02 \% \quad 33.5 \%$ SHEGETSYIR

$0.02 \% 33.5 \%$ GSPHYFSPFRPY

$0.01 \% \quad 10.8 \%$ DIKPDNLLLDSK

$0.01 \% \quad 10.8 \%$ LSDFGLCTGLK

$0.01 \% \quad 10.8 \%$ LSDFGLCTGLKK

$99.7 \% \quad 39.5$

$99.4 \% \quad 24.2$

$\begin{array}{lll}98.4 \% & 22.4\end{array}$

$99.2 \% \quad 19.3$

$98.6 \% \quad 22.2$

$99.7 \% \quad 39.8$

$99.7 \% \quad 31.4$

$99.7 \% \quad 28.9$

$99.7 \% \quad 45.5$

$99.6 \% \quad 27.2$

$99.7 \% 39.7$

$99.7 \% \quad 41.2$

$96.6 \% 17.5$

$99.7 \% \quad 46.8$

$99.7 \% \quad 52.2$

$0.01 \% \quad 10.8 \%$ NLNHSLPSDFTFQNMNSK

$0.01 \% \quad 10.8 \%$ RFEGLTAR

$0.02 \% \quad 13.6 \%$ LGLDDFESLK
$99.7 \% \quad 28.5$

$99.0 \% \quad 42.6$

$99.7 \% \quad 39.8$
1304.66

1432.75

918.50

1783.71

1308.62

1876.95

1043.53

1621.76

1130.62

1123.58

853.43

1030.59

1424.70

1526.77

1640.82

1175.51

1579.84

1030.59

1289.61

1574.76

1064.54

1401.73

1122.62

1135.61

1719.90

1073.54

1621.76

2378.10

1244.68

989.51

1016.49

1942.82

1178.48

1246.68

1142.65

1132.45

1354.59

1138.56

1178.54

1454.69

1370.75

1210.61

1338.71

2109.97

949.52

1136.58
$80 \quad 90$

80

$67 \quad 83$

2102

28

$\begin{array}{ll}29 & 37 \\ 44 & 57\end{array}$

$76 \quad 85$

$89 \quad 98$

$91 \quad 98$

$\begin{array}{ll}110 & 118 \\ 119 & 129\end{array}$

$130 \quad 143$

$144 \quad 158$

$76 \quad 85$

$112 \quad 12$

$132 \quad 143$

$32 \quad 145$

$146 \quad 154$

$162 \quad 174$

$13 \quad 24$

$13 \quad 29$

38

$45 \quad 58$

$\begin{array}{ll}45 & 65 \\ 7 & 87\end{array}$

$79 \quad 8$

$98 \quad 105$

$98 \quad 112$

$113 \quad 121$

$16 \quad 26$

$73 \quad 8$

$133 \quad 144$

$145 \quad 154$

$172 \quad 181$

$210 \quad 221$

$228 \quad 238$

$228 \quad 239$

$248 \quad 265$

$447 \quad 454$ 
Serine/threonine-protein kinase 38-like GN=STK38L ST38L_HUMAN $54.01 \quad 100.0 \%$ Serine/threonine-protein kinase 38-like GN=STK38L ST38L_HUMAN $54.01 \quad 100.0 \%$ Serine/threonine-protein kinase 38-like GN=STK38L ST38L_HUMAN 54.01 $100.0 \%$ Serine/threonine-protein kinase 38-like GN=STK38L ST38L HUMAN $54.01 \quad 100.0 \%$ Serine/threonine-protein kinase 38-like GN=STK38L ST38L_HUMAN $54.01 \quad 100.0 \%$ Serine/threonine-protein kinase 38-like GN=STK38L ST38L_HUMAN $54.01 \quad 100.0 \%$ Serine/threonine-protein kinase MARK2 GN=MARK2 MARK2_HUMAN $87.91 \quad 100.0 \%$ Serine/threonine-protein kinase MARK2 GN=MARK2 MARK2_HUMAN $87.91 \quad 100.0 \%$ Serine/threonine-protein kinase mTOR GN=MTOR MTOR HUMAN $288.90 \quad 100.0 \%$ Serine/threonine-protein kinase mTOR GN=MTOR MTOR_HUMAN $288.90 \quad 100.0 \%$ Serine/threonine-protein kinase mTOR GN=MTOR MTOR_HUMAN $288.90 \quad 100.0 \%$ Serine/threonine-protein kinase mTOR GN=MTOR MTOR_HUMAN $288.90 \quad 100.0 \%$ Serine/threonine-protein kinase mTOR GN=MTOR MTOR_HUMAN $288.90 \quad 100.0 \%$ Serine/threonine-protein kinase RIO1 GN=RIOK1 RIOK1_HUMAN $65.58 \quad 100.0 \%$ Serine/threonine-protein kinase RIO1 GN=RIOK1 RIOK1_HUMAN $65.58 \quad 100.0 \%$ Serine/threonine-protein kinase RIO1 GN=RIOK1 RIOK1_HUMAN $65.58 \quad 100.0 \%$ Serine/threonine-protein kinase RIO1 GN=RIOK1 RIOK1_HUMAN $65.58 \quad 100.0 \%$ Serine/threonine-protein kinase RIO1 GN=RIOK1 RIOK1_HUMAN $65.58 \quad 100.0 \%$ Serine/threonine-protein kinase RIO1 GN=RIOK1 RIOK1_HUMAN $65.58 \quad 100.0 \%$ Serine/threonine-protein kinase RIO1 GN=RIOK1 RIOK1_HUMAN $65.58 \quad 100.0 \%$ Serine/threonine-protein kinase RIO1 GN=RIOK1 RIOK1_HUMAN $65.58 \quad 100.0 \%$ Serine/threonine-protein kinase RIO1 GN=RIOK1 RIOK1_HUMAN $65.58 \quad 100.0 \%$ Serine/threonine-protein kinase RIO1 GN=RIOK1 RIOK1_HUMAN $65.58 \quad 100.0 \%$ Serine/threonine-protein kinase RIO1 GN=RIOK1 RIOK1_HUMAN $65.58 \quad 100.0 \%$ Serine/threonine-protein kinase RIO1 GN=RIOK1 RIOK1_HUMAN $65.58 \quad 100.0 \%$ Serine/threonine-protein kinase SMG1 GN=SMG1 SMG1_HUMAN $410.50 \quad 100.0 \%$ Serine/threonine-protein kinase SMG1 GN=SMG1 SMG1_HUMAN $410.50 \quad 100.0 \%$ Serine/threonine-protein kinase SMG1 GN=SMG1 SMG1_HUMAN $410.50 \quad 100.0 \%$ Serine/threonine-protein kinase SMG1 GN=SMG1 SMG1_HUMAN $410.50 \quad 100.0 \%$ Serine/threonine-protein kinase SMG1 GN=SMG1 SMG1 HUMAN $410.50 \quad 100.0 \%$ Serine/threonine-protein kinase SMG1 GN=SMG1 SMG1_HUMAN $410.50 \quad 100.0 \%$

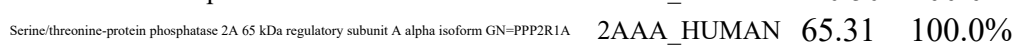
IRIA 2AAA_HUMAN $65.31 \quad 100.0 \%$ A 2AAA_HUMAN $65.31 \quad 100.0 \%$ 2AAA_HUMAN $65.31 \quad 100.0 \%$ A PP2AA_HUMAN $35.58 \quad 100.0 \%$ 2CA PP2AA_HUMAN $35.58 \quad 100.0 \%$ PPP6 HUMAN $35.14 \quad 100.0 \%$ C PPP6_HUMAN $35.14 \quad 100.0 \%$ PPP6_HUMAN $35.14 \quad 100.0 \%$ PPP6_HUMAN $35.14 \quad 100.0 \%$ PPP6_HUMAN $35.14 \quad 100.0 \%$ PPP6_HUMAN $35.14 \quad 100.0 \%$ $100.0 \%$ $100.0 \%$

6

6

4

4
4
4

$4 \quad$

$0.02 \% \quad 13.6 \%$ LGLDDFESLKVIGR $0.02 \% \quad 13.6 \%$ LSDFGLCTGLK

$0.02 \% \quad 13.6 \%$ LSDFGLCTGLKK

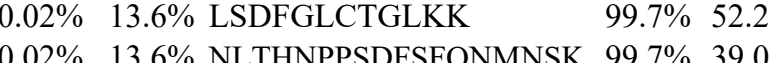
$0.02 \% \quad 13.6 \%$ ERPAAIPIEIK $0.02 \% \quad 13.6 \%$ RFEGLTQR

$0.00 \% \quad 3.6 \%$ VPASPLPGLER $0.00 \% \quad 3.6 \%$ TTPTPSTNSVLSTSTNR $0.01 \% \quad 2.3 \%$ DASAVSLSESK $0.01 \% \quad 2.3 \%$ LFDAPEAPLPSR $0.01 \% \quad 2.3 \%$ TLDQSPELR $0.01 \% \quad 2.3 \%$ TLVLLLGVDPSR $0.01 \% \quad 2.3 \%$ IQSIAPSLQVITSK $0.04 \% \quad 21.7 \%$ MSTPADKVLR $0.04 \% \quad 21.7 \%$ ATVEQVLDPR $0.04 \% \quad 21.7 \%$ ATVEQVLDPRTR $0.04 \% \quad 21.7 \%$ GIITEINGCISTGK $0.04 \% \quad 21.7 \%$ LNTAEIPCPEPIMLR $0.04 \% \quad 21.7 \%$ NVQLSESKAR $0.04 \% \quad 21.7 \%$ ELYLQVIQYMR $0.04 \% \quad 21.7 \%$ DCANVNDFFMR $0.04 \% \quad 21.7 \%$ HSVAVMTVR

$0.04 \% \quad 21.7 \%$ AMEIASQR

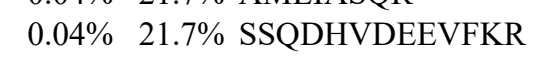
$0.04 \% \quad 21.7 \%$ TLNEVKNYER $0.01 \% \quad 1.9 \%$ SIEVQLLR $0.01 \% \quad 1.9 \%$ IKEQTVPIR $0.01 \% \quad 1.9 \%$ LLAQCSEVQLGK $0.01 \% \quad 1.9 \%$ KVVDNASQGEGVR $0.01 \% \quad 1.9 \%$ HYSVTPLGTR

$0.01 \% \quad 1.9 \%$ NLATSADTPPSTVPGTGK $0.01 \% \quad 8.0 \%$ LSTIALALGVER $0.01 \% \quad 8.0 \% \quad$ YMVADKFTELQK $0.01 \% \quad 8.0 \%$ VLAMSGDPNYLHR $0.01 \% \quad 8.0 \%$ MAGDPVANVR $0.00 \% \quad 8.4 \%$ QITQVYGFYDECLRK $0.00 \% \quad 8.4 \% \quad$ YSFLQFDPAPR $0.01 \% \quad 27.2 \%$ APLDLDKYVEIAR $\begin{array}{ll}0.01 \% & 27.2 \% \text { TGGQVPDTNYIFMGDFVDR } \\ 0.01 \% & 27.2 \% \text { QITQVYGFYDECQTK }\end{array}$ $0.01 \% \quad 27.2 \%$ VTNEFVHINNLK $0.01 \% \quad 27.2 \%$ LVTVWSAPNYCYR $0.01 \% 27.2 \%$ CGNIASIMVFK $0.03 \% 38.4 \%$ QALQLAACGLAGGSAAVLFSAVAVGKPR $0.03 \% \quad 38.4 \%$ NVESGEEELASK $0.03 \% 38.4 \%$ NVESGEEELASKLDHYK $0.03 \% \quad 38.4 \%$ HSQYHVDGSLEKDR
$99.7 \% \quad 40.2$

$99.0 \% \quad 36.8$

$99.7 \% \quad 28.6$

1236.73

1006.54

1135.65 $\begin{array}{llllllll}99.7 \% & 34.4 & 25.0 & 34.4 & 1 & 0 & 0 & 1763.88\end{array}$

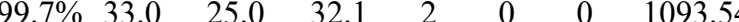
$\begin{array}{llll}99.7 \% & 34.4 & 25.0 & 29.3\end{array}$ $99.7 \% \quad 29.3 \quad 25.0 \quad 27.7 \quad 3$ $99.7 \% \quad 34.2 \quad 25.0 \quad 34.0$ $99.7 \% \quad 34.2 \quad 25.0 \quad 30.4$ $99.7 \% \quad 42.8 \quad 25.0 \quad 31.8$ $99.7 \% \quad 39.4 \quad 25.0 \quad 33.1$ $\begin{array}{llll}99.4 \% & 22.6 & 25.0 & 20.9\end{array}$ $99.7 \% \quad 67.2 \quad 25.0 \quad 63.6$ $99.7 \% \quad 41.7 \quad 25.0 \quad 39.4$ $\begin{array}{lllll}99.7 \% & 38.9 & 25.0 & 35.6 & 4\end{array}$ $99.7 \% \quad 53.2 \quad 25.0 \quad 48.0$ $\begin{array}{llll}99.7 \% & 60.2 & 25.0 & 60.2\end{array}$ $\begin{array}{llll}99.1 \% & 21.9 & 25.0 & 19.2\end{array}$ $\begin{array}{llll}99.0 \% & 36.9 & 25.0 & 13.8\end{array}$ $99.7 \% \quad 57.6 \quad 25.0 \quad 52.0$ $\begin{array}{llll}96.4 \% & 22.1 & 25.0 & 12.1\end{array}$ $\begin{array}{llll}99.0 \% & 33.1 & 25.0 & 14.4\end{array}$ $\begin{array}{llll}99.6 \% & 23.6 & 25.0 & 22.0\end{array}$ $\begin{array}{llll}99.6 \% & 27.5 & 25.0 & 24.1\end{array}$ $\begin{array}{llll}99.5 \% & 25.0 & 25.0 & 19.1\end{array}$ $\begin{array}{llll}96.2 \% & 20.2 & 25.0 & 12.1\end{array}$

1312.69 1058.55

1282.77

1484.87

1133.60

1127.61

1384.75

1462.76

1769.89

1131.61

1455.77

1404.57

1015.54

905.45

1575.74

1265.65

957.57

1083.65

1345.71

1358.70

1130.60

1713.87 $99.7 \% \quad 58.7$ $\begin{array}{lll}99.7 \% & 39.5\end{array}$ $99.7 \% \quad 46.8$ $99.7 \% \quad 34.6$ $99.4 \% 27.6$ $99.7 \% \quad 38.6$ $99.7 \% \quad 56.0$ $\begin{array}{ll}99.7 \% & 68.4 \\ 99.7 \% & 55.8\end{array}$ $99.7 \% \quad 63.2$ $99.7 \% \quad 30.7$ $99.7 \% \quad 51.0$

$\begin{array}{ll}25.0 & 29.8\end{array}$

$5.0 \quad 57.0$


Serpin B3 GN=SERPINB3

Serpin $B 3$ GN=SERPINB3

Serpin B3 GN=SERPINB3

Serpin B6 GN=SERPINB6

Serpin B6 GN=SERPINB6

Serpin $\mathrm{H} 1 \mathrm{GN}=$ SERPINH1

Serpin $\mathrm{H} 1 \mathrm{GN}=$ SERPINH1

Serpin H1 GN=SERPINH1

Serpin $\mathrm{H} 1 \mathrm{GN}=$ SERPINH1

Serpin $\mathrm{H} 1 \mathrm{GN}=$ SERPINH1

Serpin H1 GN=SERPINH1

Serpin $\mathrm{H} 1 \mathrm{GN}=$ SERPINH1

Serum albumin $\mathrm{GN}=\mathrm{ALB}$

Serum albumin $\mathrm{GN}=\mathrm{ALB}$

Serum albumin $\mathrm{GN}=\mathrm{ALB}$

Serum albumin $\mathrm{GN}=\mathrm{ALB}$

Serum albumin $\mathrm{GN}=\mathrm{ALB}$

Sestrin -2 GN $=$ SESN2

Sestrin-2 GN=SESN 2
SPB3 HUMAN $44.57 \quad 100.0 \%$ SPB3_HUMAN $44.57 \quad 100.0 \%$ SPB3_HUMAN $44.57 \quad 100.0 \%$ SPB6 HUMAN $42.62 \quad 100.0 \%$ SPB6_HUMAN $42.62 \quad 100.0 \%$ SERPH_HUMAN $46.44 \quad 100.0 \%$ SERPH HUMAN $46.44 \quad 100.0 \%$ SERPH_HUMAN $46.44 \quad 100.0 \%$ SERPH_HUMAN $46.44 \quad 100.0 \%$ SERPH HUMAN $46.44 \quad 100.0 \%$ SERPH_HUMAN $46.44 \quad 100.0 \%$ SERPH HUMAN $46.44 \quad 100.0 \%$ ALBU_HUMAN $69.37 \quad 100.0 \%$ ALBU_HUMAN $69.37 \quad 100.0 \%$ ALBU HUMAN $69.37 \quad 100.0 \%$ ALBU_HUMAN $69.37 \quad 100.0 \%$ ALBU HUMAN $69.37 \quad 100.0 \%$ SESN2 HUMAN $54.50 \quad 100.0 \%$ SESN2_HUMAN $54.50 \quad 100.0 \%$ ACDSB HUMAN $47.49 \quad 100.0 \%$$$
\begin{aligned}
& 8 \\
& 8 \\
& 11
\end{aligned}
$$

$\begin{array}{llll} & 25.0 & 37.2\end{array}$ $\begin{array}{llll}99.7 \% & 58.3 & 25.0 & 50.2\end{array}$

$0.03 \% \quad 38.4 \%$ QEEDSYEIFICHANVIR

$0.03 \% \quad 38.4 \%$ TLGDTGFMPPDK

$0.02 \% \quad 23.0 \%$ NVQLTENEIR

$0.02 \% \quad 23.0 \%$ QSLETICLLLAYK

$0.02 \% \quad 23.0 \%$ IKYPENFFLLR

$0.02 \% \quad 23.0 \%$ IYGFYDECK

$0.02 \% \quad 23.0 \%$ AHQVVEDGYEFFAK

$0.02 \% \quad 23.0 \%$ AHQVVEDGYEFFAKR

$0.01 \% \quad 26.0 \%$ IVQMTEAEVR

$0.01 \% \quad 26.0 \%$ ICGDIHGQYTDLLR

$0.01 \% \quad 26.0 \%$ QSLETICLLLAYK

$0.01 \% \quad 26.0 \%$ IKYPENFFLLR

$0.01 \% \quad 26.0 \%$ IYGFYDECK

$0.01 \% \quad 26.0 \%$ GVSFTFGADVVSK

$0.01 \% \quad 26.0 \%$ AHQVVEDGYEFFAK

$0.01 \% \quad 26.0 \%$ AHQVVEDGYEFFAKR

$0.01 \% \quad 25.7 \%$ TVDFTQDSNYLLTGGQDK

0.01\% $25.7 \%$ IYDLNKPEAEPK

$0.01 \% \quad 25.7 \%$ SIAFHSAVSLDPIK

$0.01 \% 25.7 \%$ YDYNSGEELESYK

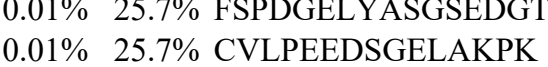

$0.00 \% \quad 9.2 \%$ VLHFDQVTENTTGK

$0.00 \% \quad 9.2 \%$ INSWVESQTNEK

$0.00 \% \quad 9.2 \%$ GLVLSGVLHK

$0.00 \% \quad 6.7 \%$ IAELLSPGSVDPLTR

$0.00 \% \quad 6.7 \%$ LVLVNAVYFR

$0.03 \% \quad 22.2 \%$ SAGLAFSLYQAMAK

$0.03 \% \quad 22.2 \%$ AVLSAEQLRDEEVHAGLGELLR $99.7 \% 57.9$

$\begin{array}{lllll}0.03 \% & 22.2 \% & \text { LGSRLYGPSSVSFADDFVR } & 99.7 \% & 39.4\end{array}$

$0.03 \% \quad 22.2 \%$ LYGPSSVSFADDFVR

$0.03 \% \quad 22.2 \%$ GVVEVTHDLQK

$0.03 \% 22.2 \%$ HLAGLGLTEAIDKNK

$0.03 \% \quad 22.2 \%$ DTQSGSLLFIGR

$\begin{array}{lll}0.12 \% & 7.6 \% & \text { CASLQKFGER } \\ 0.12 \% & 7.6 \% & \text { YICENQDSISSK }\end{array}$

\section{$0.12 \% \quad 7.6 \%$ KVPQVSTPTLVEVSR}

$0.12 \% \quad 7.6 \%$ CCTESLVNR

$0.00 \% \quad 4.8 \%$ GPSAFIPVEEVLR

$0.00 \% \quad 4.8 \%$ MQAALLYALR

$99.7 \% 51.2$

$99.7 \% 40.6$

$\begin{array}{llll}99.7 \% & 32.8\end{array}$

$99.7 \% \quad 44.0$

$\begin{array}{llll}99.7 \% & 32.4\end{array}$

$99.7 \% \quad 55.3$

$99.7 \% 49.3$

$99.7 \% \quad 51.6$

$99.7 \% \quad 42.7$

0.03\% $37.3 \%$ FAQEQIAPLVSTMDENSK $99.7 \% \quad 54.4$

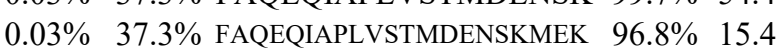

1551.85

1439.80

1194.51

1313.67
1639.78

1795.88

2001.94

1416.74

1484.81

1596.67

1900.86

1671.83

1588.80

1434.69

1022.64

1567.87

1193.70

1457.75

2405.28

2073.04

1659.80

1224.66

1579.88

1293.68

1195.59

1443.64

1639.94

1511.84

1138.50

1413.77
1149.64

2007.97 2428.14 


\begin{tabular}{|c|c|c|c|c|c|c|c|c|c|c|c|c|c|c|c|c|c|c|}
\hline trtbranched chain specific acyl-COA dehydrogenas & ACDSB_HUMAN & 47.49 & $100.0 \%$ & 13 & 16 & 29 & $0.03 \%$ & 37.3\% ATYLPQLTTEK & $99.7 \%$ & 33.9 & 25.0 & 33.9 & 2 & 0 & 0 & 1264.68 & 160 & 170 \\
\hline Short branched chain specific acyl-COA dehydrogenase, mitochondrial GN=ACADSB & ACDSB_HUMAN & 47.49 & $100.0 \%$ & 13 & 16 & 29 & $0.03 \%$ & $37.3 \%$ VGSFCLSEAGAGSDSFALK & $99.7 \%$ & 33.2 & 25.0 & 33.2 & 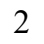 & 0 & 0 & 1902.89 & 171 & 89 \\
\hline Shortbranched chain specific acyl-CoA dehydrogenase, mitochondrial GN=ACADSB & ACDSB_HUMAN & 47.49 & $100.0 \%$ & 13 & 16 & 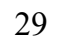 & $.03 \%$ & 37.3\% ADKEGDYYVLNGSK & $99.7 \%$ & 43.0 & 25.0 & 43.0 & & 0 & & 1558.74 & 192 & 205 \\
\hline Shortbranched chain specific acyl-CoA dehydrogenase, mitochondrial GN=ACADSB & ACDSB_HUMAN & 47.49 & $100.0 \%$ & 13 & 16 & 9 & $0.03 \%$ & $37.3 \%$ GITSFLVDR & $99.7 \%$ & 36.8 & 25.0 & 28.0 & & 0 & 0 & 1007.55 & 231 & 39 \\
\hline Shortbranched chain specific acyl-COA dehydrogenase, mitochondrial GN=ACADSB & ACDSB_HUMAN & 47.49 & $100.0 \%$ & 13 & 6 & 9 & $.03 \%$ & $37.3 \%$ ASSTCPLTFENVK & $99.7 \%$ & 55.6 & 25.0 & 50.5 & & 0 & 0 & 453.70 & 257 & 269 \\
\hline hortbranched chain specific acyl-COA dehydrogenase, mitochondrial GN=ACADSB & ACDSB_HUMAN & 47.49 & $100.0 \%$ & 13 & 16 & 9 & $0.03 \%$ & 37.3\% VPEANILGQIGHGYK & $99.7 \%$ & 53.0 & 25.0 & 48.8 & & & 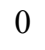 & 1595.85 & 270 & 284 \\
\hline Shortbranched chain specific acyl-CoA dehydrogenase, mitcchondrial GN=ACADSB & ACDSB_HUMAN & 47.49 & $100.0 \%$ & 13 & 16 & 9 & $0.03 \%$ & $37.3 \%$ YAIGSLNEGR & $99.7 \%$ & 65.6 & 25.0 & 49.0 & & 0 & 0 & 1079.55 & 285 & 294 \\
\hline Shortbranched chain specific acyl-CoA dehydrogenase, mitochondrial GN=ACADSB & ACDSB_HUMAN & 47.49 & $100.0 \%$ & 13 & 6 & 9 & $.03 \%$ & $37.3 \%$ LLTYNAAR & $99.0 \%$ & 46.1 & 25.0 & 33.2 & & 0 & 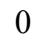 & 921.52 & 348 & 355 \\
\hline hortbranched chain specific acyl-COA dehydrogenase, mitochondrial GN=ACADSB & ACDSB_HUMAN & 47.49 & $100.0 \%$ & 13 & 16 & 9 & $0.03 \%$ & 37.3\% LLEAGKPFIK & $99.7 \%$ & 40.9 & 25.0 & 24.2 & & 0 & 0 & 1115.68 & 356 & 365 \\
\hline Shortbranched chain specific acyl-CoA dehydrogenase, mitochondrial GN=ACADSB & ACDSB_HUMAN & 47.49 & $100.0 \%$ & 13 & 16 & 29 & $0.03 \%$ & $37.3 \%$ YYASEIAGQTTSK & $99.7 \%$ & \#\#\#\# & 25.0 & 96.1 & & 0 & 0 & 1418.68 & 372 & 384 \\
\hline Shortbranched chain specific acyl-CoA dehydrogenase, mitochondrial GN=ACADSB & ACDSB_HUMAN & 47.49 & $100.0 \%$ & 13 & 16 & 29 & $0.03 \%$ & 37.3\% IGTIYEGASNIQLNTIAK & $99.7 \%$ & 76.7 & 25.0 & 76.7 & & 0 & 0 & 1906.03 & 409 & 426 \\
\hline Sideroflexin-1 GN=SFXN1 & SFXN1_HUMAN & 35.62 & $100.0 \%$ & 10 & 5 & 3 & $0.03 \%$ & $37.6 \%$ WDQSTFIGR & $99.3 \%$ & 61.2 & 25.0 & 0.0 & & 0 & & .54 & 16 & 24 \\
\hline Sideroflexin-1 GN=SFXN1 & SFXN1_HUMAN & 35.62 & $100.0 \%$ & 10 & 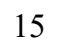 & 3 & $03 \%$ & $37.6 \%$ ANHFFTVTDPR & $99.7 \%$ & 30.1 & 25.0 & 23.8 & & - & & & 25 & 35 \\
\hline Sideroflexin-1 GN=SFXN1 & SFXN1_HUMAN & 35.62 & $100.0 \%$ & 10 & 15 & 23 & $0.03 \%$ & $37.6 \%$ NILLTNEQLESAR & $99.7 \%$ & 46.7 & 25.0 & 46.7 & & 0 & 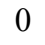 & .80 & 36 & 48 \\
\hline Sideroflexin-1 GN=SFXN1 & SFXN1_HUMAN & 35.62 & $100.0 \%$ & 10 & 15 & 3 & $0.03 \%$ & $37.6 \%$ YIYDSAFHPDTGEK & $99.7 \%$ & 78.4 & 25.0 & 77.3 & & 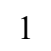 & 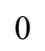 & .74 & 73 & 86 \\
\hline Sideroflexin-1 GN=SFXN1 & SFXN1_HUMAN & 35.62 & $100.0 \%$ & 10 & & 3 & $3 \%$ & $\%$ HVSPLIGR & $99.0 \%$ & 40.4 & 25.0 & 35.5 & & 0 & & & 171 & 178 \\
\hline Sideroflexin-1 GN=SFXN1 & SFXN1_HUMAN & 35.62 & $100.0 \%$ & 10 & 1 & 3 & $0.03 \%$ & AVAAANCINIPLMR & $99.7 \%$ & 32.8 & 25.0 & 32.8 & 1 & 2 & 0 & .09 & 179 & 197 \\
\hline Sideroflexin-1 GN=SFXN1 & SFXN1_HUMAN & 35.62 & $100.0 \%$ & 10 & 1 & 3 & $0.03 \%$ & $37.6 \%$ VGIPVTDENGNR & $99.7 \%$ & 34.5 & 25.0 & 34.5 & & 0 & 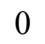 & .64 & 203 & 214 \\
\hline Sideroflexin-1 GN=SFXN1 & SFXN1_HUMAN & 5.62 & $00.0 \%$ & 0 & & 3 & $3 \%$ & $37.6 \%$ QAITQVVVSR & $99.0 \%$ & 22.6 & 25.0 & 21.7 & 1 & 0 & & & 224 & 233 \\
\hline $\mathrm{N}=\mathrm{SFXN} 1$ & SFXN1_HUMAN & 35.62 & 100 & 10 & & 3 & $3 \%$ & $37.6 \% \mathrm{~S}$ & $99.7 \%$ & 61.5 & 25.0 & 61.5 & 3 & 0 & 0 & & 291 & 305 \\
\hline Sideroflexin-1 GN=SFXN1 & SFXN1_HUMAN & 35.62 & $100.0 \%$ & 10 & 1 & 3 & $0.03 \%$ & $37.6 \%$ IQ & $99.7 \%$ & 28.5 & 25.0 & 25.5 & 1 & 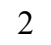 & 0 & 68 & 306 & 315 \\
\hline Sideroflexin-4 GN=SFXN4 & SFXN4_HUMAN & 38.00 & $\%$ & 6 & & 12 & $.01 \%$ & NVR & $99.7 \%$ & 47.8 & 25.0 & 42.0 & & 0 & & & 19 & 30 \\
\hline Sideroflexin-4 GN=SFXN4 & SFXN4_HUMAN & 38.00 & $\% \%$ & 6 & I & 2 & $1 \%$ & SSPASADQR & $99.7 \%$ & 66.6 & 25.0 & 66.6 & 2 & 0 & 0 & & 67 & 84 \\
\hline Sideroflexin-4 GN=SFXN4 & SFXN4_HUMAN & 38.00 & $100.0 \%$ & 6 & 7 & 2 & $0.01 \%$ & HPDSSNLIPK & $99.7 \%$ & 40.8 & 25.0 & 34.7 & r & 1 & 0 & .85 & 92 & 106 \\
\hline Sideroflexin-4 GN=SFXN4 & SFXN4_HUMAN & 8.00 & $\%$ & 6 & 7 & 2 & $1 \%$ & $\% \mathrm{~S}$ & $99.7 \%$ & 35.2 & 25.0 & 31.2 & & 0 & & & 156 & 164 \\
\hline Sideroflexin-4 GN=SFXN4 & SFXN4_HUMAN & 38.00 & $\%$ & 6 & 7 & 2 & $1 \%$ & EGNVLGHSR & $99.7 \%$ & 32.6 & 25.0 & 32.6 & 0 & 1 & 0 & & 224 & 239 \\
\hline Sideroflexin- 4 GN=SFXN4 & SFXN4_HUMAN & 38.00 & 100 & 6 & 7 & 2 & $\%$ & $24.9 \% \mathrm{IC}$ & $99.7 \%$ & 29.9 & 25.0 & 28.9 & 0 & 0 & 0 & & 322 & 335 \\
\hline Signal recognition particle receptor subunit beta $\mathrm{GN}=\mathrm{SRPRB}$ & SRPRB_HUMAN & 29.70 & 100 & 6 & 6 & 14 & $\%$ & $28.4 \% \mathrm{~A}$ & $99.7 \%$ & 40.0 & 25.0 & 40.0 & 2 & 0 & 0 & & 66 & 77 \\
\hline Signal recognition particle receptor subunit beta $\mathrm{GN}=\mathrm{SRPRB}$ & SRPRB_HUMAN & 29.70 & $100.0 \%$ & 6 & 6 & 14 & $2 \%$ & CAVYR & $99.7 \%$ & 79.4 & 25.0 & 79.4 & 2 & 0 & 0 & & 91 & 104 \\
\hline Signal recognition particle receptor subunit beta $\mathrm{GN}=\mathrm{SRPRB}$ & SRPRB_HUMAN & 29.70 & $100.0 \%$ & 6 & 6 & 14 & $0.02 \%$ & $28.4 \% \mathrm{NT}$ & $99.7 \%$ & 34.3 & 25.0 & 31.1 & 2 & 0 & 0 & & 171 & 181 \\
\hline Signal recognition particle receptor subunit beta $\mathrm{GN}=\mathrm{SRPRB}$ & SRPRB_HUMAN & 29.70 & 100 & 6 & 6 & 14 & $2 \%$ & $28.4 \% \mathrm{LIC}$ & $99.0 \%$ & 38.8 & 25.0 & 15.4 & 2 & 0 & 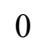 & & 192 & 199 \\
\hline Signal recognition particle receptor subunit beta $\mathrm{GN}=\mathrm{SRPRB}$ & SRPRB_HUMAN & 29.70 & $100.0 \%$ & 6 & 6 & 14 & $2 \%$ & DSSSTAPAQLGK & $99.7 \%$ & 55.5 & 25.0 & 55.5 & 2 & 0 & 0 & 90 & 209 & 227 \\
\hline Signal recognition particle receptor subunit beta $\mathrm{GN}=\mathrm{SRPRB}$ & SRPRB_HUMAN & 29.70 & $100.0 \%$ & 6 & 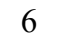 & 14 & $0.02 \%$ & $28.4 \%$ GDVGSA & $99.7 \%$ & 59.7 & 25.0 & 51.7 & 2 & 0 & 0 & & 253 & 265 \\
\hline Signal recognition particle subunit SRP68 GN=SRP68 & SRP68_HUMAN & 70.73 & $100.0 \%$ & 7 & 8 & 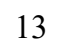 & $0.01 \%$ & $14.5 \%$ AAEKQVPGGGGGGGSGGGGGSGGGGSGGGR & $99.7 \%$ & 44.3 & 25.0 & 41.1 & c & 2 & 0 & & 2 & 31 \\
\hline Signal recognition particle subunit SRP68 GN=SRP68 & SRP68_HUMAN & 70.73 & $100.0 \%$ & 7 & 8 & 3 & $.01 \%$ & $14.5 \%$ QVPGGGGGGGSGGGGGSGGGGSGGGR & $99.7 \%$ & 40.8 & 25.0 & 38.8 & 2 & 0 & 0 & 80 & 6 & 31 \\
\hline Signal recognition particle subunit SRP68 GN=SRP68 & SRP68_HUMAN & 70.73 & $100.0 \%$ & 7 & 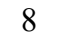 & 3 & $.01 \%$ & IKENERPSAGSK & $98.4 \%$ & 22.9 & 25.0 & 14.4 & 0 & 2 & 0 & & 32 & 49 \\
\hline Signal recognition particle subunit SRP68 GN=SRP68 & SRP68_HUMAN & 70.73 & $100.0 \%$ & 7 & 8 & 13 & & $14.5 \%$ VEEIS & $99.7 \%$ & 29.4 & 25.0 & 29.4 & 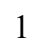 & 0 & 0 & & 237 & 245 \\
\hline Signal recognition particle subunit SRP68 GN=SRP68 & SRP68_HUMAN & 70.73 & $100.0 \%$ & 7 & 8 & 3 & $0.01 \%$ & 14.5\% ALLQQQPEDDSKR & $99.7 \%$ & 32.4 & 25.0 & 32.4 & 1 & 2 & 0 & .78 & 405 & 417 \\
\hline Signal recognition particle subunit SRP68 GN=SRP68 & SRP68_HUMAN & 70.73 & $100.0 \%$ & 7 & 8 & 13 & $0.01 \%$ & NSDAGAFK & $99.7 \%$ & 58.2 & 25.0 & 50.4 & 1 & 0 & 0 & 63 & 492 & 504 \\
\hline Signal recognition particle subunit SRP68 GN=SRP68 & SRP68_HUMAN & 70.73 & & 7 & 8 & 13 & & $14.5 \%$ SGLTGYIK & $99.0 \%$ & 34.0 & 25.0 & 25.6 & 2 & 0 & 0 & & 613 & 620 \\
\hline Signal recognition particle subunit SRP72 GN=SRP72 & SRP72_HUMAN & 74.61 & $100.0 \%$ & 3 & 3 & 4 & $0.00 \%$ & $5.7 \%$ VLANNSLSFEK & $99.7 \%$ & 41.4 & 25.0 & 32.5 & 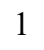 & 0 & 0 & .65 & 74 & 84 \\
\hline Signal recognition particle subunit SRP72 GN=SRP72 & SRP72_HUMAN & 74.61 & $100.0 \%$ & 3 & 3 & 4 & $0.00 \%$ & $5.7 \%$ LTNAEGVEFK & $99.7 \%$ & 28.6 & 25.0 & 22.4 & 1 & 0 & 0 & 1107.57 & 288 & 297 \\
\hline Signal recognition particle subunit SRP72 GN=SRP72 & SRP72_HUMAN & 74.61 & & 3 & 3 & 4 & & ATAGASSELDASK & $99.7 \%$ & 87.5 & 25.0 & 86.6 & 2 & 0 & 0 & & 601 & 617 \\
\hline Sister chromatid cohesion protein PDS5 homolog A GN=PDS5A & PDS5A_HUMAN & 150.84 & $100.0 \%$ & 5 & 5 & 11 & $0.01 \%$ & $5.0 \%$ LLVACCLADIFR & $99.7 \%$ & 62.1 & 25.0 & 60.0 & 2 & 0 & 0 & 1450.75 & 88 & 99 \\
\hline Sister chromatid cohesion protein PDS5 homolog A GN=PDS5A & PDS5A_HUMAN & 150.84 & $100.0 \%$ & 5 & 5 & 11 & $0.01 \%$ & $5.0 \%$ DLALVNDQLLGFVR & $99.7 \%$ & 61.4 & 25.0 & 60.0 & 2 & 0 & 0 & 1572.87 & 391 & 404 \\
\hline ister chromatid cohesion protein PDS5 homolog A GN=PDS5A & PDS5A_HUMAN & 150.84 & $100.0 \%$ & 5 & 5 & 11 & & $5.0 \%$ NTGHKIETDLPQIR & $99.0 \%$ & 24.1 & 25.0 & 23.8 & 0 & 2 & 0 & 1621.87 & 704 & 717 \\
\hline Sister chromatid cohesion protein PDS5 homolog A GN=PDS5A & PDS5A_HUMAN & 150.84 & $100.0 \%$ & 5 & 5 & 11 & $0.01 \%$ & $5.0 \%$ STLIPILHQK & $99.7 \%$ & 32.2 & 25.0 & 32.2 & 4 & 0 & 0 & 1149.70 & 718 & 727 \\
\hline
\end{tabular}



Small subunit processome component 20 homolog GN=UTP20 UTP20_HUMAN $318.40 \quad 100.0 \%$ SNW domain-containing protein $1 \mathrm{GN}=\mathrm{SNW} 1 \mathrm{SNW} 1$ HUMAN $61.50 \quad 100.0 \%$ SNW domain-containing protein $1 \mathrm{GN}=\mathrm{SNW} 1 \mathrm{SNW} 1$ HUMAN $61.50 \quad 100.0 \%$ SNW domain-containing protein $1 \mathrm{GN}=\mathrm{SNW} 1 \mathrm{SNW} 1$ HUMAN $61.50 \quad 100.0 \%$ SNW domain-containing protein $1 \mathrm{GN}=\mathrm{SNW} 1$ SNW1_HUMAN $61.50 \quad 100.0 \%$ SNW domain-containing protein $1 \mathrm{GN}=\mathrm{SNW} 1$ SNW1_HUMAN $61.50 \quad 100.0 \%$ SNW domain-containing protein $1 \mathrm{GN}=\mathrm{SNW} 1 \mathrm{SNW} 1$ HUMAN $61.50 \quad 100.0 \%$ Sodium/potassium-transporting ATPase subunit alpha-1 GN=ATP1A1 AT1A1_HUMAN $112.90 \quad 100.0 \%$ Sodium/potassium-transporting ATPase subunit alpha-1 GN=ATP1A1 AT1A1_HUMAN $112.90 \quad 100.0 \%$ Sodium/potassium-transporting ATPase subunit alpha-1 GN=ATPIA1 AT1A1_HUMAN $112.90 \quad 100.0 \%$ Sodium/potassium-transporting ATPase subunit alpha-1 GN=ATP1A1 AT1A1_HUMAN $112.90 \quad 100.0 \%$ Sodium/potassium-transporting ATPase subunit alpha-1 GN=ATP1A1 AT1A1_HUMAN $112.90 \quad 100.0 \%$ Sodium/potassium-transporting ATPase subunit alpha-1 GN=ATP1A1 AT1A1_HUMAN $112.90 \quad 100.0 \%$ Sodium/potassium-transporting ATPase subunit alpha-1 GN=ATP1A1 AT1A1_HUMAN $112.90 \quad 100.0 \%$ Sodium/potassium-transporting ATPase subunit alpha-1 GN=ATP1A1 AT1A1_HUMAN $112.90 \quad 100.0 \%$ Sodium/potassium-transporting ATPase subunit alpha-1 GN=ATPIA1 AT1A1_HUMAN $112.90 \quad 100.0 \%$ Sodium/potassium-transporting ATPase subunit alpha-1 GN=ATP1A1 AT1A1_HUMAN $112.90 \quad 100.0 \%$ Sodium/potassium-transporting ATPase subunit alpha-1 GN=ATP1A1 AT1A1_HUMAN $112.90 \quad 100.0 \%$ Solute carrier family 25 member $33 \mathrm{GN}=$ SLC25A33 S2533_HUMAN $35.38 \quad 100.0 \%$ Solute carrier family 25 member $33 \mathrm{GN}=$ SLC25A33 S2533 HUMAN $35.38 \quad 100.0 \%$ Solute carrier family 25 member $40 \mathrm{GN}=$ SLC25A40 S2540_HUMAN $38.13 \quad 100.0 \%$ Solute carrier family 25 member $40 \mathrm{GN}=$ SLC25A40 S2540_HUMAN $38.13 \quad 100.0 \%$ Solute carrier family 25 member $40 \mathrm{GN}=\mathrm{SLC} 25 \mathrm{~A} 40 \mathrm{~S} 2540$ HUMAN $38.13 \quad 100.0 \%$ Sorting nexin-1 GN=SNX1 Sorting nexin $-1 \mathrm{GN}=\mathrm{SNX} 1$ SNX1_HUMAN $59.07 \quad 100.0 \%$ SNX1_HUMAN $59.07 \quad 100.0 \%$ Spectrin beta chain, non-erythrocytic $1 \mathrm{GN}=$ SPTBN1 SPTB2_HUMAN $274.61 \quad 100.0 \%$ Spectrin beta chain, non-erythrocytic 1 GN=SPTBN1 SPTB2_HUMAN $274.61 \quad 100.0 \%$ Spectrin beta chain, non-erythrocytic $1 \mathrm{GN}=$ SPTBN1 SPTB2 HUMAN $274.61 \quad 100.0 \%$ Spermatid perinuclear RNA-binding protein GN=STRBP STRBP_HUMAN $73.65 \quad 100.0 \%$ Spermatid perinuclear RNA-binding protein GN=STRBP STRBP_HUMAN $73.65 \quad 100.0 \%$ Spermatid perinuclear RNA-binding protein GN=STRBP STRBP_HUMAN $73.65 \quad 100.0 \%$ Spermatid perinuclear RNA-binding protein GN=STRBP STRBP_HUMAN $73.65 \quad 100.0 \%$ Spermatid perinuclear RNA-binding protein GN=STRBP STRBP HUMAN $73.65 \quad 100.0 \%$ Spermatid perinuclear RNA-binding protein GN=STRBP STRBP_HUMAN $73.65 \quad 100.0 \%$ Spermatid perinuclear RNA-binding protein GN=STRBP STRBP_HUMAN $73.65 \quad 100.0 \%$ Spermatid perinuclear RNA-binding protein GN=STRBP STRBP HUMAN $73.65 \quad 100.0 \%$ Spermatid perinuclear RNA-binding protein GN=STRBP STRBP_HUMAN $73.65 \quad 100.0 \%$

4
4
4

4

3

3
2
2

2

7

$\begin{array}{ll}6 & 7 \\ 6 & 7 \\ 6 & 7\end{array}$

$\begin{array}{cc}6 & 7 \\ 6 & 7 \\ 11 & 1\end{array}$

6

11

11
11
11

11

11

2
2
3

3

3
3

3
3

3

\begin{tabular}{|c|c|c|c|c|c|}
\hline $0.01 \%$ & $5.0 \%$ LLSAMLVSEGDLTEQKR & $99.7 \%$ & 29.5 & 25.0 & 28.8 \\
\hline $0.01 \%$ & $5.0 \%$ LLVACCLADIFR & $99.7 \%$ & 62.1 & 25.0 & 60.0 \\
\hline $0.01 \%$ & $5.0 \%$ YALQSAAGKDAAK & $99.7 \%$ & 41.9 & 25.0 & 35.6 \\
\hline $0.01 \%$ & $5.0 \%$ STTYSLESPKDPVLPAR & $99.5 \%$ & 23.4 & 25.0 & 21.1 \\
\hline $0.01 \%$ & $5.0 \% \quad$ FFTQPDKNFSNTK & $99.0 \%$ & 24.5 & 25.0 & 24.5 \\
\hline $0.01 \%$ & $5.0 \%$ TTNVLGAVNKPLSSAGK & $98.9 \%$ & 23.4 & 25.0 & 23.4 \\
\hline $0.01 \%$ & 48.6\% QPCQPPPVCPTPK & $99.7 \%$ & 41.4 & 25.0 & 38.3 \\
\hline $0.01 \%$ & 48.6\% СРЕРСРРРК & $99.7 \%$ & 44.8 & 25.0 & 44.4 \\
\hline $0.01 \%$ & 48.6\% CPPVTPSPPCQPK & $98.1 \%$ & 17.9 & 25.0 & 17.9 \\
\hline $0.00 \%$ & $0.9 \%$ LGSESQYSPTPLLK & $99.2 \%$ & 20.1 & 25.0 & 20.1 \\
\hline $0.00 \%$ & $0.9 \%$ LAVSAQSEPAR & $99.7 \%$ & 55.0 & 25.0 & 50.2 \\
\hline $0.01 \%$ & $13.1 \%$ SRQTSLVSSR & $99.7 \%$ & 33.5 & 25.0 & 28.8 \\
\hline $0.01 \%$ & 13.1\% AADKLAPAQYIR & $99.7 \%$ & 46.5 & 25.0 & 45.4 \\
\hline $0.01 \%$ & 13.1\% GYTIPLDKR & $99.7 \%$ & 35.9 & 25.0 & 23.1 \\
\hline $0.01 \%$ & 13.1\% GLQTVHINENFAK & $99.6 \%$ & 24.3 & 25.0 & 24.3 \\
\hline $0.01 \%$ & $13.1 \%$ LAEALYIADR & $99.7 \%$ & 48.1 & 25.0 & 43.6 \\
\hline $0.01 \%$ & 13.1\% TSNEVQYDQRLFNQSK & $99.5 \%$ & 24.0 & 25.0 & 24.0 \\
\hline $0.03 \%$ & $15.4 \%$ VDNSSLTGESEPQTR & $99.7 \%$ & 39.2 & 25.0 & 39.0 \\
\hline $0.03 \%$ & $15.4 \%$ SPDFTNENPLETR & $99.7 \%$ & 66.1 & 25.0 & 63.0 \\
\hline $0.03 \%$ & 15.4\% NIAFFSTNCVEGTAR & $99.7 \%$ & 68.5 & 25.0 & 68.5 \\
\hline $0.03 \%$ & 15.4\% GIVVYTGDRTVMGR & $97.9 \%$ & 16.5 & 25.0 & 16.5 \\
\hline $0.03 \%$ & 15.4\% AVFQANQENLPILK & $99.7 \%$ & 28.2 & 25.0 & 26.0 \\
\hline $0.03 \%$ & 15.4\% AVAGDASESALLK & $99.7 \%$ & 57.7 & 25.0 & 53.7 \\
\hline $0.03 \%$ & 15.4\% GVGIISEGNETVEDIAAR & $99.7 \%$ & 66.3 & 25.0 & 66.3 \\
\hline $0.03 \%$ & $15.4 \%$ LNIPVSQVNPR & $99.7 \%$ & 44.5 & 25.0 & 44.5 \\
\hline $0.03 \%$ & 15.4\% LIIVEGCQR & $99.7 \%$ & 34.9 & 25.0 & 28.3 \\
\hline $0.03 \%$ & $15.4 \%$ QGAIVAVTGDGVNDSPALKK & $98.5 \%$ & 18.2 & 25.0 & 18.2 \\
\hline $0.03 \%$ & 15.4\% ADIGVAMGIAGSDVSK & $99.7 \%$ & 48.8 & 25.0 & 48.8 \\
\hline $0.00 \%$ & $5.3 \%$ AVYFACYSK & $99.7 \%$ & 29.5 & 25.0 & 29.1 \\
\hline $0.00 \%$ & $5.3 \%$ GLFAQLIR & $99.0 \%$ & 27.9 & 25.0 & 13.7 \\
\hline $0.00 \%$ & $12.1 \%$ LQAQNNPLPK & $99.7 \%$ & 47.3 & 25.0 & 31.2 \\
\hline $0.00 \%$ & $12.1 \%$ LGENETCIPIVAGIVAR & $99.7 \%$ & 36.2 & 25.0 & 36.2 \\
\hline $0.00 \%$ & $12.1 \%$ FGAVTVISPLELIR & $99.7 \%$ & 49.1 & 25.0 & 25.9 \\
\hline $0.00 \%$ & 4.8\% VTTQTSLPLFR & $97.8 \%$ & 16.2 & 25.0 & 16.2 \\
\hline $0.00 \%$ & $4.8 \%$ AVGTQTLSGAGLLK & $99.7 \%$ & 56.1 & 25.0 & 50.2 \\
\hline $0.01 \%$ & $1.6 \%$ YKEVAELTR & $99.4 \%$ & 20.9 & 25.0 & 20.9 \\
\hline $0.01 \%$ & 1.6\% QALQDTLALYK & $99.6 \%$ & 30.7 & 25.0 & 20.4 \\
\hline $0.01 \%$ & $1.6 \%$ SQNIVTDSSSLSAEAIR & $99.7 \%$ & 65.0 & 25.0 & 65.0 \\
\hline $0.01 \%$ & $16.2 \%$ SFANDDRHVMVK & $97.1 \%$ & 17.0 & 25.0 & 16.4 \\
\hline $0.01 \%$ & $16.2 \%$ CLNALASLR & $99.6 \%$ & 26.0 & 25.0 & 20.5 \\
\hline $0.01 \%$ & $16.2 \%$ ANGLKSCVIVLR & $99.1 \%$ & 37.8 & 25.0 & 0.0 \\
\hline $0.01 \%$ & $16.2 \%$ LSAFGQIYK & $99.7 \%$ & 36.4 & 25.0 & 31.5 \\
\hline $0.01 \%$ & 16.2\% LNQIRPGLQYK & $99.7 \%$ & 42.2 & 25.0 & 36.7 \\
\hline $0.01 \%$ & $16.2 \%$ TAKLHVAVK & $99.7 \%$ & 42.0 & 25.0 & 41.2 \\
\hline $0.01 \%$ & $16.2 \%$ NPVMELNEK & $99.7 \%$ & 38.4 & 25.0 & 32.3 \\
\hline $0.01 \%$ & $16.2 \%$ GLKYELISETGGSHDK & $99.0 \%$ & 24.4 & 25.0 & 24.4 \\
\hline $0.01 \%$ & $16.2 \%$ YELISETGGSHDKR & $99.7 \%$ & 32.0 & 25.0 & 29.6 \\
\hline
\end{tabular}

Page 142 of Table S-1-6 
Spermatid perinuclear RNA-binding protein GN=STRBP STRBP_HUMAN $73.65 \quad 100.0 \%$ (100.0\% Spermidine synthase GN=SRM Spermidine synthase $\mathrm{GN}=\mathrm{SRM}$ Spermidine synthase GN=SRM Spermidine synthase GN=SRM Spermidine synthase GN=SRM Spermidine synthase GN=SRM SPEE HUMAN $33.82 \quad 100.0 \%$ SPEE HUMAN $33.82 \quad 100.0 \%$ SPEE_HUMAN $33.82 \quad 100.0 \%$ SPEE_HUMAN $33.82 \quad 100.0 \%$ SPEE HUMAN $33.82 \quad 100.0 \%$ SPEE_HUMAN $33.82 \quad 100.0 \%$ Sphingomyelin phosphodiesterase $4 \mathrm{GN}=$ SMPD4 NSMA3 HUMAN $93.3599 .6 \%$ Sphingomyelin phosphodiesterase 4 GN=SMPD4 NSMA3_HUMAN $93.35 \quad 99.6 \%$ Spindlin-1 GN=SPIN1

Spindlin-1 GN=SPIN1 SPIN1_HUMAN $29.60 \quad 100.0 \%$ SPIN1_HUMAN $29.60 \quad 100.0 \%$ SPIN1_HUMAN $29.60 \quad 100.0 \%$ Spindlin-1 GN=SPIN1 DX39B_HUMAN $48.99 \quad 100.0 \%$ $\begin{array}{lll}\text { Spliceosome RNA helicase DDX39B GN=DDX39 } & \\ \text { Spliceosome RNA helicase DDX39B GN=DDX39B DX39B_HUMAN } 48.99 & 100.0 \%\end{array}$ $\begin{array}{llll}\text { Spliceosome RNA helicase DDX39B GN=DDX39B DX39B_HUMAN } & 48.99 & 100.0 \% \\ \text { Spliceosome RNA helicase DDX39B GN=DDX39B } & \text { DX39B_HUMAN } 48.99 & 100.0 \%\end{array}$ Spliceosome RNA helicase DDX39B GN=DDX39B DX39B HUMAN $48.99 \quad 100.0 \%$ Spliceosome RNA helicase DDX39B GN=DDX39B DX39B_HUMAN $48.99 \quad 100.0 \%$ Spliceosome RNA helicase DDX39B GN=DDX39B DX39B_HUMAN $48.99 \quad 100.0 \%$ Splicing factor $3 \mathrm{~B}$ subunit $1 \mathrm{GN}=\mathrm{SF} 3 \mathrm{~B} 1 \quad \mathrm{SF} 3 \mathrm{~B} 1 \mathrm{HUMAN} 145.84 \quad 100.0 \%$ Splicing factor $3 \mathrm{~B}$ subunit $1 \mathrm{GN}=\mathrm{SF} 3 \mathrm{~B} 1$ Splicing factor $3 \mathrm{~B}$ subunit $1 \mathrm{GN}=\mathrm{SF} 3 \mathrm{~B} 1$ Splicing factor $3 \mathrm{~B}$ subunit $1 \mathrm{GN}=\mathrm{SF} 3 \mathrm{~B} 1$ Splicing factor $3 \mathrm{~B}$ subunit $1 \mathrm{GN}=\mathrm{SF} 3 \mathrm{~B} 1$ Splicing factor $3 \mathrm{~B}$ subunit $1 \mathrm{GN}=\mathrm{SF} 3 \mathrm{~B} 1$ Splicing factor $3 B$ subunit $1 \mathrm{GN}=\mathrm{SF} 3 \mathrm{~B} 1$ Splicing factor $3 \mathrm{~B}$ subunit $1 \mathrm{GN}=\mathrm{SF} 3 \mathrm{~B} 1$ Splicing factor $3 \mathrm{~B}$ subunit $1 \mathrm{GN}=\mathrm{SF} 3 \mathrm{~B} 1$ Splicing factor $3 \mathrm{~B}$ subunit $1 \mathrm{GN}=\mathrm{SF} 3 \mathrm{~B} 1$ Splicing factor $3 \mathrm{~B}$ subunit $1 \mathrm{GN}=\mathrm{SF} 3 \mathrm{~B} 1$ Splicing factor $3 B$ subunit $1 \mathrm{GN}=\mathrm{SF} 3 \mathrm{~B} 1$ Splicing factor $3 \mathrm{~B}$ subunit $1 \mathrm{GN}=\mathrm{SF} 3 \mathrm{~B} 1$ Splicing factor $3 \mathrm{~B}$ subunit $1 \mathrm{GN}=\mathrm{SF} 3 \mathrm{~B} 1$ Splicing factor $3 B$ subunit $1 \mathrm{GN}=\mathrm{SF} 3 \mathrm{~B} 1$ Splicing factor $3 \mathrm{~B}$ subunit $1 \mathrm{GN}=\mathrm{SF} 3 \mathrm{~B} 1$ Splicing factor $3 \mathrm{~B}$ subunit $1 \mathrm{GN}=\mathrm{SF} 3 \mathrm{~B} 1$ Splicing factor $3 \mathrm{~B}$ subunit $1 \mathrm{GN}=\mathrm{SF} 3 \mathrm{~B} 1$ Splicing factor $3 \mathrm{~B}$ subunit $1 \mathrm{GN}=\mathrm{SF} 3 \mathrm{~B} 1$ Splicing factor $3 \mathrm{~B}$ subunit $1 \mathrm{GN}=\mathrm{SF} 3 \mathrm{~B} 1$ Splicing factor $3 \mathrm{~B}$ subunit $1 \mathrm{GN}=\mathrm{SF} 3 \mathrm{~B} 1$ Splicing factor $3 \mathrm{~B}$ subunit $1 \mathrm{GN}=\mathrm{SF} 3 \mathrm{~B} 1$ Splicing factor $3 \mathrm{~B}$ subunit $3 \mathrm{GN}=\mathrm{SF} 3 \mathrm{~B} 3$ Splicing factor $3 \mathrm{~B}$ subunit $3 \mathrm{GN}=\mathrm{SF} 3 \mathrm{~B} 3$ Splicing factor $3 \mathrm{~B}$ subunit $3 \mathrm{GN}=\mathrm{SF} 3 \mathrm{~B} 3$ Splicing factor $3 \mathrm{~B}$ subunit $3 \mathrm{GN}=\mathrm{SF} 3 \mathrm{~B} 3$ Splicing factor $3 \mathrm{~B}$ subunit $3 \mathrm{GN}=\mathrm{SF} 3 \mathrm{~B} 3$ Splicing factor $3 \mathrm{~B}$ subunit $3 \mathrm{GN}=\mathrm{SF} 3 \mathrm{~B} 3$
SF3B1_HUMAN $145.84 \quad 100.0 \% \quad 22$ SF3B1_HUMAN $145.84 \quad 100.0 \% \quad 22$ SF3B1_HUMAN $145.84 \quad 100.0 \% \quad 22$ SF3B1_HUMAN $145.84 \quad 100.0 \% \quad 22$ SF3B1_HUMAN $145.84 \quad 100.0 \% \quad 22$ SF3B1_HUMAN $145.84 \quad 100.0 \% \quad 22$ SF3B1_HUMAN $145.84 \quad 100.0 \% \quad 22$ SF3B1_HUMAN $145.84 \quad 100.0 \% \quad 22$ SF3B1_HUMAN $145.84 \quad 100.0 \% \quad 22$ SF3B1_HUMAN $145.84 \quad 100.0 \% \quad 22$ SF3B1_HUMAN $145.84 \quad 100.0 \% \quad 22$ SF3B1_HUMAN $145.84 \quad 100.0 \% \quad 22$ SF3B1_HUMAN $145.84 \quad 100.0 \% \quad 22$ SF3B1_HUMAN $145.84 \quad 100.0 \% \quad 22$ SF3B1_HUMAN $145.84 \quad 100.0 \% \quad 22$ SF3B1_HUMAN $145.84 \quad 100.0 \% \quad 22$ SF3B1_HUMAN $145.84 \quad 100.0 \% \quad 22$ SF3B1_HUMAN $145.84 \quad 100.0 \% \quad 22$ SF3B1_HUMAN $145.84 \quad 100.0 \% \quad 22$ SF3B1_HUMAN $145.84 \quad 100.0 \% \quad 22$ SF3B1_HUMAN $145.84 \quad 100.0 \% \quad 22$ SF3B3_HUMAN $135.58 \quad 100.0 \%$ SF3B3 HUMAN $135.58 \quad 100.0 \%$ SF3B3_HUMAN $135.58 \quad 100.0 \%$ SF3B3_HUMAN $135.58 \quad 100.0 \%$ SF3B3_HUMAN $135.58 \quad 100.0 \%$ SF3B3_HUMAN $135.58 \quad 100.0 \%$
SAALAALEK

$\begin{array}{llllllll}99.7 \% & 40.1 & 25.0 & 29.6 & 4 & 0 & 0 & 1280.62\end{array}$ $99.7 \% \quad 33.9$

$99.0 \% \quad 39.4$

$99.7 \% \quad 57.3$

$0.01 \% \quad 25.5 \%$ KVLIIGGGDGGVLR

$\begin{array}{lll}95.3 \% & 19.3\end{array}$

$0.01 \% \quad 25.5 \%$ FLPGMAIGYSSSK

$0.01 \% \quad 25.5 \%$ NPSTNFQEPVQPLTQQQVAQMQLK

$0.01 \% \quad 25.5 \%$ YYNSDVHR

$0.01 \% \quad 25.5 \%$ AAFVLPEFAR

$0.00 \% \quad 2.8 \%$ YAPDKQAPGSDSQPR

$99.0 \% 38.6$

$99.7 \% \quad 36.5$

$95.8 \% \quad 14.9$

$97.2 \% 23.9$

$0.00 \% \quad 2.8 \%$ LFVGFLNR

$0.01 \% \quad 14.9 \%$ SRADAGHAGVSANMMK

$0.01 \% \quad 14.9 \%$ SSVGPSKPVSQPR

$0.01 \% \quad 14.9 \%$ VSALEVLPDR

$0.01 \% \quad 12.4 \%$ ELAFQISK

$0.01 \% \quad 12.4 \%$ VAVFFGGLSIK

$0.01 \% \quad 12.4 \%$ YQQFKDFQR

$0.01 \% \quad 12.4 \%$ RILVATNLFGR

$0.01 \% \quad 12.4 \%$ ILVATNLFGR

$0.01 \% \quad 12.4 \%$ GLAITFVSDENDAK

$0.06 \% \quad 15.8 \%$ VVNGAAASQPPSKR

$0.06 \% \quad 15.8 \%$ RWDQTADQTPGATPK

$0.06 \% \quad 15.8 \%$ WDQTADQTPGATPK

$99.7 \% \quad 38.6$

$99.7 \% \quad 64.8$

$99.7 \% \quad 58.2$

$\begin{array}{lll}99.0 \% & 27.8\end{array}$

$97.1 \% \quad 18.2$

$96.7 \% 19.1$

$99.6 \% \quad 25.8$

$99.7 \% \quad 59.0$

$99.7 \% \quad 36.3$

$99.7 \% \quad 35.2$

$99.1 \% \quad 18.8$

$99.7 \% \quad 47.7$

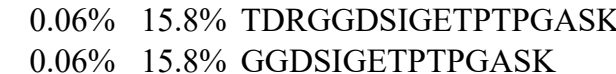

$49 \quad 0.06 \% \quad 15.8 \%$ GKGLAAFLK

$49 \quad 0.06 \% \quad 15.8 \%$ EVMLILIR

$49 \quad 0.06 \% \quad 15.8 \%$ TEILPPFFK

$49 \quad 0.06 \% \quad 15.8 \%$ QLVDTTVELANK

$49 \quad 0.06 \% \quad 15.8 \%$ QLVDTTVELANKVGAAEIISR

$49 \quad 0.06 \% \quad 15.8 \%$ VGAAEIISR

$49 \quad 0.06 \% \quad 15.8 \%$ VRQQAADLISR

$49 \quad 0.06 \% \quad 15.8 \%$ QQAADLISR

$49 \quad 0.06 \% \quad 15.8 \%$ AIVNVIGMHK

$49 \quad 0.06 \% \quad 15.8 \%$ MTPPIKDLLPR

$49 \quad 0.06 \% \quad 15.8 \%$ VQENCIDLVGR

$49 \quad 0.06 \% \quad 15.8 \%$ IADRGAEYVSAR

$49 \quad 0.06 \% \quad 15.8 \%$ RATVNTFGYIAK

$49 \quad 0.06 \% \quad 15.8 \%$ ATVNTFGYIAK

$49 \quad 0.06 \% \quad 15.8 \%$ VPELNVQNGVLK

$49 \quad 0.06 \% \quad 15.8 \%$ MLQYCLQGLFHPAR

$99.7 \% \quad 40.4$

$99.7 \% \quad 45.6$

$99.2 \% \quad 22.0$

$99.0 \% \quad 31.3$

$99.7 \% \quad 33.5$

$99.7 \% \quad 56.4$

$\begin{array}{ll}99.7 \% & 30.8 \\ 99.7 \% & 71.3\end{array}$

$99.7 \% \quad 51.9$

$\begin{array}{ll}99.7 \% & 51.9 \\ 99.7 \% & 36.5\end{array}$

$99.7 \% \quad 36.3$

$98.7 \% \quad 19.5$

$99.7 \% \quad 48.0$

$99.6 \% \quad 25.7$

$99.1 \% \quad 24.2$

$99.7 \% \quad 56.3$

$99.7 \% \quad 53.5$

$99.7 \% \quad 32.9$

$0.06 \% \quad 15.8 \%$ IYNSIYIGSQDALIAHYPR $\quad 99.7 \% \quad 43.2$

$\begin{array}{lll}99.7 \% & 60.3\end{array}$

$99.7 \% \quad 54.9$

$99.7 \% 53.1$

$\begin{array}{lll}99.7 \% & 54.3\end{array}$

$99.7 \% \quad 48.3$

$99.7 \% \quad 57.2$

1053.47

1120.61

1616.77

965.56

1634.74

1325.72

1098.62

935.52

1137.67

1259.62

1259.76

1103.66

1479.73

1381.75

1671.81

1515.71

1745.83

1373.65

904.56

986.61

1091.61

1330.72

2227.23

915.53

1256.71

1001.54

1097.61

1296.73

1302.65

1307.67

1340.73

1184.63

1309.75

1733.86

2194.13

$0.05 \% \quad 7.3 \%$ NFGDQPDIR

$0.05 \% \quad 7.3 \% \quad$ FLAVGLVDNTVR

$0.05 \% \quad 7.3 \%$ TVLDPVTGDL SDTRTR

$0.05 \% \quad 7.3 \%$ SVAGGFVYTYK 
Splicing factor 3B subunit $3 \mathrm{GN}=\mathrm{SF} 3 \mathrm{~B} 3 \quad$ SF3B3_HUMAN $135.58 \quad 100.0 \%$ Splicing factor 3B subunit 3 GN=SF3B3 SF3B3_HUMAN $135.58 \quad 100.0 \%$ Splicing factor U2AF $35 \mathrm{kDa}$ subunit GN=U2AF1 U2AF1_HUMAN $27.87 \quad 100.0 \%$ Splicing factor U2AF $35 \mathrm{kDa}$ subunit GN=U2AF1 U2AF1 HUMAN $27.87 \quad 100.0 \%$ Splicing factor U2AF $35 \mathrm{kDa}$ subunit GN=U2AF1 U2AF1_HUMAN $27.87 \quad 100.0 \%$ Splicing factor U2AF $35 \mathrm{kDa}$ subunit GN=U2AF1 U2AF1_HUMAN $27.87 \quad 100.0 \%$ Splicing factor U2AF $35 \mathrm{kDa}$ subunit GN=U2AF1 U2AF1_HUMAN $27.87 \quad 100.0 \%$ Splicing factor U2AF $35 \mathrm{kDa}$ subunit GN=U2AF1 U2AF1_HUMAN $27.87 \quad 100.0 \%$ Splicing factor $\mathrm{U} 2 \mathrm{AF} 35 \mathrm{kDa}$ subunit $\mathrm{GN}=\mathrm{U} 2 \mathrm{AF} 1 \mathrm{U} 2 \mathrm{AF} 1 \_$HUMAN $27.87 \quad 100.0 \%$ Splicing factor U2AF $65 \mathrm{kDa}$ subunit GN=U2AF2 U2AF2_HUMAN $53.50 \quad 100.0 \%$ Splicing factor U2AF $65 \mathrm{kDa}$ subunit GN=U2AF2 U2AF2_HUMAN $53.50 \quad 100.0 \%$ Splicing factor U2AF $65 \mathrm{kDa}$ subunit GN=U2AF2 U2AF2_HUMAN $53.50 \quad 100.0 \%$ Splicing factor U2AF $65 \mathrm{kDa}$ subunit GN=U2AF2 U2AF2_HUMAN $53.50 \quad 100.0 \%$ Splicing factor U2AF $65 \mathrm{kDa}$ subunit GN=U2AF2 U2AF2_HUMAN $53.50 \quad 100.0 \%$ Splicing factor U2AF $65 \mathrm{kDa}$ subunit GN=U2AF2 U2AF2_HUMAN $53.50 \quad 100.0 \%$ Splicing factor U2AF $65 \mathrm{kDa}$ subunit GN=U2AF2 U2AF2_HUMAN $53.50 \quad 100.0 \%$ Splicing factor U2AF $65 \mathrm{kDa}$ subunit GN=U2AF2 U2AF2_HUMAN $53.50 \quad 100.0 \%$ Splicing factor U2AF $65 \mathrm{kDa}$ subunit GN=U2AF2 U2AF2_HUMAN $53.50 \quad 100.0 \%$ Splicing factor, arginine/serine-rich $15 \mathrm{GN}=\mathrm{SCAF} 4$ SFR15_HUMAN $125.87 \quad 100.0 \%$ Splicing factor, arginine/serine-rich $15 \mathrm{GN}=\mathrm{SCAF} 4 \mathrm{SFR} 15$ _HUMAN $125.87 \quad 100.0 \%$ Splicing factor, proline- and glutamine-rich GN=SFPQ SFPQ_HUMAN $76.15 \quad 100.0 \%$ Splicing factor, proline- and glutamine-rich GN=SFPQ SFPQ_HUMAN $76.15 \quad 100.0 \%$ Splicing factor, proline- and glutamine-rich GN=SFPQ SFPQ_HUMAN $76.15 \quad 100.0 \%$ Splicing factor, proline- and glutamine-rich GN=SFPQ SFPQ_HUMAN $76.15 \quad 100.0 \%$ Splicing factor, proline- and glutamine-rich $\mathrm{GN}=\mathrm{SFPQ}$ SFPQ HUMAN $76.15 \quad 100.0 \%$ Splicing factor, proline- and glutamine-rich GN=SFPQ SFPQ_HUMAN $76.15 \quad 100.0 \%$ $\begin{array}{llll}\text { SRSF protein kinase } 1 \mathrm{GN}=\text { SRPK1 SRPK1_HUMAN } & 74.33 \quad 100.0 \%\end{array}$ SRSF protein kinase $1 \mathrm{GN}=$ SRPK1 SRPK1_HUMAN $74.33 \quad 100.0 \%$ Staphylococcal nuclease domain-containing protein $1 \mathrm{GN}=\mathrm{SND} 1$ SND1_HUMAN $102.00 \quad 100.0 \%$ Staphylococcal nuclease domain-containing protein $1 \mathrm{GN}=\mathrm{SND} 1$ SND1_HUMAN $102.00 \quad 100.0 \%$ Stomatin-like protein 2, mitochondrial GN=STOML2 STML2_HUMAN $38.53 \quad 100.0 \%$ Stomatin-like protein 2, mitochondrial GN=STOML2 STML2_HUMAN $38.53 \quad 100.0 \%$ Stomatin-like protein 2, mitochondrial GN=STOML2 STML2_HUMAN $38.53 \quad 100.0 \%$ Stomatin-like protein 2, mitochondrial GN=STOML2 STML2_HUMAN $38.53 \quad 100.0 \%$ Stomatin-like protein 2, mitochondrial GN=STOML2 STML2_HUMAN $38.53 \quad 100.0 \%$ Stomatin-like protein 2, mitochondrial GN=STOML2 STML2_HUMAN $38.53 \quad 100.0 \%$ Stomatin-like protein 2, mitochondrial GN=STOML2 STML2_HUMAN $38.53 \quad 100.0 \%$ Stomatin-like protein 2, mitochondrial GN=STOML2 STML2_HUMAN $38.53 \quad 100.0 \%$ Stomatin-like protein 2, mitochondrial GN=STOML2 STML2_HUMAN $38.53 \quad 100.0 \%$ Stress-70 protein, mitochondrial GN=HSPA9 GRP75_HUMAN $73.68 \quad 100.0 \%$ Stress-70 protein, mitochondrial GN=HSPA9 GRP75_HUMAN $73.68 \quad 100.0 \%$ Stress-70 protein, mitochondrial GN=HSPA9 GRP75_HUMAN $73.68 \quad 100.0 \%$ Stress-70 protein, mitochondrial GN=HSPA9 GRP75_HUMAN $73.68 \quad 100.0 \%$ Stress-70 protein, mitochondrial GN=HSPA9 GRP75_HUMAN $73.68 \quad 100.0 \%$ Stress-70 protein, mitochondrial GN=HSPA9 GRP75_HUMAN $73.68 \quad 100.0 \%$ Stress-70 protein, mitochondrial GN=HSPA9 GRP75_HUMAN $73.68 \quad 100.0 \%$ Stress-70 protein, mitochondrial GN=HSPA9 GRP75_HUMAN $73.68 \quad 100.0 \%$

6

6
6

6

2

2

2

2
9

18

8

18

\section{$\begin{array}{lll}7.3 \% & \text { TPVEEVPAAIAPFQGR } \\ & 7.3 \% & \text { NVSEELDRTPPEVSK }\end{array}$}

$0.03 \% \quad 39.2 \%$ VNCSFYFK

$0.03 \% \quad 39.2 \%$ NPQNSSQSADGLR

$0.03 \% \quad 39.2 \%$ YGEVEEMNVCDNLGDHLVGNVYVK

$0.03 \% \quad 39.2 \%$ AVIDLNNR

$0.03 \% \quad 39.2 \%$ WFNGQPIHAELSPVTDFR

$0.03 \% \quad 39.2 \%$ QYEMGECTR

$0.03 \% 39.2 \%$ GGFCNFMHLKPISR

$0.02 \% \quad 22.3 \%$ GAKEEHGGLIR

$0.02 \% \quad 22.3 \%$ SVDETTQAMAFDGIIFQGQSLK

$0.02 \% \quad 22.3 \%$ AFNLVKDSATGLSK

$0.02 \% \quad 22.3 \%$ SIEIPRPVDGVEVPGCGK

$0.02 \% \quad 22.3 \%$ IFVEFTSVFDCQK

$0.02 \% \quad 22.3 \%$ AMQGLTGRK

$0.02 \% \quad 22.3 \%$ FANRVVVTK

22.3\% YCDPDSYHR

$0.02 \% \quad 22.3 \%$ YCDPDSYHRR

$0.00 \% \quad 2.5 \%$ HQFGTDKDVFGPR

$0.00 \% \quad 2.5 \%$ DLSIGNPIPTVVSGAR

$0.01 \% \quad 8.8 \%$ GFGFIKLESR

$0.01 \% \quad 8.8 \%$ FATHAAALSVR

$0.01 \% \quad 8.8 \%$ AVVIVDDRGR

$0.01 \% \quad 8.8 \%$ STGKGIVEFASKPAAR

$0.01 \% \quad 8.8 \%$ GIVEFASKPAAR

$0.01 \% \quad 8.8 \%$ FGQGGAGPVGGQGPR

$0.00 \% \quad 3.5 \%$ STAGNFLVNPLEPK

$0.00 \% \quad 3.5 \%$ HFTEDIQTR

$0.00 \% \quad 2.6 \%$ LGTLSPAFSTR

$0.00 \% \quad 2.6 \%$ VITEYLNAQESAK

$0.02 \% \quad 37.9 \%$ NTVVLFVPQQEAWVVER

$0.02 \% 37.9 \%$ ILEPGLNILIPVLDR

0.02\% 37.9\% ASYGVEDPEYAVTQLAQTTMR

$0.02 \% \quad 37.9 \%$ ATVLESEGTR

$0.02 \% 37.9 \%$ ESAINVAEGKK

$0.02 \% 37.9 \%$ QAQILASEAEK

$0.02 \% \quad 37.9 \%$ AEQINQAAGEASAVLAK

$0.02 \% 37.9 \%$ APVPGTPDSLSSGSSR

$0.02 \% \quad 37.9 \%$ DVQGTDASLDEELDRVK

$0.07 \% \quad 29.2 \%$ VLENAEGAR

0.07\% 29.2\% TTPSVVAFTADGER

$0.07 \% \quad 29.2 \%$ QAVTNPNNTFYATK

$0.07 \% \quad 29.2 \%$ QAVTNPNNTFYATKR

$0.07 \% \quad 29.2 \%$ RYDDPEVQK

$0.07 \% \quad 29.2 \%$ NVPFKIVR

$0.07 \% \quad 29.2 \%$ ASNGDAWVEAHGK

$0.07 \% \quad 29.2 \%$ MKETAENYLGHTAK
$99.7 \% \quad 64.1$ $94.7 \% \quad 16.1$ $99.0 \% \quad 49.9$ $99.7 \% \quad 54.1$ $\begin{array}{ll}99.7 \% & 54.7 \\ 99.0 \% & 48.3\end{array}$ $99.0 \% \quad 48.3$ $99.7 \% \quad 52.8$ $99.7 \% \quad 34.8$ $99.7 \% \quad 56.2$ $99.7 \% \quad 37.9$ $99.7 \% \quad 49.9$ $\begin{array}{ll}99.7 \% & 39.5 \\ 99.7 \% & 46.2\end{array}$ $\begin{array}{llll}99.4 \% & 32.2\end{array}$ $99.7 \% \quad 37.8$ $99.3 \% \quad 22.0$ $97.0 \% \quad 16.4$ $99.3 \% \quad 23.5$ $99.1 \% \quad 19.4$ $99.7 \% \quad 36.8$ $99.7 \% \quad 31.9$ $99.7 \% \quad 37.4$ $99.7 \% \quad 32.7$ $99.7 \% \quad 37.3$ $99.7 \% \quad 46.0$ $99.4 \% \quad 22.8$ $99.7 \% \quad 29.9$ $95.9 \% \quad 21.8$ $\begin{array}{lll}99.6 \% & 26.3\end{array}$

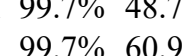
$99.7 \% 74.9$ $\begin{array}{ll}99.7 \% & 55.1 \\ 99.7 \% & 55.4\end{array}$ $99.7 \% \quad 55.4$ $99.6 \% \quad 26.3$ $\begin{array}{ll}99.7 \% & 47.0\end{array}$ $99.7 \% \quad 43.0$ $\begin{array}{rr}99.7 \% & 61.0 \\ 99.7 \% & 65.5\end{array}$ $\begin{array}{lll}99.7 \% & 88.3\end{array}$ $99.7 \% \quad 79.3$ $99.7 \% \quad 37.4$ $99.7 \% \quad 44.9$ $99.0 \% \quad 25.2$ $\begin{array}{lll}99.7 \% & 49.2\end{array}$ $99.7 \% \quad 39.0$
2114.05

1173.47

1663.82

1166.63

2386.16

1450.79

1908.99

1619.78

961.52

1033.62

1212.47

1368.58

1503.73

1595.88

1153.64

1143.63

1099.62

1618.89

1245.70

1341.67

1486.79

1146.55

1149.63

1465.75

2014.08

1675.02

2330.10

1062.54

1145.62

1187.63

1670.87

1514.74

1889.91

958.50

1450.72

1568.77

1724.87

1149.55

972.60

1341.62 1592.77

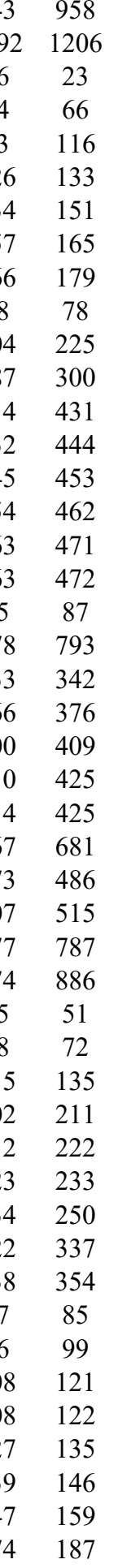


Stress-70 protein, mitochondrial GN=HSPA9 GRP75_HUMAN $73.68 \quad 100.0 \% \quad 18$

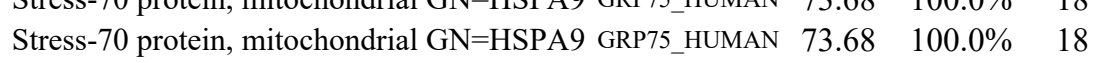
Stress-70 protein, mitochondrial GN=HSPA9 GRP75_HUMAN $73.68 \quad 100.0 \% \quad 18$ Stress-70 protein, mitochondrial GN=HSPA9 GRP75 HUMAN $73.68 \quad 100.0 \%$ Stress-70 protein, mitochondrial GN=HSPA9 GRP75_HUMAN $73.68 \quad 100.0 \% \quad 18$ Stress-70 protein, mitochondrial GN=HSPA9 GRP75_HUMAN $73.68 \quad 100.0 \% \quad 18$ Stress-70 protein, mitochondrial GN=HSPA9 GRP75_HUMAN $73.68 \quad 100.0 \% \quad 18$ Stress-70 protein, mitochondrial GN=HSPA9 GRP75_HUMAN $73.68 \quad 100.0 \% \quad 18$ Stress-70 protein, mitochondrial GN=HSPA9 GRP75 HUMAN $73.68 \quad 100.0 \%$ Stress-70 protein, mitochondrial GN=HSPA9 GRP75_HUMAN $73.68 \quad 100.0 \% \quad 18$ Structural maintenance of chromosomes protein 1A GN=SMC1A SMC1A_HUMAN $143.24 \quad 100.0 \%$ Structural maintenance of chromosomes protein $1 \mathrm{~A}$ GN=SMC1A SMC1A HUMAN $143.24 \quad 100.0 \%$ Structural maintenance of chromosomes protein $1 \mathrm{~A}$ GN=SMC1A SMC1A_HUMAN $143.24 \quad 100.0 \%$ Structural maintenance of chromosomes protein $1 \mathrm{~A}$ GN=SMC1A SMC1A_HUMAN $143.24 \quad 100.0 \%$ Structural maintenance of chromosomes protein $1 \mathrm{~A}$ GN=SMC1A SMC1A_HUMAN $143.24 \quad 100.0 \%$ Structural maintenance of chromosomes protein $1 \mathrm{~A}$ GN=SMC1A SMC1A_HUMAN $143.24 \quad 100.0 \%$ Structural maintenance of chromosomes protein $1 \mathrm{~A}$ GN=SMC1A SMC1A HUMAN $143.24 \quad 100.0 \%$ Structural maintenance of chromosomes protein $1 \mathrm{~A}$ GN=SMC1A SMC1A_HUMAN $143.24 \quad 100.0 \%$ Structural maintenance of chromosomes protein 1A GN=SMC1A SMC1A_HUMAN $143.24 \quad 100.0 \%$ Structural maintenance of chromosomes protein 1A GN=SMC1A SMC1A_HUMAN $143.24 \quad 100.0 \%$ Structural maintenance of chromosomes protein $1 \mathrm{~A}$ GN=SMC1A SMC1A_HUMAN $143.24 \quad 100.0 \%$ Structural maintenance of chromosomes protein $1 \mathrm{~A}$ GN=SMC1A SMC1A HUMAN $143.24 \quad 100.0 \%$ Structural maintenance of chromosomes protein 1A GN=SMC1A SMC1A_HUMAN $143.24 \quad 100.0 \%$ Structural maintenance of chromosomes protein $1 \mathrm{~A}$ GN=SMC1A SMC1A_HUMAN $143.24 \quad 100.0 \%$ Structural maintenance of chromosomes protein $1 \mathrm{~A}$ GN=SMC1A SMC1A HUMAN $143.24 \quad 100.0 \%$ Structural maintenance of chromosomes protein $1 \mathrm{~A}$ GN=SMC1A SMC1A_HUMAN $143.24 \quad 100.0 \%$ Structural maintenance of chromosomes protein 1A GN=SMC1A SMC1A_HUMAN $143.24 \quad 100.0 \%$ Structural maintenance of chromosomes protein $1 \mathrm{~A}$ GN=SMC1A SMC1A_HUMAN $143.24 \quad 100.0 \%$ Structural maintenance of chromosomes protein $1 \mathrm{~A}$ GN=SMC1A SMC1A_HUMAN $143.24 \quad 100.0 \%$ Structural maintenance of chromosomes protein $2 \mathrm{GN}=\mathrm{SMC} 2 \mathrm{SMC} 2 \mathrm{HUMAN} 135.66100 .0 \%$ Structural maintenance of chromosomes protein $2 \mathrm{GN}=\mathrm{SMC} 2 \mathrm{SMC2}$ HUMAN $135.66 \quad 100.0 \%$ Structural maintenance of chromosomes protein $2 \mathrm{GN}=\mathrm{SMC2}$ SMC2_HUMAN $135.66 \quad 100.0 \%$ Structural maintenance of chromosomes protein $2 \mathrm{GN}=\mathrm{SMC} 2 \mathrm{SMC} 2 \mathrm{HUMAN} 135.66 \quad 100.0 \%$ Structural maintenance of chromosomes protein $2 \mathrm{GN}=\mathrm{SMC} 2 \mathrm{SMC2}$ HUMAN $135.66 \quad 100.0 \%$ Structural maintenance of chromosomes protein $2 \mathrm{GN}=\mathrm{SMC} 2 \mathrm{SMC} 2 \mathrm{HUMAN} 135.66100 .0 \%$ Structural maintenance of chromosomes protein $3 \mathrm{GN}=\mathrm{SMC} 3 \mathrm{SMC} 3$ HUMAN $141.55100 .0 \%$ Structural maintenance of chromosomes protein $3 \mathrm{GN}=\mathrm{SMC} 3 \mathrm{SMC} 3$ _HUMAN $141.55 \quad 100.0 \%$ Structural maintenance of chromosomes protein $3 \mathrm{GN}=\mathrm{SMC} 3 \mathrm{SMC} 3$ HUMAN $141.55 \quad 100.0 \%$ Structural maintenance of chromosomes protein $3 \mathrm{GN}=\mathrm{SMC} 3 \mathrm{SMC} 3$ _HUMAN $141.55 \quad 100.0 \%$ Structural maintenance of chromosomes protein $3 \mathrm{GN}=\mathrm{SMC} 3 \mathrm{SMC} 3$ HUMAN $141.55 \quad 100.0 \%$ Structural maintenance of chromosomes protein $3 \mathrm{GN}=\mathrm{SMC} 3 \mathrm{SMC} 3 \mathrm{HUMAN} 141.55100 .0 \%$ Structural maintenance of chromosomes protein $3 \mathrm{GN}=\mathrm{SMC} 3 \mathrm{SMC} 3$ _HUMAN $141.55100 .0 \%$ Structural maintenance of chromosomes protein $3 \mathrm{GN}=\mathrm{SMC} 3 \mathrm{SMC} 3$ HUMAN $141.55100 .0 \%$ Structural maintenance of chromosomes protein $4 \mathrm{GN}=\mathrm{SMC} 4 \mathrm{SMC} 4$ HUMAN $147.19 \quad 100.0 \%$ Structural maintenance of chromosomes protein 4 GN=SMC4 SMC4_HUMAN $147.19 \quad 100.0 \%$ Structural maintenance of chromosomes protein $4 \mathrm{GN}=\mathrm{SMC} 4 \mathrm{SMC} 4 \mathrm{HUMAN} 147.19 \quad 100.0 \%$ Structural maintenance of chromosomes protein $4 \mathrm{GN}=\mathrm{SMC} 4$ SMC4_HUMAN $147.19 \quad 100.0 \%$

22

22

22

9

19

19
19
19

$0.07 \% \quad 29.2 \%$ NAVITVPAYFNDSQR

$\begin{array}{ll}0.07 \% & 29.2 \% \text { DAGQISGLNVLR }\end{array}$

$0.07 \% \quad 29.2 \%$ ETGVDLTKDNMALQR

$0.07 \% \quad 29.2 \%$ AQFEGIVTDLIR

$0.07 \% \quad 29.2 \%$ SDIGEVILVGGMTR

$0.07 \% \quad 29.2 \%$ VQQTVQDLFGR

$0.07 \% \quad 29.2 \%$ VQQTVQDLFGRAPSK

$0.07 \% \quad 29.2 \%$ SQVFSTAADGQTQVEIK

$0.07 \% \quad 29.2 \%$ QAASSLQQASLK

$0.04 \% \quad 19.0 \%$ QIIGPFQR

$0.04 \% \quad 19.0 \%$ FTAIIGPNGSGK

$0.04 \% \quad 19.0 \%$ SNLMDAISFVLGEK

$0.04 \% \quad 19.0 \%$ DLIHGAPVGKPAANR

$0.04 \% \quad 19.0 \%$ AFVSMVYSEEGAEDRTFAR

$0.04 \% \quad 19.0 \%$ TALFEEISR

$0.04 \%$ 19.0\% SGELAQEYDKR

$0.04 \% \quad 19.0 \%$ LYPGSVYGR

$0.04 \% \quad 19.0 \%$ ALQYACGNALVCDNVEDARR

$0.04 \% \quad 19.0 \%$ HKTVALDGTLFQK

$0.04 \% \quad 19.0 \%$ TVALDGTLFQK

$0.04 \% \quad 19.0 \%$ SGVISGGASDLKAK

$0.04 \% \quad 19.0 \%$ LTEELKEQMK

$0.04 \% \quad 19.0 \%$ EAELRQVQSQAHGLQMR

$0.04 \% \quad 19.0 \%$ LKYSQSDLEQTK

$0.04 \% \quad 19.0 \%$ HLALNLQEK

$0.04 \% \quad 19.0 \%$ SKLESELANFGPR

$0.04 \% \quad 19.0 \%$ LNEQQSVLQR

$\begin{array}{lllllll}0.01 \% & 19.0 \% & \text { VLTFDLTKYPDANPNPNEQ } & 99.7 \% & 51.9 & 25.0 & 51.9 \\ 0.01 \% & 6.3 \% & \text { ASNLQDLVYKNGQAGITK } & 99.7 \% & 34.9 & 25.0 & 34.9\end{array}$

$0.01 \% \quad 6.3 \% \quad$ NKYLINGVNANNTR

$0.01 \% \quad 6.3 \% \quad$ TILEEEITPTIQK

$0.01 \% \quad 6.3 \%$ SLEDALAEAQR

$0.01 \% \quad 6.3 \%$ SQAASILTK

$0.01 \% \quad 6.3 \% \quad$ FVDGVSTVAR

$0.02 \% \quad 7.6 \%$ QVIIQGFR

$0.02 \% \quad 7.6 \%$ LALLHEGTGPR

$0.02 \% \quad 7.6 \%$ INQMATAPDSQR

$0.02 \% \quad 7.6 \%$ ALEYTIYNQELNETR

$0.02 \% \quad 7.6 \%$ LAQATQERTDLYAK

$0.02 \% \quad 7.6 \%$ SMEVSTQLAR

$0.02 \% \quad 7.6 \% \quad$ ALDQFVNFSEQKEK

$0.02 \% \quad 7.6 \% \quad$ NFSEVFQK

$0.05 \% \quad 22.1 \%$ LMITHIVNQNFK

$99.7 \% \quad 32.2$

$\begin{array}{lll}99.7 \% & 32.8\end{array}$

$99.7 \% \quad 34.4$

$99.7 \% \quad 27.7$

$\begin{array}{lll}99.7 \% & 56.9\end{array}$

$99.0 \% \quad 37.8$

$99.7 \% \quad 46.5$

$99.7 \% \quad 27.1$

$99.7 \% \quad 58.7$

$99.7 \% \quad 35.9$

$99.7 \% \quad 51.6$

$99.7 \% \quad 31.1$

$96.7 \% \quad 21.6$

$\begin{array}{lll}99.7 \% & 37.7\end{array}$

$0.05 \% \quad 22.1 \%$ TACRDNTSVYHISGK

$0.05 \% \quad 22.1 \%$ TFKDVGNLLR $\begin{array}{ll}99.0 \% & 24.5 \\ 99.5 \% & 23.5\end{array}$

$99.7 \% \quad 32.2$
1694.85

1670.92

1242.68

1706.8

1361.74

1462.76

1290.68

1673.90

1808.90

1231.66

958.55

1161.63

1539.77

1515.84

2165.00

1065.56

1295.62

1011.53

2295.06

1457.8

1192.66

1289.71

1248.65

1981.00

1439.74

1065.61

1447.75

1214.65

2176.06

1920.02

1590.83

1514.83

1202.60

918.53

1050.56

960.56

1163.65

1347.63

1856.90

1607.84

1121.56

1682.84

998.49

1457.79

2473.19

1708.81 1162.66

$\begin{array}{cc}88 & 202 \\ 03 & 218 \\ 07 & 218 \\ 93 & 307 \\ 49 & 360 \\ 78 & 391 \\ 95 & 405 \\ 95 & 409 \\ 69 & 485 \\ 35 & 646 \\ 9 & 26 \\ 7 & 38 \\ 9 & 52 \\ 3 & 77 \\ 8 & 96 \\ 52 & 160 \\ 61 & 171 \\ 10 & 518 \\ 08 & 627 \\ 36 & 648 \\ 38 & 648 \\ 49 & 662 \\ 81 & 690 \\ 95 & 711 \\ 12 & 723 \\ 26 & 734 \\ 35 & 747 \\ 10 & 1019 \\ 15 & 1233 \\ 9 & 76 \\ 13 & 126 \\ 97 & 209 \\ 98 & 308 \\ 69 & 677 \\ 61 & 1170 \\ 5 & 12 \\ 2 & 72 \\ 44 & 155 \\ 22 & 236 \\ 65 & 378 \\ 35 & 644 \\ 86 & 999 \\ 39 & 1046 \\ 2 & 93 \\ 67 & 187 \\ 88 & 202 \\ 05 & 214 \\ & \end{array}$

Page 145 of Table S-1-6 
Structural maintenance of chromosomes protein 4 GN=SMC4 SMC4_HUMAN $147.19 \quad 100.0 \% \quad 23$ $\begin{array}{llll}\text { Structural maintenance of chromosomes protein } 4 \text { GN=SMC4 SMC4_HUMAN } 147.19 & 100.0 \% & 23\end{array}$ Structural maintenance of chromosomes protein 4 GN=SMC4 SMC4_HUMAN $147.19 \quad 100.0 \% 23$ Structural maintenance of chromosomes protein $4 \mathrm{GN}=$ SMC4 SMC4_HUMAN $147.19 \quad 100.0 \% \quad 23$ Structural maintenance of chromosomes protein 4 GN=SMC4 SMC4_HUMAN $147.19 \quad 100.0 \% 23$ Structural maintenance of chromosomes protein 4 GN=SMC4 SMC4_HUMAN $147.19 \quad 100.0 \% \quad 23$ Structural maintenance of chromosomes protein 4 GN=SMC4 SMC4_HUMAN $147.19 \quad 100.0 \% 23$ Structural maintenance of chromosomes protein 4 GN=SMC4 SMC4_HUMAN $147.19 \quad 100.0 \% 23$ Structural maintenance of chromosomes protein $4 \mathrm{GN}=\mathrm{SMC} 4$ SMC4_HUMAN $147.19 \quad 100.0 \%$ Structural maintenance of chromosomes protein 4 GN=SMC4 SMC4_HUMAN $147.19 \quad 100.0 \% 23$ Structural maintenance of chromosomes protein 4 GN=SMC4 SMC4_HUMAN $147.19 \quad 100.0 \% \quad 23$ Structural maintenance of chromosomes protein 4 GN=SMC4 SMC4_HUMAN $147.19 \quad 100.0 \% \quad 23$ Structural maintenance of chromosomes protein 4 GN=SMC4 SMC4_HUMAN $147.19 \quad 100.0 \% \quad 23$ Structural maintenance of chromosomes protein $4 \mathrm{GN}=$ SMC4 SMC4_HUMAN $147.19 \quad 100.0 \% 23$ Structural maintenance of chromosomes protein 4 GN=SMC4 SMC4_HUMAN $147.19 \quad 100.0 \%$ Structural maintenance of chromosomes protein 4 GN=SMC4 SMC4_HUMAN $147.19 \quad 100.0 \% 23$ Structural maintenance of chromosomes protein $4 \mathrm{GN}=\mathrm{SMC} 4 \mathrm{SMC} 4$ HUMAN $147.19 \quad 100.0 \%$ Structural maintenance of chromosomes protein 4 GN=SMC4 SMC4_HUMAN $147.19 \quad 100.0 \% 23$ Structural maintenance of chromosomes protein 4 GN=SMC4 SMC4_HUMAN $147.19 \quad 100.0 \% \quad 23$ Succinyl-CoA ligase [ADP/GDP-forming] subunit alpha, mitochondrial GN=SUCLGI SUCA HUMAN $36.25 \quad 100.0 \%$ Succinyl-CoA ligase [ADP/GDP-forming] subunit alpha, mitochondrial GN=SUCLGI SUCA_HUMAN $36.25 \quad 100.0 \%$ Succinyl-CoA ligase [ADP/GDP-forming] subunit apha, mitochondrial GN=SUCLG1 SUCA_HUMAN $36.25 \quad 100.0 \%$ Succinyl-CoA ligase [ADP/GDP-forming] subunit apha, mitochondrial GN=SUCLG1 SUCA_HUMAN $36.25 \quad 100.0 \%$ Succinyl-CoA ligase [ADP/GDP-forming] subunit apha, mitochondrial GN=SUCLG1 SUCA_HUMAN $36.25 \quad 100.0 \%$ Succinyl-CoA ligase [ADP/GDP-forming] subunit alpha, mitochondrial GN=SUCLGI SUCA_HUMAN 36.25 Succinyl-CoA ligase [ADP/GDP-forming] subunit alpha, mitochondrial GN=SUCLGI SUCA_HUMAN 36.25 Succinyl-CoA ligase [ADP-forming] subunit beta, mitochondrial GN=SUCLA2 SUCB1_HUMAN 50.32 Succinyl-CoA ligase [ADP-forming] subunit beta, mitochondrial GN=SUCLA2 SUCB1_HUMAN $50.32 \quad 100.0$ Succinyl-CoA ligase [ADP-forming] subunit beta, mitochondrial GN=SUCLA2 SUCB1_HUMAN $50.32 \quad 100.0^{\circ}$, Succinyl-CoA ligase [ADP-forming] subunit beta, mitochondrial GN=SUCLA2 SUCB1_HUMAN $50.32 \quad 100.0^{\circ}$ Succinyl-CoA ligase [ADP-forming] subunit beta, mitochondrial GN=SUCLA2 SUCB1_HUMAN $50.32 \quad 100.0 \%$ Succinyl-CoA ligase [ADP-forming] subunit beta, mitochondrial GN=SUCLA2 SUCB1_HUMAN 50.32 Succinyl-CoA ligase [ADP-forming] subunit beta, mitochondrial GN=SUCLA2 SUCB1_HUMAN 50.32 Succinyl-COA ligase [ADP-forming] subunit beta, mitochondrial GN=SUCLA2 SUCB1_HUMAN 50.32 Succinyl-CoA ligase [ADP-forming] subunit beta, mitochondrial GN=SUCLA2 SUCB1_HUMAN 50.32 Succinyl-COA ligase [AD 作 作 ligase [GDP-forming] subunit beta, mitochondrial GN=SUCLG2 SUCB2 HUMAN 46.51 100.0\% Succinyl-CoA ligase [GDP-forming] subunit beta, mitochondrial GN=SUCLG2 SUCB2_HUMAN $46.51 \quad 100.0 \%$ Succinyl-CoA ligase [GDP-forming] subunit beta, mitochondrial GN=SUCLG2 SUCB2_HUMAN $46.51 \quad 100.0$ Succinyl-CoA ligase [GDP-forming] subunit beta, mitochondrial GN=SUCLG2 SUCB2_HUMAN 46.51 100.0\% Succinyl-CoA ligase [GDP-forming] subunit beta, mitochondrial GN=SUCLG2 SUCB2_HUMAN $46.51 \quad 100.0 \%$ Succinyl-CoA ligase [GDP-forming] subunit beta, mitcochondrial GN=SUCLG2 SUCB2 HUMAN 46.51 100.0\% Succinyl-CoA ligase [GDP-forming] subunit beta, mitochondrial GN=SUCLG2 SUCB2_HUMAN $46.51 \quad 100.0 \%$ Succinyl-CoA ligase [GDP-forming] subunit beta, mitochondrial GN=SUCLG2 SUCB2_HUMAN 46.51 $100.0^{\circ}$ Succinyl-CoA ligase [GDP-forming] subunit beta, mitochondrial GN=SUCLG2 SUCB2 HUMAN 46.51 100.0\% Succinyl-COA ligase [GDP-forming] subunit beta, mitochondrial GN=SUCLG2 SUCB2_HUMAN $46.51 \quad 100.0 \%$

1

11
11
11

1

11

1

14
14

14

14
14
14

14
14 $\begin{array}{lll}0.05 \% & 22.1 \% & \text { LNEPIKVLCR }\end{array}$ $0.05 \% \quad 22.1 \%$ IAEMETQKEK $0.05 \% \quad 22.1 \%$ IHEDTKEINEK $0.05 \% \quad 22.1 \%$ SNNIINETTTR $0.05 \% \quad 22.1 \%$ HNTAVSQLTK $0.05 \% \quad 22.1 \%$ EALIAASETLKER $0.05 \% \quad 22.1 \%$ GKVLDAIIQEK $0.05 \% \quad 22.1 \%$ VLDAIIQEK $0.05 \% \quad 22.1 \%$ QNIGVATFIGLDK $0.05 \% \quad 22.1 \%$ MTEIQTPENTPR $\begin{array}{lll}0.05 \% & 22.1 \% & \text { VVTLQGQIIEQSGTMTGG } \\ 0.05 \% & 22.1 \% & \text { AMQIQEQKVQLEER }\end{array}$ $0.05 \% \quad 22.1 \%$ NTLEKFTASIQR $0.05 \% \quad 22.1 \%$ LLEENVSAFKTEYDAVAEK $0.05 \% \quad 22.1 \%$ NTNAAEESLPEIQKEHR $0.05 \% \quad 22.1 \%$ VIQENEHALQK $0.05 \% \quad 22.1 \%$ VAELDKITYER $0.05 \% \quad 22.1 \%$ IFNLSGGEK $0.05 \% \quad 22.1 \%$ SVAVNPKEIASK $0.03 \% 24.9 \%$ QHLYVDKNTK $0.03 \% \quad 24.9 \%$ IICQGFTGK $0.03 \% \quad 24.9 \%$ QGTFHSQQALEYGTK $0.03 \% \quad 24.9 \%$ LVGGTTPGK $0.03 \% \quad 24.9 \%$ GGQTHLGLPVFNTVK $0.03 \% \quad 24.9 \%$ LIGPNCPGVINPGECK $0.03 \% \quad 24.9 \%$ MGHAGAIIAGGK $0.03 \% \quad 24.8 \%$ SPDEAYAIAK $0.03 \% \quad 24.8 \%$ IVFSPEEAK $0.03 \% \quad 24.8 \%$ AVSSQMIGKK $0.03 \% \quad 24.8 \%$ ICNQVLVCER $0.03 \% \quad 24.8 \%$ EQALQLAQK $0.03 \% \quad 24.8 \%$ INFDSNSAYR $0.03 \% \quad 24.8 \%$ CDVIAQGIVMAVK $0.03 \% \quad 24.8 \%$ DLEIKIPVVVR $0.03 \% \quad 24.8 \%$ ILACDDLDEAAR $0.03 \% \quad 24.8 \%$ LSEIVTLAK $0.03 \% \quad 24.8 \%$ QAHVDVKFQLPI $0.04 \% \quad 31.9 \%$ FFVADTANEALEAAK $0.04 \% \quad 31.9 \%$ FFVADTANEALEAAKR $0.04 \% 31.9 \%$ DPNVVGQLAK $0.04 \% \quad 31.9 \%$ QMIGYNLATK $0.04 \% \quad 31.9 \%$ VMVAEALDISR $0.04 \% \quad 31.9 \%$ ETYLAILMDR $0.04 \% \quad 31.9 \%$ MAENLGFVGPLK $0.04 \% \quad 31.9 \%$ INFDDNAEFR $0.04 \% \quad 31.9 \%$ EAQVYQAFK

$99.7 \% \quad 33.2$ $95.5 \% \quad 22.9$ $\begin{array}{lll}97.5 \% & 16.4\end{array}$ $99.7 \% 55.6$ $99.7 \% \quad 41.6$ $99.7 \% 61$.

$99.7 \% \quad 52.7$ $99.7 \% \quad 37.8$ $99.7 \% \quad 43.9$ $99.7 \% \quad 41.1$

\section{$99.7 \% \quad 68.2$}

$99.7 \% 33.3$

$99.7 \% \quad 55.6$

$99.7 \% 32.2$

$99.2 \% \quad 21.0$

$99.7 \% \quad 40.4$

$99.4 \% \quad 34.0$

$99.7 \% \quad 43.4$

$99.4 \% \quad 23.2$

$99.7 \% \quad 42.5$

$99.7 \% \quad 50.0$

$99.5 \% \quad 24.5$

$\begin{array}{lll}99.7 \% & 58.3\end{array}$

$99.7 \% \quad 55.8$

$99.7 \% \quad 56.2$

$99.7 \% \quad 55.0$

$99.6 \% \quad 25.5$

$99.5 \% \quad 31.3$

$99.7 \% \quad 67.6$

$99.7 \% \quad 51.3$

$99.7 \% \quad 57.3$

$99.7 \% \quad 54.0$

$99.7 \% \quad 46.5$

$99.7 \% 70.6$

$99.7 \% \quad 46.9$

$\begin{array}{lll}98.8 \% & 25.8\end{array}$

$\begin{array}{lll}99.7 \% & 86.7\end{array}$ $\begin{array}{ccc}1241.70 & 263 & 272 \\ 1206.60 & 334 & 343 \\ 1355.68 & 344 & 354 \\ 1262.63 & 435 & 445 \\ 1098.59 & 513 & 522 \\ 1430.79 & 525 & 537 \\ 1213.72 & 597 & 607 \\ 1028.60 & 599 & 607 \\ 1375.76 & 661 & 673 \\ 1416.68 & 681 & 692 \\ 2091.08 & 737 & 757 \\ 1729.89 & 790 & 803 \\ 1407.76 & 816 & 827 \\ 2156.08 & 858 & 876 \\ 1965.96 & 975 & 991 \\ 1308.69 & 999 & 1009 \\ 1336.71 & 1107 & 1117 \\ 964.51 & 1188 & 1196 \\ 1242.71 & 1274 & 1285 \\ 1245.66 & 48 & 57 \\ 1023.53 & 58 & 66 \\ 1694.81 & 67 & 81 \\ 829.48 & 82 & 90 \\ 1567.86 & 91 & 105 \\ 1724.85 & 167 & 182 \\ 1098.57 & 297 & 308 \\ 1064.53 & 79 & 88 \\ 1019.54 & 121 & 129 \\ 1048.58 & 130 & 139 \\ 1290.63 & 151 & 160 \\ 1028.57 & 217 & 225 \\ 1186.55 & 275 & 284 \\ 1403.74 & 384 & 396 \\ 1280.79 & 397 & 407 \\ 1361.64 & 427 & 438 \\ 973.59 & 443 & 451 \\ 1394.78 & 452 & 463 \\ 1596.79 & 59 & 73 \\ 1752.89 & 59 & 74 \\ 1732.97 & 102 & 118 \\ 1040.57 & 109 & 118 \\ 1154.59 & 119 & 128 \\ 1203.64 & 140 & 150 \\ 1224.63 & 151 & 160 \\ 1291.67 & 207 & 218 \\ 1240.56 & 260 & 269 \\ 1083.55 & 339 & 347 \\ & & \end{array}$ 
Symplekin GN=SYMPK

Symplekin GN=SYMPK

Symplekin GN=SYMPK

Symplekin GN=SYMPK

Synembryn-A GN=RIC8A

Synembryn-A GN=RIC8A

Syntaxin-18 GN=STX18

Syntaxin-18 GN=STX18

Syntaxin-18 GN=STX18

Syntaxin-18 GN=STX18

Syntaxin-binding protein $3 \mathrm{GN}=$ STXBP3 STXB3 HUMAN $67.77 \quad 100.0 \%$

Syntaxin-binding protein $3 \mathrm{GN}=$ STXBP3 STXB3_HUMAN $67.77 \quad 100.0 \%$

TAR DNA-binding protein 43 GN=TARDBP TADBP_HUMAN $44.74 \quad 100.0 \%$

SYMPK_HUMAN $141.15 \quad 100.0 \%$

SYMPK_HUMAN $141.15 \quad 100.0 \%$ SYMPK HUMAN $141.15 \quad 100.0 \%$ RIC8A_HUMAN $59.71 \quad 100.0 \%$ RIC8A_HUMAN $59.71 \quad 100.0 \%$ STX18 HUMAN $38.67 \quad 100.0 \%$ STX18_HUMAN $38.67 \quad 100.0 \%$ STX18_HUMAN $38.67 \quad 100.0 \%$
$0.04 \% \quad 31.9 \%$
0

$0.01 \% \quad 9.5 \%$ NLILAGVK

$0.01 \% \quad 9.5 \%$ VSQGVEDGPDTK

$0.01 \% \quad 9.5 \% \quad$ VSQGVEDGPDTKR

$99.0 \% \quad 36.4$

$\begin{array}{lll}99.7 \% & 35.8\end{array}$

$99.7 \% \quad 45.1$

$99.0 \% \quad 24.5$

$0.01 \% \quad 9.5 \% \quad$ AKLDSSETTMVK

$99.0 \% \quad 19.0$

$\begin{array}{llllll}0.00 \% & 4.7 \% & \text { TQRVDDPQDVFKPTTSR } & 99.7 \% & 32.5\end{array}$

$\begin{array}{llll}0.00 \% & 4.7 \% & \text { TQRVDDPQDVFK } \\ 0.00 \% & 3.4 \% & \text { DSSPHFQAEQR }\end{array}$

$0.00 \% \quad 3.4 \% \quad$ IRPTAVTLEHVPK

$0.01 \% \quad 3.9 \% \quad$ SFYQFQHYR

$0.01 \% \quad 3.9 \%$ VIQKVEAFEHR

$0.01 \% \quad 3.9 \% \quad$ LTEQLAGPLR

$0.01 \% \quad 3.9 \%$ MTDVFEGSIIR

$0.00 \% \quad 6.6 \%$ VMEPLTASR

$0.00 \% \quad 6.6 \% \quad$ VNLNTIKR

$0.00 \% \quad 6.6 \%$ VGGSDEEASGIPSR

$\begin{array}{lll}98.4 \% & 20.1\end{array}$

$99.7 \% \quad 26.9$

$99.7 \% \quad 30.2$

$99.7 \% \quad 37.6$

$99.7 \% \quad 58.7$

$99.7 \% \quad 51.7$

$99.7 \% \quad 35.1$

$99.0 \% \quad 37.0$

$97.9 \% \quad 23.8$

$0.02 \% \quad 5.4 \%$ SVTPLIMACNAYEL SVK $99.7 \% \quad 59.7$

$0.02 \% \quad 5.4 \%$ APSSLSDAVPQR

$0.02 \% \quad 5.4 \%$ GADQKPTSADCAVR

$0.02 \% \quad 5.4 \%$ RATTGTQTLLSSGTR

$0.02 \% \quad 5.4 \%$ ATTGTQTLLSSGTR

$0.01 \% \quad 11.6 \%$ NGDICETSGKPK

$0.01 \% \quad 11.6 \%$ ETCVVVYTGYGNR

$0.01 \% \quad 11.6 \%$ LGPGKPGLK

$0.02 \% \quad 6.0 \%$ SVCLIGDKEQR

$0.02 \% \quad 6.0 \% \quad$ YLVIDEAHR

$0.02 \% \quad 6.0 \%$ MVVLDKLLPK

$0.02 \% \quad 6.0 \%$ VLIFSQMTR

$0.02 \% \quad 6.0 \%$ VSEPKAPK

$0.02 \% \quad 6.0 \%$ TIGYKVPR

$0.02 \% \quad 6.0 \%$ ALDTKIGR

$0.01 \% \quad 3.7 \%$ AVACSGAAQVR $0.01 \% \quad 3.7 \%$ VVLEAPLITESALEVVR $0.01 \% \quad 3.7 \%$ GAETLVTR

$0.01 \% \quad 3.7 \%$ LGGFVMNILSR

$0.00 \% \quad 4.1 \% \quad$ ALLIFLEK

$0.00 \% \quad 4.1 \% \quad$ YTGYGNAAGLLAAR

$\begin{array}{lll}99.7 \% & 51.0\end{array}$

$99.7 \% \quad 39.0$

$98.8 \% 18.6$

$99.7 \% \quad 57.1$

$99.7 \% \quad 35.8$

$99.7 \% \quad 71.8$

$\begin{array}{lll}99.7 \% & 30.1\end{array}$

$99.7 \% \quad 61.0$

$99.7 \% \quad 33.1$

$\begin{array}{lll}98.3 \% & 20.2\end{array}$

$\begin{array}{lll}99.7 \% & 36.2\end{array}$

$94.6 \% \quad 14.2$

$99.0 \% \quad 25.2$

$99.0 \% \quad 31.9$

$\begin{array}{lll}98.6 \% & 26.0\end{array}$

$99.7 \% 34.9$

$99.0 \% \quad 33.3$

$99.7 \% \quad 38.1$

$99.0 \% \quad 28.0$

$99.7 \% \quad 88.4$

$99.7 \% \quad 61.6$

$98.9 \% \quad 23.2$

$0.01 \% \quad 17.0 \%$ TEAHKEIHSQQVK

$\begin{array}{lll}98.3 \% & 23.7\end{array}$

$0.01 \% \quad 17.0 \%$ LIGEMNSLFDEVR

$99.7 \% \quad 50.9$

$99.1 \% \quad 25.2$

$98.9 \% \quad 34.9$

$0.00 \% \quad 3.4 \%$ SAEETFQLSR

$0.01 \% \quad 7.3 \%$ KMDETDASSAVK
1216.62

2055.10

2183.19

827.54

1231.58

1387.68

1309.67

2086.05

1990.00

1301.59

1460.86

1275.59

1355.74

1097.63

1267.64

1003.52

957.58

1360.63

1895.96

1227.63

1475.69

1549.83

1393.73

1305.6

1517.71

866.55

1304.66

1115.58

1171.71

1094.60

855.49

933.55

873.52

1089.55

1838.06

846.47

1206.67

946.60

1397.72

1205.59

1534.80

2344.09

1522.76

1140.63

1167.56 1297.59

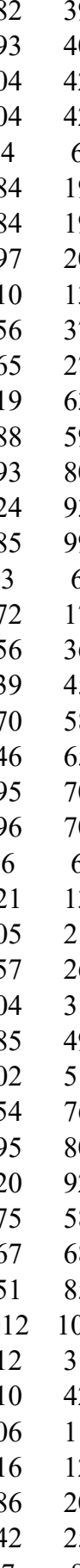

Page 14 
TAR DNA-binding protein 43 GN=TARDBP TADBP_HUMAN $44.74 \quad 100.0 \%$ Target of rapamycin complex subunit LST8 GN=MLST8 LST8_HUMAN $35.88 \quad 100.0 \%$ Target of rapamycin complex subunit LST8 GN=MLST8 LST8_HUMAN $35.88 \quad 100.0 \%$ TATA-binding protein-associated factor $172 \mathrm{GN}=\mathrm{BTAF} 1$ BTAF1_HUMAN $206.89 \quad 100.0 \%$ TATA-binding protein-associated factor 172 GN=BTAF1 BTAF1_HUMAN $206.89 \quad 100.0 \%$ TATA-binding protein-associated factor $172 \mathrm{GN}=\mathrm{BTAF} 1 \quad \mathrm{BTAF} 1$ HUMAN $206.89 \quad 100.0 \%$ TATA-binding protein-associated factor $172 \mathrm{GN}=\mathrm{BTAF} 1$ BTAF1_HUMAN $206.89 \quad 100.0 \%$ TATA-binding protein-associated factor $172 \mathrm{GN}=\mathrm{BTAF} 1$ BTAF1_HUMAN $206.89 \quad 100.0 \%$ TATA-binding protein-associated factor 2N GN=TAF15 RBP56 HUMAN $61.83 \quad 100.0 \%$ TATA-binding protein-associated factor 2N GN=TAF15 RBP56_HUMAN $61.83 \quad 100.0 \%$ TATA-binding protein-associated factor 2N GN=TAF15 RBP56_HUMAN $61.83 \quad 100.0 \%$ TATA-binding protein-associated factor 2N GN=TAF15 RBP56 HUMAN $61.83 \quad 100.0 \%$ $\mathrm{TBC} 1$ domain family member $15 \mathrm{GN}=\mathrm{TBC} 1 \mathrm{D} 15 \mathrm{TBC} 15$ _HUMAN $79.49 \quad 100.0 \%$ TBC1 domain family member $15 \mathrm{GN}=\mathrm{TBC} 1 \mathrm{D} 15$ TBC15_HUMAN $79.49 \quad 100.0 \%$ T-complex protein 1 subunit alpha GN=TCP1 TCPA_HUMAN $60.35 \quad 100.0 \%$ T-complex protein 1 subunit alpha GN=TCP1 TCPA_HUMAN 60.35 T-complex protein 1 subunit alpha GN=TCP1 TCPA_HUMAN 60.35 T-complex protein 1 subunit alpha GN=TCP1 TCPA_HUMAN 60.35 T-complex protein 1 subunit alpha GN=TCP1 TCPA_HUMAN 60.3 T-complex protein 1 subunit alpha GN=TCP1 TCPA_HUMAN 60.35 T-complex protein 1 subunit alpha GN=TCP1 TCPA_HUMAN 60.35 T-complex protein 1 subunit alpha GN=TCP1 TCPA_HUMAN 60.35 T-complex protein 1 subunit alpha GN=TCP1 TCPA_HUMAN 60.35 T-complex protein 1 subunit alpha GN=TCP1 TCPA_HUMAN 60.3 T-complex protein 1 subunit alpha GN=TCP1 TCPA HUMAN 60.35 T-complex protein 1 subunit alpha GN=TCP1 TCPA_HUMAN 60.35 T-complex protein 1 subunit alpha GN=TCP1 TCPA_HUMAN 60.3s T-complex protein 1 subunit alpha GN=TCP1 TCPA_HUMAN 60.3s T-complex protein 1 subunit alpha GN=TCP1 TCPA_HUMAN 60.3s T-complex protein 1 subunit alpha GN=TCP1 TCPA HUMAN 60.3s T-complex protein 1 subunit alpha GN=TCP1 TCPA_HUMAN 60.35 T-complex protein 1 subunit alpha GN=TCP1 TCPA_HUMAN 60.3 T-complex protein 1 subunit alpha GN=TCP1 TCPA_HUMAN 60.35 T-complex protein 1 subunit alpha GN=TCP1 TCPA_HUMAN 60.35 T-complex protein 1 subunit alpha GN=TCP1 TCPA_HUMAN 60.35 T-complex protein 1 subunit alpha GN=TCP1 TCPA_HUMAN 60.3 T-complex protein 1 subunit alpha GN=TCP1 TCPA_HUMAN 60.3 T-complex protein 1 subunit alpha GN=TCP1 TCPA_HUMAN 60.3 T-complex protein 1 subunit alpha GN=TCP1 TCPA_HUMAN 60.35 T-complex protein 1 subunit alpha GN=TCP1 TCPA_HUMAN 60.3 T-complex protein 1 subunit alpha GN=TCP1 TCPA_HUMAN 60.35 T-complex protein 1 subunit alpha GN=TCP1 TCPA_HUMAN 60.3s T-complex protein 1 subunit alpha GN=TCP1 TCPA_HUMAN 60.3s T-complex protein 1 subunit alpha GN=TCP1 TCPA_HUMAN 60.35 T-complex protein 1 subunit alpha GN=TCP1 TCPA_HUMAN 60.3 T-complex protein 1 subunit alpha GN=TCP1 TCPA_HUMAN 60.35 T-complex protein 1 subunit beta $\mathrm{GN}=\mathrm{CCT} 2$ TCPB_HUMAN 57.49
0.0

$\begin{array}{llll}0.3 \% & \text { FGGNPGGFGNQGGFGNSR } \quad 99.7 \% \quad 64.5\end{array}$ $\begin{array}{lllll}0.00 \% & 11.0 \% & \text { TVQHQDSQVNALEVTPDR } & 99.7 \% & 28.6\end{array}$

$\begin{array}{llllll}0.00 \% & 11.0 \% & \text { FSPDSTLLATCSADQTCK } & 99.7 \% & 32.1\end{array}$

$0.01 \% \quad 3.1 \%$ AAAQQLGEVVK

$0.01 \% \quad 3.1 \%$ IAAGQAVEAIVK

$0.01 \% \quad 3.1 \% \quad$ IANVVINQSANDSK

$0.01 \% \quad 3.1 \%$ NTIDINNFDGK

$\begin{array}{lllll}0.01 \% & 11.5 \% & \text { TGKPMINLYTDKDTGKPK } & 98.3 \% & 24.0 \\ 0.01 \% & 11.5 \% & \text { GEATVSFDDPPSAK } & 99.7 \% & 54.7\end{array}$

$0.01 \% \quad 11.5 \%$ SGGGYGGDRGGGYGGDR $99.7 \% 29.0$

$0.00 \% \quad 3.3 \%$ TNDQDGLISGILR

$0.00 \% \quad 3.3 \%$ VTNYIFDSLR

$100.0 \% \quad 32$

$100.0 \% \quad 32$

$100.0 \% \quad 32$

$100.0 \% \quad 32$

$100.0 \% \quad 32$

$100.0 \% \quad 32$

$100.0 \% \quad 32$

$100.0 \% \quad 32$

$100.0 \% \quad 32$

$100.0 \% \quad 32$

$100.0 \% \quad 32$

$100.0 \% \quad 32$

$100.0 \% \quad 32$

$100.0 \% \quad 32$

$100.0 \% \quad 32$

$100.0 \% \quad 32$

$100.0 \% \quad 32$

$100.0 \% \quad 32$

$100.0 \% \quad 32$

$100.0 \% \quad 32$

$100.0 \% \quad 32$

$100.0 \% \quad 32$

$100.0 \% \quad 32$

$100.0 \% \quad 32$

$100.0 \% \quad 32$

$100.0 \% \quad 32$

$100.0 \% \quad 32$

$100.0 \% \quad 32$

$100.0 \% \quad 32$

$100.0 \% \quad 32$

$100.0 \% \quad 32$

$100.0 \% \quad 32$

$100.0 \% \quad 4$
$115 \quad 0.13 \% \quad 54.5 \%$ SSLGPVGLDK

$115 \quad 0.13 \% \quad 54.5 \%$ MLVDDIGDVTITNDGATILK $99.7 \%$

$115 \quad 0.13 \% \quad 54.5 \%$ LLEVEHPAAK

$115 \quad 0.13 \% \quad 54.5 \%$ NADELVKQK

$115 \quad 0.13 \% \quad 54.5 \%$ QKIHPTSVISGYR

$115 \quad 0.13 \% \quad 54.5 \%$ IHPTSVISGYR

$\begin{array}{ll}99.7 \% & 58.3 \\ 99.7 \% & 55.3\end{array}$

$99.7 \% \quad 30.0$

$99.7 \% \quad 29.4$

$99.7 \% \quad 26.7$

$115 \quad 0.13 \% \quad 54.5 \%$ YINENLIVNTDELGRDCLINAAK

$115 \quad 0.13 \% \quad 54.5 \%$ DCLINAAK

$115 \quad 0.13 \% \quad 54.5 \%$ YTDIRGQPR

$115 \quad 0.13 \% \quad 54.5 \%$ YPVNSVNILK

$115 \quad 0.13 \% \quad 54.5 \%$ IACLDFSLQK

$115 \quad 0.13 \% \quad 54.5 \%$ IACLDFSLQKTK

$\begin{array}{ll}99.0 \% & 40.6\end{array}$

$99.5 \% \quad 25.5$

$99.7 \% \quad 55.3$

$99.7 \% \quad 56.0$

$99.7 \% \quad 39.2$

44

44

$115 \quad 0.13 \% \quad 54.5 \%$ ICDDELILIK

$44 \quad 115 \quad 0.13 \% \quad 54.5 \%$ ICDDELILIKNTK

$44 \quad 115 \quad 0.13 \% \quad 54.5 \%$ TSASIILR

$44 \quad 115 \quad 0.13 \% \quad 54.5 \%$ GANDFMCDEMER

$44 \quad 115 \quad 0.13 \% \quad 54.5 \%$ SLHDALCVVK

$44 \quad 115 \quad 0.13 \% \quad 54.5 \%$ SLHDALCVVKR

$44 \quad 115 \quad 0.13 \% \quad 54.5 \%$ EQLAIAEFAR

$44 \quad 115 \quad 0.13 \% \quad 54.5 \%$ SLLVIPNTLAVNAAQDSTDLVAK

$44 \quad 115 \quad 0.13 \% \quad 54.5 \%$ LRAFHNEAQVNPER

$44 \quad 115 \quad 0.13 \% \quad 54.5 \%$ AFHNEAQVNPER

$44 \quad 115 \quad 0.13 \% \quad 54.5 \%$ AFHNEAQVNPERK

$44 \quad 115 \quad 0.13 \% \quad 54.5 \%$ WIGLDLSNGKPR

$44 \quad 115 \quad 0.13 \% \quad 54.5 \%$ DNKQAGVFEPTIVK

$44 \quad 115 \quad 0.13 \% \quad 54.5 \%$ QAGVFEPTIVK

$44 \quad 115 \quad 0.13 \% \quad 54.5 \%$ SLKFATEAAITILR

$44 \quad 115 \quad 0.13 \% \quad 54.5 \%$ FATEAAITILR

$44 \quad 115 \quad 0.13 \% \quad 54.5 \%$ DDKHGSYEDAVHSGALND

$9 \quad 0.01 \% \quad 8.0 \%$ AGADEERAETAR
$115 \quad 0.13 \% \quad 54.5 \%$ STGETIRSQNVMAAASIANIVK $99.7 \% \quad 43.5$

$115 \quad 0.13 \% \quad 54.5 \%$ SQNVMAAASIANIVK $\quad 99.7 \% \quad 84.5$
$96.1 \% \quad 22.8$

$99.7 \% \quad 35.5$

$99.7 \% \quad 54.3$

$99.7 \% \quad 53.1$

$99.7 \% \quad 28.0$

$98.3 \% 24.0$

$\begin{array}{ll}99.7 \% & 54.7 \\ 99.7 \% & 54.3\end{array}$

$99.7 \% \quad 65.3$

$99.7 \% \quad 58.3$

1113.63

1169.69

1472.77

954.57

1250.60

2023.05

1420.66

1748.72

1544.65

1401.73

1227.64

2277.19

1516.82

972.54

2120.08

1106.62

1044.57

1485.82

1229.66

2648.34

904.46

1105.58

1146.65

1194.62

1423.76

1923.09

1231.66

1574.85

860.52

1474.54

1141.60

1297.70

1147.61

2353.30

1680.86

1411.67

1539.77

1355.74

1545.83

1188.66

1533.90

$\begin{array}{llllllll}99.7 \% & 65.2 & 25.0 & 53.3 & 6 & 0 & 0 & 1205.69 \\ 99.6 \% & 24.5 & 25.0 & 24.5 & 0 & 2 & 0 & 1929.82\end{array}$

$\begin{array}{llllllll}99.7 \% & 65.2 & 25.0 & 53.3 & 6 & 0 & 0 & 1205.69 \\ 99.6 \% & 24.5 & 25.0 & 24.5 & 0 & 2 & 0 & 1929.82\end{array}$

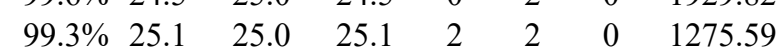

$\begin{array}{cc}76 & 293 \\ 7 & 54 \\ 28 & 245 \\ 4 & 34 \\ 0 & 71 \\ 49 & 262 \\ 45 & 753 \\ 59 & 1069 \\ 66 & 283 \\ 84 & 297 \\ 23 & 441 \\ 51 & 467 \\ 7 & 39 \\ 53 & 262 \\ 2 & 33 \\ 9 & 33 \\ 4 & 43 \\ 4 & 63 \\ 4 & 73 \\ 03 & 111 \\ 10 & 122 \\ 12 & 122 \\ 31 & 153 \\ 46 & 153 \\ 81 & 189 \\ 90 & 199 \\ 34 & 243 \\ 34 & 245 \\ 48 & 264 \\ 56 & 365 \\ 56 & 368 \\ 71 & 378 \\ 79 & 390 \\ 91 & 400 \\ 91 & 401 \\ 34 & 443 \\ 44 & 466 \\ 67 & 480 \\ 69 & 480 \\ 69 & 481 \\ 85 & 496 \\ 97 & 510 \\ 00 & 510 \\ 13 & 526 \\ 16 & 526 \\ 39 & 556 \\ 4 & 25 \\ & \end{array}$

Page 148 of Table S-1-6 
T-complex protein 1 subunit beta GN=CCT2 TCPB_HUMAN $57.49 \quad 100.0 \%$ T-complex protein 1 subunit beta GN=CCT2 TCPB_HUMAN $57.49 \quad 100.0 \%$ T-complex protein 1 subunit beta GN=CCT2 TCPB_HUMAN $57.49 \quad 100.0 \%$ T-complex protein 1 subunit delta GN=CCT4 TCPD HUMAN $57.93 \quad 100.0 \%$ T-complex protein 1 subunit delta GN=CCT4 TCPD_HUMAN $57.93 \quad 100.0 \%$ T-complex protein 1 subunit delta GN=CCT4 TCPD_HUMAN $57.93 \quad 100.0 \%$ T-complex protein 1 subunit delta GN=CCT4 TCPD_HUMAN $57.93 \quad 100.0 \%$ T-complex protein 1 subunit delta GN=CCT4 TCPD_HUMAN $57.93 \quad 100.0 \%$ T-complex protein 1 subunit delta GN=CCT4 TCPD_HUMAN $57.93 \quad 100.0 \%$ T-complex protein 1 subunit delta GN=CCT4 TCPD_HUMAN $57.93 \quad 100.0 \%$ T-complex protein 1 subunit delta GN=CCT4 TCPD_HUMAN $57.93 \quad 100.0 \%$ T-complex protein 1 subunit delta GN=CCT4 TCPD_HUMAN $57.93 \quad 100.0^{\circ}$ T-complex protein 1 subunit delta GN=CCT4 TCPD_HUMAN $57.93 \quad 100.0 \%$ T-complex protein 1 subunit delta GN=CCT4 TCPD_HUMAN $57.93 \quad 100.0 \%$ T-complex protein 1 subunit delta GN=CCT4 TCPD_HUMAN $57.93 \quad 100.0 \%$ T-complex protein 1 subunit delta GN=CCT4 TCPD_HUMAN $57.93 \quad 100.0 \%$ T-complex protein 1 subunit delta GN=CCT4 TCPD HUMAN $57.93 \quad 100.0 \%$ T-complex protein 1 subunit delta GN=CCT4 TCPD_HUMAN $57.93 \quad 100.0 \%$ T-complex protein 1 subunit epsilon GN=CCT5 TCPE_HUMAN $59.67 \quad 100.0 \%$ T-complex protein 1 subunit epsilon GN=CCT5 TCPE_HUMAN $59.67 \quad 100.0 \%$ T-complex protein 1 subunit epsilon GN=CCT5 TCPE_HUMAN $59.67 \quad 100.0 \%$ T-complex protein 1 subunit epsilon GN=CCT5 TCPE_HUMAN $59.67 \quad 100.0 \%$ T-complex protein 1 subunit epsilon GN=CCT5 TCPE_HUMAN $59.67 \quad 100.0 \%$ T-complex protein 1 subunit epsilon GN=CCT5 TCPE_HUMAN $59.67 \quad 100.0 \%$ T-complex protein 1 subunit epsilon GN=CCT5 TCPE HUMAN $59.67 \quad 100.0 \%$ T-complex protein 1 subunit epsilon GN=CCT5 TCPE_HUMAN $59.67 \quad 100.0 \%$ T-complex protein 1 subunit epsilon GN=CCT5 TCPE_HUMAN $59.67 \quad 100.0 \%$ T-complex protein 1 subunit gamma GN=CCT3 TCPG_HUMAN $60.54 \quad 100.0 \%$ T-complex protein 1 subunit gamma GN=CCT3 TCPG_HUMAN $60.54 \quad 100.0 \%$ T-complex protein 1 subunit gamma GN=CCT3 TCPG_HUMAN $60.54 \quad 100.0 \%$ T-complex protein 1 subunit gamma GN=CCT3 TCPG_HUMAN $60.54 \quad 100.0 \%$ T-complex protein 1 subunit gamma GN=CCT3 TCPG_HUMAN $60.54 \quad 100.0 \%$ T-complex protein 1 subunit gamma GN=CCT3 TCPG_HUMAN $60.54 \quad 100.0 \%$ T-complex protein 1 subunit gamma GN=CCT3 TCPG_HUMAN $60.54 \quad 100.0 \%$ T-complex protein 1 subunit gamma GN=CCT3 TCPG_HUMAN $60.54 \quad 100.0 \%$ T-complex protein 1 subunit gamma GN=CCT3 TCPG_HUMAN $60.54 \quad 100.0 \%$ T-complex protein 1 subunit gamma GN=CCT3 TCPG_HUMAN $60.54 \quad 100.0 \%$ T-complex protein 1 subunit gamma GN=CCT3 TCPG_HUMAN $60.54 \quad 100.0 \%$ T-complex protein 1 subunit gamma GN=CCT3 TCPG_HUMAN $60.54 \quad 100.0 \%$ T-complex protein 1 subunit gamma GN=CCT3 TCPG_HUMAN $60.54 \quad 100.0 \% \quad 2$ T-complex protein 1 subunit gamma GN=CCT3 TCPG_HUMAN $60.54 \quad 100.0 \% \quad 24$ T-complex protein 1 subunit gamma GN=CCT3 TCPG_HUMAN $60.54 \quad 100.0 \% \quad 24$ T-complex protein 1 subunit gamma GN=CCT3 TCPG_HUMAN $60.54 \quad 100.0 \% \quad 24$ T-complex protein 1 subunit gamma GN=CCT3 TCPG_HUMAN $^{6} 60.54 \quad 100.0 \% \quad 24$ T-complex protein 1 subunit gamma GN=CCT3 TCPG_HUMAN $^{6} 60.54 \quad 100.0 \% \quad 24$ T-complex protein 1 subunit gamma GN=CCT3 TCPG_HUMAN $60.54 \quad 100.0 \% 24$ T-complex protein 1 subunit gamma GN=CCT3 TCPG_HUMAN $60.54 \quad 100.0 \% \quad 24$
$9 \quad 0.01 \% \quad 8.0 \% \quad$ LAVEAVLR $0.01 \% \quad 8.0 \% \quad$ LKGSGNL $0.01 \% \quad 8.0 \%$ HGINCFINR

$0.05 \% \quad 32.1 \%$ GAYQDRDKPAQIR $0.05 \% \quad 32.1 \%$ FSNISAAK $0.05 \% \quad 32.1 \%$ AVADAIRTSLGPK $0.05 \% \quad 32.1 \%$ QMQVLHPAAR $0.05 \% \quad 32.1 \%$ GIHPTIISESFQK $0.05 \% \quad 32.1 \%$ VIDPATATSVDLR $0.05 \% \quad 32.1 \%$ VSNSGITRVEK $0.05 \% \quad 32.1 \%$ IGLIQFCLSAPK $0.05 \% \quad 32.1 \%$ AYILNLVK $0.05 \% \quad 32.1 \%$ TGCNVLLIQK $0.05 \% \quad 32.1 \%$ DALSDLALHFLNK $0.05 \% \quad 32.1 \%$ GSNKLVIEEAER $0.05 \% \quad 32.1 \%$ SIHDALCVIR $0.05 \% \quad 32.1 \%$ ALIAGGGAPEIELALR $0.05 \% \quad 32.1 \%$ TLSGMESYCVR $0.02 \% \quad 16.8 \%$ TSLGPNGLDK $0.02 \% \quad 16.8 \%$ IADGYEQAAR $0.02 \% \quad 16.8 \%$ DVDFELIKVEGK $0.02 \% \quad 16.8 \%$ GVIVDKDFSHPQMPK $0.02 \% \quad 16.8 \%$ IAILTCPFEPPKPK $0.02 \% \quad 16.8 \%$ MIIEEAKR $0.02 \% \quad 16.8 \%$ SLHDALCVIR $0.02 \% \quad 16.8 \%$ KQQISLATQMVR $0.02 \% \quad 16.8 \%$ QQISLATQMVR $0.08 \% \quad 44.8 \%$ MLLDPMGGIVMTNDGNAILR $0.08 \% \quad 44.8 \%$ EIQVQHPAAK $0.08 \% \quad 44.8 \%$ ALDDMISTLK $0.08 \% \quad 44.8 \%$ ALDDMISTLKK $0.08 \% \quad 44.8 \%$ WSSLACNIALDAVK $0.08 \% \quad 44.8 \%$ MVQFEENGRK $0.08 \% \quad 44.8 \%$ VEKIPGGIIEDSCVLR $0.08 \% \quad 44.8 \%$ IPGGIIEDSCVLR $0.08 \% \quad 44.8 \%$ GVMINKDVTHPR $0.08 \% \quad 44.8 \%$ IVLLDSSLEYK $0.08 \% \quad 44.8 \%$ IVLLDSSLEYKK $0.08 \% \quad 44.8 \%$ GISDLAQHYLMR $0.08 \% \quad 44.8 \%$ ANITAIRR

$0.08 \% \quad 44.8 \%$ IGDEYFTFITDCKDPK $0.08 \% \quad 44.8 \%$ GASKEILSEVER $0.08 \% \quad 44.8 \%$ EILSEVER

$0.08 \% \quad 44.8 \%$ NLQDAMQVCR $0.08 \% \quad 44.8 \%$ NVLLDPQLVPGGGASEMAVAH $0.08 \% \quad 44.8 \%$ AVAQALEVIPR $\begin{array}{llllllll}99.0 \% & 46.0 & 25.0 & 21.4 & 2 & 0 & 0 & 870.54\end{array}$ $95.0 \% \quad 15.6 \quad 25.0=15.6$ $99.7 \% \quad 34.1$ $\begin{array}{lll}25.0 & 30.4\end{array}$ $99.0 \% \quad 48.8 \quad 25.0 \quad 34.6$ $\begin{array}{llll}99.7 \% & 45.8 & 25.0 & 36.3\end{array}$ $99.7 \% \quad 45.0 \quad 25.0 \quad 42.8$ $\begin{array}{llll}99.3 \% & 27.1 & 25.0 & 27.1\end{array}$ $99.7 \% \quad 61.9 \quad 25.0 \quad 52.4$ $99.7 \% \quad 53.8 \quad 25.0 \quad 42.2$ $\begin{array}{lllll}99.7 \% & 52.0 & 25.0 & 52.0 & 8\end{array}$ $\begin{array}{llll}99.0 \% & 30.4 & 25.0 & 26.2\end{array}$ $99.7 \% \quad 32.8 \quad 25.0 \quad 17.3$ $99.7 \% \quad 70.1 \quad 25.0 \quad 65.9$ $\begin{array}{llll}99.7 \% & 30.3 & 25.0 & 24.7\end{array}$ $99.2 \% \quad 60.0 \quad 25.0 \quad 0.0$ $\begin{array}{llll}99.7 \% & 54.9 & 25.0 & 54.9\end{array}$ $\begin{array}{llll}99.7 \% & 32.3 & 25.0 & 32.3\end{array}$ $\begin{array}{llll}99.7 \% & 46.8 & 25.0 & 37.6\end{array}$ $\begin{array}{llll}99.7 \% & 45.5 & 25.0 & 33.7\end{array}$ $\begin{array}{llll}99.7 \% & 52.5 & 25.0 & 52.4\end{array}$ $\begin{array}{llll}99.7 \% & 31.4 & 25.0 & 31.4\end{array}$ $\begin{array}{llll}99.3 \% & 21.3 & 25.0 & 21.3\end{array}$ $\begin{array}{llll}99.0 \% & 29.4 & 25.0 & 17.6\end{array}$ $\begin{array}{llll}99.2 \% & 60.0 & 25.0 & 0.0\end{array}$

$\begin{array}{llll}99.7 \% & 29.3 & 25.0 & 25.9\end{array}$

$\begin{array}{llll}99.7 \% & 35.7 & 25.0 & 33.2\end{array}$ $\begin{array}{llll}98.1 \% & 48.2 & 25.0 & 14.7\end{array}$ $\begin{array}{llll}99.7 \% & 46.8 & 25.0 & 38.8\end{array}$ $\begin{array}{llll}99.7 \% & 56.5 & 25.0 & 37.3\end{array}$ $\begin{array}{llll}99.7 \% & 42.3 & 25.0 & 42.3\end{array}$ $\begin{array}{llll}99.7 \% & 76.6 & 25.0 & 71.0\end{array}$ $\begin{array}{llll}99.5 \% & 25.7 & 25.0 & 17.6\end{array}$ $\begin{array}{llll}99.7 \% & 36.5 & 25.0 & 34.5\end{array}$ $99.7 \% \quad 44.9 \quad 25.0 \quad 35.7$ $\begin{array}{llll}99.7 \% & 50.8 & 25.0 & 49.7\end{array}$ $\begin{array}{llll}99.7 \% & 56.2 & 25.0 & 53.1\end{array}$ $\begin{array}{llll}99.7 \% & 45.8 & 25.0 & 43.6\end{array}$ $\begin{array}{llll}99.7 \% & 46.0 & 25.0 & 46.0\end{array}$ $\begin{array}{llll}99.0 \% & 22.1 & 25.0 & 18.4\end{array}$ $\begin{array}{llll}94.7 \% & 16.0 & 25.0 & 13.5\end{array}$ $\begin{array}{llll}99.7 \% & 61.1 & 25.0 & 49.0\end{array}$ $\begin{array}{llll}99.0 \% & 36.3 & 25.0 & 12.2\end{array}$ $\begin{array}{llll}99.7 \% & 53.2 & 25.0 & 48.4\end{array}$ $\begin{array}{llll}99.5 \% & 23.0 & 25.0 & 22 .\end{array}$ $\begin{array}{llll}99.7 \% & 43.9 & 25.0 & 41.0\end{array}$ $\begin{array}{llll}99.7 \% & 69.3 & 25.0 & 42.9\end{array}$ 1492.88 1130.55 1517.78 837.45 1298.74 1150.62 1456.78 1357.73

1189.65

1346.75

933.58

1145.63

1456.78

1344.71

1183.63

1550.89

1318.58

1001.53

1093.53

1391.74

1713.86

1610.90

989.54

1183.63

1402.78

1290.68

2147.07

1120.61

1106.58

1234.67

1547.79

1237.60

1784.96

1428.75

1366.73

1279.71

1407.81

1419.71

914.55

1948.90

1317.70

974.52

1234.57

2633.36

1337.63 1166.69

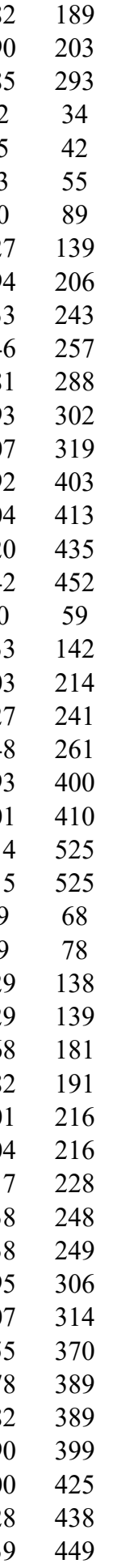



$\begin{array}{llllllll}\text { T-complex protein } 1 \text { subunit gamma GN=CCT3 TCPG_HUMAN } & 60.54 & 100.0 \% & 24 & 31 & 67 & 0.08 \% & 44.8 \% \\ \text { TLIQNCGASTIR }\end{array}$ T-complex protein 1 subunit gamma GN=CCT3 TCPG_HUMAN $60.54 \quad 100.0 \% \quad 2$ T-complex protein 1 subunit gamma GN=CCT3 TCPG_HUMAN $60.54 \quad 100.0 \%$ T-complex protein 1 subunit theta GN=CCT8 TCPQ_HUMAN $59.62 \quad 100.0 \%$ T-complex protein 1 subunit theta GN=CCT8 TCPQ_HUMAN $59.62 \quad 100.0 \%$ T-complex protein 1 subunit theta GN=CCT8 TCPQ_HUMAN $59.62 \quad 100.0 \%$ T-complex protein 1 subunit theta GN=CCT8 TCPQ_HUMAN $59.62 \quad 100.0 \%$ T-complex protein 1 subunit theta GN=CCT8 TCPQ HUMAN $59.62 \quad 100.0 \%$ T-complex protein 1 subunit theta GN=CCT8 TCPQ_HUMAN $59.62 \quad 100.0 \%$ T-complex protein 1 subunit theta $\mathrm{GN}=\mathrm{CCT} 8 \mathrm{TCPQ}$ HUMAN $59.62 \quad 100.0 \%$ T-complex protein 1 subunit zeta GN=CCT6A TCPZ HUMAN $58.03 \quad 100.0^{\circ}$ T-complex protein 1 subunit zeta GN=CCT6A TCPZ_HUMAN $58.03 \quad 100.0 \%$ T-complex protein 1 subunit zeta GN=CCT6A TCPZ_HUMAN $58.03 \quad 100.0 \%$ T-complex protein 1 subunit zeta GN=CCT6A TCPZ_HUMAN $58.03 \quad 100.0 \%$ T-complex protein 1 subunit zeta GN=CCT6A TCPZ_HUMAN $58.03 \quad 100.0 \%$ T-complex protein 1 subunit zeta GN=CCT6A TCPZ HUMAN $58.03 \quad 100.0 \%$ T-complex protein 1 subunit zeta GN=CCT6A TCPZ_HUMAN $58.03 \quad 100.0 \%$ T-complex protein 1 subunit zeta GN=CCT6A TCPZ_HUMAN $58.03 \quad 100.0 \%$ T-complex protein 1 subunit zeta GN=CCT6A TCPZ_HUMAN $58.03 \quad 100.0 \%$ T-complex protein 1 subunit zeta GN=CCT6A TCPZ_HUMAN $58.03 \quad 100.0 \%$ T-complex protein 1 subunit zeta GN=CCT6A TCPZ_HUMAN $58.03 \quad 100.0 \%$ T-complex protein 1 subunit zeta GN=CCT6A TCPZ_HUMAN $58.03 \quad 100.0 \%$ T-complex protein 1 subunit zeta GN=CCT6A TCPZ_HUMAN $58.03 \quad 100.0 \%$ T-complex protein 1 subunit zeta GN=CCT6A TCPZ HUMAN $58.03 \quad 100.0 \%$ T-complex protein 1 subunit zeta GN=CCT6A TCPZ_HUMAN $58.03 \quad 100.0 \%$ T-complex protein 1 subunit zeta GN=CCT6A TCPZ_HUMAN $58.03 \quad 100.0 \%$ T-complex protein 1 subunit zeta GN=CCT6A TCPZ_HUMAN $58.03 \quad 100.0 \%$ T-complex protein 1 subunit zeta GN=CCT6A TCPZ_HUMAN $58.03 \quad 100.0 \%$ T-complex protein 1 subunit zeta $\mathrm{GN}=\mathrm{CCT} 6 \mathrm{~A}$ TCPZ HUMAN $58.03 \quad 100.0 \%$ TELO2-interacting protein 1 homolog GN=TTI1 TTI1_HUMAN $122.07 \quad 100.0 \%$ TELO2-interacting protein 1 homolog GN=TTI1 TTI1_HUMAN $122.07 \quad 100.0 \%$ Testis-expressed sequence 10 protein GN=TEX10 TEX10_HUMAN $105.68 \quad 100.0 \%$ Testis-expressed sequence 10 protein GN=TEX10 TEX10_HUMAN $105.68 \quad 100.0 \%$ Testis-expressed sequence 10 protein GN=TEX10 TEX10 HUMAN $105.68 \quad 100.0 \%$ Testis-expressed sequence 10 protein GN=TEX10 TEX10_HUMAN $105.68 \quad 100.0 \%$ Testis-expressed sequence 264 protein GN=TEX264 TX264_HUMAN $34.19 \quad 100.0 \%$ Testis-expressed sequence 264 protein GN=TEX264 TX264 HUMAN $34.19 \quad 100.0 \%$ Tetratricopeptide repeat protein 37 GN=TTC37 TTC37_HUMAN $175.49 \quad 100.0 \%$ Tetratricopeptide repeat protein $37 \mathrm{GN}=$ TTC37 TTC37_HUMAN $175.49 \quad 100.0 \%$ Tetratricopeptide repeat protein $37 \mathrm{GN}=\mathrm{TTC} 37$ TTC37 HUMAN $175.49 \quad 100.0 \%$ Tetratricopeptide repeat protein 37 GN=TTC37 TTC37_HUMAN $175.49 \quad 100.0 \%$ Tetratricopeptide repeat protein $37 \mathrm{GN}=\mathrm{TTC} 37$ TTC37 HUMAN $175.49 \quad 100.0 \%$ Tetratricopeptide repeat protein $37 \mathrm{GN}=\mathrm{TTC} 37$ TTC37_HUMAN $175.49 \quad 100.0 \%$ Tetratricopeptide repeat protein 37 GN=TTC37 TTC37_HUMAN $175.49 \quad 100.0 \%$ Tetratricopeptide repeat protein $37 \mathrm{GN}=\mathrm{TTC} 37$ TTC37 HUMAN $175.49 \quad 100.0 \%$ TGF-beta-activated kinase 1 and MAP3K7-binding protein $1 \mathrm{GN}=\mathrm{TAB} 1$ TAB1_HUMAN $54.64 \quad 100.0 \%$
$0.08 \% \quad 44.8 \%$ TAVETAVLLLR

$0.08 \% \quad 44.8 \%$ IDDIVSGHK

$0.08 \% \quad 44.8 \%$ IDDIVSGHKK

$0.01 \% \quad 16.2 \%$ HFSGLEEAVYR

$0.01 \% \quad 16.2 \%$ NLRDIDEVSSLLR

$0.01 \% \quad 16.2 \%$ QYGNEVFLAK

$0.01 \% \quad 16.2 \%$ AIADTGANVVVTGGK

$0.01 \% \quad 16.2 \%$ LVPGGGATEIELAK

$0.01 \% \quad 16.2 \%$ FAEAFEAIPR

$0.01 \% \quad 16.2 \%$ ALAENSGVKANEVISK

$0.07 \% \quad 39.4 \%$ TLNPKAEVAR

$0.07 \% \quad 39.4 \%$ AQAALAVNISAAR

$0.07 \% \quad 39.4 \%$ MLVSGAGDIKLTK

$0.07 \% \quad 39.4 \%$ DGNVLLHEMQIQHPTASLIAK

$0.07 \% \quad 39.4 \%$ QADLYISEGLHPR

$0.07 \% \quad 39.4 \%$ IITEGFEAAK

$0.07 \% \quad 39.4 \%$ IITEGFEAAKEK

$0.07 \% \quad 39.4 \%$ ALQFLEEVKVSR

$0.07 \% \quad 39.4 \%$ EMDRETLIDVAR

$0.07 \% \quad 39.4 \%$ HKSETDTSLIR

$0.07 \% \quad 39.4 \%$ SETDTSLIR

$0.07 \% \quad 39.4 \%$ GLVLDHGAR

$0.07 \% \quad 39.4 \%$ VCGDSDKGFVVINQK

$0.07 \% \quad 39.4 \%$ GIDPFSLDALSK

$0.07 \% \quad 39.4 \%$ EGIVALRR

$0.07 \% \quad 39.4 \%$ GPNKHTLTQIK

$0.07 \% \quad 39.4 \%$ HTLTQIKDAVR

$0.07 \% \quad 39.4 \%$ AQLGVQAFADALLIIPK

$0.07 \% \quad 39.4 \%$ VLAQNSGFDLQETLVK

$0.00 \% \quad 2.0 \%$ DAPLAVLR

$0.00 \% \quad 2.0 \%$ LAGSLVTQAPISAR

$0.01 \% \quad 4.1 \%$ LQNATPTNFK

$0.01 \% \quad 4.1 \%$ FLQALADGSSR

$0.01 \% \quad 4.1 \%$ AVYTLYQQR

$0.01 \% \quad 4.1 \%$ SLQATALR

$0.00 \% \quad 8.0 \%$ LFTESCSISPK

$0.00 \% \quad 8.0 \%$ ETSAATLSPGASSR

$0.02 \% \quad 5.6 \%$ SGPGLIGLGIK

$0.02 \% \quad 5.6 \%$ IVDNLGASGNSLYQR

$0.02 \% \quad 5.6 \%$ AALNELLK

$0.02 \% \quad 5.6 \%$ CLLTSAIYALQGR

$0.02 \% \quad 5.6 \%$ VVAQYAQR

$0.02 \% \quad 5.6 \% \quad$ ISEAETLCTK

$0.02 \% \quad 5.6 \%$ VVYQPGYPK

$0.01 \% \quad 13.1 \%$ VLLQAFDVVER
$0.02 \% \quad 5.6 \%$ SNPDQPAVILLLR

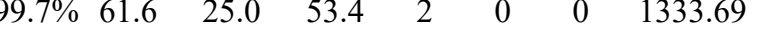

$\begin{array}{lllll}99.7 \% & 70.9 & 25.0 & 62.9 & 2\end{array}$

$\begin{array}{lllll}99.7 \% & 44.6 & 25.0 & 31.3 & 2\end{array}$

$\begin{array}{llll}98.7 \% & 25.4 & 25.0 & 13.8\end{array}$

$\begin{array}{llll}99.5 \% & 23.7 & 25.0 & 23.7\end{array}$

$\begin{array}{llll}99.7 \% & 33.2 & 25.0 & 28.3\end{array}$

$\begin{array}{lllll}99.4 \% & 24.8 & 25.0 & 23.8\end{array}$

$\begin{array}{lllll}99.7 \% & 84.9 & 25.0 & 77.4 & 2\end{array}$

$\begin{array}{llll}97.6 \% & 24.1 & 25.0 & 10.0\end{array}$

$\begin{array}{llll}99.7 \% & 55.9 & 25.0 & 50.1\end{array}$

$99.7 \% \quad 28.4 \quad 25.0 \quad 26.1$

$99.7 \% \quad 45.2 \quad 25.0 \quad 39.2$

$\begin{array}{llll}99.7 \% & 55.5 & 25.0 & 55.5\end{array}$

$\begin{array}{llll}99.7 \% & 55.4 & 25.0 & 51.8\end{array}$

$\begin{array}{llll}99.7 \% & 27.9 & 25.0 & 27.9\end{array}$

$\begin{array}{llll}99.7 \% & 53.8 & 25.0 & 44.6\end{array}$

$99.7 \% \quad 44.9 \quad 25.0 \quad 29.8$

$\begin{array}{llll}99.7 \% & 52.1 & 25.0 & 51.2\end{array}$

$\begin{array}{llll}99.7 \% & 57.4 & 25.0 & 48.0\end{array}$

$\begin{array}{llll}99.7 \% & 41.8 & 25.0 & 41.4\end{array}$

$\begin{array}{llll}99.2 \% & 19.4 & 25.0 & 19.4\end{array}$

$\begin{array}{llll}99.7 \% & 46.0 & 25.0 & 34.5\end{array}$

$\begin{array}{llll}99.7 \% & 48.4 & 25.0 & 36.1\end{array}$

$99.7 \% \quad 35.1 \quad 25.0 \quad 34.2$

$99.7 \% \quad 56.5 \quad 25.0 \quad 25.2$

$\begin{array}{llll}99.0 \% & 44.6 & 25.0 & 23.4\end{array}$

$\begin{array}{llll}94.7 \% & 19.6 & 25.0 & 13.3\end{array}$

$98.0 \% \quad 18.6 \quad 25.0 \quad 16.7$

$99.7 \%$ \#\#\#\# $25.0 \quad$ \#\#\#\#

$99.7 \% \quad 78.8 \quad 25.0 \quad 78.8$

$\begin{array}{llll}99.0 \% & 25.5 & 25.0 & 19.8\end{array}$

$\begin{array}{llll}99.7 \% & 66.8 & 25.0 & 66.8\end{array}$

$\begin{array}{llll}99.7 \% & 39.0 & 25.0 & 34.1\end{array}$

$\begin{array}{llll}99.7 \% & 53.1 & 25.0 & 48.0\end{array}$

$\begin{array}{llll}99.7 \% & 62.1 & 25.0 & 53.4\end{array}$

$\begin{array}{llll}99.0 \% & 37.9 & 25.0 & 22.3\end{array}$

$\begin{array}{llll}96.1 \% & 15.2 & 25.0 & 15.2\end{array}$

$99.7 \% \quad 48.4 \quad 25.0 \quad 43.5$

$\begin{array}{llll}99.7 \% & 53.1 & 25.0 & 47.5\end{array}$

$\begin{array}{llll}99.7 \% & 60.3 & 25.0 & 60.3\end{array}$

$\begin{array}{llll}99.0 \% & 32.5 & 25.0 & 18.6\end{array}$

$\begin{array}{lllll}99.7 \% & 73.0 & 25.0 & 69.5 & 2\end{array}$

$\begin{array}{llll}99.0 \% & 38.1 & 25.0 & 29.4\end{array}$

$99.7 \% \quad 53.8 \quad 25.0 \quad 53.8$

$\begin{array}{llll}99.7 \% & 36.1 & 25.0 & 34.4\end{array}$

$99.7 \% \quad 41.4 \quad 25.0 \quad 41.4 \quad 2$

$\begin{array}{llll}99.7 \% & 41.2 & 25.0 & 41.2\end{array}$
1185.72

983.52

1111.6

1307.64

1529.83

1168.60

1372.74

1354.76

1150.59

1629.88

1098.63

1255.71

1348.75

2315.22

1498.77

1078.58

1335.72

1418.80

1447.72

1286.67

1021.52

937.52

1665.83

1262.66

913.56

1236.71

1281.73

1768.04

1761.94

854.51

1383.80

1133.60

1164.60

1141.60

859.50

1268.62

1334.65

1011.62

1606.82

871.52

1465.78

934.51

1151.56

1435.83

1050.56

1288.73

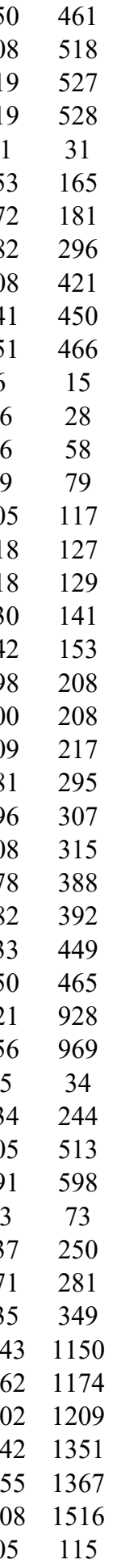

Page 150 of Table S-1-6 
THO complex subunit $2 \mathrm{GN}=\mathrm{THOC} 2$

THO complex subunit $2 \mathrm{GN}=\mathrm{THOC} 2$

THO complex subunit $2 \mathrm{GN}=\mathrm{THOC}$

THO complex subunit $2 \mathrm{GN}=\mathrm{THOC} 2$

THO complex subunit $2 \mathrm{GN}=\mathrm{THOC}$

THO complex subunit $2 \mathrm{GN}=\mathrm{THOC} 2$

THO complex subunit $3 \mathrm{GN}=\mathrm{THOC}$

THO complex subunit $3 \mathrm{GN}=\mathrm{THOC}$

THO complex subunit $3 \mathrm{GN}=\mathrm{THOC} 3$

THO complex subunit $3 \mathrm{GN}=\mathrm{THOC} 3$

THO complex subunit 4 GN=ALYREF

THO complex subunit 4 GN=ALYREF

THO complex subunit $4 \mathrm{GN}=\mathrm{ALYREF}$

THOC2_HUMAN $182.78 \quad 100.0 \%$ THOC2_HUMAN $182.78 \quad 100.0 \%$ THOC2 HUMAN $182.78 \quad 100.0 \%$ THOC2_HUMAN $182.78 \quad 100.0 \%$ THOC2 HUMAN $182.78 \quad 100.0 \%$ THOC2_HUMAN $182.78 \quad 100.0 \%$ THOC3_HUMAN $38.77 \quad 100.0 \%$ THOC3 HUMAN $38.77 \quad 100.0 \%$ THOC3_HUMAN $38.77 \quad 100.0 \%$ THOC3_HUMAN $38.77 \quad 100.0 \%$ THOC4 HUMAN $26.89 \quad 100.0 \%$ THOC4_HUMAN $26.89 \quad 100.0 \%$ THOC4 HUMAN $26.89 \quad 100.0^{\circ}$ THUMP domain-containing protein 3 GN=THUMPD3 THUM3_HUMAN $57.00 \quad 100.0 \%$ THUMP domain-containing protein $3 \mathrm{GN}=$ THUMPD3 THUM3_HUMAN $57.00 \quad 100.0 \%$ THUMP domain-containing protein $3 \mathrm{GN}=$ THUMPD3 THUM3 HUMAN $57.00 \quad 100.0 \%$ THUMP domain-containing protein 3 GN=THUMPD3 THUM3_HUMAN $57.00 \quad 100.0 \%$ Thyroid hormone receptor-associated protein $3 \mathrm{GN}=\mathrm{THRAP} 3 \mathrm{TR} 150$ HUMAN $108.67 \quad 100.0 \%$ Thyroid hormone receptor-associated protein $3 \mathrm{GN}=$ THRAP3 TR150_HUMAN $108.67 \quad 100.0 \%$ Thyroid hormone receptor-associated protein 3 GN=THRAP3 TR150_HUMAN $108.67 \quad 100.0 \%$ Thyroid hormone receptor-associated protein $3 \mathrm{GN}=$ THRAP3 TR150 HUMAN $108.67 \quad 100.0 \%$ Thyroid hormone receptor-associated protein 3 GN=THRAP3 TR150_HUMAN $108.67 \quad 100.0 \%$ Thyroid hormone receptor-associated protein $3 \mathrm{GN}=$ THRAP3 TR150_HUMAN $108.67 \quad 100.0 \%$ Thyroid hormone receptor-associated protein $3 \mathrm{GN}=$ THRAP3 TR150_HUMAN $108.67 \quad 100.0 \%$ Thyroid hormone receptor-associated protein 3 GN=THRAP3 TR150_HUMAN $108.67 \quad 100.0 \%$ Thyroid hormone receptor-associated protein $3 \mathrm{GN}=$ THRAP3 TR150 HUMAN $108.67 \quad 100.0 \%$ Thyroid hormone receptor-associated protein 3 GN=THRAP3 TR150_HUMAN $108.67 \quad 100.0 \%$ Thyroid transcription factor 1-associated protein $26 \mathrm{GN}=$ CCDC59 TAP26_HUMAN $28.67 \quad 100.0 \%$ Thyroid transcription factor 1-associated protein $26 \mathrm{GN}=\mathrm{CCDC} 59 \mathrm{TAP} 26 \mathrm{HUMAN} 28.67 \quad 100.0 \%$ Thyroid transcription factor 1-associated protein $26 \mathrm{GN}=\mathrm{CCDC} 59$ TAP26_HUMAN $28.67 \quad 100.0 \%$ Thyroid transcription factor 1-associated protein $26 \mathrm{GN}=\mathrm{CCDC} 59$ TAP26_HUMAN $28.67 \quad 100.0 \%$ Thyroid transcription factor 1-associated protein $26 \mathrm{GN}=\mathrm{CCDC} 59$ TAP26_HUMAN $28.67 \quad 100.0 \%$ Tight junction protein $\mathrm{ZO}-1 \mathrm{GN}=\mathrm{TJP} 1$ Tight junction protein $\mathrm{ZO}-1 \mathrm{GN}=\mathrm{TJP} 1$ Tight junction protein $\mathrm{ZO}-1 \mathrm{GN}=\mathrm{TJP} 1$ Tight junction protein $\mathrm{ZO}-1 \mathrm{GN}=\mathrm{TJP} 1$ TP53-regulating kinase $\mathrm{GN}=\mathrm{TP} 53 \mathrm{RK}$ TP53-regulating kinase $\mathrm{GN}=\mathrm{TP} 53 \mathrm{RK}$ ZO1_HUMAN $195.46 \quad 100.0 \%$ ZO1_HUMAN $195.46 \quad 100.0 \%$ ZO1_HUMAN $195.46 \quad 100.0 \%$ ZO1_HUMAN $195.46 \quad 100.0 \%$ PRPK_HUMAN $28.16 \quad 100.0 \%$ PRPK_HUMAN $28.16 \quad 100.0 \%$ 作 TraB domain-containing protein GN=TRABD TRABD_HUMAN $42.32 \quad 100.0 \%$ TraB domain-containing protein GN=TRABD TRABD_HUMAN $42.32 \quad 100.0 \%$ TraB domain-containing protein GN=TRABD TRABD HUMAN $42.32 \quad 100.0 \%$ Trafficking protein particle complex subunit 8 GN=TRAPPC8 TPPC8_HUMAN $161.00 \quad 100.0 \%$
$0.01 \% \quad 13.1 \%$ YGYTDIDLLSAAK $0.01 \% \quad 13.1 \%$ QTSLDAVAQAVVDR $0.01 \% \quad 13.1 \%$ IHSDTFASGGER

$0.01 \% \quad 13.1 \%$ VYPVSVPYSSAQSTSK

$6 \quad 0.02 \% \quad 3.8 \%$ LGLLEALLK

$16 \quad 0.02 \% \quad 3.8 \% \quad$ LTKENVKPSGR

$0.02 \% \quad 3.8 \%$ FLQLCIFPR

$16 \quad 0.02 \% \quad 3.8 \%$ CIFSAIDAVYCAR

$16 \quad 0.02 \% \quad 3.8 \%$ FVELVHQQK

$0.02 \% \quad 3.8 \%$ VLNLGQALER

$0.01 \% \quad 8.6 \%$ YVLGMQELFR

$0.01 \% \quad 8.6 \%$ TASVFLLEK

$0.01 \% \quad 8.6 \%$ TASVFLLEKDR

$0.01 \% \quad 8.6 \%$ TLSFSHDGK

$0.01 \% 21.4 \%$ QLPDKWQHDLFDSGFGGGAGVETGGK

$0.01 \% \quad 21.4 \%$ SLGTADVHFER

$0.01 \% \quad 21.4 \%$ QQLSAEELDAQLDAYNAR

$0.01 \% \quad 8.7 \%$ STLAYGMLR

$0.01 \% \quad 8.7 \%$ AANNIASLLTK

$0.01 \% \quad 8.7 \%$ TGSVDIIVTDLPFGKR

$0.01 \% \quad 8.7 \%$ AAVYVLIR

$99.7 \% \quad 69.8$

$99.7 \% \quad 47.5$

$99.7 \% \quad 31.0$

$99.7 \% \quad 35.2$

$\begin{array}{lll}99.7 \% & 32.7\end{array}$

$95.2 \% 18.8$

$99.7 \% \quad 35.9$

$99.7 \% \quad 43.4$

$99.7 \% 33.4$

$99.7 \% \quad 57.4$

$99.7 \% \quad 40.7$

$97.1 \% \quad 18.1$

$99.7 \% \quad 57.8$

$99.7 \% \quad 27.2$

$99.7 \% \quad 48.3$

$99.7 \% \quad 60.6$

$9.7 \% 76.8$

$99.6 \% \quad 25.5$

$99.7 \% \quad 47.4$

$99.7 \% \quad 37.4$

$99.0 \% \quad 29.4$

$0.06 \% \quad 10.8 \%$ ASAVSELSPR

$0.06 \% \quad 10.8 \%$ ASAVSELSPRER

$0.06 \% \quad 10.8 \%$ SPALKSPLQSVVVR

$0.06 \% \quad 10.8 \%$ SPLQSVVVR

$49 \quad 0.06 \% \quad 10.8 \%$ GSFSDTGLGDGK

$0.06 \% \quad 10.8 \%$ KTEELEEESFPER

$0.06 \% \quad 10.8 \%$ GFVPEKNFR

$0.06 \% \quad 10.8 \%$ VTAYKAVQEK

$0.06 \% \quad 10.8 \%$ SIFQHIQSAQSQR

$0.01 \% \quad 19.5 \%$ GEGVSTVGYR

$0.01 \% \quad 19.5 \%$ EGQGFAFR

$0.01 \% \quad 19.5 \%$ HLYLAEEER

$0.01 \% \quad 19.5 \%$ TVNSFTIPK

$0.01 \% \quad 19.5 \%$ AQEEYEQIQAK

$0.01 \% \quad 2.5 \%$ MSARAAAAK

$0.01 \% \quad 2.5 \%$ SVASSQPAKPTK

$0.01 \% \quad 2.5 \%$ EISQDSLAAR

$0.01 \% \quad 2.5 \%$ DGNIQEGDVVLK

$0.00 \% \quad 7.1 \%$ TPQGLSNLAK

$0.00 \% \quad 7.1 \%$ TIGQVLAR

$0.01 \% \quad 13.8 \%$ TVTQLVAEDGSR

$0.01 \% \quad 13.8 \%$ EVQPDVVVVELCQYR

$0.01 \% \quad 13.8 \%$ MDESTLLR

$0.01 \% \quad 13.8 \%$ TASLVLSLPAAQYCLQR

$0.00 \% \quad 2.7 \%$ IAVSNIVTQPPQPGAIRK
.

$99.7 \% \quad 50.9$

$99.7 \% \quad 40.1$

$99.3 \% \quad 28.8$

$99.7 \% \quad 49.7$

$99.7 \% \quad 62.0$

$99.7 \% \quad 29.2$

$99.7 \% \quad 33.0$

$99.7 \% \quad 38.0$

$99.7 \% \quad 57.0$

$99.7 \% \quad 50.9$

$99.0 \% \quad 25.4$

$99.7 \% \quad 47.2$

$98.1 \% \quad 21.5$

$99.7 \% \quad 65.4$

$99.2 \% \quad 33.6$

$99.7 \% 34.1$

$99.7 \% \quad 37.3$

$99.6 \% 25.3$

$99.7 \% \quad 34.8$

$97.1 \% \quad 36.2$

$99.7 \% 59.1$

$99.7 \% \quad 67.5$

$99.0 \% \quad 37.0$

$99.7 \% \quad 39.4$

$99.6 \% \quad 25.6$
1472.77

1276.59

1699.85

969.63

1228.70

1193.65

1545.72

1127.62

1112.64

1255.65

1007.58

1278.71

991.48

2703.28

1231.61

2034.97

1011.53

1115.64

1717.95

904.56

2054.94

1016.54

1301.68

1480.88

984.58

1140.52

1622.75

1093.58

1136.63

1529.78

1024.51

911.44

1159.57

1006.56

1336.64

876.47

1200.66

1089.55

1286.66

1028.57

857.52

1275.65

1832.92

964.48

1891.01

1889.10

$\begin{array}{cc}0 & 262 \\ 20 & 333 \\ 37 & 348 \\ 37 & 402 \\ 46 & 354 \\ 56 & 566 \\ 77 & 985 \\ 66 & 998 \\ 99 & 1007 \\ 37 & 1146 \\ 4 & 43 \\ 8 & 86 \\ 8 & 88 \\ 71 & 279 \\ 2 & 107 \\ 45 & 155 \\ 36 & 253 \\ 05 & 313 \\ 59 & 369 \\ 97 & 412 \\ 77 & 484 \\ 16 & 235 \\ 36 & 245 \\ 36 & 247 \\ 48 & 261 \\ 53 & 261 \\ 76 & 387 \\ 86 & 498 \\ 14 & 522 \\ 23 & 532 \\ 09 & 621 \\ 9 & 28 \\ 1 & 58 \\ 5 & 103 \\ 53 & 161 \\ 72 & 182 \\ 1 & 9 \\ 75 & 186 \\ 10 & 219 \\ 20 & 231 \\ 35 & 144 \\ 45 & 152 \\ 3 & 74 \\ 7 & 111 \\ 17 & 124 \\ 53 & 369 \\ & 87 \\ & \end{array}$


Trafficking protein particle complex subunit 8 GN=TRAPPC8 TPPC8 HUMAN $161.00 \quad 100.0 \%$ Trafficking protein particle complex subunit 8 GN=TRAPPC8 TPPC8_HUMAN $161.00 \quad 100.0 \%$ Transcription activator BRG1 GN=SMARCA4 SMCA4_HUMAN $184.65 \quad 100.0 \%$ Transcription activator BRG1 GN=SMARCA4 SMCA4_HUMAN $184.65 \quad 100.0 \%$ Transcription activator BRG1 GN=SMARCA4 SMCA4_HUMAN $184.65 \quad 100.0 \%$ Transcription activator BRG1 GN=SMARCA4 SMCA4_HUMAN $184.65 \quad 100.0 \%$ Transcription activator BRG1 GN=SMARCA4 SMCA4_HUMAN $184.65 \quad 100.0 \%$ Transcription activator BRG1 GN=SMARCA4 SMCA4_HUMAN $184.65 \quad 100.0 \%$ Transcription activator BRG1 GN=SMARCA4 SMCA4 HUMAN $184.65 \quad 100.0 \%$ Transcription activator BRG1 GN=SMARCA4 SMCA4_HUMAN $184.65 \quad 100.0 \%$ Transcription activator BRG1 GN=SMARCA4 SMCA4_HUMAN $184.65 \quad 100.0 \%$ Transcription activator BRG1 GN=SMARCA4 SMCA4_HUMAN $184.65100 .0 \%$ Transcription activator BRG1 GN=SMARCA4 SMCA4_HUMAN $184.65 \quad 100.0 \%$ Transcription termination factor 1, mitochondrial GN=MTERF1 MTEF1 HUMAN $45.78 \quad 100.0 \%$ Transcription termination factor 1, mitochondrial GN=MTERF1 MTEF1 HUMAN $45.78 \quad 100.0 \%$ Transcriptional activator protein Pur-alpha GN=PURA PURA_HUMAN $34.91 \quad 100.0 \%$ Transcriptional activator protein Pur-alpha GN=PURA PURA HUMAN $34.91 \quad 100.0 \%$ Transcriptional activator protein Pur-alpha GN=PURA PURA_HUMAN $34.91 \quad 100.0 \%$ Transcriptional activator protein Pur-alpha GN=PURA PURA_HUMAN $34.91 \quad 100.0 \%$ Transcriptional activator protein Pur-alpha GN=PURA PURA_HUMAN $34.91 \quad 100.0 \%$ Transcriptional activator protein Pur-beta GN=PURB PURB_HUMAN $33.24 \quad 100.0 \%$ Transcriptional activator protein Pur-beta GN=PURB PURB HUMAN $33.24 \quad 100.0 \%$ Transcriptional activator protein Pur-beta GN=PURB PURB_HUMAN $33.24 \quad 100.0 \%$ Transcriptional adapter 1 GN=TADA1 TADA1_HUMAN $37.38 \quad 100.0 \%$ Transcriptional adapter $1 \mathrm{GN}=$ TADA1 $100.0 \%$ Transducin beta-like protein 3 GN=TBL3 TBL3_HUMAN $89.03 \quad 100.0 \%$ Transducin beta-like protein 3 GN=TBL3 TBL3_HUMAN $89.03 \quad 100.0 \%$ Transformation/transcription domain-associated protein GN=TRRAP TRRAP HUMAN $437.60 \quad 100.0 \%$ Transformation/transcription domain-associated protein GN=TRRAP TRRAP_HUMAN $437.60 \quad 100.0 \%$ Transformation/transcription domain-associated protein GN=TRRAP TRRAP HUMAN $437.60 \quad 100.0 \%$ Transformation/transcription domain-associated protein GN=TRRAP TRRAP_HUMAN $437.60 \quad 100.0 \%$ Transformation/transcription domain-associated protein GN=TRRAP TRRAP_HUMAN $437.60 \quad 100.0 \%$ Transformation/transcription domain-associated protein GN=TRRAP TRRAP HUMAN $437.60 \quad 100.0 \%$ Transformation/transcription domain-associated protein GN=TRRAP TRRAP_HUMAN $437.60 \quad 100.0 \%$ Transformation/transcription domain-associated protein GN=TRRAP TRRAP_HUMAN $437.60 \quad 100.0 \%$ Transformation/transcription domain-associated protein GN=TRRAP TRRAP_HUMAN $437.60 \quad 100.0 \%$ Transformation/transcription domain-associated protein GN=TRRAP TRRAP_HUMAN $437.60 \quad 100.0 \%$ 年 Transformer-2 protein homolog alpha GN=TRA2A TRA2A_HUMAN $32.69 \quad 100.0 \%$ Transformer-2 protein homolog alpha GN=TRA2A TRA2A_HUMAN $32.69 \quad 100.0 \%$ Transformer-2 protein homolog alpha GN=TRA2A TRA2A_HUMAN $32.69 \quad 100.0 \%$ Transformer-2 protein homolog alpha GN=TRA2A TRA2A_HUMAN $32.69 \quad 100.0 \%$ Transformer-2 protein homolog alpha GN=TRA2A TRA2A_HUMAN $32.69 \quad 100.0 \%$ Transformer-2 protein homolog alpha GN=TRA2A TRA2A_HUMAN $32.69 \quad 100.0 \%$ Transformer-2 protein homolog alpha GN=TRA2A TRA2A_HUMAN $32.69 \quad 100.0 \%$ Transformer-2 protein homolog alpha GN=TRA2A TRA2A HUMAN $32.69 \quad 100.0 \%$ Transformer-2 protein homolog alpha GN=TRA2A TRA2A_HUMAN $32.69 \quad 100.0 \%$
$0.00 \% \quad 2.7 \% \quad$ YSEAAALLIR $0.00 \% \quad 2.7 \%$ GKQDLEIQGPR $0.02 \% \quad 6.9 \% \quad$ ITPIQKPR $0.02 \% \quad 6.9 \%$ DTALETALNAK $0.02 \% \quad 6.9 \% \quad$ AVATYHANTER $0.02 \% \quad 6.9 \% \quad$ ILTGTDAPK $0.02 \% \quad 6.9 \% \quad$ YMIVDEGHR $0.02 \% \quad 6.9 \% \quad$ LTQVLNTHYVAPR $0.02 \% \quad 6.9 \%$ ASGKFELLDR $0.02 \% \quad 6.9 \% \quad$ LCTVNSVEEK $0.02 \% \quad 6.9 \% \quad$ YKLNVDQK $0.02 \% \quad 6.9 \% \quad$ VIQAGMFDQK $0.02 \% \quad 6.9 \%$ DSDAGSSTPTTSTR $0.00 \% \quad 4.8 \%$ FLYSVGLTR $0.00 \% \quad 4.8 \% \quad$ VLDSSISTLK $0.01 \% \quad 23.9 \%$ YYMDLKENQR $0.01 \% \quad 23.9 \%$ GPGLGSTQGQTIALPAQGLIEFR $0.01 \% \quad 23.9 \%$ LIDDYGVEEEPAELPEGTSLTVDNKR $0.01 \% \quad 23.9 \%$ FFFDVGSNK $0.01 \% \quad 23.9 \%$ VSEVKPTYR $0.01 \% \quad 11.5 \%$ GGGGGPCGFQPASR $0.01 \% \quad 11.5 \%$ GGGEQETQELASK $0.01 \% \quad 11.5 \%$ VSEVKPSYR $0.00 \% \quad 7.5 \%$ NLSEALGDNVK $0.00 \% \quad 7.5 \% \quad$ YAFGSNVTPQPYLK $0.00 \% \quad 3.3 \%$ FKTNYAVER $0.00 \% \quad 3.3 \% \quad$ NTAPDNGPILLQAQTTQR $0.02 \% \quad 2.8 \%$ APGEAQFIPNK $0.02 \% \quad 2.8 \%$ AIETALDCLK $0.02 \% \quad 2.8 \%$ TIPNVIISHR $0.02 \% \quad 2.8 \%$ EVTSPNSTVR $0.02 \% \quad 2.8 \% \quad$ DVLAANPNR $0.02 \% \quad 2.8 \%$ GLSVDSAQEVKR $0.02 \% \quad 2.8 \%$ TATGAISAVFGR $0.02 \% \quad 2.8 \%$ VIYEGLTNYEK $0.02 \% \quad 2.8 \%$ RAQATAQDPVFQK $0.02 \% \quad 2.8 \%$ AQATAQDPVFQK $0.02 \% \quad 2.8 \%$ VVAVSPQMR

$0.04 \% \quad 36.2 \%$ ANPDPNTCLGVFGLSLYTTER $0.04 \% \quad 36.2 \%$ DLREVFSR

$0.04 \% \quad 36.2 \%$ YGPLSGVNVVYDQR $0.04 \% \quad 36.2 \%$ GFAFVYFER $0.04 \% \quad 36.2 \%$ IDDSKEAMER $0.04 \% \quad 36.2 \%$ ANGMELDGRR $0.04 \% \quad 36.2 \%$ IRVDYSITK $0.04 \% \quad 36.2 \%$ VDYSITKR $0.04 \% \quad 36.2 \%$ GYDRYEDYDYR $\begin{array}{llllllll}99.7 \% & 54.6 & 25.0 & 46.2 & 2 & 0 & 0 & 1106.62\end{array}$ $99.7 \% \quad 44.7$ $95.6 \% \quad 15.8$ $99.7 \% \quad 51.5$ $99.7 \% \quad 30.6$ $99.6 \% \quad 32.2$ $99.7 \% 27.3$ $99.7 \% \quad 61.9$ $99.6 \% 26.4$ $99.7 \% \quad 39.0$ $95.7 \% \quad 21.5$ $99.7 \% \quad 46.5$ $99.7 \% \quad 71.3$ $99.7 \% \quad 48.5$ $99.6 \% \quad 27.5$ $99.7 \% \quad 40.8$ $9.7 \% \quad 46.1$ $99.7 \% \quad 40.2$ $99.3 \% \quad 24.5$ $99.7 \% \quad 30.7$ $99.7 \% \quad 56.7$ $99.7 \% \quad 36.0$ $99.6 \% \quad 26.4$ $99.7 \% \quad 58.2$ $\begin{array}{lll}95.5 \% & 19.5\end{array}$

$99.7 \% \quad 53.8$ $99.7 \% 28.2$ $99.7 \% 33.5$ $\begin{array}{lll}99.4 \% & 21.2\end{array}$ $99.3 \% 31$. $99.7 \% \quad 27.1$ $99.7 \% \quad 59.2$ $99.7 \% \quad 45.8$ $99.7 \% \quad 50.6$ $99.6 \% 27.0$ $97.2 \% \quad 18.4$ $97.2 \% \quad 17.5$ $99.7 \% \quad 50.3$ $98.1 \% \quad 20.5$ $99.7 \% \quad 56.8$ $99.7 \% \quad 61.2$ $99.7 \% \quad 68.6$ $98.0 \% \quad 17.5$ $99.7 \% \quad 43.9$ $98.2 \% \quad 23.2$ $98.5 \% \quad 21.5$ 240.66

952.59

1146.60

1232.60

915.51

1119.53

1511.83

1135.61

1178.57

1007.55

1136.58

1382.60

1055.59

1062.60

1359.64

2311.24

2889.40

1060.51

1078.59

1304.58

1333.62

1064.57

1159.60

1584.8

1127.58

1938.00

1171.6

1133.59

1149.67

1089.55

969.51

1288.69

1150.62

1328.67

1459.77

1303.66

1002.54

2325.12

1021.54

1566.79

1135.56

1193.55

1118.54

1094.62

981.54 1514.62

$\begin{array}{cc}19 & 528 \\ 74 & 884 \\ 52 & 359 \\ 27 & 437 \\ 03 & 513 \\ 27 & 635 \\ 77 & 885 \\ 93 & 905 \\ 78 & 1087 \\ 04 & 1213 \\ 20 & 1227 \\ 28 & 1237 \\ 16 & 1429 \\ 82 & 190 \\ 51 & 360 \\ 55 & 164 \\ 77 & 199 \\ 05 & 230 \\ 31 & 239 \\ 46 & 254 \\ 1 & 24 \\ 5 & 37 \\ 47 & 255 \\ 4 & 24 \\ 06 & 219 \\ 1 & 19 \\ 59 & 476 \\ 69 & 579 \\ 42 & 951 \\ 97 & 1006 \\ 48 & 1257 \\ 02 & 1610 \\ 49 & 2060 \\ 63 & 2074 \\ 49 & 2259 \\ 03 & 3415 \\ 04 & 3415 \\ 74 & 3582 \\ 13 & 133 \\ 34 & 141 \\ 42 & 155 \\ 61 & 169 \\ 70 & 179 \\ 80 & 189 \\ 90 & 198 \\ 92 & 199 \\ 45 & 255 \\ & \end{array}$

Page 152 of Table S-1-6 

Transformer-2 protein homolog beta GN=TRA2B TRA2B_HUMAN $33.67 \quad 100.0 \%$ Transformer- 2 protein homolog beta GN=TRA2B TRA2B_HUMAN $33.67 \quad 100.0 \%$ Transformer-2 protein homolog beta GN=TRA2B TRA2B_HUMAN $33.67 \quad 100.0 \%$ Transformer- 2 protein homolog beta GN=TRA2B TRA2B_HUMAN $33.67 \quad 100.0 \%$ Transformer-2 protein homolog beta GN=TRA2B TRA2B HUMAN $33.67 \quad 100.0 \%$ Transformer-2 protein homolog beta GN=TRA2B TRA2B_HUMAN $33.67 \quad 100.0 \%$ Transformer-2 protein homolog beta GN=TRA2B TRA2B_HUMAN $33.67 \quad 100.0 \%$ Transformer-2 protein homolog beta GN=TRA2B TRA2B_HUMAN $33.67 \quad 100.0 \%$ Transformer-2 protein homolog beta GN=TRA2B TRA2B_HUMAN $33.67 \quad 100.0 \%$ Transformer-2 protein homolog beta GN=TRA2B TRA2B HUMAN $33.67 \quad 100.0 \%$ Translation initiation factor eIF-2B subunit alpha GN=EIF2B1 EI2BA_HUMAN $33.71 \quad 100.0 \%$ Translation initiation factor eIF-2B subunit alpha GN=EIF2B1 EI2BA_HUMAN $33.71 \quad 100.0 \%$ Translation initiation factor eIF-2B subunit alpha GN=EIF2B1 EI2BA_HUMAN $33.71 \quad 100.0 \%$ Translation initiation factor eIF-2B subunit alpha GN=EIF2B1 EI2BA_HUMAN $33.71 \quad 100.0 \%$ Translation initiation factor eIF-2B subunit alpha GN=EIF2B1 EI2BA_HUMAN $33.71 \quad 100.0 \%$ Translation initiation factor eIF-2B subunit beta GN=EIF2B2 EI2BB HUMAN $38.99 \quad 100.0 \%$ Translation initiation factor eIF-2B subunit beta GN=EIF2B2 EI2BB_HUMAN $38.99 \quad 100.0 \%$ Translation initiation factor eIF-2B subunit beta GN=EIF2B2 EI2BB_HUMAN $38.99 \quad 100.0 \%$ Translation initiation factor eIF-2B subunit beta GN=EIF2B2 EI2BB_HUMAN $38.99 \quad 100.0 \%$ Translation initiation factor eIF-2B subunit delta GN=EIF2B4 EI2BD_HUMAN $57.56 \quad 100.0 \%$ Translation initiation factor eIF-2B subunit delta GN=EIF2B4 EI2BD HUMAN $57.56 \quad 100.0 \%$ Translation initiation factor eIF-2B subunit delta GN=EIF2B4 EI2BD_HUMAN $57.56 \quad 100.0 \%$ Translational activator GCN1 GN=GCN1L1 GCN1L_HUMAN $292.76100 .0 \%$ Translational activator GCN1 GN=GCN1L1 GCN1L_HUMAN $292.76 \quad 100.0 \%$ Translational activator GCN1 GN=GCN1L1 GCN1L_HUMAN $292.76 \quad 100.0 \%$ Translational activator GCN1 GN=GCN1L1 GCN1L HUMAN $292.76100 .0 \%$ Translational activator GCN1 GN=GCN1L1 GCN1L_HUMAN $292.76 \quad 100.0 \%$ Translational activator GCN1 GN=GCN1L1 GCN1L_HUMAN $292.76 \quad 100.0 \%$ Translational activator GCN1 GN=GCN1L1 GCN1L_HUMAN $292.76 \quad 100.0 \%$ Translational activator GCN1 GN=GCN1L1 GCN1L_HUMAN $292.76 \quad 100.0 \%$ Translational activator GCN1 GN=GCN1L1 GCN1L_HUMAN $292.76 \quad 100.0 \%$ Translational activator GCN1 GN=GCN1L1 GCN1L_HUMAN $292.76 \quad 100.0 \%$ Translational activator GCN1 GN=GCN1L1 GCN1L_HUMAN $292.76 \quad 100.0 \%$ Translational activator GCN1 GN=GCN1L1 GCN1L HUMAN 292.76 Translational activator GCN1 GN=GCN1L1 GCN1L_HUMAN $292.76 \quad 100.0 \%$ Translational activator GCN1 GN=GCN1L1 GCN1L_HUMAN $292.76 \quad 100.0 \%$ Translational activator GCN1 GN=GCN1L1 GCN1L_HUMAN $292.76 \quad 100.0 \%$ Translational activator GCN1 GN=GCN1L1 GCN1L_HUMAN $292.76 \quad 100.0 \%$ Translational activator GCN1 GN=GCN1L1 GCN1L HUMAN $292.76100 .0 \%$ Translational activator GCN1 GN=GCN1L1 GCN1L_HUMAN $292.76 \quad 100.0 \%$ Translational activator GCN1 GN=GCN1L1 GCN1L_HUMAN $292.76 \quad 100.0 \%$ Translational activator GCN1 GN=GCN1L1 GCN1L_HUMAN $292.76 \quad 100.0 \%$ Translational activator GCN1 GN=GCN1L1 GCN1L_HUMAN $292.76 \quad 100.0 \%$

$39 \quad 0.04 \% \quad 36.2 \%$ RSPSPYYSR

$0.04 \%$

$99.7 \% \quad 36.0$

$0.07 \% \quad 38.5 \%$ ANPDPNCCLG

$0.07 \% \quad 38.5 \%$ DLREVFSK

$0.07 \% \quad 38.5 \%$ YGPIADVSIVYDQQSR

$0.07 \% 38.5 \%$ GFAFVYFENVDDAK

$\begin{array}{llll}0.07 \% & 38.5 \% & \text { GFAFVYFENVDDAKEAK } \quad 99.7 \% \quad 39.5\end{array}$

$0.07 \% \quad 38.5 \%$ ANGMELDGRR

$0.07 \% \quad 38.5 \%$ IRVDFSITK

$0.07 \% \quad 38.5 \%$ GYDDRDYYSR

$0.07 \% \quad 38.5 \%$ AAQDRDQIYR

$\begin{array}{ll}0.07 \% & 38.5 \% \\ 0.07 \% & 38.5 \% \text { SPSPYYSR }\end{array}$

$0.07 \% \quad 38.5 \%$ SPSPYYSR

$0.01 \% \quad 19.3 \%$ SQMKEDPDMASAVAAIR $99.5 \% \quad 31$.

$0.01 \% \quad 19.3 \%$ DKGETIQGLR

$0.01 \% \quad 19.3 \%$ DGATILTHAYSR

$0.01 \% \quad 19.3 \%$ VLEAAVAAK

$0.01 \% \quad 19.3 \%$ IGTNQMAVCAK

$0.01 \% \quad 14.0 \%$ IESFVETLKR

$0.01 \% \quad 14.0 \%$ SDESDQQESLHK

$0.01 \% \quad 14.0 \%$ AVTGTHTLALAAK

$0.01 \% \quad 14.0 \%$ LSPQFPNEEDSFHK

$0.00 \% \quad 7.8 \%$ ELPESGIQLGTPR

$0.00 \% \quad 7.8 \%$ VSLFSHLPQYSR

$0.00 \% \quad 7.8 \%$ LGLQYSQGLVSGSNAR

$141 \quad 0.16 \% \quad 18.8 \%$ ALQAAIQQLAEAQPEATAK $99.7 \% \quad 68.7$

$141 \quad 0.16 \% \quad 18.8 \%$ GIKEEVQLTSK

$141 \quad 0.16 \% \quad 18.8 \%$ ALGTLVSHVTLR

$141 \quad 0.16 \% \quad 18.8 \%$ ASPNTPPGRVDENGPI

$141 \quad 0.16 \% \quad 18.8 \%$ QAGAEALSQAVAR

$141 \quad 0.16 \% \quad 18.8 \%$ LMEIYQEK

$141 \quad 0.16 \% \quad 18.8 \%$ LYRPPPVLDALGR

$141 \quad 0.16 \% \quad 18.8 \%$ NAPNDASYDAVR

$141 \quad 0.16 \% \quad 18.8 \%$ KGAAYGLAGLVK

$141 \quad 0.16 \% \quad 18.8 \%$ GAAYGLAGLVK $96.7 \% \quad 22.8$ $99.7 \% \quad 53.7$ $99.0 \% 25.6$

$\begin{array}{ll}99.7 \% & 60.9 \\ 99.7 \% & 43.0\end{array}$

$99.7 \% \quad 49.9$

$98.0 \% \quad 17.5$

$99.7 \% \quad 49.7$

$99.7 \% \quad 31.9$

$99.7 \% \quad 39.0$

$99.7 \% \quad 36.0$

$\begin{array}{lll}96.7 \% & 22.8\end{array}$

$\begin{array}{ll}99.7 \% & 33.9\end{array}$

$99.7 \% \quad 33.6$

$99.7 \% \quad 55.8$

$\begin{array}{lll}99.7 \% & 47.7\end{array}$

$98.8 \% 21.0$

$99.7 \% \quad 64.4$

$99.7 \% \quad 58.5$

$96.0 \% \quad 16.2$

$99.2 \% \quad 28.5$

$99.4 \% \quad 21.5$

$99.7 \% \quad 54.0$

$99.0 \% \quad 23.6$

$99.7 \% \quad 62.8$

$97.6 \% \quad 23.1$

$99.7 \% \quad 41.9$

$99.7 \% \quad 53.0$

$98.1 \% \quad 16.6$

$99.7 \% \quad 47.8$

$99.7 \% \quad 60.5$

$99.6 \% \quad 23.7$

$99.0 \% \quad 34.6$

$99.7 \% \quad 39.5$

\begin{tabular}{ll}
$99.7 \% \quad 59.0$ \\
\hline
\end{tabular}

956.45

2384.10

993.54

1810.90

1967.00

1621.75

1949.93

1118.54

1078.63

1309.54

1235.61

1112.55

956.45

1851.86

1116.60

1304.66

871.52

1208.58

1221.68

1402.61

1253.72

1674.78

1396.74

1433.75

1649.86

1059.58

1952.04

1440.78

1087.55

1320.70

1130.62

1443.6

1118.57

941.61

1320.70

991.57

1231.69

1266.75

2116.08

1238.64

$99.7 \% \quad 37.6$

$99.7 \% \quad 58.5$

$99.0 \% \quad 30.5$

$98.0 \% \quad 16.5$

$99.7 \% \quad 56.2$

$99.1 \% 27.3$

$99.7 \% \quad 53.0$

1271.67

1053.53

1466.85

1292.59

1147.68

1019.59 
Translational activator GCN1 GN=GCN1L1 GCN1L_HUMAN $292.76 \quad 100.0 \%$ Translational activator GCN1 GN=GCN1L1 GCN1L_HUMAN $292.76 \quad 100.0 \% \quad 45$ Translational activator GCN1 GN=GCN1L1 GCN1L_HUMAN $292.76 \quad 100.0 \% \quad 4$ Translational activator GCN1 GN=GCN1L1 GCN1L_HUMAN $292.76 \quad 100.0 \%$ Translational activator GCN1 GN=GCN1L1 GCN1L_HUMAN $292.76 \quad 100.0 \% \quad 45$ Translational activator GCN1 GN=GCN1L1 GCN1L_HUMAN $292.76 \quad 100.0 \%$ Translational activator GCN1 GN=GCN1L1 GCN1L_HUMAN $292.76 \quad 100.0 \%$ Translational activator GCN1 GN=GCN1L1 GCN1L_HUMAN $292.76 \quad 100.0 \%$ Translational activator GCN1 GN=GCN1L1 GCN1L HUMAN $292.76 \quad 100.0 \%$ Translational activator GCN1 GN=GCN1L1 GCN1L_HUMAN $292.76 \quad 100.0 \% \quad 4$ Translational activator GCN1 GN=GCN1L1 GCN1L_HUMAN $292.76 \quad 100.0 \% \quad 4$ Translational activator GCN1 GN=GCN1L1 GCN1L_HUMAN $292.76 \quad 100.0 \%$ Translational activator GCN1 GN=GCN1L1 GCN1L_HUMAN $292.76 \quad 100.0 \%$ Translational activator GCN1 GN=GCN1L1 GCN1L HUMAN $292.76 \quad 100.0 \% \quad 45$ Translational activator GCN1 GN=GCN1L1 GCN1L_HUMAN $292.76 \quad 100.0 \% \quad 45$ Translational activator GCN1 GN=GCN1L1 GCN1L_HUMAN $292.76 \quad 100.0 \% \quad 4$ Translational activator GCN1 GN=GCN1L1 GCN1L HUMAN $292.76 \quad 100.0 \% \quad 45$ Translational activator GCN1 GN=GCN1L1 GCN1L_HUMAN $292.76 \quad 100.0 \% \quad 45$ Translational activator GCN1 GN=GCN1L1 GCN1L_HUMAN $292.76 \quad 100.0 \% \quad 4$ Translational activator GCN1 GN=GCN1L1 GCN1L HUMAN $292.76 \quad 100.0 \%$ Translational activator GCN1 GN=GCN1L1 GCN1L_HUMAN $292.76 \quad 100.0 \%$ Translational activator GCN1 GN=GCN1L1 GCN1L HUMAN $292.76 \quad 100.0 \%$ Translational activator GCN1 GN=GCN1L1 GCN1L_HUMAN $292.76 \quad 100.0 \%$ Translational activator GCN1 GN=GCN1L1 GCN1L_HUMAN $292.76 \quad 100.0 \%$ Transmembrane protein $201 \mathrm{GN}=\mathrm{TMEM} 201$ TM201 HUMAN $72.24 \quad 100.0 \%$ Transmembrane protein 201 GN=TMEM201 TM201_HUMAN $72.24 \quad 100.0 \%$ Transmembrane protein 201 GN=TMEM201 TM201_HUMAN $72.24 \quad 100.0 \%$ Transportin-1 GN=TNPO Transportin- $1 \mathrm{GN}=\mathrm{TNPO}$ Transportin-1 GN=TNPO Transportin-1 GN=TNPO1 Transportin-1 GN=TNPO (2) Tricarboxylate transport protein, mitochondrial GN=SLC25A1 TXTP_HUMAN $34.01 \quad 100.0 \%$ Tricarboxylate transport protein, mitochondrial GN=SLC25A1 TXTP HUMAN $34.01 \quad 100.0 \%$ Tricarboxylate transport protein, mitochondrial GN=SLC25A1 TXTP HUMAN $34.01 \quad 100.0^{\circ} \%$ Tricarboxylate transport protein, mitochondrial GN=SLC25A1 TXTP HUMAN 34.01 100.0\% Tricarboxylate transport protein, mitochondrial GN=SLC25A1 TXTP HUMAN 34.01 $100.0^{\circ}$ Tricarboxylate transport protein, mitochondrial GN=SLC25A1 TXTP_HUMAN $34.01 \quad 100.0 \%$ Tricarboxylate transport protein, mitochondrial GN=SLC25A1 TXTP_HUMAN $34.01 \quad 100.0 \%$ Trifunctional enzyme subunit alpha, mitochondrial GN=HADHA ECHA_HUMAN $83.00 \quad 100.0 \%$ Trifunctional enzyme subunit alpha, mitochondrial GN=HADHA ECHA_HUMAN $83.00 \quad 100.0 \%$ Trifunctional enzyme subunit alpha, mitochondrial GN=HADHA ECHA_HUMAN $83.00 \quad 100.0 \%$ Trifunctional enzyme subunit alpha, mitochondrial GN=HADHA ECHA HUMAN $83.00 \quad 100.0 \%$ Trifunctional enzyme subunit alpha, mitochondrial GN=HADHA ECHA HUMAN $83.00 \quad 100.0 \%$ Trifunctional enzyme subunit alpha, mitochodi GN=HADHA ECHA_HUMAN $83.00 \quad 100.0^{\circ}$ Trifunctional enzyme subunit alpha, mitochondrial GN=HADHA ECHA_HUMAN $83.00 \quad 100.0 \%$

8

$141 \quad 0.16 \% \quad 18.8 \%$ AVMSNLSAHGVK

$141 \quad 0.16 \% \quad 18.8 \%$ AGSVELLGAMAYCAPK

$141 \quad 0.16 \% \quad 18.8 \%$ QLSSCLPNIVPK

$141 \quad 0.16 \% \quad 18.8 \%$ LTEVLTDSHVK

$141 \quad 0.16 \% \quad 18.8 \%$ LTEVLTDSHVKVQK

$141 \quad 0.16 \% \quad 18.8 \%$ ASLLDPVPEVR

$141 \quad 0.16 \% \quad 18.8 \%$ LMPEIVATASK

$141 \quad 0.16 \% \quad 18.8 \%$ VDIAPHVR

$141 \quad 0.16 \% \quad 18.8 \%$ ALADENEFVR

$141 \quad 0.16 \% \quad 18.8 \%$ ALADENEFVRDTALR

$141 \quad 0.16 \% \quad 18.8 \%$ MTTETASEDDNFGTAQSNK

$141 \quad 0.16 \% \quad 18.8 \%$ AIITALGVERR

$141 \quad 0.16 \% \quad 18.8 \%$ VLAGLYMGR

$141 \quad 0.16 \% \quad 18.8 \%$ SDTQLVVR

$141 \quad 0.16 \% \quad 18.8 \%$ DAVLYFSESLVPTAR

$141 \quad 0.16 \% \quad 18.8 \%$ VLAFLSSVAGDALTR

$141 \quad 0.16 \% \quad 18.8 \%$ QAAAIILNIYCSR

$141 \quad 0.16 \% \quad 18.8 \%$ ADYTSHLR

$141 \quad 0.16 \% \quad 18.8 \%$ GVTSILPVLR

$141 \quad 0.16 \% \quad 18.8 \%$ EGVLTGSPEQKEEAAK

$141 \quad 0.16 \% \quad 18.8 \%$ LTSADALRPSVVSITGPLIR

$141 \quad 0.16 \% \quad 18.8 \%$ ALQDSNRGVR

$141 \quad 0.16 \% \quad 18.8 \%$ HHIETGGGQLPAK

$141 \quad 0.16 \% \quad 18.8 \%$ QGEEVFQSLSK

$0.01 \% \quad 5.0 \%$ ALLLSHQFK

$0.01 \% \quad 5.0 \%$ EADQTHAQNFSSAVK

$0.01 \% \quad 5.0 \% \quad$ SPVQVILLR

$13 \quad 0.01 \% \quad 6.5 \% \quad$ ESQSPDTTIQR

$13 \quad 0.01 \% \quad 6.5 \%$ SLSGLILKNNVK

$13 \quad 0.01 \% \quad 6.5 \% \quad$ ATVGILITTIASK

$13 \quad 0.01 \% \quad 6.5 \% \quad$ YSDIDIILLK

$13 \quad 0.01 \% \quad 6.5 \% \quad$ TLLENTAITIGR

$32 \quad 0.04 \% \quad 23.5 \%$ TQLQLDER

$32 \quad 0.04 \% \quad 23.5 \%$ SHGVLGLYR

$32 \quad 0.04 \% \quad 23.5 \%$ GLSSLLYGSIPK

$\quad 0.04 \% \quad 23.5 \%$ VKFIHDQTSPNPK

$32 \quad 0.04 \% \quad 23.5 \%$ FIHDQTSPNPK

$32 \quad 0.04 \% \quad 23.5 \%$ GTYQGLTATVLK

$32 \quad 0.04 \% \quad 23.5 \%$ FFVMTSLR

$32 \quad 0.04 \% \quad 23.5 \%$ NTWDCGLQILK

$16 \quad 0.02 \% \quad 15.2 \%$ TLQEVTQLSQEAQR

$16 \quad 0.02 \% \quad 15.2 \%$ TILKDATLTALDR

$16 \quad 0.02 \% \quad 15.2 \%$ DTSASAVAVGLKQGK

$16 \quad 0.02 \% \quad 15.2 \%$ VIIVVKDGPGFYTTR

$16 \quad 0.02 \% \quad 15.2 \%$ CLAPMMSEVIR

$16 \quad 0.02 \% \quad 15.2 \%$ ILQEGVDPK

$0.02 \% \quad 15.2 \%$ HVAEDLGKVFGER
$99.7 \% \quad 48.8$

$99.7 \% \quad 63.8$

$98.4 \% \quad 24.6$

$99.7 \% \quad 52.3$

$99.2 \% \quad 21.7$

$\begin{array}{lll}99.7 \% & 35.6\end{array}$

$96.8 \% 16.6$

$\begin{array}{lll}99.0 \% & 35.2\end{array}$

$99.7 \% \quad 44.2$

$99.1 \% \quad 22.7$

$\begin{array}{ll}98.0 \% & 19.3\end{array}$

$96.2 \% 15.1$

$99.7 \% \quad 34.8$

$99.0 \% \quad 54.6$

$99.4 \% \quad 24.3$

$99.7 \% \quad 33.8$

$\begin{array}{lll}99.7 \% & 52.7\end{array}$

$99.0 \% \quad 38.1$

$\begin{array}{lll}98.7 \% & 18.4\end{array}$

$99.7 \% \quad 45.1$

$95.4 \% \quad 19.8$

$99.0 \% \quad 24.3$

$99.7 \% \quad 31.0$

$99.7 \% \quad 32.5$

$99.7 \% \quad 57.1$

$99.7 \% \quad 56.6$

$99.7 \% \quad 42.5$

$99.7 \% \quad 40.7$

$99.7 \% \quad 50.2$

$97.2 \% \quad 21.1$

$99.7 \% \quad 61.7$

$99.0 \% \quad 48.0$

$99.7 \% \quad 35.2$

$99.7 \% \quad 43.1$

$96.1 \% \quad 16.5$

$99.7 \% \quad 57.3$

$99.7 \% \quad 56.6$

$99.0 \% \quad 47.3$

$99.7 \% \quad 37.6$

$99.7 \% \quad 68.8$

$99.7 \% \quad 28.4$

$99.7 \% \quad 47.5$

$99.7 \% \quad 44.3$

$98.9 \% \quad 26.0$

$99.7 \% \quad 34.2$

$95.4 \% \quad 20.9$
1637.80

1355.74

1241.67

1596.90

1195.67

1159.64

906.52

1163.57

1719.87

2046.86

1198.73

979.54

917.51

1667.86

1519.85

1492.79

962.47

1054.66

1672.84

2066.20

1115.59

1344.70

1251.62

1056.62

1632.76

1024.65

1261.60

1285.78

1287.79

1192.68

1301.74

1002.52

1001.55

1234.70

1510.80

1283.64

1251.69

1000.53

1347.67

1630.84

1430.82

1431.78

1664.94

1306.63

998.55

1456.75
$15 \quad 1530$

$\begin{array}{ll}31 & 1542 \\ 543 & 1553\end{array}$

$1543 \quad 1556$

$1664 \quad 1674$

$1735 \quad 1745$

$1746 \quad 1753$

17851794

$1785 \quad 1799$

$\begin{array}{ll}853 & 1871 \\ 872 & 1882\end{array}$

$1885 \quad 1893$

$1894 \quad 1901$

19972011

$2093 \quad 2107$

21692181

$2184 \quad 2191$

$\begin{array}{ll}260 & 2269 \\ 270 & 2285\end{array}$

$2293 \quad 2312$

$2355 \quad 2364$

$2538 \quad 2550$

$2624 \quad 2634$

$\begin{array}{ll}84 & 192 \\ 195 & 209\end{array}$

$195 \quad 209$

$210 \quad 218$

$29 \quad 39$

74
16

$318 \quad 327$

$\begin{array}{ll}774 & 785\end{array}$

$77 \quad 85$

$86 \quad 97$

$148 \quad 160$

$179 \quad 160$

$199 \quad 206$

$258 \quad 268$

$112 \quad 125$

$387 \quad 399$

$520 \quad 534$

$535 \quad 549$

$550 \quad 560$

$561 \quad 569$

$\begin{array}{ll}598 & 610\end{array}$ 
Trifunctional enzyme subunit alpha, mitochondrial GN=HADHA ECHA_HUMAN $83.00 \quad 100.0 \%$ Trifunctional enzyme subunit alpha, mitochondrial GN=HADHA ECHA_HUMAN $83.00 \quad 100.0 \%$ Trifunctional enzyme subunit beta, mitochondrial GN=HADHB ECHB_HUMAN $51.30 \quad 100.0 \%$ Trifunctional enzyme subunit beta, mitochondrial GN=HADHB ECHB HUMAN $51.30100 .0 \%$ Trifunctional enzyme subunit beta, mitochondrial GN=HADHB ECHB_HUMAN $51.30 \quad 100.0 \%$ Trifunctional enzyme subunit beta, mitochondrial GN=HADHB ECHB_HUMAN $51.30 \quad 100.0 \%$ Trifunctional enzyme subunit beta, mitochondrial GN=HADHB ECHB_HUMAN $51.30 \quad 100.0 \%$ Trifunctional enzyme subunit beta, mitochondrial GN=HADHB ECHB_HUMAN $51.30 \quad 100.0 \%$ Trifunctional enzyme subunit beta, mitochondrial GN=HADHB ECHB HUMAN $51.30 \quad 100.0 \%$ Trifunctional enzyme subunit beta, mitochondrial GN=HADHB ECHB_HUMAN $51.30 \quad 100.0 \%$ Trifunctional enzyme subunit beta, mitochondrial GN=HADHB ECHB_HUMAN $51.30 \quad 100.0 \%$ Trifunctional enzyme subunit beta, mitochondrial GN=HADHB ECHB_HUMAN 51.30 Trifunctional enzyme subunit beta, mitochondrial GN=HADHB ECHB_HUMAN 51.30 Trifunctional enzyme subunit beta, mitochondrial GN=HADHB ECHB_HUMAN 51.30 Trifunctional enzyme subunit beta, mitochondrial GN=HADHB ECHB_HUMAN 51.30 Trifunctional purine biosynthetic protein adenosine-3 GN=GART PUR2 HUMAN $107.77 \quad 100.0 \%$ Trifunctional purine biosynthetic protein adenosine-3 GN=GART PUR2_HUMAN $107.77 \quad 100.0 \%$ Trifunctional purine biosynthetic protein adenosine-3 GN=GART PUR2_HUMAN $107.77 \quad 100.0 \%$ Trifunctional purine biosynthetic protein adenosine-3 GN=GART PUR2 HUMAN $107.77 \quad 100.0 \%$ Trifunctional purine biosynthetic protein adenosine-3 GN=GART PUR2_HUMAN $107.77 \quad 100.0 \%$ tRNA (cytosine(34)-C(5))-methyltransferase GN=NSUN2 NSUN2 HUMAN $86.47 \quad 100.0 \%$ tRNA (cytosine(34)-C(5))-methyltransferase GN=NSUN2 NSUN2_HUMAN $86.47 \quad 100.0 \%$ tRNA (cytosine(34)-C(5))-methyltransferase GN=NSUN2 NSUN2_HUMAN $86.47 \quad 100.0 \%$ tRNA (cytosine(34)-C(5))-methyltransferase GN=NSUN2 NSUN2_HUMAN $86.47 \quad 100.0 \%$ tRNA (cytosine(34)-C(5))-methyltransferase GN=NSUN2 NSUN2_HUMAN $86.47 \quad 100.0 \%$ tRNA (cytosine(34)-C(5))-methyltransferase GN=NSUN2 NSUN2_HUMAN $86.47 \quad 100.0 \%$ tRNA (cytosine(34)-C(5))-methyltransferase GN=NSUN2 NSUN2 HUMAN $86.47 \quad 100.0 \%$ tRNA (cytosine(34)-C(5))-methyltransferase GN=NSUN2 NSUN2_HUMAN $86.47 \quad 100.0 \%$ tRNA selenocysteine 1-associated protein $1 \mathrm{GN}=$ TRNAU1AP TSAP1 HUMAN $32.50 \quad 100.0 \%$ tRNA selenocysteine 1-associated protein $1 \mathrm{GN}=$ TRNAU1AP $\quad$ TSAP1_HUMAN $32.50 \quad 100.0 \%$ tRNA selenocysteine 1-associated protein $1 \mathrm{GN}=$ TRNAU1AP TSAP1_HUMAN $32.50 \quad 100.0 \%$ tRNA-splicing ligase RtcB homolog GN=RTCB RTCB HUMAN $55.21 \quad 100.0 \%$ tRNA-splicing ligase RtcB homolog GN=RTCB RTCB_HUMAN $55.21 \quad 100.0 \%$ tRNA-splicing ligase RtcB homolog GN=RTCB RTCB_HUMAN $55.21 \quad 100.0 \%$ tRNA-splicing ligase RtcB homolog GN=RTCB RTCB_HUMAN $55.21 \quad 100.0 \%$ Tuberin $\mathrm{GN}=\mathrm{TSC} 2$

Tuberin $\mathrm{GN}=\mathrm{TSC} 2$

Tubulin alpha-1A chain GN=TUBA1A Tubulin alpha-1A chain GN=TUBA1A Tubulin alpha-1A chain GN=TUBA1A Tubulin alpha-1A chain GN=TUBA1A Tubulin alpha-1A chain GN=TUBA1A Tubulin alpha-1A chain GN=TUBA1A Tubulin alpha-1A chain GN=TUBA1A Tubulin alpha-1A chain GN=TUBA1A Tubulin alpha- $1 \mathrm{~A}$ chain $\mathrm{GN}=\mathrm{TUBA} 1 \mathrm{~A}$
TSC2_HUMAN $200.61 \quad 100.0 \%$ TSC2 HUMAN $200.61 \quad 100.0 \%$ TBA1A_HUMAN $50.14 \quad 100.0 \%$ TBA1A_HUMAN $50.14 \quad 100.0 \%$ TBA1A HUMAN $50.14 \quad 100.0 \%$ TBA1A_HUMAN $50.14 \quad 100.0 \%$ TBA1A_HUMAN $50.14 \quad 100.0 \%$ TBA1A_HUMAN $50.14 \quad 100.0 \%$ TBA1A_HUMAN $50.14 \quad 100.0 \%$ TBA1A_HUMAN $50.14 \quad 100.0 \%$ TBA1A_HUMAN $50.14 \quad 100.0 \%$

6

4

$0.03 \% \quad 28.3 \%$ NVVVVDGVR

$99.7 \% \quad 38.9$

$0.03 \% \quad 28.3 \%$ TPFLLSGTSYKDLMPHDLAR

$0.03 \% \quad 28.3 \%$ AALTGLLHR

$0.03 \% \quad 28.3 \%$ KLMLDLNK

$0.03 \% \quad 28.3 \%$ LSLISKFR

$0.03 \% \quad 28.3 \%$ LAAAFAVSR

$0.03 \% \quad 28.3 \%$ LEQDEYALR

$0.03 \% \quad 28.3 \%$ ALAMGYKPK

$0.03 \% \quad 28.3 \%$ TKVGLPPLEK

$0.03 \% \quad 28.3 \%$ VGLPPLEK

$0.03 \% \quad 28.3 \%$ LVMAAANR

$0.03 \% \quad 28.3 \%$ EGGQYGLVAACAAGGQGHAMIVEAYP

$0.01 \% \quad 6.8 \%$ ASGLAAGKGVIVAK

$0.01 \% \quad 6.8 \%$ IKDTVLQR

$0.01 \% \quad 6.8 \%$ AIAFLQQPR

$0.01 \% \quad 6.8 \%$ IYSHSLLPVLR

$0.01 \% \quad 6.8 \%$ AFAHITGGGLLENIPR

$0.01 \% \quad 6.8 \%$ AAVAGLDKAER

$0.02 \% \quad 10.7 \%$ ILDMCAAPGSK

$0.02 \% \quad 10.7 \%$ IATRGAEQLAEGGR

$0.02 \% \quad 10.7 \%$ GAEQLAEGGR

$0.02 \% \quad 10.7 \%$ NVLLNNSEK

$0.02 \% \quad 10.7 \%$ LAQEGIYTLYPFINSR

$0.02 \% \quad 10.7 \%$ IITVSMEDVK

$0.02 \% \quad 10.7 \%$ ILLTQENPFFR

$0.02 \% \quad 10.7 \%$ KLSSETYSQAK

$0.01 \% \quad 11.1 \%$ AFATMGETVMSVK

$0.01 \% \quad 11.1 \%$ FKLNYATYGK

$0.01 \% \quad 11.1 \%$ FTDELEQKR

$0.01 \% \quad 9.7 \%$ GGGVGGFLPAMK

$0.01 \% \quad 9.7 \%$ QIGNVAALPGIVHR

$0.01 \% \quad 9.7 \%$ MLQADPNKVSAR

$0.01 \% \quad 9.7 \%$ VEQHVVDGKER

$0.00 \% \quad 0.9 \%$ DFVPFITK

$0.00 \% \quad 0.9 \% \quad$ SPSGLRPR

$99.7 \% \quad 42.3$

$\begin{array}{lll}99.7 \% & 49.3\end{array}$

$99.0 \% \quad 35.3$

$99.0 \% \quad 30.9$

$99.7 \% \quad 52.9$

$99.7 \% \quad 58.2$

$99.3 \% \quad 21.8$

$99.7 \% \quad 27.0$

$99.0 \% \quad 24.1$

$99.0 \% \quad 40.4$

$99.7 \% 72.3$

$99.5 \% \quad 24.2$

$99.0 \% \quad 33.5$

$99.7 \% \quad 36.6$

$99.7 \% \quad 32.5$

$99.7 \% \quad 28.7$

$99.7 \% \quad 40.6$

$99.7 \% \quad 33.3$

$99.7 \% 33.6$

$99.7 \% \quad 50.4$

$98.8 \% \quad 23.1$

$98.7 \% \quad 18.5$

$97.2 \% \quad 19.8$

$99.7 \% \quad 64.4$

$99.7 \% \quad 49.5$

$98.3 \% \quad 35.7$

$99.6 \% \quad 29.6$

$99.7 \% \quad 58.5$

$99.0 \% \quad 23.6$

$99.7 \% \quad 29.3$

$\begin{array}{lll}99.7 \% & 28.2\end{array}$

$99.7 \% \quad 34.9$

$96.5 \% \quad 21.6$

$95.6 \% \quad 22.6$

$0.01 \% \quad 60.8 \%$ TIGGGDDSFNTFFSETGAGK $\quad 99.7 \% \quad 65.8$

$\begin{array}{lllll}0.01 \% & 60.8 \% & \text { TIGGGDDSFNTFFSETGAGKHVPR } & 99.7 \% & 39.5\end{array}$

$0.01 \% \quad 60.8 \%$ AVFVDLEPTVIDEVR $\quad 99.7 \% \quad 55.1$

$\begin{array}{llll}0.01 \% & 60.8 \% & \text { AVFVDLEPTVIDEVRTGTYR } 99.7 \% & 45.6\end{array}$

$0.01 \% \quad 60.8 \%$ QLFHPEQLITGKEDAANNYAR $99.7 \% \quad 61.6$

$0.01 \% \quad 60.8 \%$ GHYTIGKEIIDLVLDR

$0.01 \% \quad 60.8 \%$ EIIDLVLDR

$0.01 \% \quad 60.8 \%$ EIIDLVLDRIR

$99.7 \% \quad 39.7$

$99.7 \% \quad 55.2$

$99.6 \% \quad 24.9$

$0.01 \% \quad 60.8 \%$ LSVDYGKK
$99.0 \% \quad 47.0$
359.7

912.56

956.55

2278.15

951.57

990.57

963.60

905.52

1136.56

994.54

1081.66

852.52

845.47

2721.28

1241.76

972.58

1043.60

1297.76

1665.91

1100.61

1178.55

1428.76

987.49

1030.55

1884.99

1134.61

1377.75

1241.64

1387.66

1204.64

1165.58

1090.57

1444.84

1329.69

1295.67

966.53

869.50

2007.89

2497.17

1701.91

2280.19

2415.21

1842.01

1085.62

1354.81

909.50
635

$\begin{array}{ll}45 & 52 \\ 53 & 61\end{array}$

628

188

$196 \quad 203$

$230 \quad 238$

$239 \quad 247$

$26 \quad 334$

$409 \quad 416$

444

$448 \quad 474$

$50 \quad 257$

$425 \quad 433$

$661 \quad 671$

$677 \quad 692$

$845 \quad 855$

$180 \quad 190$

$302 \quad 315$

315
569
577

$603 \quad 618$

$619 \quad 628$

$629 \quad 639$

$640 \quad 650$

$22 \quad 3$

$144 \quad 15$

$56 \quad 67$

$68 \quad 8$

$199 \quad 210$

$358 \quad 368$

$907 \quad 914$

$41 \quad 60$

$41 \quad 64$

$65 \quad 79$

$65 \quad 84$

$85 \quad 105$

$106 \quad 121$

$113 \quad 121$

$113 \quad 123$ 
Tubulin alpha- $1 \mathrm{~A}$ chain $\mathrm{GN}=\mathrm{TUBA} 1 \mathrm{~A}$ Tubulin alpha-1A chain GN=TUBA1A Tubulin alpha- $1 \mathrm{~A}$ chain $\mathrm{GN}=\mathrm{TUBA} 1 \mathrm{~A}$ Tubulin alpha-1A chain $\mathrm{GN}=\mathrm{TUBA} 1 \mathrm{~A}$ Tubulin alpha- $1 \mathrm{~A}$ chain $\mathrm{GN}=\mathrm{TUBA} 1 \mathrm{~A}$ Tubulin alpha- $1 \mathrm{~A}$ chain $\mathrm{GN}=\mathrm{TUBA} 1 \mathrm{~A}$

Tubulin alpha- $1 \mathrm{~A}$ chain $\mathrm{GN}=\mathrm{TUBA} 1 \mathrm{~A}$ Tubulin alpha-1A chain GN=TUBA1A Tubulin alpha- $1 \mathrm{~A}$ chain $\mathrm{GN}=\mathrm{TUBA} 1 \mathrm{~A}$ Tubulin alpha- $1 \mathrm{~A}$ chain $\mathrm{GN}=\mathrm{TUBA} 1 \mathrm{~A}$ Tubulin alpha-1A chain GN=TUBA1A Tubulin alpha-1A chain $\mathrm{GN}=\mathrm{TUBA} 1 \mathrm{~A}$ Tubulin alpha-1A chain GN=TUBA1A Tubulin alpha- $1 \mathrm{~A}$ chain $\mathrm{GN}=\mathrm{TUBA} 1 \mathrm{~A}$ Tubulin alpha- $1 \mathrm{~A}$ chain $\mathrm{GN}=\mathrm{TUBA} 1 \mathrm{~A}$ Tubulin alpha- $1 \mathrm{~A}$ chain $\mathrm{GN}=\mathrm{TUBA} 1 \mathrm{~A}$ Tubulin alpha-1A chain $\mathrm{GN}=\mathrm{TUBA} 1 \mathrm{~A}$ Tubulin alpha- $1 \mathrm{~A}$ chain $\mathrm{GN}=\mathrm{TUBA} 1 \mathrm{~A}$ Tubulin alpha- $1 \mathrm{~A}$ chain $\mathrm{GN}=\mathrm{TUBA} 1 \mathrm{~A}$ Tubulin alpha- $1 \mathrm{~B}$ chain $\mathrm{GN}=\mathrm{TUBA} 1 \mathrm{~B}$ Tubulin alpha- $1 \mathrm{~B}$ chain $\mathrm{GN}=\mathrm{TUB} A 1 \mathrm{~B}$ Tubulin alpha- $1 \mathrm{~B}$ chain $\mathrm{GN}=\mathrm{TUB} A 1 \mathrm{~B}$ Tubulin alpha-1B chain GN=TUBA1B Tubulin alpha- $1 \mathrm{~B}$ chain $\mathrm{GN}=\mathrm{TUBA} 1 \mathrm{~B}$ Tubulin alpha- $1 \mathrm{~B}$ chain $\mathrm{GN}=\mathrm{TUBA} 1 \mathrm{~B}$ Tubulin alpha- $1 \mathrm{~B}$ chain $\mathrm{GN}=\mathrm{TUBA} 1 \mathrm{~B}$ Tubulin alpha-1B chain GN=TUBA1B Tubulin alpha-1B chain $\mathrm{GN}=\mathrm{TUBA} 1 \mathrm{~B}$ Tubulin alpha- $1 \mathrm{~B}$ chain $\mathrm{GN}=\mathrm{TUBA} 1 \mathrm{~B}$ Tubulin alpha- $1 \mathrm{~B}$ chain $\mathrm{GN}=\mathrm{TUBA} 1 \mathrm{~B}$ Tubulin alpha-1B chain GN=TUBA1B Tubulin alpha- $1 \mathrm{~B}$ chain $\mathrm{GN}=\mathrm{TUBA} 1 \mathrm{~B}$ Tubulin alpha-1B chain GN=TUBA1B Tubulin alpha- $1 \mathrm{~B}$ chain $\mathrm{GN}=\mathrm{TUB} A 1 \mathrm{~B}$ Tubulin alpha- $1 \mathrm{~B}$ chain $\mathrm{GN}=\mathrm{TUBA} 1 \mathrm{~B}$ Tubulin alpha- $1 \mathrm{~B}$ chain $\mathrm{GN}=\mathrm{TUBA} 1 \mathrm{~B}$ Tubulin alpha-1B chain GN=TUBA1B Tubulin alpha-1B chain $\mathrm{GN}=\mathrm{TUBA} 1 \mathrm{~B}$ Tubulin alpha- $1 \mathrm{~B}$ chain $\mathrm{GN}=\mathrm{TUB} A 1 \mathrm{~B}$ Tubulin alpha- $1 \mathrm{~B}$ chain $\mathrm{GN}=\mathrm{TUBA} 1 \mathrm{~B}$

Tubulin alpha- $1 \mathrm{~B}$ chain $\mathrm{GN}=\mathrm{TUBA} 1 \mathrm{~B}$ Tubulin alpha-1B chain GN=TUBA1B Tubulin alpha-1B chain GN=TUBA1B Tubulin alpha- $1 \mathrm{~B}$ chain $\mathrm{GN}=\mathrm{TUBA} 1 \mathrm{~B}$ Tubulin alpha- $1 \mathrm{~B}$ chain $\mathrm{GN}=\mathrm{TUBA} 1 \mathrm{~B}$ Tubulin alpha-1B chain GN=TUBA1B Tubulin alpha-1B chain GN=TUBA1B
BAIA_HUMAN $50.14 \quad 100.0 \%$ BA1A_HUMAN $50.14 \quad 100.0 \%$ TBA1A_HUMAN $50.14 \quad 100.0 \%$ TBA1A_HUMAN $50.14 \quad 100.0 \%$ TBA1A_HUMAN $50.14 \quad 100.0 \%$ TBA1A_HUMAN $50.14 \quad 100.0 \%$ TBA1A_HUMAN $50.14 \quad 100.0 \%$ TBA1A_HUMAN $50.14 \quad 100.0 \%$ TBA1A HUMAN $50.14 \quad 100.0 \%$ TBA1A HUMAN $50.14 \quad 100.0 \%$ TBA1A_HUMAN $50.14 \quad 100.0 \%$ TBA1A HUMAN $50.14 \quad 100.0 \%$ TBA1A_HUMAN $50.14 \quad 100.0 \%$ TBA1A_HUMAN $50.14 \quad 100.0 \%$ TBA1A HUMAN $50.14 \quad 100.0 \%$ TBA1A_HUMAN $50.14 \quad 100.0 \%$ TBA1A HUMAN $50.14 \quad 100.0 \%$ TBA1A HUMAN $50.14 \quad 100.0 \%$ TBA1A_HUMAN $50.14 \quad 100.0 \%$ TBA1B HUMAN $50.15 \quad 100.0 \%$ TBA1B_HUMAN $50.15 \quad 100.0 \% \quad 28$ TBA1B_HUMAN $50.15 \quad 100.0 \% \quad 28$ TBA1B HUMAN $50.15 \quad 100.0 \% \quad 28$ TBA1B_HUMAN $50.15 \quad 100.0 \% \quad 28$ TBA1B HUMAN $50.15 \quad 100.0 \% \quad 28$ TBA1B_HUMAN $50.15 \quad 100.0 \% \quad 28$ TBA1B_HUMAN $50.15 \quad 100.0 \% \quad 28$ TBA1B HUMAN $50.15 \quad 100.0 \% \quad 28$ TBA1B_HUMAN $50.15 \quad 100.0 \% \quad 28$ TBA1B HUMAN $50.15 \quad 100.0 \% \quad 28$ TBA1B_HUMAN $50.15 \quad 100.0 \% \quad 28$ TBA1B_HUMAN $50.15 \quad 100.0 \% \quad 28$ TBA1B HUMAN $50.15 \quad 100.0 \% \quad 28$ TBA1B_HUMAN $50.15 \quad 100.0 \% \quad 28$ TBA1B HUMAN $50.15 \quad 100.0 \% \quad 28$ TBA1B HUMAN $50.15 \quad 100.0 \% \quad 28$ TBA1B_HUMAN $50.15 \quad 100.0 \% \quad 28$ TBA1B HUMAN $50.15 \quad 100.0 \% \quad 28$ TBA1B_HUMAN $50.15 \quad 100.0 \% \quad 28$ TBA1B_HUMAN $50.15 \quad 100.0 \% \quad 28$ TBA1B HUMAN $50.15 \quad 100.0 \% \quad 28$ TBA1B_HUMAN $50.15 \quad 100.0 \% \quad 28$ TBA1B HUMAN $50.15 \quad 100.0 \% \quad 28$ TBA1B HUMAN $50.15 \quad 100.0 \% \quad 28$ TBA1B_HUMAN $50.15 \quad 100.0 \% \quad 28$ TBA1B_HUMAN $50.15 \quad 100.0 \% \quad 28$ TBA1B_HUMAN $50.15 \quad 100.0 \% \quad 28$
$0.01 \% \quad 60.8 \%$ RNLDIERPTYTNLNR $0.01 \% \quad 60.8 \%$ NLDIERPTYTNLNR $0.01 \% \quad 60.8 \%$ LIGQIVSSITASLR

$\begin{array}{llll}99.1 \% & 22.8 & 25.0 & 22.8\end{array}$ $99.7 \% \quad 53.0$ $99.7 \% \quad 34.8$ 0.01\% 60.8\% FDGALNVDLTEFQTNLVPYPR $99.7 \% \quad 47.9$ $0.01 \% \quad 60.8 \%$ IHFPLATYAPVISAEK $99.7 \% \quad 57.5$ $0.01 \% \quad 60.8 \%$ AYHEQLSVAEITNACFEPANQMVK $0.01 \% \quad 60.8 \%$ HGKYMACCLLYR $0.01 \% \quad 60.8 \%$ YMACCLLYR

$0.01 \% \quad 60.8 \%$ YMACCLLYRGDVVPK $0.01 \% \quad 60.8 \%$ GDVVPKDVNAAIATIK $0.01 \% \quad 60.8 \%$ DVNAAIATIK

$0.01 \% \quad 60.8 \%$ DVNAAIATIKTK

$0.01 \% \quad 60.8 \%$ RTIQFVDWCPTGFK

$0.01 \% \quad 60.8 \%$ TIQFVDWCPTGFK

$99.7 \% \quad 53.3$ $99.7 \% \quad 52.2$ $99.7 \% 40.1$ $98.4 \% \quad 17.5$ $99.7 \% \quad 45.8$ $99.7 \% 59.1$ $99.7 \% 52.0$ $99.7 \% \quad 42.2$ $99.7 \% \quad 58.8$

0.01\% 60.8\% TIPFVDCPTGFKVGNYOPPTVYPGGDLAK $\quad 99.7 \% \quad 53.1$

$0.01 \% \quad 60.8 \%$ VGINYQPPTVVPGGDLAK $99.7 \% \quad 52.7$ $\begin{array}{lllll}0.01 \% & 60.8 \% & \text { VGINYQPPTVVPGGDLAKVQR } & 99.7 \% & 30.6\end{array}$

$0.01 \% \quad 60.8 \%$ AVCMLSNTTAIAEAWAR $99.7 \% \quad 67.9$

$0.01 \% \quad 60.8 \%$ LDHKFDLMYAK $99.7 \% \quad 35.5$

$308 \quad 0.35 \% \quad 60.8 \%$ TIGGGDDSFNTFFSETGAGK $\quad 99.7 \% \quad 65.8$

$308 \quad 0.35 \% \quad 60.8 \%$ TIGGGDDSFNTFFSETGAGKHVPR $\quad 99.7 \% \quad 39.5$

$308 \quad 0.35 \% \quad 60.8 \%$ AVFVDLEPTVIDEVR $\quad 99.7 \% \quad 55.1$

$308 \quad 0.35 \% \quad 60.8 \%$ AVFVDLEPTVIDEVRTGTYR $99.7 \% \quad 45.6$

$308 \quad 0.35 \% \quad 60.8 \%$ QLFHPEQLITGKEDAANNYAR $99.7 \% \quad 61.6$

$308 \quad 0.35 \% \quad 60.8 \%$ GHYTIGKEIIDLVLDR $\quad 99.7 \% \quad 39.7$

$308 \quad 0.35 \% \quad 60.8 \%$ EIIDLVLDR

$308 \quad 0.35 \% \quad 60.8 \%$ EIIDLVLDRIR

$308 \quad 0.35 \% \quad 60.8 \%$ LSVDYGKK

$308 \quad 0.35 \% \quad 60.8 \%$ RNLDIERPTYTNLNR

$308 \quad 0.35 \% \quad 60.8 \%$ NLDIERPTYTNLNR

$308 \quad 0.35 \% \quad 60.8 \%$ LISQIVSSITASLR

$308 \quad 0.35 \% \quad 60.8 \%$ FDGALNVDLTEFQTNLVPYPR

$99.7 \% \quad 55.2$

$99.6 \% \quad 24.9$

$99.0 \% \quad 47.0$

$99.1 \% \quad 22.8$

$99.7 \% \quad 53.0$

$99.7 \% \quad 60.2$

0.35\% $\quad 60.8 \%$ IHFPLATYAPVISAEK

$99.7 \% \quad 57.5$

45

45
$308 \quad 0.35 \% \quad 60.8 \%$ AYHEQLSVAEITNACFEPANQMVK

$308 \quad 0.35 \% \quad 60.8 \%$ HGKYMACCLLYR

$308 \quad 0.35 \% \quad 60.8 \%$ YMACCLLYR

$308 \quad 0.35 \% \quad 60.8 \%$ YMACCLLYRGDVVPK

$308 \quad 0.35 \% \quad 60.8 \%$ GDVVPKDVNAAIATIK

$308 \quad 0.35 \% \quad 60.8 \%$ DVNAAIATIK

$308 \quad 0.35 \% \quad 60.8 \%$ DVNAAIATIKTK

$308 \quad 0.35 \% \quad 60.8 \%$ RSIQFVDWCPTGFK

$308 \quad 0.35 \% \quad 60.8 \%$ SIQFVDWCPTGFK

$99.7 \% \quad 53.3$

$99.7 \% \quad 52.2$

$99.7 \% \quad 40.1$

$98.4 \% \quad 17.5$

$99.7 \% \quad 45.8$

$99.7 \% \quad 59.1$

$99.7 \% \quad 52.0$

$99.7 \% \quad 52.2$

$99.7 \% \quad 47.3$

$\begin{array}{llll} & \\ & 99.7 \% & 47.3\end{array}$

$308 \quad 0.35 \% \quad 60.8 \%$ VGINYQPPTVVPGGDLAK $\quad 99.7 \% \quad 52.7$

$308 \quad 0.35 \% \quad 60.8 \%$ VGINYQPPTVVPGGDLAKVQR $\quad 99.7 \% \quad 30.6$

$\begin{array}{lll}30.35 \% & 60.8 \% & \text { AVCMLSNTTAIAEAWAR } \quad 99.7 \% \quad 67.9\end{array}$

$308 \quad 0.35 \% \quad 60.8 \%$ LDHKFDLMYAK

$99.7 \% \quad 35.5$ 
Tubulin alpha- $1 \mathrm{C}$ chain $\mathrm{GN}=\mathrm{TUBA} 1 \mathrm{C}$ Tubulin alpha- $1 \mathrm{C}$ chain $\mathrm{GN}=\mathrm{TUBA} 1 \mathrm{C}$ Tubulin alpha- $1 \mathrm{C}$ chain $\mathrm{GN}=\mathrm{TUBA} 1 \mathrm{C}$ Tubulin alpha- $1 \mathrm{C}$ chain $\mathrm{GN}=\mathrm{TUBA} 1 \mathrm{C}$ Tubulin alpha- $1 \mathrm{C}$ chain $\mathrm{GN}=\mathrm{TUBA} 1 \mathrm{C}$ Tubulin alpha- $1 \mathrm{C}$ chain $\mathrm{GN}=\mathrm{TUBA} 1 \mathrm{C}$ Tubulin alpha- $1 \mathrm{C}$ chain $\mathrm{GN}=\mathrm{TUBA} 1 \mathrm{C}$ Tubulin alpha- $1 \mathrm{C}$ chain GN=TUBA1C Tubulin alpha- $1 \mathrm{C}$ chain $\mathrm{GN}=\mathrm{TUBA} 1 \mathrm{C}$ Tubulin alpha- $1 \mathrm{C}$ chain $\mathrm{GN}=\mathrm{TUBA} 1 \mathrm{C}$ Tubulin alpha- $1 \mathrm{C}$ chain $\mathrm{GN}=\mathrm{TUBA} 1 \mathrm{C}$ Tubulin alpha- $1 \mathrm{C}$ chain $\mathrm{GN}=\mathrm{TUBA} 1 \mathrm{C}$ Tubulin alpha- $1 \mathrm{C}$ chain $\mathrm{GN}=\mathrm{TUBA} 1 \mathrm{C}$ Tubulin alpha- $1 \mathrm{C}$ chain $\mathrm{GN}=\mathrm{TUBA} 1 \mathrm{C}$ Tubulin alpha- $1 \mathrm{C}$ chain $\mathrm{GN}=\mathrm{TUBA} 1 \mathrm{C}$ Tubulin alpha- $1 \mathrm{C}$ chain $\mathrm{GN}=\mathrm{TUBA} 1 \mathrm{C}$ Tubulin alpha- $1 \mathrm{C}$ chain $\mathrm{GN}=\mathrm{TUBA} 1 \mathrm{C}$ Tubulin alpha- $1 \mathrm{C}$ chain $\mathrm{GN}=\mathrm{TUBA} 1 \mathrm{C}$ Tubulin alpha- $1 \mathrm{C}$ chain $\mathrm{GN}=\mathrm{TUBA} 1 \mathrm{C}$ Tubulin alpha- $1 \mathrm{C}$ chain $\mathrm{GN}=\mathrm{TUBA} 1 \mathrm{C}$ Tubulin alpha- $1 \mathrm{C}$ chain $\mathrm{GN}=\mathrm{TUBA} 1 \mathrm{C}$ Tubulin alpha- $1 \mathrm{C}$ chain $\mathrm{GN}=\mathrm{TUBA} 1 \mathrm{C}$ Tubulin alpha- $1 \mathrm{C}$ chain $\mathrm{GN}=\mathrm{TUBA} 1 \mathrm{C}$ Tubulin alpha- $1 \mathrm{C}$ chain $\mathrm{GN}=\mathrm{TUBA} 1 \mathrm{C}$ Tubulin alpha- $1 \mathrm{C}$ chain $\mathrm{GN}=\mathrm{TUBA} 1 \mathrm{C}$ Tubulin alpha- $1 \mathrm{C}$ chain GN=TUBA1C Tubulin alpha- $1 \mathrm{C}$ chain $\mathrm{GN}=\mathrm{TUBA} 1 \mathrm{C}$ Tubulin alpha- $1 \mathrm{C}$ chain $\mathrm{GN}=\mathrm{TUBA} 1 \mathrm{C}$ Tubulin beta chain GN=TUBB

Tubulin beta chain $\mathrm{GN}=\mathrm{TUBB}$

Tubulin beta chain GN=TUBB

Tubulin beta chain GN=TUBB

Tubulin beta chain $\mathrm{GN}=\mathrm{TUB}$

Tubulin beta chain GN=TUBB

Tubulin beta chain $\mathrm{GN}=\mathrm{TUBB}$

Tubulin beta chain $\mathrm{GN}=\mathrm{TUBB}$

Tubulin beta chain GN=TUBH

Tubulin beta chain $\mathrm{GN}=\mathrm{TUBB}$

Tubulin beta chain GN=TUBB

Tubulin beta chain $\mathrm{GN}=\mathrm{TUBB}$

Tubulin beta chain $\mathrm{GN}=\mathrm{TUBB}$

Tubulin beta chain GN=TUBB

Tubulin beta chain $\mathrm{GN}=\mathrm{TUBB}$

Tubulin beta chain GN=TUBB

Tubulin beta chain $\mathrm{GN}=\mathrm{TUBB}$

Tubulin beta chain $\mathrm{GN}=\mathrm{TUBE}$

Tubulin beta chain $\mathrm{GN}=$ TUBB
TBAIC_HUMAN $49.90 \quad 100.0 \%$ TBA1C_HUMAN $49.90 \quad 100.0 \%$ TBA1C_HUMAN $49.90 \quad 100.0 \%$ TBA1C HUMAN $49.90 \quad 100.0 \%$ TBA1C_HUMAN $49.90 \quad 100.0 \%$ TBA1C_HUMAN $49.90 \quad 100.0 \%$ TBA1C HUMAN $49.90 \quad 100.0 \%$ TBA1C_HUMAN $49.90 \quad 100.0 \%$ TBAIC HUMAN $49.90 \quad 100.0 \%$ TBA1C_HUMAN $49.90 \quad 100.0 \%$ TBA1C_HUMAN $49.90 \quad 100.0 \%$ TBA1C HUMAN $49.90 \quad 100.0 \%$ TBA1C_HUMAN $49.90 \quad 100.0 \%$ TBA1C_HUMAN $49.90 \quad 100.0 \%$ TBA1C HUMAN $49.90 \quad 100.0 \%$ TBA1C_HUMAN $49.90 \quad 100.0 \%$ TBAIC HUMAN $49.90 \quad 100.0 \%$ TBA1C HUMAN $49.90 \quad 100.0 \%$ TBA1C_HUMAN $49.90 \quad 100.0 \%$ TBAIC HUMAN $49.90 \quad 100.0 \%$ TBA1C_HUMAN $49.90 \quad 100.0 \%$ TBA1C_HUMAN $49.90 \quad 100.0 \%$ TBA1C_HUMAN $49.90 \quad 100.0 \%$ TBA1C_HUMAN $49.90 \quad 100.0 \%$ TBAIC HUMAN $49.90 \quad 100.0 \%$ TBA1C_HUMAN $49.90 \quad 100.0 \% \quad 2$ TBA1C_HUMAN $49.90 \quad 100.0 \% \quad 2$ TBA1C HUMAN $49.90 \quad 100.0 \%$ TBB5_HUMAN $49.67 \quad 100.0 \% \quad 33$ TBB5 HUMAN $49.67 \quad 100.0 \% \quad 33$ TBB5_HUMAN $49.67 \quad 100.0 \% \quad 33$ TBB5_HUMAN $49.67 \quad 100.0 \% \quad 33$ TBB5 HUMAN $49.67 \quad 100.0 \% \quad 33$ TBB5_HUMAN $49.67 \quad 100.0 \% \quad 33$ TBB5 HUMAN $49.67 \quad 100.0 \% \quad 33$ TBB5 HUMAN $49.67 \quad 100.0 \%$ TBB5_HUMAN $49.67 \quad 100.0 \% \quad 33$ TBB5 HUMAN $49.67 \quad 100.0 \% \quad 33$ TBB5_HUMAN $49.67 \quad 100.0 \% \quad 33$ TBB5 HUMAN $49.67 \quad 100.0 \% \quad 33$ TBB5_HUMAN $49.67 \quad 100.0 \% \quad 33$ TBB5_HUMAN $49.67 \quad 100.0 \% \quad 33$ TBB5 HUMAN $49.67 \quad 100.0 \% \quad 33$ TBB5 HUMAN $49.67 \quad 100.0 \% \quad 33$ TBB5_HUMAN $49.67 \quad 100.0 \% \quad 33$ TBB5 HUMAN $49.67 \quad 100.0 \% \quad 33$ TBB5_HUMAN $49.67 \quad 100.0 \% \quad 33$ $0.01 \% \quad 61.0 \%$ TIGGGDDSFNTFESETGAC $\begin{array}{lllll}0.01 \% & 61.0 \% & \text { AVFVDLEPTVIDEVR } & 99.7 \% & 55.1\end{array}$ $\begin{array}{lllll}0.01 \% & 61.0 \% & \text { AVFVDLEPTVIDEVRTGTYR } & 99.7 \% & 45.6 \\ 0.01 \% & 61.0 \% & \text { QLFHPEQLITGKEDAANNYAR } & 99.7 \% & 61.6\end{array}$ $\begin{array}{lllll}0.01 \% & 61.0 \% & \text { QLFHPEQLITGKEDAANNYAR } & 99.7 \% & 61.6 \\ 0.01 \% & 61.0 \% & \text { GHYTIGKEIIDLVLDR } & 99.7 \% & 39.7\end{array}$ $99.7 \% \quad 55.2$ $0.01 \% \quad 61.0 \%$ EIIDLVLDR $0.01 \% \quad 61.0 \%$ EIIDLVLDRIR $0.01 \% \quad 61.0 \%$ LSVDYGKK $0.01 \% \quad 61.0 \%$ RNLDIERPTYTNLNR $0.01 \% \quad 61.0 \%$ NLDIERPTYTNLNR $99.6 \% \quad 24.9$ $99.0 \% \quad 47.0$ $99.1 \% \quad 22.8$ $99.7 \% \quad 53.0$ $0.01 \% \quad 61.0 \%$ LISQIVSSITASLR

$99.7 \% \quad 60.2$

$0.01 \% \quad 61.0 \%$ FDGALNVDLTEFQTNLVPYPR $\quad 99.7 \% \quad 47.9$ $0.01 \% \quad 61.0 \%$ IHFPLATYAPVISAEK $\quad 99.7 \% \quad 57.5$ $0.01 \% \quad 61.0 \%$ AYHEQLTVAEITNACFEPANQMVK $\quad 97.8 \% \quad 17.7$ $0.01 \% \quad 61.0 \%$ HGKYMACCLLYR $0.01 \% \quad 61.0 \%$ YMACCLLYR

$0.01 \% \quad 61.0 \%$ YMACCLLYRGDVVPK $0.01 \% \quad 61.0 \%$ GDVVPKDVNAAIATIK $0.01 \% \quad 61.0 \%$ DVNAAIATIK $0.01 \% \quad 61.0 \%$ DVNAAIATIKTK

$0.01 \% \quad 61.0 \%$ RTIQFVDWCPTGFK

$99.7 \% \quad 52.2$ $99.7 \% \quad 40.1$

$98.4 \% 17.5$ $99.7 \% \quad 45.8$ $99.7 \% \quad 59$. $99.7 \% 52.0$ $99.7 \% \quad 42.2$ $0.01 \% \quad 61.0 \%$ TIQFVDWCPTGFK $99.7 \% \quad 58.8$ $0.01 \% \quad 61.0 \%$ TIPFVDWCPTGFKVGINYQPPTVVPGGDLAK $\quad 99.7 \% \quad 53.1$ $0.01 \% \quad 61.0 \%$ VGINYQPPTVVPGGDLAK $99.7 \% \quad 52.7$ $\begin{array}{lllll}0.01 \% & 61.0 \% & \text { VGINYQPPTVVPGGDLAKVQR } & 99.7 \% & 30.6\end{array}$

$0.01 \% \quad 61.0 \%$ AVCMLSNTTAVAEAWAR $\quad 99.7 \% \quad 52.4$

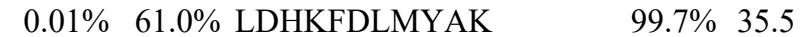

$452 \quad 0.51 \% \quad 71.2 \%$ MREIVHIQAGQCGNQIGAK $\quad 99.3 \% \quad 55.2$ $452 \quad 0.51 \% \quad 71.2 \%$ EIVHIQAGQCGNQIGAK $\quad 99.2 \% \quad 54.2$ $452 \quad 0.51 \% \quad 71.2 \%$ ISVYYNEATGGK $99.7 \% \quad 57.4$
1844.89

1610.91

1015.58

1244.72

1754.87

1598.77

3404.74

1824.99

2208.21

1866.88

1396.69

2110.06

1822.92

1301.64

1816.92

1615.84

2798.34

1958.98

2087.08

3327.53

1077.53

1319.70

2724.33

1130.60

1258.69

1287.72

1143.63

1636.83

1659.90

2706.31

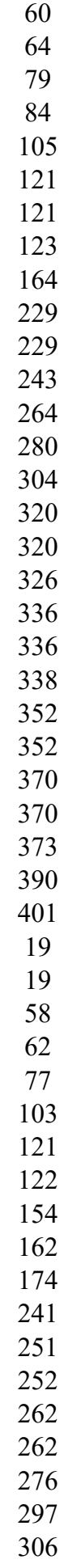


Tubulin beta chain GN=TUBB Tubulin beta chain $\mathrm{GN}=\mathrm{TUBB}$ Tubulin beta chain $\mathrm{GN}=\mathrm{TUBB}$ Tubulin beta chain $\mathrm{GN}=\mathrm{TUBB}$ Tubulin beta chain GN=TUBB Tubulin beta chain GN=TUBB

Tubulin beta chain $\mathrm{GN}=\mathrm{TUBB}$ Tubulin beta chain GN=TUBB Tubulin beta chain GN=TUBB Tubulin beta chain GN=TUBB Tubulin beta chain GN=TUBB Tubulin beta chain GN=TUBB Tubulin beta chain GN=TUBB Tubulin beta chain GN=TUBB

Tubulin beta-2A chain GN=TUBB2A Tubulin beta-2A chain $\mathrm{GN}=\mathrm{TUBB} 2 \mathrm{~A}$ Tubulin beta-2A chain GN=TUBB2A Tubulin beta-2A chain $\mathrm{GN}=\mathrm{TUBB} 2 \mathrm{~A}$ Tubulin beta-2A chain GN=TUBB2A

Tubulin beta- $2 A$ chain $\mathrm{GN}=\mathrm{TUBB} 2 \mathrm{~A}$ Tubulin beta- $2 A$ chain $\mathrm{GN}=\mathrm{TUBB} 2 \mathrm{~A}$ Tubulin beta- $2 A$ chain $\mathrm{GN}=\mathrm{TUBB} 2 \mathrm{~A}$ Tubulin beta- $2 A$ chain $\mathrm{GN}=\mathrm{TUBB} 2 \mathrm{~A}$ Tubulin beta-2A chain GN=TUBB2A Tubulin beta- $2 A$ chain $\mathrm{GN}=\mathrm{TUBB} 2 \mathrm{~A}$ Tubulin beta- $2 A$ chain $\mathrm{GN}=\mathrm{TUBB} 2 \mathrm{~A}$ Tubulin beta-2A chain $\mathrm{GN}=\mathrm{TUBB} 2 \mathrm{~A}$ Tubulin beta-2A chain $\mathrm{GN}=\mathrm{TUBB} 2 \mathrm{~A}$ Tubulin beta- $2 A$ chain $\mathrm{GN}=\mathrm{TUBB} 2 \mathrm{~A}$ Tubulin beta- $2 A$ chain $\mathrm{GN}=\mathrm{TUBB} 2 \mathrm{~A}$ Tubulin beta-2A chain GN=TUBB2A Tubulin beta-2A chain GN=TUBB2A Tubulin beta- $2 \mathrm{~A}$ chain $\mathrm{GN}=\mathrm{TUBB} 2 \mathrm{~A}$ Tubulin beta- $2 A$ chain $\mathrm{GN}=\mathrm{TUBB} 2 \mathrm{~A}$ Tubulin beta-2A chain $\mathrm{GN}=\mathrm{TUBB} 2 \mathrm{~A}$ Tubulin beta-2A chain GN=TUBB2A Tubulin beta- $2 \mathrm{~A}$ chain $\mathrm{GN}=\mathrm{TUBB} 2 \mathrm{~A}$ Tubulin beta- $2 A$ chain $\mathrm{GN}=\mathrm{TUBB} 2 \mathrm{~A}$ Tubulin beta- $2 \mathrm{~A}$ chain $\mathrm{GN}=\mathrm{TUBB} 2 \mathrm{~A}$ Tubulin beta-2A chain GN=TUBB2A Tubulin beta-2A chain $\mathrm{GN}=\mathrm{TUBB} 2 \mathrm{~A}$ Tubulin beta-2A chain $\mathrm{GN}=\mathrm{TUBB} 2 \mathrm{~A}$ Tubulin beta- 3 chain $\mathrm{GN}=$ TUBB3

Tubulin beta- 3 chain GN=TUBB3

Tubulin beta- 3 chain GN=TUBB3

Tubulin beta- 3 chain GN=TUBB3 Tubulin beta- 3 chain GN=TUBB 3
TBB5_HUMAN $49.67 \quad 100.0 \% \quad 33 \quad 64 \quad 452 \quad 0.51 \% \quad 71.2 \%$ NMMAACDPR TBB5_HUMAN $49.67 \quad 100.0 \% \quad 33$ TBB5_HUMAN $49.67 \quad 100.0 \% \quad 33$ TBB5 HUMAN $49.67 \quad 100.0 \% \quad 33$ TBB5_HUMAN $49.67 \quad 100.0 \% \quad 33$ TBB5_HUMAN $49.67 \quad 100.0 \% \quad 33$ TBB5 HUMAN $49.67 \quad 100.0 \% \quad 33$ TBB5_HUMAN $49.67 \quad 100.0 \% \quad 33$ TBB5 HUMAN $49.67 \quad 100.0 \% \quad 33$ TBB5_HUMAN $49.67 \quad 100.0 \% \quad 33$ TBB5_HUMAN $49.67 \quad 100.0 \% \quad 33$ TBB5 HUMAN $49.67 \quad 100.0 \% \quad 33$ TBB5_HUMAN $49.67 \quad 100.0 \% \quad 33$ TBB5_HUMAN $49.67 \quad 100.0 \% \quad 33$ TBB2A HUMAN $49.91 \quad 100.0 \% \quad 4$ TBB2A_HUMAN $49.91 \quad 100.0 \% \quad 4$ TBB2A HUMAN $49.91 \quad 100.0 \% \quad 4$ TBB2A HUMAN $49.91 \quad 100.0 \%$ TBB2A_HUMAN $49.91 \quad 100.0 \%$ TBB2A HUMAN $49.91 \quad 100.0 \%$ TBB2A_HUMAN $49.91 \quad 100.0 \% \quad 4$ TBB2A_HUMAN $49.91 \quad 100.0 \% \quad 4$ TBB2A_HUMAN $49.91 \quad 100.0 \%$ TBB2A_HUMAN $49.91 \quad 100.0 \%$ TBB2A HUMAN $49.91 \quad 100.0 \%$ TBB2A_HUMAN $49.91 \quad 100.0 \%$ TBB2A_HUMAN $49.91 \quad 100.0 \%$ TBB2A HUMAN $49.91 \quad 100.0 \%$ TBB2A_HUMAN $49.91 \quad 100.0 \%$ TBB2A HUMAN $49.91 \quad 100.0 \%$ TBB2A_HUMAN $49.91 \quad 100.0 \%$ TBB2A_HUMAN $49.91 \quad 100.0 \%$ TBB2A HUMAN $49.91 \quad 100.0 \% \quad 4$ TBB2A_HUMAN $49.91 \quad 100.0 \%$ TBB2A_HUMAN $49.91 \quad 100.0 \%$ TBB2A HUMAN $49.91 \quad 100.0 \%$ TBB2A_HUMAN $49.91 \quad 100.0 \%$ TBB2A HUMAN $49.91 \quad 100.0 \%-4$ TBB2A_HUMAN $49.91 \quad 100.0 \%$ TBB2A_HUMAN $49.91 \quad 100.0 \%$ TBB2A HUMAN $49.91 \quad 100.0 \%$ TBB2A_HUMAN $49.91 \quad 100.0 \%$ TBB3_HUMAN $50.43 \quad 100.0 \% \quad 2$ TBB3_HUMAN $50.43 \quad 100.0 \%$ TBB3_HUMAN $50.43 \quad 100.0 \%$ TBB3 HUMAN $50.43 \quad 100.0 \%$ TBB3_HUMAN $50.43 \quad 100.0 \%$

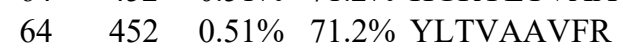

$64 \quad 452 \quad 0.51 \% \quad 71.2 \%$ YLTVAAVFRGR

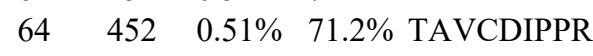

64

64

64

6

6 $64 \quad 452 \quad 0.51 \% \quad 71.2 \%$ HGRYLTVAAVFR

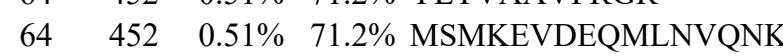

$64 \quad 452 \quad 0.51 \% \quad 71.2 \%$ EVDEQMLNVQNK

$64 \quad 452 \quad 0.51 \% \quad 71.2 \%$ NSSYFVEWIPNNVK

$64 \quad 452 \quad 0.51 \% \quad 71.2 \%$ TAVCDIPPRGLK

$64 \quad 452 \quad 0.51 \% \quad 71.2 \%$ MAVTFIGNSTAIQELFK
1065.43

1389.77

1039.59

1252.72

1971.88

1446.69

1696.83

1028.52

1326.72

1885.97

2042.07

1385.70

1229.60

1385.70

2110.06

1822.92

1870.94

1615.84

2798.34

1958.98

2087.08

1077.53

2724.33

1130.60

1258.69

1287.72

1143.63

1636.83

1723.86

1065.43

1053.61

1266.73

1971.88

1446.69

1696.83

1028.52

1326.72

1857.94

2014.04

1385.70

1229.60

1385.70

2110.06

1822.92

1615.84

1958.98 2087.08

$\begin{array}{cc}98 & 306 \\ 07 & 318 \\ 10 & 318 \\ 10 & 320 \\ 21 & 336 \\ 25 & 336 \\ 37 & 350 \\ 51 & 359 \\ 51 & 362 \\ 63 & 379 \\ 63 & 380 \\ 80 & 390 \\ 81 & 390 \\ 81 & 391 \\ 1 & 19 \\ 3 & 19 \\ 7 & 62 \\ 3 & 77 \\ 8 & 103 \\ 04 & 121 \\ 04 & 122 \\ 55 & 162 \\ 17 & 241 \\ 42 & 251 \\ 42 & 252 \\ 52 & 262 \\ 53 & 262 \\ 63 & 276 \\ 83 & 297 \\ 98 & 306 \\ 10 & 318 \\ 10 & 320 \\ 21 & 336 \\ 25 & 336 \\ 37 & 350 \\ 51 & 359 \\ 51 & 362 \\ 63 & 379 \\ 63 & 380 \\ 80 & 390 \\ 81 & 390 \\ 81 & 391 \\ 1 & 19 \\ & 19 \\ & \end{array}$


Tubulin beta- 3 chain GN=TUBB3 Tubulin beta- 3 chain $\mathrm{GN}=$ TUBB 3 Tubulin beta- 3 chain GN=TUBB3 Tubulin beta- 3 chain GN=TUBB3 Tubulin beta- 3 chain GN=TUBB3 Tubulin beta- 3 chain $\mathrm{GN}=$ TUBB 3

Tubulin beta- 3 chain $\mathrm{GN}=\mathrm{TUBB} 3$ Tubulin beta- 3 chain GN=TUBB3 Tubulin beta- 3 chain GN=TUBB3 Tubulin beta- 3 chain GN=TUBB3 Tubulin beta- 3 chain GN=TUBB3 Tubulin beta- 3 chain GN=TUBB3 Tubulin beta- 3 chain GN=TUBB3 Tubulin beta-4A chain $\mathrm{GN}=\mathrm{TUBB} 4 \mathrm{~A}$

Tubulin beta-4A chain GN=TUBB4A

Tubulin beta- $4 \mathrm{~A}$ chain $\mathrm{GN}=\mathrm{TUBB} 4 \mathrm{~A}$

Tubulin beta-4A chain GN=TUBB4A

Tubulin beta-4A chain GN=TUBB4A

Tubulin beta-4A chain GN=TUBB4A

Tubulin beta-4A chain $\mathrm{GN}=\mathrm{TUBB} 4 \mathrm{~A}$

Tubulin beta- $4 \mathrm{~A}$ chain $\mathrm{GN}=\mathrm{TUBB} 4 \mathrm{~A}$

Tubulin beta-4A chain $\mathrm{GN}=\mathrm{TUBB} 4 \mathrm{~A}$

Tubulin beta-4A chain GN=TUBB4A

Tubulin beta- $4 \mathrm{~A}$ chain $\mathrm{GN}=\mathrm{TUBB} 4 \mathrm{~A}$

Tubulin beta-4A chain $\mathrm{GN}=\mathrm{TUBB} 4 \mathrm{~A}$

Tubulin beta-4A chain GN=TUBB4A

Tubulin beta-4A chain $\mathrm{GN}=\mathrm{TUBB} 4 \mathrm{~A}$

Tubulin beta-4A chain $\mathrm{GN}=\mathrm{TUBB} 4 \mathrm{~A}$

Tubulin beta- $4 \mathrm{~A}$ chain $\mathrm{GN}=\mathrm{TUBB} 4 \mathrm{~A}$

Tubulin beta- $4 \mathrm{~A}$ chain $\mathrm{GN}=\mathrm{TUBB} 4 \mathrm{~A}$

Tubulin beta- $4 \mathrm{~A}$ chain $\mathrm{GN}=\mathrm{TUBB} 4 \mathrm{~A}$

Tubulin beta-4A chain GN=TUBB4A

Tubulin beta-4A chain $\mathrm{GN}=\mathrm{TUBB} 4$

Tubulin beta-4A chain $\mathrm{GN}=\mathrm{TUBB} 4 \mathrm{~A}$

Tubulin beta- $4 \mathrm{~A}$ chain $\mathrm{GN}=\mathrm{TUBB} 4 \mathrm{~A}$

Tubulin beta-4A chain GN=TUBB4A

Tubulin beta-4A chain $\mathrm{GN}=\mathrm{TUBB} 4 \mathrm{~A}$

Tubulin beta-4A chain $\mathrm{GN}=\mathrm{TUBB} 4$

Tubulin beta- $4 \mathrm{~B}$ chain $\mathrm{GN}=\mathrm{TUBB} 4 \mathrm{~B}$

Tubulin beta-4B chain GN=TUBB4B

Tubulin beta- $4 \mathrm{~B}$ chain $\mathrm{GN}=\mathrm{TUBB} 4 \mathrm{~B}$

Tubulin beta- $4 \mathrm{~B}$ chain $\mathrm{GN}=\mathrm{TUBB} 4 \mathrm{~B}$

Tubulin beta-4B chain GN=TUBB4B

Tubulin beta-4B chain GN=TUBB4B

Tubulin beta- $4 \mathrm{~B}$ chain $\mathrm{GN}=\mathrm{TUBB} 4 \mathrm{~B}$

Tubulin beta-4B chain $\mathrm{GN}=\mathrm{TUBB} 4 \mathrm{~B}$

Tubulin beta- $4 \mathrm{~B}$ chain $\mathrm{GN}=\mathrm{TUBB} 4 \mathrm{~B}$ \begin{tabular}{lllllll} 
TBB3_HUMAN 50.43 & $100.0 \%$ & 2 & 3 & 5 & $0.01 \%$ & $34.0 \%$ \\
\hline IMNTFSVVPSPK
\end{tabular} $\begin{array}{lllllll}\text { TBB3 HUMAN } 50.43 & 100.0 \% & 2 & 3 & 5 & 0.01 \% & 34.0 \% \\ \end{array}$ BBB3_HUMAN $50.43 \quad 100.0 \%$ TBB3 HUMAN $50.43 \quad 100.0 \%$ TBB3_HUMAN $50.43 \quad 100.0 \%$ TBB3_HUMAN $50.43 \quad 100.0 \%$ TBB3 HUMAN $50.43 \quad 100.0 \%$ TBB3_HUMAN $50.43 \quad 100.0 \%$ TBB3 HUMAN $50.43 \quad 100.0 \%$ TBB3 HUMAN $50.43 \quad 100.0 \%$ TBB3 HUMAN $50.43 \quad 100.0 \%$ TBB3_HUMAN $50.43 \quad 100.0 \%$ TBB3_HUMAN $50.43 \quad 100.0 \%$ TBB4A_HUMAN $49.59 \quad 100.0 \%$ TBB4A HUMAN $49.59 \quad 100.0 \%$ TBB4A_HUMAN $49.59 \quad 100.0 \%$ TBB4A HUMAN $49.59 \quad 100.0 \%$ TBB4A HUMAN $49.59 \quad 100.0 \%$ TBB4A_HUMAN $49.59 \quad 100.0 \%$ TBB4A HUMAN $49.59 \quad 100.0 \%$ TBB4A_HUMAN $49.59 \quad 100.0 \%$ TBB4A_HUMAN $49.59 \quad 100.0 \%$ TBB4A HUMAN $49.59 \quad 100.0 \%$ TBB4A_HUMAN $49.59 \quad 100.0 \%$ TBB4A_HUMAN $49.59 \quad 100.0 \%$ TBB4A_HUMAN $49.59 \quad 100.0 \%$ TBB4A_HUMAN $49.59 \quad 100.0 \%$ TBB4A HUMAN $49.59 \quad 100.0 \%$ TBB4A_HUMAN $49.59 \quad 100.0 \%$ TBB4A HUMAN $49.59 \quad 100.0 \%$ TBB4A HUMAN $49.59 \quad 100.0 \%$ TBB4A_HUMAN $49.59 \quad 100.0 \%$ TBB4A HUMAN $49.59 \quad 100.0 \%$ TBB4A_HUMAN $49.59 \quad 100.0 \%$ TBB4A_HUMAN $49.59 \quad 100.0 \%$ TBB4A HUMAN $49.59 \quad 100.0 \%$ TBB4A_HUMAN $49.59 \quad 100.0 \%$ TBB4A HUMAN $49.59 \quad 100.0 \%$ TBB4B_HUMAN $49.83 \quad 100.0 \%$ TBB4B_HUMAN $49.83 \quad 100.0 \%$ TBB4B HUMAN $49.83 \quad 100.0 \%$ TBB4B_HUMAN $49.83 \quad 100.0 \%$ TBB4B HUMAN $49.83 \quad 100.0 \%$ TBB4B HUMAN $49.83 \quad 100.0 \%$ TBB4B_HUMAN $49.83 \quad 100.0 \%$ TBB4B_HUMAN $49.83 \quad 100.0 \%$ TBB4B_HUMAN $49.83 \quad 100.0 \%$

$0.01 \% \quad 57.9 \%$ KLAVNMVPFPR
$99.7 \% 59.6$ $99.7 \% \quad 56.5$ $99.7 \% \quad 33.2$ $99.7 \% \quad 54.8$ $99.7 \% \quad 59.4$ $99.7 \% \quad 46.2$ $99.7 \% \quad 39.2$ $99.7 \% \quad 45.9$ $99.7 \% \quad 62.0$ $0.01 \% 34.0 \%$ KLAVNMVPFPR $0.01 \% \quad 34.0 \%$ LAVNMVPFPR $0.01 \% \quad 34.0 \%$ ALTVPELTQQMFDAK $0.01 \% \quad 34.0 \%$ NMMAACDPR $0.01 \% \quad 34.0 \%$ NSSYFVEWIPNNVK $0.01 \% 34.0 \%$ MSSTFIGNSTAIQELFK $0.01 \% 34.0 \%$ MSSTFIGNSTAIQELFKR $0.01 \% \quad 34.0 \%$ RISEQFTAMFR $0.01 \% \quad 34.0 \%$ ISEQFTAMFR $0.01 \% \quad 34.0 \%$ ISEQFTAMFRR $99.5 \% \quad 31.7$ $99.7 \% 30.1$ $99.7 \% \quad 60.4$ $99.3 \% \quad 24.8$ 0.01\% 57.9\% MREIVHLQAGQCGNQIGAK $99.3 \% 55.2$ $0.01 \% \quad 57.9 \%$ EIVHLQAGQCGNQIGAK $\quad 99.2 \% \quad 54.2$ $0.01 \% \quad 57.9 \%$ AVLVDLEPGTMDSVR $\quad 99.7 \% \quad 52.4$ $0.01 \% \quad 57.9 \%$ SGPFGQIFRPDNFVFGQSGAGNNWAK $\quad 99.7 \% \quad 47.1$ $0.01 \% \quad 57.9 \%$ EAescDClQGFQlthsLgGgtGSGMGtLlisk $99.0 \% 79.2$ $0.01 \% 57.9 \%$ IMNTFSVVPSPK $99.7 \% 59.6$

$0.01 \% \quad 57.9 \%$ LTTPTYGDLNHLVSATMSGVTTCLR $99.7 \% \quad 52.4$

$0.01 \% \quad 57.9 \%$ FPGQLNADLR

$0.01 \% \quad 57.9 \%$ FPGQLNADLRK

$0.01 \% \quad 57.9 \%$ LAVNMVPFPR

$0.01 \% \quad 57.9 \%$ LHFFMPGFAPLTSR

$0.01 \% \quad 57.9 \%$ ALTVPELTQQMFDAK

$0.01 \% \quad 57.9 \%$ NMMAACDPR

$0.01 \% \quad 57.9 \%$ HGRYLTVAAVFR

$0.01 \% \quad 57.9 \%$ YLTVAAVFR

$0.01 \% \quad 57.9 \%$ YLTVAAVFRGR

$0.01 \% \quad 57.9 \%$ NSSYFVEWIPNNVK

$0.01 \% \quad 57.9 \%$ TAVCDIPPR

$0.01 \% \quad 57.9 \%$ TAVCDIPPRGLK

$99.7 \% \quad 56.5$

$99.7 \% \quad 33.2$

$99.7 \% \quad 54.8$

$99.7 \% \quad 59.4$

$99.7 \% \quad 50.3$

$99.7 \% \quad 46.2$

$99.7 \% \quad 39.2$

$99.7 \% \quad 55.4$

$99.7 \% \quad 58.2$

$99.7 \% \quad 35.6$

$99.7 \% \quad 45.9$

$99.7 \% \quad 54.8$

$99.7 \% \quad 33.6$

$0.01 \% \quad 57.9 \%$ MAATFIGNSTAIQELFK $\quad 99.5 \% 75.8$

$0.01 \% \quad 57.9 \%$ MAATFIGNSTAIQELFKR $99.0 \% \quad 60.7$

$0.01 \% \quad 57.9 \%$ RISEQFTAMFR

$0.01 \% \quad 57.9 \%$ ISEQFTAMFR

$99.7 \% \quad 30.1$

$99.7 \% \quad 60.4$

$99.3 \% \quad 24.8$

$0.01 \% \quad 57.9 \%$ ISEQFTAMFRR

$99.3 \% \quad 55.2$

$0.06 \% \quad 71.0 \%$ EIVHLQAGQCGNQIGAK $\quad 99.2 \% \quad 54.2$

$0.06 \% \quad 71.0 \%$ INVYYNEATGGK

$99.7 \% \quad 57.4$

$\begin{array}{lllll}0.06 \% & 71.0 \% & \text { INVYYNEATGGKYVPR } \quad 99.7 \% & 39.6\end{array}$

$0.06 \% \quad 71.0 \%$ AVLVDLEPGTMDSVR $\quad 99.7 \% \quad 52.4$

$0.06 \% \quad 71.0 \%$ SGPFGQIFRPDNFVFGQSGAGNNWAK $99.7 \% \quad 47.1$

$\begin{array}{lllll}0.06 \% & 71.0 \% & \text { GHYTEGAELVDSVLDVVR } & 99.7 \% & 40.2\end{array}$

$0.06 \% \quad 71.0 \%$ GHYTEGAELVDSVLDVVRK $99.7 \% 53.8$

$0.06 \% \quad 71.0 \%$ EAESCDCLQGFQLTHSLGGGTGSGMGTLLISK $\quad 99.0 \% \quad 79.2$
1130.60

1258.69

1287.72

1143.63

1691.87

1065.43

1696.83

1873.94

2030.04

1385.70

1229.60

1385.70

2110.06

1822.92

1617.82

2798.34

3327.53

1319.70

2724.33

1130.60

1258.69

1287.72

1143.63

1636.83

1691.87

1065.43

1389.77

1039.59

1252.72

1696.83

1028.52

1326.72

1857.94

2014.04

1385.70

1229.60

1385.70

2110.06

1822.92

1328.65

1843.93

1617.82

2798.34

1958.98

$\begin{array}{cccccc}25.0 & 53.3 & 2 & 6 & 0 & 2087.08 \\ 25.0 & 0.0 & 0 & 4 & 0 & 3327.53\end{array}$

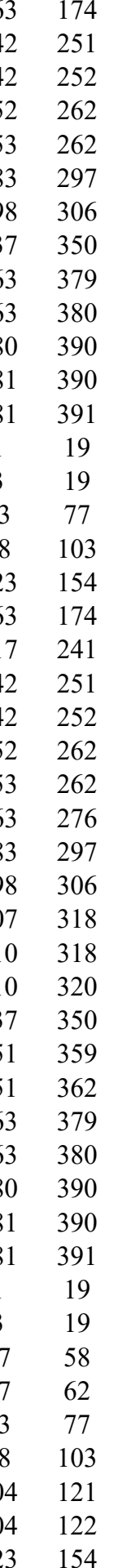

Page 159 of Table S-1-6 
Tubulin beta- $4 \mathrm{~B}$ chain $\mathrm{GN}=\mathrm{TUBB} 4 \mathrm{~B}$ Tubulin beta- $4 \mathrm{~B}$ chain $\mathrm{GN}=\mathrm{TUBB} 4 \mathrm{H}$ Tubulin beta- $4 \mathrm{~B}$ chain $\mathrm{GN}=\mathrm{TUBB} 4 \mathrm{H}$ Tubulin beta- $4 \mathrm{~B}$ chain $\mathrm{GN}=\mathrm{TUBB} 4$ Tubulin beta- $4 \mathrm{~B}$ chain $\mathrm{GN}=\mathrm{TUBB} 4 \mathrm{~B}$ Tubulin beta- $4 \mathrm{~B}$ chain $\mathrm{GN}=\mathrm{TUBB} 4 \mathrm{~B}$

Tubulin beta- $4 \mathrm{~B}$ chain $\mathrm{GN}=\mathrm{TUBB} 4 \mathrm{~B}$ Tubulin beta- $4 \mathrm{~B}$ chain $\mathrm{GN}=\mathrm{TUBB} 4 \mathrm{~F}$ Tubulin beta- $4 \mathrm{~B}$ chain $\mathrm{GN}=\mathrm{TUBB} 4 \mathrm{E}$ Tubulin beta- $4 \mathrm{~B}$ chain $\mathrm{GN}=\mathrm{TUBB} 4 \mathrm{~B}$ Tubulin beta- $4 \mathrm{~B}$ chain $\mathrm{GN}=\mathrm{TUBB} 4 \mathrm{~B}$ Tubulin beta- $4 \mathrm{~B}$ chain $\mathrm{GN}=\mathrm{TUBB} 4 \mathrm{~B}$ Tubulin beta $-4 \mathrm{~B}$ chain $\mathrm{GN}=\mathrm{TUBB} 4 \mathrm{~B}$ Tubulin beta- $4 \mathrm{~B}$ chain $\mathrm{GN}=\mathrm{TUBB} 4 \mathrm{~B}$

Tubulin beta- $4 \mathrm{~B}$ chain $\mathrm{GN}=\mathrm{TUBB} 4 \mathrm{~B}$

Tubulin beta- $4 \mathrm{~B}$ chain $\mathrm{GN}=\mathrm{TUBB} 4 \mathrm{~B}$

Tubulin beta-4B chain $\mathrm{GN}=\mathrm{TUBB} 4 \mathrm{~B}$

Tubulin beta- $4 \mathrm{~B}$ chain $\mathrm{GN}=\mathrm{TUBB} 4 \mathrm{~B}$

Tubulin beta- $4 \mathrm{~B}$ chain $\mathrm{GN}=\mathrm{TUBB} 4 \mathrm{~B}$

Tubulin beta- $4 \mathrm{~B}$ chain $\mathrm{GN}=\mathrm{TUBB} 4 \mathrm{~B}$

Tubulin beta- $4 \mathrm{~B}$ chain $\mathrm{GN}=\mathrm{TUBB} 4 \mathrm{P}$

Tubulin beta- $4 \mathrm{~B}$ chain $\mathrm{GN}=\mathrm{TUBB} 4 \mathrm{~B}$

Tubulin beta- $4 \mathrm{~B}$ chain $\mathrm{GN}=\mathrm{TUBB} 4 \mathrm{~B}$

Tubulin beta -6 chain $\mathrm{GN}=$ TUBB 6

Tubulin beta- 6 chain $\mathrm{GN}=$ TUBB 6

Tubulin beta- 6 chain GN=TUBB6

Tubulin beta- 6 chain GN=TUBB 6

Tubulin beta- 6 chain $\mathrm{GN}=$ TUBB 6

Tubulin beta- 6 chain GN=TUBB 6

Tubulin beta- 6 chain GN=TUBB

Tubulin beta- 6 chain GN=TUBB6

Tubulin beta- 6 chain GN=TUBB 6

Tubulin beta- 6 chain $\mathrm{GN}=\mathrm{TUBB} 6$

Tubulin beta- 6 chain GN=TUBB6

Tubulin gamma- 1 chain $\mathrm{GN}=\mathrm{TUBG}$

Tubulin gamma- 1 chain $\mathrm{GN}=\mathrm{TUBG}$

Tubulin gamma-1 chain GN=TUBG

Tubulin gamma-1 chain $\mathrm{GN}=\mathrm{TUBG}$

Tubulin gamma- 1 chain $\mathrm{GN}=\mathrm{TUBG} 1$

Tubulin gamma- 1 chain $\mathrm{GN}=\mathrm{TUBG}$

Tubulin gamma-1 chain GN=TUBG

Tubulin-specific chaperone D GN=TBCD TBCD_HUMAN $132.60 \quad 100.0 \%$

Tubulin-specific chaperone D GN=TBCD TBCD HUMAN $132.60 \quad 100.0 \%$

Tubulin-specific chaperone D GN=TBCD TBCD_HUMAN $132.60 \quad 100.0 \%$

Tubulin-specific chaperone D GN=TBCD TBCD_HUMAN $132.60 \quad 100.0 \%$

Tyrosine-protein kinase BAZ1B GN=BAZ1B BAZ1B_HUMAN $170.91 \quad 100.0 \%$

Tyrosine-protein kinase BAZ1B GN=BAZ1B BAZ1B_HUMAN $170.91 \quad 100.0 \%$

TBB4B_HUMAN $49.83 \quad 100.0 \%$

B HUMAN $49.83 \quad 100.0 \%$

TBB4B_HUMAN $49.83 \quad 100.0 \%$

TBB4B HUMAN $49.83 \quad 100.0 \%$

TBB4B_HUMAN $49.83 \quad 100.0 \%$

$\begin{array}{ll} & 100.0 \%\end{array}$

MAN $49.83 \quad 100.0 \%$

TBB4B HUMAN $49.83 \quad 100.0 \%$

TBB4B HUMAN $49.83 \quad 100.0 \%$

AAN $49.83 \quad 100.0 \%$

TBB4B HUMAN $49.83 \quad 100.0 \%$

TBB4B_HUMAN $49.83 \quad 100.0 \%$

UMAN $49.83 \quad 100.0 \%$

TBB6_HUMAN $49.86 \quad 100.0 \%$

TBB6_HUMAN $49.86 \quad 100.0 \%$

TBB6_HUMAN $49.86 \quad 100.0 \%$

100.0\%

TBB6 HUMAN $49.86 \quad 100.0 \%$

\begin{tabular}{ll} 
TBB_HUMAN 49.86 & $100.0 \%$ \\
\hline
\end{tabular}

TBB6 HUMAN $49.86 \quad 100.0 \%$

IBB6_HUMAN $49.86 \quad 100.0 \%$

.

TBG1_HUMAN $51.17 \quad 100.0 \%$

TBG1_HUMAN $51.17 \quad 100.0 \%$

$51.17 \quad 100.0 \%$

UMAN $51.17 \quad 100.0 \%$

TBG1_HUMAN $51.17 \quad 100.0 \%$

TBG1 HUMAN $51.17 \quad 100.0 \%$
$51 \quad 0.06 \% \quad 71.0 \%$ IREEYPDR

$0.06 \% \quad 71.0 \%$ IMNTFSV

$0.06 \% \quad 71.0 \%$ LTTPTYGDLNHLVSAT

$99.0 \% \quad 44.5$

$99.7 \% \quad 59.6$

$0.06 \% \quad 71.0 \%$ FPGQLNADLRK

$0.06 \% \quad 71.0 \%$ KLAVNMVPFPR

$0.06 \% \quad 71.0 \%$ LAVNMVPFPR

$0.06 \% \quad 71.0 \%$ LHFFMPGFAPLTSR

$0.06 \% \quad 71.0 \%$ ALTVPELTQQMFDAK

$0.06 \% \quad 71.0 \%$ NMMAACDPR

$0.06 \% \quad 71.0 \%$ HGRYLTVAAVFR

$0.06 \% \quad 71.0 \%$ YLTVAAVFR

$0.06 \% \quad 71.0 \%$ YLTVAAVFRGR

$0.06 \% 71.0 \%$ MSMKEVDEQMLNVQNK

$0.06 \% \quad 71.0 \%$ EVDEQMLNVQNK

$0.06 \% \quad 71.0 \%$ NSSYFVEWIPNNVK

$0.06 \% \quad 71.0 \%$ TAVCDIPPR

$0.06 \% \quad 71.0 \%$ TAVCDIPPRGLK

$0.06 \% \quad 71.0 \%$ MSATFIGNSTAIQELFK

$0.06 \% \quad 71.0 \%$ MSATFIGNSTAIQELFKR

$0.06 \% \quad 71.0 \%$ RISEQFTAMFR

$0.06 \% \quad 71.0 \%$ ISEQFTAMFR

$0.06 \% \quad 71.0 \%$ ISEQFTAMFRR

$0.01 \% \quad 23.8 \%$ AALVDLEPGTMDSVR

$0.01 \% \quad 23.8 \%$ FPGQLNADLR

$0.01 \% \quad 23.8 \%$ FPGQLNADLRK

$0.01 \% \quad 23.8 \%$ KLAVNMVPFPR

$0.01 \% \quad 23.8 \%$ LAVNMVPFPR

$0.01 \% \quad 23.8 \%$ LHFFMPGFAPLTSR

$0.01 \% \quad 23.8 \%$ ALTVPELTQQMFDAR

$0.01 \% \quad 23.8 \%$ NMMAACDPR

$0.01 \% \quad 23.8 \%$ NSSYFVEWIPNNVK

$0.01 \% \quad 23.8 \%$ MASTFIGNSTAIQELFK

$0.01 \% \quad 23.8 \%$ MASTFIGNSTAIQELFKR

$0.02 \% \quad 17.5 \%$ AVLLDLEPR

$0.02 \% \quad 17.5 \%$ VIHSILNSPYAK

$\begin{array}{lllll}0.02 \% & 17.5 \% & \text { RLTQNADCVVVLDNTALNR } & 99.7 \% & 49.7\end{array}$

$0.02 \% \quad 17.5 \%$ LTQNADCVVVLDNTALNR $99.7 \% \quad 40.2$

$0.02 \% \quad 17.5 \%$ LHFLMTGYTPLTTDQSVASVR

$0.02 \% \quad 17.5 \%$ KTTVLDVMR

$0.02 \% \quad 17.5 \%$ SPYLPSAHR

$0.01 \% \quad 3.7 \%$ ILQIAESYLIVSDK

$0.01 \% \quad 3.7 \%$ DAAAVLVSR

$0.01 \% \quad 3.7 \%$ AASAAFQENVGR

$0.01 \% \quad 3.7 \%$ LQQVLTGLR

$0.00 \% \quad 1.6 \%$ SALSCVISK

$0.00 \% \quad 1.6 \%$ GGLGYVEETSEFEAR $\begin{array}{llll}99.7 \% & 56.5 & 25.0 & 44.9\end{array}$

$99.7 \% \quad 59.4 \quad 25.0 \quad 50.3$

$\begin{array}{lllll}99.7 \% & 50.3 & 25.0 & 43.9 & 22\end{array}$

$\begin{array}{lllll}99.7 \% & 46.2 & 25.0 & 46.2 & 16\end{array}$

$\begin{array}{llll}99.7 \% & 39.2 & 25.0 & 39.2\end{array}$

$99.7 \% \quad 55.4 \quad 25.0 \quad 50.6 \quad 2$

$\begin{array}{llll}99.7 \% & 58.2 & 25.0 & 45.5\end{array}$

$99.7 \% \quad 35.6$

$.7 \% \quad 54.9$

$99.7 \% \quad 45.9$

$99.7 \% \quad 54.8$

$99.7 \% 33.6$

$99.2 \% \quad 66.5$

$99.7 \% \quad 60.4$

$99.3 \% \quad 24.8$

$99.7 \% \quad 54.3$

$99.7 \% \quad 56.5$

$99.7 \% \quad 33.2$

$99.7 \% \quad 54.8$

$99.7 \% \quad 59.4$

$99.7 \% \quad 50.3$

$99.7 \% \quad 36.1$

$99.7 \% \quad 39.2$

$99.7 \% \quad 45.9$

$97.0 \% \quad 60.0$

$99.2 \% 35.2$

$99.6 \% \quad 33.7$

$99.7 \% \quad 47.2$

$99.7 \% \quad 51.6$

$99.6 \% 26.3$

$96.0 \% \quad 15.1$

$99.7 \% \quad 46.7$

$99.7 \% \quad 63.5$

$99.7 \% \quad 45.6$

$99.7 \% \quad 46.1$

$98.1 \% 22.0$

$99.7 \% \quad 40.4$
1319.70

2724.33

1130.60

1258.69

1287.72

1143.63

1636.83

1691.87

1065.43

1389.77

1039.59

1252.72

1971.88

1446.69

1696.83

1028.52

1326.72

1857.94

2014.04

1385.70

1229.60

1385.70

1589.78

1130.60

1258.69

1287.72

1143.63

1636.83

1719.87

1065.43

1696.83

1857.94

2014.04

1025.60

1341.75

2172.12

2016.02

2353.19

1062.60

1027.53

1591.89

901.51

1220.60

1027.63

964.51

1643.75 $\begin{array}{cc}55 & 162 \\ 63 & 174 \\ 17 & 241 \\ 42 & 251 \\ 42 & 252 \\ 52 & 262 \\ 53 & 262 \\ 63 & 276 \\ 83 & 297 \\ 98 & 306 \\ 07 & 318 \\ 10 & 318 \\ 10 & 320 \\ 21 & 336 \\ 25 & 336 \\ 37 & 350 \\ 51 & 359 \\ 51 & 362 \\ 63 & 379 \\ 63 & 380 \\ 80 & 390 \\ 81 & 390 \\ 81 & 391 \\ 3 & 77 \\ 42 & 251 \\ 42 & 252 \\ 52 & 262 \\ 53 & 262 \\ 63 & 276 \\ 83 & 297 \\ 98 & 306 \\ 37 & 350 \\ 63 & 379 \\ 63 & 380 \\ 4 & 72 \\ 3 & 84 \\ 94 & 212 \\ 95 & 212 \\ 66 & 286 \\ 87 & 295 \\ 64 & 372 \\ 89 & 202 \\ 05 & 213 \\ 09 & 520 \\ 91 & 799 \\ 93 & 501 \\ 69 & 1083 \\ & \end{array}$

Page 160 of Table S-1-6 
Tyrosine--tRNA ligase, cytoplasmic GN=YARS SYYC HUMAN $59.15 \quad 100.0 \%$ Tyrosine--tRNA ligase, cytoplasmic GN=YARS SYYC_HUMAN $59.15 \quad 100.0 \% \quad 17$ Tyrosine--tRNA ligase, cytoplasmic GN=YARS SYYC_HUMAN $59.15 \quad 100.0 \% \quad 1$ Tyrosine--tRNA ligase, cytoplasmic GN=YARS SYYC_HUMAN $59.15 \quad 100.0 \%$ $\begin{array}{llll}\text { Tyrosine--tRNA ligase, cytoplasmic GN=YARS SYYC_HUMAN } 59.15 & 100.0 \% & 17\end{array}$ Tyrosine--tRNA ligase, cytoplasmic GN=YARS SYYC_HUMAN $59.15 \quad 100.0 \%$ Tyrosine--tRNA ligase, cytoplasmic GN=YARS SYYC_HUMAN $59.15 \quad 100.0 \% \quad 17$ Tyrosine--tRNA ligase, cytoplasmic GN=YARS SYYC_HUMAN $59.15 \quad 100.0 \% \quad 17$ Tyrosine--tRNA ligase, cytoplasmic GN=YARS SYYC HUMAN $59.15 \quad 100.0 \% \quad 17$ Tyrosine--tRNA ligase, cytoplasmic GN=YARS SYYC_HUMAN $59.15 \quad 100.0 \% \quad 17$ $\begin{array}{llll}\text { Tyrosine--tRNA ligase, cytoplasmic GN=YARS SYYC_HUMAN } & 59.15 & 100.0 \% & 17\end{array}$ Tyrosine--tRNA ligase, cytoplasmic GN=YARS SYYC HUMAN $59.15 \quad 100.0 \%$ Tyrosine--tRNA ligase, cytoplasmic GN=YARS SYYC_HUMAN $59.15 \quad 100.0 \% \quad 17$ Tyrosine--tRNA ligase, cytoplasmic GN=YARS SYYC_HUMAN $59.15 \quad 100.0 \%$ $\begin{array}{llll}\text { Tyrosine--tRNA ligase, cytoplasmic GN=YARS SYYC_HUMAN } & 59.15 & 100.0 \% & 17\end{array}$ Tyrosine--tRNA ligase, cytoplasmic GN=YARS SYYC_HUMAN $59.15 \quad 100.0 \%$ Tyrosine--tRNA ligase, cytoplasmic GN=YARS SYYC HUMAN $59.15 \quad 100.0 \%$ $\begin{array}{llll}\text { U1 small nuclear ribonucleoprotein } 70 \mathrm{kDa} \text { GN=SNRNP70 } & \text { RU17_HUMAN } 51.56 \quad 100.0 \%\end{array}$ U1 small nuclear ribonucleoprotein $70 \mathrm{kDa}$ GN=SNRNP70 RU17_HUMAN $51.56 \quad 100.0 \%$ U1 small nuclear ribonucleoprotein $70 \mathrm{kDa} \mathrm{GN=SNRNP70} \mathrm{RU17} \mathrm{HUMAN} 51.56 \quad 100.0 \%$ U1 small nuclear ribonucleoprotein $70 \mathrm{kDa}$ GN=SNRNP70 RU17_HUMAN $51.56 \quad 100.0 \%$ U1 small nuclear ribonucleoprotein A GN=SNRPA SNRPA_HUMAN $31.28100 .0 \%$ U1 small nuclear ribonucleoprotein A GN=SNRPA SNRPA_HUMAN $31.28 \quad 100.0 \%$ U2 small nuclear ribonucleoprotein A' GN=SNRPA1 RU2A_HUMAN $28.42 \quad 100.0 \%$ 2 small nuclear ribonucleoprotein $\mathrm{A}^{\prime} \mathrm{GN}=\mathrm{SNRPA} 1$ RU2A_HUMAN $28.42 \quad 100.0 \%$ U2 small nuclear ribonucleoprotein $\mathrm{A}^{\prime}$ GN=SNRPA1 RU2A_HUMAN $28.42 \quad 100.0 \%$ U2 small nuclear ribonucleoprotein $\mathrm{A}^{\prime}$ GN=SNRPA1 RU2A_HUMAN $28.42 \quad 100.0 \%$ U2 small nuclear ribonucleoprotein A' GN=SNRPA1 RU2A_HUMAN $28.42 \quad 100.0 \%$ U2 snRNP-associated SURP motif-containing protein GN=U2SURP SR140_HUMAN $118.30 \quad 100.0 \%$ U2 snRNP-associated SURP motif-containing protein GN=U2SURP SR140 HUMAN 118.30 100.0\% U3 small nucleolar ribonucleoprotein protein IMP4 GN=IMP4 IMP4_HUMAN $33.76 \quad 100.0 \%$ U3 small nucleolar ribonucleoprotein protein IMP4 GN=IMP4 IMP4_HUMAN $33.76 \quad 100.0 \%$ 4/U6 small nuclear ribonucleoprotein Prp31 GN=PRPF31 PRP31_HUMAN 55.46 100.0\% U4/U6 small nuclear ribonucleoprotein Prp31 GN=PRPF31 PRP31_HUMAN 55.46 $100.0 \%$ U4/U6 small nuclear ribonucleoprotein Prp31 GN=PRPF31 PRP31_HUMAN $55.46 \quad 100.0 \%$ U4/U6 small nuclear ribonucleoprotein Prp31 GN=PRPF31 PRP31_HUMAN 55.46 100.0\% U4/U6 small nuclear ribonucleoprotein Prp31 GN=PRPF31 PRP31_HUMAN 55.46 100.0\% U4/U6 small nuclear ribonucleoprotein Prp31 GN=PRPF31 PRP31 HUMAN 55.46 $100.0^{\circ}$ U4/U6 small nuclear ribonucleoprotein Prp31 GN=PRPF31 PRP31_HUMAN 55.46 $100.0 \%$ U4/U6 small nuclear ribonucleoprotein Prp31 GN=PRPF31 PRP31_HUMAN 55.46 100.0\% U4/U6 small nuclear ribonucleoprotein Prp31 GN=PRPF31 PRP31_HUMAN $55.46100 .0 \%$ U4/U6 small nuclear ribonucleoprotein Prp31 GN=PRPF31 PRP31_HUMAN 55.46 $100.0 \%$ U4/U6 small nuclear ribonucleoprotein Prp31 GN=PRPF31 PRP31_HUMAN 55.46 $100.0^{\circ}$ U4/U6 small nuclear ribonucleoprotein Prp31 GN=PRPF31 PRP31_HUMAN 55.46 100.0\% U4/U6 small nuclear ribonucleoprotein Prp31 GN=PRPF31 PRP31_HUMAN 55.46 100.0\% U4/U6 small nuclear ribonucleoprotein Prn31 GN=PRPF31 PRP31 HUMAN 55.46 100.0\% U4/U6 small nuclear ribonucleoprotein Prp31 GN=PRPF31 PRP31_HUMAN $55.46 \quad 100.0 \%$

17

7

17
17

(28.

$\begin{array}{ll}0.03 \% & 33.7 \% \\ 0.03 \% & 33.7 \% \text { LSSVVTQHDSKK } \\ 0.03 \% & 33.7 \% \text { YLPALGYSK }\end{array}$

$0.03 \% \quad 33.7 \%$ YLPALGYSK

$\begin{array}{lllll}99.3 \% & 25.4 & 25.0 & 25.4 & 0\end{array}$ $\begin{array}{lllll}99.7 \% & 34.4 & 25.0 & 26.8 & 2\end{array}$ $\begin{array}{lllll}99.7 \% & 34.4 & 25.0 & 26.8 & 2 \\ 97.1 \% & 24.5 & 25.0 & 11.3 & 1\end{array}$ $0.03 \% \quad 33.7 \%$ AFCEPGNVENNGVLSFIK $0.03 \% 33.7 \%$ NSVEVALNK

$99.7 \% 27.6$

$0.03 \% \quad 33.7 \%$ FNTPALKK

$99.7 \% \quad 55.4$

$99.7 \% \quad 40.3$

$97.2 \% \quad 23.3$

$0.03 \% \quad 33.7 \%$ LASAAYPDPSK

$99.7 \% \quad 59.4$

$0.03 \% \quad 33.7 \%$ LASAAYPDPSKQKPMAK $95.9 \% \quad 18.5$

$0.03 \% \quad 33.7 \%$ NSEPEEVIPSR

$0.03 \% \quad 33.7 \%$ NSEPEEVIPSRLDIR

$99.7 \% \quad 28.5$

$99.7 \% \quad 29.6$

$99.7 \% \quad 34.8$

$\begin{array}{lll}0.03 \% & 33.7 \% & \text { IDVGEAEPR } \\ 0.03 \% & 33.7 \% & \text { TVVSGLVQFVPK }\end{array}$

$99.7 \% \quad 36.7$

$0.03 \% \quad 33.7 \%$ GVESQGMLLCASIEGINR $99.7 \% \quad 46.3$

$0.03 \% \quad 33.7 \%$ QVEPLDPPAGSAPGEHVFVK $99.3 \% 20.6$

$0.03 \% \quad 33.7 \%$ GYEKGQPDEELKPK

$0.03 \% \quad 33.7 \%$ GQPDEELKPK

$0.01 \% \quad 8.5 \%$ RQQEVETELK

$0.01 \% \quad 8.5 \%$ VNYDTTESK

$0.01 \% \quad 8.5 \%$ EFEVYGPIKR

$0.01 \% \quad 8.5 \%$ GGADVNIR

$0.01 \% \quad 9.2 \%$ GQAFVIFK

$\begin{array}{ll}99.7 \% & 32.3\end{array}$

$98.5 \% \quad 19.5$

$99.5 \% \quad 32.4$

$97.0 \% \quad 15.7$

$99.2 \% \quad 20.3$

$99.0 \% \quad 40.0$

$99.0 \% \quad 44.9$

$0.01 \% \quad 9.2 \%$ HDIAFVEFDNEVQAGAAR $99.7 \% \quad 28.4$

$0.01 \% \quad 21.2 \%$ KLDGFPLLR

$0.01 \% \quad 21.2 \%$ TLLVNNNR

$0.01 \% \quad 21.2 \%$ GGPSPGDVEAIK

$0.01 \% \quad 21.2 \%$ NAIANASTLAEVER

$0.01 \% \quad 21.2 \%$ GLLQSGQIPGR

$0.00 \% \quad 2.1 \%$ NLLALIHR

$0.00 \% \quad 2.1 \%$ LYLVSDVLYNSSAK

$0.00 \% \quad 6.2 \% \quad$ LIPTELRR

$0.00 \% \quad 6.2 \% \quad$ NVELTEVGPR

$0.05 \% \quad 36.5 \%$ ASEVMGPVEAAPEYR

$0.05 \% \quad 36.5 \%$ TVKELGNSLDK

$0.05 \% \quad 36.5 \%$ HRIYEYVESR

$0.05 \% \quad 36.5 \%$ IYEYVESR

$\begin{array}{llll}95.8 \% & 25.1 & 25.0 & 7.6\end{array}$

$\begin{array}{llll}99.7 \% & 32.5 & 25.0 & 23.6\end{array}$

$99.7 \% \quad 74.1 \quad 25.0 \quad 71.8$

$99.7 \% \quad 49.6 \quad 25.0 \quad 25.6$

$\begin{array}{llll}99.0 \% & 31.8 & 25.0 & 31.8\end{array}$

$99.7 \% \quad 57.8 \quad 25.0 \quad 57.8$

$\begin{array}{llll}97.4 \% & 20.2 & 25.0 & 13.1\end{array}$

$99.7 \% \quad 43.4 \quad 25.0 \quad 32.2$

$\begin{array}{llll}99.7 \% & 58.2 & 25.0 & 58.2\end{array}$

$99.2 \% \quad 28.1 \quad 25.0 \quad 14.6$

$99.7 \% \quad 29.8 \quad 25.0 \quad 27.6$

$\begin{array}{llll}99.0 \% & 46.0 & 25.0 & 30.8\end{array}$

$0.05 \% \quad 36.5 \%$ MSFIAPNLSIIIGASTAAK $99.7 \% \quad 45.9$

$0.05 \% \quad 36.5 \%$ IMGVAGGLTNLSK

$0.05 \% \quad 36.5 \%$ MPACNIMLLGAQR

$0.05 \% \quad 36.5 \%$ VDSFHESTEGK

$0.05 \% \quad 36.5 \%$ QVKPLPAPLDGQR

$99.7 \% \quad 43.7$

$99.7 \% \quad 51.9$

$99.1 \% 26.3$

$99.0 \% \quad 61.5$

$99.7 \% \quad 51.3$

$98.0 \% \quad 22.4$

$99.7 \% \quad 58.7$

$0.05 \% \quad 36.5 \%$ VRQTQVNEATK

$0.05 \% \quad 36.5 \%$ QTQVNEATKAR

$\begin{array}{lllll}0.05 \% & 36.5 \% & \text { SSGTASSVAFTPLQGLEIVNPQAAEK } & 99.7 \% & 43.1 \\ 0.05 \% & 36.5 \% & \text { SSGTASSVAFTPLQGLEIVNPQAAEKK } & 99.7 \% & 44.7\end{array}$
1950.94

1328.72

1011.55

1167.65

1994.96

973.53

918.54

1119.57

1818.94

1256.61

1753.91

985.50

1273.75

1933.95

2074.06

1617.81

1140.59

1259.66

1056.48

1237.66

801.42

909.52

1988.95

1058.64

943.53

1126.57

1458.75

1125.64

949.59

1571.83

997.62

1113.59

1621.75

1203.66

1351.68

1058.52

1921.05

1276.69

1490.73

1235.55

1418.81

929.58

1273.69

1245.65

1307.73

2602.34 2730.43

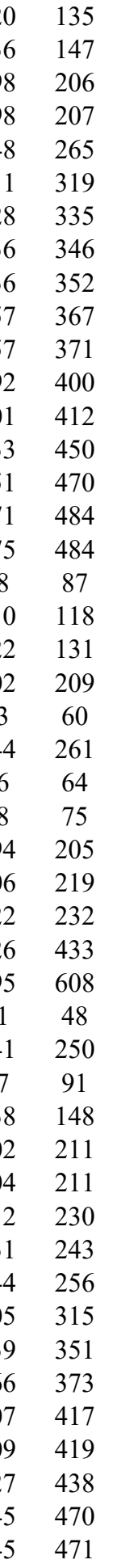

Page 161 of Table S-1-6 

U4/U6 small nuclear ribonucleoprotein Prp31 GN=PRPF31 PRP31_HUMAN 55.46 $100.0 \% \quad 17$ U4/U6 small nuclear ribonucleoprotein Prp4 GN=PRPF4 PRP4_HUMAN 58.45 $100.0 \%$ U4/U6 small nuclear ribonucleoprotein Prp4 GN=PRPF4 PRP4 HUMAN 58.45 $100.0 \%$ U4/U6 small nuclear ribonucleoprotein Prp4 GN=PRPF4 PRP4_HUMAN 58.45 $100.0 \%$ U5 small nuclear ribonucleoprotein $200 \mathrm{kDa}$ helicase GN=SNRNP200 U520_HUMAN $244.51 \quad 100.0 \%$ U5 small nuclear ribonucleoprotein $200 \mathrm{kDa}$ helicase GN=SNRNP200 U520_HUMAN $244.51 \quad 100.0 \%$ U5 small nuclear ribonucleoprotein $200 \mathrm{kDa}$ helicase GN=SNRNP200 $\quad$ U520_HUMAN $244.51 \quad 100.0 \%$ U5 small nuclear ribonucleoprotein $200 \mathrm{kDa}$ helicase GN=SNRNP200 U520 HUMAN $244.51 \quad 100.0 \%$ U5 small nuclear ribonucleoprotein $200 \mathrm{kDa}$ helicase GN=SNRNP200 U520_HUMAN $244.51 \quad 100.0 \% 35$ U5 small nuclear ribonucleoprotein $200 \mathrm{kDa}$ helicase GN=SNRNP200 U520_HUMAN $244.51 \quad 100.0 \% \quad 35$ U5 small nuclear ribonucleoprotein $200 \mathrm{kDa}$ helicase GN=SNRNP200 U520_HUMAN $244.51 \quad 100.0 \% \quad 35$ U5 small nuclear ribonucleoprotein $200 \mathrm{kDa}$ helicase GN=SNRNP200 U520_HUMAN $244.51 \quad 100.0 \% \quad 35$ U5 small nuclear ribonucleoprotein $200 \mathrm{kDa}$ helicase GN=SNRNP200 U520 HUMAN $244.51 \quad 100.0 \% 35$ U5 small nuclear ribonucleoprotein $200 \mathrm{kDa}$ helicase GN=SNRNP200 U520 HUMAN $244.51 \quad 100.0 \% \quad 35$ U5 small nuclear ribonucleoprotein $200 \mathrm{kDa}$ helicase GN=SNRNP200 U520_HUMAN $244.51 \quad 100.0 \% \quad 35$ U5 small nuclear ribonucleoprotein $200 \mathrm{kDa}$ helicase GN=SNRNP200 U520_HUMAN $244.51 \quad 100.0 \%$ U5 small nuclear ribonucleoprotein $200 \mathrm{kDa}$ helicase GN=SNRNP200 U520_HUMAN $244.51 \quad 100.0 \% \quad 35$ U5 small nuclear ribonucleoprotein $200 \mathrm{kDa}$ helicase GN=SNRNP200 U520_HUMAN $244.51 \quad 100.0 \%$ U5 small nuclear ribonucleoprotein $200 \mathrm{kDa}$ helicase GN=SNRNP200 U520 HUMAN $244.51 \quad 100.0 \% \quad 35$ U5 small nuclear ribonucleoprotein $200 \mathrm{kDa}$ helicase GN=SNRNP200 U520_HUMAN $244.51 \quad 100.0 \%$ U5 small nuclear ribonucleoprotein $200 \mathrm{kDa}$ helicase GN=SNRNP200 U520 HUMAN $244.51 \quad 100.0 \% \quad 35$ U5 small nuclear ribonucleoprotein $200 \mathrm{kDa}$ helicase GN=SNRNP200 U520 HUMAN $244.51 \quad 100.0 \%$ U5 small nuclear ribonucleoprotein $200 \mathrm{kDa}$ helicase GN=SNRNP200 U520 HUMAN $244.51 \quad 100.0 \% 35$ 45 small nuclear ribonucleoprotein $200 \mathrm{kDa}$ helicase GN=SNRNP200 U520_HUMAN $244.51 \quad 100.0 \%$ U5 small nuclear ribonucleoprotein $200 \mathrm{kDa}$ helicase GN=SNRNP200 U520_HUMAN $244.51 \quad 100.0 \% \quad 35$ U5 small nuclear ribonucleoprotein $200 \mathrm{kDa}$ helicase GN=SNRNP200 U520_HUMAN $244.51 \quad 100.0 \% \quad 35$ U5 small nuclear ribonucleoprotein $200 \mathrm{kDa}$ helicase GN=SNRNP200 U520 HUMAN $244.51 \quad 100.0 \%$ U5 small nuclear ribonucleoprotein $200 \mathrm{kDa}$ helicase GN=SNRNP200 U520_HUMAN $244.51 \quad 100.0 \%$ U5 small nuclear ribonucleoprotein $200 \mathrm{kDa}$ helicase GN=SNRNP200 U520 HUMAN $244.51 \quad 100.0 \% \quad 35$ U5 small nuclear ribonucleoprotein $200 \mathrm{kDa}$ helicase GN=SNRNP200 U520_HUMAN $244.51 \quad 100.0 \%$ U5 small nuclear ribonucleoprotein $200 \mathrm{kDa}$ helicase GN=SNRNP200 U520_HUMAN $244.51 \quad 100.0 \%$ 45 small nuclear ribonucleoprotein $200 \mathrm{kDa}$ helicase GN=SNRNP200 U520 HUMAN $244.51 \quad 100.0 \% 35$ U5 small nuclear ribonucleoprotein $200 \mathrm{kDa}$ helicase GN=SNRNP200 U520_HUMAN $244.51 \quad 100.0 \% \quad 35$ U5 small nuclear ribonucleoprotein $200 \mathrm{kDa}$ helicase GN=SNRNP200 U520 HUMAN $244.51 \quad 100.0 \% \quad 35$ U5 small nuclear ribonucleoprotein $200 \mathrm{kDa}$ helicase GN=SNRNP200 U520 HUMAN $244.51 \quad 100.0 \%$ U5 small nuclear ribonucleoprotein $200 \mathrm{kDa}$ helicase GN=SNRNP200 U520_HUMAN $244.51 \quad 100.0 \% \quad 35$ U5 small nuclear ribonucleoprotein $200 \mathrm{kD}$ a helicase GN=SNRNP200 U520_HUMAN $244.51 \quad 100.0 \%$ U5 small nuclear ribonucleoprotein $200 \mathrm{kDa}$ helicase GN=SNRNP200 U520_HUMAN $244.51 \quad 100.0 \% \quad 35$ U5 small nuclear ribonucleoprotein $200 \mathrm{kDa}$ helicase GN=SNRNP200 $\quad$ U520_HUMAN $244.51 \quad 100.0 \% 3$ U5 small nuclear ribonucleoprotein $40 \mathrm{kDa}$ protein GN=SNRNP40 SNR40 HUMAN $39.31 \quad 100.0 \%$ U5 small nuclear ribonucleoprotein $40 \mathrm{kDa}$ protein GN=SNRNP40 SNR40_HUMAN $39.31 \quad 100.0 \%$ U5 small nuclear ribonucleoprotein $40 \mathrm{kDa}$ protein GN=SNRNP40 SNR40 HUMAN $39.31 \quad 100.0 \%$ U5 small nuclear ribonucleoprotein $40 \mathrm{kDa}$ protein GN=SNRNP40 SNR40 HUMAN $39.31 \quad 100.0 \%$

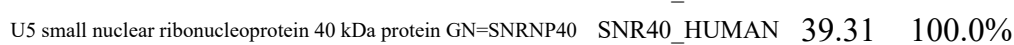
UAP56-interacting factor GN=FYTTD1 UIF HUMAN $35.82 \quad 100.0 \%$ UAP56-interacting factor GN=FYTTD1 UIF_HUMAN $35.82 \quad 100.0 \%$
$6 \quad 0.01 \% \quad 7.1 \%$ LHKEIPETTR

$0.01 \% \quad 7.1 \%$ GHNTNVGAIVFHPK

$104 \quad 0.12 \% \quad 15.6 \%$ ANSNLVLQADR

$104 \quad 0.12 \% \quad 15.6 \%$ FYDDAIVSQK

$104 \quad 0.12 \% \quad 15.6 \%$ KADEVLEILK

$104 \quad 0.12 \% \quad 15.6 \%$ ADEVLEILK

$104 \quad 0.12 \% \quad 15.6 \%$ YAQAGFEGFK

$104 \quad 0.12 \% \quad 15.6 \%$ AALETDENLLLCA

$04 \quad 0.12 \% \quad 15.6 \%$ TNVALMCMLR

$104 \quad 0.12 \% \quad 15.6 \%$ SLVQEMVGSFGK

$104 \quad 0.12 \% \quad 15.6 \%$ SLVQEMVGSFGKR

$104 \quad 0.12 \% \quad 15.6 \%$ NIEMTQEDVR

$104 \quad 0.12 \% \quad 15.6 \%$ FQIMNEIVYEK

$104 \quad 0.12 \% \quad 15.6 \%$ NQVLVFVHSR

$104 \quad 0.12 \% \quad 15.6 \%$ DTLGLFLR

$104 \quad 0.12 \% \quad 15.6 \%$ EGSASTEVLR

$98.7 \% \quad 19.0 \quad 25.0$

$99.7 \% 32.4$

$99.7 \% \quad 34.7$

$99.4 \% \quad 22.5$

$99.6 \% \quad 25.7$

$99.7 \% \quad 65.9$

$99.7 \% \quad 49.8$

$99.7 \% \quad 63.4$

$99.7 \% \quad 31.5$

$99.7 \% \quad 50.5$

$99.7 \% \quad 59.8$

$99.7 \% \quad 42.2$

$99.7 \% \quad 52.8$

$99.7 \% \quad 43.8$

$99.7 \% \quad 44.4$

$99.7 \% \quad 46.7$

$99.7 \% \quad 47.7$

$99.0 \% \quad 37.5$

$99.7 \% \quad 55.0$

$104 \quad 0.12 \% \quad 15.6 \%$ EGSASTEVLRTEAEQCK $\quad 96.2 \% \quad 14.8$

$104 \quad 0.12 \% \quad 15.6 \%$ GTQVYSPEK

$104 \quad 0.12 \% \quad 15.6 \%$ TGNFQVTELGR

$104 \quad 0.12 \% \quad 15.6 \%$ VFSLSSEFK

$104 \quad 0.12 \% \quad 15.6 \%$ VPIPVKESIEEPSAK

$104 \quad 0.12 \% \quad 15.6 \%$ ESIEEPSAK

$104 \quad 0.12 \% \quad 15.6 \%$ KLPEEVVK

$104 \quad 0.12 \% \quad 15.6 \%$ LELSVHLQPITR

$104 \quad 0.12 \% \quad 15.6 \%$ TICAEFAILR

$104 \quad 0.12 \% \quad 15.6 \%$ MLLQSSEGR

$104 \quad 0.12 \% \quad 15.6 \%$ KVVLLTGETSTDLK

$104 \quad 0.12 \% \quad 15.6 \%$ VVLLTGETSTDLK

$104 \quad 0.12 \% \quad 15.6 \%$ IVALSSSLSNAK

$104 \quad 0.12 \% \quad 15.6 \%$ LLSMAKPVYHAITK

$104 \quad 0.12 \% \quad 15.6 \%$ KPVIVFVPSR

$104 \quad 0.12 \% \quad 15.6 \%$ LTAIDILTTCAADIQR

$104 \quad 0.12 \% \quad 15.6 \%$ CVIMCQGSK

$104 \quad 0.12 \% \quad 15.6 \%$ MTQNPNYYNLQGISHR

$104 \quad 0.12 \% \quad 15.6 \%$ TNLLLQAHLSR

$104 \quad 0.12 \% \quad 15.6 \%$ SNSLISIK

$104 \quad 0.12 \% \quad 15.6 \%$ SNSLISIKR

$8 \quad 0.01 \% \quad 19.0 \%$ FHPNGSTLASAGFDR $0.01 \% \quad 19.0 \%$ TVAVWDSETGER

$0.01 \% \quad 19.0 \%$ LKGHTSFVNSCYPAR $0.01 \% \quad 19.0 \%$ GPQLVCTGSDDGTVK $0.01 \% \quad 19.0 \%$ IFQGNVHNFEK

$19 \quad 0.02 \% \quad 32.1 \%$ LVGATATSSPPPK

$19 \quad 0.02 \% \quad 32.1 \%$ LLQQSGAQQFR
$99.7 \% \quad 28.5$

$99.7 \% \quad 61.8$

$99.7 \% \quad 32.7$

$95.8 \% \quad 16.9$

$99.5 \% \quad 28.0$

$95.0 \% \quad 19.0$

$96.6 \% \quad 16.6$

$99.7 \% \quad 53.2$

$99.7 \% \quad 48.7$

$99.2 \% \quad 20.2$

$99.7 \% \quad 45.3$

$99.7 \% \quad 87.3$

$99.2 \% \quad 19.7$

$99.7 \% \quad 51.2$

$99.7 \% \quad 53.3$

$98.1 \% 21.6$

$99.7 \% \quad 35.4$

$99.7 \% \quad 53.9$

$94.9 \% \quad 14.5$

$99.7 \% \quad 56.7$

$99.4 \% 25.1$

$99.7 \% \quad 32.0$

$94.9 \% 13.6$

$99.2 \% \quad 20.2$

$99.7 \% \quad 45.6$

$99.7 \% \quad 48.7$

$99.7 \% \quad 53.7$
197

1978.96

1238.58

1352.78

1223.67

1490.79

1200.63

1185.58

1157.68

1029.58

1117.53

1943.97

1208.59

1297.65

1437.75

1234.57

1413.71

1198.67

934.54

1048.53

1894.88

1008.50

1221.62

1043.54

1622.90

989.48

941.57

1405.82

1193.63

1020.51

1503.86

1375.77

1189.68

1587.89

1141.71

1774.94

1082.48

1935.91

1265.73

861.50

1017.61

1576.75

1349.63

1736.85

1533.72

1332.67

1225.68

1275.68 $\begin{array}{cc}72 & 488 \\ 79 & 488 \\ 4 & 26 \\ 98 & 207 \\ 71 & 284 \\ 5 & 25 \\ 75 & 284 \\ 85 & 294 \\ 86 & 294 \\ 70 & 479 \\ 91 & 509 \\ 10 & 519 \\ 46 & 557 \\ 46 & 558 \\ 38 & 647 \\ 01 & 711 \\ 19 & 728 \\ 46 & 753 \\ 54 & 763 \\ 54 & 770 \\ 30 & 838 \\ 76 & 986 \\ 17 & 1025 \\ 44 & 1058 \\ 50 & 1058 \\ 34 & 1141 \\ 84 & 1195 \\ 57 & 1366 \\ 67 & 1375 \\ 04 & 1417 \\ 05 & 1417 \\ 87 & 1498 \\ 39 & 1552 \\ 57 & 1566 \\ 71 & 1586 \\ 02 & 1710 \\ 64 & 1779 \\ 91 & 1901 \\ 73 & 2080 \\ 73 & 2081 \\ 4 & 88 \\ 32 & 143 \\ 47 & 161 \\ 63 & 177 \\ 76 & 286 \\ 8 & 20 \\ 7 & 67 \\ & \end{array}$

Page 162 of Table S-1-6 
UAP56-interacting factor GN=FYTTD1 UIF_HUMAN $35.82 \quad 100.0 \%$ UAP56-interacting factor GN=FYTTD1 UIF_HUMAN $35.82 \quad 100.0 \%$ UAP56-interacting factor GN=FYTTD1 UAP56-interacting factor GN=FYTTD1 UAP56-interacting factor GN=FYTTD1 UIF_HUMAN $35.82 \quad 100.0 \%$ UIF HUMAN $35.82 \quad 100.0 \%$ UIF_HUMAN $35.82 \quad 100.0 \%$ UIF_HUMAN $35.82 \quad 100.0 \%$ Ubiquitin carboxyl-terminal hydrolase 24 GN=USP24 UBP24_HUMAN $294.37 \quad 100.0 \%$ Ubiquitin carboxyl-terminal hydrolase 24 GN=USP24 UBP24_HUMAN $294.37 \quad 100.0 \%$ Ubiquitin carboxyl-terminal hydrolase 24 GN=USP24 UBP24_HUMAN $294.37 \quad 100.0 \%$ Ubiquitin thioesterase OTUB1 GN=OTUB1 OTUB1_HUMAN $31.28 \quad 100.0 \%$ Ubiquitin thioesterase OTUB1 GN=OTUB1 OTUB1_HUMAN $31.28 \quad 100.0 \%$ Ubiquitin-40S ribosomal protein S27a GN=RPS27A RS27A_HUMAN $17.97 \quad 100.0 \%$ Ubiquitin-40S ribosomal protein S27a GN=RPS27A RS27A_HUMAN $17.97 \quad 100.0 \%$ Ubiquitin-40S ribosomal protein S27a GN=RPS27A RS27A_HUMAN $17.97 \quad 100.0 \%$ Ubiquitin-40S ribosomal protein S27a GN=RPS27A RS27A_HUMAN $17.97 \quad 100.0 \%$ Ubiquitin-40S ribosomal protein S27a GN=RPS27A RS27A_HUMAN $17.97 \quad 100.0 \%$ Ubiquitin-40S ribosomal protein S27a GN=RPS27A RS27A HUMAN $17.97 \quad 100.0 \%$ Ubiquitin-40S ribosomal protein S27a GN=RPS27A RS27A_HUMAN $17.97 \quad 100.0 \%$ Ubiquitin-40S ribosomal protein S27a GN=RPS27A RS27A_HUMAN $17.97 \quad 100.0 \%$ Ubiquitin-40S ribosomal protein S27a GN=RPS27A RS27A_HUMAN $17.97 \quad 100.0 \%$ Ubiquitin-associated domain-containing protein 2 GN=UBAC2 UBAC2_HUMAN $38.97 \quad 100.0 \%$ Ubiquitin-associated domain-containing protein $2 \mathrm{GN}=\mathrm{UBAC} 2$ UBAC2_HUMAN $38.97 \quad 100.0 \%$ Ubiquitin-associated domain-containing protein 2 GN=UBAC2 UBAC2_HUMAN $38.97 \quad 100.0 \%$ Ubiquitin-conjugating enzyme E2 S GN=UBE2S UBE2S_HUMAN $23.85 \quad 100.0 \%$ Ubiquitin-conjugating enzyme E2 S GN=UBE2S UBE2S_HUMAN $23.85 \quad 100.0 \%$ Ubiquitin-like modifier-activating enzyme $1 \mathrm{GN}=$ UBA1 UBA1_HUMAN $117.85 \quad 100.0 \%$ Ubiquitin-like modifier-activating enzyme 1 GN=UBA1 UBA1_HUMAN $117.85 \quad 100.0 \%$ Ubiquitin-protein ligase E3A GN=UBE3A UBE3A_HUMAN $100.69 \quad 100.0 \%$ Ubiquitin-protein ligase E3A GN=UBE3A UBE3A_HUMAN $100.69 \quad 100.0 \%$ Ubiquitin-protein ligase E3A GN=UBE3A UBE3A_HUMAN $100.69100 .0 \%$ Uncharacterized protein C19orf52 GN=C19orf52 CS052_HUMAN $29.23 \quad 100.0 \%$ Uncharacterized protein C19orf52 GN=C19orf52 CS052_HUMAN $29.23 \quad 100.0 \%$ Uncharacterized protein $\mathrm{C} 3$ orf $17 \mathrm{GN}=\mathrm{C} 3$ orf17 $\mathrm{CC} 017$ HUMAN $64.55 \quad 100.0 \%$ Uncharacterized protein $\mathrm{C} 3$ orf $17 \mathrm{GN}=\mathrm{C} 3$ orf17 $\quad$ CC017_HUMAN $64.55 \quad 100.0 \%$ Unconventional myosin-Ib GN=MYO1B MYO1B_HUMAN $131.99 \quad 100.0 \%$ Unconventional myosin-Ib GN=MYO1B MYO1B_HUMAN $131.99 \quad 100.0 \%$ Unconventional myosin-Ib GN=MYO1B MYO1B_HUMAN $131.99 \quad 100.0 \%$ Unconventional myosin-Ic GN=MYO1C $\quad$ MYO1C_HUMAN $121.68 \quad 100.0 \%$ Unconventional myosin-Ic GN=MYO1C MYO1C_HUMAN $121.68 \quad 100.0 \%$ Unconventional myosin-Id GN=MYO1D MYO1D_HUMAN $116.21 \quad 100.0 \%$ Unconventional myosin-Id GN=MYO1D MYO1D_HUMAN $116.21 \quad 100.0 \%$ Unconventional myosin-Id GN=MYO1D MYO1D_HUMAN $116.21 \quad 100.0 \%$ Unconventional myosin-Va GN=MYO5A MYO5A_HUMAN $215.41 \quad 100.0 \%$ Unconventional myosin-Va GN=MYO5A MYO5A_HUMAN $215.41 \quad 100.0 \%$ Unconventional myosin-Va GN=MYO5A MYO5A_HUMAN $215.41 \quad 100.0 \%$ Unconventional myosin-Va GN=MYO5A MYO5A_HUMAN $215.41 \quad 100.0 \%$ Unconventional myosin-Va GN=MYO5A MYO5A_HUMAN $215.41 \quad 100.0 \%$
$19 \quad 0.02 \% \quad 32.1 \%$ KNNIPANFTR $99.7 \% \quad 37.0$

$108 \quad 0.12 \% \quad 42.3 \%$ TLTGKTITLEVEPSDTIENVK

$108 \quad 0.12 \% \quad 42.3 \%$ TITLEVEPSDTIENVK

$108 \quad 0.12 \% \quad 42.3 \%$ TITLEVEPSDTIEN

$108 \quad 0.12 \% \quad 42.3 \%$ LIFAGKQLEDGR

$108 \quad 0.12 \% \quad 42.3 \%$ QLEDGRTLSDYNIQK

$108 \quad 0.12 \% \quad 42.3 \%$ TLSDYNIQK

$108 \quad 0.12 \% \quad 42.3 \%$ TLSDYNIQKESTLHLVLR

$108 \quad 0.12 \% \quad 42.3 \%$ ESTLHLVLR

$0.00 \% \quad 13.4 \%$ MFTSTGSSGLYK

$99.7 \% \quad 81.1$

25.0

81

1

(2)

$0.00 \% \quad 13.4 \%$ QSEPAAPPLEVSEEQVAR

$0.00 \% \quad 13.4 \%$ ASNNDLNVATNFLLQH

$0.00 \% \quad 10.8 \%$ DWTAELGIR

$0.00 \% \quad 10.8 \%$ LLTEIHGGAGGPSGR

$0.01 \% \quad 2.2 \% \quad$ LQTSSVLVSGLR

$0.01 \% \quad 2.2 \% \quad$ LKSDTAAAAVR

$0.00 \% \quad 4.3 \% \quad$ IGDSSQGDNNLQK

$0.00 \% \quad 4.3 \% \quad$ NLVNDDDAIVAASK

$0.00 \% \quad 4.3 \%$ VDPLETELGVK

$\begin{array}{lll}0.00 \% & 6.5 \% & \text { ESEAFVQR }\end{array}$

$0.00 \% \quad 6.5 \% \quad$ VLDVGFVGR

$0.00 \% \quad 5.1 \% \quad$ INVQNNVDLGQPVK

$0.00 \% \quad 5.1 \% \quad$ QLLNSGVSMPVIQTK

$0.00 \% \quad 3.2 \%$ LGNIEFKPESR

$0.00 \% \quad 3.2 \% \quad$ VSTTLNVAQAYYAR

$0.00 \% \quad 3.2 \% \quad$ NLQTKNPNYIR

$0.00 \% \quad 1.6 \%$ YLGLLENLR

$0.00 \% \quad 1.6 \% \quad$ KYEAFLQR

$0.01 \% \quad 3.1 \%$ SNCVLEAFGNAK

$0.01 \% \quad 3.1 \%$ SYIHEVAR

$0.01 \% \quad 3.1 \%$ SIPASDLPQVR

$0.01 \% \quad 4.3 \%$ NQSIIVSGESGAGK

$0.01 \% \quad 4.3 \% \quad$ LGNADNFNYTK

$0.01 \% \quad 4.3 \%$ ISAAGFPSR

$0.01 \% \quad 4.3 \% \quad$ AGQVAYLEK

$0.01 \% \quad 4.3 \%$ SAPEVTAPGAPAYR

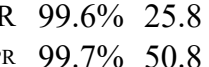

$96.2 \% \quad 16.6$

$99.7 \% \quad 46.5$

$99.7 \% \quad 34.6$

$99.7 \% \quad 45.1$

$99.7 \% \quad 32.3$

$99.7 \% 54.6$

$99.7 \% \quad 55.4$

$99.7 \% \quad 62.3$

$99.7 \% \quad 57.7$

$\begin{array}{lll}99.7 \% & 34.0\end{array}$

$99.7 \% \quad 51.7$

$99.1 \% \quad 26.4$

$98.9 \% \quad 20.0$

$\begin{array}{lll}99.7 \% & 49.8\end{array}$

$\begin{array}{lll}99.7 \% & 38.6\end{array}$

$99.7 \% \quad 57.6$

$99.7 \% \quad 29.6$

$99.7 \% 55.4$

$99.7 \% \quad 33.3$

$99.7 \% \quad 47.1$

$99.7 \% \quad 44.5$

$99.7 \% \quad 38.0$

$99.7 \% \quad 48.1$

$99.7 \% \quad 53.6$

$97.2 \% 16.7$

$98.1 \% \quad 26.4$

$99.7 \% \quad 51.5$

$99.7 \% \quad 45.6$

$97.7 \% \quad 16.8$

$99.4 \% \quad 24.5$

$99.7 \% \quad 37.4$

$96.2 \% \quad 15.3$

$97.4 \% 16.1$

$98.0 \% \quad 23.5$

$99.7 \% \quad 59.0$

$95.2 \% \quad 14.9$

$99.5 \% \quad 23.8$

$99.7 \% \quad 33.4$

$99.7 \% \quad 50.2$

$99.6 \% \quad 28.8$

$99.7 \% \quad 46.0$

$99.6 \% 27.6$
117 1884.01

2040.11

2911.49

963.55

1373.74

1167.62

1264.71

943.58

1723.93

1050.59

2288.22

1787.93

1987.06

1523.78

1346.74

1779.89

1081.55

2130.16

1067.62

1278.60

1936.96

1770.88

1060.54

1421.75

1259.73

1102.62

1375.65

1444.73

1199.65

965.47

961.55

1537.83

1630.88

1289.68

1556.81

1360.73

1090.63

1054.57

1309.62

974.51

1182.65

1346.69

1256.59

905.48

978.53

1386.70

\begin{tabular}{cc}
166 & 175 \\
199 & 215 \\
199 & 216 \\
222 & 249 \\
253 & 261 \\
273 & 285 \\
153 & 162 \\
174 & 1184 \\
2236 & 2244 \\
37 & 51 \\
177 & 185 \\
7 & 27 \\
12 & 27 \\
12 & 29 \\
30 & 42 \\
43 & 54 \\
49 & 63 \\
55 & 63 \\
55 & 72 \\
64 & 72 \\
1 & 12 \\
295 & 312 \\
329 & 344 \\
102 & 110 \\
150 & 164 \\
70 & 81 \\
527 & 537 \\
214 & 226 \\
360 & 373 \\
425 & 435 \\
105 & 112 \\
163 & 171 \\
285 & 298 \\
505 & 519 \\
281 & 291 \\
336 & 349 \\
584 & 594 \\
648 & 656 \\
667 & 674 \\
141 & 152 \\
738 & 745 \\
791 & 801 \\
156 & 169 \\
279 & 289 \\
692 & 700 \\
& 760 \\
\hline
\end{tabular}

Page 163 of Table S-1-6 
Unconventional myosin-Va GN=MYO5A MYO5A_HUMAN $215.41 \quad 100.0 \%$ Unconventional myosin-Va GN=MYO5A MYO5A_HUMAN $215.41 \quad 100.0 \%$ Unconventional myosin-Vb GN=MYO5B MYO5B_HUMAN $213.68 \quad 100.0 \%$ Unconventional myosin-Vb GN=MYO5B MYO5B_HUMAN $213.68 \quad 100.0 \%$ Unconventional myosin-Vb GN=MYO5B MYO5B_HUMAN $213.68 \quad 100.0 \%$ Unconventional myosin- $\mathrm{Vb}$ GN=MYO5B MYO5B_HUMAN $213.68 \quad 100.0 \%$ Unhealthy ribosome biogenesis protein 2 homolog GN=URB2 URB2_HUMAN $170.55100 .0 \%$ Unhealthy ribosome biogenesis protein 2 homolog GN=URB2 URB2_HUMAN $170.55 \quad 100.0 \%$ Unhealthy ribosome biogenesis protein 2 homolog GN=URB2 URB2 HUMAN $170.55100 .0 \%$ Unhealthy ribosome biogenesis protein 2 homolog GN=URB2 URB2_HUMAN $170.55 \quad 100.0 \%$ UPF0488 protein C8orf33 GN=C8orf33 CH033_HUMAN $24.99 \quad 100.0 \%$ UPF0488 protein $\mathrm{C} 8$ orf33 $\mathrm{GN}=\mathrm{C} 8$ orf33 3 CH033 HUMAN $24.99 \quad 100.0^{\circ}$ UPF0488 protein C8orf33 GN=C8orf33 CH033_HUMAN $24.99 \quad 100.0 \%$ UPF0488 protein C8orf33 GN=C8orf33 CH033_HUMAN $24.99 \quad 100.0 \%$ UPF0488 protein C8orf33 GN=C8orf33 CH033_HUMAN $24.99 \quad 100.0 \%$ UPF0488 protein C8orf33 GN=C8orf33 CH033_HUMAN $24.99 \quad 100.0 \%$ Uridine 5 '-monophosphate synthase GN=UMPS UMPS HUMAN $52.22 \quad 100.0 \%$ Uridine 5'-monophosphate synthase GN=UMPS UMPS_HUMAN $52.22 \quad 100.0 \%$ Uridine 5'-monophosphate synthase GN=UMPS UMPS_HUMAN $52.22 \quad 100.0 \%$ Uridine-cytidine kinase $2 \mathrm{GN}=\mathrm{UCK} 2$ Uridine-cytidine kinase $2 \mathrm{GN}=\mathrm{UCK} 2$ Uridine-cytidine kinase $2 \mathrm{GN}=\mathrm{UCK} 2$ Uridine-cytidine kinase $2 \mathrm{GN}=\mathrm{UCK} 2$ Vacuolar protein sorting-associated protein $13 \mathrm{C}$ GN=VPS13C VP13C_HUMAN $422.40 \quad 100.0 \%$ Vacuolar protein sorting-associated protein $13 \mathrm{C}$ GN=VPS13C VP13C_HUMAN $422.40 \quad 100.0 \%$ Vacuolar protein sorting-associated protein 26A GN=VPS26A VP26A_HUMAN $38.17 \quad 100.0 \%$ Vacuolar protein sorting-associated protein 26A GN=VPS26A VP26A_HUMAN $38.17 \quad 100.0 \%$ Vacuolar protein sorting-associated protein 26A GN=VPS26A VP26A_HUMAN $38.17 \quad 100.0 \%$ Vacuolar protein sorting-associated protein 26A GN=VPS26A VP26A_HUMAN $38.17 \quad 100.0 \%$ Vacuolar protein sorting-associated protein 26B GN=VPS26B VP26B HUMAN $39.16 \quad 100.0 \%$ Vacuolar protein sorting-associated protein 26B GN=VPS26B VP26B_HUMAN $39.16 \quad 100.0 \%$ Very-long-chain (3R)-3-hydroxyacyl-CoA dehydratase 3 GN=HACD3 HACD3_HUMAN $43.16 \quad 100.0 \%$ Very-long-chain (3R)-3-hydroxyacyl-CoA dehydratase 3 GN=HACD3 HACD3_HUMAN $43.16 \quad 100.0 \%$ Very-long-chain (3R)-3-hydroxyacyl-CoA dehydratase 3 GN=HACD3 HACD3_HUMAN $43.16 \quad 100.0 \%$ Very-long-chain (3R)-3-hydroxyacyl-CoA dehydratase $3 \mathrm{GN}=\mathrm{HACD} 3$ HACD3_HUMAN $43.16100 .0 \%$ Very-long-chain (3R)-3-hydroxyacyl-CoA dehydratase 3 GN=HACD3 HACD3_HUMAN $43.16100 .0 \%$ Very-long-chain (3R)-3-hydroxyacyl-CoA dehydratase $3 \mathrm{GN}=\mathrm{HACD} 3$ HACD3_HUMAN $43.16 \quad 100.0 \%$ Very-long-chain 3-oxoacyl-CoA reductase GN=HSD17B12 DHB12_HUMAN $34.33 \quad 100.0 \%$ Very-long-chain 3-oxoacyl-CoA reductase GN=HSD17B12 DHB12_HUMAN $34.33 \quad 100.0 \%$ Very-long-chain 3-oxoacyl-CoA reductase GN=HSD17B12 DHB12_HUMAN $34.33 \quad 100.0 \%$ Very-long-chain 3-oxoacyl-CoA reductase GN=HSD17B12 DHB12_HUMAN $34.33 \quad 100.0 \%$ Very-long-chain enoyl-CoA reductase GN=TECR TECR_HUMAN $36.04 \quad 100.0 \%$ Very-long-chain enoyl-CoA reductase GN=TECR TECR HUMAN $36.04 \quad 100.0 \%$ Very-long-chain enoyl-CoA reductase GN=TECR TECR_HUMAN $36.04 \quad 100.0 \%$ Vesicle-associated membrane protein-associated protein $\mathrm{B} / \mathrm{C}$ GN=VAPB VAPB_HUMAN $27.23 \quad 100.0 \%$ $\begin{array}{llll}\text { Vesicle-fusing ATPase GN=NSF } & \text { NSF_HUMAN } & 82.60 & 100.0 \%\end{array}$
$0.01 \% \quad 4.3 \% \quad$ IEASLQHEITR $0.01 \% \quad 4.3 \%$ HADYLNDDQKVR $0.01 \% \quad 2.2 \%$ NQSIIVSGESGAGK $0.01 \% \quad 2.2 \% \quad$ YIQIGFDKR $0.01 \% \quad 2.2 \%$ AGQVAYLEK $0.01 \% \quad 2.2 \% \quad$ VRELEQER $0.01 \% \quad 3.5 \%$ VAEFSLSGSQR $0.01 \% \quad 3.5 \%$ SLDSSTPLPIVR $0.01 \% \quad 3.5 \%$ GEIAQNLLSLVK $0.01 \% \quad 3.5 \%$ ITAFLSSSKPYTEAASSK $0.01 \% \quad 21.8 \%$ LPGPVSSAR $0.01 \% \quad 21.8 \%$ AHPLGDEGGTASK $0.01 \% \quad 21.8 \%$ AHPLGDEGGTASKK $0.01 \% \quad 21.8 \%$ QKEQAIGAIR

$0.01 \% \quad 21.8 \%$ AAAYSAQVQPVDGATR $0.01 \% \quad 21.8 \%$ AAAYSAQVQPVDGATRK $0.00 \% \quad 6.7 \% \quad$ SGLSSPIYIDLR $0.00 \% \quad 6.7 \%$ GLQEVGLPLHR $0.00 \% \quad 6.7 \%$ AAWEAYLSR $0.01 \% \quad 16.1 \%$ IVQLLGQNEVDYR $0.01 \% \quad 16.1 \%$ QVVILSQDSFYR $0.01 \% \quad 16.1 \%$ TLKEITEGK $0.01 \% \quad 16.1 \%$ YADVIIPR $0.00 \% \quad 0.7 \%$ ESLSAATAQAAER $0.00 \% \quad 0.7 \% \quad$ EALSTATVQAAER $0.01 \% \quad 16.2 \%$ VNLAFKQPGK $0.01 \% \quad 16.2 \%$ ELALPGELTQSR $0.01 \% \quad 16.2 \%$ EITGIGPSTTTETETIAK $0.01 \% \quad 16.2 \%$ LFLAGYDPTPTMR $0.00 \% \quad 6.9 \%$ SMSHQAAIASQR $0.00 \% \quad 6.9 \%$ FEGTTSLGEVR $0.02 \% \quad 14.6 \%$ VELSDVQNPAISITENVLHFK $0.02 \% \quad 14.6 \%$ QVNITVQK $0.02 \% \quad 14.6 \%$ QVNITVQKK $0.02 \% \quad 14.6 \%$ KVSQWWER $0.02 \% \quad 14.6 \%$ LRLESEGSPETLTNLR $0.02 \% \quad 14.6 \%$ LESEGSPETLTNLR $0.01 \% \quad 15.1 \%$ ISYSLFTALR $0.01 \% \quad 15.1 \%$ MININILSVCK $0.01 \% \quad 15.1 \%$ MTQLVLPGMVER $0.01 \% \quad 15.1 \%$ KPTLDKPSPETFVK $0.02 \% \quad 10.1 \%$ SLKDEDVLQK $0.02 \% \quad 10.1 \%$ LPVGTTATLYFR $0.02 \% \quad 10.1 \%$ LLETLFVHR $0.00 \% \quad 8.2 \%$ GPFTDVVTTNLK $0.00 \% \quad 8.2 \%$ TETPIVSK $0.02 \% \quad 7.7 \%$ GILLYGPPGCGK $\begin{array}{llll}96.4 \% & 23.1 & 25.0 & 19.6\end{array}$ $\begin{array}{llll}97.7 \% & 21.8 & 25.0 & 21.8\end{array}$ $\begin{array}{llll}99.7 \% & 33.4 & 25.0 & 27.1\end{array}$ $\begin{array}{llll}98.6 \% & 22.3 & 25.0 & 22.3\end{array}$ $99.7 \% \quad 46.0 \quad 25.0 \quad 32.8$ $\begin{array}{llll}94.6 \% & 7.8 & 25.1 & (8.2)\end{array}$ $99.7 \% \quad 94.2 \quad 25.0 \quad 83.2$ $\begin{array}{lllll}99.7 \% & 46.9 & 25.0 & 46.9 & 2\end{array}$ $\begin{array}{llll}99.7 \% & 45.9 & 25.0 & 45.9\end{array}$ $\begin{array}{llll}99.7 \% & 39.3 & 25.0 & 39.2\end{array}$ $\begin{array}{lllll}99.7 \% & 42.5 & 25.0 & 21.3 & 2\end{array}$ $99.7 \% \quad 41.7 \quad 25.0 \quad 38.5$ $\begin{array}{llll}99.7 \% & 28.4 & 25.0 & 28.4\end{array}$ $\begin{array}{llll}99.7 \% & 43.4 & 25.0 & 31.4\end{array}$ $\begin{array}{llll}99.7 \% & 69.9 & 25.0 & 68.5\end{array}$ $\begin{array}{llll}99.7 \% & 53.4 & 25.0 & 49.4\end{array}$ $\begin{array}{llll}99.7 \% & 44.5 & 25.0 & 27.9\end{array}$ $\begin{array}{llll}96.0 \% & 17.3 & 25.0 & 13.9\end{array}$ $\begin{array}{llll}99.5 \% & 26.3 & 25.0 & 22.1\end{array}$ $\begin{array}{llll}99.7 \% & 61.1 & 25.0 & 61.1\end{array}$ $\begin{array}{llll}99.7 \% & 51.6 & 25.0 & 49.9\end{array}$ $\begin{array}{llll}95.3 \% & 16.3 & 25.0 & 12.6\end{array}$ $\begin{array}{llll}99.0 \% & 46.5 & 25.0 & 41.9\end{array}$ $\begin{array}{llll}99.7 \% & 37.2 & 25.0 & 37.2\end{array}$ $99.7 \% \quad 41.4 \quad 25.0 \quad 35.5$ $\begin{array}{llll}97.9 \% & 16.6 & 25.0 & 16.6\end{array}$ $99.7 \% \quad 60.1 \quad 25.0 \quad 57.5$ $\begin{array}{llll}99.7 \% & 47.4 & 25.0 & 47.4\end{array}$ $\begin{array}{lllll}99.7 \% & 49.0 & 25.0 & 46.7 & 2\end{array}$ $\begin{array}{llll}95.8 \% & 18.8 & 25.0 & 13.2\end{array}$ $\begin{array}{llll}99.7 \% & 57.7 & 25.0 & 48.4\end{array}$ $\begin{array}{llll}99.2 \% & 19.9 & 25.0 & 19.9\end{array}$ $\begin{array}{llll}99.0 \% & 46.7 & 25.0 & 33.1\end{array}$ $\begin{array}{llll}96.2 \% & 16.4 & 25.0 & 14.4\end{array}$ $\begin{array}{llll}95.8 \% & 25.6 & 25.0 & 5.4\end{array}$ $\begin{array}{llll}99.4 \% & 23.1 & 25.0 & 19.0\end{array}$ $99.7 \% \quad 59.7 \quad 25.0 \quad 51.1$ $99.7 \% \quad 61.1 \quad 25.0 \quad 58.0$ $\begin{array}{llll}99.7 \% & 44.3 & 25.0 & 44.3\end{array}$ $99.6 \% \quad 30.0 \quad 25.0 \quad 24.6$ $\begin{array}{llll}99.6 \% & 25.0 & 25.0 & 25.0\end{array}$ $99.7 \% \quad 53.0 \quad 25.0 \quad 45.1$ $\begin{array}{llll}99.7 \% & 40.9 & 25.0 & 40.9\end{array}$ $\begin{array}{llll}99.7 \% & 55.4 & 25.0 & 38.0\end{array}$ $\begin{array}{llll}99.7 \% & 36.4 & 25.0 & 31.4\end{array}$ $\begin{array}{llll}99.0 \% & 27.6 & 25.0 & 18.5\end{array}$ $99.7 \% \quad 35.2 \quad 25.0 \quad 24.6$

$\begin{array}{ccc}1296.69 & 1397 & 1407 \\ 1473.71 & 1519 & 1530 \\ 1346.69 & 156 & 169 \\ 1139.62 & 223 & 231 \\ 978.53 & 750 & 758 \\ 1058.56 & 1153 & 1160 \\ 1180.60 & 107 & 117 \\ 1284.72 & 555 & 566 \\ 1284.75 & 868 & 879 \\ 1887.97 & 1026 & 1043 \\ 883.50 & 28 & 36 \\ 1239.60 & 57 & 69 \\ 1367.69 & 57 & 70 \\ 1113.64 & 134 & 143 \\ 1604.80 & 183 & 198 \\ 1732.90 & 183 & 199 \\ 1320.72 & 30 & 41 \\ 1218.70 & 353 & 363 \\ 1066.53 & 469 & 477 \\ 1546.82 & 40 & 52 \\ 1454.76 & 55 & 66 \\ 1018.58 & 97 & 105 \\ 946.54 & 203 & 210 \\ 1304.64 & 1212 & 1224 \\ 1346.69 & 1727 & 1739 \\ 1101.64 & 52 & 61 \\ 1313.71 & 94 & 105 \\ 1848.94 & 215 & 232 \\ 1497.74 & 250 & 262 \\ 1302.62 & 302 & 313 \\ 1195.60 & 314 & 324 \\ 2353.24 & 23 & 43 \\ 929.54 & 77 & 84 \\ 1057.64 & 77 & 85 \\ 1118.57 & 85 & 92 \\ 1814.96 & 131 & 146 \\ 1545.78 & 133 & 146 \\ 1170.65 & 26 & 35 \\ 1320.70 & 157 & 167 \\ 1405.72 & 168 & 179 \\ 1586.88 & 244 & 257 \\ 1174.63 & 58 & 67 \\ 1338.74 & 68 & 79 \\ 1127.66 & 142 & 150 \\ 1291.69 & 20 & 31 \\ 874.49 & 148 & 155 \\ 1231.65 & 255 & 266 \\ & & \end{array}$

Page 164 of Table S-1-6 
Vesicle-fusing ATPase GN=NSF Vesicle-fusing ATPase GN=NSF Vesicle-fusing ATPase $\mathrm{GN}=\mathrm{NSF}$ Vesicle-fusing ATPase $\mathrm{GN}=\mathrm{NSF}$ Vesicle-fusing ATPase $\mathrm{GN}=\mathrm{NSF}$ Vimentin GN=VIM

Vimentin GN=VIM

Vimentin $\mathrm{GN}=\mathrm{VIM}$

Vimentin GN=VIM

Vimentin GN=VIM

Vimentin $\mathrm{GN}=\mathrm{VIM}$

Vimentin GN=VIM

Vimentin GN=VIM

Vimentin GN=VIM

Vimentin GN=VIM

Vimentin GN=VIM

Vimentin $\mathrm{GN}=\mathrm{VIM}$

Vimentin GN=VIM

Vimentin GN=VIM

Vimentin GN=VIM

Vimentin GN=VIM

Vimentin GN=VIM

Vimentin GN=VIM

Vimentin GN=VIM

Vimentin GN=VIM

Vimentin GN=VIM

Vimentin GN=VIM

Vimentin GN=VIM

Vimentin GN=VIM

Vimentin GN=VIM

Vimentin GN=VIM

Vimentin GN=VIM

Vimentin GN=VIM

Vimentin GN=VIM

Vimentin GN=VIM

Vimentin GN=VIM

Vimentin GN=VIM

Vimentin $\mathrm{GN}=\mathrm{VIM}$

Vimentin GN=VIM

Vimentin GN=VIM
Vimentin GN=VIM

$\begin{array}{llllllll}\text { NSF HUMAN } 82.60 & 100.0 \% & 6 & 6 & 21 & 0.02 \% & 7.7 \% & \text { NFSGAELEGLVR }\end{array}$

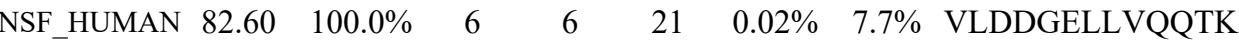
NSF_HUMAN $82.60 \quad 100.0 \%$ NSF HUMAN $82.60 \quad 100.0 \%$ NSF_HUMAN $82.60 \quad 100.0 \%$ VIME_HUMAN $53.65 \quad 100.0 \%$ VIME HUMAN $53.65 \quad 100.0 \% \quad 36$ VIME_HUMAN $53.65 \quad 100.0 \% \quad 36$ VIME HUMAN $53.65 \quad 100.0 \% \quad 36$ VIME_HUMAN $53.65 \quad 100.0 \% \quad 36$ VIME_HUMAN $53.65 \quad 100.0 \% \quad 36$ VIME HUMAN $53.65 \quad 100.0 \% \quad 36$ VIME_HUMAN $53.65 \quad 100.0 \% \quad 36$ VIME_HUMAN $53.65 \quad 100.0 \% \quad 36$ VIME HUMAN $53.65 \quad 100.0 \% \quad 36$ VIME_HUMAN $53.65 \quad 100.0 \% \quad 36$ VIME HUMAN $53.65 \quad 100.0 \% \quad 36$ VIME_HUMAN $53.65 \quad 100.0 \% \quad 36$ VIME_HUMAN $53.65 \quad 100.0 \% \quad 36$ VIME HUMAN $53.65 \quad 100.0 \% \quad 36$ VIME_HUMAN $53.65 \quad 100.0 \% \quad 36$ VIME HUMAN $53.65 \quad 100.0 \% \quad 36$ VIME HUMAN $53.65 \quad 100.0 \% \quad 36$ VIME_HUMAN $53.65 \quad 100.0 \% \quad 36$ VIME HUMAN $53.65 \quad 100.0 \% \quad 36$ VIME_HUMAN $53.65 \quad 100.0 \% \quad 36$ VIME_HUMAN $53.65 \quad 100.0 \% \quad 36$ VIME HUMAN $53.65 \quad 100.0 \% \quad 36$ VIME_HUMAN $53.65 \quad 100.0 \% \quad 36$ VIME HUMAN $53.65 \quad 100.0 \% \quad 36$ VIME_HUMAN $53.65 \quad 100.0 \% \quad 36$ VIME_HUMAN $53.65 \quad 100.0 \% \quad 36$ VIME HUMAN $53.65 \quad 100.0 \% \quad 36$ VIME_HUMAN $53.65 \quad 100.0 \% \quad 36$ VIME_HUMAN $53.65 \quad 100.0 \% \quad 36$ VIME HUMAN $53.65 \quad 100.0 \% \quad 36$ VIME_HUMAN $53.65 \quad 100.0 \% \quad 36$ VIME HUMAN $53.65 \quad 100.0 \% \quad 36$ VIME_HUMAN $53.65 \quad 100.0 \% \quad 36$ VIME_HUMAN $53.65 \quad 100.0 \% \quad 36$ VIME HUMAN $53.65 \quad 100.0 \% \quad 36$ $\begin{array}{llll} & \end{array}$ Voltage-dependent anion-selective channel protein $1 \mathrm{GN}=\mathrm{VDAC1}$ VDAC1_HUMAN $30.77 \quad 100.0 \%$ Voltage-dependent anion-selective channel protein $1 \mathrm{GN}=\mathrm{VDACl}$ VDAC1_HUMAN $30.77 \quad 100.0 \%$ Voltage-dependent anion-selective channel protein $1 \mathrm{GN}=\mathrm{VDACl}$ VDAC1 HUMAN $30.77 \quad 100.0 \%$ Voltage-dependent anion-selective channel protein $1 \mathrm{GN}=\mathrm{VDACl}$ VDAC1_HUMAN $30.77 \quad 100.0 \%$ Voltage-dependent anion-selective channel protein 2 GN=VDAC2 VDAC2_HUMAN $31.57 \quad 100.0 \%$

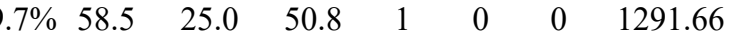

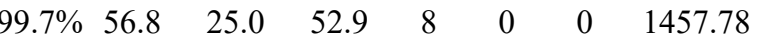

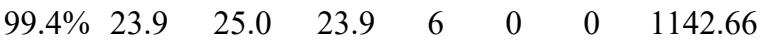

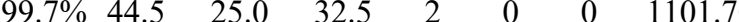

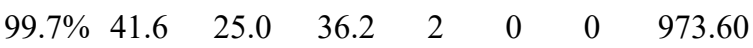
$\begin{array}{llllllll}99.3 \% & 25.0 & 25.0 & 25.0 & 0 & 1 & 0 & 1650.81\end{array}$

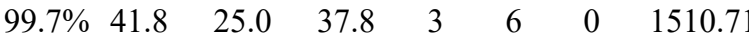
$\begin{array}{llllllll}99.0 \% & 50.2 & 25.0 & 45.4 & 7 & 0 & 0 & 914.46\end{array}$

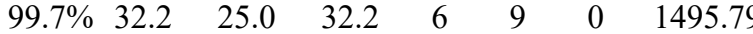

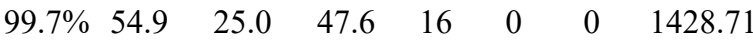
$\begin{array}{llllllll}99.5 \% & 28.7 & 25.0 & 15.6 & 3 & 0 & 0 & 970.58\end{array}$ 2126.07 2497.26

1125.61

1169.71

1539.91

1254.57

1060.53

1287.67

1688.83

1088.53

1533.85

1393.71

1023.51

1309.6

1524.73

1093.53

1776.86

1490.75

2377.17

1527.83

1121.58

1295.67

1423.76

1060.56

2484.35

1570.90

1824.95

1173.72

2423.11

1836.80 854.48

1213.62

1414.63

2103.18

1030.61 $\begin{array}{llll}99.7 \% & 46.0 & 25.0 & 46.0\end{array}$

$11 \quad 0.01 \% \quad 21.6 \%$ YQIDPDACFSAK $\begin{array}{lll}99.7 \% & 54.3\end{array}$ $99.2 \% \quad 43.7$ $99.0 \% \quad 31.9$ $\begin{array}{cc}35 & 446 \\ 17 & 529 \\ 08 & 617 \\ 39 & 648 \\ 40 & 648 \\ 3 & 28 \\ 4 & 28 \\ 9 & 36 \\ 7 & 50 \\ 1 & 64 \\ 0 & 78 \\ 9 & 97 \\ 9 & 100 \\ 14 & 122 \\ 30 & 139 \\ 30 & 143 \\ 46 & 155 \\ 60 & 168 \\ 60 & 170 \\ 71 & 184 \\ 08 & 217 \\ 23 & 235 \\ 71 & 282 \\ 74 & 282 \\ 83 & 292 \\ 83 & 294 \\ 95 & 304 \\ 95 & 310 \\ 22 & 334 \\ 22 & 342 \\ 79 & 390 \\ 82 & 390 \\ 91 & 401 \\ 91 & 402 \\ 02 & 410 \\ 03 & 424 \\ 11 & 424 \\ 25 & 440 \\ 41 & 450 \\ 46 & 466 \\ 51 & 466 \\ 1 & 28 \\ 64 & 174 \\ 25 & 236 \\ 37 & 256 \\ 57 & 266 \\ & 39\end{array}$

Page 165 of Table S-1-6 

WD repeat-containing protein 5 GN=WDR5 WDR5_HUMAN $36.59 \quad 100.0 \%$ WD repeat-containing protein 5 GN=WDR5 WDR5_HUMAN $36.59 \quad 100.0 \%$ WD repeat-containing protein $5 \mathrm{GN}=$ WDR 5 WDR5 HUMAN $36.59 \quad 100.0 \%$ WD repeat-containing protein 5 GN=WDR5 WDR5_HUMAN $36.59 \quad 100.0 \%$ WD repeat-containing protein 5 GN=WDR5 WDR5_HUMAN $36.59 \quad 100.0 \%$ WD repeat-containing protein $82 \mathrm{GN}=$ WDR82 WDR82 HUMAN $35.08 \quad 100.0 \%$ WD repeat-containing protein $82 \mathrm{GN}=$ WDR82 WDR82_HUMAN $35.08 \quad 100.0 \%$ WD repeat-containing protein $82 \mathrm{GN}=$ WDR82 WDR82_HUMAN $35.08 \quad 100.0 \%$ WD repeat-containing protein $82 \mathrm{GN}=$ WDR82 WDR82_HUMAN $35.08 \quad 100.0 \%$ WD repeat-containing protein $82 \mathrm{GN}=$ WDR82 WDR82_HUMAN $35.08 \quad 100.0 \%$ WD repeat-containing protein $82 \mathrm{GN}=$ WDR82 WDR82 HUMAN $35.08 \quad 100.0 \%$ WD repeat-containing protein 82 GN=WDR82 WDR82_HUMAN $35.08 \quad 100.0 \%$

0

10

42

$2 \quad 0$

$99.7 \% \quad 33.1$ $99.7 \% \quad 48.9$ $\begin{array}{ll}99.7 \% & 48.9 \\ 99.7 \% & 62.8\end{array}$ $99.0 \% \quad 53.0$

$0.05 \% \quad 39.8 \%$ NNFAVGYR

$0.05 \% \quad 39.8 \%$ TGDFQLHTNVNDGTEFGGSIYQK

$99.7 \% \quad 47.3$ $99.7 \% \quad 53.0$

$\begin{array}{llll}0.05 \% & 39.8 \% & \text { VNNSSLIGVGYTQTLRPGVK } \quad 99.7 \% \quad 73.0\end{array}$

$0.05 \% \quad 39.8 \%$ LTLSALVDGK

$99.7 \% \quad 65.3$ $99.0 \% \quad 27.7$

$0.03 \% \quad 39.6 \%$ GYGFGMVK

$\begin{array}{ll}99.7 \% & 35.3\end{array}$

$30 \quad 0.03 \% \quad 39.6 \%$ YKVCNYGLTFTQK

$0.03 \% \quad 39.6 \%$ VCNYGLTFTQK

$0.03 \% \quad 39.6 \%$ LTLDTIFVPNTGK

$0.03 \% 39.6 \%$ LTLDTIFVPNTGKK

$0.03 \% 39.6 \%$ LSQNNFALGYK

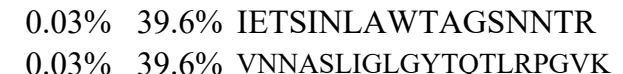

$\begin{array}{lll}0.03 \% & 39.6 \% & \text { LTLSALIDGK }\end{array}$

$0.01 \% \quad 2.6 \%$ EVEYIALSR

$0.01 \% \quad 2.6 \%$ VNAGTLAVLQR

$0.01 \% \quad 2.6 \%$ IGAVSAPIYNAHEK

$0.01 \% \quad 2.6 \%$ RGELEPQLGSPQQKPK

$0.00 \% \quad 2.9 \%$ GVNVSALSR

$0.00 \% \quad 2.9 \%$ TVISQSLSK

$0.01 \% \quad 12.0 \%$ AYLESFYK

$0.01 \% \quad 12.0 \%$ LYPEGLAQLAR

$0.01 \% \quad 12.0 \%$ NVADYYPEYK

$0.01 \% \quad 12.0 \%$ LLFEGAGSNPGDK

$0.00 \% \quad 4.6 \%$ VSIFFDYAR

$0.00 \% \quad 4.6 \%$ QLQSEQPQTAAAR

$0.01 \% \quad 8.3 \%$ VFASLPQVER

$0.01 \% \quad 8.3 \%$ YAPSGFYIASGDVSGK

$0.01 \% \quad 8.3 \%$ IAVVGEGREK

$0.01 \% \quad 8.3 \%$ LYSILGTTLKDEGK

$17 \quad 0.02 \% \quad 23.4 \%$ FTLAGHTK

$7 \quad 0.02 \% \quad 23.4 \%$ TLPAHSDPVSAVHFNR

$17 \quad 0.02 \% \quad 23.4 \%$ DGSLIVSSSYDGLCR

$17 \quad 0.02 \% \quad 23.4 \%$ TLIDDDNPPVSFVK

$17 \quad 0.02 \% \quad 23.4 \%$ YILAATLDNTLK

$17 \quad 0.02 \% \quad 23.4 \%$ YCIFANFSVTGGK

$0.02 \% \quad 27.2 \%$ MKLTDSVLR

$\begin{array}{llll}9.7 \% & 35.3 & 25.0 & 35.3\end{array}$

$\begin{array}{llll}9.7 \% & 25.0 & 34.9 \\ 99.7 \% & 52.5 & 25.0 & 52.5\end{array}$

$\begin{array}{lllll}99.7 \% & 53.3 & 25.0 & 52.2 & 2\end{array}$

$\begin{array}{llll}99.7 \% & 33.8 & 25.0 & 33.8\end{array}$

$\begin{array}{lllll}99.7 \% & 58.9 & 25.0 & 45.4 & 4\end{array}$

$\begin{array}{lllll}9.7 \% & 89.0 & 25.0 & 89.0 & 2 \\ 99.7 \% & 33.9 & 25.0 & 33.9 & 0\end{array}$

$\begin{array}{llll}99.2 \% & 43.7 & 25.0 & 0.0\end{array}$

$\begin{array}{lllll}99.7 \% & 36.5 & 25.0 & 28.8\end{array}$

$\begin{array}{lllll}99.7 \% & 66.8 & 25.0 & 58.5\end{array}$

$\begin{array}{llll}96.5 \% & 15.6 & 25.0 & 15.6\end{array}$

$\begin{array}{llll}99.0 \% & 19.1 & 25.0 & 19.1\end{array}$

$\begin{array}{llll}99.7 \% & 51.2 & 25.0 & 38.9\end{array}$

$\begin{array}{llll}99.7 \% & 31.8 & 25.0 & 31.4\end{array}$

$99.0 \% \quad 24.4 \quad 25.0 \quad 16.5$

$\begin{array}{lllll}99.7 \% & 50.3 & 25.0 & 44.3 & 2\end{array}$

$99.7 \% \quad 42.4 \quad 25.0 \quad 42.4$

$\begin{array}{lllll}97.7 \% & 29.6 & 25.0 & 23.9\end{array}$

$\begin{array}{lllll}99.7 \% & 43.1 & 25.0 & 40.7 & 2\end{array}$

$\begin{array}{llll}99.7 \% & 51.4 & 25.0 & 42.3\end{array}$

$\begin{array}{llll}99.7 \% & 28.9 & 25.0 & 26.7\end{array}$

$\begin{array}{llll}99.7 \% & 36.4 & 25.0 & 29.5\end{array}$

$\begin{array}{llll}99.7 \% & 32.7 & 25.0 & 21.2\end{array}$

$\begin{array}{llll}99.7 \% & 35.5 & 25.0 & 28.2\end{array}$

$99.0 \% \quad 29.6 \quad 25.0 \quad 16.4$

$\begin{array}{llll}99.7 \% & 31.8 & 25.0 & 29.1\end{array}$

$\begin{array}{llll}99.7 \% & 55.9 & 25.0 & 55.9\end{array}$

$99.7 \% \quad 45.5 \quad 25.0 \quad 45.5$

$\begin{array}{llll}99.7 \% & 51.6 & 25.0 & 51.6\end{array}$

$\begin{array}{lllll}99.7 \% & 41.4 & 25.0 & 41.4 & 2\end{array}$

$\begin{array}{llll}98.8 \% & 28.6 & 25.0 & 11.2\end{array}$

$0.02 \% \quad 27.2 \%$ YTHAANTVVYSSNK

$99.7 \% \quad 67.5$

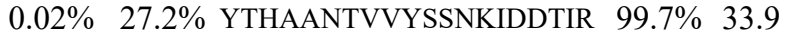

$\begin{array}{llll}99.7 \% & 33.9 & 25.0 & 33.6\end{array}$

$\begin{array}{llll}99.7 \% & 33.9 & 25.0 & 29.3\end{array}$

$\begin{array}{lllllll}0.02 \% & 27.2 \% & \text { VVALSMSPVDDTFISGSLDK } & 99.7 \% & 63.8 & 25.0 & 63.8\end{array}$ $0.02 \% \quad 27.2 \%$ SFDKGPFATFK 
WD repeat-containing protein $82 \mathrm{GN}=$ WDR82 WDR82_HUMAN $35.08 \quad 100.0 \%$ X-ray repair cross-complementing protein $5 \mathrm{GN}=\mathrm{XRCC} 5$ XRCC5_HUMAN $82.71 \quad 100.0 \%$ X-ray repair cross-complementing protein $5 \mathrm{GN}=\mathrm{XRCC} 5 \mathrm{XRCC5}$ _HUMAN $82.71 \quad 100.0 \%$ X-ray repair cross-complementing protein $5 \mathrm{GN}=\mathrm{XRCC} 5 \mathrm{XRCC} 5$ HUMAN $82.71 \quad 100.0 \%$ X-ray repair cross-complementing protein $5 \mathrm{GN}=\mathrm{XRCC} 5 \mathrm{XRCC} 5$ HUMAN $82.71 \quad 100.0 \%$ X-ray repair cross-complementing protein $5 \mathrm{GN}=\mathrm{XRCC} 5 \mathrm{XRCC5}$ _HUMAN $82.71 \quad 100.0 \%$ X-ray repair cross-complementing protein $5 \mathrm{GN}=\mathrm{XRCC} 5$ XRCC5_HUMAN $82.71 \quad 100.0 \%$ X-ray repair cross-complementing protein $5 \mathrm{GN}=\mathrm{XRCC} 5 \mathrm{XRCC5} 5$ HUMAN $82.71 \quad 100.0 \%$ X-ray repair cross-complementing protein $5 \mathrm{GN}=\mathrm{XRCC} 5 \mathrm{XRCC} 5$ HUMAN $82.71 \quad 100.0 \%$ X-ray repair cross-complementing protein $6 \mathrm{GN}=$ XRCC6 XRCC6_HUMAN $69.85 \quad 100.0 \%$ X-ray repair cross-complementing protein $6 \mathrm{GN}=$ XRCC6 XRCC6_HUMAN $69.85 \quad 100.0 \%$ X-ray repair cross-complementing protein $6 \mathrm{GN}=$ XRCC6 $\mathrm{XRCC}_{\text {H HUMAN }} 69.85 \quad 100.0^{\circ}$ X-ray repair cross-complementing protein $6 \mathrm{GN}=\mathrm{XRCC} 6$ XRCC6_HUMAN $69.85 \quad 100.0 \%$ X-ray repair cross-complementing protein $6 \mathrm{GN}=\mathrm{XRCC6}$ XRCC6_HUMAN $69.85 \quad 100.0 \%$ X-ray repair cross-complementing protein $6 \mathrm{GN}=\mathrm{XRCC} 6$ XRCC6_HUMAN $69.85 \quad 100.0 \%$ X-ray repair cross-complementing protein $6 \mathrm{GN}=\mathrm{XRCC} 6$ XRCC6_HUMAN $69.85 \quad 100.0 \%$ X-ray repair cross-complementing protein $6 \mathrm{GN}=\mathrm{XRCC} 6 \mathrm{XRCC} 6$ HUMAN $69.85 \quad 100.0 \%$ X-ray repair cross-complementing protein $6 \mathrm{GN}=\mathrm{XRCC} 6$ XRCC6_HUMAN $69.85 \quad 100.0 \%$ X-ray repair cross-complementing protein $6 \mathrm{GN}=\mathrm{XRCC} 6$ XRCC6_HUMAN $69.85 \quad 100.0 \%$ YTH domain-containing family protein $2 \mathrm{GN}=$ YTHDF2 YTHD2_HUMAN $62.33100 .0 \%$ YTH domain-containing family protein $2 \mathrm{GN}=$ YTHDF2 YTHD2_HUMAN $62.33 \quad 100.0 \%$ YTH domain-containing family protein $2 \mathrm{GN}=$ YTHDF2 YTHD2 HUMAN $62.33 \quad 100.0 \%$ YTH domain-containing family protein $2 \mathrm{GN}=$ YTHDF2 YTHD2_HUMAN $62.33 \quad 100.0 \%$ YTH domain-containing protein $1 \mathrm{GN}=$ YTHDC1 YTDC1_HUMAN $84.70 \quad 100.0 \%$ YTH domain-containing protein $1 \mathrm{GN}=$ YTHDC1 YTDC1_HUMAN $84.70 \quad 100.0 \%$ YTH domain-containing protein $1 \mathrm{GN}=$ YTHDC1 YTDC1_HUMAN $84.70 \quad 100.0 \%$ YTH domain-containing protein $1 \mathrm{GN}=$ YTHDC1 YTDC1_HUMAN $84.70 \quad 100.0 \%$ Zinc finger $\mathrm{CCCH}$ domain-containing protein $11 \mathrm{~A} \mathrm{GN}=\mathrm{ZC} 3 \mathrm{H} 11 \mathrm{~A}$ ZC11A_HUMAN $89.13 \quad 100.0 \%$ Zinc finger $\mathrm{CCCH}$ domain-containing protein $11 \mathrm{~A} \mathrm{GN}=\mathrm{ZC} 3 \mathrm{H} 11 \mathrm{~A}$ ZC11A_HUMAN $89.13 \quad 100.0 \%$ Zinc finger CCCH domain-containing protein $13 \mathrm{GN}=\mathrm{ZC} 3 \mathrm{H} 13$ ZC3HD HUMAN $196.64100 .0 \%$ Zinc finger CCCH domain-containing protein $13 \mathrm{GN}=\mathrm{ZC} 3 \mathrm{H} 13$ ZC3HD_HUMAN $196.64 \quad 100.0 \%$ Zinc finger CCCH domain-containing protein $18 \mathrm{GN}=\mathrm{ZC} 3 \mathrm{H} 18$ ZCH18_HUMAN $106.38 \quad 100.0 \%$ Zinc finger $\mathrm{CCCH}$ domain-containing protein $18 \mathrm{GN}=\mathrm{ZC} 3 \mathrm{H} 18 \mathrm{ZCH} 18$ HUMAN $106.38 \quad 100.0 \%$ Zinc finger CCCH domain-containing protein $18 \mathrm{GN}=\mathrm{ZC} 3 \mathrm{H} 18 \mathrm{ZCH} 18$ _HUMAN $106.38 \quad 100.0 \%$ Zinc finger $\mathrm{CCCH}$ domain-containing protein $4 \mathrm{GN}=\mathrm{ZC} 3 \mathrm{H} 4 \mathrm{ZC} 3 \mathrm{H} 4$ _HUMAN $140.26 \quad 100.0 \%$ Zinc finger $\mathrm{CCCH}$ domain-containing protein $4 \mathrm{GN}=\mathrm{ZC} 3 \mathrm{H} 4 \quad \mathrm{ZC} 3 \mathrm{H} 4 \_\mathrm{HUMAN} \quad 140.26 \quad 100.0 \%$ Zinc finger CCCH-type antiviral protein $1 \mathrm{GN}=\mathrm{ZC} 3 \mathrm{HAV} 1 \mathrm{ZCCHV}$ HUMAN $101.43 \quad 100.0 \%$ Zinc finger CCCH-type antiviral protein $1 \mathrm{GN}=\mathrm{ZC} 3 \mathrm{HAV} 1 \mathrm{ZCCHV}$ HUMAN $101.43 \quad 100.0 \%$ Zinc finger CCCH-type antiviral protein $1 \mathrm{GN}=\mathrm{ZC} 3 \mathrm{HAV} 1 \mathrm{ZCCHV} \_H U M A N \quad 101.43 \quad 100.0 \%$ Zinc finger CCCH-type antiviral protein $1 \mathrm{GN}=\mathrm{ZC} 3 \mathrm{HAV} 1 \mathrm{ZCCHV} \_H U M A N \quad 101.43 \quad 100.0 \%$ Zinc finger CCCH-type antiviral protein $1 \mathrm{GN}=\mathrm{ZC} 3 \mathrm{HAV} 1 \mathrm{ZCCHV}$ HUMAN $101.43 \quad 100.0 \%$ Zinc finger CCCH-type antiviral protein $1 \mathrm{GN}=\mathrm{ZC} 3 \mathrm{HAV} 1 \mathrm{ZCCHV} \_H U M A N \quad 101.43 \quad 100.0 \%$ Zinc finger CCHC domain-containing protein $3 \mathrm{GN}=\mathrm{ZCCHC} 3 \mathrm{ZCHC} 3$ HUMAN $43.62 \quad 100.0 \%$ Zinc finger $\mathrm{CCHC}$ domain-containing protein $3 \mathrm{GN}=\mathrm{ZCCHC} 3 \mathrm{ZCHC} 3$ _HUMAN $43.62 \quad 100.0 \%$ Zinc finger $\mathrm{CCHC}$ domain-containing protein $3 \mathrm{GN}=\mathrm{ZCCHC} 3 \mathrm{ZCHC} 3$ HUMAN $43.62 \quad 100.0 \%$ Zinc finger $\mathrm{CCHC}$ domain-containing protein $3 \mathrm{GN}=\mathrm{ZCCHC} 3 \mathrm{ZCHC} 3$ _HUMAN $43.62 \quad 100.0 \%$ Zinc finger $\mathrm{CCHC}$ domain-containing protein $3 \mathrm{GN}=\mathrm{ZCCHC} 3 \mathrm{ZCHC} 3$ _HUMAN $43.62 \quad 100.0 \%$

10

3

3

$\begin{array}{ll}29 & 0.0 \\ 29 & 0.0\end{array}$

$0.03 \% \quad 8.9 \%$ HIEIFTDLSSR

$0.03 \% \quad 8.9 \%$ LGGHGPSFPLK

$0.03 \% \quad 8.9 \% \quad$ CFSVLGFCK

$0.03 \% \quad 8.9 \%$ LFQCLLHR

$0.03 \% \quad 8.9 \% \quad$ SQIPLSKIK

$0.03 \% \quad 8.9 \%$ IKTLFPLIEAK

$0.03 \% \quad 8.9 \%$ TLFPLIEAK

$0.04 \% \quad 20.2 \%$ DSLIFLVDASK

$0.04 \% 20.2 \%$ NIYVLQELDNPGAK

$0.04 \% \quad 20.2 \%$ NIYVLQELDNPGAKR

$0.04 \% 20.2 \%$ ILELDQFKGQQGQK

$\begin{array}{ll}0.04 \% & 20.2 \% \text { IMLFTNEDNPHGNDSAK } \\ 0.04 \% & 20.2 \% \text { TFNTSTGGLLLPSDTKR }\end{array}$

$\begin{array}{ll}0.04 \% & 20.2 \% \\ 0.04 \% & 20.2 \% \\ \text { CLEKEVAALCR }\end{array}$

$0.04 \% \quad 20.2 \%$ IMATPEQVGK

$0.04 \% 20.2 \%$ SDSFENPVLQQHFR

$0.04 \% \quad 20.2 \%$ VEYSEEELKTHISK

$0.01 \% \quad 7.4 \%$ LGSTEVASNVPK

$0.01 \% \quad 7.4 \%$ SYSEDDIHR

$0.01 \% \quad 7.4 \%$ LENNENKPVTNSR

$0.01 \% \quad 7.4 \%$ DTQEVPLEK

$0.02 \% \quad 6.9 \%$ QLVSKPLSSSVSNNKR

$0.02 \% \quad 6.9 \%$ GISPIVFDR

$0.02 \% \quad 6.9 \%$ SGSSASESYAGSEK

$\begin{array}{llll}17 & 0.02 \% & 6.9 \% & \text { SNNHENVSLAK }\end{array}$

$0.01 \% \quad 2.8 \%$ LSVQSNPSPQLR

$0.01 \% \quad 2.8 \%$ TVVLPPIVASR

$0.00 \% \quad 1.4 \%$ LLSQVVRPQESR

$0.00 \% \quad 1.4 \%$ ASLLSNLGPCCK

$0.00 \% \quad 3.7 \%$ GGQYENFR

$0.00 \% \quad 3.7 \%$ TLSGSGSGSGSSYSGSSSR

$0.00 \% \quad 3.7 \%$ AVEDAIAR

$0.00 \% \quad 2.5 \%$ HVEASGGSGPGDSGPSDPR

$0.00 \% \quad 2.5 \%$ ATEPAADTGAQPK

$0.02 \% \quad 8.9 \% \quad$ ASLEDAPVDDLTR

$0.02 \% \quad 8.9 \% \quad$ KFTYLGSQDR

$\begin{array}{lll}0.02 \% & 8.9 \% & \text { ATDLGGTSQAGTSQR }\end{array}$

$0.02 \% \quad 8.9 \% \quad$ TVFSPTLPAAR

$\quad 0.02 \% \quad 8.9 \% \quad$ SSLGSLQTPEAVTTR

$\begin{array}{llll}0.02 \% & 8.9 \% & \text { IQDAGPASRDVQATGR }\end{array}$

$1 \quad 0.01 \% \quad 14.6 \%$ ICFQGDEGACPTR

$11 \quad 0.01 \% \quad 14.6 \%$ DFVVGALILR

$11 \quad 0.01 \% \quad 14.6 \%$ SAEKLALFLR

$11 \quad 0.01 \% \quad 14.6 \%$ HCDVLAVPVK

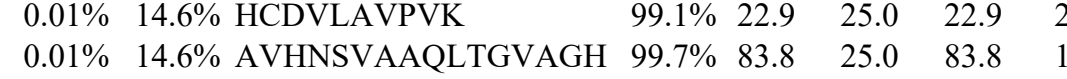

$\begin{array}{llll}99.0 \% & 29.7 & 25.0 & 23.6\end{array}$

$\begin{array}{lllll}99.7 \% & 49.7 & 25.0 & 45.0 & 5\end{array}$

$\begin{array}{llll}99.4 \% & 26.0 & 25.0 & 17.3\end{array}$

$\begin{array}{llll}99.7 \% & 38.3 & 25.0 & 32.5\end{array}$

$99.0 \% \quad 42.3 \quad 25.0 \quad 30.7$

$\begin{array}{llll}95.1 \% & 14.4 & 25.0 & 14.4\end{array}$

$\begin{array}{llll}99.7 \% & 48.7 & 25.0 & 39.9\end{array}$

$\begin{array}{llll}96.9 \% & 24.4 & 25.0 & 19.3\end{array}$

$\begin{array}{llll}99.7 \% & 52.7 & 25.0 & 46.5\end{array}$

$\begin{array}{llll}99.7 \% & 52.8 & 25.0 & 52.8\end{array}$

$\begin{array}{lllll}99.7 \% & 46.8 & 25.0 & 46.8 & 2\end{array}$

$\begin{array}{llll}99.7 \% & 59.0 & 25.0 & 59.0\end{array}$

$\begin{array}{llll}99.7 \% & 32.5 & 25.0 & 32.5\end{array}$

$\begin{array}{llll}99.7 \% & 34.5 & 25.0 & 34.5\end{array}$

$\begin{array}{llll}99.7 \% & 37.1 & 25.0 & 36.2 \\ 99.7 \% & 47.3 & 25.0 & 38.5\end{array}$

$\begin{array}{llll}99.7 \% & 64.2 & 25.0 & 64.2\end{array}$

$\begin{array}{llll}99.6 \% & 25.9 & 25.0 & 22.4\end{array}$

$\begin{array}{lllll}99.7 \% & 55.4 & 25.0 & 50.3 & 4\end{array}$

$\begin{array}{lllll}99.7 \% & 26.7 & 25.0 & 26.7 & 1\end{array}$

$\begin{array}{lllll}98.9 \% & 25.3 & 25.0 & 16.7 & 0\end{array}$

$\begin{array}{llll}99.7 \% & 29.4 & 25.0 & 25.5\end{array}$

$\begin{array}{lllll}99.7 \% & 40.1 & 25.0 & 40.1 & 0\end{array}$

$\begin{array}{llll}99.4 \% & 26.4 & 25.0 & 18.5\end{array}$

$\begin{array}{lllll}99.7 \% & 61.9 & 25.0 & 61.2 & 2\end{array}$

$\begin{array}{lllll}99.7 \% & 44.7 & 25.0 & 43.8 & 4\end{array}$

$\begin{array}{llll}99.7 \% & 44.4 & 25.0 & 29.9\end{array}$

$\begin{array}{llll}99.4 \% & 20.7 & 25.0 & 20.7\end{array}$

$96.0 \% \quad 16.2 \quad 25.0 \quad 14.2$

$\begin{array}{llll}99.6 \% & 24.0 & 25.0 & 22.4\end{array}$

$\begin{array}{llll}99.0 \% & 22.3 & 25.0 & 19.7\end{array}$

$\begin{array}{cccc}99.7 \% & 53.6 & 25.0 & 53.6 \\ 97.8 \% & 25.7 & 25.0 & 8.6\end{array}$

$\begin{array}{llll}94.8 \% & 13.8 & 25.0 & 13.8\end{array}$

$\begin{array}{llll}99.7 \% & 35.4 & 25.0 & 31.9\end{array}$

$\begin{array}{llll}99.7 \% & 45.2 & 25.0 & 36.2\end{array}$

$\begin{array}{llll}99.7 \% & 31.1 & 25.0 & 27.3\end{array}$

$\begin{array}{llll}99.7 \% & 59.8 & 25.0 & 59.8\end{array}$

$\begin{array}{llll}99.2 \% & 22.0 & 25.0 & 21.1\end{array}$

$\begin{array}{llll}99.7 \% & 57.0 & 25.0 & 53.5\end{array}$

$\begin{array}{llll}98.4 \% & 20.1 & 25.0 & 16.2\end{array}$

$\begin{array}{llll}99.7 \% & 41.0 & 25.0 & 41.0\end{array}$

$\begin{array}{llll}99.7 \% & 40.2 & 25.0 & 40.2\end{array}$

$\begin{array}{lllll}99.7 \% & 38.0 & 25.0 & 37.1 & 2 \\ 99.1 \% & 22.9 & 25.0 & 22.9 & 2\end{array}$
1467.70

1009.55

1317.68

1109.61

1117.52

1086.59

1013.64

1272.79

1031.61

1207.66

1573.82

1729.92

1631.88

1902.87

1807.96

1348.67

1089.56

1703.81

1691.85

1201.64

1121.49

1514.76

1058.54

1743.97

1003.56

1346.57

1212.60

1325.72

1151.71

1411.80

1319.64

970.44

1707.74

844.45

1765.77

1256.61

1401.69

1214.62

1449.69

1159.65

1546.81

1641.83

1510.64

1102.66

1147.68

1137.61

1531.80 \begin{tabular}{cc}
37 & 4 \\
131 & 14 \\
185 & 195 \\
339 & 347 \\
490 & 497 \\
526 & 534 \\
533 & 543 \\
535 & 54 \\
36 & 46 \\
101 & 114 \\
101 & 115 \\
116 & 129 \\
166 & 182 \\
302 & 318 \\
389 & 399 \\
452 & 461 \\
475 & 488 \\
557 & 570 \\
194 & 205 \\
417 & 425 \\
515 & 527 \\
528 & 536 \\
68 & 83 \\
306 & 314 \\
315 & 328 \\
362 & 372 \\
125 & 136 \\
443 & 453 \\
863 & 874 \\
1582 & 1593 \\
382 & 389 \\
683 & 701 \\
937 & 944 \\
873 & 891 \\
1160 & 1172 \\
283 & 295 \\
296 & 305 \\
315 & 329 \\
375 & 385 \\
386 & 400 \\
462 & 477 \\
170 & 182 \\
183 & 192 \\
219 & 228 \\
277 & 286 \\
389 & 404 \\
& \\
\hline 35
\end{tabular}

Page 167 of Table S-1-6 
Zinc finger protein $346 \mathrm{GN}=\mathrm{ZNF} 346$ Zinc finger protein $346 \mathrm{GN}=\mathrm{ZNF} 346$ Zinc finger protein $346 \mathrm{GN}=Z \mathrm{ZNF} 346$ Zinc finger protein $346 \mathrm{GN}=\mathrm{ZNF} 346$ Zinc finger protein $346 \mathrm{GN}=\mathrm{ZNF} 346$ Zinc finger protein $346 \mathrm{GN}=\mathrm{ZNF} 346$ Zinc finger protein $346 \mathrm{GN}=\mathrm{ZNF} 346$ Zinc finger protein $512 \mathrm{GN}=\mathrm{ZNF} 512$ Zinc finger protein $512 \mathrm{GN}=\mathrm{ZNF} 512$ Zinc finger protein $512 \mathrm{GN}=\mathrm{ZNF} 512$ Zinc finger protein $512 \mathrm{GN}=\mathrm{ZNF} 512$ Zinc finger protein $638 \mathrm{GN}=\mathrm{ZNF} 638$ Zinc finger protein $638 \mathrm{GN}=\mathrm{ZNF} 638$ Zinc finger protein $638 \mathrm{GN}=\mathrm{ZNF} 638$ Zinc finger protein $638 \mathrm{GN}=\mathrm{ZNF} 638$ Zinc finger protein $768 \mathrm{GN}=\mathrm{ZNF} 768$ Zinc finger protein $768 \mathrm{GN}=Z \mathrm{NNF} 768$ Zinc finger Zinc finger RNA-binding protein GN=ZFR ZFR HUMAN $117.01 \quad 100.0 \%$ Zinc finger RNA-binding protein GN=ZFR ZFR HUMAN $117.01 \quad 100.0 \%$ Zinc finger RNA-binding protein GN=ZFR ZFR_HUMAN $117.01 \quad 100.0 \%$ Zinc finger RNA-binding protein GN=ZFR ZFR HUMAN $117.01 \quad 100.0 \%$ Zinc finger RNA-binding protein GN=ZFR ZFR_HUMAN $117.01 \quad 100.0 \%$ Zinc finger RNA-binding protein GN=ZFR ZFR_HUMAN $117.01 \quad 100.0 \%$ Zinc finger RNA-binding protein GN=ZFR ZFR HUMAN $117.01 \quad 100.0 \%$

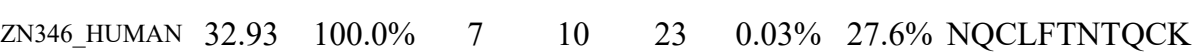

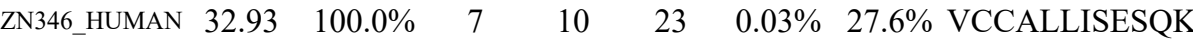
ZN346 HUMAN $32.93 \quad 100.0 \%$ ZN346_HUMAN $32.93 \quad 100.0 \%$ ZN346_HUMAN $32.93 \quad 100.0 \%$ ZN346 HUMAN $32.93 \quad 100.0 \%$ ZN512_HUMAN $64.68 \quad 100.0 \%$ ZN512 HUMAN $64.68 \quad 100.0 \%$ ZN512_HUMAN $64.68 \quad 100.0 \%$ ZN638 HUMAN $220.63 \quad 100.0 \%$ ZN638_HUMAN $220.63 \quad 100.0 \%$ ZN638_HUMAN $220.63 \quad 100.0 \%$ ZN638 HUMAN $220.63 \quad 100.0 \%$ ZN768_HUMAN $60.23 \quad 100.0 \%$ ZN768_HUMAN $60.23 \quad 100.0 \%$ 0
0

$0 \%$
$0 \%$
8

$\begin{array}{llll}10 & 23 & 0.03 \% & 27.6 \% \text { VCCALLISESQK } \\ 10 & 23 & 0.03 \% & 27.6 \% \text { YLAIHGMETLK }\end{array}$

$10 \quad 23$

1023

10

4

4

4

4

4

4

4

$0.01 \% \quad 9.4 \%$ AGLAYHLR

$0.01 \% \quad 9.4 \%$ VLQDLVPDDR

$0.01 \% \quad 2.3 \% \quad$ ALEDVVQR

$\begin{array}{lll}0.01 \% & 2.3 \% & \text { AVEIVTSTSAAK }\end{array}$

$0.00 \% \quad 3.7 \%$ AFADSSYLLR

$0.00 \% \quad 3.7 \%$ AFGDSSYLLR

$0.02 \% \quad 10.1 \%$ INFVGGNK

$0.02 \% \quad 10.1 \%$ KVNPDLQVEVKPSIR

$0.02 \% \quad 10.1 \%$ NVNLVLLCSEKPSK

$0.02 \% \quad 10.1 \%$ ANGLQSCVIIIR
$0.03 \% \quad 27.6 \%$ TVASSLGQIPMQR

$0.01 \% \quad 2.3 \%$ TSSGTKPSVKPTSATK

$99.7 \% \quad 65.8$

$\begin{array}{llllll}0.01 \% & 9.4 \% & \text { LGAVPATSGPTTFKQQR } & 99.4 \% & 22.8\end{array}$

$\begin{array}{llll}0.01 \% & 9.4 \% & \text { IKPAATSHVEGSGGVSAK } \quad 99.1 \% & 22.1\end{array}$

$99.0 \% \quad 54.3$

$99.7 \% \quad 40.9$

$99.0 \% \quad 42.6$

$97.8 \% \quad 18.1$

$98.6 \% 19.6$

$99.7 \% \quad 30.6$

$99.7 \% \quad 44.8$

$99.7 \% \quad 44.7$

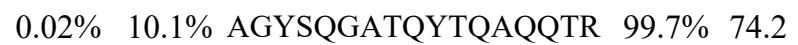

$0.02 \% \quad 10.1 \%$ GLTTTGNSSLNSTSNTK $\quad 99.7 \% \quad 77.4$

$97.1 \% \quad 19.9$

$99.7 \% \quad 50.1$

$99.7 \% \quad 45.3$

$99.7 \% \quad 48.9$

$99.7 \% 39.7$

$99.7 \% \quad 35.7$

8 
Proten $\frac{\text { Spectral counts (SCs) }}{\text { Vector control(VC) }}$

Protein name

Accession number Gene name

$\frac{\text { Vector control (VC) }}{\text { Rep 1 Rep 2 Rep 3 }} \frac{\text { NS1 protein (NS1) }}{\text { Rep 1 Rep 2 Rep 3 }}$

Phosphatidylinositol 3-kinase regulatory subunit beta

P85B_HUMAN PIK3R2

Polyadenylate-binding protein 2

Hsp70-binding protein 1

Inosine-5'-monophosphate dehydrogenase 2

Scaffold attachment factor B2

Spliceosome RNA helicase DDX39B

ATP-dependent RNA helicase DHX8

Ethylmalonyl-CoA decarboxylase

Insulin-like growth factor 2 mRNA-binding protein 2

Regulation of nuclear pre-mRNA domain-containing protein $1 \mathrm{~A}$

14-3-3 protein gamma

Double-stranded RNA-binding protein Staufen homolog 1

Acidic fibroblast growth factor intracellular-binding protein

PABP2 HUMAN PABPN1

HPBP1_HUMAN HSPBP1

IMDH2_HUMAN IMPDH2

SAFB2_HUMAN SAFB2

DX39B HUMAN DDX39B

DHX8_HUMAN DHX8

ECHD1_HUMAN ECHDC1

IF2B2_HUMAN IGF2BP2

RPR1A_HUMAN RPRD1A

1433G_HUMAN YWHAG

STAU1_HUMAN STAU1

FIBP HUMAN FIBP

U2 small nuclear ribonucleoprotein $\mathrm{A}^{\prime}$

RU2A HUMAN SNRPA1

Interferon-inducible double-stranded RNA-dependent protein kinase activator A PRKRA_HUMAN PRKRA

DnaJ homolog subfamily B member 6

RNA-binding protein PNO1

Citron Rho-interacting kinase

U5 small nuclear ribonucleoprotein $40 \mathrm{kDa}$ protein

26S proteasome non-ATPase regulatory subunit 6

Malate dehydrogenase, mitochondrial

RNA binding motif protein, X-linked-like-1

Tubulin alpha-1A chain

14-3-3 protein eta

DNJB6_HUMAN DNAJB6

PNO1_HUMAN PNO1

CTRO_HUMAN CIT

SNR40_HUMAN SNRNP40

PSMD6_HUMAN PSMD6

MDHM HUMAN MDH2

RMXL1_HUMAN RBMXL1

TBA1A_HUMAN TUBA1A

1433F_HUMAN YWHAH

Heat shock $70 \mathrm{kDa}$ protein 4

Septin-2

Probable ATP-dependent RNA helicase DDX47

Huntingtin

HSP74 HUMAN HSPA4

SEPT2_HUMAN SEPT2

DDX47_HUMAN DDX47

HD_HUMAN HTT

Complement component 1 Q subcomponent-binding protein, mitochondrial C1QBP_HUMAN C1QBP

Polypyrimidine tract-binding protein 1

Protein diaphanous homolog 1

PTBP1_HUMAN PTBP1

DIAP1_HUMAN DIAPH1

1433T_HUMAN YWHAQ

Zinc finger RNA-binding protein

ZFR_HUMAN

ZFR

$\begin{array}{ll}0 & 0 \\ 0 & 0 \\ 0 & 0 \\ 0 & 0 \\ 0 & 0 \\ 0 & 0 \\ 0 & 0 \\ 0 & 0 \\ 0 & 0 \\ 0 & 0 \\ 0 & 0 \\ 2 & 0 \\ 0 & 0 \\ 0 & 0 \\ 0 & 2 \\ 0 & 0 \\ 0 & 0 \\ 0 & 0 \\ 0 & 0 \\ 5 & 0 \\ 0 & 0 \\ 0 & 0 \\ 0 & 0 \\ 0 & 0 \\ 0 & 0 \\ 0 & 0 \\ 0 & 0 \\ 0 & 0 \\ 0 & 0 \\ 7 & 0 \\ 0 & 0 \\ 0 & 0 \\ 0 & 0 \\ & \\ 0 \\ 0\end{array}$

$\mathrm{SC}$ ratio of $\mathrm{NS} 1 / \mathrm{VC}^{\mathrm{a}}$ 
Nuclear receptor coactivator 5

Probable ATP-dependent RNA helicase YTHDC2

RNA-binding protein Musashi homolog 1

Ribosome biogenesis protein BRX1 homolog

Scaffold attachment factor B1

Ancient ubiquitous protein 1

Pre-mRNA-splicing factor ISY1 homolog

14-3-3 protein beta/alpha

Lysophospholipid acyltransferase 7

Fanconi anemia group D2 protein

Cytoplasmic dynein 2 heavy chain 1

DnaJ homolog subfamily B member 11

Pre-mRNA-splicing factor SYF1

T-complex protein 1 subunit beta

Multiple myeloma tumor-associated protein 2

60S ribosomal protein L7-like 1

Casein kinase II subunit alpha

Probable serine carboxypeptidase CPVL

Filaggrin-2

Oxygen-dependent coproporphyrinogen-III oxidase, mitochondrial 14-3-3 protein epsilon

Glutaminyl-peptide cyclotransferase

Annexin A2

Nicotinamide/nicotinic acid mononucleotide adenylyltransferase 1

Ribosome biogenesis protein NSA2 homolog

Heterogeneous nuclear ribonucleoprotein A3

Fanconi anemia group I protein

Protein ELYS

Pre-mRNA-processing factor 19

Aldose reductase

MKI67 FHA domain-interacting nucleolar phosphoprotein

Zinc finger protein 638

Tight junction protein ZO-1

GTP-binding protein 10

AP-3 complex subunit delta-1

mRNA turnover protein 4 homolog

ATP-dependent RNA helicase DDX39A

RNA-binding protein Musashi homolog 2
NCOA5_HUMAN NCOA5

YTDC2_HUMAN YTHDC2

MSI1H_HUMAN MSI1

BRX1_HUMAN BRIX1

SAFB1_HUMAN SAFB

AUP1_HUMAN AUP1

ISY1_HUMAN ISY1

1433B_HUMAN YWHAB

MBOA7 HUMAN MBOAT7

FACD2_HUMAN FANCD2

DYHC2_HUMAN DYNC2H1

DJB11_HUMAN DNAJB11

SYF1_HUMAN XAB2

TCPB HUMAN CCT2

MMTA2_HUMAN MMTAG2

RL7L HUMAN RPL7L1

CSK21 HUMAN CSNK2A1

CPVL_HUMAN CPVL

FILA2_HUMAN FLG2

HEM6 HUMAN CPOX

1433E_HUMAN YWHAE

QPCT_HUMAN QPCT

ANXA2_HUMAN ANXA2

NMNA1 HUMAN NMNAT1

NSA2_HUMAN NSA2

ROA3_HUMAN HNRNPA3

FANCI_HUMAN FANCI

ELYS HUMAN AHCTF1

PRP19 HUMAN PRPF19

ALDR_HUMAN AKR1B1

MK67I_HUMAN NIFK

ZN638 HUMAN ZNF638

ZO1_HUMAN TJP1

GTPBA_HUMAN GTPBP10

AP3D1_HUMAN AP3D1

MRT4_HUMAN MRTO4

DX39A HUMAN DDX39A

MSI2H_HUMAN MSI2 
2-methoxy-6-polyprenyl-1,4-benzoquinol methylase, mitochondrial Cytosolic Fe-S cluster assembly factor NUBP2

Keratinocyte proline-rich protein

5'-AMP-activated protein kinase subunit gamma-1

Mitochondrial ribonuclease $\mathrm{P}$ protein 1

Glutaredoxin-3

Hypoxia up-regulated protein 1

DnaJ homolog subfamily B member 12

Peroxisomal membrane protein PMP34

Heterogeneous nuclear ribonucleoprotein D0

Desmoglein-1

Double-stranded RNA-binding protein Staufen homolog 2

Sister chromatid cohesion protein PDS5 homolog B

Filaggrin

Ribonucleoside-diphosphate reductase subunit M2 B

Ig alpha-1 chain $\mathrm{C}$ region

Protein transport protein Sec16A

Dual specificity protein phosphatase 9

Eukaryotic translation initiation factor 3 subunit M

Ubiquitin thioesterase OTUB1

Heat shock $70 \mathrm{kDa}$ protein $4 \mathrm{~L}$

Nucleosome assembly protein 1-like 1

Protein S100-A8

Histone $\mathrm{H} 4$

Methionyl-tRNA formyltransferase, mitochondrial

Cyclin-dependent kinase 9

PIN2/TERF1-interacting telomerase inhibitor 1

Peroxisomal multifunctional enzyme type 2

Chloride intracellular channel protein 1

$3^{\prime}\left(2^{\prime}\right), 5^{\prime}$-bisphosphate nucleotidase 1

Nucleolar GTP-binding protein 2

Proteasome activator complex subunit 3

Serine/threonine-protein kinase 38

Casein kinase I isoform alpha

F-box only protein 22

Annexin A1

Prelamin-A/C

SAFB-like transcription modulator

\begin{tabular}{|c|c|}
\hline COQ5_HUMAN & COQ5 \\
\hline NUBP2_HUMAN & NUBP2 \\
\hline KPRP_HUMAN & KPRP \\
\hline AAKG 1 IHUMAN & PRKAG1 \\
\hline MRRP1_HUMAN & TRMT10C \\
\hline GLRX3_HUMAN & GLRX3 \\
\hline HYOU1_HUMAN & HYOU1 \\
\hline DJB12_HUMAN & DNAJB12 \\
\hline PM34_HUMAN & SLC25A17 \\
\hline HNRPD_HUMAN & HNRNPD \\
\hline DSG1_HUMAN & DSG1 \\
\hline STAU2_HUMAN & STAU2 \\
\hline PDS5B_HUMAN & PDS5B \\
\hline FILA_HUMAN & FLG \\
\hline RIR2B_HUMAN & RRM2B \\
\hline IGHA1_HUMAN & IGHA1 \\
\hline SC16A_HUMAN & SEC16A \\
\hline DUS9_HUMAN & DUSP9 \\
\hline EIF3M_HUMAN & EIF3M \\
\hline OTUB1_HUMAN & OTUB1 \\
\hline HS74L_HUMAN & HSPA4L \\
\hline NP1L1_HUMAN & NAP1L1 \\
\hline S10A8_HUMAN & S100A8 \\
\hline H4_HŪMAN & HIST1H4A \\
\hline FMT_HUMAN & MTFMT \\
\hline CDK9_HUMAN & CDK9 \\
\hline PINX1_HUMAN & PINX1 \\
\hline DHB4_HUMAN & HSD17B4 \\
\hline CLIC1_HUMAN & CLIC1 \\
\hline BPNT1_HUMAN & BPNT1 \\
\hline NOG2_HUMAN & GNL2 \\
\hline PSME3_HUMAN & PSME3 \\
\hline STK38_HUMAN & STK38 \\
\hline KC1A_HUMAN & CSNK1A1 \\
\hline FBX22_HUMAN & FBXO22 \\
\hline ANXĀ1_HUMAN & ANXA1 \\
\hline LMNA_HUMAN & LMNA \\
\hline SLTM_HUMAN & SLTM \\
\hline
\end{tabular}


Small proline-rich protein $2 \mathrm{E}$

Interferon-induced, double-stranded RNA-activated protein kinase

F-actin-capping protein subunit alpha-1

Mitochondrial ribosome-associated GTPase 1

Atypical kinase ADCK3, mitochondrial

Nucleolar protein 7

L-aminoadipate-semialdehyde dehydrogenase-phosphopantetheinyl transferase

Probable ATP-dependent RNA helicase DHX37

COP9 signalosome complex subunit 4

DNA-directed RNA polymerase III subunit RPC1

Antigen KI-67

Nischarin

Iron-sulfur protein NUBPL

Heterogeneous nuclear ribonucleoprotein U-like protein 2

Mitochondrial ornithine transporter 1

Protein SON

Tubulin alpha-1C chain

Pentatricopeptide repeat-containing protein 2, mitochondrial

PHD finger protein 6

RNA/RNP complex-1-interacting phosphatase

Proteasome subunit alpha type-1

ATPase family AAA domain-containing protein 1

Myelin expression factor 2

Tubulin beta-4A chain

Phosphoserine aminotransferase

E3 ubiquitin-protein ligase MYCBP2

Caspase-14

DNA repair protein RAD50

F-box/LRR-repeat protein 12

RISC-loading complex subunit TARBP2

Nuclear pore complex protein Nup160

Zinc finger $\mathrm{CCCH}$ domain-containing protein $11 \mathrm{~A}$

1-acyl-sn-glycerol-3-phosphate acyltransferase epsilon

Biliverdin reductase A

Leucine-rich repeat-containing protein 59

Uncharacterized protein C19orf52

Phosphatidate cytidylyltransferase, mitochondrial

Heterogeneous nuclear ribonucleoprotein Q
SPR2E_HUMAN SPRR2E

E2AK2 HUMAN EIF2AK2

CAZA1_HUMAN CAPZA1

MTG1_HUMAN MTG1

ADCK3_HUMAN ADCK3

NOL7 HUMAN NOL7

ADPPT_HUMAN AASDHPPT

DHX37_HUMAN DHX37

CSN4 HUMAN COPS4

RPC1_HUMAN POLR3A

KI67_HUMAN MKI67

NISCH_HUMAN NISCH

NUBPL HUMAN NUBPL

HNRL2_HUMAN HNRNPUL2

ORNT1_HUMAN SLC25A15

SON_HUMAN SON

TBA1C HUMAN TUBA1C

PTCD2_HUMAN PTCD2

PHF6_HUMAN PHF6

DUS11_HUMAN DUSP11

PSA1_HUMAN PSMA1

ATAD1_HUMAN ATAD1

MYEF2_HUMAN MYEF2

TBB4A HUMAN TUBB4A

SERC HUMAN PSAT1

MYCB2_HUMAN MYCBP2

CASPE HUMAN CASP14

RAD50 HUMAN RAD50

FXL12 HUMAN FBXL12

TRBP2_HUMAN TARBP2

NU160_HUMAN NUP160

ZC11A HUMAN ZC3H11A

PLCE HUMAN AGPAT5

BIEA_HUMAN BLVRA

LRC59 HUMAN LRRC59

CS052 HUMAN C19orf52

TAM4 1 HUMAN TAMM41

HNRPQ_HUMAN SYNCRIP 
Farnesyl pyrophosphate synthase

DNA dC->dU-editing enzyme APOBEC-3B

ELAV-like protein 2

Desmoplakin

Hemoglobin subunit alpha

Neurofibromin

Cornifin-B

SNW domain-containing protein 1

39S ribosomal protein L4, mitochondrial

Replication initiator 1

Serpin B3

DNA polymerase alpha catalytic subunit

$\mathrm{AH}$ receptor-interacting protein

Heterogeneous nuclear ribonucleoprotein $\mathrm{H} 3$

Target of rapamycin complex subunit LST8

Unconventional myosin-Ib

Small subunit processome component 20 homolog

U3 small nucleolar ribonucleoprotein protein IMP4

BRISC and BRCA1-A complex member 1

Serine/threonine-protein phosphatase PP1-alpha catalytic subunit

Malonyl-CoA-acyl carrier protein transacylase, mitochondrial

Serine palmitoyltransferase 1

DNA repair protein RAD51 homolog 3

26S proteasome non-ATPase regulatory subunit 8

Elongation factor 1-beta

Etoposide-induced protein 2.4 homolog

NADH dehydrogenase [ubiquinone] flavoprotein 1, mitochondrial

Chromodomain-helicase-DNA-binding protein 1

Peroxisomal biogenesis factor 3

Proteasome subunit alpha type-7

Stomatin-like protein 2, mitochondrial

Retinitis pigmentosa 1 -like 1 protein

Sister chromatid cohesion protein PDS5 homolog A

Mitochondrial import inner membrane translocase subunit TIM44

Interleukin enhancer-binding factor 2

Golgi phosphoprotein 3

E3 ubiquitin-protein ligase RING2

Mitogen-activated protein kinase 1

\begin{tabular}{|c|c|}
\hline FPPS_HUMAN & FDPS \\
\hline ABC3B_HUMAN & AРОВЕС3В \\
\hline ELAV2_HUMAN & ELAVL2 \\
\hline DESP_HUMAN & DSP \\
\hline HBA HUMAN & HBA1 \\
\hline NF1_HUMAN & NF1 \\
\hline SPR1B_HUMAN & SPRR1B \\
\hline SNW1 HUMAN & SNW1 \\
\hline RM04_HUMAN & MRPL4 \\
\hline REPI1_HUMAN & REPIN1 \\
\hline SPB3_HUMAN & SERPINB3 \\
\hline DPOLA_HUMAN & POLA1 \\
\hline AIP_HUMAN & AIP \\
\hline HNRH3_HUMAN & HNRNPH3 \\
\hline LST8_HUMAN & MLST8 \\
\hline MYO1B_HUMAN & MYO1B \\
\hline UTP20_HUMAN & UTP20 \\
\hline IMP4_HUMAN & IMP4 \\
\hline BABA1_HUMAN & BABAM1 \\
\hline PP1A_HUMAN & PPP1CA \\
\hline FABD_HUMAN & MCAT \\
\hline SPTC1_HUMAN & SPTLC1 \\
\hline RA51C_HUMAN & RAD51C \\
\hline PSMD8_HUMAN & PSMD8 \\
\hline EF1B_HUMAN & EEF1B2 \\
\hline EI24_HUMAN & EI24 \\
\hline NDUV1_HUMAN & NDUFV1 \\
\hline CHD1_HUMAN & CHD1 \\
\hline PEX3_HUMAN & PEX3 \\
\hline PSA7_HUMAN & PSMA7 \\
\hline STML2_HUMAN & STOML2 \\
\hline RP1L1_HUMAN & RP1L1 \\
\hline PDS5A_HUMAN & PDS5A \\
\hline TIM44_HUMAN & TIMM44 \\
\hline ILF2_HUMAN & ILF2 \\
\hline GOLP3_HUMAN & GOLPH3 \\
\hline RING2_HUMAN & RNF2 \\
\hline MK01_HUMAN & MAPK1 \\
\hline
\end{tabular}

4.129

4.110

4.101

4.077

4.000

3.947

3.919

3.906

3.905

3.896

3.886

3.886

3.864

3.858

3.853

3.853

3.853

3.853

3.853

3.852

3.842

3.831

3.831

3.809

3.799

3.799

3.799

3.798

3.755

3.755

3.684

3.667

3.666

3.644

3.569

3.552

3.530

3.530

Page 5 of Table S-2 
Large neutral amino acids transporter small subunit 1

Creatine kinase B-type

Inorganic pyrophosphatase

Tubulin beta-3 chain

Nuclear pore membrane glycoprotein 210

GTPase-activating protein and VPS9 domain-containing protein 1

RNA-binding motif, single-stranded-interacting protein 1

Proteasome subunit alpha type-3

TraB domain-containing protein

Zinc transporter 7

Ribosomal RNA-processing protein 7 homolog A

Estradiol 17-beta-dehydrogenase 11

tRNA pseudouridine synthase A, mitochondrial

Heterogeneous nuclear ribonucleoprotein D-like

Serine/threonine-protein kinase SMG1

Transcription factor A, mitochondrial

Dynactin subunit 1

Mediator of DNA damage checkpoint protein 1

Aldehyde dehydrogenase $\mathrm{X}$, mitochondrial

L-2-hydroxyglutarate dehydrogenase, mitochondrial

Regulator of nonsense transcripts 1

Heat shock $70 \mathrm{kDa}$ protein 1A/1B

Putative RNA-binding protein Luc7-like 2

60S ribosomal protein $\mathrm{L} 28$

tRNA selenocysteine 1 -associated protein 1

ATP-binding cassette sub-family E member 1

Guanine nucleotide-binding protein $G(i)$ subunit alpha-2

HLA class I histocompatibility antigen, A-2 alpha chain

Lymphoid-specific helicase

RNA-binding protein $12 \mathrm{~B}$

U1 small nuclear ribonucleoprotein $70 \mathrm{kDa}$

Probable ATP-dependent RNA helicase DDX46

Core histone macro-H2A.1

Lactadherin

Uridine-cytidine kinase 2

OTU domain-containing protein 4

Glutamate--cysteine ligase regulatory subunit

Transcriptional adapter 1

\begin{tabular}{|c|c|}
\hline LAT1_HUMAN & SLC7A5 \\
\hline KCRB_HUMAN & $\mathrm{CKB}$ \\
\hline IPYR_HUMAN & PPA1 \\
\hline TBB3_HUMAN & TUBB3 \\
\hline PO210_HUMAN & NUP210 \\
\hline GAPD1_HUMAN & GAPVD1 \\
\hline RBMS1_HUMAN & RBMS1 \\
\hline PSA3_HUMAN & PSMA3 \\
\hline TRABD_HUMAN & TRABD \\
\hline ZNT7_HUMAN & SLC30A7 \\
\hline RRP7A_HUMAN & RRP7A \\
\hline DHB11_HUMAN & HSD17B11 \\
\hline TRUA_HUMAN & PUS1 \\
\hline HNRDL_HUMAN & HNRNPDL \\
\hline SMG1_HUMAN & SMG1 \\
\hline TFAM_HUMAN & TFAM \\
\hline DCTN1_HUMAN & DCTN1 \\
\hline MDC1_HUMAN & MDC1 \\
\hline AL1B1_HUMAN & ALDH1B1 \\
\hline L2HDH_HUMAN & L2HGDH \\
\hline RENT1_HUMAN & UPF1 \\
\hline HSP71_HUMAN & HSPA1A \\
\hline LC7L2_HUMAN & LUC7L2 \\
\hline RL28_HUMAN & RPL28 \\
\hline TSAP1_HUMAN & TRNAU1AP \\
\hline ABCE1_HUMAN & ABCE1 \\
\hline GNAI2_HUMAN & GNAI2 \\
\hline 1A02_HUMAN & HLA-A \\
\hline HELLS_HUMAN & HELLS \\
\hline RB12B_HUMAN & RBM12B \\
\hline RU17_HUMAN & SNRNP70 \\
\hline DDX46_HUMAN & DDX46 \\
\hline H2AY_HUMAN & $\mathrm{H} 2 \mathrm{AFY}$ \\
\hline MFGM_HUMAN & MFGE8 \\
\hline UCK2_HUMAN & UCK2 \\
\hline OTUD4_HUMAN & OTUD4 \\
\hline GSH0_HUMAN & GCLM \\
\hline TADA1_HUMAN & TADA1 \\
\hline
\end{tabular}

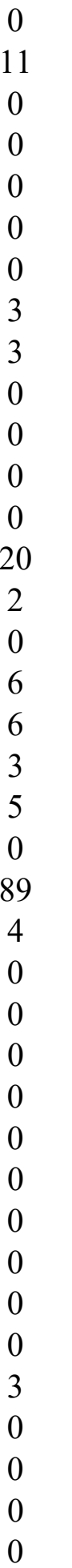


Serine/threonine-protein phosphatase 2A catalytic subunit alpha isoform Heterogeneous nuclear ribonucleoprotein $\mathrm{H} 2$

Immunoglobulin-binding protein 1

Elongator complex protein 1

Ferrochelatase, mitochondrial

Glyoxylate reductase/hydroxypyruvate reductase

Synembryn-A

Cytosolic acyl coenzyme A thioester hydrolase

Parafibromin

Sestrin-2

Dimethyladenosine transferase 1, mitochondrial

Heterogeneous nuclear ribonucleoproteins $\mathrm{C} 1 / \mathrm{C} 2$

Protein O-GlcNAcase

Regulatory-associated protein of mTOR

Calcyclin-binding protein

Immunoglobulin lambda-like polypeptide 5

Rab-like protein 2B

26S proteasome non-ATPase regulatory subunit 13

$28 \mathrm{~S}$ ribosomal protein $\mathrm{S} 2$, mitochondrial

Glycerol-3-phosphate dehydrogenase 1-like protein

Cell division cycle 5-like protein

Zinc finger protein 346

Nucleolar pre-ribosomal-associated protein 1

Very-long-chain enoyl-CoA reductase

Nascent polypeptide-associated complex subunit alpha, muscle-specific form

Protein S100-A9

RRP12-like protein

Phosphatidylserine decarboxylase proenzyme

Ubiquitin-40S ribosomal protein $\mathrm{S} 27 \mathrm{a}$

RNA-binding protein Raly

Translation initiation factor eIF-2B subunit alpha

Leucine--tRNA ligase, cytoplasmic

RuvB-like 1

RNA-binding protein 4B

Symplekin

28S ribosomal protein S34, mitochondrial

Poly(rC)-binding protein 2

DNA repair protein RAD51 homolog 2
PP2AA_HUMAN PPP2CA

HNRH2 HUMAN HNRNPH2

IGBP1_HUMAN IGBP1

ELP1_HUMAN IKBKAP

HEMH_HUMAN FECH

GRHPR_HUMAN GRHPR

RIC8A_HUMAN RIC8A

BACH_HUMAN ACOT7

CDC73 HUMAN CDC73

SESN2 HUMAN SESN2

TFB1M_HUMAN TFB1M

HNRPC HUMAN HNRNPC

OGA HUMAN MGEA5

RPTOR HUMAN RPTOR

CYBP_HUMAN CACYBP

IGLL5_HUMAN IGLL5

RBL2B HUMAN RABL2B

PSD13_HUMAN PSMD13

RT02_HUMAN MRPS2

GPD1L HUMAN GPD1L

CDC5L HUMAN CDC5L

ZN346_HUMAN ZNF346

NPA1P_HUMAN URB1

TECR HUMAN TECR

NACAM_HUMAN NACA

S10A9_HUMAN S100A9

RRP12 HUMAN RRP12

PISD HUMAN PISD

RS27A_HUMAN RPS27A

RALY_HUMAN RALY

EI2BA_HUMAN EIF2B1

SYLC HUMAN LARS

RUVB1_HUMAN RUVBL1

RBM4B_HUMAN RBM4B

SYMPK HUMAN SYMPK

RT34 HUMAN MRPS34

PCBP2 HUMAN PCBP2

RA51B_HUMAN RAD51B
3.164

3.153

3.142

3.131

3.131

3.131

3.131

3.131

3.131

3.131

3.118

3.102

3.098

3.098

3.098

3.098

3.088

3.079

3.065

3.064

3.062

3.053

3.032

3.012

3.009

3.000

2.915

2.904

2.875

2.868

2.865

2.864

2.864

2.864

2.863

2.863

2.862

2.853

Page 7 of Table S-2 
Rapamycin-insensitive companion of mTOR ATP-dependent RNA helicase DHX36

Actin, alpha skeletal muscle

Replication protein A $32 \mathrm{kDa}$ subunit

Pentatricopeptide repeat-containing protein 1, mitochondrial

Heterogeneous nuclear ribonucleoprotein $\mathrm{L}$

GDP-mannose 4,6 dehydratase

Ribosome-binding protein 1

Isoleucine--tRNA ligase, cytoplasmic

Aflatoxin B1 aldehyde reductase member 2

ATP-dependent RNA helicase DDX19A

Aspartate--tRNA ligase, cytoplasmic

ATP-dependent RNA helicase DDX24

Nesprin-1

39S ribosomal protein L28, mitochondrial

Calponin-3

Trimethyllysine dioxygenase, mitochondrial

AP-2 complex subunit mu

RuvB-like 2

Zinc finger $\mathrm{CCCH}$ domain-containing protein 8

Zinc finger CCHC-type and RNA-binding motif-containing protein 1

ATP-dependent Clp protease proteolytic subunit, mitochondrial

Structural maintenance of chromosomes protein 4

Serpin B12

Alpha-enolase

tRNA-splicing ligase RtcB homolog

Matrin-3

Protein-glutamine gamma-glutamyltransferase E

Motile sperm domain-containing protein 2

Hemoglobin subunit beta

Heat shock protein $105 \mathrm{kDa}$

Phosphoribosyl pyrophosphate synthase-associated protein 1

NADPH:adrenodoxin oxidoreductase, mitochondrial

Cell differentiation protein RCD1 homolog

Activating signal cointegrator 1 complex subunit 3

LINE-1 retrotransposable element ORF1 protein

Ubiquitin carboxyl-terminal hydrolase 24

Spermatid perinuclear RNA-binding protein

\begin{tabular}{|c|c|}
\hline RICTR_HUMAN & RICTOR \\
\hline DHX36_HUMAN & DHX36 \\
\hline ACTS_HUMAN & ACTA1 \\
\hline RFA2_HUMAN & RPA2 \\
\hline PTCD1_HUMAN & PTCD1 \\
\hline HNRPL_HUMAN & I HNRNPL \\
\hline GMDS_HUMAN & GMDS \\
\hline RRBP1_HUMAN & RRBP1 \\
\hline SYIC_HUMAN & IARS \\
\hline ARK $\overline{72}$ _HUMAN & AKR7A2 \\
\hline DD19A_HUMAN & DDX19A \\
\hline SYDC_HUMAN & DARS \\
\hline DDX24_HUMAN & DDX24 \\
\hline SYNE1_HUMAN & SYNE1 \\
\hline RM28_HUMAN & MRPL28 \\
\hline CNN3_HUMAN & CNN3 \\
\hline TMLH_HUMAN & TMLHE \\
\hline AP2M1_HUMAN & AP2M1 \\
\hline RUVB2_HUMAN & I RUVBL2 \\
\hline ZC3H8_HUMAN & ZC3H8 \\
\hline ZCRB1_HUMAN & ZCRB1 \\
\hline CLPP_HUMAN & CLPP \\
\hline SMC4_HUMAN & SMC4 \\
\hline SPB12_HUMAN & SERPINB12 \\
\hline ENOA_HUMAN & ENO1 \\
\hline RTCB_HUMAN & RTCB \\
\hline MATR3_HUMAN & I MATR3 \\
\hline TGM3_HUMAN & TGM3 \\
\hline MSPD2_HUMAN & MOSPD2 \\
\hline HBB_HUMAN & HBB \\
\hline HS105_HUMAN & HSPH1 \\
\hline KPRA_HUMAN & PRPSAP1 \\
\hline ADRO_HUMAN & FDXR \\
\hline RCD1_HUMAN & RQCD1 \\
\hline ASCC3_HUMAN & ASCC3 \\
\hline LORF1_HUMAN & L1RE1 \\
\hline UBP24_HUMAN & USP24 \\
\hline STRBP_HUMAN & STRBP \\
\hline
\end{tabular}


Protein lin-28 homolog B Junction plakoglobin

Protein arginine N-methyltransferase 1

von Willebrand factor A domain-containing protein 8

ER membrane protein complex subunit 2

TELO2-interacting protein 1 homolog

3-ketoacyl-CoA thiolase, mitochondrial

Serpin B6

5'-3' exoribonuclease 1

$\mathrm{TBC} 1$ domain family member 15

39S ribosomal protein L12, mitochondrial

Galectin-7

Aurora kinase B

FACT complex subunit SPT16

Protein FAM207A

Dedicator of cytokinesis protein 1

Geranylgeranyl transferase type-2 subunit beta

G-rich sequence factor 1

Myeloid leukemia factor 2

Dual specificity mitogen-activated protein kinase kinase 3

Beta-1,3-galactosyltransferase 6

Sodium/potassium-transporting ATPase subunit beta-3

Cytochrome c oxidase subunit 2

DNA dC->dU-editing enzyme APOBEC-3C

Lupus La protein

39S ribosomal protein L24, mitochondrial

Nucleoside diphosphate kinase 7

Splicing factor, arginine/serine-rich 15

GPN-loop GTPase 1

Vacuolar protein sorting-associated protein 26B

Proteasome subunit alpha type-5

Four and a half LIM domains protein 1

Phosphoglycerate kinase 1

NADH dehydrogenase [ubiquinone] iron-sulfur protein 3, mitochondrial Far upstream element-binding protein 3

MAP7 domain-containing protein 1

Phosphotriesterase-related protein

RNA polymerase II-associated protein 1

$\begin{array}{ll}\text { LN28B_HUMAN } & \text { LIN28B } \\ \text { PLAK_HUMAN } & \text { JUP } \\ \text { ANM1_HUMAN } & \text { PRMT1 } \\ \text { VWA8_HUMAN } & \text { VWA8 } \\ \text { EMC2_HUMAN } & \text { EMC2 } \\ \text { TTI1_HUMAN } & \text { TTI1 } \\ \text { THIM_HUMAN } & \text { ACAA2 } \\ \text { SPB6_HUMAN } & \text { SERPINB6 } \\ \text { XRN1_HUMAN } & \text { XRN1 } \\ \text { TBC15_HUMAN } & \text { TBC1D15 } \\ \text { RM12_HUMAN } & \text { MRPL12 } \\ \text { LEG7_HUMAN } & \text { LGALS7 } \\ \text { AURKB_HUMAN } & \text { AURKB } \\ \text { SP16H_HUMAN } & \text { SUPT16H } \\ \text { F207A_HUMAN } & \text { FAM207A } \\ \text { DOCK1_HUMAN } & \text { DOCK1 } \\ \text { PGTB2_HUMAN } & \text { RABGGTB } \\ \text { GRSF1_HUMAN } & \text { GRSF1 } \\ \text { MLF2_HUMAN } & \text { MLF2 } \\ \text { MP2K3_HUMAN } & \text { MAP2K3 } \\ \text { B3GT6_HUMAN } & \text { B3GALT6 } \\ \text { AT1B3_HUMAN } & \text { ATP1B3 } \\ \text { COX2_HUMAN } & \text { MT-CO2 } \\ \text { ABC3C_HUMAN } & \text { APOBEC3C } \\ \text { LA_HUMAN } & \text { SSB } \\ \text { RM24_HUMAN } & \text { MRPL24 } \\ \text { NDK7_HUMAN } & \text { NME7 } \\ \text { SFR15_HUMAN } & \text { SCAF4 } \\ \text { GPN1_HUMAN } & \text { GPN1 } \\ \text { VP26B_HUMAN } & \text { VPS26B } \\ \text { PSA5_HUMAN } & \text { PSMA5 } \\ \text { FHL1_HUMAN } & \text { FHL1 } \\ \text { PGK1_HUMAN } & \text { PGK1 } \\ \text { NDUS3_HUMAN } & \text { NDUFS3 } \\ \text { FUBP3_HUMAN } & \text { FUBP3 } \\ \text { MA7D1_HUMAN } & \text { MAP7D1 } \\ \text { PTER_HUMAN } & \text { PTER } \\ \text { RPAP1_HUMAN } & \text { RPAP1 }\end{array}$


RNA polymerase-associated protein CTR9 homolog Peptidyl-prolyl cis-trans isomerase $\mathrm{E}$

Chitobiosyldiphosphodolichol beta-mannosyltransferase COP9 signalosome complex subunit 3 $60 \mathrm{~S}$ ribosomal protein $\mathrm{L} 14$

5-methylcytosine rRNA methyltransferase NSUN4

Probable proline--tRNA ligase, mitochondrial

Geranylgeranyl pyrophosphate synthase

Serine/threonine-protein kinase ATR

Plectin

Nicotinamide phosphoribosyltransferase

E3 ubiquitin-protein ligase HUWE1

Mitochondrial carnitine/acylcarnitine carrier protein

Alpha-2-HS-glycoprotein

DNA replication licensing factor MCM2

Splicing factor 3B subunit 2

Histone deacetylase 8

WD repeat-containing protein 6

Gamma-glutamylcyclotransferase

ATP-dependent RNA helicase A

Putative helicase MOV-10

Protein SET

Interleukin enhancer-binding factor 3

14-3-3 protein zeta/delta

2-amino-3-ketobutyrate coenzyme A ligase, mitochondrial CCAAT/enhancer-binding protein zeta

GTPase Era, mitochondrial

Guanine nucleotide-binding protein-like 3-like protein

Mitotic checkpoint protein BUB3

DNA mismatch repair protein Msh2

Insulin receptor substrate 4

Condensin complex subunit 1

Activator of $90 \mathrm{kDa}$ heat shock protein ATPase homolog 1

Electron transfer flavoprotein subunit beta

Unhealthy ribosome biogenesis protein 2 homolog

Nucleoporin NUP188 homolog

Ran-specific GTPase-activating protein

General transcription factor 3C polypeptide 1

\begin{tabular}{|c|c|}
\hline CTR9_HUMAN & CTR9 \\
\hline PPIE_HUMAN & PPIE \\
\hline ALG1_HUMAN & ALG1 \\
\hline CSN3_HUMAN & COPS3 \\
\hline RL14_HUMAN & RPL14 \\
\hline NSUN4_HUMAN & NSUN4 \\
\hline SYPM_HUMAN & PARS2 \\
\hline GGPPS_HUMAN & GGPS1 \\
\hline ATR_HUMAN & ATR \\
\hline PLEC__HUMAN & PLEC \\
\hline NAMPT_HUMAN & NAMPT \\
\hline HUWE1_HUMAN & HUWE1 \\
\hline MCAT_HUMAN & SLC25A20 \\
\hline FETUA_HUMAN & AHSG \\
\hline MCM2_HUMAN & MCM2 \\
\hline SF3B2_HUMAN & SF3B2 \\
\hline HDAC8_HUMAN & HDAC8 \\
\hline WDR6_HUMAN & WDR6 \\
\hline GGCT_HUMAN & GGCT \\
\hline DHX9_HUMAN & DHX9 \\
\hline MOV10_HUMAN & MOV10 \\
\hline SET_HUMAN & SET \\
\hline ILF3_HUMAN & ILF3 \\
\hline 1433Z̄_HUMAN & YWHAZ \\
\hline KBL_HUMAN & GCAT \\
\hline CEBPZ_HUMAN & CEBPZ \\
\hline ERAL1_HUMAN & ERAL1 \\
\hline GNL3L_HUMAN & GNL3L \\
\hline BUB3_HUMAN & BUB3 \\
\hline MSH2_HUMAN & MSH2 \\
\hline IRS4_HUMAN & IRS4 \\
\hline CND1_HUMAN & NCAPD2 \\
\hline AHSA1_HUMAN & AHSA1 \\
\hline ETFB_HUMAN & ETFB \\
\hline URB2_HUMAN & URB2 \\
\hline NU188_HUMAN & NUP188 \\
\hline RANG_HUMAN & RANBP1 \\
\hline TF3C1_HUMAN & GTF3C1 \\
\hline
\end{tabular}


GTP-binding nuclear protein Ran

Protein VPRBP

mRNA export factor

cAMP-dependent protein kinase catalytic subunit beta E3 ubiquitin-protein ligase HERC2

V-type proton ATPase subunit $\mathrm{H}$

Chloride intracellular channel protein 4

Adenylosuccinate lyase

Hydroxyacylglutathione hydrolase, mitochondrial

DNA ligase 3

Helicase SKI2W

Trafficking protein particle complex subunit 8

Cyclin-G-associated kinase

Carbonic anhydrase 2

Uridine 5'-monophosphate synthase

Nuclear pore complex protein Nup155

Ribonuclease 3

CCR4-NOT transcription complex subunit 8

SUMO-activating enzyme subunit 1

Heterogeneous nuclear ribonucleoprotein A/B

E3 ubiquitin-protein ligase UBR4

Heat shock cognate $71 \mathrm{kDa}$ protein

40S ribosomal protein $\mathrm{S} 11$

Rab3 GTPase-activating protein non-catalytic subunit

Dimethyladenosine transferase 2, mitochondrial

Poly [ADP-ribose] polymerase 2

Protein YIF1B

PTB domain-containing engulfment adapter protein 1 40S ribosomal protein S23

tRNA pseudouridine synthase-like 1

Inosine triphosphate pyrophosphatase

60S ribosome subunit biogenesis protein NIP7 homolog

Histone lysine demethylase PHF8

COP9 signalosome complex subunit 6

Protein timeless homolog

Protein FAM45B

DNA-directed RNA polymerase II subunit RPB1

Proline-, glutamic acid- and leucine-rich protein 1

\begin{tabular}{|c|c|}
\hline RAN_HUMAN & RAN \\
\hline VPRBP_HUMAN & VPRBP \\
\hline RAE1L_HUMAN & RAE1 \\
\hline KAPCB_HUMAN & J PRKACB \\
\hline HERC2_HUMAN & HERC2 \\
\hline VATH_HUMAN & ATP6V1H \\
\hline CLIC4_HUMAN & CLIC4 \\
\hline PUR8_HUMAN & ADSL \\
\hline GLO2_HUMAN & HAGH \\
\hline DNLI3_HUMAN & LIG3 \\
\hline SKIV2_HUMAN & SKIV2L \\
\hline TPPC8_HUMAN & TRAPPC8 \\
\hline GAK_HUMAN & GAK \\
\hline CAH2_HUMAN & $\mathrm{CA} 2$ \\
\hline UMPS_HUMAN & UMPS \\
\hline NU155_HUMAN & NUP155 \\
\hline RNC_HUMAN & DROSHA \\
\hline CNOT8_HUMAN & CNOT8 \\
\hline SAE1_HUMAN & SAE1 \\
\hline ROAA_HUMAN & HNRNPAB \\
\hline UBR4_HUMAN & UBR4 \\
\hline HSP7C_HUMAN & HSPA8 \\
\hline RS11_HUMAN & RPS11 \\
\hline RBGPי_R_HUMAN & RAB3GAP2 \\
\hline TFB2M_HUMAN & TFB2M \\
\hline PARP2_HUMAN & PARP2 \\
\hline YIF1B_HUMAN & YIF1B \\
\hline GULP1_HUMAN & GULP1 \\
\hline RS23_HUMAN & RPS23 \\
\hline PUSL1_HUMAN & PUSL1 \\
\hline ITPA_HUMAN & ITPA \\
\hline NIP7_HUMAN & NIP7 \\
\hline PHF8_HUMAN & PHF8 \\
\hline CSN6_HUMAN & COPS6 \\
\hline TIM_HUMAN & TIMELESS \\
\hline FA45B_HUMAN & FAM45B \\
\hline RPB1_HUMAN & POLR2A \\
\hline PELP1_HUMAN & PELP1 \\
\hline
\end{tabular}


E3 ubiquitin-protein ligase TRIM21

Calcium uniporter protein, mitochondrial

Pre-mRNA-splicing factor SPF27

Thioredoxin domain-containing protein 5

Guanine nucleotide-binding protein $\mathrm{G}(\mathrm{k})$ subunit alpha

39S ribosomal protein L38, mitochondrial

28 S ribosomal protein $\mathrm{S} 22$, mitochondrial

39S ribosomal protein L37, mitochondrial

Solute carrier family 25 member 40

Lon protease homolog, mitochondrial

WD repeat-containing protein 81

Radical S-adenosyl methionine domain-containing protein 1, mitochondrial

\section{Talin-1}

Prolyl 4-hydroxylase subunit alpha-1

Ras GTPase-activating protein-binding protein 2

39S ribosomal protein L10, mitochondrial

Kinesin-like protein KIF11

Tubulin beta-2B chain

Zinc finger RNA-binding protein 2

TATA box-binding protein-like protein 2

RNA-binding protein with serine-rich domain 1

Argininosuccinate synthase

F-box/SPRY domain-containing protein 1

Ig lambda-2 chain $\mathrm{C}$ regions

Neuronal-specific septin-3

Bleomycin hydrolase

Bifunctional ATP-dependent dihydroxyacetone kinase/FAD-AMP lyase (cyclizing)

Legumain

Elongator complex protein 3

RNA-binding protein 4

YTH domain-containing family protein 2

Structural maintenance of chromosomes protein $1 \mathrm{~A}$

Importin subunit alpha-5

Dual specificity mitogen-activated protein kinase kinase 4

Crk-like protein

Chromodomain-helicase-DNA-binding protein 4

Protein TBRG4

Heterogeneous nuclear ribonucleoprotein $\mathrm{F}$

\begin{tabular}{|c|c|}
\hline RO52_HUMAN & TRIM21 \\
\hline MCU_HUMAN & $\mathrm{MCU}$ \\
\hline SPF27_HUMAN & BCAS2 \\
\hline TXND5_HUMAN & TXNDC5 \\
\hline GNAI3_HUMAN & GNAI3 \\
\hline RM38_HUMAN & MRPL38 \\
\hline RT22_HUMAN & MRPS22 \\
\hline RM37_HUMAN & MRPL37 \\
\hline S2540_HUMAN & SLC25A40 \\
\hline LONM_HUMAN & LONP1 \\
\hline WDR81_HUMAN & WDR81 \\
\hline RSAD1_HUMAN & RSAD1 \\
\hline TLN1_HUMAN & TLN1 \\
\hline P4HA1_HUMAN & P4HA1 \\
\hline G3BP2_HUMAN & G3BP2 \\
\hline RM10_HUMAN & MRPL10 \\
\hline KIF11_HUMAN & KIF11 \\
\hline TBB2B_HUMAN & TUBB2B \\
\hline ZFR2_HUMAN & ZFR2 \\
\hline TBPL2_HUMAN & TBPL2 \\
\hline RNPS1_HUMAN & RNPS1 \\
\hline ASSY_HUMAN & ASS1 \\
\hline FBSP1_HUMAN & FBXO45 \\
\hline LAC2_HUMAN & IGLC2 \\
\hline SEPT3_HUMAN & SEPT3 \\
\hline BLMH_HUMAN & BLMH \\
\hline DHAK_HUMAN & DAK \\
\hline LGMN_HUMAN & LGMN \\
\hline ELP3_HUMAN & ELP3 \\
\hline RBM4_HUMAN & RBM4 \\
\hline YTHD2_HUMAN & YTHDF2 \\
\hline SMC1A_HUMAN & SMC1A \\
\hline IMA5_HUMAN & KPNA1 \\
\hline MP2K4_HUMAN & MAP2K4 \\
\hline CRKL_HUMAN & CRKL \\
\hline CHD4_HUMAN & CHD4 \\
\hline TBRG4_HUMAN & TBRG4 \\
\hline HNRPF_HUMAN & HNRNPF \\
\hline
\end{tabular}


Midasin

RNA-binding motif protein, X chromosome

Heterogeneous nuclear ribonucleoprotein A1

Kinesin-like protein KIF14

PCI domain-containing protein 2

Nuclear RNA export factor 1

Short/branched chain specific acyl-CoA dehydrogenase, mitochondrial 39S ribosomal protein L11, mitochondrial

Transformation/transcription domain-associated protein

Bystin

Heterogeneous nuclear ribonucleoproteins A2/B1

Probable rRNA-processing protein EBP2

DNA mismatch repair protein Msh6

Putative ATP-dependent RNA helicase DHX57

Vacuolar protein sorting-associated protein 33B

Cleavage and polyadenylation specificity factor subunit 1

Ubiquitin-like modifier-activating enzyme 1

Ribosome production factor 2 homolog

Erythrocyte band 7 integral membrane protein

Heterogeneous nuclear ribonucleoprotein $\mathrm{R}$

DNA polymerase delta catalytic subunit

Protein flightless-1 homolog

Thyroid transcription factor 1-associated protein 26

Mitochondrial 2-oxoglutarate/malate carrier protein

Nucleoprotein TPR

Pyruvate dehydrogenase protein X component, mitochondrial

High mobility group protein B1

HEAT repeat-containing protein $5 \mathrm{~B}$

Dehydrogenase/reductase SDR family member 4

Intron-binding protein aquarius

Glucose-6-phosphate translocase

Focadhesin

Ubiquitin-conjugating enzyme E2 S

Developmentally-regulated GTP-binding protein 2

U2 snRNP-associated SURP motif-containing protein

Filamin-B

Gem-associated protein 5

Zinc finger $\mathrm{CCCH}$ domain-containing protein 4

$\begin{array}{ll}\text { MDN1_HUMAN } & \text { MDN1 } \\ \text { RBMX_HUMAN } & \text { RBMX } \\ \text { ROA1_HUMAN } & \text { HNRNPA1 } \\ \text { KIF14_HUMAN } & \text { KIF14 } \\ \text { PCID2_HUMAN } & \text { PCID2 } \\ \text { NXF1_HUMAN } & \text { NXF1 } \\ \text { ACDSB_HUMAN } & \text { ACADSB } \\ \text { RM11_HUMAN } & \text { MRPL11 } \\ \text { TRRAP_HUMAN } & \text { TRRAP } \\ \text { BYST_HUMAN } & \text { BYSL } \\ \text { ROA2_HUMAN } & \text { HNRNPA2B1 } \\ \text { EBP2_HUMAN } & \text { EBNA1BP2 } \\ \text { MSH6_HUMAN } & \text { MSH6 } \\ \text { DHX57_HUMAN } & \text { DHX57 } \\ \text { VP33B_HUMAN } & \text { VPS33B } \\ \text { CPSF1_HUMAN } & \text { CPSF1 } \\ \text { UBA1_HUMAN } & \text { UBA1 } \\ \text { RPF2_HUMAN } & \text { RPF2 } \\ \text { STOM_HUMAN } & \text { STOM } \\ \text { HNRPR_HUMAN } & \text { HNRNPR } \\ \text { DPOD1_HUMAN } & \text { POLD1 } \\ \text { FLII_HUMAN } & \text { FLII } \\ \text { TAP26_HUMAN } & \text { CCDC59 } \\ \text { M2OM_HUMAN } & \text { SLC25A11 } \\ \text { TPR_HUMAN } & \text { TPR } \\ \text { ODPX_HUMAN } & \text { PDHX } \\ \text { HMGB1_HUMAN } & \text { HMGB1 } \\ \text { HTR5B_HUMAN } & \text { HEATR5B } \\ \text { DHRS4_HUMAN } & \text { DHRS4 } \\ \text { AQR_HUMAN } & \text { AQR } \\ \text { G6PT1_HUMAN } & \text { SLC37A4 } \\ \text { FOCAD_HUMAN } & \text { FOCAD } \\ \text { UBE2S_HUMAN } & \text { UBE2S } \\ \text { DRG2_HUMAN } & \text { DRG2 } \\ \text { SR140_HUMAN } & \text { U2SURP } \\ \text { FLNB_HUMAN } & \text { FLNB } \\ \text { GEMI5_HUMAN } & \text { GEMIN5 } \\ \text { ZC3H4_HUMAN } & \text { ZC3H4 }\end{array}$

$\begin{array}{cccc}26 & 28 & 25 & 1.935 \\ 212 & 208 & 217 & 1.924 \\ 194 & 210 & 180 & 1.915 \\ 2 & 4 & 5 & 1.913 \\ 17 & 15 & 16 & 1.908 \\ 4 & 4 & 4 & 1.904 \\ 26 & 24 & 29 & 1.888 \\ 0 & 9 & 0 & 1.887 \\ 26 & 18 & 21 & 1.879 \\ 4 & 5 & 2 & 1.876 \\ 345 & 319 & 283 & 1.860 \\ 18 & 17 & 15 & 1.854 \\ 19 & 22 & 22 & 1.851 \\ 5 & 6 & 7 & 1.844 \\ 7 & 0 & 0 & 1.843 \\ 35 & 43 & 34 & 1.836 \\ 16 & 5 & 8 & 1.832 \\ 11 & 17 & 15 & 1.832 \\ 5 & 7 & 4 & 1.830 \\ 174 & 145 & 147 & 1.830 \\ 6 & 12 & 11 & 1.818 \\ 14 & 12 & 13 & 1.807 \\ 6 & 5 & 9 & 1.800 \\ 54 & 53 & 18 & 1.797 \\ 0 & 2 & 2 & 1.776 \\ 0 & 2 & 2 & 1.776 \\ 0 & 2 & 2 & 1.776 \\ 0 & 0 & 3 & 1.765 \\ 0 & 0 & 3 & 1.765 \\ 0 & 0 & 3 & 1.765 \\ 0 & 0 & 3 & 1.765 \\ 0 & 0 & 3 & 1.765 \\ 0 & 0 & 3 & 1.765 \\ 0 & 0 & 3 & 1.765 \\ 0 & 0 & 3 & 1.765 \\ 0 & 0 & 3 & 1.765 \\ 0 & 0 & 3 & 1.765 \\ 0 & 0 & 3 & 1.765\end{array}$

Page 13 of Table S-2 
HLA class I histocompatibility antigen, $\mathrm{Cw}-7$ alpha chain Ribosome maturation protein SBDS

F-actin-capping protein subunit alpha-2

$28 \mathrm{~S}$ ribosomal protein $\mathrm{S} 25$, mitochondrial Importin-7

DDB1- and CUL4-associated factor 7

Exportin-7

Importin subunit alpha-1

La-related protein 7

E3 ubiquitin-protein ligase RNF213

Y-box-binding protein 3

Aldehyde dehydrogenase, mitochondrial

FAS-associated factor 2

DNA repair protein $\mathrm{XRCC} 3$

Basic leucine zipper and $\mathrm{W} 2$ domain-containing protein 1

Glutathione S-transferase omega-1

DnaJ homolog subfamily $\mathrm{C}$ member 7

Nucleolar protein 9

3-hydroxyisobutyryl-CoA hydrolase, mitochondrial

Kinesin-like protein KIF20B

Presqualene diphosphate phosphatase

Phospholipase ABHD3

Armadillo repeat-containing protein 8

AP-3 complex subunit sigma-1

Lysocardiolipin acyltransferase 1

Exosome complex component RRP45

Transcription termination factor 1 , mitochondrial

Testis-expressed sequence 264 protein

Mitochondrial ribonuclease $P$ protein 3

Helicase-like transcription factor

39S ribosomal protein L44, mitochondrial

Zinc finger CCHC domain-containing protein 3

Septin-9

Double-stranded RNA-specific adenosine deaminase

Phosphoglycerate mutase 1

Kinesin-like protein KIF23

Renin receptor

Arginine and glutamate-rich protein 1

\begin{tabular}{|c|c|}
\hline 1C07_HUMAN & HLA-C \\
\hline SBDS_HUMAN & SBDS \\
\hline CAZĀ2_HUMAN & CAPZA2 \\
\hline RT25_HUMAN & MRPS25 \\
\hline IPO7_HUMAN & IPO7 \\
\hline DCAF7_HUMAN & DCAF7 \\
\hline XPO7_HUMAN & XPO7 \\
\hline IMA1_HUMAN & KPNA2 \\
\hline LARP7_HUMAN & LARP7 \\
\hline RN213_HUMAN & RNF213 \\
\hline YBOX3_HUMAN & YBX3 \\
\hline ALDH2_HUMAN & ALDH2 \\
\hline FAF2_HUMAN & FAF2 \\
\hline XRCC3_HUMAN & XRCC3 \\
\hline BZW1_-̄HUMAN & BZW1 \\
\hline GSTO1_HUMAN & GSTO1 \\
\hline DNJC7_HUMAN & DNAJC7 \\
\hline NOP9_-̄HUMAN & NOP9 \\
\hline HIBCH_HUMAN & $\mathrm{HIBCH}$ \\
\hline KI20B_HUMAN & KIF20B \\
\hline PPAC2_HUMAN & PPAPDC2 \\
\hline ABHD3_HUMAN & ABHD3 \\
\hline ARMC8_HUMAN & ARMC8 \\
\hline AP3S1_HUMAN & AP3S1 \\
\hline LCLT1_HUMAN & LCLAT1 \\
\hline EXOS9_HUMAN & EXOSC9 \\
\hline MTEF1_HUMAN & MTERF1 \\
\hline TX264_HUMAN & TEX264 \\
\hline MRRP3_HUMAN & KIAA0391 \\
\hline HLTF_HUMAN & HLTF \\
\hline RM44_HUMAN & MRPL44 \\
\hline ZCHC3_HUMAN & $\mathrm{ZCCHC} 3$ \\
\hline SEPT9_HUMAN & SEPT9 \\
\hline DSRAD_HUMAN & ADAR \\
\hline PGAM1_HUMAN & PGAM1 \\
\hline KIF23_HUMAN & KIF23 \\
\hline RENR_HUMAN & ATP6AP2 \\
\hline ARGL1_HUMAN & ARGLU1 \\
\hline
\end{tabular}


Arginase-1

Serine-threonine kinase receptor-associated protein

Splicing factor U2AF $35 \mathrm{kDa}$ subunit

Protein SEC13 homolog

Probable ubiquitin carboxyl-terminal hydrolase FAF-X

ER membrane protein complex subunit 3

Eukaryotic translation initiation factor 4 gamma 1

Ribonuclease $\mathrm{P}$ protein subunit $\mathrm{p} 30$

28S ribosomal protein $\mathrm{S} 9$, mitochondrial

Probable glutamate--tRNA ligase, mitochondrial

Polymerase delta-interacting protein 3

Guanine nucleotide-binding protein subunit beta-like protein 1

Flotillin-2

Serine-protein kinase ATM

U3 small nucleolar RNA-associated protein 18 homolog

Serine/threonine-protein kinase haspin

Zinc finger CCHC domain-containing protein 8

Clathrin interactor 1

Acidic leucine-rich nuclear phosphoprotein 32 family member B

5 '-nucleotidase domain-containing protein 2

Nucleoporin SEH1

3-hydroxyacyl-CoA dehydrogenase type-2

NAD(P) transhydrogenase, mitochondrial

Ras suppressor protein 1

Rhomboid domain-containing protein 2

Putative tRNA (cytidine(32)/guanosine(34)-2'-O)-methyltransferase

Lactotransferrin

Phosphoribosyltransferase domain-containing protein 1

Homeobox protein Hox-B9

Histidine ammonia-lyase

Haptoglobin

Phosphoribosyl pyrophosphate synthase-associated protein 2

Heterogeneous nuclear ribonucleoprotein A0

Proteasome-associated protein ECM29 homolog

Polymerase delta-interacting protein 2

Pescadillo homolog

Peroxisomal membrane protein PEX16

Pre-mRNA-processing-splicing factor 8
ARGI1_HUMAN ARG1

STRAP_HUMAN STRAP

U2AF1 HUMAN U2AF1

SEC13_HUMAN SEC13

USP9X HUMAN USP9X

EMC3_HUMAN EMC3

IF4G1_HUMAN EIF4G1

RPP30_HUMAN RPP30

RT09 HUMAN MRPS9

SYEM_HUMAN EARS2

PDIP3_HUMAN POLDIP3

GNB1L_HUMAN GNB1L

FLOT2 HUMAN FLOT2

ATM HUMAN ATM

UTP18_HUMAN UTP18

HASP_HUMAN GSG2

ZCHC8 HUMAN ZCCHC8

EPN4_HUMAN CLINT1

AN32B_HUMAN ANP32B

NT5D2 HUMAN NT5DC2

SEH1_HUMAN SEH1L

HCD2_HUMAN HSD17B10

NNTM_HUMAN NNT

RSU1 HUMAN RSU1

RHBD2_HUMAN RHBDD2

TRM7_HUMAN FTSJ1

TRFL_HUMAN LTF

PRDC1 HUMAN PRTFDC1

HXB9 HUMAN HOXB9

HUTH_HUMAN HAL

HPT HUMAN HP

KPRB HUMAN PRPSAP2

ROA0 HUMAN HNRNPA0

ECM29_HUMAN ECM29

PDIP2 HUMAN POLDIP2

PESC HUMAN PES1

PEX16 HUMAN PEX16

PRP8_HUMAN PRPF8

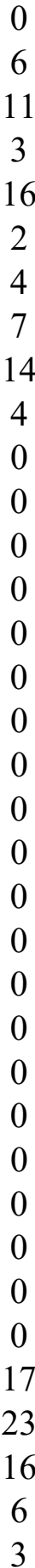

2


Golgi-specific brefeldin A-resistance guanine nucleotide exchange factor 1 GBF1_HUMAN GBF1

Melanoma-associated antigen D2

MAGD2_HUMAN MAGED2

NUMA1_HUMAN NUMA1

ELMO domain-containing protein 2

ELMD2_HUMAN ELMOD2

Insulin-like growth factor $2 \mathrm{mRNA}$-binding protein 1

IF2B1_HUMAN IGF2BP1

Fatty acid synthase

FAS_HUMAN FASN

SYFA_HUMAN FARSA

MBB1A_HUMAN MYBBP1A

Myb-binding protein 1A

NADH-cytochrome b5 reductase 3

EH domain-containing protein 1

NB5R3_HUMAN CYB5R3

EHD1_HUMAN EHD1

Plasma membrane calcium-transporting ATPase 1

AT2B1_HUMAN ATP2B1

KH domain-containing, RNA-binding, signal transduction-associated protein 1 KHDR1_HUMAN KHDRBS1

Actin-related protein 2

Syntaxin-18

RNA binding protein fox-1 homolog 2

Cat eye syndrome critical region protein 5

Paired amphipathic helix protein Sin3a

Replication factor $\mathrm{C}$ subunit 2

Clathrin heavy chain 1

Nuclear pore complex protein Nup214

Nck-associated protein 1

Mitochondrial import receptor subunit TOM40 homolog

ATPase family AAA domain-containing protein 3B

Bifunctional purine biosynthesis protein PURH

Putative ATP-dependent RNA helicase DHX30

ARP2_HUMAN ACTR2

STX18_HUMAN STX18

RFOX2_HUMAN RBFOX2

CECR5_HUMAN CECR5

SIN3A_HUMAN SIN3A

RFC2 HUMAN RFC2

CLH1_HUMAN CLTC

NU214_HUMAN NUP214

NCKP1_HUMAN NCKAP1

TOM40_HUMAN TOMM40

ATD3B_HUMAN ATAD3B

PUR9_HUMAN ATIC

DHX30_HUMAN DHX30

U4/U6 small nuclear ribonucleoprotein Prp4

PRP4_HUMAN PRPF4

Crooked neck-like protein 1

CRNL1_HUMAN CRNKL1

MTNA_HUMAN MRI1

HNRPK HUMAN HNRNPK

Methylthioribose-1-phosphate isomerase

Heterogeneous nuclear ribonucleoprotein $\mathrm{K}$

$\begin{array}{lr}\text { Serine/threonine-protein phosphatase 2A } 65 \mathrm{kDa} \text { regulatory subunit A alpha isoform } 2 \mathrm{AAA} \text { HUMAN PPP2R1A } \\ \text { ELAV-like protein } 1 & \text { ELAV1_HUMAN ELAVL1 }\end{array}$

Adenylate kinase 4, mitochondrial

KAD4 HUMAN AK4

ADP/ATP translocase 1

ADT1_HUMAN SLC25A4

DPOE1_HUMAN POLE

DNA polymerase epsilon catalytic subunit A

Tubulin beta-2A chain

TBB2A_HUMAN TUBB2A

$\begin{array}{cccc}9 & 12 & 13 & 1.630 \\ 129 & 134 & 116 & 1.628 \\ 14 & 21 & 18 & 1.615 \\ 15 & 23 & 13 & 1.613 \\ 9 & 10 & 7 & 1.601 \\ 130 & 114 & 98 & 1.600 \\ 10 & 15 & 7 & 1.593 \\ 162 & 133 & 167 & 1.591 \\ 64 & 43 & 56 & 1.587 \\ 5 & 6 & 5 & 1.585 \\ 77 & 53 & 82 & 1.578 \\ 0 & 3 & 5 & 1.577 \\ 10 & 5 & 8 & 1.576 \\ 0 & 4 & 4 & 1.572 \\ 11 & 13 & 17 & 1.571 \\ 19 & 19 & 14 & 1.566 \\ 3 & 6 & 7 & 1.566 \\ 9 & 0 & 4 & 1.563 \\ 26 & 22 & 24 & 1.547 \\ 3 & 6 & 2 & 1.541 \\ 29 & 22 & 21 & 1.539 \\ 33 & 26 & 50 & 1.539 \\ 5 & 5 & 5 & 1.538 \\ 3 & 0 & 3 & 1.532 \\ 16 & 11 & 19 & 1.525 \\ 8 & 8 & 6 & 1.523 \\ 7 & 7 & 9 & 1.512 \\ 80 & 82 & 75 & 1.510 \\ 8 & 3 & 6 & 1.509 \\ 3 & 4 & 5 & 1.507 \\ 21 & 27 & 21 & 1.507 \\ 99 & 73 & 72 & 1.507 \\ 9 & 3 & 6 & 1.501 \\ 86 & 97 & 101 & 1.499 \\ 10 & 9 & 13 & 1.486 \\ 8 & 9 & 8 & 1.486 \\ 16 & 19 & 12 & 1.481 \\ 25 & 22 & 22 & 1.480\end{array}$


Exosome complex exonuclease RRP44

Splicing factor 3B subunit 1

T-complex protein 1 subunit delta

60S ribosomal protein $\mathrm{L} 27 \mathrm{a}$

Acyl-coenzyme A thioesterase 8

AP-1 complex subunit beta-1

MICOS complex subunit MIC27

Putative RNA-binding protein 15

Dihydrolipoyllysine-residue acetyltransferase component of pyruvate dehydrogenase complex, mitochondrial

Lipopolysaccharide-responsive and beige-like anchor protein

Protein MON2 homolog

Ribonucleases P/MRP protein subunit POP1

Mannose-1-phosphate guanyltransferase alpha

Dolichol-phosphate mannosyltransferase subunit 1

39S ribosomal protein L3, mitochondrial

Pyruvate dehydrogenase E1 component subunit alpha, somatic form, mitochondrial

Eukaryotic translation initiation factor 4 gamma 2

Insulin-like growth factor $2 \mathrm{mRNA}$-binding protein 3

Leucine-rich PPR motif-containing protein, mitochondrial

Integrator complex subunit 1

Guanine nucleotide-binding protein $\mathrm{G}(\mathrm{s})$ subunit alpha isoforms short

Probable ATP-dependent RNA helicase DDX56

Neuroblastoma-amplified sequence

Glutaminyl-peptide cyclotransferase-like protein

DBIRD complex subunit ZNF326

Tubulin alpha-1B chain

Neurofilament medium polypeptide

Replication factor $\mathrm{C}$ subunit 5

E3 ubiquitin-protein ligase TRIP12

Sarcoplasmic/endoplasmic reticulum calcium ATPase 2

Sodium/potassium-transporting ATPase subunit alpha-1

Tubulin beta- 6 chain

$116 \mathrm{kDa}$ U5 small nuclear ribonucleoprotein component

Eukaryotic translation initiation factor 3 subunit $\mathrm{H}$

Brefeldin A-inhibited guanine nucleotide-exchange protein 2

Baculoviral IAP repeat-containing protein 6

Vacuolar protein sorting-associated protein 13C

Histone-lysine N-methyltransferase, H3 lysine-79 specific
RRP44_HUMAN DIS3

SF3B1 HUMAN SF3B1

TCPD_HUMAN CCT4

RL27A_HUMAN RPL27A

ACOT8 HUMAN ACOT8

AP1B1_HUMAN AP1B1

MIC27_HUMAN APOOL

RBM15_HUMAN RBM15

ODP2 HUMAN DLAT

LRBA HUMAN LRBA

MON2_HUMAN MON2

POP1_HUMAN POP1

GMPPA HUMAN GMPPA

DPM1 HUMAN DPM1

RM03_HUMAN MRPL3

ODPA_HUMAN PDHA1

IF4G2 HUMAN EIF4G2

IF2B3_HUMAN IGF2BP3

LPPRC_HUMAN LRPPRC

INT1 HUMAN INTS1

GNA $\bar{S} 2$ HUMAN GNAS

DDX56_HUMAN DDX56

NBAS_HUMAN NBAS

QPCTL HUMAN QPCTL

ZN326 HUMAN ZNF326

TBA1B_HUMAN TUBA1B

NFM HUMAN NEFM

RFC5 HUMAN RFC5

TRIPC HUMAN TRIP12

AT2A2_HUMAN ATP2A2

AT1A1 HUMAN ATP1A1

TBB6 HUMAN TUBB6

U5S1_HUMAN EFTUD2

EIF3H_HUMAN EIF3H

BIG2 HUMAN ARFGEF2

BIRC6 HUMAN BIRC6

VP13C_HUMAN VPS13C

DOT1L_HUMAN DOT1L 
Tyrosine-protein kinase BAZ1B

Alkyldihydroxyacetonephosphate synthase, peroxisomal

Protein LTV1 homolog

7SK snRNA methylphosphate capping enzyme

Interferon-related developmental regulator 2

Periodic tryptophan protein 1 homolog

DnaJ homolog subfamily B member 1

Proto-oncogene tyrosine-protein kinase Src

Vesicle-associated membrane protein-associated protein B/C

Minor histocompatibility antigen $\mathrm{H} 13$

Protein disulfide-isomerase A4

Brefeldin A-inhibited guanine nucleotide-exchange protein 1

SAC3 domain-containing protein 1

Sorting nexin-1

Putative methyltransferase NSUN3

Eukaryotic translation initiation factor 6

COP9 signalosome complex subunit $7 \mathrm{a}$

Rab-like protein 3

Galactokinase

Replication protein A 70 kDa DNA-binding subunit

DNA replication licensing factor MCM6

Signal recognition particle receptor subunit beta

Tetratricopeptide repeat protein 37

Collagen alpha-2(IV) chain

Epiplakin

Filamin-C

Isobutyryl-CoA dehydrogenase, mitochondrial

Syntaxin-binding protein 1

Cytochrome c1, heme protein, mitochondrial

Protein AAR2 homolog

Phosphatidylglycerophosphatase and protein-tyrosine phosphatase 1

Tumor necrosis factor receptor type 1-associated DEATH domain protein Flotillin-1

WD repeat-containing protein 18

SWI/SNF-related matrix-associated actin-dependent regulator of chromatin subfamily A containing DEAD/H box 1

Proto-oncogene tyrosine-protein kinase ROS

39S ribosomal protein L47, mitochondrial

Trafficking protein particle complex subunit 5

\begin{tabular}{|c|c|}
\hline BAZ1B_HUMAN & BAZ1B \\
\hline ADAS_HUMAN & AGPS \\
\hline LTV1_HUMAN & LTV1 \\
\hline MEPCE_HUMAN & MEPCE \\
\hline IFRD2_HUMAN & IFRD2 \\
\hline PWP1_HUMAN & PWP1 \\
\hline DNJB1_HUMAN & DNAJB1 \\
\hline SRC HUMAN & $\mathrm{SRC}$ \\
\hline VAPB_HUMAN & VAPB \\
\hline HM13_HUMAN & HM13 \\
\hline PDIA4_HUMAN & PDIA4 \\
\hline BIG1_HUMAN & ARFGEF1 \\
\hline SAC31_HUMAN & SAC3D1 \\
\hline SNX1_HUMAN & SNX1 \\
\hline NSUN3_HUMAN & NSUN3 \\
\hline IF6_HUMAN & EIF6 \\
\hline CSN7A_HUMAN & COPS7A \\
\hline RABL3_HUMAN & RABL3 \\
\hline GALK1_HUMAN & GALK1 \\
\hline RFA1_HUMAN & RPA1 \\
\hline MCM6_HUMAN & MCM6 \\
\hline SRPRB_HUMAN & SRPRB \\
\hline TTC37_HUMAN & TTC37 \\
\hline CO4A2_HUMAN & COL4A2 \\
\hline EPIPL_HUMAN & EPPK1 \\
\hline FLNC_HUMAN & FLNC \\
\hline ACAD8_HUMAN & ACAD8 \\
\hline STXB1_HUMAN & STXBP1 \\
\hline CY1_HUMAN & CYC1 \\
\hline AAR2_HUMAN & AAR2 \\
\hline PTPM1_HUMAN & PTPMT1 \\
\hline TRADD_HUMAN & TRADD \\
\hline FLOT1_HUMAN & FLOT1 \\
\hline WDR18_HUMAN & WDR18 \\
\hline SMRCD_HUMAN & SMARCAD1 \\
\hline ROS1_HUMAN & ROS1 \\
\hline RM47_HUMAN & MRPL47 \\
\hline TPPC5_HUMAN & TRAPPC5 \\
\hline
\end{tabular}

1.399
1.399
1.399
1.399
1.399
1.399
1.399
1.399
1.399
1.399
1.399
1.399
1.399
1.399
1.399
1.399
1.399
1.399
1.394
1.389
1.388
1.383
1.377
1.377
1.377
1.377
1.377
1.377
1.377
1.377
1.377
1.377
1.377
1.377
1.377
1.377
1.377
1.377
18 of Table S-2 
UPF0428 protein CXorf56

Gamma-tubulin complex component 6

Histone acetyltransferase type B catalytic subunit

Zinc finger protein $\mathrm{OZF}$

RNA-binding protein $8 \mathrm{~A}$

Cyclin-dependent kinase 4

Acidic leucine-rich nuclear phosphoprotein 32 family member A

Mannose-P-dolichol utilization defect 1 protein

Probable methyltransferase-like protein 15

Eukaryotic initiation factor 4A-III

Bifunctional glutamate/proline--tRNA ligase

$28 \mathrm{~S}$ ribosomal protein $\mathrm{S} 31$, mitochondrial

RNA-binding protein 25

26S proteasome non-ATPase regulatory subunit 7

Guanine nucleotide-binding protein $\mathrm{G}(\mathrm{I}) / \mathrm{G}(\mathrm{S}) / \mathrm{G}(\mathrm{T})$ subunit beta-2 Ataxin-10

DNA topoisomerase 2-alpha

Fructose-bisphosphate aldolase A

Gem-associated protein 4

AP-1 complex subunit mu-1

Putative ATP-dependent RNA helicase DHX33

Histone H2B type 1-C/E/F/G/I

Squamous cell carcinoma antigen recognized by T-cells 3

Terminal uridylyltransferase 7

Condensin-2 complex subunit G2

Histone-arginine methyltransferase CARM1

Mitochondrial folate transporter/carrier

Alcohol dehydrogenase class-3

DNA primase small subunit

Sterol-4-alpha-carboxylate 3-dehydrogenase, decarboxylating

Zinc finger protein 771

Nucleoside diphosphate-linked moiety X motif 19, mitochondrial

RNA-binding protein FUS

2-oxoisovalerate dehydrogenase subunit alpha, mitochondrial

Putative RNA-binding protein Luc7-like 1

Beta-lactamase-like protein 2

28S ribosomal protein S30, mitochondrial

BRCA2 and CDKN1A-interacting protein

$\begin{array}{ll}\text { CX056_HUMAN } & \text { CXorf56 } \\ \text { GCP6_HUMAN } & \text { TUBGCP6 } \\ \text { HAT1_HUMAN } & \text { HAT1 } \\ \text { OZF_HUMAN } & \text { ZNF146 } \\ \text { RBM8A_HUMAN } & \text { RBM8A } \\ \text { CDK4_HUMAN } & \text { CDK4 } \\ \text { AN32A_HUMAN } & \text { ANP32A } \\ \text { MPU1_HUMAN } & \text { MPDU1 } \\ \text { MET15_HUMAN } & \text { METTL15 } \\ \text { IF4A3_HUMAN } & \text { EIF4A3 } \\ \text { SYEP_HUMAN } & \text { EPRS } \\ \text { RT31_HUMAN } & \text { MRPS31 } \\ \text { RBM25_HUMAN } & \text { RBM25 } \\ \text { PSMD7_HUMAN } & \text { PSMD7 } \\ \text { GBB2_HUMAN } & \text { GNB2 } \\ \text { ATX10_HUMAN } & \text { ATXN10 } \\ \text { TOP2A_HUMAN } & \text { TOP2A } \\ \text { ALDOA_HUMAN } & \text { ALDOA } \\ \text { GEMI4_HUMAN } & \text { GEMIN4 } \\ \text { AP1M1_HUMAN } & \text { AP1M1 } \\ \text { DHX33_HUMAN } & \text { DHX33 } \\ \text { H2B1C_HUMAN } & \text { HIST1H2BC } \\ \text { SART3_HUMAN } & \text { SART3 } \\ \text { TUT7_HUMAN } & \text { ZCCHC6 } \\ \text { CNDG2_HUMAN NCAPG2 } & \text { CARM1_HUMAN CARM1 } \\ \text { MFTC_HUMAN } & \text { SLC25A32 } \\ \text { ADHX_HUMAN } & \text { ADH5 } \\ \text { PRI1_HUMAN } & \text { PRIM1 } \\ \text { NSDHL_HUMAN NSDHL } \\ \text { ZN771_HUMAN } & \text { ZNF771 } \\ \text { NUD19_HUMAN } & \text { NUDT19 } \\ \text { FUS_HUMAN } & \text { FUS } \\ \text { ODBA_HUMAN } & \text { BCKDHA } \\ \text { LUC7L_HUMAN } & \text { LUC7L } \\ \text { LACB2_HUMAN } & \text { LACTB2 } \\ \text { RT30_HUMAN } & \text { MRPS30 } \\ \text { BCCIP_HUMAN } & \text { BCCIP } \\ & \end{array}$

1.377
1.377
1.377
1.377
1.377
1.377
1.377
1.377
1.374
1.368
1.366
1.362
1.358
1.350
1.342
1.341
1.341
1.340
1.338
1.335
1.335
1.333
1.333
1.333
1.333
1.333
1.333
1.333
1.333
1.333
1.333
1.333
1.333
1.333
1.333
1.333
1.333
1.333
19 of Table S-2 
60S ribosomal protein $\mathrm{L} 11$

Medium-chain specific acyl-CoA dehydrogenase, mitochondrial Cyclin-dependent kinase 2

pre-rRNA processing protein FTSJ3

RNA 3'-terminal phosphate cyclase

Phosphatidylinositol 4-kinase alpha

$26 \mathrm{~S}$ protease regulatory subunit $10 \mathrm{~B}$

Erlin-1

28S ribosomal protein $\mathrm{S} 35$, mitochondrial

39S ribosomal protein L46, mitochondrial

Lysozyme C

Dual specificity mitogen-activated protein kinase kinase 2

TATA-binding protein-associated factor 172

28S ribosomal protein $\mathrm{S} 27$, mitochondrial

Eukaryotic translation initiation factor 3 subunit D

Protein transport protein Sec61 subunit alpha isoform 1

Isocitrate dehydrogenase [NADP], mitochondrial

Monocarboxylate transporter 1

DNA-directed RNA polymerase II subunit RPB3

Splicing factor U2AF $65 \mathrm{kDa}$ subunit

Replication factor C subunit 3

D-3-phosphoglycerate dehydrogenase

La-related protein 1

Protein DEK

Puromycin-sensitive aminopeptidase

AP-1 complex subunit gamma-1

Transmembrane protein 126A

Poly(rC)-binding protein 1

ATP-dependent zinc metalloprotease YME1L1

Probable ATP-dependent RNA helicase DDX5

CCR4-NOT transcription complex subunit 1

THO complex subunit 3

Lamin-B receptor

Protein virilizer homolog

HEAT repeat-containing protein 1

Exosome complex component RRP43

60S acidic ribosomal protein $\mathrm{P} 0$

ATP synthase subunit alpha, mitochondrial

\begin{tabular}{|c|c|c|c|c|c|c|c|c|}
\hline RL11_HUMAN & RPL11 & 10 & 0 & 4 & 0 & 16 & 12 & 1.333 \\
\hline ACADM_HUMAN & ACADM & 7 & 8 & 6 & 13 & 14 & 16 & 1.333 \\
\hline CDK2_HUMAN & $\mathrm{CDK} 2$ & 10 & 15 & 4 & 23 & 21 & 12 & 1.329 \\
\hline SPB1_HUMAN & FTSJ3 & 0 & 0 & 11 & 7 & 12 & 13 & 1.326 \\
\hline RTCA_HUMAN & RTCA & 12 & 10 & 3 & 16 & 16 & 15 & 1.322 \\
\hline PI4KA_HUMAN & PI4KA & 5 & 0 & 0 & 2 & 5 & 4 & 1.316 \\
\hline PRS10_HUMAN & PSMC6 & 29 & 29 & 20 & 55 & 49 & 52 & 1.315 \\
\hline ERLN1_HUMAN & ERLIN1 & 18 & 15 & 8 & 33 & 28 & 19 & 1.314 \\
\hline RT35_HUMAN & MRPS35 & 7 & 7 & 8 & 16 & 17 & 13 & 1.308 \\
\hline RM46_HUMAN & MRPL46 & 0 & 3 & 5 & 8 & 5 & 7 & 1.306 \\
\hline LYSC_HUMAN & LYZ & 3 & 0 & 0 & 6 & 0 & 0 & 1.302 \\
\hline MP2K2_HUMAN & MAP2K2 & 2 & 2 & 3 & 5 & 7 & 3 & 1.301 \\
\hline BTAF1_HUMAN & BTAF1 & 6 & 4 & 6 & 8 & 13 & 12 & 1.299 \\
\hline RT27_HUMAN & MRPS27 & 15 & 12 & 11 & 28 & 21 & 27 & 1.297 \\
\hline EIF3D_HUMAN & EIF3D & 18 & 21 & 5 & 29 & 21 & 31 & 1.296 \\
\hline S61A1_HUMAN & SEC61A1 & 15 & 18 & 19 & 37 & 35 & 35 & 1.287 \\
\hline IDHP_HUMAN & IDH2 & 25 & 29 & 19 & 49 & 43 & 51 & 1.286 \\
\hline MOT1_HUMAN & SLC16A1 & 8 & 9 & 6 & 16 & 16 & 13 & 1.281 \\
\hline RPB3_HUMAN & POLR2C & 2 & 0 & 2 & 4 & 5 & 0 & 1.280 \\
\hline U2AF2_HUMAN & U2AF2 & 13 & 16 & 8 & 33 & 16 & 22 & 1.274 \\
\hline RFC3_HUMAN & RFC3 & 11 & 15 & 19 & 34 & 30 & 30 & 1.272 \\
\hline SERA_HUMAN & PHGDH & 26 & 24 & 28 & 56 & 54 & 48 & 1.271 \\
\hline LARPי̄1_HUMAN & LARP1 & 21 & 11 & 17 & 33 & 29 & 36 & 1.270 \\
\hline DEK_HUMAN & DEK & 9 & 12 & 7 & 20 & 17 & 17 & 1.267 \\
\hline PSA_HUMAN & NPEPPS & 22 & 18 & 14 & 27 & 35 & 41 & 1.264 \\
\hline AP1G1_HUMAN & AP1G1 & 5 & 5 & 0 & 5 & 6 & 7 & 1.263 \\
\hline T126A_HUMAN & TMEM126A & 4 & 0 & 0 & 0 & 7 & 0 & 1.257 \\
\hline PCBP1_HUMAN & PCBP1 & 30 & 29 & 22 & 56 & 49 & 51 & 1.257 \\
\hline YMEL1_HUMAN & YME1L1 & 0 & 2 & 0 & 3 & 2 & 0 & 1.256 \\
\hline DDX5_ḦUMAN & DDX5 & 63 & 77 & 63 & 133 & 129 & 132 & 1.245 \\
\hline CNOT1_HUMAN & CNOT1 & 8 & 8 & 4 & 15 & 11 & 11 & 1.244 \\
\hline THOC3_HUMAN & THOC3 & 7 & 5 & 0 & 7 & 5 & 9 & 1.243 \\
\hline LBR_HŪMAN & LBR & 29 & 37 & 12 & 44 & 48 & 48 & 1.240 \\
\hline VIR_HUMAN & KIAA1429 & 6 & 0 & 6 & 8 & 8 & 10 & 1.239 \\
\hline HEAT1_HUMAN & HEATR1 & 8 & 13 & 6 & 15 & 17 & 18 & 1.238 \\
\hline EXOS8_HUMAN & EXOSC8 & 7 & 5 & 0 & 7 & 8 & 6 & 1.237 \\
\hline RLA0_HUMAN & RPLP0 & 54 & 56 & 27 & 88 & 91 & 71 & 1.232 \\
\hline ATPA_HUMAN & ATP5A1 & 114 & 100 & 90 & 198 & 196 & 184 & 1.229 \\
\hline
\end{tabular}




\section{Protein DENND6A}

40S ribosomal protein $\mathrm{S} 4, \mathrm{X}$ isoform

Heat shock protein beta-1

Elongation factor 2

Inactive hydroxysteroid dehydrogenase-like protein 1

Glyceraldehyde-3-phosphate dehydrogenase

Probable tRNA N6-adenosine threonylcarbamoyltransferase

Required for meiotic nuclear division protein 1 homolog

Kinetochore-associated protein 1

Poly [ADP-ribose] polymerase 1

Peroxiredoxin-1

Structural maintenance of chromosomes protein 2

Endoplasmin

Translation initiation factor eIF-2B subunit delta

Phosphoglycolate phosphatase

Vimentin

ATP-binding cassette sub-family B member 7, mitochondrial

F-actin-capping protein subunit beta

DEN6A_HUMAN DENND6A

RS4X_HUMAN RPS4X

HSPB1_HUMAN HSPB1

EF2_HÜMAN EEF2

HSDL1_HUMAN HSDL1

G3P_HÜMAN GAPDH

OSGEP HUMAN OSGEP

RMND1_HUMAN RMND1

KNTC1_HUMAN KNTC1

PARP1_HUMAN PARP1

PRDX1_HUMAN PRDX1

SMC2_HUMAN SMC2

ENPL HUMAN HSP90B1

EI2BD HUMAN EIF2B4

PGP_HUMAN PGP

VIME HUMAN VIM

ABCB7 HUMAN ABCB7

CAPZB HUMAN CAPZB

[Pyruvate dehydrogenase (acetyl-transferring)] kinase isozyme 1, mitochondrial PDK1_HUMAN PDK1

Mitochondrial import inner membrane translocase subunit TIM50

TIM50 HUMAN TIMM50

RM19_HUMAN MRPL19

EIF3K HUMAN EIF3K

Eukaryotic translation initiation factor 3 subunit $\mathrm{K}$

$\begin{array}{lll}\text { Putative mitochondrial import inner membrane translocase subunit Tim23B } & \text { TI23B_HUMAN } & \text { TIMM23B } \\ \text { Aminoacyl tRNA synthase complex-interacting multifunctional protein } 2 & \text { AIMP2 HUMAN } & \text { AIMP2 }\end{array}$

[Pyruvate dehydrogenase (acetyl-transferring)] kinase isozyme 3, mitochondrial PDK3 HUMAN PDK3

Probable ATP-dependent RNA helicase DDX23

Replication factor C subunit 1

NF-kappa-B-repressing factor

Tubulin beta chain

WD repeat-containing protein 5

Coatomer subunit alpha

28 S ribosomal protein S23, mitochondrial

Structural maintenance of chromosomes protein 3

Trifunctional purine biosynthetic protein adenosine-3

Elongation factor 1-alpha 1

tRNA (cytosine(34)-C(5))-methyltransferase

Serine/threonine-protein phosphatase 6 catalytic subunit

tRNA (adenine(58)-N(1))-methyltransferase non-catalytic subunit TRM6
DDX23_HUMAN DDX23

RFC1_HUMAN RFC1

NKRF HUMAN NKRF

TBB5 HUMAN TUBB

WDR5_HUMAN WDR5

COPA HUMAN COPA

RT23 HUMAN MRPS23

SMC3 HUMAN SMC3

PUR2_HUMAN GART

EF1A 1 _HUMAN EEF1A1

NSUN2 HUMAN NSUN2

PPP6 HUMAN PPP6C

TRM6_HUMAN TRMT6 $\begin{array}{llll}4 & 0 & 0 & 1.229\end{array}$

$\begin{array}{llll}96 & 110 & 77 & 1.228\end{array}$

$\begin{array}{llll}5 & 0 & 5 & 1.221\end{array}$

$\begin{array}{llll}80 & 81 & 75 & 1.218\end{array}$

$\begin{array}{llll}15 & 13 & 11 & 1.217\end{array}$

$\begin{array}{llll}41 & 32 & 37 & 1.216\end{array}$

$\begin{array}{llll}13 & 13 & 14 & 1.216\end{array}$

$\begin{array}{llll}5 & 8 & 6 & 1.215\end{array}$

$\begin{array}{llll}13 & 13 & 10 & 1.213\end{array}$

$\begin{array}{llll}103 & 77 & 85 & 1.212\end{array}$

$\begin{array}{llll}7 & 26 & 7 & 1.209\end{array}$

$\begin{array}{llll}12 & 10 & 8 & 1.202\end{array}$

$\begin{array}{llll}4 & 4 & 0 & 1.193\end{array}$

$\begin{array}{llll}9 & 5 & 4 & 1.192\end{array}$

$\begin{array}{llll}9 & 9 & 6 & 1.192\end{array}$

$\begin{array}{llll}251 & 225 & 192 & 1.188\end{array}$

$\begin{array}{cccc}3 & 0 & 3 & 1.187\end{array}$

$\begin{array}{llll}4 & 5 & 3 & 1.185\end{array}$

$\begin{array}{llll}5 & 3 & 0 & 1.184\end{array}$

$\begin{array}{llll}33 & 31 & 32 & 1.183\end{array}$

$\begin{array}{llll}14 & 13 & 10 & 1.182\end{array}$

$\begin{array}{llll}0 & 8 & 0 & 1.182\end{array}$

$\begin{array}{llll}0 & 8 & 0 & 1.182\end{array}$

$\begin{array}{llll}15 & 21 & 11 & 1.181\end{array}$

$\begin{array}{llll}4 & 3 & 3 & 1.178\end{array}$

$\begin{array}{llll}3 & 3 & 3 & 1.174\end{array}$

$\begin{array}{llll}8 & 8 & 6 & 1.168\end{array}$

$\begin{array}{llll}10 & 17 & 16 & 1.167\end{array}$

$\begin{array}{llll}491 & 453 & 452 & 1.166\end{array}$

$\begin{array}{llll}14 & 9 & 17 & 1.165\end{array}$

$\begin{array}{llll}30 & 27 & 44 & 1.163\end{array}$

$\begin{array}{llll}0 & 13 & 6 & 1.155\end{array}$

$\begin{array}{llll}24 & 21 & 22 & 1.154\end{array}$

$\begin{array}{llll}14 & 14 & 13 & 1.150\end{array}$

$\begin{array}{llll}233 & 235 & 231 & 1.148\end{array}$

$\begin{array}{llll}17 & 19 & 21 & 1.147\end{array}$

$\begin{array}{llll}12 & 10 & 12 & 1.146\end{array}$

$\begin{array}{llll}3 & 3 & 0 & 1.141\end{array}$

Page 21 of Table S-2 
ATP-dependent RNA helicase DDX54

CAD protein

Very-long-chain 3-oxoacyl-CoA reductase

60S ribosomal protein L10

YTH domain-containing protein 1

Glomulin

Katanin p60 ATPase-containing subunit A1

Probable ATP-dependent RNA helicase DDX27

ATP synthase subunit beta, mitochondrial

Ubiquitin-associated domain-containing protein 2

S1 RNA-binding domain-containing protein 1

NADH dehydrogenase [ubiquinone] 1 alpha subcomplex subunit 9, mitochondrial

Pyruvate dehydrogenase E1 component subunit beta, mitochondrial

SURP and G-patch domain-containing protein 2

Superkiller viralicidic activity 2-like 2

Probable ATP-dependent RNA helicase DDX41

Transformer-2 protein homolog beta

TATA-binding protein-associated factor $2 \mathrm{~N}$

Proteasomal ATPase-associated factor 1

RNA-binding protein 39

40S ribosomal protein $\mathrm{S} 8$

Translation initiation factor eIF-2B subunit gamma

Protein YIPF5

Nuclease-sensitive element-binding protein 1

General transcription factor $3 \mathrm{C}$ polypeptide 5

Flap endonuclease 1

7-dehydrocholesterol reductase

SUN domain-containing protein 1

Lethal(2) giant larvae protein homolog 1

Serpin H1

Cytoplasmic dynein 1 heavy chain 1

$\mathrm{X}$-ray repair cross-complementing protein 6

Protein polybromo-1

60S ribosomal protein L34

Bromodomain adjacent to zinc finger domain protein 1A

Transcriptional activator protein Pur-beta

Succinyl-CoA ligase [GDP-forming] subunit beta, mitochondrial

Replication factor $\mathrm{C}$ subunit 4

\begin{tabular}{|c|c|}
\hline DDX54_HUMAN & DDX54 \\
\hline PYR1_HUMAN & CAD \\
\hline DHB12_HUMAN & HSD17B12 \\
\hline RL10_HUMAN & RPL10 \\
\hline YTDC1_HUMAN & YTHDC1 \\
\hline GLMN_HUMAN & GLMN \\
\hline KTNA1_HUMAN & KATNA1 \\
\hline DDX27_HUMAN & DDX 27 \\
\hline ATPB_HUMAN & ATP5B \\
\hline UBAC̄2_HUMAN & UBAC2 \\
\hline SRBD1_HUMAN & SRBD1 \\
\hline NDUA9_HUMAN & NDUFA9 \\
\hline ODPB_HUMAN & PDHB \\
\hline SUGP2_HUMAN & SUGP2 \\
\hline SK2L2_HUMAN & SKIV2L2 \\
\hline DDX41_HUMAN & DDX41 \\
\hline TRA2B_HUMAN & TRA2B \\
\hline RBP56_HUMAN & TAF15 \\
\hline PAAF1_HUMAN & PAAF1 \\
\hline RBM39_HUMAN & RBM39 \\
\hline RS8_HUMAN & RPS8 \\
\hline EI2BG_HUMAN & EIF2B3 \\
\hline YIPF5_HUMAN & YIPF5 \\
\hline YBOX1_HUMAN & YBX1 \\
\hline TF3C5_HUMAN & GTF3C5 \\
\hline FEN1_HUMAN & FEN1 \\
\hline DHCR7_HUMAN & DHCR7 \\
\hline SUN1_HUMAN & SUN1 \\
\hline L2GL1_HUMAN & LLGL1 \\
\hline SERPH_HUMAN & SERPINH1 \\
\hline DYHC1_HUMAN & DYNC1H1 \\
\hline XRCC6_HUMAN & XRCC6 \\
\hline PB1_HŪMAN & PBRM1 \\
\hline RL34_HUMAN & RPL34 \\
\hline BAZ1A_HUMAN & BAZ1A \\
\hline PURB_HUMAN & PURB \\
\hline SUCB2_HUMAN & SUCLG2 \\
\hline RFC4_HUMAN & RFC4 \\
\hline
\end{tabular}


Serine hydroxymethyltransferase, mitochondrial Translational activator GCN1

U5 small nuclear ribonucleoprotein $200 \mathrm{kDa}$ helicase

Origin recognition complex subunit 5

MMS19 nucleotide excision repair protein homolog

Pumilio homolog 1

Serine/arginine-rich splicing factor 9

Guanine nucleotide-binding protein-like 3

Cleavage and polyadenylation specificity factor subunit 7

Protein RRP5 homolog

Probable ATP-dependent RNA helicase DDX52

Guanine nucleotide-binding protein subunit beta-2-like 1

Mannose-1-phosphate guanyltransferase beta

Ribose-phosphate pyrophosphokinase 2

Vacuolar protein sorting-associated protein 26A

ADP/ATP translocase 2

28S ribosomal protein $\mathrm{S} 18 \mathrm{~b}$, mitochondrial

26S proteasome non-ATPase regulatory subunit 11

Coiled-coil domain-containing protein 47

Pyruvate kinase PKM

Cytoskeleton-associated protein 5

Zinc finger $\mathrm{CCCH}$ domain-containing protein 13

Pyrroline-5-carboxylate reductase 2

Serine/threonine-protein kinase 4

V-type proton ATPase subunit d 1

ATP-dependent Clp protease ATP-binding subunit clpX-like, mitochondrial

Isocitrate dehydrogenase [NAD] subunit gamma, mitochondrial

Poly(U)-binding-splicing factor PUF60

Tuberin

DNA-directed RNA polymerases I and III subunit RPAC1

E3 SUMO-protein ligase RanBP2

Erlin-2

Casein kinase II subunit alpha'

60S ribosomal protein L18

39S ribosomal protein L39, mitochondrial

Ubiquitin-protein ligase E3A

$28 \mathrm{~S}$ ribosomal protein $\mathrm{S} 5$, mitochondrial

Eukaryotic initiation factor 4A-I

\begin{tabular}{|c|c|}
\hline GLYM_HUMAN & SHMT2 \\
\hline GCN1L_HUMAN & GCN1L1 \\
\hline U520_HUMAN & SNRNP200 \\
\hline ORC5_HUMAN & ORC5 \\
\hline MMS19_HUMAN & MMS19 \\
\hline PUM1_HUMAN & PUM1 \\
\hline SRSF9_HUMAN & SRSF9 \\
\hline GNL3 HUMAN & GNL3 \\
\hline CPSF7_HUMAN & CPSF7 \\
\hline RRP5_HUMAN & PDCD11 \\
\hline DDX52_HUMAN & DDX52 \\
\hline GBLP_HUMAN & GNB2L1 \\
\hline GMPPB_HUMAN & GMPPB \\
\hline PRPS2_HUMAN & PRPS2 \\
\hline VP26A_HUMAN & VPS26A \\
\hline ADT2_HUMAN & SLC25A5 \\
\hline RT18B_HUMAN & MRPS18B \\
\hline PSD11_HUMAN & PSMD11 \\
\hline CCD47_HUMAN & $\mathrm{CCDC} 47$ \\
\hline KPYM_HUMAN & PKM \\
\hline CKAP5_HUMAN & CKAP5 \\
\hline ZC3HD_HUMAN & ZC3H13 \\
\hline P5CR2_HUMAN & PYCR2 \\
\hline STK4_HUMAN & STK4 \\
\hline VA0D1_HUMAN & ATP6V0D1 \\
\hline CLPX_HUMAN & CLPX \\
\hline IDH3G_HUMAN & IDH3G \\
\hline PUF60_HUMAN & PUF60 \\
\hline TSC2_HUMAN & $\mathrm{TSC} 2$ \\
\hline RPAC1_HUMAN & POLR1C \\
\hline RBP2_HUMAN & RANBP2 \\
\hline ERLN2_HUMAN & ERLIN2 \\
\hline CSK22_HUMAN & CSNK2A2 \\
\hline RL18_HUMAN & RPL18 \\
\hline RM39_HUMAN & MRPL39 \\
\hline UBE3A_HUMAN & UBE3A \\
\hline RT05_HUMAN & MRPS5 \\
\hline IF4A1_HUMAN & EIF4A1 \\
\hline
\end{tabular}

$\begin{array}{ccc}9 & 6 & 7 \\ 130 & 111 & 31 \\ 86 & 75 & 41 \\ 3 & 0 & 4 \\ 5 & 0 & 0 \\ 5 & 0 & 0 \\ 12 & 9 & 8 \\ 17 & 17 & 21 \\ 2 & 0 & 0 \\ 43 & 35 & 17 \\ 5 & 5 & 0 \\ 20 & 22 & 19 \\ 3 & 0 & 0 \\ 0 & 4 & 4 \\ 6 & 7 & 0 \\ 78 & 66 & 50 \\ 8 & 13 & 7 \\ 3 & 4 & 0 \\ 0 & 4 & 3 \\ 94 & 94 & 47 \\ 9 & 10 & 7 \\ 6 & 7 & 0 \\ 51 & 49 & 27 \\ 0 & 2 & 0 \\ 4 & 3 & 5 \\ 0 & 14 & 15 \\ 7 & 5 & 6 \\ 8 & 16 & 11 \\ 0 & 0 & 2 \\ 7 & 9 & 4 \\ 8 & 12 & 0 \\ 47 & 41 & 34 \\ 4 & 4 & 5 \\ 34 & 4 & 15 \\ 11 & 11 & 5 \\ 0 & 3 & 3 \\ 14 & 13 & 13 \\ 40 & 35 & 17\end{array}$

1.061

1.057

1.057

1.056

1.055

1.055

1.054

1.050

1.050

1.049

1.045

1.044

1.041

1.039

1.036

1.033

1.032

1.032

1.032

1.032

1.030

1.028

1.025

1.024

1.022

1.021

1.020

1.017

1.014

1.012

1.009

1.005

1.002

1.002

1.000

1.000

0.999

0.999

Page 23 of Table S-2 
GPI-anchor transamidase

WD repeat-containing protein 82

Anaphase-promoting complex subunit 1

Actin, cytoplasmic 1

Cyclin-dependent kinase 1

WD repeat-containing protein 1

Tubulin beta-4B chain

$28 \mathrm{~S}$ ribosomal protein $\mathrm{S} 29$, mitochondrial

Chromosome transmission fidelity protein 18 homolog

Nucleolin

Leucine-rich repeat-containing protein 47

Heterogeneous nuclear ribonucleoprotein M

UAP56-interacting factor

Probable ATP-dependent RNA helicase DDX28

Peroxiredoxin-2

Polyadenylate-binding protein 1

Tyrosine--tRNA ligase, cytoplasmic

Cyclin-dependent-like kinase 5

Electron transfer flavoprotein subunit alpha, mitochondrial

Coatomer subunit epsilon

Activator of basal transcription 1

FAST kinase domain-containing protein 5

RNA-binding protein 14

Voltage-dependent anion-selective channel protein 3

Nucleoporin-like protein 2

60S ribosomal protein L15

Heterogeneous nuclear ribonucleoprotein $U$

FAST kinase domain-containing protein 3

26S proteasome non-ATPase regulatory subunit 4

Serine/threonine-protein phosphatase PP1-beta catalytic subunit

TP53-regulating kinase

Acetyl-CoA acetyltransferase, mitochondrial

Alpha-internexin

Transformer-2 protein homolog alpha

THO complex subunit 4

Cancer-related nucleoside-triphosphatase

Beta-galactosidase

Cellular tumor antigen p53

$\begin{array}{ll}\text { GPI8_HUMAN } & \text { PIGK } \\ \text { WDR82_HUMAN } & \text { WDR82 } \\ \text { APC1_HUMAN } & \text { ANAPC1 } \\ \text { ACTB_HUMAN } & \text { ACTB } \\ \text { CDK1_HUMAN } & \text { CDK1 } \\ \text { WDR1_HUMAN } & \text { WDR1 } \\ \text { TBB4B_HUMAN } & \text { TUBB4B } \\ \text { RT29_HUMAN } & \text { DAP3 } \\ \text { CTF18_HUMAN } & \text { CHTF18 } \\ \text { NUCL_HUMAN } & \text { NCL } \\ \text { LRC47_HUMAN } & \text { LRRC47 } \\ \text { HNRPM_HUMAN HNRNPM } \\ \text { UIF_HUMAN } & \text { FYTTD1 } \\ \text { DDX28_HUMAN } & \text { DDX28 } \\ \text { PRDX2_HUMAN } & \text { PRDX2 } \\ \text { PABP1_HUMAN } & \text { PABPC1 } \\ \text { SYYC_HUMAN } & \text { YARS } \\ \text { CDK5_HUMAN } & \text { CDK5 } \\ \text { ETFA_HUMAN } & \text { ETFA } \\ \text { COPE_HUMAN } & \text { COPE } \\ \text { ABT1_HUMAN } & \text { ABT1 } \\ \text { FAKD5_HUMAN } & \text { FASTKD5 } \\ \text { RBM14_HUMAN } & \text { RBM14 } \\ \text { VDAC3_HUMAN } & \text { VDAC3 } \\ \text { NUPL2_HUMAN } & \text { NUPL2 } \\ \text { RL15_HUMAN } & \text { RPL15 } \\ \text { HNRPU_HUMAN } & \text { HNRNPU } \\ \text { FAKD3_HUMAN } & \text { FASTKD3 } \\ \text { PSMD4_HUMAN } & \text { PSMD4 } \\ \text { PP1B_HUMAN } & \text { PPP1CB } \\ \text { PRPK_HUMAN } & \text { TP53RK } \\ \text { THIL_HUMAN } & \text { ACAT1 } \\ \text { AINX_HUMAN } & \text { INA } \\ \text { TRA2A_HUMAN } & \text { TRA2A } \\ \text { THOC4_HUMAN } & \text { ALYREF } \\ \text { NTPCR_HUMAN } & \text { NTPCR } \\ \text { BGAL_HUMAN } & \text { GLB1 } \\ \text { P53_HUMAN } & \text { TP53 }\end{array}$

5

5

$\begin{array}{lll}7 & 16 & 7\end{array}$

$\begin{array}{lll}11 & 4 & 5\end{array}$

$\begin{array}{lll}188 & 193 & 123\end{array}$

$43 \quad 61 \quad 32$

$0 \quad 6 \quad 4$

$\begin{array}{lll}41 & 42 & 29\end{array}$

$\begin{array}{lll}16 & 15 & 16\end{array}$

$\begin{array}{lll}0 & 3 & 0\end{array}$

$\begin{array}{lll}103 & 77 & 52\end{array}$

3

327

0

0
237

$14 \quad 13 \quad 10$

$\begin{array}{lll}9 & 20 & 13\end{array}$

1200

166

$\begin{array}{lll}8 & 24 & 18\end{array}$

$\begin{array}{lll}3 & 4 & 4\end{array}$

19

7

7

0

30

27

0

18

177

0

24

24

0

8

6

10

43

21

16

14

10

$\begin{array}{cccc}11 & 5 & 9 & 0.996 \\ 14 & 14 & 17 & 0.995 \\ 11 & 9 & 10 & 0.995 \\ 262 & 243 & 247 & 0.987 \\ 75 & 80 & 48 & 0.985 \\ 5 & 6 & 6 & 0.984 \\ 59 & 58 & 51 & 0.984 \\ 27 & 22 & 24 & 0.982 \\ 3 & 0 & 2 & 0.980 \\ 126 & 114 & 100 & 0.978 \\ 4 & 0 & 0 & 0.977 \\ 529 & 420 & 424 & 0.973 \\ 19 & 17 & 19 & 0.973 \\ 27 & 13 & 24 & 0.970 \\ 0 & 15 & 0 & 0.969 \\ 238 & 216 & 222 & 0.968 \\ 36 & 14 & 28 & 0.967 \\ 5 & 8 & 4 & 0.967 \\ 32 & 23 & 16 & 0.967 \\ 5 & 3 & 7 & 0.967 \\ 10 & 8 & 10 & 0.967 \\ 3 & 4 & 5 & 0.964 \\ 36 & 42 & 41 & 0.963 \\ 49 & 49 & 30 & 0.962 \\ 4 & 3 & 5 & 0.959 \\ 21 & 21 & 18 & 0.959 \\ 213 & 207 & 206 & 0.958 \\ 5 & 5 & 4 & 0.957 \\ 27 & 26 & 27 & 0.953 \\ 6 & 5 & 8 & 0.952 \\ 9 & 11 & 3 & 0.944 \\ 13 & 6 & 11 & 0.941 \\ 28 & 16 & 23 & 0.938 \\ 54 & 47 & 39 & 0.935 \\ 19 & 19 & 13 & 0.933 \\ 0 & 16 & 4 & 0.932 \\ 26 & 9 & 20 & 0.931 \\ 16 & 16 & 15 & 0.928\end{array}$

Page 24 of Table S-2 
Zinc finger $\mathrm{CCCH}$ domain-containing protein 18

DnaJ homolog subfamily A member 3, mitochondrial

DnaJ homolog subfamily A member 2

Polyadenylate-binding protein 4

DNA topoisomerase 2-beta

DNA-dependent protein kinase catalytic subunit

Voltage-dependent anion-selective channel protein 2

Serine/threonine-protein phosphatase PGAM5, mitochondrial

Isocitrate dehydrogenase [NAD] subunit beta, mitochondrial

Guanine nucleotide-binding protein subunit alpha-11

C-terminal-binding protein 1

Ras GTPase-activating-like protein IQGAP1

Serine/arginine-rich splicing factor 10

THUMP domain-containing protein 3

2-oxoisovalerate dehydrogenase subunit beta, mitochondrial

Serine/arginine-rich splicing factor 2

Acyl-CoA dehydrogenase family member 9, mitochondrial

Eukaryotic translation initiation factor 3 subunit L

Stress-70 protein, mitochondrial

Elongation factor 1-delta

Probable ATP-dependent RNA helicase DDX17

Eukaryotic translation initiation factor 3 subunit E

Ribose-phosphate pyrophosphokinase 1

Peroxisomal 2,4-dienoyl-CoA reductase

Annexin A6

Nuclear pore complex protein Nup205

40S ribosomal protein S6

Exportin-1

GPI transamidase component PIG-T

Major centromere autoantigen B

Aminoacyl tRNA synthase complex-interacting multifunctional protein 1 Importin-11

Pachytene checkpoint protein 2 homolog

DnaJ homolog subfamily $\mathrm{C}$ member 13

60S ribosomal protein $\mathrm{L} 9$

Coiled-coil domain-containing protein 137

Nucleolar protein 58

Aspartate aminotransferase, mitochondrial

\begin{tabular}{|c|c|}
\hline ZCH18_HUMAN & $\mathrm{ZC} 3 \mathrm{H} 18$ \\
\hline DNJA3_HUMAN & DNAJA3 \\
\hline DNJA2_HUMAN & DNAJA2 \\
\hline PABP4_HUMAN & PABPC4 \\
\hline TOP2B_HUMAN & TOP2B \\
\hline PRKDC_HUMAN & PRKDC \\
\hline VDAC2_HUMAN & VDAC2 \\
\hline PGAM5_HUMAN & PGAM5 \\
\hline IDH3B_HUMAN & IDH3B \\
\hline GNA11_HUMAN & GNA11 \\
\hline CTBP1_HUMAN & CTBP1 \\
\hline IQGA1_HUMAN & IQGAP1 \\
\hline SRS10_HUMAN & SRSF10 \\
\hline THUM3_HUMAN & THUMPD3 \\
\hline ODBB_HUMAN & BCKDHB \\
\hline SRSF2_HUMAN & SRSF2 \\
\hline ACAD9_HUMAN & ACAD9 \\
\hline EIF3L_HUMAN & EIF3L \\
\hline GRP75_HUMAN & HSPA9 \\
\hline EF1D_HUMAN & EEF1D \\
\hline DDX17_HUMAN & DDX17 \\
\hline EIF3E_HUMAN & EIF3E \\
\hline PRPS1_HUMAN & PRPS1 \\
\hline DECR2_HUMAN & DECR2 \\
\hline ANXA6_HUMAN & ANXA6 \\
\hline NU205_HUMAN & NUP205 \\
\hline RS6_HUMAN & RPS6 \\
\hline XPO-1_HUMAN & XPO1 \\
\hline PIGT_HUMAN & PIGT \\
\hline CENPB_HUMAN & CENPB \\
\hline AIMP1_HUMAN & AIMP1 \\
\hline IPO11_HUMAN & IPO11 \\
\hline PCH2_HUMAN & TRIP13 \\
\hline DJC13_HUMAN & DNAJC13 \\
\hline RL9_HUMAN & RPL9 \\
\hline CC137_HUMAN & CCDC137 \\
\hline NOP58_HUMAN & NOP58 \\
\hline AATM_HUMAN & GOT2 \\
\hline
\end{tabular}


HCLS1-associated protein X-1 Unconventional myosin-Id

Probable arginine--tRNA ligase, mitochondrial

L-lactate dehydrogenase B chain

Citrate synthase, mitochondrial

$26 \mathrm{~S}$ protease regulatory subunit $6 \mathrm{~A}$

Glioma tumor suppressor candidate region gene 2 protein

Serine/threonine-protein kinase mTOR

T-complex protein 1 subunit theta

40S ribosomal protein SA

40 S ribosomal protein $\mathrm{S} 7$

Suppressor of SWI4 1 homolog

Derlin-1

Ig kappa chain V-II region RPMI 6410

Heat shock protein HSP 90-beta

H/ACA ribonucleoprotein complex subunit 4

Signal recognition particle subunit SRP68

$60 \mathrm{kDa}$ heat shock protein, mitochondrial

Coatomer subunit beta'

Nucleolar protein 56

Mitochondrial dicarboxylate carrier

Arginine--tRNA ligase, cytoplasmic

Methylosome subunit pICln

Probable dimethyladenosine transferase

Tricarboxylate transport protein, mitochondrial

Nucleolar GTP-binding protein 1

Centromere protein $\mathrm{V}$

General vesicular transport factor p115

Cell cycle and apoptosis regulator protein 2

Serine/arginine-rich splicing factor 1

Adenylate kinase 2, mitochondrial

Coatomer subunit delta

Condensin complex subunit 2

Proteasome subunit alpha type- 4

Constitutive coactivator of PPAR-gamma-like protein 1

Probable tRNA pseudouridine synthase 2

Aladin

$\begin{array}{llccccccc}\text { HAX1_HUMAN } & \text { HAX1 } & 13 & 14 & 6 & 15 & 11 & 16 & 0.867 \\ \text { MYO1D_HUMAN MYO1D } & 7 & 0 & 3 & 4 & 5 & 5 & 0.865 \\ \text { SYRM_HUMAN } & \text { RARS2 } & 0 & 6 & 8 & 6 & 10 & 6 & 0.865 \\ \text { LDHB_HUMAN } & \text { LDHB } & 81 & 89 & 78 & 117 & 119 & 99 & 0.864 \\ \text { CISY_HUMAN } & \text { CS } & 3 & 0 & 0 & 0 & 0 & 3 & 0.862 \\ \text { PRS6A_HUMAN } & \text { PSMC3 } & 17 & 16 & 2 & 21 & 10 & 11 & 0.860 \\ \text { GSCR2_HUMAN } & \text { GLTSCR2 } & 3 & 2 & 3 & 4 & 4 & 3 & 0.857 \\ \text { MTOR_HUMAN } & \text { MTOR } & 14 & 13 & 5 & 18 & 10 & 12 & 0.856 \\ \text { TCPQ_HUMAN } & \text { CCT8 } & 5 & 11 & 11 & 17 & 9 & 12 & 0.856 \\ \text { RSSA_HUMAN } & \text { RPSA } & 11 & 12 & 14 & 20 & 16 & 15 & 0.854 \\ \text { RS7_HUMAN } & \text { RPS7 } & 26 & 4 & 7 & 0 & 32 & 12 & 0.851 \\ \text { SSF1_HUMAN } & \text { PPAN } & 4 & 4 & 5 & 9 & 5 & 4 & 0.849 \\ \text { DERL1_HUMAN } & \text { DERL1 } & 3 & 0 & 0 & 0 & 3 & 0 & 0.846 \\ \text { KV206_HUMAN } & - & 59 & 63 & 50 & 75 & 72 & 77 & 0.844 \\ \text { HS90B_HUMAN } & \text { HSP90AB1 } & 160 & 157 & 89 & 184 & 166 & 162 & 0.843 \\ \text { DKC1_HUMAN } & \text { DKC1 } & 5 & 10 & 12 & 17 & 9 & 12 & 0.843 \\ \text { SRP68_HUMAN } & \text { SRP68 } & 10 & 11 & 6 & 12 & 9 & 13 & 0.842 \\ \text { CH60_HUMAN } & \text { HSPD1 } & 29 & 40 & 26 & 49 & 29 & 45 & 0.841 \\ \text { COPB2_HUMAN } & \text { COPB2 } & 6 & 4 & 5 & 9 & 7 & 4 & 0.840 \\ \text { NOP56_HUMAN } & \text { NOP56 } & 14 & 18 & 11 & 20 & 16 & 19 & 0.840 \\ \text { DIC_HUMAN } & \text { SLC25A10 } & 20 & 23 & 22 & 28 & 31 & 27 & 0.838 \\ \text { SYRC_HUMAN } & \text { RARS } & 38 & 33 & 14 & 41 & 34 & 29 & 0.838 \\ \text { ICLN_HUMAN } & \text { CLNS1A } & 26 & 26 & 14 & 27 & 31 & 24 & 0.834 \\ \text { DIM1_HUMAN } & \text { DIMT1 } & 16 & 18 & 14 & 14 & 22 & 25 & 0.830 \\ \text { TXTP_HUMAN } & \text { SLC25A1 } & 24 & 28 & 29 & 37 & 38 & 32 & 0.828 \\ \text { NOG1_HUMAN } & \text { GTPBP4 } & 13 & 12 & 6 & 14 & 14 & 10 & 0.828 \\ \text { CENPV_HUMAN } & \text { CENPV } & 23 & 21 & 12 & 24 & 23 & 22 & 0.827 \\ \text { USO1_HUMAN } & \text { USO1 } & 5 & 6 & 4 & 7 & 6 & 6 & 0.827 \\ \text { CCAR2_HUMAN CCAR2 } & 7 & 3 & 4 & 10 & 4 & 4 & 0.825 \\ \text { SRSF1_HUMAN } & \text { SRSF1 } & 49 & 52 & 44 & 63 & 69 & 54 & 0.825 \\ \text { KAD2_HUMAN } & \text { AK2 } & 0 & 0 & 2 & 0 & 3 & 0 & 0.824 \\ \text { COPD_HUMAN } & \text { ARCN1 } & 5 & 17 & 12 & 20 & 10 & 15 & 0.823 \\ \text { CND2_HUMAN } & \text { NCAPH } & 0 & 3 & 0 & 0 & 3 & 0 & 0.822 \\ \text { PSA4_HUMAN } & \text { PSMA4 } & 13 & 13 & 17 & 20 & 16 & 21 & 0.820 \\ \text { F120A_HUMAN } & \text { FAM120A } & 9 & 7 & 7 & 8 & 11 & 10 & 0.817 \\ \text { TRUB2_HUMAN TRUB2 } & 5 & 4 & 3 & 7 & 5 & 3 & 0.816 \\ \text { AAAS_HUMAN } & \text { AAAS } & 4 & 6 & 4 & 11 & 3 & 4 & 0.816\end{array}$

Page 26 of Table S-2 
Alpha-aminoadipic semialdehyde synthase, mitochondrial Cytochrome b-c1 complex subunit 1, mitochondrial

T-complex protein 1 subunit alpha

Adenine phosphoribosyltransferase

2',3'-cyclic-nucleotide 3'-phosphodiesterase

Heterogeneous nuclear ribonucleoprotein U-like protein 1

Transportin-1

Isocitrate dehydrogenase [NAD] subunit alpha, mitochondrial

THO complex subunit 2

Condensin-2 complex subunit D3

Importin-4

T-complex protein 1 subunit gamma

Transmembrane protein 33

ATP synthase subunit gamma, mitochondrial

Probable tRNA pseudouridine synthase 1

60 S ribosomal protein $\mathrm{L} 5$

Isoleucine--tRNA ligase, mitochondrial

Nuclear pore complex protein Nup107

AP-2 complex subunit alpha-1

ADP/ATP translocase 3

Mitochondrial-processing peptidase subunit beta

Long-chain fatty acid transport protein 4

Methionine--tRNA ligase, mitochondrial

Transcription activator BRG1

Splicing factor, proline- and glutamine-rich

Mitochondrial 10-formyltetrahydrofolate dehydrogenase

Transmembrane protein 201

Non-POU domain-containing octamer-binding protein

Survival motor neuron protein

Cytoplasmic FMR1-interacting protein 1

40S ribosomal protein S9

Dihydropyrimidinase-related protein 4

Transcription elongation factor, mitochondrial

Ribosomal RNA processing protein 1 homolog A

60S ribosomal protein $\mathrm{L} 13 \mathrm{a}$

Bloom syndrome protein

T-complex protein 1 subunit zeta

Alanine--tRNA ligase, mitochondrial

\begin{tabular}{|c|c|}
\hline AASS_HUMAN & AASS \\
\hline QCR1_HUMAN & UQCRC1 \\
\hline TCPA_HUMAN & TCP1 \\
\hline APT_HUMAN & APRT \\
\hline CN37_HUMAN & CNP \\
\hline HNRL1_HUMAN & HNRNPUL1 \\
\hline TNPO1_HUMAN & TNPO1 \\
\hline IDH3A HUMAN & IDH3A \\
\hline THOC2_HUMAN & THOC2 \\
\hline CNDD3_HUMAN & NCAPD3 \\
\hline IPO4_HUMAN & IPO4 \\
\hline TCPG_HUMAN & СCT3 \\
\hline TMM33_HUMAN & TMEM33 \\
\hline ATPG_HUMAN & ATP5C1 \\
\hline TRUB1_HUMAN & TRUB1 \\
\hline RL5_HUMAN & RPL5 \\
\hline SYIM_HUMAN & IARS2 \\
\hline NU10̄﹎HUMAN & NUP107 \\
\hline AP2A1_HUMAN & AP2A1 \\
\hline ADT3_HUMAN & SLC25A6 \\
\hline MPPB_HUMAN & PMPCB \\
\hline S27A4_HUMAN & SLC27A4 \\
\hline SYMM_HUMAN & MARS2 \\
\hline SMCA4_HUMAN & SMARCA4 \\
\hline SFPQ_HUMAN & SFPQ \\
\hline AL1L2_HUMAN & ALDH1L2 \\
\hline TM201_HUMAN & TMEM201 \\
\hline NONO_HUMAN & NONO \\
\hline SMN_HUMAN & SMN1 \\
\hline CYFP1_HUMAN & CYFIP1 \\
\hline RS9_HUMAN & RPS9 \\
\hline DPYL44_HUMAN & DPYSL4 \\
\hline TEFM_HUMAN & TEFM \\
\hline RRP1_HUMAN & RRP1 \\
\hline RL13A_HUMAN & RPL13A \\
\hline BLM_HUMAN & BLM \\
\hline TCPZ_HUMAN & ССТ6А \\
\hline SYAM HUMAN & AARS2 \\
\hline
\end{tabular}

$5 \quad 7 \quad 3$


V-type proton ATPase catalytic subunit A

Eukaryotic translation initiation factor 3 subunit A

Nuclear pore complex protein Nup85

L-lactate dehydrogenase A chain

Enoyl-CoA hydratase, mitochondrial

Calcium-binding mitochondrial carrier protein Aralar2

Bifunctional methylenetetrahydrofolate dehydrogenase/cyclohydrolase, mitochondrial

C-1-tetrahydrofolate synthase, cytoplasmic

Very-long-chain (3R)-3-hydroxyacyl-CoA dehydratase 3

Importin-5

Pyrroline-5-carboxylate reductase 3

DnaJ homolog subfamily C member 11

Translation initiation factor eIF-2B subunit beta

Leucine-rich repeat-containing protein 40

ATPase family AAA domain-containing protein $3 \mathrm{~A}$

Elongation factor 1-gamma

Tuftelin-interacting protein 11

60S ribosomal protein $\mathrm{L} 17$

Cytoplasmic dynein 1 light intermediate chain 1

Hornerin

Histone H1x

Chromodomain-helicase-DNA-binding protein 1-like

26S protease regulatory subunit 4

Phosphate carrier protein, mitochondrial

Serine/arginine-rich splicing factor 3

$78 \mathrm{kDa}$ glucose-regulated protein

$\mathrm{N}$-alpha-acetyltransferase 10

$60 \mathrm{kDa}$ SS-A/Ro ribonucleoprotein

26S proteasome non-ATPase regulatory subunit 3

Glycogen phosphorylase, liver form

Uncharacterized protein C3orf17

Phosphoacetylglucosamine mutase

Anaphase-promoting complex subunit 7

60S ribosomal protein L19

Methylosome protein 50

40 S ribosomal protein $\mathrm{S} 5$

Ornithine aminotransferase, mitochondrial

Exosome complex component MTR3

\begin{tabular}{|c|c|}
\hline VATA_HUMAN & ATP6V1A \\
\hline EIF3A_HUMAN & EIF3A \\
\hline NUP85_HUMAN & NUP85 \\
\hline LDHA_HUMAN & LDHA \\
\hline ECHM_HUMAN & ECHS1 \\
\hline CMC2_HUMAN & SLC25A13 \\
\hline MTDC_HUMAN & MTHFD2 \\
\hline C1TC_HUMAN & MTHFD1 \\
\hline HACD3_HUMAN & HACD3 \\
\hline IPO5_HÜMAN & IPO5 \\
\hline P5CR3_HUMAN & PYCRL \\
\hline DJC11_HUMAN & DNAJC11 \\
\hline EI2BB_HUMAN & EIF2B2 \\
\hline LRC40_HUMAN & LRRC40 \\
\hline ATD3A_HUMAN & ATAD3A \\
\hline EF1G_HUMAN & EEF1G \\
\hline TFP11_HUMAN & TFIP11 \\
\hline RL17_HUMAN & RPL17 \\
\hline DC1L1_HUMAN & DYNC1LI1 \\
\hline HORN_HUMAN & HRNR \\
\hline H1X_HUMAN & H1FX \\
\hline CHD1L_HUMAN & CHD1L \\
\hline PRS4_HUMAN & PSMC1 \\
\hline MPCP_HUMAN & SLC25A3 \\
\hline SRSF3_HUMAN & SRSF3 \\
\hline GRP78_HUMAN & HSPA5 \\
\hline NAA10_HUMAN & NAA10 \\
\hline RO60_HUMAN & TROVE2 \\
\hline PSMD3_HUMAN & PSMD3 \\
\hline PYGL_HUMAN & PYGL \\
\hline CC017_HUMAN & C3orf17 \\
\hline AGM1_HUMAN & PGM3 \\
\hline APC7_HUMAN & ANAPC7 \\
\hline RL19_HUMAN & RPL19 \\
\hline MEP50_HUMAN & WDR77 \\
\hline RS5_HŪMAN & RPS5 \\
\hline OAT_HUMAN & OAT \\
\hline EXOS6 HUMAN & EXOSC6 \\
\hline
\end{tabular}

\begin{tabular}{ccc}
2 & 4 & 0 \\
52 & 46 & 23 \\
7 & 11 & 7 \\
107 & 100 & 87 \\
0 & 0 & 3 \\
40 & 42 & 26 \\
8 & 6 & 11 \\
24 & 18 & 17 \\
25 & 26 & 6 \\
14 & 13 & 11 \\
10 & 12 & 10 \\
11 & 18 & 6 \\
6 & 5 & 6 \\
13 & 12 & 7 \\
63 & 78 & 58 \\
22 & 27 & 16 \\
0 & 0 & 3 \\
34 & 6 & 9 \\
5 & 10 & 6 \\
58 & 22 & 20 \\
18 & 26 & 25 \\
6 & 7 & 3 \\
9 & 17 & 11 \\
66 & 79 & 58 \\
21 & 6 & 4 \\
47 & 37 & 17 \\
8 & 8 & 8 \\
5 & 8 & 0 \\
43 & 55 & 34 \\
18 & 12 & 6 \\
0 & 3 & 3 \\
4 & 7 & 10 \\
5 & 14 & 10 \\
20 & 14 & 5 \\
131 & 137 & 86 \\
17 & 0 & 7 \\
42 & 44 & 30 \\
6 & 14 & 11 \\
\hline
\end{tabular}


60S ribosomal protein $\mathrm{L} 7 \mathrm{a}$

Probable ATP-dependent RNA helicase DDX20

Trifunctional enzyme subunit beta, mitochondrial

60S ribosomal protein L18a

Condensin complex subunit 3

rRNA 2'-O-methyltransferase fibrillarin

Ribonuclease $\mathrm{P}$ protein subunit $\mathrm{p} 38$

Transcriptional activator protein Pur-alpha

SWI/SNF-related matrix-associated actin-dependent regulator of chromatin subfamily A member 5

Prohibitin

Lamin-B1

Staphylococcal nuclease domain-containing protein 1

Cytoplasmic tRNA 2-thiolation protein 1

RRP15-like protein

ATP synthase subunit $\mathrm{O}$, mitochondrial

60S ribosomal protein $\mathrm{L} 13$

60S ribosomal protein L6

SRSF protein kinase 1

Charged multivesicular body protein $4 \mathrm{~b}$

DDRGK domain-containing protein 1

60S ribosomal protein $\mathrm{L} 3$

Heat shock protein $75 \mathrm{kDa}$, mitochondrial

Importin subunit beta-1

5'-3' exoribonuclease 2

Nucleolar complex protein 4 homolog

Lamin-B2

60S ribosomal protein $\mathrm{L} 21$

Apoptosis-inducing factor 1, mitochondrial

Dynamin-2

Probable cytosolic iron-sulfur protein assembly protein CIAO1

Serine racemase

Exportin-2

Eukaryotic translation initiation factor 2 subunit 1

Lys-63-specific deubiquitinase BRCC36

60S ribosomal protein L23a

Eukaryotic translation initiation factor 3 subunit C

Sideroflexin-4

Tubulin-specific chaperone D

\begin{tabular}{|c|c|}
\hline RL7A_HUMAN & RPL7A \\
\hline DDX20_HUMAN & DDX20 \\
\hline ECHB_HUMAN & HADHB \\
\hline RL18A_HUMAN & RPL18A \\
\hline CND3_HUMAN & NCAPG \\
\hline FBRL_HUMAN & FBL \\
\hline RPP38_HUMAN & RPP38 \\
\hline PURA HUMAN & PURA \\
\hline SMCA5_HUMAN & SMARCA5 \\
\hline PHB_HUMAN & PHB \\
\hline LMNB1_HUMAN & LMNB1 \\
\hline SND1_HUMAN & SND1 \\
\hline CTU1_HUMAN & CTU1 \\
\hline RRP15_HUMAN & RRP15 \\
\hline ATPO_HUMAN & ATP5O \\
\hline RL13_HUMAN & RPL13 \\
\hline RL6_HUMAN & RPL6 \\
\hline SRPK̄1_HUMAN & SRPK1 \\
\hline CHM4B_HUMAN & CHMP4B \\
\hline DDRGK_HUMAN & DDRGK1 \\
\hline RL3_HŪMAN & RPL3 \\
\hline TRAP1_HUMAN & TRAP1 \\
\hline IMB1_HUMAN & KPNB1 \\
\hline XRN2_HUMAN & XRN2 \\
\hline NOC4L_HUMAN & NOC4L \\
\hline LMNB2_HUMAN & LMNB2 \\
\hline RL21_HUMAN & RPL21 \\
\hline AIFM-̄1_HUMAN & AIFM1 \\
\hline DYN2_HUMAN & DNM2 \\
\hline CIAO1_HUMAN & CIAO1 \\
\hline SRR_HUMAN & SRR \\
\hline XPO2_HUMAN & CSE1L \\
\hline IF2A_HUMAN & EIF2S1 \\
\hline BRCC3_HUMAN & BRCC3 \\
\hline RL23A_HUMAN & RPL23A \\
\hline EIF3C_HUMAN & EIF3C \\
\hline SFXN4_HUMAN & SFXN4 \\
\hline TBCD_HUMAN & TBCD \\
\hline
\end{tabular}

$\begin{array}{lllllll}5 & 4 & 6 & 6 & 5 & 6 & 0.700\end{array}$

$\begin{array}{lllllll}24 & 25 & 19 & 25 & 22 & 26 & 0.699\end{array}$

$\begin{array}{lllllll}58 & 3 & 13 & 0 & 48 & 24 & 0.698\end{array}$

$\begin{array}{lllllll}5 & 4 & 4 & 3 & 7 & 4 & 0.698\end{array}$

$\begin{array}{lllllll}40 & 35 & 36 & 39 & 42 & 40 & 0.697\end{array}$

$\begin{array}{lllllll}7 & 7 & 14 & 11 & 12 & 10 & 0.697\end{array}$

$\begin{array}{lllllll}11 & 9 & 13 & 12 & 12 & 13 & 0.695\end{array}$

$\begin{array}{lllllll}16 & 13 & 14 & 20 & 13 & 14 & 0.693\end{array}$

$\begin{array}{lllllll}87 & 87 & 55 & 93 & 85 & 62 & 0.691\end{array}$

$\begin{array}{lllllll}113 & 107 & 54 & 111 & 86 & 82 & 0.686\end{array}$

$\begin{array}{lllllll}3 & 0 & 0 & 0 & 0 & 2 & 0.683\end{array}$

$\begin{array}{lllllll}3 & 0 & 0 & 0 & 0 & 2 & 0.683\end{array}$

$\begin{array}{lllllll}6 & 5 & 5 & 6 & 5 & 6 & 0.682\end{array}$

$\begin{array}{lllllll}19 & 3 & 10 & 0 & 21 & 11 & 0.681\end{array}$

$\begin{array}{lllllll}76 & 69 & 66 & 81 & 66 & 77 & 0.681\end{array}$

$\begin{array}{lllllll}98 & 92 & 86 & 102 & 101 & 89 & 0.678\end{array}$

$\begin{array}{lllllll}5 & 0 & 5 & 4 & 4 & 4 & 0.678\end{array}$

$\begin{array}{lllllll}7 & 5 & 6 & 6 & 7 & 6 & 0.673\end{array}$

$\begin{array}{lllllll}3 & 3 & 4 & 5 & 3 & 3 & 0.673\end{array}$

$\begin{array}{lllllll}106 & 103 & 71 & 101 & 92 & 93 & 0.673\end{array}$

$\begin{array}{lllllll}17 & 14 & 5 & 15 & 11 & 9 & 0.673\end{array}$

$\begin{array}{lllllll}20 & 23 & 13 & 25 & 15 & 17 & 0.672\end{array}$

$\begin{array}{lllllll}13 & 8 & 0 & 12 & 7 & 0 & 0.671\end{array}$

$\begin{array}{lllllll}0 & 6 & 5 & 5 & 3 & 5 & 0.670\end{array}$

$\begin{array}{lllllll}37 & 39 & 27 & 35 & 38 & 32 & 0.669\end{array}$

$\begin{array}{lllllll}30 & 4 & 8 & 0 & 27 & 12 & 0.667\end{array}$

$\begin{array}{lllllll}23 & 19 & 7 & 16 & 18 & 13 & 0.666\end{array}$

$\begin{array}{lllllll}10 & 9 & 9 & 9 & 10 & 10 & 0.664\end{array}$

$\begin{array}{lllllll}6 & 5 & 6 & 8 & 5 & 5 & 0.662\end{array}$

$\begin{array}{lllllll}0 & 4 & 0 & 2 & 2 & 0 & 0.661\end{array}$

$\begin{array}{lllllll}35 & 43 & 25 & 28 & 38 & 36 & 0.658\end{array}$

$\begin{array}{lllllll}5 & 4 & 6 & 6 & 5 & 5 & 0.657\end{array}$

$\begin{array}{lllllll}4 & 7 & 4 & 4 & 5 & 6 & 0.657\end{array}$

$\begin{array}{lllllll}11 & 7 & 5 & 0 & 12 & 9 & 0.657\end{array}$

$\begin{array}{lllllll}8 & 0 & 0 & 0 & 4 & 3 & 0.656\end{array}$

$\begin{array}{lllllll}6 & 12 & 15 & 12 & 12 & 12 & 0.656\end{array}$

$\begin{array}{lllllll}4 & 6 & 4 & 3 & 5 & 6 & 0.655\end{array}$

Page 29 of Table S-2 


\section{Protein PRRC2C}

Integrator complex subunit 11

Chromatin target of PRMT1 protein

Dolichyl-diphosphooligosaccharide--protein glycosyltransferase subunit 1 Neutral alpha-glucosidase AB

Splicing factor $3 \mathrm{~B}$ subunit 3

$26 \mathrm{~S}$ protease regulatory subunit $6 \mathrm{~B}$

Serine/threonine-protein kinase 38-like

$26 \mathrm{~S}$ protease regulatory subunit 7

Serum albumin

Zinc finger protein 512

ATP-dependent RNA helicase DDX3X

Plasminogen activator inhibitor 1 RNA-binding protein 60S ribosomal protein $\mathrm{L} 7$

$\mathrm{N}$-alpha-acetyltransferase 25 , NatB auxiliary subunit

Myosin-14

Threonine--tRNA ligase, mitochondrial

General transcription factor 3C polypeptide 4

Tyrosine-protein kinase JAK1

Pericentriolar material 1 protein

Conserved oligomeric Golgi complex subunit 5

Mediator of RNA polymerase II transcription subunit 24

Methyl-CpG-binding domain protein 3

TGF-beta-activated kinase 1 and MAP3K7-binding protein 3

Serine/arginine-rich splicing factor 4

Exosome complex component CSL4

39S ribosomal protein L48, mitochondrial

Acetolactate synthase-like protein

Developmentally-regulated GTP-binding protein 1

Cleavage and polyadenylation specificity factor subunit 2

NADH dehydrogenase [ubiquinone] 1 alpha subcomplex subunit 10, mitochondrial Alpha-centractin

40S ribosomal protein S3

Rac GTPase-activating protein 1

Voltage-dependent anion-selective channel protein 1

Serine/arginine-rich splicing factor 7

Succinyl-CoA ligase [ADP/GDP-forming] subunit alpha, mitochondrial

Serine/threonine-protein phosphatase $2 \mathrm{~A} 56 \mathrm{kDa}$ regulatory subunit delta isoform
PRC2C_HUMAN PRRC2C

INT11_HUMAN CPSF3L CHTOP_HUMAN CHTOP

RPN1_HUMAN RPN1

GANAB_HUMAN GANAB

SF3B3_HUMAN SF3B3

PRS6B_HUMAN PSMC4

ST38L_HUMAN STK38L

PRS7_HUMAN PSMC2

ALBU_HUMAN ALB

ZN512_HUMAN ZNF512

DDX3X_HUMAN DDX3X

PAIRB_HUMAN SERBP1

RL7_HUMAN RPL7

NAA25_HUMAN NAA25

MYH14_HUMAN MYH14

SYTM_HUMAN TARS2

TF3C4_HUMAN GTF3C4

JAK1_HUMAN JAK1

PCM1_HUMAN PCM1

COG5_HUMAN COG5

MED24_HUMAN MED24

MBD3_HUMAN MBD3

TAB3_HUMAN TAB3

SRSF4_HUMAN SRSF4

EXOS1_HUMAN EXOSC1

RM48_HUMAN MRPL48

ILVBL_HUMAN ILVBL

DRG1_HUMAN DRG1

CPSF2_HUMAN CPSF2

NDUAA_HUMAN NDUFA10

ACTZ_HUMAN ACTR1A

RS3_HUMAN RPS3

RGAP1_HUMAN RACGAP1

VDAC1_HUMAN VDAC1

SRSF7_HUMAN SRSF7

SUCA HUMAN SUCLG1

2A5D_HUMAN PPP2R5D $\begin{array}{lllllll}0 & 3 & 0 & 0 & 2 & 0 & 0.653\end{array}$

$\begin{array}{lllllll}0 & 3 & 0 & 0 & 2 & 0 & 0.653\end{array}$

$\begin{array}{lllllll}21 & 26 & 32 & 31 & 28 & 25 & 0.652\end{array}$

$\begin{array}{lllllll}15 & 12 & 8 & 10 & 11 & 13 & 0.652\end{array}$

$\begin{array}{lllllll}7 & 6 & 0 & 5 & 4 & 3 & 0.650\end{array}$

$\begin{array}{lllllll}59 & 58 & 21 & 50 & 39 & 41 & 0.649\end{array}$

$\begin{array}{lllllll}18 & 17 & 13 & 21 & 16 & 11 & 0.648\end{array}$

$\begin{array}{lllllll}22 & 22 & 20 & 29 & 17 & 19 & 0.646\end{array}$

$\begin{array}{lllllll}26 & 31 & 14 & 25 & 20 & 23 & 0.646\end{array}$

$\begin{array}{lllllll}118 & 119 & 86 & 120 & 93 & 105 & 0.643\end{array}$

$\begin{array}{ccccccc}8 & 8 & 5 & 4 & 8 & 8 & 0.639\end{array}$

$\begin{array}{lllllll}58 & 55 & 49 & 57 & 53 & 50 & 0.636\end{array}$

$\begin{array}{lllllll}5 & 6 & 6 & 4 & 7 & 6 & 0.634\end{array}$

$\begin{array}{lllllll}45 & 45 & 41 & 42 & 43 & 44 & 0.632\end{array}$

$\begin{array}{lllllll}2 & 0 & 0 & 0 & 0 & 0 & 0.630\end{array}$

$\begin{array}{lllllll}2 & 0 & 0 & 0 & 0 & 0 & 0.630\end{array}$

$\begin{array}{lllllll}2 & 0 & 0 & 0 & 0 & 0 & 0.630\end{array}$

$\begin{array}{lllllll}2 & 0 & 0 & 0 & 0 & 0 & 0.630\end{array}$

$\begin{array}{lllllll}2 & 0 & 0 & 0 & 0 & 0 & 0.630\end{array}$

$\begin{array}{lllllll}2 & 0 & 0 & 0 & 0 & 0 & 0.630\end{array}$

$\begin{array}{lllllll}2 & 0 & 0 & 0 & 0 & 0 & 0.630\end{array}$

$\begin{array}{lllllll}2 & 0 & 0 & 0 & 0 & 0 & 0.630\end{array}$

$\begin{array}{lllllll}2 & 0 & 0 & 0 & 0 & 0 & 0.630\end{array}$

$\begin{array}{lllllll}2 & 0 & 0 & 0 & 0 & 0 & 0.630\end{array}$

$\begin{array}{lllllll}2 & 0 & 0 & 0 & 0 & 0 & 0.630\end{array}$

$\begin{array}{lllllll}2 & 0 & 0 & 0 & 0 & 0 & 0.630\end{array}$

$\begin{array}{lllllll}2 & 0 & 0 & 0 & 0 & 0 & 0.630\end{array}$

$\begin{array}{llllllll}11 & 17 & 4 & 14 & 0 & 14 & 0.629\end{array}$

$\begin{array}{lllllll}3 & 0 & 6 & 5 & 5 & 0 & 0.627\end{array}$

$\begin{array}{lllllll}3 & 2 & 0 & 3 & 0 & 0 & 0.623\end{array}$

$\begin{array}{lllllll}12 & 12 & 15 & 12 & 16 & 11 & 0.621\end{array}$

$\begin{array}{lllllll}19 & 17 & 11 & 20 & 9 & 15 & 0.619\end{array}$

$\begin{array}{lllllll}98 & 105 & 74 & 90 & 96 & 76 & 0.618\end{array}$

$\begin{array}{llllllll}5 & 6 & 7 & 7 & 6 & 5 & 0.616\end{array}$

$\begin{array}{lllllll}15 & 13 & 5 & 5 & 13 & 11 & 0.616\end{array}$

$\begin{array}{lllllll}51 & 56 & 50 & 47 & 58 & 46 & 0.615\end{array}$

$\begin{array}{lllllll}33 & 35 & 23 & 30 & 28 & 27 & 0.615\end{array}$

$\begin{array}{lllllll}0 & 2 & 0 & 0 & 0 & 0 & 0.614\end{array}$

Page 30 of Table S-2 
Anaphase-promoting complex subunit 5

APC5_HUMAN ANAPC5

CQ085_HUMAN C17orf85

RNH2A HUMAN RNASEH2A

Ribonuclease $\mathrm{H} 2$ subunit A

$\begin{array}{lr}\text { Arf-GAP with coiled-coil, ANK repeat and PH domain-containing protein } 2 & \text { ACAP2_HUMAN ACAP2 } \\ \text { Tetratricopeptide repeat protein } 4 & \text { TTC4 HUMAN TTC4 }\end{array}$

Tetratricopeptide repeat protein 4

EXOS4_HUMAN EXOSC4

3-keto-steroid reductase

DNA-binding protein SATB2

Kelch-like ECH-associated protein 1

Cullin-associated NEDD8-dissociated protein 1

Hydroxysteroid dehydrogenase-like protein 2

NADH-ubiquinone oxidoreductase $75 \mathrm{kDa}$ subunit, mitochondrial

Methionine--tRNA ligase, cytoplasmic

Nucleoporin NDC1

Ribosomal L1 domain-containing protein 1

Proliferating cell nuclear antigen

Heterochromatin protein 1-binding protein 3

Asparagine synthetase [glutamine-hydrolyzing]

Emerin

Pre-mRNA 3'-end-processing factor FIP1

DHB7_HUMAN HSD17B7

SATB2_HUMAN SATB2

KEAP1-HUMAN KEAP1

CAND1_HUMAN CAND1

HSDL2_HUMAN HSDL2

NDUS1_HUMAN NDUFS1

SYMC HUMAN MARS

NDC1_HUMAN NDC1

RL1D1_HUMAN RSL1D1

PCNA_HUMAN PCNA

HP1B3 HUMAN HP1BP3

ASNS_HUMAN ASNS

EMD_HUMAN EMD

FIP1_HUMAN FIP1L1

Dolichyl-diphosphooligosaccharide--protein glycosyltransferase $48 \mathrm{kDa}$ subunit OST $\overline{4} 8$ HUMAN DDOST

DNA replication licensing factor MCM3

Lysine--tRNA ligase

60S ribosomal protein $\mathrm{L} 10 \mathrm{a}$

Carbonyl reductase [NADPH] 1

DNA topoisomerase 1

Serine/arginine-rich splicing factor 5

Phenylalanine--tRNA ligase beta subunit

Long-chain-fatty-acid--CoA ligase 3

Eukaryotic translation initiation factor 3 subunit $\mathrm{F}$

60 S ribosomal protein $\mathrm{L} 4$

60S ribosomal protein L24

ATP-citrate synthase

60S ribosomal protein L29

Zinc finger protein 768

Cell growth-regulating nucleolar protein

Signal recognition particle subunit SRP72

Mitochondrial inner membrane protein OXA1L

MCM3_HUMAN MCM3

SYK_HUMAN KARS

RL10A HUMAN RPL10A

CBR1_HUMAN CBR1

TOP1_HUMAN TOP1

SRSF5_HUMAN SRSF5

SYFB_HUMAN FARSB

ACSL3 HUMAN ACSL3

EIF3F_HUMAN EIF3F

RL4 HUMAN RPL4

RL24 HUMAN RPL24

ACLY HUMAN ACLY

RL29_HUMAN RPL29

ZN768_HUMAN ZNF768

LYAR HUMAN LYAR

SRP72-HUMAN SRP72

OXA1L_HUMAN OXA1L 
$\mathrm{N}$-acetyltransferase 10

Programmed cell death 6-interacting protein

Protein pelota homolog

Prolactin-inducible protein

Spermidine synthase

Cell division cycle protein 23 homolog

DnaJ homolog subfamily A member 1

Spindlin-1

40S ribosomal protein $\mathrm{S} 3 \mathrm{a}$

Elongation factor Tu, mitochondrial

Acetyl-CoA carboxylase 1

Putative transferase CAF17, mitochondrial

Solute carrier family 25 member 33

Ribosome biogenesis protein BMS1 homolog

Ig kappa chain V-I region Lay

KRR1 small subunit processome component homolog

$\mathrm{N}$-acylneuraminate cytidylyltransferase

Magnesium transporter protein 1

DNA-directed RNA polymerase I subunit RPA1

Dehydrogenase/reductase SDR family member 7B

Cleavage and polyadenylation specificity factor subunit 4

Tubulin gamma-1 chain

Dihydropyrimidinase-related protein 1

ATP-binding cassette sub-family D member 3

Sideroflexin-1

TAR DNA-binding protein 43

39S ribosomal protein L45, mitochondrial

40S ribosomal protein $\mathrm{S} 2$

Protein PRRC2A

Succinyl-CoA ligase [ADP-forming] subunit beta, mitochondrial

Eukaryotic translation initiation factor 3 subunit I

Cytochrome b-c1 complex subunit 2, mitochondrial

Histone H1.2

Dedicator of cytokinesis protein 11

DNA replication licensing factor MCM7

Ribosomal RNA processing protein 1 homolog B

Coatomer subunit gamma-1

\begin{tabular}{|c|c|c|c|c|c|c|c|c|}
\hline NAT10_HUMAN & NAT10 & 9 & 9 & 7 & 8 & 8 & 6 & 0.571 \\
\hline PDC6I_HUMAN & PDCD6IP & 5 & 4 & 8 & 3 & 7 & 6 & 0.570 \\
\hline PELO_HUMAN & PELO & 8 & 12 & 16 & 10 & 17 & 7 & 0.570 \\
\hline PIP_HÜMAN & PIP & 4 & 4 & 0 & 5 & 0 & 0 & 0.569 \\
\hline SPEE_HUMAN & SRM & 13 & 13 & 8 & 9 & 8 & 12 & 0.569 \\
\hline CDC23_HUMAN & $\mathrm{CDC} 23$ & 0 & 4 & 7 & 7 & 2 & 3 & 0.569 \\
\hline DNJA1_HUMAN & DNAJA1 & 10 & 9 & 8 & 11 & 9 & 4 & 0.568 \\
\hline SPIN1_HUMAN & SPIN1 & 20 & 28 & 23 & 30 & 23 & 11 & 0.567 \\
\hline RS3A_HUMAN & RPS3A & 104 & 103 & 80 & 94 & 86 & 70 & 0.565 \\
\hline EFTU_HUMAN & TUFM & 110 & 116 & 103 & 100 & 91 & 98 & 0.563 \\
\hline ACACA_HUMAN & ACACA & 9 & 6 & 0 & 7 & 0 & 4 & 0.561 \\
\hline CAF17_HUMAN & IBA57 & 3 & 0 & 2 & 0 & 0 & 3 & 0.560 \\
\hline S2533_HUMAN & SLC25A33 & 3 & 3 & 0 & 0 & 0 & 3 & 0.559 \\
\hline BMS1_HUMAN & BMS1 & 7 & 3 & 5 & 4 & 3 & 6 & 0.557 \\
\hline KV113̄_HUMAN & - & 10 & 7 & 9 & 10 & 6 & 7 & 0.556 \\
\hline KRR1_HUMAN & KRR1 & 11 & 11 & 4 & 7 & 10 & 4 & 0.556 \\
\hline NEUA_HUMAN & CMAS & 3 & 3 & 3 & 4 & 0 & 3 & 0.556 \\
\hline MAGT1_HUMAN & MAGT1 & 4 & 7 & 4 & 5 & 7 & 0 & 0.555 \\
\hline RPA1_HUUMAN & POLR1A & 0 & 3 & 2 & 0 & 2 & 2 & 0.553 \\
\hline DRS7B_HUMAN & DHRS7B & 7 & 19 & 9 & 14 & 12 & 4 & 0.552 \\
\hline CPSF4_HUMAN & CPSF4 & 3 & 4 & 0 & 4 & 0 & 0 & 0.550 \\
\hline TBG1_HUMAN & TUBG1 & 22 & 19 & 8 & 14 & 10 & 15 & 0.548 \\
\hline DPYL1_HUMAN & CRMP1 & 0 & 6 & 7 & 6 & 4 & 3 & 0.548 \\
\hline ABCD3_HUMAN & ABCD3 & 14 & 8 & 7 & 10 & 8 & 6 & 0.547 \\
\hline SFXN1_HUMAN & SFXN1 & 28 & 30 & 24 & 22 & 24 & 23 & 0.545 \\
\hline TADBP_HUMAN & TARDBP & 14 & 12 & 9 & 13 & 8 & 8 & 0.541 \\
\hline RM45_HUMAN & MRPL45 & 0 & 4 & 0 & 0 & 0 & 2 & 0.540 \\
\hline RS2_HUMAN & RPS2 & 109 & 114 & 84 & 90 & 97 & 67 & 0.538 \\
\hline PRC̄A_HUMAN & PRRC2A & 3 & 0 & 4 & 2 & 3 & 2 & 0.537 \\
\hline SUCB1_HUMAN & SUCLA2 & 36 & 30 & 37 & 36 & 26 & 26 & 0.534 \\
\hline EIF3I_HUMAN & EIF3I & 29 & 41 & 38 & 35 & 31 & 26 & 0.534 \\
\hline QCR2_HUMAN & UQCRC2 & 42 & 45 & 22 & 32 & 23 & 31 & 0.532 \\
\hline H12_HUMAN & HIST1H1C & 299 & 318 & 296 & 244 & 260 & 256 & 0.532 \\
\hline DOC̄11_HUMAN & DOCK11 & 3 & 0 & 4 & 3 & 0 & 3 & 0.530 \\
\hline MCM7_HUMAN & MCM7 & 56 & 53 & 39 & 48 & 35 & 37 & 0.530 \\
\hline RRP1B_HUMAN & RRP1B & 39 & 33 & 17 & 20 & 26 & 23 & 0.529 \\
\hline COPG1_HUMAN & COPG1 & 26 & 17 & 6 & 16 & 10 & 11 & 0.528 \\
\hline
\end{tabular}

Page 32 of Table S-2 
CTP synthase 1

39S ribosomal protein L15, mitochondrial

Protein SDA1 homolog

Mitochondrial glutamate carrier 1

Histone deacetylase 1

Serine/arginine-rich splicing factor 6

Unconventional myosin-Ic

Cullin-associated NEDD8-dissociated protein 2

Adenylosuccinate synthetase isozyme 2

Pyrroline-5-carboxylate reductase 1, mitochondrial

Far upstream element-binding protein 2

Nucleophosmin

RNA 3'-terminal phosphate cyclase-like protein

Deoxynucleoside triphosphate triphosphohydrolase SAMHD1

Trifunctional enzyme subunit alpha, mitochondrial

FAST kinase domain-containing protein 2

PYRG1_HUMAN CTPS1

RM15_HUMAN MRPL15

SDA1_HUMAN SDAD1

GHC1_HUMAN SLC25A22

HDAC1_HUMAN HDAC1

SRSF6 HUMAN SRSF6

MYO1C_HUMAN MYO1C

CAND2_HUMAN CAND2

PURA2 HUMAN ADSS

P5CR1_HUMAN PYCR1

FUBP2_HUMAN KHSRP

NPM_HUMAN NPM1

RCL1_HUMAN RCL1

SAMH'1 HUMAN SAMHD1

ECHA_HUMAN HADHA

FAKD2_HUMAN FASTKD2

[3-methyl-2-oxobutanoate dehydrogenase [lipoamide]] kinase, mitochondrial BCKD_HUMAN BCKDK

Apoptotic chromatin condensation inducer in the nucleus

Poly(A) RNA polymerase, mitochondrial

Cullin-1

HAUS augmin-like complex subunit 5

Cell division cycle and apoptosis regulator protein 1

BRCA1-associated ATM activator 1

Thyroid adenoma-associated protein

40S ribosomal protein $\mathrm{S} 30$

Cullin-4B

Protein FRG1

Ran-binding protein 9

Mediator of RNA polymerase II transcription subunit 16

RAD50-interacting protein 1

Ribosome biogenesis regulatory protein homolog

Serine/threonine-protein kinase TBK1

ACINU HUMAN ACIN1

PAPD1_HUMAN MTPAP

CUL1_HUMAN CUL1

HAUS5 HUMAN HAUS5

CCAR1_HUMAN CCAR1

BRAT1_HUMAN BRAT1

THADA_HUMAN THADA

RS30 HUMAN FAU

CUL4B_HUMAN CUL4B

FRG1_HUMAN FRG1

RANB9_HUMAN RANBP9

MED16 HUMAN MED16

RINT1_HUMAN RINT1

RRS1_HUMAN RRS1

TBK1 HUMAN TBK1

Succinate dehydrogenase [ubiquinone] flavoprotein subunit, mitochondrial

Ran GTPase-activating protein 1

Exportin-5

Myosin-10

Pre-mRNA-processing factor 6

Eukaryotic translation initiation factor 3 subunit B
SDHA_HUMAN SDHA

RAGP1_HUMAN RANGAP1

XPO5 HUMAN XPO5

MYH10_HUMAN MYH10

PRP6 HUMAN PRPF6

EIF3B_HUMAN EIF3B $\begin{array}{lllllll}36 & 35 & 21 & 27 & 23 & 23 & 0.528\end{array}$

$\begin{array}{lllllll}21 & 22 & 11 & 13 & 15 & 14 & 0.526\end{array}$

$\begin{array}{lllllll}10 & 9 & 12 & 6 & 11 & 9 & 0.525\end{array}$

$\begin{array}{lllllll}17 & 20 & 13 & 17 & 15 & 8 & 0.520\end{array}$

$\begin{array}{lllllll}0 & 7 & 6 & 6 & 0 & 5 & 0.520\end{array}$

$\begin{array}{lllllll}70 & 68 & 51 & 49 & 49 & 52 & 0.520\end{array}$

$\begin{array}{lllllll}9 & 3 & 0 & 6 & 0 & 2 & 0.518\end{array}$

$\begin{array}{lllllll}4 & 3 & 4 & 3 & 3 & 3 & 0.514\end{array}$

$\begin{array}{lllllll}5 & 4 & 0 & 5 & 0 & 0 & 0.512\end{array}$

$\begin{array}{lllllll}25 & 24 & 17 & 14 & 21 & 16 & 0.510\end{array}$

$\begin{array}{lllllll}8 & 8 & 6 & 4 & 6 & 7 & 0.509\end{array}$

$\begin{array}{lllllll}86 & 65 & 53 & 56 & 57 & 45 & 0.509\end{array}$

$\begin{array}{lllllll}7 & 6 & 7 & 5 & 4 & 7 & 0.508\end{array}$

$\begin{array}{lllllll}7 & 10 & 9 & 8 & 7 & 6 & 0.507\end{array}$

$\begin{array}{lllllll}23 & 27 & 8 & 12 & 14 & 16 & 0.506\end{array}$

$\begin{array}{lllllll}0 & 5 & 6 & 0 & 6 & 3 & 0.506\end{array}$

$\begin{array}{lllllll}10 & 9 & 6 & 8 & 5 & 6 & 0.502\end{array}$

$\begin{array}{lllllll}53 & 37 & 37 & 32 & 32 & 34 & 0.502\end{array}$

$\begin{array}{lllllll}0 & 6 & 5 & 8 & 0 & 0 & 0.490\end{array}$

$\begin{array}{lllllll}3 & 0 & 0 & 0 & 0 & 0 & 0.488\end{array}$

$\begin{array}{lllllll}3 & 0 & 0 & 0 & 0 & 0 & 0.488\end{array}$

$\begin{array}{lllllll}3 & 0 & 0 & 0 & 0 & 0 & 0.488\end{array}$

$\begin{array}{lllllll}3 & 0 & 0 & 0 & 0 & 0 & 0.488\end{array}$

$\begin{array}{lllllll}3 & 0 & 0 & 0 & 0 & 0 & 0.488\end{array}$

$\begin{array}{lllllll}3 & 0 & 0 & 0 & 0 & 0 & 0.488\end{array}$

$\begin{array}{lllllll}3 & 0 & 0 & 0 & 0 & 0 & 0.488\end{array}$

$\begin{array}{lllllll}3 & 0 & 0 & 0 & 0 & 0 & 0.488\end{array}$

$\begin{array}{lllllll}3 & 0 & 0 & 0 & 0 & 0 & 0.488\end{array}$

$\begin{array}{lllllll}3 & 0 & 0 & 0 & 0 & 0 & 0.488\end{array}$

$\begin{array}{lllllll}3 & 0 & 0 & 0 & 0 & 0 & 0.488\end{array}$

$\begin{array}{lllllll}3 & 0 & 0 & 0 & 0 & 0 & 0.488\end{array}$

$\begin{array}{lllllll}3 & 0 & 0 & 0 & 0 & 0 & 0.488\end{array}$

$\begin{array}{lllllll}3 & 0 & 0 & 0 & 0 & 0 & 0.488\end{array}$

$\begin{array}{lllllll}7 & 13 & 9 & 6 & 8 & 8 & 0.488\end{array}$

$\begin{array}{lllllll}5 & 0 & 3 & 5 & 0 & 0 & 0.487\end{array}$

$\begin{array}{lllllll}29 & 24 & 19 & 15 & 18 & 20 & 0.486\end{array}$

$\begin{array}{lllllll}24 & 20 & 14 & 14 & 12 & 16 & 0.481\end{array}$

$29 \quad 33 \quad 11$ 
60S ribosomal protein $\mathrm{L} 8$

Propionyl-CoA carboxylase alpha chain, mitochondrial

Cystathionine beta-synthase

Cell division control protein 45 homolog

General transcription factor $3 \mathrm{C}$ polypeptide 2

Neurofilament light polypeptide

TRMT1-like protein

6-phosphogluconolactonase

Gamma-tubulin complex component 3

ATP-binding cassette sub-family B member 10, mitochondrial

Tryptophan--tRNA ligase, cytoplasmic

RUS1 family protein C16orf58

Putative methyltransferase C9orf114

Prohibitin-2

Unconventional myosin-Va

Kinesin-1 heavy chain

A-kinase anchor protein 8-like

Coatomer subunit beta

Nucleolar transcription factor 1

Vesicle-fusing ATPase

Cytoplasmic FMR1-interacting protein 2

Cleavage and polyadenylation specificity factor subunit 6

NADH dehydrogenase [ubiquinone] iron-sulfur protein 2, mitochondrial Phosphoenolpyruvate carboxykinase [GTP], mitochondrial

Isovaleryl-CoA dehydrogenase, mitochondrial

Transportin-3

Protein unc-45 homolog A

Conserved oligomeric Golgi complex subunit 1

Testis-expressed sequence 10 protein

Dolichyl-phosphate beta-glucosyltransferase

Exocyst complex component 8

26S protease regulatory subunit 8

Protein CMSS1

Ketosamine-3-kinase

DNA replication licensing factor MCM4

Probable 28S rRNA (cytosine(4447)-C(5))-methyltransferase

Lamina-associated polypeptide 2 , isoform alpha

Protein arginine N-methyltransferase 5

$\begin{array}{ll}\text { RL8_HUMAN } & \text { RPL8 } \\ \text { PCCA_HUMAN } & \text { PCCA } \\ \text { CBS_HUMAN } & \text { CBS } \\ \text { CDC45_HUMAN } & \text { CDC45 } \\ \text { TF3C2_HUMAN } & \text { GTF3C2 } \\ \text { NFL_HUMAN } & \text { NEFL } \\ \text { TRM1__HUMAN } & \text { TRMT1L } \\ \text { 6PGL_HUMAN } & \text { PGLS } \\ \text { GCP3_HUMAN } & \text { TUBGCP3 } \\ \text { ABCBA_HUMAN } & \text { ABCB10 } \\ \text { SYWC_HUMAN } & \text { WARS } \\ \text { RUS1_HUMAN } & \text { C16orf58 } \\ \text { CI114_HUMAN } & \text { C9orf14 } \\ \text { PHB2_HUMAN } & \text { PHB2 } \\ \text { MYO5A_HUMAN } & \text { MYO5A } \\ \text { KINH_HUMAN } & \text { KIF5B } \\ \text { AKP8L_HUMAN } & \text { AKAP8L } \\ \text { COPB_HUMAN } & \text { COPB1 } \\ \text { UBF1_HUMAN } & \text { UBTF } \\ \text { NSF_HUMAN } & \text { NSF } \\ \text { CYFP2_HUMAN } & \text { CYFIP2 } \\ \text { CPSF6_HUMAN } & \text { CPSF6 } \\ \text { NDUS2_HUMAN } & \text { NDUFS2 } \\ \text { PCKGM_HUMAN } & \text { PCK2 } \\ \text { IVD_HUMAN } & \text { IVD } \\ \text { TNPO3_HUMAN } & \text { TNPO3 } \\ \text { UN45A_HUMAN } & \text { UNC45A } \\ \text { COG1_HUMAN } & \text { COG1 } \\ \text { TEX10_HUMAN } & \text { TEX10 } \\ \text { ALG5_HUMAN } & \text { ALG5 } \\ \text { EXOC8_HUMAN } & \text { EXOC8 } \\ \text { PRS8_HUMAN } & \text { PSMC5 } \\ \text { CMS1_HUMAN } & \text { CMSS1 } \\ \text { KT3K_HUMAN } & \text { FN3KRP } \\ \text { MCM4_HUMAN } & \text { MCM4 } \\ \text { NOP2_HUMAN } & \text { NOP2 } \\ \text { LAP2A_HUMAN } & \text { TMPO } \\ \text { ANM5_HUMAN } & \text { PRMT5 }\end{array}$


Filamin-A

AP-3 complex subunit beta-1

Basic leucine zipper and W2 domain-containing protein 2

Acyl-coenzyme A thioesterase 9, mitochondrial

T-complex protein 1 subunit epsilon

$\mathrm{X}$-ray repair cross-complementing protein 5

DNA repair protein XRCC1

G-protein coupled receptor-associated sorting protein 2

Probable ATP-dependent RNA helicase DDX31

General transcription factor $3 \mathrm{C}$ polypeptide 3

UDP-N-acetylglucosamine--peptide N-acetylglucosaminyltransferase $110 \mathrm{kDa}$ subunit

Dedicator of cytokinesis protein 7

Methylcytosine dioxygenase TET2

Mitochondrial Rho GTPase 1

RNA-binding protein 5

AP-2 complex subunit alpha-2

Protein RFT1 homolog

Fragile X mental retardation syndrome-related protein 2

Nuclear cap-binding protein subunit 1

Nucleolar RNA helicase 2

Syntaxin-binding protein 3

Surfeit locus protein 6

Armadillo repeat-containing protein 6

GPI transamidase component PIG-S

26S proteasome non-ATPase regulatory subunit 1

Heat shock protein HSP 90-alpha

Glutamine--tRNA ligase

Myosin-9

Nuclear pore complex protein Nup93

T-complex protein 1 subunit eta

Graves disease carrier protein

Protein Njmu-R1

Syntaxin-binding protein 2

26S proteasome non-ATPase regulatory subunit 14

S-adenosylmethionine synthase isoform type-2

Nucleolar complex protein 3 homolog

Putative oxidoreductase GLYR1

RNA-binding protein 7

\begin{tabular}{|c|c|}
\hline FLNA_HUMAN & FLNA \\
\hline AP3B1_HUMAN & AP3B1 \\
\hline BZW2_HUMAN & BZW2 \\
\hline ACOT'̄9_HUMAN & ACOT9 \\
\hline TCPE_HUMAN & ССТ5 \\
\hline XRCC5_HUMAN & XRCC5 \\
\hline XRCC1_HUMAN & $\mathrm{XRCC} 1$ \\
\hline GASP2 HUMAN & GPRASP2 \\
\hline DDX31_HUMAN & DDX31 \\
\hline TF3C3_HUMAN & GTF3C3 \\
\hline OGT1_HUMAN & OGT \\
\hline DOCK7_HUMAN & DOCK 7 \\
\hline TET2_HUMAN & TET2 \\
\hline MIRO1_HUMAN & RHOT1 \\
\hline RBM5_HUMAN & RBM5 \\
\hline AP2A2_HUMAN & AP2A2 \\
\hline RFT1_HUMAN & RFT1 \\
\hline FXR2_HUMAN & FXR2 \\
\hline NCBP1_HUMAN & NCBP1 \\
\hline DDX21_HUMAN & DDX21 \\
\hline STXB3_HUMAN & STXBP3 \\
\hline SURF6_HUMAN & SURF6 \\
\hline ARMC6_HUMAN & ARMC6 \\
\hline PIGS_HUMAN & PIGS \\
\hline PSMD̄1_HUMAN & PSMD1 \\
\hline HS90A_HUMAN & HSP90AA1 \\
\hline SYQ_HUMAN & QARS \\
\hline MYH9_HUMAN & MYH9 \\
\hline NUP93_HUMAN & NUP93 \\
\hline TCPH_HUMAN & СCT7 \\
\hline GDC_HUMAN & SLC25A16 \\
\hline NJMŪ_HUMAN & C17orf75 \\
\hline STXB2_HUMAN & STXBP2 \\
\hline PSDE_HUMAN & PSMD14 \\
\hline METK'ㄹ_HUMAN & MAT2A \\
\hline NOC3L_HUMAN & NOC3L \\
\hline GLYR1_HUMAN & GLYR1 \\
\hline RBM7_HUMAN & RBM7 \\
\hline
\end{tabular}


Beta-adrenergic receptor kinase 1

Fatty acyl-CoA reductase 1

Protein EFR3 homolog A

CLIP-associating protein 2

Chromobox protein homolog 8

ATP synthase subunit s-like protein

Nucleolar MIF4G domain-containing protein 1

$\mathrm{N}$-alpha-acetyltransferase 15 , NatA auxiliary subunit

Protein phosphatase 1B

Fragile X mental retardation protein 1

Uridine-cytidine kinase-like 1

Multifunctional protein ADE2

U4/U6.U5 tri-snRNP-associated protein 1

Exocyst complex component 6

Protein VAC14 homolog

Serine/threonine-protein kinase Nek7

DNA-directed RNA polymerase I subunit RPA34

rRNA methyltransferase 3, mitochondrial

Eukaryotic translation initiation factor 3 subunit $\mathrm{G}$

U4/U6 small nuclear ribonucleoprotein Prp31

MICOS complex subunit MIC60

Probable ATP-dependent RNA helicase DHX40

Plakophilin-2

39S ribosomal protein L2, mitochondrial

ATP-dependent 6-phosphofructokinase, platelet type

Exportin- $\mathrm{T}$

Protein KRI1 homolog

Methyltransferase-like protein 13

Dual specificity mitogen-activated protein kinase kinase 7

Proteasome inhibitor PI31 subunit

Oxysterol-binding protein-related protein 8

Transducin beta-like protein 3

Serine/threonine-protein kinase MRCK alpha

Acyl-coenzyme A thioesterase 1

Pentatricopeptide repeat domain-containing protein 3, mitochondrial

Catenin delta-1

Nucleolar complex protein 2 homolog

Calcium-binding mitochondrial carrier protein SCaMC-1

$\begin{array}{ll}\text { ARBK1_HUMAN ADRBK1 } \\ \text { FACR1_HUMAN } & \text { FAR1 } \\ \text { EFR3A_HUMAN } & \text { EFR3A } \\ \text { CLAP2_HUMAN } & \text { CLASP2 } \\ \text { CBX8_HUMAN } & \text { CBX8 } \\ \text { AT5SL_HUMAN } & \text { ATP5SL } \\ \text { NOM1_HUMAN } & \text { NOM1 } \\ \text { NAA15_HUMAN NAA15 } \\ \text { PPM1B_HUMAN } & \text { PPM1B } \\ \text { FMR1_HUMAN } & \text { FMR1 } \\ \text { UCKL1_HUMAN } & \text { UCKL1 } \\ \text { PUR6_HUMAN } & \text { PAICS } \\ \text { SNUT1_HUMAN } & \text { SART1 } \\ \text { EXOC6_HUMAN EXOC6 } \\ \text { VAC14_HUMAN } & \text { VAC14 } \\ \text { NEK7_HUMAN } & \text { NEK7 } \\ \text { RPA34_HUMAN } & \text { CD3EAP } \\ \text { MRM3_HUMAN } & \text { RNMTL1 } \\ \text { EIF3G_HUMAN } & \text { EIF3G } \\ \text { PRP31_HUMAN } & \text { PRPF31 } \\ \text { MIC60_HUMAN } & \text { IMMT } \\ \text { DHX40_HUMAN } & \text { DHX40 } \\ \text { PKP2_HUMAN } & \text { PKP2 } \\ \text { RM02_HUMAN } & \text { MRPL2 } \\ \text { PFKAP_HUMAN } & \text { PFKP } \\ \text { XPOT_HUMAN } & \text { XPOT } \\ \text { KRI1_HUMAN } & \text { KRI1 } \\ \text { MET13_HUMAN } & \text { METTL13 } \\ \text { MP2K7_HUMAN } & \text { MAP2K7 } \\ \text { PSMF1_HUMAN } & \text { PSMF1 } \\ \text { OSBL8_HUMAN } & \text { OSBPL8 } \\ \text { TBL3_HUMAN } & \text { TBL3 } \\ \text { MRCKA_HUMAN } & \text { CDC42BPA } \\ \text { ACOT1_HUMAN } & \text { ACOT1 } \\ \text { PTCD3_HUMAN } & \text { PTCD3 } \\ \text { CTND1_HUMAN CTNND1 } \\ \text { NOC2L_HUMAN NOC2L } \\ \text { SCMC1_HUMAN SLC25A24 }\end{array}$

0.354 
ATP-dependent RNA helicase DDX18

Calcium-binding mitochondrial carrier protein Aralar1

Exocyst complex component 4

AP-3 complex subunit mu-1

Serine/arginine repetitive matrix protein 2

Rabankyrin-5

EH domain-containing protein 4

Neutral amino acid transporter $\mathrm{B}(0)$

Pantothenate kinase 4

Dual specificity protein kinase CLK2

Hermansky-Pudlak syndrome 6 protein

Serine/threonine-protein kinase MARK2

Pre-mRNA-splicing factor ATP-dependent RNA helicase DHX15

Procollagen-lysine,2-oxoglutarate 5-dioxygenase 1

Probable leucine--tRNA ligase, mitochondrial

Methyltransferase-like protein 17, mitochondrial

Acylglycerol kinase, mitochondrial

DnaJ homolog subfamily C member 9

Coilin

Ribosomal protein S6 kinase alpha-3

Dynamin-like $120 \mathrm{kDa}$ protein, mitochondrial

Protein arginine N-methyltransferase 3

Guanine nucleotide-binding protein $\mathrm{G}(\mathrm{I}) / \mathrm{G}(\mathrm{S}) / \mathrm{G}(\mathrm{T})$ subunit beta-1

RNA pseudouridylate synthase domain-containing protein 3

Dedicator of cytokinesis protein 4

Manganese-transporting ATPase 13A1

CTP synthase 2

Protein LSM14 homolog A

Proteasomal ubiquitin receptor ADRM1

Pyridoxal phosphate phosphatase

Striatin-interacting protein 1

RNA-binding protein 28

Vacuolar protein sorting-associated protein 52 homolog

Thyroid hormone receptor-associated protein 3

Cysteine desulfurase, mitochondrial

26S proteasome non-ATPase regulatory subunit 2

Protein LYRIC

ATP-dependent 6-phosphofructokinase, muscle type
DDX18_HUMAN DDX18

CMC1_HUMAN SLC25A12

EXOC4_HUMAN EXOC4

AP3M1_HUMAN AP3M1

SRRM2_HUMAN SRRM2

ANFY1_HUMAN ANKFY1

EHD4_HUMAN EHD4

AAAT_HUMAN SLC1A5

PANK 4 HUMAN PANK4

CLK2_HUMAN CLK2

HPS6_HUMAN HPS6

MARK2_HUMAN MARK2

DHX15 HUMAN DHX15

PLOD1_HUMAN PLOD1

SYLM_HUMAN LARS2

MET17 HUMAN METTL17

AGK HUMAN AGK

DNJC9_HUMAN DNAJC9

COIL_HUMAN COIL

KS6A3_HUMAN RPS6KA3

OPA1_HUMAN OPA1

ANM3_HUMAN PRMT3

GBB1_HUMAN GNB1

RUSD3_HUMAN RPUSD3

DOCK4 HUMAN DOCK4

AT131_HUMAN ATP13A1

PYRG2_HUMAN CTPS2

LS14A HUMAN LSM14A

ADRM1 HUMAN ADRM1

PLPP_HUMAN PDXP

STRP1_HUMAN STRIP1

RBM28_HUMAN RBM28

VPS52 HUMAN VPS52

TR150_HUMAN THRAP3

NFS1 HUMAN NFS1

PSMD2 HUMAN PSMD2

LYRIC_HUMAN MTDH

PFKAM_HUMAN PFKM $\begin{array}{lllllll}17 & 18 & 12 & 7 & 7 & 8 & 0.309\end{array}$

43

$\begin{array}{lllllll}7 & 3 & 3 & 3 & 0 & 2 & 0.303\end{array}$

$\begin{array}{lllllll}5 & 6 & 0 & 3 & 0 & 0 & 0.302\end{array}$

$\begin{array}{lllllll}105 & 116 & 66 & 46 & 46 & 35 & 0.294\end{array}$

0.293

0.292

0.292

0.290

0.283

0.281

0.281

0.277

0.276

0.276

0.276

0.276

0.276

0.276

0.275

0.275

0.275

0.273

0.268

0.268

0.267

0.264

0.264

0.260

0.258

0.258

0.254

0.254

0.254

0.252

0.251

0.250

0.249

Page 37 of Table S-2 
DNA replication licensing factor MCM5

Pyridoxal-dependent decarboxylase domain-containing protein 1

COBW domain-containing protein 1

Dynein assembly factor 5, axonemal

$\mathrm{H} / \mathrm{ACA}$ ribonucleoprotein complex subunit 1

Adenosylhomocysteinase

Serine/threonine-protein phosphatase PP1-gamma catalytic subunit

Gem-associated protein 2

Sentrin-specific protease 3

Aldehyde dehydrogenase family 16 member A1

AFG3-like protein 2

5'-AMP-activated protein kinase catalytic subunit alpha-1

Histone $\mathrm{H} 1.5$

TGF-beta-activated kinase 1 and MAP3K7-binding protein 1

Nuclear pore complex protein Nup133

Protein NipSnap homolog 1

Exosome complex component RRP4

Sec1 family domain-containing protein 1

Bcl-2-associated transcription factor 1

Nicalin

Peroxiredoxin-6

ATP-dependent RNA helicase DDX51

Transmembrane protein 199

Signal transducer and activator of transcription 1-alpha/beta

Cleavage and polyadenylation specificity factor subunit 5

ATP-dependent RNA helicase DDX1

Spectrin beta chain, non-erythrocytic 1

Cytochrome c oxidase assembly protein COX15 homolog

Transcription initiation factor TFIID subunit 4

DnaJ homolog subfamily $\mathrm{C}$ member 10

U7 snRNA-associated Sm-like protein LSm11

Vacuolar protein sorting-associated protein 51 homolog

MOB kinase activator 2

Vacuolar protein sorting-associated protein 35

Hydroxyacyl-coenzyme A dehydrogenase, mitochondrial

COUP transcription factor 2

Transferrin receptor protein 1

Ubiquitin carboxyl-terminal hydrolase 15

\begin{tabular}{|c|c|}
\hline MCM5_HUMAN & MCM5 \\
\hline PDXD1_HUMAN & PDXDC1 \\
\hline CBWD1_HUMAN & CBWD1 \\
\hline DAAF5_HUMAN & DNAAF5 \\
\hline GAR1_HUMAN & GAR1 \\
\hline SAHH_HUMAN & AHCY \\
\hline PP1G_HUMAN & PPP1CC \\
\hline GEMI2_HUMAN & GEMIN2 \\
\hline SENP3_HUMAN & SENP3 \\
\hline A16A1_HUMAN & ALDH16A1 \\
\hline AFG32_HUMAN & AFG3L2 \\
\hline AAPK1_HUMAN & PRKAA1 \\
\hline H15_HUMAN & HIST1H1B \\
\hline TAB1_HUMAN & TAB1 \\
\hline NU133̄_HUMAN & NUP133 \\
\hline NIPS1_HUMAN & NIPSNAP1 \\
\hline EXOS2_HUMAN & EXOSC2 \\
\hline SCFD1_HUMAN & SCFD1 \\
\hline BCLF1_HUMAN & BCLAF1 \\
\hline NCLN_HUMAN & NCLN \\
\hline PRDX6_HUMAN & PRDX6 \\
\hline DDX51_HUMAN & DDX51 \\
\hline TM199_HUMAN & TMEM199 \\
\hline STAT1_HUMAN & STAT1 \\
\hline CPSF5_HUMAN & NUDT21 \\
\hline DDX1_HUMAN & DDX1 \\
\hline SPTB2_HUMAN & SPTBN1 \\
\hline COX15_HUMAN & COX15 \\
\hline TAF4_HUMAN & TAF4 \\
\hline DJC10_HUMAN & DNAJC10 \\
\hline LSM11_HUMAN & LSM11 \\
\hline VPS51_HUMAN & VPS51 \\
\hline MOB2_HUMAN & MOB2 \\
\hline VPS35_HUMAN & VPS35 \\
\hline HCDH_HUMAN & HADH \\
\hline COT2_HUMAN & NR2F2 \\
\hline TFR1_HUMAN & TFRC \\
\hline UBP15 HUMAN & USP15 \\
\hline
\end{tabular}

$41-40 \quad 19$

$4 \quad 4 \quad 0$

$\begin{array}{lllllll}3 & 5 & 0 & 0 & 0 & 0 & 0.243\end{array}$


39S ribosomal protein L1, mitochondrial Polynucleotide 5'-hydroxyl-kinase NOL9

ATP-dependent 6-phosphofructokinase, liver type

Surfeit locus protein 4

Signal transducer and activator of transcription 3

Translation initiation factor eIF-2B subunit epsilon

Malectin

Delta-1-pyrroline-5-carboxylate synthase

Glycogen [starch] synthase, muscle

U1 small nuclear ribonucleoprotein A

ATPase WRNIP1

Monofunctional C1-tetrahydrofolate synthase, mitochondrial ATP-dependent RNA helicase DDX50

Serine/threonine-protein kinase RIO1

Sphingomyelin phosphodiesterase 4

Coatomer subunit gamma-2

Phosphatidylinositol 4-phosphate 5-kinase type-1 gamma

Probable C-mannosyltransferase DPY19L1

E3 UFM1-protein ligase 1

Mitochondrial thiamine pyrophosphate carrier

Nuclear pore complex protein Nup88

6-phosphofructo-2-kinase/fructose-2,6-bisphosphatase 3

RNA-binding protein 10

Coordinator of PRMT5 and differentiation stimulator

Microtubule-associated protein 1B

Eukaryotic translation initiation factor $4 \mathrm{~B}$

Fibronectin

TGF-beta-activated kinase 1 and MAP3K7-binding protein 2

Centromere/kinetochore protein zw10 homolog

Mitochondrial Rho GTPase 2

Deoxyribose-phosphate aldolase

Sideroflexin-2

SCY1-like protein 2

Chloride channel CLIC-like protein 1

Apolipoprotein C-III

Paraspeckle component 1

Ribosomal biogenesis protein LAS1L

ATP-binding cassette sub-family F member 2
RM01 HUMAN MRPL1

NOL9 HUMAN NOL9

PFKAL_HUMAN PFKL

SURF4_HUMAN SURF4

STAT3 HUMAN STAT3

EI2BE_HUMAN EIF2B5

MLEC_HUMAN MLEC

P5CS_HUMAN ALDH18A1

GYS1 HUMAN GYS1

SNRPA_HUMAN SNRPA

WRIP1_HUMAN WRNIP1

C1TM HUMAN MTHFD1L

DDX50 HUMAN DDX50

RIOK1_HUMAN RIOK1

NSMA3_HUMAN SMPD4

COPG2 HUMAN COPG2

PI51C HUMAN PIP5K1C

D19L1_HUMAN DPY19L1

UFL1_HUMAN UFL1

TPC HUMAN SLC25A19

NUP88 HUMAN NUP88

F263_HUMAN PFKFB3

RBM10_HUMAN RBM10

COPRS HUMAN COPRS

MAP1B HUMAN MAP1B

IF4B_HUMAN EIF4B

FINC HUMAN FN1

TAB2 HUMAN TAB2

ZW10 HUMAN ZW10

MIRO2_HUMAN RHOT2

DEOC HUMAN DERA

SFXN2 HUMAN SFXN2

SCYL2_HUMAN SCYL2

CLCC1_HUMAN CLCC1

APOC3 HUMAN APOC3

PSPC1 HUMAN PSPC1

LAS1L_HUMAN LAS1L

ABCF2_HUMAN ABCF2
0.182

0.182

0.181

0.174

0.172

0.170

0.168

0.168

0.167

0.167

0.161

0.160

0.159

0.157

0.156

0.156

0.155

0.155

0.154

0.151

0.151

0.137

0.136

0.135

0.132

0.123

0.120

0.117

0.115

0.115

0.114

0.111

0.111

0.109

0.109

0.105

0.103

0.096

Page 39 of Table S-2 
Mitogen-activated protein kinase kinase kinase 7

RING finger protein 219

Glutamine--fructose-6-phosphate aminotransferase [isomerizing] 1

SUN domain-containing protein 2

Calmodulin-regulated spectrin-associated protein 3

Girdin

4F2 cell-surface antigen heavy chain

Pinin

Unconventional myosin- $\mathrm{Vb}$

Spectrin alpha chain, non-erythrocytic 1

MAX gene-associated protein

Dermcidin

Protein Daple

Telomere-associated protein RIF1

$\begin{array}{llccccccc}\text { M3K7_HUMAN } & \text { MAP3K7 } & 7 & 12 & 3 & 0 & 0 & 0 & 0.090 \\ \text { RN219_HUMAN } & \text { RNF219 } & 8 & 12 & 15 & 0 & 2 & 2 & 0.088 \\ \text { GFPT1_HUMAN } & \text { GFPT1 } & 7 & 7 & 7 & 0 & 0 & 0 & 0.086 \\ \text { SUN2_HUMAN } & \text { SUN2 } & 18 & 27 & 11 & 3 & 0 & 3 & 0.083 \\ \text { CAMP3_HUMAN CAMSAP3 } & 18 & 10 & 20 & 0 & 2 & 3 & 0.078 \\ \text { GRDN_HUMAN } & \text { CCDC88A } & 11 & 9 & 6 & 0 & 0 & 0 & 0.073 \\ \text { 4F2_HUMAN } & \text { SLC3A2 } & 7 & 11 & 8 & 0 & 0 & 0 & 0.070 \\ \text { PININ_HUMAN } & \text { PNN } & 9 & 11 & 8 & 0 & 0 & 0 & 0.066 \\ \text { MYO5B_HUMAN MYO5B } & 30 & 24 & 27 & 0 & 2 & 5 & 0.064 \\ \text { SPTN1_HUMAN } & \text { SPTAN1 } & 40 & 35 & 6 & 3 & 2 & 0 & 0.052 \\ \text { MGAP_HUMAN } & \text { MGA } & 24 & 20 & 0 & 0 & 0 & 0 & 0.048 \\ \text { DCD_HUMAN } & \text { DCD } & 26 & 27 & 0 & 0 & 0 & 0 & 0.040 \\ \text { DAPLE_HUMAN CCDC88C } & 18 & 16 & 13 & 0 & 0 & 0 & 0.040 \\ \text { RIF1_HUMAN } & \text { RIF1 } & 55 & 31 & 14 & 0 & 0 & 0 & 0.020\end{array}$

${ }^{a}$ The value was obtained by the mean normalized SC of NS1 vector (NS1) divided by that of control vector (VC). Proteins with ratios larger than the mean plus two SD (the ratios were above 7.194) and detected in more than two replicates of the NS1 group are defined as NS1 interacting partners. 